This article is a contribution to the special issue in honour of Zbyněk Roček.

\title{
A review of the palaeoclimatic inference potential of Iberian Quaternary fossil batrachians
}

\author{
Jorge M. Lobo ${ }^{1} \bullet$ Iñigo Martínez-Solano² • Borja Sanchiz ${ }^{3}$
}

1 Jorge M. Lobo: Department of Biogeography and Global Change. National Museum of Natural Sciences, MNCN-CSIC. José Gutiérrez Abascal 2. E-28006 Madrid, Spain.

2 Iñigo Martínez-Solano: Department of Wetland Ecology. Doñana Biological Station, EBD-CSIC. Américo Vespucio s/n. E-41092 Sevilla, Spain. Corresponding author.

3 Borja Sanchiz: Department of Palaeobiology. National Museum of Natural Sciences, MNCN-CSIC. José Gutiérrez Abascal 2. E-28006 Madrid, Spain.

Authorship in alphabetical order.

\begin{abstract}
Ecological suitability analysis aims to model the potential or probable distribution of species using environmental variables and available species occurrence information as predictors. Most of the European fossil Quaternary amphibians belong to extant species, and being physiologically ectothermic animals, their current ecological niches could become a reliable inference tool to infer past environmental conditions. However, this expectation has never been properly verified. The validity and accuracy of palaeoclimatic inferences based on batrachian species ranges is tested on the Iberian Peninsula, using both palaeofaunistic and recent distribution data, and an updated database of georeferenced species occurences is provided. The difficulties of using current geographic information to represent the full spectrum of environmental conditions at which a species occurs are critically examined. A palaeofaunistic review of the role played by historical factors as dispersal limitations for present amphibian species ranges is presented using the available phylogeographical scenarios. Virtual hypothetical taxa can be devised by considering the distributions of several species together and relating their known joint presences with the environmental conditions in these locations. Species Distribution Models based on these virtual taxa provide the best advisable inferential procedure. For direct raw inferences of the mutual climatic range method, contrary to expectations, the combined taxa sets do not increase their accuracy with the number of species included. This preliminary review shows that Iberian amphibian palaeoclimatic inferences are both valid and reliable enough, a sufficient approximation to complement other techniques. The precision, however, is quite variable among taxa, reflecting the effect of non-climatic distributional constraints.
\end{abstract}


Keywords: Quaternary; Iberia; Amphibia; palaeoclimatology; palaeofaunistics

\section{Introduction}

The compilation and availability of species occurrence data (e.g. http://www.gbif.org/) and the accessibility of digital cartography on environmental variables (e.g. http://www.worldclim.org/) has facilitated the modelling of realised or potential distributions of species. Biogeographic modelling has become a successful field of research (Lobo et al. 2010), often omitting the lessons provided by many previous relevant studies (Sutherst 2014). Because amphibian species are physiologically ectothermic, their ranges should be delimited largely by environmental conditions, even if other factors, such as biotic interactions and historical and dispersal limitations, might also constrain their distributions (Baselga et al. 2012). However, considering that most amphibian species have narrow climatic niches, and that climatic conditions are the main factors that determine amphibian environmental requirements (Bonetti and Wiens 2014), we may hypothesise that the relationship between species distributions and the environment can be used as an analytical tool for palaeoclimatic inference. The principal strength of such a tool relies on providing quantitative inferences of past conditions based on faunistic assemblages recovered at fossil sites (Varela et al. 2011). However, the expectation that ecological niches based on extant occurrences could offer reliable information about past environments should be verified before using this procedure (Peterson et al. 1999; Harris et al. 2014). The purpose of this article is to present a preliminary test of the validity and accuracy of batrachian (i.e. salamanders and frogs) palaeoclimatic inference by reviewing the Iberian Peninsula fauna as a pilot case study using both palaeofaunistic and Recent distribution data.

A combination of circumstances converges in the study of Iberian Quaternary amphibians. First, the known fossil record almost completely comprises living lineages at the species level; only a few residual Pliocene taxa, such as Albanerpeton (Albanerpetontidae) or Latonia (Discoglossidae), potentially might be found in the future in lowermost Pleistocene strata. Second, extensive molecular biological research has been conducted in recent years, and detailed phylogeographic analyses are now available for most species. These evolutionary hypotheses of relationships incorporate time and spatial components and thus allow the characterisation of range dynamics, including climatemediated range expansions and contractions. Finally, large quantities of batrachian fossils have been obtained as a by-product of microvertebrate palaeontological research in archaeological excavations in Spain.

In this study, we provide an example of the usefulness of amphibian occurrence data to reconstruct ancient environments and show that the study of past species assemblages can provide important evidence to understand the ecology of extant species. Such evidence includes fossil assemblages with species that do not presently have overlapping ranges; this information can only be derived from palaeontological sources, and it is currently impossible to obtain this information from scientific disciplines other than palaeontology (see for instance Williams et al. 2013). 


\section{Methods and technical procedures}

Updated information on Iberian amphibian distributions is presented on the web page of the Asociación Herpetológica Española (AHE) (http://www.herpetologica.es/), which also provides links to other databases, such as the New Atlas of Amphibians and Reptiles of Europe NA2RE (http://na2re.ismai.pt/).

Information on the geographical ranges of modern species was taken from data compiled for the Spanish National Herpetological Atlas by Pleguezuelos et al. (2002), which was constructed on a UTM projection with a resolution of $10 \times 10 \mathrm{~km}$ grid cells. An update of this National Atlas is currently accessible at the Spanish Amphibians and Reptiles Information Server SIARE (http://siare.herpetologica.es/index.php). The distribution of Portuguese amphibians was obtained from Loureiro et al. (2008), but we have updated the Triturus species ranges after Themudo and Arntzen (2007) and Arntzen and Themudo (2008), and the distribution of Pelodytes spp. after DíazRodríguez et al. (2015).

Environmental variables, originally taken from the WorldClim database (Hijmans et al. 2005; http://www.worldclim.org), were facilitated by the Laboratory of Informatic Biogeography of the Spanish National Museum of Natural Sciences (http://www.mncn.csic.es/). Species distributions and their predicted ranges are from Araújo et al. (2011).

\section{Taxonomic identifications}

We have reviewed, directly or through descriptive publications, the available information on the amphibian fossil record of the Iberian Quaternary by using taxonomic identification criteria taken from Böhme (1977) and Bailon (1999) for anurans, and Haller-Probst and Schleich (1994) and Buckley and Sanchiz (2012) for urodeles. The details of this review are unnecessary here because taxonomic identifications in the published faunistic lists are considered accurate. However, for some sites or strata, the available fossil material is too incomplete to differentiate among all the lberian species. Furthermore, there are instances in which morphological distinction is uncertain or impossible between similar forms. This fact, in the absence of a museum osteological series that could be statistically analysed, prevents any palaeoclimatic analysis at the species level (see below).

\section{Environmental niche error sources}

Species Distribution Models (SDM) aim to predict species ranges using information from several types of environmental variables, usually climatic ones, and the available database information on species occurrences (generally only presence information). Niche Models are those devoted to unveiling the fundamental niche of a species from extant distribution data. Many modelling techniques have been used to predict distributions or infer niches, and the caveats, possibilities and inconveniences of these procedures have been recently examined (Aarts et al. 2012; Hijmans 2012; Hortal et al. 2012; Hastie and Fithian 2013). The main drawback of this approach most likely is Hutchinson's duality (Colwell and Rangel 2009), or the inability of current geographic information to represent the full spectrum of environmental conditions at which a species may have a net positive demographic rate, mainly caused by the role played by contingent, historical factors in the 
conformation of species ranges (the discrepancy between FN and DFN in Fig. 1). However, when we aim to derive climatic data from fossil occurrences, the assumption of uniformitarianism should be considered an important drawback. The uniformitarianism assumption is widespread in evolutionary biology and indicates that currently acting and observable natural processes should be similar to those operating in the past (Baker 1998). Thus, inferring climatic data from past distributions may imply a double assumption. The first assumes that the species identified in the fossil record have similar niches to their extant equivalents, and the second assumes that the current distributional information of these species is mainly determined by the climatic factors that we aim to predict. In the case of palaeobiogeography, both Hutchinson's duality and the uniformitarianism assumption preclude us from considering absence data or complex modelling techniques capable of fitting any type of dataset (Hortal et al. 2012); absences can be uninformative because of their contingent origin, and the use of simple methods is preferred to overparameterisation. Thus, we used simple methods to estimate niches, which are only based on the available presence information. One of these simple methods, for example, is a generalised intersection procedure based in set theory (see Varela et al. 2011 and Jiménez-Valverde et al. 2011 for a complete rationale of this proposal): i.e. estimating the extreme maximum and minimum environmental values of the localities inhabited by a species to subsequently delimit the suitable conditions in the multidimensional environmental space. This methodological proposal will be referred as "niche inference" from now on.

A general list of common error sources in palaeobiogeography that might affect estimation of the environmental niche when inferred from occurrence data is presented in Table 1, which also includes suggested adjustment techniques. Some of these errors are directly related to the imprecision of the data coming from basic observational and faunistic surveys, even considering that biodiversity information is increasing rapidly, and the resolution and standardising of mapping projects is improving. The general resolution of the available Iberian herpetological atlas is at most $10 \times 10 \mathrm{~km}$, but usually each range has many grid cells, and the basic statistics derived from these samples are considered robust even if marginal or false presences or absences are included.

Other error sources are inherent to methodological assumptions, such as niche stability, the inexistence of niche shifts through time (but see for instance Takahashi et al. 2014 for an assumption-free test of ecological divergence) or the previously mentioned uniformitarianism assumption. These biases can be suspected, as we will show in the case of the Atapuerca complex, but are not easily corrected.

For some species, the local study zone can be only a fraction of its complete range. In these cases, the environmental predictors are clearly incomplete, the subsample might be biased and it is not random. This error source disappears with the use of intersection procedures, such as the simple Mutual Climatic Range (MCR) (e.g. Blain 2005; Blain et al. 2013) because, in practice, at least one component of the joint assemblage has an endemic range in the study area. Other error sources are caused by taphonomic absences, which are common in fossil assemblages. It should never be considered that taxon absence in a deposit indicates that the particular taxon was absent in the palaeoenvironment, and a taxon's presence should not be assumed even if it can be statistically deduced from the faunistic lists of other strata at the same site.

To minimise all the previously mentioned error sources on niche inferences, we advocate using a combination of two different palaeoclimatic procedures in the case of fossil assemblages. First, data derived from niche inferences are preferable to raw observational data, but only if they are 
properly filtered by palaeofaunistic and phylogeographical information. Second, we consider that because of the bias and scarceness of palaeontological data, it is more convenient to jointly analyse different species groups or even complete assemblages, building a hypothetical supra-specific virtual taxon, rather than combining the individual results obtained for each species. This Mutual Climatic Range Method (MCR), which uses the environmental information of the places in which all the species of the assemblage have been observed as input, can also be similarly applied to the places covered by the joint potential distributions of all the taxa involved. However, the mean of the niche predictions for a climatic variable made by sets with different species numbers does not appear to significantly improve when the species number increases (see below).

\section{Validity and accuracy of batrachian palaeoclimatic inference}

The validity and accuracy of palaeoclimatic inferences based on Iberian batrachian ranges has been tested in several ways. A set of 19 bioclimatic variables (see abbreviations) has been analysed, taking their average values on the UTM grid cells for which this information is available, nearly completely covering the Iberian geography. Amphibian species ranges can thus be considered biased samples of cells taken from this reference population (RP). A random sample of 50 UTM cells (each 99-101 $\mathrm{km}^{2}$ ) was subsequently selected from the RP, and observed values for each variable in each cell were compared with the average of the mean range-wide values of all the living species that have been recorded in these cells. To make all the variables comparable, we used standardised Z-scores (i.e. using the standard deviations on a standard normal distribution as measurement units). For the 19 variables, the mean error between the RP values and those predicted by the batrachian assemblage was $Z=0.66$, with a maximum-minimum of $0.83-0.47$, representing a $0.66 \sigma$-error, an accuracy of approximately $75 \%$. The general correlation between the predicted and the real values $(\mathrm{N}=19 \times 50=950)$ was statistically significant but not high (Pearson correlation coefficient; $r=0.62$, $\mathrm{p}<0.001)$. Other tests produced similar results. For example, following the same procedure, we estimated values of the variable BIO1 (annual mean temperature) for 71 places in which fossil sites are known, and the mean difference (Z-scores) between the real and predicted values was $Z=0.57$ (i.e. $0.57 \sigma$-error), an accuracy of approximately $78 \%$, with a significant but moderate correlation ( $r=$ $0.45, p<0.001)$. When the central values of the maximum-minimum ranges are considered instead of the means, the predictions are also significant, but their accuracy is much lower $(r=0.23, p<0.001)$ because extreme outliers are frequently found.

These results confirm that amphibian species distributions are truly delimited by an important climatic component, as can be seen by the accuracy of the climatic predictions based on present conditions when derived from its extant fauna. The batrachian inference tool is consequently valid, although its accuracy is variable and cannot be particularly high.

Being a multispecies inference tool, the question arises of whether the number of species in the assemblage is related to the accuracy of the prediction. Table 2 shows the results of the standardised (Z-scores) predictions made by assemblages of different numbers of taxa on the observed values. The peninsular Eurosiberian ecozone examined corresponds to the Spanish part of region 2.2 in Fig. 2; the regions were obtained by a K-means clustering procedure using the previously mentioned 19 climatic variables. 
Concerning the random sample $(\mathrm{N}=50)$, we found no significant correlation between the number of species in the assemblage and the error level in the predictions for any of the variables. For all the variables considered together ( $\mathrm{N}=950$ cases), there is no significant correlation between prediction error and species number $(r=0.00)$. Similar results were obtained for the 71 fossil localities mentioned above $(r=0.14)$. However, if the errors between the real values and those of the central maximum-minimum ranges are considered, a significant negative correlation $(r=-0.38)$ is found.

For the analysis of fossil assemblages, the number of different groups that can be devised with $n$ species found in the same strata is $2^{n}-1$, a very large number if we consider all the lberian native species. For this reason, any tabulation would be impractical, so we have prepared a database called QIBER-ANF that allows different types of searches to be conducted for more specific analyses. This spreadsheet database is provided as supplemental material 1 (ESM 1) to this article.

\section{Iberian amphibian palaeofaunistics}

Information on palaeofaunistic history is derived from two disciplines, palaeontology and evolutionary biology. A general palaeofaunistic summary of the Iberian Neogene amphibians based on fossils can be found in Barbadillo et al. (1997) and Rage and Roček (2003). In this section, we briefly examine the known Quaternary fossil record and evolutionary population relationships of the lberian species in relation to their spatial ranges. This information attempts to assess to what extent the present species range covers the complete physiological habitat suitability of the species or whether it is incomplete because of direct historical factors.

The Iberian Quaternary fossil record is summarised in Table 3 (Caudata) and Table 4 (Anura). In the supplementary material 2 (ESM 2), a selected bibliography on the palaeobatrachology of these sites can be found. The distribution maps (Figs. 3, 4, 5, 6, 7, 8, 9, 10, 11, 12, 13, 14, 15, 16, $17,18,19,20,21,22,23,24,25,26$ and 27) show the present known ranges (UTM grid $10 \times 10 \mathrm{~km}$ ), excluding anthropic introductions, their potential distributions after Araújo et al. (2011) and a selection of relevant fossil sites.

\section{Abbreviations of Bioclimatic variables}

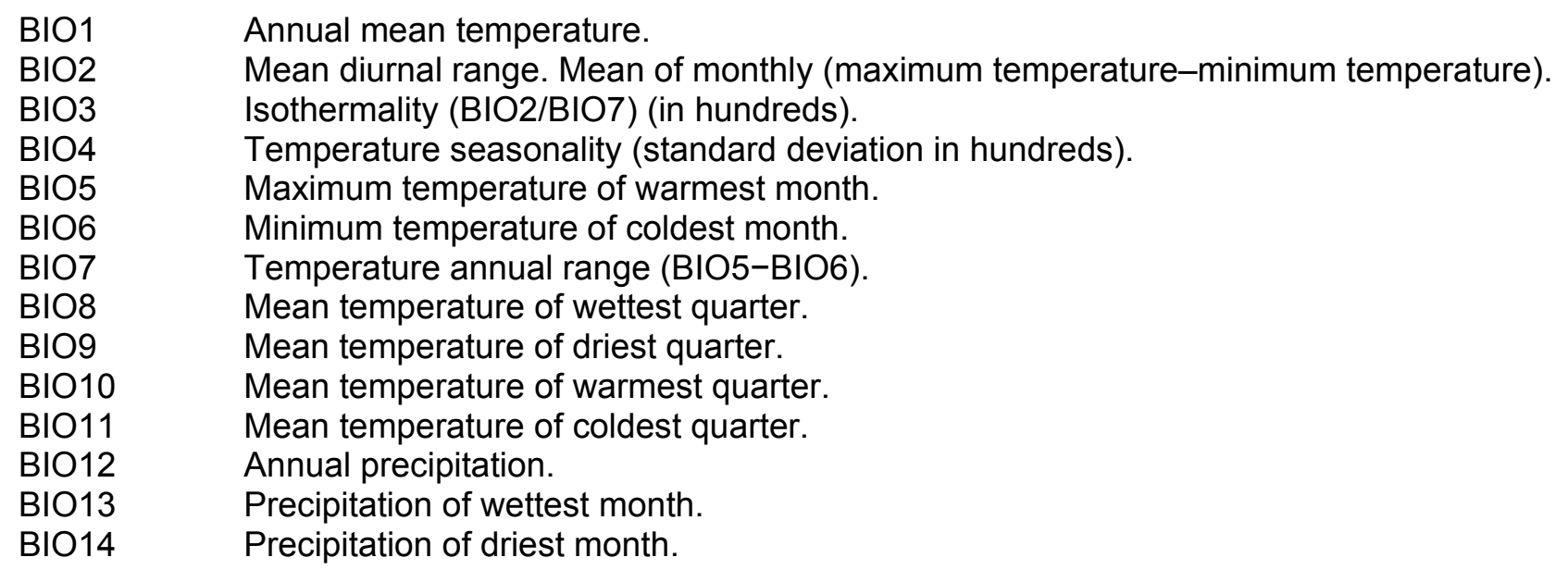


BIO15 Precipitation seasonality (coefficient of variation).

BIO16 Precipitation of wettest quarter.

BIO17 Precipitation of driest quarter.

BIO18 Precipitation of warmest quarter.

BIO19 Precipitation of coldest quarter.

\section{Remarks on genera shown in distribution maps (Figs. 3-27)}

Order Caudata Fischer von Waldheim, 1813

Family Salamandridae Goldfuss, 1820

Genus Calotriton Gray, 1858

(Fig. 3)

Remarks: Calotriton is a newt genus endemic to the Pyrenees that most likely originated at the end of the Miocene, approximately 8.3 Ma ago (Carranza and Amat 2005). This genus includes two living species: the widespread Pyrenean Brook newt Calotriton asper and the relict Calotriton arnoldi that is geographically restricted to the Montseny Massif in Barcelona province. The Pyrenean and Montseny brook newts are estimated to have diverged about $1.1 \mathrm{Ma}$ (Carranza and Amat 2005), with ancestral populations of Calotriton arnoldi becoming isolated with respect to the Pyrenean populations. Calotriton arnoldi has no fossil record and most likely always has been approximately restricted to its present range, which is too small to allow statistical palaeoclimatic inferences. The Holocene stratum of Colomera Cave (Sant Esteve de la Sarga, Lleida province) is the only site where fossil Calotriton asper has been recovered (López-García et al. 2010).

Spatial patterns of genetic diversity and structure in the two Calotriton species have been investigated with mitochondrial DNA (mtDNA) analysis, amplified fragment length polymorphisms (AFLPs), allozymes and nuclear DNA (Montori et al. 2008; Milà et al. 2010; Valbuena-Ureña et al. 2013; de Pous et al. 2015). Both species diverged in the Pleistocene and exhibit strong geographic structure. In Calotriton asper, there is extremely low variation in mtDNA sequences and allozymes, but AFLPs show marked differences between populations within four major river drainages, within each drainage, and even between populations separated by less than 4 kilometres. In Calotriton arnoldi, two major population groups have been delineated within its restricted range, corresponding to an east-west division (Valbuena-Ureña et al. 2013).

Comparing Fig. 3 and Fig. 5 clearly shows that the known ranges of Calotriton asper and Ichthyosaura alpestris are parapatric, whereas their potential habitat suitability largely overlaps. Considering this, it is notable that a possible Calotriton extralimital record has been reported from Cueva de las Hienas in Asturias (Sanchiz and Martín 2004), quite far from the present range of this genus. This material is undescribed, and its generic adscription remains in doubt, but if the identification made by Sanchiz and Martín 2004 is correct, it would argue in favour of competitive exclusion between these Calotriton and Ichthyosaura species because the former is only found in the older levels of the site, whereas the latter appears restricted to younger strata. 
If we assume competitive exclusion, the combined potential distributions of Calotriton asper and Ichthyosaura alpestris should be jointly considered for palaeoclimatic inferences and not considered separately, even in cases in which only one of them is recovered as a fossil.

\section{Genus Chioglossa Bocage, 1864}

(Fig. 4)

Remarks: Chioglossa represents an ancient lineage, with molecular estimates dating the Chioglossa-Mertensiella split to 40-70 Ma (Zhang et al. 2008). The genus contains only one living species, the Golden-Striped salamander (Chioglossa lusitanica), endemic to the Iberian Peninsula. This genus is known in many Central European Tertiary localities, but fossils of Chioglossa lusitanica have been found only in the Holocene strata of Valdavara Cave in Lugo province (Blain et al. 2009; López-García et al. 2011).

Studies based on the analysis of mtDNA, nuclear DNA and allozymes in Chioglossa lusitanica have revealed two genetically differentiated population groups south and north of the Mondego River in northern Portugal (Alexandrino et al. 2000, 2002; Sequeira et al. 2005, 2008). The split between those groups has been dated as a Pleistocene event. Patterns of genetic diversity show a marked decrease from south to north, with the northern part of the current distribution in Spain inferred to result from a postglacial expansion, suggesting the current range does not represent the full spectrum of habitable conditions for the species. However, this species shows remarkable morphological and ecological specialisation, and its known and potential ranges are most likely adequate for palaeoclimatic inference without the need of any correction.

Genus Icthyosaura Latreille, 1801

(Fig. 5)

Remarks: The Alpine newt (Ichthyosaura alpestris) has an extensive range across Europe, including all three southern peninsulas. In Iberia, there is a disjunct population group corresponding to the subspecies Ichthyosaura alpestris cyreni. According to Sotiropoulos et al. (2007) and Recuero et al. (2014), the I. a. alpestris - I. a. cyreni split dates to the Pleistocene, with an estimated time to the most recent common ancestor of 0.9 or $1.6 \mathrm{Ma}$, respectively. Studies based on allozymes and nuclear and mtDNA show moderate levels of genetic variation in this group, with an east-west division into two major population groups (Arano et al. 1991; Recuero et al. 2014). Occurences in Madrid province represent a human-introduced population (Arntzen et al. 2016).

The only fossil that could represent this species was found (Sanchiz and Martín 2004) in the upper Pleistocene locality of Cueva de las Hienas (Asturias). As indicated above, for climatic inferences it seems best to combine the potential range of this newt with that of Calotriton asper.

Genus Lissotriton Bell, 1839

(Figs. 6 and 7) 
Remarks: The two species of Lissotriton present in lberia show contrasting patterns of genetic diversity and structure. Based on mtDNA and nuclear DNA sequence analyses (Martínez-Solano et al. 2006; Teixeira et al. 2015), the old Iberian endemic Bosca's newt Lissotriton boscai is strongly structured, with two major lineages that had already diverged by the late Miocene (6-12 Ma). Each lineage, in turn, is subdivided into several geographically structured population groups. Lissotriton boscai has no reliable fossil record.

The Palmate newt Lissotriton helveticus is widely distributed in western Europe. On the Iberian Peninsula, this species shows much shallower genetic structure than Lissotriton boscai, with four major population groups that originated in the Pleistocene. One population group is inferred to have given rise to all current central and northern European populations (Recuero and García-París 2011). A Lissotriton aff. helveticus form has been recorded from the late Pliocene (dated ca. 3.2 Ma) at the Camp dels Ninots site in Girona province (Gómez et al. 2012). The Quaternary fossil record of this newt includes several northern Spanish localities dating from the early to late Pleistocene (Table 3 ), the middle Pleistocene of Central Europe and the middle to upper Pleistocene and Holocene of Great Britain (Holman 1998).

Genus Pleurodeles Michahelles, 1830

(Fig. 8)

Remarks: Two major clades have been characterised in the Sharp-ribbed salamander Pleurodeles walt based on the analysis of mtDNA, nuclear DNA and microsatellites (Carranza and Arnold 2004; Veith et al. 2004; Van De Vliet et al. 2014). Their divergence has been estimated to date back to the early Pleistocene or late Miocene, with conflicting estimates ranging from 1.6-6.9 Ma. These lineages occupy the western and eastern halves of the Iberian Peninsula, with the eastern clade also occurring in northwestern Morocco. Genetic diversity within lineages is low, although southern populations appear to have higher genetic variation.

The genus represents an old salamandrid lineage, and it is known in lberia at least from the Iberian middle to late Miocene when it was represented by a probable new species currently under study. The undescribed material (Mazo and Van der Made 2003) from the Pliocene of Las Higueruelas (Ciudad Real province), dated ca. 3.0-3.3 Ma, most likely represents the oldest species record known. Pleurodeles waltl is present in several upper Pleistocene localities in central (Madrid) and southern (Algarve, Cádiz, Gibraltar and Málaga) Iberia and in lower and upper Pleistocene and Holocene localities in Morocco (e.g. Bailon et al. 2011).

Genus Salamandra Laurenti, 1768

(Fig. 9)

Remarks: This is a very old Salamandrinae genus with an extensive fossil record indicating its presence since the Eocene. The Fire salamander (Salamandra salamandra) has diversified extensively on the Iberian Peninsula, where studies based on allozymes, mtDNA and nuclear DNA 
(Steinfartz et al. 2000; García-París et al. 2003; Martínez-Solano et al. 2005a; Reis et al. 2011; Vences et al. 2014b) have revealed many well-differentiated lineages, mostly Pleistocene in origin. In these lineages, genetic diversity is mostly concentrated in the western (Atlantic) half of the Iberian Peninsula, decreasing towards the east where the species is also less abundant (except in the north). The Sistema Central and Cantabrian and Pyrenean Mountains are exceptions, harbouring extensive genetic variation, including contact zones of well-differentiated lineages.

Salamandra salamandra has a large fossil record in Europe, at least from the Pliocene, with earlier records unconfirmed. On the Iberian Peninsula, it has been found in lower and upper Pleistocene and Holocene localities (see Supplementary information 2 (ESM 2)). The morphological distinction between the living group of species Salamandra (salamandra) with respect to the Miocene Salamandra sansaniensis is small but distinct (e.g. Sanchiz and Młynarski 1979). This possibility is important because Salamandra sansaniensis is recorded from palaeoenvironments during the Oligocene and Miocene (e.g. Böhme 2003) that are very different from environments where Salamandra occurs today.

The most divergent Iberian lineage, S. s. longirostris (Penibetic salamander), is found south of the Guadalquivir River in southern Spain. Further studies with regard to its distinctiveness as an incipient species are required. The osteology of this form has never been studied, but a lower Pleistocene Salamandra record from El Chaparral in Cádiz province (Giles et al. 2011) might belong to this form on geographical grounds.

For the purpose of climatic inference, we recommend using the complete Iberian Salamandra range until more information on the taxonomic status and osteology of the Penibetic salamander is available.

Genus Triturus Rafinesque, 1815

(Figs. 10 and 11)

Remarks: The two species of the genus present on the Iberian Peninsula, Triturus marmoratus and Triturus pygmaeus, have mostly parapatric ranges, with the former occupying the northern half of Iberia and the latter present in the south, although there are "enclaves" of Triturus marmoratus within the range of Triturus pygmaeus in western Portugal (Arntzen and Themudo 2008). In Triturus marmoratus, the southern populations show stronger genetic structure, whereas no obvious geographic trend of genetic diversity patterns has been documented in Triturus pygmaeus (Themudo and Arntzen 2007; Wielstra et al. 2013).

The osteology of Triturus pygmaeus is not well studied, and the distinction between both Iberian species from fossil fragments is unclear. Nevertheless, Triturus pygmaeus has been recorded from the upper Pleistocene of Gibraltar (Blain et al. 2013). Possible Triturus marmoratus remains have been found in the lower Pleistocene of the Atapuerca complex (Blain 2008a, b; Blain et al. 2010a); those are the oldest Iberian record, but similar vertebral morphologies are common in the western European Neogene (e.g. Rage and Hossini 2000), so their specific assignment remains uncertain. 
Order Anura Fischer von Waldheim, 1813

Family Alytidae Fitzinger, 1843

Genus Alytes Wagler, 1829

(Figs. 12, 13 and 14)

Remarks: Alytid anurans represent one of the oldest lineages in the order, originating in the Early Cretaceous (Blackburn et al. 2010). The living species of Midwife toads (genus Alytes) have diversified since the middle Miocene in western Europe, and there is a single pre-Quaternary fossil known (Bastir et al. 2014).

Alytes shows remarkable genetic structure at the finest spatial scales (Gonçalves et al. 2009, 2015; Maia-Carvalho et al. 2013; Dias et al. 2015). Based on analyses of mtDNA, nuclear DNA and microsatellites, four major population groups that originated in the Pleistocene have been delineated in the Iberian endemic Alytes cisternasii, with most of the diversity concentrated in south-western Iberia. Similarly, four groups with a Pleistocene origin can be delimited in the Betic Midwife toad (Alytes dickhilleni). Finally, up to six lineages (five of them exclusive of the Iberian Peninsula), again of Pleistocene origin, have been identified in the Common Midwife toad (Alytes obstetricans) (Gonçalves et al. 2015). Most lineages, as in the other species in the genus, have restricted ranges, but one lineage has expanded north through the western end of the Pyrenees, and it is from this lineage from which all extant Central European populations have originated.

Neogene palaeogeographic barriers such as the late Miocene North Betic Strait were most likely highly important for the diversification of extant species of Alytes, and their present ranges clearly reflect this history, particularly for the endemic species (Arntzen and Garcia-París 1995; Martínez-Solano et al. 2004; Gonçalves et al. 2007; Maia-Carvalho et al. 2014). Thus, species are morphologically and ecologically similar, and their potential ranges largely overlap at the studied scale. As indicated in Table 4, Alytes cisternasii has been recorded only from one site in Madrid province, and Alytes dickhilleni has no reliable fossil record; however, Alytes obstetricans is present in many lberian sites since the early Pleistocene, all of them within its present range.

Family Discoglossidae Günther, 1858

Genus Discoglossus Otth, 1837

(Figs. 15 and16)

Remarks: Discoglossids are the sister lineage of Alytidae, with a Cretaceous origin (Blackburn et al. 2010). The extant Painted frogs (genus Discoglossus) are currently restricted to a circumMediterranean distribution and include two major endemic lberian lineages, referred to as separate species (Discoglossus galganoi and Discoglossus jeanneae) or as subspecies of Discoglossus galganoi by different authors (García-París and Jockusch 1999; Martínez-Solano 2004; Real et al. 2005; Zangari et al. 2006; Velo-Anton et al. 2008; Pabijan et al. 2012; Vences et al. 2014a). These two lineages are widespread across western and eastern Iberia, respectively. The western lineage shows higher genetic diversity, with two major population groups separated in the Pleistocene by the Duero River, whereas the eastern lineage shows little diversity and structure over its range (Martínez-Solano 2004). 
The distributions of both Iberian lineages might correspond to environmental non-climatic differences, such as geological substrate aspects relevant for larval life, as well as to the major palaeofaunistic barrier caused by the North Betic Strait (García-París and Jockusch 1999; Real et al. 2005). Osteological criteria based on two iliac angles are the only ones that have been devised for their taxonomic identification (López-García et al. 2011). However, the lberian palaeontological records of this genus are frequently based on fragmentary bones, and the application of these criteria is not always possible. The Iberian Discoglossus identification at the species or subspecies level consequently has been based on geographical grounds, which necessitates using the qualifier "cf." (see Table 3). Therefore, Discoglossus palaeoclimatic inferences frequently need to be based on the combined presence and potential ranges of both lineages.

Even if we consider a single Iberian species (Discoglossus galganoi), it is notable that its range is still expanding in the north Iberian Peninsula. This fact, consistent with low levels of genetic diversity found in populations currently inhabiting this area (Martínez-Solano 2004), can be deduced from its absence in tardiglacial and lower Holocene sites of the Cantabrian provinces, while at least in two Asturian fossil localities it is the most frequent anuran currently being predated in situ (Sanchiz 1977; Rey and Sanchiz 2005). The colonisation of the eastern Cantabrian areas appears to be slower than the colonisation rate of the introduced (in the 1960s) Discoglossus pictus in the Iberian northwest (Montori et al. 2007).

Family Pelobatidae Goldfuss, 1820

Genus Pelobates Wagler, 1830

(Fig. 17)

Remarks: Pelobates is a very ancient genus, with an abundant fossil record from the European Miocene onwards (e.g. Böhme and Ilg 2003). The Iberian Spadefoot toad (Pelobates cultripes) is a nearly endemic form, sister species of the North African Pelobates varaldii (Busack et al. 1985). There is little information about patterns of genetic diversity in Pelobates cultripes, although molecular evidence shows extremely low genetic diversity and no obvious pattern of geographic structuring of genetic variation (Crottini et al. 2010; Fitó et al. 2012). The distributional range of this species appears to have been unaffected by Neogene palaeogeographic barriers, nor is it restricted by other species, and could be considered quite reliable for palaeoclimatic inferences.

Family Pelodytidae Bonaparte, 1850

Genus Pelodytes Bonaparte, 1838

(Fig. 18)

Remarks: Pelodytes currently contains one Caucasian species (Pelodytes caucasicus) and one species group that until recently included the western European Pelodytes punctatus, the southern Iberian endemic Pelodytes ibericus and the extinct Iberian Miocene form Pelodytes arevacus (Sánchez-Herráiz et al. 2000). However, recent studies on Iberian Pelodytes have revealed cryptic, geographically structured genetic variation, with four major lineages considered candidate species that diverged in the Plio-Pleistocene (Van De Vliet et al. 2012; Díaz-Rodríguez et al. 2015). One of 
these lineages, although not recognised as a species, is endemic to Portugal, and another (Pelodytes ibericus) is mostly distributed south of the Guadalquivir River. A third lineage is widespread in central and eastern Spain, and a fourth lineage is found in northeastern Spain, France and northwestern Italy; both of these currently are considered Pelodytes punctatus. Genetic diversity within each lineage generally is low, with the exception of the northeastern clade, which comprises two major subclades.

Currently, at the species level, only the Spanish range of Pelodytes punctatus could be useful for palaeoclimatic inference because the Portuguese candidate species is osteologically unknown and its range delimitation in relation to Pelodytes ibericus requires further local surveys (DíazRodríguez et al. 2015). Until this situation is clarified, combined genetic inference would be adequate for the level of resolution needed for palaeoclmatic inference.

Family Bufonidae Gray, 1825

Genus Bufo Laurenti, 1768

(Fig. 19)

Remarks: The Iberian populations traditionally assigned to the widespread Common toad (Bufo bufo) have been recently shown (Recuero et al. 2012; Arntzen et al. 2013a, b) to represent a welldifferentiated species, Bufo spinosus. Studies based on the analysis of mtDNA, nuclear DNA and microsatellites have shown extensive genetic variation in Iberian Bufo spinosus, although there is no clear pattern of geographic structuring of this variation (Martínez-Solano and González 2008; GarcíaPorta et al. 2012; Recuero et al. 2012). This species is frequently found in the Quaternary fossil record, where its widespread range provides a valid but poor basis for making palaeoclimatic inferences.

Genus Bufotes Rafinesque, 1814

Remarks: The genus Bufotes, formerly the Bufo (viridis) species group, is not currently considered to be a living Iberian native species. However, Blain et al. (2010b) have shown the likely presence of Bufotes in the three lower Pleistocene Mediterranean sites (Castellón, Murcia and Granada provinces). No specific identification is currently possible for the Iberian fossils, which could either represent the last representatives of the Iberian Miocene Bufotes or extinct North African Bufotes boulengeri arrivals. Bufotes also currently occurs in the nearby Balearic Islands, but it is considered an anthropic immigrant (e.g. Alcover 2008). The numerous species and wide distribution of the genus Bufotes preclude its use for Iberian palaeoclimatic inference.

Genus Epidalea Cope, 1864

(Fig. 20)

Remarks: The Natterjack toad (Epidalea calamita, formerly Bufo calamita) is considered a textbook example illustrating marked latitudinal trends (loss in genetic diversity) associated with the 
colonisation of northern Europe from the Iberian refugium after the Pleistocene glaciations (Rowe et al. 2006; Oromi et al. 2012). However, patterns of genetic structure and diversity within the Iberian Peninsula are little known.

Fossil sites in which Epidalea calamita is present are not uncommon in the Iberian Quaternary (e.g. Blain et al. 2008a, 2010a, 2014; Blain 2009). Its Iberian range is informative because it most likely directly reflects environmental adaptations with no past palaeogeographic or biotic constraints. The species is widespread in the peninsular Mediterranean realm and absent in large areas of the northern Eurosiberian zone where fossil occurences have been reported (Fig. 20).

Family Hylidae Rafinesque, 1815

Genus Hyla Laurenti, 1768

(Figs. 21 and 22)

Remarks: The genus Hyla is considered a Miocene immigrant to Europe, with two distinct species groups (Stöck et al. 2012; Gvozdík et al. 2015). The two species of Hyla on in the Iberian Peninsula have very different evolutionary histories. Hyla meridionalis has disjunct population groups in southwestern and northeastern Iberia, each with different origins in North Africa (Recuero et al. 2007). Both population groups show low levels of genetic variation as assessed with mtDNA sequences. However, the Iberian endemic Hyla molleri belongs to the Hyla (arborea) species group and is closely related to the eastern European species Hyla orientalis (Stöck et al. 2012; Gvozdík et al. 2015). Preliminary analyses about patterns of genetic variation in lberia based on mtDNA have shown limited diversity and structure (Barth et al. 2011).

Competitive interactions between both Iberian species are possible, because they are often syntopic, although this has not yet been studied in detail (but see Barbadillo and Lapeña 2003; Moreira 2012). However, their partially overlapping ranges can be considered reliable for climatic inferences, particularly for the endemic Hyla molleri.

Family Ranidae Rafinesque, 1814

Genus Pelophylax Fitzinger, 1843

(Fig. 23)

Remarks: There is very little available information about patterns of genetic variation in the Iberian endemic Green frog Pelophylax perezi, although molecular evidence suggests little diversity and structure in this species (Harris et al. 2003). The evolutionary origins of this frog are unclear, but a sister group relationship with the North African taxon Pelophylax saharicus has been suggested in molecular systematics studies (Lymberakis et al. 2007). The genus is frequently found in the European Tertiary and is represented on the Iberian Peninsula by the species Pelophylax pueyoi, known to be extant until at least the terminal Miocene.

The distribution of Pelophylax perezi covers much of the peninsular area, except some northern mountain areas and some arid central-eastern ones, the latter affected by severe anthropic 
environmental changes. The diversity of habitats occupied by the species in its native range suggests a good match between the potential and realised distributions.

Genus Rana Linnaeus, 1758

(Figs. 24, 25, 26 and 27)

Remarks: Four species of Brown frogs (Rana) are present on the Iberian Peninsula, each showing different patterns of genetic structure and diversity. The Common frog (Rana temporaria) shows high levels of genetic diversity and occurs throughout northern Iberia, where two major population groups have been identified based on mtDNA and nuclear DNA corresponding to an east-west division (Veith et al. 2012). By contrast, the Agile frog (Rana dalmatina) shows little structure across its range, with the few isolated populations remaining in lberia being strongly differentiated as assessed with microsatellites (Sarasola-Puente et al. 2011). Both species are widely distributed in Europe, with many areas of postglacial colonisation, especially in the case of Rana temporaria (Vences et al. 2013).

The Common frog, Rana temporaria, is the most common ranid species found as a fossil in Iberian Quaternary sites of the current Eurosiberian ecozone, always within or near its extant observed range. By contrast, Rana dalmatina is a relict species with a marginal distribution on the Iberian Peninsula, present only in a few populations, but with an upper Pleistocene record in the Basque Country (Esteban and Sanchiz 1985). It has also been reported with doubt by Blain et al. (2008a, 2008b) as an extralimital form in the lower and middle Pleistocene of the Atapuerca complex (Burgos province).

Little information is available about the Iberian endemic Rana iberica, although populations along the Sistema Central Mountains have been shown to harbour reduced genetic diversity compared to populations within the core range of the species (Martínez-Solano et al. 2005b). Similar to Rana dalmatina, populations of Rana iberica are strongly differentiated even at short geographical distances, as shown by microsatellite analyses of genotypes (Martínez-Solano et al. 2005b). Fossils of Rana iberica have been found in a few upper Pleistocene sites in the Madrid Mountains and in Asturias, as well as extralimitally in Burgos province (Esteban and Sanchiz 1990; López-Garcia et al. 2011; Laplana et al. 2013; Blain et al. 2014). This species also has been recorded with doubt in the middle Pleistocene of the Atapuerca complex (Blain et al. 2008a, 2008b). Competitive exclusion among Iberian Rana species is a possibility that requires further testing, but there is evidence for niche segregation with respect to breeding site selection in $R$. iberica vs. $R$. temporaria in northwestern Spain (Galán 1982).

The Pyrenean frog Rana pyrenaica is the sister species of Rana temporaria and, as expected based on its restricted range, shows extremely low levels of genetic variation (Carranza and Arribas 2008; Vences et al. 2013). This species is restricted to the Pyrenees, its osteology remains unstudied and presumably it lacks a known fossil record.

The anuran assemblages from several sites within the Atapuerca complex, particularly in Gran Dolina and Sima del Elefante, indicate the coexistence of Brown frogs of the genus Rana in the same strata that have been referred with doubt to Rana dalmatina, Rana iberica and Rana temporaria (Blain et al. 2008a, b, 2011; Blain 2009). Regardless of the difficulties of unequivocal 
species identification, it is clear that members of the Rana (temporaria) species group occur in these strata jointly with unmistakable remains of the Spadefoot toad Pelobates cultripes (Blain et al. 2008a; Blain 2009), a very unlikely association that is rarely, if ever, observed in the present.

\section{Discussion}

Our results confirm that regional amphibian ranges are delimited by an important climatic component, as inferred from the prediction of present climatic conditions in a locality based on its extant fauna. While we explored a relatively limited set of cases, any combination of taxa and spatial range can be easily tested with the database available in Supplementary Information 1 (ESM 1). Iberian amphibian assemblages predict the current climatic values with acceptable accuracy, but the prediction does not appear to improve significantly as a function of the number of species included in the set. Thus, similar precision degrees can be obtained from different taxonomic assemblages, and the inferences are therefore robust enough in the presence of taphonomic bias. The latter is an important result because many of the sites (karstic or sedimentary layers) are archaeological excavations in which taphonomical changes are a relevant factor because of human influence, or other biases associated with accumulation by mammalian and raptor predators.

Making past climatic inferences based on ecological amphibian biogeography is a reliable approach in this case, as has been proposed in other groups (Birks 1995; Elias 2010; Chang et al. 2015). However, the peculiarities of each taxon require consideration when delimiting its information content. As explained above, we decided to use only observed presence as primary input to devise potential SDM and MCR analyses, and we assumed that the herpetological surveys were not extremely biased. Within this research strategy, it becomes necessary to establish the historical opportunities that each taxon has had to live in all the suitable places of its fundamental niche that were geographically accessible, and whether the Iberian sample of those places is statistically representative. Table 5 summarises the Iberian fauna in this respect.

Other difficulties that we have found for the application of this palaeoclimatic batrachological inference tool are expected to be merely transitory. Herpetological surveys are currently being conducted at higher geographical resolution ( $5 \times 5$ and $1 \times 1 \mathrm{~km})$ in many European areas, and climatic information can be interpolated and scaled to any desired grid size. These improvements in the quality of distributional data will reduce much of the noise detailed in Table 1. However, Quaternary palaeontology mostly includes studies with fragmentary bone remains, and the osteological knowledge of most species remains poor. Some species have never been studied from this point of view (Calotriton arnoldi, Rana pyrenaica, Triturus pygmaeus), and information is also lacking for genetically well-differentiated entities (Salamandra salamandra longirostris, Portuguese Pelodytes). Data on population osteological variability are incomplete, but specific identification is not problematic if the samples are common. Finally, it should considered that fossil amphibians are also quite relevant for palaeoenvironmental inferences other than palaeoclimatic ones, such as taphonomic, habitat and landscape reconstruction, seasonality of the deposit formation and other inferences. 


\section{Acknowledgements}

We are glad to participate in this issue dedicated to Prof. Zbyněk Roček, who has achived the merit of preserving comparative anatomy as a fruitful field of research. Manuel Sánchez Ruiz collaborated with the QIBER-ANF database. We thank Sarah Crews and the guest editor Jim Gardner for linguistic corrections and comments. This work has received support from the Spanish grant CGL2011-28877-BTE (BS). We are grateful to H. A. Blain and an anonymous reviewer for their comments that helped improve the manuscript. IMS is currently supported by funding from the Spanish Severo Ochoa Program (SEV-2012-0262).

\section{References}

Aarts, G., Fieberg, J., \& Matthiopoulos, J. (2012). Comparative interpretation of count, presenceabsence and point methods for species distribution models. Methods in Ecology and Evolution, 3, 177-187.

Alcover, J.A. (2008). The first mallorcans: prehistoric colonization in the Western Mediterranean. Journal of World Prehistory, 21, 19-84.

Alexandrino, J., Froufe, E., Arntzen, J.W., \& Ferrand, N. (2000). Genetic subdivision, glacial refugia and postglacial recolonization in the golden-striped salamander, Chioglossa lusitanica (Amphibia: Urodela). Molecular Ecology, 9, 771-781.

Alexandrino, J., Arntzen, J.W., \& Ferrand, N. (2002). Nested clade analysis and the genetic evidence for population expansion in the phylogeography of the golden-striped salamander, Chioglossa Iusitanica (Amphibia: Urodela). Heredity, 88, 66-74.

Arano, B., Arntzen, J.W., Herrero, P., \& García-París, M. (1991). Genetic differentiation among Iberian populations of the Alpine newt, Triturus alpestris. Amphibia-Reptilia, 12, 409-421.

Araújo, M.B., Guilhaumon, F., Neto, D.R., Pozo, I., \& Calmaestra, R. (2011). Impactos, vulnerabilidad y adaptación al cambio climático de la Biodiversidad española. 2 Fauna de vertebrados ( $p$. 640). Madrid: Dirección General del Medio Natural y Política Forestal. Ministerio de Medio Ambiente y Medio Rural y Marino.

Arntzen, J.W., \& García-París, M. (1995). Morphological and allozyme studies of midwife toads (genus Alytes), including the description of two new taxa from Spain. Contributions to Zoology, $65,5-34$.

Arntzen, J.W., \& Themudo, G.E. (2008). Environmental parameters that determine species geographical range limits as a matter of time and space. Journal of Biogeography, 35, 11771186.

Arntzen, J.W., Recuero, E., Canestrelli, D., \& Martínez-Solano, Í. (2013a) How complex is the Bufo bufo species group? Molecular Phylogenetics and Evolution, 69, 1203-1208. 
Arntzen, J.W., McAtear, J., Recuero, E., Ziermann, J.M., Ohler, A., van Alphen, J., \& MartínezSolano, Í. (2013b). Morphological and genetic differentiation of Bufo toads: two cryptic species in Western Europe (Anura, Bufonidae). Contributions to Zoology, 82, 147-169.

Arntzen, J.W., King, T.M., Denoël, M., Martínez-Solano, Í., \& Wallis, G.P. (2016) Provenance of Ichthyosaura alpestris (Caudata: Salamandridae) introductions to France and New Zealand assessed by mitochondrial DNA analysis. The Herpetological Journal, 26, 49-56.

Bailon, S. (1999). Différenciation ostéologique des anoures (Amphibia, Anura) de France. Fiches d'Osteologie Animale pour l'Archeologie (Serie C: Varia), 1, 41 pp.

Bailon, S., Rage, J.C., \& Stoetzel, E. (2011). First fossil representative of the salamander crowngroup from a Gondwanan continent: Pleurodeles cf. waltl from the Quaternary of Morocco. Amphibia-Reptilia, 32, 245-252.

Baker, V.R. (1998) Catastrophism and unifortarianism: logical roots and current relevance in geology. In: D.J. Blundell \& A.C Scott (Eds.), Lyell: the past is the key to the present. (pp. 171-182). London: Geological Society, Special Publications. 376 pp.

Barbadillo, L.J., \& Lapeña, M. (2003) Hibridación natural de Hyla arborea (Linnaeus, 1758) e Hyla meridionalis (Boettger, 1874) en la Península Ibérica. Munibe (Suplemento), 16, 140-145.

Barbadillo, L.J., García-París, M., \& Sanchiz, B. (1997). Orígenes y relaciones evolutivas de la herpetofauna ibérica. In: J.M. Pleguezuelos (Ed.), Distribución y biogeografía de los anfibios y reptiles en España y Portugal (pp. 47-100). Granada: Universidad de Granada \& Asociación Herpetológica Española. 542 pp.

Barth, A., Galan, P., Donaire, D., González de la Vega, J.P., Pabijan, M., \& Vences, M. (2011). Mitochondrial uniformity in populations of the treefrog Hyla molleri across the Iberian Peninsula. Amphibia-Reptilia, 32, 557-564.

Baselga, A., Gómez-Rodríguez, C., \& Lobo, J.M. (2012). Historical legacies in world amphibian diversity revealed by the turnover and nestedness components of beta diversity. PLOS ONE, 7 , e32341.

Bastir, M., Böhme, M., \& Sanchiz, B. (2014). Middle Miocene remains of Alytes (Anura, Alytidae) as an example of the unrecognized value of fossil fragments for evolutionary morphology studies. Journal of Vertebrate Paleontology, 34, 69-79.

Birks, H.J.B. (1995). Quantitative palaeoenvironmental reconstructions. In D. Maddy \& J.J. Brew (Eds.), Statistical modelling of Quaternary science data (pp. 161-254). Cambridge: Quaternary Research Association.

Blackburn, D.C., Bickford, D.P., Diesmos, A.C., Iskandar, D.T., \& Brown, R.M. (2010). An ancient origin for the enigmatic flat-headed frogs (Bombinatoridae: Barbourula) from the islands of Southeast Asia. PLoS ONE, 5, e12090.

Blain, H.A. (2005). Contribution de la paléoherpétofaune (Amphibia; Squamata) à la connaissance de l'évolution du climat et du paysage du Pliocène supérieur au Pléistocène moyen d'Espagne. Thèse du Museum National d'Histoire Naturelle de Paris, Institut de Paléontologie Humaine, France. 402 pp., 67 plates. 
Blain, H.A. (2009). Contribution de la paléoherpétofaune (Amphibia \& Squamata) à la connaissance de l'évolution du climat et du paysage du Pliocène supérieur au Pléistocène moyen d'Espagne. Treballs del Museu de Geologia de Barcelona, 16, 39-170.

Blain, H.A., Bailon, S., \& Cuenca-Bescós, G. (2008a). The Early-Middle Pleistocene palaeoenvironmental change based on the squamate reptile and amphibian proxy at the Gran Dolina site, Atapuerca, Spain. Palaeogeography, Palaeoclimatology, Palaeoecology, 261, 177192.

Blain, H.A., Bailon, S., \& Cuenca-Bescós, G. (2008b). Los anfibios y escamosos del Pleistoceno inferior-medio de Gran Dolina (Atapuerca, Burgos, España): Una perspectiva paleobiogeográfica. Studia Geologica Salmanticensia, 8, 71-84.

Blain, H.A., López-García, J.M., Cuenca-Bescós, G., Alonso, C., Vaquero, M., \& Alonso, S. (2009). Première mise en évidence fossile du Chioglosse portugais Chioglossa lusitanica (Amphibia, Caudata) et son implication pour l'histoire biogéographique de l'espèce. Comptes Rendus Palevol, 8, 693-703.

Blain, H.A., Bailon, S., Cuenca-Bescós, G., Bennàsar, M., Rofes, J., López-García, J.M., Huguet, R., Arsuaga, J.L., Bermúdez de Castro, J.M., \& Carbonell, E. (2010a). Climate and environment of the earliest West European hominids inferred from amphibian and squamate reptile assemblages: Sima del Elefante Lower Red Unit, Atapuerca, Spain. Quarternary Science Reviews, 29, 3034-3044.

Blain, H.A., Gibert, L., \& Ferràndez-Cañadell, C. (2010b). First report of a green toad (Bufo viridis sensu lato) in the early Pleistocene of Spain: palaeobiogeographical and palaeoecological implications. Comptes Rendus Palevol, 9, 487-497.

Blain, H.A., López-García, J.M., \& Cuenca-Bescós, G. (2011). A very diverse amphibian and reptile assemblage from the late Middle Pleistocene of the Sierra de Atapuerca (Sima del Elefante, Burgos, northwestern Spain). Geobios, 44, 157-172.

Blain, H.A., Gleed-Owen, C.P., López-García, J.M., Sebastián Carrión, S.J., Jennings, R., Finlayson, G., Finlayson, C., \& Giles, F. (2013). Climatic conditions for the last neanderthals: herpetofaunal record of Gorham's Cave, Gibraltar. Journal of Human Evolution, 64, 289-299.

Blain, H.A., Laplana, C., Sevilla, P., Arsuaga, J.L., Baquedano, E., \& Pérez-González, A. (2014). MIS $5 / 4$ transition in a mountain environment: herpetofaunal assemblages from Cueva del Camino, central Spain. Boreas, 43, 107-120.

Böhme, G. (1977). Zur Bestimmung quartärer Anuren Europas an Hand von Skelettelementen. Wissenschaftliche Zeitschrift der Humboldt-Universität zu Berlin. Mathematischnaturwissenschaftliche Reihe, 36, 283-300.

Böhme, M. (2003). The Miocene Climatic Optimum: evidence from ectothermic vertebrates of Central Europe. Palaeogeography, Palaeoclimatology, Palaeoecology, 195, 389-401.

Böhme, M., \& Ilg, A. (2003). fosFARbase. www.wahre-staerke.com. (accessed 2015). 
Bonetti, M.F., \& Wiens, J.J. (2014). Evolution of climatic niche specialization: a phylogenetic analysis in amphibians. Proceedings of the Royal Society B: Biological Sciences, 281(1795). Doi: $10.1098 /$ rspb.2013.3229

Buckley, D., \& Sanchiz, B. (2012). Untrained versus specialized palaeontological systematics: a phylogenetic validity test using morphostructural conspicuity as character weight. Spanish Journal of Palaeontology, 27, 131-142.

Busack, S.D., Maxson, L.R., \& Wilson, M.A. (1985). Pelobates varaldii (Anura: Pelobatidae): a morphologically conservative species. Copeia, 1985, 107-112.

Carranza, S., \& Amat, F. (2005). Taxonomy, biogeography and evolution of Euproctus (Amphibia: Salamandridae), with the resurrection of the genus Calotriton and the description of a new endemic species from the Iberian Peninsula. Zoological Journal of the Linnean Society, 145, $555-582$.

Carranza, S., \& Arnold, E. (2004). History of west Mediterranean newts, Pleurodeles (Amphibia: Salamandridae), inferred from old and recent DNA sequences. Systematics and Biodiversity, 1 , 327-337.

Carranza, S., \& Arribas, O. (2008). Genetic uniformity of Rana pyrenaica Serra-Cobo, 1993 across its distribution range, a preliminary study with mtDNA sequences. Amphibia-Reptilia, 29, 579582.

Chang, J.C., Shulmeister, J., Woodward, C., Steinberger, L., Tibby, J., \& Barr, C. (2015). A chironomid-inferred summer temperature reconstruction from subtropical Australia during the last glacial maximum (LGM) and the last deglaciation. Quaternary Science Reviews, 122, 282292.

Colwell, R.K., \& Rangel, T.F. (2009). Hutchinson's duality: the once and future niche. Proceedings of the National Academy of Sciences, USA, 106, 19651-19658.

Crottini, A., Galan, P., \& Vences, M. (2010). Mitochondrial diversity of Western spadefoot toads, Pelobates cultripes, in northwestern Spain. Amphibia-Reptilia, 31, 443-448.

Dias, G., Beltrán, J.F., Tejedo, M., Benítez, M., González Miras, E., Ferrand, N., \& Gonçalves, H. (2015). Limited gene flow and high genetic diversity in the threatened Betic midwife toad (Alytes dickhilleni): evolutionary and conservation implications. Conservation Genetics, 16, 459-476.

Díaz-Rodríguez, J., Gonçalves, H., Sequeira, F., Sousa-Neves, T., Tejedo, M., Ferrand, N., \& Martínez-Solano, Í. (2015). Molecular evidence for cryptic candidate species in Iberian Pelodytes (Anura, Pelodytidae). Molecular Phylogenetics and Evolution, 83C, 224-241.

Elias, S. (2010). Advances in Quaternary Entomology. Amsterdam: Elsevier. 307 pp.

Esteban, M.L., \& Sanchiz, B. (1985). Herpetofauna de Erralla. Munibe. Antropología y Arqueología, $37,81-86$.

Esteban, M.L., \& Sanchiz, B. (1990). Sobre la presencia de Rana iberica en el Pleistoceno burgalés. Revista Española de Herpetologia, 5, 93-99 (published 1991). 
Fitó, F., Rivera, X., Roca, J., Donaire, D., González de la Vega, J.P., Barnestein, J.A.M., MaluquerMargalef, J., \& Carranza, S. (2012). Extremely low level of genetic variability in Iberian Pelobates cultripes (Cuvier, 1829) (Amphibia; Anura; Pelobatidae). Butlletí de la Societat Catalana de Herpetologia, 19, 21-28.

Galán, P. (1982). Biología de la reproducción de Rana iberica Boulenger, 1879 en zonas simpátridas con Rana temporaria Linneo, 1758. Doñana, Acta Vertebrata, 9, 85-98.

García-París, M., \& Jockusch, E. (1999). A mitochondrial DNA perspective on the evolution of Iberian Discoglossus (Amphibia: Anura). Journal of Zoology, 248, 209-218.

García-París, M., Alcobendas, M., Buckley, D., \& Wake, D.B. (2003). Dispersal of viviparity across contact zones in Iberian populations of fire salamanders (Salamandra) inferred from discordance of genetic and morphological traits. Evolution, 57, 129-143.

Garcia-Porta, J., Litvinchuk, S.N., Crochet, P.A., Romano, A., Geniez, P.A., Lo-Valvo, M., Lymberakis, P., \& Carranza, S. (2012). Molecular phylogenetics and historical biogeography of the west-Palearctic common toads (Bufo bufo species complex). Molecular Phylogenetics and Evolution, 63, 113-130.

Giles, F., Santiago, A., Gutiérrez, J.M., López-García, J.M., Blain, H.A., Cuenca-Bescós, G., Van der Made, J., Cáceres, I., \& García, N. (2011). The early Pleistocene paleontological site in the Sierra del Chaparral (Villaluenga del Rosario, Cádiz, southwestern Spain). Quaternary International, 243, 92-104.

Gómez, B., Campeny, G., Van der Made, J., Oms, O., Agustí, J., Sala, R., Blain, H.A., Burjachs, F., Claude, J., García Catalán, S., Riba, D., \& Rosillo, R. (2012). A new key locality for the Pliocene vertebrate record of Europe: the Camp dels Ninots maar (NE Spain). Geologica Acta, $10,1-17$.

Gonçalves, H., Martínez-Solano, Í., Ferrand, N., \& García-París, M. (2007). Conflicting phylogenetic signal of nuclear vs mitochondrial DNA markers in midwife toads (Anura, Discoglossidae, Alytes): deep coalescence or ancestral hybridization? Molecular Phylogenetics and Evolution, 44, 494-500.

Gonçalves, H., Martínez-Solano, I., Pereira, R.J., Carvalho, B, García-París, M., \& Ferrand, N. (2009). High levels of population subdivision in a morphologically conserved Mediterranean toad (Alytes cisternasii) result from recent, multiple refugia: evidence from mtDNA, microsatellites and nuclear genealogies. Molecular Ecology, 18, 5143-5160.

Gonçalves, H., Maia-Carvalho, B., Sousa-Neves, T., García-París, M., Sequeira, F., Ferrand, N., \& Martínez-Solano, Í. (2015). Multilocus phylogeography of the common midwife toad, Alytes obstetricans (Anura, Alytidae): contrasting patterns of lineage diversification and genetic structure in the Iberian refugium. Molecular Phylogenetics and Evolution, 93, 363-379.

Gvozdík, V., Canestrelli, D., García-París, M., Moravec, J., Nascetti, G., Recuero, E., Teixeira, J., \& Kotlík, P. (2015). Speciation history and widespread introgression in the European short-call tree frogs (Hyla arborea sensu lato, $H$. intermedia and $H$. sarda). Molecular Phylogenetics and Evolution, 83, 143-155. 
Haller-Probst, M., \& Schleich, H.H. (1994). Vergleichende osteologische Untersuchungen an einigen Urodelen Eurasiens (Amphibia: Urodela, Salamandridae, Proteidae). Courier Forschungsinstitut Senckenberg, 173, 23-77.

Harris, D.J., Batista, V., \& Carretero, M. (2003). Diversity of $12 S$ mitochondrial DNA sequences in Iberian and North-west African water frogs across predicted geographic barriers. Herpetozoa, 16, 81-83.

Harris, A.J., Papeş, M., Gao, Y.D., \& Watson, L. (2014). Estimating paleoenvironments using ecological niche models of nearest living relatives: a case study of Eocene Aesculus L. Journal of Systematics and Evolution, 52, 16-34.

Hastie, T., \& Fithian, W. (2013) Inference from presence-only data; the ongoing controversy. Ecography, 36, 864-867.

Hijmans, R.J. (2012). Cross-validation of species distribution models: removing spatial sorting and calibration with a null model bias. Ecology, 93, 679-688.

Hijmans, R.J., Cameron, S.E., Parra, J.L., Jones, P.G., \& Jarvis, A. (2005). Very high resolution interpolated climate surfaces for global land areas. International Journal of Climatology, 25, 1965-1978.

Holman, J.A. (1998). Pleistocene amphibians and reptiles in Britain and Europe. Oxford: Oxford University Press. 254 pp.

Hortal, J., Lobo J.M., \& Jiménez-Valverde, A. (2012) Basic questions in biogeography and the (lack of) simplicity of species distributions: putting species distribution models in the right place. Natureza \& Conservação - Brazilian Journal of Nature Conservation, 10, 108-118. doi:10.4322/natcon.2012.029.

Jiménez-Valverde, A., Peterson, A.T., Soberon, J., Overton, J.M., Aragon, P., \& Lobo, J.M. (2011). Use of niche models in invasive species risk assessments. Biological Invasions, 13, 27852797.

Laplana, C., Blain, H.A., Sevilla, P., Arsuaga, J.L., Baquedano, E., \& Pérez-González, A. (2013). Un assemblage de petits vertébrés hautement diversifié de la fin du MIS 5 dans un environnement montagnard au centre de l'Espagne (Cueva del Camino, Pinilla del Valle, Communauté Autonome de Madrid). Quaternaire, 24, 207-216.

Lobo, J.M., Jimenez-Valverde, A., \& Hortal, J. (2010). The uncertain nature of absences and their importance in species distribution modeling. Ecography, 33, 103-114.

López-García, J.M., Blain, H.A., Allué, E., Bañuls, S., Bargalló, A., Martín, P., Morales, J.I., Pedro, M., Rodríguez, A., Solé, A., \& Oms, F.X. (2010). First fossil evidence of an 'interglacial refugium' in the Pyrenean region. Naturwissenschaften, 97, 753-761.

López-García, J.M., Blain, H.A., Cuenca-Bescós, G., Alonso, C., Alonso, S., \& Vaquero, M. (2011). Small vertebrates (Amphibia, Squamata, Mammalia) from the late Pleistocene-Holocene of Valdavara-1 cave (Galicia, northwestern Spain). Geobios, 44, 253-269. 
Loureiro, A., Ferrand de Almeida, N., Carretero, M.A., \& Paulo, O.S. (2008). Atlas dos anfibios e répteis de Portugal (p. 257). Lisboa: Instituto da Conservaçâo da Naturaleza e da Biodiversidade.

Lymberakis, P., Poulakakis, N., Manthalou, G., Tsigenopoulos, C.S., Magoulas, A., \& Mylonas, M. (2007). Mitochondrial phylogeography of Rana (Pelophylax) populations in the Eastern Mediterranean region. Molecular Phylogenetics and Evolution, 44, 115-125.

Maia-Carvalho, B., Gonçalves, H., Martínez-Solano, I., Gutiérrez-Rodríguez, J., Lopes, S., Ferrand N., \& Sequeira, F. (2013). Intraspecific genetic variation in the common midwife toad (Alytes obstetricans): subspecies assignment using mitochondrial and microsatellite markers. Journal of Zoological Systematics and Evolutionary Research, 52, 170-175.

Maia-Carvalho, B., Gonçalves, H., Ferrand, N. \& Martínez-Solano, Í. (2014). Multilocus assessment of phylogenetic relationships in Alytes (Anura, Alytidae). Molecular Phylogenetics and Evolution, 79, 270-278.

Martínez-Solano, Í. (2004). Phylogeography of Iberian Discoglossus (Anura: Discoglossidae). Journal of Zoological Systematics and Evolutionary Research, 42, 298-305.

Martínez-Solano, Í., \& González, E.G. (2008). Patterns of gene flow and source-sink dynamics in high altitude populations of the common toad Bufo bufo (Anura: Bufonidae). Biological Journal of the Linnean Society, 95, 824-839.

Martínez-Solano, Í., Gonçalves, H., Arntzen, J.W., \& García-París, M. (2004). Phylogenetic relationships and biogeography of midwife toads (Discoglossidae: Alytes). Journal of Biogeography, 31, 603-618.

Martínez-Solano, Í., Alcobendas, M., Buckley, D., \& García-París, M. (2005a). Molecular characterization of the endangered Salamandra salamandra almanzoris (Caudata, Salamandridae). Annales Zoologici Fennici, 42, 57-68.

Martínez-Solano, Í., Rey, I., \& García-París, M. (2005b). The impact of historical and recent factors on genetic variability in a mountain frog: the case of Rana iberica (Anura: Ranidae). Animal Conservation, 8, 431-441.

Martínez-Solano, Í., Teixeira, J., Buckley, D., \& García-París, M. (2006). Mitochondrial DNA phylogeography of Lissotriton boscai (Caudata, Salamandridae): evidence for old, multiple refugia in an Iberian endemic. Molecular Ecology, 15, 3375-3388.

Mazo, A.V., \& Van der Made, J. (2003). Hace 3 millones de años. Yacimiento de Las Higueruelas. (p. 54). Spain: Fundación de Cultura y Deporte de Castilla - La Mancha. Junta de Comunidades de Castilla - La Mancha.

Milà, B., Carranza, S., Guillaume, O., \& Clobert, J. (2010). Marked genetic structuring and extreme dispersal limitation in the Pyrenean brook newt Calotriton asper (Amphibia: Salamandridae) revealed by genome-wide AFLP but not mtDNA. Molecular Ecology, 19, 108-120.

Montori, A., Llorente, G.A., Richter-Boix, A., Villero, D., Franch, M., \& Garriga, N. (2007). Colonización y efectos potenciales de la especie invasora Discoglossus pictus sobre las especies nativas. Munibe (Suplemento), 25, 14-27. 
Montori, A., Llorente, G., \& García-París, M. (2008). Allozyme differentiation among populations of the Pyrenean newt Calotriton asper (Amphibia: Caudata) does not mirror their morphological diversification. Zootaxa, 1945, 39-50.

Moreira, C.N. (2012). Population analysis of Hyla arborea and Hyla meridionalis (Amphibia, Anura) in Portugal: a molecular genetic and bioacoustic approach. Ph.D. Thesis, University of Lisboa: $281 \mathrm{pp}$.

Oromi, N., Richter-Boix, A., Sanuy, D., \& Fibla, J. (2012). Genetic variability in geographic populations of the natterjack toad (Bufo calamita). Ecology and Evolution, 2, 2018-2026.

Pabijan, M., Crottini, A., Reckwell, D., Irisarri, I., Hauswaldt, S., \& Vences, M. (2012). A multigene species tree for Western Mediterranean painted frogs (Discoglossus). Molecular Phylogenetics and Evolution, 64, 690-696.

Peterson, A.T., Soberón, J., \& Sánchez-Cordero, V. (1999). Conservatism of ecological niches in evolutionary time. Science, 285, 1265-1267.

Pleguezuelos, J.M., Márquez, R., \& Lizana, M. (Eds.) (2002). Atlas y Libro Rojo de los anfibios y reptiles de España. (p. 587). Madrid: Dirección General de Conservación de la Naturaleza \& Asociación Herpetológica Española.

Pous, P. de, Montori, A., Amat, F., \& Sanuy, D. (2015). Range contraction and loss of genetic variation of the Pyrenean endemic newt Calotriton asper due to climate change. Regional Environmental Change, 1-15. doi:10.1007/s10113-015-0804-3.

Rage, J.C., \& Hossini, S. (2000). Les amphibiens du Miocène moyen de Sansan. Mémoires du Muséum National d'Histoire Naturelle, 183, 177-217.

Rage, J.C., \& Roček, Z. (2003). Evolution of anuran assemblages in the Tertiary and Quaternary of Europe, in the context of palaeoclimate and palaeogeography. Amphibia-Reptilia, 24, 133-167.

Real, R., Barbosa, A.M., Martínez-Solano, Í., \&. García-París, M. (2005). Distinguishing the distributions of two cryptic frogs (Anura: Discoglossidae) using molecular data and environmental modeling. Canadian Journal of Zoology, 83, 536-545.

Recuero, E., \& García-París, M. (2011). Evolutionary history of Lissotriton helveticus: multilocus assessment of ancestral vs. recent colonization of the Iberian Peninsula. Molecular Phylogenetics and Evolution, 60, 170-182.

Recuero, E., Iraola, A., Rubio, X., Machordom, A., \& García-París, M. (2007). Mitochondrial differentiation and biogeography of Hyla meridionalis (Anura: Hylidae): an unusual phylogeographical pattern. Journal of Biogeography, 34, 1207-1219.

Recuero, E., Canestrelli, D., Vörös, J., Szabó, K., Poyarkov, N.A., Arntzen, J.W., Crnobrnja-Isalovic, J., Kidov, A.A., Cogalniceanu, D., Caputo, F.P., Nascetti, G., \& Martínez-Solano, Í. (2012). Multilocus species tree analyses resolve the radiation of the widespread Bufo bufo species group (Anura, Bufonidae). Molecular Phylogenetics and Evolution, 62, 71-86.

Recuero, E., Buckley, D., García-París, M., Arntzen, J.W., Cogalniceanu, D., \& Martínez-Solano, Í. (2014). Evolutionary history of Ichthyosaura alpestris (Caudata, Salamandridae) inferred from 
the combined analysis of nuclear and mitochondrial markers. Molecular Phylogenetics and Evolution, 81, 207-220.

Reis, D.M., Cunha, R.L., Patrão, C., Rebelo, R., \& Castilho, R. (2011). Salamandra salamandra (Amphibia: Caudata: Salamandridae) in Portugal: not all black and yellow. Genetica, 139, 1095-1105.

Rey, J.M., \& Sanchiz, B. (2005). Differential anuran bone preservation in a taphocenotic sample of Barn owl pellets. Munibe, 57, 505-509.

Rowe, G., Harris, D., \& Beebee, T. (2006). Lusitania revisited: a phylogeographic analysis of the natterjack toad Bufo calamita across its entire biogeographical range. Molecular Phylogenetics and Evolution, 39, 335-346.

Sánchez-Herráiz, M.J., Barbadillo, L.J., Machordom, A., \& Sanchiz, B. (2000). A new species of pelodytid frog from the Iberian Peninsula. Herpetologica, 56, 105-118.

Sanchiz, B. (1977). Nuevos anfibios del Neógeno y Cuaternario de Europa. Origen, desarrollo y relaciones de la batracofauna española. Ph.D. Thesis, Universidad Complutense de Madrid. 863 pp. Available at http://digital.csic.es/handle/10261/109567.

Sanchiz, B., \& Martín, C. (2004). Salamándridos pleistocenos de la Cueva de las Hienas (Asturias). (In: Libro de Resúmenes. $8^{\circ}$ Congreso Luso-Español y $12^{\circ}$ Congreso Español de Herpetología. (pp. 47), p. 134. Asociación Herpetológica Española: Málaga.

Sanchiz, B., \& Młynarski, M. (1979). Pliocene salamandrids (Amphibia, Caudata) from Poland. Acta Zoologica Cracoviensia, 24, 175-188.

Sarasola-Puente, V., Madeira, M.J., Gosá, A., Lizana, M., \& Gómez-Moliner, B. (2011). Population structure and genetic diversity of Rana dalmatina in the Iberian Peninsula. Conservation Genetics, 13, 197-209. doi:10.1007/s10592-011-0276-z.

Sequeira, F., Alexandrino, J., Rocha, S., Arntzen, J.W., \& Ferrand, N. (2005). Genetic exchange across a hybrid zone within the Iberian endemic golden-striped salamander, Chioglossa Iusitanica. Molecular Ecology, 14, 245-254.

Sequeira, F., Alexandrino, J., Weiss, S., \& Ferrand, N. (2008). Documenting the advantages and limitations of different classes of molecular markers in a well-established phylogeographic context: lessons from the Iberian endemic Golden-striped salamander, Chioglossa lusitanica (Caudata: Salamandridae). Biological Journal of the Linnean Society, 95, 371-387.

Sotiropoulos, K., Eleftherakos, K., Džukić, G., Kalezić, M.L., Legakis, A., \& Polymeni, R.M. (2007). Phylogeny and biogeography of the alpine newt Mesotriton alpestris (Salamandridae, Caudata), inferred from mtDNA sequences. Molecular Phylogenetics and Evolution, 45, 211226.

Steinfartz, S., Veith, M., \& Tautz, D. (2000). Mitochondrial sequence analysis of Salamandra taxa suggests old splits of major lineages and postglacial recolonizations of central Europe from distinct source populations of Salamandra salamandra. Molecular Ecology, 9, 397-410.

Stöck, M., Dufresnes, C., Litvinchuk, S.N., Lymberakis, P., Biollay, S., Berroneau, M., Borzée, A., Ghali, K., Ogielska, M., \& Perrin, N. (2012). Cryptic diversity among Western Palearctic tree 
frogs. Postglacial range expansion, range limits, and secondary contacts of three European tree frog lineages (Hyla arborea group). Molecular Phylogenetics and Evolution, 65, 1-9.

Sutherst, R.W. (2014). Pest species distribution modelling: origins and lessons from history. Biological Invasions, 16, 239-256.

Takahashi, M.K., Eastman, J.M., Griffin, D.A., Baumsteiger, J., Parris, M.J., \& Storfer, A. (2014) A stable niche assumption-free test of ecological divergence. Molecular Phylogenetics and Evolution, 76, 211-226

Teixeira, J., Martínez-Solano, Í., Buckley, D., Tarroso, P., García-París, M., \& Ferrand, N. (2015). Genealogy of the nuclear $\beta$-fibrinogen intron 7 in Lissotriton boscai (Caudata, Salamandridae): concordance with mtDNA and implications for phylogeography and speciation. Contributions to Zoology, 84(3) 193-215.

Themudo, G.E., \& Arntzen, J.W. (2007). Newts under siege: range expansion of Triturus pygmaeus isolates populations of its sister species. Diversity and Distributions, 13, 580-586.

Valbuena-Ureña, E., Amat, F., \& Carranza, S. (2013). Integrative Phylogeography of Calotriton newts (Amphibia, Salamandridae), with special remarks on the conservation of the endangered Montseny brook newt (Calotriton arnoldi). PLoS ONE, 8, e62542.

Van De Vliet, M.S., Beebee, T.J., \& Diekmann, O.E. (2012). Genetic evidence for a distinct Pelodytes lineage in southwest Portugal: implications for the use of pre-developed microsatellite markers. Conservation Genetics, 13, 605-611.

Van De Vliet, M.S., Diekmann, O.E., Machado, M., Beebee, T.J., Beja, P., \& Serrão, E.A. (2014). Genetic divergence for the Amphibian Pleurodeles waltl in Southwest Portugal: Dispersal barriers shaping geographic patterns. Journal of Herpetology, 48, 38-44.

Varela, S. Lobo, J.M., \& Hortal, J. (2011). Using species distribution models in paleobiogeography: a matter of data, predictors and concepts. Palaeogeography, Palaeoclimatology, Palaeoecology, $310,451-463$.

Veith, M., Mayer, C., Samraoui, B., Donaire Barroso, D., \& Bogaerts, S. (2004). From Europe to Africa and vice versa: evidence for multiple intercontinental dispersal in ribbed salamanders (genus Pleurodeles). Journal of Biogeography, 31, 159-171.

Veith, M., Baumgart, A., Dubois, A., Ohler, A., Galán, P., Vieites, D.R., Nieto-Román, S., \& Vences, M. (2012). Discordant patterns of nuclear and mitochondrial introgression in Iberian populations of the European Common frog (Rana temporaria). Journal of Heredity, 103, 240-249.

Velo-Anton, G., Martínez-Solano, I., \& García-París, M. (2008). B-fibrinogen intron 7 variation in Discoglossus (Anura: Discoglossidae): implications for the taxonomic assessment of morphologically cryptic species. Amphibia-Reptilia, 29, 523-533.

Vences, M., Hauswaldt, J.S., Steinfartz, S., Rupp, O., Goesmann, A, Künzel, S., Orozco-terWengel, P., Vieites, D.R., Nieto-Roman, S., Haas, S., Laugsch, C., Gehara, M., Bruchmann, S., Pabijan, M, Ludewig, A.K., Rudert, D., Angelini, C., Borkin, L.J., Crochet, P.A., Crottini, A., Dubois, A., Ficetola, G.F., Galán, P., Geniez, P., Hachtel, M., Jovanovic, O., Litvinchuk, S.N., Lymberakis, P., Ohler, A., \& Smirnov, N.A. (2013). Radically different phylogeographies and patterns of 
genetic variation in two European brown frogs, genus Rana. Molecular Phylogenetics and Evolution, 68, 657-670.

Vences, M., Pous, P. de, Nicolas, V., Díaz-Rodríguez, J., Donaire, D., Hugemann, K, Hauswaldt, J.S., Amat, F., Barnestein, J.A.M., Bogaerts, S., Bouazza, A., Carranza, S., Galán, P., González de la Vega, J.P., Joger, U., Lansari, A., El Mouden, E.H., Ohler, A.M., Sanuy, D. Slimani, T., \& Tejedo, M. (2014a). New insights on phylogeography and distribution of painted frogs (Discoglossus) in northern Africa and the Iberian Peninsula. Amphibia-Reptilia, 35, 305320.

Vences, M., Sanchez, E., Hauswaldt, J.S., Eikelmann, D., Rodríguez, A., Carranza, S., Donaire, D., Gehara, M., Helfer, V., Lötters, S., Werner, P., Schulz, S., \& Steinfartz, S. (2014b). Nuclear and mitochondrial multilocus phylogeny and survey of alkaloid content in true salamanders of the genus Salamandra (Salamandridae). Molecular Phylogenetics and Evolution, 73, 208-216.

Wielstra, B., Crnobrnja-Isailović, J., Litvinchuk, S.N., Reijnen, B.T., Skidmore, A.K., Sotiropoulos, K., Toxopeus, A.G., Tzankov, N., Vukov, T., \& Arntzen, J.W. (2013). Tracing glacial refugia of Triturus newts based on mitochondrial DNA phylogeography and species distribution modeling. Frontiers in Zoology, 10(13), 1-14. doi: 10.1186/1742-9994-10-13.

Williams, J.W., Blois, J.L., Gill, J.L., Gonzales, L.M., Grimm E.C., Ordonez, A., Shuman, B., \& Veloz S.D. (2013). Model systems for a no-analog future: species associations and climates during the last deglaciation. Annals of the New York Academy of Sciences, 1297, 29-43.

Zangari, F., Cimmaruta, R., \& Nascetti, G. (2006). Genetic relationships of the western Mediterranean painted frogs based on allozymes and mitochondrial markers: evolutionary and taxonomic inferences (Amphibia, Anura, Discoglossidae). Biological Journal of the Linnean Society, 87, 515-536.

Zhang, P., Papenfuss, T.J., Wake, M.H., Qu, L., \& Wake, D.B. (2008). Phylogeny and biogeography of the family Salamandridae (Amphibia: Caudata) inferred from complete mitochondrial genomes. Molecular Phylogenetics and Evolution, 49, 586-597. 


\section{Figure legends}

Fig. 1. Theoretical framework of biogeographical relationships that provide the realised distribution $(R D)$. The derived fundamental niche (DFN) is inferred from the current distribution (occurrence data) and ecophysiological adaptations are used to infer, in turn, a derived potential distribution (DPD), which is larger than the RD but smaller than the potential distribution (PD) inferred from ecophysiological adaptations alone.

Fig. 2. Results of a K-means cluster analysis $(n=3)$ showing the three major bioclimatic regions in the Iberian Peninsula using the 19 bioclimatic variables provided by the WorldClim database as input (Hijmans et al. 2005; http://www.worldclim.org) at a $0.08^{\circ}$ resolution.

Fig. 3. Realised (dark blue) and potential (light blue) distribution of Calotriton asper based on Araújo et al. (2011). The red dot represents the only known fossil site.

Fig. 4. Realised (dark blue) and potential (light blue) distribution of Chioglossa lusitanica based on Araújo et al. (2011). The red dot represents the only known fossil site.

Fig. 5. Realised (dark blue) and potential (light blue) distribution of Ichthyosaura alpestris based on Araújo et al. (2011). The red dot represents the only known lberian fossil site.

Fig. 6. Realised (dark blue) and potential (light blue) distribution of Lissotriton boscai based on Araújo et al. (2011).

Fig. 7. Realised (dark blue) and potential (light blue) distribution of Lissotriton helveticus based on Araújo et al. (2011). Red dots represent known Iberian fossil sites.

Fig. 8. Realised (dark blue) and potential (light blue) distribution of Pleurodeles waltl based on Araújo et al. (2011). Red dots represent known Iberian fossil sites.

Fig. 9. Realised (dark blue) and potential (light blue) distribution of Salamandra salamandra based on Araújo et al. (2011). Red dots represent known Iberian fossil sites. Distribution of the subspecies S. s. longirostris is in green.

Fig. 10. Realised (dark blue) and potential (light blue) distribution of Triturus marmoratus based on Araújo et al. (2011). Red dots represent known Iberian fossil sites.

Fig. 11. Realised (dark blue) and potential (light blue) distribution of Triturus pygmaeus based on Araújo et al. (2011). The red dot represents the only known fossil site.

Fig. 12. Realised (dark blue) and potential (light blue) distribution of Alytes cisternasii based on Araújo et al. (2011). The red dot represents the only known fossil site.

Fig. 13. Realised (dark blue) and potential (light blue) distribution of Alytes dickhilleni based on Araújo et al. (2011).

Fig. 14. Realised (dark blue) and potential (light blue) distribution of Alytes obstetricans based on Araújo et al. (2011). Red dots represent known Iberian fossil sites. 
Fig. 15. Realised (dark blue) and potential (light blue) distribution of Discoglossus galganoi based on Araújo et al. (2011). The red dot represents the only known fossil site.

Fig. 16. Realised (dark blue) and potential (light blue) distribution of Discoglossus jeanneae based on Araújo et al. (2011). Morphologically indistinct from D. galganoi, the red dots represent the presumed fossil record.

Fig. 17. Realised (dark blue) and potential (light blue) distribution of Pelobates cultripes based on Araújo et al. (2011). Red dots represent known Iberian fossil localities.

Fig. 18. Realised (dark blue) and potential (light blue) distribution of Pelodytes punctatus based on Araújo et al. (2011). Realised distributions of Pelodytes ibericus (green) and a Portuguese candidate species (red). The red dots represent the Iberian known fossil sites for the genus.

Fig. 19. Realised (dark blue) and potential (light blue) distribution of Bufo spinosus based on Araújo et al. (2011). Red dots represent known Iberian fossil sites.

Fig. 20. Realised (dark blue) and potential (light blue) distribution of Epidalea calamita based on Araújo et al. (2011). Red dots represent known Iberian fossil sites.

Fig. 21. Realised (dark blue) and potential (light blue) distribution of Hyla meridionalis based on Araújo et al. (2011). Red dots represent the presumed fossil record of the species. Green dots indicate fossil Hyla records for which specific assignment is uncertain.

Fig. 22. Realised (dark blue) and potential (light blue) distribution of Hyla molleri based on Araújo et al. (2011). Red dots represent known Iberian fossil sites. As in figure 21, green dots refer to sites where specific assignment of Hyla fossils is uncertain.

Fig. 23. Realised (dark blue) and potential (light blue) distribution of Pelophylax perezi based on Araújo et al. (2011). Red dots represent known Iberian fossil sites.

Fig. 24. Realised (dark blue) and potential (light blue) distribution of Rana dalmatina based on Araújo et al. (2011). Red dots represent Iberian known fossil sites.

Fig. 25. Realised (dark blue) and potential (light blue) distribution of Rana iberica based on Araújo et al. (2011). Red dots represent known fossil sites.

Fig. 26. Realised (dark blue) and potential (light blue) distribution of Rana pyrenaica based on Araújo et al. (2011).

Fig. 27. Realised (dark blue) and potential (light blue) distribution of Rana temporaria based on Araújo et al. (2011). Red dots represent known Iberian fossil sites. 
Table 1 Primary error sources in the inference of the fundamental environmental niche.

\begin{tabular}{|l|l|l|l|}
\hline INFO NOISE & DESCRIPTION & IDENTIFICATION & ADJUSTMENT \\
\hline Sampling & Incomplete or not random & Database history & Standardised efforts \\
\hline Averaging & Highly heterogeneous environment & $\begin{array}{l}\text { Geographic techniques } \\
\text { (downscaling) }\end{array}$ \\
\hline Niche shift & Evolutionary intraspecific niche change & $\begin{array}{l}\text { Community set; } \\
\text { phylogeography }\end{array}$ & $\begin{array}{l}\text { Phylogeography-based } \\
\text { ecodivergence tests }\end{array}$ \\
\hline Autocorrelation & $\begin{array}{l}\text { Clustering or overdispersion of spatial data } \\
\text { values }\end{array}$ & Spatial data & Spatial data analysis \\
\hline $\begin{array}{l}\text { Marginal } \\
\text { presence }\end{array}$ & Species absent in most of the study area & Geography & SDM models \\
\hline False presence & Incomplete postglacial migration & Phylogeography & SDM models \\
\hline False absence & Biotic interactions, competitive exclusion & Chorologic & SDM models \\
\hline True absence & Environmental non-climatic factors & Autoecology & SDM models \\
\hline Local territory & Range outside local study area not considered & Geography & MCR assemblages \\
\hline $\begin{array}{l}\text { Taphonomic } \\
\text { absence }\end{array}$ & Species not present as fossils & Taphonomic & None \\
\hline
\end{tabular}


Table 2 Climatic inferences based on extant amphibian species assemblages of different sizes in the northern Iberian Eurosiberian realm. The standardised Z-scores of the variable distribution indicate that the results represent the difference between the mean of the species predictions and the real value for each place.

\begin{tabular}{|c|c|c|c|c|c|c|}
\hline SPECIES & $\mathbf{N}$ & BIO 1 & BIO 5 & BIO 6 & BIO 12 & BIO 14 \\
\hline $\mathbf{2}$ & 50 & 0.45 & 0.78 & 0.65 & 0.77 & 0.50 \\
\hline $\mathbf{3}$ & 51 & 0.52 & 0.84 & 0.76 & 0.86 & 0.48 \\
\hline $\mathbf{4}$ & 57 & 0.64 & 0.66 & 0.89 & 0.80 & 0.48 \\
\hline $\mathbf{5}$ & 61 & 0.60 & 0.62 & 0.81 & 0.71 & 0.43 \\
\hline $\mathbf{6}$ & 88 & 0.56 & 0.67 & 0.78 & 0.65 & 0.62 \\
\hline $\mathbf{7}$ & 67 & 0.46 & 0.66 & 0.69 & 0.81 & 0.53 \\
\hline $\mathbf{8}$ & 50 & 0.46 & 0.65 & 0.78 & 0.66 & 0.46 \\
\hline $\mathbf{9}$ & 42 & 0.61 & 0.55 & 0.78 & 0.67 & 0.44 \\
\hline $\mathbf{1 0}$ & 44 & 0.54 & 0.69 & 0.87 & 0.75 & 0.37 \\
\hline $\mathbf{1 1}$ & 49 & 0.50 & 0.78 & 0.76 & 0.68 & 0.37 \\
\hline $\mathbf{1 2}$ & 16 & 0.56 & 0.82 & 0.97 & 0.83 & 0.27 \\
\hline $\mathbf{1 3}$ & 18 & 0.54 & 0.85 & 0.94 & 0.64 & 0.29 \\
\hline
\end{tabular}


Table 3. Quaternary fossil record of the Iberian Caudata fauna. Ca: Calotriton asper. Cl: Chioglossa Iusitanica. Ia: Ichthyosaura alpestris. Lh: Lissotriton helveticus. Pw: Pleurodeles waltl. Ss: Salamandra salamandra. Tm: Triturus marmoratus. Tp: Triturus pygmaeus. T: Triturus sp. Other species have no fossil record. Age abbreviations are as in Table 4. cf: All the observable features are consistent with the referred taxon, but they are not diagnostic enough to make the identification certain.

\begin{tabular}{|c|c|c|c|c|c|c|c|c|c|c|c|}
\hline FOSSIL SITE & Province & AGE & $\mathrm{Ca}$ & $\mathrm{Cl}$ & la & Lh & Pw & Ss & $\mathrm{Tm}$ & Tp & $\mathbf{T}$ \\
\hline Chaparral & Cádiz & $\mathrm{LP}$ & & & & & & $\mathrm{X} 1$ & & & \\
\hline Colomera $(\mathrm{H})$ & Lleida & $\mathrm{H}$ & $x$ & & & & & & & & \\
\hline Conde & Asturias & UP & & & & & & $x$ & & & \\
\hline Cova Rosa & Asturias & UP & & & & & & $X$ & $x$ & & \\
\hline Errekatxuetako Atxa & Vizcaya & $\mathrm{H}$ & & & & & & $x$ & & & \\
\hline Figueira Brava & Setúbal & UP & & & & & & $x$ & & & \\
\hline Gorham & Gibraltar & UP & & & & & $x$ & & & cf & \\
\hline Gran Dolina TD-03 & Burgos & $\mathrm{LP}$ & & & & & & & & & $x$ \\
\hline Gran Dolina TD-04 (East) & Burgos & LP & & & & & & & & & $x$ \\
\hline Gran Dolina TD-04 (West) & Burgos & $\mathrm{LP}$ & & & & & & & & & $x$ \\
\hline Gran Dolina TD-05 & Burgos & LP & & & & cf & & & & & \\
\hline Guia & Algarve & UP & & & & & $\mathrm{x}$ & & & & \\
\hline Hienas & Asturias & UP & & & $\mathrm{cf}$ & & & $x$ & & & \\
\hline Higueral de Valleja & Cádiz & UP & & & & & $x$ & & & & \\
\hline Huesos & Asturias & UP & & & & & & $x$ & & & \\
\hline Incarcal & Girona & $\mathrm{LP}$ & & & & $\mathrm{cf}$ & & & & & \\
\hline Laminak & Vizcaya & UP & & & & $x$ & & $x$ & & & \\
\hline Mirón & Cantabria & $\mathrm{H}$ & & & & & & $x$ & & & \\
\hline Oscura & Asturias & UP & & & & & & $x$ & & & \\
\hline Pontones & Jaén & $\mathrm{H}$ & & & & & & $x$ & & & \\
\hline Sidrón & Asturias & UP & & & & & & $x$ & & & \\
\hline Sima Elefante (TE-LRU) & Burgos & $\mathrm{LP}$ & & & & & & $x$ & cf & & \\
\hline Sima Elefante (TE-URU) & Burgos & $\mathrm{MP}$ & & & & $x$ & & $x$ & & & \\
\hline Teixoneres & Barcelona & UP & & & & & & $x$ & & & \\
\hline Valdavara 1 & Lugo & $\mathrm{H}$ & & $\mathrm{x}$ & & & & & & & \\
\hline Vanguard & Gibraltar & UP & & & & & $x$ & & & $x$ & \\
\hline Ventana $(\mathrm{P})$ & Madrid & UP & & & & & $x$ & & & & \\
\hline Zafarraya & Málaga & UP & & & & & $x$ & & & & \\
\hline
\end{tabular}


Table 4. Quaternary fossil record of the Iberian Anura fauna. H: Holocene. LP: Lower Pleistocene. MP: Middle Pleistocene. M-UP: Middle or Upper Pleistocene. UP: Upper Pleistocene. PRV: Province. AB: Albacete. AG: Algarve. AS: Asturias. B: Barcelona. BI: Vizcaya. BU: Burgos. CA: Cádiz. CO: Córdoba. CS: Castellón. CU: Cuenca. GI: Girona. GR: Granada. J: Jaén. L: Lleida. LU: Lugo. M: Madrid. MA: Málaga. MU: Murcia. N: Navarra. S: Cantabria. SG: Segovia. SO: Soria. SS: Guipúzcoa. ST: Setúbal. T: Tarragona. UK: Gibraltar. VI: Álava. Z: Zaragoza. Ac: Alytes cisternasii. Ao: Alytes obstetricans. Bs: Bufo spinosus. Bv: Bufotes. Dg: Discoglossus galganoi. Ec: Epidalea calamita. H: Hyla sp. Hm: Hyla meridionalis. Ho: Hyla molleri. Pc: Pelobates cultripes. Pi: Pelodytes ibericus. Pp: Pelodytes punctatus. Pz: Pelophylax perezi. Rd: Rana dalmatina. Ri: Rana iberica. Rt: Rana temporaria. R: Rana sp. Other species have no fossil record.

\begin{tabular}{|c|c|c|c|c|c|c|c|c|c|c|c|c|c|c|c|c|c|c|c|}
\hline FOSSIL SITE & PRV & AGE & Ac & Ao & $\mathrm{Dg}$ & Pc & $\mathrm{Pp}$ & $\mathbf{P i}$ & Bs & Bv & Ec & $\mathrm{Hm}$ & Ho & $\mathbf{H}$ & $\mathbf{P z}$ & $\mathbf{R d}$ & $\mathbf{R i}$ & Rt & $\mathbf{R}$ \\
\hline Abric Romaní & $\mathrm{B}$ & UP & & & & & & & $x$ & & $\mathrm{x}$ & & & & & & & $\mathrm{x}$ & \\
\hline Abrigo del Monte & $\mathrm{M}$ & UP & & & & & & & & & & & & & & & $\mathrm{X}$ & & \\
\hline Aitzbitarte 4 & SS & UP & & & & & & & $x$ & & & & & & & & & $\mathrm{X}$ & \\
\hline Aizkoltxo & SS & $\mathrm{H}$ & & & & & & & & & $\mathrm{X}$ & & & & & & & & \\
\hline Almenara-Casablanca 1 & CS & LP & & & $\mathrm{cf}$ & & $\mathrm{cf}$ & & $x$ & & & & & & $\mathrm{cf}$ & & & & \\
\hline Almenara-Casablanca 3 & CS & LP & & & $x$ & $x$ & $\mathrm{x}$ & & $x$ & $\mathrm{cf}$ & & & & & $\mathrm{x}$ & & & & \\
\hline Almenara-Casablanca 4 & CS & $\mathrm{LP}$ & & & & & cf & & $x$ & & & & & & $\mathrm{cf}$ & & & & \\
\hline Alquería & GR & LP & & & & & & & $\mathrm{cf}$ & & & & & & & & & & \\
\hline Amarejo & $A B$ & $\mathrm{H}$ & & & & & & & & & $x$ & & & & & & & & \\
\hline Ambrona & SO & MP & & & $\mathrm{x}$ & $x$ & $x$ & & $x$ & & $x$ & & $\mathrm{x}$ & & $\mathrm{X}$ & & & & \\
\hline Amutxate & NA & UP & & & & & & & & & & & & & & & & & $\mathrm{x}$ \\
\hline Angel & $\mathrm{CO}$ & MP & & & $x$ & & & & $x$ & & $x$ & & & & & & & & \\
\hline Antoliñaco Koba & $\mathrm{BI}$ & UP & & & & & & & & & & & & & & & & $x$ & \\
\hline Arbreda & $\mathrm{G}$ & $\mathrm{H}$ & & & & & $\mathrm{x}$ & & $x$ & & $\mathrm{x}$ & & & $x$ & & & & & \\
\hline Arbreda & $\mathrm{G}$ & UP & & cf & & $\mathrm{x}$ & $x$ & & $\mathrm{x}$ & & $x$ & & & $\mathrm{x}$ & & & & & $\mathrm{x}$ \\
\hline Arcaraz & $\mathrm{M}$ & MP & & & & $x$ & & & & & & & & & $\mathrm{X}$ & & & & \\
\hline Aridos 1 & $\mathrm{M}$ & MP & & & $\mathrm{X}$ & $x$ & & & $\mathrm{x}$ & & & & & $\mathrm{X}$ & $\mathrm{X}$ & & & & \\
\hline Arriaga 1 & $\mathrm{M}$ & MP & & & & $x$ & & & $x$ & & & & & & $x$ & & & & \\
\hline Atapuerca (SH) & $\mathrm{BU}$ & MP & & $x$ & & $\mathrm{cf}$ & $x$ & & $x$ & & $x$ & & & & & & & $x$ & $x$ \\
\hline Atapuerca (Tres Simas) & $\mathrm{BU}$ & $\mathrm{MP}$ & & $x$ & & & & & & & $x$ & & & & & & & & $\mathrm{x}$ \\
\hline Bagur 1 & G & $\mathrm{MP}$ & & & & $\mathrm{x}$ & $\mathrm{X}$ & & $x$ & & $\mathrm{X}$ & & & & & & & & \\
\hline Bagur 2 & $\mathrm{G}$ & LP & & & & $x$ & $x$ & & $x$ & & $x$ & & & & & & & & \\
\hline Barranco Conejos & GR & LP & & & $x$ & & & & & & & & & & $x$ & & & & \\
\hline Barranco León D & GR & LP & & & $x$ & $x$ & & & $x$ & $\mathrm{cf}$ & $x$ & $\mathrm{x}$ & & & $\mathrm{X}$ & & & & \\
\hline Buena Pinta & $\mathrm{M}$ & UP & & & & & & & & & & & & & & & $\mathrm{X}$ & & \\
\hline Cabeza de la Fuente & $\mathrm{CU}$ & $\mathrm{H}$ & & & & & $x$ & & $x$ & & & & & & & & & & \\
\hline Cal Guardiola & $B$ & LP & & & & & & & $x$ & & $\mathrm{X}$ & & & & & & & $\mathrm{X}$ & \\
\hline Caldas & AS & UP & & & & & & & & & & & & & & & & $\mathrm{x}$ & \\
\hline Calor & $\mathrm{MU}$ & $\mathrm{H}$ & & & & & & & $\mathrm{x}$ & & & & & & $\mathrm{X}$ & & & & \\
\hline Camino & $\mathrm{M}$ & UP & & $x$ & & $x$ & & & $\mathrm{x}$ & & $\mathrm{x}$ & & & $\mathrm{X}$ & $\mathrm{X}$ & & $\mathrm{X}$ & & \\
\hline Can Altisench & $\mathrm{B}$ & $\mathrm{LP}$ & & & & $x$ & $\mathrm{x}$ & & $x$ & & & & & & & & & & \\
\hline Canyars & $B$ & UP & & & & & $\mathrm{x}$ & & $x$ & & $\mathrm{x}$ & & & & & & & & \\
\hline Cañada de Murcia 1 & GR & LP & & & & & & & & & & & & & $\mathrm{X}$ & & & & \\
\hline Castelldefels & $\mathrm{B}$ & $\mathrm{LP}$ & & & & & & & $x$ & & & & & & & & & & \\
\hline Castillo & $\mathrm{S}$ & UP & & & & & & & $x$ & & & & & & & & & $x$ & \\
\hline Chaparral & CA & LP & & & $x$ & & & cf & $x$ & & $x$ & & & & & & & & \\
\hline Chufín & $\mathrm{S}$ & UP & & & & & & & $x$ & & & & & & & & & & $\mathrm{x}$ \\
\hline
\end{tabular}




\begin{tabular}{|c|c|c|c|c|c|c|c|c|c|c|c|c|c|c|c|c|c|c|c|}
\hline FOSSIL SITE & PRV & AGE & Ac & Ao & $\mathrm{Dg}$ & Pc & $\mathrm{Pp}$ & $\mathbf{P i}$ & Bs & Bv & Ec & $\mathrm{Hm}$ & Ho & $\mathbf{H}$ & Pz & Rd & $\mathbf{R i}$ & Rt & $\mathbf{R}$ \\
\hline Cobrante & $\mathrm{S}$ & UP & & $x$ & & & & & $\mathrm{x}$ & & $x$ & & & & & & & $x$ & \\
\hline Colomera $(\mathrm{H})$ & $\mathrm{L}$ & $\mathrm{H}$ & & $\mathrm{x}$ & & & & & & & & & & & & & & $\mathrm{x}$ & \\
\hline Colomera $(\mathrm{P})$ & $\mathrm{L}$ & UP & & $x$ & & & & & & & & & & & & & & $x$ & \\
\hline Conde & AS & UP & & $\mathrm{x}$ & & & & & $\mathrm{X}$ & & & & & & & & & $x$ & \\
\hline Cortes de Baza & GR & LP & & & $\mathrm{cf}$ & & & & & & & & & & $\mathrm{cf}$ & & & & \\
\hline Cova Rosa & AS & UP & & $x$ & & & & & $x$ & & $x$ & & & & & & $x$ & $x$ & \\
\hline Cova-120 & $\mathrm{G}$ & $\mathrm{H}$ & & $x$ & & $x$ & & & & & & & & & & & & & \\
\hline Cueto de la Mina & AS & UP & & & & & & & $\mathrm{X}$ & & & & & & & & & $x$ & \\
\hline Cueva Victoria & $\mathrm{MU}$ & $\mathrm{LP}$ & & & & & $\mathrm{cf}$ & & $X$ & $\mathrm{cf}$ & & & & & cf & & & & \\
\hline Ekain & SS & UP & & & & & & & $x$ & & & & & & & & & $x$ & $x$ \\
\hline Erralla & SS & UP & & $\mathrm{x}$ & & & & & $x$ & & & & & & & $\mathrm{x}$ & & $x$ & \\
\hline Errekatxuetako Atxa & $\mathrm{BI}$ & $\mathrm{H}$ & & $x$ & & & & & $\mathrm{x}$ & & & & & & & & & $\mathrm{x}$ & \\
\hline Escala & $\mathrm{G}$ & UP & & & & & cf & & cf & & & & & & & & & & \\
\hline Figueira Brava & ST & UP & & & & $x$ & & & & & & & & & & & & & \\
\hline Fuente Nueva 2 & GR & $\mathrm{LP}$ & & & & & & & & & & & & & $\mathrm{X}$ & & & & \\
\hline Fuente Nueva 3 & GR & $\mathrm{LP}$ & & & $x$ & $x$ & & & $\mathrm{X}$ & & & & & & $x$ & & & & \\
\hline Galera $1 \mathrm{H}$ & GR & $\mathrm{LP}$ & & & & & & & & & & & & & $\mathrm{cf}$ & & & & \\
\hline Galera 2 & GR & $\mathrm{LP}$ & & & $\mathrm{x}$ & & & & cf & & & & & & cf & & & & \\
\hline Galería (TN 4-6) & $\mathrm{BU}$ & $\mathrm{MP}$ & & $\mathrm{x}$ & & & & & & & $x$ & & & & & & & & \\
\hline Galls Carboners & $T$ & UP & & $\mathrm{x}$ & & & & & & & $x$ & & & & & & & $x$ & \\
\hline Gegant & B & UP & & & & $x$ & $\mathrm{cf}$ & & $\mathrm{cf}$ & & $x$ & & & & & & & & \\
\hline Gorham & UK & UP & & & $\mathrm{X}$ & $\mathrm{x}$ & & & $\mathrm{x}$ & & $\mathrm{x}$ & $\mathrm{X}$ & & & $\mathrm{cf}$ & & & & \\
\hline Grajas & $\mathrm{MA}$ & $\mathrm{MP}$ & & & $\mathrm{x}$ & & & & $\mathrm{x}$ & & $\mathrm{x}$ & & & & $x$ & & & & \\
\hline Gran Dolina TD-03 & $\mathrm{BU}$ & LP & & $\mathrm{x}$ & & $\mathrm{cf}$ & $\mathrm{x}$ & & $\mathrm{x}$ & & $x$ & & & & & & & $\mathrm{x}$ & $\mathrm{x}$ \\
\hline Gran Dolina TD-04 (Est) & $\mathrm{BU}$ & $\mathrm{LP}$ & & $x$ & & & $\mathrm{X}$ & & & & $\mathrm{x}$ & & & & & & & & $x$ \\
\hline Gran Dolina TD-04 (West & $\mathrm{BU}$ & LP & & $x$ & & cf & $x$ & & & & $x$ & & & & & & & & $x$ \\
\hline Gran Dolina TD-04+05 & $\mathrm{BU}$ & $\mathrm{LP}$ & & $\mathrm{x}$ & & $\mathrm{cf}$ & $\mathrm{X}$ & & $\mathrm{X}$ & & $x$ & & & & $\mathrm{cf}$ & & & & $x$ \\
\hline Gran Dolina TD-05 & $\mathrm{BU}$ & LP & & $x$ & & cf & $x$ & & $\mathrm{X}$ & & $x$ & & & & cf & & & & $x$ \\
\hline Gran Dolina TD-06 (s. lato) & $\mathrm{BU}$ & $\mathrm{LP}$ & & $\mathrm{x}$ & & $\mathrm{x}$ & $x$ & & $\mathrm{X}$ & & $x$ & & & & cf & cf & & & $x$ \\
\hline Gran Dolina TD-06a & $\mathrm{BU}$ & $\mathrm{LP}$ & & $x$ & & $x$ & $x$ & & $x$ & & $x$ & & & & cf & & & & $x$ \\
\hline Gran Dolina TD-06b & $\mathrm{BU}$ & $\mathrm{LP}$ & & $x$ & & $x$ & $\mathrm{x}$ & & $x$ & & $\mathrm{x}$ & & & & cf & & & & $x$ \\
\hline Gran Dolina TD-07 & $\mathrm{BU}$ & $\mathrm{MP}$ & & $\mathrm{x}$ & & & $\mathrm{X}$ & & $\mathrm{X}$ & & $\mathrm{X}$ & & & & & & & & $\mathrm{X}$ \\
\hline Gran Dolina TD-08 & $\mathrm{BU}$ & MP & & $x$ & & $x$ & $\mathrm{x}$ & & $\mathrm{x}$ & & $x$ & & $x$ & & $\mathrm{cf}$ & & & & $x$ \\
\hline Gran Dolina TD-10 & $\mathrm{BU}$ & MP & & $\mathrm{x}$ & & $x$ & $\mathrm{x}$ & & $\mathrm{X}$ & & $x$ & & $\mathrm{x}$ & & & $\mathrm{cf}$ & & $\mathrm{x}$ & \\
\hline Gran Dolina TD-11 & $\mathrm{BU}$ & MP & & $x$ & & $x$ & $x$ & & $x$ & & $x$ & & $\mathrm{cf}$ & & cf & & $\mathrm{cf}$ & & \\
\hline Guia & $A G$ & UP & & & & $x$ & & & $x$ & & $x$ & & & & $\mathrm{X}$ & & & & \\
\hline HAT & $\mathrm{M}$ & UP & & & & $\mathrm{x}$ & $\mathrm{cf}$ & & $\mathrm{X}$ & & & & & & $\mathrm{X}$ & & & & \\
\hline Hienas & AS & UP & & $x$ & & & & & $x$ & & $x$ & & & & & & & $x$ & \\
\hline Higueral de Valleja & CA & UP & & & $x$ & & $\mathrm{cf}$ & & cf & & $x$ & & & $x$ & cf & & & & \\
\hline Horá & GR & UP & & & $x$ & & & & $x$ & & $\mathrm{x}$ & & & & $x$ & & & & \\
\hline Huesos & AS & UP & & & & & & & $\mathrm{X}$ & & & & & & & & & & \\
\hline Incarcal & $\mathrm{G}$ & $\mathrm{LP}$ & & & & & & & $x$ & & & & & & & & & & \\
\hline Jarama 2 & GU & UP & & & & & & & $x$ & & & & & & & & & & \\
\hline Jarama 6 & GU & UP & & & & $x$ & & & $x$ & & & & & & & & & & \\
\hline Kobeaga 2 & $\mathrm{BI}$ & $\mathrm{H}$ & & $\mathrm{cf}$ & & & & & & & & & & & & & & & \\
\hline Laminak & $\mathrm{BI}$ & UP & & $x$ & & & & & $x$ & & & & & & & & & $x$ & \\
\hline Lezika & $\mathrm{BI}$ & UP & & & & & & & & & $x$ & & & & & & & & $x$ \\
\hline Loma Quemada & $\mathrm{BU}$ & $\mathrm{LP}$ & & & $\mathrm{x}$ & & & & & & & & & & & & & & \\
\hline Millán & $\mathrm{BU}$ & UP & & & & & & & & & & & & & & & $x$ & & \\
\hline Mirador $(\mathrm{H})$ & $\mathrm{BU}$ & $\mathrm{H}$ & & & & & & & & & & & $\mathrm{cf}$ & & & & & & \\
\hline Mirador (P) & $\mathrm{BU}$ & UP & & $x$ & & & & & $x$ & & $x$ & & $x$ & & & & & & $x$ \\
\hline Mirón & $\mathrm{S}$ & $\mathrm{H}$ & & $x$ & & & & & $x$ & & & & & & & & & $x$ & \\
\hline Mortero & $\mathrm{S}$ & UP & & & & & & & & & & & & & & & & $x$ & \\
\hline Musclos & B & UP & & & & $x$ & $x$ & & & & & & & & & & & & \\
\hline Olopte B & $\mathrm{G}$ & $\mathrm{MP}$ & & & & & $x$ & & & & $x$ & & & & & & & $x$ & \\
\hline
\end{tabular}




\begin{tabular}{|c|c|c|c|c|c|c|c|c|c|c|c|c|c|c|c|c|c|c|c|}
\hline FOSSIL SITE & PRV & AGE & Ac & Ao & $\mathrm{Dg}$ & Pc & $\mathrm{Pp}$ & $\mathbf{P i}$ & Bs & Bv & Ec & $\mathrm{Hm}$ & Ho & H & $\mathbf{P z}$ & $\mathbf{R d}$ & $\mathbf{R i}$ & Rt & $\mathbf{R}$ \\
\hline Orce (Guardia Civil) & GR & LP & & & & & & & & & & & & & $\mathrm{cf}$ & & & & \\
\hline Orce 1 & GR & LP & & & & & & & & & & & & & $\mathrm{cf}$ & & & & \\
\hline Orce 4 & $\mathrm{GR}$ & $\mathrm{LP}$ & & & $\mathrm{X}$ & & & & & & & & & & $\mathrm{X}$ & & & & \\
\hline Orce D & GR & $\mathrm{LP}$ & & & & & & & & & & & & & $\mathrm{cf}$ & & & & \\
\hline Oscura & AS & UP & & & & & & & & & & & & & $\mathrm{cf}$ & & & & \\
\hline Paloma & AS & UP & & & & & & & $x$ & & $x$ & & & & & & & $x$ & \\
\hline Peña de Estebanvela & SE & UP & & & & & & & & & $x$ & & & & & & & & \\
\hline Peña Larga & $\mathrm{VI}$ & $\mathrm{H}$ & & & & & & & & & & & & & & & & $\mathrm{X}$ & \\
\hline Pinilla del Valle & $\mathrm{M}$ & MP & & & & & & & $x$ & & $x$ & & & & & & & & \\
\hline Pontones & $\mathrm{J}$ & $\mathrm{H}$ & & & & & & & & & & & & & & & & & \\
\hline Portalón & $\mathrm{BU}$ & UP & & $x$ & & & & & $x$ & & $x$ & & & & & & & $x$ & \\
\hline Preresa & $\mathrm{M}$ & UP & & & & $\mathrm{X}$ & cf & & $x$ & & $x$ & & & $\mathrm{X}$ & $\mathrm{X}$ & & & & \\
\hline Quibas & $\mathrm{MU}$ & $\mathrm{LP}$ & & & & & & & $\mathrm{X}$ & & & & & & & & & & \\
\hline Reixac & G & $\mathrm{H}$ & & & & $\mathrm{X}$ & & & & & & & & & & & & & \\
\hline Rincón de la Victoria & MA & UP & & & & & & & & & & & & & $\mathrm{X}$ & & & & \\
\hline Rinoceront & $\mathrm{B}$ & M-UP & & & & & & & $\mathrm{X}$ & & & & & & & & & & \\
\hline Roa F (Zújar) & GR & $\mathrm{LP}$ & & & & & & & & & & & & & $\mathrm{cf}$ & & & & \\
\hline Sidrón & AS & UP & & & & & & & $\mathrm{X}$ & & & & & & & & & $\mathrm{X}$ & \\
\hline Sima Elefante (TE-LRU) & $\mathrm{BU}$ & LP & & cf & & $\mathrm{X}$ & $\mathrm{X}$ & & $\mathrm{X}$ & & $x$ & & $\mathrm{cf}$ & & cf & & & & $x$ \\
\hline Sima Elefante (TE-URU) & $\mathrm{BU}$ & $\mathrm{MP}$ & & cf & $\mathrm{X}$ & $\mathrm{X}$ & $\mathrm{X}$ & & $\mathrm{X}$ & & $x$ & & $\mathrm{cf}$ & & & & & & $\mathrm{cf}$ \\
\hline Solana del Zamborino & GR & $\mathrm{MP}$ & & & $x$ & & & & & & & & & & & & & & \\
\hline Tafesa & $\mathrm{M}$ & MP & & & & $\mathrm{X}$ & & & & & & & & & & & & & \\
\hline Tamariz & $Z$ & $\mathrm{H}$ & & & & $\mathrm{X}$ & & & & & $\mathrm{X}$ & & & & & & & & \\
\hline Teixoneres & $\mathrm{B}$ & UP & & $\mathrm{X}$ & & & $\mathrm{X}$ & & $\mathrm{X}$ & & $\mathrm{X}$ & & & & & & & $\mathrm{X}$ & \\
\hline Tomba & G & $\mathrm{H}$ & & & & $x$ & & & & & $x$ & & & & & & & & \\
\hline Valdavara 1 & $\mathrm{LU}$ & $\mathrm{H}$ & & & & & & & & & & & & & & & & & \\
\hline Valdeganga 7 & $A B$ & LP & & & $x$ & & & & & & & & & & & & & & \\
\hline Valdocarros 2 & $\mathrm{M}$ & $\mathrm{MP}$ & & $\mathrm{cf}$ & & $x$ & $\mathrm{cf}$ & & $\mathrm{X}$ & & $\mathrm{X}$ & & $x$ & & $\mathrm{X}$ & & & & \\
\hline Vallparadis & $\mathrm{B}$ & $\mathrm{LP}$ & & & & $\mathrm{X}$ & & & & & & & & & & & & & \\
\hline Vanguard & UK & UP & & & & $x$ & & & $x$ & & $x$ & $X$ & & & $\mathrm{cf}$ & & & & \\
\hline Venta Micena 1 & GR & LP & & & $X$ & & & & & & & & & & $X$ & & & & \\
\hline Ventana $(\mathrm{H})$ & $\mathrm{M}$ & $\mathrm{H}$ & $x$ & & $x$ & $x$ & & & & & $x$ & & & & $\mathrm{X}$ & & & & \\
\hline Ventana $(\mathrm{P})$ & $\mathrm{M}$ & UP & & & & $x$ & & & & & $x$ & & & & $\mathrm{X}$ & & & & \\
\hline Villacastín & SE & MP & & & & & & & & & $x$ & & & & & & & & \\
\hline Xaragalls & $\mathrm{T}$ & UP & & $x$ & & & $\mathrm{cf}$ & & & & $\mathrm{X}$ & & & & & & & & \\
\hline Yedras & $\mathrm{GR}$ & MP & & & & & & & $x$ & & & & & & & & & & \\
\hline Zafarraya & $\mathrm{MA}$ & UP & & & & $x$ & & $\mathrm{cf}$ & $x$ & & $x$ & & & $\mathrm{X}$ & $\mathrm{X}$ & & & & \\
\hline
\end{tabular}


Table 5. Historical constraints and error sources of niche inferences for Iberian amphibian species. Iberian endemism is to be considered sensu lato when most of the species range is peninsular. In cases of presumed competition, the inference should combine both species.

\begin{tabular}{|l|l|l|l|}
\hline Species & $\begin{array}{l}\text { Iberia } \\
\text { range size }\end{array}$ & Main error source & Inference \\
\hline Calotriton arnoldi & endemic & Small sample size & unusable \\
\hline Calotriton asper & endemic & Competitive exclusion & combined \\
\hline Chioglossa lusitanica & endemic & Incomplete postglacial colonisation & valid \\
\hline Ichthyosaura alpestris & marginal & Competitive exclusion & combined \\
\hline Lissotriton boscai & endemic & & valid \\
\hline Lissotriton helveticus & marginal & Iberian range is marginal & biased \\
\hline Pleurodeles waltl & endemic & & valid \\
\hline Salamandra salamandra & marginal & Extensive intraspecific genetic differentiation & biased \\
\hline Triturus marmoratus & large & Iberian range is marginal & biased \\
\hline Triturus pygmaeus & endemic & Fossil identification unstudied & unusable \\
\hline Alytes cisternasii & endemic & Palaeogeographic restrictions & biased \\
\hline Alytes dickhilleni & endemic & Palaeogeographic restrictions & biased \\
\hline Alytes obstetricans & large & Iberian range is marginal; extensive intraspecific genetic differentiation & biased \\
\hline Discoglossus galganoi & endemic & Incomplete postglacial colonisation & valid \\
\hline Pelobates cultripes & endemic & & valid \\
\hline Pelodytes punctatus & large & Iberian range is marginal & biased \\
\hline Pelodytes ibericus & endemic & Distribution not well-known & unusable \\
\hline Bufo spinosus & large & Iberian range is marginal & valid \\
\hline Epidalea calamita & large & Iberian range is marginal & valid \\
\hline Hyla meridionalis & marginal & Iberian range is marginal & biased \\
\hline Hyla molleri & endemic & & valid \\
\hline Pelophylax perezi & endemic & & valid \\
\hline Rana dalmatina & marginal & Iberian range is marginal; small sample size & unusable \\
\hline Rana iberica & endemic & Competitive exclusion & biased \\
\hline Rana pyrenaica & endemic & Fossil identification unstudied & unusable \\
\hline Rana temporaria & marginal & Iberian range marginal & biased \\
\hline
\end{tabular}


Observed occurrences

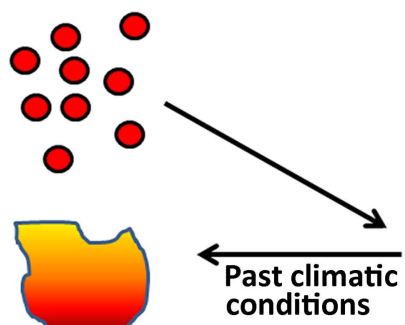

$\mathrm{DPD} \geq \mathrm{RD}$
Ecophysiological adaptations
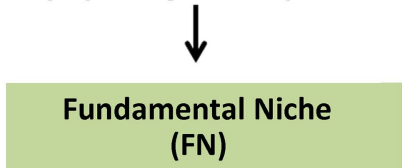

$$
\text { II } \quad \mathrm{FN} \geq \mathrm{FN}
$$

Derived Fundamental Niche

(DFN)

$$
\text { PD } \geq \text { DPD }
$$

Realized Distribution (RD)
Derived Potential Distribution (DPD)
Potential Distribution (PD) 


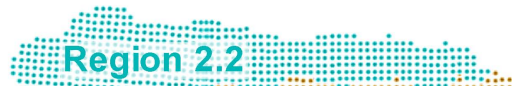

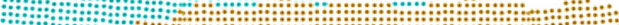

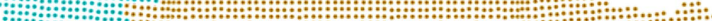

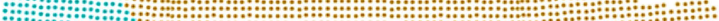

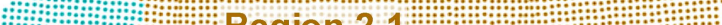

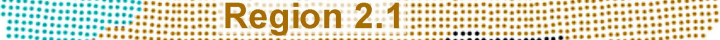

:

:

r.,

:

;

;

; n

;

20,

F

:

:

:

$\bullet$

:

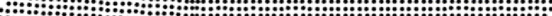

,

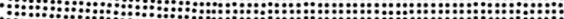

:

:

:

$:$

$\mathrm{B}_{1}$

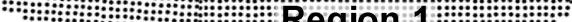

$\because: v_{0}$

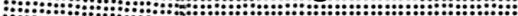

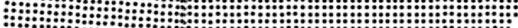

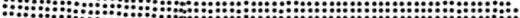

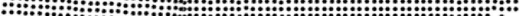

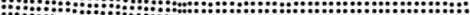

.

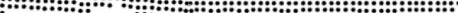

Ұ:::

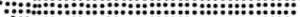

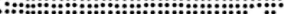

:

$\because$

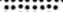

$\because:: 8:$ 


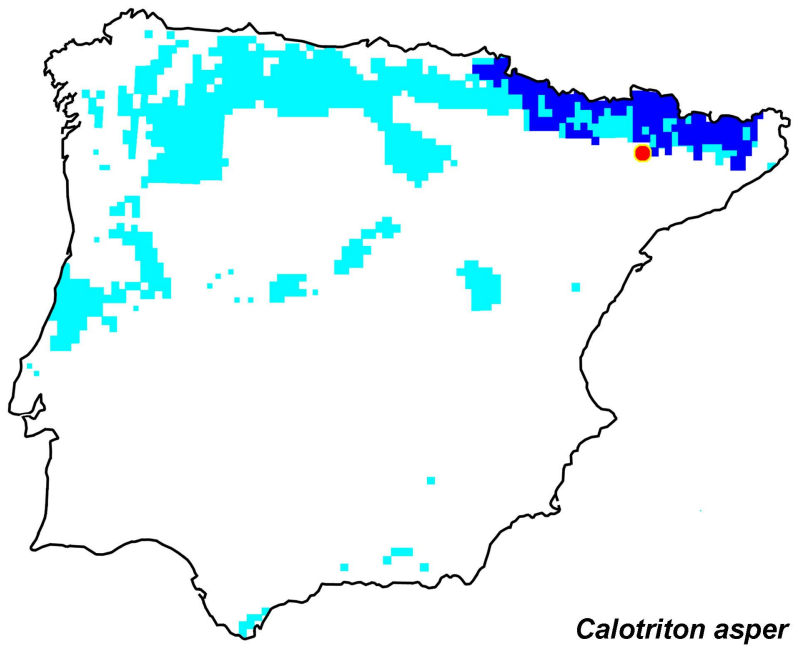




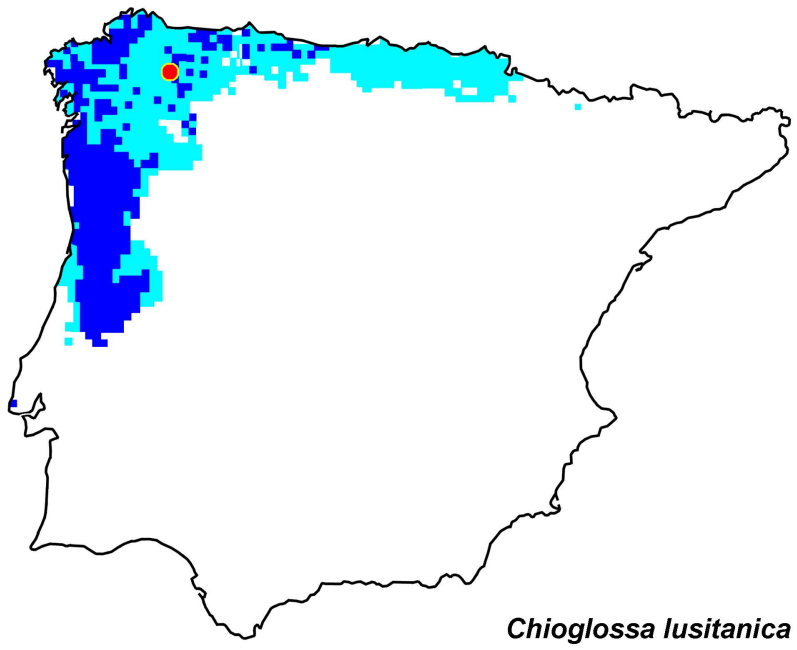




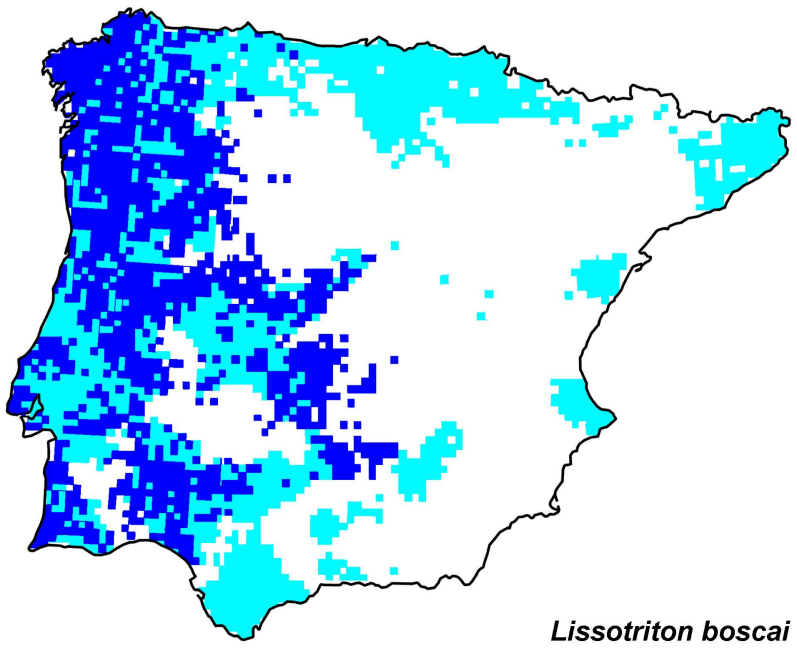




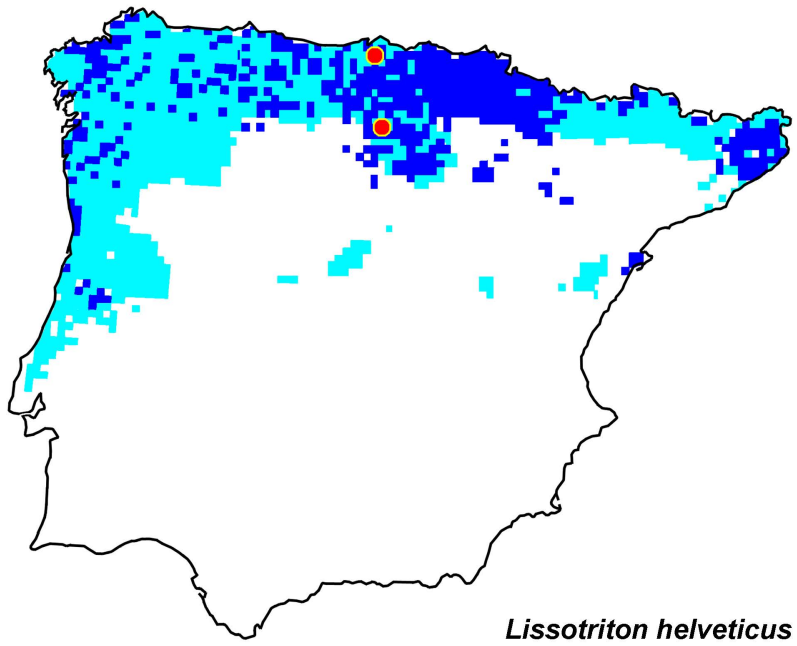




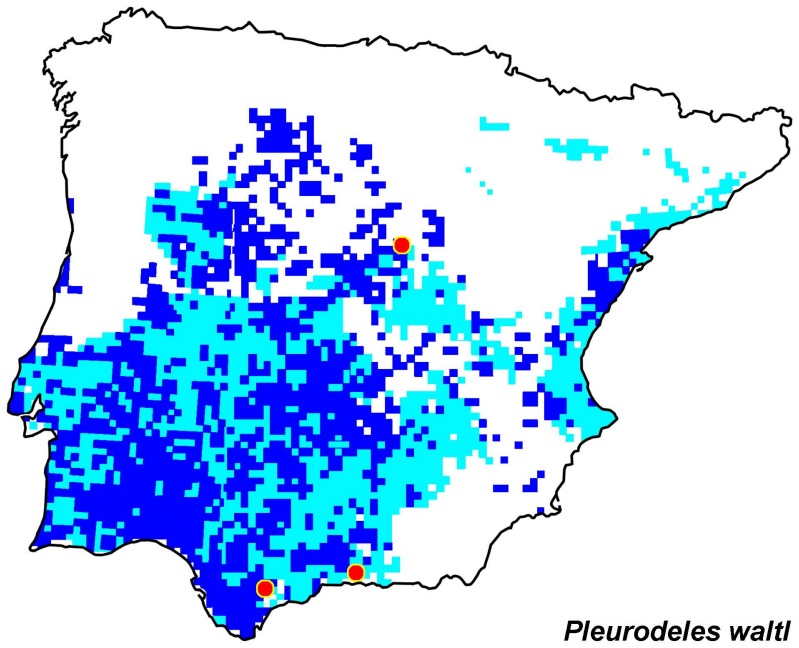




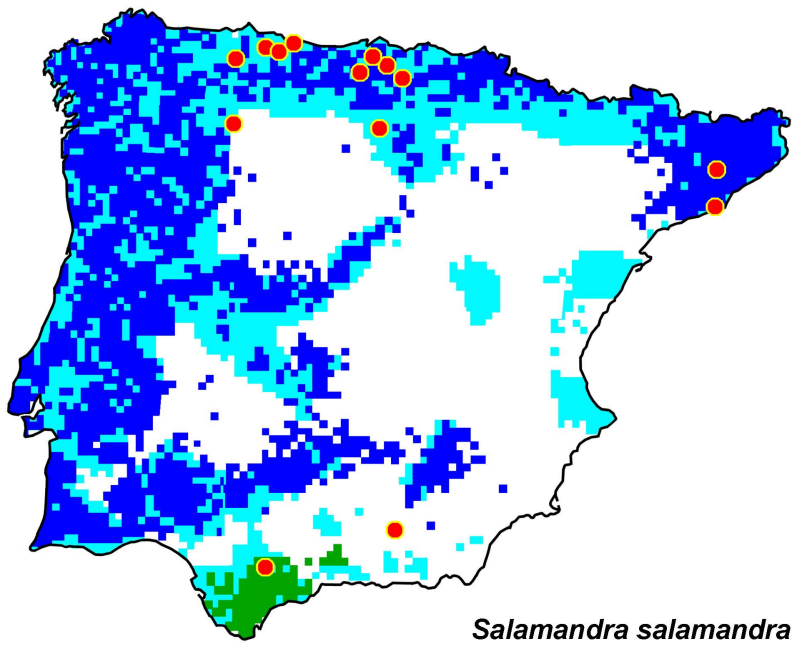




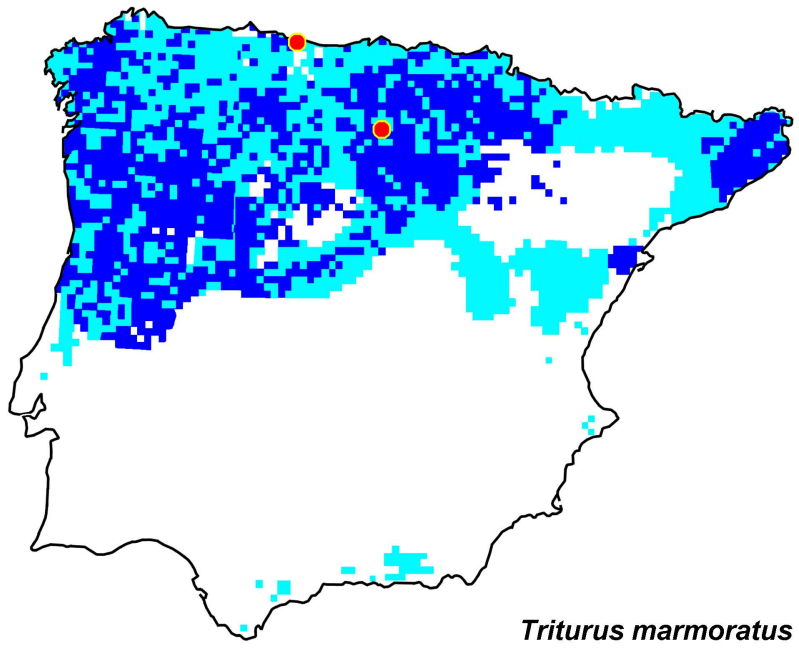




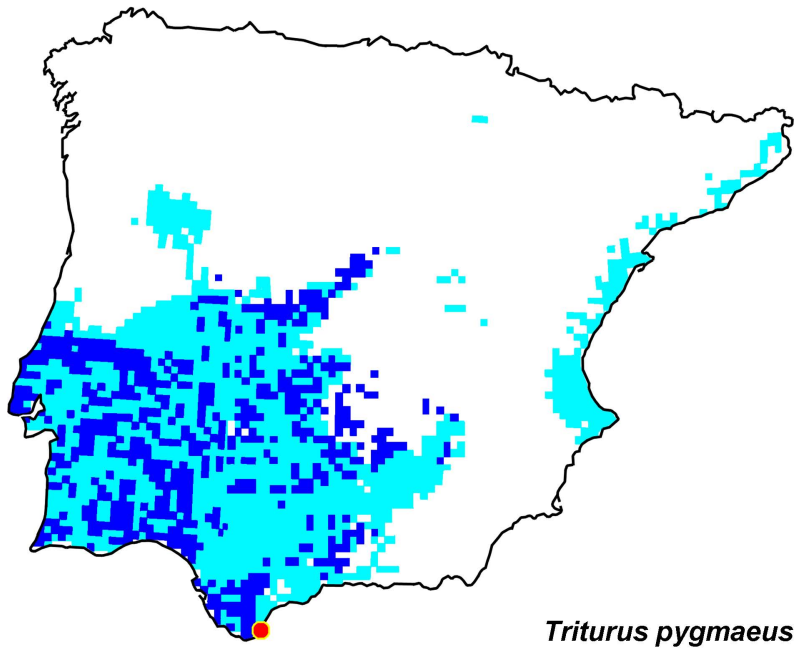




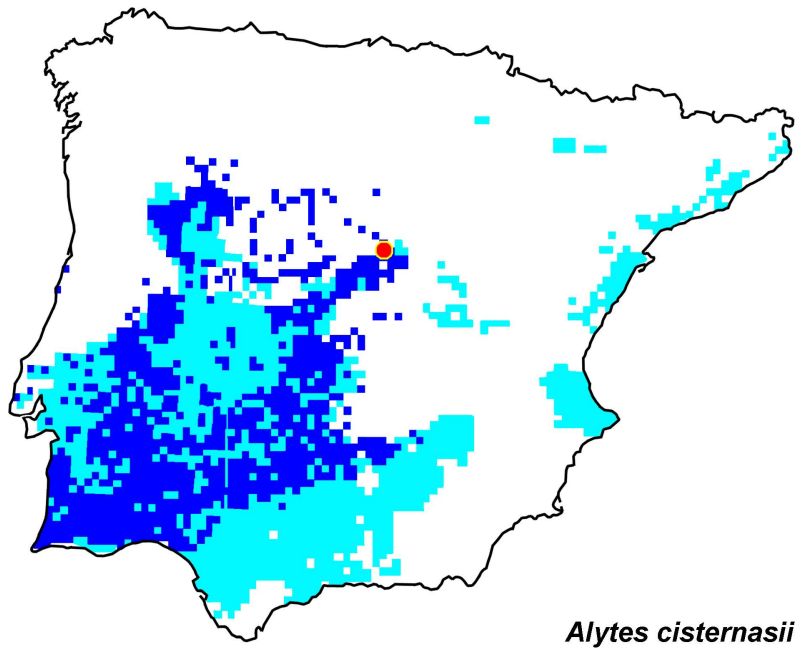




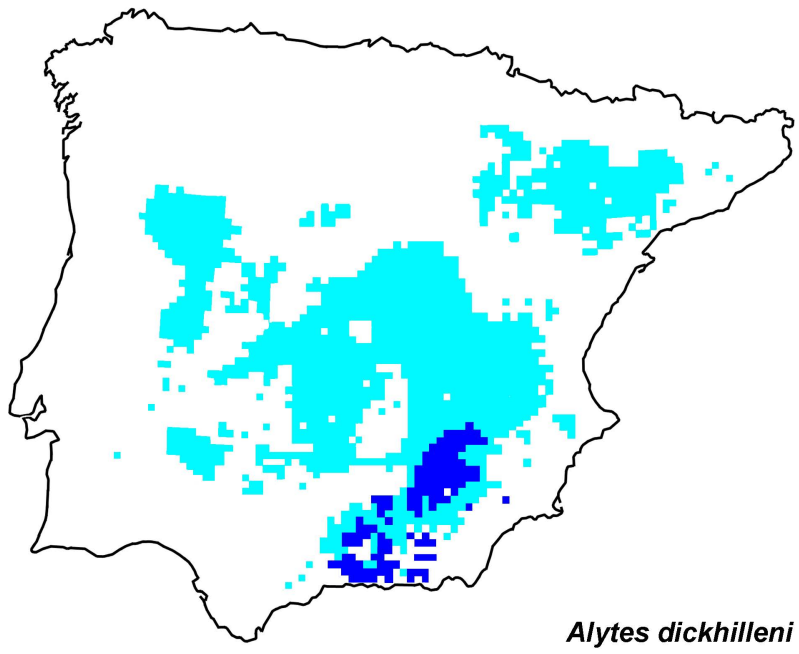




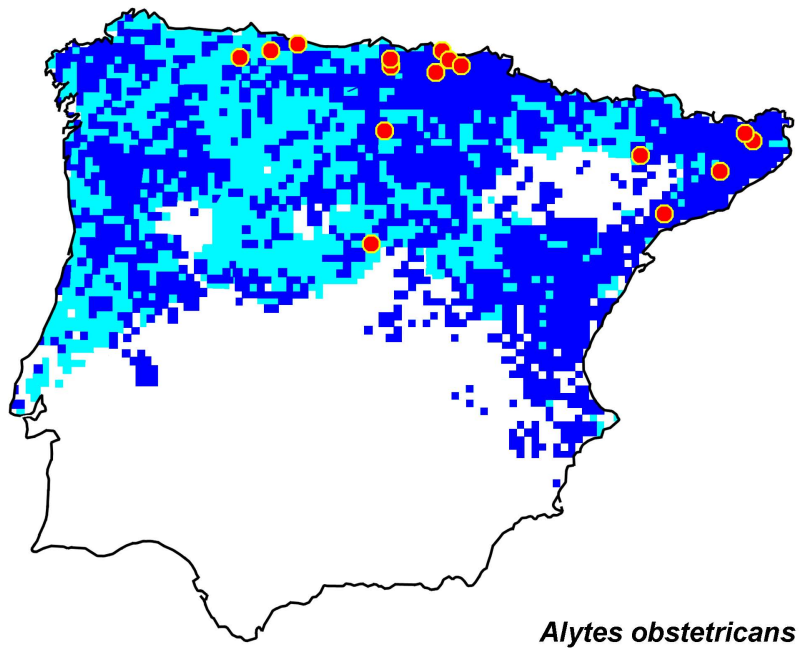




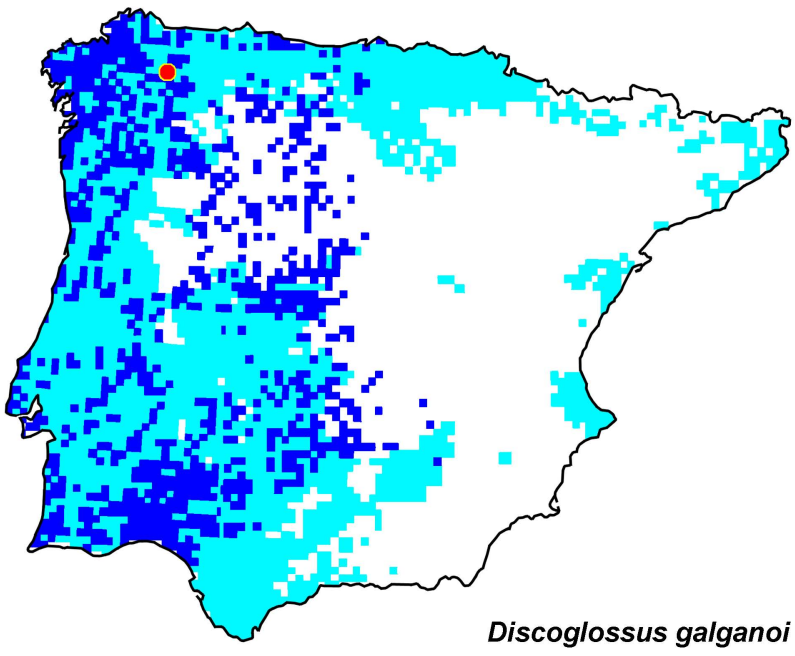




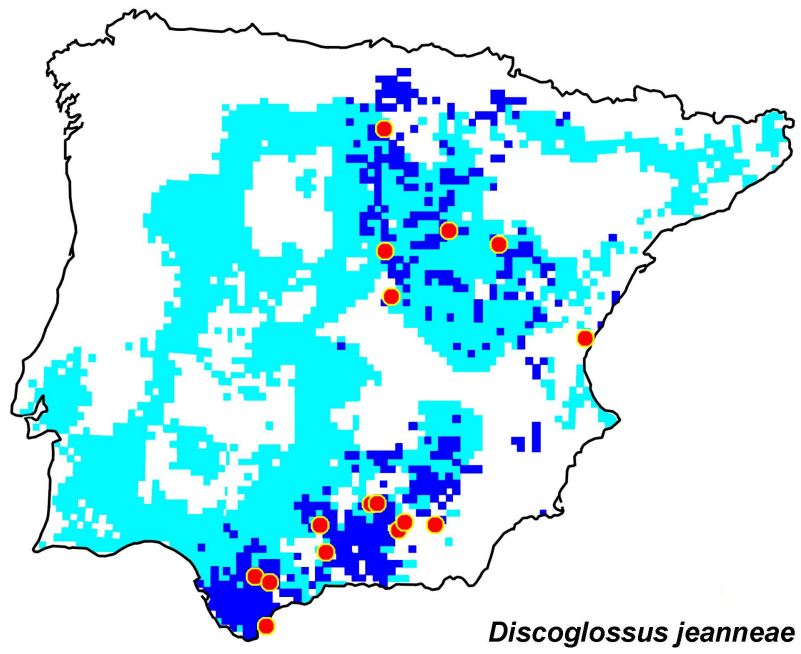




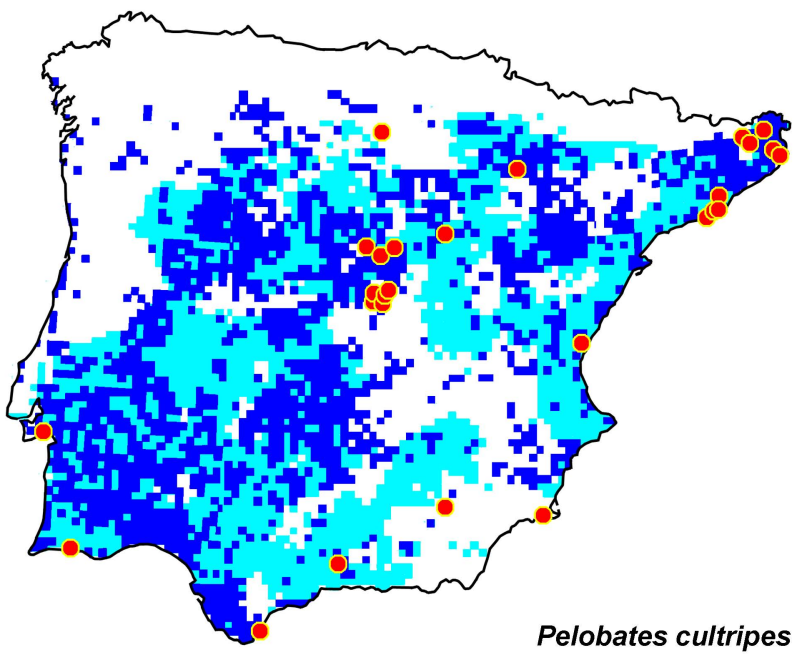




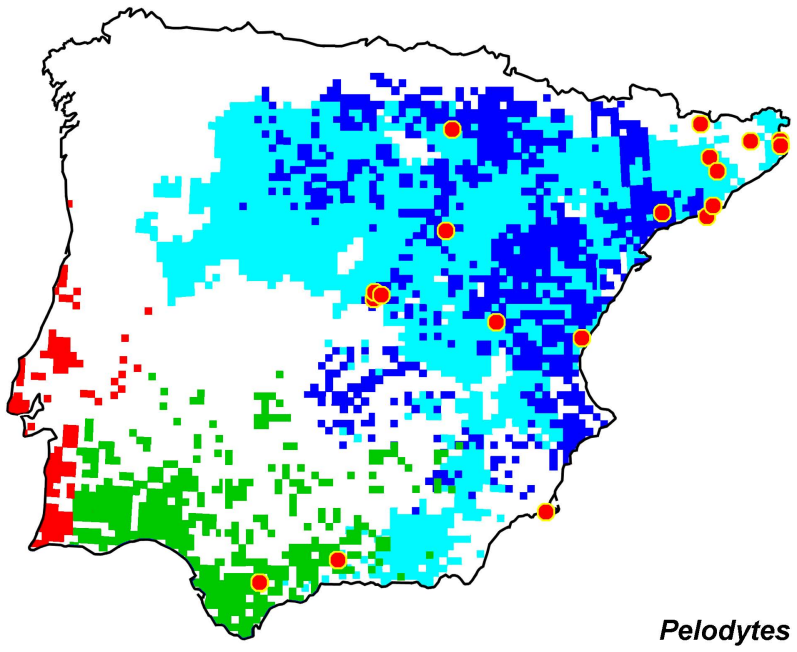




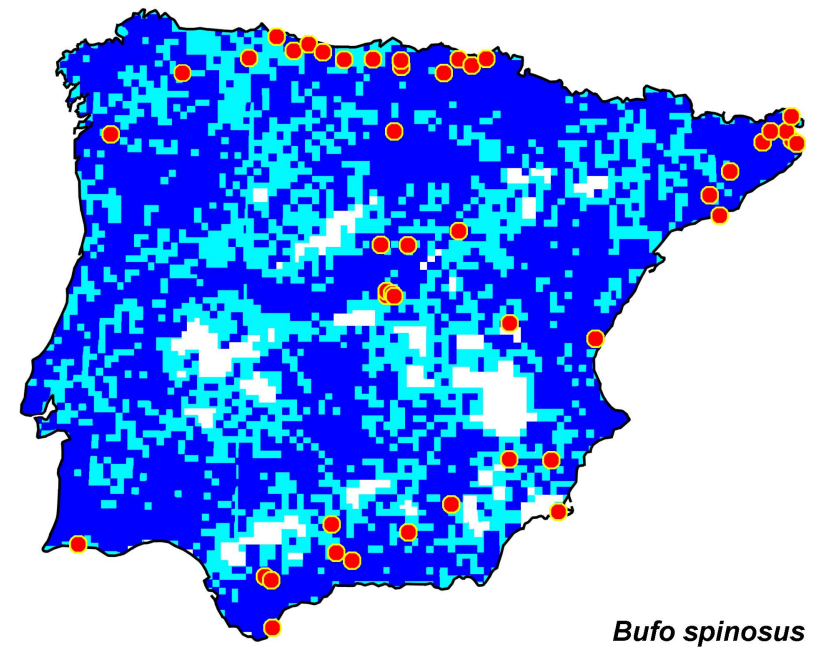




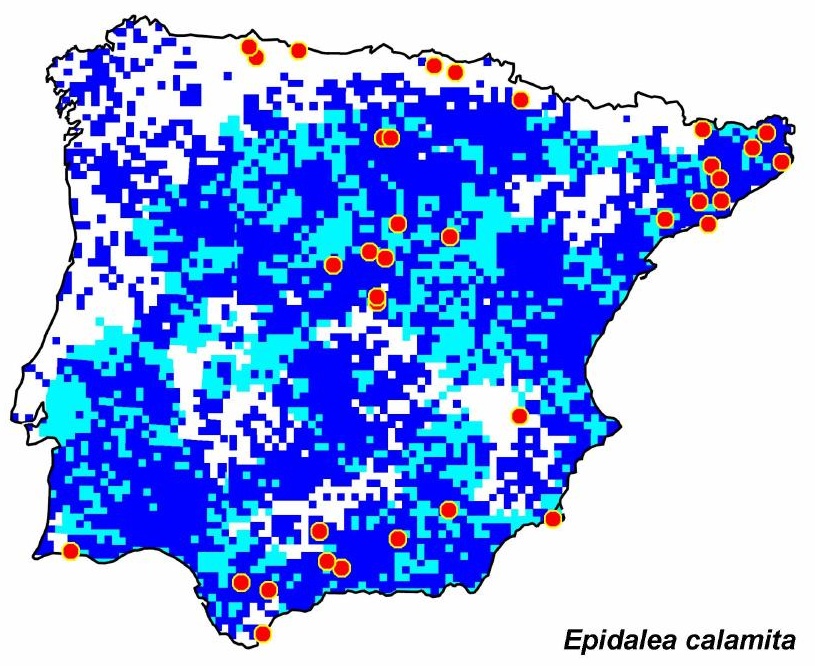




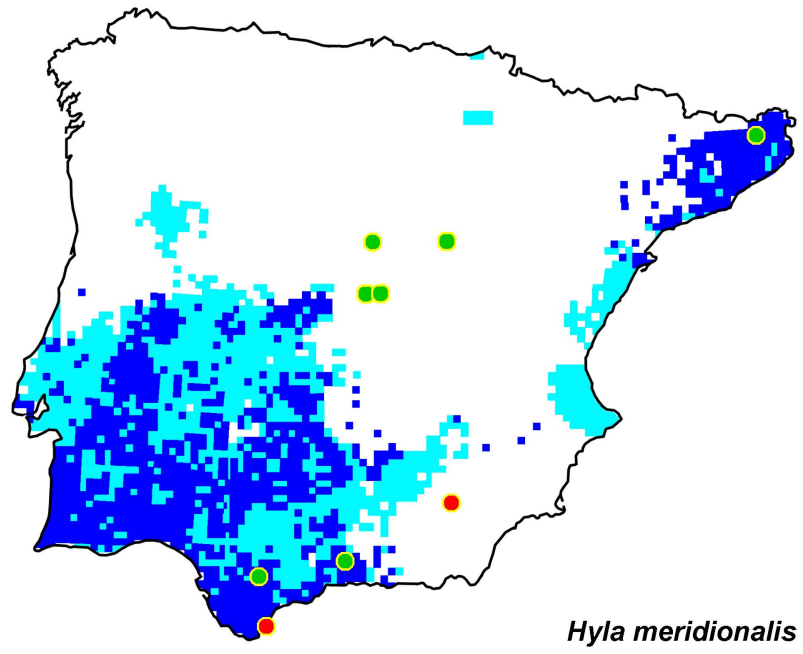




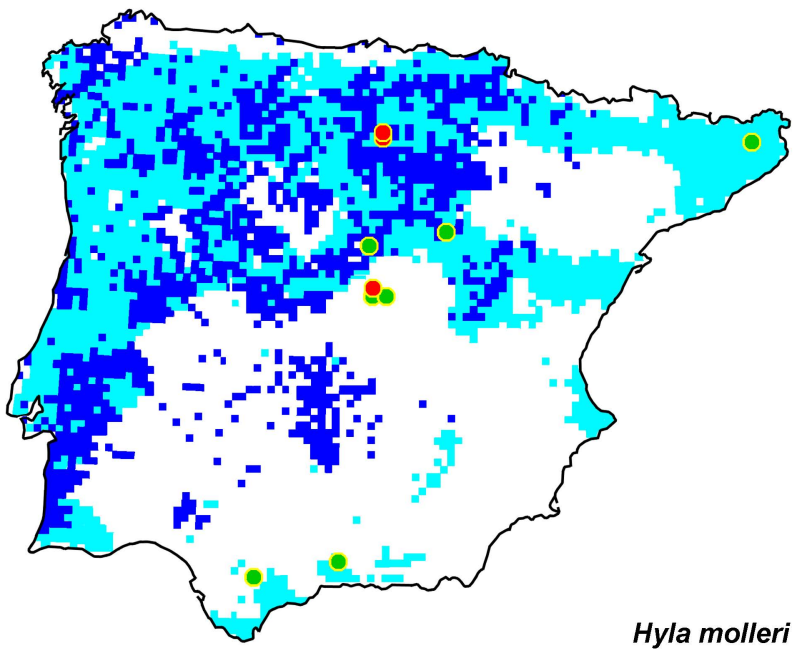




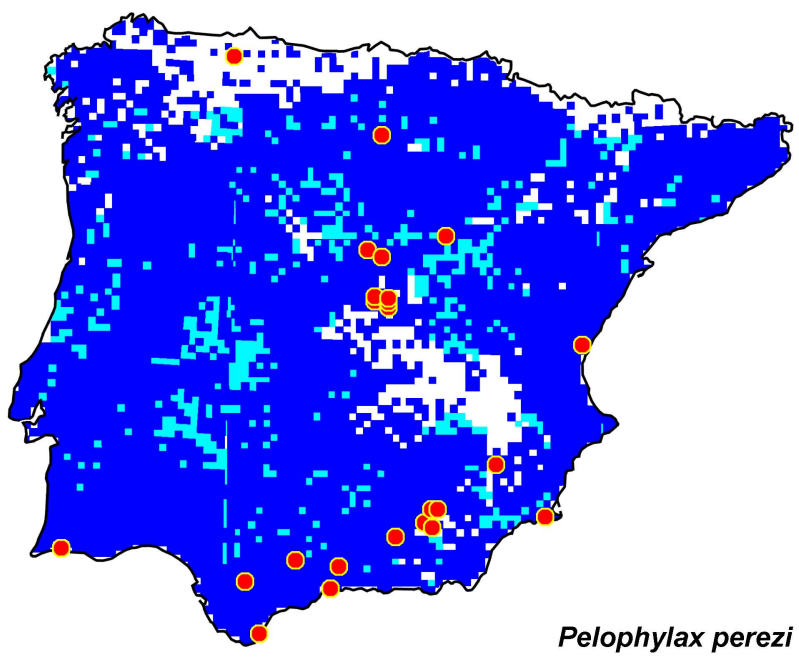




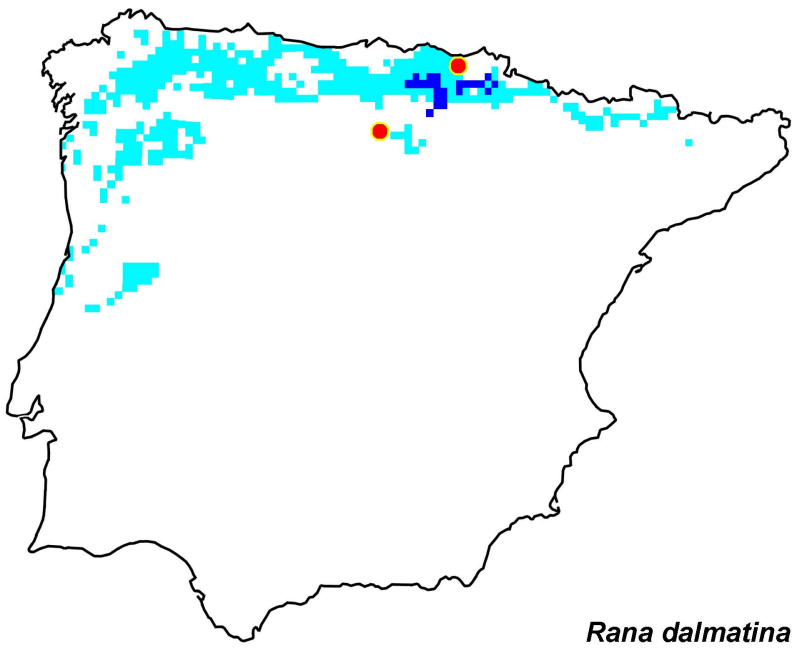




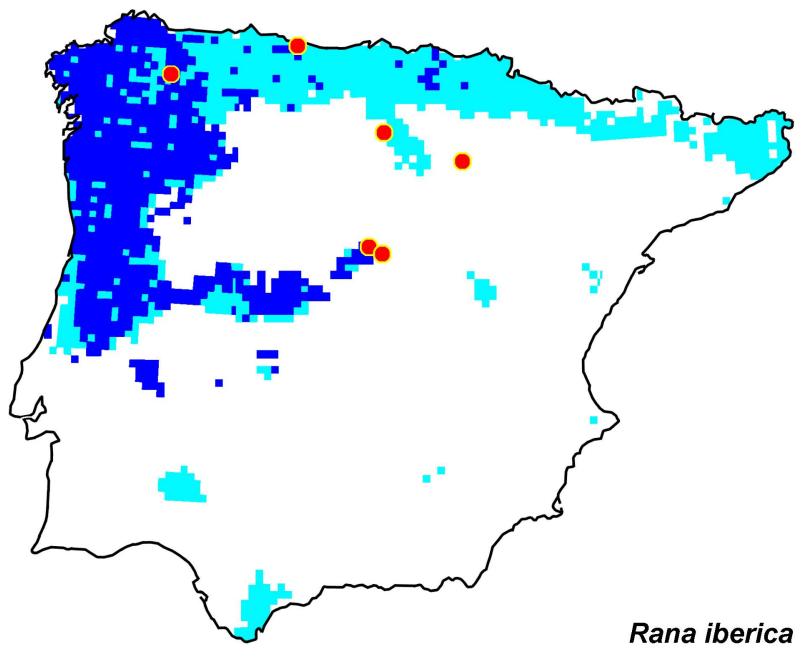




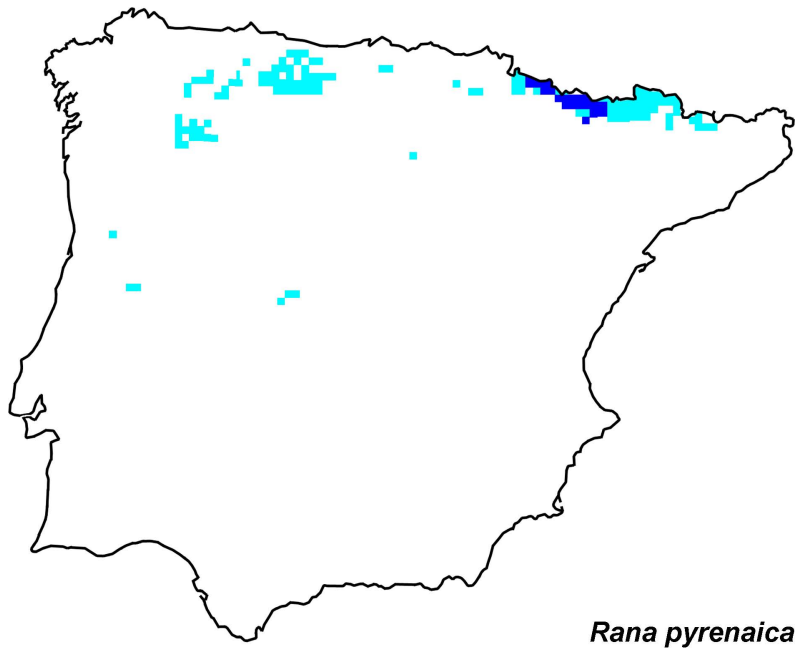




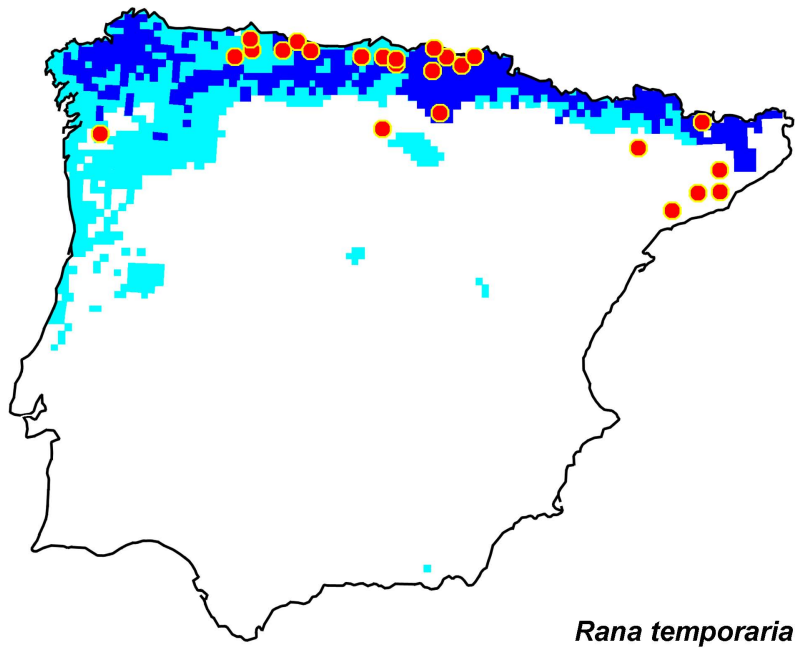




\begin{tabular}{|c|c|c|c|c|c|c|c|c|c|c|c|c|c|c|c|c|c|c|c|c|c|}
\hline TAXON & UTM & $\mathrm{km} 2$ & BIO1 & B1O2 & $\mathrm{BIO3}$ & B104 & B105 & B106 & B107 & B108 & B109 & BIO10 & BIO11 & BIO12 & B1013 & B1014 & 81015 & B1016 & B1017 & B1018 & \begin{tabular}{|l|} 
BIO19 \\
\end{tabular} \\
\hline Alytes cisternasii & 29SMD70 & 101,00 & 148,41 & 71,26 & 40,70 & 3610,41 & 242,95 & 69,60 & 173,35 & 110,39 & 191,61 & 195,28 & 102,18 & 819,75 & 125,51 & 4,69 & 64,12 & 366,94 & 35,28 & 37,52 & 344,42 \\
\hline Alytes cisternasii & $295 \mathrm{SM} 80$ & 101,00 & 155,19 & 74,75 & 40,26 & 3803,25 & 256,91 & 73,98 & \begin{tabular}{|l|l|}
182,93 \\
\end{tabular} & \begin{tabular}{|l|l|}
115,18 \\
\end{tabular} & 201,22 & 205,14 & 107,34 & 778,76 & 117,50 & 4,20 & 63,64 & 346,89 & 32,86 & 35,49 & 330,61 \\
\hline Alytes cisternasii & $295 \mathrm{SM} 81$ & 101,00 & 150,37 & 72,32 & 40,14 & 3700,78 & 248,21 & 70,74 & 177,47 & 111,64 & 195,10 & 198,73 & 103,66 & 795,14 & 120,81 & 4,60 & 62,82 & $\begin{array}{l}352,40 \\
352,42\end{array}$ & 34,73 & 37,59 & 335,04 \\
\hline Alytes cisternasii & 29SMD84 & 101,00 & 154,34 & 64,55 & 40,99 & 3237,16 & 236,09 & 80,47 & 155,62 & 120,55 & \begin{tabular}{|l|l|}
192,73 \\
\end{tabular} & 195,36 & 112,40 & 698,05 & 113,05 & 4,00 & 62,10 & 309,29 & 30,02 & 35,43 & 289,73 \\
\hline Alytes cisternasii & 29SMD98 & 58,00 & 154,47 & 68,99 & 42,01 & 3275,73 & 239,79 & 77,49 & 162,30 & \begin{tabular}{|l|}
119,74 \\
\end{tabular} & \begin{tabular}{|l|l|}
193,37 \\
\end{tabular} & \begin{tabular}{|l|l|}
195,76 \\
\end{tabular} & 111,73 & 752,49 & 116,18 & 5,30 & 59,35 & 321,62 & 37,58 & 44,10 & 307,90 \\
\hline Alytes cisternasii & 29SNB12 & 83,00 & 163,34 & 86,34 & 44,66 & 3628,14 & 271,70 & 80,42 & 191,27 & 128,07 & 207,95 & 212,23 & 119,51 & 516,43 & 83,19 & 1,00 & 68,47 & 241,95 & 18,35 & 19,41 & 231,30 \\
\hline Alytes cisternasii & 29 SNB13 & 51,00 & 165,90 & 86,91 & 44,25 & 3706,64 & 276,06 & 81,89 & 194,17 & 129,33 & 211,51 & 215,80 & 121,01 & 513,94 & 82,24 & 1,00 & 68,10 & 240,26 & 18,46 & 19,60 & 229,58 \\
\hline Alytes cisternasii & 29SNB14 & 19,00 & 166,42 & 87,92 & 44,00 & 3803,89 & 279,44 & 81,19 & 198,25 & 128,75 & 213,33 & 217,72 & 120,36 & 522,64 & 82,56 & 1,00 & 67,69 & 243,06 & 18,89 & 19,89 & 232,81 \\
\hline Alytes cisternasii & 29SNB21 & 101,00 & 166,71 & 86,81 & 43,34 & 3809,92 & 278,55 & 80,58 & \begin{tabular}{|l|l|}
197,97 \\
\end{tabular} & \begin{tabular}{|l|}
129,16 \\
\end{tabular} & 214,36 & 218,16 & 120,69 & $\begin{array}{l}498,75 \\
\end{array}$ & 80,82 & 0,90 & 69,59 & 237,30 & 16,71 & 17,97 & 225,62 \\
\hline Alytes cisternasii & 29SNB22 & 101,00 & 159,48 & 88,59 & 43,57 & 3863,33 & 274,21 & 73,06 & 201,15 & 121,65 & 207,70 & 211,89 & 113,22 & 545,39 & 86,20 & 1,08 & 67,90 & 254,36 & 19,78 & 20,69 & 243,97 \\
\hline Alytes cisternasii & $295 N B 23$ & 101,00 & 160,57 & 89,23 & 43,49 & 3904,89 & 276,69 & 73,70 & 202,99 & 122,19 & 209,27 & 213,56 & 113,87 & 548,35 & 86,14 & 1,15 & 67,36 & 254,48 & 20,17 & 21,04 & 244,38 \\
\hline Alytes cisternasii & 29SNB24 & 100,00 & 162,44 & 89,79 & 43,41 & 3953,88 & 280,03 & 75,26 & 204,76 & 123,45 & 211,84 & 216,11 & 115,18 & 546,36 & 85,42 & 1,08 & 67,06 & 252,79 & 20,07 & 20,88 & 242,88 \\
\hline Alytes cisternasii & 29 SNB25 & 100,00 & 164,72 & 90,25 & 43,24 & 3981,16 & 283,08 & $\begin{array}{ll}77,15 \\
\end{array}$ & 205,94 & 125,25 & 214,24 & 218,62 & 116,82 & 543,22 & 84,29 & 1,00 & 66,73 & 250,47 & 20,04 & 20,94 & 240,79 \\
\hline Alytes cisternasii & 29SNB27 & 101,00 & 164,85 & 91,51 & 43,02 & 4077,94 & 286,17 & 76,15 & 210,02 & 124,01 & 215,44 & 219,99 & 115,74 & 565,10 & 86,24 & 1,72 & 65,40 & 256,79 & 22,20 & 22,99 & 248,03 \\
\hline Alytes cisternasii & $295 N B 28$ & 101,00 & 163,45 & 91,99 & 42,92 & 4134,08 & 286,67 & 74,44 & 212,23 & 121,86 & 214,92 & 219,54 & 113,86 & 584,01 & 88,30 & 2,00 & 64,69 & 263,26 & 23,58 & 24,30 & 255,08 \\
\hline Alytes cisternasii & 29SNB29 & 101,00 & 164,16 & 92,20 & 42,84 & 4175,37 & 288,44 & 74,92 & 213,52 & 122,01 & 216,06 & 220,71 & 113,97 & 590,88 & 88,76 & 2,00 & 64,15 & 265,09 & 24,11 & 24,86 & 257,27 \\
\hline Alytes cisternasii & 29 SNB31 & 100,00 & 169,93 & 88,04 & 42,32 & 3993,05 & 285,92 & 80,82 & 205,09 & \begin{tabular}{|l|l|l|}
130,58 \\
\end{tabular} & 220,37 & 224,08 & 121,95 & 491,29 & 79,47 & 0,87 & 69,85 & 235,53 & 15,71 & 17,27 & 223,19 \\
\hline Alytes cisternasii & 29 SNB32 & 100,00 & 157,21 & 90,43 & 42,89 & 4051,06 & 276,71 & 68,08 & 208,63 & 117,62 & 208,32 & 212,39 & 109,04 & 568,47 & 89,90 & 1,46 & 67,30 & 263,84 & 21,14 & 22,08 & 253,54 \\
\hline Alytes cisternasii & 29SNB33 & 101,00 & 153,17 & 91,73 & 42,96 & 4104,42 & 275,13 & 63,85 & 211,28 & 113,12 & 205,01 & 209,21 & 104,51 & 597,67 & 93,49 & 1,78 & 66,16 & 273,78 & 23,43 & 24,04 & 264,44 \\
\hline Alytes cisternasii & 29SNB35 & 101,00 & 167,48 & 91,98 & 42,96 & 4111,58 & 289,42 & 77,29 & 212,13 & 126,46 & 219,01 & 223,26 & 118,07 & 528,77 & 82,62 & 1,01 & 67,01 & 244,88 & 19,08 & 20,13 & 235,08 \\
\hline Alytes cisternasii & $295 N B 36$ & 101,00 & 165,93 & 92,97 & 42,95 & 4165,94 & 289,95 & 75,37 & 214,58 & 124,09 & 217,99 & 222,40 & 115,90 & 546,52 & 84,50 & 1,23 & 66,02 & 250,43 & 20,62 & 21,50 & 241,41 \\
\hline \begin{tabular}{|l} 
Alytes cisternasii \\
\end{tabular} & 295NB37 & 100,00 & 164,94 & 93,73 & 42,83 & 4219,59 & $\begin{array}{l}290,82 \\
290\end{array}$ & 74,07 & 216,75 & $\begin{array}{l}\mid 122,57 \\
12,0\end{array}$ & 217,72 & 222,23 & 114,44 & \begin{tabular}{|l|l|l|l|}
561,68 \\
\end{tabular} & 85,97 & 1,82 & $\begin{array}{l}0,0<17 \\
65,17\end{array}$ & 254,92 & 22,07 & 22,89 & 246,65 \\
\hline Alytes cisternasii & $295 N B 38$ & 101,00 & 165,56 & 94,17 & 42,70 & 4258,45 & 292,73 & 74,44 & 218,29 & 122,77 & 218,79 & 223,35 & 114,49 & 567,57 & 86,11 & 2,00 & 64,57 & 256,00 & 22,76 & 23,43 & 248,21 \\
\hline Alytes cisternasii & 295NB39 & 100,00 & 165,48 & 94,48 & 42,38 & 4301,43 & 293,85 & 74,15 & 219,70 & 122,07 & 219,27 & 223,98 & 114,02 & 576,49 & 86,88 & 2,00 & 64,22 & 258,47 & 23,19 & 24,02 & 251,19 \\
\hline Alytes cisternasii & 29 SNB41 & 101,00 & 170,42 & 89,54 & 42,32 & 4071,24 & 288,31 & 79,58 & 208,73 & 130,01 & 221,89 & 225,72 & 121,66 & 494,19 & 80,91 & 1,00 & 69,76 & 237,45 & 15,99 & 17,53 & 224,66 \\
\hline Alytes cisternasii & 295NB42 & 101,00 & 163,34 & 91,49 & 42,31 & 4153,20 & 284,97 & 71,88 & 213,09 & 122,27 & 215,89 & 219,81 & 113,77 & \begin{tabular}{|l|l|}
536,63 \\
\end{tabular} & 86,44 & 1,15 & 68,24 & 252,48 & 18,58 & 19,76 & 241,22 \\
\hline Alytes cisternasii & 295NB43 & 100,00 & $\begin{array}{l}100,34 \\
158,19\end{array}$ & $\begin{array}{l}31,49 \\
93,15\end{array}$ & $\begin{array}{l}42,11 \\
42,49\end{array}$ & 4 & $\mid \frac{204,91}{282,90}$ & $\begin{array}{l}\mid, 1,0 \\
66,29\end{array}$ & 212,03 & $\begin{array}{ll}12,27 \\
116,56\end{array}$ & $\begin{array}{l}211,09 \\
211,49\end{array}$ & $\mid 215,67$ & 108,04 & | 530,05 & $\begin{array}{l}00,44 \\
90,55 \\
\end{array}$ & $\begin{array}{l}1,113 \\
1,33\end{array}$ & $\begin{array}{l}\mid 00,44 \\
66,86 \\
\end{array}$ & \begin{tabular}{|l|}
253,40 \\
263,84
\end{tabular} & $\begin{array}{l}10,00 \\
21,04\end{array}$ & 21,89 & 253,89 \\
\hline Alytes cisternasii & 29SNB44 & 101,00 & 165,33 & 93,32 & 42,45 & 4231,12 & 290,31 & 73,10 & 217,20 & 123,17 & 218,62 & 222,87 & 114,75 & 534,47 & 84,80 & 1,00 & 67,20 & 248,69 & 18,80 & 19,94 & 238,53 \\
\hline Alytes cisternasii & 29SNB46 & 100,00 & 161,56 & 95,68 & 42,42 & 4340,36 & 291,18 & 68,73 & 222,45 & 118,32 & 216,23 & 220,75 & 109,95 & 570,36 & 88,19 & 1,79 & 65,12 & 258,97 & 22,44 & 23,13 & 250,85 \\
\hline Alytes cisternasii & 29SNB47 & 100,00 & 163,18 & 96,28 & 42,48 & 4369,40 & 293,99 & 70,04 & 223,95 & 119,40 & 218,06 & 222,73 & 111,14 & 569,30 & 87,22 & 2,00 & 64,67 & 257,01 & 22,82 & 23,42 & 249,30 \\
\hline Alytes cisternasii & $295 N B 48$ & 101,00 & 167,66 & 96,33 & 42,62 & 4369,44 & 298,26 & 74,38 & 223,87 & 123,46 & 222,40 & 226,92 & 115,25 & 551,81 & 83,96 & 2,00 & 64,54 & 248,81 & 21,95 & 22,84 & 241,24 \\
\hline Alytes cisternasii & 29SNB49 & 101,00 & 168,13 & 96,77 & 42,39 & 4402,72 & 299,73 & 74,62 & 225,11 & \begin{tabular}{|l|l|}
123,45 \\
\end{tabular} & 223,21 & 227,86 & 115,34 & 557,31 & 84,01 & 2,00 & 64,01 & 249,32 & 22,72 & 23,49 & 242,42 \\
\hline Alytes cisternasii & $295 N B 51$ & 100,00 & 169,62 & 90,95 & 42,34 & 4135,12 & 289,13 & 77,28 & 211,85 & 128,81 & 221,94 & 225,75 & 120,05 & 502,62 & 83,26 & 1,00 & 69,36 & 241,57 & 16,27 & 18,05 & 228,53 \\
\hline Alytes cisternasii & 29SNB52 & 101,00 & 164,37 & 92,97 & 42,21 & 4241,13 & 288,17 & 71,28 & 216,89 & 122,52 & 218,10 & 222,13 & 113,81 & 533,03 & 86,93 & 1,00 & 68,19 & 251,74 & 17,99 & 19,46 & 240,04 \\
\hline Alytes cisternasii & 29 SNB53 & 100,00 & 164,55 & 94,13 & 42,0 & 4297,53 & 290,68 & 70,92 & 219,76 & 121,89 & 218,86 & 223,08 & 113,30 & 535,86 & 86,47 & 1,0 & 67,62 & 251,14 & 18,31 & 19,68 & 240,12 \\
\hline Alytes cisternasii & 29 SNB54 & 101,00 & 161,55 & 95,59 & 42,24 & 4358,38 & 290,54 & 67,43 & 223,11 & 118,29 & 216,73 & 220,94 & 109,71 & 557,76 & 88,57 & 1,26 & 66,41 & 257,43 & 20,39 & 21,41 & 247,70 \\
\hline Alytes cisternasii & 29 SNB55 & 100,00 & 162,91 & 96,57 & 42,24 & 4398,71 & 293,67 & 68,26 & 225,41 & 118,99 & 218,50 & 222,80 & 110,58 & 555,57 & 87,30 & 1,36 & 65,95 & 254,66 & 20,70 & 21,57 & 245,62 \\
\hline Alytes cisternasii & 295NB56 & 101,00 & 159,93 & 97,96 & 42,07 & 4473,81 & 293,72 & 64,86 & 228,86 & 115,26 & 216,56 & 221,03 & 106,94 & 579,15 & 89,53 & 2,00 & 64,59 & 261,53 & 23,14 & 23,72 & 253,80 \\
\hline Alytes cisternasii & 29 SNB57 & 101,00 & 165,13 & 98,47 & 42,25 & 4481,33 & 299,41 & 69,77 & 229,64 & 119,95 & 221,66 & 226,18 & 111,69 & 554,76 & 85,12 & 1,99 & 64,53 & 250,30 & 21,91 & 22,56 & 242,74 \\
\hline Alytes cisternasii & 29SNB59 & 100,00 & 168,86 & 99,21 & 42,32 & 4520,42 & 304,48 & 73,29 & 231,19 & 122,86 & 225,62 & 230,19 & 114,75 & 547,27 & 82,53 & 2,00 & 63,86 & 244,05 & 22,02 & 22,64 & 237,48 \\
\hline Alytes cisternasii & $295 N B 62$ & 100,00 & 164,87 & 94,21 & 42,18 & 4299,61 & 290,15 & 70,25 & 219,91 & 122,35 & 219,43 & 223,56 & 113,72 & 533,42 & 87,70 & $\begin{array}{l}1,01 \\
1,01\end{array}$ & 68,11 & 252,20 & 17,90 & 19,49 & 240,04 \\
\hline Alytes cisternasii & $29 \mathrm{SNB63}$ & 101,00 & 160,97 & 95,93 & 42,07 & 4400,78 & 290,09 & 65,53 & 224,56 & 117,48 & 216,88 & 221,05 & 108,72 & \begin{tabular}{|l|l|}
558,03 \\
\end{tabular} & 89,99 & 1,27 & 66,82 & 259,41 & 19,80 & 21,14 & 248,62 \\
\hline Alytes cisternasii & 295NB64 & 100,00 & 158,55 & 97,46 & 42,01 & 4485,71 & 291,07 & 62,47 & 228,60 & $\begin{array}{l}114,12 \\
114,12\end{array}$ & 215,45 & 219,80 & 105,29 & 576,21 & 91,25 & $\begin{array}{l}1,79 \\
1,79\end{array}$ & $\begin{array}{l}65,55 \\
6525\end{array}$ & 263,75 & 21,95 & 23,02 & 254,29 \\
\hline Alytes cisternasii & 29 SNB65 & 100,00 & 162,17 & 98,47 & 42,03 & 4511,04 & 296,07 & 65,55 & 230,53 & 117,11 & 219,31 & 223,70 & 108,42 & 559,05 & 87,77 & 1,7 & 65,36 & 255,09 & 20,98 & 22,00 & 246,12 \\
\hline Alytes cisternasii & 29 SNB66 & 101,00 & 162,98 & 99,69 & 42,06 & 4555,55 & 299,11 & 66,03 & 233,08 & 117,41 & 220,63 & 225,06 & 108,82 & 559,86 & 86,75 & 1,99 & 64,56 & 253,15 & 21,71 & 22,47 & 245,11 \\
\hline \begin{tabular}{|l} 
Alytes cisternasii \\
\end{tabular} & 295NB67 & 100,00 & \begin{tabular}{|l|}
165,05 \\
16,05
\end{tabular} & \begin{tabular}{|l|}
100,68 \\
100
\end{tabular} & $\frac{42,0}{42,1}$ & 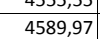 & $\mid \begin{array}{l}302,86 \\
302,1\end{array}$ & $\begin{array}{l}60,03 \\
67,74\end{array}$ & $\begin{array}{l}23,00 \\
235,12\end{array}$ & $\begin{array}{l}\mid 11,41 \\
118,94\end{array}$ & $\begin{array}{l}\mid 223,03 \\
223,03\end{array}$ & 227,53 & \begin{tabular}{|l|l|l|l|l|l}
110,40 \\
\end{tabular} & $\begin{array}{l}553,00 \\
553,32\end{array}$ & $\mid 80,75$ & 2,00 & $\begin{array}{l}4,30,32 \\
64,\end{array}$ & 248,44 & 21,63 & 22,47 & 2441,14 \\
\hline Alytes cisternasii & 29SNB68 & 101,00 & 164,04 & 101,89 & 42,18 & 4647,18 & 304,28 & 66,41 & 237,87 & 117,29 & 222,77 & 227,32 & 108,81 & 564,32 & 85,29 & 2,00 & 63,15 & 250,55 & 23,05 & 23,58 & 244,48 \\
\hline Alytes cisternasii & 29SNB69 & 101,00 & 167,56 & 102,06 & 42,17 & 4654,46 & 307,85 & 69,73 & 238,13 & 120,29 & 226,15 & 230,81 & 111,92 & 549,62 & 82,76 & 2,00 & 63,20 & 243,19 & 22,15 & 23,03 & 237,45 \\
\hline Alytes cisternasii & 29SNB72 & 101,00 & 158,56 & 95,96 & 42,03 & 4413,77 & 287,27 & 62, & 224,82 & 114,93 & 214,69 & 218,96 & 106,39 & 571,05 & 92,86 & 1,49 & 66,85 & 265,98 & 20,14 & 21,88 & 254,31 \\
\hline Alytes cisternasii & 29SNB73 & 101,00 & 155 & 97 & 42,01 & 451 . & 287 & 58 & 229, & \begin{tabular}{|l|l|l|}
110,50 \\
\end{tabular} & 212,56 & 216,92 & 102,06 & 594,00 & 94,58 & 1,2 & 65,52 & 272,01 & 22,33 & 23,79 & 261,73 \\
\hline Alytes cisternasii & 29SNB74 & 100,00 & | & 98,99 & 42,00 & 4582,57 & 290,88 & 57,98 & 232,90 & 109,87 & 213,81 & 218,20 & 101,36 & 595,08 & 93,54 & 2,00 & 64,75 & 269,91 & 23,20 & 24,36 & 260,62 \\
\hline Alytes cisternasii & 295NB75 & 101,00 & 159,78 & 100,28 & 42,00 & 4621,93 & 297,04 & 61,54 & 235,50 & 113,35 & 218,43 & 222,83 & 105,05 & 572,95 & 89,41 & 2,00 & 64,65 & 259,20 & 22,04 & 23,10 & 250,47 \\
\hline Alytes cisternasii & 29 SNB76 & 100,00 & 161,25 & 101,73 & 42,01 & 4676,71 & 301,01 & 62,32 & 238,69 & 114,21 & 220,53 & 224,98 & 105,82 & 567,53 & 87,48 & 2,00 & 63,97 & 254,77 & 22,03 & 23,01 & 247,03 \\
\hline Alytes cisterna & 29 SNB77 & 101,00 & 162,11 & 103,12 & 42,01 & 4726,24 & 304,2 & 62, & 241,60 & 114,45 & 221,96 & 226,48 & 106,06 & 566,85 & 86,19 & 2,00 & 63,50 & 252,11 & 22,82 & 23,23 & 245,35 \\
\hline Alytes cisternasii & 29SNB78 & 100,00 & & & 42,08 & $4 / 6$ & 307 & 63,36 & 244,05 & 115,13 & 223,53 & 228,26 & 106,63 & 564,42 & 85,12 & 2,1 & 63,00 & 248,94 & 23,12 & 23,48 & 243,17 \\
\hline Alytes cisternasii & 29SNB79 & 100,00 & $\begin{array}{l}166,09 \\
166,4\end{array}$ & 105,06 & 42,25 & 4779,42 & 311,19 & 66,12 & 245,07 & 117,61 & 226,48 & 231,18 & 109,12 & 553,21 & 83,07 & 2,00 & 62,53 & 242,47 & 22,90 & 23,34 & 237,38 \\
\hline Alytes cisternasii & 295NB81 & 101,00 & 162,83 & $\begin{array}{l}94,57 \\
94\end{array}$ & 42,07 & 4366,06 & 287,94 & 66,33 & 221,61 & \begin{tabular}{|l|l|}
119,65 \\
\end{tabular} & 218,25 & 222,48 & 111,04 & 548,10 & 91,22 & 1,09 & 67,97 & 259,42 & 18,07 & 20,46 & 245,71 \\
\hline Alytes cisternasii & 29 SNB82 & 101,00 & 157,12 & 96,63 & 41,94 & 4496,11 & 287,34 & 59,58 & 227,76 & 112,64 & 214,29 & 218,59 & 103,89 & 581,80 & 93,91 & 1,63 & 66,26 & 269,03 & 20,85 & 22,90 & 257,09 \\
\hline Alytes cistern & 29SNB83 & 99,00 & 153 & 98,4 & 41,9 & 4596, & 288, & 55,5 & 232,47 & 108,30 & 212,29 & 216 & 99 & 603, & 95 & 2,03 & 64,86 & 274,47 & 22,96 & 24,69 & 264,03 \\
\hline \begin{tabular}{|l} 
Alytes cisternasii \\
\end{tabular} & 295NB84 & 101,00 & 156,82 & 99,72 & $\begin{array}{l}41,959 \\
41,99\end{array}$ & 4649,05 & 293,62 & 58,02 & 235,60 & 110,58 & 215,99 & 220,47 & \begin{tabular}{|l|l|}
101,90 \\
\end{tabular} & 587,33 & \begin{tabular}{ll|}
91,97 \\
1
\end{tabular} & 2,00 & $\begin{array}{l}4,306 \\
64,52\end{array}$ & 265,77 & 22,60 & 24,20 & 255,97 \\
\hline
\end{tabular}




\begin{tabular}{|c|c|c|c|c|c|c|c|c|c|c|c|c|c|c|c|c|c|c|c|c|c|}
\hline TAXON & UTM & $\mathrm{km} 2$ & B101 & B102 & $\mathrm{BIO3}$ & B104 & B105 & B106 & B107 & B108 & B109 & BIO10 & B1011 & BIO12 & B1013 & B1014 & 81015 & B1016 & B1017 & B1018 & $\begin{array}{l}\text { BIO19 } \\
\end{array}$ \\
\hline Alytes cisternasii & 29SNB85 & 101,00 & 160,15 & 101,33 & 42,00 & 4701,10 & 299,33 & 60,68 & 238,64 & $113,07 \mid$ & 219,98 & 224,36 & 104,50 & 569,56 & 88,36 & 2,00 & 64,34 & 256,54 & 21,87 & 23,07 & 247,50 \\
\hline Alytes cisternasii & 295NB86 & 100,00 & 162,07 & 103,04 & 42,00 & 4757,32 & 303,96 & 61,80 & 242,16 & 114,11 & 222,48 & 226,92 & 105,67 & 561,37 & 85,89 & 2,00 & 63,65 & 250,74 & 22,00 & 23,10 & 242,69 \\
\hline Alytes cisternasii & 29SNB87 & 101,00 & 164,19 & 104,66 & 42,02 & 4802,14 & 308,43 & 63,30 & 245,14 & 115,60 & 225,09 & 229,45 & 107,14 & 552,20 & 83,83 & 2,00 & 63,11 & 244,63 & 22,16 & 23,00 & 237,50 \\
\hline Alytes cisternasii & 29SNB89 & 100,00 & 165,90 & 107,83 & 42,29 & 4898,78 & 315,21 & 63,79 & 251,42 & \begin{tabular}{|l|l|}
115,99 \\
\end{tabular} & 227,84 & 232,60 & 107,52 & 549,89 & 82,33 & 2,00 & 61,86 & 238,70 & 23,05 & 23,82 & 233,98 \\
\hline Alytes cisternasii & 29SNB91 & 101,00 & 158,51 & 95,20 & 41,90 & 4472,75 & 285,95 & 60,85 & 225,10 & \begin{tabular}{|l|l|}
114,12 \\
\end{tabular} & 215,32 & 219,49 & \begin{tabular}{ll|}
105,46 \\
\end{tabular} & 573,59 & 93,32 & 1,59 & 66,76 & 267,24 & 19,59 & 22,46 & 253,81 \\
\hline Alytes cisternasii & 29 SNB92 & 100,00 & 150,90 & 97,38 & 41,39 & 4624,20 & 284,06 & 52,19 & 231,87 & 105,03 & 209,76 & 213,97 & 96,25 & 620,53 & 97,73 & 1,99 & 64,87 & 281,73 & 23,16 & 25,60 & 270,38 \\
\hline Alytes cisternasii & 29 SNB93 & 101,00 & 154,65 & 98,68 & 41,62 & 4663,30 & 289,92 & 55,33 & 234,59 & 108,13 & 214,02 & 218,37 & 99,52 & 599,00 & 93,82 & 2,02 & 64,50 & 271,15 & 22,54 & 24,85 & 260,13 \\
\hline Alytes cisternasii & 29SNB94 & 100,00 & 159,33 & 99,98 & 41,80 & 4709,88 & 296,68 & 59,39 & 237,29 & 112,16 & 219,24 & 223,63 & 103,63 & 571,80 & 89,02 & 2,00 & 64,30 & 258,27 & 21,49 & 23,73 & 247,61 \\
\hline Alytes cisternasii & 29SNB95 & 100,00 & 162,10 & 101,68 & 41,85 & 4764,64 & 301,97 & 61,28 & 240,69 & 114,21 & 222,62 & 226,94 & 105,44 & 557,84 & 85,81 & 2,00 & 63,79 & 250,25 & 21,36 & 23,25 & 240,45 \\
\hline Alytes cisternasii & 29SNB96 & 101,00 & 163,94 & 103,58 & 42,00 & 4820,32 & 306,60 & 62,39 & 244,21 & 115,39 & 225,06 & 229,47 & 106,53 & 548,79 & 83,65 & 2,00 & 63,29 & 244,15 & 21,60 & 23,07 & 235,36 \\
\hline Alytes cisternasii & 29SNB97 & 100,00 & 164,92 & 105,55 & 42,00 & 4874,85 & 310,72 & 62,35 & 248,37 & 115,44 & 226,73 & 231,23 & 106,64 & 545,94 & 82,66 & 2,00 & 62,55 & 240,46 & 21,97 & 23,29 & 232,84 \\
\hline Alytes cisternasii & 29SNB99 & 101,00 & 165,62 & 110,00 & 42,07 & 5015,02 & 318,32 & 61,18 & 257,14 & 114,36 & 229,15 & 233,73 & 105,83 & 547,67 & 81,68 & 2,00 & 61,23 & 235,78 & 23,44 & 23,94 & 231,03 \\
\hline Alytes cisternasii & 29 SNC17 & 101,00 & 170,53 & 86,68 & 41,03 & 4232,24 & 291,12 & 82,37 & 208,75 & 126,37 & 222,68 & 227,27 & 118,88 & 648,25 & 95,83 & 3,00 & 62,78 & 286,50 & 27,00 & 29,86 & 278,50 \\
\hline Alytes cisternasii & 29SNC18 & 101,00 & 170,36 & 85,57 & 40,95 & 4216,61 & 289,75 & 82,38 & 207,36 & 126,20 & 222,34 & 226,68 & 118,63 & 654,34 & 96,99 & 3,00 & 62,89 & 288,89 & 27,13 & 30,05 & 280,95 \\
\hline Alytes cisternasii & $295 N C 20$ & 100,00 & 163,43 & 92,33 & 42,46 & 4224,95 & 288,91 & 73,92 & 214,99 & 120,64 & 215,90 & 220,69 & 112,66 & 606,74 & 90,73 & 2,30 & 63,70 & 270,56 & 25,52 & 26,30 & 263,18 \\
\hline Alytes cisternasii & $295 N C 21$ & 101,00 & 164,38 & 92,12 & 42,16 & 4247,06 & 290,22 & 74,66 & 215,56 & 121,27 & 217,10 & 221,97 & 113,42 & 612,68 & 91,38 & 2,49 & 63,49 & 272,22 & 25,95 & 26,81 & 265,08 \\
\hline Alytes cisternasii & 29 SNC22 & 99,00 & 166,10 & 91,82 & 42,02 & 4275,52 & 292,11 & 76,33 & 215,78 & 122,47 & 219,16 & 224,04 & 114,58 & 614,17 & 91,45 & 2,67 & 63,12 & 272,23 & 26,19 & 27,32 & 265,21 \\
\hline Alytes cisternasii & $29 \mathrm{SNC23}$ & 101,00 & 168,86 & 91,32 & 42,00 & 4281,82 & 294,32 & 78,88 & 215,44 & 124,77 & 221,79 & 226,66 & 116,93 & 608,71 & 90,47 & 2,99 & 63,12 & 269,53 & 25,78 & 27,64 & 262,48 \\
\hline Alytes cisternasii & 29 SNC30 & 100,00 & 164,80 & 94,76 & 42,16 & 4339,40 & 294,27 & 73,09 & 221,18 & 120,82 & 218,96 & 223,73 & 112,79 & 591,55 & 88,55 & 2,06 & 63,69 & 263,40 & 24,27 & 24,90 & 256,82 \\
\hline Alytes cisternasii & 29SNC31 & 101,00 & 161,27 & 94,95 & 42,00 & 4402,58 & 292,56 & 69,61 & 222,95 & 116,77 & 216,36 & 221,20 & 108,72 & 624,36 & 92,71 & 2,89 & 62,71 & 274,96 & 27,25 & 27,68 & 269,36 \\
\hline Alytes cisternasii & $295 N C 32$ & 101,00 & 164,58 & 94,37 & 41,92 & 4412,68 & 295,47 & 72,80 & 222,67 & 119,62 & 219,70 & 224,62 & 111,69 & 614,58 & 90,98 & 2,73 & 62,64 & 270,49 & 26,43 & 27,17 & 264,92 \\
\hline \begin{tabular}{|l} 
Alytes cisternasii \\
\end{tabular} & $295 N C 33$ & 100,00 & 167,77 & 93,79 & 41,93 & 4408,51 & 297,79 & 76,01 & 221,78 & 122,43 & 222,68 & 227,53 & 1114,64 & 605,45 & 89,46 & 2,95 & $\begin{array}{ll}62,79 \\
\end{array}$ & 266,27 & 25,92 & 26,94 & 260,68 \\
\hline Alytes cisternasii & $295 N C 40$ & 101,00 & 167,25 & 97,05 & 42,15 & 4438,80 & 300,13 & 73,75 & 226,38 & \begin{tabular}{|l|l|}
122,15 \\
\end{tabular} & 222,81 & 227,46 & 114,11 & 570,75 & 85,50 & 2,00 & 63,50 & 253,58 & 23,46 & 24,21 & 247,48 \\
\hline Alytes cisternasii & $295 N C 41$ & 101,00 & 166,46 & 97,10 & 42,00 & 4485,43 & 300,43 & 72,71 & 227,71 & 120,71 & 222,62 & 227,24 & 112,62 & 584,59 & 86,96 & 2,10 & 63,03 & 257,83 & 24,48 & 25,09 & 252,44 \\
\hline Alytes cisternasii & 29 SNC42 & 99,00 & 168,70 & 96,55 & 42,00 & 4483,66 & 302,16 & 75,09 & 227,07 & 122,67 & 224,64 & 229,38 & 114,78 & 580,33 & 85,94 & 2,06 & 62,96 & 255,20 & 24,26 & 25,13 & 250,04 \\
\hline Alytes cisternasii & $295 N C 45$ & 101,00 & 169,94 & 94,46 & 41,41 & 4514,58 & 302,27 & 76,89 & 225,38 & 123,17 & 226,18 & 230,97 & 115,35 & 601,31 & 87,88 & 3,00 & 61,71 & 260,69 & 26,58 & 27,74 & 256,66 \\
\hline Alytes cisternasii & 295NC46 & 100,00 & $\begin{array}{l}10,58,48 \\
168,4\end{array}$ & $\begin{array}{l}34,401 \\
93,61\end{array}$ & $\begin{array}{l}41,4+1 \\
41,02\end{array}$ & $\begin{array}{l}4534,50 \\
4534,77\end{array}$ & $\mid \begin{array}{l}30<, 27 \\
300,59\end{array}$ & 70,03 & 2224,97 & $\begin{array}{ll}123,11 \\
121,42\end{array}$ & $\mid 225,07$ & 229,66 & $\begin{array}{l}\mid 113,53 \\
113,51\end{array}$ & $\mid 619,70$ & $\begin{array}{l}1,000 \\
90,45 \\
\end{array}$ & 3,03 & $\begin{array}{ll}61,34 \\
61,3\end{array}$ & \begin{tabular}{|l|}
$260,03,23$ \\
\end{tabular} & $\begin{array}{l}20,30 \\
27,81\end{array}$ & 29,05 & 263,86 \\
\hline Alytes cisternasii & 29SNC51 & 101,00 & 169,44 & 99,28 & 42,04 & 4569,18 & 306,46 & 73,87 & 232,59 & 122,67 & 226,81 & 231,38 & 114,65 & 560,00 & 83,21 & 2,00 & 62,58 & 245,94 & 23,75 & 24,40 & 240,90 \\
\hline Alytes cisternasii & 295NC56 & 101,00 & $\begin{array}{l}164,47 \\
\end{array}$ & 95,36 & 40,94 & 4653,64 & 300,76 & 70,51 & 230,25 & 116,51 & $\begin{array}{l}222,78 \\
22,78\end{array}$ & 227,54 & 108,55 & 636,12 & $\begin{array}{l}\mid c 0,11 \\
92,18\end{array}$ & 3,69 & \begin{tabular}{|l|l|}
60,01 \\
60
\end{tabular} & 2740,33 & 30,59 & 31,18 & 268,80 \\
\hline Alytes cisternasii & 29 SNC57 & 100,00 & 163,63 & 94,28 & 40,87 & 4652,67 & 298,97 & 70,09 & 228,88 & 115,47 & 221,89 & 226,65 & 107,55 & 653,05 & 94,55 & 4,00 & 59,70 & 276,30 & 32,10 & 32,64 & 275,18 \\
\hline Alytes cisternasii & $295 N C 58$ & 101,00 & 166,18 & 93,38 & 40,73 & 4621,51 & 299,98 & 72,89 & 227,09 & 118,19 & 224,19 & 228,68 & 110,35 & 646,13 & 93,50 & 4,00 & 59,70 & 273,34 & 31,76 & 32,74 & 271,86 \\
\hline \begin{tabular}{|l} 
Alytes cisternasii \\
\end{tabular} & $\begin{array}{l}25 \text { SNNC59 } \\
\end{array}$ & 101,00 & $\begin{array}{l}10,100 \\
166,11\end{array}$ & $\begin{array}{l}30,50 \\
92,51\end{array}$ & $\begin{array}{l}40,31 \\
40,31\end{array}$ & $\begin{array}{l}402,1,1 \\
4606,06\end{array}$ & \begin{tabular}{|l|}
298,89 \\
298,89
\end{tabular} & 73,02 & 225,86 & $\begin{array}{l}\mid 118,19 \\
118,06\end{array}$ & $\begin{array}{l}223,13 \\
223,91\end{array}$ & $\begin{array}{l}228,00 \\
228,27\end{array}$ & $\begin{array}{l}\mid 110,24 \\
110,24\end{array}$ & $\begin{array}{l}\mid \frac{840,13}{657,11} \\
\end{array}$ & $\begin{array}{l}30,00 \\
95,19\end{array}$ & 4,400 & $\begin{array}{ll}59,58 \\
59,\end{array}$ & \begin{tabular}{|l|l|}
277,46 \\
277
\end{tabular} & 32,31 & 33,59 & $\begin{array}{l}71,00 \\
275,99\end{array}$ \\
\hline Alytes cisternasii & $295 \mathrm{SNC62}$ & 101,00 & 169,70 & 101,47 & 42,00 & 4702,51 & 310,90 & 72,32 & 238,58 & 121,60 & 228,84 & 233,60 & 113,19 & 557,38 & 81,73 & 2,03 & 61,72 & 241,28 & 24,33 & 24,76 & 237,62 \\
\hline Alytes cisternasii & 29SNC64 & 100,00 & 167,67 & 99,66 & 41,58 & 4728,05 & 308,14 & 71,10 & 237,04 & 118,99 & 227,06 & 231,73 & 110,79 & 586,38 & 84,68 & 2,98 & 60,50 & 249,87 & 27,36 & 27,77 & 247,77 \\
\hline Alytes cisternasii & 29 SNC68 & 101,00 & 163,25 & 94,70 & 40,3 & 4730,67 & 300,30 & 68,96 & 231,34 & 111,72 & 222,91 & 227,37 & 106,33 & 657,62 & 94,41 & 4,00 & 58,85 & 274,96 & 33,71 & 34,14 & 274,80 \\
\hline Alytes cisternasii & $295 N C 69$ & 100,00 & 165,62 & 94,16 & 40,24 & 4717,41 & 301,63 & 71,25 & 230,38 & 115,59 & 224,87 & 229,36 & 108,58 & 652,73 & $\begin{array}{l}93,69 \\
3\end{array}$ & 4,00 & 58,75 & 272,66 & 33,34 & 34,18 & 272,37 \\
\hline Alytes cisternasii & 29 SNC70 & 101,00 & 166,79 & 105,49 & 42,09 & 4809,92 & 312,99 & 66,70 & 246,29 & 117,83 & 227,47 & 232,23 & 109,28 & 554,83 & 82,57 & 2,00 & 61,93 & 241,11 & 23,42 & 23,73 & 236,96 \\
\hline Alytes cisternasii & $295 N C 71$ & 100,00 & 167,97 & 105,13 & 42,01 & 4818,71 & 314,16 & 68,10 & 246,06 & 118,71 & 228,77 & 233,40 & 110,28 & 553,44 & 81,62 & 2,00 & 61,39 & 238,80 & 23,73 & 24,02 & 235,39 \\
\hline Alytes cisternasii & $29 \mathrm{SNC72}$ & 101,00 & 168,99 & 104,16 & 42,00 & 4819,09 & 314,36 & 69,59 & 244,77 & 119,59 & 229,74 & 234,33 & 111,15 & 554,55 & 80,84 & 2,28 & 61,04 & 237,65 & 24,72 & 25,06 & 234,67 \\
\hline Alytes cisternasii & $29 \mathrm{SNC73}$ & 101,00 & 167,30 & 103,29 & 41,9 & 4840,16 & 312,68 & 68,40 & 244,28 & 117,58 & 228,25 & 233,07 & 109,32 & 571,18 & 81,99 & 3,00 & 59,96 & 242,07 & 27,26 & 27,38 & 240,14 \\
\hline Alytes cisternasii & $295 N C 74$ & 101,00 & $\begin{array}{l}164,58 \\
\end{array}$ & 101,83 & 41,3 & 4855,15 & 309,36 & 66,51 & 242,84 & 114,73 & 226,27 & 230,53 & 106,55 & 594,93 & $\begin{array}{l}84,98 \\
84,\end{array}$ & 3,00 & 59,55 & 250,03 & 28,86 & 28,86 & 249,31 \\
\hline Alytes cisternasii & 29 SNC75 & 100,00 & 164,53 & 100,09 & 41,03 & 4838,18 & 307,66 & 67,28 & 240,38 & 114,29 & 226,21 & 230,19 & 106,54 & 604,28 & 86,00 & 3,00 & 59,13 & 252,46 & 30,18 & 30,18 & 252,28 \\
\hline Alytes cisternasii & $295 N C 76$ & 101,00 & 160,29 & $\begin{array}{l}98,06 \\
98,06\end{array}$ & 40,77 & 4851,99 & 302,55 & $\begin{array}{l}\mid 64,27 \\
64,27\end{array}$ & 238,27 & 104,42 & 223,43 & 226,39 & 102,36 & 641,73 & 91,18 & 3,81 & 58,25 & 266,81 & 33,29 & 33,29 & 266,81 \\
\hline Alytes cisternasii & 29 SNC79 & 101,00 & 163,50 & 95,29 & 40,00 & 4822,36 & 302,59 & 68, & 234,43 & 106,34 & 224,34 & 228,70 & 105,38 & 659,75 & 93,87 & 4,00 & 57,83 & 273,29 & 35,38 & 35,75 & 273,29 \\
\hline Alytes cisternasii & 29 SNC80 & 101,00 & 165,24 & 108,90 & 42,22 & 4951,82 & 316,80 & 62,73 & 254,06 & 114,69 & 227,97 & 232,64 & 106,17 & 558,11 & 82,71 & 2,06 & 61,14 & 239,67 & 24,29 & 24,41 & 236,34 \\
\hline \begin{tabular}{|l} 
Alytes cisternasii \\
\end{tabular} & $295 N C 81$ & $\begin{array}{l}101,00 \\
100\end{array}$ & \begin{tabular}{|l|}
165,59 \\
165
\end{tabular} & $\begin{array}{l}108,62 \\
10,0\end{array}$ & $\begin{array}{l}42,2,0 \\
42,09 \\
\end{array}$ & $\begin{array}{ll}4951,064 \\
4964,21\end{array}$ & $\begin{array}{l}\mid 10,00 \\
317,28\end{array}$ & $\begin{array}{l}0,13 \\
63,29\end{array}$ & $\begin{array}{l}253,009 \\
253,99\end{array}$ & $\begin{array}{l}114,09 \\
11489\end{array}$ & 228,42 & $\begin{array}{l}\mid 53,04 \\
233,08\end{array}$ & \begin{tabular}{|l|l|}
106,27 \\
\end{tabular} & | 5601,88 & 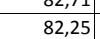 & 2,18 & $\begin{array}{l}60,46 \\
60,4\end{array}$ & 239,21 & 25,24 & 25,36 & 236,65 \\
\hline Alytes cisternasii & $295 N C 82$ & 99,00 & 167,03 & $\begin{array}{l}107,19 \\
\end{array}$ & 42,01 & 4950,75 & 317,14 & 65,50 & 251,64 & 116,11 & 229,61 & 234,29 & 107,79 & 559,42 & 80,96 & 2,64 & 60,02 & 236,69 & 26,40 & 26,50 & 234,41 \\
\hline Alytes cisternasii & $29 \mathrm{SNC} 83$ & 101,00 & 165,01 & 105,72 & 41,89 & 4963,12 & 314,42 & 64,19 & 250,23 & 113,99 & 228,62 & 232,37 & 105,65 & 577,32 & 82,20 & 3,00 & 59,25 & 241,88 & 28,08 & 28,08 & 240,77 \\
\hline Alytes cisternasii & $295 N C 84$ & 101,00 & 163,50 & 103,66 & 41,22 & 4958,27 & 311, & 63,87 & 247,52 & 112,01 & 227,62 & 230,76 & 104,36 & 593,2 & 83,70 & 3, & 58,59 & 246,40 & 29,81 & 29,81 & 246,24 \\
\hline Alytes cisternasii & $29 \mathrm{SNC} 85$ & 100,00 & 163,64 & 101,55 & 41,01 & 13 & 309 & 65 & 244 & 108 & 227 & 230,59 & 104,60 & 598, & 84,16 & 3,00 & 58,12 & 247,69 & 30,76 & 30,76 & 247,69 \\
\hline Alytes cisternasii & $295 N C 86$ & 100,00 & 161,19 & 99,26 & 40,70 & 4930,57 & 305,38 & 63,90 & 241,49 & \begin{tabular}{|l|l|l|l}
102,56 \\
\end{tabular} & 226,06 & 228,18 & 102,29 & 624,39 & 87,51 & 3,77 & 57,59 & 257,09 & 33,38 & 33,38 & 257,09 \\
\hline Alytes cisternasii & $295 N C 87$ & 100,00 & 157,48 & 97,19 & 40,03 & 4938,52 & 300,59 & 61,44 & 239,15 & 98,67 & 223,75 & 224,75 & 98,67 & 661,51 & 92,89 & 4,07 & 57,07 & 271,88 & 36,14 & 36,14 & 271,88 \\
\hline Alytes cisternasii & 29 SNC89 & 100,00 & 163,08 & 96,52 & 40,01 & 4922,84 & 304,76 & 66,54 & 238,22 & \begin{tabular}{|l|l|}
104,04 \\
\end{tabular} & 225,79 & 229,75 & \begin{tabular}{|l|}
103,99 \\
\end{tabular} & 654,01 & 92,12 & 4,03 & 57,18 & 268,90 & 36,06 & 36,14 & 268,90 \\
\hline Alytes cisterna & 29 SNC92 & 101,00 & 165, & 10 & 42,00 & 5080,16 & 270 & 61,6 & 258,15 & 113,12 & 230,16 & 234,41 & 104,70 & 562,89 & 80,75 & 2,8 & 59,01 & 235,45 & 27,29 & 27,30 & 233,49 \\
\hline Alytes cisternasii & 29 SNC93 & 0 & & & 41, & 5076 & & 60, & 255,49 & 111, & 228,91 & 232, & 102,78 & 580,06 & 81,76 & $3, \mathrm{C}$ & 58,43 & 240,55 & 28,79 & 28,79 & 239,58 \\
\hline Alytes cisternasii & 29SNC94 & 100,00 & 161,65 & 105,11 & 41,13 & 5062,79 & 312,44 & 60,52 & 251,92 & 107,12 & 228,18 & 230,52 & 101,29 & 597,04 & 83,31 & 3,19 & 57,84 & 245,71 & 30,75 & 30,75 & 245,55 \\
\hline Alytes cisternasii & 29 SNC95 & 101,00 & 162,26 & 102,82 & 40,99 & 5036,47 & 310,58 & 62,31 & 248,27 & 103,86 & 228,90 & 230,65 & 102,00 & 598,80 & 83,23 & 3,07 & 57,54 & 245,44 & 31,23 & 31,23 & 245,44 \\
\hline Alytes cisternasii & 29 SNC97 & 101,00 & 160,32 & 98,67 & 40,00 & 5013,92 & 305,33 & 62,47 & 242,87 & 100,35 & 227,13 & 228,47 & 100,35 & 630,48 & 87,14 & 4,00 & 56,21 & 256,55 & 35,39 & 35,39 & 256,55 \\
\hline Alytes cis & 29SNC98 & 101,00 & 160 & 97,9 & 40,0 & 5019, & 305 & 62, & 242,46 & 100,33 & 226,64 & 228,62 & 100,33 & 646 & 89 & 4,01 & 56,42 & 263,36 & 36,37 & 36,37 & 263 \\
\hline \begin{tabular}{|l} 
Alytes cisternasii \\
\end{tabular} & 295 NC99 & 100,00 & $\begin{array}{l}10,4,60 \\
162,60\end{array}$ & 97,82 & 39,99 & 5028,22 & 307,13 & 64,41 & $\begin{array}{l}24,40 \\
242,72\end{array}$ & $\begin{array}{l}102,16 \\
\end{array}$ & 226,96 & 230,84 & 102,16 & $\begin{array}{ll}649,82 \\
649\end{array}$ & 90,50 & $4,4,00$ & \begin{tabular}{|l|l|}
56,37 \\
\end{tabular} & $\begin{array}{l}264,99 \\
264\end{array}$ & 36,64 & 36,65 & 264,99 \\
\hline
\end{tabular}




\begin{tabular}{|c|c|c|c|c|c|c|c|c|c|c|c|c|c|c|c|c|c|c|c|c|c|}
\hline TAXON & UTM & $\mathrm{km} 2$ & BIO1 & B102 & $\mathrm{BIO3}$ & B104 & B105 & B106 & B107 & B108 & B109 & BIO10 & BIO11 & BIO12 & B1013 & B1014 & 81015 & B1016 & B1017 & B1018 & B1019 \\
\hline Alytes cisternasii & 29SND04 & 100,00 & 159,03 & 74,02 & 40,93 & 3672,60 & 257,33 & 78,10 & 179,23 & 120,14 & 203,57 & 206,64 & 112,38 & 713,86 & 109,86 & 4,02 & 61,19 & 311,14 & 31,96 & 36,53 & 298,65 \\
\hline Alytes cisternasii & 29SND08 & 101,00 & 154,16 & 73,18 & 41,81 & 3476,62 & 247,18 & 74,14 & \begin{tabular}{ll|}
173,04 \\
\end{tabular} & 117,32 & 195,93 & 198,56 & 109,29 & 778,49 & 117,54 & 5,62 & 58,76 & 330,55 & 39,95 & 45,65 & 319,44 \\
\hline Alytes cisternasii & 29SND13 & 100,00 & 162,92 & 79,09 & 40,77 & 3927,40 & 270,65 & 78,49 & \begin{tabular}{|l|l|}
192,16 \\
\end{tabular} & \begin{tabular}{ll|}
121,42 \\
\end{tabular} & 211,05 & 214,49 & 113,77 & 702,38 & 105,55 & 4,00 & 61,02 & 304,83 & 31,85 & 35,66 & 295,47 \\
\hline Alytes cisternasii & 29SND30 & 101,00 & 168,25 & 87,76 & 40,79 & 4347,72 & 291,76 & 78,26 & 213,50 & 122,54 & 222,27 & 226,40 & \begin{tabular}{|l|l|}
114,98 \\
\end{tabular} & 663,01 & 97,42 & 3,95 & 60,75 & 285,61 & 30,54 & 32,95 & 280,85 \\
\hline Alytes cisternasii & 29SND36 & 101,00 & 163,01 & 85,30 & 40,99 & 4139,85 & 279,47 & 73,62 & 205,86 & \begin{tabular}{|l|l|}
118,69 \\
\end{tabular} & 214,20 & 217,29 & 110,95 & 745,59 & 109,38 & 5,01 & 58,52 & 313,82 & 38,47 & 41,99 & 309,20 \\
\hline Alytes cisternasii & 29 SND42 & 101,00 & 165,60 & 88,53 & 40,27 & 4423,03 & 291,14 & 74,42 & 216,71 & 118,99 & 220,79 & 224,66 & 111,24 & 694,78 & 101,68 & 4,13 & 59,47 & 294,52 & 33,99 & 36,29 & 291,45 \\
\hline Alytes cisternasii & 29 SND45 & 101,00 & 165,76 & 88,03 & 40,78 & 4321,19 & 288,15 & 74,32 & 213,82 & 119,42 & 219,42 & 222,85 & 111,97 & 723,74 & 105,79 & 4,87 & 58,48 & 304,00 & 37,37 & 40,32 & 300,70 \\
\hline Alytes cisternasii & 29SND50 & 101,00 & 167,79 & 91,83 & 40,21 & 4577,92 & 299,08 & 74,61 & 224,47 & 119,69 & 225,07 & 229,25 & 111,94 & 656,23 & 95,12 & 4,00 & 59,42 & 277,02 & 32,25 & 33,94 & 275,19 \\
\hline Alytes cisternasii & 29SND59 & 101,00 & 155,63 & 92,85 & 40,48 & 4542,00 & 286,69 & 60,08 & 226,61 & 100,20 & 212,94 & 215,92 & 99,49 & \begin{tabular}{|l|l|}
886,67 \\
\end{tabular} & 128,71 & 7,65 & 56,03 & 363,69 & 53,16 & 54,72 & 363,69 \\
\hline Alytes cisternasii & 29SND62 & 100,00 & 166,34 & 92,62 & 40,02 & 4682,53 & 300,06 & 71,66 & 228,40 & $\begin{array}{ll}116,55 \\
\end{array}$ & 225,23 & 229,08 & 109,13 & $\begin{array}{l}689,45 \\
\end{array}$ & 99,47 & 4,62 & 58,18 & 287,12 & 36,23 & 37,75 & 286,52 \\
\hline Alytes cisternasii & 29SND64 & 100,00 & 163,53 & 92,14 & 39,99 & 4671,31 & 296,93 & 68,86 & 228,06 & 112,76 & 222,46 & 226,16 & 106,44 & 739,71 & 107,19 & 5,24 & 57,64 & 306,74 & 40,06 & 41,67 & 306,59 \\
\hline Alytes cisternasii & $295 N D 66$ & 101,00 & 165,61 & 93,09 & 40,11 & 4654,14 & 298,53 & 69,45 & 229,09 & 114,68 & 224,13 & 227,40 & 108,00 & 751,99 & 108,81 & 5,59 & 57,07 & 310,31 & 41,83 & 44,10 & 310,05 \\
\hline Alytes cisternasii & 29SND70 & 101,00 & 166,85 & 95,14 & 40,07 & 4804,47 & 305,03 & 70,95 & 234,08 & 113,76 & 227,38 & 231,65 & 108,60 & 651,19 & 92,75 & 4,00 & 57,94 & 269,61 & 34,63 & 35,48 & 269,59 \\
\hline Alytes cisternasii & 29SND72 & 101,00 & 167,56 & 94,45 & 40,00 & 4800,62 & 304,86 & 71,40 & 233,45 & \begin{tabular}{|l|l|}
115,69 \\
\end{tabular} & 228,11 & 232,07 & 109,13 & 676,64 & 96,79 & 4,45 & 57,64 & 279,63 & 36,56 & 37,84 & 279,55 \\
\hline Alytes cisternasii & 29SND79 & 101,00 & 153,58 & 94,51 & 39,06 & 4917,92 & 293,90 & 55,02 & 238,88 & $\begin{array}{l}93,68 \\
\end{array}$ & 216,89 & 219,49 & 93,68 & \begin{tabular}{|l|l|}
919,63 \\
\end{tabular} & 133,97 & 8,12 & 55,83 & 377,20 & 56,25 & 56,71 & 377,20 \\
\hline Alytes cisternasii & 29SND80 & 101,00 & 166,63 & 96,48 & 40,00 & 4914,35 & 307,64 & 69,17 & \begin{tabular}{|l|}
238,47 \\
\end{tabular} & \begin{tabular}{|l|l|}
107,97 \\
\end{tabular} & 228,70 & 232,91 & 107,09 & 646,56 & 91,14 & 4,00 & 57,21 & 265,65 & 35,67 & 36,13 & 265,65 \\
\hline Alytes cisternasii & 29 SND81 & 101,00 & 168,40 & 96,43 & 40,00 & 4914,53 & 308,99 & 70,55 & 238,44 & 113,75 & 230,43 & 234,46 & 108,68 & 649,91 & 91,89 & 4,05 & 57,22 & 267,05 & 35,42 & 36,48 & 267,05 \\
\hline Alytes cisternasii & 29 SND87 & 101,00 & 163,28 & 95,93 & 39,23 & 5002,83 & 305,49 & 63,42 & 242,07 & 102,54 & 227,23 & 230,24 & 102,16 & 794,42 & 114,52 & 6,29 & 56,04 & 325,44 & 46,72 & 48,10 & 325,44 \\
\hline Alytes cisternasii & 29SND89 & 101,00 & 153,44 & 94,66 & 38,42 & 5085,55 & 297,12 & 53,67 & 243,45 & 91,82 & 219,37 & 221,80 & 91,82 & 921,40 & 134,45 & 8,01 & 55,71 & 377,72 & 56,39 & 56,68 & 377,72 \\
\hline Alytes cisternasii & 29SND90 & 100,00 & 165,34 & 97,75 & 39,97 & 5033,34 & 309,49 & 66,49 & 243,01 & 104,96 & 229,23 & 233,44 & 104,66 & 649,04 & 90,68 & 4,01 & 56,50 & 264,87 & 36,60 & 36,92 & 264,87 \\
\hline Alytes cisternasii & 29SND91 & 100,00 & 165,52 & 97,41 & 39,74 & 5042,61 & 309,69 & 66,78 & 242,92 & 105,51 & 229,67 & 233,77 & \begin{tabular}{|l|l|}
104,78 \\
\end{tabular} & 666,33 & 93,51 & 4,71 & 56,51 & 272,06 & 38,02 & 38,47 & 272,06 \\
\hline \begin{tabular}{|l} 
Alytes cisternasii \\
\end{tabular} & 29SND94 & 100,00 & 164,63 & 96,36 & 39,00 & 5094,30 & 309,10 & 60,31 & 243,79 & \begin{tabular}{|l|l|}
103,10 \\
\end{tabular} & 229,80 & 233,27 & 103,05 & 729,34 & \begin{tabular}{|r|r|r|r|r|}
103,74 \\
\end{tabular} & $\begin{array}{ll}4,3,38 \\
5,18\end{array}$ & 56,13 & 298,24 & $\begin{array}{l}40,26 \\
42,26\end{array}$ & 43,34 & 298,24 \\
\hline Alytes cisternasii & 29 SND97 & 100,00 & 163,64 & 96,61 & 38,69 & 5152,31 & 309,19 & 62,41 & 246,78 & 101,27 & 229,80 & 232,76 & 100,99 & 789,01 & 113,33 & 6,22 & 55,85 & 322,31 & 46,76 & 48,03 & 322,31 \\
\hline Alytes cisternasii & 29SND98 & 101,00 & 159,65 & $\begin{array}{l}96,07 \\
9,10\end{array}$ & 38,20 & 5204,60 & 306,12 & 58,25 & 247,87 & \begin{tabular}{|l|}
96,60 \\
\end{tabular} & 226,80 & 229,56 & 96,60 & 842,70 & 121,84 & 6,97 & 55,70 & 344,44 & 50,83 & 51,66 & 344,44 \\
\hline Alytes cisternasii & 29SND99 & 100,00 & 157,27 & 95,94 & 38,03 & 5233,99 & 304,20 & 55,38 & 248,82 & 93,83 & 224,97 & 227,49 & 93,83 & 880,99 & 127,97 & 7,45 & 55,45 & 360,06 & 53,78 & 54,41 & 360,06 \\
\hline Alytes cisternasii & $29 S P B 01$ & 101,00 & 162,03 & 94,36 & 41,61 & 4497,07 & 288,29 & 63,89 & 224,40 & \begin{tabular}{|l|l|}
117,19 \\
\end{tabular} & 218,91 & 223,10 & 108,31 & 555,68 & 89,50 & 1,30 & 66,64 & 258,63 & 18,44 & 21,93 & 244,09 \\
\hline Alytes cisternasii & 29SPBO2 & 100,00 & $\begin{array}{l}156,21 \\
156,21\end{array}$ & $\begin{array}{l}34,00 \\
96,72\end{array}$ & $\begin{array}{l}41,10 \\
41,06\end{array}$ & 4645,49 & $\mid \begin{array}{l}280,23 \\
288,15\end{array}$ & $\mid \begin{array}{l}\mid c, 0,77 \\
56,77\end{array}$ & $\begin{array}{ll}234,40 \\
231,38\end{array}$ & $\mid \begin{array}{l}\mid 11,19 \\
109,81\end{array}$ & \begin{tabular}{|l|}
215,06 \\
215,06
\end{tabular} & 219,32 & $\begin{array}{l}100,94 \\
100,94\end{array}$ & | 58,00 | & $\begin{array}{l}\mid l 5,30 \\
92,50\end{array}$ & $\begin{array}{l}\frac{1,00}{1,92} \\
\end{array}$ & $\begin{array}{l}60,949 \\
64,92\end{array}$ & \begin{tabular}{|l|}
268,405 \\
268,40
\end{tabular} & $\mid \frac{10,44}{21,17}$ & 24,40 & $\begin{array}{l}244,03 \\
255,58\end{array}$ \\
\hline Alytes cisternasii & 29SPB03 & 101,00 & 158,06 & 98,16 & 41,13 & 4706,17 & 292,82 & 57,77 & 235,05 & 110,68 & 217,75 & 221,95 & 101,91 & 579,27 & 90,05 & 1,99 & 64,43 & 262,06 & 21,21 & 24,19 & 249,89 \\
\hline Alytes cisternasii & $295 \mathrm{SB} 04$ & 101,00 & 162,26 & 99,50 & 41,29 & 4747,51 & 299,03 & 61,25 & 237,78 & 114,29 & 222,41 & 226,65 & 105,52 & 555,11 & 85,60 & 1,98 & $\begin{array}{l}64,07 \\
64,0\end{array}$ & 250,12 & 20,58 & 23,46 & 238,41 \\
\hline Alytes cisternasii & $295 P B 05$ & 100,00 & 163,97 & 101,37 & 41,34 & 4816,27 & 303,75 & 62,08 & 241,66 & 115,01 & 224,98 & 229,16 & 106,18 & 546,64 & 83,50 & 2,00 & 63,37 & 244,04 & 20,84 & 23,48 & 233,34 \\
\hline Alytes cisternasii & $295 P B 06$ & 101,00 & 166,78 & 103,09 & 41,77 & 4864,45 & 308,96 & 64,24 & 244,73 & \begin{tabular}{|l|l|l|l|}
117,18 \\
\end{tabular} & 228,35 & 232,62 & 108,45 & 531,27 & 80,81 & 1,99 & 62,92 & 235,55 & 20,77 & 23,04 & 225,63 \\
\hline \begin{tabular}{|l} 
Alytes cisternasii \\
\end{tabular} & 295PBO7 & 101,00 & $\begin{array}{l}10,100 \\
166,32\end{array}$ & $\begin{array}{l}105,44 \\
105\end{array}$ & $\begin{array}{ll}41,17 \\
41,88\end{array}$ & $\begin{array}{l}4004,437 \\
4943,26\end{array}$ & $\begin{array}{l}300,90 \\
312,49\end{array}$ & $\begin{array}{ll}62,73 \\
62,73\end{array}$ & $\begin{array}{l}244,73 \\
249,76\end{array}$ & $\begin{array}{l}\mid 11,10 \\
115,83\end{array}$ & \begin{tabular}{|l|}
229,00 \\
22,0
\end{tabular} & 233,25 & 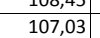 & | $53,1,87$ & $\begin{array}{l}80,01 \\
80,73 \\
\end{array}$ & $\frac{1,290}{2,00}$ & $\begin{array}{l}\mid c 2,025 \\
62,05 \\
\end{array}$ & \begin{tabular}{|l|l|}
234,58 \\
234,
\end{tabular} & 21,63 & 23,64 & 226,01 \\
\hline Alytes cisternasii & 29SPBO9 & 100,00 & 166,65 & 110,11 & 42,02 & 5078,42 & 319,97 & 61,01 & 258,96 & 114,61 & 231,07 & 235,43 & 105,78 & 538,22 & 79,76 & 2,00 & 60,83 & 230,49 & 23,08 & 24,19 & 224,76 \\
\hline Alytes cisternasii & 29SPB10 & 83,00 & 172,73 & 90,49 & 41,49 & 4345,16 & 291,22 & 75,65 & 215,57 & 128,91 & 227,13 & 231,16 & 120,17 & 499,02 & 81,41 & 1,00 & 68,00 & 236,81 & 14,28 & 18,78 & 220,00 \\
\hline Alytes cisternasii & 29SPB11 & 99,00 & 168,63 & 92,33 & 41,0 & 4481,92 & 291,86 & 70,19 & 221,67 & 123,23 & 224,88 & 228,95 & 114,35 & 520,10 & 83,18 & 1,01 & 66,93 & 242,62 & 16,15 & 20,50 & 226,66 \\
\hline Alytes cisternasii & $29 S P B 12$ & 101,00 & 159,55 & 95,59 & 40,93 & 4684,63 & 290,54 & 59,33 & 231,21 & 112,27 & 218,81 & 222,92 & 103,22 & 570,01 & 88,50 & 1,90 & 64,84 & 258,87 & 19,90 & 23,92 & 244,94 \\
\hline Alytes cisternasii & 29SPB13 & 100,00 & 163,67 & 96,69 & 40,97 & 4727,12 & 296,40 & 62,81 & 233,59 & 115,68 & 223,35 & 227,42 & 106,75 & 545,74 & 84,32 & 1,70 & 64,48 & 246,99 & 19,23 & 23,10 & 233,35 \\
\hline Alytes cisternasii & $295 P B 14$ & 100,00 & 164,15 & 98,47 & 40,99 & 4808,23 & 300,24 & 62,28 & 237,96 & 114,95 & 224,83 & 228,98 & 106,16 & 543,03 & 83,13 & 1,86 & 63,62 & 243,27 & 19,80 & 23,49 & 230,58 \\
\hline Alytes cisternasii & 29SPB15 & 101,00 & 166,02 & 100,20 & 41,00 & 4869,35 & 304,94 & 63,33 & 241,61 & 115,96 & 227,46 & 231,61 & 107,26 & 532,74 & 81,03 & 1,93 & 63,12 & 236,72 & 20,00 & 23,43 & 224,84 \\
\hline Alytes cisternasii & 29SPB16 & 100,00 & 169,62 & 101,78 & 41,12 & 4908,01 & 310,38 & 66,19 & 244,19 & 118,84 & 231,52 & 235,58 & 110,12 & 514,27 & 77,93 & 1,73 & 62,67 & 227,15 & 19,65 & 22,79 & 215,99 \\
\hline Alytes cisternasii & 29SPB17 & 100,00 & $\begin{array}{l}168,05 \\
160\end{array}$ & 104,46 & 41,20 & 5005,48 & 313,51 & 63,50 & 250,01 & $\mid 116,38$ & 231,39 & 235,43 & 107,52 & 524,31 & 78,49 & 1,98 & 61,72 & 228,42 & 21,01 & 23,75 & 218,70 \\
\hline Alytes cisternasii & 29SPB18 & 101,00 & 168,43 & 106,74 & 41,49 & 5064,67 & 317,17 & 62,97 & 254,19 & 116,14 & 232,58 & 236,60 & 107,19 & 524,31 & 77,78 & 2,00 & 60,91 & 225,94 & 21,78 & 23,97 & 217,52 \\
\hline Alytes cisternasii & $295 P B 19$ & 100,00 & $\begin{array}{l}168,67 \\
\end{array}$ & 108,60 & 41,74 & 5121,81 & 320,40 & 62,43 & 257,97 & 115,63 & 233,61 & 237,66 & 106,71 & 525,02 & 77,21 & 2,00 & $\begin{array}{l}00,35 \\
60,35\end{array}$ & 223,97 & 22,44 & 24,26 & 216,79 \\
\hline Alytes cisternasii & 29SPB21 & 97,00 & 172,04 & 90,53 & 40,61 & 4512,68 & 293,65 & 73,35 & 220,30 & 125,89 & 228,34 & 232,29 & 116,95 & 501,29 & 79,80 & 1,00 & 66,59 & 232,37 & 14,78 & 20,05 & 215,44 \\
\hline Alytes cisternasii & $295 P B 22$ & 100,00 & 166,31 & 93,15 & 40,33 & 4667,96 & 293,92 & 66,12 & 227,81 & 118,69 & 224,99 & 228,93 & 109,63 & 531,05 & 82,62 & 1,25 & 65,03 & 241,44 & 17,40 & 22,36 & 225,77 \\
\hline \begin{tabular}{|l} 
Alytes cisternasii \\
\end{tabular} & 295PBL23 & $\begin{array}{l}101,00 \\
\end{array}$ & \begin{tabular}{|l|l|}
168,25 \\
\end{tabular} & $\begin{array}{l}3,15 \\
94,56 \\
\end{array}$ & $\begin{array}{l}40,35 \\
40,32 \\
\end{array}$ & 4735,29 & \begin{tabular}{|l|}
298,46 \\
298,46
\end{tabular} & $\begin{array}{l}0,12 \\
67,19\end{array}$ & $\begin{array}{l}231,01 \\
231,27\end{array}$ & $\begin{array}{l}119,09 \\
119,61\end{array}$ & \begin{tabular}{|l|}
227,77 \\
22,75
\end{tabular} & $\begin{array}{l}23,30 \\
231,71\end{array}$ & \begin{tabular}{|l|l|l|l|l}
110,66 \\
\end{tabular} & $\begin{array}{l}51,03 \\
519,73\end{array}$ & $\begin{array}{l}8<, 0<2 \\
80,23\end{array}$ & $\begin{array}{l}\frac{1,25}{1,19} \\
\end{array}$ & $\begin{array}{l}64,47 \\
64,4\end{array}$ & $\begin{array}{l}24,44,68 \\
234,68\end{array}$ & $\begin{array}{l}17,40 \\
17,37\end{array}$ & 22,16 & 219,59 \\
\hline Alytes cisternasii & $295 P B 24$ & 100,00 & 165,69 & 97,05 & 40,46 & 4849,47 & 300,64 & 63,40 & 237,24 & \begin{tabular}{|l|l|}
115,70 \\
\end{tabular} & 226,89 & 230,83 & 107,08 & 533,69 & 81,11 & 1,86 & 63,31 & 237,35 & 19,21 & 23,72 & 223,55 \\
\hline Alytes cisternasii & 29SPB25 & 100,00 & 169,33 & 98,40 & 40,57 & 4894,24 & 306,29 & 66,31 & 239,97 & $\begin{array}{ll}118,59 \\
\end{array}$ & 231,09 & 234,90 & 110,06 & 513,84 & 77,78 & 1,62 & 62,78 & 227,38 & 18,76 & 23,11 & 214,10 \\
\hline Alytes cisternasii & $295 P B 26$ & 101,00 & 169,08 & 100,77 & 40,72 & 4972,45 & 309,87 & 64,94 & 244,5 & 117,62 & 231,85 & 235,79 & 108,74 & 516 & 77,31 & 1, & 61,6 & 225,79 & 19,77 & 23,69 & 213,66 \\
\hline Alytes cisternasii & $295 P B 27$ & 100,00 & 167 & 103,45 & 40, & 5076,86 & 31 & 61 & 250, & 11 & 231,33 & 235,27 & 105,58 & 528 & 78,16 & 2,00 & 61,08 & 228,12 & 21,14 & 24,51 & 217,42 \\
\hline Alytes cisternasii & $295 P B 28$ & 100,00 & 167,52 & 105,62 & 40,98 & 5143,11 & 316,07 & 60,92 & 255,16 & 113,99 & 232,69 & 236,56 & 105,07 & 527,53 & 77,44 & 2,00 & 60,50 & 225,69 & 21,84 & 24,69 & 216,24 \\
\hline Alytes cisternasii & $295 P B 29$ & 101,00 & 167,13 & 107,53 & 41,02 & 5203,95 & 318,63 & 59,81 & 258,82 & 112,92 & 233,18 & 237,07 & 103,92 & 531,36 & 77,24 & 2,00 & 59,86 & 225,10 & 22,59 & 25,19 & 216,82 \\
\hline Alytes cisternasii & $295 P B 32$ & 101,00 & 173,23 & 90,13 & 39,87 & 4653,86 & 296,81 & 73,27 & 223,54 & 124,94 & 231,23 & 234,90 & 115,92 & 493,39 & 76,86 & 1,00 & 65,25 & 224,21 & 14,76 & 20,66 & 206,99 \\
\hline Alytes cisterna & 29SPB33 & 100,00 & 172,24 & 92,08 & 39,85 & 4756,22 & 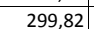 & 71,13 & 228,69 & 122,83 & 231,68 & 235,45 & 113,82 & 497,2 & 76,39 & 1,00 & 64,32 & 223,32 & 15,71 & 21,49 & 206,86 \\
\hline Alytes cisternasii & 29SPB34 & 101,00 & 170 & & 39 & 4859,98 & & 68,46 & 234,07 & 120,14 & 231,78 & 235,50 & 111 & 504,14 & 76,40 & & 63,32 & 223,70 & 16,99 & 22,58 & 208,22 \\
\hline Alytes cisternasii & $295 P B 35$ & 101,00 & 169,60 & 96,90 & 39,96 & 4957,53 & 305,73 & 65,96 & 239,77 & 117,77 & 231,96 & 235,63 & 109,06 & 511,72 & 76,62 & 1,60 & 62,32 & 224,38 & 18,45 & 23,57 & 210,04 \\
\hline Alytes cisternasii & $295 P B 36$ & 99,00 & 171,07 & 98,97 & 40,02 & 5027,06 & 310,27 & 66,23 & 244,03 & 118,48 & 234,36 & 238,01 & 109,54 & 504,43 & 74,85 & 1,80 & 61,47 & 219,22 & 19,03 & 23,80 & 205,73 \\
\hline Alytes cisternasii & 29SPB37 & 101,00 & 168,89 & 101,83 & 40,13 & 5123,45 & 312,79 & 62,74 & 250,05 & 115,32 & 233,65 & 237,34 & 106,44 & 517,24 & 75,86 & 2,00 & 60,68 & 222,11 & 20,43 & 24,79 & 209,98 \\
\hline Alytes cisterna & $295 P B 38$ & 100,00 & 165 & 104 & 40,2 & 5217,5 & & 58,5 & 255,59 & 111 & 231,94 & 235 & 102 & 536 & 77,76 & 2,00 & 60,14 & 227 & 22,05 & 25,60 & 217,14 \\
\hline \begin{tabular}{|l} 
Alytes cisternasii \\
\end{tabular} & $295 \mathrm{SB} 39$ & 100,00 & 165,47 & 106,32 & $\begin{array}{ll}40,20 \\
40,48\end{array}$ & 5275,48 & $\mid \begin{array}{l}\mid 14,11 \\
316,66\end{array}$ & 57,26 & 259,40 & $\begin{array}{l}11,40,34 \\
110\end{array}$ & 232,63 & 236,23 & $\begin{array}{l}101,60 \\
\end{array}$ & 539,62 & 77,46 & 2,16 & \begin{tabular}{|l|l|}
59,39 \\
\end{tabular} & 226,96 & 23,19 & 26,27 & 217,56 \\
\hline
\end{tabular}




\begin{tabular}{|c|c|c|c|c|c|c|c|c|c|c|c|c|c|c|c|c|c|c|c|c|c|}
\hline TAXON & UTM & $\mathrm{km2}$ & B101 & $\mathrm{B1O2}$ & $\mathrm{BIO3}$ & B104 & B105 & B106 & B107 & B108 & B109 & 81010 & B1011 & BIO12 & BIO13 & 81014 & B1015 & B1016 & B1017 & BIO18 & B1019 \\
\hline Alytes cisternasii & 29SPB41 & 45,00 & 175,94 & 86,66 & 39,08 & 4616,81 & 295,17 & 76,89 & 218,28 & 127,66 & 233,08 & 236,77 & 118,75 & 478,98 & 74,89 & 1,00 & 66,06 & 217,60 & 13,19 & 20,19 & 199,08 \\
\hline Alytes cisternasii & 29SPB42 & 100,00 & 174,39 & 87,81 & \begin{tabular}{|l|l|}
39,07 \\
\end{tabular} & 4705,30 & 296,40 & 74,27 & 222,13 & 125,04 & 232,76 & 236,31 & 116,11 & 486,66 & 74,96 & 1,00 & 65,00 & 218,79 & 14,07 & 21,01 & 200,46 \\
\hline Alytes cisternasii & 29SPB43 & 100,00 & 171,07 & 90,36 & 39,05 & 4835,05 & 298,26 & 69,46 & 228,80 & 120,41 & 231,39 & 234,94 & 111,54 & 503,00 & 76,14 & 1,00 & 63,58 & 223,05 & 15,97 & 22,78 & 205,61 \\
\hline Alytes cisternasii & 29SPB44 & 100,00 & 168,94 & 93,08 & 39,08 & 4953,04 & 301,00 & 65,92 & 235,08 & 116,97 & 230,92 & 234,64 & 108,21 & 514,36 & 76,65 & 1,65 & 62,62 & 225,14 & 17,70 & 24,14 & 208,76 \\
\hline Alytes cisternasii & 29SPB45 & 101,00 & $\begin{array}{ll}167,17 \\
\end{array}$ & 95,93 & 39,15 & 5057,97 & 303,87 & 62,46 & 241,41 & \begin{tabular}{|l|}
114,03 \\
\end{tabular} & 230,75 & 234,29 & 105,23 & 524,81 & 77,31 & 1,95 & 61,65 & 227,20 & 19,13 & 25,01 & 212,03 \\
\hline Alytes cisternasii & 29SPB47 & 100,00 & 168,88 & 100,49 & 39,82 & 5191,89 & 311,99 & 61,96 & 250,03 & 114,28 & 234,42 & 237,89 & 105,12 & 517,01 & 75,01 & 2,00 & 60,66 & 220,39 & 20,28 & 25,11 & 207,22 \\
\hline Alytes cisternasii & 29SPB48 & 100,00 & 167,76 & 102,78 & 39,96 & 5275,35 & 314,51 & 59,57 & 254,94 & 112,04 & 234,53 & 238,02 & 103,20 & 523,92 & 75,31 & 2,00 & 59,87 & 221,33 & 21,22 & 25,76 & 209,24 \\
\hline Alytes cisternasii & \begin{tabular}{|l|}
$295 P B 49$ \\
\end{tabular} & 100,00 & 166,50 & 105,08 & 40,00 & 5340,31 & 316,69 & 57,41 & 259,28 & 110,07 & 234,41 & 237,71 & 101,40 & 532,89 & 75,91 & 2,06 & 59,35 & 223,19 & 22,59 & 26,21 & 212,30 \\
\hline Alytes cisternasii & 29SPB52 & 100,00 & 175,19 & 85,50 & 38,19 & 4763,32 & 295,72 & 74,92 & 220,80 & 124,69 & 233,97 & 237,43 & 115,81 & 482,36 & 73,92 & 1,00 & 64,48 & 214,43 & 13,55 & 21,57 & 194,99 \\
\hline Alytes cisternasii & 29SPB53 & 101,00 & 172,90 & 87,90 & 38,16 & 4887,35 & 298,20 & 71,02 & 227,18 & 121,10 & 233,55 & 236,92 & 112,13 & 493,46 & 74,73 & 1,01 & 63,42 & 216,54 & 15,33 & 23,12 & 197,79 \\
\hline Alytes cisternasii & 29SPB54 & 101,00 & 170,45 & 90,94 & 38,30 & 5007,82 & 300,94 & 66,97 & 233,97 & 117,41 & 232,94 & 236,36 & 108,48 & 506,42 & 75,65 & 1,51 & 62,28 & 219,73 & 17,00 & 24,36 & 202,13 \\
\hline Alytes cisternasii & 29SPB55 & 99,00 & 166,69 & 94,61 & 38,71 & 5134,48 & 303,20 & 61,36 & 241,84 & 112,48 & 231,25 & 234,60 & 103,59 & 528,04 & 77,56 & 2,00 & 61,28 & 226,42 & 19,01 & 25,85 & 210,22 \\
\hline \begin{tabular}{|l} 
Alytes cisternasii \\
\end{tabular} & 29SPB56 & 100,00 & 168,05 & 96,89 & 38,95 & 5204,47 & 307,65 & 61,30 & \begin{tabular}{|l|}
241,0435 \\
\end{tabular} & \begin{tabular}{|l|l|}
112,94 \\
\end{tabular} & 233,58 & 236,92 & 103,94 & 520,95 & 76,11 & 2,00 & $\begin{array}{l}01,20 \\
60,74\end{array}$ & $\begin{array}{l}221,98 \\
221,9\end{array}$ & $\frac{19,0}{19,40}$ & 25,68 & 206,68 \\
\hline Alytes cisternasii & 29SPB57 & 100,00 & 168,52 & 99,30 & $\begin{array}{l}39,05 \\
\end{array}$ & 5265,48 & 311,35 & 60,62 & 250,73 & 112,74 & 235,06 & 238,25 & 103,76 & 519,26 & 75,34 & 2,00 & 60,09 & 219,62 & 20,12 & 25,82 & 205,28 \\
\hline Alytes cisternasii & 29SPB58 & 101,00 & 165,17 & 102,30 & 39,26 & 5365,91 & 312,87 & 56,02 & 256,85 & 108,46 & 233,42 & 236,58 & 99,60 & 539,10 & 77,02 & 2,18 & 59,31 & 225,79 & 22,22 & 27,10 & 212,91 \\
\hline Alytes cisternasii & 29SPB59 & 100,00 & 166,71 & 104,28 & 39,71 & 5416,16 & 316,71 & 56,52 & 260,20 & 109,16 & 235,61 & 238,69 & 100,55 & 531,41 & 75,54 & 2,18 & 58,79 & 221,23 & 22,63 & 27,04 & 209,20 \\
\hline Alytes cisternasii & 29SPB62 & 100,00 & 176,32 & 82,94 & 37,30 & 4827,46 & 295,47 & 75,96 & 219,51 & 124,72 & 235,65 & 238,97 & 115,88 & 476,06 & 73,79 & 1,00 & 64,06 & 209,23 & 13,14 & 22,10 & 188,61 \\
\hline Alytes cisternasii & 29SPB63 & 100,00 & 173,50 & 85,69 & 37,29 & 4955,21 & 297,65 & 71,32 & 226,33 & 120,63 & 234,78 & 237,93 & 111,59 & 490,51 & 75,08 & 1,01 & 62,88 & 213,02 & 14,88 & 23,59 & 193,09 \\
\hline Alytes cisternasii & 29SPB64 & 100,00 & 171,35 & 89,14 & 37,69 & 5074,96 & 300,92 & 67,29 & 233,63 & 117,19 & 234,48 & 237,69 & 108,34 & 502,45 & 75,84 & 1,52 & 62,03 & 215,97 & 16,64 & 24,62 & $\begin{array}{ll}197,18 \\
\end{array}$ \\
\hline Alytes cisternasii & 29SPB65 & 101,00 & 170,61 & 92,24 & 37,94 & 5171,80 & 304,69 & 64,81 & 239,88 & $\mid 115,30$ & 235,21 & 238,42 & $\mid 106,43$ & 507,57 & 75,85 & 1,94 & 61,13 & 216,36 & 17,85 & 25,54 & 198,55 \\
\hline Alytes cisternasii & 29SPB67 & 101,00 & 167,34 & 98,94 & 38,73 & 5365,73 & 310,99 & 58,12 & 252,87 & 110,08 & 235,12 & 238,06 & 101,04 & 527,78 & 76,87 & 2,00 & 59,80 & 221,55 & 20,25 & 26,49 & 206,39 \\
\hline Alytes cisternasii & 29SPB68 & 99,00 & 161,51 & 102,50 & 38,98 & 5475,86 & 310,95 & 50,86 & 260,09 & 103,49 & 231,21 & 234,26 & | & 565,09 & 80,49 & 2,59 & 58,77 & 234,47 & 24,03 & 29,36 & 221,11 \\
\hline Alytes cisternasii & 29SPB69 & 101,00 & 160,85 & 104,80 & $\begin{array}{l}39,03 \\
\end{array}$ & 5543,35 & 313,78 & 49,17 & 264,61 & 102,18 & 231,74 & 234,69 & 93,30 & 569,54 & 80,36 & 2,99 & 57,97 & 234,49 & 25,62 & 30,24 & 222,24 \\
\hline Alytes cisternasii & 29SPB72 & 100,00 & 177,28 & 80,30 & 36,32 & 4889,62 & 294,83 & 76,74 & 218,10 & 124,96 & 237,14 & 240,23 & 115,76 & 471,86 & 74,05 & 1,00 & 63,85 & 205,10 & 12,65 & 22,54 & 183,14 \\
\hline Alytes cisternasii & 29SPB74 & 100,00 & 174,51 & 86,77 & 36,99 & 5116,97 & 301,96 & 70,11 & 231,86 & 119,42 & 237,91 & 240,89 & 110,45 & 487,26 & 74,79 & 1,03 & 62,14 & 208,15 & 15,20 & 24,17 & 187,95 \\
\hline Alytes cisternasii & 29SPB75 & 100,00 & 173,17 & 90,78 & 37,35 & 5223,84 & 306,17 & 66,62 & 239,55 & 116,95 & 238,22 & 241,18 & 108,03 & 497,01 & 75,2 & 1,71 & 61,08 & 210,63 & 16,92 & 25,31 & 191,71 \\
\hline \begin{tabular}{|l} 
Alytes cisternasii \\
\end{tabular} & 29SPB76 & 101,00 & 172,13 & 94,68 & 37,97 & 5322,15 & 310,30 & 63,59 & 246,72 & 115,01 & $\begin{array}{l}238,91 \\
238\end{array}$ & $\begin{array}{l}241,79 \\
241\end{array}$ & 105,99 & 504,11 & 75,30 & $\begin{array}{l}1,1,99 \\
1\end{array}$ & $\begin{array}{ll}1,00,38 \\
\end{array}$ & 212,14 & 18,20 & 25,85 & 194,57 \\
\hline Alytes cisternasii & 29SPB77 & 100,00 & 169,75 & 98,39 & 38,18 & 5425,29 & 313,11 & 59,47 & 253,64 & 111,36 & 238,29 & 241,06 & 102,64 & 517,79 & 76,19 & 2,01 & 59,74 & 216,32 & 19,64 & 26,46 & 200,12 \\
\hline Alytes cisternasii & 29SPB78 & 101,00 & 163,20 & 102,44 & 38,68 & 5548,81 & 313,16 & 51,22 & 261,94 & 104,07 & 233,97 & 236,76 & 95,18 & 557,05 & 79,98 & 2,45 & 58,67 & 230,14 & 23,44 & 29,16 & 215,80 \\
\hline Alytes cisternasii & 29SPB79 & 100,00 & 158,60 & 105,26 & 38,94 & 5641,23 & 313,68 & 45,54 & 268,14 & 98,76 & 231,00 & 233,69 & 89,80 & 585,79 & 82,62 & 3,10 & 57,73 & 239,91 & 26,44 & 31,26 & 227,16 \\
\hline Alytes cisternasii & 29SPB82 & 101,00 & 177,98 & 79,33 & 35,82 & 4964,47 & 295,56 & 76,60 & 218,96 & 144,32 & 238,62 & 241,52 & 115,22 & 472,48 & 74,62 & 1,00 & 63,57 & 203,23 & 12,62 & 23,47 & 180,27 \\
\hline \begin{tabular}{|l} 
Alytes cisternasii \\
\end{tabular} & \begin{tabular}{|l|} 
29SPB83 \\
\end{tabular} & 99,00 & 177,82 & 81,79 & 35,02 & 50667,99 & 299,41 & 74,67 & 224,73 & \begin{tabular}{|l|}
1446,24 \\
140
\end{tabular} & \begin{tabular}{|l|}
$239,98<$ \\
230
\end{tabular} & \begin{tabular}{|l|l|}
242,83 \\
\end{tabular} & 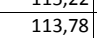 & \begin{tabular}{|l|}
473,24 \\
\end{tabular} & $\begin{array}{l}74,27 \\
74,2\end{array}$ & $\begin{array}{l}1,000 \\
1,00\end{array}$ & $\begin{array}{ll}62,87 \\
6\end{array}$ & \begin{tabular}{|l|}
202,07 \\
\end{tabular} & \begin{tabular}{|l|l|l|}
13,64 \\
\end{tabular} & $\begin{array}{ll}23,87 \\
23,8\end{array}$ & 179,64 \\
\hline Alytes cisternasii & 29SPB84 & 101,00 & 174,38 & 87,23 & 36,64 & 5210,35 & 303,54 & 68,52 & 235,02 & 120,05 & 239,13 & 241,89 & 109,09 & 493,86 & 76,00 & 1,26 & 61,76 & 209,21 & 15,46 & 24,91 & 188,50 \\
\hline Alytes cisternasii & 29SPB85 & 100,00 & 172,92 & 91,72 & 37,08 & 5321,27 & 307,98 & 64,69 & 243,29 & 115,49 & 239,49 & 242,16 & 106,45 & 504,88 & 76,49 & 1,83 & 61,00 & 212,53 & 17,19 & 25,68 & 193,27 \\
\hline Alytes cisternasii & 29SPB86 & 100,00 & 169,77 & 96,12 & 37,83 & 5442,40 & 311,10 & 59,32 & 251,78 & 111,16 & 238,45 & 241,03 & 102,23 & 523,43 & 77,89 & 2,00 & 60,25 & 218,73 & 18,97 & 26,66 & 201,01 \\
\hline Alytes cisternasii & 29SPB87 & 100,00 & 168,34 & 99,61 & 38,00 & 5531,28 & 314,37 & 56,26 & 258,11 & 108,81 & 238,52 & 241,06 & $\begin{array}{l}99,98 \\
99\end{array}$ & 531,65 & 78,12 & 2,02 & 59,57 & 220,72 & 20,46 & 27,36 & 204,23 \\
\hline \begin{tabular}{|l} 
Alytes cisternasii \\
\end{tabular} & 29SPB89 & $\begin{array}{l}100,00 \\
100\end{array}$ & $\begin{array}{l}10,53,82 \\
153,82\end{array}$ & $\begin{aligned} 306,01 \\
106,46\end{aligned}$ & 38,23 & 5757,84 & 312,54 & $\begin{array}{l}30,20 \\
38,85 \\
\end{array}$ & \begin{tabular}{|l|}
273,691 \\
273,6
\end{tabular} & \begin{tabular}{|c|}
100,01 \\
92,73
\end{tabular} & \begin{tabular}{|l|}
228,07 \\
228
\end{tabular} & $\begin{array}{l}241,000 \\
230,59\end{array}$ & $\begin{array}{l}5,70 \\
83,71\end{array}$ & \begin{tabular}{|l|l|}
620,39 \\
620
\end{tabular} & $\begin{array}{l}\mid 0,112 \\
86,93\end{array}$ & 2,404 & $\begin{array}{ll}57,47 \\
5,47\end{array}$ & $\begin{array}{l}252,59 \\
252,5\end{array}$ & $\begin{array}{l}0,40 \\
28,53 \\
\end{array}$ & $\begin{array}{l}21,50 \\
33,33\end{array}$ & 239,85 \\
\hline Alytes cisternasii & 29SPB91 & 91,00 & 176,63 & 82,44 & 36,29 & 4991,09 & 297,27 & 73,43 & 223,85 & 129,05 & 238,21 & 241,18 & 113,96 & 495,43 & 77,43 & 1,00 & 63,73 & 213,67 & 13,84 & 23,77 & 191,63 \\
\hline Alytes cisternasii & 29SPB92 & 101,00 & 176,34 & 83,35 & \begin{tabular}{|c|}
36,08 \\
\end{tabular} & 5092,33 & 299,59 & 72,02 & 227,57 & 134,69 & 239,17 & 242,06 & 112,29 & 493,55 & 77,15 & 1,00 & 63,20 & 211,19 & 14,05 & 24,00 & 189,05 \\
\hline Alytes cisternasii & 29SPB93 & 100,00 & 178,35 & 85,09 & 36,17 & 5167,99 & 304,21 & 72,76 & 231,45 & 147,42 & 242,25 & 244,99 & 113,29 & 482,24 & 75,46 & 1,00 & 62,70 & 205,42 & 14,09 & 24,00 & 183,32 \\
\hline Alytes cisternasii & 29SPB94 & 101,00 & 174,68 & 89,65 & 36,7 & 5315,18 & 307,38 & 66,53 & 240,84 & 122,55 & 241,05 & 24 & 108,15 & 502,46 & 77,16 & 1,28 & 61,65 & 212,05 & 15,74 & 24,94 & 191,58 \\
\hline \begin{tabular}{|l} 
Alytytes cisternasii \\
\end{tabular} & $\begin{array}{l}295 \mathrm{PD} 94 \\
29 \mathrm{SB95}\end{array}$ & $\begin{array}{l}\quad 10,100 \\
99,00\end{array}$ & $\begin{array}{l}1 / 7,00 \\
169,82\end{array}$ & $\begin{array}{l}9,, 03 \\
94,92\end{array}$ & 30,37 & \begin{tabular}{|l}
351,10 \\
5462,90
\end{tabular} & $\begin{array}{l}30,50 \\
310,08\end{array}$ & \begin{tabular}{|l|l|}
50,33 \\
58,89
\end{tabular} & \begin{tabular}{|l|}
251,194 \\
2519
\end{tabular} & \begin{tabular}{|l|}
110,79 \\
110,7
\end{tabular} & \begin{tabular}{|l|}
238,72 \\
238,7
\end{tabular} & $\mid \begin{array}{l}\mid 243,1,25 \\
241,25\end{array}$ & \begin{tabular}{|l|}
101,85 \\
101,85
\end{tabular} & \begin{tabular}{|l|}
531,43 \\
531,43
\end{tabular} & $\begin{array}{l}1,10 \\
79,77 \\
\end{array}$ & $\begin{array}{l}\frac{1,200}{2,00} \\
\end{array}$ & $\begin{array}{l}01,003 \\
60,74\end{array}$ & $\begin{array}{l}222,35 \\
222, \\
\end{array}$ & $\begin{array}{l}18,4 \\
18,52 \\
\end{array}$ & $\begin{array}{l}24,44 \\
26,68\end{array}$ & $\begin{array}{l}203,61 \\
203,61\end{array}$ \\
\hline Alytes cisternasii & 29SPB96 & 100,00 & 169,28 & 98,16 & 37,82 & 5549,99 & 313,89 & 56,72 & 257,17 & 109,34 & 239,57 & 242,12 & 100,46 & 534,59 & 79,41 & 2,00 & 60,10 & 222,36 & 19,56 & 27,16 & 204,72 \\
\hline Alytes cisternasii & 29SPB97 & 100,00 & 170,11 & 100,77 & 38,00 & 5609,81 & 317,98 & 56,11 & 261,87 & 109,56 & 241,47 & 243,77 & 100,57 & 529,92 & 78,18 & 2,00 & 59,68 & 219,39 & 20,10 & 27,11 & 202,56 \\
\hline Alytes cisternasii & 29SPB99 & 100,00 & 152,23 & 107,69 & 38,00 & 5848,46 & 313,92 & 35,78 & 278,14 & 90,23 & 227,96 & 230,29 & 81,17 & 635,97 & 88,7 & 3,60 & 57,37 & 257,79 & 29,35 & 34,22 & 245,06 \\
\hline \begin{tabular}{|l} 
Alytes cisternasii \\
\end{tabular} & $295 \mathrm{PCO0}$ & 101,00 & 165,29 & 112,18 & 42,05 & 5145,05 & 322, & $\begin{array}{ll}59,05 \\
\end{array}$ & 263,01 & \begin{tabular}{|l|}
112,51 \\
125
\end{tabular} & 230,68 & 235,07 & \begin{tabular}{|l|}
103,90 \\
\end{tabular} & 548,84 & 80,47 & 2,00 & 59,99 & 232,29 & 24,28 & 25,03 & $\begin{array}{l}24,007 \\
228,07\end{array}$ \\
\hline Alytes cisternasii & 29SPC01 & 100,00 & 165,98 & 111,91 & 42,01 & 5165,10 & 322 & 59,96 & 263,01 & 112,77 & 231,50 & 236,05 & 104,19 & 549,03 & 79,49 & 2,02 & 59,40 & 230,39 & 25,61 & 25,86 & 226,94 \\
\hline Alytes cisternasii & 29SPC02 & 101,00 & 166,33 & 110,50 & 41,87 & 5160,53 & 322,00 & 60,85 & 261,15 & 112,99 & 231,84 & 236,18 & 104,34 & 552,50 & 78,82 & 2,58 & 58,68 & 229,86 & 26,91 & 27,28 & 227,05 \\
\hline Alytes cisternasii & 29SPC03 & 101,00 & 160,69 & 108,62 & 41,23 & 5185,48 & 316,10 & 56,55 & 259,55 & 107,39 & 227,90 & 231,14 & 98,85 & 592,32 & 82,64 & 3,04 & 57,66 & 243,29 & 30,44 & 30,45 & 242,18 \\
\hline Alytes cisternasii & 29SPC04 & 100,00 & 161,82 & 106,48 & 41,04 & 5164,14 & 314,94 & 58,80 & 256,14 & 108,27 & 229,01 & 231,91 & 100,14 & 589,98 & 81,44 & 3,02 & 57,23 & 241,04 & 30,93 & 30,93 & 240,44 \\
\hline \begin{tabular}{|l|l} 
Alytes cisternasii \\
\end{tabular} & \begin{tabular}{|l|}
$295 \mathrm{PCO}$ \\
$29 \mathrm{PC} 5$
\end{tabular} & $\begin{array}{l}101,00 \\
101,00\end{array}$ & $\begin{array}{l}101,02 \\
163,99\end{array}$ & $\begin{array}{l}10,40 \\
104,51\end{array}$ & $\begin{array}{l}41,04 \\
40,97\end{array}$ & $\begin{array}{l}1104,14 \\
5131,42\end{array}$ & 314 & $\begin{array}{l}30,000 \\
61,82 \\
\end{array}$ & $\begin{array}{l}30,14 \\
252,78 \\
\end{array}$ & 109,97 & 230,79 & 233,51 & 102,35 & 583,41 & 80,05 & 3,00 & 57,05 & 237,34 & 31,10 & 31,10 & 236,97 \\
\hline Alytes cisternasii & 29SPC06 & 100,00 & 163,16 & 102,61 & 40,53 & 5122,15 & 312,29 & 62,04 & 250,25 & 105,59 & 229,36 & 232,55 & 101,71 & 596,58 & 81,61 & 3,75 & 56,34 & 241,45 & 33,24 & 33,24 & 241,42 \\
\hline Alytes cisternasii & 29SPC07 & 101.00 & 162,37 & 101,10 & 40,03 & 5119,50 & 310,44 & 61,96 & 248,48 & $\mid 101.92$ & 229,31 & 231,74 & $\mid 100,87$ & 613,08 & 83,86 & 4,00 & 55,95 & 247,58 & 35,10 & 35,10 & 247,58 \\
\hline Alytes cisternasii & 29SPC08 & 100,00 & 160,69 & 99,94 & 39,98 & 5139,34 & 308,49 & 60,77 & 247,72 & 99,37 & 228,08 & 230,42 & 99,08 & 640,14 & 87,99 & 4,12 & 55,88 & 258,78 & 36,81 & 36,81 & 258,78 \\
\hline Alytes cisternasii & $29 S P C 09$ & 100,00 & 162,42 & 99,67 & 39,97 & 5141,97 & 309,99 & 62,39 & 247,60 & 101,25 & 228,39 & 233 & 100,70 & 646,09 & 89,10 & 4,1 & 55,93 & 261,45 & 37,30 & 37,32 & 26 \\
\hline Alytes cisternasii & $295 P C 10$ & 101,00 & 168,64 & 109,86 & 41,74 & 5166,21 & 322,54 & 61,98 & 260,56 & 115,16 & 234,22 & 238,31 & 106,22 & 527,47 & 76,84 & 2,00 & 59,79 & 222,91 & 23,19 & 24,74 & 216,76 \\
\hline Alytes cisternasii & 29SPC12 & 99,00 & 167,73 & 109,94 & 41,19 & 5225,10 & 323,02 & 60,97 & 262,05 & 113,38 & 234,04 & 238,20 & 104,57 & 540,49 & 76,70 & 2,27 & 58,39 & 224,17 & 26,18 & 27,20 & 219,97 \\
\hline 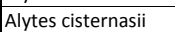 & 29SPC13 & 101,00 & 160,51 & 109,02 & 41,00 & 5282,23 & 317,10 & 54,79 & 262,31 & 105,93 & 228,42 & 232,21 & 97,33 & 589,14 & 81,72 & 3,00 & 57,24 & 240,98 & 30,63 & 30,77 & 238,69 \\
\hline Alytes cisternasii & 29SPC14 & 101,00 & 162,18 & 107,55 & 40,99 & 5257,45 & 316,92 & 57,16 & 259,76 & 107 & 229, & 233 & 99 & 584,99 & 80,21 & 3,18 & 56,79 & 237,86 & 31,36 & 31,48 & 236,03 \\
\hline Alytes cisternasii & $295 P C 15$ & 99,00 & 165,51 & 106,22 & 40,89 & 5234,90 & 318,45 & 60,80 & 257,65 & 110,85 & 232,12 & 236,15 & 102,37 & 570,58 & 77,63 & 3,01 & 56,58 & 231,28 & 30,94 & 31,19 & 229,58 \\
\hline
\end{tabular}




\begin{tabular}{|c|c|c|c|c|c|c|c|c|c|c|c|c|c|c|c|c|c|c|c|c|c|}
\hline TAXON & UTM & $\mathrm{km2}$ & BIO1 & B102 & BIO3 & BIO4 & B105 & B106 & B107 & B108 & B109 & BIO10 & BIO11 & B1012 & BIO13 & BIO14 & BIO15 & BIO16 & BIO17 & BIO18 & BIO19 \\
\hline Alytes cisternasii & 29SPC16 & 101,00 & 164,63 & 104,87 & 40,48 & 5233,01 & 316,59 & 60,68 & 255,91 & 109,99 & 231,29 & 235,31 & 101,53 & 584,22 & 79,00 & 3,59 & 56,01 & 235,55 & 32,65 & 32,69 & 234,44 \\
\hline Alytes cisternasii & $295 P C 17$ & 99,00 & 163,81 & 103,55 & 40,05 & 5233,55 & 314,91 & $\begin{array}{ll}60,52 \\
\end{array}$ & 254,39 & $\begin{array}{l}108,59 \\
\end{array}$ & \begin{tabular}{|l|l|}
230,76 \\
\end{tabular} & 234,53 & \begin{tabular}{|l|l|}
100,84 \\
\end{tabular} & 601,24 & 81,32 & 4,00 & \begin{tabular}{|l|l|}
55,57 \\
\end{tabular} & 241,35 & 34,91 & 34,91 & 240,92 \\
\hline Alytes cisternasii & 29SPC18 & 101,00 & 160,60 & 102,15 & 39,90 & 5255,88 & 311,74 & 58,30 & 253,45 & \begin{tabular}{ll|l}
102,59 \\
\end{tabular} & 228,97 & 231,89 & \begin{tabular}{ll|l}
97,68 \\
\end{tabular} & \begin{tabular}{|l|l|}
638,67 \\
\end{tabular} & 86,96 & 4,34 & 55,44 & 256,29 & 37,43 & 37,43 & 256,26 \\
\hline Alytes cisternasii & 29SPC19 & 101,00 & 161,79 & 101,60 & 39,82 & 5264,89 & 312,60 & 59,40 & 253,21 & \begin{tabular}{l|l|l}
104,32 \\
\end{tabular} & 229,51 & 233,04 & $\begin{array}{l}98,68 \\
\end{array}$ & \begin{tabular}{|l|l|}
646,77 \\
\end{tabular} & 88,31 & 4,52 & 55,33 & \begin{tabular}{|l|l|}
259,77 \\
\end{tabular} & 38,18 & 38,21 & 259,71 \\
\hline Alytes cisternasii & 29SPC20 & 100,00 & 167,25 & 108,79 & 41,00 & 5254,52 & 320,84 & 59,51 & 261,33 & 112,50 & \begin{tabular}{|l|l|}
233,96 \\
\end{tabular} & 237,92 & 103,49 & 532,54 & 76,72 & 2,00 & 59,38 & 223,71 & 23,36 & 25,51 & 216,45 \\
\hline Alytes cisternasii & 29SPC23 & 100,00 & 165,26 & 109,13 & 40,97 & 5331,75 & 321,37 & 57,58 & 263,80 & \begin{tabular}{ll|}
109,62 \\
\end{tabular} & 233,19 & 237,03 & 100,88 & 556,98 & 77,25 & 3,00 & 57,18 & 227,79 & 28,54 & 29,44 & 223,46 \\
\hline Alytes cisternasii & 29SPC24 & 100,00 & 165,85 & 108,43 & 40,86 & 5334,76 & 321,51 & 58,32 & 263,18 & \begin{tabular}{ll|}
109,86 \\
\end{tabular} & 233,76 & 237,63 & 101,18 & 558,27 & 76,57 & 3,00 & 56,60 & \begin{tabular}{|l|l|}
226,87 \\
\end{tabular} & 29,57 & 30,35 & 223,10 \\
\hline Alytes cisternasii & 29SPC25 & 101,00 & 165,01 & 107,59 & 40,39 & 5344,68 & 320,41 & 58,02 & 262,39 & \begin{tabular}{|l|l|}
109,00 \\
\end{tabular} & 233,26 & 236,94 & $\begin{array}{l}100,45 \\
\end{array}$ & \begin{tabular}{|l|l|}
569,88 \\
\end{tabular} & 77,21 & 3,12 & 55,98 & 230,09 & 31,34 & 31,72 & 227,01 \\
\hline Alytes cisternasii & $29 \mathrm{SPC26}$ & 100,00 & 163,38 & 106,58 & 40,03 & 5357,52 & 318,45 & 57,03 & \begin{tabular}{|l|l|}
261,42 \\
\end{tabular} & \begin{tabular}{|l|l|l|l}
107,29 \\
\end{tabular} & \begin{tabular}{|l|l|}
231,94 \\
\end{tabular} & 235,68 & 98,68 & 588,79 & $\begin{array}{l}78,97 \\
\end{array}$ & 3,99 & 55,43 & 236,50 & 33,58 & 33,74 & 234,22 \\
\hline Alytes cisternasii & $29 S P C 28$ & 100,00 & 159,59 & 104,11 & 39,72 & 5380,03 & 313,91 & 54,76 & 259,15 & 102,98 & 229,49 & 232,40 & 95,14 & 642,65 & 86,77 & 4,51 & 54,97 & 256,99 & 38,20 & 38,24 & 255,93 \\
\hline Alytes cisternasii & 29SPC29 & 100,00 & 158,40 & 102,98 & 39,39 & 5393,15 & 312,64 & 54,31 & 258,34 & \begin{tabular}{|l|l|}
102,07 \\
\end{tabular} & \begin{tabular}{|l|l|}
228,38 \\
\end{tabular} & 231,60 & 94,01 & 668,10 & 90,58 & 5,07 & 54,64 & 267,01 & $\begin{array}{ll}40,43 \\
\end{array}$ & \begin{tabular}{l|l|}
40,47 \\
\end{tabular} & 266,42 \\
\hline Alytes cisternasii & 29SPC30 & 101,00 & 166,07 & 107,70 & 40,62 & 5327,15 & 319,31 & \begin{tabular}{|l|l|}
57,17 \\
\end{tabular} & 262,14 & 110,25 & 233,87 & 237,53 & 101,40 & 538,07 & 76,59 & 2,32 & 58,83 & 224,42 & 24,33 & 27,07 & 215,93 \\
\hline Alytes cisternasii & 295 PC31 & 100,00 & 166,25 & 108,74 & \begin{tabular}{l|l}
40,75 \\
\end{tabular} & 5373,15 & 321,21 & 56,92 & 264,29 & \begin{tabular}{|l|}
109,87 \\
\end{tabular} & 234,71 & 238,28 & \begin{tabular}{|l|}
101,01 \\
\end{tabular} & 540,34 & 75,98 & 2,89 & 57,64 & 223,15 & 26,13 & 28,48 & 215,62 \\
\hline Alytes cisternasii & 29SPC32 & 100,00 & 168,44 & 108,99 & \begin{tabular}{ll|}
40,68 \\
\end{tabular} & 5377,66 & 323,78 & 58,78 & 265,00 & \begin{tabular}{|l|l|}
111,72 \\
\end{tabular} & 236,88 & 240,46 & 103,10 & 530,80 & 74,13 & 2,80 & \begin{tabular}{l|l|}
57,45 \\
\end{tabular} & \begin{tabular}{|l|}
218,09 \\
\end{tabular} & 26,20 & 28,24 & 211,01 \\
\hline Alytes cisternasii & $295 P C 33$ & 100,00 & 168,65 & 109,01 & 40,48 & 5392,90 & 324,63 & \begin{tabular}{|l|l|}
58,97 \\
\end{tabular} & 265,66 & \begin{tabular}{|l|l|}
111,64 \\
\end{tabular} & 237,36 & 240,86 & 103,12 & 533,38 & 73,80 & 2,99 & \begin{tabular}{|l|l}
56,89 \\
\end{tabular} & 217,75 & 27,26 & \begin{tabular}{l|l}
28,95 \\
\end{tabular} & 211,42 \\
\hline Alytes cisternasii & $29 \mathrm{SPC} 34$ & 101,00 & 167,87 & 109,05 & 40,35 & 5414,99 & 324,48 & 58,33 & 266,15 & 110,67 & \begin{tabular}{|l|l|}
236,92 \\
\end{tabular} & 240,31 & 102,11 & $\begin{array}{ll}542,35 \\
\end{array}$ & 74,31 & 3,00 & 56,41 & 220,05 & 28,47 & 29,80 & 214,46 \\
\hline Alytes cisternasii & 29SPC35 & 100,00 & 167,02 & 108,80 & 40,12 & 5433,43 & 323,99 & 57,58 & 266,41 & 109,55 & 236,34 & 239,79 & $\begin{array}{ll}101,03 \\
\end{array}$ & 553,34 & 75,23 & 3,16 & 55,95 & 223,18 & 30,26 & 31,26 & 218,25 \\
\hline Alytes cisternasii & $29 \mathrm{SPC} 36$ & 101,00 & 164,36 & 108,31 & 40,00 & 5467,16 & 321,97 & 55,28 & 266,69 & \begin{tabular}{|l|l|}
106,72 \\
\end{tabular} & \begin{tabular}{|l|l|l|}
234,42 \\
\end{tabular} & 237,79 & $\begin{array}{l}98,15 \\
\end{array}$ & 577,66 & 77,96 & 3,98 & 55,18 & 231,45 & 33,13 & 33,78 & 227,34 \\
\hline Alytes cisternasii & 29SPC37 & 100,00 & 165,27 & 107,92 & 40,00 & 5472,45 & 322,58 & 56,23 & 266,34 & \begin{tabular}{|l|l|l|l}
107,39 \\
\end{tabular} & 235,64 & 238,79 & \begin{tabular}{|l|l|}
98,97 \\
\end{tabular} & 581,16 & $\begin{array}{l}78,36 \\
\end{array}$ & 4,00 & \begin{tabular}{l|l|l|l|}
54,85 \\
\end{tabular} & 232,22 & 34,01 & 34,58 & 228,44 \\
\hline Alytes cisternasii & 29SPC38 & 100,00 & 162,29 & 106,91 & 39,89 & 5492,93 & 319,66 & 54,09 & 265,57 & 104,35 & \begin{tabular}{|l|l|}
233,02 \\
\end{tabular} & 236,21 & 95,8 & 614,36 & 82,31 & 4,41 & 54,5 & 244,89 & 36,96 & 37,18 & 241,92 \\
\hline Alytes cisternasii & 29SPC40 & 101,00 & 164,01 & 106,92 & 40,01 & 5409,63 & 317,65 & 54,14 & 263,51 & \begin{tabular}{|l|l|}
107,14 \\
\end{tabular} & \begin{tabular}{|l|l|}
233,05 \\
\end{tabular} & 236,42 & 98,43 & 550,22 & 77,29 & 2,92 & \begin{tabular}{l|l|}
57,95 \\
\end{tabular} & 227,62 & 25,75 & 28,88 & 218,07 \\
\hline Alytes cisternasii & 29SPC41 & 100,00 & 166,05 & 108,00 & 40,01 & 5437,09 & 321,08 & 55,40 & 265,69 & \begin{tabular}{ll|l}
108,56 \\
\end{tabular} & 235,40 & 238,69 & 99,84 & \begin{tabular}{|l|l|}
540,63 \\
\end{tabular} & 75,50 & 3,00 & \begin{tabular}{l|l}
57,42 \\
\end{tabular} & 222,30 & 26,20 & 29,02 & 213,41 \\
\hline Alytes cisternasii & 29SPC42 & 100,00 & 168,63 & 108,80 & \begin{tabular}{ll|}
40,06 \\
\end{tabular} & 5456,22 & 324,43 & 57,49 & 266,93 & 110,51 & 238,29 & 241,35 & 102,19 & 527,43 & 73,36 & 2,99 & 56,99 & 215,81 & 26,20 & 28,86 & 207,36 \\
\hline Alytes cisternasii & 29SPC43 & 101,00 & 167,88 & 109,24 & 40,02 & 5501,38 & 325,44 & 56,36 & 269,08 & $\begin{array}{ll}109,36 \\
\end{array}$ & 238,23 & 241,34 & \begin{tabular}{|l|}
100,77 \\
\end{tabular} & 533,92 & 73,76 & 3,00 & \begin{tabular}{|l|l|}
56,68 \\
\end{tabular} & 217,10 & 27,27 & 29,37 & 209,34 \\
\hline Alytes cisternasii & 29SPC44 & 100,00 & 168,91 & 109,81 & 40,04 & 5516,29 & 327,01 & \begin{tabular}{|l|l|}
57,07 \\
\end{tabular} & 269,94 & \begin{tabular}{ll|}
110,10 \\
\end{tabular} & 239,67 & 242,44 & 101,43 & 531,63 & 73,28 & 3,00 & 56,19 & 215,10 & 27,82 & 29,73 & 207,85 \\
\hline Alytes cisternasii & 29SPC45 & 100,00 & 168,72 & 109,90 & 40,02 & 5520,70 & 327,46 & 56,84 & 270,62 & 109,73 & 239,59 & 242,28 & 101,23 & 536,43 & 73,75 & 3,02 & 55,77 & 215,92 & 28,96 & 30,40 & 209,14 \\
\hline Alytes cisternasii & 29SPC46 & 100,00 & 168,21 & 110,05 & 40,00 & 5541,22 & 327,67 & 56,19 & 271,48 & $\begin{array}{ll}108,93 \\
\end{array}$ & 239,34 & 242,04 & \begin{tabular}{ll|}
100,49 \\
\end{tabular} & 546,01 & 74,72 & 3,51 & $\begin{array}{l}55,06 \\
\end{array}$ & 218,49 & \begin{tabular}{l|l}
31,15 \\
\end{tabular} & 32,31 & 212,21 \\
\hline Alytes cisternasii & 29SPC47 & 101,00 & 167,52 & 110,02 & 40,00 & 5572,71 & 327,53 & \begin{tabular}{l|l|}
55,35 \\
\end{tabular} & 272,18 & 107,90 & 239,20 & 241,86 & 99,60 & 557,72 & 76,07 & 3,98 & 54,43 & 222,23 & 32,93 & 33,83 & 216,36 \\
\hline Alytes cisternasii & 29SPC48 & 100,00 & 166,22 & 109,81 & 39,98 & 5599,39 & 326,71 & 54,12 & 272,59 & \begin{tabular}{|l|l|}
106,36 \\
\end{tabular} & 238,41 & 241,00 & 98,04 & 575,10 & 78,17 & 4,08 & 54,29 & 228,73 & 34,55 & \begin{tabular}{l|l}
35,15 \\
\end{tabular} & 223,27 \\
\hline Alytes cisternasii & 29SPC49 & 101,00 & 165,01 & 109,48 & 39,91 & 5613,73 & 325,70 & 53,33 & 272,37 & \begin{tabular}{|l|}
105,11 \\
\end{tabular} & \begin{tabular}{|l|l|}
237,55 \\
\end{tabular} & 240,08 & 96,82 & 595,18 & 80,41 & 4,58 & 53,77 & 236,19 & 36,72 & 37,23 & 231,34 \\
\hline Alytes cisternasii & 29SPC50 & 100,00 & 165,21 & 106,32 & 39,84 & 5479,81 & 318,78 & 54,19 & 264,59 & \begin{tabular}{|l|}
107,29 \\
\end{tabular} & \begin{tabular}{|l|l|}
235,18 \\
\end{tabular} & 238,30 & \begin{tabular}{l|l}
98,45 \\
\end{tabular} & 542,76 & 76,27 & 2,73 & 57,73 & 223,62 & 25,01 & 28,78 & 212,74 \\
\hline Alytes cisternasii & 29SPC51 & 101,00 & 167,10 & 107,59 & 39,88 & 5507,90 & 322,31 & 55,03 & 267,28 & 108,55 & 237,41 & 240,46 & 99,80 & 533,46 & 74,70 & 3,00 & 57,20 & 218,51 & 25,75 & 29,11 & 208,22 \\
\hline Alytes cisternasii & 29SPC52 & 100,00 & 168,43 & 108,65 & 39,99 & 5543,99 & 325,30 & 55,72 & 269,58 & \begin{tabular}{|l|l|}
109,37 \\
\end{tabular} & 239,34 & \begin{tabular}{|l|}
242,17 \\
\end{tabular} & 100,59 & 526,22 & 73,52 & 3,00 & 56,66 & 214,39 & 26,14 & 29,12 & 204,65 \\
\hline Alytes cisternasii & 29SPC53 & 100,00 & 166,86 & 109,71 & 39,99 & 5586,67 & 325,93 & 53,65 & 272,28 & 107,14 & 238,44 & 241,20 & 98,53 & 537,68 & 74,58 & 3,00 & 56,35 & 217,67 & 27,47 & 29,91 & 208,80 \\
\hline Alytes cisternasii & 29SPC54 & 100,00 & 167,86 & 110,35 & 40,00 & 5602,91 & 327,94 & 54,27 & 273,67 & \begin{tabular}{|l|}
107,78 \\
\end{tabular} & 239,81 & 242,30 & 99,23 & 534,37 & 73,98 & 3,03 & 55,77 & 215,26 & 28,15 & 30,24 & 206,77 \\
\hline Alytes cisternasii & 29SPC55 & 101,00 & 166,82 & 111,02 & 39,95 & 5639,14 & 328,46 & 52,88 & 275,58 & \begin{tabular}{|l|l|l|}
106,43 \\
\end{tabular} & \begin{tabular}{|l|l|}
239,38 \\
\end{tabular} & 241,86 & 97,84 & 543,21 & 74,81 & 3,39 & \begin{tabular}{|l|l|}
54,97 \\
\end{tabular} & 217,40 & 30,10 & 31,80 & 209,48 \\
\hline Alytes cisternasii & 29SPC56 & 100,00 & 166,97 & 111,41 & 39,97 & 5663,56 & 329,39 & 52,77 & 276,63 & 106,25 & 240,07 & 242,45 & 97,86 & 546,35 & 75,01 & 3,92 & 54,31 & 217,49 & 31,92 & 33,19 & 209,91 \\
\hline Alytes cisternasii & 29SPC57 & 100,00 & 168,13 & 111,79 & 39,96 & 5684,87 & 331,09 & 53,09 & 278,00 & \begin{tabular}{ll|}
106,93 \\
\end{tabular} & 241,54 & 243,71 & $\begin{array}{l}98,65 \\
\end{array}$ & 543,91 & 74,76 & 3,99 & 53,94 & 215,79 & 32,57 & 33,71 & 208,22 \\
\hline Alytes cisternasii & 29SPC59 & 100,00 & 167,52 & 112,36 & 39,84 & 5728,25 & 331,77 & 51,96 & 279,81 & \begin{tabular}{ll|}
105,68 \\
\end{tabular} & 241,69 & 243,64 & $\begin{array}{l}97,36 \\
\end{array}$ & 562,54 & 76,98 & 4,1 & 53,4 & 222,29 & $\begin{array}{l}5,05 \\
\end{array}$ & 5,62 & 215,23 \\
\hline Alytes cisternasii & 29SPC60 & 100,00 & 163,18 & 106,26 & 39,15 & 5569,55 & 317,99 & 50,66 & 267,33 & 104,12 & 234,43 & 237,22 & 95,19 & 556,04 & 78,26 & 2,98 & 57,41 & 227,75 & 25,89 & 29,93 & 216,04 \\
\hline Alytes cisternasii & 29SPC61 & 100,00 & 162,79 & 107,89 & \begin{tabular}{|l|l|}
39,17 \\
\end{tabular} & 5622,32 & 320,55 & 49,19 & \begin{tabular}{|l|l|}
271,36 \\
\end{tabular} & \begin{tabular}{|l|l|l|}
103,19 \\
\end{tabular} & 234,95 & 237,86 & 94,22 & 558,30 & 78,06 & 3,08 & \begin{tabular}{|l|l|}
56,97 \\
\end{tabular} & 227,34 & 26,79 & 30,50 & 216,45 \\
\hline Alytes cisternasii & 29SPC62 & 100,00 & 167,16 & 108,97 & 39,37 & 5633,15 & 325,76 & 52,92 & 272,84 & 107,02 & 239,42 & 241,86 & 98,14 & 532,84 & 74,71 & 3,00 & 56,49 & 216,13 & 26,27 & 29,60 & 205,40 \\
\hline Alytes cisternasii & 29SPC63 & 101,00 & 165,10 & 110,21 & 39,51 & 5678,03 & 326,27 & 50,42 & 275,85 & 104,51 & 238,20 & 240,63 & 95,64 & 545,39 & 75,90 & 3,00 & 56,10 & 219,89 & 27,74 & 30,49 & 209,94 \\
\hline Alytes cisternasii & 29SPC64 & 101,00 & 165,09 & 111,09 & 39,43 & 5713,22 & 327,85 & 49,66 & 278,20 & 104,05 & 238,78 & 241,18 & 95 & 546,52 & 75,67 & 3,30 & 55,16 & 218,88 & 9,32 & \begin{tabular}{l|l|l}
1,59 \\
\end{tabular} & 209,42 \\
\hline Alytes cisternasii & \begin{tabular}{|l|l|}
$295 P C 65$ \\
\end{tabular} & 99,00 & 164,63 & 111,94 & 39,49 & 5746,92 & 328,91 & 48,54 & 280,37 & 103,08 & 238,90 & 241,08 & 94, & 551,15 & 75,98 & 3,93 & 54,29 & 219,39 & 31,55 & 33,24 & 210,27 \\
\hline Alytes cisternasii & 29SPC67 & 100,00 & 163,22 & 112,86 & 39,25 & 5799,65 & 329,68 & 46,44 & 283,24 & 101,10 & 238,40 & 240,30 & 92,4 & 565,42 & 77,51 & 4,10 & 53,61 & 223,34 & 34,08 & 35,10 & 214,86 \\
\hline Alytes cisternasii & 29SPC68 & 101,00 & 165,88 & 113,77 & 39,39 & 5827,84 & 333,01 & 48,04 & \begin{tabular}{|l|l|}
284,97 \\
\end{tabular} & $\begin{array}{ll}102,98 \\
\end{array}$ & \begin{tabular}{ll|}
241,62 \\
\end{tabular} & 243,26 & \begin{tabular}{l|l}
94,45 \\
\end{tabular} & 550,29 & 75,81 & 4,00 & \begin{tabular}{|l|l|}
53,27 \\
\end{tabular} & 216,66 & 33,90 & 34,73 & 207,97 \\
\hline Alytes cisternasii & 29SPC69 & 100,00 & 168,82 & 114,62 & 39,47 & 5851,69 & 336,48 & 49,70 & 286,78 & 105,11 & 244,84 & 246,10 & 96,77 & 535,56 & 74,10 & 4,00 & 52,84 & 210,37 & 33,94 & 34,49 & 201,39 \\
\hline Alytes cisternasii & 29SPC70 & 100,00 & 161,09 & 106,73 & 38,95 & 5675,07 & 318,19 & 46,80 & 271,38 & 100,66 & 233,89 & 236,54 & 91,70 & \begin{tabular}{|l|l|}
571,07 \\
\end{tabular} & 80,41 & 3,15 & 57,24 & 232,70 & 26,59 & 31,03 & 220,35 \\
\hline Alytes cisternasii & $29 S P C 71$ & 101,00 & 158,40 & 108,44 & 38,92 & 5732,58 & 318,87 & 43,40 & 275,47 & 97,48 & 232,29 & 234,86 & 88,52 & 587,30 & 81,78 & 3,33 & 56,56 & 237,71 & 28,70 & 32,39 & 226,39 \\
\hline Alytes cisternasii & 29SPC72 & 100,00 & 165,22 & 109,58 & 39,03 & 5735,12 & 326,20 & 49,42 & 276,78 & 103,68 & \begin{tabular}{|l|l|}
239,04 \\
\end{tabular} & 241,32 & 95,01 & 543,63 & 76,32 & 3,01 & \begin{tabular}{l|l}
56,35 \\
\end{tabular} & 219,52 & \begin{tabular}{l|l|}
26,65 \\
\end{tabular} & 30,28 & 208,00 \\
\hline Alytes cisternasii & $29 \mathrm{SPC73}$ & 100,00 & 164,62 & 110,88 & 39,01 & 5774,34 & 327,87 & 47,88 & 279,99 & 102,55 & 239,21 & 241,35 & 94,00 & 546,35 & 76,21 & 3,05 & 55,68 & 219,18 & 27,99 & 31,12 & 208,24 \\
\hline Alytes cisternasii & 29SPC75 & 100,00 & 160,62 & 112,54 & 38,99 & 5859,96 & 327,79 & 43,08 & 284,70 & 97,82 & 236,75 & 238,66 & 89,31 & 570,99 & 78,4 & 4,01 & 54,31 & 226,36 & 32,31 & 34,26 & 216,50 \\
\hline Alytes cisternasii & 29SPC76 & 101,00 & 159,65 & 113,05 & 39,0 & 5884 & 328 & 41, & 286 & 96 , & 236 & 238 & 88, & 578,22 & 79,15 & 4,05 & 33, & 228,21 & 33,88 & 35,32 & 218 \\
\hline Alytes cisternasii & $29 S P C 77$ & 99,00 & 161,64 & 113,86 & 39,01 & 5906,86 & 330,81 & 43,08 & \begin{tabular}{|l|l|}
287,73 \\
\end{tabular} & \begin{tabular}{|c|}
97,98 \\
\end{tabular} & \begin{tabular}{|l|l|}
238,62 \\
\end{tabular} & 240,14 & 89,56 & 564,18 & 77,44 & 4,05 & 53,31 & 221,79 & 34,09 & 35,34 & 212,05 \\
\hline Alytes cisternasii & $295 P C 78$ & 101,00 & 164,72 & 114,89 & 39,01 & 5922,38 & 334,61 & \begin{tabular}{|l|l}
44,63 \\
\end{tabular} & 289,98 & 100,47 & \begin{tabular}{|l|l|}
241,89 \\
\end{tabular} & 243,01 & 92,16 & 543,85 & 75,06 & 4,00 & 52,70 & 213,05 & 33,86 & 34,86 & 202,97 \\
\hline Alytes cisternasii & 29SPC80 & 101,00 & 154,66 & 107,93 & 38,41 & 5795,37 & 315,84 & \begin{tabular}{|l|}
39,03 \\
\end{tabular} & 276,81 & 93,23 & \begin{tabular}{|l|l|}
229,63 \\
\end{tabular} & 232,06 & 84,21 & 614,21 & 85,61 & 3,64 & 56,86 & 248,62 & 29,24 & 33,59 & 236,45 \\
\hline Alytes c & 29SPC81 & 99,00 & 15 & & 38,81 & 50 & & 42,6 & & \begin{tabular}{|l|l|}
97,08 \\
\end{tabular} & & 236,60 & 88,26 & 583,86 & 81,56 & 9 & 56 & 235,44 & & 32,34 & 22 \\
\hline Alytes cisternasii & 29SPC82 & 101,00 & 160,19 & 110,52 & 38,84 & 5854,6 & 324,5 & 42,86 & 281,71 & 97,50 & 235,97 & 238,01 & 88,63 & 575,40 & 80,09 & 3,43 & 55,90 & 230,86 & 28,88 & 32,50 & 219, \\
\hline Alytes cisternasii & $295 \mathrm{SP} 84$ & 101,00 & 157,50 & 112,40 & 38,91 & 5936,03 & 326,01 & 39,01 & 286,99 & 93,97 & 234,75 & 236,48 & 85,22 & 589,00 & 80,89 & 4,03 & 54,68 & 233,65 & 32,11 & 34,68 & 222,91 \\
\hline
\end{tabular}




\begin{tabular}{|c|c|c|c|c|c|c|c|c|c|c|c|c|c|c|c|c|c|c|c|c|c|}
\hline TAXON & UTM & $\mathrm{km2}$ & B101 & $\mathrm{B1O2}$ & $\mathrm{BIO3}$ & $\mathrm{B104}$ & B105 & B106 & B107 & B108 & B109 & 81010 & B1011 & BIO12 & BIO13 & BIO14 & BIO15 & BIO16 & B1017 & BIO18 & B1019 \\
\hline Alytes cisternasii & 29SPC85 & 100,00 & 154,08 & 112,77 & 38,61 & 5968,82 & 324,12 & 35,77 & 288,36 & 90,35 & 231,94 & 233,88 & 81,75 & 611,60 & 83,11 & 4,36 & 53,93 & 241,21 & 34,97 & 36,92 & 231,16 \\
\hline Alytes cisternasii & 29SPC86 & 100,00 & 156,27 & 113,57 & 38,80 & 5976,05 & 326,95 & 37,27 & 289,67 & 92,08 & 234,28 & 235,96 & 83,77 & 595,57 & 81,03 & 4,27 & 53,38 & 233,99 & 35,05 & 36,73 & 223,79 \\
\hline Alytes cisternasii & 29SPC90 & 100,00 & 155,39 & 109,04 & 38,17 & 5882,69 & 318,88 & 38,08 & 280,80 & 92,63 & 231,65 & 233,82 & 83,79 & 613,37 & 85,57 & 3,45 & 56,86 & 247,51 & 28,96 & 33,52 & 234,93 \\
\hline Alytes cisternasii & 29SPC91 & 101,00 & 158,57 & 110,27 & 38,30 & 5915,33 & 323,67 & 40,32 & 283,35 & 95,27 & 235,23 & 237,27 & 86,32 & 589,82 & 82,32 & 3,35 & 56,42 & 237,01 & 28,48 & 32,65 & 224,46 \\
\hline Alytes cisternasii & 29SPC92 & 99,00 & 153,35 & 111,44 & 38,22 & 5977,65 & 321,58 & $\begin{array}{ll}34,63 \\
\end{array}$ & 286,95 & 89,59 & 231,15 & 233,13 & 80,78 & 621,02 & 85,31 & 3,99 & 55,51 & 247,66 & 31,83 & 35,31 & 236,26 \\
\hline Alytes cisternasii & 29SPC94 & 99,00 & 158,64 & 113,32 & 38,53 & 6010,83 & 329,04 & 38,53 & 290,51 & 93,99 & 236,90 & 238,53 & 85,32 & 581,60 & 79,89 & 3,74 & 54,58 & 230,01 & 31,40 & 34,26 & 218,55 \\
\hline Alytes cisternasii & 29SPC95 & 101,00 & 153,03 & 113,44 & 38,21 & 6051,86 & 325,26 & 33,25 & 292,01 & 88,29 & 232,23 & 233,77 & 79,68 & 615,80 & 83,41 & 4,51 & 53,75 & 241,99 & 35,09 & 37,22 & 231,30 \\
\hline Alytes cisternasii & 29SPC99 & 100,00 & 165,35 & 116,18 & 38,94 & 6062,52 & 338,82 & 42,56 & 296,26 & $\begin{array}{l}0,26 \\
99,26 \\
\end{array}$ & 244,25 & 245,25 & 90,75 & 516,90 & $\begin{array}{l}0,11+06 \\
71\end{array}$ & 4,00 & 51,87 & 200,16 & 32,14 & 34,00 & 187,97 \\
\hline Alytes cisternasii & 29SPD00 & 101,00 & 164,58 & 99,37 & 39,79 & 5146,66 & 311,81 & 64,14 & 247,67 & 103,56 & 230,05 & 234,15 & 102,51 & 650,04 & 89,94 & 4,54 & 55,90 & 263,25 & 37,71 & 38,10 & 263,25 \\
\hline Alytes cisternasii & 29SPD02 & 100,00 & 167,21 & 98,91 & 39,28 & 5169,43 & 314,35 & 66,14 & 248,21 & 109,00 & 233,19 & 236,94 & 104,65 & 665,74 & 92,82 & 4,97 & 55,84 & 270,11 & 38,65 & 39,55 & 270,11 \\
\hline Alytes cisternasii & 29SPD04 & 101,00 & 167,18 & 98,12 & 39,00 & 5207,99 & 314,58 & 65,51 & 249,07 & 108,01 & 233,88 & 237,27 & 104,14 & 701,80 & 98,94 & 5,02 & 55,98 & \begin{tabular}{|l|l|}
285,48 \\
\end{tabular} & 40,41 & 41,68 & 285,48 \\
\hline Alytes cisternasii & 29SPD05 & 100,00 & 164,19 & 97,09 & 38,45 & 5241,36 & 311,97 & 63,09 & 248,88 & 101,06 & 231,63 & 234,92 & 100,91 & 747,79 & 106,27 & 5,92 & 55,64 & 304,62 & 44,26 & 45,40 & 304,62 \\
\hline Alytes cisternasii & 29SPD06 & 101,00 & 162,42 & 96,54 & 38,07 & 5278,41 & 310,58 & 61,03 & 249,54 & 98,67 & 230,34 & 233,67 & 98,67 & 781,05 & 111,75 & 6,01 & 55,70 & 318,61 & 46,15 & 47,22 & 318,61 \\
\hline Alytes cisternasii & 29SPD07 & 100,00 & 163,07 & 96,93 & $\begin{array}{l}38,15 \\
\end{array}$ & 5303,94 & 311,69 & 60,67 & 251,02 & 99,04 & 231,54 & 234,37 & 98,93 & 789,75 & 113,19 & 6,18 & 55,53 & \begin{tabular}{|l|l|}
321,77 \\
\end{tabular} & 47,18 & 48,37 & 321,77 \\
\hline Alytes cisternasii & 29SPD08 & 101,00 & 164,65 & 97,86 & 38,19 & 5326,48 & 313,87 & 60,86 & 253,01 & 100,50 & 233,51 & 235,92 & 99,80 & 788,15 & 112,94 & 6,20 & 55,25 & 320,35 & 47,34 & 48,77 & 320,35 \\
\hline Alytes cisternasii & 29SPD09 & 101,00 & 161,29 & 97,32 & 37,86 & 5371,68 & 311,23 & 57,29 & 253,94 & 96,06 & 230,99 & 233,26 & 96,06 & 833,96 & 120,30 & 6,85 & 55,16 & 339,27 & 50,81 & 51,89 & 339,27 \\
\hline Alytes cisternasii & 29SPD10 & 100,00 & 161,34 & 100,52 & 39,30 & 5273,02 & 312,03 & 59,57 & 252,46 & $\begin{array}{r}102,42 \\
\end{array}$ & 228,95 & 232,85 & 98,11 & 669,64 & 92,03 & 4,97 & 55,26 & 269,45 & 39,96 & 40,06 & 269,45 \\
\hline Alytes cisternasii & 29SPD11 & 101,00 & 164,59 & 100,59 & 39,14 & 5276,51 & 314,93 & 62,16 & 252,77 & $\begin{array}{l}107,17 \\
\end{array}$ & 232,23 & 235,88 & \begin{tabular}{|c|}
101,03 \\
\end{tabular} & 662,80 & 91,24 & 5,00 & 55,36 & 266,99 & 39,18 & 39,92 & 266,87 \\
\hline Alytes cisternasii & 29SPD12 & 100,00 & 166,36 & 100,31 & \begin{tabular}{|l|l|}
39,03 \\
\end{tabular} & 5282,65 & 316,66 & 63,77 & 252,89 & 110,21 & 234,10 & 237,65 & 102,66 & 666,77 & 92,14 & 5,00 & 55,42 & 268,94 & 39,34 & 40,14 & 268,71 \\
\hline Alytes cisternasii & 29SPD13 & 100,00 & 165,32 & 99,37 & 38,84 & 5312,71 & 315,68 & 63,01 & $252,67 \mid$ & $\mid 107,43$ & 233,46 & 237,16 & $\mid 101,29$ & 694,89 & 96,87 & 5,21 & 55,44 & 280,93 & 41,01 & 42.06 & 280,87 \\
\hline Alytes cisternasii & 29SPD14 & 101,00 & 165,21 & 98,75 & 38,55 & 5330,92 & 315,60 & 62,83 & 252,77 & 106,32 & 233,90 & 237,29 & 101,11 & 714,56 & 100,17 & 5,54 & 55,28 & 289,08 & 42,56 & 43,73 & 289,07 \\
\hline Alytes cisternasii & $29 S P D 15$ & 99,00 & 162,46 & 97,29 & 38,02 & 5371,46 & 312,91 & 60,64 & 252,27 & 98,53 & 231,79 & 235,15 & \begin{tabular}{|l|l}
97,96 \\
\end{tabular} & 757,44 & 107,32 & 5,99 & 55,27 & 307,57 & 45,20 & 46,33 & 307,57 \\
\hline Alytes cisternasii & 29SPD16 & 100,00 & 161,78 & 96,94 & $\begin{array}{ll}37,96 \\
\end{array}$ & 5407,71 & 312,48 & 59,44 & 253,04 & 96,84 & 231,64 & 234,87 & 96,84 & 780,17 & 111,29 & 6,00 & 55,41 & \begin{tabular}{|l|l|}
317,28 \\
\end{tabular} & 46,43 & 47,58 & 317,28 \\
\hline Alytes cisternasii & 29SPD17 & 100,00 & 162,40 & 97,18 & 37,83 & 5441,73 & 313,80 & 59,03 & 254,77 & 97,30 & 232,95 & 235,84 & 96,87 & 787,81 & 112,55 & 6,00 & 55,10 & 319,82 & 47,48 & 48,64 & 319,82 \\
\hline Alytes cisternasii & 29SPD18 & 100,00 & 165,73 & 98,61 & 37,78 & 5466,37 & 317,80 & 60,42 & 257,38 & 102,76 & 236,73 & 238,93 & 99,37 & 766,83 & 109,26 & 6,00 & 55,04 & 310,27 & 46,09 & 47,75 & 310,24 \\
\hline Alytes cisternasii & 29SPD19 & 100,00 & 163,73 & 98,30 & 37,49 & 5511,66 & 316,45 & 57,86 & 258,59 & 99,38 & 235,47 & 237,44 & 96,75 & 798,04 & 114,38 & 6,44 & 54,99 & 322,98 & 48,53 & 49,92 & 322,95 \\
\hline \begin{tabular}{|l} 
Alytes cisternasii \\
\end{tabular} & 29SPD20 & 100,00 & 159,85 & 102,48 & 39,07 & 5401,49 & 313,94 & 55,83 & 258,10 & \begin{tabular}{|c|}
103,21 \\
\end{tabular} & 229,40 & 233,08 & 95,22 & 674,09 & \begin{tabular}{|c|}
91,73 \\
91,3
\end{tabular} & 5,03 & 54,81 & 269,90 & $\begin{array}{l}40,77 \\
40,77\end{array}$ & 40,90 & 269,22 \\
\hline Alytes cisternasii & 29SPD23 & 101,00 & 162,56 & 99,87 & 38,44 & 5420,56 & 315,60 & 59,50 & 256,09 & 105,28 & 232,51 & 236,07 & 97,74 & 712,61 & 98,85 & 5,84 & 54,81 & 286,88 & 43,34 & 44,26 & 286,62 \\
\hline Alytes cisternasii & $29 S P D 25$ & 101,00 & 160,69 & 97,33 & 37,76 & 5474,17 & 313,32 & 58,49 & 254,84 & 98,78 & 231,64 & 235,06 & 95,46 & 766,08 & $\begin{array}{r}108,18 \\
\end{array}$ & 6,11 & 55,04 & 309,96 & 46,21 & 47,49 & 309,96 \\
\hline Alytes cisternasii & $29 S P D 26$ & 101,00 & 160,01 & 96,71 & 37,40 & 5512,44 & 312,78 & 57,41 & 255,37 & 95,55 & 231,52 & 234,88 & 94,22 & 787,61 & 111,94 & 6,14 & 55,06 & 319,04 & 47,62 & 48,89 & 319,04 \\
\hline Alytes cisternasii & 29SPD27 & 100,00 & 161,47 & 97,40 & 37,06 & 5567,78 & 315,33 & 57,12 & 258,21 & 98,03 & 233,97 & 236,64 & 94,68 & 784,94 & 111,68 & 6,06 & 54,87 & 317,36 & 47,71 & 48,92 & 317,33 \\
\hline \begin{tabular}{|l} 
Alytes cisternasii \\
\end{tabular} & 29SPD28 & 101,00 & 163,53 & $\begin{array}{l}19,4 \\
98,34\end{array}$ & 37,12 & 5619,06 & 318,43 & 57,26 & \begin{tabular}{|l|}
261,16 \\
\end{tabular} & $\begin{array}{r}0,120 \\
101,12 \\
\end{array}$ & 236,92 & 238,95 & $\begin{array}{l}34,06 \\
95,64\end{array}$ & \begin{tabular}{|l|l|}
774,94 \\
\end{tabular} & $\begin{array}{l}110,22 \\
110\end{array}$ & 5,09 & $\begin{array}{l}44,719 \\
54,7\end{array}$ & 312,52 & $\begin{array}{l}47,14 \\
47,14\end{array}$ & $\begin{array}{ll}48,58 \\
48,58\end{array}$ & 312,37 \\
\hline Alytes cisternasii & 29SPD29 & 101,00 & 165,74 & 99,41 & 37,31 & 5638,23 & 320,90 & 57,92 & 262,98 & 103,96 & 239,38 & 240,89 & 97,06 & 762,84 & 108,38 & 5,99 & 54,66 & 306,90 & 46,46 & 48,16 & 306,55 \\
\hline Alytes cisternasii & 29SPD30 & 100,00 & 161,50 & 105,37 & 39,15 & 5515,50 & 318,91 & 54,19 & 264,71 & 103,47 & 232,66 & 236,00 & 95,16 & 649,40 & 87,17 & 5,00 & 54,22 & 259,03 & 39,70 & 40,00 & 256,64 \\
\hline Alytes cisternasii & 29SPD31 & 101,00 & 164,08 & 105,16 & 39,06 & 5516,52 & 321,40 & 56,66 & 264,73 & 105,84 & 235,25 & 238,34 & 97,68 & 647,09 & 86,94 & 5,00 & 54,20 & 258,42 & 39,55 & 40,13 & 255,93 \\
\hline Alytes cisternasii & $29 S P D 32$ & 101,00 & 164,90 & 104,14 & 38,99 & 5524,03 & 321,94 & 57,97 & 263,97 & 106,51 & 236,26 & 239,30 & 98,44 & 659,01 & 89,18 & 5,07 & 54,34 & 263,67 & 40,15 & 41,02 & 261,42 \\
\hline \begin{tabular}{|l} 
Alytes cisternasii \\
\end{tabular} & $\begin{array}{l}\text { 29SPDS34 } \\
\end{array}$ & 101,00 & 100,24 & $\begin{array}{r}04,14 \\
99,30\end{array}$ & 37,85 & 5520,03 & 315,39 & 56,72 & \begin{tabular}{|l|}
258,67 \\
257
\end{tabular} & \begin{tabular}{|l|}
102,24 \\
102,1
\end{tabular} & 232,29 & $\mid 235,74$ & $\begin{array}{ll}0,44,27 \\
94,\end{array}$ & $\mid$\begin{tabular}{|l|}
$\mid 740,95$ \\
740
\end{tabular} & \begin{tabular}{|c|}
103,04 \\
103
\end{tabular} & $\frac{6,01}{6,14}$ & $\begin{array}{l}44,440 \\
54,40\end{array}$ & 298,01 & $\begin{array}{l}40,110 \\
45,47 \\
\end{array}$ & $\begin{array}{l}41,02 \\
46,65\end{array}$ & $\begin{array}{l}201,42 \\
297,21\end{array}$ \\
\hline Alytes cisternasii & 29SPD35 & 100,00 & 150,96 & 93,90 & 36,71 & 5549,48 & 303,30 & 51,48 & 251,82 & 87,76 & 223,30 & 227,27 & 86,22 & 847,69 & 120,82 & 7,24 & 54,84 & 343,56 & 52,06 & 53,06 & 343,56 \\
\hline Alytes cisternasii & 29SPD36 & 101,00 & 153,98 & 94,90 & 36,77 & 5604,19 & 307,60 & 52,43 & 255,18 & 91,66 & 227,18 & 230,49 & 87,92 & 831,12 & 118,49 & 6,95 & 54,64 & 336,25 & 51,13 & 52.08 & 336,14 \\
\hline Alytes cisternasii & 29SPD37 & 100,00 & 162,36 & 98,66 & 37,05 & 5674,95 & 318,45 & 56,13 & 262,32 & 101,76 & 236,42 & 238,79 & 94,20 & 758,86 & 106,97 & 5,99 & 54,36 & 305,26 & 46,45 & 47,80 & 304,45 \\
\hline Alytes cisternasii & 29SPD38 & 101,00 & 162,82 & 98,87 & 36,98 & 5732,46 & 319,80 & 55,39 & 264,41 & 101,39 & 237,89 & 239,77 & 93,75 & 761,73 & 107,66 & 5,93 & 54,35 & 305,98 & 46,83 & 48,18 & 305,15 \\
\hline \begin{tabular}{|l} 
Alytytes cisternasii \\
\end{tabular} & $\begin{array}{l}2950500 \\
29 P D 40\end{array}$ & $\begin{array}{l}100,00 \\
100,0\end{array}$ & $\begin{array}{l}10,02 \\
160,85\end{array}$ & $\begin{array}{r}9,07,11 \\
107,88\end{array}$ & $\begin{array}{l}30,96 \\
39,32\end{array}$ & 5634,39 & $\begin{array}{l}31,80 \\
321,61\end{array}$ & \begin{tabular}{|l|l}
50,65 \\
50,
\end{tabular} & \begin{tabular}{|l|}
270,41 \\
270,96
\end{tabular} & \begin{tabular}{|l|l|}
101,18 \\
10,
\end{tabular} & $\mid \frac{\mid 5 l, 09}{233,86}$ & $\mid \begin{array}{l}236,68 \\
236,17\end{array}$ & $\begin{array}{l}93,15 \\
93,03\end{array}$ & \begin{tabular}{|l|l|}
641,53 \\
643
\end{tabular} & \begin{tabular}{|l|}
85,81 \\
851
\end{tabular} & $\begin{array}{l}, 95 \\
5,19\end{array}$ & $\begin{array}{l}4,35 \\
53,71 \\
\end{array}$ & \begin{tabular}{|l}
303,90 \\
254,70
\end{tabular} & $\begin{array}{l}40,30 \\
40,13 \\
\end{array}$ & $\begin{array}{l}40,10 \\
40,43 \\
\end{array}$ & $\begin{array}{l}30,13 \\
250,73\end{array}$ \\
\hline Alytes cisternasii & $29 S P D 43$ & 99,00 & 163,16 & 104,89 & \begin{tabular}{|c|}
38,67 \\
\end{tabular} & 5647,58 & 323,13 & 54,71 & 268,42 & 103,38 & 236,58 & 239,30 & 95,26 & 675,98 & 91,26 & 5,35 & 53,69 & 269,65 & 42,25 & 43,30 & 266,46 \\
\hline Alytes cisternasii & 29SPD44 & 101,00 & 155,18 & 99,28 & \begin{tabular}{|c|}
37,57 \\
\end{tabular} & 5640,11 & 312,16 & 51,31 & 260,85 & 96,60 & 228,72 & 232,15 & 88,58 & 767,07 & 106,42 & 6,42 & 54,01 & 307,69 & 47,74 & 48,74 & 306,19 \\
\hline Alytes cisternasii & 29SPD45 & 99,00 & 145,56 & 94,44 & 36,50 & 5659,10 & 300,09 & 44,74 & 255,35 & 86,12 & 220,27 & 223,39 & 79,69 & 866,89 & 122,89 & 7,64 & 54,20 & 348,96 & 54,20 & 54,73 & 348,51 \\
\hline \begin{tabular}{|l} 
Alytes cisternasii \\
\end{tabular} & 29SPD46 & 100,00 & 156,64 & 97,92 & 36,98 & 5715,55 & 313,60 & 51,85 & 261,75 & $\begin{array}{l}0,12 \\
96,79 \\
\end{array}$ & 231,46 & 234,36 & 88,84 & 779,71 & \begin{tabular}{|l|l|}
109,38 \\
\end{tabular} & 6,38 & 54,05 & $\begin{array}{l}340,009 \\
313,09\end{array}$ & 48,41 & 49,55 & 311,72 \\
\hline Alytes cisternasii & 29SPD47 & 100,00 & 161,78 & 99,90 & 37,00 & 5777,09 & 320,23 & 53,95 & 266,28 & 100,13 & 237,49 & 239,55 & 92,44 & 738,82 & 103,05 & 5,96 & 53,79 & 295,82 & 45,84 & 47,24 & 293,69 \\
\hline Alytes cisternasii & $29 S P D 49$ & 99,00 & 164,02 & 100,39 & 36,89 & 5853,23 & 323,01 & 53,88 & 269,13 & 100,56 & 240,91 & 242,15 & 93,07 & 730,46 & 102,34 & 5,78 & 53,71 & 291,92 & 45,35 & 46,81 & 289,43 \\
\hline Alytes cisternasii & $29 S P D 52$ & 101,00 & 166,26 & 111,13 & 39,15 & 5767,16 & 331,38 & 51,92 & 279,45 & 104,00 & 241,34 & 243,14 & 96,06 & 610,44 & 82,21 & 4,99 & 52,86 & 241,30 & 38,96 & 39,79 & 235,35 \\
\hline Alytes cisternasii & 29SPD53 & 101,00 & 162,51 & 107,88 & 38,71 & 5768,06 & 326,25 & 50,88 & 275,37 & 100,99 & 237,82 & 239,95 & 92,98 & 656,75 & 87,85 & 5,19 & 52,99 & 260,40 & 41,79 & 42,66 & 255,47 \\
\hline \begin{tabular}{|l} 
Alytes cisternasii \\
\end{tabular} & 29SPD54 & 100,00 & 159,58 & $\frac{10}{10}$ & $\begin{array}{l}30, \\
37,\end{array}$ & 5772,25 & 321 & $\begin{array}{l}0,000 \\
50,21\end{array}$ & \begin{tabular}{|l|}
271,00 \\
\end{tabular} & \begin{tabular}{|l|l|}
98,48 \\
98,
\end{tabular} & \begin{tabular}{|l|}
235,00 \\
230
\end{tabular} & \begin{tabular}{|l|}
237,44 \\
\end{tabular} & $\begin{array}{l}32,50 \\
90,46\end{array}$ & \begin{tabular}{|l|l|}
698,68 \\
\end{tabular} & \begin{tabular}{l|l|}
94,38 \\
94,3
\end{tabular} & $\frac{1,19}{5,69}$ & $\begin{array}{ll}2,3,15 \\
53,\end{array}$ & 277,90 & $\begin{array}{l}41,19 \\
44,20\end{array}$ & $\begin{array}{l}42,00 \\
45,22\end{array}$ & $\begin{array}{l}23,43,87 \\
273,87\end{array}$ \\
\hline Alytes cisternasii & 29SPD55 & 101,00 & 155,24 & 100,88 & 37,30 & 5793,53 & 315,14 & 48,08 & 267,07 & 94,52 & 231,21 & 233,80 & 86,40 & 749,56 & 103,06 & 6,22 & 53,30 & 298,95 & 47,35 & 48,26 & 295,74 \\
\hline Alytes cisternasii & $29 S P D 56$ & 101,00 & 157,86 & 100,85 & $37,00 \mid$ & 5829,21 & 317,95 & 49,67 & 268,29 & 96,27 & 234,37 & 236,51 & 88,25 & 735,80 & 101,26 & 6.06 & 53,23 & 293,24 & 46,52 & 47.58 & 289,84 \\
\hline Alytes cisternasii & 29SPD58 & 101,00 & 160,07 & 100,45 & 36,76 & 5897,48 & 320,11 & 50,25 & 269,86 & 96,85 & 237,75 & 239,16 & 89,13 & 729,97 & 101,25 & 5,89 & 53,19 & 290,69 & 45,96 & 47,07 & 287,24 \\
\hline Alytes cisternasii & $29 S P D 59$ & 101,00 & 163,90 & 101,51 & 36,84 & 5918,49 & 324,06 & 52,29 & 271,77 & 99,59 & 241,73 & 242,68 & 92 & 700,88 & 96,96 & 5,47 & 53,10 & 278,58 & 43,96 & 45,45 & 274,74 \\
\hline Alytes cisternasii & 29SPD61 & 100,00 & 167,71 & 115,31 & 39,86 & 5882,00 & 336,11 & 48,61 & 287,49 & 103,42 & 244,34 & 245,41 & 95,43 & 563,84 & 77,06 & 4,32 & 52,19 & 220,94 & 36,92 & 37,50 & 212,62 \\
\hline Alytes cisternasii & 29SPD62 & 100,00 & 165,88 & 114,38 & 39,38 & 5882,08 & 334,61 & 48,07 & 286,54 & 101,80 & 242,73 & 243,80 & 93,97 & 590,70 & 79,85 & 4,86 & 52,16 & \begin{tabular}{|l|l|}
231,85 \\
\end{tabular} & 38,45 & 39,20 & 224,20 \\
\hline Alytes ci & 29SPD63 & 99,00 & 165,28 & 111,71 & 39,01 & 5881.51 & 332,24 & 49,14 & 283,10 & 101.48 & 242.15 & 243,45 & 93,61 & 608,40 & 81,64 & 4.91 & 52.16 & 239,24 & 39,44 & 40,35 & 23205 \\
\hline Alytes cisternasii & 29SPD64 & 101,00 & 163,57 & 108,86 & 38,40 & 5889,68 & 329,05 & 49,39 & 279,66 & 100,14 & 240,79 & 242 , & 92, & 634,25 & 84,37 & 5,02 & 52,28 & 249,93 & 40,92 & 41,94 & 243,47 \\
\hline Alytes cisternasii & 29 SPD65 & 99,00 & 159,07 & 105,07 & 37,66 & 5905,09 & 322,77 & 47,30 & 275,47 & 96,15 & 236,66 & 238,35 & 88,16 & 682,61 & 91,35 & 5,51 & 52,42 & 269,79 & 43,77 & 44,68 & 264,17 \\
\hline
\end{tabular}




\begin{tabular}{|c|c|c|c|c|c|c|c|c|c|c|c|c|c|c|c|c|c|c|c|c|c|}
\hline TAXON & UTM & $\mathrm{km} 2$ & B101 & B102 & $\mathrm{BIO3}$ & B104 & B105 & B106 & B107 & B108 & B109 & BIO10 & BIO11 & BIO12 & 81013 & BIO14 & BIO15 & B1016 & B1017 & BIO18 & B1019 \\
\hline Alytes cisternasii & 29SPD67| & 100,00 & 160,17 & 102,90 & 37,00 & 5953,39 & 322,70 & 48,59 & 274,10 & 96,39 & 238,64 & 239,99 & 88,50 & 689,63 & 93,57 & 5,52 & 52,62 & 272,83 & 43,92 & 45,00 & 267,58 \\
\hline Alytes cisternasii & 29SPD68 & 100,00 & 162,31 & 102,78 & 37,01 & 5974,32 & 324,56 & 49,86 & 274,70 & 97,69 & 240,99 & 242,01 & 89,96 & 677,68 & 92,17 & 5,34 & 52,48 & 267,94 & 43,03 & 44,25 & 262,65 \\
\hline Alytes cisternasii & 29SPD69 & 99,00 & 163,36 & 102,63 & 36,88 & 5985,69 & 325,23 & 50,46 & 274,77 & 98,32 & 242,23 & 242,91 & 90,58 & 672,44 & 91,76 & 5,20 & 52,53 & 265,70 & 42,64 & 44,03 & 260,42 \\
\hline Alytes cisternasii & 29SPD70 & 101,00 & 168,47 & 116,41 & 39,00 & 5985,76 & 339,92 & 46,32 & 293,60 & 102,76 & 246,63 & 247,24 & 94,58 & 521,55 & 72,42 & 4,00 & 51,71 & 202,79 & 34,94 & 35,31 & 192,28 \\
\hline Alytes cisternasii & 29SPD71 & 100,00 & 168,40 & 116,38 & 39,05 & 5976,06 & 339,55 & 46,77 & 292,79 & 102,82 & 246,31 & 247,10 & 94,75 & 533,62 & 73,51 & 4,00 & 51,58 & 207,55 & 35,67 & 36,27 & 197,40 \\
\hline Alytes cisternasii & 29SPD73 & 100,00 & 164,64 & 112,88 & 38,83 & 5980,29 & 333,86 & 46,27 & 287,60 & 99,49 & 242,99 & 243,82 & 91,55 & 586,46 & 78,71 & 4,75 & 51,56 & 228,94 & 38,45 & 39,36 & 220,19 \\
\hline Alytes cisternasii & 29SPD74 & 101,00 & 160,95 & 109,50 & 38,06 & 5989,27 & 328,78 & 45,17 & 283,62 & 96,34 & 239,74 & 240,83 & 88,44 & 626,49 & 83,05 & 5,03 & 51,66 & 245,22 & 40,97 & 41,77 & 237,36 \\
\hline Alytes cisternasii & 29SPD75 & 100,00 & 160,41 & 107,47 & 37,79 & 6004,66 & 327,26 & 45,64 & \begin{tabular}{|l|}
281,61 \\
\end{tabular} & 95,76 & 239,45 & 240,56 & 87,78 & 640,06 & 84,48 & 5,02 & 51,79 & 250,86 & 41,51 & 42,46 & 243,36 \\
\hline Alytes cisternasii & 29SPD77 & 100,00 & 163,55 & 105,60 & 37,01 & 6029,43 & 328,94 & 49,05 & 279,88 & 98,36 & 243,08 & 243,80 & 90,37 & 630,06 & 83,43 & 4,99 & 51,70 & 246,92 & 40,79 & 42,02 & 239,72 \\
\hline Alytes cisternasii & 29SPD78 & 101,00 & 163,18 & 104,46 & 36,98 & $\begin{array}{ll}6042,43 \\
\end{array}$ & 327,73 & 48,82 & 278,91 & 97,58 & 242,86 & 243,48 & 89,67 & 638,86 & 85,31 & 4,99 & 51,72 & 250,58 & 41,22 & 42,48 & 243,70 \\
\hline Alytes cisternasii & 29SPD79 & 100,00 & 164,08 & 103,93 & 36,99 & 6046,74 & 328,12 & 49,56 & 278,56 & 98,21 & 243,88 & 244,25 & 90,47 & 634,59 & 85,11 & 4,96 & 51,67 & 248,84 & 40,90 & 42,10 & 242,06 \\
\hline Alytes cisternasii & 29SPD80 & 100,00 & 166,48 & 116,63 & 39,00 & 6016,54 & 338,82 & 43,80 & 295,03 & 101,63 & 244,73 & 245,60 & 92,25 & 515,78 & 71,39 & 4,00 & 51,66 & 200,01 & 33,50 & 34,65 & 188,28 \\
\hline \begin{tabular}{|l} 
Alytes cisternasii \\
\end{tabular} & 29SPD81 & 100,00 & 167,66 & 116,18 & 39,00 & 6007,36 & 339,61 & 45,34 & 294,27 & $\begin{array}{l}101,59 \\
\end{array}$ & $\begin{array}{l}245,93 \\
\end{array}$ & 246,56 & 93,46 & 517,34 & 71,18 & 4,00 & 51,31 & 200,32 & 33,97 & 35,08 & 188,84 \\
\hline Alytes cisternasii & 29SPD82 & 100,00 & 167,14 & 115,38 & 38,95 & 6039,30 & 339,05 & 45,73 & 293,31 & 101,06 & 246,31 & 246,66 & 93,00 & 532,86 & 72,48 & 4,00 & 51,25 & 206,41 & 35,04 & 35,95 & 195,55 \\
\hline Alytes cisternasii & 29SPD83 & 100,00 & 164,86 & 113,41 & 38,41 & 6057,41 & 336,19 & 44,88 & 291,31 & 98,84 & 244,34 & 244,99 & 90,78 & 559,73 & 75,01 & 4,28 & 51,20 & 216,95 & 36,56 & 37,66 & 206,87 \\
\hline Alytes cisternasii & 29SPD84 & 100,00 & 164,51 & 111,56 & 38,02 & 6072,79 & 334,88 & 45,70 & 289,18 & 98,41 & 244,35 & 244,90 & 90,37 & 571,99 & 76,07 & 4,41 & 51,20 & 222,03 & 37,21 & 38,09 & 212,37 \\
\hline Alytes cisternasii & $29 \mathrm{SPD} 86$ & 100,00 & 160,82 & 107,20 & 37,01 & 6100,64 & 329,33 & 44,68 & 284,66 & 94,91 & 241,38 & 242,02 & 86,92 & 614,69 & 80,48 & 4,97 & 51,01 & 238,84 & 40,42 & 41,25 & 230,18 \\
\hline Alytes cisternasii & 29SPD87 & 100,00 & 162,66 & 106,46 & 37,01 & 6105,22 & 330,23 & 46,67 & 283,56 & 96,46 & 243,22 & 243,79 & 88,46 & 606,97 & 79,40 & 4,95 & 50,99 & 235,81 & 40,01 & 41,02 & 227,34 \\
\hline Alytes cisternasii & 29SPD95 & 100,00 & 161,11 & 109,48 & 37,20 & 6168,92 & 332,58 & 42,74 & 289,84 & 94,19 & 242,64 & 242,97 & 86,19 & 580,94 & 75,82 & 4,72 & 50,47 & 223,68 & 38,61 & 39,40 & 213,55 \\
\hline Alytes cisternasii & 29SPE00 & 100,00 & 156,61 & 96,31 & 37,36 & 5412,16 & 306,87 & 52,65 & 254,22 & 91,06 & 227,34 & 229,15 & 91,06 & 892,60 & 129,81 & 7,50 & 55,12 & 363,46 & 55,07 & 55,67 & 363,46 \\
\hline Alytes cisternasii & 29SPE10 & 100,00 & 159,18 & 97,18 & 36,95 & 5576,36 & 312,60 & 53,12 & 259,48 & 91,49 & 232,06 & 233,77 & 91,49 & 854,46 & 123,62 & 6,97 & 54,95 & 346,49 & 52,60 & 53,47 & 346,49 \\
\hline Alytes cisternasii & 29SPE12 & 100,00 & 151,78 & 95,52 & 36,56 & 5580,80 & 303,98 & 46,12 & 257,86 & 84,14 & 225,44 & 226,36 & 84,14 & 943,37 & 138,41 & 8,12 & 55,08 & \begin{tabular}{|l|l|}
383,08 \\
\end{tabular} & 58,69 & 59,05 & 383,08 \\
\hline Alytes cisternasii & 29SPE20 & 100,00 & 159,02 & 97,11 & 36,27 & 5736,83 & 315,15 & 51,62 & 263,53 & 91,49 & 234,44 & 235,76 & 89,70 & 838,95 & 120,98 & 6,83 & 54,74 & 338,78 & 51,89 & 52,70 & 338,73 \\
\hline Alytes cisternasii & 29SPE21 & 100,00 & 157,59 & 97,04 & 36,15 & 5765,61 & 313,94 & 49,60 & 264,34 & 88,08 & 233,56 & 234,55 & 87,85 & 858,44 & 124,23 & 7,02 & 54,74 & 346,39 & 53,52 & 54,15 & 346,39 \\
\hline Alytes cisternasii & 29SPE30 & 100,00 & 165,01 & 99,91 & 36,85 & 5785,91 & 322,58 & 55,11 & 267,47 & 101,66 & 240,95 & 241,99 & 94,62 & 754,97 & 106,97 & 6,00 & 54,14 & 302,59 & 46,47 & 48,13 & 301,33 \\
\hline Alytes cisternasii & 29SPE32 & 100,00 & 155,12 & 96,91 & 36,01 & 5844,35 & 312,09 & 46,21 & 265,88 & 88,22 & 232,29 & 232,95 & 84,38 & 856,54 & 123,96 & 7,15 & 54,26 & 343,94 & 53,86 & 54,35 & 343,80 \\
\hline \begin{tabular}{|l} 
Alytes cisternasii \\
\end{tabular} & 29SPE40 & 101,00 & 164,31 & 100,45 & 36,85 & 5868,35 & 323,23 & $\begin{array}{l}53,36 \\
53,\end{array}$ & 269,86 & \begin{tabular}{|l|}
100,41 \\
\end{tabular} & 241,48 & 242,36 & $\begin{array}{l}94,306 \\
92,96\end{array}$ & $\mid 733,33$ & 103,07 & 5,98 & 53,64 & 292,77 & 45,60 & 47,25 & 290,38 \\
\hline Alytes cisternasii & 29SPE41 & 100,00 & 163,53 & 100,25 & 36,75 & 5876,42 & 322,10 & 52,19 & 269,90 & 99,20 & 240,77 & 241,49 & 91,83 & 744,16 & 105,12 & 6,05 & 53,53 & 296,93 & 46,41 & 48,04 & 294,75 \\
\hline Alytes cisternasii & 29SPE42 & 99,00 & 156,54 & 97,94 & 36,04 & 5903,14 & 314,45 & 46,30 & 268,15 & 92,15 & 234,38 & 234,94 & 84,72 & 808,24 & 115,72 & 6,78 & 53,88 & 322,90 & 50,98 & 51,71 & 321,60 \\
\hline Alytes cisternasii & 29SPE50 & 100,00 & 163,77 & 101,27 & 36,87 & 5932,29 & 323,69 & 51,76 & 271,94 & 99,08 & 241,85 & 242,54 & 91,55 & 705,68 & 98,12 & 5,53 & 53,11 & 280,54 & 44,12 & 45,66 & 276,80 \\
\hline Alytes cisternasii & 29SPE51 & 101,00 & 162,83 & 100,88 & 36,68 & 5941,95 & 322,45 & 50,59 & 271,86 & 97,88 & 241,23 & 241,63 & 90,42 & 716,97 & 100,21 & 5,86 & 53,12 & 284,78 & 45,20 & 46,64 & 281,24 \\
\hline \begin{tabular}{|l} 
Alytes cisternasii \\
\end{tabular} & 29SPE52 & 101,00 & 157,55 & $\begin{array}{r}99,13 \\
99,13\end{array}$ & 36,10 & 5958,68 & 316,43 & $\mid \frac{10,10}{46,10}$ & 270,33 & $\begin{array}{ll}1,2,54 \\
92,5\end{array}$ & $\begin{array}{l}236,26 \\
236\end{array}$ & $\begin{array}{l}236,52 \\
230\end{array}$ & $\begin{array}{l}00,424 \\
84,95\end{array}$ & 761,84 & \begin{tabular}{|l|}
107,67 \\
\end{tabular} & $\begin{array}{l}3,000 \\
6,19\end{array}$ & 53,17 & 302,85 & $\begin{array}{ll}4,2,50 \\
480\end{array}$ & $\begin{array}{l}40,49 \\
49,19\end{array}$ & 300,00 \\
\hline Alytes cisternasii & 29SPE60 & 101,00 & 160,83 & 101,30 & 36,43 & 6005,53 & 322,03 & 48,31 & 273,71 & 95,56 & 240,07 & 240,54 & 87,79 & 697,13 & 96,08 & 5,66 & 52,50 & 275,62 & 44,60 & 45,66 & 270,71 \\
\hline Alytes cisternasii & 29SPE61 & 99,00 & 159,52 & 100,65 & 36,13 & 6011,88 & 320,19 & 46,94 & 273,24 & 94,04 & 238,99 & 239,26 & 86,33 & 709,88 & 98,39 & 5,94 & 52,45 & 280,56 & 45,79 & 46,52 & 275,97 \\
\hline Alytes cisternasii & 29SPE62 & 100,00 & 155,44 & 99,42 & 36,04 & 6016,15 & 315,34 & 43,59 & 271,75 & 90,01 & 235,19 & 235,31 & 82,29 & 739,68 & 103,40 & 6,29 & 52,52 & 292,50 & 48,01 & 48,30 & 288,25 \\
\hline Alytes cisternasii & 29SPE70 & 101,00 & 160,68 & 102,50 & 36,39 & 6061,68 & 323,93 & 46,84 & 277,09 & 94,72 & 240,89 & 241,08 & 86,94 & 661,91 & 89,78 & 5,25 & 51,91 & 259,85 & 42,67 & 43,48 & 253,48 \\
\hline \begin{tabular}{|l} 
Alytes cisternasii \\
\end{tabular} & 29SPE71 & 100,00 & $\begin{array}{l}10,00 \\
159,82\end{array}$ & 101,92 & 36,35 & $\begin{array}{l}6000,100 \\
606,58\end{array}$ & 322,31 & $\begin{array}{l}40,04 \\
45,97 \\
\end{array}$ & 276,34 & $\begin{array}{ll}4,1 / 2 \\
93,66\end{array}$ & $\begin{array}{l}\mid 240,09 \\
240,05\end{array}$ & \begin{tabular}{|l|}
240,17 \\
240
\end{tabular} & $\begin{array}{l}0,34,82 \\
85,\end{array}$ & \begin{tabular}{|l|l|}
670,65 \\
\end{tabular} & $\begin{array}{l}03,10 \\
91,49\end{array}$ & $\begin{array}{l}3,255 \\
5,45\end{array}$ & 51,84 & \begin{tabular}{|l|l|}
263,29 \\
263,29
\end{tabular} & $\begin{array}{l}4,3,56 \\
43,\end{array}$ & $\begin{array}{l}45,406 \\
44,06\end{array}$ & $\begin{array}{l}25,40 \\
257,20\end{array}$ \\
\hline Alytes cisternasii & 29SPE72 & 101,00 & 157,64 & 101,21 & 36,08 & 6065,15 & 319,49 & 44,06 & 275,43 & 91,42 & 237,94 & 238,00 & 83,62 & 684,95 & 93,96 & 5,83 & 51,77 & 268,81 & 45,03 & 45,28 & 262,93 \\
\hline Alytes cisternasii & 29SPE81 & 100,00 & 160,04 & 103,15 & 36,37 & 6120,16 & 324,52 & 44,95 & 279,57 & 93,18 & 240,99 & 241,01 & 85,30 & $|632.97|$ & 84,87 & 5,11 & 51,11 & 246,61 & 41,57 & 41,67 & 239,18 \\
\hline Alytes cisternasii & 29SPE82 & 100,00 & 156,19 & 101,95 & 36,03 & 6125,07 & 319,99 & 41,74 & 278,25 & 89,41 & 237,48 & 237,48 & 81,48 & 657,45 & 88,73 & 5,76 & 50,90 & 256,01 & 44,06 & 44,06 & 248,87 \\
\hline Alytes cisternasii & 29SPE92 & 101,00 & 158,55 & 103,70 & 36,20 & 6167,91 & 324,27 & 42,50 & 281,77 & 90,89 & 240,40 & 240,40 & 83,11 & 606,08 & 80,10 & 5,12 & 50,16 & 234,10 & 40,88 & 40,88 & 225,58 \\
\hline \begin{tabular}{|l} 
Alytytes cisternasii \\
\end{tabular} & 29SOBOSO1 & $\begin{array}{l}100,00 \\
100,0\end{array}$ & $\begin{array}{l}13,50 \\
177,03\end{array}$ & $\begin{array}{r}0,10 \\
85,80\end{array}$ & 30,20 & | & $\begin{array}{l}3 \angle 4,27 \\
301,93 \\
\end{array}$ & $\begin{array}{ll}4,30 \\
71,36\end{array}$ & \begin{tabular}{|l|}
230,57 \\
237
\end{tabular} & $\mid$ & \begin{tabular}{|l|}
240,260 \\
240
\end{tabular} & \begin{tabular}{|l|}
$240,40,19$ \\
\end{tabular} & \begin{tabular}{|c|}
03,11 \\
113,39
\end{tabular} & \begin{tabular}{|l|}
505,90 \\
505,93
\end{tabular} & $\begin{array}{l} \\
78,73\end{array}$ & $\begin{array}{l}3,1,0 \\
1,00\end{array}$ & $\begin{array}{l}00,10 \\
63,83 \\
\end{array}$ & $\begin{array}{l}354,10 \\
218,10\end{array}$ & \begin{tabular}{|l|}
40,00 \\
14,01
\end{tabular} & $\begin{array}{l}4,00 \\
23,13\end{array}$ & $\begin{array}{l}22,30 \\
196,75\end{array}$ \\
\hline Alytes cisternasii & $29 \mathrm{SQBO2}$ & 100,00 & 175,71 & 87,83 & 36,78 & 5211,77 & 304,69 & 68,22 & 236,47 & 121,68 & 240,67 & 243,42 & 110,32 & 511,72 & 79,20 & 1,00 & 63,09 & 218,53 & 14,72 & 23,99 & 197,38 \\
\hline Alytes cisternasii & 29SQB03 & 100,00 & 176,62 & 90,04 & 36,92 & 5313,06 & 309,19 & 67,62 & 241,57 & 130,20 & 243,06 & 245,67 & 110,08 & 505,56 & 78,12 & 1,00 & 62,66 & 214,59 & 15,01 & 23,97 & 193,80 \\
\hline Alytes cisternasii & 29SQB06 & 101,00 & 165,53 & 101,65 & 37,97 & 5683,37 & 315,98 & 50,49 & 265,49 & 104,53 & 238,24 & 240,44 & 95,45 & 566,49 & 83,17 & 2,0 & 59,96 & 234,53 & 21,17 & 28,32 & 217,67 \\
\hline \begin{tabular}{|l} 
Alytes cisternasii \\
\end{tabular} & 29SQB07 & 100,00 & 164,82 & 104,21 & 38,00 & 5762,46 & 319,25 & $\begin{array}{ll}4,3434 \\
\end{array}$ & \begin{tabular}{|l|}
270,91 \\
\end{tabular} & \begin{tabular}{|l|l|}
102,79 \\
\end{tabular} & 238,75 & 240,87 & \begin{tabular}{l|l|}
$3,, 43$ \\
3
\end{tabular} & 569,38 & $\begin{array}{l}82,7 \\
82,7\end{array}$ & 2,2 & 59,36 & 234,26 & 22,28 & 28,82 & 218,29 \\
\hline Alytes cisternasii & 29SQB08 & 100,00 & 163,17 & 106,56 & 38,00 & 5835,67 & 321,68 & 45,53 & 276,15 & 100,43 & 238,34 & 240,40 & 91,52 & 576,80 & 82,82 & 2,68 & 58,52 & 235,69 & 23,96 & 29,93 & 220,70 \\
\hline Alytes cisternasii & 29SQB09 & 101,00 & 149,98 & 109,34 & 38,00 & 5955,40 & 315,23 & 31,79 & 283,43 & 86,71 & 227,37 & 229,53 & 77,75 & 655,52 & 90,98 & 3,83 & 57,21 & 264,65 & 30,41 & 35,23 & 252,11 \\
\hline Alytes cisternasii & 29SQB10 & 96,00 & 177,80 & 87,58 & 37,01 & 5066,93 & 303,78 & 71,44 & 232,34 & 130,63 & 241,16 & 244,08 & 114,66 & 518,74 & 80,20 & 1,00 & 64,27 & 224,79 & 14,00 & 22,93 & 204,25 \\
\hline Alytes cisternasii & 29SQB11 & 100,00 & 178,60 & 89,13 & 37,01 & 5175,99 & 307,72 & 70,57 & 237,15 & 130,95 & 243,40 & 246,23 & 113,90 & 513,12 & 79,52 & 1,00 & 63,83 & 220,93 & 14,38 & 23,00 & 200,28 \\
\hline \begin{tabular}{|l|l} 
Alytes cisternasii \\
\end{tabular} & \begin{tabular}{|l}
$295 \mathrm{SOB11}$ \\
2
\end{tabular} & $\begin{array}{l}00,090 \\
99,00\end{array}$ & $\begin{array}{l}1 / 1,00 \\
177,09\end{array}$ & $\begin{array}{l}0,10 \\
91,82\end{array}$ & 37,01 & 5318,58 & 311,16 & 67,03 & \begin{tabular}{|l|}
244,13 \\
243
\end{tabular} & 119,89 & 244,00 & 246,56 & 110,55 & 519,52 & 80,10 & 1,00 & 63,16 & 221,75 & 15,04 & 23,39 & 201,42 \\
\hline Alytes cisternasii & 29SQB14 & 100,00 & 177,04 & 97,18 & 37,40 & 5528,40 & 319,21 & 63,27 & 255,94 & 117,12 & 247,02 & 249,25 & 108,02 & 518,64 & 79,16 & 1,11 & 62,08 & 218,60 & 16,14 & 24,15 & 199,43 \\
\hline Alytes cisternasii & 29SQB15 & 100,00 & 171,39 & 101,11 & $37.85 \mid$ & 5671,57 & 320,33 & 55,58 & 264,75 & 110,05 & 243,75 & 245,90 & 101,01 & 548,55 & 81,87 & 1,99 & 60,71 & $228,67 \mid$ & 19,41 & 26,72 & 210,85 \\
\hline Alytes cisternasii & 295 QB16 & 99,00 & 168,83 & 104,02 & 38,00 & 5771,93 & 322,70 & 51,44 & 271,26 & 106,39 & 242,73 & 244,82 & 97,38 & 560,74 & 82,61 & 2,01 & 60,17 & 232,12 & 20,69 & 27,51 & 215,31 \\
\hline Alytes cisternasii & 29SQB17 & 101,00 & 163,36 & 107,06 & 38,00 & 5877,79 & 322,84 & 44,57 & 278 & 99,97 & 239,10 & 241 & 90,98 & 589,06 & 85,03 & 2,50 & 59,22 & 241,64 & 23,35 & 29,53 & 226 \\
\hline \begin{tabular}{|l}
$|l| l$ \\
Alytes cisternasii
\end{tabular} & 29SQB18 & $\begin{array}{l}100,00 \\
100\end{array}$ & $\begin{array}{l}1059,01 \\
159,01\end{array}$ & $\begin{array}{l}10,09 \\
10934\end{array}$ & $\begin{array}{l}30,000 \\
38,00\end{array}$ & 5957,20 & $\begin{array}{l}32,04 \\
322,97 \\
\end{array}$ & $\begin{array}{l}44,31 \\
39,38 \\
\end{array}$ & $\begin{array}{l}280,27 \\
283,59 \\
\end{array}$ & 95,16 & 236,25 & 238,07 & 86,15 & 610,38 & 86,62 & 2,97 & 58,25 & 248,23 & 25,93 & 31,53 & 233,97 \\
\hline Alytes cisternasii & 29SQB19 & 99,00 & 151,81 & 111,03 & 38,00 & 6028,69 & 319,92 & 31,80 & 288,13 & 87,58 & 230,39 & 232,23 & 78,65 & 649,94 & 90,32 & 3,61 & 57,35 & 262,00 & 29,59 & 34,50 & 249,20 \\
\hline 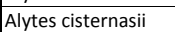 & 29SQB21 & 101,00 & 179,80 & 92,42 & 37,20 & 5285,69 & 313,51 & 69,27 & 244,24 & 131,97 & 246,44 & 249,12 & 113,76 & 522,48 & 80,46 & 1,00 & 63,68 & 224,48 & 15,00 & 22,31 & 204,82 \\
\hline Alytes cisternasii & 29SQB26 & 101,00 & 165,03 & 108,10 & 38,00 & 5908,15 & 325,85 & 45,03 & 280,81 & 101,40 & 241,2 & 243,1 & 92,26 & 594,59 & 86,44 & 2,06 & 60 & 245,36 & 22,21 & 28,46 & 229,72 \\
\hline Alytes cisternasii & 29SQB27 & 100,00 & 162,82 & 109,90 & 38,00 & 5980,37 & 327,18 & 41,83 & 285,35 & 98,45 & 240,34 & 242,12 & 89,41 & 602,57 & 86,51 & 2,57 & 59,20 & 246,70 & 24,01 & 29,90 & 231,84 \\
\hline
\end{tabular}




\begin{tabular}{|c|c|c|c|c|c|c|c|c|c|c|c|c|c|c|c|c|c|c|c|c|c|}
\hline TAXON & UTM & $\mathrm{km2}$ & B101 & $\mathrm{B1O2}$ & $\mathrm{BIO3}$ & B104 & B105 & B106 & B107 & B108 & B109 & 81010 & B1011 & BIO12 & BIO13 & 81014 & B1015 & B1016 & B1017 & BIO18 & B1019 \\
\hline Alytes cisternasii & 29SQB28 & 100,00 & 158,95 & 111,69 & 38,00 & 6054,53 & 326,96 & 37,32 & 289,64 & 94,01 & 237,72 & 239,36 & 85,00 & 619,95 & 87,61 & 2,99 & 58,42 & 251,77 & 26,12 & 31,53 & 237,91 \\
\hline Alytes cisternasii & 29SQB29 & 100,00 & 158,47 & 112,97 & 38,00 & 6098,34 & 328,68 & 36,09 & 292,59 & 92,97 & 237,91 & 239,45 & 83,95 & 619,05 & 86,71 & 3,20 & 57,68 & 249,70 & 27,20 & 32,28 & 236,40 \\
\hline Alytes cisternasii & 29SQB32 & 100,00 & 179,88 & 99,43 & 37,81 & 5541,95 & 324,76 & 64,30 & 260,46 & 119,66 & 250,41 & 252,84 & 110,82 & 540,01 & 82,50 & 1,00 & 63,43 & 230,37 & 16,01 & 22,43 & 212,05 \\
\hline Alytes cisternasii & 29SQB33 & 100,00 & 178,05 & 103,27 & 37,99 & 5681,46 & 329,20 & 60,05 & 269,14 & 116,39 & 250,78 & 252,92 & 107,42 & 549,83 & 83,33 & 1,00 & 62,64 & 232,79 & 17,50 & 23,88 & 215,05 \\
\hline Alytes cisternasii & 29SQB37 & 100,00 & 165,23 & 112,90 & 38,01 & 6067,55 & 333,76 & 42,02 & 291,74 & $\begin{array}{ll}99,63 \\
\end{array}$ & 243,99 & 245,63 & 90,71 & 602,17 & 86,41 & 2,31 & 59,48 & 246,70 & 23,48 & 28,98 & 232,27 \\
\hline Alytes cisternasii & 29SQB38 & 101,00 & 165,25 & 114,19 & 38,03 & 6120,83 & 336,06 & 41,25 & 294,81 & 99,12 & 244,91 & 246,42 & 90,10 & 596,49 & 84,86 & 2,55 & 58,82 & 242,79 & 24,17 & 29,42 & 228,80 \\
\hline Alytes cisternasii & 29SQB39 & 100,00 & 163,07 & 115,24 & 38,00 & 6172,04 & 336,21 & 38,54 & 297,66 & 96,41 & 243,54 & 244,97 & 87,38 & 601,53 & 84,57 & 2,78 & 58,19 & 242,94 & 25,49 & 30,41 & 229,54 \\
\hline Alytes cisternasii & 29SQB43 & 100,00 & 180,23 & 108,01 & 38,05 & 5804,21 & 338,22 & 59,06 & 279,16 & $\mid \begin{array}{r}117,10 \\
\end{array}$ & 254,92 & 256,92 & 108,11 & 558,84 & 84,54 & 1,00 & 62,92 & 237,05 & 17,80 & 23,23 & 220,29 \\
\hline Alytes cisternasii & 29SQB44 & 101,00 & 180,49 & 111,05 & 38,36 & 5900,58 & 342,96 & 57,41 & 285,55 & 116,18 & 256,64 & 258,40 & 107,23 & 556,03 & 83,69 & 1,12 & 62,60 & 234,70 & 18,32 & 23,41 & 218,49 \\
\hline Alytes cisternasii & 29SQB45 & 99,00 & 179,99 & 113,45 & 38,61 & 5980,75 & 346,22 & 55,51 & 290,71 & 114,92 & 257,41 & 259,01 & 105,74 & 555,42 & 82,92 & 1,41 & 61,79 & 232,99 & 18,81 & 24,00 & 217,38 \\
\hline Alytes cisternasii & 29SQB47 & 101,00 & 169,77 & 116,00 & 38,36 & 6146,51 & 342,23 & 44,27 & 297,96 & 103,11 & 249,79 & 251,23 & 94,08 & 591,41 & 85,13 & 2,04 & 59,97 & 242,96 & 22,34 & 27,42 & 228,87 \\
\hline Alytes cisternasii & 29SQB48 & 99,00 & 165,34 & 116,84 & 38,20 & 6207,25 & 340,24 & 39,51 & 300,73 & 98,16 & 246,41 & 247,64 & 89,31 & 606,48 & 85,72 & 2,53 & 58,92 & 246,50 & 24,30 & 29,31 & 233,16 \\
\hline Alytes cisternasii & 29SQB49 & 99,00 & 160,27 & 117,41 & 38,07 & 6265,76 & 337,49 & 34,39 & 303,10 & 92,76 & 242,46 & 243,63 & 83,80 & 624,67 & 86,79 & 3,01 & 58,13 & 251,52 & 26,41 & 31,25 & 238,92 \\
\hline Alytes cisternasii & 29SQB55 & 100,00 & 182,80 & 117,92 & \begin{tabular}{|l|}
38,98 \\
\end{tabular} & 6077,18 & 354,84 & 55,47 & 299,36 & 116,50 & 261,79 & 263,16 & 107,47 & 559,71 & 83,53 & 1,13 & 62,24 & 235,80 & 18,43 & 23,01 & 221,17 \\
\hline Alytes cisternasii & 29SQB56 & 100,00 & 176,11 & 118,63 & 38,93 & 6163,05 & 350,68 & 48,61 & 302,07 & 109,00 & 256,31 & 257,66 & 100,02 & 582,65 & 85,06 & 1,97 & 61,03 & 242,14 & 20,77 & 25,32 & 228,14 \\
\hline Alytes cisternasii & 29SQB58 & 100,00 & 164,45 & 119,16 & 38,45 & 6288,16 & 342,96 & 37,21 & 305,74 & 96,54 & 246,97 & 248,00 & 87,55 & 621,15 & 87,10 & 2,57 & 59,09 & 252,23 & 24,62 & 29,52 & 239,62 \\
\hline Alytes cisternasii & 29SQB59 & 100,00 & 161,72 & 119,53 & 38,08 & 6337,03 & 341,97 & 34,20 & 307,77 & 93,37 & 244,95 & 245,92 & 84,36 & 626,22 & 86,57 & 2,97 & 58,34 & 251,97 & 25,99 & 30,74 & 239,89 \\
\hline Alytes cisternasii & $295 Q B 67$ & 43,00 & 170,53 & 120,97 & 38,97 & 6280,84 & 349,67 & 42,23 & 307,44 & 102,34 & 252,81 & 253,81 & 93,31 & 608,03 & 86,59 & 2,00 & 60,22 & 249,81 & 22,67 & 27,20 & 236,97 \\
\hline Alytes cisternasii & 29SQB68 & 45,00 & 165,08 & 120,71 & 38,64 & 6333,68 & 345,70 & 36,77 & 308,92 & 96,58 & 248,45 & 249,27 & 87,58 & 624,02 & 87,17 & 2,32 & 59,42 & 253,56 & 24,21 & 28,88 & 241,35 \\
\hline Alytes cisternasii & $2950 \mathrm{co0}$ & 100,00 & 152.57 & 110,61 & 38,01 & 5987,54 & 319,70 & 33,50 & 286,20 & 88,75 & 230,46 & 232,42 & 79,85 & 634.96 & 88,02 & 3,70 & 56,71 & 255,20 & 30,10 & 34.59 & 242,76 \\
\hline Alytes cisternasii & 29SQC01 & 100,00 & 150,73 & 111,68 & 38,02 & 6030,24 & 320,13 & 31,31 & 288,82 & 86,57 & 229,46 & 231,34 & 77,71 & 643,26 & 88,33 & 4,06 & 56,03 & 256,93 & 31,92 & 35,85 & 245,11 \\
\hline Alytes cisternasii & $295 \mathrm{SCO}$ & 101,00 & 150,90 & 112,55 & 38,00 & 6064,71 & 322,05 & 30,95 & 291,10 & 86,38 & 230,08 & 231,97 & 77,51 & 638,97 & 87,25 & 4,11 & 55,41 & 253,83 & 32,80 & 36,32 & 242,32 \\
\hline Alytes cisternasii & 29SQC05 & 100,00 & 151,69 & 114,27 & $\begin{array}{l}38,05 \\
\end{array}$ & \begin{tabular}{|c|}
6140,97 \\
\end{tabular} & 326,38 & 30,66 & 295,72 & 85,99 & 232,26 & 233,59 & 77,36 & 622,94 & 83,87 & 4,57 & 53,71 & 243,87 & 35,20 & 37,55 & 232,90 \\
\hline Alytes cisternasii & $295 Q C 06$ & 100,00 & 151,43 & 114,50 & 38,00 & 6152,60 & 326,90 & 30,33 & 296,57 & 85,56 & 232,32 & 233,59 & 77,10 & 619,90 & 83,06 & 4,68 & 53,24 & 241,60 & 36,05 & 38,10 & 230,70 \\
\hline Alytes cisternasii & $29 \mathrm{SQC07}$ & 101,00 & 159,48 & 115,70 & 38,13 & 6144,17 & 334,83 & 36,68 & 298,15 & 92,88 & 239,97 & 240,98 & 84,56 & 561,93 & 76,14 & 4,06 & 52,88 & 218,36 & 32,93 & 35,15 & 206,60 \\
\hline Alytes cisternasii & $29 \mathrm{SQC10}$ & 101,00 & 157,87 & 112,11 & 38,00 & 6052,92 & 326,94 & 36,77 & 290,16 & 92,90 & 236,66 & 238,34 & 84,15 & 608,89 & 85, & 3,21 & 57,12 & 244,71 & 27,85 & 32,59 & 231,55 \\
\hline \begin{tabular}{|l} 
Alytes cisternasii \\
\end{tabular} & $29 \mathrm{SQC11}$ & 100,00 & 148,36 & 113,07 & 38,00 & 6121,03 & 320,93 & 27,46 & 293,47 & 83,27 & 228,53 & 230,22 & $\begin{array}{l}74,29 \\
74,2\end{array}$ & \begin{tabular}{|l|l|}
662,73 \\
\end{tabular} & $\begin{array}{l}0,34 \\
90,34\end{array}$ & $\begin{array}{l}3,26 \\
4,26\end{array}$ & 56,03 & 263,69 & 32,92 & $\begin{array}{ll}36,88 \\
36,8\end{array}$ & 252,11 \\
\hline Alytes cisternasii & 29SQC14 & 101,00 & 159,23 & 115,59 & 38,01 & 6171,35 & 334,37 & 35,95 & 298,41 & 92,41 & 239,95 & 241,13 & 83,86 & 579,12 & 79,00 & 3,69 & 54,64 & 227,61 & 30,38 & 33,67 & 215,52 \\
\hline Alytes cisternasii & $29 \mathrm{SQC15}$ & 100,00 & 153,88 & 115,50 & 38,00 & 6216,08 & 330,77 & 31,06 & 299,71 & 87,03 & 235,64 & 236,60 & 78,50 & 607,10 & 81,63 & 4,19 & 53,79 & 236,94 & 33,57 & 36,28 & 225,45 \\
\hline Alytes cisternasii & $29 S Q C 16$ & 100,00 & 158,39 & 116,15 & 38,01 & 6218,94 & 335,43 & 34,82 & 300,61 & 91,30 & 240,07 & 241,02 & 82,66 & 573,53 & 77,26 & 4,05 & 53,32 & 222,97 & 32,25 & 34,93 & 211,15 \\
\hline Alytes cisternasii & $29 \mathrm{SQC22}$ & 100,00 & 152,88 & 115,44 & 38,00 & 6225,07 & 329,21 & 29,54 & 299,66 & 86,07 & 234,56 & 235,86 & 77,28 & 632,78 & 85,95 & 3,97 & 55,60 & 250,05 & 31,60 & 35,43 & 238,19 \\
\hline \begin{tabular}{|l} 
Alytes cisternasii \\
\end{tabular} & $295 \mathrm{SQC24}$ & 99,00 & 155,97 & 116,49 & 38,00 & 6269,81 & 334,19 & 31,82 & 302,37 & 88,53 & \begin{tabular}{|l|}
238,37 \\
\end{tabular} & \begin{tabular}{|l|}
239,35 \\
\end{tabular} & 79,85 & $\begin{array}{l}601,12 \\
\end{array}$ & $\begin{array}{l}0,90 \\
80,98 \\
\end{array}$ & 3,94 & 54,55 & 235,10 & 31,61 & $\begin{array}{l}34,45 \\
34,93\end{array}$ & 223,33 \\
\hline Alytes cisternasii & 29 SQC25 & 100,00 & 154,87 & 116,72 & 38,00 & 6296,31 & 333,94 & 30,57 & 303,37 & 86,94 & 237,62 & 238,51 & 78,50 & 601,18 & 80,36 & 4,00 & 53,84 & 233,81 & 32,68 & 35,64 & 222,19 \\
\hline Alytes cisternasii & $295 \mathrm{SQC28}$ & 101,00 & 162,42 & 117,04 & 38,00 & 6296,73 & 341,58 & 37,15 & 304,44 & 93,96 & 245,39 & 245,72 & 85,55 & 537,24 & 71,40 & 3,97 & 52,31 & 206,15 & 31,56 & 33,13 & 193,92 \\
\hline Alytes cisternasii & $295 Q C 29$ & 99,00 & 163,70 & 116,98 & 37,99 & 6310,48 & 342,96 & 38,34 & 304,62 & 94,99 & 247,14 & 247,18 & 86,50 & 523,24 & 69,29 & 3,71 & 51,97 & 200,01 & 30,94 & 31,56 & 187,75 \\
\hline Alytes cisternasii & $295 \mathrm{SQC31}$ & 101,00 & 143,35 & 115,71 & 37,99 & 6285,63 & 321,80 & 20,01 & 301,79 & 76,51 & 226,30 & 227,65 & 67,74 & 700,80 & 93,93 & 4,65 & 55,87 & 276,69 & 34,98 & 38,88 & 265,89 \\
\hline \begin{tabular}{|l} 
Alytes cisternasii \\
\end{tabular} & $295 \mathrm{SOC32}$ & $\begin{array}{l}100,00 \\
100\end{array}$ & $\begin{array}{l}1450,07 \\
150,07\end{array}$ & $\begin{array}{ll}111,1 / 12 \\
116,82\end{array}$ & 38,00 & | & 329,47 & 25,56 & \begin{tabular}{|l|}
303,92 \\
302
\end{tabular} & \begin{tabular}{|l|l|}
82,63 \\
\end{tabular} & \begin{tabular}{|l|l|}
233,28 \\
\end{tabular} & \begin{tabular}{|l|}
234,30 \\
\end{tabular} & $\begin{array}{l}\mid 73,90 \\
73,9\end{array}$ & $\begin{array}{l}652,92 \\
652\end{array}$ & \begin{tabular}{|l|l|}
37,76 \\
87
\end{tabular} & $\begin{array}{l}4,406 \\
4,06\end{array}$ & $\begin{array}{l}5,5,58 \\
55,\end{array}$ & $\begin{array}{l}257,04 \\
250\end{array}$ & $\begin{array}{l}32,400 \\
32,41\end{array}$ & $\begin{array}{l}0,00 \\
36,21\end{array}$ & $\begin{array}{l}20,05 \\
245,72\end{array}$ \\
\hline Alytes cisternasii & $29 \mathrm{SQC} 33$ & 100,00 & 153,02 & 117,28 & 38,00 & 6330,62 & 333,25 & 27,94 & 305,31 & 85,31 & 236,62 & 237,48 & 76,49 & 627,71 & 84,15 & 4,00 & 55,13 & 245,93 & 31,71 & 35,48 & 234,45 \\
\hline Alytes cisternasii & $295 Q C 35$ & 100,00 & 153,54 & 117,59 & 38,00 & 6363,24 & 335,03 & 28,24 & 306,79 & 85,10 & 237,65 & 238,31 & 76,50 & 609,65 & 80,58 & 4,00 & 54,00 & 236,09 & 32.50 & 35,71 & 224,86 \\
\hline Alytes cisternasii & $295 Q C 36$ & 100,00 & 157,07 & 117,85 & 38,00 & 6360,65 & 338,56 & 31,38 & 307,18 & 88,35 & 241,04 & 241,64 & 79,81 & 581,93 & 76,87 & 4,00 & 53,48 & 224,35 & 31,94 & 34,76 & 212,76 \\
\hline Alytes cisternasii & $295 Q C 40$ & 101,00 & 158,58 & 118,01 & 38,01 & 6304,75 & 337,41 & 32,34 & 305,07 & 90,67 & 241,28 & 242,38 & 81,72 & 626,43 & 86,06 & 3,03 & 57,45 & 250,37 & 27,34 & 32,01 & 238,25 \\
\hline \begin{tabular}{|l} 
Alytytes cisternasii \\
\end{tabular} & $2950<41$ & $\begin{array}{l}\quad 10,100 \\
99,00\end{array}$ & $\begin{array}{l}130,50 \\
150,44\end{array}$ & $\begin{array}{l}111,01 \\
117,83\end{array}$ & 38,01 & $\mid \begin{array}{ll}\mid 6304,1 / 23 \\
6353,23\end{array}$ & 331,26 & $\begin{array}{l}2,, 34 \\
24,82\end{array}$ & \begin{tabular}{|l|}
003,01 \\
306,44
\end{tabular} & $\begin{array}{l}0,01 \\
82,53\end{array}$ & \begin{tabular}{|l|}
234,27 \\
234,27
\end{tabular} & \begin{tabular}{|l|}
235,31 \\
235
\end{tabular} & $\begin{array}{l}\mid \frac{1,1 / 2}{73,66} \\
\end{array}$ & \begin{tabular}{|l|}
620,45 \\
662,91
\end{tabular} & $\begin{array}{l}80,00 \\
89,17 \\
\end{array}$ & $\begin{array}{l}3,00 \\
3,90\end{array}$ & $\begin{array}{l}1,45 \\
56,33 \\
\end{array}$ & $\begin{array}{l}260,817 \\
261,88\end{array}$ & $\begin{array}{l}2,34 \\
31,52 \\
\end{array}$ & $\begin{array}{ll}32,01 \\
35,70\end{array}$ & $\begin{array}{l}230,25 \\
250,75\end{array}$ \\
\hline Alytes cisternasii & $29 \mathrm{SQC42}$ & 101,00 & 152,95 & 118,39 & 38,00 & 6376,73 & 334,71 & 26,75 & 307,97 & 84,57 & 237,21 & 237,92 & 75,77 & 640,44 & 85,79 & 3,86 & 55,69 & 251,67 & 31,08 & 35,10 & 240,44 \\
\hline Alytes cisternasii & $29 \mathrm{SQC45}$ & 101,00 & 155,37 & 118,87 & 38,00 & 6435,91 & 338,99 & 28,40 & 310,59 & 85,98 & 240,62 & 240,92 & 77,21 & 600,77 & 79,28 & 3,96 & 54,09 & 231,94 & 31,57 & 34,04 & 220,74 \\
\hline Alytes cisternasii & $295 Q C 46$ & 100,00 & 159,70 & 119,06 & 37,99 & 6443,91 & 343,06 & 32,26 & 310,81 & 89,84 & 244,80 & 244,96 & 81,12 & 569,21 & $75, \mathrm{C}$ & 3,69 & 53,64 & 218,71 & 30,47 & 32,42 & 207,26 \\
\hline \begin{tabular}{|l} 
Alytes cisternasii \\
\end{tabular} & $295 Q C 47$ & 99,00 & 162,97 & 118,88 & 37,99 & $\begin{array}{l}6437,15 \\
6437 \\
\end{array}$ & 345,9 & 35,39 & \begin{tabular}{|l|l|}
310,55 \\
\end{tabular} & $\begin{array}{l}32,87 \\
92,8 \\
\end{array}$ & 248,00 & 248,04 & $\begin{array}{l}1,12 \\
84,26 \\
\end{array}$ & 542,14 & 71,5 & 3,23 & 53,43 & 207,59 & $\begin{array}{ll}29,09 \\
\end{array}$ & 30,04 & 195,96 \\
\hline Alytes cisternasii & $295 Q C 48$ & 101,00 & 164,45 & 118,63 & \begin{tabular}{|l|l|}
37,97 \\
\end{tabular} & 6434,42 & 347,13 & 37,04 & 310,09 & 94,36 & 249,40 & 249,46 & 85,73 & 525,70 & 69, & 3,06 & 52,98 & 200,26 & 28,72 & 29,29 & 188,50 \\
\hline Alytes cisternasii & $2950 C 49$ & 99,00 & 163,25 & 117,95 & 37,60 & 6448,65 & 346,10 & 36,12 & 309,98 & 92,98 & 248,56 & 248,66 & 84,46 & 523,97 & 68,46 & 3,31 & 52,23 & 198,42 & 29,73 & 30,41 & 186,63 \\
\hline Alytes cisternasii & $29 S Q C 50$ & 100,00 & 154,05 & 119,27 & 38,01 & 6389,85 & 336,10 & 27,00 & 309,10 & 85,45 & 238,34 & 239,30 & 76,60 & 656,46 & 88,95 & 3,43 & 57,26 & 260,95 & 29,22 & 33,80 & 249,81 \\
\hline Alytes cisternasii & $29 \mathrm{SQC51}$ & 100,00 & 157,25 & 120,01 & 38,00 & 6413,78 & 340,24 & 29,40 & 310,84 & 88,09 & 241,84 & 242,56 & 79,16 & 631,14 & 85,14 & 3,27 & 56,81 & 249,59 & 28,48 & 32,89 & 238,35 \\
\hline \begin{tabular}{|l} 
Alytes cisternasii \\
\end{tabular} & 29SOC52 & 100,00 & 158,74 & 120,32 & 38,00 & 6435, 63 & 342,47 & $\begin{array}{l}30,48 \\
30,48\end{array}$ & \begin{tabular}{|l|}
311,99 \\
3109
\end{tabular} & $\begin{array}{l}80,039 \\
89,27\end{array}$ & $\begin{array}{l}241,74 \\
243,72 \\
\end{array}$ & \begin{tabular}{|l|}
244,24 \\
24,2
\end{tabular} & 80,33 & $\mid$\begin{tabular}{|l|l|l|l|}
613,54 \\
\end{tabular} & $\begin{array}{l}5,14 \\
82,38\end{array}$ & 3,19 & $\frac{0,01}{56,22}$ & \begin{tabular}{|l|}
241,10 \\
2430
\end{tabular} & $\begin{array}{l}20,400 \\
28,37 \\
\end{array}$ & $\begin{array}{l}32,03 \\
32,57\end{array}$ & $\begin{array}{l}250,03 \\
229,94\end{array}$ \\
\hline Alytes cisternasii & $29 \mathrm{SQC53}$ & 100,00 & 152,34 & 119,87 & 38,00 & 6469,16 & 337,34 & 24,95 & 312,39 & 82,86 & 237,97 & 238,62 & 74,10 & 638,24 & 84,75 & 3,94 & 55,30 & 248,30 & 31,58 & 35,35 & 237,69 \\
\hline Alytes cisternasii & 29 SQC55 & 100,00 & 158,21 & 120,08 & 38,00 & 6492,21 & 343,57 & 29,89 & 313,68 & 87,86 & 244,27 & 244,42 & 79,23 & 588,23 & 77,81 & 3,70 & 54,34 & 226,40 & 30,18 & 32,39 & 215,47 \\
\hline Alytes cisternasii & $295 Q C 56$ & 99,00 & 160,23 & 120,02 & 37,93 & 6499,58 & 345,58 & 31,79 & 313,79 & 89,49 & 246,42 & 246,50 & 81,13 & 566,80 & 74,75 & 3,33 & 53,84 & 216,93 & 29,53 & 31,24 & 205,9 \\
\hline Alytes cisternasii & $29 S Q C 57$ & 101,00 & 157,18 & 119,37 & 37,73 & 6509,74 & 342,79 & 29,19 & 313,61 & 86,55 & 243,60 & 243,67 & 77,96 & 573,23 & 74,97 & 3,87 & 53,01 & 217,74 & 31,36 & 32,25 & 206 \\
\hline \begin{tabular}{|l}
$|l| l$ \\
Alytes cisternasii
\end{tabular} & $2950 C 58$ & $\begin{array}{l}100,00 \\
100\end{array}$ & $\begin{array}{l}15,10 \\
160,35\end{array}$ & $\begin{array}{l}1119,09 \\
119,\end{array}$ & 37,65 & $\begin{array}{l}650310,78 \\
6510,4\end{array}$ & 345,55 & $\begin{array}{l}\mid 3,113 \\
32,21 \\
\end{array}$ & \begin{tabular}{|l|}
313,33 \\
3130
\end{tabular} & 89,57 & 246,70 & 246,74 & 81,06 & 547,69 & 71,51 & 3,60 & 52,61 & 207,06 & 30,33 & 30,64 & 195,84 \\
\hline Alytes cisternasii & $2950 C 59$ & 100,00 & 160,74 & 118,62 & 37,32 & 6523,95 & 345,77 & 32,92 & 312,85 & 90,06 & 247,48 & 247,51 & 81,41 & 535,84 & $|69,69|$ & 3,57 & 52,03 & 201,52 & 30,46 & 30,61 & 190,22 \\
\hline 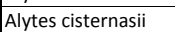 & $29 \mathrm{SQC60}$ & 32,00 & 155,24 & 120,45 & 38,00 & 6427,15 & 339,05 & 27,25 & 311,80 & 86,07 & 240,15 & 240,95 & 77,16 & 654,55 & 88,64 & 3,35 & 57,42 & 259,98 & 28,73 & 33,25 & 249,11 \\
\hline Alytes cisternasii & $2950 C 61$ & 36,00 & 161,81 & 121,29 & 38,02 & 6448,65 & 345,96 & 32,98 & 312,98 & 92,10 & 246,90 & 247,6 & 83, & 611,21 & 82,88 & 3,02 & 57,23 & 242,10 & 26,58 & 31,02 & 230,92 \\
\hline Alytes cisternasii & $295 Q C 62$ & 30,00 & 158,40 & 121,10 & 38,00 & 6484,80 & 343,60 & 29,48 & 314,13 & 88,45 & 244,20 & 244,60 & 79,50 & 619,28 & 83,18 & 3,25 & 56,40 & 242,82 & 28,33 & 32,40 & 232,15 \\
\hline
\end{tabular}




\begin{tabular}{|c|c|c|c|c|c|c|c|c|c|c|c|c|c|c|c|c|c|c|c|c|c|}
\hline TAXON & UTM & $\mathrm{km} 2$ & B101 & B102 & $\mathrm{BIO3}$ & BIO4 & B105 & B106 & B107 & B108 & B109 & B1010 & B1011 & BIO12 & B1013 & BIO14 & BIO15 & B1016 & B1017 & BIO18 & B1019 \\
\hline Alytes cisternasii & 29SQC63 & 22,00 & 148,95 & 120,27 & 37,98 & 6508,00 & 335,43 & 21,27 & 314,16 & 79,09 & 235,43 & 235,86 & 70,36 & 658,91 & 87,20 & 4,20 & 55,09 & 255,39 & 32,91 & 35,98 & 245,32 \\
\hline Alytes cisternasii & 29SQD04 & 101,00 & 162,14 & 111,49 & 37,17 & 6234,84 & 336,32 & 41,53 & 294,79 & 94,29 & 244,50 & 244,68 & 86,19 & 547,03 & 71,38 & 4,06 & 50,53 & 209,08 & 35,45 & 35,94 & 197,72 \\
\hline Alytes cisternasii & 29SQD17 & 100,00 & 159,88 & 107,54 & 36,00 & 6335,02 & 333,55 & 40,64 & 292,92 & 91,31 & 244,13 & 244,13 & 83,15 & 544,58 & 68,94 & 4,05 & 49,74 & 205,57 & 36,49 & 36,51 & 194,10 \\
\hline Alytes cisternasii & 29SQD21 & 101,00 & 167,54 & 115,88 & 37,93 & 6306,67 & 345,66 & 42,66 & 302,99 & 98,62 & 250,56 & 250,69 & 90,15 & 493,85 & 65,03 & 3,03 & 51,52 & 187,80 & 29,46 & 30,62 & 175,35 \\
\hline Alytes cisternasii & 29SQD22 & 99,00 & 166,10 & 114,86 & 37,35 & 6329,11 & 344,38 & 41,63 & 302,75 & 96,99 & 249,73 & 249,83 & 88,67 & 500,07 & 65,06 & 3,38 & 50,77 & 189,08 & 31,18 & 31,49 & 176,83 \\
\hline Alytes cisternasii & 29SQD23 & 100,00 & 162,78 & 113,37 & 37,00 & 6357,80 & 341,02 & 39,52 & 301,50 & 93,64 & 247,12 & 247,14 & 85,36 & 515,75 & 66,36 & 4,00 & 50,40 & 194,20 & 32,93 & 33,12 & 182,06 \\
\hline Alytes cisternasii & 29SQD31 & 100,00 & 165,92 & 116,10 & 37,53 & 6383,78 & 346,06 & 40,36 & 305,70 & 96,25 & 250,19 & 250,23 & 87,68 & 499,24 & 64,97 & 3,08 & 51,30 & 188,50 & 29,97 & 30,39 & 176,32 \\
\hline Alytes cisternasii & 29SQD32 & 99,00 & 163,79 & 115,06 & 37,05 & 6406,58 & 344,01 & 38,80 & 305,22 & 94,02 & 248,83 & 248,84 & 85,67 & 506,41 & 65,30 & 3,67 & 50,66 & 190,02 & 31,50 & 31,52 & 177,81 \\
\hline Alytes cisternasii & 29SQD33 & 100,00 & 159,75 & 113,57 & 36,93 & 6431,24 & 339,81 & 35,92 & 303,89 & 90,02 & 245,19 & 245,19 & 81,60 & 523,70 & 66,91 & 4,03 & 50,19 & 195,72 & 33,60 & 33,66 & 183,56 \\
\hline Alytes cisternasii & 29SQD35 & 99,00 & 158,47 & 110,82 & 36,14 & 6450,33 & 337,36 & 36,26 & 301,10 & 88,72 & 244,43 & 244,43 & 80,42 & 519,96 & 66,67 & 4,00 & 49,57 & 192,81 & 34,79 & 34,79 & 180,51 \\
\hline Alytes cisternasii & 29SQD38 & 100,00 & 162,23 & 109,03 & 36,06 & 6418,17 & 338,20 & 40,89 & 297,31 & 92,29 & 247,74 & 247,74 & 84,08 & 488,93 & 61,73 & 4,00 & 48,59 & 180,47 & 33,92 & 33,92 & 168,29 \\
\hline Alytes cisternasii & 29SQD39 & 99,00 & 158,01 & 108,29 & 36,00 & 6420,54 & 333,44 & 37,18 & 296,26 & 88,09 & 243,70 & 243,70 & 79,96 & 505,57 & 62,88 & 4,44 & 48,10 & 186,62 & 35,82 & 35,82 & 174,49 \\
\hline Alytes cisternasii & 29SQD40 & 100,00 & 167,71 & 117,67 & 37,59 & 6440,08 & 349,40 & 40,25 & 309,15 & 97,20 & 252,73 & 252,73 & 88,58 & 494,36 & 64,55 & 3,00 & 52,06 & 186,50 & 28,03 & 28,13 & 174,54 \\
\hline Alytes cisternasii & 29SQD41 & 100,00 & 167,40 & 116,77 & 37,13 & 6444,88 & 349,11 & 40,70 & 308,41 & 96,92 & 252,81 & 252,81 & 88,49 & 488,53 & 63,47 & 3,01 & 51,48 & 183,45 & 28,49 & 28,51 & 171,45 \\
\hline Alytes cisternasii & 29SQD42 & 101,00 & 163,45 & 115,65 & 37,00 & 6467,77 & 345,24 & 37,56 & $\begin{array}{l}307,68 \\
\end{array}$ & 92,97 & 249,25 & 249,25 & 84,56 & 501,69 & 64,52 & 3,59 & 50,63 & 187,05 & 30,86 & 30,86 & 175,00 \\
\hline Alytes cisternasii & 29SQD44 & 100,00 & 153,60 & 112,60 & 36,38 & 6501,45 & 334,92 & 30,10 & 304,82 & 83,36 & 240,45 & 240,45 & 75,10 & 541,58 & 69,07 & 4,51 & 49,49 & 199,98 & 36,22 & 36,23 & 187,85 \\
\hline Alytes cisternasii & 29SQD47 & 100,00 & 160,86 & 110,70 & 36,07 & 6477,91 & 339,36 & 37,98 & 301,38 & 90,34 & 247,32 & 247,32 & 82,02 & 484,05 & 62,15 & 4,00 & 48,47 & 177,12 & 33,49 & 33,49 & 164,73 \\
\hline Alytes cisternasii & 29SQD48 & 101,00 & 161,55 & 110,35 & 36,08 & 6466,01 & 339,07 & 38,76 & 300,31 & 90,95 & 247,84 & 247,84 & 82,85 & 475,51 & 60,13 & 4,00 & 48,11 & 173,82 & 33,42 & 33,42 & 161,51 \\
\hline Alytes cisternasii & 29SQD51 & 100,00 & 168,69 & 117,58 & 37,14 & 6495,95 & 351,42 & 40,79 & 310,63 & 97,43 & 254,64 & 254,64 & 88,89 & 478,98 & 62,25 & 3,00 & 51,94 & 179,24 & 27,14 & 27,14 & 167,53 \\
\hline Alytes cisternasii & 29SQD56 & 87,00 & 157,94 & 112,30 & 36,01 & 6536,19 & 338,98 & 33,71 & 305,27 & 86,92 & 245,25 & 245,25 & 78,64 & 492,20 & 63,35 & 4,02 & 48,53 & 179,17 & 33,79 & 33,79 & 166,85 \\
\hline Alytes cisternasii & 29SQD57 & 80,00 & 160,28 & 111,88 & 36,03 & 6511,11 & 340,08 & 36,26 & 303,83 & 89,31 & 247,30 & 247,30 & 81,00 & 474,24 & 60,6 & 4,00 & 48,02 & 172,21 & 33,12 & 33,12 & 159,87 \\
\hline Alytes cisternasii & 29 SQD59 & 77,00 & 158,03 & 110,91 & 36,04 & 6482,15 & 336,26 & 34,92 & 301,34 & 87,37 & 244,79 & 244,79 & 79,16 & 471,49 & 58,59 & 4,33 & 47,20 & $\begin{array}{l}170,65 \\
\end{array}$ & $\begin{array}{l}34,29 \\
34\end{array}$ & 34,29 & 158,17 \\
\hline Alytes cisternasii & 29SQE50 & 70,00 & 159,94 & 110,91 & 36,59 & \begin{tabular}{ll|l|}
6450,74 \\
\end{tabular} & 336,84 & 36,84 & 300,00 & 89,39 & 246,15 & 246,15 & 81,11 & 456,27 & 56,13 & 4,02 & 46,66 & 165,05 & 33,50 & 33,50 & 152,85 \\
\hline Alytes cisternasii & 29SQE51 & 63,00 & 158,98 & 110,69 & 36,68 & 6427,51 & 334,89 & 36,06 & 298,83 & 88,21 & 244,68 & 244,68 & 80,34 & 454,36 & 55,83 & 4,50 & 46,13 & 164,21 & 34,23 & 34,23 & 151,88 \\
\hline Alytes cisternasii & 29TPE23 & 100,00 & 136,93 & 89,41 & 34,98 & 5655,55 & 286,47 & 34,08 & 252,39 & 69,31 & 212,77 & 212,88 & 69,31 & 1072,25 & 160,25 & 9,60 & 55,52 & 436,33 & 65,86 & 65,86 & 436,33 \\
\hline Alytes cisternasii & 29TPE37 & 100,00 & 126,44 & 86,62 & 34,39 & 5632,12 & 272,12 & 24,14 & 247,98 & 58,40 & 201,32 & 201,39 & 58,40 & 1136,45 & 171,51 & 10,64 & 55,48 & 461,98 & 70,81 & 73,01 & 461,98 \\
\hline \begin{tabular}{|l} 
Alytes cisternasii \\
\end{tabular} & 29TPE43 & 101,00 & 153,35 & $\begin{array}{l}97,14 \\
97,14\end{array}$ & 35,97 & 5887,56 & 310,18 & $\mid 43,60$ & 266,59 & 89,12 & 231,20 & 231,48 & 81,69 & \begin{tabular}{|l|}
837,38 \\
\end{tabular} & $\mid 120,72$ & $\begin{array}{l}0,0,00 \\
7,00\end{array}$ & 53,85 & 334,35 & 53,38 & 53,65 & 333,63 \\
\hline Alytes cisternasii & 29TPE44 & 100,00 & 149,48 & 96,03 & 35,86 & 5860,33 & 304,97 & 40,37 & 264,60 & 84,59 & 226,95 & 227,18 & 78,09 & 871,44 & 126,58 & 7,52 & 54,06 & 348,36 & 55,63 & 55,78 & 347,93 \\
\hline Alytes cisternasii & 29TPE45 & 101,00 & 142,38 & 93,54 & 35,41 & 5824,43 & 295,68 & 34,92 & 260,76 & 74,84 & 219,54 & 219,65 & 71,49 & 934,96 & 137,33 & 8,42 & 54,35 & 374,92 & 59,48 & 59,90 & 374,91 \\
\hline Alytes cisternasii & 29TPE53 & 100,00 & 151,91 & 97,36 & 35,85 & 5953,50 & 309,70 & 41,55 & 268,15 & 87,23 & 230,81 & 231,01 & 79,58 & 808,77 & 115,52 & 6,97 & 53,33 & 321,81 & 52,04 & 52,23 & 319,62 \\
\hline Alytes cisternasii & 29TPE54 & 100,00 & 147,75 & 95,98 & 35,62 & 5933,51 & 304,19 & 38,06 & 266,13 & 83,16 & 226,32 & 226,50 & 75,69 & 844,05 & 121,51 & 7,38 & 53,61 & 335,96 & 54,66 & 54,79 & 334,47 \\
\hline \begin{tabular}{|l} 
Alytes cisternasii \\
\end{tabular} & 29TPE55 & 100,00 & 139,99 & 93,16 & 35,09 & 5892,53 & 294,01 & 32,20 & 261,81 & $\frac{30,16}{76,16}$ & \begin{tabular}{|l|}
218,11 \\
213
\end{tabular} & \begin{tabular}{|l|}
218,19 \\
\end{tabular} & 68,40 & \begin{tabular}{|l|}
909,11 \\
\end{tabular} & \begin{tabular}{|l|l|}
132,39 \\
\end{tabular} & 8,41 & 53,90 & $\begin{array}{l}362,66 \\
360\end{array}$ & 58,54 & $\begin{array}{ll}59,38 \\
\end{array}$ & 361,92 \\
\hline Alytes cisternasii & 29TPE56 & 101,00 & 128,25 & 88,22 & 34,20 & 5835,14 & 278,60 & 23,79 & 254,82 & 62,95 & 205,80 & 206,08 & 57,84 & 1007,41 & 148,40 & 9,62 & 54,15 & 403,27 & 64,49 & 67,35 & 403,21 \\
\hline Alytes cisternasii & 29TPE63 & 100,00 & 147,31 & 96,56 & 35,56 & 6005,60 & 305,46 & 37,25 & 268,21 & 82,40 & 227,14 & 227,18 & 74,60 & 805,58 & 114,23 & 7,23 & 52,82 & 319,18 & 52,55 & 52,87 & 315,84 \\
\hline Alytes cisternasii & 29TPE64 & 101,00 & 148,18 & 97,18 & 35,78 & 5989,67 & 305,84 & 37,38 & 268,45 & 82,93 & 227,58 & 227,62 & 75,21 & 797,19 & 113,21 & 7,17 & 52,86 & 315,68 & 52,29 & 52,49 & 312,48 \\
\hline Alytes cisternasii & 29TPE65 & 100,00 & 129,91 & 90,14 & 34,26 & 5929,70 & 283,01 & 23,91 & 259,10 & 66,46 & 208,92 & 209,16 & 58,67 & 944,84 & 136,77 & 9,21 & 53,25 & 375,78 & 61,54 & 63,95 & 373,87 \\
\hline \begin{tabular}{|l} 
Alytes cisternasii \\
\end{tabular} & 29TPE66 & 100,00 & 121,79 & $\begin{array}{ll}0,149 \\
86,97\end{array}$ & $\frac{4,420}{33,72}$ & 5881,62 & 272,26 & \begin{tabular}{|l|l|}
17,83 \\
1
\end{tabular} & \begin{tabular}{|l|}
254,43 \\
\end{tabular} & $\mid 59,20$ & \begin{tabular}{|l|}
200,18 \\
\end{tabular} & \begin{tabular}{|l|}
200,57 \\
\end{tabular} & 51,21 & $\begin{array}{r}34,404 \\
1009,52\end{array}$ & \begin{tabular}{|l|}
147,16 \\
\end{tabular} & \begin{tabular}{|c|}
10,10 \\
10,
\end{tabular} & $\begin{array}{l}53,25 \\
53,46\end{array}$ & $\mid$ & $\begin{array}{l}1,34 \\
65,82\end{array}$ & $\begin{array}{l}3,59,68 \\
69,\end{array}$ & $\begin{array}{l}300,97 \\
400,97\end{array}$ \\
\hline Alytes cisternasii & \begin{tabular}{|l|} 
29TPE68 \\
\end{tabular} & 99,00 & 124,21 & 89,65 & 34,41 & 5871,67 & 275,38 & 18,51 & 256,87 & 60,36 & 201,86 & 202,53 & 53,08 & 971,17 & 141,44 & 9,89 & 53,21 & 386,12 & 64,70 & 67,43 & 385,41 \\
\hline Alytes cisternasii & 29TPE69 & 101,00 & 123,25 & 90,59 & 34,72 & 5856,27 & 274,74 & 17,18 & 257,56 & 58,81 & 200,55 & 201,39 & 52,01 & 969,08 & 141,09 & 10,03 & 53,06 & 385,06 & 65,36 & 67,80 & 384,65 \\
\hline Alytes cisternasii & 29TPE73 & 100,00 & 150,30 & 98,84 & 35,77 & 6062,09 & 310,71 & 38,27 & 272,44 & 84,43 & 230,77 & 230,80 & 76,58 & 739,65 & 102,88 & 6,62 & 51,89 & 290,90 & 49,06 & 49,23 & 285,78 \\
\hline Alytes cisternasii & 29TPE74 & 100,00 & 151,09 & 99,45 & 35,99 & 6044,12 & 311,10 & 38,55 & 272,55 & 85,01 & 231,27 & 231,27 & 77,25 & 730,10 & 101,60 & 6,54 & 51,86 & 286,93 & 48,63 & 48,65 & 281,99 \\
\hline Alytes cisternasii & 29TPE75 & 99,00 & 135,54 & 94,15 & 34,92 & 6008,58 & 292,03 & 26,54 & 265,49 & 70,70 & 215,39 & 215,63 & 62,83 & 847,52 & 119,95 & 8,43 & 52,10 & 334,35 & 56,87 & 58,58 & 330,22 \\
\hline Alytes cisternasii & 29TPE79 & 99,00 & 124,77 & 93,29 & 35,09 & 5934,79 & 279,08 & 16,71 & 262,37 & 60,47 & 203,18 & 204,08 & 52,60 & 896,75 & 127,89 & 9,73 & 51,82 & 353,66 & 62,66 & 64,50 & 351,17 \\
\hline Alytes cisternasii & 29TPE83 & 100,00 & 155,39 & 101,75 & 36,05 & 6107,25 & 318,29 & 40,92 & 277,37 & 88,51 & 236,29 & 236,29 & 80,65 & 662,07 & 89,77 & 5,86 & 50,92 & 258,07 & 44,53 & 44,53 & 251,09 \\
\hline Alytes cisternasii & 29TPE84 & 101,00 & 146,87 & 99,36 & 35,82 & 6104,88 & 308,40 & 33,98 & 274,42 & 80,31 & 227,97 & 228,03 & 72,56 & 717,78 & 98,46 & 6,86 & 51,03 & 280,18 & 49,20 & 49,35 & 273,80 \\
\hline \begin{tabular}{|l} 
Alytes cisternasii \\
\end{tabular} & 29TPE85 & 101,00 & 126,42 & 93,40 & 34,64 & $\begin{array}{l}6044,36 \\
6040\end{array}$ & 283,86 & $\begin{array}{ll}18,13 \\
18,\end{array}$ & 265,73 & $\begin{array}{l}60,919 \\
61,90\end{array}$ & 207,17 & 207,49 & 54,01 & 867,71 & \begin{tabular}{|l|}
120,90 \\
\end{tabular} & $\begin{array}{l}9,30 \\
9,38 \\
\end{array}$ & 51,16 & 339,84 & $\begin{array}{l}50,08 \\
60,\end{array}$ & $\frac{62,81}{62,}$ & 334,06 \\
\hline Alytes cisternasii & 29TPE87 & 100,00 & 124,01 & 93,18 & 34,67 & 6018,82 & 280,22 & 15,67 & 264,55 & 59,25 & 203,85 & 204,61 & 51,39 & 866,80 & 121,19 & 9,70 & 50,97 & 339,73 & 60,96 & 63,50 & 334,53 \\
\hline Alytes cisternasii & 29TPE97 & 101,00 & 123,33 & 95,54 & 35,03 & 6081,09 & 282,39 & 13,56 & 268,83 & 57,85 & 204,07 & 204,93 & 50,15 & 815,68 & 111,21 & 9,77 & 49,60 & 316,66 & 59,75 & 62.02 & 309,32 \\
\hline Alytes cisternasii & 29TPE99 & 100,00 & 129,38 & 99,10 & 35,98 & 6061,66 & 289,52 & 17,34 & 272,18 & 63,10 & 209,68 & 210,36 & 55,57 & 750,64 & 101,66 & 8,98 & 49,19 & 290,90 & 56,43 & 57,15 & 283,99 \\
\hline Alytes cisternasii & 29TPF31 & 100,00 & 122,01 & 91,03 & 35,81 & 5592,34 & 269,00 & 17,97 & 251,03 & 53,63 & 195,80 & 196,16 & 53,63 & 1153,91 & 174,51 & 11,85 & 55,18 & 469,29 & 75,12 & 77,18 & 469,29 \\
\hline \begin{tabular}{|l|l} 
Alytes cisternasii \\
\end{tabular} & \begin{tabular}{|l|} 
29TPF35 \\
29TF
\end{tabular} & $\begin{array}{l}101,00 \\
100\end{array}$ & $\begin{array}{ll}12,01 \\
137,94\end{array}$ & $\begin{array}{l}1,05 \\
105,49\end{array}$ & $\begin{array}{l}35, \\
39,\end{array}$ & 5607,72 & 292,00 & $\begin{array}{l}1,751 \\
25,79\end{array}$ & $\begin{array}{l}261,05 \\
266,52 \\
\end{array}$ & 67,82 & 211,25 & 211,27 & 67,82 & 982,27 & 146,01 & 10,54 & 54,18 & 395,49 & 65,43 & 65,51 & 395,49 \\
\hline Alytes cisternasii & 29TPF36 & 100,00 & 136,08 & 105,63 & 39,20 & 5593,92 & 290,39 & 23,96 & 266,43 & 66,31 & 209,21 & 209,21 & 66,31 & 987,88 & 145,90 & 11,16 & 53,79 & 397,09 & 67,05 & 67,16 & 397,09 \\
\hline Alytes cisternasii & \begin{tabular}{|l|} 
29TPF37 \\
\end{tabular} & 101,00 & 136,96 & 106,85 & 39,44 & 5597,15 & 291,74 & 23,96 & 267,78 & 66,93 & 209,96 & 209,98 & 66,93 & 970,32 & 142,26 & 11,30 & 53,38 & 388,98 & 66,55 & 66,61 & 388,98 \\
\hline Alytes cisternasii & 29TPF43 & 100,00 & 128,47 & 98,78 & 37,29 & 5690,11 & 281,10 & 19,51 & 261,59 & 58,25 & 203,40 & 203,53 & 58,25 & $\mid$\begin{tabular}{|l|l|}
1018,61 \\
\end{tabular} & $\mid 151,77$ & \begin{tabular}{ll|l}
11,11 \\
\end{tabular} & 54,11 & 410,75 & 69,20 & 69,37 & 410,7 \\
\hline Alytes cisternasii & 29TPF44 & 100,00 & 132 & 102,47 & 38,08 & 5697,92 & 287,24 & 21,71 & 265,53 & 62,03 & 207 & 207 & 62,03 & 972,21 & 144,25 & 10,68 & 53,94 & 391,00 & 66,10 & 66,10 & 391 \\
\hline \begin{tabular}{|l} 
Alytes cisternasii \\
\end{tabular} & $\begin{array}{l}\text { 29TPF 45 } \\
\end{array}$ & $\begin{array}{l}100,00 \\
\end{array}$ & $\begin{array}{l}13,10,70 \\
140,\end{array}$ & $\begin{array}{l}10,41 \\
105,77\end{array}$ & $\begin{array}{l}0,00 \\
38,89 \\
\end{array}$ & $\begin{array}{l}563,7,42 \\
5667,\end{array}$ & $\begin{array}{l}20,295,95 \\
295\end{array}$ & $\begin{array}{l}1,1 / 3 \\
27,37 \\
\end{array}$ & \begin{tabular}{|l|}
263,58 \\
268,5
\end{tabular} & \begin{tabular}{|l|l|}
70,06 \\
70,
\end{tabular} & \begin{tabular}{|l|}
214,86 \\
210
\end{tabular} & \begin{tabular}{|l|}
214,86 \\
214
\end{tabular} & $\begin{array}{l}6,, 05 \\
69,73 \\
\end{array}$ & \begin{tabular}{|l|l|}
898,03 \\
\end{tabular} & \begin{tabular}{|l|}
131,61 \\
131,61
\end{tabular} & \begin{tabular}{|c|}
$\mid 20,00$ \\
9,86
\end{tabular} & $\begin{array}{ll}53,24 \\
53,24\end{array}$ & \begin{tabular}{|l|l|}
358,68 \\
350
\end{tabular} & $\begin{array}{l}0,10 \\
60,80 \\
\end{array}$ & $\begin{array}{l}60,80 \\
60,10\end{array}$ & 358,68 \\
\hline Alytes cisternasii & 29TPF46 & 101,00 & 123,35 & 101,60 & 38,00 & 5663,76 & 277,73 & 13,58 & 264,15 & 53,73 & 198,39 & 198,39 & 53,73 & 1028,48 & 151,52 & 12,73 & 53,08 & 413,96 & 73,53 & 73,53 & 413,96 \\
\hline 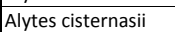 & \begin{tabular}{|l|} 
29TPF47 \\
\end{tabular} & 99,00 & 132,70 & 105,43 & 38,83 & 5659,92 & 288,25 & 20,00 & 268,25 & 62,32 & 207,06 & 207,06 & 62,32 & 938,61 & 136,65 & 11,66 & 52,49 & 375,35 & 66,55 & 66,55 & 375,35 \\
\hline Alytes cisternasii & \begin{tabular}{|l|} 
29TPF48 \\
\end{tabular} & 101,00 & 140,12 & 107,65 & 39,32 & 5646,39 & 295,76 & 25,48 & 270,27 & 69,34 & 214,06 & 214,06 & 69,34 & 865,86 & 123,90 & 10,87 & 51,73 & 343,18 & 61,50 & 61,50 & 343,18 \\
\hline Alytes cisternasii & 29TPF51 & 101,00 & 131,64 & 96,88 & 36,43 & 5782,81 & 284,82 & 22,60 & 262,23 & 60,43 & 208,01 & 208,14 & 60,43 & 944,00 & 138,90 & 9,93 & 53,56 & 377,33 & 64,01 & 64,23 & 377,33 \\
\hline
\end{tabular}




\begin{tabular}{|c|c|c|c|c|c|c|c|c|c|c|c|c|c|c|c|c|c|c|c|c|c|}
\hline TAXON & UTM & $\mathrm{km} 2$ & B101 & B102 & $\mathrm{BIO3}$ & B104 & B105 & B106 & B107 & B108 & B109 & BIO10 & BIO11 & BIO12 & B1013 & BIO14 & BIO15 & BIO16 & BIO17 & B1018 & B1019 \\
\hline Alytes cisternasii & 29TPF53 & 100,00 & 141,10 & 103,66 & 38,12 & 5763,83 & 296,81 & 28,05 & 268,76 & 69,62 & 216,60 & 216,60 & 69,12 & 850,97 & 123,81 & 9,14 & 52,78 & 337,87 & 57,88 & 57,88 & 337,83 \\
\hline Alytes cisternasii & 29TPF54 & 101,00 & 142,68 & 105,21 & 38,51 & 5744,58 & 298,77 & 28,79 & 269,97 & 72,03 & 217,84 & 217,84 & 70,80 & 832,23 & 120,63 & 9,06 & 52,52 & 329,99 & 56,84 & 56,84 & 329,90 \\
\hline Alytes cisternasii & 29TPF55 & 100,00 & 143,81 & 106,25 & 38,74 & 5720,69 & 300,02 & 29,27 & 270,76 & 74,26 & 218,64 & 218,64 & 72,02 & 814,43 & 117,22 & 9,14 & 52,12 & 322,14 & 56,22 & 56,22 & 321,98 \\
\hline Alytes cisternasii & 29TPF56 & 100,00 & 139,49 & 105,69 & 38,59 & 5705,64 & 295,63 & 25,55 & 270,08 & 70,99 & 214,41 & 214,41 & 68,22 & 837,54 & 120,32 & 9,97 & 51,84 & 331,83 & 59,22 & 59,22 & 331,53 \\
\hline Alytes cisternasii & 29TPF57 & 101,00 & 134,38 & 105,98 & 38,67 & 5715,32 & 291,15 & 20,48 & 270,66 & 63,93 & 209,56 & 209,56 & 63,28 & 863,64 & 124,24 & 11,01 & 51,61 & 343,18 & \begin{tabular}{ll|}
62,44 \\
\end{tabular} & 62,44 & 343,14 \\
\hline Alytes cisternasii & 29TPF59 & 101,00 & 140,06 & 107,68 & 39,02 & 5679,65 & 296,10 & 24,35 & 271,75 & 70,61 & 214,39 & 214,39 & 68,77 & 794,76 & 111,26 & 10,91 & 50,28 & 312,01 & 58,91 & 58,91 & 312,01 \\
\hline Alytes cisternasii & 29TPF61 & 100,00 & 132,16 & 97,93 & 36,39 & 5855,03 & 287,09 & 21,78 & 265,31 & 64,63 & 209,47 & 209,65 & 59,93 & 881,01 & 127,52 & 9,52 & 52,48 & 348,64 & 61,25 & 61,44 & 348,50 \\
\hline Alytes cisternasii & 29TPF62 & 100,00 & 131,94 & 99,50 & 36,82 & 5846,01 & 287,62 & 20,89 & 266,74 & 63,30 & 209,20 & 209,32 & 59,75 & 870,22 & 125,57 & 9,66 & 52,26 & 344,02 & $\begin{array}{l}61,16 \\
\end{array}$ & 61,35 & 343,96 \\
\hline Alytes cisternasii & 29TPF63 & 101,00 & 134,25 & 101,94 & 37,38 & 5835,98 & 290,96 & 21,88 & 269,08 & 63,60 & 211,38 & 211,38 & 61,97 & 844,73 & 121,62 & 9,68 & 52,03 & 333,64 & 59,71 & 59,71 & 333,62 \\
\hline Alytes cisternasii & 29TPF64 & 99,00 & 141,58 & 105,17 & 38,20 & 5807,07 & 298,94 & 27,17 & 271,77 & 72,58 & 217,82 & 217,82 & 69,07 & 782,20 & 111,55 & 8,88 & 51,52 & 307,77 & 55,02 & 55,02 & 307,29 \\
\hline Alytes cisternasii & 29TPF65 & 101,00 & 133,16 & 104,27 & 37,93 & 5804,01 & 290,69 & 19,73 & 270,97 & 62,06 & 209,68 & 209,68 & 61,14 & 831,42 & 118,91 & 10,13 & 51,36 & 328,13 & 60 & 60,39 & 328,13 \\
\hline Alytes cisternasii & 29TPF66 & 100,00 & 138,95 & 106,55 & 38,53 & 5783,69 & 296,75 & 23,90 & 272,85 & 68,93 & 214,97 & 214,97 & 66,74 & 780,99 & 110,72 & 9,66 & 50,94 & 307,18 & 56,57 & 56,57 & 306,92 \\
\hline Alytes cisternasii & 29TPF67 & 100,00 & 138,89 & 107,36 & 38,83 & 5764,51 & 296,72 & 23,36 & 273,36 & 69,09 & 214,57 & 214,57 & 66,78 & 768,30 & 108,26 & 9,93 & 50,41 & 301,58 & 56,62 & 56,62 & 301,41 \\
\hline Alytes cisternasii & \begin{tabular}{|l|} 
29TPF68 \\
\end{tabular} & 101,00 & 125,92 & 105,07 & 38,24 & 5746,97 & 283,86 & 12,69 & 271,17 & 55,71 & 201,92 & 201,94 & 54,87 & 847,90 & 119,58 & \begin{tabular}{l|l|l|}
11,95 \\
\end{tabular} & 50,01 & 334,57 & 65,86 & 65,90 & 334,55 \\
\hline Alytes cisternasii & 29TPF71 & 100,00 & 127,17 & 97,36 & 36,08 & 5919,39 & 283,19 & 17,05 & 266,14 & 62,28 & 205,32 & 205,96 & 54,80 & 856,38 & 121,62 & 9,80 & 51,38 & 336,79 & 61,71 & 62,35 & 334,93 \\
\hline Alytes cisternasii & 29TPF72 & 100,00 & 127,59 & 99,08 & 36,53 & 5904,58 & 284,36 & 16,52 & 267,84 & 62,55 & 205,84 & 205,97 & 55,05 & 843,94 & 119,73 & 9,89 & 51,16 & 331,56 & 61,64 & 61,79 & 330,15 \\
\hline Alytes cisternasii & \begin{tabular}{|l|} 
29TPF73 \\
\end{tabular} & 100,00 & 133,46 & 102,44 & 37,27 & 5891,66 & 291,47 & 20,37 & 271,10 & 67,96 & 211,44 & 211,44 & 60,61 & 792,11 & 111,81 & 9,37 & 50,82 & 310,49 & 57,83 & 57,83 & 309,20 \\
\hline Alytes cisternasii & 29TPF74 & 101,00 & 141,89 & 105,77 & 38,07 & 5862,92 & 300,65 & 26,54 & 274,11 & 75,85 & 218,98 & 218,98 & 68,70 & 723,89 & 101,04 & 8,58 & 50,33 & 282,67 & 52,56 & 52,56 & 280,76 \\
\hline Alytes cisternasii & $\begin{array}{l}\text { 29TPF75 } \\
\end{array}$ & 99,00 & 134,33 & 105,26 & 37,99 & 5864,59 & 293,29 & 19,66 & 273,63 & 67,46 & 211,71 & 211,71 & 61,42 & 765,39 & 107,37 & 9,63 & 50,20 & 299,43 & 57,12 & 57,12 & 298,61 \\
\hline Alytes cisternasii & 29TPF76 & 101,00 & 133,84 & 105,95 & 38,20 & 5841,09 & 292,79 & 18,91 & 273,88 & 66,99 & 210,85 & 210,86 & 61,26 & 757,77 & 105,79 & 9,82 & 49,82 & 296,32 & 57,40 & 57,40 & 295,41 \\
\hline Alytes cisternasii & 29TPF77 & 100,00 & 137,67 & 107,68 & 38,62 & 5820,77 & 296,98 & 21,54 & 275,44 & 71,36 & 214,26 & 214,26 & 64,96 & 721,04 & 99,86 & 9,74 & 49,31 & 281,24 & 54,96 & 54,96 & 280,28 \\
\hline Alytes cisternasii & 29TPF78 & 100,00 & 129,88 & 107,05 & 38,40 & 5809,03 & 289,73 & 14,60 & 275,14 & 62,27 & 206,69 & 206,69 & 57,73 & 759,94 & 105,55 & 10,85 & 49,07 & 297,53 & 59,92 & 59,92 & 297,20 \\
\hline Alytes cisternasii & 29TPF80 & 100,00 & 124,54 & 96,64 & 35,69 & 5984,11 & 281,57 & 14,38 & 267,19 & 59,31 & 203,48 & 204,49 & 51,68 & 829,57 & 115,42 & 9,69 & 50,31 & 324,36 & 60,92 & 62,19 & 319,90 \\
\hline Alytes cisternasii & 29TPF81 & 100,00 & 126,60 & 98,86 & 36,16 & 5977,64 & 284,65 & 15,28 & 269,37 & 60,96 & 205,60 & 206,19 & 53,50 & 801,99 & 111,22 & 9,53 & 50,05 & 313,21 & 59,84 & 60,40 & 308,99 \\
\hline Alytes cisternasii & \begin{tabular}{|l|} 
29TPF86 \\
\end{tabular} & 100,00 & 126,57 & 105,56 & 37,85 & 5900,58 & 287,13 & 11,93 & 275,19 & 60,90 & 204,84 & 204,84 & 53,61 & 744,61 & 101,80 & 10,30 & 48,49 & 289,46 & 59,65 & 59,65 & 287,21 \\
\hline Alytes cisternasii & \begin{tabular}{|l|} 
29TPF87 \\
\end{tabular} & 99,00 & 128,44 & 106,95 & 38,07 & 5880,29 & 289,34 & 12,93 & 276,42 & 62,64 & 206,21 & 206,21 & 55,45 & 721,95 & 98,36 & 10,32 & 48,11 & 280,52 & 58,36 & 58,36 & 278,59 \\
\hline \begin{tabular}{|l} 
Alytes cisternasii \\
\end{tabular} & 29TPF88 & 101,00 & 131,27 & 108,01 & 38,51 & 5851,74 & 291,97 & $\begin{array}{ll}14,96 \\
14,9\end{array}$ & 277,01 & 65,44 & \begin{tabular}{|l|}
208,61 \\
\end{tabular} & 208,61 & 58,38 & 695,99 & $\begin{array}{l}0,18 \\
94,18 \\
\end{array}$ & 10,34 & $\begin{array}{l}47,11 \\
47,79\end{array}$ & 270,13 & 56 & 56,85 & 268,09 \\
\hline Alytes cisternasii & 29TPF89 & 100,00 & 127,67 & 108,27 & 38,52 & 5831,94 & 288,98 & 11,46 & 277,52 & 62,03 & 204,89 & 204,89 & 55,23 & 706,50 & 95,57 & 11,02 & 47,46 & 274,56 & 59,14 & 59,14 & 273,30 \\
\hline Alytes cisternasii & 29TPF90 & 100,00 & 128,32 & 100,02 & 36,06 & 6047,87 & 288,53 & 15,82 & 272,71 & 61,90 & 208,45 & 209,05 & 54,46 & 745,06 & 100,55 & 9,00 & 48,82 & 288,52 & 56,83 & 57,33 & 281,68 \\
\hline Alytes cisternasii & 29TPF91 & 101,00 & 127,38 & 101,04 & 36,35 & 6036,27 & 287,82 & 14,43 & 273,39 & 60,91 & 207,49 & 207,84 & 53,55 & 739,90 & 99,64 & 9,21 & 48,60 & 286,37 & 57,43 & 57,71 & 279,78 \\
\hline Alytes cisternasii & \begin{tabular}{|l|l|} 
29TPF95 \\
\end{tabular} & 100,00 & 123,98 & 105,18 & 37,72 & 5972,06 & 285,81 & 9,47 & 276,34 & 57,90 & 203,57 & 203,57 & 50,66 & 712,27 & 94,80 & 9,98 & 47,46 & 274,87 & 58,80 & 58,80 & 269,70 \\
\hline \begin{tabular}{|l} 
Alytes cisternasii \\
\end{tabular} & 29TPF97 & 101,00 & 119,67 & 106,41 & 37,99 & 5930,73 & $\begin{array}{l}28,01 \\
282,07\end{array}$ & $\begin{array}{l}, 4,67 \\
4,6\end{array}$ & 277,39 & 53,80 & \begin{tabular}{|l|}
198,61 \\
\end{tabular} & \begin{tabular}{|l|}
198,61 \\
\end{tabular} & $\begin{array}{l}40,605 \\
46,5\end{array}$ & 718,31 & $\begin{array}{l}4,00 \\
95,14 \\
\end{array}$ & | & 46,70 & 276,97 & \begin{tabular}{l|l|}
61,95 \\
\end{tabular} & $\begin{array}{l}0,100 \\
61,95\end{array}$ & 272,98 \\
\hline Alytes cisternasii & 29TPF98 & 100,00 & 120,57 & 107,46 & 38,12 & 5908,98 & 283,11 & 5,07 & 278,03 & 54,57 & 199,09 & 199,09 & 47,67 & 701,41 & 92,47 & \begin{tabular}{|l|l|}
11,18 \\
\end{tabular} & 46,30 & 270,26 & 61,39 & 61,39 & 266,71 \\
\hline Alytes cisternasii & 29TPF99 & 100,00 & 130,68 & 109,56 & 38,84 & 5876,27 & 292,54 & 13,18 & 279,36 & 64,36 & 208,23 & 208,23 & 57,49 & 638,01 & 83,60 & 10,49 & 46,07 & 245,56 & 55,23 & 55,23 & 241,94 \\
\hline Alytes cisternasii & 29TPG40 & 100,00 & 139,68 & 107,25 & 39,28 & 5619,81 & 294,02 & 24,54 & 269,48 & 69,90 & 213,18 & 213,18 & 69,41 & 839,87 & 116,78 & 11,78 & 50,19 & 329,39 & 62,42 & 62,42 & 329,39 \\
\hline Alytes cisternasii & 29TPG51 & 100,00 & 135,10 & 106,82 & 38,97 & 5652,70 & 290,36 & 19,93 & 270,43 & 68,85 & 209,35 & 209,35 & 64,65 & 802,20 & 109,94 & 12,67 & 48,85 & 313,40 & 63,25 & 63,25 & 313,23 \\
\hline Alytes cisternasii & 29TPG80 & 100,00 & 121,05 & 107,95 & 38,31 & 5805,80 & 283,05 & 5,75 & 277,30 & 55,69 & 198,22 & 198,22 & 49,43 & 736,72 & 99,75 & 12,07 & 47,20 & 287,01 & \begin{tabular}{|l|l|}
63,76 \\
\end{tabular} & 63,76 & 286,57 \\
\hline Alytes cisternasii & 29TPG84 & 100,00 & 101,08 & 104,58 & 38,04 & 5694,84 & 260,62 & $-10,39$ & 271,01 & 38,15 & 177,42 & 177,42 & 31,99 & 848,62 & 111,77 & 19,55 & 43,67 & 325,23 & 86,52 & 86,52 & 320,86 \\
\hline Alytes cisternasii & 29TPG90 & 101,00 & 125,92 & 109,62 & 38,77 & 5856,70 & 288,50 & 8,71 & 279,79 & 60,02 & 203,44 & 203,44 & 53,20 & 655,17 & 85,95 & 11,25 & 45,79 & 252,45 & 58,32 & 58,32 & 249,87 \\
\hline Alytes cisternasii & 29TPG93 & 100,00 & 114,11 & 109,10 & 38,82 & 5783,44 & 276,86 & $-1,48$ & 278,34 & 48,78 & 191,09 & 191,09 & 42,76 & 707,57 & 93,88 & 14,70 & 44,40 & 271,75 & 69,24 & 69,24 & 270,03 \\
\hline Alytes cisternasii & 29TQE16 & 100,00 & 126,83 & 100,71 & 35,60 & 6194,17 & 292,02 & 13,50 & 278,52 & 59,89 & 209,38 & 209,97 & 52,39 & 705,71 & 90,99 & 9,18 & 47,08 & 267,62 & 55,30 & 56,81 & 256,77 \\
\hline Alytes cisternasii & 29TQE17 & 100,00 & 116,90 & 99,27 & 35,58 & 6162,49 & 280,77 & 5,20 & 275,57 & 50,61 & 198,90 & 199,93 & 43,24 & 757,81 & 97,69 & 10,55 & 46,63 & 287,30 & 60,86 & 63,32 & 276,08 \\
\hline Alytes cisternasii & 29TQE18 & 101,00 & 125,54 & 101,80 & 36,00 & 6169,60 & 290,29 & 11,75 & 278,54 & 58,30 & 207,24 & 208,30 & 51,04 & 686,06 & 88,32 & 9,12 & 46,56 & 260,12 & 55,46 & 56,49 & 249,12 \\
\hline Alytes cisternasii & 29TQE25 & 100,00 & 144,28 & 105,56 & 36,23 & 6274,53 & 313,42 & 26,70 & 286,71 & 75,50 & 227,90 & 227,97 & 67,85 & 568,92 & 72,27 & 6,71 & 46,51 & 212,81 & 44,44 & 44,51 & 201,38 \\
\hline Alytes cisternasii & 29TQE37 & 99,00 & 132,68 & 106,64 & 36,72 & 6260,68 & 302,26 & 15,30 & 286,96 & 64,04 & 216,10 & 216,41 & 56,71 & 576,18 & 72,79 & 8,43 & 44,17 & 212,34 & 49,52 & 49,99 & 199,15 \\
\hline \begin{tabular}{|l} 
Alytes cisternasii \\
\end{tabular} & 29TQE38 & 100,00 & 110,46 & 103,62 & 36,32 & 6198,67 & 278,44 & $-3,04$ & 281,49 & 43,78 & 193,30 & \begin{tabular}{|l|}
194,22 \\
\end{tabular} & \begin{tabular}{|l|l|}
36,73 \\
\end{tabular} & 697,16 & 88,05 & $\begin{array}{l}0.45 \\
11,78 \\
\end{array}$ & 43,03 & 256,34 & \begin{tabular}{|l|l|}
63,16 \\
6
\end{tabular} & $\begin{array}{l}65,78 \\
65,\end{array}$ & 241,57 \\
\hline Alytes cisternasii & 29TQE45 & 100,00 & 151,61 & 109,59 & 37,00 & 6324,97 & 323,68 & 30,62 & 293,06 & 81,56 & 235,82 & 235,82 & 74,03 & 473,99 & 59,14 & 5,99 & 44,33 & 172,29 & 39,09 & 39,09 & 159,80 \\
\hline Alytes cisternasii & 29TQE48 & 99,00 & 117,99 & 107,09 & 36,82 & 6247,59 & 288,57 & $\begin{array}{c}3,733 \\
1,73 \\
\end{array}$ & 286,85 & 50,00 & 201,22 & 202,15 & 43,11 & 606,94 & 75,98 & 10,64 & 41,83 & 219,55 & 57,39 & 58,73 & 204,08 \\
\hline Alytes cisternasii & 29TQE49 & 100,00 & 111,13 & 106,74 & 36,98 & 6218,89 & 281,23 & $-3,86$ & 285,09 & 43,78 & 193,70 & 195,11 & 36,90 & 629,64 & 78,99 & 11,61 & 41,15 & 227,45 & 61,36 & 63,11 & 210,94 \\
\hline Alytes cisternasii & 29TQE55 & 57,00 & 150,76 & 110,57 & 37,00 & 6358,67 & 323,98 & 28,98 & 295,00 & 80,15 & 235,62 & 235,62 & 72,85 & 458,15 & 56,78 & 6,03 & 43,63 & 164,68 & 39,14 & 39,14 & 151,80 \\
\hline \begin{tabular}{|l} 
Alytes cisternasii \\
\end{tabular} & $\begin{array}{l}\text { 29TQE57 } \\
\end{array}$ & 42,00 & 139,19 & 110,38 & 37,06 & 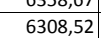 & 311,71 & \begin{tabular}{|l|l|}
18,79 \\
18,
\end{tabular} & $\begin{array}{l}292,92 \\
292\end{array}$ & $\mid \frac{\mid 0,110}{69,40}$ & $\begin{array}{l}223,40 \\
2230\end{array}$ & \begin{tabular}{|l|}
223,47 \\
220
\end{tabular} & \begin{tabular}{l|l}
62,26 \\
62,
\end{tabular} & $\mid$\begin{tabular}{|l|}
480,13 \\
486,51
\end{tabular} & $\begin{array}{l}0,10 \\
60,44 \\
\end{array}$ & $\begin{array}{l}, 05 \\
7,65\end{array}$ & $\begin{array}{l}42,35 \\
42,35\end{array}$ & $\begin{array}{l}104,00 \\
174,30\end{array}$ & \begin{tabular}{|l|l|l|l|}
44,42 \\
\end{tabular} & $\begin{array}{l}35,44 \\
44,45\end{array}$ & $\begin{array}{l}151,00 \\
160,43\end{array}$ \\
\hline Alytes cisternasii & 29TQE58 & 47,00 & 134,90 & 110,69 & 37,23 & 6298,43 & 307,31 & 14,87 & 292,44 & 65,49 & 219,16 & 219,25 & 58,23 & 493,18 & 61,34 & 8,28 & 41,59 & 176,15 & 46,67 & 46,74 & 161,74 \\
\hline Alytes cisternasii & 29TQF05 & 99,00 & 122,03 & 106,32 & 37,58 & 6018,77 & 285,45 & 6,53 & 278,92 & 55,32 & 202,18 & 202,18 & 48,14 & 667,94 & 85,85 & 10,00 & 45,79 & 255,06 & 58,03 & 58,03 & 247,19 \\
\hline Alytes cisternasii & 29TQF07 & 100,00 & 124,47 & 108,48 & 38,15 & 5975,92 & 288,21 & 7,85 & 280,36 & 57,62 & 203,80 & 203,80 & 50,69 & 634,57 & 81,31 & 10,33 & 45,02 & 241,67 & 56,70 & 56,70 & 235,0 \\
\hline Alytes cisternasii & 29TQF08 & 100,00 & 119,33 & 108,56 & 38,17 & 5959,95 & 283,31 & 3,05 & 280,26 & 52,92 & 198,65 & 198,65 & 45,99 & 654,23 & 84,20 & 11,16 & 44,66 & 249,16 & 60,21 & 60,21 & 24 \\
\hline \begin{tabular}{|l} 
Alytes cisternasii \\
\end{tabular} & 29TQFO9 & $\begin{array}{l}101,00 \\
100\end{array}$ & 126,93 & $\begin{array}{l}10,50 \\
110,16\end{array}$ & $\begin{array}{l}0,11 \\
38,94 \\
\end{array}$ & 5930,54 & $\begin{array}{l}20,51 \\
290,50\end{array}$ & $\begin{array}{l}3,03 \\
9,14 \\
\end{array}$ & \begin{tabular}{|l|}
281,36 \\
286
\end{tabular} & $\begin{array}{l}2,3<2 \\
60,20\end{array}$ & \begin{tabular}{|l|}
$205,50,5$ \\
\end{tabular} & \begin{tabular}{|l|}
205,50 \\
200
\end{tabular} & $\begin{array}{l}53,32 \\
53,\end{array}$ & \begin{tabular}{|l|}
605,30 \\
6050
\end{tabular} & $\begin{array}{l}4,46 \\
78,18\end{array}$ & $\begin{array}{l}11,10 \\
10,60\end{array}$ & $\begin{array}{l}44,49 \\
44,49\end{array}$ & $\begin{array}{l}24,10 \\
230,27\end{array}$ & \begin{tabular}{|l|}
55,42 \\
\end{tabular} & $\begin{array}{l}0,214 \\
55,42\end{array}$ & $\begin{array}{l}243,12 \\
224,78\end{array}$ \\
\hline Alytes cisternasii & 29TQF10 & 99,00 & 123,20 & 103,09 & 36,52 & 6140,43 & 287,72 & 8,99 & 278,73 & 56,01 & 204,47 & 205,41 & 48,67 & 673,72 & 86,64 & 9,59 & 45,73 & 255,00 & 56,69 & 57,43 & 243,76 \\
\hline 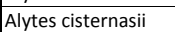 & 29TQF15 & 101,00 & 120,75 & 107,73 & 37,95 & 6071,48 & 286,05 & 4,44 & 281,61 & 53,44 & 201,50 & 201,50 & 46,21 & 621,94 & 79,17 & 10,14 & 43,99 & 234,15 & \begin{tabular}{|l|l|}
57,15 \\
\end{tabular} & 57,15 & 223,71 \\
\hline Alytes cisternasii & 29TQF16 & 100,00 & 119,86 & 108,46 & 38,00 & 6049,59 & 285,22 & 3,36 & 281,85 & 52,53 & 200,33 & 200, & 45 & 616,45 & 78,70 & 10,64 & 43,43 & 231,63 & 58,12 & 58,12 & 221, \\
\hline Alytes cisternasii & 29TQF17 & 99,00 & 126,84 & 110,00 & 38,23 & 6022,16 & 292,13 & 8,85 & 283,28 & 59,28 & 206,62 & 206,62 & 52,31 & 571,63 & 73,31 & $\begin{array}{r}, 0,92 \\
9,92\end{array}$ & 43,27 & 214,56 & 53,54 & 53,54 & 205,38 \\
\hline
\end{tabular}




\begin{tabular}{|c|c|c|c|c|c|c|c|c|c|c|c|c|c|c|c|c|c|c|c|c|c|}
\hline TAXON & UTM & $\mathrm{km2}$ & B101 & $\mathrm{B1O2}$ & $\mathrm{BIO3}$ & B104 & B105 & B106 & B107 & B108 & B109 & 81010 & B1011 & BIO12 & B1013 & 81014 & B1015 & B1O16 & B1017 & BIO18 & B1019 \\
\hline Alytes cisternasii & 29TQF18 & 100,00 & 122,60 & 110,21 & 38,40 & 6005,49 & 287,87 & 4,76 & 283,11 & 55,36 & 202,28 & 202,28 & 48,48 & 585,02 & 75,58 & 10,69 & 43,04 & 219,49 & 56,23 & 56,23 & 210,90 \\
\hline Alytes cisternasii & 29TQF19 & 100,00 & 118,95 & 110,37 & 38,70 & 5982,06 & 284,32 & 1,44 & 282,88 & 52,01 & 198,36 & 198,36 & 45,22 & 596,50 & 77,51 & 11,53 & 42,49 & 223,55 & 59,05 & 59,05 & 215,39 \\
\hline Alytes cisternasii & 29TQF20 & 100,00 & 122,60 & 105,19 & 36,93 & 6179,35 & 289,29 & 7,16 & 282,13 & 54,98 & 204,59 & 205,36 & 47,62 & 629,76 & 80,45 & 9,78 & 44,21 & 235,08 & 55,74 & 56,30 & 221,92 \\
\hline Alytes cisternasii & 29TQF27 & 101,00 & 120,53 & 110,64 & 38,04 & 6077,37 & 287,51 & 2,25 & 285,26 & 52,64 & 201,23 & 201,23 & 45,72 & 554,07 & 71,52 & 10,61 & 41,49 & 204,46 & 55,79 & 55,79 & 192,65 \\
\hline Alytes cisternasii & 29TQF28 & 100,00 & 120,82 & 111,21 & 38,30 & 6056,09 & 287,94 & 2,60 & 285,34 & 53,22 & 201,28 & 201,28 & 46,19 & 543,86 & 70,42 & 10,86 & 41,16 & 200,26 & 55,77 & 55,77 & 188,94 \\
\hline Alytes cisternasii & 29TQF29 & 100,00 & 120,33 & 111,61 & 38,78 & 6032,92 & 287,25 & 1,88 & 285,36 & 52,66 & 200,29 & 200,29 & 45,80 & 541,55 & 70,40 & 11,25 & 40,85 & 199,19 & 56,50 & 56,50 & 188,40 \\
\hline Alytes cisternasii & 29TQF37 & 100,00 & 118,55 & 111,76 & 38,46 & 6114,85 & 287,34 & 0,26 & 287,08 & 51,81 & 199,80 & 199,80 & 43,42 & 515,96 & 66,72 & 10,98 & 39,88 & 186,47 & 55,52 & 55,52 & 172,01 \\
\hline Alytes cisternasii & 29TQF38 & 100,00 & 117,16 & 112,03 & 38,93 & \begin{tabular}{|l|l|l|l|l|}
6097,53 \\
\end{tabular} & 285,87 & $-0,68$ & 286,55 & 50,01 & 198,18 & 198,18 & 42,05 & 517,13 & 66,94 & 11,24 & 39,33 & 186,47 & 57,05 & 57,05 & 172,52 \\
\hline Alytes cisternasii & 29TQF39 & 101,00 & 117,53 & 112,34 & \begin{tabular}{l|l|}
38,95 \\
\end{tabular} & 6073,13 & 286,20 & $-0,80$ & 287,00 & 54,47 & 198,29 & 198,29 & 42,66 & 509,77 & 66,10 & 11,77 & 38,87 & 183,34 & 57,22 & 57,22 & 169,97 \\
\hline Alytes cisternasii & 29TQF46 & 101,00 & 118,96 & 112,92 & 38,60 & 6153,76 & 289,35 & 0,24 & 289,11 & 76,52 & 200,76 & 200,76 & 43,42 & 481,04 & 62,11 & 10,63 & 38,93 & 171,84 & 54,16 & 54,16 & 153,67 \\
\hline Alytes cisternasii & 29TQF47 & 100,00 & 116,77 & 112,93 & 38,80 & 6141,71 & 287,25 & $-1,44$ & 288,68 & 76,17 & 198,53 & 198,53 & 41,46 & 481,72 & 62,16 & 11,00 & 38,46 & 171,64 & 55,31 & 55,31 & 153,66 \\
\hline Alytes cisternasii & 29TQF48 & 100,00 & 116,89 & 113,23 & 38,97 & 6130,25 & 286,98 & $-1,75$ & 288,73 & 76,96 & 198,25 & 198,25 & 41,58 & 475,93 & 61,37 & 11,24 & 37,99 & 169,20 & 55,66 & 55,66 & 151,72 \\
\hline Alytes cisternasii & 29TQF49 & 100,00 & 119,58 & 113,50 & \begin{tabular}{|l|l|}
38,97 \\
\end{tabular} & 6115,42 & 289,29 & 0,01 & 289,29 & 80,05 & 200,47 & 200,48 & 43,96 & 459,76 & 59,24 & 11,05 & 37,64 & 163,38 & 54,36 & 54,37 & 146,34 \\
\hline Alytes cisternasii & 29TQG00 & 99,00 & 123,09 & 110,27 & 38,96 & 5918,68 & 286,88 & 5,41 & 281,47 & 56,58 & 201,70 & 201,70 & 49,72 & 619,22 & 80,70 & 11,43 & 44,19 & 235,64 & 58,29 & 58,29 & 230,85 \\
\hline Alytes cisternasii & 29TQG01 & 101,00 & 120,16 & 110,37 & 39,00 & 5890,61 & 283,96 & 2,77 & 281,19 & 54,07 & 198,46 & 198,46 & 47,29 & 630,02 & 82,67 & 12,21 & 43,76 & 239,57 & 60,81 & 60,81 & 235,47 \\
\hline Alytes cisternasii & 29TQG02 & 100,00 & 118,31 & 110,55 & 39,00 & 5867,35 & 282,03 & 1,14 & 280,89 & 52,36 & 196,31 & 196,31 & 45,68 & 636,56 & 84,01 & 13,14 & 43,33 & 241,71 & 63,07 & 63,07 & 237,84 \\
\hline Alytes cisternasii & 29TQG03 & 100,00 & 114,88 & 110,19 & 38,98 & 5844,04 & 278,26 & $-1,66$ & 279,92 & 49,20 & 192,60 & 192,60 & 42,71 & 654,32 & 86,67 & 14,58 & 42,81 & 247,97 & 66,98 & 66,98 & 243,35 \\
\hline Alytes cisternasii & 29TQG10 & 101,00 & 116,77 & 110,67 & 39,00 & 5974,82 & 282,16 & $-0,12$ & 282,28 & 50,13 & 196,21 & 196,21 & 43,23 & 602,56 & 78,66 & 12,23 & 42,09 & 225,51 & 61,11 & 61,11 & 217,74 \\
\hline Alytes cisternasii & 29TQG11 & 99,00 & 115,18 & 110,82 & \begin{tabular}{|l|}
38,98 \\
\end{tabular} & 5954,86 & 280,36 & $-1,87$ & 282,23 & 48,68 & 194,38 & 194,38 & 41,81 & 608,24 & 79,75 & 13,07 & 41,70 & 227,39 & 63,06 & 63,06 & 219,83 \\
\hline Alytes cisternasii & 29T0G14 & 100,00 & 106,12 & 110,05 & 38,93 & 5890,84 & 270,36 & $-10,14$ & 280,50 & 40,21 & $\mid 184,73$ & \begin{tabular}{|l|l|}
184,73 \\
\end{tabular} & 33,77 & $\mid 662,20$ & 87,05 & 17,70 & 39,73 & 245,46 & 75,48 & 75,48 & 235,49 \\
\hline Alytes cisternasii & 29TQG20 & 100,00 & 116,37 & 111,62 & 38,94 & 6018,44 & 283,37 & $-1,28$ & 284,65 & 49,07 & 196,27 & 196,27 & 42,19 & 557,49 & 72,66 & 12,32 & 40,29 & 204,73 & 59,88 & 59,88 & 194,08 \\
\hline Alytes cisternasii & 29TQG30 & 99,00 & 118,24 & 112,71 & 38,98 & 6054,24 & 286,54 & $-0,55$ & 287,09 & 58,13 & 198,47 & 198,47 & 43,35 & 504,83 & 65,56 & 12,00 & 38,70 & 181,38 & 57,28 & 57,28 & 168,57 \\
\hline Alytes cisternasii & 29TQG32 & 101,00 & 115,15 & 112,95 & 39,00 & 6022,04 & 283,26 & \begin{tabular}{|c|}
$-3,62$ \\
\end{tabular} & 286,87 & 62,35 & \begin{tabular}{|l|l|}
194,93 \\
\end{tabular} & 194,93 & 40,52 & 521,67 & 67,79 & 13,77 & 37,72 & 187,15 & 62,19 & 62,19 & 173,83 \\
\hline Alytes cisternasii & 29TQG44 & 87,00 & 113,50 & 113,96 & 39,00 & 6017,14 & 282,27 & $-6,12$ & 288,39 & 75,18 & 193,18 & 193,18 & 38,84 & 510,74 & 65,61 & 15,50 & 35,49 & 183,36 & 67,18 & 67,18 & 163,04 \\
\hline Alytes cisternasii & 30STG39 & 40,00 & 170,22 & 122,02 & 38,84 & 6377,82 & 352,44 & 40,78 & 311,65 & 100,87 & 253,89 & 254,67 & 91,93 & 593,58 & 82,44 & 2,22 & 59,20 & 239,95 & 22,91 & 27,60 & 228,11 \\
\hline Alytes cisternasii & 30STG47 & 100,00 & 175,54 & 122,95 & 39,06 & 6315,07 & 356,46 & 45,87 & 310,59 & 106,78 & 258,24 & 259,07 & 97,82 & 593,90 & 84,53 & 1,76 & 60,90 & 245,11 & 20,94 & 25,34 & 232,64 \\
\hline \begin{tabular}{|l} 
Alytes cisternasii \\
\end{tabular} & 30STG48 & 100,00 & 174,66 & 123,03 & 39,00 & 6355,98 & 356,75 & $\begin{array}{l}44,67 \\
44,5\end{array}$ & \begin{tabular}{|l|l|}
312,08 \\
\end{tabular} & 105,38 & 258,06 & 258,77 & $\begin{array}{ll}96,49 \\
96\end{array}$ & 588,01 & 82,80 & 2,04 & 60,20 & $\mid$\begin{tabular}{|l|}
240,29 \\
\end{tabular} & 21,39 & 25,70 & 228,30 \\
\hline Alytes cisternasii & 30STG49 & 100,00 & 165,69 & 122,71 & 38,70 & 6434,94 & 349,90 & 35,92 & 313,99 & 95,88 & 250,41 & 251,07 & 87,03 & 620,24 & 85,77 & 2,65 & 58,86 & 249,59 & 24,31 & 29,03 & 238,44 \\
\hline Alytes cisternasii & 30STG57 & 100,00 & 178,89 & 124,02 & 39,27 & 6320,81 & 360,30 & 48,86 & 311,45 & 110,09 & 261,71 & 262,37 & 100,99 & 584,72 & 83,77 & 1,46 & 61,38 & 241,95 & 19,40 & 23,80 & 229,87 \\
\hline Alytes cisternasii & 30STG58 & 100,00 & 168,71 & 123,92 & 39,00 & 6427,23 & 353,35 & 38,44 & 314,92 & 99,08 & 253,38 & 254,00 & 90,12 & 621,32 & 87,25 & 2,01 & 59,98 & 252,34 & 22,64 & 27,19 & 241,33 \\
\hline Alytes cisternasii & 30STG59 & 100,00 & 162,75 & 123,58 & 38,49 & 6489,78 & 349,12 & 32,60 & 316,52 & 92,60 & 248,53 & 249,06 & 83,68 & 639,22 & 88,46 & 2,57 & 58,97 & 255,99 & 24,94 & 29,09 & 245,75 \\
\hline \begin{tabular}{|l} 
Alytes cisternasii \\
\end{tabular} & \begin{tabular}{|l|l|}
30 STG67 \\
\end{tabular} & 100,00 & 175,46 & 124,19 & 39,23 & 6358,80 & 357,91 & $\begin{array}{ll}45,78 \\
45\end{array}$ & $\begin{array}{ll}312,14 \\
\end{array}$ & 106,27 & \begin{tabular}{|l|}
259,13 \\
\end{tabular} & $\begin{array}{l}259,64 \\
250\end{array}$ & $\begin{array}{ll}97,48 \\
97\end{array}$ & \begin{tabular}{|l|l|}
605,06 \\
\end{tabular} & 87,20 & 1,63 & 61,45 & 249,46 & $\begin{array}{l}4,4,86 \\
19,\end{array}$ & 24,03 & 238,20 \\
\hline Alytes cisternasii & 30STG68 & 100,00 & 168,27 & 124,46 & 38,92 & 6463,01 & 353,97 & 37,80 & 316,17 & 98,27 & 253,63 & 253,86 & 89,14 & 629,00 & 88,82 & 2,00 & 60,12 & 254,86 & 22,39 & 25,94 & 244,62 \\
\hline Alytes cisternasii & 30STG69 & 100,00 & 158,30 & 123,72 & 38,13 & 6543,04 & 346,16 & 27,98 & 318,18 & 87,73 & 245,06 & 245,34 & 78,92 & 664,30 & 91,73 & 2,86 & 58,72 & 264,30 & 26,15 & 28,46 & 255,15 \\
\hline Alytes cisternasii & 30STG79 & 100,00 & 158,45 & 124,13 & 38,25 & 6569,95 & 347,11 & 27,77 & 319,34 & 87,62 & 245,74 & 245,83 & 78,66 & 668,05 & 92,56 & 2,95 & 58,80 & 264,92 & 25,84 & 27,06 & 256,60 \\
\hline Alytes cisternasii & $\begin{array}{l}\text { 30STG88 } \\
\end{array}$ & 100,00 & 171,70 & 124,24 & 38,91 & 6496,07 & 357,21 & 40,91 & 316,29 & $\mid \begin{array}{l}101,11 \\
\end{array}$ & 257,59 & 257,70 & 92,28 & 624,53 & 89,52 & 2,00 & 60,71 & 252,07 & 20,61 & 22,20 & 243,36 \\
\hline \begin{tabular}{|l} 
Alytes cisternasii \\
\end{tabular} & $\begin{array}{l}\text { 30STG89 } \\
309\end{array}$ & 100,00 & 165,30 & $\begin{array}{l}124,24 \\
124,77\end{array}$ & 38,45 & $\begin{array}{l}0458,0,47 \\
6580,4\end{array}$ & 353,79 & $\begin{array}{l}3,74 \\
33,74 \\
\end{array}$ & \begin{tabular}{|l|}
320,05 \\
320
\end{tabular} & \begin{tabular}{|l|}
101,11 \\
93,88
\end{tabular} & 252,60 & 252,63 & $\begin{array}{l}32,06 \\
85,04\end{array}$ & \begin{tabular}{|l|l|}
643,30 \\
643
\end{tabular} & $\begin{array}{l}95,32 \\
90,31\end{array}$ & 2,47 & 59,56 & \begin{tabular}{|l|}
255,34 \\
25,
\end{tabular} & \begin{tabular}{|l|}
23,07 \\
23
\end{tabular} & $\begin{array}{l}23,72 \\
23,2\end{array}$ & $\begin{array}{l}24,30 \\
247,64\end{array}$ \\
\hline Alytes cisternasii & 30STG98 & 100,00 & 173,99 & 123,66 & 38,80 & 6501,44 & 358,65 & 43,13 & 315,52 & 103,21 & 260,03 & 260,10 & 94,35 & 621,06 & 89,58 & 1,93 & 61,14 & 250,08 & 19,47 & 20,25 & 242,25 \\
\hline Alytes cisternasii & 30STG99 & 100,00 & 168,38 & 124,53 & 38,18 & 6596,17 & 356,69 & 36,42 & 320,27 & 96,58 & 256,00 & 256,02 & 87,88 & 634,99 & 89,69 & 2,26 & 59,99 & 251,33 & 21.56 & 21,75 & 244,56 \\
\hline Alytes cisternasii & 30STH40 & 100,00 & 160,71 & 122,37 & 38,23 & 6479,99 & 346,34 & 31,07 & 315,27 & 90,63 & 246,38 & 246,83 & 81,72 & 633,15 & 86,42 & 2,97 & 58,00 & 251,74 & 26,43 & 30,23 & 241,17 \\
\hline Alytes cisternasii & 30STH41 & 100,00 & 160,59 & 122,44 & 38,03 & 6501,08 & 346,94 & 30,69 & 316,24 & 90,13 & 246,60 & 246,97 & 81,27 & 623,32 & 84,5 & 3,05 & 57,23 & 245,85 & 26,93 & 30,72 & 235,46 \\
\hline \begin{tabular}{|l} 
Alytytes cisternasii \\
\end{tabular} & \begin{tabular}{|l}
$3005 T H 41$ \\
$305 T H 2$
\end{tabular} & 100,00 & $\begin{array}{l}10,51,34 \\
151,34\end{array}$ & $\begin{array}{l}12,44 \\
121,54\end{array}$ & 38,03 & $\begin{array}{l}6504,1,30 \\
6547\end{array}$ & $\begin{array}{l}340,94 \\
339,06\end{array}$ & \begin{tabular}{|l|l|}
22,35 \\
22,
\end{tabular} & $\begin{array}{l}3510,24 \\
316,71 \\
\end{array}$ & \begin{tabular}{|l|}
80,06 \\
81,06
\end{tabular} & $\begin{array}{l}238,40 \\
238,43\end{array}$ & \begin{tabular}{|l|}
238,74 \\
238,7
\end{tabular} & \begin{tabular}{|l|l|l|}
72,14 \\
7
\end{tabular} & $\begin{array}{l}23,32 \\
658,05 \\
\end{array}$ & $\begin{array}{l}84,59 \\
87,87\end{array}$ & $\begin{array}{l}3,00 \\
3,93 \\
\end{array}$ & $\begin{array}{l}3,2,25 \\
55,88\end{array}$ & \begin{tabular}{|l|}
256,05 \\
25,05
\end{tabular} & $\begin{array}{l}2,05 \\
31,06\end{array}$ & $\begin{array}{ll}30,12 \\
34,19\end{array}$ & $\begin{array}{l}23,40 \\
246,37\end{array}$ \\
\hline Alytes cisternasii & 30STH43 & 100,00 & 152,44 & 121,60 & 38,00 & 6564,90 & 340,64 & 23,11 & 317,53 & 81,97 & 239,73 & 240,03 & 72,92 & 641,43 & 85,26 & 4,01 & 55,44 & 247,99 & 30,97 & 34,01 & 238,21 \\
\hline Alytes cisternasii & 30STH45 & 100,00 & 156,29 & 121,34 & 37,90 & 6582,55 & 344,70 & 26,89 & 317,80 & 85,22 & 243,84 & 243,96 & 76,47 & 599,57 & 79,15 & 3,77 & 54,35 & 229,14 & 30,18 & 31,53 & 219,06 \\
\hline Alytes cisternasii & 30STH46 & 100,00 & 155,29 & 120,92 & 37,69 & 6598,03 & 343,72 & 26,13 & 317,59 & 83,97 & 243,16 & 243,18 & 75,32 & 593,16 & 77,76 & 3,9 & 53,64 & 225,08 & 30,95 & 31,10 & 214,95 \\
\hline \begin{tabular}{|l} 
Alytes cisternasii \\
\end{tabular} & 30STH48 & 100,00 & 157,44 & 119,95 & $\frac{37,1}{37,1}$ & |6597,95 & 344,129 & 28,26 & 316,73 & 85,84 & 245,26 & 245,27 & 77,32 & 561,16 & 72,90 & $3,-5$ & 52,53 & 210,48 & \begin{tabular}{|l|l|}
31,05 \\
3,0
\end{tabular} & 31,16 & 199,90 \\
\hline Alytes cisternasii & 30STH49 & 100,00 & 161,22 & 119,45 & $37, \mathrm{C}$ & 6578,13 & 347,86 & 32,22 & 315,64 & 89,57 & 248,72 & 248,72 & 80,99 & 532,09 & 69,6 & 3,46 & 52,21 & 198,78 & 29,68 & 29,68 & 187,99 \\
\hline Alytes cisternasii & 30STH50 & 100,00 & 154,55 & 122,76 & 38,00 & 6541,03 & 342,21 & 24,70 & 317,51 & 84,12 & 241,26 & 241,71 & 75,17 & 667,25 & 90,76 & 3,32 & 57,67 & 263,34 & 28,34 & 32.51 & 253,95 \\
\hline Alytes cisternasii & 30STH51 & 100,00 & 153,72 & 122,75 & 38,00 & 6576,28 & 342,43 & 23,63 & 318,80 & 82,89 & 241,05 & 241,33 & 74,09 & 661,33 & 89,25 & 3,54 & 56,83 & 258,68 & 29,39 & 32,99 & 249,47 \\
\hline Alytes cisternasii & 30STH52 & 100,00 & 154,26 & 122,84 & 38,00 & 6601,11 & 343,57 & 24,05 & 319,52 & 83,09 & 242,07 & 242,18 & 74,22 & 646,74 & 86,7 & 3,61 & 56,34 & 251,10 & 29,43 & 31,63 & 241,95 \\
\hline \begin{tabular}{|l} 
Alytes cisternasii \\
\end{tabular} & $\begin{array}{l}\text { 30STH53 } \\
30 \text { TH }\end{array}$ & 100,00 & 154,20 & 122,75 & 38,00 & $\begin{array}{l}6001,11 \\
665\end{array}$ & 344,73 & 24,51 & $\begin{array}{l}320,22 \\
320\end{array}$ & $\begin{array}{l}\mid 20,035 \\
83,45\end{array}$ & \begin{tabular}{|l|}
243,01 \\
\end{tabular} & \begin{tabular}{|l|}
243,06 \\
240
\end{tabular} & 74,60 & $\mid \begin{array}{l}\mid 640,1,4 \\
631,86\end{array}$ & $\begin{array}{l}\mid 00,14 \\
84,23\end{array}$ & $\begin{array}{ll}3,01 \\
3,78\end{array}$ & $\begin{array}{ll}0,53,64 \\
5,64\end{array}$ & $\mid 243,45$ & $\begin{array}{ll}29,58 \\
29,58\end{array}$ & $\begin{array}{l}1,03 \\
30,37\end{array}$ & 234,31 \\
\hline Alytes cisternasii & 30STH54 & 100,00 & 154,50 & 122,49 & 37,96 & 6634,03 & 344,70 & 23,91 & 320,79 & 82,82 & 243,02 & 243,02 & 74,04 & 621,54 & 82,39 & 4,00 & 55,00 & 237,79 & 30,11 & 30,11 & 228,58 \\
\hline Alytes cisternasii & 30STH56 & 100,00 & 156,51 & 121,87 & 37,81 & 6632,01 & 346,29 & 26,18 & 320,11 & 84,64 & 244,90 & 244,91 & 76,15 & 588,28 & 77,20 & 3,90 & 53,72 & 222.09 & 30,26 & 30,38 & 212,54 \\
\hline Alytes cisternasii & 30STH57 & 100,00 & 158,29 & 121,34 & 37,48 & 6635,21 & 347,64 & 28,06 & 319,58 & 86,25 & 246,79 & 246,79 & 77,69 & 566,59 & 74,11 & 3,67 & 53,32 & 212,71 & 29,75 & 29,75 & 202,91 \\
\hline Alytes cisternasii & 30STH58 & 100,00 & 160,03 & 120,83 & 37,06 & 6641,15 & 348,80 & 29,68 & 319 & 87,60 & 248,34 & 248,34 & 79,01 & 546,29 & 71,27 & 3,55 & 52,77 & 203,87 & 29,41 & 29,41 & 193 \\
\hline \begin{tabular}{|l} 
Alytes cisternasii \\
\end{tabular} & \begin{tabular}{|c|}
30 STH59 \\
305
\end{tabular} & $\begin{array}{l}100,00 \\
\end{array}$ & $\begin{array}{l}10,05 \\
158,08\end{array}$ & $\begin{array}{l}120,03 \\
120,01\end{array}$ & 37,01 & $\mid 60444,11$ & $\begin{array}{l}34,00 \\
346,61\end{array}$ & $\begin{array}{l}28,00 \\
28,50\end{array}$ & \begin{tabular}{|l|l|}
318,10 \\
\end{tabular} & $\begin{array}{l}1,00 \\
85,85 \\
\end{array}$ & \begin{tabular}{|l|}
$246,64,69$ \\
\end{tabular} & \begin{tabular}{|l|}
246,69 \\
2469
\end{tabular} & $\begin{array}{l}77,37 \\
77,37\end{array}$ & \begin{tabular}{|l|l|}
543,94 \\
543
\end{tabular} & $\begin{array}{l}71,27 \\
70,90\end{array}$ & 㐌, & 51,89 & \begin{tabular}{|l|}
201,49 \\
201
\end{tabular} & \begin{tabular}{|l}
$3,4,76$ \\
30,76
\end{tabular} & 30,76 & $\begin{array}{l}150,00 \\
191,24\end{array}$ \\
\hline Alytes cisternasii & 30STH60 & 100,00 & 154,76 & 123,63 & 38,00 & 6584,50 & 343,96 & 24,34 & 319,62 & 83,79 & 242,28 & 242,47 & 74,96 & 669,32 & 91,24 & 3,44 & 57,66 & 263,09 & 28,16 & 29,76 & 254,51 \\
\hline 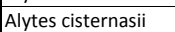 & 30STH61 & 100,00 & 152,05 & 123,47 & 38,00 & 6622,53 & 342,36 & 21,54 & 320,82 & 80,86 & 240,30 & 240,46 & 72,04 & 670,25 & 90,40 & 3,68 & 56,78 & 260,80 & 29,55 & 31,25 & 252,50 \\
\hline Alytes cisternasii & 30STH62 & 100,00 & 157,57 & 123,87 & 38,00 & 6630,11 & 347,98 & 26,14 & 321,84 & 85,75 & 245,83 & 245, & 76, & 634,27 & 85,54 & 3,25 & 56,54 & 245,70 & 27,79 & 28,80 & 237,15 \\
\hline Alytes cisternasii & 30STH63 & 100,00 & 157,68 & 123,72 & 38,00 & 6652,56 & 348,56 & 26,31 & 322,26 & 85,60 & 246,30 & 246,33 & 76,89 & 621,23 & 83,23 & 3,33 & 56,03 & 238,75 & 28,07 & 28,60 & 230,16 \\
\hline
\end{tabular}




\begin{tabular}{|c|c|c|c|c|c|c|c|c|c|c|c|c|c|c|c|c|c|c|c|c|c|}
\hline TAXON & UTM & $\mathrm{km} 2$ & B101 & B102 & $\mathrm{BIO3}$ & B104 & B105 & B106 & B107 & B108 & B109 & BIO10 & BIO11 & BIO12 & B1013 & BIO14 & BIO15 & B1016 & B1017 & BIO18 & B1019 \\
\hline Alytes cisternasii & 30STH64 & 100,00 & 154,32 & 123,17 & 37,97 & 6682,70 & 345,85 & 23,28 & 322,57 & 82,10 & 243,38 & 243,40 & 73,25 & 623,00 & 82,64 & 4,00 & 54,93 & 236,89 & 30,16 & 30,75 & 228,46 \\
\hline Alytes cisternasii & 30STH68 & 100,00 & 158,55 & 121,57 & 37,19 & 6686,85 & 349,00 & 27,63 & 321,37 & 85,77 & 247,87 & 247,87 & 77,34 & 551,79 & 72,81 & 3,78 & 52,64 & 204,48 & 29,63 & 29,63 & 195,11 \\
\hline Alytes cisternasii & 30STH69 & 100,00 & 160,45 & 120,86 & 37,00 & 6684,73 & 350,04 & 29,56 & 320,48 & 87,46 & 249,60 & 249,60 & 79,00 & 529,86 & 69,74 & 3,37 & 52,25 & 195,47 & 28,90 & 28,90 & 185,73 \\
\hline Alytes cisternasii & 30STH70 & 100,00 & 151,81 & 123,86 & 38,00 & 6621,13 & 342,24 & 21,17 & 321,08 & 80,58 & 240,03 & 240,17 & 71,88 & 685,67 & 93,23 & 3,73 & 57,39 & 267,92 & 29,08 & 30,53 & 260,25 \\
\hline Alytes cisternasii & 30STH72 & 100,00 & 161,12 & 124,65 & 38,00 & 6671,75 & 352,56 & 28,79 & 323,77 & 88,78 & 249,95 & 249,95 & 79,81 & 621,28 & 84,23 & 3,12 & 57,01 & 239,88 & 26,17 & 26,17 & 232,06 \\
\hline Alytes cisternasii & 30STH73 & 100,00 & 157,96 & 124,19 & 38,00 & 6695,41 & 350,16 & 25,70 & 324,46 & 85,29 & 247,26 & 247,26 & 76,62 & 621,96 & 83,71 & 3,38 & 55,96 & 237,66 & 27,83 & 27,83 & 229,96 \\
\hline Alytes cisternasii & 30STH75 & 100,00 & 155,29 & 123,65 & 37,63 & 6738,76 & 348,04 & 23,29 & 324,75 & 82,23 & 245,27 & 245,27 & 73,59 & 606,42 & 81,36 & 4,00 & 54,31 & 227,60 & 29,78 & 29,78 & 219,78 \\
\hline Alytes cisternasii & \begin{tabular}{|l|}
$30 S T H 76$ \\
\end{tabular} & 100,00 & 152,99 & 122,95 & 37,08 & 6744,62 & 346,10 & 21,23 & 324,86 & 80,04 & 243,23 & 243,23 & 71,27 & 602,77 & 80,62 & 4,09 & 53,45 & 224,19 & 31,37 & 31,37 & 216,19 \\
\hline Alytes cisternasii & 30STH77 & 100,00 & 153,77 & 122,52 & $\begin{array}{l}37,05 \\
\end{array}$ & 6741,82 & 346,30 & 22,12 & 324,18 & 80,67 & 243,93 & 243,93 & 72,03 & 585,37 & 78,13 & 4,07 & 52,76 & 216,22 & 31,41 & 31,41 & 207,88 \\
\hline Alytes cisternasii & 30STH78 & 100,00 & 158,94 & 122,04 & \begin{tabular}{|l|l|}
37,07 \\
\end{tabular} & \begin{tabular}{|l|l|}
6726,54 \\
\end{tabular} & 350,29 & 27,17 & 323,12 & 85,86 & 248,81 & 248,81 & 77,15 & 548,75 & 73,09 & 3,63 & 52,59 & 201,97 & 29,17 & 29,17 & 193,23 \\
\hline Alytes cisternasii & 30STH79 & 100,00 & 161,64 & 121,60 & 37,05 & 6709,72 & 352,14 & 29,99 & 322,15 & 88,46 & 251,24 & 251,24 & 79,87 & 522,23 & 69,38 & 3,30 & 52,32 & 191,36 & 28,09 & 28,09 & 182,27 \\
\hline Alytes cisternasii & 30STH80 & 100,00 & 159,47 & 124,72 & 38,00 & 6639,36 & 350,07 & 27,82 & 322,25 & 87,76 & 247,96 & 247,97 & 78,89 & 656,20 & 90,41 & 3,03 & 58,29 & 256,68 & 25,59 & 25,70 & 249,59 \\
\hline Alytes cisternasii & 30STH81 & 100,00 & 164,93 & 124,97 & 38,00 & 6662,85 & 355,81 & 32,29 & 323,52 & 92,55 & 253,64 & 253,64 & 83,63 & 622,20 & 85,72 & 2,64 & 58,18 & 241,91 & 23,87 & 23,87 & 234,87 \\
\hline Alytes cisternasii & 30STH82 & 100,00 & 160,47 & 124,88 & 37,99 & 6717,64 & 353,05 & 27,63 & 325,43 & 87,61 & 250,08 & 250,08 & 78,63 & 626,84 & 85,41 & 3,14 & 57,05 & 240,49 & 26,13 & 26,13 & 233,82 \\
\hline Alytes cisternasii & 30STH86 & 100,00 & 156,58 & 123,79 & \begin{tabular}{|l|l|}
37,37 \\
\end{tabular} & 6782,16 & 350,26 & 23,82 & 326,44 & 82,86 & 247,33 & 247,33 & 74,38 & 585,63 & 79,31 & 3,89 & 53,74 & 216,73 & 29,32 & 29,32 & 209,48 \\
\hline Alytes cisternasii & 30STH87 & 100,00 & 153,78 & 123,07 & 37,00 & 6781,37 & 347,53 & 21,35 & 326,18 & 80,12 & 244,73 & 244,73 & 71,63 & 582,79 & 78,53 & 4,11 & 52,72 & 213,69 & 31,03 & 31,03 & 206,22 \\
\hline Alytes cisternasii & 30STH88 & 100,00 & 155,86 & 122,67 & 37,00 & 6769,27 & 348,66 & 23,55 & 325,12 & 82,16 & 246,48 & 246,48 & 73,69 & 559,13 & 75,05 & 3,98 & 52,15 & 203,81 & 30,58 & 30,58 & 195,84 \\
\hline Alytes cisternasii & 30STH89 & 100,00 & 160,79 & 122,07 & 37,01 & 6751,70 & 352,34 & 28,51 & 323,83 & 87,16 & 251,17 & 251,17 & 78,56 & 523,03 & 69,94 & 3,46 & 52,02 & 189,93 & 28,30 & 28,30 & 181,55 \\
\hline Alytes cisternasii & 30STH90 & 100,00 & 165,87 & 124,90 & 38,01 & 6649,20 & 356,02 & 33,41 & 322,61 & 93,65 & 254,33 & 254,33 & 84,77 & 634,47 & 88,36 & 2,52 & 59,05 & 247,76 & 22,97 & 22,97 & 241,61 \\
\hline Alytes cisternasii & 30STH91 & 100,00 & 163,51 & 124,97 & 37,99 & 6701,95 & 355,13 & 30,47 & 324,66 & 90,71 & 252,71 & 252,71 & 81,61 & 631,52 & 87,42 & 2,86 & 58,05 & 243,73 & 24,30 & 24,30 & 237,81 \\
\hline Alytes cisternasii & 30STH92 & 100,00 & 154,90 & 124,82 & 37,90 & 6763,98 & 348,95 & 22,06 & 326,90 & 81,84 & 245,55 & 245,55 & 72,92 & 651,22 & 89,7 & 3,59 & 56,58 & 247,49 & 28,03 & 28,03 & 241,99 \\
\hline Alytes cisternasii & 30STH94 & 100,00 & 155,75 & 124,84 & 37,59 & 6791,60 & 350,71 & 22,55 & 328,16 & 82,34 & \begin{tabular}{|l|l|}
246,94 \\
\end{tabular} & 246,94 & 73,25 & \begin{tabular}{|l|l|}
617,97 \\
\end{tabular} & 85,14 & 3,79 & 55,09 & 230,59 & 28,66 & 28,66 & 224,83 \\
\hline Alytes cisternasii & 30STH95 & 100,00 & 154,11 & 124,24 & \begin{tabular}{|l|l}
37,09 \\
\end{tabular} & 6804,66 & 349,13 & 21,09 & 328,03 & 80,45 & 245,41 & 245,41 & 71,63 & 609,40 & 83,61 & 4,01 & 54,18 & 225,23 & 29,96 & 29,96 & 219,28 \\
\hline Alytes cisternasii & 30STH96 & 100,00 & 157,38 & 124,00 & 37,00 & 6813,07 & 351,76 & 24,01 & 327,75 & 83,35 & 248,63 & 248,63 & 74,69 & 580,56 & 79,52 & 3,74 & 53,94 & 213,48 & 28,42 & 28,42 & 207,10 \\
\hline Alytes cisternasii & 30STH97 & 100,00 & 159,33 & 123,80 & 37,09 & 6807,79 & 353,41 & 25,99 & 327,42 & 85,22 & 250,69 & 250,69 & 76,50 & 555,60 & 75,74 & 3,37 & 53,54 & 203,08 & 27,64 & 27,64 & 196,31 \\
\hline Alytes cisternasii & 30STH99 & 100,00 & 157,95 & 122,70 & 37,00 & 6791,74 & 350,87 & 24,91 & 325,97 & 83,74 & 248,87 & 248,87 & 75,27 & 532,52 & 71,53 & 3,95 & 51,32 & 191,25 & 29,83 & 29,83 & 183,63 \\
\hline \begin{tabular}{|l} 
Alytes cisternasii \\
\end{tabular} & 30STJ40 & 100,00 & 164,92 & 118,90 & 37,14 & 6555,99 & 350,43 & 36,02 & 314,41 & 93,29 & 252,11 & 252,11 & 84,69 & \begin{tabular}{|l|l|l|l|l|}
503,79 \\
\end{tabular} & $\begin{array}{l}1,1,3 \\
65,32\end{array}$ & 3,11 & 51,78 & $\begin{array}{l}187,58 \\
\end{array}$ & 28,46 & 28,46 & 176,44 \\
\hline Alytes cisternasii & 30STJ49 & 71,00 & 156,13 & 111,76 & 36,26 & 6505,03 & 335,34 & 32,39 & 302,95 & 85,06 & 243,28 & 243,28 & 77,19 & 468,44 & 57,95 & 4,65 & 46,47 & 168,19 & 34,86 & 34,86 & 155,72 \\
\hline Alytes cisternasii & 30STIS1 & 100,00 & 166,13 & 118,88 & 37,00 & 6600,50 & 352,20 & 36,54 & 315,66 & 93,81 & 254,05 & 254,05 & 85,33 & 485,22 & 62,98 & 3,01 & 51,23 & 178,56 & 28,03 & 28,03 & 167,71 \\
\hline Alytes cisternasii & 30STJ57 & 100,00 & 153,24 & 113,56 & 36,34 & 6576,88 & 335,72 & 27,88 & 307,84 & 81,56 & 241,36 & 241,36 & 73,40 & 485,68 & 61,27 & 4,99 & 46,87 & 173,18 & 35,75 & 35,75 & 160,91 \\
\hline Alytes cisternasii & 30STJ60 & 100,00 & 162,60 & 120,19 & 37,01 & 6670,16 & 351,09 & 32,07 & 319,02 & 89,56 & 251,53 & 251,53 & 81,13 & 507,73 & 66,73 & 3,06 & 51,73 & 186,28 & 28,21 & 28,21 & 176,27 \\
\hline \begin{tabular}{|l} 
Alytes cisternasii \\
\end{tabular} & $30 \mathrm{STJ} 62$ & 100,00 & 166,71 & 118,79 & 37,00 & 6630,30 & 352,93 & $\begin{array}{ll}36,76 \\
\end{array}$ & \begin{tabular}{|l|}
316,17 \\
\end{tabular} & 93,99 & \begin{tabular}{|l|}
255,07 \\
\end{tabular} & \begin{tabular}{|l|}
255,07 \\
\end{tabular} & $\begin{array}{ll}1,15 \\
85,52\end{array}$ & 466,96 & $\begin{array}{l}0,83 \\
60,83\end{array}$ & 3,00 & 50,72 & $\begin{array}{l}169,80 \\
100\end{array}$ & $\begin{array}{l}\mid 27,38 \\
27,38\end{array}$ & $\begin{array}{l}27,21 \\
27,38\end{array}$ & 159,24 \\
\hline Alytes cisternasii & 30STJ66 & 100,00 & 144,41 & 114,81 & 36,21 & 6629,29 & 329,64 & 18,39 & 311,25 & 72,59 & 233,64 & 233,64 & 64,67 & 524,45 & 65,76 & 5,75 & 46,24 & 185,41 & 39,55 & 39,55 & 173,24 \\
\hline Alytes cisternasii & 30STJ70 & 100,00 & 162,94 & 120,93 & 37,00 & 6711,61 & 352,53 & 31,34 & 321,19 & 89,45 & 252,49 & 252,49 & 80,99 & 503,63 & 66,61 & 3,16 & 51,62 & 183,48 & 27,84 & 27,84 & 174,04 \\
\hline Alytes cisternasii & 30STJ72 & 100,00 & 164,69 & 119,43 & 37,00 & 6680,79 & 352,41 & 33,97 & 318,44 & 91,25 & 253,77 & 253,77 & 82,93 & 471,15 & 61,59 & 3,05 & 50,33 & 169,71 & 27,75 & 27,75 & 159,65 \\
\hline Alytes cisternasii & 30STJ76 & 100,00 & 140,27 & 115,77 & 36,36 & 6661,01 & 326,81 & 13,58 & 313,23 & 68,12 & 230,10 & 230,10 & 60,34 & 531,60 & 65,98 & 6,25 & 45,55 & 185,83 & 41,36 & 41,36 & 173,77 \\
\hline Alytes cisternasii & 30STIJ7 & 100,00 & 147,64 & 115,50 & 36,43 & 6635,54 & 332,56 & 20,52 & 312,04 & 75,32 & 236,87 & 236,87 & 67,48 & 485,83 & 60,11 & 5,42 & 45,44 & 169,46 & 37,52 & 37,52 & 157,28 \\
\hline Alytes cisternasii & $30 \mathrm{STJ} 7$ & 100,00 & 149,32 & 115,03 & 36,47 & 6607,44 & 332,96 & 22,44 & 310,52 & 77,11 & 238,01 & 238,01 & 69,21 & 468,16 & 57,26 & 5,28 & 44,98 & 162,83 & 36,89 & 36,89 & 150,40 \\
\hline Alytes cisternasii & 30STJ80 & 100,00 & 162,30 & 121,46 & 37,00 & 6739,35 & 352,98 & 30,08 & 322,90 & 88,63 & 252,38 & 252,38 & 79,85 & 502,74 & 66,85 & 3,20 & 51,45 & 181,68 & 27,79 & 27,79 & 172,88 \\
\hline Alytes cisternasii & 30STJ82 & 100,00 & 159,71 & 120,06 & 37,00 & 6722,78 & 349,14 & 28,61 & 320,54 & 86,01 & 249,70 & 249,70 & 77,87 & 486,66 & 63,75 & 3,78 & 49,62 & 173,27 & 29,86 & 29,86 & 163,70 \\
\hline Alytes cisternasii & 30STJ83 & 100,00 & 164,26 & 119,30 & 37,00 & 6693,97 & 351,82 & 33,32 & 318,50 & 91,13 & 253,90 & 253,90 & 82,54 & 454,95 & 59,16 & 3,09 & 49,66 & 161,80 & 27,59 & 27,59 & 151,82 \\
\hline Alytes cisternasii & 30STJ86 & 100,00 & 140,42 & 116,69 & 36,62 & 6683,16 & 327,95 & 12,71 & 315,23 & 67,77 & 230,58 & 230,58 & 60,09 & 519,05 & 64,15 & 6,31 & 44,92 & 179,38 & 41,07 & 41,07 & 167,52 \\
\hline Alytes cisternasii & 30STJ87 & 100,00 & 139,50 & 116,00 & 36,29 & 6660,10 & 326,07 & 12,18 & 313,89 & 67,07 & 229,44 & 229,44 & 59,43 & 510,14 & 62,04 & 6,55 & 44,22 & 175,34 & 41,84 & 41,84 & 162,97 \\
\hline Alytes cisternasii & 30STJ91 & 100,00 & 160,67 & 121,29 & 37,00 & 6770,12 & 351,61 & 28,18 & 323,43 & 86,43 & 251,34 & 251,34 & 78,01 & 491,08 & 64,97 & 3,69 & 50,11 & 174,53 & 29,03 & 29,03 & 165,92 \\
\hline Alytes cisternasii & 30STJ92 & 100,00 & 162,71 & 120,71 & 37,00 & 6751,35 & 352,47 & 30,39 & 322,09 & 91,52 & 253,05 & 253,05 & 80,01 & 468,96 & 61,53 & 3,40 & 49,86 & 165,95 & 28,06 & 28,06 & 156,97 \\
\hline \begin{tabular}{|l} 
Alytes cisternasii \\
\end{tabular} & 305TJ96 & 100,00 & 141,01 & 117,50 & 36,58 & 6708,53 & 329,46 & $\begin{array}{l}\mid 12,15 \\
12,\end{array}$ & 317,31 & 68,05 & 231,51 & 231,51 & $\begin{array}{l}60,23 \\
60,\end{array}$ & 505,65 & $\begin{array}{l}62,12 \\
62\end{array}$ & 6,26 & 44,46 & 172,77 & 40,59 & 40,59 & 161,21 \\
\hline Alytes cisternasii & $30 \mathrm{STJg}$ & 100,00 & 132,35 & 115,84 & 36,44 & 6643,61 & 318,84 & 5,84 & 313,00 & 60,65 & 222,37 & 222,40 & 53,04 & 517,27 & 60,93 & 7,73 & 42,39 & 174,55 & 46,10 & 46,14 & 161,46 \\
\hline Alytes cisternasii & $\begin{array}{l}\text { 30STK40 } \\
\end{array}$ & 70,00 & 157,68 & 111,55 & 36,40 & 6477,31 & 335,56 & 33,93 & 301,63 & 86,53 & 244,31 & 244,31 & 78,84 & 455,27 & 55,76 & 4,71 & 46,00 & 163,25 & 34,57 & 34,57 & 150,81 \\
\hline Alytes cisternasii & 30STK41 & 70,00 & 160,83 & 111,62 & 36,88 & 6438,31 & 337,22 & 37,00 & 300,22 & 89,67 & 246,68 & 246,68 & 81,92 & 435,49 & 53,34 & 4,25 & 45,75 & 156,26 & 32,98 & 32,98 & 143,93 \\
\hline Alytes cisternasii & 30STK50 & 100,00 & 156,29 & 112,45 & 36,60 & 6502,26 & 335,23 & 31,58 & 303,65 & 84,67 & 243,05 & 243,05 & 76,90 & 448,24 & 54,49 & 4,83 & 45,40 & 159,08 & 34,72 & 34,72 & 146,56 \\
\hline \begin{tabular}{|l|l} 
Alytes cisternasii \\
\end{tabular} & 30 STK5 & 100,00 & $\begin{array}{l}150,25 \\
161,28\end{array}$ & $\begin{array}{ll}11,2,45 \\
112,52\end{array}$ & $\begin{array}{l}30,00 \\
36,93\end{array}$ & $\begin{array}{l}050,2,20 \\
6469,97\end{array}$ & 33,25 & $\begin{array}{l}1,00 \\
36,40\end{array}$ & \begin{tabular}{|l|}
003,003 \\
302,13
\end{tabular} & 89,56 & 247,40 & 247,40 & 81,93 & 420,85 & 51,29 & 4,13 & 45,34 & 149,64 & 32,44 & 32,44 & 137,23 \\
\hline Alytes cisternasii & 30STK60 & 100,00 & 157,27 & 113,56 & 36,92 & 6518,93 & 336,98 & 31,42 & 305,56 & 85,42 & 244,50 & 244,50 & 77,66 & 429,95 & 51,95 & 4,62 & 44,91 & 150,92 & 33,77 & 33,77 & 138,42 \\
\hline Alytes cisternasii & 30STK61 & 100,00 & 161,41 & 113,45 & 37,00 & 6464,10 & 339,30 & 35,73 & 303,57 & 89,90 & 247,71 & 247,71 & 82,00 & 405,86 & 49,08 & 4,07 & 44,62 & 142,62 & 31,97 & 31,97 & 130,32 \\
\hline Alytes cisternasii & 30STK62 & 100,00 & 161,23 & 113,17 & 37,00 & 6446,28 & 338,29 & 35,91 & 302,38 & 90,04 & 247,23 & 247,23 & 82,02 & 399,55 & 48,23 & 4,74 & 43,82 & 139,96 & 32,74 & 32,74 & 127,5 \\
\hline Alytes cisternasii & 30STK70 & 100,00 & 155,58 & 114,38 & 36,93 & 6548,73 & 336,36 & 28,76 & 307,60 & 84,62 & 243,10 & 243,10 & 75,64 & 423,57 & 50,69 & 4,94 & 44,09 & 146,71 & 34,22 & 34,22 & 13 \\
\hline \begin{tabular}{|l} 
Alytes cisternasii \\
\end{tabular} & 30SUG09 & $\begin{array}{l}100,00 \\
\end{array}$ & $\begin{array}{l}13,50 \\
171,41\end{array}$ & $\begin{array}{l}114,50 \\
123,90\end{array}$ & $\begin{array}{l}30,50 \\
38,02\end{array}$ & $\begin{array}{ll}034,0,1 / 14 \\
6600,14\end{array}$ & 35 & $\begin{array}{l}\mid 0,10 \\
39,39 \\
\end{array}$ & $\begin{array}{l}319,72 \\
319\end{array}$ & $\begin{array}{l}44,6<2 \\
99,62\end{array}$ & \begin{tabular}{|l|}
259,17 \\
250
\end{tabular} & \begin{tabular}{|l|}
259,17 \\
250
\end{tabular} & $\begin{array}{l}50,60 \\
90,4\end{array}$ & | 629,89 & $\begin{array}{l}0,05 \\
89,50 \\
\end{array}$ & $\begin{array}{ll}2,434 \\
2,11\end{array}$ & $\begin{array}{l}4,40,41 \\
60\end{array}$ & \begin{tabular}{|l|}
248,30 \\
\end{tabular} & $\begin{array}{l}4,202 \\
20,38 \\
\end{array}$ & $\begin{array}{l}20,24 \\
20,38\end{array}$ & $\begin{array}{l}254,25 \\
242,66\end{array}$ \\
\hline Alytes cisternasii & 30SUG17 & 100,00 & 176,59 & 120,83 & 38,41 & 6426,45 & 357,16 & 46,85 & 310,31 & 106,78 & 261,70 & 261,72 & 97,71 & 630,39 & 92,22 & 2,00 & 62,09 & 254,40 & 18,00 & 18,23 & 248,02 \\
\hline 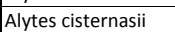 & 30SUG19 & 100,00 & 170,83 & 123,41 & 38,00 & 6637,60 & 358,88 & 38,45 & 320,44 & 98,80 & 259,16 & 259,16 & 89,47 & 637,10 & 91,01 & 2,26 & 60,45 & 249,29 & 20,32 & 20,32 & 245,07 \\
\hline Alytes cisternasii & 30SUG39 & 100,00 & 172,72 & 121,66 & 37,46 & 6673,92 & 360,28 & 39,74 & 320,5 & 103,10 & 261,75 & 261 , & 90, & 634,97 & 94,36 & 2,40 & 60,84 & 247,91 & 19,40 & 19,40 & 242,96 \\
\hline Alytes cisternasii & 30SUG49 & 100,00 & 177,84 & 119,92 & 37,05 & 6641,07 & 362,81 & 45,38 & 317,43 & 108,48 & 266,49 & 266,49 & 96,15 & 608,36 & 91,39 & 2,03 & 61,38 & 238,32 & 17,34 & 17,34 & 233 \\
\hline
\end{tabular}




\begin{tabular}{|c|c|c|c|c|c|c|c|c|c|c|c|c|c|c|c|c|c|c|c|c|c|}
\hline TAXON & UTM & $\mathrm{km} 2$ & B101 & B102 & $\mathrm{BIO3}$ & BIO4 & B105 & B106 & B107 & B108 & B109 & B1010 & B1011 & BIO12 & B1013 & BIO14 & BIO15 & BIO16 & BIO17 & B1018 & B1019 \\
\hline Alytes cisternasii & 30SUHOO & 100,00 & 165,63 & 124,63 & 38,00 & 6680,67 & 356,48 & 32,82 & 323,66 & 93,24 & 254,76 & 254,76 & 84,18 & 638,97 & 89,64 & 2,68 & 59,13 & 247,83 & 22,80 & 22,80 & 242,89 \\
\hline Alytes cisternasii & 30SUHO2 & 100,00 & 151,15 & 124,70 & 37,43 & 6797,93 & 346,13 & 18,10 & 328,02 & 79,88 & 242,27 & 242,27 & 68,97 & 665,09 & 92,69 & 3,96 & 56,19 & 250,52 & 29,42 & 29,42 & 245,90 \\
\hline Alytes cisternasii & 30SUHO3 & 100,00 & 156,72 & 124,97 & 37,22 & 6812,88 & 351,83 & 22,94 & 328,90 & 84,97 & 248,16 & 248,16 & 73,96 & 629,18 & 88,10 & 3,43 & 56,14 & 235,71 & 27,18 & 27,18 & 231,01 \\
\hline Alytes cisternasii & 30SUHO4 & 100,00 & 152,84 & 124,93 & $\begin{array}{l}37,05 \\
\end{array}$ & 6831,90 & 348,81 & 19,41 & 329,40 & 81,84 & 244,76 & 244,76 & 70,04 & 628,36 & 87,41 & 3,97 & 54,82 & 232,80 & 29,55 & 29,55 & 227,64 \\
\hline Alytes cisternasii & 30SUH06 & 100,00 & 156,69 & 124,19 & \begin{tabular}{|l|l|}
37,01 \\
\end{tabular} & $\begin{array}{ll}6840,76 \\
\end{array}$ & 351,82 & 22,84 & 328,98 & 84,58 & 248,40 & 248,40 & 73,47 & 581,11 & 80,24 & 3,99 & 53,46 & 211,54 & 29,10 & 29,10 & 206,06 \\
\hline Alytes cisternasii & 30SUH08 & 100,00 & 156,61 & 123,59 & 37,00 & 6837,61 & 350,97 & 22,84 & 328,13 & 81,95 & 248,43 & 248,43 & 73,45 & 549,13 & 74,76 & 3,80 & 52,03 & 197,04 & 29,49 & 29,49 & 190,72 \\
\hline Alytes cisternasii & 30SUH10 & 100,00 & 160,43 & 124,05 & 37,94 & 6743,60 & 352,50 & 27,41 & 325,09 & 89,12 & 250,70 & 250,70 & 78,31 & 659,05 & 93,60 & 3,05 & 58,55 & 253,14 & 24,49 & 24,49 & 249,34 \\
\hline Alytes cisternasii & 30SUH11 & 100,00 & 153,44 & 124,32 & 37,41 & 6790,20 & 347,48 & 20,28 & 327,20 & 82,93 & 244,46 & 244,46 & 71,11 & 668,52 & 94,50 & 3,88 & 56,90 & 253,99 & 27,99 & 27,99 & 249,24 \\
\hline Alytes cisternasii & 30SUH12 & 100,00 & 152,39 & 124,68 & 37,23 & 6821,05 & 347,75 & 19,14 & 328,61 & 81,93 & 243,99 & 243,99 & 69,83 & 657,64 & 92,90 & 3,98 & 56,20 & 247,94 & 28,79 & 28,79 & 242,44 \\
\hline Alytes cisternasii & 30SUH13 & 100,00 & 154,20 & 124,93 & \begin{tabular}{|l|l|}
37,09 \\
\end{tabular} & 6841,54 & 350,06 & 20,50 & 329,56 & 83,68 & 246,18 & 246,18 & 71,38 & 636,21 & 89,85 & 3,75 & 55,83 & 238,13 & 28,24 & 28,24 & 232,44 \\
\hline Alytes cisternasii & 30SUH14 & 100,00 & 150,81 & 124,97 & 37,02 & 6860,81 & 347,49 & 17,34 & 330,15 & 80,42 & 243,28 & 243,28 & 67,93 & 632,93 & 88,78 & 4,17 & 54,50 & 234,54 & 30,24 & 30,24 & 228,31 \\
\hline Alytes cisternasii & 30SUH17 & 100,00 & 159,76 & 124,03 & 37,00 & 6852,95 & 354,63 & 25,22 & 329,41 & 88,66 & 251,68 & 251,68 & 76,34 & 548,21 & 75,84 & 3,42 & 53,12 & 197,20 & 27,31 & 27,31 & 191,87 \\
\hline Alytes cisternasii & 30SUH18 & 100,00 & 160,50 & 123,94 & 37,00 & 6853,55 & 354,88 & 26,04 & 328,84 & 87,45 & 252,51 & 252,51 & 76,96 & 528,38 & 72,45 & 3,32 & 52,48 & 188,55 & 27,29 & 27,29 & 183,01 \\
\hline Alytes cisternasii & 30SUH19 & 100,00 & 156,72 & 123,25 & 37,00 & 6850,13 & 351,13 & 22,66 & 328,47 & 82,51 & 248,74 & 248,74 & 73,43 & 527,22 & 71,32 & 3,82 & 51,09 & 186,22 & 29,49 & 29,49 & 180,06 \\
\hline Alytes cisternasii & $30 \mathrm{SUH} 20$ & 100,00 & 164,69 & 123,62 & 37,62 & 6753,70 & 356,12 & 31,21 & 324,91 & 94,63 & 255,00 & 255,00 & 82,13 & 645,91 & 93,62 & 2,86 & 59,03 & 248,81 & 22,74 & 22,74 & 244,30 \\
\hline Alytes cisternasii & $30 \mathrm{SUH} 21$ & 100,00 & 155,18 & 124,01 & 37,13 & 6815,08 & 349,27 & 21,83 & 327,44 & 84,73 & 246,69 & 246,69 & 72,49 & 660,60 & 94,63 & 3,78 & 57,17 & 251,76 & 27,13 & 27,13 & 245,69 \\
\hline Alytes cisternasii & $30 \mathrm{SUH} 22$ & 100,00 & 157,27 & 124,38 & \begin{tabular}{|c|}
37,08 \\
\end{tabular} & 6836,77 & 352,36 & 23,58 & 328,78 & 86,77 & 249,13 & 249,13 & 74,42 & 638,21 & 91,70 & 3,51 & 56,67 & 241,62 & 26,43 & 26,43 & 235,18 \\
\hline Alytes cisternasii & $30 \mathrm{SUH} 23$ & 100,00 & 149,64 & 124,64 & 37,01 & 6867,08 & 346,31 & 16,29 & 330,03 & 79,18 & 242,11 & 242,11 & 66,75 & 647,95 & 91,83 & 4,34 & 54,98 & 242,28 & 30,37 & 30,37 & 235,08 \\
\hline Alytes cisternasii & $30 \mathrm{SUH} 24$ & 100,00 & 152,59 & 124,99 & 37,00 & 6879,76 & 349,49 & 18,78 & 330,70 & 82,04 & 245,28 & 245,28 & 69,63 & 621,17 & 88,01 & 4,03 & 54,46 & 230,47 & 29,16 & 29,16 & 223,26 \\
\hline Alytes cisternasii & 30 SUH25 & 100,00 & 155,16 & 124,99 & $37,00 \mid$ & 6879,92 & 351,62 & 20,82 & 330,80 & 84,49 & 247,76 & 247,76 & $|71.97|$ & 596,25 & 84,09 & 3,99 & 54,09 & 219,10 & 28,85 & 28,85 & 212,30 \\
\hline Alytes cisternasii & 30 SUH26 & 100,00 & 157,27 & 124,76 & 37,00 & 6887,23 & 353,44 & 22,57 & 330,86 & 86,49 & 249,83 & 249,83 & 73,66 & 571,73 & 80,10 & 3,89 & 53,37 & 207,64 & 28,53 & 28,53 & 201,17 \\
\hline Alytes cisternasii & $30 \mathrm{SUH} 28$ & 100,00 & 159,77 & 124,01 & 37,00 & 6870,03 & 354,71 & 25,01 & 329,70 & 88,82 & 252,06 & 252,06 & 76,10 & 525,57 & 72,21 & 3,41 & 52,07 & 186,35 & 27,45 & 27,45 & 180,92 \\
\hline Alytes cisternasii & 30SUH29 & 100,00 & 159,68 & 123,59 & 37,00 & 6866,72 & 354,01 & 24,97 & 329,04 & 89,87 & 251,91 & 251,91 & 76,03 & 509,45 & 69,12 & 3,47 & 51,26 & 178,71 & 27,92 & 27,92 & 173,23 \\
\hline Alytes cisternasii & $30 \mathrm{SUH} 30$ & 100,00 & 162,30 & 122,87 & 37,04 & 6771,33 & 354,04 & 29,24 & 324,80 & 92,31 & 253,16 & 253,16 & 80,00 & 647,49 & 94,59 & 3,26 & 58,61 & 249,89 & 23,69 & 23,69 & 243,64 \\
\hline Alytes cisternasii & 30SUH31 & 100,00 & 159,11 & 123,50 & $\begin{array}{l}37,05 \\
\end{array}$ & 6820,64 & 352,68 & 25,53 & 327,15 & 88,65 & 250,72 & 250,72 & 76,22 & 643,77 & 93,65 & 3,54 & 57,47 & 246,45 & 25,46 & 25,46 & 239,30 \\
\hline Alytes cisternasii & 30SUH32 & 100,00 & 156,88 & 123,97 & 37,00 & 6859,15 & 351,87 & 22,99 & 328,88 & 86,10 & 249,13 & 249,13 & 73,61 & 635,38 & 92, & 3,77 & 56,51 & 240,96 & 26,70 & 26,70 & 233,23 \\
\hline \begin{tabular}{|l} 
Alytes cisternasii \\
\end{tabular} & 30SUH33 & 100,00 & 155,03 & 124,15 & 37,00 & $\mid 6882,36$ & 351,03 & 20,96 & \begin{tabular}{|l|}
330,08 \\
\end{tabular} & 84,19 & \begin{tabular}{|l|}
247,63 \\
\end{tabular} & 247,63 & $\begin{array}{l}71,67 \\
1,61\end{array}$ & \begin{tabular}{|l|l|}
625,04 \\
\end{tabular} & $\begin{array}{l}2,11 \\
89,89 \\
\end{array}$ & 3,97 & 55,43 & 234,58 & 27,97 & 27,97 & 226,59 \\
\hline Alytes cisternasii & 30 SUH34 & 100,00 & 152,05 & 124,73 & 37,00 & 6907,64 & 348,98 & 17,85 & 331,13 & 81,11 & 245,16 & 245,16 & 68,66 & 617,62 & 87,99 & 4,11 & 54,31 & 229,10 & 29,42 & 29,42 & 220,93 \\
\hline Alytes cisternasii & 30SUH35 & 100,00 & 153,47 & 124,96 & 37,00 & 6914,82 & 350,41 & 18,82 & 331,59 & 82,61 & 246,64 & 246,64 & 69,85 & 595,47 & 84,36 & 4,00 & 53,71 & 218,63 & 29,03 & 29,03 & 210,82 \\
\hline Alytes cisternasii & 30SUH36 & 100,00 & 156,80 & 124,81 & 37,00 & 6903,97 & 353,21 & 21,85 & 331,37 & 86,01 & 249,63 & 249,63 & 72,98 & 566,97 & 79,78 & 3,86 & 53,20 & 205,78 & 28,44 & 28,44 & 198,61 \\
\hline Alytes cisternasii & 30SUH37 & 100,00 & 158,19 & 124,25 & 37,00 & 6893,18 & 353,98 & 23,16 & 330,82 & 87,52 & 250,85 & 250,85 & 74,40 & 543,75 & 75,72 & 3,51 & 52,56 & 194,90 & 27,77 & 27,77 & 188,42 \\
\hline \begin{tabular}{|l} 
Alytes cisternasii \\
\end{tabular} & 30SUH38 & 100,00 & 160,64 & 124,02 & 37,00 & |685, & 355,60 & 25,47 & \begin{tabular}{|l|}
330,13 \\
3302
\end{tabular} & $\begin{array}{l}89,97 \\
89\end{array}$ & $\begin{array}{l}253,13 \\
250\end{array}$ & $\begin{array}{l}253,13 \\
\end{array}$ & 76,72 & 517,02 & 71,21 & 3,28 & 52,03 & 182,91 & 26,94 & 26,94 & 177,24 \\
\hline Alytes cisternasii & $30 \mathrm{SUH} 40$ & 100,00 & 166,59 & 121,69 & 37,01 & 6766,19 & 356,73 & 33,38 & 323,35 & 96,41 & 257,32 & 257,32 & 83,97 & 627,45 & 92,90 & 3,00 & 58,99 & 243,12 & 22,05 & 22,05 & 235,93 \\
\hline Alytes cisternasii & $30 \mathrm{SUH} 41$ & 100,00 & 163,68 & 122,52 & 37,00 & 6815,77 & 355,97 & 29,91 & 326,06 & 93,17 & 255,18 & 255,18 & 80,68 & 621,48 & 91,61 & 3,31 & 57,85 & 238,69 & 23,62 & 23,62 & 230,69 \\
\hline Alytes cisternasii & $30 \mathrm{SUH} 42$ & 100,00 & 159,93 & 123,20 & 37,00 & 6866,91 & 354,13 & 25,70 & 328,43 & 88,95 & 252,18 & 252,18 & 76,42 & 618,63 & 90,50 & 3,56 & 56,64 & 235,22 & 25,44 & 25,44 & 226,66 \\
\hline Alytes cisternasii & $30 \mathrm{SUH} 43$ & 100,00 & 154,47 & 123,89 & 37,00 & 6906,66 & 350,66 & 20,31 & 330,36 & 83,37 & 247,52 & 247,52 & 70,86 & 619,21 & 89,46 & 3,99 & 55,09 & 232,34 & 28,04 & 28,04 & 223,41 \\
\hline \begin{tabular}{|l} 
Alytes cisternasii \\
\end{tabular} & 30SUH44 & 100,00 & 151,10 & $\begin{array}{l}124,05 \\
124,14\end{array}$ & 37,00 & 6930,100 & 348,41 & \begin{tabular}{|l|l|}
16,70 \\
16,
\end{tabular} & \begin{tabular}{|l|}
331,71 \\
331
\end{tabular} & $\mid \begin{array}{l}\mid l 3,13 \\
79,95\end{array}$ & \begin{tabular}{|l|}
244,71 \\
241
\end{tabular} & \begin{tabular}{|l|}
244,71 \\
241
\end{tabular} & $\begin{array}{l}60,00 \\
67,39\end{array}$ & \begin{tabular}{|l|l|}
613,34 \\
\end{tabular} & $\begin{array}{l}x_{30,400} \\
87,64\end{array}$ & $\frac{4,59}{4,10}$ & $\begin{array}{l}3,009 \\
53,95\end{array}$ & 227,34 & \begin{tabular}{|l|}
29,64 \\
29,66
\end{tabular} & $\begin{array}{l}29,046 \\
29,66\end{array}$ & 218,34 \\
\hline Alytes cisternasii & 30SUH45 & 100,00 & 153,57 & 124,49 & 37,00 & 6930,52 & 350,69 & 18,71 & 331,98 & 82,64 & 247,05 & 247,05 & 69,74 & 587,65 & 83,48 & 4,00 & 53,46 & 215,42 & 28,93 & 28,93 & 206,93 \\
\hline Alytes cisternasii & 30SUH47 & 100,00 & 156,62 & 124,50 & 37,00 & 6912,72 & 352,90 & 21,42 & 331,48 & 85,87 & 249,65 & 249,65 & 72,71 & 541,91 & 75,45 & 3,73 & 52,08 & 193,57 & 28,44 & 28,44 & 186,43 \\
\hline Alytes cisternasii & $30 \mathrm{SUH} 48$ & 100,00 & 158,87 & 124,11 & 37,00 & 6901,36 & 354,40 & 23,56 & 330,84 & 88,28 & 251,73 & 251,73 & 75,01 & 516,26 & 70,91 & 3,53 & 51,42 & 181,79 & 27,87 & 27,87 & 175,64 \\
\hline Alytes cisternasii & 30 SUH49 & 100,00 & 156,20 & 124,03 & 37,00 & 6904,72 & 351,85 & 21,02 & 330,83 & 85,84 & 249,25 & 249,25 & 72,32 & 508,38 & 68,64 & 3,86 & 50,16 & 176,05 & 29,40 & 29,40 & 170,30 \\
\hline Alytes cisternasii & 30 SUH5O & 100,00 & 175,19 & 119,49 & 37,00 & 6695,72 & 361,25 & 42,80 & $\begin{array}{l}318,44 \\
\end{array}$ & \begin{tabular}{|l|}
105,48 \\
\end{tabular} & 264,70 & 264,70 & 93,00 & 587,42 & 87,73 & 2,28 & 59,74 & 228,21 & 18,78 & 18,78 & 221,46 \\
\hline Alytes cisternasii & 30SUH53 & 100,00 & 151,46 & 123,55 & 37,00 & 6923,90 & 347,84 & 17,35 & 330,49 & 80,16 & 244,83 & 244,83 & 67,78 & 620,32 & 89,50 & 4,44 & 54,35 & 232,18 & 29,65 & 29,65 & 222,21 \\
\hline Alytes cisternasii & 30SUH54 & 100,00 & 150,88 & 123,99 & 37,00 & 6938,76 & 347,95 & 16,38 & 331,58 & 79,54 & 244,46 & 244,46 & 67,07 & 605,83 & 86,74 & 4,39 & 53,43 & 224,08 & 30,25 & 30,25 & 214,33 \\
\hline Alytes cisternasii & 30SUH56 & 100,00 & 156,92 & 124,19 & 37,00 & 6927,64 & 353,20 & 21,55 & 331,65 & 85,88 & 250,18 & 250,18 & 72,80 & 550,41 & 77,53 & 3,89 & 52,44 & 198,71 & 28,34 & 28,34 & 190,68 \\
\hline Alytes cisternasii & 30SUH57 & 100,00 & 151,04 & 124,89 & 37,00 & 6933,85 & 348,3 & 15,91 & 332,42 & 80,23 & 244,52 & 244,52 & 67,21 & 552,66 & 76,26 & 4,34 & 50,95 & 195,91 & 31,15 & 31,15 & 188,14 \\
\hline Alytes cisternasii & 30SUH61 & 100,00 & 168,19 & 119,91 & 36,98 & 6799,46 & 357 & 35,53 & 322,10 & 98,02 & 259,55 & 259,55 & 85,31 & 583,79 & 86,68 & 3,14 & 57,68 & 224,48 & 22,09 & 22,09 & 215,60 \\
\hline Alytes cisternasii & 30SUH62 & 100,00 & 159,36 & 121,62 & 36,99 & 6883,64 & 352,88 & 26,08 & 326,81 & 88,66 & 252,18 & 252,18 & 76,03 & 598,82 & 88,01 & 3,83 & 55,69 & 227.40 & 26,00 & 26,00 & 217,16 \\
\hline Alytes cisternasii & 30SUH64 & 100,00 & 150,72 & 123,71 & 37,00 & 6944,50 & 347,86 & 16,61 & 331,26 & 79,53 & 244,57 & 244,57 & 67,15 & 596,67 & 85,45 & 4,58 & 52,90 & 220,07 & 30,67 & 30,67 & 209,74 \\
\hline Alytes cisternasii & 30SUH65 & 100,00 & 153,88 & 123,98 & 37,00 & 6938,73 & 350,60 & 19,02 & 331,58 & 82,97 & 247,51 & 247,51 & 69,97 & 568,39 & 80,88 & 4,03 & 52,71 & 207,44 & 29,00 & 29,00 & 198,00 \\
\hline \begin{tabular}{|l} 
Alytes cisternasii \\
\end{tabular} & 30SUH66 & 100,00 & $\begin{array}{l}13,00 \\
147,75\end{array}$ & $\begin{array}{l}124,50 \\
124,62\end{array}$ & 37,00 & | $6951,1,08$ & 345,61 & $\begin{array}{ll}13,05 \\
13,0\end{array}$ & \begin{tabular}{|l|}
332,56 \\
336
\end{tabular} & 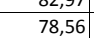 & \begin{tabular}{|l|}
241,74 \\
241
\end{tabular} & \begin{tabular}{|l|}
241,74 \\
241
\end{tabular} & $\mid 64,00$ & $\mid \begin{array}{l}\mid 573,10 \\
573\end{array}$ & $\begin{array}{l}0,000 \\
79,68\end{array}$ & 4,80 & $\begin{array}{l}2,1 / 2 \\
50,88\end{array}$ & 204,96 & 232,71 & 32,71 & $\begin{array}{l}190,05 \\
19586\end{array}$ \\
\hline Alytes cisternasii & 30SUH67 & 100,00 & 149,16 & 124,99 & 37,00 & 6940,01 & 346,73 & 13,99 & 332,74 & 88,94 & 242,86 & 242,86 & 65,36 & 549,43 & 75,42 & 4,36 & 50,23 & 194,17 & 32,05 & 32,05 & 185,56 \\
\hline Alytes cisternasii & 30SUH68 & 100,00 & 153,25 & 124,97 & 37,00 & $\mid 6928,40$ & 350,03 & 17,89 & 332,15 & $\mid 104.50$ & $\mid 246,76$ & 2466,76 & 69,48 & 517,11 & 70,02 & 4.09 & 49,73 & 180,85 & 30,47 & 30,47 & 172,72 \\
\hline Alytes cisternasii & 30SUH69 & 100,00 & 148,55 & 125,02 & 37,00 & 6936,00 & 345,94 & 13,06 & 332,88 & 116,64 & 242,25 & 242,25 & 64,80 & 517,39 & 68,56 & 4,43 & 48,32 & 179,27 & 32,96 & 32,96 & 169,88 \\
\hline Alytes cisternasii & 30SUH71 & 100,00 & 173,71 & 117,85 & 36,75 & 6743,01 & 359,66 & 42,01 & 317,65 & 103,97 & 264,08 & 264,08 & 91 & 550,19 & 81,64 & 2,86 & 57,58 & 211,40 & 20,33 & 20,33 & 203 \\
\hline \begin{tabular}{|l} 
Alytes cisternasii \\
\end{tabular} & \begin{tabular}{|c|} 
OSOSUH73 \\
$30 \mathrm{~S}$
\end{tabular} & $\begin{array}{l}100,00 \\
\end{array}$ & 150,43 & $\begin{array}{l}11,1,05 \\
122,52\end{array}$ & 30,8 & $\begin{array}{l}6973,015 \\
6938 \\
\end{array}$ & 3436,58 & $\begin{array}{l}2,310 \\
16,95 \\
\end{array}$ & \begin{tabular}{|l|}
329,64 \\
32,0
\end{tabular} & \begin{tabular}{|l|}
79,37 \\
79
\end{tabular} & \begin{tabular}{|l|}
244,260 \\
\end{tabular} & \begin{tabular}{|l|}
244,260 \\
24
\end{tabular} & $\begin{array}{l}|c|, 15 \\
66,90\end{array}$ & \begin{tabular}{|c|}
603,05 \\
603,05
\end{tabular} & $\begin{array}{l}1,044 \\
87,12\end{array}$ & 4,00 & $\begin{array}{ll}1,30 \\
53,18\end{array}$ & 224,50 & \begin{tabular}{|l|l|}
20,80 \\
30,80
\end{tabular} & \begin{tabular}{|l|l|}
20,830 \\
30,80
\end{tabular} & $\begin{array}{l}202,00 \\
213,05\end{array}$ \\
\hline Alytes cisternasii & 30SUH74 & 100,00 & 151,78 & 123,02 & 37,00 & 6941,81 & 348,19 & $\begin{array}{ll}17,94 \\
\end{array}$ & 330,25 & 80,72 & 245,66 & 245,66 & 68,25 & 582,21 & 83,49 & 4,44 & 52,59 & 214,36 & 30,20 & 30,20 & 203,55 \\
\hline 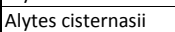 & 30SUH75 & 100,00 & 148,38 & 123,98 & 37,00 & 6945,49 & 345,76 & 14,17 & 331,59 & 81,12 & 242,28 & 242,28 & 64,94 & 577,95 & 81,45 & 4,75 & 51,44 & 209,36 & 32,20 & 32,20 & 198,97 \\
\hline Alytes cisternasii & 30SUH76 & 100,00 & 141,94 & 124,88 & 37,00 & 6962,21 & 340,69 & 7,44 & 333,25 & 90,01 & 236,19 & 236 , & 58, & 583,66 & 80,33 & 5,47 & 49 & 208,01 & 35,86 & 35,86 & 197,16 \\
\hline Alytes cisternasii & 30SUH78 & 100,00 & 147,51 & 125,44 & 37,00 & 6943,53 & 345,35 & 11,86 & 333,49 & 101,89 & 241,28 & 241,28 & 63,78 & 527,11 & 70,51 & 4,52 & 48,64 & 184,42 & 33,20 & 33,20 & 174,00 \\
\hline
\end{tabular}




\begin{tabular}{|c|c|c|c|c|c|c|c|c|c|c|c|c|c|c|c|c|c|c|c|c|c|}
\hline TAXON & UTM & $\mathrm{km2}$ & B101 & $\mathrm{B1O2}$ & $\mathrm{BIO3}$ & $\mathrm{B104}$ & B105 & B106 & 8107 & B108 & B109 & 81010 & B1011 & BIO12 & BIO13 & 81014 & B1015 & B1O16 & B1017 & BIO18 & B1019 \\
\hline Alytes cisternasii & 30SUH81 & 100,00 & 173,46 & 116,62 & 36,23 & 6739,70 & 358,49 & 42,42 & 316,07 & 103,77 & 263,92 & 263,92 & 91,24 & 537,50 & 79,71 & 2,97 & 57,01 & 206,38 & 20,59 & 20,59 & 197,35 \\
\hline Alytes cisternasii & $30 \mathrm{SUH} 82$ & 100,00 & 158,93 & 119,88 & \begin{tabular}{|l|}
36,38 \\
\end{tabular} & 6896,57 & 351,39 & 26,70 & 324,69 & 88,28 & 252,11 & 252,11 & 75,77 & 578,24 & 85,17 & 4,16 & 54,55 & 218,97 & 26,85 & 26,85 & 207,22 \\
\hline Alytes cisternasii & 30SUH83 & 100,00 & 150,42 & 121,94 & 36,52 & 6952,54 & 346,31 & 17,11 & 329,19 & 79,19 & 244,50 & 244,50 & 66,77 & 593,26 & 85,86 & 4,98 & 52,75 & 220,49 & 31,11 & 31,11 & 208,25 \\
\hline Alytes cisternasii & 30SUH84 & 100,00 & 154,04 & 122,48 & 36,91 & 6943,70 & 349,56 & 20,06 & 329,49 & 83,92 & 247,77 & 247,77 & 70,27 & 563,59 & 80,97 & 4,26 & 52,42 & 207,25 & 29,19 & 29,19 & 196,12 \\
\hline Alytes cisternasii & 30SUH85 & 100,00 & 141,49 & 124,08 & 37,00 & 6965,81 & 339,93 & 7,69 & 332,24 & 91,04 & 235,90 & 235,90 & 58,33 & 591,33 & 82,19 & 5,76 & 49,85 & 213,17 & 36,21 & 36,21 & 200,69 \\
\hline Alytes cisternasii & 30SUH87 & 100,00 & 146,01 & 125,26 & 37,00 & 6949,86 & 344,13 & 10,88 & 333,25 & 99,38 & 240,03 & 240,03 & 62,22 & 539,66 & 72,92 & 4,84 & 48,75 & 191,20 & 33,88 & 33,88 & 179,09 \\
\hline Alytes cisternasii & 30SUH93 & 100,00 & 157,60 & 120,31 & 36,39 & 6920,18 & 350,89 & 25,01 & 325,88 & 91,03 & 251,12 & 251,12 & 74,21 & 557,10 & 81,35 & 4,24 & 53,21 & 207,95 & 27,88 & 27,88 & 195,62 \\
\hline Alytes cisternasii & 30SUH94 & 100,00 & 155,04 & 121,73 & 36,89 & 6927,27 & 349,65 & 21,51 & 328,14 & 100,29 & 248,67 & 248,67 & 71,53 & 549,85 & 78,94 & 4,31 & 52,02 & 202,57 & 29,14 & 29,14 & 190,15 \\
\hline Alytes cisternasii & 30SUH95 & 100,00 & 140,41 & 124,03 & 37,00 & 6966,58 & 338,94 & 6,78 & 332,16 & 92,96 & 235,03 & 235,03 & 57,38 & 584,27 & 80,83 & 5,92 & 49,15 & 211,03 & 37,01 & 37,01 & 196,48 \\
\hline Alytes cisternasii & 30SUH96 & 100,00 & 146,94 & 124,51 & 37,00 & 6950,51 & 344,40 & 12,19 & 332,21 & 100,02 & 240,92 & 240,92 & 63,40 & 542,94 & 74,48 & 4,81 & 49,26 & 195,16 & 33,37 & 33,37 & 181,33 \\
\hline Alytes cisternasii & 30SUH97 & 100,00 & 146,86 & 125,39 & 37,00 & 6938,87 & 344,56 & 11,62 & 332,94 & 100,52 & 240,75 & 240,75 & 63,27 & 525,40 & 70,56 & 4,64 & 48,40 & 186,60 & 33,58 & 33,58 & 173,00 \\
\hline Alytes cisternasii & 30SUJO0 & 100,00 & 159,71 & 122,47 & 37,00 & 6806,31 & 352,25 & 26,32 & 325,93 & 85,56 & 250,84 & 250,84 & 76,86 & 505,27 & 67,58 & 3,79 & 50,66 & 178,87 & 29,16 & 29,16 & 171,45 \\
\hline Alytes cisternasii & 30SUJ01 & 100,00 & 160,82 & 121,92 & 37,00 & 6783,25 & 352,34 & 27,82 & 324,52 & 89,92 & 251,71 & 251,71 & 78,15 & 485,01 & 64,20 & 3,49 & 50,32 & 170,88 & 28,56 & 28,56 & 162,91 \\
\hline Alytes cisternasii & 30SUJ02 & 100,00 & 159,36 & 121,10 & 37,00 & 6790,35 & 350,59 & 26,64 & 323,95 & 89,07 & 250,54 & 250,54 & 76,72 & 476,07 & 62,28 & 3,92 & 49,00 & 166,33 & 29,72 & 29,72 & 157,84 \\
\hline Alytes cisternasii & 30SUJ03 & 100,00 & 158,62 & 120,52 & 37,00 & 6769,54 & 348,91 & 26,27 & 322,64 & 99,67 & 249,47 & 249,47 & 76,11 & 465,44 & 60,16 & 3,94 & 48,21 & 161,70 & 30,25 & 30,25 & 152,66 \\
\hline Alytes cisternasii & 30SUJ07 & 100,00 & 135,85 & 117,40 & 36,73 & 6696,52 & 323,94 & 7,25 & 316,69 & 68,95 & 226,28 & 226,28 & 55,45 & 503,10 & 60,02 & 7,08 & 42,81 & 168,60 & 43,59 & 43,59 & 156,38 \\
\hline Alytes cisternasii & 30SUJO9 & 100,00 & 145,21 & 116,46 & 36,88 & 6640,38 & 330,17 & 16,56 & 313,60 & 96,42 & 234,72 & 234,72 & 64,74 & 440,33 & 51,25 & 6,19 & 42,26 & 147,34 & 38,79 & 38,79 & 134,21 \\
\hline Alytes cisternasii & 30SUJ10 & 100,00 & 160,25 & 122,95 & 37,00 & 6834,18 & 353,38 & 26,25 & 327,13 & 88,09 & 251,96 & 251,96 & 76,84 & 497,58 & 66,73 & 3,46 & 50,66 & 174,90 & 28,12 & 28,12 & 168,17 \\
\hline Alytes cisternasii & 30SUJ11 & 100,00 & 157,28 & 122,27 & 37,00 & 6821,56 & 350,13 & 23,83 & 326,31 & 87,09 & 248,91 & 248,91 & 74,36 & 493,68 & 65,26 & 4,00 & 49,40 & 171,72 & 30,24 & 30,24 & 164,36 \\
\hline Alytes cisternasii & 30 SUJ12 & 100,00 & 158,19 & 121,74 & $37,00 \mid$ & 6812,73 & 350,10 & 25,05 & 325,05 & 103,86 & 249,71 & 249,71 & 75,26 & 474,85 & 61.96 & 3,89 & 48,81 & $\mid$\begin{tabular}{|l|l|}
164,18 \\
\end{tabular} & 29,88 & 29,88 & 156,28 \\
\hline Alytes cisternasii & 30SUJ13 & 100,00 & 156,64 & 121,00 & 37,00 & 6801,50 & 347,80 & 23,78 & 324,02 & 105,67 & 248,01 & 248,01 & 73,92 & 465,89 & 59,87 & 4, & 47,67 & 160,01 & 31,00 & 31,00 & 151,35 \\
\hline Alytes cisternasii & 30SUJ14 & 100,00 & 158,51 & 120,24 & 37,00 & 6776,48 & 348,22 & 25,77 & 322,45 & 113,71 & 249,50 & 249,50 & 75,81 & 446,28 & 56,61 & 4,03 & 47,15 & 153,15 & 30,48 & 30,48 & 143,51 \\
\hline Alytes cisternasii & 30SUJ15 & 100,00 & 156,77 & 119,64 & \begin{tabular}{|l|}
36,98 \\
\end{tabular} & 6758,22 & 345,78 & 24,61 & 321,17 & 114,42 & 247,55 & 247,55 & 74,36 & 439,26 & 54,84 & 4,23 & 46,27 & 149,96 & 31,43 & 31,43 & 139,35 \\
\hline Alytes cisternasii & 30SUJ17 & 100,00 & 144,12 & 118,10 & 36,65 & 6722,19 & 332,29 & 13,95 & 318,35 & 112,25 & 234,75 & 234,75 & 62,97 & 459,73 & 54,85 & 6,05 & 42,98 & 153,58 & 38,86 & 38,86 & 141,30 \\
\hline Alytes cisternasii & 30SUJ19 & 100,00 & 148,04 & 116,97 & 36,97 & 6669,21 & 333,37 & 18,23 & 315,14 & 109,39 & 237,87 & 237,87 & 67,00 & 421,03 & 48,61 & 5,94 & 41,92 & 140,41 & 37,41 & 37,41 & 126,60 \\
\hline Alytes cisternasii & 30 SUJ 20 & 100,00 & 156,96 & 123,03 & 37,00 & 6860,53 & 351,14 & 22,51 & 328,63 & 86,62 & 249,08 & 249,08 & 73,57 & 503,85 & 67,41 & 3,88 & 50,11 & 174,82 & 29,59 & 29,59 & 168,86 \\
\hline \begin{tabular}{|l} 
Alytes cisternasii \\
\end{tabular} & 30SUJ21 & 100,00 & 150,90 & 122,81 & 37,00 & 6860,03 & 345,34 & 17,14 & 328,20 & $\begin{array}{l}0,030 \\
83,00\end{array}$ & 243,38 & 243,38 & 67,96 & 511,42 & $\begin{array}{l}67,13 \\
67+1\end{array}$ & $\begin{array}{ll}3,000 \\
4,54\end{array}$ & 48,50 & $\begin{array}{l}175,59 \\
17\end{array}$ & 32,87 & 32,87 & 168,88 \\
\hline Alytes cisternasii & 30 SUJ22 & 100,00 & 154,62 & 122,09 & 37,00 & 6835,34 & 347,53 & 20,91 & 326,62 & 106,33 & 246,51 & 246,51 & 71,58 & 481,43 & 62,50 & 4,12 & 48,03 & 164,49 & 31,29 & 31,29 & 157,19 \\
\hline Alytes cisternasii & 30 SUJ 23 & 100,00 & 154,21 & 121,51 & 37,00 & 6828,54 & 346,38 & 21,01 & 325,37 & 117,96 & 246,11 & 246,11 & 71,29 & 468,02 & 59,81 & 4,23 & 47,12 & 159,10 & 31,90 & 31,90 & 150,66 \\
\hline Alytes cisternasii & 30SUJ24 & 100,00 & 155,18 & 120,80 & 37,00 & 6806,05 & 346,03 & 22,25 & 323,78 & 119,90 & 246,76 & 246,76 & 72,42 & 450,64 & 56,65 & 4,29 & 46,35 & 153,20 & 31,85 & 31,85 & 143,24 \\
\hline Alytes cisternasii & 30 SUJ 25 & 100,00 & 154,72 & 120,04 & 36,99 & 6787,16 & 344,53 & 21,95 & 322,58 & 120,57 & 246,02 & 246,02 & 72,17 & 439,75 & 54,41 & 4,44 & 45,49 & 148,96 & 32,50 & 32,50 & 138,06 \\
\hline \begin{tabular}{|l} 
Alytes cisternasii \\
\end{tabular} & 30SUJ26 & 100,00 & 152,32 & 119,27 & 36,81 & 6771,48 & 341,38 & \begin{tabular}{|l|}
20,07 \\
20
\end{tabular} & 321,31 & \begin{tabular}{|l|}
122,77 \\
\end{tabular} & \begin{tabular}{|l|}
243,51 \\
240
\end{tabular} & \begin{tabular}{|l|}
243,51 \\
240
\end{tabular} & 70,08 & |435,45 & $\begin{array}{l}4,41+76 \\
52,6\end{array}$ & $\begin{array}{l}4,440 \\
4,90\end{array}$ & $\begin{array}{ll}44,34 \\
44,36\end{array}$ & \begin{tabular}{|l|l|}
$146,68,0$ \\
\end{tabular} & $\begin{array}{l}34,10 \\
34,10\end{array}$ & 34,10 & 134,77 \\
\hline Alytes cisternasii & 30SUJ27 & 100,00 & 144,30 & 118,69 & 36,73 & 6749,11 & 333,08 & 13,26 & 319,82 & 127,03 & 235,39 & 235,39 & 62,75 & 450,37 & 53,29 & 5,94 & 42,70 & 150,73 & 38,40 & 38,40 & $\begin{array}{ll}136,93 \\
\end{array}$ \\
\hline Alytes cisternasii & 30 SUJ28 & 100,00 & 144,97 & 117,94 & 36,74 & 6718,73 & 332,18 & 14,32 & 317,86 & 127,65 & 235,58 & 235,58 & 63,70 & 436,21 & 50,57 & 6,14 & 41,94 & 145,34 & 38,68 & 38,68 & 130,82 \\
\hline Alytes cisternasii & 30 SUJ 29 & 100,00 & 145,47 & 117,08 & 36,76 & 6683,31 & 331,32 & 15,28 & 316,03 & 122,78 & 235,70 & 235,70 & 64,65 & 422,31 & 48,16 & 6,32 & 41,13 & 140,39 & 38,88 & 38,88 & 124,91 \\
\hline Alytes cisternasii & 30SUJ30 & 100,00 & 155,59 & 123,52 & 37,00 & 6887,42 & 350,41 & 20,78 & 329,63 & 88,74 & 248,21 & 248,21 & 71,77 & 501,47 & 66,86 & 4,02 & 49,37 & 172,05 & 30,23 & 30,23 & 166,73 \\
\hline Alytes cisternasii & 30SUJ31 & 100,00 & 150,96 & 123,14 & 37,00 & 6882,02 & 345,94 & 16,56 & 329,38 & 115,15 & 243,83 & 243,83 & 67,74 & 502,99 & 65,85 & 4,31 & 48,20 & 171,38 & 32,64 & 32,64 & 164,81 \\
\hline Alytes cisternasii & 30SUJ32 & 100,00 & 151,82 & 122,74 & 37,00 & \begin{tabular}{ll|l}
6864,87 \\
\end{tabular} & 345,74 & 17,56 & 328,18 & 132,25 & 244,36 & 244,36 & 68,72 & 484,56 & 62,45 & 4,38 & 47,40 & 164,73 & 32,69 & 32,69 & 156,66 \\
\hline Alytes cisternasii & 30SUJ35 & 100,00 & 152,93 & 120,36 & 37,00 & 6810,05 & 343,39 & 19,86 & 323,53 & 133,26 & 244,65 & 244,65 & 70,08 & 439,24 & 53,72 & 4,65 & 44,76 & 148,41 & 33,46 & 33,46 & 136,42 \\
\hline Alytes cisternasii & 30SUJ36 & 100,00 & 152,20 & 119,78 & 36,92 & 6784,40 & 341,57 & 19,43 & 322,15 & 134,07 & 243,51 & 243,51 & 69,69 & 428,59 & 51,38 & 4,99 & 43,87 & 144,37 & 34,22 & 34,22 & 131,29 \\
\hline Alytes cisternasii & 30SUJ37 & 100,00 & 144,70 & 119,00 & 36,7 & 6775,17 & 333,91 & 12,81 & 321,10 & 128,67 & 236,24 & 236,24 & 62,83 & 441,99 & 51,7 & 5,98 & 42,35 & 148,48 & 38,34 & 38,34 & 132,89 \\
\hline Alytes cisternasii & 305UJ38 & 100,00 & 131,12 & 117,91 & 36,48 & 6727,14 & 319,99 & 1,57 & 318,42 & 114,04 & 222,45 & 222,45 & 50,72 & 480,95 & 55,18 & 8,10 & 40,09 & \begin{tabular}{l|}
160,68 \\
160,0
\end{tabular} & 46,89 & 46,89 & 141,54 \\
\hline Alytes cisternasii & 30SUJ39 & 100,00 & 138,86 & 117,22 & 36,46 & 6705,00 & 325,71 & 8,61 & 317,10 & 122,84 & 229,62 & 229,62 & 58,14 & 437,96 & 50,32 & 7,14 & 40,21 & 146,02 & 42,50 & 42,50 & 127,45 \\
\hline Alytes cisternasii & 30SUJ40 & 100,00 & 152,11 & 124,00 & 37,00 & 6903,59 & 347,91 & 17,13 & 330,78 & 115,87 & 245,17 & 245,17 & 68,48 & 506,47 & 67,03 & 4,21 & 48,74 & 173,36 & 31,73 & 31,73 & 166,86 \\
\hline Alytes cisternasii & 30SUJ43 & 100,00 & 145,44 & 122,64 & 37,00 & 6874,67 & 339,72 & 11,30 & 328,42 & 128,48 & 238,21 & 238,21 & 62,43 & 485,61 & 60,68 & 5,23 & 45,29 & 165,68 & 36,31 & 36,31 & 152,99 \\
\hline \begin{tabular}{|l} 
Alytes cisternasii \\
\end{tabular} & 30sUJ44 & 100,00 & 150,27 & 121,69 & 37,00 & 6850,13 & 342,60 & 16,21 & $\begin{array}{l}326,39 \\
\end{array}$ & \begin{tabular}{|l|}
133,96 \\
\end{tabular} & 242,56 & 242,56 & $\begin{array}{ll}67,19 \\
67,19\end{array}$ & \begin{tabular}{|l|l|}
455,08 \\
455
\end{tabular} & $\begin{array}{l}56,06 \\
56,0\end{array}$ & 4,84 & $\begin{array}{ll}45,25 \\
45,04\end{array}$ & $\begin{array}{l}154,78 \\
\end{array}$ & $\begin{array}{l}34,32 \\
34,\end{array}$ & 34,32 & $\begin{array}{ll}141,87 \\
\end{array}$ \\
\hline Alytes cisternasii & 30SUJ45 & 100,00 & 150,62 & 120,88 & 36,99 & 6831,53 & 341,75 & 17,01 & 324,75 & 134,62 & 242,70 & 242,70 & 67,85 & 440,17 & 53,18 & 4,99 & 44,07 & 149,37 & 34,59 & 34,59 & 135,15 \\
\hline Alytes cisternasii & $\begin{array}{l}30 \text { SUJ46 } \\
\end{array}$ & 100,00 & 149,38 & 120,01 & 36,91 & 6803,76 & 339,39 & 16,32 & 323,06 & 133,49 & 241,15 & 241,15 & 66,78 & 431,73 & 51,15 & 5,34 & 43,24 & 146,16 & 35,74 & 35,74 & 130,47 \\
\hline Alytes cisternasii & 30SUJ47 & 100,00 & 139,20 & 119,04 & 36,58 & 6777,43 & 328,92 & 7,78 & 321,14 & 122,71 & 231,06 & 231,06 & 57,63 & 456,81 & 52,81 & 6,85 & 41,34 & 153,92 & 41,97 & 41,97 & 135,41 \\
\hline Alytes cisternasii & 30 SUJ 48 & 100,00 & 128,70 & 118,21 & 36,60 & 6735,84 & 318,01 & $-0,92$ & 318,93 & 111,44 & 220,25 & 220,25 & 48,31 & 482,80 & 55,92 & 8,52 & 39,42 & 161,99 & 48,59 & 48,59 & 140,19 \\
\hline \begin{tabular}{|l|l} 
Alytes cisternasii \\
\end{tabular} & \begin{tabular}{|l}
50503449 \\
3050
\end{tabular} & 100,00 & $\frac{12,16}{140,21}$ & $\begin{array}{l}110,21 \\
117,42\end{array}$ & 36,00 & $\begin{array}{l}0753,04 \\
6738,94 \\
\end{array}$ & 327,38 & $\begin{array}{l}-0,54 \\
9,10\end{array}$ & \begin{tabular}{|l|}
318,27 \\
318,27
\end{tabular} & 124,44 & 231,39 & 231,39 & 58,99 & 427,31 & 49,60 & 6,98 & 39,94 & 142,94 & 41,89 & 41,89 & 123,03 \\
\hline Alytes cisternasii & 30SUJ50 & 100,00 & 148,90 & 124,47 & 37,00 & 6917,34 & 345,44 & 13,79 & 331,64 & 128,63 & 242,25 & 242,25 & 65,34 & 509,58 & 66,83 & 4,47 & 47,94 & 175,40 & 33,10 & 33,10 & 166,39 \\
\hline Alytes cisternasii & 30SUJ51 & 100,00 & 150,69 & 124,01 & 37,00 & 6903,21 & 346,19 & 15,61 & 330,58 & 133,95 & 243,75 & 243,75 & 67,07 & 486,99 & 62,77 & 4,30 & 47,21 & 167.55 & 32.59 & 32.59 & 156,91 \\
\hline Alytes cisternasii & 30SUJ53 & 100,00 & 149,64 & 122,92 & 37,00 & 6866,68 & 343,38 & 14,90 & 328,48 & 133,16 & 242,41 & 242,41 & 66,54 & 462,56 & 57,40 & 4,74 & 45,35 & 158,46 & 34,27 & 34,27 & 144,74 \\
\hline Alytes cisternasii & 30SUJ55 & 100,00 & 146,73 & 121,31 & 37,00 & 6863,51 & 338,99 & 12,70 & 326,29 & 130,64 & 239,38 & 239,38 & 63,78 & 446,39 & 53,20 & 5,31 & 43,38 & 152,17 & 36,42 & 36,42 & 135 \\
\hline \begin{tabular}{|l} 
Alytes cisternasii \\
\end{tabular} & \begin{tabular}{|l|l}
$3050 J 56$ \\
3050
\end{tabular} & $\begin{array}{l}100,00 \\
\end{array}$ & $\begin{array}{l}140,13 \\
144,03\end{array}$ & $\begin{array}{ll}121,01 \\
120,42\end{array}$ & 36,71 & $\begin{array}{ll}6003,11 \\
683,28\end{array}$ & $\begin{array}{l}335,41 \\
335,41\end{array}$ & $\begin{array}{l}10,61 \\
10,0\end{array}$ & \begin{tabular}{|l|l|}
324,80 \\
324
\end{tabular} & \begin{tabular}{|l|}
127,69 \\
127
\end{tabular} & \begin{tabular}{|l|}
236,51 \\
230
\end{tabular} & \begin{tabular}{|l|}
236,51 \\
235
\end{tabular} & $\begin{array}{l}31,60 \\
61,60\end{array}$ & \begin{tabular}{|l|l|}
443,45 \\
443,45
\end{tabular} & $\begin{array}{l}30,20 \\
51,75 \\
\end{array}$ & $\begin{array}{l}3,11 \\
5,95 \\
\end{array}$ & $\begin{array}{l}43,30 \\
42,22\end{array}$ & \begin{tabular}{|l|}
150,82 \\
150,
\end{tabular} & $\begin{array}{l}30,44 \\
38,71\end{array}$ & $\begin{array}{l}0,424 \\
38,71\end{array}$ & $\begin{array}{l}132,20 \\
132,20\end{array}$ \\
\hline Alytes cisternasii & 30SUJ57 & 100,00 & 132,87 & 119,36 & 36,71 & 6787,24 & 323,47 & 1,64 & 321,84 & 115,81 & 224,95 & 224,97 & 51,61 & 473,97 & 54,74 & 7,79 & 40,19 & 160,11 & 46,02 & 46,03 & 138,46 \\
\hline 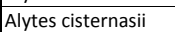 & 30SUJ58 & 100,00 & 131,10 & 118,38 & 36,48 & 6761,15 & 320,51 & 0,67 & 319,85 & 114,06 & 222,93 & 222,93 & 50,26 & 467,69 & 54,66 & 8,25 & 39,29 & 157,42 & 47,50 & 47,50 & 134,38 \\
\hline Alytes cisternasii & 30SUJ59 & 100,00 & 139,33 & 117,47 & 36,02 & 6758,71 & 326,81 & 7,85 & 318,96 & 123,33 & 230,5 & 230, & 57,93 & 426,18 & 49,96 & 7,13 & 39,41 & 142,91 & 42,85 & 42,85 & 121, \\
\hline Alytes cisternasii & 30 SUJ60 & 100,00 & 144,95 & 125,02 & 37,00 & 6931,42 & 342,47 & 9,61 & 332,86 & 127,68 & 238,68 & 238,68 & 61,42 & 513,86 & 66,62 & 4,90 & $\begin{array}{ll}47,07 \\
\end{array}$ & 177,92 & 35,18 & 35,18 & 165,95 \\
\hline
\end{tabular}




\begin{tabular}{|c|c|c|c|c|c|c|c|c|c|c|c|c|c|c|c|c|c|c|c|c|c|}
\hline TAXON & UTM & $\mathrm{km2}$ & B101 & $\mathrm{B1O2}$ & $\mathrm{BIO3}$ & B104 & B105 & B106 & B107 & B108 & $\mathrm{BIO9}$ & 81010 & B1011 & BIO12 & BIO13 & 81014 & BIO15 & B1O16 & B1017 & BIO18 & B1019 \\
\hline Alytes cisternasii & 30SUJ61 & 100,00 & 147,49 & 124,72 & 37,00 & 6918,40 & 343,85 & 11,91 & 331,94 & 130,79 & 240,96 & 240,96 & 63,70 & 489,01 & 62,27 & 4,62 & 46,51 & 169,13 & 34,19 & 34,19 & 155,95 \\
\hline Alytes cisternasii & 30SUJ63 & 100,00 & 145,25 & 123,52 & 37,00 & 6890,92 & 340,28 & 10,49 & 329,79 & 128,27 & 238,45 & 238,45 & 62,09 & 469,25 & 57,34 & 5,25 & 44,38 & 161,49 & 36,57 & 36,57 & 145,12 \\
\hline Alytes cisternasii & 30SUJ64 & 100,00 & 145,08 & 122,74 & 37,00 & 6870,34 & 338,94 & 10,49 & 328,45 & 128,49 & 238,01 & 238,01 & 62,12 & 457,61 & 54,77 & 5,32 & 43,57 & 157,08 & 37,04 & 37,04 & 139,56 \\
\hline Alytes cisternasii & 30SUJ65 & 100,00 & 141,45 & 121,91 & 36,99 & 6863,46 & 334,63 & 7,48 & 327,16 & 124,84 & 234,37 & 234,37 & 58,69 & 459,14 & 53,75 & 5,96 & 42,35 & 157,07 & 39,61 & 39,61 & 137,65 \\
\hline Alytes cisternasii & 30SUJ66 & 100,00 & $\begin{array}{lll}138,87 & \end{array}$ & 120,82 & 36,84 & 6853,41 & 330,98 & 5,46 & 325,52 & 122,02 & 231,64 & 231,64 & 56,39 & 456,53 & 52,59 & 6,61 & 41,24 & 155,54 & 41,78 & 41,78 & 134,68 \\
\hline Alytes cisternasii & 30SUJ67 & 100,00 & 133,27 & 119,57 & 36,55 & 6810,94 & 324,28 & 1,23 & 323,05 & 116,30 & 225,70 & 225,72 & 51,75 & 467,28 & 54,22 & 7,76 & 39,82 & 158,18 & 45,99 & 46,01 & 135,44 \\
\hline Alytes cisternasii & 30SUJ68 & 100,00 & 127,92 & 118,44 & 36,46 & 6771,95 & 317,75 & $-2,49$ & 320,25 & 110,53 & 220,03 & 220,03 & 47,24 & 475,21 & 56,03 & 8,85 & 38,49 & 160,12 & 49,94 & 49,94 & 135,27 \\
\hline Alytes cisternasii & \begin{tabular}{|l|}
$305 U J 69$ \\
\end{tabular} & 100,00 & 138,46 & 117,39 & 36,06 & 6776,79 & 326,03 & 6,79 & 319,24 & 122,33 & 230,29 & 230,29 & 56,83 & 426,07 & 50,24 & 7,51 & 38,77 & 142,88 & 43,81 & 43,81 & 120,28 \\
\hline Alytes cisternasii & 30SUJ70 & 100,00 & 149,86 & 125,35 & 37,00 & 6926,91 & 346,50 & 13,57 & 332,92 & 133,03 & 243,32 & 243,32 & 66,07 & 485,27 & 62,41 & 4,04 & 47,35 & 168,93 & 32,20 & 32,20 & 156,07 \\
\hline Alytes cisternasii & 30SUJ71 & 100,00 & 150,08 & 125,08 & 37,00 & 6909,14 & 346,05 & 13,92 & 332,12 & 133,77 & 243,34 & 243,34 & 66,37 & 469,68 & 59,18 & 4,21 & 46,36 & 163,15 & 32,79 & 32,79 & 148,78 \\
\hline Alytes cisternasii & 30SUJ73 & 100,00 & 140,36 & 124,17 & 37,00 & 6901,19 & 336,28 & 5,26 & 331,02 & 123,41 & 233,78 & 233,78 & 57,29 & 478,84 & 57,47 & 5,66 & 43,40 & 165,37 & 39,18 & 39,18 & 146,33 \\
\hline Alytes cisternasii & 30SUJ74 & 100,00 & 143,51 & 123,26 & 37,00 & 6884,85 & 337,84 & 8,47 & 329,36 & 126,77 & 236,64 & 236,64 & 60,49 & 455,14 & 53,60 & 5,38 & 42,92 & 156,66 & 37,91 & 37,91 & 137,36 \\
\hline Alytes cisternasii & 30SUJ75 & 100,00 & 140,25 & 122,33 & 37,00 & 6876,04 & 333,81 & 5,96 & 327,85 & 123,67 & 233,36 & 233,36 & 57,40 & 456,66 & 52,75 & 6,19 & 41,78 & 156,56 & 40,66 & 40,66 & 135,52 \\
\hline Alytes cisternasii & 30SUJ76 & 100,00 & 131,62 & 121,11 & 36,99 & 6845,36 & 324,71 & $-0,64$ & 325,36 & 114,22 & 224,64 & 224,64 & 49,95 & 478,72 & 55,45 & 7,72 & 40,05 & 163,20 & 46,50 & 46,50 & 139,57 \\
\hline Alytes cisternasii & 30SUJ77 & 100,00 & 129,08 & 119,84 & 36,69 & 6811,62 & 320,59 & $-2,58$ & 323,17 & 111,64 & 221,71 & 221,73 & 47,82 & 479,38 & 56,10 & 8,50 & 38,99 & 162,42 & 49,09 & 49,11 & 137,63 \\
\hline Alytes cisternasii & 30SUJ78 & 100,00 & 129,47 & 118,53 & 36,27 & 6797,85 & 319,50 & $-1,77$ & 321,27 & 112,44 & 221,84 & 221,86 & 48,38 & 467,19 & 55,19 & 8,76 & 38,21 & 157,42 & 49,51 & 49,52 & 132,25 \\
\hline Alytes cisternasii & 30SUJ79 & 100,00 & 140,64 & 117,26 & 36,00 & 6813,01 & 328,23 & 8,23 & 319,99 & 124,71 & 232,97 & 232,97 & 58,34 & 417,31 & 49,25 & 7,44 & 38,68 & 139,88 & 43,10 & 43,10 & 117,30 \\
\hline Alytes cisternasii & 30 SUJ 82 & 100,00 & 142,16 & 125,58 & 37,00 & 6902,37 & 338,97 & 6,55 & 332,42 & 125,21 & 235,64 & 235,64 & 59,16 & 475,08 & 57,40 & 5,16 & 44,01 & 165,12 & 37,56 & 37,56 & 146,14 \\
\hline Alytes cisternasii & 30SUJ84 & 100,00 & 147,10 & 123,58 & 37,00 & 6891,58 & 341,06 & 11,29 & 329,77 & 130,97 & 240,20 & 240,20 & 63,63 & 435,05 & 50,60 & 5,04 & 43,12 & 150,06 & 36,03 & 36,03 & 130,50 \\
\hline Alytes cisternasii & 30 SUJ85 & 100,00 & 139,86 & 122.68 & $37,00 \mid$ & 6883,90 & 333,48 & 5,15 & 328,33 & $\mid 123,22$ & 233,10 & 233,10 & 57,01 & 452,03 & 52,22 & 6,18 & 41,36 & $\mid 154.99$ & 41,14 & 41,14 & 133,15 \\
\hline Alytes cisternasii & 30SUJ86 & 100,00 & 139,18 & 121,51 & 37,00 & 6872,99 & 331,72 & 5,03 & 326,69 & 122,69 & 232,32 & 232,32 & 56,42 & 445,18 & 51,66 & 6,5 & 40,38 & 151,85 & 42,23 & 42,23 & 129,33 \\
\hline Alytes cisternasii & 30SUJ87 & 100,00 & 128,53 & 120,22 & 36,90 & 6825,34 & 320,44 & $-3,11$ & 323,55 & 111,06 & 221,42 & 221,42 & 47,25 & 476,95 & 56,08 & 8,54 & 38,63 & $\begin{array}{l}161,68 \\
\end{array}$ & $\begin{array}{l}49,58 \\
425\end{array}$ & 49,58 & 136,07 \\
\hline Alytes cisternasii & 30SUJ88 & 100,00 & 137,01 & 118,73 & $\begin{array}{ll}36,06 \\
\end{array}$ & $\begin{array}{ll}6843,51 \\
\end{array}$ & 326,82 & 3,88 & 322,94 & 120,65 & 229,86 & 229,86 & 54,64 & 436,48 & 51,38 & 7,67 & 38,58 & 147,06 & 45,13 & 45,13 & 123,42 \\
\hline Alytes cisternasii & 30SUJ89 & 100,00 & 141,21 & 117,18 & 36,00 & 6841,64 & 328,87 & 8,27 & 320,60 & 125,26 & 233,80 & 233,80 & 58,44 & 415,03 & 48,84 & 7,40 & 38,23 & 138,75 & 43,40 & 43,40 & 116,36 \\
\hline Alytes cisternasii & 30SUJ92 & 100,00 & 146,89 & 126,23 & 37,28 & 6888,05 & 342,90 & 10,26 & 332,64 & 130,50 & 239,83 & 239,83 & 63,38 & 447,19 & 53,12 & 4,36 & 44,15 & 155,79 & 34,83 & 34,83 & 136,70 \\
\hline Alytes cisternasii & 30SUJ97 & 100,00 & 132,15 & 120,44 & 36,84 & 6851,92 & 324,03 & $-0,53$ & 324,56 & 115,20 & 225,31 & 225,31 & 50,23 & 460,33 & 54,11 & 8,08 & 38,49 & 155,84 & 47,81 & 47,81 & 130,91 \\
\hline \begin{tabular}{|l} 
Alytes cisternasii \\
\end{tabular} & 30SUJ98 & 100,00 & 131,73 & 118,86 & 36,18 & 6842,66 & 322,13 & $\begin{array}{l}-0,47 \\
-0,47 \\
\end{array}$ & 322,60 & 114,83 & $\begin{array}{l}224,72 \\
22,7\end{array}$ & \begin{tabular}{|l|}
224,73 \\
\end{tabular} & 49,97 & 454,45 & $\begin{array}{l}4,11 \\
53,69\end{array}$ & 8,53 & $\begin{array}{l}0,47,87 \\
37,\end{array}$ & $\begin{array}{l}152,77 \\
15,4\end{array}$ & \begin{tabular}{|l}
48,10 \\
48,75
\end{tabular} & 48,75 & 127,88 \\
\hline Alytes cisternasii & 30SUKOO & 100,00 & 154,22 & 116,00 & 36,98 & 6606,87 & 336,84 & 25,18 & 311,66 & 111,86 & 242,90 & 242,90 & 73,32 & 397,89 & 46,22 & 5,18 & 42,40 & 134,44 & 34,42 & 34,42 & 120,55 \\
\hline Alytes cisternasii & 30SUKO1 & 100,00 & 154,70 & 115,56 & 37,00 & 6570,73 & 335,95 & 26,02 & 309,94 & 112,48 & 242,89 & 242,89 & 74,18 & 386,27 & 44,60 & 5,27 & 41,76 & 130,38 & 34,47 & 34,47 & 115,88 \\
\hline Alytes cisternasii & 30SUKO2 & 100,00 & 157,32 & 115,00 & 37,00 & 6535,01 & 336,74 & 28,77 & 307,97 & 115,01 & 244,70 & 244,70 & 76,95 & 368,51 & 42,81 & 5,00 & 41,51 & 125,01 & 33,47 & 33,47 & 109,88 \\
\hline Alytes cisternasii & 30SUK12 & 100,00 & 155,81 & 115,07 & 37,00 & 6556,55 & 335,75 & 26,94 & 308,82 & 113,23 & 243,57 & 243,57 & 75,22 & 366,27 & 42,02 & 5,35 & 40,46 & 123,19 & 34,38 & 34,38 & 107,31 \\
\hline \begin{tabular}{|l} 
Alytes cisternasii \\
\end{tabular} & $\begin{array}{l}30 \mathrm{SUN} 30 \\
\end{array}$ & 100,00 & $\begin{array}{l}150,01 \\
150,69\end{array}$ & 116,42 & 36,44 & |6677,44 & 334,52 & \begin{tabular}{|l|}
19,78 \\
19
\end{tabular} & \begin{tabular}{|l|}
314,74 \\
\end{tabular} & $\begin{array}{l}120,12 \\
120\end{array}$ & \begin{tabular}{|l|}
240,44 \\
\end{tabular} & \begin{tabular}{|l|}
240,44 \\
\end{tabular} & $\begin{array}{l}69,27 \\
69,2\end{array}$ & 389,56 & $\begin{array}{l}44,36 \\
44,33\end{array}$ & 5, & $\begin{array}{l}0,40 \\
40,58 \\
\end{array}$ & $\begin{array}{l}129,62 \\
125,\end{array}$ & $\begin{array}{l}4,607 \\
36,67 \\
\end{array}$ & $\begin{array}{l}34,60 \\
36,67\end{array}$ & 113,05 \\
\hline Alytes cisternasii & 30SUK32 & 100,00 & 151,96 & 115,00 & 36,26 & 6621,24 & 332,95 & 22,09 & 310,85 & 111,36 & 240,81 & 240,81 & 70,95 & 366,31 & 42,20 & 6,19 & 39,38 & 121,68 & 36,48 & 36,48 & 104,07 \\
\hline Alytes cisternasii & 30SUK40 & 100,00 & 146,53 & 116,44 & 36,23 & 6706,19 & 331,25 & 15,48 & 315,77 & 129,94 & 236,95 & 236,95 & 65,07 & 397,08 & 46,01 & 6,48 & 39,79 & 131,86 & 39,04 & 39,04 & 113,41 \\
\hline Alytes cisternasii & 30 SUK42 & 100,00 & 153,17 & 114,75 & 36,09 & 6644,08 & 333,95 & 22,73 & 311,21 & 112,53 & 242,41 & 242,41 & 71,86 & 359,77 & 41,62 & 6,11 & 39,30 & 119,29 & 36,19 & 36,19 & 101,33 \\
\hline Alytes cisternasii & 30SUK50 & 100,00 & 146,51 & 116,31 & 36,01 & 6737,53 & 331,38 & 14,77 & 316,62 & 131,71 & 237,39 & 237,39 & 64,44 & 394,60 & 45,99 & 6,64 & 39,18 & 131,05 & 39,60 & 39,60 & 111,67 \\
\hline \begin{tabular}{|l} 
Alytes cisternasii \\
\end{tabular} & 30SUK51 & 100,00 & $\begin{array}{l}14,51,50 \\
149,50\end{array}$ & $\begin{array}{l}110,51 \\
115,26\end{array}$ & 36,00 & 6702,48 & 332,43 & 18,28 & \begin{tabular}{|l|}
314,14 \\
314
\end{tabular} & $\mid \begin{array}{l}\mid 51,1,10 \\
128,10\end{array}$ & $\mid \begin{array}{l}\mid 239,76 \\
23,76\end{array}$ & \begin{tabular}{|l|}
239,76 \\
23,7
\end{tabular} & $\begin{array}{l}64,44 \\
67,73\end{array}$ & \begin{tabular}{|l|l|}
376,604 \\
376,
\end{tabular} & | & $\frac{0,044}{6,52}$ & $\begin{array}{l}3,10 \\
38,94 \\
\end{array}$ & \begin{tabular}{|l|}
124,28 \\
12,
\end{tabular} & $\begin{array}{l}35,00 \\
38,22 \\
\end{array}$ & $\begin{array}{l}38,20 \\
38,22\end{array}$ & 105,82 \\
\hline Alytes cisternasii & 30SUK52 & 100,00 & 152,38 & 114,18 & 36,00 & 6671,95 & 333,40 & 21,64 & 311,76 & 112,48 & 242,03 & 242,03 & 70,64 & 359,69 & 41,82 & 6,31 & 38,75 & 119,06 & 36,95 & 36,95 & 100,44 \\
\hline Alytes cisternasii & 30SUK60 & 100,00 & 145,95 & 116,11 & 36,00 & 6769,99 & 331,10 & 13,71 & 317,39 & 130,61 & 237,25 & 237,25 & 63,46 & 394,45 & 46,21 & 6,86 & 38,87 & 131,01 & 40,37 & 40,37 & 110,80 \\
\hline Alytes cisternasii & 30SUK80 & 100,00 & 149,30 & 115,40 & 35,95 & 6835,18 & 334,28 & 16,19 & 318,09 & 128,56 & 241,51 & 241,51 & 65,95 & 384,66 & 44,56 & 6,71 & 38,52 & 127,14 & 39,66 & 39,66 & 107,63 \\
\hline Alytes cisternasii & 30SUK90 & 100,00 & 143,16 & 115,31 & 35,8 & 6860,69 & 329,16 & 10,21 & 318,95 & 127,38 & 235,93 & 235,93 & 60,10 & 404,49 & 47,19 & 7,82 & 37,34 & 133,31 & 43,97 & 43,97 & 112,35 \\
\hline \begin{tabular}{|l} 
Alytytes cisternasii \\
\end{tabular} & \begin{tabular}{|l|}
$30 \mathrm{SVH}$ H01 \\
\end{tabular} & 100,00 & $\begin{array}{l}14,10 \\
173,25\end{array}$ & $\begin{array}{l}111,31 \\
114,34\end{array}$ & $\begin{array}{l}30,81 \\
36,00\end{array}$ & $\begin{array}{l}0800,09 \\
6739,98 \\
\end{array}$ & $\begin{array}{l}32,10 \\
356,56\end{array}$ & \begin{tabular}{l|}
0,14 \\
43,78
\end{tabular} & \begin{tabular}{|l|}
10,95 \\
312,78
\end{tabular} & \begin{tabular}{|l|}
103,74 \\
103,4
\end{tabular} & \begin{tabular}{|l|}
263,85 \\
263,86
\end{tabular} & $\mid \frac{\mid 35,95}{263,86}$ & $\begin{array}{ll}90,104 \\
91,44\end{array}$ & \begin{tabular}{|l|}
511,77 \\
511,77
\end{tabular} & 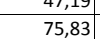 & \begin{tabular}{l|l}
, 282 \\
3,23
\end{tabular} & $\begin{array}{l}35,43 \\
55,60\end{array}$ & \begin{tabular}{|l|}
193,31 \\
195,58
\end{tabular} & \begin{tabular}{|l|}
21,62 \\
219
\end{tabular} & $\begin{array}{l}4,91,62 \\
21\end{array}$ & $\begin{array}{l}11,35 \\
185,27 \\
\end{array}$ \\
\hline Alytes cisternasii & $30 \mathrm{SVHO2}$ & 100,00 & 166,13 & 116,79 & 36,00 & 6846,37 & 354,41 & 35,08 & 319,33 & 96,84 & 258,37 & 258,37 & 83,31 & 530,30 & 78,73 & 3,62 & 54,44 & 201,04 & 24,27 & 24,27 & 188,86 \\
\hline Alytes cisternasii & 30SVHO3 & 100,00 & 155,87 & 119,93 & 36,17 & 6936,06 & 349,27 & 23,47 & 325,80 & 103,94 & 249,62 & 249,62 & 72,41 & 553,67 & 80,94 & 4,54 & 52,48 & 207,08 & 29,00 & 29,00 & 192,78 \\
\hline Alytes cisternasii & 30SVHO4 & 100,00 & 152,67 & 121,54 & 36,70 & 6943,12 & 347,59 & 19,47 & 328,12 & 105,63 & 246,53 & 246,53 & 69, & 547,43 & 78,3 & 4,60 & 51,14 & 02,35 & 30,55 & 30,55 & 187,44 \\
\hline \begin{tabular}{|l} 
Alytes cisternasii \\
\end{tabular} & 30SVH05 & 100,00 & 144,87 & 123,50 & 37,00 & 6956,21 & 342,06 & $\begin{array}{l}11,07 \\
11,07\end{array}$ & 330,99 & $\begin{array}{l}97,66 \\
97,0\end{array}$ & 239,15 & 239,15 & 61,62 & 557,74 & 77,28 & 5,44 & 49,29 & 202,56 & 34,99 & 34,99 & 186,84 \\
\hline Alytes cisternasii & 30SVH08 & 100,00 & 146,68 & 126,35 & 37,34 & 6917,47 & 344,27 & 10,82 & 333,44 & 123,90 & 240,12 & 240,12 & 63,49 & 495,58 & 64,1 & 4,31 & 46,88 & 175,07 & 33,86 & 33,86 & 159,05 \\
\hline Alytes cisternasii & 30SVH11 & 100,00 & 173,27 & 113,34 & 36,00 & 6740,93 & 355,86 & 44,18 & 311,68 & 103,58 & 263,83 & 263,83 & 91,41 & 500,60 & 74,46 & 3,27 & 55,22 & 191,21 & 21,66 & 21,66 & 180,09 \\
\hline Alytes cisternasii & 30SVH12 & 100,00 & 165,95 & 116,11 & 36,00 & 6846,00 & 353,68 & 35,44 & 318,24 & 105,58 & 258,18 & 258,18 & 83,22 & 519,72 & 77,25 & 3,74 & 53,92 & 197,10 & 24,62 & 24,62 & 183,63 \\
\hline Alytes cisternasii & 30SVH14 & 100,00 & 157,62 & 120,27 & 36,56 & 6901,44 & 350,06 & 24,96 & 325,10 & 110,93 & 250,79 & 250,79 & 74 & 518,31 & 74,11 & 4,22 & 51,24 & 192,18 & 28,63 & 28,63 & 176,88 \\
\hline \begin{tabular}{|l} 
Alytes cisternasii \\
\end{tabular} & 30SVH15 & 100,00 & 155,79 & 121,83 & 36,99| & | $68098,91 \mid$ & 349,23 & 24,23 & 327,01 & \begin{tabular}{|l|}
109,29 \\
10,25
\end{tabular} & \begin{tabular}{|l|}
248,88 \\
\end{tabular} & \begin{tabular}{|l|}
248,88 \\
\end{tabular} & 72,53 & $\mid$\begin{tabular}{|l|l|l|l|}
506,77 \\
\end{tabular} & $\begin{array}{l}\mid 4,11 \\
70,68\end{array}$ & $\begin{array}{l}4,26 \\
4,16\end{array}$ & $\begin{array}{l}1,4 \\
50,15\end{array}$ & \begin{tabular}{|l|l|}
185,38 \\
18,0
\end{tabular} & \begin{tabular}{|l|l|}
29,403 \\
29,4
\end{tabular} & $\begin{array}{l}2,0,49 \\
29,4\end{array}$ & $\begin{array}{l}1 / 10,00 \\
170,10\end{array}$ \\
\hline Alytes cisternasii & $30 \mathrm{SVH} 21$ & 100,00 & 175,23 & 112,19 & 36,00 & 6708,16 & 355,88 & 46,71 & 309,18 & 107,21 & 265,28 & 265,28 & 93,80 & 478,04 & 70,70 & 3,01 & 54,79 & 181,60 & 20,69 & 20,69 & 170,99 \\
\hline Alytes cisternasii & $30 \mathrm{SVH} 22$ & 100,00 & 167,66 & 115,08 & 36,00 & 6811,41 & 353,58 & 37,68 & 315,90 & $\begin{array}{l}117,58 \\
\end{array}$ & 259,44 & 259,44 & 85,38 & 498,74 & 73,72 & 3,62 & 53,34 & $\mid 188,84$ & 24,08 & 24,08 & 174,98 \\
\hline Alytes cisternasii & 30 SVH 25 & 100,00 & 145,86 & 122,79 & 36,97 & 6929,03 & 341,56 & 12,40 & 329,17 & 98,79 & 239,69 & 239,69 & 62,92 & 532,36 & 72,99 & 5,53 & 48,12 & 193,73 & 35,29 & 35,29 & 175,10 \\
\hline Alytes cisternasii & 30 SVH 26 & 100,00 & 149,29 & 123,54 & 37,00 & 6905,60 & 344,42 & 15,08 & 329,34 & 102,72 & 242,76 & 242 & 66 & 502,27 & 67,41 & 4,82 & 47,70 & 180,86 & 33,34 & 33,34 & 16 \\
\hline \begin{tabular}{|l}
$|l| l$ \\
Alytes cisternasii
\end{tabular} & $\begin{array}{l}05 V \text { I } \\
30 \mathrm{VH} 33\end{array}$ & $\begin{array}{l}100,00 \\
100\end{array}$ & $\begin{array}{l}14,29 \\
163,99\end{array}$ & $\begin{array}{l}12,54 \\
116,79\end{array}$ & 36,00 & 6826,59 & $\begin{array}{l}34,41,34 \\
351,34\end{array}$ & $\begin{array}{l}10,0 \\
33,03 \\
\end{array}$ & 318,31 & 117,36 & 255,90 & 255,90 & 81,46 & 484,88 & 69,84 & 3,89 & 51,35 & 181,73 & 26,11 & 26,11 & 165,59 \\
\hline Alytes cisternasii & 30SVH34 & 100,00 & 153,79 & 120,08 & 36,59 & 6892,22 & 345,85 & 21,45 & 324,40 & 106,64 & 246,91 & 246,91 & 71,05 & 508,68 & 71,43 & 4,85 & 49,44 & 188,17 & 31,19 & 31,19 & 169,55 \\
\hline Alytes cisternasii & 30SVH35 & 100,00 & 140,37 & 123,03 & 37,00 & 6930,83 & 336,74 & 7,07 & 329,67 & 92,90 & 234,50 & 234,50 & 57,87 & 542,59 & 73,30 & 6,44 & 46,68 & 196,41 & 38,99 & 38,99 & 175,76 \\
\hline Alytes cisternasii & 30 SVH36 & 100,00 & 147,72 & 123,40 & 37,00 & 6898,34 & 342,58 & 13,64 & 328,94 & 101,11 & 241,08 & 241,08 & 64 & 497,93 & 66,21 & 5,07 & 46,86 & 178,98 & 34,49 & 34,49 & 160,34 \\
\hline Alytes cisternasii & $30 \mathrm{SVH} 42$ & 100,00 & 168,91 & 114,17 & 36,00 & 6738,83 & 351,87 & 39,52 & 312,34 & 122,59 & 259,43 & 259,43 & 87,43 & 461,65 & 66,40 & 3,64 & 51,84 & 173,28 & 24,00 & 24,00 & 158,57 \\
\hline
\end{tabular}




\begin{tabular}{|c|c|c|c|c|c|c|c|c|c|c|c|c|c|c|c|c|c|c|c|c|c|}
\hline TAXON & UTM & $\mathrm{km} 2$ & B101 & B102 & $\mathrm{BIO3}$ & BIO4 & B105 & B106 & B107 & B108 & B109 & B1010 & BIO11 & BIO12 & B1013 & BIO14 & B1015 & BIO16 & BIO17 & BIO18 & B1019 \\
\hline Alytes cisternasii & $30 \mathrm{SVH} 43$ & 100,00 & 163,33 & 116,73 & 36,05 & 6798,84 & 349,91 & 32,62 & 317,29 & 116,79 & 254,96 & 254,96 & 81,34 & 471,24 & 66,79 & 4,03 & 50,53 & 175,58 & 26,70 & 26,70 & 158,96 \\
\hline Alytes cisternasii & $30 \mathrm{SVH} 44$ & 100,00 & 148,33 & 120,66 & 36,76 & 6890,83 & 341,28 & 15,92 & 325,37 & 100,84 & 241,58 & 241,58 & 65,94 & 515,72 & 70,99 & 5,67 & 47,88 & 189,17 & 34,67 & 34,67 & 168,88 \\
\hline Alytes cisternasii & $30 \mathrm{SVH} 45$ & 100,00 & 135,75 & 123,29 & 37,00 & 6915,99 & 332,29 & 3,01 & 329,29 & 87,90 & 229,84 & 229,84 & 53,68 & 550,14 & 72,97 & 7,40 & 45,32 & 197,48 & 42,56 & 42,56 & 175,34 \\
\hline Alytes cisternasii & $30 \mathrm{SVH} 46$ & 100,00 & 146,07 & 123,18 & 37,00 & 6878,33 & 340,31 & 12,33 & 327,98 & 99,86 & 239,18 & 239,18 & 63,76 & 494,85 & 65,02 & 5,43 & 45,99 & 177,10 & 36,01 & 36,01 & 157,28 \\
\hline Alytes cisternasii & 30SVH53 & 100,00 & 163,20 & 116,49 & 36,24 & \begin{tabular}{|c|c|}
6752,17 \\
\end{tabular} & 348,31 & 32,62 & 315,69 & 116,77 & 254,13 & 254,13 & 81,79 & 455,50 & 63,27 & 4,01 & 49,48 & 168,26 & 26,90 & 26,90 & 151,61 \\
\hline Alytes cisternasii & 30SVH54 & 100,00 & 152,54 & 119,68 & 36,80 & 6830,84 & 342,73 & 20,42 & 322,31 & 105,50 & 244,79 & 244,79 & 70,64 & 485,61 & 65,96 & 5,25 & 47,56 & 177,26 & 32,77 & 32,77 & 157,69 \\
\hline Alytes cisternasii & 30SVH55 & 100,00 & 144,77 & 121,94 & 37,00 & 6869,73 & 338,06 & 11,91 & 326,15 & 97,47 & 237,79 & 237,79 & 62,63 & 502,61 & 66,60 & 6,10 & 45,87 & 180,92 & 37,33 & 37,33 & 159,71 \\
\hline Alytes cisternasii & \begin{tabular}{|l|}
30 SVH56 \\
\end{tabular} & 100,00 & 144,76 & 122,97 & 37,00 & 6864,75 & 338,35 & 11,25 & 327,10 & 104,27 & 237,83 & 237,83 & 62,92 & 490,56 & 63,53 & 5,96 & 45,01 & 174,62 & 37,62 & 37,62 & 153,92 \\
\hline Alytes cisternasii & 30SVH62 & 100,00 & 164,73 & 114,86 & 36,16 & 6674,53 & 346,68 & 35,18 & 311,50 & 118,38 & 254,51 & 254,51 & 84,26 & 441,02 & 60,50 & 4,08 & 49,19 & 162,05 & 26,24 & 26,24 & 146,58 \\
\hline Alytes cisternasii & 30SVH63 & 100,00 & $\begin{array}{ll}164,47 \\
\end{array}$ & 116,01 & 36,64 & 6684,56 & 347,21 & 34,17 & 313,04 & 118,42 & 254,30 & 254,30 & 83,66 & 433,40 & 58,56 & 3,93 & 48,54 & 157,97 & 26,50 & 26,50 & 142,27 \\
\hline Alytes cisternasii & 30SVH64 & 100,00 & 154,19 & 119,16 & 36,95 & 6780,69 & 342,24 & 22,47 & 319,76 & 107,34 & 245,70 & 245,70 & 72,69 & 464,67 & 61,84 & 5,05 & 46,69 & 168,01 & 32,31 & 32,31 & 148,91 \\
\hline Alytes cisternasii & 30SVH65 & 100,00 & 145,01 & 121,56 & 37,00 & 6830,51 & 336,83 & 12,36 & 324,47 & 98,63 & 237,55 & 237,55 & 63,40 & 490,13 & 63,78 & 6,22 & 44,91 & 175,06 & 37,89 & 37,89 & 153,67 \\
\hline Alytes cisternasii & 30 SVH74 & 100,00 & 156,35 & 118,46 & 37,00 & 6713,76 & 341,89 & 24,83 & 317,06 & 109,79 & 246,80 & 246,80 & 75,59 & 442,10 & 57,42 & 4,87 & 45,98 & 158,07 & 31,52 & 31,52 & 139,85 \\
\hline Alytes cisternasii & 30SVH75 & 100,00 & 148,09 & 120,87 & 37,00 & 6772,70 & 337,37 & 15,63 & 321,74 & 110,62 & 239,64 & 239,64 & 66,96 & 466,38 & 59,56 & 5,92 & 44,41 & 165,41 & 36,67 & 36,67 & 144,59 \\
\hline Alytes cisternasii & 30 SVH76 & 100,00 & 142,16 & 122,42 & 37,00 & 6812,50 & 333,83 & 9,07 & 324,76 & 123,00 & 234,41 & 234,41 & 60,91 & 480,67 & 60,20 & 6,83 & 42,80 & 170,17 & 40,83 & 40,83 & 146,37 \\
\hline Alytes cisternasii & 30SVH97 & 100,00 & 139,67 & 122,69 & 37,56 & 6736,95 & 329,12 & 6,52 & 322,60 & 120,83 & 230,82 & 230,82 & 59,15 & 465,53 & 57,73 & 7,51 & 40,27 & 163,32 & 44,75 & 44,75 & 135,38 \\
\hline Alytes cisternasii & 30SVJOO & 100,00 & 148,87 & 127,44 & 38,00 & 6881,30 & 345,65 & 11,99 & 333,65 & 132,29 & 241,78 & 241,78 & 65,87 & 452,13 & 55,12 & 4,00 & 45,43 & 158,93 & 32,90 & 32,90 & 140,79 \\
\hline Alytes cisternasii & 30 SVJ05 & 100,00 & 130,97 & 123,47 & 37,00 & 6870,26 & 325,77 & $-2,56$ & 328,33 & 113,57 & 224,31 & 224,31 & 48,85 & 475,61 & 55,56 & 7,50 & 39,55 & 162,95 & 47,10 & 47,10 & 137,71 \\
\hline Alytes cisternasii & 30SVJ08 & 100,00 & 128,99 & 118,95 & 36,32 & 6836,28 & 319,54 & $-2,78$ & 322,32 & 111,71 & 221,98 & 222,00 & 47,55 & 465,26 & 54,82 & 9,07 & 37,28 & 155,83 & 51,08 & 51,10 & 130,69 \\
\hline Alytes cisternasii & 30SvJo9 & 100,00 & 139,00 & 117,17 & 36,00 & 6873,60 & 327,36 & 5,94 & 321.43 & $\mid 123,10$ & 232,25 & 232,25 & 56,13 & 423,66 & 49,44 & 8,03 & 37,47 & 140,40 & 45,81 & 45,81 & 118,53 \\
\hline Alytes cisternasii & 30SVJ15 & 100,00 & 133,32 & 123,81 & 37,00 & 6870,43 & 327,87 & $-0,78$ & 328,66 & 116,26 & 226,57 & 226,57 & 51,09 & 461,95 & 54,07 & 7,10 & 39,51 & 158,08 & 45,73 & 45,73 & 133,26 \\
\hline Alytes cisternasii & $30 \mathrm{SVJ} 23$ & 100,00 & 145,52 & 126,56 & 37,99 & 6840,83 & 340,04 & 8,74 & 331,30 & 129,61 & 237,74 & 237,74 & 62,74 & 420,08 & 50,24 & 4,60 & 42,20 & 145,53 & 36,85 & 36,85 & 123,39 \\
\hline Alytes cisternasii & $30 \mathrm{SVJ} 26$ & 100,00 & 131,86 & 122,48 & 37,00 & 6854,60 & 324,92 & $-1,52$ & 326,44 & 114,67 & 224,86 & 224,86 & 49,79 & 461,87 & 53,92 & 7,87 & 38,37 & 156,21 & 48,18 & 48,18 & 131,69 \\
\hline Alytes cisternasii & $30 \mathrm{SVJ} 36$ & 100,00 & 135,57 & 122,39 & 37,00 & 6858,08 & 328,01 & 1,46 & 326,55 & 118,81 & 228,45 & 228,45 & 53,19 & 446,68 & 51,84 & 7,35 & 38,52 & 150,40 & 46,07 & 46,07 & 127,53 \\
\hline Alytes cisternasii & 30SVJ37 & 100,00 & 139,10 & 120,68 & 36,88 & 6864,69 & 329,58 & 4,81 & 324,77 & 123,21 & 231,79 & 231,79 & 56,30 & 431,93 & 49,58 & 7,11 & 38,28 & 143,32 & 44,71 & 44,71 & 122,90 \\
\hline Alytes cisternasii & 30 SVJ44 & 100,00 & 134,94 & 124,47 & 37,18 & 6837,59 & 328,72 & 0,39 & 328,33 & 117,92 & 227,52 & 227,52 & 52,91 & 457,44 & 53,8 & 7,13 & 39,26 & 156,41 & 46,03 & 46,03 & 131,50 \\
\hline \begin{tabular}{|l} 
Alytes cisternasii \\
\end{tabular} & 305VKO0 & 100,00 & 142,08 & 115,15 & 35,59 & 6885,85 & 328,40 & 8,99 & \begin{tabular}{|l|}
319,41 \\
\end{tabular} & 126,45 & 235,29 & 235,29 & 58,85 & 410,00 & $\begin{array}{l}5,00 \\
47,49 \\
\end{array}$ & 8,07 & 36,99 & 134,34 & 45,10 & 45,10 & 114,06 \\
\hline Alytes cisternasii & 30SVK11 & 100,00 & 148,71 & 112,90 & 35,00 & 6894,10 & 332,38 & 15,75 & 316,62 & 106,71 & 241,81 & 241,81 & 64,72 & 390,78 & 44,25 & 7,80 & 37,00 & 127,62 & 42,60 & 42,60 & 109,72 \\
\hline Alytes cisternasii & 30 SVK20 & 100,00 & 141,35 & 115,29 & 35,82 & 6871,42 & 327,40 & 8,79 & 318,62 & 109,46 & 234,14 & 234,14 & 58,06 & 418,41 & 47,17 & 8,19 & 36,83 & 135,77 & 45,66 & 45,66 & 118,28 \\
\hline Alytes cisternasii & 30SVK31 & 100,00 & 146,79 & 113,32 & 35,32 & 6849,82 & 330,11 & 14,84 & 315,27 & 102,71 & 238,96 & 238,96 & 63,23 & 403,49 & 45,93 & 7,89 & 37,22 & 134,38 & 42,99 & 42,99 & 115,95 \\
\hline Alytes cisternasii & 30SWH06 & 100,00 & 138,07 & 121,96 & 37,75 & 6697,72 & 326,27 & 5,68 & 320,59 & 118,73 & 228,64 & 228,64 & 58,33 & 468,66 & 58,71 & 8,10 & 39,86 & 164,30 & 46,44 & 46,44 & 135,13 \\
\hline \begin{tabular}{|l} 
Alytes cisternasii \\
\end{tabular} & 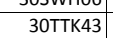 & 60,00 & 149,16 & 110,74 & 36,88 & 6409,49 & 324,89 & $\begin{array}{l}, 00 \\
26,98 \\
\end{array}$ & \begin{tabular}{|l|}
297,91 \\
\end{tabular} & 年 & 234,93 & \begin{tabular}{|l|}
234,934 \\
\end{tabular} & \begin{tabular}{|l|l|}
71,07 \\
\end{tabular} & $\begin{array}{l}468,07 \\
4680\end{array}$ & $\begin{array}{l}5,26 \\
57,26\end{array}$ & $\frac{1,10}{5,87}$ & $\begin{array}{l}3,11 \\
44,11\end{array}$ & 167,16 & 38,90 & 38,90 & 154,18 \\
\hline Alytes cisternasii & 30TTK49 & 40,00 & 115,98 & 109,66 & 37,29 & 6252,05 & 288,25 & $-1,39$ & 289,64 & 47,76 & 199,29 & 200,29 & 41,29 & 562,68 & 69,73 & 11,05 & 39,69 & 198,97 & 57,68 & 58,81 & 182,14 \\
\hline Alytes cisternasii & 30TTK64 & 100,00 & 125,55 & 110,94 & 36,79 & 6392,01 & 302,50 & 4,83 & 297,67 & 56,05 & 211,25 & 211,87 & 49,11 & 535,59 & 64,29 & 9,79 & 40,50 & 185,12 & 51,99 & 53,12 & 169,90 \\
\hline Alytes cisternasii & 30TTK69 & 100,00 & 116,55 & 112,76 & 38,00 & 6255,50 & 290,74 & $-2,36$ & 293,10 & 54,45 & 199,44 & 200,97 & 41,45 & 504,86 & 61,34 & 11,15 & 37,32 & 171,90 & 56,85 & 57,70 & 154,59 \\
\hline Alytes cisternasii & 30TTK75 & 100,00 & 81,44 & 107,65 & 36,44 & 6263,92 & 257,81 & $-33,16$ & 290,97 & 16,03 & 166,67 & 167,38 & 9,72 & 767,13 & 90,58 & 19,21 & 36,84 & 259,87 & 83,75 & 88,86 & 241,18 \\
\hline \begin{tabular}{|l} 
Alytes cisternasii \\
\end{tabular} & $\begin{array}{l}\text { 30TTK78 } \\
\end{array}$ & 100,00 & $\begin{array}{l}0,14,44 \\
114,63\end{array}$ & 112,80 & 37,91 & $\begin{array}{l}\mid 0203,152 \\
6271,61\end{array}$ & 289,86 & \begin{tabular}{|c|c|}
$-4,61$ \\
$-4,61$
\end{tabular} & \begin{tabular}{|l|}
294,47 \\
\end{tabular} & $\begin{array}{l}0,035 \\
55,68\end{array}$ & $\begin{array}{l}197,59 \\
197\end{array}$ & \begin{tabular}{|l|l|}
199,56 \\
\end{tabular} & \begin{tabular}{|l|l|}
39,69 \\
3
\end{tabular} & 504,84 & $\begin{array}{l}\mid c 0,30 \\
60,39 \\
\end{array}$ & $\begin{array}{ll}11,21,68 \\
11,\end{array}$ & $\begin{array}{l}0,044 \\
36,46\end{array}$ & 168,65 & $\begin{array}{l}57,1,96 \\
5,96\end{array}$ & $\begin{array}{l}59,24 \\
59,24\end{array}$ & $\begin{array}{l}241,10 \\
151,39\end{array}$ \\
\hline Alytes cisternasii & 30TTK79 & 100,00 & 116,93 & 113,89 & 38,05 & 6247,73 & 291,87 & $-2,66$ & 294,53 & 73,70 & 199,32 & 201,36 & 41,94 & 479,76 & 57,49 & 11,22 & 36,02 & 159,91 & 56,53 & 57,49 & 142,51 \\
\hline Alytes cisternasii & 30TTK88 & 100,00 & 115,08 & 113,70 & \begin{tabular}{|l|l|}
37,98 \\
\end{tabular} & 6268,39 & 290,92 & $-5,17$ & 296,09 & 72,80 & $\begin{array}{l}197,78 \\
\end{array}$ & 200,01 & 40,13 & 480,61 & 56,77 & 11,78 & 35,36 & 157,37 & 57,66 & 58,97 & 139,60 \\
\hline Alytes cisternasii & 30TTK94 & 100,00 & 150,38 & 114,48 & 37,00 & 6451,97 & 328,03 & 24,12 & 303,91 & 108,28 & 236,77 & 236,78 & 71,27 & 381,23 & 44,71 & 6,37 & 39,86 & 128,30 & 37,38 & 37,38 & 113,13 \\
\hline Alytes cisternasii & 30TTK98 & 100,00 & 111,33 & 113,54 & 37,94 & 6252,65 & 287,35 & $-8,85$ & 296,19 & 70,37 & 194,08 & 196,31 & 37,04 & 480,69 & 57,37 & 12,67 & 34,32 & 155,03 & 60,19 & 61,95 & 135,37 \\
\hline Alytes cisternasii & 30TTL58 & 100,00 & 118,25 & 114,45 & 39,00 & 6157,61 & 289,66 & $-1,44$ & 291,09 & 78,51 & \begin{tabular}{|l|}
199,50 \\
\end{tabular} & \begin{tabular}{|l|l|}
199,90 \\
\end{tabular} & 42,43 & 4 & 54,25 & 10,94 & 36,63 & 150,60 & 53,39 & 53,63 & 128,16 \\
\hline Alytes cisternasii & 30TTL59 & 100,00 & 120,08 & 114,38 & 38,99 & 6142,13 & 290,93 & $-0,17$ & 291,10 & 80,44 & 200,75 & 201,21 & 44,09 & 416,59 & 52,89 & 10,56 & 36,11 & 146,84 & 52,66 & 52,95 & 125,25 \\
\hline Alytes cisternasii & 30TTL60 & 100,00 & 114,36 & 113,21 & 38,01 & 6233,21 & 288,24 & $-4,33$ & 292,57 & 69,27 & 197,00 & 198,49 & 39,50 & 502,62 & 61,29 & 11,47 & 36,97 & 171,10 & 58,14 & 58,96 & 152,82 \\
\hline Alytes cisternasii & 30TTL69 & 100,00 & 122,06 & 115,03 & 39,00 & 6155,46 & 293,2 & 0,89 & 292,40 & 82,50 & 201,72 & 203,25 & 45,71 & 378,28 & 47,02 & 9,83 & 35,32 & 131,58 & 49,88 & 50,85 & 107,96 \\
\hline \begin{tabular}{|l} 
Alytes cisternasii \\
\end{tabular} & 30TTL72 & 100,00 & 116,09 & 116,63 & 39,11 & 6185,27 & 290,3 & \begin{tabular}{|c|c|}
$-3,85$ \\
\end{tabular} & 294,19 & 75,68 & $\begin{array}{l}198,19 \\
\end{array}$ & \begin{tabular}{|l|}
199,27 \\
\end{tabular} & \begin{tabular}{|l|l|}
41,39 \\
\end{tabular} & 4433,39 & 53,56 & $\begin{aligned}, 003 \\
11,38\end{aligned}$ & \begin{tabular}{|l|l|}
35,13 \\
\end{tabular} & 150,09 & 56,90 & 57,37 & 127,97 \\
\hline Alytes cisternasii & 30TTL73 & 100,00 & 120,48 & 118,22 & 39,59 & 6217,77 & 295,16 & $-0,53$ & 295,68 & 79,94 & 203,51 & 203,67 & 44,79 & 414,32 & 50,82 & 10,99 & 35,68 & 142,51 & 53,90 & 53,97 & 118,64 \\
\hline Alytes cisternasii & 30TTL75 & 100,00 & 118,36 & 117,62 & 39,62 & 6170,04 & 292,09 & $\begin{array}{l}-1,89 \\
\end{array}$ & 293,97 & 78,08 & 200,76 & 200,92 & 43,20 & \begin{tabular}{|l|l|}
394,29 \\
\end{tabular} & 49,00 & 11,00 & 36,49 & 137,82 & 53,90 & 53,96 & 108,48 \\
\hline Alytes cisternasii & 30TTL76 & 100,00 & 115,98 & 116,93 & 39,04 & 6154,60 & 289,42 & $-4,00$ & 293,42 & 75,96 & 197,03 & 198,15 & 40,83 & 399,35 & 49,00 & 11,38 & 35,69 & 138,35 & 54,94 & 55,48 & 110,35 \\
\hline Alytes cisternasii & 30TTL87 & 100,00 & 117,45 & 117,01 & 39,01 & 6128,10 & 290,28 & $-3,02$ & 293,30 & 77,47 & 196,72 & 199,04 & 42,31 & 381,31 & 46,22 & 11,59 & 33,62 & 128,43 & 54,19 & 55,82 & 103,11 \\
\hline \begin{tabular}{|l|l} 
Alytes cisternasii \\
\end{tabular} & 30TTL91 & 100,00 & $\begin{array}{l}11,45 \\
117,60\end{array}$ & 1116,18 & 39,01 & 6136 & 291 & $\begin{array}{l}-2,04 \\
-2,71\end{array}$ & \begin{tabular}{|l|}
294,00 \\
294
\end{tabular} & 77,22 & 197,47 & 200,64 & 43,65 & 418,35 & 50,18 & 11,39 & 32,73 & 133,71 & 56,42 & 58,07 & 115,02 \\
\hline Alytes cisternasii & 30TTM50 & 100,00 & 118,92 & 114,25 & 39,00 & 6119,15 & 289,53 & $-1,20$ & 290,73 & 79,56 & 199,50 & 199,86 & 43,12 & 425,39 & 54,04 & 11,10 & 35,80 & 150,07 & 54,46 & 54,70 & 128,83 \\
\hline Alytes cisternasii & 30TTM60 & 100,00 & 120,34 & 115,00 & 39,00 & 6131,49 & 291,38 & $-0,43$ & 291,81 & 80,93 & 199,72 & 201,24 & 44,30 & 389,94 & 48,50 & 10,63 & 34,65 & 135,93 & 52,24 & 53,13 & 112,21 \\
\hline Alytes cisternasii & 30TUKO3 & 100,00 & 156,90 & 114,99 & 37,00 & 6503,86 & 335,39 & 28,88 & 306,51 & 114,68 & 243,94 & 243,94 & 76,89 & 361,34 & 42,13 & 5,25 & 40,71 & 122,40 & 33,81 & 33,81 & 106,76 \\
\hline Alytes cisternasii & 30TUK04 & 100,00 & 152,48 & 114,92 & 37,00 & 6473,37 & 330,21 & 25,06 & 305,15 & 110,58 & 239,14 & 239,14 & 72,90 & 365,59 & 42,55 & 6,31 & 39,21 & 122,56 & 36,52 & 36,52 & 106 \\
\hline \begin{tabular}{|l} 
Alytes cisternasii \\
\end{tabular} & $\begin{array}{l}\text { 30TUK08 } \\
\end{array}$ & $\begin{array}{l}100,00 \\
\end{array}$ & $\begin{array}{l}13,40 \\
105,93 \\
\end{array}$ & 114,52 & 37,83 & 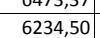 & $\begin{array}{l}30,21 \\
282,07\end{array}$ & $\begin{array}{l}2.2,00 \\
-14,19 \\
\end{array}$ & \begin{tabular}{|l|l|}
296,26 \\
296
\end{tabular} & \begin{tabular}{|l|l|}
64,14 \\
64
\end{tabular} & \begin{tabular}{|l|}
188,86 \\
18,8
\end{tabular} & \begin{tabular}{|l|}
190,86 \\
19,4
\end{tabular} & $\begin{array}{ll}32,37 \\
32\end{array}$ & \begin{tabular}{|l|l|}
495,59 \\
4959
\end{tabular} & \begin{tabular}{|c|}
60,24 \\
60,
\end{tabular} & $0,14,20$ & \begin{tabular}{|l|l}
33,61 \\
33,
\end{tabular} & 157,74 & $\begin{array}{l}00,54 \\
64,29\end{array}$ & $\begin{array}{l}0,32 \\
66,78 \\
\end{array}$ & $\begin{array}{l}136,18 \\
136,18\end{array}$ \\
\hline Alytes cisternasii & 30TUK13 & 100,00 & 153,80 & 115,00 & 37,00 & 6529,68 & 332,82 & 25,31 & 307,51 & $\mid \begin{array}{l}111,49 \\
\end{array}$ & 241,18 & 241,18 & 73,63 & 362,19 & $\mid 41,65$ & 5,97 & 39,65 & 121,37 & 35,44 & 35,44 & 104,84 \\
\hline 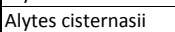 & 30TUK14 & 100,00 & 151,35 & 114,68 & 37,00 & 6499,67 & 329,40 & 23,35 & 306,06 & 109,40 & 238,49 & 238,49 & 71,49 & 361,03 & 41,78 & 6,41 & 38,95 & 120,26 & 36,98 & 36,98 & 103,24 \\
\hline Alytes cisternasii & 30TUK19 & 100,00 & 92,96 & 111,70 & 37,53 & 6162,45 & 268,20 & $-25,55$ & 293,75 & 55,26 & 175,56 & 177, & 21, & 536,76 & 66,86 & 17,20 & 32 & 168,07 & 73,77 & 77,81 & 143,09 \\
\hline Alytes cisternasii & 30TUK23 & 100,00 & 151,83 & 114,95 & 37,00 & 6558,41 & 331,25 & 23,05 & 308,19 & 109,52 & 239,88 & 239,88 & 71,45 & 361,57 & 41,58 & 6,19 & 39,18 & 120,32 & 36,54 & 36,54 & 102,94 \\
\hline
\end{tabular}




\begin{tabular}{|c|c|c|c|c|c|c|c|c|c|c|c|c|c|c|c|c|c|c|c|c|c|}
\hline TAXON & UTM & $\mathrm{km2}$ & B101 & $\mathrm{B1O2}$ & $\mathrm{BIO3}$ & B104 & B105 & B106 & B107 & B108 & B109 & 81010 & B1011 & BIO12 & BIO13 & 81014 & B1015 & B1O16 & B1017 & BIO18 & B1019 \\
\hline Alytes cisternasii & 30TUK24 & 100,00 & 148,45 & 114,23 & 37,00 & 6501,82 & 326,70 & 20,22 & 306,48 & 106,40 & 235,77 & 235,77 & 68,69 & 362,49 & 42,40 & 6,90 & 38,08 & 119,71 & 38,77 & 38,77 & 101,54 \\
\hline Alytes cisternasii & 30TUK29 & 100,00 & 97,39 & 111,69 & $\begin{array}{l}37,25 \\
\end{array}$ & 6172,59 & 272,32 & $-22,07$ & 294,39 & 77,13 & 179,98 & 181,63 & 24,99 & 497,97 & 64,06 & 16,68 & 32,32 & 155,57 & 71,03 & 74,46 & 127,42 \\
\hline Alytes cisternasii & 30TUK33 & 100,00 & 148,26 & 114,36 & 36,68 & 6573,51 & 328,10 & 19,23 & 308,86 & 110,18 & 236,68 & 236,68 & 67,90 & 366,73 & 43,08 & 6,69 & 38,38 & 120,75 & 38,74 & 38,74 & 102,31 \\
\hline Alytes cisternasii & 30TUK35 & 100,00 & 129,37 & 113,05 & 36,90 & 6435,29 & 307,23 & 3,53 & 303,71 & 102,52 & 215,81 & 216,31 & 51,82 & 408,73 & 50,69 & 10,20 & 35,68 & 132,82 & 50,62 & 51,16 & 108,39 \\
\hline Alytes cisternasii & 30TUK39 & 100,00 & 104,10 & 111,62 & 37,10 & 6184,29 & 278,08 & $-17,14$ & 295,22 & 97,69 & 186,34 & 188,11 & 30,71 & 449,96 & 60,10 & 15,34 & 32,89 & 142,87 & 66,47 & 69,05 & 109,53 \\
\hline Alytes cisternasii & 30TUK43 & 100,00 & 145,94 & 114,02 & 36,11 & 6601,61 & 326,07 & $\begin{array}{ll}16,37 \\
\end{array}$ & 309,70 & 117,03 & 234,62 & 234,62 & 65,32 & 370,04 & 44,08 & 7,20 & 37,97 & 121,24 & 40,37 & 40,37 & 101,62 \\
\hline Alytes cisternasii & 30TUK44 & 100,00 & 137,53 & 113,39 & 36,27 & 6544,31 & 316,55 & 9,15 & 307,40 & 116,17 & 225,59 & 225,62 & 57,96 & 384,04 & 47,22 & 8,61 & 36,50 & 125,24 & 45,59 & 45,61 & 102,26 \\
\hline Alytes cisternasii & 30TUK45 & 100,00 & 146,31 & 112,88 & 36,51 & 6512,57 & 323,18 & $\begin{array}{ll}17,87 \\
17\end{array}$ & 305,31 & 107,34 & 233,69 & 233,69 & 66,26 & 353,29 & 42,51 & 7,55 & 37,12 & 115,64 & 40,71 & 40,71 & 94,95 \\
\hline Alytes cisternasii & 30TUK48 & 100,00 & 88,76 & 110,42 & 37,00 & 6176,06 & 264,24 & $-29,81$ & 294,05 & 71,09 & 172,36 & 173,36 & 17,44 & 539,78 & 70,30 & 18,85 & 31,91 & 171,63 & 78,73 & 83,12 & 134,92 \\
\hline Alytes cisternasii & 30TUK49 & 100,00 & 106,49 & 110,67 & 37,00 & 6192,96 & 279,53 & $-15,58$ & 295,10 & 120,31 & 188,72 & 190,49 & 32,85 & 428,51 & 58,98 & 14,66 & 33,71 & 138,90 & 64,95 & 67,18 & 100,21 \\
\hline Alytes cisternasii & 30TUK53 & 100,00 & 150,74 & 113,37 & 36,00 & 6632,21 & 330,08 & 20,54 & 309,54 & 109,54 & 239,77 & 239,77 & 69,22 & 357,35 & 42,01 & 6,85 & 38,16 & 117,52 & 38,30 & 38,30 & 98,42 \\
\hline Alytes cisternasii & 30TUK55 & 100,00 & 140,85 & 112,00 & 36,01 & 6541,56 & 318,01 & 12,68 & 305,33 & 110,79 & 228,88 & 228,88 & 60,92 & 365,31 & 44,80 & 8,45 & 35,97 & 118,38 & 44,29 & 44,29 & 96,25 \\
\hline Alytes cisternasii & 30TUK56 & 100,00 & 118,29 & 111,17 & 36,41 & 6398,64 & 294,72 & $-5,92$ & 300,64 & 92,11 & 204,53 & 204,95 & 41,94 & 438,19 & 55,93 & 12,85 & 34,18 & 141,45 & 59,34 & 60,68 & 111,31 \\
\hline Alytes cisternasii & 30TUK57 & 100,00 & 117,59 & 110,53 & 36,51 & 6344,52 & 292,32 & $-6,49$ & 298,81 & 102,44 & 202,68 & 203,47 & 41,46 & 410,25 & 54,77 & 12,60 & 34,25 & 132,62 & 58,94 & 59,81 & 98,93 \\
\hline Alytes cisternasii & 30TUK59 & 100,00 & 103,59 & 109,52 & 36,96 & 6183,07 & 275,94 & $-17,90$ & 293,85 & 121,31 & 186,10 & 187,49 & 30,31 & 432,48 & 60,85 & 15,26 & 34,09 & 142,54 & 67,51 & 69,93 & 97,73 \\
\hline Alytes cisternasii & 30TUK63 & 100,00 & 151,11 & 112,77 & 36,00 & 6661,99 & 330,47 & 20,64 & 309,84 & 108,24 & 240,56 & 240,56 & 69,26 & 357,44 & 41,84 & 7,00 & 37,62 & 117,66 & 38,88 & 38,88 & 98,11 \\
\hline Alytes cisternasii & 30TUK64 & 100,00 & 143,47 & 111,86 & 36,00 & 6613,83 & 321,64 & 14,24 & 307,40 & 113,18 & 232,51 & 232,51 & 62,66 & 368,43 & 44,41 & 8,08 & 36,43 & 120,08 & 43,36 & 43,36 & 98,32 \\
\hline Alytes cisternasii & 30TUK65 & 100,00 & 132,66 & 111,17 & 36,00 & 6534,47 & 309,78 & 5,08 & 304,70 & 113,12 & 220,75 & 220,75 & 53,25 & 387,33 & 48,71 & 9,88 & 35,14 & 125,27 & 49,91 & 49,91 & 99,34 \\
\hline Alytes cisternasii & 30TUK66 & 100,00 & 113,97 & 110,31 & 36,34 & 6387,97 & 290,11 & $-9,62$ & 299,73 & 93,62 & 200,12 & 200,66 & 38,09 & 443,80 & 57,94 & 13,48 & 33,95 & 143,79 & 62,19 & 63,67 & 109,62 \\
\hline Alytes cisternasii & 30TUK69 & 100,00 & 100,89 & 108,38 & 36,53 & 6170,98 & 272,44 & $-20,11$ & 292.55 & $\mid 118,39$ & 183,75 & $\mid 184,77$ & 28,19 & $\mid 441.47$ & 62,70 & $\mid 16,10$ & 34,16 & 146,82 & 70,40 & 73,12 & 97,69 \\
\hline Alytes cisternasii & 30TUK74 & 100,00 & 148,29 & 111,08 & 35,77 & 6661,16 & 326,08 & 18,42 & 307,66 & 106,53 & 237,77 & 237,77 & 66,49 & 360,88 & 42,33 & 7,73 & 36,76 & 118,60 & 41,34 & 41,34 & 97,94 \\
\hline Alytes cisternasii & 30TUK75 & 100,00 & 136,04 & 110,17 & 35,75 & 6585,37 & 312,70 & 8,06 & 304,64 & 107,44 & 224,68 & 224,68 & 55,91 & 383,44 & 47,17 & 9,64 & 35,07 & 123,98 & 48,72 & 48,72 & 99,62 \\
\hline Alytes cisternasii & 30TUK76 & 100,00 & 126,44 & 109,29 & 35,91 & 6486,12 & 301,51 & 0,41 & 301,10 & 104,01 & 213,75 & 214,03 & 48,02 & 399,10 & 51,13 & 11,25 & 34,41 & 128,63 & 54,68 & 54,91 & 99,41 \\
\hline Alytes cisternasii & 30TUK77 & 100,00 & 128,57 & 108,45 & 35,97 & 6458,48 & 301,79 & 2,79 & 299,00 & 98,53 & 215,16 & 215,53 & 50,03 & 387,77 & 49,53 & 11,21 & 34,19 & 124,92 & 53,75 & 54,05 & 96,10 \\
\hline Alytes cisternasii & 30TUK85 & 100,00 & 145,18 & 109,17 & 35,10 & 6648,13 & 321,11 & 16,44 & 304,68 & 102,51 & 234,40 & 234,40 & 63,61 & 368,66 & 42,96 & 8,57 & 35,71 & 121,13 & 43,99 & 43,99 & 99,45 \\
\hline Alytes cisternasii & 30TUK86 & 100,00 & 133,66 & 108,22 & 35,36 & 6561,83 & 308,14 & 6,79 & 301,35 & 98,74 & 221,89 & 222,00 & 53,67 & 390,65 & 47,58 & 10,50 & 34,35 & 125,95 & 51,28 & 51,34 & 101,24 \\
\hline \begin{tabular}{|l} 
Alytes cisternasii \\
\end{tabular} & $\begin{array}{l}\text { 30TUK87 } \\
\end{array}$ & 100,00 & 133,51 & 107,34 & 35,38 & 6530,87 & 306,06 & 7,06 & 299,00 & 93,52 & 220,89 & 221,09 & 53,58 & 385,86 & $\begin{array}{l}47,13 \\
470\end{array}$ & 10,80 & 34,08 & 124,41 & 51,68 & 51,78 & 99,15 \\
\hline Alytes cisternasii & 30TUK88 & 100,00 & 120,92 & 106,42 & 35,70 & 6408,92 & 291,84 & $-2,97$ & 294,81 & 109,49 & 205,88 & 207,34 & 43,50 & 407,06 & 52,75 & 12,92 & 33,55 & 130,32 & 59,09 & 60,40 & 98,12 \\
\hline Alytes cisternasii & 30TUK95 & 100,00 & 145,68 & 108,31 & 35,00 & 6683,45 & 321,35 & 16,88 & 304,47 & 102,77 & 235,29 & 235,29 & 63,46 & 376,91 & 43,02 & 8,79 & 35,68 & 124,77 & 44,47 & 44,47 & 103,72 \\
\hline Alytes cisternasii & 30TUK96 & 100,00 & 142,41 & 107,19 & 35,01 & 6629,52 & 316,24 & 14,88 & 301,36 & 100,00 & 231,30 & 231,30 & 60,84 & 380,83 & 44,26 & 9,53 & 35,10 & 125,81 & 46,72 & 46,72 & 103,71 \\
\hline Alytes cisternasii & 30TUK97 & 100,00 & 130,01 & 106,23 & 35,08 & 6535,23 & 302,11 & 4,72 & 297,39 & 91,01 & 217,24 & 217,90 & 50,46 & 406,46 & 48,70 & 11,65 & 33,54 & 131,35 & 54,53 & 54,97 & 105,93 \\
\hline \begin{tabular}{|l} 
Alytes cisternasii \\
\end{tabular} & 30TUK98 & 100,00 & 117,08 & 105,55 & 35,46 & |6424,03 & 287,68 & $\begin{array}{ll}-5,43 \\
-5,43\end{array}$ & 293,11 & $\begin{array}{ll}1,2,36 \\
92,\end{array}$ & $\begin{array}{l}202,24 \\
20\end{array}$ & 203,76 & 39,80 & $\begin{array}{l}433,53 \\
43\end{array}$ & 54,70 & \begin{tabular}{l|l}
14,08 \\
14,
\end{tabular} & 32,57 & \begin{tabular}{|l|}
137,60 \\
13,0
\end{tabular} & $\begin{array}{l}4,23 \\
62,24 \\
\end{array}$ & 64,39 & 106,93 \\
\hline Alytes cisternasii & 30TUK99 & 100,00 & 96,32 & 106,41 & $\begin{array}{l}36,45 \\
\end{array}$ & 6227,65 & 266,97 & $-21,79$ & 288,76 & 105,56 & 180,69 & 181,32 & 24,05 & 503,34 & 65,66 & 18,77 & 31,15 & 161,06 & 76,80 & 81,29 & 120,12 \\
\hline Alytes cisternasii & 30TULO9 & 100,00 & 124,48 & 117,00 & 39,01 & 6110,66 & 296,34 & 1,98 & 294,37 & 85,50 & 202,91 & 205,33 & 48,39 & 362,45 & 42,43 & 11,87 & 31,51 & 119,34 & 53,11 & 55,39 & 96,87 \\
\hline Alytes cisternasii & 30TUL11 & 100,00 & 112,50 & 114,35 & 38,20 & 6142,97 & 285,96 & $-8,51$ & 294,47 & 77,47 & 193,01 & 195,76 & 38,67 & 418,29 & 52,93 & 12,89 & 32,10 & 130,44 & 59,94 & 62,39 & 107,87 \\
\hline Alytes cisternasii & \begin{tabular}{|l|} 
30TUL18 \\
\end{tabular} & 100,00 & 123,31 & 116,90 & 39,00 & 6114,50 & 295,28 & 1,28 & 293,99 & 83,96 & 201,97 & 204,40 & 47,29 & 368,44 & 43,48 & 11,85 & 31,01 & 118,60 & 53,89 & 56,66 & 98,44 \\
\hline \begin{tabular}{|l} 
Alytes cisternasii \\
\end{tabular} & $\begin{array}{l}\text { 30TUL22 } \\
\end{array}$ & 100,00 & $\begin{array}{ll}12,313,64 \\
113,64\end{array}$ & 113,85 & 38,04 & $\mid 6132,68$ & 286,00 & $\begin{array}{r}-1,20 \\
-7,79 \\
\end{array}$ & \begin{tabular}{|l|}
293,79 \\
\end{tabular} & \begin{tabular}{|l|}
130,43 \\
10,4
\end{tabular} & \begin{tabular}{|l|}
193,77 \\
\end{tabular} & $\begin{array}{l}196,52 \\
196,4\end{array}$ & $\begin{array}{l}41,25 \\
39,75 \\
\end{array}$ & \begin{tabular}{|l|}
4001,84 \\
401,84
\end{tabular} & $\begin{array}{l}35,406 \\
51,69\end{array}$ & \begin{tabular}{l|l}
1,2039 \\
12,96
\end{tabular} & $\frac{1,01}{31,82}$ & $\begin{array}{l}125,55 \\
125\end{array}$ & $\begin{array}{l}5,090 \\
59,50\end{array}$ & $\frac{62,28}{62,28}$ & $\begin{aligned} 50,44 \\
100,61\end{aligned}$ \\
\hline Alytes cisternasii & 30TUL23 & 100,00 & 116,90 & 114,53 & 38,55 & 6121,92 & 288,76 & $-4,31$ & 293,07 & 129,16 & 196,38 & 199,30 & 42,62 & 388,19 & 49,19 & 12,16 & 31,45 & 120,77 & 57,43 & 60,30 & 98,07 \\
\hline Alytes cisternasii & 30TUL29 & 100,00 & 124,35 & 116,46 & 39,00 & 6110,26 & 295,87 & 1,75 & 294,12 & 85,78 & 202,97 & 205,22 & 47,91 & 377,03 & 44,03 & 12,18 & 30,50 & 120,93 & 54,84 & 58,46 & 101,84 \\
\hline Alytes cisternasii & 30TUL39 & 100,00 & 124,29 & 115,97 & 39,00 & 6127,98 & 295,91 & 2,29 & 293,62 & 85,70 & 203,32 & 205,50 & 47,89 & 385,62 & 44,94 & 12,25 & 30,20 & 122,30 & 55,58 & 59,60 & 105,06 \\
\hline Alytes cisternasii & 30TUL50 & 100,00 & 106,06 & 109,31 & 36,96 & 6168,92 & 277,19 & $-15,90$ & 293,08 & 124,70 & 188,09 & 189,54 & 32,53 & 414,73 & 58,77 & 15,01 & 34,32 & 137,72 & 65,86 & 68,31 & 92,25 \\
\hline Alytes cisternasii & 30TUL54 & 100,00 & 119,36 & 110,76 & 37,59 & 6209,85 & 288,73 & $-2,57$ & 291,29 & 140,60 & 200,38 & 202,50 & 43,13 & 386,54 & 49,22 & 12,74 & 31,26 & 122,31 & 57,77 & 61,86 & 95,20 \\
\hline Alytes cisternasii & 30TUL5 & 100,00 & 122,10 & 112,07 & 38,00 & 6182,96 & 291,54 & $-0,10$ & 291,64 & 108,31 & 202,33 & 204,53 & 45,69 & 388,29 & 47,19 & 12,05 & 30,90 & 120,47 & 56,23 & 61,05 & 100,49 \\
\hline Alytes cisternasii & 30TUL57 & 100,00 & 123,07 & 112,78 & 38,02 & 6181,97 & 293,06 & 0,34 & 292,72 & 84,41 & 203,18 & 205,50 & 46,37 & 391,90 & 46,43 & 12,03 & 30,66 & 121,94 & 56,41 & 61,21 & 103,59 \\
\hline Alytes cisternasii & 30TUL58 & 100,00 & 123,85 & 113,52 & 38,29 & 6158,24 & 294,08 & 1,67 & 292,41 & 85,56 & 203,82 & 205,75 & 47,39 & 397,03 & 46,06 & 12,08 & 30,10 & 123,65 & 56,97 & 61,73 & 106,99 \\
\hline \begin{tabular}{|l} 
Alytes cisternasii \\
\end{tabular} & $\begin{array}{l}\text { 30TUL59 } \\
\end{array}$ & 100,00 & 124,59 & 114,18 & 38,41 & 6141,55 & 294,91 & 2,19 & 292,73 & $\begin{array}{l}86,62 \\
86,\end{array}$ & \begin{tabular}{|l|}
203,97 \\
\end{tabular} & 205,89 & 47,84 & \begin{tabular}{|l|l|}
403,19 \\
\end{tabular} & 46,57 & $\begin{array}{ll}12,80 \\
12\end{array}$ & 29,82 & 125,94 & 57,73 & 62,66 & 110,59 \\
\hline Alytes cisternasii & 30TULE & 100,00 & 104 & 107,76 & 36,22 & 6148,58 & 274,42 & $-17,22$ & 291,64 & 122,81 & 186,65 & 187,74 & 31,39 & 412,56 & 60,01 & 15,35 & 35,14 & 139,47 & 67,69 & 70,06 & 87,97 \\
\hline Alytes cisternasii & 30TUL63 & 100,00 & 116,76 & 108,44 & 36,98 & 6228,86 & 284,87 & $-5,48$ & 290,36 & 137,23 & 198,50 & 200,40 & 40,95 & 395,52 & 51,62 & 13,19 & 32,04 & 127,21 & 60,18 & 64,31 & 94,06 \\
\hline Alytes cisternasii & 30TUL70 & 100,00 & 95,84 & 107,16 & 36,46 & 6136,64 & 265,89 & $-23,49$ & 289,38 & 112,59 & 178,64 & 179,37 & 24,13 & 465,38 & 65,18 & 17,91 & 33,21 & 154,68 & 75,01 & 79,26 & 103,41 \\
\hline Alytes cisternasii & 30TUL71 & 100,00 & 106,17 & 106,36 & 36,08 & 6191,89 & 274,05 & $-15,29$ & 289,34 & 124,98 & 188,57 & 189,81 & 32,22 & 418,26 & 58,89 & 15,86 & 34,05 & 140,14 & 67,73 & 71,37 & 91,20 \\
\hline \begin{tabular}{|l} 
Alytes cisternasii \\
\end{tabular} & 30TUL81 & 100,00 & 10 & 104,96 & 35,99| & $\begin{array}{l}\mid 6154,130 \\
6247\end{array}$ & 272,87 & $\begin{array}{l}-14,25 \\
-14,65\end{array}$ & \begin{tabular}{|l|}
287,52 \\
28,
\end{tabular} & \begin{tabular}{|l|}
124,39 \\
124
\end{tabular} & \begin{tabular}{|l|}
189,19 \\
189
\end{tabular} & \begin{tabular}{|l|}
190,15 \\
1901
\end{tabular} & $\begin{array}{l}32,2<4 \\
31,43\end{array}$ & \begin{tabular}{|l|}
440,81 \\
40,0
\end{tabular} & $\begin{array}{l}\mid 0,030 \\
59,41\end{array}$ & $\begin{array}{l}\mid 0,00 \\
16,20\end{array}$ & 32,55 & \begin{tabular}{|l|}
$144,80,80$ \\
\end{tabular} & $\begin{array}{l}69,11 \\
69\end{array}$ & $\begin{array}{ll}1,131 \\
73,87\end{array}$ & $\begin{array}{l}51,20 \\
100,32\end{array}$ \\
\hline Alytes cisternasii & 30TUL89 & 100,00 & 115,78 & 109,77 & 37,20 & 6117,25 & 282,95 & $-6,84$ & 289,78 & 126,76 & 196,10 & 197,42 & 40,47 & 440,64 & 51,64 & 14,72 & 28,99 & 135,42 & 63,55 & 73,62 & 114,46 \\
\hline Alytes cisternasii & 30TUL91 & 100,00 & 103,04 & 104,20 & 36,11 & 6268,38 & 269,75 & $-15,97$ & 285,72 & 120,93 & 187,10 & 187,99 & 28,96 & 474,41 & 61,07 & 16,82 & 31.16 & $\mid 152,40$ & 72,34 & 78,09 & 112,79 \\
\hline Alytes cisternasii & 30TUMOO & 100,00 & 121,52 & 117,00 & 39,00 & 6099,22 & 293,63 & $-0,48$ & 294,12 & 82,95 & 199,86 & 202,31 & 45,59 & 376,10 & 44,12 & 12,70 & 31,45 & 124,40 & 55,38 & 58,17 & 101,02 \\
\hline Alytes cisternasii & 30TUM40 & 100,00 & 122,15 & 115,78 & 39,00 & 6114,58 & 293,78 & 0,52 & 293,26 & 78,23 & 201,19 & 203 & 45,84 & 410,07 & 47,6 & 13,35 & 29,65 & 129,07 & 58,92 & 63,97 & 113 \\
\hline \begin{tabular}{|l} 
Alytes cisternasii \\
\end{tabular} & 30TUM50 & 100,00 & $\begin{array}{l}124,15 \\
124,34\end{array}$ & $\begin{array}{l}1114,90 \\
114,90\end{array}$ & 38,89 & $\begin{array}{l}\mid 614,40 \\
6106,90\end{array}$ & $\begin{array}{l}295,10 \\
295,01\end{array}$ & $\frac{0,32}{2,06}$ & \begin{tabular}{|l|}
292,94 \\
292
\end{tabular} & $\begin{array}{l}0,23 \\
62,07 \\
\end{array}$ & \begin{tabular}{|l|}
203,37 \\
20
\end{tabular} & \begin{tabular}{|l|}
205,14 \\
2010
\end{tabular} & $\begin{array}{l}45,94 \\
47,94 \\
\end{array}$ & \begin{tabular}{|l|l|}
412,16 \\
\end{tabular} & \begin{tabular}{|l|}
47,900 \\
47,90
\end{tabular} & \begin{tabular}{|l|}
13,03 \\
13,03
\end{tabular} & $\begin{array}{l}29,80 \\
29,8\end{array}$ & \begin{tabular}{|l|}
130,10 \\
130
\end{tabular} & \begin{tabular}{|l|l|}
58,24 \\
58,
\end{tabular} & $\begin{array}{l}5,54 \\
63,54 \\
\end{array}$ & $\begin{array}{l}111,05 \\
115,23\end{array}$ \\
\hline Alytes cisternasii & 30TUM70 & 100,00 & 120,65 & 112,09 & 38,00 & 6069,25 & 288,93 & $-2,75$ & 291,68 & 88,68 & 199,90 & 201,46 & 45,47 & 426,42 & 49,18 & 14,18 & 29,31 & 132,47 & 60,36 & 69,57 & 113,54 \\
\hline 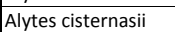 & 30TVK06 & 100,00 & 142,47 & 106,21 & 35,00 & 6653,52 & 315,94 & 15,49 & 300,45 & 99,92 & 231,60 & 231,60 & 60,65 & 393,55 & 45,92 & 9,78 & 35,14 & 131,53 & 47,31 & 47,31 & 110,19 \\
\hline Alytes cisternasii & 30TVK07 & 100,00 & 138,22 & 105,19 & 35,00 & 6599,22 & 309,76 & 12,52 & 297,24 & 95,99 & 226,14 & 226 & 57, & 400,96 & 47,07 & 10,68 & 34,48 & 133,24 & 50,14 & 50,30 & 110 , \\
\hline Alytes cisternasii & 30TVK08 & 100,00 & 124,39 & 104,41 & 35,06 & 6501,56 & 294,21 & 1,24 & 292,97 & 83,41 & 209,89 & 211,86 & 45,44 & 432,64 & 51,12 & 13,14 & 32,69 & 139,51 & 58,66 & 60,32 & 113,69 \\
\hline
\end{tabular}




\begin{tabular}{|c|c|c|c|c|c|c|c|c|c|c|c|c|c|c|c|c|c|c|c|c|c|}
\hline TAXON & UTM & $\mathrm{km} 2$ & B101 & B102 & $\mathrm{BIO3}$ & 8104 & B105 & B106 & B107 & B108 & B109 & BIO10 & B1011 & BIO12 & B1013 & BIO14 & BIO15 & B1016 & B1017 & B1018 & B1019 \\
\hline Alytes cisternasii & 30TVK09 & 100,00 & 113,60 & 104,19 & 35,39 & 6407,64 & 282,44 & $-7,01$ & 289,45 & 85,27 & 198,75 & 200,05 & 36,88 & 464,05 & 56,18 & 15,15 & 31,66 & 147,87 & 65,86 & 69,08 & 118,12 \\
\hline Alytes cisternasii & 30TVK15 & 100,00 & 142,04 & 106,75 & \begin{tabular}{|l|l|}
34,97 \\
\end{tabular} & 6705,94 & 317,49 & 14,75 & 302,73 & 99,14 & 231,96 & 231,96 & 59,81 & 408,66 & 47,75 & 9,86 & 35,56 & 137,26 & 47,68 & 47,68 & 117,06 \\
\hline Alytes cisternasii & 30TVK16 & 100,00 & 139,82 & 105,44 & 34,99 & 6661,84 & 313,12 & 13,97 & 299,15 & 97,24 & 229,09 & 229,09 & 58,00 & 414,38 & 49,04 & 10,47 & 35,36 & 139,58 & 49,25 & 49,25 & 118,99 \\
\hline Alytes cisternasii & 30TVK17 & 100,00 & 138,91 & 104,25 & 34,96 & 6616,96 & 310,09 & 13,86 & 296,23 & 96,55 & 227,31 & 227,31 & 57,37 & 414,99 & 49,71 & 10,90 & 35,08 & 140,19 & 50,32 & 50,32 & 118,99 \\
\hline Alytes cisternasii & 30TVK18 & 100,00 & 131,85 & 103,41 & \begin{tabular}{|l|l|}
34,97 \\
\end{tabular} & \begin{tabular}{|l|l|}
6562,13 \\
\end{tabular} & 301,39 & 8,21 & 293,18 & 90,01 & 218,54 & 219,79 & 51,45 & 430,06 & 51,12 & 11,99 & 33,87 & 143,24 & 54,72 & 55,46 & 120,27 \\
\hline Alytes cisternasii & 30TVK19 & 100,00 & 122,10 & 103,03 & 35,01 & 6504,33 & 290,27 & 0,24 & 290,03 & 80,60 & 207,63 & 209,40 & 43,13 & 452,22 & 52,58 & 13,31 & 32,24 & 146,66 & 60,58 & 63,19 & 121,45 \\
\hline Alytes cisternasii & 30TVK28 & 100,00 & 134,52 & 102,71 & 34,77 & 6590,42 & 303,93 & 11,24 & 292,69 & 92,35 & 222,28 & 222,54 & 53,49 & 438,63 & 53,81 & 11,70 & 34,89 & 149,35 & 53,68 & 53,80 & 127,92 \\
\hline Alytes cisternasii & $\begin{array}{l}30 \text { TVK29 } \\
\end{array}$ & 100,00 & 123,83 & 102,72 & 35,00 & 6522,81 & 292,25 & 2,43 & 289,82 & 82,35 & 209,81 & 211,40 & 44,65 & 461,17 & 55,11 & 13,13 & 33,00 & 152,18 & 60,21 & 62,15 & 128,16 \\
\hline Alytes cisternasii & 30TVK37 & 100,00 & 138,10 & 102,94 & 34,50 & 6626,82 & 309,23 & 14,46 & 294,77 & 95,56 & 226,59 & 226,59 & 56,19 & 444,80 & 56,12 & 11,12 & 36,95 & 155,32 & 50,47 & 50,47 & 134,92 \\
\hline Alytes cisternasii & 30TVK38 & 100,00 & 136,31 & 102,21 & 34,23 & 6602,03 & 306,29 & 13,06 & 293,23 & 93,77 & 224,52 & 224,52 & 54,94 & 443,90 & 56,36 & 11,18 & 36,47 & 154,53 & 51,94 & 51,94 & 132,50 \\
\hline Alytes cisternasii & 30TVK39 & 100,00 & 132,33 & 102,09 & $\begin{array}{l}34,58 \\
\end{array}$ & 6564,50 & 301,02 & 9,65 & 291,37 & 90,28 & 219,68 & 220,00 & 51,72 & 447,13 & 56,23 & 11,54 & 35,06 & 153,56 & 55,03 & 55,22 & 130,17 \\
\hline Alytes cisternasii & 30TVK43 & 100,00 & 146,90 & 110,28 & 35,02 & 6784,14 & 326,59 & 17,10 & 309,49 & 103,19 & 237,63 & 237,63 & 63,67 & 408,17 & 49,26 & 8,35 & 37,78 & 140,62 & 42,91 & 42,91 & 120,14 \\
\hline Alytes cisternasii & 30TVK47 & 100,00 & $\begin{array}{lll}137,47 \\
\end{array}$ & 103,58 & 34,19 & 6659,03 & 310,34 & 12,61 & 297,73 & 94,24 & 226,32 & 226,32 & 55,21 & 449,72 & 58,83 & 10,81 & 38,01 & 159,53 & 49,71 & 49,71 & 136,32 \\
\hline Alytes cisternasii & 30TVK48 & 100,00 & 135,62 & 103,27 & 34,38 & 6631,22 & 307,45 & 11,59 & 295,86 & 92,62 & 224,08 & 224,08 & 53,97 & 449,55 & 59,09 & 10,81 & 37,42 & 159,03 & 51,06 & 51,06 & 134,80 \\
\hline Alytes cisternasii & 30TVK49 & 100,00 & 134,81 & 102,96 & 34,73 & 6603,20 & 305,15 & \begin{tabular}{|l|l|}
11,37 \\
\end{tabular} & 293,78 & 92,12 & 222,82 & 222,82 & 53,66 & 442,82 & 58,10 & 10,74 & 36,60 & 155,84 & 52,14 & 52,14 & 130,55 \\
\hline Alytes cisternasii & 30TVK53 & 100,00 & 144,53 & 111,16 & 35,28 & 6768,78 & 324,73 & 14,94 & 309,79 & 100,76 & 235,02 & 235,02 & 61,71 & 415,71 & 50,65 & 8,66 & 37,63 & 143,47 & 44,26 & 44,26 & 121,99 \\
\hline Alytes cisternasii & 30TVK59 & 100,00 & 135,08 & 104,62 & 34,94 & 6619,79 & 306,93 & 11,33 & 295,60 & 92,02 & 223,11 & 223,11 & 54,05 & 437,96 & 58,92 & 10,32 & 37,44 & 156,24 & 50,69 & 50,69 & 128,61 \\
\hline Alytes cisternasii & 30TVK68 & 100,00 & 136,47 & 108,46 & 35,96 & 6623,71 & 311,34 & 12,18 & 299,16 & 92,69 & 224,35 & 224,35 & 55,92 & 432,86 & 59,86 & 9,67 & 39,16 & 158,13 & 47,77 & 47,77 & 128,14 \\
\hline Alytes cisternasii & 30TVK69 & 100,00 & 130,82 & 105,62 & 35,28 & 6593,60 & 302,23 & 8,04 & 294,19 & 87,81 & 218,64 & 218,64 & 50,92 & 440,21 & 58,48 & 10,84 & 36,21 & 155,32 & 53,21 & 53,21 & 125,62 \\
\hline Alytes cisternasii & 30TVK73 & 100,00 & 141,02 & 113,14 & 36,00 & $\mid 6727,66$ & 321,23 & 11,60 & 309,64 & 97,50 & 230,97 & 230,97 & 59,09 & 419,19 & 50,42 & 9,30 & 36,39 & $\mid 142.58$ & 47,14 & 47,14 & 119,64 \\
\hline Alytes cisternasii & 30TVL02 & 100,00 & 104,18 & 102,76 & 35,80 & 6328,72 & 269,13 & $-14,21$ & 283,34 & 120,89 & 188,74 & 189,91 & 29,02 & 496,09 & 60,40 & 16,33 & 30,06 & 155,61 & 73,06 & 80,28 & 123,40 \\
\hline Alytes cisternasii & 30TVL06 & 100,00 & 116,71 & 104,10 & 36,00 & 6302,46 & 280,64 & $-3,95$ & 284,59 & 87,64 & 199,84 & 201,07 & 39,69 & 450,05 & 52,20 & 13,92 & 29,64 & 138,92 & 64,53 & 72,95 & 115,98 \\
\hline Alytes cisternasii & 30TVL10 & 100,00 & 112,46 & 102,96 & 35,38 & $\begin{array}{ll}6427,44 \\
\end{array}$ & 279,75 & $-7,11$ & 286,86 & 80,22 & \begin{tabular}{|l|}
197,93 \\
\end{tabular} & 199,25 & 35,60 & 478,21 & 56,21 & 15,01 & 30,94 & 150,99 & 67,21 & 71,88 & 123,97 \\
\hline Alytes cisternasii & 30TVL20 & 100,00 & 116,65 & 102,55 & 35,13 & 6465,02 & 284,01 & $-3,38$ & 287,39 & 75,82 & 202,20 & 203,73 & 38,82 & \begin{tabular}{|c|c|}
477,18 \\
\end{tabular} & 55,71 & 14,20 & 31,40 & 153,59 & 64,93 & 68,63 & 128,32 \\
\hline Alytes cisternasii & 30TVL21 & 100,00 & 84,19 & 106,10 & 36,89 & 6169,99 & 254,29 & $-29,16$ & 283,45 & 61,23 & 168,71 & 169,10 & 14,22 & 607,58 & 72,58 & 23,35 & 27,95 & 188,62 & 92,03 & 95,29 & 156,05 \\
\hline Alytes cisternasii & 30TVL25 & 100,00 & 108,37 & 102,99 & 35,99 & 6326,98 & 272,63 & $-10,23$ & 282,85 & 93,76 & 192,45 & 193,55 & 32,51 & 493,86 & 56,84 & 15,78 & 28,86 & 151,52 & 71,94 & 80,44 & 127,86 \\
\hline \begin{tabular}{|l} 
Alytes cisternasii \\
\end{tabular} & 30TVL30 & 100,00 & 119,57 & 102,73 & 35,07 & 6498,95 & 287,51 & \begin{tabular}{r|}
$-0,85$ \\
-0,
\end{tabular} & 288,36 & 77,69 & 205,32 & 206,90 & 41,19 & $\begin{array}{l}495,000 \\
476,05 \\
\end{array}$ & 56,83 & 13,65 & 32,14 & \begin{tabular}{|l|l|l|l|l|}
156,14 \\
\end{tabular} & 63,41 & 60,05 & 131,37 \\
\hline Alytes cisternasii & 30TVL31 & 100,00 & 112,12 & 103,04 & 35,52 & 6428,78 & 279,39 & $-6,72$ & 286,11 & 73,78 & 197,50 & 198,75 & 35,20 & 496,87 & 58,38 & 15,25 & 30,58 & 158,92 & 69,08 & 73,27 & 133,32 \\
\hline Alytes cisternasii & 30TVL40 & 100,00 & 127,79 & 102,91 & 35,01 & 6550,89 & 296,39 & 5,74 & 290,64 & 85,55 & 214,56 & 215,24 & 47,88 & 454,56 & 57,17 & 12,01 & 34,19 & $\begin{array}{l}154,78 \\
\end{array}$ & 57,89 & 58,64 & 129,23 \\
\hline Alytes cisternasii & 30TVL41 & 100,00 & 120,84 & 102,69 & 35,08 & 6501,78 & 288,23 & 0,27 & 287,97 & 79,02 & 206,51 & 207,87 & 42,13 & 468,87 & 56,71 & 13,27 & 31,97 & 154,61 & 63,08 & 65,25 & 129,18 \\
\hline Alytes cisternasii & 30TVL42 & 100,00 & 106,04 & 103,99 & 36,08 & 6376,62 & 273,74 & $-11,87$ & 285,61 & 69,50 & 191,23 & 192,10 & 30,35 & 516,25 & 60,00 & 16,95 & 29,25 & 161,85 & 74,57 & 79,67 & 136,35 \\
\hline \begin{tabular}{|l} 
Alytes cisternasii \\
\end{tabular} & \begin{tabular}{|l|l|} 
30TVL43 \\
\end{tabular} & 100,00 & 109,23 & 103,29 & 36,00 & 6385,04 & 275,66 & $\begin{array}{r}-1,0,20 \\
\end{array}$ & \begin{tabular}{|l|}
284,861 \\
\end{tabular} & $\begin{array}{ll}68,98 \\
60\end{array}$ & $\begin{array}{l}194,21 \\
\end{array}$ & 195,12 & 32,98 & 499,32 & 56,90 & $\begin{array}{l}0,039 \\
15,97\end{array}$ & 29,15 & $\begin{array}{l}155,92 \\
150\end{array}$ & 72,09 & 77,84 & 131,74 \\
\hline Alytes cisternasii & 30TVL44 & 100,00 & 95,01 & 105,03 & 36,40 & 6252,22 & 262,72 & $-21,24$ & 283,96 & 86,56 & 179,36 & 179,79 & 21,82 & 555,86 & 64,66 & 20,44 & 27,23 & 170,18 & 84,87 & 90,53 & 143,55 \\
\hline Alytes cisternasii & 30TVL50 & 100,00 & 133,14 & 103,39 & 35,00 & 6579,67 & 302,35 & 10,41 & 291,94 & 90,44 & 220,66 & 220,69 & 52,75 & 434,01 & 57,10 & 10,67 & 35,80 & 152,12 & 53,20 & 53,21 & 124,29 \\
\hline Alytes cisternasii & 30TVL51 & 100,00 & 128,43 & 102,74 & 35,00 & 6538,75 & 296,04 & 6,70 & 289,35 & 86,38 & 215,28 & 215,54 & 48,77 & 440,69 & 55,86 & 11,65 & 33,64 & 149,99 & 57,75 & 58,04 & 122,79 \\
\hline Alytes cisternasii & \begin{tabular}{l|} 
30TVL52 \\
\end{tabular} & 100,00 & 119,14 & 103,05 & 35,49 & 6471,71 & 286,06 & $-0,94$ & 286,99 & 77,81 & 204,90 & 205,77 & 40,94 & 466,92 & 55,77 & 13,73 & 31,05 & 151,94 & 65,03 & 67,44 & 126,10 \\
\hline \begin{tabular}{|l} 
Alytes cisternasii \\
\end{tabular} & \begin{tabular}{|l} 
SOTVL53 \\
30TL
\end{tabular} & 100,00 & 109,88 & 103,92 & 3 & $\begin{array}{l}\mid 641,1 / 1 \\
6394,79 \\
\end{array}$ & 270,00 & $\begin{array}{l}-8,543 \\
-8,73 \\
\end{array}$ & \begin{tabular}{|l|}
285,74 \\
28,4
\end{tabular} & $\begin{array}{l}\mid 1,101 \\
72,46\end{array}$ & \begin{tabular}{|l|}
195,03 \\
\end{tabular} & $\begin{array}{l}195,80 \\
\end{array}$ & $\begin{array}{l}40,54,5 \\
33,52\end{array}$ & $\begin{array}{l}400,52 \\
497,35\end{array}$ & 57,41 & $\mid$\begin{tabular}{l|}
16,26 \\
16,26
\end{tabular} & $\begin{array}{l}1,009 \\
28,98\end{array}$ & \begin{tabular}{|l|}
155,85 \\
15,8
\end{tabular} & $\begin{array}{l}\mid 72,635 \\
72,63\end{array}$ & $\begin{array}{l}01,744 \\
77,34\end{array}$ & 131,28 \\
\hline Alytes cisternasii & 30TVL54 & 100,00 & 97,28 & 105,44 & 36,44 & 6285,75 & 265,47 & $-19,77$ & 285,24 & 84,53 & 181,84 & 182,24 & 23,39 & 546,22 & 63,27 & 20,09 & 26,97 & 166,33 & 83,72 & 89,91 & 141,45 \\
\hline Alytes cisternasii & 30TVL60 & 100,00 & 126,06 & 104,05 & 35,02 & 6558,47 & 295,12 & 4,32 & 290,81 & 83,61 & 213,47 & 213,51 & 46,63 & 447,94 & 57,04 & 11,99 & 33,66 & 152,69 & 58,60 & 58,63 & 124,06 \\
\hline Alytes cisternasii & 30TVL61 & 100,00 & 121,44 & 103,71 & 35,33 & 6520,14 & 289,47 & 0,86 & 288,61 & 79,56 & 208,07 & 208,63 & 42,72 & \begin{tabular}{|c|c|}
457,78 \\
\end{tabular} & 56,02 & 13,16 & 31,80 & 151,47 & 63,16 & 63,89 & 124,21 \\
\hline Alytes cisternasii & 30TVL62 & 100,00 & 122,19 & 103,14 & 35, & 6491,62 & 288,90 & 1,52 & 287,38 & 80,64 & 208,18 & 208,88 & 43,69 & 450,45 & 54,49 & 13,15 & 31,25 & 147,72 & 63,30 & 64,48 & 120,74 \\
\hline Alytes cisternasii & 30TVL70 & 100,00 & 124,57 & 103,99 & 35,16 & 6556,40 & 292,94 & 3,20 & 289,73 & 82,36 & 212,23 & 212,23 & 45,64 & 442,06 & 55,17 & 12,34 & 32,79 & 148,33 & 59,95 & 59,96 & 118,65 \\
\hline Alytes cisternasii & 30TVL71 & 100,00 & 120,88 & 103,79 & 35,43 & 6518,66 & 288,58 & 0,21 & 288,37 & 79,19 & 207,66 & 208,00 & 42,49 & 451,60 & 54,44 & 13,41 & 31,27 & 147,68 & 64,06 & 64,58 & 119,43 \\
\hline Alytes cisternasii & 30TVL80 & 100,00 & 128,46 & 102,32 & \begin{tabular}{|l|l|}
35,07 \\
\end{tabular} & 6577,84 & 294,21 & 6,89 & 287,32 & 86,39 & 216,18 & 216,18 & 49,14 & 414,96 & 51,50 & 11,70 & 32,79 & 138,37 & 57,21 & 57,21 & 106,89 \\
\hline Alytes cisternasii & 30TVL81 & 100,00 & 125,82 & 102,84 & 35,1 & 6542,43 & 291,63 & 4,37 & 287,25 & 84,01 & 213,03 & 213,07 & 46,97 & 423,35 & 51,04 & 12,59 & 31,28 & 138,47 & 60,82 & 60,87 & 108,85 \\
\hline \begin{tabular}{|l} 
Alytes cisternasii \\
\end{tabular} & 30TVM40 & 100,00 & 113,46 & 104,42 & 36,5 & 6135,33 & 276,98 & $-5,46$ & 282,45 & \begin{tabular}{|l|}
122,49 \\
129
\end{tabular} & 194,55 & \begin{tabular}{|l|l|}
195,09 \\
\end{tabular} & 38,56 & 472,12 & 54,16 & $\begin{array}{l}17,76 \\
17,7\end{array}$ & $\begin{array}{ll}1,260 \\
26,23 \\
\end{array}$ & $\begin{array}{l}142,26 \\
\end{array}$ & $\begin{array}{l}74,12< \\
74,1\end{array}$ & $\begin{array}{l}0,71,77 \\
\end{array}$ & $\begin{array}{l}121,43 \\
120\end{array}$ \\
\hline Alytes dickhilleni & 30STF93 & 100,00 & 166,98 & 89,40 & 40,09 & 4514,49 & 288,77 & 68,36 & 220,41 & 122,21 & 224,76 & 228,44 & 113,05 & 735,55 & 125,81 & 1,13 & 72,92 & 356,18 & 15,45 & 23,38 & 336,01 \\
\hline Alytes dickhilleni & 30SUF89 & 100,00 & 138,18 & 113,21 & 38,01 & 6037,40 & 308,46 & 15,46 & 293,00 & 75,24 & 219,99 & 219,99 & 66,65 & 639,85 & 88,60 & 5,89 & 57,88 & 261,41 & 29,57 & 29,63 & 252,07 \\
\hline Alytes dickhilleni & 30SUF99 & 100,00 & 131,28 & 115,92 & 38,00 & 6159,14 & 307,14 & 6,72 & 300,42 & 67,43 & 214,93 & 214,93 & 58,55 & 651,95 & 87,41 & 7,08 & 55,91 & 259,09 & 33,13 & 33,13 & 251,82 \\
\hline Alytes dickhilleni & 30SUG84 & 100,00 & 153,59 & 113,48 & 36,98 & 6436,52 & 331,44 & 27,62 & 303,83 & 84,82 & 240,74 & 240,74 & 76,60 & 607,21 & 80,98 & 4,97 & 57,11 & 237,89 & 26,17 & 26,17 & 233,38 \\
\hline $\begin{array}{l}\text { Alytes dickhilleni } \\
\text { al }\end{array}$ & 3050SOG & 100,00 & $\begin{array}{l}124,09 \\
124,09\end{array}$ & $\begin{array}{l}111,40 \\
117,99\end{array}$ & 37,5 & $\begin{array}{l}0450,025 \\
6306,11\end{array}$ & 305,62 & $\mid-1,53$ & \begin{tabular}{|l|}
307,15 \\
307,15
\end{tabular} & $\begin{array}{l}4,062 \\
58,80\end{array}$ & \begin{tabular}{|l|}
210,03 \\
210
\end{tabular} & \begin{tabular}{|l|}
210,03 \\
\end{tabular} & $\begin{array}{l}40,90 \\
49,98\end{array}$ & $\begin{array}{l}\mid c 00,21 \\
696,79\end{array}$ & $\begin{array}{l}00,30 \\
91,66 \\
\end{array}$ & $\begin{array}{ll}4,28 \\
8,28\end{array}$ & $\begin{array}{l}, 1,1 \\
54,52\end{array}$ & \begin{tabular}{|l|}
269,74 \\
2690
\end{tabular} & $\begin{array}{l}\mid 0,11 \\
38,04\end{array}$ & $\begin{array}{l}20,11 \\
38,04\end{array}$ & $\begin{array}{l}25,040 \\
264,54\end{array}$ \\
\hline Alytes dickhilleni & 30SVF08 & 100,00 & 133,56 & 113,95 & 38,03 & 6023,94 & 304,68 & 10,38 & 294,30 & 71,01 & 215,36 & 215,38 & 62,47 & 616,68 & 84,16 & 7,03 & 55,93 & 246,27 & 32,40 & 32,95 & 237,63 \\
\hline Alytes dickhilleni & 30SVFO9 & 100,00 & 136,99 & 115,65 & 38,00 & 6143,62 & 311,83 & 11,90 & 299,92 & 72,73 & 220,46 & 220,46 & 64,20 & 596,54 & 80,01 & 6,42 & 55,62 & 238,08 & 29,95 & 29,95 & 229,69 \\
\hline Alytes dickhilleni & 30 SVF16 & & & & & & & & & & & & & & & & & & & & \\
\hline Alytes dickhilleni & 30SVF17 & 100,00 & 159,46 & 103,53 & 38,1 & 5540,32 & 309,17 & 42,39 & 266,78 & 101,41 & 233,86 & 233 & 93, & 458,48 & 67,69 & 3,80 & 59,34 & 196,04 & 19,99 & 20,58 & 183,33 \\
\hline \begin{tabular}{|l|l} 
Alytes dickhilleni \\
\end{tabular} & \begin{tabular}{|l|}
$305 V F 18$ \\
30578
\end{tabular} & $\begin{array}{l}100,00 \\
100\end{array}$ & $\begin{array}{l}13,40 \\
126,82\end{array}$ & 117,46 & 年0,19 & $\begin{array}{l}304,025 \\
6171,08\end{array}$ & 304,79 & \begin{tabular}{|r|}
$4 L, 35$ \\
1,30
\end{tabular} & \begin{tabular}{|l|}
200,10 \\
303,49 \\
\end{tabular} & $\begin{array}{ll}63,14 \\
\end{array}$ & 210,80 & 210,83 & 54,17 & 631,64 & 82,95 & 7,90 & 53,93 & 245,10 & 35,22 & 35,73 & 239,22 \\
\hline Alytes dickhilleni & 30SVF19 & 100,00 & 139,25 & 116,15 & 38,00 & 6168,30 & 314,74 & \begin{tabular}{ll|}
13,34 \\
\end{tabular} & 301,40 & 74,45 & 223,03 & 223,03 & 65,97 & 561,14 & 75,10 & 6,36 & 54,89 & 222,64 & 28,74 & 28,74 & 214,12 \\
\hline Alytes dickhilleni & 30SVF26 & & & & & & & & & & & & & & & & & & & & \\
\hline Alytes dickhilleni & 30SVF27 & 100,00 & 26 & 1. & 38 & 70,76 & 6,13 & 19,53 & 286,61 & 0,52 & 0,65 & 220,71 & 71, & 34,35 & 72,65 & 6,17 & 55,57 & 213,17 & 28,24 & 29,07 & 205,1 \\
\hline Alytes dickhilleni & 30 SVF28 & 100,00 & 132,77 & 117,33 & 38,04 & 6163,82 & 309,87 & 6,88 & 302,99 & 69,12 & 216,59 & 216,59 & 59,94 & 577,46 & 76,14 & 7,13 & 53,57 & 224,27 & 31,52 & 31,52 & 218 \\
\hline
\end{tabular}




\begin{tabular}{|c|c|c|c|c|c|c|c|c|c|c|c|c|c|c|c|c|c|c|c|c|c|}
\hline TAXON & UTM & $\mathrm{km} 2$ & B101 & B102 & $\mathrm{BIO3}$ & BIO4 & B105 & B106 & B107 & B108 & B109 & BIO10 & BIO11 & BIO12 & B1013 & BIO14 & BIO15 & B1016 & B1017 & BIO18 & B1019 \\
\hline Alytes dickhilleni & 30SVF29 & 100,00 & 135,92 & 117,76 & 38,00 & 6238,52 & 314,48 & 9,06 & 305,41 & 70,73 & 220,70 & 220,70 & 62,00 & 564,20 & 74,42 & 6,97 & 53,54 & 218,67 & 30,59 & 30,59 & 211,99 \\
\hline Alytes dickhilleni & 30SVF37 & 100,00 & 154,58 & 107,92 & 38,13 & 5726,31 & 312,32 & 34,15 & 278,18 & 94,73 & 231,64 & 231,68 & 86,07 & 441,92 & 61,35 & 4,36 & 56,31 & 180,91 & 21,02 & 21,48 & 171,45 \\
\hline Alytes dickhilleni & 30SVF38 & 100,00 & 127,31 & 118,64 & 38,00 & 6235,23 & 307,54 & 0,59 & 306,95 & 63,47 & 212,11 & 212,11 & 53,92 & 596,31 & 77,20 & 8,08 & 52,06 & 225,13 & 35,01 & 35,01 & 221,38 \\
\hline Alytes dickhilleni & 30SVF47 & 100,00 & 159,54 & 105,76 & 38,09 & 5649,02 & 313,34 & 40,31 & 273,04 & 100,56 & 235,24 & 235,39 & 91,74 & 405,70 & 56,34 & 3,81 & 56,20 & 165,65 & 18,68 & 20,10 & 157,14 \\
\hline Alytes dickhilleni & 30SVF48 & 100,00 & 144,43 & $\begin{array}{ll}115,47 \\
\end{array}$ & 38,02 & 6075,72 & 316,82 & 18,45 & 298,38 & 81,20 & 226,66 & 226,66 & 72,07 & 482,90 & 65,27 & 5,73 & 53,36 & 187,41 & 25,48 & 25,48 & 181,11 \\
\hline Alytes dickhilleni & 30SVF49 & 100,00 & 144,52 & 117,92 & 38,00 & 6222,36 & 322,06 & 16,38 & 305,67 & 79,48 & 228,90 & 228,90 & 70,24 & 488,69 & 66,22 & 5,89 & 52,86 & 187,38 & 25,87 & 25,87 & 181,41 \\
\hline Alytes dickhilleni & 30SVF58 & 100,00 & 151,65 & 111,24 & 38,00 & 5928,96 & 316,66 & 28,35 & 288,31 & 89,96 & 231,53 & 231,60 & 80,85 & 437,84 & 59,44 & 5,03 & 53,48 & 169,94 & 22,82 & 24,13 & 163,64 \\
\hline Alytes dickhilleni & $\begin{array}{l}30 \text { SVF59 } \\
\end{array}$ & 100,00 & 104,01 & 121,17 & 37,92 & 6446,90 & 292,30 & $-23,95$ & 316,25 & 45,38 & \begin{tabular}{|l|l|}
192,09 \\
\end{tabular} & 192,42 & 29,21 & 717,51 & 89,99 & $\begin{array}{ll}14,93 \\
14\end{array}$ & 46,53 & 256,12 & 59,06 & 62,18 & 247,05 \\
\hline Alytes dickhilleni & 30SVF67 & 100,00 & 138,51 & 113,04 & 38,00 & 6002,14 & 307,75 & 14,95 & 292,80 & 77,56 & 219,50 & 220,01 & 67,56 & 494,65 & 64,81 & 6,81 & 51,52 & 184,87 & 29,65 & 36,48 & 181,19 \\
\hline Alytes dickhilleni & 30SVF68 & 100,00 & 145,95 & 111,88 & 38,00 & 5986,90 & 313,21 & 22,53 & 290,68 & 85,22 & 226,68 & 226,92 & 74,84 & 459,45 & 61,02 & 5,88 & 51,92 & 172,95 & 26,35 & 31,35 & 168,28 \\
\hline Alytes dickhilleni & 30SVF69 & 100,00 & 72,97 & 122,82 & 37,61 & 6587,29 & 267,50 & $-54,97$ & 322,48 & 21,67 & 163,66 & 164,27 & $-2,03$ & 900,79 & 109,13 & 25,20 & 41,06 & 314,29 & 93,63 & 97,06 & 292,93 \\
\hline Alytes dickhilleni & 30SVF78 & 100,00 & 137,54 & 114,66 & 38,00 & 6125,11 & 310,65 & 12,40 & 298,25 & 77,14 & 220,24 & 220,87 & 65,25 & 491,79 & 63,45 & 7,00 & 50,06 & 179,05 & 30,47 & 38,11 & 176,57 \\
\hline Alytes dickhilleni & 30SVF79 & 100,00 & 84,24 & 121,90 & 37,75 & 6536,23 & 276,12 & $-43,49$ & 319,61 & 33,94 & 173,84 & 174,68 & 9,40 & 816,99 & 99,13 & 21,72 & 41,68 & 285,37 & 81,84 & 86,32 & 266,44 \\
\hline Alytes dickhilleni & 30SVF97 & 100,00 & 157,29 & 101,36 & 37,74 & 5594,42 & 306,41 & 40,82 & 265,58 & 100,68 & 231,47 & 233,33 & 90,53 & 366,20 & 48,44 & 3,94 & 51,79 & 137,63 & 19,61 & 26,57 & 134,02 \\
\hline Alytes dickhilleni & 30SVF98 & 100,00 & 154,21 & 104,91 & 37,83 & 5767,85 & 309,91 & 35,00 & 274,91 & 95,56 & 231,09 & 232,62 & 85,49 & 383,14 & 50,11 & 4,41 & 50,69 & 141,25 & 21,40 & 28,81 & 138,01 \\
\hline Alytes dickhilleni & 30 SVG00 & 100,00 & 140,34 & 115,24 & 37,99 & 6202,73 & 315,66 & 15,01 & 300,65 & 74,86 & 224,61 & 224,61 & 66,69 & 582,23 & 79,01 & 6,38 & 55,46 & 231,74 & 29,46 & 29,46 & 222,61 \\
\hline Alytes dickhilleni & 30SVG02 & 100,00 & 150,38 & 113,64 & $\begin{array}{l}37,05 \\
\end{array}$ & 6307,82 & 325,61 & 24,74 & 300,86 & 82,49 & 236,10 & 236,10 & 75,05 & 546,70 & 74,73 & 5,65 & 55,64 & 217,00 & 26,42 & 26,42 & 207,91 \\
\hline Alytes dickhilleni & 30SVG03 & 100,00 & 144,25 & 116,31 & 37,00 & 6493,53 & 326,55 & 16,71 & 309,84 & 75,08 & 232,55 & 232,55 & 66,95 & 591,22 & 77,10 & 6,41 & 54,50 & 226,69 & 29,73 & 29,73 & 221,93 \\
\hline Alytes dickhilleni & 30SVG10 & 100,00 & 146,56 & 114,97 & 37,99 & 6181,29 & 320,53 & 20,79 & 299,74 & 80,53 & 230,58 & 230,58 & 72,92 & 519,77 & 71,88 & 5,83 & 55,21 & 208,73 & 26,13 & 26,13 & 197,66 \\
\hline Alytes dickhilleni & 30SVG12 & 100,00 & 149,03 & 114,67 & 37,13 & 6337,57 & 325,89 & 22.51 & 303,38 & 80,62 & 235,18 & 235,18 & 73,41 & 525,07 & 72,16 & 5,99 & 54.51 & 205,95 & 27,16 & 27,16 & 196,40 \\
\hline Alytes dickhilleni & 30SVG13 & 100,00 & 138,03 & 118,49 & 37,01 & 6573,18 & 324,53 & 9,28 & 315,26 & 68,87 & 227,57 & 227,57 & 60,05 & 604,05 & 78,08 & 7,40 & 53,03 & 225,93 & 32,95 & 32,95 & 222,81 \\
\hline Alytes dickhilleni & 30 SVG22 & 100,00 & 153,52 & 114,99 & 37,21 & 6338,62 & 330,23 & 26,31 & 303,92 & 84,42 & 239,78 & 239,78 & 77,80 & 473,18 & 65,41 & 5,45 & 54,03 & 185,84 & 24,53 & 24,53 & 175,09 \\
\hline Alytes dickhilleni & 30SVG23 & 100,00 & 143,48 & 118,29 & $\begin{array}{l}37,00 \\
\end{array}$ & 6569,32 & 329,22 & 14,20 & 315,02 & 73,80 & 232,93 & 232,93 & 65,32 & 558,01 & 71,92 & 6,87 & 52,63 & 208,01 & 30,10 & 30,10 & 204,63 \\
\hline Alytes dickhilleni & 30SVG24 & 100,00 & 144,54 & 117,80 & 36,96 & 6647,62 & 331,67 & 15,37 & 316,30 & 75,56 & 235,03 & 235,03 & 65,56 & 568,15 & 74,36 & 6,89 & 52,60 & 210,27 & 30,69 & 30,69 & 207,29 \\
\hline Alytes dickhilleni & 30SVG25 & 100,00 & 130,21 & 120,26 & 36,87 & 6743,06 & 322,75 & 0,62 & 322,12 & 61,14 & 222,23 & 222,23 & 50,70 & 642,81 & 86,59 & 8,94 & 50,67 & 236,40 & 39,79 & 39,79 & 228,93 \\
\hline Alytes dickhilleni & 30SVG32 & 100,00 & 155,35 & 116,17 & \begin{tabular}{|c|}
37,27 \\
\end{tabular} & 6367,30 & 333,48 & 27,03 & 306,45 & 86,06 & 241,90 & 241,90 & 79,03 & 449,20 & 60,9 & 5,31 & 53,20 & 174,40 & 23,25 & 23,25 & 164,69 \\
\hline Alytes dickhilleni & 30 SVG33 & 100,00 & 145,52 & 118,63 & 37,00 & 6567,88 & 331,36 & 15,78 & 315,57 & 76,20 & 235,00 & 235,00 & 67,37 & 530,49 & $\begin{array}{l}68,97 \\
\end{array}$ & 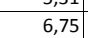 & 52,08 & $\begin{array}{l}196,18 \\
\end{array}$ & 29,18 & 29,18 & 192,47 \\
\hline Alytes dickhilleni & 30 SVG34 & 100,00 & 139,93 & 119,43 & 36,99 & 6683,69 & 329,45 & 9,99 & 319,46 & 71,39 & 231,01 & 231,01 & 60,73 & 574,29 & 75,90 & 7,53 & 51,31 & 209,78 & 33,08 & 33,08 & 206,13 \\
\hline Alytes dickhilleni & 30 SVG36 & 100,00 & 132,62 & 119,55 & 36,53 & 6795,28 & 325,48 & 2,86 & 322,62 & 75,23 & 225,41 & 225,41 & 52,59 & 626,85 & 85,85 & 9,01 & 50,08 & 230,35 & 40,13 & 40,13 & 219,61 \\
\hline Alytes dickhilleni & 30 SVG 40 & 100,00 & 145,38 & 119,73 & 38,00 & 6347,76 & 327,09 & 15,72 & 311,37 & 78,74 & 231,55 & 231,55 & 69,68 & 491,34 & 66,55 & 5,95 & 52,60 & 186,27 & 25,97 & 25,97 & 180,81 \\
\hline Alytes dickhilleni & 30SVG41 & 100,00 & 153,30 & 119,43 & 37,94 & 6373,83 & 334,49 & 23,04 & 311,45 & 85,31 & 239,83 & 239,83 & 76,87 & 453,80 & 62,06 & 5,21 & 53,01 & 173,27 & 22,75 & 22,75 & 166,64 \\
\hline Alytes dickhilleni & 30SVG44 & 100,00 & 139,33 & 119,77 & 37,00 & $\begin{array}{l}6682,62 \\
6682\end{array}$ & 329,05 & $\begin{array}{l}3,07 \\
9,4\end{array}$ & \begin{tabular}{|l|l|}
319,98 \\
\end{tabular} & $\begin{array}{l}\mid 79,28 \\
79,2\end{array}$ & \begin{tabular}{|l|}
230,30 \\
\end{tabular} & \begin{tabular}{|l|}
230,30 \\
\end{tabular} & $\begin{array}{ll}0,10 \\
60,18\end{array}$ & 564,60 & 74,91 & \begin{tabular}{l|l}
, 21 \\
7,68
\end{tabular} & $\begin{array}{l}50,60 \\
50\end{array}$ & 204,73 & 33,72 & 33,72 & 200,23 \\
\hline Alytes dickhilleni & 30SVG48 & 100,00 & 160,46 & 112,17 & 35,26 & 6796,60 & 345,24 & 32,91 & 312,34 & 105,88 & 252,39 & 252,39 & 79,30 & 527,44 & 78,75 & 5,40 & 53,53 & 202,94 & 26,89 & 26,89 & 187,64 \\
\hline Alytes dickhilleni & 30 SVG50 & 100,00 & 111,64 & 121,25 & 37,95 & 6483,53 & 300,34 & $-16,90$ & 317,23 & 53,95 & 200,07 & 200,32 & 36,09 & 673,94 & 85,04 & 12,65 & 47,20 & 240,43 & 51.48 & 55,05 & 233,93 \\
\hline Alytes dickhilleni & 30SVG51 & 100,00 & 137,77 & 120,31 & 37,80 & 6468,57 & 323,32 & 7,91 & 315,41 & 72,75 & 225,69 & 225,71 & 61,08 & 533,14 & 69,61 & 7,34 & 50,53 & 192,97 & 31,75 & 32,01 & 190,72 \\
\hline Alytes dickhilleni & 30SVG52 & 100,00 & 121,04 & 121,37 & 37,53 & 6577,65 & 311,27 & $-8,14$ & 319,41 & 69,02 & 210,81 & 210,84 & 44,02 & 627,20 & 80,32 & 10,60 & 47,88 & 223,75 & 44,60 & 45,24 & 217,73 \\
\hline $\begin{array}{l}\text { Alytes dickhilleni } \\
\text { al }\end{array}$ & \begin{tabular}{|l|}
30 SVG53 \\
\end{tabular} & 100,00 & 132,54 & 120,41 & 37,09 & |6610,03 & 321,70 & 2,59 & \begin{tabular}{|l|}
319,11 \\
31,4
\end{tabular} & $\begin{array}{l}59,4<2 \\
79,42\end{array}$ & $\mid \begin{array}{l}\mid 10,01 \\
222,59\end{array}$ & $\mid \begin{array}{l}\mid 10,04 \\
222,61\end{array}$ & $\begin{array}{ll}54,58 \\
54,5\end{array}$ & $\mid \begin{array}{l}\mid 27,20,19 \\
576\end{array}$ & $\begin{array}{l}00,324 \\
74,64\end{array}$ & $\frac{10,00}{8,94}$ & \begin{tabular}{|l}
4,00 \\
49,04
\end{tabular} & \begin{tabular}{|l|}
206,32 \\
\end{tabular} & 38,22 & $\begin{array}{l}48,24 \\
38,56\end{array}$ & 200,98 \\
\hline Alytes dickhilleni & 30 SVG56 & 100,00 & 135,86 & 119,61 & 36,73 & 6767,58 & 327,38 & 5,70 & 321,69 & 87,11 & 227,97 & 227,97 & 55,90 & 579,11 & 78,55 & 8,52 & 48,84 & 211,90 & 38,31 & 38,31 & 198,88 \\
\hline Alytes dickhilleni & 30SVG57 & 100,00 & 119,51 & 121,43 & 36,87 & 6806,40 & 314,62 & $-10,48$ & 325,10 & 69,97 & 212,57 & 212,58 & 40,06 & 653,93 & 86,56 & 11,92 & 45,99 & 235,78 & 51,76 & 51,94 & 217,53 \\
\hline Alytes dickhilleni & 30SVG58 & 100,00 & 148,94 & 115,90 & 36,12 & 6782,17 & 336,74 & 19,89 & 316,85 & 100,73 & 240,96 & 240,96 & 68,35 & 539,85 & 76,30 & 6,80 & 50,24 & 201,74 & 32,99 & 32,99 & 185,82 \\
\hline Alytes dickhilleni & 30SVG61 & 100,00 & 112,41 & 121,28 & 37,8 & 6532,90 & 301,90 & $-16,22$ & 318,13 & 62,72 & 201,56 & 201,79 & 36,41 & 659,49 & $82, \varepsilon$ & 12,84 & 46,09 & 233,59 & 52,19 & 55,75 & 224,71 \\
\hline Alytes dickhilleni & 30SVG62 & 100,00 & 122,76 & 120,85 & 37,48 & 6557,57 & 311,71 & \begin{tabular}{|c|c|}
$-6,24$ \\
\end{tabular} & 317,96 & 74,06 & 212,14 & 212,21 & $\begin{array}{l}45,92 \\
452\end{array}$ & 605,29 & 77,14 & 10, & 47,20 & 215,44 & 43,91 & 45,90 & 207,94 \\
\hline Alytes dickhilleni & 30SVG63 & 100,00 & 122,08 & 121,11 & 37,19 & 6612,23 & 312,55 & $-7,40$ & 319,95 & 73,26 & 212,25 & 212,32 & 44,72 & 613,89 & 78,69 & 10,86 & 46,73 & 218,94 & 45,77 & 47,06 & 208,89 \\
\hline Alytes dickhilleni & 30SVG65 & 100,00 & 135,93 & 119,71 & $37, \mathrm{C}$ & 6691,84 & 325,60 & 5,58 & 320,03 & 87,42 & 226,97 & 226,97 & 56,80 & 556,57 & 73,86 & 8,38 & 48,16 & 201,59 & 37,38 & 37,38 & 190,13 \\
\hline Alytes dickhilleni & 30 SVG66 & 100,00 & 137,12 & 119,37 & 36,8 & 6732,43 & 327,30 & 6,80 & 320,50 & 88,49 & 228,65 & 228,65 & 57,50 & 556,55 & 74, & 8, & 48,10 & 202,79 & 37,60 & 37,60 & 189,02 \\
\hline $\begin{array}{l}\text { Alytes dickhilleni } \\
\end{array}$ & 30SVG67 & 100,00 & 132,71 & 119,32 & 36,6 & 6757,97| & 323,71 & 2,81 & 320,90 & $\begin{array}{l}\mid 80,43 \\
83,86 \\
\end{array}$ & 224,71 & 224,71 & 53,13 & 581,53 & 77 & $\begin{array}{ll}9,2 \\
, 4\end{array}$ & $\begin{array}{ll}40,01 \\
47,01\end{array}$ & 211,09 & 42,71 & 42,82 & 194,21 \\
\hline Alytes dickhilleni & 30SVG68 & 100,00 & 152,33 & 115,31 & 36,18 & 6711,34 & 337,47 & 23,54 & 313,94 & 104,62 & 243,16 & 243,16 & 72,34 & 504,23 & 70,05 & 6,20 & 49,64 & 186,92 & 30,95 & 30,95 & 171,88 \\
\hline Alytes dickhilleni & 30 SVG80 & 100,00 & 70,94 & 122,64 & 37,35 & 6633,80 & 266,05 & $-57,28$ & 323,33 & 19,60 & 162,10 & 163,00 & $-4,47$ & 893,20 & 108,67 & 27,35 & 38,32 & 309,13 & 100,59 & 102,94 & 280,06 \\
\hline Alytes dickhilleni & 30SVG93 & 100,00 & 129,06 & 118,02 & 37,19 & 6480,29 & 312,71 & 1,07 & 311,64 & 80,73 & 216,99 & 217,51 & 53,18 & 538,44 & 66,96 & 9,71 & 44,88 & 189,25 & 42,22 & 48,92 & 177,36 \\
\hline Alytes dickhilleni & 30SVG94 & 100,00 & 137,81 & 116,80 & 37,03 & 6468,53 & 319,42 & 9,71 & 309,71 & 90,09 & 225,38 & 225,91 & 61,62 & 497,66 & 62,30 & 8,00 & 45,82 & 175,46 & 36,53 & 43,52 & 164,63 \\
\hline $\begin{array}{l}\text { Alytes dickhilleni } \\
\text { al }\end{array}$ & \begin{tabular}{|l|} 
30SVG97 \\
\end{tabular} & 100,00 & 15 & $\begin{array}{l}111,00 \\
113,49\end{array}$ & 36,09| & $\mid 6438,83$ & 330,70 & \begin{tabular}{|r|r|}
26,98 \\
26
\end{tabular} & \begin{tabular}{|l|}
303,72 \\
30,1
\end{tabular} & \begin{tabular}{|c|}
107,68 \\
107
\end{tabular} & \begin{tabular}{|l|}
240,95 \\
245
\end{tabular} & $\mid$ & $\begin{array}{l}1,026 \\
77,26\end{array}$ & \begin{tabular}{|l|l|}
434,65 \\
43,05
\end{tabular} & $\begin{array}{l}5,30,14 \\
\end{array}$ & $0,0,55$ & $\begin{array}{l}3,, 064 \\
46,94\end{array}$ & \begin{tabular}{|l|}
154,05 \\
15,0
\end{tabular} & $\begin{array}{l}0,35 \\
29,32 \\
\end{array}$ & $\begin{array}{ll}43,25 \\
33,38\end{array}$ & $\begin{array}{l}104,03 \\
142,86\end{array}$ \\
\hline Alytes dickhilleni & 30SVG98 & 100,00 & 138,54 & 117,48 & 37,01 & 6605,31 & 323,07 & 9,57 & 313,50 & 90,52 & 227,97 & 228,16 & 60,40 & 507,78 & 64,38 & 8,58 & 44,35 & 179,71 & 41,02 & 43,36 & 161,53 \\
\hline Alytes dickhilleni & 30SVG99 & 100,00 & 148,60 & 115,92 & 37,00 & 6562,74 & 329,82 & 20,00 & 309,82 & 101,51 & 237,17 & 237,29 & 70,40 & 463,21 & 59,05 & 6,64 & 45,31 & 164,47 & 34,75 & 36,81 & 148,06 \\
\hline Alytes dickhilleni & 30SVH9O & 100,00 & 157,60 & 114,58 & 37,00 & 6514,66 & 335,62 & 29,21 & 306,41 & 111,28 & 245,21 & 245,31 & 79,36 & 423,56 & 53,86 & 5,10 & 46,10 & 150,25 & 29,61 & 31,51 & 135,57 \\
\hline Alytes dickhilleni & 30SWF08 & 100,00 & 137,34 & 109,31 & 37,88 & 5970,86 & 302,06 & 15,92 & 286,14 & 82,48 & 217,38 & 219,10 & 67,16 & 467,47 & 59,30 & 7,89 & 47,35 & 165,75 & 33,92 & 41,08 & 160 \\
\hline \begin{tabular}{|l} 
Alytes dickhilleni \\
Al
\end{tabular} & $\begin{array}{l}30 \text { SOSWF17 } \\
30\end{array}$ & $\begin{array}{l}100,00 \\
\end{array}$ & $\begin{array}{l}151,18 \\
151,18\end{array}$ & $\begin{array}{l}90,31 \\
99,22\end{array}$ & 年, 37,40 & 5556,79 & 290,50 & $\begin{array}{l}0,54 \\
36,55 \\
\end{array}$ & \begin{tabular}{|l|}
260,1496 \\
261
\end{tabular} & 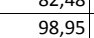 & \begin{tabular}{|l|}
224,63 \\
22,
\end{tabular} & \begin{tabular}{|l|}
227,24 \\
2210
\end{tabular} & $\begin{array}{l}1,10 \\
85,36\end{array}$ & \begin{tabular}{|l|}
387,70 \\
387,70
\end{tabular} & $\begin{array}{l}30,30 \\
50,30\end{array}$ & $\begin{array}{l}3,03 \\
5,71 \\
\end{array}$ & \begin{tabular}{|l|l|}
49,20 \\
49,
\end{tabular} & \begin{tabular}{|l|}
140,50 \\
140
\end{tabular} & $\begin{array}{ll}26,11 \\
26,11\end{array}$ & $\begin{array}{l}1,00 \\
32,34 \\
\end{array}$ & $\begin{array}{l}100,40 \\
135,14\end{array}$ \\
\hline Alytes dickhilleni & 30SWF18 & 100,00 & 96,85 & 118,61 & 37,85 & 6405,28 & 281,46 & $-29,14$ & 310,60 & 46,89 & 184,04 & 185,72 & 23,59 & 700,28 & 88,84 & 19,01 & 40,02 & 242,45 & 72,24 & 77,01 & 221,70 \\
\hline Alytes dickhilleni & 30SWF19 & 100,00 & 130,46 & 111,75 & 37,81 & 6109,05 & 300,50 & 7,40 & 293.10 & 78,34 & 212,63 & 214,39 & 58.97 & 498,17 & 62.45 & 9,34 & 44.82 & 172,25 & 39.73 & 46,65 & 165,68 \\
\hline Alytes dickhilleni & 30SWG00 & 100,00 & 91,45 & 120,29 & 37,60 & 6517,73 & 280,53 & $-35,74$ & 316,27 & 41,14 & 180, & 181, & 16 & 743,27 & 92,87 & 20,85 & 39,38 & 257,27 & 78,97 & 83,08 & 233,23 \\
\hline Alytes dickhilleni & 30SWG02 & 100,00 & 118,62 & 118,01 & 37,52 & 6441,29 & 302,00 & $-8,44$ & 310,44 & 69,90 & 206,17 & 207,05 & 43,79 & 581,40 & 72,56 & 12,42 & 42,76 & 202,16 & 51,45 & 57,94 & 187,32 \\
\hline
\end{tabular}




\begin{tabular}{|c|c|c|c|c|c|c|c|c|c|c|c|c|c|c|c|c|c|c|c|c|c|}
\hline TAXON & UTM & $\mathrm{km} 2$ & B101 & B102 & $\mathrm{BIO3}$ & BIO4 & B105 & B106 & B107 & B108 & B109 & BIO10 & BIO11 & BIO12 & 81013 & BIO14 & BIO15 & B1016 & B1017 & BIO18 & B1019 \\
\hline Alytes dickhilleni & 30SWG03 & 100,00 & 112,13 & 119,29 & 37,38 & 6521,42 & 298,87 & $-15,51$ & 314,38 & 62,80 & 200,97 & 201,69 & 36,74 & 620,72 & 77,48 & 14,42 & 41,36 & 215,71 & 58,83 & 64,42 & 196,34 \\
\hline Alytes dickhilleni & 30SWG06 & 100,00 & 146,83 & 114,45 & 37,00 & 6411,38 & 323,90 & 19,77 & 304,13 & 99,96 & 233,36 & 233,69 & 70,77 & 448,55 & 55,63 & 6,58 & 45,28 & 156,92 & 33,01 & 38,71 & 145,03 \\
\hline Alytes dickhilleni & 30SWG07 & 100,00 & 139,87 & 116,56 & 37,01 & 6514,90 & 321,19 & 11,47 & 309,72 & 92,14 & 227,87 & 228,22 & 62,84 & 484,39 & 60,38 & 8,08 & 43,87 & 169,69 & 39,10 & 43,90 & 153,57 \\
\hline Alytes dickhilleni & 30SWG08 & 100,00 & 114,83 & 120,64 & 37,04 & 6665,08 & 304,94 & $-14,35$ & 319,29 & 66,73 & 205,73 & 205,99 & 37,30 & 607,25 & 75,59 & 14,07 & 39,93 & 210,27 & 61,06 & 63,95 & 184,67 \\
\hline Alytes dickhilleni & 30SWG09 & 100,00 & 121,09 & 120,41 & \begin{tabular}{|l|l|}
37,09 \\
\end{tabular} & $\begin{array}{ll}6669,44 \\
\end{array}$ & 310,41 & $-8,41$ & 318,82 & 79,84 & 211,79 & 212,10 & 43,19 & 574,48 & 71,75 & 12,40 & 40,50 & 199,80 & 56,02 & 58,31 & 174,50 \\
\hline Alytes dickhilleni & 30SWG10 & 100,00 & 103,26 & 118,05 & 37,69 & 6418,95 & 287,19 & $-22,94$ & 310,14 & 53,60 & 190,52 & 191,94 & 29,32 & 663,94 & 83,67 & 17,52 & 40,18 & 228,83 & 67,81 & 72,75 & 208,69 \\
\hline Alytes dickhilleni & 30SWG12 & 100,00 & 101,44 & 119,38 & 37,42 & 6512,31 & 288,48 & $-25,79$ & 314,27 & 51,48 & 190,12 & 191,34 & 26,44 & 673,90 & 84,83 & 18,07 & 39,16 & 232,05 & 70,73 & 75,03 & 208,34 \\
\hline Alytes dickhilleni & 30SWG13 & 100,00 & 99,91 & 119,76 & 37,30 & 6547,08 & 288,19 & $-27,56$ & 315,75 & 49,82 & 189,21 & 190,23 & 24,62 & 683,86 & 85,86 & 18,71 & 38,55 & 234,97 & 73,59 & 77,43 & 209,17 \\
\hline Alytes dickhilleni & 30SWG18 & 100,00 & 124,05 & 119,03 & 37,19 & 6575,96 & 309,64 & $-4,69$ & 314,32 & 88,28 & 213,40 & 213,81 & 47,07 & 549,98 & 69,08 & 11,94 & 40,32 & 190,03 & 53,89 & 57,21 & 166,22 \\
\hline Alytes dickhilleni & 30SWG19 & 100,00 & 102,99 & 121,55 & $\begin{array}{l}37,25 \\
\end{array}$ & 6684,30 & 294,93 & $-25,91$ & 320,84 & 79,69 & 194,39 & 194,80 & 25,85 & 658,50 & 82,24 & 17,84 & 37,02 & 226,52 & 74,95 & 76,55 & 192,90 \\
\hline Alytes dickhilleni & 30SWG20 & 100,00 & 131,47 & 111,31 & 37,74 & 6116,16 & 300,77 & 8,53 & 292,24 & 81,84 & 213,68 & 215,52 & 59,95 & 487,65 & 61,24 & 9,45 & 43,62 & 166,63 & 40,55 & 47,17 & 158,65 \\
\hline Alytes dickhilleni & 30SWG22 & 100,00 & 101,21 & 118,70 & 37,38 & 6485,48 & 286,99 & $-25,45$ & 312,44 & 51,23 & 189,61 & 190,87 & 26,50 & 668,34 & 84,71 & 18,64 & 38,13 & 228,60 & 72,73 & 76,59 & 203,33 \\
\hline Alytes dickhilleni & 30SWG23 & 100,00 & 128,17 & 115,04 & 37,61 & 6322,85 & 304,92 & 2,49 & 302,43 & 80,31 & 213,63 & 214,81 & 54,24 & 511,63 & 64,55 & 10,46 & 41,77 & 174,92 & 45,77 & 51,87 & 160,67 \\
\hline Alytes dickhilleni & 30SWG27 & 100,00 & 143,06 & 114,67 & 37,36 & 6352,62 & 318,23 & 15,94 & 302,29 & 105,84 & 228,60 & 229,33 & 67,80 & 443,23 & 55,81 & 7,42 & 42,33 & 151,55 & 37,64 & 43,30 & 136,21 \\
\hline Alytes dickhilleni & 30SWG28 & 100,00 & 130,69 & 117,71 & 37,32 & \begin{tabular}{|l|l|}
6494,73 \\
\end{tabular} & 312,40 & 2,30 & 310,10 & 107,79 & 218,55 & 219,21 & 54,36 & 504,53 & 64,02 & 10,30 & 40,24 & 173,95 & 48,59 & 52,84 & 151,06 \\
\hline Alytes dickhilleni & 30SWG29 & 100,00 & 110,30 & 120,44 & 37,52 & 6619,50 & 298,79 & $-18,26$ & 317,05 & 87,32 & 200,58 & 201,02 & 33,63 & 610,67 & 77,00 & 16,02 & 37,12 & 210,14 & 68,94 & 70,97 & 177,13 \\
\hline Alytes dickhilleni & 30SWG32 & 100,00 & 108,31 & 116,88 & \begin{tabular}{|c|}
37,58 \\
\end{tabular} & 6403,72 & 289,88 & $-17,44$ & 307,32 & 58,95 & 195,25 & 196,76 & 34,38 & 619,90 & 78,99 & 16,83 & 38,24 & 210,41 & 66,78 & 70,91 & 187,42 \\
\hline Alytes dickhilleni & 30SWG33 & 100,00 & 135,56 & 112,17 & 37,69 & 6190,07 & 306,04 & 11,34 & 294,70 & 88,76 & 218,78 & 220,29 & 62,79 & 463,58 & 58,39 & \begin{tabular}{|l|}
8,76 \\
\end{tabular} & 41,95 & 156,30 & 40,33 & 46,45 & 144,90 \\
\hline Alytes dickhilleni & 30SWG38 & 100,00 & 134,64 & 116,67 & 37,80 & 6414,44 & 312,78 & 6,73 & 306,05 & 113,44 & 221,11 & 221,89 & 58,84 & 474,94 & 60,64 & 9,41 & 39,96 & 162,93 & 45,98 & 50,41 & 140,35 \\
\hline Alytes dickhilleni & 30SWG39 & 100,00 & 122.08 & 119,02 & 37,76 & 6531,97 & 305,88 & $-6,37$ & 312,25 & 99,95 & $\mid 210,69$ & 211,26 & 45,77 & 538,32 & $68,69 \mid$ & $\mid 12,72$ & 37,90 & $\mid 185,42$ & 58.18 & 61.05 & 155,37 \\
\hline Alytes dickhilleni & 30SWG42 & 100,00 & 108,77 & 116,04 & 37,70 & 6363,33 & 288,35 & $-16,43$ & 304,78 & 69,62 & 194,99 & 196,67 & 35,45 & 611,50 & 78, & 17,09 & 37,39 & 206,11 & 67,97 & 71,68 & 182,05 \\
\hline Alytes dickhilleni & 30SWG43 & 100,00 & 143,50 & 108,73 & 37,84 & 6021,64 & 306,44 & 21,31 & 285,14 & \begin{tabular}{|l|}
105,51 \\
\end{tabular} & 223,97 & 225,81 & 72,36 & 415,18 & 51,79 & 7,17 & 42,11 & \begin{tabular}{|l|l|}
137,89 \\
\end{tabular} & 35,13 & 41,23 & 129,15 \\
\hline Alytes dickhilleni & 30SWG48 & 100,00 & 133,42 & 116,38 & \begin{tabular}{|l|l|}
37,97 \\
\end{tabular} & 6375,05 & 310,23 & 5,79 & 304,44 & 112,25 & 219,40 & 220,26 & 58,35 & 472,79 & 60,70 & 9,84 & 38,89 & 161,44 & 47,91 & 51,92 & 137,14 \\
\hline Alytes dickhilleni & 30SWG52 & 100,00 & 118,74 & 113,35 & 37,86 & 6231,44 & 291,99 & $-5,15$ & 297,14 & 94,74 & 202,79 & 204,69 & 46,57 & 548,09 & 70,14 & 14,23 & 38,14 & 183,59 & 58,63 & 62,94 & 163,17 \\
\hline Alytes dickhilleni & 30SWG59 & 100,00 & 132,38 & 117,02 & 38,00 & 6359,18 & 308,74 & 4,14 & 304,60 & 111,25 & 217,97 & 218,96 & 57,32 & 470,81 & 60,97 & 10,31 & 37,72 & 160,66 & 50,57 & 53,86 & 132,38 \\
\hline Alytes dickhilleni & 30SWG77 & 100,00 & 125,93 & 115,18 & \begin{tabular}{|l|l|}
37,97 \\
\end{tabular} & 6262,87 & 298,96 & $-0,24$ & 299,21 & 103,99 & 210,25 & 211,69 & 52,67 & 498,77 & 64,43 & 12,68 & 36,12 & 167,36 & 57,72 & 60,85 & 137,99 \\
\hline Alytes dickhilleni & 30SWHOO & 100,00 & 135,70 & 118,81 & 37,07 & 6620,45 & 321,12 & $\begin{array}{r}-2,249 \\
5,99\end{array}$ & 315,12 & \begin{tabular}{|c|}
97,55 \\
97,3
\end{tabular} & 225,36 & 225,55 & 57,45 & 503,33 & 63,04 & $\begin{array}{l}2,04 \\
9,04 \\
\end{array}$ & $\frac{10,12}{42,12}$ & $\begin{array}{l}176,09 \\
\end{array}$ & 44,77 & $\begin{array}{l}46,68 \\
46,\end{array}$ & 153,98 \\
\hline Alytes dickhilleni & 30SWHO1 & 100,00 & 131,25 & 119,80 & 37,08 & 6658,89 & 318,57 & 1,16 & 317,42 & 100,95 & 221,56 & 221,69 & 52,66 & 522,87 & 65,45 & 10,09 & 41,08 & 182,81 & 49,46 & 50,68 & 157,44 \\
\hline Alytes dickhilleni & 30SWHO2 & 100,00 & 144,42 & 118,63 & 37,09 & 6611,24 & 328,17 & 14,06 & 314,11 & 115,59 & 233,70 & 233,81 & 65,58 & 459,73 & 57,65 & 7,20 & 42,47 & 160,87 & 39,82 & 40,88 & 139,07 \\
\hline Alytes dickhilleni & 30SWHO4 & 100,00 & 153,38 & 118,44 & 37,31 & 6570,38 & 334,75 & 22,41 & 312,34 & 134,77 & 241,78 & 241,81 & 74,35 & 415,06 & 52,06 & 5,56 & 42,79 & 144,82 & 34,95 & 35,32 & 123,95 \\
\hline Alytes dickhilleni & 30SWHO5 & 100,00 & 146,81 & 120,28 & 37,49 & 6636,79 & 331,49 & 14,79 & 316,69 & 128,08 & 236,24 & 236,24 & 67,31 & 437,31 & 54,96 & 6,57 & 41,47 & 153,16 & 39,79 & 39,86 & 128,39 \\
\hline Alytes dickhilleni & 30SWHO6 & 100,00 & 138,07 & 121,96 & 37,75 & 6697,72 & 326,27 & \begin{tabular}{|l|l|}
5,68 \\
4
\end{tabular} & 320,59 & \begin{tabular}{|l|}
118,7300 \\
\end{tabular} & $\begin{array}{l}228,64 \\
224\end{array}$ & \begin{tabular}{|l|}
228,64 \\
\end{tabular} & 58,33 & | & 58,71 & 8,10 & $\begin{array}{ll}41,4976 \\
39,86\end{array}$ & \begin{tabular}{|l|}
164,30 \\
\end{tabular} & $\begin{array}{ll}46,44 \\
4\end{array}$ & $\begin{array}{l}5,400 \\
46,44\end{array}$ & 135,13 \\
\hline Alytes dickhilleni & 30SWH10 & 100,00 & 119,81 & 120,31 & \begin{tabular}{|l|l|}
37,38 \\
\end{tabular} & 6638,95 & 308,01 & $-9,60$ & 317,61 & 94,93 & 210,08 & 210,42 & 42,17 & 569,87 & 71,55 & 13,20 & 38,99 & 197,38 & 59,80 & 61,74 & 168,19 \\
\hline Alytes dickhilleni & 30SWH11 & 100,00 & 134,09 & 119,02 & 37,29 & 6587,66 & 318,37 & 4,40 & 313,97 & 111,43 & 223,24 & 223,42 & 56,20 & 498,22 & 62,81 & 9,64 & 40,51 & 173,14 & 48,17 & 50,10 & 147,80 \\
\hline Alytes dickhilleni & 30SWH12 & 100,00 & 134,78 & 119,67 & 37,38 & 6609,19 & 319,85 & 4,54 & 315,31 & 114,20 & 224,19 & 224,34 & 56,55 & 491,51 & 62,07 & 9,38 & 40,19 & 171,31 & 48,13 & 49,49 & 144,39 \\
\hline Alytes dickhilleni & 30SWH13 & 100,00 & 136,64 & 120,31 & 37,53 & 6623,65 & 322,19 & 5,76 & 316,43 & 116,56 & 226,25 & 226,32 & 58,05 & 478,28 & 60,61 & 8,73 & 40,08 & 167,22 & 46,82 & 47,43 & 139,38 \\
\hline $\begin{array}{l}\text { Alytes dickhilleni } \\
\text { al }\end{array}$ & 30SWH14 & 100,00 & $\begin{array}{l}13,04,97 \\
148,97\end{array}$ & 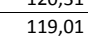 & 37,71 & $\begin{array}{l}6025,000 \\
6557,42\end{array}$ & 330,43 & \begin{tabular}{|l|l|}
17,86 \\
\end{tabular} & \begin{tabular}{|l|}
312,57 \\
\end{tabular} & \begin{tabular}{|l|}
130,21 \\
10,0
\end{tabular} & $\mid \begin{array}{l}\mid 237,24 \\
23,25\end{array}$ & \begin{tabular}{|l|}
237,24 \\
237
\end{tabular} & $\begin{array}{l}30,035 \\
70,45\end{array}$ & $\mid$\begin{tabular}{|l|}
422,51 \\
42,0
\end{tabular} & $\begin{array}{l}50,01 \\
53,51\end{array}$ & $\frac{0,15}{6,37}$ & \begin{tabular}{|l|l|}
41,31 \\
41
\end{tabular} & \begin{tabular}{|l|}
147,08 \\
14,20
\end{tabular} & $\begin{array}{l}38,62 \\
38,62\end{array}$ & $\begin{array}{l}48,45 \\
38,94\end{array}$ & $\begin{array}{l}13,00 \\
123,22\end{array}$ \\
\hline Alytes dickhilleni & 30SWH20 & 100,00 & 97,98 & 121,82 & 37,70 & 6678,92 & 289,86 & $-30,73$ & 320,59 & 74,45 & 189,41 & 189,81 & 21,11 & 674,38 & 84,46 & 19,71 & 35,07 & 231,49 & 82,36 & 82,62 & 191,90 \\
\hline Alytes dickhilleni & 30SWH21 & 100,00 & 108,66 & 121,42 & 37,75 & 6662,13 & 298,65 & $-20,64$ & 319,29 & 85,88 & 199,53 & 199,80 & 31,31 & 615,27 & 77,37 & 16,50 & 36,18 & 212,34 & 72,30 & 72,93 & 175,07 \\
\hline Alytes dickhilleni & 30SWH22 & 100,00 & 129,43 & 120,05 & 37,79 & 6589,29 & 314,54 & $-0,47$ & 315,01 & 108,49 & 218,69 & 218,97 & 51,83 & 507,32 & \begin{tabular}{r|r}
64,45 \\
\end{tabular} & 10,86 & 38,66 & 176,13 & 53,73 & 54,77 & 145,49 \\
\hline Alytes dickhilleni & 30SWH23 & 100,00 & 135,81 & 119,95 & 37,88 & 6573,86 & 319,58 & 5,31 & 314,27 & 115,67 & 224,68 & 224,79 & 57,81 & $\begin{array}{ll}473,78 \\
\end{array}$ & 60,36 & 9,25 & 39,12 & 164,77 & 48,83 & 49,47 & 135,25 \\
\hline Alytes dickhilleni & 30SWH24 & 100,00 & 144,52 & 119,50 & 37,97 & 6537,57 & 326,10 & \begin{tabular}{r|r|}
13,49 \\
\end{tabular} & 312,61 & 125,46 & 232,60 & 232,66 & 66,33 & 431,48 & 55,08 & 7,3 & 39,93 & 149,76 & 42,48 & 42,80 & 123,02 \\
\hline Alytes dickhilleni & 30SWH25 & 100,00 & 140,51 & 120,64 & 38,00 & 6580,19 & 324,05 & $\begin{array}{ll}8,9,96 \\
8,96\end{array}$ & 315,09 & 121,21 & 229,27 & 229,33 & 61,99 & 444,95 & 56,81 & 7,98 & 39,07 & 154,85 & 46,07 & 46,40 & 125,01 \\
\hline Alytes dickhilleni & 30SWH30 & 100,00 & 102,13 & 120,83 & $\begin{array}{l}37,45 \\
\end{array}$ & 6632,01 & 291,64 & $-26,36$ & 318,00 & 78,76 & 192,94 & 193,40 & 25,83 & 644,83 & 81,33 & 18,94 & 34,79 & 221,03 & 79,58 & 80,12 & 181,02 \\
\hline Alytes dickhilleni & 30SWH31 & 100,00 & 108,29 & 121,08 & 37,7 & 6625,97 & 297,12 & $-20,70$ & 317,82 & 85,36 & 198,76 & 199,10 & 31,57 & 606,90 & 76,8 & 16,7 & 35,28 & 209,08 & 73,52 & 73,98 & 169,73 \\
\hline $\begin{array}{l}\text { Alytes dickhilleni } \\
\end{array}$ & 30SWH32 & 100,00 & 114,08 & 121,17 & 37,5 & 6616,64 & 301,82 & $-15,40$ & $\begin{array}{l}117,22 \\
317\end{array}$ & $\begin{array}{l}51,90 \\
91,9\end{array}$ & 204,23 & 204,44 & 36,99 & 573,92 & $72, \varepsilon$ & 15,6 & $\begin{array}{l}3,20 \\
35,73 \\
\end{array}$ & $\begin{array}{l}198,20 \\
\end{array}$ & 68,40 & 68,88 & 159,72 \\
\hline Alytes dickhilleni & $30 \mathrm{SWH}$ & 100,00 & 115,28 & 121,64 & 37,99 & 6624,59 & 303,36 & $-14,60$ & 317,95 & 93,55 & 205,45 & 205,58 & 37,90 & 563,74 & 71,58 & 14,55 & 35,49 & 195,09 & 67,78 & 68,03 & 155,56 \\
\hline Alytes dickhilleni & 30 SWH34 & 100,00 & 127,64 & 121,06 & 37,99 & 6585,76 & 312,86 & $-2,88$ & 315,74 & \begin{tabular}{|l|l|}
107,04 \\
\end{tabular} & 216,92 & 217,02 & 50,06 & 499,64 & 63,86 & 11,34 & 36,86 & 173,19 & 57,30 & 57,69 & 137,60 \\
\hline Alytes dickhilleni & 30SWH35 & 100,00 & 135,10 & 120,94 & 38,00 & 6562,45 & 318,66 & 3,99 & 314,68 & 115,32 & 223,75 & 223,83 & 57,18 & 461,17 & 59,19 & 9,41 & 37,62 & 159,92 & 51,44 & 51,82 & 126,39 \\
\hline Alytes dickhilleni & 30SWH36 & 100,00 & 126,54 & 122,05 & 38,00 & 6610,75 & 312,94 & $-4,77$ & 317,70 & 106,23 & 216,08 & 216,18 & 48,37 & 497,56 & 63,25 & 11,47 & 36,08 & 172,49 & 58,95 & 59,70 & 134,27 \\
\hline $\begin{array}{l}\text { Alytes dickhilleni } \\
\text { al }\end{array}$ & 30SWH40 & 100,00 & $\frac{111}{111}$ & $\begin{array}{l}12,03 \\
119,94\end{array}$ & 37,86 & 6555,71 & 296, & $\begin{array}{l}--17,14 \\
-17,14\end{array}$ & 314,12 & \begin{tabular}{|l|l|}
80,25 \\
88,53
\end{tabular} & \begin{tabular}{|l|}
200,57 \\
\end{tabular} & $\mid$\begin{tabular}{|l|}
201,16 \\
\end{tabular} & $\begin{array}{l}40,317 \\
35,33\end{array}$ & $\begin{array}{l}587,22 \\
\end{array}$ & | & $\begin{array}{l}11,46 \\
16,23\end{array}$ & $\begin{array}{l}0,060 \\
35,18\end{array}$ & \begin{tabular}{|l|}
201,40 \\
\end{tabular} & $\mid 71,21$ & $\frac{72,18}{72,18}$ & 164,27 \\
\hline Alytes dickhilleni & 30SWH41 & 100,00 & 104,01 & 120,89 & 37,87 & 6607,13 & 292,17 & $-24,69$ & 316,87 & 80,68 & 194,50 & $\begin{array}{l}194,73 \\
\end{array}$ & 27,95 & 624,24 & 79,20 & 18,58 & 33,92 & 213,93 & 79,32 & 79,43 & 171,15 \\
\hline Alytes dickhilleni & 30SWH42 & 100,00 & 117,07 & 120,59 & 37,97 & 6569,31 & 302,61 & $-12,38$ & 314,99 & $\begin{array}{l}90,905 \\
94,95\end{array}$ & 206,40 & 206,77 & 40,55 & 550,65 & 70,50 & $\begin{array}{l}14,40 \\
14,42\end{array}$ & \begin{tabular}{|l|l|}
35,34 \\
\end{tabular} & $\begin{array}{l}189,73 \\
\end{array}$ & 66,72 & 67,18 & 150,78 \\
\hline Alytes dickhilleni & 30SWH43 & 100,00 & 126,58 & 120,40 & 37,99 & 6533,06 & 309,88 & $-3,61$ & 313,49 & 105,78 & 215,07 & 215,37 & 49,71 & 500,56 & 64,43 & 11,81 & 36,40 & 172,66 & 58,66 & 59,34 & 136,50 \\
\hline Alytes dickhilleni & 30 SWH44 & 100,00 & 120,14 & 121,30 & 38,00 & 6578,54 & 305,68 & $-10,05$ & 315 & 98,81 & 209,57 & 205 & 42,99 & 529,28 & 67 & 13,53 & 35,21 & 182,61 & 64,91 & 65,25 & 142 \\
\hline \begin{tabular}{|l} 
Alytes dickhilleni \\
Al
\end{tabular} & 30SWH45 & $\begin{array}{l}100,00 \\
\end{array}$ & 122,26 & $\begin{array}{l}121,50 \\
121,51\end{array}$ & 38,00 & | 6578,14 & 307,00 & \begin{tabular}{|c|c|}
$-8,31$ \\
$-8,31$
\end{tabular} & \begin{tabular}{|l|}
315,95 \\
315
\end{tabular} & \begin{tabular}{|r|r|}
101,38 \\
10,0
\end{tabular} & \begin{tabular}{|l|}
211,55 \\
210
\end{tabular} & \begin{tabular}{|l|}
211,58 \\
21
\end{tabular} & \begin{tabular}{|l|}
44,91 \\
44,91
\end{tabular} & $\mid$ & $\begin{array}{l}\mid l, 1,1 \\
65,98\end{array}$ & \begin{tabular}{|l|l|}
13,00 \\
13,0
\end{tabular} & \begin{tabular}{|l|l}
35,23 \\
35,
\end{tabular} & \begin{tabular}{|c|}
178,04 \\
178,0
\end{tabular} & $\begin{array}{l}4,113 \\
63,34 \\
\end{array}$ & $\begin{array}{l}5,25 \\
64,24 \\
\end{array}$ & $\begin{array}{l}142,50 \\
137,55\end{array}$ \\
\hline Alytes dickhilleni & 30SWH46 & 100,00 & 115,51 & 122,13 & 38,00 & 6610,28 & 302,89 & $-14,96$ & 317,85 & 94,21 & 205,38 & 205,49 & 38,10 & 545,61 & 69,02 & 14,80 & 33,92 & 188,01 & 69,40 & 70,86 & 143,76 \\
\hline Alytes dickhilleni & 30SWH47 & 100,00 & 121,31 & 122.45 & 38,00 & 6603,47 & 307,74 & -9.66 & 317.40 & $\mid 100,72$ & 210,66 & 210,88 & 43.54 & 512.44 & 64.99 & 13,08 & 34.31 & 176,73 & 64.28 & 66.55 & 134,06 \\
\hline Alytes dickhilleni & 30SWH48 & 100,00 & 128,17 & 122,68 & 38,01 & 6592,98 & 313,42 & $-3,22$ & 316,64 & 108,55 & 217,20 & 217 & 50 & 475,49 & 60,40 & 11,24 & 34 & 163,85 & 58,73 & 61,09 & 123,44 \\
\hline Alytes dickhilleni & 30SWH50 & 100,00 & 120,56 & 118,94 & 38,00 & 6466,86 & 302,08 & $-7,79$ & 309,87 & 98,62 & 208,15 & 208,87 & 44,98 & 530,73 & 68,54 & 13,60 & 35,69 & 181,69 & 62,95 & 64,42 & 146,11 \\
\hline
\end{tabular}




\begin{tabular}{|c|c|c|c|c|c|c|c|c|c|c|c|c|c|c|c|c|c|c|c|c|c|}
\hline TAXON & UTM & $\mathrm{km} 2$ & B101 & B102 & $\mathrm{BIO3}$ & BIO4 & B105 & B106 & B107 & B108 & B109 & BIO10 & BIO11 & BIO12 & 81013 & BIO14 & BIO15 & B1016 & B1017 & B1018 & B1019 \\
\hline Alytes dickhilleni & 30SWH51 & 100,00 & 102,68 & 120,33 & 37,85 & 6578,31 & 289,47 & $-25,73$ & 315,19 & 79,39 & 192,83 & 193,01 & 26,90 & 627,86 & 79,82 & 19,57 & 32,97 & 214,10 & 82,39 & 82,44 & 169,05 \\
\hline Alytes dickhilleni & 30SWH52 & 100,00 & 116,10 & 120,35 & 38,00 & 6533,21 & 300,31 & $-12,83$ & 313,14 & 94,07 & 205,03 & 205,38 & 40,06 & 548,71 & 70,60 & 14,86 & 34,53 & 188,31 & 68,69 & 68,93 & 147,66 \\
\hline Alytes dickhilleni & 30SWH53 & 100,00 & 123,01 & 120,28 & 38,00 & 6502,48 & 305,49 & $-6,56$ & 312,05 & 101,84 & 211,27 & 211,45 & 46,66 & 513,34 & 66,25 & 13,13 & 35,28 & 176,21 & 63,08 & 63,49 & 137,18 \\
\hline Alytes dickhilleni & 30SWH54 & 100,00 & 131,29 & 120,31 & 38,04 & 6476,47 & 312,01 & 1,13 & 310,89 & 110,88 & 218,81 & 218,99 & 54,62 & 468,32 & 60,97 & 10,81 & 36,17 & 161,00 & 56,14 & 56,56 & 124,16 \\
\hline Alytes dickhilleni & 30SWH55 & 100,00 & 121,66 & 121,17 & 38,03 & \begin{tabular}{|l|l|}
6532,07 \\
\end{tabular} & 305,32 & $-8,37$ & 313,69 & 100,71 & 210,34 & 210,44 & 44,90 & 514,17 & 65,99 & 13,58 & 34,55 & \begin{tabular}{|l|l|}
176,47 \\
\end{tabular} & 65,08 & 66,08 & 134,49 \\
\hline Alytes dickhilleni & 30SWH56 & 100,00 & 117,42 & 121,80 & 38,00 & 6568,34 & 302,79 & $-12,63$ & 315,42 & 96,35 & 206,74 & 206,80 & 40,53 & 530,40 & 67,58 & 14,62 & 33,55 & 182,10 & 68,66 & 70,37 & 137,23 \\
\hline Alytes dickhilleni & 30SWH57 & 100,00 & 114,82 & 122,09 & 38,00 & 6587,10 & 300,95 & $-15,36$ & 316,31 & 93,56 & 204,25 & 204,32 & 37,72 & 539,45 & 68,25 & 15,29 & 32,92 & \begin{tabular}{|l|l|}
185,07 \\
\end{tabular} & 70,97 & 73,38 & 138,21 \\
\hline Alytes dickhilleni & 30SWH58 & 100,00 & 122,45 & 122,13 & 38,04 & 6566,99 & 307,29 & \begin{tabular}{|l|l|} 
& $-8,44$ \\
\end{tabular} & 315,72 & 102,03 & 211,29 & 211,42 & 45,01 & 497,48 & 63,23 & 13,07 & 33,58 & 170,77 & 64,33 & 67,10 & 126,25 \\
\hline Alytes dickhilleni & 30SWH60 & 100,00 & 124,15 & 118,25 & 38,00 & 6404,44 & 302,79 & $-3,59$ & 306,38 & 102,50 & 210,65 & 211,57 & 49,02 & 506,06 & 65,76 & 12,78 & 35,65 & 172,45 & 60,49 & 62,05 & 137,26 \\
\hline Alytes dickhilleni & 30SWH61 & 100,00 & 108,09 & 119,62 & 37,93 & 6511,14 & 291,89 & $-19,90$ & 311,79 & 85,27 & 197,10 & $\begin{array}{ll}197,38 \\
\end{array}$ & 32,68 & 592,88 & 75,97 & 18,10 & 33,04 & 201,65 & 78,14 & 78,20 & 157,47 \\
\hline Alytes dickhilleni & 30SWH62 & 100,00 & 122,64 & 119,54 & 38,00 & 6448,83 & 303,26 & $-6,08$ & 309,34 & 101,19 & 210,08 & 210,48 & 47,03 & 510,83 & 66,39 & 13,34 & 34,84 & 174,56 & 63,86 & 64,27 & 135,26 \\
\hline Alytes dickhilleni & 30SWH63 & 100,00 & 130,89 & 119,69 & 38,07 & 6418,81 & 309,65 & 1,35 & 308,30 & 110,42 & 217,51 & 217,96 & 54,92 & 467,12 & 61,21 & 11,03 & 35,84 & 159,75 & 56,89 & 57,26 & 122,81 \\
\hline Alytes dickhilleni & 30SWH64 & 100,00 & 143,58 & 119,04 & 38,44 & 6357,51 & 318,63 & 13,18 & 305,45 & 124,52 & 228,84 & 229,14 & 67,52 & 406,88 & 53,85 & 8,03 & 37,66 & 138,73 & 46,86 & 47,79 & 106,31 \\
\hline Alytes dickhilleni & 30SWH65 & 100,00 & 137,79 & 120,16 & 38,44 & 6408,61 & 315,40 & 7,05 & 308,36 & 118,61 & 224,08 & 224,23 & 61,37 & 430,13 & 56,60 & 9,38 & 36,48 & 146,97 & 52,01 & 52,64 & 110,77 \\
\hline Alytes dickhilleni & 30SWH66 & 100,00 & 125,89 & 121,30 & 38,14 & 6490,78 & 307,56 & $-4,69$ & 312,25 & 105,67 & 213,69 & 213,75 & 49,07 & 483,00 & 62,73 & 12,45 & 34,30 & 165,42 & 62,13 & 63,59 & 122,54 \\
\hline Alytes dickhilleni & 30SWH67 & 100,00 & 121,15 & 121,71 & 38,09 & 6519,50 & 304,16 & $-9,30$ & 313,46 & 100,49 & 209,50 & 209,64 & 44,39 & 503,36 & 64,59 & 13,88 & 33,23 & 172,13 & 66,52 & 69,38 & 126,38 \\
\hline Alytes dickhilleni & 30SWH68 & 100,00 & 120,79 & 121,99 & 38,05 & 6529,85 & 304,34 & $-9,69$ & 314,03 & 100,02 & 209,21 & 209,41 & 43,87 & 500,94 & 63,86 & 13,86 & 32,85 & 171,14 & 66,71 & 70,40 & 124,62 \\
\hline Alytes dickhilleni & 30SWH71 & 100,00 & 119,08 & 118,76 & 38,03 & 6412,77 & 298,25 & $-8,89$ & 307,14 & 97,06 & 205,94 & 206,61 & 44,11 & 528,87 & 68,66 & 14,74 & 34,00 & 179,50 & 67,99 & 68,50 & 138,95 \\
\hline Alytes dickhilleni & 30SWH72 & 100,00 & 116,62 & 119,38 & 38,00 & 6439,80 & 297,18 & $-11,63$ & 308,81 & 94,75 & 204,30 & 204,62 & 41,43 & 539,06 & 69,85 & 15,50 & 33,44 & 183,02 & 71,05 & 71,07 & 140,00 \\
\hline Alytes dickhilleni & 30SWH73 & 100,00 & 122,36 & 119,87 & 38,13 & 6426,94 & 301,87 & $-6,58$ & 308,45 & 101,08 & 209,64 & 209,83 & 47,00 & 505,47 & 65,92 & 13,66 & 34,00 & 171,94 & 65,78 & 65,79 & 129,99 \\
\hline Alytes dickhilleni & 30SWH74 & 100,00 & 141,05 & 119,23 & 38,77 & 6329,09 & 315,33 & \begin{tabular}{|l|l|}
10,57 \\
\end{tabular} & 304,76 & 121,84 & 225,88 & 226,24 & 65,34 & 414,05 & 55,10 & 8,77 & 36,85 & 140,58 & 50,00 & 50,60 & 105,82 \\
\hline Alytes dickhilleni & 30SWH76 & 100,00 & 132,95 & 120,81 & 38,82 & 6408,51 & 311,01 & 2,16 & 308,85 & 113,34 & 219,48 & 219,49 & 56,69 & 444,69 & 58,68 & 10,75 & 35,01 & 151,40 & 57,19 & 58,24 & 110,40 \\
\hline Alytes dickhilleni & 30SWH77 & 100,00 & 123,18 & 121,17 & 38,41 & 6470,92 & 304,12 & $-7,16$ & 311,29 & 102,78 & 210,74 & 210,77 & 46,77 & 489,06 & \begin{tabular}{|c|}
63,27 \\
\end{tabular} & 13,52 & 33,29 & \begin{tabular}{|l|l|}
166,43 \\
\end{tabular} & \begin{tabular}{|c|}
65,67 \\
\end{tabular} & 68,23 & 120,31 \\
\hline Alytes dickhilleni & 30SWH78 & 100,00 & 119,50 & 121,59 & 38,33 & 6494,99 & 301,59 & $-10,78$ & 312,37 & 98,80 & 207,46 & 207,51 & 43,04 & 504,06 & 64,44 & 14,59 & 32,28 & 171,28 & 69,07 & 72,55 & 122,98 \\
\hline Alytes dickhilleni & 30SWH81 & 100,00 & 133,70 & 117,66 & 38,62 & 6270,47 & 306,62 & 5,01 & 301,61 & 113,16 & 217,97 & 218,81 & 59,57 & 450,95 & 59,38 & 10,58 & 35,94 & 152,00 & 54,51 & 56,62 & 117,47 \\
\hline Alytes dickhilleni & 30SWH82 & 100,00 & 123,14 & 118,79 & 38,38 & 6366,40 & 300,15 & $-5,17$ & 305,32 & 101,86 & 209,27 & 209,86 & 48,48 & 502,28 & 65,59 & 13,74 & 33,91 & 169,65 & 65,89 & 66,19 & 128,66 \\
\hline Alytes dickhilleni & 30SWH83 & 100,00 & 127,20 & 119,13 & 38,56 & 6355,33 & 303,63 & $-1,80$ & \begin{tabular}{|l|l|}
305,43 \\
\end{tabular} & 106,50 & 213,11 & 213,46 & 52,27 & \begin{tabular}{|l|}
479,97 \\
\end{tabular} & 63,04 & 12,64 & 34,44 & 162,31 & $\begin{array}{l}62,58 \\
625\end{array}$ & 200,96 & 121,56 \\
\hline Alytes dickhilleni & 30SWH86 & 100,00 & 139,91 & 120,07 & 38,97 & 6323,97 & 314,17 & 9,01 & 305,16 & 120,78 & 225,01 & 225,06 & 64,40 & 410,44 & 54,92 & 9,30 & 36,04 & 138,60 & 52,97 & 53,56 & 99,77 \\
\hline Alytes dickhilleni & 30SWH87 & 100,00 & 130,85 & 120,71 & 38,95 & 6393,79 & 308,12 & 0,47 & 307,66 & 111,27 & 217,19 & 217,21 & 55,06 & 448,12 & 59,10 & 11,66 & 34,21 & 151,61 & 60,12 & 62,05 & 107,57 \\
\hline Alytes dickhilleni & 30SWH91 & 100,00 & 141,29 & 117,12 & 38,93 & 6162,53 & 309,87 & 12,71 & 297,16 & 121,52 & 223,81 & 224,52 & 67,92 & 415,86 & 54,98 & 9,03 & 37,18 & 138,75 & 48,73 & 52,23 & 107,13 \\
\hline Alytes dickhilleni & 30SWH92 & 100,00 & 137,53 & 117,82 & 38,78 & 6220,34 & 308,26 & 8,64 & 299,62 & 117,55 & 220,95 & 221,68 & 63,68 & 433,09 & 57,22 & 10,15 & 36,25 & 144,87 & 53,48 & 55,89 & 109,89 \\
\hline Alytes dickhilleni & 30SWH93 & 100,00 & 141,58 & 118,42 & 39,03 & 6211,47 & 311,88 & $\begin{array}{ll}0,11966 \\
11,96\end{array}$ & \begin{tabular}{|l|}
299,92 \\
\end{tabular} & $\begin{array}{ll}122,12 \\
12\end{array}$ & \begin{tabular}{|l|l|}
224,78 \\
\end{tabular} & 225,34 & $\begin{array}{l}67,37 \\
67\end{array}$ & \begin{tabular}{|l|l|}
411,29 \\
\end{tabular} & 54,77 & $\begin{array}{l}0,06 \\
9,06\end{array}$ & $\begin{array}{ll}36,28 \\
36,84\end{array}$ & $\begin{array}{l}137,69 \\
137,\end{array}$ & 50,45 & 52,65 & $\begin{array}{l}103,01 \\
\end{array}$ \\
\hline Alytes dickhilleni & 30SWH96 & 100,00 & 146,16 & 119,44 & 39,02 & 6231,48 & 316,62 & 15,25 & 301,38 & 127,58 & 229,58 & 229,75 & 71,24 & 384,08 & 51,70 & 8,15 & 37,09 & 128,34 & 49,41 & 50,04 & 91,68 \\
\hline Alytes dickhilleni & 30 SXG28 & 100,00 & 150,61 & 113,57 & 39,63 & 5862,45 & 308,13 & 24,37 & 283,76 & 120,82 & 228,34 & 229,78 & 80,49 & 383,29 & 50,60 & 7,32 & 39,63 & 129,49 & 40,27 & 48,06 & 100,86 \\
\hline Alytes dickhilleni & $30 S \times G 29$ & 100,00 & 135,25 & 115,02 & 39,09 & 6045,20 & 299,51 & 8,79 & 290,73 & 110,42 & 215,94 & 217,42 & 63,70 & 455,83 & 58,89 & 11,65 & 35,79 & 149,59 & 56,40 & 61,37 & 116,24 \\
\hline Alytes dickhilleni & 30SXHO3 & 100,00 & 159,70 & 117,63 & 39,90 & 6014,01 & 322,24 & 29,60 & 292,64 & 132,09 & 239,51 & 239,92 & 86,75 & 339,37 & 45,99 & 5,39 & 40,88 & 113,35 & 36,12 & 42,16 & 84,78 \\
\hline $\begin{array}{l}\text { Alytes dickhilleni } \\
\text { al }\end{array}$ & 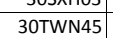 & 100,00 & 108,38 & $\begin{array}{r}1,00,08 \\
90,08\end{array}$ & 39,01 & $\begin{array}{l}\mid 4032,58 \\
4932\end{array}$ & 239,01 & $\begin{array}{l}3,27 \\
11,27 \\
\end{array}$ & $\mid \begin{array}{l}\mid 22,04,75 \\
227\end{array}$ & \begin{tabular}{|l|}
55,25 \\
55,25
\end{tabular} & \begin{tabular}{|l|}
171,85 \\
171,5
\end{tabular} & \begin{tabular}{|l|}
173,45 \\
175
\end{tabular} & $\begin{array}{ll}48,43 \\
48,\end{array}$ & \begin{tabular}{|l|l|}
998,88 \\
998,1
\end{tabular} & \begin{tabular}{|l|}
110,42 \\
110,42
\end{tabular} & \begin{tabular}{r|}
50,92 \\
50
\end{tabular} & $\begin{array}{l}4,00 \\
18,72\end{array}$ & $\mid \begin{array}{l}\mid 1,307,34 \\
07\end{array}$ & \begin{tabular}{|l|}
50,14 \\
189,19
\end{tabular} & \begin{tabular}{|l|}
420,92 \\
190,92
\end{tabular} & $\begin{array}{l}04,10 \\
289,05\end{array}$ \\
\hline Alytes dickhilleni & 30TWN46 & 100,00 & 123,61 & 83,98 & 39,18 & 4612,31 & 243,96 & 32,62 & 211,34 & 73,60 & 181,61 & 184,19 & 67,65 & 1057,52 & 120,02 & 50,76 & 20,66 & 333,64 & 191,58 & 200,33 & 315,99 \\
\hline Alytes obstetricans & 29SMC69 & 100,00 & 147,96 & 70,09 & 41,09 & 3488,38 & 238,79 & 70,50 & 168,29 & 111,22 & 189,22 & 193,04 & 102,87 & 825,55 & 127,97 & 5,09 & 64,31 & 370,27 & 36,55 & 38,54 & 344,46 \\
\hline Alytes obstetricans & 29SMC79 & 100,00 & 150,21 & 73,67 & 40,95 & 3685,18 & 248,04 & 70,05 & 177,99 & 111,34 & 194,26 & 198,41 & 103,30 & 825,94 & 128,66 & 4,51 & 64,91 & 371,05 & 34,95 & 36,68 & 348,66 \\
\hline Alytes obstetricans & 29SMD61 & 56,00 & 151,29 & 65,25 & 41,09 & 3287,54 & 233,99 & 76,85 & 157,14 & 116,75 & 189,82 & 193,05 & 108,30 & 756,94 & 120,51 & 4,18 & 63,64 & 340,78 & 32,10 & 35,60 & 314,88 \\
\hline Alytes obstetricans & 29SMD84 & 101,00 & 154,34 & 64,55 & 40,99 & 3237,16 & 236,09 & $\begin{array}{ll}0,47 \\
80,0\end{array}$ & \begin{tabular}{|l|}
155,62 \\
\end{tabular} & 120,55 & 192,73 & 195,36 & 112,40 & 698,05 & 113,05 & 4,00 & 62,10 & 309,29 & 30,02 & 35,43 & 289,73 \\
\hline Alytes obstetricans & 29SMD94 & 100,00 & 154,66 & 69,63 & 40,84 & 3484,84 & 245,83 & 77,01 & 168,82 & 118,17 & 196,54 & 199,51 & 110,10 & 725,66 & 113,71 & 4,11 & 61,57 & 318,32 & 32,08 & 36,79 & 302,73 \\
\hline Alytes obstetricans & 29SMD98 & 58,00 & 154,47 & 68,99 & 42,01 & 3275,73 & 239,79 & 77,49 & 162,30 & 119,74 & 193,37 & 195,76 & 111,73 & 752,49 & 116,18 & 5,30 & 59,35 & 21,62 & 37,58 & 44,10 & 307,90 \\
\hline Alytes obstetricans & 29SND18 & 100,00 & 150,32 & 77,86 & 41,17 & 3751,52 & 253,42 & 66,79 & 186,64 & 110,63 & 196,26 & 199,05 & 102,79 & 842,71 & 124,44 & 6,59 & 57,92 & 354,03 & 45,62 & 49,85 & 346,48 \\
\hline Alytes obstetricans & $295 N D 27$ & 101,00 & 147,54 & 81,31 & 40,44 & 4037,86 & 260,08 & $\begin{array}{ll}61,37 \\
\end{array}$ & $\begin{array}{l}\mid 198,71 \\
198,71\end{array}$ & $\begin{array}{l}105,03 \\
100\end{array}$ & $\begin{array}{l}197,73 \\
\end{array}$ & 200,82 & 97,41 & \begin{tabular}{|l|}
880,62 \\
88,1
\end{tabular} & \begin{tabular}{|l|l|}
129,94 \\
\end{tabular} & $\begin{array}{l}7,08 \\
7,0\end{array}$ & 57,73 & 368,51 & $\begin{array}{l}48,65 \\
48,65 \\
\end{array}$ & $\begin{array}{l}45,27 \\
51,27\end{array}$ & $\begin{array}{l}340,40 \\
363,81 \\
\end{array}$ \\
\hline Alytes obstetricans & 29SND37 & 100,00 & 157,30 & 85,38 & 40,79 & 4154,40 & 274,52 & 67,86 & 206,66 & 112,97 & 208,89 & 211,94 & 105,38 & 810,35 & 118,84 & 6,19 & 57,83 & 338,33 & 44,14 & 47,12 & 334,79 \\
\hline Alytes obstetricans & 29 SND38 & 101,00 & 154,11 & 86,06 & 40,92 & 4160,23 & 272,22 & 64,23 & 207,99 & 109,68 & 205,85 & 208,84 & 101,98 & 852,33 & 124,75 & 6,88 & 57,12 & 353,53 & 48,20 & 50,95 & 350,97 \\
\hline Alytes obstetricans & 29 SND59 & 101,00 & 155,63 & 92,85 & 40,48 & 4542,00 & 286,69 & 60,08 & 226,61 & 100,20 & 212,94 & 215,92 & 99,49 & 886,67 & 128,71 & 7,65 & 56,03 & 363,69 & 53,16 & 54,72 & 363,69 \\
\hline Alytes obstetricans & 29SND68 & 101,00 & 159,67 & 93,99 & 40,01 & 4703,47 & 294,69 & 62,56 & 232,14 & 102,14 & 219,35 & 222,32 & 101,68 & 838,90 & 121,61 & 6,79 & 56,21 & 67 & 49,30 & 50,85 & 344,67 \\
\hline Alytes obstetricans & 29SND89 & 101,00 & 153,44 & $\begin{array}{l}90,656 \\
94,66\end{array}$ & 38,42 & 5085, 5 & 297,12 & $\begin{array}{l}53,67 \\
53 \\
\end{array}$ & $\mid$\begin{tabular}{|l|l|l|l|}
243,45 \\
\end{tabular} & 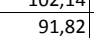 & \begin{tabular}{|l|}
219,37 \\
219
\end{tabular} & \begin{tabular}{|l|}
221,80 \\
220
\end{tabular} & \begin{tabular}{|l|}
101,82 \\
91,82
\end{tabular} & $\begin{array}{l}\mid \\
921,40\end{array}$ & $\begin{array}{l}\mid 21,01 \\
134,45\end{array}$ & 8,01 & 50,21 & $\begin{array}{l}344,01 \\
377,72\end{array}$ & 56,39 & $\begin{array}{l}50,000 \\
56,68\end{array}$ & 374,72 \\
\hline Alytes obstetricans & 29SND98 & 101,00 & 159,65 & 96,07 & 38,20 & 5204,60 & 306,12 & 58,25 & 247,87 & 96,60 & 226,80 & 229,56 & 96,60 & 842,70 & 121,84 & 6,97 & 55,70 & 344,44 & 50,83 & 51,66 & 344,44 \\
\hline Alytes obstetricans & 29SND99 & 100,00 & 157,27 & 95,94 & 38,03 & 5233,99 & 304,20 & 55,38 & 248,8 & 93,83 & 224,97 & 227,49 & 93,83 & 880,99 & $\mid 127.96$ & 7,45 & 55,45 & 360,06 & 53,78 & 54,41 & 360,06 \\
\hline Alytes obstetricans & 29SNE01 & 71,00 & 155,54 & 75,36 & 43,04 & 3391,56 & 246,96 & 73,98 & 172,98 & 118,78 & 195,81 & 198,16 & 110,94 & 820,20 & 120,06 & 6,99 & 56,68 & 341,42 & 46,29 & 53,10 & 331,97 \\
\hline Alytes obstetricans & 29SNE10 & 101,00 & 155,98 & 79,34 & 42,57 & 3622,00 & 256,06 & 71,49 & 184,58 & 116,98 & 199,76 & 202 & 109,14 & 821,60 & 119,97 & 6,60 & 56,95 & 341,94 & 45,99 & 51,55 & 33 \\
\hline Alytes obstetricans & 29SNE11 & 101,00 & 155,21 & 80,06 & 42,88 & 3601,97 & 254,96 & 70,29 & $\begin{array}{ll}184,66 \\
\end{array}$ & \begin{tabular}{|l|l|}
116,16 \\
\end{tabular} & 198,65 & 201,09 & 108,34 & 845,97 & 122,64 & 7,29 & 56,16 & 349,90 & 48,92 & 54,74 & 343,15 \\
\hline Alytes obstetricans & 29SNE12 & 101,00 & 154,19 & 80,64 & 43,08 & 3581,21 & 253,36 & 68,70 & 184,66 & 115,14 & 197,19 & 199,53 & 107,27 & 874,10 & 125,94 & 7,94 & 55,56 & 359,32 & 52,16 & 58,23 & 353,13 \\
\hline Alytes obstetricans & 29SNE61 & 100,00 & 151,40 & 95,90 & 40,15 & 4750,56 & 289,01 & 52,56 & 236,45 & 92,84 & 211,99 & 214,58 & 92,84 & 973,54 & 141,32 & 9,16 & 55,04 & 397,64 & 61,64 & 62,21 & 397,64 \\
\hline Alytes obstetricans & 29SNE62 & 100,00 & 141,47 & 93,16 & 39,39 & 4773,60 & 277,94 & 44,03 & 132 & 83,16 & 204 & 205,2 & 83, & 1091,31 & 160,04 & 10,87 & 54,99 & 445,90 & 69,95 & 70,01 & 445 \\
\hline Alytes obstetricans & 29SNE71 & 100,00 & 147,42 & 94,63 & 38,97 & 4938,86 & 288,14 & 48,14 & 240,01 & 87,19 & 211,97 & 213,50 & 87,19 & 1016,43 & 148,84 & 9,58 & 55,22 & 415,88 & 63,99 & 64,14 & 415,88 \\
\hline
\end{tabular}




\begin{tabular}{|c|c|c|c|c|c|c|c|c|c|c|c|c|c|c|c|c|c|c|c|c|c|}
\hline TAXON & UTM & $\mathrm{km2}$ & B101 & B1O2 & $\mathrm{BIO3}$ & $\mathrm{B104}$ & B105 & B106 & B107 & B108 & B109 & 81010 & B1011 & BIO12 & BIO13 & 81014 & B1015 & B1O16 & B1017 & B1018 & B1019 \\
\hline Alytes obstetricans & 29SNE72 & 101,00 & 147,01 & 95,68 & 39,19 & 4934,79 & 287,99 & 46,80 & 241,19 & 86,58 & 211,29 & 212,84 & 86,58 & 1037,05 & 151,67 & 10,03 & 55,00 & 423,37 & 66,27 & 66,45 & 423,37 \\
\hline Alytes obstetricans & 29SNE81 & 100,00 & 139,59 & 91,18 & 37,40 & 5112,34 & 281,58 & 41,21 & 240,36 & 78,28 & 208,20 & 208,53 & 78,28 & 1095,12 & 162,51 & 10,33 & 55,64 & 449,06 & 67,73 & 67,73 & 449,06 \\
\hline Alytes obstetricans & 29SNE90 & 100,00 & 144,25 & 91,88 & 37,01 & 5263,55 & 289,66 & 44,62 & 245,03 & 81,28 & 214,68 & 215,34 & 81,28 & 1026,81 & 151,79 & 9,32 & 55,69 & 420,93 & 63,00 & 63,03 & 420,93 \\
\hline Alytes obstetricans & 29SNE91 & 100,00 & 133,40 & 88,25 & 36,15 & 5252,89 & 276,32 & 35,82 & 240,49 & 71,19 & 204,67 & 204,67 & 71,19 & 1151,78 & 172,48 & 10,85 & 55,87 & 472,69 & 70,36 & 70,36 & 472,69 \\
\hline Alytes obstetricans & 29SNE92 & 100,00 & 141,13 & 92,11 & 37,01 & 5261,34 & 286,09 & 40,61 & 245,48 & 77,82 & 211,52 & 211,83 & 77,82 & \begin{tabular}{|l|l|}
1085,70 \\
\end{tabular} & 161,39 & 10,10 & 55,59 & 444,37 & 67,32 & 67,38 & 444,37 \\
\hline Alytes obstetricans & 29SPC57 & 100,00 & 168,13 & 111,79 & 39,96 & \begin{tabular}{ll|}
5684,87 \\
\end{tabular} & 331,09 & 53,09 & 278,00 & 106,93 & 241,54 & 243,71 & 98,65 & 543,91 & 74,76 & 3,99 & 53,94 & 215,79 & 32,57 & 33,71 & 208,22 \\
\hline Alytes obstetricans & 29SPD17 & 100,00 & 162,40 & 97,18 & \begin{tabular}{|l|l|}
37,83 \\
\end{tabular} & 5441,73 & 313,80 & 59,03 & 254,77 & 97,30 & 232,95 & 235,84 & 96,87 & 787,81 & 112,55 & 6,00 & 55,10 & 319,82 & 47,48 & 48,64 & 319,82 \\
\hline Alytes obstetricans & 29SPD19 & 100,00 & 163,73 & 98,30 & 37,49 & 5511,66 & 316,45 & 57,86 & 258,59 & 99,38 & 235,47 & 237,44 & 96,75 & 798,04 & 114,38 & 6,44 & 54,99 & 322,98 & 48,53 & 49,92 & 322,95 \\
\hline Alytes obstetricans & 29SPD26 & 101,00 & 160,01 & 96,71 & 37,40 & 5512,44 & 312,78 & 57,41 & 255,37 & 95,55 & 231,52 & 234,88 & 94,22 & 787,61 & 111,94 & 6,14 & 55,06 & 319,04 & 47,62 & 48,89 & 319,04 \\
\hline Alytes obstetricans & 29SPD33 & 100,00 & 162,66 & 101,92 & 38,40 & 5533,15 & 318,94 & 57,36 & 261,57 & 104,52 & 234,36 & 237,56 & 96,38 & 699,47 & 95,88 & 5,75 & 54,18 & 280,39 & 43,21 & 44,24 & 278,84 \\
\hline Alytes obstetricans & 29SPD34 & 101,00 & 160,24 & 99,30 & $\begin{array}{l}37,85 \\
\end{array}$ & 5550,93 & 315,39 & 56,72 & 258,67 & 102,24 & 232,29 & 235,74 & 94,27 & 740,95 & 103,04 & 6,14 & 54,40 & 298,01 & 45,47 & 46,65 & 297,21 \\
\hline Alytes obstetricans & 29SPD35 & 100,00 & 150,96 & 93,90 & 36,71 & 5549,48 & 303,30 & 51,48 & 251,82 & 87,76 & 223,30 & 227,27 & 86,22 & 847,69 & 120,82 & 7,24 & 54,84 & 343,56 & 52,06 & 53,06 & 343,56 \\
\hline Alytes obstetricans & 29SPD36 & 101,00 & 153,98 & 94,90 & 36,77 & 5604,19 & 307,60 & 52,43 & 255,18 & 91,66 & 227,18 & 230,49 & 87,92 & 831,12 & 118,49 & 6,95 & 54,64 & 336,25 & 51,13 & 52,08 & 336,14 \\
\hline Alytes obstetricans & 29SPD37 & 100,00 & 162,36 & 98,66 & $\begin{array}{l}37,05 \\
\end{array}$ & 5674,95 & 318,45 & 56,13 & 262,32 & 101,76 & 236,42 & 238,79 & 94,20 & 758,86 & 106,97 & 5,99 & 54,36 & 305,26 & 46,45 & 47,80 & 304,45 \\
\hline Alytes obstetricans & 29SPD43 & 99,00 & 163,16 & 104,89 & \begin{tabular}{|l|}
38,67 \\
\end{tabular} & 5647,58 & 323,13 & 54,71 & 268,42 & 103,38 & 236,58 & 239,30 & 95,26 & 675,98 & 91,26 & 5,35 & 53,69 & 269,65 & 42,25 & 43,30 & 266,46 \\
\hline Alytes obstetricans & 29SPD44 & 101,00 & 155,18 & 99,28 & 37,57 & 5640,11 & 312,16 & 51,31 & 260,85 & 96,60 & 228,72 & 232,15 & 88,58 & 767,07 & 106,42 & 6,42 & 54,01 & 307,69 & 47,74 & 48,74 & 306,19 \\
\hline Alytes obstetricans & 29SPD45 & 99,00 & 145,56 & 94,44 & 36,50 & 5659,10 & 300,09 & 44,74 & 255,35 & 86,12 & 220,27 & 223,39 & 79,69 & 866,89 & 122,89 & 7,64 & 54,20 & 348,96 & 54,20 & 54,73 & 348,51 \\
\hline Alytes obstetricans & 29SPD46 & 100,00 & 156,64 & 97,92 & 36,98 & 5715,55 & 313,60 & 51,85 & 261,75 & 96,79 & 231,46 & 234,36 & 88,84 & 779,71 & 109,38 & 6,38 & 54,05 & 313,09 & 48,41 & 49,55 & 311,72 \\
\hline Alytes obstetricans & 29SPD48 & 100,00 & 163,51 & 100,30 & 37,01 & 5812,85 & 322,29 & 54,38 & 267,91 & 100,95 & 239,86 & 241,48 & 93,31 & 729,76 & 101,92 & 5,83 & 53,78 & 291,85 & 45,22 & 46,76 & 289,49 \\
\hline Alytes obstetricans & 29SPD53 & 101,00 & 162,51 & 107,88 & 38,71 & 5768,06 & 326,25 & 50,88 & 275,37 & 100,99 & 237,82 & 239,95 & 92,98 & 656,75 & 87,85 & 5,19 & 52,99 & 260,40 & 41,79 & 42,66 & 255,47 \\
\hline Alytes obstetricans & 29SPD54 & 100,00 & 159,58 & 104,37 & 37,96 & 5772,25 & 321,21 & 50,21 & 271,00 & 98,48 & 235,00 & 237,44 & 90,46 & 698,68 & 94,38 & 5,69 & 53,15 & 277,95 & 44,20 & 45,22 & 273,87 \\
\hline Alytes obstetricans & 29SPD55 & 101,00 & 155,24 & 100,88 & 37,30 & 5793,53 & 315,14 & 48,08 & 267,07 & 94,52 & 231,21 & 233,80 & 86,40 & 749,56 & \begin{tabular}{|r|}
103,06 \\
\end{tabular} & 6,22 & 53,30 & 298,95 & 47,35 & 48,26 & 295,74 \\
\hline Alytes obstetricans & 29SPD57 & 100,00 & 158,85 & 100,45 & 36,94 & 5864,96 & 318,85 & 50,03 & 268,81 & 96,40 & 235,90 & 237,80 & 88,58 & 735,08 & 101,59 & 6,03 & 53,27 & 292,83 & 46,55 & 47,62 & 289,41 \\
\hline Alytes obstetricans & 29SPE01 & 101,00 & 148,83 & 94,02 & 36,76 & 5429,34 & 298,03 & 45,95 & 252,07 & 83,36 & 220,92 & 221,77 & 83,36 & 983,23 & 144,85 & 8,69 & 55,36 & 401,42 & 60,77 & 60,98 & 401,42 \\
\hline Alytes obstetricans & 29SPE02 & 101,00 & 138,63 & 90,45 & 36,04 & 5409,04 & 285,24 & 37,94 & 247,30 & 73,95 & 211,46 & 211,53 & 73,95 & 1097,44 & 163,97 & 10,08 & 55,76 & 449,22 & 67,41 & 67,41 & 449,22 \\
\hline Alytes obstetricans & 29SPE11 & 101,00 & 157,91 & 97,35 & 36,95 & 5583,85 & 311,32 & 51,39 & 259,93 & 90,01 & 231,04 & 232,51 & 90,01 & 875,06 & 127,01 & 7,26 & 54,90 & 354,47 & 54,36 & 55,11 & 354,47 \\
\hline Alytes obstetricans & 29SPE12 & 100,00 & 151,78 & 95,52 & 36,56 & 5580,80 & 303,98 & 46,12 & 257,86 & 84,14 & 225,44 & 226,36 & 84,14 & 943,37 & 138,41 & 8,12 & 55,08 & \begin{tabular}{|l|}
383,08 \\
\end{tabular} & 58,69 & $\begin{array}{l}59,05 \\
59,0\end{array}$ & 383,08 \\
\hline Alytes obstetricans & 29SPE20 & 100,00 & 159,02 & 97,11 & 36,27 & 5736,83 & 315,15 & 51,62 & 263,53 & 91,49 & 234,44 & 235,76 & 89,70 & 838,95 & 120,98 & 6,83 & 54,74 & 338,78 & 51,89 & 52,70 & 338,73 \\
\hline Alytes obstetricans & 29SPE42 & 99,00 & 156,54 & 97,94 & 36,04 & 5903,14 & 314,45 & 46,30 & 268,15 & 92,15 & 234,38 & 234,94 & 84,72 & 808,24 & 115,72 & 6,78 & 53,88 & 322,90 & 50,98 & 51,71 & 321,60 \\
\hline Alytes obstetricans & 29SPE72 & 101,00 & 157,64 & 101,21 & 36,08 & 6065,15 & 319,49 & 44,06 & 275,43 & 91,42 & 237,94 & 238,00 & 83,62 & 684,95 & 93,96 & 5,83 & 51,77 & 268,81 & 45,03 & 45,28 & 262,93 \\
\hline Alytes obstetricans & 29SQA39 & 100,00 & 178,93 & 88,43 & 37,01 & 5120,94 & 306,79 & 71,23 & 235,55 & 143,96 & 243,43 & 246,48 & 115,26 & 540,45 & 82,58 & 1,00 & 64,61 & 233,88 & 14,96 & 22,00 & 214,68 \\
\hline Alytes obstetricans & 29SQE51 & 63,00 & 158,98 & $\begin{array}{l}0,0,40 \\
110,69\end{array}$ & 36,68 & 6427,51 & 334,89 & $\begin{array}{l}1,25 \\
36,06\end{array}$ & \begin{tabular}{|l|l|}
298,83 \\
\end{tabular} & $\begin{array}{r}8,21 \\
88,21 \\
\end{array}$ & \begin{tabular}{|l|}
2434,68 \\
245
\end{tabular} & \begin{tabular}{|l|}
244,468 \\
244
\end{tabular} & 80,34 & \begin{tabular}{|l|}
454,36 \\
\end{tabular} & $\begin{array}{ll}5,80 \\
55,83\end{array}$ & 4,50 & $\begin{array}{l}4,10 \\
46,13 \\
\end{array}$ & \begin{tabular}{|l|}
164,21 \\
\end{tabular} & 34,23 & 34,23 & 151,88 \\
\hline Alytes obstetricans & 29TMH85 & 76,00 & 139,86 & 60,66 & 38,86 & 3227,67 & 224,58 & 70,50 & 154,08 & 109,07 & 179,49 & 182,91 & 99,89 & 1022,70 & 146,27 & 27,14 & 42,50 & 405,09 & 116,07 & 140,82 & 344,98 \\
\hline Alytes obstetricans & 29TMH91 & 46,00 & 146,53 & 59,04 & 38,62 & 3311,15 & 229,18 & 78,01 & 151,16 & 113,22 & 187,59 & 189,99 & 104,65 & 1143,04 & 161,42 & 26,24 & 45,56 & 458,00 & 110,67 & 134,49 & 409,85 \\
\hline Alytes obstetricans & 29TMH94 & 96,00 & 134,43 & 62,32 & 38,30 & 3383,03 & 224,15 & 63,56 & 160,59 & 101,66 & 176,79 & 179,88 & 92,99 & 1163,86 & 165,96 & 30,57 & 43,29 & 460,44 & 125,92 & 149,26 & 407,56 \\
\hline Alytes obstetricans & 29TMH95 & 101,00 & 132,06 & 62,84 & 38,29 & 3379,81 & 222,68 & 60,82 & 161,87 & 99,50 & 174,35 & 177,58 & 90,84 & 1161,49 & 163,83 & 31,54 & 42,44 & 457,27 & 129,28 & 152,73 & 403,12 \\
\hline Alyty obstetricans & 29TMH96 & 101,00 & 132,67 & $\begin{array}{l}62,04 \\
62,76 \\
\end{array}$ & 38,41 & 3336,99 & 222,47 & $\begin{array}{l}0,025 \\
61,55 \\
\end{array}$ & $\begin{array}{l}161,0,92 \\
160,\end{array}$ & \begin{tabular}{|l|}
100,76 \\
100
\end{tabular} & \begin{tabular}{|l|l|}
174,14 \\
140
\end{tabular} & $\begin{array}{l}177,72 \\
172\end{array}$ & $\begin{array}{l}90,04 \\
91,95\end{array}$ & $\begin{array}{l}110,49,29 \\
1134,2\end{array}$ & \begin{tabular}{|l|}
158,505 \\
158,
\end{tabular} & $\begin{array}{l}\mid 1,145 \\
31,50\end{array}$ & $\begin{array}{l}4,44 \\
41,88\end{array}$ & \begin{tabular}{|l|}
447,27 \\
444,68
\end{tabular} & \begin{tabular}{|l|}
129,01 \\
\end{tabular} & \begin{tabular}{|l|}
152,87 \\
15,8
\end{tabular} & 389,79 \\
\hline Alytes obstetricans & 29TMH97 & 100,00 & 138,07 & 61,86 & 38,93 & 3246,93 & 224,66 & 67,91 & 156,75 & 107,19 & 178,13 & 181,82 & 98,28 & 1062,28 & 147,82 & 29,67 & 41,14 & 415,54 & 122,71 & 147,29 & 360,00 \\
\hline Alytes obstetricans & 29TMH98 & 28,00 & 142,80 & 61,16 & 39,53 & 3177,18 & 226,53 & 73,42 & 153,11 & 112,60 & 181,80 & 185,62 & 103,67 & \begin{tabular}{|l|}
1013,53 \\
\end{tabular} & 141,49 & 28,18 & 41,00 & 395,73 & 117,49 & 142,60 & 341,07 \\
\hline Alytes obstetricans & 29TNE14 & 94,00 & 153,37 & 80,69 & 43,99 & 3489,40 & 249,04 & 67,60 & 181,44 & 114,96 & 194,89 & 196,96 & 106,94 & 915,43 & 130,14 & 8,93 & 54,31 & 372,73 & 57,22 & 64,43 & 366,66 \\
\hline Alytes obstetricans & 29TNE15 & 95,00 & 152,10 & 79,87 & 44,23 & 3433,91 & 244,94 & 66,57 & 178,37 & 114,04 & 192,57 & 194,69 & 106,07 & 940,82 & 132,95 & 9,80 & 53,87 & 381,66 & 60,01 & 67,97 & 375,23 \\
\hline Alytes obstetricans & $\begin{array}{l}\text { 29TNE17 } \\
\end{array}$ & 40,00 & 151,00 & 77,70 & 44, & 3321,38 & 237,20 & 65,97 & 171,23 & 113,99 & 189,58 & 191,34 & 105,62 & 973,01 & 136,21 & 10,34 & 53,00 & 393,07 & $\begin{array}{l}63,24 \\
\end{array}$ & 72,89 & 385,45 \\
\hline Alytes obstetricans & 29TNE26 & 100,00 & 152,32 & 84,16 & $\begin{array}{l}44,45 \\
\end{array}$ & 3581,52 & 250,69 & 63,32 & 187,37 & 112,44 & 194,77 & 196,81 & 104,39 & 969,56 & 136,02 & 10,03 & 53,09 & 390,74 & 63,01 & 70,94 & 385,71 \\
\hline Alytes obstetricans & 29TNE27 & 100,00 & 150,94 & 81,77 & 44,72 & 3491,93 & 244,10 & 63,03 & 181,07 & 111,95 & 191,99 & 193,90 & 103,76 & 988,28 & 138,04 & 10,85 & 52,79 & 397,95 & 65,18 & 74,10 & 391,49 \\
\hline Alytes obstetricans & 29TNE28 & 101,00 & 149,73 & 78,91 & 45,04 & 3384,36 & 236,65 & 63,11 & 173,54 & 111,73 & 189,05 & 190,76 & 103,37 & 1002,72 & 139,53 & 11,00 & 52,55 & 403,88 & 66,14 & 76,54 & 395,56 \\
\hline Alytes obstetricans & 29TNE45 & 101,00 & 159,50 & 98,46 & | 43,040 & 4164,52 & 283,32 & $\begin{array}{l}60,82 \\
60,\end{array}$ & 222,49 & 108,75 & 210,58 & 212,78 & 105,32 & \begin{tabular}{|l|l|}
936,35 \\
\end{tabular} & \begin{tabular}{|l|}
130,70 \\
\end{tabular} & 9,70 & 52,90 & $\begin{array}{l}374,25 \\
374,0\end{array}$ & 62,54 & 67,44 & 374,14 \\
\hline Alytes obstetricans & 29TNE49 & 100,00 & 151,63 & 89,81 & \begin{tabular}{|l|l|}
43,97 \\
\end{tabular} & 3905,53 & 258,44 & 56,55 & 201,90 & 107,68 & 198,79 & 200,54 & 99,55 & \begin{tabular}{|l|}
1025,40 \\
\end{tabular} & 142,39 & 11,30 & 52,40 & 412,01 & 68,11 & 78,33 & 403,22 \\
\hline Alytes obstetricans & 29TNE53 & 101,00 & 151,81 & 98,81 & 41,57 & 4545,58 & 286,84 & 52,19 & 234,65 & 94,84 & 209,36 & 211,64 & 94,84 & 1002,83 & 143,49 & 10,28 & 53,94 & 406,24 & 66,25 & 67,75 & 406,24 \\
\hline Alytes obstetricans & 29TNE55 & 99,00 & 150,55 & 100,13 & 42,22 & 4497,70 & 284,29 & 49,83 & 234,45 & 93,64 & 207,01 & 209,27 & 93,64 & 1043,22 & 148,06 & 11,27 & 53,18 & 419,77 & 70,97 & 73,17 & 419,77 \\
\hline Alytes obstetricans & 29TNE56 & 101,00 & 150,10 & 99,40 & 42,3 & 4444,24 & 281,01 & 49,47 & 231,54 & 93,55 & 205,67 & 207,82 & 93,41 & 1053,40 & 149,12 & 11,49 & 52,88 & 422,23 & 71,75 & 75,15 & 422,23 \\
\hline Alytes obstetricans & 29TNE57 & $\begin{array}{l}101,00 \\
100\end{array}$ & 148,69 & $\begin{array}{ll}0,404 \\
97,64\end{array}$ & $\frac{42}{42}$ & $\begin{array}{l}4444,424 \\
4378,99\end{array}$ & 275,62 & $\begin{array}{l}4,4,79 \\
48,79\end{array}$ & \begin{tabular}{|l|}
226,84 \\
22,4
\end{tabular} & \begin{tabular}{|l|l|}
97,88 \\
97,8
\end{tabular} & \begin{tabular}{|l|}
203,34 \\
\end{tabular} & \begin{tabular}{|l|}
205,27 \\
\end{tabular} & $\begin{array}{l}0,414 \\
92,45\end{array}$ & \begin{tabular}{|l|l|l|l|l|}
1070,57 \\
\end{tabular} & \begin{tabular}{|l|}
1451,49 \\
151
\end{tabular} & $\begin{array}{l}1,49 \\
11,72 \\
\end{array}$ & $\begin{array}{l}2,2,00 \\
52,86\end{array}$ & \begin{tabular}{|l|}
428,0303 \\
\end{tabular} & $\mid \frac{1,13}{72,49}$ & 77,32 & $\begin{array}{l}42,27,56 \\
422,56\end{array}$ \\
\hline Alytes obstetricans & 29TNE63 & 101,00 & 130,56 & 89,14 & 38,42 & 4769,88 & 264,01 & 35,22 & 228,79 & 72,92 & 194,23 & 194,62 & 72,92 & 1221,84 & 181,18 & 12,82 & 55,21 & 499,16 & 78,16 & 78,31 & 499,16 \\
\hline Alytes obstetricans & 29TNE64 & 100,00 & 155,81 & 101,81 & $41,50 \mid$ & 4683,46 & 294,72 & 53,07 & 241,64 & 96,83 & 215,14 & 217,20 & 96,83 & 978,93 & 139,33 & 9,92 & 53,46 & 394.96 & 65,10 & 67,15 & 394,96 \\
\hline Alytes obstetricans & 29TNE65 & 101,00 & 154,92 & 102,10 & 41,75 & 4672,85 & 292,96 & 51,79 & 241,18 & 95,81 & 213,88 & 216,01 & 95,81 & 997,15 & 141,65 & 10,31 & 53,17 & 401,08 & 66,87 & 69,43 & 401,08 \\
\hline Alytes obstetricans & 29TNE68 & 101,00 & 134,72 & 93,55 & 40, & 4632,53 & 264,80 & 36,08 & 228 & 80, & 194,14 & 195,64 & 76,89 & 1229,75 & 179,29 & 13,54 & 53,76 & 495,74 & 82,40 & 85,19 & 495 \\
\hline \begin{tabular}{|l|l}
$\mid l y$ \\
Alytes obtricans
\end{tabular} & $\begin{array}{l}\text { 29TNE69 } \\
\end{array}$ & $\begin{array}{l}101,00 \\
100\end{array}$ & 128,02 & \begin{tabular}{|l|}
3,03 \\
91,01
\end{tabular} & $\begin{array}{l}40,41 \\
39,86\end{array}$ & \begin{tabular}{|l}
402,350 \\
4638,69 \\
\end{tabular} & $\begin{array}{l}204,00 \\
256,21\end{array}$ & \begin{tabular}{|l|l}
30,00 \\
30,75
\end{tabular} & $\begin{array}{l}225,47 \\
225,4 \\
\end{array}$ & 73,66 & 187,77 & 189,16 & 70,46 & 1311,34 & 192,53 & 14,74 & 54,03 & 529,92 & 88,13 & 90,71 & 529,25 \\
\hline Alytes obstetricans & 29TNE73 & 100,00 & 130,48 & 89,04 & 37,71 & 4935,42 & 267,29 & 34,12 & 233,17 & 71,19 & 196,84 & 196,95 & 71,19 & 1223,43 & 182,48 & 12,47 & 55,44 & 500,58 & 77,23 & 77,23 & 500,58 \\
\hline Alytes obstetricans & 29TNE74 & 100,00 & 144,66 & 96,62 & 39,51 & 4909,73 & 284,97 & 43,52 & 241,46 & 84,22 & 208,62 & 209,88 & 84,22 & 1088,21 & 159,07 & 10,86 & 54,50 & 442,33 & 70,82 & 71,38 & 442,33 \\
\hline Alytes obstetricans & 29TNE75 & 101,00 & 154,08 & 101,29 & 40,8 & 4855,81 & 295,17 & 49,96 & 245,2 & 93,12 & 215, & 217 & 93, & 998,76 & 143,36 & 9,90 & 53,72 & 402,78 & 65,75 & 68,01 & 402 , \\
\hline Alytes obstetricans & 29TNE76 & $\begin{array}{l}101,00 \\
\end{array}$ & 154,06 & 101,53 & 41,08 & 4813,66 & 293,38 & 49,62 & $\mid$ & 93,18 & 215,14 & 216,88 & 93,18 & 005,56 & 43,97 & 9,99 & 53,47 & 404,01 & 66,34 & 69,56 & 404,01 \\
\hline
\end{tabular}




\begin{tabular}{|c|c|c|c|c|c|c|c|c|c|c|c|c|c|c|c|c|c|c|c|c|c|}
\hline TAXON & UTM & $\mathrm{km2}$ & BIO1 & B102 & $\mathrm{BIO3}$ & BIO4 & B105 & B106 & B107 & B108 & B109 & BIO10 & BIO11 & $\overline{B 1012}$ & BIO13 & BIO14 & BIO15 & BIO16 & BIO17 & BIO18 & BIO19 \\
\hline Alytes obstetricans & 29TNE79 & 101,00 & 134,17 & 94,47 & 39,91 & 4800,60 & 267,62 & 33,70 & 233,92 & 76,77 & 196,11 & 197,26 & 74,32 & 1237,77 & 181,96 & 13,33 & 54,13 & 499,57 & 81,97 & 84,94 & 499,52 \\
\hline Alytes obstetricans & 29TNE83 & 100,00 & 136,83 & 91,53 & 37,62 & 5092,52 & 278,06 & 37,73 & 240,33 & 75,38 & 204,90 & 205,18 & 75,38 & 1153,36 & 171,78 & 11,27 & $\begin{array}{l}55,46 \\
\end{array}$ & \begin{tabular}{|l|l|}
471,89 \\
\end{tabular} & 72,49 & 72,49 & 471,89 \\
\hline Alytes obstetricans & 29TNE84 & 101,00 & $\begin{array}{ll}133,66 \\
\end{array}$ & 90,79 & 37,47 & 5087,30 & 273,82 & 34,71 & 239,11 & 72,27 & 201,61 & 201,88 & \begin{tabular}{l|l|}
72,27 \\
\end{tabular} & 1197,70 & \begin{tabular}{ll|l}
179,06 \\
\end{tabular} & 11,86 & 55,43 & \begin{tabular}{|l|l|}
489,74 \\
\end{tabular} & 75,49 & 75,49 & 489,74 \\
\hline Alytes obstetricans & 29TNE85 & 100,00 & 147,50 & 97,92 & 39,26 & 5042,36 & 289,99 & 44,08 & 245,90 & 85,04 & \begin{tabular}{|l|l|}
212,90 \\
\end{tabular} & \begin{tabular}{|l|l|}
214,17 \\
\end{tabular} & 85,04 & 1059,06 & 155,04 & 10,29 & 54,51 & 429,45 & 68,30 & 69,66 & 429,45 \\
\hline Alytes obstetricans & 29TNE86 & 100,00 & 150,11 & 99,94 & 39,99] & 5010,48 & 292,48 & 45,38 & $247,10 \mid$ & 87,50 | & 214,40 & 215,94 & 87,50 & 1037,19 & 150,83 & 10,03 & 54,12 . & $418,79 \mid$ & 67,60| & 69,74 & 418,79| \\
\hline Alytes obstetricans & 29TNE87 & 101,00 & 151,38 & 100,69 & 40,36 & 4969,05 & 292,32 & 46,06 & 246,27 & \begin{tabular}{l|l|}
88,92 \\
\end{tabular} & 214,94 & 216,39 & 88,82 & 1027,25 & 148,92 & 9,93 & 53,91 & 413,26 & 66,69 & 70,08 & 413,26 \\
\hline Alytes obstetricans & 29TNE89 & 99,00 & 143,28 & 98,96 & 40,16 & 4954,20 & 281,94 & 38,90 & 243,03 & 81,35 & 206,81 & 207,99 & 80,99 & 1124,35 & 164,80 & 11,31 & $\begin{array}{l}54,06 \\
\end{array}$ & 452,74 & \begin{tabular}{l|l}
73,25 \\
\end{tabular} & 77,10 & 452,74 \\
\hline Alytes obstetricans & 29TNE93 & 101,00 & 140,56 & 92,62 & 37,11 & 5261,71 & 285,37 & \begin{tabular}{l|l}
39,35 \\
\end{tabular} & \begin{tabular}{|l|l|}
246,03 \\
\end{tabular} & 77,01 & 210,76 & \begin{tabular}{|l|l|}
211,08 \\
\end{tabular} & 77,01 & 1102,34 & 164,09 & 10,29 & 55,49 & \begin{tabular}{ll|}
450,73 \\
\end{tabular} & $\begin{array}{ll}68,82 \\
\end{array}$ & 68,84 & 450,73 \\
\hline Alytes obstetricans & 29TNE95 & 101,00 & 127,45 & 87,81 & 36,31 & 5197,31 & 267,32 & 28,99 & 238,32 & 65,12 & \begin{tabular}{ll|l}
196,99 \\
\end{tabular} & 197,21 & 65,12 & 1266,14 & 191,66 & 12,29 & 55,95 & 518,23 & 78,40 & 78,48 & 518,23 \\
\hline Alytes obstetricans & 29TNE96 & 100,00 & 144,25 & 96,90 & 38,48 & 5194,21 & 288,55 & 39,98 & 248,56 & 80,12 . & 211,84 & 212,90 & 80,12 & 1084,89 & 160,45 & 10,32 & 54,88 & 440,40 & 69,82 & 70,58 & 440,40 \\
\hline Alytes obstetricans & 29TNF25 & 28,00 & 144,51 & 85,81 & 44,94 & 3674,23 & 243,21 & 54,34 & \begin{tabular}{|l|l|}
188,87 \\
\end{tabular} & \begin{tabular}{|l|l|}
104,47 \\
\end{tabular} & 189,36 & \begin{tabular}{|l|l|}
191,38 \\
\end{tabular} & 97,09 & 1183,21 & 162,30 & 14,83 & \begin{tabular}{|l|l|}
51,15 \\
\end{tabular} & $\begin{array}{ll}472,75 \\
\end{array}$ & 81,40 & $\begin{array}{l}99,72 \\
\end{array}$ & 460,91 \\
\hline Alytes obstetricans & 29TNF26 & 68,00 & 143,71 & 84,72 & 45,01 & 3658,17 & 241,52 & 55,50 & \begin{tabular}{|l|l|}
186,02 \\
\end{tabular} & \begin{tabular}{|l|l|l|}
99,99 \\
\end{tabular} & \begin{tabular}{ll|}
188,56 \\
\end{tabular} & $\begin{array}{l}190,46 \\
\end{array}$ & \begin{tabular}{|l|l|}
97,07 \\
\end{tabular} & 1215,52 & 165,55 & 15,08 & 51,03 & 482,21 & 83,56 & 100,72 & 480,78 \\
\hline Alytes obstetricans & 29TNF27 & 83,00 & 143,39 & 83,67 & 44,84 & 3665,84 & 241,48 & 56,50 & \begin{tabular}{|l|l|l|l|}
184,98 \\
\end{tabular} & 98,16 & $\begin{array}{l}188,60 \\
\end{array}$ & $\begin{array}{l}190,35 \\
\end{array}$ & 96,94 & 1229,74 & 168,04 & 15,06 & 51,32 & 488,82 & 83,48 & \begin{tabular}{l|l}
101,82 \\
\end{tabular} & 488,58 \\
\hline Alytes obstetricans & 29TNF31 & 101,00 & 148,07 & 83,26 & 44,69 & 3597,97 & 241,68 & 57,46 & \begin{tabular}{l|l|l|l}
184,22 \\
\end{tabular} & \begin{tabular}{|l|}
107,87 \\
\end{tabular} & $\begin{array}{l}190,73 \\
\end{array}$ & \begin{tabular}{|l|l|}
192,50 \\
\end{tabular} & $\begin{array}{l}99,47 \\
\end{array}$ & 1065,36 & \begin{tabular}{ll|l}
146,05 \\
\end{tabular} & 12,24 & 52,00 & \begin{tabular}{|l|l}
429,98 \\
\end{tabular} & \begin{tabular}{ll|}
71,06 \\
\end{tabular} & 85,21 & 414,46 \\
\hline Alytes obstetricans & 29TNF34 & 101,00 & 142,93 & 88,24 & 44,24 & 3832,79 & 246,60 & $\begin{array}{l}49,26 \\
\end{array}$ & 197,34 & $\begin{array}{ll}100,95 \\
\end{array}$ & 189,74 & 191,72 & 92,80 & \begin{tabular}{ll|}
1169,53 \\
\end{tabular} & 160,71 & 14,84 & 51,92 & \begin{tabular}{ll|}
475,06 \\
\end{tabular} & \begin{tabular}{l|l}
79,95 \\
\end{tabular} & 99,15 & 447,97 \\
\hline Alytes obstetricans & 29TNF35 & 101,00 & 143,79 & 89,17 & 44,34 & 3853,99 & 248,86 & 50,08 & 198,78 & 101,82 & \begin{tabular}{|l|l|}
191,19 \\
\end{tabular} & 193,23 & 93,92 & 1176,16 & 162,85 & 15,00 & 51,60 & \begin{tabular}{ll|}
476,56 \\
\end{tabular} & 80,52 & \begin{tabular}{ll|}
100,90 \\
\end{tabular} & 450,62 \\
\hline Alytes obstetricans & 29TNF39 & 100,00 & $\begin{array}{ll}142,67 \\
\end{array}$ & 85,68 & 43,22 & 3921,25 & 249,19 & 53,49 & \begin{tabular}{ll|l}
195,69 \\
\end{tabular} & 97,62 & \begin{tabular}{|l|l|}
191,73 \\
\end{tabular} & 193,13 & 93,16 & 1252,93 & \begin{tabular}{ll|}
169,96 \\
\end{tabular} & 15,41 & 51,40 & $\begin{array}{l}497,59 \\
\end{array}$ & 84,71 & \begin{tabular}{ll|}
104,50 \\
\end{tabular} & 496,90 \\
\hline Alytes obstetricans & 29TNF41 & 101,00 & 142,38 & 89,36 & 43,37 & 3991,40 & 250,94 & 47,24 & 203,70 & 98,11 & $\begin{array}{l}191,25 \\
\end{array}$ & 193,01 & 90,04 & 1145,99 & 159,30 & 13,48 & \begin{tabular}{l|l|}
52,06 \\
\end{tabular} & 462,52 & 77,32 & 89,31 & 448,96 \\
\hline Alytes obstetricans & 29TNF42 & 100,00 & 139,86 & 89,98 & 43,29 & 4039,26 & 249,99 & 44,34 & 205,65 & 95,41 & \begin{tabular}{ll|l}
189,66 \\
\end{tabular} & \begin{tabular}{l|l|}
191,42 \\
\end{tabular} & 87,24 & 1184,27 & 164,08 & 14,18 & 52,01 & \begin{tabular}{ll|}
478,82 \\
\end{tabular} & \begin{tabular}{l|l}
80,25 \\
\end{tabular} & 93,42 & 462,77 \\
\hline Alytes obstetricans & 29TNF45 & 100,00 & 143,60 & 92,24 & 43,84 & 4070,49 & 255,27 & 46,97 & 208,31 & 98,94 & \begin{tabular}{l|l|l|}
194,03 \\
\end{tabular} & 195,90 & 91,1 & \begin{tabular}{ll|}
1174,73 \\
\end{tabular} & \begin{tabular}{l|l|}
159,85 \\
\end{tabular} & 14,5 & 51, & 475,51 & \begin{tabular}{|l|l|}
79,77 \\
\end{tabular} & 98,42 & 452,40 \\
\hline Alytes obstetricans & 29TNF46 & 101,00 & 139,99 & 92,04 & 43,58 & 4124,76 & 253,26 & 44,26 & 208,99 & $\begin{array}{l}94,91 \\
\end{array}$ & \begin{tabular}{|l|l|}
191,59 \\
\end{tabular} & 193,29 & 87,44 & 1229,65 & 167,21 & 15,41 & 51,34 & \begin{tabular}{ll|}
495,06 \\
\end{tabular} & 84,11 & $\begin{array}{ll}101,93 \\
\end{array}$ & 478,38 \\
\hline Alytes obstetricans & 29TNF47 & 100,00 & 139,14 & 91,24 & 43,32 & 4147,14 & 252,84 & \begin{tabular}{l|l}
44,35 \\
\end{tabular} & 208,48 & $\begin{array}{ll}93,89 \\
\end{array}$ & $\begin{array}{l}191,25 \\
1\end{array}$ & $\begin{array}{l}192,76 \\
\end{array}$ & 86,61 & 1253,11 & 169,91 & 15,81 & 51,14 & \begin{tabular}{|l|l|}
501,37 \\
\end{tabular} & 86,32 & \begin{tabular}{|l|l|l|}
103,48 \\
\end{tabular} & 491,26 \\
\hline Alytes obstetricans & \begin{tabular}{l|l} 
29TNF50 \\
\end{tabular} & 101,00 & 139,58 & 92,61 & 42,17 & 4304,23 & 258,99 & \begin{tabular}{|l|l}
41,99 \\
\end{tabular} & 217,01 & \begin{tabular}{|l|l|}
92,04 \\
\end{tabular} & $\begin{array}{l}193,36 \\
\end{array}$ & \begin{tabular}{|l|}
195,11 \\
\end{tabular} & 84,30 & 1181,11 & 167,89 & 13,43 & 52,76 & \begin{tabular}{|l|l|}
475,58 \\
\end{tabular} & 79,54 & \begin{tabular}{|l|l|}
87,48 \\
\end{tabular} & 468,92 \\
\hline Alytes obstetricans & 29TNF51 & 101,00 & 130,68 & 90,91 & 41,39 & 4383,84 & 251,56 & 34,36 & 217,20 & 83,11 & \begin{tabular}{|l|l|}
186,06 \\
\end{tabular} & \begin{tabular}{|l|l|}
187,79 \\
\end{tabular} & 75,27 & \begin{tabular}{ll|}
1291,53 \\
\end{tabular} & 185,22 & 15,29 & 52,99 & 520,41 & 88,04 & 94,96 & 515,26 \\
\hline Alytes obstetricans & 29TNF52 & 100,00 & 128,82 & 90,79 & 41,34 & 4388,35 & 249,56 & 32,56 & 217,00 & 80,65 & 184,49 & 186,10 & 73,51 & 1319,05 & 188,56 & 15,87 & 52,82 & 531,86 & 90,28 & 98,23 & 525,29 \\
\hline Alytes obstetricans & \begin{tabular}{|l|l|}
$29 T N F 53$ \\
\end{tabular} & 101,00 & 139,12 & 93,95 & 42,65 & 4304,01 & 258,06 & 40,55 & 217,52 & \begin{tabular}{|l|l|}
91,75 \\
\end{tabular} & 192,97 & 194,65 & 83,83 & 1206,82 & 168,46 & 14,26 & 52,14 & 487,19 & 81,32 & 94,06 & 473,32 \\
\hline Alytes obstetricans & 29TNF54 & 101,00 & 143,24 & 94,76 & 43,14 & 4278,36 & 261,19 & \begin{tabular}{ll|}
44,06 \\
\end{tabular} & 217,13 & \begin{tabular}{l|l}
96,03 \\
\end{tabular} & \begin{tabular}{ll|}
196,62 \\
\end{tabular} & \begin{tabular}{ll|}
198,24 \\
\end{tabular} & \begin{tabular}{l|l|}
88,15 \\
\end{tabular} & 1165,91 & 160,49 & 13,81 & \begin{tabular}{|l|l|}
51,97 \\
\end{tabular} & \begin{tabular}{ll|}
470,68 \\
\end{tabular} & 78,26 & 93,43 & 453,65 \\
\hline Alytes obstetricans & 29TNF55 & 100,00 & 140,87 & 95,08 & 42,94 & 4326,04 & 260,24 & 41,73 & 218,51 & 93,30 & 195,21 & \begin{tabular}{ll|}
196,68 \\
\end{tabular} & 85,53 & 1202,49 & 165,11 & 14,53 & \begin{tabular}{l|l|}
51,85 \\
\end{tabular} & \begin{tabular}{ll|l}
484,56 \\
\end{tabular} & 81,28 & 96,84 & 468,84 \\
\hline Alytes obstetricans & 29TNF59 & 101,00 & 139,94 & 93,48 & 42,13 & 4393,00 & 261,73 & 42,64 & 219,10 & \begin{tabular}{|l|l|}
91,63 \\
\end{tabular} & \begin{tabular}{|l|l|}
195,73 \\
\end{tabular} & 196,85 & 84,56 & \begin{tabular}{|l|l|}
1243,58 \\
\end{tabular} & 167,10 & 16,12 & 50,99 & \begin{tabular}{|l|l|}
493,44 \\
\end{tabular} & 87,40 & 103,38 & 487,78 \\
\hline Alytes obstetricans & 29TNF60 & 100,00 & 135,03 & 94,39 & 41,03 & 4585,71 & 262,88 & 35,58 & 227,30 & 84,44 & 193,27 & \begin{tabular}{ll|}
194,86 \\
\end{tabular} & \begin{tabular}{|l|l|}
77,17 \\
\end{tabular} & 1237,64 & 179,24 & 13,79 & 53,37 & \begin{tabular}{|l|l|}
498,24 \\
\end{tabular} & \begin{tabular}{|l|l|}
82,88 \\
\end{tabular} & 88,33 & 495,79 \\
\hline Alytes obstetricans & 29TNF61 & 100,00 & 135,59 & 94,12 & 41,30 & 4545,64 & 261,58 & 36,27 & 225,31 & 84,47 & \begin{tabular}{|l|l|}
193,36 \\
\end{tabular} & \begin{tabular}{|l|l|}
194,77 \\
\end{tabular} & 78,12 & 1233,48 & 177,66 & 13,94 & 53,23 & \begin{tabular}{|l|l|}
497,11 \\
\end{tabular} & 82,71 & 89,56 & 492,25 \\
\hline Alytes obstetricans & 29TNF62 & 101,00 & 119,24 & 89,37 & 39,56 & 4648,32 & 246,04 & 23,36 & 222,68 & 65,19 & $\begin{array}{l}179,50 \\
\end{array}$ & 180,74 & 62,13 & 1421,55 & 207,84 & 17,24 & 53,69 & 573,99 & 97,86 & \begin{tabular}{ll|}
101,46 \\
\end{tabular} & 572,57 \\
\hline Alytes obstetricans & 29TNF63 & 100,00 & 137,18 & 96,37 & 41,92 & 4552,30 & 263,63 & 36,45 & 227,18 & \begin{tabular}{l|l|}
87,09 \\
\end{tabular} & \begin{tabular}{|l|l|}
194,87 \\
\end{tabular} & \begin{tabular}{ll|}
196,22 \\
\end{tabular} & 79,29 & 1227,80 & 174,69 & 14,04 & 52,72 & 494,00 & \begin{tabular}{l|l}
82,05 \\
\end{tabular} & 92,22 & 486,62 \\
\hline Alytes obstetricans & 29TNF64 & 100,00 & 139,87 & 96,89 & 42,25 & 4533,38 & 265,28 & 38,81 & 226,47 & \begin{tabular}{|l|}
89,13 \\
\end{tabular} & \begin{tabular}{|l|l|}
197,19 \\
\end{tabular} & 198,52 & 82,13 & 1200,42 & 169,04 & 13,86 & 52,38 & 482,70 & 80,33 & 92,20 & 473,27 \\
\hline Alytes obstetricans & 29TNF65 & 101,00 & 141,16 & 97,96 & 42,54 & 4548,34 & 267,19 & 39,49 & 227,70 & \begin{tabular}{|c|}
90,78 \\
\end{tabular} & \begin{tabular}{|l|l|}
198,67 \\
\end{tabular} & 199,98 & 83,18 & 1191,76 & 166,29 & 13,82 & 52,13 & \begin{tabular}{ll|}
478,12 \\
\end{tabular} & \begin{tabular}{|l|}
79,78 \\
\end{tabular} & $\begin{array}{l}93,05 \\
\end{array}$ & 468,42 \\
\hline Alytes obstetricans & 29TNF67 & 100,00 & 139,03 & 97,85 & $\begin{array}{l}42,15 \\
\end{array}$ & 4589,24 & 266,73 & \begin{tabular}{|l|}
37,67 \\
\end{tabular} & 229,06 & 88,29 & \begin{tabular}{|l|l|}
197,36 \\
\end{tabular} & 198,49 & 80,91 & 1225,60 & 168,33 & 14,86 & 51,72 & 488,61 & 83,77 & 97,47 & 482,14 \\
\hline Alytes obstetricans & 29TNF68 & 101,00 & 137,90 & 97,23 & 41,97 & 4606,79 & 266,17 & $\begin{array}{l}37,05 \\
\end{array}$ & 229,12 & 87,12 & \begin{tabular}{l|l|}
196,63 \\
\end{tabular} & 197,66 & 79,77 & 1240,93 & 168,44 & 15,51 & 51,33 & 492,91 & 86,19 & 99,84 & 488,19 \\
\hline Alytes obstetricans & 29TNF70 & 100,00 & 131,12 & 93,82 & 39,84 & 4794,23 & 263,60 & 31,18 & 232,42 & 74,29 & \begin{tabular}{|l|l|}
193,10 \\
\end{tabular} & 194,21 & 71,49 & \begin{tabular}{|l|l|}
1276,03 \\
\end{tabular} & 187,97 & 13,92 & \begin{tabular}{|l|l|l|}
54,17 \\
\end{tabular} & 515,51 & 84,71 & \begin{tabular}{l|l}
88,05 \\
\end{tabular} & 514,91 \\
\hline Alytes obstetricans & 29TNF71 & 101,00 & 138,55 & 97,23 & 41,02 & 748,50 & 270,65 & 36,33 & 234,32 & 84,96 & \begin{tabular}{|l|l|}
199,28 \\
\end{tabular} & 200,42 & 78,59 & 1195,33 & 173,64 & 12,9 & 53,50 & 480,83 & 8,99 & 85,21 & 478,45 \\
\hline Alytes obstetricans & 29TNF72 & 100,00 & 124,75 & 93,12 & 39,79 & 4811,33 & 256,79 & 25,56 & 231,23 & 67,57 & 187,14 & 188,20 & 65,25 & 1354,86 & 199,64 & 15,47 & 54,07 & 547,42 & 91,22 & \begin{tabular}{|l|l|}
94,88 \\
\end{tabular} & 546,90 \\
\hline Alytes obstetricans & 29TNF73 & 100,00 & \begin{tabular}{|l|l|}
125,97 \\
\end{tabular} & 94,19 & \begin{tabular}{ll|}
40,16 \\
\end{tabular} & 4798,34 & 257,82 & 26,19 & \begin{tabular}{|l|}
231,62 \\
\end{tabular} & \begin{tabular}{|c|}
69,94 \\
\end{tabular} & \begin{tabular}{|l|l|}
188,03 & \\
\end{tabular} & \begin{tabular}{|l|l|}
189,07 \\
\end{tabular} & \begin{tabular}{|c|}
66,37 \\
\end{tabular} & \begin{tabular}{|l|l|}
1340,38 \\
\end{tabular} & \begin{tabular}{|l|l|}
195,83 \\
\end{tabular} & 15,66 & \begin{tabular}{l|l|}
53,65 \\
\end{tabular} & 540,51 & \begin{tabular}{|c|}
90,73 \\
\end{tabular} & \begin{tabular}{|c|}
95,98 \\
\end{tabular} & 538,99 \\
\hline Alytes obstetricans & 29TNF74 & 101,00 & 128,99 & 95,57 & 40,63 & 4783,60 & 260,61 & 28,37 & 232,24 & 72,85 & 190,58 & 191,63 & 69,3 & 1309,76 & 189,73 & 15,35 & 53,31 & 527,26 & 88,82 & $\begin{array}{l}95,55 \\
\end{array}$ & 524,72 \\
\hline Alytes obstetricans & 29TNF75 & 100,00 & 137,44 & 99,71 & 41,73 & 4775,34 & 270,14 & 34,08 & 236,05 & 82,59 & \begin{tabular}{|l|l|}
198,39 \\
\end{tabular} & \begin{tabular}{|l|l|}
199,50 \\
\end{tabular} & 77,09 & 1223,22 & 174,59 & 13,90 & 52,80 & \begin{tabular}{|l|l|}
489,74 \\
\end{tabular} & 81,78 & 91,80 & 486,31 \\
\hline Alytes obstetricans & 29TNF76 & 101,00 & 141,79 & 100,39 & 41,9 & 48,21 & ct & 37,90 & 236,17 & 87, & 202,21 & 203,32 & 81,5 & 1172,75 & 164,56 & 13,40 & 52, & 67,99 & 2 & 90,37 & 462,94 \\
\hline Alytes obstetricans & 29TNF77 & 100,00 & 139,96 & 100,63 & 41,82 & 4786,69 & 27 & 35,96 & 237,83 & 85 & 201,14 & 201,93 & 79,4 & 1195,50 & 166,38 & 14,04 & 52,04 & \begin{tabular}{|l|l|}
475,06 \\
\end{tabular} & 81,10 & 92,96 & 472,06 \\
\hline Alytes obstetricans & 29TNF79 & 101,00 & 124,43 & 95,81 & 40,47 & 4841,80 & 258,19 & 24,30 & 233,89 & 65,58 & \begin{tabular}{|l|l|}
187,19 \\
\end{tabular} & 188,09 & 64,6 & 1349,39 & 185,11 & 18,55 & 51,51 & 536,28 & 98,47 & \begin{tabular}{|l|}
107,09 \\
\end{tabular} & 536,16 \\
\hline Alytes obstetricans & 29TNF81 & 101,00 & 138,58 & 98,97 & 40,41 & 4957,04 & 276,29 & 34,33 & 241,95 & $\begin{array}{ll}78,33 \\
\end{array}$ & 202,15 & 203,23 & \begin{tabular}{l|l|}
76,25 \\
\end{tabular} & 1184,88 & $\begin{array}{l}174,47 \\
\end{array}$ & 12,24 & 54,20 & \begin{tabular}{|l|l|}
477,17 \\
\end{tabular} & \begin{tabular}{l|l}
77,25 \\
\end{tabular} & 82,20 & 477,00 \\
\hline Alytes obstetricans & 29TNF82 & 100,00 & 133,58 & 98,23 & 40,21 & 4971,25 & 271,19 & 30,14 & 241,06 & 73,00 & 197,70 & 198,66 & 71,47 & 1244,51 & 184,08 & 13,26 & 54,36 & 502,42 & 81,71 & 86,36 & 502,12 \\
\hline Alytes obstetricans & 29TNF83 & 101,00 & 109,14 & 87,77 & 37,62 & 4975,93 & 242,62 & 12,70 & 229,92 & \begin{tabular}{|l|l|}
49,47 \\
\end{tabular} & 175,17 & \begin{tabular}{|l|l|}
175,58 \\
\end{tabular} & 49,2 & 1493,52 & 222,19 & 18,53 & 54,42 & \begin{tabular}{|l|l|}
606,03 \\
\end{tabular} & \begin{tabular}{|l|}
102,49 \\
\end{tabular} & \begin{tabular}{|l|l|}
103,59 \\
\end{tabular} & 606,01 \\
\hline Alytes obstetricans & 29TNF84 & 101,00 & 118,90 & 93,61 & 39,19 & 4982,55 & 254,88 & 19,09 & 235 , & 58,2 & 184,21 & 184,84 & 57,85 & 1397,56 & 206,45 & 16,64 & 54,06 & 565,62 & 95,33 & \begin{tabular}{|l|}
98,47 \\
\end{tabular} & 565,51 \\
\hline Alytes obstetricans & 29TNF85 & 100,00 & 136,01 & 101,39 & 41,17 & 4965,90 & 274,28 & 30,99 & 243,29 & \begin{tabular}{ll|}
75,89 \\
\end{tabular} & \begin{tabular}{|l|l|}
199,76 \\
\end{tabular} & 200,67 & 73,51 & 1222,05 & 177,54 & 13,56 & 53,63 & \begin{tabular}{l|l}
490,55 \\
\end{tabular} & 81,16 & 89,01 & 489,57 \\
\hline Alytes obstetricans & 29TNF86 & 101,00 & 125,67 & 98,43 & 40,38 & 4998,73 & 264,11 & 23,07 & 241,04 & \begin{tabular}{|l|l|l|l|}
64,83 \\
\end{tabular} & \begin{tabular}{|l|l|}
190,54 \\
\end{tabular} & $\begin{array}{l}191,36 \\
\end{array}$ & 63,74 & 1325,58 & 192,39 & 15,93 & \begin{tabular}{|l|l|}
53,57 \\
\end{tabular} & 533,46 & 91,11 & 96,93 & 533,22 \\
\hline Alytes obstetricans & 29TNF87 & 101,00 & 135,01 & 101,65 & \begin{tabular}{|l|l|}
41,07 & \\
\end{tabular} & \begin{tabular}{|l|l|}
4987,46 \\
\end{tabular} & 274,44 & 29,83 & 244,61 & \begin{tabular}{|l|l|}
74,73 \\
\end{tabular} & \begin{tabular}{|l|l|}
199,17 \\
\end{tabular} & 199,92 & 72,50 & 1223,35 & 174,13 & 14,38 & 52,8 & 488,05 & 83,36 & 92,32 & 487,44 \\
\hline Alytes obstetricans & 29TNF88 & 99,00 & & 103,14 & 41, & 4974, & 281 & 35,06 & 246 & 83,7 & 205 & 206 & 78, & \begin{tabular}{|l|l|}
1144,18 \\
\end{tabular} & 158,88 & 13 & 52, & \begin{tabular}{|l|l|}
452,19 \\
\end{tabular} & 8,01 & 89,11 & 451, \\
\hline Alytes obstetricans & 29TNF89 & 101,00 & 138,03 & 102,06 & $\begin{array}{l}40,95 \\
\end{array}$ & 4999,15 & 277,95 & 31,91 & \begin{tabular}{|l|l|}
246,04 \\
\end{tabular} & 78,21 & 202,41 & 202,92 & 75,17 & 1176,14 & 161,05 & 14,66 & 51,68 & 463,52 & 82,57 & 92,81 & 463,14 \\
\hline Alytes obstetricans & 29TNF90 & 100,00 & 135,74 & 97,24 & 39,11 & 5140,79 & 277,09 & 31,58 & 245,51 & 71,87 & 202,41 & 203,33 & 71,87 & 1192,29 & 178,24 & 11,99 & 54,96 & 483,60 & 77,32 & 79,46 & 483,60 \\
\hline Alytes obstetricans & 29TNF91 & 100,00 & 132,75 & 97,32 & 39,23 & 5137,78 & 273,84 & 28,79 & \begin{tabular}{|l|l|}
245,06 \\
\end{tabular} & \begin{tabular}{|l|l|}
68,99 \\
\end{tabular} & $\begin{array}{l}199,50 \\
\end{array}$ & 200,32 & 68,99 & 1228,40 & 184,01 & 12,60 & 55,01 & \begin{tabular}{|l|l|}
498,40 \\
\end{tabular} & \begin{tabular}{|l|}
79,94 \\
\end{tabular} & \begin{tabular}{l|l}
82,35 \\
\end{tabular} & 498,40 \\
\hline Alytes o & $29 \mathrm{TNF}$ & 101,00 & & & $39, \mathrm{C}$ & 10205 & & & 243, & 63, & & & 63, & 1295 & 194,83 & & 55, & 526 & & \begin{tabular}{l|l}
87,05 \\
\end{tabular} & 526 \\
\hline Alytes obstetricans & 29TNF93 & 100,00 & 112,22 & 89,85 & 37,50 & 5123,48 & 249,7 & 13,6 & 236,13 & 50,27 & 180,26 & 180,45 & 50,27 & 1440,64 & 216,60 & 16,93 & 55,02 & 587,21 & $97,41 \mid$ & 97,51 & 587, \\
\hline Alytes obstetricans & 29TNF94 & 100,00 & 117,18 & 94,18 & 38,63 & 5143,77 & 257,13 & 16,22 & 240,91 & 54,41 & \begin{tabular}{|l|l|}
184,94 \\
\end{tabular} & 185,37 & 54,41 & \begin{tabular}{ll|}
1388,86 \\
\end{tabular} & 207,75 & 16,25 & 54,85 & 564,88 & 94,28 & 95,58 & 564,88 \\
\hline
\end{tabular}




\begin{tabular}{|c|c|c|c|c|c|c|c|c|c|c|c|c|c|c|c|c|c|c|c|c|c|}
\hline TAXON & UTM & $\mathrm{km2}$ & B101 & $\mathrm{B1O2}$ & $\mathrm{BIO3}$ & $\mathrm{B104}$ & B105 & B106 & B107 & B108 & $\mathrm{BIO9}$ & 81010 & B1011 & BIO12 & $\mathrm{B1O13}$ & 81014 & B1015 & B1016 & B1017 & BIO18 & B1019 \\
\hline Alytes obstetricans & 29TNF96 & 100,00 & 122,41 & 99,04 & 39,60 & 5160,22 & 265,41 & 18,77 & 246,64 & 58,88 & 189,82 & 190,40 & 58,88 & 1327,04 & 195,32 & 16,05 & 54,19 & 536,19 & 91,36 & 95,12 & 536,19 \\
\hline Alytes obstetricans & 29TNF97 & 100,00 & 115,88 & 95,90 & 39,03 & 5136,17 & 257,03 & 14,56 & 242,47 & 53,35 & 183,44 & 183,91 & 53,35 & 1372,61 & 199,44 & 17,95 & 53,49 & 553,49 & 98,06 & 101,01 & 553,49 \\
\hline Alytes obstetricans & 29TNF98 & 101,00 & 121,02 & 98,41 & 39,61 & 5139,73 & 263,22 & 17,96 & 245,26 & 57,91 & 188,29 & 188,76 & 57,91 & 1316,53 & 188,74 & 17,26 & 53,01 & 528,34 & 94,25 & 98,83 & 528,34 \\
\hline Alytes obstetricans & 29TNF99 & 100,00 & 135,05 & 103,43 & 40,67 & 5161,06 & 279,51 & 27,52 & 251,99 & 71,37 & 201,96 & 202,26 & 70,61 & 1168,49 & 163,49 & 14,49 & 52,32 & 463,38 & 81,88 & 88,21 & 463,32 \\
\hline Alytes obstetricans & 29TNG11 & 68,00 & 142,97 & 75,17 & \begin{tabular}{|l|l|}
42,97 \\
\end{tabular} & 3566,09 & 236,70 & $\begin{array}{ll}63,82 \\
\end{array}$ & 172,88 & 98,36 & 187,37 & 188,68 & 98,36 & \begin{tabular}{ll|l|}
1288,24 \\
\end{tabular} & 180,59 & 15,17 & 52,45 & 518,55 & 83,56 & 108,22 & 518,55 \\
\hline Alytes obstetricans & 29TNG12 & 87,00 & 137,29 & 73,96 & 42,06 & 3627,14 & 232,43 & 58,62 & 173,81 & 92,83 & 182,87 & 184,29 & 92,14 & 1378,35 & 191,82 & 19,18 & 51,61 & 553,01 & 96,64 & 118,57 & 552,97 \\
\hline Alytes obstetricans & 29TNG13 & 86,00 & 140,49 & 72,13 & \begin{tabular}{|l|l|}
41,64 \\
\end{tabular} & 3603,62 & 234,13 & 62,90 & 171,23 & 100,04 & 185,70 & 187,01 & 95,30 & 1358,91 & 189,08 & 19,68 & 51,07 & 544,43 & 96,92 & 119,11 & 541,84 \\
\hline Alytes obstetricans & 29TNG14 & 99,00 & 141,35 & 69,97 & 41,01 & 3592,14 & 233,55 & 65,01 & 168,54 & 103,58 & 186,44 & 187,73 & 96,16 & \begin{tabular}{|l|l|}
1368,59 \\
\end{tabular} & 193,12 & 21,54 & 50,70 & 549,61 & \begin{tabular}{r|}
101,51 \\
\end{tabular} & 122,99 & 542,04 \\
\hline Alytes obstetricans & 29TNG15 & 101,00 & 132,16 & 69,72 & 40,14 & 3685,33 & 227,32 & 55,75 & 171,56 & 93,81 & 178,93 & 180,33 & 86,39 & 1509,91 & 227,25 & 27,33 & 50,50 & 609,48 & 119,62 & 138,03 & 604,19 \\
\hline Alytes obstetricans & 29TNG17 & 33,00 & 149,14 & 62,22 & 38,97 & 3510,00 & 234,61 & 76,97 & 157,64 & 112,28 & 193,11 & 194,33 & 104,31 & 1294,33 & 179,89 & 25,03 & 48,31 & 519,61 & 107,44 & 128,50 & 486,56 \\
\hline Alytes obstetricans & 29TNG18 & 45,00 & 144,43 & 61,74 & 38,37 & 3541,20 & 231,42 & 73,05 & 158,37 & 107,44 & 189,24 & 190,36 & 99,57 & 1364,63 & 199,30 & 28,12 & 48,48 & 549,64 & 116,34 & 136,83 & 520,34 \\
\hline Alytes obstetricans & 29TNG19 & 57,00 & 145,12 & 59,99 & \begin{tabular}{|l|l|}
37,97 \\
\end{tabular} & 3519,84 & 230,93 & 75,11 & 155,82 & 108,43 & 189,61 & 191,00 & 100,84 & 1316,97 & 192,33 & 28,91 & 47,32 & 528,09 & 117,50 & 139,10 & 493,80 \\
\hline Alytes obstetricans & 29TNG20 & 101,00 & 138,63 & 80,62 & 42,90 & 3774,84 & 239,93 & 54,36 & \begin{tabular}{|l|l|}
185,56 \\
\end{tabular} & \begin{tabular}{|c|}
91,40 \\
91
\end{tabular} & \begin{tabular}{|l|l|}
185,97 \\
\end{tabular} & 187,32 & $\begin{array}{l} \\
91,40 \\
\end{array}$ & 1326,01 & 182,29 & $\begin{array}{l}20,11 \\
16,74\end{array}$ & 51,84 & 531,55 & 89,82 & 110,74 & 531,55 \\
\hline Alytes obstetricans & 29TNG21 & 100,00 & 140,46 & 79,05 & 42,58 & 3766,11 & 241,19 & 57,32 & 183,88 & 93,37 & 187,78 & 188,95 & 93,37 & 1319,70 & 182,44 & 16,80 & 51,79 & 528,80 & 89,38 & 111,32 & 528,80 \\
\hline Alytes obstetricans & 29TNG22 & 101,00 & 137,87 & 77,71 & 41,84 & 3802,67 & 239,14 & 55,51 & 183,63 & 92,15 & 185,93 & 187,09 & 90,40 & 1364,18 & 189,74 & 19,11 & 51,39 & 545,54 & 96,55 & 117,25 & 545,41 \\
\hline Alytes obstetricans & 29TNG23 & 100,00 & 133,12 & 76,64 & 41,04 & 3855,64 & 235,53 & 51,17 & 184,36 & 88,49 & 182,12 & 183,32 & 85,21 & 1450,79 & 209,92 & 22,81 & 50,88 & 581,76 & 108,37 & 126,68 & 581,25 \\
\hline Alytes obstetricans & 29TNG24 & 99,00 & 142,72 & 73,68 & 40,92 & 3762,67 & 240,82 & 62,56 & 178,27 & 101,27 & 190,16 & 191,21 & 95,21 & 1360,54 & 195,29 & 21,41 & 50,56 & 545,50 & 101,24 & 121,49 & 538,65 \\
\hline Alytes obstetricans & 29TNG25 & 101,00 & 142,44 & 71,61 & 40,21 & 3755,29 & 239,25 & 63,49 & 175,77 & 101,68 & 189,94 & 190,94 & 95,01 & 1394,60 & 206,60 & 23,94 & 50,39 & 561,40 & 107,55 & 126,99 & 552,19 \\
\hline Alytes obstetricans & 29TNG26 & 100,00 & 137,42 & 70,38 & 39,69 & 3792,18 & 234,78 & 59,26 & 175,52 & 95,03 & 185,76 & 186,73 & 89,89 & \begin{tabular}{|l|l|}
1494,19 \\
\end{tabular} & 233,27 & 28,30 & 50,67 & 605,16 & 120,03 & 137,69 & 598,49 \\
\hline Alytes obstetricans & 29TNG27 & 80,00 & 142,23 & 66,90 & 39,02 & 3729,91 & 235,55 & 66,17 & $\mid 169,38$ & 100,94 & $|189,67|$ & $\mid 190,59$ & 95,20 & 1456,53 & 226,75 & 28,89 & 50,29 & 590,88 & 119,23 & 137,56 & 576,63 \\
\hline Alytes obstetricans & 29TNG28 & 86,00 & 139,17 & 65,44 & 38,37 & 3735,36 & 232,63 & 64,36 & 168,28 & 99,83 & 186,87 & 187,97 & 92,44 & 1463,59 & 227,46 & 31,15 & 49,23 & 589,78 & 125,44 & 144,09 & 572,35 \\
\hline Alytes obstetricans & 29TNG29 & 72,00 & 142,90 & 62,57 & 37,89 & 3707,49 & 233,27 & 70,12 & 163,15 & 103,57 & 190,24 & 191,12 & 96,35 & \begin{tabular}{|l|}
1394,43 \\
\end{tabular} & 212,13 & 30,94 & 48,26 & 558,48 & 122,62 & 142,96 & 533,75 \\
\hline Alytes obstetricans & 29TNG30 & 100,00 & 142,44 & 84,53 & \begin{tabular}{|l|l|}
42,87 \\
\end{tabular} & \begin{tabular}{|l|l|}
3938,87 \\
\end{tabular} & 249,38 & 54,16 & 195,22 & 95,44 & \begin{tabular}{|l|l|}
191,86 \\
\end{tabular} & 193,10 & 92,81 & 1270,66 & 172,69 & 15,94 & 51,41 & 505,15 & 86,42 & 106,61 & 504,88 \\
\hline Alytes obstetricans & 29TNG31 & 101,00 & 138,13 & 83,65 & 42,12 & 3997,59 & 246,81 & 50,50 & 196,31 & 90,32 & 188,70 & 189,82 & 88,05 & 1338,81 & 185,48 & 18,15 & 51,15 & 533,35 & 94,35 & 113,34 & 533,25 \\
\hline Alytes obstetricans & 29TNG32 & 101,00 & 142,57 & 82,02 & 41,84 & 3972,07 & 249,88 & 55,81 & 194,06 & 98,75 & 192,74 & 193,71 & 92,50 & 1300,19 & 180,92 & 17,88 & 51,01 & 516,76 & 92,01 & 111,91 & 515,34 \\
\hline Alytes obstetricans & 29TNG33 & 100,00 & 128,02 & 80,92 & 40,79 & 4087,55 & 238,12 & 41,92 & 196,20 & 79,68 & 180,45 & 181,48 & 77,39 & 1483,19 & 217,87 & 24,47 & 50,58 & 592,61 & 114,75 & 129,94 & 592,45 \\
\hline Alytes obstetricans & 29TNG34 & 100,00 & 130,47 & 79,59 & 40,55 & 4068,19 & 239,44 & $\begin{array}{ll}4,25 \\
45,08\end{array}$ & 194,36 & 84,61 & $\begin{array}{l}182,58 \\
\end{array}$ & 183,56 & 79,95 & \begin{tabular}{|l|l|}
1482,56 \\
\end{tabular} & 223,25 & 25,55 & 50,53 & \begin{tabular}{|l|}
593,07 \\
\end{tabular} & $\begin{array}{l}116,73 \\
14,\end{array}$ & 132,15 & 591,82 \\
\hline Alytes obstetricans & 29TNG36 & 101,00 & 144,76 & 73,61 & 39,76 & 3928,62 & 246,38 & 62,98 & 183,40 & 101,35 & 194,70 & 195,47 & 95,00 & 1380,58 & 213,07 & 25,50 & 50,08 & 554,99 & 110,69 & 128,51 & 543,54 \\
\hline Alytes obstetricans & 29TNG39 & 101,00 & 136,77 & 68,86 & 38,12 & 3933,53 & 236,40 & 58,27 & 178,13 & 94,66 & 187,42 & 188,34 & 87,94 & 1478,41 & 235,28 & 33,27 & 48,80 & 590,26 & 130,99 & 148,84 & 576,22 \\
\hline Alytes obstetricans & 29TNG40 & 101,00 & 145,85 & 88,48 & 42,53 & 4128,39 & 258,94 & 53,25 & 205,69 & 100,52 & 197,76 & 198,85 & 93,45 & 1208,74 & 163,53 & 15,25 & 50,98 & 478,58 & 83,25 & 102,33 & 474,61 \\
\hline Alytes obstetricans & 29TNG41 & 100,00 & 138,67 & 87,77 & 41,79 & 4212,47 & 254,27 & 46,55 & 207,72 & $\begin{array}{l}\mid 92,38 \\
92,\end{array}$ & 192,13 & 193,18 & 85,67 & 1304,64 & 181,44 & 18,13 & 50,77 & 517,18 & 94,26 & 111,32 & 514,42 \\
\hline Alytes obstetricans & 29TNG42 & 100,00 & 137,73 & 86,50 & 4 & 4229,46 & 253,40 & $\begin{array}{l}40,41 \\
46,41\end{array}$ & \begin{tabular}{|l|l|}
206,99 \\
\end{tabular} & \begin{tabular}{|l|}
90,97 \\
9
\end{tabular} & 191,60 & $\begin{array}{l}192,52 \\
192,0\end{array}$ & $\begin{array}{l}34,68 \\
84\end{array}$ & \begin{tabular}{|l|l|}
1324,39 \\
\end{tabular} & \begin{tabular}{|l|}
187,27 \\
\end{tabular} & $\begin{array}{l}\mid 0,15 \\
19,51 \\
\end{array}$ & 50,38 & 524,80 & $\begin{array}{l}4,20 \\
98,47 \\
\end{array}$ & 114,94 & 521,03 \\
\hline Alytes obstetricans & 29TNG43 & 101,00 & 137,51 & 85,64 & 40,89 & 4235,56 & 253,34 & 46,66 & 206,68 & 91,15 & 191,53 & 192,29 & 84,30 & 1342,99 & 195,19 & 21,10 & 50,03 & 532,19 & 103,16 & 118,92 & 527,01 \\
\hline Alytes obstetricans & 29TNG44 & 100,00 & 130,60 & 84,27 & 40,42 & 4270,75 & 246,88 & 40,75 & 206,14 & 84,49 & 185,44 & 186,28 & 77,45 & 1431,34 & 214,47 & 24,88 & 49,83 & 567,90 & 1115,32 & 129,11 & 563,75 \\
\hline Alytes obstetricans & 29TNG45 & 101,00 & 142,30 & 82,14 & 40,13 & 4197,28 & 255,32 & 53,36 & 201,96 & 96,35 & 195,81 & 196,38 & 89,24 & 1323,49 & 199,84 & 23,13 & 49,47 & 524,75 & 106,82 & 122,21 & 513,46 \\
\hline Alytes obstetricans & 29TNG48 & 100,00 & 128,16 & 78,41 & 39,08 & 4198,61 & 239,79 & 41,84 & 197,95 & 83,04 & 182,58 & 183,64 & 76,66 & 1502,07 & 239,28 & 32,79 & 48,85 & 595,05 & 133,86 & 147,87 & 587,57 \\
\hline Alyty obstetricans & 29TNG49 & 101,00 & $\begin{array}{l}125,10 \\
125,64\end{array}$ & 77,56 & 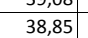 & $\begin{array}{l}4150,01 \\
4165,73\end{array}$ & 237,61 & $\begin{array}{l}1,04 \\
39,97 \\
\end{array}$ & \begin{tabular}{|l|l|}
197,64 \\
\end{tabular} & $\begin{array}{l}30,1,13 \\
81\end{array}$ & \begin{tabular}{|l|}
$\mid 179,306$ \\
179,86
\end{tabular} & $\begin{array}{l}1831,09 \\
181\end{array}$ & 75,07 & $\begin{array}{l}1508,88 \\
1508\end{array}$ & $\mid$ & \begin{tabular}{|c|c|}
34,66 \\
34,6
\end{tabular} & $\begin{array}{l}4,05 \\
47,92\end{array}$ & \begin{tabular}{|l|}
594,55 \\
595
\end{tabular} & $\begin{array}{l}138,65 \\
138,6\end{array}$ & $\begin{array}{l}14,01 \\
153,11\end{array}$ & 584,39 \\
\hline Alytes obstetricans & 29TNG50 & 101,00 & 140,38 & 92,44 & 41,82 & 4400,09 & 262,18 & 43,75 & 218,44 & 91,96 & 196,36 & 197,28 & 84,86 & 1243,80 & 168,81 & 16,54 & 50,69 & 492,03 & 88,82 & 104,69 & 487,03 \\
\hline Alytes obstetricans & 29TNG51 & 100,00 & 138,16 & 91,40 & 41,41 & 4425,39 & 260,50 & 42,19 & 218,31 & 89,59 & 194,64 & 195,49 & 82,54 & 1274,66 & 176,06 & 17,98 & 50,29 & 503,34 & 93,86 & 109,01 & 498,60 \\
\hline Alytes obstetricans & 29TNG52 & 100,00 & 130,71 & 89 & 40,70 & 4468,95 & 253,57 & 35,99 & 217,57 & 81,64 & 188,20 & 188,95 & 75,02 & 1357,70 & 191,48 & 21, & 49,95 & 535,88 & 104,88 & 117,86 & 532,10 \\
\hline Alytes obstetricans & 29TNG53 & 101,00 & 131,96 & 89,04 & 40, & 4465,45 & 254,88 & 37,47 & 217,42 & 83,37 & 189,44 & 190,19 & 76,41 & 1345,19 & 193,52 & 21 & 49,53 & 529,65 & 106,91 & 119,50 & 523,62 \\
\hline $\begin{array}{l}\text { Ay } \\
\text { Alytes obstetricans }\end{array}$ & 29TNG54 & $\begin{array}{l}101,00 \\
101,00\end{array}$ & $\begin{array}{l}13,90 \\
107,50\end{array}$ & $\begin{array}{l}5,, 44 \\
82,47\end{array}$ & $\begin{array}{l}30, \\
38,\end{array}$ & $\begin{array}{l}4460,45 \\
4465,10\end{array}$ & 228,68 & $\begin{array}{l}1,44 \\
18,35 \\
\end{array}$ & \begin{tabular}{|l|}
210,33 \\
210,
\end{tabular} & $\begin{array}{l}63,3 \prime \\
60,80 \\
\end{array}$ & \begin{tabular}{|l|}
$109,44,06$ \\
166
\end{tabular} & $\mid$\begin{tabular}{|l}
$\mid 190,19$ \\
167,06
\end{tabular} & $\begin{array}{l}\mid 0,41 \\
54,06\end{array}$ & \begin{tabular}{|l}
154,19 \\
1555,27
\end{tabular} & $\begin{array}{l}\mid, 93,32 \\
221,33\end{array}$ & \begin{tabular}{|l|}
30,16 \\
30
\end{tabular} & $\begin{array}{l}44,53 \\
48,53\end{array}$ & $\begin{array}{l}25,03 \\
611,15 \\
\end{array}$ & $\begin{array}{l}134,21 \\
134\end{array}$ & 142,65 & $\begin{array}{l}32,02 \\
608,70\end{array}$ \\
\hline Alytes obstetricans & 29TNG55 & 100,00 & 132,57 & 86,93 & 39,88 & 4446,63 & 254,36 & 39,24 & 215,13 & 84,11 & 189,82 & 190,56 & 77,19 & 1347,31 & 201,06 & 24,82 & 48,65 & 528,58 & 114,33 & 126,30 & 517,21 \\
\hline Alytes obstetricans & 29TNG56 & 101,00 & 134,95 & 86,64 & 39,8 & 4443,65 & 256,33 & 41,37 & 214,96 & 86,19 & 192,04 & 192,69 & 79,37 & 1329,41 & 202,14 & 25,73 & 48,28 & 520,27 & 115,85 & 126,77 & 506,14 \\
\hline Alytes obstetricans & 29TNG58 & 99,00 & 113,23 & 81,48 & 38,8 & 4356,27 & 232,03 & 24,34 & 207,69 & 66,96 & 170,34 & 171,53 & 61,18 & 1517,29 & 227,58 & 34,32 & 47,03 & 591,85 & 42 & 152,52 & 583,34 \\
\hline Alytes obstetricans & 29TNG61 & 101,00 & 129,52 & $\begin{array}{l}91,406 \\
92,96\end{array}$ & $\begin{array}{l}40, \\
40,\end{array}$ & 4652,63 & 257,84 & 31,49 & 226,34 & 76,71 & 189,55 & 190,32 & $\begin{array}{ll}1,160 \\
11,80\end{array}$ & 1320,79 & \begin{tabular}{|l|l|}
179,13 \\
\end{tabular} & \begin{tabular}{l|l}
19,68 \\
19
\end{tabular} & 50,09 & 520,45 & 100,31 & 111,37 & 517,43 \\
\hline Alytes obstetricans & 29TNG & 101,00 & 115,32 & 87,95 & 39,30 & 464 & 241,85 & 21,15 & 220,70 & 62,37 & 176,03 & 176,82 & 58,84 & 1450,71 & 198,80 & 24,5 & 49,68 & 571,37 & $\begin{array}{l}116,97 \\
\end{array}$ & 125,53 & 570,44 \\
\hline Alytes obstetricans & 29TNG63 & 100,00 & 123,83 & 90,23 & 39,73 & 4660,90 & 251,54 & 27,50 & 224,04 & 72,50 & 184,36 & 185,01 & 66,47 & 1369,05 & 192,82 & 23,31 & 49,05 & 536,57 & 111,71 & 121,10 & 531,94 \\
\hline Alytes obstetricans & 29TNG64 & 101,00 & 110,77 & 85,49 & 38,75 & 4618,93 & 235,92 & 18,21 & 217,71 & 61,90 & 171,38 & 172,25 & 55,21 & 1481,37 & 208,95 & 28,14 & 48,52 & 579,94 & 126,96 & 135,08 & 577,66 \\
\hline Alytes obstetricans & 29TNG65 & 100,00 & 104,96 & 83,10 & 38,21 & 4573,78 & 228,97 & 14,35 & 214,62 & 57,06 & 165,27 & 166,23 & 50,52 & 1523,45 & 215,64 & 31,05 & 47,71 & 87 & 135,51 & 143,03 & 591,62 \\
\hline Alytes obstetricans & 29TNG66 & 100,00 & 132,97 & 90 & 39 & $\begin{array}{l}437,10 \\
4650,79\end{array}$ & $\begin{array}{l}25,59,97 \\
259,9\end{array}$ & 35,22 & \begin{tabular}{|l|}
$224,75<$ \\
\end{tabular} & $\begin{array}{l}1,1,72 \\
81\end{array}$ & \begin{tabular}{|l|}
193,13 \\
\end{tabular} & \begin{tabular}{|l|}
193,56 \\
\end{tabular} & $\begin{array}{ll}0,35,17 \\
75\end{array}$ & $\begin{array}{l}13269,45 \\
1269,36\end{array}$ & \begin{tabular}{|l|}
188,81 \\
188,
\end{tabular} & $\begin{array}{l}\mid 1,03 \\
24,75\end{array}$ & 47,50 & \begin{tabular}{|l|}
491,39 \\
491
\end{tabular} & \begin{tabular}{|l|}
112,81 \\
11,8
\end{tabular} & $\begin{array}{l}14,03 \\
122,05\end{array}$ & $47,0,26$ \\
\hline Alytes obstetricans & 29TNG68 & 101,00 & 125,16 & 85,59 & 38,95 & 4545,41 & 247,24 & 30,58 & 216,66 & 75,50 & 184,41 & 185,20 & 69,87 & 1345,60 & 201,85 & 29,79 & 46,67 & 519,66 & 125,28 & 137,12 & 507,16 \\
\hline Alytes obstetricans & 29TNG70 & 100,00 & 125,96 & 95,39 & 40,34 & 4836,55 & 259,46 & 25,65 & 233,80 & 69,04 & $\mid 188,61$ & 189,35 & 66,06 & 1323,33 & 177,65 & $\mid 18,87$ & 50,92 & 523,00 & 98.51 & 107,73 & 522,32 \\
\hline Alytes obstetricans & 29TNG71 & 101,00 & 123,47 & 93,49 & 39,85 & 4824,53 & 255,95 & 24,26 & 231,69 & 67,47 & 186,21 & 186,93 & 64,12 & 1335,23 & 178,47 & 20,38 & 50,23 & 525,75 & 102,88 & 111,40 & 524,43 \\
\hline Alytes obstetricans & 29TNG72 & 100,00 & 97,65 & 83 & 37,4 & 4745,83 & 225,53 & 6,75 & 218 & 42,20 & 160,59 & 16 & 41,58 & 1545,54 & 206,22 & 28,51 & 49,13 & 607,76 & 130,75 & 134,74 & 60 \\
\hline Alytes obstetricans & $\begin{array}{l}\text { 29TNG73 } \\
\end{array}$ & $\begin{array}{l}100,00 \\
\end{array}$ & $\begin{array}{l}315,03 \\
115,12\end{array}$ & $\begin{array}{l}3,112 \\
89,06\end{array}$ & 年, 38,83 & $\begin{array}{l}474,205 \\
4792,36\end{array}$ & 245,33 & \begin{tabular}{|c|}
0,7 \\
18,81 \\
\end{tabular} & \begin{tabular}{|l|}
226,53 \\
22,1
\end{tabular} & $\begin{array}{l}42,206 \\
61,56\end{array}$ & \begin{tabular}{|l|l|}
177,89 \\
\end{tabular} & \begin{tabular}{|l|}
178,53 \\
17,5
\end{tabular} & $\begin{array}{l}1,06 \\
57,06\end{array}$ & 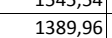 & \begin{tabular}{|l|l|}
190,55 \\
190,5
\end{tabular} & \begin{tabular}{|l|}
24,75 \\
24,75
\end{tabular} & $\begin{array}{l}4,15 \\
48,83 \\
\end{array}$ & $\begin{array}{l}543,13 \\
5\end{array}$ & \begin{tabular}{|l|l|}
116,06 \\
113
\end{tabular} & 122,88 & 540,40 \\
\hline Alytes obstetricans & 29TNG74 & 100,00 & 118,22 & 89,85 & 39,04 & 4792,53 & 248,44 & 20,96 & 227,47 & 66,63 & 181,05 & 181,57 & 60,02 & 1355,98 & 189,64 & 24,99 & 48,16 & 527,67 & 115,35 & 123,03 & 523,51 \\
\hline Alytes obstetricans & 29TNG75 & 100,00 & 95,31 & 81,82 & 37,30 & 4670,94 & 221,61 & 5,29 & 216,32 & 47,01 & 157,29 & 158,27 & 40,48 & 1539,21 & 211,15 & 32,58 & 47,17 & 598,54 & 140,23 & 145,68 & 596,0 \\
\hline Alytes ob: & 29TNG77 & 101,00 & 133,18 & 91,21 & 39,10 & 819,46 & 261,81 & 31,66 & 230,15 & 79,49 & 195 & 196 & 73, & 1193,18 & 176,81 & 24,51 & 46,56 & 456,50 & 108,58 & 116,42 & 442 \\
\hline Alytes obstetricans & 29TNG78 & 100,00 & 139,06 & 89,04 & 38,86 & 4789,06 & 264,12 & 37,72 & 226,40 & 85,44 & 201,18 & 201,45 & 79,82 & 1126,93 & 67,65 & 24,12 & 45,96 & 428,39 & 104,06 & 112,19 & 412,40 \\
\hline
\end{tabular}





\begin{tabular}{|c|c|c|c|c|c|c|c|c|c|c|c|c|c|c|c|c|c|c|c|c|c|}
\hline TAXON & UTM & $\mathrm{km} 2$ & BIO1 & B102 & $B 103$ & BIO4 & B105 & B106 & B107 & B108 & B109 & B1010 & BIO11 & BIO12 & BIO13 & BIO14 & BIO15 & B1016 & B1017 & B1018 & 81019 \\
\hline Alytes obstetricans & 29TNH76 & 100,00 & 123,45 & 80,75 & 40,48 & 3913,96 & 234,63 & 37,28 & 197,35 & 81,06 & 174,02 & 176,74 & 77,42 & 1263,07 & 175,84 & 36,85 & 40,71 & 472,81 & 140,15 & 157,23 & 448,44 \\
\hline Alytes obstetricans & 29TNH78 & 100,00 & 125,41 & 78,00 & 40,75 & 3774,11 & 231,87 & 42,35 & 189,52 & 85,45 & 173,73 & 176,95 & 80,70 & 1203,79 & 163,01 & 36,49 & 39,10 & 448,58 & 138,77 & 157,20 & 420,48 \\
\hline Alytes obstetricans & 29TNH79 & 101,00 & 127,95 & 76,35 & \begin{tabular}{ll|}
40,99 \\
\end{tabular} & 3677,10 & 230,73 & 46,82 & 183,90 & 89,37 & $\begin{array}{l}174,66 \\
\end{array}$ & \begin{tabular}{ll|}
178,06 \\
\end{tabular} & 84,01 & $\begin{array}{l}1160,08 \\
\end{array}$ & $\begin{array}{l}154,75 \\
\end{array}$ & 35,67 & 38,39 & 431,51 & $\begin{array}{l}135,97 \\
\end{array}$ & $\begin{array}{l}155,20 \\
\end{array}$ & 401,73 \\
\hline Alytes obstetricans & 29TNH80 & 101,00 & 121,66 & 87,60 & 38,94 & 4624,64 & 246,68 & 24,51 & 222,16 & 70,44 & 182,41 & 183,22 & 66,42 & $\begin{array}{l}1237,66 \\
\end{array}$ & $\begin{array}{l}179,48 \\
\end{array}$ & 30,18 & 44,30 & 469,27 & 122,14 & $\begin{array}{l}134,09 \\
\end{array}$ & 456,60 \\
\hline Alytes obstetricans & 29TNH86 & 101,00 & 115,94 & 82,36 & 40,29 & 4041,46 & 230,32 & 28,34 & 201,98 & 72,10 & 168,44 & 170,87 & 68,70 & 1270,44 & 175,37 & 37,83 & 39,99 & 473,87 & 143,78 & 159,12 & 450,46 \\
\hline Alytes obstetricans & 29TNH87 & 100,00 & 120,24 & 81,21 & 40,53 & 3948,06 & 231,67 & 33,64 & 198,03 & 77,44 & 171,24 & 173,84 & 73,78 & $\begin{array}{l}1223,72 \\
\end{array}$ & 167,01 & 37,04 & 39,34 & 454,95 & 140,50 & 157,10 & 429,47 \\
\hline Alytes obstetricans & 29TNH88 & 101,00 & 120,39 & 79,96 & 40,75 & 3879,56 & 229,84 & 35,39 & 194,45 & 78,82 & 170,37 & 173,09 & 74,51 & \begin{tabular}{|l|}
1209,88 \\
\end{tabular} & 163,08 & 37,42 & 38,62 & 448,59 & 141,75 & 158,84 & 421,24 \\
\hline Alytes obstetricans & 29TNH89 & 100,00 & 118,54 & 78,92 & \begin{tabular}{l|l|l}
40,75 \\
\end{tabular} & 3828,43 & 226,61 & $\begin{array}{l}34,99 \\
\end{array}$ & $\begin{array}{l}191,62 \\
\end{array}$ & 77,91 & 167,77 & 170,85 & 73,56 & 1211,67 & $\begin{array}{l}161,56 \\
\end{array}$ & 38,36 & 37,93 & 448,19 & 144,90 & 162,40 & 419,19 \\
\hline Alytes obstetricans & 29TNH91 & 101,00 & 118,31 & 88,03 & 39,00 & 4616,37 & 244,04 & 21,27 & 222,77 & $\begin{array}{ll}67,07 \\
\end{array}$ & $\begin{array}{ll}178,96 \\
\end{array}$ & \begin{tabular}{|l|}
179,91 \\
\end{tabular} & 63,44 & 1205,83 & $\begin{array}{l}171,39 \\
\end{array}$ & 30,83 & 43,10 & \begin{tabular}{ll|l|}
454,83 \\
\end{tabular} & $\begin{array}{l}123,06 \\
\end{array}$ & $\begin{array}{l}135,26 \\
\end{array}$ & 441,25 \\
\hline Alytes obstetricans & 29TNH93 & 100,00 & 120,09 & 86,50 & 39,86 & 4380,79 & 240,84 & 26,01 & 214,82 & 71,35 & 177,34 & \begin{tabular}{ll|}
178,84 \\
\end{tabular} & 68,32 & 1192,53 & $\begin{array}{l}167,75 \\
\end{array}$ & 32,62 & 41,76 & \begin{tabular}{|l|l|}
446,68 \\
\end{tabular} & 127,21 & 141,04 & 429,09 \\
\hline Alytes obstetricans & 29TNH95 & 101,00 & 120,38 & 84,72 & 40,10 & $\begin{array}{ll}4199,03 \\
\end{array}$ & 237,33 & 29,28 & 208,05 & 73,99 & $\begin{array}{l}175,04 \\
\end{array}$ & 176,95 & 70,86 & 1186,55 & 164,11 & 34,36 & 40,28 & \begin{tabular}{ll|l}
441,78 \\
\end{tabular} & $\begin{array}{l}132,04 \\
\end{array}$ & $\begin{array}{ll}146,98 \\
\end{array}$ & 420,39 \\
\hline Alytes obstetricans & 29TNH97 & 100,00 & 122,66 & 82,42 & $\begin{array}{l}40,76 \\
\end{array}$ & 4034,11 & 235,08 & 34,51 & 200,57 & 78,55 & $\begin{array}{l}174,71 \\
\end{array}$ & $\begin{array}{l}177,24 \\
\end{array}$ & 74,77 & 1155,42 & 156,30 & 35,05 & 38,88 & 427,68 & 133,61 & $\begin{array}{ll}150,03 \\
\end{array}$ & 402,29 \\
\hline Alytes obstetricans & 29TNH98 & 101,00 & 121,27 & 81,36 & 40,79 & 3959,32 & 232,09 & 34,47 & 197,61 & 78,34 & 172,28 & 174,98 & 74,29 & 1159,91 & 155,18 & 36,09 & 38,11 & 428,21 & 137,12 & 153,85 & 401,04 \\
\hline Alytes obstetricans & 29TNH99 & 100,00 & 121,31 & 80,24 & \begin{tabular}{|l|l|}
40,97 \\
\end{tabular} & 3889,75 & 230,11 & 36,08 & 194,03 & 79,50 & 171,34 & \begin{tabular}{ll|}
174,06 \\
\end{tabular} & 75,10 & 1152,55 & \begin{tabular}{|l|l|}
152,47 \\
\end{tabular} & 36,63 & 37,43 & $\begin{array}{l}424,45 \\
\end{array}$ & 138,80 & $\begin{array}{l}156,01 \\
\end{array}$ & 395,57 \\
\hline Alytes obstetricans & 29TNJ40 & 18,00 & 140,90 & 67,00 & 41,90 & 3225,38 & 226,97 & 68,62 & 158,34 & 109,17 & 180,34 & \begin{tabular}{ll|}
184,66 \\
\end{tabular} & 101,00 & 1040,24 & $\begin{array}{l}135,86 \\
\end{array}$ & 30,03 & 39,00 & 394,31 & 1119,52 & 142,10 & 359,59 \\
\hline Alytes obstetricans & 29TNJ50 & 35,00 & 140,32 & 69,33 & \begin{tabular}{l|l|l}
42,05 \\
\end{tabular} & 3314,98 & 229,41 & 66,90 & 162,51 & 106,79 & \begin{tabular}{|l|l|}
181,08 \\
\end{tabular} & 185,25 & 99,56 & $\begin{array}{l}1041,52 \\
\end{array}$ & $\begin{array}{l}135,65 \\
\end{array}$ & $\begin{array}{l}30,56 \\
\end{array}$ & 38,54 & 392,02 & 120,49 & 142,51 & 359,29 \\
\hline Alytes obstetricans & 29TNJ61 & 82,00 & 138,78 & 70,46 & 42,23 & 3350,75 & 229,34 & 64,74 & $\begin{array}{l}164,60 \\
\end{array}$ & 104,63 & 180,27 & 184,22 & 97,70 & $\begin{array}{l}1035,07 \\
\end{array}$ & \begin{tabular}{|l|l|}
133,93 \\
\end{tabular} & 31,48 & 37,61 & \begin{tabular}{|l|l|}
386,40 \\
\end{tabular} & 123,21 & $\begin{array}{l}144,96 \\
\end{array}$ & 352,94 \\
\hline Alytes obstetricans & 29TNJ71 & 101,00 & 129,37 & 73,82 & 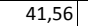 & 3531,06 & 227,00 & 51,70 & 175,30 & 92,88 & 173,72 & \begin{tabular}{|l|l|}
177,51 \\
\end{tabular} & 86,87 & 1112,83 & $\mid 144,77$ & $\mid 35,26$ & 37,04 & 412,33 & 135,00 & 155,22 & 379,66 \\
\hline Alytes obstetricans & 29TNJ72 & 101,00 & 133,10 & 72,15 & 42,08 & 3432,01 & 226,92 & 57,35 & 169,57 & 97,92 & 175,90 & 179,71 & 91,45 & 1067,50 & 137,07 & 34,02 & 36,65 & 394,97 & 131,15 & 152,16 & 360,88 \\
\hline Alytes obstetricans & 29TNJ80 & 100,00 & 122,17 & 77,45 & \begin{tabular}{|l|l|}
40,97 \\
\end{tabular} & 3732,97 & 226,80 & $\begin{array}{ll}40,28 \\
\end{array}$ & $\begin{array}{l}186,52 \\
\end{array}$ & 82,75 & 169,73 & 173,01 & 77,78 & $\begin{array}{l}1168,66 \\
\end{array}$ & 153,90 & 37,45 & 37,24 & 431,41 & 141,75 & 160,10 & 400,68 \\
\hline Alytes obstetricans & 29TNJ81 & 100,00 & 123,92 & 76,14 & 41,25 & 3653,63 & 225,79 & 43,65 & 182,14 & 85,62 & 170,26 & $\begin{array}{l}173,78 \\
\end{array}$ & 80,28 & 1142,11 & \begin{tabular}{|l|l|}
148,61 \\
\end{tabular} & 37,10 & 36,76 & 420,70 & 140,61 & $\begin{array}{l}159,65 \\
\end{array}$ & 388,46 \\
\hline Alytes obstetricans & 29TNJ83 & 101,00 & 130,18 & 72,98 & \begin{tabular}{l|l|}
41,98 \\
\end{tabular} & 3479,40 & 225,55 & 53,48 & \begin{tabular}{ll|}
172,07 \\
\end{tabular} & 94,38 & \begin{tabular}{ll|}
173,69 \\
\end{tabular} & $\begin{array}{l}177,47 \\
\end{array}$ & 88,12 & 1072,64 & 137,44 & 35,55 & 35,79 & $\begin{array}{l}393,85 \\
\end{array}$ & $\begin{array}{ll}135,68 \\
\end{array}$ & $\begin{array}{ll}156,29 \\
\end{array}$ & 358,51 \\
\hline Alytes obstetricans & 29TNJ84 & 31,00 & 128,75 & 72,62 & $\begin{array}{l}42,07 \\
4\end{array}$ & 3463,58 & \begin{tabular}{ll|}
223,64 \\
\end{tabular} & 52,51 & 171,13 & 93,16 & 172,00 & $\begin{array}{l}175,75 \\
\end{array}$ & 86,98 & 1079,11 & $\begin{array}{l}138,18 \\
\end{array}$ & 36,49 & 35,25 & 395,05 & $\begin{array}{l}138,64 \\
\end{array}$ & $\begin{array}{l}159,35 \\
\end{array}$ & 358,69 \\
\hline Alytes obstetricans & 29TNJ91 & 101,00 & 119,44 & 78,01 & 41,06 & 3765,45 & 224,70 & 37,15 & 187,55 & 79,81 & 167,50 & \begin{tabular}{|l|l|}
170,67 \\
\end{tabular} & 74,70 & 1154,74 & 149,70 & 38,31 & 36,17 & 423,15 & 144,50 & 162,42 & 391,05 \\
\hline Alytes obstetricans & 29TPE05 & 101,00 & 126,58 & 86,64 & 35,51 & 5336,17 & 268,16 & 27,58 & 240,57 & 62,81 & 198,19 & 198,24 & 62,81 & $\begin{array}{l}1256,14 \\
\end{array}$ & 190,94 & 11,95 & 56,14 & 514,50 & 76,92 & 76,93 & 514,50 \\
\hline Alytes obstetricans & 29TPE06 & 100,00 & 135,12 & 91,66 & 36,74 & 5328,00 & 278,88 & 32,86 & 246,03 & 70,31 & 205,51 & 205,99 & 70,31 & 1164,94 & 175,36 & 11,03 & 55,58 & 475,27 & 73,03 & 73,29 & 475,27 \\
\hline Alytes obstetricans & 29TPE07 & 101,00 & 141,90 & 96,20 & 37,94 & 5321,55 & 287,46 & 36,82 & 250,64 & 76,22 & 211,36 & 212,15 & 76,22 & 1091,34 & 162,71 & \begin{tabular}{l|l|}
10,26 \\
\end{tabular} & 55,15 & 443,22 & 69,66 & 70,37 & 443,22 \\
\hline Alytes obstetricans & 29TPE08 & 100,00 & 144,63 & 98,44 & 38,54 & 5297,72 & 290,27 & 38,25 & 252,02 & 78,79 & 213,46 & 214,23 & 78,79 & 1062,03 & 157,71 & $\begin{array}{l}9,92 \\
\end{array}$ & 54,88 & 429,93 & 67,87 & 69,61 & 429,93 \\
\hline Alytes obstetricans & 29TPE15 & 99,00 & 129,26 & 87,30 & 35,12 & 5467,14 & 273,53 & 28,66 & 244,87 & 63,75 & 202,52 & 202,53 & 63,75 & $\begin{array}{l}1199,32 \\
\end{array}$ & \begin{tabular}{|l|l|}
181,90 \\
\end{tabular} & \begin{tabular}{|l|l|}
11,09 \\
\end{tabular} & 55,96 & 490,30 & 73,40 & 73,40 & 490,30 \\
\hline Alytes obstetricans & 29TPE16 & 100,00 & 89,37 & 73,79 & 32,38 & 5308,01 & 222,81 & $-1,45$ & 224,25 & 29,35 & 162,23 & 162,23 & 29,35 & $\begin{array}{l}1627,76 \\
\end{array}$ & 249,32 & $\begin{array}{l}17,25 \\
\end{array}$ & 56,10 & 663,37 & 100,90 & 100,90 & 663,37 \\
\hline Alytes obstetricans & 29TPE17 & 100,00 & 105,52 & 77,94 & 33,30 & 5333,84 & 240,87 & 11,12 & 229,75 & 43,46 & 177,77 & $\begin{array}{l}177,83 \\
\end{array}$ & 43,46 & 1488,39 & 230,10 & 14,23 & 56,81 & $\begin{array}{l}610,46 \\
\end{array}$ & 89,59 & $\begin{array}{ll}89,68 \\
\end{array}$ & 610,46 \\
\hline Alytes obstetricans & 29TPE18 & 101,00 & 138,06 & 94,81 & 37,17 & 5436,40 & 284,38 & 32,78 & 251,60 & 71,02 & 209,38 & 209,73 & 71,02 & $\mid 1101,46$ & $\mid 165,42$ & \begin{tabular}{|l|l|}
10,36 \\
\end{tabular} & 55,31 & $\mid 447,47$ & 70,05 & 70,65 & $\begin{array}{l}447,47 \\
\end{array}$ \\
\hline Alytes obstetricans & 29TPE19 & 101,00 & 138,73 & 96,68 & 37,72 & 5420,53 & 285,38 & 32,53 & 252,85 & 71,60 & 209,64 & 209,95 & 71,60 & $\begin{array}{l}1094,17 \\
\end{array}$ & \begin{tabular}{|l|l|}
164,30 \\
\end{tabular} & $\begin{array}{l}10,36 \\
\end{array}$ & 55,31 & \begin{tabular}{|l|l|}
444,18 \\
\end{tabular} & 69,92 & 70,79 & 444,18 \\
\hline Alytes obstetricans & 29TPE23 & 100,00 & 136,93 & 89,41 & 34,9 & 5655,55 & 286,47 & 34,08 & 252,39 & 69,31 & 212,77 & 212,88 & 69,31 & 1072,25 & 160,25 & 9,60 & 55,52 & 436,33 & 65,86 & 65,86 & 436,33 \\
\hline Alytes obstetricans & 29TPE24 & 100,00 & 142,68 & 92,77 & $\begin{array}{l}35,65 \\
\end{array}$ & 5654,12 & 293,58 & 37,45 & 256,12 & 74,19 & 217,73 & 218,05 & 74,19 & $\begin{array}{l}1014,30 \\
\end{array}$ & \begin{tabular}{|l|l|}
150,67 \\
\end{tabular} & \begin{tabular}{l|l}
8,95 \\
\end{tabular} & 55,21 & \begin{tabular}{|l|l|}
411,38 \\
\end{tabular} & 63,29 & 63,31 & 411,38 \\
\hline Alytes obstetricans & 29TPE25 & 101,00 & 137,34 & 90,80 & \begin{tabular}{l|l|}
35,35 \\
\end{tabular} & 5606,22 & 285,74 & 33,34 & 252,40 & 69,51 & 211,78 & 212,03 & 69,51 & 1075,73 & $\begin{array}{l}161,29 \\
\end{array}$ & 9,71 & 55,46 & 437,30 & 66,83 & $\begin{array}{ll}66,87 \\
\end{array}$ & 437,30 \\
\hline Alytes obstetricans & 29TPE26 & 101,00 & 103,49 & 76,74 & 32,49 & 5450,47 & 240,55 & 9,06 & 231,49 & 40,44 & 177,45 & $\begin{array}{l}177,47 \\
\end{array}$ & 40,44 & 1460,65 & 224,47 & 13,97 & 56,51 & 598,38 & $\begin{array}{ll}87,92 \\
\end{array}$ & 88,13 & 598,38 \\
\hline Alytes obstetricans & 29TPE27 & 100,00 & 106,99 & 77,23 & 32,68 & 5450,44 & 243,96 & 11,69 & 232,27 & 43,10 & 180,52 & 180,54 & 43,10 & 1421,80 & 219,17 & 13,32 & 56,76 & 583,80 & 85,34 & 86,46 & 583,80 \\
\hline Alytes obstetricans & 29TPE28 & 100,00 & 115,82 & 82,63 & 34,00 & 5469,42 & 255,98 & 17,15 & 238,83 & 50,50 & 188,84 & 188,97 & 50,50 & 1311,44 & 200,81 & 12,45 & 56,23 & 537,03 & 80,49 & 82,35 & 537,03 \\
\hline Alytes obstetricans & 29TPE29 & 101,00 & 140,71 & 97,32 & 37,40 & 5537,38 & 289,73 & 33,15 & 256,58 & 72,15 & 213,23 & 213,42 & 72,15 & 1031,62 & $\begin{array}{l}154,36 \\
\end{array}$ & \begin{tabular}{l|l|}
9,59 \\
\end{tabular} & 55,08 & \begin{tabular}{|l|l|}
417,47 \\
\end{tabular} & 65,82 & $\begin{array}{ll}66,46 \\
\end{array}$ & 417,47 \\
\hline Alytes obstetricans & 29TPE34 & 100,00 & 144,07 & 93,37 & 35,58 & 5763,97 & 297,00 & \begin{tabular}{l|l}
37,53 \\
\end{tabular} & 259,47 & 74,25 & 220,63 & 220,80 & 74,25 & $\begin{array}{l}963,29 \\
\end{array}$ & \begin{tabular}{ll|}
142,08 \\
\end{tabular} & 8,48 & 54,82 & $\begin{array}{l}388,56 \\
\end{array}$ & 60,65 & $\begin{array}{ll}60,78 \\
\end{array}$ & 388,56 \\
\hline Alytes obstetricans & 29TPE35 & 100,00 & 142,56 & 93,42 & 35,63 & 5737,22 & 294,59 & $\begin{array}{ll}35,97 \\
\end{array}$ & 258,62 & 72,78 & 218,54 & \begin{tabular}{|l|}
218,67 \\
\end{tabular} & 72,78 & 976,71 & $\begin{array}{l}144,52 \\
\end{array}$ & 8,80 & 54,84 & $\begin{array}{l}394,12 \\
\end{array}$ & 61,76 & $\begin{array}{ll}61,99 \\
\end{array}$ & 394,12 \\
\hline Alytes obstetricans & 29TPE36 & 101,00 & 139,74 & 92,73 & 35,61 & \begin{tabular}{|l|l|}
5699,14 \\
\end{tabular} & 290,19 & 33,56 & 256,64 & 70,23 & 215,06 & 215,18 & 70,23 & 1004,28 & 149,39 & 9,13 & 54,98 & 05,67 & 63,55 & 64,08 & 405,67 \\
\hline Alytes obstetricans & 29TPE37 & 100,00 & 126,44 & 86,62 & 34,39 & 5632,12 & 272,12 & 24,14 & 247,98 & 58,40 & 201,32 & 201,39 & 58,40 & 1136,45 & 171,51 & 10,64 & 55,48 & 461,98 & 70,81 & 73,01 & 461,98 \\
\hline Alytes obstetricans & 29TPE38 & 101,00 & 108,42 & 77,78 & 32,55 & 5536,88 & 247,27 & 11,75 & 235,51 & 42,64 & 182,53 & 182,68 & 42,64 & $\begin{array}{l}1323,69 \\
\end{array}$ & 202,22 & 12,65 & 56,09 & 541,51 & 81,32 & 87,37 & 541,51 \\
\hline Alytes obstetricans & 29TPE39 & 99,00 & 129,36 & 90,95 & 35, & 5612,20 & 276,53 & 24,79 & 251,73 & 60,76 & 203,41 & 203,57 & 60,76 & 1096,85 & 165,15 & 10,54 & 55,27 & 444,89 & 69,91 & 71,83 & 444,89 \\
\hline Alytes obstetricans & 29TPE44 & 100,00 & 149,48 & 96,03 & 35,86 & 5860,33 & \begin{tabular}{|l|l|}
304,97 \\
\end{tabular} & $\begin{array}{ll}40,37 \\
\end{array}$ & 264,60 & 84,59 & 226,95 & 227,18 & 78,09 & 871,44 & \begin{tabular}{ll|}
126,58 \\
\end{tabular} & 7,52 & 54,06 & $\begin{array}{l}348,36 \\
\end{array}$ & $\begin{array}{ll}55,63 \\
\end{array}$ & 55,78 & 347,93 \\
\hline Alytes obstetricans & 29TPE46 & 99,00 & 140,79 & 93,71 & 35,62 & 5799,87 & 293,41 & 33,34 & 260,08 & 71,02 & 217,52 & 217,64 & 70,04 & 944,75 & 139,10 & 8,62 & 54,33 & 378,87 & 60,64 & 61,32 & 378,87 \\
\hline Alytes obstetricans & 29TPE47 & 101,00 & 132,53 & 90,33 & 34,91 & 5754,58 & 282,24 & 27,16 & 255,08 & 62,33 & 208,59 & 208,83 & 62,33 & 1017,71 & 151,31 & 9,63 & 54,73 & 409,90 & 64,86 & 66,79 & 409,90 \\
\hline Alytes obstetricans & 29TPE48 & 99,00 & 117,54 & 82,71 & 33, & 5674,60 & 261,50 & 16,91 & 244,60 & \begin{tabular}{ll|}
48,96 \\
\end{tabular} & $\begin{array}{l}192,78 \\
\end{array}$ & $\begin{array}{l}193,24 \\
\end{array}$ & 48,96 & $\begin{array}{l}1155,77 \\
\end{array}$ & \begin{tabular}{ll|}
173,94 \\
\end{tabular} & 11,18 & 55,15 & 468,54 & 73,04 & 77,68 & 468,54 \\
\hline Alytes obstetricans & 29TPE49 & 101,00 & 125,55 & $\begin{array}{ll}88,94 \\
\end{array}$ & 34,86 & 5693,66 & 273,09 & 21,39 & 251,70 & 56,06 & 200,71 & \begin{tabular}{|l|l|}
201,07 \\
\end{tabular} & 56,06 & 1071,79 & 160,32 & 10,53 & 54,81 & 432,91 & 69,15 & 71,71 & 432,91 \\
\hline Alytes obstetricans & 29TPE53 & 100,00 & 151,91 & 97,36 & 35,85 . & 5953,50 & 309,70 & 41,55 & 268,15 & 87,23 & 230,81 & 231,01 & 79,58 & 808,77 & 115,52 & 6,97 & 53,33 & 321,81 & 52,04 & 52,23 & 319,62 \\
\hline Alytes obstetricans & 29TPE54 & 100,00 & 147,75 & 95,98 & 35,62 & 5933,51 & 304,19 & 38,06 & 666,13 & 83,16 & 226,32 & 226,50 & 75 & 844,05 & 121 & 7,38 & 53 & 96 & 54,66 & 54,79 & 33 \\
\hline Alytes obstetricans & 29TP & 100 & 139 & 93 & 35 & & & 32,20 & 26 & 76,16 & & & 68,40 & 909,11 & 132 & 8,41 & 53,90 & $\begin{array}{l}362,66 \\
\end{array}$ & 58,54 & 59,38 & 361,92 \\
\hline Alytes obstetricans & 29TPE56 & 101,00 & 128,25 & 88,22 & 34,20 & \begin{tabular}{|l|l|}
5835,14 \\
\end{tabular} & 278,60 & 23,79 & 254,82 & 62,95 & 205,80 & 206,08 & 57,84 & 1007,41 & \begin{tabular}{|l|l|}
148,40 \\
\end{tabular} & 9,62 & 54,15 & 403,27 & 64,49 & 67,35 & 403,21 \\
\hline Alytes obstetricans & 29TPE57 & 100,00 & 122,18 & 85,75 & 33,73 & 5797,09 & 270,24 & 19,26 & 250,98 & 53,93 & 199,19 & $\begin{array}{l}199,57 \\
\end{array}$ & 52,20 & 1057,68 & \begin{tabular}{ll|l}
156,75 \\
\end{tabular} & 10,24 & 54,34 & $\begin{array}{l}424,65 \\
\end{array}$ & 67,76 & 71,56 & 424,64 \\
\hline Alytes obstetricans & 29TPE58 & 101,00 & 120,47 & 85,76 & 33,81 . & 5774,86 & 268,03 & 17,55 & 250,48 & 51,08 & 196,97| & 197,58 & 50,51 & 1064,41 & 157,89 & 10,49 & 54,30 & 427,55 & 68,80 & 72,51 & 427,55 \\
\hline Alytes obste & 2 & 10 & & & 35 & & 305,84 & 8 & & & 22 & 227 & 75 & 797,19 & 1113,21 & 7,17 & & 31 & 52,29 & 52,49 & 312,48 \\
\hline Alytes obstetricans & 29TPE65 & 100,00 & 129,91 & 90,14 & 34,26 & 5929,70 & 283,01 & 23,91 & 259,10 & 66,46 & 208,92 & 209,16 & 58,67 & 944,84 & 136,77 & 9,21 & 53,25 & \begin{tabular}{|l|l|}
375,78 \\
\end{tabular} & 61,54 & 63,95 & 373,87 \\
\hline Alytes obstetricans & 29TPE66 & 100,00 & 121,79 & 86,97 & 33,72 & 5881,62 & 272,26 & 17,83 & 254,43 & 59,20 & 200,18 & 200,57 & 51,21 & 1009,52 & \begin{tabular}{|l|l|}
147,16 \\
\end{tabular} & 10,10 & 53,46 & 402,21 & 65,82 & 69,68 & 400,97 \\
\hline
\end{tabular}




\begin{tabular}{|c|c|c|c|c|c|c|c|c|c|c|c|c|c|c|c|c|c|c|c|c|c|}
\hline TAXON & UTM & $\mathrm{km2}$ & B101 & B1O2 & $\mathrm{BIO3}$ & $\mathrm{B104}$ & B105 & B106 & B107 & B108 & B109 & B1010 & B1011 & BIO12 & BIO13 & BIO14 & B1015 & BIO16 & B1017 & B1018 & B1019 \\
\hline Alytes obstetricans & 29TPE67| & 101,00 & 125,29 & 89,10 & 34,18 & 5888,96 & 276,66 & 19,84 & 256,83 & 61,99 & 203,34 & 203,90 & 54,13 & 971,07 & 141,31 & 9,83 & 53,26 & 386,21 & 64,13 & 66,99 & 385,15 \\
\hline Alytes obstetricans & 29TPE68 & 99,00 & 124,21 & 89,65 & 34,41 & 5871,67 & 275,38 & 18,51 & 256,87 & 60,36 & 201,86 & 202,53 & 53,08 & 971,17 & 141,44 & 9,89 & 53,21 & 386,12 & 64,70 & 67,43 & 385,41 \\
\hline Alytes obstetricans & 29TPE69 & 101,00 & 123,25 & 90,59 & 34,72 & 5856,27 & 274,74 & 17,18 & 257,56 & 58,81 & 200,55 & 201,39 & 52,01 & 969,08 & 141,09 & 10,03 & 53,06 & 385,06 & 65,36 & 67,80 & 384,65 \\
\hline Alytes obstetricans & 29TPE73 & 100,00 & 150,30 & 98,84 & 35,77 & 6062,09 & 310,71 & 38,27 & 272,44 & 84,43 & 230,77 & 230,80 & 76,58 & 739,65 & 102,88 & 6,62 & 51,89 & 290,90 & 49,06 & 49,23 & 285,78 \\
\hline Alytes obstetricans & 29TPE76 & 101,00 & 116,20 & \begin{tabular}{ll|}
87,38 \\
\end{tabular} & 33,60 & 5936,45 & 267,97 & 12,02 & 255,95 & 53,37 & 195,55 & 196,01 & 45,46 & 998,94 & 143,22 & \begin{tabular}{|l|l|}
10,53 \\
\end{tabular} & 52,42 & \begin{tabular}{|l|l|}
395,43 \\
\end{tabular} & 67,06 & 71,63 & 392,21 \\
\hline Alytes obstetricans & \begin{tabular}{|l|} 
29TPE77 \\
\end{tabular} & 100,00 & 122,37 & 90,04 & 34,30 & 5945,46 & 275,26 & 16,19 & 259,07 & 58,62 & 201,30 & 201,94 & 50,77 & 938,22 & 134,22 & 9,98 & 52,23 & 370,92 & 63,72 & 66,87 & 367,88 \\
\hline Alytes obstetricans & \begin{tabular}{|l|} 
29TPE78 \\
\end{tabular} & 101,00 & 123,45 & 91,55 & 34,80 & 5941,90 & 276,94 & 16,45 & 260,49 & 59,43 & 202,15 & 202,87 & 51,50 & 917,39 & 131,03 & 9,84 & 52,04 & 362,22 & 63,19 & 65,75 & 359,37 \\
\hline Alytes obstetricans & 29TPE85 & 101,00 & 126,42 & 93,40 & 34,64 & 6044,36 & 283,86 & 18,13 & 265,73 & 61,90 & 207,17 & 207,49 & 54,01 & 867,71 & 120,90 & 9,38 & 51,16 & 339,84 & $\begin{array}{l}60,08 \\
60\end{array}$ & 62,81 & 334,06 \\
\hline Alytes obstetricans & 29TPE86 & 100,00 & 117,60 & 90,52 & 34,02 & 6008,49 & 272,64 & 11,27 & 261,36 & 53,76 & 197,92 & 198,45 & 45,95 & 928,26 & 130,25 & 10,32 & 51,22 & \begin{tabular}{|l|l|}
364,31 \\
\end{tabular} & 64,53 & 68,45 & 358,97 \\
\hline Alytes obstetricans & 29TPE87 & 100,00 & 124,01 & 93,18 & \begin{tabular}{|l|l|}
34,67 \\
\end{tabular} & 6018,82 & 280,22 & \begin{tabular}{|l|l|}
15,67 \\
\end{tabular} & 264,55 & 59,25 & 203,85 & 204,61 & 51,39 & 866,80 & 121,19 & 9,70 & 50,97 & 339,73 & 60,96 & 63,50 & 334,53 \\
\hline Alytes obstetricans & 29TPE89 & 101,00 & 124,13 & 95,26 & 35,25 & 5995,30 & 280,81 & 14,85 & 265,97 & 59,14 & 203,39 & 204,31 & 51,43 & 843,46 & 117,63 & 9,60 & 50,67 & \begin{tabular}{|c|}
330,28 \\
\end{tabular} & 60,83 & 62,57 & 325,45 \\
\hline Alytes obstetricans & 29TPE94 & 99,00 & 150,74 & 101,88 & 36,05 & 6149,45 & 314,58 & 35,85 & 278,73 & 83,35 & 232,37 & 232,43 & 75,59 & 651,22 & 87,12 & 6,18 & 50,01 & 251,82 & 45,26 & 45,42 & 243,87 \\
\hline Alytes obstetricans & 29TPE95 & 100,00 & 133,71 & 97,47 & 35,24 & 6122,54 & 294,97 & 22,26 & 272,71 & 67,52 & 215,21 & 215,54 & 59,77 & 762,82 & 103,58 & 8,34 & 49,95 & 295,84 & 54,36 & 55,87 & 288,21 \\
\hline Alytes obstetricans & 29TPE96 & 100,00 & 121,66 & 94,40 & 34,79 & 6085,22 & 280,54 & 12,66 & 267,88 & 56,49 & 202,72 & 203,40 & 48,71 & 839,86 & 114,81 & 9,92 & 49,81 & \begin{tabular}{|l|l|}
326,27 \\
\end{tabular} & 60,70 & 63,49 & 318,88 \\
\hline Alytes obstetricans & 29TPE97 & 101,00 & 123,33 & 95,54 & 35,03 & 6081,09 & 282,39 & 13,56 & 268,83 & 57,85 & 204,07 & 204,93 & 50,15 & 815,68 & 111,21 & 9,77 & 49,60 & 316,66 & 59,75 & 62,02 & 309,32 \\
\hline Alytes obstetricans & 29TPE98 & 100,00 & 128,77 & 98,03 & 35,72 & 6080,10 & 288,79 & 17,22 & 271,56 & 62,50 & 209,12 & 209,95 & 54,96 & 765,26 & 103,76 & 9,16 & 49,35 & 296,62 & 56,86 & 57,99 & 289,48 \\
\hline Alytes obstetricans & 29TPF00 & 101,00 & 139,06 & 98,71 & 38,88 & 5279,84 & 283,75 & 32,90 & 250,85 & 73,23 & 207,69 & 208,26 & 73,23 & 1127,70 & 168,86 & 10,94 & 55,06 & 457,17 & 72,42 & 74,61 & 457,17 \\
\hline Alytes obstetricans & 29TPF02 & 100,00 & 120,33 & 92,91 & 37,62 & 5265,34 & 262,17 & 18,53 & 243,64 & 55,99 & 189,91 & 190,07 & 55,99 & 1328,52 & 201,64 & 14,36 & 55,81 & \begin{tabular}{|l|l|}
542,65 \\
\end{tabular} & 87,32 & 87,58 & 542,65 \\
\hline Alytes obstetricans & 29TPF05 & 100,00 & 142,96 & 106,65 & 40,84 & 5279,31 & 290,93 & 32,77 & 258,16 & 78,24 & 210,95 & 211,44 & 76,34 & 1091,92 & 161,79 & \begin{tabular}{|l|l|}
10,97 \\
\end{tabular} & 54,62 & 439,34 & 70,24 & 76,22 & 439,25 \\
\hline Alytes obstetricans & 29TPF06 & 100,00 & 141,31 & 108,38 & $\begin{array}{l}40,93 \\
\end{array}$ & 5312,79 & 291,76 & 30,46 & 261,30 & 79,60 & 209,92 & 210,29 & 74,38 & 1113,87 & 165,33 & \begin{tabular}{|l|l|l|}
11,38 \\
\end{tabular} & 54,92 & 449,72 & 71,98 & 77,73 & 448,75 \\
\hline Alytes obstetricans & 29TPF07 & 101,00 & 129,25 & 104,96 & \begin{tabular}{|l|l|}
40,17 \\
\end{tabular} & 5320,59 & 279,02 & 21,27 & 257,75 & 69,15 & 198,58 & 198,93 & 63,25 & 1223,92 & \begin{tabular}{ll|}
181,16 \\
\end{tabular} & 14,1 & 54,73 & 496,20 & 82,95 & 87,13 & 494,77 \\
\hline Alytes obstetricans & 29TPF08 & 100,00 & 108,66 & 93,52 & 38,00 & 5223,34 & 250,90 & 8,30 & 242,61 & 45,75 & 178,02 & 178,18 & 45,68 & 1370,44 & 197,65 & 19,63 & 52,80 & 551,13 & 101,85 & 103,26 & 551,12 \\
\hline Alytes obstetricans & 29TPF09 & 100,00 & 111,77 & $\begin{array}{ll}94,08 \\
\end{array}$ & \begin{tabular}{|l|}
38,18 \\
\end{tabular} & 5213,47 & 253,83 & 10,63 & 243,20 & 48,68 & 180,74 & 180,98 & 48,68 & 1325,43 & 188,43 & $\begin{array}{l}19,36 \\
\end{array}$ & 52,06 & 530,87 & 99,87 & 101,47 & 530,87 \\
\hline Alytes obstetricans & 29TPF10 & 100,00 & 136,14 & 97,26 & 37,92 & 5414,49 & 282,79 & 29,94 & 252,85 & 69,04 & 207,02 & 207,27 & 69,04 & 1121,47 & 169,00 & 10,83 & 55,29 & 455,61 & 72,08 & 72,82 & 455,61 \\
\hline Alytes obstetricans & 29TPF11 & 100,00 & 128,63 & 95,37 & $37.60 \mid$ & 5404,76 & 274,24 & 23.95 & 250,29 & 62.05 & 199,63 & 199,88 & 62.05 & 1200,90 & 182,25 & 12.14 & 55.80 & $|489,67|$ & 77.94 & 78,26 & 489,67 \\
\hline Alytes obstetricans & 29TPF12 & 100,00 & 118,88 & 91,96 & 36,84 & 5385,78 & 262,58 & 16,65 & 245,93 & 53,27 & 190,27 & 190,32 & 53,27 & 1295,22 & 197,19 & 13,90 & 55,95 & 529,52 & 84,37 & 85,12 & 529,52 \\
\hline Alytes obstetricans & 29TPF13 & 101,00 & 121,03 & 95,23 & 37,65 & 5397,58 & 266,55 & 17,10 & 249,45 & 54,91 & $\begin{array}{l}192,27 \\
\end{array}$ & 192,40 & 54,91 & 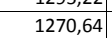 & 192,82 & 13,83 & 55,64 & 518,67 & $\begin{array}{ll}43,82 \\
33\end{array}$ & $\begin{array}{l}0,113 \\
84,37\end{array}$ & 518,67 \\
\hline Alytes obstetricans & 29TPF14 & 100,00 & 124,50 & 99,18 & 38,54 & 5414,99 & 272,28 & 18,51 & 253,77 & 57,77 & 195,61 & 195,77 & 57,77 & 1234,38 & 186,67 & 13,56 & 55,38 & 502,96 & 82,15 & 83,12 & 502,96 \\
\hline Alytes obstetricans & 29TPF15 & 100,00 & 140,38 & 106,18 & 40,16 & 5405,68 & 290,95 & 29,63 & 261,32 & 73,99 & 210,42 & 210,69 & 72,49 & 1074,86 & 160,31 & 10,99 & 54,83 & 433,77 & 69,73 & 73,32 & 433,71 \\
\hline Alytes obstetricans & 29TPF18 & 101,00 & 116,77 & 98,81 & 38,68 & 5375,05 & 264,19 & 11,86 & 252,33 & 51,10 & 187,58 & 187,81 & 51,10 & 1252,20 & 182,52 & 16,84 & 53,27 & 505,01 & 90,84 & 91,97 & 505,01 \\
\hline Alytes obstetricans & 29TPF19 & 101,00 & 113,80 & 96,73 & 38,31 & 5336,32 & 259,53 & 10,18 & 249,36 & 48,93 & $\begin{array}{ll}184,38 \\
\end{array}$ & 184,52 & 48,93 & 1255,75 & 179,85 & 18,12 & 52,30 & \begin{tabular}{|c|}
503,68 \\
\end{tabular} & 94,08 & 94,80 & 503,68 \\
\hline Alytes obstetricans & 29TPF20 & 100,00 & 131,99 & \begin{tabular}{|l|l|}
94,76 \\
\end{tabular} & 36,96 & 5520,84 & 279,47 & 26,29 & \begin{tabular}{|l|l|}
253,18 \\
\end{tabular} & $\begin{array}{ll}40,939 \\
63,93\end{array}$ & 204,61 & \begin{tabular}{|l|}
204,73 \\
\end{tabular} & $\begin{array}{l}63,93 \\
63,93\end{array}$ & 1119,52 & \begin{tabular}{|l|l|}
169,25 \\
\end{tabular} & $\begin{array}{l}10,14 \\
10,95\end{array}$ & 55,43 & \begin{tabular}{|l|}
455,27 \\
\end{tabular} & $\begin{array}{l}4,00 \\
72,09 \\
\end{array}$ & 72,60 & 455,27 \\
\hline Alytes obstetricans & 29TPF21 & 101,00 & 126,21 & 93,56 & \begin{tabular}{|l|}
36,68 \\
\end{tabular} & 5513,60 & 272,97 & 21,53 & 251,44 & 58,52 & 198,83 & 198,97 & 58,52 & 1172,13 & 177,94 & 11,92 & 55,70 & \begin{tabular}{|l|l|}
477,64 \\
\end{tabular} & 75,95 & 76,74 & 477,64 \\
\hline Alytes obstetricans & 29TPF22 & 100,00 & 123,09 & 94,03 & 36,88 & 5506,71 & 269,90 & 18,45 & 251,45 & 55,53 & 195,71 & 195,79 & 55,53 & 1199,46 & 182,05 & 12,66 & 55,60 & 488,99 & 78,61 & 79,60 & 488,99 \\
\hline Alytes obstetricans & 29TPF26 & 100,00 & 140,98 & 107,60 & 39,89 & 5514,54 & 294,66 & 28,42 & 266,25 & 73,20 & 212,58 & 212,65 & 71,78 & 1005,65 & 149,08 & 10,67 & 54,36 & 404,49 & 66,37 & 67,06 & 404,46 \\
\hline Alytes obstetricans & 29TPF27 & 101,00 & 127,74 & 104,65 & 39,24 & 5523,54 & 281,02 & 17,96 & 263,06 & 61,29 & 200,19 & 200,25 & 59,37 & 1117,23 & 165,84 & 13,31 & 54,31 & 451,90 & 77,02 & 77,42 & 451,81 \\
\hline Alyty obstetricans & 29TPF28 & 101,00 & 124,70 & $\begin{array}{l}103,28 \\
103,28\end{array}$ & 39,13 & 5499,98 & $27,0,02$ & $\begin{array}{l}15,72 \\
15,72\end{array}$ & \begin{tabular}{|l|}
260,840 \\
\end{tabular} & $\begin{array}{l}\mid c 1,29 \\
56,85\end{array}$ & \begin{tabular}{|l|}
197,01 \\
197
\end{tabular} & \begin{tabular}{|l|l|}
197,03 \\
\end{tabular} & 56,85 & $\begin{array}{l}111,24,99 \\
112,9\end{array}$ & \begin{tabular}{|l|}
$163,04,65$ \\
105
\end{tabular} & $\begin{array}{l}14,31 \\
14,44\end{array}$ & 53,30 & $\begin{array}{l}453,, 90 \\
453,16\end{array}$ & 80,03 & 80,49 & 4453,16 \\
\hline Alytes obstetricans & 29TPF29 & 100,00 & 119,33 & 100,64 & 38,58 & 5460,93 & 269,38 & 12,14 & 257,24 & 52,55 & 191,46 & 191,47 & 52,55 & 1147,42 & 165,13 & 16,19 & 52,33 & \begin{tabular}{|l|l|}
460,08 \\
\end{tabular} & 85,13 & 85,52 & 460,08 \\
\hline Alytes obstetricans & 29TPF30 & 101,00 & 138,54 & 97,73 & 37,13 & 5630,05 & 289,25 & 30,10 & 259,15 & 68,92 & 212,42 & 212,50 & 68,92 & \begin{tabular}{|l|}
1001,01 \\
\end{tabular} & 149,52 & 9,60 & 54,78 & 403,99 & 64,84 & 65,10 & 403,99 \\
\hline Alytes obstetricans & 29TPF31 & 100,00 & 122,01 & 91,03 & 35,8 & 5592,34 & 269,00 & 17,97 & 251,03 & 53,63 & 195,80 & 196,16 & 53,63 & 1153,91 & 174,51 & 11,85 & 55,18 & 469,29 & 75,12 & 77,18 & 469,29 \\
\hline Alytes obstetricans & 29TPF33 & 101,00 & 117,67 & 93,44 & 36,4 & 5576,81 & 265,92 & 13,04 & 252,89 & 49,59 & 191,29 & 191,61 & 49,59 & 1180,34 & 177,86 & 13,1 & 54,92 & 479,81 & 79,46 & 81,04 & 479,81 \\
\hline $\begin{array}{l}\text { Ay } \\
\text { Alytes obstetricans }\end{array}$ & 29TPF36 & $\begin{array}{l}100,00 \\
100,0\end{array}$ & $\begin{array}{l}11,01 \\
136,08\end{array}$ & 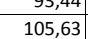 & $\begin{array}{l}30,47 \\
39,20\end{array}$ & 5593,81 & 200,92 & $\begin{array}{l}23,3406 \\
23,96\end{array}$ & \begin{tabular}{|l|}
$262,09,43$ \\
\end{tabular} & \begin{tabular}{|c|}
49,39 \\
66,31
\end{tabular} & $\mid$\begin{tabular}{|l|}
209,21 \\
\end{tabular} & $\begin{array}{l}191,01 \\
209,21\end{array}$ & $\begin{array}{l}45,39 \\
66,31 \\
\end{array}$ & $\begin{array}{r}\quad 1180,34 \\
987,88 \\
\end{array}$ & \begin{tabular}{|l|}
145,90 \\
140
\end{tabular} & $\begin{array}{l}13,10 \\
11,16\end{array}$ & 53,79 & \begin{tabular}{|l|}
$4 / 97,01$ \\
397,09
\end{tabular} & $\begin{array}{l}\mid 7,400 \\
67,05 \\
\end{array}$ & $\begin{array}{l}1,044 \\
67,16\end{array}$ & $\begin{array}{l}4 / 8,81 \\
397,09\end{array}$ \\
\hline Alytes obstetricans & 29TPF37 & 101,00 & 136,96 & 106,85 & 39,44 & 5597,15 & 291,74 & 23,96 & 267,78 & $\begin{array}{l}0,93 \\
66,93\end{array}$ & 209,96 & 209,98 & 66,93 & 970,32 & 142,26 & 11,30 & 53,38 & 388,98 & 66,55 & 66,61 & 388,98 \\
\hline Alytes obstetricans & 29TPF39 & 101,00 & 128,98 & 104,90 & 39,08 & 5570,40 & 282,66 & 17,49 & 265,18 & 60,08 & 202,29 & 202,29 & 60,08 & 1002,01 & 143,85 & 13,58 & 51,97 & 400,05 & 73,12 & 73,12 & 400,05 \\
\hline Alytes obstetricans & 29TPF40 & 100,00 & 133,53 & 95,41 & 36,31 & 5720,40 & 284,69 & 25,68 & 259,01 & 63,05 & 208,84 & 209,07 & 63,05 & 991,53 & 147,47 & 9,75 & 54,42 & 398,90 & 65,13 & 65,67 & 398,90 \\
\hline Alytes obstetricans & 29TPF41 & 100,00 & 130,09 & $\begin{array}{ll}0,4,51 \\
\end{array}$ & 36,44 & 5704,54 & 281,07 & 22,43 & 258,64 & 59,81 & $\begin{array}{l}205,16 \\
\end{array}$ & 205,40 & 59,81 & 1019,40 & 152,10 & 10,51 & 54,47 & \begin{tabular}{|l|l|}
410,99 \\
350,0
\end{tabular} & 67,65 & 68,26 & 410,99 \\
\hline Alytes obstetricans & 29TPF42 & 101,00 & 129,46 & 97,21 & 36,5 & 5693,92 & 281 & 21,12 & 260,10 & 59,25 & 204,42 & 204,60 & 59,25 & 1019,33 & 152,01 & 10,78 & 54,30 & 410,91 & 68,29 & 68,78 & 410,91 \\
\hline Alytes obstetricans & 29TPF43 & 100,00 & 128,47 & 98,78 & 37,29 & 5690,11 & 281,10 & 19,51 & 261,59 & 58,25 & 203,40 & 203,53 & 58,25 & 1018,61 & 151,77 & 11,11 & 54,11 & \begin{tabular}{|l|l|}
410,75 \\
\end{tabular} & 69,20 & 69,37 & 410,75 \\
\hline Alytes obstetricans & 29TPF46 & 101,00 & 123,35 & 101,60 & 38,00 & 5663,76 & 277,73 & 13,58 & 264,15 & 53,73 & 198,39 & 198,39 & 53,73 & 1028,48 & 151,52 & 12,73 & 53,08 & 413,96 & 73,53 & 73,53 & 413,96 \\
\hline Alytes obstetricans & 29TPF49 & 100,00 & 137,42 & 106,91 & 39,23 & 5629,61 & 292,32 & 23,10 & 269,23 & 67,23 & 211,12 & 211,12 & 66,99 & 873,61 & 123,63 & 11,76 & 51,03 & 345,28 & 63,87 & 63,87 & 345,28 \\
\hline Alyty obstetricans & $\begin{array}{l}\text { 29TPF52 } \\
\text { 29T4 }\end{array}$ & 100,00 & $\begin{array}{ll}13 \\
13 \\
\end{array}$ & $\frac{10}{10}$ & 37,46 & 5779,03 & 292,46 & $\begin{array}{l}25,10 \\
25,97\end{array}$ & \begin{tabular}{|l|}
265,250 \\
266,49 \\
\end{tabular} & 65,88 & 213,69 & 213,69 & 65,70 & 888,20 & 129,97 & 9,39 & 53,19 & 353,77 & 60,27 & 60,27 & 353,77 \\
\hline Alytes obstetricans & \begin{tabular}{|l|} 
29TPF53 \\
\end{tabular} & 100,00 & 141,10 & 103,66 & 38,12 & 5763,83 & 296,81 & 28,05 & 268,76 & 69,62 & 216,60 & 216,60 & 69,12 & 850,97 & 123,81 & 9,14 & 52,78 & 337,87 & 57,88 & 57,88 & 337,83 \\
\hline Alytes obstetricans & \begin{tabular}{|l|} 
29TPF58 \\
\end{tabular} & 99,00 & 136,87 & 107,07 & 38,82 & 5702,16 & 293,58 & 22,00 & 271,58 & 65,83 & 211,69 & 211,69 & 65,64 & 829,85 & 117,91 & 11,02 & 50,93 & \begin{tabular}{|l|l|}
327,95 \\
\end{tabular} & 60,81 & 60,81 & 327,95 \\
\hline Alytes obstetricans & 29TPF59 & 101,00 & 140,06 & 107,68 & 39,02 & 5679,65 & 296,10 & 24,35 & 271,75 & 70,61 & 214,39 & 214,39 & 68,77 & 794,76 & 111,26 & 10,91 & 50,28 & 312,01 & 58,91 & 58,91 & 312,01 \\
\hline Alytes obstetricans & 29TPF62 & 100,00 & 131,94 & 99,50 & $36, \varepsilon$ & 5846,01 & 287,62 & 20,89 & 266,74 & 63,30 & 209,20 & 205 & 59 & 870,22 & 125,57 & \begin{tabular}{l|l}
9,66 \\
\end{tabular} & 52,26 & 344,02 & 61,16 & 61,35 & 34 \\
\hline \begin{tabular}{|l|l}
$\mid l y$ \\
Alytes obtricans
\end{tabular} & \begin{tabular}{|l|} 
29TPF63 \\
\end{tabular} & $\begin{array}{l}101,00 \\
100\end{array}$ & 134,25 & \begin{tabular}{|c|}
101,94 \\
100
\end{tabular} & | 30,02 & $\begin{array}{l}304,0101 \\
5835,98\end{array}$ & 290,02 & $\begin{array}{l}2,839 \\
21,88\end{array}$ & $\begin{array}{l}260,09,4 \\
269\end{array}$ & 63,60 & 211,38 & 211,38 & 61,97 & 844,73 & 121,62 & 9,68 & 52,03 & 333,64 & 59,71 & 59,71 & 333,62 \\
\hline Alytes obstetricans & 29TPF68 & 101,00 & 125,92 & 105,07 & 38,24 & 5746,97 & 283,86 & 12,69 & 271,17 & 55,71 & 201,92 & 201,94 & 54,87 & 847,90 & 119,58 & 11,95 & 50,01 & 334,57 & 65,86 & 65,90 & 334,55 \\
\hline Alytes obstetricans & 29TPF69 & 100,00 & 124,72 & 105,60 & 38,38 & 5737,43 & 282,95 & 11,12 & 271,83 & 53,84 & 200,67 & 200,69 & 53,80 & 842,56 & 118,37 & 12,49 & 49,51 & \begin{tabular}{|c|}
332,58 \\
\end{tabular} & 66,68 & 66,71 & 332,58 \\
\hline Alytes obstetricans & 29TPF71 & 100,00 & 127,17 & 97,36 & 36,08 & 5919,39 & 283,19 & 17,0 & 266,14 & 62,28 & 205, & 205,96 & 54,80 & 856,38 & 121,62 & 9,80 & 51,38 & 336,79 & 61,71 & 62,35 & 334,93 \\
\hline Alytes obstetricans & 29TPF72 & 100,00 & 127,59 & 99,08 & 36,53 & 5904,58 & 284,36 & 16,52 & 267,88 & 62,55 & 205,84 & 205,97 & 55,05 & 843,94 & 19,73 & 9,89 & 51,16 & 331,56 & 61,64 & 61,79 & 330,15 \\
\hline
\end{tabular}




\begin{tabular}{|c|c|c|c|c|c|c|c|c|c|c|c|c|c|c|c|c|c|c|c|c|c|}
\hline TAXON & UTM & $\mathrm{km} 2$ & B101 & B102 & $\mathrm{BIO3}$ & B104 & B105 & B106 & B107 & B108 & B109 & B1010 & BIO11 & BIO12 & B1013 & BIO14 & BIO15 & BIO16 & BIO17 & BIO18 & B1019 \\
\hline Alytes obstetricans & 29TPF73 & 100,00 & 133,46 & 102,44 & 37,27 & 5891,66 & 291,47 & 20,37 & 271,10 & 67,96 & 211,44 & 211,44 & 60,61 & 792,11 & 111,81 & 9,37 & 50,82 & 310,49 & 57,83 & 57,83 & 309,20 \\
\hline Alytes obstetricans & 29TPF81 & 100,00 & 126,60 & 98,86 & 36,16 & 5977,64 & 284,65 & 15,28 & 269,37 & 60,96 & 205,60 & 206,19 & 53,50 & 801,99 & 111,22 & 9,53 & 50,05 & 313,21 & 59,84 & 60,40 & 308,99 \\
\hline Alytes obstetricans & \begin{tabular}{l|l} 
29TPF86 \\
\end{tabular} & 100,00 & 126,57 & 105,56 & 37,85 & 5900,58 & 287,13 & 11,93 & 275,19 & 60,90 & 204,84 & 204,84 & 53,61 & 744,61 & 101,80 & 10,30 & 48,49 & 289,46 & 59,65 & 59,65 & 287,21 \\
\hline Alytes obstetricans & 29TPF89 & 100,00 & 127,67 & 108,27 & 38,52 & 5831,94 & 288,98 & 11,46 & 277,52 & 62,03 & 204,89 & 204,89 & 55,23 & 706,50 & 95,57 & \begin{tabular}{ll|}
11,02 \\
\end{tabular} & 47,46 & 274,56 & 59,14 & 59,14 & 273,30 \\
\hline Alytes obstetricans & 29TPF95 & 100,00 & 123,98 & 105,18 & 37,72 & 5972,06 & 285,81 & 9,47 & 276,34 & 57,90 & 203,57 & 203,57 & 50,66 & 712,27 & 94,80 & 9,98 & 47,46 & $\begin{array}{ll}274,87 \\
\end{array}$ & 58,80 & 58,80 & 269,70 \\
\hline Alytes obstetricans & 29TPF96 & 100,00 & 125,79 & 106,55 & 38,02 & 5947,17 & 287,79 & 10,27 & 277,52 & 59,50 & 204,76 & 204,76 & 52,34 & 691,95 & 91,70 & 10,15 & 47,00 & 266,69 & 57,95 & 57,95 & 261,99 \\
\hline Alytes obstetricans & \begin{tabular}{|l|} 
29TPF97 \\
\end{tabular} & 101,00 & 119,67 & 106,41 & 37,99 & 5930,73 & 282,07 & 4,67 & 277,39 & 53,80 & 198,61 & 198,61 & 46,65 & 718,31 & 95,14 & 11,02 & 46,70 & 276,97 & 61,95 & 61,95 & 272,98 \\
\hline Alytes obstetricans & 29TPG00 & 101,00 & 128,55 & 101,51 & 39,68 & 5268,55 & 274,20 & 21,32 & 252,88 & 63,34 & \begin{tabular}{|l|l|}
197,31 \\
\end{tabular} & \begin{tabular}{|l|l|}
197,49 \\
\end{tabular} & 63,30 & 1164,34 & \begin{tabular}{|l|l|}
161,88 \\
\end{tabular} & 15,93 & 51,68 & 461,28 & 85,32 & 88,02 & 461,28 \\
\hline Alytes obstetricans & 29TPG01 & 100,00 & 111,76 & 92,42 & 37,99 & 5168,72 & 251,69 & 11,49 & 240,20 & 49,41 & 180,21 & 180,35 & 49,41 & 1289,31 & 176,79 & 20,77 & 50,47 & 510,67 & 101,87 & 103,85 & 510,67 \\
\hline Alytes obstetricans & 29TPG02 & 100,00 & 106,85 & 88,80 & 37,21 & 5111,32 & 244,26 & 9,02 & 235,24 & 45,71 & 174,80 & 174,99 & 45,71 & 1310,86 & 176,48 & 22,83 & 49,52 & 516,13 & 107,83 & 110,31 & 516,13 \\
\hline Alytes obstetricans & 29TPG03 & 101,00 & 100,34 & 86,02 & 36,70 & 5053,09 & 235,86 & 4,79 & 231,07 & 40,97 & 167,75 & 168,01 & 40,55 & 1349,43 & 178,69 & 25,66 & 48,45 & 527,55 & 116,37 & 118,48 & 527,53 \\
\hline Alytes obstetricans & 29TPG04 & 100,00 & 105,08 & 88,21 & 37,23 & 5064,05 & 241,28 & 7,38 & 233,90 & 49,16 & 172,41 & 172,65 & 44,73 & 1295,86 & 171,56 & 25,20 & 47,82 & 502,97 & 113,33 & 115,43 & 502,81 \\
\hline Alytes obstetricans & 29TPG05 & 101,00 & 119,89 & 93,96 & 38,26 & 5155,67 & 258,22 & 15,84 & 242,38 & 63,14 & 187,92 & 188,01 & 57,21 & 1153,20 & 156,06 & 22,16 & 47,08 & 443,66 & 100,34 & 101,71 & 440,77 \\
\hline Alytes obstetricans & 29TPG07 & 100,00 & 123,10 & 93,56 & 38,15 & 5116,46 & 259,22 & 18,05 & 241,17 & 66,16 & 190,42 & 190,56 & 60,93 & 1099,61 & 152,97 & 23,37 & 45,42 & 418,36 & 101,12 & 104,45 & 411,31 \\
\hline Alytes obstetricans & 29TPG10 & 100,00 & 126,91 & 102,29 & 39,40 & 5384,67 & 275,27 & 18,51 & 256,76 & 60,43 & 197,61 & 197,66 & 60,43 & 1124,66 & 158,03 & 15,63 & 51,73 & 446,89 & 82,92 & 83,49 & 446,89 \\
\hline Alytes obstetricans & 29TPG11 & 100,00 & 130,59 & 102,55 & 39,37 & 5379,72 & 278,26 & 21,08 & 257,18 & 63,94 & 201,00 & 201,04 & 63,94 & 1069,72 & 146,26 & 15,45 & 50,64 & 420,48 & 80,50 & 80,87 & 420,48 \\
\hline Alytes obstetricans & 29TPG12 & 100,00 & 115,84 & 95,37 & 38,04 & 5283,63 & 259,08 & 11,91 & 247,16 & 51,65 & 185,68 & 185,71 & 51,65 & 1176,26 & 158,86 & 19,73 & 49,55 & 462,11 & 95,00 & 95,45 & 462,11 \\
\hline Alytes obstetricans & 29TPG13 & 101,00 & 114,59 & 94,29 & 37,88 & 5258,16 & 256,75 & 11,16 & 245,59 & 51,08 & 184,25 & 184,28 & 50,83 & 1171,31 & 155,10 & 20,77 & 48,71 & 457,27 & 97,45 & 97,95 & 457,27 \\
\hline Alytes obstetricans & 29TPG14 & 101,00 & 113,99 & 93,88 & 37,92 & 5231,74 & 255,38 & 10,69 & 244,69 & 55,23 & 183,38 & 183,44 & 50,77 & 1159,41 & 152,44 & 21,83 & 47,73 & 449,20 & 99,54 & 100,49 & 449,09 \\
\hline Alytes obstetricans & 29TPG15 & 99,00 & 117,40 & 94,81 & 38,05 & 5235,88 & 258,51 & 12,64 & 245,87 & 59,84 & $\mid 186,75$ & $\mid 186,77$ & 53,92 & 1115,37 & $\mid 149,09$ & 21,82 & 46,89 & 429,50 & 97,90 & 99,06 & 427,21 \\
\hline Alytes obstetricans & 29TPG16 & 101,00 & 115,22 & 93,66 & 37,91 & 5183,58 & 254,83 & 11,28 & 243,54 & 58,25 & 183,88 & 183,96 & 52,68 & 1123,78 & 151,97 & 23,44 & 45,97 & 431,18 & 102,31 & 103,57 & 427,11 \\
\hline Alytes obstetricans & 29TPG20 & 100,00 & 116,55 & 98,57 & 38,25 & 5422,90 & 264,90 & 10,39 & 254,51 & 50,42 & 188,25 & 188,27 & 50,42 & 1146,33 & 161,59 & 17,49 & 51,15 & 456,30 & 88,32 & 88,41 & 456,30 \\
\hline Alytes obstetricans & 29TPG22 & 101,00 & 133,16 & 103,27 & 39,01 & 5460,32 & 282,04 & 21,44 & 260,59 & 66,48 & 204,71 & 204,71 & 65,46 & 970,41 & 130,05 & \begin{tabular}{ll|}
15,04 \\
\end{tabular} & 49,31 & 377,52 & 75,53 & 75,53 & 377,52 \\
\hline Alytes obstetricans & 29TPG23 & 100,00 & 128,44 & 100,89 & 38,75 & 5426,73 & 275,36 & 18,16 & 257,20 & 64,68 & 199,68 & 199,68 & 61,42 & 993,49 & 130,73 & 16,78 & 48,38 & 385,02 & 80,62 & 80,62 & 384,57 \\
\hline Alytes obstetricans & 29TPG24 & 100,00 & 128,78 & 100,20 & 38,64 & 5413,35 & 274,57 & 18,36 & 256,21 & 68,08 & 199,94 & 199,94 & 62,10 & 972,87 & 127,05 & 17,39 & 47,39 & 374,59 & 81,45 & 81,45 & 372,83 \\
\hline Alytes obstetricans & 29TPG26 & 101,00 & 105,01 & 92,90 & 37,58 & 5216,32 & 246,69 & 2,59 & 244,09 & 48,25 & 174,52 & 174,57 & 42,60 & 1153,25 & 153,62 & 25,51 & 45,44 & 443,06 & 108,79 & 109,53 & 438,97 \\
\hline Alytes obstetricans & 29TPG 30 & 101,00 & 129,20 & 104,36 & 38,86 & 5549,78 & 281,83 & $\begin{array}{l}, 2,57 \\
17,57\end{array}$ & 264,26 & $\begin{array}{ll}60,49 \\
60,49\end{array}$ & 202,10 & 202,10 & $\begin{array}{ll}60,49 \\
60\end{array}$ & 983,61 & \begin{tabular}{|l|l|}
138,69 \\
\end{tabular} & 14,19 & $\begin{array}{l}51,07 \\
51,4\end{array}$ & 390,06 & 73,76 & $\begin{array}{l}73,76 \\
7\end{array}$ & 390,06 \\
\hline Alytes obstetricans & 29TPG31 & 99,00 & 119,83 & 101,17 & 38,41 & 5507,86 & 270,92 & 10,81 & 260,12 & 52,25 & 192,70 & 192,70 & 52,25 & \begin{tabular}{|l|}
1040,03 \\
\end{tabular} & 144,93 & 16,75 & 50,13 & 412,02 & 81,99 & 81,99 & 412,02 \\
\hline Alytes obstetricans & 29TPG32 & 100,00 & 121,65 & 101,25 & 38,42 & 5496,12 & 272,07 & 11,98 & 260,09 & 54,58 & 194,31 & 194,31 & 54,26 & 1006,25 & 137,16 & 16,95 & 49,15 & 395,01 & 81,34 & 81,34 & 395,01 \\
\hline Alytes obstetricans & 29TPG33 & 100,00 & 121,95 & 100,70 & 38,33 & 5475,42 & 271,29 & 12,10 & 259,19 & 57,53 & 194,34 & 194,34 & 54,80 & 986,87 & 131,60 & 17,61 & 48,16 & 384,05 & 82,26 & 82,26 & 383,95 \\
\hline Alytes obstetricans & 29TPG34 & 101,00 & 119,10 & 99,36 & 38,15 & 5438,35 & 267,03 & 10,11 & 256,92 & 58,52 & 191,03 & 191,03 & 52,56 & 996,47 & 130,92 & 19,09 & 47,19 & 385,91 & 86,18 & 86,18 & 385,02 \\
\hline Alytes obstetricans & 29TPG37 & 100,00 & 81,18 & 89,85 & $\begin{array}{ll}36,97 \\
6,97\end{array}$ & 5161,60 & 223,24 & $\frac{10,1}{-16,66}$ & \begin{tabular}{|l|}
239,90 \\
\end{tabular} & 26,61 & 150,66 & 150,77 & 20,92 & \begin{tabular}{|l|}
1289,79 \\
\end{tabular} & \begin{tabular}{|l|}
168,92 \\
1682
\end{tabular} & 33,27 & $\frac{43,10}{43,10}$ & 490,73 & $\begin{array}{l}0,10 \\
134,79\end{array}$ & $\begin{array}{l}0,10 \\
135,32\end{array}$ & 482,049 \\
\hline Alytes obstetricans & 29TPG38 & 100,00 & 96,75 & 92,85 & 37,72 & 5178,34 & 238,76 & $-4,64$ & 243,39 & 40,47 & 165,90 & 165,96 & 35,20 & 1152,50 & 153,75 & 28,99 & 43,10 & 438,96 & 118,41 & 119,17 & 430,55 \\
\hline Alytes obstetricans & 29TPG40 & 100,00 & 139,68 & 107,25 & 39,28 & 5619,81 & 294,02 & 24,54 & 269,48 & 69,90 & 213,18 & 213,18 & 69,41 & 839,87 & 116,78 & \begin{tabular}{|c|}
11,78 \\
\end{tabular} & 50,19 & 329,39 & 62,42 & 62,42 & 329,39 \\
\hline Alytes obstetricans & 29TPG43 & 100,00 & 117,15 & 101,03 & 38,13 & 5522,05 & 268,85 & 7,27 & 261,57 & 52,89 & 190,41 & 190,41 & 49,60 & 966,51 & 130,02 & 18,09 & 47,76 & 377,38 & 82,60 & 82,60 & 377,30 \\
\hline Alytes obstetricans & 29TPG44 & 100,00 & 113,68 & 99,82 & 38,01 & 5485,88 & 264,16 & 4,66 & 259,50 & 52,80 & 186,67 & 186,67 & 46,81 & 981,93 & 129,95 & 19,66 & 46,90 & 381,73 & 87,10 & 87,10 & 380,84 \\
\hline Alyty obstetricans & 29TPG47 & 101,00 & $\begin{array}{r}11,00 \\
87,27\end{array}$ & $\begin{array}{ll}9,02 \\
93,12\end{array}$ & $\frac{0,01}{37,28}$ & $\begin{array}{l}340,0,00 \\
5272,05\end{array}$ & 232,57 & \begin{tabular}{|c|}
$-4,00$ \\
$-13,80$
\end{tabular} & \begin{tabular}{|l|}
246,38 \\
240
\end{tabular} & $\begin{array}{l}32,00 \\
30,69\end{array}$ & \begin{tabular}{|l|}
158,08 \\
158,0
\end{tabular} & $\begin{array}{l}158,12 \\
158,12\end{array}$ & $\begin{array}{l}25,08 \\
25,08\end{array}$ & $\mid$ & \begin{tabular}{|l|}
154,82 \\
154,
\end{tabular} & 30,25 & $\begin{array}{ll}43,01 \\
43\end{array}$ & 449,01 & 123,01 & $\begin{array}{l}0,10 \\
123,16\end{array}$ & $\begin{array}{l}30,04 \\
441,24\end{array}$ \\
\hline Alytes obstetricans & 29TPG48 & 100,00 & 108,67 & 96,86 & 37,97 & 5314,99 & 253,42 & 2,25 & 251,18 & 49,64 & 179,27 & 179,29 & 44,47 & 997,65 & 133,38 & 24,48 & 42,97 & 380,02 & 101,32 & 101,38 & 371,02 \\
\hline Alytes obstetricans & 29TPG49 & 101,00 & 118,67 & 97,49 & 38,41 & 5283,64 & 261,09 & 10,54 & 250,55 & 58,99 & 188,28 & 188,28 & 54,20 & 919,91 & 123,69 & 22,59 & 42,35 & 348,53 & 93,97 & 93,97 & 337,24 \\
\hline Alytes obstetricans & 29TPG50 & 100,00 & 137,60 & 107,47 & 39,01 & 5663,99 & 293,42 & 22,08 & 271,34 & 69,40 & 211,95 & 211,95 & 66,82 & 797,61 & 110,60 & 11,75 & 49,53 & 312,43 & 60,95 & 60,95 & 312,37 \\
\hline Alytes obstetricans & 29TPG51 & 100,00 & 135,10 & 106,82 & 38,97 & 5652,70 & 290,36 & 19,93 & 270,43 & 68,85 & 209,35 & 209,35 & 64,65 & 802,20 & 109,94 & 12,67 & 48,85 & 313,40 & 63,25 & 63,25 & 313,23 \\
\hline Alytes obstetricans & 29TPG52 & 99,00 & 126,28 & 105,19 & 38, & 5629,65 & 281,48 & 12,63 & 268,85 & 59,49 & 200,62 & 200,62 & 56,60 & $\begin{array}{l}851,88 \\
\end{array}$ & 116,31 & 14,69 & 48,20 & 333,63 & 70,27 & 70,27 & 333,50 \\
\hline Alytes obstetricans & 29TPG53 & 101,00 & 118,10 & 103,22 & 38,19 & 5593,68 & 272,73 & 6,29 & 266,44 & 54,78 & 192,35 & 192,35 & 49,42 & 897,29 & 121,15 & 16,78 & 47,42 & 350,83 & 77,64 & 77,64 & 350,43 \\
\hline Alytes obstetricans & 29TPG54 & 100,00 & 112,14 & 101,49 & 37,99 & 5549,06 & 265,44 & 2,10 & 263,34 & 50,57 & 186,01 & 186,01 & 44,43 & 933,69 & 123,73 & 19,01 & 46,45 & 363,30 & 84,68 & 84,68 & 361,72 \\
\hline Alytes obstetricans & 29TPG55 & 101,00 & $\begin{array}{ll}101,87 \\
\end{array}$ & 98,62 & 37,70 & 5478,45 & 253,21 & $-4,90$ & 258,12 & 41,72 & 175,11 & 175,11 & 35,82 & 1007,10 & 132,54 & 22,70 & 45,05 & 89,16 & 96,94 & 96,94 & 385,59 \\
\hline Alytes obstetricans & 29TPG59 & 101,00 & 120,87 & 90,02 & 38, & 5362,54 & 265,42 & 10,95 & \begin{tabular}{|l|}
254,47 \\
\end{tabular} & $\begin{array}{l}59,95 \\
59\end{array}$ & 191,56 & 191,56 & $\begin{array}{l}55,12< \\
5\end{array}$ & 854,10 & \begin{tabular}{|l|}
114,17 \\
14,
\end{tabular} & 21,06 & 41,95 & 323,58 & 88,29 & 88,29 & 31,47 \\
\hline Alytes obstetricans & 29TPG62 & 101,00 & 117,17 & 104,76 & 38,23 & 5659,64 & 274,68 & 4,41 & 270,26 & 52,34 & $\begin{array}{l}192,27 \\
\end{array}$ & 192,27 & 47,48 & 857,09 & 117,25 & 15,25 & 47,61 & 336,34 & 74,11 & 74,11 & 336,18 \\
\hline Alytes obstetricans & 29TPG63 & 100,00 & 112,97 & 103,74 & 38,15 & 5628,42 & 269,69 & $\frac{1,47}{1,35}$ & 268,34 & 50,38 & 187,93 & 187,93 & 44,10 & 878,27 & 118,15 & 16,94 & 46,75 & 343,20 & 79,00 & 79,00 & 342,17 \\
\hline Alytes obstetricans & 29TPG64 & 100,00 & 104,22 & 101,47 & 37,91 & 5587,04 & 259,60 & $-4,87$ & 264,47 & 42,66 & 178,99 & 178,99 & 36,56 & 935,40 & 123,39 & 19,90 & 45,50 & 363,13 & 88,84 & 88,84 & 360,58 \\
\hline Alytes obstetricans & 29TPG65 & 100,00 & 91,21 & 98,25 & 37,45 & 5510,92 & 244,11 & $-14,60$ & 258 & 31,40 & 165,31 & 165,32 & 25,41 & 1036,29 & 135,29 & 25,12 & 43,62 & 79 & 105,96 & 106,01 & 391,05 \\
\hline Alytes obstetricans & 29TPG66 & 100,00 & & $\begin{array}{l}0,20 \\
97,01\end{array}$ & $\frac{37,45}{37,38}$ & 5459,42 & 236,65 & $\begin{array}{l}-19,00 \\
-19,18 \\
\end{array}$ & \begin{tabular}{|l|}
255,841 \\
\end{tabular} & $\begin{array}{l}1,404 \\
26,37 \\
\end{array}$ & $\begin{array}{l}\mid 103,5,1 \\
158,82\end{array}$ & $\begin{array}{l}103,32,85 \\
158,85\end{array}$ & 20,53 & \begin{tabular}{|l|l|l|l|l|l|}
1082,19 \\
\end{tabular} & \begin{tabular}{|l|}
$\mid 30,29$ \\
140,94
\end{tabular} & 28,45 & $\begin{array}{ll}4,320 \\
42,32\end{array}$ & $\begin{array}{l}350,13 \\
410,84\end{array}$ & 115,68 & 115,73 & 402,63 \\
\hline Alytes obstetricans & 29TPG67 & 101,00 & 90,62 & 98,13 & 37,76 & 5449,74 & 241,65 & $-15,01$ & 256,66 & 31,18 & 163,81 & 163,81 & 25,53 & 1033,16 & 135,57 & 27,56 & 41,95 & 391,99 & 111,28 & 111,28 & 382,79 \\
\hline Alytes obstetricans & 29TPG68 & 101,00 & 95,38 & 98,77 & 37,99 & 5429,41 & 245,36 & $-11,17$ & 256,53 & 35,56 & 168,01 & 168,01 & 30,21 & 994,16 & 131,08 & 26,93 & 41.40 & 376,34 & 108,56 & 108,56 & 365,59 \\
\hline Alytes obstetricans & 29TPG69 & 100,00 & 109,58 & 99,72 & 38,42 & 5401,83 & 256,87 & 0,74 & 256,13 & 48,89 & 181,12 & 181,12 & 43,70 & 891,67 & 118,02 & 23,64 & 41,01 & 336,82 & 96,95 & 96,95 & 323,83 \\
\hline Alytes obstetricans & 29TPG70 & 101,00 & 120,49 & 106,61 & 38,2 & 5758,56 & 281,01 & 6,19 & 274,81 & 50,93 & 197,05 & 197,05 & 49,40 & 797,41 & 110,24 & 12,70 & 48,25 & 313,45 & 66,84 & 66,84 & 31 \\
\hline Alytes obstetricans & 29TPG71 & 99,00 & 106,29 & 103,38 & 37,79 & 5709,64 & 265,63 & $-4,35$ & 269,98 & 41,02 & 182,72 & 182,73 & 36,85 & 887,24 & 120,34 & 15,88 & 47,03 & 346,53 & 79,77 & 79,77 & 346,12 \\
\hline Alytes obstetricans & 29TPG73 & 100,00 & 111,26 & 105,36 & 38,08 & 5681,64 & 270,72 & $-1,27$ & 271,99 & 48,18 & 187,11 & 187,11 & 41,70 & 830,16 & 111,22 & 16,29 & 46,11 & 324,27 & 76,84 & 76,84 & 322,77 \\
\hline Alytes obstetricans & 29TPG74 & 100,00 & 102.89 & 103,19 & 37,94 & 5639.26 & 260,53 & -7.56 & 268.10 & 40,61 & 178,40 & 178,40 & 34,42 & 888.01 & 117.14 & 19,58 & 44,67 & 343,11 & 87.15 & 87.15 & 339,61 \\
\hline Alytes obstetricans & 29TPG76 & 100,00 & 69,20 & 95,75 & 37,03 & 5474,24 & 221,21 & $-33,69$ & 254,90 & 11,2 & 143, & 143 & 5, & 1166,78 & 148,91 & 33,61 & 40 & 435 & 133,11 & 134,16 & 423,2 \\
\hline Alytes obstetricans & 29TPG77 & 100,00 & 72,02 & 96,50 & 37,33 & 5454,39 & 223,74 & \begin{tabular}{|c|}
$-31,34$ \\
-3
\end{tabular} & 255,08 & $\begin{array}{ll}13,92 \\
\end{array}$ & 145,64 & 145,74 & 7,94 & 1141,30 & 146,33 & 33,84 & 39,61 & 424,73 & 132,61 & 133,18 & 4111,98 \\
\hline
\end{tabular}




\begin{tabular}{|c|c|c|c|c|c|c|c|c|c|c|c|c|c|c|c|c|c|c|c|c|c|}
\hline TAXON & UTM & $\mathrm{km2}$ & B101 & $\mathrm{B1O2}$ & $\mathrm{BIO3}$ & $\mathrm{B104}$ & B105 & B106 & B107 & B108 & B109 & 81010 & B1011 & BIO12 & BIO13 & BIO14 & BIO15 & BIO16 & BIO17 & BIO18 & B1019 \\
\hline Alytes obstetricans & 29TPG78 & 99,00 & 84,24 & 98,73 & 37,94 & 5461,01 & 235,92 & $-21,51$ & 257,42 & 24,81 & 157,54 & 157,55 & 19,16 & 1035,81 & 134,64 & 30,25 & 39,76 & 387,35 & 119,61 & 119,70 & 374,39 \\
\hline Alytes obstetricans & 29TPG80 & 100,00 & 121,05 & 107,95 & 38,31 & 5805,80 & 283,05 & 5,75 & 277,30 & 55,69 & 198,22 & 198,22 & 49,43 & 736,72 & 99,75 & 12,07 & 47,20 & 287,01 & 63,76 & 63,76 & 286,57 \\
\hline Alytes obstetricans & 29TPG81 & 100,00 & 112,63 & 106,89 & 38,07 & 5769,69 & 274,83 & $-0,95$ & 275,78 & 47,70 & 189,63 & 189,63 & 41,79 & 781,52 & 105,21 & 13,80 & 46,54 & 304,45 & 70,73 & 70,73 & 304,31 \\
\hline Alytes obstetricans & 29TPG82 & 101,00 & 115,92 & 108,05 & 38,48 & 5741,87 & 278,21 & 1,19 & 277,01 & 49,20 & 192,39 & 192,39 & 45,23 & 751,50 & 101,08 & 13,75 & 46,42 & 293,71 & 68,50 & 68,50 & 293,50 \\
\hline Alytes obstetricans & 29TPG83 & 100,00 & 114,34 & 107,76 & \begin{tabular}{|c|}
38,57 \\
\end{tabular} & 5717,94 & 275,96 & $-0,14$ & 276,10 & 49,76 & \begin{tabular}{|l|}
190,63 \\
\end{tabular} & \begin{tabular}{|l|}
190,63 \\
\end{tabular} & 43,99 & 756,43 & 100,89 & 14,92 & 45,71 & 294,30 & 71,12 & 71,12 & 293,56 \\
\hline Alytes obstetricans & 29TPG84 & 100,00 & 101,08 & 104,58 & 38,04 & 5694,84 & 260,62 & $-10,39$ & 271,01 & 38,15 & 177,42 & 177,42 & 31,99 & 848,62 & 111,77 & 19,55 & 43,67 & 325,23 & 86,52 & 86,52 & 320,86 \\
\hline Alytes obstetricans & 29TPG85 & 99,00 & 90,22 & 102,10 & 37,74 & 5649,05 & 247,58 & $-18,81$ & 266,39 & 28,47 & 166,10 & 166,16 & 22,38 & 931,97 & 121,43 & 24,22 & 41,70 & 352,40 & 101,25 & 101,38 & 344,17 \\
\hline Alytes obstetricans & 29TPG86 & 101,00 & 80,34 & 100,06 & 37,57 & 5586,05 & 235,83 & $\begin{array}{l}-26,54 \\
-25\end{array}$ & 262,37 & 19,98 & 155,48 & 155,64 & 13,90 & 1015,72 & 130,94 & 29,10 & 40,06 & 379,28 & 116,18 & 116,72 & 367,84 \\
\hline Alytes obstetricans & 29TPG87 & 100,00 & 60,76 & 96,29 & 37,14 & 5479,39 & 213,40 & $-41,90$ & 255,30 & 3,18 & 134,78 & 135,09 & $-3,08$ & 1192,08 & 150,36 & 37,89 & 37,67 & 436,76 & 145,06 & 146,84 & 421,17 \\
\hline Alytes obstetricans & 29TPG88 & 101,00 & 75,96 & 99,19 & \begin{tabular}{|l|l|}
37,83 \\
\end{tabular} & 5498,03 & 229,16 & $-29,65$ & 258,81 & 16,66 & 149,91 & 149,95 & 10,69 & 1056,83 & 135,57 & 32,94 & 38,18 & 389,90 & 128,19 & 128,45 & 374,70 \\
\hline Alytes obstetricans & 29TPG89 & 100,00 & 93,45 & 101,35 & 38,41 & 5516,40 & 245,72 & $-15,37$ & 261,10 & 32,30 & 167,04 & 167,05 & 26,82 & 919,95 & 119,41 & 27,68 & 38,68 & 341,52 & 110,07 & 110,10 & 325,83 \\
\hline Alytes obstetricans & 29TPG91 & 100,00 & 118,94 & 109,38 & 38,64 & 5827,16 & 282,27 & 2,54 & 279,73 & 53,38 & 196,21 & 196,21 & 46,87 & 687,62 & 90,57 & 12,47 & 45,58 & 265,21 & 63,42 & 63,42 & 264,07 \\
\hline Alytes obstetricans & 29TPG92 & 100,00 & 117,79 & 109,49 & 38,73 & 5801,07 & 281,12 & 1,55 & 279,58 & 51,24 & 194,91 & 194,91 & 45,98 & 690,75 & 91,31 & 13,20 & 45,22 & 266,29 & 65,12 & 65,12 & 265,58 \\
\hline Alytes obstetricans & 29TPG93 & 100,00 & 114,11 & 109,10 & 38,82 & 5783,44 & 276,86 & $-1,48$ & 278,34 & 48,78 & 191,09 & 191,09 & 42,76 & 707,57 & 93,88 & 14,70 & 44,40 & 271,75 & 69,24 & 69,24 & 270,03 \\
\hline Alytes obstetricans & 29TPG94 & 101,00 & 110,64 & 108,34 & 38,65 & 5772,11 & 272,62 & $-4,27$ & 276,90 & 45,99 & 187,51 & 187,51 & 39,68 & 726,49 & 96,60 & 16,51 & 43,40 & 277,94 & 73,92 & 73,92 & 274,29 \\
\hline Alytes obstetricans & 29TPG95 & 101,00 & 102,24 & 106,49 & 38,29 & 5749,81 & 262,78 & $-11,04$ & 273,82 & 38,15 & 179,12 & 179,12 & 32,12 & 781,86 & 103,44 & 20,04 & 41,76 & 296,35 & 84,39 & 84,39 & 288,95 \\
\hline Alytes obstetricans & 29TPG96 & 100,00 & 97,20 & 105,45 & 38,22 & 5715,20 & 256,35 & $-15,01$ & 271,35 & 33,71 & 173,68 & 173,68 & 27,75 & 820,67 & 107,87 & 22,87 & 40,53 & 308,33 & 92,64 & 92,64 & 298,22 \\
\hline Alytes obstetricans & 29TPG97 & 100,00 & 73,90 & 100,69 & 37,78 & 5591,12 & 229,81 & $-32,99$ & 262,80 & 13,84 & 149,23 & 149,36 & 7,62 & 1021,92 & 130,38 & 32,26 & 37,71 & 374,88 & 125,27 & 125,90 & 359,55 \\
\hline Alytes obstetricans & 29TPG99 & 100,00 & 92,81 & 103,41 & 38,64 & 5591,63 & 247,49 & $-17,53$ & 265,03 & 30,74 & 167,42 & 167,42 & 24,99 & 875,06 & 113,22 & 27,37 & 37,78 & 322,53 & 108,10 & 108,16 & 305,90 \\
\hline Alytes obstetricans & 29TPH03 & 101,00 & 122,39 & 88,14 & 39,68 & 4526,51 & 245,68 & 25,57 & 220,12 & 71,62 & 181,60 & 182,66 & 68,41 & 1110,45 & 154,52 & 30,34 & 41,20 & 414,15 & 119,09 & 132,83 & 396,58 \\
\hline Alytes obstetricans & 29TPH05 & 100,00 & 120,25 & 86,16 & 40,00 & 4330,66 & 239,66 & 26,82 & 212,84 & 72,25 & 176,64 & 178,33 & 68,88 & 1130,62 & 154,64 & 32,99 & 39,74 & 419,44 & 127,24 & 141,76 & 397,95 \\
\hline Alytes obstetricans & 29TPHOG & 100,00 & 122,37 & 85,04 & 40,24 & 4221,63 & 238,92 & 30,56 & 208,36 & 75,70 & 177,15 & 178,95 & 72,04 & 1114,61 & 150,96 & 33,28 & 38,97 & 412,09 & 127,86 & 143,18 & 388,61 \\
\hline Alytes obstetricans & 29TPH07 & 100,00 & 123,13 & 83,78 & 40,52 & 4121,32 & 237,34 & 33,13 & 204,21 & 77,79 & \begin{tabular}{|l|}
176,53 \\
\end{tabular} & 178,70 & 74,12 & 1106,65 & 148,29 & 33,80 & 38,24 & 408,04 & 129,36 & 145,35 & 382,48 \\
\hline Alytes obstetricans & 29TPH08 & 100,00 & 124,56 & 82,49 & 40,96 & 4047,40 & 236,24 & 36,13 & 200,11 & 80,26 & 176,78 & 179,07 & 76,20 & 1090,69 & 144,51 & 34,03 & 37,66 & 400,97 & 129,85 & 146,52 & 373,57 \\
\hline Alytes obstetricans & 29TPHO9 & 100,00 & 122,75 & 81,56 & 40,98 & 3966,66 & 232,91 & 35,86 & 197,05 & 79,73 & 173,76 & 176,37 & 75,50 & 1103,86 & 144,75 & 35,37 & 36,96 & 404,69 & 134,34 & 151,17 & 375,61 \\
\hline Alytes obstetricans & 29TPH14 & 100,00 & 127,77 & 88,45 & 39,92 & 4530,25 & 250,04 & 30,10 & 219,94 & 76,72 & 186,71 & 187,88 & 73,19 & 1014,92 & 138,48 & 28,44 & 39,90 & 375,81 & 111,82 & 126,42 & 355,63 \\
\hline Alytes obstetricans & 29TPH16 & 101,00 & 125,04 & 86,30 & 40,07 & 4330,92 & 243,26 & 31,13 & 212,13 & 76,77 & 181,15 & 182,83 & 73,01 & \begin{tabular}{|l|l|l|l|}
1042,90 \\
\end{tabular} & 139,56 & 31,21 & 38,41 & 383,96 & 120,74 & 136,01 & 359,84 \\
\hline Alytes obstetricans & 29TPH17 & 100,00 & 126,18 & 84,96 & 40,36 & 4216,44 & 241,65 & 34,25 & 207,40 & 79,44 & 180,65 & 182,65 & 75,51 & 1038,06 & 137,45 & 31,90 & 37,78 & 381,03 & 122,60 & 138,47 & 354,94 \\
\hline Alytes obstetricans & 29TPH 20 & 100,00 & 128,59 & 94,28 & 38,67 & 5087,38 & 263,24 & 21,88 & 241,35 & 70,80 & 195,16 & 195,28 & 66,58 & 936,27 & 128,52 & 22,83 & 42,26 & 350,85 & 94,21 & 97,52 & 337,98 \\
\hline Alytes obstetricans & 29TPH 25 & 100,00 & 126,69 & 88,78 & 40,00 & 4525,55 & 249,07 & 29,25 & 219,82 & 75,85 & 185,51 & 186,73 & 72,08 & 981,64 & 131,10 & 28,68 & 38,56 & 361,47 & 112,42 & 126,98 & 338,67 \\
\hline Alytes obstetricans & 29TPH26 & 100,00 & 121,66 & 87,84 & 40,00 & 4444,56 & 243,07 & 26,02 & 217,05 & 71,93 & 179,43 & 180,73 & 68,04 & 1026,71 & 136,01 & 31,28 & 37,83 & 377,12 & 121,13 & 135,50 & 352,61 \\
\hline Alytes obstetricans & 29TPH27 & 100,00 & 123,01 & $\begin{array}{l}86,66 \\
86,66\end{array}$ & 40,23 & 4337,90 & 241,68 & \begin{tabular}{|l|l|}
29,27 \\
2
\end{tabular} & 212,41 & 74,82 & 179,25 & 180,94 & 70,80 & 1019,81 & \begin{tabular}{|l|l|}
133,69 \\
\end{tabular} & 31,80 & $\begin{array}{l}3,00 \\
37,10\end{array}$ & 373,07 & 122,70 & 137,63 & 346,56 \\
\hline Alytes obstetricans & 29TPH31 & 101,00 & 119,04 & 94,44 & 38,82 & 5059,74 & 255,30 & 14,04 & 241,25 & 62,01 & 185,63 & 185,73 & 57,79 & 967,60 & 131,02 & 25,32 & 41,14 & 362,64 & 102,89 & 105,66 & 347,87 \\
\hline Alytes obstetricans & 29TPH37 & 101,00 & 115,11 & 88,43 & \begin{tabular}{|l|l|}
40,03 \\
\end{tabular} & 4458,08 & 237,97 & 19,80 & 218,17 & 65,63 & 173,12 & 174,59 & 61,61 & 1040,39 & 135,09 & 33,49 & 36,41 & 379,57 & 128,52 & 142,10 & 352,46 \\
\hline Alytes obstetricans & 29TPH41 & 101,00 & 110,45 & 95,49 & 38,66 & 5128,06 & 250,03 & 5,65 & 244,38 & 52,96 & 178,23 & 178,27 & 48,54 & 986,46 & 132,08 & 26,80 & 40,55 & 370,31 & 108,08 & 108,69 & 355,08 \\
\hline Alytes obstetricans & 29TPH50 & 99,00 & 103,52 & 97,16 & 38,31 & 5267,63 & 247,89 & $-2,19$ & 250,08 & 44,77 & 173,39 & 173,39 & 40,01 & 986,10 & 131,01 & 27,03 & 40,63 & 371,34 & 108,83 & 108,87 & 357,52 \\
\hline Alytes obstetricans & 29TPH51 & 100,00 & 92,45 & 95,33 & 38,24 & 5173,82 & 235,67 & $-10,10$ & 245,76 & 35,76 & 161,46 & 161,51 & 30,84 & 1078,35 & 141,86 & 31,88 & 39,27 & 402,52 & 125,19 & 125,91 & 386,28 \\
\hline Alytes obstetricans & 29TPH52 & 100,00 & 95,85 & 95,19 & 38,70 & 5107,97 & 237,01 & $-6,60$ & 243,60 & 39,57 & 163,73 & 163,78 & 34,81 & \begin{tabular}{|l|}
1057,17 \\
\end{tabular} & 138,92 & 31,84 & 38,58 & 392,95 & 124,87 & 126,52 & 374,61 \\
\hline Alytes obstetricans & 29TPH55 & 101,00 & 115,59 & 93,60 & 39,80 & 4824,02 & 247,23 & 14,03 & 233,20 & 61,30 & 178,62 & 179,20 & 57,08 & 937,10 & 121,15 & 29,23 & 36,63 & 342,96 & 114,97 & 125,70 & 317,72 \\
\hline Alytes obstetricans & 29TPH56 & 100,00 & 112,59 & 92,57 & 39,92 & 4721,95 & 242,36 & 12,91 & 229,45 & 59,88 & 174,30 & 175,10 & 55,56 & 969,45 & 124,37 & 31,62 & 35,72 & 352,59 & 122,46 & 134,51 & 325,18 \\
\hline Alytes obstetricans & 29TPH58 & 99,00 & 111,89 & 90,21 & 40, & 4511,60 & 236,79 & 15,61 & 221,18 & 62,19 & 170,64 & 171,93 & 57,57 & 1001,05 & 128,05 & 34,69 & 34,26 & 360,09 & 131,93 & 144,69 & 328,66 \\
\hline $\begin{array}{l}\text { Ay } \\
\text { Alytes obstetricans }\end{array}$ & $\begin{array}{l}\text { 29TPH60 } \\
\end{array}$ & $\begin{array}{r}99,000 \\
101,00\end{array}$ & $\begin{array}{l}11,04,75 \\
104,75\end{array}$ & $\begin{array}{l}90,14 \\
99,05\end{array}$ & $\begin{array}{l}40, \\
38,4\end{array}$ & $\begin{array}{l}51,100 \\
5352,43\end{array}$ & 251,30 & \begin{tabular}{|c|}
1,201 \\
$-2,77$
\end{tabular} & \begin{tabular}{|l|}
254,06 \\
25,0
\end{tabular} & 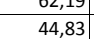 & 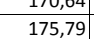 & \begin{tabular}{|l|l|l|l|}
175,79 \\
\end{tabular} & $\begin{array}{l}39,87 \\
39,85\end{array}$ & \begin{tabular}{|l|l|l|l|l|l|l|}
926,98 \\
\end{tabular} & \begin{tabular}{|l|}
122,05 \\
122,54
\end{tabular} & $\begin{array}{l}35,403 \\
25,86\end{array}$ & $\begin{array}{l}4,20 \\
40,07 \\
\end{array}$ & $\begin{array}{l}30,09 \\
348,48\end{array}$ & 104,41 & $\begin{array}{l}144,09 \\
104,43 \\
\end{array}$ & $\begin{array}{l}32,00 \\
333,57 \\
\end{array}$ \\
\hline Alytes obstetricans & 29TPH61 & 101,00 & 98,60 & 97,92 & 38,58 & 5271,68 & 243,83 & $-6,88$ & 250,72 & 40,01 & 168,65 & 168,65 & 35,12 & 979,21 & 128,64 & 28,89 & 38,95 & 365,30 & 114,69 & 114,77 & 348,13 \\
\hline Alytes obstetricans & 29TPH62 & 100,00 & 100,06 & 97,43 & 38,86 & 5205,83 & 243,35 & $-4,92$ & 248,28 & 41,99 & 169,03 & 169,06 & 37,23 & 973,89 & 127,40 & 29,47 & 38,08 & 361,44 & 116,54 & 116,88 & 342,10 \\
\hline Alytes obstetricans & 29TPH63 & 100,00 & 96,65 & 96,45 & 38,5 & 5119,07 & 238,28 & $-6,57$ & 244,86 & 39,94 & 164,49 & 164,55 & 35,18 & 1010,04 & 131,23 & 31,90 & 37,11 & 372,28 & 124,46 & 125,75 & 350,78 \\
\hline Alytes obstetricans & 29TPH64 & 100,00 & 101, & 95,94 & 39,16 & 5028,11 & 240,07 & $-1,63$ & 241,70 & 45,30 & 167,53 & \begin{tabular}{|l|l|}
167,73 \\
\end{tabular} & 40,68 & $\begin{array}{r}08,44 \\
986,45\end{array}$ & 127,35 & 31,77 & 36,41 & 361,41 & 123,68 & 127,55 & 337,53 \\
\hline Alytes obstetricans & 29TPH67 & 100,00 & 111,40 & 92,64 & 40,16 & 4672,44 & 240,37 & 12,48 & 227,89 & 59,48 & 172,27 & 173,21 & 54,89 & 959,28 & 123,40 & 33,20 & 34,14 & 344,70 & 127,14 & 138,91 & 313,97 \\
\hline Alytes obstetricans & 29TPH68 & 100,00 & 112,91 & 91,50 & 40,35 & 4561,33 & 239,10 & 15,52 & 223,58 & 62,99 & 172,22 & 173,42 & 57,89 & 963,04 & 124,25 & 34,13 & 33,53 & 344,15 & 129,85 & 142,22 & 311,33 \\
\hline Alytes obstetricans & 29TPH70 & 99,00 & 120,04 & 101,98 & 38,92 & 5464,69 & 267,27 & 7,93 & 259,34 & 57,30 & 191,79 & 191,79 & 52,47 & 768,84 & 101,73 & 20,23 & 40,17 & 290,06 & 85,34 & 85,34 & 274,12 \\
\hline Alytes obstetricans & 29TPH71 & 100,00 & 113,94 & 100,82 & 38,97 & 5392,16 & 260,03 & 3,76 & 256,27 & 52,37 & 184,91 & 184,91 & 47,68 & 816,87 & 107,39 & 22,93 & 39,03 & 305,75 & 94,65 & 94,65 & 287,50 \\
\hline Alyty obstetricans & \begin{tabular}{|l|}
$29 T P H 72$ \\
2
\end{tabular} & 100,00 & $\frac{1}{10}$ & $\begin{array}{r}0,02 \\
99,74\end{array}$ & 38 & 5300,89 & 251,67 & $\begin{array}{c}\frac{3,10}{-0,98} \\
\end{array}$ & $\begin{array}{l}250,27 \\
252,65\end{array}$ & 46,96 & $\begin{array}{l}176,72 \\
\end{array}$ & 176,72 & 42,12 & 876,57 & 114,23 & 26,39 & 37,74 & 324,95 & 106,04 & 106,04 & 304,42 \\
\hline Alytes obstetricans & $\begin{array}{l}\text { 29TPH73 } \\
\end{array}$ & 101,00 & 86,82 & 97,28 & 38,88 & 5179,44 & 231,19 & $-16,28$ & 247,47 & 30,10 & 155,82 & 155,92 & 25,01 & \begin{tabular}{|l|}
1044,37 \\
\end{tabular} & 133,86 & 35,11 & 35,84 & 381,04 & 134,58 & 135,46 & 358,23 \\
\hline Alytes obstetricans & 29TPH74 & 100,00 & 79,80 & 95,67 & 38,76 & 5085,43 & 222,37 & $-21,16$ & 243,53 & 24,80 & 147,66 & 147,86 & 19,67 & 1114,89 & 141,35 & 39,34 & 34,79 & 402,99 & 148,23 & 150,17 & 377,98 \\
\hline Alytes obstetricans & 29TPH78 & 100,00 & 114,42 & 92,48 & 40,65 & 4583,52 & 241,15 & 16,33 & 224,81 & 67,71 & 173,87 & 175,05 & 58,89 & 927,82 & 120,75 & 33,81 & 32,65 & 328,82 & 128,45 & 140,50 & 294,39 \\
\hline Alytes obstetricans & 29TPH81 & 99,00 & 126,87 & 102,37 & 39, & 5448,44 & 272,65 & 13,83 & 258 & 63,77 & 197,98 & 197,98 & 59, & 694,68 & 91,52 & 18,59 & 38,74 & 259,96 & 80,41 & 80,41 & 239 \\
\hline Alytes obstetricans & $\begin{array}{l}\text { 29TPH82 } \\
\text { 29T- }\end{array}$ & $\begin{array}{l}9,00 \\
99,00\end{array}$ & $\begin{array}{l}12,01 \\
115,22\end{array}$ & 101,69 & 39,04 & $\begin{array}{l}5348,444 \\
5381,48\end{array}$ & 260,87 & $\begin{array}{r}3,03 \\
4,64 \\
\end{array}$ & \begin{tabular}{|l|}
$256,23,23$ \\
\end{tabular} & $\begin{array}{ll}53,53 \\
53\end{array}$ & \begin{tabular}{|l|}
185,86 \\
185
\end{tabular} & \begin{tabular}{|l|}
185,86 \\
185
\end{tabular} & $\begin{array}{l}35,01 \\
48,75\end{array}$ & \begin{tabular}{|l|}
776,09 \\
76,09
\end{tabular} & \begin{tabular}{|l|}
1,32 \\
101,55
\end{tabular} & $\begin{array}{l}10,35 \\
22,88 \\
\end{array}$ & $\begin{array}{l}0,1 / 4 \\
37,42 \\
\end{array}$ & 287,61 & $\begin{array}{l}0,41 \\
94,74\end{array}$ & $\begin{array}{l}0,41 \\
94,74\end{array}$ & $\begin{array}{l}25,04 \\
265,39\end{array}$ \\
\hline Alytes obstetricans & 29TPH84 & 99,00 & 84,45 & 98,01 & 39,11 & 5161,57 & 228,83 & $-18,65$ & 247,48 & 28,14 & 153,10 & 153,23 & 22,80 & 1035,10 & 131,26 & 37,17 & 34,15 & 372,30 & 140,47 & 142,00 & 346,19 \\
\hline Alytes obstetricans & 29TPH93 & 101,00 & 107,31 & 102,32 & 39,65 & 5336,26 & 253,68 & $-1,99$ & 255,66 & 46,81 & 177,48 & 177,48 & 41,85 & 807,54 & 105,61 & 26,68 & 35,10 & 293,24 & 106,52 & 106,52 & 267,56 \\
\hline Alytes obstetricans & 29TPH94 & 100,00 & 95,70 & 100,75 & 39,7 & 5221,88 & 241,01 & $-10,36$ & 251,37 & 37,77 & 164 & 164 & 32,52 & 909,10 & 117,19 & 32,61 & 33 & 325,71 & 125,11 & 125,58 & 298 \\
\hline Alytes obstetricans & 29TPH99 & 100,00 & 108,61 & 94,29 & 41,21 & 4552,55 & 236,75 & 10,74 & 226,01 & 78,20 & 167,68 & 168,99 & 53,66 & 937,18 & 23,02 & 37,91 & 30,22 & 325,54 & 140,37 & 151,17 & 284,43 \\
\hline
\end{tabular}





\begin{tabular}{|c|c|c|c|c|c|c|c|c|c|c|c|c|c|c|c|c|c|c|c|c|c|}
\hline TAXON & UTM & $\mathrm{km2}$ & B101 & $\mathrm{B1O2}$ & $\mathrm{BIO3}$ & B104 & B105 & B106 & B107 & B108 & B109 & 81010 & B1011 & B1012 & B1013 & 81014 & B1015 & B1O16 & B1017 & B1018 & B1019 \\
\hline Alytes obstetricans & 29тQH49 & 36,00 & 119,17 & 96,75 & 43,23 & 4295,38 & 243,54 & 22,00 & 221,54 & 96,79 & 173,94 & 176,08 & 67,15 & 850,54 & 115,13 & 41,21 & 27,98 & 287,88 & 146,23 & 154,65 & 224,27 \\
\hline Alytes obstetricans & 29TQJ00 & 100,00 & 113,08 & 92,84 & 41,78 & \begin{tabular}{ll|}
4381,67 \\
\end{tabular} & 236,87 & 17,31 & 219,56 & 88,49 & 169,52 & 171,28 & 60,21 & 922,77 & 122,26 & 39,35 & 29,15 & 317,84 & 143,82 & 154,93 & 269,66 \\
\hline Alytes obstetricans & 29TQJ11 & 99,00 & 116,27 & 91,42 & 42,38 & 4195,11 & 235,68 & 22,75 & 212,93 & $\begin{array}{l}93,97 \\
93,9\end{array}$ & 169,88 & 172,19 & 65,80 & 923,49 & 123,35 & 41,56 & 28,29 & 315,14 & \begin{tabular}{|l|l|}
149,59 \\
\end{tabular} & 160,54 & 260,00 \\
\hline Alytes obstetricans & 29TOJ21 & 99,00 & 125,99 & 89,26 & 42,98 & 4019,27 & 239,73 & 34,48 & 205,25 & 105,42 & 176,76 & 179,55 & 77,59 & 879,09 & 119,14 & 40,58 & 28,35 & 298,48 & 145,41 & 156,50 & 237,74 \\
\hline Alytes obstetricans & 29TQJ32 & 74,00 & 134,23 & 83,35 & 43,00 & 3796,84 & 238,70 & 46,89 & \begin{tabular}{|l|l|}
191,82 \\
\end{tabular} & 116,10 & 181,84 & 185,14 & 88,38 & 858,30 & 117,33 & 40,27 & 28,58 & 290,85 & \begin{tabular}{ll|}
144,00 \\
\end{tabular} & 156,31 & 226,00 \\
\hline Alytes obstetricans & 30 SVK21 & 100,00 & 149,35 & 112,96 & 35,06 & 6871,38 & 332,62 & 16,78 & 315,84 & 105,12 & 241,92 & 241,92 & 65,45 & 392,59 & 44,66 & 7,59 & 37,04 & 129,84 & 41,85 & 41,85 & 111,98 \\
\hline Alytes obstetricans & 30SVK31 & 100,00 & 146,79 & 113,32 & 35,32 & 6849,82 & 330,11 & 14,84 & 315,27 & 102,71 & 238,96 & 238,96 & 63,23 & 403,49 & 45,93 & 7,89 & 37,22 & 134,38 & 42,99 & 42,99 & 115,95 \\
\hline Alytes obstetricans & \begin{tabular}{|l|}
$305 V K 41$ \\
\end{tabular} & 100,00 & 142,28 & 113,99 & 35,88 & 6815,05 & 326,08 & 11,25 & 314,82 & \begin{tabular}{|l|}
98,38 \\
98,
\end{tabular} & 234,01 & 234,01 & 59,56 & 419,66 & 47,72 & 8,47 & 36,83 & 139,45 & 45,42 & 45,42 & 120,79 \\
\hline Alytes obstetricans & 30SVK50 & 100,00 & 141,80 & 116,19 & 36,00 & 6809,98 & 326,92 & 9,91 & 317,01 & 98,08 & 233,49 & 233,49 & 59,15 & 420,79 & 47,14 & 8,24 & 36,94 & 138,66 & 45,49 & 45,49 & 120,36 \\
\hline Alytes obstetricans & 30SVK51 & 100,00 & 137,96 & 114,91 & 36,00 & 6787,16 & 322,16 & 7,38 & 314,78 & 94,31 & 229,40 & 229,40 & 55,82 & 434,20 & 49,43 & 9,05 & 36,12 & 143,43 & 48,20 & 48,20 & 124,39 \\
\hline Alytes obstetricans & 30SVK52 & 100,00 & 137,69 & 113,25 & 35,91 & 6776,92 & 320,43 & 7,99 & 312,44 & 94,01 & 228,81 & 228,81 & 55,47 & 436,55 & 50,94 & 9,66 & 36,10 & 146,20 & 49,04 & 49,04 & 125,81 \\
\hline Alytes obstetricans & 30SVK60 & 100,00 & 139,02 & 116,75 & 36,24 & 6777,45 & 324,12 & 7,48 & 316,64 & 95,39 & 230,31 & 230,31 & 57,01 & 429,71 & 48,00 & 8,84 & 36,29 & 140,55 & 47,74 & 47,74 & 121,94 \\
\hline Alytes obstetricans & 30SVK62 & 100,00 & 135,78 & 114,25 & 36,00 & 6753,80 & 318,47 & 6,13 & 312,34 & 92,13 & 226,51 & 226,51 & 53,86 & 441,54 & 51,41 & 9,88 & 35,40 & 147,05 & 50,42 & 50,42 & 126,23 \\
\hline Alytes obstetricans & 30SVK70 & 100,00 & 136,90 & 117,44 & 36,87 & 6761,28 & 321,82 & 5,38 & 316,44 & 93,44 & 227,84 & 227,84 & 55,18 & 435,76 & 48,33 & 9,24 & 35,39 & 141,32 & 50,07 & 50,07 & 122,33 \\
\hline Alytes obstetricans & 30SVK71 & 100,00 & 134,83 & 116,33 & 36,39 & 6746,15 & 318,93 & 4,34 & 314,59 & 91,50 & 225,55 & 225,55 & 53,50 & 441,65 & 49,72 & 9,93 & 35,16 & 143,91 & 51,44 & 51,44 & 124,45 \\
\hline Alytes obstetricans & 30SVK72 & 100,00 & 135,36 & 114,94 & 36,16 & 6738,88 & 317,93 & 5,55 & 312,38 & 91,84 & 225,73 & 225,73 & 53,86 & 439,48 & 50,73 & 10,01 & 35,34 & 145,48 & 51,10 & 51,10 & 124,22 \\
\hline Alytes obstetricans & 30SVK92 & 100,00 & 130,35 & 116,84 & 37,00 & 6687,69 & 312,98 & 0,40 & 312,58 & 87,72 & 220,08 & 220,08 & 49,64 & 452,51 & 50,42 & 11,47 & 33,09 & 143,81 & 57,44 & 57,44 & 123,53 \\
\hline Alytes obstetricans & 30SWH54 & 100,00 & 131,29 & 120,31 & 38,04 & 6476,47 & 312,01 & 1,13 & 310,89 & 110,88 & 218,81 & 218,99 & 54,62 & 468,32 & 60,97 & 10,81 & 36,17 & 161,00 & 56,14 & 56,56 & 124,16 \\
\hline Alytes obstetricans & 30SWJ52 & 100,00 & 133,79 & 122,73 & 38,44 & 6540,52 & 316,21 & 1,21 & 315,00 & 115,63 & 221,32 & 221,88 & 55,37 & 436,92 & 53,67 & 10,58 & 33,69 & 148,18 & 56,80 & 61,01 & 107,97 \\
\hline Alytes obstetricans & 30 SWJ63 & 100,00 & 139,42 & 121,88 & 38,66 & 6476,65 & 318,48 & 6,85 & 311,63 & 121,98 & 225,89 & 226,30 & 61,45 & 407,33 & 49,67 & 10,00 & 33,82 & 136,73 & 54,03 & 58,35 & 97,93 \\
\hline Alytes obstetricans & 30SWJ71 & 100,00 & 140,99 & 121,03 & 38,99 & 6405,53 & 317,45 & 9,01 & 308,44 & 123,35 & 226,69 & 227,11 & 64,01 & 396,14 & 51,00 & 9,06 & 35,01 & 133,14 & 52,21 & 56,97 & 93,13 \\
\hline Alytes obstetricans & 30SWJ72 & 100,00 & 140,90 & 121,02 & 38,99 & 6413,58 & 317,47 & 8,82 & 308,65 & 123,37 & 226,51 & 227,22 & 63,86 & 397,18 & 50,02 & 9,66 & 34,19 & 132,86 & 53,63 & 58,14 & 92,94 \\
\hline Alytes obstetricans & 30SWJ73 & 100,00 & 139,85 & 121,01 & 38,91 & 6432,06 & 316,79 & 7,47 & 309,32 & 122,52 & 225,70 & 226,13 & 62,48 & \begin{tabular}{|l|l|}
401,63 \\
\end{tabular} & 49,43 & 10,00 & 33,68 & 134,13 & 54,66 & 59,55 & 93,92 \\
\hline Alytes obstetricans & 30 SWJ83 & 100,00 & 140,19 & 120,33 & 38,96 & 6376,46 & 314,89 & 8,38 & 306,51 & 130,22 & 225,23 & 225,65 & 63,33 & 396,96 & 49,09 & 10,11 & 33,46 & 131,78 & 55,82 & 61,02 & 90,37 \\
\hline Alytes obstetricans & 30 SWJ84 & 100,00 & 138,64 & 120,26 & 38,88 & 6389,12 & 313,60 & 6,79 & 306,81 & 121,05 & 223,71 & 224,19 & 61,56 & 405,77 & 48,75 & 10,81 & 32,57 & 134,10 & 57,99 & 63,25 & 92,36 \\
\hline Alytes obstetricans & 30SWJ90 & 100,00 & 141,90 & 119,98 & 39,00 & 6294,25 & 314,21 & 10,86 & 303,35 & 158,90 & 226,03 & 226,10 & 66,03 & 387,29 & 51,81 & 9,47 & 35,49 & 131,19 & 53,06 & 58,49 & 86,56 \\
\hline Alytes obstetricans & 30SWJ91 & 100,00 & 142,76 & 119,69 & 39,00 & 6296,21 & 314,50 & 11,69 & 302,81 & 159,82 & 226,60 & 226,88 & 60,62 & 383,25 & 50,56 & 9,65 & $\begin{array}{l}35,45 \\
35,45\end{array}$ & 130,12 & 53,18 & 58,84 & 84,64 \\
\hline Alytes obstetricans & 30SWK12 & 100,00 & 124,11 & 119,03 & 37,44 & 6643,19 & 307,64 & $-5,88$ & 313,52 & 107,91 & 212,52 & 213,62 & 44,65 & 474,90 & 54,89 & 13,53 & 31,11 & 151,70 & 64,56 & 66,55 & 125,21 \\
\hline Alytes obstetricans & 30SWK42 & 100,00 & 118,96 & 122,49 & 38,00 & 6575,44 & 303,35 & $-13,16$ & 316,51 & 102,26 & 206,49 & 207,52 & 40,20 & 504,10 & 60,59 & 16,25 & 29,16 & 165,07 & 74,16 & 79,16 & 127,66 \\
\hline Alytes obstetricans & 30SWK50 & 100,00 & 125,16 & 123,33 & 38,37 & 6553,50 & 308,84 & $-7,75$ & 316,59 & 108,28 & 212,31 & 213,35 & 46,30 & 480,84 & 57,70 & 14,56 & 29,73 & 158,89 & 69,96 & 74,75 & 119,88 \\
\hline Alytes obstetricans & 30SWK52 & 100,00 & 116,43 & 123,60 & 38,21 & 6551,48 & 301,21 & $-16,38$ & 317,58 & 99,40 & 203,56 & 204,86 & 37,84 & 519,30 & 63,09 & 17,45 & 28,70 & 171,20 & 78,46 & 84,58 & 129,87 \\
\hline Alytes obstetricans & 30SWK62 & 100,00 & 118,32 & 124,13 & 38,55 & 6525,96 & 302,51 & $\begin{array}{l}-15,08 \\
-15,0\end{array}$ & \begin{tabular}{|l|l|}
317,60 \\
\end{tabular} & \begin{tabular}{|l|}
101,30 \\
\end{tabular} & \begin{tabular}{|l|}
205,01 \\
\end{tabular} & 206,36 & \begin{tabular}{l|l|}
39,88 \\
3
\end{tabular} & 514,53 & 63,03 & $\begin{array}{l}1,4,47 \\
17,4\end{array}$ & 28,62 & $\begin{array}{l}170,18 \\
170\end{array}$ & 79,20 & $\begin{array}{l}84,50 \\
85,58\end{array}$ & 127,06 \\
\hline Alytes obstetricans & $30 \mathrm{SXH} 08$ & 100,00 & 135,18 & 119,70 & 39,00 & 6288,88 & 307,47 & 4,86 & 302,62 & 115,81 & 219,69 & 219,73 & 60,03 & 424,28 & 56,12 & 11,18 & 34,43 & 140,84 & 59,71 & 61,71 & 96,69 \\
\hline Alytes obstetricans & $30 \mathrm{SXH35}$ & 100,00 & 153,01 & 118,34 & 40,13 & 5995,92 & 314,72 & 22,88 & 291,85 & 122,76 & 232,63 & 233,05 & 80,42 & 373,44 & 50,75 & 7,56 & 38,94 & 123,15 & 45,81 & 51.91 & 86,98 \\
\hline Alytes obstetricans & $30 \mathrm{~S} \times \mathrm{H} 36$ & 100,00 & 146,88 & 117,98 & 40,00 & 6050,49 & 310,16 & 17,26 & 292,90 & 125,80 & 227,36 & 228,03 & 74,01 & 395,32 & 51,84 & 9,04 & 36,91 & 127,41 & 52,43 & 56,84 & 90,37 \\
\hline Alytes obstetricans & $\begin{array}{l}30 \mathrm{SXH} 37 \\
\end{array}$ & 100,00 & 143,78 & 117,68 & 39,80 & 6078,03 & 307,79 & 14,75 & 293,04 & 125,21 & 224,82 & 225,29 & 70,81 & 406,04 & 52,48 & 9,99 & 35,65 & 130,06 & 56,65 & 59,47 & 91,44 \\
\hline Alyty obstetricans & 30SXH44 & 100,00 & $\begin{array}{l}1458,30 \\
158,34\end{array}$ & $\begin{array}{l}11,00 \\
118,55\end{array}$ & $\frac{15,00}{40,55}$ & 5904,42 & 317,16 & 28,03 & $\begin{array}{l}285,144 \\
289,14\end{array}$ & \begin{tabular}{|l|}
126,46 \\
12,1
\end{tabular} & $\begin{array}{l}\mid 234,0<4 \\
236,41\end{array}$ & 237,12 & $\begin{array}{l}0,10 \\
86,62\end{array}$ & $\begin{array}{l}300,04 \\
359,19\end{array}$ & $\begin{array}{l}32,40 \\
51,39\end{array}$ & $\begin{array}{l}3,393 \\
6,35 \\
\end{array}$ & $\begin{array}{l}3,001 \\
41,01\end{array}$ & \begin{tabular}{|l|}
122,340 \\
120
\end{tabular} & $\begin{array}{l}30,051 \\
40,51\end{array}$ & 50,44 & $\begin{array}{l}1,1,44 \\
84,57\end{array}$ \\
\hline Alytes obstetricans & $30 \mathrm{SXH} 45$ & 100,00 & 153,31 & 117,88 & 40,10 & 5951,01 & 313,14 & 23,56 & 289,58 & 127,44 & 232,03 & 232,93 & 81,24 & 378,31 & 52,56 & 7,68 & 38,99 & 126,14 & 46,28 & 54,47 & 87,53 \\
\hline Alytes obstetricans & $30 \mathrm{~S} \times \mathrm{H} 46$ & 100,00 & 148,49 & 117,36 & 39,99 & 5991,87 & 309,28 & 19,41 & 289,87 & 148,49 & 227,92 & 228,73 & 76,22 & 396,39 & 53,53 & 9,01 & 37.29 & $\mid 129,54$ & 51,91 & 58,53 & 90,28 \\
\hline Alytes obstetricans & $30 \mathrm{SXH} 47$ & 100,00 & 139,29 & 116,61 & 39,69 & 6063,79 & 302,22 & 11,19 & 291,03 & 128,43 & 220,07 & 220,89 & 66,78 & 433,17 & 55,26 & 11,52 & 34,49 & 137,38 & 62,04 & 65,94 & 97,50 \\
\hline Alytes obstetricans & $30 \mathrm{~S} \times \mathrm{H} 48$ & 100,00 & 137,41 & 116,19 & 39,42 & 6078,15 & 300,53 & 9,62 & 290,91 & 130,16 & 218,48 & 219,18 & 64,59 & 439,88 & 55,64 & 12,19 & 33,73 & 139,74 & 65,08 & 68,10 & 97,91 \\
\hline Alytes obstetricans & $30 \mathrm{SXH54}$ & 100,00 & 156,87 & 117,74 & 40, & 5866,33 & 314,06 & \begin{tabular}{|l|l}
27,24 \\
27
\end{tabular} & 286,82 & 133,13 & 234,34 & 235,11 & 85,81 & 370,83 & 53,79 & 6,99 & 40,52 & 127,31 & 42,57 & 53,45 & 86,72 \\
\hline Alytes obstetricans & $30 \mathrm{SXH55}$ & 100,00 & 149,62 & 116,87 & 40,09 & 5924,36 & 308,35 & 21,08 & 287,27 & 144,40 & 228,17 & 229,04 & 78,28 & 401,15 & 55,61 & 8,96 & 37,98 & 133,87 & 50,79 & 59,59 & 92,51 \\
\hline Alytes obstetricans & $30 \mathrm{SXH56}$ & 100,00 & 146,71 & 116,34 & 40,01 & 5950,56 & 305,92 & 18,71 & 287,21 & 155,11 & 225,60 & 226,49 & 75,18 & 411,71 & 56,05 & 9,79 & 36,74 & 135,81 & 54,56 & 62,28 & 93,67 \\
\hline Alytes obstetricans & 30SXH57 & 100,00 & 141,69 & 115,62 & 39,89 & 5984,79 & 301,64 & \begin{tabular}{ll|}
14,37 \\
\end{tabular} & 287,27 & 151,79 & 221,27 & 222,22 & 69,91 & 432,56 & 57,13 & 11,32 & 34,87 & 140,41 & 60,76 & 66,92 & 97,39 \\
\hline Alytes obstetricans & 30SXH58 & 100,00 & 142,56 & 115,13 & $\begin{array}{l}39, \\
39,\end{array}$ & $\begin{array}{l}5982,00 \\
\end{array}$ & 301,7 & 15,49 & 286,25 & 152,41 & 222,02 & 222,81 & 70,77 & $\begin{array}{l}428,47 \\
428,47\end{array}$ & 56,95 & 11,2 & 34,88 & \begin{tabular}{|l|l|}
140,04 \\
\end{tabular} & 61,05 & 67,12 & 95,49 \\
\hline Alytes obstetricans & $30 \mathrm{SXH59}$ & 100,00 & 135,55 & 114,40 & 39,23 & 6036,75 & 296 & 9,44 & 286,77 & 145,05 & 215,97 & 216,92 & 63,60 & 456,20 & 57,92 & 13,4 & 32,73 & 145,29 & 69,34 & 73,31 & 100,69 \\
\hline Alytes obstetricans & 30 SXH64 & 100,00 & 151,17 & 116,24 & 40,11 & 5860,56 & 307,67 & 23,06 & 284,61 & 137,29 & 228,65 & 229,75 & 80,54 & 401,33 & 57,18 & 8,61 & 38,69 & 137,03 & 48,79 & 59,51 & 93,54 \\
\hline Alytes obstetricans & $30 \mathrm{~S} \times \mathrm{H} 65$ & 100,00 & 144,24 & 115,33 & 39,92 & 5911,52 & 302,10 & 17,10 & 285,01 & 139,66 & 222,62 & 223,77 & 73,39 & 432,05 & 58,99 & 10,63 & 36,29 & 143,74 & 56,97 & 65,91 & 99,61 \\
\hline Alytes obstetricans & $30 \mathrm{~S} \times \mathrm{H} 66$ & 100,00 & 149,38 & 115,34 & 40,01 & 5874,64 & 305,55 & 22,10 & 283,45 & 159,56 & 227,07 & 228,18 & 78,64 & 410,53 & 58,13 & 9,49 & 37,49 & 9,62 & 53,10 & 63,02 & 93,43 \\
\hline Alytes obstetricans & $\begin{array}{l}30 \mathrm{~S} \times \mathrm{H} 6 \mathrm{67} \\
\end{array}$ & 100,00 & $\begin{array}{l}14,30,41 \\
149,4\end{array}$ & 114 & $\begin{array}{l}40, \\
40,\end{array}$ & \begin{tabular}{|l|}
5872,88 \\
587
\end{tabular} & 305,05 & 22,55 & \begin{tabular}{|l|}
282,49 \\
282,49
\end{tabular} & \begin{tabular}{|l|}
159,75 \\
159,0
\end{tabular} & $\mid 227,07$ & $\mid \begin{array}{l}\mid 228,20 \\
2280\end{array}$ & 78,63 & $\begin{array}{l}410,25 \\
411,25 \\
\end{array}$ & 58,21 & $\begin{array}{l}3,49 \\
9,72\end{array}$ & $\begin{array}{l}37,44 \\
37,14\end{array}$ & \begin{tabular}{|l|}
$140,16<$ \\
140
\end{tabular} & 54,33 & $\begin{array}{l}03,0< \\
63,98\end{array}$ & $\begin{array}{l}52,45 \\
92,81\end{array}$ \\
\hline Alytes obstetricans & $305 \times H 68$ & 100,00 & 142,02 & 113,82 & 39,87 & 5933,72 & 298,99 & 16,03 & 282,95 & 152,27 & 220,73 & 221,85 & 70,98 & 441,90 & 59,60 & 11,88 & 34,58 & 146,62 & 62,88 & 70,57 & 98,86 \\
\hline Alytes obstetricans & $305 \times H 69$ & 100,00 & 134,60 & 112,94 & 39,23 & 5987,64 & 292,94 & 9,47 & 283,47 & $|144,47|$ & 214,34 & 215,40 & $\mid 63,29$ & $|472,17|$ & $60,75 \mid$ & $\mid 14,14$ & 32,32 & $\mid 152,42$ & 71,63 & $|77,29|$ & 104,75 \\
\hline Alytes obstetricans & 30 SXH75 & 100,00 & 149,40 & 114,43 & 40,08 & 5814,46 & 303,77 & 22,72 & 281,06 & 156,23 & 226,13 & 227,51 & 79,30 & 419,80 & 60,28 & 9,59 & 37,78 & 144,82 & 52,92 & 64,41 & 96,90 \\
\hline Alytes obstetricans & $30 \mathrm{~S} \times \mathrm{H} 76$ & 100,00 & 142,36 & 113,50 & 39,83 & 5868 & 297,99 & 16,76 & 281,22 & 146,74 & 220,05 & 221,49 & 72,16 & 452,18 & 61,99 & 11,76 & 35,44 & 151,84 & 61,42 & 71,16 & 103 \\
\hline Alytes obstetricans & 30 XNH87 & 100,00 & 153,86 & 111,85 & 40,23 & 5709,21 & 303,69 & 29,32 & \begin{tabular}{l|l}
274,37 \\
\end{tabular} & 165,01 & 228,82 & 230,47 & 85,08 & 419,51 & 63,23 & 9,43 & 38,86 & $\begin{array}{l}151,08 \\
15\end{array}$ & 52,95 & 66,84 & 95,90 \\
\hline Alytes obstetricans & $30 \mathrm{~S} \times \mathrm{H} 89$ & 100,00 & 148,21 & 110,09 & 39,95 & 5750,68 & 298,07 & 25,22 & 272,85 & 159,33 & 223,96 & 225,60 & 79,03 & 446,46 & 64,77 & 11,42 & 36,43 & 157,67 & 60,70 & 73,58 & 101,23 \\
\hline Alytes obstetricans & $30 \mathrm{SXH} 90$ & 100,00 & 179,64 & 110,48 & 41,03 & 5337,68 & 320,01 & 54,99 & 265,02 & 160,94 & 248,46 & 250,44 & 113,81 & 293,90 & 55,32 & 3,97 & 53,07 & 124,36 & 24,82 & 41,74 & 71,05 \\
\hline Alytes obstetricans & 30SXH94 & 100,00 & 170,06 & 112,04 & 41,00 & 5492,12 & 314,73 & 44,80 & 269, & 182,2 & 241, & 243 & 103,08 & 350,82 & 60,63 & 5,69 & 46,96 & 138,28 & 36,41 & 53,73 & 80,22 \\
\hline Alytes obstetricans & $30 \mathrm{SXH95}$ & 100,00 & 162,30 & 111,57 & 40,77 & 5574,44 & 308,95 & 37,72 & 271,23 & 172,71 & 235,08 & 237,00 & 94,60 & \begin{tabular}{|c|}
89,55 \\
\end{tabular} & 62,99 & 7,53 & 43,21 & 147,42 & 44,34 & 60,79 & 89, \\
\hline
\end{tabular}




\begin{tabular}{|c|c|c|c|c|c|c|c|c|c|c|c|c|c|c|c|c|c|c|c|c|c|}
\hline TAXON & UTM & $\mathrm{km} 2$ & B101 & B102 & $\mathrm{BIO3}$ & B104 & B105 & B106 & B107 & B108 & B109 & BIO10 & BIO11 & BIO12 & B1013 & BIO14 & BIO15 & B1016 & B1017 & 81018 & B1019 \\
\hline Alytes obstetricans & 30SXH96 & 100,00 & 148,28 & 110,82 & 40,10 & 5709,03 & 298,50 & 24,74 & 273,76 & 156,32 & 223,42 & 225,22 & 79,91 & 452,91 & 66,12 & 10,99 & 37,57 & 160,68 & 58,26 & 72,30 & 105,57 \\
\hline Alytes obstetricans & 30SXH97 & 100,00 & 140,39 & 109,89 & \begin{tabular}{|l|l|}
39,67 \\
\end{tabular} & 5779,53 & 292,01 & 17,73 & 274,28 & 148,18 & 216,67 & 218,58 & 71,50 & 489,68 & 67,88 & 13,31 & 34,66 & 168,39 & 67,32 & 79,84 & 113,96 \\
\hline Alytes obstetricans & 30 XH98 & 100,00 & 144,32 & 109,36 & 39,72 & 5737,64 & 294,20 & 22,01 & 272,20 & 155,50 & 219,91 & 221,75 & 75,75 & 475,68 & 67,75 & 12,47 & 35,70 & 166,80 & 64,63 & 78,26 & 110,11 \\
\hline Alytes obstetricans & 30SXH99 & 100,00 & 142,93 & 108,45 & 39,56 & 5746,21 & 292,33 & 21,17 & 271,16 & 154,30 & 218,71 & 220,58 & 74,29 & 482,94 & 68,26 & 13,15 & 34,97 & 168,86 & 67,18 & 80,69 & 111,19 \\
\hline Alytes obstetricans & $305 \times 103$ & 100,00 & 141,64 & 118,23 & 39,00 & \begin{tabular}{|l|l|}
6262,27 \\
\end{tabular} & 311,12 & 11,56 & 299,56 & 159,29 & 225,27 & 225,43 & 66,05 & 391,23 & 48,32 & 10,75 & 33,55 & 129,99 & 58,16 & 62,01 & 85,15 \\
\hline Alytes obstetricans & $305 \times J 27$ & 100,00 & 135,49 & 113,62 & 38,55 & 6222,47 & 299,38 & 8,49 & 290,89 & 153,20 & 218,48 & 218,69 & 60,57 & 418,58 & 49,97 & 14,38 & 29,99 & 134,59 & 71,86 & 73,58 & 87,35 \\
\hline Alytes obstetricans & $305 \times 129$ & 100,00 & 126,43 & 112,75 & 38,00 & 6289,60 & 291,53 & 0,37 & 291,16 & 144,61 & 210,27 & 210,82 & 51,06 & 446,32 & 55,21 & 17,49 & 28,18 & 145,12 & 80,79 & 84,38 & 91,66 \\
\hline Alytes obstetricans & $305 \times 131$ & 100,00 & 124,68 & 115,86 & 39,00 & 6219,28 & 292,20 & $-1,71$ & 293,91 & 124,81 & 208,66 & 208,66 & 51,00 & 481,85 & 57,84 & 16,12 & 30,18 & 154,47 & 78,00 & 78,19 & 104,80 \\
\hline Alytes obstetricans & $305 \times 133$ & 100,00 & 139,47 & 114,34 & 39,00 & 6115,22 & 301,54 & 12,79 & 288,75 & 155,04 & 221,14 & 221,32 & 65,93 & 416,18 & 51,27 & 12,63 & 32,18 & 132,69 & 67,44 & 67,82 & 88,33 \\
\hline Alytes obstetricans & $305 \times 135$ & 100,00 & 142,52 & 112,52 & 39,00 & \begin{tabular}{|l|l|}
6093,07 \\
\end{tabular} & 302,14 & 16,90 & 285,25 & 155,35 & 223,78 & 223,99 & 69,16 & 403,19 & 50,40 & 12,57 & 31,85 & 129,24 & 66,36 & 67,54 & 84,77 \\
\hline Alytes obstetricans & $305 \times 137$ & 100,00 & 129,43 & 112,05 & 38,30 & 6210,37 & 291,93 & 4,19 & 287,74 & 146,47 & 212,47 & 212,64 & 55,10 & 445,05 & 52,90 & 16,54 & 28,95 & 142,84 & 79,29 & 80,87 & 91,56 \\
\hline Alytes obstetricans & $305 \times 138$ & 100,00 & 124,98 & 111,35 & 38,03 & 6245,07 & 288,08 & 0,40 & 287,68 & 142,25 & 208,58 & 208,88 & 50,44 & 457,55 & 55,49 & 18,08 & 28,18 & 147,89 & 83,66 & 86,22 & 93,11 \\
\hline Alytes obstetricans & $305 \times 139$ & 100,00 & 119,33 & 110,82 & 38,00 & 6279,90 & 283,03 & $-4,71$ & 287,74 & 136,68 & 203,39 & 203,80 & 44,63 & 475,85 & 58,88 & 20,06 & 27,44 & 155,07 & 89,13 & 93,15 & 96,12 \\
\hline Alytes obstetricans & $305 \times 341$ & 100,00 & 129,09 & 114,49 & 39,00 & 6139,06 & 292,84 & 3,12 & 289,71 & 128,17 & 211,46 & 211,85 & 56,24 & 470,14 & 56,35 & 15,28 & 30,65 & 147,94 & 76,71 & 77,18 & 101,78 \\
\hline Alytes obstetricans & $305 \times 144$ & 100,00 & 140,11 & 111,85 & 39,00 & 6047,78 & 298,26 & 15,07 & 283,19 & 148,88 & 220,62 & 221,10 & 67,41 & 421,24 & 53,22 & 13,29 & 31,82 & 134,69 & 69,05 & 71,11 & 88,64 \\
\hline Alytes obstetricans & $305 \times 145$ & 100,00 & 147,24 & 110,23 & 39,00 & 5982,31 & 301,92 & 23,03 & 278,89 & 156,40 & 226,66 & 227,11 & 74,90 & 395,45 & 52,44 & 11,97 & 33,08 & 130,62 & 63,16 & 67,46 & 82,81 \\
\hline Alytes obstetricans & $305 \times 146$ & 100,00 & 140,77 & 109,92 & 38,90 & 6050,06 & 297,10 & 16,81 & 280,29 & 150,23 & 221,32 & 221,66 & 67,97 & 413,15 & 52,03 & 13,81 & 31,29 & 132,51 & 70,02 & 72,27 & 85,21 \\
\hline Alytes obstetricans & $305 \times 148$ & 100,00 & 126,77 & 109,15 & 38,01 & 6183,54 & 286,05 & 3,45 & 282,60 & 143,61 & 209,52 & 209,62 & 52,92 & 454,79 & 54,45 & 18,17 & 28,26 & 145,25 & 84,73 & 85,71 & 91,40 \\
\hline Alytes obstetricans & 305XJ51 & 100,00 & 133,18 & 112,97 & 39,00 & 6048,94 & 293,03 & 8,12 & 284,91 & 139,41 & 213,86 & 214,76 & 61,01 & 463,61 & 57,82 & 14,67 & 31,29 & 146,88 & 74,18 & 77,11 & 100,44 \\
\hline Alytes obstetricans & $305 \times 152$ & 100,00 & 129,60 & 112,21 & 38,96 & 6071,79 & 289,74 & 5,25 & 284.49 & $\mid 131,89$ & 210,86 & 211,45 & 57,43 & 478,03 & 58,38 & $\mid 16,09$ & 30,25 & $\mid 151.48$ & 78,93 & 81,26 & 102,80 \\
\hline Alytes obstetricans & $305 \times 153$ & 100,00 & 132,83 & 111,44 & 38,99 & 6054,51 & 291,36 & 8,81 & 282,55 & 143,03 & 213,66 & 214,39 & 60,61 & 461,08 & 57,05 & 15,37 & 30,49 & 146,18 & 76,52 & 79,16 & 98,14 \\
\hline Alytes obstetricans & $305 \times 154$ & 100,00 & 138,76 & 110,19 & 39,02 & 6004,92 & 294,48 & \begin{tabular}{r|r|}
15,13 \\
\end{tabular} & 279,34 & 147,93 & 218,64 & 219,31 & $\begin{array}{l}66,72 \\
66,7\end{array}$ & 435,97 & 55,88 & 14,11 & 31,42 & 141,36 & 71,40 & 75,39 & 91,89 \\
\hline Alytes obstetricans & $305 \times 155$ & 100,00 & 148,64 & 108,27 & 39,01 & 5905,81 & 299,69 & 25,99 & 273,70 & 157,78 & 226,81 & 227,51 & 77,32 & 400,95 & 55,10 & 12,10 & 33,61 & 136,10 & 62,95 & 69,85 & 84,22 \\
\hline Alytes obstetricans & $305 \times 156$ & 100,00 & 142,36 & 107,81 & 38,90 & 5975,50 & 294,88 & 20,05 & 274,84 & 151,12 & 221,59 & 222,31 & 70,39 & 417,13 & 54,42 & 13,94 & 31,68 & 137,42 & 69,68 & 74,75 & 86,15 \\
\hline Alytes obstetricans & $305 \times 157$ & 100,00 & 135,43 & 107,41 & 38,28 & 6046,96 & 289,62 & 13,45 & 276,17 & 144,99 & 215,97 & 216,39 & 62,89 & 435,39 & 53,66 & 15,97 & 29,95 & 139,20 & 77,11 & 80,02 & 88,35 \\
\hline Alytes obstetricans & $305 \times 158$ & 100,00 & 127,50 & 106,93 & \begin{tabular}{|l|l|}
37,98 \\
\end{tabular} & 6110,70 & 283,45 & 5,91 & 277,54 & 142,05 & 209,36 & 209,55 & 54,73 & 458,52 & 54,60 & 18,52 & 28,35 & 144,68 & 85,95 & 86,95 & 91,62 \\
\hline Alytes obstetricans & $305 \times 159$ & 100,00 & 120,95 & 106,30 & 37,90 & 6167,78 & $\begin{array}{l}27,47,81 \\
277\end{array}$ & 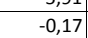 & 277,97 & $\begin{array}{l}137,32 \\
13,\end{array}$ & 163,31 & \begin{tabular}{|l|}
203,76 \\
\end{tabular} & 47,78 & \begin{tabular}{|l|l|}
477,04 \\
\end{tabular} & 57,77 & 20,75 & 27,53 & $\begin{array}{l}152,52 \\
\end{array}$ & $\begin{array}{l}92,88 \\
92,0\end{array}$ & $\begin{array}{l}93,98 \\
93,9\end{array}$ & 93,77 \\
\hline Alytes obstetricans & $305 \times 161$ & 100,00 & 137,99 & 111,40 & 39,21 & 5952,97 & 293,82 & 13,92 & 279,90 & 147,24 & 217,15 & 218,16 & 66,81 & 456,65 & 59,88 & 13,80 & 32,50 & 149,99 & 70,42 & 76,63 & 99,55 \\
\hline Alytes obstetricans & $305 \times 162$ & 100,00 & 140,55 & 110,31 & 39,25 & 5927,19 & 294,52 & 17,05 & 277,47 & 150,31 & 219,21 & 220,26 & 69,46 & 446,74 & 59,58 & 13,52 & 32,87 & 148,61 & 69,04 & 75,92 & 96,71 \\
\hline Alytes obstetricans & $305 \times 163$ & 100,00 & 144,75 & 109,03 & 39,27 & 5877,77 & 296,22 & 22,16 & 274,06 & 154,58 & 222,55 & 223,61 & 74,08 & 430,61 & 59,06 & 12,83 & 33,59 & $\begin{array}{l}146,08 \\
\end{array}$ & 66,01 & 74,06 & 92,64 \\
\hline Alytes obstetricans & $305 \times 164$ & 100,00 & 149,53 & 107,54 & 39,27 & 5826,07 & 298,32 & 27,84 & 270,48 & 159,32 & 226,47 & 227,62 & 79,22 & 412,81 & 58,55 & 12,10 & 34,66 & 143,23 & 62,50 & 71,75 & 88,25 \\
\hline Alytes obstetricans & $305 \times 165$ & 100,00 & 140,37 & 107,06 & 38,91 & 5923,89 & 291,50 & $\begin{array}{l}19,09 \\
19,\end{array}$ & 272,41 & \begin{tabular}{|l|}
149,81 \\
1998
\end{tabular} & 218,99 & $\begin{array}{l}219,93 \\
21\end{array}$ & 69,25 & \begin{tabular}{|l|l|}
438,99 \\
\end{tabular} & \begin{tabular}{|l|l|}
58,03 \\
\end{tabular} & $\begin{array}{ll}14,58 \\
140\end{array}$ & 31,61 & \begin{tabular}{|l|}
143,353 \\
146,3
\end{tabular} & 71,97 & 78,82 & $\begin{array}{l}92,03 \\
92,03\end{array}$ \\
\hline Alytes obstetricans & 305XJ67 & 100,00 & 134,58 & 105,47 & \begin{tabular}{|l|}
38,08 \\
\end{tabular} & 5986,80 & 286,09 & 14,12 & 271,97 & 143,41 & 214,29 & 214,93 & 63,03 & 449,14 & 56,28 & 16,73 & 29,75 & 145,65 & 79,29 & 84,23 & 91,38 \\
\hline Alytes obstetricans & $305 \times 168$ & 100,00 & 122,35 & 105,18 & 37,93 & 6098,75 & 276,92 & 2,28 & 274,63 & 136,46 & 203,99 & 204,38 & 50,08 & 487,44 & 57,57 & 20,50 & 27,48 & 153,17 & 92,86 & 94,41 & 97,42 \\
\hline Alytes obstetricans & $305 \times 169$ & 100,00 & 130,08 & 103,49 & 37,92 & 6039,47 & 281,31 & 10,47 & 270,84 & 141,93 & 203,62 & 210,93 & 58,12 & 452,30 & 55,16 & 18,70 & 29,05 & 145,00 & 85,51 & 88,67 & 88,76 \\
\hline Alytes obstetricans & $30 \mathrm{~S} \times \mathrm{J71}$ & 100,00 & 129,27 & 109,91 & 39,00 & 5973,05 & 285,19 & 6,64 & 278,55 & 139,33 & 208,87 & 210,05 & 58,50 & 504,70 & 63,75 & 16,71 & 30,28 & 162,69 & 80,68 & 86,76 & 111,01 \\
\hline Alytes obstetricans & $305 \times 172$ & 100,00 & 135,05 & 108,85 & 39,00 & 5916,15 & 288,28 & 13,03 & 275,26 & 145,11 & 213,66 & 214,93 & 64,58 & 480,25 & 62,86 & 15,44 & 31,38 & 158,73 & 75,77 & 83,35 & 104,77 \\
\hline Alytes obstetricans & $305 \times 173$ & 100,00 & 134,74 & 107,78 & 38,92 & 5912,92 & 287,08 & 13,31 & 273,78 & 144,68 & 213,34 & 214,45 & 64,27 & 479,66 & 62,49 & 15,88 & 30,90 & 158,43 & 77,23 & 84,66 & 103,68 \\
\hline Alytes obstetricans & $305 \times 174$ & 100,00 & 144,64 & 106,00 & \begin{tabular}{|l|l|}
38,97 \\
\end{tabular} & 5808,97 & 292,51 & 24,30 & 268,21 & 154,66 & 221,46 & 222,71 & 74,91 & 443,42 & 61,79 & 13,75 & 33,54 & $\mid 153,08$ & 68,48 & 78,70 & 95,51 \\
\hline Alytes obstetricans & $305 \times 176$ & 100,00 & 136,34 & 104,40 & 38,32 & 5894,38 & 285,41 & 16,88 & 268,53 & 145,73 & 214,62 & 215,66 & 65,99 & 462,44 & 60,29 & 16,51 & 30,46 & 154,06 & 78,14 & 86,10 & 96,48 \\
\hline Alytes obstetricans & $305 \times \mathrm{J77}$ & 100,00 & 129,46 & 103,84 & 38,05 & 5965,21 & 280,00 & 10,43 & 269,57 & 138,84 & 208,95 & 209,79 & 58,54 & 479,80 & 59,22 & 18,64 & 28,75 & 155,00 & 85,94 & 91,66 & 98,22 \\
\hline Alytes obstetricans & $305 \times 178$ & 100,00 & 134,17 & 102,25 & 37,95 & 5919,14 & 282,15 & $\begin{array}{ll}16,04 \\
16,4\end{array}$ & 266,11 & 144,01 & 212,92 & 213,66 & 63,56 & 458,25 & 58,45 & 17,81 & 29,83 & 151,35 & 81,92 & 88,97 & 92,58 \\
\hline Alytes obstetricans & $305 \times 180$ & 100,00 & 144,00 & 109,08 & 39,48 & 5785,34 & 294,12 & 21,79 & 272,33 & 154,88 & 220,38 & 221,94 & 74,64 & 463,92 & 65,44 & 12,84 & 34,78 & 161,16 & 66,09 & 78,03 & 104,46 \\
\hline Alytes obstetricans & $305 \times 181$ & 100,00 & 139,38 & 108,16 & 39,12 & 5823,71 & 290,00 & $\begin{array}{ll}17,87 \\
\end{array}$ & 272,13 & 150,14 & 216,53 & 217,97 & 69,86 & 480,55 & 65,73 & 14,34 & 32,98 & 164,05 & 71,62 & 82,44 & 107,25 \\
\hline Alytes obstetricans & $305 \times 182$ & 100,00 & 142,61 & 106,86 & 39,12 & 5781,11 & 291,03 & 22,04 & 268,99 & 153,31 & 219,00 & 220,57 & 73,45 & 468,84 & 65,57 & 13,90 & 33,69 & 162,69 & 69,65 & 81,45 & 104,05 \\
\hline Alytes obstetricans & $305 \times 183$ & 100,00 & 143,86 & 105,54 & 39,10 & 5758,33 & 290,70 & 24,10 & 266,60 & 154,37 & 219,85 & 221,39 & 74,88 & 464,10 & 65,49 & & 33,84 & 162,18 & 69,61 & 81,77 & 102,29 \\
\hline Alytes obstetricans & $305 \times 184$ & 100,00 & 143,71 & 104,29 & 39,00 & 5747,43 & 289,46 & 24,87 & 264,59 & 154,15 & 219,55 & 221,15 & 75,00 & 462,29 & 65 & 14 & 33,59 & 161,71 & 70,50 & 82,78 & 100,98 \\
\hline Alytes obstetricans & $305 \times 185$ & 100,00 & 151,95 & 102,27 & 38,99 & 5649,61 & 293,41 & 34,26 & 259,15 & 162,57 & 226,08 & 227,78 & 83,80 & \begin{tabular}{|l|l|}
435,08 \\
\end{tabular} & 65,18 & 12,88 & 35,90 & 158,16 & 63,79 & 78,46 & 94,93 \\
\hline Alytes obstetricans & $305 \times 186$ & 100,00 & 143,03 & 101,81 & 38,50 & 5747,54 & 286,85 & 25,65 & 261,20 & 153,06 & 218,83 & 220,32 & 74,19 & 457,23 & 63,92 & 15,32 & 32,73 & 159,77 & 72,87 & 85,12 & 97,37 \\
\hline Alytes obstetricans & $305 \times 187$ & 100,00 & 134,47 & 101,46 & 38,03 & 5847,57 & 280,78 & 17,18 & 263,60 & 143,95 & 212,11 & 213,25 & 64,92 & 477,32 & 62,23 & 17,79 & 30,15 & 60,24 & 82,06 & 91,49 & 99,19 \\
\hline Alytes obstetricans & $305 \times 188$ & 100,00 & 150,47 & $\begin{array}{r}90,40 \\
98,58\end{array}$ & $\frac{50}{38}$ & 5662,01 & $\begin{array}{l}200,10 \\
289,49\end{array}$ & $\begin{array}{l}1,10 \\
34,899\end{array}$ & \begin{tabular}{|l|}
254,60 \\
250
\end{tabular} & \begin{tabular}{|l|}
160,34 \\
160,34
\end{tabular} & \begin{tabular}{|l|l|l|l|l|}
224,78 \\
\end{tabular} & \begin{tabular}{|l|}
226,36 \\
226
\end{tabular} & $\begin{array}{l}4,2,20 \\
82,\end{array}$ & \begin{tabular}{|l|}
425,20 \\
42,
\end{tabular} & $\begin{array}{l}62,30 \\
62,30\end{array}$ & $\mid \begin{array}{l}\mid 1,, 3,31 \\
14,\end{array}$ & 34,76 & \begin{tabular}{|l|}
153,35 \\
15,3
\end{tabular} & $\begin{array}{l}62,00 \\
67,35\end{array}$ & $\begin{array}{l}31,43 \\
81,33\end{array}$ & 88,84 \\
\hline Alytes obstetricans & 305XI89 & 100,00 & 151,22 & 97,45 & 38,00 & 5660,88 & 289,16 & 36,08 & 253,09 & 160,92 & 225,42 & 226,98 & 82,86 & 416,22 & 60,92 & 14,41 & 34,58 & 150,62 & 67,12 & 81,19 & 85,54 \\
\hline Alytes obstetricans & $30 \mathrm{~S} \times \mathrm{J91}$ & 100,00 & 154,65 & 105,88 & 39,80 & 5600,81 & 298,09 & 34,84 & 263,25 & 166,33 & 227,97 & 230,00 & 87,14 & 446,79 & 68,62 & $\mid 11.06$ & 38,44 & $\mid 165,52$ & 58,81 & 75,95 & 102,75 \\
\hline Alytes obstetricans & $305 \times 192$ & 100,00 & 157,11 & 104,43 & 39,78 & 5563,59 & 298,29 & 38,17 & 260,11 & 168,70 & 229,72 & 231,88 & 89,87 & 440,43 & 69,03 & 10,91 & 39,15 & 165,36 & 57,65 & 75,60 & 101,15 \\
\hline Alytes obstetricans & $305 \times 193$ & 100,00 & 161,82 & 102,37 & 39,76 & 5482,65 & 299,51 & 44,50 & 255,01 & 173,54 & 233,14 & 235 & 95,32 & 428,66 & 69,86 & 10,31 & 40,90 & 165,05 & 54,69 & 74,34 & 98 \\
\hline \begin{tabular}{|l|l}
$\mid l y$ \\
Alytes obtricans
\end{tabular} & 305xy94 & 100,00 & $\begin{array}{l}101,02 \\
154,36\end{array}$ & 101,60 & 39,15 & $\begin{array}{l}340,200 \\
5556,76\end{array}$ & 293,62 & $\begin{array}{l}34,50 \\
37,51 \\
\end{array}$ & \begin{tabular}{|l|}
256,10 \\
25,1
\end{tabular} & 165,70 & 227,05 & 229,12 & 87,33 & 448,82 & $\begin{array}{ll}69,43 \\
\end{array}$ & 12,38 & 37,73 & 167,25 & 62,05 & 79,83 & 101,26 \\
\hline Alytes obstetricans & $305 \times 195$ & 100,00 & 154,12 & 100,07 & 38,95 & 5546,10 & 291,99 & 38,17 & 253,82 & 165,20 & 226,60 & 228,75 & 87,31 & 447,85 & 69,32 & 12,82 & 37,47 & 166,93 & 63,14 & 81,01 & 100,04 \\
\hline Alytes obstetricans & $305 \times 196$ & 100,00 & 159,01 & 9791 & 38.99 & 5464.39 & 293,27 & 44.80 & 248.46 & 170,22 & 230,17 & 232.46 & 92.96 & 432,22 & 69,69 & 12,20 & 39,07 & 165,26 & 59,58 & 78.93 & 96,29 \\
\hline Alytes obstetricans & $305 \times 197$ & 100,00 & 157,92 & 96,72 & 38,69 & 5480,10 & 291,59 & 44,24 & 247,3 & 168, & 229, & 231, & 91, & 430,08 & 68,64 & 12,78 & 38,43 & 163,54 & 61,12 & 80,02 & 94,32 \\
\hline Alytes obstetricans & $305 \times 198$ & 100,00 & 161,99 & 95,04 & 38,54 & 5418,89 & 292,97 & 49,34 & 243,62 & 172,81 & 232,29 & 234,62 & 96,34 & 414,44 & 67,98 & 12,27 & 39,74 & 160,49 & 58,30 & 78,11 & 90,18 \\
\hline
\end{tabular}




\begin{tabular}{|c|c|c|c|c|c|c|c|c|c|c|c|c|c|c|c|c|c|c|c|c|c|}
\hline TAXON & UTM & $\mathrm{km2}$ & B101 & $\mathrm{B1O2}$ & $\mathrm{BIO3}$ & B104 & B105 & B106 & B107 & B108 & $\mathrm{BIO9}$ & 81010 & B1011 & BIO12 & BIO13 & 81014 & BIO15 & B1016 & B1017 & BIO18 & B1019 \\
\hline Alytes obstetricans & 30SXJ99 & 100,00 & 156,57 & 94,70 & 38,02 & 5501,31 & 289,38 & 43,62 & 245,76 & 166,92 & 228,32 & 230,32 & 90,09 & 420,21 & 65,46 & 13,67 & 37,23 & 158,42 & 63,57 & 81,59 & 88,81 \\
\hline Alytes obstetricans & 30SXK00 & 100,00 & 117,03 & 117,58 & 38,22 & 6405,90 & 290,68 & $-11,81$ & 302,48 & $\begin{array}{l}99,08 \\
\end{array}$ & 202,55 & 203,36 & 40,19 & 491,68 & 61,76 & 19,42 & 27,18 & 160,49 & 85,47 & 92,59 & 107,13 \\
\hline Alytes obstetricans & 30 XXK10 & 100,00 & 119,41 & 114,96 & 38,03 & 6364,99 & 289,05 & $-7,86$ & 296,91 & 134,11 & 204,31 & 205,06 & 43,17 & 474,57 & 59,86 & 19,29 & 27,44 & 154,89 & 85,25 & 91,36 & 99,81 \\
\hline Alytes obstetricans & $30 S \times K 21$ & 100,00 & 105,33 & 112,06 & 37,97 & 6370,31 & 273,35 & $-19,68$ & 293,03 & 123,00 & 190,63 & 191,50 & 29,87 & 527,39 & 67,49 & 24,47 & 26,25 & \begin{tabular}{|l|l|}
174,19 \\
\end{tabular} & 100,69 & 108,91 & 107,95 \\
\hline Alytes obstetricans & $305 \times K 22$ & 100,00 & 105,08 & 111,26 & 37,82 & 6372,31 & 272,03 & $\begin{array}{l}-19,79 \\
\end{array}$ & 291,83 & 123,10 & 188,12 & \begin{tabular}{|l|}
191,08 \\
\end{tabular} & 29,40 & 520,37 & 67,76 & 24,79 & 26,65 & $\begin{array}{ll}173,16 \\
\end{array}$ & 101,24 & 109,76 & 104,98 \\
\hline Alytes obstetricans & $305 \times K 30$ & 100,00 & 117,71 & 110,05 & 37,95 & 6293,58 & 280,91 & $-6,02$ & 286,93 & 135,21 & 201,84 & 202,31 & 42,81 & 476,10 & 60,00 & 20,90 & 27,42 & 156,32 & 91,20 & 95,71 & 94,79 \\
\hline Alytes obstetricans & 30SXK31 & 100,00 & 113,36 & 109,34 & 37,76 & 6319,51 & 276,69 & \begin{tabular}{|l|l|}
$-10,14$ \\
\end{tabular} & 286,82 & 131,17 & 140,04 & 198,55 & 38,41 & 486,33 & 62,48 & 22,50 & 27,36 & 161,19 & 94,60 & 101,05 & 95,69 \\
\hline Alytes obstetricans & 30SXK32 & 100,00 & 108,52 & 108,46 & 37,33 & 6339,29 & 271,47 & $-14,69$ & 286,15 & 126,45 & \begin{tabular}{|l|}
58,98 \\
\end{tabular} & \begin{tabular}{|l|l|}
194,06 \\
\end{tabular} & 33,24 & \begin{tabular}{|l|l|}
499,43 \\
\end{tabular} & 65,36 & 24,27 & 27,34 & 167,26 & 97,03 & 107,17 & $\begin{array}{ll}97,07 \\
\end{array}$ \\
\hline Alytes obstetricans & $305 \times K 40$ & 100,00 & 116,01 & 107,73 & 37,78 & 6252,44 & 276,27 & $-6,16$ & 282,43 & 133,03 & 123,01 & 200,16 & 41,92 & 485,12 & 60,79 & 22,01 & 27,28 & $\mid 158,67$ & 94,35 & 98,94 & 95,01 \\
\hline Alytes obstetricans & $305 \times K 41$ & 100,00 & 113,97 & 106,82 & 37,28 & 6276,32 & 273,90 & $-7,82$ & 281,73 & 131,38 & 40,80 & 198,58 & 39,77 & 483,34 & 61,95 & 22,85 & 27,58 & 159,95 & 92,75 & 101,60 & 92,75 \\
\hline Alytes obstetricans & $30 \mathrm{XXK50}$ & 100,00 & 127,65 & 104,81 & 37,71 & 6135,18 & 281,71 & 6,70 & 275,01 & 142,82 & 92,14 & 209,82 & 54,41 & 442,77 & 54,53 & 19,12 & 28,90 & 142,62 & 84,56 & 87,90 & 84,95 \\
\hline Alytes obstetricans & 30SXK51 & 100,00 & 121,03 & 104,12 & 37,22 & 6191,15 & 276,05 & 0,70 & 275,35 & 137,93 & 48,32 & 204,10 & 47,33 & 458,95 & 57,95 & 21,34 & 28,56 & 149,92 & 86,45 & 95,23 & 86,45 \\
\hline Alytes obstetricans & $305 \times K 52$ & 100,00 & 116,95 & 103,14 & 37,03 & 6232,40 & 272,18 & $-2,82$ & 275,00 & 134,51 & 42,97 & 200,73 & 42,97 & 464,15 & 60,12 & 22,83 & 28,82 & \begin{tabular}{|l|}
154,08 \\
\end{tabular} & 85,43 & 100,12 & 85,43 \\
\hline Alytes obstetricans & $305 \times 60$ & 100,00 & 133,08 & 102,24 & 37,55 & 6028,01 & 282,71 & 13,90 & 268,81 & 144,14 & 135,44 & 213,70 & 61,01 & 432,27 & 53,45 & 18,14 & 29,76 & 139,75 & 81,08 & 85,84 & 82,95 \\
\hline Alytes obstetricans & 30SXK61 & 100,00 & 121,73 & 102,01 & 37,02 & 6146,47 & 274,28 & 2,65 & 271,63 & 138,39 & 48,60 & 204,06 & 48,60 & 461,33 & 57,58 & 21,59 & 28,58 & 148,96 & 86,06 & 95,50 & 86,06 \\
\hline Alytes obstetricans & $305 \times K 62$ & 100,00 & 106,15 & 101,78 & 36,92 & 6218,09 & 261,26 & $-12,13$ & 273,40 & 122,72 & 32,84 & 190,04 & 32,84 & 520,18 & 66,47 & 26,72 & 27,06 & 171,32 & 97,31 & 113,83 & 97,31 \\
\hline Alytes obstetricans & 30SXK70 & 100,00 & 129,53 & 100,59 & 37,27 & 5995,70 & 277,80 & 11,79 & 266,01 & 140,13 & 119,53 & 209,80 & 58,06 & 456,08 & 56,17 & 19,62 & 29,24 & 147,22 & 85,81 & 92,48 & 88,02 \\
\hline Alytes obstetricans & 30SXK71 & 100,00 & 116,02 & 100,53 & 36,95 & 6112,56 & 267,73 & $-1,27$ & 269,01 & 131,13 & 43,85 & 198,16 & 43,85 & 495,53 & 61,02 & 23,65 & 27,54 & 158,38 & 93,56 & 103,52 & 93,56 \\
\hline Alytes obstetricans & $305 \times K 72$ & 100,00 & 95,77 & 100,65 & 36,45 & 6182,98 & 250,53 & $-21,31$ & 271,84 & 111,17 & 23,68 & 179,33 & 23,68 & 584,80 & 73,13 & 30,58 & 25,11 & 189,64 & 113,11 & 126,81 & 113,11 \\
\hline Alytes obstetricans & $305 \times K 80$ & 100,00 & 133,40 & 98,33 & 37,20 & 5881,55 & 277,88 & 17,42 & 260,45 & 142,60 & 180,96 & 212,31 & 63,21 & 457,53 & 58,17 & 18,99 & 29,97 & 152,34 & 84,32 & 93,37 & 89,68 \\
\hline Alytes obstetricans & 30 XSK81 & 100,00 & 107,43 & 99,34 & 36,75 & 6087,26 & 258,74 & $-8,79$ & 267,52 & 121,45 & 36,15 & 189,55 & 36,15 & 548,46 & 66,48 & 26,89 & 25,90 & 173,45 & 106,31 & 115,03 & 106,31 \\
\hline Alytes obstetricans & 30SXK82 & 100,00 & 95,14 & 99,06 & 36,21 & 6135,27 & 247,94 & $-20,86$ & 268,79 & 110,04 & 23,55 & 178,07 & 23,55 & 600,15 & 73,97 & 31,18 & 24,62 & 192,01 & 117,01 & 128,30 & 117,01 \\
\hline Alytes obstetricans & 305XK90 & 100,00 & 137,15 & 96,17 & 37,23 & 5766,21 & 277,84 & 22,66 & 255,19 & 146,16 & 210,50 & 214,60 & 68,34 & 461,90 & 60,83 & 18,45 & 30,90 & 158,33 & 82,55 & 94,14 & 92,39 \\
\hline Alytes obstetricans & 30SXK91 & 100,00 & 118,16 & 97,05 & 36,70 & 5962,03 & 264,77 & 3,03 & 261,74 & 128,88 & 86,00 & 198,45 & 47,94 & 516,47 & 61,85 & 23,82 & 27,32 & 164,19 & 99,90 & 108,37 & 100,35 \\
\hline Alytes obstetricans & $305 \times K 92$ & 100,00 & 118,22 & 96,24 & 36,31 & 5976,35 & 264,32 & 3,29 & 261,02 & 129,84 & 58,95 & 198,64 & 47,90 & 505,18 & 61,45 & 23,95 & 27,82 & 160,42 & 95,62 & 107,63 & 95,73 \\
\hline Alytes obstetricans & 30SYHO4 & 100,00 & 173,90 & 109,71 & 41,00 & 5389,70 & 314,83 & 50,47 & 264,37 & 186,78 & 243,55 & 245,87 & 107,85 & 346,29 & 62,2 & 5,29 & 49,14 & 141,70 & 34,85 & 53,52 & 78,97 \\
\hline Alytes obstetricans & 30SYHO6 & 100,00 & 144,42 & 108,84 & 39,61 & 5689,09 & 293,55 & 22,42 & 271,13 & \begin{tabular}{|l|l|}
144,48 \\
\end{tabular} & 219,20 & 221,28 & $\begin{array}{l}76,49 \\
76,0\end{array}$ & \begin{tabular}{|l|l|}
486,58 \\
\end{tabular} & $\begin{array}{l}69,47 \\
69,4\end{array}$ & $\frac{1,26}{12,40}$ & $\begin{array}{l}36,53 \\
36,53\end{array}$ & 172,01 & $\begin{array}{l}4,03,57 \\
63\end{array}$ & 78,33 & 115,60 \\
\hline Alytes obstetricans & 30SYH07 & 100,00 & 145,51 & 108,53 & 39,83 & 5677,36 & 293,93 & 23,77 & 270,16 & 156,67 & 220,10 & 222,15 & 77,61 & 484,35 & 69,80 & 12,21 & 36,42 & 172,25 & 63,45 & 78,80 & 114,59 \\
\hline Alytes obstetricans & 30SYHO8 & 100,00 & 133,87 & 107,45 & 39,09 & 5786,82 & 284,80 & 13,19 & 271,61 & 144,48 & 210,39 & 212,43 & 65,38 & 534,69 & 71,73 & 15,72 & 32,70 & 181,60 & 76,45 & 89,32 & 125,78 \\
\hline Alytes obstetricans & 30SYH14 & 84,00 & 180,26 & 107,10 & 41,00 & 5257,41 & 316,59 & 58,60 & 257,99 & 193,68 & 247,77 & 250,42 & 115,62 & 336,75 & 63,16 & 4,36 & 52,08 & 143,41 & 31,77 & 51,94 & 77,46 \\
\hline Alytes obstetricans & 30SYH15 & 100,00 & 175,28 & 107,31 & 40,93 & 5313,91 & 313,30 & 53,72 & 259,57 & 188,76 & 243,76 & 246,37 & 110,37 & 366,35 & 65,66 & 5,46 & 49,10 & 151,58 & 37,05 & 57,48 & 84,94 \\
\hline Alytes obstetricans & 30SYH16 & 100,00 & 159,20 & 107,47 & 40,10 & 5490,83 & 302,30 & $\begin{array}{ll}3,7,95 \\
37\end{array}$ & \begin{tabular}{|l|l|}
264,34 \\
\end{tabular} & $\begin{array}{l}169,42 \\
\end{array}$ & 230,56 & \begin{tabular}{|l|}
233,14 \\
23,15
\end{tabular} & | & \begin{tabular}{|l|l|}
442,74 \\
\end{tabular} & $\begin{array}{l}69,88 \\
690\end{array}$ & 8,99 & 41,99 & $\begin{array}{l}168,76 \\
168,\end{array}$ & 51,36 & $\begin{array}{l}1,40 \\
70,57\end{array}$ & $\begin{array}{l}0,06,53 \\
106\end{array}$ \\
\hline Alytes obstetricans & 30SYH17 & 100,00 & 137,58 & 106,62 & 39,14 & 5704,24 & 286,43 & 17,54 & 268,89 & 126,61 & 212,69 & 215,01 & 69,98 & 534,91 & 73,47 & 14,70 & 34,32 & 186,51 & 72,75 & 87,84 & $\begin{array}{ll}129,03 \\
\end{array}$ \\
\hline Alytes obstetricans & 30SYH18 & 100,00 & 135,72 & 105,93 & 39,01 & 5715,70 & 284,32 & 16,26 & 268,07 & 135,22 & 211,13 & 213,36 & 68,11 & 545,95 & 74,34 & 15,54 & 33,65 & 189,00 & 76,09 & 91,16 & 130,99 \\
\hline Alytes obstetricans & 30SYH19 & 100,00 & 140,82 & 105,29 & 39,20 & 5663,73 & 287,27 & 21,68 & 265,59 & 149,01 & 215,32 & 217,56 & 73,55 & 529,39 & 74,34 & 14,42 & 35,07 & 187,23 & 72,32 & 89,16 & 126,96 \\
\hline Alytes obstetricans & $\begin{array}{l}30 \mathrm{SYH} 26 \\
\end{array}$ & 100,00 & 162,06 & 105,68 & 40,10 & 5418,68 & 302,65 & 42,09 & 260,56 & 164,62 & 232,30 & 235,03 & 96,54 & 452,93 & 72,10 & |8,67 & 43,43 & 176,14 & 50,53 & 71,93 & 112,25 \\
\hline Alytes obstetricans & 30SYH27 & 100,00 & 138,36 & 105,00 & 39,08 & 5652,75 & 285,28 & 19,41 & 265,87 & 113,91 & 212,66 & 215,09 & 71,39 & 550,86 & 75,99 & 14,68 & 34,98 & 195,63 & 73,13 & 90,20 & 135,87 \\
\hline Alytes obstetricans & 30SYH28 & 100,00 & 143,83 & 104,61 & 39,25 & 5600,58 & 288,71 & 25,05 & 263,66 & 129,31 & 217,22 & 219,66 & 77,15 & 534,83 & 76,21 & 13,50 & 36,49 & 193,59 & 69,20 & 88,25 & 132,28 \\
\hline Alytes obstetricans & 30 SYH29 & 100,00 & 157,11 & 103,99 & 39,83 & 5462,54 & 297,39 & 38,60 & 258,79 & 160,71 & 228,11 & 230,76 & 91,36 & 495,67 & 76,34 & 10,57 & 41,07 & 189,27 & 58,63 & 81,85 & 124,46 \\
\hline Alytes obstetricans & 30SYH37 & 100,00 & 156,46 & 103,95 & 39,66 & 5443,78 & 297,10 & 37,91 & 259,19 & 131,88 & 227,12 & 229,92 & 90,96 & 507,02 & 76,68 & 10,34 & 41,72 & 195,70 & 57,87 & 81,19 & 130,93 \\
\hline Alytes obstetricans & 30SYH38 & 100,00 & 130,60 & 102,73 & 38, & 5683,61 & 277,40 & 13,50 & 263,90 & 103,87 & 205,45 & 208,02 & 63,76 & 603,69 & 79,8 & 17,44 & 33,08 & 211,11 & 83,60 & 100,75 & 150,39 \\
\hline Alytes obstetricans & 30 SYH 46 & 30,00 & 180,65 & 102,84 & 40,40 & $\mid$\begin{tabular}{|l|l|}
5191,81 \\
\end{tabular} & 313,65 & 62,23 & 251,42 & 158,72 & 246,81 & 249,93 & 116,88 & 444,02 & 74,6 & 5,37 & 51,47 & |191,30 & 39,09 & 67,95 & 123,14 \\
\hline Alytes obstetricans & 30SYH47 & 100,00 & 161,13 & 102,73 & 39,57 & 5376,77 & 299,46 & 43,28 & 256,17 & 137,70 & 230,58 & 233,57 & 96,22 & 517,59 & 78,54 & 9,54 & 44,19 & 206,86 & 55,42 & 81,62 & 139,68 \\
\hline Alytes obstetricans & 30SYH48 & 100,00 & 147,95 & 101,86 & 39,00 & 5496,58 & 289,23 & 30,96 & 258,27 & 123,39 & 219,55 & 222,47 & 82,43 & 565,97 & 80,80 & 12,82 & 39,29 & 214,74 & 68,09 & 92,00 & 148,93 \\
\hline Alytes obstetricans & 30SYJO2 & 100,00 & 169,80 & 101,78 & 40,00 & 5352,22 & 304,00 & 52,88 & 251,12 & 182,31 & 238,94 & 241 & 104,55 & 424,42 & $72, \varepsilon$ & 8,66 & 44,99 & 70,37 & 48,57 & 72,18 & 101,98 \\
\hline Alytes obstetricans & $305 Y \mathrm{~J} 06$ & 100,00 & 165,44 & 95,01 & 39,6 & $\begin{array}{l}5293,51 \\
\end{array}$ & 293,86 & $\begin{array}{ll}53,87 \\
5\end{array}$ & 239,99 & $\begin{array}{l}177,42 \\
\end{array}$ & 233,86 & \begin{tabular}{|l|l|}
236,68 \\
\end{tabular} & $\begin{array}{l}101,27 \\
\end{array}$ & $\begin{array}{l}438,06 \\
438,4\end{array}$ & 75,3 & 0 & $\begin{array}{l}42,87 \\
42,5\end{array}$ & 174,73 & 55,44 & 79,30 & 101,17 \\
\hline Alytes obstetricans & 30SYJ07 & 100,00 & 166,40 & 93,37 & 38,95 & 5267,47 & 293,03 & 55,71 & 237,33 & 178,25 & 234,31 & 237,26 & 102,52 & 431,58 & 74, & 11,56 & 43,03 & 173,01 & 55,33 & 79,25 & 98,46 \\
\hline Alytes obstetricans & 30SYYO8 & 100,00 & 167,01 & 92,15 & 38,61 & 5261,87 & 292,83 & 56,86 & 235,97 & 178,53 & 234,81 & 237,69 & 103,18 & 421,74 & 73,28 & 11,57 & 42,99 & 169,44 & 55,16 & 78,88 & 94,67 \\
\hline Alytes obstetricans & $30 \mathrm{SYJO9}$ & 100,00 & 160,41 & 92,08 & 37,99 & 5362,79 & 288,70 & 49,75 & 238,95 & 171,34 & 230,00 & 232,42 & 95,51 & 428,82 & 69,92 & 13,27 & 39,42 & 166,71 & 61,35 & 82,93 & 93,31 \\
\hline Alytes obstetricans & 30SYJ11 & 100,00 & 169,64 & 102,15 & 40,01 & 5328,99 & 304,21 & 52,64 & 251,57 & 182,70 & 238,42 & 241,24 & 104,81 & 445,22 & 75,33 & 8,56 & 45,40 & 08 & 49,42 & 74,85 & 110,63 \\
\hline Alytes obstetricans & $30 \mathrm{SYJ}$ & 100,00 & $\begin{array}{l}10,04 \\
175,42\end{array}$ & $\begin{array}{l}90,13 \\
99,84\end{array}$ & 40 & \begin{tabular}{|l}
5239,15 \\
5239
\end{tabular} & 305 & $\begin{array}{l}2,049 \\
59,97\end{array}$ & \begin{tabular}{|l|}
246,01 \\
\end{tabular} & $\begin{array}{l}18<, 6,69 \\
188,\end{array}$ & \begin{tabular}{|l|}
$240,42,74$ \\
\end{tabular} & \begin{tabular}{|l|}
245,67 \\
\end{tabular} & \begin{tabular}{|l|}
111,35 \\
11,3
\end{tabular} & \begin{tabular}{|l|}
$443,2<$ \\
431,18
\end{tabular} & $\begin{array}{l}\mid 7,235 \\
76,26\end{array}$ & $\begin{array}{l}0,000 \\
8,03\end{array}$ & $\begin{array}{l}5,404 \\
47,87 \\
\end{array}$ & \begin{tabular}{|l|}
178,21 \\
\end{tabular} & $\begin{array}{l}45,44 \\
46,04 \\
\end{array}$ & 73,26 & $\begin{array}{l}107,03 \\
107,94\end{array}$ \\
\hline Alytes obstetricans & 30 SYJ14 & 100,00 & 175,11 & 95,80 & 39,95 & 5162,86 & 301,05 & 63,02 & 238,03 & 188,26 & 241,27 & 244,49 & 112,14 & 434,26 & 78,86 & 8,61 & 48,27 & 181,00 & 47,58 & 75,66 & 107,15 \\
\hline Alytes obstetricans & 30SYJ16 & 100,00 & 171,46 & 92,07 & 39,13 & 5121,67 & 294,22 & 62,56 & 231,66 & 184,23 & 237,18 & 240,61 & 109,48 & 442,56 & 80,93 & 10,23 & 47,32 & 183,66 & 51,43 & 79,50 & 106,04 \\
\hline Alytes obstetricans & 30 SYJ17 & 100,00 & 170,87 & 90,37 & 39,00 & 5111,14 & 292,25 & 62,94 & 229,31 & 183,49 & 236,36 & 239,79 & 108,94 & 441,61 & 80,99 & 10,95 & 46,75 & 183,14 & 52,74 & 80,69 & 104,02 \\
\hline Alytes obstetricans & 30 SYJ18 & 100,00 & 167,99 & 89,79 & 38,51 & 5159,09 & 290,30 & 59,94 & 230,36 & 180,15 & 234,19 & 237 & 105,51 & 438,38 & 77,94 & 11,82 & 44,56 & 179,09 & 55,45 & 82,12 & 100 \\
\hline Alytes obstetricans & 305YI19 & $\begin{array}{l}100,00 \\
\end{array}$ & $\begin{array}{l}10,55,37 \\
155\end{array}$ & $\begin{array}{l}0,1,99 \\
90,99\end{array}$ & $\begin{array}{l}30,11 \\
37,79 \\
\end{array}$ & $\begin{array}{l}5357,42 \\
5357\end{array}$ & 283,63 & $\begin{array}{l}5,5,56 \\
456\end{array}$ & \begin{tabular}{|l|}
238,07 \\
230
\end{tabular} & \begin{tabular}{|l|}
166,40 \\
166,40
\end{tabular} & \begin{tabular}{|l|}
224,88 \\
22,8
\end{tabular} & \begin{tabular}{|l|}
227,57 \\
227
\end{tabular} & \begin{tabular}{|c|c|}
00,93 \\
90,
\end{tabular} & \begin{tabular}{|l|}
458,909 \\
458,99
\end{tabular} & $\begin{array}{l}71,34 \\
72,35\end{array}$ & \begin{tabular}{l|l}
$1,0<6$ \\
14,63
\end{tabular} & $\begin{array}{l}44,00 \\
38,07 \\
\end{array}$ & $\begin{array}{l}175,92 \\
170\end{array}$ & $\begin{array}{l}5,43 \\
67,17 \\
\end{array}$ & $\begin{array}{l}2,11 \\
89,65 \\
\end{array}$ & $\begin{array}{l}100,94 \\
100,94\end{array}$ \\
\hline Alytes obstetricans & 30 SYJ21 & 100,00 & 165,65 & 101,30 & 39,79 & 5339,22 & 300,55 & 49,14 & 251,41 & 176,73 & 234,67 & 237,43 & 100,84 & 481,21 & 78,40 & 9,51 & 44,28 & 190,88 & 54,07 & 80,95 & 122,79 \\
\hline Alytes obs & 30 SYJ22 & 100,00 & 168.81 & 9936 & 3981 & 5279,18 & 300,68 & 53,71 & 246.97 & 182.04 & 236,77 & 239,79 & 104,65 & 475,11 & 79.52 & 9,31 & 45.55 & $\mid 191.42$ & 52.57 & 80,87 & 121.54 \\
\hline Alytes obstetricans & 30 SYJ23 & 100,00 & 173,90 & 97,01 & 39,91 & 5186,52 & 301,71 & 60,73 & 240,98 & 187, & 240,30 & 243 & 110 & 460,88 & 80,59 & 8,63 & 48 & 190,34 & $4 \mathrm{~s}$ & 79,16 & 118,22 \\
\hline Alytes obstetricans & $30 \mathrm{SYJ} 25$ & 100,00 & 176,56 & 92,18 & 39,57 & 5054,61 & 297,92 & 67,46 & 230,45 & 190,01 & 240,95 & 244,55 & 115,05 & 446,92 & 82,85 & 8,90 & 49,95 & 189,43 & 48,38 & 79,53 & 112,10 \\
\hline
\end{tabular}





\begin{tabular}{|c|c|c|c|c|c|c|c|c|c|c|c|c|c|c|c|c|c|c|c|c|c|}
\hline TAXON & UTM & $\mathrm{km2}$ & BIO1 & B102 & B103 & B104 & B105 & B106 & B107 & B108 & B109 & BIO10 & BIO11 & $\overline{B 1012}$ & BIO13 & BIO14 & BIO15 & BIO16 & BIO17 & B1018 & BIO19 \\
\hline Alytes obstetricans & 30TTL98 & 100,00 & 120,71 & 117,00 & 39,00 & 6116,87 & 293,11 & $-0,66$ & 293,78 & 81,40 & 199,52 & 202,03 & 45,15 & 367,73 & 43,89 & 11,57 & 32,38 & 121,95 & 53,17 & 55,27 & 98,40 \\
\hline Alytes obstetricans & 30TTL99 & 100,00 & 123,40 & 116,79 & 39,00 & 6113,62 & 295,29 & 1,44 & 293,85 & 84,35 & 202,00 & 204,42 & 47,40 & 361,10 & 42,50 & $\begin{array}{l}11,65 \\
\end{array}$ & 32,23 & \begin{tabular}{l|l|}
120,58 \\
\end{tabular} & 52,20 & 54,24 & 97,04 \\
\hline Alytes obstetricans & 30TTM50 & 100,00 & \begin{tabular}{ll|}
118,92 \\
\end{tabular} & 114,25 & 39,00 & 6119,15 & 289,53 & $-1,20$ & 290,73 & 79,56 & \begin{tabular}{ll|l}
199,50 \\
\end{tabular} & $\begin{array}{l}199,86 \\
\end{array}$ & 43,12 & 425,39 & 54,04 & 11,10 & 35,80 & $\begin{array}{l}150,07 \\
\end{array}$ & 54,46 & 54,70 & 128,83 \\
\hline Alytes obstetricans & 30TTM63 & 100,00 & 119,25 & 115,18 & 39,00 & 6062,60 & 289,37 & $-1,77$ & 291,14 & 80,81 & \begin{tabular}{|l|l|}
199,31 \\
\end{tabular} & 199,31 & 43,73 & 429,64 & 53,58 & 13,31 & 33,78 & \begin{tabular}{ll|}
152,42 \\
\end{tabular} & \begin{tabular}{|c|}
60,47 \\
\end{tabular} & 60,47 & 126,97 \\
\hline Alytes obstetricans & 30тTM68 & 100,00 & 115,66 & 115,14 & 39,30 & 5920,82 & 283,44 & $-4,84$ & 288,27 & $\begin{array}{l}78,75 \\
\end{array}$ & \begin{tabular}{|l|l|}
193,59 \\
\end{tabular} & 193,59 & 41,14 & 510,51 & 65,92 & 19,61 & 33,18 & $\begin{array}{l}186,15 \\
\end{array}$ & 78,70 & 78,70 & 149,35 \\
\hline Alytes obstetricans & 30тTM69 & 100,00 & 114,35 & 114,99 & 39,66 & 5869,97 & 281,20 & $-6,07$ & 287,28 & 77,94 & \begin{tabular}{|l|l|}
191,56 \\
\end{tabular} & 191,56 & 40,43 & \begin{tabular}{l|l}
531,65 \\
\end{tabular} & 69,26 & 21,31 & 33,10 & $\begin{array}{l}194,55 \\
\end{array}$ & 83,77 & 83,77 & 154,35 \\
\hline Alytes obstetricans & 30TTM70 & 100,00 & 123,60 & 115,39 & 39,00 & 6134,25 & 294,63 & 1,73 & 292,90 & 84,40 & 202,34 & 204,45 & 47,04 & 363,72 & 44,02 & 10,25 & 33,86 & 125,23 & 50,36 & 51,65 & 100,75 \\
\hline Alytes obstetricans & 30TTM75 & 100,00 & 119,06 & 115,99 & 39,01 & 6000,19 & 289,02 & $-2,23$ & 291,25 & 81,85 & \begin{tabular}{|l|l|}
198,19 \\
\end{tabular} & $\begin{array}{l}198,19 \\
\end{array}$ & 43,90 & 441,94 & 55,03 & 15,57 & 32,62 & \begin{tabular}{|l|l|}
157,67 \\
\end{tabular} & \begin{tabular}{ll|}
66,79 \\
\end{tabular} & 66,79 & 126,77 \\
\hline Alytes obstetricans & 30TTM90 & 100,00 & 120,98 & 116,89 & 39,01 & 6105,73 & 292,91 & \begin{tabular}{ll|}
$-0,66$ \\
\end{tabular} & 293,57 & 82,10 & \begin{tabular}{l|l|l|l|}
199,48 \\
\end{tabular} & 201,74 & \begin{tabular}{|l|l}
45,03 \\
\end{tabular} & 373,56 & 43,81 & 12,30 & 31,86 & \begin{tabular}{l|l|}
125,32 \\
\end{tabular} & 54,53 & 56,83 & 100,95 \\
\hline Alytes obstetricans & 30тTM96 & 100,00 & 117, 91 . & 116,07 & 39,13 & 5937,17 & 287,51 . & $-4,03$ & 291,53 & 82,30 . & 196,05 & 196,30 & 43,35 & $448,11 \mid$ & 55,80 & 17,87 & 31,11 & 157,64 & $73,34[$ & 73,50 & 122,49 \\
\hline Alytes obstetricans & 30TTN53 & 58,00 & 93,44 & 109,66 & 39,99 & 5543,63 & 251,73 & $-19,50$ & 271,23 & $\begin{array}{ll}60,25 \\
\end{array}$ & \begin{tabular}{|l|l|}
166,97 \\
\end{tabular} & \begin{tabular}{|l|l|}
166,97 \\
\end{tabular} & 25,44 & \begin{tabular}{|l|l|}
749,48 \\
\end{tabular} & 97,07 & 33,26 & 30,23 & 266,40 & 122,49 & 122,49 & 220,42 \\
\hline Alytes obstetricans & 30TTN54 & 50,00 & 85,92 & 107,32 & 39,96 & 5432,77 & 240,95 & $-24,42$ & 265,37 & 54,00 & \begin{tabular}{l|l|l|l|l}
157,99 \\
\end{tabular} & \begin{tabular}{|l|l|}
157,99 \\
\end{tabular} & 19,85 & 827,83 & 105,94 & 37,45 & 29,26 & 289,86 & \begin{tabular}{|l|}
136,27 \\
\end{tabular} & 136,33 & 244,65 \\
\hline Alytes obstetricans & 30TTN55 & 50,00 & 79,17 & 104,95 & 39,92 & 5315,20 & 230,87 & $-28,43$ & 259,29 & 48,47 & \begin{tabular}{l|l|l|}
149,83 \\
\end{tabular} & \begin{tabular}{|l|l|}
149,87 \\
\end{tabular} & 15,01 & \begin{tabular}{|l|l|}
905,48 \\
\end{tabular} & 114,81 & 41,61 & 28,36 & \begin{tabular}{|l|l|}
312,87 \\
\end{tabular} & \begin{tabular}{|l|l|}
149,93 \\
\end{tabular} & 150,00 & 268,33 \\
\hline Alytes obstetricans & 30TTN59 & 34,00 & 107,65 & 97,71 & 42,53 & 4464,14 & 236,69 & 9,24 & 227,45 & 84,37 & \begin{tabular}{ll|l}
165,18 \\
\end{tabular} & \begin{tabular}{ll|l}
167,02 \\
\end{tabular} & 53,90 & 894,86 & 118,92 & 43,80 & 27,39 & 303,14 & \begin{tabular}{ll|}
154,69 \\
\end{tabular} & 162,37 & 241,67 \\
\hline Alytes obstetricans & 30TTN60 & 100,00 & 112,30 & 114,63 & 39,92 & 5825,36 & 278,29 & $-7,38$ & 285,67 & 76,30 & \begin{tabular}{|l|l|}
189,01 \\
\end{tabular} & 189,01 & \begin{tabular}{|l|}
39,02 \\
\end{tabular} & 557,37 & 73,12 & 23,3 & 32, & 204,20 & 89,71 & 89,71 & 160,39 \\
\hline Alytes obstetricans & 30TTN61 & 100,00 & 109,29 & 114,10 & 39,99 & 5768,96 & 273,99 & $-9,38$ & 283,37 & 73,76 & 185,24 & 185,24 & 36,90 & 590,31 & 77,69 & 25,53 & 32,54 & 215,87 & 96,86 & 96,86 & 168,97 \\
\hline Alytes obstetricans & 30TTN63 & 100,00 & 97,88 & 110,95 & 40,00 & 5567,66 & 257,41 & $-16,42$ & 273,84 & 64,54 & $\begin{array}{l}171,46 \\
1\end{array}$ & $\begin{array}{l}171,46 \\
\end{array}$ & 28,97 & \begin{tabular}{ll|}
704,86 \\
\end{tabular} & 91,85 & 32,32 & 30,37 & 252,02 & \begin{tabular}{ll|}
118,46 \\
\end{tabular} & $\begin{array}{l}118,46 \\
\end{array}$ & 202,02 \\
\hline Alytes obstetricans & 30TTN64 & 100,00 & 88,79 & 108,26 & 40,01 & 5445,67 & 244,62 & $-22,48$ & 267,11 & 56,85 & \begin{tabular}{ll|}
160,94 \\
\end{tabular} & 160,94 & 22,20 & 795,50 & 102,14 & 37,00 & 28,97 & 279,16 & 134,13 & 134,13 & 230,18 \\
\hline Alytes obstetricans & 30TTN66 & 100,00 & 75,87 & 102,94 & 40,22 & 5193,28 & 223,88 & $-29,61$ & 253,49 & 46,30 & \begin{tabular}{l|l|l|l|l|}
144,83 \\
\end{tabular} & $\begin{array}{l}144,96 \\
\end{array}$ & 13,51 & 955,68 & 120,26 & 45,30 & 27,28 & 325,99 & $\begin{array}{l}161,73 \\
\end{array}$ & 162,86 & 279,55 \\
\hline Alytes obstetricans & 30TTN68 & 100,00 & 101,04 & 100,21 & 41,91 & 4702,54 & 235,95 & $-0,29$ & 236,24 & 75,69 & \begin{tabular}{ll|}
162,18 \\
\end{tabular} & \begin{tabular}{ll|}
163,41 \\
\end{tabular} & 44,1 & 883,46 & 116,07 & 43,3 & 27,2 & 300,97 & \begin{tabular}{|l|l|}
153,54 \\
\end{tabular} & 160,40 & 241,76 \\
\hline Alytes obstetricans & 30TTN75 & 100,00 & 78,74 & 105,74 & 39,91 & 5340,06 & 231,84 & $-29,75$ & 261,59 & \begin{tabular}{|l|l}
48,48 \\
\end{tabular} & \begin{tabular}{|l|l|}
149,70 \\
\end{tabular} & 149,71 & \begin{tabular}{l|l}
14,15 \\
\end{tabular} & 879,32 & $\begin{array}{ll}110,85 \\
\end{array}$ & 42,46 & 27,29 & 302,26 & 151,78 & 151,81 & 252,92 \\
\hline Alytes obstetricans & 30TTN77 & 100,00 & 98,10 & 102,69 & 41,42 & 4924,04 & 238,68 & $-6,54$ & 245,21 & 71,23 & \begin{tabular}{|l|l|}
162,47 \\
\end{tabular} & $\begin{array}{l}163,09 \\
\end{array}$ & 38,12 & 840,56 & 109,74 & 41,76 & 27,21 & 288,74 & $\begin{array}{l}148,36 \\
\end{array}$ & $\begin{array}{l}153,87 \\
\end{array}$ & 229,47 \\
\hline Alytes obstetricans & 30TTN81 & 100,00 & 112,09 & 115,44 & 39,99 & 5801,20 & 278,79 & $-8,02$ & 286,81 & $\begin{array}{ll}77,48 \\
\end{array}$ & \begin{tabular}{|l|l|}
188,47 \\
\end{tabular} & \begin{tabular}{|l|l|}
188,47 \\
\end{tabular} & \begin{tabular}{l|l|}
38,95 \\
\end{tabular} & 549,74 & 72,17 & 22,12 & 32,53 & 201,18 & 96,41 & 96,41 & \begin{tabular}{ll|l}
148,43 \\
\end{tabular} \\
\hline Alytes obstetricans & 30TTN82 & 100,00 & 108,29 & 114,24 & 40,00 & 5713,11 & 272,77 & $-10,27$ & 283,04 & 74,53 & \begin{tabular}{ll|}
183,56 \\
\end{tabular} & \begin{tabular}{ll|}
183,56 \\
\end{tabular} & 36,55 & 591,44 & 77,61 & 24,31 & 31,73 & 214,95 & $\begin{array}{l}104,96 \\
\end{array}$ & 104,96 & 159,59 \\
\hline Alytes obstetricans & 30TTN83 & 100,00 & 100,81 & 111,97 & 40,01 & 5578,91 & 261,61 & $-14,78$ & 276,39 & 68,47 & \begin{tabular}{ll|}
174,49 \\
\end{tabular} & 174,49 & 31,46 & \begin{tabular}{ll|}
662,58 \\
\end{tabular} & 86,12 & 30,41 & 30,02 & 236,55 & \begin{tabular}{|l|l|}
117,88 \\
\end{tabular} & 117,88 & 180,73 \\
\hline Alytes obstetricans & 30TTN85 & 100,00 & $\begin{array}{l}81,85 \\
\end{array}$ & 106,21 & 39,96 & 5333,53 & 235,12 & $-27,29$ & 262,41 & 52,04 & 152,64 & 152,66 & 17,04 & 846,14 & \begin{tabular}{|l|l|}
106,77 \\
\end{tabular} & 41,86 & 27,03 & 290,70 & 149,41 & 149,46 & 238,33 \\
\hline Alytes obstetricans & 30TTN88 & 100,00 & 110,02 & 98,86 & 42,09 & 4609,07 & 240,93 & 8,93 & 232,00 & 86,32 & $\begin{array}{l}169,63 \\
1\end{array}$ & $\begin{array}{ll}170,88 \\
\end{array}$ & 53,76 & 820,57 & 109,09 & 41,97 & 27,09 & 279,84 & $\begin{array}{l}148,35 \\
\end{array}$ & 155,84 & 213,51 \\
\hline Alytes obstetricans & 30TTN90 & 100,00 & 115,60 & 114,52 & 39,93 & 5754,04 & 280,47 & $-4,69$ & 285,16 & 82,10 & \begin{tabular}{|l|l|}
191,30 \\
\end{tabular} & 191,30 & \begin{tabular}{|l|l}
42,93 \\
\end{tabular} & 521,09 & 67,51 & 23,59 & 31,24 & \begin{tabular}{|l|l|}
187,63 \\
\end{tabular} & 91,22 & 91,22 & 139,00 \\
\hline Alytes obstetricans & 30TTN91 & 100,00 & 112,42 & 114,10 & 39,99 & 5708,68 & 276,63 & $-6,76$ & 283,39 & 79,24 & \begin{tabular}{|l|l|}
187,61 \\
\end{tabular} & 187,61 & 40,64 & 551,70 & 71,77 & 24,11 & 31,20 & 198,91 & \begin{tabular}{l|l}
98,15 \\
\end{tabular} & 98,15 & 146,58 \\
\hline Alytes obstetricans & 30TTN92 & 100,00 & 107,67 & 113,09 & 40,00 & 5642,44 & 270,31 & $-10,03$ & 280,35 & 75,30 & 182,14 & 182,14 & 36,94 & 595,94 & 77,47 & 26,22 & \begin{tabular}{l|l}
30,55 \\
\end{tabular} & 213,70 & 107,31 & 107,31 & 158,62 \\
\hline Alytes obstetricans & 30TTN93 & 100,00 & 101,07 & 111,23 & 40,01 & 5538,27 & 260,69 & $-14,21$ & 274,90 & \begin{tabular}{ll|}
69,69 \\
\end{tabular} & \begin{tabular}{|l|l|}
174,09 \\
\end{tabular} & \begin{tabular}{ll|l}
174,09 \\
\end{tabular} & 32,15 & 658,48 & 84,97 & 31,07 & 29,28 & 233,02 & \begin{tabular}{|l|l|}
119,10 \\
\end{tabular} & 119,10 & 176,86 \\
\hline Alytes obstetricans & 30TTN94 & 100,00 & 93,59 & 108,77 & 40,01 & 5418,02 & 249,74 & $-18,79$ & 268,53 & 63,35 & $\begin{array}{ll}165,26 \\
\end{array}$ & 165,26 & 26,95 & 733,11 & 93,67 & 36,51 & 27,87 & 255,42 & 132,52 & 132,52 & 199,38 \\
\hline Alytes obstetricans & 30TTN96 & 100,00 & 67,08 & 102,48 & 39,64 & 5231,01 & 217,01 & $-38,30$ & 255,30 & 38,78 & \begin{tabular}{ll|}
136,90 \\
\end{tabular} & 137,01 & 4,63 & $\begin{array}{l}974,58 \\
\end{array}$ & 119,49 & 49,01 & 25,20 & 325,77 & $\begin{array}{l}172,95 \\
\end{array}$ & 173,32 & 277,70 \\
\hline Alytes obstetricans & 30TTP60 & 100,00 & 129,66 & 89,93 & 43,73 & 3918,14 & 241,79 & \begin{tabular}{|l|l|}
38,42 \\
\end{tabular} & 203,37 & 111,05 & \begin{tabular}{|l|l|}
178,84 \\
\end{tabular} & $\begin{array}{l}181,95 \\
\end{array}$ & 82,53 & 850,03 & 116,32 & 42,40 & 28,38 & \begin{tabular}{|l|l|}
284,03 \\
\end{tabular} & \begin{tabular}{|l|l|}
149,06 \\
\end{tabular} & 158,09 & 214,18 \\
\hline Alytes obstetricans & 30TTP62 & 99,00 & 135,89 & 79,64 & 42,56 & 3713,09 & 235,61 & 50,83 & \begin{tabular}{|l|l|l|}
184,78 \\
\end{tabular} & 118,95 & 182,44 & \begin{tabular}{|l|l|}
185,98 \\
\end{tabular} & \begin{tabular}{l|l}
91,25 \\
\end{tabular} & 853,17 & 117,04 & 41,15 & 28,65 & 288,29 & \begin{tabular}{ll|}
146,45 \\
\end{tabular} & 158,71 & 219,36 \\
\hline Alytes obstetricans & \begin{tabular}{|l|} 
30TTP70 \\
\end{tabular} & 100,00 & 129,49 & 87,84 & 43,33 & 3916,04 & 239,58 & 39,05 & 200,53 & \begin{tabular}{|l|l|}
111,44 \\
\end{tabular} & \begin{tabular}{|l|l|}
178,87 \\
\end{tabular} & 181,95 & 82,37 & 844,56 & $\begin{array}{l}115,45 \\
\end{array}$ & 42,68 & 28,30 & 282,58 & \begin{tabular}{l|l|}
149,95 \\
\end{tabular} & 159,09 & 211,07 \\
\hline Alytes obstetricans & 30TTP82 & 60,00 & 138,75 & 71,62 & 40,72 & 3679,04 & 230,37 & \begin{tabular}{l|l}
56,65 \\
\end{tabular} & 173,71 & 122,63 & \begin{tabular}{|l|}
185,16 \\
\end{tabular} & 188,74 & $\begin{array}{l}94,25 \\
\end{array}$ & 829,42 & 113,76 & 40,20 & 28,83 & 282,16 & 143,90 & 157,39 & 211,51 \\
\hline Alytes obstetricans & 30TTP90 & 100,00 & 125,74 & 85,39 & 42,02 & 4035,10 & 235,66 & \begin{tabular}{|l|l|}
34,97 \\
\end{tabular} & 200,69 & 107,35 & \begin{tabular}{|l|l|}
177,08 \\
\end{tabular} & \begin{tabular}{ll|}
179,92 \\
\end{tabular} & 76,99 & 839,03 & 113,34 & 42,6 & 27,70 & 283,30 & \begin{tabular}{|l|l|}
151,08 \\
\end{tabular} & 161,13 & 211,51 \\
\hline Alytes obstetricans & 30TTP92 & 50,00 & 134,30 & 74,18 & 40,98 & 3749,07 & 229,58 & 50,70 & \begin{tabular}{ll|}
178,88 \\
\end{tabular} & \begin{tabular}{ll|}
117,98 \\
\end{tabular} & 181,69 & \begin{tabular}{ll|}
184,95 \\
\end{tabular} & 88,85 & 849,13 & 115,64 & 41,84 & 28,09 & 288,26 & 149,61 & 162,86 & 216,03 \\
\hline Alytes obstetricans & 30TUK04 & 100,00 & 152,48 & 114,92 & 37,00 & 6473,37 & 330,21 & 25,06 & 305,15 & 110,58 & 239,14 & 239,14 & 72,90 & \begin{tabular}{|l|}
365,59 \\
\end{tabular} & 42,55 & 6,31 & 39,21 & 122,56 & 36,52 & 36,52 & 106,51 \\
\hline Alytes obstetricans & 30TUK06 & 100,00 & 80,47 & 110,13 & 36,98 & 6240,22 & 258,27 & $-35,89$ & 294,16 & 23,13 & \begin{tabular}{|l|l|}
165,30 \\
\end{tabular} & \begin{tabular}{|l|l|}
166,20 \\
\end{tabular} & 9,0 & 683,23 & 79,23 & 20,24 & 33,51 & \begin{tabular}{|l|l|}
219,28 \\
\end{tabular} & 84,51 & 89,35 & 198,20 \\
\hline Alytes obstetricans & 30TUK07 & 100,00 & 76,67 & 109,66 & 37,02 & 6199,42 & 253,59 & $-38,70$ & 292,29 & 15,36 & \begin{tabular}{|l|l|}
161,19 \\
\end{tabular} & \begin{tabular}{|l|l|}
161,95 \\
\end{tabular} & 5,96 & 693,74 & 80,34 & 21,14 & 32,93 & 222,01 & 87,41 & 93,44 & 200,16 \\
\hline Alytes obstetricans & 30TUK15 & 100,00 & 107,17 & 112,56 & 37,00 & 6357,38 & 286,19 & $-14,32$ & \begin{tabular}{|l|}
300,52 \\
\end{tabular} & \begin{tabular}{|l|l|}
71,97 \\
\end{tabular} & \begin{tabular}{|l|l|}
192,81 \\
\end{tabular} & \begin{tabular}{ll|}
193,76 \\
\end{tabular} & \begin{tabular}{|l|l|}
32,42 \\
\end{tabular} & 526,62 & 62,91 & 14,19 & 34,84 & \begin{tabular}{ll|}
168,06 \\
\end{tabular} & \begin{tabular}{|l|l|}
64,68 \\
\end{tabular} & 66,84 & 147,18 \\
\hline Alytes obstetricans & 30TUK16 & 100,00 & 82,40 & 110,78 & 37,00 & 41,99 & 1 & $-34,80$ & 295,5 & 35,77 & 167,32 & 168, & 10 & $\begin{array}{l}646,15 \\
\end{array}$ & 76,49 & 19,6 & 32,8 & 203,86 & 82,49 & 87,53 & 181,66 \\
\hline Alytes obstetricans & 30TUK18 & 100,00 & 85,68 & 110,95 & 37,17 & 6184,79 & 261 & $-31,63$ & 293,44 & 40,94 & 169,28 & 170,44 & 14, & 600,66 & 72,73 & 19,18 & 32, & 188,44 & \begin{tabular}{|l|l|}
80,13 \\
\end{tabular} & 85,09 & 164,78 \\
\hline Alytes obstetricans & 30TUK19 & 100,00 & 92,96 & 111,70 & 37,53 & 6162,45 & 268,20 & $-25,55$ & 293,75 & 55,26 & \begin{tabular}{ll|}
175,56 \\
\end{tabular} & \begin{tabular}{|l|l|}
177,18 \\
\end{tabular} & 21,1 & 536,76 & 66,86 & 17,20 & 32,19 & \begin{tabular}{|l|l|}
168,07 \\
\end{tabular} & 73,77 & 77,81 & 143,09 \\
\hline Alytes obstetricans & 30TUK24 & 100,00 & 148,45 & 114,23 & 37,00 & 6501,82 & 326,70 & 20,22 & 306,48 & \begin{tabular}{ll|l}
106,40 \\
\end{tabular} & 235,77 & 235,77 & 68,69 & 362,49 & 42,40 & 6,90 & 38,08 & \begin{tabular}{|l|}
119,71 \\
\end{tabular} & 38,77 & 38,77 & 101,54 \\
\hline Alytes obstetricans & 30TUK25 & 100,00 & 135,47 & 113,90 & 37,00 & 6441,15 & 313,42 & 9,08 & 304,35 & \begin{tabular}{|l|}
104,99 \\
\end{tabular} & 222,13 & 222,33 & 57,18 & 389,31 & 47,34 & 8,90 & 36,26 & 126,13 & 46,22 & 46,31 & 105,63 \\
\hline Alytes obstetricans & 30TUK26 & 100,00 & 94,91 & 111,68 & 37,00 & 277,75 & 272,94 & $-24,75$ & \begin{tabular}{|l|l|}
297,69 \\
\end{tabular} & 72,72 & 179,80 & 180,69 & 21,9 & 555,93 & 68,55 & 16,80 & 33,22 & 175,91 & \begin{tabular}{|l|}
73,17 \\
\end{tabular} & 76,48 & 149,86 \\
\hline Alytes obstetricans & 30TUK27 & 100,00 & 89,82 & 111,24 & 37,00 & 6224,85 & 266,71 & $-28,78$ & 295,48 & 70,00 & 173,92 & 174,90 & 17,89 & 566,20 & 70,59 & 18,04 & 32,43 & 178,04 & 76,65 & 80,72 & 150,68 \\
\hline Alytes obstetricans & 30 TUK28 & 100,00 & 80,02 & 110,48 & 37,01 & 6176,16 & 256,19 & $-36,62$ & 292,81 & \begin{tabular}{l|l}
47,95 \\
\end{tabular} & \begin{tabular}{ll|}
163,94 \\
\end{tabular} & \begin{tabular}{ll|}
164,79 \\
\end{tabular} & 9,42 & 625,94 & 76,25 & 21,04 & 31,64 & \begin{tabular}{|l|l|}
195,47 \\
\end{tabular} & 85,60 & 91,35 & 169,35 \\
\hline Alytes obstetricans & 30TUK36 & 100,00 & 90,23 & 111,35 & 37,00 & 6263,98 & 268,25 & $-29,08$ & 297,34 & 71,25 & \begin{tabular}{|l|l}
175,15 \\
\end{tabular} & \begin{tabular}{|l|l|}
175,99 \\
\end{tabular} & $\begin{array}{ll}18,05 \\
\end{array}$ & 568,18 & 71,19 & 17,99 & 32,66 & 180,80 & 77,02 & 80,79 & 149,91 \\
\hline Alytes obstetricans & 30TUK37 & 100,00 & 95,44 & $\mid 111,44$ & 37,00 & 6240,27 & 272,10 & $-24,57$ & 296,67 & 77,51 & 179,49 & 180,74 & 22,86 & 520,51 & 67,05 . & 16,80 & 32,7 & 165,76 & 72,71 & 76,01 & 133,20 \\
\hline Alytes obstetricans & $30 \mathrm{TUK}$ & 100,00 & 85,05 & 110,75 & 37,0 & 4 & 261 & $-32,7$ & 293 & 65, & 168 & 169,68 & 13, & 576,70 & $72, \varepsilon$ & 19 , & 31 & 181 & 81,46 & 86,51 & $14 \mathrm{C}$ \\
\hline Alytes obstetricans & 30TUK46 & 100,00 & 100,93 & 111,37 & 36,83 & 6305,77 & 278,33 & $-20,28$ & 298,61 & 82,70 & \begin{tabular}{|l|}
186,21 \\
\end{tabular} & \begin{tabular}{|l|l|}
186,97 \\
\end{tabular} & 27,26 & 508,86 & 65,08 & 15,92 & 33,13 & \begin{tabular}{|l|}
163,43 \\
\end{tabular} & 70,14 & 72,82 & 130,45 \\
\hline Alytes obstetricans & 30TUK47 & 100,00 & 114,25 & 111,30 & 36,96 & 6312,72 & 289,66 & $-9,22$ & 298,88 & 98,77 & \begin{tabular}{|l|l|}
198,49 \\
\end{tabular} & 199,77 & 38,77 & 421,32 & 56,28 & 12,95 & 34,11 & 136,14 & 60,19 & 61,26 & 102,46 \\
\hline Alytes obstetricans & 30TUK58 & 100,00 & 96,35 & 109,92 & 36,98 & 6196,46 & 270,65 & $-23,76$ & 294,41 & 85,99 & \begin{tabular}{|l|l|}
179,84 \\
\end{tabular} & $\begin{array}{ll}180,83 \\
\end{array}$ & 24,11 & 484,28 & 65,80 & 16,94 & 32,88 & \begin{tabular}{|l|l|l|}
156,43 \\
\end{tabular} & 73,19 & 76,41 & 114,71 \\
\hline Alytes o & 30TUK99 & 10 & & & 36 & 6 & & $-21,79$ & & 105,56 & 180, & 18 & & 503,34 & 65,6 & & & 161 & 76,80 & 81,29 & 12 \\
\hline Alytes obstetricans & 30TUL04 & 100,00 & 118,51 & 116,89 & 39,44 & $6066,89]$ & 290,5 & $-2,02$ & 292,56 & 78,15 & 196,72 & 200,28 & 44,73 & 384,11 & 46,77 & 11,48 & $31,17 \mid$ & 120,88 & 56,10 & 58,44 & 101,31 \\
\hline Alytes obstetricans & 30TUL05 & 100,00 & 119,92 & 117,01 & 39,21 & 6073,97 & 292,05 & $-0,88$ & 292,92 & 79,81 & 198,15 & 201,49 & \begin{tabular}{|l|l|}
45,87 \\
\end{tabular} & 374,10 & 45,45 & 11,11 & 31,60 & 119,13 & 54,34 & 56,68 & 98,92 \\
\hline
\end{tabular}




\begin{tabular}{|c|c|c|c|c|c|c|c|c|c|c|c|c|c|c|c|c|c|c|c|c|c|}
\hline TAXON & UTM & $\mathrm{km2}$ & B101 & $\mathrm{B1O2}$ & $\mathrm{BIO3}$ & B104 & B105 & B106 & B107 & B108 & B109 & 81010 & B1011 & BIO12 & BIO13 & 81014 & BIO15 & B1016 & B1017 & BIO18 & B1019 \\
\hline Alytes obstetricans & 30TUL06 & 100,00 & 120,28 & 117,02 & 39,16 & 6083,57 & 292,61 & $-0,73$ & 293,34 & 80,51 & 198,68 & 201,75 & 45,65 & 371,36 & 44,96 & 11,37 & 31,54 & 119,15 & 54,14 & 56,68 & 98,24 \\
\hline Alytes obstetricans & 30TUL09 & 100,00 & 124,48 & 117,00 & 39,01 & 6110,66 & 296,34 & 1,98 & 294,37 & 85,50 & 202,91 & 205,33 & 48,39 & 362,45 & 42,43 & 11,87 & 31,51 & 119,34 & 53,11 & 55,39 & 96,87 \\
\hline Alytes obstetricans & 30TUL14 & 100,00 & 119,47 & 116,01 & 39,00 & 6096,91 & 291,40 & $-1,53$ & 292,94 & 79,08 & 198,12 & 201,34 & 44,98 & 379,21 & 46,62 & 11,81 & 30,89 & 118,57 & 56,08 & 58,75 & 98,30 \\
\hline Alytes obstetricans & 30TUL18 & 100,00 & 123,31 & 116,90 & 39,00 & 6114,50 & 295,28 & 1,28 & 293,99 & 83,96 & 201,97 & 204,40 & 47,29 & 368,44 & 43,48 & 11,85 & 31,01 & 118,60 & 53,89 & 56,66 & 98,44 \\
\hline Alytes obstetricans & 30TUL24 & 100,00 & 119,42 & 114,94 & \begin{tabular}{|l|}
38,87 \\
\end{tabular} & 6127,27 & 291,15 & $-1,90$ & 293,05 & 93,05 & 198,64 & 201,77 & 44,47 & 379,32 & 47,25 & 12,00 & 31,03 & 118,09 & 56,54 & 59,31 & 97,02 \\
\hline Alytes obstetricans & 30TUL29 & 100,00 & 124,35 & 116,46 & 39,00 & 6110,26 & 295,87 & 1,75 & 294,12 & 85,78 & 202,97 & 205,22 & 47,91 & 377,03 & 44,03 & 12,18 & 30,50 & 120,93 & 54,84 & 58,46 & 101,84 \\
\hline Alytes obstetricans & 30TUL38 & 100,00 & 122,01 & 115,66 & 39,00 & 6139,48 & 293,63 & 0,19 & 293,44 & 82,82 & 201,31 & 203,60 & 45,82 & 386,17 & 45,38 & 12,31 & 30,30 & 121,43 & 56,31 & 60,28 & 103,48 \\
\hline Alytes obstetricans & \begin{tabular}{|l|} 
30TUL39 \\
\end{tabular} & 100,00 & 124,29 & 115,97 & 39,00 & 6127,98 & 295,91 & 2,29 & 293,62 & 85,70 & 203,32 & 205,50 & 47,89 & 385,62 & 44,94 & 12,25 & 30,20 & 122,30 & 55,58 & 59,60 & 105,06 \\
\hline Alytes obstetricans & 30TUL56 & 100,00 & 122,10 & 112,07 & 38,00 & 6182,96 & 291,54 & $-0,10$ & 291,64 & 108,31 & 202,33 & 204,53 & 45,69 & 388,29 & 47,19 & 12,05 & 30,90 & 120,47 & 56,23 & 61,05 & 100,49 \\
\hline Alytes obstetricans & \begin{tabular}{|l|} 
30TUL57 \\
\end{tabular} & 100,00 & 123,07 & 112,78 & 38,02 & 6181,97 & 293,06 & 0,34 & 292,72 & 84,41 & 203,18 & 205,50 & 46,37 & 391,90 & 46,43 & 12,03 & 30,66 & 121,94 & 56,41 & 61,21 & 103,59 \\
\hline Alytes obstetricans & 30TUL58 & 100,00 & 123,85 & 113,52 & 38,29 & 6158,24 & 294,08 & 1,67 & 292,41 & 85,56 & 203,82 & 205,75 & 47,39 & 397,03 & 46,06 & 12,08 & 30,10 & 123,65 & 56,97 & 61,73 & 106,99 \\
\hline Alytes obstetricans & 30TUL59 & 100,00 & 124,59 & 114,18 & 38,41 & 6141,55 & 294,91 & 2,19 & 292,73 & 86,62 & 203,97 & 205,89 & 47,84 & 403,19 & 46,57 & 12,84 & 29,82 & 125,94 & 57,73 & 62,66 & 110,59 \\
\hline Alytes obstetricans & \begin{tabular}{|l|} 
30TUL66 \\
\end{tabular} & 100,00 & 121,00 & 110,45 & 37,55 & $\mid 6210,75$ & 289,58 & $\begin{array}{c}-1,94 \\
-0,94 \\
\end{array}$ & 290,52 & \begin{tabular}{|l|l|}
122,36 \\
\end{tabular} & 201,98 & \begin{tabular}{|l|}
204,01 \\
\end{tabular} & |44,47 & 398,79 & 48,28 & 12,53 & 30,18 & 123,56 & 58,21 & 263,56 & 102,40 \\
\hline Alytes obstetricans & 30TUL67 & 100,00 & 122,54 & 111,32 & 37,93 & 6189,27 & 291,36 & $-0,03$ & 291,39 & 90,32 & 203,01 & 204,96 & 45,99 & 399,58 & 47,35 & 12,35 & 30,15 & 123,99 & 57,42 & 63,21 & 104,70 \\
\hline Alytes obstetricans & 30TUL69 & 100,00 & 122,60 & 112,92 & 38,06 & 6127,94 & 292,03 & $-0,01$ & 292,04 & 85,78 & 202,30 & 203,99 & 46,31 & 412,80 & 47,56 & 13,17 & 29,66 & 128,49 & 58,56 & 65,24 & 111,82 \\
\hline Alytes obstetricans & 30TUL71 & 100,00 & 106,17 & 106,36 & 36,08 & 6191,89 & 274,05 & $-15,29$ & 289,34 & 124,98 & 188,57 & 189,81 & 32,22 & 418,26 & 58,89 & 15,86 & 34,05 & 140,14 & 67,73 & 71,37 & 91,20 \\
\hline Alytes obstetricans & 30TUL78 & 100,00 & 120,36 & 110,48 & 37,54 & 6159,98 & 288,13 & $-2,19$ & 290,31 & 96,41 & 200,69 & 202,44 & 44,06 & 417,91 & 48,99 & 13,38 & 29,81 & 129,16 & 59,82 & 67,49 & 109,73 \\
\hline Alytes obstetricans & 30TUL79 & 100,00 & 116,90 & 111,40 & 37,96 & 6113,09 & 285,53 & $-5,35$ & 290,88 & 86,07 & 196,91 & 198,48 & 41,60 & 432,60 & 50,56 & 14,06 & 29,12 & 133,23 & 61,81 & 70,69 & 114,12 \\
\hline Alytes obstetricans & 30TUL80 & 100,00 & 92,66 & 106,66 & 36,56 & 6150,71 & 262,51 & $-25,10$ & 287,61 & 107,84 & 176,05 & 176,55 & 21,48 & 499,76 & 67,25 & 19,42 & 31,58 & 162,96 & 78,63 & 83,80 & 115,60 \\
\hline Alytes obstetricans & 30TUL81 & 100,00 & 105,88 & 104,96 & 35,99 & 6242,37 & 272,87 & $-14,65$ & 287,52 & 124,39 & 189,19 & 190,15 & 31,43 & 440,81 & 59,41 & 16,20 & 32,55 & 144,80 & 69,11 & 73,87 & 100,32 \\
\hline Alytes obstetricans & 30TUL85 & 100,00 & 118,67 & 106,09 & 36,48 & 6282,12 & 284,33 & $-2,83$ & 287,16 & 132,30 & 201,23 & 202,92 & 41,71 & 421,34 & 50,8 & 13,09 & 30,66 & 131,34 & 61,16 & 67,74 & 106,22 \\
\hline Alytes obstetricans & 30TUL89 & 100,00 & 115,78 & 109,77 & 37,20 & 6117,25 & 282,95 & $-6,84$ & 289,78 & 126,76 & 196,10 & 197,42 & 40,47 & 440,64 & 51,64 & 14,72 & 28,99 & 135,42 & 63,55 & 73,62 & 114,46 \\
\hline Alytes obstetricans & 30TUL90 & 100,00 & 88,55 & 106,60 & \begin{tabular}{|l|l|}
36,78 \\
\end{tabular} & $\begin{array}{ll}6147,86 \\
\end{array}$ & 258,66 & $-27,33$ & 285,99 & 96,43 & 172,41 & 172,71 & 18,22 & 541,27 & 69,75 & 20,88 & 30,08 & 172,62 & 83,43 & 88,12 & 130,46 \\
\hline Alytes obstetricans & 30TUL91 & 100,00 & 103,04 & 104,20 & 36,11 & 6268,38 & 269,75 & $-15,97$ & 285,72 & 120,93 & 187,10 & 187,99 & 28,96 & 474,41 & 61,07 & 16,82 & 31,16 & 152,40 & 72,34 & 78,09 & 112,79 \\
\hline Alytes obstetricans & 30TUL94 & 100,00 & 117,12 & 103,36 & $\begin{array}{l}35,95 \\
\end{array}$ & 6352,82 & 280,98 & $-3,91$ & 284,89 & 125,22 & 200,77 & 202,35 & 39,72 & 439,99 & 52,49 & 13,18 & 30,68 & 137,03 & 63,16 & 70,18 & 111,11 \\
\hline Alytes obstetricans & 30TUM05 & 100,00 & 118,77 & 116,27 & 39,11 & 5941,20 & 288,57 & $-3,38$ & 291,95 & 83,72 & 195,41 & 197,28 & 44,28 & 433,29 & $52,-$ & 17,20 & 30,21 & 149,11 & 69,51 & 71,34 & 117,04 \\
\hline Alytes obstetricans & 30TUM06 & 100,00 & 118,18 & 115,99 & 39,44 & 5893,34 & 287,03 & $\begin{array}{l}-3,50 \\
-3,74 \\
\end{array}$ & 290,76 & 83,73 & $\begin{array}{l}194,35 \\
194,\end{array}$ & $\begin{array}{l}196,05 \\
\end{array}$ & $\begin{array}{l}44,21 \\
44,21\end{array}$ & 448,20 & 55,47 & 18,38 & $\begin{array}{l}30,23 \\
30,23\end{array}$ & \begin{tabular}{|l|}
155,69 \\
155,1
\end{tabular} & 73,56 & 74,99 & 120,66 \\
\hline Alytes obstetricans & 30TUM11 & 100,00 & 118,37 & 117,00 & 39,00 & 6073,24 & 290,72 & $-3,53$ & 294,26 & 80,71 & 196,67 & 199,01 & 42,72 & 399,96 & 47,04 & 14,32 & 30,24 & 131,10 & 59,76 & 63,84 & 108,02 \\
\hline Alytes obstetricans & 30TUM17 & 100,00 & 117,29 & 115,08 & 39,24 & 5806,82 & 284,13 & $-4,69$ & 288,82 & 84,79 & 192,30 & 194,02 & 44,52 & 469,07 & 58,02 & 20,24 & 29,21 & 161,68 & 78,54 & 80,92 & 124,26 \\
\hline Alytes obstetricans & 30TUM22 & 100,00 & 116,34 & 117,00 & 39,00 & 6033,32 & 288,63 & $-5,76$ & 294,39 & 80,11 & 194,44 & 196,61 & 41,35 & 421,60 & 49,58 & 15,54 & 29,37 & 136,94 & 63,37 & 68,72 & 114,20 \\
\hline Alytes obstetricans & 30TUM27 & 100,00 & 117,38 & 114,55 & 39,09 & 5749,96 & 282,96 & $-4,90$ & 287,87 & 86,52 & 191,98 & 193,45 & 45,56 & 473,03 & 57,88 & 20,51 & 28,42 & 160,59 & 78,11 & 82,48 & 124,39 \\
\hline Alytes obstetricans & $\begin{array}{l}\text { 30TUM28 } \\
\end{array}$ & 100,00 & 116,00 & 113,62 & 39,21 & 5688,18 & 279,92 & $-5,54$ & $\begin{array}{l}285,46 \\
\end{array}$ & $\begin{array}{l}30,75 \\
85,75 \\
\end{array}$ & 189,75 & \begin{tabular}{|l|}
191,17 \\
\end{tabular} & $\begin{array}{ll}44,94 \\
440\end{array}$ & \begin{tabular}{|l|l|}
494,83 \\
\end{tabular} & $\begin{array}{l}1,100 \\
61,05 \\
\end{array}$ & 22,19 & 28,15 & \begin{tabular}{|l|l}
169,00 \\
\end{tabular} & 83,81 & $\begin{array}{l}2,4,40 \\
87,49\end{array}$ & 129,43 \\
\hline Alytes obstetricans & 30TUM34 & 100,00 & 120,10 & 116,06 & 39,00 & 5897,92 & 289,35 & $-3,58$ & 292,93 & 87,40 & $\begin{array}{l}196,63 \\
\end{array}$ & 198,19 & 46,40 & 432,74 & 51,34 & 17,12 & 28,79 & 141,74 & 65,51 & 72,43 & 115,91 \\
\hline Alytes obstetricans & 30TUM38 & 100,00 & 114,84 & 112,86 & 39,01 & 5647,56 & 277,71 & $-6,86$ & 284,57 & 86,00 & 188,38 & 189,59 & 44,63 & 503,23 & 61,25 & 22,71 & 27,38 & 169,15 & 83,95 & 89,87 & 130,77 \\
\hline Alytes obstetricans & 30TUM40 & 100,00 & 122,15 & 115,78 & 39,00 & 6114,58 & 293,78 & 0,52 & 293,26 & 78,23 & 201,19 & 203,18 & 45,84 & 410,07 & 47,65 & 13,35 & 29,65 & 129,07 & 58,92 & 63,97 & 113,83 \\
\hline Alytes obstetricans & 30TUM41 & 100,00 & 116,48 & 116,22 & 39,00 & 6077,18 & 289,07 & $-5,09$ & 294,16 & 77,72 & 195,67 & 197,33 & 41,18 & 432,19 & 50,04 & 14,91 & 29,02 & 135,79 & 62,79 & 69,55 & 119,23 \\
\hline Alyty obstetricans & $\begin{array}{l}\text { 30TUM48 } \\
\end{array}$ & 100,00 & $\begin{array}{l}113,40 \\
113,35\end{array}$ & $\begin{array}{ll}1112,22 \\
112,18\end{array}$ & 39,00 & 5604,36 & 275,24 & $\begin{array}{l}-3,05 \\
-8,78 \\
\end{array}$ & 284,02 & 86,09 & \begin{tabular}{|l|}
186,47 \\
196
\end{tabular} & $\begin{array}{l}187,52 \\
187\end{array}$ & $\begin{array}{l}1,10 \\
43,78\end{array}$ & \begin{tabular}{|l|}
513,62 \\
513,6
\end{tabular} & $\frac{30,04}{61,56}$ & $\begin{array}{l}24,37 \\
23,37 \\
\end{array}$ & 26,75 & \begin{tabular}{|l|}
169,87 \\
150
\end{tabular} & $\begin{array}{l}2,1,42 \\
84,4\end{array}$ & $\begin{array}{l}92,81 \\
92,\end{array}$ & 132,54 \\
\hline Alytes obstetricans & 30TUM50 & 100,00 & 124,34 & 114,90 & 38,89 & 6106,90 & 295,01 & 2,06 & 292,94 & 62,07 & 203,37 & 205,14 & 47,94 & 412,16 & 47,90 & 13,03 & 29,88 & 130,10 & 58,24 & 63,54 & 115,23 \\
\hline Alytes obstetricans & 30TUM51 & 100,00 & 122,95 & 115,51 & \begin{tabular}{|c|}
38,98 \\
\end{tabular} & 6066,38 & 293,71 & 0,46 & 293,25 & 63,90 & 201,60 & 203,15 & 46,92 & 423,85 & 49,38 & 13,88 & 29,50 & 134,49 & 59,79 & 66,21 & 119,16 \\
\hline Alytes obstetricans & 30TUM52 & 100,00 & 119,45 & 115,87 & 39,0 & 5989,92 & 290,00 & $-4,09$ & 294,09 & 85,37 & 197,37 & 198,91 & 44,80 & 435,69 & 50,38 & 15,16 & 28,94 & 137,52 & 61,99 & 70,81 & 119,59 \\
\hline Alytes obstetricans & 30TUM60 & 100,00 & 122,48 & 113,60 & 38, & 6089,17 & 292,07 & $-0,49$ & 292,56 & 86,07 & 201,70 & 203,24 & 46,55 & 419,17 & 48, & 13,43 & 29,68 & 131,25 & 58,86 & 66,41 & 114,57 \\
\hline Alytes obstetricans & 30TUM61 & 100,00 & 120,32 & 114,40 & 38, & 6036,22 & 290,06 & \begin{tabular}{|c|c|}
$-3,431$ \\
\end{tabular} & 293,37 & 85,23 & 198,96 & 200,41 & 45,18 & 431,13 & 49,6 & 14,44 & 29,26 & 134,87 & 60,73 & 69,65 & 117,55 \\
\hline Alytes obstetricans & $\begin{array}{l}\text { 30TUM62 } \\
\end{array}$ & 100,00 & 122,40 & 114,68 & 38,59 & 5961,61 & 291,22 & $-2,43$ & 293,65 & 90,55 & 200,06 & 201,50 & 48,14 & 428,31 & 49,35 & 14,77 & 29,23 & 135,19 & 59,98 & 70,13 & 115,71 \\
\hline Alytes obstetricans & 30TUM63 & 100,00 & 119,17 & 115,22 & 38,41 & 5885,32 & 287,68 & $-7,44$ & 295,12 & 89,93 & 195,93 & 197,41 & 46,32 & 439,86 & 50,41 & 16,09 & 29,01 & 138,04 & 62,10 & 75,25 & 115,75 \\
\hline Alytes obstetricans & 30TUM64 & 100,00 & 116 & 115,26 & 38,2 & 5815,91 & 283,9 & $-11,75$ & 295,66 & 89,12 & 192,21 & 193 & 44,57 & 454,02 & 52,1 & 17,5 & 28,65 & 142,29 & 64,78 & 80,12 & 117,01 \\
\hline Alytes obstetricans & 30TUM66 & 100,0 & 118 & 113,53 & 38 & 5661,01 & 282, & $-8,95$ & 291,03 & $\begin{array}{l}54,38 \\
94,\end{array}$ & \begin{tabular}{|l|}
192,27 \\
\end{tabular} & 19 & 48,90 & | 467,21 & 53,6 & & 27,83 & $\begin{array}{l}148,82 \\
\end{array}$ & 69,35 & 84,41 & 118,20 \\
\hline Alytes obstetricans & 30TUM68 & 100,00 & 114 & 110,01 & 38,80 & 5524,72 & 273 & $-8,14$ & 281,38 & 90,16 & 186,78 & 187,56 & 46,52 & 518,49 & 60,62 & 23,5 & 26,12 & 167,51 & 82,83 & 94,81 & 131,75 \\
\hline Alytes obstetricans & 30TUM69 & 100,00 & 111,43 & 108,16 & 38,76 & 5459,33 & 267,92 & $-8,51$ & 276,42 & 86,93 & 183,06 & 183,58 & 44,34 & 551,94 & 65,01 & 25,76 & 25,35 & 179,23 & 91,25 & 101,52 & 140,89 \\
\hline Alytes obstetricans & 30TUM70 & 100,00 & 120,65 & 112,09 & 38,00 & 6069,25 & 288,93 & $-2,75$ & 291,68 & 88,68 & 199,90 & 201,46 & 45,47 & 426,42 & 49,18 & 14,18 & 29,31 & 132,47 & 60,36 & 69,57 & 113,54 \\
\hline Alytes obstetricans & 30TUM74 & 100,00 & 121,31 & 113,99 & 38,00 & 5780,65 & 286,95 & $-7,65$ & 294,60 & 103,09 & 196,71 & 197,91 & 50,21 & 438,37 & 50,55 & 16,69 & 29,02 & 136,96 & 61,24 & 77,77 & 111,05 \\
\hline Alytes obstetricans & 30TUM? & 100,00 & 118 & 113,79 & $\begin{array}{l}30, \\
38,\end{array}$ & \begin{tabular}{|l|l|}
5711,37 \\
\end{tabular} & $\begin{array}{l}200,53 \\
283,52\end{array}$ & \begin{tabular}{|c|c|}
$-1,0,29$ \\
$-10,29$
\end{tabular} & 293,81 & \begin{tabular}{|l|}
104,70 \\
1040
\end{tabular} & $\begin{array}{l}193,40 \\
193,1\end{array}$ & $\begin{array}{l}194,54 \\
194\end{array}$ & $\begin{array}{l}0,212 \\
49,02\end{array}$ & \begin{tabular}{|l|l|}
450,319 \\
454
\end{tabular} & $\mid \begin{array}{l}\mid 5,15 \\
52,15\end{array}$ & 18,0 & 28,52 & $\begin{array}{l}141,93 \\
140\end{array}$ & $\begin{array}{l}1,24 \\
64,84\end{array}$ & 82,43 & 111,05 \\
\hline Alytes obstetricans & 30TUM79 & 100,00 & 111,89 & 106,71 & 38,25 & 5428,82 & 266,68 & $\begin{array}{l}-7,42 \\
\end{array}$ & 274,10 & 87,91 & 183,20 & 183,58 & 45,18 & 555,44 & 64,72 & 25,89 & 25,01 & 178,71 & 91,41 & 102,15 & 141,46 \\
\hline Alytes obstetricans & 30TUM80 & 100,00 & 118,00 & 110,56 & 37,59 & 6067,71 & 284,98 & $-5,22$ & 290,20 & 105,01 & 197,54 & 198,71 & 43,04 & 437,78 & 50,68 & 14,66 & 28,99 & 135,09 & 62,41 & 72,84 & 114,67 \\
\hline Alytes obstetricans & 30TUM91 & 100,00 & 115,85 & 109,53 & 37,30 & 6011,67 & 281,66 & $-7,52$ & 289,18 & 121,26 & 194,78 & 195,85 & 41,82 & 450,98 & 52,22 & 15,98 & 28,32 & 138,54 & 65,35 & 77,33 & 116,20 \\
\hline Alytes obstetricans & 30TUM92 & 100,00 & 115,57 & 109,85 & 37,54 & 5949,25 & 280,94 & $-8,21$ & 289,15 & 118,36 & 193,69 & 194 & 42,41 & 455,61 & 52,67 & 16,73 & 28,10 & 139,89 & 66,34 & 79,40 & 116 \\
\hline Alytes obstetricans & 30TUM95 & 100,00 & 117,54 & $\begin{array}{l}10,05 \\
108,95\end{array}$ & 37,84 & | 5730,65 & $\begin{array}{l}20,54 \\
278,82\end{array}$ & $\begin{array}{l}-0,21 \\
-6,41 \\
\end{array}$ & \begin{tabular}{|l|}
285,23 \\
285
\end{tabular} & $\begin{array}{r}\quad 10,030 \\
92,02 \\
\end{array}$ & $\begin{array}{l}192,58 \\
192\end{array}$ & $\begin{array}{l}194,1 / 3 \\
193,36\end{array}$ & $\begin{array}{l}42,41+8 \\
46,88\end{array}$ & \begin{tabular}{|l|}
472,01 \\
472,01
\end{tabular} & $\begin{array}{l}2,309 \\
52,98\end{array}$ & \begin{tabular}{|l|}
19,47 \\
19
\end{tabular} & $\begin{array}{l}2,10 \\
26,93 \\
\end{array}$ & \begin{tabular}{|l|}
146,03 \\
146,03
\end{tabular} & \begin{tabular}{|l|}
70,81 \\
70,81
\end{tabular} & $\begin{array}{l}17,40 \\
84,98\end{array}$ & $\begin{array}{l}1119,02 \\
119,02\end{array}$ \\
\hline Alytes obstetricans & 30TUM96 & 100,00 & 113,27 & 108,10 & 37,92 & 5665,31 & 273,44 & $-9,11$ & 282,55 & 87,18 & 187,76 & 188,23 & 43,72 & 500,03 & 55,74 & 21,76 & 25,99 & 154,71 & 77,24 & 91,33 & 126,07 \\
\hline Alytes obstetricans & 30TUM99 & 100,00 & 112,43 & 102,95 & 38,00 & 5414,49 & 264,02 & $-3,80$ & 267,82 & 87,41 & 183,62 & 183,69 & 45,63 & 564,68 & 64,61 & 26,34 & 24,06 & 179,09 & 93,83 & 101,38 & 144,31 \\
\hline Alytes obstetricans & 30TUN05 & 100,00 & 80,94 & 105,08 & 39,84 & 5291,33 & 233,09 & $-27,70$ & 260,79 & 52,4 & 151,28 & 151, & 16,81 & 841,23 & 104,65 & 42,91 & 25 & 284 & 152,84 & 153,09 & 231,68 \\
\hline Alytes obstetricans & \begin{tabular}{|l|}
30 TUN06 \\
\end{tabular} & 100,00 & 67,79 & 102,16 & 39,56 & 5215,84 & 217,31 & $-37,60$ & 254,91 & 40,02 & 137,45 & 137,62 & 5,61 & 963,07 & 117,60 & 49,21 & 24,66 & 320,48 & 173,26 & 173,77 & 271,29 \\
\hline
\end{tabular}




\begin{tabular}{|c|c|c|c|c|c|c|c|c|c|c|c|c|c|c|c|c|c|c|c|c|c|}
\hline TAXON & UTM & $\mathrm{km2}$ & BIO1 & B102 & $\mathrm{BIO3}$ & B104 & B105 & B106 & B107 & B108 & B109 & BIO10 & BIO11 & B1012 & BIO13 & BIO14 & BIO15 & BIO16 & BIO17 & BIO18 & BlO19 \\
\hline Alytes obstetricans & 30TUN07 & 100,00 & 74,75 & 100,90 & 39,99 & 5084,37 & 219,96 & $-29,25$ & 249,21 & 48,05 & 142,29 & 142,70 & 13,83 & 947,55 & 117,25 & 48,74 & 24,89 & 316,92 & 171,84 & 174,25 & 263,42 \\
\hline Alytes obstetricans & 30TUN08 & 100,00 & 104,95 & 97,14 & 41,16 & 4688,53 & 236,60 & 3,67 & 232,94 & 81,42 & 165,94 & 167,09 & 47,70 & 829,06 & $\begin{array}{l}108,07 \\
\end{array}$ & 42,92 & 26,34 & 282,16 & 152,16 & 159,10 & 216,77 \\
\hline Alytes obstetricans & 30TUN16 & 100,00 & 78,12 & 102,39 & 39,84 & 5167,15 & 226,15 & $-28,03$ & 254,18 & 51,17 & $\begin{array}{l}146,75 \\
\end{array}$ & $\begin{array}{l}147,05 \\
\end{array}$ & 15,97 & 888,69 & 109,61 & \begin{tabular}{|l|l|}
45,98 \\
\end{tabular} & 24,75 & 297,35 & \begin{tabular}{ll|}
162,91 \\
\end{tabular} & \begin{tabular}{ll|}
163,98 \\
\end{tabular} & 243,87 \\
\hline Alytes obstetricans & 30TUN17 & 100,00 & 79,01 & 100,01 & 39,96 & 5033,41 & 222,44 & $-24,72$ & 247,16 & 53,18 & \begin{tabular}{|l|l|}
145,73 \\
\end{tabular} & $\begin{array}{l}146,35 \\
\end{array}$ & 18,47 & 921,48 & 114,09 & 47,83 & 24,58 & 307,72 & \begin{tabular}{ll|}
168,94 \\
\end{tabular} & \begin{tabular}{|l|}
171,41 \\
\end{tabular} & 252,54 \\
\hline Alytes obstetricans & 30TUN18 & 100,00 & 89,65 & 97,48 & 40,52 & 4836,49 & 226,22 & $-11,92$ & $238,14 \mid$ & 65,36 [ & $153,17 \mid$ & $154,21]$ & 31,25 - & 898,12 & 113,38 & 46,80 & 24,96 & 301,86 & $165,37]$ & 170,20 & 241,54 \\
\hline Alytes obstetricans & 30TUN24 & 100,00 & 90,07 & 105,16 & 39,77 & 5281,60 & 241,81 & $-20,16$ & 261,97 & 62,69 & 160,11 & 160,14 & 25,69 & 760,14 & 94,15 & 38,96 & 25,36 & 256,25 & 140,39 & \begin{tabular}{|l|l|}
140,77 \\
\end{tabular} & 203,05 \\
\hline Alytes obstetricans & 30TUN25 & 100,00 & 83,33 & 103,26 & 39,81 & 5209,53 & 232,64 & $-24,53$ & 257,17 & 56,47 & 152,47 & 152,62 & 20,19 & 828,77 & 101,93 & \begin{tabular}{ll|}
42,87 \\
\end{tabular} & 24,62 & 277,06 & 152,97 & \begin{tabular}{|l|l|}
153,39 \\
\end{tabular} & 224,02 \\
\hline Alytes obstetricans & 30TUN26 & 100,00 & 73,81 & 101,07 & 39,60 & 5150,06 & 221,03 & $-31,47$ & 252,51 & 47,44 & \begin{tabular}{l|l}
142,43 \\
\end{tabular} & \begin{tabular}{|l|l|}
142,67 \\
\end{tabular} & 12,10 & \begin{tabular}{|l|l|}
917,93 \\
\end{tabular} & 111,60 & 47,71 & 23,88 & 303,48 & \begin{tabular}{ll|}
168,51 \\
\end{tabular} & $\begin{array}{l}169,33 \\
\end{array}$ & 252,25 \\
\hline Alytes obstetricans & 30TUN27 & 100,00 & 75,72 & 99,31 & 39,73 & 5038,60 & 219,20 & $-27,67$ & 246,87 & 50,11 & \begin{tabular}{|l|l|}
142,64 \\
\end{tabular} & 143,19 & \begin{tabular}{ll|l}
15,47 \\
\end{tabular} & 937,74 & 114,70 & \begin{tabular}{ll|}
48,99 \\
\end{tabular} & 23,88 & 310,48 & \begin{tabular}{ll|}
172,98 \\
\end{tabular} & \begin{tabular}{ll|l}
174,52 \\
\end{tabular} & 257,13 \\
\hline Alytes obstetricans & 30TUN29 & 100,00 & 120,79 & 86,30 & 40,72 & 4299,01 & 236,04 & 26,43 & $209,61 \mid$ & 101,17 & $176,11 \mid$ & 178,13 & 68,15 & 816,80 & 107,64 & 40,96 & 26,72 & 278,91 & 147,87 & 158,09 & 210,73] \\
\hline Alytes obstetricans & 30TUN35 & 100,00 & 83,84 & 102,02 & 39,59 & 5166,43 & 231,60 & $-23,32$ & 254,91 & 57,79 & \begin{tabular}{ll|l}
152,46 \\
\end{tabular} & 152,70 & 21,45 & 828,77 & 101,18 & \begin{tabular}{|l|l|}
42,98 \\
\end{tabular} & 24,12 & 275,09 & \begin{tabular}{ll|}
153,42 \\
\end{tabular} & \begin{tabular}{|l|l|}
153,77 \\
\end{tabular} & 222,86 \\
\hline Alytes obstetricans & 30TUN37 & 100,00 & 79,28 & 97,90 & 39,70 & 4982,78 & 220,31 & $-23,47$ & 243,78 & 54,46 & 145,36 & \begin{tabular}{|l|l|}
145,99 \\
\end{tabular} & 19,53 & 923,41 & 112,72 & 48,30 & 23,67 & \begin{tabular}{|l|l|}
304,85 \\
\end{tabular} & \begin{tabular}{|l|l|}
171,00 \\
\end{tabular} & $\begin{array}{l}172,65 \\
\end{array}$ & 251,05 \\
\hline Alytes obstetricans & 30TUN38 & 100,00 & 77,77 & 95,54 & $\begin{array}{l}39,75 \\
\end{array}$ & 4880,97 & 215,01 & $-22,60$ & 237,61 & 52,92 & $\begin{array}{l}142,35 \\
\end{array}$ & $\begin{array}{l}143,25 \\
\end{array}$ & 19,38 & \begin{tabular}{|l|l|}
971,99 \\
\end{tabular} & 118,52 & $\begin{array}{l}50,96 \\
\end{array}$ & 23,61 & 319,81 & $\begin{array}{l}179,35 \\
\end{array}$ & 182,11 & 265,67 \\
\hline Alytes obstetricans & 30TUN39 & 100,00 & 107,75 & 88,69 & 40,18 & 4470,70 & 229,18 & \begin{tabular}{l|l|}
11,69 \\
\end{tabular} & 217,48 & 87,06 & \begin{tabular}{ll|}
165,69 \\
\end{tabular} & $\begin{array}{l}167,45 \\
\end{array}$ & 53,23 & 867,20 & 111,23 & 44,20 & 25,51 & 293,17 & \begin{tabular}{|l|l}
158,73 \\
\end{tabular} & $\begin{array}{l}167,19 \\
\end{array}$ & 228,33 \\
\hline Alytes obstetricans & 30TUN44 & 100,00 & 83,80 & 102,75 & 39,18 & 5232,73 & 233,68 & $-24,74$ & \begin{tabular}{l|l}
258,42 \\
\end{tabular} & 57,72 & 153,55 & 153,56 & 20,65 & 801,07 & 96,52 & 41,3 & 23,6 & 263,35 & \begin{tabular}{|l|l|}
146,87 \\
\end{tabular} & $\begin{array}{l}147,75 \\
\end{array}$ & 214,32 \\
\hline Alytes obstetricans & 30TUN45 & 100,00 & 76,39 & 100,89 & 39,15 & 5173,28 & 224,06 & $-29,82$ & 253,88 & 50,36 & \begin{tabular}{|l|l|}
145,58 \\
\end{tabular} & 145,65 & \begin{tabular}{ll|}
14,36 \\
\end{tabular} & $\begin{array}{l}876,55 \\
\end{array}$ & \begin{tabular}{|l|l|}
104,95 \\
\end{tabular} & 45,73 & 23,18 & 286,34 & \begin{tabular}{|l|l|}
161,28 \\
\end{tabular} & 161,54 & 237,51 \\
\hline Alytes obstetricans & 30TUN47 & 100,00 & 66,54 & 97,04 & 39,20 & 5034,80 & 209,15 & $-35,25$ & 244,41 & 40,70 & \begin{tabular}{|l|l|}
134,10 \\
1
\end{tabular} & \begin{tabular}{|l|l|}
134,40 \\
\end{tabular} & 6,82 & 1002,78 & $\begin{array}{l}119,17 \\
\end{array}$ & 52,86 & 22,54 & 324,81 & \begin{tabular}{ll|}
184,95 \\
\end{tabular} & \begin{tabular}{ll|}
185,50 \\
\end{tabular} & 276,72 \\
\hline Alytes obstetricans & 30TUN48 & 100,00 & 67,51 & 94,53 & 39,34 & 4919,88 & 205,76 & $-31,83$ & 237,59 & 39,98 & 133,37 & 134,05 & 9,35 & 1040,16 & \begin{tabular}{|l|l|}
123,97 \\
\end{tabular} & 54,86 & 22,76 & \begin{tabular}{|l|l|}
337,29 \\
\end{tabular} & \begin{tabular}{ll|}
191,38 \\
\end{tabular} & \begin{tabular}{|l|}
193,21 \\
\end{tabular} & 288,05 \\
\hline Alytes obstetricans & 30TUN49 & 100,00 & 100,95 & 88,36 & 39,92 & 4525,81 & 223,92 & 5,10 & 218,82 & \begin{tabular}{l|l}
80,02 \\
\end{tabular} & \begin{tabular}{l|l|l|}
159,82 \\
\end{tabular} & \begin{tabular}{ll|}
161,59 \\
\end{tabular} & 46,13 & 905,04 & \begin{tabular}{l|l|}
113,95 \\
\end{tabular} & 46,21 & 24,80 & 303,52 & \begin{tabular}{ll|}
165,79 \\
\end{tabular} & \begin{tabular}{|l|l|}
173,43 \\
\end{tabular} & 241,78 \\
\hline Alytes obstetricans & 30TUN50 & 100,00 & 108,18 & 107,94 & 39,00 & 5427,27 & 264,00 & $-9,95$ & 273,95 & 82,67 & \begin{tabular}{ll|}
179,40 \\
\end{tabular} & \begin{tabular}{ll|}
179,86 \\
\end{tabular} & 41,3 & 581,56 & 69,70 & 27,7 & 25, & \begin{tabular}{|l|l|}
191,44 \\
\end{tabular} & 99,60 & \begin{tabular}{ll|}
107,21 \\
\end{tabular} & 149,70 \\
\hline Alytes obstetricans & 30TUN51 & 100,00 & 102,94 & 106,35 & 39,00 & 5369,64 & 256,83 & $-12,45$ & 269,28 & 77,30 & \begin{tabular}{|l|l|}
173,72 \\
\end{tabular} & 173,89 & 37,00 & \begin{tabular}{ll|}
628,56 \\
\end{tabular} & 75,55 & 30,81 & 24,62 & 206,99 & 110,28 & \begin{tabular}{l|l}
115,75 \\
\end{tabular} & 162,79 \\
\hline Alytes obstetricans & 30TUN55 & 100,00 & 67,09 & 99,61 & 38,96 & 5184,02 & 214,98 & $-37,53$ & 252,51 & 40,85 & \begin{tabular}{|l|l|}
137,07 \\
13
\end{tabular} & \begin{tabular}{|l|l|}
137,07 \\
13
\end{tabular} & $\begin{array}{l}5,56 \\
5\end{array}$ & 938,72 & $\begin{array}{l}109,96 \\
\end{array}$ & 49,34 & 22,30 & 301,20 & \begin{tabular}{|l|l|}
171,41 \\
\end{tabular} & \begin{tabular}{|l|l|l|}
171,43 \\
\end{tabular} & 256,99 \\
\hline Alytes obstetricans & 30TUN56 & 100,00 & 54,14 & 97,61 & 38,77 & 5154,62 & 200,68 & $-47,84$ & 248,52 & 24,53 & \begin{tabular}{|l|l|}
124,04 \\
\end{tabular} & \begin{tabular}{l|l|}
124,04 \\
\end{tabular} & $-6,25$ & 1057,32 & 122,17 & 56,16 & \begin{tabular}{l|l|l|}
21,65 \\
\end{tabular} & \begin{tabular}{|l|l|}
335,88 \\
\end{tabular} & $\begin{array}{l}192,65 \\
\end{array}$ & \begin{tabular}{ll|}
192,66 \\
\end{tabular} & 294,61 \\
\hline Alytes obstetricans & 30TUN57 & 100,00 & 76,96 & 95,17 & 39,27 & 4934,79 & 215,46 & $-24,06$ & 239,52 & 52,90 & \begin{tabular}{ll|l}
142,68 \\
\end{tabular} & \begin{tabular}{|l|l|}
143,37 \\
\end{tabular} & \begin{tabular}{l|l|l}
18,05 \\
\end{tabular} & 952,74 & 114,06 & $\begin{array}{ll}49,92 \\
\end{array}$ & 22,76 & 310,09 & $\begin{array}{l}176,30 \\
\end{array}$ & \begin{tabular}{|l|l|}
177,79 \\
\end{tabular} & 259,61 \\
\hline Alytes obstetricans & 30TUN58 & 100,00 & 64,12 & 93,81 & \begin{tabular}{l|l|}
39,15 \\
\end{tabular} & 4927,86 & 202,28 & $-34,64$ & 236,92 & 36,02 & 130,13 & 130,90 & 6,13 & 1062,61 & 125,24 & \begin{tabular}{l|l}
56,25 \\
\end{tabular} & 22,1 & 342,21 & \begin{tabular}{|l|l|}
195,97 \\
\end{tabular} & \begin{tabular}{ll|}
197,36 \\
\end{tabular} & 294,85 \\
\hline Alytes obstetricans & 30TUN59 & 100,00 & 114,75 & 83,58 & 39,86 & 4343,91 & 229,66 & 21,50 & 208,16 & 95,38 & $\begin{array}{l}170,75 \\
\end{array}$ & 172,82 & 61,66 & 863,78 & 110,35 & 42,60 & 25,75 & 293,55 & 155,75 & 166,59 & 229,39 \\
\hline Alytes obstetricans & 30TUN61 & 100,00 & 103,72 & 104,85 & 38,99 & 5328,17 & 255,71 & $-11,23$ & 266,94 & 79,01 & \begin{tabular}{l|l|}
174,02 \\
\end{tabular} & 174,09 & 38,44 & 631,21 & 75,10 & 30,81 & 24,13 & 205,94 & \begin{tabular}{|l|l|}
109,97 \\
\end{tabular} & \begin{tabular}{ll|}
115,17 \\
\end{tabular} & 163,11 \\
\hline Alytes obstetricans & 30TUN64 & 100,00 & 80,02 & 100,06 & 38,98 & 5184,33 & 227,28 & $-26,53$ & 253,81 & 54,72 & \begin{tabular}{ll|l}
149,56 \\
\end{tabular} & $\begin{array}{l}149,56 \\
\end{array}$ & \begin{tabular}{|l|l|}
17,97 \\
\end{tabular} & 837,02 & 98,52 & 43,42 & 22,52 & 269,66 & \begin{tabular}{ll|}
152,69 \\
\end{tabular} & \begin{tabular}{ll|}
152,69 \\
\end{tabular} & 224,50 \\
\hline Alytes obstetricans & 30TUN65 & 100,00 & 69,90 & 98,53 & 38,94 & 5144,39 & 215,94 & $-34,28$ & 250,22 & 43,91 & \begin{tabular}{|l|l|}
139,24 \\
\end{tabular} & 139,24 & 8,80 & 926,83 & 108,09 & 48,77 & 21,90 & 296,21 & \begin{tabular}{|l|l|}
169,89 \\
\end{tabular} & \begin{tabular}{|l|l|}
169,89 \\
\end{tabular} & 252,41 \\
\hline Alytes obstetricans & 30TUN66 & 100,00 & 64,93 & 96,69 & 38,92 & 5085,61 & 208,57 & $-37,11$ & 245,68 & \begin{tabular}{|l|l|}
39,03 \\
\end{tabular} & $\begin{array}{l}133,55 \\
\end{array}$ & 133,73 & $\begin{array}{ll}4,92 \\
\end{array}$ & $\begin{array}{l}990,62 \\
\end{array}$ & 115,28 & 52,41 & 21,68 & 315,93 & \begin{tabular}{|l|l|}
182,13 \\
\end{tabular} & $\begin{array}{l}182,35 \\
\end{array}$ & 272,32 \\
\hline Alytes obstetricans & 30TUN68 & 100,00 & 96,86 & 88,38 & \begin{tabular}{|l|}
39,26 \\
\end{tabular} & 4626,31 & 222,21 & 0,02 & 222,19 & 75,25 & \begin{tabular}{|l|l|}
157,31 \\
\end{tabular} & 158,81 & 40,88 & 912,28 & 112,01 & \begin{tabular}{l|l}
46,25 \\
\end{tabular} & \begin{tabular}{|l|l|}
23,97 \\
\end{tabular} & 302,74 & $\begin{array}{ll}166,82 \\
\end{array}$ & \begin{tabular}{ll|}
173,13 \\
\end{tabular} & 246,33 \\
\hline Alytes obstetricans & 30TUN69 & 100,00 & 117,26 & 81,33 & 39,36 & 4297,31 & 229,34 & 25,31 & 204,04 & 98,33 & \begin{tabular}{|l|l|}
172,43 \\
\end{tabular} & 174,63 & 64,57 & \begin{tabular}{|l|l|}
870,67 \\
\end{tabular} & 110,78 & 42,19 & 25,82 & 296,73 & 155,49 & 167,92 & 233,20 \\
\hline Alytes obstetricans & 30TUN70 & 100,00 & 108,62 & 104,73 & \begin{tabular}{|l|}
38,47 \\
\end{tabular} & 5357,18 & 260,88 & $-7,79$ & 268,68 & 84,45 & \begin{tabular}{|l|l|}
179,17 \\
\end{tabular} & $\begin{array}{l}179,25 \\
\end{array}$ & 42,87 & 593,01 & 69,56 & 28,22 & \begin{tabular}{l|l|}
24,35 \\
\end{tabular} & \begin{tabular}{|l|l|}
191,54 \\
\end{tabular} & \begin{tabular}{|l|l|}
100,47 \\
\end{tabular} & \begin{tabular}{|l|l|}
108,47 \\
\end{tabular} & 152,06 \\
\hline Alytes obstetricans & 30TUN71 & 100,00 & 103,74 & 103,20 & \begin{tabular}{|l|}
38,69 \\
\end{tabular} & 5300,40 & 254,09 & $-10,03$ & 264,13 & 79,26 & \begin{tabular}{|l|l|}
173,72 \\
\end{tabular} & \begin{tabular}{|l|l|}
173,73 \\
\end{tabular} & 38,92 & 638,52 & 75,21 & 31,10 & 23,84 & 206,53 & \begin{tabular}{|l|}
110,94 \\
\end{tabular} & \begin{tabular}{|l|l}
114,36 \\
\end{tabular} & 165,02 \\
\hline Alytes obstetricans & 30TUN75 & 100,00 & 83,51 & 96,70 & 38,99 & 5049,08 & 225,18 & $-20,38$ & 245,56 & 59,29 & \begin{tabular}{|l|l|}
151,16 \\
\end{tabular} & 151,18 & 22,95 & 856,41 & 101,02 & 44,38 & 22,20 & 276,21 & 158,04 & 158,04 & 229,83 \\
\hline Alytes obstetricans & 30TUN76 & 100,00 & 80,56 & 94,80 & 38,99 & 4971,70 & 219,32 & $-21,07$ & 240,39 & 56,74 & \begin{tabular}{|l|l|l|l|l}
147,03 & \\
\end{tabular} & \begin{tabular}{|l|l|}
147,40 \\
\end{tabular} & 21,09 & 907,74 & \begin{tabular}{|l|l|}
107,14 \\
\end{tabular} & \begin{tabular}{|l|l}
47,28 \\
\end{tabular} & 22,14 & 292,77 & 168,25 & $\begin{array}{ll}168,85 \\
\end{array}$ & 245,53 \\
\hline Alytes obstetricans & 30TUN79 & 100,00 & 123,58 & 78,04 & 39,04 & 4201,48 & 231,11 & 33,69 & 197,42 & 105,42 & 177,32 & 179,72 & 71,90 & 867,25 & 110,66 & 40,79 & 26,48 & 298,05 & 152,39 & \begin{tabular}{ll|}
167,59 \\
\end{tabular} & 234,12 \\
\hline Alytes obstetricans & 30TUN81 & 100,00 & 106,50 & 101,19 & 38,20 & 5260,10 & 254,22 & $-6,16$ & 260,38 & 82,25 & \begin{tabular}{|l|l|}
175,87 \\
\end{tabular} & \begin{tabular}{|l|l|}
175,88 \\
\end{tabular} & \begin{tabular}{ll|}
41,89 \\
\end{tabular} & \begin{tabular}{ll|}
635,95 \\
\end{tabular} & 74,48 & 30,76 & 23,36 & 204,92 & $\begin{array}{l}110,45 \\
\end{array}$ & 112,24 & 164,48 \\
\hline Alytes obstetricans & 30TUN83 & 100,00 & 97,92 & 97,97 & 38,6 & 5124,45 & 241,13 & $-9,80$ & 250,94 & 73,74 & \begin{tabular}{ll|}
166,08 \\
\end{tabular} & 166,08 & 35, & 729,99 & 85,87 & 36,4 & 22,6 & 235,61 & \begin{tabular}{|l|l|}
131,57 \\
\end{tabular} & $\begin{array}{l}131,59 \\
\end{array}$ & 192,01 \\
\hline Alytes obstetricans & 30TUN84 & 100,00 & 95,87 & 95,97 & 38,7 & 5037,41 & 235,94 & $-9,26$ & 245,21 & 72,10 & 163,01 & 163,01 & 34,6 & \begin{tabular}{|l|l|}
773,53 \\
\end{tabular} & 91,48 & 38,99 & 22,5 & 250,52 & 141,46 & 141,46 & 205,00 \\
\hline Alytes obstetricans & 30TUN85 & 100,00 & 75,40 & 95,93 & 38,82 & 5077,38 & 217,77 & $-27,32$ & 245,09 & 50,12 & $\begin{array}{l}143,84 \\
14\end{array}$ & \begin{tabular}{l|l|}
143,85 \\
\end{tabular} & \begin{tabular}{ll|}
14,98 \\
\end{tabular} & \begin{tabular}{ll|}
908,83 \\
\end{tabular} & \begin{tabular}{ll|}
105,03 \\
\end{tabular} & \begin{tabular}{ll|}
47,62 \\
\end{tabular} & 21,45 & \begin{tabular}{|l|l|}
288,47 \\
\end{tabular} & \begin{tabular}{ll|}
167,41 \\
\end{tabular} & \begin{tabular}{ll|}
167,41 \\
\end{tabular} & 246,18 \\
\hline Alytes obstetricans & \begin{tabular}{|l|l|}
$30 T U N 86$ \\
\end{tabular} & 100,00 & 66,77 & 94,64 & 38,78 & 5038,34 & 207,94 & $-33,90$ & 241,84 & 40,28 & 134,84 & 135,01 & 7,35 & 990,20 & 113,64 & 52,54 & 21,05 & 312,65 & 183,28 & 183,33 & 271,50 \\
\hline Alytes obstetricans & 30TUN87 & 100,00 & 88,78 & 89,96 & 38,97 & 4779,18 & 219,30 & $-9,24$ & 228,53 & \begin{tabular}{ll|}
66,52 \\
\end{tabular} & 151,61 & 153,06 & 31,26 & $\begin{array}{ll}919,68 \\
\end{array}$ & 109,43 & \begin{tabular}{|l|l|}
47,08 \\
\end{tabular} & 22,49 & 299,16 & \begin{tabular}{|l|l|}
169,77 \\
\end{tabular} & \begin{tabular}{|l|l|}
173,11 \\
\end{tabular} & 249,70 \\
\hline Alytes obstetricans & 30TUN88 & 100,00 & 112,28 & 82,25 & 38,9 & 4422,59 & 7 & 18,89 & 209,08 & \begin{tabular}{|c|}
92,69 \\
\end{tabular} & \begin{tabular}{|l|l|}
169,27 \\
\end{tabular} & 171,39 & 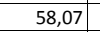 & \begin{tabular}{l|l}
878,46 \\
\end{tabular} & \begin{tabular}{l|l|}
108,95 \\
\end{tabular} & 42,3 & 24,8 & 296,31 & \begin{tabular}{|l|l|}
157,07 \\
\end{tabular} & 168,16 & 237,92 \\
\hline Alytes obstetricans & \begin{tabular}{|l|} 
30TUN93 \\
\end{tabular} & 100,00 & 101,05 & 95,72 & 38,19 & 5085,48 & 2 & $-4,99$ & 246,51 & 76,96 & 168,68 & 168,68 & 38 & 728,04 & 85,35 & 35,5 & 22, & 234,67 & 131,51 & 131,51 & 192,18 \\
\hline Alytes obstetricans & 30TUN94 & 100,00 & 97,51 & 94,17 & 38,50 & 5005,21 & 235,48 & $-6,21$ & 241,69 & 73,75 & $\begin{array}{l}164,15 \\
\end{array}$ & \begin{tabular}{l|l|}
164,25 \\
\end{tabular} & 36, & \begin{tabular}{|l|l|}
776,04 \\
\end{tabular} & 91,17 & 38,84 & 22,19 & 250,43 & \begin{tabular}{l|l|}
142,05 \\
\end{tabular} & \begin{tabular}{l|l}
142,05 \\
\end{tabular} & 206,47 \\
\hline Alytes obstetricans & 30TUN95 & 100,00 & 78,28 & 94,44 & \begin{tabular}{|l|l|}
38,47 \\
\end{tabular} & 5046,53 & 218,68 & $-23,58$ & 242,26 & 53,54 & $\begin{array}{l}146,15 \\
\end{array}$ & \begin{tabular}{ll|l}
146,33 \\
\end{tabular} & \begin{tabular}{ll|}
18,04 \\
\end{tabular} & $\begin{array}{l}901,17 \\
\end{array}$ & $\begin{array}{ll}103,65 \\
\end{array}$ & \begin{tabular}{l|l|}
46,95 \\
\end{tabular} & 21,24 & 285,22 & $\begin{array}{l}166,28 \\
\end{array}$ & $\begin{array}{l}166,34 \\
\end{array}$ & 244,29 \\
\hline Alytes obstetricans & 30TUN96 & 100,00 & 78,44 & 92,35 & 38,73 & 4948,25 & 215,06 & $-21,10$ & 236,15 & 54,41 & 144,41 & 145,20 & 19,4 & $\begin{array}{l}937,75 \\
\end{array}$ & 108,48 & 48,88 & 21,28 & 298,43 & \begin{tabular}{|l|l|}
173,79 \\
\end{tabular} & $\begin{array}{ll}174,56 \\
\end{array}$ & \\
\hline Alytes obstetricans & \begin{tabular}{|l|}
$30 T U N 97$ \\
\end{tabular} & 100,00 & 96,77 & 86,74 & 38,76 & 4674,80 & 222,08 & 0,53 & 221,54 & 75,08 & \begin{tabular}{|l|l|}
157,79 \\
\end{tabular} & 159,46 & 40,0 & 905,34 & 108,19 & 45,2 & 22,97 & 296,79 & \begin{tabular}{|l|l|}
165,17 \\
\end{tabular} & \begin{tabular}{|l|l|}
171,07 \\
\end{tabular} & 246,67 \\
\hline Alytes obstetricans & 30TUN98 & 100,00 & 117,02 & 79,04 & 38,54 & 4334,54 & 228,44 & 25,87 & 202,56 & 97,81 & 172,57 & 174,82 & 63,6 & 887,01 & 109,93 & 41,75 & 25,30 & 300,98 & 156,30 & \begin{tabular}{|l|l|}
170,18 \\
\end{tabular} & 242,66 \\
\hline Alytes obstetricans & 30TUN99 & 100,00 & 129,86 & 72,59 & 38,23 & 4062,29 & 231,07 & 43,82 & 187,25 & 112,45 & 181,34 & \begin{tabular}{|l|l|}
183,99 \\
\end{tabular} & 79,52 & 896,31 & 113,76 & 40,26 & 27,29 & 311,29 & \begin{tabular}{|l|l|}
153,49 \\
\end{tabular} & \begin{tabular}{ll|}
173,86 \\
\end{tabular} & 247,30 \\
\hline Alytes obstetricans & 30TUP00 & 100,00 & 126,74 & 83,46 & 41,44 & 4057,12 & 235,08 & 36,23 & 198,85 & \begin{tabular}{ll|}
108,39 \\
\end{tabular} & \begin{tabular}{|l|l|l|l|l|}
178,43 & \\
\end{tabular} & 181,14 & 77,34 & 829,34 & 111,57 & 41,76 & 27,54 & 281,62 & \begin{tabular}{|l|l|}
149,04 \\
\end{tabular} & \begin{tabular}{ll|}
159,96 \\
\end{tabular} & 210,49 \\
\hline Alytes obstetricans & 30TUP01 & 98,00 & 132,84 & 77,05 & 40,95 & 3870,73 & 232,49 & 46,63 & 185,86 & 115,81 & 181,85 & 184,96 & 85,6 & 834,29 & 112,99 & 41, & 27,6 & 284,33 & 147,81 & $160,77 \mid$ & 212, \\
\hline Alytes obstetricans & 30TUP02 & 40,00 & & 73,30 & 40,6 & 3764 & & 52,4 & 178, & 119 & 183 & 186 & 90, & 839,39 & 114,00 & 40, & 28, & 286 & \begin{tabular}{|l|l|}
147,48 \\
\end{tabular} & 161,79 & 215 \\
\hline Alytes obstetricans & 30TUP10 & 100,00 & 128,41 & 81,58 & 40,93 & 4066,27 & 235,21 & 38,27 & \begin{tabular}{|l|l|}
196,94 \\
\end{tabular} & 110,11 & \begin{tabular}{|l|l|}
180,23 \\
\end{tabular} & 182,88 & 78,61 & 820,87 & \begin{tabular}{|l|l|}
109,97 \\
\end{tabular} & 40,75 & 27,43 & \begin{tabular}{|l|}
280,47 \\
\end{tabular} & \begin{tabular}{|l|l|}
146,78 \\
\end{tabular} & \begin{tabular}{ll|}
158,76 \\
\end{tabular} & 210,20 \\
\hline Alytes obstetricans & 30TUP11 & 96,00 & 128,99 & 78,27 & 40,69 & 3961,70 & 231,50 & 41,54 & \begin{tabular}{ll|}
189,96 \\
\end{tabular} & \begin{tabular}{ll|}
111,36 \\
\end{tabular} & \begin{tabular}{|l|l|}
179,31 \\
\end{tabular} & 182,19 & 80,64 & 846,18 & 113,34 & 41,76 & \begin{tabular}{l|l}
27,45 \\
\end{tabular} & 289,11 & 150,50 & 163,76 & 218,27 \\
\hline Alytes obstetricans & 30TUP12 & 20,00 & 136,32 & 73,40 & 40,36 & 3793,60 & 231,56 & 52,20 & \begin{tabular}{ll|}
179,36 \\
\end{tabular} & 120,20 & \begin{tabular}{|l|l|}
184,20 \\
\end{tabular} & 187,40 & \begin{tabular}{|c|}
90,04 \\
\end{tabular} & 836,84 & 113,28 & 40,60 & 28,04 & 287,08 & \begin{tabular}{|l|l|}
147,12 \\
\end{tabular} & $\begin{array}{ll}161,92 \\
\end{array}$ & 215,56 \\
\hline Alytes & 30TUP20 & 100,00 & & 77,8 & 40,29 & 3995 & & 46,4 & 190, & & 185,62 & 188 & 85 & 802 & 10 & 38 & 27, & 276 & & 155,20 & \\
\hline Alytes obstetricans & 30TUP21 & 65,00 & 132,62 & 76,72 & 40,33 & 3942,74 & 233, & 45,64 & \begin{tabular}{|l|l|}
187,64 \\
\end{tabular} & 115, & $\begin{array}{ll}182,62 \\
\end{array}$ & 185,54 & $84,31 \mid$ & 833,38 & 111,64 & 40,50 & 27,68 & 286,53 & 147,33 & 161,81 & 215, \\
\hline Alytes obstetricans & 30TUP30 & 100,00 & 126,56 & 80,18 & 40,24 & 4107,21 & 233,28 & 36,55 & 196,73 & 108,50 & \begin{tabular}{|l|l|}
178,94 \\
\end{tabular} & 181,48 & 76,06 & 836,94 & 110,50 & 40,98 & 27,01 & 287,16 & 149,31 & 162,56 & 217,93 \\
\hline
\end{tabular}




\begin{tabular}{|c|c|c|c|c|c|c|c|c|c|c|c|c|c|c|c|c|c|c|c|c|c|}
\hline TAXON & UTM & $\mathrm{km2}$ & B101 & $\mathrm{B1O2}$ & $\mathrm{BIO3}$ & B104 & B105 & B106 & B107 & B108 & B109 & 81010 & B1011 & BIO12 & BIO13 & BIO14 & B1015 & BIO16 & BIO17 & B1018 & B1019 \\
\hline Alytes obstetricans & 30TUP31 & 47,00 & 138,43 & 74,00 & 40,01 & 3894,79 & 235,65 & 52,49 & 183,16 & 121,57 & 187,60 & 190,48 & 90,33 & 816,59 & 109,47 & 38,40 & 28,28 & 283,51 & 141,96 & 158,43 & 213,59 \\
\hline Alytes obstetricans & 30TUP40 & 100,00 & 125,65 & 79,37 & 39,98 & 4126,27 & 232,18 & 35,84 & 196,34 & 107,63 & 178,33 & 180,71 & 74,97 & 848,13 & 111,03 & 41,13 & 26,89 & 291,40 & 150,82 & 164,76 & 223,18 \\
\hline Alytes obstetricans & 30TUP41 & 33,00 & 138,78 & 73,41 & 39,85 & 3899,74 & 235,78 & 53,22 & 182,57 & 122,20 & 187,98 & 190,93 & 90,63 & 823,13 & 109,76 & 38,24 & 28,22 & 286,70 & 142,54 & 160,09 & 217,26 \\
\hline Alytes obstetricans & 30TUP90 & 55,00 & 139,28 & 68,17 & 38,04 & 3876,10 & 233,27 & 56,65 & 176,62 & 123,02 & 187,99 & 190,92 & 91,08 & 899,96 & 116,01 & 39,06 & 28,81 & 317,35 & \begin{tabular}{|l|}
150,91 \\
\end{tabular} & 175,76 & 250,17 \\
\hline Alytes obstetricans & 30TVK09 & 100,00 & 113,60 & 104,19 & 35,39 & 6407,64 & 282,44 & $-7,01$ & 289,45 & 85,27 & 198,75 & 200,05 & 36,88 & 464,05 & 56,18 & 15,15 & 31,66 & 147,87 & $\begin{array}{l}65,86 \\
\end{array}$ & 69,08 & 118,12 \\
\hline Alytes obstetricans & 30TVK53 & 100,00 & 144,53 & 111,16 & 35,28 & 6768,78 & 324,73 & 14,94 & 309,79 & 100,76 & 235,02 & 235,02 & 61,71 & 415,71 & 50,65 & 8,66 & 37,63 & 143,47 & 44,26 & 44,26 & 121,99 \\
\hline Alytes obstetricans & 30TVK63 & 100,00 & 141,18 & 112,37 & 36,00 & 6743,88 & 321,63 & 11,90 & 309,73 & 97,42 & 231,27 & 231,27 & 58,88 & 423,68 & 51,31 & 9,18 & 36,88 & 144,92 & \begin{tabular}{|l|l|}
46,64 \\
\end{tabular} & 46,64 & 122,68 \\
\hline Alytes obstetricans & $\begin{array}{l}\text { 30TVK64 } \\
\end{array}$ & 100,00 & 135,64 & 111,39 & 35,88 & 6717,81 & 315,40 & 7,72 & 307,68 & 91,90 & 225,52 & 225,52 & 54,00 & 443,15 & 54,57 & 10,44 & 36,41 & 151,81 & 50,33 & 50,33 & 128,69 \\
\hline Alytes obstetricans & 30TVK65 & 100,00 & 136,33 & 110,13 & 35,57 & \begin{tabular}{|l|l|}
6706,47 \\
\end{tabular} & 314,83 & 9,29 & 305,54 & 92,67 & 225,97 & 225,97 & 54,79 & 441,00 & 56,15 & 10,42 & 37,09 & 154,02 & 49,42 & 49,42 & 129,26 \\
\hline Alytes obstetricans & 30TVK73 & 100,00 & 141,02 & 113,14 & 36,00 & 6727,66 & 321,23 & 11,60 & 309,64 & 97,50 & 230,97 & 230,97 & 59,09 & 419,19 & 50,42 & 9,30 & 36,39 & 142,58 & 47,14 & 47,14 & 119,64 \\
\hline Alytes obstetricans & 30TVK74 & 100,00 & 132,79 & 112,49 & 36,00 & 6702,53 & 312,62 & 5,07 & 307,55 & 89,18 & 222,58 & 222,58 & 51,62 & 446,31 & 53,93 & 10,94 & 35,29 & 150,76 & 52,65 & 52,65 & 126,82 \\
\hline Alytes obstetricans & 30TVK75 & 100,00 & 133,78 & 111,15 & 36,00 & 6683,05 & 311,94 & 6,99 & 304,95 & 90,26 & 223,04 & 223,04 & 52,85 & 440,63 & 54,90 & \begin{tabular}{|c|}
11,08 \\
\end{tabular} & 35,72 & 151,22 & 51,74 & 51,74 & 125,60 \\
\hline Alytes obstetricans & 30TVK76 & 100,00 & 127,98 & 110,16 & 36,00 & 6648,33 & 304,79 & 2,62 & 302,17 & 84,65 & 216,96 & 216,96 & 47,77 & 456,99 & 56,81 & 12,23 & 34,59 & 155,52 & 55,91 & 55,91 & 129,05 \\
\hline Alytes obstetricans & 30TVK77 & 100,00 & 127,52 & 108,89 & 36,00 & 6620,45 & 302,52 & 3,27 & 299,25 & 84,27 & 215,94 & 215,94 & 47,71 & 453,90 & 57,35 & 12,08 & 34,72 & 155,45 & 56,17 & 56,17 & 127,52 \\
\hline Alytes obstetricans & 30TVK79 & 100,00 & 130,23 & 104,81 & 35,19 & 6592,21 & 299,79 & 7,80 & 291,99 & 87,36 & 218,03 & 218,03 & 50,57 & 428,29 & 55,77 & \begin{tabular}{|l|l|}
10,97 \\
\end{tabular} & 34,90 & 148,50 & 54,04 & 54,04 & 117,38 \\
\hline Alytes obstetricans & 30TVK84 & 100,00 & 136,38 & 112,93 & 36,00 & 6688,14 & 315,22 & 8,16 & 307,06 & 93,16 & 225,78 & 225,78 & 55,40 & 427,51 & 51,14 & 10,45 & 35,06 & 143,71 & 50,99 & 50,99 & 119,44 \\
\hline Alytes obstetricans & 30TVK86 & 100,00 & 129,06 & 110,40 & 36,00 & 6643,83 & 305,12 & 3,24 & 301,89 & 85,92 & 217,78 & 217,78 & 48,93 & 445,04 & 54,00 & 12,35 & 33,79 & 149,01 & 56,37 & 56,37 & 122,41 \\
\hline Alytes obstetricans & 30TVK87 & 100,00 & 125,00 & 109,19 & 36,00 & 6611,96 & 299,33 & 1,01 & 298,32 & 82,09 & 213,40 & 213,40 & 45,56 & 453,26 & 54,74 & 12,95 & 32,86 & 150,36 & 59,67 & 59,67 & 123,08 \\
\hline Alytes obstetricans & 30TVK89 & 100,00 & 126,58 & 104,72 & 35,36 & 6585,39 & 295,38 & 4,42 & 290,96 & 84,21 & 214,39 & 214,50 & 47,38 & 431,15 & 53,18 & \begin{tabular}{|l|l|}
12,27 \\
\end{tabular} & 32,92 & 143,65 & 58,45 & 58,59 & 113,28 \\
\hline Alytes obstetricans & 30TVK97 & 100,00 & 123,63 & 110,05 & 36,23 & $\mid 6604,72$ & 298,12 & -0.97 & 299,09 & 81,07 & 211.95 & 212,10 & 44,30 & 453,05 & 52.52 & 13,91 & 31,63 & 146,16 & 62.44 & 62,60 & 119,96 \\
\hline Alytes obstetricans & 30TVK98 & 100,00 & 124,56 & 108,02 & 36,03 & 6591,40 & 296,51 & 0,65 & 295,86 & 82,17 & 212,64 & 212,74 & 45,40 & 441,87 & 51,74 & 13,47 & 31,56 & 143,03 & 61,68 & 61,82 & 115,46 \\
\hline Alytes obstetricans & 30TVK99 & 100,00 & 120,32 & 107,32 & 36,00 & 6555,77 & 291,08 & $-2,42$ & 293,49 & 78,23 & 207,61 & 208,11 & 41,79 & 453,08 & 52,21 & 14,56 & 30,42 & 143,92 & 65,75 & 66,43 & 116,97 \\
\hline Alytes obstetricans & 30TVL00 & 100,00 & 103,47 & 104,36 & 35,96 & 6315,89 & 271,61 & $-14,89$ & 286,50 & 97,34 & 188,25 & 189,18 & 29,18 & 495,14 & 61,23 & $\begin{array}{ll}17,16 \\
\end{array}$ & 30,66 & 156,36 & 73,01 & 77,93 & 122,97 \\
\hline Alytes obstetricans & 30TVL01 & 100,00 & 80,62 & 106,71 & 37,19 & 6073,35 & 250,45 & $-32,06$ & 282,52 & 83,05 & 164,19 & 164,30 & 12,32 & 595,66 & 74,22 & 23,49 & 28,36 & 187,09 & 91,97 & 95,44 & 147,75 \\
\hline Alytes obstetricans & 30TVL02 & 100,00 & 104,18 & 102,76 & 35,80 & 6328,72 & 269,13 & $-14,21$ & 283,34 & 120,89 & 188,74 & 189,91 & 29,02 & 496,09 & 60,40 & 16,33 & 30,06 & 155,61 & 73,06 & 80,28 & 123,40 \\
\hline Alytes obstetricans & 30TVL03 & 100,00 & 111,68 & 101,23 & 35,18 & 6409,99 & 274,44 & $-7,84$ & 282,27 & 123,56 & 196,60 & 198,14 & 34,33 & 477,20 & 56,09 & 14,21 & 30,30 & 148,11 & 68,19 & 76,25 & 121,31 \\
\hline Alytes obstetricans & 30TVL10 & 100,00 & 112,46 & 102,96 & 35,38 & $\mid 6427,44$ & 279,75 & \begin{tabular}{|c|}
$-7,11$ \\
\end{tabular} & 286,86 & $\begin{array}{l}0,22 \\
80\end{array}$ & 197,93 & $\begin{array}{l}199,25 \\
\end{array}$ & 35,60 & 478,21 & 56,21 & 15,01 & 30,94 & 150,99 & 67,21 & 71,88 & 123,97 \\
\hline Alytes obstetricans & 30TVL11 & 100,00 & 77,29 & 106,95 & 37,36 & 6068,16 & 247,71 & $-34,23$ & 281,95 & 70,78 & 161,14 & 161,28 & 9,66 & 626,03 & 76,40 & 24,97 & 27,68 & 194,81 & 96,49 & 99,25 & 157,99 \\
\hline Alytes obstetricans & 30TVL12 & 100,00 & 82,73 & 105,64 & 37,01 & 6128,99 & 251,27 & $-30,42$ & 281,69 & 86,58 & 166,66 & 167,03 & 13,17 & 603,08 & 72,94 & 23,32 & 27,85 & 187,35 & 92,53 & 97,16 & 152,35 \\
\hline Alytes obstetricans & 30TVL14 & 100,00 & 107,35 & 102,19 & 35,99 & 6359,05 & 271,21 & $-11,09$ & 282,30 & 116,53 & 192,19 & 193,14 & 31,24 & 496,32 & 57,82 & 15,51 & 29,34 & 152,82 & 71,83 & 80,63 & 127,33 \\
\hline Alytes obstetricans & 30TVL19 & 100,00 & 115,14 & 105,68 & 36,66 & 6155,45 & 279,34 & $-5,68$ & 285,02 & 107,13 & 196,25 & 197,19 & 39,82 & 457,84 & 52,77 & 15,62 & 27,99 & 140,09 & 67,60 & 77,27 & 117,99 \\
\hline Alytes obstetricans & 30TVL21 & 100,00 & 84,19 & 106,10 & 30,09 & $\mid 6169,99$ & 254,29 & $-29,16$ & \begin{tabular}{|l|}
283,45 \\
285
\end{tabular} & \begin{tabular}{|c|}
61,23 \\
61,3
\end{tabular} & 168,71 & 169,10 & $\begin{array}{ll}3,, 262 \\
14,22\end{array}$ & \begin{tabular}{|l|l|}
607,58 \\
\end{tabular} & 72,58 & 23,35 & 27,95 & 188,62 & $\begin{array}{l}92,03 \\
\end{array}$ & 95,29 & 156,05 \\
\hline Alytes obstetricans & 30TVL22 & 100,00 & 89,15 & 105,22 & 36,69 & 6195,81 & 257,50 & $-25,31$ & 282,81 & 82,82 & 173,58 & 173,95 & 18,03 & 575,22 & 68,69 & 21,29 & 27,97 & 177,58 & 86,99 & 92,20 & $\begin{array}{ll}146,47 \\
\end{array}$ \\
\hline Alytes obstetricans & 30TVL23 & 100,00 & 72,79 & 106,73 & 37,51 & 6045,02 & 242,56 & $-38,25$ & 280,81 & 68,29 & 156,35 & 156,48 & 5,44 & 658,42 & 78,70 & 27,16 & 26,32 & 202,81 & 103,42 & 105,63 & 167,97 \\
\hline Alytes obstetricans & 30TVL24 & 100,00 & 93,79 & 104,32 & 36,48 & 6221,50 & 260,20 & $-21,89$ & 282,09 & 103,11 & 177,89 & 178,38 & 21,18 & 554,28 & 65,42 & 19,96 & 27,84 & 170,44 & 83,91 & 90,92 & 141,50 \\
\hline Alytes obstetricans & $\begin{array}{l}\text { 30TVL37 } \\
\end{array}$ & 100,00 & 107,35 & 104,11 & 36,11 & 6255,96 & 272,44 & $-11,06$ & 283,50 & 105,80 & 190,72 & 191,32 & 32,04 & 494,47 & 56,99 & 17,06 & 27,40 & 150,43 & 74,52 & 83,17 & 127,57 \\
\hline Alyty obstetricans & $\begin{array}{l}\text { 30TVL39 } \\
\end{array}$ & 100,00 & 107,55 & 104,97 & 30,112 & 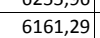 & 272,40 & $-11,12$ & $\begin{array}{l}\mid 283,50 \\
283,52 \\
\end{array}$ & \begin{tabular}{|l|l|}
123,65 \\
120
\end{tabular} & 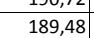 & \begin{tabular}{|l|}
190,04 \\
1904
\end{tabular} & $\begin{array}{l}32,04 \\
33,00\end{array}$ & \begin{tabular}{|l|}
454,41 \\
492,28 \\
\end{tabular} & $\begin{array}{l}30,35 \\
56,88 \\
\end{array}$ & 18,05 & 26,70 & 149,55 & $\begin{array}{l}7,35,81 \\
\end{array}$ & $\begin{array}{l}30,11 \\
85,15\end{array}$ & 126,47 \\
\hline Alytes obstetricans & 30TVL45 & 100,00 & 94,63 & 105,17 & 36,48 & 6228,27 & 262,01 & $-21,67$ & 283,68 & 89,50 & 178,54 & 178,99 & 21,54 & 555,45 & 64,78 & 20,73 & 26,73 & 169,10 & 85,71 & 92,87 & 143,01 \\
\hline Alytes obstetricans & 30TVL49 & 100,00 & 103,11 & 105,19 & 36,68 & 6153,76 & 268,55 & $-14,83$ & 283,38 & 119,62 & 185,19 & 185,55 & 29,06 & 512,73 & 59,46 & 19,73 & 25,87 & 155,59 & 80,97 & 90,08 & 131,61 \\
\hline Alytes obstetricans & 30TVL54 & 100,00 & 97,28 & 105,44 & 36,44 & 6285,75 & 265,47 & $-19,77$ & 285,24 & 84,53 & 181,84 & 182,24 & 23,39 & 546,22 & 63,27 & 20,09 & 26,97 & 166,33 & 83,72 & 89,91 & 141,45 \\
\hline Alytes obstetricans & 30TVL55 & 100,00 & 76,54 & 107,27 & 37, & 6122,88 & 246,61 & $-37,30$ & 283,90 & 87,02 & 160,33 & 160,37 & 6,47 & 648,73 & 76,29 & 27,79 & 24,67 & 197,61 & 105,10 & 107,78 & 166,35 \\
\hline Alytes obstetricans & $\begin{array}{l}\text { 30TVL56 } \\
\end{array}$ & 100,00 & 98,65 & 105,45 & 36,47 & 6247,34 & 265,84 & $-18,73$ & 284,57 & \begin{tabular}{|l|}
108,90 \\
\end{tabular} & 182,44 & 182,74 & 24,61 & 536,54 & 62,27 & 20,27 & 26,21 & 162,15 & 83,91 & 91,55 & 138,26 \\
\hline Alytes obstetricans & 30TVL59 & 100,00 & 108,00 & 105,03 & 36,61 & 6185,94 & 273,14 & $-10,25$ & 283,39 & 124,27 & 190,18 & 190,51 & 33,01 & 493,92 & 57,00 & 18,96 & 25,70 & 148,62 & 78,66 & 86,02 & 127,11 \\
\hline Alytes obstetricans & 30TVL62 & 100,00 & 122,19 & 103,14 & 35,32 & 6491,62 & 288,90 & 1,52 & 287,38 & 80,64 & 208,18 & 208,88 & 43,69 & 450,45 & 54,49 & 13,15 & 31,25 & 147,72 & 63,30 & 64,48 & 120,74 \\
\hline Alytes obstetricans & 30TVL66 & 100,00 & 76,30 & 107,84 & 37,4 & 6119,81 & 246,56 & $-38,21$ & 284,77 & 90,68 & 159,88 & 159,89 & 5,98 & 651,92 & 76,56 & 28,84 & 23,88 & 198,39 & 107,84 & 110,04 & 166,99 \\
\hline Alytes obstetricans & 30TVL67 & 100,00 & 100,57 & 106,06 & 36, & \begin{tabular}{|l|l|}
6237,13 \\
\end{tabular} & 268,0 & $-17,44$ & 285,45 & \begin{tabular}{|r|}
118,41 \\
\end{tabular} & \begin{tabular}{|l|}
184,05 \\
\end{tabular} & \begin{tabular}{|l|}
184,31 \\
\end{tabular} & 26,33 & 527,83 & 61,34 & 20,66 & 25,47 & 159,01 & $\begin{array}{r}84,49 \\
\end{array}$ & $\begin{array}{l}1,404 \\
91,42 \\
\end{array}$ & 135,66 \\
\hline Alytes obstetricans & 30TVL68 & 100,00 & 108,25 & 105,39 & 36,51 & 6236,98 & 274,3 & $-10,43$ & 284,81 & 125,95 & 191,41 & 191,62 & 33,21 & 493,10 & 56,96 & 18,9 & 25,61 & 147,88 & 78,89 & 85,53 & 126,82 \\
\hline Alytes obstetricans & 30TVL73 & 100,00 & 112,34 & 104,94 & 36,00 & 6424,94 & 280,08 & $-7,36$ & 287,45 & 72,50 & 197,80 & 198,45 & 35,42 & 480,68 & 55,10 & 16,20 & 28,44 & 149,45 & 72,21 & 75,72 & 125,06 \\
\hline Alytes obstetricans & 30 TVL76 & 100,00 & 84,50 & 108,12 & 37,05 & 6186,52 & 254,92 & $-32,07$ & 286,99 & 100,32 & 168,44 & 168,50 & 12,55 & 608,11 & 71,52 & 26,34 & 23,99 & 184,73 & 100,57 & 106,50 & 155,64 \\
\hline Alytes obstetricans & 30TVL80 & 100,00 & 128,46 & 102,32 & 35,07 & 6577,84 & 294,21 & 6,89 & 287,32 & 86,39 & 216,18 & 216,18 & 49,14 & 414,96 & 51,50 & 11,70 & 32,79 & 138,37 & 57,21 & 57,21 & 106,89 \\
\hline Alytes obstetricans & 30TVL86 & 100,00 & $\begin{array}{r}20,40 \\
8,62\end{array}$ & 108,83 & 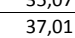 & 6219,83 & 25 & \begin{tabular}{|l|l|}
$-29,34$ \\
-29
\end{tabular} & \begin{tabular}{|l|}
288,71 \\
28,
\end{tabular} & \begin{tabular}{|l|}
105,40 \\
10,40
\end{tabular} & \begin{tabular}{|l|}
172,68 \\
170
\end{tabular} & \begin{tabular}{|l|}
172,75 \\
170
\end{tabular} & $\begin{array}{l}45,67 \\
15,6\end{array}$ & $\begin{array}{l}14,, 00 \\
588,72\end{array}$ & $\begin{array}{l}1,0934 \\
69,34\end{array}$ & 25,68 & 23,87 & 178,59 & \begin{tabular}{|l|}
3,21 \\
98,32
\end{tabular} & \begin{tabular}{|l|}
104,12 \\
10,1
\end{tabular} & 150,35 \\
\hline Alytes obstetricans & \begin{tabular}{|l|}
$30 T V L 87$ \\
\end{tabular} & 100,00 & 94,49 & 108,47 & 37,00 & 6223,54 & 264,29 & $-24,13$ & 288,42 & 111,81 & 178,15 & 178,29 & 20,81 & 559,91 & 65,81 & 24,12 & 23,88 & 169,43 & 93,76 & 100,73 & 143,13 \\
\hline Alytes obstetricans & 30TVL88 & 100,00 & 102,05 & 107,89 & 37,00 & 6222,84 & 270,60 & $-17,08$ & 287,69 & 120,28 & 185,22 & 185,51 & 27,69 & 523,70 & 61,33 & 22,14 & 24,10 & 157,90 & 87,73 & 94,40 & 133,97 \\
\hline Alytes obstetricans & 30TVL91 & 100,00 & 121,90 & 104,96 & 35,73 & 6522,61 & 289,31 & $-0,26$ & 289,56 & 80,44 & 208,64 & 208,92 & 43,39 & 436,13 & 50,64 & 14,20 & 29,76 & 137,75 & 65,45 & 66,21 & 110,47 \\
\hline Alytes obstetricans & 30TVL92 & 100,00 & 120,83 & 105,11 & 35,93 & 6492,10 & 287,99 & $-1,00$ & 288,99 & 79,70 & 206,94 & 207,49 & 42,66 & 438 & 50,65 & 14 & 28,94 & 136,86 & 67,03 & 68,37 & 11 \\
\hline Alytes obstetricans & $\begin{array}{l}\text { SOTVL93 } \\
\text { 30T }\end{array}$ & $\begin{array}{l}100,00 \\
\end{array}$ & $\begin{array}{l}12,03 \\
115,93 \\
\end{array}$ & 106,16 & $\begin{array}{l}3,50 \\
36,04\end{array}$ & $\mid 64543,86$ & 283,94 & $\begin{array}{l}-1,0,49 \\
-5,4\end{array}$ & \begin{tabular}{|l|}
$289,42,49$ \\
\end{tabular} & 76,12 & \begin{tabular}{|l|}
201,56 \\
\end{tabular} & \begin{tabular}{|l|}
202,12 \\
20
\end{tabular} & $\begin{array}{l}4,, 00 \\
38,45 \\
\end{array}$ & \begin{tabular}{|l}
$450,3,06$ \\
458,06
\end{tabular} & $\begin{array}{l}0,030 \\
53,33\end{array}$ & $\begin{array}{l}14,15 \\
16,36\end{array}$ & $\begin{array}{l}27,454 \\
27,60\end{array}$ & $\begin{array}{l}130,00 \\
139,58\end{array}$ & $\begin{array}{l}\mid l, 03 \\
71,74\end{array}$ & $\begin{array}{l}\mid 0,0,31 \\
74,50\end{array}$ & 1115,90 \\
\hline Alytes obstetricans & 30TVL97 & 100,00 & 95,54 & 109,50 & 37,04 & 6239,01 & 266,14 & $-24,09$ & 290,22 & 113,26 & 179,30 & 179,44 & 21,46 & 556,16 & 65,73 & 24,58 & 23,43 & 168,52 & 94,61 & 101,49 & 141,73 \\
\hline Alytes obstetricans & 30TVM01 & 100,00 & 115,13 & 107,86 & 37,00 & 6026,62 & 279,86 & $-6,93$ & 286,79 & 120,48 & 194,45 & 195,32 & 41,08 & 457,26 & 52,80 & $\begin{array}{l}16,45 \\
\end{array}$ & 27,97 & 139,88 & 67,56 & 78,95 & 117,33 \\
\hline Alytes obstetricans & 30TVM05 & 100,00 & 112,95 & 107,09 & 37,28 & 5760,54 & 274,08 & $-8,37$ & 282,45 & 90,29 & 188,68 & 189 & 42, & 491,35 & 55,07 & 20,69 & 25,91 & 150,16 & 76,06 & 88,95 & 124,25 \\
\hline Alytes obstetricans & 30TVM06 & 100,00 & 113,92 & 105,86 & 37,31 & 5681,69 & 272,60 & $\begin{array}{l}-6,31 \\
-1,1\end{array}$ & 278,90 & \begin{tabular}{|l|l}
86,09 \\
\end{tabular} & 188,46 & 188,94 & \begin{tabular}{|l|l}
43,75 \\
\end{tabular} & 502,32 & 55,56 & 21,98 & 25,36 & 154,82 & 79,12 & \begin{tabular}{|l|}
91,04 \\
1
\end{tabular} & 127,23 \\
\hline
\end{tabular}




\begin{tabular}{|c|c|c|c|c|c|c|c|c|c|c|c|c|c|c|c|c|c|c|c|c|c|}
\hline TAXON & UTM & $\mathrm{km} 2$ & B101 & B102 & $\mathrm{BIO3}$ & B104 & B105 & B106 & B107 & B108 & B109 & BIO10 & BIO11 & BIO12 & B1013 & BIO14 & BIO15 & BIO16 & B1017 & B1018 & B1019 \\
\hline Alytes obstetricans & 30TVM10 & 100,00 & 116,10 & 106,11 & 36,93 & 6097,96 & 280,07 & $-4,93$ & 285,01 & 107,70 & 196,38 & 197,21 & 41,09 & 455,39 & 52,32 & 15,94 & 27,82 & 139,40 & 67,54 & 77,48 & 117,18 \\
\hline Alytes obstetricans & 30TVM11 & 100,00 & 114,51 & 106,49 & 37,00 & 6042,88 & 278,37 & $-6,55$ & 284,92 & 115,84 & 194,09 & 194,96 & 40,25 & 462,86 & 53,24 & $\begin{array}{ll}16,96 \\
\end{array}$ & 27,29 & 141,17 & 69,51 & 80,18 & 118,63 \\
\hline Alytes obstetricans & 30TVM12 & 100,00 & 112,73 & 106,63 & 37,00 & 5981,48 & 276,42 & $-8,06$ & 284,48 & 123,04 & 191,60 & 192,36 & 39,31 & 472,45 & 54,27 & 18,01 & 26,84 & 143,71 & 71,90 & 83,22 & 120,59 \\
\hline Alytes obstetricans & 30TVM15 & 100,00 & 111,19 & 105,43 & 37,01 & 5789,24 & 271,59 & $-7,88$ & 279,47 & 82,72 & 187,42 & 187,72 & 39,77 & 500,25 & 55,85 & 21,35 & 25,09 & \begin{tabular}{|l|l|}
151,78 \\
\end{tabular} & 79,31 & 90,31 & 126,99 \\
\hline Alytes obstetricans & 30TVM16 & 100,00 & $\begin{array}{lll}111,97 \\
\end{array}$ & 104,21 & 37,01 & 5715,59 & 270,18 & $-6,01$ & 276,18 & 82,35 & 186,99 & 187,33 & 41,24 & 511,24 & 56,15 & 22,66 & 24,54 & $\begin{array}{l}155,95 \\
\end{array}$ & 82,46 & 92,47 & 129,83 \\
\hline Alytes obstetricans & 30TVM17 & 100,00 & 110,73 & 103,01 & 37,13 & 5638,93 & 266,86 & $-5,55$ & 272,42 & 81,73 & 184,87 & 185,04 & 40,97 & 532,14 & 58,37 & 24,53 & 23,95 & 163,16 & 87,60 & 94,81 & 135,47 \\
\hline Alytes obstetricans & 30TVM22 & 100,00 & 113,55 & 105,43 & 37,00 & 6006,30 & 276,36 & $-6,03$ & 282,39 & 118,28 & 192,68 & 193,21 & 39,70 & 472,53 & 53,98 & 18,31 & 26,17 & 142,92 & 73,27 & 83,16 & 120,81 \\
\hline Alytes obstetricans & $30 \mathrm{TVM} 23$ & 100,00 & 109,67 & 105,44 & 37,00 & 5941,56 & 272,32 & $\begin{array}{l}-9,19 \\
-9,19 \\
\end{array}$ & 281,50 & 125,40 & 188,09 & 188,45 & 36,70 & 491,21 & 56,07 & 20,01 & 25,35 & 148,21 & 77,60 & 87,96 & 125,23 \\
\hline Alytes obstetricans & 30TVM24 & 100,00 & 109,50 & 104,90 & 37,00 & 5880,93 & 271,14 & $-8,71$ & 279,85 & 106,82 & 187,10 & 187,48 & 37,17 & 498,61 & 56,35 & 20,91 & 25,01 & 149,86 & 79,75 & 89,26 & 126,97 \\
\hline Alytes obstetricans & 30TVM25 & 100,00 & 111,49 & 103,89 & 37,00 & \begin{tabular}{|l|l|}
5813,87 \\
\end{tabular} & 271,12 & $-5,72$ & 276,84 & 79,86 & 187,97 & 188,22 & 39,69 & 501,24 & 55,78 & 21,67 & 24,59 & 151,04 & 81,29 & 90,25 & 127,60 \\
\hline Alytes obstetricans & 30TVM27 & 100,00 & 109,36 & 101,58 & 37,00 & 5678,57 & 265,35 & $-5,01$ & 270,37 & 78,58 & 183,95 & 184,03 & 38,87 & 536,70 & 58,13 & 25,04 & 23,22 & 162,80 & 90,19 & 95,39 & 137,09 \\
\hline Alytes obstetricans & 30TVM28 & 100,00 & 106,77 & 100,34 & 37,02 & 5602,76 & 260,64 & $-5,78$ & 266,42 & 76,42 & 180,51 & 180,51 & 37,33 & 565,93 & 61,75 & 27,25 & 22,64 & 172,47 & 96,81 & 98,44 & 145,12 \\
\hline Alytes obstetricans & 30TVM29 & 100,00 & 103,68 & 98,99 & 37,13 & 5518,38 & 255,18 & $-6,58$ & 261,75 & 74,01 & 176,60 & 176,60 & 35,58 & 601,44 & 66,36 & 29,42 & 22,04 & \begin{tabular}{|l|l|}
184,45 \\
\end{tabular} & 104,62 & 105,03 & 155,32 \\
\hline Alytes obstetricans & 30 TVM 30 & 100,00 & 113,54 & 104,84 & \begin{tabular}{|l|}
36,68 \\
\end{tabular} & 6124,35 & 277,16 & $-5,93$ & 283,09 & 117,41 & 194,40 & 195,11 & 38,66 & 470,29 & 53,89 & $\begin{array}{l}17,29 \\
\end{array}$ & 26,70 & $\begin{array}{l}142,25 \\
\end{array}$ & 72,34 & 80,95 & 121,05 \\
\hline Alytes obstetricans & 30TVM31 & 100,00 & 116,31 & 104,60 & 36,68 & 6072,02 & 278,74 & $-3,36$ & 282,10 & 103,63 & 196,28 & 196,77 & 41,52 & 463,01 & 52,81 & $\begin{array}{l}17,39 \\
\end{array}$ & 26,34 & \begin{tabular}{|l|l|}
140,08 \\
\end{tabular} & 71,91 & 80,16 & 118,98 \\
\hline Alytes obstetricans & 30TVM32 & 100,00 & 112,25 & 104,83 & 36,97 & 6015,64 & 274,71 & $-6,50$ & 281,21 & 123,59 & 191,55 & 191,91 & 38,29 & 479,94 & 54,83 & \begin{tabular}{|l|l|}
19,08 \\
\end{tabular} & 25,51 & 144,56 & 76,05 & 84,79 & 123,00 \\
\hline Alytes obstetricans & 30TVM33 & 100,00 & 108,27 & 104,77 & 37,00 & 5964,49 & 270,72 & $-9,20$ & 279,92 & 126,45 & 187,12 & 187,39 & 35,21 & 498,45 & 56,83 & 20,76 & 24,88 & 149,79 & 80,56 & 89,25 & 127,45 \\
\hline Alytes obstetricans & 30TVM34 & 100,00 & 106,97 & 104,04 & 37,00 & 5908,60 & 268,39 & $-9,57$ & 277,97 & 121,96 & $\begin{array}{ll}185,07 \\
\end{array}$ & 185,15 & 34,46 & 511,04 & 57,86 & 22,09 & 24,09 & 152,90 & 83,91 & 91,86 & 130,41 \\
\hline Alytes obstetricans & 30 TVM36 & 100,00 & 107,53 & 102,06 & 37,00 & 5790,03 & 265,81 & $-6,63$ & 272,44 & 79,54 & 183,78 & 183,81 & 35,90 & 526,94 & 58,12 & 24,18 & 23,20 & \begin{tabular}{|l|l|}
157,04 \\
\end{tabular} & 88,99 & 92,82 & 134,78 \\
\hline Alytes obstetricans & 30TVM37 & 100,00 & 106,62 & 100,78 & $37,00 \mid$ & 5733,36 & 263,24 & $-6,06$ & 269,30 & 74,05 & $\mid 182.03$ & 182.05 & 35,59 & 543,52 & 58.96 & 25,78 & 22.52 & $\mid 162,43$ & 93,38 & 95,74 & 139,28 \\
\hline Alytes obstetricans & 30TVM38 & 100,00 & 106,07 & 99,22 & 37,00 & 5654,97 & 260,06 & $-4,72$ & 264,78 & 73,92 & 180,35 & 180,35 & 35,83 & 565,09 & 60,68 & 27,50 & 22,06 & 170,20 & 98,48 & 99,15 & 145,37 \\
\hline Alytes obstetricans & 30TVM39 & 100,00 & 102,91 & 97,88 & 37,01 & 5555,62 & 254,18 & $-5,56$ & 259,75 & 71,68 & 176,22 & 176,22 & 34,31 & 602,44 & 65,96 & 29,75 & 21,75 & 183,21 & 106,31 & 106,31 & 156,24 \\
\hline Alytes obstetricans & 30TVM40 & 100,00 & 113,46 & 104,42 & 36,52 & 6135,33 & 276,98 & $-5,46$ & 282,45 & 122,49 & 194,55 & 195,09 & 38,56 & 472,12 & 54,16 & 17,76 & 26,23 & $\begin{array}{ll}142,26 \\
\end{array}$ & 74,12 & 81,77 & 121,43 \\
\hline Alytes obstetricans & 30TVM41 & 100,00 & 115,39 & 104,04 & 36,71 & 6081,07 & 277,89 & $-3,05$ & 280,94 & 108,31 & 195,63 & 195,91 & 40,63 & 467,45 & 53,33 & 18,07 & 25,81 & 140,75 & 74,19 & 81,43 & 120,23 \\
\hline Alytes obstetricans & 30TVM42 & 100,00 & 111,55 & 104,21 & 36,99 & 6041,66 & 274,06 & $-6,11$ & 280,17 & 129,77 & 191,33 & 191,65 & 37,41 & 484,68 & 55,41 & 19,70 & 24,98 & 145,36 & 78,42 & 84,94 & 124,35 \\
\hline Alytes obstetricans & 30TVM43 & 100,00 & 107,22 & 104,07 & 37,00 & $\begin{array}{ll}5987,94 \\
\end{array}$ & 269,58 & $-9,39$ & 278,97 & 125,28 & 186,45 & 186,49 & 33,98 & 506,27 & 57,85 & 21,60 & 24,22 & 151,88 & 83,48 & 90,24 & 129,68 \\
\hline Alytes obstetricans & 30TVM44 & 100,00 & 105,16 & 103,69 & 37,00 & 5929,56 & 266,49 & $\mid-10,45$ & 276,94 & 122,79 & $\begin{array}{l}183,57 \\
\end{array}$ & 183,60 & 32,48 & 520,90 & $\begin{array}{l}59,21 \\
5,21\end{array}$ & 23,12 & 23,55 & 155,71 & $\begin{array}{l}\mid 0,406 \\
87,36 \\
\end{array}$ & 93,38 & 133,58 \\
\hline Alytes obstetricans & 30 TVM 45 & 100,00 & 106,31 & 102,81 & 37,00 & 5873,44 & 266,03 & $-8,04$ & 274,06 & 121,05 & 183,90 & 183,92 & 34,19 & 523,97 & 58,84 & 23,95 & 23,05 & 155,33 & 89,15 & 92,81 & 134,59 \\
\hline Alytes obstetricans & 30TVM 46 & 100,00 & 102,56 & 102,01 & 37,00 & 5811,44 & 261,32 & $-10,13$ & 271,45 & 111,71 & 179,48 & 179,48 & 31,14 & 548,59 & 61,10 & 26,01 & 22,41 & 161,84 & 94,85 & 95,70 & 141,36 \\
\hline Alytes obstetricans & 30TVM47 & 100,00 & 103,58 & 100,47 & 37,00 & 5754,95 & 260,05 & $-7,40$ & 267,45 & 78,16 & 179,56 & 179,56 & 32,73 & 555,10 & 60,95 & 27,10 & 22,00 & 163,67 & 97,40 & 97,87 & 143,66 \\
\hline Alytes obstetricans & 30TVM48 & 100,00 & 101,72 & 99,07 & \begin{tabular}{|c|}
37,07 \\
\end{tabular} & 5679,72 & 255,82 & $-7,16$ & 262,98 & 68,78 & 176,82 & 176,82 & 31,73 & 578,09 & 62,43 & 28,77 & 21,59 & 171,22 & 102,78 & 102,78 & 150,41 \\
\hline Alytes obstetricans & 30 TVM49 & 100,00 & 102,13 & 97,24 & 37,12 & 5571,20 & 252,62 & $\begin{array}{l}-4,45 \\
-4,45 \\
\end{array}$ & \begin{tabular}{|l|}
257,07 \\
\end{tabular} & $\begin{array}{l}69,98 \\
69,\end{array}$ & \begin{tabular}{|l|l|l|l|l|}
175,98 \\
\end{tabular} & $\begin{array}{l}175,98 \\
175\end{array}$ & 33,61 & 602,61 & $\begin{array}{l}6,454 \\
65,5\end{array}$ & 29,99 & 21,43 & 181,30 & \begin{tabular}{|l|}
108,10 \\
\end{tabular} & 108,10 & 158,06 \\
\hline Alytes obstetricans & 30TVM50 & 100,00 & 110,55 & 104,77 & 36,84 & 6143,94 & 274,70 & $-7,78$ & 282,48 & 122,81 & 191,94 & 192,25 & 35,78 & 485,23 & 55,82 & 19,06 & 25,37 & \begin{tabular}{|l|l|}
145,75 \\
\end{tabular} & 78,05 & 85,01 & 124,84 \\
\hline Alytes obstetricans & 30TVM51 & 100,00 & 113,26 & 104,34 & 36,74 & 6101,44 & 276,36 & $-4,91$ & 281,27 & 126,94 & 193,83 & 194,16 & 38,61 & 476,93 & 54,66 & 19,11 & 25,11 & 142,94 & 77,42 & 84,06 & 122,55 \\
\hline Alytes obstetricans & 30TVM55 & 100,00 & 101,93 & 103,01 & 37,03 & 5877,10 & 262,16 & $-11,48$ & 273,65 & 118,18 & 179,87 & 179,87 & 30,22 & 547,68 & 61,75 & 25,84 & 22,42 & 162,52 & 95,08 & 96,40 & 141,54 \\
\hline Alytes obstetricans & 30TVM58 & 100,00 & 98,86 & 99,24 & 37,44 & 5667,41 & 252,48 & $-9,10$ & 261,58 & 69,68 & 174,25 & 174,25 & 29,75 & 600,95 & 65,14 & 30,32 & 21,19 & \begin{tabular}{|l|l|}
176,48 \\
\end{tabular} & 108,41 & 108,41 & 158,28 \\
\hline Alytes obstetricans & 30TVM59 & 100,00 & 99,00 & 97,41 & 37,52 & 5574,17 & 249,40 & $-6,82$ & 256,22 & 66,52 & 173,22 & 173,22 & 31,22 & 624,74 & 66,83 & 31,49 & 21,03 & 185,39 & 113,75 & 113,75 & 166,05 \\
\hline Alytes obstetricans & 30TVM60 & 100,00 & 111,15 & 105,20 & 36,93 & 6157,40 & 275,67 & $-7,15$ & 282,81 & 129,52 & 192,69 & 192,96 & 36,12 & 484,53 & 55,92 & 19,53 & 24,88 & 145,21 & 79,38 & 85,17 & 124,46 \\
\hline Alytes obstetricans & 30TVM63 & 100,00 & 101,94 & 105,06 & 37,04 & 5997,43 & 265,26 & $-13,73$ & 278,99 & 119,57 & 181,64 & 181,66 & 29,21 & 537,35 & 61,60 & 24,48 & 22.84 & $\mid 161,06$ & 92,35 & 96,47 & 138,56 \\
\hline Alytes obstetricans & 30TVM64 & 100,00 & 95,36 & 104,86 & 37,20 & 5925,16 & 258,21 & $-18,69$ & 276,90 & 111,96 & 174,48 & 174,49 & 24,00 & 577,95 & 65,75 & 27,61 & 22,01 & 172,62 & 101,03 & 102,07 & 149,71 \\
\hline Alytes obstetricans & 30TVM 65 & 100,00 & 99,66 & 103,47 & 37,1 & 5877,67 & 260,07 & $-13,36$ & 273,44 & 116,60 & 177,81 & 177,81 & 28,24 & 565,63 & 63,77 & 27,44 & 21,85 & 167,67 & \begin{tabular}{|l|}
99,91 \\
\end{tabular} & 100,37 & 146,89 \\
\hline Alytes obstetricans & 30TVM68 & 100,00 & 93,86 & 100,04 & 37,83 & 5660,56 & 248,30 & $-14,12$ & 262,42 & 72,58 & |169,56 & 169,56 & 25,44 & \begin{tabular}{|l|l|}
641,77 \\
\end{tabular} & 69,19 & 33,05 & 20,53 & 186,60 & $\mid$ & \begin{tabular}{|l|}
117,08 \\
\end{tabular} & 170,02 \\
\hline Alytes obstetricans & 30TVM69 & 100,00 & 98,16 & 97,64 & 37,81 & 5565,22 & 248,23 & $\mid-7,76$ & 255,99 & 65,35 & 172,37 & 172,37 & 30,50 & 646,26 & 68,22 & 32,82 & 20,34 & 190,43 & 118,83 & 118,83 & 172,83 \\
\hline Alytes obstetricans & 30TVM72 & 100,00 & 106,10 & 105,89 & 37,01 & 6061,74 & 270,43 & $-10,91$ & 281,34 & 124,35 & 186,61 & 186,65 & 32,47 & 516,80 & 59,62 & 23,21 & 23,02 & \begin{tabular}{|l|l|}
154,97 \\
\end{tabular} & 89,04 & 93,36 & 133,00 \\
\hline Alytes obstetricans & 30TVM73 & 100,00 & 98,56 & 105,98 & 37,1 & 5997,22 & 262,84 & $-17,20$ & 280,04 & 115,77 & 178,54 & 178 & 26 & 559,55 & 64,1 & 26,39 & 22,13 & 67,59 & 98,07 & 99,80 & 144,61 \\
\hline Alytes obstetricans & 30TVM74 & 100,00 & 100,22 & 105,01 & 37,2 & 5943,49 & 262,73 & $-14,36$ & \begin{tabular}{|l|}
277,09 \\
\end{tabular} & 117,38 & 179,39 & 179,40 & 28,16 & 559,96 & 63, & 26,99 & 21,78 & $\begin{array}{l}166,78 \\
\end{array}$ & $\begin{array}{l}99,11 \\
99,1\end{array}$ & 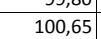 & 145,18 \\
\hline Alytes obstetricans & $30 \mathrm{TVM}$ & 100,00 & 100,45 & 103,88 & 37,2 & 5882,88 & 261,01 & $-12,85$ & 273,87 & 117,54 & 178,77 & 178,77 & 28,93 & 569,77 & 64,18 & 28,18 & 21,36 & 168,50 & 102,01 & 102,59 & 148,42 \\
\hline Alytes obstetricans & 30TVM76 & 100,00 & 87,60 & 103,64 & 37,90 & 5792,22 & 247,70 & $-23,53$ & 271,22 & 102,96 & 165,40 & 165,40 & 18,18 & 656,62 & 72,67 & 34,20 & 20,29 & 192,43 & 119,18 & 119,18 & 172,73 \\
\hline Alytes obstetricans & 30TVM78 & 100,00 & 88,24 & 101,01 & 38,00 & 5655,53 & 243,54 & $-19,99$ & 263,53 & 69,76 & 164,02 & 164,02 & 20,13 & 687,79 & 73,85 & 36,12 & 19,78 & 198,62 & 126,73 & 126,73 & 183,08 \\
\hline Alytes obstetricans & 30TVM79 & 100,00 & 98,67 & 98,00 & 37,93 & 5559,87 & 248,47 & $-7,68$ & 256,15 & 64,45 & 172,70 & 172,72 & 31,04 & 659,48 & 69,32 & 33,73 & 19,95 & 193,11 & 122,43 & 122,43 & 177,13 \\
\hline Alytes obstetricans & $30 \mathrm{TVM}$ & 100,00 & $\begin{array}{l}50,01 \\
107,37\end{array}$ & $\begin{array}{l}5,000 \\
107,21\end{array}$ & 37,07 & $\frac{503}{612}$ & $\begin{array}{l}240,47 \\
273,23\end{array}$ & \begin{tabular}{|c|c|}
$-1,00$ \\
$-11,05$
\end{tabular} & \begin{tabular}{|l|}
284,28 \\
\end{tabular} & \begin{tabular}{|l|}
125,88 \\
125
\end{tabular} & 188,52 & \begin{tabular}{|l|l|l|l|l|}
188,66 \\
\end{tabular} & $\begin{array}{l}31,04 \\
33,26\end{array}$ & \begin{tabular}{|l|}
509,37 \\
509,3
\end{tabular} & $\begin{array}{l}59,12 \\
59,19\end{array}$ & 22,79 & 23,06 & $\begin{array}{l}\mid 53,11 \\
152,96\end{array}$ & 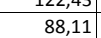 & $\begin{array}{l}\mid c \angle, 450 \\
93,40\end{array}$ & 130,80 \\
\hline Alytes obstetricans & 30TVM82 & 100,00 & 101,36 & 107,39 & 37,35 & 6056,29 & 267,30 & $-15,85$ & 283,15 & 119,08 & 182,21 & 182,22 & 28,29 & 543,64 & 62,84 & 25,53 & 22,24 & \begin{tabular}{|l|l|}
163,19 \\
\end{tabular} & 95,59 & 99,04 & 140,21 \\
\hline Alytes obstetricans & 30TVM83 & 100,00 & 98,03 & 106,97 & $\begin{array}{l}37,55 \\
\end{array}$ & 6000,19 & 263,21 & $-18,06$ & 281,27 & 115,23 & $\mid 178,17$ & 178,18 & 25,65 & 568,01 & 65,21 & 27.55 & 21,58 & $\mid 169,93$ & $\mid$\begin{tabular}{|l|l|}
101,13 \\
\end{tabular} & $\mid \begin{array}{l}104,28 \\
\end{array}$ & 147,14 \\
\hline Alytes obstetricans & 30TVM84 & 100,00 & 97,05 & 106,23 & 37,68 & 5944,40 & 260,66 & $-17,95$ & 278,60 & 114,03 & 176,37 & 176,37 & 25,10 & 583,63 & 66,38 & 29,07 & 21,05 & 173,67 & 105,01 & 107,08 & 151,81 \\
\hline Alytes obstetricans & $30 \mathrm{TVM}$ & 100,00 & 87,08 & 105,51 & 37,98 & 5859,40 & 249,67 & $-25,81$ & 275,48 & 102,62 & 165,79 & 165,79 & 16,95 & 654,34 & 73,23 & 34,11 & 20,19 & 193,01 & 119,14 & 119,61 & 17 \\
\hline Alytes obstetricans & \begin{tabular}{|c|}
30 TVM 86 \\
\end{tabular} & 100,00 & $\begin{array}{l}8,00 \\
88,57\end{array}$ & 104,39 & 年, 38,00 & $\begin{array}{l}3059,40 \\
579,97\end{array}$ & $\begin{array}{l}24,01 \\
249,07\end{array}$ & $\begin{array}{l}-23,01 \\
-23,21 \\
\end{array}$ & \begin{tabular}{|l|}
272,28 \\
272
\end{tabular} & \begin{tabular}{|l|}
$102,0<9$ \\
103,98
\end{tabular} & \begin{tabular}{|l|l|}
166,36 \\
103
\end{tabular} & \begin{tabular}{|l|l|}
166,36 \\
103
\end{tabular} & \begin{tabular}{l|l|}
18,99 \\
18,9
\end{tabular} & \begin{tabular}{|l|l|}
659,17 \\
659,17
\end{tabular} & | & | 34,11 & $\begin{array}{l}2,19 \\
19,81\end{array}$ & $\begin{array}{l}53,01 \\
193,02 \\
\end{array}$ & \begin{tabular}{|l|}
120,91 \\
129
\end{tabular} & \begin{tabular}{|l|}
120,91 \\
12
\end{tabular} & $\begin{array}{l}1 / 1,00 \\
173,76\end{array}$ \\
\hline Alytes obstetricans & 30TVM87 & 100,00 & 69,26 & 103,39 & 38,00 & 5696,11 & 228,73 & $-39,70$ & 268,43 & 82,56 & 146,46 & 146,46 & 2,19 & 800,97 & 86,39 & 43,73 & 18,76 & 231,33 & 148,06 & 148,06 & 213,46 \\
\hline Alytes obstetricans & 30TVM88 & 100,00 & 90,20 & 101,26 & 37,99 & 5654,98 & 245,08 & $-18,43$ & 263,51 & 76,82 & 165,95 & 165,95 & 22,02 & 690,99 & 74,06 & 36,42 & 19,29 & \begin{tabular}{|l|l|}
199,16 \\
\end{tabular} & 128,53 & 128,53 & 184,51 \\
\hline Alytes obstetricans & 30TVM89 & 100,00 & 103,03 & 97,94 & 37,92 & 5556,56 & 251,82 & $-4,1$ & 255, & 65,56 & 176, & 176 & 35, & 653,00 & 68,64 & 33,29 & 19,55 & 191 & 122,43 & 122,43 & 175,85 \\
\hline Alytes obstetricans & 30TVM91 & 100,00 & 105,88 & 108,52 & 37,18 & 6119,48 & 273,03 & $-13,45$ & 286,48 & 124,41 & 187,18 & 187,24 & 31,70 & 520,76 & 60,75 & 24,19 & 22,38 & 156,58 & 91,88 & 96,24 & 133,75 \\
\hline
\end{tabular}




\begin{tabular}{|c|c|c|c|c|c|c|c|c|c|c|c|c|c|c|c|c|c|c|c|c|c|}
\hline TAXON & UTM & $\mathrm{km} 2$ & BIO1 & B102 & $B 103$ & BIO4 & B105 & B106 & B107 & B108 & B109 & B1010 & BIO11 & B1012 & BIO13 & B1014 & BIO15 & B1016 & B1017 & B1018 & 81019 \\
\hline Alytes obstetricans & 30TVM92 & 100,00 & 100,07 & 108,72 & 37,73 & 6058,65 & 267,23 & $-17,95$ & 285,18 & 117,93 & 180,93 & 180,94 & 27,00 & 556,12 & 64,39 & 26,95 & 21,52 & 166,86 & 99,45 & 103,55 & 143,63 \\
\hline Alytes obstetricans & 30TVM93 & 100,00 & 95,84 & 108,37 & 37,98 & 6002,07 & 262,09 & $-20,98$ & 283,07 & 112,94 & 176,07 & 176,09 & 23,52 & 587,12 & 67,38 & 29,36 & 20,87 & 175,48 & 106,11 & 108,37 & 152,44 \\
\hline Alytes obstetricans & 30TVM94 & 100,00 & 93,69 & 107,52 & 37,99 & 5940,38 & 258,53 & $-21,79$ & 280,32 & 110,41 & $\begin{array}{l}173,17 \\
\end{array}$ & \begin{tabular}{|l|}
173,17 \\
\end{tabular} & 22,16 & 609,52 & 69,25 & 31,33 & 20,35 & $\begin{array}{l}181,15 \\
\end{array}$ & 111,26 & 112,79 & 159,04 \\
\hline Alytes obstetricans & 30TVM95 & 100,00 & 73,65 & 106,18 & 38,00 & 5824,96 & 237,28 & $-38,38$ & 275,67 & 87,98 & 152,53 & 152,53 & 4,92 & 747,79 & 82,90 & 40,55 & 19,10 & 219,58 & 137,90 & $\begin{array}{l}137,99 \\
\end{array}$ & 197,28 \\
\hline Alytes obstetricans & 30TVM96 & 100,00 & 83,40 & 105,32 & 38,00 & 5793,34 & 244,72 & $-28,48$ & 273,21 & 98,52 & 161,39 & 161,39 & 14,36 & 701,13 & 77,27 & 37,58 & 19,15 & 204,79 & 129,98 & 129,98 & 185,41 \\
\hline Alytes obstetricans & 30TVM97 & 100,00 & 71,52 & 103,63 & 38,00 & 5701,55 & 230,87 & $-37,93$ & 268,80 & 85,05 & 148,69 & 148,69 & 4,16 & 797,59 & 86,10 & 43,69 & 18,42 & 230,23 & 148,77 & 148,77 & 212,75 \\
\hline Alytes obstetricans & 30TVM98 & 100,00 & 91,12 & 101,98 & 38,00 & 5661,91 & 246,27 & $-18,21$ & 264,47 & 84,41 & 166,85 & 166,85 & 22,79 & 696,98 & 74,72 & 36,97 & 18,87 & 200,20 & 130,80 & 130,80 & 186,20 \\
\hline Alytes obstetricans & 30TVM99 & 100,00 & 102,76 & 98,85 & \begin{tabular}{|l|l|}
37,97 \\
\end{tabular} & 5568,33 & 252,12 & $-5,18$ & 257,30 & 60,80 & 176,65 & $\begin{array}{l}176,71 \\
\end{array}$ & 34,77 & 662,93 & 69,71 & 34,25 & 19,01 & $\begin{array}{l}192,52 \\
\end{array}$ & $\begin{array}{l}125,39 \\
\end{array}$ & $\begin{array}{l}125,39 \\
\end{array}$ & 178,41 \\
\hline Alytes obstetricans & 30TVN02 & 100,00 & $\begin{array}{ll}94,93 \\
\end{array}$ & 97,31 & 38,01 & 5225,65 & 240,01 & $-12,12$ & 252,13 & 69,28 & $\begin{array}{l}164,63 \\
\end{array}$ & $\begin{array}{ll}164,63 \\
\end{array}$ & 31,41 & 724,43 & 82,86 & 36,32 & 21,84 & 228,54 & $\begin{array}{ll}129,62 \\
\end{array}$ & $\begin{array}{ll}129,62 \\
\end{array}$ & 191,08 \\
\hline Alytes obstetricans & 30TVN03 & 100,00 & $\begin{array}{ll}98,08 \\
\end{array}$ & $\begin{array}{ll}94,63 \\
\end{array}$ & \begin{tabular}{|l|l|}
38,07 \\
\end{tabular} & 5091,35 & 238,07 & $-6,49$ & 244,56 & 73,30 & 165,73 & 165,91 & 36,01 & 748,90 & 86,70 & 37,29 & 21,95 & 239,08 & 135,73 & 135,79 & 199,06 \\
\hline Alytes obstetricans & 30TVN05 & 100,00 & 95,42 & 90,73 & 38,30 & 4910,96 & 228,77 & $-4,67$ & 233,44 & 71,96 & 159,71 & 161,12 & 35,86 & 832,84 & 97,31 & 41,76 & 21,96 & 268,27 & 152,96 & $\begin{array}{l}154,50 \\
\end{array}$ & 224,96 \\
\hline Alytes obstetricans & 30TVN06 & 100,00 & 93,48 & 88,85 & 38,40 & 4816,21 & 223,41 & $-4,68$ & 228,10 & 70,61 & $\begin{array}{l}156,37 \\
\end{array}$ & 158,01 & 35,10 & 882,73 & 103,43 & 44,41 & 22,11 & 285,17 & 162,07 & $\begin{array}{l}165,37 \\
\end{array}$ & 240,34 \\
\hline Alytes obstetricans & 30TVN12 & 100,00 & 97,30 & 95,50 & 38,00 & 5209,78 & 240,46 & $-8,07$ & 248,53 & 71,01 & 166,72 & 166,72 & 33,68 & 720,35 & 81,96 & 35,95 & 21,62 & 226,56 & 129,66 & 129,66 & 190,89 \\
\hline Alytes obstetricans & 30TVN13 & 100,00 & 100,03 & 92,71 & \begin{tabular}{l|l|}
37,99 \\
\end{tabular} & 5074,66 & 237,86 & $-3,24$ & 241,09 & 74,87 & 167,07 & 167,61 & 37,92 & 750,81 & 86,35 & 37,08 & 21,81 & 239,05 & 136,11 & $\begin{array}{l}136,80 \\
\end{array}$ & 200,91 \\
\hline Alytes obstetricans & 30TVN15 & 100,00 & 96,76 & 89,05 & 38,07 & 4883,89 & 227,97 & $-2,11$ & 230,09 & 73,03 & 160,45 & 162,12 & 37,23 & 841,59 & $\begin{array}{l}97,63 \\
\end{array}$ & 41,88 & 21,90 & 270,43 & $\begin{array}{ll}153,84 \\
\end{array}$ & 156,64 & 228,98 \\
\hline Alytes obstetricans & 30TVN16 & 100,00 & 99,13 & 86,20 & 38,09 & 4748,31 & 225,22 & 2,60 & 222,62 & 76,54 & 160,81 & 162,70 & 41,35 & $\begin{array}{l}876,76 \\
\end{array}$ & $\begin{array}{l}102,58 \\
\end{array}$ & 43,28 & 22,32 & 284,48 & $\begin{array}{ll}159,04 \\
\end{array}$ & $\begin{array}{ll}164,78 \\
\end{array}$ & 240,62 \\
\hline Alytes obstetricans & 30TVN17 & 100,00 & 113,51 & 79,24 & 38,01 & 4450,67 & 227,75 & 21,95 & 205,80 & 93,08 & 170,64 & 172,86 & 58,77 & 894,42 & \begin{tabular}{|l|l|}
107,47 \\
\end{tabular} & \begin{tabular}{ll|}
41,87 \\
\end{tabular} & 24,48 & 299,30 & 157,15 & $\begin{array}{l}170,29 \\
\end{array}$ & 248,74 \\
\hline Alytes obstetricans & 30TVN19 & 100,00 & 133,52 & 67,70 & 37,55 & 3946,92 & 229,38 & 51,28 & 178,10 & 116,49 & 183,18 & $\mid 186,10$ & 84,48 & \begin{tabular}{|l|l|}
947,99 \\
\end{tabular} & \begin{tabular}{|l|l|}
118,90 \\
\end{tabular} & \begin{tabular}{|l|l|}
40,98 \\
\end{tabular} & 28,14 & 331,66 & $\mid 158,69$ & $\mid \begin{array}{l}184,71 \\
\end{array}$ & 268,72 \\
\hline Alytes obstetricans & 30TVN22 & 100,00 & 98,18 & 94,05 & $37,97 \mid$ & 5211,92 & 239,98 & $-5,71$ & 245,69 & 71,22 & 167,44 & 167,58 & 34,47 & $722,47]$ & 81,64 & 35,99 & 21,27 & 226,16 & 130,84 & 130,90 & 192,53 \\
\hline Alytes obstetricans & 30TVN23 & 100,00 & $\begin{array}{ll}97,04 \\
\end{array}$ & 91,99 & 37,98 & 5098,92 & 234,97 & $-4,75$ & 239,73 & 70,94 & 164,45 & 165,11 & 34,86 & \begin{tabular}{|l|l|}
768,87 \\
\end{tabular} & 87,3 & 38,34 & 21,30 & 242,35 & 140,32 & 140,99 & 207,25 \\
\hline Alytes obstetricans & 30TVN24 & 100,00 & 101,35 & 88,78 & 37,93 & 4946,85 & 233,22 & 1,82 & 231,41 & 76,64 & $\begin{array}{l}165,72 \\
\end{array}$ & $\begin{array}{l}167,33 \\
\end{array}$ & 40,81 & \begin{tabular}{ll|}
798,72 \\
\end{tabular} & $\begin{array}{l}91,63 \\
\end{array}$ & 39,16 & 21,85 & 255,50 & $\begin{array}{l}144,76 \\
\end{array}$ & \begin{tabular}{|l|l|}
147,93 \\
\end{tabular} & 217,80 \\
\hline Alytes obstetricans & 30TVN25 & 100,00 & $\begin{array}{ll}99,07 \\
\end{array}$ & 87,23 & 38,01 & 4861,28 & 227,97 & 1,48 & 226,50 & 75,07 & 162,11 & 163,98 & 39,72 & 847,18 & 97,49 & 41,77 & 21,85 & 271,79 & \begin{tabular}{ll|}
153,74 \\
\end{tabular} & $\begin{array}{ll}158,29 \\
\end{array}$ & 232,81 \\
\hline Alytes obstetricans & 30TVN26 & 100,00 & $\begin{array}{ll}99,52 \\
\end{array}$ & 84,82 & 38,02 & 4741,43 & 224,38 & 4,32 & 220,06 & 76,76 & 160,99 & \begin{tabular}{ll|}
163,08 \\
\end{tabular} & 41,78 & 890,45 & 103,09 & 43,70 & 22,14 & 287,85 & 160,75 & 167,71 & 246,91 \\
\hline Alytes obstetricans & 30TVN27 & 100,00 & 107,99 & 79,62 & 37,86 & 4511,05 & 224,35 & 16,62 & 207,73 & 86,80 & 166,03 & 168,27 & 52,73 & 923,58 & 108,73 & 43,79 & 23,61 & 305,11 & 163,16 & 175,73 & 259,52 \\
\hline Alytes obstetricans & 30TVN30 & 100,00 & 99,40 & 96,63 & 37,33 & 5448,19 & 247,74 & $-7,01$ & 254,75 & 69,27 & 171,72 & 171,72 & 32,52 & 648,39 & 71,83 & 32,34 & 21,29 & $\begin{array}{l}198,45 \\
\end{array}$ & 115,93 & 115,93 & 170,14 \\
\hline Alytes obstetricans & 30TVN31 & 100,00 & 96,78 & 95,23 & 37,79 & 5345,47 & 242,09 & $-7,86$ & 249,95 & 67,83 & 167,90 & 167,90 & 31,47 & 694,26 & 77,24 & 34,87 & 21,03 & 213,68 & 125,51 & 125,51 & 184,37 \\
\hline Alytes obstetricans & 30TVN32 & 100,00 & 98,01 & 93,01 & 37,90 & 5220,81 & 238,88 & $-4,56$ & 243,45 & 70,10 & 167,05 & $\begin{array}{l}167,62 \\
\end{array}$ & 34,19 & 729,61 & 81,65 & 36,42 & 21,10 & 226,93 & 132,83 & 133,19 & 196,12 \\
\hline Alytes obstetricans & 30TVN33 & 100,00 & $\begin{array}{ll}99,88 \\
\end{array}$ & 90,41 & 37,83 & 5087,54 & 235,72 & $-0,61$ & 236,32 & 73,30 & 166,10 & 167,68 & $\begin{array}{l}37,62 \\
\end{array}$ & \begin{tabular}{|l|l|}
768,08 \\
\end{tabular} & 86,51 & 37,99 & 21,23 & 241,69 & 139,82 & 141,61 & 209,01 \\
\hline Alytes obstetricans & 30TVN34 & 100,00 & 102,11 & 87,56 & \begin{tabular}{ll|}
37,89 \\
\end{tabular} & 4943,68 & 232,54 & 3,78 & 228,76 & 76,89 & 166,15 & 168,01 & 41,55 & 807,40 & \begin{tabular}{|c|}
91,67 \\
\end{tabular} & 39,47 & 21,58 & 257,15 & 145,83 & 150,27 & 222,41 \\
\hline Alytes obstetricans & 30TVN35 & 100,00 & 100,09 & 85,70 & \begin{tabular}{ll|}
37,99 \\
\end{tabular} & 4839,53 & 227,32 & 3,92 & 223,40 & 75,82 & 162,73 & 164,78 & 41,04 & 860,57 & $\begin{array}{l}98,02 \\
\end{array}$ & 42,14 & 21,75 & 275,25 & $\begin{array}{l}155,33 \\
\end{array}$ & 161,40 & 239,24 \\
\hline Alytes obstetricans & 30TVN36 & 100,00 & 98,50 & 83,98 & 37,94 & 4741,51 & 222,92 & 4,39 & 218,54 & 75,08 & 159,90 & 161,99 & 40,86 & $\begin{array}{l}910,65 \\
\end{array}$ & \begin{tabular}{|l|l|}
104,03 \\
\end{tabular} & 44,72 & 21,92 & $\begin{array}{l}292,47 \\
\end{array}$ & $\begin{array}{l}164,27 \\
\end{array}$ & $\begin{array}{ll}171,98 \\
\end{array}$ & 255,13 \\
\hline Alytes obstetricans & 30TVN37 & 100,00 & 106,25 & 78,95 & 37,64 & 4519,87 & 222,60 & 15,81 & 206,80 & 83,86 & 164,41 & 166,69 & 51,04 & \begin{tabular}{|l|l|}
948,49 \\
\end{tabular} & 110,55 & 45,01 & 23,36 & 311,21 & 167,55 & 180,65 & 269,49 \\
\hline Alytes obstetricans & 30TVN38 & 100,00 & 119,03 & 72,34 & 37,31 & 4230,64 & 224,61 & 33,44 & 191,17 & 99,75 & 172,79 & 175,52 & 66,93 & 976,64 & \begin{tabular}{|l|l|}
117,27 \\
\end{tabular} & 43,96 & 25,55 & 330,01 & 167,08 & 187,87 & 281,71 \\
\hline Alytes obstetricans & 30TVN40 & 100,00 & 100,81 & 95,65 & 37,49 & 5453,55 & 247,77 & $-3,97$ & 251,74 & 69,92 & 173,08 & 173,21 & 33,90 & 645,41 & 70,98 & 32,20 & 21,06 & \begin{tabular}{ll|}
196,42 \\
\end{tabular} & 116,78 & 116,78 & 171,18 \\
\hline Alytes obstetricans & 30TVN41 & 100,00 & $\begin{array}{ll}97,97 \\
\end{array}$ & 94,24 & 37,84 & 5348,75 & 242,03 & $-5,08$ & 247,11 & 68,22 & 168,75 & 169,27 & 32,69 & \begin{tabular}{|c|}
695,17 \\
\end{tabular} & 76,59 & 34,88 & 20,91 & 212,73 & $\begin{array}{l}126,85 \\
\end{array}$ & $\begin{array}{ll}126,95 \\
\end{array}$ & $\begin{array}{l}186,38 \\
\end{array}$ \\
\hline Alytes obstetricans & 30TVN42 & 100,00 & 94,73 & 92,92 & \begin{tabular}{|l|l|}
37,97 \\
\end{tabular} & 5248,90 & 235,92 & $-6,76$ & 242,68 & 66,10 & 163,77 & 164,82 & 30,91 & \begin{tabular}{ll|}
748,93 \\
\end{tabular} & 82,50 & 37,81 & 20,56 & 230,02 & $\begin{array}{l}137,79 \\
\end{array}$ & $\begin{array}{ll}137,95 \\
\end{array}$ & 202,92 \\
\hline Alytes obstetricans & 30TVN43 & 100,00 & 94,96 & 90,73 & 37,93 & 5126,11 & 232,01 & $-4,57$ & 236,57 & 67,53 & 161,78 & $\begin{array}{l}163,49 \\
\end{array}$ & 32,63 & 793,42 & 87,77 & 39,94 & 20,51 & 245,95 & $\begin{array}{l}145,83 \\
\end{array}$ & $\begin{array}{l}147,30 \\
\end{array}$ & 217,37 \\
\hline Alytes obstetricans & 30TVN44 & 100,00 & 99,73 & 87,26 & 37,82 & 4960,01 & 230,43 & 2,49 & 227,94 & 73,85 & 164,09 & 165,94 & 39,32 & 829,36 & 92,90 & 40,81 & 21,28 & 261,53 & 150,31 & 155,01 & 230,64 \\
\hline Alytes obstetricans & 30TVN45 & 100,00 & 103,27 & 83,95 & $\begin{array}{ll}37,82 \\
\end{array}$ & $\begin{array}{lll}4805,38 \\
\end{array}$ & 228,38 & 8,55 & 219,83 & 78,79 & 165,41 & 167,48 & 44,52 & 868,29 & 98,77 & 41,92 & 21,89 & 277,71 & 155,42 & 63,40 & 244,62 \\
\hline Alytes obstetricans & 30TVN46 & 100,00 & 101,68 & 82,19 & 37,70 & 4705,55 & 224,07 & 8,78 & 215,30 & 78,10 & 162,36 & 164,63 & 44,20 & $\begin{array}{l}919,65 \\
\end{array}$ & \begin{tabular}{|l|l|}
105,53 \\
\end{tabular} & 44,48 & 22,03 & 295,47 & $\begin{array}{l}164,43 \\
\end{array}$ & $\begin{array}{ll}174,03 \\
\end{array}$ & 261,18 \\
\hline Alytes obstetricans & 30TVN47 & 100,00 & 84,44 & 84,65 & \begin{tabular}{ll|}
37,98 \\
\end{tabular} & 4773,45 & 211,57 & $-8,16$ & 219,73 & 50,17 & 146,53 & \begin{tabular}{ll|}
148,96 \\
\end{tabular} & 27,38 & 1012,71 & $\begin{array}{l}114,26 \\
\end{array}$ & 51,64 & 20,71 & \begin{tabular}{|l|l|}
319,08 \\
\end{tabular} & 186,35 & \begin{tabular}{|l|l|}
192,27 \\
\end{tabular} & 286,46 \\
\hline Alytes obstetricans & 30TVN48 & 100,00 & $\begin{array}{ll}94,57 \\
\end{array}$ & 79,63 & 37,77 & 4553,22 & 213,35 & 5,26 & 208,09 & 65,35 & 153,28 & 155,92 & 39,71 & $\begin{array}{l}1037,07 \\
\end{array}$ & \begin{tabular}{|l|l|}
120,07 \\
\end{tabular} & 50,90 & 22,20 & 334,28 & $\begin{array}{ll}186,41 \\
\end{array}$ & $\begin{array}{ll}198,12 \\
\end{array}$ & 297,73 \\
\hline Alytes obstetricans & 30TVN50 & 100,00 & 100,50 & 95,25 & 37,68 & 5447,36 & 246,48 & $-3,64$ & 250,12 & 69,33 & 172,36 & 172,86 & 33,82 & $656,37]$ & 70,75 & 32,93 & 20,83 & 197,61 & 120,26 & 120,34 & 176,11 \\
\hline Alytes obstetricans & 30TVN52 & 100,00 & 98,95 & 91,42 & 37,73 & 5221,31 & 237,64 & $-1,86$ & 239,51 & 70,07 & 167,23 & 168,60 & 35,30 & 749,14 & 81,75 & 7,43 & 20,46 & 229,92 & 137,40 & 139,13 & 205,45 \\
\hline Alytes obstetricans & $30 \mathrm{TVNS}$ & 100,00 & 113,55 & 80,20 & 37,1 & 4694,17 & 233,01 & 20,75 & 212 & 89,81 & 173,80 & 175,99 & 55,64 & 865,90 & 100,81 & 40,08 & 22,87 & 280,37 & 151,47 & 163,42 & 249,80 \\
\hline Alytes obstetricans & 30TVN56 & 100,00 & 106,14 & 80,16 & $\begin{array}{l}37,35 \\
\end{array}$ & 4654,46 & 225,83 & 14,56 & 211,27 & 82,72 & 165,90 & 168,30 & 49,16 & $\begin{array}{l}930,85 \\
\end{array}$ & $\begin{array}{ll}108,16 \\
\end{array}$ & 44,22 & 22,41 & 299,67 & 164,75 & 176,64 & 268,72 \\
\hline Alytes obstetricans & 30TVN57 & 100,00 & 90,49 & 82,57 & $\begin{array}{l}37,85 \\
3\end{array}$ & 4709,62 & 214,55 & $-0,90$ & 215,45 & 52,83 & 151,43 & $\begin{array}{l}153,93 \\
\end{array}$ & 33,92 & $\begin{array}{l}1014,97 \\
\end{array}$ & $\begin{array}{l}115,98 \\
\end{array}$ & 50,75 & 21,14 & 321,54 & 184,65 & \begin{tabular}{|l|l|}
193,13 \\
\end{tabular} & 291,03 \\
\hline Alytes obstetricans & 30TVN58 & 100,00 & $\begin{array}{ll}108,37 \\
\end{array}$ & 74,56 & 37 & $\begin{array}{lll}4385,44 \\
\end{array}$ & 219,45 & 21,93 & 197,52 & 82,71 & 164,34 & \begin{tabular}{|l|l|}
167,09 \\
\end{tabular} & 54,88 & 1034,62 & \begin{tabular}{|l|l|}
123,48 \\
\end{tabular} & \begin{tabular}{ll|}
48,07 \\
\end{tabular} & 23,87 & 39,52 & 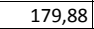 & 97,78 & 305,10 \\
\hline Alytes obstetricans & 30TVN59 & 100,00 & 126,02 & 66,15 & 36,59 & \begin{tabular}{|l|l|l|l}
4031,09 \\
\end{tabular} & 223,35 & \begin{tabular}{ll|l|}
45,27 \\
\end{tabular} & $\mid$\begin{tabular}{|l|l|}
178,07 \\
\end{tabular} & $\mid$\begin{tabular}{|l|l|}
107,64 \\
\end{tabular} & $\mid 176,66$ & \begin{tabular}{|l|l|}
179,72 \\
\end{tabular} & 76,24 & 1066,38 & $\mid 132,93$ & \begin{tabular}{|c|c|}
45,83 \\
\end{tabular} & 27,00 & $\mid 363,23$ & \begin{tabular}{|c|c|}
176,75 \\
\end{tabular} & 205,10 & 322,81 \\
\hline Alytes obstetricans & $30 \mathrm{TVN}$ & 100,00 & 111 & 88,30 & 37,3 & 5124,11 & 244,29 & 11,61 & 232,68 & 81,37 & \begin{tabular}{ll|}
177,68 \\
\end{tabular} & \begin{tabular}{ll|}
179,32 \\
\end{tabular} & 48,27 & \begin{tabular}{|l|l|}
728,47 \\
\end{tabular} & 80,75 & 34,84 & 21,01 & 226,71 & 131,29 & 136,11 & 203,84 \\
\hline Alytes obstetricans & 30TVN63 & 100,00 & 107,20 & 87,07 & 37,60 & 5038,53 & 238,05 & 9,28 & 228,77 & 79,07 & 172,23 & 174,21 & 45,30 & 785,92 & 87,87 & 38,01 & 20,95 & 245,04 & 141,95 & $\mid \begin{array}{l}147,61 \\
\end{array}$ & 221,72 \\
\hline Alytes obstetricans & 30TVN65 & 100,00 & 108,42 & 81,64 & \begin{tabular}{|l|l|}
37,37 \\
\end{tabular} & 4761,87 & 230,73 & 15,28 & 215,45 & 82,29 & 169,62 & 171,90 & 50,06 & 889,65 & 102,73 & 42,10 & 21,96 & 283,26 & 157,77 & 168,31 & 257,69 \\
\hline Alytes obstetricans & 30TVN66 & 100,00 & 105,04 & 80,32 & 37,3 & 4675,92 & 225,36 & 13,67 & 11,68 & 74,50 & 164,97 & 167,42 & 47,88 & 950,00 & $\begin{array}{l}110,36 \\
\end{array}$ & 45 & 22,03 & 303,34 & 168,65 & 180,39 & 276 \\
\hline Alytes obstetricans & $30 \mathrm{TV}$ & 100 & 101,25 & 79 & 37 & & 219 & 11,59 & & 65,66 & 160,21 & 162,83 & & 1010,80 & 117,99 & 48 & 22,10 & 323,75 & 179,86 & 192,51 & 296 \\
\hline Alytes obstetricans & 30TVN72 & 100,00 & 106,97 & $\begin{array}{ll}89,83 \\
\end{array}$ & 37,74 & 5181,20 & 242,08 & 6,58 & 235,50 & 73,49 & $\begin{array}{l}174,00 \\
\end{array}$ & 175,75 & 43,37 & 749,71 & 82,34 & 36,79 & 20,27 & 229,53 & $\begin{array}{l}137,57 \\
\end{array}$ & \begin{tabular}{|l|l|}
141,17 \\
\end{tabular} & 209,90 \\
\hline Alytes obstetricans & 30TVN73 & 100,00 & \begin{tabular}{ll|}
112,44 \\
\end{tabular} & 85,79 & 37,43 & 5006,60 & 241,04 & 14,90 & 226,15 & 83,56 & $\begin{array}{l}176,85 \\
\end{array}$ & 178,75 & 50,72 & 786,61 & 88,77 & \begin{tabular}{ll|l}
37,40 \\
\end{tabular} & 21,15 & 245,54 & 141,27 & $\begin{array}{ll}148,32 \\
\end{array}$ & 225,13 \\
\hline Alytes obstetricans & 30TVN74 & 100,00 & 107,62 & 84,58 & 37,51 & 4912,95 & 234,44 & 12,03 & 222,40 & 74,75 & 170,82 & 172,86 & 47,35 & 851,06 & 96,70 & 40,89 & 21,06 & $266,57]$ & 153,21 & 160,98 & 245,17 \\
\hline Alytes obste & & 100, & 105 & 82,77 & 37, & 307, & & 11,75 & 3 & 67,09 & 16 & & 46 & 910,55 & 104 & $4: 3>>3$ & 2 & 28 & 16 & 172,66 & 264,81 \\
\hline Alytes obstetricans & 30 TVN 7 & 100,00 & 122,34 & 71,61 & 36,7 & 4342,73 & 229,04 & 36,54 & 192,50 & 98,41 & 177,24 & 179,90 & 68,68 & 1009,67 & 123,94 & 44,06 & 25,19 & 332,97 & 169,58 & $\begin{array}{ll}190,88 \\
\end{array}$ & 310,96 \\
\hline Alytes obstetricans & 30TVN78 & 100,00 & 120,92 & 69,74 & 36,68 & 4244,12 & 224,77 & 37,20 & 187,57 & 91,57 & 174,43 & $\begin{array}{l}177,29 \\
\end{array}$ & 68,58 & 1066,48 & 131,83 & 46,55 & 25,63 & 353,54 & 178,62 & 202,15 & 330,37 \\
\hline
\end{tabular}




\begin{tabular}{|c|c|c|c|c|c|c|c|c|c|c|c|c|c|c|c|c|c|c|c|c|c|}
\hline TAXON & UTM & $\mathrm{km2}$ & B101 & B1O2 & $\mathrm{BIO3}$ & $\mathrm{B104}$ & B105 & B106 & B107 & B108 & $\mathrm{BIO9}$ & 81010 & B1011 & BIO12 & BIO13 & 81014 & B1015 & B1016 & B1017 & BIO18 & B1019 \\
\hline Alytes obstetricans & 30TVN79 & 100,00 & 123,75 & 66,45 & 36,40 & 4096,70 & 222,63 & 42,77 & 179,86 & 95,72 & 175,16 & 178,28 & 73,33 & 1118,18 & 140,30 & 47,95 & 26,70 & 374,65 & 184,63 & 212,21 & 350,73 \\
\hline Alytes obstetricans & 30TVN82 & 100,00 & 103,17 & 91,27 & 37,89 & 5220,71 & 240,35 & 2,42 & 237,93 & 60,00 & 170,94 & 172,61 & 39,31 & 771,66 & 84,04 & 38,65 & 19,54 & 233,49 & 143,87 & 146,24 & 215,95 \\
\hline Alytes obstetricans & 30TVN83 & 100,00 & 104,94 & 88,13 & 37,73 & 5072,27 & 237,26 & 6,80 & 230,46 & 63,63 & 170,70 & 172,44 & 42,99 & 820,28 & 91,21 & 40,44 & 20,14 & 252,12 & 150,79 & 155,49 & 233,70 \\
\hline Alytes obstetricans & 30TVN84 & 100,00 & 103,96 & 86,15 & $\begin{array}{l}37,85 \\
\end{array}$ & 4963,33 & 233,21 & 7,87 & 225,33 & 55,78 & 167,96 & 170,04 & 43,42 & 871,21 & 98,06 & 42,76 & 20,30 & 269,96 & 159,22 & 165,50 & 250,88 \\
\hline Alytes obstetricans & 30TVN85 & 100,00 & 104,85 & \begin{tabular}{ll|}
83,38 \\
\end{tabular} & 37,74 & 4828,90 & 229,94 & 11,22 & 218,72 & 54,11 & 166,92 & 169,21 & 45,99 & 924,90 & 105,84 & 44,83 & 20,84 & 290,18 & 167,04 & 175,80 & 270,28 \\
\hline Alytes obstetricans & 30TVN86 & 100,00 & 105,44 & 80,40 & 37,56 & 4686,24 & 225,87 & 14,56 & 211,31 & 57,21 & 165,48 & 167,92 & 48,38 & 987,13 & 114,97 & 47,12 & 21,75 & 313,49 & 175,99 & 187,50 & 293,23 \\
\hline Alytes obstetricans & 30TVN87 & 100,00 & 124,55 & 70,93 & 36,59 & 4335,24 & 230,32 & 39,18 & 191,14 & 88,84 & 179,24 & 181,90 & 70,99 & 1029,46 & 127,20 & 44,41 & 25,55 & 338,75 & 171,69 & 193,69 & 322,91 \\
\hline Alytes obstetricans & 30TVN88 & 100,00 & 126,70 & 67,62 & 36,38 & 4189,88 & 227,43 & 44,06 & 183,37 & 89,67 & 179,27 & 182,15 & 74,93 & 1088,14 & 136,91 & 45,96 & 26,80 & 362,44 & 178,49 & 204,42 & 347,08 \\
\hline Alytes obstetricans & 30TVN89 & 100,00 & 128,19 & 64,79 & 36,19 & 4057,18 & 224,63 & 47,99 & 176,64 & 90,41 & 178,88 & 181,96 & 78,10 & 1143,30 & 145,65 & 47,71 & 27,72 & 384,24 & 185,29 & 214,87 & 368,93 \\
\hline Alytes obstetricans & 30TVN90 & 100,00 & 115,81 & 94,12 & \begin{tabular}{|l|l|}
37,79 \\
\end{tabular} & 5412,15 & 256,61 & 9,92 & 246,69 & 84,13 & 185,79 & $\begin{array}{l}186,93 \\
\end{array}$ & 48,72 & 646,25 & 68,58 & 31,89 & 19,62 & 192,76 & 122,05 & 123,07 & 176,65 \\
\hline Alytes obstetricans & 30TVN92 & 100,00 & 117,27 & 88,59 & 37,62 & 5141,02 & 249,09 & 16,71 & 232,37 & 86,20 & 183,32 & 184,93 & 53,60 & 738,05 & 81,65 & 35,49 & 20,21 & 225,82 & 135,85 & 140,65 & 209,57 \\
\hline Alytes obstetricans & 30TVN93 & 100,00 & 115,36 & 86,42 & 37,65 & 5019,65 & 244,13 & 17,40 & 226,73 & 80,67 & 179,86 & 181,60 & 53,52 & 797,27 & 89,48 & 38,23 & 20,47 & 246,02 & 145,48 & 151,88 & 229,88 \\
\hline Alytes obstetricans & 30TVN94 & 100,00 & 108,73 & 85,55 & 37,76 & 4938,92 & 236,51 & 12,67 & 223,84 & $\mid 62,07$ & 172,20 & $\begin{array}{l}174,24 \\
\end{array}$ & 48,30 & 872,13 & $\begin{array}{l}90,460 \\
98,54 \\
\end{array}$ & 42,44 & 20,30 & 270,24 & $\begin{array}{l}159,39 \\
159,4\end{array}$ & 166,11 & 253,37 \\
\hline Alytes obstetricans & 30TVN95 & 100,00 & 106,38 & 83,55 & 37,77 & 4828,87 & 231,28 & 12,65 & 218,63 & 56,30 & 168,32 & 170,60 & 47,55 & 938,21 & 107,38 & 45,50 & 20,76 & 293,76 & 170,03 & 178,55 & 276,05 \\
\hline Alytes obstetricans & 30TVN96 & 100,00 & 119,40 & 76,09 & \begin{tabular}{|l|l|}
37,08 \\
\end{tabular} & 4543,25 & 232,90 & 30,66 & 202,24 & 72,38 & 177,02 & 179,58 & 63,58 & 990,60 & 118,93 & 44,53 & 23,73 & 319,32 & 170,56 & 186,73 & 305,49 \\
\hline Alytes obstetricans & 30TVN97 & 100,00 & 127,89 & 70,10 & 36,50 & 4311,79 & 232,34 & 43,09 & 189,25 & 84,19 & 182,03 & 184,80 & 74,59 & 1051,79 & 130,99 & 44,68 & 26,18 & 346,75 & 173,91 & 196,73 & 336,28 \\
\hline Alytes obstetricans & $\begin{array}{l}0 \text { TVN98 } \\
\end{array}$ & 100,00 & 127,89 & 67,50 & 36,38 & 4192,74 & 228,50 & 45,43 & 183,07 & 84,73 & 180,31 & 183,21 & 76,13 & 1115,08 & 140,70 & 46,87 & 27,06 & 370,99 & 182,25 & 208,23 & 361,25 \\
\hline Alytes obstetricans & 30TVN99 & 92,00 & 132,29 & 63,55 & 35,85 & 4036,25 & 226,96 & 52,44 & 174,52 & 89,47 & 182,50 & 185,60 & 82,34 & 1168,21 & 150,77 & 47,53 & 28,83 & 394,26 & 186,08 & 217,14 & 387,18 \\
\hline Alytes obstetricans & 30TVP00 & 64,00 & 137,12 & 66,61 & 37,79 & 3851,80 & 230,15 & 55,92 & 174,23 & 120,96 & 185,16 & 188,49 & 89,16 & 941,17 & 120,19 & 40,62 & 28,75 & 331,77 & 157,24 & 184,34 & 264,64 \\
\hline Alytes obstetricans & 30TVP10 & 91,00 & 140,29 & 63,68 & 37,35 & 3761,53 & 229,76 & 61,62 & $\mid 168,14$ & 124.53 & $\mid 180,70$ & 190,41 & 93,41 & 969,80 & $\mid 123,50$ & 40,83 & 29,56 & 344,03 & $\mid 159,72$ & 190,60 & 276,50 \\
\hline Alytes obstetricans & 30TVP11 & 3,00 & 142,42 & 61,75 & 37,17 & 3685,50 & 228,75 & 65,08 & 163,67 & 126,75 & 171,08 & 191,25 & 96,33 & 988,92 & 126,33 & 41,25 & 30,00 & 352,42 & 161,17 & 195,08 & 283,42 \\
\hline Alytes obstetricans & 30TVP21 & 27,00 & 140,55 & 60,16 & 37,02 & 3639,68 & 225,79 & 65,43 & 160,36 & 125,52 & 168,52 & 189,21 & 95,34 & 1037,54 & 131,59 & 43,05 & 30,11 & 369,63 & 167,59 & 205,20 & 300,34 \\
\hline Alytes obstetricans & 30TVP30 & 86,00 & 138,58 & \begin{tabular}{|l|l|}
60,93 \\
\end{tabular} & \begin{tabular}{|l|l|}
36,75 \\
\end{tabular} & 3722,42 & 226,02 & 62,32 & 163,70 & 122,92 & 174,77 & 188,31 & 92,36 & 1043,38 & 131,23 & 43,16 & 29,64 & 369,18 & 169,38 & 204,99 & 306,25 \\
\hline Alytes obstetricans & 30TVP31 & 33,00 & 141,27 & 58,56 & 36,50 & 3605,85 & 224,90 & 67,10 & 157,79 & 126,46 & 168,79 & 189,33 & 96,25 & 1070,27 & 135,50 & 43,90 & 30,44 & 381,94 & 170,77 & 211,92 & 313,67 \\
\hline Alytes obstetricans & 30TVP50 & 100,00 & 135,87 & 60,90 & 36,17 & 3806,96 & 224,75 & 58,97 & 165,78 & 119,22 & 183,13 & 186,40 & 88,57 & 1097,40 & 139,97 & 45,10 & 29,04 & 382,13 & 177,06 & 212,35 & 336,43 \\
\hline Alytes obstetricans & 30TVP51 & 62,00 & 139,49 & 58,70 & 36,04 & 3704,47 & 224,75 & 64,47 & 160,28 & 123,59 & 181,65 & 188,60 & 93,16 & 1118,94 & 143,78 & 45,42 & 29,88 & 393,06 & 179,04 & 217,62 & 343,98 \\
\hline Alytes obstetricans & 30TVP60 & 70,00 & 135,37 & $\begin{array}{ll}61,27 \\
6\end{array}$ & 36,10 & 3860,41 & 225,37 & 57,86 & 167,51 & 118,11 & $\begin{array}{l}183,29 \\
\end{array}$ & \begin{tabular}{|l|}
186,66 \\
\end{tabular} & 87,44 & $\begin{array}{l}1113,97 \\
111,97\end{array}$ & $\begin{array}{l}142,87 \\
\end{array}$ & $\begin{array}{l}45,54 \\
45,54\end{array}$ & 28,87 & 384,38 & $\begin{array}{l}178,76 \\
\end{array}$ & 213,35 & 349,47 \\
\hline Alytes obstetricans & 30TVP61 & 17,00 & 137,40 & 59,60 & 36,00 & 3760,60 & 224,27 & 61,20 & 163,07 & 120,93 & 183,73 & 187,13 & 90,33 & 1137,47 & 146,53 & 46,27 & 29,33 & 395,47 & 181,73 & 219,20 & 356,13 \\
\hline Alytes obstetricans & 30TWK08 & 100,00 & 117,18 & 110,49 & 36,62 & 6554,75 & 291,14 & $-7,25$ & 298,38 & 86,93 & 204,43 & 205,12 & 38,86 & 470,95 & 54,56 & 16,27 & 29,46 & 145,60 & 69,44 & 71,26 & 120,81 \\
\hline Alytes obstetricans & 30TWK09 & 100,00 & 117,86 & 109,08 & 36,42 & 6537,21 & 289,89 & $-5,92$ & 295,81 & 85,81 & 204,90 & 205,53 & 39,51 & 461,75 & 53,70 & 16,00 & 29,13 & 142,66 & 69,23 & 70,94 & 117,59 \\
\hline Alytes obstetricans & 30TWK15 & 100,00 & 121,89 & 115,47 & 37,00 & 6600,66 & 300,89 & $-5,96$ & 306,85 & 105,50 & 209,64 & 210,62 & 42,82 & 469,47 & 54,55 & 14,92 & 29,95 & 146,71 & 66,94 & 68,73 & 121,89 \\
\hline Alytes obstetricans & 30TWK16 & 100,00 & 127,79 & 113,26 & 36,87 & 6594,18 & 303,69 & 0,04 & $\begin{array}{l}00,605 \\
303,65\end{array}$ & 99,34 & \begin{tabular}{|l|}
215,59 \\
\end{tabular} & \begin{tabular}{|l|}
216,07 \\
210
\end{tabular} & $\begin{array}{ll}42,362 \\
48,31\end{array}$ & 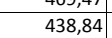 & $\begin{array}{l}4,0,71 \\
50\end{array}$ & $\begin{array}{l}4,3,74 \\
13\end{array}$ & 30,57 & 137,36 & 60,54 & $\begin{array}{l}6,1,34 \\
63,4\end{array}$ & 113,30 \\
\hline Alytes obstetricans & 30TWK18 & 100,00 & 120,12 & 111,49 & 36,94 & 6549,52 & 294,01 & $-5,69$ & 299,71 & 99,00 & 207,06 & 207,89 & 41,36 & 457,38 & 53,90 & 16,17 & 28,94 & 141,10 & 68,84 & 70,79 & 115,82 \\
\hline Alytes obstetricans & 30TWK23 & 100,00 & 120,92 & 119,29 & 37,89 & 6612,43 & 303,79 & $-9,18$ & 312,96 & 104,58 & 209,08 & 210,13 & 41,89 & 485,16 & 57,10 & 15,03 & 29,88 & 155,44 & 68,97 & 71,95 & 125,63 \\
\hline Alytes obstetricans & 30TWK25 & 100,00 & 125,32 & 116,25 & 37,10 & 6590,00 & 303,86 & $-3,68$ & 307,55 & 110,08 & 212,66 & 213,78 & 45,93 & 454,83 & 53,64 & 14,42 & 29,77 & 143,11 & 65,92 & 67,82 & 116,49 \\
\hline Alytes obstetricans & 30TWK35 & 100,00 & 121,19 & 117,90 & 37,73 & 6561,97 & 300,68 & $-8,71$ & 309,39 & 105,44 & 208,23 & 209,28 & 42,12 & 474,27 & 57,05 & 15,95 & 28,80 & 151,19 & 71,10 & 74,64 & 119,71 \\
\hline Alyty obstetricans & \begin{tabular}{|l|l}
$30 \mathrm{TWK} 43$ \\
\end{tabular} & 100,00 & $\begin{array}{l}12,153 \\
115,33\end{array}$ & $\begin{array}{ll}121,93 \\
120\end{array}$ & 38,00 & 6504,51 & 290,00 & \begin{tabular}{|l|l|}
$-0,1 / 16$ \\
$-16,16$
\end{tabular} & \begin{tabular}{|l|}
315,60 \\
31,6
\end{tabular} & \begin{tabular}{|l|}
08,445 \\
98,45
\end{tabular} & \begin{tabular}{|l|}
202,97 \\
\end{tabular} & \begin{tabular}{|l|}
204,06 \\
24,0
\end{tabular} & $\begin{array}{l}42,124 \\
36,84\end{array}$ & \begin{tabular}{|l|l|}
515,11 \\
\end{tabular} & $\mid 62,31$ & $\begin{array}{l}\mid 10,35 \\
17,43 \\
\end{array}$ & 28,00 & 168,05 & $\mid 1,10$ & $\begin{array}{l}42,04 \\
82,94\end{array}$ & 129,92 \\
\hline Alytes obstetricans & 30TWK44 & 100,00 & 117,18 & 120,75 & 38,00 & 6553,74 & 299,33 & $-14,11$ & 313,44 & 100,87 & 204,27 & 205,45 & 38,40 & 501,49 & 60,99 & 17,23 & 28,42 & 162,63 & 76,19 & 81,35 & 125,84 \\
\hline Alytes obstetricans & 30TWK49 & 100,00 & 106,46 & 115,14 & \begin{tabular}{|l|l|}
37,57 \\
\end{tabular} & 6454,86 & 281,33 & $-21,36$ & 302,69 & 90,44 & 192,08 & 193,16 & 28,95 & 510,99 & 64,31 & 21,77 & 25,87 & 161,34 & 86,29 & 93,58 & 123,12 \\
\hline Alytes obstetricans & 30TWK53 & 100,00 & 111,27 & 122,96 & 38,1 & 6545,77 & 295,52 & $-20,88$ & 316,40 & 94,02 & 198,63 & 199,73 & 33,01 & 537,06 & 65,77 & 19,21 & 27,92 & 176,51 & 83,23 & 90,26 & 133,53 \\
\hline Alytes obstetricans & 30TWK55 & 100,00 & 117,21 & 120,50 & 38, & 6520,51 & 297,60 & $-14,60$ & 312,20 & 101,16 & 203,63 & 204,84 & 38,57 & 496,81 & 61,68 & 18,01 & 27,89 & 161,19 & 78,59 & 84,40 & 122,10 \\
\hline $\begin{array}{l}\text { Ay } \\
\text { Alytes obstetricans }\end{array}$ & \begin{tabular}{|l|}
$30 \mathrm{TWK} 57$ \\
3
\end{tabular} & 100,00 & $\begin{array}{l}11,21 \\
119,51\end{array}$ & $\begin{array}{l}1117,14 \\
117\end{array}$ & 30,4 & $\begin{array}{l}0320,151 \\
6488,75\end{array}$ & 295,00 & $\begin{array}{l}-10,00 \\
-10,90 \\
\end{array}$ & $\begin{array}{l}12,00 \\
306,00\end{array}$ & \begin{tabular}{|l|}
104,30 \\
10,0
\end{tabular} & \begin{tabular}{|l|}
205,19 \\
205,19
\end{tabular} & \begin{tabular}{|l|}
206,34 \\
206,31
\end{tabular} & \begin{tabular}{|l|}
$30,3 / 9$ \\
40,91
\end{tabular} & \begin{tabular}{|l}
490,01 \\
466,33
\end{tabular} & $\begin{array}{l}1,06 \\
58,95 \\
\end{array}$ & \begin{tabular}{|l|}
10,01 \\
17,86
\end{tabular} & $\begin{array}{l}2,, 59 \\
27,57\end{array}$ & $\begin{array}{l}101,19 \\
149,15\end{array}$ & $\begin{array}{l}\mid 0,39 \\
76,57 \\
\end{array}$ & $\begin{array}{l}81,40 \\
81,97\end{array}$ & $\begin{array}{l}12,11,85 \\
111,85\end{array}$ \\
\hline Alytes obstetricans & 30TWK58 & 100,00 & 118,81 & 115,73 & 37,71 & 6474,79 & 292,47 & $-11,08$ & 303,55 & 103,83 & 204,13 & 205,10 & 40,08 & 460,90 & 58,77 & 18,36 & 27,27 & 146,40 & 77,21 & 82,94 & 109,38 \\
\hline Alytes obstetricans & 30TWK65 & 100,00 & 107,89 & 120,93 & 38,03 & 6496,11 & 288,47 & $-23,49$ & 311,97 & 91,01 & 194,28 & 195,47 & 30,04 & 537,18 & 67,66 & 21,30 & 26,92 & 175,45 & 88,84 & 97,11 & 129,26 \\
\hline Alytes obstetricans & 30TWK66 & 100,00 & 114,23 & 119,39 & 38,00 & 6481,22 & 292,02 & $-17,12$ & 309,14 & 98,42 & 200,04 & 201,21 & 36,14 & 498,53 & 63,48 & 19,64 & 27,18 & 61,69 & 83,12 & 90,30 & 118,71 \\
\hline Alytes obstetricans & 30TWK67 & 100,00 & 110,23 & 117, & 38,0 & $\begin{array}{ll}6400,26,58 \\
6468\end{array}$ & 286,09 & \begin{tabular}{|l|l|l|}
$-20,18$ \\
\end{tabular} & 306,27 & $\begin{array}{l}90,212 \\
94,\end{array}$ & 195,76 & $\begin{array}{l}196,93 \\
192\end{array}$ & 32,25 & 505,56 & $\begin{array}{l}64,96 \\
64,0\end{array}$ & 21, & 26,69 & 162,87 & \begin{tabular}{|l|l|}
86,71 \\
\end{tabular} & 94,60 & 118,85 \\
\hline Alytes obstetricans & 30TWK & 100,00 & 113 & 123,69 & 38, & 6497,97 & 295,96 & $-19,97$ & 315,93 & 96,05 & 199,46 & 200,74 & 34,86 & 533,75 & 66,63 & 19, & 27,77 & 176,55 & 86,49 & 94,15 & 128,91 \\
\hline Alytes obstetricans & 30TWK75 & 100,00 & 109,20 & 120,60 & 38,14 & 6473,89 & 288,21 & $-22,43$ & 310,64 & 92,58 & 195,14 & 196,34 & 31,22 & 528,06 & 67,51 & 21,41 & 26,89 & 172,83 & 89,73 & 98,27 & 124,22 \\
\hline Alytes obstetricans & 30TWK78 & 100,00 & 97,08 & 115,41 & 37,98 & 6407,53 & 270,31 & $-31,59$ & 301,90 & 109,17 & 182,16 & 183,24 & 20,19 & 550,90 & 72,06 & 26,03 & 25,54 & 178,22 & 100,62 & 111,84 & 125,32 \\
\hline Alytes obstetricans & 30TWK79 & 100,00 & 93,35 & 114,29 & 37,94 & 6378,58 & 265,36 & $-34,21$ & 299,57 & 112,60 & 178,20 & 179,19 & 16,96 & 562,22 & 73,74 & 27,55 & 25,18 & 72 & 104,53 & 116,45 & 127,31 \\
\hline Alytes obstetricans & 30TWK & 100,00 & 102,58 & 120,26 & 38 & 6 & 28 & $-27,89$ & 310 & 84,56 & 189,01 & 190,08 & 25,43 & 562,12 & 71,36 & 23,60 & 26,19 & 184,82 & \begin{tabular}{|c|}
96,95 \\
96
\end{tabular} & 106,93 & 129,77 \\
\hline Alytes obstetricans & 30TWK84 & 100,00 & 96,47 & 118,36 & 38,01 & 6457,47 & 274,20 & $-32,79$ & 306,99 & 78,13 & 182,81 & 183,78 & 19,61 & 580,26 & 74,21 & 25,90 & 25,51 & 189,63 & 102,94 & 114,16 & 132,22 \\
\hline Alytes obstetricans & 30TWK85 & 100,00 & 95,13 & 1117,38 & 38,00 & 6441,05 & 271,36 & $-33,71$ & 305,07 & 78,52 & 181,13 & 182,19 & 18,36 & 578,71 & 74,69 & 26.55 & 25,51 & 188,32 & $\mid 104,36$ & 115,87 & 131,04 \\
\hline Alytes obstetricans & 30TWK86 & 100,00 & 88,77 & 115,56 & 37,99 & 6414,97 & 263,32 & $-38,73$ & 302,05 & 92,32 & 174,60 & 175,45 & 12,55 & 600,71 & 77,74 & 29,01 & 24,95 & 194,99 & 110,73 & 123,49 & 135,10 \\
\hline Alytes obstetricans & 30TWK & 100,00 & 91,65 & 114,86 & 37,6 & 6400,00 & 264,45 & $-36,16$ & 300, & 106,94 & 176,90 & 177,95 & 15,38 & 579,10 & 75,79 & 28,23 & 25,25 & 188,82 & 107,97 & 120,48 & 12 \\
\hline Alytes obstetricans & \begin{tabular}{|l|}
$30 \mathrm{TWK} 88$ \\
\end{tabular} & $\begin{array}{l}100,00 \\
\end{array}$ & $\begin{array}{l}1,100 \\
86,30\end{array}$ & $\begin{array}{l}113,60 \\
113,60\end{array}$ & 37,80 & $\begin{array}{l}040,000 \\
6367,38 \\
\end{array}$ & 257,78 & $\begin{array}{l}-30,10 \\
-40,42 \\
\end{array}$ & \begin{tabular}{|l|}
$290,, 21$ \\
298,
\end{tabular} & \begin{tabular}{|l|}
$104,73,7$ \\
\end{tabular} & $\begin{array}{l}171,25 \\
171\end{array}$ & $\begin{array}{l}172,19 \\
\end{array}$ & $\begin{array}{l}0,00 \\
10,56 \\
\end{array}$ & 599,53 & 78,42 & \begin{tabular}{|l|}
30,40 \\
30,40
\end{tabular} & $\begin{array}{l}24,25 \\
24,72\end{array}$ & $\begin{array}{l}100,02 \\
196,11\end{array}$ & \begin{tabular}{|l|}
113,56 \\
11,5
\end{tabular} & $\begin{array}{l}127,40 \\
127,13\end{array}$ & $\begin{array}{l}12,33,66 \\
33\end{array}$ \\
\hline Alytes obstetricans & 30TWK89 & 100,00 & 87,80 & 112,80 & 37,62 & 6350,86 & 257,53 & \begin{tabular}{|c|}
$-39,03$ \\
\end{tabular} & 296,56 & 106,71 & 172,23 & 173,13 & 11,91 & 584,62 & 77,23 & 30,11 & 25,07 & 192,41 & 112,14 & 125,67 & 129,43 \\
\hline \begin{tabular}{|l|l|l|l|l} 
Alytes obs \\
\end{tabular} & 30TWK94 & 100,00 & 92,23 & 116,03 & $38,00 \mid$ & 6430.56 & 267.20 & -35.36 & 302.56 & 88.19 & 178,35 & 179,33 & 16,06 & 590.88 & 76,23 & 27.84 & 25.12 & 192,64 & 108,68 & 120,74 & 130,77 \\
\hline Alytes obstetricans & 30TWK95 & 100,00 & 92,36 & 115,23 & 38,00 & 6416,55 & 265,77 & $-35,26$ & 301,03 & 104,8 & $178, \mathrm{C}$ & 179 & 16,05 & 583,27 & 75,98 & 28,08 & 25 & 190 & 108,82 & 121,12 & 128,16 \\
\hline Alytes obstetricans & 30TWK96 & 100,00 & 85,48 & 113,66 & 37,82 & 6392,18 & 257,51 & $-40,91$ & 298,42 & 103,58 & 170,97 & 171,90 & 9,68 & 610,64 & 79,62 & 0,81 & 24,78 & 200,34 & 116,10 & 129,69 & 133,84 \\
\hline
\end{tabular}




\begin{tabular}{|c|c|c|c|c|c|c|c|c|c|c|c|c|c|c|c|c|c|c|c|c|c|}
\hline TAXON & UTM & $\mathrm{km2}$ & BIO1 & $\mathrm{B1O2}$ & $\mathrm{BIO3}$ & B104 & B105 & B106 & 8107 & B108 & 8109 & 81010 & B1011 & B1O12 & BIO13 & 81014 & B1015 & B1016 & B1017 & B1018 & B1019 \\
\hline Alytes obstetricans & 30TWK97| & 100,00 & 80,60 & 112,32 & 37,32 & 6361,69 & 251,36 & $-44,86$ & 296,22 & 98,38 & 165,82 & 166,64 & 5,25 & 630,88 & 82,18 & 32,84 & 24,31 & 207,19 & 121,55 & 136,08 & 138,47 \\
\hline Alytes obstetricans & 30TWK98 & 100,00 & 80,94 & 111,58 & 37,14 & 6340,80 & 250,10 & $-44,57$ & 294,66 & 98,89 & 165,63 & 166,52 & 5,51 & 622,34 & 81,77 & 32,99 & 24,56 & 205,50 & 121,34 & 136,15 & 135,74 \\
\hline Alytes obstetricans & 30TWK99 & 100,00 & 85,59 & 111,09 & 37,27 & 6324,33 & 252,81 & $-40,40$ & 293,21 & 104,34 & 169,66 & 170,64 & 9,83 & 589,39 & 78,67 & 31,47 & 25,33 & 196,45 & 116,27 & 130,66 & 127,00 \\
\hline Alytes obstetricans & 30TWL01 & 100,00 & 112,37 & 108,54 & 36,55 & 6474,92 & 283,21 & $-10,34$ & 293,56 & 93,09 & 198,60 & 199,14 & 34,89 & 477,49 & 56,35 & 17,70 & 27,35 & 145,03 & 74,67 & 77,99 & 120,09 \\
\hline Alytes obstetricans & 30TWL03 & 100,00 & \begin{tabular}{|l|l|}
118,13 \\
\end{tabular} & 107,04 & 36,16 & $\begin{array}{ll}6446,04 \\
\end{array}$ & 286,24 & $-4,34$ & 290,58 & 86,60 & 203,59 & 204,21 & 40,31 & 4446,77 & 52,88 & 16,51 & 27,15 & 134,88 & 71,42 & 74,17 & 111,64 \\
\hline Alytes obstetricans & 30TWL04 & 100,00 & 111,49 & 108,35 & 36,71 & 6393,51 & 280,81 & $-10,72$ & 291,53 & 108,95 & 196,57 & 196,98 & 34,78 & 476,03 & 56,68 & 18,80 & 25,92 & 142,80 & 77,88 & 82,26 & 119,36 \\
\hline Alytes obstetricans & 30TWL06 & 100,00 & 102,56 & 109,90 & 37,02 & 6299,10 & 273,06 & $-18,99$ & 292,06 & 121,29 & 186,60 & 186,96 & 27,32 & 520,55 & 62,08 & 22,55 & 23,99 & 157,77 & 88,47 & 94,78 & 131,51 \\
\hline Alytes obstetricans & 30TWL07 & 100,00 & 97,13 & 110,66 & 37,37 & 6252,88 & 268,36 & $-23,79$ & 292,15 & 115,05 & 180,97 & 181,10 & 22,64 & 549,99 & 65,41 & 24,94 & 23,07 & 167,04 & 95,15 & 102,44 & 139,62 \\
\hline Alytes obstetricans & 30TWL13 & 100,00 & 114,15 & 109,12 & 36,77 & 6428,10 & 283,77 & $-9,39$ & 293,16 & 102,65 & 199,37 & 200,05 & 36,77 & 463,86 & 55,97 & 18,51 & 26,19 & 140,01 & 76,30 & 80,35 & 114,78 \\
\hline Alytes obstetricans & 30TWL14 & 100,00 & 111,38 & 109,54 & 37,00 & 6393,14 & 281,39 & $-11,82$ & 293,21 & 127,34 & 196,38 & 196,90 & 34,62 & 475,03 & 57,42 & 19,64 & 25,46 & 143,82 & 79,57 & 84,34 & 117,86 \\
\hline Alytes obstetricans & 30TWL15 & 100,00 & 106,60 & 110,39 & 37,01 & 6345,94 & 277,34 & $-16,30$ & 293,64 & 126,11 & 191,14 & 191,59 & 30,58 & 498,56 & 60,19 & 21,57 & 24,45 & 151,73 & 85,03 & 90,95 & 124,40 \\
\hline Alytes obstetricans & 30TWL17 & 100,00 & 103,53 & 111,29 & 37,17 & 6279,43 & 274,65 & $-19,02$ & 293,67 & 122,61 & 187,15 & 187,58 & 28,16 & 519,04 & 62,40 & 23,79 & 23,10 & 158,25 & 91,01 & 97,74 & 130,71 \\
\hline Alytes obstetricans & 30TWL19 & 100,00 & $\begin{array}{lll}110,87 \\
\end{array}$ & 111,19 & 37,55 & 6229,64 & 280,75 & $-11,81$ & 292,56 & 130,53 & 193,55 & 193,84 & 35,34 & 490,44 & 58,62 & 22,78 & 22,84 & 148,93 & 87,42 & 93,05 & 124,01 \\
\hline Alytes obstetricans & 30TWL23 & 100,00 & 107,73 & 111,14 & 37,00 & 6395,07 & 279,09 & $-16,64$ & 295,73 & 117,25 & \begin{tabular}{|l|l|}
192,73 \\
\end{tabular} & 193,40 & 30,99 & 492,52 & 60,48 & 21,39 & 25,13 & 150,85 & 83,67 & 89,55 & 120,92 \\
\hline Alytes obstetricans & 30TWL24 & 100,00 & $\begin{array}{ll}107,67 \\
\end{array}$ & 111,21 & 37,00 & 6371,25 & 278,73 & $-16,60$ & 295,33 & 127,47 & 192,42 & 192,95 & 31,09 & \begin{tabular}{|l|l|}
491,85 \\
\end{tabular} & 60,39 & 21,70 & 24,67 & 150,90 & 84,58 & 90,68 & 121,06 \\
\hline Alytes obstetricans & 30TWL26 & 100,00 & 105,36 & 111,83 & 37,18 & 6306,08 & 276,62 & $-18,44$ & 295,06 & 124,83 & 189,21 & 189,83 & 29,54 & 506,69 & 61,87 & 23,41 & 23,57 & 155,68 & 89,50 & 96,17 & 125,79 \\
\hline Alytes obstetricans & $\begin{array}{l}30 \text { TWL27 } \\
\end{array}$ & 100,00 & 103,26 & 112,48 & 37,56 & 6274,36 & 274,86 & $-20,32$ & 295,18 & 122,43 & 186,79 & 187,23 & 27,83 & 520,87 & 63,32 & 24,73 & 22,91 & 159,92 & 93,13 & 100,17 & 130,19 \\
\hline Alytes obstetricans & 30TWL30 & 100,00 & 120,48 & 111,99 & 37,01 & 6479,73 & 291,73 & $-6,48$ & 298,21 & 106,04 & 205,97 & 206,87 & 41,95 & 442,85 & 54,92 & 17,53 & 27,35 & 137,01 & 72,47 & 76,33 & 107,34 \\
\hline Alytes obstetricans & 30TWL31 & 100,00 & 109,99 & 112,48 & 37,02 & 6438,92 & 282,18 & $-16,21$ & 298,39 & 95,99 & 195,36 & 196,18 & 32,47 & 486,30 & 60,61 & 20,92 & 25,80 & 150,60 & 82,16 & 88,14 & 117,84 \\
\hline Alytes obstetricans & 30TWL34 & 100,00 & 103,25 & 112,50 & 37,45 & 6352,49 & 274,90 & $\mid-21,79$ & 296,68 & 122,84 & 187,75 & $\mid 188,19$ & 26,94 & 512,13 & 63,82 & 24,03 & 24,14 & $\mid 159,32$ & 90,44 & 98,01 & 124,74 \\
\hline Alytes obstetricans & 30TWL35 & 100,00 & 101,26 & 112,75 & 37,71 & 6319,27 & 272,95 & $-23,49$ & 296,44 & 120,55 & 185,24 & 185,87 & 25,27 & 523,95 & 65,03 & 25,26 & 23,49 & 162,96 & 93,88 & 101,78 & 128,29 \\
\hline Alytes obstetricans & 30TWL36 & 100,00 & 100,93 & 113,00 & 37,98 & 6291,45 & 272,63 & $-23,75$ & 296,38 & 120,11 & 184,61 & 185,22 & 25,24 & 528,39 & 65,26 & 25,80 & 23,01 & 164,10 & 95,48 & 103,54 & 130,21 \\
\hline Alytes obstetricans & 30TWL39 & 100,00 & \begin{tabular}{|l|l|}
109,03 \\
\end{tabular} & 113,99 & 38,00 & \begin{tabular}{|l|l|}
6221,73 \\
\end{tabular} & 280,64 & \begin{tabular}{|c|}
$-15,73$ \\
\end{tabular} & 296,38 & 128,99 & \begin{tabular}{|l|l|}
191,51 \\
\end{tabular} & 191,92 & 33,55 & 503,57 & 61,23 & 25,10 & 22,12 & 154,73 & 92,94 & 99,47 & 126,49 \\
\hline Alytes obstetricans & 30TWL45 & 100,00 & 101,42 & 113,01 & 37,96 & 6313,14 & 272,55 & $-24,05$ & 296,60 & 120,94 & 185,25 & 185,75 & 25,16 & 521,14 & 65,67 & 25,74 & 23,55 & 163,99 & 95,18 & 103,92 & 125,89 \\
\hline Alytes obstetricans & 30TWL46 & 100,00 & 101,78 & 113,18 & 38,00 & 6287,87 & 272,96 & $-23,51$ & 296,47 & 121,38 & 185,08 & 185,94 & 25,77 & 522,12 & 65,52 & 26,11 & 23,19 & 163,97 & 96,14 & 104,76 & 126,84 \\
\hline Alytes obstetricans & 30TWL49 & 100,00 & 106,99 & 114,69 & 38,00 & 6217,22 & 278,67 & $-18,62$ & 297,29 & 126,85 & 189,35 & 189,79 & 31,42 & 514,24 & 63,20 & 26,27 & 22,00 & 159,39 & 96,54 & 104,10 & 128,16 \\
\hline Alytes obstetricans & 30TWL50 & 100,00 & 101,92 & 114,58 & 37,76 & 6412,23 & 275,04 & $\begin{array}{l}-25,82 \\
-25,\end{array}$ & 300,86 & \begin{tabular}{|l|l|}
109,78 \\
\end{tabular} & 187,09 & 187,90 & \begin{tabular}{l|l}
24,84 \\
24,88
\end{tabular} & 523,77 & $\begin{array}{l}67,23 \\
67\end{array}$ & 24,00 & 25,31 & \begin{tabular}{|l|l|}
165,98 \\
\end{tabular} & $\begin{array}{l}0,2,66 \\
92\end{array}$ & $\begin{array}{l}101,70 \\
\end{array}$ & 123,35 \\
\hline Alytes obstetricans & 30TWL51 & 100,00 & 106,28 & 113,61 & 37,56 & 6404,01 & 277,77 & $-21,32$ & 299,08 & 126,63 & 190,97 & 191,94 & 28,86 & 497,92 & 64,29 & 22,93 & 25,53 & 158,24 & 88,77 & 97,15 & 116,70 \\
\hline Alytes obstetricans & 30TWL53 & 100,00 & 101,51 & 112,99 & 37,61 & 6349,80 & 271,94 & $-25,38$ & 297,32 & 121,62 & 185,56 & 186,44 & 24,71 & 515,94 & 66,49 & 25,20 & 24,58 & 164,75 & 94,61 & 103,99 & 121,27 \\
\hline Alytes obstetricans & 30TWL54 & 100,00 & 98,00 & 113,00 & 37,85 & 6319,16 & 268,42 & $-28,34$ & 296,76 & 117,66 & 181,79 & 182,50 & 21,83 & 533,39 & 68,43 & 26,86 & 23,96 & 170,27 & 99,07 & 109,13 & 126,11 \\
\hline Alytes obstetricans & 30TWL55 & 100,00 & 100,28 & 113,00 & 38,00 & 6305,38 & 270,42 & $-25,85$ & 296,27 & 120,17 & 183,82 & 184,44 & 24,16 & 523,34 & 67,03 & 26,47 & 23,74 & 166,91 & 97,78 & 107,47 & 124,24 \\
\hline Alytes obstetricans & $\begin{array}{l}30 \text { TWL57 } \\
\end{array}$ & 100,00 & 109,50 & 113,14 & 37,89 & 6275,19 & 278,71 & $\begin{array}{l}-2,05 \\
-17,05 \\
\end{array}$ & 295,76 & \begin{tabular}{|l|l|}
130,26 \\
\end{tabular} & 192,22 & $\begin{array}{l}192,81 \\
192,8\end{array}$ & 32,96 & \begin{tabular}{|l|l|}
484,23 \\
\end{tabular} & $\begin{array}{l}62,01 \\
62\end{array}$ & $\begin{array}{l}24,4,46 \\
24,4\end{array}$ & 23,93 & \begin{tabular}{|l|l|}
154,03 \\
\end{tabular} & $\begin{array}{l}1,11 \\
91,10\end{array}$ & 99,48 & $\begin{array}{ll}1124,74 \\
15,77\end{array}$ \\
\hline Alytes obstetricans & 30TWL58 & 100,00 & 105,42 & 113,92 & 38,00 & 6237,12 & 275,58 & $-21,05$ & 296,62 & 125,66 & \begin{tabular}{|l|l|}
187,77 \\
\end{tabular} & 188,27 & 29,52 & 512,34 & 64,56 & 26,47 & 22,81 & 161,72 & 97,19 & 106,07 & 124,56 \\
\hline Alytes obstetricans & 30TWL59 & 100,00 & 101,72 & 114,83 & 38,00 & 6195,27 & 272,78 & $-24,05$ & 296,83 & 121,25 & 183,77 & 184,08 & 26,56 & 541,03 & 67,11 & 28,44 & 21,87 & 169,30 & 103,28 & 112,47 & 133,71 \\
\hline Alytes obstetricans & 30TWL60 & 100,00 & 94,10 & 114,24 & 37,96 & 6381,00 & 266,57 & $-33,26$ & 299,83 & 113,47 & 178,96 & 179,83 & 17,73 & 558,08 & 72,39 & 27,06 & 24,92 & 179,49 & 102,08 & 113,34 & 129,12 \\
\hline Alytes obstetricans & 30TWL61 & 100,00 & 101,79 & 113,57 & 37,77 & 6377,40 & 272,29 & $-25,99$ & 298,28 & 122,08 & 186,20 & 187,18 & 24,97 & 514,26 & 67,48 & 24,75 & 25,52 & 166,23 & 94,57 & 104,59 & 118,06 \\
\hline Alytes obstetricans & 30TWL62 & 100,00 & 101,37 & 113,01 & 37,79 & 6352,98 & 271,03 & $-25,93$ & 296,96 & 121,79 & 185,60 & 186,39 & 24,84 & 512,22 & 67,35 & 25,23 & 25,26 & 166,09 & 95,40 & $\begin{array}{l}105,62 \\
\end{array}$ & 117,44 \\
\hline Alytes obstetricans & 30TWL63 & 100,00 & 96,81 & 112,75 & 37,77 & 6317,62 & 266,10 & $-29,95$ & 296,05 & 116,80 & 180,55 & 181,35 & 20,76 & 534,33 & 69,84 & 27,17 & 24,62 & 173,16 & 100,73 & 111,84 & 123,35 \\
\hline Alytes obstetricans & 30TWL65 & 100,00 & 99,31 & 112,50 & 37,70 & 6279,44 & 267,61 & $-27,34$ & 294,95 & 119,48 & 182,29 & 182,98 & 23,38 & 523,26 & 68,26 & 27,16 & 24,29 & 169,50 & 99,93 & $\mid 110,74$ & 121,65 \\
\hline Alytes obstetricans & 30TWL66 & 100,00 & 114,62 & 111,92 & 37,67 & 6300,59 & 281,14 & $-12,89$ & 294,03 & 136,46 & 197,15 & 197,90 & 37,27 & 450,62 & 59,66 & 22,53 & 25,83 & 146,55 & 85,56 & 94,23 & 103,89 \\
\hline Alytes obstetricans & 30TWL67 & 100,0 & 115,46 & 112,12 & 37, & 6277,88 & 282 , & $-11,88$ & 294,02 & 137,19 & 197,70 & 198,35 & 38,25 & 450,56 & 59,37 & 22,7 & 25,38 & 146,03 & 85,86 & 94,40 & 104,77 \\
\hline $\begin{array}{l}\text { Ay } \\
\text { Alytes obstetricans }\end{array}$ & 30TWL68 & 100,00 & $\begin{array}{ll}1112,40 \\
112,19\end{array}$ & $\begin{array}{l}11,2,12 \\
112,81\end{array}$ & $\frac{3,02}{38,00}$ & $\begin{array}{l}027,1,80 \\
6249,8\end{array}$ & $\begin{array}{l}279, \\
279\end{array}$ & $\begin{array}{l}-14,00 \\
-14,71 \\
\end{array}$ & $\begin{array}{l}294,50 \\
290,50\end{array}$ & \begin{tabular}{|l|}
133,40 \\
13,4
\end{tabular} & $\begin{array}{l}19,1,21 \\
194,21\end{array}$ & \begin{tabular}{|l|}
$194,, 73$ \\
194,
\end{tabular} & $\begin{array}{l}30,23 \\
35,50\end{array}$ & \begin{tabular}{|l|}
450,50 \\
472,48
\end{tabular} & $\begin{array}{l}51,37 \\
61,37 \\
\end{array}$ & 24,3 & $\begin{array}{l}24,30 \\
24,31\end{array}$ & $\begin{array}{l}150,05 \\
152,06 \\
\end{array}$ & $\begin{array}{l}5,000 \\
90,60\end{array}$ & $\begin{array}{l}4,40 \\
99,71 \\
\end{array}$ & 1104,62 \\
\hline Alytes obstetricans & 30TWL69 & 100,00 & 105,75 & 113,71 & 38,00 & 6203,22 & 274,63 & $-20,59$ & 295,21 & 126,26 & 187,52 & 188,01 & 30,14 & 513,90 & 65,31 & 27,15 & 22,89 & 163,44 & 99,22 & 109,04 & 124,14 \\
\hline Alytes obstetricans & 30TWL70 & 100,00 & 91,25 & 113,37 & 37,78 & 6353,50 & 261,86 & $-35,97$ & 297,83 & 110,50 & 175,78 & 176,58 & 15,10 & 567,06 & 74,54 & 28,58 & 25,04 & 185,02 & 106,81 & 119,27 & 128,13 \\
\hline Alytes obstetricans & 30TWL72 & 100,00 & 97,97 & 112,17 & 37,4 & 6323,04 & 265,56 & $-29,31$ & 4,87 & 118,24 & \begin{tabular}{ll|l}
181,43 \\
\end{tabular} & 182,42 & 21,56 & 523,62 & 69,92 & 26,82 & 25,62 & 72,54 & 47 & 112,13 & 117,24 \\
\hline Alytes obstetricans & 30TWL81 & 100,00 & 97,90 & 111,48 & 37, & 6321,05 & 263,62 & $-29,84$ & 293,47 & 118,21 & $\begin{array}{l}181,409 \\
181,09\end{array}$ & $\frac{10}{18}$ & 21,06 & 519,85 & 70, & $\begin{array}{l}20,060 \\
27,08 \\
\end{array}$ & 26,58 & $\begin{array}{l}174,08 \\
17,4\end{array}$ & $\begin{array}{l}101,85 \\
\end{array}$ & 1114,20 & 112,77 \\
\hline Alytes obstetricans & $30 \mathrm{TWL}$ & 100,00 & 97,99 & 110,86 & 37,43 & 6299,36 & 262,66 & $-29,66$ & 292,32 & 118,45 & 180,81 & 181,82 & 21,38 & 515,71 & 70,2 & 27, & 26,64 & \begin{tabular}{|l|}
173,13 \\
\end{tabular} & 101,89 & 114,38 & 111,89 \\
\hline Alytes obstetricans & 30TWL84 & 100,00 & 94,99 & 110,46 & 37,41 & 6252,49 & 259,02 & $-32,06$ & 291,09 & 115,23 & $\begin{array}{l}177,24 \\
\end{array}$ & 178,15 & 18,86 & 531,21 & 71,79 & 28,95 & 25,79 & 177,66 & 106,02 & 119,22 & 117,09 \\
\hline Alytes obstetricans & 30TWL85 & 100,00 & 103,23 & 110,33 & 37,60 & 6248,02 & 266,10 & $-24,21$ & 290,31 & 124,35 & 184,99 & 185,88 & 26,57 & 489,99 & 67,06 & 26,40 & 26,77 & 164,80 & 97,84 & 109,98 & 107,51 \\
\hline Alytes obstetricans & 30TWL86 & 100,00 & 111,77 & 110,10 & 37,39 & 6253,30 & 273,98 & $-16,06$ & 290,04 & 133,62 & 193,20 & 194,05 & 34,47 & 452,72 & 62,41 & 23,91 & 27,49 & 152,45 & 89,84 & 100,90 & 99,51 \\
\hline Alytes obstetricans & 30TWL88 & 100,00 & $\frac{1}{10}$ & $\frac{11}{11}$ & 37 & | 6253,30 & 272 & $\begin{array}{l}-17,40 \\
-17,42\end{array}$ & $\begin{array}{l}290,27 \\
290,27\end{array}$ & \begin{tabular}{|l|}
$131,20<$ \\
131
\end{tabular} & $\begin{array}{l}193,20 \\
190,69\end{array}$ & $\begin{array}{l}191,42 \\
191\end{array}$ & $\begin{array}{ll}4,474 \\
32,94\end{array}$ & $\begin{array}{l}452,1<2 \\
474,43\end{array}$ & $\begin{array}{l}64,41 \\
64,01\end{array}$ & \begin{tabular}{|l|l|}
25,48 \\
25
\end{tabular} & 26,03 & \begin{tabular}{|l|}
157,47 \\
15,4
\end{tabular} & $\begin{array}{l}5,04 \\
94,00\end{array}$ & $\begin{array}{l}105,57 \\
\end{array}$ & $\begin{array}{l}307,51 \\
107,5\end{array}$ \\
\hline Alytes obstetricans & 30TWL96 & 100,00 & 114,84 & 108,49 & 37,00 & 6238,10 & 273,88 & $-13,25$ & 287,14 & 137,29 & 134,40 & 196,50 & 37,36 & 432,44 & 61,23 & 23,08 & 29,47 & 148,54 & 87,15 & 98,77 & 91,95 \\
\hline Alytes obstetricans & 30TWL97 & 100,00 & 118,41 & 108,62 & 37,10 & 6235,06 & 277,77 & $-9,18$ & 286,95 & 141,18 & 192,44 & \begin{tabular}{|l|l|}
199,92 \\
\end{tabular} & 40,81 & 423,72 & 59,67 & 22,31 & 29,14 & $\mid 144,52$ & 84.56 & 95,77 & 91,52 \\
\hline Alytes obstetricans & 30TWL98 & 100,00 & 113,05 & 109,24 & 37,46 & 6207,38 & 273,55 & $-14,03$ & 287,58 & 135,14 & 193,65 & 194,38 & 36,22 & 453,66 & 62,75 & 24,44 & 27,61 & 153,12 & 90,73 & 102,77 & 100,08 \\
\hline Alytes obstetricans & 30TWMO & 100,00 & 97 & 110,42 & 37 & 6061,51 & 266,39 & $-21,04$ & 287 & 115,60 & 178,84 & 178 & 24,96 & 574,46 & 66,58 & 28,80 & 20,96 & 172,38 & 104,40 & 107,16 & 148,76 \\
\hline Alytes obstetricans & $\begin{array}{l}\text { 30TWM03 } \\
\end{array}$ & $\begin{array}{l}100,00 \\
\end{array}$ & $\begin{array}{l}1,30 \\
93,98 \\
\end{array}$ & $\begin{array}{l}1109,42 \\
109,78\end{array}$ & $\begin{array}{ll}38,00 \\
38,00\end{array}$ & $\begin{array}{l}60001,04 \\
600\end{array}$ & $\begin{array}{l}20,50,56 \\
261,56\end{array}$ & $\begin{array}{l}-23,04 \\
-23,63\end{array}$ & \begin{tabular}{|l|}
285,19 \\
\end{tabular} & $\begin{array}{l}110,94 \\
110,\end{array}$ & $\begin{array}{l}17,04 \\
174,33\end{array}$ & \begin{tabular}{|l|l|}
174,365 \\
\end{tabular} & $\begin{array}{l}24,81 \\
21,81\end{array}$ & $\begin{array}{l}705,37 \\
605\end{array}$ & $\begin{array}{l}60,00 \\
69,45 \\
\end{array}$ & $\begin{array}{l}0,00 \\
31,18 \\
\end{array}$ & 20,27 & $\begin{array}{l}180,79 \\
180\end{array}$ & \begin{tabular}{|l|l|}
110,97 \\
\end{tabular} & $\begin{array}{l}113,23 \\
110\end{array}$ & $\begin{array}{l}140,10 \\
157,66\end{array}$ \\
\hline Alytes obstetricans & 30TWMO4 & 100,00 & 85,75 & 108,61 & 38,00 & 5923,26 & 251,68 & $-29,78$ & 281,46 & 101,73 & 165,23 & 165,23 & 14,97 & 666,40 & 75,31 & 35,51 & 19,49 & 197,55 & 123,31 & $\begin{array}{l}124,57 \\
\end{array}$ & 174,60 \\
\hline Alytes obstetricans & 30TWM05 & 100,00 & 70,14 & 106,53 & 38,00 & 5815,45 & 233,82 & $-42,16$ & 275,98 & 84,29 & 148,92 & 148,92 & 1,64 & 779,62 & 86,31 & 42,85 & 18,61 & 228,66 & 145,29 & 145,29 & 205,86 \\
\hline Alytes obstetricans & 30TWM06 & 100,00 & 91,56 & 106,05 & 38,00 & 5817,45 & 252,79 & $-21,79$ & 274,57 & 107,69 & 169,41 & 169 & 21,56 & 661,18 & 73,31 & 35,29 & 19,10 & 193 & 124,01 & 124,21 & 174,34 \\
\hline Alytes obstetricans & 30TWM07 & 100,00 & 70,76 & 104,27 & 38,01 & 5708,69 & 230,51 & $-39,31$ & 269,82 & 84,63 & 148,01 & 148,01 & 3,28 & 811,61 & 87,62 & 44,84 & 18,14 & 234,22 & 152,54 & 152,54 & 216,71 \\
\hline
\end{tabular}




\begin{tabular}{|c|c|c|c|c|c|c|c|c|c|c|c|c|c|c|c|c|c|c|c|c|c|}
\hline TAXON & UTM & $\mathrm{km} 2$ & BIO1 & B102 & $\mathrm{BIO3}$ & B104 & B105 & B106 & B107 & B108 & B109 & B1010 & BIO11 & BIO12 & B1013 & BIO14 & BIO15 & B1016 & B1017 & B1018 & B1019 \\
\hline Alytes obstetricans & 30TWM08 & 100,00 & 89,97 & 103,04 & 38,06 & 5672,90 & 245,93 & $-20,14$ & 266,06 & 100,88 & 165,91 & 165,91 & 21,54 & 712,04 & 76,42 & 38,20 & 18,40 & 204,14 & 134,80 & 134,80 & 190,31 \\
\hline Alytes obstetricans & 30TWM09 & 100,00 & 110,86 & 98,72 & \begin{tabular}{|l|l|}
37,98 \\
\end{tabular} & 5573,69 & 258,66 & 1,71 & 256,95 & 78,18 & 184,26 & 184,34 & 42,14 & 629,40 & 66,34 & 32,35 & 18,93 & 182,56 & 120,69 & 120,69 & 168,21 \\
\hline Alytes obstetricans & 30TWM10 & 100,00 & 108,22 & 111,68 & 37,99 & 6182,10 & 278,25 & $-14,00$ & 292,25 & 127,44 & 190,30 & 190,62 & 33,28 & 510,07 & 60,55 & 24,45 & 22,13 & 154,48 & 91,96 & 97,78 & 129,99 \\
\hline Alytes obstetricans & 30TWM11 & 100,00 & 103,61 & 112,07 & 38,00 & 6125,34 & 273,87 & $-17,73$ & 291,61 & 122,12 & 185,23 & 185,33 & 29,68 & 541,47 & 63,54 & 26,93 & 21,18 & 163,32 & 98,87 & 104,65 & 139,26 \\
\hline Alytes obstetricans & 30TWM12 & 100,00 & 97,65 & \begin{tabular}{|l|l|}
111,98 \\
\end{tabular} & 38,00 & \begin{tabular}{|l|l|}
6063,67 \\
\end{tabular} & 267,47 & $-22,53$ & 290,01 & 115,41 & 178,63 & \begin{tabular}{ll|}
178,69 \\
\end{tabular} & 24,68 & 582,73 & 67,62 & 30,02 & 20,29 & 174,84 & 107,47 & 111,59 & 151,12 \\
\hline Alytes obstetricans & 30TWM13 & 100,00 & 96,87 & 111,31 & 38,04 & 6017,11 & 265,36 & $-22,23$ & 287,59 & 114,39 & 177,16 & 177,21 & 24,34 & 596,68 & 68,64 & 31,22 & 19,93 & 178,25 & 110,88 & 114,29 & 155,30 \\
\hline Alytes obstetricans & 30TWM14 & 100,00 & 79,04 & 109,12 & 38,02 & 5905,41 & 245,44 & $-36,45$ & 281,89 & 94,44 & 158,69 & 158,69 & 9,01 & 716,27 & 80,58 & 38,98 & 18,83 & 211,92 & 133,97 & 134,53 & 188,09 \\
\hline Alytes obstetricans & 30TWM15 & 100,00 & 68,97 & 107,08 & 38,02 & 5817,98 & 232,96 & $-43,81$ & 276,77 & 83,09 & $\begin{array}{l}147,78 \\
\end{array}$ & $\begin{array}{l}147,78 \\
\end{array}$ & 0,019 & 794,58 & 87,97 & 44,08 & 18,21 & 233,03 & 149,38 & $\begin{array}{l}149,38 \\
\end{array}$ & 209,87 \\
\hline Alytes obstetricans & 30TWM16 & 100,00 & 80,61 & 106,79 & 38,04 & 5796,00 & 242,94 & $-32,60$ & 275,54 & 95,78 & 158,64 & 158,64 & 11,50 & 737,33 & 81,18 & 40,38 & 18,32 & 215,15 & 139,25 & 139,33 & 195,45 \\
\hline Alytes obstetricans & 30TWM17 & 100,00 & 93,83 & 105,35 & 38,08 & 5763,45 & 252,61 & \begin{tabular}{|l|l|}
$-19,24$ \\
\end{tabular} & 271,85 & 110,11 & 170,63 & 170,63 & 24,09 & 674,93 & 74,07 & 36,31 & 18,55 & 196,01 & 128,47 & 128,65 & 178,33 \\
\hline Alytes obstetricans & 30TWM18 & 100,00 & 110,04 & 102,28 & 38,03 & 5706,21 & 262,98 & $-2,26$ & 265,24 & 124,43 & 185,29 & 185,29 & 39,92 & 602,75 & 65,87 & 31,60 & 18,93 & 173,77 & 116,27 & 116,44 & 157,84 \\
\hline Alytes obstetricans & 30TWM19 & 100,00 & 120,28 & 98,44 & \begin{tabular}{|l|l|}
37,98 \\
\end{tabular} & 5591,73 & 266,30 & 9,67 & 256,62 & 88,06 & 193,38 & 193,38 & 50,78 & 581,66 & 62,07 & 29,70 & 19,11 & 168,78 & 113,38 & 113,42 & 152,68 \\
\hline Alytes obstetricans & 30TWM21 & 100,00 & 100,66 & 113,99 & 38,01 & 6121,36 & 272,66 & $-21,70$ & 294,36 & 119,20 & 182,35 & 182,44 & 26,96 & 563,46 & 66,20 & 28,99 & 20,58 & 170,03 & 104,49 & 110,10 & 145,54 \\
\hline Alytes obstetricans & 30TWM22 & 100,00 & 96,86 & 113,61 & 38,16 & 6066,54 & 268,07 & $-24,41$ & 292,48 & 114,77 & 177,89 & 177,97 & 24,04 & 594,34 & 68,98 & 31,16 & 19,96 & 178,36 & 111,02 & 115,83 & 154,58 \\
\hline Alytes obstetricans & 30TWM23 & 100,00 & 100,11 & 113,02 & 38,18 & 6033,19 & 269,86 & $-20,79$ & 290,66 & 118,09 & 180,38 & 180,43 & 27,22 & 585,53 & 67,66 & 30,79 & 19,88 & 175,20 & 110,05 & 114,06 & 152,42 \\
\hline Alytes obstetricans & 30TWM24 & 100,00 & 76,56 & 109,64 & 38,18 & 5900,86 & 243,23 & $-39,27$ & 282,50 & 91,92 & 156,19 & 156,19 & 6,65 & 738,56 & 83,14 & 40,72 & 18,55 & 218,56 & 139,47 & 140,34 & 193,94 \\
\hline Alytes obstetricans & 30TWM25 & 100,00 & 68,24 & 107,45 & 38,15 & 5819,86 & 232,22 & $-45,10$ & 277,32 & 82,59 & 147,03 & 147,03 & $-0,29$ & 807,14 & 89,42 & 45,16 & 17,94 & 236,86 & 153,03 & 153,23 & 212,90 \\
\hline Alytes obstetricans & 30TWM26 & 100,00 & 88,12 & 108,23 & 38,21 & 5828,86 & 251,09 & $-27,02$ & 278,11 & \begin{tabular}{r|}
104,26 \\
\end{tabular} & 166,05 & 166,05 & 18,05 & 698,10 & 77,51 & 38,12 & 18,28 & 204,48 & 132,99 & 133,36 & 184,37 \\
\hline Alytes obstetricans & 30TWM27 & 100,00 & 91,55 & 106,67 & 38,27 & \begin{tabular}{|l|l|l}
577,84 \\
\end{tabular} & 251,68 & $-22,38$ & 274,06 & 107,79 & 168,63 & 168,63 & 21,84 & 694,45 & 76,45 & 37,87 & 18,18 & 202,16 & 133,02 & 133,16 & 183,65 \\
\hline Alytes obstetricans & 30TWM28 & 100,00 & 99,88 & 104,49 & 38,32 & 5719,76 & 255,82 & $-12,94$ & 268,76 & 116,42 & 175,71 & 175,71 & 30,24 & 666,60 & 72,70 & 36,00 & 18,18 & 192,58 & 128,78 & 128,95 & 175,86 \\
\hline Alytes obstetricans & 30TWM29 & 100,00 & 120,41 & 100,10 & 38,02 & 5642,81 & 268,08 & 8,30 & 259,78 & 117,56 & 194,07 & 194,07 & 50,30 & 572,70 & 62,4 & 29,95 & 18,94 & 165,38 & 113,07 & 113,23 & 147,71 \\
\hline Alytes obstetricans & 30TWM31 & 100,00 & 103,45 & 115,62 & 38,23 & 6134,85 & 276,37 & $-20,69$ & 297,06 & 122,47 & 184,84 & 185,21 & 29,02 & 554,93 & 65,48 & 28,72 & 20,44 & 167,84 & 104,20 & 110,61 & 143,26 \\
\hline Alytes obstetricans & 30TWM32 & 100,00 & 100,33 & 115,52 & \begin{tabular}{|l|l|}
38,74 \\
\end{tabular} & $\begin{array}{ll}6085,66 \\
\end{array}$ & 272,95 & $-22,71$ & 295,66 & 118,86 & 181,43 & 181,54 & 26,86 & 582,24 & 67,90 & 30,58 & 19,91 & 175,02 & 110,07 & 115,38 & 151,54 \\
\hline Alytes obstetricans & 30TWM33 & 100,00 & 99,18 & 114,38 & 38,68 & 6035,13 & 269,98 & $-22,77$ & 292,75 & 117,33 & 179,49 & 179,60 & 26,17 & 597,93 & 69,21 & 31,78 & 19,53 & 179,08 & 113,60 & 119,15 & 155,93 \\
\hline Alytes obstetricans & 30TWM34 & 100,00 & 85,60 & 111,58 & 38,56 & 5936,16 & 253,40 & $-32,75$ & 286,15 & 102,03 & 165,18 & 165,19 & 14,49 & 689,98 & 78,33 & 37,81 & 18,55 & 204,94 & 131,59 & 133,87 & 180,82 \\
\hline Alytes obstetricans & 30TWM35 & 100,00 & 73,56 & 108,60 & 38,32 & 5840,88 & 238,10 & $-41,36$ & 279,45 & 88,67 & 152,30 & 152,30 & 4,19 & 778,78 & 86,81 & 43,56 & 17,84 & 229,28 & 148,81 & 149,08 & 205,05 \\
\hline Alytes obstetricans & 30TWM 36 & 100,00 & 86,13 & 108,96 & 38,61 & 5831,72 & 249,59 & $-29,72$ & 279,31 & \begin{tabular}{|l|}
102,28 \\
\end{tabular} & 164,16 & 164,16 & 16,16 & 717,70 & $\begin{array}{l}\mid 00,10 \\
79,76\end{array}$ & 39,59 & $\begin{array}{l}18,04 \\
18,01\end{array}$ & 210,42 & \begin{tabular}{|l|}
137,64 \\
137
\end{tabular} & $\begin{array}{l}138,29 \\
130\end{array}$ & 189,70 \\
\hline Alytes obstetricans & 30TWM37 & 100,00 & 96,07 & 107,64 & 38,54 & 5802,31 & 256,53 & $-19,25$ & 275,78 & 113,14 & 173,14 & 173,14 & 25,69 & 672,42 & 74,59 & 36,74 & 18,16 & 196,71 & 129,78 & 130,72 & 176,85 \\
\hline Alytes obstetricans & 30TWM38 & 100,00 & 101,31 & 105,51 & 38,45 & 5753,02 & 257,99 & $-12,79$ & 270,79 & 118,73 & 177,34 & 177,35 & 31,06 & 658,51 & 72,71 & 35,99 & 18,21 & 191,93 & 128,10 & 128,79 & 172,10 \\
\hline Alytes obstetricans & 30TWM39 & 100,00 & 119,79 & 101,93 & 38,06 & 5702,21 & 269,49 & 6,12 & 263,36 & 138,85 & 194,02 & 194,02 & 48,82 & 563,84 & 63,13 & 30,29 & 19,03 & 164,95 & 112,64 & 113,63 & 142,30 \\
\hline Alytes obstetricans & 30TWM40 & 100,00 & 106,05 & 115,52 & 38,05 & 6179,69 & 278,45 & $-19,45$ & 297,90 & 125,65 & 187,90 & 188,35 & 30,78 & 530,34 & 64,28 & 27,42 & 21,32 & 162,98 & 100,19 & 107,63 & 134,11 \\
\hline Alytes obstetricans & 30TWM41 & 100,00 & 105,43 & \begin{tabular}{|l|}
116,28 \\
116,
\end{tabular} & 38,43 & 6140,06 & 278,34 & $\begin{array}{l}-19,40 \\
-19,78 \\
\end{array}$ & 298,12 & $\begin{array}{ll}124,92 \\
\end{array}$ & $\begin{array}{l}186,82 \\
186\end{array}$ & \begin{tabular}{|l|l|}
187,18 \\
\end{tabular} & 30,50 & \begin{tabular}{|l|l|}
546,13 \\
\end{tabular} & $\begin{array}{l}4,260 \\
65,24\end{array}$ & 28,45 & 20,74 & 166,35 & \begin{tabular}{|l|l|}
103,75 \\
\end{tabular} & $\begin{array}{l}110,58 \\
\end{array}$ & $\begin{array}{l}140,07 \\
140\end{array}$ \\
\hline Alytes obstetricans & 30TWM42 & 100,00 & 103,64 & 116,72 & 38,95 & 6096,81 & 276,75 & $-20,97$ & 297,71 & 122,70 & 184,62 & 184,78 & 29,42 & 568,59 & 66,79 & 29,94 & 19,90 & 171,65 & 108,52 & 115,21 & 147,62 \\
\hline Alytes obstetricans & 30TWM43 & 100,00 & 101,79 & 115,45 & 38,91 & 6050,05 & 273,08 & $-21,62$ & 294,71 & 120,42 & 182,06 & 182,21 & 28,19 & 586,40 & 68,46 & 31,32 & 19,54 & 176,49 & 112,42 & 119,54 & 152,32 \\
\hline Alytes obstetricans & 30TWM44 & 100,00 & 91,01 & 112,88 & 38,79 & 5964,44 & 259,40 & $-29,18$ & 288,57 & 108,27 & 170,54 & 170,55 & 19,05 & 662,31 & 75,82 & 36,30 & 18,65 & 197,60 & 127,36 & 131,80 & 173,05 \\
\hline Alytes obstetricans & 30TWM45 & 100,00 & 82,08 & 110,24 & 38,58 & 5878,70 & 247,42 & $-35,12$ & 282,54 & 98,21 & 160,86 & 160,86 & 11,45 & 731,03 & 82,29 & 40,77 & 17,89 & 216,24 & 140,76 & 141,49 & 191,97 \\
\hline Alyty obstetricans & 30TWM46 & 100,00 & $\begin{array}{l}2,006 \\
80,56\end{array}$ & \begin{tabular}{|l|}
108,70 \\
108,
\end{tabular} & 38,54 & S819,04 & 243,60 & $\begin{array}{l}-34,16 \\
-34,96\end{array}$ & $\mid \begin{array}{l}\mid 202,344 \\
278,56\end{array}$ & $\begin{array}{ll}0,214 \\
96,40\end{array}$ & $\begin{array}{l}158,600 \\
158,60\end{array}$ & $\begin{array}{l}158,60 \\
1580\end{array}$ & $\begin{array}{l}1,45 \\
10,80\end{array}$ & $\mid 757,90$ & \begin{tabular}{l|l|}
84,18 \\
84,18
\end{tabular} & 42,44 & $\begin{array}{ll}1,05 \\
17,65\end{array}$ & $\begin{array}{l}21,0,24 \\
222,38\end{array}$ & \begin{tabular}{|l|}
146,11 \\
146,1
\end{tabular} & $\begin{array}{l}141,455 \\
146,57 \\
\end{array}$ & 200,06 \\
\hline Alytes obstetricans & 30TWM47 & 100,00 & 97,51 & 108,40 & 38,58 & 5830,24 & 258,38 & $-19,01$ & 277,40 & 115,15 & 174,78 & 174,78 & 26,59 & 667,01 & 74,69 & 36,66 & 18,24 & 196,31 & 129,31 & 130,20 & 174,48 \\
\hline Alytes obstetricans & 30TWM48 & 100,00 & 105,81 & 106,21 & \begin{tabular}{|c|}
38,58 \\
\end{tabular} & 5790,45 & 262,59 & $-9,79$ & 272,38 & 124,10 & 181,99 & 181,99 & 34,73 & $\begin{array}{ll}631,48 \\
\end{array}$ & 70,85 & 34,70 & 18,56 & 185,93 & 123,74 & 124,95 & 162,81 \\
\hline Alytes obstetricans & 30TWM49 & 100,00 & $\begin{array}{ll}126,24 \\
\end{array}$ & 102,65 & 38,02 & 5775,38 & 276,19 & 10,47 & 265,72 & 146,67 & 195,92 & 200,91 & 54,01 & 508,37 & 59,42 & 27,88 & 20,34 & 153,06 & 104,01 & 107,40 & 122,04 \\
\hline Alytes obstetricans & 30TWM50 & 100,0 & 107,07 & 115,01 & 38,01 & 6181,32 & 278,07 & $-18,90$ & 296,97 & 127,18 & 188,72 & 189,23 & 31,86 & 520,60 & 64,2 & 27 & 21,79 & 162,18 & 99,62 & 107,97 & 129,36 \\
\hline $\begin{array}{l}\text { Ay } \\
\text { Alytes obstetricans }\end{array}$ & $\begin{array}{l}30 \mathrm{TWM} 51 \\
3\end{array}$ & 100,00 & 106,51 & $\begin{array}{l}113,01 \\
115,54\end{array}$ & $\begin{array}{l}30, \\
38,\end{array}$ & $\begin{array}{l}\mid 018,1,52 \\
6147,29 \\
\end{array}$ & 277,73 & $\begin{array}{l}-19,9 \\
-19,11 \\
\end{array}$ & \begin{tabular}{|l|}
290,917 \\
294
\end{tabular} & \begin{tabular}{|l|}
126,08 \\
12,0
\end{tabular} & \begin{tabular}{|l|}
$180,7 / 2$ \\
187,71
\end{tabular} & \begin{tabular}{|l|}
187,25 \\
187,97
\end{tabular} & $\begin{array}{l}1,1,51 \\
31,51 \\
\end{array}$ & 535, 50 & $\begin{array}{l}64,21 \\
65,18 \\
\end{array}$ & 28 & $\begin{array}{l}21,1,02 \\
21\end{array}$ & $\begin{array}{l}10,10 \\
165,40\end{array}$ & \begin{tabular}{|l|}
$95,02,76$ \\
102,6
\end{tabular} & $\begin{array}{l}110,74 \\
110\end{array}$ & $\begin{array}{l}121,30 \\
134,96\end{array}$ \\
\hline Alytes obstetricans & 30TWM52 & 100,00 & 101,71 & 115,63 & 38,63 & 6093,30 & 273,15 & $-22,72$ & 295,87 & 120,85 & 182,51 & 182,69 & 27,64 & 574,92 & 68,56 & 30,83 & 20,09 & 175,47 & 110,84 & 118,72 & 147,09 \\
\hline Alytes obstetricans & 30TWM53 & 100,00 & 99,08 & 114,75 & 38,75 & 6046,90 & 269,09 & $-24,29$ & 293,38 & 117,79 & 179,33 & 179,43 & 25,55 & 601,88 & 70,87 & 32,60 & 19,51 & 182,47 & 116,30 & 123,77 & 154,95 \\
\hline Alytes obstetricans & 30TWM54 & 100,00 & 84,73 & 111,67 & 38,62 & 5938,56 & 251,56 & $-34,74$ & 286,30 & 101,62 & 164,07 & 164,10 & 13,18 & 701,31 & 80,52 & 39,10 & 18,36 & 210,06 & 135,73 & 139,05 & 182,08 \\
\hline Alytes obstetricans & 30 TWM55 & 100,00 & 88,05 & 110,97 & 38,7 & 5908,63 & 253,3 & $-30,57$ & 283,90 & $\begin{array}{l}105,21 \\
\end{array}$ & 166,83 & 166,84 & $\begin{array}{ll}16,68 \\
16,68\end{array}$ & 696,33 & $\begin{array}{l}0,152 \\
79,36\end{array}$ & 38,76 & 18,22 & 207,43 & \begin{tabular}{|l|l|}
134,85 \\
\end{tabular} & $\begin{array}{l}136,98 \\
\end{array}$ & 181,61 \\
\hline Alytes obstetricans & 30TWM & 100,00 & 92,81 & 109,93 & 38, & 5880,87 & 255,93 & $-25,41$ & 281,34 & 110,30 & 170,93 & 170,93 & 21,33 & 683,68 & 77,52 & 37,95 & 18,29 & 202,97 & 132,50 & \begin{tabular}{|l|}
134,67 \\
\end{tabular} & 178,30 \\
\hline Alytes obstetricans & 30TWM57 & 100,00 & 98,21 & 108,81 & 38,69 & 5848,62 & 259,01 & $\begin{array}{l}-29,15 \\
-19,4\end{array}$ & 278,16 & 116,20 & 175,60 & 175,60 & 26,84 & 668,28 & 75,31 & 36,92 & 18,31 & 197,56 & $\begin{array}{l}129,69 \\
\end{array}$ & 131,56 & 174,25 \\
\hline Alytes obstetricans & 30TWM58 & 100,00 & 109,72 & 106,79 & 38,52 & 5832,45 & 266,50 & $-7,27$ & 273,77 & 128,72 & 186,08 & 186,09 & 37,64 & 609,73 & 69,41 & 33,60 & 18,94 & 181,50 & 119,68 & 121,36 & 155,08 \\
\hline Alytes obstetricans & 30TWM59 & 100,00 & 127,97 & 103,66 & 38,01 & 5820,68 & 278,78 & 10,88 & 267,90 & 148,81 & 191,49 & 203,04 & 54,83 & 495,98 & 59,03 & 27,62 & 20,81 & 52,26 & 101,55 & 105,95 & 115,83 \\
\hline Alytes obstetricans & 30TWM & 100,00 & $\mid$ & \begin{tabular}{|l|}
112,84 \\
1120
\end{tabular} & $\frac{50}{38}$ & $\begin{array}{l}302,018,94 \\
601,4\end{array}$ & 259,63 & \begin{tabular}{r|}
11,00 \\
$-30,03$
\end{tabular} & \begin{tabular}{|l|l|}
289,66 \\
\end{tabular} & \begin{tabular}{|l|}
110,270 \\
110,27
\end{tabular} & \begin{tabular}{|l|}
171,93 \\
171,93
\end{tabular} & \begin{tabular}{|l|}
172,04 \\
1704
\end{tabular} & $\begin{array}{l}4,303 \\
19,11 \\
\end{array}$ & \begin{tabular}{|l|}
640,81 \\
6401
\end{tabular} & $\begin{array}{l}\mid 35,050 \\
75,90\end{array}$ & 35,5 & $\begin{array}{l}20,01 \\
19,41\end{array}$ & $\begin{array}{l}19,26,60 \\
195,60\end{array}$ & \begin{tabular}{|l|}
124,72 \\
12,
\end{tabular} & \begin{tabular}{|l|}
131,51 \\
13,5
\end{tabular} & $\begin{array}{l}111,03,30 \\
163\end{array}$ \\
\hline Alytes obstetricans & 30TWM64 & 100,00 & 91,17 & 111,90 & 38,49 & 5971,71 & 257,24 & $-29,86$ & 287,10 & 109,08 & 170,47 & 170,52 & 18,71 & 661,68 & 77,32 & 36,82 & 18,96 & 200,35 & 128,66 & 132,58 & 169,82 \\
\hline Alytes obstetricans & 30TWM65 & 100,00 & 91,99 & 111,00 & 38,69 & 5931,07 & 256,52 & $-27,79$ & 284,32 & 109,95 & 170,67 & 170,70 & 19,94 & 673,25 & 77,72 & 37,49 & 18,67 & 202,23 & 130,87 & 134,42 & 173,94 \\
\hline Alytes obstetricans & 30TWM66 & 100,00 & 97,99 & 110,15 & 38,76 & 5916,93 & 260,65 & $-21,48$ & 282,12 & 116,42 & 176,20 & 176,23 & 25,69 & 653,75 & 75,19 & 36,20 & 18,76 & 195,80 & 126,85 & 130,21 & 168,89 \\
\hline Alytes obstetricans & 30TWN & 100,00 & 105,56 & 108,59 & 38, & 5898,47 & 265,38 & $-13,16$ & 278,54 & 124,65 & 183,04 & 183 & 32,92 & 625,73 & 71,84 & 34,36 & 19,22 & 187,22 & 121,40 & 124,74 & 16 \\
\hline Alytes obstetricans & 30TWM68 & 100,00 & $\begin{array}{l}114,52 \\
1140\end{array}$ & \begin{tabular}{|l|l|}
106,87 \\
1067
\end{tabular} & 30,47 & 58568,51 & $\begin{array}{l}20,50 \\
270,81\end{array}$ & $\mid$\begin{tabular}{|c|c|c|}
$-3,59$ \\
-3
\end{tabular} & \begin{tabular}{|l|}
274,41 \\
27,4
\end{tabular} & \begin{tabular}{|l|}
134,390 \\
134
\end{tabular} & \begin{tabular}{|l|}
191,104 \\
191
\end{tabular} & \begin{tabular}{|l|}
191,13 \\
191,13
\end{tabular} & $\begin{array}{ll}2,, 25 \\
41,65\end{array}$ & \begin{tabular}{|l|l|}
589,48 \\
\end{tabular} & $\begin{array}{l}1,, 044 \\
67,82\end{array}$ & $\begin{array}{l}34,20 \\
32,29 \\
\end{array}$ & $\begin{array}{l}10,26 \\
19,56\end{array}$ & $\begin{array}{l}10,22 \\
176,80\end{array}$ & $\begin{array}{l}11,4,20 \\
115,\end{array}$ & $\begin{array}{l}118,20 \\
118,4\end{array}$ & $\begin{array}{l}100,53 \\
148,52\end{array}$ \\
\hline Alytes obstetricans & 30TWM71 & 100,00 & 101,91 & 112,94 & 38,00 & 6127,89 & 268,84 & $-23,36$ & 292,20 & 121,79 & 182,53 & 182,80 & 26,99 & 551,28 & 69,26 & 30,10 & 22,04 & 174,53 & 107,93 & 118,84 & 134,36 \\
\hline Alytes obstetricans & 30TWM72 & 100,00 & 99,36 & 112,68 & 38,05 & 6087,58 & 266,03 & $-24,67$ & 290,70 & 119,00 & 179,66 & 179,81 & 25,04 & 578,93 & 71,36 & 31,90 & 21,09 & 181,13 & 113,30 & 123,71 & 143,23 \\
\hline Alytes obstetricans & 30TWM & 100,00 & 98,35 & 112,10 & 38,12 & 6048,86 & 264,16 & $-24,80$ & 288,95 & 117,78 & 178, & 178 & 24 & 600,17 & 72,80 & 33,19 & 20,39 & 185,91 & 117,19 & 126,24 & 150,12 \\
\hline Alytes obstetricans & 30TWM74 & 100,00 & 104,64 & 111,38 & 38,15 & 6037,67 & 268,88 & $-18,07$ & 286,95 & 124,35 & 183,90 & 184,07 & 30,39 & 579,31 & 70,04 & 31,70 & 20,70 & 178,88 & 112,50 & 119,76 & 145 \\
\hline
\end{tabular}




\begin{tabular}{|c|c|c|c|c|c|c|c|c|c|c|c|c|c|c|c|c|c|c|c|c|c|}
\hline TAXON & UTM & $\mathrm{km} 2$ & BIO1 & B102 & $B 103$ & BIO4 & B105 & B106 & B107 & 8108 & 8109 & B1010 & BIO11 & B1012 & BIO13 & BIO14 & BIO15 & B1016 & B1017 & B1018 & 81019 \\
\hline Alytes obstetricans & 30TWM75 & 100,00 & 105,81 & 110,60 & 38,19 & 6005,52 & 268,75 & $-15,87$ & 284,62 & 125,63 & 184,67 & 184,71 & 31,91 & 589,35 & 70,32 & 32,27 & 20,32 & 180,49 & 114,13 & 120,21 & 148,72 \\
\hline Alytes obstetricans & 30TWM76 & 100,00 & 108,27 & 109,80 & 38,40 & 5979,02 & 269,63 & $-12,52$ & 282,15 & 128,21 & 186,54 & 186,61 & 34,49 & 593,73 & 69,97 & 32,39 & 20,06 & 180,44 & 114,66 & 121,32 & 150,67 \\
\hline Alytes obstetricans & 30TWM77 & 100,00 & 122,10 & 107,81 & 38,04 & 5973,97 & 279,65 & 1,33 & $\begin{array}{ll}278,32 \\
\end{array}$ & \begin{tabular}{|l|l|}
143,23 \\
\end{tabular} & $\begin{array}{l}199,55 \\
\end{array}$ & $\begin{array}{l}199,65 \\
\end{array}$ & 47,51 & 536,37 & 63,52 & 28,69 & 20,92 & 163,45 & $\begin{array}{l}103,33 \\
\end{array}$ & $\begin{array}{l}108,63 \\
\end{array}$ & 133,39 \\
\hline Alytes obstetricans & 30TWM80 & 100,00 & 100,41 & 111,41 & 38,00 & 6140,50 & 265,03 & $-24,86$ & 289,89 & 120,77 & 181,07 & $\begin{array}{l}181,43 \\
\end{array}$ & 25,11 & 542,10 & $\begin{array}{l}70,08 \\
\end{array}$ & 29,99 & 23,26 & 175,30 & 107,45 & 120,22 & 128,10 \\
\hline Alytes obstetricans & 30TWM81 & 100,00 & 95,19 & 111,13 & 38,00 & 6093,47 & 259,76 & $-28,84$ & $288,61 \mid$ & 114,84 & $175,50 \mid$ & 175,73 & 20,67 & 584,71 & 73,75 & 32,71 & 21,90 & 186,25 & 115,83 & 127,53 & 140,88 \\
\hline Alytes obstetricans & 30TWM82 & 100,00 & 93,96 & 110,92 & 38,00 & 6058,28 & 258,25 & $-29,35$ & 287,60 & 113,12 & 173,90 & 173,96 & 19,82 & 607,35 & 75,29 & 34,08 & 21,12 & 191,30 & 119,85 & 131,13 & 148,50 \\
\hline Alytes obstetricans & 30TWM83 & 100,00 & 102,29 & 111,08 & 38,01 & 6063,83 & 266,08 & $-21,32$ & 287,40 & 122,23 & 181,75 & 182,01 & 27,54 & 575,06 & 71,24 & 31,73 & 21,45 & 180,48 & 112,34 & 123,17 & 141,63 \\
\hline Alytes obstetricans & 30TWM84 & 100,00 & 112,56 & 110,32 & 38,00 & 6074,30 & 274,85 & $-10,78$ & 285,63 & 133,44 & \begin{tabular}{|l|l|l|}
191,83 \\
\end{tabular} & 191,95 & 37,15 & $\begin{array}{l}536,46 \\
\end{array}$ & 66,46 & 28,88 & 22,09 & 167,91 & 103,46 & 111,82 & 132,19 \\
\hline Alytes obstetricans & 30TWM85 & 100,00 & 120,81 & 109,32 & 38,00 & $\begin{array}{ll}6070,69 \\
\end{array}$ & 281,26 & $-2,30$ & 283,56 & 142,39 & \begin{tabular}{|l|l|}
199,63 \\
\end{tabular} & \begin{tabular}{|l|l|}
199,70 \\
\end{tabular} & 45,06 & 512,43 & 63,00 & 27,03 & 22,39 & 159,30 & 97,77 & \begin{tabular}{|l|l|}
106,13 \\
\end{tabular} & 126,51 \\
\hline Alytes obstetricans & 30TWM86 & 100,00 & 114,20 & $\begin{array}{ll}109,04 \\
\end{array}$ & 38,09 & $\begin{array}{ll}6006,60 \\
\end{array}$ & 274,05 & $-7,30$ & 281,35 & \begin{tabular}{|l|l|}
134,91 \\
\end{tabular} & \begin{tabular}{|l|l|}
192,58 \\
\end{tabular} & \begin{tabular}{|l|}
192,63 \\
\end{tabular} & 39,61 & 570,80 & 67,81 & 30,55 & 20,97 & 174,04 & $\begin{array}{lll}108,84 \\
\end{array}$ & 113,47 & 144,47 \\
\hline Alytes obstetricans & 30TWM87 & 100,00 & 128,35 & 107,02 & 38,02 & \begin{tabular}{|l|}
5975,87 \\
\end{tabular} & 284,11 & 7,13 & 276,98 & 149,45 & 205,52 & 205,54 & 53,25 & 532,35 & 62,14 & 27,45 & 21,42 & 160,02 & 100,23 & 104,59 & 134,85 \\
\hline Alytes obstetricans & 30TWM88 & 100,00 & 134,35 & 105,10 & 38,04 & 5889,37 & 286,21 & 14,87 & 271,33 & 132,12 & 210,31 & 210,31 & 60,31 & 546,65 & 61,38 & 27,62 & 21,02 & 160,87 & 102,44 & \begin{tabular}{|l|l}
104,23 \\
\end{tabular} & 141,00 \\
\hline Alytes obstetricans & 30TWM89 & 100,00 & 131,38 & 104,44 & 38,28 & 5824,87 & 281,87 & 13,37 & 268,50 & 108,01 & 206,61 & 206,61 & 58,00 & 599,62 & 65,11 & 30,34 & 20,55 & 175,85 & 111,50 & 111,85 & 158,52 \\
\hline Alytes obstetricans & 30TWM91 & 100,00 & 87,84 & 108,99 & 37,95 & 6050,08 & 249,71 & $-35,05$ & 284,76 & 106,85 & 167,60 & 167,79 & 13,94 & 624,44 & 78,82 & 35,82 & 21,71 & 199,61 & 125,27 & 139,48 & 148,70 \\
\hline Alytes obstetricans & 30TWM92 & 100,00 & 72,64 & 106,71 & 37,77 & $\begin{array}{l}5954,64 \\
\end{array}$ & 233,16 & $-46,25$ & 279,41 & 89,69 & 152,01 & \begin{tabular}{ll|}
152,06 \\
\end{tabular} & 0,86 & 739,71 & 89,38 & 43,41 & 19,55 & 230,16 & 148,20 & 155,56 & 180,58 \\
\hline Alytes obstetricans & 30TWM93 & 100,00 & 108,87 & 109,70 & 38,00 & $\begin{array}{ll}6087,02 \\
\end{array}$ & 270,50 & $-15,03$ & $\begin{array}{ll}285,53 \\
\end{array}$ & 129,85 & \begin{tabular}{|l|l|}
188,27 \\
\end{tabular} & 188,40 & 33,36 & 539,83 & 68,31 & 29,30 & 22,86 & 171,31 & 104,81 & 115,50 & 130,99 \\
\hline Alytes obstetricans & 30TWM94 & 100,00 & 116,65 & 109,32 & 38,00 & 6088,93 & 277,28 & $-6,85$ & 284,12 & 138,12 & $\begin{array}{l}195,80 \\
\end{array}$ & $\begin{array}{l}195,84 \\
\end{array}$ & 40,77 & 518,92 & 65,08 & 27,44 & 23,06 & 163,27 & 99,03 & $\begin{array}{l}108,04 \\
\end{array}$ & 127,24 \\
\hline Alytes obstetricans & 30TWM95 & 100,00 & 125,99 & 108,46 & 38,00 & 6076,73 & 284,75 & 2,67 & 282,08 & 148,08 & 204,72 & 204,73 & 49,95 & 501,18 & 61,53 & 25,72 & 22,97 & 154,93 & $\begin{array}{ll}94,08 \\
\end{array}$ & 100,50 & 124,61 \\
\hline Alytes obstetricans & 30тWM96 & 100,00 & 131,71 & 107,23 & 38,00 & 6028,23 & 288,08 & 9,28 & 278,79 & 153,84 & 209,61 & 209,62 & 55,88 & 508,03 & 60,32 & 25,39 & 22,64 & 153,29 & 94,21 & 97,98 & 128,91 \\
\hline Alytes obstetricans & 30TWM98 & 100,00 & 132,69 & 105,57 & 38,03 & \begin{tabular}{|l|}
5901,17 \\
\end{tabular} & 285,19 & 12,88 & 272,31 & \begin{tabular}{|l|l|}
98,97 \\
\end{tabular} & 208,86 & 208,86 & 58,47 & $\begin{array}{l}581,45 \\
\end{array}$ & 64,16 & 28,73 & 21,48 & 171,39 & 106,18 & $\begin{array}{l}106,63 \\
\end{array}$ & 155,19 \\
\hline Alytes obstetricans & 30TWM99 & 100,00 & 131,07 & 104,91 & 38,25 & 5841,19 & 282,14 & 12,33 & 269,81 & 95,75 & 206,50 & 206,50 & 57,70 & $\begin{array}{l}635,06 \\
\end{array}$ & 70,00 & 31,24 & 21,29 & \begin{tabular}{ll|}
189,54 \\
\end{tabular} & $\begin{array}{ll}114,88 \\
\end{array}$ & 115,15 & 174,14 \\
\hline Alytes obstetricans & 30TWNO0 & 100,00 & 120,38 & $\begin{array}{ll}94,44 \\
\end{array}$ & 37,97 & 5419,18 & 260,53 & 13,68 & 246,85 & 88,49 & $\begin{array}{l}190,40 \\
\end{array}$ & \begin{tabular}{|l|}
191,40 \\
\end{tabular} & 53,06 & \begin{tabular}{ll|}
629,12 \\
\end{tabular} & 66,32 & 31,18 & 19,25 & $\begin{array}{l}187,06 \\
\end{array}$ & \begin{tabular}{ll|}
120,44 \\
\end{tabular} & $\begin{array}{ll}121,28 \\
\end{array}$ & 170,86 \\
\hline Alytes obstetricans & 30TWN01 & 100,00 & 120,28 & 91,73 & 37,94 & 5288,90 & 256,13 & 16,42 & 239,71 & \begin{tabular}{l|l}
88,03 \\
\end{tabular} & 188,49 & $\begin{array}{l}189,70 \\
\end{array}$ & 54,88 & $\begin{array}{l}677,58 \\
\end{array}$ & 72,94 & 33,23 & 19,58 & 203,86 & 128,09 & $\begin{array}{l}130,50 \\
\end{array}$ & 187,86 \\
\hline Alytes obstetricans & 30TWN02 & 100,00 & 122,30 & 88,59 & 37,80 & 5134,56 & 253,13 & 21,27 & 231,85 & 92,57 & 188,13 & 189,59 & 58,65 & 725,80 & 80,04 & 34,78 & 20,01 & 221,58 & 134,57 & $\begin{array}{ll}139,36 \\
\end{array}$ & 206,13 \\
\hline Alytes obstetricans & 30TWNO3 & 100,00 & 116,25 & 87,55 & 37,88 & 5049,03 & 246,02 & 17,38 & 228,64 & 76,28 & 181,08 & 182,81 & 54,08 & 797,32 & 88,72 & 38,69 & 19,84 & 243,94 & 147,58 & \begin{tabular}{|l|l|}
152,84 \\
\end{tabular} & 229,04 \\
\hline Alytes obstetricans & 30TWN04 & 100,00 & 108,15 & 86,93 & 37,99 & 4972,08 & 237,41 & 11,42 & 225,99 & 55,08 & 172,15 & 174,14 & 47,45 & 881,71 & 98,74 & 43,52 & 19,67 & 271,41 & 163,24 & 168,67 & 255,44 \\
\hline Alytes obstetricans & 30TWN05 & 100,00 & 111,15 & 83,25 & 37,86 & 4804,25 & 234,88 & 17,47 & 217,42 & 60,22 & 172,58 & 174,81 & 52,45 & 940,18 & 107,73 & 45,27 & 20,77 & 294,35 & 170,42 & 179,21 & 278,61 \\
\hline Alytes obstetricans & 30TWN06 & 100,00 & 120,93 & 76,99 & 37,38 & 4558,16 & 235,22 & 31,95 & 203,28 & 72,35 & 178,65 & 181,13 & 65,04 & $\begin{array}{l}998,87 \\
\end{array}$ & \begin{tabular}{|l|l|}
119,07 \\
\end{tabular} & 45,23 & 23,21 & 320,68 & $\begin{array}{l}173,37 \\
\end{array}$ & $\begin{array}{ll}188,61 \\
\end{array}$ & 308,02 \\
\hline Alytes obstetricans & 30TWN07 & 100,00 & 127,93 & 71,26 & 36,86 & 4332,40 & 233,84 & 43,26 & $\begin{array}{ll}190,58 \\
\end{array}$ & 82,01 & 182,27 & \begin{tabular}{ll|}
185,03 \\
\end{tabular} & 74,73 & 1069,85 & $\begin{array}{l}132,35 \\
\end{array}$ & 45,96 & 25,77 & 351,14 & $\begin{array}{ll}178,23 \\
\end{array}$ & \begin{tabular}{|l|l|}
199,87 \\
\end{tabular} & 343,06 \\
\hline Alytes obstetricans & 30TWN08 & 100,00 & 130,79 & 67,22 & 36,46 & \begin{tabular}{|l|l|}
4178,09 \\
\end{tabular} & 230,99 & \begin{tabular}{|l|l|}
49,14 \\
\end{tabular} & 181,86 & 84,61 & \begin{tabular}{ll|l|}
182,80 \\
\end{tabular} & 185,90 & 79,44 & \begin{tabular}{|l|}
1139,08 \\
\end{tabular} & \begin{tabular}{|l|l|}
144,30 \\
\end{tabular} & 47,36 & 27,59 & 380,12 & \begin{tabular}{ll|l}
184,84 \\
\end{tabular} & 211,30 & 374,92 \\
\hline Alytes obstetricans & 30TWN09 & 99,00 & 138,12 & 61,59 & 35,64 & 3978,81 & 229,93 & $\begin{array}{ll}59,82 \\
\end{array}$ & 170,11 & 90,52 & 187,26 & $\begin{array}{l}190,50 \\
\end{array}$ & 88,95 & 1202,85 & \begin{tabular}{ll|l|}
157,78 \\
\end{tabular} & 47,29 & 30,38 & 411,24 & $\begin{array}{l}187,22 \\
\end{array}$ & 220,79 & 410,73 \\
\hline Alytes obstetricans & 30TWN10 & 100,00 & 121,39 & 95,73 & 38,00 & 5462,53 & 262,62 & 13,45 & 249,18 & 88,99 & 192,30 & $\mid$\begin{tabular}{|l|l|}
192,78 \\
\end{tabular} & 53,50 & $\mid 617,79$ & 64,51 & 31,17 & $\begin{array}{ll}18,99 \\
\end{array}$ & $\mid \begin{array}{l}181,58 \\
\end{array}$ & 120,47 & 120,61 & 165,39 \\
\hline Alytes obstetricans & 30TWN11 & 100,00 & 121,17 & 92,97 & 38,03 & 5325,25 & 258,05 & 16,19 & 241,87 & 87,30 & 189,92 & 190,83 & 55,10 & 671,24 & 71,31 & 33,48 & 19,01 & 200,12 & 129,18 & 130,57 & 183,99 \\
\hline Alytes obstetricans & 30TWN12 & 100,00 & 116,42 & 91,61 & 38,06 & 5218,73 & 251,37 & 13,86 & 237,50 & 78,65 & 183,78 & 185,01 & 51,99 & 741,39 & 80,05 & 37,07 & 18,90 & 222,10 & 141,43 & 143,53 & 207,29 \\
\hline Alytes obstetricans & 30TWN13 & 100,00 & 117,52 & 88,77 & 38,00 & 5076,73 & 248,27 & \begin{tabular}{|l|l}
17,84 \\
\end{tabular} & 230,43 & 75,49 & 182,56 & 184,25 & 54,99 & $\begin{array}{l}795,94 \\
\end{array}$ & 87,64 & 39,16 & 19,33 & 241,68 & 149,44 & 153,49 & 227,16 \\
\hline Alytes obstetricans & 30TWN14 & 100,00 & 114,06 & 86,70 & 38,04 & \begin{tabular}{l|l|l|}
4951,83 \\
\end{tabular} & 242,09 & 17,31 & 224,79 & 60,66 & \begin{tabular}{|l|l|l|l}
177,48 \\
\end{tabular} & $\begin{array}{l}179,45 \\
\end{array}$ & 53,44 & 873,38 & 97,76 & 42,79 & 19,69 & 268,69 & 161,95 & $\begin{array}{ll}167,58 \\
\end{array}$ & 253,84 \\
\hline Alytes obstetricans & 30TWN15 & 100,00 & 110,09 & 85,02 & 38,03 & 4845,20 & 235,85 & 15,60 & 220,25 & 58,25 & 172,10 & $\begin{array}{l}174,23 \\
\end{array}$ & 51,07 & $\begin{array}{l}950,45 \\
\end{array}$ & 107,55 & 46,56 & 19,95 & 295,50 & $\begin{array}{l}174,82 \\
\end{array}$ & $\begin{array}{l}181,79 \\
\end{array}$ & 279,59 \\
\hline Alytes obstetricans & 30TWN16 & 100,00 & $\begin{array}{ll}98,64 \\
\end{array}$ & 85,16 & 38,28 & \begin{tabular}{|l|l|}
4807,67 \\
\end{tabular} & 225,03 & 5,69 & 219,33 & 47,92 & 160,34 & 162,73 & 40,71 & 1045,75 & $\begin{array}{l}118,43 \\
\end{array}$ & 52,56 & 19,70 & 326,01 & $\begin{array}{l}193,81 \\
\end{array}$ & $\begin{array}{ll}199,88 \\
\end{array}$ & 307,97 \\
\hline Alytes obstetricans & 30TWN17 & 100,00 & 128,64 & 72,98 & 37,36 & 4354,73 & 236,46 & 43,81 & 192,65 & 82,11 & 183,14 & 186,01 & 75,52 & 1079,46 & \begin{tabular}{|l|l|}
131,80 \\
\end{tabular} & 47,04 & 24,96 & 352,18 & 181,94 & 201,95 & 344,04 \\
\hline Alytes obstetricans & 30TWN18 & 100,00 & 134,32 & 68,06 & 36,94 & \begin{tabular}{|l|l|}
4171,27 \\
\end{tabular} & 235,38 & 53,62 & 181,75 & 89,29 & 186,00 & 189,16 & 83,60 & $\begin{array}{l}1148,38 \\
\end{array}$ & 144,51 & 47,86 & 27,29 & 381,57 & 186,91 & 212,95 & 377,88 \\
\hline Alytes obstetricans & 30TWN19 & 100,00 & 136,81 & 64,62 & 36,64 & 4030,81 & 233,08 & 59,18 & 173,91 & 91,57 & 186,35 & 189,85 & 88,01 & 1213,41 & \begin{tabular}{|l|l|}
155,48 \\
\end{tabular} & 49,45 & 28,69 & 408,53 & $\begin{array}{l}193,61 \\
\end{array}$ & 224,12 & 406,77 \\
\hline Alytes obstetricans & 30TWN20 & 100,00 & 126,10 & 96,62 & 38,00 & 5507,50 & 267,48 & 16,71 & 250,77 & 94,30 & \begin{tabular}{|l|l|}
197,64 \\
\end{tabular} & 197,75 & 57,42 & 585,64 & 61,84 & 29,9 & 18,98 & 170,90 & 1116,21 & $\begin{array}{l}116,25 \\
\end{array}$ & 153,13 \\
\hline Alytes obstetricans & 30TWN21 & 100,00 & 110,79 & 96,77 & 38,36 & 5416,85 & 252,98 & 4,19 & 79 & 66,36 & 182,05 & 182,15 & 44 & 711,86 & 74,3 & 37,2 & 17,99 & 207,94 & 38,90 & 138,90 & 192,77 \\
\hline Alytes obstetricans & 30TWN22 & 100,00 & 111,72 & 94,34 & 38,29 & \begin{tabular}{|l|}
5288,91 \\
\end{tabular} & 250,19 & 7,67 & 242,52 & 61,67 & 180,75 & 181,31 & 46,66 & $\begin{array}{l}758,46 \\
\end{array}$ & 80,55 & 39,13 & 18,04 & 223,91 & 147,33 & 147,51 & 209,39 \\
\hline Alytes obstetricans & 30TWN23 & 100,00 & 112,54 & 91,62 & 38,28 & 5147,34 & 246,88 & 11,33 & 235,56 & 60,18 & 178,85 & 180,25 & 49,36 & 813,72 & 88,10 & 41,36 & 18,36 & 244,33 & 156,34 & 157,56 & 229,17 \\
\hline Alytes obstetricans & 30TWN24 & 100,00 & 119,93 & 86,90 & 38,16 & 4940,64 & 247,10 & 22,81 & 224,29 & 66,12 & 182,88 & 184,78 & 59,15 & 862,41 & 95,99 & 42,06 & 19,59 & 264,73 & 160,61 & 165,94 & 250,16 \\
\hline Alytes obstetricans & 30TWN25 & 100,00 & 117,45 & 84,69 & 38,13 & 4802,05 & 241,38 & 23,20 & 218,18 & 65,44 & \begin{tabular}{|l|l|}
178,44 \\
\end{tabular} & \begin{tabular}{ll|}
180,66 \\
\end{tabular} & 58,75 & $\begin{array}{l}945,48 \\
\end{array}$ & \begin{tabular}{|l|l|}
107,01 \\
\end{tabular} & 45,75 & 20,05 & 294,32 & 173,45 & $\begin{array}{ll}180,86 \\
\end{array}$ & 279,21 \\
\hline Alytes obstetricans & 30TWN26 & 100,00 & 113,08 & 82,98 & 38,30 & 4690,10 & 234,8 & 21,53 & 7 & 2 & 172,61 & $\begin{array}{l}175,10 \\
\end{array}$ & 56,11 & $\begin{array}{l}1031,02 \\
\end{array}$ & \begin{tabular}{ll|}
118,07 \\
\end{tabular} & \begin{tabular}{ll|}
49,92 \\
\end{tabular} & 20,60 & 324,36 & 187,44 & 33 & 308,42 \\
\hline Alytes obstetricans & $30 \mathrm{TWI}$ & 100,00 & 120,50 & 77,90 & 38 & 4471 & 234,66 & 33,45 & 201,21 & 72,74 & 176,71 & 17 & $\begin{array}{l}66,37 \\
\end{array}$ & \begin{tabular}{|l|}
1097,43 \\
\end{tabular} & 129,37 & 50,81 & 22,51 & 352,25 & 192,55 & 207,20 & 338,87 \\
\hline Alytes obstetricans & 30 TWN & 100,00 & 132,12 & 71,51 & 37,82 & 4217,71 & 237,05 & $\begin{array}{ll}50,52 \\
\end{array}$ & $\begin{array}{ll}186,53 \\
\end{array}$ & $\begin{array}{ll}86,93 \\
\end{array}$ & \begin{tabular}{l|l|l|l}
184,41 \\
\end{tabular} & $\begin{array}{l}187,61 \\
\end{array}$ & 81,19 & $\begin{array}{l}1160,03 \\
\end{array}$ & 142,02 & 50,33 & 25,43 & $\begin{array}{ll}381,14 \\
\end{array}$ & 194,15 & 216,73 & 372,79 \\
\hline Alytes obstetricans & $\mid$ & 100,00 & 136,55 & 67,88 & 37,67 & $\mid 4062,26$ & 236,21 & 58,40 & 177,81 & $\begin{array}{ll}93,08 \\
\end{array}$ & $\mid 186,50$ & \begin{tabular}{|c|c|}
190,04 \\
\end{tabular} & 87,82 & \begin{tabular}{|l|l|}
1216,98 \\
\end{tabular} & $\mid \begin{array}{l}151,89 \\
\end{array}$ & 51,40 & 26,91 & 405,01 & \begin{tabular}{|l|l|}
199,13 \\
\end{tabular} & 226,79 & 398,51 \\
\hline Alytes obstetricans & 30TWN30 & 100,00 & 127,14 & 98,39 & 38,01 & 5580,14 & 270,47 & 15,84 & 254,63 & 115,86 & 199,45 & 199,45 & 57,31 & 562,21 & 61,32 & 29,66 & 19,05 & 162,42 & 113,49 & 113,76 & 142,64 \\
\hline Alytes obstetricans & 30TWN31 & 100,00 & 112, & 98,18 & 38,56 & 5463,45 & 255,92 & 4,41 & 251,51 & 69,11 & 184,18 & 184,18 & 45,19 & \begin{tabular}{|l|l|}
698,07 \\
\end{tabular} & 73,03 & 37,09 & 17,75 & 201,94 & 137,27 & 137,27 & 186,42 \\
\hline Alytes obstetricans & $30 \mathrm{TWI}$ & 100,00 & 108 & 96,39 & 38,7 & 5341 & 249 & 3,40 & 246,24 & 51,29 & \begin{tabular}{|l|l|}
179,08 \\
\end{tabular} & 179,08 & 43,24 & 775,71 & 81,65 & \begin{tabular}{|l|l|}
40,84 \\
\end{tabular} & 17,59 & 227,76 & 150,97 & 150,97 & 212,72 \\
\hline Alytes obstetricans & 30TWN33 & 100,00 & 103,56 & 94,58 & 38,90 & 5221,61 & 242,10 & 1,07 & 241,03 & 47,20 & 172,36 & $\begin{array}{l}172,57 \\
\end{array}$ & 39,87 & 862,93 & 92,57 & 45,23 & 17,73 & 257,56 & 166,55 & 166,66 & 241,63 \\
\hline Alytes obstetricans & 30TWN34 & 100,00 & 118,90 & 89,15 & 38,76 & 4985,27 & 248,45 & 20,54 & 227,91 & $\begin{array}{ll}64,53 \\
\end{array}$ & 182,50 & 184,28 & 57,72 & 871,82 & 95,63 & 43,42 & 18,82 & 265,85 & 65,05 & $\begin{array}{ll}168,09 \\
\end{array}$ & 249,88 \\
\hline Alytes obstetricans & 30TWN35 & 100,00 & 112,87 & 87,58 & 38,92 & 4872,46 & 240,42 & 17,16 & 23,26 & 60,24 & 175,05 & 177 & 53,48 & 969,30 & $\begin{array}{l}108,05 \\
\end{array}$ & 48,34 & 19,18 & 299 & 181,38 & 185,61 & 282,65 \\
\hline Alytes obstetricans & & 100 & & 83 & & & & 2 & & 6 & \begin{tabular}{|l|l|}
177,68 \\
\end{tabular} & & 62,58 & 1040,38 & 118,50 & 50,06 & 20,62 & $32,0 z$ & 188,78 & 19,11 & 311,32 \\
\hline Alytes obstetricans & 30TWN37 & 100,00 & 126,97 & 78,23 & 38,76 & 4416,47 & 240,09 & 40,70 & 199,39 & 79,37 & 182,17 & 185,09 & 73,65 & 1110,02 & 130,25 & 51,03 & 22,59 & 356,79 & 194,15 & 209,22 & 342,71 \\
\hline Alytes obstetricans & 30TWN38 & 100,00 & 125,53 & 76,22 & 38,88 & 4295,56 & 235,67 & 41,87 & 193,80 & 79,55 & 178,97 & 182,14 & 73,98 & 1184,68 & \begin{tabular}{|l|l|}
140,08 \\
\end{tabular} & 54,29 & 23,10 & 383,79 & 205,43 & 223,01 & 368,89 \\
\hline
\end{tabular}




\begin{tabular}{|c|c|c|c|c|c|c|c|c|c|c|c|c|c|c|c|c|c|c|c|c|c|}
\hline TAXON & UTM & $\mathrm{km} 2$ & B101 & B102 & $\mathrm{BIO3}$ & 8104 & B105 & B106 & B107 & B108 & 8109 & BIO10 & BIO11 & BIO12 & 81013 & BIO14 & BIO15 & B1016 & B1017 & B1018 & B1019 \\
\hline Alytes obstetricans & 30TWN39 & 100,00 & 130,98 & 72,34 & 38,82 & 4113,23 & 235,15 & 51,13 & 184,02 & 87,08 & 181,70 & 185,18 & 81,85 & 1246,81 & 150,37 & 55,51 & 24,49 & 409,47 & 211,22 & 234,16 & 396,09 \\
\hline Alytes obstetricans & 30TWN40 & 100,00 & 128,64 & 100,21 & 38,06 & 5669,25 & 273,99 & 15,27 & 258,73 & 148,38 & 191,98 & 201,80 & 57,55 & 533,26 & 60,36 & 29,04 & 19,70 & 156,83 & 109,49 & 112,01 & 130,23 \\
\hline Alytes obstetricans & 30TWN41 & 100,00 & 113,05 & 99,65 & 38,75 & 5511,61 & 257,95 & 3,55 & 254,40 & 78,84 & 185,14 & 185,14 & 44,99 & 697,21 & 73,21 & 37,48 & 17,57 & 200,54 & $\begin{array}{l}137,18 \\
\end{array}$ & 137,18 & 184,62 \\
\hline Alytes obstetricans & 30TWN42 & 100,00 & 111,66 & 97,48 & 38,97 & 5372,17 & 253,22 & 4,92 & 248,30 & 55,80 & 182,10 & 182,10 & 45,54 & 765,08 & 79,88 & 40,51 & 17,51 & 223,68 & 149,08 & 149,08 & 207,95 \\
\hline Alytes obstetricans & 30TWN43 & 100,00 & 104,69 & 95,80 & 39,00 & 5253,68 & 244,22 & 1,10 & 243,12 & 47,78 & \begin{tabular}{|l|l|}
173,98 \\
\end{tabular} & 173,98 & 40,45 & 867,38 & $\begin{array}{l}92,76 \\
\end{array}$ & 45,79 & 17,66 & 258,43 & 167,34 & 167,34 & 241,97 \\
\hline Alytes obstetricans & 30TWN44 & 100,00 & 116,32 & 91,52 & 39,00 & 5041,25 & 248,65 & 16,52 & 232,13 & 61,40 & 180,99 & 182,51 & 54,49 & 893,15 & 97,14 & 45,32 & 18,33 & 271,42 & 170,94 & 171,69 & 254,05 \\
\hline Alytes obstetricans & 30TWN45 & 100,00 & 108,38 & 90,08 & 39,01 & 4932,58 & 239,01 & 11,27 & 227,75 & 55,25 & $\begin{array}{ll}171,85 \\
\end{array}$ & 173,45 & 48,43 & 998,88 & 110,42 & 50,92 & 18,72 & 307,34 & 189,19 & 190,92 & 289,05 \\
\hline Alytes obstetricans & 30TWN46 & 100,00 & 123,61 & 83,98 & 39,18 & 4612,31 & 243,96 & 32,62 & 211,34 & 73,60 & 181,61 & 184,19 & 67,65 & 1057,52 & 120,02 & 50,76 & 20,66 & 333,64 & $\begin{array}{l}191,58 \\
\end{array}$ & 200,33 & 315,99 \\
\hline Alytes obstetricans & 30TWN47 & 100,00 & 127,37 & 80,59 & 39,48 & \begin{tabular}{ll|}
4414,46 \\
\end{tabular} & 242,24 & 40,45 & 201,79 & 79,66 & 182,45 & 185,32 & 74,13 & 1134,07 & 130,68 & 53,16 & 21,75 & 362,79 & 200,85 & 213,87 & 344,92 \\
\hline Alytes obstetricans & 30TWN48 & 100,00 & 130,07 & 77,45 & 39,64 & 4246,62 & 240,05 & 46,70 & 193,35 & 84,39 & 182,71 & 185,86 & 79,20 & 1204,46 & 140,81 & 55,47 & 22,78 & 389,75 & 209,58 & 226,82 & 372,07 \\
\hline Alytes obstetricans & 30TWN49 & 83,00 & 135,59 & 73,79 & 39,59 & 4081,88 & 239,93 & 55,56 & 184,37 & 91,69 & 185,64 & 189,10 & 86,91 & 1255,69 & 149,38 & 56,31 & 24,10 & 411,33 & 213,84 & 236,38 & 394,56 \\
\hline Alytes obstetricans & 30TWN50 & 100,00 & 128,81 & 101,63 & 38,17 & 5707,35 & 275,59 & 14,16 & 261,43 & 149,29 & \begin{tabular}{ll|}
178,54 \\
\end{tabular} & 202,48 & 57,20 & 531,73 & 60,97 & 29,42 & 19,74 & 159,20 & 108,66 & 111,32 & 127,16 \\
\hline Alytes obstetricans & 30TWN51 & 100,00 & 117,27 & 100,71 & 38,83 & 5560,53 & 262,85 & 6,08 & 256,77 & 96,97 & 189,70 & 189,70 & 48,22 & 677,80 & 71,69 & 36,57 & 17,82 & 194,92 & 133,18 & 133,23 & 177,28 \\
\hline Alytes obstetricans & 30TWN52 & 100,00 & 111,01 & 98,69 & 38,99 & 5410,56 & 253,88 & 3,30 & 250,58 & 54,19 & \begin{tabular}{ll|}
181,92 \\
\end{tabular} & 181,92 & 44,35 & 784,16 & 81,97 & 41,74 & 17,60 & 229,51 & 151,86 & 151,86 & 213,21 \\
\hline Alytes obstetricans & 30TWN53 & 100,00 & 99,05 & 97,23 & 39,00 & 5289,83 & 240,71 & $-5,51$ & 246,22 & 42,19 & 169,02 & 169,02 & 34,61 & 912,83 & 98,09 & 48,79 & 17,47 & 272,35 & 174,91 & 174,91 & 255,66 \\
\hline Alytes obstetricans & 30TWN54 & 100,00 & 108,16 & 93,91 & 39,01 & 5109,92 & 243,98 & 6,90 & 237,08 & 52,94 & 175,02 & 175,43 & 45,78 & 945,86 & \begin{tabular}{|l|l|}
103,08 \\
\end{tabular} & 49,09 & 18,18 & 287,36 & 180,52 & 180,55 & 269,18 \\
\hline Alytes obstetricans & 30TWN55 & 100,00 & 101,96 & 91,96 & 39,17 & 4992,10 & 235,34 & 3,58 & 231,76 & 48,52 & 167,24 & 168,02 & 41,50 & 1042,61 & 115,05 & 54,16 & 18,39 & 320,16 & 197,85 & 198,55 & 300,92 \\
\hline Alytes obstetricans & 30TWN56 & 100,00 & 121,30 & 86,70 & 39,73 & 4667,95 & 244,58 & 28,76 & 215,83 & 70,68 & 180,08 & 182,54 & 64,62 & \begin{tabular}{|l|}
1082,56 \\
\end{tabular} & 121,58 & 52,97 & 20,11 & 340,60 & 198,55 & 204,39 & 320,05 \\
\hline Alytes obstetricans & 30TWN57 & 100,00 & 121,94 & 84,15 & 40,03 & 4490,28 & 240,93 & 32,96 & 207,97 & 73,57 & 178,16 & 180,97 & 67,85 & $\mid 1167,68$ & 132,45 & 56,49 & 20,77 & 371,32 & 210,95 & 220,01 & 349,71 \\
\hline Alytes obstetricans & 30TWN58 & 100,00 & 128,13 & 80,12 & 40,23 & 4265,19 & 240,38 & 43,60 & 196,79 & 82,32 & 180,89 & 184,14 & 77,08 & 1240,29 & 142,68 & 58,48 & 21,94 & 399,49 & 218,99 & 233,70 & 377,46 \\
\hline Alytes obstetricans & 30TWN59 & 44,00 & 139,91 & 75,83 & 40,32 & 4069,49 & 244,87 & 58,97 & 185,90 & 95,91 & \begin{tabular}{|l|l|}
189,63 \\
\end{tabular} & 193,12 & 91,12 & 1259,76 & 147,65 & 57,2 & 23,51 & 411,15 & 216,65 & 238,33 & 390,14 \\
\hline Alytes obstetricans & 30TWN60 & 100,00 & 128,49 & 102,42 & 38,65 & 5712,74 & 275,91 & 13,51 & 262,40 & \begin{tabular}{|c|}
148,66 \\
\end{tabular} & 202,28 & 202,28 & 56,78 & 570,93 & 63 & 30,87 & 19,23 & $\begin{array}{l}168,39 \\
169\end{array}$ & 113,13 & 114,32 & 141,37 \\
\hline Alytes obstetricans & 30TWN61 & 100,00 & 123,57 & 101,06 & 38,90 & 5586,07 & 268,85 & 11,30 & 257,55 & 97,75 & \begin{tabular}{|l|l|}
195,97 \\
\end{tabular} & 195,97 & 53,90 & 664,02 & 70,13 & 35,35 & 18,29 & 191,84 & 129,09 & 129,09 & 173,33 \\
\hline Alytes obstetricans & 30TWN62 & 100,00 & 116,46 & 99,48 & 39,00 & 5443,10 & 259,68 & 7,43 & 252,25 & 61,06 & 187,44 & 187,44 & 49,16 & 775,19 & 81,60 & 40,88 & 18,03 & 228,47 & 148,49 & 148,49 & 211,26 \\
\hline Alytes obstetricans & 30TWN63 & 100,00 & 103,32 & 97,94 & 39,01 & 5316,96 & 245,23 & $-2,27$ & 247,50 & 45,76 & 173,31 & 173,31 & 38,25 & 914,81 & 99,12 & 48,44 & 17,94 & 274,80 & 173,71 & 173,71 & 257,41 \\
\hline Alytes obstetricans & 30TWN64 & 100,00 & 104,07 & 95,58 & 39,10 & 5166,61 & 242,19 & 1,56 & 240,63 & 48,36 & 172,21 & 172,21 & 41,03 & 984,99 & 108,32 & 51,52 & 18,30 & 300,55 & 186,36 & 186,36 & 281,81 \\
\hline Alytes obstetricans & 30TWN65 & 100,00 & 114,75 & 92,10 & 39,59 & 4941,28 & 246,34 & $\begin{array}{l}1,16,24 \\
16\end{array}$ & 230,10 & $\begin{array}{ll}60,1,12 \\
61\end{array}$ & 178,84 & |179,67 & 54,48 & \begin{tabular}{|l|}
1037,83 \\
\end{tabular} & |115,65 & 52,42 & 19,30 & 323,01 & $\begin{array}{l}194,30 \\
\end{array}$ & $\begin{array}{l}195,10 \\
\end{array}$ & 302,10 \\
\hline Alytes obstetricans & 30TWN66 & 100,00 & 130,98 & 86,46 & 40,11 & 4575,07 & 251,84 & 39,33 & 212,51 & 81,00 & 188,09 & 190,77 & 75,39 & \begin{tabular}{|l|}
1103,43 \\
\end{tabular} & 124,59 & 52,88 & 20,87 & 350,55 & 199,35 & 206,77 & 327,82 \\
\hline Alytes obstetricans & 30TWN67 & 100,00 & 123,06 & 85,63 & 40,39 & 4495,82 & 243,12 & 33,38 & 209,73 & 74,62 & 179,28 & 182,14 & 68,95 & 1199,36 & 135,85 & 58,32 & 20,85 & 382,33 & 217,09 & 225,01 & 358,30 \\
\hline Alytes obstetricans & 30TWN68 & 100,00 & 128,29 & 82,14 & 40,94 & 4248,49 & 241,72 & 43,40 & 198,32 & 82,67 & 180,87 & 184,08 & 77,57 & 1282,11 & 145,99 & 61,18 & 21,70 & 412,56 & 227,80 & 241,07 & 386,77 \\
\hline Alytes obstetricans & 30TWN69 & 47,00 & 142,35 & 77,38 & 40,97 & 4040,34 & 247,61 & 61,04 & 186,56 & 98,65 & 191,69 & 195,08 & 93,94 & 1284,21 & 149,00 & 59,06 & 23,20 & 418,49 & 222,79 & 243,99 & 393,32 \\
\hline Alytes obstetricans & 30TWN70 & 100,00 & 128,26 & 103,05 & 38,81 & 5722,17 & 276,35 & $\begin{array}{l}1,245 \\
12,53 \\
\end{array}$ & $\begin{array}{ll}263,82 \\
\end{array}$ & \begin{tabular}{|c|}
117,08 \\
17,0
\end{tabular} & 202,17 & 202,17 & 56,39 & \begin{tabular}{|l|}
621,40 \\
\end{tabular} & \begin{tabular}{|l|l|}
66,86 \\
\end{tabular} & 32,47 & 19,35 & \begin{tabular}{|l|}
180,75 \\
180,7
\end{tabular} & \begin{tabular}{|l|}
118,47 \\
\end{tabular} & \begin{tabular}{|l|}
118,66 \\
11,6
\end{tabular} & 161,95 \\
\hline Alytes obstetricans & 30TWN71 & 100,00 & 122,45 & 101,95 & 38,96 & 5618,81 & 269,19 & 9,36 & 259,82 & 75,45 & 195,46 & 195,46 & 52,41 & 709,88 & 75,19 & 37,01 & 18,93 & 208,65 & 134,01 & 134,01 & 191,71 \\
\hline Alytes obstetricans & 30TWN72 & 100,00 & 120,18 & 100,16 & 39,00 & 5473,56 & 264,10 & 10,08 & 254,02 & 59,92 & \begin{tabular}{|l|}
191,43 \\
\end{tabular} & 191,43 & 52,22 & 795,65 & 86,12 & 40,98 & 18,93 & 239,09 & 148,78 & 148,78 & 221,42 \\
\hline Alytes obstetricans & 30TWN73 & 100,00 & 103,41 & 98,80 & 39,01 & 5350,09 & 246,23 & $-3,39$ & 249,61 & 45,57 & 173,73 & 173,73 & 37,87 & 936,65 & \begin{tabular}{|l|l|}
102,89 \\
\end{tabular} & 49,35 & 18,41 & 283,47 & 175,99 & 175,99 & 265,79 \\
\hline Alytes obstetricans & 30TWN74 & 100,00 & 100,62 & 96,62 & 39,21 & 5208,45 & 240,12 & $-2,82$ & 242,94 & 44,68 & 169,38 & 169,38 & 37,17 & 1021,25 & 113,47 & 53,57 & 18,56 & 312,86 & 191,86 & 191,86 & 293,94 \\
\hline Alytes obstetricans & 30TWN75 & 100,00 & 108,49 & 94,04 & 39,53 & 5036,57 & 243,08 & 7,88 & 235,20 & 54,16 & 174,61 & 174,66 & 46,97 & 1073,28 & 120,82 & 54,95 & 19,36 & 334,82 & 200,40 & 200,40 & 313,61 \\
\hline Alytes obstetricans & 30TWN76 & 100,00 & 111,01 & 90,73 & 39,88 & 4809,98 & 239,75 & 14,90 & 224,85 & 59,29 & 172,92 & 174,38 & 52,67 & 1155,76 & 130,57 & 58,44 & 19,83 & 363,66 & 213,91 & 216,84 & 340,62 \\
\hline Alytes obstetricans & 30TWN77 & 100,00 & 129,54 & 85,98 & 40,78 & 4449,01 & 248,19 & 39,74 & 208,45 & 81,29 & 184,82 & 187,75 & 75,75 & 1224,90 & 139,65 & 59,02 & 21,43 & 393,34 & 220,21 & 229,16 & 366,76 \\
\hline Alytes obstetricans & 30TWN78 & 100,00 & 136,02 & 82,26 & 41,51 & 4169,84 & 247,28 & 51,34 & 195,95 & 90,94 & 187,18 & 190,48 & 86,04 & 1306,41 & 148,74 & 62,01 & 22,07 & 422,21 & 231,31 & 246,37 & 393,01 \\
\hline Alytes obstetricans & 30TWN79 & 55,00 & 142,54 & 79,19 & 41,49 & 4050,54 & 248,44 & 59,70 & 188,74 & 98,79 & 191,96 & 195,32 & 93,85 & 1318,53 & 152,11 & 61,78 & 22,71 & 428,98 & 231,91 & 252,33 & 399,74 \\
\hline Alytes obstetricans & 30TWN82 & 100,00 & 122,08 & 101,03 & 38,99 & 5523,64 & 267,28 & 10,41 & 256,87 & 61,07 & 193,86 & 193,86 & 53,14 & 830,67 & 93,74 & 41, & 20,33 & 255,99 & 150,78 & 150,78 & 238,30 \\
\hline Alytes obstetricans & $\begin{array}{l}30 \text { TWN83 } \\
\end{array}$ & 100,00 & 110,64 & 99,59 & 39,01 & 5397,98 & 254,13 & $\frac{2,25+25}{2,25}$ & 251,88 & 51,75 & 181,21 & 181,21 & 43,90 & 943,14 & \begin{tabular}{|c|}
106,92 \\
\end{tabular} & 48,21 & 19,84 & 291,81 & 172,73 & 172,73 & 273,47 \\
\hline Alytes obstetricans & 30TWN84 & 100,00 & 91,57 & 97,49 & 39,01 & 5276,41 & 233,10 & $-13,28$ & 246,38 & 35,46 & \begin{tabular}{|l|l|}
161,44 \\
\end{tabular} & 161,44 & 27,57 & 1060,01 & 118,21 & 56,62 & 18,24 & 23,42 & 199,51 & 199,51 & 305,06 \\
\hline Alytes obstetricans & 30TWN85 & 100,00 & 106,58 & 95,36 & 39,4 & 5114,41 & 243,07 & 4,09 & 238,99 & 51,34 & 173,73 & 173,73 & 43,91 & 1099,31 & 25,91 & 56,20 & 19,88 & 45,57 & 03,27 & 03,27 & 324,35 \\
\hline Alytes obstetricans & 30TWN86 & 100,00 & 113, & 92,50 & $\begin{array}{l}39, \\
39,\end{array}$ & 4893,48 & 244,21 & $\begin{array}{ll}14,93 \\
\end{array}$ & 229,28 & 60,58 & $\begin{array}{l}176,77 \\
176,1\end{array}$ & 177,71 & $\begin{array}{ll}53,68 \\
\end{array}$ & 1171,81 & 135,21 & 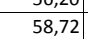 & 20,63 & 373,55 & 215,77 & 216,84 & 349,65 \\
\hline Alytes obstetricans & $30 \mathrm{TWI}$ & 100,00 & 11 & 90,20 & 40,28 & $\begin{array}{ll}4714,87 \\
\end{array}$ & 240,70 & 19,19 & 221,50 & 63,64 & 174,15 & 176,25 & 57,07 & 1253,24 & 144,73 & 62,59 & 20,78 & 401,85 & 230,62 & 233,34 & 375,75 \\
\hline Alytes obstetricans & 30TWN88 & 100,00 & 129,64 & 84,99 & 41,19 & 4340,68 & 245,11 & 41,00 & 204,11 & 82,85 & 183,45 & 186,52 & 77,15 & \begin{tabular}{|l|}
1323,19 \\
\end{tabular} & 152,53 & 64,33 & 21,75 & 428,25 & 238,60 & 250,17 & 398,13 \\
\hline Alytes obstetricans & 30TWN89 & 84,00 & 141,98 & 80,34 & 41,12 & 4147,07 & 249,07 & 56,16 & 192,91 & 97,07 & 192,83 & 196,01 & 91,49 & 1324,87 & 154,41 & 63,41 & 22,63 & 431,54 & 237,27 & 257,20 & 400,51 \\
\hline Alytes obstetricans & 30TWN90 & 100,00 & 130,41 & 103,87 & 38,51 & 5766,03 & 279,85 & 13,29 & 266,56 & 90,01 & 204,94 & 204,94 & 57,74 & 694,81 & 78,47 & 33,90 & 21,38 & 210,72 & 124,39 & 124,39 & 195,88 \\
\hline Alytes obstetricans & 30TWN & 100,00 & 12 & $\frac{10}{10}$ & 38, & | 5672,55 & 277 & $\begin{array}{l}1,25 \\
14,55 \\
\end{array}$ & \begin{tabular}{|l|}
262,73 \\
\end{tabular} & $\mid \frac{0,01}{67,71}$ & 202,94 & \begin{tabular}{|l|}
202,99 \\
\end{tabular} & 58,42 & \begin{tabular}{|l|}
$\mid 767,01$ \\
767,09
\end{tabular} & 80,85 & $\begin{array}{l}30,06 \\
37,06\end{array}$ & $\begin{array}{l}21,30 \\
21,72\end{array}$ & 238,28 & \begin{tabular}{|l|}
135,92 \\
13,92
\end{tabular} & $\begin{array}{l}135,92 \\
13,9 \\
\end{array}$ & $\begin{array}{l}2,72,00 \\
222,37\end{array}$ \\
\hline Alytes obstetricans & 30TWN92 & 100,00 & 124,90 & 101,77 & 38,94 & 5574,60 & 271,25 & 11,91 & 259,34 & 63,38 & 197,29 & 197,29 & 55,07 & 861,72 & 101,88 & 41,69 & 22,23 & 272,79 & 151,59 & 151,59 & 255,62 \\
\hline Alytes obstetricans & 30TWN93 & 100,00 & 114,54 & 100,49 & 39,01 & 5454,66 & 259,17 & 4,41 & 254,76 & 54,88 & 185,74 & 185,74 & 46,83 & 966,57 & 113,87 & 48,01 & 21,46 & 306,26 & $\mid 172,27$ & $|172,27|$ & 287,92 \\
\hline Alytes obstetricans & 30TWN94 & 100,00 & 112,33 & 98,54 & 39,03 & 5324,67 & 253,68 & 5,05 & 248,64 & 54,25 & 181,91 & 181,91 & 46,41 & 1044,64 & 123,47 & 52,04 & 21,45 & 333,16 & 187,74 & 187,74 & 313,34 \\
\hline Alytes obstetricans & 30TWN95 & 100,00 & 112 & 96,45 & 39,30 & 5169,92 & 249,99 & 7,99 & 242,00 & 56,38 & 180,13 & 180 & 48,65 & 1115,28 & 131,91 & 55,58 & 21,42 & 357,89 & 201,88 & 201,88 & 336 \\
\hline Alytes obstetricans & \begin{tabular}{|l|l|}
30 TWN96 \\
\end{tabular} & $\begin{array}{l}100,00 \\
\end{array}$ & $\begin{array}{l}111,404,13 \\
104\end{array}$ & $\begin{array}{l}0,40 \\
94,60\end{array}$ & $\begin{array}{l}39,59 \\
39,59\end{array}$ & 5054,56 & $\begin{array}{l}24,5899 \\
238,99\end{array}$ & 2,51 & \begin{tabular}{|l|}
236,48 \\
\end{tabular} & $\begin{array}{l}0,00 \\
49,88 \\
\end{array}$ & $\begin{array}{l}170,515 \\
170,57 \\
\end{array}$ & \begin{tabular}{|l|}
170,57 \\
170,
\end{tabular} & $\begin{array}{l}40,30 \\
42,31 \\
\end{array}$ & $\begin{array}{l}11187,40 \\
118,49\end{array}$ & \begin{tabular}{|l|}
138,57 \\
138
\end{tabular} & $\begin{array}{l}30,62 \\
60,62\end{array}$ & $\begin{array}{l}20,42 \\
20,39\end{array}$ & $\begin{array}{l}37,050 \\
378,00 \\
\end{array}$ & $\begin{array}{l}219,52 \\
219\end{array}$ & \begin{tabular}{|l|}
219,52 \\
21,5
\end{tabular} & 年350,21 \\
\hline Alytes obstetricans & 30TWN97 & 100,00 & 110,60 & 91,78 & 40,00 & 4839,21 & 239,44 & 12,53 & 226,92 & 58,56 & 172,80 & 174,20 & 51,36 & 1259,47 & 147,50 & 63,49 & 20,90 & 404,84 & 233,16 & 234,64 & 379,23 \\
\hline Alytes obstetricans & 30TWN98 & 100,00 & 120,70 & 87,94 & 40,59 & 4563,81 & 241,46 & 27,30 & 214,15 & 71,55 & 177,77 & 180,49 & 64,91 & 1332,12 & 156,15 & 66,26 & 21,49 & 431,84 & 244,48 & 251,74 & 402,44 \\
\hline Alytes obstetricans & 30TWN99 & 100,00 & 133,51 & 83,01 & 40,83 & 4317,29 & 244,87 & $\begin{array}{lll}43,87 \\
\end{array}$ & 201,0 & 90,02 & 186,91 & 189,8 & 80, & 1355 & 159,45 & 66,82 & 22,10 & 441,31 & 248,15 & 264,33 & 409 \\
\hline Alytes obstetricans & 30TWP10 & 94,00 & 132,38 & 64,68 & 36,92 & 3975,66 & 228,22 & 55,49 & 172,72 & 89,86 & 181,32 & 184,84 & 84,41 & 266,20 & 160,96 & 52,91 & 27,98 & 425,57 & 204,62 & 235,59 & 420, \\
\hline
\end{tabular}




\begin{tabular}{|c|c|c|c|c|c|c|c|c|c|c|c|c|c|c|c|c|c|c|c|c|c|}
\hline TAXON & UTM & $\mathrm{km} 2$ & B101 & B102 & $\mathrm{BIO3}$ & 8104 & B105 & B106 & B107 & B108 & B109 & B1010 & BIO11 & BIO12 & B1013 & BIO14 & BIO15 & B1016 & B1017 & B1018 & B1019 \\
\hline Alytes obstetricans & 30TWP20 & 75,00 & 136,08 & 66,31 & 37,61 & 3978,94 & 233,33 & 59,44 & 173,89 & 93,78 & 184,80 & 188,46 & 88,51 & 1263,98 & 158,65 & 53,35 & 27,25 & 422,90 & 205,95 & 236,04 & 415,55 \\
\hline Alytes obstetricans & 30TWP90 & 28,00 & 138,83 & 80,55 & 40,75 & 4220,05 & 245,72 & 50,41 & 195,31 & 105,70 & 190,86 & 193,91 & 86,75 & 1355,98 & 160,34 & 66,73 & 22,59 & 442,94 & 248,83 & 269,58 & 409,41 \\
\hline Alytes obstetricans & $\begin{array}{l}\text { 30TXKO4 } \\
\end{array}$ & 100,00 & 91,29 & 113,85 & 37,81 & 6408,16 & 263,32 & $\mid-35,17$ & 298,49 & 109,31 & 177,06 & 1777,95 & 15,51 & 588,74 & 76,51 & 28,84 & 25,23 & 193,61 & $\begin{array}{l}411,69 \\
1106\end{array}$ & 123,91 & 126,51 \\
\hline Alytes obstetricans & 30TXK05 & 100,00 & 85,42 & 112,53 & 37,48 & 6386,84 & 256,24 & $-40,19$ & 296,44 & 103,25 & 170,92 & 171,92 & 9,99 & 611,81 & 79,73 & 31,25 & 24,81 & 201,77 & 117,99 & 131,47 & 131,33 \\
\hline Alytes obstetricans & 30TXK06 & 100,00 & 79,90 & $\begin{array}{lll}111,37 \\
\end{array}$ & 37,18 & \begin{tabular}{|l|l|}
6361,73 \\
\end{tabular} & 249,61 & $-44,79$ & 294,40 & 97,32 & 165,13 & 165,92 & 4,81 & 636,51 & 82,84 & 33,56 & 24,36 & 209,90 & 124,25 & 138,84 & 136,99 \\
\hline Alytes obstetricans & 30TXK07 & 100,00 & 76,83 & 110,40 & 37,03 & 6336,85 & 245,38 & $-47,18$ & 292,56 & 94,26 & 161,80 & 162,60 & 1,99 & 646,58 & 84,44 & 34,85 & 24,10 & 213,76 & 127,65 & 142,93 & 139,03 \\
\hline Alytes obstetricans & 30TXK08 & 100,00 & 77,03 & 109,66 & 37,08 & 6312,45 & 243,99 & $-46,97$ & 290,96 & 94,68 & 161,59 & 162,30 & 2,12 & 639,09 & 84,13 & 35,02 & 24,46 & 212,45 & 127,62 & 143,21 & 136,57 \\
\hline Alytes obstetricans & $\begin{array}{l}\text { 30TXK09 } \\
\end{array}$ & 100,00 & 79,59 & 109,00 & 37,00 & 6294,38 & 244,64 & $-44,95$ & 289,60 & 97,81 & 162,42 & $\begin{array}{l}164,38 \\
\end{array}$ & 4,53 & 617,75 & 82,36 & 34,29 & 25,07 & 206,99 & 124,88 & 140,40 & 130,87 \\
\hline Alytes obstetricans & 30TXK15 & 100,00 & 82,18 & 110,27 & 37,05 & 6359,69 & 250,24 & $-41,86$ & 292,10 & 99,40 & 166,42 & 168,26 & 7,14 & 624,09 & 81,44 & 33,05 & 24,62 & 207,10 & 123,55 & 137,40 & 131,11 \\
\hline Alytes obstetricans & 30TXK16 & 100,00 & 80,38 & 109,45 & 37,00 & 6342,31 & 247,30 & $\begin{array}{l}-43,47 \\
\end{array}$ & 290,77 & 97,85 & 161,94 & 166,18 & 5,42 & 626,66 & 82,40 & 33,88 & 24,82 & 208,97 & 125,47 & 140,04 & 131,01 \\
\hline Alytes obstetricans & 30TXK17 & 100,00 & 81,07 & 108,66 & 37,00 & 6320,35 & 246,23 & $-42,92$ & 289,15 & 98,94 & 129,53 & 166,37 & 6,01 & 614,81 & 81,79 & 33,82 & 25,33 & 206,54 & 124,02 & 139,62 & 127,34 \\
\hline Alytes obstetricans & 30TXK18 & 100,00 & 75,69 & 107,67 & 37,00 & 6288,67 & 239,92 & $-47,22$ & 287,14 & 93,29 & 120,62 & 160,59 & 1,25 & 642,11 & 84,96 & 36,08 & 24,72 & 215,03 & 130,37 & 147,04 & 134,20 \\
\hline Alytes obstetricans & 30TXK19 & 100,00 & 83,36 & 107,15 & 37,00 & 6276,76 & 244,69 & $-41,06$ & 285,75 & 102,17 & $\begin{array}{ll}44,08 \\
\end{array}$ & 167,57 & 8,08 & 586,94 & 80,05 & 33,30 & 26,64 & 200,45 & 118,56 & 137,53 & 119,29 \\
\hline Alytes obstetricans & $30 \mathrm{TXK23}$ & 100,00 & 100,11 & 110,21 & 37,39 & 6373,31 & 266,38 & $-24,35$ & 290,73 & 118,26 & 146,67 & 186,21 & 24,56 & 535,75 & 70,58 & 26,75 & 26,57 & 179,48 & 105,99 & 116,16 & 107,35 \\
\hline Alytes obstetricans & 30TXK24 & 100,00 & 93,48 & 109,31 & 37,07 & 6365,55 & 259,06 & $-30,55$ & 289,61 & 111,53 & 86,95 & 179,53 & 18,15 & 561,96 & 74,46 & 29,25 & 26,24 & 188,91 & 111,88 & 124,59 & 112,80 \\
\hline Alytes obstetricans & 30TXK25 & 100,00 & 87,44 & 108,39 & 37,00 & 6344,98 & 252,18 & $-36,29$ & 288,47 & 105,20 & 63,33 & 173,14 & 12,24 & 588,16 & 78,06 & 31,61 & 25,82 & 197,97 & 118,21 & 132,53 & 118,65 \\
\hline Alytes obstetricans & $30 \mathrm{TXK26}$ & 100,00 & 87,08 & 107,41 & 37,00 & 6329,36 & 250,13 & $-36,45$ & 286,58 & 105,25 & 49,88 & 172,45 & 11,81 & 580,73 & 78,10 & 31,95 & 26,41 & 197,09 & 115,44 & 133,34 & 115,90 \\
\hline Alytes obstetricans & 30TXK27 & 100,00 & 90,92 & 106,46 & 36,99 & 6310,71 & 251,44 & $-33,16$ & 284,60 & 109,82 & 15,49 & 175,78 & 15,49 & 549,27 & 75,58 & 30,67 & 27,89 & 189,27 & 106,92 & 128,99 & 106,92 \\
\hline Alytes obstetricans & 30 TXK28 & 100,00 & 84,80 & 105,77 & 36,99 & 6281,25 & 244,63 & $-38,76$ & 283,39 & 103,45 & 18,02 & 169,19 & 9,79 & 578,01 & 79,11 & 32,97 & 27,26 & 198,66 & 113,88 & 137,05 & 113,97 \\
\hline Alytes obstetricans & 30TXK33 & 100,00 & 99,45 & 107,62 & 37,00 & 6345,18 & 262,45 & $-23,41$ & 285,86 & 117,12 & 40,71 & 185,07 & 24,05 & 535,92 & 70,68 & 27,60 & 26,84 & 180,35 & 104,38 & 118,53 & 104,49 \\
\hline Alytes obstetricans & 30тХK34 & 100,00 & 96,54 & 106,77 & 37,00 & 6341,71 & 258,65 & $-26,12$ & 284,78 & 114,40 & 23,29 & 182,16 & 21,10 & 541,29 & 72,33 & 28,84 & 27,11 & 183,53 & 104,59 & 122,41 & 104,60 \\
\hline Alytes obstetricans & 30TXK35 & 100,00 & 91,11 & 105,96 & 37,00 & 6329,52 & 252,52 & $-31,06$ & 283,59 & 109,05 & 34,57 & 176,71 & 16,12 & 562,28 & 75,46 & 30,82 & 26,95 & 191,22 & 109,01 & 129,35 & 109,10 \\
\hline Alytes obstetricans & 30TXK36 & 100,00 & 89,36 & 105,15 & 36,96 & \begin{tabular}{|l|l|}
6310,23 \\
\end{tabular} & 249,32 & $-33,01$ & 282,33 & 107,46 & 14,43 & \begin{tabular}{ll|}
174,49 \\
\end{tabular} & 14,43 & 562,61 & 76,48 & 31,49 & 27,46 & 192,96 & 108,06 & 132,04 & 108,06 \\
\hline Alytes obstetricans & 30TXK37 & 100,00 & 96,51 & 103,75 & 36,84 & 6301,96 & 252,85 & $-26,35$ & 279,20 & 115,90 & 21,12 & 181,14 & 21,12 & 510,25 & 71,81 & 27,73 & 30,17 & 179,23 & 93,54 & 123,62 & 93,54 \\
\hline Alytes obstetricans & 30TXK38 & 100,00 & 95,22 & 102,94 & 36,59 & 6273,83 & 249,72 & $-28,17$ & 277,89 & 115,05 & 19,50 & 179,20 & 19,50 & 508,38 & 72,46 & 27,36 & 30,95 & 180,26 & 92,49 & 125,50 & 92,49 \\
\hline Alytes obstetricans & 30TXK39 & 100,00 & 96,64 & 102,03 & 36,50 & 6237,25 & 248,21 & $-27,50$ & 275,72 & 117,08 & 20,75 & 179,66 & 20,75 & 493,07 & 71,48 & 25,97 & 32,38 & 177,07 & 88,36 & 124,17 & 88,36 \\
\hline Alytes obstetricans & 30TXK45 & 100,00 & 100,83 & 103,15 & 36,74 & 6318,85 & $\begin{array}{l}25,24,94 \\
257,9\end{array}$ & $-20,10$ & 278,04 & 119,41 & 25,62 & 186,08 & 25,62 & 503,32 & $\begin{array}{l}11,406 \\
69,24\end{array}$ & 27,13 & 29,50 & 174,30 & \begin{tabular}{|l|l|}
91,03 \\
9
\end{tabular} & 118,84 & $\begin{array}{ll}91,03 \\
91,5\end{array}$ \\
\hline Alytes obstetricans & 30TXK46 & 100,00 & 100,39 & 102,03 & 36,38 & 6310,30 & 255,61 & $-20,58$ & 276,19 & 119,41 & 25,17 & 185,30 & 25,17 & 494,29 & 69,28 & 26,03 & 30,70 & 173,50 & 87,49 & 119,83 & 87,49 \\
\hline Alytes obstetricans & 30TXK47 & 100,00 & 105,58 & 100,56 & 36,06 & 6302,53 & 257,69 & $-15,92$ & 273,61 & 125,56 & 29,86 & 189,98 & 29,86 & 456,05 & 66,08 & 22,62 & 33,51 & 163,82 & 76,81 & 114,08 & 76,81 \\
\hline Alytes obstetricans & 30TXK48 & 100,00 & 106,64 & 99,68 & 36,05 & 6268,44 & 255,85 & $-15,66$ & 271,51 & 127,33 & 30,49 & 190,24 & 30,49 & 442,42 & 65,35 & 21,40 & 35,04 & 161,32 & 73,19 & 113,16 & 73,19 \\
\hline Alytes obstetricans & 30TXK49 & 100,00 & 105,09 & 99,04 & 36,05 & 6222,95 & 251,72 & $-18,01$ & 269,73 & 126,24 & 29,09 & 187,64 & 29,09 & 443,49 & 66,29 & 21,18 & 35,94 & 163,25 & 73,09 & 115,32 & 73,09 \\
\hline Alytes obstetricans & $\begin{array}{l}30 \text { TXK53 } \\
\end{array}$ & 100,00 & 104,61 & 102,85 & 36,96 & $\mid 6278,89$ & 261,26 & \begin{tabular}{|l|l|}
$-14,89$ \\
$-14,8$
\end{tabular} & 276,15 & $\begin{array}{l}122,03 \\
\end{array}$ & 30,58 & $\begin{array}{l}189,31 \\
\end{array}$ & 30,58 & |509,56 & $\begin{array}{l}0,23 \\
67,23\end{array}$ & 26,95 & $\begin{array}{l}5,05 \\
28,05\end{array}$ & $\begin{array}{l}171,62 \\
172\end{array}$ & $\begin{array}{l}3,03 \\
93,89 \\
\end{array}$ & 114,91 & 93,89 \\
\hline Alytes obstetricans & 30TXK54 & 100,00 & 110,14 & 101,39 & 36,45 & 6285,68 & 264,95 & $-9,05$ & 274,00 & 128,37 & 35,58 & 194,76 & 35,58 & 469,38 & 63,75 & 24,51 & 30,30 & 161,03 & 82,34 & 108,75 & 82,34 \\
\hline Alytes obstetricans & 30TXK55 & 100,00 & 113,78 & 99,76 & 36,03 & 6306,82 & 267,17 & $-5,13$ & 272,30 & 132,75 & 38,54 & 198,56 & 38,54 & 438,72 & 61,46 & 21,63 & 32,73 & 153,64 & 73,11 & 104,93 & 73,11 \\
\hline Alytes obstetricans & 30TXK56 & 100,00 & 112,06 & 98,56 & 35,93 & 6318,25 & 264,44 & $-6,62$ & 271,06 & 131,48 & 36,42 & 196,96 & 36,42 & 432,95 & 62,20 & 20,58 & 34,39 & 154,45 & 69,78 & 107,29 & 69,78 \\
\hline Alytes obstetricans & $\begin{array}{l}30 T \times K 57 \\
\end{array}$ & 100,00 & 106,68 & 98,29 & 35,97 & 6290,38 & 257,41 & $-12,77$ & 270,18 & 126,34 & 31,34 & 191,11 & 31,34 & 450,32 & 65,32 & 21,55 & 34,45 & 162,01 & 73,28 & 113,87 & 73,28 \\
\hline Alytes obstetricans & 30TXK58 & 100,00 & 99,21 & 98,50 & 36,00 & 6242,60 & 248,40 & $-21,20$ & 269,60 & 118,93 & 24,26 & 182,72 & 24,26 & 484,26 & 69,93 & 24,02 & 33,15 & 173,81 & 81,65 & 123,21 & 81,65 \\
\hline Alytes obstetricans & 30TXK59 & 100,00 & 94,94 & 98,25 & 36,00 & 6198,18 & 243,00 & $-25,97$ & 268,97 & 114,45 & 20,13 & 177,62 & 20,13 & 503,23 & 72,60 & 25,45 & 32,69 & 180,55 & 86,46 & 128,89 & 86,46 \\
\hline Alytes obstetricans & 30TXK63 & 100,00 & 82,82 & 102,00 & 36,40 & 6236,43 & 241,01 & $-35,06$ & 276,07 & 98,15 & 38,77 & 167,37 & 10,31 & 644,46 & 81,18 & 35,28 & 24,06 & 210,51 & 127,79 & 140,53 & 127,99 \\
\hline Alytes obstetricans & 30TXK64 & 100,00 & 87,24 & 100,95 & 36,13 & 6239,38 & 243,50 & $-30,71$ & 274,21 & 103,31 & 23,44 & 171,63 & 14,31 & 605,14 & 78,26 & 33,42 & 25,65 & 201,08 & 116,08 & 137,66 & 116,18 \\
\hline Alytes obstetricans & 30TXK65 & 100,00 & 101,19 & 98,94 & 36,00 & 6251,87 & 254,13 & $-16,56$ & 270,68 & 118,92 & 27,25 & 185,38 & 27,25 & 510,44 & 69,27 & 26,68 & 29,66 & 174,93 & 89,85 & 121,25 & 89,85 \\
\hline Alytes obstetricans & 30TXK66 & 100,00 & 108,23 & 97,32 & 35,94 & 6269,53 & 259,48 & \begin{tabular}{l|}
$-9,12$ \\
\end{tabular} & 268,61 & 126,95 & 33,81 & 192,60 & 33,81 & 458,11 & 64,67 & 22,13 & 33,10 & 161,26 & 74,98 & 112,78 & 74,98 \\
\hline Alytes obstetricans & 30TXK67 & 100,00 & 104,56 & 96,94 & 35,79 & 6246,24 & 254,15 & $-13,47$ & 267,62 & 123,62 & 30,08 & 188,43 & 30,08 & 469,72 & 66,91 & 22,78 & 33,33 & 166,56 & 77,30 & 117,66 & 77,30 \\
\hline Alytes obstetricans & 30TXK69 & 100,00 & 100,38 & 96,35 & 35,97 & 6177,58 & 245,97 & $-19,36$ & 265,34 & 120,29 & 25,86 & 182,75 & 25,86 & 478,58 & 69,53 & 23,12 & 34,12 & 172,34 & 79,11 & 123,21 & 79,11 \\
\hline Alytes obstetricans & 30TXK73 & 100,00 & 90,47 & 99,95 & 36,11 & 6192,30 & 245,25 & $-26,30$ & 271,55 & 106,12 & 20,42 & 174,21 & 18,38 & 604,95 & 76,52 & 32,69 & 25,01 & 197,56 & 116,88 & 134,35 & 116,88 \\
\hline Alytes obstetricans & 30TXK74 & 100,00 & 91 & 99,13 & 36,0 & 6192,24 & 244,61 & $-25,81$ & 270,42 & 107,01 & $\begin{array}{l}20,426 \\
18,69\end{array}$ & 174,65 & $\begin{array}{l}\mid 0,036 \\
18,69 \\
\end{array}$ & \begin{tabular}{|l|l|}
590,92 \\
\end{tabular} & $\begin{array}{ll}7,16,16 \\
\end{array}$ & 32,35 & 25,95 & $\begin{array}{l}195,32 \\
\end{array}$ & $\begin{array}{l}111,80 \\
11182\end{array}$ & 134,20 & $\begin{array}{ll}111,80 \\
111,82\end{array}$ \\
\hline Alytes obstetricans & 30TXK75 & 100,00 & 103,40 & 97,31 & 35,99 & 6193,90 & 254,00 & $-13,27$ & 267,27 & 120,72 & 30,15 & 186,71 & 30,15 & 508,76 & 68,34 & 26, & 29,45 & $\begin{array}{l}172,57 \\
\end{array}$ & 89,17 & 119,69 & 89,17 \\
\hline Alytes obstetricans & $\begin{array}{l}30 T X K 76 \\
\end{array}$ & 100,00 & 96,20 & 97,25 & 35,99 & 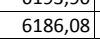 & 246,59 & $\begin{array}{l}-20,73 \\
\end{array}$ & 267,32 & 113,50 & 23,07 & 179,41 & 23,07 & 539,14 & 72,73 & 28,49 & 28,82 & 183,65 & 95,95 & 128,89 & 95,95 \\
\hline Alytes obstetricans & 30TXK77 & 100,00 & 88,03 & 97,19 & 36,00 & 6165,48 & 238,27 & $-29,22$ & 267,50 & 105,11 & 15,14 & 170,92 & 15,14 & 579,55 & 77,91 & 31,66 & 27,76 & 197,02 & 105,96 & 139,66 & 105,96 \\
\hline Alytes obstetricans & 30TXK78 & 100,00 & 86,79 & 96,62 & 35,98 & 6147,74 & 235,81 & $-30,66$ & 266,47 & 104,22 & 13,87 & 169,33 & 13,87 & 581,24 & 78,81 & 31,64 & 28,28 & 198,74 & 105,94 & 141,88 & 105,94 \\
\hline Alytes obstetricans & 30 TKK & 100,00 & $\begin{array}{l}0,17 \\
90,39\end{array}$ & $\begin{array}{l}90,006 \\
96,06\end{array}$ & $\begin{array}{l}35, \\
35,\end{array}$ & 6131 & 237,29 & $\begin{array}{l}-37,00 \\
-27,62\end{array}$ & \begin{tabular}{|l|}
$260,4,91$ \\
\end{tabular} & \begin{tabular}{|l|}
$108,73,73$ \\
\end{tabular} & $\begin{array}{l}\mid 0,01 \\
17,29\end{array}$ & $\begin{array}{l}172,42 \\
172\end{array}$ & $\begin{array}{l}10,06 \\
17,29 \\
\end{array}$ & $\mid \begin{array}{l}\mid 551,11 \\
51,1\end{array}$ & $\begin{array}{l}\mid 0,10 \\
76,38 \\
\end{array}$ & $\begin{array}{l}1,1044 \\
28,97\end{array}$ & $\begin{array}{l}\mid 20,00 \\
30,00\end{array}$ & \begin{tabular}{|l|}
$191,40,4$ \\
\end{tabular} & $\begin{array}{r}\mid c 0,34 \\
97,79 \\
\end{array}$ & $\begin{array}{l}14,00 \\
137,19\end{array}$ & $\begin{array}{r}00,34 \\
97,79\end{array}$ \\
\hline Alytes obstetricans & 30TXK83 & 100,00 & 106,31 & 97,56 & 36,03 & 6113,81 & 256,51 & $-9,25$ & 265,75 & 122,37 & 34,74 & 188,70 & 34,74 & 529,97 & 67,17 & 27,57 & 27,21 & 171,99 & 98,04 & 116,27 & 98,04 \\
\hline Alytes obstetricans & 30TXK84 & 100,00 & 112,75 & 96,24 & 36,00 & 6107,56 & 261,01 & $-2,94$ & 263,95 & 129,66 & 40,69 & 194,68 & 40,69 & 489,16 & 63,42 & 25,33 & 29,25 & 160,66 & 86,92 & 109,36 & 86,92 \\
\hline Alytes obstetricans & 30 TXK85 & 100,00 & 113,47 & 95,37 & 35,96 & 6117,38 & 260,95 & $-1,89$ & 262,84 & 130,88 & 41,07 & 195,58 & 41,07 & 474,12 & 63,06 & 23,84 & 30,62 & 158,27 & 81,69 & 108,52 & 81,69 \\
\hline Alytes obstetricans & 30TXK87 & 100,00 & 86,28 & 96,04 & 35,94 & 6125,23 & 235,37 & $-29,68$ & 265,04 & 102,63 & 14,27 & 168,73 & 14,27 & 603,92 & 79,63 & 33,52 & 26 & 202,00 & 112,33 & 142,80 & 112 \\
\hline Alytes obstetricans & 30TXK89 & 100,00 & 89,89 & 95,19 & 35,86 & 6094,73 & 236,24 & $-26,91$ & 263,15 & 107,44 & 17,72 & 171,58 & 17,72 & 566,46 & 77,28 & 30,17 & 28,85 & 193,84 & $\begin{array}{l}101,71 \\
\end{array}$ & 138,72 & 101,71 \\
\hline Alytes obstetricans & 30TXK93 & 100,00 & 115,89 & 95,69 & 36,00 & 6010,63 & 262,18 & 1,05 & 261,12 & 130,54 & 45,08 & 196,67 & 45,08 & 502,89 & 62,32 & 24,72 & 28,11 & 159,14 & 93,18 & 108,58 & 93,18 \\
\hline Alytes obstetricans & 30TXK94 & 100,00 & 119,28 & 94,74 & 36,00 & 6011,05 & 264,14 & 4,03 & 260,11 & 134,87 & 48,01 & 199,74 & 48,01 & 479,71 & 60,69 & 23,89 & 29,46 & 153,64 & 86,55 & 104,66 & 86,55 \\
\hline Alytes obstetricans & 30TXK95 & 100,00 & 108,05 & 94,79 & 35,99 & 6058,85 & 254,35 & $-6,84$ & 261,19 & 124,64 & 36,56 & 189 & 36, & 518,90 & 67,10 & 27,16 & 28 & 169,40 & 93,58 & 116,73 & 93 \\
\hline Alytes obstetricans & 30 TXK96 & 100,00 & 87,55 & 95,38 & 35,88 & 6087,28 & 236,15 & $-27,25$ & 263,40 & 103,18 & 16,42 & 169,58 & 16,42 & 20,63 & 79,56 & 34,40 & 25,38 & 202,81 & 117,91 & 141,56 & 117,91 \\
\hline
\end{tabular}




\begin{tabular}{|c|c|c|c|c|c|c|c|c|c|c|c|c|c|c|c|c|c|c|c|c|c|}
\hline TAXON & UTM & $\mathrm{km2}$ & BIO1 & $\begin{array}{l}\mathrm{BIO2} \\
\end{array}$ & $\mathrm{BIO3}$ & B104 & B105 & B106 & B107 & B108 & B109 & BIO10 & BIO11 & B1012 & BIO13 & BIO14 & BIO15 & BIO16 & BIO17 & B1018 & BlO19 \\
\hline Alytes obstetricans & 30TХK97 & 100,00 & 76,32 & 95,25 & 35,61 & 6078,79 & 225,79 & $-38,10$ & 263,89 & 91,31 & 5,56 & 158,37 & 5,56 & 684,15 & 86,82 & 39,06 & 23,75 & 222,42 & 133,91 & 155,19 & 133,91 \\
\hline Alytes obstetricans & 30ТХК98 & 100,00 & 82,76 & 94,76 & 35,80 & 6063,78 & 230,25 & $-32,22$ & 262,47 & 98,75 & 11,65 & 164,31 & 11,65 & 634,63 & 82,64 & 35,73 & 25,51 & 209,67 & \begin{tabular}{l|l|}
120,22 \\
\end{tabular} & 148,25 & 120,22 \\
\hline Alytes obstetricans & 30TXK99 & 100,00 & 87,85 & 94,31 & 35,77 & 6050,55 & 233,66 & $-27,96$ & 261,61 & 104,72 & 16,28 & \begin{tabular}{|l|l|}
168,97 \\
\end{tabular} & 16,28 & 596,15 & 79,43 & 32,70 & 27,18 & $\begin{array}{l}199,91 \\
\end{array}$ & $\begin{array}{l}109,85 \\
\end{array}$ & 142,78 & 109,85 \\
\hline Alytes obstetricans & 30TXLO0 & 100,00 & 87,40 & 108,49 & 37,00 & 6279,95 & 249,65 & $-38,55$ & 288,19 & \begin{tabular}{ll|}
106,84 \\
\end{tabular} & 120,01 & $\begin{array}{l}171,49 \\
\end{array}$ & 11,81 & 564,10 & 77,31 & 31,40 & 26,81 & \begin{tabular}{|l|l|}
192,40 \\
\end{tabular} & \begin{tabular}{|l|l|}
115,47 \\
\end{tabular} & 130,72 & 116,72 \\
\hline Alytes obstetricans & 30TXL06 & 100,00 & 114,08 & 106,94 & 37,01 & 6214,52 & 270,16 & $-13,74$ & 283,90 & \begin{tabular}{ll|}
136,69 \\
\end{tabular} & 47,45 & \begin{tabular}{|l|l|}
195,19 \\
\end{tabular} & 36,60 & \begin{tabular}{l|l}
429,45 \\
\end{tabular} & 62,00 & 23,40 & 30,77 & 150,01 & \begin{tabular}{|l|l|}
84,97 \\
\end{tabular} & 100,88 & 88,75 \\
\hline Alytes obstetricans & 30TXL08 & 100,00 & 119,31 & 107,56 & 37,04 & 6208,37 & 276,96 & $-7,71$ & 284,68 & \begin{tabular}{|l|l|}
141,99 \\
\end{tabular} & \begin{tabular}{|l|l|}
146,18 \\
\end{tabular} & 200,12 & 41,69 & 421,86 & 60,06 & 22,40 & \begin{tabular}{l|l|l|}
29,85 \\
\end{tabular} & 144,91 & \begin{tabular}{l|l}
84,45 \\
\end{tabular} & 96,62 & 90,46 \\
\hline Alytes obstetricans & 30TXL09 & 100,00 & 104,34 & 107,92 & 37,44 & 6146,02 & 263,21 & $-21,23$ & 284,44 & 125,70 & \begin{tabular}{ll|}
180,56 \\
\end{tabular} & \begin{tabular}{|l|l|}
184,90 \\
\end{tabular} & 28,30 & 500,73 & 68,44 & 28,05 & 26,75 & $\begin{array}{ll}168,42 \\
\end{array}$ & 101,68 & 115,77 & 111,09 \\
\hline Alytes obstetricans & 30TXL11 & 100,00 & 91,93 & 105,71 & 37,00 & 6228,03 & 248,16 & $-34,27$ & 282,43 & \begin{tabular}{|l|l|}
112,37 \\
\end{tabular} & 15,75 & $\begin{array}{l}174,65 \\
\end{array}$ & 15,75 & 523,98 & 74,38 & 30,10 & 29,51 & \begin{tabular}{|l|l|}
184,00 \\
\end{tabular} & \begin{tabular}{|l|l}
102,93 \\
\end{tabular} & 127,41 & 102,93 \\
\hline Alytes obstetricans & 30TXL13 & 100,00 & 98,47 & 104,71 & 37,00 & 6186,85 & 251,01 & $-28,75$ & 279,77 & 120,31 & 31,71 & $\begin{array}{l}179,94 \\
\end{array}$ & 22,29 & 482,34 & 70,19 & 26,68 & 31,63 & \begin{tabular}{ll|}
172,32 \\
\end{tabular} & \begin{tabular}{|c|}
92,00 \\
\end{tabular} & 119,73 & 93,40 \\
\hline Alytes obstetricans & 30TXL14 & 100,00 & 99,84 & 104,72 & 37,00 & 6169,05 & 252,13 & $-27,52$ & 279,65 & 121,90 & 33,18 , & 180,88 & 23,67 & 477,12 & 69,48 & 26,47 & 31,68 , & 170,33 & 90,88 _ & 118,34 & 93,38 \\
\hline Alytes obstetricans & 30TXL17 & 100,00 & 121,68 & 105,77 & 37,00 & 6202,64 & 276,23 & $-5,73$ & \begin{tabular}{|l|l|}
281,96 \\
\end{tabular} & 144,75 & 55,25 & 202,24 & 43,94 & 401,23 & 58,88 & 21,34 & \begin{tabular}{|l|}
32,08 \\
\end{tabular} & \begin{tabular}{ll|l}
141,06 \\
\end{tabular} & 78,01 & 93,91 & 82,10 \\
\hline Alytes obstetricans & 30TXL18 & 100,00 & 120,30 & 106,30 & 37,00 & 6192,00 & 275,99 & $-6,49$ & \begin{tabular}{|l|l|}
282,48 \\
\end{tabular} & \begin{tabular}{|l|l|l|}
143,19 \\
\end{tabular} & 64,53 & 200,77 & 42,88 & \begin{tabular}{ll|l}
415,63 \\
\end{tabular} & \begin{tabular}{ll|l}
60,05 \\
\end{tabular} & 22,16 & 30,99 & \begin{tabular}{|l|l|}
144,16 \\
\end{tabular} & 82,69 & 96,31 & 87,34 \\
\hline Alytes obstetricans & 30TXL20 & 100,00 & 90,82 & 103,97 & 36,94 & 6227,62 & 245,18 & $-34,25$ & 279,44 & \begin{tabular}{|l|l|}
110,87 \\
\end{tabular} & \begin{tabular}{l|l|l|l|}
15,03 \\
\end{tabular} & \begin{tabular}{ll|}
173,66 \\
\end{tabular} & \begin{tabular}{l|l|l|l|}
15,03 \\
\end{tabular} & 527,99 & 75,08 & 29,67 & 30,20 & \begin{tabular}{l|l}
186,55 \\
\end{tabular} & 100,45 & 130,35 & 100,45 \\
\hline Alytes obstetricans & 30TXL21 & 100,00 & 97,52 & 102,87 & 36,87 & 6191,58 & 247,66 & $-28,73$ & \begin{tabular}{|l|}
276,39 \\
\end{tabular} & \begin{tabular}{l|l|}
119,02 \\
\end{tabular} & 26,43 & \begin{tabular}{ll|}
179,32 \\
\end{tabular} & 21,33 & 482,29 & 70,89 & 25,56 & 33,13 & \begin{tabular}{|l|l}
174,63 \\
\end{tabular} & \begin{tabular}{|l|l|}
88,47 \\
\end{tabular} & 122,35 & 88,61 \\
\hline Alytes obstetricans & 30TXL22 & 100,00 & 99,03 & 102,34 & 36,82 & 6166,32 & 247,45 & $-27,74$ & \begin{tabular}{|l|l|}
275,19 \\
\end{tabular} & 121,14 & 32,12 & 180,13 & 22,89 & \begin{tabular}{l|l}
470,05 \\
\end{tabular} & $69, \varepsilon$ & 24,30 & 33, & \begin{tabular}{|l|l|}
171,59 \\
\end{tabular} & $\begin{array}{l}84,86 \\
\end{array}$ & 120,63 & 85,96 \\
\hline Alytes obstetricans & 30TXL23 & 100,00 & 101,91 & 102,08 & 36,85 & 6139,68 & 248,97 & $-25,49$ & 274,47 & 124,33 & 35,14 & 182,20 & 25,52 & 455,18 & 68,36 & 23,12 & 34,76 & 167,11 & 80,94 & 117,21 & 83,37 \\
\hline Alytes obstetricans & $30 T \times L 24$ & 100,00 & 96,83 & 102,61 & 36,90 & 6129,49 & 245,92 & $-29,65$ & 275,58 & 118,51 & 30,43 & \begin{tabular}{|l|l|}
177,20 \\
\end{tabular} & 20,92 & 487,09 & 71,41 & 26,08 & 32,53 & \begin{tabular}{ll|}
175,48 \\
\end{tabular} & 90,18 & 123,84 & 92,75 \\
\hline Alytes obstetricans & 30TXL26 & 100,00 & 110,44 & 103,49 & 37,00 & 6142,37 & 260,58 & $-16,69$ & 277,27 & \begin{tabular}{ll|}
133,28 \\
\end{tabular} & 44,19 & $\begin{array}{l}190,35 \\
\end{array}$ & 33,72 & 432,69 & 64,38 & 23,15 & 33,33 & $\begin{array}{l}155,67 \\
\end{array}$ & 80,09 & 107,27 & 83,98 \\
\hline Alytes obstetricans & 30TXL28 & 100,00 & 115,43 & 104,94 & 37,00 & 6159,67 & 269,21 & $-10,72$ & \begin{tabular}{|l|l|}
279,93 \\
\end{tabular} & 138,01 & 53,04 & \begin{tabular}{|l|l|}
195,47 \\
\end{tabular} & 38,42 & 432,49 & 62,91 & 23,68 & 31,19 & \begin{tabular}{|l|l|}
151,27 \\
\end{tabular} & 84,84 & 102,32 & 89,23 \\
\hline Alytes obstetricans & 30TXL29 & 100,00 & 129,03 & 105,79 & 37,00 & 6199,42 & 284,79 & 2,71 & 282,08 & \begin{tabular}{l|l|}
152,03 \\
\end{tabular} & \begin{tabular}{ll|}
186,86 \\
\end{tabular} & 209,20 & 51,42 & 390,97 & 56,82 & 19,7 & 31, & 134,55 & \begin{tabular}{|l|l|}
76,47 \\
\end{tabular} & 87,68 & 83,30 \\
\hline Alytes obstetricans & $30 T X L 30$ & 100,00 & 102,60 & 100,66 & 36,42 & 6193,90 & 249,52 & $-22,81$ & 272,34 & 124,19 & 28,63 & 184,34 & 26,32 & \begin{tabular}{|l|l|}
452,95 \\
\end{tabular} & 67,82 & 22,46 & 35,47 & 166,78 & \begin{tabular}{l|l}
77,95 \\
\end{tabular} & \begin{tabular}{|l|l|}
117,45 \\
\end{tabular} & 77,98 \\
\hline Alytes obstetricans & 30TXL31 & 100,00 & 104,71 & 99,65 & 36,29 & 6145,01 & 248,19 & $-21,79$ & \begin{tabular}{|l|l|}
269,98 \\
\end{tabular} & \begin{tabular}{|l|l|}
127,27 \\
\end{tabular} & 37,75 & \begin{tabular}{ll|l}
185,23 \\
\end{tabular} & 28,40 & 435,22 & 66,48 & 20,53 & 37,38 & $\begin{array}{l}162,89 \\
\end{array}$ & 72,70 & 115,31 & 73,72 \\
\hline Alytes obstetricans & $30 T \times L 32$ & 100,00 & 102,32 & 99,48 & 36,27 & 6111,27 & 244,66 & $-24,75$ & 269,41 & \begin{tabular}{ll|l}
124,86 \\
\end{tabular} & 35,49 & 182,03 & 26,05 & 444,99 & 67,97 & 20,99 & 37,29 & \begin{tabular}{ll|l}
166,56 \\
\end{tabular} & 74,21 & $\begin{array}{ll}118,63 \\
\end{array}$ & 76,57 \\
\hline Alytes obstetricans & 30TXL33 & 100,00 & 100,56 & 99,81 & 36,35 & 6097,72 & 243,69 & $-26,50$ & 270,19 & \begin{tabular}{l|l|}
122,92 \\
\end{tabular} & 33,88 & \begin{tabular}{|l|l|}
180,03 \\
\end{tabular} & 24,34 & 455,56 & 69,13 & 21,99 & 36,32 & \begin{tabular}{|l|l|}
169,37 \\
\end{tabular} & \begin{tabular}{l|l}
77,45 \\
\end{tabular} & 120,71 & 80,36 \\
\hline Alytes obstetricans & 30TXL34 & 100,00 & 106,06 & 100,24 & 36,46 & 6100,01 & 249,72 & $-21,32$ & 271,04 & \begin{tabular}{l|l|}
128,83 \\
\end{tabular} & 39,46 & 185,23 & 29,41 & 435,01 & $\begin{array}{l}66,35 \\
\end{array}$ & \begin{tabular}{|l|l|}
21,07 \\
\end{tabular} & 36,42 & \begin{tabular}{|l|l|}
161,47 \\
\end{tabular} & \begin{tabular}{l|l}
74,15 \\
\end{tabular} & 113,91 & 77,61 \\
\hline Alytes obstetricans & $30 T \times L 35$ & 100,00 & 106,74 & 100,94 & 36,57 & 6099,30 & 252,09 & $-20,23$ & 272,32 & 129,56 & 40,47 & 185,94 & 30,32 & \begin{tabular}{|l|l|}
436,62 \\
\end{tabular} & 66,18 & 21,77 & 35,22 & 160,59 & 76,35 & 112,66 & 79,99 \\
\hline Alytes obstetricans & 30TXL39 & 100,00 & 136,03 & 105,08 & 37,00 & 6222,39 & 291,81 & $\begin{array}{l}9,97 \\
\end{array}$ & \begin{tabular}{|l|l|}
281,83 \\
\end{tabular} & \begin{tabular}{|l|l|}
159,19 \\
\end{tabular} & 209,55 & 216,24 & 57,93 & 367,27 & 54,08 & $\begin{array}{l}17,66 \\
\end{array}$ & 32,27 & \begin{tabular}{|l|l|}
126,19 \\
\end{tabular} & \begin{tabular}{|l|}
70,79 \\
\end{tabular} & 76,56 & 77,73 \\
\hline Alytes obstetricans & 30TXL40 & 100,00 & 98,19 & 99,03 & 36,00 & 6177,33 & 244,29 & $-25,42$ & 269,70 & \begin{tabular}{ll|l}
119,08 \\
\end{tabular} & 23,32 & \begin{tabular}{ll|}
179,94 \\
\end{tabular} & 22,66 & 477,14 & $\begin{array}{l}70,56 \\
\end{array}$ & 23,76 & 34,72 & \begin{tabular}{ll|}
174,42 \\
\end{tabular} & 81,71 & $\begin{array}{l}124,25 \\
\end{array}$ & 81,71 \\
\hline Alytes obstetricans & 30TXL41 & 100,00 & 97,45 & 98,44 & 36,00 & 6130,43 & 241,32 & $-27,00$ & 268,32 & \begin{tabular}{|l|l|}
118,89 \\
\end{tabular} & 27,51 & 178,22 & 21,91 & \begin{tabular}{|l|l|}
474,47 \\
\end{tabular} & 70,94 & 23,18 & \begin{tabular}{l|l}
35,55 \\
\end{tabular} & \begin{tabular}{|l|}
175,01 \\
\end{tabular} & 80,73 & 125,40 & 81,19 \\
\hline Alytes obstetricans & 30TXL42 & 100,00 & 103,06 & 97,26 & 36,00 & 6075,59 & 241,99 & $-23,24$ & 265,22 & 125,75 & 36,52 & 182,22 & 27,15 & 437,31 & \begin{tabular}{ll|l}
67,55 \\
\end{tabular} & 19,54 & 38,94 & \begin{tabular}{|l|l|}
165,59 \\
\end{tabular} & \begin{tabular}{|l|l|}
69,53 \\
\end{tabular} & 118,96 & 72,10 \\
\hline Alytes obstetricans & 30TXL43 & 100,00 & 103,52 & 97,70 & 36,03 & 6064,31 & 242,87 & $-22,97$ & 265,83 & 126,45 & 37,18 & \begin{tabular}{ll|}
182,36 \\
\end{tabular} & 27,64 & \begin{tabular}{|l|l|}
437,57 \\
\end{tabular} & 67,50 & \begin{tabular}{ll|}
19,82 \\
\end{tabular} & 38,29 & \begin{tabular}{|l|l|}
165,04 \\
\end{tabular} & 70,36 & 118,27 & 73,68 \\
\hline Alytes obstetricans & $30 \mathrm{TXL44}$ & 100,00 & 99,57 & 98,60 & 36,16 & 6063,16 & 241,76 & $-26,03$ & 267,80 & 121,83 & 33,31 & 178,59 & 23,97 & 462,21 & 69,90 & 22,22 & 35,83 & 171,22 & 78,36 & 122,62 & 81,31 \\
\hline Alytes obstetricans & 30TXL45 & 100,00 & 103,29 & 99,36 & 36,30 & 6071,57 & 246,90 & $-22,48$ & 269,38 & \begin{tabular}{l|l|}
125,80 \\
\end{tabular} & 37,30 & 182,32 & 27,53 & \begin{tabular}{ll|l}
450,06 \\
\end{tabular} & 68,11 & 22,12 & \begin{tabular}{|l|}
35,47 \\
\end{tabular} & $\begin{array}{ll}165,82 \\
\end{array}$ & 77,56 & \begin{tabular}{|l|l|}
117,56 \\
\end{tabular} & 80,82 \\
\hline Alytes obstetricans & 30TXL50 & 100,00 & 91,90 & 98,01 & 36,01 & 6162,41 & 238,94 & $-29,51$ & 268,45 & 111,65 & 17,40 & 173,98 & 17,40 & 515,99 & 74,51 & 26,49 & 32,53 & 185,27 & 89,94 & 132,90 & 89,94 \\
\hline Alytes obstetricans & 30TXL51 & 100,00 & 87,73 & 98,07 & 36,00 & 6124,77 & 234,65 & $-33,71$ & 268,35 & \begin{tabular}{|l|l|}
107,34 \\
\end{tabular} & 13,52 & 169,11 & 13,46 & 539,12 & 77,24 & 28,50 & 31,44 & 192,34 & $\begin{array}{l}96,55 \\
\end{array}$ & 138,61 & 96,55 \\
\hline Alytes obstetricans & 30TXL52 & 100,00 & 95,48 & 97,20 & 36,00 & 6089,01 & 238,10 & $-27,74$ & 265,83 & \begin{tabular}{ll|}
116,36 \\
\end{tabular} & 26,76 & 175,60 & 20,49 & 487,24 & 72,39 & 23,87 & 34,90 & 178,61 & \begin{tabular}{|l|l|}
83,15 \\
\end{tabular} & 128,89 & 83,55 \\
\hline Alytes obstetricans & $30 \mathrm{TXL53}$ & 100,00 & 93,34 & 97,36 & 36,00 & 6066,05 & 236,19 & $-29,89$ & 266,08 & 114,21 & 26,24 & 173,12 & 18,58 & 500,72 & 73,83 & 25,11 & 34,01 & 182,28 & 87,26 & 131,60 & 88,09 \\
\hline Alytes obstetricans & 30TXL54 & 100,00 & 90,49 & 97,91 & 36,00 & 6048,23 & 234,72 & $-32,40$ & 267,12 & \begin{tabular}{|l|l|}
111,02 \\
\end{tabular} & 24,29 & 169,99 & \begin{tabular}{ll|}
16,06 \\
\end{tabular} & 520,93 & 75,81 & 27,03 & 32,34 & \begin{tabular}{|l|l|}
187,29 \\
\end{tabular} & 93,71 & 135,29 & 94,70 \\
\hline Alytes obstetricans & 30TXL55 & 100,00 & 99,63 & 98,26 & 36,01 & 6049,87 & 242,98 & $-24,70$ & 267,68 & 121,47 & 33,74 & $\begin{array}{l}178,65 \\
\end{array}$ & 24,53 & 472,58 & 70,42 & 23,61 & 34,1 & 172,20 & 2,48 & 122,96 & 84,61 \\
\hline Alytes obstetricans & 30TXL60 & 100,00 & 94,83 & 96,48 & 36,00 & 6139,80 & 239,94 & $-25,42$ & 265,35 & 114,68 & 20,78 & 176,50 & 20,78 & 505,03 & 73,01 & 25,25 & 33,01 & 181,19 & 86,05 & 130,33 & 86,05 \\
\hline Alytes obstetricans & 30TXL61 & 100,00 & 90,23 & 96,60 & 35,99 & 6104,58 & 235,41 & $-30,41$ & \begin{tabular}{|l|l|}
265,82 \\
\end{tabular} & $\begin{array}{ll}109,78 \\
\end{array}$ & 16,47 & \begin{tabular}{|l|l|}
171,37 \\
\end{tabular} & \begin{tabular}{ll|l}
16,47 \\
\end{tabular} & 529,44 & $\begin{array}{l}75,96 \\
\end{array}$ & 27,37 & 31,93 & $\begin{array}{l}188,81 \\
\end{array}$ & 92,93 & 136,23 & 92,93 \\
\hline Alytes obstetricans & 30TXL62 & 100,00 & 93,88 & 96,39 & 36,00 & 6076,15 & 237,07 & $-27,70$ & 264,77 & 114,11 & 21,47 & 174,17 & 19,72 & 505,76 & 73,78 & 25,51 & 33,43 & 182,48 & 87,48 & \begin{tabular}{|l|l|}
131,67 \\
\end{tabular} & 87,48 \\
\hline Alytes obstetricans & 30TXL63 & 100,00 & 90,23 & 96,66 & 36,00 & 6052,86 & 234,09 & $-31,12$ & 265,21 & \begin{tabular}{ll|}
110,10 \\
\end{tabular} & \begin{tabular}{ll|}
19,00 \\
\end{tabular} & $\begin{array}{l}170,15 \\
\end{array}$ & \begin{tabular}{ll|}
16,26 \\
\end{tabular} & 527,51 & 76,18 & 27,39 & \begin{tabular}{|l|l|}
31,97 \\
\end{tabular} & \begin{tabular}{|l|l|}
188,53 \\
\end{tabular} & \begin{tabular}{l|l}
94,05 \\
\end{tabular} & 136,34 & 94,05 \\
\hline Alytes obstetricans & 30TXL64 & 100,00 & 97,19 & 96,94 & 36,00 & 6042,81 & 240,17 & $-25,19$ & 265,35 & \begin{tabular}{ll|}
118,09 \\
\end{tabular} & 31,02 & 176,54 & 22,75 & 489,91 & 72,06 & 24,70 & 33,49 & \begin{tabular}{|l|l|}
176,98 \\
\end{tabular} & 5,80 & 126,94 & 86,37 \\
\hline Alytes obstetricans & 30TXL65 & 100,00 & 107,50 & 97,78 & 36,00 & 6055,16 & 250,82 & $-16,10$ & 266,92 & 129,47 & 41,66 & 186,47 & 32,33 & \begin{tabular}{|l|l|}
441,42 \\
\end{tabular} & 66,32 & 21,81 & 34, & 160,91 & 75,92 & 113,19 & 77,19 \\
\hline Alytes obstetricans & 30TXL68 & 100,00 & 123,29 & 101,80 & 36,25 & 6140,66 & 274,94 & $-0,96$ & 275,90 & $145, \varepsilon$ & \begin{tabular}{l|l|}
57,65 \\
\end{tabular} & 203,00 & 46,6 & 396,42 & 58,78 & 21,01 & 32,39 & \begin{tabular}{|l|}
139,89 \\
\end{tabular} & 74,69 & 93,15 & 75,25 \\
\hline Alytes obstetricans & 30TXL70 & 100,00 & 91,62 & 95,82 & \begin{tabular}{l|l|}
35,95 \\
\end{tabular} & 6104,33 & 237,03 & $-26,92$ & 263,95 & \begin{tabular}{l|l|}
110,41 \\
\end{tabular} & \begin{tabular}{ll|}
18,39 \\
\end{tabular} & \begin{tabular}{|l|l|}
173,10 \\
\end{tabular} & 18,39 & 535,96 & 75,51 & 27,64 & \begin{tabular}{ll|}
30,93 \\
\end{tabular} & \begin{tabular}{ll|}
188,29 \\
\end{tabular} & 93,76 & 135,37 & 93,76 \\
\hline Alytes obstetricans & 30TXL71 & 100,00 & 88,97 & 95,70 & 35,92 & 6076,17 & 234,03 & $-29,79$ & 263,82 & 107,70 & 15,86 & 169,95 & 15,86 & 549,70 & 77,34 & 28,97 & 30,4 & $\begin{array}{l}192,75 \\
\end{array}$ & 97,80 & 139,05 & 97,80 \\
\hline Alytes obstetricans & 30TXL72 & 100,00 & 101,13 & 95,36 & 35,98 & 6059,70 & 243,06 & $-19,58$ & 262,65 & \begin{tabular}{|l|l|}
121,64 \\
\end{tabular} & 27,75 & 181,10 & 27,18 & 478,34 & 70,08 & 23,47 & 34,08 & \begin{tabular}{ll|}
172,16 \\
\end{tabular} & 80,84 & 123,14 & 80,84 \\
\hline Alytes obstetricans & $30 T X L 73$ & 100,00 & 年9,16 & 95,91 & 35,99 & 6045,63 & 241,52 & $-22,07$ & 263,58 & 119,70 & 27,72 & 178,85 & 25,26 & 487,42 & 71,25 & 24,47 & 33,50 & 174,96 & 83,98 & 125,23 & 83,98 \\
\hline Alytes obstetricans & $30 T X L 75$ & 100,00 & 114,92 & 97,98 & 36,00 & 6066,83 & 259,62 & $-8,03$ & 267,65 & 136,97 & \begin{tabular}{|l|l}
48,13 \\
\end{tabular} & \begin{tabular}{|l|l|}
194,08 \\
\end{tabular} & 39,80 & \begin{tabular}{|l|l|}
419,59 \\
\end{tabular} & 62,66 & 20,99 & 34,60 & \begin{tabular}{|l|}
151,11 \\
\end{tabular} & 72,50 & 104,34 & 72,64 \\
\hline Alytes obstetricans & 30TXL78 & 100,00 & 123,44 & 101,37 & 36,06 & 6119,33 & 275,03 & $-0,11$ & 275,14 & $\begin{array}{ll}145,86 \\
\end{array}$ & 52,43 & 203,01 & 47,20 & 399,68 & 58,42 & 21,03 & 31,61 & 139,80 & 74,66 & 93,08 & 74,68 \\
\hline Alytes obstetricans & 30TXL79 & 100,00 & 127,20 & 102,48 & 36,18 & 6146,71 & 281,60 & 3,56 & 278,04 & \begin{tabular}{|l|l|}
149,99 \\
\end{tabular} & \begin{tabular}{|l|l|}
54,67 \\
\end{tabular} & 207,17 & \begin{tabular}{|l|l|}
50,63 \\
\end{tabular} & 391,98 & 56,4 & 20,06 & 30,5 & $\begin{array}{ll}135,25 \\
\end{array}$ & 75,40 & 88,81 & 75,40 \\
\hline Alytes obstetricans & 30TXL80 & 100,00 & 92,12 & 94,9 & 35,88 & 6074 & & $-25,42$ & 262 & 110 & 19, & 173 & 19, & 548,33 & 75,97 & 28,7 & 29, & 189,62 & 97,12 & 135,95 & 97,12 \\
\hline Alytes obstetricans & 30TXL81 & 100,00 & 90,67 & 94,95 & 35,90 & 6049,47 & 235,18 & $-27,06$ & 262,24 & \begin{tabular}{|l|}
109,03 \\
\end{tabular} & 18,25 & 171,36 & 18,25 & 555,37 & 77,05 & 29,46 & 29,80 & \begin{tabular}{ll|}
191,96 \\
\end{tabular} & $\begin{array}{l}99,52 \\
\end{array}$ & 138,05 & 99,52 \\
\hline Alytes obstetricans & $30 T \times L 82$ & 100,00 & 105,61 & 95,06 & 36,00 & 6036,24 & 247,85 & $-14,08$ & 261,93 & \begin{tabular}{ll|}
125,84 \\
\end{tabular} & 32,08 & \begin{tabular}{|l|l|}
185,38 \\
\end{tabular} & 32,08 & \begin{tabular}{|l|l|}
471,49 \\
\end{tabular} & 68,23 & 23,19 & 33,44 & 167,17 & 79,96 & 118,27 & 79,96 \\
\hline Alytes obstetricans & 30TXL84 & 100,00 & 115,72 & 96,93 & 36,00 & 6040,90 & 259,44 & $-6,17$ & \begin{tabular}{|l|l|}
265,62 \\
\end{tabular} & 137,23 & 43,16 & \begin{tabular}{|l|l|}
194,89 \\
\end{tabular} & 41,48 & 427,11 & 62,83 & 21,12 & 34,23 & $\begin{array}{ll}151,85 \\
\end{array}$ & 72,94 & 104,76 & 72,94 \\
\hline Alytes o & $30 \mathrm{TX}$ & 100,00 & & & 36,00 & 6051,52 & 25 & $-5,50$ & 267, & 138 & 43,75 & 195 & 42,05 & \begin{tabular}{l|l}
424,05 \\
\end{tabular} & 62, & & 33 & 150 & 73,66 & 102,92 & \\
\hline Alytes obstetricans & $30 T \times L 86$ & 100,00 & 126,49 & 99,79 & 36,01 & 6088,22 & 275,16 & 2,99 & 272,17 & 148,82 & 52,40 & 205,93 & 51,04 & 391,26 & 57,25 & 20,01 & 33,19 & 137,14 & $\begin{array}{ll}69,25 \\
\end{array}$ & 91,28 & 69,25 \\
\hline Alytes obstetricans & 30TXL87 & 100,00 & 132,95 & 101,34 & 36,00 & 6120,77 & 284,55 & $\begin{array}{l}8,68 \\
\end{array}$ & $275,87 \mid$ & 155,74 & 56,94 & 212,68 & 56,86 & 373,65 & 53,97 & 18,64 & 32,14 & 129,19 & 67,90 & 84,27 & 67,90 \\
\hline
\end{tabular}




\begin{tabular}{|c|c|c|c|c|c|c|c|c|c|c|c|c|c|c|c|c|c|c|c|c|c|}
\hline TAXON & UTM & $\mathrm{km2}$ & B101 & $\mathrm{B1O2}$ & $\mathrm{BIO3}$ & B104 & B105 & B106 & B107 & B108 & B109 & 81010 & B1011 & BIO12 & B1013 & 81014 & B1015 & B1O16 & B1017 & BIO18 & B1019 \\
\hline Alytes obstetricans & 30TXL89 & 100,00 & 136,03 & 103,14 & 36,15 & 6159,41 & 291,93 & 11,69 & 280,24 & 159,19 & 59,18 & 216,21 & 59,18 & 370,19 & 51,84 & 18,06 & 29,77 & 125,34 & 70,01 & 80,77 & 70,01 \\
\hline Alytes obstetricans & 30TXL90 & 100,00 & 93,26 & 94,10 & 35,88 & 6037,54 & 237,51 & $-23,38$ & 260,88 & 110,95 & 21,41 & 173,85 & 21,41 & 560,38 & 76,22 & 29,78 & 28,83 & 190,28 & 100,83 & 135,84 & 100,83 \\
\hline Alytes obstetricans & 30TXL91 & 100,00 & 92,79 & 94,06 & 35,91 & 6024,18 & 236,62 & $-24,29$ & 260,91 & 110,82 & 20,82 & 173,14 & 20,82 & 558,18 & 76,49 & 29,75 & 29,18 & 190,50 & 100,44 & 136,29 & 100,44 \\
\hline Alytes obstetricans & 30TXL92 & 100,00 & 108,34 & 94,90 & 35,97 & 6013,94 & 250,88 & $-10,67$ & 261,55 & 128,18 & 35,46 & 187,89 & 35,46 & 475,73 & 67,67 & 23,81 & 32,43 & 165,47 & 81,84 & 115,82 & 81,84 \\
\hline Alytes obstetricans & 30TXL94 & 100,00 & 121,76 & 97,31 & 36,00 & 6022,52 & 266,54 & 0,07 & 266,46 & 143,10 & 48,05 & 200,89 & 48,05 & 420,08 & 60,59 & 21,03 & 33,48 & 146,01 & 72,48 & 98,88 & 72,48 \\
\hline Alytes obstetricans & 30TXL95 & 100,00 & 119,29 & 97,91 & 36,00 & 6025,98 & 265,34 & $-2,58$ & 267,92 & 140,63 & 45,32 & 198,40 & 45,32 & 428,44 & 61,70 & 21,84 & 32,63 & 148,84 & 75,02 & 101,15 & 75,02 \\
\hline Alytes obstetricans & 30TXL96 & 100,00 & 134,56 & 100,49 & 36,02 & 6076,06 & 284,31 & 10,75 & 273,56 & 157,00 & 59,40 & 213,91 & 59,40 & 377,88 & 53,95 & 18,37 & 32,59 & 129,18 & 67,32 & 84,10 & 67,32 \\
\hline Alytes obstetricans & 30TXM01 & 100,00 & 95,38 & 108,00 & 37,85 & 6071,08 & 255,01 & $-28,10$ & 283,11 & 115,35 & 174,92 & 175,13 & 20,77 & 577,34 & 74,88 & 32,82 & 23,46 & 187,54 & \begin{tabular}{|l|l|}
116,08 \\
\end{tabular} & 129,63 & 134,59 \\
\hline Alytes obstetricans & 30TXM02 & 100,00 & 100,94 & 108,08 & 37,93 & \begin{tabular}{|l|l|}
6066,93 \\
\end{tabular} & 260,75 & $-22,31$ & 283,06 & 121,12 & 180,29 & 180,39 & 26,02 & 566,20 & 72,63 & 31,53 & 23,29 & 181,91 & 112,00 & 124,01 & 134,25 \\
\hline Alytes obstetricans & 30TXM03 & 100,00 & 119,16 & 108,53 & 37,97 & 6123,89 & 278,95 & $-5,19$ & 284,14 & 140,97 & 198,70 & 198,78 & 42,79 & 490,67 & 63,53 & 25,64 & 24,61 & 157,00 & 93,63 & 102,45 & 117,71 \\
\hline Alytes obstetricans & 30TXM04 & 100,00 & 128,32 & 108,00 & 37,95 & 6113,23 & 286,81 & 4,12 & 282,69 & 150,56 & 207,32 & 207,38 & 51,53 & 475,79 & 60,21 & 23,86 & 24,52 & 149,16 & 88,55 & 94,31 & 116,81 \\
\hline Alytes obstetricans & 30TXM05 & 100,00 & 133,34 & 107,29 & 37,99 & 6057,35 & 290,14 & 10,14 & 279,99 & 155,39 & 211,64 & 211,64 & 57,25 & 485,86 & 59,23 & 23,80 & 23,70 & 148,22 & 89,40 & 92,39 & 122,30 \\
\hline Alytes obstetricans & 30TXM06 & 100,00 & 134,37 & $\begin{array}{ll}106,67 \\
\end{array}$ & 37,99 & 6021,66 & 289,83 & 12,23 & 277,60 & 155,06 & 212,27 & 212,27 & 58,71 & 513,80 & 60,26 & 25,03 & 22,90 & 152,93 & 93,81 & 95,71 & 132,79 \\
\hline Alytes obstetricans & 30TXM07 & 100,00 & 136,85 & 105,91 & 38,00 & 5960,25 & 290,10 & 15,45 & 274,65 & 102,64 & 213,73 & 213,73 & 61,61 & 545,48 & 61,27 & 26,12 & 22,41 & 161,47 & 98,66 & 98,93 & 144,92 \\
\hline Alytes obstetricans & 30TXM08 & 100,00 & 134,51 & 105,33 & 38,00 & 5906,84 & 286,66 & 14,23 & 272,43 & 98,32 & 210,73 & 210,73 & 60,05 & 595,02 & 66,05 & 28,54 & 22,00 & 178,07 & 106,76 & 106,98 & 162,32 \\
\hline Alytes obstetricans & 30TXM09 & 100,00 & 131,31 & 105,03 & 38,08 & 5861,17 & 282,84 & 12,12 & 270,72 & 94,86 & 207,03 & 207,03 & 57,59 & 657,07 & 74,70 & 31,62 & 21,99 & 198,86 & 116,63 & 116,63 & 184,39 \\
\hline Alytes obstetricans & 30TXM12 & 100,00 & 117,64 & 107,61 & 37,63 & 6132,64 & 276,22 & $-6,61$ & 282,83 & 139,49 & 197,34 & 197,41 & 41,34 & 477,46 & 63,91 & 25,09 & 26,04 & 156,16 & 92,14 & 101,36 & 111,16 \\
\hline Alytes obstetricans & 30TXM13 & 100,00 & 121,44 & 107,69 & 37,73 & 6119,63 & 279,95 & $-2,63$ & 282,58 & 143,28 & 200,77 & 200,86 & 44,90 & 481,73 & 63,05 & 24,77 & 25,32 & 154,56 & 91,31 & 100,01 & 115,08 \\
\hline Alytes obstetricans & 30TXM14 & 100,00 & 132,42 & 107,17 & 37,69 & 6099,90 & 289,75 & 8,56 & 281,19 & 154,72 & 211,33 & 211,37 & 55,81 & 466,15 & 59,06 & 22,67 & 24,96 & 145,23 & 85,77 & 88,68 & 114,99 \\
\hline Alytes obstetricans & 30TXM15 & 100,00 & 137,34 & 106,54 & 37,96 & 6040,20 & 292,78 & 14,55 & 278,22 & 159,61 & 215,33 & 215,33 & 61,35 & 480,36 & 58,18 & 22,85 & 24,02 & 145,01 & 87,32 & 89,54 & 122,01 \\
\hline Alytes obstetricans & 30TXM16 & 100,00 & 136,42 & 106,17 & 38,00 & 6012,49 & 291,15 & 14,39 & 276,76 & 134,60 & 213,97 & 213,97 & 60,58 & 516,44 & 60,18 & 24,55 & 23,20 & 152,87 & 93,38 & 95,00 & 134,77 \\
\hline Alytes obstetricans & 30TXM18 & 100,00 & 130,54 & 105,84 & 38,00 & 5931,66 & 283,74 & $\begin{array}{l}9,80 \\
9,8 \\
\end{array}$ & 273,94 & 94,21 & 207,13 & 207,13 & 55,90 & 618,58 & 69,70 & 29,63 & 22,02 & 185,17 & $\begin{array}{r}110,02 \\
\end{array}$ & 110,09 & 170,60 \\
\hline Alytes obstetricans & 30TXM19 & 100,00 & 130,52 & 105,12 & 38,01 & 5871,83 & 282,08 & 10,50 & 271,58 & 94,28 & 206,24 & 206,24 & 56,29 & 673,35 & 77,95 & 31,95 & 22,21 & 205,12 & 118,55 & 118,55 & 191,28 \\
\hline Alytes obstetricans & 30TXM23 & 100,00 & 133,82 & 106,67 & 37,25 & 6133,99 & 291,05 & 9,61 & 281,44 & 156,30 & 213,06 & 213,06 & 56,85 & 437,57 & 57,78 & 20,95 & 26,66 & 139,33 & 80,58 & 82,35 & 104,92 \\
\hline Alytes obstetricans & 30TXM24 & 100,00 & 138,28 & 106,28 & 37,48 & 6087,83 & 294,44 & 15,01 & 279,43 & 160,78 & 216,96 & 216,96 & 61,71 & 449,59 & 56,90 & 21,03 & 25,46 & 138,72 & 81,65 & 82,90 & 111,29 \\
\hline Alytes obstetricans & 30TXM25 & 100,00 & 135,71 & 106,21 & 37,74 & 6045,86 & 291,28 & 12,96 & 278,32 & 157,97 & 213,74 & 213,74 & 59,53 & 487,17 & 59,36 & 23,02 & 24,15 & 147,02 & 88,34 & 90,45 & 123,83 \\
\hline Alytes obstetricans & $30 \mathrm{TXM} 27$ & 100,00 & 133,69 & 105,99 & 38,00 & 5966,34 & 287,39 & 12,47 & 274,92 & 年, & 210,66 & 210,66 & 58,58 & 564,81 & $\begin{array}{l}53,52 \\
63\end{array}$ & 26,71 & 22,52 & \begin{tabular}{|l|l|}
167,48 \\
\end{tabular} & $\mid$\begin{tabular}{|c|}
101,29 \\
\end{tabular} & 102,42 & 151,60 \\
\hline Alytes obstetricans & 30TXM34 & 100,00 & 139,01 & 106,00 & 37,13 & 6091,52 & 295,14 & 16,02 & 279,12 & 161,30 & 217,59 & 217,59 & 62,35 & 445,40 & 56,66 & 20,54 & 25,57 & 137,27 & 80,77 & 82,81 & 109,71 \\
\hline Alytes obstetricans & 30TXM41 & 100,00 & 138,05 & 105,43 & 37,00 & 6186,51 & 295,37 & 13,80 & 281,57 & 160,80 & 218,13 & 218,13 & 60,69 & 379,92 & 54,90 & 17,58 & 31,18 & 126,83 & 69,95 & 70,45 & 84,77 \\
\hline Alytes obstetricans & 30TXM48 & 100,00 & 120,32 & 104,88 & 38,03 & 5861,92 & 272,18 & 0,66 & 271,51 & 84,90 & 196,10 & 196,10 & 46,53 & 641,09 & 70,74 & 31,44 & 20,65 & 187,44 & 117,89 & 119,70 & 171,65 \\
\hline Alytes obstetricans & 30TXM49 & 100,00 & 111,52 & 104,06 & 38,12 & 5778,43 & 261,90 & $-6,27$ & 268,17 & 76,92 & 186,52 & 186,52 & 39,16 & 720,40 & 78,95 & 36,34 & 19,71 & 210,17 & 133,69 & 136,21 & 195,68 \\
\hline Alytes obstetricans & 30TXM50 & 100,00 & 127,07 & 103,95 & 36,12 & 6172,05 & 282,81 & $\begin{array}{l}-2,29 \\
2,99 \\
\end{array}$ & \begin{tabular}{|l|}
279,82 \\
\end{tabular} & \begin{tabular}{|l|}
149,81 \\
\end{tabular} & \begin{tabular}{|l|l|}
172,08 \\
\end{tabular} & \begin{tabular}{|l|}
207,02 \\
\end{tabular} & 50,14 & 398,22 & $\begin{array}{l}58,16 \\
58,1\end{array}$ & 20,01 & 30,77 & \begin{tabular}{|l|}
136,78 \\
\end{tabular} & \begin{tabular}{|l|}
78,05 \\
78
\end{tabular} & 88,28 & 82,88 \\
\hline Alytes obstetricans & 30TXM51 & 100,00 & 139,49 & 105,15 & 37,00 & 6207,42 & 297,79 & 16,05 & 281,74 & 162,24 & 220,04 & 220,05 & 62,15 & 370,43 & 54,14 & 16,79 & 31,68 & 124,02 & 67,68 & 68,56 & 81,76 \\
\hline Alytes obstetricans & 30TXM52 & 100,00 & 143,09 & 105,50 & 37,00 & 6185,55 & 301,45 & 19,96 & 281,49 & 165,82 & 223,27 & 223,27 & 65,90 & 376,27 & 52,77 & 16,77 & 29,73 & 122,47 & 68,11 & 69,04 & 85,61 \\
\hline Alytes obstetricans & 30TXM53 & 100,00 & 132,01 & 105,19 & 37,00 & 6110,04 & 289,16 & 9,31 & 279,85 & 154,31 & 211,09 & 211,12 & 55,67 & 426,69 & 57,63 & 20,29 & 26,89 & 137,25 & 79,52 & 81,85 & 98,06 \\
\hline Alytes obstetricans & 30TXM56 & 100,00 & 131,77 & 105,01 & 37,91 & 5949,14 & 285,46 & 10,50 & 274,96 & 153,61 & 208,60 & 208,63 & 57,17 & 509,43 & 60,64 & 24,06 & 22,18 & 151,01 & 94,66 & 98,75 & 127,41 \\
\hline Alytes obstetricans & 30TXM57 & 100,00 & 124,80 & 104,84 & 38,00 & 5881,56 & 277,18 & 4,57 & 272,62 & 137,31 & 200,75 & 200,76 & 50,84 & 569,34 & 65,41 & 27,60 & 20,89 & 165,63 & \begin{tabular}{|l|}
106,48 \\
\end{tabular} & 109,27 & 145,84 \\
\hline Alytes obstetricans & 30TXM58 & 100,00 & 113,90 & 103,95 & 38,00 & 5797,35 & 264,50 & $-4,35$ & 268,85 & 116,61 & 188,90 & 188,90 & 41,18 & 649,11 & 72,57 & 32,71 & 19,63 & 186,95 & 122,80 & 126,16 & 168,81 \\
\hline Alytes obstetricans & 30TXM59 & 100,00 & 103,55 & 102,68 & 38,04 & 5708,48 & 252,07 & $-12,97$ & 265,04 & 93,71 & 177,73 & 177,74 & 32,32 & 734,06 & 79,99 & 38,29 & 18,39 & 209,68 & 140,80 & 144,08 & 193,00 \\
\hline Alytes obstetricans & 30TXM67 & 100,00 & 118,97 & 103,90 & 38,00 & 5817,41 & 270,15 & 0,01 & 270,13 & 139,65 & 194,19 & 194,25 & 46,15 & 572,81 & 66,77 & 28,48 & 20,11 & 168,26 & 110,30 & 114,96 & 141,91 \\
\hline Alytes obstetricans & 30TXM68 & 100,00 & 109,32 & 102,91 & 38,01 & 5729,41 & 258,29 & $-7,86$ & 266,14 & 129,00 & 183,44 & 183,52 & 37,62 & 649,78 & 73,60 & 33, & 18,82 & 188,19 & 126,30 & 131,44 & 164,01 \\
\hline $\begin{array}{l}\text { Ay } \\
\text { Alytes obstetricans }\end{array}$ & $\begin{array}{l}300 \mathrm{TM} 69 \\
309\end{array}$ & 100,00 & $\begin{array}{l}90,32 \\
96,15\end{array}$ & 101,10 & $\frac{3,011}{38,05}$ & \begin{tabular}{|l|}
$3 / 2,41$ \\
5631,87
\end{tabular} & 242,63 & \begin{tabular}{|c|c|}
$-1,000$ \\
$-18,79$
\end{tabular} & \begin{tabular}{|l|}
260,1442 \\
261
\end{tabular} & $\begin{array}{l}113,00 \\
113\end{array}$ & \begin{tabular}{|l|}
$163,44,56$ \\
169
\end{tabular} & \begin{tabular}{|l|}
163,52 \\
169,58
\end{tabular} & $\begin{array}{l}1,026 \\
26,19 \\
\end{array}$ & \begin{tabular}{|l|}
753,18 \\
753,18
\end{tabular} & $83, \mathrm{C}$ & $\begin{array}{l}30,50 \\
40,55\end{array}$ & $\begin{array}{l}10,02 \\
17,42\end{array}$ & \begin{tabular}{|l|}
215,76 \\
215,7
\end{tabular} & \begin{tabular}{|l|l|}
148,84 \\
140
\end{tabular} & 151,44 & $\begin{array}{l}104,01 \\
192,26\end{array}$ \\
\hline Alytes obstetricans & 30TXM70 & 100,00 & 139,91 & 104,45 & 36,05 & 6233,91 & 299,11 & 15,36 & 283,75 & 163,46 & 148,13 & 220,96 & 62,00 & 362,75 & 50,22 & 17,38 & 28,79 & 122,03 & 71,01 & 77,63 & 71,93 \\
\hline Alytes obstetricans & 30TXM71 & 100,00 & 146,76 & 105,24 & 36,17 & 6257,39 & 307,56 & 21,90 & 285,66 & 170,51 & 227,09 & 227,87 & 68,17 & 356,92 & 46,94 & 16,56 & 26,97 & 116,55 & 69,08 & 73,65 & 72,93 \\
\hline Alytes obstetricans & 30TXM77 & 100,00 & 114,39 & 102,89 & 38,00 & 5741,08 & 263,99 & $-3,34$ & 267,33 & 134,57 & 188,62 & 188,75 & 42,53 & 574,25 & 67,66 & 29,05 & 19,62 & 59,91 & 113,86 & 118,68 & 137,66 \\
\hline Alytes obstetricans & 30TXM78 & 100,00 & 105,11 & 101,80 & 38,00 & 5660,68 & 252,52 & \begin{tabular}{|c|c|}
$-11,02$ \\
$-11,0$
\end{tabular} & 263,54 & 124,45 & \begin{tabular}{|l|l|}
178,48 \\
178,4
\end{tabular} & 17 & $\begin{array}{l}42,35 \\
34,44 \\
\end{array}$ & 651,86 & 74,57 & 34,13 & 18,21 & \begin{tabular}{|l|l|}
189,92 \\
\end{tabular} & $\begin{array}{l}130,24 \\
130\end{array}$ & 135,19 & 159,73 \\
\hline Alytes obstetricans & 30TXM79 & 100,00 & 94 & 100,14 & 38,01 & 5578,12 & 239,18 & $-20,06$ & 259,24 & 112,36 & 166,83 & 166,86 & 24,87 & 748,31 & 83,2 & 40, & 16,95 & 215,23 & 151,02 & 156,15 & 186,56 \\
\hline Alytes obstetricans & $30 \mathrm{TXM} 80$ & 100,00 & 145,28 & 104,63 & 36,21 & 6190,31 & 303,61 & 20,15 & 283,46 & 168,93 & $\begin{array}{l}79,03 \\
\end{array}$ & 225,67 & 67,72 & 355,22 & 47,42 & 16,52 & 28,16 & 116,99 & 69,07 & 74,27 & 69,08 \\
\hline Alytes obstetricans & 30TXM81 & 100,00 & 144,28 & 104,85 & 36,36 & 6169,93 & 303,16 & 19,72 & 283,44 & 167,74 & 140,13 & 224,41 & 66,73 & 363,76 & 47,59 & 16,95 & 26,93 & 118,23 & 71,85 & 75,41 & 72,28 \\
\hline Alytes obstetricans & 30TXM89 & 100,00 & 102,23 & 100,74 & 38,23 & 5560,33 & 246,57 & $-12,78$ & 259,35 & 120,78 & 174,27 & & 32,76 & 687,58 & 76,95 & 36,54 & 17,18 & 197,48 & 140,41 & 144,25 & 167,70 \\
\hline Alytes obstetricans & $30 \mathrm{TX}$ & 100,00 & $\frac{14}{14}$ & 104,34 & $\begin{array}{l}30, \\
36,\end{array}$ & | & 302,47 & $\begin{array}{l}-21,05 \\
21,05\end{array}$ & \begin{tabular}{|l|}
281,42 \\
\end{tabular} & 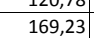 & $\begin{array}{l}\mid 4 /, 21 \\
69,32 \\
\end{array}$ & 225 & $\begin{array}{ll}69,32 \\
69,\end{array}$ & $\mid$ & $\mid \begin{array}{l}\mid 0,353 \\
47,36\end{array}$ & \begin{tabular}{|c|}
16,340 \\
16,40
\end{tabular} & $\begin{array}{ll}28,40 \\
28\end{array}$ & \begin{tabular}{|l|}
116,04 \\
11,04
\end{tabular} & $\begin{array}{l}\frac{14,444}{68,17} \\
\end{array}$ & $\begin{array}{r}43,25 \\
73,87\end{array}$ & \begin{tabular}{|l|}
68,17 \\
6
\end{tabular} \\
\hline Alytes obstetricans & 30TXM92 & 100,00 & 129,35 & 103,44 & 36,99 & 5994,92 & 284,30 & 6,92 & 277,38 & 151,60 & 54,36 & 207,39 & 54,36 & 404,14 & 53,86 & 19,69 & 26,35 & 131,16 & 79,34 & 86,07 & 79,34 \\
\hline Alytes obstetricans & 30TXN01 & 100,00 & 122,08 & 104,38 & 38,45 & 5749,16 & 272,88 & 5,07 & 267,82 & 58,33 & 196,59 & 196,59 & 49,94 & 823,10 & 98,48 & 39,67 & 22,73 & 259,36 & 142,68 & 142,68 & 244,35 \\
\hline Alytes obstetricans & 30 TXNO2 & 100,00 & 118,55 & 103,34 & 38,71 & 5664,61 & 267,93 & 3,58 & 264,35 & 56,29 & 192,16 & 192,16 & 47,55 & 908,59 & 110,43 & 43,78 & 23,08 & 291,15 & 156,75 & 156,75 & 274,93 \\
\hline Alytes obstetricans & 30TXN03 & 100,00 & 117,28 & 101,84 & $38, \varepsilon$ & 5563,04 & 264,31 & 4,46 & 259,85 & 56,19 & $18 \mathrm{~s}$ & 185 & 47,87 & 987,76 & 121,64 & 47,40 & 23,51 & 321,10 & 170,42 & 170,42 & 303 \\
\hline Alytes obstetricans & \begin{tabular}{|l|}
30 TXNO4 \\
\end{tabular} & 100,00 & $\begin{array}{l}111,20 \\
120,11\end{array}$ & $\begin{array}{r}01,04 \\
99,69\end{array}$ & $\begin{array}{l}0,01 \\
38,96 \\
\end{array}$ & 5424,70 & 263,16 & $\begin{array}{l}4,40 \\
9,95 \\
\end{array}$ & \begin{tabular}{|l|}
253,21 \\
25,2
\end{tabular} & $\begin{array}{l}0,57 \\
60,57 \\
\end{array}$ & \begin{tabular}{|l|}
190,76 \\
190,1
\end{tabular} & \begin{tabular}{|l|}
190,76 \\
190,7
\end{tabular} & $\begin{array}{l}41,10 \\
52,43\end{array}$ & | & \begin{tabular}{|l|}
130,95 \\
130,
\end{tabular} & $\begin{array}{l}41,40,27 \\
50,\end{array}$ & 23,53 & \begin{tabular}{|l|l|}
346,91 \\
34
\end{tabular} & \begin{tabular}{|l|l|}
182,97 \\
\end{tabular} & 182,97 & $\begin{array}{l}30,30 \\
327,25\end{array}$ \\
\hline Alytes obstetricans & 30TXN05 & 100,00 & 110,26 & 97,76 & 39,07 & 5256,90 & 249,72 & 3,59 & 246,12 & 53,32 & \begin{tabular}{|c|c|}
179,04 \\
\end{tabular} & \begin{tabular}{|c|c|}
179,04 \\
\end{tabular} & 45,21 & 1130,85 & $\mid 136,25$ & 56,18 & 21,96 & 365,42 & 203,32 & 203,32 & 344,20 \\
\hline Alytes obstetricans & 30TXN06 & 100,00 & 106,18 & 95,55 & 39,43 & 5116,10 & 241,79 & 2,54 & 239,25 & 50,97 & 173,27 & 173,27 & 43,10 & 1195,82 & 142,30 & 60,52 & 21,15 & 384,30 & 219,61 & 219,61 & 361,55 \\
\hline Alytes obstetricans & 30TXN07 & 100,00 & 120,29 & 91,28 & 39,95 & 346,52 & 246,87 & 20,70 & 226,18 & 68,22 & 181,79 & 183 & 60, & \begin{tabular}{|l|l|}
1249,93 \\
\end{tabular} & 149,77 & 62,11 & 21,78 & 406 & 230,56 & 234,53 & 379,90 \\
\hline Alytes obstetricans & 30TXN08 & 100,00 & 127,35 & 87,62 & 40,13 & 4626,20 & 246,63 & 31,30 & 215,33 & 79,84 & 185,25 & 187,69 & 69,99 & 1304,00 & 156,08 & 64,90 & 21,99 & 425,17 & 241,37 & 251,01 & 395 , \\
\hline
\end{tabular}




\begin{tabular}{|c|c|c|c|c|c|c|c|c|c|c|c|c|c|c|c|c|c|c|c|c|c|}
\hline TAXON & UTM & $\mathrm{km} 2$ & BIO1 & BIO2 & $B 103$ & BIO4 & B105 & B106 & B107 & B108 & B109 & B1010 & BIO11 & BIO12 & BIO13 & B1014 & BIO15 & B1016 & B1017 & B1018 & 81019 \\
\hline Alytes obstetricans & 30TXN09 & 67,00 & 131,10 & 84,45 & 40,21 & 4476,51 & 244,47 & 37,44 & 207,04 & 90,90 & 186,80 & 189,40 & 75,49 & 1344,08 & 160,62 & 67,51 & 22,10 & 438,57 & 250,79 & 265,82 & 405,86 \\
\hline Alytes obstetricans & 30TXN10 & 100,00 & 123,99 & 105,02 & 38,19 & 5829,79 & 275,63 & 5,13 & 270,50 & 65,01 & 199,39 & 199,39 & 50,54 & 757,65 & 89,75 & 36,32 & 22,51 & 234,27 & 132,08 & 132,08 & 221,01 \\
\hline Alytes obstetricans & 30TXN11 & 100,00 & 112,57 & $\begin{array}{l}104,39 \\
\end{array}$ & 38,63 & 5739,69 & 263,64 & $-3,90$ & 267,55 & 49,56 & $\begin{array}{l}187,27 \\
\end{array}$ & \begin{tabular}{|l|}
187,27 \\
\end{tabular} & 40,99 & 859,66 & 101,79 & 42,53 & 21,75 & 267,27 & 151,36 & 151,36 & 252,99 \\
\hline Alytes obstetricans & 30TXN12 & 100,00 & 104,16 & $\begin{array}{l}102,64 \\
\end{array}$ & 38,87 & 5612,40 & 252,62 & $-9,53$ & 262,15 & 43,29 & 177,51 & 177,51 & 34,44 & 941,64 & 110,28 & 47,85 & 20,74 & 291,98 & 169,21 & 169,21 & 276,37 \\
\hline Alytes obstetricans & 30TXN13 & 100,00 & 118,26 & 102,80 & 38,63 & 5631,79 & 266,64 & 3,42 & 263,22 & 56,39 & 191,36 & 191,36 & 47,70 & 996,28 & 125,80 & 47,05 & 24,63 & 327,85 & 169,48 & 169,48 & 310,93 \\
\hline Alytes obstetricans & 30TXN14 & 100,00 & 114,75 & 100,62 & 38,90 & 5484,35 & 259,12 & 3,13 & 255,99 & 54,69 & 186,16 & 186,16 & 46,05 & 1064,60 & 132,53 & 51,37 & 23,62 & 348,62 & 185,86 & 185,86 & 329,79 \\
\hline Alytes obstetricans & 30TXN15 & 100,00 & 107,71 & 98,34 & 39,02 & 5316,13 & 247,88 & $-0,46$ & 248,34 & 50,04 & 177,17 & 177,17 & 41,58 & 1130,84 & 136,92 & 56,58 & 21,81 & 364,65 & 204,42 & 204,42 & 344,08 \\
\hline Alytes obstetricans & 30TXN16 & 100,00 & $\begin{array}{ll}94,84 \\
\end{array}$ & 95,87 & 39,18 & 5175,51 & 231,62 & $-9,67$ & 241,29 & 39,67 & 162,94 & 162,95 & 31,27 & \begin{tabular}{|l|}
1194,21 \\
\end{tabular} & $\begin{array}{l}139,45 \\
\end{array}$ & 62,56 & 19,60 & 376,12 & 224,05 & 224,05 & 354,54 \\
\hline Alytes obstetricans & 30TXN17 & 100,00 & 121,06 & 92,23 & 39,79 & $\begin{array}{lll}4938,64 \\
\end{array}$ & 248,44 & 18,70 & 229,73 & 67,68 & 183,71 & 185,35 & 59,33 & 1233,22 & \begin{tabular}{l|l|}
149,93 \\
\end{tabular} & $\begin{array}{l}61,36 \\
\end{array}$ & 22,18 & 402,18 & 228,79 & 233,11 & 376,19 \\
\hline Alytes obstetricans & 30TXN18 & 100,00 & $\begin{array}{ll}117,03 \\
\end{array}$ & 90,82 & \begin{tabular}{|l|l}
39,96 \\
\end{tabular} & \begin{tabular}{ll|l}
4835,37 \\
\end{tabular} & 241,98 & 16,72 & 225,26 & 65,70 & 178,11 & 180,21 & 56,93 & \begin{tabular}{|l|l|}
1297,17 \\
\end{tabular} & 156,49 & 65,53 & 21,61 & 421,85 & 243,14 & 248,53 & 394,30 \\
\hline Alytes obstetricans & 30TXN19 & 26,00 & 129,97 & 85,70 & 39,96 & 4614,73 & 244,82 & 32,49 & 212,33 & 96,22 & 187,60 & 189,94 & 71,90 & $\begin{array}{l}1314,87 \\
\end{array}$ & \begin{tabular}{|l|l|}
159,18 \\
\end{tabular} & 66,88 & 22,29 & 431,17 & 249,34 & 264,29 & 396,94 \\
\hline Alytes obstetricans & 30TXN21 & 100,00 & 110,77 & 103,97 & 38,69 & 5720,06 & 260,75 & $-5,38$ & 266,14 & 48,12 & 185,19 & \begin{tabular}{|l|}
185,19 \\
\end{tabular} & 39,23 & 858,42 & \begin{tabular}{|l|l|}
100,73 \\
\end{tabular} & 42,72 & 21,16 & 264,27 & $\begin{array}{l}153,29 \\
\end{array}$ & $\begin{array}{l}153,29 \\
\end{array}$ & 250,21 \\
\hline Alytes obstetricans & 30TXN22 & 100,00 & 103,37 & 102,39 & 38,82 & 5608,17 & 251,24 & $-10,44$ & 261,68 & 42,50 & 176,68 & 176,68 & 33,57 & 936,79 & 109,38 & 47,68 & 20,38 & 288,82 & 169,79 & 169,79 & 273,40 \\
\hline Alytes obstetricans & 30TXN23 & 100,00 & 111,31 & 102,05 & 38,93 & 5571,81 & 257,65 & $-2,50$ & 260,15 & 50,36 & 183,84 & 183,84 & 41,60 & $\begin{array}{l}988,25 \\
\end{array}$ & 120,37 & 48,46 & 22,30 & 315,84 & 175,14 & \begin{tabular}{|l|l|}
175,14 \\
\end{tabular} & 299,01 \\
\hline Alytes obstetricans & 30TXN24 & 100,00 & 105,82 & 100,25 & \begin{tabular}{|l|l|}
38,97 \\
\end{tabular} & 5446,53 & 249,11 & $-5,28$ & 254,39 & 46,76 & 176,99 & \begin{tabular}{ll|}
176,99 \\
\end{tabular} & 37,91 & $\begin{array}{l}1056,73 \\
\end{array}$ & \begin{tabular}{|l|l|}
127,07 \\
\end{tabular} & 53,08 & 21,29 & 336,13 & 191,33 & 191,33 & 317,75 \\
\hline Alytes obstetricans & 30TXN25 & 100,00 & 100,82 & 98,30 & 39,01 & 5322,00 & 240,78 & $-7,48$ & 248,25 & 43,32 & 170,44 & \begin{tabular}{ll|}
170,44 \\
\end{tabular} & 34,87 & $\begin{array}{ll}1122,83 \\
\end{array}$ & \begin{tabular}{|l|}
133,32 \\
\end{tabular} & 57,64 & 20,37 & 355,39 & 207,64 & 207,64 & 335,49 \\
\hline Alytes obstetricans & 30 TXN26 & 89,00 & 93,17 & 96,25 & 39,11 & 5206,27 & 230,03 & $-12,54$ & 242,57 & 37,57 & 161,61 & \begin{tabular}{ll|}
161,63 \\
\end{tabular} & 28,95 & 1181,31 & $\begin{array}{l}137,49 \\
\end{array}$ & 62,37 & 19,12 & $\begin{array}{ll}369,64 \\
\end{array}$ & 223,78 & \begin{tabular}{|l|l|}
223,78 \\
\end{tabular} & 348,52 \\
\hline Alytes obstetricans & 30TXN27 & 72,00 & 109,27 & 94,73 & 39,63 & 5078,57 & 241,06 & 4,33 & 236,72 & 54,34 & 174,58 & 175,53 & \begin{tabular}{|l|l|}
45,96 \\
\end{tabular} & 1221,24 & $\mid 147,16$ & 62,18 & 21,02 & 393,30 & 230,13 & 231,38 & 369,47 \\
\hline Alytes obstetricans & 30TXN28 & 100,00 & 112,90 & 92,41 & 39,88 & 4942,30 & 239,95 & 9,99 & 229,95 & 59,69 & \begin{tabular}{ll|}
175,67 \\
\end{tabular} & 177,35 & 51,08 & $\begin{array}{l}1269,48 \\
\end{array}$ & \begin{tabular}{|l|l|}
153,18 \\
\end{tabular} & 64,76 & 21,08 & 410,29 & 240,76 & 245,22 & 384,35 \\
\hline Alytes obstetricans & 30TXN29 & 28,00 & 124,35 & 88,39 & 39,99 & 4757,15 & 243,02 & 23,58 & 219,44 & 85,54 & 184,21 & 186,09 & 64,29 & \begin{tabular}{|l|l|}
1294,07 \\
\end{tabular} & 157,29 & 66,15 & 21,94 & 422,26 & 247,30 & 260,13 & 391,01 \\
\hline Alytes obstetricans & 30TXN32 & 100,00 & 113,49 & 102,85 & 38,92 & 5636,46 & 260,48 & $-2,03$ & 262,51 & 51,78 & 186,71 & \begin{tabular}{|l|}
186,71 \\
\end{tabular} & 42,65 & 896,38 & \begin{tabular}{|l|l|}
106,61 \\
\end{tabular} & 44,13 & 21,28 & 279,60 & 161,46 & 161,46 & 264,25 \\
\hline Alytes obstetricans & 30TXN34 & 100,00 & 102,45 & 99,88 & 39,00 & 5425,73 & 244,40 & $-8,52$ & 252,92 & 43,64 & 173,20 & 173,20 & 34,78 & 1043,23 & \begin{tabular}{|l|l|}
122,97 \\
\end{tabular} & 53,41 & 20,09 & $\begin{array}{l}326,28 \\
\end{array}$ & $\begin{array}{l}193,20 \\
\end{array}$ & $\begin{array}{l}193,20 \\
\end{array}$ & 308,08 \\
\hline Alytes obstetricans & 30TXN35 & 100,00 & 91,78 & 97,76 & 38,99 & 5311,18 & 231,03 & $-16,31$ & 247,34 & 35,01 & 161,50 & 161,50 & 26,25 & $\begin{array}{l}1113,44 \\
\end{array}$ & 128,04 & 59,14 & 18,53 & 343,19 & 211,70 & 211,70 & 323,82 \\
\hline Alytes obstetricans & 30TXN36 & 81,00 & 90,19 & 96,37 & 39,05 & 5227,71 & 226,97 & $-16,30$ & 243,27 & 34,44 & 158,80 & 158,81 & 25,69 & 1166,10 & 134,19 & 62,39 & 18,37 & 360,71 & 223,80 & 223,80 & 340,07 \\
\hline Alytes obstetricans & 30TXN37 & & & & & & & & & & & & & & & & & & & & \\
\hline Alytes obstetricans & 30TXN38 & 10,00 & 120,55 & 92,86 & \begin{tabular}{|l|l|}
39,97 \\
\end{tabular} & 4970,73 & 245,95 & 15,35 & 230,60 & 73,98 & 183,47 & 184,90 & 57,65 & 1211,15 & 147,21 & 61,21 & 21,39 & 391,34 & 230,73 & 239,12 & 366,19 \\
\hline Alytes obstetricans & 30TXN39 & & & & & & & & & & & & & & & & & & & & \\
\hline Alytes obstetricans & $30 \mathrm{TXN} 40$ & 100,00 & 108,21 & 103,44 & 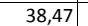 & 5707,76 & 256,78 & $-8,56$ & 265,34 & $\mid 71,64$ & 182,34 & 182,34 & 36,77 & 781,12 & 86,62 & 39,74 & 19,31 & 229,63 & $\mid 145,28$ & \begin{tabular}{|l|l|}
146,48 \\
\end{tabular} & 215,80 \\
\hline Alytes obstetricans & 30TXN41 & 100,00 & 119,31 & 103,47 & 38,94 & 5672,28 & 266,17 & 1,97 & 264,20 & 81,03 & 192,59 & 192,59 & 47,78 & $\begin{array}{l}796,64 \\
\end{array}$ & 92,31 & 38,74 & 20,62 & 243,00 & 145,39 & 445,78 & 228,46 \\
\hline Alytes obstetricans & 30 TXN44 & 100,00 & 88,07 & 98,23 & \begin{tabular}{|l|l|}
38,93 \\
\end{tabular} & 5375,46 & 228,34 & $-21,44$ & 249,78 & 30,71 & 158,55 & 158,55 & 21,58 & 1053,74 & 117,87 & 56,95 & 17,45 & 316,51 & 203,15 & 203,15 & 298,49 \\
\hline Alytes obstetricans & 30TXN45 & 100,00 & 85,92 & $\begin{array}{ll}97,14 \\
\end{array}$ & \begin{tabular}{|l|l|}
38,97 \\
\end{tabular} & 5304,76 & 224,21 & $-21,97$ & 246,18 & 29,51 & 155,51 & 155,51 & 20,47 & $\begin{array}{l}1105,56 \\
\end{array}$ & \begin{tabular}{|l|l|}
123,97 \\
\end{tabular} & 60,19 & 17,23 & 333,86 & 214,72 & 214,72 & 314,68 \\
\hline Alytes obstetricans & 30TXN46 & 75,00 & 86,27 & 96,27 & 39,05 & 5234,26 & 222,50 & $-20,60$ & 243,10 & 30,64 & 154,88 & 154,91 & 21,63 & 1150,02 & 129,98 & 62,58 & 17,33 & 350,31 & 224,32 & 224,35 & 329,99 \\
\hline Alytes obstetricans & 30TXN50 & 100,00 & 104,72 & 102,40 & 38,53 & 5650,83 & 251,56 & $-11,08$ & 262,63 & 76,05 & 178,11 & 178,11 & 34,09 & 777,70 & 84,18 & 40,27 & 18,30 & 225,41 & 148,41 & 150,99 & 209,58 \\
\hline Alytes obstetricans & 30TXN51 & 100,00 & 108,88 & 102,45 & 38,88 & 5601,82 & 254,21 & $\begin{array}{l}-6,87 \\
\end{array}$ & 261,08 & 73,79 & 181,44 & 181,44 & 38,63 & 810,39 & 89,62 & 41,22 & 18,58 & 239,75 & 153,41 & 154,05 & 224,22 \\
\hline Alytes obstetricans & 30 TXN53 & 100,00 & 99,49 & 100,32 & 38,99 & 5455,79 & 241,25 & $-12,97$ & 254,22 & 40,27 & 170,50 & 170,50 & 31,29 & \begin{tabular}{|l|l|}
945,43 \\
\end{tabular} & \begin{tabular}{|l|l|}
105,78 \\
\end{tabular} & 49,59 & 17,88 & 282,90 & 181,64 & 181,64 & 266,11 \\
\hline Alytes obstetricans & 30TXN54 & 100,00 & 91,52 & $\begin{array}{ll}98,72 \\
\end{array}$ & 38,99 & $\begin{array}{l}5372,49 \\
\end{array}$ & 231,15 & $-18,93$ & 250,08 & 33,87 & 161,74 & \begin{tabular}{ll|}
161,74 \\
\end{tabular} & 24,79 & 1018,51 & 113,14 & 54,83 & 17,13 & \begin{tabular}{|l|l|}
304,08 \\
\end{tabular} & $\begin{array}{l}198,37 \\
\end{array}$ & $\begin{array}{l}198,37 \\
\end{array}$ & 286,13 \\
\hline Alytes obstetricans & 30TXN55 & 100,00 & 83,60 & 96,82 & \begin{tabular}{l|l|l|}
38,95 \\
\end{tabular} & 5296,25 & 221,06 & $-24,57$ & 245,62 & 27,39 & 153,08 & 153,08 & 18,14 & 1091,06 & 120,27 & 60,17 & 16,46 & 324,97 & 215,11 & 215,11 & 305,78 \\
\hline Alytes obstetricans & 30 XN56 & 37,00 & 79,52 & 95,46 & 38,96 & 5231,69 & 215,01 & $-27,01$ & 242,02 & 24,21 & 148,19 & 148,19 & 14,99 & 1149,13 & 126,64 & 64,19 & 16,15 & 343,11 & 228,41 & 228,41 & 322,84 \\
\hline Alytes obstetricans & 30TXN60 & 100,00 & 96,16 & 100,88 & 38,2 & 5581,02 & 241,26 & $-18,22$ & 259,48 & 85,60 & 168,81 & 168,82 & 26,77 & 795,91 & 85,27 & 2,70 & 17,05 & 26,86 & 56,68 & 86 & 207,69 \\
\hline Alytes obstetricans & 30 TXN61 & 100,00 & 103,46 & 101,43 & 38,79 & 5547,82 & 247,30 & $-11,17$ & 258,47 & 72,57 & 175,39 & 175,41 & 34,01 & 809,72 & 86,63 & 42,30 & 17,41 & 234,79 & 157,77 & 159,76 & 217,41 \\
\hline Alytes obstetricans & 30TXN62 & 100,00 & 102,55 & 100,90 & 38,94 & 5489,47 & 244,74 & $-11,35$ & 256,10 & 66,79 & 173,81 & \begin{tabular}{ll|}
173,82 \\
\end{tabular} & 33,73 & $\begin{array}{l}857,75 \\
\end{array}$ & 92,71 & \begin{tabular}{ll|}
44,94 \\
\end{tabular} & 17,23 & 250,88 & 167,34 & $\begin{array}{ll}168,63 \\
\end{array}$ & 233,86 \\
\hline Alytes obstetricans & 30TXN63 & 100,00 & 94,94 & 99,57 & \begin{tabular}{l|l}
38,95 \\
\end{tabular} & 5416,45 & 235,38 & $-17,14$ & 252,52 & 42,68 & 165,40 & 165,40 & 27,29 & 934,84 & 101,29 & 50,20 & 16,66 & 273,25 & 183,96 & 184,22 & 256,22 \\
\hline Alytes obstetricans & 30TXN64 & 100,00 & 83,53 & 97,27 & 38,80 & 5341,30 & 221,56 & $-25,87$ & 247,43 & 26,82 & 153,35 & 153,35 & 17,30 & 1027,09 & 110,20 & 57,12 & 15,75 & 298,96 & 204,99 & 205,07 & 280,60 \\
\hline Alytes obstetricans & 30TXN65 & 92,00 & 75, & 95,36 & 38,7 & 5277,87 & 211,78 & $-31,52$ & 30 & 20,16 & 145,08 & 145,08 & 10,64 & 1101,25 & 117,80 & 2,58 & 15,22 & 20,67 & 221,68 & 221,68 & 301,24 \\
\hline Alytes obstetricans & 30 XNN66 & 6,00 & 87,25 & 96,60 & 39, & 5232,89 & 221,79 & $-20,99$ & 24 & 31,36 & 155,43 & 155,50 & 22,10 & 1101,02 & 121,46 & 60,74 & 16,26 & 328,58 & 220,57 & 220,71 & 308,65 \\
\hline Alytes obstetricans & $30 T \times N 7$ & 100,00 & 93,34 & 99,94 & 38,19 & 5532,25 & 236,91 & $-20,37$ & 257,28 & 102,67 & 165,38 & 165,39 & 24,60 & 791,18 & 85,56 & 43,09 & 16,42 & 224,03 & 159,32 & 163,03 & 201,26 \\
\hline Alytes obstetricans & 30TXN72 & 100,00 & 99,76 & 100,32 & 38,92 & 5452,55 & 240,74 & $-13,67$ & 254,42 & 68,84 & $\begin{array}{l}170,46 \\
\end{array}$ & 170,51 & 31,48 & $\begin{array}{l}845,69 \\
\end{array}$ & 88,74 & 45,10 & 16,26 & 243,56 & 168,79 & $\begin{array}{l}170,71 \\
\end{array}$ & 224,78 \\
\hline Alytes obstetricans & 30TXN73 & 100,00 & 85,05 & 97,78 & 38,79 & 5374,32 & 223,78 & $-25,52$ & 249,30 & 41,20 & 155,22 & 155,22 & 18,37 & 957,36 & 99,77 & 53,41 & 15,22 & 272,27 & 193,53 & 94,56 & 254,34 \\
\hline Alytes obstetricans & 30 TXN74 & 100,00 & 67,09 & 93,69 & 38,16 & 5304,14 & 202,82 & $-39,59$ & 242,41 & 15,92 & 136,99 & 136,99 & 2,03 & 1089,61 & 112,52 & 63,81 & 14,30 & 307,78 & 223,36 & 223,49 & 288,38 \\
\hline Alytes obstetricans & $30 T \mathrm{TN}$ & 83,00 & 65 & 93,03 & 38,28 & 5259 & 199,91 & $-40,09$ & 240,00 & 10,91 & 134,93 & 134,93 & 1,10 & 1131,74 & 117,47 & 66,48 & 14,20 & 322,24 & 232,28 & 232,28 & 302,19 \\
\hline Alytes obstetricans & 30TXN80 & 100,00 & 95,74 & 99,77 & 38,26 & 5501,36 & 238,35 & \begin{tabular}{|l|l|}
$-18,12$ \\
\end{tabular} & 256,46 & \begin{tabular}{|l|}
111,46 \\
\end{tabular} & 167,05 & \begin{tabular}{|l|}
167,16 \\
\end{tabular} & 27,15 & 759,75 & $\begin{array}{l}82,89 \\
\end{array}$ & 41,34 & 16,27 & 215,49 & 155,52 & 160,27 & 188,89 \\
\hline Alytes obstetricans & 30TXN82 & 100,00 & 89,62 & 98,52 & 38,72 & 5404,83 & 229,01 & $-22,31$ & 251,32 & 68,85 & 159,91 & 159,98 & 22,28 & 875,33 & 91,00 & 48,59 & 15,18 & 246,25 & 79,37 & 82,28 & 225,52 \\
\hline Alytes obstetricans & 30TXN83 & 100,00 & 75,68 & 95,40 & 38,34 & 5342,54 & 212,55 & $-33,13$ & 45,68 & 55,34 & 145, & 145,72 & 9,74 & \begin{tabular}{l|l}
993,85 \\
\end{tabular} & \begin{tabular}{ll|}
102,26 \\
\end{tabular} & 44 & 14,39 & 278,46 & 205,26 & 206,54 & 25 \\
\hline Alytes obstetricans & $30 T X$ & 100,00 & 50,41 & 89,26 & 37, & & $\begin{array}{ll}183,66 \\
\end{array}$ & $-53,41$ & 23 & 35,53 & 120,55 & 12 & $-13,35$ & 1171,25 & $\begin{array}{l}119,66 \\
\end{array}$ & 11 & 13,39 & 325,22 & 244,61 & 244,93 & 302,94 \\
\hline Alytes obstetricans & 30TXN85 & 53,00 & 42,17 & 86,92 & 36,71 & 5231,16 & $\begin{array}{l}173,46 \\
\end{array}$ & $-60,17$ & 233,62 & 9,99 & 112,02 & 112,02 & $-20,73$ & \begin{tabular}{|l|}
1248,27 \\
\end{tabular} & 126,53 & 77,25 & 13,13 & 346,39 & 261,15 & 261,15 & 324,94 \\
\hline Alytes obstetricans & 30TXN90 & 100,00 & $\begin{array}{ll}93,84 \\
\end{array}$ & $\begin{array}{ll}99,07 \\
\end{array}$ & $\begin{array}{l}38,37 \\
\end{array}$ & 5463,30 & 235,24 & $-19,39$ & 254,62 & 1111,83 & $\begin{array}{l}164,67 \\
\end{array}$ & $\begin{array}{l}164,93 \\
\end{array}$ & 25,66 & 755,96 & 83,18 & 41,68 & 15,97 & 215,56 & $\begin{array}{ll}158,02 \\
\end{array}$ & 162,15 & 183,27 \\
\hline Alytes obstetricans & 30TXN91 & 100,00 & 94,57 & 99,19 & 38,74 & 5424,62 & 234,78 & $-18,37$ & 253,15 & 100,32 & 164,88 & 165,09 & 26,64 & $\begin{array}{l}790,45 \\
\end{array}$ & 84,67 & 43,56 & 15,38 & 222,04 & 164,76 & 169,02 & 195,90 \\
\hline $\begin{array}{ll}\text { Alytes o } \\
\end{array}$ & $30 \mathrm{TXI}$ & 100,00 & 80 & 96 & 38, & 376,12 & & $\mid-29,57$ & & 91 & y & 150 & & $911,97 \mid$ & 95,94 & 5 & 39 & & 190,97 & 194,87 & 22 \\
\hline Alytes obstetricans & $30 \mathrm{TXNS}$ & 100,00 & 48,20 & 88,18 & \begin{tabular}{|c|}
36,68 \\
\end{tabular} & 5295,76 & 181,29 & $-55,86$ & 237,16 & 58,64 & \begin{tabular}{|l|}
118,67 \\
\end{tabular} & \begin{tabular}{|l|}
118,67 \\
\end{tabular} & $-15,74$ & \begin{tabular}{|l|}
1150,99 \\
\end{tabular} & \begin{tabular}{|l|l|}
119,68 \\
\end{tabular} & 71,05 & 13,38 & 322,05 & 242,88 & 243,18 & 291,27 \\
\hline Alytes obstetricans & 30TXN94 & 50,00 & 49,03 & 88,31 & 36,92 & 5266,55 & 181,26 & $-54,64$ & 235,91 & 53,19 & $\begin{array}{l}119,07 \\
\end{array}$ & $\begin{array}{l}119,07 \\
\end{array}$ & $-14,66$ & 1173,98 & 120,41 & 72,41 & 13,14 & 326,20 & 247,68 & 248,08 & 300,06 \\
\hline
\end{tabular}




\begin{tabular}{|c|c|c|c|c|c|c|c|c|c|c|c|c|c|c|c|c|c|c|c|c|c|}
\hline TAXON & UTM & $\mathrm{km} 2$ & B101 & B102 & $\mathrm{BIO3}$ & B104 & B105 & B106 & B107 & B108 & B109 & BIO10 & BIO11 & BIO12 & B1013 & BIO14 & BIO15 & B1016 & B1017 & BIO18 & B1019 \\
\hline Alytes obstetricans & 30ТYК03 & 100,00 & 121,97 & 93,96 & 36,01 & 5896,13 & 264,49 & 7,97 & 256,52 & 131,42 & 70,05 & 201,18 & 52,27 & 500,34 & 61,01 & 23,30 & 28,63 & 161,39 & 94,81 & 108,03 & 95,10 \\
\hline Alytes obstetricans & 30TYK04 & 100,00 & 123,28 & 93,37 & 36,00 & 5899,78 & 264,98 & 9,00 & 255,98 & 132,69 & 57,10 & 202,31 & 53,42 & 485,57 & 60,07 & 22,98 & 29,46 & 156,54 & 90,19 & 105,87 & 90,23 \\
\hline Alytes obstetricans & 30TYK05 & 100,00 & 100,61 & 94,21 & 35,98 & 6014,84 & 246,59 & $-13,39$ & 259,98 & 116,11 & 30,21 & 181,51 & 30,21 & 575,43 & 72,34 & 30,21 & 26,24 & 183,80 & 108,59 & 126,76 & 108,59 \\
\hline Alytes obstetricans & 30TYK06 & 100,00 & 82,51 & 94,53 & 35,76 & 6042,75 & 230,55 & $-31,23$ & 261,78 & 97,21 & 12,21 & 164,17 & 12,21 & 668,16 & 83,47 & 36,83 & 23,72 & 213,93 & 130,97 & 147,32 & 130,97 \\
\hline Alytes obstetricans & 30TYK07 & 100,00 & 68,33 & 94,32 & 35,40 & 6042,30 & 217,98 & $-44,36$ & 262,34 & 82,14 & $-1,25$ & 150,22 & $-1,25$ & 753,29 & 92,79 & 42,78 & 21,72 & 239,41 & 152,74 & 163,50 & 152,74 \\
\hline Alytes obstetricans & 30TYK08 & 100,00 & 75,69 & 93,84 & 35,46 & 6025,71 & 223,34 & $-37,81$ & 261,16 & 90,59 & 5,51 & 156,97 & 5,51 & 697,84 & 87,99 & 39,66 & 23,44 & 224,99 & 137,49 & 155,86 & 137,49 \\
\hline Alytes obstetricans & 30TYK09 & 100,00 & 86,99 & 93,51 & 35,51 & 6011,49 & 232,11 & $-27,88$ & 259,99 & 103,30 & 16,13 & 167,61 & 16,13 & 620,20 & 80,92 & 34,51 & 26,07 & 204,10 & 116,77 & 143,94 & 116,77 \\
\hline Alytes obstetricans & \begin{tabular}{|l|} 
30TYK13 \\
\end{tabular} & 100,00 & 133,52 & 91,90 & 36,12 & 5720,51 & 270,72 & 20,66 & 250,06 & 141,93 & 190,10 & 210,40 & 65,70 & 480,60 & 60,84 & 20,39 & 30,59 & 163,49 & 89,91 & 102,94 & 94,05 \\
\hline Alytes obstetricans & 30TYK14 & 100,00 & 123,12 & 92,46 & 36,00 & 5828,78 & 263,21 & 9,57 & 253,64 & 131,23 & 74,62 & 201,51 & 54,37 & 506,39 & 61,50 & 23,19 & 28,91 & 164,30 & 96,57 & 110,36 & 96,83 \\
\hline Alytes obstetricans & 30TYK15 & 100,00 & 107,86 & 92,99 & 35,94 & 5930,00 & 251,03 & $-5,59$ & 256,62 & 121,00 & 39,34 & 187,61 & 38,37 & 561,84 & 69,31 & 27,93 & 26,82 & 177,01 & 107,34 & 122,82 & 107,34 \\
\hline Alytes obstetricans & 30TYK16 & 100,00 & 89,12 & 93,38 & 35,75 & 5989,60 & 234,93 & $-23,77$ & 258,70 & 103,82 & 19,38 & 169,94 & 19,38 & 647,59 & 80,16 & 34,49 & 24,11 & 204,66 & 126,70 & 141,65 & 126,70 \\
\hline Alytes obstetricans & 30TYK17 & 100,00 & 79,80 & 93,19 & 35,45 & 5998,27 & 226,32 & $-32,95$ & 259,27 & 94,19 & 10,12 & 160,93 & 10,12 & 696,13 & 86,12 & 38,19 & 23,01 & 220,55 & 138,31 & 152,19 & 138,31 \\
\hline Alytes obstetricans & 30TYK18 & 100,00 & 82,81 & 92,92 & 35,28 & 5984,08 & 228,21 & $-30,54$ & 258,75 & 97,72 & 12,92 & 163,42 & 12,92 & 670,47 & 84,31 & 37,02 & 23,94 & 214,57 & \begin{tabular}{|l|}
131,01 \\
\end{tabular} & 148,71 & 131,01 \\
\hline Alytes obstetricans & 30TYK19 & 100,00 & 84,04 & 92,84 & 35,36 & 5973,25 & 228,81 & $-29,69$ & 258,50 & 99,50 & 14,15 & 164,42 & 14,15 & 658,21 & 83,72 & 36,58 & 24,62 & 212,06 & 127,53 & 148,67 & 127,53 \\
\hline Alytes obstetricans & 30TYK23 & 100,00 & 144,56 & 89,52 & 36,22 & 5531,22 & 276,12 & 33,26 & 242,86 & 153,56 & 217,08 & 218,90 & 78,57 & 466,90 & 64,05 & 17,85 & 33,37 & 167,93 & 80,47 & 98,66 & 94,84 \\
\hline Alytes obstetricans & 30TYK24 & 100,00 & 128,92 & 91,07 & 36,01 & 5715,12 & 265,81 & 16,21 & 249,60 & 137,03 & 174,89 & 205,76 & 61,53 & 508,72 & 62,90 & 21,82 & 29,73 & 170,49 & 96,40 & 109,53 & 100,30 \\
\hline Alytes obstetricans & 30TYK25 & 100,00 & 107,68 & 92,12 & 35,88 & 5869,38 & 249,48 & $-5,07$ & 254,55 & 118,68 & 48,43 & 186,86 & 39,12 & 584,87 & 70,64 & 28,20 & 26,23 & 183,42 & 114,63 & 126,74 & 114,80 \\
\hline Alytes obstetricans & 30TYK26 & 100,00 & 100,24 & 92,26 & 35,75 & 5912,12 & 243,11 & $-12,43$ & 255,55 & 114,83 & 31,38 & 179,99 & 31,38 & 609,25 & 74,69 & 30,53 & 25,43 & 189,27 & 118,88 & 132,87 & 118,88 \\
\hline Alytes obstetricans & 30TYK27 & 100,00 & 94,48 & 92,16 & 35,46 & 5924,91 & 237,75 & $-18,30$ & 256,05 & 108,97 & 25,47 & 174,32 & 25,47 & 632,28 & 78,20 & 32,69 & 24,78 & 198,42 & 123,46 & 138,70 & 123,46 \\
\hline Alytes obstetricans & 30TYK28 & 100,00 & 91,93 & 92,03 & 35,40 & 5929,76 & 235,15 & $-21,11$ & 256,26 & 107,05 & 22,75 & 171,87 & 22,75 & 639,74 & 79,87 & 33,69 & 24,73 & 202,01 & 124,61 & $\begin{array}{ll}141,07 \\
\end{array}$ & 124,61 \\
\hline Alytes obstetricans & 30TYK29 & 100,00 & 106,46 & 92,37 & 35,61 & 5904,93 & 247,78 & $-7,97$ & 255,75 & 123,05 & 37,10 & 185,51 & 37,10 & 561,23 & 72,01 & 28,34 & 27,61 & 178,99 & 105,47 & 124,78 & 105,47 \\
\hline Alytes obstetricans & $\begin{array}{l}\text { 30TYK33 } \\
\end{array}$ & 100,00 & 157,83 & 86,51 & 36,28 & 5315,71 & 282,90 & 48,26 & 234,65 & 167,63 & 226,74 & 229,22 & 93,87 & 445,78 & 66,24 & 15,17 & 37,56 & 170,38 & 69,38 & 93,29 & 93,96 \\
\hline Alytes obstetricans & 30TYK34 & 100,00 & 142,37 & 88,91 & 36,01 & 5524,07 & 273,70 & 30,99 & 242,71 & 150,77 & 214,97 & 216,80 & 76,91 & 486,08 & 65,09 & 18,55 & 32,92 & $\mid 173,11$ & 84,74 & 103,44 & 99,05 \\
\hline Alytes obstetricans & 30TYK35 & 100,00 & 130,75 & 90,27 & 35,99 & 5665,03 & 265,95 & 18,15 & 247,80 & 138,52 & 179,23 & 206,97 & 64,04 & 516,23 & 64,66 & 21,47 & 30,31 & 174,27 & 96,55 & 111,27 & 102,75 \\
\hline Alytes obstetricans & 30TYK36 & 100,00 & 120,48 & 90,97 & 35,82 & 5759,56 & 258,38 & 7,41 & 250,97 & 128,45 & 105,86 & 197,99 & 52,83 & 546,76 & 66,65 & 24,28 & 28,53 & 176,65 & 105,75 & 118,76 & 107,49 \\
\hline Alytes obstetricans & 30TYK37 & 100,00 & 114,97 & 91,26 & 35,73 & 5801,89 & 254,09 & 1,70 & 252,38 & 124,68 & 54,33 & 193,03 & 46,97 & 560,99 & 68,52 & 25,89 & 27,74 & 177,86 & 109,10 & 122,68 & 109,30 \\
\hline Alytes obstetricans & 30TYK38 & 100,00 & 105,05 & 91,56 & 35,64 & 5850,46 & 245,73 & $\begin{array}{c}-7,82 \\
-1,82\end{array}$ & 253,55 & \begin{tabular}{|l|}
119,73 \\
\end{tabular} & 36,66 & $\begin{array}{l}183,72 \\
\end{array}$ & 36,64 & 594,96 & $\begin{array}{l}73,63 \\
73,63\end{array}$ & 28,94 & 26,24 & 184,55 & 115,64 & 129,85 & 115,64 \\
\hline Alytes obstetricans & 30TYK39 & 100,00 & 113,69 & 92,18 & 35,97 & 5842,47 & 253,56 & $-0,98$ & 254,55 & 125,77 & 46,14 & 191,87 & 44,99 & 552,52 & 69,58 & 26,05 & 28,10 & 173,67 & 105,55 & 120,14 & 105,55 \\
\hline Alytes obstetricans & 30TYK43 & 100,00 & 160,71 & 85,01 & 36,01 & 5244,10 & 283,73 & 51,85 & 231,88 & 170,75 & 228,53 & 231,13 & 97,66 & 453,06 & 67,77 & 14,71 & 38,72 & 175,56 & 68,20 & 94,68 & 97,40 \\
\hline Alytes obstetricans & 30TYK44 & 100,00 & 154,11 & 86,76 & 36,03 & 5356,39 & 280,45 & 43,74 & 236,70 & 162,89 & 224,01 & 226,19 & 90,39 & 469,68 & 67,13 & 16,07 & 36,26 & 175,98 & 75,34 & 99,29 & 98,57 \\
\hline Alytes obstetricans & 30TYK46 & 100,00 & 135,10 & 89,75 & 35,99 & 5606,18 & 268,66 & 22,27 & 246,39 & 142,36 & 206,40 & 210,55 & 69,29 & 518,79 & 65,81 & 20,37 & 31,31 & 177,99 & 94,90 & 111,56 & 104,65 \\
\hline Alytes obstetricans & 30TYK47 & 100,00 & 121,71 & \begin{tabular}{|l|l|}
90,79 \\
\end{tabular} & 35,97 & 5728,22 & 258,75 & $\begin{aligned} 2,35 \\
8,35\end{aligned}$ & \begin{tabular}{|l|}
250,40 \\
\end{tabular} & \begin{tabular}{|l|}
128,71 \\
\end{tabular} & $\begin{array}{l}137,52 \\
\end{array}$ & \begin{tabular}{|l|}
198,86 \\
\end{tabular} & 54,79 & 557,17 & $\begin{array}{l}0,10 \\
67,35 \\
\end{array}$ & 23,85 & $\begin{array}{l}1,113 \\
28,58\end{array}$ & $\begin{array}{l}180,73 \\
\end{array}$ & \begin{tabular}{|c|}
108,31 \\
\end{tabular} & 120,55 & 110,92 \\
\hline Alytes obstetricans & 30TYK48 & 100,00 & 108,78 & 91,05 & 35,78 & 5802,24 & 248,13 & $-3,89$ & 252,02 & 117,16 & 45,72 & 186,98 & 41,16 & 602,38 & 72,99 & 27,83 & 26,31 & 186,16 & 119,52 & 130,85 & 119,58 \\
\hline Alytes obstetricans & 30TYK49 & 100,00 & 112,81 & 91,67 & 35,87 & 5799,99 & 252,14 & $-1,10$ & 253,24 & 120,85 & 46,74 & 190,63 & 44,90 & 578,67 & 71,28 & 26,39 & 27,33 & 179,76 & 113,38 & 125,70 & 113,40 \\
\hline Alytes obstetricans & 30TYK53 & 60,00 & 165,35 & 83,90 & 36,00 & 5208,10 & 286,17 & 56,26 & 229,91 & 175,53 & 232,55 & 235,01 & 102,42 & 451,74 & 68,84 & 13,92 & 40,39 & 178,36 & 65,44 & 94,38 & 98,85 \\
\hline Alytes obstetricans & $\begin{array}{l}\text { 30TYK54 } \\
\end{array}$ & 60,00 & 153,71 & 86,33 & 36,02 & 5332,60 & 279,54 & 43,44 & 236,10 & 162,32 & 223,34 & 225,66 & 90,49 & 486,86 & 69,44 & 16,11 & 36,36 & 182,61 & 77,08 & 102,47 & 103,82 \\
\hline Alytes obstetricans & 30TYK55 & 50,00 & 149,13 & 87,66 & 36,01 & 5415,34 & 277,37 & 37,77 & 239,60 & 156,94 & 220,15 & 222,02 & 85,26 & 496,01 & 68,51 & 17,13 & 34,70 & 181,50 & 82,24 & 105,34 & 103,52 \\
\hline Alytes obstetricans & 30TYK58 & 40,00 & 119,33 & 90,92 & 35,93 & 5731,61 & 256,69 & 5,82 & 250,87 & 125,82 & 149,34 & 196,54 & 52,54 & 578,41 & 69,30 & 24,59 & 28,00 & 185,54 & 113,25 & 124,67 & 116,23 \\
\hline Alytes obstetricans & 30TYK59 & 40,00 & 112,86 & 91,12 & 35,82 & 5774,23 & 251,69 & $-0,48$ & 252,17 & 119,95 & 59,28 & 190,71 & 45,66 & 595,51 & 72,06 & 26,45 & 26,98 & 185,86 & 118,42 & 128,97 & 118,77 \\
\hline Alytes obstetricans & 30TYLO0 & 100,00 & 100,68 & 93,65 & 35,72 & 5991,09 & 243,55 & $-15,63$ & 259,18 & 118,49 & 29,31 & 180,54 & 29,31 & 540,35 & 72,88 & 28,51 & 29,16 & 180,99 & 97,22 & 127,50 & 97,22 \\
\hline Alytes obstetricans & 30TYL01 & 100,00 & 95,05 & 93,76 & 35,76 & 5986,23 & 238,47 & $-21,30$ & 259,77 & 112,71 & 23,67 & 174,78 & 23,67 & 564,13 & 76,12 & 30,37 & 28,37 & 189,44 & 102,78 & 134,63 & 102,78 \\
\hline Alytes obstetricans & 30TYLO2 & 100,00 & 108,92 & 94,52 & 36,00 & 5980,92 & 251,53 & $-9,03$ & 260,56 & 128,27 & 36,94 & 188,23 & 36,94 & 492,30 & 68,41 & 25,25 & 31,07 & 167,44 & 86,54 & 116,54 & 86,54 \\
\hline Alytes obstetricans & $\begin{array}{l}\text { 30TYL04 } \\
\end{array}$ & 100,00 & 128,06 & 97,86 & 36,00 & 6000,80 & 273,61 & 6,32 & 267,29 & 149,40 & 54,93 & 206,99 & 54,88 & 414,35 & $\begin{array}{l}58,48 \\
58,4\end{array}$ & 20,44 & 32,87 & 140,48 & 72,46 & 93,32 & 72,46 \\
\hline Alytes obstetricans & 30TYL05 & 100,00 & 135,72 & 99,61 & 36,04 & 6025,13 & 283,62 & 12,59 & 271,03 & 157,66 & 61,97 & 214,66 & 61,74 & 388,46 & 54,65 & 18,39 & 32,93 & 130,68 & 68,50 & 85,03 & 68,50 \\
\hline Alytes obstetricans & 30TYL06 & 100,00 & 142,20 & 101,20 & 36,22 & 6042,49 & 292,40 & 18,20 & 274,20 & 164,69 & 68,48 & 221,25 & 67,81 & 368,36 & 51,33 & 16,74 & 32,70 & 22,58 & 65,86 & 78,34 & 65,86 \\
\hline Alytes obstetricans & 30TYLO9 & 100,00 & 148,51 & 104,01 & 36, & 6077,60 & 303,15 & 23,56 & 279,59 & \begin{tabular}{|l|}
171,91 \\
\end{tabular} & $\begin{array}{l}0,460 \\
72,67\end{array}$ & 227,53 & $\begin{array}{l}1,2,67 \\
72\end{array}$ & $\begin{array}{l}353,00 \\
350\end{array}$ & 47, & 15,67 & 30,28 & 114,69 & $\begin{array}{l}0,30 \\
65,39 \\
\end{array}$ & 72,80 & $\begin{array}{l}65,39 \\
65\end{array}$ \\
\hline Alytes obstetricans & 30TYL10 & 100,00 & 102,54 & 93,13 & 35,82 & 5950,25 & 244,84 & $-13,08$ & 257,92 & 120,08 & 32,05 & 181,99 & 32,05 & 552,67 & 72,99 & 29,41 & 28,32 & 181,29 & 101,44 & 126,59 & 101,44 \\
\hline Alytes obstetricans & 30TYL11 & 100,00 & 106,53 & 93,56 & 35,70 & 5941,94 & 248,77 & \begin{tabular}{|l|}
$-10,01$ \\
\end{tabular} & 258,77 & 124,49 & 35,74 & 185,55 & 35,74 & 528,69 & 70,90 & 27,69 & 29,27 & 174,84 & 95,94 & 121,62 & 95,94 \\
\hline Alytes obstetricans & 30TYL12 & 100,00 & 114,35 & 94,74 & 35,98 & 5948,82 & 256,97 & $-3,66$ & 260,62 & 133,53 & 42,95 & 193,27 & 42,95 & 488,99 & 66,71 & 25,01 & 30,69 & 162,80 & 87,40 & 111,36 & 87,40 \\
\hline Alytes obstetricans & 30TYL13 & 100,00 & 120,96 & 96,19 & 36,00 & 5955,15 & 264,72 & 1,18 & 263,54 & 140,97 & 49,06 & 199,65 & 49,06 & 458,44 & 63,28 & 22,79 & 31,53 & 153,08 & 81,40 & 103,08 & 81,40 \\
\hline Alytes obstetricans & $30 \mathrm{TYL}$ & 100,00 & 12 & $\begin{array}{l}\mid c 0,119 \\
97,79 \\
\end{array}$ & 36, & | 5971,89 & 273,129 & $\begin{array}{l}\frac{1,10}{6,11} \\
\end{array}$ & \begin{tabular}{|l|}
260,98 \\
266,98
\end{tabular} & \begin{tabular}{|l|}
148,28 \\
\end{tabular} & $\begin{array}{l}45,17 \\
55,17\end{array}$ & 206,20 & $\begin{array}{ll}55,06 \\
55\end{array}$ & \begin{tabular}{|l|}
$430,44,76$ \\
431
\end{tabular} & $\begin{array}{l}\mid c 5,60 \\
59,89\end{array}$ & 20,81 & $\begin{array}{l}1,35 \\
32,13 \\
\end{array}$ & $\begin{array}{l}143,95 \\
143,95\end{array}$ & $\begin{array}{l}1,404 \\
76,56\end{array}$ & $\begin{array}{r}05,00 \\
95,36\end{array}$ & $\begin{array}{l}01,40 \\
76,56\end{array}$ \\
\hline Alytes obstetricans & 30TYL15 & 100,00 & 137,35 & 99,78 & 36,18 & 5990,26 & 285,10 & 14,33 & 270,77 & 159,05 & 65,33 & 215,87 & 64,22 & 398,05 & 55,03 & 18,12 & 32,69 & 131,48 & 70,89 & 84,97 & 70,89 \\
\hline Alytes obstetricans & 30TYL16 & 100,00 & 146,32 & 101,65 & 36,68 & 6010,72 & 296,19 & 22,16 & 274,02 & 168,23 & 78,09 & 224,96 & 72,52 & 370,77 & $\begin{array}{l}50,68 \\
50\end{array}$ & $\begin{array}{l}x_{10,12} \\
16,07\end{array}$ & 32,89 & 120,83 & 66,73 & 76,48 & $\begin{array}{l}6,0,73 \\
\end{array}$ \\
\hline Alytes obstetricans & 30TYL20 & 100,00 & 110,80 & 92,95 & 35,91 & 5895,90 & 251,75 & $-4,60$ & 256,35 & 128,26 & 40,93 & 189,42 & 40,93 & 535,13 & 69,78 & 26,77 & 28,71 & 172,13 & 99,11 & 118,94 & 99,11 \\
\hline Alytes obstetricans & 30TYL21 & 100,00 & 123,69 & 94,50 & 36,00 & 5880,54 & 264,86 & 5,84 & 259,02 & 140,88 & 55,55 & 201 & 53,63 & 480,97 & 63,68 & 22,64 & 30,88 & 154,82 & 87,78 & 104,53 & 87, \\
\hline Alytes obstetricans & $\begin{array}{l}\text { 30TYL22 } \\
\end{array}$ & $\begin{array}{l}100,00 \\
\end{array}$ & $\begin{array}{l}12,03 \\
121,20\end{array}$ & $\begin{array}{l}4,30 \\
95,16 \\
\end{array}$ & 30,00 & $\begin{array}{l}50005,73 \\
5905\end{array}$ & $\begin{array}{l}204,00 \\
263,52\end{array}$ & $\frac{3,044}{2,64}$ & \begin{tabular}{|l|}
$260,88<$ \\
268
\end{tabular} & \begin{tabular}{|l|} 
\\
$139,69,69$ \\
\end{tabular} & \begin{tabular}{|l|l|}
51,91 \\
51
\end{tabular} & \begin{tabular}{|l|}
199,39 \\
\end{tabular} & $\begin{array}{l}50,53 \\
503\end{array}$ & \begin{tabular}{|l|l|}
484,13 \\
\end{tabular} & $\begin{array}{l}30,00 \\
64,79 \\
\end{array}$ & $\mid \begin{array}{l}23,24 \\
23,21\end{array}$ & $\begin{array}{l}0,00 \\
30,65 \\
\end{array}$ & $\begin{array}{l}157,38 \\
158 \\
\end{array}$ & $\begin{array}{l}8,160 \\
88,16\end{array}$ & 105,77 & $\begin{array}{l}8,17 \\
88,17 \\
\end{array}$ \\
\hline Alytes obstetricans & 30TYL23 & 100,00 & 129,53 & 96,95 & 36,01 & 5917,39 & 273,45 & 9,05 & 264,40 & 149,44 & 60,86 & 207,72 & 58,37 & 449,66 & 60,72 & 20,57 & 31,81 & 146,05 & 81,33 & 96,20 & 81,34 \\
\hline Alytes ob & 30TYL24 & 100,00 & 134,76 & 98.59 & 36.18 & 593888 & 280,62 & 1299 & 267.63 & 155,68 & 67.53 & 213,03 & 63,11 & 427.03 & 57.93 & 19,04 & 32.34 & 13871 & 7701 & 90,07 & 7703 \\
\hline Alytes obstetricans & 30TYL25 & 100,00 & 142,00 & 100,52 & 36,74 & 5961,88 & 289,83 & 18,81 & 271,02 & 161,28 & 75,85 & 220,33 & 69 & 400,61 & 54,32 & 17,21 & 32 & 129,56 & 72,24 & 82,60 & 72,25 \\
\hline Alytes obstetricans & 30TYL26 & 100,00 & 147,16 & 102,06 & 36,92 & 5984,36 & 296,88 & 22,70 & 274,18 & 160,48 & 82,08 & 225,53 & 73,97 & 381,64 & 51,51 & 16,00 & 33,10 & 123,42 & 68,83 & 77,54 & 68,86 \\
\hline
\end{tabular}




\begin{tabular}{|c|c|c|c|c|c|c|c|c|c|c|c|c|c|c|c|c|c|c|c|c|c|}
\hline TAXON & UTM & $\mathrm{km2}$ & BIO1 & B102 & $\mathrm{BIO3}$ & BIO4 & B105 & B106 & B107 & B108 & B109 & BIO10 & BIO11 & $\overline{B 1012}$ & BIO13 & BIO14 & BIO15 & BIO16 & BIO17 & BIO18 & BlO19 \\
\hline Alytes obstetricans & 30TYL30 & 100,00 & 118,61 & 93,06 & 35,99 & 5838,37 & 258,66 & 2,61 & 256,04 & 131,25 & 51,76 & 196,54 & 49,72 & 527,06 & 67,34 & 24,41 & 29,16 & 166,63 & 99,49 & 115,73 & 99,57 \\
\hline Alytes obstetricans & 30TYL32 & 100,00 & 133,59 & 96,09 & 36,10 & 5848,65 & 275,59 & 13,99 & 261,60 & 140,98 & 69,86 & 210,97 & 63,95 & 464,46 & 60,79 & 19,82 & 31,84 & \begin{tabular}{|l|l|}
149,59 \\
\end{tabular} & 85,77 & \begin{tabular}{l|l|}
97,49 \\
\end{tabular} & 86,31 \\
\hline Alytes obstetricans & 30TYL33 & 100,00 & 136,96 & 97,60 & 36,23 & 5872,92 & 280,81 & \begin{tabular}{|l|}
16,10 \\
\end{tabular} & 264,72 & \begin{tabular}{ll|}
444,41 \\
\end{tabular} & 73,30 & 214,55 & 66,74 & 447,91 & 59,08 & 18,85 & 32,32 & \begin{tabular}{ll|}
144,72 \\
\end{tabular} & 82,19 & 92,25 & 82,85 \\
\hline Alytes obstetricans & 30TYL34 & 100,00 & 142,34 & 99,50 & 36,76 & 5901,58 & 288,19 & 19,92 & 268,27 & \begin{tabular}{|l|l|l|l|}
146,99 \\
\end{tabular} & 78,78 & 220,24 & 71,52 & 423,89 & 56,32 & 17,36 & \begin{tabular}{|c|}
32,97 \\
\end{tabular} & \begin{tabular}{ll|l}
137,90 \\
\end{tabular} & 76,94 & 85,89 & 77,94 \\
\hline Alytes obstetricans & 30TYL35 & 100,00 & 143,02 & 100,82 & 36,70 . & 5940,71 & $290,94[$ & 19,49 & 271,45 | & $150,37 \mid$ & 78,90 _ & 221,16 & 71,21 & $414,94[$ & 55,39 & 17,11 & $32,87 \mid$ & $134,25 \mid$ & 75,32 & $83,91]$ & 75,83 \\
\hline Alytes obstetricans & 30 TYL36 & 100,00 & 149,20 & 102,61 & 36,94 & 5967,16 & 298,83 & 24,44 & 274,39 & \begin{tabular}{l|l|}
153,92 \\
\end{tabular} & 85,32 & 227,44 & 76,60 & 390,97 & 52,10 & 15,74 & 33,37 & 128,10 & 70,41 & 78,03 & 71,10 \\
\hline Alytes obstetricans & 30TYL40 & 100,00 & 109,39 & 91,87 & 35,70 & 5823,57 & 249,52 & $-4,65$ & 254,17 & 122,61 & 42,23 & 187,43 & 41,16 & $\begin{array}{l}589,35 \\
\end{array}$ & 73,23 & 27,54 & 26,94 & 182,63 & 115,19 & 128,43 & 115,21 \\
\hline Alytes obstetricans & 30TYL41 & 100,00 & 119,24 & 93,51 & 35,97 & 5819,53 & 259,90 & 2,94 & 256,97 & 129,11 & 54,79 & 196,99 & 50,72 & 543,12 & 68,61 & 24,24 & 28,79 & \begin{tabular}{ll|}
170,06 \\
\end{tabular} & $\begin{array}{ll}104,42 \\
\end{array}$ & 117,63 & 104,67 \\
\hline Alytes obstetricans & 30TYL43 & 100,00 & 133,19 & 97,27 & \begin{tabular}{|l|}
36,27 \\
\end{tabular} & 5854,53 & 276,90 & 12,92 & \begin{tabular}{|l|l|}
263,97 \\
\end{tabular} & 138,21 & \begin{tabular}{ll|l}
69,69 \\
\end{tabular} & 210,85 & 63,74 & 481,13 & 62,31 & 19,97 & 31,23 & 154,15 & \begin{tabular}{l|l|}
89,95 \\
\end{tabular} & \begin{tabular}{l|l}
99,95 \\
\end{tabular} & 90,99 \\
\hline Alytes obstetricans & 30TYL44 & 100,00 & 140,32 & 99,42 & 36,68 _ & 5888,21 & 286,16 & 18,08 & 268,09 & 143,57 & $76,69 \mid$ & 218,13 & 70,13 & 450,49 & 58,86 & 18,01 & 32,39 & 146,43 & $82,97 \mid$ & 90,82 & 84,47 \\
\hline Alytes obstetricans & 30TYL45 & 100,00 & 145,58 & 101,43 & \begin{tabular}{l|l}
36,95 \\
\end{tabular} & 5916,80 & 293,39 & 21,75 & 271,64 & \begin{tabular}{|l|l|}
149,00 \\
\end{tabular} & 81,82 & 223,47 & 74,58 & 426,60 & 56,07 & 16,75 & 33,06 & \begin{tabular}{l|l|}
139,95 \\
\end{tabular} & 77,66 & 84,61 & 79,26 \\
\hline Alytes obstetricans & 30TYL46 & 100,00 & 150,73 & 103,24 & 37,00 & 5957,93 & 300,52 & 25,43 & \begin{tabular}{|l|l|}
275,08 \\
\end{tabular} & 153,39 & 86,88 & 228,96 & $\begin{array}{l}78,75 \\
\end{array}$ & 402,34 & 52,94 & 15,59 & 33,55 & \begin{tabular}{|l|l|}
133,19 \\
\end{tabular} & 72,40 & 78,88 & 74,04 \\
\hline Alytes obstetricans & 30TYL50 & 39,00 & 110,93 & 91,70 & 35,70 & 5798,36 & 250,68 & $-2,77$ & 253,45 & \begin{tabular}{l|l|}
120,29 \\
\end{tabular} & 45,79 & 188,80 & 43,29 & \begin{tabular}{|l|l|}
598,38 \\
\end{tabular} & 73,23 & 27,07 & 26,75 & \begin{tabular}{ll|}
184,88 \\
\end{tabular} & 118,50 & \begin{tabular}{l|l}
130,05 \\
\end{tabular} & 118,63 \\
\hline Alytes obstetricans & 30TYL51 & 30,00 & 120,18 & 93,35 & 36,00 & 5791,27 & 260,47 & 4,02 & 256,45 & \begin{tabular}{l|l|}
127,02 \\
\end{tabular} & 56,69 & $\begin{array}{l}197,64 \\
\end{array}$ & 52,31 & 556,07 & 69,22 & 23,95 & 28,58 & $\begin{array}{l}174,89 \\
\end{array}$ & $\begin{array}{l}108,18 \\
\end{array}$ & $\begin{array}{ll}121,33 \\
\end{array}$ & 108,84 \\
\hline Alytes obstetricans & 30 TYL54 & 20,00 & 136,03 & 98,91 & 36,57 & 5875,89 & 281,49 & 14,34 & 267,14 & \begin{tabular}{|l|l|}
139,37 \\
\end{tabular} & 72,29 & 213,83 & \begin{tabular}{|c|}
66,17 \\
\end{tabular} & 478,94 & 61,80 & 19,17 & 31,37 & 153,89 & 89,77 & 98,31 & 91,17 \\
\hline Alytes obstetricans & 30TYM08 & 100,00 & 88,36 & 97,26 & 37,60 & 5508,18 & 230,50 & $-24,23$ & 254,73 & 105,88 & 160,23 & 160,39 & 20,16 & 720,99 & 83,39 & 40,79 & 17,43 & 213,13 & \begin{tabular}{ll|}
154,64 \\
\end{tabular} & 158,41 & 164,13 \\
\hline Alytes obstetricans & 30TYM09 & 100,00 & 93,51 & 98,46 & 38,09 & 5475,67 & 235,12 & $-19,66$ & 254,78 & \begin{tabular}{ll|l}
111,59 \\
\end{tabular} & $\begin{array}{ll}164,52 \\
\end{array}$ & 164,91 & 25,38 & 714,28 & 81,03 & 39,71 & 16,65 & \begin{tabular}{|l|l|}
207,72 \\
\end{tabular} & \begin{tabular}{ll|}
152,62 \\
\end{tabular} & \begin{tabular}{l|l|}
155,93 \\
\end{tabular} & 165,51 \\
\hline Alytes obstetricans & \begin{tabular}{|l|l|}
30 TYM19 \\
\end{tabular} & 100,00 & 88,36 & 97,19 & 37,89 & 5459,20 & 228,76 & $-23,99$ & 252,76 & $\begin{array}{ll}105,96 \\
\end{array}$ & \begin{tabular}{|l|l|}
159,32 \\
\end{tabular} & 159,69 & 20,57 & 748,71 & 84,95 & 42,66 & \begin{tabular}{l|l}
16,45 \\
\end{tabular} & 218,88 & 162,66 & $\begin{array}{ll}166,63 \\
\end{array}$ & 170,54 \\
\hline Alytes obstetricans & 30TYM23 & 100,00 & 133,82 & 104,75 & 37,54 & 5886,82 & 286,82 & \begin{tabular}{|l|}
10,93 \\
\end{tabular} & 275,89 & 156,65 & 59,92 & 210,54 & \begin{tabular}{l|l|}
59,92 \\
\end{tabular} & 404,49 & 52,69 & 19,04 & 27,00 & \begin{tabular}{ll|}
127,86 \\
\end{tabular} & 75,98 & 85,29 & 75,98 \\
\hline Alytes obstetricans & 30TYM28 & 100,00 & 80,47 & 94,96 & 37,23 & 5496,64 & 220,75 & $-30,73$ & 251,48 & \begin{tabular}{|l|l}
97,38 \\
\end{tabular} & 95,71 & $\begin{array}{l}152,59 \\
\end{array}$ & 12,6 & 787, & 90,38 & 46,20 & \begin{tabular}{ll|l}
16,86 \\
\end{tabular} & 233,47 & \begin{tabular}{ll|}
172,16 \\
\end{tabular} & \begin{tabular}{|l|l|}
178,97 \\
\end{tabular} & 174,81 \\
\hline Alytes obstetricans & 30TYM29 & 100,00 & 84,97 & 96,22 & 37,69 & 5469,22 & 224,84 & $-26,98$ & 251,82 & 102,39 & 136,47 & \begin{tabular}{ll|l}
156,46 \\
\end{tabular} & 17,19 & 778,39 & 88,14 & 45,28 & 16,32 & 228,35 & \begin{tabular}{|l|l|}
171,44 \\
\end{tabular} & \begin{tabular}{ll|}
176,99 \\
\end{tabular} & 174,64 \\
\hline Alytes obstetricans & 30TYM31 & 100,00 & 131,14 & 104,62 & 37,01 & 5981,44 & 285,08 & 6,98 & 278,10 & 154,00 & 56,63 & 209,23 & 56,63 & 419,51 & 55,75 & 20,03 & 28,22 & $\begin{array}{l}135,46 \\
\end{array}$ & 76,51 & $\begin{array}{l}90,58 \\
\end{array}$ & 76,51 \\
\hline Alytes obstetricans & 30TYM34 & 100,00 & 128,81 & 104,79 & \begin{tabular}{ll|}
37,88 \\
\end{tabular} & 5843,16 & 280,60 & 6,17 & 274,43 & 151,32 & 55,13 & 204,69 & 55,13 & 434,10 & 55,61 & 21,29 & 25,61 & \begin{tabular}{ll|}
136,36 \\
\end{tabular} & 81,52 & \begin{tabular}{l|l}
93,95 \\
\end{tabular} & 81,52 \\
\hline Alytes obstetricans & 30TYM39 & 100,00 & 80,08 & 94,72 & 37,34 & 5482,13 & 219,26 & $-30,90$ & 250,15 & \begin{tabular}{|l|}
97,07 \\
\end{tabular} & \begin{tabular}{|l|l|}
71,04 \\
\end{tabular} & 151,82 & 12,33 & 831,24 & 93,34 & 49,55 & \begin{tabular}{ll|}
15,96 \\
\end{tabular} & \begin{tabular}{|l|l|}
244,17 \\
\end{tabular} & 184,12 & $\begin{array}{l}192,69 \\
\end{array}$ & 185,37 \\
\hline Alytes obstetricans & 30TYM44 & 90,00 & 125,50 & 104,97 & 37,73 & 5892,04 & 278,01 & 2,38 & 275,64 & \begin{tabular}{ll|}
148,18 \\
\end{tabular} & 51,16 & 202,16 & 51,16 & 461,30 & 58,73 & 23,45 & 25,10 & \begin{tabular}{ll|}
145,44 \\
\end{tabular} & 86,27 & \begin{tabular}{|l|l|}
102,47 \\
\end{tabular} & 86,27 \\
\hline Alytes obstetricans & 30TYM47 & 80,00 & 103,99 & 100,19 & 37,82 & 5630,26 & 248,97 & $-12,48$ & 261,45 & 123,89 & 33,43 & 177,30 & 33,43 & $\begin{array}{ll}621,35 \\
\end{array}$ & 73,81 & 34,77 & 19,80 & \begin{tabular}{|l|l|}
188,02 \\
\end{tabular} & \begin{tabular}{l|l|}
126,75 \\
\end{tabular} & \begin{tabular}{|l|l|}
143,15 \\
\end{tabular} & 126,75 \\
\hline Alytes obstetricans & 30TYN00 & 100,00 & 89,01 & 97,77 & 38,10 & 5436,31 & 229,17 & $-23,37$ & 252,54 & 106,64 & \begin{tabular}{ll|}
159,62 \\
\end{tabular} & 159,92 & 21,38 & \begin{tabular}{|l|l|}
777,07 \\
\end{tabular} & \begin{tabular}{l|l}
85,95 \\
\end{tabular} & 43,85 & 15,60 & 223,04 & \begin{tabular}{ll|}
165,59 \\
\end{tabular} & $\begin{array}{l}170,13 \\
\end{array}$ & 184,36 \\
\hline Alytes obstetricans & 30TYN01 & 100,00 & 87,26 & 97,46 & 38,44 & 5402,29 & 226,07 & $-24,44$ & 250,51 & 104,60 & \begin{tabular}{l|l|}
157,51 \\
\end{tabular} & 157,71 & 20,01 & 824,62 & 89,14 & 46,93 & 14,90 & 233,53 & \begin{tabular}{ll|}
175,42 \\
\end{tabular} & \begin{tabular}{ll|}
179,88 \\
\end{tabular} & 199,54 \\
\hline Alytes obstetricans & 30TYN02 & 100,00 & 68,75 & 93,02 & \begin{tabular}{|l|}
37,67 \\
\end{tabular} & 5353,69 & 204,51 & $-39,25$ & 243,76 & 84,01 & \begin{tabular}{|l|l|}
139,07 \\
\end{tabular} & 139,08 & 2,90 & 982,46 & 104,07 & 58,76 & 13,90 & 276,88 & 209,18 & 212,16 & 242,29 \\
\hline Alytes obstetricans & 30TYN03 & 99,00 & 36,88 & 84,36 & 35,64 & 5266,47 & 167,53 & $-65,62$ & 233,15 & \begin{tabular}{ll|l}
48,42 \\
\end{tabular} & \begin{tabular}{|l|l|l|l|}
107,42 & \\
\end{tabular} & \begin{tabular}{|l|l|}
107,42 \\
\end{tabular} & $-25,95$ & 1224,93 & 127,53 & 77,30 & 13,04 & 343,70 & 260,60 & 260,76 & 307,40 \\
\hline Alytes obstetricans & 30TYN04 & 24,00 & 37,92 & 84,46 & 35,90 & 5244,13 & 168,00 & $\begin{array}{l}-64,05 \\
\end{array}$ & 232,05 & 49,61 & $\begin{array}{l}108,08 \\
\end{array}$ & \begin{tabular}{ll|}
108,08 \\
\end{tabular} & $-24,88$ & 1240,59 & 127,92 & 78,29 & 12,91 & 345,81 & 264,09 & 264,09 & 313,63 \\
\hline Alytes obstetricans & 30TYN10 & 100,00 & 93,66 & 98,44 & 38,40 & 5430,73 & 233,61 & $-19,36$ & 252,97 & 111,80 & \begin{tabular}{|l|l|}
163,89 \\
\end{tabular} & $\begin{array}{l}164,45 \\
\end{array}$ & 25,85 & 740,29 & 82,48 & 41,61 & \begin{tabular}{l|l|l|}
15,92 \\
\end{tabular} & 213,22 & $\begin{array}{l}160,45 \\
\end{array}$ & \begin{tabular}{ll|}
164,06 \\
\end{tabular} & 171,17 \\
\hline Alytes obstetricans & 30TYN11 & 100,00 & 88,63 & 97,46 & 38,54 & 5397,75 & 226,94 & $-23,45$ & 250,39 & 106,24 & \begin{tabular}{l|l|l|}
158,62 \\
\end{tabular} & 158,93 & \begin{tabular}{l|l|}
21,25 \\
\end{tabular} & 810,72 & 88,09 & 46,50 & 14,91 & 230,73 & $\begin{array}{l}175,15 \\
\end{array}$ & \begin{tabular}{|l|l|}
179,47 \\
\end{tabular} & 192,09 \\
\hline Alytes obstetricans & 30TYN12 & 100,00 & 59,95 & 90,18 & 37,03 & 5337,92 & \begin{tabular}{ll|}
193,96 \\
\end{tabular} & $-46,36$ & 240,32 & 74,31 & 130,37 & 130,42 & $-5,22$ & 1041,24 & 110,51 & 63,90 & 13,66 & 294,87 & 224,28 & 227,15 & 253,79 \\
\hline Alytes obstetricans & 30TYN13 & 100,00 & 47,94 & 86,82 & 36,42 & 5292,12 & \begin{tabular}{|l|l|}
179,49 \\
\end{tabular} & $-55,73$ & 235,22 & 60,84 & \begin{tabular}{|l|l|}
118,25 \\
\end{tabular} & 118,25 & $-16,06$ & 1150,14 & 120,31 & 72,13 & $\begin{array}{ll}13,03 \\
\end{array}$ & 323,51 & 247,41 & 248,28 & 284,42 \\
\hline Alytes obstetricans & 30TYN14 & 42,00 & 31,99 & 81,89 & 35,16 & 5231,31 & $\begin{array}{ll}160,33 \\
\end{array}$ & $-69,29$ & 229,62 & \begin{tabular}{ll|}
42,90 \\
\end{tabular} & \begin{tabular}{|l|l|}
102,19 \\
\end{tabular} & 102,19 & $-30,23$ & 1279,76 & 132,24 & 81,80 & 12,62 & \begin{tabular}{|l|l|}
357,57 \\
\end{tabular} & 274,11 & 274,11 & 321,20 \\
\hline Alytes obstetricans & 30 TYN20 & 100,00 & 79,04 & 94,91 & 37,70 & 5429,96 & 217,15 & $-31,43$ & 248,58 & \begin{tabular}{|l|l|}
95,84 \\
\end{tabular} & \begin{tabular}{|l|l|}
149,84 \\
\end{tabular} & 150,06 & 11,87 & 852,74 & 94,30 & 50,61 & 15,16 & 247,23 & 187,08 & \begin{tabular}{|l|l|}
193,73 \\
\end{tabular} & 196,25 \\
\hline Alytes obstetricans & 30TYN21 & 100,00 & 66,17 & 91,41 & 37,11 & 5384,10 & 201,54 & $-41,29$ & 242,83 & 81,39 & \begin{tabular}{|l|l|}
137,00 \\
\end{tabular} & \begin{tabular}{|l|l|}
137,03 \\
\end{tabular} & 0,17 & 975,38 & \begin{tabular}{ll|}
105,45 \\
\end{tabular} & 59,65 & 14,11 & 279,86 & 212,92 & 216,61 & 230,55 \\
\hline Alytes obstetricans & 30TYN22 & 100,00 & 50,84 & 86,83 & 36,1 & 5324,42 & 183,01 & $-53,86$ & 236,86 & 64,18 & 121,53 & 121,54 & $-13,60$ & 1107,97 & 117,49 & 69,53 & 13,33 & 314,53 & 240,49 & 242,34 & 268,20 \\
\hline Alytes obstetricans & 30 TYN23 & 100,00 & 31,49 & 80,98 & 34,68 & \begin{tabular}{|l|l|}
5249,75 \\
\end{tabular} & 159,70 & $-70,20$ & 229,90 & 42,31 & 101,95 & 101,95 & $-30,77$ & 1263,16 & 131,94 & 81,12 & 12,65 & 355,52 & 272,37 & 273,15 & 312,09 \\
\hline Alytes obstetricans & 30TYN24 & 45,00 & 12,23 & 75,01 & 33,06 & 5179,52 & \begin{tabular}{ll|}
136,49 \\
\end{tabular} & $-86,88$ & 223,37 & 20,55 & 82,48 & 82,48 & $-47,96$ & 1414,76 & 146,01 & 92,52 & \begin{tabular}{ll|l}
12,06 \\
\end{tabular} & \begin{tabular}{ll|}
395,43 \\
\end{tabular} & \begin{tabular}{|l|l|}
303,44 \\
\end{tabular} & \begin{tabular}{|l|l|}
303,44 \\
\end{tabular} & 355,09 \\
\hline Alytes obstetricans & 30TYN31 & 100,00 & 70,22 & 92,07 & 37,21 & 5403,92 & 205,96 & $-38,19$ & 244,15 & 85,95 & \begin{tabular}{|l|l|}
140,27 \\
\end{tabular} & 141,19 & 3,76 & 955,42 & 103,40 & 58,53 & 14,31 & 274,77 & 210,92 & 216,40 & 222,30 \\
\hline Alytes obstetricans & 30TYN32 & 100,00 & 53,61 & 87,07 & \begin{tabular}{|l|l|}
36,17 \\
\end{tabular} & 5340,93 & \begin{tabular}{|l|l|}
185,78 \\
\end{tabular} & $-51,45$ & 237,22 & 67,34 & \begin{tabular}{ll|}
124,30 \\
\end{tabular} & \begin{tabular}{|l|l|}
124,31 \\
\end{tabular} & $-11,23$ & 1094,52 & 116,32 & 69,00 & 13,39 & 311,69 & \begin{tabular}{|l|}
239,92 \\
\end{tabular} & 243,42 & 261,42 \\
\hline Alytes obstetricans & 30TYN33 & 73,00 & 24,93 & 78,12 & 33,91 & 42,21 & \begin{tabular}{ll|l}
151,45 \\
\end{tabular} & $-75,5$ & 227,03 & 34,8 & 95, & 95,59 & $-36,7$ & 1312,23 & 137,11 & 85,3 & 12,4 & 369,86 & 284,55 & 284,55 & 322,51 \\
\hline Alytes obstetricans & 30TYN34 & 5,00 & 19,10 & 76,05 & 33,38 & 5195,92 & 143,6 & $-80,59$ & 224,21 & 28,24 & 89, & 89,30 & $-41,75$ & 1371,27 & 141,84 & 89,65 & 12,14 & 383,84 & 296,44 & 296,44 & 340,91 \\
\hline Alytes obstetricans & 30TYN40 & 70,00 & 89,56 & 96,93 & 37,94 & 5489,93 & 228,94 & $-23,40$ & 252,34 & 107,73 & \begin{tabular}{|l|l}
44,83 \\
\end{tabular} & \begin{tabular}{l|l|}
161,25 \\
\end{tabular} & 21,0 & 802,61 & 88,80 & 47,57 & 15,63 & 233,72 & \begin{tabular}{|l|l|}
177,42 \\
\end{tabular} & \begin{tabular}{ll|}
186,76 \\
\end{tabular} & 178,20 \\
\hline Alytes obstetricans & 30TYN41 & 60,00 & 68,64 & 91,25 & \begin{tabular}{l|l}
36,95 \\
\end{tabular} & 5417,10 & 204,09 & $-39,29$ & 243,38 & 84,25 & $\begin{array}{l}128,36 \\
1\end{array}$ & \begin{tabular}{|l|l|}
139,81 \\
\end{tabular} & 2,00 & 977,54 & 105,69 & 60,61 & \begin{tabular}{l|l|l|l|}
14,23 \\
\end{tabular} & 281,73 & \begin{tabular}{|l|l|}
217,47 \\
\end{tabular} & 223,80 & 225,39 \\
\hline Alytes obstetricans & 30TYN42 & 60,00 & 32,27 & 79,78 & 34,22 & 5289,33 & \begin{tabular}{|l|l|}
160,47 \\
\end{tabular} & $-69,20$ & 229,68 & \begin{tabular}{|l|l}
43,05 \\
\end{tabular} & \begin{tabular}{|l|l|}
103,33 \\
\end{tabular} & 103,33 & $-30,38$ & 1247,89 & 131,84 & 80,87 & $12, \varepsilon$ & 354,47 & 272,80 & 273,09 & 300,99 \\
\hline Alytes obstetricans & 30TYN43 & 7,00 & 32,10 & 79,82 & 34,30 & 5264,38 & 159,53 & $-69,34$ & 228,88 & 42,99 & 102,71 & 102,71 & $-30,40$ & 1270,33 & 132,88 & 82,49 & 12 & \begin{tabular}{ll|}
358,52 \\
\end{tabular} & 277,48 & 278,31 & 309,23 \\
\hline Alytes obstetricans & $31 \mathrm{SBE}$ & 6,00 & 171,25 & 83,00 & 36,00 & 5146,13 & 289,75 & $\begin{array}{ll}62,75 \\
\end{array}$ & 227,00 & \begin{tabular}{|l|l|l|}
181,88 \\
\end{tabular} & 237,38 & 240,13 & 108,75 & 440,88 & \begin{tabular}{|c|}
69,88 \\
\end{tabular} & 12,38 & 42,88 & 179,25 & \begin{tabular}{|l|l|}
60,13 \\
\end{tabular} & 91,38 & 98,25 \\
\hline Alytes obstetricans & \begin{tabular}{|l|} 
31TBE43 \\
\end{tabular} & 42,00 & 168,69 & 83,80 & 36,00 & 5191,27 & 288,73 & 59,20 & 229,53 & 178,49 & \begin{tabular}{|l|l|}
235,78 \\
\end{tabular} & 238,10 & \begin{tabular}{l|l|}
105,92 \\
\end{tabular} & \begin{tabular}{|l|l|}
450,08 \\
\end{tabular} & 69,67 & 13,00 & 41,61 & \begin{tabular}{|l|l|}
180,04 \\
\end{tabular} & \begin{tabular}{|c|}
63,59 \\
\end{tabular} & \begin{tabular}{l|l|}
94,02 \\
\end{tabular} & 98,96 \\
\hline Alytes obstetricans & 31TBE44 & 53,00 & 153,70 & 86,17 & 36,00 & 5322,66 & 279,40 & \begin{tabular}{ll|l}
43,45 \\
\end{tabular} & 235,94 & 162,33 & \begin{tabular}{|l|l|}
223,42 \\
\end{tabular} & 225,59 & 90,90 & 497,59 & 71,08 & 16,06 & 36,24 & \begin{tabular}{|l|l|}
186,84 \\
\end{tabular} & \begin{tabular}{|l|l|}
77,97 \\
\end{tabular} & $\begin{array}{l}104,35 \\
\end{array}$ & 107,06 \\
\hline Alytes obstetricans & 31TBE45 & 57,00 & 153,66 & 87,05 & 36,01 & 5360,26 & 280,27 & 42,42 & 237,85 & \begin{tabular}{|l|l|}
161,39 \\
\end{tabular} & 223,80 & 225,93 & 90,54 & 493,76 & \begin{tabular}{ll|}
69,85 \\
\end{tabular} & 16,15 & 36,06 & \begin{tabular}{|l|l}
184,06 \\
\end{tabular} & 79,28 & \begin{tabular}{|l|}
104,61 \\
\end{tabular} & 104,30 \\
\hline Alytes obstetricans & 31TBE & 47,00 & 131,15 & 90,93 & $36, \mathrm{C}$ & 564 & 266 & \begin{tabular}{|l|}
17,18 \\
\end{tabular} & 249 & 131 & 203 & 207,20 & 65,56 & 547, & 67,10 & 21,13 & 30,26 & 183 & 101,84 & \begin{tabular}{|l|l|}
117,48 \\
\end{tabular} & 110,67 \\
\hline Alytes obstetricans & \begin{tabular}{|l|} 
31TBE49 \\
\end{tabular} & 40,00 & 119,56 & 91,25 & 35,92 & 5731,29 & 257,22 & $\begin{array}{l}5,59 \\
\end{array}$ & 251,63 & 125,81 & \begin{tabular}{|l|l|}
145,69 \\
\end{tabular} & 196,73 & 52,88 & 581,34 & 69,86 & 24,46 & 28,17 & \begin{tabular}{l|l|}
185,85 \\
\end{tabular} & \begin{tabular}{|l|l|}
113,97 \\
\end{tabular} & 125,36 & 116,83 \\
\hline Alytes obstetricans & 31TBE53 & & & & & & & & & & & & & & & & & & & & \\
\hline Alytes obstetricans & 31TBE54 & 80,00 & 164,95 & 85,25 & 36,02 & 226,37 & 287,26 & 54,61 & 232,65 & 173,45 & 233,00 & 235,31 & 103,00 & 473,82 & 71,71 & 13,63 & 9,91 & \begin{tabular}{|l|l|}
185,67 \\
\end{tabular} & \begin{tabular}{ll|}
69,66 \\
\end{tabular} & $\begin{array}{l}99,72 \\
\end{array}$ & 103,14 \\
\hline Alytes o & $31 \mathrm{TBE}$ & 100,00 & & & & & & $48, \mathrm{C}$ & & & 2 & 23 & & 8 & 71, & & & & 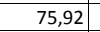 & \begin{tabular}{l|l}
4,02 \\
\end{tabular} & \\
\hline Alytes obstetricans & 31TBE58 & 99,00 & 141,84 & $90,77 \mid$ & 36,05 & 5544,7 & 274,6 & 27,44 & 247,26 & 146,9 & 215, & 216,60 & 77,80 & 533,31 & 69,25 & 18,57 & 32,74 & 186,03 & \begin{tabular}{|l|l}
94,08 \\
\end{tabular} & 114,15 & 109, \\
\hline Alytes obstetricans & 31TBE59 & 100,00 & 126,75 & 91,35 & 36,00 & 5672,10 & 263,16 & \begin{tabular}{l|l|}
12,45 \\
\end{tabular} & 250,71 & 132,39 & 198,51 & 203,30 & 61,11 & 573,99 & 69,69 & 22,45 & \begin{tabular}{|l|l|}
29,45 \\
\end{tabular} & 188,32 & 108,58 & 122,88 & 117,01 \\
\hline
\end{tabular}







\begin{tabular}{|c|c|c|c|c|c|c|c|c|c|c|c|c|c|c|c|c|c|c|c|c|c|}
\hline TAXON & UTM & $\mathrm{km} 2$ & BIO1 & B102 & $\mathrm{BIO3}$ & B104 & B105 & B106 & B107 & B108 & B109 & BIO10 & BIO11 & BIO12 & B1013 & BIO14 & BIO15 & BIO16 & B1017 & BIO18 & B1019 \\
\hline Alytes obstetricans & 31TCG88 & 100,00 & 63,33 & 76,98 & 32,89 & 5497,30 & 195,29 & $-35,57$ & 230,86 & 73,67 & 28,23 & 137,52 & $-0,41$ & 1098,87 & 119,62 & 68,98 & 15,87 & 316,04 & 231,11 & 263,61 & 235,88 \\
\hline Alytes obstetricans & 31TCG89 & 99,00 & 66,22 & 77,80 & $\begin{array}{l}33,05 \\
\end{array}$ & 5506,40 & 198,47 & $-33,72$ & 232,19 & 78,52 & 20,48 & 140,17 & 1,86 & $\begin{array}{l}1083,69 \\
\end{array}$ & 118,31 & 67,99 & 16,35 & 313,94 & 227,60 & 264,52 & 231,28 \\
\hline Alytes obstetricans & 31TCG90 & 101,00 & 136,36 & 75,89 & 32,62 & 5509,64 & 261,97 & 32,01 & 229,96 & 171,63 & 69,87 & 209,50 & 69,87 & 671,94 & 76,56 & 34,14 & 24,21 & 207,62 & 126,49 & 167,94 & 126,49 \\
\hline Alytes obstetricans & 31TCG91 & 100,00 & 140,15 & 77,09 & 32,88 & 5541,55 & 266,71 & 34,44 & 232,27 & 189,30 & 72,56 & 213,35 & 72,56 & 643,38 & 74,75 & 33,67 & 25,04 & 200,76 & 115,29 & 166,79 & 115,29 \\
\hline Alytes obstetricans & 31TCG95 & 101,00 & 111,81 & 80,22 & 33,02 & 5654,02 & 244,94 & 6,04 & 238,90 & 127,50 & 43,42 & 186,65 & 43,42 & 788,95 & $\begin{array}{l}94,18 \\
\end{array}$ & 39,23 & 25,53 & $\begin{array}{l}246,95 \\
\end{array}$ & 135,20 & 217,09 & 135,20 \\
\hline Alytes obstetricans & 31TCG96 & 101,00 & 83,33 & 77,80 & 32,93 & 5542,42 & 215,76 & $-16,57$ & 232,33 & 95,44 & 20,50 & 157,85 & 18,52 & 965,67 & 108,47 & 57,35 & 18,90 & 283,52 & 192,36 & 241,41 & 193,01 \\
\hline Alytes obstetricans & 31TCG97 & 100,00 & 71,85 & 76,80 & \begin{tabular}{|l|l|}
32,78 \\
\end{tabular} & 5500,74 & 203,82 & $-26,53$ & 230,35 & 81,58 & 21,96 & 146,11 & 8,09 & 1042,29 & 114,65 & 64,51 & 16,80 & 300,67 & 216,33 & 253,16 & 218,34 \\
\hline Alytes obstetricans & 31TCG98 & 101,00 & 64,66 & 76,27 & 32,77 & 5478,46 & 196,19 & $-33,27$ & 229,46 & 73,71 & 26,64 & \begin{tabular}{|l|l|}
138,66 \\
\end{tabular} & 1,43 & 1092,72 & 118,86 & 68,90 & 15,71 & 312,52 & 231,01 & 261,60 & 235,04 \\
\hline Alytes obstetricans & 31TCG99 & 99,00 & 73,05 & 78,05 & 33,11 & 5513,07 & 205,46 & $-26,95$ & 232,41 & 85,52 & 20,57 & 146,93 & 8,37 & 1043,01 & 114,88 & 64,81 & 16,92 & \begin{tabular}{|l|l|}
303,95 \\
\end{tabular} & 215,59 & 257,31 & 218,58 \\
\hline Alytes obstetricans & 31TCHOO & 100,00 & 68,79 & 87,23 & \begin{tabular}{|l|l|}
35,48 \\
\end{tabular} & 5555,01 & 204,79 & $\begin{array}{l}-37,87 \\
\end{array}$ & 242,66 & 84,29 & 9,62 & 142,24 & 1,25 & \begin{tabular}{|l|}
1069,98 \\
\end{tabular} & 114,43 & 69,85 & 14,91 & 311,25 & 233,39 & 257,94 & 234,06 \\
\hline Alytes obstetricans & $31 \mathrm{TCHO2}$ & 95,00 & 16,76 & 72,03 & 31,69 & 5314,50 & 142,11 & $-81,48$ & 223,59 & 25,51 & 72,44 & 88,96 & $-44,56$ & 1402,13 & 146,60 & 93,52 & 12,24 & \begin{tabular}{|l|l|}
394,75 \\
\end{tabular} & 310,47 & 310,92 & 335,91 \\
\hline Alytes obstetricans & $31 \mathrm{TCH} 10$ & 101,00 & 70,82 & 86,96 & 35,20 & 5577,10 & 206,95 & $-36,13$ & 243,08 & 86,42 & 10,36 & 144,48 & 2,97 & 1077,72 & 114,90 & 70,09 & 15,04 & 313,38 & 233,40 & 262,96 & 234,27 \\
\hline Alytes obstetricans & 31TCH11 & 99,00 & 40,14 & 78,04 & 33,24 & 5413,46 & 169,87 & $-60,88$ & 230,75 & 51,68 & 42,97 & 112,88 & $-23,66$ & 1250,71 & 132,46 & 83,15 & 13,13 & 357,02 & 278,78 & 286,50 & 287,67 \\
\hline Alytes obstetricans & $31 \mathrm{TCH} 13$ & & & & & & & & & & & & & & & & & & & & \\
\hline Alytes obstetricans & 31TCH14 & & & & & & & & & & & & & & & & & & & & \\
\hline Alytes obstetricans & $31 \mathrm{TCH} 20$ & 99,00 & 29,54 & 74,46 & 32,24 & 5393,53 & 158,03 & $-69,34$ & 227,37 & 39,43 & 54,78 & 102,71 & $-32,76$ & 1309,39 & 138,61 & 86,76 & 12,76 & 371,32 & 291,52 & 295,71 & 303,96 \\
\hline Alytes obstetricans & $31 \mathrm{TCH} 21$ & 100,00 & 28,59 & 74,34 & 32,22 & 5380,76 & 156,52 & $-70,36$ & 226,89 & 38,52 & 49,77 & 101,43 & $-33,76$ & 1327,84 & 139,92 & 88,51 & 12,64 & 375,89 & 294,86 & 300,09 & 310,24 \\
\hline Alytes obstetricans & $31 \mathrm{TCH} 22$ & 100,00 & 36,77 & 76,64 & 32,94 & 5390,09 & 165,55 & $-63,34$ & 228,89 & 47,95 & 40,53 & 109,38 & $-26,45$ & 1286,02 & 135,51 & 86,24 & 12,79 & 365,47 & 286,99 & 294,17 & 298,24 \\
\hline Alytes obstetricans & $31 \mathrm{TCH} 23$ & 101,00 & 39,35 & 77,48 & 33,21 & 5379,69 & 168,15 & $-61,19$ & 229,34 & 50,94 & 43,30 & 111,59 & $-24,16$ & 1278,98 & 134,37 & 86,22 & 12,74 & \begin{tabular}{|l|l|}
363,34 \\
\end{tabular} & 286,52 & 294,29 & 297,12 \\
\hline Alytes obstetricans & $31 \mathrm{TCH} 30$ & 101,00 & 34,97 & 75,26 & 32,50 & 5415,06 & 164,19 & $-64,10$ & 228,29 & 45,33 & 41,12 & 108,31 & $-27,73$ & 1280,86 & 135,90 & 84,92 & 13,07 & 364,04 & 284,49 & 292,27 & 294,25 \\
\hline Alytes obstetricans & $311 \mathrm{TCH} 31$ & 101,00 & 16,34 & 70,81 & 31,23 & 5342,24 & 142,52 & $-80,45$ & 222,97 & 24,73 & 73,74 & 89,29 & $-44,29$ & 1407,13 & 147,27 & 93,70 & 12,09 & 394,26 & 312,75 & 313,65 & 334,46 \\
\hline Alytes obstetricans & 31 TCH32 & 100,00 & 30,59 & 74,37 & 32,30 & 5365,39 & 158,33 & $-67,99$ & 226,33 & 40,75 & 55,22 & 103,22 & $-31,65$ & 1322,80 & 139,29 & 88,89 & 12,41 & 374,10 & 296,83 & 300,48 & 308,79 \\
\hline Alytes obstetricans & $31 \mathrm{TCH} 40$ & 99,00 & 67,52 & 82,72 & 34,24 & 5557,99 & 201,88 & \begin{tabular}{|l|l|}
$-36,39$ \\
\end{tabular} & 238,27 & 81,69 & 12,90 & 141,48 & 0,85 & 1089,40 & $\begin{array}{ll}118,08 \\
\end{array}$ & 70,05 & 15,66 & \begin{tabular}{|l|l|}
319,18 \\
\end{tabular} & 231,33 & 268,49 & 233,07 \\
\hline Alytes obstetricans & $31 \mathrm{TCH} 41$ & 100,00 & 63,26 & 81,99 & 34,13 & 5523,37 & 196,65 & $-40,04$ & 236,68 & 77,13 & 9,88 & 136,79 & $-2,89$ & 1124,23 & 120,96 & 73,64 & 14,88 & 327,29 & 242,00 & 272,27 & 244,91 \\
\hline Alytes obstetricans & $31 \mathrm{TCH} 42$ & 100,00 & 53,73 & 80,04 & \begin{tabular}{|l|l|}
33,75 \\
\end{tabular} & 5467,77 & 185,45 & $-48,06$ & 233,50 & 66,64 & 18,61 & 126,77 & $-11,23$ & 1190,48 & 126,61 & 79,35 & 13,87 & 342,55 & 260,50 & 283,88 & 266,82 \\
\hline Alytes obstetricans & $31 \mathrm{TCH} 50$ & 100,00 & 71,39 & 82,70 & 34,26 & 5567,46 & 205,94 & $-32,33$ & 238,27 & 85,79 & 11,74 & 145,40 & 4,63 & 1063,64 & 116,05 & 67,96 & 16,14 & 313,12 & 222,89 & 264,81 & 224,47 \\
\hline Alytes obstetricans & 31TCH51 & 101,00 & 67,54 & 82,16 & 34,13 & 5539,02 & 201,42 & $\begin{array}{l}-35,78 \\
-35\end{array}$ & 237,21 & 81,70 & 15,01 & $\begin{array}{l}141,19 \\
\end{array}$ & $\begin{array}{l}, 0 \\
1,18 \\
\end{array}$ & 1094,70 & 118,56 & 70,96 & 15,47 & 320,44 & 232,44 & 270,99 & 235,29 \\
\hline Alytes obstetricans & 31TCH52 & 99,00 & 38,21 & 75,38 & 32,56 & 5400,44 & 167,34 & $-60,59$ & 227,93 & 48,91 & 33,73 & 111,10 & $-24,56$ & 1280,87 & 135,31 & 85,82 & 12,83 & 362,94 & 284,53 & 296,30 & 295,04 \\
\hline Alytes obstetricans & $31 \mathrm{TCH} 60$ & 100,00 & 43,75 & 75,39 & 32,54 & 5429,16 & 173,81 & $-54,41$ & 228,22 & 54,28 & 15,13 & 117,26 & $-18,95$ & 1231,44 & 131,27 & 81,77 & 13,31 & 349,41 & 271,67 & 285,63 & 278,23 \\
\hline Alytes obstetricans & $31 \mathrm{TCH} 71$ & 16,00 & 42,06 & 74,86 & 32,44 & 5413,72 & 171,80 & $-55,63$ & 227,43 & 52,47 & 31,98 & 115,36 & $-20,23$ & 1250,03 & 132,67 & 82,76 & 13,23 & 353,38 & 273,94 & 289,90 & 285,08 \\
\hline Alytes obstetricans & $31 \mathrm{TCH} 90$ & 57,00 & 22,38 & 69,87 & 31,00 & 5348,90 & 149,96 & $-71,69$ & 221,65 & 20,28 & 76,64 & 95,73 & $-36,89$ & $\begin{array}{l}1376,73 \\
\end{array}$ & 142,64 & 89,22 & 12,14 & 377,34 & 303,91 & 305,72 & 327,94 \\
\hline Alytes obstetricans & 31TDF06 & 37,00 & $\begin{array}{ll}157,68 \\
15,0\end{array}$ & $\begin{array}{l}70,70 \\
70\end{array}$ & 32,57 & 5176,48 & 272,55 & 58,09 & 214,45 & \begin{tabular}{|l|l|}
168,68 \\
\end{tabular} & 224,93 & 226,84 & $\begin{array}{l}0,00 \\
95,61 \\
\end{array}$ & $\mid 632,00$ & \begin{tabular}{|c|}
88,0407 \\
88,0
\end{tabular} & $\begin{array}{l}24,34 \\
24,3 \\
\end{array}$ & 30,05 & 222,25 & 117,84 & 148,61 & 131,50 \\
\hline Alytes obstetricans & \begin{tabular}{|l|} 
31TDF07 \\
\end{tabular} & 100,00 & 148,43 & 71,25 & 32,08 & 5291,64 & 266,58 & 48,21 & 218,37 & 159,33 & 217,47 & 219,19 & 85,31 & 668,64 & 85,49 & 27,15 & 27,00 & 223,53 & 127,41 & 155,86 & 139,43 \\
\hline Alytes obstetricans & 31TDF08 & 101,00 & 149,24 & 72,06 & 32,09 & 5339,18 & 268,69 & 47,90 & 220,79 & 159,90 & 173,09 & 220,30 & 85,04 & 650,99 & 81,38 & 28,46 & 26,38 & 215,60 & 128,65 & 156,33 & 131,18 \\
\hline Alytes obstetricans & 31TDF09 & 100,00 & 157,57 & 73,07 & 32,23 & 5337,48 & 276,76 & 54,45 & 222,32 & 168,05 & 93,54 & 228,09 & 92,38 & 597,40 & 76,89 & 27,83 & 27,82 & 201,93 & 114,38 & 150,33 & 114,39 \\
\hline Alytes obstetricans & 31TDF16 & & & & & & & & & & & & & & & & & & & & \\
\hline Alytes obstetricans & 31TDF17 & 101,00 & 160,92 & 70,50 & 32,28 & 5174,62 & 276,34 & 61,01 & 215,33 & 171,39 & 221,88 & 229,63 & 98,42 & 629,25 & 90,08 & 24,99 & 31,01 & 224,52 & 120,14 & 150,01 & 129,05 \\
\hline Alytes obstetricans & 31TDF18 & 99,00 & 160,91 & 71,10 & 32,03 & 5239,75 & 277,92 & 59,79 & 218,13 & 171,23 & 130,82 & 230,38 & 97,46 & 609,35 & 84,18 & 26,58 & 29,69 & 213,79 & 118,71 & 150,19 & 120,98 \\
\hline Alytes obstetricans & 31TDF19 & 101,00 & 158,29 & 71,93 & 31,99 & 5322,04 & 277,37 & 55,97 & 221,40 & 169,71 & 96,54 & 228,56 & 93,61 & 602,55 & 78,29 & 29,03 & 27,86 & 204,69 & 115,31 & 153,16 & 115,54 \\
\hline Alytes obstetricans & 31TDF27 & 85,00 & 166,22 & 70,16 & 32,17 & 5089,19 & 280,30 & 66,64 & 213,66 & 176,56 & 218,22 & 233,41 & 104,49 & 618,62 & 94,89 & 23,92 & 33,86 & 229,10 & 117,70 & 148,27 & 125,51 \\
\hline Alytes obstetricans & 31TDF28 & 101,00 & 158,99 & 70,16 & 31,69 & 5227,88 & 276,22 & 58,85 & 217,37 & 169,24 & 158,51 & 228,43 & $\begin{array}{l}95,97 \\
\end{array}$ & 626,99 & 86,51 & 27,97 & 28,92 & 218,95 & 124,19 & 154,23 & 126,40 \\
\hline Alytes obstetricans & 31TDF29 & 101,00 & 159,89 & 70,96 & 31,86 & 5280,03 & 278,34 & 58,46 & 219,88 & \begin{tabular}{ll|}
175,16 \\
\end{tabular} & 99,82 & 229,64 & 95,80 & 601,07 & 80,09 & 29,35 & 28,43 & 206,58 & 115,70 & 153,82 & 116,03 \\
\hline Alytes obstetricans & 31TDF37 & & & & & & & & & & & & & & & & & & & & \\
\hline Alytes obstetricans & 31TDF38 & 52,00 & 163,90 & 70,18 & 32,17 & 5079,68 & 278,78 & 64,25 & 14,53 & 174,00 & 199,54 & 230,92 & 102,04 & 607,25 & 90,54 & 25,82 & 32,14 & 220,47 & 117,99 & 149,53 & 122,51 \\
\hline Alytes obstetricans & 31TDF39 & 99,00 & 159,05 & 70,45 & 1,7 & 5221,53 & 276,62 & 58,24 & 218,38 & 169,22 & 122,48 & 227,97 & 95,63 & 625,82 & 85,89 & 29,41 & 28,45 & 215,99 & 124,66 & 157,10 & 125,50 \\
\hline Alytes obstetricans & 31TDF49 & 74,00 & 155,34 & 69,84 & 31 & 5248,01 & 273,44 & 54,54 & 218,91 & $\begin{array}{l}166,02 \\
\end{array}$ & $\begin{array}{l}191,46 \\
\end{array}$ & 224,66 & $\begin{array}{l}91,70 \\
91,70\end{array}$ & \begin{tabular}{|l|l|}
669,03 \\
\end{tabular} & \begin{tabular}{|l|l|}
91,23 \\
1
\end{tabular} & $\begin{array}{l}31,05 \\
31,0\end{array}$ & 27,32 & 226,69 & 133,39 & 164,11 & 139,00 \\
\hline Alytes obstetricans & $31 \mathrm{TDF}$ & 14,00 & 16. & 69,94 & 31,41 & 5210,88 & 278,76 & 60,24 & 218,53 & $\begin{array}{l}171,76 \\
\end{array}$ & 216,00 & 230,12 & 98,29 & 649,65 & 96,41 & 27,29 & 30,94 & 228,76 & 121,53 & 155,41 & 138,59 \\
\hline Alytes obstetricans & 31TDG00 & 100,00 & 147,12 & 74,17 & 32,10 & 5444,61 & 269,96 & 43,25 & 226,71 & 187,89 & 81,00 & 219,13 & 81,00 & 632,84 & 75,08 & 32,57 & 25,41 & 202,78 & 118,11 & 161,49 & 118,11 \\
\hline Alytes obstetricans & 31TDG01 & 101,00 & 148,37 & 75,39 & 32,31 & 5488,51 & 272,64 & 43,17 & 229,47 & 196,91 & 81,18 & 220,65 & 81,18 & 613,92 & 72,77 & 32,55 & 25,69 & 197,42 & 109,00 & 162,21 & 109,00 \\
\hline Alytes obstetricans & 31TDG02 & 101,00 & 146 , & 76,64 & 32,4 & 5543,49 & 272,71 & 40,25 & 232,46 & 195,43 & 78,39 & 219,41 & 78,39 & 612,12 & 72,23 & 31,38 & 26,17 & 17 & 03,62 & 166,15 & 103,62 \\
\hline Alytes obstetricans & 31TDG03 & $\begin{array}{l}100,00 \\
100\end{array}$ & & $\frac{10,04}{77,70}$ & 32 & 55495,96 & 267,33 & $\begin{array}{l}32,206 \\
32,06\end{array}$ & \begin{tabular}{|l|}
235,27 \\
25,0
\end{tabular} & \begin{tabular}{|l|}
185,64 \\
185,
\end{tabular} & $\mid 70,21$ & $\frac{11}{212}$ & $\begin{array}{l}0,035 \\
70,21\end{array}$ & \begin{tabular}{|l|l|l|l|l|}
646,98 \\
\end{tabular} & $\begin{array}{l}\mid 2,25 \\
76,68\end{array}$ & $\begin{array}{l}31,00 \\
31,46\end{array}$ & 26,92 & 203,51 & 105,68 & $\begin{array}{l}100,15 \\
179,85\end{array}$ & $\begin{array}{l}105,02 \\
05,68\end{array}$ \\
\hline Alytes obstetricans & 31TDG04 & 100,00 & 133,54 & 78,74 & 32,86 & 5641,89 & 263,69 & 26,12 & 237,57 & 158,12 & 64,30 & 207,59 & 64,30 & 674,76 & 81,50 & 31,44 & 27,99 & 212,37 & 107,54 & 190,92 & 107,54 \\
\hline Alytes obstetricans & 31TDG05 & 100,00 & 127,55 & 79,61 & 32,97 & 5659,60 & 259,13 & 19,95 & 239,18 & $\begin{array}{ll}144,45 \\
\end{array}$ & 58,10 & 201,78 & 58,10 & 706,09 & 86,06 & 32,36 & 28,71 & 225,31 & 111,86 & 203,49 & 111,86 \\
\hline Alytes obstetricans & 31TDG06 & 100,00 & 106,21 & 79,00 & 32,99 & 5609,13 & 238,65 & 2,26 & 236,39 & 121,23 & 39,69 & 180,73 & 38,92 & 829,94 & 97,73 & 43,36 & 24,43 & 255,93 & 147,61 & 225,40 & 147,75 \\
\hline Alytes obstetricans & 31TDG07 & 101,00 & 97 & 79,20 & 33, & 5585,81 & 230,65 & $-4,96$ & 23 & 112,18 & 32,50 & 172,05 & 31,12 & 884,39 & 102,25 & 48 & 21,83 & 268,99 & 165,19 & 234,06 & 165 \\
\hline Alytes obstetricans & \begin{tabular}{|l|} 
31TDG08 \\
31 D
\end{tabular} & $\begin{array}{l}101,00 \\
100\end{array}$ & $\begin{array}{ll}1,110 \\
67,80\end{array}$ & $\begin{array}{l}75,20 \\
75,83\end{array}$ & 32,65 & 5456,06,88 & 199,08 & $\begin{array}{l}-4,50 \\
-29,52 \\
\end{array}$ & \begin{tabular}{|l|}
228,60 \\
22,0
\end{tabular} & \begin{tabular}{r|}
11,10 \\
74,25
\end{tabular} & $\begin{array}{l}2,30 \\
253\end{array}$ & $\begin{array}{l}14,, 74 \\
141,7\end{array}$ & $\begin{aligned} 4,84 \\
412\end{aligned}$ & \begin{tabular}{|l|l|}
$007,45,86$ \\
1075
\end{tabular} & \begin{tabular}{|l|l|}
116,99 \\
116,
\end{tabular} & $\begin{array}{l}40,10 \\
67,49 \\
\end{array}$ & $\begin{array}{l}1,03 \\
15,94\end{array}$ & $\begin{array}{l}300,93 \\
307,24\end{array}$ & 226,72 & 258,04 & $\begin{array}{l}20,030 \\
230,88\end{array}$ \\
\hline Alytes obstetricans & 31TDG09 & 101,00 & 88,07 & 79,57 & 33,42 & 5552,21 & 221,40 & $-13,35$ & 234,75 & 102,11 & 28,74 & 162,03 & 22,14 & 952,05 & 107,28 & 56,50 & 18,73 & \begin{tabular}{|l|l|}
284,35 \\
\end{tabular} & 188,33 & 243,10 & 189,54 \\
\hline Alytes obstetricans & 31TDG10 & 100,00 & 143,65 & 72,82 & 31,99 & 5436,23 & 266,45 & 41,19 & 225,27 & 191,40 & 78,13 & 215,81 & 78,13 & 661,58 & 76,92 & 35,13 & 24,44 & 210,32 & 124,08 & 170,04 & 124,08 \\
\hline Alytes obstetricans & 31TDG11 & 100,00 & 130,92 & 73,96 & 32,00 & 5506,36 & 256,72 & 28,36 & 228,36 & 179,89 & 64,96 & 204 & 64 & 711,82 & 81,20 & 37,69 & 23,64 & 220,30 & 129,34 & 187,13 & 129,34 \\
\hline Alytes obstetricans & 31TDG12 & 101,00 & 138,82 & 74,97 & 31,99 & 5534,36 & 264,97 & 34,06 & 230,90 & 187,60 & 71,46 & 211,89 & 71,46 & 664,54 & 77,32 & 33,73 & 25,52 & 209,84 & 113,45 & 180,96 & 113,45 \\
\hline
\end{tabular}





\begin{tabular}{|c|c|c|c|c|c|c|c|c|c|c|c|c|c|c|c|c|c|c|c|c|c|}
\hline TAXON & UTM & $\mathrm{km} 2$ & B101 & BIO2 & $\mathrm{BIO3}$ & B104 & BIO5 & B106 & B107 & 8108 & B109 & B1010 & B1011 & $\mathrm{BIO12}$ & B1013 & B1014 & BIO15 & B1016 & B1017 & B1018 & B1019 \\
\hline Alytes obstetricans & 31TDG74 & 101,00 & 148,67 & 70,75 & 30,06 & 5587,62 & 272,30 & 40,82 & 231,48 & 177,15 & 209,99 & 221,44 & 79,36 & 785,67 & 106,68 & 38,35 & 24,72 & 244,16 & 159,67 & 167,53 & 169,21 \\
\hline Alytes obstetricans & 31TDG75 & 101,00 & 138,71 & 72,55 & 30,92 & 5523,73 & 263,75 & 32,51 & 231,24 & 182,50 & 104,51 & 211,21 & 71,13 & 832,95 & \begin{tabular}{|l|l|}
103,27 \\
\end{tabular} & 43,47 & 22,28 & 247,40 & 173,37 & 186,58 & 174,80 \\
\hline Alytes obstetricans & 31TDG76 & 100,00 & 143,13 & 74,41 & 31,20 & 5552,16 & 269,17 & 35,16 & 234,01 & $\begin{array}{l}185,68 \\
\end{array}$ & $\begin{array}{l}111,35 \\
113\end{array}$ & 215,67 & 74,65 & 784,79 & $\begin{array}{l}99,79 \\
\end{array}$ & 41,08 & 22,69 & 235,03 & 163,83 & $\begin{array}{l}173,85 \\
\end{array}$ & 164,27 \\
\hline Alytes obstetricans & 31TDG77 & 100,00 & 138,85 & 75,89 & \begin{tabular}{l|l|l}
31,95 \\
\end{tabular} & 5538,66 & 266,13 & 30,97 & 235,15 & 177,79 & 103,96 & 211,36 & 70,83 & 782,67 & 97,23 & 41,56 & 21,97 & 231,89 & 164,30 & 174,28 & 164,77 \\
\hline Alytes obstetricans & 31TDG78 & 93,00 & 127,93 & 77,01 & 32,06 & 5514,09 & 256,73 & 21,64 & 235,10 & 166,72 & 73,70 & 200,46 & 60,95 & 827,53 & 96,41 & 45,54 & 20,13 & 238,31 & 175,62 & 187,78 & $\begin{array}{l}175,90 \\
\end{array}$ \\
\hline Alytes obstetricans & 31TDG79 & 46,00 & 113,70 & 77,44 & 32,85 & 5476,17 & 243,58 & 10,14 & 233,44 & 142,50 & 62,03 & 186,30 & 48,28 & 879,16 & 98,03 & 50,52 & 18,20 & 248,55 & 189,73 & 200,52 & 191,48 \\
\hline Alytes obstetricans & 31TDG81 & 58,00 & 156,33 & 69,67 & 30,77 & 5324,65 & 274,68 & 52,23 & 222,45 & 166,76 & 221,85 & 226,11 & 91,01 & 700,06 & \begin{tabular}{|l|l|}
108,38 \\
\end{tabular} & 27,85 & 32,13 & 241,39 & 125,74 & 155,80 & 153,82 \\
\hline Alytes obstetricans & 31TDG82 & 99,00 & 151,01 & 69,29 & 30,32 & 5396,79 & 270,51 & 46,31 & 224,20 & 161,54 & 221,06 & 221,71 & 84,91 & 744,17 & 109,39 & 31,64 & 28,92 & 246,43 & 139,20 & 164,30 & 163,79 \\
\hline Alytes obstetricans & 31TDG83 & 101,00 & 152,89 & 69,74 & 30,10 & 5483,13 & 273,79 & 46,21 & 227,58 & 163,03 & 223,94 & 224,33 & 85,14 & 738,58 & 109,55 & 31,46 & 29,01 & 243,75 & 137,25 & 159,43 & $\begin{array}{ll}163,03 \\
\end{array}$ \\
\hline Alytes obstetricans & 31TDG84 & 101,00 & 151,60 & 71,06 & 30,56 & 5502,87 & 273,56 & 44,03 & 229,53 & 161,75 & 222,87 & 223,26 & 83,40 & 745,99 & 107,99 & 33,42 & 27,63 & 240,70 & 143,15 & 156,73 & 162,27 \\
\hline Alytes obstetricans & 31TDG85 & 101,00 & 151,47 & 73,02 & 31,16 & 5489,76 & 274,51 & 43,28 & 231,23 & 163,92 & 222,63 & 222,94 & 83,53 & 727,58 & 104,06 & 33,71 & 26,96 & 232,38 & 143,45 & \begin{tabular}{ll|l}
154,74 \\
\end{tabular} & 155,45 \\
\hline Alytes obstetricans & 31TDG86 & 100,00 & 150,17 & 74,92 & 31,76 & 5484,51 & 274,44 & 41,47 & 232,96 & 160,93 & 221,32 & 221,62 & 82,25 & 708,14 & 99,79 & 33,60 & 26,14 & 224,22 & 142,91 & 150,56 & 149,80 \\
\hline Alytes obstetricans & 31TDG87 & 101,00 & 149,24 & 76,75 & 32,16 & 5487,27 & 274,86 & 39,84 & 235,02 & 160,05 & 216,56 & 220,80 & 81,28 & 689,46 & $\begin{array}{l}96,19 \\
\end{array}$ & 32,82 & 25,71 & 217,65 & 140,02 & 146,09 & 146,16 \\
\hline Alytes obstetricans & \begin{tabular}{|l|l|}
$31 T D G 88$ \\
\end{tabular} & 100,00 & 145,31 & 78,30 & $\begin{array}{l}32,55 \\
\end{array}$ & 5499,28 & 272,62 & 35,72 & 236,90 & 157,99 & 205,09 & 217,05 & 77,44 & 700,65 & 94,38 & 33,65 & 24,44 & 217,15 & 142,92 & 147,29 & 151,21 \\
\hline Alytes obstetricans & 31TDG89 & 82,00 & 138,88 & 79,63 & 32,99 & 5506,15 & 267,94 & 29,75 & 238,19 & 152,98 & 186,80 & 211,01 & 71,29 & 724,75 & 93,55 & 35,45 & 22,99 & 219,97 & 148,58 & 152,88 & 159,90 \\
\hline Alytes obstetricans & 31TDG92 & 90,00 & 150,89 & 70,44 & 31,30 & 5265,40 & 268,98 & 47,70 & 221,29 & 161,82 & 218,54 & 220,26 & 86,91 & 712,95 & \begin{tabular}{|l|l|}
106,85 \\
\end{tabular} & 28,68 & 30,50 & 240,38 & 130,56 & 156,86 & 156,52 \\
\hline Alytes obstetricans & 31TDG93 & 101,00 & 149,48 & 71,06 & 31,22 & 5302,24 & 268,45 & 45,39 & 223,06 & 160,19 & 218,27 & 219,19 & 84,88 & 722,41 & $\begin{array}{l}106,15 \\
\end{array}$ & 30,10 & 29,09 & 238,99 & 135,13 & 158,25 & 157,90 \\
\hline Alytes obstetricans & 31TDG94 & 101,00 & 148,97 & 72,30 & 31,68 & 5318,50 & 269,01 & 43,99 & 225,02 & 159,60 & 218,08 & 218,93 & 84,16 & 721,56 & 104,28 & 31,32 & 28,05 & 234,82 & 138,13 & 157,69 & 156,27 \\
\hline Alytes obstetricans & 31TDG95 & 100,00 & 155,34 & 74,30 & \begin{tabular}{ll|}
32,15 \\
\end{tabular} & 5331,84 & 276,12 & 48,17 & 227,95 & 165,50 & 224,38 & 224,95 & 89,64 & \begin{tabular}{|c|}
666,18 \\
\end{tabular} & 100,65 & 28,02 & 29,82 & 222,45 & 124,31 & 143,50 & 143,07 \\
\hline Alytes obstetricans & 31TDG96 & 101,00 & 154,32 & 76,03 & 32,57 & 5354,37 & 276,69 & 46,32 & 230,38 & \begin{tabular}{ll|l}
164,47 & \\
\end{tabular} & 223,78 & 224,28 & 88,29 & 645,72 & 96,88 & 27,87 & 29,30 & 214,89 & 123,38 & 138,33 & 136,76 \\
\hline Alytes obstetricans & 31TDG97 & 101,00 & 154,91 & 77,94 & 32,98 & 5376,61 & 278,77 & 45,78 & 232,99 & 164,75 & 224,66 & 225,07 & 88,52 & \begin{tabular}{l|l|}
620,55 \\
\end{tabular} & 93,45 & 26,50 & 29,39 & 207,71 & 118,15 & 129,83 & 131,77 \\
\hline Alytes obstetricans & 31TDG98 & 101,00 & 154,16 & 79,68 & 33,31 & 5404,67 & 279,85 & 43,98 & 235,87 & 163,77 & 224,38 & 224,69 & 87,42 & 614,88 & 91,59 & 25,70 & 28,95 & 205,24 & 114,78 & 123,02 & 133,82 \\
\hline Alytes obstetricans & 31TDG99 & 101,00 & 144,56 & 80,52 & 33,46 & 5443,28 & 272,35 & 34,86 & 237,48 & 151,97 & 215,52 & 215,81 & 77,70 & 669,90 & \begin{tabular}{|l|l|}
92,67 \\
\end{tabular} & 29,61 & 25,82 & 213,72 & 128,84 & 135,24 & 149,82 \\
\hline Alytes obstetricans & 31TDHOO & 28,00 & 50,10 & 74,04 & 32,22 & 5406,83 & 179,99 & $-45,96$ & 225,95 & $\begin{array}{ll}54,34 \\
\end{array}$ & 38,71 & 123,44 & $-11,53$ & \begin{tabular}{|l|}
1195,66 \\
\end{tabular} & \begin{tabular}{l|l|}
126,85 \\
\end{tabular} & 77,40 & 13,68 & 334,47 & 260,85 & 277,01 & 270,95 \\
\hline Alytes obstetricans & 31TDH80 & 1,00 & 143,90 & 82,12 & 33,46 & 5540,21 & 274,54 & 32,40 & 242,14 & 151,89 & 212,72 & 216,18 & 75,45 & 677,58 & 90,55 & 30,60 & 24,48 & 211,47 & 130,48 & 131,98 & 154,59 \\
\hline Alytes obstetricans & 31TDH90 & 17,00 & 130,04 & 80,65 & 33,43 & 5452,04 & 259,87 & 22,49 & 237,38 & 119,93 & 201,55 & 201,87 & 63,90 & 750,58 & 95,23 & 35,71 & 22,82 & 229,15 & 150,32 & 154,35 & 172,62 \\
\hline Alytes obstetricans & 31TEG02 & 28,00 & 159,86 & 72,57 & 32,57 & 5126,33 & 275,57 & 56,43 & 219,14 & $\begin{array}{l}170,95 \\
\end{array}$ & 218,33 & 227,33 & 97,29 & 631,48 & 102,14 & 21,71 & 35,33 & 225,67 & 106,76 & 137,62 & 139,43 \\
\hline Alytes obstetricans & 31TEG03 & 93,00 & 153,07 & 72,72 & \begin{tabular}{l|l|}
32,65 \\
\end{tabular} & 5129,58 & 269,70 & 50,30 & 219,40 & 164,14 & 219,05 & 220,85 & 91,19 & 659,64 & 100,74 & 24,89 & 31,94 & 226,71 & 118,30 & 144,85 & 143,42 \\
\hline Alytes obstetricans & 31TEG04 & 100,00 & 156,39 & 74,26 & 33,10 & 5126,21 & 273,53 & 52,28 & 221,25 & \begin{tabular}{|l|}
167,27 \\
\end{tabular} & 222,84 & 223,95 & 94,16 & 632,72 & 98,18 & 23,59 & 32,44 & 219,16 & $\mid 112,16$ & 137,79 & 137,12 \\
\hline Alytes obstetricans & 31TEG06 & 97,00 & 158,23 & 77,35 & \begin{tabular}{|l|l|}
33,63 \\
\end{tabular} & 5215,84 & 278,52 & 51,12 & 227,39 & 168,48 & 225,83 & 226,54 & 94,18 & 597,79 & 93,37 & 22,87 & 32,11 & 207,20 & 107,21 & \begin{tabular}{|l|}
128,67 \\
\end{tabular} & 128,37 \\
\hline Alytes obstetricans & 31TEG07 & 99,00 & 158,76 & 79,15 & 33,82 & 5266,93 & 280,93 & 50,05 & 230,89 & 168,66 & 227,07 & 227,46 & 93,87 & 582,46 & 91,29 & 22,05 & 32,32 & 202,72 & 103,44 & 119,33 & 126,14 \\
\hline Alytes obstetricans & 31TEG08 & 101,00 & 156,38 & 80,48 & 33,99 & 5305,64 & 280,52 & 46,90 & 233,62 & 166,31 & 225,23 & 225,66 & 90,90 & 587,55 & 90,46 & 22,33 & 31,40 & 202,46 & 103,81 & 119,66 & 129,73 \\
\hline Alytes obstetricans & 31TEG09 & 90,00 & 144,42 & 80,68 & 33,90 & 5361,71 & 271,10 & 35,65 & 235,45 & 153,62 & 214,34 & 214,71 & 78,84 & 656,66 & 92,80 & 27,31 & 27,12 & 213,79 & 121,92 & 133,07 & 148,59 \\
\hline Alytes obstetricans & 31TEG13 & 37,00 & 159,26 & 74,63 & 33,92 & 4974,95 & 273,68 & 56,92 & 216,76 & 170,61 & 210,58 & 225,08 & 99,42 & 587,89 & 94,26 & 19,53 & 35,63 & 211,92 & 100,21 & 130,21 & 126,39 \\
\hline Alytes obstetricans & 31TEG14 & 82,00 & 158,10 & 75,46 & 34,12 & 4968,86 & 273,17 & 55,60 & 217,57 & 169,46 & 218,00 & 223,94 & 98,45 & 581,97 & 92,08 & 19,95 & 34,63 & 207,98 & 101,27 & 129,57 & 123,84 \\
\hline Alytes obstetricans & 31TEG17 & 27,00 & 152,47 & 79,42 & 34,11 & 5163,58 & 274,11 & 45,63 & 228,47 & 162,74 & 219,58 & 220,32 & 89,89 & 597,79 & 91,05 & 21,89 & 31,53 & 206,53 & 105,05 & 127,42 & 132,21 \\
\hline Alytes obstetricans & 31TEG18 & 92,00 & 150,02 & 80,18 & 34,19 & 5227,00 & 273,39 & 42,56 & 230,83 & 160,23 & 218,03 & 218,70 & 86,39 & 614,06 & 91,62 & 23,13 & 30,37 & 208,97 & 108,82 & 128,38 & 137,49 \\
\hline Alytes obstetricans & 31TEG19 & 30,00 & 151,89 & 82,00 & 34,39 & 5309,02 & 277,59 & 42,27 & 235,32 & 161,70 & 220,98 & 221,36 & 86,77 & 602,16 & 90,39 & 22,30 & 30,66 & 205,52 & 104,05 & 120,39 & 137,52 \\
\hline Alytes obstetricans & 31TEG28 & 31,00 & 152,98 & 80,93 & 34,83 & 5170,83 & 275,50 & 45,63 & 229,88 & 163,23 & 220,27 & 220,98 & 90,05 & 588,20 & 90,30 & 20,48 & 32,55 & 205,35 & 99,82 & 120,45 & 132,93 \\
\hline Alytes obstetricans & 31TEHOO & 8,00 & 143,60 & 82,49 & 34,1 & 5406,03 & 272,29 & 33,72 & 238,57 & 147,51 & 214,13 & 214,46 & 77,38 & 656,68 & 91,94 & 26,81 & 27,44 & 213,72 & 119,09 & 127,74 & 152,85 \\
\hline Bufo spinosus & $295 M C 69$ & 100,00 & 147,96 & 70,09 & 41,09 & 3488,38 & 238,79 & 70,50 & 168,29 & 111,22 & 189,22 & 193,04 & 102,87 & 825,55 & \begin{tabular}{|c|}
127,97 \\
\end{tabular} & 5,09 & 64,31 & 370,27 & 36,55 & 38,54 & 344,46 \\
\hline Bufo spinosus & 29SMC77 & 7,00 & 165,36 & 77,64 & 41,14 & 3779,50 & 268,86 & 83,14 & 185,71 & 125,50 & 210,64 & 215,21 & 118,00 & 717,43 & 110,43 & 4,00 & 64,07 & 323,64 & 30,07 & 32,79 & 306,79 \\
\hline Bufo spinosus & 29SMC78 & 84,00 & 158,27 & 75,36 & 41,23 & 3702,77 & 257,79 & 77,44 & 180,35 & 119,08 & 202,40 & 206,80 & 111,26 & 771,92 & 120,92 & 4,01 & 64,95 & 348,70 & 31,93 & 34,07 & 328,03 \\
\hline Bufo spinosus & 29SMC79 & 100,00 & 150,21 & 73, & 40,95 & 3685,18 & 248,04 & 70,05 & 177,99 & 11 & 194,26 & 198,41 & 103,30 & 825,94 & 128,66 & 4,51 & 64,91 & 371,05 & 34,95 & 36,68 & 348,66 \\
\hline \begin{tabular}{|l|} 
Bufo spinosus \\
\end{tabular} & $295 \mathrm{SMC} 85$ & 48,00 & 162,61 & 81, & 41,70 & 3901,56 & 272,91 & 79,16 & 193,75 & 122,18 & 209,94 & 214,84 & 114,66 & 712,75 & 108,22 & 3,94 & 63,17 & 318,22 & 31,22 & 33,31 & 304,73 \\
\hline Bufo spinosus & $295 \mathrm{SMC} 86$ & $\begin{array}{l}60,00 \\
60,\end{array}$ & 166 & $\begin{array}{l}81,36 \\
81,36\end{array}$ & 41,33 & 3924,44 & 276,58 & 82,44 & $\begin{array}{l}194,15 \\
\end{array}$ & $\begin{array}{l}125,29 \\
12,2\end{array}$ & 213,76 & 218,67 & 117,97 & 698,01 & \begin{tabular}{|l|l|}
106,28 \\
\end{tabular} & 3,82 & 63,62 & \begin{tabular}{|l|l|l|l|}
313,06 \\
\end{tabular} & $\begin{array}{ll}1,29 \\
29,58\end{array}$ & $\begin{array}{l}3,19 \\
32,19 \\
\end{array}$ & 299,45 \\
\hline Bufo spinosus & 29SMC87 & 85,00 & 166,33 & 80,39 & 41,04 & 3928,81 & 275,72 & 82,47 & 193,25 & 125,15 & 213,91 & 218,71 & 117,74 & 709,73 & 108,26 & 3,85 & 63,78 & 318,88 & 29,62 & 32,39 & 304,79 \\
\hline Bufo spinosus & 29SMC88 & 76,00 & 164,78 & 79,29 & $40,77 \mid$ & 3947,81 & 273,54 & 81,14 & 192,41 & $\mid 123,28$ & 212,72 & 217,3 & 115,89 & 731,80 & $\mid 111,36$ & 3,84 & 63,98 & $\mid 328,19$ & 30,27 & 32.97 & 314,90 \\
\hline Bufo spinosus & $295 M C 89$ & 101,00 & 162,23 & 77,29 & 40,59 & 3890,32 & 267,64 & 79,42 & 188,21 & 121,02 & 209,27 & 213,48 & 113,54 & 744,37 & 113,05 & 3,82 & 64,03 & 33,09 & 30,62 & 33,27 & 318,85 \\
\hline \begin{tabular}{|l} 
Bufo spinosus \\
\end{tabular} & $295 \mathrm{SMC} 95$ & 57,00 & 161 & 83 & & & 277,25 & 76, & & $12 C$ & & 21 & 6 & 112 & 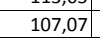 & 3, & 77 & 316,56 & 31,18 & 33,15 & 305,23 \\
\hline Bufo spinosus & 29SMC96 & 101,00 & 166,61 & 83,55 & 41,10 & 4057,78 & 281,52 & 81,08 & 200,44 & 124,31 & 216,16 & 221,07 & 116,95 & 689,66 & 104,09 & 3,57 & 63,35 & 308,21 & 28,87 & 31,62 & 296,61 \\
\hline Bufo spinosus & 29SMC97 & 83,00 & 169,59 & 82,84 & 41,01 & 4055,47 & 283,64 & 84,10 & 199,54 & 127,08 & 219,11 & 223,74 & 119,69 & 677,60 & 102,26 & 3,02 & 63,56 & 303,42 & 27,61 & 30,84 & 291,77 \\
\hline Bufo spinosus & 29SMD60 & 71,00 & 150,13 & 67,85 & \begin{tabular}{ll|l}
41,05 & \\
\end{tabular} & 3399,25 & 237,06 & 73,70 & 163,36 & 114,29 & 190,23 & 193,60 & 105,75 & 791,66 & 123,77 & 4,56 & 64,30 & 356,92 & 33,85 & 36,46 & 330,30 \\
\hline Bufo spinosus & 29SMD61 & 56,00 & 151,29 & 65,25 & 41,09 & 3287,54 & 233,99 & 76,85 & \begin{tabular}{|l|l|}
157,14 \\
\end{tabular} & 116,75 & \begin{tabular}{ll|l}
189,82 & \\
\end{tabular} & 193,05 & 108,30 & 756,94 & 120,51 & 4,18 & 63,64 & 78 & 32,10 & 35,60 & 314,88 \\
\hline \begin{tabular}{|l} 
Bufo spinosus \\
\end{tabular} & 29SMD63 & 9,00 & 153,06 & 59,78 & 41,09 & 3022,06 & 226,25 & 82,44 & 143,81 & 121,75 & $\begin{array}{l}188,06 \\
\end{array}$ & 190,53 & 113,19 & 692,31 & 114,81 & 4,00 & 62,66 & 310,81 & 29,66 & 34,88 & 285,31 \\
\hline Bufo spinosus & 29SMD70 & 101,00 & 148,41 & 71,26 & 40,70 & 3610,41 & 242,95 & 69,60 & $\begin{array}{l}173,35 \\
\end{array}$ & 110,39 & 191,61 & 195,28 & 102,18 & 819,75 & 125,51 & 4,69 & 64,12 & 366,94 & 35,28 & 37,52 & 344,42 \\
\hline Bufo spinosus & 29SMD71 & 100,00 & 150,71 & 68,40 & 40,60 & 3472,66 & 240,14 & 73,81 & 166,34 & 114,08 & 192,05 & 195,36 & 105,94 & 776,94 & 121,19 & 4,36 & 63,53 & 348,12 & 33,01 & 36,16 & 325,55 \\
\hline Bufo spinosus & 29SMD73 & 101,00 & 153,51 & 62,06 & 41,03 & 3133,32 & 231,06 & 81,41 & 149,66 & 120,85 & 190,32 & 193,01 & 112,66 & 696,19 & 114,21 & 4,00 & 62,63 & 311,64 & 29,42 & 34,60 & 288,44 \\
\hline Bufo spinosus & $295 M D 74$ & 88,00 & 151,73 & 59,61 & 41,0 & 3010,96 & 224,95 & 81 & 143, & 120 & & 189 & & 688,41 & \begin{tabular}{|l|l|}
114,38 \\
\end{tabular} & 3,95 & 62,44 & 306,13 & 29,59 & 35,33 & 283,54 \\
\hline \begin{tabular}{|l} 
Bufo spinosus \\
\end{tabular} & $295 M D 75$ & 89,00 & 151,32 & 57,80 & 41,23 & 2903,17 & 220,92 & 82,61 & 138,31 & 121,57 & 185,03 & 187,33 & 113,25 & 677,61 & 113,71 & 3,95 & 62,35 & 300,55 & 29,35 & $\begin{array}{l}35,85 \\
35\end{array}$ & 277,62 \\
\hline
\end{tabular}




\begin{tabular}{|c|c|c|c|c|c|c|c|c|c|c|c|c|c|c|c|c|c|c|c|c|c|}
\hline TAXON & UTM & $\mathrm{km} 2$ & B101 & B102 & $\mathrm{BIO3}$ & B104 & BIO5 & B106 & B107 & B108 & B109 & B1010 & BIO11 & B1012 & B1013 & BIO14 & B1015 & BIO16 & BIO17 & B1018 & B1019 \\
\hline Bufo spinosus & 29SMD80 & 101,00 & 155,19 & 74,75 & 40,26 & 3803,25 & 256,91 & 73,98 & 182,93 & 115,18 & 201,22 & 205,14 & 107,34 & 778,76 & 117,50 & 4,20 & 63,64 & 346,89 & 32,86 & 35,49 & 330,61 \\
\hline Bufo spinosus & 29SMD81 & 101,00 & 150,37 & 72,32 & 40,14 & 3700,78 & 248,21 & 70,74 & 177,47 & 111,64 & 195,10 & 198,73 & 103,66 & 795,14 & 120,81 & 4,60 & 62,82 & 352,42 & 34,73 & 37,59 & 335,04 \\
\hline Bufo spinosus & 29SMD82 & 101,00 & 153,03 & 69,44 & 40,40 & 3534,30 & 244,96 & 75,42 & 169,54 & 116,00 & 195,51 & 198,77 & 108,01 & 749,30 & 116,86 & 4,18 & 62,60 & 333,04 & 32,12 & 35,86 & 314,60 \\
\hline Bufo spinosus & 29SMD83 & 100,00 & 153,13 & 66,84 & \begin{tabular}{|l|l|}
40,67 \\
\end{tabular} & 3384,17 & 239,89 & 77,50 & 162,39 & 117,72 & 193,62 & 196,54 & 109,72 & 725,88 & 115,35 & 4,19 & 62,31 & 322,08 & 31,21 & 35,70 & 303,04 \\
\hline Bufo spinosus & 29SMD84 & 101,00 & 154,34 & 64,55 & 40,99 & 3237,16 & 236,09 & \begin{tabular}{|l|l|}
80,47 \\
\end{tabular} & 155,62 & 120,55 & \begin{tabular}{|l|}
192,73 \\
\end{tabular} & 195,36 & 112,40 & 698,05 & 113,05 & 4,00 & 62,10 & 309,29 & 30,02 & 35,43 & 289,73 \\
\hline Bufo spinosus & 29SMD85 & 99,00 & 153,92 & 63,22 & 41,25 & $\begin{array}{ll}3141,44 \\
\end{array}$ & 232,59 & 81,14 & 151,45 & 121,16 & 190,92 & 193,39 & 113,04 & 693,97 & 113,00 & 4,06 & 61,81 & 305,79 & 30,54 & 36,53 & 286,46 \\
\hline Bufo spinosus & 29SMD86 & 79,00 & 154,64 & 62,85 & 41,60 & 3081,51 & 231,56 & 82,21 & 149,35 & 122,49 & 190,84 & 193,19 & 114,37 & 691,11 & 112,46 & 4,04 & 61,43 & 302,84 & 30,71 & 37,30 & 284,19 \\
\hline \begin{tabular}{|l} 
Bufo spinosus \\
\end{tabular} & 29SMD90 & 83,00 & 162,53 & 77,54 & 40,45 & 3918,62 & 268,93 & 79,41 & 189,52 & 121,24 & 210,21 & 214,18 & 113,53 & 723,44 & 109,03 & 3,60 & 63,15 & 321,26 & 30,05 & 33,21 & 308,79 \\
\hline Bufo spinosus & 29SMD91 & 101,00 & 156,95 & 75,62 & 40,22 & 3847,59 & 260,60 & 75,08 & 185,53 & 116,65 & 203,88 & 207,54 & 108,80 & 750,88 & 113,34 & 4,19 & 62,47 & 331,62 & 32,32 & 35,53 & 318,31 \\
\hline Bufo spinosus & 29SMD93 & 101,00 & 152,29 & 71,58 & 40,51 & 3628,03 & 248,35 & 73,27 & $\begin{array}{l}175,08 \\
\end{array}$ & 114,35 & 196,21 & 199,45 & 106,42 & 760,12 & 116,88 & 4,63 & 61,56 & 333,05 & 34,29 & 38,16 & 318,27 \\
\hline Bufo spinosus & 29SMD94 & 100,00 & 154,66 & 69,63 & 40,84 & 3484,84 & 245,83 & 77,01 & 168,82 & 118,17 & 196,54 & 199,51 & 110,10 & 725,66 & 113,71 & 4,11 & 61,57 & 318,32 & \begin{tabular}{|c|}
32,08 \\
\end{tabular} & 36,79 & 302,73 \\
\hline Bufo spinosus & 29SMD95 & 101,00 & 154,16 & 68,46 & 41,02 & 3399,61 & 242,54 & 77,46 & 165,08 & 118,55 & 194,88 & 197,66 & 110,52 & 724,99 & 114,07 & 4,23 & 61,16 & 316,49 & 32,79 & 38,09 & 300,91 \\
\hline \begin{tabular}{|l} 
Bufo spinosus \\
\end{tabular} & 29SMD96 & 101,00 & 153,52 & 67,99 & $\begin{array}{l}41,25 \\
\end{array}$ & 3337,48 & 240,05 & 77,19 & 162,86 & 118,46 & 193,38 & 195,98 & 110,44 & 732,84 & 115,06 & 4,58 & 60,60 & 317,84 & 34,29 & 40,05 & 302,60 \\
\hline Bufo spinosus & 29SMD98 & 58,00 & 154,47 & 68,99 & 42,01 & 3275,73 & 239,79 & 77,49 & 162,30 & 119,74 & 193,37 & 195,76 & 111,73 & 752,49 & 116,18 & 5,30 & 59,35 & 321,62 & 37,58 & 44,10 & 307,90 \\
\hline Bufo spinosus & 29SMD99 & 35,00 & 152,45 & 70,03 & 42,11 & 3291,15 & 238,72 & 74,76 & 163,96 & 117,54 & 191,64 & 194,07 & 109,53 & 788,54 & 119,77 & 6,00 & 58,43 & 334,07 & 41,22 & 47,77 & 321,45 \\
\hline Bufo spinosus & 29SNB12 & 83,00 & 163,34 & 86,34 & 44,66 & 3628,14 & 271,70 & 80,42 & 191,27 & 128,07 & 207,95 & 212,23 & 119,51 & 516,43 & 83,19 & 1,00 & 68,47 & 241,95 & 18,35 & 19,41 & 231,30 \\
\hline Bufo spinosus & $29 \mathrm{SNB} 13$ & 51,00 & 165,90 & 86,91 & $\begin{array}{l}44,25 \\
\end{array}$ & 3706,64 & 276,06 & 81,89 & 194,17 & 129,33 & 211,51 & 215,80 & 121,01 & 513,94 & 82,24 & 1,00 & 68,10 & 240,26 & 18,46 & 19,60 & 229,58 \\
\hline Bufo spinosus & 29SNB14 & 19,00 & 166,42 & 87,92 & 44,00 & 3803,89 & 279,44 & 81,19 & 198,25 & 128,75 & 213,33 & 217,72 & 120,36 & 522,64 & 82,56 & 1,00 & 67,69 & 243,06 & 18,89 & 19,89 & 232,81 \\
\hline Bufo spinosus & 29SNB16 & 24,00 & 167,33 & 88,92 & 43,73 & 3885,90 & 282,76 & 81,06 & 201,69 & 128,55 & 215,29 & 219,73 & 120,39 & 539,57 & 83,76 & 1,00 & 66,53 & 248,24 & 20,00 & 21,00 & 238,41 \\
\hline Bufo spinosus & 29SNB17 & 20,00 & 167,92 & 89,56 & 43,36 & 3939,44 & 285,08 & 81,17 & 203,92 & 128,25 & 216,47 & 221,03 & 120,08 & 549,53 & 84,28 & 1,56 & 65,78 & 250,86 & 21,03 & 22,08 & 241,44 \\
\hline Bufo spinosus & 29SNB19 & 31,00 & 168,49 & 90,07 & 43,00 & 4041,32 & 288,02 & 80,83 & 207,20 & 127,34 & 218,22 & 222,93 & 119,46 & 569,29 & 86,15 & 2,00 & 64,95 & 257,37 & 22,49 & 23,78 & 248,22 \\
\hline Bufo spinosus & 29 SNB21 & 101,00 & 166,71 & 86,81 & 43,34 & 3809,92 & 278,55 & 80,58 & 197,97 & 129,16 & 214,36 & 218,16 & 120,69 & 498,75 & 80,82 & 0,90 & 69,59 & 237,30 & 16,71 & 17,97 & 225,62 \\
\hline Bufo spinosus & 29SNB22 & 101,00 & 159,48 & 88,59 & \begin{tabular}{|l|l|}
43,57 \\
\end{tabular} & 3863,33 & 274,21 & 73,06 & 201,15 & 121,65 & 207,70 & 211,89 & 113,22 & 545,39 & 86,20 & 1,08 & 67,90 & 254,36 & $\begin{array}{ll}19,78 \\
\end{array}$ & 20,69 & 243,97 \\
\hline Bufo spinosus & 29SNB23 & 101,00 & 160,57 & 89,23 & 43,49 & 3904,89 & 276,69 & 73,70 & 202,99 & 122,19 & 209,27 & 213,56 & 113,87 & 548,35 & 86,14 & 1,15 & 67,36 & 254,48 & \begin{tabular}{|l|l|}
20,17 \\
\end{tabular} & 21,04 & 244,38 \\
\hline Bufo spinosus & 29SNB24 & 100,00 & 162,44 & 89,79 & 43,41 & 3953,88 & 280,03 & 75,26 & 204,76 & 123,45 & 211,84 & 216,11 & 115,18 & 546,36 & 85,42 & 1,08 & 67,06 & 252,79 & 20,07 & 20,88 & 242,88 \\
\hline Bufo spinosus & 29SNB25 & 100,00 & 164,72 & 90,25 & 43,24 & 3981,16 & 283,08 & 77,15 & 205,94 & 125,25 & 214,24 & 218,62 & 116,82 & 543,22 & 84,29 & 1,00 & 66,73 & 250,47 & 20,04 & 20,94 & 240,79 \\
\hline Bufo spinosus & 29SNB26 & 101,00 & 167,37 & 90,54 & | 43,07 & 4006,83 & 286,40 & 79,38 & 207,03 & 127,37 & 217,05 & 221,60 & $\begin{array}{l}119,02 \\
119\end{array}$ & \begin{tabular}{|l|l|}
539,28 \\
\end{tabular} & $\begin{array}{l}4,43,16 \\
83\end{array}$ & 1,06 & 66,34 & 247,82 & $\begin{array}{l}20,04 \\
20,04\end{array}$ & 21,07 & 238,29 \\
\hline Bufo spinosus & 29SNB27 & 101,00 & 164,85 & 91,51 & 43,02 & 4077,94 & 286,17 & 76,15 & 210,02 & 124,01 & 215,44 & 219,99 & 115,74 & 565,10 & 86,24 & 1,72 & 65,40 & 256,79 & 22,20 & 22,99 & 248,03 \\
\hline Bufo spinosus & 29SNB28 & 101,00 & 163,45 & 91,99 & 42,92 & 4134,08 & 286,67 & 74,44 & 212,23 & 121,86 & 214,92 & 219,54 & 113,86 & 584,01 & 88,30 & 2,00 & 64,69 & 263,26 & 23,58 & 24,30 & 255,08 \\
\hline Bufo spinosus & 29 SNB29 & 101,00 & 164,16 & 92,20 & 42,84 & 4175,37 & 288,44 & 74,92 & 213,52 & 122,01 & 216,06 & 220,71 & 113,97 & 590,88 & 88,76 & 2,00 & 64,15 & 265,09 & 24,11 & 24,86 & 257,27 \\
\hline Bufo spinosus & $29 \mathrm{SNB} 30$ & 26,00 & 171,04 & 87,22 & 42,22 & 3973,35 & 285,61 & 82,09 & 203,52 & 131,74 & 221,13 & 224,74 & 123,26 & 482,91 & 78,78 & 0,48 & 70,65 & 233,09 & 14,83 & 16,48 & 220,22 \\
\hline \begin{tabular}{|l} 
Bufo spinosus \\
\end{tabular} & $29 \mathrm{SNB} 31$ & 100,00 & 169,93 & 88,04 & 42,32 & 3993,05 & 285,92 & 80,82 & 205,09 & 130,58 & 220,37 & 224,08 & 121,95 & 491,29 & 79,47 & 0,87 & 69,85 & 235,53 & $\begin{array}{l}15,71 \\
\end{array}$ & 17,27 & 223,19 \\
\hline Bufo spinosus & 29SNB32 & 100,00 & 157,21 & 90,43 & 42,89 & 4051,06 & 276,71 & 68,08 & 208,63 & 117,62 & 208,32 & 212,39 & 109,04 & 568,47 & 89,90 & 1,46 & 67,30 & 263,84 & 21,14 & 22,08 & 253,54 \\
\hline Bufo spinosus & 29SNB33 & 101,00 & 153,17 & 91,73 & 42,96 & 4104,42 & 275,13 & 63,85 & 211,28 & 113,12 & 205,01 & 209,21 & 104,51 & 597,67 & 93,49 & 1,78 & 66,16 & 273,78 & 23,43 & 24,04 & 264,44 \\
\hline Bufo spinosus & 29 SNB34 & 100,00 & 160,98 & 91,92 & 42,89 & 4116,92 & 283,24 & 71,08 & 212,15 & 120,35 & 212,75 & 217,05 & 111,80 & 557,87 & 87,50 & 1,29 & 66,59 & 257,51 & 20,82 & 21,67 & 247,82 \\
\hline Bufo spinosus & 29 SNB35 & 101,00 & 167,48 & 91,98 & 42,96 & 4111,58 & 289,42 & 77,29 & 212,13 & 126,46 & 219,01 & 223,26 & 118,07 & 528,77 & 82,62 & 1,01 & 67,01 & 244,88 & 19,08 & 20,13 & 235,08 \\
\hline Bufo spinosus & 29SNB36 & $\begin{array}{l}101,00 \\
100\end{array}$ & $\begin{array}{l}10,40 \\
165,93\end{array}$ & $\begin{array}{l}1,00 \\
92,97\end{array}$ & 年 42,95 & $\begin{array}{ll}4111,50 \\
4165,94\end{array}$ & $\begin{array}{l}20,42 \\
289,95\end{array}$ & $\begin{array}{l}75,37 \\
75,37\end{array}$ & \begin{tabular}{|l|}
214,58 \\
213
\end{tabular} & \begin{tabular}{|l|}
124,09 \\
1240
\end{tabular} & $\mid$ & 222,40 & \begin{tabular}{|l|}
115,90 \\
150
\end{tabular} & 546,52 & $\begin{array}{l}2,0<2 \\
84,50\end{array}$ & $\frac{1,01}{1,23}$ & $\begin{array}{l}66,02 \\
66,\end{array}$ & 2540,43 & $\begin{array}{l}1,0,02 \\
20,62\end{array}$ & $\frac{20,150}{21,50}$ & $\begin{array}{l}25,01,41 \\
241\end{array}$ \\
\hline Bufo spinosus & 29SNB37 & 100,00 & 164,94 & 93,73 & 42,83 & 4219,59 & 290,82 & 74,07 & 216,75 & 122,57 & 217,72 & 222,23 & 114,44 & 561,68 & 85,97 & 1,82 & 65,17 & 254,92 & 22,07 & 22,89 & 246,65 \\
\hline Bufo spinosus & 295NB38 & 101,00 & 165,56 & 94,17 & $\mid 42,70$ | & 4258.45 & 292,73 & 74,44 & 218,29 & $\mid 122,77$ & $\mid 218,79$ & 223,35 & $\mid 114,49$ & 567.57 & 86,11 & 2,00 & 64.57 & 256,00 & 22,76 & 23,43 & 248,21 \\
\hline Bufo spinosus & 29SNB39 & 100,00 & 165,48 & 94,48 & 42,38 & 4301,43 & 293,85 & 74,15 & 219,70 & 122,07 & 219,27 & 223,98 & 114,02 & 576,49 & 86,88 & 2,00 & 64,22 & 258,47 & 23,19 & 24,02 & 251,19 \\
\hline \begin{tabular}{|l} 
Bufo spinosus \\
\end{tabular} & 29SNB40 & 40,00 & 169,94 & 88,87 & 42,02 & 4031,70 & 286,43 & 79,40 & 207,02 & 130,30 & 221,06 & 224,83 & 121,79 & 494,32 & 81,45 & 1,00 & 69,98 & 238,64 & 15,89 & 17,36 & 225,43 \\
\hline \begin{tabular}{|l} 
Bufo spinosus \\
\end{tabular} & 29SNB41 & 101,00 & 170,42 & 89,54 & 42,32 & 4071,24 & 288,31 & 79,58 & 208,73 & 130,01 & 221,89 & 225,72 & 121,66 & 494,19 & 80,91 & 1,00 & 69,76 & 237,45 & 15,99 & 17,53 & 224,66 \\
\hline Bufo spinosus & 29 SNB42 & 101,00 & 163,34 & 91,49 & 42,31 & 4153,20 & 284,97 & 71,88 & 213,09 & 122,27 & 215,89 & 219,81 & 113,77 & 536,63 & 86,44 & 1,15 & 68,24 & 252,48 & 18,58 & 19,76 & 241,22 \\
\hline Bufo spinosus & 29SNB43 & 100,00 & 158,19 & 93,15 & 42,49 & 4219,30 & 282,90 & 66,29 & 216,61 & 116,56 & 211,49 & 215,67 & 108,04 & 570,05 & 90,55 & 1,33 & 66,86 & 263,84 & 21,04 & 21,89 & 253,89 \\
\hline Bufo spinosus & 29SNB44 & 101,00 & 165,33 & 93,32 & 42,4 & 4231,12 & 290,31 & 73,10 & 217,20 & 123,17 & 218,62 & 222,87 & 114,75 & 534,47 & 84,80 & 1,00 & 67,20 & 48,69 & 18,80 & 19,94 & 238,53 \\
\hline Bufo spinosus & 29SNB45 & 101,00 & 165,68 & 94,29 & $\frac{42}{42}$ & $\begin{array}{l}4251,12 \\
4266,08\end{array}$ & 292,32 & 73,34 & 218,98 & 122,99 & 219,44 & 223,80 & $\begin{array}{l}144,73 \\
14,\end{array}$ & \begin{tabular}{|l|l|}
538,78 \\
\end{tabular} & $\begin{array}{l}4,, 606 \\
84,63\end{array}$ & 1,02 & $\begin{array}{l}66,67 \\
6,2\end{array}$ & 248,75 & 19,45 & 20,42 & 239,24 \\
\hline Bufo spinosus & 29SNB46 & 100,00 & 161,56 & 95,68 & 42,42 & 4340,36 & 291,18 & 68,73 & 222,45 & 118,32 & 216,23 & 220,75 & 109,95 & 570,36 & 88,19 & 1,79 & 65,12 & 258,97 & 22,44 & 23,13 & 250,85 \\
\hline Bufo spinosus & 29SNB47 & 100,00 & 163,18 & 96,28 & 42,48 & 4369,40 & 293,99 & 70,04 & 223,95 & 119,40 & 218,06 & 222,73 & 111,14 & 569,30 & 87,22 & 2,00 & 64,67 & 257,01 & 22,82 & 23,42 & 249,30 \\
\hline Bufo spinosus & 29SNB48 & 101,00 & 167,66 & 96,33 & 42,62 & 4369,44 & 298,26 & 74,38 & 223,87 & 123,46 & 222,40 & 226,92 & 115,25 & 551,81 & 83,96 & 2,00 & 64,54 & 248,81 & 21,95 & 22,84 & 241,24 \\
\hline Bufo spinosus & 29SNB49 & 101,00 & 168,13 & 96,77 & 42,3 & 4402,72 & 299,73 & 74,62 & 225,11 & 123,45 & 223,21 & 227 & 115,34 & 557,31 & 84,01 & 2,00 & 64,01 & 249,32 & 22,72 & 23,49 & 242,42 \\
\hline Bufo spinosus & 29SNB51 & $\begin{array}{l}100,00 \\
100\end{array}$ & $\begin{array}{l}100,15 \\
169,62\end{array}$ & 90,95 & - 42,34 & 440435,12 & 289,13 & $\begin{array}{ll}77,28 \\
77,28\end{array}$ & \begin{tabular}{|l|}
211,85 \\
21,1
\end{tabular} & \begin{tabular}{|l|}
128,81 \\
128
\end{tabular} & $\begin{array}{l}221,94 \\
221 \\
\end{array}$ & \begin{tabular}{|l|}
225,75 \\
200
\end{tabular} & $\begin{array}{l}120,05 \\
120,\end{array}$ & \begin{tabular}{|l|}
502,62 \\
502
\end{tabular} & $\begin{array}{l}43,101 \\
83,26\end{array}$ & $\frac{1,00}{1,00}$ & $\begin{array}{l}69,10 \\
69,36\end{array}$ & $\begin{array}{l}24,24 \\
241,57\end{array}$ & 16,27 & $\begin{array}{l}20,45 \\
18,05 \\
\end{array}$ & 228,45 \\
\hline Bufo spinosus & 29SNB52 & 101,00 & 164,37 & 92,97 & 42,21 & 4241,13 & 288,17 & 71,28 & 216,89 & 122,52 & 218,10 & 222,13 & 113,81 & 533,03 & 86,93 & 1,00 & 68,19 & 251,74 & 17,99 & 19,46 & 240,04 \\
\hline Bufo spinosus & 29SNB53 & 100,00 & 164,55 & 94,13 & 42,08 | & 4297,53 & 290,68 & 70,92 & 219,76 & $\mid 121,89$ & 218,86 & 223,08 & 113,30 & 535,86 & 86,47 & 1.00 & 67,62 & 251,14 & 18,31 & 19,68 & 240,12 \\
\hline Bufo spinosus & 29 SNB54 & 101,00 & 161,55 & 95,59 & 42,24 & 4358,38 & 290,54 & 67,43 & 223,11 & 118,29 & 216,73 & 220,94 & 109,71 & 557,76 & 88,57 & 1,26 & 66,41 & 257,43 & 20,39 & 21,41 & 247,70 \\
\hline Bufo spinosus & 29 SNB55 & 100,00 & 162,91 & 96,57 & 42,24 & 4398,71 & 293,67 & 68,26 & 225,41 & 118,99 & 218,50 & 222,80 & 110,58 & 555,57 & 87,30 & 1,36 & 65,95 & 254,66 & 20,70 & 21,57 & 245,62 \\
\hline \begin{tabular}{|l} 
Bufo spinosus \\
\end{tabular} & 29 SNB56 & 101,00 & 159,93 & 97,96 & 42,07 & 4473,81 & 293,72 & 64,86 & 228,86 & \begin{tabular}{l|l|}
115,26 \\
\end{tabular} & 216,56 & 221,03 & 106,94 & | 579,15 & 89,53 & 2,00 & 64,59 & 261,53 & 23,14 & 23,72 & 253,80 \\
\hline Bufo spinosus & 29SNB57 & 101,00 & 165,13 & 98,47 & 42,25 & 4481,33 & 299,41 & 69,77 & 229,64 & 119,95 & 221,66 & 226,18 & 111,69 & 554,76 & 85,12 & 1,99 & 64,53 & 250,30 & 21,91 & 22,56 & 242,74 \\
\hline Bufo spinosus & 29SNB58 & 100,00 & 167.38 & 98,91 & 42,36 & 4491.59 & 302.26 & 7200 & 230,26 & $\mid 121.99$ & 223.90 & 228.48 & 113,80 & 548.53 & 83,37 & 200 & 64.49 & 246,13 & 21.50 & 22,24 & 239,15 \\
\hline Bufo spinosus & 29SNB59 & 100,00 & 168,86 & 99,21 & 42,32 & 4520,42 & 304,48 & 73,29 & 231,19 & 122,86 & 225,62 & 230, & 114 & 547,27 & 82,53 & 2,00 & 63,86 & 244,05 & 22,02 & 22,64 & 237,48 \\
\hline Bufo spinosus & 29 SNB62 & 100,00 & 164,87 & 94,21 & 42,18 & 4299,61 & 290,15 & 70,25 & 219,91 & 122,35 & 219,43 & 223,56 & 113,72 & 533,42 & 87,70 & 1,01 & 68,11 & 252,20 & 17,90 & 19,49 & 240,04 \\
\hline
\end{tabular}




\begin{tabular}{|c|c|c|c|c|c|c|c|c|c|c|c|c|c|c|c|c|c|c|c|c|c|}
\hline TAXON & UTM & $\mathrm{km} 2$ & B101 & B102 & $\mathrm{BIO3}$ & B104 & B105 & B106 & B107 & B108 & B109 & B1010 & BIO11 & BIO12 & BIO13 & BIO14 & BIO15 & B1016 & B1017 & BIO18 & B1019 \\
\hline Bufo spinosus & 29SNB63 & 101,00 & 160,97 & 95,93 & 42,07 & 4400,78 & 290,09 & 65,53 & 224,56 & 117,48 & 216,88 & 221,05 & 108,72 & 558,03 & 89,99 & 1,27 & 66,82 & 259,41 & 19,80 & 21,14 & 248,62 \\
\hline Bufo spinosus & 29SNB64 & 100,00 & 158,55 & 97,46 & 42,01 & 4485,71 & 291,07 & 62,47 & 228,60 & 114,12 & 215,45 & 219,80 & 105,29 & 576,21 & 91,25 & 1,79 & 65,55 & 263,75 & 21,95 & 23,02 & 254,29 \\
\hline Bufo spinosus & 29 SNB65 & 100,00 & 162,17 & 98,47 & 42,03 & 4511,04 & 296,07 & 65,55 & 230,53 & 117,11 & 219,31 & 223,70 & 108,42 & 559,05 & 87,77 & 1,70 & 65,36 & 255,09 & 20,98 & 22,00 & 246,12 \\
\hline Bufo spinosus & 29SNB66 & 101,00 & 162,98 & 99,69 & 42,06 & 4555,55 & 299,11 & 66,03 & 233,08 & 117,41 & 220,63 & 225,06 & 108,82 & 559,86 & 86,75 & 1,99 & 64,56 & 253,15 & 21,71 & 22,47 & 245,11 \\
\hline Bufo spinosus & 29SNB67 & 100,00 & 165,05 & 100,68 & 42,10 & $\begin{array}{lll}4589,97 \\
\end{array}$ & 302,86 & 67,74 & 235,12 & 118,94 & 223,03 & 227,53 & 110,40 & 553,32 & 84,75 & 2,00 & 64,32 & 248,44 & 21,63 & 22,47 & 241,14 \\
\hline Bufo spinosus & 29SNB68 & 101,00 & 164,04 & 101,89 & 42,18 & 4647,18 & 304,28 & 66,41 & 237,87 & 117,29 & 222,77 & 227,32 & 108,81 & 564,32 & 85,29 & 2,00 & 63,15 & 250,55 & 23,05 & 23,58 & 244,48 \\
\hline Bufo spinosus & 29SNB69 & 101,00 & 167,56 & 102,06 & \begin{tabular}{|l|l|}
42,17 \\
\end{tabular} & 4654,46 & 307,85 & 69,73 & 238,13 & 120,29 & 226,15 & 230,81 & 111,92 & 549,62 & 82,76 & 2,00 & 63,20 & 243,19 & 22,15 & 23,03 & 237,45 \\
\hline \begin{tabular}{|l} 
Bufo spinosus \\
\end{tabular} & 29SNB71 & 100,00 & 165,37 & 93,75 & 42,25 & 4281,43 & 288,74 & 70,12 & 218,62 & 123,08 & 219,68 & 223,82 & 114,36 & 532,25 & 89,16 & 1,00 & 68,54 & 253,83 & 17,50 & 19,48 & 240,31 \\
\hline Bufo spinosus & 29SNB72 & 101,00 & 158,56 & 95,96 & 42,03 & 4413,77 & 287,27 & 62,45 & 224,82 & 114,93 & 214,69 & 218,96 & 106,39 & 571,05 & 92,86 & 1,49 & 66,85 & 265,98 & 20,14 & 21,88 & 254,31 \\
\hline Bufo spinosus & 29SNB73 & 101,00 & 155,11 & 97,55 & 42,01 & 4511,24 & 287,61 & 58,42 & 229,19 & 110,50 & 212,56 & 216,92 & 102,06 & 594,00 & 94,58 & 1,85 & 65,52 & 272,01 & 22,33 & 23,79 & 261,73 \\
\hline Bufo spinosus & 29 SNB74 & 100,00 & 155,46 & 98,99 & 42,00 & 4582,57 & 290,88 & 57,98 & 232,90 & 109,87 & 213,81 & 218,20 & 101,36 & \begin{tabular}{|l|l|}
595,08 \\
\end{tabular} & 93,54 & 2,00 & 64,75 & 269,91 & 23,20 & 24,36 & 260,62 \\
\hline Bufo spinosus & 29SNB75 & 101,00 & 159,78 & 100,28 & 42,00 & 4621,93 & 297,04 & 61,54 & 235,50 & 113,35 & 218,43 & 222,83 & 105,05 & 572,95 & 89,41 & 2,00 & 64,65 & 259,20 & 22,04 & 23,10 & 250,47 \\
\hline \begin{tabular}{|l} 
Bufo spinosus \\
\end{tabular} & 29SNB76 & 100,00 & 161,25 & 101,73 & 42,01 & 4676,71 & 301,01 & 62,32 & 238,69 & 114,21 & 220,53 & 224,98 & 105,82 & 567,53 & 87,48 & 2,00 & 63,97 & 254,77 & 22,03 & 23,01 & 247,03 \\
\hline Bufo spinosus & 29SNB77 & 101,00 & 162,11 & 103,12 & 42,01 & 4726,24 & 304,26 & 62,65 & 241,60 & 114,45 & 221,96 & 226,48 & 106,06 & 566,85 & 86,19 & 2,00 & 63,50 & 252,11 & 22,82 & 23,23 & 245,35 \\
\hline Bufo spinosus & 29SNB78 & 100,00 & 163,24 & 104,39 & \begin{tabular}{|l|l|}
42,08 \\
\end{tabular} & 4765,14 & 307,41 & 63,36 & 244,05 & 115,13 & 223,53 & 228,26 & 106,63 & 564,42 & 85,12 & 2,00 & 63,00 & 248,94 & 23,12 & 23,48 & 243,17 \\
\hline Bufo spinosus & 29 SNB80 & 97,00 & 169,36 & 92,45 & 42,75 & 4192,89 & 288,39 & 74,36 & 214,03 & 128,18 & 222,39 & 226,50 & 119,50 & 515,13 & 88,79 & 1,00 & 69,74 & 249,99 & 15,82 & 18,36 & 234,58 \\
\hline Bufo spinosus & $29 \mathrm{SNB} 81$ & 101,00 & 162,83 & 94,57 & 42,07 & 4366,06 & 287,94 & 66,33 & 221,61 & 119,65 & 218,25 & 222,48 & 111,04 & 548,10 & 91,22 & 1,09 & 67,97 & 259,42 & 18,07 & 20,46 & 245,71 \\
\hline Bufo spinosus & 29SNB82 & 101,00 & 157,12 & 96,63 & 41,94 & 4496,11 & 287,34 & 59,58 & 227,76 & 112,64 & 214,29 & 218,59 & 103,89 & 581,80 & 93,91 & 1,63 & 66,26 & 269,03 & 20,85 & 22,90 & 257,09 \\
\hline Bufo spinosus & 29SNB83 & 99,00 & 153,72 & 98,40 & 41,99 & 4596,25 & 288,04 & 55,56 & 232,47 & 108,30 & 212,29 & 216,57 & 99,42 & 603,65 & 95,34 & 2,03 & 64,86 & 274,47 & 22,96 & 24,69 & 264,03 \\
\hline Bufo spinosus & 29SNB84 & 101,00 & 156,82 & 99,72 & 41,99 & 4649,05 & 293,62 & 58,02 & 235,60 & 110,58 & 215,99 & 220,47 & 101,90 & 587,33 & 91,97 & 2,00 & 64,52 & 265,77 & 22,60 & 24,20 & 255,97 \\
\hline Bufo spinosus & 29SNB85 & 101,00 & 160,15 & 101,33 & 42,00 & 4701,10 & 299,33 & 60,68 & 238,64 & 113,07 & 219,98 & 224,36 & 104,50 & 569,56 & 88,36 & 2,00 & 64,34 & 256,54 & 21,87 & 23,07 & 247,50 \\
\hline Bufo spinosus & 29SNB87 & 101,00 & 164,19 & 104,66 & 42,02 & 4802,14 & 308,43 & 63,30 & 245,14 & 115,60 & 225,09 & 229,45 & 107,14 & 552,20 & 83,83 & 2,00 & 63,11 & 244,63 & 22,16 & 23,00 & 237,50 \\
\hline Bufo spinosus & 29SNB88 & 101,00 & 164,83 & 106,41 & \begin{tabular}{l|l}
42,05 \\
\end{tabular} & $\begin{array}{lll}4854,87 \\
\end{array}$ & 311,95 & 63,26 & 248,70 & 115,54 & 226,35 & 230,92 & \begin{tabular}{|l|}
107,07 \\
\end{tabular} & 551,99 & 83,25 & 2,00 & 62,32 & 242,05 & 22,81 & 23,29 & 236,15 \\
\hline Bufo spinosus & 29 SNB90 & 101,00 & 167,65 & 92,61 & 42,31 & 4268,22 & 287,80 & 71,63 & 216,17 & 125,45 & 221,67 & 225,81 & 116,87 & 525,16 & 88,98 & 1,00 & 69,10 & 252,34 & 16,11 & 19,09 & 236,77 \\
\hline Bufo spinosus & 29SNB91 & 101,00 & 158,51 & 95,20 & 41,90 & 4472,75 & 285,95 & 60,85 & 225,10 & 114,12 & 215,32 & 219,49 & 105,46 & 573,59 & 93,32 & 1,59 & 66,76 & 267,24 & 19,59 & 22,46 & 253,81 \\
\hline Bufo spinosus & 29SNB92 & 100,00 & 150,90 & 97,38 & 41,39 & 4624,20 & 284,06 & 52,19 & 231,87 & 105,03 & 209,76 & 213,97 & 96,25 & 620,53 & 97,73 & 1,99 & 64,87 & 281,73 & 23,16 & 25,60 & 270,38 \\
\hline Bufo spinosus & 29SNB93 & 101,00 & 154,65 & 98,68 & 年11,62 & 4663,30 & 289,92 & 55,33 & 234,59 & $\begin{array}{l}108,13 \\
\end{array}$ & 214,02 & 218,37 & 99,52 & 599,00 & 93,82 & $\begin{array}{l}2,03 \\
2,02\end{array}$ & 64,50 & 271,15 & 22,54 & 24,85 & 260,13 \\
\hline Bufo spinosus & 29SNB94 & 100,00 & 159,33 & 99,98 & 41,80 & 4709,88 & 296,68 & 59,39 & 237,29 & 112,16 & 219,24 & 223,63 & 103,63 & 571,80 & 89,02 & 2,00 & 64,30 & 258,27 & 21,49 & 23,73 & 247,61 \\
\hline Bufo spinosus & 29SNB95 & 100,00 & 162,10 & 101,68 & 41,85 & 4764,64 & 301,97 & 61,28 & 240,69 & 114,21 & 222,62 & 226,94 & 105,44 & 557,84 & 85,81 & 2,00 & 63,79 & 250,25 & 21,36 & 23,25 & 240,45 \\
\hline Bufo spinosus & 29SNB97 & 100,00 & 164,92 & 105,55 & 42,00 & 4874,85 & 310,72 & 62,35 & 248,37 & 115,44 & 226,73 & 231,23 & 106,64 & 545,94 & 82,66 & 2,00 & 62,55 & 240,46 & 21,97 & 23,29 & 232,84 \\
\hline Bufo spinosus & 29SNB99 & 101,00 & 165,62 & 110,00 & 42,07 & 5015,02 & 318,32 & 61,18 & 257,14 & 114,36 & 229,15 & 233,73 & 105,83 & 547,67 & 81,68 & 2,00 & 61,23 & 235,78 & 23,44 & 23,94 & 231,03 \\
\hline Bufo spinosus & $295 \mathrm{NCO5}$ & 13,00 & 170,30 & 85,90 & 42, 41,70 & 4110,10 & 287,80 & $\begin{array}{l}1,10 \\
83,50 \\
\end{array}$ & 204,30 & \begin{tabular}{|l|}
127,60 \\
12,0
\end{tabular} & \begin{tabular}{|l|}
220,80 \\
\end{tabular} & 225,50 & $\begin{array}{l}120,40 \\
120\end{array}$ & $\begin{array}{l}441,60 \\
644,60\end{array}$ & $\begin{array}{l}91,00 \\
96,70\end{array}$ & 2,10 & $\begin{array}{ll}1,2,80 \\
63,80\end{array}$ & 287,90 & 26,40 & 29,30 & 277,70 \\
\hline Bufo spinosus & 29SNC06 & 92,00 & 166,43 & 85,60 & \begin{tabular}{l|l|l|l|}
41,05 \\
\end{tabular} & 4169,39 & 285,32 & 79,35 & 205,97 & 122,99 & 217,60 & 222,47 & 115,64 & \begin{tabular}{|l|l|}
681,47 \\
\end{tabular} & 101,62 & 3,41 & 63,05 & 302,61 & 28,84 & 31,25 & 293,11 \\
\hline Bufo spinosus & 29SNC07 & 101,00 & 169,51 & 84,83 & 40,99 & 4161,27 & 287,38 & 82,44 & 204,94 & 125,92 & 220,59 & 225,31 & 118,66 & 667,01 & 99,49 & 3,01 & 63,32 & 296,84 & 27,18 & 30,14 & 287,32 \\
\hline Bufo spinosus & 29 SNC08 & 88,00 & 170,53 & 83,66 & 40,89 & 4135,33 & 286,57 & 83,89 & 202,68 & 127,01 & 221,21 & 225,76 & 119,78 & 664,00 & 99,33 & 3,00 & 63,24 & 295,24 & 26,97 & 30,01 & 285,61 \\
\hline Bufo spinosus & $29 \mathrm{SNCO9}$ & 44,00 & 169,96 & 82,41 & 40,92 & 4094,55 & 283,96 & 83,82 & 200,14 & 126,75 & 220,06 & 224,33 & 119,35 & 666,27 & 99,81 & 3,00 & 63,11 & 295,30 & 27,00 & 30,45 & 285,77 \\
\hline Bufo spinosus & 29SNC10 & 74,00 & 168,25 & $\begin{array}{ll}82,49 \\
89,65\end{array}$ & 42,91 & $\begin{array}{l}4034,53 \\
404,68\end{array}$ & $\begin{array}{l}200,50 \\
287,78\end{array}$ & $\begin{array}{l}30,78 \\
80,78\end{array}$ & \begin{tabular}{|l|}
207,00 \\
\end{tabular} & \begin{tabular}{|l|l|}
127,19 \\
\end{tabular} & \begin{tabular}{|l|}
218,07 \\
\end{tabular} & \begin{tabular}{|l|}
222,81 \\
228
\end{tabular} & \begin{tabular}{|l|}
119,20 \\
19,0
\end{tabular} & $\begin{array}{l}\mid 000,27 \\
583,03\end{array}$ & $\begin{array}{l}35,01 \\
87,85\end{array}$ & 2,00 & $\begin{array}{l}3,11 \\
64,57\end{array}$ & \begin{tabular}{|l|}
262,35 \\
265
\end{tabular} & 23,98 & $\begin{array}{l}0,45 \\
24,99\end{array}$ & 253,35 \\
\hline Bufo spinosus & 29SNC14 & 18,00 & 171,34 & 89,19 & 41,84 & 4214,47 & 293,56 & 82,31 & 211,25 & 127,59 & 223,09 & 228,06 & 119,66 & 612,06 & 91,03 & 3,00 & 63,09 & 271,59 & 26,00 & 28,00 & 263,56 \\
\hline Bufo spinosus & 29SNC16 & 88,00 & 171,19 & 87,51 & $\begin{array}{l}41,15 \\
\end{array}$ & 4225,15 & 292,32 & 82,74 & 209,58 & 127,11 & 223,20 & 227,95 & 119,56 & 635,06 & 94,05 & 3,00 & 62,94 & 281,42 & 26,54 & 29,02 & 273,28 \\
\hline Bufo spinosus & 29SNC19 & 100,00 & 169,45 & 84,33 & 40,73 & 4178,78 & 286,88 & 81,82 & 205,06 & 125,35 & 220,79 & 225,15 & 117,87 & 663,76 & 98,49 & 3,00 & 62,52 & 292,10 & 27,61 & 30,92 & 284,15 \\
\hline Bufo spinosus & 29 SNC20 & 100,00 & 163,43 & 92,33 & 42,46 & 4224,95 & 288,91 & 73,92 & 214,99 & 120,64 & 215,90 & 220,69 & 112,66 & 606,74 & 90,7 & 2,30 & 63,70 & 270,56 & 25,52 & 26,30 & 263,18 \\
\hline \begin{tabular}{|l} 
Bufo spinoususus \\
Bufo spinos
\end{tabular} & 295 NC21 & 101,00 & $\begin{array}{l}\frac{10,45}{164,38} \\
\end{array}$ & $\begin{array}{l}2,35 \\
92,12\end{array}$ & $\begin{array}{l}42,40 \\
42,16\end{array}$ & $\begin{array}{l}424,453 \\
424,06\end{array}$ & 280,91 & $\begin{array}{l}73,5266 \\
74,66\end{array}$ & \begin{tabular}{|l|}
214,596 \\
215,5
\end{tabular} & \begin{tabular}{|l|}
121,27 \\
127
\end{tabular} & $\frac{\mid 13,90}{217,10}$ & \begin{tabular}{|l|}
221,99 \\
221
\end{tabular} & $\begin{array}{l}112,00 \\
113,42 \\
\end{array}$ & $\begin{array}{l}\mid 000,14 \\
612,68\end{array}$ & $\begin{array}{l}90,15 \\
91,38\end{array}$ & $2,2,49$ & $\begin{array}{l}3,1,49 \\
63,49\end{array}$ & $\begin{array}{l}270,20 \\
272,22 \\
\end{array}$ & $\begin{array}{l}\mid 25,95 \\
25,95 \\
\end{array}$ & $\begin{array}{l}26,81 \\
26,81\end{array}$ & $\begin{array}{l}203,10 \\
265,08 \\
\end{array}$ \\
\hline Bufo spinosus & 29 SNC22 & 99,00 & 166,10 & 91,82 & 42,02 & 4275,52 & 292,11 & 76,33 & 215,78 & 122,47 & 219,16 & 224,04 & 114,58 & 614,17 & 91,45 & 2,67 & 63,12 & 272,23 & 26,19 & 27,32 & 265,21 \\
\hline Bufo spinosus & $295 N C 23$ & 101,00 & 168,86 & 91,32 & 42,00 & 4281,82 & 294,32 & 78,88 & 215,44 & 124,77 & 221,79 & 226,66 & 116,93 & 608,71 & 90,47 & 2,99 & 63,12 & 269,53 & 25,78 & 27,64 & 262,48 \\
\hline Bufo spinosus & 29SNC24 & 100,00 & 170,19 & 90,79 & $41, \varepsilon$ & 4295,90 & 295,24 & 80,06 & 215,18 & 125,66 & 223,30 & 228,07 & 117,87 & 612,17 & 90,7 & 2,98 & 62,43 & 270,48 & 26,14 & 27,79 & 263,54 \\
\hline Bufo spinosus & 29 SNC25 & 72,00 & 171,37 & 90,26 & $\frac{41}{41}$ & 4305,01 & 296,38 & $\begin{array}{l}0,00 \\
81,59 \\
\end{array}$ & 214,79 & 126,64 & 224,69 & 229,51 & 119,16 & $\begin{array}{l}611,59 \\
\end{array}$ & 90,23 & 3,00 & $\begin{array}{l}2,4,83 \\
62,\end{array}$ & 269,90 & $\begin{array}{l}25,147 \\
25,77\end{array}$ & 27,76 & 263,10 \\
\hline \begin{tabular}{|l} 
Bufo spinosus \\
\end{tabular} & $295 N C 26$ & 88,00 & 170,97 & 89,48 & 41,11 & 4314,14 & 295,55 & 81,21 & 214,34 & 126,11 & 224,43 & 229,03 & 118,54 & 625,67 & $92, \mathrm{c}$ & 3,00 & 62,56 & 275,11 & 26,84 & 29,01 & 268,52 \\
\hline Bufo spinosus & 29SNC30 & 100,00 & 164,80 & 94,76 & 42,16 & 4339,40 & 294,27 & 73,09 & 221,18 & 120,82 & 218,96 & 223,73 & 112,79 & 591,55 & 88,55 & 2.06 & 63,69 & 263,40 & 24,27 & 24,90 & 256,82 \\
\hline Bufo spinosus & 29 SNC31 & 101,00 & 161,27 & 94,95 & 42,00 & 4402,58 & 292,56 & 69,61 & 222,95 & 116,77 & 216,36 & 221,20 & 108,72 & 624,36 & 92,71 & 2,89 & 62,71 & 274,96 & 27,25 & 27,68 & 269,36 \\
\hline Bufo spinosus & 29 SNC32 & 101,00 & 164,58 & 94,37 & 41,92 & 4412,68 & 295,47 & 72,80 & 222,67 & 119,62 & 219,70 & 224,62 & 111,69 & 614,58 & 90,98 & 2,73 & 62,64 & 270,49 & 26,43 & 27,17 & 264,92 \\
\hline \begin{tabular}{|l} 
Bufo spinosus \\
\end{tabular} & $295 \mathrm{SCF}$ & $\begin{array}{l}100,00 \\
100\end{array}$ & $\begin{array}{l}104,50 \\
167,77\end{array}$ & $\begin{array}{l}4,31 \\
93,79\end{array}$ & 41 & $\begin{array}{l}441,200 \\
4408,51 \\
\end{array}$ & 297,79 & $\begin{array}{l}72,00 \\
76,01\end{array}$ & \begin{tabular}{|l|}
221,78 \\
221
\end{tabular} & 122,43 & 222,68 & 227,53 & 114,64 & 605,45 & 89,46 & 2,95 & 62,79 & 266,27 & 25,92 & 26,94 & 260,68 \\
\hline Bufo spinosus & 29SNC34 & 101,00 & 169,72 & 93,09 & 41,86 & 4404,57 & 299,00 & 78,24 & 220,76 & 124,28 & 224,49 & 229,21 & 116,51 & 603,04 & 88,72 & 2,98 & 62,63 & 264,73 & 25,86 & 26,98 & 259,18 \\
\hline Bufo spinosus & 29SNC35 & 101,00 & 171,03 & 92,25 & $|41,48|$ & 4404,83 & 299,52 & 79,46 & 220,05 & $\mid 125,40$ & 225,77 & 230,49 & 117,50 & 604,24 & 88,76 & 3,00 & 62.41 & $\mid 264,68$ & 25,77 & 27.49 & 259,25 \\
\hline Bufo spinosus & 29 SNC36 & 100,00 & 169,00 & 91,56 & 41,06 & 4431,00 & 297,64 & 77,78 & 219,86 & 122,84 & 224,17 & 228,71 & 115,32 & 627,90 & 92,08 & 3,00 & 61,85 & 273,39 & 27,58 & 29,37 & 268,5 \\
\hline Bufo spinosus & 29 SNC37 & 101,00 & 169,03 & 90,66 & 40,99 & 4427,78 & 296,69 & 77,94 & 218,75 & 122,70 & 224,05 & 228,61 & 115,18 & 636,97 & 93, & 3,05 & 61,64 & 276,64 & 28,14 & 30,01 & 271, \\
\hline \begin{tabular}{|l} 
Bufo spinosus \\
\end{tabular} & 29SNC39 & $\begin{array}{l}100,00 \\
100\end{array}$ & $\begin{array}{l}10,08,15 \\
168\end{array}$ & $\begin{array}{l}80,60 \\
88,67\end{array}$ & 年 40,81 & $\begin{array}{l}44 \angle, 1,90 \\
4385,91 \\
\end{array}$ & 293,38 & $\begin{array}{l}71,743 \\
77,73\end{array}$ & $\begin{array}{l}10,1 / 1 \\
215,65 \\
\end{array}$ & 122,21 & 222,70 & 227,00 & 114,55 & 657,82 & 96,56 & 3,71 & 61,08 & 283,95 & 29,97 & 32,20 & 279,29 \\
\hline Bufo spinosus & 29SNC41 & 101,00 & 166,46 & 97,10 & 42,00 & 4485,43 & 300,43 & 72,71 & 227,71 & 120,71 & 222,62 & 227,24 & 112,62 & 584,59 & 86,96 & 2,10 & 63,03 & 257,83 & 24,48 & 25,09 & 252,44 \\
\hline Bufo spinosus & $295 N C 42$ & 99,00 & 16870 & 96,55 & 42.00 & 4483.66 & 302.16 & 75,09 & 227.07 & $|122,67|$ & 224,64 & 229,38 & 114,78 & 580,33 & 85.94 & 206 & 62.96 & 255,20 & 24,26 & 25.13 & 250,04 \\
\hline Bufo spinosus & 29SNC43 & 101,00 & 169,53 & 95,90 & 42,00 & 4501,04 & 302,69 & 76,17 & 226,52 & 123,27 & 225, & 230,51 & 115 & 585,04 & 86,01 & 2,62 & 62,24 & 255,76 & 25,29 & 26,29 & 251,02 \\
\hline Bufo spinosus & $295 N C 44$ & 101,00 & 169,99 & 95,22 & 41,79 & 4509,82 & 302,72 & 76,65 & 226,07 & 123,49 & 226,24 & 231,00 & 115,48 & 591,50 & 86,65 & 2,87 & 61,89 & 257,60 & 25,84 & 27,04 & 253,18 \\
\hline
\end{tabular}




\begin{tabular}{|c|c|c|c|c|c|c|c|c|c|c|c|c|c|c|c|c|c|c|c|c|c|}
\hline TAXON & UTM & $\mathrm{km} 2$ & BIO1 & BIO2 & $B 103$ & BIO4 & B105 & B106 & B107 & 8108 & 8109 & B1010 & BIO11 & B1012 & BIO13 & B1014 & B1015 & B1016 & B1017 & B1018 & 81019 \\
\hline Bufo spinosus & 29SNC45 & 101,00 & 169,94 & 94,46 & 41,41 & 4514,58 & 302,27 & 76,89 & 225,38 & 123,17 & 226,18 & 230,97 & 115,35 & 601,31 & 87,88 & 3,00 & 61,71 & 260,69 & 26,58 & 27,74 & 256,66 \\
\hline Bufo spinosus & 29SNC46 & 100,00 & 168,48 & 93,61 & 41,02 & 4534,77 & 300,59 & 75,62 & 224,97 & 121,42 & 225,07 & 229,66 & 113,51 & 619,70 & 90,45 & 3,03 & 61,34 & 267,23 & 27,81 & 29,05 & 263,86 \\
\hline Bufo spinosus & 29SNC47 & 100,00 & 167,73 & 92,62 & $\begin{array}{l}40,97 \\
\end{array}$ & 4524,31 & 299,07 & 75,36 & 223,71 & $\begin{array}{l}120,67 \\
\end{array}$ & 224,19 & 228,77 & 112,91 & 635,36 & 92,66 & 3,44 & \begin{tabular}{ll|}
60,82 \\
\end{tabular} & 272,81 & 29,39 & 30,81 & 269,64 \\
\hline Bufo spinosus & 29SNC48 & 101,00 & 167,37 & 91,63 & 40,88 & 4518,73 & 297,60 & 75,26 & 222,34 & 120,13 & 223,69 & 228,17 & 112,45 & \begin{tabular}{ll|l|}
647,64 \\
\end{tabular} & 94,44 & 3,90 & 60,49 & 277,18 & 30,66 & 32,10 & 274,15 \\
\hline Bufo spinosus & 29SNC50 & 101,00 & 169,36 & 99,40 & 42,16 & 4546,86 & 305,86 & 73,78 & 232,08 & 122,96 & 226,42 & 231,14 & 114,82 & 551,54 & 82,71 & 2,00 & 63,51 & 244,19 & 22,46 & 23,32 & 238,44 \\
\hline Bufo spinosus & 295NC51 & $\mid 101,00$ & 169,44 & 99,28 & \begin{tabular}{|l|l|}
22,04 \\
\end{tabular} & 4569,18 & 306,46 & 73,87 & 232,59 & $\mid 122,67$ & 226,81 & 231,38 & 114,65 & 560,00 & 83,21 & 2,00 & 62,58 & 245,94 & 23,75 & 24,40 & 240,90 \\
\hline Bufo spinosus & 29SNC52 & 101,00 & 169,67 & 98,88 & 42,01 & 4587,13 & 306,68 & 74,25 & 232,43 & 122,60 & 227,16 & 231,83 & 114,48 & 566,97 & 83,56 & 2,08 & 62,27 & 247,49 & 24,29 & 24,99 & 243,05 \\
\hline Bufo spinosus & 29SNC53 & 100,00 & 170,04 & 98,17 & \begin{tabular}{|l|l|}
41,97 \\
\end{tabular} & 4596,44 & 306,70 & 74,80 & 231,89 & \begin{tabular}{|l|l|}
122,87 \\
\end{tabular} & 227,55 & 232,26 & $\begin{array}{l}114,58 \\
\end{array}$ & 573,44 & 83,86 & 2,58 & 61,79 & 248,75 & 25,34 & 26,21 & 244,83 \\
\hline Bufo spinosus & 29SNC54 & 101,00 & 168,58 & 97,49 & \begin{tabular}{l|l|l|l|}
41,65 \\
\end{tabular} & 4619,20 & 305,30 & 73,76 & \begin{tabular}{|l|l|}
231,54 \\
\end{tabular} & \begin{tabular}{|l|l|}
121,07 \\
\end{tabular} & 226,41 & 231,19 & \begin{tabular}{|l|}
113,01 \\
\end{tabular} & \begin{tabular}{ll|}
590,22 \\
\end{tabular} & 85,94 & 2,99 & 61,12 & 254,27 & 26,74 & 27,45 & 251,14 \\
\hline Bufo spinosus & 29SNC55 & 100,00 & 168,90 & 96,51 & 41,20 & 4621,95 & 304,91 & 74,40 & 230,51 & 121,21 & 226,82 & 231,37 & \begin{tabular}{|l|}
113,07 \\
\end{tabular} & 597,31 & 86,69 & 3,00 & 60,85 & 256,22 & 27,24 & 28,15 & 253,45 \\
\hline Bufo spinosus & 29SNC56 & 101,00 & 164,47 & 95,36 & 40,94 & \begin{tabular}{ll|l|}
4653,64 \\
\end{tabular} & 300,76 & 70,51 & 230,25 & 116,51 & 222,78 & 227,54 & 108,55 & 636,12 & 92,18 & 3,69 & 60,01 & 270,33 & 30,59 & 31,18 & 268,80 \\
\hline Bufo spinosus & 29SNC57 & 100,00 & 163,63 & 94,28 & $\begin{array}{l}40,87 \\
4\end{array}$ & \begin{tabular}{ll|l|}
4652,67 \\
\end{tabular} & 298,97 & 70,09 & $\begin{array}{ll}228,88 \\
\end{array}$ & 115,47 & 221,89 & 226,65 & 107,55 & 653,05 & 94,55 & 4,00 & 59,70 & 276,30 & 32,10 & 32,64 & 275,18 \\
\hline Bufo spinosus & 295NC58 & 101,00 & 166,18 & 93,38 & 40,73 & 4621,51 & 299,98 & 72,89 & 227,09 & 118,19 & 224,19 & 228,68 & 110,35 & 646,13 & 93,50 & 4,00 & 59,70 & 273,34 & 31,76 & 32,74 & 271,86 \\
\hline Bufo spinosus & 29SNC59 & 101,00 & 166,11 & 92,51 & 40,31 & 4606,06 & 298,89 & 73,02 & 225,86 & 118,06 & 223,91 & 228,27 & 110,24 & 657,11 & 95,19 & 4,00 & 59,58 & 277,46 & 32,31 & 33,59 & 275,99 \\
\hline Bufo spinosus & 29SNC60 & 100,00 & 168,91 & 102,19 & 42,14 & \begin{tabular}{ll|l|}
4666,86 \\
\end{tabular} & 309,80 & 71,14 & 238,66 & 121,42 & 227,67 & 232,32 & \begin{tabular}{|l|l|}
113,08 \\
\end{tabular} & $\begin{array}{l}548,16 \\
\end{array}$ & 81,95 & 2,00 & 62,98 & 240,78 & 22,67 & 23,01 & 235,76 \\
\hline Bufo spinosus & 29SNC63 & 100,00 & 169,43 & 100,65 & $\begin{array}{l}41,97 \\
\end{array}$ & 4709,57 & 310,18 & 72,45 & $\begin{array}{l}237,73 \\
\end{array}$ & $\begin{array}{ll}120,91 \\
\end{array}$ & $\begin{array}{ll}228,61 \\
\end{array}$ & 233,21 & 112,84 & 567,75 & 82,31 & 2,86 & \begin{tabular}{ll|l|}
60,67 \\
\end{tabular} & 243,66 & 26,02 & 26,75 & 240,76 \\
\hline Bufo spinosus & 29SNC65 & 101,00 & 165,21 & 98,42 & 41,09 & 4744,75 & 305,35 & 69,42 & \begin{tabular}{|l|l|}
235,94 \\
\end{tabular} & $\begin{array}{l}116,34 \\
\end{array}$ & \begin{tabular}{|l|l|}
224,94 \\
\end{tabular} & \begin{tabular}{|l|l|}
229,67 \\
\end{tabular} & $\begin{array}{l}108,29 \\
\end{array}$ & $\begin{array}{l}609,86 \\
6\end{array}$ & 87,75 & 3,01 & $\begin{array}{ll}60,04 \\
\end{array}$ & 257,88 & 29,32 & 29,53 & 256,77 \\
\hline Bufo spinosus & 295NC66 & 100,00 & 163,32 & 96,95 & \begin{tabular}{|l|l|}
40,96 \\
\end{tabular} & 4748,38 & 302,52 & 68,20 & 234,32 & 113,71 & 223,07 & 227,75 & 106,26 & \begin{tabular}{|c|c|}
633,58 \\
\end{tabular} & 90,95 & 3,66 & 59,27 & 266,10 & 31,68 & 31,91 & 265,71 \\
\hline Bufo spinosus & 295NC67 & 101,00 & 160,92 & 95,55 & 40,51 & 4762,73 & 299,50 & 66,41 & 233,08 & 108,31 & 221,06 & 225,57 & 103,85 & 660,70 & 94,83 & 4,00 & 58,89 & 276,39 & 33,88 & 33,97 & 276,32 \\
\hline Bufo spinosus & 29SNC68 & 101,00 & 163,25 & 94,70 & 40,31 & \begin{tabular}{ll|}
4730,67 \\
\end{tabular} & 300,30 & $\begin{array}{ll}68,96 \\
\end{array}$ & 231,34 & 111,72 & 222,91 & 227,37 & 106,33 & 657,62 & 94,41 & 4,00 & 58,85 & 274,96 & 33,71 & 34,14 & 274,80 \\
\hline Bufo spinosus & 29SNC70 & 101,00 & 166,79 & 105,49 & 42,09 & 4809,92 & 312,99 & 66,70 & 246,29 & 117,83 & \begin{tabular}{|l|l|}
227,47 \\
\end{tabular} & 232,23 & 109,28 & 554,83 & 82,57 & 2,00 & 61,93 & 241,11 & 23,42 & 23,73 & 236,96 \\
\hline \begin{tabular}{|l|} 
Bufo spinosus \\
\end{tabular} & 29SNC72 & 101,00 & 168,99 & 104,16 & 42,00 & 4819,09 & $\begin{array}{l}314,36 \\
\end{array}$ & 69,59 & 244,77 & $\begin{array}{ll}119,59 \\
\end{array}$ & \begin{tabular}{|l|l|}
229,74 \\
\end{tabular} & 234,33 & 111,15 & $\begin{array}{l}554,55 \\
\end{array}$ & 80,84 & 2,28 & 61,04 & 237,65 & 24,72 & 25,06 & 234,67 \\
\hline Bufo spinosus & 29SNC73 & 101,00 & 167,30 & $\begin{array}{l}103,29 \\
\end{array}$ & 41,94 & $\begin{array}{l}4840,16 \\
\end{array}$ & $\begin{array}{ll}312,68 \\
\end{array}$ & 68,40 & 244,28 & $\begin{array}{ll}117,58 \\
\end{array}$ & 228,25 & 233,07 & 109,32 & 571,18 & 81,99 & 3,00 & $\begin{array}{l}59,96 \\
\end{array}$ & \begin{tabular}{|l|l|}
242,07 \\
\end{tabular} & 27,26 & 27,38 & 240,14 \\
\hline Bufo spinosus & 29SNC74 & 101,00 & 164,58 & 101,83 & 41,31 & 4855,15 & 309,36 & 66,51 & 242,84 & 114,73 & 226,27 & 230,53 & 106,55 & 594,93 & 84,98 & 3,00 & 59,55 & 250,03 & 28,86 & 28,86 & 249,31 \\
\hline Bufo spinosus & 29SNC75 & 100,00 & 164,53 & 100,09 & 41,03 & 4838,18 & 307,66 & 67,28 & 240,38 & 114,29 & 226,21 & 230,19 & 106,54 & 604,28 & 86,00 & 3,00 & 59,13 & 252,46 & 30,18 & 30,18 & 252,28 \\
\hline Bufo spinosus & 29SNC76 & 101,00 & 160,29 & 98,06 & 40,77 & 4851,99 & 302,55 & 64,27 & 238,27 & 104,42 & 223,43 & 226,39 & 102,36 & 641,73 & 91,18 & 3,81 & 58,25 & 266,81 & 33,29 & 33,29 & 266,81 \\
\hline Bufo spinosus & 29SNC77 & 101,00 & 158,54 & 96,49 & \begin{tabular}{l|l}
40,18 \\
\end{tabular} & 4855,58 & 299,73 & 63,38 & 236,35 & 100,76 & 222,23 & 224,66 & 100,60 & 666,05 & 94,64 & 4,08 & 57,82 & 276,19 & 35,39 & 35,39 & 276,19 \\
\hline Bufo spinosus & 29SNC78 & 99,00 & 160,21 & 95,62 & 40,11 & 4836,39 & 300,15 & 65,21 & 234,94 & 102,41 & 222,25 & 225,85 & 102,35 & 6699,04 & 95,14 & 4,02 & 57,86 & 277,31 & 35,75 & 35,75 & 277,31 \\
\hline Bufo spinosus & 29SNC80 & 101,00 & 165,24 & 108,90 & 42,22 & $\begin{array}{l}4951,82 \\
\end{array}$ & 316,80 & $\begin{array}{ll}62,73 \\
\end{array}$ & 254,06 & 114,69 & 227,97 & 232,64 & 106,17 & 558,11 & 82,71 & 2,06 & 61,14 & 239,67 & 24,29 & 24,41 & 236,34 \\
\hline \begin{tabular}{|l|} 
Bufo spinosus \\
\end{tabular} & 29SNC81 & 101,00 & 165,59 & 108,62 & \begin{tabular}{l|l|}
42,09 \\
\end{tabular} & 4964,21 & $\begin{array}{ll}317,28 \\
\end{array}$ & 63,29 & \begin{tabular}{|l|l|}
253,99 \\
\end{tabular} & $\begin{array}{ll}114,89 \\
\end{array}$ & $\begin{array}{ll}228,42 \\
\end{array}$ & 233,08 & 106,27 & $\begin{array}{l}561,88 \\
\end{array}$ & 82,25 & 2,18 & \begin{tabular}{ll|l|}
60,46 \\
\end{tabular} & 239,21 & 25,24 & 25,36 & 236,65 \\
\hline Bufo spinosus & 29SNC83 & 101,00 & 165,01 & 105,72 & 41,89 & 4963,12 & 314,42 & 64,19 & \begin{tabular}{|l|l|}
250,23 \\
\end{tabular} & 113,99 & $\begin{array}{ll}228,62 \\
\end{array}$ & 232,37 & 105,65 & 577,32 & 82,20 & 3,00 & 59,25 & \begin{tabular}{ll|}
241,88 \\
\end{tabular} & 28,08 & $\begin{array}{ll}28,08 \\
\end{array}$ & 240,77 \\
\hline Bufo spinosus & $295 \mathrm{NC} 84$ & $\mid 101,00$ & 163,50 & $\mid 103,66$ & $\begin{array}{lll}41,22 \\
\end{array}$ & 4958,27 & 311,40 & 63,87 & 247,52 & 112,01 & 227,62 & 230,76 & $\mid 104,36$ & 593,24 & 83,70 & 3,01 & 58,59 & 246,40 & 29,81 & 29,81 & 246,24 \\
\hline Bufo spinosus & 29SNC86 & 100,00 & 161,19 & $\begin{array}{ll}99,26 \\
\end{array}$ & 40,70 & 4930,57 & 305,38 & 63,90 & 241,49 & 102,56 & 226,06 & 228,18 & 102,29 & 624,39 & 87,51 & 3,77 & 57,59 & 257,09 & 33,38 & 33,38 & 257,09 \\
\hline Bufo spinosus & 29SNC87 & 100,00 & 157,48 & 97,19 & $\begin{array}{ll}40,03 \\
\end{array}$ & 4938,52 & 300,59 & \begin{tabular}{|c|}
61,44 \\
\end{tabular} & 239,15 & \begin{tabular}{|l|l|}
98,67 \\
\end{tabular} & 223,75 & 224,75 & 98,67 & 661,51 & 92,89 & 4,07 & 57,07 & 271,88 & 36,14 & 36,14 & 271,88 \\
\hline Bufo spinosus & 29SNC88 & 101,00 & 158,80 & 96,51 & 39,99 & $\begin{array}{l}4931,32 \\
\end{array}$ & 301,25 & 62,78 & \begin{tabular}{|l|l|}
238,47 \\
\end{tabular} & \begin{tabular}{ll|}
100,02 \\
\end{tabular} & 224,18 & 225,94 & 100,02 & $\begin{array}{l}667,61 \\
\end{array}$ & 93,90 & 4,19 & 56,95 & 274,30 & 36,84 & 36,84 & 274,30 \\
\hline \begin{tabular}{|l|} 
Bufo spinosus \\
\end{tabular} & 29SNC92 & 101,00 & 165,37 & 109,80 & 42,00 & 5080,16 & \begin{tabular}{ll|}
319,78 \\
\end{tabular} & $\begin{array}{ll}61,63 \\
\end{array}$ & $\begin{array}{ll}258,15 \\
\end{array}$ & $\begin{array}{ll}113,12 \\
\end{array}$ & 230,16 & 234,41 & $\begin{array}{l}104,70 \\
\end{array}$ & 562,89 & 80,75 & 2,80 & 59,01 & 235,45 & 27,29 & 27,30 & 233,49 \\
\hline Bufo spinosus & 29SNC93 & 100,00 & 163,36 & 107,68 & 41,78 & 5076,10 & $\begin{array}{l}316,32 \\
\end{array}$ & $\begin{array}{ll}60,82 \\
\end{array}$ & 255,49 & 111,17 & 228,91 & 232,37 & 102,78 & 580,06 & 81,76 & 3,00 & 58,43 & 240,55 & 28,79 & 28,79 & 239,58 \\
\hline Bufo spinosus & 29SNC94 & 100,00 & 161,65 & 105,11 & 41,13 & 5062,79 & 312,44 & 60,52 & 251,92 & 107,12 & 228,18 & 230,52 & 101,29 & 597,04 & 83,31 & 3,19 & 57,84 & 245,71 & 30,75 & 30,75 & 245,55 \\
\hline Bufo spinosus & 29SNC99 & 100,00 & 162,60 & 97,82 & 39,99 & 5028,22 & 307,13 & 64,41 & 242,72 & 102,16 & 226,96 & 230,84 & 102,16 & 649,82 & 90,50 & 4,00 & 56,37 & 264,99 & 36,64 & 36,65 & 264,99 \\
\hline Bufo spinosus & 29SND03 & 101,00 & 160,54 & 75,24 & \begin{tabular}{ll|}
40,72 \\
\end{tabular} & 3756,82 & 261,73 & 78,79 & \begin{tabular}{|l|l|}
182,94 \\
\end{tabular} & 120,86 & 206,23 & 209,56 & 113,18 & 707,24 & $\begin{array}{l}108,25 \\
\end{array}$ & 3,99 & 61,58 & 309,55 & 31,18 & 35,44 & 297,42 \\
\hline Bufo spinosus & 29SND05 & 101,00 & 155,97 & 73,29 & $\begin{array}{l}40,97 \\
4\end{array}$ & 3622,09 & 252,84 & 75,74 & $\begin{array}{l}177,10 \\
\end{array}$ & 117,80 & $\begin{array}{ll}199,97 \\
\end{array}$ & 202,88 & 109,98 & \begin{tabular}{|l|l|}
738,07 \\
\end{tabular} & \begin{tabular}{l|l|}
113,12 \\
\end{tabular} & 4,51 & 60,61 & 319,44 & 34,41 & 39,11 & 307,22 \\
\hline Bufo spinosus & 29SND06 & 101,00 & 149,04 & 73,22 & \begin{tabular}{ll|}
40,77 \\
\end{tabular} & 3633,73 & 246,47 & $\begin{array}{ll}68,94 \\
\end{array}$ & $\begin{array}{ll}177,54 \\
\end{array}$ & 111,00 & \begin{tabular}{|l|l|}
193,27 \\
\end{tabular} & 196,21 & \begin{tabular}{|l|}
103,07 \\
\end{tabular} & 806,23 & 121,74 & 5,64 & 59,51 & $\begin{array}{l}345,03 \\
\end{array}$ & 40,37 & 44,62 & 333,78 \\
\hline Bufo spinosus & 29SND07 & 100,00 & 150,55 & 72,97 & 41,12 & 3560,35 & 245,85 & 70,64 & 175,21 & 112,96 & 193,75 & $\begin{array}{l}196,39 \\
\end{array}$ & 105,14 & 801,02 & 121,01 & 5,7 & \begin{tabular}{ll|}
59,06 \\
\end{tabular} & 41,15 & 40,96 & 45 & 329,98 \\
\hline Bufo spinosus & 29SND08 & 101,00 & 154,16 & 73,18 & 41,81 & $\begin{array}{l}3476,62 \\
\end{array}$ & 247,18 & 74,14 & \begin{tabular}{|l|l|}
173,04 \\
\end{tabular} & 117,32 & 195,93 & $\begin{array}{l}198,56 \\
\end{array}$ & 109,29 & 778,49 & 117,54 & 5,62 & 58,76 & 330,55 & 39,95 & 45,65 & 319,44 \\
\hline Bufo spinosus & 29SND09 & 101,00 & 152,42 & 73,80 & 42,05 & 3457,76 & 245,39 & 72,05 & 173,34 & 115,68 & 193,97 & 196,45 & 107,71 & 810,14 & 120,76 & 6,13 & 57,97 & 341,25 & 43,40 & 49,26 & 330,91 \\
\hline Bufo spinosus & 29SND12 & 101,00 & 166,69 & 80,13 & 40,82 & 3974,29 & 276,01 & 81,52 & 194,50 & 124,59 & 215,32 & 218,92 & 117,01 & 675,43 & 101,78 & 3,45 & 61,80 & 295,13 & 29,08 & 32,92 & 285,80 \\
\hline Bufo spinosus & 29SND13 & 100,00 & 162,92 & 79,09 & \begin{tabular}{ll|}
40,77 \\
\end{tabular} & 3927,40 & 270,65 & 78,49 & \begin{tabular}{|l|l|}
192,16 \\
\end{tabular} & 121,42 & 211,05 & 214,49 & \begin{tabular}{|l|}
113,77 \\
\end{tabular} & \begin{tabular}{ll|}
702,38 \\
\end{tabular} & $\begin{array}{l}105,55 \\
\end{array}$ & 4,00 & 61,02 & $\begin{array}{l}304,83 \\
\end{array}$ & 31,85 & 35,66 & 295,47 \\
\hline Bufo spinosus & 29SND16 & 100,00 & 153,84 & 77,45 & \begin{tabular}{ll|}
40,77 \\
\end{tabular} & 3808,84 & 257,99 & 70,53 & $\begin{array}{lll}187,46 \\
\end{array}$ & 113,59 & 200,48 & 203, & 105,87 & 788,12 & \begin{tabular}{|l|l|}
117,47 \\
\end{tabular} & 5,51 & $\begin{array}{l}59,16 \\
\end{array}$ & 335,49 & 39,89 & $\begin{array}{ll}43,88 \\
\end{array}$ & 326,82 \\
\hline Bufo spinosus & 29SND17 & 101,00 & 140,89 & 77,42 & 40,20 & 3896,44 & 247,82 & 57,69 & 190,13 & 100,32 & 189,19 & 192,27 & 92,55 & 923,35 & 136,53 & 7,84 & 57,81 & 387,36 & 51,57 & 54,11 & 380,57 \\
\hline Bufo spinosus & 29SND18 & 100,00 & 150,32 & 77,86 & $\begin{array}{l}41,17 \\
4\end{array}$ & 3751,52 & 253,42 & $\begin{array}{ll}66,79 \\
\end{array}$ & $\begin{array}{ll}186,64 \\
\end{array}$ & $\begin{array}{ll}110,63 \\
\end{array}$ & $\begin{array}{ll}196,26 \\
\end{array}$ & $\begin{array}{l}199,05 \\
\end{array}$ & 102,79 & 842,71 & 124,44 & 6,59 & 57,92 & 354,03 & 45,62 & $\begin{array}{ll}49,85 \\
\end{array}$ & 346,48 \\
\hline Bufo spinosus & 29SND19 & 100,00 & 155,32 & 78,63 & 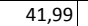 & 3664,69 & 256,27 & 71,28 & 184,99 & $\mid 116,06$ & \begin{tabular}{|l|l|}
199,79 \\
\end{tabular} & 202,38 & $\mid \begin{array}{l}108,15 \\
\end{array}$ & 810,80 & $\mid$\begin{tabular}{|l|l|}
119,14 \\
\end{tabular} & 6,25 & 57,62 & 339,55 & $\mid 44,17$ & 49,25 & 331,81 \\
\hline Bufo spinosus & 29SND20 & 100,00 & 168,46 & 85,41 & 40,66 & 4240,96 & 287,78 & 79,95 & 207,83 & $123,80 \mid$ & 220,89 & 224,97 & 116,20 & 665,77 & 98,32 & 3,52 & 61,55 & 289,62 & 29,26 & 32,28 & 283,13 \\
\hline Bufo spinosus & 29SND21 & 101,00 & 168,28 & 84,36 & \begin{tabular}{l|l|}
40,69 \\
\end{tabular} & 4184,02 & 285,37 & 80,20 & 205,17 & 124,08 & 219,84 & 22 & 116,43 & 668,57 & 98,90 & 3,69 & 61,35 & 290,17 & 29,67 & 32,85 & 283,33 \\
\hline Bufo spinosus & 29SND23 & 101,00 & 166,88 & 82,44 & \begin{tabular}{l|l|}
40,89 \\
\end{tabular} & \begin{tabular}{|l|l|}
4062,76 \\
\end{tabular} & 279,72 & 79,88 & \begin{tabular}{|l|l|}
199,84 \\
\end{tabular} & \begin{tabular}{|l|l|}
123,67 \\
\end{tabular} & 216,86 & 220,34 & 116,05 & 680,99 & $\begin{array}{l}101,13 \\
\end{array}$ & 4,00 & 60,87 & 293,59 & 31,14 & \begin{tabular}{|l|l}
34,84 \\
\end{tabular} & 286,27 \\
\hline Bufo spinosus & 29SND24 & 100,00 & 164,81 & 81,94 & \begin{tabular}{|l|l|}
40,97 \\
\end{tabular} & \begin{tabular}{|l|l|}
4020,68 \\
\end{tabular} & 276,34 & 78,16 & \begin{tabular}{|l|l|}
198,18 \\
\end{tabular} & 122,04 & 214,24 & 217,55 & 114,29 & 700,91 & \begin{tabular}{|l|l|}
103,93 \\
\end{tabular} & 4,00 & 60,20 & 300,66 & 33,15 & 36,90 & 293,36 \\
\hline Bufo spinosus & 29SND26 & \begin{tabular}{|l|l}
101,00 \\
\end{tabular} & \begin{tabular}{|l|l|}
159,71 \\
\end{tabular} & 81,56 & 41,01 & 3964,80 & 269,88 & 73,31 & \begin{tabular}{|l|l|}
196,58 \\
\end{tabular} & $\mid 117,48$ & 208,47 & 211,54 & $\mid$\begin{tabular}{|l|l|}
109,77 \\
\end{tabular} & 756,41 & \begin{tabular}{|l|l|}
111,66 \\
\end{tabular} & 5,06 & $\mid 58,96$ & 320,51 & 38,33 & 42,25 & 313,91 \\
\hline Bufo spinosus & 29SND27 & 101,00 & 147,54 & 81,31 & 40,44 & 4037,86 & 260,08 & 61,37 & 198,71 & 105,03 & 197,73 & 200,82 & 97,41 & 880,62 & 129,94 & 7,08 & 57 & 368 & $\begin{array}{l}48,65 \\
\end{array}$ & 51,27 & $36=$ \\
\hline Bufo spinosus & 295 & 101,00 & 144,18 & 81,60 & 40 & & 25 & 57,77 & 19 & 10 & 194,40 & & $\begin{array}{ll}93,999 \\
\end{array}$ & $\begin{array}{l}927,78 \\
\end{array}$ & 136,62 & 7,98 & 57,12 & 385,76 & 53 & 55,56 & 381,90 \\
\hline Bufo spinosus & 29SND29 & 99,00 & 151,13 & 82,99 & 41,45 & 3942,27 & 261,95 & 63,73 & 198,22 & 109,08 & 199,74 & 202,52 & 101,35 & 876,15 & 128,23 & 7,39 & 56,91 & 363,50 & 50,06 & 53,62 & 359,24 \\
\hline Bufo spinosus & 29SND30 & 101,00 & 168,25 & 87,76 & 40,79 & 4347,72 & 291,76 & 78,26 & 213,50 & 122,54 & 222,27 & 226,40 & 114,98 & 663,01 & 97,42 & 3,95 & 60,75 & 285,61 & 30,54 & 32,95 & 280,85 \\
\hline
\end{tabular}




\begin{tabular}{|c|c|c|c|c|c|c|c|c|c|c|c|c|c|c|c|c|c|c|c|c|c|}
\hline TAXON & UTM & $\mathrm{km} 2$ & BIO1 & B102 & $B 103$ & BIO4 & B105 & B106 & B107 & 8108 & 8109 & B1010 & BIO11 & B1012 & BIO13 & BIO14 & BIO15 & B1016 & B1017 & B1018 & 81019 \\
\hline Bufo spinosus & 29SND31 & 100,00 & 167,67 & 86,84 & 40,60 & 4312,47 & 289,58 & 78,11 & 211,47 & 122,13 & 221,16 & 225,22 & 114,66 & 672,53 & 98,92 & 3,92 & 60,59 & 289,03 & 31,02 & 33,73 & 284,16 \\
\hline Bufo spinosus & 29SND32 & 101,00 & 166,77 & 86,02 & 40,55 & 4269,76 & 287,08 & 77,51 & 209,56 & 121,58 & 219,75 & 223,47 & 114,09 & 684,15 & 100,70 & 4,00 & 60,36 & 293,18 & 31,87 & 34,80 & 288,13 \\
\hline Bufo spinosus & 29SND34 & 100,00 & 166,83 & 85,17 & 40,92 & $\begin{array}{l}4174,14 \\
\end{array}$ & 283,97 & 77,71 & 206,26 & $\begin{array}{ll}122,48 \\
\end{array}$ & 218,47 & 221,85 & \begin{tabular}{|l|}
114,71 \\
\end{tabular} & \begin{tabular}{ll|l}
695,73 \\
\end{tabular} & 102,21 & 4,03 & 59,65 & \begin{tabular}{|l|l|}
296,03 \\
\end{tabular} & 33,76 & 37,29 & 290,63 \\
\hline Bufo spinosus & 29SND35 & 101,00 & 166,06 & 85,14 & 40,97 & \begin{tabular}{ll|l}
4148,63 \\
\end{tabular} & 282,49 & 76,77 & 205,72 & 121,66 & 217,32 & 220,53 & \begin{tabular}{ll|}
113,93 \\
\end{tabular} & $\begin{array}{l}709,63 \\
\end{array}$ & \begin{tabular}{|l|l|}
104,27 \\
\end{tabular} & 4,45 & 59,05 & 300,66 & 35,14 & 38,83 & 295,42 \\
\hline Bufo spinosus & 29SND36 & 101,00 & 163,01 & 85,30 & 40,99 & 4139,85 | & 279,47 & 73,62 & 205,86 & $118,69 \mid$ & 214,20 & 217,29 & 110,95 & 745,59 & 109,38 & 5,01 & 58,52 & 313,82 & 38,47 & 41,99 & 309,20 \\
\hline Bufo spinosus & 29SND37 & 100,00 & 157,30 & 85,38 & 40,79 & 4154,40 & 274,52 & 67,86 & 206,66 & 112,97 & 208,89 & 211,94 & 105,38 & 810,35 & $\mid 118,84$ & 6,19 & 57,83 & 338,33 & 44,14 & \begin{tabular}{|l|l|}
47,12 \\
\end{tabular} & 334,79 \\
\hline Bufo spinosus & 29SND38 & 101,00 & 154,11 & 86,06 & 40,92 & 4160,23 & 272,22 & 64,23 & 207,99 & 109,68 & 205,85 & 208,84 & 101,98 & 852,33 & 124,75 & 6,88 & 57,12 & 353,53 & 48,20 & 50,95 & 350,97 \\
\hline Bufo spinosus & 29SND39 & 101,00 & 153,96 & 87,16 & 41,14 & 4137,05 & 272,16 & 63,43 & 208,73 & 109,60 & 205,40 & 208,28 & 102,00 & 870,46 & 126,93 & 7,33 & 56,63 & 359,14 & 50,47 & 53,44 & 357,18 \\
\hline Bufo spinosus & 29SND40 & 100,00 & 168,20 & 89,94 & 40,42 & 4473,58 & 295,80 & 76,41 & 219,39 & \begin{tabular}{|l|l|}
121,14 \\
\end{tabular} & 223,95 & 228,03 & 113,50 & 657,81 & $\begin{array}{l}96,03 \\
\end{array}$ & 4,00 & 60,04 & 280,67 & 31,31 & 33,32 & 277,32 \\
\hline Bufo spinosus & 29SND41 & 101,00 & 168,65 & 89,19 & 40,51 & 4432,78 & 294,78 & 77,14 & 217,64 & 121,91 & 223,91 & 227,95 & 114,21 & \begin{tabular}{ll|}
662,52 \\
\end{tabular} & $\begin{array}{l}96,85 \\
\end{array}$ & 4,00 & 60,02 & 282,14 & 31,64 & 34,01 & 278,72 \\
\hline Bufo spinosus & 29SND43 & 101,00 & 165,55 & 88,08 & 40,38 & 4386,48 & 289,87 & 74,40 & 215,47 & 119,04 & 220,25 & 223,94 & 111,32 & 704,16 & 103,05 & 4,47 & 59,20 & 297,69 & 35,20 & 37,73 & 294,37 \\
\hline Bufo spinosus & 29SND47 & 101,00 & 163,11 & 89,05 & 40,96 & 4309,41 & 285,90 & 70,68 & 215,21 & 116,77 & 216,77 & 219,84 & $\begin{array}{l}109,16 \\
\end{array}$ & \begin{tabular}{ll|l}
770,68 \\
\end{tabular} & $\begin{array}{l}112,25 \\
\end{array}$ & 5,77 & 57,55 & 320,32 & 42,06 & 45,06 & 318,06 \\
\hline Bufo spinosus & 29SND48 & 100,00 & 160,19 & 89,82 & 41,00 & 4310,84 & 283,68 & 67,29 & 216,38 & 113,66 & 213,89 & 216,89 & 106,16 & 813,88 & 118,38 & 6,42 & 56,90 & 336,12 & 46,13 & 48,98 & 334,85 \\
\hline Bufo spinosus & 29SND49 & 101,00 & 159,09 & 90,97 & 41,13 & 4312,25 & 283,37 & 65,34 & 218,03 & 111,86 | & 212,82 & 215,70 & 104,90 & 840,45 & 121,77 & 7,01 & 56,19 & 345,12 & 49,12 & 51,90 & 344,49 \\
\hline Bufo spinosus & 29SND50 & 101,00 & 167,79 & 91,83 & 40,21 & \begin{tabular}{ll|l}
4577,92 \\
\end{tabular} & 299,08 & 74,61 & 224,47 & 119,69 & 225,07 & 229,25 & $\begin{array}{l}111,94 \\
\end{array}$ & 656,23 & 95,12 & 4,00 & 59,42 & 277,02 & 32,25 & 33,94 & 275,19 \\
\hline Bufo spinosus & 29SND53 & 100,00 & 164,97 & 90,36 & 40,04 & $\begin{array}{l}4544,14 \\
\end{array}$ & 294,20 & 71,92 & 222,29 & $\begin{array}{ll}116,87 \\
\end{array}$ & 221,92 & 225,62 & 109,24 & 712,40 & 103,62 & 4,94 & 58,43 & 298,19 & 37,14 & 39,10 & 296,69 \\
\hline Bufo spinosus & 29SND54 & 100,00 & 163,62 & 90,20 & 40,02 & 4533,12 & 292,51 & 70,56 & 221,95 & 115,70 & 220,47 & 224,08 & 107,92 & 735,01 & \begin{tabular}{|l|l|}
107,10 \\
\end{tabular} & 5,02 & 58,32 & $\begin{array}{l}306,96 \\
\end{array}$ & 38,58 & 40,59 & 305,63 \\
\hline Bufo spinosus & 29SND55 & 100,00 & 162,59 & 90,29 & 40,09 & 4516,73 & 291,27 & 69,36 & 221,91 & 114,68 & 219,35 & 222,82 & $\mid 107,06$ & 757,73 & $\mid 110,34$ & 5,54 & 57,69 & 315,09 & 41,03 & 43,10 & 314,16 \\
\hline Bufo spinosus & 29SND57 & 101,00 & 163,58 & 91,65 & 40,52 & $4487,99 \mid$ & 292,20 & 68,96 & 223,24 & 114,77 & 219,93 & 223,01 & 107,82 & 778,36 & 112,98 & 5,93 & 57,09 & 321,51 & 43,46 & 45,93 & 320,79 \\
\hline Bufo spinosus & 29SND58 & 99,00 & 160,41 & 92,24 & 40,51 & \begin{tabular}{ll|l}
4511,64 \\
\end{tabular} & 290,14 & 65,14 & 224,99 & 108,50 & 217,14 & 220,11 & 104,43 & 823,70 & \begin{tabular}{|l|l|}
119,57 \\
\end{tabular} & 6,61 & 56,51 & \begin{tabular}{|l|l|}
338,98 \\
\end{tabular} & 47,61 & 49,76 & 338,68 \\
\hline Bufo spinosus & 29SND59 & 101,00 & 155,63 & 92,85 & 40,48 & 4542,00 & 286,69 & 60,08 & 226,61 & 100,20 & \begin{tabular}{|l|l|}
212,94 \\
\end{tabular} & 215,92 & 99,49 & $\begin{array}{l}886,67 \\
\end{array}$ & 128,71 & 7,65 & 56,03 & $\begin{array}{l}363,69 \\
\end{array}$ & 53,16 & 54,72 & 363,69 \\
\hline \begin{tabular}{|l|} 
Bufo spinosus \\
\end{tabular} & 29SND62 & 100,00 & 166,34 & 92,62 & 40,02 & 4682,53 & 300,06 & 71,66 & 228,40 & $\begin{array}{ll}116,55 \\
\end{array}$ & \begin{tabular}{|l|l|}
225,23 \\
\end{tabular} & 229,08 & 109,13 & $\begin{array}{l}689,45 \\
6\end{array}$ & $\begin{array}{l}99,47 \\
\end{array}$ & 4,62 & 58,18 & 287,12 & 36,23 & 37,75 & 286,52 \\
\hline Bufo spinosus & 29SND63 & 101,00 & 164,31 & 92,28 & 39,99 & 4680,84 & \begin{tabular}{|l|l|}
298,07 \\
\end{tabular} & 69,76 & 228,31 & $\begin{array}{l}114,41 \\
\end{array}$ & 223,45 & 227,20 & 107,21 & 718,88 & \begin{tabular}{|l|}
103,97 \\
\end{tabular} & 5,00 & 57,95 & 298,56 & 38,39 & 39,92 & 298,32 \\
\hline Bufo spinosus & 29SND64 & 100,00 & 163,53 & $\begin{array}{ll}92,14 \\
\end{array}$ & 39,99 & 4671,31 & 296,93 & 68,86 & 228,06 & 112,76 & 222,46 & 226,16 & 106,44 & 739,71 & 107,19 & 5,24 & 57,64 & 306,74 & 40,06 & 41,67 & 306,59 \\
\hline Bufo spinosus & 29SND65 & 101,00 & 162,54 & 92,21 & 39,99 & 4676,03 & 296,03 & 67,49 & 228,53 & 110,27 & 221,56 & 225,14 & 105,29 & 763,63 & 110,71 & 5,94 & 57,23 & 315,68 & 42,68 & 44,36 & 315,62 \\
\hline Bufo spinosus & 29SND66 & 101,00 & 165,61 & 93,09 & 40,11 & 4654,14 & 298,53 & 69,45 & 229,09 & 114,68 & 224,13 & 227,40 & 108,00 & 751,99 & 108,81 & 5,59 & 57,07 & 310,31 & 41,83 & 44,10 & 310,05 \\
\hline Bufo spinosus & 29SND67 & 100,00 & 162,12 & 93,45 & 40,02 & 4683,37 & 296,33 & 65,63 & 230,70 & 106,61 & 221,41 & 224,52 & 104,51 & 799,38 & 115,80 & 6,27 & 56,69 & 329,00 & 45,86 & 47,63 & 328,94 \\
\hline Bufo spinosus & 29SND69 & 100,00 & 156,26 & 94,39 & 39,99 & 4724,42 & 292,26 & 58,78 & 233,49 & $\begin{array}{ll}98,11 \\
\end{array}$ & 216,29 & 219,20 & 98,11 & $\begin{array}{l}888,65 \\
\end{array}$ & \begin{tabular}{l|l|}
129,02 \\
\end{tabular} & 7,71 & 55,92 & $\begin{array}{l}364,47 \\
\end{array}$ & 53,76 & 54,91 & 364,47 \\
\hline Bufo spinosus & 29SND71 & 100,00 & 168,11 & 94,80 & 40,01 & 4798,65 & 305,51 & 71,85 & 233,66 & \begin{tabular}{|l|l|}
116,48 \\
\end{tabular} & 228,52 & 232,59 & $\begin{array}{l}109,66 \\
\end{array}$ & $\begin{array}{l}657,29 \\
\end{array}$ & $\begin{array}{l}93,77 \\
\end{array}$ & 4,01 & 57,93 & 271,99 & 34,92 & 36,13 & 271,84 \\
\hline \begin{tabular}{|l|} 
Bufo spinosus \\
\end{tabular} & 29SND72 & 101,00 & 167,56 & 94,45 & 40,00 & 4800,62 & $\begin{array}{ll}304,86 \\
\end{array}$ & 71,40 & 233,45 & $\begin{array}{ll}115,69 \\
\end{array}$ & 228,11 & \begin{tabular}{|l|}
232,07 \\
\end{tabular} & 109,13 & $\begin{array}{l}676,64 \\
\end{array}$ & 96,79 & 4,45 & 57,64 & $\begin{array}{l}279,63 \\
\end{array}$ & 36,56 & 37,84 & 279,55 \\
\hline Bufo spinosus & 29SND74 & 101,00 & 163,90 & 93,73 & 39,83 & 4823,81 & 301,46 & 67,69 & 233,77 & 106,79 & 225,15 & 228,75 & $\begin{array}{l}105,49 \\
\end{array}$ & $\begin{array}{l}737,46 \\
\end{array}$ & \begin{tabular}{|l|l|}
106,23 \\
\end{tabular} & 5,32 & 57,22 & $\begin{array}{l}304,37 \\
\end{array}$ & 41,04 & 42,31 & 304,37 \\
\hline Bufo spinosus & 29SND75 & 100,00 & 164,11 & 93,99 & 39,71 & 4828,13 & 301,70 & 67,27 & 234,44 & 106,90 & 225,40 & 228,76 & 105,26 & 751,74 & 108,35 & 5,77 & 56,91 & 309,75 & 42,51 & \begin{tabular}{|l|l|l|}
43,99 \\
\end{tabular} & 309,75 \\
\hline Bufo spinosus & 29SND76 & 101,00 & 166,34 & 94,80 & 39,87 & 4805,36 & 303,58 & \begin{tabular}{|c|}
68,38 \\
\end{tabular} & 235,21 & 111,06 & 227,19 & 230,44 & 107,33 & 748,79 & 107,79 & 5,66 & 56,58 & \begin{tabular}{|l|l|}
307,78 \\
\end{tabular} & 42,49 & 44,37 & 307,73 \\
\hline Bufo spinosus & 29SND77 & 101,00 & 163,16 & 94,90 & 39,62 & 4845,10 & 301,51 & 64,80 & 236,71 & 105,01 & 224,73 & 227,83 & 103,70 & 794,91 & \begin{tabular}{ll|}
114,82 \\
\end{tabular} & 6,29 & 56,23 & $\begin{array}{l}326,38 \\
\end{array}$ & 46,21 & 47,79 & 326,38 \\
\hline Bufo spinosus & 29SND78 & 100,00 & 156,18 & 94,27 & 39,20 & \begin{tabular}{|l|l|}
4899,09 \\
\end{tabular} & 295,88 & \begin{tabular}{|l|l|}
58,04 \\
\end{tabular} & \begin{tabular}{|l|l|}
237,84 \\
\end{tabular} & $\begin{array}{ll}96,54 \\
\end{array}$ & $\begin{array}{ll}218,78 \\
\end{array}$ & 221,83 & \begin{tabular}{ll|}
96,54 \\
\end{tabular} & $\begin{array}{l}877,66 \\
\end{array}$ & $\begin{array}{l}127,63 \\
\end{array}$ & 7,38 & 56,02 & 360,54 & $\begin{array}{ll}52,64 \\
\end{array}$ & 53,34 & 360,54 \\
\hline \begin{tabular}{|l|} 
Bufo spinosus \\
\end{tabular} & 29SND79 & 101,00 & 153,58 & 94,51 & 39,06 & \begin{tabular}{ll|l}
4917,92 \\
\end{tabular} & 293,90 & 55,02 & $\begin{array}{ll}238,88 \\
\end{array}$ & $\begin{array}{ll}93,68 \\
\end{array}$ & 216,89 & 219,49 & 93,68 & $\begin{array}{l}919,63 \\
\end{array}$ & \begin{tabular}{|l|l|}
133,97 \\
\end{tabular} & 8,12 & 55,83 & \begin{tabular}{|l|l|}
377,20 \\
\end{tabular} & 56,25 & 56,71 & 377,20 \\
\hline Bufo spinosus & 29SND80 & 101,00 & 166,63 & 96,48 & 40,00 & 4914,35 & \begin{tabular}{ll|}
307,64 \\
\end{tabular} & 69,17 & $\begin{array}{ll}238,47 \\
\end{array}$ & 107,97 & 228,70 & 232,91 & 107,09 & $\begin{array}{l}646,56 \\
6\end{array}$ & 91,14 & 4,00 & 57,21 & 265,65 & 35,67 & 36,13 & 265,65 \\
\hline Bufo spinosus & 29SND84 & 101,00 & 166,20 & 95,57 & 39,56 & 4949,48 & 307,08 & 67,86 & 239,22 & 107,46 & 229,05 & 232,68 & 105,90 & \begin{tabular}{|l|l|}
717,25 \\
\end{tabular} & 102,55 & 5,08 & 56,79 & 294,66 & 40,21 & 41,54 & 294,66 \\
\hline Bufo spinosus & 29SND85 & 99,00 & 163,36 & 95,07 & 39,14 & 4975,53 & 304,82 & 65,19 & 239,63 & 103,05 & 226,75 & 230,31 & 103,01 & 759,23 & 109,09 & 5,89 & 56,40 & 311,86 & 43,72 & 44,89 & 311,86 \\
\hline Bufo spinosus & 29SND88 & 99,00 & 154,56 & 94,24 & 38,52 & 5066,11 & 297,74 & 55,48 & 242,26 & 93,30 & 220,01 & 222,74 & 93,30 & 894,16 & 130,22 & 7,64 & 55,91 & 366,97 & 54,09 & 54,49 & 366,97 \\
\hline Bufo spinosus & 29SND89 & 101,00 & 153,44 & 94,66 & 38,42 & 5085,55 & 297,12 & 53,67 & 243,45 & $\begin{array}{ll}91,82 \\
\end{array}$ & 219,37 & 221,80 & 91,82 & \begin{tabular}{|l|l|}
921,40 \\
\end{tabular} & $\begin{array}{l}134,45 \\
\end{array}$ & 8,01 & 55,71 & 377,72 & 56,39 & 56,68 & 377,72 \\
\hline Bufo spinosus & 29SND90 & 100,00 & 165,34 & 97,75 & 39,97 & 5033,34 & $\begin{array}{l}309,49 \\
\end{array}$ & 66,49 & 243,01 & 104,96 & 229,23 & 233,44 & \begin{tabular}{ll|}
104,66 \\
\end{tabular} & $\begin{array}{l}649,04 \\
\end{array}$ & $\begin{array}{l}90,68 \\
\end{array}$ & 4,01 & 56,50 & 264,87 & 36,60 & 36,92 & 264,87 \\
\hline Bufo spinosus & 29SND91 & 100,00 & 165,52 & 97,41 & 39,74 & 5042,61 & 309,69 & 66,78 & 242,92 & 105,51 & 229,67 & 233,77 & $\begin{array}{l}104,78 \\
\end{array}$ & 666,33 & 93,51 & 4,7 & 56,51 & 272,06 & 38,02 & 38,47 & 272,06 \\
\hline Bufo spinosus & 29SND92 & 100,00 & 167,01 & 97,38 & 39,53 & $\begin{array}{l}5049,72 \\
\end{array}$ & 311,14 & $\begin{array}{ll}67,58 \\
\end{array}$ & 243,55 & $\begin{array}{l}108,42 \\
\end{array}$ & 231,32 & 235,16 & \begin{tabular}{|l|}
105,97 \\
\end{tabular} & 672,80 & 94,69 & 4,91 & 56,41 & 274,65 & 38,37 & 39,36 & 274,65 \\
\hline Bufo spinosus & 29SND93 & 100,00 & 166,58 & 97,03 & 39,23 & 5067,16 & 310,69 & 67,06 & 243,63 & 107,18 & 231,19 & 234,92 & 105,31 & 693,44 & 98,05 & 5,00 & 56,36 & 283,46 & 39,40 & 40,47 & 283,46 \\
\hline Bufo spinosus & 29SND94 & 100,00 & 164,63 & 96,36 & 39,00 & 5094,30 & 309,10 & 65,31 & 243,79 & 103,10 & 229,80 & 233,27 & 103,05 & 729,34 & 103,74 & 5,38 & 56,13 & 298,24 & 42,26 & 43,34 & 298,24 \\
\hline Bufo spinosus & 29SND95 & 101,00 & 164,40 & 96,29 & 38,97 & 5107,33 & $\begin{array}{l}308,97 \\
\end{array}$ & 64,56 & \begin{tabular}{|l|l|}
244,41 \\
\end{tabular} & 102,61 & 229,69 & 233,08 & \begin{tabular}{ll|}
102,46 \\
\end{tabular} & \begin{tabular}{|l|l|}
749,64 \\
\end{tabular} & $\begin{array}{l}107,05 \\
\end{array}$ & 5,86 & 56,03 & $\begin{array}{l}306,62 \\
\end{array}$ & 43,75 & 44,92 & 306,62 \\
\hline Bufo spinosus & 29SND96 & 101,00 & 161,90 & 95,79 & 38,71 & 5140,64 & 307,12 & 61,99 & 245,13 & $\begin{array}{ll}99,61 \\
\end{array}$ & 227,89 & 231, & $\begin{array}{ll}99,61 \\
\end{array}$ & $\begin{array}{l}788,45 \\
7\end{array}$ & 113,31 & 6,03 & 55,97 & 322,89 & 46,10 & 47,06 & 322,89 \\
\hline Bufo spinosus & 29SND98 & 101,00 & 159,65 & 96,07 & 38,20 & 5204,60 & 306,12 & 58,25 & 247,87 & 96,60 & 226,80 & 225 & 96,60 & 842,70 & 121,84 & 6,97 & 55,70 & 344,44 & 50,83 & 51,66 & 344,44 \\
\hline Bufo spinosus & 29SND99 & 100,00 & 157,27 & $\begin{array}{ll}95,94 \\
\end{array}$ & 38,03 & 5233,99 & 304,20 & 55,38 & $\begin{array}{ll}248,82 \\
\end{array}$ & $\begin{array}{ll}93,83 \\
\end{array}$ & $\begin{array}{l}224,97 \\
\end{array}$ & 227,49 & 93,83 & 880,99 & \begin{tabular}{|l|l|}
127,97 \\
\end{tabular} & 7,45 & 55,45 & 360,06 & 53,78 & 54,41 & 360,06 \\
\hline Bufo spinosus & 29SNE00 & 96,00 & \begin{tabular}{ll|}
154,65 \\
\end{tabular} & 74,30 & 42,69 & 3403,58 & 245,97 & 73,88 & 172,10 & 118,09 & $\begin{array}{l}195,25 \\
\end{array}$ & \begin{tabular}{|l|l|}
197,60 \\
\end{tabular} & $\begin{array}{l}110,13 \\
\end{array}$ & 807,95 & 119,72 & 6,29 & 57,39 & 338,62 & 44,00 & 50,49 & 328,45 \\
\hline Bufo spinosus & 29SNE01 & 71,00 & 155,54 & 75,36 & 43,04 & 3391,56 & 246,96 & 73,98 & 172,98 & 118,78 & 195,81 & 198,16 & 110,94 & 820,20 & 120,06 & 6,99 & 56,68 & 341,42 & 46,29 & 53,10 & 331,97 \\
\hline Bufo spinosus & 29SNE02 & 37,00 & 154,45 & 76,67 & 43,41 & 3404,48 & 246,83 & 72,06 & 174,77 & \begin{tabular}{|l|l|}
117,64 \\
\end{tabular} & $\begin{array}{ll}195,06 \\
\end{array}$ & 197 & 109,50 & 851,18 & 123,02 & 7,56 & 55,97 & 351,79 & \begin{tabular}{ll|}
49,67 \\
\end{tabular} & 56,62 & 343,38 \\
\hline Bufo spinosus & 29SNE10 & 101,00 & 155,98 & 79,34 & 42, & 3622,00 & 256,06 & 71,49 & $\begin{array}{l}184,58 \\
\end{array}$ & 116,98 & $\begin{array}{l}199,76 \\
\end{array}$ & 202,30 & 109,14 & 821,60 & \begin{tabular}{|l|l|}
119,97 \\
\end{tabular} & 6,60 & 56,95 & 341,94 & 45,99 & 51,55 & 334,68 \\
\hline Bufo spinosus & 29SNE11 & 101,00 & 155,21 & 80,06 & 42,88 & 3601,97 & 254,96 & 70,29 & 184,66 & 116,16 & 198,65 & 201,09 & 108,34 & 845,97 & \begin{tabular}{|l|l|}
122,64 \\
\end{tabular} & 7,29 & 56,16 & 349,90 & 48,92 & 54,74 & 343,15 \\
\hline Bufo spinosus & 29SNE12 & 101,00 & 154,19 & $\begin{array}{ll}80,64 \\
\end{array}$ & 43,08 & 3581,21 & 253,36 & 68,70 & \begin{tabular}{ll|l}
184,66 \\
\end{tabular} & 115,14 & \begin{tabular}{|l|l|}
197,19 \\
\end{tabular} & $\begin{array}{l}199,53 \\
\end{array}$ & 107,27 & 874,10 & 125,94 & 7,94 & 55,56 & 359,32 & 52,16 & 58,23 & 353,13 \\
\hline Bufo spinosus & 29SNE20 & 101,00 & 152,52 & 84,09 & 41,92 & 3904,09 & 262,92 & 64,42 & 198,50 & 110,37 & 200,48 & 203 & 102,82 & 879,72 & $128, \mathrm{C}$ & 7,63 & 56,25 & 363,10 & 51,42 & 55,46 & 355 \\
\hline Bufo spinosus & 295 & 100 & 154 & 85,30 & 42 & & 264 & 65 & 198,45 & & 20 & 20 & 104 & 879 & 12 & 7,92 & 55,83 & 361,05 & 52,38 & 56,89 & 357,44 \\
\hline Bufo spinosus & 29SNE30 & 100,00 & 151,17 & 88,04 & 41,29 & \begin{tabular}{ll|l|}
4146,76 \\
\end{tabular} & 270,31 & 60,08 & 210,23 & 106,59 & 202,74 & 205,56 & 99,05 & 915,09 & 132,98 & 8,19 & 55,99 & 375,21 & 54,94 & 57,61 & 374,22 \\
\hline Bufo spinosus & 29SNE31 & 101,00 & 153,26 & 89,56 & 41,83 & 4109,05 & 272,14 & 61,12 & 211,03 & 107,35 & 204,18 & 206,82 & $\mid 101,14$ & 913,92 & 131,86 & 8,50 & 55,35 & 373,01 & 56,08 & 59,22 & 372,06 \\
\hline
\end{tabular}




\begin{tabular}{|c|c|c|c|c|c|c|c|c|c|c|c|c|c|c|c|c|c|c|c|c|c|}
\hline TAXON & UTM & $\mathrm{km} 2$ & BIO1 & BIO2 & $\mathrm{BIO3}$ & B104 & BIO5 & B106 & B107 & B108 & 8109 & B1010 & BIO11 & B1012 & BIO13 & B1014 & BIO15 & B1016 & B1017 & B1018 & B1019 \\
\hline Bufo spinosus & 29SNE32 & 100,00 & 153,67 & 90,88 & 42,44 & 4083,90 & 272,45 & 60,72 & 211,73 & 106,56 & 204,07 & 206,71 & 101,62 & 929,17 & 133,19 & 8,90 & 54,84 & 377,49 & 58,40 & 61,82 & 376,70 \\
\hline \begin{tabular}{|l|} 
Bufo spinosus \\
\end{tabular} & 29SNE40 & 101,00 & 155,32 & 91,90 & 41,29 & 4330,14 & 280,92 & 61,01 & 219,91 & 104,81 & 209,47 & 212,15 & 100,99 & \begin{tabular}{|l|l|}
894,76 \\
\end{tabular} & 129,51 & 7,94 & 55,79 & 365,99 & 54,14 & 56,49 & 365,92 \\
\hline \begin{tabular}{|l} 
Bufo spinosus \\
\end{tabular} & 29SNE41 & 101,00 & 152,76 & 93,14 & 41,49 & 4345,88 & 279,68 & 57,65 & 222,03 & $\begin{array}{l}98,66 \\
\end{array}$ & 207,16 & 209,86 & $\begin{array}{l}98,28 \\
98\end{array}$ & 939,08 & \begin{tabular}{|l|l|}
135,46 \\
\end{tabular} & 8,86 & 55,12 & 382,81 & 58,79 & 60,79 & 382,81 \\
\hline Bufo spinosus & 29SNE42 & 100,00 & 150,50 & 94,55 & 41,80 & 4357,86 & 278,69 & 54,41 & 224,29 & 95,73 & 205,08 & 207,75 & 95,73 & $\begin{array}{l}981,85 \\
\end{array}$ & 141,10 & 9,75 & 54,39 & 398,97 & 63,27 & 65,08 & 398,97 \\
\hline Bufo spinosus & 29SNE50 & 101,00 & 152,49 & 93,64 & 40,52 & 4559,42 & 284,73 & 56,28 & 228,45 & 96,01 & 210,15 & 213,00 & 96,01 & \begin{tabular}{|l|l|}
936,03 \\
\end{tabular} & $\begin{array}{l}135,86 \\
\end{array}$ & 8,58 & 55,59 & 383,17 & 57,83 & 59,04 & 383,17 \\
\hline Bufo spinosus & 29SNE51 & $\mid 101,00$ & 150,79 & 94,81 & 40,71 & \begin{tabular}{|l|l|l|}
4567,43 \\
\end{tabular} & 283,90 & 53,75 & 230,15 & 94,13 & 208,58 & 211,30 & 94,13 & \begin{tabular}{|l|l|}
971,58 \\
\end{tabular} & $|140,67|$ & $\begin{array}{lll}9,29 & \end{array}$ & 54,97 & 396,61 & 61,51 & 62,51 & 396,61 \\
\hline Bufo spinosus & 29SNE60 & 100,00 & 156,03 & 95,70 & 40,18 & 4727,17 & 292,76 & 57,48 & 235,28 & 97,60 & 216,06 & 218,82 & 97,60 & 909,29 & 131,69 & 8,14 & 55,40 & 371,90 & 56,08 & 57,23 & 371,90 \\
\hline Bufo spinosus & 29SNE61 & 100,00 & 151,40 & 95,90 & $\begin{array}{l}40,15 \\
\end{array}$ & 4750,56 & 289,01 & 52,56 & 236,45 & 92,84 & 211,99 & 214,58 & 92,84 & 973,54 & 141,32 & 9,16 & 55,04 & 397,64 & 61,64 & 62,21 & 397,64 \\
\hline Bufo spinosus & 29SNE62 & 100,00 & 141,47 & 93,16 & 39,39 & 4773,60 & 277,94 & 44,03 & 233,92 & 83,16 & 204,14 & 205,27 & 83,16 & 1091,31 & 160,04 & 10,87 & 54,99 & 445,90 & 69,95 & 70,01 & 445,90 \\
\hline Bufo spinosus & 29SNE70 & 101,00 & 154,33 & 95,89 & 39,32 & 4917,30 & 295,29 & 54,54 & 240,75 & 94,07 & 217,36 & 219,94 & 94,07 & 929,76 & 135,19 & 8,27 & 55,35 & 380,43 & 57,70 & 58,26 & 380,43 \\
\hline Bufo spinosus & 29SNE71 & 100,00 & 147,42 & 94,63 & 38,97 & 4938,86 & 288,14 & 48,14 & 240,01 & 87,19 & 211,97 & 213,50 & 87,19 & \begin{tabular}{|l|l|l|l|}
1016,43 \\
\end{tabular} & 148,84 & 9,58 & 55,22 & 415,88 & 63,99 & 64,14 & 415,88 \\
\hline Bufo spinosus & 29SNE72 & 101,00 & 147,01 & 95,68 & 39,19 & 4934,79 & 287,99 & 46,80 & 241,19 & 86,58 & 211,29 & 212,84 & 86,58 & 1037,05 & 151,67 & 10,03 & 55,00 & 423,37 & 66,27 & 66,45 & 423,37 \\
\hline Bufo spinosus & 29SNE80 & 101,00 & 147,36 & 93,38 & 38,00 & 5105,65 & 290,68 & 48,02 & 242,66 & 85,73 & 214,97 & 216,08 & 85,73 & \begin{tabular}{|l|l|}
999,48 \\
\end{tabular} & 146,99 & 9,09 & 55,62 & 409,81 & 61,75 & 61,78 & 409,81 \\
\hline Bufo spinosus & 29SNE81 & 100,00 & 139,59 & 91,18 & 37,40 & 5112,34 & 281,58 & 41,21 & 240,36 & 78,28 & 208,20 & 208,53 & 78,28 & $\begin{array}{l}1095,12 \\
\end{array}$ & 162,51 & 10,33 & 55,64 & 449,06 & 67,73 & 67,73 & 449,06 \\
\hline Bufo spinosus & 29SNE82 & 101,00 & 142,45 & 93,26 & \begin{tabular}{l|l|l}
37,95 \\
\end{tabular} & 5101,60 & 285,13 & 42,50 & 242,63 & 80,70 & 210,18 & 210,85 & 80,70 & 1080,88 & 159,84 & 10,28 & 55,32 & 442,08 & 67,84 & 67,92 & 442,08 \\
\hline Bufo spinosus & 29SNE90 & 100,00 & 144,25 & 91,88 & 37,01 & 5263,55 & 289,66 & 44,62 & 245,03 & 81,28 & 214,68 & 215,34 & 81,28 & 1026,81 & 151,79 & 9,32 & 55,69 & 420,93 & 63,00 & 63,03 & 420,93 \\
\hline \begin{tabular}{|l|} 
Bufo spinosus \\
\end{tabular} & 29SNE91 & 100,00 & 133,40 & 88,25 & \begin{tabular}{|c|c|}
36,15 \\
\end{tabular} & 5252,89 & 276,32 & 35,82 & 240,49 & 71,19 & 204,67 & 204,67 & 71,19 & 1151,78 & 172,48 & 10,85 & 55,87 & 472,69 & 70,36 & 70,36 & 472,69 \\
\hline Bufo spinosus & 29SNE92 & 100,00 & 141,13 & 92,11 & 37,01 & 5261,34 & 286,09 & 40,61 & 245,48 & 77,82 & 211,52 & 211,83 & 77,82 & 1085,70 & 161,39 & 10,10 & 55,59 & 444,37 & 67,32 & 67,38 & 444,37 \\
\hline Bufo spinosus & 29SPB01 & 101,00 & 162,03 & 94,36 & 41,61 & \begin{tabular}{|l|l|}
4497,07 \\
\end{tabular} & 288,29 & 63,89 & 224,40 & 117,19 & 218,91 & 223,10 & 108,31 & 555,68 & 89,50 & 1,30 & 66,64 & 258,63 & 18,44 & 21,93 & 244,09 \\
\hline Bufo spinosus & 29SPB02 & 100,00 & 156,21 & 96,72 & 41,06 & 4645,49 & 288,15 & 56,77 & 231,38 & \begin{tabular}{ll|}
109,81 \\
\end{tabular} & 215,06 & 219,32 & 100,94 & 589,35 & 92,50 & 1,92 & 64,92 & 268,40 & 21,17 & 24,40 & 255,58 \\
\hline Bufo spinosus & 29SPB03 & 101,00 & 158,06 & 98,16 & 41,13 & 4706,17 & 292,82 & 57,77 & 235,05 & \begin{tabular}{|l|l|}
110,68 \\
\end{tabular} & 217,75 & 221,95 & 101,91 & 579,27 & 90,05 & 1,99 & 64,43 & 262,06 & 21,21 & 24,19 & 249,89 \\
\hline Bufo spinosus & 29SPB04 & 101,00 & 162,26 & 99,50 & 41,29 & 4747,51 & 299,03 & 61,25 & 237,78 & 114,29 & 222,41 & 226,65 & 105,52 & 555,11 & 85,60 & 1,98 & 64,07 & 250,12 & 20,58 & 23,46 & 238,41 \\
\hline Bufo spinosus & 29SPB05 & 100,00 & 163,97 & 101,37 & 41,34 & 4816,27 & 303,75 & 62,08 & 241,66 & 115,01 & 224,98 & 229,16 & 106,18 & 546,64 & 83,50 & 2,00 & 63,37 & 244,04 & 20,84 & 23,48 & 233,34 \\
\hline Bufo spinosus & 29SPB06 & 101,00 & 166,78 & 103,09 & \begin{tabular}{|l|l|}
41,77 \\
\end{tabular} & 4864,45 & 308,96 & 64,24 & 244,73 & 117,18 & 228,35 & 232,62 & 108,45 & 531,27 & 80,81 & 1,99 & 62,92 & 235,55 & 20,77 & 23,04 & 225,63 \\
\hline Bufo spinosus & 29SPB07 & 101,00 & 166,32 & 105,44 & 41,88 & 4943,26 & 312,49 & 62,73 & 249,76 & 115,83 & 229,00 & 233,25 & 107,03 & 535,87 & 80,73 & 2,00 & 62,05 & 234,58 & 21,63 & 23,64 & 226,01 \\
\hline Bufo spinosus & 29SPB09 & 100,00 & 166,65 & 110,11 & 42,02 & 5078,42 & 319,97 & 61,01 & 258,96 & 114,61 & 231,07 & 235,43 & 105,78 & 538,22 & 79,76 & 2,00 & 60,83 & 230,49 & 23,08 & 24,19 & 224,76 \\
\hline Bufo spinosus & 29SPB10 & 83,00 & 172,73 & 90,49 & \begin{tabular}{|l|l|}
41,49 \\
\end{tabular} & 4345,16 & 291,22 & 75,65 & 215,57 & 128,91 & 227,13 & 231,16 & 120,17 & 499,02 & 81,41 & 1,00 & 68,00 & 236,81 & 14,28 & 18,78 & 220,00 \\
\hline Bufo spinosus & 29SPB11 & 99,00 & 168,63 & 92,33 & 41,09 & 4481,92 & 291,86 & 70,19 & 221,67 & 123,23 & 224,88 & 228,95 & 114,35 & 520,10 & 83,18 & 1,01 & 66,93 & 242,62 & 16,15 & 20,50 & 226,66 \\
\hline Bufo spinosus & 29SPB12 & 101,00 & 159,55 & 95,59 & 40,93 & 4684,63 & 290,54 & 59,33 & 231,21 & \begin{tabular}{|l|l|}
112,27 \\
\end{tabular} & 218,81 & 222,92 & 103,22 & 570,01 & 88,50 & 1,90 & 64,84 & 258,87 & 19,90 & 23,92 & 244,94 \\
\hline Bufo spinosus & 29SPB13 & 100,00 & 163,67 & 96,69 & \begin{tabular}{|l|}
40,97 \\
\end{tabular} & 4727,12 & 296,40 & 62,81 & 233,59 & 115,68 & 223,35 & 227,42 & 106,75 & 545,74 & 84,32 & 1,70 & 64,48 & 246,99 & 19,23 & 23,10 & 233,35 \\
\hline Bufo spinosus & 29SPB14 & 100,00 & 164,15 & 98,47 & 40,99 & 4808,23 & 300,24 & 62,28 & 237,96 & 114,95 & 224,83 & 228,98 & 106,16 & 543,03 & 83,13 & 1,86 & 63,62 & 243,27 & 19,80 & 23,49 & 230,58 \\
\hline Bufo spinosus & 29SPB15 & 101,00 & 166,02 & 100,20 & 41,00 & 4869,35 & 304,94 & 63,33 & 241,61 & 115,96 & 227,46 & 231,61 & 107,26 & 532,74 & 81,03 & 1,93 & 63,12 & 236,72 & 20,00 & 23,43 & 224,84 \\
\hline Bufo spinosus & 29SPB16 & 100,00 & 169,62 & 101,78 & 41,12 & 4908,01 & 310,38 & 66,19 & 244,19 & 118,84 & 231,52 & 235,58 & 110,12 & 514,27 & 77,93 & 1,73 & 62,67 & 227,15 & 19,65 & 22,79 & 215,99 \\
\hline Bufo spinosus & 29SPB17 & 100,00 & 168,05 & 104,46 & 41,20 & 5005,48 & 313,51 & 63,50 & 250,01 & 116,38 & 231,39 & 235,43 & 107,52 & 524,31 & 78,49 & 1,98 & 61,72 & 228,42 & 21,01 & 23,75 & 218,70 \\
\hline Bufo spinosus & 29SPB18 & 101,00 & 168,43 & 106,74 & 41,49 & 5064,67 & 317,17 & 62,97 & 254,19 & \begin{tabular}{|l|l|}
116,14 \\
\end{tabular} & 232,58 & 236,60 & 107,19 & 524,31 & 77,78 & 2,00 & 60,91 & 225,94 & 21,78 & 23,97 & 217,52 \\
\hline \begin{tabular}{|l} 
Bufo spinosus \\
\end{tabular} & 29SPB19 & 100,00 & 168,67 & 108,60 & 41,74 & 5121,81 & 320,40 & 62,43 & 257,97 & 115,63 & 233,61 & 237,66 & 106,71 & 525,02 & 77,21 & 2,00 & 60,35 & 223,97 & 22,44 & 24,26 & 216,79 \\
\hline Bufo spinosus & 29SPB21 & 97,00 & 172,04 & 90,53 & 40,61 & 4512,68 & 293,65 & 73,35 & 220,30 & 125,89 & 228,34 & 232,29 & 116,95 & 501,29 & 79,80 & 1,00 & 66,59 & 232,37 & $\begin{array}{l}14,78 \\
\end{array}$ & 20,05 & 215,44 \\
\hline Bufo spinosus & 29SPB22 & 100,00 & 166,31 & 93,15 & \begin{tabular}{|l|l|}
40,33 \\
\end{tabular} & 4667,96 & 293,92 & 66,12 & 227,81 & 118,69 & 224,99 & 228,93 & 109,63 & 531,05 & 82,62 & 1,25 & 65,03 & 241,44 & 17,40 & 22,36 & 225,77 \\
\hline Bufo spinosus & 29SPB23 & 101,00 & 168,25 & 94,56 & 40,32 & 4735,29 & 298,46 & 67,19 & 231,27 & 119,61 & 227,77 & 231,71 & 110,66 & 519,73 & 80,23 & 1,19 & 64,47 & 234,68 & 17,37 & 22,16 & 219,59 \\
\hline Bufo spinosus & 29SPB24 & 100,00 & 165,69 & 97,05 & 40,46 & 4849,47 & 300,64 & 63,40 & 237,24 & 115,70 & 226,89 & 230,83 & 107,08 & 533,69 & 81,11 & 1,86 & 63,31 & 237,35 & 19,21 & 23,72 & 223,55 \\
\hline \begin{tabular}{|l} 
Bufo spinosus \\
\end{tabular} & $295 P B 25$ & 100,00 & 169,33 & 98,40 & 40,57 & 4894,24 & 306,29 & 66,31 & 239,97 & 118,59 & 231,09 & 234,90 & 110,06 & 513,84 & 77,78 & 1,62 & 62,78 & 227,38 & 18,76 & 23,11 & 214,10 \\
\hline Bufo spinosus & 29SPB26 & 101,00 & 169,08 & 100,77 & \begin{tabular}{ll|}
40,72 \\
\end{tabular} & 4972,45 & 309,87 & 64,94 & 244,93 & 117,62 & 231,85 & 235,79 & 108,74 & 516,25 & 77,31 & 1,88 & 61,94 & 225,79 & 19,77 & 23,69 & 213,66 \\
\hline Bufo spinosus & 29SPB27 & 100,00 & 167,14 & 103,45 & 40,86 & 5076,86 & 312,47 & 61,61 & 250,86 & 114,53 & 231,33 & 235,27 & 105,58 & 528,04 & 78,16 & 2,00 & 61,08 & 228,12 & 21,14 & 24,51 & 217,42 \\
\hline Bufo spinosus & 29SPB29 & 101,00 & 167,13 & 107,53 & 41,02 & 5203,95 & 318,63 & 59,81 & 258,82 & 112,92 & 233,18 & 237,07 & 103,92 & 531,36 & 77,24 & 2,00 & 59,86 & 225,10 & 22,59 & 25,19 & 216,82 \\
\hline Bufo spinosus & 29SPB31 & 58,00 & 174,81 & 88,67 & 40,00 & 4559,20 & 295,23 & 75,87 & 219,36 & \begin{tabular}{|l|l|}
127,54 \\
\end{tabular} & 231,51 & 235 & 118,59 & 486,49 & 76,64 & 1,00 & 65,94 & 222,86 & 14,03 & 19,99 & 205,03 \\
\hline \begin{tabular}{|l} 
Bufo spinosus \\
\end{tabular} & 29SPB32 & 101,00 & 173,23 & 90,13 & 39,87 & 4653,86 & 296,81 & 73,27 & 223,54 & 124,94 & 231,23 & 234,90 & 115,92 & 493,39 & 76,86 & 1,00 & 65,25 & 224,21 & 14,76 & 20,66 & 206,99 \\
\hline Bufo spinosus & 29SPB33 & 100,00 & 172,24 & 92,08 & 39,85 & 4756,22 & 299,82 & 71,13 & 228,69 & 122,83 & 231,68 & 235,45 & 113,82 & 497,26 & 76,39 & 1,00 & 64,32 & 223,32 & 15,71 & 21,49 & 206,86 \\
\hline Bufo spinosus & 29SPB34 & 101,00 & 170,86 & 94,32 & $39,90 \mid$ & 4859,98 & 302.54 & 68.46 & 234,07 & 120,14 & 231.78 & 235,50 & $\mid 111,38$ & 504,14 & 76,40 & 1,15 & 63,32 & 223,70 & 16,99 & 22.58 & 208,22 \\
\hline Bufo spinosus & 29SPB35 & 101,00 & 169,60 & 96,90 & 39,96 & 4957,53 & 305,73 & 65,96 & 239,77 & 117,77 & 231,96 & 235,63 & 109,06 & 511,72 & 76,62 & 1,60 & 62,32 & 24,38 & 18,45 & 23,57 & 210,04 \\
\hline \begin{tabular}{|l} 
Bufo spinosus \\
\end{tabular} & 29SPB36 & 99,00 & 171,07 & 98,97 & 40,02 & 5027,06 & 310,27 & 66,23 & 244,03 & 118,48 & 234,36 & 23 & 109,54 & 504,43 & 74,85 & 1,80 & 61,47 & 219,22 & 19,03 & 23,80 & 205,73 \\
\hline Bufo spinosus & 29SPB37 & 101,00 & 168,89 & \begin{tabular}{|l|}
101,83 \\
\end{tabular} & \begin{tabular}{|l|l|}
40,13 \\
\end{tabular} & 5123,45 & 312,79 & 62,74 & 250,05 & 115,32 & 233,65 & 237,34 & 106,44 & 517,24 & 75,86 & 2,00 & 60,68 & 222,11 & 20,43 & 24,79 & 209,98 \\
\hline \begin{tabular}{|l|} 
Bufo spinosus \\
\end{tabular} & $295 \mathrm{SB} 38$ & 100,00 & 165,74 & 104,48 & 40,26 & 5217,51 & 314,11 & 58,52 & 255,59 & 111,43 & 231,94 & 235,57 & 102,43 & 536,33 & 77,76 & 2,00 & 60,14 & 227,63 & 22,05 & 25,60 & 217,14 \\
\hline Bufo spinosus & 29SPB39 & 100,00 & 165,47 & 106,32 & \begin{tabular}{|l|l|}
40,48 \\
\end{tabular} & 5275,48 & 316,66 & 57,26 & 259,40 & \begin{tabular}{|l|l|}
110,34 \\
\end{tabular} & 232,63 & 236,23 & 101,60 & 539,62 & 77,46 & 2,16 & 59,39 & 226,96 & 23,19 & 26,27 & 217,56 \\
\hline Bufo spinosus & 29SPB42 & 100,00 & 174,39 & 87,8 & 39,07 & 4705,30 & 296,40 & 74,27 & 222,13 & 125,04 & 232,76 & & 11 & 486,66 & 74,96 & 1,00 & 65,00 & 218,79 & 14,07 & 21,01 & 200,46 \\
\hline \begin{tabular}{|l} 
Bufo spinosus \\
\end{tabular} & 29SPB43 & 100,00 & 171,07 & $\begin{array}{ll}90,36 \\
\end{array}$ & 39,05 & 4835,05 & 298,26 & 69,46 & 228,80 & 120,41 & 231,39 & 234,94 & 111,54 & 503,00 & 76,14 & 1,00 & 63,58 & 223,05 & 15,97 & 22,78 & 205,61 \\
\hline Bufo spinosus & 29SPB44 & 100,00 & 168,94 & 93,08 & \begin{tabular}{|l|l|}
39,08 \\
\end{tabular} & 4953,04 & 301,00 & 65,92 & 235,08 & 116,97 & 230,92 & 234,64 & 108,21 & 514,36 & 76,65 & 1,65 & 62,62 & 225,14 & 17,70 & 24,14 & 208,76 \\
\hline Bufo spinosus & 29SPB45 & 101,00 & 167,17 & $\begin{array}{l}95,93 \\
\end{array}$ & \begin{tabular}{ll|l}
39,15 \\
\end{tabular} & 5057,97 & 303,87 & 62,46 & 241,41 & 114,03 & 230,75 & 234,29 & \begin{tabular}{|l|l|}
105,23 \\
\end{tabular} & 524,81 & 77,31 & 1,95 & 61,65 & 227,20 & $\mid 19,13$ & 25,01 & 212,03 \\
\hline Bufo spinosus & 29SPB47 & 100,00 & 168,88 & 100,49 & 39,82 & 5191,89 & 311,99 & 61,96 & 250,03 & 114,28 & 234,42 & 237,89 & 105,12 & 517,01 & 75,01 & 2,00 & 60,66 & 220,39 & 20,28 & 25,11 & 207,22 \\
\hline Bufo spinosus & 29SPB48 & 100,00 & 167,76 & 102,78 & 39,96 & 5275,35 & 314,51 & 59,57 & 254 & 112 & 234 & 238 & & 523,92 & 75,31 & 2,00 & 59,87 & 221,33 & 21,22 & 25,76 & 205 \\
\hline \begin{tabular}{|l} 
Bufo spinosus \\
\end{tabular} & 29SPB49 & 100,00 & 166,50 & 105,08 & 40,00 & 5340,31 & 316,69 & 57,41 & 259,28 & $\begin{array}{l}110,07 \\
12,0\end{array}$ & 234,41 & 237,71 & 101,40 & 532,89 & 75,91 & 2,06 & 59,35 & 223,19 & 22,59 & 26,21 & 212,30 \\
\hline
\end{tabular}




\begin{tabular}{|c|c|c|c|c|c|c|c|c|c|c|c|c|c|c|c|c|c|c|c|c|c|}
\hline TAXON & UTM & $\mathrm{km} 2$ & BIO1 & BIO2 & $\mathrm{BIO3}$ & BIO4 & BIO5 & B106 & B107 & B108 & 8109 & BIO10 & BIO11 & B1012 & 81013 & BIO14 & BIO15 & B1016 & B1017 & B1018 & 81019 \\
\hline Bufo spinosus & 29SPB51 & & & & & & & & & & & & & & & & & & & & \\
\hline Bufo spinosus & 29SPB52 & 100,00 & 175,19 & 85,50 & 38,19 & 4763,32 & 295,72 & 74,92 & 220,80 & 124,69 & 233,97 & 237,43 & 115,81 & 482,36 & 73,92 & 1,00 & 64,48 & 214,43 & 13,55 & 21,57 & $\begin{array}{l}194,99 \\
197,70\end{array}$ \\
\hline Bufo spinosus & 29SPB53 & 101,00 & 172,90 & 87,90 & 38,16 & 4887,35 & 298,20 & 71,02 & 227,18 & 121,10 & 233,55 & 236,92 & 112,13 & $\begin{array}{l}493,46 \\
\end{array}$ & $\begin{array}{ll}74,73 \\
756\end{array}$ & 1,01 & 63,42 & 216,54 & 15,33 & 23,12 & 197,79 \\
\hline Bufo spinosus & 29SPB54 & 101,00 & 170,45 & 90,94 & 38,30 & 5007,82 & 300,94 & 66,97 & 233,97 & 117,41 & 232,94 & 236,36 & 108,48 & $\begin{array}{l}506,42 \\
\end{array}$ & 75,65 & 1,51 & 62,28 & 219,73 & 17,00 & 24,36 & 202,13 \\
\hline Bufo spinosus & 29SPB55 & 99,00 & 166,69 & 94,61 & 38,71 & 5134,48 & 303,20 & 61,36 & 241,84 & 112,48 & 231,25 & 234,60 & 103,59 & 528,04 & 77,56 & 2,00 & 61,28 & 226,42 & 19,01 & 25,85 & 210,22 \\
\hline Bufo spinosus & 29SPB56 & 100,00 & 168,05 & 96,89 & 38,95 & 5204,47 & 307,65 & 61,30 & 246,35 & $\begin{array}{ll}112,94 \\
\end{array}$ & 233,58 & 236,92 & 103,94 & 520,95 & 76,11 & 2,00 & 60,74 & 221,98 & 19,40 & 25,68 & 206,68 \\
\hline Bufo spinosus & 29SPB57 & 100,00 & 168,52 & 99,30 & 39,05 & 5265,48 & 311,35 & 60,62 & 250,73 & 112,74 & 235,06 & 238,25 & 103,76 & 519,26 & 75,34 & 2,00 & 60,09 & 219,62 & 20,12 & 25,82 & 205,28 \\
\hline Bufo spinosus & 29SPB58 & 101,00 & 165,17 & 102,30 & 39,26 & 5365,91 & 312,87 & 56,02 & 256,85 & 108,46 & 233,42 & 236,58 & 99,60 & 539,10 & 77,02 & 2,18 & 59,31 & 225,79 & 22,22 & 27,10 & 212,91 \\
\hline Bufo spinosus & 29SPB59 & 100,00 & 166,71 & 104,28 & 39,71 & $\begin{array}{l}5416,16 \\
\end{array}$ & 316,71 & 56,52 & 260,20 & 109,16 & 235,61 & 238,69 & 100,55 & 531,41 & 75,54 & 2,18 & 58,79 & 221,23 & 22,63 & 27,04 & 209,20 \\
\hline Bufo spinosus & 29SPB62 & 100,00 & 176,32 & 82,94 & 37,30 & 4827,46 & 295,47 & 75,96 & 219,51 & 124,72 & 235,65 & 238,97 & 115,88 & 476,06 & 73,79 & 1,00 & 64,06 & 209,23 & 13,14 & 22,10 & 188,61 \\
\hline Bufo spinosus & 29SPB63 & 100,00 & 173,50 & 85,69 & 37,29 & \begin{tabular}{|l|}
4955,21 \\
\end{tabular} & 297,65 & 71,32 & $\begin{array}{l}226,33 \\
\end{array}$ & $\begin{array}{ll}120,63 \\
\end{array}$ & 234,78 & 237,93 & 111,59 & 490,51 & 75,08 & 1,01 & 62,88 & 213,02 & 14,88 & 23,59 & 193,09 \\
\hline Bufo spinosus & 29SPB64 & 100,00 & 171,35 & 89,14 & 37,69 & 5074,96 & 300,92 & 67,29 & $\begin{array}{ll}233,63 \\
\end{array}$ & 117,19 & $\begin{array}{ll}234,48 \\
\end{array}$ & \begin{tabular}{|l|l|}
237,69 \\
\end{tabular} & \begin{tabular}{|l|l|}
108,34 \\
\end{tabular} & \begin{tabular}{l|l|}
502,45 \\
\end{tabular} & 75,84 & 1,52 & 62,03 & 215,97 & 16,64 & 24,62 & 197,18 \\
\hline Bufo spinosus & 29SPB65 & 101,00 & 170,61 & 92,24 & 37,94 & 5171,80 & 304,69 & 64,81 & 239,88 & 115,30 & 235,21 & 238,42 & 106,43 & 507,57 & 75,85 & 1,94 & 61,13 & 216,36 & 17,85 & 25,54 & 198,55 \\
\hline Bufo spinosus & 29SPB66 & 100,00 & 167,46 & 96,09 & 38,26 & 5281,79 & 307,19 & 59,68 & 247,51 & 111,22 & 233,90 & 237,04 & 102,17 & 526,75 & 77,38 & 2,00 & 60,41 & 222,67 & 19,45 & 26,22 & 206,49 \\
\hline Bufo spinosus & 29SPB67 & 101,00 & 167,34 & 98,94 & 38,73 & 5365,73 & 310,99 & 58,12 & 252,87 & 110,08 & 235,12 & 238,06 & 101,04 & 527,78 & 76,87 & 2,00 & 59,80 & 221,55 & 20,25 & 26,49 & 206,39 \\
\hline Bufo spinosus & 29SPB68 & 99,00 & 161,51 & 102,50 & 38,98 & 5475,86 & 310,95 & 50,86 & 260,09 & 103,49 & 231,21 & 234,26 & 94,64 & 565,09 & 80,49 & 2,59 & 58,77 & 234,47 & 24,03 & 29,36 & 221,11 \\
\hline Bufo spinosus & 29SPB69 & 101,00 & 160,85 & 104,80 & 39,03 & 5543,35 & 313,78 & 49,17 & 264,61 & 102,18 & 231,74 & 234,69 & 93,30 & 569,54 & 80,36 & 2,99 & 57,97 & 234,49 & 25,62 & 30,24 & 222,24 \\
\hline Bufo spinosus & 29SPB72 & 100,00 & 177,28 & 80,30 & 36,32 & 4889,62 & 294,83 & 76,74 & 218,10 & 124,96 & 237,14 & 240,23 & 115,76 & $\begin{array}{l}471,86 \\
\end{array}$ & 74,05 & 1,00 & 63,85 & 205,10 & 12,65 & 22,54 & 183,14 \\
\hline Bufo spinosus & 29SPB73 & 101,00 & 176,50 & 82,76 & 36,45 & 5001,32 & 298,23 & 74,25 & 223,98 & 123,65 & 237,87 & 240,98 & 113,67 & 476,04 & 74,01 & 1,00 & 63,01 & 204,82 & 13,89 & 23,71 & 183,47 \\
\hline Bufo spinosus & 29SPB74 & 100,00 & 174,51 & 86,77 & 36,99 & 5116,97 & 301,96 & 70,11 & 231,86 & 119,42 & 237,91 & 240,89 & 110,45 & 487,26 & 74,79 & 1,03 & 62,14 & 208,15 & 15,20 & 24,17 & 187,95 \\
\hline Bufo spinosus & 29SPB75 & 100,00 & 173,17 & 90,78 & 37,35 & 5223,84 & 306,17 & 66,62 & 239,55 & 116,95 & 238,22 & 241,18 & 108,03 & 497,01 & 75,20 & 1,71 & 61,08 & 210,63 & 16,92 & 25,31 & 191,71 \\
\hline Bufo spinosus & 29SPB76 & 101,00 & 172,13 & 94,68 & 37,97 & 5322,15 & 310,30 & 63,59 & 246,72 & 115,01 & 238,91 & 241,79 & 105,99 & 504,11 & 75,30 & 1,99 & 60,38 & 212,14 & 18,20 & 25,85 & 194,57 \\
\hline Bufo spinosus & 29SPB77 & 100,00 & 169,75 & 98,39 & 38,18 & $5425,29 \mid$ & 313,11 & 59,47 & 253,64 & 111,36 & 238,29 & 241,06 & 102,64 & 517,79 & 76,19 & 2,01 & 59,74 & 216,32 & 19,64 & 26,46 & 200,12 \\
\hline Bufo spinosus & 29SPB78 & 101,00 & 163,20 & 102,44 & 38,68 & 5548,81 & 313,16 & 51,22 & 261,94 & 104,07 & 233,97 & 236,76 & 95,18 & 557,05 & 79,98 & 2,45 & 58,67 & 230,14 & 23,44 & 29,16 & 215,80 \\
\hline Bufo spinosus & 29SPB79 & 100,00 & 158,60 & 105,26 & 38,94 & 5641,23 & 313,68 & 45,54 & 268,14 & 98,76 & 231,00 & 233,69 & 89,80 & 585,79 & 82,62 & 3,10 & 57,73 & 239,91 & 26,44 & 31,26 & 227,16 \\
\hline Bufo spinosus & 29SPB81 & 49,00 & 177,89 & 79,56 & 36,00 & 4901,23 & 294,59 & 76,90 & 217,69 & 136,93 & 238,02 & 241,00 & 116,18 & 476,69 & 75,25 & 1,00 & 63,82 & 206,57 & 12,51 & 22,87 & 183,93 \\
\hline Bufo spinosus & 29SPB82 & 101,00 & 177,98 & 79,33 & 35,82 & 4964,47 & 295,56 & 76,60 & 218,96 & 144,32 & 238,62 & 241,52 & 115,22 & 472,48 & 74,62 & 1,00 & 63,57 & 203,23 & 12,62 & 23,47 & 180,27 \\
\hline Bufo spinosus & 29SPB83 & 99,00 & 177,82 & 81,79 & 35,97 & $5067,99 \mid$ & 299,41 & 74,67 & 224,73 & 146,24 & 239,98 & 242,83 & 113,78 & 473,24 & 74,27 & 1,00 & 62,87 & 202,07 & 13,64 & 23,87 & 179,64 \\
\hline Bufo spinosus & 29SPB84 & 101,00 & 174,38 & 87,23 & 36,64 & 5210,35 & 303,54 & 68,52 & 235,02 & 120,05 & 239,13 & 241,89 & 109,09 & 493,86 & 76,00 & 1,26 & 61,76 & 209,21 & 15,46 & 24,91 _ & 188,50 \\
\hline Bufo spinosus & 29SPB85 & 100,00 & 172,92 & 91,72 & 37,08 & 5321,27 & 307,98 & 64,69 & 243,29 & $\begin{array}{l}115,49 \\
\end{array}$ & 239,49 & 242,16 & 106,45 & \begin{tabular}{|l|l|}
504,88 \\
\end{tabular} & 76,49 & 1,83 & 61,00 & 212,53 & 17,19 & 25,68 & 193,27 \\
\hline Bufo spinosus & 29SPB86 & 100,00 & 169,77 & 96,12 & 37,83 & 5442,40 & 311,10 & 59,32 & 251,78 & 111,16 & 238,45 & 241,03 & 102,23 & 523,43 & 77,89 & 2,00 & 60,25 & 218,73 & 18,97 & 26,66 & 201,01 \\
\hline Bufo spinosus & 29SPB87 & 100,00 & 168,34 & $\begin{array}{ll}99,61 \\
\end{array}$ & 38,00 & 5531,28 & 314,37 & 56,26 & 258,11 & 108,81 & 238,52 & 241,06 & 99,98 & 531,65 & 78,12 & 2,02 & 59,57 & 220,72 & 20,46 & 27,36 & 204,23 \\
\hline Bufo spinosus & 29SPB89 & 100,00 & 153,82 & 106,46 & 38,23 & 5757,84 & 312,54 & 38,85 & 273,69 & 92,73 & 228,07 & 230,59 & 83,71 & 620,39 & 86,93 & 3,43 & 57,47 & 252,59 & 28,53 & 33,33 & 239,85 \\
\hline Bufo spinosus & 29SPB90 & & & & & & & & & & & & & & & & & & & & \\
\hline Bufo spinosus & 29SPB91 & 91,00 & 176,63 & 82,44 & 36,29 & 4991,09 & 297,27 & 73,43 & 223,85 & 129,05 & 238,21 & 241,18 & 113,96 & 495,43 & 77,43 & 1,00 & 63,73 & 213,67 & 13,84 & 23,77 & 191,63 \\
\hline Bufo spinosus & 29SPB92 & 101,00 & 176,34 & 83,35 & 36,08 & 5092,33 & 299,59 & 72,02 & 227,57 & 134,69 & 239,17 & 242,06 & 112,29 & 493,55 & 77,15 & 1,00 & 63,20 & 211,19 & 14,05 & 24,00 & 189,05 \\
\hline Bufo spinosus & 29SPB93 & 100,00 & 178,35 & 85,09 & 36,17 & 5167,99 & 304,21 & 72,76 & 231,45 & $\begin{array}{ll}147,42 \\
\end{array}$ & 242,25 & 244,99 & $\begin{array}{l}113,29 \\
\end{array}$ & 482,24 & 75,46 & 1,00 & 62,70 & 205,42 & 14,09 & 24,00 & 183,32 \\
\hline Bufo spinosus & 29SPB94 & 101,00 & 174,68 & 89,65 & 36,78 & 5315,18 & 307,38 & 66,53 & 240,84 & 122,55 & 241,05 & 243,73 & 108,15 & 502,46 & 77,16 & 1,28 & 61,65 & 212,05 & 15,74 & 24,94 & 191,58 \\
\hline Bufo spinosus & 29SPB95 & 99,00 & 169,82 & $\begin{array}{ll}44,92 \\
\end{array}$ & 37,18 & 5462,90 & 310,08 & 58,89 & 251,19 & 110,79 & 238,72 & 241,25 & 101,85 & 531,43 & 79,77 & 2,00 & 60,74 & 222,38 & 18,52 & 26,68 & 203,61 \\
\hline Bufo spinosus & 29SPB96 & 100,00 & 169,28 & 98,16 & 37,82 & 5549,99 & 313,89 & 56,72 & 257,17 & 109,34 & 239,57 & 242,12 & 100,46 & 534,59 & 79,41 & 2,00 & 60,10 & 222,36 & 19,56 & 27,16 & 204,72 \\
\hline Bufo spinosus & 29SPB97 & 100,00 & 170,11 & 100,77 & 38,00 & 5609,81 & 317,98 & 56,11 & 261,87 & 109,56 & 241,47 & 243,77 & 100,57 & 529,92 & 78,18 & 2,00 & 59,68 & 219,39 & 20,10 & 27,11 & 202,56 \\
\hline Bufo spinosus & 29SPB98 & 100,00 & 164,84 & 104,28 & 38,01 & 5721,95 & 318,91 & 49,21 & 269,70 & 103,34 & 238,19 & 240,41 & 94,44 & 558,94 & 80,74 & 2,5 & 58,66 & 229,30 & 23,06 & 29,22 & 214,00 \\
\hline Bufo spinosus & 29SPB99 & 100,00 & 152,23 & 107,69 & 38,00 & 5848,46 & 313,92 & 35,78 & 278,14 & 90,23 & 227,96 & 230,2 & 81,17 & $635,97]$ & 88, & 3,60 & 57,37 & 257,79 & 29,35 & 34,22 & 245,06 \\
\hline Bufo spinosus & 29SPC00 & 101,00 & 165,29 & 112,18 & 42,05 & 5145,05 & 322,05 & 59,05 & 263,01 & 112,51 & 230,68 & 235,07 & 103,90 & 548,84 & 80,47 & 2,00 & 59,99 & 232,29 & 24,28 & 25,03 & 228,07 \\
\hline Bufo spinosus & 29SPC02 & 101,00 & 166,33 & 110,50 & 41,87 & 5160,53 & 322,00 & 60,85 & 261,15 & 112,99 & 231,84 & 236,18 & 104,34 & 552,50 & 78,82 & 2,58 & 58,68 & 229,86 & 26,91 & 27,28 & 227,05 \\
\hline Bufo spinosus & 29SPC03 & 101,00 & 160,69 & 108,62 & 41,23 & 5185,48 & 316,10 & 56,55 & 259,55 & 107,39 & 227,90 & 231,14 & 98,85 & 592,32 & 82,64 & 3,04 & 57,66 & 243,29 & 30,44 & 30,45 & 242,18 \\
\hline Bufo spinosus & 29SPC04 & 100,00 & 161,82 & 106,48 & 41,04 & 5164,14 & 314,94 & 58,80 & 256,14 & 108,27 & 229,01 & 231,91 & 100,14 & 589,98 & 81,44 & 3,02 & 57,23 & 41,04 & 30,93 & 30,93 & 240,44 \\
\hline Bufo spinosus & 29SPC05 & 101,00 & 163,99 & 104,51 & 40,97 & 5131,42 & 314,60 & 61,82 & 252,78 & 109,97 & 230,79 & 233,51 & 102,35 & 583,41 & 80,05 & 3,00 & 57,05 & 237,34 & 31,10 & 31,10 & 236,97 \\
\hline Bufo spinosus & 29SPC06 & 100,00 & 163,16 & 102,61 & 40,53 & 512 & 312,29 & 62,04 & 250,25 & 105,59 & 229,36 & 23 & 101,71 & $\begin{array}{l}596,58 \\
\end{array}$ & 81, & 3,75 & 56,34 & 241,45 & 33,24 & 33,24 & 241,42 \\
\hline Bufo spinosus & 29SPC08 & 100,00 & 160,69 & 99,94 & 39,98 & 5139,34 & 308,49 & 60,77 & 247,72 & 99,37 & 228,08 & 230,42 & 99,08 & 640,14 & 87,99 & 4,12 & 55,88 & 258,78 & 36,81 & 36,81 & 258,78 \\
\hline Bufo spinosus & 29SPC10 & 101,00 & \begin{tabular}{ll|}
168,64 \\
\end{tabular} & 109,86 & 41,74 & 5166,21 & 322,54 & $\begin{array}{ll}61,98 \\
\end{array}$ & 260,56 & 115,16 & 234,22 & 238,31 & 106,22 & \begin{tabular}{|l|l|}
527,47 \\
\end{tabular} & 76,84 & 2,00 & 59,79 & 222,91 & 23,19 & 24,74 & 216,76 \\
\hline Bufo spinosus & 29SPC13 & 101,00 & 160,51 & 109,02 & 41,00 & 5282,23 & 317,10 & 54,79 & 262,31 & 105,93 & 228,42 & 232,21 & 97,33 & 589,14 & 81,72 & 3,00 & 57,24 & 240,98 & 30,63 & 30,77 & 238 \\
\hline Bufo spinosus & 29SPC18 & 101,00 & 160,60 & 102,15 & 39,90 & 5255,88 & 311,74 & 58,30 & 253,45 & 102,59 & 228,97 & 231,89 & 97,68 & 638,67 & 86,96 & 4,34 & 55,44 & 256,29 & 37,43 & 37,43 & 256,26 \\
\hline Bufo spinosus & 29SPC19 & 101,00 & 161,79 & 101,60 & 39,82 & 5264,89 & 312,60 & 59,40 & 253,21 & 104,32 & 229,51 & 233,04 & 98,68 & 646,77 & 88,31 & 4,52 & 55,33 & 259,77 & 38,18 & 38,21 & 259,71 \\
\hline Bufo spinosus & $295 P C 20$ & 100,00 & 167,25 & 108,79 & 41,00 & 5254,52 & 320,84 & 59,51 & 261,33 & 112,50 & 233,96 & 237,92 & $\begin{array}{l}103,49 \\
\end{array}$ & 532,54 & 76,72 & 2,00 & 59,38 & 223,71 & 23,36 & 25,51 & 216,45 \\
\hline Bufo spinosus & 29SPC21 & 100,00 & 168,08 & 109,25 & 41,01 & 5274,95 & 322,74 & 60,09 & 262,65 & 113,04 & 235,19 & 238,98 & 104,03 & 530,51 & 75,64 & 2,06 & 58,64 & 220,93 & 24,62 & 26,39 & 214,4 \\
\hline Bufo spinosus & 29SPC22 & 101,00 & 168,42 & 109,29 & 40,99 & 5297,34 & 323,47 & 60,32 & 263,15 & 113,02 & 235,75 & 239,61 & 104,16 & 533,19 & 75,13 & 2,37 & 58,07 & 220,33 & & 27,36 & 21 \\
\hline Bufo spinosus & 295 & 100,00 & 16 & 109,13 & 40,97 & & 321,37 & 57,58 & 263,80 & 109,62 & 233,19 & & 100,88 & 556,98 & 77 & 3,00 & 57,18 & 227,79 & 28,54 & 29,44 & 223,46 \\
\hline Bufo spinosus & 29SPC26 & 100,00 & 163,38 & 106,58 & 40,03 & 5357,52 & 318,45 & 57,03 & 261,42 & $\begin{array}{r}107,29 \\
\end{array}$ & 231,94 & 235,68 & 98,68 & 588,79 & 78,97 & 3,99 & 55,43 & 236,50 & 33,58 & 33,74 & 234,22 \\
\hline Bufo spinosus & 295PC27 & 101,00 & 163,06 & 105,66 & 40,00 & 5364,20 & 317,54 & 57,23 & 260,31 & 106,79 & 231,86 & 235,42 & 98,44 & 602,02 & 80,68 & 4,00 & 55,12 & 240,99 & 35,23 & 35,36 & 239,16 \\
\hline
\end{tabular}




\begin{tabular}{|c|c|c|c|c|c|c|c|c|c|c|c|c|c|c|c|c|c|c|c|c|c|}
\hline TAXON & UTM & $\mathrm{km} 2$ & B101 & B102 & $\mathrm{BIO3}$ & B104 & B105 & B106 & B107 & B108 & B109 & B1010 & BIO11 & BIO12 & B1013 & BIO14 & BIO15 & B1016 & B1017 & B1018 & B1019 \\
\hline Bufo spinosus & 29SPC28 & 100,00 & 159,59 & 104,11 & 39,72 & 5380,03 & 313,91 & 54,76 & 259,15 & 102,98 & 229,49 & 232,40 & 95,14 & 642,65 & 86,77 & 4,51 & 54,97 & 256,99 & 38,20 & 38,24 & 255,93 \\
\hline Bufo spinosus & 29SPC29 & 100,00 & 158,40 & 102,98 & 39,39 & 5393,15 & 312,64 & 54,31 & 258,34 & 102,07 & 228,38 & 231,60 & 94,01 & 668,10 & 90,58 & 5,07 & 54,64 & 267,01 & 40,43 & 40,47 & 266,42 \\
\hline Bufo spinosus & 29SPC31 & 100,00 & 166,25 & 108,74 & 40,75 & 5373,15 & 321,21 & 56,92 & 264,29 & $\begin{array}{l}109,87 \\
\end{array}$ & 234,71 & 238,28 & 101,01 & 540,34 & 75,98 & 2,89 & 57,64 & 223,15 & 26,13 & 28,48 & 215,62 \\
\hline Bufo spinosus & 29SPC32 & 100,00 & 168,44 & 108,99 & 40,68 & 5377,66 & 323,78 & 58,78 & 265,00 & 111,72 & 236,88 & 240,46 & 103,10 & 530,80 & 74,13 & 2,80 & 57,45 & 218,09 & 26,20 & 28,24 & 211,01 \\
\hline Bufo spinosus & 29SPC35 & 100,00 & 167,02 & 108,80 & 40,12 & 5433,43 & 323,99 & 57,58 & 266,41 & 109,55 & 236,34 & 239,79 & 101,03 & 553,34 & 75,23 & 3,16 & 55,95 & 223,18 & 30,26 & 31,26 & 218,25 \\
\hline Bufo spinosus & 29SPC37 & 100,00 & 165,27 & 107,92 & 40,00 & 5472,45 & 322,58 & 56,23 & 266,34 & 107,39 & 235,64 & 238,79 & 98,97 & 581,16 & 78,36 & 4,00 & 54,85 & 232,22 & 34,01 & 34,58 & 228,44 \\
\hline Bufo spinosus & 29SPC38 & 100,00 & 162,29 & 106,91 & 39,89 & 5492,93 & 319,66 & 54,09 & 265,57 & 104,35 & 233,02 & 236,21 & 95,88 & 614,36 & 82,31 & 4,41 & 54,57 & 244,89 & 36,96 & 37,18 & 241,92 \\
\hline \begin{tabular}{|l} 
Bufo spinosus \\
\end{tabular} & \begin{tabular}{|l|}
$295 P C 39$ \\
\end{tabular} & 101,00 & 158,32 & 105,42 & 39,32 & 5511,46 & 315,80 & 51,43 & 264,37 & 100,70 & 229,73 & 232,91 & 92,33 & 658,86 & 88,45 & 5,04 & 54,28 & 262,54 & 40,31 & 40,40 & 260,37 \\
\hline Bufo spinosus & 29SPC40 & 101,00 & 164,01 & 106,92 & 40,01 & 5409,63 & 317,65 & 54,14 & 263,51 & 107,14 & 233,05 & 236,42 & 98,43 & 550,22 & 77,29 & 2,92 & 57,95 & 227,62 & 25,75 & 28,88 & 218,07 \\
\hline Bufo spinosus & 29SPC41 & 100,00 & 166,05 & 108,00 & 40,01 & 5437,09 & 321,08 & 55,40 & 265,69 & 108,56 & 235,40 & 238,69 & 99,84 & 540,63 & 75,50 & 3,00 & 57,42 & 222,30 & 26,20 & 29,02 & 213,41 \\
\hline Bufo spinosus & $29 S P C 42$ & 100,00 & 168,63 & 108,80 & 40,06 & 5456,22 & 324,43 & 57,49 & 266,93 & 110,51 & 238,29 & 241,35 & 102,19 & 527,43 & 73,36 & 2,99 & 56,99 & 215,81 & 26,20 & 28,86 & 207,36 \\
\hline Bufo spinosus & 29SPC43 & 101,00 & 167,88 & 109,24 & 40,02 & 5501,38 & 325,44 & 56,36 & 269,08 & 109,36 & 238,23 & 241,34 & 100,77 & 533,92 & 73,76 & 3,00 & 56,68 & 217,10 & 27,27 & 29,37 & 209,34 \\
\hline \begin{tabular}{|l} 
Bufo spinosus \\
\end{tabular} & 29SPC44 & 100,00 & 168,91 & 109,81 & 40,04 & 5516,29 & 327,01 & 57,07 & 269,94 & 110,10 & 239,67 & 242,44 & 101,43 & 531,63 & 73,28 & 3,00 & 56,19 & 215,10 & 27,82 & 29,73 & 207,85 \\
\hline Bufo spinosus & 29SPC46 & 100,00 & 168,21 & 110,05 & 40,00 & 5541,22 & 327,67 & 56,19 & 271,48 & 108,93 & 239,34 & 242,04 & 100,49 & 546,01 & 74,72 & 3,51 & 55,06 & 218,49 & 31,15 & 32,31 & 212,21 \\
\hline Bufo spinosus & 29SPC47 & 101,00 & 167,52 & 110,02 & 40,00 & 5572,71 & 327,53 & 55,35 & 272,18 & 107,90 & 239,20 & 241,86 & 99,60 & 557,72 & 76,07 & 3,98 & 54,43 & 222,23 & 32,93 & 33,83 & 216,36 \\
\hline Bufo spinosus & 29SPC48 & 100,00 & 166,22 & 109,81 & 39,98 & 5599,39 & 326,71 & 54,12 & 272,59 & 106,36 & 238,41 & 241,00 & 98,04 & 575,10 & 78,17 & 4,08 & 54,29 & 228,73 & 34,55 & 35,15 & 223,27 \\
\hline Bufo spinosus & 29SPC50 & 100,00 & 165,21 & 106,32 & 39,84 & 5479,81 & 318,78 & 54,19 & 264,59 & 107,29 & 235,18 & 238,30 & 98,45 & 542,76 & 76,27 & 2,73 & 57,73 & 223,62 & 25,01 & 28,78 & 212,74 \\
\hline Bufo spinosus & 29SPC51 & 101,00 & 167,10 & 107,59 & 39,88 & 5507,90 & 322,31 & 55,03 & 267,28 & 108,55 & 237,41 & 240,46 & 99,80 & 533,46 & 74,70 & 3,00 & 57,20 & 218,51 & 25,75 & 29,11 & 208,22 \\
\hline Bufo spinosus & 29SPC52 & 100,00 & 168,43 & 108,65 & 39,99 & 5543,99 & 325,30 & 55,72 & 269,58 & 109,37 & 239,34 & 242,17 & 100,59 & 526,22 & 73,52 & 3,00 & 56,66 & 214,39 & 26,14 & 29,12 & 204,65 \\
\hline Bufo spinosus & 29SPC53 & 100,00 & 166,86 & 109,71 & 39,99 & 5586,67 & 325,93 & 53,65 & 272,28 & 107,14 & 238,44 & 241,20 & 98,53 & 537,68 & 74,58 & 3,00 & 56,35 & 217,67 & 27,47 & 29,91 & 208,80 \\
\hline Bufo spinosus & 29SPC54 & 100,00 & 167,86 & 110,35 & 40,00 & 5602,91 & 327,94 & 54,27 & 273,67 & 107,78 & 239,81 & 242,30 & 99,23 & 534,37 & 73,9 & 3,03 & 55,77 & 215,26 & 28,15 & 30,24 & 206,77 \\
\hline \begin{tabular}{|l} 
Bufo spinosus \\
\end{tabular} & 29SPC57 & 100,00 & 168,13 & 111,79 & 39,96 & 5684,87 & 331,09 & 53,09 & 278,00 & 106,93 & 241,54 & 243,71 & 98,65 & 543,91 & 74,76 & 3,99 & 53,94 & 215,79 & 32,57 & 33,71 & 208,22 \\
\hline Bufo spinosus & 29SPC59 & 100,00 & 167,52 & 112,36 & 39,84 & 5728,25 & 331,77 & 51,96 & 279,81 & 105,68 & 241,69 & 243,64 & 97,36 & 562,54 & 76,98 & 4,17 & 53,42 & 222,29 & 35,05 & 35,62 & 215,23 \\
\hline Bufo spinosus & 29SPC60 & 100,00 & 163,18 & 106,26 & 39,15 & 5569,55 & 317,99 & 50,66 & 267,33 & 104,12 & 234,43 & 237,22 & 95,19 & 556,04 & 78,26 & 2,98 & 57,41 & 227,75 & 25,89 & 29,93 & 216,04 \\
\hline Bufo spinosus & 29SPC61 & 100,00 & 162,79 & 107,89 & 39,17 & 5622,32 & 320,55 & 49,19 & 271,36 & 103,19 & 234,95 & 237,86 & 94,22 & 558,30 & 78,06 & 3,08 & 56,97 & 227,34 & 26,79 & 30,50 & 216,45 \\
\hline Bufo spinosus & 29SPC62 & 100,00 & 167,16 & 108,97 & 39,37 & 5633,15 & 325,76 & 52,92 & 272,84 & 107,02 & 239,42 & 241,86 & 98,14 & 532,84 & 74,71 & 3,00 & 56,49 & 216,13 & 26,27 & 29,60 & 205,40 \\
\hline Bufo spinosus & 29SPC63 & 101,00 & 165,10 & 110,21 & 39,51 & 5678,03 & 326,27 & 50,42 & 275,85 & \begin{tabular}{|l|l|}
104,51 \\
\end{tabular} & 238,20 & 240,63 & 95,64 & 545,39 & 75,90 & 3,00 & 56,10 & 219,89 & 27,74 & 30,49 & 209,94 \\
\hline Bufo spinosus & 29SPC64 & 101,00 & 165,09 & 111,09 & 39,43 & 5713,22 & 327,85 & 49,66 & 278,20 & 104,05 & 238,78 & 241,18 & 95,33 & 546,52 & 75,67 & 3,30 & 55,16 & 218,88 & 29,32 & 31,59 & 209,42 \\
\hline Bufo spinosus & 29SPC65 & 99,00 & 164,63 & 111,94 & 39,49 & 5746,92 & 328,91 & 48,54 & 280,37 & 103,08 & 238,90 & 241,08 & 94,49 & 551,15 & 75,98 & 3,93 & 54,29 & 219,39 & 31,55 & 33,24 & 210,27 \\
\hline Bufo spinosus & $29 S P C 70$ & 100,00 & 161,09 & 106,73 & 38,95 & 5675,07 & 318,19 & 46,80 & 271,38 & 100,66 & 233,89 & 236,54 & 91,70 & 571,07 & 80,41 & 3,15 & 57,24 & 232,70 & 26,59 & 31,03 & 220,35 \\
\hline Bufo spinosus & 29SPC71 & 101,00 & 158,40 & 108,44 & 38,92 & 5732,58 & 318,87 & 43,40 & 275,47 & 97,48 & 232,29 & 234,86 & 88,52 & 587,30 & 81,78 & 3,33 & 56,56 & 237,71 & 28,70 & 32,39 & 226,39 \\
\hline \begin{tabular}{|l} 
Bufo spinosus \\
\end{tabular} & 29SPC72 & 100,00 & 165,22 & 109,58 & 39,03 & 5735,12 & 326,20 & 49,42 & 276,78 & 103,68 & 239,04 & 241,32 & 95,01 & 543,63 & 76,32 & 3,01 & 56,35 & 219,52 & 26,65 & 30,28 & 208,00 \\
\hline Bufo spinosus & 29SPC73 & 100,00 & 164,62 & 110,88 & 39,01 & 5774,34 & 327,87 & 47,88 & 279,99 & 102,55 & 239,21 & 241,35 & 94,00 & 546,35 & 76,21 & 3,05 & 55,68 & 219,18 & 27,99 & 31,12 & 208,24 \\
\hline Bufo spinosus & 29SPC74 & 100,00 & 162,33 & 111,87 & 39,01 & 5819,58 & 327,60 & 45,12 & 282,49 & 99,79 & 237,63 & 239,69 & 91,24 & 560,86 & 77,53 & 3,71 & 54,81 & 223,50 & 30,66 & 33,10 & 213,25 \\
\hline Bufo spinosus & 29SPC75 & 100,00 & 160,62 & 112,54 & 38,99 & 5859,96 & 327,79 & 43,08 & 284,70 & 97,82 & 236,75 & 238,66 & 89,31 & 570,99 & 78,47 & 4,01 & 54,31 & 226,36 & 32,31 & 34,26 & 216,50 \\
\hline Bufo spinosus & $295 P C 76$ & 101,00 & 159,65 & 113,05 & 39,00 & 5884,03 & 328,04 & 41,70 & 286,34 & 96,49 & 236,10 & 238,09 & 88,08 & 578,22 & 79,15 & 4,05 & 53,77 & 228,21 & 33,88 & 35,32 & 218,64 \\
\hline Bufo spinosus & 29SPC79 & 99,00 & $\begin{array}{l}13,06,67 \\
166,67\end{array}$ & $\begin{array}{l}1115,05 \\
115,78\end{array}$ & 39,06 & $\begin{array}{l}5004,40,78 \\
594,8\end{array}$ & 337,34 & $\begin{array}{l}45,49 \\
45,49\end{array}$ & \begin{tabular}{|l|}
291,85 \\
291,8
\end{tabular} & \begin{tabular}{|l|}
101,73 \\
101,73
\end{tabular} & 240, & \begin{tabular}{|l|}
245,09 \\
245
\end{tabular} & $\begin{array}{l}0,00 \\
93,47 \\
\end{array}$ & \begin{tabular}{|l|}
$531,21,21$ \\
\end{tabular} & $\mid 73,60$ & $4,4,00$ & 52,15 & \begin{tabular}{|l|}
207,01 \\
207,08
\end{tabular} & $\begin{array}{l}30,00 \\
34,50\end{array}$ & $\begin{array}{l}35,25 \\
35,24 \\
\end{array}$ & $\begin{array}{l}190,04 \\
196,76\end{array}$ \\
\hline Bufo spinosus & 29SPC80 & 101,00 & 154,66 & 107,93 & 38,41 & 5795,37 & 315,84 & 39,03 & 276,81 & 93,23 & 229,63 & 232,06 & 84,21 & 614,21 & 85,61 & 3,64 & 56,86 & 248,62 & 29,24 & 33,59 & 236,45 \\
\hline Bufo spinosus & $29 S P C 81$ & 99,00 & 159,18 & 109,25 & 38,81 & 5818,30 & 321,64 & 42,67 & 278,97 & 97,08 & 234,43 & 236,60 & 88,26 & 583,86 & 81.56 & 3,29 & 56,41 & 235,44 & 28,32 & 32,34 & 223,32 \\
\hline Bufo spinosus & 29SPC82 & 101,00 & 160,19 & 110,52 & 38,84 & 5854,69 & 324,58 & 42,86 & 281,71 & 97,50 & 235,97 & 238,01 & 88,63 & 575,40 & 80,09 & 3,43 & 55,90 & 230,86 & 28,88 & 32,50 & 219,15 \\
\hline Bufo spinosus & 29SPC83 & 100,00 & 162,91 & 111,65 & 38,9 & 5873,63 & 328,54 & 44,51 & 284,04 & 99,78 & 238,88 & 240,86 & 91,00 & 557,23 & 77,57 & 3,3 & 55,43 & 222,59 & 28,81 & 32,01 & 210,99 \\
\hline \begin{tabular}{|l} 
Bufo spinosus \\
\end{tabular} & $295 \mathrm{SC} 86$ & 100,00 & 156,27 & 113,57 & 38,80 & 5976,05 & 326,95 & 37,27 & 289,67 & 92,08 & 234,28 & 235,96 & 83,77 & 595,57 & 81,03 & 4,27 & 53,38 & 233,99 & $\begin{array}{l}30,010 \\
35,05\end{array}$ & 36,73 & 223,79 \\
\hline Bufo spinosus & 29SPC90 & 100,00 & 155,39 & 109,04 & 38,17 & 5882,69 & 318,88 & 38,08 & 280,80 & 92,63 & 231,65 & 233,82 & 83,79 & 613,37 & 85,57 & 3,45 & 56,86 & 247,51 & 28,96 & 33,52 & 234,93 \\
\hline Bufo spinosus & 29SPC91 & 101,00 & 158,57 & 110,27 & 38,30 & 5915,33 & 323,67 & 40,32 & 283,35 & 95,27 & 235,23 & 237,27 & 86,32 & 589,82 & 82,32 & 3,35 & 56,42 & 237,01 & 28,48 & 32,65 & 224,46 \\
\hline Bufo spinosus & 29SPC92 & 99,00 & 153,35 & 111,44 & 38,22 & 5977,65 & 321,58 & 34,63 & 286,95 & 89,59 & 231,15 & 233,13 & 80,78 & 621,02 & 85,3 & 3,99 & 55,51 & 247,66 & 31,83 & 35,31 & 236,26 \\
\hline Bufo spinosus & 29SPC94 & $\begin{array}{l}99,00 \\
99\end{array}$ & 158,64 & 113,32 & $30,38,5$ & 6010,83 & 329,04 & 38,53 & 290,51 & \begin{tabular}{|l|l|}
93,99 \\
3
\end{tabular} & 236,90 & \begin{tabular}{|l|l|}
238,53 \\
\end{tabular} & 85,32 & | 581,60 & $\begin{array}{l}\mid 79,89 \\
79,8\end{array}$ & 3,74 & 54,58 & 230,01 & 31,40 & $\begin{array}{l}3,261 \\
34,26\end{array}$ & 218,55 \\
\hline Bufo spinosus & 29SPC95 & 101,00 & 153,03 & 113,44 & 38,21 & 6051,86 & 325,26 & 33,25 & 292,01 & 88,29 & 232,23 & 233,77 & 79,68 & 615,80 & 83,41 & 4,51 & 53,75 & 241,99 & 35,09 & 37,22 & 231,30 \\
\hline \begin{tabular}{|l} 
Bufo spinosus \\
\end{tabular} & \begin{tabular}{|l|}
$295 P C 98$ \\
\end{tabular} & 100,00 & 163,77 & 115,99 & 38,94 & 6055,62 & 337,09 & 41,36 & 295,74 & $\begin{array}{l}97,97 \\
9\end{array}$ & 242,82 & 243,82 & 89,72 & 531,38 & $\begin{array}{l}72,98 \\
\end{array}$ & 4,00 & 52,47 & 206,67 & 32,15 & 34,00 & 194,75 \\
\hline Bufo spinosus & $29 S P D 01$ & 101,00 & 164,77 & 98,75 & 39,30 & 5155,83 & 311,99 & 64,27 & 247,72 & 104,12 & 230,51 & 234,52 & 102,75 & 667,05 & 92,81 & 5,00 & 55,91 & 270,59 & 38,92 & 39,36 & 270,59 \\
\hline Bufo spinosus & $29 S P D 02$ & 100,00 & 167,21 & 98,91 & 39,28 & 5169,43 & 314,35 & 66,14 & 248,21 & 109,00 & 233,19 & 236,94 & 104,65 & 665,74 & 92,82 & 4,97 & 55,84 & 270,11 & 38,65 & 39,55 & 270,11 \\
\hline \begin{tabular}{|l} 
Bufo spinosus \\
\end{tabular} & \begin{tabular}{|l|}
$295 \mathrm{PDOL}$ \\
29SPD03
\end{tabular} & $\begin{array}{l}101,00 \\
101,00\end{array}$ & $\frac{10,21}{167,25}$ & $\begin{array}{l}0,51 \\
98,55\end{array}$ & | & 5191,98 & 314,55 & $\begin{array}{l}0,14 \\
65,88 \\
\end{array}$ & \begin{tabular}{|l|}
248,211 \\
2488
\end{tabular} & 109,20 & 233,68 & 237,16 & 104,42 & 682,99 & 95,73 & 5,00 & 55,90 & 277,45 & 39,46 & 40,56 & 277,45 \\
\hline Bufo spinosus & 29SPD04 & 101,00 & 167,18 & 98,12 & 39,00 & 5207,99 & 314,58 & 65,51 & 249,07 & 108,01 & 233,88 & 237,27 & 104,14 & 701,80 & 98,94 & 5,02 & 55,98 & 285,48 & 40,41 & 41,68 & 285,48 \\
\hline Bufo spinosus & 29SPD05 & 100,00 & 164,19 & 97,09 & $\begin{array}{l}38,45 \\
\end{array}$ & 5241,36 & 311,97 & 63,09 & 248,88 & $\mid 101.06$ & 231,63 & 234,92 & 100,91 & $\mid 747,79$ & $|106,27|$ & 5,92 & 55,64 & 304,62 & 44,26 & 45,40 & 304,62 \\
\hline Bufo spinosus & 29SPD06 & 101,00 & 162,42 & 96,54 & 38,07 & 5278,41 & 310,58 & 61,03 & 249,54 & 98,67 & 230,34 & 233,67 & 98,67 & 781,05 & 111,75 & 6,01 & 55,70 & 318,61 & 46,15 & 47,22 & 318,61 \\
\hline Bufo spinosus & 29SPD08 & 101,00 & 164,65 & 97,86 & 38,19 & 5326,48 & 313,87 & 60,86 & 253,01 & 100,50 & 233,51 & 235,92 & 99,80 & 788,15 & 112,94 & 6,20 & 55,25 & 320,35 & 47,34 & 48,77 & $32 C$ \\
\hline \begin{tabular}{|l} 
Bufo spinosus \\
\end{tabular} & 29SPD09 & 101,00 & 161,29 & 97,32 & 37,86 & 5371,68 & 311,23 & 57,29 & 253,94 & $\begin{array}{l}36,06 \\
96,0\end{array}$ & 230,99 & 233,26 & 96,06 & 833,96 & 120,30 & 6,85 & 55,16 & 339,27 & 50,81 & 51,89 & 339,27 \\
\hline Bufo spinosus & 29SPD10 & 100,00 & 161,34 & 100,52 & 39,30 & 5273,02 & 312,03 & 59,57 & 252,46 & 102,42 & 228,95 & 232,85 & 98,11 & 669,64 & 92,03 & 4,97 & 55,26 & 269,45 & 39,96 & 40,06 & 269,45 \\
\hline Bufo spinosus & 29SPD11 & 101,00 & 164,59 & 100,59 & 39,14 & 5276,51 & 314,93 & 62,16 & 252,77 & 107,17 & 232,23 & 235,88 & 101,03 & 662,80 & 91,24 & 5,00 & 55,36 & 266,99 & 39,18 & 39,92 & 266,87 \\
\hline Bufo spinosus & 29SPD12 & 100,00 & 166,36 & 100,31 & 39,03 & 5282,65 & 316,66 & 63,7 & 252,89 & 110,2 & 234,10 & 237 & 102,66 & 666,77 & 92,14 & 5,00 & 55,42 & 268,94 & 39,34 & 40,14 & 26 \\
\hline Bufo spinosus & 29SPD13 & 100,00 & 165,32 & 99,37 & 38,84 & 5312,71 & 315,68 & 63,01 & 252,67 & 107,43 & 233,46 & 237,16 & 101,29 & 694,89 & 96,87 & 5,21 & 55,44 & 280,93 & 41,01 & 42,06 & 280,87 \\
\hline
\end{tabular}




\begin{tabular}{|c|c|c|c|c|c|c|c|c|c|c|c|c|c|c|c|c|c|c|c|c|c|}
\hline TAXON & UTM & $\mathrm{km2}$ & B101 & $\mathrm{B1O2}$ & $\mathrm{BIO3}$ & $\mathrm{B104}$ & B105 & B106 & B107 & B108 & B109 & 81010 & B1011 & BIO12 & BIO13 & BIO14 & BIO15 & BIO16 & B1017 & B1018 & B1019 \\
\hline Bufo spinosus & 29SPD14 & 101,00 & 165,21 & 98,75 & 38,55 & 5330,92 & 315,60 & 62,83 & 252,77 & 106,32 & 233,90 & 237,29 & 101,11 & 714,56 & 100,17 & 5,54 & 55,28 & 289,08 & 42,56 & 43,73 & 289,07 \\
\hline Bufo spinosus & 29SPD15 & 99,00 & 162,46 & 97,29 & 38,02 & 5371,46 & 312,91 & 60,64 & 252,27 & $\begin{array}{l}98,53 \\
\end{array}$ & 231,79 & 235,15 & 97,96 & 757,44 & 107,32 & 5,99 & 55,27 & 307,57 & 45,20 & 46,33 & 307,57 \\
\hline Bufo spinosus & 29SPD16 & 100,00 & 161,78 & 96,94 & 37,96 & 5407,71 & 312,48 & 59,44 & 253,04 & 96,84 & 231,64 & 234,87 & 96,84 & 780,17 & 111,29 & 6,00 & 55,41 & 317,28 & 46,43 & 47,58 & 317,28 \\
\hline Bufo spinosus & 29SPD17 & 100,00 & 162,40 & 97,18 & 37,83 & 5441,73 & 313,80 & 59,03 & 254,77 & 97,30 & 232,95 & 235,84 & 96,87 & 787,81 & 112,55 & 6,00 & 55,10 & \begin{tabular}{|l|l|}
319,82 \\
\end{tabular} & 47,48 & 48,64 & 319,82 \\
\hline Bufo spinosus & 29SPD19 & 100,00 & 163,73 & 98,30 & \begin{tabular}{|l|l|}
37,49 \\
\end{tabular} & 5511,66 & 316,45 & 57,86 & 258,59 & 99,38 & 235,47 & 237,44 & 96,75 & 798,04 & 114,38 & 6,44 & 54,99 & \begin{tabular}{|l|l|}
322,98 \\
\end{tabular} & 48,53 & 49,92 & 322,95 \\
\hline Bufo spinosus & 29SPD20 & 100,00 & 159,85 & 102,48 & 39,07 & 5401,49 & 313,94 & 55,83 & 258,10 & 103,21 & 229,40 & 233,08 & 95,22 & 674,09 & 91,73 & 5,03 & 54,81 & 269,90 & 40,77 & 40,90 & 269,22 \\
\hline Bufo spinosus & 29SPD21 & 100,00 & 164,55 & 102,79 & 39,06 & 5396,16 & 318,34 & 59,78 & 258,56 & 107,75 & 233,89 & 237,44 & 99,64 & 654,05 & 88,96 & 5,00 & 54,91 & 262,27 & 39,32 & 39,95 & 261,14 \\
\hline \begin{tabular}{|l} 
Bufo spinosus \\
\end{tabular} & 29SPD22 & 100,00 & 166,06 & 102,14 & 39,02 & 5404,88 & 319,60 & 61,34 & 258,25 & 109,06 & 235,63 & 238,95 & $\begin{array}{r}100,95 \\
\end{array}$ & 661,05 & 90,44 & 5,06 & 54,90 & 265,60 & 39,65 & 40,57 & 264,47 \\
\hline Bufo spinosus & 29SPD23 & 101,00 & 162,56 & 99,87 & 38,44 & 5420,56 & 315,60 & 59,50 & 256,09 & 105,28 & 232,51 & 236,07 & 97,74 & 712,61 & 98,85 & 5,84 & 54,81 & 286,88 & 43,34 & 44,26 & 286,62 \\
\hline Bufo spinosus & 29SPD24 & 100,00 & 163,64 & 99,38 & \begin{tabular}{|l|}
38,08 \\
\end{tabular} & 5448,06 & 316,78 & \begin{tabular}{|l|l|}
60,27 \\
\end{tabular} & 256,51 & 106,05 & 234,11 & 237,44 & 98,42 & 720,95 & 100,47 & 5,90 & 54,74 & 290,40 & 43,93 & 45,10 & 290,08 \\
\hline Bufo spinosus & $29 S P D 25$ & 101,00 & 160,69 & 97,33 & 37,76 & 5474,17 & 313,32 & 58,49 & 254,84 & 98,78 & 231,64 & 235,06 & 95,46 & 766,08 & 108,18 & 6,11 & 55,04 & 309,96 & 46,21 & 47,49 & 309,96 \\
\hline Bufo spinosus & 29SPD26 & 101,00 & 160,01 & 96,71 & 37,40 & 5512,44 & 312,78 & 57,41 & 255,37 & 95,55 & 231,52 & 234,88 & 94,22 & 787,61 & 111,94 & 6,14 & 55,06 & 319,04 & 47,62 & 48,89 & 319,04 \\
\hline \begin{tabular}{|l} 
Bufo spinosus \\
\end{tabular} & 29SPD27 & 100,00 & $\begin{array}{lll}161,47 \\
\end{array}$ & 97,40 & 37,06 & 5567,78 & 315,33 & 57,12 & 258,21 & 98,03 & 233,97 & 236,64 & 94,68 & 784,94 & 111,68 & 6,06 & 54,87 & 317,36 & 47,71 & 48,92 & 317,33 \\
\hline Bufo spinosus & 29SPD28 & 101,00 & 163,53 & 98,34 & 37,12 & 5619,06 & 318,43 & 57,26 & 261,16 & 101,12 & 236,92 & 238,95 & 95,64 & 774,94 & 110,22 & 5,99 & 54,79 & 312,52 & 47,14 & 48,58 & 312,37 \\
\hline Bufo spinosus & 29SPD29 & 101,00 & 165,74 & 99,41 & 37,31 & 5638,23 & 320,90 & 57,92 & 262,98 & 103,96 & 239,38 & 240,89 & 97,06 & 762,84 & 108,38 & 5,99 & 54,66 & 306,90 & 46,46 & 48,16 & 306,55 \\
\hline Bufo spinosus & $29 S P D 30$ & 100,00 & 161,50 & 105,37 & 39,15 & 5515,50 & 318,91 & 54,19 & 264,71 & 103,47 & 232,66 & 236,00 & 95,16 & 649,40 & 87,17 & 5,00 & 54,22 & 259,03 & 39,70 & 40,00 & 256,64 \\
\hline Bufo spinosus & 29SPD31 & 101,00 & 164,08 & 105,16 & 39,06 & 5516,52 & 321,40 & 56,66 & 264,73 & 105,84 & 235,25 & 238,34 & 97,68 & 647,09 & 86,94 & 5,00 & 54,20 & 258,42 & 39,55 & 40,13 & 255,93 \\
\hline Bufo spinosus & 29SPD32 & 101,00 & 164,90 & 104,14 & 38,99 & 5524,03 & 321,94 & 57,97 & 263,97 & 106,51 & 236,26 & 239,30 & 98,44 & 659,01 & 89,18 & 5,07 & 54,34 & 263,67 & 40,15 & 41,02 & 261,42 \\
\hline Bufo spinosus & 29SPD33 & 100,00 & 162,66 & 101,92 & 38,40 & 5533,15 & 318,94 & 57,36 & 261,57 & 104,52 & 234,36 & 237,56 & 96,38 & 699,47 & 95,88 & 5,75 & 54,18 & 280,39 & 43,21 & 44,24 & 278,84 \\
\hline Bufo spinosus & 29SPD34 & 101,00 & 160,24 & 99,30 & $\begin{array}{l}37,85 \\
\end{array}$ & 5550,93 & 315,39 & 56,72 & 258,67 & 102,24 & 232,29 & 235,74 & 94,27 & 740,95 & 103,04 & 6,14 & 54,40 & 298,01 & 45,47 & 46,65 & 297,21 \\
\hline Bufo spinosus & 29SPD35 & 100,00 & 150,96 & 93,90 & 36,71 & 5549,48 & 303,30 & 51,48 & 251,82 & 87,76 & 223,30 & 227,27 & 86,22 & 847,69 & 120,82 & 7,24 & 54,84 & 343,56 & 52,06 & 53,06 & 343,56 \\
\hline \begin{tabular}{|l} 
Bufo spinosus \\
\end{tabular} & 29SPD36 & 101,00 & 153,98 & 94,90 & 36,77 & 5604,19 & 307,60 & 52,43 & 255,18 & 91,66 & 227,18 & 230,49 & 87,92 & 831,12 & 118,49 & 6,95 & 54,64 & 336,25 & 51,13 & 52,08 & 336,14 \\
\hline Bufo spinosus & 29SPD37 & 100,00 & 162,36 & 98,66 & $\begin{array}{l}37,05 \\
\end{array}$ & 5674,95 & 318,45 & 56,13 & 262,32 & 101,76 & 236,42 & 238,79 & 94,20 & 758,86 & 106,97 & 5,99 & 54,36 & $\begin{array}{l}305,26 \\
\end{array}$ & 46,45 & 47,80 & 304,45 \\
\hline Bufo spinosus & 29SPD38 & 101,00 & 162,82 & 98,87 & 36,98 & 5732,46 & 319,80 & 55,39 & 264,41 & 101,39 & 237,89 & 239,77 & 93,75 & 761,73 & 107,66 & 5,93 & 54,35 & \begin{tabular}{|c|}
305,98 \\
\end{tabular} & 46,83 & 48,18 & 305,15 \\
\hline Bufo spinosus & 29SPD39 & 101,00 & 163,06 & 99,01 & 36,69 & 5777,13 & 320,64 & 54,43 & 266,21 & 100,55 & 238,81 & 240,35 & 93,17 & 767,51 & 108,81 & 5,99 & 54,15 & 307,94 & 47,38 & 48,78 & 307,06 \\
\hline Bufo spinosus & 29SPD40 & 100,00 & 160,85 & 107,88 & 39,32 & 5634,39 & 321,61 & 50,65 & 270,96 & 101,18 & 233,86 & 236,68 & 93,03 & 641,53 & 85,81 & 5,19 & 53,71 & 254,70 & 40,13 & 40,43 & 250,73 \\
\hline Bufo spinosus & $29 S P D 41$ & 100,00 & 162,43 & 107,64 & 39,01 & 5644,46 & 323,51 & 52,29 & 271,22 & \begin{tabular}{|l|l|}
102,49 \\
\end{tabular} & $\begin{array}{l}235,74 \\
230\end{array}$ & 238,27 & 94,25 & 645,10 & $\begin{array}{l}0,01 \\
86,31 \\
\end{array}$ & 5,02 & \begin{tabular}{|l|l|}
53,74 \\
\end{tabular} & 256,50 & $\begin{array}{l}40,14 \\
40,14 \\
\end{array}$ & 40,40, & 252,58 \\
\hline Bufo spinosus & $29 S P D 42$ & 100,00 & 164,73 & 107,12 & 39,01 & 5646,44 & 325,62 & 54,64 & 270,98 & 104,53 & 238,01 & 240,52 & 96,53 & 643,72 & 86,33 & 5,01 & 53,71 & 256,23 & 39,98 & 40,80 & 252,39 \\
\hline Bufo spinosus & 29SPD43 & 99,00 & 163,16 & 104,89 & \begin{tabular}{|l|}
38,67 \\
\end{tabular} & 5647,58 & 323,13 & 54,71 & 268,42 & 103,38 & 236,58 & 239,30 & 95,26 & 675,98 & 91,26 & 5,35 & 53,69 & 269,65 & 42,25 & 43,30 & 266,46 \\
\hline Bufo spinosus & 29SPD44 & 101,00 & 155,18 & 99,28 & 37,57 & 5640,11 & 312,16 & 51,31 & 260,85 & 96,60 & 228,72 & 232,15 & 88,58 & 767,07 & 106,42 & 6,42 & 54,01 & 307,69 & 47,74 & 48,74 & 306,19 \\
\hline Bufo spinosus & 29SPD45 & 99,00 & 145,56 & 94,44 & 36,50 & 5659,10 & 300,09 & 44,74 & 255,35 & 86,12 & 220,27 & 223,39 & 79,69 & 866,89 & 122,89 & 7,64 & 54,20 & 348,96 & 54,20 & 54,73 & 348,51 \\
\hline Bufo spinosus & 29SPD46 & 100,00 & 156,64 & $\begin{array}{l}44,44 \\
97,92\end{array}$ & 36,98 & 5715,55 & 313,60 & 51,85 & 261,75 & $\begin{array}{l}\mid c 0,12 \\
96,79 \\
\end{array}$ & \begin{tabular}{|l|}
231,46 \\
\end{tabular} & \begin{tabular}{|l|}
234,36 \\
\end{tabular} & 88,84 & \begin{tabular}{|l|}
779,71 \\
\end{tabular} & \begin{tabular}{|l|}
109,38 \\
109,
\end{tabular} & 6,04 & 54,05 & $\begin{array}{l}340,009 \\
313,09\end{array}$ & 48,41 & 49,55 & 311,72 \\
\hline Bufo spinosus & 29SPD47 & 100,00 & 161,78 & 99,90 & 37,00 & 5777,09 & 320,23 & 53,95 & 266,28 & 100,13 & 237,49 & 239,55 & 92,44 & 738,82 & 103,05 & 5,96 & 53,79 & 295,82 & 45,84 & 47,24 & 293,69 \\
\hline Bufo spinosus & 29SPD49 & 99,00 & 164,02 & 100,39 & 36,89 & 5853,23 & 323,01 & 53,88 & 269,13 & 100,56 & 240,91 & 242,15 & 93,07 & 730,46 & 102,34 & 5,78 & 53,71 & 291,92 & 45,35 & 46,81 & 289,43 \\
\hline Bufo spinosus & $29 S P D 50$ & 101,00 & 161,35 & 110,94 & 39,34 & 5753,36 & 325,81 & 47,58 & 278,22 & 99,84 & 236,19 & 238,25 & 91,60 & 621,37 & 83,68 & 5,08 & 53,01 & 245,32 & 39,71 & 39,97 & 239,52 \\
\hline Bufo spinosus & 29SPD51 & 100,00 & 164,01 & 111,44 & 39,36 & 5761,51 & 328,97 & 49,73 & 279,23 & 102,11 & 239,04 & 240,87 & 93,99 & 614,70 & 82,82 & 4,99 & 52,89 & 242,76 & 39,40 & 39,88 & 236,78 \\
\hline Bufo spinosus & $\begin{array}{l}\text { 29PSDS52 } \\
\text { 29SP }\end{array}$ & 101,00 & 106,01 & $\begin{array}{l}111,44 \\
111,13\end{array}$ & 39,15 & 5767,16 & 331,38 & $\begin{array}{ll}51,92 \\
51,92\end{array}$ & 279,45 & \begin{tabular}{|l|}
104,00 \\
10,1
\end{tabular} & \begin{tabular}{|l|}
241,34 \\
243
\end{tabular} & \begin{tabular}{|l|}
243,14 \\
243
\end{tabular} & $\begin{array}{l}30,09 \\
96,06\end{array}$ & $\begin{array}{l}610,44 \\
610,0\end{array}$ & $\begin{array}{l}2,, 202 \\
82,21\end{array}$ & $\begin{array}{l}, 599 \\
4,99 \\
\end{array}$ & $\begin{array}{ll}2,309 \\
52,86\end{array}$ & $\begin{array}{l}242,10 \\
241,30\end{array}$ & $\begin{array}{l}30,40 \\
38,96\end{array}$ & $\begin{array}{l}39,79 \\
39,79 \\
\end{array}$ & 235,35 \\
\hline Bufo spinosus & 29SPD53 & 101,00 & 162,51 & 107,88 & 38,71 & 5768,06 & 326,25 & 50,88 & 275,37 & 100,99 & 237,82 & 239,95 & 92,98 & 656,75 & 87,85 & 5,19 & 52,99 & 260,40 & 41,79 & 42,66 & 255,47 \\
\hline Bufo spinosus & 29SPD54 & 100,00 & 159,58 & 104,37 & 37,96 & 5772,25 & 321,21 & 50,21 & 271,00 & 98,48 & 235,00 & 237,44 & 90,46 & 698,68 & 94,38 & 5,69 & 53,15 & 277,95 & 44,20 & 45,22 & 273,87 \\
\hline Bufo spinosus & 29SPD59 & 101,00 & 163,90 & 101,51 & 36,84 & 5918,49 & 324,06 & 52,29 & 271,77 & 99,59 & 241,73 & 242,68 & 92,03 & 700,88 & 96,96 & 5,47 & 53,10 & 278,58 & 43,96 & 45,45 & 274,74 \\
\hline Bufo spinosus & $29 S P D 60$ & 100,00 & 168,81 & 115,08 & 39,66 & 5867,40 & 337,01 & 49,50 & 287,52 & 104,80 & 245,21 & 246,19 & 96,54 & 544,56 & 75,00 & 4,03 & 52,36 & 213,40 & 35,45 & 35,99 & 204,68 \\
\hline \begin{tabular}{|l} 
Bufo spinosus \\
\end{tabular} & 29SPD61 & 100,00 & 167,71 & 115,31 & 39,86 & 5882,00 & 336,11 & 48,61 & 287,49 & 103,42 & 244,34 & 245,41 & 95,43 & 563,84 & 77,06 & 4,32 & 52,19 & 220,94 & 36,92 & 37,50 & 212,62 \\
\hline Bufo spinosus & 29SPD63 & 99,00 & 165,28 & 111,71 & 39,01 & 5881,51 & 332,24 & 49,14 & 283,10 & 101,48 & 242,15 & 243,45 & 93,61 & 608,40 & 81,64 & 4,91 & 52,16 & 239,24 & 39,44 & 40,35 & 232,05 \\
\hline Bufo spinosus & 29SPD70 & 101,00 & 168,47 & 116,41 & 39,00 & 5985,76 & 339,92 & 46,32 & 293,60 & 102,76 & 246,63 & 247,24 & 94,58 & 521,55 & 72,42 & 4,00 & 51,71 & 202,79 & 34,94 & 35,31 & 192,28 \\
\hline Bufo spinosus & 29SPD71 & 100,00 & 168,40 & 116,38 & 39,05 & 5976,06 & 339,55 & 46,77 & 292,79 & 102,82 & 246,31 & 247,10 & 94,75 & 533,62 & 73,51 & 4,00 & 51,58 & 207,55 & 35,67 & 36,27 & 197,40 \\
\hline Bufo spinosus & 29SPD72 & 101,00 & 167,95 & 115,53 & 39,09 & 5969,52 & 338,12 & 47,37 & 290,75 & $\begin{array}{l}\mid 02,02 \\
102,45 \\
\end{array}$ & 245,99 & 246,49 & 94,50 & \begin{tabular}{|l|l|}
549,09 \\
\end{tabular} & 74,84 & 4,03 & 51,63 & 214,01 & $\begin{array}{l}30,08 \\
36,08\end{array}$ & 36,81 & 204,42 \\
\hline \begin{tabular}{|l} 
Bufo spinosus \\
\end{tabular} & 29SPD82 & 100,00 & 167,14 & 115,38 & 38,95 & 6039,30 & 339,05 & 45,73 & 293,31 & 101,06 & 246,31 & 246,66 & 93,00 & 532,86 & 72,48 & 4,00 & 51,25 & 206,41 & 35,04 & 35,95 & 195,55 \\
\hline Bufo spinosus & 29SPD83 & 100,00 & 164,86 & 113,41 & 38,41 & 6057,41 & 336,19 & 44,88 & 291,31 & 98,84 & 244,34 & 244,99 & 90,78 & 559,73 & 7,01 & 4,28 & 51,20 & 216,9 & 36,56 & 37,66 & 206,87 \\
\hline Bufo spinosus & $29 S P D 86$ & 100,00 & 160,82 & 107,20 & 37,01 & 6100,64 & 329,33 & 44,68 & 284,66 & 94,91 & 241,38 & 242,02 & 86,92 & 614,69 & 80,48 & 4,97 & 51,01 & 238,84 & 40,42 & 41,25 & 230,18 \\
\hline Bufo spinosus & 29SPD91 & 100,00 & 167,55 & 116,01 & 38,92 & 6065,25 & 340,68 & 44,52 & 296,16 & 100,92 & 246,76 & 247,12 & 92,68 & 507,18 & 69,28 & 4,00 & 51,26 & 195,74 & 32,31 & 33,62 & 183,51 \\
\hline \begin{tabular}{|l} 
Bufo spinosus \\
\end{tabular} & \begin{tabular}{|l|}
$295 P D D 93$ \\
$29 S P 3$
\end{tabular} & $\begin{array}{l}100,00 \\
\end{array}$ & $\frac{10,53}{163,21}$ & $\begin{array}{l}11,013,01 \\
113,0\end{array}$ & | & $\begin{array}{l}600,25,61 \\
6135,61\end{array}$ & 336 & $\begin{array}{l}4,322 \\
42,49 \\
\end{array}$ & \begin{tabular}{|l|}
$290,72,7$ \\
29
\end{tabular} & \begin{tabular}{|c|}
96,36 \\
96
\end{tabular} & 243,83 & 244,27 & 88,26 & 551,54 & 73,30 & 4,07 & 51,00 & 212,45 & 35,73 & 36,68 & 201,47 \\
\hline \begin{tabular}{|l|} 
Bufo spinosus \\
\end{tabular} & $295 P D 94$ & 101,00 & 162,61 & 111,41 & 37,79 & 6154,11 & 335,04 & 43,05 & 291,99 & 95,77 & 243,83 & 244,16 & 87,60 & 563,05 & 74,21 & 4,31 & 50,71 & 216,84 & 36,79 & 37,66 & 206,23 \\
\hline Bufo spinosus & 29SPD97 & 100,00 & 162,45 & 107,19 & \begin{tabular}{|l|l|}
36,97 \\
\end{tabular} & 6180,94 & 332,20 & 45,06 & 287,14 & 95,38 & 244,22 & 244,52 & 87,40 & 580,10 & 75,34 & 4,52 & 50,45 & 223,50 & 38,32 & 39,01 & 213,86 \\
\hline Bufo spinosus & 29SPE00 & 100,00 & 156,61 & 96,31 & 37,36 & 5412,16 & 306,87 & 52,65 & 254,22 & 91,06 & 227,34 & 229,15 & 91,06 & 892,60 & 129,81 & 7,50 & 55,12 & 363,46 & 55,07 & 55,67 & 363,46 \\
\hline Bufo spinosus & 29SPE11 & 101,00 & 157,91 & 97,35 & 36,95 & 5583,85 & 311,32 & 51,39 & 259,93 & 90,01 & 231,04 & 233 & 90,01 & 875,06 & 127,01 & 7,26 & 54,90 & 354,47 & 54,36 & 55,11 & 35 \\
\hline \begin{tabular}{|l} 
Bufo spinosus \\
\end{tabular} & 29SPE12 & 100,00 & 151,78 & 95,52 & 36,56 & 5580,80 & 303,98 & 46,12 & 257,86 & 84,14 & 225,44 & 226,36 & 84,14 & $\begin{array}{l}943,37 \\
\end{array}$ & 138,41 & 8,12 & 55,08 & 383,08 & 58,69 & 59,05 & 383,08 \\
\hline Bufo spinosus & 29SPE20 & 100,00 & 159,02 & 97,11 & 36,27 & 5736,83 & 315,15 & 51,62 & 263,53 & 91,49 & 234,44 & 235,76 & 89,70 & 838,95 & 120,98 & 6,83 & 54,74 & \begin{tabular}{|c|}
338,78 \\
\end{tabular} & 51,89 & 52,70 & 338,73 \\
\hline Bufo spinosus & 29SPE21 & 100,00 & 157,59 & 97,04 & 36,15 & 5765,61 & 313,94 & 49,60 & 264,34 & 88,08 & 233,56 & 234,55 & 87,85 & 858,44 & 124,23 & 7,02 & 54,74 & 346,39 & 53,52 & 54,15 & 346,39 \\
\hline Bufo spinosus & 29SPE22 & 100,00 & 153,76 & 96,17 & 36,13 & 5741,76 & 308,91 & 46,21 & 262,70 & 84,23 & 229,40 & 230 & 84 & 900,23 & 131,32 & 7,73 & 54 & 363,70 & 56,48 & 56,78 & 363,70 \\
\hline Bufo spinosus & 29SPE30 & 100,00 & 165,01 & 99,91 & 36,85 & 5785,91 & 322,58 & 55,11 & 267,47 & 101,66 & 240,95 & 241,99 & 94,62 & 754,97 & 106,97 & 6,00 & 54,14 & 302,59 & 46,47 & 48,13 & 301,33 \\
\hline
\end{tabular}




\begin{tabular}{|c|c|c|c|c|c|c|c|c|c|c|c|c|c|c|c|c|c|c|c|c|c|}
\hline TAXON & UTM & $\mathrm{km} 2$ & BI01 & BIO2 & $B 103$ & BIO4 & B105 & B106 & B107 & B108 & B109 & B1010 & BIO11 & BIO12 & BIO13 & B1014 & BIO15 & B1016 & B1017 & B1018 & 81019 \\
\hline Bufo spinosus & 29SPE31 & 101,00 & $\begin{array}{r}157,49 \\
\end{array}$ & 97,29 & 36,01 & 5870,90 & 315,45 & 48,45 & 267,00 & 91,57 & 234,94 & 235,83 & 86,60 & 833,36 & 120,00 & 6,90 & 54,25 & 334,68 & 52,14 & 52,80 & 334,45 \\
\hline Bufo spinosus & 29SPE32 & 100,00 & 155,12 & 96,91 & 36,01 & 5844,35 & 312,09 & 46,21 & 265,88 & 88,22 & 232,29 & 232,95 & 84,38 & 856,54 & 123,96 & 7,15 & 54,26 & 343,94 & 53,86 & 54,35 & 343,80 \\
\hline Bufo spinosus & 29SPE40 & 101,00 & 164,31 & 100,45 & 36,85 & 5868,35 & 323,23 & 53,36 & 269,86 & 100,41 & 241,48 & 242,36 & 92,96 & 733,33 & \begin{tabular}{|l|}
103,07 \\
\end{tabular} & 5,98 & 53,64 & 292,77 & 45,60 & 47,25 & 290,38 \\
\hline Bufo spinosus & 29SPE41 & 100,00 & 163,53 & 100,25 & 36,75 & 5876,42 & 322,10 & 52,19 & 269,90 & 99,20 & 240,77 & 241,49 & 91,83 & 744,16 & 105,12 & 6,05 & 53,53 & 296,93 & 46,41 & 48,04 & 294,75 \\
\hline Bufo spinosus & 29SPE50 & 100,00 & 163,77 & 101,27 & 36,87 | & 5932,29 & 323,69 & 51,76 & 271,94 & 99,08 & 241,85 & 242,54 & 91,55 & 705,68 & 98,12 & 5,53 & 53,11 & 280,54 & 44,12 & 45,66 & 276,80 \\
\hline Bufo spinosus & 29SPE51 & 101,00 & 162,83 & 100,88 & 36,68 | & 5941,95 & 322,45 & 50,59 & 271,86 & 97,88 & 241,23 & 241,63 & 90,42 & 716,97 & 100,21 & 5,86 & 53,12 & 284,78 & 45,20 & \begin{tabular}{|l|l|}
46,64 \\
\end{tabular} & 281,24 \\
\hline Bufo spinosus & 29SPE52 & 101,00 & 157,55 & 99,13 & 36,10 & 5958,68 & 316,43 & 46,10 & 270,33 & 92,54 & 236,26 & 236,52 & 84,95 & 761,84 & 107,67 & 6,19 & 53,17 & 302,85 & 48,50 & 49,19 & 300,00 \\
\hline Bufo spinosus & 29SPE60 & 101,00 & 160,83 & 101,30 & 36,43 & 6005,53 & 322,03 & \begin{tabular}{ll|}
48,31 \\
\end{tabular} & 273,71 & 95,56 & 240,07 & 240,54 & 87,79 & 697,13 & 96,08 & 5,66 & 52,50 & 275,62 & 44,60 & $\begin{array}{l}45,66 \\
\end{array}$ & 270,71 \\
\hline Bufo spinosus & 29SPE61 & 99,00 & 159,52 & 100,65 & 36,13 & $\begin{array}{ll}6011,88 \\
\end{array}$ & 320,19 & \begin{tabular}{ll|}
46,94 \\
\end{tabular} & 273,24 & 94,04 & 238,99 & 239,26 & 86,33 & \begin{tabular}{ll|l}
709,88 \\
\end{tabular} & 98,39 & 5,94 & 52,45 & 280,56 & 45,79 & 46,52 & 275,97 \\
\hline Bufo spinosus & 29SPE71 & 100,00 & 159,82 & 101,92 & $\begin{array}{l}36,35 \\
\end{array}$ & $\begin{array}{lll}6065,58 \\
\end{array}$ & 322,31 & 45,97 & 276,34 & $\begin{array}{l}93,66 \\
\end{array}$ & 240,05 & 240,17 & 85,82 & $\begin{array}{l}670,65 \\
\end{array}$ & 91,49 & 5,45 & 51,84 & 263,29 & 43,56 & 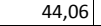 & 257,20 \\
\hline Bufo spinosus & 29SPE72 & 101,00 & 157,64 & 101,21 & 36,08 & 6065,15 & 319,49 & 44,06 & 275,43 & \begin{tabular}{|c|c|}
91,42 \\
\end{tabular} & 237,94 & 238,00 & 83,62 & 684,95 & \begin{tabular}{|l|l|l}
93,96 &
\end{tabular} & 5,83 & 51,77 & 268,81 & \begin{tabular}{|c|c|}
45,03 \\
\end{tabular} & \begin{tabular}{|c|c|}
45,28 \\
\end{tabular} & 262,93 \\
\hline Bufo spinosus & 29SQA19 & 10,00 & 178,00 & 87,00 & 37,00 & $\begin{array}{lll}4992,64 \\
\end{array}$ & 302,64 & 72,00 & 230,64 & 136,73 & 240,55 & 243,45 & \begin{tabular}{ll|}
115,64 \\
\end{tabular} & \begin{tabular}{|l|l|}
523,27 \\
\end{tabular} & 80,91 & 1,00 & 64,91 & 227,91 & 14,00 & 22,00 & 207,55 \\
\hline Bufo spinosus & 29SQA29 & 85,00 & 178,83 & 87,79 & 37,13 & 5027,68 & 304,23 & 72,22 & 232,02 & 143,22 & 241,99 & 245,02 & 116,11 & 528,25 & 81,26 & 1,00 & 64,74 & 230,03 & 14,15 & 22,00 & 210,30 \\
\hline Bufo spinosus & 29SQA36 & 95,00 & 177,07 & 84,66 & 38,31 & 4649,30 & 293,27 & 75,19 & 218,08 & 153,02 & 235,24 & 238,90 & \begin{tabular}{|l|l|}
119,87 \\
\end{tabular} & 554,28 & 90,71 & 0,00 & 66,75 & 246,68 & 13,00 & 20,40 & 228,02 \\
\hline Bufo spinosus & 29SQA37 & 70,00 & 177,22 & 84,36 & \begin{tabular}{l|l|l}
37,45 \\
\end{tabular} & 4807,11 & 296,27 & 74,12 & 222,15 & 152,46 & 237,56 & 241,03 & \begin{tabular}{ll|}
117,86 \\
\end{tabular} & \begin{tabular}{|l|l|}
551,16 \\
\end{tabular} & 87,79 & 0,53 & 65,83 & 242,48 & 13,59 & 21,43 & 223,57 \\
\hline Bufo spinosus & 29SQA43 & 19,00 & 179,33 & 70,04 & 35,96 & 4462,26 & \begin{tabular}{|l|l|}
279,67 \\
\end{tabular} & 86,48 & 193,19 & 158,41 & 234,30 & \begin{tabular}{|l|l|}
238,67 \\
\end{tabular} & 123,78 & $\begin{array}{l}609,26 \\
\end{array}$ & 105,11 & 0,93 & 68,96 & 264,70 & $\begin{array}{l}11,96 \\
\end{array}$ & 22,00 & 248,44 \\
\hline Bufo spinosus & 29SQA45 & 69,00 & 176,93 & 76,35 & 36,36 & 4649,63 & 286,27 & 79,15 & 207,12 & 153,94 & 234,81 & 238,93 & $\begin{array}{l}119,44 \\
\end{array}$ & 587,01 & 95,92 & 0,38 & 66,81 & 255,15 & 13,02 & 21,31 & 237,94 \\
\hline Bufo spinosus & 29SQA47 & 99,00 & 176,25 & 80,88 & 35,97 & 4931,20 & 295,24 & 73,49 & 221,75 & 150,49 & 238,23 & 241,92 & 115,29 & 568,75 & 88,95 & 0,97 & 65,60 & 246,05 & 14,79 & \begin{tabular}{|l|l|}
21,97 \\
\end{tabular} & 227,88 \\
\hline Bufo spinosus & 29SQA52 & & & & & & & & & & & & & & & & & & & & \\
\hline Bufo spinosus & 29SQA53 & 100,00 & 177,64 & 70,43 & 35,65 & 4493,07 & 279,11 & 84,29 & 194,82 & 143,26 & 232,93 & 237,52 & 121,50 & 635,77 & 110,43 & 1,00 & 69,06 & 277,45 & 13,16 & 23,23 & 262,34 \\
\hline Bufo spinosus & 29SQA54 & 93,00 & 177,06 & 70,42 & 34,92 & 4627,92 & 281,23 & 82,24 & 198,99 & 149,73 & 234,27 & 238,95 & $\begin{array}{l}119,38 \\
\end{array}$ & 623,61 & $\begin{array}{l}105,06 \\
\end{array}$ & 1,00 & 68,15 & 269,05 & 13,48 & 23,19 & 253,37 \\
\hline Bufo spinosus & 29SQA56 & 100,00 & 173,87 & 72,93 & 33,94 & 4924,18 & 286,72 & 74,69 & 212,03 & 144,30 & 235,60 & 239,56 & 112,85 & \begin{tabular}{ll|}
606,72 \\
\end{tabular} & 95,02 & 1,00 & 65,93 & 257,52 & 15,55 & 23,43 & 241,52 \\
\hline Bufo spinosus & 29SQA60 & & & & & & & & & & & & & & & & & & & & \\
\hline Bufo spinosus & 29SQA61 & 69,00 & 173,72 & 74,04 & $37,77 \mid$ & 4251,75 & 275,40 & 81,89 & 193,51 & 129,78 & 226,25 & 230,55 & 120,81 & 723,45 & 126,98 & 0,92 & 71,45 & 326,94 & 14,62 & 23,06 & 313,23 \\
\hline Bufo spinosus & 29SQA62 & 96,00 & 173,91 & 72,69 & 36,69 & 4381,85 & 276,29 & 80,88 & 195,42 & 128,33 & 228,08 & 232,35 & 119,18 & $\begin{array}{l}703,15 \\
\end{array}$ & 122,12 & 1,00 & 70,45 & 313,64 & 14,39 & 23,54 & 299,47 \\
\hline Bufo spinosus & 29SQA63 & 91,00 & 174,26 & 71,55 & 35,73 & 4530,08 & 278,14 & 80,13 & 198,02 & 127,05 & 230,42 & 234,79 & 117,85 & 680,79 & 116,33 & 1,00 & 69,49 & 299,66 & 14,39 & 23,80 & 284,77 \\
\hline Bufo spinosus & 29SQA64 & 82,00 & 173,11 & 71,60 & 34,77 & 4697,90 & 280,25 & 77,27 & 202,98 & $\begin{array}{l}123,76 \\
\end{array}$ & 231,64 & 235,93 & 114,68 & 667,31 & \begin{tabular}{|l|l|}
111,07 \\
\end{tabular} & 1,00 & 68,47 & 289,70 & 14,79 & 24,00 & 274,71 \\
\hline Bufo spinosus & 29SQA65 & 87,00 & 173,45 & 71,17 & 33,89 & 4832,19 & 282,94 & 76,20 & 206,74 & 123,52 & 233,76 & 237,93 & $\begin{array}{l}113,34 \\
\end{array}$ & $\begin{array}{l}646,16 \\
\end{array}$ & \begin{tabular}{l|l|l|}
104,12 \\
\end{tabular} & 1,00 & 67,41 & 276,87 & 15,43 & 23,97 & 261,60 \\
\hline Bufo spinosus & 29SQA66 & 81,00 & 172,10 & 71,69 & 33,18 & 5004,39 & 285,84 & 72,94 & 212,90 & 120,75 & 234,93 & 238,95 & 110,16 & 634,60 & $\begin{array}{l}98,66 \\
\end{array}$ & 1,00 & 66,61 & 268,96 & \begin{tabular}{|l|l|}
16,27 \\
\end{tabular} & 24,00 & 253,05 \\
\hline Bufo spinosus & 29SQB00 & 46,00 & 176,74 & 85,34 & 37,00 & 5008,82 & 299,92 & 71,94 & 227,98 & 123,20 & 239,08 & 242,08 & $\begin{array}{l}114,04 \\
\end{array}$ & $\begin{array}{l}511,26 \\
\end{array}$ & 79,38 & 1,00 & 64,36 & 221,58 & 14,00 & 23,00 & 200,42 \\
\hline Bufo spinosus & 29SQB01 & 100,00 & 177,03 & 85,80 & 36,91 & 5086,65 & 301,93 & 71,36 & 230,57 & 128,89 & 240,26 & 243,19 & 1113,39 & \begin{tabular}{|l|l|}
505,93 \\
\end{tabular} & 78,73 & 1,00 & 63,83 & 218,10 & 14,01 & 23,13 & 196,75 \\
\hline Bufo spinosus & 29SQB02 & 100,00 & 175,71 & 87,83 & 36,78 & 5211,77 & 304,69 & $\begin{array}{ll}68,22 \\
\end{array}$ & 236,47 & 121,68 & 240,67 & 243,42 & 110,32 & 511,72 & 79,20 & 1,00 & 63,09 & 218,53 & 14,72 & 23,99 & 197,38 \\
\hline Bufo spinosus & 29SQB03 & 100,00 & 176,62 & $\begin{array}{ll}90,04 \\
\end{array}$ & \begin{tabular}{l|l}
36,92 \\
\end{tabular} & 5313,06 & 309,19 & 67,62 & 241,57 & 130,20 & 243,06 & 245,67 & 110,08 & 505,56 & 78,12 & 1,00 & 62,66 & 214,59 & 15,01 & 23,97 & 193,80 \\
\hline Bufo spinosus & 29SQB04 & 100,00 & 175,53 & 93,32 & $\begin{array}{ll}37,02 \\
\end{array}$ & 5425,44 & 312,93 & 64,53 & 248,41 & 120,14 & 243,71 & 246,19 & $\begin{array}{ll}107,63 \\
\end{array}$ & 511,63 & 78,33 & 1,29 & 61,96 & 215,68 & 16,04 & 24,62 & 195,76 \\
\hline Bufo spinosus & 29SQB05 & 101,00 & 169,79 & 97,85 & 37,29 & 5573,42 & 314,27 & 56,43 & 257,84 & 109,60 & 240,50 & 242,85 & 100,61 & $\begin{array}{l}543,49 \\
\end{array}$ & 81,20 & 2,00 & 60,59 & 226,67 & \begin{tabular}{l|l|}
19,23 \\
\end{tabular} & 27,11 & 208,41 \\
\hline Bufo spinosus & 29SQB06 & 101,00 & 165,53 & 101,65 & \begin{tabular}{|l|l|}
37,97 \\
\end{tabular} & 5683,37 & 315,98 & 50,49 & 265,49 & 104,53 & 238,24 & 240,44 & 95,45 & $\begin{array}{l}566,49 \\
\end{array}$ & 83,17 & 2,01 & 59,96 & 234,53 & 21,17 & 28,32 & 217,67 \\
\hline Bufo spinosus & 295QB07 & 100,00 & 164,82 & $\mid 104,21$ & 38,00 & 5762,46 & 319,25 & 48,34 & 270,91 & 102,79 & 238,75 & 240,87 & $\begin{array}{ll}93,82 \\
\end{array}$ & 569,38 & 82,77 & 2,29 & 59,36 & 234,26 & 22,28 & 28,82 & 218,29 \\
\hline Bufo spinosus & 295QB08 & 100,00 & 163,17 & 106,56 & 38,00 & 5835,67 & 321,68 & 45,53 & 276,15 & 100,43 & 238,34 & 240,40 & 91,52 & 576,80 & 82,82 & 2,68 & 58,52 & 235,69 & 23,96 & 29,93 & 220,70 \\
\hline Bufo spinosus & 29SQB09 & 101,00 & 149,98 & 109,34 & 38,00 & 5955,40 & 315,2 & 31,79 & 283,43 & 86,71 & 227,37 & 229,53 & 77,75 & 655,52 & 90,98 & 3,83 & 57,21 & 264,65 & 30,41 & 35,23 & 252,11 \\
\hline Bufo spinosus & 29SQB10 & 96,00 & 177,80 & 87,58 & 37,01 & 5066,93 & 303,78 & 71,44 & 232,34 & 130,63 & 241,16 & 244,08 & 114,66 & 518,74 & 80,20 & 1,00 & 64,27 & 224,79 & 14,00 & 22,93 & 204,25 \\
\hline Bufo spinosus & 29SQB12 & 99,00 & $\begin{array}{l}177,09 \\
\end{array}$ & $\begin{array}{ll}91,82 \\
\end{array}$ & 37,01 & 5318,58 & 311,16 & $\begin{array}{ll}67,03 \\
\end{array}$ & 244,13 & 119,89 & 244,00 & 246,56 & 110,55 & \begin{tabular}{ll|}
519,52 \\
\end{tabular} & 80,10 & 1,00 & 63,16 & 221,75 & 15,04 & 23,39 & 201,42 \\
\hline Bufo spinosus & 29SQB13 & 101,00 & 175,23 & $\begin{array}{ll}94,79 \\
\end{array}$ & $\begin{array}{l}37,05 \\
\end{array}$ & 5452,54 & 314,19 & $\begin{array}{ll}62,94 \\
\end{array}$ & 251,25 & 116,11 & 244,04 & 246,46 & 107,10 & $\begin{array}{l}528,76 \\
\end{array}$ & 80,87 & 1,01 & 62,52 & 224,05 & 15,94 & 24,02 & 204,34 \\
\hline Bufo spinosus & 29SQB14 & 100,00 & 177,04 & 97,18 & 37,40 & 5528,40 & 319,21 & 63,27 & 255,94 & 117,12 & 247,02 & 249,25 & 108,02 & 518,64 & 79,16 & 1,11 & 62,08 & 218,60 & 16,14 & 24,15 & 199,43 \\
\hline Bufo spinosus & 29SQB15 & 100,00 & 171,39 & 101,11 & 37,85 . & 5671,57 & 320,33 & 55,58 & 264,75 & 110,05 & 243,75 & 245,90 & $\mid$\begin{tabular}{|l|l|}
101,01 \\
\end{tabular} & 548,55 & 81,87 & $\begin{array}{lll}1,99 \\
\end{array}$ & 60,71 & 228,67 & $\mid \frac{\mid 9,41}{3}$ & 26,72 & 210,85 \\
\hline Bufo spinosus & 29SQB16 & 99,00 & 168,83 & 104,02 & 38,00 & 5771,93 & 322 & 51,44 & 271,26 & 106,39 & 242,73 & 244,82 & 97,38 & 560,74 & 82,61 & 2,01 & 60,17 & 232,12 & 20,69 & 27,51 & 215,31 \\
\hline Bufo spinosus & 29SQB17 & 101,00 & 163,36 & 107,06 & 38,00 & 5877,79 & 322,84 & $\begin{array}{l}44,57 \\
\end{array}$ & 278,27 & \begin{tabular}{ll|l}
99,97 \\
\end{tabular} & 239,10 & 241,08 & 90,98 & 589,06 & 85,03 & 2,50 & 59,22 & 241,64 & 23,35 & 29,53 & 226,20 \\
\hline Bufo spinosus & 29SQB18 & 100,00 & 159,01 & 109,34 & 38,00 & 5957,20 & 322,97 & 39,38 & 283,59 & 95,16 & 236,25 & \begin{tabular}{|l|}
238,07 \\
\end{tabular} & 86,15 & \begin{tabular}{ll|l}
610,38 \\
\end{tabular} & $\begin{array}{l}86,62 \\
\end{array}$ & 2,97 & 58,25 & 248,23 & 25,93 & 31,53 & 233,97 \\
\hline Bufo spinosus & 29SQB19 & 99,00 & 151,81 & \begin{tabular}{|l|l|}
111,03 \\
\end{tabular} & 38,00 & 6028,69 & 319,92 & 31,80 & 288,13 & 87,58 & 230,39 & 232,23 & 78,65 & 649,94 & 90,32 & 3,61 & 57,35 & 262,00 & 29,59 & 34,50 & 249,20 \\
\hline Bufo spinosus & 29SQB20 & 100,00 & 179,04 & 89,73 & 37,08 & 5151,40 & 308,35 & 70,87 & 237,48 & 134,68 & 243,99 & 246,81 & $\begin{array}{l}114,96 \\
\end{array}$ & 524,89 & 80,86 & 1,00 & 64,52 & 227,17 & 14,90 & 22,01 & 207,32 \\
\hline Bufo spinosus & 29SQB21 & 101,00 & 179,80 & 92,42 & 37,20 & 5285,69 & 313,51 & \begin{tabular}{|c|}
69,27 \\
\end{tabular} & 244,24 & 131,97 & 246,44 & 249,12 & \begin{tabular}{ll|}
113,76 \\
\end{tabular} & \begin{tabular}{|l|l|}
522,48 \\
\end{tabular} & 80,46 & 1,00 & 63,68 & 224,48 & 15,00 & 22,31 & 204,82 \\
\hline Bufo spinosus & 29SQB22 & 100,00 & $\begin{array}{l}178,30 \\
\end{array}$ & 95,58 & 37,40 & 5428,78 & 317,33 & 65,47 & 251,87 & 119,33 & 247,04 & 249,51 & 110,55 & 529,87 & 81,28 & 1,00 & 63,28 & 226,09 & 15,47 & 22,99 & 206,78 \\
\hline Bufo spinosus & 29SQB24 & 100,00 & 175,60 & 101,94 & 37,95 [ & 5673,27 & 325,06 & 58,67 & 266,40 & 114,06 & 248,11 & 250,25 & 104,99 & 543,60 & $81,97 \mid$ & 1,36 & 61,76 & 228,44 & 18,02 & 24,99 & 210,41 \\
\hline Bufo spinosus & 29SQB26 & 101,00 & 165,03 & 108,10 & 38,00 & 5908,15 & 325,85 & 45,03 & 280,81 & 101,40 & 241,28 & 24 & 92,26 & 594,59 & 86,44 & $2, c$ & 60,03 & 245,36 & 22 & 28,46 & 229 \\
\hline Bufo spinosus & $295 Q B$ & 100,00 & 162,82 & 109,90 & 38,00 & 598 & 327 & 41,83 & & 98,45 & 240,34 & & 89,41 & $\begin{array}{l}602,57 \\
\end{array}$ & 86,51 & 2,57 & 59,20 & 246,70 & 24,01 & 29,90 & 231,84 \\
\hline Bufo spinosus & 29SQB29 & 100,00 & 158,47 & 112,97 & 38,00 & $\begin{array}{lll}6098,34 \\
\end{array}$ & 328,68 & 36,09 & 292,59 & \begin{tabular}{ll|}
92,97 \\
\end{tabular} & 237,91 & 239,45 & 83,95 & $\begin{array}{l}619,05 \\
\end{array}$ & 86,71 & 3,20 & 57,68 & 249,70 & 27,20 & 32,28 & 236,40 \\
\hline Bufo spinosus & 29SQB31 & 100,00 & 180,39 & $\begin{array}{ll}95,44 \\
\end{array}$ & 37,43 & 5399,35 & 319,24 & $\begin{array}{ll}67,63 \\
\end{array}$ & 251,61 & 121,85 & 248,92 & 251,55 & $\begin{array}{l}113,18 \\
\end{array}$ & $\begin{array}{l}535,35 \\
\end{array}$ & 82,11 & 1,00 & 63,83 & 229,68 & 15,20 & 22,00 & 210,79 \\
\hline Bufo spinosus & 295QB32 & 100,00 & $\mid 779,88$ & 99,43 & 37,81 & 5541,95 & 324,76 & 64,30 & 260,46 & 119,66 & 250,41 & 252,84 & 110,82 & 540,01 & 82,50 & 1,00 & 63,43 & 230,37 & 16,01 & 22,43 & 212,05 \\
\hline Bufo spinosus & 295QB34 & 100,0 & 179 & 106, & 38,0 & 5772,33 & 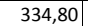 & 59,57 & 775,24 & 2 & $25:$ & & 107 & 542 & 81,89 & 1,01 & 62,08 & 22 & 18 & 23,92 & 21 \\
\hline Bufo spinosus & 29SQB35 & 101,00 & 175,74 & 109,07 & \begin{tabular}{l|l|}
38,05 \\
\end{tabular} & 5890,17 & 336,24 & 54,13 & 282,11 & 1111,61 & 251,58 & 253,3 & 102,63 & $\begin{array}{l}558,45 \\
\end{array}$ & 83,11 & 1,74 & 61,18 & 233,21 & 19,53 & 25,44 & 216,83 \\
\hline Bufo spinosus & 29SQB36 & 100,00 & 170,21 & 111,26 & 38,03 & 5991,56 & 335,15 & 47,61 & 287,54 & 105,24 & 247,70 & 249,40 & 96,23 & 581,49 & 85,01 & 2,00 & 60,50 & 240,69 & 21,21 & 26,95 & 225,24 \\
\hline
\end{tabular}




\begin{tabular}{|c|c|c|c|c|c|c|c|c|c|c|c|c|c|c|c|c|c|c|c|c|c|}
\hline TAXON & UTM & $\mathrm{km2}$ & B101 & $\mathrm{B1O2}$ & $\mathrm{BIO3}$ & B104 & B105 & B106 & B107 & B108 & B109 & 81010 & B1011 & BIO12 & BIO13 & 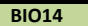 & BIO15 & B1O16 & B1017 & B1018 & B1019 \\
\hline Bufo spinosus & 29SQB37 & 100,00 & 165,23 & 112,90 & 38,01 & 6067,55 & 333,76 & 42,02 & 291,74 & 99,63 & 243,99 & 245,63 & 90,71 & 602,17 & 86,41 & 2,31 & 59,48 & 246,70 & 23,48 & 28,98 & 232,27 \\
\hline Bufo spinosus & 29SQB38 & 101,00 & 165,25 & 114,19 & 38,03 & 6120,83 & 336,06 & 41,25 & 294,81 & 99,12 & 244,91 & 246,42 & 90,10 & 596,49 & 84,86 & 2,55 & 58,82 & 242,79 & 24,17 & 29,42 & 228,80 \\
\hline Bufo spinosus & 29SQB39 & 100,00 & 163,07 & 115,24 & 38,00 & 6172,04 & 336,21 & 38,54 & 297,66 & 96,41 & 243,54 & 244,97 & 87,38 & 601,53 & 84,57 & 2,78 & 58,19 & 242,94 & 25,49 & 30,41 & 229,54 \\
\hline Bufo spinosus & 29SQB45 & 99,00 & 179,99 & 113,45 & 38,61 & 5980,75 & 346,22 & 55,51 & 290,71 & 114,92 & 257,41 & 259,01 & 105,74 & 555,42 & 82,92 & 1,41 & 61,79 & 232,99 & 18,81 & 24,00 & 217,38 \\
\hline Bufo spinosus & 29SQB46 & 99,00 & 173,66 & 115,02 & 38,40 & $\begin{array}{ll}6082,63 \\
\end{array}$ & 343,56 & 48,44 & 295,12 & \begin{tabular}{|l|}
107,63 \\
\end{tabular} & 252,68 & 254,05 & 98,53 & 579,42 & 84,77 & 2,00 & 60,85 & 240,38 & 20,83 & 25,98 & 225,57 \\
\hline Bufo spinosus & 29SQB48 & 99,00 & 165,34 & 116,84 & 38,20 & 6207,25 & 340,24 & 39,51 & 300,73 & 98,16 & 246,41 & 247,64 & 89,31 & 606,48 & 85,72 & 2,53 & 58,92 & 246,50 & 24,30 & 29,31 & 233,16 \\
\hline Bufo spinosus & 29SQB49 & 99,00 & 160,27 & 117,41 & 38,07 & 6265,76 & 337,49 & 34,39 & 303,10 & 92,76 & 242,46 & 243,63 & 83,80 & 624,67 & 86,79 & 3,01 & 58,13 & 251,52 & 26,41 & 31,25 & 238,92 \\
\hline \begin{tabular}{|l} 
Bufo spinosus \\
\end{tabular} & $29 S Q B 55$ & 100,00 & 182,80 & 117,92 & 38,98 & 6077,18 & 354,84 & 55,47 & 299,36 & 116,50 & 261,79 & 263,16 & \begin{tabular}{|l|}
107,47 \\
\end{tabular} & 559,71 & 83,53 & 1,13 & 62,24 & 235,80 & 18,43 & 23,01 & 221,17 \\
\hline Bufo spinosus & 29SQB56 & 100,00 & 176,11 & 118,63 & 38,93 & 6163,05 & 350,68 & 48,61 & 302,07 & 109,00 & 256,31 & 257,66 & 100,02 & 582,65 & 85,06 & 1,97 & 61,03 & 242,14 & 20,77 & 25,32 & 228,14 \\
\hline Bufo spinosus & 29SQB58 & 100,00 & 164,45 & 119,16 & 38,45 & 6288,16 & 342,96 & 37,21 & 305,74 & 96,54 & 246,97 & 248,00 & 87,55 & 621,15 & 87,10 & 2,57 & 59,09 & 252,23 & 24,62 & 29,52 & 239,62 \\
\hline Bufo spinosus & 29SQB59 & 100,00 & 161,72 & 119,53 & 38,08 & 6337,03 & 341,97 & 34,20 & 307,77 & 93,37 & 244,95 & 245,92 & 84,36 & 626,22 & 86,57 & 2,97 & 58,34 & 251,97 & 25,99 & 30,74 & 239,89 \\
\hline Bufo spinosus & 29SQB63 & 57,00 & 184,32 & 116,90 & 39,00 & 5995,94 & 353,94 & 58,03 & 295,91 & 119,06 & 262,14 & 263,82 & 110,10 & 574,31 & 86,98 & 1,00 & 63,84 & 245,33 & 18,05 & 22,11 & 230,18 \\
\hline \begin{tabular}{|l} 
Bufo spinosus \\
\end{tabular} & 29SQB64 & 54,00 & 184,91 & 120,33 & 39,01 & 6101,45 & 359,34 & 55,90 & 303,44 & 118,35 & 264,13 & 265,64 & 109,23 & 571,64 & 86,08 & 1,00 & 63,33 & 243,27 & 18,19 & 22,17 & 228,95 \\
\hline Bufo spinosus & 29SQB65 & 54,00 & 185,05 & 120,77 & 39,04 & 6134,68 & 360,27 & 56,13 & 304,14 & 118,00 & 264,73 & 266,16 & 108,92 & 561,39 & 83,79 & 1,00 & 62,83 & 237,35 & 18,06 & 22,06 & 223,32 \\
\hline \begin{tabular}{|l|} 
Bufo spinosus \\
\end{tabular} & $295 \mathrm{SB67}$ & 43,00 & 170,53 & 120,97 & 38,97 & 6280,84 & 349,67 & 42,23 & 307,44 & $\mid 102,34$ & 252,81 & 253,81 & 93,31 & 608,03 & 86,59 & 2,00 & 60,22 & 249,81 & 22,67 & 27,20 & 236,97 \\
\hline Bufo spinosus & 29SQB69 & 40,00 & 164,02 & 121,00 & 38,38 & 6377,10 & 346,10 & 35,40 & 310,70 & 95,05 & 247,85 & 248,63 & 86,07 & 620,57 & 85,65 & 2,72 & 58,52 & 249,95 & 25,08 & 29,77 & 238,12 \\
\hline Bufo spinosus & $29 \mathrm{SQC00}$ & 100,00 & 152,57 & 110,61 & 38,01 & 5987,54 & 319,70 & 33,50 & 286,20 & 88,75 & 230,46 & 232,42 & 79,85 & 634,96 & 88,02 & 3,70 & 56,71 & 255,20 & 30,10 & 34,59 & 242,76 \\
\hline Bufo spinosus & $29 \mathrm{SQC01}$ & 100,00 & 150,73 & 111,68 & 38,02 & 6030,24 & 320,13 & 31,31 & 288,82 & 86,57 & 229,46 & 231,34 & 77,71 & 643,26 & 88,33 & 4,06 & 56,03 & 256,93 & 31,92 & 35,85 & 245,11 \\
\hline Bufo spinosus & $295 Q C 02$ & 101,00 & 150,90 & 112,55 & 38,00 & 6064,71 & 322,05 & 30,95 & 291,10 & 86,38 & 230,08 & 231,97 & 77,51 & 638,97 & 87,25 & 4,11 & 55,41 & 253,83 & 32,80 & 36,32 & 242,32 \\
\hline Bufo spinosus & 29SQC04 & 100,00 & 162,19 & 114,61 & 38,27 & 6086,43 & 334,44 & 40,11 & 294,33 & 96,37 & 241,55 & 242,96 & 87,75 & 558,28 & 76,98 & 3,34 & 54,69 & 220,37 & 29,30 & 32,56 & 208,18 \\
\hline Bufo spinosus & 29SQC05 & 100,00 & 151,69 & 114,27 & 38,05 & 6140,97 & 326,38 & 30,66 & 295,72 & 85,99 & 232,26 & 233,59 & 77,36 & 622,94 & $83, \varepsilon$ & 4,57 & 53,71 & 243,87 & 35,20 & 37,55 & 232,90 \\
\hline Bufo spinosus & $295 Q C 06$ & 100,00 & 151,43 & 114,50 & 38,00 & 6152,60 & 326,90 & 30,33 & 296,57 & 85,56 & 232,32 & 233,59 & 77,10 & 619,90 & 83,06 & 4,68 & 53,24 & 241,60 & 36,05 & 38,10 & 230,70 \\
\hline Bufo spinosus & 29SQC07 & 101,00 & 159,48 & 115,70 & 38,13 & \begin{tabular}{|c|}
6144,17 \\
\end{tabular} & 334,83 & 36,68 & 298,15 & 92,88 & 239,97 & 240,98 & 84,56 & 561,93 & 76,14 & 4,06 & 52,88 & 218,36 & 32,93 & 35,15 & 206,60 \\
\hline Bufo spinosus & 29SQC10 & 101,00 & $\begin{array}{lll}157,87 & \end{array}$ & 112,11 & 38,00 & 6052,92 & 326,94 & 36,77 & 290,16 & 92,90 & 236,66 & 238,34 & 84,15 & 608,89 & 85,03 & 3,21 & 57,12 & 244,71 & 27,85 & 32,59 & 231,55 \\
\hline Bufo spinosus & $29 \mathrm{SQC11}$ & 100,00 & 148,36 & 113,07 & 38,00 & 6121,03 & 320,93 & 27,46 & 293,47 & 83,27 & 228,53 & 230,22 & 74,29 & 662,73 & 90,34 & 4,26 & 56,03 & 263,69 & 32,92 & 36,88 & 252,11 \\
\hline Bufo spinosus & $29 \mathrm{SQC12}$ & 100,00 & 150,30 & 113,83 & 38,00 & 6146,70 & 324,17 & 28,77 & 295,39 & 84,84 & 230,91 & 232,48 & 75,97 & 644,97 & 87,7 & 4,05 & 55,47 & 255,49 & 32,72 & 36,30 & 243,86 \\
\hline Bufo spinosus & $29 \mathrm{SQC13}$ & 100,00 & 157,54 & $\begin{array}{l}114,05 \\
114,97\end{array}$ & 38,01 & 6161,86 & 331,80 & 34,74 & 297,06 & 91,12 & 238,20 & 239,41 & 82,41 & 594,93 & 81,35 & 3,71 & 55,09 & \begin{tabular}{|l|}
234,82 \\
\end{tabular} & 30,46 & 33,99 & $\begin{array}{l}24,00 \\
222,73\end{array}$ \\
\hline Bufo spinosus & 29SQC14 & 101,00 & 159,23 & 115,59 & 38,01 & 6171,35 & 334,37 & 35,95 & 298,41 & 92,41 & 239,95 & 241,13 & 83,86 & 579,12 & 79,00 & 3,69 & 54,64 & 227,61 & 30,38 & 33,67 & 215,52 \\
\hline Bufo spinosus & $29 \mathrm{SQC15}$ & 100,00 & 153,88 & 115,50 & 38,00 & 6216,08 & 330,77 & 31,06 & 299,71 & 87,03 & 235,64 & 236,60 & 78,50 & 607,10 & 81,63 & 4,19 & 53,79 & 236,94 & $|33,57|$ & 36,28 & 225,45 \\
\hline Bufo spinosus & $29 S Q C 16$ & 100,00 & 158,39 & 116,15 & 38,01 & 6218,94 & 335,43 & 34,82 & 300,61 & 91,30 & 240,07 & 241,02 & 82,66 & 573,53 & 77,26 & 4,05 & 53,32 & 222,97 & 32,25 & 34,93 & 211,15 \\
\hline Bufo spinosus & $29 \mathrm{SQC20}$ & 100,00 & 158,69 & 114,03 & 38,00 & 6141,20 & 330,86 & 35,80 & 295,06 & 92,59 & 238,82 & 240,27 & 83,67 & 610,75 & 84,96 & 3,20 & 57,20 & 244,88 & 27,67 & 32,37 & 231,93 \\
\hline Bufo spinosus & $295 \mathrm{SQC22}$ & 100,00 & 152,88 & 115,44 & 38,00 & 6225,07 & 329,21 & $\begin{array}{l}0,00 \\
29,54 \\
\end{array}$ & 299,66 & \begin{tabular}{|l|l|}
86,07 \\
\end{tabular} & $\begin{array}{l}230,56 \\
234,5\end{array}$ & \begin{tabular}{|l|}
235,86 \\
\end{tabular} & $\begin{array}{l}7,28 \\
77,28\end{array}$ & \begin{tabular}{|l|l|}
632,78 \\
\end{tabular} & $\begin{array}{l}4,00 \\
85,95 \\
\end{array}$ & 3,97 & 55,60 & \begin{tabular}{|l|}
250,05 \\
\end{tabular} & 31,60 & 35,43 & 238,19 \\
\hline Bufo spinosus & $295 Q C 24$ & 99,00 & 155,97 & 116,59 & 38,00 & 6269,81 & 334,19 & 31,82 & 302,37 & 88,53 & 238,37 & 239,35 & 79,85 & 601,12 & 80,98 & 3,94 & 54,55 & 235,10 & 31,61 & 34,93 & 223,33 \\
\hline Bufo spinosus & $29 \mathrm{SQC} 25$ & 100,00 & 154,87 & 116,72 & 38,00 & 6296,31 & 333,94 & 30,57 & 303,37 & 86,94 & 237,62 & 238,51 & 78,50 & 601,18 & 80,36 & 4,00 & 53,84 & 233,81 & 32,68 & 35,64 & 222,19 \\
\hline Bufo spinosus & $295 Q C 31$ & 101,00 & 143,35 & 115,71 & 37,99 & 6285,63 & 321,80 & 20,01 & 301,79 & 76,51 & 226,30 & 227,65 & 67,74 & 700,80 & 93,93 & 4,65 & 55,87 & 276,69 & 34,98 & 38,88 & 265,89 \\
\hline Bufo spinosus & $295 Q C 32$ & 100,00 & 150,07 & 116,82 & 38,00 & 6311,19 & 329,47 & 25,56 & 303,92 & 82,63 & 233,28 & 234,30 & 73,90 & 652,92 & 87,76 & 4,06 & 55,58 & 257,04 & 32,41 & 36,21 & 245,72 \\
\hline \begin{tabular}{|l} 
Bufo spinosus \\
\end{tabular} & $295 Q C 38$ & 100,00 & 163,23 & 117,86 & 38,00 & 6367,95 & 344,36 & 36,86 & 307,50 & 93,88 & 247,29 & 247,38 & 85,35 & 532,76 & 70,17 & 3,44 & 52,54 & 203,66 & 30,08 & 31,66 & 191,64 \\
\hline Bufo spinosus & $29 \mathrm{SQC} 40$ & 101,00 & 158,58 & 118,01 & 38,01 & 6304,75 & 337,41 & 32,34 & 305,07 & 90,67 & 241,28 & 242,38 & 81,72 & 626,43 & 86,06 & 3,03 & 57,45 & 250,37 & 27,34 & 32,01 & 238,25 \\
\hline Bufo spinosus & $29 S Q C 41$ & 99,00 & 150,44 & 117,83 & 38,00 & 6353,23 & 331,26 & 24,82 & 306,44 & 82,53 & 234,27 & 235,31 & 73,66 & 662,91 & 89,17 & 3,90 & 56,33 & 261,88 & 31,52 & 35,70 & 250,75 \\
\hline Bufo spinosus & $29 S Q C 42$ & 101,00 & 152,95 & 118,39 & 38,00 & 6376,73 & 334,71 & 26,75 & 307,97 & 84,57 & 237,21 & 237,92 & 75,77 & 640,44 & 85,79 & 3,86 & 55,69 & 251,67 & 31,08 & 35,10 & 240,44 \\
\hline Bufo spinosus & $295 Q C 47$ & 99,00 & 162,97 & 118,88 & 37,99 & 6437,15 & 345,94 & 35,39 & 310,55 & 92,87 & 248,00 & 248,04 & 84,26 & 542,14 & 71,52 & 3,2 & 53,43 & 207,59 & 29,09 & 30,04 & 195,96 \\
\hline \begin{tabular}{|l} 
Bufo spinosus \\
\end{tabular} & $295 Q C 49$ & 99,00 & 163,25 & 117,95 & 37,60 & 6448,65 & 346,10 & 36,12 & \begin{tabular}{|l|l|}
309,98 \\
\end{tabular} & 92,98 & 248,56 & 248,66 & 84,46 & 523,97 & 68,46 & 3,31 & 52,23 & 198,42 & 29,73 & 30,41 & 186,63 \\
\hline Bufo spinosus & $29 S Q C 50$ & 100,00 & 154,05 & 119,27 & 38,01 & 6389,85 & 336,10 & 27,00 & 309,10 & 85,45 & 238,34 & 239,30 & 76,60 & 656,46 & 88,95 & 3,43 & 57,26 & 260,95 & 29,22 & 33,80 & 249,81 \\
\hline Bufo spinosus & $29 \mathrm{SQC51}$ & 100,00 & 157,25 & 120,01 & 38,00 & 6413,78 & 340,24 & 29,40 & 310,84 & 88,09 & 241,84 & 242,56 & 79,16 & 631,14 & 85,14 & 3,27 & 56,81 & 249,59 & 28,48 & 32,89 & 238,35 \\
\hline Bufo spinosus & $29 S Q C 52$ & 100,00 & 158,74 & 120,32 & 38,00 & 6435,63 & 342,47 & 30,48 & 311,99 & 89,27 & 243,72 & 244,24 & 80,33 & 613,54 & 82, & 3,19 & 56,22 & 241,10 & 28,37 & 32,57 & 229,94 \\
\hline Bufo spinosus & $2950 C 54$ & 100,00 & 153,33 & 119,90 & 38,00 & 6458,27 & 338,89 & 25,67 & 313,23 & 83,50 & \begin{tabular}{|l|}
239,37 \\
\end{tabular} & 239,85 & 74,71 & \begin{tabular}{|l|l|}
623,19 \\
\end{tabular} & $\begin{array}{l}2,50 \\
82,50\end{array}$ & $\begin{array}{l}4,00 \\
4,00\end{array}$ & \begin{tabular}{|l|l|}
54,77 \\
\end{tabular} & 241,07 & 31,37 & 34,32 & 230,40 \\
\hline Bufo spinosus & $29 \mathrm{SQC55}$ & 100,00 & 158,21 & 120,08 & 38,00 & 6492,21 & 343,57 & 29,89 & 313,68 & 87,86 & 244,27 & 244,42 & 79,23 & 588,23 & 77,81 & 3,70 & 54,34 & 226,40 & 30,18 & 32,39 & 215,47 \\
\hline \begin{tabular}{|l} 
Bufo spinosus \\
\end{tabular} & $29 S a C 57$ & 101,00 & 157,18 & 119,37 & 37,73 & 6509,74 & 342,79 & 29,19 & 313,61 & 86,55 & 243,60 & 243,67 & 77,96 & 573,23 & 74,97 & 3,87 & 53,01 & 217,74 & 31,36 & 32,25 & 206,81 \\
\hline Bufo spinosus & $295 Q C 60$ & 32,00 & 155,24 & 120,45 & 38,00 & 6427,15 & 339,05 & 27,25 & 311,80 & 86,07 & 240,15 & 240,95 & 77,16 & 654,55 & 88,64 & 3,35 & 57,42 & 259,98 & 28,73 & 33,25 & 249,11 \\
\hline Bufo spinosus & $295 Q C 61$ & 36,00 & 161,81 & 121,29 & 38,02 & 6448,65 & 345,96 & 32,98 & 312,98 & 92,10 & 246,90 & 247,63 & 83,29 & 611,21 & 82,88 & 3,02 & 57,23 & 242,10 & 26,58 & 31,02 & 230,92 \\
\hline \begin{tabular}{|l} 
Bufo spinosus \\
\end{tabular} & \begin{tabular}{|l|}
$2950<01$ \\
2952
\end{tabular} & 30,0 & $\frac{101,01}{158,40}$ & $\begin{array}{l}121,29 \\
121,10\end{array}$ & $\begin{array}{l}30,02 \\
38,00 \\
\end{array}$ & \begin{tabular}{|l|}
64404,03 \\
648,80
\end{tabular} & 343,50 & $\begin{array}{ll}2,390 \\
29,48\end{array}$ & \begin{tabular}{|l|}
314,13 \\
313
\end{tabular} & 88,45 & 244,20 & 244,60 & 79,50 & $\begin{array}{ll}619,28 \\
\end{array}$ & 83,18 & 3,25 & 56,40 & 242,82 & 28,33 & 32,40 & 232,15 \\
\hline Bufo spinosus & $29 \mathrm{SQC63}$ & 22,00 & 148,95 & 120,27 & 37,98 & 6508,00 & 335,43 & 21,27 & 314,16 & 79,09 & 235,43 & 235,86 & 70,36 & 658,91 & 87,20 & 4,20 & 55,09 & 255,39 & 32,91 & 35,98 & 245,32 \\
\hline Bufo spinosus & 29SQD13 & 101,00 & 161,91 & 112,93 & 37,27 & 6289,60 & 338,44 & 39,80 & 298,64 & 93,62 & 245,15 & 245,26 & 85,32 & $|532,07|$ & 69,11 & 4,03 & 50,50 & $\mid 201.98$ & 34,28 & 34,72 & 190,05 \\
\hline Bufo spinosus & 29SQD21 & 101,00 & 167,54 & 115,88 & 37,93 & 6306,67 & 345,66 & 42,66 & 302,99 & 98,62 & 250,56 & 250,69 & 90,15 & 493,85 & 65,03 & 3,03 & 51,52 & 187,80 & 29,46 & 30,62 & 175,35 \\
\hline Bufo spinosus & 29SQD23 & 100,00 & 162,78 & 113,37 & 37,00 & 6357,80 & 341,02 & 39,52 & 301,50 & 93,64 & 247,12 & 247,14 & 85,36 & 515,75 & 66,36 & 4,00 & 50,40 & 194,20 & 32,93 & 33,12 & 182 \\
\hline \begin{tabular}{|l} 
Bufo spinosus \\
\end{tabular} & 29SQD39 & 99,00 & 158,01 & 108,29 & 36,00 & 6420,54 & 333,44 & $\begin{array}{ll}37,18 \\
3\end{array}$ & 296,26 & 88,09 & 243,70 & 243,70 & 79,96 & 505,57 & 62,88 & 4,44 & 48,10 & 186,62 & 35,82 & 35,82 & 174,49 \\
\hline Bufo spinosus & 29SQD41 & 100,00 & 167,40 & 116,77 & 37,13 & 6444,88 & 349,11 & 40,70 & 308,41 & 96,92 & 252,81 & 252,81 & 88,49 & 488,53 & 63,47 & 3,01 & 51,48 & 183,45 & 28,49 & 28,51 & 171,45 \\
\hline Bufo spinosus & 29SQD44 & 100,00 & 153,60 & 112,60 & 36,38 & 6501,45 & 334,92 & 30,10 & 304,82 & 83,36 & 240,45 & 240,45 & 75,10 & 541,58 & 69,07 & 4,51 & 49,49 & 199,98 & 36,22 & 36,23 & 187,85 \\
\hline Bufo spinosus & 29SQD50 & 100,00 & 165,70 & 118,08 & 37,15 & 6507,03 & 349,50 & 37,54 & 311,96 & 94,54 & 251,86 & 251, & 85, & 502,35 & 65,33 & 3,00 & 51,91 & 188,30 & 28,59 & 28,59 & 176,77 \\
\hline Bufo spinosus & 29SQD52 & 92,00 & 167,44 & 116,65 & 37,00 & 6497,98 & 349,78 & 40,09 & 309,69 & 96,03 & 253,58 & 253,58 & 87,75 & 477,86 & 61,55 & 3,01 & 50,82 & 177,33 & 28,63 & 28,63 & 165,58 \\
\hline
\end{tabular}




\begin{tabular}{|c|c|c|c|c|c|c|c|c|c|c|c|c|c|c|c|c|c|c|c|c|c|}
\hline TAXON & UTM & $\mathrm{km} 2$ & B101 & B102 & $\mathrm{BIO3}$ & BIO4 & BIO5 & B106 & B107 & B108 & B109 & BIO10 & BIO11 & BIO12 & BIO13 & B1014 & BIO15 & BIO16 & B1017 & B1018 & B1019 \\
\hline Bufo spinosus & 29SQD55 & 82,00 & 156,69 & 113,12 & 36,23 & 6542,17 & 338,71 & 32,22 & 306,49 & 85,59 & 244,25 & 244,25 & 77,52 & 505,80 & 65,25 & 4,08 & 48,90 & 184,66 & 34,11 & 34,11 & 172,52 \\
\hline Bufo spinosus & 29SQD56 & 87,00 & 157,94 & 112,30 & 36,01 & 6536,19 & 338,98 & 33,71 & 305,27 & 86,92 & 245,25 & 245,25 & 78,64 & 492,20 & 63,35 & 4,02 & 48,53 & 1799,17 & 33,79 & 33,79 & 166,85 \\
\hline Bufo spinosus & 29SQE40 & 100,00 & 159,59 & 109,72 & 36,16 & 6430,23 & 335,48 & 37,50 & 297,98 & 89,04 & 245,33 & 245,33 & 81,16 & 473,60 & 58,51 & 4,28 & 47,20 & 172,99 & 34,49 & 34,49 & 160,75 \\
\hline Bufo spinosus & 29SQE50 & 70,00 & 159,94 & 110,91 & 36,59 & 6450,74 & 336,84 & 36,84 & 300,00 & 89,39 & 246,15 & 246,15 & 81,11 & 456,27 & 56,13 & 4,02 & 46,66 & $\begin{array}{l}165,05 \\
\end{array}$ & 33,50 & 33,50 & 152,85 \\
\hline Bufo spinosus & 29SQE51 & 63,00 & 158,98 & 110,69 & 36,68 & 6427,51 & 334,89 & 36,06 & 298,83 & 88,21 & 244,68 & 244,68 & 80,34 & 454,36 & 55,83 & 4,50 & 46,13 & \begin{tabular}{|l|l|}
164,21 \\
\end{tabular} & 34,23 & 34,23 & 151,88 \\
\hline Bufo spinosus & 29SQE52 & 66,00 & 155,05 & 110,34 & 36,55 & 6425,27 & 330,51 & 32,56 & 297,95 & 84,20 & 240,69 & 240,69 & 76,57 & 463,73 & 57,01 & 5,01 & 45,64 & 167,40 & 36,06 & 36,06 & 154,87 \\
\hline Bufo spinosus & 29TMH83 & & & & & & & & & & & & & & & & & & & & \\
\hline Bufo spinosus & 29TMH85 & 76,00 & 139,86 & 60,66 & 38,86 & 3227,67 & 224,58 & 70,50 & 154,08 & 109,07 & 179,49 & 182,91 & 99,89 & 1022,70 & 146,27 & 27,14 & 42,50 & 405,09 & 116,07 & 140,82 & 344,98 \\
\hline Bufo spinosus & 29TMH86 & 101,00 & 140,88 & 60,43 & 39,01 & 3189,41 & 224,79 & 71,89 & 152,90 & 110,68 & 179,94 & 183,48 & 101,52 & 1001,25 & $\mid 143,27$ & 27,08 & 41,99 & \begin{tabular}{|l|l|}
395,29 \\
\end{tabular} & 115,62 & 140,68 & 334,91 \\
\hline Bufo spinosus & 29TMH91 & 46,00 & 146,53 & 59,04 & 38,62 & 3311,15 & 229,18 & 78,01 & 151,16 & 113,22 & 187,59 & 189,99 & 104,65 & 1143,04 & 161,42 & 26,24 & 45,56 & 458,00 & 1110,67 & 134,49 & 409,85 \\
\hline Bufo spinosus & 29TMH92 & 25,00 & 141,23 & 60,49 & 38,14 & 3378,23 & 227,51 & 71,47 & 156,05 & $\mid 107,72$ & $\mid 183,44$ & $\mid$\begin{tabular}{|l|}
185,91 \\
\end{tabular} & $\begin{array}{l}99,12 \\
\end{array}$ & 1175,86 & $\mid 168,47$ & 28,44 & 44,98 & \begin{tabular}{|l|l|}
469,60 \\
\end{tabular} & $\mid \begin{array}{l}117,91 \\
\end{array}$ & 141,35 & 420,91 \\
\hline Bufo spinosus & 29тMH93 & 45,00 & 142,97 & 60,38 & 38,58 & 3303,65 & 228,01 & 73,36 & 154,65 & 110,67 & 183,91 & 186,81 & 101,71 & 1081,97 & 153,14 & 26,94 & 44,01 & 431,12 & 113,87 & 138,10 & 376,59 \\
\hline \begin{tabular}{|l} 
Bufo spinosus \\
\end{tabular} & 29TMH94 & 96,00 & 134,43 & 62,32 & 38,30 & 3383,03 & 224,15 & 63,56 & 160,59 & 101,66 & 176,79 & 179,88 & 92,99 & 1163,86 & 165,96 & 30,57 & 43,29 & \begin{tabular}{|l|l|}
460,44 \\
\end{tabular} & 125,92 & 149,26 & 407,56 \\
\hline Bufo spinosus & 29TMH95 & 101,00 & 132,06 & 62,84 & 38,29 & 3379,81 & 222,68 & 60,82 & 161,87 & 99,50 & 174,35 & 177,58 & 90,84 & 1161,49 & 163,83 & 31,54 & 42,44 & \begin{tabular}{|l|l|}
457,27 \\
\end{tabular} & 129,28 & 152,73 & 403,12 \\
\hline Bufo spinosus & 29TMH96 & 101,00 & 132,67 & 62,76 & 38,41 & 3336,99 & 222,47 & 61,55 & 160,92 & 100,76 & 174,14 & 177,72 & 91,95 & $\begin{array}{l}1134,29 \\
\end{array}$ & 158,51 & 31,50 & 41,88 & \begin{tabular}{|l|l|}
444,68 \\
\end{tabular} & 129,01 & 152,87 & 389,79 \\
\hline Bufo spinosus & 29TMH97 & 100,00 & 138,07 & 61,86 & 38,93 & \begin{tabular}{|l|l|}
3246,93 \\
\end{tabular} & 224,66 & 67,91 & 156,75 & 107,19 & 178,13 & 181,82 & 98,28 & 1062,28 & 147,82 & 29,67 & 41,14 & 415,54 & 122,71 & 147,29 & 360,00 \\
\hline Bufo spinosus & 29TMH98 & 28,00 & 142,80 & 61,16 & 39,53 & 3177,18 & 226,53 & 73,42 & 153,11 & 112,60 & 181,80 & 185,62 & 103,67 & 1013,53 & 141,49 & 28,18 & 41,00 & 395,73 & 117,49 & 142,60 & 341,07 \\
\hline Bufo spinosus & 29TNE14 & 94,00 & 153,37 & 80,69 & \begin{tabular}{|l|l|}
43,99 \\
\end{tabular} & 3489,40 & 249,04 & 67,60 & 181,44 & 114,96 & 194,89 & 196,96 & 106,94 & 915,43 & 130,14 & 8,93 & 54,31 & 372,73 & 57,22 & 64,43 & 366,66 \\
\hline Bufo spinosus & 29TNE15 & 95,00 & 152,10 & 79,87 & 44,23 & 3433,91 & 244,94 & 66,57 & 178,37 & 114,04 & 192,57 & 194,69 & 106,07 & 940,82 & 132,95 & 9,80 & 53,87 & 381,66 & 60,01 & 67,97 & 375,23 \\
\hline Bufo spinosus & 29TNE17 & 40,00 & 151,00 & 77,70 & 44,97 & 3321,38 & 237,20 & 65,97 & 171,23 & 113,99 & 189,58 & 191,34 & 105,62 & 973,01 & 136,21 & 10,34 & 53,00 & \begin{tabular}{|l|l|}
393,07 \\
\end{tabular} & 63,24 & 72,89 & 385,45 \\
\hline Bufo spinosus & 29TNE26 & 100,00 & 152,32 & 84,16 & \begin{tabular}{l|l|l}
44,45 & \\
\end{tabular} & 3581,52 & 250,69 & 63,32 & 187,37 & 112,44 & 194,77 & 196,81 & 104,39 & 969,56 & 136,02 & 10,03 & 53,09 & 390,74 & 63,01 & 70,94 & 385,71 \\
\hline Bufo spinosus & 29TNE27 & 100,00 & 150,94 & 81,77 & 44,72 & 3491,93 & 244,10 & 63,03 & 181,07 & 111,95 & 191,99 & 193,90 & 103,76 & 988,28 & 138,04 & 10,85 & 52,79 & \begin{tabular}{|l|l|}
397,95 \\
\end{tabular} & 65,18 & 74,10 & 391,49 \\
\hline Bufo spinosus & 29TNE28 & 101,00 & 149,73 & 78,91 & 45,04 & 3384,36 & 236,65 & 63,11 & 173,54 & 111,73 & 189,05 & 190,76 & 103,37 & 1002,72 & 139,53 & 11,00 & 52,55 & \begin{tabular}{|l|l|}
403,88 \\
\end{tabular} & 66,14 & 76,54 & 395,56 \\
\hline Bufo spinosus & 29TNE29 & 91,00 & 148,62 & 76,34 & \begin{tabular}{|l|l|}
45,23 \\
\end{tabular} & 3286,96 & 230,02 & 63,25 & 166,77 & 111,66 & 186,35 & 187,93 & 103,07 & 1017,60 & 140,94 & 11,13 & 52,35 & $\begin{array}{l}410,05 \\
\end{array}$ & 67,19 & 78,96 & 399,81 \\
\hline Bufo spinosus & 29TNE33 & 101,00 & 158,16 & 92,64 & 43,21 & 4010,56 & 275,56 & 64,01 & 211,56 & 112,29 & 207,16 & 209,62 & 106,24 & 902,78 & 127,94 & 8,74 & 54,15 & 364,73 & 57,45 & 61,96 & 363,85 \\
\hline Bufo spinosus & 29TNE34 & 100,00 & 158,71 & 92,86 & 43,79 & 3959,58 & 274,19 & 64,23 & 209,97 & 114,31 & 206,84 & 209,11 & 106,97 & 911,58 & 128,28 & 9,09 & 53,73 & 366,69 & 58,88 & 64,19 & 365,55 \\
\hline Bufo spinosus & 29TNE36 & 101,00 & 153,32 & $\begin{array}{l}90,79 \\
90,79\end{array}$ & 44,05 & 3857,75 & 263,38 & 59,66 & 203,71 & $\begin{array}{l}110,21 \\
11\end{array}$ & 199,93 & $\begin{array}{l}201,99 \\
201\end{array}$ & 102,41 & 984,04 & 137,65 & \begin{tabular}{|c|}
$, 0,85$ \\
10,8
\end{tabular} & 52,91 & 394,26 & $\begin{array}{l}0,0,0 \\
65,75 \\
\end{array}$ & 72,21 & 391,82 \\
\hline Bufo spinosus & 29TNE37 & 100,00 & 151,92 & 88,12 & 44,21 & 3760,17 & 256,36 & 59,47 & 196,88 & 109,94 & 196,99 & 198,97 & 101,90 & 999,56 & 139,38 & 11,00 & 52,72 & 400,87 & 66,69 & 74,56 & 396,25 \\
\hline Bufo spinosus & 29TNE38 & 100,00 & 151,17 & 85,28 & \begin{tabular}{|l|l|}
44,48 \\
\end{tabular} & 3655,62 & 249,50 & 59,88 & 189,62 & 110,04 & 194,48 & 196,30 & 101,87 & 1009,27 & 140,22 & 11,01 & 52,38 & 405,38 & 67,20 & 76,61 & 398,25 \\
\hline Bufo spinosus & 29TNE39 & 101,00 & 149,99 & 83,28 & 44,75 & 3590,40 & 244,10 & 59,58 & 184,53 & 109,52 & 192,36 & 194,02 & 101,25 & 1023,95 & 141,72 & 11,49 & 52,18 & 411,92 & 68,18 & 79,27 & 402,06 \\
\hline Bufo spinosus & 29TNE43 & 100,00 & 152,01 & 96,88 & 42,29 & 4334,80 & 280,95 & 54,54 & 226,42 & 97,23 & 206,12 & 208,63 & 97,14 & 988,34 & 140,82 & 10,21 & 53,90 & 399,77 & 65,27 & 67,43 & 399,77 \\
\hline \begin{tabular}{|l} 
Bufo spinosus \\
\end{tabular} & 29TNE44 & 101,00 & 157,36 & 99,73 & 43,31 & 4271,78 & 286,11 & 58,28 & 227,83 & 102,93 & 210,29 & 212,65 & 102,55 & 952,53 & 133,76 & 10,00 & 53,12 & 382,72 & 63,82 & 67,21 & 382,71 \\
\hline Bufo spinosus & 29TNE45 & 101,00 & 159,50 & 98,46 & 43,90 & 4164,52 & 283,32 & 60,82 & 222,49 & 108,75 & 210,58 & 212,78 & 105,32 & 936,35 & 130,70 & 9,70 & 52,90 & \begin{tabular}{|l|l|}
374,25 \\
\end{tabular} & 62,54 & 67,44 & 374,14 \\
\hline Bufo spinosus & 29TNE46 & 100,00 & 155,75 & 96,92 & 43,75 . & 4129,05 & 276,81 & 57,49 & 219,32 & $|107,60|$ & 206,33 & 208,40 & $\mid 101,84$ & 981,31 & $\mid 136.99$ & 10,65 & 52.63 & 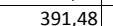 & 66,27 & $71,75 \mid$ & 391,01 \\
\hline Bufo spinosus & 29TNE47 & 101,00 & 154,50 & 94,07 & 43,94 & 4033,16 & 269,87 & 57,67 & 212,19 & 109,24 & 203,70 & 205,62 & 101,39 & 992,43 & 138,39 & 10,73 & 52,51 & 396,70 & 66,59 & 73,58 & 393,77 \\
\hline Bufo spinosus & 29TNE48 & 101,00 & 153,62 & 91,44 & 44,01 & 3947,35 & 263,56 & 57,81 & 205,75 & 109,17 & 201,37 & 203,17 & 101,12 & 1001,46 & 139,26 & 10,96 & 52,41 & 401,25 & 66,83 & 75,53 & 395,36 \\
\hline \begin{tabular}{|l} 
Bufo spinosus \\
\end{tabular} & 29TNE49 & 100,00 & 151,63 & 89,81 & 43,97 & 3905,53 & 258,44 & 56,55 & 201,90 & 107,68 & 198,79 & 200,54 & $\begin{array}{l}|c| 1,55 \\
99,55\end{array}$ & 1025,40 & 142,39 & 11,30 & 52,40 & 412,01 & 68,11 & 78,33 & 403,22 \\
\hline Bufo spinosus & 29TNE53 & 101,00 & 151,81 & 98,81 & \begin{tabular}{|c|}
41,57 \\
\end{tabular} & 4545,58 & 286,84 & 52,19 & 234,65 & 94,84 & 209,36 & 211,64 & 94,84 & 1002,83 & 143,49 & 10,28 & 53,94 & 406,24 & 66,25 & 67,75 & 406,24 \\
\hline Bufo spinosus & 29TNE54 & 101,00 & 156,27 & 102,18 & 42.50 & 4514,23 & 292,22 & 54,61 & 237,61 & 99,02 & 212,75 & 215,25 & 99,02 & 975,79 & $\mid 137,69$ & $\mid 10,19$ & 53,13 & 392.97 & 65,87 & 68,08 & 392.97 \\
\hline Bufo spinosus & 29TNE55 & 99,00 & 150,55 & 100,13 & 42,22 & 4497,70 & 284,29 & 49,83 & 234,45 & 93,64 & 207,01 & 209,27 & 93,64 & 1043,22 & 148,06 & 11,27 & 53,18 & 419,77 & 70,97 & 73,17 & 419,77 \\
\hline Bufo spinosus & 29TNE56 & 101,00 & 150,10 & 99,40 & 42,36 & 4444,24 & 281,01 & 49,47 & 231,54 & 93,55 & 205,67 & 207,82 & 93,41 & 1053,40 & 149,12 & 11,49 & 52,88 & 422,23 & 71,75 & 75,15 & 422,23 \\
\hline \begin{tabular}{|l} 
Bufo spinosus \\
\end{tabular} & 29TNE57 & 101,00 & 148,69 & 97,64 & 42,53 & 4378,99 & 275,62 & 48,79 & 226,84 & 97,88 & 203,34 & 205,27 & 92,45 & 1070,57 & 151,49 & 11,72 & 52,86 & 428,03 & 72,49 & 77,32 & 427,56 \\
\hline Bufo spinosus & 29TNE58 & 100,00 & 146,09 & 95,18 & $\begin{array}{l}42,45 \\
\end{array}$ & 4321,16 & 268,92 & 47,29 & 221,63 & 98,02 & 199,92 & 201,72 & 90,42 & 1099,79 & 155,99 & 12,10 & 52,83 & 440,82 & 74,02 & 80,08 & 438,16 \\
\hline Bufo spinosus & 29TNE59 & 101,00 & 145,60 & 94,24 & 42,64 & 4275,39 & 265,54 & 47,09 & 218,45 & 98,05 & 198,66 & 200,38 & 90,22 & 1107,62 & 156,50 & 12,31 & 52,68 & 444,74 & 74,34 & 82,05 & 439,23 \\
\hline Bufo spinosus & 29TNE63 & 101,00 & 130,56 & 89,14 & 38, & 4769,88 & 264,01 & 35,22 & 228,79 & 72,92 & 194,23 & 194,62 & 72,92 & 1221,84 & 181,18 & 12,8 & 55,21 & 99,16 & 78,16 & 78,31 & 499,16 \\
\hline \begin{tabular}{|l} 
Bufo spinosus \\
\end{tabular} & 29TNE64 & 100,00 & 155,81 & 101,81 & 4 & 4683,46 & 294,72 & 53,07 & 241,64 & 96,83 & 215,14 & 217,20 & 96,83 & 978,93 & 139,33 & 9,92 & 53,46 & 394,96 & 65,10 & 67,15 & 394,96 \\
\hline Bufo spinosus & 29TNE65 & 101,00 & 154,92 & 102,10 & 41, & 4672,85 & 292,96 & 51,79 & 241,18 & 95,81 & 213,88 & 216,01 & 95,81 & 997,15 & 141,65 & 10,31 & 53,17 & \begin{tabular}{|l|l|}
401,08 \\
\end{tabular} & 66,87 & 69,43 & 401,08 \\
\hline \begin{tabular}{|l} 
Bufo spinosus \\
\end{tabular} & 29TNE66 & 100,00 & 156,09 & 101,84 & 42,18 & 4606,32 & 291,36 & 52,82 & 238,53 & 97,33 & 213,92 & 215,92 & 97,29 & 989,81 & 139,97 & 10,23 & 52,97 & 396,23 & 66,28 & 70,18 & 396,23 \\
\hline Bufo spinosus & 29TNE67 & 100,00 & 151,69 & 99,91 & 42,00 & 4573,47 & 284,14 & 49,24 & 234,90 & 97,01 & 209,18 & 210,97 & 93,25 & 1039,96 & 147,79 & 10,93 & 53,01 & 415,86 & 69,58 & 74,15 & 415,82 \\
\hline Bufo spinosus & 29TNE68 & 101,00 & 134,72 & 93,55 & 40,41 & 4632,53 & 264,80 & 36,08 & 228,72 & 80,31 & 194,14 & 195,64 & 76,89 & 1229,75 & 179,29 & 13,54 & 53,76 & 495,74 & 82,40 & 85,19 & 495,61 \\
\hline \begin{tabular}{|l} 
Bufo spinosus \\
\end{tabular} & $\begin{array}{l}\text { 29TNE69 } \\
\end{array}$ & $\begin{array}{l}101,00 \\
101\end{array}$ & 128,02 & 91 & $\begin{array}{l}30, \\
39,\end{array}$ & 59 & $\begin{array}{l}204,00 \\
256,21\end{array}$ & \begin{tabular}{|l|l}
30,00 \\
30,75
\end{tabular} & $\begin{array}{l}220,1 / 4 \\
225,47 \\
\end{array}$ & 73,66 & 187,77 & 189,16 & 70,46 & 1311,34 & 192,53 & 14,74 & 54,03 & 529,92 & 88,13 & 90,71 & 529,25 \\
\hline Bufo spinosus & 29TNE73 & 100,00 & 130,48 & 89,04 & 37,71 & 4935,42 & 267,29 & 34,12 & 233,17 & 71,19 & 196,84 & 196,95 & 71,19 & 1223,43 & \begin{tabular}{|l|l|}
182,48 \\
\end{tabular} & 12,47 & 55,44 & 500,58 & 77,23 & 77,23 & 500,58 \\
\hline Bufo spinosus & 29TNE74 & 100,00 & 144,66 & 96,62 & 39,51 & 4909,73 & 284,97 & 43,52 & 241,46 & 84,22 & 208,62 & 209,88 & 84,22 & 1088,21 & $|159,07|$ & 10,86 & 54,50 & 442,33 & 70,82 & 71,38 & 442,33 \\
\hline Bufo spinosus & 29TNE75 & 101,00 & 154,08 & 101,29 & 40,82 & 4855,81 & 295,17 & 49,96 & 245,21 & 93,12 & 215,94 & 217,84 & 93,12 & 998,76 & 143,36 & 9,90 & 53,72 & 402,78 & 65,75 & 68,01 & 402,78 \\
\hline Bufo spinosus & 29TNE76 & 101,00 & 154,06 & 101,53 & $41, \mathrm{C}$ & 4813,66 & 293,38 & 49,62 & 243,76 & 93,18 & 215,14 & 216,88 & 93,18 & 1005,56 & 143,97 & 9,99 & 53,47 & 404,01 & 66,34 & 69,56 & 404 \\
\hline Bufo spinosus & 29TNE78 & 100,00 & 148,15 & 99,57 & 41,25 & 4758,31 & 283,45 & 44,56 & 238,88 & 92,48 & 208,55 & 209,97 & 87,76 & 1076,81 & 155,12 & 11,07 & 53,44 & 431,68 & 70,90 & 75,54 & 431,42 \\
\hline Bufo spinosus & 29TNE79 & 101,00 & 134,17 & 94,47 & 39,91 & 4800,60 & 267,62 & 33,70 & 233,92 & 76,77 & 196,11 & 197,26 & 74,32 & 1237,77 & 181,96 & 13,33 & 54,13 & 499,57 & 81,97 & 84,94 & 499,52 \\
\hline Bufo spinosus & 29TNE83 & 100,00 & 136.83 & 91,53 & 37,62 & 5092.52 & 278,06 & 37.73 & 240,33 & 75,38 & 204.90 & 205,18 & 75,38 & 1153,36 & 171.78 & 11,27 & 55,46 & 471.89 & 72.49 & 72.49 & 471.89 \\
\hline Bufo spinosus & 29TNE84 & 101,00 & 133,66 & 90,79 & 37,47 & 5087,30 & 273,82 & 34,71 & 239,11 & 72,27 & 201,61 & 201 , & 72, & 1197,70 & 179,06 & 11,86 & 55,43 & 489,74 & 75,49 & 75,49 & 489 \\
\hline Bufo spinosus & 29TNE85 & 100,00 & 147,50 & 97,92 & 39,26 & 5042,36 & 289,99 & 44,08 & 245,90 & 85,04 & 212,90 & 214,17 & 85,04 & 1059,06 & 155,04 & 10,29 & 54,51 & 429,45 & 68,30 & 69,66 & 429,45 \\
\hline
\end{tabular}




\begin{tabular}{|c|c|c|c|c|c|c|c|c|c|c|c|c|c|c|c|c|c|c|c|c|c|}
\hline TAXON & UTM & $\mathrm{km} 2$ & B101 & B102 & $\mathrm{BIO3}$ & B104 & BIO5 & B106 & B107 & B108 & B109 & BIO10 & BIO11 & BIO12 & B1013 & BIO14 & BIO15 & BIO16 & BIO17 & BIO18 & B1019 \\
\hline Bufo spinosus & 29TNE86 & 100,00 & 150,11 & 99,94 & 39,99 & 5010,48 & 292,48 & 45,38 & 247,10 & 87,50 & 214,40 & 215,94 & 87,50 & 1037,19 & 150,83 & 10,03 & 54,12 & 418,79 & 67,60 & 69,74 & 418,79 \\
\hline Bufo spinosus & 29TNE87 & 101,00 & 151,38 & 100,69 & 40,36 & 4969,05 & 292,32 & 46,06 & 246,27 & 88,92 & 214,94 & 216,39 & 88,82 & 1027,25 & 148,92 & 9,93 & 53,91 & 413,26 & 66,69 & 70,08 & 413,26 \\
\hline Bufo spinosus & 29TNE88 & 101,00 & 149,07 & 100,28 & 40,46 & 4943,27 & 288,54 & 43,95 & 244,59 & 88,11 & 212,25 & 213,54 & 86,67 & 1056,45 & 153,52 & 10,50 & 53,85 & 424,47 & 68,67 & 72,72 & 424,47 \\
\hline Bufo spinosus & 29TNE89 & 99,00 & 143,28 & 98,96 & 40,16 & 4954,20 & 281,94 & 38,90 & 243,03 & 81,35 & 206,81 & 207,99 & 80,99 & 1124,35 & 164,80 & 11,31 & 54,06 & 452,74 & 73,25 & 77,10 & 452,74 \\
\hline Bufo spinosus & 29TNE93 & 101,00 & 140,56 & 92,62 & 37,11 & 5261,71 & 285,37 & 39,35 & 246,03 & 77,01 & 210,76 & 211,08 & 77,01 & 1102,34 & 164,09 & 10,29 & 55,49 & 450,73 & 68,82 & 68,84 & 450,73 \\
\hline Bufo spinosus & 29TNE95 & 101,00 & 127,45 & 87,81 & 36,31 & 5197,31 & 267,32 & 28,99 & 238,32 & 65,12 & 196,99 & 197,21 & 65,12 & 1266,14 & 191,66 & 12,29 & 55,95 & 518,23 & 78,40 & 78,48 & 518,23 \\
\hline Bufo spinosus & 29TNE96 & 100,00 & 144,25 & 96,90 & \begin{tabular}{|l|}
38,48 \\
\end{tabular} & 5194,21 & 288,55 & 39,98 & 248,56 & 80,12 & 211,84 & 212,90 & 80,12 & 1084,89 & 160,45 & 10,32 & 54,88 & 440,40 & 69,82 & 70,58 & 440,40 \\
\hline \begin{tabular}{|l} 
Bufo spinosus \\
\end{tabular} & 29TNE97 & 100,00 & 147,75 & 99,20 & 39,25 & 5155,38 & 291,58 & 42,09 & 249,49 & 83,40 & 214,19 & 215,39 & 83,40 & 1050,55 & 154,38 & \begin{tabular}{|l|l|}
9,97 \\
\end{tabular} & 54,49 & 424,55 & 67,60 & 69,74 & 424,55 \\
\hline Bufo spinosus & 29TNE99 & 101,00 & 143,90 & 99,38 & 39,62 & 5127,85 & 286,19 & 38,18 & 248,01 & 79,91 & 210,06 & 211,01 & 79,71 & 1097,89 & 162,19 & 10,71 & 54,52 & 443,23 & 70,70 & 73,80 & 443,23 \\
\hline Bufo spinosus & 29TNF20 & 39,00 & 148,11 & 75,99 & 45,39 & $\begin{array}{ll}3278,87 \\
\end{array}$ & 228,40 & 62,72 & 165,68 & 111,24 & 185,74 & 187,30 & 102,70 & 1033,57 & 142,44 & 11,91 & 52,02 & 416,51 & 68,59 & 81,88 & 404,38 \\
\hline Bufo spinosus & 29TNF25 & 28,00 & 144,51 & 85,81 & 44,94 & 3674,23 & 243,21 & 54,34 & 188,87 & 104,47 & 189,36 & 191,38 & 97,09 & 1183,21 & 162,30 & 14,83 & 51,15 & 472,75 & 81,40 & 99,72 & 460,91 \\
\hline Bufo spinosus & 29TNF26 & 68,00 & 143,71 & 84,72 & 45,01 & 3658,17 & 241,52 & 55,50 & 186,02 & 99,99 & 188,56 & 190,46 & 97,07 & 1215,52 & 165,55 & 15,08 & 51,03 & 482,21 & 83,56 & 100,72 & 480,78 \\
\hline \begin{tabular}{|l} 
Bufo spinosus \\
\end{tabular} & 29TNF27 & 83,00 & 143,39 & 83,67 & 44,84 & 3665,84 & 241,48 & 56,50 & 184,98 & 98,16 & 188,60 & 190,35 & 96,94 & 1229,74 & 168,04 & 15,06 & 51,32 & 488,82 & 83,48 & 101,82 & 488,58 \\
\hline Bufo spinosus & 29TNF28 & 101,00 & 142,97 & 82,67 & \begin{tabular}{|l|l|}
44,28 \\
\end{tabular} & 3688,89 & 241,72 & 57,07 & 184,65 & 96,45 & 188,66 & 190,33 & 96,40 & 1246,49 & 171,06 & 15,08 & 51,64 & 496,82 & 83,70 & 103,29 & 496,82 \\
\hline Bufo spinosus & 29TNF29 & 100,00 & 143,40 & 81,55 & 43,81 & 3705,16 & 242,68 & 58,44 & 184,24 & 96,74 & 189,45 & 190,99 & 96,74 & 1253,60 & 172,57 & 14,95 & 51,94 & 500,80 & 83,10 & 104,21 & 500,80 \\
\hline Bufo spinosus & 29TNF30 & 97,00 & 149,38 & 82,52 & 44,75 & 3564,68 & 241,69 & 59,15 & 182,54 & 109,24 & 191,41 & 193,03 & 100,90 & 1039,18 & 143,20 & 11,86 & 52,06 & 418,81 & 69,12 & 81,84 & 406,13 \\
\hline Bufo spinosus & 29TNF31 & 101,00 & 148,07 & 83,26 & 44,69 & 3597,97 & 241,68 & 57,46 & 184,22 & 107,87 & 190,73 & 192,50 & 99,47 & 1065,36 & 146,05 & 12,24 & 52,00 & 429,98 & 71,06 & 85,21 & 414,46 \\
\hline Bufo spinosus & 29TNF32 & 101,00 & 145,57 & 84,92 & 44,51 & 3682,73 & 242,81 & 53,91 & 188,90 & 104,71 & 189,77 & 191,53 & 96,39 & 1108,58 & 151,23 & 13,26 & 51,97 & 448,35 & 74,67 & 90,24 & 429,45 \\
\hline Bufo spinosus & 29TNF33 & 100,00 & 143,08 & 86,64 & 44,26 & 3769,42 & 244,08 & 50,32 & 193,75 & 101,57 & 188,84 & 190,75 & 93,44 & 1153,38 & 156,89 & 14,21 & 51,96 & 467,44 & 78,42 & 95,49 & 444,94 \\
\hline Bufo spinosus & 29TNF34 & 101,00 & 142.93 & 88,24 & 44,24 & 3832,79 & 246,60 & 49,26 & $\mid 197,34$ & 100,95 & $\mid 189,74$ & \begin{tabular}{|l|l|}
191,72 \\
\end{tabular} & 92,80 & 1169,53 & $\mid 160,71$ & 14,84 & 51,92 & 475,06 & 79,95 & 99,15 & 447.97 \\
\hline Bufo spinosus & 29TNF35 & 101,00 & 143,79 & 89,17 & 44,34 & 3853,99 & 248,86 & 50,08 & 198,78 & 101,82 & 191,19 & 193,23 & 93,92 & 1176,16 & 162,85 & 15,00 & 51,60 & 476,56 & 80,52 & 100,90 & 450,62 \\
\hline Bufo spinosus & 29TNF37 & 101,00 & 143,27 & 87,78 & 44,23 & 3880,42 & 248,43 & 52,12 & 196,31 & 100,95 & 191,39 & 193,10 & 93,98 & 1219,17 & 165,45 & 15,05 & 51,07 & 485,64 & 82,94 & 101,87 & 478,73 \\
\hline Bufo spinosus & 29TNF39 & 100,00 & $\begin{array}{ll}142,67 \\
\end{array}$ & 85,68 & 43,22 & 3921,25 & 249,19 & 53,49 & 195,69 & 97,62 & \begin{tabular}{|l|l|}
191,73 \\
\end{tabular} & \begin{tabular}{|l|}
193,13 \\
\end{tabular} & 93,16 & 1252,93 & 169,96 & 15,41 & 51,40 & 497,59 & 84,71 & 104,50 & 496,90 \\
\hline Bufo spinosus & 29TNF41 & 101,00 & 142,38 & 89,36 & 43,37 & 3991,40 & 250,94 & 47,24 & 203,70 & 98,11 & 191,25 & 193,01 & 90,04 & 1145,99 & 159,30 & 13,48 & 52,06 & 462,52 & 77,32 & 89,31 & 448,96 \\
\hline Bufo spinosus & 29TNF42 & 100,00 & 139,86 & 89,98 & 43,29 & 4039,26 & 249,99 & 44,34 & 205,65 & 95,41 & 189,66 & 191,42 & 87,24 & 1184,27 & 164,08 & 14,18 & 52,01 & 478,82 & 80,25 & 93,42 & 462,77 \\
\hline Bufo spinosus & \begin{tabular}{|l|l|} 
29TNF45 \\
\end{tabular} & 100,00 & 143,60 & 92,24 & 43,84 & 4070,49 & 255,27 & 46,97 & 208,31 & 98,94 & 194,03 & 195,90 & 91,10 & 1174,73 & 159,85 & 14,55 & 51,68 & 475,51 & 79,77 & 98,42 & 452,40 \\
\hline Bufo spinosus & 29TNF46 & 101,00 & 139,99 & 92,04 & 年3,,58 & 4124,76 & 253,26 & $\begin{array}{l}44,26 \\
44,5\end{array}$ & 208,99 & 94,91 & $\begin{array}{l}191,59 \\
\end{array}$ & $\begin{array}{l}193,29 \\
\end{array}$ & 87,44 & 1229,65 & 167,21 & 15,41 & 51,34 & 495,06 & 84,11 & 1001,93 & 478,38 \\
\hline Bufo spinosus & 29TNF47 & 100,00 & 139,14 & 91,24 & 43,32 & 4147,14 & 252,84 & 44,35 & 208,48 & 93,89 & 191,25 & 192,76 & 86,61 & 1253,11 & 169,91 & 15,81 & 51,14 & 501,37 & 86,32 & 103,48 & 491,26 \\
\hline Bufo spinosus & 29TNF49 & 101,00 & 139,80 & 89,86 & 42,66 & 4175,54 & 254,55 & 46,33 & 208,22 & 94,19 & 192,55 & 193,76 & 87,19 & 1270,24 & 171,95 & 16,30 & 51,01 & 504,73 & 88,23 & 105,84 & 500,86 \\
\hline Bufo spinosus & 29TNF50 & 101,00 & 139,58 & 92,61 & 42,17 & 4304,23 & 258,99 & 41,99 & 217,01 & 92,04 & 193,36 & 195,11 & 84,30 & 1181,11 & 167,89 & 13,43 & 52,76 & 475,58 & 79,54 & 87,48 & 468,92 \\
\hline Bufo spinosus & 29TNF52 & 100,00 & 128,82 & 90,79 & 41,34 & 4388,35 & 249,56 & 32,56 & 217,00 & 80,65 & 184,49 & 186,10 & 73,51 & 1319,05 & 188,56 & 15,87 & 52,82 & 531,86 & 90,28 & 98,23 & 525,29 \\
\hline Bufo spinosus & 29TNF53 & 101,00 & 139,12 & \begin{tabular}{|c|}
03,95 \\
93
\end{tabular} & 年1, 42,65 & 4 & 258,06 & $\begin{array}{l}2,50 \\
40,55 \\
\end{array}$ & 217,52 & $\begin{array}{l}\mid 00,00 \\
91,75 \\
\end{array}$ & \begin{tabular}{|l|}
192,97 \\
\end{tabular} & 194,65 & 83,83 & $\begin{array}{l}1206,82 \\
120\end{array}$ & \begin{tabular}{|l|l|}
168,46 \\
\end{tabular} & $\begin{array}{l}14,26 \\
14,26\end{array}$ & 52,14 & 487,19 & 81,32 & $\begin{array}{l}0,20 \\
94,06\end{array}$ & 473,32 \\
\hline Bufo spinosus & 29TNF54 & 101,00 & 143,24 & 94,76 & 43,14 & 4278,36 & 261,19 & 44,06 & 217,13 & 96,03 & 196,62 & 198,24 & 88,15 & 1165,91 & 160,49 & 13,81 & 51,97 & 470,68 & 78,26 & 93,43 & 453,65 \\
\hline Bufo spinosus & 29TNF55 & 100,00 & 140,87 & 95,08 & 42,94 & 4326,04 & 260,24 & 41,73 & 218,51 & 93,30 & 195,21 & 196,68 & 85,53 & 1202,49 & 165,11 & 14,53 & 51,85 & 484,56 & 81,28 & 96,84 & 468,84 \\
\hline Bufo spinosus & 29TNF56 & 101,00 & 139,94 & 95,13 & \begin{tabular}{l|l}
42,95 \\
\end{tabular} & 4354,26 & 260,13 & 41,13 & 219,00 & 92,16 & 194,79 & 196,27 & 84,56 & 1221,82 & 166,99 & 14,97 & 51,64 & 490,56 & 83,17 & 98,86 & 477,69 \\
\hline Bufo spinosus & 29TNF57 & 101,00 & 136,33 & 94,43 & 42,54 & 4395,62 & 257,89 & 38,43 & 219,46 & 88,25 & 192,09 & 193,38 & 80,76 & 1271,83 & 173,49 & 15,97 & 51,45 & 508,53 & 87,85 & 102,68 & 500,28 \\
\hline Bufo spinosus & 29TNF59 & 101,00 & $\begin{array}{l}139,50 \\
139,94\end{array}$ & $\begin{array}{l}4,45 \\
93,48 \\
\end{array}$ & 年L, 42,13 & $\begin{array}{l}4359,02 \\
43390\end{array}$ & 261,73 & $\begin{array}{l}0,435 \\
42,64\end{array}$ & 219,10 & \begin{tabular}{l|l|l|l|l|l|}
91,63 \\
\end{tabular} & $\begin{array}{l}192,03,73 \\
195\end{array}$ & \begin{tabular}{|l|l|}
196,85 \\
196,5
\end{tabular} & $\begin{array}{ll}0,105 \\
84,56\end{array}$ & \begin{tabular}{|l|l|l|l|l|}
1243,58 \\
\end{tabular} & \begin{tabular}{|l|}
167,10 \\
167,
\end{tabular} & $\begin{array}{l}1,3,12 \\
16,12\end{array}$ & $\begin{array}{l}1,145 \\
50,99\end{array}$ & $\begin{array}{l}40,53,44 \\
493,4\end{array}$ & $\begin{array}{l}01,00 \\
87,40\end{array}$ & $\begin{array}{l}103,00 \\
10,38\end{array}$ & $\begin{array}{l}30,20 \\
487,78\end{array}$ \\
\hline Bufo spinosus & 29TNF60 & 100,00 & 135,03 & 94,39 & 41,03 & 4585,71 & 262,88 & 35,58 & 227,30 & 84,44 & 193,27 & 194,86 & 77,17 & 1237,64 & 179,24 & 13,79 & 53,37 & 498,24 & 82,88 & 88,33 & 495,79 \\
\hline Bufo spinosus & 29TNF61 & 100,00 & 135,59 & 94,12 & 41,30 & 4545,64 & 261,58 & 36,27 & 225,31 & 84,47 & 193,36 & 194,77 & 78,12 & 1233,48 & 177,66 & 13,94 & 53,23 & 497,11 & 82,71 & 89,56 & 492,25 \\
\hline Bufo spinosus & 29TNF62 & 101,00 & 119,24 & 89,37 & 39,56 & 4648,32 & 246,04 & 23,36 & 222,68 & 65,19 & 179,50 & 180,74 & 62,13 & 1421,55 & 207,84 & 17,24 & 53,69 & 573,99 & 97,86 & 101,46 & 572,57 \\
\hline \begin{tabular}{|l} 
Bufo spinosus \\
\end{tabular} & 29TNFG3 & 100,00 & 137,18 & 96,37 & 41, & 4552,30 & 263,63 & 36,45 & 227,18 & 87,09 & 194,87 & 196,22 & 79,29 & 1227,80 & 174,69 & 14,04 & 52,72 & 494,00 & 82,05 & 92,22 & 486,62 \\
\hline \begin{tabular}{|l} 
Bufo spinosus \\
\end{tabular} & 29TNFG4 & 100,00 & 139,87 & 96,89 & 42, & 4533,38 & 265,28 & 38,81 & 226,47 & 89,13 & 197,19 & 198,52 & 82,13 & 1200,42 & 169,04 & 13,86 & 52,38 & 482,70 & 80,33 & 92,20 & 473,27 \\
\hline Bufo spinosus & 29TNF65 & 101,00 & 141,16 & 97,96 & 42,54 & 4548,34 & 267,19 & 39,49 & 227,70 & 90,78 & 198,67 & 199,98 & 83,18 & 1191,76 & 166,29 & 13,82 & 52,13 & 478,12 & 79,78 & 93,05 & 468,42 \\
\hline Bufo spinosus & \begin{tabular}{|l|} 
29TNF67 \\
\end{tabular} & 100,00 & 139,03 & 97,85 & 42,15 & 4589,24 & 266,73 & $\begin{array}{ll}37,67 \\
\end{array}$ & 229,06 & 88,29 & 197,36 & 198,49 & 80,91 & 1225,60 & 168,33 & 14,86 & 51,72 & 488,61 & 83,77 & 97,47 & 482,14 \\
\hline Bufo spinosus & 29TNF68 & 101,00 & 137,90 & 97,23 & 41, & 4606,79 & 266,17 & 37,05 & 229,12 & 87,12 & 196,63 & 197,66 & 79,77 & 1240,93 & 168,44 & 15,51 & 51,33 & 92,91 & 86,19 & 99,84 & 488,19 \\
\hline Bufo spinosus & 29TNF69 & 100,00 & 135,31 & 96,15 & 4 & 4630,85 & 264,13 & 35,32 & 228,80 & $\begin{array}{l}83,85 \\
83,85\end{array}$ & 194,67 & $\begin{array}{l}195,62 \\
\end{array}$ & 77,28 & \begin{tabular}{|l|l|}
1267,98 \\
\end{tabular} & $\begin{array}{l}170,11 \\
\end{array}$ & $\begin{array}{l}16,66 \\
16,6\end{array}$ & 50,99 & 502,08 & 90,32 & 103,32 & $\begin{array}{l}400,19 \\
498,82 \\
4\end{array}$ \\
\hline \begin{tabular}{|l} 
Bufo spinosus \\
\end{tabular} & 29TNF70 & 100,00 & 131,12 & 93,82 & 39,84 & 4794,23 & 263,60 & 31,18 & 232,42 & 74,29 & 193,10 & 194,21 & 71,49 & 1276,03 & 187,97 & 13,9 & 54,17 & 515,51 & 84,71 & 88,05 & 514,91 \\
\hline Bufo spinosus & 29TNF71 & 101,00 & 138,55 & 97,23 & 41,02 & 4748,50 & 270,65 & 36,33 & 234,32 & 84,96 & 199,28 & 200,42 & 78,59 & 1195,33 & 173,64 & 12.91 & 53,50 & 480,83 & 78,99 & 85,21 & 478,45 \\
\hline Bufo spinosus & 29TNF72 & 100,00 & 124,75 & 93,12 & 39,79 & 4811,33 & 256,79 & 25,56 & 231,23 & 67,57 & 187,14 & 188,20 & 65,25 & 1354,86 & 199,64 & 15,47 & 54,07 & 547,42 & 91,22 & 94,88 & 546,90 \\
\hline Bufo spinosus & 29TNF73 & 100,00 & 125,97 & 94,19 & 40,16 & 4798,34 & 257,82 & 26,19 & 231,62 & 69,94 & 188,03 & 189,07 & 66,37 & 1340,38 & 195,83 & 15,66 & 53,65 & 51 & 90,73 & 95,98 & 538,99 \\
\hline \begin{tabular}{|l} 
Bufo spinosus \\
\end{tabular} & \begin{tabular}{|l|} 
29TNF74 \\
\end{tabular} & $\begin{array}{l}101,00 \\
100\end{array}$ & $\begin{array}{ll}128,97 \\
128,99\end{array}$ & $\begin{array}{l}34,15 \\
95,57 \\
\end{array}$ & 40 & $\begin{array}{l}475,53,60 \\
4783,60\end{array}$ & 260,61 & $\begin{array}{l}\mid 20,113 \\
28,37\end{array}$ & $\begin{array}{l}51,024 \\
232,24 \\
\end{array}$ & 72,85 & $\begin{array}{l}190,58 \\
\end{array}$ & 191,63 & 69,36 & \begin{tabular}{|l|}
1309,76 \\
\end{tabular} & 189,73 & 15,3 & 53,31 & 527,26 & 88,82 & 95,55 & 524,72 \\
\hline Bufo spinosus & 29TNF76 & 101,00 & 141,79 & 100,39 & 41,96 & 4748,21 & 274,06 & 37,90 & 236,17 & 87,98 & 202,21 & 203,32 & 81,53 & 1172,75 & 164,56 & 13,40 & 52,24 & 467,99 & 78,52 & 90,37 & 462,94 \\
\hline Bufo spinosus & 29TNF79 & 101,00 & 124,43 & 95,81 & $|40,47|$ & 4841.80 & 258,19 & 24,30 & 233,89 & 65,58 & $\mid 187,19$ & $\mid 188,09$ & 64,62 & 1349,39 & 185,11 & 18.55 & 51.51 & 536,28 & 98.47 & 107,09 & 536,16 \\
\hline Bufo spinosus & 29TNF80 & 101,00 & 137,26 & 97,59 & 39,95 & 4966,71 & 275,12 & 33,90 & 241,22 & 75,65 & 201,18 & 202,29 & 75,13 & 1195,95 & 176,73 & 12,38 & 54,37 & 482,82 & 78,28 & 81,81 & 482,81 \\
\hline Bufo spinosus & 29TNF81 & 101,00 & 138,58 & 98,97 & 40,41 & 4957,04 & 276,29 & 34,33 & 241,95 & 78,33 & 202,15 & 203 & 76,25 & 1184,88 & 174,47 & 12,24 & 54,20 & 477,17 & 77,25 & 82,20 & 477 \\
\hline \begin{tabular}{|l} 
Bufo spinosus \\
\end{tabular} & 29TNF82 & 100,00 & 133,58 & 98,23 & 40,21 & 4971,25 & 271,19 & 30,14 & 241,06 & 73,00 & 197,70 & 198,66 & 71,47 & 1244,51 & \begin{tabular}{|l|l|}
184,08 \\
\end{tabular} & 13,26 & 54,36 & 502,42 & 81,71 & 86,36 & 502,12 \\
\hline Bufo spinosus & 29TNF83 & 101,00 & 109,14 & 87,77 & 37,62 & 4975,93 & 242,62 & 12,70 & 229,92 & 49,47 & 175,17 & 175,58 & 49,22 & 1493,52 & 222,19 & 18,53 & 54,42 & 606,03 & 102,49 & 103,59 & 606,01 \\
\hline Bufo spinosus & 29TNF84 & 101,00 & 118,90 & 93,61 & 39,19 & 4982,55 & 254,88 & 19,09 & 235,79 & 58,28 & 184,21 & 184,84 & 57,85 & 1397,56 & 206,45 & 16,64 & 54,06 & 565,62 & 95,33 & 98,47 & 565,51 \\
\hline Bufo spinosus & 29TNF85 & 100,00 & 136,01 & 101,39 & 41,17 & 965,90 & 274,28 & 30,99 & 243,29 & 75,89 & 199,76 & 200,67 & 73, & 1222,05 & 177,54 & 13,56 & 53,63 & 490,55 & 81,16 & 89,01 & 489 \\
\hline Bufo spinosus & 29TNF86 & 101,00 & 125,67 & 98,43 & 40,38 & 4998,73 & 264,11 & 23,07 & 241,04 & 64,83 & 190,54 & 191,36 & 63,74 & 1325,58 & 192,39 & 15,93 & 53,57 & 533,46 & 91,11 & 96,93 & 533,22 \\
\hline
\end{tabular}




\begin{tabular}{|c|c|c|c|c|c|c|c|c|c|c|c|c|c|c|c|c|c|c|c|c|c|}
\hline TAXON & UTM & $\mathrm{km} 2$ & B101 & B102 & $\mathrm{BIO3}$ & B104 & BIO5 & B106 & B107 & B108 & B109 & B1010 & BIO11 & BIO12 & B1013 & BIO14 & BIO15 & B1016 & BIO17 & BIO18 & B1019 \\
\hline Bufo spinosus & 29TNF87 & 101,00 & 135,01 & 101,65 & 41,07 & 4987,46 & 274,44 & 29,83 & 244,61 & 74,73 & 199,17 & 199,92 & 72,50 & 1223,35 & 174,13 & 14,38 & 52,84 & 488,05 & 83,36 & 92,32 & 487,44 \\
\hline Bufo spinosus & 29TNF88 & 99,00 & 141,71 & 103,14 & 41,42 & 4974,24 & 281,45 & 35,06 & 246,39 & 83,10 & 205,58 & 206,22 & 78,92 & 1144,18 & 158,88 & 13,41 & 52,08 & 452,19 & 78,01 & 89,11 & 451,23 \\
\hline Bufo spinosus & 29TNF89 & 101,00 & 138,03 & 102,06 & 40,95 & 4999,15 & 277,95 & 31,91 & 246,04 & 78,21 & 202,41 & 202,92 & 75,17 & 1176,14 & 161,05 & 14,66 & 51,68 & 463,52 & 82,57 & 92,81 & 463,14 \\
\hline Bufo spinosus & 29TNF91 & 100,00 & 132,75 & 97,32 & 39,23 & 5137,78 & 273,84 & 28,79 & 245,06 & 68,99 & 199,50 & 200,32 & 68,99 & 1228,40 & 184,01 & 12,60 & 55,01 & 498,40 & 79,94 & 82,35 & 498,40 \\
\hline Bufo spinosus & 29TNF92 & 101,00 & 126,83 & 96,14 & 39,03 & 5143,95 & 267,40 & 23,92 & 243,48 & 63,31 & 193,92 & 194,57 & 63,31 & 1295,64 & 194,83 & 13,75 & 55,18 & 526,94 & 85,17 & 87,05 & 526,94 \\
\hline Bufo spinosus & 29TNF93 & 100,00 & 112,22 & 89,85 & 37,50 & 5123,48 & 249,76 & 13,62 & 236,13 & 50,27 & 180,26 & 180,45 & 50,27 & 1440,64 & 216,60 & 16,93 & 55,02 & 587,21 & 97,41 & 97,51 & 587,21 \\
\hline Bufo spinosus & 29TNF94 & 100,00 & 117,18 & 94,18 & 38,63 & 5143,77 & 257,13 & 16,22 & 240,91 & 54,41 & 184,94 & 185,37 & 54,41 & 1388,86 & 207,75 & 16,25 & 54,85 & 564,88 & 94,28 & 95,58 & 564,88 \\
\hline \begin{tabular}{|l} 
Bufo spinosus \\
\end{tabular} & 29TNF95 & 101,00 & 138,40 & 103,35 & 40,82 & 5122,49 & 281,31 & 31,16 & 250,14 & 75,40 & 204,41 & 205,04 & 74,01 & 1168,52 & 171,57 & 12,46 & 54,07 & 469,70 & 76,62 & 82,85 & 469,33 \\
\hline Bufo spinosus & 29TNF96 & 100,00 & 122,41 & 99,04 & 39,60 & 5160,22 & 265,41 & 18,77 & 246,64 & 58,88 & 189,82 & 190,40 & 58,88 & 1327,04 & 195,32 & 16,05 & 54,19 & 536,19 & 91,36 & 95,12 & 536,19 \\
\hline Bufo spinosus & 29TNF97 & 100,00 & 115,88 & 95,90 & \begin{tabular}{|l|l|}
39,03 \\
\end{tabular} & 5136,17 & 257,03 & 14,56 & 242,47 & 53,35 & 183,44 & 183,91 & 53,35 & 1372,61 & 199,44 & 17,95 & 53,49 & 553,49 & 98,06 & 101,01 & 553,49 \\
\hline Bufo spinosus & 29TNF98 & 101,00 & 121,02 & 98,41 & 39,61 & 5139,73 & 263,22 & 17,96 & 245,26 & 57,91 & 188,29 & 188,76 & 57,91 & 1316,53 & 188,74 & 17,26 & 53,01 & 528,34 & 94,25 & 98,83 & 528,34 \\
\hline Bufo spinosus & 29TNF99 & 100,00 & 135,05 & 103,43 & \begin{tabular}{|l|l|}
40,67 \\
\end{tabular} & 5161,06 & 279,51 & 27,52 & 251,99 & 71,37 & 201,96 & 202,26 & 70,61 & 1168,49 & 163,49 & 14,49 & 52,32 & 463,38 & 81,88 & 88,21 & 463,32 \\
\hline \begin{tabular}{|l} 
Bufo spinosus \\
\end{tabular} & 29TNG11 & 68,00 & 142,97 & 75,17 & \begin{tabular}{|l|l|}
42,97 \\
\end{tabular} & 3566,09 & 236,70 & 63,82 & 172,88 & 98,36 & 187,37 & 188,68 & 98,36 & 1288,24 & 180,59 & 15,17 & 52,45 & 518,55 & 83,56 & 108,22 & 518,55 \\
\hline Bufo spinosus & 29TNG12 & 87,00 & 137,29 & 73,96 & 42,06 & 3627,14 & 232,43 & 58,62 & 173,81 & 92,83 & 182,87 & 184,29 & 92,14 & 1378,35 & 191,82 & 19,18 & 51,61 & 553,01 & 96,64 & 118,57 & 552,97 \\
\hline Bufo spinosus & 29TNG13 & 86,00 & 140,49 & 72,13 & 41,64 & 3603,62 & 234,13 & 62,90 & 171,23 & 100,04 & 185,70 & 187,01 & 95,30 & 1358,91 & 189,08 & 19,68 & 51,07 & 544,43 & 96,92 & 119,11 & 541,84 \\
\hline Bufo spinosus & 29TNG14 & $\begin{array}{ll}99,00 \\
\end{array}$ & 141,35 & 69,97 & 411,01 & $\mid 3592,14$ & 233,55 & 65,01 & $\mid 168,54$ & 103,58 & $\mid$\begin{tabular}{|l|l|}
186,44 \\
\end{tabular} & $\mid \begin{array}{l}187,73 \\
\end{array}$ & $\mid 96,16$ & $\mid 1368,59$ & \begin{tabular}{|l|l|}
193,12 \\
\end{tabular} & 21,54 & 50,70 & 549,61 & 101,51 & $\begin{array}{lll}122,99 \\
\end{array}$ & 542,04 \\
\hline Bufo spinosus & 29TNG15 & 101,00 & 132,16 & 69,72 & 40,14 & 3685,33 & 227,32 & 55,75 & 171,56 & 93,81 & 178,93 & 180,33 & 86,39 & 1509,91 & 227,25 & 27,33 & 50,50 & 609,48 & 119,62 & 138,03 & 604,19 \\
\hline Bufo spinosus & 29TNG16 & 63,00 & 144,91 & 65,38 & 39,81 & 3554,55 & 233,48 & 71,05 & 162,43 & 107,66 & 189,68 & 190,80 & 99,84 & 1361,27 & 195,80 & 24,69 & 49,54 & 549,03 & 108,17 & 128,84 & 528,42 \\
\hline Bufo spinosus & 29TNG17 & 33,00 & 149,14 & 62,22 & 38,97 & 3510,00 & 234,61 & 76,97 & 157,64 & 112,28 & 193,11 & 194,33 & 104,31 & \begin{tabular}{|l|l|}
1294,33 \\
\end{tabular} & 179,89 & 25,03 & 48,31 & 519,61 & 107,44 & 128,50 & 486,56 \\
\hline Bufo spinosus & 29TNG18 & 45,00 & 144,43 & 61,74 & 38,37 & 3541,20 & 231,42 & 73,05 & 158,37 & 107,44 & 189,24 & 190,36 & 99,57 & \begin{tabular}{|l|l|}
1364,63 \\
\end{tabular} & 199,30 & 28,12 & 48,48 & 549,64 & 116,34 & 136,83 & 520,34 \\
\hline Bufo spinosus & 29TNG19 & 57,00 & 145,12 & 59,99 & \begin{tabular}{|l|l|}
37,97 \\
\end{tabular} & 3519,84 & 230,93 & 75,11 & 155,82 & 108,43 & 189,61 & 191,00 & 100,84 & 1316,97 & 192,33 & 28,91 & 47,32 & 528,09 & 117,50 & 139,10 & 493,80 \\
\hline Bufo spinosus & 29TNG20 & 101,00 & 138,63 & 80,62 & 42,90 & 3774,84 & 239,93 & 54,36 & 185,56 & $\begin{array}{l}|c|, 40 \\
91,40\end{array}$ & \begin{tabular}{|l|}
185,97 \\
\end{tabular} & 187,32 & \begin{tabular}{|c|c|}
91,40 \\
\end{tabular} & 1326,01 & 182,29 & 16,74 & 51,84 & 531,55 & 89,82 & 110,74 & 531,55 \\
\hline Bufo spinosus & 29TNG21 & 100,00 & 140,46 & 79,05 & \begin{tabular}{|l|l|}
42,58 \\
\end{tabular} & 3766,11 & 241,19 & 57,32 & 183,88 & 93,37 & 187,78 & 188,95 & 93,37 & \begin{tabular}{|l|}
1319,70 \\
\end{tabular} & 182,44 & 16,80 & 51,79 & 528,80 & 89,38 & 111,32 & 528,80 \\
\hline Bufo spinosus & 29TNG22 & 101,00 & $\begin{array}{lll}137,87 & \end{array}$ & 77,71 & 41,84 & 3802,67 & 239,14 & 55,51 & 183,63 & 92,15 & 185,93 & 187,09 & 90,40 & 1364,18 & 189,74 & 19,11 & 51,39 & 545,54 & 96,55 & 117,25 & 545,41 \\
\hline Bufo spinosus & 29TNG23 & 100,00 & 133,12 & 76,64 & 41,04 & 3855,64 & 235,53 & 51,17 & 184,36 & 88,49 & 182,12 & 183,32 & 85,21 & 1450,79 & 209,92 & 22,81 & 50,88 & 581,76 & 108,37 & 126,68 & 581,25 \\
\hline Bufo spinosus & 29TNG24 & 99,00 & 142,72 & 73,68 & 40,92 & 3762,67 & 240,82 & 62,56 & 178,27 & 101,27 & 190,16 & 191,21 & 95,21 & 1360,54 & 195,29 & 21,41 & 50,56 & 545,50 & 101,24 & 121,49 & 538,65 \\
\hline Bufo spinosus & 29TNG25 & 101,00 & 142,44 & 71,61 & 40,21 & 3755,29 & 239,25 & 63,49 & 175,77 & 101,68 & $\begin{array}{l}189,94 \\
\end{array}$ & 190,94 & $\begin{array}{l}95,01 \\
95,\end{array}$ & 1394,60 & 206,60 & 23,94 & 50,39 & 561,40 & 107,55 & 126,99 & 552,19 \\
\hline Bufo spinosus & 29TNG26 & 100,00 & 137,42 & 70,38 & 39,69 & 3792,18 & 234,78 & 59,26 & 175,52 & 95,03 & 185,76 & 186,73 & 89,89 & 1494,19 & 233,27 & 28,30 & 50,67 & 605,16 & 120,03 & 137,69 & 598,49 \\
\hline Bufo spinosus & 29TNG27 & 80,00 & 142,23 & 66,90 & 39,02 & 3729,91 & 235,55 & 66,17 & 169,38 & 100,94 & 189,67 & 190,59 & 95,20 & 1456,53 & 226,75 & 28,89 & 50,29 & 590,88 & 119,23 & 137,56 & 576,63 \\
\hline Bufo spinosus & 29TNG28 & 86,00 & 139,17 & 65,44 & 38,37 & 3735,36 & 232,63 & 64,36 & 168,28 & 99,83 & 186,87 & 187,97 & 92,44 & 1463,59 & 227,46 & 31,15 & 49,23 & 589,78 & 125,44 & 144,09 & 572,35 \\
\hline Bufo spinosus & 29TNG29 & 72,00 & 142,90 & 62,57 & 37,89 & 3707,49 & 233,27 & 70,12 & 163,15 & 103,57 & 190,24 & 191,12 & 96,35 & 1394,43 & 212,13 & 30,94 & 48,26 & 558,48 & 122,62 & 142,96 & 533,75 \\
\hline Bufo spinosus & 29TNG30 & 100,00 & 142,44 & 84,53 & $\mid 42,87$ & 3938,87 & 249,38 & 54,16 & $\begin{array}{l}195,22 \\
\end{array}$ & 95,44 & $\begin{array}{l}191,86 \\
\end{array}$ & \begin{tabular}{|l|}
193,10 \\
\end{tabular} & $\begin{array}{ll}0,351 \\
92,81\end{array}$ & $\begin{array}{l}1270,66 \\
\end{array}$ & \begin{tabular}{|l|l|}
172,69 \\
\end{tabular} & 15,94 & $\begin{array}{ll}51,41 \\
51,2\end{array}$ & 505,15 & 86,42 & 106,61 & 504,88 \\
\hline Bufo spinosus & 29TNG31 & 101,00 & 138,13 & 83,65 & 42,12 & 3997,59 & 246,81 & 50,50 & 196,31 & 90,32 & 188,70 & 189,82 & 88,05 & 1338,81 & 185,48 & 18,15 & 51,15 & 533,35 & 94,35 & 113,34 & 533,25 \\
\hline Bufo spinosus & 29TNG32 & 101,00 & 142,57 & 82,02 & 41,84 & 3972,07 & 249,88 & 55,81 & 194,06 & 98,75 & 192,74 & 193,71 & 92,50 & \begin{tabular}{|l|}
1300,19 \\
\end{tabular} & 180,92 & 17,88 & 51,01 & 516,76 & 92,01 & 111,91 & 515,34 \\
\hline Bufo spinosus & 29TNG33 & 100,00 & 128,02 & 80,92 & 40,79 & 4087,55 & 238,12 & 41,92 & 196,20 & 79,68 & 180,45 & 181,48 & 77,39 & 1483,19 & 217,87 & 24,47 & 50,58 & 592,61 & 114,75 & 129,94 & 592,45 \\
\hline Bufo spinosus & 29TNG34 & 100,00 & 130,47 & 79,59 & 40,55 & 4068,19 & 239,44 & 45,08 & 194,36 & 84,61 & 182,58 & 183,56 & 79,95 & 1482,56 & 223,25 & 25,55 & 50,53 & 593,07 & 116,73 & 132,15 & 591,82 \\
\hline \begin{tabular}{|l} 
Bufo spinosus \\
\end{tabular} & 29TNG35 & 100,00 & 145,15 & 76,03 & 40,07 & 3941,12 & 248,67 & 61,79 & 186,88 & $\begin{array}{l}101,87 \\
\end{array}$ & 195,09 & 195,83 & 95,17 & 1342,05 & 200,47 & 22,86 & 50,10 & 537,04 & 104,42 & 122,88 & 526,61 \\
\hline Bufo spinosus & 29TNG36 & 101,00 & 144,76 & 73,61 & 39,76 & 3928,62 & 246,38 & 62,98 & 183,40 & 101,35 & 194,70 & 195,47 & 95,00 & 1380,58 & 213,07 & 25,50 & 50,08 & 554,99 & 110,69 & 128,51 & 543,54 \\
\hline Bufo spinosus & 29TNG37 & 100,00 & 139,44 & 72,37 & $\mid 39,17$ & 3952,22 & 241,01 & 58,61 & $\mid 182,39$ & 95,37 & 190,05 & \begin{tabular}{|l|l|}
190,83 \\
\end{tabular} & 89,86 & 1472,17 & 236,44 & 29,55 & 50,39 & 593,97 & 122,06 & 138,70 & 586,24 \\
\hline Bufo spinosus & 29TNG38 & 88,00 & 139,79 & 70,11 & 38,73 & 3935,64 & 239,20 & 60,43 & 178,77 & 97,45 & 190,29 & 191,03 & 90,49 & 1461,61 & 233,79 & 31,05 & 49,66 & 586,56 & 124,93 & 141,71 & 575,20 \\
\hline Bufo spinosus & 29TNG39 & 101,00 & 136,77 & 68,86 & 38,12 & 3933,53 & 236,40 & 58,27 & 178,13 & 94,66 & 187,42 & 188,34 & 87,94 & 1478,41 & 235,28 & 33,27 & 48,80 & 590,26 & 130,99 & 148,84 & 576,22 \\
\hline \begin{tabular}{|l} 
Bufo spinosus \\
\end{tabular} & 29TNG40 & 101,00 & 145,85 & 88,48 & 42,5 & 4128,39 & 258,94 & 53,25 & 205,69 & 100,52 & 197,76 & 198,85 & 93,45 & 1208,74 & 163,53 & 15,25 & 50,98 & 478,58 & 83,25 & 102,33 & 474,61 \\
\hline Bufo spinosus & 29TNG43 & 101,00 & 137,51 & 85,64 & 40,89 & 4235,56 & 253,34 & 46,66 & 206,68 & 91,15 & 191,53 & 192,29 & 84,30 & 1342,99 & 195,19 & 21,10 & 50,03 & 532,19 & 103,16 & 118,92 & 527,01 \\
\hline Bufo spinosus & 29TNG44 & 100,00 & 130,60 & 84,27 & 40,42 & 4270,75 & 246,88 & 40,75 & 206,14 & 84,49 & 185,44 & 186,28 & 77,45 & 1431,34 & 214,47 & 24,88 & 49,83 & 567,90 & 115,32 & 129,11 & 563,75 \\
\hline Bufo spinosus & 29TNG45 & 101,00 & 142,30 & 82,14 & 40,1 & 4197,28 & 255,32 & 53,36 & 201,96 & 96,35 & 195,81 & 196,38 & 89,24 & 1323,49 & 199,84 & 23,13 & 49,47 & 24,75 & 106,82 & 122,21 & 513,46 \\
\hline \begin{tabular}{|l} 
Bufo spinosus \\
\end{tabular} & \begin{tabular}{|l|} 
29TNG46 \\
\end{tabular} & 101,00 & 143,29 & $\begin{array}{l}80,28 \\
80,4\end{array}$ & 39,9 & $\begin{array}{l}417,20 \\
4175,75 \\
\end{array}$ & 254,49 & $\begin{array}{ll}55,52 \\
5,50\end{array}$ & 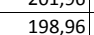 & 97,62 & 196,56 & 197 & 90,47 & 1332,85 & 205,65 & 24,82 & 49,20 & 528,98 & 110,47 & 125,52 & 515,79 \\
\hline Bufo spinosus & 29TNG48 & 100,00 & 128,16 & 78,41 & 39,08 & 4198,61 & 239,79 & 41,84 & 197,95 & 83,04 & 182,58 & 183,64 & 76,66 & 1502,07 & 239,28 & 32,79 & 48,85 & 595,05 & 133,86 & $\begin{array}{ll}147,87 \\
\end{array}$ & 587,57 \\
\hline Bufo spinosus & 29TNG49 & 101,00 & 125,64 & 77,56 & 38,85 & 4165,73 & 237,61 & 39,97 & 197,64 & 81,13 & 179,86 & 181,09 & 75,07 & 1508,88 & 237.59 & 34,66 & 47,92 & 594,55 & 138,65 & 153,11 & 584,39 \\
\hline Bufo spinosus & 29TNG50 & 101,00 & 140,38 & 92,44 & 41,82 & 4400,09 & 262,18 & 43,75 & 218,44 & 91,96 & 196,36 & 197,28 & 84,86 & 1243,80 & 168,81 & 16,54 & 50,69 & 492,03 & 88,82 & 104,69 & 487,03 \\
\hline Bufo spinosus & 29TNG51 & 100,00 & 138,16 & 91,40 & 41,4 & 4425,39 & 260,50 & 42,19 & 218 & 89,59 & 194,64 & 195,49 & 82,54 & 1274,66 & 176,06 & 17,98 & 50,29 & 503,34 & 93,86 & 109,01 & 498,60 \\
\hline \begin{tabular}{|l} 
Bufo spinosus \\
\end{tabular} & $\begin{array}{l}\text { 29TNG52 } \\
\text { 29TNG }\end{array}$ & 100,00 & $\begin{array}{l}130,10 \\
130,71\end{array}$ & $\begin{array}{l}1,40 \\
89,65\end{array}$ & 40 & $\begin{array}{l}442,39 \\
4468,95 \\
4\end{array}$ & 253,57 & $\begin{array}{l}4 L, 119 \\
35,99 \\
\end{array}$ & \begin{tabular}{|l|}
217,57 \\
217,5
\end{tabular} & 81,64 & 188,20 & 188,95 & 75,02 & 1357,70 & 191,48 & 21,14 & 49,95 & 535,88 & 104,88 & 117,86 & 532,10 \\
\hline Bufo spinosus & 29TNG53 & 101,00 & 131,96 & 89,04 & 40,50 & 4465,45 & 254,88 & 37,47 & 217,42 & 83,37 & 189,44 & 190,19 & 76,41 & 1345,19 & 193,52 & 21,98 & 49,53 & 529,65 & 106,91 & 119,50 & 523,62 \\
\hline Bufo spinosus & 29TNG54 & 101,00 & 107,50 & 82,47 & 38,62 & 4465,10 & 228,68 & 18,35 & 210,33 & 60,80 & $\mid 166,06$ & $\mid 167.06$ & 54,06 & 1555,27 & 221,33 & 30,16 & 48,53 & 611,15 & 134,21 & 142,65 & 608,70 \\
\hline Bufo spinosus & 29TNG55 & 100,00 & 132,57 & 86,93 & 39,88 & 4446,63 & 254,36 & 39,24 & 215,13 & 84,11 & 189,82 & 190,56 & 77,19 & 1347,31 & 201,06 & 24,82 & 48,65 & 528,58 & 114,33 & 126,30 & 517,21 \\
\hline Bufo spinosus & 29TNG56 & 101,00 & 134,95 & 86,64 & 39,84 & 4443,65 & 256,33 & 41,37 & 214,96 & 86,19 & 192,04 & 192,69 & 79,37 & 1329,41 & 202,14 & 25,73 & 48,28 & 520,27 & 115,85 & 126,77 & 506 \\
\hline \begin{tabular}{|l} 
Bufo spinosus \\
\end{tabular} & 29TNG58 & 99,00 & 113,23 & 81,48 & 38,81 & 4356,27 & 232,03 & 24,34 & 207,69 & 66,96 & 170,34 & 171,53 & 61,18 & 1517,29 & 227,58 & 34,32 & 47,03 & 591,85 & 141,42 & 152,52 & 583,34 \\
\hline Bufo spinosus & 29TNG59 & 100,00 & 113,55 & 80,92 & 38,72 & 4310,81 & 231,79 & 25,08 & 206,71 & 67,71 & 170,02 & 171,45 & 62,24 & 1509,61 & 226,36 & 35,67 & 46,38 & 586,61 & 144,05 & 155,97 & 575,97 \\
\hline Bufo spinosus & 29TNG60 & 100,00 & 134,74 & 95,32 & 41,24 & 644,93 & 263,68 & 35,02 & 228,66 & 83,36 & 194,34 & 195,08 & 76,56 & 1273,15 & 170,29 & 17,49 & 50,72 & 502,46 & 92,99 & 105,74 & 499,23 \\
\hline Bufo spinosus & 29TNG61 & 101,00 & 129,52 & 92,96 & 40,52 & 52,63 & 257,84 & 31,49 & 226,34 & 76,7 & 189 & 190 & 71, & 1320,79 & 179,13 & 19,68 & 50 & 520,45 & 100,31 & 111,37 & 517,43 \\
\hline Bufo spinosus & 29TNG62 & 101,00 & 115,32 & 87,95 & 39,30 & 4647,57 & 241,85 & 21,15 & 220,70 & 62,37 & 176,03 & 176,82 & 58,84 & 1450,71 & 198,80 & 24,52 & 49,68 & 571,37 & 116,97 & 125,53 & 570,44 \\
\hline
\end{tabular}




\begin{tabular}{|c|c|c|c|c|c|c|c|c|c|c|c|c|c|c|c|c|c|c|c|c|c|}
\hline TAXON & UTM & $\mathrm{km} 2$ & B101 & B102 & $\mathrm{BIO3}$ & BIO4 & BIO5 & B106 & B107 & B108 & 8109 & BIO10 & BIO11 & BIO12 & BIO13 & BIO14 & BIO15 & B1016 & B1017 & B1018 & B1019 \\
\hline Bufo spinosus & 29TNG63 & 100,00 & 123,83 & 90,23 & 39,73 & 4660,90 & 251,54 & 27,50 & 224,04 & 72,50 & 184,36 & 185,01 & 66,47 & 1369,05 & 192,82 & 23,31 & 49,05 & 536,57 & 111,71 & 121,10 & 531,94 \\
\hline Bufo spinosus & 29TNG64 & 101,00 & 110,77 & 85,49 & 38,75 & $\begin{array}{ll}4618,93 \\
\end{array}$ & 235,92 & 18,21 & 217,71 & 61,90 & 171,38 & 172,25 & 55,21 & \begin{tabular}{|l|}
1481,37 \\
\end{tabular} & 208,95 & 28,14 & 48,52 & 579,94 & 126,96 & 135,08 & 577,66 \\
\hline Bufo spinosus & 29TNG65 & 100,00 & 104,96 & 83,10 & 38,21 & 4573,78 & 228,97 & 14,35 & 214,62 & 57,06 & 165,27 & 166,23 & 50,52 & 1523,45 & 215,64 & 31,05 & 47,71 & 594,87 & 135,51 & 143,03 & 591,62 \\
\hline Bufo spinosus & 29TNG66 & 100,00 & 132,97 & 90,07 & 39,70 & 4650,79 & 259,97 & 35,22 & 224,75 & 81,72 & 193,13 & 193,56 & 75,17 & 1269,36 & 188,81 & 24,75 & 47,50 & 491,39 & 112,81 & 122,05 & 476,26 \\
\hline Bufo spinosus & 29TNG67 & 101,00 & 131,55 & 88,09 & 39,38 & \begin{tabular}{|l|l|}
4616,44 \\
\end{tabular} & 255,96 & 34,71 & 221,25 & 80,76 & \begin{tabular}{|l|l|}
191,40 \\
\end{tabular} & 191,92 & 74,53 & 1285,02 & \begin{tabular}{|l|l|}
193,17 \\
\end{tabular} & 26,55 & 47,19 & 496,80 & 116,35 & 126,10 & 482,80 \\
\hline Bufo spinosus & 29TNG68 & 101,00 & 125,16 & 85,59 & 38,95 & 4545,41 & 247,24 & 30,58 & 216,66 & 75,50 & 184,41 & 185,20 & 69,87 & 1345,60 & 201,85 & 29,79 & 46,67 & 519,66 & 125,28 & 137,12 & 507,16 \\
\hline Bufo spinosus & 29TNG70 & 100,00 & 125,96 & 95,39 & 40,34 & 4836,55 & 259,46 & 25,65 & 233,80 & 69,04 & \begin{tabular}{ll|l|}
188,61 \\
\end{tabular} & 189,35 & 66,06 & 1323,33 & 177,65 & 18,87 & 50,92 & 523,00 & 98,51 & 107,73 & 522,32 \\
\hline \begin{tabular}{|l} 
Bufo spinosus \\
\end{tabular} & 29TNG71 & 101,00 & 123,47 & 93,49 & 39,85 & 4824,53 & 255,95 & 24,26 & 231,69 & 67,47 & 186,21 & 186,93 & 64,12 & 1335,23 & 178,47 & 20,38 & 50,23 & 525,75 & \begin{tabular}{r|}
102,88 \\
\end{tabular} & 111,40 & 524,43 \\
\hline Bufo spinosus & 29TNG72 & 100,00 & 97,65 & 83,12 & 37,48 & 4745,83 & 225,53 & 6,75 & 218,78 & 42,20 & 160,59 & 161,38 & 41,58 & 1545,54 & 206,22 & 28,51 & 49,13 & 607,76 & 130,75 & 134,74 & 607,72 \\
\hline Bufo spinosus & 29TNG73 & 100,00 & 115,12 & 89,06 & 38,83 & 4792,36 & 245,33 & 18,81 & 226,53 & 61,56 & 177,89 & 178,53 & 57,06 & 1389,96 & 190,55 & 24,75 & 48,83 & 543,13 & 116,06 & 122,88 & 540,40 \\
\hline Bufo spinosus & 29TNG74 & 100,00 & 118,22 & 89,85 & 39,04 & 4792,53 & 248,44 & 20,96 & 227,47 & 66,63 & 181,05 & 181,57 & 60,02 & 1355,98 & 189,64 & 24,99 & 48,16 & 527,67 & 115,35 & 123,03 & 523,51 \\
\hline Bufo spinosus & 29TNG75 & 100,00 & 95,31 & 81,82 & 37,30 & 4670,94 & 221,61 & 5,29 & 216,32 & 47,01 & 157,29 & 158,27 & 40,48 & 1539,21 & 211,15 & 32,58 & 47,17 & 598,54 & 140,23 & 145,68 & 596,07 \\
\hline \begin{tabular}{|l} 
Bufo spinosus \\
\end{tabular} & 29TNG77 & 101,00 & 133,18 & 91,21 & 39,10 & 4819,46 & 261,81 & 31,66 & 230,15 & 79,49 & 195,82 & 196,10 & 73,70 & \begin{tabular}{|l|}
1193,18 \\
\end{tabular} & 176,81 & 24,51 & 46,56 & 456,50 & 108,58 & 116,42 & 442,62 \\
\hline Bufo spinosus & 29TNG80 & 101,00 & 112,87 & 91,32 & 38,75 & 4947,97 & 247,61 & 15,16 & 232,45 & 53,01 & 177,90 & 178,60 & 53,01 & 1400,14 & 192,11 & 21,42 & 51,11 & 556,51 & 107,68 & 112,99 & 556,51 \\
\hline Bufo spinosus & 29TNG81 & 99,00 & 115,24 & 91,50 & 38,82 & 4947,70 & 249,65 & 16,98 & 232,68 & 55,94 & 180,29 & 180,76 & 55,18 & 1364,75 & $\begin{array}{l}183,45 \\
\end{array}$ & 21,60 & 50,37 & 539,13 & 106,90 & 111,89 & 538,88 \\
\hline Bufo spinosus & 29TNG82 & 101,00 & 108,29 & 87,72 & 38,01 & 4896,41 & 240,41 & 12,73 & 227,68 & 49,93 & 172,98 & 173,49 & 49,60 & 1410,36 & 187,29 & 24,39 & 49,53 & 554,55 & 115,56 & 120,32 & 554,48 \\
\hline Bufo spinosus & 29TNG83 & 100,00 & 95,35 & 82,54 & 36,89 & 4825,88 & 224,96 & 4,18 & 220,77 & 39,97 & 159,66 & 160,33 & 38,78 & 1502,75 & 199,67 & 29,19 & 48,38 & 587,88 & 130,81 & 134,52 & 587,87 \\
\hline Bufo spinosus & 29TNG84 & 101,00 & 115,06 & 89,61 & 38,44 & 4900,82 & 247,18 & 17,13 & 230,05 & 62,29 & 179,62 & 180,01 & 55,89 & 1330,30 & 182,38 & 24,65 & 48,11 & 516,80 & 113,30 & 119,51 & 514,85 \\
\hline Bufo spinosus & 29TNG86 & 100,00 & 118,55 & 89,98 & 38,52 & 4887,39 & 249,84 & 19,15 & 230,69 & 65,38 & 182,86 & 183,30 & 59,50 & 1277,69 & 180,86 & 25,94 & 46,84 & 491,94 & 114,51 & 120,97 & 485,73 \\
\hline Bufo spinosus & 29TNG87 & 100,00 & 131,52 & 92,63 & 38,90 & 4978,81 & 263,13 & 27,19 & 235,94 & 75,96 & 196,55 & $\mid 196,79$ & 70,46 & 1135,81 & $\mid 164,80$ & 23,53 & 46,00 & 431,70 & 103,51 & 109,38 & 420,30 \\
\hline Bufo spinosus & 29TNG88 & 100,00 & 134,92 & 90,86 & 38,50 & 4962,84 & 263,78 & 30,42 & 233,36 & 79,33 & $\begin{array}{ll}199,65 \\
\end{array}$ & 199,84 & 74,12 & 1091,09 & 159,33 & 23,65 & 45,35 & 411,98 & 101,28 & \begin{tabular}{|l|}
106,87 \\
\end{tabular} & 399,33 \\
\hline \begin{tabular}{|l} 
Bufo spinosus \\
\end{tabular} & 29TNG90 & 100,00 & 120,45 & 96,51 & 39,18 & 5118,80 & 260,85 & 17,93 & 242,93 & 57,81 & 187,52 & 187,92 & 57,81 & $\begin{array}{l}1287,23 \\
\end{array}$ & 177,84 & 18,68 & 51,39 & 510,95 & 96,68 & 101,54 & 510,95 \\
\hline Bufo spinosus & 29TNG91 & 101,00 & 106,49 & 88,55 & 37,63 & 5026,95 & 242,03 & 9,90 & 232,12 & 46,30 & 173,06 & 173,50 & 46,30 & 1386,53 & 188,86 & 23,03 & 50,32 & 548,86 & 111,20 & 114,51 & 548,86 \\
\hline Bufo spinosus & 29TNG92 & 101,00 & 104,70 & 86,50 & 37,29 & 4987,78 & 238,55 & 9,44 & 229,12 & 45,29 & 170,90 & 171,31 & 45,29 & 1385,85 & 185,38 & 24,36 & 49,44 & 545,62 & 114,51 & 117,69 & 545,62 \\
\hline Bufo spinosus & 29TNG93 & 100,00 & 96,32 & 83,47 & 36,63 & 4929,91 & 228,39 & 3,62 & 224,77 & 39,17 & 162,07 & 162,53 & 38,30 & 1441,20 & 190,75 & 27,84 & 48,34 & 563,31 & 125,34 & 128,21 & 563,31 \\
\hline Bufo spinosus & 29TNG94 & 100,00 & 104,76 & 86,30 & 37,24 & 4947,62 & 237,78 & 9,36 & 228,42 & 50,88 & 170,56 & 170,87 & 45,91 & 1358,63 & 181,85 & 26,28 & 47,98 & 528,21 & 118,26 & 122,51 & 528,04 \\
\hline Bufo spinosus & 29TNG97 & 101,00 & 128,47 & 93,28 & 38,48 & 5077,27 & 262,36 & 22,92 & \begin{tabular}{|l|}
239,45 \\
23,4
\end{tabular} & $\begin{array}{l}71,720 \\
\end{array}$ & 194,96 & \begin{tabular}{|l|}
195,08 \\
\end{tabular} & 66,47 & \begin{tabular}{|l|l|}
1102,83 \\
\end{tabular} & 156,57 & 22,98 & 45,68 & 418,49 & 100,50 & $\begin{array}{l}103,93 \\
\end{array}$ & 409,70 \\
\hline Bufo spinosus & 29TNG98 & 101,00 & 137,22 & 92,45 & 37,87 & 5162,84 & 269,37 & 28,60 & 240,77 & 79,01 & 204,71 & 204,75 & 73,95 & 989,93 & 142,03 & 21,46 & 44,79 & 370,10 & 91,71 & 93,81 & 359,00 \\
\hline Bufo spinosus & 29TNG99 & 101,00 & 134,39 & 91,03 & 38,14 & 5016,64 & 264,07 & 28,52 & 235,55 & 77,88 & \begin{tabular}{|l|l|}
199,94 \\
\end{tabular} & 200,11 & 73,24 & 1026,37 & 147,59 & 23,51 & 44,20 & 384,14 & 97,82 & 102,91 & 372,22 \\
\hline Bufo spinosus & 29TNHOO & 16,00 & 147,29 & 59,00 & 38,48 & 3400,52 & 230,67 & 78,95 & 151,71 & 112,29 & 190,24 & 191,67 & 104,38 & 1225,90 & 174,48 & 26,95 & 46,81 & 491,57 & 111,81 & 134,71 & 450,57 \\
\hline Bufo spinosus & 29TNHO1 & 40,00 & 144,58 & 59,91 & 38,18 & 3389,01 & 229,52 & 75,00 & 154,52 & 110,27 & 186,96 & 189,12 & 101,96 & 1190,85 & 170,30 & 27,81 & 45,66 & 475,97 & 115,04 & 138,49 & 430,70 \\
\hline Bufo spinosus & 29TNHO3 & 72,00 & 140,28 & 62,04 & 38,15 & 3441,65 & 229,47 & 68,97 & \begin{tabular}{|l|}
160,50 \\
\end{tabular} & $\begin{array}{l}106,00 \\
\end{array}$ & 183,51 & 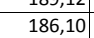 & 地, & \begin{tabular}{|l|l|}
1187,87 \\
\end{tabular} & 170,53 & $\begin{array}{l}29,84 \\
29,8\end{array}$ & $\begin{array}{ll}44,38 \\
44,38\end{array}$ & 470,94 & $\begin{array}{l}121,46 \\
\end{array}$ & $\begin{array}{l}144,58 \\
14,5\end{array}$ & 424,12 \\
\hline Bufo spinosus & 29TNH05 & 99,00 & 130,21 & 64,82 & 38,15 & 3496,92 & 225,11 & 57,22 & 167,89 & 96,18 & 174,38 & 177,55 & 87,89 & 1236,42 & 176,17 & 33,76 & 42,70 & 484,35 & 135,19 & 157,82 & 436,14 \\
\hline Bufo spinosus & 29TNH06 & 101,00 & 130,82 & 64,73 & 38,44 & 3443,75 & 224,58 & 58,12 & 166,45 & 97,50 & 174,06 & 177,48 & 89,05 & \begin{tabular}{|l|}
1201,01 \\
\end{tabular} & 168,81 & 33,56 & 41,93 & 468,53 & 134,43 & 157,51 & 418,84 \\
\hline Bufo spinosus & 29TNH07 & 101,00 & 135,56 & 63,77 & 38,93 & 3340,52 & 225,72 & 63,71 & 162,01 & 103,33 & 176,99 & 180,78 & 94,75 & 1124,75 & 155,33 & 31,65 & 41,14 & 437,83 & 128,10 & 152,02 & 386,81 \\
\hline Bufo spinosus & 29TNH08 & 81,00 & 139,86 & 62,83 & 39,45 & 3245,91 & 226,50 & 68,94 & 157,55 & 108,65 & 179,71 & 183,68 & 99,93 & 1066,54 & 146,17 & 30,11 & 40,82 & 414,13 & 122,84 & 147,26 & 363,35 \\
\hline Bufo spinosus & 29TNHO9 & $\begin{array}{l}1,00 \\
36,00\end{array}$ & $\begin{array}{l}13,00 \\
140,84\end{array}$ & $\begin{array}{l}2,305 \\
62,53\end{array}$ & $\begin{array}{l}3,49 \\
39,81\end{array}$ & 3197,92 & 225,89 & \begin{tabular}{|l|l|}
70,47 \\
70,
\end{tabular} & $\begin{array}{l}51,30 \\
155,42\end{array}$ & $\begin{array}{l}110,27 \\
110,\end{array}$ & 179,88 & \begin{tabular}{|l|}
184,00 \\
184,0
\end{tabular} & \begin{tabular}{|l|}
101,47 \\
101
\end{tabular} & $\begin{array}{l}100,36,33 \\
104,\end{array}$ & $\mid$ & $\begin{array}{l}30,11 \\
29,83\end{array}$ & $\begin{array}{ll}40,06 \\
40,06\end{array}$ & $\begin{array}{l}414,15 \\
404,94\end{array}$ & $\begin{array}{l}121,86 \\
121\end{array}$ & $\begin{array}{l}146,56 \\
146,5 \\
\end{array}$ & 354,73 \\
\hline Bufo spinosus & 29TNH10 & 61,00 & 146,39 & 60,06 & 37,91 & 3519,36 & 232,27 & 76,11 & 156,16 & 109,72 & 190,75 & 192,23 & 101,94 & 1275,06 & 185,37 & 28,73 & 46,99 & 509,45 & 116,28 & 138,47 & 472,93 \\
\hline Bufo spinosus & 29TNH11 & 40,00 & 146,34 & 60,45 & 37,82 & 3518,47 & 233,20 & 75,68 & 157,53 & 109,97 & 190,80 & 192,50 & 102,30 & \begin{tabular}{|l|}
1241,93 \\
\end{tabular} & 180,28 & 28,89 & 46,24 & 494,43 & 116,57 & 139,20 & 455,66 \\
\hline Bufo spinosus & 29TNH12 & 80,00 & 143,85 & 61,84 & 37,90 & 3527,18 & 233,33 & 72,06 & 161,27 & 107,84 & 188,46 & 190,54 & 99,85 & 1225,40 & 177,83 & 29,87 & 45,22 & 485,94 & 119,86 & 142,71 & 444,59 \\
\hline Bufo spinosus & 29TNH13 & 101,00 & 134,28 & 65,16 & 37,83 & 3618,45 & 230,51 & 60,17 & 170,34 & 97,99 & 180,32 & 182,90 & 90,05 & 1306,88 & 191,55 & 33,69 & 44,61 & 514,94 & 132,93 & 154,63 & 475,23 \\
\hline \begin{tabular}{|l} 
Bufo spinosus \\
\end{tabular} & 29TNH14 & 100,00 & 133,17 & $\begin{array}{l}6,01 \\
66,01\end{array}$ & 37,97 & 3607,29 & 230,45 & 58,59 & 171,85 & 97,29 & 178,97 & 181,81 & 89,22 & 1284,45 & 186,08 & 34,10 & 43,76 & 503,35 & $\begin{array}{ll}134,48 \\
\end{array}$ & 156,51 & 461,63 \\
\hline \begin{tabular}{|l} 
Bufo spinosus \\
\end{tabular} & 29TNH15 & 101,00 & 131,49 & 66,60 & 38,05 & 3585,35 & 229,44 & 56,70 & 172,74 & 96,06 & 176,92 & 180,04 & 88,01 & 1269,31 & 181,60 & 34,69 & 42,87 & 494,86 & 136,62 & 158,82 & 451,55 \\
\hline Bufo spinosus & 29TNH16 & 100,00 & 129,53 & 66,99 & 38,23 & 3553,02 & 227,55 & 54,86 & 172,69 & 94,82 & \begin{tabular}{ll|}
174,47 \\
\end{tabular} & 177,92 & 86,69 & 1258,25 & 177,72 & 35,39 & 41,99 & 487,99 & 139,03 & 161,37 & 443,71 \\
\hline Bufo spinosus & 29TNH18 & 99,00 & 138,18 & 64,56 & 39,53 & 3317,71 & 227,61 & 66,00 & 161,61 & 106,04 & 179,15 & 183,05 & 97,47 & \begin{tabular}{|l|}
1106,27 \\
\end{tabular} & 150,80 & 31,46 & 40,66 & 427,34 & 126,22 & 50,06 & 380,75 \\
\hline Bufo spinosus & 29TNH19 & 64,00 & 140, & 63,56 & 39,93 & 3223,95 & 227,1 & $\begin{array}{l}0,70,77 \\
\end{array}$ & 157,34 & $\begin{array}{l}109,84 \\
\end{array}$ & 180,43 & 184,43 & \begin{tabular}{|l|}
101,17 \\
\end{tabular} & 1059,58 & $\begin{array}{l}143,29 \\
143\end{array}$ & 30,28 & 40,01 & 408,67 & 122,48 & $\begin{array}{l}146,75 \\
140,0\end{array}$ & 361,63 \\
\hline Bufo spinosus & 29TNH2O & 100,00 & 140,04 & 63,04 & 37,60 & 3718,64 & 232,42 & $\begin{array}{lll}66,87 \\
\end{array}$ & 165,55 & 101,01 & 187,74 & 188,88 & 93,81 & 1395,50 & 212,46 & 32,4 & 47,52 & 556,28 & 127,28 & $\begin{array}{l}147,77 \\
\end{array}$ & 529,68 \\
\hline Bufo spinosus & 29TNH21 & 101,00 & 143,07 & 62,99 & 37,73 & 3680,33 & 234,96 & 69,79 & 165,16 & 104,60 & 190,07 & 191,50 & 97,21 & 1313,98 & 195,41 & 31,39 & 46,36 & 520,52 & $\mid 123,46$ & 145,06 & 488,04 \\
\hline Bufo spinosus & 29TNH22 & 98,00 & 142,56 & 64,37 & 37,83 & 3673,06 & 236,45 & 68,27 & 168,18 & 104,48 & 189,39 & 191,20 & 97,00 & 1282,23 & 189,18 & 31,60 & 45,59 & 505,62 & 124,06 & 445,95 & 470,89 \\
\hline Bufo spinosus & 29TNH23 & 100,00 & 140,69 & 65,81 & 37,91 & 3675,02 & 236,85 & 65,44 & 171,42 & 102,96 & 187,49 & 189,76 & 95,38 & 1268,02 & 185,23 & 32,23 & 44,81 & 97,28 & 126,63 & 148,60 & 460,75 \\
\hline \begin{tabular}{|l} 
Bufo spinosus \\
\end{tabular} & \begin{tabular}{|l|}
$29 T N H 24$ \\
29TN
\end{tabular} & $\begin{array}{l}101,00 \\
100\end{array}$ & $\frac{144}{139}$ & $\begin{array}{l}3,01 \\
66,85 \\
\end{array}$ & $\begin{array}{l}1,14 \\
38,14\end{array}$ & 3657,53 & 237,04 & $\begin{array}{l}3,44 \\
63,64 \\
\end{array}$ & $\begin{array}{l}17,44 \\
173,40 \\
\end{array}$ & 102,32 & 185,96 & 188,60 & 94,54 & 1247,55 & 180,10 & 32,75 & 43,93 & 486,78 & 128,33 & 150,59 & 448,39 \\
\hline Bufo spinosus & 29TNH25 & 101,00 & 134,22 & 68,49 & 38,02 & 3679,17 & 235,07 & 57,13 & 177,94 & 97,31 & 180,95 & 184,04 & 89,61 & \begin{tabular}{|l|}
1277,87 \\
\end{tabular} & 182,81 & 34,92 & 42,98 & 495,32 & 135,80 & 157,76 & 456,50 \\
\hline Bufo spinosus & 29TNH26 & 101,00 & 129,38 & 69,40 & 38,11 & 3658,94 & 231,39 & 52,28 & 179,10 & 93,09 & 175,81 & $\mid 179,24$ & 85,42 & 1295,09 & $\mid 183,16$ & 36,61 & 42,07 & 499,18 & $\mid 141,72$ & 163,38 & 459,85 \\
\hline Bufo spinosus & 29TNH27 & 100,00 & 129,17 & 68,83 & 38,77 & 3574,89 & 228,79 & 53,35 & 175,45 & 94,07 & 174,25 & 178,02 & 86,21 & 1259,95 & 175,62 & 36,27 & 41,11 & 484,03 & 140,94 & 162,85 & 443,5 \\
\hline Bufo spinosus & 29TNH28 & 101,00 & 138,15 & 66,22 & 39,76 & 3371,93 & 229,55 & 64,80 & 164,75 & 105,12 & 179,97 & 183,87 & 96,86 & 1124,24 & 152,92 & 32,00 & 40,55 & 432,17 & 126,98 & 150,29 & 389 \\
\hline \begin{tabular}{|l} 
Bufo spinosus \\
\end{tabular} & 29 TNH29 & 39,00 & 138,94 & 65,60 & 40,11 & 3300,89 & 227,96 & 66,33 & 161,63 & $\begin{array}{l}106,78 \\
\end{array}$ & 179,56 & 183,64 & 98,28 & 1096,42 & 147,44 & 31,46 & 39,97 & 420,50 & 125,51 & 149,00 & 378,18 \\
\hline Bufo spinosus & 29TNH33 & 101,00 & 140,89 & 68,88 & 37,78 & 3814,67 & 241,68 & 61,72 & 179,97 & 101,09 & 189,69 & 191,86 & 94,03 & 1286,69 & 188,93 & 32,96 & 44,87 & 500,80 & 127,77 & 149,09 & 469,14 \\
\hline Bufo spinosus & 29TNH34 & 100,00 & 137,98 & 70,61 & 37,67 & 3829,36 & 242,21 & 57,25 & 184,96 & 98,68 & 186,96 & 189,58 & 91,35 & \begin{tabular}{|l|}
1297,37 \\
\end{tabular} & 188,15 & 34,52 & 43,99 & 501,72 & 132,89 & 154,22 & 468,82 \\
\hline Bufo spinosus & 29TNH35 & 101,00 & 132,84 & 72,28 & 37,68 & 3838,58 & 240,40 & 50,95 & 189, & 94,15 & 182,04 & 185 & 86, & 1326,75 & 190,10 & 36,64 & 10 & 509,81 & 140,19 & 161,30 & 476 \\
\hline Bufo spinosus & 29TNH36 & 101,00 & 129,84 & 72,27 & 38,05 & 3774,65 & 236,38 & 49,07 & 187,31 & 92,04 & 178,03 & 181,37 & 84,62 & 1317,82 & 86,12 & 37,45 & 42,10 & 504,27 & 143,19 & 164,27 & 469, \\
\hline
\end{tabular}




\begin{tabular}{|c|c|c|c|c|c|c|c|c|c|c|c|c|c|c|c|c|c|c|c|c|c|}
\hline TAXON & UTM & $\mathrm{km} 2$ & BIO1 & B102 & $B 103$ & BIO4 & B105 & B106 & B107 & B108 & B109 & B1010 & BIO11 & BIO12 & BIO13 & BIO14 & BIO15 & B1016 & B1017 & B1018 & 81019 \\
\hline Bufo spinosus & 29TNH37 & 101,00 & 127,82 & 71,68 & 38,69 & 3685,61 & 231,99 & 48,85 & 183,14 & 91,12 & 174,58 & 178,31 & 83,80 & 1296,43 & 180,66 & 37,63 & 41,15 & 494,57 & 144,29 & 165,38 & 458,65 \\
\hline Bufo spinosus & 29TNH38 & 100,00 & 130,25 & 69,90 & 39,58 & 3529,25 & 228,82 & 54,21 & 174,62 & 95,40 & 174,66 & 178,55 & 87,84 & 1225,75 & 167,86 & 35,84 & 40,29 & 467,01 & $\begin{array}{ll}138,82 \\
\end{array}$ & $\begin{array}{ll}160,53 \\
\end{array}$ & 429,77 \\
\hline Bufo spinosus & 29TNH39 & 66,00 & 137,72 & 67,21 & 40,50 & 3335,65 & 228,27 & 64,37 & 163,90 & 104,80 & 178,85 & \begin{tabular}{|l|l|}
182,93 \\
\end{tabular} & 96,84 & $\begin{array}{l}1111,28 \\
\end{array}$ & $\begin{array}{l}148,76 \\
\end{array}$ & 32,07 & 39,82 & 423,65 & 126,76 & $\begin{array}{ll}149,62 \\
\end{array}$ & 385,50 \\
\hline Bufo spinosus & 29TNH41 & 99,00 & 124,50 & 76,53 & 38,28 & 4087,47 & 236,72 & 39,20 & 197,52 & 81,28 & 177,72 & $\begin{array}{l}179,47 \\
\end{array}$ & 75,52 & 1486,55 & 227,30 & 37,16 & 46,14 & 578,92 & 144,31 & 160,36 & 561,84 \\
\hline Bufo spinosus & 29TNH42 & 100,00 & 132,13 & 74,96 & 37,98 ] & 4042,12 & 242,29 & 47,15 & 195,13 & 89,34 & 184,54 & 186,42 & 83,32 & 1407,67 & 212,28 & 35,99 & 45,57 & 545,52 & 138,23 & 156,49 & 523,46 \\
\hline Bufo spinosus & 29TNH43 & 101,00 & 140,12 & 72,87 & \begin{tabular}{|l|l|}
37,98 \\
\end{tabular} & 3953,22 & 246,17 & 56,53 & 189,64 & 98,34 & 190,91 & 193,06 & 91,84 & 1293,19 & 190,16 & 33,42 & 44,74 & 499,02 & 128,68 & 149,06 & 471,50 \\
\hline Bufo spinosus & $29 \mathrm{TNH} 44$ & 99,00 & 134,34 & 75,62 & 37,50 & 4016,51 & 247,01 & 47,82 & 199,18 & 92,76 & 186,25 & 188,81 & 86,23 & 1354,82 & 196,79 & 36,70 & 43,95 & 518,70 & 139,25 & 159,31 & 490,94 \\
\hline Bufo spinosus & 29TNH45 & 100,00 & 133,85 & 75,41 & 37,71 & 3948,35 & 245,54 & \begin{tabular}{|l|l|}
48,08 \\
\end{tabular} & 197,45 & 93,39 & $\begin{array}{l}184,49 \\
\end{array}$ & $\begin{array}{l}187,60 \\
\end{array}$ & 86,62 & \begin{tabular}{|l|}
1327,24 \\
\end{tabular} & \begin{tabular}{ll|}
189,42 \\
\end{tabular} & 36,86 & 42,92 & 505,97 & $\begin{array}{ll}139,84 \\
\end{array}$ & 160,39 & 476,27 \\
\hline Bufo spinosus & 29TNH46 & 100,00 & 133,61 & 74,17 & 38,49 & 3807,22 & 241,03 & 50,75 & $\begin{array}{l}190,27 \\
\end{array}$ & 94,78 & 182,11 & 185,54 & 87,87 & $\begin{array}{l}1277,88 \\
\end{array}$ & $\begin{array}{l}179,38 \\
\end{array}$ & 36,11 & 41,96 & 486,11 & \begin{tabular}{|l|l|}
137,91 \\
\end{tabular} & $\begin{array}{ll}158,76 \\
\end{array}$ & 454,57 \\
\hline Bufo spinosus & 29TNH47 & 101,00 & 129,79 & 73,67 & 39,01 & 3726,10 & 235,43 & $\begin{array}{ll}48,83 \\
\end{array}$ & 186,61 & 92,02 & 177,26 & 180,80 & 85,29 & 1276,81 & \begin{tabular}{|l|l|}
177,09 \\
\end{tabular} & 37,02 & 41,03 & 484,24 & 141,41 & 162,11 & 451,80 \\
\hline Bufo spinosus & 29TNH48 & 99,00 & 130,64 & 71,90 & 39,94 & 3580,81 & 231,16 & 52,91 & 178,25 & 94,65 & \begin{tabular}{|l|}
175,87 \\
\end{tabular} & 179,58 & 87,62 & 1222,47 & $\begin{array}{l}166,76 \\
\end{array}$ & 35,87 & 40,09 & 463,07 & 138,08 & 159,15 & 429,36 \\
\hline Bufo spinosus & 29TNH49 & 99,00 & 138,44 & 68,49 & \begin{tabular}{ll|}
41,26 \\
\end{tabular} & 3334,69 & 228,73 & 64,79 & 163,94 & 105,25 & 179,57 & \begin{tabular}{|l|l|}
183,74 \\
\end{tabular} & 97,48 & 1091,49 & 144,73 & 31,59 & 39,26 & 413,86 & 124,45 & $\begin{array}{ll}146,72 \\
\end{array}$ & 379,25 \\
\hline Bufo spinosus & 29TNH50 & 101,00 & 115,81 & 80,39 & 38,78 & 4246,05 & 232,99 & 27,72 & 205,27 & 70,53 & 171,45 & 172,95 & 65,34 & 1493,95 & 224,52 & 36,57 & 45,84 & 578,78 & 145,19 & 158,22 & 565,92 \\
\hline Bufo spinosus & 29TNH53 & 101,00 & 136,65 & 77,41 & 38,54 & 4049,65 & 247,69 & 49,24 & 198,45 & 93,11 & 188,96 & 191,10 & 87,81 & 1301,01 & 191,18 & 34,07 & 44,30 & 497,36 & 130,92 & 149,73 & 473,88 \\
\hline Bufo spinosus & 29TNH54 & 100,00 & 137,07 & 77,10 & 38,52 & 3993,02 & 247,76 & 50,07 & 197,69 & $\begin{array}{l}94,62 \\
\end{array}$ & 188,50 & $\begin{array}{l}191,06 \\
\end{array}$ & 89,04 & $\begin{array}{l}1279,09 \\
\end{array}$ & \begin{tabular}{|l|l|}
184,57 \\
\end{tabular} & 34,47 & 43,47 & 486,83 & $\begin{array}{ll}131,67 \\
\end{array}$ & $\begin{array}{ll}151,22 \\
\end{array}$ & 461,07 \\
\hline Bufo spinosus & 29TNH55 & 101,00 & 132,55 & 77,84 & $\begin{array}{l}38,55 \\
\end{array}$ & 3952,98 & 244,93 & 45,58 & 199,35 & 91,08 & 183,42 & 186,37 & 85,47 & $\begin{array}{l}1311,62 \\
\end{array}$ & $\begin{array}{l}186,78 \\
\end{array}$ & 36,64 & 42,66 & $\begin{array}{ll}496,98 \\
\end{array}$ & $\begin{array}{l}138,85 \\
\end{array}$ & $\begin{array}{l}158,30 \\
\end{array}$ & 470,35 \\
\hline Bufo spinosus & 29TNH56 & 101,00 & 131,83 & 76,71 & 38,90 & 3858,57 & 241,48 & 46,94 & 194,54 & 91,76 & 181,28 & $\begin{array}{l}184,54 \\
\end{array}$ & 85,86 & $\begin{array}{l}1281,64 \\
\end{array}$ & \begin{tabular}{|l|}
179,77 \\
\end{tabular} & 36,54 & 41,76 & $\begin{array}{l}484,46 \\
\end{array}$ & $\begin{array}{l}138,73 \\
\end{array}$ & $\begin{array}{ll}158,58 \\
\end{array}$ & 456,12 \\
\hline Bufo spinosus & 29TNH57 & 100,00 & 129,49 & 75,79 & 39,47 & 3760,92 & 236,42 & 46,84 & $\mid \begin{array}{l}189,58 \\
\end{array}$ & 90,69 & 177,58 & $\mid \begin{array}{l}181,00 \\
\end{array}$ & 84,70 & 1264,25 & \begin{tabular}{|l|l|}
174,91 \\
\end{tabular} & $\mid 36,84$ & 40,79 & 476,82 & 140,23 & $\mid 160,14$ & 447,24 \\
\hline Bufo spinosus & 29TNH58 & 101,00 & 136,43 & 72,36 & 40,72 & 3553,90 & \begin{tabular}{|l|}
234,25 \\
\end{tabular} & 58,55 & 175,70 & 100,03 & 181,02 & 184,78 & 93,25 & 1141,24 & 154,04 & 33,02 & 39,87 & 430,70 & 128,01 & 149,16 & 399,31 \\
\hline Bufo spinosus & 29TNH59 & 98,00 & 140,77 & 69,91 & 41,80 & 3381,91 & 231,80 & 66,23 & 165,56 & 106,31 & 182,51 & 186,54 & $\begin{array}{ll}99,09 \\
\end{array}$ & $\begin{array}{l}1058,70 \\
\end{array}$ & \begin{tabular}{ll|}
139,63 \\
\end{tabular} & 30,57 & 39,04 & 399,41 & 120,42 & 142,28 & 367,09 \\
\hline Bufo spinosus & 29TNH60 & 100,00 & 118,94 & 83,20 & 38,98 & 4353,18 & 238,48 & 27,84 & 210,64 & 71,76 & 175,90 & $\begin{array}{l}177,36 \\
\end{array}$ & 67,11 & $\begin{array}{l}1409,20 \\
\end{array}$ & 210,16 & 34,42 & 45,45 & 541,88 & 137,56 & 150,38 & 528,85 \\
\hline \begin{tabular}{|l|} 
Bufo spinosus \\
\end{tabular} & 29TNH61 & 101,00 & 119,95 & 82,67 & 39,13 & 4262,34 & \begin{tabular}{|l|l|}
238,07 \\
\end{tabular} & 29,73 & 208,34 & 73,64 & 175,70 & $\begin{array}{l}177,29 \\
\end{array}$ & 69,46 & 1400,04 & 207,77 & 35,43 & 44,95 & \begin{tabular}{|l|l|}
536,38 \\
\end{tabular} & $\begin{array}{ll}139,36 \\
\end{array}$ & \begin{tabular}{|l|l|}
153,01 \\
\end{tabular} & 521,48 \\
\hline Bufo spinosus & 29TNH63 & 100,00 & 127,69 & 81,29 & 39,80 & 4046,96 & 241,44 & 39,35 & 202,09 & 83,45 & 180,25 & 182,44 & 79,89 & 1331,88 & $\begin{array}{l}194,42 \\
\end{array}$ & 35,67 & 43,65 & 505,65 & 137,02 & $\begin{array}{l}153,53 \\
\end{array}$ & 485,67 \\
\hline Bufo spinosus & 29TNH64 & 101,00 & 133,27 & 80,09 & 39,73 & 3986,03 & 244,84 & 45,28 & 199,56 & 89,76 & 184,79 & 187,14 & 85,81 & 1267,58 & 182,28 & 34,57 & 42,88 & 479,13 & 132,16 & 150,26 & 456,27 \\
\hline Bufo spinosus & 29TNH66 & 101,00 & 129,58 & 78,71 & \begin{tabular}{|l|l|}
39,87 \\
\end{tabular} & 3857,86 & 239,18 & 44,01 & 195,17 & 88,47 & 179,21 & 182,21 & 83,81 & 1260,61 & 176,24 & 36,25 & 41,21 & 474,02 & 137,71 & 156,45 & 447,92 \\
\hline Bufo spinosus & 29TNH67 & 100,00 & 126,03 & 77,79 & 40,01 & 3800,28 & 234,24 & 42,32 & 191,92 & 86,01 & 174,86 & 178,03 & 81,18 & \begin{tabular}{|l|}
1264,47 \\
\end{tabular} & 174,59 & 37,33 & 40,38 & 474,41 & 141,64 & 160,31 & 446,85 \\
\hline Bufo spinosus & 29TNH68 & 101,00 & 134,85 & 74,68 & \begin{tabular}{|l|l|}
40,77 \\
\end{tabular} & 3631,25 & 235,43 & 54,60 & 180,83 & 96,81 & 180,73 & 184,20 & 90,95 & 1139,74 & $\begin{array}{l}153,76 \\
\end{array}$ & 33,40 & 39,51 & 427,46 & 128,78 & 149,04 & 397,92 \\
\hline Bufo spinosus & 29TNH69 & 95,00 & 138,76 & 72,50 & 41,54 & 3500,36 & 233,97 & 61,39 & 172,57 & 102,55 & 182,52 & 186,15 & 95,99 & 1070,00 & 141,51 & 31,45 & 38,83 & 401,11 & 122,61 & 143,65 & 370,04 \\
\hline Bufo spinosus & 29TNH70 & 101,00 & 121,99 & 85,74 & 39,01 & 4488,05 & 244,15 & 27,49 & 216,65 & 72,54 & 180,79 & \begin{tabular}{|l|l|}
181,86 \\
\end{tabular} & 68,41 & \begin{tabular}{|l|}
1311,15 \\
\end{tabular} & \begin{tabular}{|l|l|}
193,43 \\
\end{tabular} & 31,86 & 44,90 & 500,27 & 128,43 & 141,17 & 487,17 \\
\hline Bufo spinosus & 29TNH72 & 100,00 & 120,88 & 84,11 & $\begin{array}{ll}39,92 \\
\end{array}$ & 4229,67 & 238,74 & 30,06 & 208,68 & 74,28 & 176,17 & \begin{tabular}{ll|}
177,82 \\
\end{tabular} & 71,15 & $\begin{array}{l}1325,34 \\
\end{array}$ & 192,94 & 34,76 & 43,67 & \begin{tabular}{|l|l|}
502,72 \\
\end{tabular} & 135,75 & $\begin{array}{ll}149,76 \\
\end{array}$ & 486,41 \\
\hline Bufo spinosus & 29TNH73 & 101,00 & 126,68 & 83,29 & 40,45 & 4067,70 & 240,51 & 37,36 & 203,15 & 81,38 & 179,54 & $\begin{array}{l}181,47 \\
\end{array}$ & 78,91 & $\begin{array}{l}1275,06 \\
\end{array}$ & 184,29 & 34,28 & 43,04 & 481,31 & $\begin{array}{l}132,43 \\
\end{array}$ & $\begin{array}{l}148,01 \\
\end{array}$ & 462,41 \\
\hline Bufo spinosus & 29TNH77 & 100,00 & 122,67 & 79,66 & 40,36 & 3855,55 & 232,35 & 37,61 & 194,73 & 81,38 & 172,28 & 175,29 & 77,27 & 1252,18 & 172,13 & 37,44 & 39,90 & 467,53 & 142,08 & 159,52 & 441,33 \\
\hline Bufo spinosus & 29TNH78 & 100,00 & 125,41 & 78,00 & \begin{tabular}{l|l|l}
40,75 \\
\end{tabular} & 3774,11 & \begin{tabular}{|l|}
231,87 \\
\end{tabular} & 42,35 & 189,52 & 85,45 & 173,73 & 176,95 & 80,70 & 1203,79 & 163,01 & 36,49 & 39,10 & 448,58 & 138,77 & 157,20 & 420,48 \\
\hline Bufo spinosus & 29TNH79 & 101,00 & 127,95 & 76,35 & \begin{tabular}{l|l|l}
40,99 \\
\end{tabular} & 3677,10 & 230,73 & 46,82 & 183,90 & 89,37 & \begin{tabular}{ll|}
174,66 \\
\end{tabular} & 178,06 & 84,01 & $\begin{array}{l}1160,08 \\
\end{array}$ & $\begin{array}{l}154,75 \\
\end{array}$ & 35,67 & 38,39 & 431,51 & 135,97 & 155,20 & 401,73 \\
\hline Bufo spinosus & 29TNH84 & 100,00 & $\begin{array}{ll}127,03 \\
\end{array}$ & 83,97 & \begin{tabular}{ll|l}
40,56 \\
\end{tabular} & 4104,26 & 241,13 & 36,61 & 204,52 & 81,13 & 180,29 & 182,31 & 78,65 & $\begin{array}{l}1198,23 \\
\end{array}$ & 169,39 & 33,26 & 41,66 & 448,57 & $\begin{array}{l}128,19 \\
\end{array}$ & \begin{tabular}{|l|l|}
144,12 \\
\end{tabular} & 428,34 \\
\hline Bufo spinosus & 29TNH86 & 101,00 & 115,94 & 82,36 & \begin{tabular}{l|l|}
40,29 \\
\end{tabular} & 4041,46 & 230,32 & 28,34 & 201,98 & 72,10 & 168,44 & \begin{tabular}{ll|}
170,87 \\
\end{tabular} & 68,70 & $\begin{array}{l}1270,44 \\
\end{array}$ & $\begin{array}{l}175,37 \\
\end{array}$ & \begin{tabular}{l|l|l}
37,83 \\
\end{tabular} & 39,99 & 473,87 & $\begin{array}{ll}143,78 \\
\end{array}$ & $\begin{array}{ll}159,12 \\
\end{array}$ & 450,46 \\
\hline Bufo spinosus & 29TNH87 & 100,00 & 120,24 & 81,21 & 40,53 & 3948,06 & 231,67 & 33,64 & 198,03 & 77,44 & 171,24 & 173,84 & 73,78 & 1223,72 & 167,01 & 37,04 & 39,34 & 454,95 & 140,50 & 157,10 & 429,47 \\
\hline Bufo spinosus & 29TNH88 & 101,00 & 120,39 & 79,96 & 40,75 & 3879,56 & 229,84 & 35,39 & 194,45 & 78,82 & 170,37 & 173,09 & 74,51 & 1209,88 & 163,08 & 37,42 & 38,62 & 448,59 & 141,75 & 158,84 & 421,24 \\
\hline Bufo spinosus & 29TNH89 & 100,00 & 118,54 & 78,92 & \begin{tabular}{l|l|l}
40,75 \\
\end{tabular} & 3828,43 & 226,61 & 34,99 & 191,62 & 77,91 & 167,77 & 170,85 & 73,56 & 1211,67 & $\begin{array}{l}161,56 \\
\end{array}$ & 38,36 & 37,93 & 48,19 & 144,90 & 62,40 & 419,19 \\
\hline Bufo spinosus & 29TNH91 & 101,00 & 118,31 & 88,03 & 39,00 & 4616,37 & 244,04 & 21,27 & 222,77 & 67,07 & 178,96 & 179,91 & 63,44 & 1205,83 & 171,39 & 30,83 & 43,10 & 454,83 & 123,06 & 135,26 & 441,25 \\
\hline Bufo spinosus & 29TNH93 & 100,00 & 120,09 & 86,50 & \begin{tabular}{ll|l}
39,86 \\
\end{tabular} & 4380,79 & 240,84 & 26,01 & 214,82 & 71,35 & 177,34 & $\begin{array}{l}178,84 \\
\end{array}$ & $\begin{array}{l}68,32 \\
\end{array}$ & $\begin{array}{l}1192,53 \\
\end{array}$ & $\begin{array}{l}167,75 \\
\end{array}$ & 32,62 & 41,76 & $\begin{array}{ll}446,68 \\
\end{array}$ & 127,21 & \begin{tabular}{|l|l|}
141,04 \\
\end{tabular} & 429,09 \\
\hline Bufo spinosus & 29TNH97 & 100,00 & 122,66 & 82,42 & \begin{tabular}{ll|}
40,76 \\
\end{tabular} & 4034,11 & 235,08 & \begin{tabular}{l|l}
34,51 \\
\end{tabular} & 200,57 & 78,55 & 174,71 & \begin{tabular}{ll|}
177,24 \\
\end{tabular} & 74,77 & 1155,42 & $\begin{array}{l}156,30 \\
\end{array}$ & 35,05 & 38,88 & 427,68 & $\begin{array}{ll}133,61 \\
\end{array}$ & $\begin{array}{ll}150,03 \\
\end{array}$ & 402,29 \\
\hline Bufo spinosus & 29TNH98 & 101,00 & 121,27 & 81,36 & \begin{tabular}{|l|l|}
40,79 \\
\end{tabular} & 3959,32 & 232,09 & 34,47 & 197,61 & 78,34 & 172,28 & $\begin{array}{l}174,98 \\
\end{array}$ & 74,29 & 1159,91 & 155,18 & 36,09 & 38,11 & 28,21 & 37,12 & 85 & 401,04 \\
\hline Bufo spinosus & 29TNH99 & 100,00 & 121,31 & 80,24 & 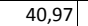 & 3889,75 & 230,11 & 36,08 & 194,03 & 79,50 & 171,34 & $\mid 174,06$ & 75,10 & 1152,55 & $\mid 152,47$ & 36,63 & 37,43 & 24,45 & 138,80 & 156,01 & 395,57 \\
\hline Bufo spinosus & 29TNJ40 & 18,00 & 140,90 & 67,00 & 41,90 & 3225,38 & 226 & 68,62 & 158,34 & 109,17 & 180,34 & 184,66 & 101,00 & 1040,24 & $\begin{array}{l}135,86 \\
\end{array}$ & 30,03 & 39,00 & 394,31 & 119,52 & 142,10 & 359,59 \\
\hline Bufo spinosus & 29TNJ50 & 35,00 & 140,32 & 69,33 & 42,05 & 3314,98 & 229,41 & 66,90 & 162,51 & 106,79 & 181,08 & 185,25 & 99,56 & $\begin{array}{l}1041,52 \\
\end{array}$ & $\begin{array}{l}135,65 \\
\end{array}$ & $\begin{array}{l}30,56 \\
\end{array}$ & 38,54 & 392,02 & 120,49 & 142,51 & 359,29 \\
\hline Bufo spinosus & 29TNJ51 & 48,00 & 137,32 & 69,06 & 42,18 & 3289,25 & 226,38 & 64,58 & 161,79 & $\begin{array}{l}104,32 \\
\end{array}$ & 177,74 & $\begin{array}{l}182,08 \\
\end{array}$ & 96,99 & $\begin{array}{l}1053,97 \\
\end{array}$ & $\begin{array}{l}136,43 \\
\end{array}$ & 32,00 & 37,81 & 395,00 & 125,51 & $\begin{array}{ll}147,40 \\
\end{array}$ & 360,88 \\
\hline Bufo spinosus & 29TNJ60 & 66,00 & 138,42 & 71,58 & 41,92 & 3427,75 & 231,34 & 62,74 & 168,59 & 103,12 & 181,05 & 184,86 & 96,42 & 1051,61 & \begin{tabular}{|l|l|}
137,08 \\
\end{tabular} & 31,55 & 38,09 & \begin{tabular}{|l|l|}
393,14 \\
\end{tabular} & 123,14 & 4,39 & 360,99 \\
\hline Bufo spinosus & 29TNJ61 & 82,00 & 138,78 & 70,46 & 42,23 & 3350,75 & 229,34 & 64,74 & $\begin{array}{l}164,60 \\
\end{array}$ & 104,63 & $\begin{array}{l}180,27 \\
\end{array}$ & 184,22 & 97,70 & $\begin{array}{l}1035,07 \\
\end{array}$ & \begin{tabular}{|l|l|}
133,93 \\
\end{tabular} & 31,48 & 37,61 & 386,40 & 123,21 & $\begin{array}{l}144,96 \\
\end{array}$ & 352,94 \\
\hline Bufo spinosus & 29 TNJ6 & 77,00 & 138 & 69,71 & \begin{tabular}{ll|}
42,42 \\
\end{tabular} & 3311,98 & 227,83 & 65,35 & 162,48 & 104,89 & 179,31 & 183,41 & 97,82 & $\begin{array}{l}1028,44 \\
\end{array}$ & 132,74 & 31,91 & 37,02 & 383,10 & 124,55 & $\begin{array}{ll}146,55 \\
\end{array}$ & 348,41 \\
\hline Bufo spinosus & \begin{tabular}{|l|l|} 
29TNJ70 \\
\end{tabular} & 100,00 & 127,38 & 75,21 & 41,21 & 3607,29 & 228,03 & 47,99 & 180,04 & 89,86 & 172,98 & 176,58 & 84,18 & $\begin{array}{l}1147,25 \\
\end{array}$ & 151,21 & 35,90 & 37,79 & 425,82 & 137,08 & 156,62 & 394,60 \\
\hline Bufo spinosus & 29TNJ71 & 101,00 & 129,37 & 73,82 & 41,56 & 3531,06 & 227,00 & 51,70 & 175,30 & 92,88 & 173,72 & 177,51 & 86,87 & 1112,83 & 144,77 & 35,26 & 37,04 & 412,33 & 135,00 & 155,22 & 379,66 \\
\hline Bufo spinosus & 29TNJ72 & 101,00 & 133,10 & 72,15 & 42,08 & 3432,01 & 226,92 & 57,35 & 169,57 & 97,92 & 175,90 & 179,71 & 91 & 1067,50 & \begin{tabular}{|l|l|}
137,07 \\
\end{tabular} & 34,02 & 36,65 & 394 & 131,15 & 152,16 & 360, \\
\hline Bufo spinosus & $29 \mathrm{TN}$ & 59,00 & 136 & 70,98 & 42 & 336 & 227 & 61,57 & 165,76 & $\begin{array}{ll}101,66 \\
\end{array}$ & 1777,81 & 181,81 & 95,03 & 1033,72 & \begin{tabular}{|l|l|}
133,07 \\
\end{tabular} & 33,30 & 36,18 & 381,82 & 128,65 & 150,28 & 346 \\
\hline Bufo spinosus & 29TNJ80 & 100,00 & 122,17 & 77,45 & \begin{tabular}{|l|l|}
40,97 \\
\end{tabular} & 3732,97 & 226,80 & 40,28 & 186,52 & 82,75 & 169,73 & 173,01 & 77,78 & $\begin{array}{l}1168,66 \\
\end{array}$ & \begin{tabular}{|l|l|}
153,90 \\
\end{tabular} & 37,45 & 37,24 & 431,41 & 141,75 & 160,10 & 400,68 \\
\hline Bufo spinosus & 29TNJ81 & 100,00 & $\begin{array}{ll}123,92 \\
\end{array}$ & 76,14 & \begin{tabular}{l|l|}
41,25 \\
\end{tabular} & 3653,63 & 225,79 & 43,65 & 182,14 & 85,62 & 170,26 & \begin{tabular}{ll|}
173,78 \\
\end{tabular} & 80,28 & 1142,11 & 148,61 & 37,10 & 36,76 & 20,70 & $\begin{array}{l}140,61 \\
\end{array}$ & 159,65 & 388,46 \\
\hline Bufo spinosus & 29TNJ82 & 100,00 & 130,16 & 74,18 & $41,87 \mid$ & 3535,37 & 227,38 & 52,20 & 175,18 & 93,44 & 174,59 & 178,24 & 87,60 & 1077,42 & 138,13 & 35,11 & 36,12 & 396,33 & 134,04 & 154,27 & 362,51 \\
\hline Bufo sp & & 101,00 & 13 & 72,98 & 10 & 179,40 & 225, & 53,4 & 172 & 94,38 & 9 & & 88 & 072,64 & 137,44 & 35 & & 39 & 68 & 156,29 & 35 \\
\hline Bufo spinosus & 29TNJ84 & 31,00 & 128,75 & 72,62 & 42,0 & 3463,58 & 223,64 & 52,51 & 171,13 & 93,16 & 172,00 & 175,75 & 86,98 & 1079,11 & \begin{tabular}{|l|l|}
138,18 \\
\end{tabular} & 36,49 & 35,25 & 395,05 & 138,64 & 159,35 & 358,69 \\
\hline Bufo spinosus & 29TNJ91 & 101,00 & 119,44 & 78,01 & 41,06 & 3765,45 & 224,70 & 37,15 & 187,55 & 79,81 & 167,50 & \begin{tabular}{ll|}
170,67 \\
\end{tabular} & 74,70 & 1154,74 & 149,70 & 38,31 & 36,17 & 423,15 & 144,50 & 162,42 & 391,05 \\
\hline
\end{tabular}




\begin{tabular}{|c|c|c|c|c|c|c|c|c|c|c|c|c|c|c|c|c|c|c|c|c|c|}
\hline TAXON & UTM & $\mathrm{km2}$ & BIO1 & B102 & $\mathrm{BIO3}$ & B104 & B105 & B106 & B107 & B108 & B109 & BIO10 & BIO11 & B1012 & BIO13 & BIO14 & BIO15 & BIO16 & BIO17 & BIO18 & BlO19 \\
\hline Bufo spinosus & 29TNJ92 & 99,00 & 122,03 & 76,58 & 41,33 & 3678,40 & 224,31 & 41,38 & 182,93 & 83,46 & 168,71 & 172,09 & 78,17 & $\begin{array}{r}1126,56 \\
\end{array}$ & 144,34 & 37,91 & 35,67 & 411,83 & 143,04 & 161,75 & 378,12 \\
\hline Bufo spinosus & 29TNJ93 & 92,00 & 133,74 & 73,98 & \begin{tabular}{|l|l|}
41,97 \\
\end{tabular} & 3525,79 & 229,64 & 55,54 & \begin{tabular}{ll|l}
174,11 \\
\end{tabular} & $\begin{array}{l}96,84 \\
\end{array}$ & $\begin{array}{l}177,87 \\
\end{array}$ & \begin{tabular}{ll|}
181,48 \\
\end{tabular} & \begin{tabular}{l|l}
91,05 \\
9
\end{tabular} & 1025,37 & 131,62 & 34,11 & 35,33 & $\begin{array}{l}374,76 \\
\end{array}$ & $\begin{array}{l}130,39 \\
\end{array}$ & 150,86 & 339,41 \\
\hline Bufo spinosus & 29TNJ94 & 26,00 & 139,35 & 72,33 & 42,44 & 3429,44 & 231,53 & 63,05 & \begin{tabular}{ll|l}
168,49 \\
\end{tabular} & \begin{tabular}{l|l|l|l|}
103,72 \\
\end{tabular} & \begin{tabular}{ll|l}
181,98 \\
\end{tabular} & \begin{tabular}{l|l|}
185,72 \\
\end{tabular} & \begin{tabular}{l|l|}
97,65 \\
\end{tabular} & \begin{tabular}{l|l|}
980,72 \\
\end{tabular} & 127,09 & 32,65 & 35,09 & 358,56 & 125,33 & \begin{tabular}{|l|l|}
146,77 \\
\end{tabular} & 322,12 \\
\hline Bufo spinosus & 29TPE05 & 101,00 & 126,58 & 86,64 & 35,51 & 5336,17 & 268,16 & 27,58 & 240,57 & 62,81 & $\begin{array}{l}198,19 \\
19\end{array}$ & \begin{tabular}{|l|l|}
198,24 \\
\end{tabular} & 62,81 & 1256,14 & 190,94 & 11,95 & 56,14 & 514,50 & 76,92 & 76,93 & 514,50 \\
\hline Bufo spinosus & 29TPE06 & 100,00 & 135,12 & 91,66 & 36,74 & 5328,00 & 278,88 & 32,86 & 246,03 & 70,31 & 205,51 & 205,99 & 70,31 & 1164,94 & 175,36 & 11,03 & 55,58 & \begin{tabular}{|l|l|}
475,27 \\
\end{tabular} & $\begin{array}{ll}73,03 \\
\end{array}$ & 73,29 & 475,27 \\
\hline Bufo spinosus & 29TPE07 & 101,00 & 141,90 & 96,20 & 37,94 & 5321,55 & 287,46 & 36,82 & 250,64 & 76,22 & 211,36 & 212,15 & 76,22 & 1091,34 & 162,71 & 10,26 & 55,15 & 443,22 & 69,66 & \begin{tabular}{|l|l|}
70,37 \\
\end{tabular} & 443,22 \\
\hline Bufo spinosus & 29TPE09 & 100,00 & 139,40 & 97,45 & 38,44 & 5293,84 & 284,18 & 33,86 & 250,32 & 73,69 & 208,42 & 209,06 & 73,69 & 1121,11 & 167,79 & 10,81 & 55,10 & \begin{tabular}{|l|l|}
454,88 \\
\end{tabular} & 72,02 & 73,49 & 454,88 \\
\hline Bufo spinosus & 29TPE14 & 101,00 & 143,73 & 93,64 & 36,32 & 5535,10 & 293,33 & 39,08 & 254,25 & 76,45 & 217,15 & 217,53 & $\begin{array}{l}76,45 \\
\end{array}$ & 1033,99 & 153,73 & 9,37 & 55,26 & \begin{tabular}{l|l}
420,45 \\
\end{tabular} & \begin{tabular}{l|l}
64,75 \\
\end{tabular} & \begin{tabular}{ll|}
64,79 \\
\end{tabular} & 420,45 \\
\hline Bufo spinosus & 29TPE15 & 99,00 & 129,26 & 87,30 & 35,12 & 5467,14 & 273,53 & 28,66 & 244,87 & 63,75 & \begin{tabular}{l|l|}
202,52 \\
\end{tabular} & 202,53 & \begin{tabular}{ll|l}
63,75 \\
\end{tabular} & \begin{tabular}{ll|}
1199,32 \\
\end{tabular} & 181,90 & 11,09 & 55,96 & $\begin{array}{l}490,30 \\
\end{array}$ & 73,40 & 73,40 & 490,30 \\
\hline Bufo spinosus & 29TPE16 & 100,00 & 89,37 & 73,79 & 32,38 & 5308,01 & 222, 281 _ & $-1,45$ & 224,25 & 29,35 [ & 162,23 & 162,23 & 29,35 & 1627,76 & 249,32 & 17,25 & 56,10 & 663,37 & 100,90 & 100,90 & 663,37 \\
\hline Bufo spinosus & 29TPE17 & 100,00 & 105,52 & 77,94 & 33,30 & 5333,84 & 240,87 & 11,12 & 229,75 & $\begin{array}{ll}43,46 \\
\end{array}$ & \begin{tabular}{|l|l|}
177,77 \\
\end{tabular} & \begin{tabular}{|l|l|}
177,83 \\
\end{tabular} & 43,46 & 1488,39 & 230,10 & 14,23 & 56,81 & \begin{tabular}{ll|l}
610,46 \\
\end{tabular} & 89,59 & 89,68 & 610,46 \\
\hline Bufo spinosus & 29TPE18 & 101,00 & 138,06 & 94,81 & \begin{tabular}{|c|}
37,17 \\
\end{tabular} & 5436,40 & 284,38 & 32,78 & \begin{tabular}{|l|l|}
251,60 \\
\end{tabular} & \begin{tabular}{ll|}
71,02 \\
\end{tabular} & 209,38 & 209,73 & 71,02 & $\begin{array}{ll}1101,46 \\
\end{array}$ & 165,42 & 10,36 & 55,31 & \begin{tabular}{|l|l|}
447,47 \\
\end{tabular} & \begin{tabular}{l|l}
70,05 \\
\end{tabular} & \begin{tabular}{l|l}
70,65 \\
\end{tabular} & 447,47 \\
\hline Bufo spinosus & 29TPE19 & 101,00 & 138,73 & 96,68 & 37,72 & 5420,53 & 285,38 & 32,53 & 252,85 & 71,60 & 209,64 & \begin{tabular}{l|l|}
209,95 \\
\end{tabular} & 71,60 & $\begin{array}{l}1094,17 \\
\end{array}$ & 164,30 & 10,36 & 55,31 & \begin{tabular}{|l|l|}
444,18 \\
\end{tabular} & \begin{tabular}{l|l|}
69,92 \\
\end{tabular} & 70,79 & 444,18 \\
\hline Bufo spinosus & 29TPE23 & 100,00 & 136,93 & 89,41 & 34,98 & 5655,55 & 286,47 & 34,08 & \begin{tabular}{|l|l|}
252,39 \\
\end{tabular} & 69,31 & 212,77 & 212,88 & 69,31 & 1072,25 & \begin{tabular}{l|l}
160,25 \\
\end{tabular} & 9,60 & 55,52 & $\begin{array}{ll}436,33 \\
\end{array}$ & 65,86 & 65,86 & 436,33 \\
\hline Bufo spinosus & 29TPE24 & 100,00 & 142,68 & 92,77 & \begin{tabular}{l|l|}
35,65 \\
\end{tabular} & 5654,12 & 293,58 & \begin{tabular}{l|l}
37,45 \\
\end{tabular} & \begin{tabular}{|l|l|}
256,12 \\
\end{tabular} & 74,19 & 217,73 & 218,05 & 74,19 & 1014,30 & 150,67 & 8,95 & 55,21 & \begin{tabular}{ll|l}
411,38 \\
\end{tabular} & 63,29 & 63,31 & 411,38 \\
\hline Bufo spinosus & 29TPE25 & 101,00 & 137,34 & 90,80 & 35,35 & 5606,22 & 285,74 & 33,34 & 252,40 & 69,51 & 211,78 & 212,03 & 69,51 & 1075,73 & 161,29 & 9,71 & 55,46 & 437,30 & \begin{tabular}{|l|l}
66,83 \\
\end{tabular} & \begin{tabular}{|l|l|}
66,87 \\
\end{tabular} & 437,30 \\
\hline Bufo spinosus & 29TPE26 & 101,00 & 103,49 & 76,74 & 32,49 & 5450,47 & 240,55 & $\begin{array}{l}9,06 \\
9\end{array}$ & 231,49 & 40,44 & $\begin{array}{l}177,45 \\
\end{array}$ & $\begin{array}{l}177,47 \\
\end{array}$ & 40,44 & 1460,65 & 224,47 & 13,97 & 56,51 & 598,38 & 87,92 & 88,13 & 598,38 \\
\hline Bufo spinosus & 29TPE27 & 100,00 & 106,99 & 77,23 & 32,68 & 5450,44 & 243,96 & \begin{tabular}{|l|l|}
11,69 \\
\end{tabular} & 232,27 & 43,10 & $\begin{array}{ll}180,52 \\
\end{array}$ & 180,54 & 43,10 & 1421,80 & 219,17 & 13,32 & 56,76 & 583,80 & 85,34 & 86,46 & 583,80 \\
\hline Bufo spinosus & 29TPE28 & 100,00 & 115,82 & 82,63 & 34,00 & 5469,42 & 255,98 & \begin{tabular}{l|l}
17,15 \\
\end{tabular} & 238,83 & 50,50 & \begin{tabular}{ll|}
188,84 \\
\end{tabular} & \begin{tabular}{|l|l|}
188,97 \\
\end{tabular} & 50,50 & 1311,44 & 200,81 & 12,45 & 56,23 & \begin{tabular}{|l|l|}
537,03 \\
\end{tabular} & 80,49 & \begin{tabular}{l|l}
82,35 \\
\end{tabular} & 537,03 \\
\hline Bufo spinosus & 29TPE33 & 101,00 & 151,94 & 96,18 & 35,97 & 5812,66 & 307,44 & 43,36 & 264,08 & 84,32 & 228,71 & 229,21 & 81,3 & \begin{tabular}{|l|l|}
887,47 \\
\end{tabular} & 129,32 & 7,58 & 54, & \begin{tabular}{|l|}
356,64 \\
\end{tabular} & 56,06 & 56,28 & 356,61 \\
\hline Bufo spinosus & 29TPE35 & 100,00 & 142,56 & 93,42 & 35,63 & 5737,22 & 294,59 & 35,97 & 258,62 & \begin{tabular}{|l|l|}
72,78 \\
\end{tabular} & 218,54 & 218,67 & 72,78 & 976,71 & 144,52 & 8,80 & 54,84 & 394,12 & 61,76 & 61,99 & 394,12 \\
\hline Bufo spinosus & 29TPE36 & 101,00 & 139,74 & 92,73 & 35,61 & 5699,14 & 290,19 & 33,56 & 256,64 & \begin{tabular}{l|l}
70,23 \\
\end{tabular} & $\begin{array}{l}215,06 \\
\end{array}$ & 215,18 & 70,23 & 1004,28 & 149,39 & 9,13 & \begin{tabular}{|l|l|}
54,98 \\
\end{tabular} & $\begin{array}{l}405,67 \\
\end{array}$ & \begin{tabular}{l|l|l}
63,55 \\
\end{tabular} & 64,08 & 405,67 \\
\hline Bufo spinosus & 29TPE37 & 100,00 & 126,44 & 86,62 & 34,39 & 5632,12 & 272,12 & 24,14 & 247,98 & 58,40 & \begin{tabular}{|l|l|}
201,32 \\
\end{tabular} & 201,39 & 58,40 & $\begin{array}{ll}1136,45 \\
\end{array}$ & 171,51 & 10,64 & \begin{tabular}{|l|l|}
55,48 \\
\end{tabular} & \begin{tabular}{|l|l|}
461,98 \\
\end{tabular} & 70,81 & 73,01 & 461,98 \\
\hline Bufo spinosus & 29TPE38 & 101,00 & 108,42 & 77,78 & 32,55 & 5536,88 & 247,27 & 11,75 & 235,51 & 42,64 & \begin{tabular}{|l|l|}
182,53 \\
\end{tabular} & \begin{tabular}{|l|l|}
182,68 \\
\end{tabular} & 42,64 & 1323,69 & 202,22 & 12,65 & 56,09 & 541,51 & 81,32 & \begin{tabular}{|l|l|}
87,37 \\
\end{tabular} & 541,51 \\
\hline Bufo spinosus & 29TPE39 & 99,00 & 129,36 & 90,95 & 35,62 & 5612,20 & 276,53 & 24,79 & 251,73 & 60,76 & 203,41 & \begin{tabular}{|l|}
203,57 \\
\end{tabular} & \begin{tabular}{ll|l}
60,76 \\
\end{tabular} & \begin{tabular}{ll|l}
1096,85 \\
\end{tabular} & 165,15 & 10,54 & 55,2 & 444,89 & 69,91 & 71,83 & 444,89 \\
\hline Bufo spinosus & 29TPE43 & 101,00 & 153,35 & 97,14 & 35,97 & 5887,56 & 310,18 & 43,60 & 266,59 & 89,12 & 231,20 & 231,48 & 81,69 & 837,38 & 120,72 & 7,00 & $\begin{array}{l}53,85 \\
\end{array}$ & \begin{tabular}{|l|l|}
334,35 \\
\end{tabular} & 53,38 & 53,65 & 333,63 \\
\hline Bufo spinosus & 29TPE44 & 100,00 & 149,48 & 96,03 & 35,86 & 5860,33 & 304,97 & \begin{tabular}{ll|}
40,37 \\
\end{tabular} & 264,60 & 84,59 & 226,95 & 227,18 & 78,09 & 871,44 & 126,58 & 7,52 & 54,06 & 348,36 & 55,63 & 55,78 & 347,93 \\
\hline Bufo spinosus & 29TPE45 & 101,00 & 142,38 & 93,54 & 35,41 & 5824,43 & 295,68 & 34,92 & 260,76 & 74,84 & 219,54 & 219,65 & 71,49 & $\begin{array}{l}934,96 \\
\end{array}$ & 137,33 & 8,42 & \begin{tabular}{l|l|l|}
54,35 \\
\end{tabular} & \begin{tabular}{ll|}
374,92 \\
\end{tabular} & 59,48 & 59,90 & 374,91 \\
\hline Bufo spinosus & 29TPE48 & 99,00 & 117,54 & 82,71 & 33,32 & 5674,60 & 261,50 & 16,91 & 244,60 & 48,96 & \begin{tabular}{|l|l|}
192,78 \\
\end{tabular} & 193,24 & 48,96 & 1155,77 & 173,94 & 11,18 & \begin{tabular}{l|l}
55,15 \\
\end{tabular} & 468,54 & 73,04 & 77,68 & 468,54 \\
\hline Bufo spinosus & 29TPE49 & 101,00 & 125,55 & 88,94 & 34,86 & 5693,66 & 273,09 & 21,39 & 251,70 & \begin{tabular}{|l|l|}
56,06 \\
\end{tabular} & 200,71 & 201,07 & 56,06 & 1071,79 & 160,32 & 10,53 & 54,81 & 432,91 & \begin{tabular}{l|l|l|}
69,15 \\
\end{tabular} & 71,71 & 432,91 \\
\hline Bufo spinosus & 29TPE53 & 100,00 & 151,91 & 97,36 & \begin{tabular}{l|l|}
35,85 \\
\end{tabular} & 5953,50 & 309,70 & \begin{tabular}{l|l}
41,55 \\
\end{tabular} & 268,15 & 87,23 & \begin{tabular}{|l|}
230,81 \\
\end{tabular} & 231,01 & 79,58 & 808,77 & 115,52 & 6,97 & 53,33 & 321,81 & 52,04 & 52,23 & 319,62 \\
\hline Bufo spinosus & 29TPE54 & 100,00 & 147,75 & 95,98 & 35,62 & 5933,51 & 304,19 & 38,06 & 266,13 & 83,16 & 226,32 & 226,50 & 75,69 & \begin{tabular}{l|l|}
844,05 \\
\end{tabular} & 121,51 & 7,38 & 53,61 & 335,96 & 54,66 & 54,79 & 334,47 \\
\hline Bufo spinosus & 29TPE55 & 100,00 & 139,99 & 93,16 & 35,09 & 5892,53 & 294,01 & 32,20 & 261,81 & 76,16 & 218,11 & 218,19 & 68,40 & 909,11 & 132,39 & 8,41 & 53,90 & 362,66 & 58,54 & 59,38 & 361,92 \\
\hline Bufo spinosus & 29TPE56 & 101,00 & 128,25 & 88,22 & 34,20 & 5835,14 & 278,60 & 23,79 & 254,82 & 62,95 & 205,80 & 206,08 & 57,84 & 1007,41 & 148,40 & 9,62 & \begin{tabular}{l|l}
54,15 \\
\end{tabular} & 403,27 & \begin{tabular}{|l|l|}
64,49 \\
\end{tabular} & 67,35 & 403,21 \\
\hline Bufo spinosus & 29TPE57 & 100,00 & 122,18 & 85,75 & 33,73 & 5797,09 & 270,24 & 19,26 & 250,98 & 53,93 & \begin{tabular}{|l|l|}
199,19 \\
\end{tabular} & \begin{tabular}{|l|l|}
199,57 \\
\end{tabular} & 52,20 & \begin{tabular}{|l|l|}
1057,68 \\
\end{tabular} & 156,75 & 10,24 & 54,34 & $\begin{array}{l}424,65 \\
\end{array}$ & 67,76 & 71,56 & 424,64 \\
\hline Bufo spinosus & 29TPE58 & 101,00 & 120,47 & 85,76 & 33,81 & 5774,86 & 268,03 & \begin{tabular}{l|l|}
17,55 \\
\end{tabular} & 250,48 & 51,08 & \begin{tabular}{|l|l|}
196,97 \\
\end{tabular} & \begin{tabular}{|l|l|l|}
197,58 \\
\end{tabular} & 50,51 & 1064,41 & 157,89 & 10,49 & 54,30 & $\begin{array}{l}427,55 \\
\end{array}$ & 68,80 & 72,51 & 427,55 \\
\hline Bufo spinosus & 29TPE63 & 100,00 & 147,31 & 96,56 & 35,56 & 6005,60 & 305,46 & \begin{tabular}{|l|l}
37,25 \\
\end{tabular} & 268,21 & 82,40 & 227,14 & 227,18 & 74,60 & 805,58 & 114,23 & 7,23 & 52,82 & 319,18 & \begin{tabular}{c|}
52,55 \\
\end{tabular} & 52,87 & 315,84 \\
\hline Bufo spinosus & 29TPE64 & 101,00 & 148,18 & 97,18 & 35,78 & 5989,67 & 305,84 & 37,38 & 268,45 & \begin{tabular}{l|l|}
82,93 \\
\end{tabular} & 227,58 & 227,62 & 75,21 & 797,19 & 113,21 & 7,17 & 52,86 & 315,68 & 52,29 & 52,49 & 312,48 \\
\hline Bufo spinosus & 29TPE65 & 100,00 & 129,91 & 90,14 & 34,26 & 5929,70 & 283,01 & 23,91 & 259,10 & 66,46 & \begin{tabular}{|l|l|}
208,92 \\
\end{tabular} & 209,16 & \begin{tabular}{|l|l|}
58,67 \\
\end{tabular} & 944,84 & 136,77 & 9,21 & 53,2 & 375,78 & 1,54 & \begin{tabular}{l|l}
3,95 \\
\end{tabular} & 373,87 \\
\hline Bufo spinosus & 29TPE66 & 100,00 & 121,79 & 86,97 & 33,72 & 5881,62 & 272,26 & \begin{tabular}{|l|l|}
17,83 \\
\end{tabular} & 254,43 & 59,20 & 200,18 & 200,57 & 51,21 & 1009,52 & 147,16 & 10,10 & 53,46 & 402,21 & 65,82 & 69,68 & 400,97 \\
\hline Bufo spinosus & 29TPE67 & 101,00 & 125,29 & 89,10 & 34,18 & 5888,96 & 276,66 & \begin{tabular}{ll|}
19,84 \\
\end{tabular} & \begin{tabular}{|l|l|}
256,83 \\
\end{tabular} & \begin{tabular}{ll|l}
61,99 \\
\end{tabular} & 203,34 & 203,90 & 54,13 & $\begin{array}{l}971,07 \\
9\end{array}$ & 141,31 & 9,83 & \begin{tabular}{ll|}
53,26 \\
\end{tabular} & 386,21 & 64,13 & 66,99 & 385,15 \\
\hline Bufo spinosus & 29TPE68 & 99,00 & 124,21 & 89,65 & 34,41 & $\begin{array}{l}5871,67 \\
\end{array}$ & 275,38 & 18,51 & 256,87 & 60,36 & 201,86 & 202,53 & 53,08 & $\begin{array}{l}971,17 \\
9\end{array}$ & 141,44 & 9,89 & 53,21 & \begin{tabular}{l|l|}
386,12 \\
\end{tabular} & 64,70 & 67,43 & 385,41 \\
\hline Bufo spinosus & 29TPE73 & 100,00 & 150,30 & 98,84 & 35,77 & 6062,09 & 310,71 & 38,27 & 272,44 & \begin{tabular}{l|l|l}
84,43 \\
\end{tabular} & 230,77 & 230,80 & 76,58 & $\begin{array}{ll}739,65 \\
\end{array}$ & \begin{tabular}{ll|}
102,88 \\
\end{tabular} & 6,62 & \begin{tabular}{|l|l|l|}
51,89 \\
\end{tabular} & 290,90 & \begin{tabular}{ll|}
49,06 \\
\end{tabular} & 49,23 & 285,78 \\
\hline Bufo spinosus & 29TPE75 & 99,00 & 135,54 & 94,15 & 34,92 & 6008,58 & 292,03 & 26,54 & 265,49 & $\begin{array}{l}70,70 \\
\end{array}$ & 215,39 & 215,63 & 62,8 & 847,52 & \begin{tabular}{l|l|}
119,95 \\
\end{tabular} & 8,43 & 52,10 & 334,35 & 6,87 & 58,58 & 330,22 \\
\hline $\begin{array}{l}\text { Bufo spinosus } \\
\end{array}$ & 29TPE76 & 101,00 & 116,20 & 87,38 & 33,60 & 5936,45 & 267,97 & 12,02 & 255,95 & 53,37 & 195,55 & 196,01 & 45,46 & 998,94 & 143,22 & 10,53 & 52,42 & \begin{tabular}{|l|l|}
395,43 \\
\end{tabular} & 67,06 & 71,63 & 392,21 \\
\hline Bufo spinosus & 29TPE77 & 100,00 & 122,37 & 90,04 & 34,30 & 5945,46 & 275,26 & 16,19 & 259,07 & 58,62 & 201,30 & 201,94 & 50,7 & 938,22 & 134,22 & 9,98 & 52,23 & \begin{tabular}{l|l|}
370,92 \\
\end{tabular} & 63,72 & \begin{tabular}{ll|l}
66,87 \\
\end{tabular} & 367,88 \\
\hline Bufo spinosus & 29TPE78 & 101,00 & 123,45 & 91,55 & 34,80 & 5941,90 & 276,94 & \begin{tabular}{l|l}
16,45 \\
\end{tabular} & \begin{tabular}{|l|l|}
260,49 \\
\end{tabular} & \begin{tabular}{|l|l}
59,43 \\
\end{tabular} & 202,15 & \begin{tabular}{|l|l|}
202,87 \\
\end{tabular} & 51,50 & \begin{tabular}{|l|l|}
917,39 \\
\end{tabular} & \begin{tabular}{|l|l|}
131,03 \\
\end{tabular} & 9,84 & 52,04 & 362,22 & 63,19 & \begin{tabular}{l|l|l}
65,75 \\
\end{tabular} & 359,37 \\
\hline Bufo spinosus & 29TPE79 & 99,00 & 124,77 & 93,29 & 35,09 & 5934,79 & 279,08 & 16,71 & 262,37 & \begin{tabular}{|l|l|}
60,47 \\
\end{tabular} & \begin{tabular}{|l|}
203,18 \\
\end{tabular} & 204,08 & 52,60 & 896,75 & 127,89 & 9,73 & 51,82 & 353,66 & 62,66 & 64,50 & 351,17 \\
\hline Bufo spinosus & 29TPE85 & 101,00 & 126,42 & 93,40 & 34,64 & 6044,36 & 283,86 & 18,13 & 265,73 & 61,90 & 207,17 & 207,49 & 54,01 & 867,71 & 120,90 & 9,38 & 51,16 & 339,84 & 60,08 & 62,81 & 334,06 \\
\hline $\begin{array}{l}\text { Bufo spinosus } \\
\end{array}$ & 29TPE86 & 100,00 & 117,60 & 90,52 & 34,02 & 6008,49 & 272,64 & 11,27 & 261,36 & 53,76 & 197,92 & 198,45 & 45,95 & 928,26 & 130,25 & 10,32 & 51,22 & 364,31 & 64,53 & 68,45 & 358,97 \\
\hline Bufo spinosus & 29TPE87 & 100,00 & 124,01 & 93,18 & 34,67 & 6018,82 & 280,22 & 15,67 & 264,55 & \begin{tabular}{l|l}
59,25 \\
\end{tabular} & 203,85 & 204,61 & 51,39 & 866,80 & \begin{tabular}{|l|}
121,19 \\
\end{tabular} & 9,70 & \begin{tabular}{|l|l|}
50,97 \\
\end{tabular} & \begin{tabular}{|l|}
339,73 \\
\end{tabular} & \begin{tabular}{|c|}
60,96 \\
\end{tabular} & 63,50 & 334,53 \\
\hline Bufo spinosus & 29TPE89 & 101,00 & 124,13 & 95,26 & 35,25 & 5995,30 & 280,81 & \begin{tabular}{l|l|l}
14,85 \\
\end{tabular} & 265,97 & 59,14 & 203,39 & 204,31 & 51,43 & 843,46 & 117,63 & 9,60 & \begin{tabular}{|l|l|l|}
50,67 \\
\end{tabular} & 330,28 & \begin{tabular}{|l|l|l|}
60,83 \\
\end{tabular} & 62,57 & 325,45 \\
\hline Bufo spinosus & 29TPE95 & 100,00 & 133,71 & 97,47 & 35,24 & 6122,54 & 294,97 & 22,26 & 272,71 & 67,52 & 215,21 & 215,54 & 59, & 762,82 & 103,58 & 8,3 & $49, \mathrm{~s}, \quad>\quad>$ & 295,84 & 54, & 55,87 & 288,21] \\
\hline Bufo spinosus & 29TPE96 & 100,00 & 12. & 94,40 & 34,79 & 6085,22 & 280 & 12,66 & $267, \varepsilon$ & 56, & 202. & 203,40 & 48 & 839,86 & 114 & 9,92 & 49 & 326,27 & 60,70 & 63,49 & $31 \varepsilon$ \\
\hline Bufo spinosus & 29TPE98 & 100,00 & 128,77 & 98,03 & 35,72 & 6080,10 & 288,79 & 17,22 & \begin{tabular}{|l|l|}
271,56 \\
\end{tabular} & 62,50 & \begin{tabular}{|l|}
209,12 \\
\end{tabular} & 209,95 & 54,96 & 765,26 & 103,76 & 9,16 & \begin{tabular}{l|l|l|l|}
49,35 \\
\end{tabular} & 296,62 & 56,86 & 57,99 & 289,48 \\
\hline Bufo spinosus & 29TPE99 & 100,00 & 129,38 & 99,10 & 35,98 & 6061,66 & 289,52 & 17,34 & 272,18 & 63,10 & 209,68 & 210,36 & 55,57 & 750,64 & $\begin{array}{ll}101,66 \\
\end{array}$ & 8,98 & 49,19 & 290,90 & 56,43 & \begin{tabular}{l|l}
57,15 \\
\end{tabular} & 283,99 \\
\hline Bufo spinosus & 29TPF00 & 101,00 & 139,06 & 98,71 & 38,88 & 5279,84 & 283,75 & 32,90 & 250,85 & 73,23 & \begin{tabular}{|l|l|}
207,69 \\
\end{tabular} & 208,26 & 73,23 & 1127,70 & 168,86 & 10,94 & 55,06 & \begin{tabular}{|l|l|}
457,17 \\
\end{tabular} & 72,42 & 74,61 & 457,17 \\
\hline Bufo spinosus & 29TPFO & 100,00 & 12 & & + & 82,38 & & 24, & 247, & 63,64 & 19 & 198,34 & \begin{tabular}{ll|}
63,64 \\
\end{tabular} & 241 & 187 & 12,69 & 55 & 505,95 & $\begin{array}{l}80,76 \\
\end{array}$ & \begin{tabular}{|l|l}
81,46 \\
\end{tabular} & 505 \\
\hline Bufo spinosus & 29TPF04 & 100,00 & 128,77 & 101,16 & 39,55 & $5306,69]$ & 275,1 & 22,47 & 252,72 & 62,85 & \begin{tabular}{|l|l|}
197,94 \\
\end{tabular} & 198,38 & 62,85 & 1242,10 & 187,23 & 13,26 & 55,32 & 505,25 & 81,75 . & 84,25 & 505,2 \\
\hline Bufo spinosus & \begin{tabular}{|l|} 
29TPF05 \\
\end{tabular} & 100,00 & 142,96 & 106,65 & 40,84 & 5279,31 & 290,93 & 32,77 & 258,16 & 78,24 & 210,95 & 211,44 & 76,34 & 1091,92 & 161,79 & 10,97 & 54,62 & 439,34 & 70,24 & 76,22 & 439,25 \\
\hline
\end{tabular}




\begin{tabular}{|c|c|c|c|c|c|c|c|c|c|c|c|c|c|c|c|c|c|c|c|c|c|}
\hline TAXON & UTM & $\mathrm{km} 2$ & BIO1 & B102 & $\mathrm{BIO3}$ & B104 & B105 & B106 & B107 & B108 & 8109 & B1010 & BIO11 & BIO12 & BIO13 & B1014 & BIO15 & B1016 & B1017 & B1018 & B1019 \\
\hline Bufo spinosus & 29TPF06 & 100,00 & 141,31 & 108,38 & 40,93 & 5312,79 & 291,76 & 30,46 & 261,30 & 79,60 & 209,92 & 210,29 & 74,38 & 1113,87 & 165,33 & 11,38 & 54,92 & 449,72 & 71,98 & 77,73 & 448,75 \\
\hline \begin{tabular}{|l|} 
Bufo spinosus \\
\end{tabular} & 29TPF07 & 101,00 & 129,25 & 104,96 & 40,17 & 5320,59 & 279,02 & 21,27 & 257,75 & 69,15 & 198,58 & $\begin{array}{ll}198,93 \\
\end{array}$ & 63,25 & 1223,92 & 181,16 & 14,12 & 54,73 & 496,20 & 82,95 & 87,13 & 494,77 \\
\hline \begin{tabular}{|l} 
Bufo spinosus \\
\end{tabular} & 29TPF08 & 100,00 & 108,66 & $\begin{array}{l}93,52 \\
\end{array}$ & 38,00 & 5223,34 & 250,90 & 8,30 & 242,61 & 45,75 & $\begin{array}{l}178,02 \\
\end{array}$ & $\begin{array}{ll}178,18 \\
\end{array}$ & 45,68 & $\begin{array}{l}1370,44 \\
1370\end{array}$ & 197,65 & 19,63 & 52,80 & 551,13 & 101,85 & \begin{tabular}{|l|}
103,26 \\
\end{tabular} & 551,12 \\
\hline Bufo spinosus & 29TPF09 & 100,00 & 111,77 & 94,08 & 38,18 & 5213,47 & 253,83 & 10,63 & 243,20 & 48,68 & 180,74 & 180,98 & 48,68 & 1325,43 & 188,43 & 19,36 & 52,06 & 530,87 & 99,87 & $\begin{array}{l}101,47 \\
\end{array}$ & 530,87 \\
\hline Bufo spinosus & 29TPF10 & 100,00 & 136,14 & 97,26 & $\begin{array}{ll}37,92 \\
\end{array}$ & 5414,49 & 282,79 & 29,94 & 252,85 & 69,04 & 207,02 & 207,27 & 69,04 & \begin{tabular}{|l|}
1121,47 \\
\end{tabular} & 169,00 & 10,83 & 55,29 & 455,61 & 72,08 & 72,82 & 455,61 \\
\hline Bufo spinosus & 29TPF11 & 100,00 & 128,63 & 95,37 & 37,60 & 5404,76 & 274,24 & 23,95 & 250,29 & 62,05 & 199,63 & 199,88 & 62,05 & 1200,90 & 182,25 & 12,14 & 55,80 & 489,67 & 77,94 & 78,26 & 489,67 \\
\hline Bufo spinosus & 29TPF12 & 100,00 & 118,88 & 91,96 & 36,84 & 5385,78 & 262,58 & 16,65 & \begin{tabular}{|l|l|}
245,93 \\
\end{tabular} & 53,27 & \begin{tabular}{|l|l|}
190,27 \\
\end{tabular} & 190,32 & 53,27 & 1295,22 & 197,19 & 13,90 & 55,95 & 529,52 & 84,37 & 85,12 & 529,52 \\
\hline Bufo spinosus & 29TPF14 & 100,00 & 124,50 & $\begin{array}{l}99,18 \\
\end{array}$ & 38,54 & 5414,99 & 272,28 & 18,51 & 253,77 & 57,77 & 195,61 & 195,77 & 57,77 & $\begin{array}{l}1234,38 \\
\end{array}$ & 186,67 & 13,56 & 55,38 & 502,96 & 82,15 & 83,12 & 502,96 \\
\hline Bufo spinosus & 29TPF15 & 100,00 & 140,38 & 106,18 & 40,16 & 5405,68 & 290,95 & 29,63 & 261,32 & 73,99 & 210,42 & 210,69 & 72,49 & 1074,86 & 160,31 & 10,99 & 54,83 & 433,77 & 69,73 & 73,32 & 433,71 \\
\hline Bufo spinosus & 29TPF18 & 101,00 & 116,77 & 98,81 & \begin{tabular}{|c|}
38,68 \\
\end{tabular} & 5375,05 & 264,19 & 11,86 & 252,33 & 51,10 & 187,58 & 187,81 & 51,10 & 1252,20 & 182,52 & 16,84 & 53,27 & 505,01 & 90,84 & 91,97 & 505,01 \\
\hline Bufo spinosus & 29TPF19 & 101,00 & 113,80 & 96,73 & 38,31 & 5336,32 & 259,53 & 10,18 & 249,36 & 48,93 & \begin{tabular}{|l|l|}
184,38 \\
\end{tabular} & 184,52 & 48,93 & 1255,75 & 179,85 & 18,12 & 52,30 & 503,68 & $\begin{array}{l}94,08 \\
\end{array}$ & 94,80 & 503,68 \\
\hline \begin{tabular}{|l|} 
Bufo spinosus \\
\end{tabular} & 29TPF20 & 100,00 & 131,99 & 94,76 & 36,96 & 5520,84 & 279,47 & 26,29 & 253,18 & 63,93 & 204,61 & 204,73 & 63,93 & 1119,52 & 169,25 & 10,95 & 55,43 & 455,27 & 72,09 & 72,60 & 455,27 \\
\hline Bufo spinosus & 29TPF21 & 101,00 & 126,21 & 93,56 & 36,68 & 5513,60 & 272,97 & 21,53 & 251,44 & 58,52 & $\begin{array}{l}198,83 \\
\end{array}$ & $\begin{array}{l}198,97 \\
\end{array}$ & 58,52 & 1172,13 & 177,94 & 11,92 & 55,70 & 477,64 & 75,95 & 76,74 & 477,64 \\
\hline Bufo spinosus & 29TPF22 & 100,00 & 123,09 & 94,03 & \begin{tabular}{|l|l|}
36,88 \\
\end{tabular} & 5506,71 & 269,90 & 18,45 & \begin{tabular}{|l|l|}
251,45 \\
\end{tabular} & 55,53 & 195,71 & 195,79 & 55,53 & 1199,46 & 182,05 & 12,66 & 55,60 & 488,99 & 78,61 & 79,60 & 488,99 \\
\hline Bufo spinosus & 29TPF23 & 100,00 & 126,79 & 98,25 & \begin{tabular}{|l|l|}
37,87 \\
\end{tabular} & 5516,59 & 275,90 & 19,95 & 255,94 & 58,64 & 199,26 & 199,34 & 58,64 & 1160,35 & $\begin{array}{l}175,66 \\
\end{array}$ & 12,24 & 55,32 & 472,38 & 76,56 & 77,15 & 472,38 \\
\hline Bufo spinosus & 29TPF24 & 101,00 & 126,75 & 100,17 & 38,32 & 5518,90 & 277,01 & 19,14 & \begin{tabular}{|l|l|}
257,87 \\
\end{tabular} & 58,60 & 199,25 & 199,32 & 58,60 & 1155,55 & 174,45 & 12,59 & 55,08 & 469,91 & 77,07 & 77,46 & 469,91 \\
\hline \begin{tabular}{|l|} 
Bufo spinosus \\
\end{tabular} & 29TPF25 & 100,00 & 140,51 & 106,44 & 39,69 & 5513,85 & 293,37 & 28,59 & 264,78 & 71,32 & 212,18 & 212,25 & 71,32 & 1019,19 & 151,94 & 10,54 & 54,60 & 410,81 & 66,63 & 67,38 & 410,81 \\
\hline Bufo spinosus & 29TPF26 & 100,00 & 140,98 & 107,60 & 39,89 & 5514,54 & 294,66 & 28,42 & 266,25 & 73,20 & 212,58 & 212,65 & 71,78 & 1005,65 & \begin{tabular}{|l|l|}
149,08 \\
\end{tabular} & 10,67 & 54,36 & 404,49 & 66,37 & 67,06 & 404,46 \\
\hline Bufo spinosus & 29TPF27 & 101,00 & 127,74 & 104,65 & 39,24 & 5523,54 & 281,02 & 17,96 & \begin{tabular}{|l|l|}
263,06 \\
\end{tabular} & 61,29 & 200,19 & 200,25 & 59,37 & 1117,23 & 165,84 & 13,31 & 54,31 & 451,90 & 77,02 & 77,42 & 451,81 \\
\hline Bufo spinosus & 29TPF28 & 101,00 & 124,70 & 103,28 & 39,13 & 5499,98 & 276,56 & 15,72 & 260,84 & 56,85 & 197,01 & 197,03 & 56,85 & $\begin{array}{l}1124,99 \\
\end{array}$ & 164,65 & 14,44 & 53,30 & 453,16 & 80,03 & 80,49 & 453,16 \\
\hline Bufo spinosus & 29TPF29 & 100,00 & 119,33 & 100,64 & 38,58 & 5460,93 & 269,38 & 12,14 & 257,24 & 52,55 & 191,46 & 191,47 & 52,55 & 1147,42 & 165,13 & 16,19 & 52,33 & 460,08 & 85,13 & 85,52 & 460,08 \\
\hline \begin{tabular}{|l} 
Bufo spinosus \\
\end{tabular} & 29TPF30 & 101,00 & 138,54 & $\begin{array}{l}97,73 \\
\end{array}$ & 37,13 & 5630,05 & 289,25 & 30,10 & 259,15 & 68,92 & 212,42 & 212,50 & 68,92 & 1001,01 & 149,52 & 9,60 & 54,78 & 403,99 & 64,84 & 65,10 & 403,99 \\
\hline Bufo spinosus & 29TPF31 & 100,00 & 122,01 & 91,03 & 35,81 & 5592,34 & 269,00 & 17,97 & \begin{tabular}{|l|l|}
251,03 \\
\end{tabular} & 53,63 & 195,80 & 196,16 & 53,63 & 1153,91 & 174,51 & 11,85 & 55,18 & 469,29 & 75,12 & 77,18 & 469,29 \\
\hline Bufo spinosus & 29TPF32 & 101,00 & 118,52 & 91,48 & \begin{tabular}{|l|}
35,98 \\
\end{tabular} & 5579,90 & 265,56 & 14,68 & 250,89 & 50,49 & 192,24 & 192,61 & 50,49 & \begin{tabular}{|l|}
1181,51 \\
\end{tabular} & 178,55 & 12,66 & 55,06 & 480,60 & 78,06 & 80,25 & 480,60 \\
\hline Bufo spinosus & 29TPF33 & 101,00 & 117,67 & 93,44 & 36,47 & 5576,81 & 265,92 & 13,04 & 252,89 & 49,59 & 191,29 & 191,61 & 49,59 & 1180,34 & 177,86 & 13,10 & 54,92 & 479,81 & 79,46 & 81,04 & 479,81 \\
\hline Bufo spinosus & 29TPF35 & 101,00 & 137,94 & 105,49 & 39,15 & 5607,72 & 292,31 & 25,79 & 266,52 & 67,82 & 211,25 & 211,27 & 67,82 & 982,27 & 146,01 & 10,54 & 54,18 & 395,49 & 65,43 & 65,51 & 395,49 \\
\hline Bufo spinosus & 29TPF36 & 100,00 & 136,08 & 105,63 & 39,20 & 5593,92 & 290,39 & 23,96 & \begin{tabular}{|l|l|}
266,43 \\
\end{tabular} & 66,31 & 209,21 & 209,21 & 66,31 & \begin{tabular}{|l|l|}
987,88 \\
\end{tabular} & \begin{tabular}{|l|l|}
145,90 \\
\end{tabular} & 11,16 & 53,79 & 397,09 & 67,05 & 67,16 & 397,09 \\
\hline Bufo spinosus & \begin{tabular}{|l|} 
29TPF37 \\
\end{tabular} & 101,00 & 136,96 & 106,85 & 39,44 & 5597,15 & 291,74 & 23,96 & \begin{tabular}{|l|l|}
267,78 \\
\end{tabular} & 66,93 & 209,96 & 209,98 & 66,93 & 970,32 & 142,26 & 11,30 & 53,38 & 388,98 & 66,55 & 66,61 & 388,98 \\
\hline Bufo spinosus & 29TPF38 & 99,00 & 135,86 & 107,09 & \begin{tabular}{|l|l|}
39,57 \\
\end{tabular} & 5593,05 & 290,65 & 22,66 & 267,99 & 66,02 & 208,89 & 208,89 & 66,02 & 963,54 & 139,80 & 11,88 & 52,75 & 385,04 & 67,49 & 67,52 & 385,04 \\
\hline Bufo spinosus & 29TPF39 & 101,00 & 128,98 & 104,90 & \begin{tabular}{|l|l|}
39,08 \\
\end{tabular} & 5570,40 & 282,66 & 17,49 & \begin{tabular}{|l|l|}
265,18 \\
\end{tabular} & 60,08 & 202,29 & 202,29 & 60,08 & 1002,01 & 143,85 & 13,58 & 51,97 & 400,05 & 73,12 & 73,12 & 400,05 \\
\hline Bufo spinosus & 29TPF42 & 101,00 & 129,46 & 97,21 & 36,92 & 5693,92 & 281,22 & 21,12 & 260,10 & 59,25 & 204,42 & 204,60 & 59,25 & 1019,33 & 152,01 & 10,78 & 54,30 & 410,91 & 68,29 & 68,78 & 410,91 \\
\hline Bufo spinosus & 29TPF43 & 100,00 & $\begin{array}{lll}128,47 \\
\end{array}$ & 98,78 & \begin{tabular}{|l|l|}
37,29 \\
\end{tabular} & 5690,11 & 281,10 & 19,51 & \begin{tabular}{|l|l|}
261,59 \\
\end{tabular} & 58,25 & 203,40 & 203,53 & 58,25 & 1018,61 & 151,77 & 11,11 & 54,11 & 410,75 & 69,20 & 69,37 & 410,75 \\
\hline Bufo spinosus & 29TPF44 & 100,00 & 132,75 & 102,47 & \begin{tabular}{|l|}
38,08 \\
\end{tabular} & 5697,92 & 287,24 & 21,71 & \begin{tabular}{|l|l|}
265,53 \\
\end{tabular} & 62,03 & 207,71 & 207,71 & 62,03 & 972,21 & 144,25 & 10,68 & 53,94 & 391,00 & 66,10 & 66,10 & 391,00 \\
\hline Bufo spinosus & $\begin{array}{l}\text { 29TPF45 } \\
\end{array}$ & 100,00 & 140,70 & 105,77 & 38,89 & 5667,42 & 295,95 & 27,37 & 268,58 & 70,06 & 214,86 & 214,86 & 69,73 & 898,03 & 131,61 & 9,86 & 53,24 & 358,68 & 60,80 & 60,80 & 358,68 \\
\hline Bufo spinosus & 29TPF46 & 101,00 & 123,35 & 101,60 & 38,00 & 5663,76 & 277,73 & 13,58 & 264,15 & 53,73 & 198,39 & 198,39 & 53,73 & $\begin{array}{l}1028,48 \\
\end{array}$ & 151,52 & 12,73 & 53,08 & 413,96 & 73,53 & 73,53 & 413,96 \\
\hline \begin{tabular}{|l} 
Bufo spinosus \\
\end{tabular} & 29TPF47 & 99,00 & 132,70 & 105,43 & 38,83 & 5659,92 & 288,25 & 20,00 & 268,25 & 62,32 & 207,06 & 207,06 & 62,32 & 938,61 & \begin{tabular}{|l|l}
136,65 \\
\end{tabular} & 11,66 & 52,49 & 375,35 & 66,55 & 66,55 & 375,35 \\
\hline Bufo spinosus & 29TPF48 & 101,00 & 140,12 & 107,65 & 39,32 & 5646,39 & 295,76 & 25,48 & $270,27 \mid$ & 69,34 & 214,06 & 214,06 & 69,34 & 865,86 & 123,90 & 10,87 & 51,73 & \begin{tabular}{|l|l|}
343,18 \\
\end{tabular} & 61,50 & 61,50 & 343,18 \\
\hline Bufo spinosus & 29TPF49 & 100,00 & 137,42 & 106,91 & \begin{tabular}{|l|l|}
39,23 \\
\end{tabular} & 5629,61 & 292,32 & 23,10 & \begin{tabular}{|l|l|}
269,23 \\
\end{tabular} & 67,23 & 211,12 & 211,12 & 66,99 & 873,61 & 123,63 & 11,76 & 51,03 & 345,28 & \begin{tabular}{|c|}
63,87 \\
\end{tabular} & \begin{tabular}{|c|}
63,87 \\
\end{tabular} & 345,28 \\
\hline Bufo spinosus & 29TPF50 & 100,00 & 126,65 & 92,55 & 35,46 & 5783,08 & 277,61 & 19,91 & 257,70 & 55,85 & 202,85 & 203,38 & 55,85 & 993,74 & 146,73 & 10,17 & 53,88 & 398,03 & 66,35 & 67,84 & 398,03 \\
\hline Bufo spinosus & 29TPF52 & 100,00 & 137,54 & 101,08 & 37,46 & 5779,03 & 292,46 & 25,97 & 266,49 & 65,88 & 213,69 & 213,69 & 65,70 & 888,20 & 129,97 & 9,39 & 53,19 & 353,77 & 60,27 & 60,27 & 353,77 \\
\hline Bufo spinosus & \begin{tabular}{|l|} 
29TPF53 \\
\end{tabular} & 100,00 & 141,10 & 103,66 & 38,12 & 5763,83 & 296,81 & 28,05 & 268,76 & 69,62 & 216,60 & 216,60 & 69,12 & 850,97 & 123,81 & 9,14 & 52,78 & 337,87 & 57,88 & 57,88 & 337,83 \\
\hline Bufo spinosus & 29TPF54 & 101,00 & 142,68 & 105,21 & 38,51 & 5744,58 & 298,77 & 28,79 & 269,97 & 72,03 & 217,84 & 217,84 & 70,80 & 832,23 & 120,63 & 9,06 & 52,52 & 329,99 & 56,84 & 56,84 & 329,90 \\
\hline Bufo spinosus & 29TPF55 & 100,00 & 143,81 & 106,25 & 38,74 & 5720,69 & 300,02 & 29,27 & \begin{tabular}{|l|l|}
270,76 \\
\end{tabular} & 74,26 & 218,64 & 218,64 & 72,02 & \begin{tabular}{|l|l|}
814,43 \\
\end{tabular} & $\mid 117,22$ & \begin{tabular}{ll|l|l|}
9,14 \\
\end{tabular} & 52,12 & 322,14 & 56,22 & 56,22 & 321,98 \\
\hline Bufo spinosus & 29TPF56 & 100,00 & 139,49 & 105,69 & 38,59 & 5705,64 & 295,63 & 25,55 & \begin{tabular}{|l|l|}
270,08 \\
\end{tabular} & 70,99 & 214,41 & 214,41 & 68,22 & 837,54 & 120,32 & 9,97 & 51,84 & 331,83 & 59,22 & 59,22 & 331,53 \\
\hline \begin{tabular}{|l|} 
Bufo spinosus \\
\end{tabular} & $\begin{array}{l}\text { 29TPF57 } \\
\end{array}$ & 101,00 & 134,38 & 105,98 & 38,67 & 5715,32 & 291,15 & 20,48 & 270,66 & 63,93 & 209,56 & 209,56 & 63,28 & 863,64 & 124,24 & 11,01 & 51,61 & 343,18 & 62,44 & 62,44 & 343,14 \\
\hline \begin{tabular}{|l} 
Bufo spinosus \\
\end{tabular} & 29TPF58 & 99,00 & 136,87 & 107,07 & 38,82 & 5702,16 & 293,58 & 22,00 & 271,58 & 65,83 & 211,69 & 211,69 & 65,64 & 829,85 & 117,91 & 11,02 & 50,93 & 327,95 & 60,81 & 60,81 & 327,95 \\
\hline Bufo spinosus & 29TPF59 & 101,00 & 140,06 & 107,68 & 39,02 & 5679,65 & 296,10 & 24,35 & 271,75 & 70,61 & 214,39 & 214,39 & 68,77 & 794,76 & 111,26 & 10,91 & 50,28 & 312,01 & 58,91 & 58,91 & 312,01 \\
\hline Bufo spinosus & 29TPF60 & 100,00 & 126,95 & 93,99 & 35,55 . & 5856,68 & 279,99 & 18,95 & 261,04 & 60,23 & 204,05 & 204,72 & 55,29 & 931,01 & $|135,27|$ & 9,88 & 52.80 & 369,36 & 63,92 & 65,18 & 369,14 \\
\hline Bufo spinosus & 29TPF61 & 100,00 & 132,16 & 97,93 & 36,39 & 5855,03 & 287,09 & 21,78 & 265,31 & 64,63 & 209,47 & 209,65 & 59,93 & 881,01 & 127,52 & 9,52 & 52,48 & 48,64 & 61,25 & 61,44 & 348,50 \\
\hline Bufo spinosus & 29TPF62 & 100,00 & 131 & 99,50 & 36,82 & 5846,01 & 287,62 & 20,89 & 266,74 & 63,30 & 209,20 & 20 & 59,75 & 870,22 & 125,57 & 9,6 & 52,26 & 344,02 & 61,16 & 61,35 & 343,96 \\
\hline Bufo spinosus & 29TPF64 & 99,00 & 141,58 & 105,17 & 38,20 & 5807,07 & 298,94 & 27,17 & 271,77 & 72,58 & 217,82 & 217,82 & 69,07 & 782,20 & 111,55 & 8,88 & 51,52 & 307,77 & 55,02 & 55,02 & 307,29 \\
\hline \begin{tabular}{|l|} 
Bufo spinosus \\
\end{tabular} & 29TPF65 & 101,00 & 133,16 & 104,27 & 37,93 & 5804,01 & 290,69 & 19,73 & 270,97 & 62,06 & 209,68 & 209,68 & 61,14 & 831,42 & 118,91 & 10,13 & 51,36 & 328,13 & 60,39 & 60,39 & 328,13 \\
\hline Bufo spinosus & 29TPF66 & 100,00 & 138,95 & 106,55 & 38,53 & 5783,69 & 296,75 & 23,90 & 272,85 & 68,93 & 214,97 & 214,97 & 66,74 & 780,99 & 110,72 & 9,66 & 50,94 & 307,18 & 56,57 & 56,57 & 306,92 \\
\hline Bufo spinosus & \begin{tabular}{|l|} 
29TPF67 \\
\end{tabular} & 100,00 & 138,89 & 107,36 & 38,8 & 5764,51 & 296,72 & 23,36 & 273,36 & 69,09 & 21 & & 66,78 & 768,30 & 108,26 & 9,93 & 50,41 & 58 & 56,62 & 56,62 & 301,41 \\
\hline \begin{tabular}{|l} 
Bufo spinosus \\
\end{tabular} & 29TPF68 & 101,00 & 125,92 & 105,07 & 38,24 & 5746,97 & 283,86 & 12,69 & 271,17 & 55,71 & 201,92 & 201,94 & 54,87 & 847,90 & 119,58 & 11,95 & 50,01 & 334,57 & 65,86 & 65,90 & 334,55 \\
\hline Bufo spinosus & 29TPF69 & 100,00 & 124,72 & 105,60 & 38,38 & 5737,43 & 282,95 & 11,12 & 271,83 & 53,84 & 200,67 & 200,69 & 53,80 & 842,56 & 118,37 & 12,49 & 49,51 & 332,58 & 66,68 & 66,71 & 332,58 \\
\hline Bufo spinosus & 29TPF70 & 101,00 & 126,52 & \begin{tabular}{c|c|}
95,46 \\
\end{tabular} & \begin{tabular}{|l|l|}
35,48 \\
\end{tabular} & 5924,88 & 281,66 & 17,39 & \begin{tabular}{|l|l|}
264,27 \\
\end{tabular} & 61,88 & 204,75 & 205,50 & 54,21 & 874,26 & $\mid 124,50$ & 9,71 & 51,57 & $\mid 344,34$ & 61,95 & 63,13 & 342,25 \\
\hline Bufo spinosus & 29TPF71 & 100,00 & 127,17 & 97,36 & 36,08 & 5919,39 & 283,19 & 17,05 & 266,14 & 62,28 & 205,32 & 205,96 & 54,80 & 856,38 & 121,62 & 9,80 & 51,38 & 336,79 & 61,71 & 62,35 & 334,93 \\
\hline Bufo spinosus & 29TPF72 & 100,00 & 127 & 99,08 & 36,53 & & 284,36 & 16,5 & 267 & 62,55 & 205 & 205 & 55,05 & 843,94 & $119, / 3$ & 9,89 ] & 51,16 & 331,56 & $61,64 \mid$ & 61,79 & 330 \\
\hline \begin{tabular}{|l} 
Bufo spinosus \\
\end{tabular} & 29TPF73 & 100,00 & 133,46 & 102,44 & 37,27 & 5891,66 & 291,47 & 20,37 & 271,10 & 67,96 & 211,44 & 211,44 & 60,61 & 792,11 & 111,81 & 9,37 & 50,82 & 310,49 & 57,83 & 57,83 & 309,20 \\
\hline
\end{tabular}




\begin{tabular}{|c|c|c|c|c|c|c|c|c|c|c|c|c|c|c|c|c|c|c|c|c|c|}
\hline TAXON & UTM & $\mathrm{km} 2$ & BIO1 & B102 & $B 103$ & BIO4 & B105 & B106 & B107 & B108 & B109 & B1010 & BIO11 & BIO12 & BIO13 & B1014 & BIO15 & B1016 & B1017 & B1018 & 81019 \\
\hline Bufo spinosus & 29TPF74 & 101,00 & 141,89 & 105,77 & 38,07 & 5862,92 & 300,65 & 26,54 & 274,11 & 75,85 & 218,98 & 218,98 & 68,70 & 723,89 & 101,04 & 8,58 & 50,33 & 282,67 & 52,56 & 52,56 & 280,76 \\
\hline Bufo spinosus & 29TPF75 & 99,00 & 134,33 & 105,26 & 37,99 & 5864,59 & 293,29 & 19,66 & 273,63 & 67,46 & 211,71 & 211,71 & 61,42 & 765,39 & 107,37 & 9,63 & 50,20 & 299,43 & 57,12 & 57,12 & 298,61 \\
\hline Bufo spinosus & 29TPF76 & 101,00 & 133,84 & 105,95 & 38,20 & 5841,09 & 292,79 & 18,91 & 273,88 & 66,99 & 210,85 & 210,86 & 61,26 & \begin{tabular}{|l|l|}
757,77 \\
\end{tabular} & 105,79 & 9,82 & 49,82 & 296,32 & 57,40 & 57,40 & 295,41 \\
\hline Bufo spinosus & 29TPF77 & 100,00 & 137,67 & 107,68 & 38,62 & 5820,77 & 296,98 & 21,54 & 275,44 & 71,36 & 214,26 & 214,26 & 64,96 & \begin{tabular}{|l|l|}
721,04 \\
\end{tabular} & 99,86 & 9,74 & 49,31 & 281,24 & $\begin{array}{l}54,96 \\
\end{array}$ & 54,96 & 280,28 \\
\hline Bufo spinosus & 29TPF78 & 100,00 & 129,88 & 107,05 & 38,40 & 5809,03 & 289,73 & 14,60 & 275,14 & 62,27 & 206,69 & 206,69 & 57,73 & 759,94 & 105,55 & 10,85 & 49,07 & 297,53 & 59,92 & 59,92 & 297,20 \\
\hline Bufo spinosus & 29TPF79 & 100,00 & 123,01 & 106,30 & 38,32 & 5778,23 & 282,90 & 8,87 & 274,03 & 54,38 & $\begin{array}{ll}199,62 \\
\end{array}$ & \begin{tabular}{|c|c|}
199,64 \\
\end{tabular} & 51,64 & 793,80 & \begin{tabular}{|l|l|}
109,92 \\
\end{tabular} & \begin{tabular}{|l|l|l|}
12,11 \\
\end{tabular} & 48,60 & 311,30 & $\mid 65,06$ & 65,08 & 311,22 \\
\hline Bufo spinosus & 29TPF81 & 100,00 & 126,60 & 98,86 & 36,16 & 5977,64 & 284,65 & 15,28 & 269,37 & 60,96 & 205,60 & 206,19 & 53,50 & 801,99 & 111,22 & 9,53 & 50,05 & 313,21 & 59,84 & 60,40 & 308,99 \\
\hline Bufo spinosus & 29TPF82 & 100,00 & 131,03 & 101,63 & 36,88 & 5965,24 & 290,16 & 18,01 & 272,15 & 64,99 & 210,07 & 210,10 & 57,57 & 761,25 & 105,14 & 9,16 & 49,85 & 296,71 & 57,24 & 57,26 & 292,83 \\
\hline Bufo spinosus & 29TPF84 & 99,00 & 136,85 & 105,53 & 37,81 & $\begin{array}{l}5927,83 \\
\end{array}$ & 296,95 & 21,49 & 275,46 & 70,53 & 215,16 & 215,16 & 63,22 & \begin{tabular}{ll|}
702,12 \\
\end{tabular} & $\begin{array}{l}96,03 \\
\end{array}$ & 8,77 & 49,13 & 272,78 & 53,29 & 53,29 & 269,14 \\
\hline Bufo spinosus & 29TPF85 & 101,00 & 133,76 & 105,84 & 37,90 & $\begin{array}{lll}5913,94 \\
\end{array}$ & 294,04 & 18,42 & 275,63 & 67,60 & 211,91 & 211,91 & 60,34 & 713,10 & 97,54 & 9,38 & 48,85 & 277,16 & 55,33 & 55,33 & 274,08 \\
\hline Bufo spinosus & 29TPF86 & 100,00 & 126,57 & 105,56 & 37,85 & 5900,58 & 287,13 & 11,93 & 275,19 & 60,90 & 204,84 & 204,84 & 53,61 & 744,61 & 101,80 & 10,30 & 48,49 & 289,46 & 59,65 & 59,65 & 287,21 \\
\hline Bufo spinosus & 29TPF88 & 101,00 & 131,27 & 108,01 & 38,51 & \begin{tabular}{|l|l|}
5851,74 \\
\end{tabular} & 291,97 & 14,96 & 277,01 & 65,44 & 208,61 & 208,61 & 58,38 & 695,99 & 94,18 & 10,34 & 47,79 & 270,13 & 56,85 & 56,85 & 268,09 \\
\hline Bufo spinosus & 29TPF89 & 100,00 & 127,67 & 108,27 & 38,52 & 5831,94 & 288,98 & 11,46 & 277,52 & 62,03 & 204,89 & 204,89 & 55,23 & 706,50 & 95,57 & $\mid 11,02$ & 47,46 & 274,56 & 59,14 & 59,14 & 273,30 \\
\hline Bufo spinosus & 29TPF90 & 100,00 & 128,32 & 100,02 & 36,06 & 6047,87 & 288,53 & 15,82 & 272,71 & 61,90 & 208,45 & 209,05 & 54,46 & 745,06 & 100,55 & 9,00 & 48,82 & 288,52 & 56,83 & 57,33 & 281,68 \\
\hline Bufo spinosus & 29TPF94 & 100,00 & 127,14 & 104,70 & 37,31 & 5992,22 & 288,67 & 12,45 & 276,22 & 60,62 & 206,74 & 206,74 & 53,35 & $\begin{array}{l}706,35 \\
\end{array}$ & $\begin{array}{l}94,23 \\
\end{array}$ & 9,63 & 47,70 & 272,59 & 57,28 & 57,28 & 267,10 \\
\hline Bufo spinosus & 29TPF95 & 100,00 & 123,98 & 105,18 & 37,72 & 5972,06 & 285,81 & 9,47 & 276,34 & 57,90 & 203,57 & 203,57 & 50,66 & \begin{tabular}{|l|l|}
712,27 \\
\end{tabular} & 94,80 & 9,98 & 47,46 & 274,87 & 58,80 & 58,80 & 269,70 \\
\hline Bufo spinosus & 29TPF96 & 100,00 & 125,79 & 106,55 & 38,02 & 5947,17 & 287,79 & 10,27 & 277,52 & 59,50 & 204,76 & 204,76 & 52,34 & \begin{tabular}{ll|l}
691,95 \\
\end{tabular} & 91,70 & 10,15 & 47,00 & 266,69 & 57,95 & 57,95 & 261,99 \\
\hline Bufo spinosus & 29TPF97 & 101,00 & 119,67 & 106,41 & 37,99 & 5930,73 & 282,07 & $\mid 4,67$ & 277,39 & 53,80 & \begin{tabular}{|l|l|}
198,61 \\
\end{tabular} & \begin{tabular}{|l|l|}
198,61 \\
\end{tabular} & 46,65 & 718,31 & 95,14 & \begin{tabular}{|l|l|}
11,02 \\
\end{tabular} & 46,70 & 276,97 & $|61,95|$ & 61,95 & 272,98 \\
\hline Bufo spinosus & 29TPF98 & 100,00 & 120,57 & 107,46 & 38,12 & 5908,98 & 283,11 & 5,07| & 278,03 & 54,57 & 199,09 & 199,09 & 47,67 & 701,41 & 92,47 & 11,18 & 46,30 & 270,26 & 61,39 & 61,39 & 266,71 \\
\hline Bufo spinosus & 29TPF99 & 100,00 & 130,68 & 109,56 & 38,84 & 5876,27 & 292,54 & 13,18 & 279,36 & 64,36 & 208,23 & 208,23 & 57,49 & 638,01 & 83,60 & 10,49 & 46,07 & 245,56 & 55,23 & 55,23 & 241,94 \\
\hline Bufo spinosus & 29TPG00 & 101,00 & 128,55 & 101,51 & 39,68 & 5268,55 & 274,20 & 21,32 & 252,88 & 63,34 & 197,31 & 197,49 & 63,30 & 1164,34 & $\begin{array}{l}161,88 \\
\end{array}$ & 15,93 & 51,68 & 461,28 & 85,32 & 88,02 & 461,28 \\
\hline \begin{tabular}{|l|} 
Bufo spinosus \\
\end{tabular} & 29TPG01 & 100,00 & 111,76 & 92,42 & 37,99 & 5168,72 & 251,69 & 11,49 & 240,20 & 49,41 & 180,21 & 180,35 & 49,41 & 1289,31 & $\begin{array}{l}176,79 \\
\end{array}$ & 20,77 & 50,47 & \begin{tabular}{|l|l|}
510,67 \\
\end{tabular} & 101,87 & 103,85 & 510,67 \\
\hline Bufo spinosus & 29TPG02 & 100,00 & 106,85 & 88,80 & 37,21 & 5111,32 & 244,26 & 9,02 & 235,24 & 45,71 & $\begin{array}{l}174,80 \\
\end{array}$ & \begin{tabular}{ll|}
174,99 \\
\end{tabular} & 45,71 & $\begin{array}{l}1310,86 \\
\end{array}$ & $\begin{array}{l}176,48 \\
\end{array}$ & 22,83 & 49,52 & 516,13 & 107,83 & 110,31 & 516,13 \\
\hline Bufo spinosus & 29TPG03 & 101,00 & 100,34 & 86,02 & 36,70 & 5053,09 & 235,86 & 4,79 & 231,07 & 40,97 & 167,75 & 168,01 & 40,55 & 1349,43 & 178,69 & 25,66 & 48,45 & 527,55 & 1116,37 & 118,48 & 527,53 \\
\hline Bufo spinosus & 29TPG04 & 100,00 & 105,08 & 88,21 & 37,23 & 5064,05 & 241,28 & 7,38 & 233,90 & 49,16 & 172,41 & 172,65 & 44,73 & $\begin{array}{l}1295,86 \\
\end{array}$ & $\begin{array}{l}171,56 \\
\end{array}$ & 25,20 & 47,82 & 502,97 & 113,33 & 115,43 & 502,81 \\
\hline Bufo spinosus & 29TPG05 & 101,00 & 119,89 & 93,96 & 38,26 & 5155,67 & 258,22 & 15,84 & 242,38 & 63,14 & 187,92 & 188,01 & 57,21 & $\begin{array}{l}1153,20 \\
\end{array}$ & 156,06 & 22,16 & 47,08 & 443,66 & 100,34 & 101,71 & 440,77 \\
\hline Bufo spinosus & 29TPG06 & 101,00 & 120,72 & 93,71 & 38,19 & 5132,34 & 258,02 & 16,47 & 241,55 & 63,99 & 188,26 & 188,35 & 58,39 & 1133,64 & 155,70 & 22,98 & 46,17 & 434,04 & 101,53 & 103,93 & 429,13 \\
\hline Bufo spinosus & 29TPG07 & 100,00 & 123,10 & 93,56 & 38,15 & 5116,46 & 259,22 & 18,05 & 241,17 & 66,16 & 190,42 & 190,56 & $\begin{array}{ll}60,93 \\
\end{array}$ & 1099,61 & \begin{tabular}{|l|l|}
152,97 \\
\end{tabular} & 23,37 & 45,42 & 418,36 & 101,12 & 104,45 & 411,31 \\
\hline Bufo spinosus & 29TPG08 & 101,00 & 122,86 & 92,65 & 38,09 & 5064,76 & 257,47 & 18,36 & 239,11 & 66,42 & \begin{tabular}{|l|l|}
189,60 \\
\end{tabular} & 189,72 & \begin{tabular}{ll|}
61,56 \\
\end{tabular} & $\begin{array}{l}1094,30 \\
\end{array}$ & 153,24 & 24,48 & 44,66 & 414,44 & $\begin{array}{l}103,56 \\
\end{array}$ & 107,31 & 405,74 \\
\hline Bufo spinosus & 29TPG09 & 99,00 & 123,31 & 91,60 & 38,18 & $\begin{array}{ll}4991,49 \\
\end{array}$ & 255,79 & $\begin{array}{ll}19,62 \\
\end{array}$ & 236,17 & 67,51 & 188,94 & 189,15 & 63,01 & 1087,23 & $\begin{array}{l}152,76 \\
\end{array}$ & 25,49 & 43,95 & 410,21 & 105,63 & 112,58 & 399,86 \\
\hline Bufo spinosus & 29TPG10 & 100,00 & 126,91 & 102,29 & 39,40 & 5384,67 & 275,27 & 18,51 & 256,76 & 60,43 & $\begin{array}{l}197,61 \\
\end{array}$ & $\begin{array}{l}197,66 \\
\end{array}$ & 60,43 & $\begin{array}{l}1124,66 \\
\end{array}$ & \begin{tabular}{ll|}
158,03 \\
\end{tabular} & 15,63 & 51,73 & $\begin{array}{l}446,89 \\
\end{array}$ & 82,92 & 83,49 & 446,89 \\
\hline Bufo spinosus & 29TPG11 & 100,00 & 130,59 & 102,55 & 39,37 & 5379,72 & 278,26 & 21,08 & 257,18 & 63,94 & 201,00 & 201,04 & 63,94 & 1069,72 & \begin{tabular}{|l|l|l|}
146,26 \\
\end{tabular} & $\mid 15,45$ & 50,64 & 420,48 & 80,50 & 80,87 & $\begin{array}{lll}420,48 \\
\end{array}$ \\
\hline Bufo spinosus & 29TPG12 & 100,00 & 115,84 & 95,37 & 38,04 & 5283,63 & 259,08 & 11,91 & 247,16 & 51,65 & 185,68 & 185,71 & 51,65 & 1176,26 & 158,86 & 19,73 & 49,55 & 462,11 & 95,00 & 95,45 & 462,11 \\
\hline Bufo spinosus & 29TPG13 & 101,00 & 114,59 & $\begin{array}{ll}94,29 \\
\end{array}$ & 37,88 & 5258,16 & 256,75 & 11,16 & 245,59 & 51,08 & 184,25 & 184,28 & 50,83 & 1171,31 & \begin{tabular}{|l|l|}
155,10 \\
\end{tabular} & 20,77 & 48,71 & 457,27 & 97,45 & 97,95 & 457,27 \\
\hline Bufo spinosus & 29TPG14 & 101,00 & 113,99 & $\begin{array}{ll}93,88 \\
\end{array}$ & 37,92 & 5231,74 & 255,38 & 10,69 & 244,69 & 55,23 & 183,38 & 183,44 & 50,77 & $\begin{array}{l}1159,41 \\
\end{array}$ & 152,44 & 21,83 & 47,73 & 449,20 & 99,54 & 100,49 & 449,09 \\
\hline \begin{tabular}{|l|} 
Bufo spinosus \\
\end{tabular} & 29TPG15 & 99,00 & 117,40 & $\begin{array}{ll}94,81 \\
\end{array}$ & $\begin{array}{l}38,05 \\
\end{array}$ & $\begin{array}{ll}5235,88 \\
\end{array}$ & 258,51 & 12,64 & 245,87 & 59,84 & 186,75 & \begin{tabular}{|l|l|}
186,77 \\
\end{tabular} & 53,92 & $\begin{array}{l}1115,37 \\
\end{array}$ & \begin{tabular}{|l|l|}
149,09 \\
\end{tabular} & 21,82 & 46,89 & 429,50 & 97,90 & $\begin{array}{ll}99,06 \\
\end{array}$ & 427,21 \\
\hline Bufo spinosus & 29TPG17 & 99,00 & 118,91 & 94,17 & 38,01 & 5173,19 & 257,53 & 13,69 & 243,84 & 61,46 & 187,16 & $\begin{array}{l}187,19 \\
\end{array}$ & 56,20 & $\begin{array}{l}1081,36 \\
\end{array}$ & $\begin{array}{l}147,99 \\
\end{array}$ & 23,39 & 45,11 & 412,32 & 100,59 & 101,89 & 406,09 \\
\hline Bufo spinosus & 29TPG18 & 100,00 & 110,04 & 91,71 & 37,90 & $\begin{array}{l}5063,02 \\
\end{array}$ & 246,93 & 8,24 & 238,69 & 54,47 & 177,24 & 177,33 & \begin{tabular}{ll|}
49,44 \\
\end{tabular} & $\begin{array}{l}1155,09 \\
\end{array}$ & 158,04 & 26,98 & 44,29 & 440,11 & 112,45 & 1115,47 & 432,49 \\
\hline Bufo spinosus & 29TPG19 & 100,00 & 120,84 & 92,62 & 38,10 & 5065,62 & 255,79 & 16,38 & 239,41 & 64,25 & 187,53 & 187,64 & 59,66 & 1054,15 & $\begin{array}{l}145,66 \\
\end{array}$ & 24,97 & 43,47 & 397,87 & 103,63 & 107,49 & 387,71 \\
\hline Bufo spinosus & 29TPG20 & 100,00 & 116,55 & 98,57 & 38,25 & 5422,90 & 264,90 & 10,39 & 254,51 & 50,42 & 188,25 & 188,27 & 50,42 & $\begin{array}{l}1146,33 \\
\end{array}$ & 161,59 & 17,49 & 51,15 & 456,30 & 88,32 & 88,41 & 456,30 \\
\hline Bufo spinosus & 29TPG21 & 101,00 & 126,25 & 102,04 & 38,88 & 5451,82 & 275,59 & 16,75 & 258,84 & $\begin{array}{ll}59,06 \\
\end{array}$ & 197,96 & $\begin{array}{l}197,96 \\
\end{array}$ & 59,06 & $\begin{array}{l}1047,46 \\
\end{array}$ & $\begin{array}{l}144,56 \\
\end{array}$ & 15,91 & 50,38 & 412,99 & 80,47 & 80,47 & 412,99 \\
\hline Bufo spinosus & 29TPG22 & 101,00 & 133,16 & 103,27 & 39,01 & 5460,32 & 282,04 & 21,44 & 260,59 & 66,48 & 204,71 & 204,71 & 65,46 & 970,41 & $\begin{array}{l}130,05 \\
\end{array}$ & 15,04 & 49,31 & $\begin{array}{l}377,52 \\
\end{array}$ & 75,53 & 75,53 & 377,52 \\
\hline Bufo spinosus & 29TPG23 & 100,00 & 128,44 & 100,89 & 38,75 & 5426,73 & 275,36 & 18,16 & 257,20 & 64,68 & $\begin{array}{l}199,68 \\
\end{array}$ & $\begin{array}{l}199,68 \\
\end{array}$ & 61,42 & $\begin{array}{l}993,49 \\
\end{array}$ & \begin{tabular}{|l|l|}
130,73 \\
\end{tabular} & 16,78 & 48,38 & 385,02 & 80,62 & 80,62 & 384,57 \\
\hline Bufo spinosus & 29TPG24 & 100,00 & 128,78 & 100,20 & 38,64 & 5413,35 & 274,57 & 18,36 & 256,21 & 68,08 & 199,94 & 199,94 & 62,10 & $\begin{array}{l}972,87 \\
9\end{array}$ & 127,05 & 17,39 & 47,39 & 374,59 & 81,45 & 81,45 & 372,83 \\
\hline Bufo spinosus & 29TPG27 & 100,00 & 92,11 & 89,78 & 37,22 & 5108,96 & 231,86 & $-6,13$ & 237,99 & 37,64 & 160,60 & 160,72 & 31,96 & 1256,74 & 167,10 & 30,40 & 44,18 & 481,01 & 125,38 & 126,75 & 474,89 \\
\hline Bufo spinosus & 29TPG28 & 101,00 & 102,96 & 91,96 & 37,86 & 5109,11 & 242,32 & 1,67 & 240,65 & 47,18 & 170,96 & 171,02 & 42,07 & $\begin{array}{l}1159,66 \\
\end{array}$ & 156,59 & 27,99 & 43,84 & 442,53 & 115,48 & 117,44 & 435,04 \\
\hline Bufo spinosus & 29TPG30 & 101,00 & 129,20 & 104,36 & 38,86 & 5549,78 & 281,83 & 17,57 & 264,26 & 60,49 & 202,10 & 202,10 & 60,49 & $983,61 \mid$ & 138,69 & 14,19 & 51,07 & 390,06 & 73,76 & 73,76 & 390,06 \\
\hline Bufo spinosus & 29TPG32 & 100,00 & 121,65 & 101,25 & 38,42 & 5496,12 & 272,07 & 11,98 & 260,09 & 54,58 & 194,31 & 194,31 & 54 & 1006,25 & 137,16 & 16,95 & 49,15 & 395,01 & 81,34 & 81,34 & 395,01 \\
\hline Bufo spinosus & 29TPG33 & 100,00 & 121,95 & 100,70 & 38, & 5475,42 & 271,29 & 12,10 & 259,19 & 57,53 & 194,34 & 194,34 & 54,80 & \begin{tabular}{|c|}
986,87 \\
\end{tabular} & \begin{tabular}{|l|}
131,60 \\
\end{tabular} & \begin{tabular}{|l|l|}
17,61 \\
\end{tabular} & 48,16 & 384,05 & 82,26 & 82,26 & 383,95 \\
\hline Bufo spinosus & 29TPG34 & 101,00 & 119,10 & 99,36 & 38,15 & 5438,35 & 267,03 & 10,11 & 256,92 & 58,52 & 191,03 & \begin{tabular}{l|l|}
191,03 \\
\end{tabular} & 52,56 & $\begin{array}{l}996,47 \\
\end{array}$ & 130,92 & 19,09 & 47,19 & $\begin{array}{ll}385,91 \\
\end{array}$ & 86,18 & 86,18 & 385,02 \\
\hline Bufo spinosus & 29TPG36 & 100,00 & 92,35 & 91,85 & 37,15 & 5240,03 & 236,01 & $-7,92$ & 243,93 & 36,12 & $\mid 162,64$ & 162,65 & 30,37 & $\mid 1200,71$ & $\mid$ & 28,37 & 44,62 & $\mid 461,06$ & $\mid$\begin{tabular}{|l|l|}
118,24 \\
\end{tabular} & \begin{tabular}{|l|l|}
118,42 \\
\end{tabular} & 456,30 \\
\hline Bufo spinosus & 29TPG37 & 100,00 & 81,18 & 89,85 & 36,97 & 5161,60 & 223,24 & $-16,66$ & 239,90 & 26,61 & 150,66 & 150,77 & 20,92 & 1289,79 & 168,92 & 33,27 & 43,10 & 490,73 & 134,79 & 135,32 & 482, \\
\hline Bufo spinosus & 29TPG38 & 100,00 & 96,75 & 92,85 & 37,72 & 5178,34 & 238,76 & $-4,64$ & 243,39 & 40,47 & 165,90 & 165,96 & 35,20 & 1152,50 & 153,75 & 28,99 & 43,10 & 438,96 & 118,41 & 119,17 & 430,55 \\
\hline Bufo spinosus & 29TPG40 & 100,00 & 139,68 & 107,25 & 39,28 & 5619,81 & 294,02 & 24,54 & 269,48 & 69,90 & 213,18 & 213,18 & 69,41 & \begin{tabular}{|l|l|}
839,87 \\
\end{tabular} & $\begin{array}{l}116,78 \\
\end{array}$ & \begin{tabular}{ll|}
11,78 \\
\end{tabular} & 50,19 & 329,39 & 62,42 & 62,42 & 329,39 \\
\hline Bufo spinosus & 29TPG41 & 100,00 & 132,24 & 105,64 & $\begin{array}{l}38,95 \\
\end{array}$ & 5603,97 & 286,01 & 18,46 & 267,55 & 63,01 & 205,82 & 205,82 & 62,58 & 880,38 & \begin{tabular}{|l|l|}
121,57 \\
\end{tabular} & 13,71 & 49,58 & 345,71 & 68,32 & 68,32 & 345,69 \\
\hline Bufo spinosus & 29TPG42 & 101,00 & 119,50 & 102,14 & 38,32 & 5551,84 & 272,26 & 8,95 & 263,32 & 51,70 & 193,03 & \begin{tabular}{|l|l|}
193,03 \\
\end{tabular} & 51,39 & 962,54 & 131,89 & 16,71 & 48,75 & $\begin{array}{ll}378,48 \\
\end{array}$ & 79,34 & 79,34 & 378,47 \\
\hline Bufo spinosus & 29TPG43 & 100,00 & 117,15 & 101,03 & 38,13 & 5522,05 & 268,85 & 7,27 & 261,57 & 52,89 & 190,41 & 190,41 & 50 & 966, & 130,02 & 18,09 & 47,76 & 377,38 & 82,60 & 82,60 & 377,30 \\
\hline Bufo spinosus & $29 \mathrm{TT}$ & 100,00 & $\begin{array}{ll}113,68 \\
\end{array}$ & 99 & 38 & $54 \varepsilon$ & 264,16 & 4,66 & 59,50 & 52,80 & $\begin{array}{l}186,67 \\
\end{array}$ & \begin{tabular}{|l|l|}
186,67 \\
\end{tabular} & 46 & \begin{tabular}{|l|l|}
981,93 \\
\end{tabular} & 129 & 19,66 & 46,90 & $38,1 / 3$ & 87,10 & 87,10 & 380,84 \\
\hline Bufo spinosus & 29TPG47 & 101,00 & 87,27 & 93,12 & 37,28 & 5272,05 & 232,57 & $-13,80$ & 246,38 & 30,69 & 158,08 & 158,12 & 25,08 & 1178,80 & 154,82 & 30,25 & 43,01 & 449,01 & 123,01 & 123,16 & 441,24 \\
\hline Bufo spinosus & 29TPG48 & 100,00 & 108,67 & 96,86 & 37,97 & 5314,99 & 253,42 & 2,25 & 251,18 & 49,64 & 179,27 & 179,29 & 44,47 & 997,65 & 133,38 & 24,48 & 42,97 & 380,02 & 101,32 & 101,38 & 371,02 \\
\hline
\end{tabular}




\begin{tabular}{|c|c|c|c|c|c|c|c|c|c|c|c|c|c|c|c|c|c|c|c|c|c|}
\hline TAXON & UTM & $\mathrm{km} 2$ & B101 & B102 & $\mathrm{BIO3}$ & BIO4 & BIO5 & B106 & B107 & B108 & B109 & BIO10 & BIO11 & BIO12 & B1013 & BIO14 & BIO15 & B1016 & B1017 & BIO18 & B1019 \\
\hline Bufo spinosus & 29TPG49 & 101,00 & 118,67 & 97,49 & 38,41 & 5283,64 & 261,09 & 10,54 & 250,55 & 58,99 & 188,28 & 188,28 & 54,20 & 919,91 & 123,69 & 22,59 & 42,35 & 348,53 & 93,97 & 93,97 & 337,24 \\
\hline Bufo spinosus & 29TPG50 & 100,00 & 137,60 & 107,47 & 39,01 & 5663,99 & 293,42 & 22,08 & 271,34 & 69,40 & 211,95 & 211,95 & 66,82 & 797,61 & 110,60 & 11,75 & 49,53 & 312,43 & 60,95 & 60,95 & 312,37 \\
\hline Bufo spinosus & 29TPG51 & 100,00 & 135,10 & 106,82 & 38,97 & 5652,70 & 290,36 & 19,93 & 270,43 & 68,85 & 209,35 & 209,35 & 64,65 & 802,20 & 109,94 & 12,67 & 48,85 & 313,40 & 63,25 & 63,25 & 313,23 \\
\hline Bufo spinosus & 29TPG52 & 99,00 & 126,28 & 105,19 & 38,73 & 5629,65 & 281,48 & 12,63 & 268,85 & 59,49 & 200,62 & 200,62 & 56,60 & 851,88 & 116,31 & 14,69 & 48,20 & 333,63 & 70,27 & 70,27 & 333,50 \\
\hline Bufo spinosus & 29TPG53 & 101,00 & 118,10 & 103,22 & 38,19 & 5593,68 & 272,73 & 6,29 & \begin{tabular}{|l|l|}
266,44 \\
\end{tabular} & 54,78 & 192,35 & 192,35 & 49,42 & 897,29 & 121,15 & 16,78 & 47,42 & 350,83 & 77,64 & 77,64 & 350,43 \\
\hline Bufo spinosus & 29TPG54 & 100,00 & 112,14 & 101,49 & 37,99 & 5549,06 & 265,44 & 2,10 & 263,34 & 50,57 & 186,01 & 186,01 & 44,43 & 933,69 & 123,73 & 19,01 & 46,45 & 363,30 & 84,68 & 84,68 & 361,72 \\
\hline Bufo spinosus & 29TPG55 & 101,00 & 101,87 & 98,62 & 37,70 & 5478,45 & 253,21 & $-4,90$ & 258,12 & 41,72 & 175,11 & 175,11 & 35,82 & 1007,10 & 132,54 & 22,70 & 45,05 & 389,16 & 96,94 & 96,94 & 385,59 \\
\hline \begin{tabular}{|l} 
Bufo spinosus \\
\end{tabular} & 29TPG56 & 100,00 & 103,96 & 98,97 & 37,87 & 5460,41 & 254,30 & $-3,50$ & 257,80 & 43,58 & 176,87 & \begin{tabular}{|l|l|}
176,87 \\
\end{tabular} & $\begin{array}{ll}37,96 \\
37\end{array}$ & 984,56 & 130,35 & 23,21 & 44,33 & 378,83 & 97,03 & 97,03 & 373,37 \\
\hline Bufo spinosus & 29TPG57 & 100,00 & 107,87 & 99,36 & 38,03 & 5437,69 & 257,09 & $-0,42$ & 257,51 & 47,28 & 180,21 & 180,21 & 41,88 & 949,49 & 126,52 & 22,96 & 43,53 & 363,96 & 95,28 & 95,28 & 356,65 \\
\hline Bufo spinosus & 29TPG58 & 99,00 & 113,24 & 99,55 & 38,22 & 5409,77 & 260,71 & 4,08 & 256,63 & 52,44 & 184,97 & 184,97 & 47,33 & 906,05 & 121,16 & 22,17 & 42,81 & 345,63 & 92,32 & 92,32 & 336,18 \\
\hline Bufo spinosus & 29TPG59 & 101,00 & 120,87 & 99,39 & 38,56 & 5362,54 & 265,42 & 10,95 & 254,47 & 59,95 & 191,56 & 191,56 & 55,12 & 854,10 & 114,17 & 21,06 & 41,95 & 323,58 & 88,29 & 88,29 & 311,47 \\
\hline Bufo spinosus & 29TPG60 & 100,00 & 123,07 & 105,87 & 38,38 & 5712,51 & 281,58 & 9,35 & 272,23 & 52,57 & 198,73 & 198,73 & 52,53 & 838,83 & 117,23 & 13,04 & 49,09 & 331,15 & 67,94 & 67,94 & 331,15 \\
\hline \begin{tabular}{|l} 
Bufo spinosus \\
\end{tabular} & 29TPG61 & 101,00 & 124,66 & 106,28 & 38,58 & 5691,35 & 282,65 & 10,37 & 272,28 & 56,10 & 199,97 & 199,97 & 54,20 & 816,66 & 112,80 & 13,43 & 48,38 & 321,04 & 67,43 & 67,43 & 320,98 \\
\hline Bufo spinosus & 29TPG62 & 101,00 & 117,17 & 104,76 & 38,23 & 5659,64 & 274,68 & 4,41 & 270,26 & 52,34 & 192,27 & 192,27 & 47,48 & 857,09 & 117,25 & 15,25 & 47,61 & 336,34 & 74,11 & 74,11 & 336,18 \\
\hline Bufo spinosus & 29TPG63 & 100,00 & 112,97 & 103,74 & 38,15 & 5628,42 & 269,69 & 1,35 & 268,34 & 50,38 & 187,93 & 187,93 & 44,10 & 878,27 & 118,15 & 16,94 & 46,75 & 343,20 & 79,00 & 79,00 & 342,17 \\
\hline Bufo spinosus & 29TPG64 & 100,00 & 104,22 & $\begin{array}{lll}101,47 \\
\end{array}$ & 37,91 & 5587,04 & 259,60 & $-4,87$ & 264,47 & \begin{tabular}{|l|l|}
42,66 \\
\end{tabular} & 178,99 & 178,99 & 36,56 & \begin{tabular}{|l|l|}
935,40 \\
\end{tabular} & 123,39 & \begin{tabular}{|l|l|}
19,90 \\
\end{tabular} & 45,50 & 363,13 & $\mid 88,84$ & 88,84 & 360,58 \\
\hline Bufo spinosus & 29TPG65 & 100,00 & 91,21 & 98,25 & 37,45 & 5510,92 & 244,11 & $-14,60$ & 258,71 & 31,40 & 165,31 & 165,32 & 25,41 & 1036,29 & 135,29 & 25,12 & 43,62 & 396,79 & 105,96 & 106,01 & 391,05 \\
\hline Bufo spinosus & 29TPG66 & 100,00 & 85,32 & 97,01 & 37,38 & 5459,42 & 236,65 & $-19,18$ & 255,84 & 26,37 & 158,82 & 158,85 & 20,53 & \begin{tabular}{|l|}
1082,19 \\
\end{tabular} & 140,94 & 28,45 & 42,32 & 410,84 & 115,68 & 115,73 & 402,63 \\
\hline Bufo spinosus & 29TPG67 & 101,00 & 90,62 & 98,13 & 37,76 & 5449,74 & 241,65 & $-15,01$ & 256,66 & 31,18 & 163,81 & 163,81 & 25,53 & \begin{tabular}{ll|}
1033,16 \\
\end{tabular} & 135,57 & 27,56 & 41,95 & 391,99 & 111,28 & 111,28 & 382,79 \\
\hline Bufo spinosus & 29TPG68 & 101,00 & 95,38 & 98,77 & 37,99 & 5429,41 & 245,36 & $-11,17$ & 256,53 & 35,56 & 168,01 & 168,01 & 30,21 & 994,16 & 131,08 & 26,93 & 41,40 & 376,34 & 108,56 & 108,56 & 365,59 \\
\hline Bufo spinosus & 29TPG69 & 100,00 & 109,58 & 99,72 & 38,42 & 5401,83 & 256,87 & 0,74 & 256,13 & 48,89 & 181,12 & 181,12 & 43,70 & 891,67 & 118,02 & 23,64 & 41,01 & 336,82 & 96,95 & 96,95 & 323,83 \\
\hline \begin{tabular}{|l} 
Bufo spinosus \\
\end{tabular} & 29TPG70 & 101,00 & 120,49 & 106,61 & 38,23 & 5758,56 & 281,01 & 6,19 & 274,81 & 50,93 & $\begin{array}{l}197,05 \\
\end{array}$ & $\begin{array}{l}197,05 \\
\end{array}$ & 49,40 & 797,41 & 110,24 & 12,70 & 48,25 & 313,45 & 66,84 & 66,84 & 313,45 \\
\hline Bufo spinosus & 29TPG71 & 99,00 & 106,29 & 103,38 & 37,79 & 5709,64 & 265,63 & $-4,35$ & 269,98 & 41,02 & 182,72 & 182,73 & 36,85 & 887,24 & 120,34 & 15,88 & 47,03 & 346,53 & 79,77 & 79,77 & 346,12 \\
\hline Bufo spinosus & 29TPG72 & 100,00 & 104,66 & 103,39 & 37,88 & 5685,59 & 263,66 & $-5,85$ & 269,52 & 42,04 & 180,79 & 180,80 & 35,52 & 889,11 & 119,21 & 17,01 & 46,29 & 346,30 & 82,30 & 82,30 & 345,29 \\
\hline Bufo spinosus & 29TPG73 & 100,00 & 111,26 & 105,36 & 38,08 & 5681,64 & 270,72 & $-1,27$ & 271,99 & 48,18 & 187,11 & 187,11 & 41,70 & 830,16 & 111,22 & 16,29 & 46,11 & 324,27 & 76,84 & 76,84 & 322,77 \\
\hline Bufo spinosus & 29TPG74 & 100,00 & 102,89 & 103,19 & 37,94 & 5639,26 & 260,53 & $-7,56$ & 268,10 & 40,61 & 178,40 & 178,40 & 34,42 & 888,01 & 117,14 & 19,58 & 44,67 & 343,11 & 87,15 & 87,15 & 339,61 \\
\hline Bufo spinosus & 29TPG76 & 100,00 & 69,20 & 95,75 & 37,03 & 5474,24 & 221,21 & $-33,69$ & 254,90 & $\begin{array}{l}40,21 \\
11,21\end{array}$ & 143,07 & 143,32 & \begin{tabular}{|c|}
5,10 \\
5,10
\end{tabular} & \begin{tabular}{|l|}
1166,78 \\
116,0
\end{tabular} & 148,91 & 33,61 & 40,03 & \begin{tabular}{|l|}
435,09 \\
\end{tabular} & \begin{tabular}{|l|l|}
133,11 \\
\end{tabular} & 134,16 & 423,21 \\
\hline Bufo spinosus & 29TPG77 & 100,00 & 72,02 & 96,50 & 37,33 & 5454,39 & 223,74 & $-31,34$ & 255,08 & 13,92 & 145,64 & 145,74 & 7,94 & 1141,30 & 146,33 & 33,84 & 39,61 & 424,73 & 132,61 & 133,18 & 411,98 \\
\hline Bufo spinosus & 29TPG78 & 99,00 & 84,24 & 98,73 & 37,94 & 5461,01 & 235,92 & $-21,51$ & 257,42 & 24,81 & 157,54 & 157,55 & 19,16 & 1035,81 & 134,64 & 30,25 & 39,76 & 387,35 & 119,61 & 119,70 & 374,39 \\
\hline Bufo spinosus & 29TPG79 & 101,00 & 115,29 & 102,23 & 38,71 & 5504,49 & 264,82 & 3,55 & 261,28 & 52,63 & 187,88 & 187,88 & 47,61 & 798,91 & 105,84 & 21,01 & 40,71 & 302,25 & 87,53 & 87,53 & 288,56 \\
\hline Bufo spinosus & 29TPG80 & 100,00 & 121,05 & 107,95 & 38,31 & 5805,80 & 283,05 & 5,75 & 277,30 & 55,69 & 198,22 & 198,22 & 49,43 & 736,72 & 99,75 & 12,07 & 47,20 & 287,01 & 63,76 & 63,76 & 286,57 \\
\hline Bufo spinosus & 29TPG81 & 100,00 & 112,63 & 106,89 & 38,07 & 5769,69 & $\begin{array}{l}27,003 \\
274,83 \\
\end{array}$ & $\begin{array}{c}-0,95 \\
-0,10\end{array}$ & 275,78 & $\begin{array}{l}40,70 \\
47,70\end{array}$ & $\begin{array}{l}189,63 \\
18,25\end{array}$ & $\begin{array}{l}189,63 \\
18,25\end{array}$ & $\begin{array}{l}43,1,79 \\
41\end{array}$ & $\begin{array}{l}781,52 \\
\end{array}$ & 105,21 & $\mid 13,80$ & 46,54 & | 304,45 & $\begin{array}{l}70,73 \\
70\end{array}$ & 70,73 & 304,31 \\
\hline Bufo spinosus & 29TPG82 & 101,00 & 115,92 & 108,05 & 38,48 & 5741,87 & 278,21 & 1,19 & 277,01 & 49,20 & 192,39 & 192,39 & 45,23 & 751,50 & 101,08 & 13,75 & 46,42 & 293,71 & 68,50 & 68,50 & 293,50 \\
\hline Bufo spinosus & 29TPG83 & 100,00 & 114,34 & 107,76 & 38,57 & 5717,94 & 275,96 & $-0,14$ & 276,10 & 49,76 & 190,63 & 190,63 & 43,99 & 756,43 & 100,89 & 14,92 & 45,71 & 294,30 & 71,12 & 71,12 & 293,56 \\
\hline Bufo spinosus & 29TPG84 & 100,00 & 101,08 & 104,58 & 38,04 & 5694,84 & 260,62 & $-10,39$ & 271,01 & 38,15 & 177,42 & 177,42 & 31,99 & 848,62 & 111,77 & 19,55 & 43,67 & 325,23 & 86,52 & 86,52 & 320,86 \\
\hline Bufo spinosus & 29TPG85 & 99,00 & 90,22 & 102,10 & 37,74 & 5649,05 & 247,58 & $-18,81$ & 266,39 & 28,47 & 166,10 & 166,16 & 22,38 & 931,97 & 121,43 & 24,22 & 41,70 & 352,40 & 101,25 & 101,38 & 344,17 \\
\hline \begin{tabular}{|l} 
Bufo spinosus \\
\end{tabular} & 29TPG86 & 101,00 & 80,34 & 100,06 & 37,57 & 5586,05 & 235,83 & $-26,54$ & 262,37 & 19,98 & 155,48 & 155,64 & 13,90 & 1015,72 & 130,94 & 29,10 & 40,06 & 379,28 & 116,18 & 116,72 & 367,84 \\
\hline Bufo spinosus & 29TPG87 & 100,00 & 60,76 & 96,29 & 37,14 & 5479,39 & 213,40 & $-41,90$ & 255,30 & 3,18 & 134,78 & 135,09 & $-3,08$ & 1192,08 & 150,36 & 37,89 & 37,67 & 436,76 & 145,06 & 146,84 & 421,17 \\
\hline Bufo spinosus & 29TPG88 & 101,00 & 75,96 & 99,19 & 37.83 & 5498,03 & 229,16 & $-29,65$ & 258,81 & $\mid 16,66$ & 149,91 & 149,95 & $\mid 10,69$ & 1056,83 & $|135,57|$ & 32.94 & 38,18 & 389,90 & $\mid 128,19$ & 128,45 & 374,70 \\
\hline Bufo spinosus & 29TPG89 & 100,00 & 93,45 & 101,35 & 38,41 & 5516,40 & 245,72 & $-15,37$ & 261,10 & 32,30 & 167,04 & 167,05 & 26,82 & 919,95 & 119,41 & 27,68 & 38,68 & 341,52 & 110,07 & 110,10 & 325,83 \\
\hline Bufo spinosus & 29TPG90 & 101,00 & 125,92 & 109,62 & 38,77 & 5856,70 & 288,50 & 8,71 & 279,79 & 60,02 & 203,44 & 203,44 & 53,20 & 655,17 & 85,95 & 11,25 & 45,79 & 252,45 & 58,32 & 58,32 & 249,87 \\
\hline \begin{tabular}{|l} 
Bufo spinosus \\
\end{tabular} & 29TPG91 & 100,00 & 118,94 & 109,38 & 38,64 & 5827,16 & 282,27 & 2,54 & 279,73 & 53,38 & 196,21 & 196,21 & 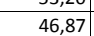 & 687,62 & 90,57 & 12,47 & 45,58 & 265,21 & 63,42 & 63,42 & 264,07 \\
\hline Bufo spinosus & 29TPG92 & 100,00 & 117,79 & 109,49 & 38,73 & \begin{tabular}{|l|}
5801,07 \\
\end{tabular} & 281,12 & 1,55 & 279,58 & 51,24 & 194,91 & 194,91 & 45,98 & 690,75 & 91,31 & 13,20 & 45,22 & 266,29 & 65,12 & 65,12 & 265,58 \\
\hline Bufo spinosus & 29TPG93 & 100,00 & 114,11 & 109,10 & 38,82 & 5783,44 & 276,86 & $-1,48$ & 278,34 & 48,78 & 191,09 & 191,09 & 42,76 & 707,57 & 93,88 & 14,70 & 44,40 & 271,75 & 69,24 & 69,24 & 270,03 \\
\hline Bufo spinosus & 29TPG94 & 101,00 & 110,64 & 108,34 & 38,65 & 5772,11 & 272,62 & $-4,27$ & 276,90 & 45,99 & 187,51 & 187,51 & 39,68 & 726,49 & 96,60 & 16,5 & 43,40 & 277,94 & 73,92 & 73,92 & 274,29 \\
\hline Bufo spinosus & 29TPG95 & 101,00 & 102,24 & 106,49 & 38, & 5749,81 & 262,78 & \begin{tabular}{|c|c|}
$-41,04$ \\
$-11,2$
\end{tabular} & 273,82 & 38,15 & $\begin{array}{l}179,12 \\
179\end{array}$ & $\begin{array}{l}179,12 \\
179\end{array}$ & 32,12 & 781,86 & \begin{tabular}{|r|}
103,44 \\
\end{tabular} & 20,0 & 41,76 & 296,35 & 84,39 & 84,39 & 288,95 \\
\hline Bufo spinosus & 29TPG96 & 100,00 & 97,20 & 105,45 & 38,22 & 5715,20 & 256,35 & $-15,01$ & 271,35 & 33,71 & 173,68 & 173,68 & 27,75 & 820,67 & 107,87 & 22,8 & 40,53 & 308,33 & 92,64 & 92,64 & 298,22 \\
\hline Bufo spinosus & \begin{tabular}{|l|} 
29TPG97 \\
\end{tabular} & 100,00 & 73,90 & 100,69 & 37,78 & 5591,12 & 229,81 & $-32,99$ & 262,80 & 13,84 & 149,23 & 149,36 & 7,62 & 1021,92 & 130,38 & 32,26 & 37,71 & 374,88 & $\mid 125,27$ & 125,90 & 359,55 \\
\hline Bufo spinosus & 29TPHOO & 101,00 & 125,61 & 90,94 & 38,56 & 4901,53 & 255,80 & 22,76 & 233,04 & 70,59 & 189,97 & 190,31 & 66,55 & \begin{tabular}{|l|}
1067,43 \\
\end{tabular} & 150,45 & 25,92 & 43,21 & 400,80 & 106,02 & 114,20 & 388,56 \\
\hline Bufo spinosus & 29TPHO1 & 100,00 & 124,98 & 90,02 & 38,96 & 4776,79 & 252,75 & 24,07 & 228,67 & 71,31 & 187,58 & 188,19 & 67,60 & 1077,54 & 151,59 & 27,30 & 42,65 & 403,69 & 109,82 & 122,46 & 389,66 \\
\hline Bufo spinosus & 29TPH05 & 100,00 & 12 & 86,16 & 40 & $\mid$ & 239,66 & 26,82 & \begin{tabular}{|l|}
212,84 \\
\end{tabular} & $\begin{array}{l}\mid 1,11 \\
72,25\end{array}$ & \begin{tabular}{|l|}
176,64 \\
1764
\end{tabular} & \begin{tabular}{|l|}
178,33 \\
178,3
\end{tabular} & $\begin{array}{ll}68,88 \\
60\end{array}$ & 1130,62 & \begin{tabular}{|l|l|}
154,64 \\
154
\end{tabular} & 32,99 & $\begin{array}{l}42,03 \\
39,74\end{array}$ & \begin{tabular}{|l|}
419,44 \\
419,4
\end{tabular} & \begin{tabular}{|l|}
127,24 \\
127
\end{tabular} & 141,76 & $\begin{array}{l}30,00 \\
397,95\end{array}$ \\
\hline Bufo spinosus & 29TPH06 & 100,00 & 122,37 & 85,04 & 40,24 & 4221,63 & 238,92 & 30,56 & 208,36 & 75,70 & 177,15 & 178,95 & 72,04 & 1114,61 & 150,96 & 33,28 & 38,97 & 412,09 & 127,86 & 143,18 & 388,61 \\
\hline Bufo spinosus & 29TPH07 & 100,00 & 123,13 & 83,78 & 40,52 & 4121,32 & 237,34 & 33,13 & 204,21 & 77,79 & 176,53 & 178,70 & 74,12 & 1106,65 & 148,29 & 33,80 & 38,24 & 408,04 & 129,36 & 145,35 & 382,48 \\
\hline Bufo spinosus & 29TPH08 & 100,00 & 124,56 & 82,49 & 40,96 & 4047,40 & 236,24 & 36,13 & 200,11 & 80,26 & 176,78 & 179,07 & 76,20 & 1090,69 & 144,51 & 34,03 & 37,66 & 400,97 & 129,85 & 146,52 & 373,57 \\
\hline Bufo spinosus & 29TPHO9 & 100,00 & 122,75 & 81,56 & 40,98 & 3966,66 & 232,91 & 35,86 & 197,05 & 79,73 & 173,76 & 176,37 & 75,50 & 1103,86 & 144,75 & 35,37 & 36,96 & 404,69 & 134,34 & 151,17 & 375 , \\
\hline \begin{tabular}{|l} 
Bufo spinosus \\
\end{tabular} & 29TPH14 & 100,00 & 127,77 & 88,45 & 39,92 & 4530,25 & 250,04 & 30,10 & 219,94 & 76,72 & 186,71 & 187,88 & 73,19 & \begin{tabular}{|l|}
1014,92 \\
\end{tabular} & 138,48 & 28,44 & 39,90 & 375,81 & 111,82 & 126,42 & 355,63 \\
\hline Bufo spinosus & 29TPH15 & 101,00 & 122,08 & 87,55 & 40,00 & 4440,51 & 243,46 & 26,58 & 216,88 & 72,40 & 179,97 & 181,29 & 68,86 & 1064,66 & 144,00 & 31,19 & 39,08 & 393,55 & 120,99 & 135,42 & 371,67 \\
\hline Bufo spinosus & 29TPH16 & 101,00 & 125,04 & 86,30 & 40,07 & 4330.92 & 243.26 & 31.13 & 212,13 & 76,77 & 181.15 & 182.83 & 73.01 & 104290 & 139.56 & 31,21 & 38.41 & 383.96 & 120.74 & 136,01 & 359,84 \\
\hline Bufo spinosus & 29TPH18 & 101,00 & 125,68 & 83,80 & 40,68 & 4123,85 & 238,95 & 35,24 & 203 & 80,25 & 178,80 & 180 & 76,07 & 1044,09 & 136,94 & 32,81 & 37,04 & 382,20 & 125,76 & 142,04 & 354,40 \\
\hline Bufo spinosus & 29TPH 26 & 100,00 & 121,66 & 87,84 & 40,00 & 4444,56 & 243,07 & 26,02 & 217,05 & 71,93 & 179,43 & 180,73 & 68,04 & 1026,71 & 136,01 & 31,28 & 37,83 & 377,12 & 121,13 & 135,50 & $352,6 \mathrm{r}$ \\
\hline
\end{tabular}




\begin{tabular}{|c|c|c|c|c|c|c|c|c|c|c|c|c|c|c|c|c|c|c|c|c|c|}
\hline TAXON & UTM & $\mathrm{km2}$ & B101 & $\mathrm{B1O2}$ & $\mathrm{BIO3}$ & B104 & B105 & B106 & B107 & B108 & $\mathrm{BIO9}$ & 81010 & B1011 & BIO12 & BIO13 & 81014 & B1015 & B1O16 & B1017 & B1018 & BIO19 \\
\hline Bufo spinosus & 29TPH27 & 100,00 & 123,01 & 86,66 & 40,23 & 4337,90 & 241,68 & 29,27 & 212,41 & 74,82 & 179,25 & 180,94 & 70,80 & 1019,81 & 133,69 & 31,80 & 37,10 & 373,07 & 122,70 & 137,63 & 346,56 \\
\hline Bufo spinosus & 29TPH30 & 100,00 & 125,13 & 95,64 & 38,73 & 5150,07 & 262,55 & 17,90 & 244,65 & 66,68 & 192,63 & 192,70 & 62,20 & 918,66 & 124,73 & 22,65 & 41,96 & 345,25 & 93,92 & 95,44 & 332,19 \\
\hline Bufo spinosus & 29TPH31 & 101,00 & 119,04 & 94,44 & 38,82 & 5059,74 & 255,30 & 14,04 & 241,25 & 62,01 & 185,63 & 185,73 & 57,79 & 967,60 & 131,02 & 25,32 & 41,14 & 362,64 & 102,89 & 105,66 & 347,87 \\
\hline Bufo spinosus & 29TPH32 & 101,00 & 111,82 & 93,24 & 38,93 & 4954,82 & 246,85 & 9,55 & 237,30 & 56,42 & 177,15 & 177,45 & 52,28 & \begin{tabular}{ll|}
1029,96 \\
\end{tabular} & 138,71 & 28,51 & 40,24 & 384,92 & 113,70 & 120,04 & 368,31 \\
\hline Bufo spinosus & 29TPH34 & 101,00 & 122,50 & 91,58 & \begin{tabular}{l|l|}
39,55 \\
\end{tabular} & \begin{tabular}{ll|l|}
4743,04 \\
\end{tabular} & 250,87 & 21,83 & 229,04 & 69,08 & 184,43 & 185,11 & 65,12 & 961,03 & 127,96 & 27,78 & 38,70 & 354,84 & 109,87 & 122,43 & 333,48 \\
\hline Bufo spinosus & 29TPH35 & 101,00 & 118,79 & 90,60 & 39,82 & 4643,16 & 245,49 & 20,12 & 225,38 & 66,82 & 179,40 & 180,40 & 62,86 & 996,47 & 131,71 & 30,01 & 37,94 & 366,67 & 117,26 & 130,42 & 343,40 \\
\hline Bufo spinosus & 29TPH38 & 101,00 & 119,86 & 87,02 & 40,46 & 4332,46 & 238,97 & 26,55 & 212,42 & 72,01 & 176,02 & 177,71 & 67,77 & 1012,15 & 129,91 & 33,23 & 35,76 & 367,39 & 127,05 & 141,69 & 338,09 \\
\hline \begin{tabular}{|l} 
Bufo spinosus \\
\end{tabular} & 29TPH39 & 100,00 & 120,33 & 85,68 & 40,81 & 4224,79 & 236,71 & 28,66 & 208,05 & 73,78 & 174,85 & 176,75 & 69,58 & 1018,56 & \begin{tabular}{|l|l|}
129,79 \\
\end{tabular} & 34,29 & 35,07 & 368,25 & 130,32 & 145,46 & 337,16 \\
\hline Bufo spinosus & 29TPH40 & 100,00 & 122,17 & 96,97 & 38,64 & 5220,98 & 262,21 & 14,28 & 247,94 & 62,99 & 190,75 & 190,76 & 58,29 & 893,50 & 120,14 & 22,50 & 41,55 & 336,45 & 93,20 & 93,37 & 322,83 \\
\hline Bufo spinosus & 29TPH42 & 99,00 & 98,73 & 93,70 & 38,60 & 5033,63 & 237,43 & $-2,60$ & 240,03 & 43,30 & 165,53 & 165,70 & 38,78 & 1084,12 & 143,75 & 31,77 & 39,41 & 404,36 & 124,83 & 128,62 & 386,95 \\
\hline Bufo spinosus & 29TPH44 & 99,00 & 109,30 & 93,09 & 39,19 & 4862,07 & 242,56 & 8,30 & 234,26 & 54,97 & 173,19 & 173,70 & 50,86 & 1015,57 & 133,86 & 30,74 & 37,96 & 375,15 & 120,36 & 129,85 & 353,36 \\
\hline Bufo spinosus & 29TPH46 & 100,00 & 109,87 & 91,19 & 39,78 & 4666,34 & 238,61 & 11,67 & 226,94 & 58,09 & 170,95 & 171,92 & 53,92 & 1027,55 & 133,24 & 33,07 & 36,41 & 375,50 & 127,47 & 139,49 & 349,42 \\
\hline \begin{tabular}{|l} 
Bufo spinosus \\
\end{tabular} & 29TPH47 & 100,00 & 113,76 & 89,87 & \begin{tabular}{|l|l|}
40,07 \\
\end{tabular} & 4540,38 & 238,84 & 17,10 & 221,75 & 63,41 & 172,88 & 174,14 & 59,13 & 1012,02 & 129,93 & 33,27 & 35,72 & 367,70 & 127,70 & 140,68 & 339,47 \\
\hline Bufo spinosus & 29TPH48 & 101,00 & 117,97 & 88,31 & 40,36 & 4404,92 & 239,19 & 23,24 & 215,96 & 69,26 & 175,12 & 176,65 & 64,93 & 993,69 & 127,02 & 33,38 & 34,98 & 359,06 & 127,50 & 141,46 & 328,68 \\
\hline Bufo spinosus & 29TPH49 & 100,00 & 124,12 & 86,46 & 40,94 & 4260,85 & 240,72 & 31,49 & 209,23 & 77,22 & 179,05 & 180,94 & 72,71 & 962,06 & 123,51 & 32,72 & 34,54 & 345,94 & 124,92 & 139,97 & 313,62 \\
\hline Bufo spinosus & 29TPH51 & 100,00 & 92,45 & 95,33 & 38,24 & 5173,82 & 235,67 & $\mid-10,10$ & 245,76 & \begin{tabular}{|l|l|}
35,76 \\
\end{tabular} & $\mid 161,46$ & $\mid 161,51$ & 30,84 & $\mid 1078,35$ & $\mid 141,86$ & \begin{tabular}{|l|l|l|}
31,88 & \\
\end{tabular} & 39,27 & 402,52 & $\mid 125,19$ & 125,91 & 386,28 \\
\hline Bufo spinosus & 29TPH52 & 100,00 & 95,85 & 95,19 & 38,70 & 5107,97 & 237,01 & $-6,60$ & 243,60 & 39,57 & 163,73 & 163,78 & 34,81 & 1057,17 & 138,92 & 31,84 & 38,58 & 392,95 & \begin{tabular}{l|l|}
124,87 \\
\end{tabular} & 126,52 & 374,61 \\
\hline Bufo spinosus & 29TPH54 & 100,00 & 115,34 & 94,76 & 39,46 & 4935,88 & 249,56 & \begin{tabular}{r|r|}
12,04 \\
\end{tabular} & 237,52 & 59,65 & 179,89 & 180,24 & 55,34 & 926,28 & 120,82 & 27,95 & 37,42 & 341,19 & 110,92 & 118,09 & 318,13 \\
\hline Bufo spinosus & 29TPH55 & 101,00 & 115,59 & 93,60 & 39,80 & 4824,02 & 247,23 & 14,03 & 233,20 & 61,30 & 178,62 & 179,20 & 57,08 & 937,10 & 121,15 & 29,23 & 36,63 & 342,96 & 114,97 & 125,70 & 317,72 \\
\hline Bufo spinosus & 29TPH56 & 100,00 & 112,59 & 92,57 & 39,92 & 4721,95 & 242,36 & 12,91 & 229,45 & 59,88 & $\mid 174,30$ & $\mid 175,10$ & 55,56 & 969,45 & $\mid 124,37$ & 31,62 & 35,72 & 352.59 & $\mid 122,46$ & 134.51 & 325,18 \\
\hline Bufo spinosus & 29TPH57 & 101,00 & 108,53 & 91,48 & 39,99 & 4634,93 & 236,83 & 10,77 & 226,06 & 57,27 & 169,01 & 170,10 & 52,83 & 1012,28 & 129,34 & 34,45 & 34,89 & 366,04 & 131,43 & 143,40 & 336,67 \\
\hline Bufo spinosus & 29TPH58 & 99,00 & 111,89 & 90,21 & 40,17 & 4511,60 & 236,79 & 15,61 & 221,18 & 62,19 & $\begin{array}{l}170,64 \\
\end{array}$ & 171,93 & 57,57 & 1001,05 & 128,05 & 34,69 & 34,26 & 360,09 & 131,93 & 144,69 & 328,66 \\
\hline Bufo spinosus & 29TPH60 & 101,00 & 104,75 & 99,05 & \begin{tabular}{|l|l|}
38,49 \\
\end{tabular} & 5352,43 & 251,30 & $-2,77$ & 254,06 & 44,83 & 175,79 & 175,79 & 39,85 & 926,98 & 122,54 & 25,86 & 40,07 & 348,48 & 104,41 & 104,43 & 333,57 \\
\hline Bufo spinosus & 29TPH62 & 100,00 & 100,06 & 97,43 & 38,86 & 5205,83 & 243,35 & $-4,92$ & 248,28 & 41,99 & 169,03 & 169,06 & 37,23 & 973,89 & 127,40 & 29,47 & 38,08 & 361,44 & 116,54 & 116,88 & 342,10 \\
\hline Bufo spinosus & 29TPH63 & 100,00 & 96,65 & 96,45 & 38,91 & 5119,07 & 238,28 & $-6,57$ & 244,86 & 39,94 & 164,49 & 164,55 & 35,18 & 1010,04 & 131,23 & 31,90 & 37,11 & 372,28 & 124,46 & 125,75 & 350,78 \\
\hline Bufo spinosus & 29TPH64 & 100,00 & 101,18 & 95,94 & 39,16 & 5028,11 & 240,07 & $-1,63$ & 241,70 & 45,30 & 167,53 & 167,73 & 40,68 & 986,45 & 127,35 & 31,77 & 36,41 & 361,41 & 123,68 & 127,55 & 337,53 \\
\hline Bufo spinosus & 29TPH65 & 100,00 & 112,94 & 95,05 & 39,80 & 4897,09 & 246,96 & $\begin{array}{l}1,0,35 \\
10\end{array}$ & 236,61 & 57,84 & $\begin{array}{l}176,96 \\
\end{array}$ & 177,34 & 53,48 & \begin{tabular}{|l|l|}
917,38 \\
\end{tabular} & 118,07 & 29,50 & \begin{tabular}{|l|l}
35,76 \\
35
\end{tabular} & \begin{tabular}{|l|}
334,18 \\
\end{tabular} & 115,83 & 124,25 & 307,60 \\
\hline Bufo spinosus & 29TPH67 & 100,00 & 111,40 & 92,64 & 40,16 & 4672,44 & 240,37 & 12,48 & 227,89 & 59,48 & 172,27 & 173,21 & 54,89 & 959,28 & 123,40 & 33,20 & 34,14 & 344,70 & 127,14 & 138,91 & 313,97 \\
\hline Bufo spinosus & 29TPH68 & 100,00 & 112,91 & 91,50 & 40,35 & 4561,33 & 239,10 & 15,52 & 223,58 & 62,99 & 172,22 & 173,42 & 57,89 & 963,04 & 124,25 & 34,13 & 33,53 & 344,15 & 129,85 & 142,22 & 311,33 \\
\hline Bufo spinosus & 29TPH70 & 99,00 & 120,04 & 101,98 & 38,92 & 5464,69 & 267,27 & 7,93 & 259,34 & 57,30 & 191,79 & 191,79 & 52,47 & 768,84 & 101,73 & 20,23 & 40,17 & 290,06 & 85,34 & 85,34 & 274,12 \\
\hline Bufo spinosus & 29TPH71 & 100,00 & 113,94 & 100,82 & 38,97 & 5392,16 & 260,03 & 3,76 & 256,27 & 52,37 & 184,91 & 184,91 & 47,68 & 816,87 & 107,39 & 22,93 & 39,03 & 305,75 & 94,65 & 94,65 & 287,50 \\
\hline Bufo spinosus & 29TPH73 & 101,00 & 86,82 & 97,28 & 38,88 & 5179,44 & 231,19 & $\begin{array}{ll}-16,28 \\
-16,10\end{array}$ & \begin{tabular}{|l|}
247,47 \\
\end{tabular} & 30,10 & $\begin{array}{l}155,82 \\
155,2\end{array}$ & $\begin{array}{l}155,92 \\
155,\end{array}$ & 25,01 & \begin{tabular}{|l|}
1044,37 \\
\end{tabular} & \begin{tabular}{|l|l|}
133,86 \\
\end{tabular} & 35,11 & $\begin{array}{l}35,84 \\
35,\end{array}$ & \begin{tabular}{|l|l|}
381,04 \\
\end{tabular} & \begin{tabular}{r|}
134,58 \\
13,5
\end{tabular} & \begin{tabular}{|l|}
135,46 \\
13,4
\end{tabular} & 358,23 \\
\hline Bufo spinosus & 29TPH74 & 100,00 & 79,80 & 95,67 & 38,76 & 5085,43 & 222,37 & $-21,16$ & 243,53 & 24,80 & 147,66 & 147,86 & 19,67 & 1114,89 & 141,35 & 39,34 & 34,79 & 402,99 & 148,23 & 150,17 & 377,98 \\
\hline Bufo spinosus & 29TPH75 & 101,00 & 94,02 & 96,11 & 39,45 & 4995,44 & 233,21 & $-7,67$ & 240,88 & 39,08 & 160,11 & 160,38 & 34,17 & 1015,93 & 129,58 & 35,50 & 34,52 & 366,79 & 135,23 & 139,76 & 339,58 \\
\hline Bufo spinosus & 29TPH77 & 101,00 & 109,22 & 93,94 & 40,19 & 4735,34 & 240,26 & 9,41 & 230,85 & 57,06 & 171,00 & 171,77 & 51,94 & 943,31 & 121,95 & 33,73 & 33,37 & 336,65 & 128,55 & 139,42 & 304,64 \\
\hline Bufo spinosus & 29TPH78 & 100,00 & 114,42 & 92,48 & 40,65 & 4583,52 & 241,15 & 16,33 & 224,81 & 67,71 & 173,87 & 175,05 & 58,89 & 927,82 & 120,75 & 33,81 & 32,65 & 328,82 & 128,45 & 140,50 & 294,39 \\
\hline Bufo spinosus & 29TPH80 & 101,00 & 115,40 & $\begin{array}{r}5,40 \\
103,38 \\
\end{array}$ & | 38,97 & $\begin{array}{l}4503,24 \\
5547,08\end{array}$ & 265,72 & $\frac{\mid 0,330}{2,60}$ & \begin{tabular}{|l|}
263,12 \\
263,12
\end{tabular} & $\begin{array}{l}1,1,78 \\
51\end{array}$ & \begin{tabular}{|l|}
188,51 \\
185
\end{tabular} & $\begin{array}{l}188,51 \\
18,5\end{array}$ & $\begin{array}{l}0,05 \\
46,90\end{array}$ & $\begin{array}{l}\mid 754,35 \\
754\end{array}$ & \begin{tabular}{|l|}
99,32 \\
99,
\end{tabular} & \begin{tabular}{|l|l|}
20,75 \\
201
\end{tabular} & $\begin{array}{l}2,00 \\
39,45 \\
\end{array}$ & \begin{tabular}{|l|l|}
283,550 \\
283
\end{tabular} & $\begin{array}{l}12,40,01 \\
87,01\end{array}$ & \begin{tabular}{|c|}
87,01 \\
87,01
\end{tabular} & $\begin{array}{l}254,53 \\
266,77\end{array}$ \\
\hline Bufo spinosus & 29TPH81 & 99,00 & 126,87 & 102,37 & 39,00 & 5448,44 & 272,65 & 13,83 & 258,82 & 63,77 & 197,98 & 197,98 & 59,01 & 694,68 & 91,52 & 18,59 & 38,74 & 259,96 & 80,41 & 80,41 & 239,84 \\
\hline Bufo spinosus & 29TPH83 & 101,00 & 103,10 & 100,38 & 39,18 & 5272,73 & 248,04 & $-4,25$ & 252,29 & 43,77 & 172,58 & 172,58 & 38,79 & 876,14 & 113,19 & 28,54 & 35,80 & 320,06 & 112,79 & 112,79 & 295,79 \\
\hline Bufo spinosus & 29TPH84 & 99,00 & 84,45 & 98,01 & 39,11 & 5161,57 & 228,83 & $-18,65$ & 247,48 & 28,14 & 153,10 & 153,23 & 22,80 & 1035,10 & 131,26 & 37,17 & 34,15 & 372,30 & 140,47 & 142,00 & 346,19 \\
\hline Bufo spinosus & 29TPH85 & 100,00 & 86,49 & 97,08 & 39,39 & 5063,74 & 228,23 & $-15,52$ & 243,75 & 31,32 & 153,68 & 153,93 & 26,09 & 1038,17 & 131,85 & 38,02 & 33,43 & 371,23 & 143,15 & 146,55 & 342,91 \\
\hline \begin{tabular}{|l} 
Bufo spinosus \\
\end{tabular} & 29TPH86 & 100,00 & 92,14 & 96,67 & 39,75 & 4962,72 & 231,10 & \begin{tabular}{|c|c|}
$-9,28$ \\
\end{tabular} & 240,38 & 37,85 & 157,69 & 158,06 & 32,74 & 1009,01 & 128,96 & 37,55 & 32,85 & 359,18 & $\begin{array}{ll}141,06 \\
\end{array}$ & 147,50 & 328,58 \\
\hline Bufo spinosus & 29TPH9O & 100,00 & 99,73 & 103,64 & 38,78 & 5565,35 & 252,92 & $-11,42$ & 264,33 & 37,12 & 173,61 & 173,61 & 31,75 & 828,61 & 107,49 & 25,79 & 37,44 & 305,64 & 103,15 & 103,15 & 287,18 \\
\hline Bufo spinosus & 29TPH91 & 100,00 & 123,96 & 104,01 & 39,00 & 5549,99 & 273,22 & 9,52 & 263,70 & 59,34 & 196,45 & 196,45 & 54,78 & 671,06 & 89,20 & 18,55 & 38,11 & 250,52 & 80,57 & 80,57 & 229,55 \\
\hline Bufo spinosus & 29TPH92 & 100,00 & 115,93 & 103,31 & 39,17 & 5449,94 & 263,7 & $\begin{array}{ll}3,94 \\
\end{array}$ & 259,82 & 53,38 & 187,38 & 187,38 & 48,47 & 733,35 & 96,86 & 22,12 & 36,71 & 70,19 & 92,33 & 92,33 & 246,59 \\
\hline Bufo spinosus & 29TPH93 & 101,00 & 107,31 & 102,32 & 39,65 & 5336,26 & 253,6 & $\begin{array}{c}-1,94 \\
-1,99 \\
\end{array}$ & \begin{tabular}{|l|}
255,66 \\
\end{tabular} & \begin{tabular}{|l|l|}
46,81 \\
\end{tabular} & \begin{tabular}{|l|l|}
177,48 \\
\end{tabular} & \begin{tabular}{|l|l|}
177,48 \\
\end{tabular} & $\begin{array}{l}40,1,85 \\
41,85\end{array}$ & 807,54 & \begin{tabular}{|r|}
105,61 \\
\end{tabular} & 26,68 & \begin{tabular}{|l|l|}
35,10 \\
\end{tabular} & 293,24 & $\begin{array}{r}106,52 \\
10,5\end{array}$ & \begin{tabular}{|c|}
106,52 \\
16,5
\end{tabular} & $\begin{array}{l}2407,56 \\
267\end{array}$ \\
\hline \begin{tabular}{|l} 
Bufo spinosus \\
\end{tabular} & 29TPH94 & 100,00 & 95,70 & 100,75 & 39,73 & 5221,88 & 241,01 & $-10,36$ & 251,37 & 37,77 & 164,72 & 164,75 & 32,52 & 909,10 & 117,19 & 32,6 & 33,67 & 325,71 & 125,11 & 125,58 & 298,14 \\
\hline Bufo spinosus & 29TPH95 & 101,00 & 82,12 & 98,49 & 39,41 & 5119,52 & 226,07 & $-20,73$ & 246,80 & 26,62 & 150,14 & 150,32 & 21,01 & 1033,23 & 130,99 & 39,47 & 32.41 & 366,08 & 147,11 & $\mid 149,18$ & 336,68 \\
\hline Bufo spinosus & 29TPH96 & 100,00 & 95,13 & 98,32 & 40,01 & 4996,45 & 234,96 & $-7,69$ & 242,65 & 43,34 & 160,89 & 161,15 & 34,80 & 956,82 & 123,38 & 36,55 & 32,03 & 337,68 & 137,32 & 142,85 & 305,49 \\
\hline Bufo spinosus & 29TPH98 & 100,00 & 111,66 & 95,51 & 41,04 & 4661,68 & 241,84 & 11,66 & 230,17 & 80,23 & 172,05 & 173,17 & 54,95 & 896,42 & 118,15 & 35,10 & 30,95 & 313,24 & 131,72 & 142,51 & 274,12 \\
\hline Bufo spinosus & 29TPJ00 & 100,00 & $\frac{11}{11}$ & 80,76 & 40 & $\begin{array}{l}4003,100 \\
393,58\end{array}$ & 227, & $\begin{array}{l}1,100 \\
31,59\end{array}$ & \begin{tabular}{|l|}
195,51 \\
195
\end{tabular} & $\begin{array}{l}\mid c 0,23 \\
75,04\end{array}$ & $\begin{array}{l}167,82 \\
167\end{array}$ & \begin{tabular}{|l|l|}
170,58 \\
\end{tabular} & $\begin{array}{l}4,35 \\
70,49\end{array}$ & \begin{tabular}{|l|}
090,45 \\
1145,39
\end{tabular} & \begin{tabular}{|l|}
148,93 \\
148,
\end{tabular} & $\begin{array}{l}30,109 \\
37,93\end{array}$ & 36,25 & \begin{tabular}{|l|}
418,76 \\
\end{tabular} & $\begin{array}{l}141,2,92 \\
142\end{array}$ & \begin{tabular}{|l|}
$152,5,58$ \\
159
\end{tabular} & 388,07 \\
\hline Bufo spinosus & 29TPJ01 & 101,00 & 112,48 & 79,91 & 40,93 & 3893,99 & 221,85 & 28,54 & 193,32 & 71,38 & 162,61 & 165,58 & 66,65 & 1180,63 & 152,27 & 40,25 & 35,61 & 430,41 & 150,73 & 167,32 & 398,02 \\
\hline Bufo spinosus & 29TPJ02 & 101,00 & 123,80 & 77,64 & 41,36 & 3730,50 & 226,94 & 41,71 & $\mid 185,24$ & 84,33 & $\mid 171,23$ & $\mid 174,39$ & 79,08 & 1089,72 & 138,96 & 36.99 & 35,12 & 396,56 & 139,64 & $\mid 158,09$ & 362,56 \\
\hline Bufo spinosus & \begin{tabular}{|l|} 
29TPJ03 \\
\end{tabular} & 101,00 & 127,49 & 76,06 & 41,66 & 3640,31 & 227,42 & 47,19 & 180,23 & 89,29 & 173,45 & 176,91 & 83,71 & 1057,71 & 135,04 & 36,25 & 34,85 & 384,15 & 137,13 & 156,45 & 348,63 \\
\hline Bufo spinosus & 29TPJ04 & 56,00 & 137,36 & 73,90 & 42,1 & 3514,50 & 232,05 & 58,87 & 173,18 & 100,53 & 181,14 & 184,83 & 94,53 & 981,99 & 127,14 & 33,35 & 34,81 & 356,73 & 127,39 & 148,12 & 315 \\
\hline \begin{tabular}{|l} 
Bufo spinosus \\
\end{tabular} & 29TPJ10 & 101,00 & 112,25 & 82,44 & 40,65 & 4047,22 & 225,37 & 25,05 & 200,32 & 68,87 & 164,45 & 167,13 & 64,32 & 1150,58 & 148,39 & 39,02 & 35,57 & 418,62 & 146,55 & 162,06 & 387,48 \\
\hline Bufo spinosus & 29TPJ11 & 99,00 & 107,59 & 81,49 & 40,67 & 4002,55 & 220,11 & 21,82 & 198,28 & 65,15 & 159,35 & 162,08 & 60,56 & 1187,50 & 151,90 & 41,50 & 34,98 & 430,71 & 154,62 & 170,05 & 397,96 \\
\hline Bufo spinosus & 29TPJ12 & 100,00 & 123,46 & 78,92 & 41,39 & 3807,52 & 228,45 & 39,93 & 188,52 & 82,91 & 171,92 & 174,97 & 77,90 & 1067,06 & 135,81 & 36,83 & 34,70 & 386,28 & 138,65 & 156,57 & 351,79 \\
\hline Bufo spinosus & 29TPJ13 & 90,00 & 132,24 & 76,74 & 41,84 & 3674,46 & 232,24 & 50,79 & 181,45 & 93, & 178, & 181, & 87, & 1000,76 & 128,78 & 34,41 & 34,42 & 361,84 & 130,66 & 149,97 & 325,86 \\
\hline Bufo spinosus & 29TPJ21 & 100,00 & 120,79 & 81,71 & 41,15 & 3971,63 & 230,49 & 34,14 & 196,35 & 77,94 & 171,70 & 174,29 & 73,26 & 1057,61 & 134,68 & 36,63 & 34,61 & 381,88 & 137,79 & 154,38 & 348,21 \\
\hline
\end{tabular}




\begin{tabular}{|c|c|c|c|c|c|c|c|c|c|c|c|c|c|c|c|c|c|c|c|c|c|}
\hline TAXON & UTM & $\mathrm{km} 2$ & B101 & B102 & $\mathrm{BIO3}$ & B104 & BIO5 & B106 & B107 & B108 & B109 & BIO10 & BIO11 & BIO12 & B1013 & BIO14 & B1015 & BIO16 & BIO17 & B1018 & B1019 \\
\hline Bufo spinosus & 29TPJ22 & 101,00 & 128,39 & 79,59 & 41,46 & 3830,80 & 233,22 & 43,66 & 189,56 & 87,41 & 177,09 & 180,01 & 82,31 & 1008,09 & 129,29 & 35,01 & 34,31 & 363,16 & 132,31 & 150,16 & 327,92 \\
\hline Bufo spinosus & 29TPJ23 & 94,00 & 133,06 & 77,66 & 41,91 & 3722,46 & 234,09 & 50,41 & 183,68 & 93,41 & 180,09 & 183,18 & 88,03 & 977,56 & 126,37 & 34,11 & 33,99 & 351,59 & 129,36 & 148,23 & 314,92 \\
\hline Bufo spinosus & 29TPJ31 & 100,00 & 135,22 & 81,16 & 41,29 & 3932,80 & 241,41 & 47,83 & \begin{tabular}{|l|}
193,58 \\
\end{tabular} & 92,40 & 185,17 & 187,79 & 87,18 & 929,59 & 120,41 & 31,68 & 34,24 & 333,90 & 121,13 & 138,70 & 299,17 \\
\hline Bufo spinosus & 29TPJ40 & 101,00 & 128,17 & 84,57 & \begin{tabular}{|l|l|}
41,07 \\
\end{tabular} & 4134,92 & 240,82 & 37,28 & 203,54 & 82,84 & 181,01 & 183,25 & 77,93 & 945,88 & 122,14 & 32,70 & 34,02 & 338,76 & \begin{tabular}{|l|l|}
124,47 \\
\end{tabular} & 140,34 & 304,66 \\
\hline Bufo spinosus & 29TPJ41 & 100,00 & 129,11 & 83,08 & 41,29 & \begin{tabular}{ll|}
4026,54 \\
\end{tabular} & 238,90 & 40,38 & 198,52 & 85,34 & 180,45 & 182,99 & 80,33 & 948,94 & 122,89 & 33,48 & 33,49 & 338,62 & 126,88 & 143,42 & 302,84 \\
\hline Bufo spinosus & 29TPJ42 & 53,00 & 137,48 & 80,69 & 41,72 & 3889,44 & 242,19 & 50,71 & 191,48 & 96,05 & 186,59 & 189,31 & 89,93 & 902,47 & 118,12 & 31,63 & 33,45 & 321,57 & 120,77 & 138,51 & 284,69 \\
\hline Bufo spinosus & 29TPJ52 & 41,00 & 139,23 & 81,22 & 41,72 & 3912,25 & 244,14 & 51,68 & 192,46 & 111,51 & 188,72 & 191,29 & 91,29 & 874,91 & 115,40 & 31,32 & 32,94 & 309,83 & 119,20 & 136,62 & 271,68 \\
\hline \begin{tabular}{|l} 
Bufo spinosus \\
\end{tabular} & $\begin{array}{l}\text { 29TPJ92 } \\
\text { 29T }\end{array}$ & 60,00 & 135,50 & 84,06 & 42,06 & 3954,26 & 243,15 & 46,30 & 196,86 & 114,32 & 185,50 & 188,13 & 87,30 & 853,51 & 114,98 & 34,70 & 30,12 & 296,43 & 128,88 & 143,72 & 246,58 \\
\hline Bufo spinosus & 29TQE04 & 100,00 & 154,81 & 104,37 & 36,24 & 6192,69 & 321,03 & 38,01 & 283,02 & 86,55 & 237,01 & 237,01 & 78,85 & 586,07 & 76,24 & 5,54 & 48,99 & 224,24 & 41,44 & 41,44 & 214,93 \\
\hline Bufo spinosus & 29TQE06 & 100,00 & 119,30 & 96,47 & \begin{tabular}{|l|l|}
34,97 \\
\end{tabular} & 6132,22 & 280,84 & 9,10 & 271,74 & 53,72 & 201,13 & 201,82 & 46,16 & 805,73 & 107,34 & 10,19 & 48,41 & 309,67 & 60,69 & 63,48 & 300,38 \\
\hline Bufo spinosus & 29TQE07 & 100,00 & 123,62 & 98,16 & 35,33 & 6135,20 & 285,67 & 12,02 & 273,65 & 57,43 & 204,98 & 205,92 & 49,78 & 759,97 & 100,67 & 9,58 & 48,27 & 291,79 & 57,97 & 59,88 & 282,52 \\
\hline Bufo spinosus & 29TQE08 & 99,00 & 125,47 & 99,36 & 35,85 & 6122,78 & 287,60 & 13,15 & 274,45 & 58,98 & 206,49 & 207,47 & 51,45 & 736,57 & 97,22 & 9,29 & 48,01 & 282,68 & 56,92 & 58,27 & 273,55 \\
\hline \begin{tabular}{|l} 
Bufo spinosus \\
\end{tabular} & 29TQE09 & 100,00 & 131,30 & 101,86 & \begin{tabular}{|l|l|}
36,17 \\
\end{tabular} & 6116,52 & 294,27 & 17,42 & 276,85 & 64,19 & 212,74 & 212,94 & 56,78 & 685,57 & 89,87 & 8,81 & 47,62 & 262,67 & 54,02 & 54,22 & 253,71 \\
\hline Bufo spinosus & 29TQE13 & 100,00 & 156,33 & 105,69 & 36,17 & 6251,36 & 324,88 & 38,28 & 286,60 & 87,52 & 239,41 & 239,41 & 79,80 & 550,07 & 70,36 & 5,31 & 48,23 & 208,15 & 39,49 & 39,49 & 197,77 \\
\hline Bufo spinosus & 29TQE16 & 100,00 & 126,83 & 100,71 & 35,60 & 6194,17 & 292,02 & 13,50 & 278,52 & 59,89 & 209,38 & 209,97 & 52,39 & 705,71 & 90,99 & 9,18 & 47,08 & 267,62 & 55,30 & 56,81 & 256,77 \\
\hline Bufo spinosus & 29TQE17 & 100,00 & 116,90 & 99,27 & 35,58 & 6162,49 & 280,77 & 5,20 & 275,57 & 50,61 & 198,90 & 199,93 & 43,24 & 757,81 & 97,69 & 10,55 & 46,63 & 287,30 & 60,86 & 63,32 & 276,08 \\
\hline Bufo spinosus & 29TQE18 & 101,00 & 125,54 & 101,80 & 36,00 & 6169,60 & 290,29 & 11,75 & 278,54 & 58,30 & 207,24 & 208,30 & 51,04 & 686,06 & 88,32 & 9,12 & 46,56 & 260,12 & 55,46 & 56,49 & 249,12 \\
\hline Bufo spinosus & 29TQE19 & 100,00 & 127,25 & 103,00 & 36,19 & 6162,70 & 292,13 & 12,80 & 279,33 & 59,83 & 209,15 & 209,75 & 52,47 & 661,92 & 85,14 & 9,13 & 46,17 & 250,62 & 54,62 & 55,15 & 239,65 \\
\hline Bufo spinosus & 29TQE24 & 99,00 & 149,99 & 106,28 & 36,22 & 6291,31 & 319,92 & 31,59 & 288,33 & 80,97 & 233,87 & 233,87 & 73,29 & 545,39 & 69,12 & 5,95 & 46,76 & 203,85 & $\begin{array}{ll}41,63 \\
\end{array}$ & 41,63 & 192,54 \\
\hline Bufo spinosus & 29TOE27 & 100,00 & 115,21 & 101.46 & 35,89 & 6193,50 & 281,50 & 2.46 & 279,03 & 48,61 & 197,91 & $\mid 198,74$ & 41,40 & 724,32 & 92,23 & 10,95 & 45,11 & 270,80 & 61,14 & 63,60 & 257.91 \\
\hline Bufo spinosus & 29TQE28 & 100,00 & 119,46 & 102,97 & 36,06 & 6199,91 & 286,09 & 5,50 & 280,59 & 52,27 & 201,76 & 202,81 & 44,99 & 678,62 & 86,57 & 10,04 & 44,90 & 253,79 & 57,87 & 59,40 & 240,81 \\
\hline \begin{tabular}{|l} 
Bufo spinosus \\
\end{tabular} & 29TQE29 & 100,00 & 116,36 & 103,20 & 36,24 & 6180,34 & 282,62 & 2,50 & 280,12 & 49,27 & 198,36 & \begin{tabular}{|l|l|}
199,41 \\
\end{tabular} & 42,10 & 682,64 & 87,11 & 10,50 & 44,39 & 254,87 & 59,63 & 61,24 & 241,53 \\
\hline Bufo spinosus & 29TQE37 & 99,00 & 132,68 & 106,64 & 36,72 & 6260,68 & 302,26 & 15,30 & 286,96 & 64,04 & 216,10 & 216,41 & 56,71 & 576,18 & 72,79 & 8,43 & 44,17 & 212,34 & 49,52 & 49,99 & 199,15 \\
\hline Bufo spinosus & 29TQE38 & 100,00 & 110,46 & 103,62 & 36,32 & 6198,67 & 278,44 & $-3,04$ & 281,49 & 43,78 & 193,30 & 194,22 & 36,73 & 697,16 & 88,05 & 11,78 & 43,03 & 256,34 & 63,16 & 65,78 & 241,57 \\
\hline Bufo spinosus & 29TQE39 & 101,00 & 109,91 & 104,34 & 36,66 & 6188,14 & 277,81 & $-3,78$ & 281,59 & 43,16 & 192,28 & 193,47 & 36,11 & 681,21 & 86,15 & 11,77 & 42,58 & 250,19 & 63,12 & 65,34 & 234,95 \\
\hline Bufo spinosus & 29TQE43 & 100,00 & 153,78 & 109,25 & 36,69 & 6364,03 & 327,23 & 32,72 & 294,51 & 83,69 & 238,77 & 238,77 & 76,06 & 479,93 & 59,67 & 5,32 & 45,56 & 174,91 & 37,56 & 37,56 & 162,53 \\
\hline Bufo spinosus & 29TQE47 & 101,00 & 140,64 & 109,38 & 37,03 & 6294,98 & 312,04 & 20,83 & 291,21 & $\mid 71,06$ & 224,69 & 224,75 & 63,78 & 502,05 & 62,86 & 7,40 & 43,31 & 182,16 & $\begin{array}{l}44,17 \\
\end{array}$ & 44,21 & 168,79 \\
\hline Bufo spinosus & 29TQE48 & 99,00 & 117,99 & 107,09 & 36,82 & 6247,59 & 288,57 & 1,73 & 286,85 & 50,00 & 201,22 & 202,15 & 43,11 & 606,94 & 75,98 & 10,64 & 41,83 & 219,55 & 57,39 & 58,73 & 204,08 \\
\hline Bufo spinosus & 29TQE49 & 100,00 & 111,13 & 106,74 & 36,98 & 6218,89 & 281,23 & $-3,86$ & 285,09 & 43,78 & 193,70 & 195,11 & 36,90 & 629,64 & 78,99 & 11,61 & 41,15 & 227,45 & 61,36 & 63,11 & 210,94 \\
\hline Bufo spinosus & 29TQE53 & 60,00 & 149,80 & 109,92 & 36,70 & 6408,64 & 324,57 & 27,94 & 296,63 & 79,16 & 235,42 & 235,42 & 71,58 & 480,32 & 59,08 & 5,85 & 44,56 & 173,02 & 39,20 & 39,20 & 160,24 \\
\hline Bufo spinosus & 29TQE56 & 50,00 & 137,16 & 109,69 & 36,99 & 6325,01 & 310,13 & 17,17 & 292,96 & 67,55 & 221,57 & 221,77 & 60,39 & 507,69 & 62,88 & 7,87 & 42,52 & 181,96 & 45,81 & 46,01 & 168,04 \\
\hline Bufo spinosus & 29TQE57 & 42,00 & 139,19 & 110,38 & 37,06 & 6308,52 & 311,71 & $\begin{array}{l}18,79 \\
18,\end{array}$ & 292,92 & 69,40 & 223,40 & 223,47 & 62,26 & \begin{tabular}{|l|}
486,51 \\
\end{tabular} & $\begin{array}{l}60,44 \\
60,\end{array}$ & 7,65 & $\begin{array}{ll}42,35 \\
42,35\end{array}$ & 174,30 & \begin{tabular}{|l|}
44,42 \\
\end{tabular} & $\begin{array}{l}\mid 40,45 \\
44,45\end{array}$ & 160,43 \\
\hline Bufo spinosus & 29TQE58 & 47,00 & 134,90 & 110,69 & 37,23 & 6298,43 & 307,31 & \begin{tabular}{ll|}
14,87 \\
\end{tabular} & 292,44 & 65,49 & 219,16 & 219,25 & 58,23 & 493,18 & 61,34 & 8,28 & 41,59 & 176,15 & 46,67 & 46,74 & 161,74 \\
\hline Bufo spinosus & 29TQE59 & 40,00 & 109,11 & 107,80 & 37,02 & 6220,82 & 280,18 & $-6,55$ & 286,74 & 41,68 & 191,77 & 193,17 & 35,12 & 618,22 & 76,86 & 12,17 & 39,94 & 220,18 & 62,66 & 64,60 & 203,06 \\
\hline Bufo spinosus & 29TQF05 & 99,00 & 122,03 & 106,32 & 37,58 & 6018,77 & 285,45 & 6,53 & 278,92 & 55,32 & 202,18 & 202,18 & 48,14 & 667,94 & 85,85 & 10,00 & 45,79 & 255,06 & 58,03 & 58,03 & 247,19 \\
\hline Bufo spinosus & 29TQF06 & 100,00 & 125,29 & 107,78 & 38,01 & 6002,93 & 288,91 & 8,85 & 280,05 & 58,28 & 204,97 & 204,97 & 51,21 & 640,23 & 82,02 & 9,97 & 45,41 & 244,05 & 56,19 & 56,19 & 236,84 \\
\hline Bufo spinosus & 29TQF07 & 100,00 & $\begin{array}{l}124,29 \\
124,47\end{array}$ & 108,48 & 30,015 & 5975,92 & 280,51 & $\begin{array}{l}\frac{0,05}{7,85} \\
\end{array}$ & \begin{tabular}{|l|}
280,360 \\
280
\end{tabular} & $\begin{array}{l}\mid c, 060 \\
57,62\end{array}$ & 203,80 & \begin{tabular}{|l|}
203,80 \\
\end{tabular} & $\begin{array}{l}1,12 \\
50,69\end{array}$ & \begin{tabular}{|l|l|}
634,57 \\
\end{tabular} & $\begin{array}{l}8,, 2<2 \\
81,31\end{array}$ & $\begin{aligned} 10,33 \\
10,\end{aligned}$ & $\begin{array}{l}4,41 \\
45,02\end{array}$ & 241,67 & \begin{tabular}{|l|}
56,70 \\
56,70
\end{tabular} & $\mid 56,70$ & $\begin{array}{l}230,04 \\
235,01\end{array}$ \\
\hline Bufo spinosus & 29TQF08 & 100,00 & 119,33 & 108,56 & 38,17 & 5959,95 & 283,31 & 3,05 & 280,26 & 52,92 & 198,65 & 198,65 & 45,99 & 654,23 & 84,20 & 11,16 & 44,66 & 249,16 & 60,21 & 60,21 & 243,12 \\
\hline Bufo spinosus & 29TQF09 & 101,00 & 126,93 & 110,16 & 38,94 & 5930,54 & 290,50 & 9,14 & 281,36 & 60,20 & 205,50 & 205,50 & 53,32 & 605,30 & 78,18 & 10,60 & 44,49 & 230,27 & 55,42 & 55,42 & 224,78 \\
\hline Bufo spinosus & 29TQF15 & 101,00 & 120,75 & 107,73 & 37,95 & 6071,48 & 286,05 & 4,44 & 281,61 & 53,44 & 201,50 & 201,50 & 46,21 & 621,94 & 79,17 & 10,14 & 43,99 & 234,15 & \begin{tabular}{|l|l|}
57,15 \\
\end{tabular} & 57,15 & 223,71 \\
\hline Bufo spinosus & 29TQF16 & 100,00 & 119,86 & 108,46 & 38,00 & 6049,59 & 285,22 & 3,36 & 281,85 & 52,53 & 200,33 & 200,33 & 45,51 & 616,45 & 78,70 & 10,64 & 43,43 & 231,63 & 58,12 & 58,12 & 221,61 \\
\hline \begin{tabular}{|l} 
Bufo spinosus \\
\end{tabular} & 29TQF17 & 99,00 & 126,84 & 110,00 & 38,2 & 6022,16 & 292,13 & 8,85 & 283,28 & 59,28 & 206,62 & 206,62 & 52,31 & 571,63 & 73,31 & 9,92 & 43,27 & 214,56 & 53,54 & 53,54 & 205,38 \\
\hline Bufo spinosus & 29TQF18 & 100,00 & 122,60 & 110,21 & 38,40 & 6005,49 & 287,87 & 4,76 & 283,11 & 55,36 & 202,28 & 202,28 & 48,48 & 585,02 & 75,58 & 10,69 & 43,04 & 219,49 & 56,23 & 56,23 & 210,90 \\
\hline Bufo spinosus & 29TQF19 & 100,00 & 118,95 & 110,37 & 38,70 & 5982,06 & 284,32 & 1,44 & 282,88 & 52,01 & 198,36 & 198,36 & 45,22 & 596,50 & 77,51 & 11,53 & 42,49 & 223,55 & 59,05 & 59,05 & 215,39 \\
\hline Bufo spinosus & 29TQF26 & 100,00 & 119,46 & 109,95 & 38,00 & 6093,24 & 286,79 & 1,91 & 284,88 & 51,71 & 200,57 & 200,57 & 44,79 & 566,95 & 72,83 & 10,62 & 41,69 & 209,51 & 56,51 & 56,51 & 196,92 \\
\hline Bufo spinosus & 29TQF27 & 101,00 & 120,53 & 110,64 & 38,04 & 60077,37 & 287,51 & 2,25 & \begin{tabular}{|l|}
285,260 \\
\end{tabular} & 52,64 & 201,23 & 201,23 & 45,72 & 554,07 & $\begin{array}{l}71,52 \\
71,52\end{array}$ & 10,61 & $\begin{array}{l}41,40 \\
41,49 \\
\end{array}$ & 204,46 & |55,79 & $\begin{array}{l}5,79 \\
55,79\end{array}$ & 192,65 \\
\hline \begin{tabular}{|l} 
Bufo spinosus \\
\end{tabular} & 29TQF28 & 100,00 & 120,82 & 111,21 & 38,30 & 6056,09 & 287,94 & 2,60 & 285,34 & 53,22 & 201,28 & 201,28 & 46,19 & 543,86 & 70,42 & 10,86 & 41,16 & 200,26 & 55,77 & 55,77 & 188,94 \\
\hline Bufo spinosus & 29TQF29 & 100,00 & 120,33 & 111,61 & 38,78 & 6032,92 & 287,25 & 1,88 & 285,36 & 52,66 & 200,29 & 200,29 & 45,80 & 541,55 & 70,40 & 11.25 & 40,85 & 199,19 & 56,50 & 56,50 & 188,40 \\
\hline Bufo spinosus & 29TQF30 & 100,00 & 119,31 & 106,94 & 37,00 & 6208,17 & 287,95 & 3,01 & 284,94 & 51,33 & 201,75 & 202,61 & 44,15 & 603,73 & 76,57 & 10,06 & 42,51 & 221,76 & 56,64 & 57,28 & 206,68 \\
\hline Bufo spinosus & 29TQF33 & 100,00 & 120,81 & 109,77 & 37,97 & 6173,76 & 289,77 & 3,13 & 286,63 & 52,61 & 203,35 & 203,35 & 45,52 & 549,90 & 69,94 & 10,01 & 41,33 & 200,86 & 54,96 & 54,96 & 185,26 \\
\hline \begin{tabular}{|l} 
Bufo spinosus \\
\end{tabular} & \begin{tabular}{|l|l|l|l}
$29 T Q F 39$ \\
\end{tabular} & $\begin{array}{l}101,00 \\
100\end{array}$ & $\begin{array}{l}12,01 \\
117,53\end{array}$ & 112,34 & 38,5 & 6 & 286,20 & $\begin{array}{c}-1,10 \\
-0,80 \\
\end{array}$ & $\begin{array}{l}280,00 \\
287,00\end{array}$ & 54,47 & 198,29 & 198,29 & 42,66 & 509,77 & 66,10 & 11,77 & 38,87 & 183,34 & 57,22 & 57,22 & 169,97 \\
\hline Bufo spinosus & 29TQF40 & 100,00 & 116,70 & 108,66 & 37,23 & 6227,32 & 287,15 & $-0,06$ & 287,21 & 48,54 & 199,46 & 200,47 & 41,83 & 578,11 & 72,63 & 10,60 & 40,89 & 208,46 & 57,44 & 58,19 & 191,94 \\
\hline Bufo spinosus & 29TQF41 & 100,00 & 120,12 & 110,06 & $\begin{array}{l}37,78 \\
\end{array}$ & 6225,63 & 290,81 & 2,18 & 288,63 & 51,64 & 203,41 & 203,55 & 44,62 & 543,12 & 68,39 & 10,07 & 40,68 & 195,64 & 55,10 & 55,19 & 178,90 \\
\hline Bufo spinosus & 29TQF42 & 100,00 & 121,21 & 111,03 & 38,00 & 6213,43 & 291,77 & 2,71 & 289,06 & 53,20 & 204,21 & 204,21 & 45,50 & 522,19 & 66,12 & 10,00 & 40,31 & 187,54 & 54,20 & 54,20 & 170,50 \\
\hline Bufo spinosus & 29TQF47 & 100,00 & 116,77 & 112,93 & 38,80 & 6141,71 & 287,25 & $-1,44$ & 288,68 & 76,17 & 198,53 & 198,53 & 41,46 & 481,72 & 62,16 & 11,00 & 38,46 & 171,64 & 55,31 & 55,31 & 153 \\
\hline \begin{tabular}{|l} 
Bufo spinosus \\
\end{tabular} & 29TQF48 & 100,00 & 116,89 & 113,23 & 38,97 & 6130,25 & 286,98 & $-1,75$ & \begin{tabular}{|l|}
288,73 \\
\end{tabular} & 76,96 & 198,25 & 198,25 & 41,58 & 475,93 & $\begin{array}{l}61,37 \\
610\end{array}$ & 11,24 & 37,99 & 169,20 & 55,66 & 55,66 & 151,72 \\
\hline Bufo spinosus & 29TQF49 & 100,00 & 119,58 & 113,50 & 38,97 & 6115,42 & 289,29 & 0,01 & 289,29 & 80,05 & 200,47 & 200,48 & 43,96 & 459,76 & 59,24 & 11,05 & 37,64 & 163,38 & 54,36 & 54,37 & 146,34 \\
\hline Bufo spinosus & 29TQF50 & 33,00 & 117,20 & 110,11 & 37,63 & 6238.59 & 288.82 & $-0,27$ & 289,09 & 48.91 & 200,27 & 201.05 & 42.04 & 550,61 & 68,77 & 1071 & 39.96 & 195,89 & 56.96 & 57,45 & 178,63 \\
\hline Bufo spinosus & 29TQF55 & 20,00 & 120,39 & 113,85 & 38,85 & 6201,03 & 291,73 & 0,48 & 291,24 & 80,33 & 202,91 & 202,91 & 44, & 462,15 & 59,55 & 10,12 & 38,76 & 165,27 & 52,79 & 52,79 & 143,82 \\
\hline Bufo spinosus & 29TQG00 & 99,00 & 123,09 & 110,27 & 38,96 & 5918,68 & 286,88 & 5,41 & 281,47 & 56,58 & 201,70 & 201,70 & 49,72 & 619,22 & 80,70 & 11,43 & 44,19 & 235,64 & 58,29 & 58,29 & 230,85 \\
\hline
\end{tabular}




\begin{tabular}{|c|c|c|c|c|c|c|c|c|c|c|c|c|c|c|c|c|c|c|c|c|c|}
\hline TAXON & UTM & $\mathrm{km} 2$ & B101 & B102 & $\mathrm{BIO3}$ & B104 & BIO5 & B106 & B107 & B108 & B109 & BIO10 & B1011 & B1012 & B1013 & B1014 & BIO15 & BIO16 & B1017 & B1018 & 81019 \\
\hline Bufo spinosus & 29TQG01 & 101,00 & 120,16 & 110,37 & 39,00 & 5890,61 & 283,96 & 2,77 & 281,19 & 54,07 & 198,46 & 198,46 & 47,29 & 630,02 & 82,67 & 12,21 & 43,76 & 239,57 & 60,81 & 60,81 & 235,47 \\
\hline Bufo spinosus & 29TQG02 & 100,00 & 118,31 & 110,55 & 39,00 & 5867,35 & 282,03 & 1,14 & 280,89 & 52,36 & 196,31 & 196,31 & 45,68 & 636,56 & 84,01 & 13,14 & 43,33 & 241,71 & 63,07 & 63,07 & 237,84 \\
\hline Bufo spinosus & 29TQG03 & 100,00 & 114,88 & 110,19 & 38,98 & 5844,04 & 278,26 & $-1,66$ & 279,92 & 49,20 & 192,60 & 192,60 & 42,71 & 654,32 & 86,67 & \begin{tabular}{l|l|}
14,58 \\
\end{tabular} & 42,81 & 247,97 & 66,98 & 66,98 & 243,35 \\
\hline Bufo spinosus & 29TQG04 & 99,00 & 107,72 & 109,04 & 38,75 & 5831,01 & 270,54 & $-7,80$ & 278,34 & 42,36 & 185,45 & 185,45 & 36,15 & 697,38 & 92,22 & \begin{tabular}{l|l|l}
17,25 \\
\end{tabular} & 41,55 & 262,69 & 75,26 & 75,26 & 255,74 \\
\hline Bufo spinosus & 29TQG05 & 99,00 & 104,21 & 108,35 & 38,61 & 5812,30 & 266,16 & \begin{tabular}{|l|l|}
$-10,78$ \\
\end{tabular} & 276,93 & 39,18 & 181,82 & 181,82 & 33,12 & 720,31 & 95,06 & 19,42 & 40,52 & 270,01 & 80,76 & 80,76 & 260,84 \\
\hline Bufo spinosus & 29TQG06 & 101,00 & 97,59 & 107,19 & 38,63 & 5777,70 & 258,37 & $-16,03$ & 274,40 & 33,35 & 174,90 & 174,90 & 27,26 & 770,14 & 100,90 & 22,35 & 39,27 & 286,20 & 90,40 & 90,40 & 274,29 \\
\hline Bufo spinosus & 29TQG07 & 100,00 & 75,27 & 102,87 & 38,12 & 5659,24 & 233,23 & $-33,33$ & 266,56 & 14,21 & 151,42 & 151,61 & 7,86 & 961,33 & 122,26 & 31,36 & 36,71 & 349,51 & 121,47 & 122,08 & 332,88 \\
\hline \begin{tabular}{|l} 
Bufo spinosus \\
\end{tabular} & 29TQG08 & 101,00 & 91,65 & 105,70 & 38,72 & 5689,42 & 249,91 & $-20,20$ & 270,11 & 28,60 & $\begin{array}{l}167,69 \\
\end{array}$ & 167,69 & 22,55 & 827,64 & 107,08 & 26,22 & 37,28 & 303,34 & 103,64 & 103,64 & 287,04 \\
\hline Bufo spinosus & 29TQG10 & 101,00 & 116,77 & 110,67 & 39,00 & 5974,82 & 282,16 & $-0,12$ & 282,28 & 50,13 & 196,21 & 196,21 & 43,23 & 602,56 & 78,66 & $\begin{array}{ll}12,23 \\
\end{array}$ & 42,09 & 225,51 & 61,11 & 61,11 & 217,74 \\
\hline Bufo spinosus & 29TQG13 & 101,00 & 111,71 & 110,86 & 39,00 & 5909,07 & 276,33 & $-5,18$ & 281,51 & 45,45 & 190,29 & 190,29 & 38,81 & 625,53 & 82,37 & 15,30 & 40,67 & 232,93 & 68,39 & 68,39 & 224,64 \\
\hline Bufo spinosus & 29TQG14 & 100,00 & 106,12 & 110,05 & 38,93 & 5890,84 & 270,36 & $-10,14$ & 280,50 & 40,21 & 184,73 & 184,73 & 33,77 & 662,20 & 87,05 & 17,70 & 39,73 & 245,46 & 75,48 & 75,48 & 235,49 \\
\hline Bufo spinosus & 29TQG16 & 100,00 & 100,74 & 109,21 & 38,89 & 5841,69 & 263,66 & $-14,63$ & 278,29 & 35,43 & 178,66 & 178,66 & 29,22 & 704,69 & 92,02 & 21,13 & 38,13 & 258,67 & 85,76 & 85,76 & 245,22 \\
\hline \begin{tabular}{|l} 
Bufo spinosus \\
\end{tabular} & 29TQG18 & 100,00 & 80,36 & 105,43 & \begin{tabular}{|l|l|}
38,57 \\
\end{tabular} & 5693,88 & 239,67 & $-30,51$ & 270,17 & 18,24 & 156,74 & 156,79 & 11,85 & 880,15 & 111,79 & 30,29 & 35,26 & 316,01 & 117,00 & 117,16 & 297,01 \\
\hline Bufo spinosus & 29TQG19 & 100,00 & 79,56 & 105,02 & 38,69 & 5646,93 & 237,74 & $-30,67$ & 268,41 & 19,16 & 155,26 & 155,32 & 11,68 & 896,95 & 113,42 & \begin{tabular}{|l|l|}
31,78 \\
\end{tabular} & 34,56 & 320,53 & 121,64 & 121,95 & 299,87 \\
\hline Bufo spinosus & 29TQG21 & 101,00 & 113,17 & 111,51 & 38,93 & 6004,49 & 280,10 & $-4,34$ & 284,44 & 46,17 & 193,10 & 193,10 & 39,30 & 572,97 & 74,83 & 13,54 & 39,72 & 210,03 & 63,41 & 63,41 & 199,39 \\
\hline Bufo spinosus & 29TQG22 & 100,00 & 112,56 & 111,70 & \begin{tabular}{|l|}
38,98 \\
\end{tabular} & 5985,53 & 279,23 & $-5,25$ & 284,47 & 45,37 & 192,16 & 192,16 & 38,74 & 576,92 & 75,50 & 14,41 & 39,31 & 211,27 & 65,18 & 65,18 & 200,58 \\
\hline Bufo spinosus & 29TQG23 & 100,00 & 110,98 & 111,77 & 38,99 & 5962,96 & 277,49 & $-6,65$ & 284,14 & 44,06 & 190,24 & 190,24 & 37,44 & 586,56 & 76,79 & 15,58 & 38,85 & 214,35 & 68,07 & 68,07 & 203,04 \\
\hline Bufo spinosus & 29TQG24 & 99,00 & 106,53 & 111,31 & 38,98 & 5942,33 & 272,67 & $-10,62$ & 283,29 & 40,28 & 185,74 & 185,74 & 33,40 & 617,64 & 80,63 & 17,53 & 38,15 & 224,86 & 74,17 & 74,17 & 212,30 \\
\hline Bufo spinosus & 29TQG25 & 101,00 & 110,34 & 111,69 & 39,00 & 5924,36 & 275,84 & $-7,58$ & 283,42 & 47,51 & 189,06 & 189,06 & 36,88 & 598,86 & 78,31 & 17,36 & 37,81 & 217,92 & 72,90 & 72,90 & 204,71 \\
\hline Bufo spinosus & 29TQG26 & 100,00 & 107,80 & 111,40 & 39,00 & 5903,09 & 272,74 & $-9,90$ & 282,63 & 53,23 & 186,34 & 186,34 & 34,78 & 619,73 & 80,76 & \begin{tabular}{ll|}
18,88 \\
\end{tabular} & 37,12 & 224,81 & 77,87 & 77,87 & 209,72 \\
\hline Bufo spinosus & 29TQG27 & 101,00 & 96,95 & 110,01 & 38,90 & 5850,44 & 261,05 & $-18,67$ & 279,72 & 45,32 & 175,08 & 175,08 & 25,39 & 700,54 & 90,26 & 23,14 & 35,87 & 251,96 & 92,35 & 92,35 & 234,13 \\
\hline \begin{tabular}{|l} 
Bufo spinosus \\
\end{tabular} & 29TQG28 & 99,00 & 90,53 & 108,82 & 38,88 & 5790,17 & 253,27 & $-23,63$ & 276,91 & 40,68 & 167,92 & 167,93 & 20,00 & 757,65 & 96,61 & 26,40 & 34,76 & 270,71 & 103,29 & 103,30 & 250,27 \\
\hline Bufo spinosus & 29TQG30 & 99,00 & 118,24 & 112,71 & \begin{tabular}{|l|}
38,98 \\
\end{tabular} & 6054,24 & 286,54 & $-0,55$ & 287,09 & 58,13 & 198,47 & 198,47 & 43,35 & 504,83 & 65,56 & 12,00 & 38,70 & 181,38 & 57,28 & 57,28 & 168,57 \\
\hline Bufo spinosus & 29TQG32 & 101,00 & 115,15 & 112,95 & 39,00 & 6022,04 & 283,26 & $-3,62$ & 286,87 & 62,35 & 194,93 & 194,93 & 40,52 & 521,67 & 67,79 & \begin{tabular}{|l|l|}
13,77 \\
\end{tabular} & 37,72 & 187,15 & 62,19 & 62,19 & 173,83 \\
\hline Bufo spinosus & 29TQG34 & 100,00 & 109,08 & 112,74 & 38,97 & 5982,61 & 276,92 & $-9,39$ & 286,31 & 65,83 & 188,59 & 188,59 & 35,17 & 564,89 & 73,18 & 16,72 & 36,65 & 202,73 & 71,26 & 71,26 & 187,20 \\
\hline Bufo spinosus & 29TQG36 & 100,00 & 111,99 & 112,95 & 39,00 & 5944,72 & 278,49 & $-7,13$ & 285,62 & 73,74 & 190,64 & 190,64 & 38,05 & 562,72 & 72,66 & 17,69 & 36,04 & 203,73 & 73,84 & 73,84 & 183,80 \\
\hline Bufo spinosus & 29TQG37 & 100,00 & 107,03 & 112,53 & 39,00 & 5911,25 & 273,25 & $\mid-11,47$ & $\begin{array}{l}284,72 \\
284\end{array}$ & 69,31 & $\begin{array}{l}185,40 \\
\end{array}$ & $\begin{array}{l}185,40 \\
\end{array}$ & 33,77 & 599,10 & 77,00 & 20,05 & 35,24 & 216,74 & 81,45 & 81,45 & $\begin{array}{l}1903,90 \\
93\end{array}$ \\
\hline Bufo spinosus & 29TQG38 & 101,00 & 106,13 & 112,22 & 39,00 & 5872,46 & 271,28 & $-11,75$ & 283,03 & 68,77 & 184,03 & 184,03 & 33,35 & 615,72 & 79,11 & 21,37 & 34,82 & 223,15 & 85,66 & 85,66 & 197,37 \\
\hline Bufo spinosus & 29TQG41 & 98,00 & 116,63 & 113,70 & 39,00 & $\begin{array}{ll}6077,83 \\
\end{array}$ & 286,10 & $-2,87$ & 288,97 & 77,60 & 197,19 & 197,19 & 41,35 & 474,35 & 61,05 & 12,53 & 36,55 & 168,65 & 58,62 & 58,62 & 151,31 \\
\hline Bufo spinosus & 29TQG42 & 95,00 & 113,63 & 113,73 & 38,99 & 6059,14 & 283,16 & $-5,64$ & 288,81 & 74,73 & 193,97 & 193,97 & 38,60 & 494,93 & 63,68 & 13,81 & 36,05 & 176,35 & 62,64 & 62,64 & 158,34 \\
\hline Bufo spinosus & 29TQG45 & 86,00 & 116,09 & 114,02 & 39,00 & 5989,02 & 284,02 & $-4,08$ & 288,09 & 78,02 & 195,22 & 195,22 & 41,51 & 506,24 & 64,85 & 15,65 & 35,28 & 182,75 & 67,67 & 67,67 & 160,55 \\
\hline \begin{tabular}{|l} 
Bufo spinosus \\
\end{tabular} & 29TQG46 & 80,00 & 114,57 & 113,95 & 39,00 & 5963,28 & 282,04 & $-5,28$ & 287,32 & 76,54 & \begin{tabular}{l|}
193,27 \\
\end{tabular} & 193,27 & 40,03 & 523,95 & 66,95 & 17,08 & 34,98 & 189,85 & 71,64 & 71,64 & 165,34 \\
\hline Bufo spinosus & 29TQG47 & 75,00 & 110,56 & 113,81 & 39,00 & 5933,95 & 278,12 & $-8,62$ & 286,74 & 72,76 & 189,15 & 189,15 & 36,70 & 553,25 & 70,70 & 19,14 & 34,52 & 200,81 & 77,97 & 77,97 & 173,41 \\
\hline Bufo spinosus & 29TQG48 & 76,00 & 111,49 & 113,62 & 39,21 & 5898,32 & 277,62 & $\begin{array}{l}-7,67 \\
\end{array}$ & 285,29 & 73,80 & 189,35 & 189,35 & 37,83 & 563,03 & 72,64 & 20,12 & 34,14 & 205,08 & 81,08 & 81,08 & 174,74 \\
\hline Bufo spinosus & 29TQHO3 & 100,00 & 97,05 & 103,23 & 39,71 & 5367,41 & 245,93 & $-11,79$ & 257,73 & 40,93 & 167,98 & 167,98 & 31,63 & 849,68 & 109,93 & 30,65 & 33,63 & 303,55 & 118,24 & 118,24 & 276,86 \\
\hline Bufo spinosus & 29TQH15 & 101,00 & 81,08 & 101,33 & 39,73 & 5205,83 & 228,01 & $-23,78$ & 251,80 & 40,02 & 150,30 & 150,34 & 18,68 & 976,59 & 124,20 & 40,07 & 30,67 & 340,54 & 147,50 & 148,47 & 307,29 \\
\hline \begin{tabular}{|l} 
Bufo spinosus \\
\end{tabular} & 29TQH27 & 100,00 & 82,73 & 100,29 & 40,40 & 5017,34 & 225,37 & $-20,01$ & 245,38 & 50,25 & 149,06 & 149,50 & 22,69 & 987,79 & 126,24 & 43,63 & 28,73 & 340,24 & 157,60 & 162,62 & 298,65 \\
\hline Bufo spinosus & 29TQH28 & 99,00 & 97,10 & 99,46 & 41,22 & 4800,88 & 233,86 & $-4,38$ & 238,24 & 69,69 & 159,76 & 160,69 & 39,17 & 924,34 & 120,79 & 41,38 & 28,39 & 318,67 & 149,58 & 157,35 & 270,33 \\
\hline Bufo spinosus & 29TQH37 & 99,00 & 76,09 & 100,54 & 40,23 & 5063,42 & 220,15 & $-26,83$ & 246,98 & 43,00 & 143,21 & 143,59 & 15,63 & 1014,50 & 128,25 & 46,39 & 27,91 & 346,75 & 165,85 & 169,67 & 304,04 \\
\hline Bufo spinosus & $29 \mathrm{TQH} 40$ & 62,00 & 109,52 & 112,79 & 39,82 & 5784,23 & 273,06 & $-8,42$ & 281,48 & 73,07 & 185,82 & 185,82 & 37,25 & 601,74 & 78,75 & 23,27 & 33,20 & 219,38 & 90,83 & 90,83 & 182,55 \\
\hline \begin{tabular}{|l} 
Bufo spinosus \\
\end{tabular} & $29 \mathrm{TQH} 42$ & 61,00 & 100,85 & 110,74 & 40,00 & 5628,50 & 260,72 & $-14,08$ & 274,80 & 66,18 & 175,30 & 175,30 & 31,25 & 690,90 & 90,27 & 29,02 & 31,64 & 248,73 & 109,09 & 109,09 & 206,38 \\
\hline Bufo spinosus & 29TQH49 & 36,00 & 119,17 & 96,75 & 43,23 & 4295,38 & 243,54 & 22,00 & 221,54 & 96,79 & 173,94 & 176,08 & 67,15 & 850,54 & 115,13 & 41,21 & 27,98 & 287,88 & 146,23 & 154,65 & 224,27 \\
\hline Bufo spinosus & 29TQJ00 & 100,00 & 113,08 & 92,84 & 41,78 & 4381,67 & 236,87 & 17,31 & 219,56 & 88,49 & 169,52 & 171,28 & 60,21 & 922,77 & 122,26 & 39,35 & 29,15 & 317,84 & 143,82 & 154,93 & 269,66 \\
\hline Bufo spinosus & 29TQJ01 & 101,00 & 126,22 & 88,44 & 42,23 & 4110,48 & 240,86 & 34,05 & 206,81 & 104,11 & 178,50 & 180,95 & 76,45 & 878,86 & 118,09 & 37,42 & 29,36 & 302,72 & 137,04 & 149,67 & 250,74 \\
\hline Bufo spinosus & 29TQJ10 & 101,00 & 112,08 & 94,18 & 42,09 & 4375,64 & 236,76 & 15,77 & 220,99 & 88,00 & 168,30 & 170,18 & 59,21 & 918,37 & 122,16 & 40,88 & 28,38 & 314,46 & 147,79 & 157,97 & 261,87 \\
\hline \begin{tabular}{|l} 
Bufo spinosus \\
\end{tabular} & $29 \mathrm{TQJ} 22$ & 90,0 & 130,15 & $\begin{array}{l}4,10 \\
85,35\end{array}$ & |ck, 42,88 & 年 3889,16 & 238,3 & 41,39 & \begin{tabular}{|l|l|}
196,92 \\
\end{tabular} & 110,84 & 179,08 & 182,20 & 83,20 & 877,27 & 119,15 & 40,31 & 28,57 & 298,33 & 144,64 & 156,96 & 237,01 \\
\hline \begin{tabular}{|l} 
Bufo spinosus \\
\end{tabular} & 29TQJ31 & 99,00 & 131,39 & 87,22 & 43,24 & 3903,44 & 241,03 & 41,51 & 199,52 & 112,27 & 180,49 & 183,54 & 84,32 & 854,72 & 116,78 & 40,39 & 28,52 & 288,99 & 144,03 & 155,08 & 224,34 \\
\hline \begin{tabular}{|l} 
Bufo spinosus \\
\end{tabular} & 29TQJ32 & 74,00 & 134,23 & 83,35 & 43,00 & 3796,84 & 238,70 & 46,89 & 191,82 & 116,10 & 181,84 & 185,14 & 88,38 & 858,30 & 117,33 & 40,27 & 28,58 & 290,85 & 144,00 & 156,31 & 226,00 \\
\hline Bufo spinosus & 30STE49 & & & & & & & & & & & & & & & & & & & & \\
\hline Bufo spinosus & 30STE59 & & & & & & & & & & & & & & & & & & & & \\
\hline Bufo spinosus & 30STE68 & & & & & & & & & & & & & & & & & & & & \\
\hline Bufo spinosus & 30STE69 & 90,00 & 166,92 & 83,47 & 39,98 & 4208,93 & 277,68 & 71,14 & 206,55 & 123,23 & 220,05 & 223,59 & 115,12 & 848,89 & 146,18 & 0,58 & 76,41 & 404,67 & 13,56 & 22,34 & 401,74 \\
\hline Bufo spinosus & 30STE79 & 80,00 & 165,85 & 86,17 & 40,60 & 4236,28 & 280,03 & 69,61 & 210,41 & $\mid 121,75$ & 219,52 & 223,38 & 1144,45 & 815,53 & $\mid 141,61$ & 0,99 & 76,60 & 396,23 & 13,03 & 22.71 & 390,32 \\
\hline Bufo spinosus & 30STE89 & 5,00 & 174,33 & 82,00 & 41,67 & 3868,33 & 279,33 & 85,00 & 194,33 & 137,00 & 223,33 & 227,33 & 128,00 & 759,67 & 139,00 & 1,00 & 77,00 & 382,33 & 12,67 & 21,00 & 366,67 \\
\hline Bufo spinosus & 30STF30 & 17,00 & 172,45 & 75,41 & 38,41 & 4164,14 & 274,41 & 81,00 & 193,41 & 129,27 & 224,23 & 228 & 120,68 & 769,41 & 134,77 & 0,41 & 72,95 & 352,82 & 14,77 & 22,41 & 344 \\
\hline \begin{tabular}{|l} 
Bufo spinosus \\
\end{tabular} & 30STF31 & 98,00 & 172,86 & 74,49 & 37,92 & 4225,17 & 274,71 & $\begin{array}{l}1,80 \\
80,89 \\
\end{array}$ & $\begin{array}{l}193,82 \\
\end{array}$ & 129,00 & 225,26 & 229,20 & 120,17 & 756,80 & 131,74 & 0,44 & 72,26 & 344,73 & 14,59 & 22,62 & 331,52 \\
\hline Bufo spinosus & 30STF32 & 90,00 & 172,06 & 73,73 & 36,93 & 4378,73 & 275,79 & 78,71 & $\begin{array}{l}197,08 \\
\end{array}$ & 126,41 & 226,50 & 230,49 & 117,51 & 741,70 & 127,34 & 1,00 & 71,14 & 333,93 & 15,08 & 23,50 & 320,08 \\
\hline Bufo spinosus & 30STF33 & 90,00 & 171,30 & 73,63 & 35,99 & 4544,89 & 278,05 & 76,28 & 201,77 & 123,77 & 228,06 & 232,17 & 114,86 & 724,33 & 122,30 & 1,00 & 70,20 & 322,57 & 15,14 & 23,99 & 307,85 \\
\hline Bufo spinosus & 30STF36 & 80,00 & 171,69 & 75,24 & 34,32 & 5009,00 & 288,16 & 71,81 & 216,3 & 118,67 & 234,80 & 238 & 109 & 657,79 & 103,48 & 1,00 & 67,23 & 283,17 & 16,55 & 23,91 & 266,49 \\
\hline Bufo spinosus & 30STF38 & 72,00 & 171,74 & 86,27 & 35,82 & 5325,61 & 303,23 & 65,21 & 238,02 & 114,89 & 239,46 & 242,79 & 106,25 & 637,94 & 97,45 & 1,00 & 65,84 & 273,76 & 17,25 & 23,73 & 256,61 \\
\hline
\end{tabular}




\begin{tabular}{|c|c|c|c|c|c|c|c|c|c|c|c|c|c|c|c|c|c|c|c|c|c|}
\hline TAXON & UTM & $\mathrm{km} 2$ & B101 & B102 & $\mathrm{BIO3}$ & B104 & B105 & B106 & B107 & B108 & B109 & B1010 & BIO11 & BIO12 & B1013 & BIO14 & BIO15 & B1016 & B1017 & B1018 & B1019 \\
\hline Bufo spinosus & 30STF40 & 79,00 & 170,05 & 77,24 & 38,86 & 4149,76 & 273,55 & 77,47 & 196,08 & 127,19 & 221,86 & 225,45 & 118,45 & 822,55 & 142,23 & 0,24 & 73,99 & 380,45 & 15,04 & 22,30 & 370,92 \\
\hline Bufo spinosus & 30STF41 & 100,00 & 172,72 & 74,78 & 38,32 & 4162,68 & 273,71 & 80,79 & 192,92 & 129,06 & 224,63 & 228,16 & 120,80 & 787,68 & 135,86 & 0,05 & 73,02 & 361,95 & 15,05 & 22,06 & 349,54 \\
\hline Bufo spinosus & 30STF42 & 100,00 & 172,28 & 74,59 & \begin{tabular}{l|l|}
37,45 \\
\end{tabular} & 4314,16 & 275,88 & 79,09 & 196,79 & 127,13 & 226,17 & 229,93 & 118,57 & 768,15 & 131,09 & 0,67 & 71,80 & 349,92 & 15,67 & 22,89 & 335,87 \\
\hline Bufo spinosus & 30STF43 & 100,00 & 171,37 & 75,07 & 36,61 & 4494,42 & 278,71 & 76,42 & 202,28 & 124,26 & 227,63 & 231,55 & 115,70 & 748,11 & 125,94 & 1,00 & 70,66 & 337,59 & 15,96 & 23,63 & 322,29 \\
\hline Bufo spinosus & 30STF44 & 100,00 & 170,27 & 76,41 & 36,06 & 4680,85 & 282,25 & 73,23 & 209,02 & 121,12 & 229,12 & 233,04 & 112,49 & 729,53 & 120,67 & 1,00 & 69,77 & 326,03 & 16,01 & 24,01 & 309,93 \\
\hline Bufo spinosus & 30STF45 & 100,00 & 169,68 & 78,14 & 35,66 & 4861,25 & 286,50 & 70,68 & 215,82 & 118,62 & 231,10 & 234,95 & 109,92 & 708,52 & 114,95 & 1,00 & 68,80 & 313,47 & 16,20 & 24,13 & 296,85 \\
\hline Bufo spinosus & 30STF46 & 100,00 & 172,40 & 79,32 & 35,49 & 4987,73 & 292,23 & 71,79 & 220,45 & 119,53 & 235,35 & 239,11 & 110,95 & 673,38 & 107,45 & 1,00 & 67,82 & 295,25 & 16,53 & 23,51 & 277,60 \\
\hline \begin{tabular}{|l} 
Bufo spinosus \\
\end{tabular} & 30STF48 & 100,00 & 171,85 & 89,53 & 36,60 & 5327,55 & 306,51 & 64,98 & 241,53 & 114,99 & 239,74 & 242,99 & 106,50 & 650,58 & 100,83 & 1,00 & 66,49 & 282,57 & 17,13 & 23,46 & 264,93 \\
\hline Bufo spinosus & 30STF50 & 100,00 & 168,95 & 78,27 & 39,21 & 4103,92 & 272,40 & 75,62 & 196,79 & 126,26 & 220,38 & 223,74 & 117,77 & 855,68 & 146,48 & 0,21 & 74,96 & 398,75 & 15,01 & 22,30 & 392,21 \\
\hline Bufo spinosus & 30STF51 & 100,00 & 167,76 & 78,74 & 38,64 & 4257,40 & 274,60 & 73,17 & 201,43 & 123,72 & 221,33 & 224,81 & 114,96 & 835,94 & 142,24 & 0,58 & 73,81 & 388,02 & 15,32 & 23,08 & 378,19 \\
\hline Bufo spinosus & 30STF52 & 100,00 & 169,60 & 77,73 & 38,01 & 4336,43 & 276,87 & 74,98 & 201,89 & 124,45 & 224,16 & 227,73 & 116,00 & 802,55 & 136,23 & 0,89 & 72,62 & 371,01 & 15,89 & 23,25 & 357,32 \\
\hline Bufo spinosus & 30STF53 & 100,00 & 171,09 & 77,64 & 37,41 & 4455,91 & 280,34 & 75,76 & 204,58 & 124,36 & 227,16 & 230,82 & 116,13 & 768,19 & 129,70 & 1,00 & 71,54 & 353,12 & 16,00 & 23,21 & 336,74 \\
\hline \begin{tabular}{|l} 
Bufo spinosus \\
\end{tabular} & 30STF54 & 100,00 & 167,50 & 81,14 & 37,10 & 4709,99 & 284,60 & 68,95 & 215,66 & 118,41 & 227,11 & 230,79 & 109,68 & 760,61 & 125,99 & 1,00 & 70,60 & 346,04 & 16,13 & 24,07 & 329,51 \\
\hline Bufo spinosus & 30STF55 & 100,00 & 165,22 & 84,72 & $\begin{array}{l}37,05 \\
\end{array}$ & 4918,91 & 289,35 & 63,82 & 225,53 & 113,95 & 227,76 & 231,43 & 105,18 & 749,39 & 121,80 & 1,00 & 69,44 & 337,26 & 17,08 & 24,59 & 320,86 \\
\hline Bufo spinosus & 30STF56 & 100,00 & 169,24 & 85,20 & 36,86 & 5007,16 & 295,14 & 67,15 & 227,99 & 116,47 & 232,86 & 236,40 & 108,03 & 708,52 & 114,43 & 1,00 & 68,59 & 316,82 & 16,82 & 23,70 & 298,76 \\
\hline Bufo spinosus & 30STF57 & 100,00 & 169,81 & 89,57 & 37,21 & 5177,85 & 302,29 & 64,88 & 237,41 & 114,88 & 235,72 & 239,06 & 106,60 & 688,84 & 109,76 & 1,00 & 67,71 & 305,73 & 17,10 & 23,52 & 287,59 \\
\hline Bufo spinosus & 30STF59 & 100,00 & 173,72 & 99,87 & 38,37 & 5464,44 & 319,76 & 63,21 & 256,55 & 115,02 & 243,65 & 246,45 & 107,12 & 643,67 & 100,88 & 1,00 & 66,33 & 282,79 & 17,21 & 22,81 & 264,69 \\
\hline Bufo spinosus & 30STF60 & 100,00 & 163,12 & 85,08 & 39,39 & 4376,18 & 278,43 & 65,18 & 213,25 & 118,40 & 218,60 & 222,23 & 109,53 & 853,79 & 144,88 & 0,93 & 75,37 & 403,55 & 14,45 & 23,76 & 398,62 \\
\hline Bufo spinosus & 30STF61 & 100,00 & 164,61 & 83,27 & 39,14 & 4365,90 & 278,12 & 67,86 & 210,26 & 120,64 & 219,93 & 223,56 & 111,16 & 840,99 & 143,07 & 1,00 & 74,27 & 396,99 & 15,20 & 23,82 & 386,95 \\
\hline Bufo spinosus & 30STF62 & 100,00 & 165,14 & 82.93 & \begin{tabular}{|c|c|c|}
38,78 \\
\end{tabular} & 4449,51 & 279,79 & 68,02 & 211,77 & 119,86 & 221,57 & 225,24 & $\mid 110,77$ | & 820,39 & $\mid 138,76$ & 1,00 & 73,24 & 384.86 & 15,59 & 23,91 & 371,59 \\
\hline Bufo spinosus & 30STF63 & 100,00 & 164,08 & 84,68 & 38,34 & 4621,54 & 283,21 & 65,09 & 218,12 & 116,82 & 222,88 & 226,50 & 107,74 & 800,63 & 133,64 & 1,0 & 71,88 & 371,84 & 16,41 & 24,50 & 356,97 \\
\hline Bufo spinosus & 30STF64 & 100,00 & 153,75 & 92,74 & 38,40 & 5017,22 & 287,09 & 48,51 & 238,58 & 102,94 & 218,40 & 221,77 & 93,13 & 819,93 & $\begin{array}{l}131,07 \\
\end{array}$ & 1,40 & 70,22 & 371,48 & 18,62 & 27,59 & 360,28 \\
\hline Bufo spinosus & 30STF65 & 100,00 & 165,30 & 87,84 & 37,91 & $\begin{array}{lll}4897,96 \\
\end{array}$ & 291,96 & 63,35 & 228,62 & 114,42 & 227,81 & 231,30 & 105,79 & 754,59 & $\begin{array}{l}123,63 \\
\end{array}$ & 1,03 & 69,99 & 344,99 & 16,89 & 24,36 & 327,48 \\
\hline Bufo spinosus & 30STF66 & 100,00 & 165,34 & 90,67 & \begin{tabular}{|c|}
37,88 \\
\end{tabular} & 5056,80 & 297,25 & 61,18 & 236,06 & 112,45 & 230,04 & 233,33 & 103,99 & 737,02 & 119,37 & 1,00 & 69,04 & 333,87 & 17,22 & 24,32 & 315,92 \\
\hline Bufo spinosus & 30STF67 & 100,00 & 168,90 & 93,03 & 38,08 & 5159,38 & 304,42 & 63,52 & 240,91 & 114,46 & 234,91 & 238,07 & 106,27 & 702,95 & 113,37 & 1,00 & 68,34 & 316,61 & 17,09 & 23,46 & 297,82 \\
\hline Bufo spinosus & 30STF68 & 100,00 & 171,47 & 97,29 & 38,64 & 5297,85 & 312,87 & $\begin{array}{ll}63,87 \\
\end{array}$ & 249,01 & 115,13 & 239,32 & 242,31 & 107,15 & 674,89 & 108,22 & 1,00 & 67,69 & 302,13 & 17,01 & 23,00 & 283,13 \\
\hline Bufo spinosus & 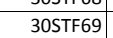 & 100,00 & 172,93 & 102,83 & 39,14 & 5452,05 & 321,68 & $\begin{array}{l}62,42 \\
62\end{array}$ & 259,26 & 114,55 & 242,83 & \begin{tabular}{|l|}
245,58 \\
\end{tabular} & 106,81 & 654,38 & \begin{tabular}{|l|l|}
104,17 \\
\end{tabular} & $\begin{array}{l}1,00 \\
1,00\end{array}$ & 67,05 & 291,10 & 16,96 & 22,61 & 272,50 \\
\hline Bufo spinosus & 30STF70 & 100,00 & 170,76 & 82,27 & 40,56 & 4070,03 & 278,45 & 77,89 & 200,57 & 129,87 & 222,10 & 225,97 & 121,34 & 806,82 & 143,07 & 1,00 & 76,03 & 396,34 & 13,86 & 22,01 & 381,87 \\
\hline Bufo spinosus & 30STF71 & 100,00 & 168,40 & 83,23 & 40,00 & 4224,27 & 279,62 & 73,68 & 205,94 & 126,16 & 221,77 & 225,72 & 117,17 & 808,52 & 141,14 & 1,00 & 75,01 & 393,01 & 14,41 & 22,69 & 376,83 \\
\hline Bufo spinosus & 30STF72 & 100,00 & 166,30 & 84,93 & 39,37 & 4410,77 & 282,35 & 69,29 & 213,06 & 121,98 & 222,38 & 226,13 & 112,89 & 800,83 & 137,35 & 1,00 & 73,74 & 383,87 & 15,21 & 23,45 & 367,23 \\
\hline Bufo spinosus & 30STF73 & 100,00 & 163,52 & 87,45 & 39,04 & 4622,44 & 285,46 & 63,84 & 221,63 & 116,84 & 222,47 & 226,19 & 107,54 & 793,29 & 133,20 & 1,00 & 72,50 & 374,14 & 15,97 & 24,37 & 357,96 \\
\hline Bufo spinosus & 30STF74 & 100,00 & 158,09 & \begin{tabular}{|l|l|l|l|l|}
92,03 \\
\end{tabular} & 38,87 & $\begin{array}{ll}402,44^{4}, 94 \\
489,4\end{array}$ & 288,79 & \begin{tabular}{|l|l|}
54,41 \\
\end{tabular} & \begin{tabular}{|l|l|}
234,38 \\
\end{tabular} & \begin{tabular}{|l|}
108,48 \\
\end{tabular} & \begin{tabular}{|l|}
221,05 \\
2217
\end{tabular} & \begin{tabular}{|l|}
224,46 \\
2213
\end{tabular} & \begin{tabular}{|l|}
98,97 \\
\end{tabular} & 797,05 & $\begin{array}{l}129,72 \\
129,0\end{array}$ & $\begin{array}{l}1,23 \\
1,23\end{array}$ & 70,83 & \begin{tabular}{|l|}
367,79 \\
\end{tabular} & 17,65 & 26,06 & 353,45 \\
\hline Bufo spinosus & 30STF75 & 100,00 & 157,73 & 94,24 & 38,77 & 5045,92 & 292,93 & 52,28 & 240,65 & 106,20 & 222,78 & 226,04 & 96,92 & 784,05 & 126,18 & 1,29 & 69,82 & 358,35 & 18,22 & 26,35 & 343,30 \\
\hline Bufo spinosus & 30STF76 & 100,00 & 162,57 & 94,47 & 38,71 & 5093,79 & 298,56 & 57,03 & 241,52 & 109,78 & 228,15 & 231,24 & 101,07 & 750,01 & 121,26 & 1,13 & 69,25 & 342,29 & 17,83 & 25,01 & 324,72 \\
\hline Bufo spinosus & 30STF77 & 100,00 & 158,26 & 99,27 & 38,87 & 5321,01 & 302,43 & 49,17 & 253,27 & 103,04 & 227,22 & 230,04 & 94,22 & 756,27 & 119,35 & 1,35 & 67,90 & 339,33 & 19,30 & 26,55 & 323,32 \\
\hline \begin{tabular}{|l} 
Bufo spinosus \\
\end{tabular} & $\begin{array}{l}\text { 30STF78 } \\
\end{array}$ & 100,00 & 164,69 & 100,93 & 38,99 & 5369,97 & 310,85 & 55,05 & 255,80 & 108,20 & 233,97 & 236,78 & 99,91 & 714,16 & 113,74 & 1,04 & 67,65 & 320,81 & 18,01 & 24,51 & 302,89 \\
\hline Bufo spinosus & 30STF80 & 43,00 & $\begin{array}{l}104,03 \\
175,91\end{array}$ & $\begin{array}{l}0,280 \\
82,28\end{array}$ & 年0,59 & $\begin{array}{l}3927,69 \\
3909,51\end{array}$ & $\begin{array}{l}31,03 \\
281,94\end{array}$ & \begin{tabular}{|l|l|}
86,09 \\
86
\end{tabular} & \begin{tabular}{|l|}
195,840 \\
150
\end{tabular} & \begin{tabular}{|l|}
137,66 \\
1306
\end{tabular} & $\mid \begin{array}{l}\mid 225,39 \\
2259\end{array}$ & 229,80 & \begin{tabular}{|c|}
129,36 \\
129,
\end{tabular} & \begin{tabular}{|l|}
749,14 \\
\end{tabular} & \begin{tabular}{|l|}
138,61 \\
13,4
\end{tabular} & $\frac{1,044}{1,00}$ & $\begin{array}{l}1,003 \\
76,92\end{array}$ & \begin{tabular}{|l|}
382,691 \\
382
\end{tabular} & $\begin{array}{l}10,01 \\
13,02\end{array}$ & $\begin{array}{l}20,77 \\
20,1\end{array}$ & $\begin{array}{l}30,03 \\
358,81\end{array}$ \\
\hline Bufo spinosus & 30STF81 & 100,00 & 173,15 & 83,09 & 40,87 & 4074,54 & 282,17 & 81,16 & 201,01 & 133,03 & 224,64 & 228,83 & 124,45 & 760,43 & 137,52 & 1,00 & 75,86 & 382,20 & 13,55 & 21,39 & 358,96 \\
\hline Bufo spinosus & 30STF82 & 100,00 & 173,59 & 83,40 & 40,32 & 4196,64 & 284,72 & 80,30 & 204,42 & 131,67 & 226,76 & 230,81 & 123,30 & 749,50 & 133,75 & 1,00 & 74,76 & 371,99 & 14,12 & 21,54 & 348,06 \\
\hline Bufo spinosus & 30STF83 & 100,00 & 173,10 & 84,66 & 39,84 & 4358,86 & 287,95 & 77,71 & 210,25 & 129,07 & 228,36 & 232,25 & 120,63 & 739,53 & 129,64 & 1,00 & 73,58 & 361,28 & 14,88 & 21,88 & 337,73 \\
\hline Bufo spinosus & 30STF84 & 100,00 & 159,27 & 93,11 & 39,2 & 4853,83 & 290,15 & 55,91 & 234,24 & 110,40 & 221,77 & 225,12 & 100,94 & 779,16 & 127,61 & 1,32 & 71,04 & 363,68 & 17,39 & 25,77 & 347,73 \\
\hline \begin{tabular}{|l} 
Bufo spinosus \\
\end{tabular} & 30STF85 & 100,00 & 147,33 & 100,24 & 39,00 & 5242,53 & 291,33 & $\begin{array}{l}37,85 \\
37\end{array}$ & 253,47 & 94,49 & 215,79 & 218,57 & 84,58 & 816,53 & 126,63 & 2,14 & 68,67 & 367,17 & 21,33 & 30,02 & 356,10 \\
\hline Bufo spinosus & 30STF86 & 100,00 & 139,97 & 104,57 & 39,00 & 5481,88 & 291,96 & 26,83 & 265,13 & 84,45 & 212,01 & 214,44 & 74,54 & 840,73 & 126,14 & 2,85 & 66,86 & 369,18 & 24,63 & 33,24 & 359,97 \\
\hline Bufo spinosus & \begin{tabular}{|l|} 
30STF87 \\
\end{tabular} & 100,00 & 144,08 & 105,08 & 39,00 & 5527,88 & 297,17 & 30,56 & 266,61 & 87,53 & 216,61 & 219,03 & 77,99 & 815,38 & 123,04 & 2,60 & 66,53 & 358,10 & 23,87 & 31,97 & 346,90 \\
\hline Bufo spinosus & 30STF88 & 100,00 & 159,18 & 103,34 & 39,01 & 5441,13 & 308,69 & 47,81 & 260,88 & 102,47 & 229,94 & 232,45 & 93,75 & 739,03 & 116,06 & 1,4 & 67,26 & 30,99 & 19,64 & 26,47 & 314,51 \\
\hline Bufo spinosus & 30STF89 & 100,00 & 164,97 & 105,62 & 39,3 & 5509,10 & 317,27 & 52,51 & 264,76 & $\begin{array}{l}106,85 \\
\end{array}$ & 236,40 & 238,74 & \begin{tabular}{|c|}
38,66 \\
98,
\end{tabular} & 703,42 & 111,41 & 1,0 & $\begin{array}{ll}67,10 \\
\end{array}$ & \begin{tabular}{|l|l|}
314,99 \\
\end{tabular} & 18,34 & 24,40 & 297,42 \\
\hline \begin{tabular}{|l} 
Bufo spinosus \\
\end{tabular} & 30STF91 & 39,00 & 176,17 & 83,33 & \begin{tabular}{|l|l|}
41,17 \\
\end{tabular} & 4017,94 & 284,50 & 85,06 & 199,44 & 137,06 & 226,75 & 231,21 & 128,54 & 719,27 & 131,94 & 1,00 & 76,06 & 365,92 & 13,00 & 20,62 & 341,06 \\
\hline Bufo spinosus & 30STF92 & 93,00 & 174,60 & 84,83 & 40,84 & 4174,83 & 286,67 & 81,19 & 205,48 & 133,55 & 227,43 & 231,57 & 124,91 & 713,66 & 128,04 & 1,00 & 74,88 & 357,33 & $\mid 13,87$ & 21,17 & 333,13 \\
\hline Bufo spinosus & 30STF93 & 100,00 & 166,98 & 89,40 & 40,09 & 4514,49 & 288,77 & 68,36 & 220,41 & 122,21 & 224,76 & 228,44 & 113,05 & 735,55 & 125,81 & 1,13 & 72,92 & 356,18 & 15,45 & 23,38 & 336,01 \\
\hline Bufo spinosus & 30STF94 & 100,00 & 159,15 & 94,59 & 39,62 & 4860,97 & 291,42 & 55,28 & 236,14 & 110,56 & 221,89 & 225,26 & 100,99 & 759,01 & 124,04 & 1,38 & 70,95 & 355,90 & 17,41 & 25,68 & 339,61 \\
\hline Bufo spinosus & 30STFG & 100,00 & $\begin{array}{l}13,131,72 \\
151\end{array}$ & \begin{tabular}{|c|}
44,35 \\
99,36
\end{tabular} & 39, & $\begin{array}{l}400,3148,58 \\
5148\end{array}$ & 293,22 & \begin{tabular}{|l|l}
43,49 \\
43
\end{tabular} & \begin{tabular}{|l|}
$249,72,7$ \\
\end{tabular} & \begin{tabular}{|l|l|}
$11,09,93$ \\
99
\end{tabular} & \begin{tabular}{|l|}
218,81 \\
2181
\end{tabular} & $\mid 221,64$ & \begin{tabular}{|c|c|}
0,19 \\
90,19
\end{tabular} & $\mid$\begin{tabular}{|c|}
$\mid 783,01$ \\
783
\end{tabular} & \begin{tabular}{|l|}
$123,22,2$ \\
\end{tabular} & $\begin{array}{l}1,100 \\
1,91\end{array}$ & $\begin{array}{ll}0,13 \\
69,12\end{array}$ & $\begin{array}{l}357,32 \\
357,\end{array}$ & $\begin{array}{l}1,4,1 \\
19,93\end{array}$ & $\begin{array}{l}28,33 \\
28,3\end{array}$ & 343,75 \\
\hline Bufo spinosus & 30STF96 & 100,00 & 140,76 & 105,24 & 39,02 & 5472,22 & 292,95 & 27,36 & 265,59 & 85,59 & 212,85 & 215,11 & 75,54 & 823,41 & 123,36 & 2,90 & 66,79 & 362,83 & 24,15 & 32,79 & 353,24 \\
\hline Bufo spinosus & 30STF97 & 100,00 & 150,34 & 103,86 & 39,00 & 5436,48 & 300,43 & 38,15 & 262,28 & 94,78 & 221,63 & 223,92 & 85,39 & 776,73 & 119,36 & 2,20 & 67,05 & 346,44 & 21,62 & 29,46 & 332,90 \\
\hline Bufo spinosus & 30STF98 & 100,00 & 156,77 & 104,40 & 39,06 & 5475,32 & 307,66 & 44,50 & 263,16 & 100,01 & 228,30 & 230,60 & 91,14 & 743,66 & 115,82 & 1,85 & 67,04 & 332,79 & 20,44 & 27,36 & 317,06 \\
\hline Bufo spinosus & 30STF99 & 100,00 & 162,62 & 106,09 & 39,23 & 5534,61 & 315,61 & 49,36 & 266,25 & 104,63 & 234,77 & 236,86 & 96,04 & 712,37 & 111,81 & 1,42 & 66,75 & 318,54 & 19,35 & 25,61 & 301 \\
\hline Bufo spinosus & 30STG44 & $\begin{array}{l}100,00 \\
\end{array}$ & $\begin{array}{l}102,02 \\
183,53\end{array}$ & \begin{tabular}{|l|}
121,81 \\
128
\end{tabular} & 39,25 & $\begin{array}{l}3030,01 \\
6117,17\end{array}$ & 358,01 & $\begin{array}{l}5,53 \\
55,53\end{array}$ & \begin{tabular}{|l|}
303,33 \\
30,3
\end{tabular} & \begin{tabular}{|l|}
116,78 \\
116,7
\end{tabular} & \begin{tabular}{|l|}
263,25 \\
263
\end{tabular} & \begin{tabular}{|l|}
264,50 \\
264
\end{tabular} & \begin{tabular}{|c|}
$50,04,12$ \\
108,12
\end{tabular} & $\begin{array}{l}12,31,99 \\
881\end{array}$ & \begin{tabular}{|c|}
11,01 \\
87,18
\end{tabular} & $\begin{array}{l}\frac{1,44}{1,00} \\
\end{array}$ & $\begin{array}{l}0,13 \\
63,46 \\
\end{array}$ & \begin{tabular}{|l|}
248,29 \\
24,2
\end{tabular} & $\mid \begin{array}{l}\mid 5,030 \\
18,00\end{array}$ & \begin{tabular}{|l|l|}
22,00 \\
22
\end{tabular} & $\begin{array}{l}301,03 \\
234,10\end{array}$ \\
\hline Bufo spinosus & 30STG45 & 100,00 & 183,83 & 122,90 & 39,83 & 6180,29 & 361,25 & 54,79 & 306,46 & 116,39 & 264,59 & 265,65 & 107,65 & 573,19 & 84,99 & 1,00 & 63,01 & 242,74 & 18,00 & 22,00 & 229,10 \\
\hline Bufo spinosus & 30STG47 & 100,00 & 175,54 & 122,95 & 39,06 & 6315,07 & 356,46 & 45,87 & 310,59 & 106,78 & 258,24 & 259,07 & 97.82 & 593,90 & 84,53 & 1.76 & 60.90 & 245,11 & 20.94 & 25,34 & 232,64 \\
\hline Bufo spinosus & 30STG48 & 100,00 & 174,66 & 123,03 & 39,00 & 6355,98 & 356,75 & $\begin{array}{ll}44,67 \\
\end{array}$ & 312,08 & 105,38 & 258,06 & 258,77 & 96 & 588,01 & 82,80 & 2,04 & 60,20 & 240,29 & 21,39 & 25,70 & 228,30 \\
\hline Bufo spinosus & 30STG49 & 100,00 & 165,69 & 122,71 & 38,70 & 6434,94 & 349,90 & 35,92 & 313,99 & 95,88 & 250,41 & 251,07 & 87,03 & 620,24 & 85,77 & 2,65 & 58,86 & 249,59 & 24,31 & 29,03 & 238,44 \\
\hline
\end{tabular}




\begin{tabular}{|c|c|c|c|c|c|c|c|c|c|c|c|c|c|c|c|c|c|c|c|c|c|}
\hline TAXON & UTM & $\mathrm{km2}$ & BIO1 & B102 & $\mathrm{BIO3}$ & B104 & B105 & B106 & B107 & B108 & B109 & BIO10 & BIO11 & BIO12 & BIO13 & BIO14 & BIO15 & BIO16 & BIO17 & B1018 & BlO19 \\
\hline Bufo spinosus & 30STG50 & 100,00 & 177,03 & 105,44 & 39,14 & 5583,52 & 329,56 & 63,59 & 265,97 & 116,68 & 248,59 & 251,21 & 108,93 & 618,46 & 96,50 & 1,00 & 66,22 & 271,26 & 16,58 & 21,61 & 253,39 \\
\hline Bufo spinosus & 30STG51 & 100,00 & 178,28 & 111,45 & 39,81 & 5734,61 & 338,11 & \begin{tabular}{ll|}
61,29 \\
\end{tabular} & $\begin{array}{ll}276,82 \\
\end{array}$ & 116,05 & 252,01 & 254,32 & \begin{tabular}{ll|}
108,26 \\
\end{tabular} & 608,31 & 94,08 & 1,00 & $\begin{array}{l}65,75 \\
\end{array}$ & 265,59 & \begin{tabular}{|l|l}
16,77 \\
\end{tabular} & 21,31 & 248,46 \\
\hline Bufo spinosus & 30STG56 & 100,00 & 183,18 & 123,41 & 39,64 & 6237,61 & 361,81 & 53,85 & 307,96 & 115,05 & \begin{tabular}{|l|l|}
264,77 \\
\end{tabular} & 265,45 & \begin{tabular}{|l|l|}
106,17 \\
\end{tabular} & 571,86 & 83,34 & 1,00 & 62,52 & 240,11 & 18,05 & 22,14 & 227,19 \\
\hline Bufo spinosus & 30STG57 & 100,00 & 178,89 & 124,02 & 39,27 & 6320,81 & 360,30 & 48,86 & 311,45 & \begin{tabular}{ll|l}
110,09 \\
\end{tabular} & 261,71 & 262,37 & 100,99 & 584,72 & 83,77 & 1,46 & 61,38 & 241,95 & 19,40 & 23,80 & 229,87 \\
\hline Bufo spinosus & 30STG58 & 100,00 & 168,71 & 123,92 & 39,00 & 6427,23 & 353,35 & 38,44 & \begin{tabular}{|l|l|}
314,92 \\
\end{tabular} & \begin{tabular}{ll|}
99,08 \\
\end{tabular} & \begin{tabular}{|l|l|}
253,38 \\
\end{tabular} & 254,00 & 90,12 & 621,32 & 87,25 & 2,01 & \begin{tabular}{|l|}
59,98 \\
\end{tabular} & 252,34 & 22,64 & 27,19 & 241,33 \\
\hline Bufo spinosus & 30STG59 & 100,00 & 162,75 & 123,58 & 38,49 & 6489,78 & 349,12 & 32,60 & 316,52 & 92,60 & 248,53 & 249,06 & 83,68 & 639,22 & 88,46 & 2,57 & 58,97 & 255,99 & 24,94 & 29,09 & 245,75 \\
\hline Bufo spinosus & 30STG60 & 100,00 & 174,76 & 108,79 & 39,92 & 5594,85 & 330,94 & 61,34 & 269,60 & \begin{tabular}{ll|}
114,40 \\
\end{tabular} & 246,56 & 249,06 & \begin{tabular}{ll|}
106,93 \\
\end{tabular} & 634,01 & 100,54 & 1,00 & \begin{tabular}{ll|}
66,62 \\
\end{tabular} & 280,69 & \begin{tabular}{|l|l|}
16,59 \\
\end{tabular} & 21,63 & 262,52 \\
\hline Bufo spinosus & 30STG61 & 100,00 & 176,62 & 114,36 & 40,43 & 5730,71 & 339,71 & 60,30 & 279,41 & $\begin{array}{ll}114,43 \\
\end{array}$ & \begin{tabular}{|l|l|}
250,25 \\
\end{tabular} & 252,50 & 107,10 & 615,43 & 97,20 & 1,00 & \begin{tabular}{ll|l}
66,46 \\
\end{tabular} & 271,11 & \begin{tabular}{|l|l|}
16,10 \\
\end{tabular} & 21,01 & 253,67 \\
\hline Bufo spinosus & 30STG67 & 100,00 & 175,46 & 124,19 & 39,23 & 6358,80 & 357,91 & 45,78 & 312,14 & \begin{tabular}{|l|l|}
106,27 \\
\end{tabular} & 259,13 & 259,64 & \begin{tabular}{ll|l}
97,48 \\
\end{tabular} & \begin{tabular}{ll|}
605,06 \\
\end{tabular} & 87,20 & 1,63 & 61,45 & 249,46 & \begin{tabular}{ll|}
19,86 \\
\end{tabular} & 24,03 & 238,20 \\
\hline Bufo spinosus & 30STG68 & 100,00 & 168,27 & 124,46 & 38,92 & $6463,01$. & 353,97 & 37,80 & 316,17 & $98,27 \mid$ & 253,63 & 253,86 & 89,14 & 629,00 & 88,82 & 2,00 & 60,12 & 254,86 & 22,39 & 25,94 & 244,62 \\
\hline Bufo spinosus & 30STG69 & 100,00 & 158,30 & 123,72 & 38,13 & 6543,04 & 346,16 & 27,98 & 318,18 & 87,73 & \begin{tabular}{|l|l|}
245,06 \\
\end{tabular} & 245,34 & 78,92 & 664,30 & 91,73 & 2,86 & 58,72 & 264,30 & 26,15 & 28,46 & 255,15 \\
\hline Bufo spinosus & 30STG78 & 100,00 & 168,50 & 124,56 & 38,92 & 6485,80 & 354,55 & \begin{tabular}{|l|l|}
37,93 \\
\end{tabular} & 316,62 & 98,37 & 254,24 & 254,40 & 89,27 & 633,13 & 89,94 & 2,00 & 60,40 & 255,87 & 21,89 & 24,68 & 246,41 \\
\hline Bufo spinosus & 30STG79 & 100,00 & 158,45 & 124,13 & 38,25 & 6569,95 & 347,11 & 27,77 & 319,34 & 87,62 & 245,74 & 245,83 & 78,66 & \begin{tabular}{ll|l}
668,05 \\
\end{tabular} & 92,56 & 2,95 & 58,80 & \begin{tabular}{|l|}
264,92 \\
\end{tabular} & 25,84 & 27,06 & 256,60 \\
\hline Bufo spinosus & 30STG86 & 100,00 & 178,99 & 122,24 & 39,78 & 6266,13 & 356,57 & 51,29 & 305,28 & \begin{tabular}{l|l|l|l|}
110,92 \\
\end{tabular} & 261,29 & 261,69 & \begin{tabular}{|l|}
102,17 \\
\end{tabular} & 605,48 & 90,01 & 1,00 & \begin{tabular}{l|l}
62,75 \\
\end{tabular} & 252,48 & 17,68 & 22,53 & 241,26 \\
\hline Bufo spinosus & 30STG88 & 100,00 & 171,70 & 124,24 & 38,91 & 6496,07 & 357,21 & 40,91 & 316,29 & \begin{tabular}{|l|l|l|}
101,11 \\
\end{tabular} & \begin{tabular}{|l|l|}
257,59 \\
\end{tabular} & 257,70 & \begin{tabular}{ll|}
92,28 \\
\end{tabular} & 624,53 & 89,52 & 2,00 & 60,71 & 252,07 & 20,61 & 22,20 & 243,36 \\
\hline Bufo spinosus & 30STG90 & 100,00 & 162,42 & 109,08 & 39,31 & 5685,62 & 320,47 & $\begin{array}{ll}46,95 \\
\end{array}$ & 273,52 & 102,55 & 236,79 & 238,63 & 94,09 & \begin{tabular}{|l|l|}
706,63 \\
\end{tabular} & 109,79 & 1,59 & 66,01 & 312,36 & 19,64 & 25,89 & 296,33 \\
\hline Bufo spinosus & 30STG91 & 100,00 & 168,78 & 111,41 & 39,80 & 5755,98 & 329,38 & 51,78 & 277,60 & \begin{tabular}{ll|}
107,57 \\
\end{tabular} & 243,88 & 245,63 & 99,31 & 672,11 & 105,18 & 1,06 & 65,85 & \begin{tabular}{|l|l|}
296,47 \\
\end{tabular} & 18,01 & 23,59 & 280,25 \\
\hline Bufo spinosus & 30STG97 & 100,00 & 180,20 & 122,08 & 39,01 & 6349,77 & 359,43 & 50,93 & 308,51 & \begin{tabular}{l|l|}
111,03 \\
\end{tabular} & \begin{tabular}{|l|l|}
263,92 \\
\end{tabular} & 264,04 & \begin{tabular}{l|l}
101,95 \\
\end{tabular} & 600,20 & 88,64 & 1,05 & 62,49 & 246,44 & 17,11 & 19,23 & 237,14 \\
\hline Bufo spinosus & 30STG98 & 100,00 & 173,99 & 123,66 & 38,80 & 6501,44 & 358,65 & 43,13 & 315,52 & \begin{tabular}{ll|}
103,21 \\
\end{tabular} & \begin{tabular}{|l|l|}
260,03 \\
\end{tabular} & 260,10 & $\begin{array}{l}94,35 \\
\end{array}$ & 621,06 & 89,58 & 1,93 & 61,14 & 250,08 & \begin{tabular}{|l|l|}
19,47 \\
\end{tabular} & \begin{tabular}{l|l}
20,25 \\
\end{tabular} & 242,25 \\
\hline Bufo spinosus & 30STH30 & 38,00 & 162,02 & 121,69 & \begin{tabular}{l|l|}
38,05 \\
\end{tabular} & 6437,09 & 346,07 & 32,84 & 313,24 & 92,33 & 246,85 & 247,60 & 83,40 & 623,24 & 85,07 & 2,93 & 57,98 & 248,53 & 26,09 & 30,42 & 237,40 \\
\hline Bufo spinosus & 30STH33 & 29,00 & 150,24 & 120,81 & 38,00 & 6543,11 & 337,22 & 21,86 & 315,35 & 79,81 & 237,11 & 237,57 & 71,22 & 652,89 & $\begin{array}{l}86,65 \\
\end{array}$ & 4,11 & 55,27 & 253,00 & 32,08 & 35,86 & 242,89 \\
\hline Bufo spinosus & 30STH40 & 100,00 & 160,71 & 122,37 & 38,23 & 6479,99 & 346,34 & \begin{tabular}{|l|l|}
31,07 \\
\end{tabular} & 315,27 & \begin{tabular}{l|l}
90,63 \\
\end{tabular} & 246,38 & 246,83 & 81,72 & 633,15 & 86,42 & 2,97 & 58,00 & 251,74 & 26,43 & 30,23 & 241,17 \\
\hline Bufo spinosus & 30STH41 & 100,00 & 160,59 & 122,44 & 38,03 & 6501,08 & 346,94 & 30,69 & 316,24 & \begin{tabular}{|l|}
90,13 \\
\end{tabular} & \begin{tabular}{|l|l|}
246,60 \\
\end{tabular} & \begin{tabular}{|l|l|}
246,97 \\
\end{tabular} & 81,27 & 623,32 & 84,59 & 3,05 & 57,23 & \begin{tabular}{|l|l|}
245,85 \\
\end{tabular} & 26,93 & 30,72 & 235,46 \\
\hline Bufo spinosus & 30STH42 & 100,00 & 151,34 & 121,54 & 37,99 & 6546,37 & 339,06 & 22,35 & 316,71 & \begin{tabular}{ll|}
81,06 \\
\end{tabular} & \begin{tabular}{|l|l|}
238,43 \\
\end{tabular} & 238,74 & 72,14 & \begin{tabular}{ll|l}
658,05 \\
\end{tabular} & 87,87 & 3,93 & 55,88 & 256,05 & 31,06 & 34,19 & 246,37 \\
\hline Bufo spinosus & 30STH43 & 100,00 & 152,44 & 121,60 & 38,00 & 6564,90 & 340,64 & 23,11 & 317,53 & 81,97 & 239,73 & 240,03 & 72,92 & 641,43 & 85,26 & 4,01 & 55,44 & 247,99 & \begin{tabular}{|l|l|}
30,97 \\
\end{tabular} & 34,01 & 238,21 \\
\hline Bufo spinosus & 30STH44 & 100,00 & 153,94 & 121,57 & 38,00 & 6575,79 & 342,36 & 24,53 & 317,83 & 83,12 & 241,33 & 241,64 & 74,22 & \begin{tabular}{|l|}
622,99 \\
\end{tabular} & 82,48 & 4,00 & 54,88 & 239,42 & 30,72 & 33,11 & 229,57 \\
\hline Bufo spinosus & 30STH45 & 100,00 & 156,29 & 121,34 & 37,90 & 6582,55 & 344,70 & 26,89 & 317,80 & 85,22 & 243,84 & 243,96 & \begin{tabular}{|l|l|}
76,47 \\
\end{tabular} & \begin{tabular}{|l|l|}
599,57 \\
\end{tabular} & $\begin{array}{l}79,15 \\
\end{array}$ & 3,77 & \begin{tabular}{l|l}
54,35 \\
\end{tabular} & 229,14 & 30,18 & 31,53 & 219,06 \\
\hline Bufo spinosus & 30STH48 & 100,00 & 157,44 & 119,95 & \begin{tabular}{|l|l|}
37,17 \\
\end{tabular} & 6597,95 & 344,99 & 28,26 & 316,73 & 85,84 & \begin{tabular}{ll|}
245,26 \\
\end{tabular} & \begin{tabular}{|l|}
245,27 \\
\end{tabular} & 77,32 & 561,16 & 72,90 & 3,99 & 52,53 & 210,48 & \begin{tabular}{l|l}
31,05 \\
\end{tabular} & 31,16 & 199,90 \\
\hline Bufo spinosus & 30STH50 & 100,00 & 154,55 & 122,76 & 38,00 & 6541,03 & 342,21 & 24,70 & 317,51 & 84,12 & 241,26 & 241,71 & 75,17 & 667,25 & 90,76 & 3,32 & \begin{tabular}{|l|l|}
57,67 \\
\end{tabular} & 263,34 & 28,34 & 32,51 & 253,95 \\
\hline Bufo spinosus & 30STH51 & 100,00 & 153,72 & 122,75 & 38,00 & 6576,28 & 342,43 & 23,63 & 318,80 & \begin{tabular}{|l|}
82,89 \\
\end{tabular} & \begin{tabular}{|l|l|}
241,05 \\
\end{tabular} & 241,33 & 74,09 & 661,33 & 89,25 & 3,54 & 56,83 & 258,68 & 29,39 & 32,99 & 249,47 \\
\hline Bufo spinosus & 30STH52 & 100,00 & 154,26 & 122,84 & 38,00 & 6601,11 & 343,57 & 24,05 & 319,52 & 83,09 & \begin{tabular}{|l|l|}
242,07 \\
\end{tabular} & 242,18 & 74,22 & 646,74 & 86,74 & 3,61 & 56,34 & 251,10 & 29,43 & 31,63 & 241,95 \\
\hline Bufo spinosus & \begin{tabular}{|l|l|}
30 STH53 \\
\end{tabular} & 100,00 & 154,90 & 122,75 & 38,00 & 6617,85 & 344,73 & 24,51 & 320,22 & 83,45 & 243,01 & 243,06 & 74,60 & 631,86 & 84,23 & 3,78 & 55,64 & 243,45 & 29,58 & 30,37 & 234,31 \\
\hline Bufo spinosus & 30STH54 & 100,00 & 154,50 & 122,49 & 37,96 & 6634,03 & 344,70 & 23,91 & 320,79 & 82,82 & \begin{tabular}{|l|l|}
243,02 \\
\end{tabular} & 243,02 & 74,04 & 621,54 & 82,39 & 4,00 & 55,00 & 237,79 & 30,11 & 30,11 & 228,58 \\
\hline Bufo spinosus & 30STH55 & 100,00 & 155,17 & 122,07 & $\begin{array}{l}37,85 \\
\end{array}$ & 6633,65 & 344,99 & 24,61 & 320,37 & 83,29 & 243,63 & 243,64 & 74,65 & 606,76 & 79,93 & 3,98 & 54,26 & 230,53 & 30,33 & 30,50 & 221,18 \\
\hline Bufo spinosus & 30STH57 & 100,00 & 158,29 & 121,34 & 37,48 & 6635,21 & 347,64 & 28,06 & 319,58 & 86,25 & 246,79 & 246,79 & 77,69 & 566,59 & 74,11 & 3,67 & 53,32 & 212,71 & 29,75 & 29,75 & 202,91 \\
\hline Bufo spinosus & 30STH59 & 100,00 & 158,08 & 120,01 & 37,01 & 6644,11 & 346,61 & 28,50 & 318,10 & 85,85 & \begin{tabular}{|l|l|}
246,69 \\
\end{tabular} & 246,69 & 77,37 & 543,94 & 70,90 & 3,76 & 51,89 & \begin{tabular}{|l|}
201,49 \\
\end{tabular} & 30,76 & 30,76 & 191,24 \\
\hline Bufo spinosus & 30STH60 & 100,00 & 154,76 & 123,63 & 38,00 & 6584,50 & 343,96 & 24,34 & 319,62 & \begin{tabular}{|l|}
83,79 \\
\end{tabular} & 242,28 & 242,47 & 74,96 & 669,32 & 91,24 & 3,44 & 57,66 & 263,09 & 28,16 & 29,76 & 254,51 \\
\hline Bufo spinosus & 30STH61 & 100,00 & 152,05 & 123,47 & 38,00 & 6622,53 & 342,36 & 21,54 & 320,82 & 80,86 & 240,30 & 240,46 & 72,04 & $\begin{array}{l}670,25 \\
\end{array}$ & 90,40 & 3,68 & 56,78 & 260,80 & 29,55 & 31,25 & 252,50 \\
\hline Bufo spinosus & 30STH62 & 100,00 & 157,57 & 123,87 & 38,00 & 6630,11 & 347,98 & 26,14 & 321,84 & 85,75 & \begin{tabular}{|l|l|}
245,83 \\
\end{tabular} & 245,90 & 76,93 & \begin{tabular}{|l|l|}
634,27 \\
\end{tabular} & 85,54 & 3,25 & 56,54 & 245,70 & 7,79 & 8,80 & 237,15 \\
\hline Bufo spinosus & \begin{tabular}{|l|}
$30 S T H 63$ \\
\end{tabular} & 100,00 & 157,68 & 123,72 & 38,00 & 6652,56 & 348,56 & 26,31 & 322,26 & 85,60 & 246,30 & 246,33 & 76,89 & 621,23 & 83,23 & 3,33 & 56,03 & 238,75 & 28,07 & 28,60 & 230,16 \\
\hline Bufo spinosus & 30STH69 & 100,00 & 160,45 & 120,86 & 37,00 & 6684,73 & 350,04 & 29,56 & \begin{tabular}{|l|l|}
320,48 \\
\end{tabular} & $\begin{array}{l}87,46 \\
\end{array}$ & \begin{tabular}{|l|l|}
249,60 \\
\end{tabular} & 249,60 & 79,00 & 529,86 & 69,74 & 3,37 & \begin{tabular}{l|l|}
52,25 \\
\end{tabular} & \begin{tabular}{|l|l|}
195,47 \\
\end{tabular} & 28,90 & 28,90 & 185,73 \\
\hline Bufo spinosus & 30STH70 & 100,00 & 151,81 & 123,86 & 38,00 & 6621,13 & 342,24 & 21,17 & 321,08 & 80,58 & \begin{tabular}{|l|l|}
240,03 \\
\end{tabular} & 240,17 & 71,88 & \begin{tabular}{|l|l|}
685,67 \\
\end{tabular} & 93,23 & 3,73 & 57,39 & 267,92 & 29,08 & 30,53 & 260,25 \\
\hline Bufo spinosus & 30STH72 & 100,00 & 161,12 & 124,65 & 38,00 & 6671,75 & 352,56 & 28,79 & 323,77 & 88,78 & \begin{tabular}{|l|l|}
249,95 \\
\end{tabular} & \begin{tabular}{l|l|}
249,95 \\
\end{tabular} & 79,81 & 621,28 & 84,23 & 3,12 & 57,01 & 239,88 & 26,17 & 26,17 & 232,06 \\
\hline Bufo spinosus & 30STH73 & 100,00 & 157,96 & 19 & 38,00 & 6695,41 & 350,16 & 25,70 & 324,46 & 85,29 & 247,26 & 247,26 & 76,62 & 621,96 & 83,71 & 3,38 & 55,96 & 237,66 & 27,83 & 27,83 & 229,96 \\
\hline $\begin{array}{l}\text { Bufo spinosus } \\
\end{array}$ & \begin{tabular}{|l|l|}
$30 S T H 75$ \\
\end{tabular} & 100,00 & 155,29 & 12 & 37,63 & 6738,76 & 348,04 & 23,29 & 324,75 & 82,23 & 245,27 & 245,27 & 73,59 & 606,42 & 81,36 & 4,00 & 54,31 & 227,60 & 29,78 & 29,78 & 219,78 \\
\hline Bufo spinosus & 30STH76 & 100,00 & 152,99 & 122,95 & \begin{tabular}{|l|}
37,08 \\
\end{tabular} & 6744,62 & 346,10 & 21,23 & 324,86 & 80,04 & 243,23 & 243,23 & \begin{tabular}{|l|l|}
71,27 \\
\end{tabular} & \begin{tabular}{|l|l|}
602,77 \\
\end{tabular} & 80,62 & 4,09 & \begin{tabular}{l|l|l|l|}
53,45 & \\
\end{tabular} & 224,19 & 31,37 & 31,37 & 216,19 \\
\hline Bufo spinosus & 30STH77 & 100,00 & 153,77 & 122,52 & \begin{tabular}{l|l}
37,05 \\
\end{tabular} & 6741,82 & 346,30 & 22,12 & 324,18 & 80,67 & \begin{tabular}{|l|l|}
243,93 \\
\end{tabular} & 243,93 & 72,03 & \begin{tabular}{|l|l|}
585,37 \\
\end{tabular} & 78,13 & 4,07 & $\begin{array}{l}52,76 \\
\end{array}$ & 216,22 & 31,41 & 31,41 & 207,88 \\
\hline Bufo spinosus & 30STH80 & 100,00 & 159,47 & 124,72 & 38,00 & 6639,36 & 350,07 & 27,82 & 322,25 & \begin{tabular}{|l|l|}
87,76 \\
\end{tabular} & 247,96 & 247,97 & 78,89 & 656,20 & 90,41 & 3,03 & 58,29 & 256,68 & 25,59 & 25,70 & 249,59 \\
\hline Bufo spinosus & 30STH81 & 100,00 & 164,93 & 124,97 & 38,00 & 6662,85 & 355,81 & 32,29 & 323,52 & 92,55 & 253,64 & 253,64 & 83,6 & 622,20 & 85,72 & 2,64 & 58,18 & 241,91 & 23,87 & 23,87 & 234,87 \\
\hline $\begin{array}{l}\text { Bufo spinosus } \\
\end{array}$ & 30STH82 & 100,00 & 160,47 & 124,88 & 37,99 & 6717,64 & 353,05 & 27,63 & 325,43 & 87,61 & 250,08 & 250,08 & 78,63 & 626,84 & 85,41 & 3,14 & 57,05 & 240,49 & 26,13 & 26,13 & 233,82 \\
\hline Bufo spinosus & 30STH83 & 100,00 & 152,89 & 124,35 & 37,89 & 6749,92 & 346,89 & 20,61 & 326,28 & 79,97 & 243,25 & 243,25 & \begin{tabular}{|l|l|}
71,38 \\
\end{tabular} & \begin{tabular}{|l|l|}
644,83 \\
\end{tabular} & 87,63 & 3,99 & \begin{tabular}{|l|}
55,49 \\
\end{tabular} & 243,88 & 29,88 & 29,88 & 237,43 \\
\hline Bufo spinosus & 30STH85 & 100,00 & 153,88 & 124,01 & 37,63 & \begin{tabular}{ll|}
6775,67 \\
\end{tabular} & 347,84 & 21,45 & 326,39 & 80,45 & \begin{tabular}{|l|l|}
244,69 \\
\end{tabular} & 244,69 & \begin{tabular}{l|l|}
72,05 \\
\end{tabular} & 611,90 & 83,02 & 4,00 & 54,14 & 227,90 & 30,21 & 30,21 & 221,07 \\
\hline Bufo spinosus & \begin{tabular}{|l|l}
30 STH86 \\
\end{tabular} & 100,00 & 156,58 & 123,79 & 37,37 & 6782,16 & 350,26 & 23,82 & 326,44 & 82,86 & 247,33 & 247,33 & 74,38 & 585,63 & 79,31 & 3,89 & 53,74 & 216,73 & 29,32 & 29,32 & 209,48 \\
\hline Bufo spinosus & 30STH89 & 100,00 & 160,79 & 122,07 & $37, \mathrm{C}$ & 6751,70 & 352 & 28, & 323 & \begin{tabular}{|l|l|}
87,16 \\
\end{tabular} & 251, & 251, & 78,56 & 523,03 & 69,94 & 3,46 & 52, & 189,93 & 28,30 & 28,30 & 181, \\
\hline Bufo spinosus & 30STH92 & 100,00 & 154,90 & 124,82 & 37,90 & 6763,98 & 348,95 & 22,06 & 326,90 & 81,84 & 245,55 & 245,55 & 72,92 & 651,22 & 89,77 & 3,59 & 56,58 & 247,49 & 28,03 & 28,03 & 241,99 \\
\hline Bufo spinosus & 30STH93 & 100,00 & 152,65 & 124,72 & \begin{tabular}{|l|l|}
37,68 \\
\end{tabular} & 6786,90 & 347,49 & \begin{tabular}{|l|l|}
19,87 \\
\end{tabular} & \begin{tabular}{l|l|}
327,63 \\
\end{tabular} & \begin{tabular}{|l|}
79,39 \\
\end{tabular} & 243,60 & 243,60 & 70,57 & \begin{tabular}{|c|c|}
645,78 \\
\end{tabular} & 88,98 & 3,84 & 55,60 & 242,73 & 29,33 & 29,33 & 237,29 \\
\hline Bufo spinosus & 30STH95 & 100,00 & 154,11 & 124,24 & 37,09 & \begin{tabular}{ll|l|}
6804,66 \\
\end{tabular} & 349,13 & 21,09 & \begin{tabular}{|l|l|}
328,03 \\
\end{tabular} & 80,45 & 245,41 & 245,41 & 71,63 & 609,40 & 83,61 & 4,01 & 54,18 & 225,23 & 29,96 & 29,96 & 219,28 \\
\hline Bufo spinosus & 30STJ51 & 100,00 & 166,13 & & 37,00 & 6600, & 252 & 36,5 & 315, & 93, & 254, & 254, & 85, & 485,22 & 62,98 & 3,01 & 51,2 & 178,56 & & 3 & \\
\hline Bufo spinosus & 30STJ60 & 100,00 & 162,60 & 120,19 & 37,01 & 6670,1 & 351, & 32,07 & 319,02 & 89,56 & 251,53 & 251,53 & 81,13 & \begin{tabular}{|l|l|}
507,73 \\
\end{tabular} & 66,73 & 3,06 & 51,13 & 186,28 & 28,21 & 28,21 & 176,27 \\
\hline Bufo spinosus & 30STJ66 & 100,00 & 144,41 & 114,81 & 36,21 & 6629,29 & 329,64 & 18,39 & 311,25 & 72,59 & 233,64 & 233,64 & \begin{tabular}{|c|}
64,67 \\
\end{tabular} & 524,45 & 65,76 & 5,75 & \begin{tabular}{|l|l|}
46,24 \\
\end{tabular} & 185,41 & 39,55 & 39,55 & 173,24 \\
\hline
\end{tabular}




\begin{tabular}{|c|c|c|c|c|c|c|c|c|c|c|c|c|c|c|c|c|c|c|c|c|c|}
\hline TAXON & UTM & $\mathrm{km} 2$ & B101 & B102 & $\mathrm{BIO3}$ & B104 & BIO5 & B106 & B107 & B108 & B109 & BIO10 & BIO11 & BIO12 & 81013 & BIO14 & BIO15 & B1016 & B1017 & B1018 & B1019 \\
\hline Bufo spinosus & 30STJ70| & 100,00 & 162,94 & 120,93 & 37,00 & 6711,61 & 352,53 & 31,34 & 321,19 & 89,45 & 252,49 & 252,49 & 80,99 & 503,63 & 66,61 & 3,16 & 51,62 & 183,48 & 27,84 & 27,84 & 174,04 \\
\hline Bufo spinosus & 30STJ76 & 100,00 & 140,27 & 115,77 & 36,36 & 6661,01 & 326,81 & 13,58 & 313,23 & 68,12 & 230,10 & 230,10 & 60,34 & 531,60 & 65,98 & 6,25 & 45,55 & 185,83 & 41,36 & 41,36 & 173,77 \\
\hline Bufo spinosus & 30STJ77 & 100,00 & 147,64 & 115,50 & 36,43 & \begin{tabular}{ll|}
6635,54 \\
\end{tabular} & 332,56 & 20,52 & 312,04 & 75,32 & 236,87 & 236,87 & 67,48 & 485,83 & 60,11 & 5,42 & 45,44 & 169,46 & 37,52 & 37,52 & 157,28 \\
\hline Bufo spinosus & 30STI86 & 100,00 & 140,42 & 116,69 & 36,62 & 6683,16 & 327,95 & 12,71 & 315,23 & 67,77 & 230,58 & 230,58 & 60,09 & 519,05 & 64,15 & 6,31 & 44,92 & 1779,38 & 41,07 & 41,07 & 167,52 \\
\hline Bufo spinosus & 30STJ87 & 100,00 & 139,50 & 116,00 & 36,29 & 6660,10 & 326,07 & 12,18 & 313,89 & 67,07 & 229,44 & 229,44 & 59,43 & 510,14 & 62,04 & 6,55 & 44,22 & 175,34 & 41,84 & 41,84 & 162,97 \\
\hline Bufo spinosus & 30STI88 & 100,00 & 139,32 & 115,41 & 36,44 & 6633,73 & 324,53 & 12,55 & 311,98 & 67,20 & 228,75 & 228,76 & 59,59 & 498,80 & 59,71 & 6,71 & 43,49 & 170,82 & 42,19 & 42,20 & 158,02 \\
\hline Bufo spinosus & 30STJ92 & 100,00 & 162,71 & 120,71 & 37,00 & 6751,35 & 352,47 & 30,39 & 322,09 & 91,52 & 253,05 & 253,05 & 80,01 & 468,96 & 61,53 & 3,40 & 49,86 & 165,95 & 28,06 & 28,06 & 156,97 \\
\hline \begin{tabular}{|l} 
Bufo spinosus \\
\end{tabular} & 30STJ96 & 100,00 & 141,01 & 117,50 & 36,58 & 6708,53 & 329,46 & 12,15 & 317,31 & 68,05 & 231,51 & 231,51 & 60,23 & 505,65 & 62,12 & 6,26 & 44,46 & 172,77 & 40,59 & 40,59 & 161,21 \\
\hline Bufo spinosus & 30STJ97 & 100,00 & 127,72 & 116,23 & 36,51 & 6662,72 & 315,44 & 1,45 & 313,99 & 55,93 & 218,06 & 218,12 & 48,59 & 552,82 & 65,80 & 8,28 & 42,71 & 187,37 & 48,65 & 48,73 & 174,55 \\
\hline Bufo spinosus & 30STJ98 & 100,00 & 132,35 & 115,84 & 36,44 & 6643,61 & 318,84 & 5,84 & 313,00 & 60,65 & 222,37 & 222,40 & 53,04 & 517,27 & 60,93 & 7,73 & 42,39 & 174,55 & 46,10 & 46,14 & 161,46 \\
\hline Bufo spinosus & 30STK41 & 70,00 & 160,83 & 111,62 & 36,88 & 6438,31 & 337,22 & 37,00 & 300,22 & 89,67 & 246,68 & 246,68 & 81,92 & 435,49 & 53,34 & 4,25 & 45,75 & 156,26 & 32,98 & 32,98 & 143,93 \\
\hline Bufo spinosus & 30SUF03 & 82,00 & 169,39 & 89,49 & \begin{tabular}{|l|l|}
40,47 \\
\end{tabular} & 4467,10 & 290,21 & 71,31 & 218,90 & 125,21 & 226,56 & 230,21 & 116,17 & 700,22 & 120,39 & 1,22 & 73,03 & 341,09 & 15,43 & 22,72 & 320,33 \\
\hline \begin{tabular}{|l} 
Bufo spinosus \\
\end{tabular} & 30SUF04 & 100,00 & 150,08 & 99,70 & 39,78 & 5072,33 & 290,43 & 42,10 & 248,32 & 99,75 & 216,34 & 219,17 & 89,69 & 772,31 & 120,92 & 2,11 & 69,39 & 353,55 & 20,02 & 28,71 & 341,47 \\
\hline Bufo spinosus & 30SUF05 & 100,00 & 145,33 & 102,83 & 39,29 & 5290,31 & 292,21 & 34,25 & 257,95 & 92,33 & 214,78 & 217,25 & 82,33 & 790,04 & 120,53 & 2,57 & 67,83 & 354,48 & 22,08 & 30,76 & 343,39 \\
\hline Bufo spinosus & 30SUF06 & 100,00 & 141,85 & 105,55 & 39,09 & 5464,68 & 294,05 & 28,43 & 265,62 & 86,67 & 213,94 & 216,01 & 76,81 & 802,06 & 120,23 & 3,02 & 66,62 & 354,21 & 24,06 & 32,49 & 343,76 \\
\hline Bufo spinosus & 30SUF07 & 100,00 & 148,85 & 104,70 & 39,04 & 5460,91 & 299,82 & 35,93 & 263,89 & 93,13 & 220,67 & 222,81 & 83,66 & 769,43 & 117,27 & 2,48 & 66,68 & 342,70 & 22,23 & 30,04 & 329,43 \\
\hline Bufo spinosus & 30SUF13 & 41,00 & 177,76 & 86,60 & 40,55 & 4321,56 & 293,13 & 81,98 & 211,15 & 135,25 & 232,73 & 236,49 & 126,22 & 639,44 & 112,78 & 1,00 & 73,62 & 317,35 & 14,11 & 20,27 & 294,35 \\
\hline Bufo spinosus & 30SUF14 & 100,00 & 164,25 & 93,61 & 40,05 & 4728,92 & 292,85 & 61,81 & 231,04 & 117,47 & 225,38 & 228,54 & 107,94 & 693,70 & 114,72 & 1,46 & 71,15 & 330,44 & 16,93 & 24,32 & 311,92 \\
\hline Bufo spinosus & 30SUF15 & 100,00 & 137,05 & 106,49 & \begin{tabular}{|l|l|}
39,38 \\
\end{tabular} & 5453,24 & 289,99 & 23,00 & 266,99 & 82,54 & 209,28 & 211,17 & 72,27 & 805,45 & 119,46 & 3,47 & 66,20 & 353,64 & 25,29 & 34,08 & 345,22 \\
\hline Bufo spinosus & 30SUF16 & 100,00 & 129,29 & 109,97 & 39,02 & 5681,03 & 290,17 & 12,23 & 277,94 & 71,73 & 205,11 & 206,59 & 61,96 & 839,94 & 121,57 & 4,46 & 64,32 & 360,19 & 29,42 & 38,14 & 352,82 \\
\hline Bufo spinosus & 30SUF17 & 100,00 & 139,45 & 108,08 & 39,01 & 5631,49 & 296,76 & 23,59 & 273,17 & 82,19 & 214,24 & 215,90 & 72,48 & 790,95 & 116,12 & 3,52 & 64,97 & 344,10 & 25,83 & 33,99 & 333,83 \\
\hline \begin{tabular}{|l} 
Bufo spinosus \\
\end{tabular} & $\begin{array}{l}\text { 30SUF18 } \\
\end{array}$ & 100,00 & 145,50 & 107,76 & 39,00 & 5650,69 & 302,14 & 29,69 & 272,45 & 87,59 & 220,36 & 221,86 & 78,06 & 764,70 & 113,56 & 3,09 & 65,04 & 334,29 & 24,24 & 31,91 & 322,21 \\
\hline Bufo spinosus & 30SUF23 & 7,00 & 179,83 & 86,00 & 40,33 & 4309,50 & 294,00 & 83,67 & 210,33 & 137,33 & 234,50 & 238,17 & 128,17 & 613,00 & 107,83 & 1,00 & 73,33 & 304,17 & 14,00 & 19,83 & 281,67 \\
\hline Bufo spinosus & 30SUF24 & 94,00 & 168,45 & 92,06 & 40,05 & 4652,58 & 293,99 & 66,92 & 227,07 & 122,51 & 228,58 & 231,67 & 113,12 & 654,52 & 109,13 & 1,48 & 71,20 & 313,71 & 16,63 & 23,23 & 294,45 \\
\hline Bufo spinosus & 30SUF25 & 100,00 & 151,94 & 100,82 & 39,72 & 5156,42 & 294,15 & 42,55 & 251,60 & 100,47 & 219,74 & 221,94 & 90,62 & 720,34 & 111,42 & 2,52 & 67,90 & 328,08 & 20,82 & 28,60 & 314,10 \\
\hline Bufo spinosus & 30SUF26 & 100,00 & 139,10 & 106,50 & 39,10 & 5504,40 & 293,23 & 24,74 & 268,49 & 83,18 & 212,23 & 213,84 & 73,82 & 778,80 & 115 , & 3,84 & 65,27 & 341,04 & 26,48 & 34,36 & 329,79 \\
\hline Bufo spinosus & 30SUF27 & 100,00 & 147,31 & 105,57 & 39,00 & 5509,06 & 299,63 & 33,14 & 266,49 & $\begin{array}{l}\mid 03,15 \\
91,15\end{array}$ & 220,22 & 221,83 & 81,75 & 740,65 & $\mid$ & 3,10 & 65,66 & 327,50 & 23,41 & 30,92 & 314,60 \\
\hline Bufo spinosus & 30SUF28 & 100,00 & 154,73 & 104,85 & 39,00 & 5515,90 & 306,01 & 40,84 & 265,16 & 98,07 & 227,66 & 229,06 & 88,86 & 712,38 & 108,45 & 2,53 & 65,93 & 317,38 & 21,69 & 28,53 & 302,36 \\
\hline Bufo spinosus & 30SUF34 & 86,00 & 168,50 & 91,96 & 39,99 & 4679,37 & 294,07 & 66,24 & 227,83 & 122,48 & 229,17 & 232,01 & 113,01 & 630,40 & 103,78 & 1,59 & 70,51 & 301,26 & 16,97 & 23,19 & 282,53 \\
\hline Bufo spinosus & 30SUF35 & 100,00 & 158,75 & 97,82 & 39,57 & 5031,04 & 295,61 & 51,20 & 244,41 & 108,57 & 224,73 & 226,96 & 98,93 & 671,78 & 105,65 & 2,26 & 68,27 & 310,74 & 19,50 & 26,30 & 294,46 \\
\hline Bufo spinosus & 30SUF36 & 100,00 & 168,44 & 94,62 & 39,09 & 4960,52 & 300,68 & 62,44 & 238,24 & 118,42 & 233,11 & 235,40 & 109,13 & 645,01 & 104,60 & 1,90 & 69,21 & 303,24 & 18,20 & 23,92 & 283,39 \\
\hline Bufo spinosus & $\begin{array}{l}30 \text { SUF } 37 \\
\end{array}$ & 100,00 & 154,78 & $\mid$\begin{tabular}{|l|}
102,31 \\
\end{tabular} & 39,00 & 5375,08 & 301,58 & $\begin{array}{l}2,4,60 \\
42,60\end{array}$ & \begin{tabular}{|l|}
258,974 \\
\end{tabular} & \begin{tabular}{|l|}
100,04 \\
10,4
\end{tabular} & \begin{tabular}{|l|}
225,88 \\
22,1
\end{tabular} & $\begin{array}{l}227,42 \\
22,4\end{array}$ & 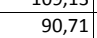 & \begin{tabular}{|l|l|}
694,24 \\
\end{tabular} & 106,26 & 2,77 & $\begin{array}{ll}6,219 \\
66,19\end{array}$ & 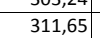 & $\begin{array}{l}\mid 0,206 \\
21,86\end{array}$ & 28,57 & 296,34 \\
\hline Bufo spinosus & 30SUF38 & 100,00 & 161,50 & 101,88 & 38,99 & 5404,44 & 307,68 & 49,02 & 258,66 & 105,83 & 232,80 & 234,28 & 96,89 & 671,02 & 103,93 & 2,26 & 66,48 & 303,10 & 20,13 & 26,24 & 286,15 \\
\hline Bufo spinosus & 30SUF39 & 100,00 & 163,16 & 103,55 & 38,99 & 5526,19 & 312,55 & 49,03 & 263,52 & 105,89 & 236,23 & 237,36 & 97,02 & 666,41 & 102,47 & 2,11 & 65,86 & 298,11 & 20,08 & 26,09 & 281,61 \\
\hline Bufo spinosus & 30SUF 45 & 100,00 & 168,58 & 92,63 & 39,20 & 4834,96 & 296,72 & 63,92 & 232,80 & 120,46 & 231,56 & 233,94 & 111,00 & 617,16 & 100,64 & 2,04 & 69,42 & 291,88 & 17,94 & 23,56 & 272,80 \\
\hline Bufo spinosus & 30SUF46 & 100,00 & 178,09 & 89,38 & 39,01 & 4774,36 & 301,57 & 74,88 & 226,69 & 130,14 & 240,01 & 242,55 & 121,06 & 595,38 & 100,12 & 1,28 & 70,45 & 285,75 & 16,65 & 21,29 & 263,75 \\
\hline \begin{tabular}{|l} 
Bufo spinosus \\
\end{tabular} & 30SUF47 & 100,00 & 173,28 & 93,60 & 38,83 & 5034,15 & 304,91 & 66,24 & 238,67 & 121,99 & 239,05 & 241,00 & 112,97 & 613,31 & 100,35 & 1,92 & 68,59 & 287,44 & 18,10 & 22,93 & 267,01 \\
\hline Bufo spinosus & 30SUF48 & 100,00 & 164,32 & 99,91 & 38,79 & 5356,79 & 307,45 & 52,37 & 255,08 & 109,16 & 235,01 & 236,27 & 100,19 & 643,47 & 100,51 & 2,44 & 66,35 & 291,23 & 20,14 & 25,76 & 273,91 \\
\hline Bufo spinosus & 30SUF49 & 100,00 & 161,69 & 103,47 & 38,72 & 5564,11 & 311,51 & 46,74 & 264,78 & 103,90 & 235,49 & 236,38 & 95,11 & 651,43 & 99,29 & 2,53 & 65,11 & 289,43 & 20,62 & 26,60 & 273,68 \\
\hline Bufo spinosus & 30SUF54 & 49,00 & 180,49 & 85,28 & 39,21 & 4478,44 & 295,30 & 80,95 & 214,34 & 136,74 & 238,13 & 241,05 & 127,16 & 556,48 & 94,54 & 1,16 & 71,26 & 271,38 & 15,97 & 20,07 & 250,74 \\
\hline Bufo spinosus & 30SUF55 & 100,00 & 166,07 & 93,57 & 39,03 & 4922,22 & 296,25 & 59,76 & 236,49 & 117,03 & 230,54 & 232,58 & 107,47 & 602,98 & 97,2 & 2,34 & 68,10 & 281,26 & 19,05 & 24,29 & 263,55 \\
\hline \begin{tabular}{|l} 
Bufo spinosus \\
\end{tabular} & 30SUF56 & 100,00 & 179,54 & 87,59 & 38,50 & 4770,36 & 300,70 & 76,10 & 224,60 & 131,76 & 241,54 & 243,85 & 122,45 & 574,20 & 97,38 & 1,66 & 70,02 & 275,22 & 17,46 & 21,11 & 253,32 \\
\hline Bufo spinosus & 30SUF57 & 100,00 & 167,71 & 95,80 & 38,66 & 5165,28 & 303,53 & 58,40 & 245,13 & 115,01 & 235,71 & 237,16 & 105,96 & 606,67 & 97,54 & 2,26 & 67,11 & 279,59 & 19,05 & 24,16 & 260,99 \\
\hline Bufo spinosus & 30SUF59 & 100,00 & 151,96 & 107,04 & 38,38 & 5743,58 & 309,15 & 34,31 & 274,84 & 92,37 & 228,85 & 229,23 & 83,52 & 661,30 & 97,48 & 3,74 & 62,77 & 285,63 & 23,96 & 28,66 & 272,52 \\
\hline Bufo spinosus & 30SUF65 & 71,00 & 178,18 & 86,28 & 38,39 & 4686,09 & 296,79 & 75,63 & 221,16 & 131,94 & 239,13 & 241,45 & 122,25 & 553,97 & 93,9 & 1,9 & 69,95 & 265,73 & 17,57 & 21,24 & 245,09 \\
\hline Bufo spinosus & 30SUF66 & 100,00 & 181, & 85,40 & 38,01 & 4749,54 & 299,71 & $\begin{array}{l}78,08 \\
\end{array}$ & 221,63 & \begin{tabular}{|l|}
134,01 \\
\end{tabular} & 243,11 & 245,35 & 124,52 & 550,63 & 94 & 1,94 & 69,57 & 263,32 & 17,94 & 21,02 & $\begin{array}{l}24,01,76 \\
241\end{array}$ \\
\hline Bufo spinosus & 30SUF67 & 100,00 & 170,32 & 93,93 & 38,20 & 5138,18 & 303,49 & 61,14 & 242,35 & 117,80 & 238,01 & 239,35 & 108,82 & 573,92 & 93,08 & 2,34 & 66,71 & 264,25 & 18,82 & 23,33 & 245,63 \\
\hline Bufo spinosus & 30SUF68 & 100,00 & 160,01 & 101,65 & 38,30 & 5489,69 & 306,78 & 45,54 & 261,24 & 103,07 & 233,11 & 233,63 & 94,37 & 604,52 & 93,12 & 3,17 & 64,03 & 268,35 & 21,43 & 25,48 & 252,56 \\
\hline Bufo spinosus & 30SUF69 & 100,00 & 148,18 & 108,52 & 38,10 & 5824,46 & 308,79 & 29,03 & 279,76 & 87,60 & 226,42 & 226,51 & 78,91 & 649,50 & 94,31 & 4,30 & 61,40 & 276,40 & 25,32 & 26,83 & 264,26 \\
\hline Bufo spinosus & 30SUF76 & 60,00 & 178,71 & 86,90 & $\begin{array}{l}37,95 \\
\end{array}$ & 4863,15 & 300,02 & 73,37 & 226,66 & 129,82 & 242,24 & 244,01 & 120,51 & 525,85 & 87,91 & 2,07 & 67,84 & 46,26 & 17,54 & 21,09 & 227,32 \\
\hline \begin{tabular}{|l} 
Bufo spinosus \\
\end{tabular} & \begin{tabular}{|l|} 
SOSUF77 \\
30 S
\end{tabular} & $\begin{array}{l}0,00,00 \\
100,0\end{array}$ & $\frac{170}{159}$ & \begin{tabular}{|l|}
00,00 \\
100,20
\end{tabular} & | & 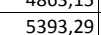 & 303,62 & | 46,13 & \begin{tabular}{|l|}
257,50 \\
250
\end{tabular} & 104,07 & 231,38 & 231,93 & 95,20 & 575,35 & 88,88 & 3,26 & 63,66 & 255,70 & 21,20 & 24,50 & 240,32 \\
\hline Bufo spinosus & 30SUF78 & 100,00 & 153,56 & 105,24 & 38,18 & 5646,55 & 307,16 & 36,49 & 270,67 & 94,86 & 229,24 & 229,34 & 86,25 & 595,17 & 89,12 & 3,87 & 61,92 & 258,15 & 22,98 & 24,53 & 244,17 \\
\hline Bufo spinosus & 30SUF79 & 100,00 & 146,45 & 109,68 & 38,06 & 5890,52 & 309,60 & 26,14 & 283,45 & 84,89 & 225,82 & 225,82 & 76,33 & 629,21 & 90,48 & $\begin{array}{l}4,67 \\
\end{array}$ & 60,19 & 264.72 & 26,09 & 26,35 & 253,12 \\
\hline Bufo spinosus & 30SUF86 & 60,00 & 174,85 & 90,24 & 38,04 & 4988,76 & 301,67 & 67,22 & 234,45 & $\begin{array}{l}124,08 \\
\end{array}$ & 240,53 & 241,71 & 115,09 & 496,94 & 80,94 & 2,22 & 65,88 & 228,36 & 17,27 & 20,95 & 211,64 \\
\hline Bufo spinosus & 30SUF87 & 100,00 & 159,96 & 100,69 & 38,35 & 5423,32 & 304,65 & 45,79 & 258,86 & 103,82 & 232,49 & 232,70 & 95,27 & 539,94 & 83,27 & 3,36 & 62,74 & 238,61 & 20,62 & 22,90 & 223,51 \\
\hline \begin{tabular}{|l} 
Bufo spinosus \\
\end{tabular} & 30SUF88 & 100,00 & 161,41 & $\begin{array}{ll}101,54 \\
\end{array}$ & 38,05 & 5530,29 & 308,63 & 45,94 & 262,69 & $\begin{array}{l}103,62 \\
\end{array}$ & 235,46 & 235,54 & 95,27 & 539,06 & 83,10 & 3,43 & 62,29 & 236,67 & 20,83 & 21,66 & 221,22 \\
\hline Bufo spinosus & 30SUF89 & 100,00 & 138,18 & 113,21 & 38,01 & 6037,40 & 308,46 & 15,46 & 293,00 & 75,24 & 219,99 & 219,99 & 66,65 & 639,85 & 88,60 & 5,89 & 57,88 & 261,41 & 29,57 & 29,63 & 252,07 \\
\hline Bufo spinosus & 30SUF96 & 57,00 & 178,52 & 89,16 & 38,00 & 4952,90 & 303,42 & 71,34 & 232,08 & 127,89 & 243,63 & 244,81 & 119,07 & 456,51 & 73,92 & 2,04 & 65,26 & 209,08 & 15,84 & 19,48 & 193,53 \\
\hline Bufo spinosus & 30SUF97 & 100,00 & 175,94 & 91,94 & 37,94 & 5114,45 & 306,17 & 66,45 & 239,7 & 123,09 & 243, & 244 & 114,42 & 464,87 & 74,74 & 2,26 & 64,55 & 210,69 & 16,53 & 20,02 & $194, \mathrm{~S}$ \\
\hline Bufo spinosus & 30SUF98 & 100,00 & 164,71 & 100,24 & 38,00 & 5490,06 & 309,73 & 49,53 & 260,20 & 107,06 & 238,20 & 238,29 & 98,92 & 499,38 & 77,35 & 3,34 & 61,90 & 218,94 & 19,81 & 20,69 & 203,59 \\
\hline
\end{tabular}




\begin{tabular}{|c|c|c|c|c|c|c|c|c|c|c|c|c|c|c|c|c|c|c|c|c|c|}
\hline TAXON & UTM & $\mathrm{km2}$ & B101 & $\mathrm{B1O2}$ & $\mathrm{BIO3}$ & B104 & B105 & B106 & B107 & B108 & B109 & 81010 & B1011 & B1012 & BIO13 & BIO14 & B1015 & BIO16 & BIO17 & B1018 & B1019 \\
\hline Bufo spinosus & 30SUF99 & 100,00 & 131,28 & 115,92 & 38,00 & 6159,14 & 307,14 & 6,72 & 300,42 & 67,43 & 214,93 & 214,93 & 58,55 & 651,95 & 87,41 & 7,08 & 55,91 & 259,09 & 33,13 & 33,13 & 251,82 \\
\hline Bufo spinosus & 30SUG12 & 100,00 & 171,03 & 111,33 & 39,06 & 5867,53 & 332,19 & 51,71 & 280,47 & 108,36 & 248,19 & 249,15 & 99,96 & 657,01 & 101,29 & 1,70 & 64,98 & 285,91 & 18,27 & 24,20 & 271,83 \\
\hline Bufo spinosus & 30SUG17 & 100,00 & 176,59 & 120,83 & 38,41 & 6426,45 & 357,16 & 46,85 & 310,31 & 106,78 & 261,70 & 261,72 & 97,71 & 630,39 & 92,22 & 2,00 & 62,09 & 254,40 & 18,00 & 18,23 & 248,02 \\
\hline Bufo spinosus & 30SUG18 & 100,00 & 178,88 & 121,59 & \begin{tabular}{|l|l|}
38,07 \\
\end{tabular} & 6495,44 & 361,50 & 48,04 & 313,46 & 108,01 & 264,87 & 264,87 & 98,88 & 614,41 & 89,36 & 2,00 & 61,87 & 245,13 & 17,57 & 17,57 & 239,64 \\
\hline Bufo spinosus & 30SUG29 & 100,00 & 171,23 & 122,66 & \begin{tabular}{|l|l|}
37,88 \\
\end{tabular} & $\begin{array}{ll}6667,74 \\
\end{array}$ & 359,38 & 38,34 & 321,03 & 100,62 & 260,12 & 260,12 & 89,40 & 638,74 & 92,99 & 2,38 & 60,78 & 248,38 & $\begin{array}{l}19,95 \\
\end{array}$ & 19,95 & 244,96 \\
\hline Bufo spinosus & 30SUG30 & 100,00 & 161,39 & 106,38 & 38,92 & 5693,89 & 316,09 & 44,78 & 271,31 & 101,95 & 236,83 & 237,75 & 93,14 & 674,11 & 101,81 & 2,51 & 64,53 & 295,99 & 21,35 & 27,45 & 281,19 \\
\hline Bufo spinosus & 30SUG37 & 100,00 & 173,29 & 119,06 & 37,97 & 6501,13 & 354,58 & 43,41 & 311,17 & 103,03 & 259,91 & 259,91 & 93,59 & 642,11 & 92,83 & 2,01 & 61,93 & 255,04 & \begin{tabular}{|l|l|}
18,79 \\
\end{tabular} & 18,79 & 251,26 \\
\hline \begin{tabular}{|l} 
Bufo spinosus \\
\end{tabular} & 30SUG38 & 100,00 & 176,44 & 120,40 & 37,75 & 6576,82 & 360,40 & 44,73 & 315,68 & 106,72 & 264,12 & 264,12 & 95,58 & $\mid 632,80$ & $\begin{array}{l}2,53,53 \\
\end{array}$ & 2,01 & 62,00 & 248,47 & 17,71 & 17,71 & 245,31 \\
\hline Bufo spinosus & 30SUG39 & 100,00 & 172,72 & 121,66 & 37,46 & 6673,92 & 360,28 & 39,74 & 320,55 & 103,10 & 261,75 & 261,75 & 90,77 & 634,97 & 94,36 & 2,40 & 60,84 & 247,91 & 19,40 & 19,40 & 242,96 \\
\hline Bufo spinosus & 30SUG40 & 100,00 & 164,62 & 104,62 & \begin{tabular}{|l|l|}
38,48 \\
\end{tabular} & 5666,15 & 316,75 & 48,21 & 268,55 & 105,23 & 239,72 & 240,42 & 96,60 & 643,79 & 97,35 & 2,44 & 64,83 & 283,87 & 20,00 & 25,60 & 268,63 \\
\hline Bufo spinosus & 30SUG41 & 100,00 & 163,92 & 107,10 & 38,08 & 5819,24 & 321,13 & 45,30 & 275,83 & 102,48 & 241,36 & 241,74 & 94,05 & 648,59 & 96,53 & 2,91 & 63,63 & 280,68 & 21,20 & 25,07 & 267,16 \\
\hline Bufo spinosus & 30SUG42 & 100,00 & 166,52 & 108,48 & 38,01 & 5933,72 & 327,02 & 46,30 & 280,72 & 103,47 & 245,39 & 245,58 & 94,90 & 641,69 & 95,17 & 2,56 & 63,31 & 274,66 & 20,23 & 22,79 & 262,42 \\
\hline Bufo spinosus & 30SUG45 & 100,00 & 173,85 & 113,65 & 37,96 & 6261,89 & 345,24 & 48,10 & 297,14 & 106,35 & 257,18 & 257,18 & 97,48 & 624,27 & 91,20 & 2,05 & 62,30 & 255,65 & 18,35 & 18,35 & 248,82 \\
\hline Bufo spinosus & 30SUG47 & 100,00 & 172,30 & 117,66 & 37,30 & 6512,78 & 352,83 & 42,70 & 310,13 & 102,23 & 259,24 & 259,24 & 92,72 & 633,68 & 91,18 & 2,39 & 61,22 & 250,11 & 19,36 & 19,36 & 247,05 \\
\hline Bufo spinosus & 30SUG49 & 100,00 & 177,84 & 119,92 & \begin{tabular}{l|l|l|}
37,05 \\
\end{tabular} & 6641,07 & 362,81 & 45,38 & 317,43 & 108,48 & 266,49 & 266,49 & 96,15 & 608,36 & 91,39 & 2,03 & 61,38 & 238,32 & 17,34 & 17,34 & 233,03 \\
\hline Bufo spinosus & 30SUG50 & 100,00 & 164,66 & 103,90 & 38,05 & 5680,63 & 316,29 & 47,89 & 268,40 & 105,03 & 240,25 & 240,61 & 96,56 & 622,40 & 93,90 & 2,99 & 63,95 & 273,02 & 20,50 & 25,05 & 257,99 \\
\hline Bufo spinosus & 30SUG51 & 100,00 & 162,12 & 107,03 & 38,00 & 5867,14 & 320,73 & 42,83 & 277,90 & 100,31 & 240,56 & 240,65 & 91,79 & 632,73 & 92,63 & 3,03 & 62,66 & 271,50 & 21,88 & 24,04 & 258,61 \\
\hline Bufo spinosus & 30SUG54 & 100,00 & 169,43 & 111,11 & \begin{tabular}{|c|}
37,68 \\
\end{tabular} & 6182,19 & 337,53 & 45,85 & 291,68 & 103,08 & 251,95 & 251,95 & 94,54 & 619,52 & 89,40 & 2,85 & 61,66 & 255,64 & 20,03 & 20,03 & 247,58 \\
\hline Bufo spinosus & 30SUG56 & 100,00 & 172,76 & 114,40 & 37,12 & 6397,20 & 348,01 & 45,56 & 302,45 & 103,79 & 258,24 & 258,24 & 94,82 & 614,39 & 87,47 & 2,53 & 61,03 & 245,24 & 19,16 & 19,16 & 241,01 \\
\hline Bufo spinosus & 30SUG57 & 100,00 & 176,82 & 115,35 & \begin{tabular}{|l|}
37,08 \\
\end{tabular} & 6451,29 & 353,91 & 48,21 & 305,70 & 107,37 & 262,91 & 262,91 & 97,94 & 600,80 & 86,33 & 2,02 & 61,42 & 236,98 & 17,28 & 17,28 & 234,25 \\
\hline Bufo spinosus & 30SUG59 & 100,00 & 177,31 & 118,25 & 37,00 & 6620,24 & 360,45 & 45,90 & 314,55 & 108,36 & 265,77 & 265,77 & 96,05 & 591,19 & 87,92 & 2,13 & 60,54 & 230,87 & 17,76 & 17,76 & 225,69 \\
\hline Bufo spinosus & 30SUG69 & 100,00 & 176,63 & 116,65 & 37,00 & 6616,37 & 358,56 & 46,02 & 312,54 & 107,87 & 265,08 & 265,08 & 95,63 & 574,91 & 84,76 & 2,27 & 59,89 & 223,89 & 18,28 & 18,28 & 218,58 \\
\hline Bufo spinosus & 30SUG70 & 100,00 & 153,02 & 108,60 & 38,00 & 5919,84 & 315,12 & 32,55 & 282,56 & 90,59 & 232,64 & 232,64 & 82,25 & 606,43 & 88,06 & 4,36 & 60,45 & 256,18 & 24,30 & 24,34 & 243,79 \\
\hline Bufo spinosus & 30SUG71 & 100,00 & 151,62 & 110,58 & 37,88 & 6072,57 & 318,97 & 29,47 & 289,50 & 87,29 & 233,57 & 233,57 & 79,09 & 616,86 & 87,21 & 4,57 & 59,53 & 255,86 & 25,25 & 25,25 & 245,22 \\
\hline Bufo spinosus & 30SUG73 & 100,00 & 160,62 & 110,39 & 37,03 & 6209,98 & 329,74 & 37,22 & 292,52 & 94,11 & 244,16 & 244,16 & 86,08 & 598,01 & 82,75 & 3,88 & 59,53 & 244,13 & 22,91 & 22,91 & 235,89 \\
\hline Bufo spinosus & 30SUG74 & 100,00 & 155,15 & 113,29 & 37,00 & 6391,20 & 331,46 & 29,64 & 301,81 & 86,90 & 241,43 & 241,43 & 78,57 & 624,57 & 84,86 & 4,55 & 58,31 & 247,93 & 25,42 & 25,42 & 242,53 \\
\hline Bufo spinosus & 30 SUG75 & 100,00 & 155,82 & 114,23 & 37,00 & 6483,09 & 334,95 & 29,28 & \begin{tabular}{|l|}
305,67 \\
\end{tabular} & 86,84 & $\begin{array}{l}41,43 \\
243,34 \\
\end{array}$ & 243,34 & 78,06 & 628,75 & $\begin{array}{l}4,600 \\
85,66\end{array}$ & 4,59 & 57,93 & 245,89 & \begin{tabular}{|l|}
25,79 \\
\end{tabular} & 25,79 & $\begin{array}{l}242,22 \\
242,2\end{array}$ \\
\hline Bufo spinosus & 30SUG77 & 100,00 & 172,85 & 113,05 & 36,76 & 6504,26 & 349,80 & 45,24 & 304,56 & 104,92 & 260,04 & 260,04 & 93,80 & 576,88 & 81,82 & 3,05 & 59,29 & 224,69 & 19,93 & 19,93 & 221,81 \\
\hline Bufo spinosus & 30SUG78 & 100,00 & 172,73 & 114,57 & 36,69 & 6593,64 & 352,94 & 43,79 & 309,15 & 104,53 & 261,20 & 261,20 & 92,47 & 576,82 & 83,54 & 3,06 & 58,88 & 224,57 & 20,27 & 20,27 & 219,54 \\
\hline Bufo spinosus & 30SUG80 & 100,00 & 145,86 & 111,84 & 38,00 & 6057,58 & 314,52 & 23,17 & 291,35 & 81,99 & 227,83 & 227,83 & 73,82 & 607,50 & 85,53 & 5,29 & 58,42 & 250,28 & 26,89 & 26,89 & 239,62 \\
\hline Bufo spinosus & 30SUG81 & 100,00 & 153,52 & 110,27 & 37,74 & 6081,48 & 320,52 & 31,07 & 289,45 & 88,59 & 235,66 & 235,66 & 80,89 & 579,69 & 82,66 & 4,74 & 58,76 & 239,96 & 24,57 & 24,57 & 228,61 \\
\hline Bufo spinosus & 30SUG82 & 100,00 & 160,03 & 108,95 & 37,09 & 6113,47 & 325,95 & 37,62 & \begin{tabular}{|l|l|}
288,34 \\
\end{tabular} & \begin{tabular}{|l|l|}
94,39 \\
94
\end{tabular} & $\begin{array}{l}242,38 \\
240\end{array}$ & $\begin{array}{l}242,38 \\
240\end{array}$ & $\begin{array}{l}0,009 \\
86,69 \\
\end{array}$ & 565,50 & $\begin{array}{l}2,000 \\
80,03\end{array}$ & 4,05 & 59,18 & 233,26 & 22,71 & 22,71 & 222,88 \\
\hline Bufo spinosus & 30SUG83 & 100,00 & 146,88 & 114,40 & 37,01 & 6387,08 & 324,88 & 21,16 & 303,71 & 78,95 & 233,39 & 233,39 & 70,75 & 626,14 & 83,73 & 5,68 & 56,84 & 246,76 & 28,60 & 28,60 & 240,65 \\
\hline Bufo spinosus & 30SUG84 & 100,00 & 153,59 & 113,48 & \begin{tabular}{|c|}
36,98 \\
\end{tabular} & 6436,52 & 331,44 & 27,62 & 303,83 & 84,82 & 240,74 & 240,74 & 76,60 & 607,21 & 80,98 & 4,97 & 57,11 & 237,89 & 26,17 & 26,17 & 233,38 \\
\hline Bufo spinosus & 30 SUG85 & 100,00 & 148,31 & 115,62 & 36,83 & 6568,63 & 331,42 & 20,96 & 310,46 & 80,28 & 237,43 & 237,43 & 69,99 & 636,94 & 86,21 & 5,68 & 56,18 & 244,56 & 29,24 & 29,24 & 241,33 \\
\hline Bufo spinosus & 30SUG86 & 100,00 & 166,49 & 112,03 & 36,32 & 6502,36 & 343,51 & 40,11 & 303,40 & 98,99 & 254,17 & 254,17 & 87,96 & 578,36 & 80,01 & 3,79 & 58,17 & 224,45 & 22,03 & 22,03 & 221,88 \\
\hline \begin{tabular}{|l} 
Bufo spinosus \\
\end{tabular} & 30SUG90 & 100,00 & 124,09 & 117,99 & 37,99 & 6306,11 & 305,62 & \begin{tabular}{|c|}
$-1,53$ \\
\end{tabular} & 307,15 & 58,80 & 210,03 & 210,03 & 49,98 & 696,79 & 91,66 & 8,28 & 54,52 & 269,74 & 38,04 & 38,04 & 264,54 \\
\hline Bufo spinosus & 30SUG91 & 100,00 & 154,26 & 110,16 & 37,51 & 6085,34 & 321,24 & 31,49 & 289,75 & 89,03 & 236,53 & 236,53 & 81,49 & 549,58 & 78,58 & 4,79 & 58,01 & 226,02 & 24,42 & 24,42 & 214,44 \\
\hline Bufo spinosus & 30 SUG92 & 100,00 & 153,51 & 111,81 & 37,11 & 6234,93 & 325,26 & 29,25 & 296,01 & 86,55 & 237,92 & 237,92 & 78,91 & 561,34 & 77,69 & 5,05 & 57,17 & 226,44 & 25,16 & 25,16 & 217,01 \\
\hline Bufo spinosus & 30SUHO2 & 100,00 & 151,15 & 124,70 & 37,43 & 6797,93 & 346,13 & 18,10 & 328,02 & 79,88 & 242,27 & 242,27 & 68,97 & 665,09 & 92,69 & 3,96 & 56,19 & 250,52 & 29,42 & 29,42 & 245,90 \\
\hline \begin{tabular}{|l} 
Bufo spinosus \\
\end{tabular} & 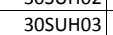 & 100,00 & 156,72 & 124,97 & 37,2 & 6812,88 & 351,83 & 22,94 & 328,90 & 84,97 & 248,16 & 248,16 & 73,96 & 629,18 & 88,10 & 3,43 & 56,14 & 235,71 & 27,18 & 27,18 & 231,01 \\
\hline \begin{tabular}{|l} 
Bufo spinosus \\
\end{tabular} & 30SUHO4 & 100,00 & 152,84 & 124,93 & 37,05 & 6831,90 & 348,81 & 19,41 & 329,40 & 81,84 & 244,76 & 244,76 & 70,04 & 628,36 & 87,41 & 3,97 & 54,82 & 232,80 & 29,55 & 29,55 & 227,64 \\
\hline Bufo spinosus & 30SUHO5 & 100,00 & 154,29 & 124,77 & 37,14 & 6832,25 & 350,07 & 20,79 & 329,28 & 83,11 & 246,08 & 246,08 & 71,36 & 606,60 & 84,11 & 4,00 & 54,17 & 222,77 & 29,59 & 29,59 & 217,47 \\
\hline Bufo spinosus & 30SUH06 & 100,00 & 156,69 & 124,19 & 37,01 & 6840,76 & 351,82 & 22,84 & 328,98 & 84,58 & 248,40 & 248,40 & 73,47 & 581,11 & 80,24 & 3,99 & 53,46 & 211,54 & 29,10 & 29,10 & 206,06 \\
\hline Bufo spinosus & 30SUH08 & 100,00 & 156,61 & 123,59 & 37,00 & 6837,61 & 350,97 & 22,84 & 328,13 & 81,95 & 248,43 & 248,43 & 73,45 & 549,13 & 74,7 & 3,80 & 52,03 & 197,04 & 29,49 & 29,49 & 190,72 \\
\hline Bufo spinosus & 30SUH11 & 100,00 & 153,44 & 124,32 & 37,41 & |6790,20 & 347,48 & 20,28 & $\begin{array}{l}327,20 \\
327,2\end{array}$ & \begin{tabular}{|l|l|}
82,93 \\
\end{tabular} & \begin{tabular}{|l|}
244,46 \\
\end{tabular} & \begin{tabular}{|l|}
244,46 \\
\end{tabular} & 71,11 & 668,52 & 94,50 & 3,08 & 56,90 & 253,99 & 2 & 27,99 & 249,24 \\
\hline Bufo spinosus & 30SUH12 & 100,00 & 152,39 & 124,68 & 37,23 & 6821,05 & 347,75 & 19,14 & 328,61 & 81,93 & 243,99 & 243,99 & 69,83 & 657,64 & 92,90 & 3,98 & 56,20 & 247,94 & 28,79 & 28,79 & 242,44 \\
\hline \begin{tabular}{|l} 
Bufo spinosus \\
\end{tabular} & 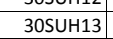 & 100,00 & 154,20 & 124,93 & 37,09 & 6841,54 & 350,06 & 20,50 & 329,56 & 83,68 & 246,18 & 246,18 & 71,38 & 636,21 & 89,85 & 3,75 & 55,83 & 238,13 & 28,24 & 28,24 & 232,44 \\
\hline Bufo spinosus & 30SUH14 & 100,00 & 150,81 & 124,97 & 37,02 & 6860,81 & 347,49 & 17,34 & 330,15 & 80,42 & 243,28 & 243,28 & 67,93 & 632,93 & 88,78 & 4,17 & 54,50 & 234,54 & 30,24 & 30,24 & 228,31 \\
\hline Bufo spinosus & 30SUH15 & 100,00 & 154,26 & 124,99 & 37,00 & 6858,90 & 350,54 & 20,44 & 330,10 & 83,81 & 246,70 & 246,70 & 71,17 & 603,60 & 84,48 & 4,00 & 54,14 & 221,67 & 29,30 & 29,30 & 215,70 \\
\hline \begin{tabular}{|l} 
Bufo spinosus \\
\end{tabular} & \begin{tabular}{|c|}
$30 S U H 17$ \\
$30 S-10$
\end{tabular} & 100,00 & 159,76 & $\begin{array}{l}124,53 \\
124,03\end{array}$ & 37,00 & 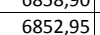 & 3504,63 & $\begin{array}{l}0,44 \\
25,22\end{array}$ & 329,41 & 88,66 & 251,68 & 251,68 & 76,34 & 548,21 & 75,84 & 3,42 & 53,12 & 197,20 & 27,31 & 27,31 & 191,87 \\
\hline Bufo spinosus & 30SUH18 & 100,00 & 160,50 & 123,94 & 37,00 & 6853,55 & 354,88 & 26,04 & 328,84 & 87,45 & 252,51 & 252,51 & 76,96 & 528,38 & 72,45 & 3,32 & 52,48 & 188,55 & 27,29 & 27,29 & 183,01 \\
\hline Bufo spinosus & $30 \mathrm{SUH} 20$ & 100,00 & 164,69 & 123,62 & 37,62 & 6753,70 & 356,12 & 31,21 & 324,91 & 94,63 & 255,00 & 255,00 & 82,13 & 645,91 & 93,62 & 2.86 & 59,03 & 248,81 & 22,74 & 22,74 & 244,30 \\
\hline Bufo spinosus & $30 \mathrm{SUH} 21$ & 100,00 & 155,18 & 124,01 & 37,13 & 6815,08 & 349,27 & 21,83 & 327,44 & 84,73 & 246,69 & 246,69 & 72,49 & 660,60 & 94,63 & 3,78 & 57,17 & 251,76 & 27,13 & 27,13 & 245,69 \\
\hline Bufo spinosus & $30 \mathrm{SUH} 22$ & 100,00 & 157,27 & 124,38 & 37,08 & 6836,77 & 352,36 & 23,58 & 328,78 & 86,77 & 249,13 & 249,13 & 74,42 & 638,21 & 91,70 & 3,51 & 56,67 & 241,62 & 26,43 & 26,43 & 235 \\
\hline \begin{tabular}{|l} 
Bufo spinosus \\
\end{tabular} & $30 \mathrm{SUH} 23$ & 100,00 & 149,64 & 124,64 & 37,01 & 6867,08 & 346,31 & 16,29 & 330,03 & 79,18 & 242,11 & 242,11 & 66,75 & $\begin{array}{l}647,95 \\
6\end{array}$ & 91,83 & 4,34 & 54,98 & 242,28 & 30,37 & 30,37 & 235,08 \\
\hline Bufo spinosus & 30SUH24 & 100,00 & 152,59 & 124,99 & 37,00 & 6879,76 & 349,49 & 18,78 & 330,70 & 82,04 & 245,28 & 245,28 & 69,63 & 621,17 & 88,01 & 4,03 & 54,46 & 230,47 & 29,16 & 29,16 & 223,26 \\
\hline Bufo spinosus & $30 \mathrm{SUH} 26$ & 100,00 & 157,27 & 124,76 & 37,00 & 6887,23 & 353,44 & 22,57 & 330,86 & 86,49 & 249,83 & 249,83 & 73,66 & 571,73 & 80,10 & 3,89 & 53,37 & 207,64 & 28,53 & 28,53 & 201,17 \\
\hline Bufo spinosus & $30 \mathrm{SUH} 28$ & 100,00 & 159,77 & 124,01 & 37,00 & 6870,03 & 354,71 & 25,01 & 329,70 & 88,82 & 252,06 & $252, \mathrm{C}$ & 76 & 525,57 & 72,21 & 3,41 & 52 & 186,35 & 27,45 & 27,45 & 180,92 \\
\hline Bufo spinosus & $30 \mathrm{SUH} 30$ & 100,00 & 162,30 & 122,87 & 37,04 & 6771,33 & 354,04 & 29,24 & 324,80 & 92,31 & 253,16 & 253,16 & 80,00 & 647,49 & 94,59 & 3,26 & 58,61 & 249,89 & 23,69 & 23,69 & 243,64 \\
\hline
\end{tabular}




\begin{tabular}{|c|c|c|c|c|c|c|c|c|c|c|c|c|c|c|c|c|c|c|c|c|c|}
\hline TAXON & UTM & $\mathrm{km} 2$ & B101 & B102 & $\mathrm{BIO3}$ & BIO4 & BIO5 & B106 & B107 & B108 & B109 & BIO10 & BIO11 & B1012 & B1013 & BIO14 & BIO15 & B1016 & B1017 & B1018 & B1019 \\
\hline Bufo spinosus & 30SUH31 & 100,00 & 159,11 & 123,50 & 37,05 & 6820,64 & 352,68 & 25,53 & 327,15 & 88,65 & 250,72 & 250,72 & 76,22 & 643,77 & 93,65 & 3,54 & 57,47 & 246,45 & 25,46 & 25,46 & 239,30 \\
\hline Bufo spinosus & $30 \mathrm{SUH} 32$ & 100,00 & 156,88 & 123,97 & 37,00 & 6859,15 & 351,87 & 22,99 & 328,88 & 86,10 & 249,13 & 249,13 & 73,61 & 635,38 & 92,01 & 3,77 & 56,51 & 240,96 & 26,70 & 26,70 & 233,23 \\
\hline Bufo spinosus & 30SUH33 & 100,00 & 155,03 & 124,15 & 37,00 & 6882,36 & 351,03 & 20,96 & 330,08 & 84,19 & 247,63 & 247,63 & 71,67 & 625,04 & 89,89 & 3,97 & 55,43 & 234,58 & 27,97 & 27,97 & 226,59 \\
\hline Bufo spinosus & 30SUH34 & 100,00 & 152,05 & 124,73 & 37,00 & 6907,64 & 348,98 & 17,85 & 331,13 & 81,11 & 245,16 & 245,16 & 68,66 & 617,62 & 87,99 & 4,11 & 54,31 & 229,10 & 29,42 & 29,42 & 220,93 \\
\hline Bufo spinosus & 30SUH35 & 100,00 & $\begin{array}{lll}153,47 & \end{array}$ & 124,96 & 37,00 & 6914,82 & 350,41 & 18,82 & 331,59 & 82,61 & 246,64 & 246,64 & 69,85 & 595,47 & 84,36 & 4,00 & 53,71 & 218,63 & 29,03 & 29,03 & 210,82 \\
\hline Bufo spinosus & 30SUH37 & 100,00 & 158,19 & 124,25 & 37,00 & 6893,18 & 353,98 & 23,16 & 330,82 & 87,52 & 250,85 & 250,85 & 74,40 & 543,75 & 75,72 & 3,51 & 52,56 & 194,90 & 27,77 & 27,77 & 188,42 \\
\hline Bufo spinosus & 30SUH38 & 100,00 & 160,64 & 124,02 & 37,00 & 6885,64 & 355,60 & 25,47 & 330,13 & 89,97 & 253,13 & 253,13 & 76,72 & 517,02 & 71,21 & 3,28 & 52,03 & 182,91 & 26,94 & 26,94 & 177,24 \\
\hline \begin{tabular}{|l} 
Bufo spinosus \\
\end{tabular} & 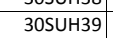 & 100,00 & 155,94 & 124,00 & 37,00 & 6899,70 & 351,46 & 21,01 & 330,45 & 85,36 & 248,87 & 248,87 & 72,04 & 516,53 & 69,93 & 3,90 & 50,60 & 179,69 & 29,56 & 29,56 & 174,11 \\
\hline Bufo spinosus & $30 \mathrm{SUH} 40$ & 100,00 & 166,59 & 121,69 & 37,01 & 6766,19 & 356,73 & 33,38 & 323,35 & 96,41 & 257,32 & 257,32 & 83,97 & 627,45 & 92,90 & 3,00 & 58,99 & 243,12 & 22,05 & 22,05 & 235,93 \\
\hline Bufo spinosus & 30SUH41 & 100,00 & 163,68 & 122,52 & 37,00 & 6815,77 & 355,97 & 29,91 & 326,06 & 93,17 & 255,18 & 255,18 & 80,68 & 621,48 & 91,61 & 3,31 & 57,85 & 238,69 & 23,62 & 23,62 & 230,69 \\
\hline Bufo spinosus & $30 \mathrm{SUH} 42$ & 100,00 & 159,93 & 123,20 & 37,00 & 6866,91 & 354,13 & 25,70 & 328,43 & 88,95 & 252,18 & 252,18 & 76,42 & 618,63 & 90,50 & 3,56 & 56,64 & 235,22 & 25,44 & 25,44 & 226,66 \\
\hline Bufo spinosus & $30 \mathrm{SUH} 43$ & 100,00 & 154,47 & 123,89 & 37,00 & 6906,66 & 350,66 & 20,31 & 330,36 & 83,37 & 247,52 & 247,52 & 70,86 & 619,21 & 89,46 & 3,99 & 55,09 & 232,34 & 28,04 & 28,04 & 223,41 \\
\hline \begin{tabular}{|l} 
Bufo spinosus \\
\end{tabular} & $30 \mathrm{SUH} 44$ & 100,00 & 151,10 & 124,14 & 37,00 & 6935,14 & 348,41 & 16,70 & 331,71 & 79,95 & 244,71 & 244,71 & 67,39 & 613,34 & 87,64 & 4,10 & 53,95 & 227,34 & 29,66 & 29,66 & 218,34 \\
\hline Bufo spinosus & $30 \mathrm{SUH} 46$ & 100,00 & 157,91 & 124,35 & 37,00 & 6911,92 & 354,04 & 22,60 & 331,45 & 87,01 & 250,81 & 250,81 & 73,84 & 555,28 & 78,31 & 3,76 & 52,91 & 201,13 & 27,90 & 27,90 & 193,54 \\
\hline Bufo spinosus & 30SUH47 & 100,00 & 156,62 & 124,50 & 37,00 & 6912,72 & 352,90 & 21,42 & 331,48 & 85,87 & 249,65 & 249,65 & 72,71 & 541,91 & 75,45 & 3,73 & 52,08 & 193,57 & 28,44 & 28,44 & $\begin{array}{l}186,43 \\
\end{array}$ \\
\hline Bufo spinosus & 30SUH48 & 100,00 & 158,87 & 124,11 & 37,00 & 6901,36 & 354,40 & 23,56 & 330,84 & 88,28 & 251,73 & 251,73 & 75,01 & 516,26 & 70,91 & 3,53 & 51,42 & 181,79 & 27,87 & 27,87 & 175,64 \\
\hline Bufo spinosus & 30SUH49 & 100,00 & 156,20 & 124,03 & 37,00 & 6904,72 & 351,85 & 21,02 & 330,83 & 85,84 & 249,25 & 249,25 & 72,32 & 508,38 & 68,64 & 3,86 & 50,16 & 176,05 & 29,40 & 29,40 & 170,30 \\
\hline Bufo spinosus & 30SUH51 & 100,00 & 167,94 & 121,13 & 37,00 & 6800,02 & 358,36 & 34,78 & 323,58 & 97,66 & 259,20 & 259,20 & 84,95 & 597,88 & 88,85 & 2,99 & 58,12 & 230,16 & 22,01 & 22,01 & 221,71 \\
\hline Bufo spinosus & 30SUH53 & 100,00 & 151,46 & 123,55 & 37,00 & 6923,90 & 347,84 & 17,35 & 330,49 & 80,16 & 244,83 & 244,83 & 67,78 & 620,32 & 89,50 & 4,44 & 54,35 & 232,18 & 29,65 & 29,65 & 222,21 \\
\hline Bufo spinosus & 30SUH55 & 100,00 & 154,13 & 124,04 & 37,00 & 6932,63 & 350,89 & 19,13 & 331,76 & 83,23 & 247,52 & 247,52 & 70,19 & 577,22 & 82,19 & 4,02 & 53,10 & 211,24 & 28,82 & 28,82 & 202,25 \\
\hline Bufo spinosus & 30SUH56 & 100,00 & 156,92 & 124,19 & 37,00 & 6927,64 & 353,20 & 21,55 & 331,65 & 85,88 & 250,18 & 250,18 & 72,80 & 550,41 & 77,53 & 3,89 & 52,44 & 198,71 & 28,34 & 28,34 & 190,68 \\
\hline \begin{tabular}{|l} 
Bufo spinosus \\
\end{tabular} & \begin{tabular}{|l|l|}
30 UUH57 \\
\end{tabular} & 100,00 & 151,04 & 124,89 & 37,00 & 6933,85 & 348,32 & 15,91 & 332,42 & 80,23 & 244,52 & 244,52 & 67,21 & 552,66 & 76,26 & 4,34 & 50,95 & 195,91 & 31,15 & 31,15 & 188,14 \\
\hline Bufo spinosus & 30SUH58 & 100,00 & 155,92 & 124,62 & 37,00 & 6916,51 & 352,13 & 20,50 & 331,63 & 87,59 & 249,11 & 249,11 & 72,13 & 518,13 & 70,77 & 3,93 & 50,58 & 181,39 & 29,22 & 29,22 & 174,72 \\
\hline Bufo spinosus & 30SUH59 & 100,00 & 153,77 & 124,58 & 37,00 & 6913,86 & 349,99 & 18,56 & 331,43 & 100,63 & 247,06 & 247,06 & 70,13 & 508,30 & 68,12 & 4,05 & 49,48 & 175,65 & 30,44 & 30,44 & 168,93 \\
\hline Bufo spinosus & 30SUH62 & 100,00 & 159,36 & 121,62 & 36,99 & 6883,64 & 352,88 & 26,08 & 326,81 & 88,66 & 252,18 & 252,18 & 76,03 & 598,82 & 88,01 & 3,83 & 55,69 & 227,40 & 26,00 & 26,00 & 217,16 \\
\hline Bufo spinosus & 30SUH64 & 100,00 & 150,72 & 123,71 & 37,00 & 6944,50 & 347,86 & 16,61 & 331,26 & 79,53 & 244,57 & 244,57 & 67,15 & 596,67 & 85,45 & 4,58 & 52,90 & 220,07 & 30,67 & 30,67 & 209,74 \\
\hline Bufo spinosus & 30SUH65 & 100,00 & 153,88 & 123,98 & 37,00 & 6938,73 & 350,60 & $\begin{array}{l}19,02 \\
\end{array}$ & $\begin{array}{l}31,58 \\
331,58\end{array}$ & 82,97 & 247,51 & 247,51 & 69,97 & 568,39 & $\begin{array}{l}0,45 \\
80,88 \\
\end{array}$ & 年, & 52,71 & 207,44 & 29,00 & 29,00 & 198,00 \\
\hline Bufo spinosus & 30SUH66 & 100,00 & 147,75 & 124,62 & 37,00 & 6951,08 & 345,61 & 13,05 & 332,56 & 78,56 & 241,74 & 241,74 & 64,00 & 573,10 & 79,68 & 4,80 & 50,88 & 204,96 & 32,71 & 32,71 & 195,86 \\
\hline Bufo spinosus & 30SUH67 & 100,00 & 149,16 & 124,99 & 37,00 & 6940,01 & 346,73 & 13,99 & 332,74 & 88,94 & 242,86 & 242,86 & 65,36 & 549,43 & 75,42 & 4,36 & 50,23 & 194,17 & 32,05 & 32,05 & 185,56 \\
\hline Bufo spinosus & 30SUH68 & 100,00 & 153,25 & 124,97 & 37,00 & 6928,40 & 350,03 & 17,89 & 332,15 & 104,50 & 246,76 & 246,76 & 69,48 & 517,11 & 70,02 & 4,09 & 49,73 & 180,85 & 30,47 & 30,47 & 172,72 \\
\hline Bufo spinosus & 30SUH69 & 100,00 & 148,55 & 125,02 & 37,00 & 6936,00 & 345,94 & 13,06 & 332,88 & 116,64 & 242,25 & 242,25 & 64,80 & 517,39 & 68,56 & 4,43 & 48,32 & 179,27 & 32,96 & 32,96 & 169,88 \\
\hline Bufo spinosus & 30SUH71 & 100,00 & 173,71 & 117,85 & 36,75 & 6743,01 & 359,66 & 42,01 & \begin{tabular}{|l|}
317,65 \\
31,05
\end{tabular} & \begin{tabular}{|l|}
103,97 \\
\end{tabular} & \begin{tabular}{|l|}
264,08 \\
\end{tabular} & \begin{tabular}{|l|}
264,08 \\
\end{tabular} & $\begin{array}{ll}4,1,19 \\
\end{array}$ & 550,19 & $\begin{array}{l}0,1,64 \\
81\end{array}$ & 2,866 & 57,58 & 211,40 & 20,33 & 20,33 & 203,06 \\
\hline Bufo spinosus & 30 SUH72 & 100,00 & 164,01 & 120,13 & \begin{tabular}{|l|l|}
36,78 \\
\end{tabular} & 6853,19 & 355,20 & 31,22 & 323,98 & 93,39 & 256,33 & 256,33 & 80,81 & 571,80 & 84,39 & 3,52 & 55,76 & 217,34 & 24,27 & 24,27 & 207,05 \\
\hline Bufo spinosus & 30SUH73 & 100,00 & 150,43 & 122,52 & 36,84 & 6938,53 & 346,58 & 16,95 & 329,64 & 79,37 & 244,26 & 244,26 & 66,90 & 603,05 & 87,12 & 4,85 & 53,18 & 224,50 & 30,80 & 30,80 & 213,05 \\
\hline Bufo spinosus & 30SUH74 & 100,00 & 151,78 & 123,02 & 37,00 & 6941,81 & 348,19 & 17,94 & 330,25 & 80,72 & 245,66 & 245,66 & 68,25 & 582,21 & 83,49 & 4,44 & 52,59 & 214,36 & 30,20 & 30,20 & 203,55 \\
\hline Bufo spinosus & 30SUH75 & 100,00 & 148,38 & 123,98 & 37,00 & 6945,49 & 345,76 & 14,17 & 331,59 & 81,12 & 242,28 & 242,28 & 64,94 & 577,95 & 81,45 & 4,75 & 51,44 & 209,36 & 32,20 & 32,20 & 198,97 \\
\hline \begin{tabular}{|l} 
Bufo spinosus \\
\end{tabular} & 30SUH76 & 100,00 & 141,94 & 124,88 & 37,00 & 6962,21 & 340,69 & 7,44 & 333,25 & 90,01 & 236,19 & 236,19 & 58,53 & 583,66 & 80,33 & 5,47 & 49,59 & 208,01 & 35,86 & 35,86 & 197,16 \\
\hline Bufo spinosus & 30SUH77 & 100,00 & 147,90 & 125,00 & 37,00 & 6946,68 & 345,71 & 12,77 & 332,94 & 101,20 & 241,78 & 241,78 & 64,02 & 543,49 & 74,16 & 4,66 & 49,51 & 192,43 & 32,81 & 32,81 & 181,97 \\
\hline Bufo spinosus & 30SUH78 & 100,00 & 147,51 & 125,44 & 37,00 & 6943,53 & 345,35 & 11,86 & 333,49 & 101,89 & 241,28 & 241,28 & 63,78 & 527,11 & 70,51 & 4,52 & 48,64 & 184,42 & 33,20 & 33,20 & 174,00 \\
\hline Bufo spinosus & 30SUH79 & 100,00 & 146,89 & 125,74 & 37,00 & 6936,43 & 344,63 & 10,99 & 333,64 & 126,48 & 240,77 & 240,77 & 63,22 & 511,78 & 67,01 & 4,52 & 47,64 & 178,23 & 33,67 & 33,67 & 166,41 \\
\hline \begin{tabular}{|l} 
Bufo spinosus \\
\end{tabular} & 30 SUH 80 & 100,00 & 177,70 & 114,64 & 36,24 & 6641,40 & 358,53 & 48,07 & 310,46 & 108,80 & 266,67 & 266,67 & 96,51 & 528,09 & 77,71 & 2,45 & 58,08 & 203,85 & 18,58 & 18,58 & 196,87 \\
\hline \begin{tabular}{|l} 
Bufo spinosus \\
\end{tabular} & 30 SUH81 & 100,00 & 173,46 & 116,62 & 36,23 & 6739,70 & 358,49 & 42,42 & 316,07 & 103,77 & 263,92 & 263,92 & 91,24 & 537,50 & 79,71 & 2,97 & 57,01 & \begin{tabular}{|l|l|}
206,38 \\
\end{tabular} & 20,59 & 20,59 & 197,35 \\
\hline Bufo spinosus & 30SUH82 & 100,00 & 158,93 & 119,88 & 36,38 & 6896,57 & 351,39 & 26,70 & 324,69 & 88,28 & 252,11 & 252,11 & 75,77 & 578,24 & 85,17 & 4,16 & 54,55 & 218,97 & 26,85 & 26,85 & 207,22 \\
\hline Bufo spinosus & 30SUH83 & 100,00 & 150,42 & 121,94 & 36,52 & 6952,54 & 346,31 & 17,11 & 329,19 & 79,19 & 244,50 & 244,50 & 66,77 & 593,26 & 85,86 & 4,98 & 52,75 & 220,49 & 31,11 & 31,11 & 208,25 \\
\hline Bufo spinosus & 30 SUH84 & 100,00 & 154,04 & 122,48 & 36,91 & 6943,70 & 349,56 & 20,06 & 329,49 & 83,92 & 247,77 & 247,77 & 70,27 & 563,59 & 80,97 & 4,26 & 52,42 & 207,25 & 29,19 & 29,19 & 196,12 \\
\hline Bufo spinosus & 30SUH 85 & 100,00 & 141,49 & $\begin{array}{l}124,08 \\
124,08\end{array}$ & 37,00 & 6965,81 & 339,93 & $\begin{array}{c}2,000 \\
7,69 \\
\end{array}$ & 332,24 & $\begin{array}{l}31,04 \\
91,0\end{array}$ & 235,90 & 235,90 & 58,33 & 591,33 & 82,19 & 5,76 & 49,85 & 213,17 & 36,21 & 36,21 & 200,69 \\
\hline Bufo spinosus & 30SUH86 & 100,00 & 145,59 & 124,74 & 37,00 & 6964,43 & 343,72 & 10,73 & 332,99 & 98,61 & 239,85 & 239,85 & 61,92 & 559,53 & 77,06 & 5,04 & 49,66 & 200,49 & 33,95 & 33,95 & 188,22 \\
\hline Bufo spinosus & 30SUH87 & 100,00 & 146,01 & 125,26 & 37,00 & 6949,86 & 344,13 & 10,88 & 333,25 & 99,38 & 240,03 & 240,03 & 62,22 & 539,66 & 72.92 & 4,84 & 48,75 & $\mid 191,20$ & 33,88 & 33,88 & 179,09 \\
\hline Bufo spinosus & 30SUH88 & 100,00 & 144,92 & 125,94 & 37,00 & 6940,05 & 343,28 & 9,27 & 334,01 & 107,70 & 238,79 & 238,79 & 61,38 & 525,05 & 69,43 & 4,77 & 47,69 & 184,06 & 34,63 & 34,63 & 171,40 \\
\hline Bufo spinosus & 30SUH89 & 100,00 & 148,44 & 126,05 & $\begin{array}{l}37,05 \\
\end{array}$ & 6923,10 & 345,99 & 12,38 & 333,61 & 131,37 & 242,10 & 242,10 & 64,94 & 493,66 & 63,99 & 4,09 & 47,51 & 172,80 & 32,73 & 32,73 & 159,31 \\
\hline \begin{tabular}{|l} 
Bufo spinosus \\
\end{tabular} & |30SUHOS & 100,00 & $\begin{array}{l}140,44 \\
173,91\end{array}$ & $\begin{array}{l}12,05 \\
115,37\end{array}$ & 36,04 & $\begin{array}{ll}052,10 \\
6737,19\end{array}$ & 357,76 & $\begin{array}{l}1,30 \\
43,66\end{array}$ & \begin{tabular}{|l|}
314,10 \\
314,1
\end{tabular} & 104,35 & 264,36 & 264,36 & 91,91 & 522,34 & 77,31 & 3,08 & 56,38 & 200,06 & 20,91 & 20,91 & 190,64 \\
\hline Bufo spinosus & 30SUH93 & 100,00 & 157,60 & 120,31 & 36,39 & 6920,18 & 350,89 & 25,01 & 325,88 & 91,03 & 251,12 & 251,12 & 74,21 & 557,10 & 81,35 & 4,24 & 53,21 & 207,95 & 27,88 & 27,88 & 195,62 \\
\hline Bufo spinosus & 30SUH94 & 100,00 & 155,04 & 121,73 & 36,89 & 6927,27 & 349,65 & 21,51 & 328,14 & 100,29 & 248,67 & 248,67 & 71,53 & 549,85 & 78,94 & 4,31 & 52,02 & 202,57 & 29,14 & 29,14 & 190,15 \\
\hline Bufo spinosus & 30SUH95 & 100,00 & 140,41 & 124,03 & 37,00 & 6966,58 & 338,94 & 6,78 & 332,16 & 92,96 & 235,03 & 235,03 & 57,38 & 584,27 & 80,83 & 5,92 & 49,15 & 211,03 & 37,01 & 37,01 & 196,48 \\
\hline Bufo spinosus & 30SUH96 & 100,00 & 146,94 & 124,51 & 37,00 & 6950,51 & 344,40 & 12,19 & 332,21 & 100,02 & 240,92 & 240,92 & 63,40 & 542,94 & 74,48 & 4,81 & 49,26 & 195,16 & 33,37 & 33,37 & 181,33 \\
\hline \begin{tabular}{|l} 
Bufo spinosus \\
\end{tabular} & 30SUH97 & 100,00 & 146,86 & 125,39 & 37,00 & 6938,87 & 344,56 & 11,62 & 332,94 & 100,52 & 240,75 & 240,75 & 63,27 & 525,40 & 70,56 & 4,64 & 48,40 & 186,60 & 33,58 & 33,58 & 173,00 \\
\hline Bufo spinosus & 30SUH98 & 100,00 & 147,00 & 125,99 & 37,00 & 6930,67 & 344,96 & 11,24 & 333,72 & 118,62 & 240,77 & 240,77 & 63,63 & 505,15 & 66,19 & 4,32 & 47,51 & 177,79 & 33,52 & 33,52 & 163,80 \\
\hline Bufo spinosus & 30SUH99 & 100,00 & 146.58 & 126,61 & 37,44 & 6909,73 & 344,29 & 10.52 & $333,77 \mid$ & 129,35 & 239.97 & 239.97 & 63,37 & 489,23 & 62.42 & 4,24 & 46,61 & 171.92 & 33.88 & 33.88 & 156,11 \\
\hline Bufo spinosus & 30SUJO0 & 100,00 & 159,71 & 122,47 & 37,00 & 6806,31 & 352,25 & 26,32 & 325,93 & 85,56 & 250,84 & 250,84 & 76 & 505,27 & 67,58 & 3,79 & 50,66 & 178,87 & 29,16 & 29,16 & 171,45 \\
\hline Bufo spinosus & 30SUJO2 & 100,00 & 159,36 & 121,10 & 37,00 & 6790,35 & 350,59 & 26,64 & 323,95 & 89,07 & 250,54 & 250,54 & 76,72 & 476,07 & 62,28 & 3,92 & 49,00 & 166,33 & 29,72 & 29,72 & 157,84 \\
\hline
\end{tabular}




\begin{tabular}{|c|c|c|c|c|c|c|c|c|c|c|c|c|c|c|c|c|c|c|c|c|c|}
\hline TAXON & UTM & $\mathrm{km} 2$ & B101 & B102 & $\mathrm{BIO3}$ & BIO4 & B105 & B106 & B107 & B108 & B109 & B1010 & BIO11 & BIO12 & B1013 & BIO14 & BIO15 & B1016 & B1017 & BIO18 & B1019 \\
\hline Bufo spinosus & 30SUJ03 & 100,00 & 158,62 & 120,52 & 37,00 & 6769,54 & 348,91 & 26,27 & 322,64 & 99,67 & 249,47 & 249,47 & 76,11 & 465,44 & 60,16 & 3,94 & 48,21 & 161,70 & 30,25 & 30,25 & 152,66 \\
\hline Bufo spinosus & 30SUJ04 & 100,00 & 156,92 & 119,92 & 37,00 & 6755,07 & 346,35 & 25,01 & 321,34 & 102,60 & 247,57 & 247,57 & 74,59 & 458,75 & 58,51 & 4,14 & 47,32 & 158,13 & 31,29 & 31,29 & 148,60 \\
\hline Bufo spinosus & 30SUJ05 & 100,00 & 153,83 & 119,08 & 36,97 & 6740,80 & 342,60 & 22,66 & 319,95 & 96,68 & 244,34 & 244,34 & 71,93 & 457,30 & 57,37 & 4,52 & 46,15 & 156,56 & 33,04 & 33,04 & 146,30 \\
\hline Bufo spinosus & 30SUJ06 & 100,00 & 149,68 & 118,42 & 36,71 & 6729,45 & 337,97 & 19,17 & 318,81 & 90,45 & 240,28 & 240,28 & 68,12 & 459,66 & 56,62 & 5,14 & 44,90 & 155,97 & 35,53 & 35,53 & 145,01 \\
\hline Bufo spinosus & 30SUJ09 & 100,00 & 145,21 & 116,46 & 36,88 & 6640,38 & 330,17 & 16,56 & 313,60 & 96,42 & 234,72 & 234,72 & 64,74 & 440,33 & 51,25 & 6,19 & 42,26 & 147,34 & 38,79 & 38,79 & 134,21 \\
\hline Bufo spinosus & 30SUJ12 & 100,00 & 158,19 & 121,74 & 37,00 & 6812,73 & 350,10 & 25,05 & 325,05 & 103,86 & 249,71 & 249,71 & 75,26 & 474,85 & 61,96 & 3,89 & 48,81 & 164,18 & 29,88 & 29,88 & 156,28 \\
\hline Bufo spinosus & 30SUJ13 & 100,00 & 156,64 & 121,00 & 37,00 & 6801,50 & 347,80 & 23,78 & 324,02 & 105,67 & 248,01 & 248,01 & 73,92 & 465,89 & 59,87 & 4,12 & 47,67 & 160,01 & 31,00 & 31,00 & 151,35 \\
\hline \begin{tabular}{|l} 
Bufo spinosus \\
\end{tabular} & 30SUJ14 & 100,00 & 158,51 & 120,24 & 37,00 & 6776,48 & 348,22 & 25,77 & 322,45 & 113,71 & 249,50 & 249,50 & 75,81 & 446,28 & 56,61 & 4,03 & 47,15 & 153,15 & 30,48 & 30,48 & 143,51 \\
\hline Bufo spinosus & 30SUJ15 & 100,00 & 156,77 & 119,64 & 36,98 & 6758,22 & 345,78 & 24,61 & 321,17 & 114,42 & 247,55 & 247,55 & 74,36 & 439,26 & 54,84 & 4,23 & 46,27 & 149,96 & 31,43 & 31,43 & 139,35 \\
\hline Bufo spinosus & 30SUJ18 & 100,00 & 139,00 & 117,31 & \begin{tabular}{|c|}
36,77 \\
\end{tabular} & 6694,77 & 326,16 & 9,66 & 316,50 & 112,17 & 229,44 & 229,45 & 58,38 & 467,38 & 54,50 & 6,79 & 41,90 & 155,04 & 41,88 & 41,89 & 141,82 \\
\hline Bufo spinosus & 30SUJ19 & 100,00 & 148,04 & 116,97 & 36,97 & 6669,21 & 333,37 & 18,23 & 315,14 & 109,39 & 237,87 & 237,87 & 67,00 & 421,03 & 48,61 & 5,94 & 41,92 & 140,41 & 37,41 & 37,41 & 126,60 \\
\hline Bufo spinosus & 30 SUJ 20 & 100,00 & 156,96 & 123,03 & 37,00 & 6860,53 & 351,14 & 22,51 & 328,63 & 86,62 & 249,08 & 249,08 & 73,57 & 503,85 & 67,41 & 3,88 & 50,11 & 174,82 & 29,59 & 29,59 & 168,86 \\
\hline Bufo spinosus & 30SUJ21 & 100,00 & 150,90 & 122,81 & 37,00 & 6860,03 & 345,34 & 17,14 & 328,20 & 83,00 & 243,38 & 243,38 & 67,96 & 511,42 & 67,13 & 4,54 & 48,50 & 175,59 & 32,87 & 32,87 & 168,88 \\
\hline Bufo spinosus & 30 SUJ22 & 100,00 & 154,62 & 122,09 & 37,00 & 6835,34 & 347,53 & 20,91 & 326,62 & 106,33 & 246,51 & 246,51 & 71,58 & 481,43 & 62,50 & 4,12 & 48,03 & 164,49 & 31,29 & 31,29 & 157,19 \\
\hline Bufo spinosus & 30 SUJ 23 & 100,00 & 154,21 & 121,51 & 37,00 & 6828,54 & 346,38 & 21,01 & 325,37 & 117,96 & 246,11 & 246,11 & 71,29 & 468,02 & 59,81 & 4,23 & 47,12 & 159,10 & 31,90 & 31,90 & 150,66 \\
\hline Bufo spinosus & 30 SUJ26 & 100,00 & 152,32 & 119,27 & 36,81 & 6771,48 & 341,38 & 20,07 & 321,31 & 122,77 & 243,51 & 243,51 & 70,08 & 435,45 & 52,76 & 4,90 & 44,36 & 146,68 & 34,10 & 34,10 & 134,77 \\
\hline Bufo spinosus & 30SUJ27 & 100,00 & 144,30 & 118,69 & 36,73 & 6749,11 & 333,08 & 13,26 & 319,82 & 127,03 & 235,39 & 235,39 & 62,75 & 450,37 & 53,29 & 5,94 & 42,70 & 150,73 & 38,40 & 38,40 & 136,93 \\
\hline Bufo spinosus & 30SUJ29 & 100,00 & 145,47 & 117,08 & 36,76 & 6683,31 & 331,32 & 15,28 & 316,03 & 122,78 & 235,70 & 235,70 & 64,65 & 422,31 & 48,16 & 6,32 & 41,13 & 140,39 & 38,88 & 38,88 & 124,91 \\
\hline Bufo spinosus & 30SUJ31 & 100,00 & 150,96 & 123,14 & 37,00 & 6882,02 & 345,94 & 16,56 & 329,38 & 115,15 & 243,83 & 243,83 & 67,74 & 502,99 & 65,85 & 4,31 & 48,20 & 171,38 & 32,64 & 32,64 & 164,81 \\
\hline Bufo spinosus & 30SUJ32 & 100,00 & 151,82 & 122,74 & 37,00 & 6864,87 & 345,74 & 17,56 & 328,18 & 132,25 & 244,36 & 244,36 & 68,72 & 484,56 & 62,45 & 4,38 & 47,40 & 164,73 & 32,69 & 32,69 & 156,66 \\
\hline Bufo spinosus & 30SUJ35 & 100,00 & 152,93 & 120,36 & 37,00 & 6810,05 & 343,39 & 19,86 & 323,53 & 133,26 & 244,65 & 244,65 & 70,08 & 439,24 & 53,72 & 4,65 & 44,76 & 148,41 & 33,46 & 33,46 & 136,42 \\
\hline Bufo spinosus & 30SUJ36 & 100,00 & 152,20 & 119,78 & 36,92 & 6784,40 & 341,57 & 19,43 & 322,15 & 134,07 & 243,51 & 243,51 & 69,69 & 428,59 & 51,38 & 4,99 & 43,87 & 144,37 & 34,22 & 34,22 & 131,29 \\
\hline Bufo spinosus & 30SUJ37 & 100,00 & 144,70 & 119,00 & 36,75 & \begin{tabular}{|c|c|}
6775,17 \\
\end{tabular} & 333,91 & 12,81 & 321,10 & 128,67 & 236,24 & 236,24 & 62,83 & 441,99 & 51,74 & 5,98 & 42,35 & 148,48 & 38,34 & 38,34 & 132,89 \\
\hline Bufo spinosus & 30SUJ38 & 100,00 & 131,12 & 117,91 & 36,48 & 6727,14 & 319,99 & 1,57 & 318,42 & 114,04 & 222,45 & 222,45 & 50,72 & 480,95 & 55,18 & 8,10 & 40,09 & 160,68 & 46,89 & 46,89 & 141,54 \\
\hline Bufo spinosus & 30SUJ39 & 100,00 & 138,86 & 117,22 & 36,46 & 6705,00 & 325,71 & 8,61 & 317,10 & 122,84 & 229,62 & 229,62 & 58,14 & 437,96 & 50,32 & 7,14 & 40,21 & 146,02 & 42,50 & 42,50 & 127,45 \\
\hline Bufo spinosus & 30SUJ40 & 100,00 & 152,11 & 124,00 & 37,00 & 6903,59 & 347,91 & 17,13 & 330,78 & 115,87 & 245,17 & 245,17 & 68,48 & 506,47 & 67,03 & 4,21 & 48,74 & 173,36 & 31,73 & 31,73 & 166,86 \\
\hline Bufo spinosus & $30 \mathrm{SUJ} 41$ & 100,00 & 150,18 & 123,80 & 37,00 & 6888,35 & 345,62 & 15,44 & \begin{tabular}{|l|l|}
330,18 \\
\end{tabular} & $\mid \begin{array}{l}\mid 133,39 \\
\end{array}$ & 243,10 & 243,10 & $\begin{array}{l}60,408 \\
66,82\end{array}$ & 497,24 & $\begin{array}{l}64,62 \\
6\end{array}$ & $\begin{array}{l}4,21 \\
4,46\end{array}$ & 47,59 & $\begin{array}{l}170,07 \\
\end{array}$ & 32,98 & 32,98 & 161,42 \\
\hline Bufo spinosus & 30 SUJ42 & 100,00 & 146,07 & 123,11 & 37,00 & 6891,55 & 341,34 & 11,74 & 329,60 & 129,14 & 239,19 & 239,19 & 62,95 & 497,35 & 63,27 & 5,08 & 46,15 & 169,92 & 35,59 & 35,59 & 158,83 \\
\hline Bufo spinosus & 30SUJ43 & 100,00 & 145,44 & 122,64 & 37,00 & 6874,67 & 339,72 & 11,30 & 328,42 & 128,48 & 238,21 & 238,21 & 62,43 & 485,61 & 60,68 & 5,23 & 45,29 & 165,68 & 36,31 & 36,31 & 152,99 \\
\hline Bufo spinosus & 30 SUJ44 & 100,00 & 150,27 & 121,69 & 37,00 & 6850,13 & 342,60 & 16,21 & 326,39 & 133,96 & 242,56 & 242,56 & 67,19 & 455,08 & 56,06 & 4,84 & 45,04 & $\begin{array}{l}154,78 \\
\end{array}$ & 34,32 & 34,32 & 141,87 \\
\hline Bufo spinosus & 30SUJ45 & 100,00 & 150,62 & 120,88 & 36,99 & 6831,53 & 341,75 & 17,01 & 324,75 & 134,62 & 242,70 & 242,70 & 67,85 & 440,17 & 53,18 & 4,99 & 44,07 & 149,37 & 34,59 & 34,59 & 135,15 \\
\hline Bufo spinosus & \begin{tabular}{|l|}
$305 U J 46$ \\
\end{tabular} & 100,00 & 149,38 & 120,01 & 36,91 & 6803,76 & 339,39 & $\begin{array}{l}1,1,32 \\
16,1\end{array}$ & 323,06 & \begin{tabular}{|l|l|}
$133,49<$ \\
\end{tabular} & 241,15 & 241,15 & $\begin{array}{l}6,, 78 \\
66,78\end{array}$ & \begin{tabular}{|l|l|}
431,73 \\
\end{tabular} & $\begin{array}{l}\mid 5,10 \\
51,15 \\
\end{array}$ & 5,34 & 43,24 & $\begin{array}{l}146,16 \\
145\end{array}$ & $\begin{array}{l}4,3,74 \\
35,\end{array}$ & 35,74 & 130,47 \\
\hline Bufo spinosus & 30SUJ47 & 100,00 & 139,20 & 119,04 & \begin{tabular}{|l|}
36,58 \\
\end{tabular} & 6777,43 & 328,92 & 7,78 & 321,14 & 122,71 & 231,06 & 231,06 & 57,63 & 456,81 & 52,81 & 6,85 & 41,34 & 153,92 & 41,97 & 41,97 & 135,41 \\
\hline Bufo spinosus & 30SUJ48 & 100,00 & 128,70 & 118,21 & 36,60 & 6735,84 & 318,01 & $-0,92$ & 318,93 & 111,44 & 220,25 & 220,25 & 48,31 & 482,80 & 55,92 & 8,52 & 39,42 & 161,99 & 48,59 & 48,59 & 140,19 \\
\hline Bufo spinosus & 30SUJ49 & 100,00 & 140,21 & 117,42 & 36,08 & 6738,94 & 327,38 & 9,10 & 318,27 & 124,44 & 231,39 & 231,39 & 58,99 & 427,31 & 49,60 & 6,98 & 39,94 & 142,94 & 41,89 & 41,89 & 123,03 \\
\hline Bufo spinosus & 30SUJ52 & 100,00 & 147,69 & 123,67 & 37,00 & 6888,11 & 342,84 & 12,90 & 329,94 & 130,79 & 240,73 & 240,73 & 64,54 & 482,92 & 60,95 & 4,93 & 45,89 & 165,87 & 34,88 & 34,88 & 153,01 \\
\hline Bufo spinosus & \begin{tabular}{|l}
$3050 J 53$ \\
3050
\end{tabular} & 100,00 & $\begin{array}{l}14,05 \\
149,64\end{array}$ & $\begin{array}{l}12,07 \\
122,92\end{array}$ & 37,00 & 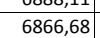 & 34,04 & $\begin{array}{l}14,90 \\
14,\end{array}$ & \begin{tabular}{|l|}
328,48 \\
\end{tabular} & $\mid \begin{array}{l}\mid 30,19 \\
133,16\end{array}$ & $\mid \begin{array}{l}\mid 240,451 \\
242,41\end{array}$ & \begin{tabular}{|l|}
242,41 \\
\end{tabular} & $\begin{array}{l}4,3454 \\
66,54\end{array}$ & \begin{tabular}{|l|l|}
$402,3<2$ \\
462,56
\end{tabular} & $\begin{array}{l}0,370 \\
57,40\end{array}$ & $\begin{array}{l}4,750 \\
4,74\end{array}$ & \begin{tabular}{|l|l|}
45,35 \\
450
\end{tabular} & \begin{tabular}{|l|}
158,46 \\
\end{tabular} & $\begin{array}{l}4,400 \\
34,27 \\
\end{array}$ & $\begin{array}{l}34,27 \\
34,27\end{array}$ & $\begin{array}{l}140,01 \\
144,74\end{array}$ \\
\hline Bufo spinosus & 30SUJ54 & 100,00 & 147,92 & 122,07 & 37,00 & 6864,75 & 340,99 & 13,44 & 327,55 & 131,67 & 240,57 & 240,57 & 64,81 & 455,88 & 55,47 & 5,07 & 44,39 & 155,87 & 35,52 & 35,52 & 140,57 \\
\hline Bufo spinosus & 30SUJ55 & 100,00 & 146,73 & 121,31 & $37,00 \mid$ & 6863,51 & 338,99 & 12,70 & 326,29 & $\mid 130,64$ & 239,38 & 239,38 & 63,78 & 446,39 & 53,20 & 5,31 & 43,38 & $\mid 152,17$ & 36,42 & 36,42 & 135,53 \\
\hline Bufo spinosus & 30SUJ56 & 100,00 & 144,03 & 120,42 & 36,71 & 6835,28 & 335,41 & 10,61 & 324,80 & 127,69 & 236,51 & 236,51 & 61,60 & 443,45 & 51,75 & 5,95 & 42,22 & 150,82 & 38,71 & 38,71 & 132,20 \\
\hline Bufo spinosus & 30SUJ57 & 100,00 & 132,87 & 119,36 & 36,71 & 6787,24 & 323,47 & $\begin{array}{ll}1,64 \\
\end{array}$ & 321,84 & 115,81 & 224,95 & 224,97 & 51,61 & 473,97 & 54,7 & 7,79 & 40,19 & 160,11 & 46,02 & 46,03 & 138,46 \\
\hline Bufo spinosus & 30SUJ58 & 100,00 & 131,10 & 118,38 & 36,48 & 6761,15 & 320,51 & 0,67 & 319,85 & 114,06 & 222,93 & 222,93 & 50,26 & 467,69 & 54,66 & 8,25 & 39,29 & $\begin{array}{l}157,42 \\
150\end{array}$ & 47,50 & 47,50 & 134,38 \\
\hline Bufo spinosus & 30SUJ59 & 100,00 & 139,33 & 117,47 & 36,02 & 6758,71 & 326,81 & 7,85 & 318,96 & 123,33 & 230,97 & 230,97 & 57,93 & 426,18 & 49,96 & 7,13 & 39,41 & 142,91 & 42,85 & 42,85 & 121,35 \\
\hline Bufo spinosus & 30SUJ60 & 100,00 & 144,95 & 125,02 & 37,00 & 6931,42 & 342,47 & 9,61 & 332,86 & 127,68 & 238,68 & 238,68 & 61,42 & 513,86 & 66,62 & 4,90 & 47,07 & 177,92 & 35,18 & 35,18 & 165,95 \\
\hline Bufo spinosus & 30SUJ61 & 100,00 & 147,49 & 124,72 & 37,00 & 6918,40 & 343,85 & 11,91 & 331,94 & 130,79 & 240,96 & 240,96 & 0 & 489,01 & 62,2 & 4,62 & 46,51 & 169,13 & 34,19 & 34,19 & 155,95 \\
\hline Bufo spinosus & 305UJ63 & 100,00 & 145,25 & 123,52 & 37,00 & 6890,92 & 340,28 & $\begin{array}{l}10,49 \\
10,\end{array}$ & $\begin{array}{l}329,79 \\
\end{array}$ & 128,27 & 238,45 & 238,45 & 62,09 & $\begin{array}{l}469,25 \\
469, \\
\end{array}$ & 57,34 & 5,2 & \begin{tabular}{|l|l|}
44,38 \\
4,5
\end{tabular} & $\begin{array}{l}161,49 \\
161\end{array}$ & $\begin{array}{l}34,15 \\
36,57 \\
\end{array}$ & 36,57 & 145,12 \\
\hline Bufo spinosus & 30SUJ64 & 100,00 & 145,08 & 122,74 & 37,00 & 6870,34 & 338,94 & 10,49 & 328,45 & 128,49 & 238,01 & 238,01 & 62,12 & 457,61 & 54,77 & 5,3 & 43,57 & 157,08 & 37,04 & 37,04 & 139,56 \\
\hline Bufo spinosus & 30SUJ65 & 100,00 & 141,45 & 121,91 & 36,99 & 6863,46 & 334,63 & 7,48 & 327,16 & 124,84 & 234,37 & 234,37 & 58,69 & 459,14 & 53,75 & 5,96 & 42,35 & $\mid 157,07$ & 39,61 & 39,61 & 137,65 \\
\hline Bufo spinosus & 30 SUJ 66 & 100,00 & 138,87 & 120,82 & 36,84 & 6853,41 & 330,98 & 5,46 & 325,52 & 122,02 & 231,64 & 231,64 & 56,39 & 456,53 & 52,59 & 6,61 & 41,24 & 155,54 & 41,78 & 41,78 & 134,68 \\
\hline Bufo spinosus & 30SUJ67 & 100,00 & 133,27 & 119,57 & 36,55 & 6810,94 & 324,28 & 1,23 & 323,05 & 116,30 & 225,70 & 225,72 & 51,75 & 467,28 & 54,22 & 7,76 & 39,82 & 158,18 & 45,99 & 46,01 & 135,44 \\
\hline \begin{tabular}{|l} 
Bufo spinosus \\
\end{tabular} & \begin{tabular}{|l|}
$305 \mathrm{~N} 6 \mathrm{~J} 68$ \\
\end{tabular} & 100,00 & $\begin{array}{l}13,27,92 \\
127\end{array}$ & 118,44 & 36,46 & $\begin{array}{l}001,144 \\
6771,95\end{array}$ & 313,20 & $\frac{\mid, 20}{-2,49}$ & $\begin{array}{l}20,030 \\
320,25 \\
\end{array}$ & 110,53 & 220,03 & 220,03 & 47,24 & 475,21 & 56,03 & 8,85 & 38,49 & 160,12 & 49,94 & 49,94 & 135,27 \\
\hline Bufo spinosus & 30SUJ69 & 100,00 & 138,46 & 117,39 & 36,06 & 6776,79 & 326,03 & 6,79 & 319,24 & 122,33 & 230,29 & 230,29 & 56,83 & 426,07 & 50,24 & 7,51 & 38,77 & 142,88 & 43,81 & 43,81 & 120,28 \\
\hline Bufo spinosus & 30SUJ71 & 100,00 & 150,08 & 125,08 & 37,00 & $\mid 6909,14$ & 346,05 & 13,92 & 332,12 & 133,77 & 243,34 & 243,34 & 66,37 & 469,68 & 59,18 & 4,21 & 46,36 & 163,15 & 32.79 & 32,79 & 148,78 \\
\hline Bufo spinosus & 30SUJ72 & 100,00 & 144,93 & 124,86 & 37,00 & 6910,35 & 341,01 & 9,19 & 331,82 & 128,45 & 238,29 & 238,29 & 61,42 & 474,52 & 58,32 & 4,97 & 44,83 & 164,41 & 36,07 & 36,07 & 147,54 \\
\hline Bufo spinosus & 30SUJ73 & 100,00 & 140,36 & 124,17 & 37,00 & 6901,19 & 336,28 & 5,26 & 331,02 & 123,41 & 233,78 & 233,78 & 57,29 & 478,84 & 57,47 & 5,66 & 43,40 & 165,37 & 39,18 & 39,18 & 146,33 \\
\hline \begin{tabular}{|l} 
Bufo spinosus \\
\end{tabular} & 30 SUJ74 & 100,00 & 143,51 & 123,26 & 37,00 & 6884,85 & 337,84 & 8,47 & 329,36 & $\begin{array}{l}126,77 \\
\end{array}$ & 236,64 & 236,64 & 60,49 & 455,14 & 53,60 & 5,38 & 42,92 & 156,66 & 37,91 & 37,91 & 137,36 \\
\hline Bufo spinosus & 30SUJ75 & 100,00 & 140,25 & 122,33 & 37,00 & 6876,04 & 333,81 & 5,96 & 327,85 & 123,67 & 233,36 & 233,36 & 57,40 & 456,66 & 52,75 & 6,19 & 41,78 & 156,56 & 40,66 & 40,66 & 135,52 \\
\hline Bufo spinosus & 30 SUJ76 & 100,00 & 131,62 & 121.11 & 36,99 & 6845,36 & 324,71 & -0.64 & 325,36 & 114,22 & 224,64 & 224,64 & 49.95 & 478,72 & 55,45 & 7,72 & 40,05 & 163,20 & 46.50 & 46.50 & 139.57 \\
\hline Bufo spinosus & 30SUJ77 & 100,00 & 129,08 & 119,84 & 36,69 & 6811,62 & 320,59 & $-2,58$ & 323,17 & 111,64 & 221,71 & 221,73 & 47 & 479,38 & 56,10 & 8,50 & 38,99 & 162,42 & 49,09 & 49,11 & 137,63 \\
\hline Bufo spinosus & 30SUJ78 & 100,00 & 129,47 & 118,53 & 36,27 & 6797,85 & 319,50 & $-1,77$ & 321,27 & 112,44 & 221,84 & 221,86 & 48,38 & 467,19 & 55,19 & 8,76 & 38,21 & 157,42 & 49,51 & 49,52 & 132,25 \\
\hline
\end{tabular}




\begin{tabular}{|c|c|c|c|c|c|c|c|c|c|c|c|c|c|c|c|c|c|c|c|c|c|}
\hline TAXON & UTM & $\mathrm{km} 2$ & B101 & B102 & $\mathrm{BIO3}$ & B104 & B105 & B106 & B107 & B108 & B109 & BIO10 & B1011 & BIO12 & B1013 & B1014 & BIO15 & BIO16 & B1017 & BIO18 & B1019 \\
\hline Bufo spinosus & 30SUJ79 & 100,00 & 140,64 & 117,26 & 36,00 & 6813,01 & 328,23 & 8,23 & 319,99 & 124,71 & 232,97 & 232,97 & 58,34 & 417,31 & 49,25 & 7,44 & 38,68 & 139,88 & 43,10 & 43,10 & 117,30 \\
\hline Bufo spinosus & 30 SUJ80 & 100,00 & 146,51 & 126,21 & $\begin{array}{l}37,15 \\
\end{array}$ & 6912,49 & 343,98 & 10,46 & 333,52 & 129,46 & 240,11 & 240,11 & 63,38 & 484,96 & 61,28 & 4,30 & 46,40 & \begin{tabular}{|l|l|}
169,49 \\
\end{tabular} & 34,09 & 34,09 & 153,91 \\
\hline Bufo spinosus & 30SUJ81 & 100,00 & 146,86 & 125,88 & 37,04 & 6901,70 & 343,59 & 10,77 & 332,83 & 130,04 & 240,18 & 240,18 & 63,61 & 470,88 & 58,30 & 4,47 & 45,48 & 164,25 & 34,40 & 34,40 & 147,42 \\
\hline Bufo spinosus & 30 SUJ82 & 100,00 & 142,16 & 125,58 & 37,00 & 6902,37 & 338,97 & 6,55 & 332,42 & 125,21 & 235,64 & 235,64 & 59,16 & 475,08 & 57,40 & 5,16 & 44,01 & \begin{tabular}{|l|l|}
165,12 \\
\end{tabular} & 37,56 & 37,56 & 146,14 \\
\hline Bufo spinosus & 30SUJ83 & 100,00 & 143,81 & 124,75 & 37,00 & \begin{tabular}{|l|l|}
6892,71 \\
\end{tabular} & 339,36 & 8,21 & 331,16 & 127,29 & 237,03 & 237,03 & 60,78 & 457,21 & 54,14 & 5,19 & 43,40 & \begin{tabular}{|l|l|}
158,38 \\
\end{tabular} & 37,21 & 37,21 & 138,80 \\
\hline Bufo spinosus & 30SUJ84 & 100,00 & 147,10 & 123,58 & 37,00 & 6891,58 & 341,06 & 11,29 & 329,77 & 130,97 & 240,20 & 240,20 & 63,63 & 435,05 & 50,60 & 5,04 & 43,12 & 150,06 & 36,03 & 36,03 & 130,50 \\
\hline Bufo spinosus & 30SUJ85 & 100,00 & 139,86 & 122,68 & 37,00 & 6883,90 & 333,48 & 5,15 & 328,33 & 123,22 & 233,10 & 233,10 & 57,01 & 452,03 & 52,22 & 6,18 & 41,36 & \begin{tabular}{|l|l|}
154,99 \\
\end{tabular} & 41,14 & 41,14 & 133,15 \\
\hline \begin{tabular}{|l} 
Bufo spinosus \\
\end{tabular} & \begin{tabular}{|l|}
$305 U נ 86$ \\
\end{tabular} & 100,00 & 139,18 & 121,51 & 37,00 & 6872,99 & 331,72 & 5,03 & 326,69 & 122,69 & 232,32 & 232,32 & 56,42 & 445,18 & 51,66 & 6,55 & 40,38 & \begin{tabular}{|l|l|l|}
151,85 \\
\end{tabular} & 42,23 & 42,23 & 129,33 \\
\hline Bufo spinosus & 30SUJ87 & 100,00 & 128,53 & 120,22 & 36,90 & 6825,34 & 320,44 & $-3,11$ & 323,55 & 111,06 & 221,42 & 221,42 & 47,25 & 476,95 & 56,08 & 8,54 & 38,63 & \begin{tabular}{|l|l|}
161,68 \\
\end{tabular} & 49,58 & 49,58 & 136,07 \\
\hline Bufo spinosus & 30SUJ88 & 100,00 & 137,01 & 118,73 & 36,06 & 6843,51 & 326,82 & 3,88 & 322,94 & 120,65 & 229,86 & 229,86 & 54,64 & 436,48 & 51,38 & 7,67 & 38,58 & 147,06 & 45,13 & 45,13 & 123,42 \\
\hline Bufo spinosus & 30SUJ90 & 100,00 & 147,43 & 126,93 & 37,81 & 6900,37 & 344,48 & 11,01 & 333,48 & 130,56 & 240,56 & 240,56 & 64,01 & 470,35 & 58,48 & 4,19 & 45,79 & 164,89 & 33,69 & 33,69 & 147,89 \\
\hline Bufo spinosus & 30SUJ91 & 100,00 & 147,66 & 126,60 & 37,53 & 6892,61 & 344,21 & 11,08 & 333,13 & 131,09 & 240,71 & 240,71 & 64,23 & 455,62 & 55,28 & 4,29 & 45,06 & 159,29 & 33,96 & 33,96 & 141,21 \\
\hline \begin{tabular}{|l} 
Bufo spinosus \\
\end{tabular} & 30SUJ92 & 100,00 & 146,89 & 126,23 & \begin{tabular}{|l|l|}
37,28 \\
\end{tabular} & 6888,05 & 342,90 & 10,26 & 332,64 & 130,50 & 239,83 & 239,83 & 63,38 & 447,19 & 53,12 & \begin{tabular}{l|l}
4,36 \\
\end{tabular} & 44,15 & 155,79 & 34,83 & 34,83 & 136,70 \\
\hline Bufo spinosus & 30SUJ93 & 100,00 & 145,83 & 125,46 & $\begin{array}{l}37,05 \\
\end{array}$ & 6882,95 & 341,08 & 9,45 & 331,63 & 129,68 & 238,78 & 238,78 & 62,57 & 441,07 & 51,63 & 4,78 & 43,28 & $\begin{array}{l}153,05 \\
\end{array}$ & 36,04 & 36,04 & 132,92 \\
\hline Bufo spinosus & 30SUJ94 & 100,00 & 144,67 & 124,35 & 37,00 & 6881,74 & 339,03 & 8,86 & 330,17 & 128,28 & 237,71 & 237,71 & 61,62 & 436,28 & 50,80 & 5,20 & 42,51 & 150,51 & 37,62 & 37,62 & 129,38 \\
\hline Bufo spinosus & 30SUJ95 & 100,00 & $\begin{array}{lll}136,17 \\
\end{array}$ & 123,12 & 37,00 & $\mid 6876,93$ & 330,38 & \begin{tabular}{|l|l|}
1,78 \\
\end{tabular} & 328,60 & \begin{tabular}{|l|l|}
119,18 \\
\end{tabular} & 229,47 & 229,47 & 53,59 & 4660,05 & 53,51 & 6,70 & 40,60 & 157,81 & $\mid$\begin{tabular}{|l|l}
43,56 \\
\end{tabular} & 43,56 & \begin{tabular}{ll|l}
134,31 \\
\end{tabular} \\
\hline Bufo spinosus & 30SUJ96 & 100,00 & 140,58 & 121,71 & 36,98 & 6881,84 & 332,97 & 5,60 & 327,37 & 124,21 & 233,66 & 233,66 & 57,52 & 435,73 & 50,77 & 6,36 & 40,32 & 148,64 & 41,68 & 41,68 & 125,90 \\
\hline Bufo spinosus & 30SUJ97 & 100,00 & 132,15 & 120,44 & 36,84 & 6851,92 & 324,03 & $-0,53$ & 324,56 & 115,20 & 225,31 & 225,31 & 50,23 & 460,33 & 54,11 & 8,08 & 38,49 & 155,84 & 47,81 & 47,81 & 130,91 \\
\hline Bufo spinosus & 30SUJ98 & 100,00 & 131,73 & 118,86 & 36,18 & 6842,66 & 322,13 & $-0,47$ & 322,60 & 114,83 & 224,72 & 224,73 & 49,97 & 454,45 & 53,69 & 8,53 & 37,87 & $\mid 152,77$ & 48,75 & 48,75 & 127,88 \\
\hline Bufo spinosus & 30SUJ99 & 100,00 & 137.42 & 117,29 & 36,00 & 6853,44 & 325,79 & 4,68 & 321.11 & $\mid 121,32$ & 230,47 & 230,47 & 54,88 & 427.42 & 50,38 & 8,04 & 37,70 & $\mid 142,60$ & 46,05 & 46,05 & 119,32 \\
\hline Bufo spinosus & 30SUK10 & 100,00 & 155,03 & 116,19 & 36,88 & \begin{tabular}{|l|l|}
6631,04 \\
\end{tabular} & 337,90 & 25,12 & 312,77 & 112,80 & 243,99 & 243,99 & 73,90 & 387,96 & 44,67 & 5,10 & 41,97 & \begin{tabular}{|l|l|}
130,74 \\
\end{tabular} & 33,97 & 33,97 & 116,10 \\
\hline Bufo spinosus & 30SUK40 & 100,00 & 146,53 & 116,44 & 36,23 & 6706,19 & 331,25 & 15,48 & 315,77 & 129,94 & 236,95 & 236,95 & 65,07 & 397,08 & 46,01 & 6,48 & 39,79 & 131,86 & 39,04 & 39,04 & 113,41 \\
\hline Bufo spinosus & 30SUK42 & 100,00 & 153,17 & 114,75 & \begin{tabular}{|l|l|}
36,09 \\
\end{tabular} & 6644,08 & 333,95 & 22,73 & 311,21 & 112,53 & 242,41 & 242,41 & 71,86 & 359,77 & 41,62 & 6,11 & 39,30 & \begin{tabular}{|l|l|}
119,29 \\
\end{tabular} & 36,19 & 36,19 & 101,33 \\
\hline Bufo spinosus & 30SUK51 & 100,00 & 149,50 & 115,26 & 36,00 & 6702,48 & 332,43 & 18,28 & 314,14 & 128,10 & 239,76 & 239,76 & 67,73 & 376,64 & 43,95 & 6,52 & 38,94 & \begin{tabular}{|l|l|}
124,28 \\
\end{tabular} & 38,22 & 38,22 & 105,82 \\
\hline Bufo spinosus & 30SUK80 & 100,00 & 149,30 & 115,40 & 35,95 & 6835,18 & 334,28 & 16,19 & 318,09 & 128,56 & 241,51 & 241,51 & 65,95 & 384,66 & 44,56 & 6,71 & 38,52 & 127,14 & 39,66 & 39,66 & 107,63 \\
\hline Bufo spinosus & 30SUK90 & 100,00 & 143,16 & 115,31 & 35,81 & 6860,69 & 329,16 & 10,21 & 318,95 & 127,38 & 235,93 & 235,93 & 60,10 & 404,49 & 47,19 & 7,82 & 37,34 & 133,31 & 43,97 & 43,97 & 112,35 \\
\hline Bufo spinosus & 30SUK91 & 100,00 & 150,90 & 113,42 & 35,24 & 6847,36 & 334,12 & $\begin{array}{l}0,24 \\
17,96\end{array}$ & 316,15 & $\begin{array}{l}119,18 \\
\end{array}$ & \begin{tabular}{|l|l|}
243,29 \\
\end{tabular} & 243,29 & $\begin{array}{l}07,14 \\
67,14\end{array}$ & 377,12 & $\mid 43,17$ & $\begin{array}{l}, 02 \\
7,22\end{array}$ & 37,55 & $\mid 123,31$ & 40,33 & 40,33 & 105,06 \\
\hline Bufo spinosus & 30SVF06 & 32,00 & 182,14 & 88,44 & 38,00 & 4926,03 & 305,81 & 75,25 & 230,56 & 131,58 & 246,78 & 248,14 & 122,78 & 418,61 & 67,00 & 2,00 & 64,61 & \begin{tabular}{|l|l|}
190,67 \\
\end{tabular} & 14,67 & 18,11 & 176,56 \\
\hline Bufo spinosus & 30SVF07 & 100,00 & 167,91 & 97,84 & 38,12 & 5325,12 & 307,58 & 54,66 & 252,93 & 112,35 & 238,92 & 239,17 & 103,99 & 454,88 & 70,73 & 2,98 & 61,86 & 201,03 & 17,95 & 19,37 & 186,34 \\
\hline Bufo spinosus & 30SVF08 & 100,00 & 133,56 & 113,95 & 38,03 & 6023,94 & 304,68 & 10,38 & 294,30 & 71,01 & 215,36 & 215,38 & 62,47 & 616,68 & 84,16 & 7,03 & 55,93 & 246,27 & 32,40 & 32,95 & 237,63 \\
\hline Bufo spinosus & 30SVF09 & 100,00 & 136,99 & 115,65 & 38,00 & 6143,62 & 311,83 & 11,90 & 299,92 & 72,73 & 220,46 & 220,46 & 64,20 & 596,54 & 80,01 & 6,42 & 55,62 & 238,08 & 29,95 & 29,95 & 229,69 \\
\hline Bufo spinosus & 30SVF16 & & & & & & & & & & $2<0,40$ & & & & & 0,42 & 然, & & & & 26,03 \\
\hline Bufo spinosus & 30SVF17 & 100,00 & 159,46 & 103,53 & 38,19 & 5540,32 & 309,17 & 42,39 & 266,78 & 101,41 & 233,86 & 233,92 & 93,12 & 458,48 & 67,69 & 3,80 & 59,34 & \begin{tabular}{|l|l|}
196,04 \\
\end{tabular} & 19,99 & 20,58 & 183,33 \\
\hline Bufo spinosus & 30SVF18 & 100,00 & 126,82 & 117,46 & 38,02 & 6171,08 & 304,79 & 1,30 & 303,49 & 63,14 & 210,80 & 210,83 & 54,17 & 631,64 & 82,95 & 7,90 & 53,93 & 245,10 & 35,22 & 35,73 & 239,22 \\
\hline Bufo spinosus & 30SVF19 & 100,00 & 139,25 & 116,15 & 38,00 & 6168,30 & 314,74 & 13,34 & 301,40 & 74,45 & 223,03 & 223,03 & 65,97 & 561,14 & 75,10 & 6,36 & 54,89 & 222,64 & 28,74 & 28,74 & 214,12 \\
\hline \begin{tabular}{|l} 
Bufo spinosus \\
\end{tabular} & $\begin{array}{l}30 \text { SVF26 } \\
\end{array}$ & & & & & & & & & & & & & & & & & & & & \\
\hline \begin{tabular}{|l} 
Bufo spinosus \\
\end{tabular} & 30SVF27 & 100,00 & 141,26 & 111,30 & 38,16 & 5870,76 & 306,13 & \begin{tabular}{|l|l|}
19,53 \\
\end{tabular} & 286,61 & 80,52 & 220,65 & 220,71 & 71,64 & 534,35 & 72,65 & 6,17 & 55,57 & 213,17 & 28,24 & 29,07 & 205,17 \\
\hline \begin{tabular}{|l|} 
Bufo spinosus \\
\end{tabular} & 30SVF28 & 100,00 & 132,77 & 117,33 & 38,04 & 6163,82 & 309,87 & 6,88 & 302,99 & 69,12 & 216,59 & 216,59 & 59,94 & 577,46 & 76,14 & 7,13 & 53,57 & 224,27 & 31,52 & 31,52 & 218,23 \\
\hline Bufo spinosus & 30 SVF29 & 100,00 & 135,92 & 117,76 & 38,00 & 6238,52 & 314,48 & 9,06 & 305,41 & 70,73 & 220,70 & 220,70 & 62,00 & 564,20 & 74,42 & 6,97 & 53,54 & \begin{tabular}{|l|l|}
218,67 \\
\end{tabular} & 30,59 & 30,59 & 211,99 \\
\hline Bufo spinosus & 30 SVF36 & 46,00 & 174,84 & 94,82 & 38,02 & 5184,26 & 309,11 & 63,31 & 245,80 & 120,82 & 243,44 & 244,08 & 112,26 & 362,41 & 53,00 & 2,33 & 60,03 & 157,21 & 14,16 & 17,56 & 146,72 \\
\hline Bufo spinosus & 30 SVF37 & 100,00 & 154,58 & 107,92 & 38,1 & 5726,31 & 312,32 & 34,15 & 278,18 & 94,73 & 231,64 & 231,68 & 86,07 & 441,92 & 61,35 & 4,36 & 56,31 & 180,91 & 21,02 & 21,48 & 171,45 \\
\hline \begin{tabular}{|l} 
Bufo spinosus \\
\end{tabular} & 30SVF38 & 100,00 & 127,31 & 118,64 & 38,00 & 6235,23 & 307,54 & \begin{tabular}{r|}
0,59 \\
0,5
\end{tabular} & 306,95 & 63,47 & 212,11 & 212,11 & 53,92 & 596,31 & 77,20 & 8,08 & 52,06 & 225,13 & 35,01 & 35,01 & 221,38 \\
\hline Bufo spinosus & 30SVF39 & 100,00 & 131,54 & 119,18 & 38,00 & 6302,90 & 313,32 & 3,82 & 309,50 & 66,47 & 217,44 & 217,44 & 57,15 & 576,55 & 75,14 & 7,64 & 52,13 & 217,65 & 33,15 & 33,15 & 213,27 \\
\hline Bufo spinosus & 30SVF46 & 39,00 & 176,27 & 94,16 & 38,00 & 5177,69 & 309,59 & 64,71 & 244,88 & 122,35 & 244,45 & 245,33 & 113,53 & 341,96 & 49,25 & 2,31 & 59,10 & \begin{tabular}{|l|l|}
146,37 \\
\end{tabular} & 13,47 & 17,37 & 137,31 \\
\hline Bufo spinosus & 30SVF47 & 100,00 & 159,54 & 105,76 & 38,09 & 5649,02 & 313,34 & 40,31 & 273,04 & 100,56 & 235,24 & 235,39 & 91,74 & 405,70 & 56,3 & 3,8 & 56,20 & 65 & 18,68 & 20,10 & 157,14 \\
\hline Bufo spinosus & 30SVF49 & 100,00 & 144,52 & 117,92 & 38,00 & $\frac{6222,36}{622,0}$ & 322, & \begin{tabular}{|l|l|}
16,38 \\
16,
\end{tabular} & 305,67 & $\begin{array}{l}79,48 \\
79\end{array}$ & 228,90 & 228,90 & 70,24 & 488,69 & 60,22 & $\begin{array}{l}, 01 \\
5,89 \\
\end{array}$ & 52,86 & $\begin{array}{l}187,38 \\
\end{array}$ & 25,87 & 25,87 & 181,41 \\
\hline \begin{tabular}{|l} 
Bufo spinosus \\
\end{tabular} & 30 SVF56 & 72,00 & 177,14 & 92,92 & \begin{tabular}{|l|l|}
37,97 \\
\end{tabular} & 5138,75 & 308,87 & 66,64 & 242,23 & 124,12 & 244,73 & 245,98 & 115,02 & 323,99 & 46,75 & 2,07 & 58,29 & \begin{tabular}{|l|l|}
137,38 \\
\end{tabular} & 12,52 & 17,56 & 129,49 \\
\hline \begin{tabular}{|l} 
Bufo spinosus \\
\end{tabular} & $\begin{array}{l}30 \text { SVF57 } \\
\end{array}$ & 100,00 & 159,37 & 105,05 & 38,01 & 5647,74 & 312,63 & 40,51 & 272,12 & $\begin{array}{l}100,78 \\
\end{array}$ & 234,96 & 235,27 & 91,68 & 398,57 & 54,91 & 3,90 & 55,24 & 159,44 & 19,14 & 22,90 & 152,46 \\
\hline Bufo spinosus & 30SVF58 & 100,00 & 151,65 & 111,24 & 38,00 & 5928,96 & 316,66 & 28,35 & 288,31 & 89,96 & 231,53 & 231,60 & 80,85 & 437,84 & 59,44 & 5,03 & 53,48 & 169,94 & 22,82 & 24,13 & 163,64 \\
\hline \begin{tabular}{|l} 
Bufo spinosus \\
\end{tabular} & $\begin{array}{l}30 \text { SVF59 } \\
\end{array}$ & 100,00 & 104,01 & 121,17 & 37,92 & 6446,90 & 292,30 & $-23,95$ & 316,25 & 45,38 & 192,09 & 192,42 & 29,21 & 717,51 & 89,99 & 14,93 & 46,53 & 256,12 & 59,06 & 62,18 & 247,05 \\
\hline \begin{tabular}{|l} 
Bufo spinosus \\
\end{tabular} & 30SVF66 & & & & & & & & & & & & & & & & & & & & \\
\hline Bufo spinosus & 30SVF67 & 100,00 & 138,51 & 113,04 & 38,00 & 6002,14 & 307,75 & 14,95 & 292,80 & 77,56 & 219,50 & 220,01 & 67,56 & 494,65 & 64,81 & 6,81 & 51,52 & \begin{tabular}{|c|}
184,87 \\
\end{tabular} & 29,65 & 36,48 & 181,19 \\
\hline \begin{tabular}{|l} 
Bufo spinosus \\
\end{tabular} & 30SVF68 & 100,00 & 145,95 & 111,88 & 38,00 & 5986,90 & 313,21 & 22,53 & 290,68 & 85,22 & 226,68 & 226,92 & 74,84 & 459,45 & 61,02 & 5,88 & 51,92 & \begin{tabular}{|l|l|}
172,95 \\
\end{tabular} & 26,35 & 31,35 & 168,28 \\
\hline Bufo spinosus & 30SVF69 & 100,00 & 72,97 & 122,82 & 37,61 & 6587,29 & 267,50 & $-54,97$ & 322,48 & 21,67 & 163,66 & 164,27 & $-2,03$ & 900,79 & 109,13 & 25,20 & 41,06 & 314,29 & 93,63 & 97,06 & 292,93 \\
\hline Bufo spinosus & 30 SVF76 & & & & & & & & & & & & & & & & & & & & \\
\hline Bufo spinosus & 30SVF77 & 100,00 & 141,47 & 111,78 & 38,00 & 5970,81 & 308,71 & 18, & 290,30 & 80,95 & 221,84 & 222,7 & 70,96 & 465 & 60,90 & 6,16 & 51,14 & 172,79 & 27,34 & 35,47 & 169,90 \\
\hline Bufo spinosus & 30SVF78 & 100,00 & 137,54 & 114,66 & 38,00 & 6125,11 & 310,65 & 12,40 & 298,25 & 77,14 & 220,24 & 220,87 & 65,25 & 491,79 & 63,45 & 7,00 & 50,06 & 179,05 & 30,47 & 38,11 & 176,57 \\
\hline Bufo spinosus & 30SVF79 & 100,00 & 84,24 & 121,90 & 37,75 & 6536,23 & 276,12 & $-43,49$ & 319,61 & 33,94 & 173,84 & 174,68 & 9,40 & 816,99 & 99,13 & 21,72 & 41,68 & 285,37 & 81,84 & 86,32 & 266,44 \\
\hline Bufo spinosus & 30SVF86 & 30,00 & 171,17 & 93,81 & 37,69 & 5251,89 & 306,11 & 59,75 & 246,36 & 117, & 240, & 242,11 & 107,92 & 311,67 & 43,47 & 2,33 & 55,06 & $\begin{array}{ll}124,75 \\
\end{array}$ & 13,64 & 19,44 & 119,36 \\
\hline Bufo spinosus & 30SVF87 & 100,00 & 148,05 & 107,66 & 37,99 & 5823,31 & 308,04 & 27,55 & 280,49 & 89,11 & 226,04 & 227,34 & 79,09 & 421,66 & 55,24 & 5,26 & 51,20 & 156,62 & 24,17 & 31,90 & 153,55 \\
\hline
\end{tabular}




\begin{tabular}{|c|c|c|c|c|c|c|c|c|c|c|c|c|c|c|c|c|c|c|c|c|c|}
\hline TAXON & UTM & $\mathrm{km} 2$ & BIO1 & B102 & $B 103$ & BIO4 & B105 & B106 & B107 & B108 & B109 & B1010 & BIO11 & BIO12 & BIO13 & B1014 & BIO15 & B1016 & B1017 & B1018 & 81019 \\
\hline Bufo spinosus & 30SVF88 & 100,00 & 136,35 & 113,95 & 37,99 & 6115,76 & 308,71 & 11,71 & 297,00 & 75,72 & 218,92 & 219,85 & 64,42 & 487,39 & 61,85 & 7,22 & 49,04 & 174,61 & 31,39 & 39,77 & 172,74 \\
\hline Bufo spinosus & 30SVF89 & 100,00 & 112,96 & 118,39 & 37,97 & 6356,66 & 295,94 & $-13,57$ & 309,51 & 60,76 & 199,37 & 200,30 & 39,15 & 628,47 & 77,78 & 13,18 & 45,06 & 221,29 & 52,71 & 59,65 & 211,40 \\
\hline Bufo spinosus & 30SVF96 & 31,00 & 172,63 & 91,29 & 37,20 & 5181,34 & $\begin{array}{l}304,29 \\
\end{array}$ & 62,76 & 241,54 & 120,05 & 240,20 & 242,66 & 110,12 & 296,85 & 41,29 & 2,17 & 54,78 & $\begin{array}{l}117,63 \\
\end{array}$ & 13,05 & 18,63 & 112,80 \\
\hline Bufo spinosus & 30SVF97 & 100,00 & 157,29 & 101,36 & 37,74 & 5594,42 & 306,41 & $\begin{array}{ll}40,82 \\
\end{array}$ & 265,58 & 100,68 & 231,47 & 233,33 & 90,53 & 366,20 & 48,44 & 3,94 & 51,79 & \begin{tabular}{|l|l|}
137,63 \\
\end{tabular} & 19,61 & 26,57 & 134,02 \\
\hline Bufo spinosus & 30SVF98 & 100,00 & 154,21 & 104,91 & 37,83 & $5767,85 \mid$ & 309,91 & 35,00 & $274,91 \mid$ & 95,56 & 231,09 & 232,62 & 85,49 & 383,14 & 50,11 & 4,41 & 50,69 & 141,25 & 21,40 & 28,81 & 138,01 \\
\hline Bufo spinosus & 30SVF99 & 100,00 & 137,76 & 111,74 & 37,86 & 6080,67 & 307,06 & 14,40 & 292,67 & 82,08 & 219,58 & 220,73 & 66,13 & $\mid 477,34$ & 60,49 & 7,68 & 47,77 & \begin{tabular}{|l|l|}
169,92 \\
\end{tabular} & 33,42 & \begin{tabular}{|l|l|l|}
40,98 & \\
\end{tabular} & $\begin{array}{ll}164,84 \\
\end{array}$ \\
\hline Bufo spinosus & 30SVG00 & 100,00 & 140,34 & 115,24 & 37,99 & 6202,73 & 315,66 & 15,01 & 300,65 & 74,86 & 224,61 & 224,61 & 66,69 & 582,23 & 79,01 & 6,38 & 55,46 & 231,74 & 29,46 & 29,46 & 222,61 \\
\hline Bufo spinosus & 30SVG01 & 100,00 & 158,93 & 109,21 & 37,43 & 6048,53 & 323,79 & 36,26 & 287,53 & \begin{tabular}{|l|l}
93,18 \\
\end{tabular} & 240,85 & 240,85 & 86,47 & $\begin{array}{l}493,41 \\
\end{array}$ & 72,84 & 4,53 & 57,51 & 204,53 & 22,43 & 22,43 & $\begin{array}{ll}190,89 \\
\end{array}$ \\
\hline Bufo spinosus & 30SVG02 & 100,00 & 150,38 & \begin{tabular}{ll|}
113,64 \\
\end{tabular} & \begin{tabular}{l|l|l}
37,05 \\
\end{tabular} & $\begin{array}{l}6307,82 \\
\end{array}$ & 325,61 & 24,74 & \begin{tabular}{ll|}
300,86 \\
\end{tabular} & 82,49 & 236,10 & 236,10 & 75,05 & 546,70 & 74,73 & 5,65 & 55,64 & 217,00 & 26,42 & 26,42 & 207,91 \\
\hline Bufo spinosus & 30SVG03 & 100,00 & 144,25 & 116,31 & 37,00 & \begin{tabular}{|l|l|}
6493,53 \\
\end{tabular} & 326,55 & 16,71 & \begin{tabular}{|l|}
309,84 \\
\end{tabular} & 75,08 & 232,55 & 232,55 & 66,95 & 591,22 & 77,10 & 6,41 & 54,50 & 226,69 & 29,73 & 29,73 & 221,93 \\
\hline Bufo spinosus & 30SVG04 & 100,00 & 153,14 & 113,90 & 36,66 & 6516,42 & 333,25 & 26,35 & 306,90 & 83,34 & 241,63 & 241,63 & 75,37 & 567,18 & 73,69 & 5,63 & 55,34 & 216,96 & 26,66 & 26,66 & 213,60 \\
\hline Bufo spinosus & 30SVG10 & 100,00 & 146,56 & $\begin{array}{l}114,97 \\
\end{array}$ & 37,99 & $\begin{array}{l}6181,29 \\
\end{array}$ & 320,53 & 20,79 & \begin{tabular}{|l|l|}
299,74 \\
\end{tabular} & 80,53 & 230,58 & 230,58 & 72,92 & 519,77 & 71,88 & 5,83 & 55,21 & 208,73 & 26,13 & 26,13 & 197,66 \\
\hline Bufo spinosus & 30SVG11 & 100,00 & 156,80 & 111,43 & 37,70 & 6116,14 & 325,09 & 32,39 & 292,70 & 89,82 & 239,79 & 239,79 & 83,49 & 465,79 & 69,00 & 4,91 & 56,07 & 191,06 & 22,99 & 22,99 & 176,59 \\
\hline Bufo spinosus & 30SVG12 & 100,00 & 149,03 & 114,67 & 37,13 & $6337,57 \mid$ & 325,89 & 22,51 & 303,38 & 80,62 & 235,18 & 235,18 & 73,41 & 525,07 & 72,16 & $5,99 \mid$ & 54,51 & 205,95 & 27,16 & 27,16 & 196,40 \\
\hline Bufo spinosus & 30SVG13 & 100,00 & 138,03 & \begin{tabular}{ll|}
118,49 \\
\end{tabular} & 37,01 & 6573,18 & 324,53 & 9,28 & $\begin{array}{l}315,26 \\
\end{array}$ & \begin{tabular}{|l|l|}
68,87 \\
\end{tabular} & 227,57 & 227,57 & 60,05 & $\begin{array}{l}604,05 \\
\end{array}$ & 78,08 & 7,40 & 53,03 & 225,93 & 32,95 & 32,95 & 222,81 \\
\hline Bufo spinosus & 30SVG14 & 100,00 & 143,62 & 1117,40 & 36,89 & 6630,32 & 330,15 & 14,90 & \begin{tabular}{l|l|}
315,25 \\
\end{tabular} & 75,28 & 233,90 & 233,90 & 64,83 & $\begin{array}{l}589,65 \\
\end{array}$ & 77,39 & 6,85 & 53,37 & 220,12 & 31,00 & 31,00 & 217,41 \\
\hline Bufo spinosus & 30SVG16 & 100,00 & 156,32 & 113,25 & 35,89 & 6725,89 & 340,77 & 29,01 & 311,77 & 87,56 & 247,53 & 247,53 & 75,98 & 573,85 & 81,39 & 5,70 & 54,92 & 221,15 & 27,11 & 27,11 & 212,48 \\
\hline Bufo spinosus & 30SVG20 & 100,00 & 145,69 & 116,98 & 38,00 & 6252,42 & 322,93 & 18,24 & 304,69 & 78,98 & 230,76 & 230,76 & 71,08 & 505,76 & 68,07 & 6,06 & 53,89 & $\mid$\begin{tabular}{|l|l|}
199,54 \\
\end{tabular} & 26,34 & 26,34 & 189,76 \\
\hline Bufo spinosus & 30SVG22 & 100,00 & 153,52 & 114,99 & $37,21]$ & 6338,62 & 330,23 & 26,31 & 303,92 & 84,42 & 239,78 & 239,78 & 77,80 & 473,18 & 65,41 & 5,45 & 54,03 & 185,84 & 24,53 & 24,53 & 175,09 \\
\hline Bufo spinosus & 30SVG23 & 100,00 & 143,48 & 118,29 & 37,00 & 6569,32 & 329,22 & 14,20 & \begin{tabular}{l|l|}
315,02 \\
\end{tabular} & 73,80 & 232,93 & 232,93 & 65,32 & 558,01 & 71,92 & 6,87 & 52,63 & 208,01 & 30,10 & 30,10 & 204,63 \\
\hline Bufo spinosus & 30SVG25 & 100,00 & 130,21 & 120,26 & 36,87 & $\begin{array}{ll}6743,06 \\
\end{array}$ & 322,75 & 0,62 & 322,12 & \begin{tabular}{|l|l|}
61,14 \\
\end{tabular} & 222,23 & 222,23 & 50,70 & \begin{tabular}{ll|}
642,81 \\
\end{tabular} & 86,59 & 8,94 & 50,67 & 236,40 & 39,79 & 39,79 & 228,93 \\
\hline Bufo spinosus & 30SVG26 & 100,00 & 138,11 & 118,47 & $\begin{array}{l}36,35 \\
\end{array}$ & 6793,43 & 329,70 & 8,59 & 321,11 & $\begin{array}{ll}69,51 \\
\end{array}$ & 230,62 & 230,62 & 57,78 & \begin{tabular}{ll|l}
620,03 \\
\end{tabular} & 85,90 & 8,01 & 51,60 & 230,96 & 36,29 & 36,29 & 221,40 \\
\hline Bufo spinosus & 30SVG27 & 100,00 & 149,35 & \begin{tabular}{|l|l}
114,96 \\
\end{tabular} & 35,68 & 6835,44 & 338,37 & 21,04 & 317,34 & 80,48 & 242,35 & 242,35 & 68,20 & 594,90 & 86,50 & 6,71 & 53,41 & 227,54 & 31,52 & 31,52 & 214,63 \\
\hline Bufo spinosus & 30SVG30 & 100,00 & 148,16 & 118,29 & 38,00 & 6278,06 & 326,89 & 19,56 & 307,33 & 81,36 & 233,53 & 233,53 & 73,22 & 479,05 & 64,55 & 5,64 & 53,49 & 187,07 & 24,65 & 24,65 & 178,29 \\
\hline Bufo spinosus & 30SVG32 & 100,00 & 155,35 & 116,17 & \begin{tabular}{|l|l|}
37,27 \\
\end{tabular} & $\begin{array}{l}6367,30 \\
\end{array}$ & 333,48 & 27,03 & $\begin{array}{l}306,45 \\
\end{array}$ & 86,06 & 241,90 & 241,90 & 79,03 & 449,20 & 60,94 & 5,31 & 53,20 & \begin{tabular}{|l|l|}
174,40 \\
\end{tabular} & 23,25 & 23,25 & 164,69 \\
\hline Bufo spinosus & 30SVG33 & 100,00 & 145,52 & 118,63 & 37,00 & 6567,88 & 331,36 & 15,78 & 315,57 & 76,20 & 235,00 & 235,00 & 67,37 & 530,49 & 68,97 & 6,75 & 52,08 & 196,18 & 29,18 & 29,18 & 192,47 \\
\hline Bufo spinosus & 30SVG34 & 100,00 & 139,93 & 119,43 & 36,99 & 6683,69 & 329,45 & $\begin{array}{l}, 99 \\
\end{array}$ & \begin{tabular}{ll|}
319,46 \\
\end{tabular} & 71,39 & 231,01 & 231,01 & 60,73 & \begin{tabular}{|l|l|}
574,29 \\
\end{tabular} & 75,90 & 7,53 & 51,31 & 209,78 & 33,08 & 33,08 & 206,13 \\
\hline Bufo spinosus & 30SVG35 & 100,00 & 126,20 & 121,18 & $|36,97|$ & 6752,57 & 319,85 & $\mid-3,67$ & 323,52 & 64,45 & 218,48 & 218,48 & 46,92 & \begin{tabular}{|l|l|l}
644,41 \\
\end{tabular} & 86,30 & \begin{tabular}{|c|c|}
9,73 \\
\end{tabular} & 49,36 & 234,17 & $\mid 42,64$ & \begin{tabular}{|c|c|}
42,64 \\
\end{tabular} & 225,70 \\
\hline Bufo spinosus & 30SVG38 & 100,00 & 172,59 & 108,24 & 35,04 & \begin{tabular}{ll|l|}
6691,36 \\
\end{tabular} & 350,72 & 47,06 & \begin{tabular}{ll|}
303,66 \\
\end{tabular} & 103,34 & 262,76 & 262,76 & 92,04 & 500,91 & 75,67 & 3,99 & 55,81 & 195,89 & 21,58 & 21,58 & 183,27 \\
\hline Bufo spinosus & 30SVG40 & 100,00 & 145,38 & 119,73 & 38,00 & $\begin{array}{l}6347,76 \\
\end{array}$ & 327,09 & 15,72 & \begin{tabular}{|l|l|}
311,37 \\
\end{tabular} & 78,74 & 231,55 & 231,55 & 69,68 & 491,34 & 66,55 & 5,95 & 52,60 & 186,27 & 25,97 & 25,97 & 180,81 \\
\hline Bufo spinosus & 30SVG41 & 100,00 & 153,30 & $\begin{array}{l}119,43 \\
\end{array}$ & 37,94 & 6373,83 & $\begin{array}{l}334,49 \\
\end{array}$ & 23,04 & 311,45 & 85,31 & 239,83 & 239,83 & 76,87 & 453,80 & 62,06 & 5,21 & 53,01 & $\begin{array}{l}173,27 \\
\end{array}$ & 22,75 & 22,75 & 166,64 \\
\hline Bufo spinosus & 30SVG42 & 100,00 & 148,23 & 119,59 & 37,30 & $\begin{array}{ll}6503,29 \\
\end{array}$ & 333,06 & 17,69 & \begin{tabular}{|l|l|}
315,37 \\
\end{tabular} & 79,29 & 236,58 & 236,58 & 70,59 & \begin{tabular}{|l|l|}
494,17 \\
\end{tabular} & 65,33 & 6,06 & 52,03 & 182,97 & 26,45 & 26,45 & 179,08 \\
\hline Bufo spinosus & 30SVG43 & 100,00 & 147,47 & 119,11 & 37,00 & 6579,18 & 333,78 & 17,30 & \begin{tabular}{|l|l|}
316,48 \\
\end{tabular} & 78,58 & 237,05 & 237,05 & 69,25 & $\begin{array}{l}511,75 \\
\end{array}$ & 66,96 & 6,32 & 51,82 & 186,44 & 27,85 & 27,85 & 184,32 \\
\hline Bufo spinosus & 30SVG44 & 100,00 & 139,33 & 1119,77 & 37,00 & 6682,62 & 329,05 & 9,07 & \begin{tabular}{|l|l|}
319,98 \\
\end{tabular} & 79,28 & 230,30 & 230,30 & 60,18 & 564,60 & 74,91 & 7,68 & 50,60 & 204,73 & 33,72 & 33,72 & 200,23 \\
\hline Bufo spinosus & 30SVG45 & 100,00 & 136,11 & 1119,86 & \begin{tabular}{|l|}
36,88 \\
\end{tabular} & \begin{tabular}{|l|l|l|}
6743,93 \\
\end{tabular} & 327,60 & 5,93 & \begin{tabular}{|l|l|}
321,68 \\
\end{tabular} & 83,75 & 228,09 & 228,09 & 56,45 & 587,08 & 79,14 & 8,34 & 49,90 & 214,21 & 36,75 & 36,75 & 205,80 \\
\hline Bufo spinosus & 30SVG47 & 100,00 & 147,62 & 116,10 & 35,98 & 6802,55 & 336,55 & $\begin{array}{ll}18,67 \\
\end{array}$ & \begin{tabular}{|l|l|}
317,88 \\
\end{tabular} & \begin{tabular}{|l|l}
93,94 \\
\end{tabular} & 239,99 & 239,99 & 66,83 & 562,77 & 80,08 & $\begin{array}{ll}6,999 \\
\end{array}$ & 51,40 & 211,26 & 32,76 & 32,76 & 197,56 \\
\hline Bufo spinosus & 30SVG48 & 100,00 & 160,46 & 112,17 & 35,26 & \begin{tabular}{|l|l|}
6796,60 \\
\end{tabular} & 345,24 & 32,91 & 312,34 & \begin{tabular}{|l|l|}
105,88 \\
\end{tabular} & 252,39 & 252,39 & 79,30 & 527,44 & 78,75 & 5,40 & 53,53 & 202,94 & 26,89 & 26,89 & 187,64 \\
\hline Bufo spinosus & 30SVG50 & 100,00 & 111,64 & 121,25 & \begin{tabular}{l|l|l}
37,95 \\
\end{tabular} & $\begin{array}{ll}6483,53 \\
\end{array}$ & 300,34 & $-16,90$ & 317,23 & 53,95 & 200,07 & 200,32 & 36,09 & 673,94 & 85,04 & 12,65 & 47,20 & 240,43 & 51,48 & 55,05 & 233,93 \\
\hline Bufo spinosus & 30SVG51 & 100,00 & 137,77 & 120,31 & 37,8 & 6468,57 & 323,32 & 7,91 & 315,41 & 72,75 & 225,69 & 225,71 & 61,08 & 533,14 & 69,61 & 7,34 & 50,53 & 92,97 & 31,75 & 32,01 & 190,72 \\
\hline Bufo spinosus & 30SVG55 & 100,00 & 134,70 & 120,19 & 37,00 & 6727,44 & 325,86 & 4,20 & 321,66 & 86,12 & 226,34 & 226,34 & 55,16 & 576,79 & 77,16 & 8,54 & 48,93 & 209,65 & 37,73 & 37,73 & 199,31 \\
\hline Bufo spinosus & 30SVG58 & 100,00 & 148,94 & 115,90 & 36,12 & \begin{tabular}{|l|l|}
6782,17 \\
\end{tabular} & $\begin{array}{l}336,74 \\
\end{array}$ & 19,89 & \begin{tabular}{l|l|}
316,85 \\
\end{tabular} & 100,73 & 240,96 & 240,96 & 68,35 & $\begin{array}{l}539,85 \\
\end{array}$ & 76,30 & 6,80 & 50,24 & 201,74 & 32,99 & 32,99 & 185,82 \\
\hline Bufo spinosus & 30SVG60 & 100,00 & 71,10 & 123,12 & \begin{tabular}{l|l|}
37,55 \\
\end{tabular} & 6632,43 & 267,01 & $-57,13$ & \begin{tabular}{|l|l|}
324,14 \\
\end{tabular} & $\begin{array}{ll}20,08 \\
\end{array}$ & 162,51 & 163,00 & $-4,30$ & $\begin{array}{l}913,97 \\
9\end{array}$ & 110,84 & 26,09 & 40,48 & \begin{tabular}{|l|l|}
318,17 \\
\end{tabular} & 96,84 & 99,76 & 294,48 \\
\hline Bufo spinosus & 30SVG61 & 100,00 & 112,41 & 121,28 & 37,8 & 6532,90 & 301,90 & $-16,22$ & 318,13 & 62,72 & 201,56 & 201,79 & 36,41 & 659,49 & 82,80 & 12,84 & 46,09 & 233,59 & 52,19 & 55,75 & 224,71 \\
\hline Bufo spinosus & 30SVG62 & 100,00 & 122,76 & 120,85 & 37,4 & 6557,57 & 311,71 & $-6,24$ & 317,96 & 74,06 & 212,14 & 212,21 & 45,92 & 605,29 & 77,14 & 10,41 & 47,20 & 215,44 & 43,91 & 45,90 & 207,94 \\
\hline Bufo spinosus & 30SVG64 & 100,00 & 136,36 & 119,84 & 37,00 & 6636, & 325,11 & 6,08 & \begin{tabular}{|l|l|}
319,03 \\
\end{tabular} & 88,25 & 226,72 & 226,73 & 57,94 & 547,77 & 71,86 & 8,15 & 48,48 & 197,16 & 35,97 & 36,09 & 188,69 \\
\hline Bufo spinosus & 30SVG65 & 100,00 & 135,93 & 119,71 & 37,00 & 6691,84 & 325,60 & 5,58 & 320,03 & 87,42 & 226,97 & 226,97 & 56,80 & 556,57 & 73,86 & 8,38 & 48,16 & 201,59 & 37,38 & 37,38 & 190,13 \\
\hline Bufo spinosus & 30SVG69 & 100,00 & 170,19 & 110,63 & 36,00 & $\begin{array}{l}6543,41 \\
\end{array}$ & $\begin{array}{l}346,04 \\
\end{array}$ & 43,41 & \begin{tabular}{|l|}
302,63 \\
\end{tabular} & 124,30 & 258,14 & 258,14 & 91,29 & \begin{tabular}{ll|}
430,62 \\
\end{tabular} & 59,77 & 3,66 & 51,49 & $\begin{array}{l}159,45 \\
\end{array}$ & 22,26 & 22,37 & 148,99 \\
\hline Bufo spinosus & 30SVG70 & 100,00 & 54,09 & 123,59 & 37,28 & \begin{tabular}{ll|l}
6697,92 \\
\end{tabular} & 252,50 & $-74,06$ & \begin{tabular}{ll|}
326,56 \\
\end{tabular} & 1,98 & 146,83 & 147,35 & $-21,36$ & $\begin{array}{ll}1016,06 \\
\end{array}$ & 121,77 & 33,74 & 37,00 & 349,64 & 120,69 & 121,91 & 315,63 \\
\hline Bufo spinosus & 30SVG72 & 100,00 & 131,32 & 119,24 & \begin{tabular}{|l|l|}
37,27 \\
\end{tabular} & 6501,60 & 316,88 & 2,31 & 314,58 & 83,27 & 219,66 & 219,80 & 54,84 & 548,03 & 69,45 & 8,87 & 47,55 & 194,36 & 38,15 & 40,92 & 187,99 \\
\hline Bufo spinosus & 30SVG73 & 100,00 & 134,85 & 119,13 & $37, \mathrm{C}$ & 6544,22 & 320,85 & 5,49 & 315,36 & 86,77 & 223,70 & 223,81 & 57,65 & 535,35 & 68,68 & 8,34 & 47,65 & 190,71 & 36,62 & 38,49 & 182,96 \\
\hline Bufo spinosus & 30SVG74 & 100,00 & \begin{tabular}{ll|}
139,94 \\
\end{tabular} & $\mid 118,44$ & 37,00 & \begin{tabular}{|l|}
6572,61 \\
\end{tabular} & 325,67 & 10,28 & \begin{tabular}{|l|l|}
315,39 \\
\end{tabular} & \begin{tabular}{|c|}
92,14 \\
\end{tabular} & 229,21 & 229,23 & 62,07 & 516,92 & 67,15 & 7,63 & 47,99 & \begin{tabular}{|l|l|}
185,14 \\
\end{tabular} & 34,32 & 35,44 & 176,46 \\
\hline Bufo spinosus & 30SVG80 & 100,00 & 70,94 & 122,64 & $\begin{array}{l}37,35 \\
\end{array}$ & 6633,80 & 266,05 & $-57,28$ & 323,33 & 19,60 & 162,10 & 163,00 & $-4,47$ & 893,20 & 108,67 & 27,35 & 38,32 & 309,13 & 100,59 & 102,94 & 280,06 \\
\hline Bufo spinosus & 30SVG81 & 100,00 & 117,90 & 119,38 & \begin{tabular}{|c|}
37,68 \\
\end{tabular} & \begin{tabular}{|l|l|}
6463,46 \\
\end{tabular} & 303,60 & $\begin{array}{l}-9,92 \\
\end{array}$ & 313 & 69,14 & 205,87 & 206,44 & 42 & 604,33 & 74,68 & 11,93 & 0 & 212,65 & 48,99 & 55,84 & 202,19 \\
\hline Bufo spinosus & $30 \mathrm{SV}$ & 100,00 & 144 & 116 & 37, & 642 & 324,13 & $\begin{array}{ll}15,93 \\
\end{array}$ & 308,20 & \begin{tabular}{|l|l|}
96,98 \\
\end{tabular} & 230,86 & 23 & \begin{tabular}{ll|}
67,69 \\
\end{tabular} & \begin{tabular}{|l|l|}
476,49 \\
\end{tabular} & 60,29 & 6,1 & 40,10 & 168 & 30,90 & 35,47 & 162,76 \\
\hline Bufo spinosus & 30SVG88 & 100,00 & \begin{tabular}{|l|l|}
163,67 \\
\end{tabular} & 111,76 & 36,80 & \begin{tabular}{|l|l|}
6443,26 \\
\end{tabular} & 338,13 & 36,77 & \begin{tabular}{|l|l|}
301,36 \\
\end{tabular} & 117,71 & 250,17 & 250,25 & 86,18 & \begin{tabular}{|l|l|}
414,98 \\
\end{tabular} & 54,20 & 4,38 & 48,68 & \begin{tabular}{|l|l|}
149,10 \\
\end{tabular} & 24,87 & 26,67 & 139,02 \\
\hline Bufo spinosus & 30SVG90 & 100,00 & 85,83 & 121,31 & $\begin{array}{l}37,58 \\
\end{array}$ & 6557,77 & 277,24 & $-41,90$ & \begin{tabular}{|l|l|}
319,14 \\
\end{tabular} & 35,25 & 175,59 & $\begin{array}{l}176,67 \\
\end{array}$ & 10,81 & 786,80 & $\begin{array}{l}97,22 \\
\end{array}$ & 22,23 & 39,53 & 273,08 & 83,72 & 87,56 & 248,57 \\
\hline Bufo spinosus & 30SVG91 & 100,00 & 123,64 & 117,72 & $\begin{array}{ll}37,63 \\
\end{array}$ & 6400,30 & 305,85 & $-3,53$ & 309,38 & 75,38 & 210,51 & 211,27 & 48,91 & 561,19 & 69,47 & 10,75 & 44,90 & 196,42 & 44,97 & 52,32 & 186,69 \\
\hline Bufo $s p$ & 30SVG92 & 100, & & 117 & 37 & 407, & 312 & 4,42 & 08 & 84,12 & 21 & & 56 & 518,62 & \begin{tabular}{|c|c|}
64,18 \\
\end{tabular} & ৪,৪চ] & & 18 & 3 & 40,37 & 173,32 \\
\hline Bufo spinosus & 30SVG93 & 100,00 & 129,06 & 118,02 & \begin{tabular}{|l|}
37,19 \\
\end{tabular} & 6480,29 & 312,71 & 1,07 & 311,64 & 80,73 & 216,99 & 217,51 & 53,18 & 538,44 & 66,96 & 9,71 & 44,88 & $\begin{array}{l}189,25 \\
\end{array}$ & 42,22 & 48,92 & 177,36 \\
\hline Bufo spinosus & 30SVG95 & 100,00 & 151,79 & 113,35 & 37,00 & 6370,99 & 327,12 & 25,09 & 302,03 & 105,32 & 237,60 & 237,94 & 75,87 & \begin{tabular}{|l|l|}
436,68 \\
\end{tabular} & 54,84 & 5,77 & 47,27 & 153,81 & 28,69 & 34,02 & 145,86 \\
\hline
\end{tabular}




\begin{tabular}{|c|c|c|c|c|c|c|c|c|c|c|c|c|c|c|c|c|c|c|c|c|c|}
\hline TAXON & UTM & $\mathrm{km} 2$ & B101 & B102 & $\mathrm{BIO3}$ & BIO4 & B105 & B106 & B107 & B108 & B109 & B1010 & B1011 & BIO12 & B1013 & BIO14 & BIO15 & B1016 & B1017 & B1018 & B1019 \\
\hline Bufo spinosus & 30SVG97 & 100,00 & 154,25 & 113,49 & 36,99 & 6438,83 & 330,70 & 26,98 & 303,72 & 107,68 & 240,95 & 241,14 & 77,26 & 434,65 & 55,14 & 5,55 & 46,94 & 154,05 & 29,32 & 33,38 & 142,86 \\
\hline Bufo spinosus & 30SVG98 & 100,00 & 138,54 & 117,48 & 37,01 & 6605,31 & 323,07 & 9,57 & 313,50 & 90,52 & 227,97 & 228,16 & 60,40 & 507,78 & 64,38 & 8,58 & 44,35 & 179,71 & 41,02 & 43,36 & 161,53 \\
\hline Bufo spinosus & 30SVG99 & 100,00 & 148,60 & 115,92 & 37,00 & 6562,74 & 329,82 & 20,00 & 309,82 & 101,51 & 237,17 & 237,29 & 70,40 & 463,21 & 59,05 & 6,64 & 45,31 & 164,47 & 34,75 & 36,81 & 148,06 \\
\hline Bufo spinosus & 30SVHO1 & 100,00 & 173,25 & 114,34 & 36,00 & 6739,98 & 356,56 & 43,78 & 312,78 & 103,74 & 263,86 & 263,86 & 91,44 & 511,77 & 75,83 & 3,23 & 55,60 & 195,58 & 21,62 & 21,62 & 185,27 \\
\hline Bufo spinosus & 30SVHO2 & 100,00 & 166,13 & 116,79 & 36,00 & \begin{tabular}{ll|l|}
6846,37 \\
\end{tabular} & 354,41 & 35,08 & 319,33 & \begin{tabular}{|l|l|}
96,84 \\
\end{tabular} & 258,37 & 258,37 & 83,31 & 530,30 & 78,73 & 3,62 & 54,44 & 201,04 & 24,27 & 24,27 & 188,86 \\
\hline Bufo spinosus & 30SVHO3 & 100,00 & 155,87 & 119,93 & 36,17 & 6936,06 & 349,27 & 23,47 & 325,80 & 103,94 & 249,62 & 249,62 & 72,41 & 553,67 & 80,94 & 4,54 & 52,48 & 207,08 & 29,00 & 29,00 & 192,78 \\
\hline Bufo spinosus & 30SVHO4 & 100,00 & 152,67 & 121,54 & 36,70 & 6943,12 & 347,59 & 19,47 & 328,12 & $\begin{array}{ll}105,63 \\
\end{array}$ & 246,53 & 246,53 & 69,13 & 547,43 & 78,34 & 4,60 & 51,14 & 202,35 & 30,55 & 30,55 & 187,44 \\
\hline \begin{tabular}{|l} 
Bufo spinosus \\
\end{tabular} & 30SVH05 & 100,00 & 144,87 & 123,50 & 37,00 & 6956,21 & 342,06 & 11,07 & 330,99 & $\begin{array}{l}97,66 \\
9\end{array}$ & 239,15 & 239,15 & 61,62 & 557,74 & 77,28 & 5,44 & 49,29 & 202,56 & 34,99 & 34,99 & 186,84 \\
\hline Bufo spinosus & 30SVH06 & 100,00 & 152,24 & 123,95 & 37,00 & 6927,25 & 348,01 & 17,46 & 330,55 & $\begin{array}{ll}105,68 \\
\end{array}$ & 245,73 & 245,73 & 68,59 & 511,84 & 70,05 & 4,21 & 49,41 & 184,61 & 30,80 & 30,80 & 170,22 \\
\hline Bufo spinosus & 30SVH07 & 100,00 & 145,28 & 125,58 & 37,04 & 6933,85 & 342,96 & 10,19 & 332,77 & 98,85 & 239,11 & 239,11 & 61,93 & 519,53 & 68,96 & 4,83 & 47,56 & 184,41 & 34,67 & 34,67 & 169,24 \\
\hline Bufo spinosus & 30SVH08 & 100,00 & 146,68 & 126,35 & 37,34 & 6917,47 & 344,27 & 10,82 & 333,44 & 123,90 & 240,12 & 240,12 & 63,49 & 495,58 & 64,12 & 4,31 & 46,88 & 175,07 & 33,86 & 33,86 & 159,05 \\
\hline Bufo spinosus & 30SVHO9 & 100,00 & 146,35 & 127,13 & \begin{tabular}{|l|l|}
37,87 \\
\end{tabular} & 6903,11 & 343,78 & 9,97 & 333,81 & 129,14 & 239,60 & 239,60 & 63,14 & 478,40 & 60,09 & 4,12 & 46,07 & 168,82 & 33,85 & 33,85 & 151,16 \\
\hline \begin{tabular}{|l} 
Bufo spinosus \\
\end{tabular} & 30SVH11 & 100,00 & 173,27 & 113,34 & 36,00 & 6740,93 & 355,86 & 44,18 & 311,68 & 103,58 & 263,83 & 263,83 & 91,41 & 500,60 & 74,46 & 3,27 & 55,22 & 191,21 & 21,66 & 21,66 & 180,09 \\
\hline Bufo spinosus & 30 SVH12 & 100,00 & 165,95 & 116,11 & 36,00 & 6846,00 & 353,68 & 35,44 & 318,24 & 105,58 & 258,18 & 258,18 & 83,22 & 519,72 & 77,25 & 3,74 & 53,92 & 197,10 & 24,62 & 24,62 & 183,63 \\
\hline Bufo spinosus & 30SVH14 & 100,00 & 157,62 & 120,27 & 36,56 & 6901,44 & 350,06 & 24,96 & 325,10 & 110,93 & 250,79 & 250,79 & 74,49 & 518,31 & 74,11 & 4,22 & 51,24 & 192,18 & 28,63 & 28,63 & 176,88 \\
\hline Bufo spinosus & 30SVH15 & 100,00 & 155,79 & 121,83 & 36,99 & 6898,91 & 349,23 & 22,23 & 327,01 & 109,29 & 248,88 & 248,88 & 72,53 & 506,77 & 70,68 & 4,16 & 50,15 & 185,38 & 29,49 & 29,49 & 170,10 \\
\hline Bufo spinosus & 30SVH16 & 100,00 & 151,04 & 123,69 & 37,00 & 6916,59 & 346,40 & 16,60 & 329,79 & $\begin{array}{l}104,47 \\
\end{array}$ & 244,47 & 244,47 & 67,67 & 505,62 & 68,55 & 4,41 & 48,62 & 182,34 & 31,85 & 31,85 & 166,40 \\
\hline Bufo spinosus & 30SVH17 & 100,00 & 147,46 & 125,23 & 37,01 & 6913,02 & 344,08 & 12,32 & 331,76 & 104,38 & 240,95 & 240,95 & 64,36 & 499,75 & 65,82 & 4,52 & 47,34 & 177,79 & 33,55 & 33,55 & 161,52 \\
\hline Bufo spinosus & $30 \mathrm{SVH} 21$ & 100,00 & 175,23 & 112,19 & 36,00 & \begin{tabular}{|l|l|}
6708,16 \\
\end{tabular} & 355,88 & 46,71 & 309,18 & 107,21 & 265,28 & 265,28 & 93,80 & 478,04 & 70,70 & 3,01 & 54,79 & 181,60 & 20,69 & 20,69 & 170,99 \\
\hline Bufo spinosus & $30 \mathrm{SVH} 22$ & 100,00 & 167,66 & 115,08 & 36,00 & 6811,41 & 353,58 & 37,68 & 315,90 & 117,58 & 259,44 & 259,44 & 85,38 & 498,74 & 73,72 & 3,62 & 53,34 & 188,84 & 24,08 & 24,08 & 174,98 \\
\hline Bufo spinosus & 30 SVH24 & 100,00 & 155,16 & 120,19 & 36,47 & 6904,58 & 347,68 & 22,64 & 325,04 & 108,23 & 248,43 & 248,43 & 72,14 & 515,62 & 73,10 & 4,60 & 50,27 & \begin{tabular}{|l|}
191,16 \\
\end{tabular} & 30,13 & 30,13 & 173,88 \\
\hline \begin{tabular}{|l} 
Bufo spinosus \\
\end{tabular} & 30 SVH 25 & 100,00 & 145,86 & 122,79 & 36,97 & 6929,03 & 341,56 & 12,40 & 329,17 & $\begin{array}{l}98,79 \\
9\end{array}$ & 239,69 & 239,69 & 62,92 & 532,36 & 72,99 & 5,53 & 48,12 & 193,73 & 35,29 & 35,29 & 175,10 \\
\hline Bufo spinosus & $30 \mathrm{SVH} 26$ & 100,00 & 149,29 & 123,54 & 37,00 & 6905,60 & 344,42 & 15,08 & 329,34 & 102,72 & 242,76 & 242,76 & 66,32 & 502,27 & 67,41 & 4,82 & 47,70 & 180,86 & 33,34 & 33,34 & $\begin{array}{ll}163,47 \\
\end{array}$ \\
\hline Bufo spinosus & 30SVH34 & 100,00 & 153,79 & 120,08 & 36,59 & 6892,22 & 345,85 & 21,45 & 324,40 & 106,64 & 246,91 & 246,91 & 71,05 & \begin{tabular}{|l|l|}
508,68 \\
\end{tabular} & 71,43 & 4,85 & 49,44 & 188,17 & 31,19 & 31,19 & 169,55 \\
\hline Bufo spinosus & 30SVH35 & 100,00 & 140,37 & 123,03 & 37,00 & 6930,83 & 336,74 & 7,07 & 329,67 & 92,90 & 234,50 & 234,50 & 57,87 & 542,59 & 73,30 & 6,44 & 46,68 & 196,41 & 38,99 & 38,99 & 175,76 \\
\hline Bufo spinosus & 30SVH37 & 100,00 & 147,75 & 124,45 & 37,01 & 6881,14 & 342,70 & 13,11 & 329,59 & $\begin{array}{ll}114,63 \\
\end{array}$ & 240,86 & 240,86 & 65,12 & 481,28 & 62,21 & 4,71 & 46,21 & 171,07 & 34,39 & 34,39 & 152,79 \\
\hline Bufo spinosus & 30SVH38 & 100,00 & 148,85 & 125,41 & 37,41 & 6858,53 & 343,64 & 13,66 & 329,98 & $\begin{array}{l}131,73 \\
13,0\end{array}$ & $\begin{array}{l}44,505 \\
241,52\end{array}$ & 241,52 & 66,19 & $\begin{array}{l}401,20 \\
460,18 \\
\end{array}$ & \begin{tabular}{|l|l|}
57,72 \\
\end{tabular} & $\begin{array}{ll}4,1 / 16 \\
4,16\end{array}$ & 45,48 & 163,18 & 33,46 & 33,46 & 143,98 \\
\hline Bufo spinosus & $30 \mathrm{SVH} 42$ & 100,00 & 168,91 & 114,17 & 36,00 & 6738,83 & 351,87 & 39,52 & 312,34 & 122,59 & 259,43 & 259,43 & 87,43 & 461,65 & 66,40 & 3,64 & 51,84 & 173,28 & 24,00 & 24,00 & 158,57 \\
\hline Bufo spinosus & 30SVH43 & 100,00 & 163,33 & 116,73 & 36,05 & 6798,84 & 349,91 & 32,62 & 317,29 & 116,79 & 254,96 & 254,96 & 81,34 & 471,24 & 66,79 & 4,03 & 50,53 & 175,58 & 26,70 & 26,70 & 158,96 \\
\hline Bufo spinosus & $30 \mathrm{SVH} 44$ & 100,00 & 148,33 & 120,66 & 36,76 & 6890,83 & 341,28 & 15,92 & 325,37 & 100,84 & 241,58 & 241,58 & 65,94 & 515,72 & 70,99 & 5,67 & 47,88 & 189,17 & 34,67 & 34,67 & 168,88 \\
\hline Bufo spinosus & $30 \mathrm{SVH} 45$ & 100,00 & 135,75 & 123,29 & 37,00 & 6915,99 & 332,29 & 3,01 & 329,29 & 87,90 & 229,84 & 229,84 & 53,68 & 550,14 & 72,97 & 7,40 & 45,32 & 197,48 & 42,56 & 42,56 & 175,34 \\
\hline Bufo spinosus & 30SVH46 & 100,00 & 146,07 & 123,18 & 37,00 & 6878,33 & 340,31 & \begin{tabular}{|c|}
12,33 \\
12
\end{tabular} & 327,98 & $\begin{array}{l}99,86 \\
99,\end{array}$ & \begin{tabular}{|l|}
239,18 \\
\end{tabular} & \begin{tabular}{|l|}
239,18 \\
\end{tabular} & $\begin{array}{l}0,00 \\
63,76\end{array}$ & \begin{tabular}{|l|l|l|l|l|}
494,85 \\
\end{tabular} & 65,02 & 5,43 & 455,99 & $\begin{array}{l}177,10 \\
\end{array}$ & 36,01 & $\begin{array}{l}36,01 \\
36,\end{array}$ & 157,28 \\
\hline Bufo spinosus & 30SVH47 & 100,00 & 145,99 & 124,14 & 37,00 & 6870,11 & 340,45 & 11,56 & 328,90 & 119,88 & 238,96 & 238,96 & 63,64 & 480,10 & 61,46 & 5,12 & 45,32 & 170,58 & 36,08 & 36,08 & 150,46 \\
\hline Bufo spinosus & $30 \mathrm{SVH} 49$ & 100,00 & 147,50 & 125,45 & 37,46 & 6835,61 & 341,49 & 11,92 & 329,56 & 130,52 & 239,71 & 239,71 & 65,16 & 447,70 & 54,38 & 4,81 & 43,65 & 157,62 & 35,58 & 35,58 & 136,44 \\
\hline Bufo spinosus & 30SVH52 & 100,00 & 170,28 & 113,68 & 36,05 & 6664,14 & 350,71 & 41,16 & 309,55 & 124,24 & 259,68 & 259,68 & 89,45 & 436,84 & 61,14 & 3,31 & 50,87 & 161,84 & 23,39 & 23,39 & 148,33 \\
\hline Bufo spinosus & 30SVH53 & 100,00 & 163,20 & 116,49 & 36,24 & 6752,17 & 348,31 & 32,62 & 315,69 & 116,77 & 254,13 & 254,13 & 81,79 & 455,50 & 63,27 & 4,01 & 49,48 & 168,26 & 26,90 & 26,90 & 151,61 \\
\hline \begin{tabular}{|l} 
Bufo spinosus \\
\end{tabular} & 30SVH54 & 100,00 & 152,54 & 119,68 & 36,80 & 6830,84 & 342,73 & 20,42 & 322,31 & 105,50 & 244,79 & 244,79 & 70,64 & 485,61 & 65,96 & 5,25 & 47,56 & 177,26 & 32,77 & 32,77 & 157,69 \\
\hline Bufo spinosus & 30 SVH56 & 100,00 & 144,76 & 122,97 & 37,00 & 6864,75 & 338,35 & 11,25 & 327,10 & 104,27 & 237,83 & 237,83 & 62,92 & 490,56 & 63,53 & 5,96 & 45,01 & 174,62 & 37,62 & 37,62 & 153,92 \\
\hline Bufo spinosus & 30SVH60 & 100,00 & 162,46 & 113,54 & 36,01 & 6671,92 & 344,00 & 34,08 & 309,92 & 115,57 & 252,36 & 252,36 & 82,38 & 462,21 & 64,74 & $4,69 \mid$ & 50,18 & 171,91 & 26,73 & 26,73 & 156,73 \\
\hline Bufo spinosus & 30 SVH64 & 100,00 & 154,19 & 119,16 & 36,95 & 6780,69 & 342,24 & 22,47 & 319,76 & 107,34 & 245,70 & 245,70 & 72,69 & 464,67 & $61, \varepsilon$ & 5,05 & 46,69 & 168,01 & 32,31 & 32,31 & 148,91 \\
\hline \begin{tabular}{|l} 
Bufo spinosus \\
\end{tabular} & 30 SVH65 & 100,00 & 145,01 & 121,56 & 37,00 & 6830,51 & 336,83 & 12,36 & 324,47 & 98,63 & 237,55 & 237,55 & 63,40 & 490,13 & 63,7 & 6,22 & 44,91 & $\begin{array}{ll}175,06 \\
\end{array}$ & 37,89 & 37,89 & 153,67 \\
\hline \begin{tabular}{|l} 
Bufo spinosus \\
\end{tabular} & 30SVH67 & 100,00 & 145,63 & 123,05 & 37,01 & 6821,12 & 337,65 & 11,86 & 325,78 & \begin{tabular}{ll|}
127,34 \\
\end{tabular} & 237,73 & 237,73 & 63,69 & 465,95 & 58,14 & 5,86 & 43,54 & 164,86 & $\begin{array}{ll}38,03 \\
38\end{array}$ & $\begin{array}{ll}1,03,03 \\
\end{array}$ & 142,61 \\
\hline Bufo spinosus & $30 \mathrm{SVH70}$ & 100,00 & 163,49 & 113,30 & 36,27 & 6589,86 & 342,51 & 35,32 & 307,18 & 117,14 & 252,12 & 252,14 & 84,23 & 435,80 & 58,97 & 4,42 & 48,99 & 159,37 & 26,10 & 26,45 & 145,56 \\
\hline Bufo spinosus & 30SVH72 & 100,00 & 159,66 & 115,97 & 36,73 & 6665,73 & 342,40 & 29,73 & 312,66 & 113,17 & 249,38 & 249,38 & 79,49 & 443,50 & 59,31 & 4,74 & 47,62 & 161,06 & 29,03 & 29,03 & 144,19 \\
\hline Bufo spinosus & 30 SVH74 & 100,00 & 156,35 & 118,46 & 37,00 & 6713,76 & 341,8 & 24,83 & 317,06 & 109,79 & 246,80 & 246,80 & 75,59 & 442,10 & 57,42 & 4, & 45,98 & 158,07 & 31,52 & 31,52 & 139,85 \\
\hline Bufo spinosus & 30SVH75 & 100,00 & 148,09 & 120,87 & 37,00 & 6772,70 & 337,3 & 15,63 & 321,74 & 110,62 & $\begin{array}{l}439,64 \\
239\end{array}$ & $\begin{array}{l}439,64 \\
2394\end{array}$ & 66,96 & $\begin{array}{l}442,10 \\
466,38 \\
\end{array}$ & 59,56 & 5,6 & 44,41 & $\begin{array}{l}165,41 \\
\end{array}$ & $\begin{array}{ll}1,26 \\
36,67\end{array}$ & 36,67 & $\begin{array}{l}144,59 \\
144,59\end{array}$ \\
\hline Bufo spinosus & 30SVH77 & 100,00 & 142,68 & 123,08 & \begin{tabular}{|l|l|}
37,03 \\
\end{tabular} & 6806,49 & 334,28 & 9,16 & 325,12 & 124,01 & 234,77 & 234,77 & 61,13 & 469,75 & 57,91 & 6,51 & 42,44 & 165,86 & 40,73 & 40,73 & 141,46 \\
\hline Bufo spinosus & 30SVH78 & 100,00 & 143,55 & 123,34 & 37,31 & 6789,82 & 334,83 & 9,47 & 325,36 & 125,28 & 235,28 & 235,28 & 62.08 & 457,77 & 56,10 & 6,16 & 41,93 & $\mid 161,07$ & 40,42 & 40,42 & 136,31 \\
\hline Bufo spinosus & 30SVH79 & 100,00 & 142,29 & 124,04 & 37,87 & 6792,63 & 333,87 & 8,03 & 325,84 & 124,32 & 234,12 & 234,12 & 60,79 & 453,68 & 55,35 & 6,31 & 41,55 & 159,05 & 41,42 & 41,42 & 133,61 \\
\hline Bufo spinosus & 30SVH84 & 100,00 & 151,55 & 119,32 & 37,00 & 6704,51 & 337,58 & 19,89 & 317,69 & 108,82 & 241,97 & 241,97 & 71,14 & 447,91 & 56,74 & 5,63 & 44,35 & 38 & 34,87 & 34,87 & 138,63 \\
\hline \begin{tabular}{|l} 
Bufo spinosus \\
\end{tabular} & \begin{tabular}{|c|}
$305 V \mathrm{NHO}$ \\
308
\end{tabular} & 100,00 & 141,78 & $\begin{array}{l}1123,04 \\
123,04\end{array}$ & 37,28 & 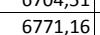 & 332 & \begin{tabular}{|l|}
75,80 \\
7,86
\end{tabular} & \begin{tabular}{|l|l|}
324,31 \\
\end{tabular} & $\begin{array}{l}123,02 \\
\end{array}$ & 233,21 & 233,21 & 60,82 & 458,14 & 56,45 & 6,96 & 41,01 & 160,90 & 42,93 & 42,93 & 134,25 \\
\hline Bufo spinosus & 30SVH90 & 100,00 & 157,60 & 114,58 & 37,00 & 6514,66 & 335,62 & 29,21 & 306,41 & 111,28 & 245,21 & 245,31 & 79,36 & 423,56 & 53,86 & 5,10 & 46,10 & 150,25 & 29,61 & 31,51 & 135,57 \\
\hline Bufo spinosus & 30SVH93 & 100,00 & 154,94 & 117,56 & 37,00 & $\mid 6602,10$ & 336,82 & 24,36 & 312,46 & $\mid 111,42$ & 243,77 & 243,82 & 75,61 & 425,90 & 53,23 & 5,27 & 44,41 & $\mid 149,47$ & 32.83 & 33,28 & 131,48 \\
\hline Bufo spinosus & 30SVH94 & 100,00 & 149,32 & 119,44 & 37,01 & 6665,62 & 334,43 & 17,92 & 316,51 & 125,98 & 239,23 & 239,23 & 69,49 & 442,82 & 55,28 & 6,04 & 43,18 & 155,66 & 36,73 & 36,77 & 134,33 \\
\hline Bufo spinosus & 30SVH95 & 100,00 & 143,64 & 121,02 & 37,12 & 6708,19 & 331,32 & 11,41 & 319,91 & 124,45 & 234,24 & 234,24 & 63,41 & 460,92 & 57,49 & 6,88 & 41,94 & 162,34 & 40,95 & 40,95 & 137,5 \\
\hline \begin{tabular}{|l} 
Bufo spinosus \\
\end{tabular} & 30SVH96 & 100,00 & 142,46 & 121,82 & 37,42 & 6720,53 & 330,88 & $\begin{array}{c}\frac{x+1,75}{9,75} \\
\end{array}$ & 321,13 & 123,38 & 233,27 & 233,27 & 62,18 & 459,70 & 57,23 & 7,12 & 41,27 & 161,69 & 42,24 & 42,24 & 135,50 \\
\hline Bufo spinosus & 30SVH98 & 100,00 & 139,86 & 122,99 & 37,83 & 6736,23 & 329,23 & 6,42 & 322,81 & 121,03 & 230,88 & 230,88 & 59,26 & 458,89 & 56,75 & 7,38 & 39,95 & 160,64 & 45,17 & 45,17 & 132,16 \\
\hline Bufo spinosus & 30SVJoo & 100,00 & 148,87 & 127.44 & 38,00 & 6881.30 & 345,65 & 11,99 & 333,65 & 132.29 & 241.78 & 241.78 & 65,87 & 452.13 & 55,12 & 4,00 & 45,43 & 158.93 & 32.90 & 32.90 & 140,79 \\
\hline Bufo spinosus & 30SVJ01 & 100,00 & 145,96 & 127,77 & 37,97 & 6873,92 & 342,90 & 8,98 & 333,92 & 129,55 & 238 & 238,77 & 63,01 & 448,95 & 53,61 & 4,16 & 44,37 & 157,40 & 34,68 & 34,68 & 137,48 \\
\hline Bufo spinosus & 30SVJ04 & 100,00 & 135,10 & 124,96 & 37,05 & 6881,69 & 330,80 & 0,21 & 330,58 & 118,02 & 228,37 & 228,37 & 52,55 & 466,01 & 54,44 & 6,42 & 40,85 & 160,88 & 43,42 & 43,42 & 136,69 \\
\hline
\end{tabular}




\begin{tabular}{|c|c|c|c|c|c|c|c|c|c|c|c|c|c|c|c|c|c|c|c|c|c|}
\hline TAXON & UTM & $\mathrm{km} 2$ & B101 & B102 & $\mathrm{BIO3}$ & BIO4 & B105 & B106 & B107 & B108 & 8109 & BIO10 & BIO11 & BIO12 & BIO13 & BIO14 & BIO15 & B1016 & B1017 & B1018 & B1019 \\
\hline Bufo spinosus & 30SVJ05 & 100,00 & 130,97 & 123,47 & 37,00 & 6870,26 & 325,77 & $-2,56$ & 328,33 & 113,57 & 224,31 & 224,31 & 48,85 & 475,61 & 55,56 & 7,50 & 39,55 & 162,95 & 47,10 & 47,10 & 137,71 \\
\hline Bufo spinosus & 30SVJ06 & 100,00 & 129,19 & 121,97 & 37,00 & 6851,31 & 322,54 & $-3,91$ & 326,45 & 111,79 & 222,27 & 222,27 & 47,47 & 477,10 & 55,90 & 8,28 & 38,71 & 162,20 & 49,38 & 49,38 & 136,52 \\
\hline Bufo spinosus & 30SVJ07 & 100,00 & 131,62 & 120,57 & 36,83 & 6862,95 & 323,58 & $-1,03$ & 324,61 & 114,59 & 224,92 & 224,92 & 49,54 & 460,03 & 54,08 & 8,21 & 38,10 & 155,29 & 48,46 & 48,46 & 130,47 \\
\hline Bufo spinosus & 305VJ08 & 100,00 & 128,99 & 118,95 & 36,32 & 6836,28 & 319,54 & $-2,78$ & 322,32 & 111,71 & 221,98 & 222,00 & 47,55 & 465,26 & 54,82 & 9,07 & 37,28 & 155,83 & 51,08 & 51,10 & 130,69 \\
\hline Bufo spinosus & 30SVJo9 & 100,00 & 139,00 & $\begin{array}{ll}117,17 \\
\end{array}$ & 36,00 & 6873,60 & 327,36 & 5,94 & \begin{tabular}{|l|l|}
321,43 \\
\end{tabular} & 123,10 & 232,25 & 232,25 & 56,13 & 423,66 & 49,44 & 8,03 & 37,47 & 140,40 & 45,81 & 45,81 & 118,53 \\
\hline Bufo spinosus & 30 SVJ10 & 100,00 & 148,49 & 128,22 & 38,00 & 6857,95 & 344,86 & 11,30 & 333,56 & 132,17 & 240,94 & 240,94 & 65,41 & 442,34 & 53,40 & 4,00 & 44,74 & 155,84 & 33,31 & 33,31 & 136,15 \\
\hline Bufo spinosus & 30SVJ11 & 100,00 & 147,16 & 128,77 & 38,00 & 6852,44 & 343,75 & 9,46 & 334,29 & \begin{tabular}{|l|l|}
131,07 \\
\end{tabular} & 239,31 & 239,31 & 64,03 & \begin{tabular}{|l|l|}
431,67 \\
\end{tabular} & 52,12 & 4,00 & 44,03 & 151,79 & 33,87 & 33,87 & 130,75 \\
\hline \begin{tabular}{|l} 
Bufo spinosus \\
\end{tabular} & $30 \mathrm{SVJ} 13$ & 100,00 & 143,91 & 126,68 & 37,89 & 6858,15 & 339,39 & 7,36 & 332,03 & 127,80 & 236,59 & 236,59 & 61,18 & 430,37 & 51,26 & 4,76 & 42,04 & 149,31 & 37,37 & 37,37 & 127,06 \\
\hline Bufo spinosus & 30SVJ14 & 100,00 & 138,22 & 125,37 & 37,23 & 6874,87 & 333,56 & 2,55 & 331,01 & 121,61 & 231,30 & 231,30 & 55,50 & 448,08 & 52,82 & 5,88 & 40,84 & 154,54 & 41,71 & 41,71 & 130,77 \\
\hline Bufo spinosus & 30SVJ15 & 100,00 & 133,32 & 123,81 & 37,00 & 6870,43 & 327,87 & $-0,78$ & 328,66 & 116,26 & 226,57 & 226,57 & 51,09 & 461,95 & 54,07 & 7,10 & 39,51 & 158,08 & 45,73 & 45,73 & 133,26 \\
\hline Bufo spinosus & 30SVJ17 & 100,00 & 131,07 & 120,62 & 36,84 & 6857,65 & 322,85 & $-1,81$ & 324,66 & 114,03 & 224,17 & 224,17 & 49,04 & 461,86 & 54,09 & 8,49 & 37,81 & 155,32 & 49,35 & 49,35 & 130,82 \\
\hline Bufo spinosus & 30SVJ18 & 100,00 & 131,14 & 119,15 & 36,31 & 6845,13 & 321,53 & $-1,08$ & 322,61 & 114,18 & 224,04 & 224,04 & 49,31 & 457,24 & 53,43 & 8,76 & 37,21 & 152,28 & 50,13 & 50,13 & 128,56 \\
\hline \begin{tabular}{|l} 
Bufo spinosus \\
\end{tabular} & 30 SVJ20 & 100,00 & 147,62 & 128,19 & 38,00 & 6846,08 & 343,72 & 10,63 & 333,09 & 131,12 & 239,85 & 239,85 & 64,75 & 437,74 & 53,16 & 4,03 & 44,23 & 154,48 & 33,94 & 33,94 & 133,55 \\
\hline Bufo spinosus & $305 \mathrm{~V} J 24$ & 100,00 & 139,28 & 125,41 & 37,44 & 6862,47 & 334,05 & 3,54 & 330,51 & 122,87 & 232,12 & 232,12 & 56,73 & 440,29 & 52,10 & 5,83 & 40,52 & 151,45 & 41,41 & 41,41 & 127,94 \\
\hline Bufo spinosus & $305 \mathrm{~V} J 30$ & 100,00 & 146,76 & 127,10 & 37,99 & 6842,75 & 342,09 & 10,56 & 331,53 & 130,08 & 239,26 & 239,26 & 64,42 & 438,42 & 53,29 & 4,09 & 43,92 & 154,52 & 34,53 & 34,53 & 133,05 \\
\hline Bufo spinosus & $305 \mathrm{~V} 332$ & 100,00 & 147,26 & 126,73 & 38,00 & 6819,47 & 341,26 & 10,77 & 330,49 & 131,51 & 239,21 & 239,21 & $\mid 64,75$ & \begin{tabular}{|l|l|}
418,02 \\
\end{tabular} & 50,40 & \begin{tabular}{ll|l|}
4,12 \\
\end{tabular} & 42,60 & \begin{tabular}{|l|l|}
145,18 \\
\end{tabular} & 35,91 & 35,91 & $\begin{array}{lll}123,62 \\
\end{array}$ \\
\hline Bufo spinosus & 30 SVJ33 & 100,00 & 146,07 & 125,88 & \begin{tabular}{|l|l|}
37,83 \\
\end{tabular} & 6835,78 & 339,76 & 9,77 & 329,99 & 130,11 & 238,23 & 238,23 & 63,47 & 417,42 & 49,97 & 4,87 & 41,82 & 144,18 & 37,16 & 37,16 & 122,00 \\
\hline Bufo spinosus & $305 \mathrm{SV} 34$ & 100,00 & 136,18 & 125,01 & \begin{tabular}{|l|l|}
37,16 \\
\end{tabular} & 6853,50 & 330,64 & 1,10 & 329,54 & 119,39 & 229,01 & 229,01 & 53,96 & 451,78 & 53,40 & 6,54 & 39,76 & 154,97 & 44,15 & 44,15 & 130,48 \\
\hline Bufo spinosus & $305 \mathrm{~V} J 35$ & 100,00 & 133,50 & 123,81 & 37,00 & 6852,51 & 327,30 & $-0,71$ & 328,01 & 116,49 & 226,45 & 226,45 & 51,56 & 458,12 & 53,57 & 7,31 & 39,04 & 155,94 & 46,49 & 46,49 & 131,32 \\
\hline Bufo spinosus & $305 \mathrm{~V} / 38$ & 100,00 & 137,88 & 119,14 & 36,31 & 6851,14 & 327,05 & 4,58 & \begin{tabular}{ll|l}
322,47 \\
\end{tabular} & 121,71 & 230,52 & 230,52 & 55,31 & 434,18 & 49,52 & 7,94 & 37,38 & 142,45 & 46,40 & 46,40 & 123,18 \\
\hline Bufo spinosus & $305 \mathrm{~V} J 40$ & 100,00 & 146,12 & 126,05 & \begin{tabular}{|l|l|}
37,97 \\
\end{tabular} & 6835,88 & 340,31 & 10,31 & 330,00 & 129,36 & 238,40 & 238,40 & 63,86 & 440,99 & 53,42 & 4,86 & 42,94 & 154,66 & 36,81 & 36,81 & 132,48 \\
\hline \begin{tabular}{|l} 
Bufo spinosus \\
\end{tabular} & $305 \mathrm{~S} J 41$ & 100,00 & 147,05 & 125,97 & 37,88 & 6826,16 & 340,68 & 11,09 & 329,58 & 130,48 & 239,14 & 239,14 & 64,89 & 427,10 & 51,63 & 4,72 & 42,48 & 148,77 & 36,68 & 36,68 & 126,86 \\
\hline Bufo spinosus & 30SVJ42 & 100,00 & 147,07 & 125,73 & 37,80 & 6824,05 & 340,22 & 11,03 & 329,18 & 130,93 & 239,08 & 239,08 & 64,71 & $\begin{array}{l}419,65 \\
\end{array}$ & 50,44 & 4,93 & 41,76 & 145,29 & 36,93 & 36,93 & 123,44 \\
\hline Bufo spinosus & $305 \mathrm{SV} 43$ & 100,00 & 146,62 & 125,01 & $\begin{array}{l}37,45 \\
\end{array}$ & 6823,15 & 339,09 & 10,59 & 328,50 & 130,47 & 238,72 & 238,72 & 64,20 & 415,36 & 49,60 & 5,00 & 41,53 & 142,82 & 37,42 & 37,42 & 121,07 \\
\hline Bufo spinosus & 30SVJ44 & 100,00 & 134,94 & 124,47 & 37,18 & 6837,59 & 328,72 & 0,39 & 328,33 & 117,92 & 227,52 & 227,52 & 52,91 & 457,44 & 53,83 & 7,13 & 39,26 & 156,41 & 46,03 & 46,03 & 131,50 \\
\hline Bufo spinosus & 30 SVJ45 & 100,00 & 128,65 & 123,56 & \begin{tabular}{|l|l|}
37,03 \\
\end{tabular} & 6835,67 & 322,47 & $-4,44$ & 326,91 & 111,14 & 221,50 & 221,50 & 47,35 & 478,31 & 55,59 & 8,50 & 37,84 & 162,32 & 50,98 & 50,98 & 136,15 \\
\hline Bufo spinosus & $305 \mathrm{~S} 46$ & 100,00 & 138,17 & 122,27 & 37,00 & 6842,14 & 329,49 & $\begin{array}{cc}-3,446 \\
3,76\end{array}$ & \begin{tabular}{|l|}
325,73 \\
\end{tabular} & $\begin{array}{l}121,55 \\
12,5\end{array}$ & 230,58 & 230,58 & 55,69 & 437,42 & 50,53 & $\begin{array}{l}7,14 \\
7,14\end{array}$ & 38,40 & $\begin{array}{l}146,42 \\
\end{array}$ & 45,07 & 45,07 & 124,66 \\
\hline Bufo spinosus & $305 \mathrm{~V} J 52$ & 100,00 & 146,53 & 124,87 & \begin{tabular}{|l|l|}
37,88 \\
\end{tabular} & 6810,31 & 338,57 & 11,10 & 327,47 & 130,18 & 238,37 & 238,37 & 64,26 & 420,59 & 50,62 & 5,00 & 41,29 & 145,68 & 37,72 & 37,72 & 123,19 \\
\hline Bufo spinosus & 30SVJ53 & 100,00 & 146,14 & 124,31 & 37,35 & 6814,92 & 337,58 & 10,36 & 327,22 & 130,06 & 238,08 & 238,08 & 63,67 & 416,54 & 49,82 & 5,19 & 41,49 & 143,32 & 38,29 & 38,29 & 120,92 \\
\hline Bufo spinosus & 30SVJ54 & 100,00 & 144,27 & 123,68 & 37,15 & 6812,25 & 335,56 & 8,92 & 326,64 & 128,22 & 236,22 & 236,22 & 61,91 & 420,01 & 49,45 & 5,94 & 39,88 & 142,70 & 40,63 & 40,63 & 121,01 \\
\hline Bufo spinosus & 30SVJ55 & 100,00 & 138,96 & 123,14 & \begin{tabular}{|l|l|}
37,03 \\
\end{tabular} & 6822,71 & 330,55 & 4,48 & 326,07 & 122,39 & 231,19 & 231,19 & 56,86 & \begin{tabular}{|c|}
436,58 \\
\end{tabular} & 50,83 & 7,02 & 38,73 & 147,13 & 44,65 & 44,65 & 124,51 \\
\hline \begin{tabular}{|l} 
Bufo spinosus \\
\end{tabular} & 30 SVJ61 & 100,00 & 146,27 & 124,13 & 37,63 & 6800,42 & 337,58 & 11,04 & 326,54 & 129,70 & 237,86 & 237,86 & 64,06 & 426,94 & 51,61 & 5,36 & 41,60 & 148,29 & 38,40 & 38,40 & 125,17 \\
\hline Bufo spinosus & 30SVJ70 & 100,00 & 145,14 & 123,99 & 37,99 & 6779,11 & 335,90 & 10,46 & 325,44 & 127,62 & 236,54 & 236,54 & 63,40 & 436,02 & 53,00 & 6,00 & 40,94 & 151,82 & 40,34 & 40,34 & 127,27 \\
\hline Bufo spinosus & 30SVJ71 & 100,00 & 144,03 & 124,00 & 38,00 & 6772,19 & 334,91 & 9,42 & 325,49 & 126,92 & 235,44 & 235,44 & 62,34 & 433,81 & 52,40 & 6,15 & 40,42 & 150,22 & 41,34 & 41,34 & 125,37 \\
\hline Bufo spinosus & 30 SVJ77 & 100,00 & 142,13 & 120,53 & 37,00 & 6778,90 & 329,51 & 8,49 & 321,02 & 126,27 & 233,47 & 233,47 & 60,07 & \begin{tabular}{|c|}
419,88 \\
\end{tabular} & 47,05 & 7,60 & 36,94 & 137,13 & 45,58 & 45,58 & 117,90 \\
\hline Bufo spinosus & $30 \mathrm{SVJ} 80$ & 100,00 & 140,69 & 123,88 & 37,93 & 6766,96 & 331,26 & 6,62 & 324,64 & 122,67 & 231,94 & 231,94 & 59,36 & 449,30 & 54,72 & 7,00 & 39,91 & 156,41 & 44,36 & 44,36 & 129,07 \\
\hline Bufo spinosus & 30SVJ90 & 100,00 & 137,31 & 123,81 & 37,97 & 6755,60 & 327,59 & 3,46 & 324,12 & 119,08 & 228,68 & 228,68 & 56,43 & 457,68 & 55,81 & 7,90 & 38,51 & 158,96 & 47,99 & 47,99 & 129,13 \\
\hline Bufo spinosus & 30SVJ92 & 100,00 & 142,75 & 123,03 & 37,95 & 6712,64 & 331,08 & 8,64 & 322,45 & 125,73 & 233,26 & 233,26 & 61,86 & 426,77 & 51,09 & 7,06 & 38,14 & 146,14 & 45,13 & 45,13 & 119,23 \\
\hline Bufo spinosus & 30SVKO0 & 100,00 & 142,08 & 115,15 & 35,59 & 6885,85 & 328,40 & 8.99 & 319,41 & 126,45 & 235,29 & 235,29 & 58,85 & 410,00 & 47,49 & 8,07 & 36,99 & 134,34 & 45,10 & 45,10 & 114,06 \\
\hline Bufo spinosus & 30SVK10 & 100,00 & 139,54 & 115,28 & 35,74 & 6879,58 & 326,16 & 7,09 & 319,07 & 121,73 & 232,81 & 232,81 & 56,51 & 420,94 & 48,24 & 8,56 & 36,62 & 136,80 & 46,77 & 46,77 & 117,76 \\
\hline Bufo spinosus & 30SVK11 & 100,00 & 148,71 & 112,90 & 35,00 & 6894,10 & 332,38 & 15,75 & 316,62 & 106,71 & 241,81 & 241,81 & 64,72 & 390,78 & 44,2 & 7,80 & 37,00 & 127,62 & 42,60 & 42,60 & 109,72 \\
\hline \begin{tabular}{|l} 
Bufo spinosus \\
\end{tabular} & 30SVK31 & 100,00 & 146,79 & 113,32 & 35,32 & 6849,82 & 330,11 & 14,84 & 315,27 & 102,71 & 238,96 & 238,96 & 63,23 & 403,49 & 45, & 7,89 & 37,22 & 134,38 & 42,99 & 42,99 & 115,95 \\
\hline Bufo spinosus & 30SVK50 & 100,00 & 141,80 & 116,19 & 36,00 & 6809,98 & 326,92 & 9,91 & 317,01 & 98,08 & 233,49 & 233,49 & 59,15 & 420,79 & 47,14 & 8,24 & 36,94 & 138,66 & 45,49 & 45,49 & 120,36 \\
\hline Bufo spinosus & 30SWF06 & 31,00 & 178,38 & 85,78 & 36,97 & 4976,35 & 301,83 & 72,30 & 229,52 & 128,25 & 242,68 & 245,75 & 118,15 & 266,20 & 37,42 & 1,63 & 55,30 & 106,15 & 11,02 & 16,27 & 100,95 \\
\hline Bufo spinosus & 30SWF07 & 100,00 & 162,90 & 96,33 & 37,43 & 5421,05 & 303,66 & 49,63 & 254,03 & 108,33 & 234,18 & 236,65 & 98,06 & 329,34 & 43, & 3,1 & 51,93 & 124,36 & 17,06 & 23,40 & 120,34 \\
\hline Bufo spinosus & 30SWF09 & 100,00 & 132,55 & 112,59 & 37,8 & 6128,55 & 303,78 & \begin{tabular}{|l|}
8,78 \\
8,7
\end{tabular} & 294,99 & $\begin{array}{l}78,87 \\
70,5\end{array}$ & 215,13 & \begin{tabular}{|l|l|}
216,48 \\
\end{tabular} & 60,73 & 494,66 & $\begin{array}{l}45, \text {, } \\
61, \\
\end{array}$ & 8,66 & 46,15 & $\begin{array}{l}172,67 \\
\end{array}$ & 37,08 & 44,53 & 167,55 \\
\hline Bufo spinosus & 30SWF16 & 78,00 & 179,02 & 83,11 & 36,68 & 4880,61 & 298,99 & 74,88 & 224,12 & 130,31 & 241,62 & 245,35 & 120,06 & 253,58 & 35,65 & 1,23 & 55,12 & 100,56 & 10,29 & 15,34 & 95,39 \\
\hline Bufo spinosus & 30SWF17 & 100,00 & 151,18 & 99,22 & 37,40 & 5556,79 & 298,51 & 36,55 & 261,96 & 98,95 & 224,63 & 227,24 & 85,36 & 387,70 & 50,30 & 5,71 & 49,20 & 140,50 & 26,11 & 32,34 & 135,14 \\
\hline Bufo spinosus & 30SWF18 & 100,00 & 96,85 & 118,61 & 37,85 & 6405,28 & 281,46 & $-29,14$ & 310,60 & 46,89 & 184,04 & 185,72 & 23,59 & 700,28 & 88,84 & 19,01 & 40,02 & 242,45 & 72,24 & 77,01 & 221,70 \\
\hline Bufo spinosus & 30SWF19 & 100,00 & 130,46 & 111,75 & 37,81 & 6109,05 & 300,50 & 7,40 & 293,10 & 78,34 & 212,63 & 214,39 & 58,97 & 498,17 & 62,45 & 9,34 & 44,82 & 172,25 & 39,73 & 46,65 & 165,68 \\
\hline \begin{tabular}{|l} 
Bufo spinosus \\
\end{tabular} & \begin{tabular}{|l}
$305 W F+29$ \\
$305 W F 29$
\end{tabular} & 100,00 & $\begin{array}{l}150,40 \\
145,65\end{array}$ & 104,86 & | & $\begin{array}{l}0102,00 \\
582,32\end{array}$ & 302,48 & $\begin{array}{r}1,40 \\
26,71 \\
\end{array}$ & $\begin{array}{l}275,76 \\
275,\end{array}$ & 91,43 & 223,29 & 225,54 & 76,95 & 406,06 & 50,43 & 6,11 & 46,27 & 140,37 & 28,82 & 35,61 & 136,85 \\
\hline Bufo spinosus & 30SWF38 & 100,00 & 142,22 & 104,11 & 37,77 & 5781,32 & 297,62 & 24,26 & 273,36 & 88,74 & 219,12 & 221,81 & 74,32 & 415,66 & 51,95 & 6,74 & 45,49 & 142,97 & 30,94 & 37,60 & 139,01 \\
\hline Bufo spinosus & 30SWF39 & 100,00 & 160,39 & 95,69 & 37,13 & 5459,98 & 301,24 & 47,45 & 253,79 & 119,38 & 232,06 & 235,10 & 95,45 & 323,93 & 39,69 & 3,71 & 47,44 & 114,23 & 20,68 & 26,78 & 110,24 \\
\hline Bufo spinosus & 30SWF47 & 40,00 & 171,80 & 84,11 & 36,39 & 4984,22 & 295,09 & 67,17 & 227,93 & 139,22 & 235,78 & 240,20 & 112,19 & 260,81 & 34,20 & 2,11 & 49,87 & 96,44 & 14,78 & 19,85 & 90,93 \\
\hline Bufo spinosus & 30SWF48 & 100,00 & 167,45 & 88,45 & 36,80 & 5150,72 & 297,08 & 59,96 & 237,12 & 132,02 & 234,32 & 238,16 & 106,17 & 281,43 & 36,18 & 2,70 & 48,55 & 102,15 & 16,97 & 22,57 & 96,69 \\
\hline \begin{tabular}{|l} 
Bufo spinosus \\
\end{tabular} & 30SWF57 & 35,00 & 180,43 & 78,35 & 36,03 & 4722,03 & 294,35 & $\begin{array}{ll}80,46 \\
\end{array}$ & 213,89 & 158,62 & 240,24 & 245,16 & 123,86 & 220,24 & 31,65 & 1,00 & 51,08 & 85,03 & 11,95 & 16,97 & 76,14 \\
\hline Bufo spinosus & 30SWF58 & 100,00 & 172,02 & 84,87 & 36,67 & 4991,31 & 295,91 & 67,38 & 228,53 & 147,44 & 236,24 & 240,65 & 112,60 & 257,20 & 34,58 & 2,17 & 49,02 & 95,14 & 15,54 & 21,12 & 87,52 \\
\hline Bufo spinosus & 30SWF59 & 100,00 & 147,86 & 100,32 & 37,53 & 5634,95 & 296,31 & 32,21 & 264,09 & 106,88 & 222,25 & 225,46 & 81,54 & 380,63 & 47,31 & 6,18 & 44,01 & 129,35 & 29,97 & 36,03 & 123,23 \\
\hline Bufo spinosus & 30SWF67 & 65,00 & 179,98 & 79,82 & 36,63 & 4714,35 & 294,94 & 79,64 & 215,30 & 158,40 & $\begin{array}{ll}239,82 \\
\end{array}$ & $244, \varepsilon$ & 123, & 225,80 & 32,51 & 1,07 & 51,71 & 87,95 & 12,02 & 18,04 & 77 \\
\hline Bufo spinosus & 30SWF76 & 41,00 & 175,49 & 81,61 & 36,94 & 4769,35 & 292,80 & 73,86 & 218,94 & 153,98 & 236,18 & 241,18 & 118,84 & 247,45 & 33,71 & 1,67 & 50,75 & 94,73 & 13,35 & 19,71 & 85,75 \\
\hline
\end{tabular}




\begin{tabular}{|c|c|c|c|c|c|c|c|c|c|c|c|c|c|c|c|c|c|c|c|c|c|}
\hline TAXON & UTM & $\mathrm{km} 2$ & BI01 & B102 & $B 103$ & BIO4 & B105 & B106 & B107 & B108 & B109 & B1010 & BIO11 & BIO12 & BIO13 & B1014 & BIO15 & B1016 & B1017 & B1018 & 81019 \\
\hline Bufo spinosus & 30SWF77 & 100,00 & 176,22 & 82,23 & 36,96 & 4798,15 & 294,35 & 74,02 & 220,33 & 154,27 & 237,42 & 242,31 & 119,29 & 244,06 & 34,03 & 1,71 & 50,29 & 93,95 & 13,52 & 19,92 & 83,53 \\
\hline Bufo spinosus & 30SWF79 & 100,00 & 163,15 & 92,40 & 37,41 & 5242,14 & 297,03 & 53,20 & 243,83 & 137,36 & 231,33 & 235,22 & 101,06 & 302,16 & 39,06 & 3,46 & 46,01 & 108,60 & 21,05 & 27,49 & 98,20 \\
\hline Bufo spinosus & 30SWF87 & 57,00 & 175,68 & 83,45 & 37,00 & 4821,32 & 294,83 & 72,54 & 222,29 & 153,54 & 237,12 & 242,00 & $\begin{array}{l}118,32 \\
\end{array}$ & 251,78 & 34,87 & 1,79 & 50,59 & 97,13 & 13,96 & 20,78 & 85,87 \\
\hline Bufo spinosus & 30SWF88 & 97,00 & 173,50 & 86,06 & 37,04 & \begin{tabular}{ll|l|}
4928,89 \\
\end{tabular} & 296,35 & 68,35 & 228,00 & 150,29 & 236,65 & 241,17 & $\begin{array}{l}114,74 \\
\end{array}$ & 260,41 & 36,10 & 2,00 & 49,24 & 99,37 & 15,50 & 22,37 & 86,88 \\
\hline Bufo spinosus & 30SWF89 & 100,00 & 171,15 & 89,01 & 37,33 & 5051,64 & 298,24 & 63,49 & 234,75 & 146,85 & 236,22 & 240,41 & 110,95 & 270,72 & 37,31 & 2,34 & 47,94 & 101,80 & 17,16 & 24,09 & 88,43 \\
\hline Bufo spinosus & 30SWF99 & 88,00 & 176,42 & 87,67 & \begin{tabular}{|l|l|}
37,69 \\
\end{tabular} & \begin{tabular}{ll|l}
4938,62 \\
\end{tabular} & 299,72 & 69,77 & 229,94 & 153,11 & 239,69 & 243,92 & 117,31 & 256,69 & 36,65 & 2,07 & 49,15 & 99,56 & 15,48 & 22,94 & 84,13 \\
\hline Bufo spinosus & 30SWG00 & 100,00 & 91,45 & 120,29 & 37,60 & 6517,73 & 280,53 & $-35,74$ & 316,27 & 41,14 & 180,47 & 181,69 & 16,76 & 743,27 & 92,87 & 20,85 & 39,38 & 257,27 & 78,97 & 83,08 & 233,23 \\
\hline Bufo spinosus & 30SWG02 & 100,00 & 118,62 & 118,01 & 37,52 & $\begin{array}{l}6441,29 \\
\end{array}$ & 302,00 & $-8,44$ & 310,44 & 69,90 & 206,17 & 207,05 & 43,79 & 581,40 & 72,56 & 12,42 & 42,76 & 202,16 & 51,45 & 57,94 & 187,32 \\
\hline Bufo spinosus & 30SWG03 & 100,00 & 112,13 & 119,29 & 37,38 & 6521,42 & 298,87 & $-15,51$ & 314,38 & 62,80 & 200,97 & 201,69 & 36,74 & \begin{tabular}{ll|}
620,72 \\
\end{tabular} & 77,48 & 14,42 & 41,36 & 215,71 & 58,83 & $\begin{array}{ll}64,42 \\
\end{array}$ & 196,34 \\
\hline Bufo spinosus & 30SWG05 & 100,00 & \begin{tabular}{ll|l|}
150,64 \\
\end{tabular} & 112,52 & 37,01 & \begin{tabular}{ll|l|}
6310,40 \\
\end{tabular} & 323,64 & 24,64 & 298,99 & 104,28 & 235,48 & 236,06 & 75,49 & 427,50 & 52,55 & 5,91 & 46,10 & 148,82 & 29,76 & 36,66 & 140,36 \\
\hline Bufo spinosus & 30SWG06 & 100,00 & 146,83 & 114,45 & 37,00 & 6411,38 & 323,90 & 19,77 & 304,13 & 99,96 & 233,36 & 233,69 & 70,77 & $\begin{array}{l}448,55 \\
\end{array}$ & 55,63 & 6,58 & 45,28 & 156,92 & 33,01 & 38,71 & 145,03 \\
\hline Bufo spinosus & 30SWG07 & 100,00 & 139,87 & 116,56 & 37,01 & 6514,90 & 321,19 & 11,47 & 309,72 & 92,14 & 227,87 & 228,22 & 62,84 & 484,39 & 60,38 & 8,08 & 43,87 & 169,69 & 39,10 & 43,90 & 153,57 \\
\hline Bufo spinosus & 30SWG09 & 100,00 & 121,09 & 120,41 & 37,09 & 6669,44 & 310,41 & $-8,41$ & 318,82 & 79,84 & 211,79 & 212,10 & 43,19 & \begin{tabular}{|l|l|}
574,48 \\
\end{tabular} & 71,75 & 12,40 & 40,50 & 199,80 & 56,02 & 58,31 & 174,50 \\
\hline Bufo spinosus & 30SWG10 & 100,00 & 103,26 & 118,05 & 37,69 & $6418,95[$ & 287,19 & $-22,94$ & 310,14 & 53,60 & 190,52 & 191,94 & 29,32 & 663,94 & 83,67 & 17,52 & 40,18 & 228,83 & 67,81 & 72,75 & 208,69 \\
\hline Bufo spinosus & 30SWG11 & 100,00 & 132,95 & 113,16 & 37,64 & \begin{tabular}{ll|}
6208,22 \\
\end{tabular} & 305,95 & 8,40 & 297,55 & 85,38 & 216,56 & 218,04 & 60,21 & $\begin{array}{l}489,86 \\
4\end{array}$ & 61,16 & 8,98 & 44,23 & $\begin{array}{l}168,36 \\
\end{array}$ & 39,18 & 46,19 & 160,45 \\
\hline Bufo spinosus & 30SWG13 & 100,00 & 99,91 & 119,76 & 37,30 & 6547,08 & 288,19 & $-27,56$ & 315,75 & 49,82 & 189,21 & $\begin{array}{l}190,23 \\
\end{array}$ & 24,62 & $\begin{array}{l}683,86 \\
\end{array}$ & 85,86 & 18,71 & 38,55 & 234,97 & 73,59 & 77,43 & 209,17 \\
\hline Bufo spinosus & 30SWG14 & 100,00 & 127,93 & \begin{tabular}{ll|}
116,64 \\
\end{tabular} & 37,28 & 6423,15 & $\begin{array}{l}308,44 \\
\end{array}$ & 0,91 & 307,53 & \begin{tabular}{ll|}
79,67 \\
\end{tabular} & 214,90 & 215,79 & 52,68 & 524,89 & 65,82 & $\begin{array}{l}10,46 \\
\end{array}$ & 42,34 & $\begin{array}{l}181,37 \\
\end{array}$ & 46,01 & 52,33 & 165,81 \\
\hline Bufo spinosus & 30SWG15 & 100,00 & 143,41 & $\begin{array}{ll}113,58 \\
\end{array}$ & 37,11 & 6319,60 & 317,77 & 17,28 & 300,49 & 96,60 & 228,55 & 229,30 & 68,56 & 448,80 & 55,77 & 7,20 & 44,06 & 154,73 & 35,01 & 41,78 & 143,45 \\
\hline Bufo spinosus & 30SWG16 & 100,00 & 149,42 & 112,81 & 37,04 & 6306,94 & 321,98 & 23,26 & 298,72 & 103,02 & 234,14 & 234,83 & 74,31 & 423,79 & 52,47 & $6,21 \mid$ & 44,50 & 145,99 & 31,96 & 38,55 & 135,13 \\
\hline Bufo spinosus & 30SWG17 & 100,00 & 141,90 & 115,60 & 37,02 & \begin{tabular}{|l|l|}
6435,08 \\
\end{tabular} & 320,18 & 13,97 & 306,21 & 94,70 & 228,68 & 229,28 & $\begin{array}{l}65,69 \\
\end{array}$ & 460,74 & 57,71 & 7,59 & 43,16 & 159,51 & 37,77 & 43,53 & 144,05 \\
\hline Bufo spinosus & 30SWG19 & 100,00 & 102,99 & 121,55 & 37,25 & 6684,30 & 294,93 & $-25,91$ & 320,84 & 79,69 & 194,39 & 194,80 & 25,85 & 658,50 & 82,24 & 17,84 & 37,02 & 226,52 & 74,95 & 76,55 & 192,90 \\
\hline \begin{tabular}{|l|} 
Bufo spinosus \\
\end{tabular} & 30SWG20 & 100,00 & 131,47 & 111,31 & 37,74 & 6116,16 & 300,77 & 8,53 & 292,24 & 81,84 & 213,68 & 215,52 & 59,95 & $\begin{array}{l}487,65 \\
4\end{array}$ & 61,24 & 9,45 & 43,62 & $\begin{array}{ll}166,63 \\
\end{array}$ & 40,55 & 47,17 & 158,65 \\
\hline Bufo spinosus & 30SWG21 & 100,00 & 126,21 & 112,80 & 37,52 & 6201,71 & 298,98 & 2,32 & 296,66 & 76,06 & 209,87 & 211,48 & 53,91 & 521,88 & 65,50 & 11,33 & 42,31 & $\begin{array}{l}177,94 \\
\end{array}$ & 47,53 & 53,39 & 165,77 \\
\hline Bufo spinosus & 30 SWG23 & 100,00 & 128,17 & 115,04 & 37,61 & 6322,85 & 304,92 & 2,49 & 302,43 & 80,31 & 213,63 & 214,81 & 54,24 & 511,63 & 64,55 & $\begin{array}{l}10,46 \\
\end{array}$ & 41,77 & 174,92 & 45,77 & 51,87 & 160,67 \\
\hline Bufo spinosus & 30SWG24 & 100,00 & 141,87 & 112,34 & 37,29 & 6229,59 & 312,96 & 16,88 & 296,08 & 95,09 & 225,51 & 226,74 & \begin{tabular}{ll|}
68,09 \\
\end{tabular} & 441,81 & 55,15 & 7,41 & 43,24 & 150,25 & 35,69 & 42,24 & 140,01 \\
\hline Bufo spinosus & 30SWG25 & 100,00 & 148,54 & 111,22 & 37,23 & 6192,77 & 317,25 & 23,82 & 293,44 & 102,47 & 231,48 & 232,64 & 74,95 & 412,52 & 51,19 & 6,22 & 43,74 & 139,83 & 32,02 & 38,50 & 130,54 \\
\hline Bufo spinosus & 30SWG26 & 100,00 & 150,31 & 111,76 & 37,27 & 6217,77 & 319,74 & $24,91]$ & 294,83 & 104,48 & 233,65 & 234,60 & 76,27 & 407,45 & 50,71 & 5,99 & 43,55 & 138,21 & 31,82 & 38,17 & 127,79 \\
\hline Bufo spinosus & 30SWG27 & 100,00 & 143,06 & 1114,67 & 37,36 & 6352,62 & 318,23 & 15,94 & 302,29 & 105,84 & 228,60 & 229,33 & 67,80 & 443,23 & 55,81 & 7,42 & 42,33 & 151,55 & $\begin{array}{ll}37,64 \\
\end{array}$ & 43,30 & 136,21 \\
\hline Bufo spinosus & 30SWG28 & 100,00 & 130,69 & 1117,71 & 37,32 & \begin{tabular}{|l|l|l|}
6494,73 \\
\end{tabular} & 312,40 & 2,30 & 310,10 & 107,79 & 218,55 & 219,21 & 54,36 & 504,53 & $\begin{array}{l}64,02 \\
\end{array}$ & 10,30 & 40,24 & 173,95 & 48,59 & \begin{tabular}{|l|l|}
52,84 \\
\end{tabular} & 151,06 \\
\hline \begin{tabular}{|l|} 
Bufo spinosus \\
\end{tabular} & 30SWG29 & 100,00 & 110,30 & \begin{tabular}{ll|}
120,44 \\
\end{tabular} & 37,52 & 6619,50 & 298,79 & $-18,26$ & 317,05 & 87,32 & 200,58 & 201,02 & 33,63 & \begin{tabular}{|l|l|}
610,67 \\
\end{tabular} & 77,00 & 16,02 & 37,12 & 210,14 & $\begin{array}{ll}68,94 \\
\end{array}$ & 70,97 & 177,13 \\
\hline Bufo spinosus & 30SWG30 & 100,00 & 150,26 & 103,06 & 37,42 & 5769,05 & $\begin{array}{l}303,53 \\
\end{array}$ & 32,27 & 271,25 & 95,54 & 226,81 & 229,25 & 81,95 & 377,09 & 45,99 & 5,37 & 45,40 & $\begin{array}{l}128,24 \\
\end{array}$ & 26,90 & 33,41 & 124,89 \\
\hline Bufo spinosus & 30SWG35 & 100,00 & 137,91 & 113,41 & 37,73 & 6255,02 & 310,44 & 12,36 & 298,08 & 104,23 & 222,05 & 223,26 & 64,15 & \begin{tabular}{|l|l|}
455,59 \\
\end{tabular} & 57,55 & 8,47 & 41,45 & 154,03 & 40,45 & 46,23 & 139,74 \\
\hline Bufo spinosus & 30SWG37 & 100,00 & 142,67 & 114,20 & 37,86 & $6298,67 \mid$ & 315,76 & 15,97 & 299,80 & 120,83 & 227,31 & 228,16 & 67,95 & 435,64 & 55,24 & 7,52 & 41,38 & 148,18 & 38,60 & 44,01 & 131,43 \\
\hline Bufo spinosus & 30SWG38 & 100,00 & 134,64 & $\begin{array}{l}116,67 \\
\end{array}$ & 37,80 & 6414,44 & 312,78 & 6,73 & 306,05 & 113,44 & 221,11 & 221,89 & 58,84 & \begin{tabular}{|l|l|}
474,94 \\
\end{tabular} & 60,64 & 9,41 & 39,96 & 162,93 & 45,98 & 50,41 & 140,35 \\
\hline Bufo spinosus & 30SWG39 & 100,00 & 122,08 & 119,02 & 37,76 & \begin{tabular}{|l|l|}
6531,97 \\
\end{tabular} & $\begin{array}{l}305,88 \\
\end{array}$ & $-6,37$ & 312,25 & 99,95 & 210,69 & 211,26 & 45,77 & 538,32 & 68,69 & 12,72 & 37,90 & 185,42 & 58,18 & 61,05 & 155,37 \\
\hline \begin{tabular}{|l|} 
Bufo spinosus \\
\end{tabular} & 30SWG41 & 100,00 & 121,78 & 112,29 & 37,66 & 6180,22 & 293,31 & $-1,59$ & 294,90 & 74,71 & 204,99 & 206,92 & 50,00 & 535,18 & 67,99 & \begin{tabular}{ll|}
13,07 \\
\end{tabular} & 39,90 & 179,45 & 53,83 & 58,79 & 163,96 \\
\hline Bufo spinosus & 30SWG43 & 100,00 & 143,50 & 108,73 & 37,84 & 6021,64 & $\begin{array}{l}306,44 \\
\end{array}$ & 21,31 & 285,14 & 105,51 & 223,97 & 225,81 & 72,36 & 415,18 & 51,79 & 7,17 & 42,11 & $\begin{array}{l}137,89 \\
\end{array}$ & 35,13 & 41,23 & 129,15 \\
\hline Bufo spinosus & 30SWG44 & 100,00 & 125,28 & 114,48 & 37,88 & 6292,01 & 300,34 & 0,19 & 300,14 & 101,58 & 210,23 & 211,67 & 51,86 & 514,18 & 65,61 & 11,80 & 39,21 & 173,75 & 51,62 & 56,37 & 154,16 \\
\hline Bufo spinosus & 30SWG48 & 100,00 & 133,42 & 116,38 & 37,97 & 6375,05 & 310,23 & 5,79 & 304,44 & 112,25 & 219,40 & 220,26 & 58,35 & 472,79 & 60,70 & 9,84 & 38,89 & $\mid 161,44$ & 47,91 & 51,92 & 137,14 \\
\hline Bufo spinosus & 30SWG49 & 100,00 & 122,95 & 118,41 & 37,96 & 6475,62 & 304,59 & $-5,06$ & 309,65 & 100,98 & 210,68 & 211,39 & 47,27 & 526,21 & 67,58 & 12,72 & 37,10 & 180,48 & 58,56 & 61,17 & 149,34 \\
\hline Bufo spinosus & 30SWG51 & 100,00 & 135,59 & 107,66 & $\begin{array}{ll}37,92 \\
\end{array}$ & $\begin{array}{l}5960,92 \\
\end{array}$ & 297,10 & 14,97 & 282,13 & 101,08 & 215,22 & 217,60 & 65,88 & $\begin{array}{l}450,66 \\
\end{array}$ & 56,53 & 9,29 & 41,14 & 149,65 & 41,48 & 47,14 & 139,36 \\
\hline Bufo spinosus & 30SWG59 & 100,00 & 132,38 & $\begin{array}{ll}117,02 \\
\end{array}$ & 38,00 & 6359,18 & $\begin{array}{l}308,74 \\
\end{array}$ & 4,14 & 304,60 & 111,25 & 217,97 & 218,96 & 57,32 & 470,81 & $\begin{array}{l}60,97 \\
\end{array}$ & 10,31 & 37,72 & $\begin{array}{ll}160,66 \\
\end{array}$ & 50,57 & 53,86 & 132,38 \\
\hline Bufo spinosus & 30SWG61 & 100,00 & 143,49 & $\begin{array}{l}104,67 \\
\end{array}$ & 37,99 & 5807,31 & 298,15 & 24,66 & 273,49 & \begin{tabular}{ll|}
116,26 \\
\end{tabular} & 220,59 & 223,24 & 75,18 & \begin{tabular}{ll|l}
403,63 \\
\end{tabular} & 9,97 & 7,29 & 41,69 & $\begin{array}{l}134,36 \\
\end{array}$ & 35,11 & 41,08 & 124,97 \\
\hline Bufo spinosus & 30SWG69 & 100,00 & 125,43 & $\begin{array}{l}117,41 \\
\end{array}$ & 38,00 & $\begin{array}{l}6367,87 \\
\end{array}$ & $\begin{array}{l}302,64 \\
\end{array}$ & $-2,10$ & 304,74 & $\begin{array}{l}103,67 \\
\end{array}$ & 211,35 & 212,27 & 50,73 & 501,81 & 65,10 & 12,45 & 36,06 & 170,50 & 58,49 & 60,77 & 137,84 \\
\hline Bufo spinosus & 30SWG70 & 100,00 & 159,69 & 95,97 & \begin{tabular}{|l|l|}
37,87 \\
\end{tabular} & 5393,61 & 298,73 & 47,05 & 251,69 & 132,57 & 230,19 & 233,77 & 95,87 & 318,72 & 40,32 & 4,03 & 44,51 & 112,52 & 23,47 & 29,96 & 101,64 \\
\hline Bufo spinosus & 30SWG77 & 100,00 & 125,93 & 115,18 & 37,97 & 6262,87 & 298,96 & $-0,24$ & 299,21 & 103,99 & 210,25 & 211,69 & 52,67 & 498,77 & 64,43 & $\mid 12,68$ & 36,12 & 167,36 & 57,72 & 60,85 & 137,99 \\
\hline Bufo spinosus & 30SWG79 & 100,00 & 128,27 & $\begin{array}{l}116,74 \\
\end{array}$ & 38,01 & 6304,95 & 302,71 & 1,07 & 301,64 & 106,82 & 213,16 & 214,17 & 54,13 & \begin{tabular}{|l|l|}
483,07 \\
\end{tabular} & \begin{tabular}{ll|}
62,92 \\
\end{tabular} & \begin{tabular}{ll|l}
11,84 \\
\end{tabular} & 36,05 & 163,21 & 56,64 & 59,17 & 130,85 \\
\hline Bufo spinosus & 30SWG80 & 100,00 & 165,59 & 93,54 & $37, \varepsilon \quad<>$ & 5247,23 & 299,58 & 54,39 & 245,19 & 139,68 & 233,77 & 237, & 103,20 & 295,56 & 39, & 3,23 & 45,72 & 107,79 & 20,76 & 27,63 & 94,16 \\
\hline Bufo spinosus & 30SWG81 & 100,00 & 160,25 & 97 & 37, & 5419 & 300,41 & 46,09 & 254 & 132,88 & 231,18 & 234,46 & 95,96 & 321,14 & 41, & 4,2 & 43,86 & 113,80 & 24,71 & 31,51 & 99,92 \\
\hline Bufo spinosus & 30SWG82 & 100,00 & 161,55 & $\begin{array}{ll}99,23 \\
\end{array}$ & 38,00 & 5469,05 & 303,05 & 46,01 & 257,04 & 133,45 & 233,16 & 236,22 & 96,45 & 317,63 & 41,41 & 4,06 & 43,88 & $\begin{array}{ll}112,54 \\
\end{array}$ & 24,57 & 31,51 & 97,51 \\
\hline Bufo spinosus & 30SWG83 & 100,00 & \begin{tabular}{ll|}
167,74 \\
\end{tabular} & 99,16 & 38,06 & 5423,78 & 307,43 & 51,92 & 255,51 & 139,93 & 238,62 & 241,43 & 102,65 & 294,92 & 40,18 & 3,23 & 44,63 & $\begin{array}{l}106,63 \\
\end{array}$ & 21,77 & 29,06 & 90,01 \\
\hline Bufo spinosus & 30SWG86 & 100,00 & 140,42 & 111,71 & 38,09 & \begin{tabular}{ll|l|}
6034,16 \\
\end{tabular} & 303,80 & 15,93 & 287,87 & 118,89 & 220,95 & 222,72 & 69,15 & \begin{tabular}{|l|l|}
421,27 \\
\end{tabular} & 53,94 & 8,70 & 38,35 & 138,72 & 43,68 & 48,79 & 118,18 \\
\hline Bufo spinosus & 30SWG89 & 100,00 & 136,07 & 115,69 & 38,32 & \begin{tabular}{ll|l|}
6195,29 \\
\end{tabular} & 305,93 & 8,76 & 297,17 & 115,41 & 219,16 & 220,26 & 62,78 & 441,31 & 57, & 9,91 & 36,84 & 147,62 & 50,23 & 53,73 & 118,40 \\
\hline Bufo spinosus & 30SWG90 & 100,00 & 162,44 & 95,17 & 37,99 & 5294,62 & 298,41 & 50,19 & 248,22 & 136,31 & 231,38 & 235,03 & 99,61 & 314,14 & 41,14 & 3,89 & 45,13 & 113,73 & 23,25 & 30,41 & 98,76 \\
\hline Bufo spinosus & 30SWG91 & 100,00 & 176,51 & 92,11 & 38,00 & 5085,30 & 304,70 & 66,04 & 238,67 & 151,54 & 242,00 & 245,68 & 115,30 & 260,83 & 37,75 & 2,15 & 48,35 & 100,20 & 16,46 & 24,27 & 82,80 \\
\hline Bufo spinosus & 30SWG92 & 100,00 & 175,27 & $\begin{array}{ll}94,86 \\
\end{array}$ & 38,15 & 5187,80 & 307,08 & $\begin{array}{ll}62,62 \\
\end{array}$ & 244,47 & 149,29 & 242,43 & 245,73 & \begin{tabular}{ll|}
112,84 \\
\end{tabular} & $\begin{array}{l}267,15 \\
\end{array}$ & 38,55 & 2,25 & 47,30 & 101,38 & 17,62 & 25,55 & 83,10 \\
\hline Bufo spinosus & 30SWG93 & 100,00 & 168,13 & 99,49 & 38,34 & 5395,51 & 307,27 & 52,05 & 255,22 & 140,55 & 238,50 & 241,33 & 103,29 & 295,93 & 40,79 & 3,30 & 44,89 & 107,88 & 21,99 & 29,78 & 89,43 \\
\hline Bufo spinosus & 305 & 100 & 135 & 11 & 37 & & 321,12 & 5,99 & & 97,55 & & & 57,45 & 503,33 & 63,04 & 9,04 & 42,12 & 176,09 & 44,77 & 46,68 & 153,98 \\
\hline Bufo spinosus & 30SWH01 & 100,00 & 131,25 & 119,80 & 37,08 & 6658,89 & 318,57 & 1,16 & 317,42 & 100,95 & 221,56 & 221,69 & 52,66 & 522,87 & 65,45 & 10,09 & 41,08 & 182,81 & 49,46 & 50,68 & 157,44 \\
\hline Bufo spinosus & 30SWHO2 & 100,00 & 144,42 & 118,63 & 37,09 & 6611,24 & 328,17 & 14,06 & 314,11 & 115,59 & 233,70 & 233,81 & 65,58 & 459,73 & 57,65 & 7,20 & 42,47 & 160,87 & 39,82 & 40,88 & $\begin{array}{ll}139,07 \\
\end{array}$ \\
\hline
\end{tabular}




\begin{tabular}{|c|c|c|c|c|c|c|c|c|c|c|c|c|c|c|c|c|c|c|c|c|c|}
\hline TAXON & UTM & $\mathrm{km} 2$ & B101 & B102 & $\mathrm{BIO3}$ & BIO4 & B105 & B106 & B107 & B108 & 8109 & B1010 & BIO11 & BIO12 & BIO13 & BIO14 & BIO15 & B1016 & B1017 & B1018 & B1019 \\
\hline Bufo spinosus & 30SWH05 & 100,00 & 146,81 & 120,28 & 37,49 & 6636,79 & 331,49 & 14,79 & 316,69 & 128,08 & 236,24 & 236,24 & 67,31 & 437,31 & 54,96 & 6,57 & 41,47 & 153,16 & 39,79 & 39,86 & 128,39 \\
\hline Bufo spinosus & 30SWHO6 & 100,00 & 138,07 & 121,96 & 37,75 & 6697,72 & 326,27 & 5,68 & 320,59 & 118,73 & 228,64 & 228,64 & 58,33 & 468,66 & 58,71 & 8,10 & 39,86 & 164,30 & 46,44 & 46,44 & 135,13 \\
\hline Bufo spinosus & 30SWHO7 & 100,00 & 136,94 & 122,64 & 37,95 & 6703,97| & 325,61 & 4,01 & 321,60 & 117,94 & 227,56 & 227,56 & 56,86 & 468,29 & 58,47 & 8,23 & 39,13 & 163,95 & 47,88 & 47,88 & 133,54 \\
\hline Bufo spinosus & 30SWHO9 & 100,00 & 134,57 & 123,45 & 37,88 & 6738,96 & 324,19 & 1,06 & 323,14 & 115,69 & 225,62 & 225,62 & 54,10 & 468,23 & 57,77 & 8,75 & 38,11 & 163,12 & 50,86 & 50,86 & 130,85 \\
\hline Bufo spinosus & 30SWH10 & 100,00 & 119,81 & 120,31 & 37,38 & 6638,95 & 308,01 & $-9,60$ & 317,61 & $\begin{array}{l}94,93 \\
\end{array}$ & 210,08 & 210,42 & 42,17 & 569,87 & 71,55 & 13,20 & 38,99 & $\begin{array}{ll}197,38 \\
\end{array}$ & 59,80 & 61,74 & 168,19 \\
\hline Bufo spinosus & 30SWH11 & 100,00 & 134,09 & 119,02 & 37,29 & 6587,66 & 318,37 & 4,40 & 313,97 & 111,43 & 223,24 & 223,42 & 56,20 & 498,22 & 62,81 & 9,64 & 40,51 & 173,14 & 48,17 & 50,10 & 147,80 \\
\hline Bufo spinosus & 30SWH12 & 100,00 & 134,78 & 119,67 & 37,38 & 6609,19 & 319,85 & 4,54 & 315,31 & 114,20 & 224,19 & 224,34 & 56,55 & 491,51 & 62,07 & 9,38 & 40,19 & 171,31 & 48,13 & 49,49 & 144,39 \\
\hline \begin{tabular}{|l} 
Bufo spinosus \\
\end{tabular} & 30SWH14 & 100,00 & 148,97 & 119,01 & 37,71 & 6557,42 & 330,43 & 17,86 & 312,57 & 130,21 & 237,24 & 237,24 & 70,45 & 422,51 & 53,51 & 6,37 & 41,31 & 147,08 & 38,62 & 38,94 & 123,22 \\
\hline Bufo spinosus & 30SWH17 & 100,00 & 134,64 & 122,57 & 38,00 & 6673,81 & 322,48 & 2,36 & 320,11 & 115,32 & 224,87 & 224,87 & 55,14 & 470,69 & 59,10 & 9,06 & 38,14 & 164,29 & 51,01 & 51,01 & 131,44 \\
\hline Bufo spinosus & 30SWH18 & 100,00 & 132,03 & 123,06 & 38,00 & 6686,59 & 320,81 & $-0,09$ & 320,90 & 112,88 & 222,55 & 222,55 & 52,58 & 477,36 & 59,50 & 9,57 & 37,33 & 166,21 & 53,54 & 53,55 & 131,90 \\
\hline Bufo spinosus & 30SWH20 & 100,00 & 97,98 & 121,82 & 37,70 & 6678,92 & 289,86 & $-30,73$ & 320,59 & 74,45 & 189,41 & 189,81 & 21,11 & 674,38 & 84,46 & 19,71 & 35,07 & 231,49 & 82,36 & 82,62 & 191,90 \\
\hline Bufo spinosus & 30SWH21 & 100,00 & 108,66 & 121,42 & 37,75 & 6662,13 & 298,65 & $-20,64$ & 319,29 & 85,88 & 199,53 & 199,80 & 31,31 & 615,27 & 77,37 & 16,50 & 36,18 & 212,34 & 72,30 & 72,93 & 175,07 \\
\hline \begin{tabular}{|l} 
Bufo spinosus \\
\end{tabular} & 30SWH22 & 100,00 & 129,43 & 120,05 & 37,79 & 6589,29 & 314,54 & $-0,47$ & 315,01 & 108,49 & 218,69 & 218,97 & 51,83 & 507,32 & \begin{tabular}{r|r}
64,45 \\
\end{tabular} & 10,86 & 38,66 & 176,13 & 53,73 & 54,77 & 145,49 \\
\hline Bufo spinosus & 30SWH23 & 100,00 & 135,81 & 119,95 & 37,88 & 6573,86 & 319,58 & 5,31 & 314,27 & 115,67 & 224,68 & 224,79 & 57,81 & 473,78 & 60,36 & 9,25 & 39,12 & 164,77 & 48,83 & 49,47 & 135,25 \\
\hline Bufo spinosus & 30SWH24 & 100,00 & 144,52 & 119,50 & 37,97 & 6537,57 & 326,10 & 13,49 & 312,61 & 125,46 & 232,60 & 232,66 & 66,33 & \begin{tabular}{|l|l|}
431,48 \\
\end{tabular} & 55,08 & 7,33 & 39,93 & 149,76 & 42,48 & 42,80 & 123,02 \\
\hline Bufo spinosus & 30SWH25 & 100,00 & 140,51 & 120,64 & 38,00 & 6580,19 & 324,05 & 8,96 & 315,09 & 121,21 & 229,27 & 229,33 & 61,99 & 444,95 & 56,81 & 7,98 & 39,07 & 154,85 & 46,07 & 46,40 & 125,01 \\
\hline Bufo spinosus & 30SWH26 & 100,00 & 142,96 & 120,98 & 38,00 & 6576,61 & 326,16 & 10,95 & 315,21 & 123,99 & 231,54 & 231,55 & 64,16 & 431,01 & 54,96 & 7,51 & 39,07 & 149,84 & 44,83 & 44,90 & 120,01 \\
\hline Bufo spinosus & 30SWH28 & 100,00 & 130,82 & 122,95 & 38,00 & 6646,01 & 318,52 & $-1,10$ & 319,62 & 111,49 & 220,70 & 220,86 & 51,95 & 476,01 & 59,69 & 9,92 & 36,66 & 165,36 & 54,88 & 55,57 & 128,99 \\
\hline Bufo spinosus & 30SWH30 & 100,00 & 102,13 & 120,83 & 37,45 & 6632,01 & 291,64 & $-26,36$ & 318,00 & 78,76 & 192,94 & 193,40 & 25,83 & 644,83 & 81,33 & 18,94 & 34,79 & 221,03 & 79,58 & 80,12 & 181,02 \\
\hline Bufo spinosus & 30SWH31 & 100,00 & 108,29 & 121,08 & 37,73 & 6625,97 & 297,12 & $-20,70$ & 317,82 & 85,36 & 198,76 & 199,10 & 31,57 & 606,90 & 76,87 & 16,75 & 35,28 & 209,08 & 73,52 & 73,98 & 169,73 \\
\hline Bufo spinosus & 30SWH33 & 100,00 & 115,28 & 121,64 & 37,99 & 6624,59 & 303,36 & $-14,60$ & 317,95 & 93,55 & 205,45 & 205,58 & 37,90 & 563,74 & 71,58 & 14,55 & 35,49 & 195,09 & 67,78 & 68,03 & 155,56 \\
\hline Bufo spinosus & 30SWH34 & 100,00 & 127,64 & 121,06 & 37,99 & 6585,76 & 312,86 & $-2,88$ & 315,74 & 107,04 & 216,92 & 217,02 & 50,06 & 499,64 & 63,86 & 11,34 & 36,86 & 173,19 & 57,30 & 57,69 & 137,60 \\
\hline Bufo spinosus & 30SWH35 & 100,00 & 135,10 & 120,94 & 38,00 & 6562,45 & 318,66 & 3,99 & 314,68 & 115,32 & 223,75 & 223,83 & 57,18 & \begin{tabular}{|l|l|}
461,17 \\
\end{tabular} & 59,19 & 9,41 & 37,62 & 159,92 & 51,44 & 51,82 & 126,39 \\
\hline Bufo spinosus & 30SWH36 & 100,00 & 126,54 & 122,05 & 38,00 & 6610,75 & 312,94 & $-4,77$ & 317,70 & 106,23 & 216,08 & 216,18 & 48,37 & 497,56 & 63,25 & 11,47 & 36,08 & 172,49 & 58,95 & 59,70 & 134,27 \\
\hline Bufo spinosus & $30 \mathrm{SWH} 40$ & 100,00 & 111,35 & 119,94 & 37,86 & 6555,71 & 296,98 & $-17,14$ & 314,12 & 88,53 & 200,57 & 201,16 & 35,33 & 587,22 & 74,95 & 16,23 & 35,18 & 201,40 & 71,21 & 72,18 & 163,32 \\
\hline Bufo spinosus & 30SWH41 & 100,00 & 104,01 & 120,89 & 37,87 & 6607,13 & 292,17 & $-24,69$ & 316,87 & 80,68 & 194,50 & 194,73 & 27,95 & 624,24 & 79,20 & 18,58 & 33,92 & 213,93 & 79,32 & 79,43 & 171,15 \\
\hline Bufo spinosus & 30SWH42 & 100,00 & 117,07 & 120,59 & 37,97 & 6569,31 & 302,61 & $-12,38$ & 314,99 & $\begin{array}{l}0,905 \\
94,95 \\
\end{array}$ & 206,40 & 206,77 & 40,55 & 550,65 & 70,50 & $\begin{array}{l}14,40 \\
14,42\end{array}$ & 35,34 & $\begin{array}{l}189,73 \\
\end{array}$ & 66,72 & 67,18 & 150,78 \\
\hline Bufo spinosus & 30SWH43 & 100,00 & 126,58 & 120,40 & 37,99 & 6533,06 & 309,88 & $-3,61$ & 313,49 & 105,78 & 215,07 & 215,37 & 49,71 & 500,56 & 64,43 & 11,81 & 36,40 & 172,66 & 58,66 & 59,34 & 136,50 \\
\hline Bufo spinosus & 30SWH44 & 100,00 & 120,14 & 121,30 & 38,00 & 6578,54 & 305,68 & $-10,05$ & 315,73 & 98,81 & 209,57 & 209,66 & 42,99 & 529,28 & 67,71 & 13,53 & 35,21 & 182,61 & 64,91 & 65,25 & 142,30 \\
\hline Bufo spinosus & 30 SWH45 & 100,00 & 122,26 & 121,51 & 38,00 & 6578,14 & 307,64 & $-8,31$ & 315,95 & 101,38 & 211,55 & 211,58 & 44,91 & 515,95 & 65,98 & 13,00 & 35,23 & 178,04 & 63,34 & 64,24 & 137,55 \\
\hline Bufo spinosus & 30SWH46 & 100,00 & 115,51 & 122,13 & 38,00 & 6610,28 & 302,89 & $-14,96$ & 317,85 & 94,21 & 205,38 & 205,49 & 38,10 & 545,61 & 69,02 & 14,80 & 33,92 & 188,01 & 69,40 & 70,86 & 143,76 \\
\hline Bufo spinosus & 30 SWH47 & 100,00 & 121,31 & 122,45 & 38,00 & 6603,47 & 307,74 & \begin{tabular}{|l|}
$-9,66$ \\
$-9,66$
\end{tabular} & 317,40 & $\begin{array}{r}100,72 \\
10,2\end{array}$ & 210,66 & \begin{tabular}{|l|}
210,88 \\
21,4
\end{tabular} & $\begin{array}{ll}30,54 \\
43,5\end{array}$ & 512,014 & 64,99 & $\begin{array}{l}4,00 \\
13,08 \\
\end{array}$ & 34,31 & $\begin{array}{l}176,73 \\
170,0\end{array}$ & $\begin{array}{l}0,4,28 \\
64,\end{array}$ & 60,05 & 134,06 \\
\hline Bufo spinosus & 30SWH48 & 100,00 & 128,17 & 122,68 & 38,01 & 6592,98 & 313,42 & $-3,22$ & 316,64 & 108,55 & 217,20 & 217,39 & 50,02 & 475,49 & 60,40 & 11,24 & 34,95 & 163,85 & 58,73 & 61,09 & 123,44 \\
\hline Bufo spinosus & 30SWH50 & 100,00 & 120,56 & 118,94 & 38,00 & 6466,86 & 302,08 & $-7,79$ & 309,87 & 98,62 & 208,15 & 208,87 & 44,98 & 530,73 & 68,54 & 13,60 & 35,69 & 181,69 & 62,95 & 64,42 & 146,11 \\
\hline Bufo spinosus & 30SWH51 & 100,00 & 102,68 & 120,33 & 37,85 & 6578,31 & 289,47 & $-25,73$ & 315,19 & 79,39 & 192,83 & 193,01 & 26,90 & 627,86 & 79,82 & 19,57 & 32,97 & 214,10 & 82,39 & 82,44 & 169,05 \\
\hline Bufo spinosus & 30SWH52 & 100,00 & 116,10 & 120,35 & 38,00 & 6533,21 & 300,31 & $-12,83$ & 313,14 & 94,07 & 205,03 & 205,38 & 40,06 & 548,71 & 70,60 & 14,86 & 34,53 & 188,31 & 68,69 & 68,93 & 147,66 \\
\hline Bufo spinosus & $\begin{array}{l}30 \text { SWH53 } \\
305\end{array}$ & 100,00 & 123,01 & $\begin{array}{l}120,28 \\
120\end{array}$ & 38,00 & 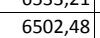 & 305,49 & $\begin{array}{l}-1,05 \\
-6,56 \\
\end{array}$ & \begin{tabular}{|l|}
312,05 \\
314
\end{tabular} & $\begin{array}{r}101,84 \\
100\end{array}$ & 211,27 & \begin{tabular}{|l|}
211,45 \\
21,0
\end{tabular} & $\begin{array}{l}40,66 \\
46,6\end{array}$ & | $540, r+34$ & $0,0,25$ & $\begin{array}{l}4,00 \\
13,13 \\
\end{array}$ & 35,28 & \begin{tabular}{|l|}
176,21 \\
176,2
\end{tabular} & $\begin{array}{l}0,03,08 \\
63,\end{array}$ & $\begin{array}{l}0,035 \\
63,49 \\
\end{array}$ & $\begin{array}{l}147,00 \\
137,18\end{array}$ \\
\hline Bufo spinosus & 30SWH54 & 100,00 & 131,29 & 120,31 & 38,04 & 6476,47 & 312,01 & 1,13 & 310,89 & 110,88 & 218,81 & 218,99 & 54,62 & 468,32 & 60,97 & 10,81 & 36,17 & 161,00 & 56,14 & 56,56 & 124,16 \\
\hline Bufo spinosus & 30SWH55 & 100,00 & 121,66 & 121,17 & 38.03 & 6532,07 & 305,32 & $-8,37$ & 313,69 & 100,71 & 210,34 & 210,44 & 44,90 & 514,17 & 65,99 & 13,58 & 34,55 & $\mid 176,47$ & 65,08 & 66,08 & 134,49 \\
\hline Bufo spinosus & 30SWH56 & 100,00 & 117,42 & 121,80 & 38,00 & 6568,34 & 302,79 & $-12,63$ & 315,42 & 96,35 & 206,74 & 206,80 & 40,53 & 530,40 & 67,58 & 14,62 & 33,55 & 182,10 & 68,66 & 70,37 & 137,23 \\
\hline \begin{tabular}{|l} 
Bufo spinosus \\
\end{tabular} & 30SWH57 & 100,00 & 114,82 & 122,09 & 38,00 & 6587,10 & 300,95 & $-15,36$ & 316,31 & 93,56 & 204,25 & 204,32 & 37,72 & 539,45 & 68,25 & 15,29 & 32,92 & 185,07 & 70,97 & 73,38 & 138,21 \\
\hline \begin{tabular}{|l} 
Bufo spinosus \\
\end{tabular} & 30SWH61 & 100,00 & 108,09 & 119,62 & 37,93 & 6511,14 & 291,89 & $-19,90$ & 311,79 & 85,27 & 197,10 & \begin{tabular}{|l|l|}
197,38 \\
\end{tabular} & 32,68 & 592,88 & 75,97 & 18,10 & 33,04 & 201,65 & 78,14 & 78,20 & 157,47 \\
\hline Bufo spinosus & 30SWH62 & 100,00 & 122,64 & 119,54 & 38,00 & 6448,83 & 303,26 & $-6,08$ & 309,34 & 101,19 & 210,08 & 210,48 & 47,03 & 510,83 & 66,39 & 13,34 & 34,84 & 174,56 & 63,86 & 64,27 & 135,26 \\
\hline Bufo spinosus & 30SWH64 & 100,00 & 143,58 & 119,04 & 38,44 & 6357,51 & 318,63 & 13,18 & 305,45 & 124,52 & 228,84 & 229,14 & 67,52 & 406,88 & 53,85 & 8,03 & 37,66 & 138,73 & 46,86 & 47,79 & 106,31 \\
\hline Bufo spinosus & 30SWH65 & 100,00 & 137,79 & 120,16 & 38,4 & 6408,61 & 315,40 & 7,05 & 308,36 & 118,61 & 224,08 & 224,23 & 61,37 & 430,13 & 56,60 & 9,38 & 36,48 & 146,97 & 52,01 & 52,64 & 110,77 \\
\hline Bufo spinosus & 30 SWH66 & 100,00 & 125,89 & 121,30 & 38 & $\begin{array}{l}6490,018 \\
6490\end{array}$ & 307,56 & $\begin{array}{l}-4,69 \\
-1,09\end{array}$ & 312,25 & $\begin{array}{l}105,67 \\
105\end{array}$ & 213,69 & 213,75 & 49,07 & 483,00 & 62,73 & \begin{tabular}{|c|}
$, 2,45$ \\
12,4
\end{tabular} & 34,30 & 165,42 & $\begin{array}{ll}62,13 \\
\end{array}$ & 63,59 & 122,54 \\
\hline \begin{tabular}{|l} 
Bufo spinosus \\
\end{tabular} & 30SWH67 & 100,00 & 121,15 & 121,71 & 38,09 & 6519,50 & 304,16 & $-9,30$ & 313,46 & 100,49 & 209,50 & 209,64 & 44,39 & 503,36 & 64,59 & 13,88 & 33,23 & \begin{tabular}{|l|}
172,13 \\
\end{tabular} & 66,52 & 69,38 & 126,38 \\
\hline \begin{tabular}{|l} 
Bufo spinosus \\
\end{tabular} & 30 SWH75 & 100,00 & 143,32 & 119,51 & 38,80 & 6318,92 & 317,40 & 12,58 & 304,82 & 124,51 & 228,17 & 228,31 & 67,60 & 402,00 & 53,56 & 8 & 37,06 & 136,37 & 48,75 & 49,31 & 101,49 \\
\hline Bufo spinosus & 30SWH77 & 100,00 & 132,95 & 120,81 & 38,82 & 6408,51 & 311,01 & 2,16 & 308,85 & 113,34 & 219,48 & 219,49 & 56,69 & 444,69 & 58,68 & 10,75 & 35,01 & 151,40 & 57,19 & 58,24 & 110,40 \\
\hline Bufo spinosus & 30SWH77 & 100,00 & 123,18 & 121,17 & 38,41 & 6470,92 & 304,12 & $-7,16$ & 311,29 & 102,78 & 210,74 & 210,77 & 46,77 & 489,06 & 63,27 & 13,52 & 33,29 & 166,43 & 65,67 & 68,23 & 120,31 \\
\hline \begin{tabular}{|l} 
Bufo spinosus \\
\end{tabular} & 305WH83 & 100,00 & $\begin{array}{l}12,10 \\
127,20\end{array}$ & $\begin{array}{ll}121,17 \\
119,13\end{array}$ & 38 & $\begin{array}{l}040,55 \\
6355,33 \\
\end{array}$ & 303,12 & $\begin{array}{l}-1,10 \\
-1,80 \\
\end{array}$ & $\begin{array}{l}31,24 \\
305,43 \\
\end{array}$ & 106,50 & 213,11 & 213,46 & 52,27 & 479,97 & 63,04 & 12,64 & 34,44 & 162,31 & 62,58 & 62,96 & 121,56 \\
\hline Bufo spinosus & 30SWH85 & 100,00 & 148,53 & 118,95 & 39,00 & 6241,77 & 319,29 & 17,79 & 301,50 & 130,34 & 231,99 & 232,27 & 73,44 & 377,51 & 50,75 & 7,36 & 37,82 & 126,92 & 45,61 & 46,44 & 93,48 \\
\hline Bufo spinosus & 30SWH86 & 100,00 & 139,91 & 120,07 & 38,97 & 6323,97 & 314,17 & 9,01 & 305,16 & 120,78 & 225,01 & 225,06 & 64,40 & 410,44 & 54,92 & 9,30 & 36,04 & 138,60 & 52.97 & 53,56 & 99,77 \\
\hline Bufo spinosus & 30SWH95 & 100,00 & 150,41 & 118,84 & 39,14 & 6175,10 & 318,85 & 19,76 & 299,09 & 132,24 & 232,81 & 233,03 & 75,88 & 370,24 & 49,90 & 7,21 & 38,17 & 123,54 & 45,03 & 46,55 & 90,10 \\
\hline Bufo spinosus & 30SWH96 & 100,00 & 146 & 119,44 & 39,02 & 6231,48 & 316,62 & 15,25 & 301,38 & 127,58 & 229,58 & 229,75 & 71,24 & 384,08 & 51,70 & 8,15 & 37,09 & 128,34 & 49,41 & 50,04 & 91 \\
\hline \begin{tabular}{|l} 
Bufo spinosus \\
\end{tabular} & 30sWJoo & 100,00 & 133,64 & 123,97 & 37,98 & 6738,74 & 323,58 & 0,03 & 323,55 & 115,06 & 224,59 & 224,63 & 53,19 & 468,19 & 57,16 & 9,00 & 37,27 & 162,41 & 51,96 & 52,12 & 129,69 \\
\hline Bufo spinosus & 30SWJO1 & 100,00 & 135,83 & 123,65 & 38,00 & 6718,88 & 324,97 & 2,06 & 322,91 & 117,75 & 226,59 & 226,64 & 55,40 & 454,33 & 55,12 & 8,55 & 37,33 & 156,72 & 50,76 & 50,82 & 125,18 \\
\hline Bufo spinosus & 30SWJO2 & 100,00 & 138.45 & 123,25 & 38,00 & 6704,66 & 326,68 & 4.44 & 322,24 & 120.94 & 228.87 & 228.95 & 57.98 & 440.06 & 52,78 & 8.14 & 37.16 & 150,69 & 49,34 & 49,43 & 120,67 \\
\hline Bufo spinosus & 30SWJ05 & 100,00 & 142,80 & 122,00 & 38,00 & 6677,09 & 328,46 & 9,07 & 319,39 & 126,64 & 232,84 & 232,84 & 62,06 & 415,44 & 47,76 & 7,96 & 36,63 & 138,89 & 47,73 & 47,73 & 112,81 \\
\hline Bufo spinosus & 30 SWJ10 & 100,00 & 133,74 & 123,38 & 38,00 & 6685,27 & 322,20 & 0,64 & 321,56 & 115,28 & 223,74 & 224,19 & 53,98 & 461,31 & 56,75 & 9,04 & 36,79 & 159,66 & 52,44 & 53,18 & 125,69 \\
\hline
\end{tabular}




\begin{tabular}{|c|c|c|c|c|c|c|c|c|c|c|c|c|c|c|c|c|c|c|c|c|c|}
\hline TAXON & UTM & $\mathrm{km2}$ & B101 & $\mathrm{B1O2}$ & $\mathrm{BIO3}$ & B104 & B105 & B106 & B107 & B108 & B109 & 81010 & B1011 & B1O12 & BIO13 & 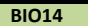 & B1015 & $\begin{array}{ll}\text { B1016 } \\
\end{array}$ & B1017 & BIO18 & B1019 \\
\hline Bufo spinosus & 30SWJ11 & 100,00 & 132,95 & 123,77 & 38,00 & 6688,70 & 321,48 & $-0,02$ & 321,50 & 114,59 & 222,89 & 223,38 & 53,13 & 461,69 & 56,23 & 9,45 & 36,06 & 159,09 & 53,73 & 54,64 & 124,72 \\
\hline Bufo spinosus & 30SWJ16 & 100,00 & 140,12 & 122,00 & 38,00 & 6666,75 & 325,28 & 6,48 & 318,80 & 123,81 & 229,56 & 229,85 & 59,51 & 421,10 & 48,23 & 8,81 & 34,97 & 139,57 & 51,18 & 51,48 & 112,48 \\
\hline Bufo spinosus & 30SWJ18 & 100,00 & 132,89 & 121,90 & 38,00 & 6659,46 & 318,55 & 0,39 & 318,16 & 116,21 & 221,58 & 222,51 & 52,86 & 448,25 & 51,58 & 10,58 & 33,21 & 147,02 & 56,87 & 58,12 & 119,06 \\
\hline Bufo spinosus & 30SWJ19 & 100,00 & 130,61 & 121,07 & \begin{tabular}{|l|l|}
37,97 \\
\end{tabular} & 6666,29 & 315,92 & $-1,29$ & 317,21 & 114,14 & 219,31 & 220,34 & 50,49 & 456,24 & 52,56 & 11,38 & 32,73 & 148,64 & 58,92 & 60,44 & 121,03 \\
\hline Bufo spinosus & 30SWJ20 & 100,00 & 131,13 & 123,12 & 38,00 & 6662,72 & 318,97 & $-1,20$ & 320,17 & 112,30 & 220,61 & 221,16 & 51,47 & \begin{tabular}{|l|l|}
467,97 \\
\end{tabular} & 57,76 & $\begin{array}{ll}10,03 \\
\end{array}$ & 35,65 & 161,54 & 55,42 & 57,01 & 124,75 \\
\hline Bufo spinosus & 30 SWJ24 & 100,00 & 140,59 & 122,61 & 38,00 & 6618,32 & 325,12 & 6,97 & 318,16 & 123,64 & 228,87 & 229,69 & 60,90 & 419,37 & 48,91 & 8,68 & 35,18 & 141,05 & 50,87 & 51,81 & 110,12 \\
\hline Bufo spinosus & 30 SWJ30 & 100,00 & 128,96 & 123,06 & 38,00 & 6630,43 & 315,81 & $-3,09$ & 318,89 & 110,17 & 218,38 & 218,71 & 49,96 & 471,51 & 58,39 & 10,96 & 34,82 & 162,29 & 57,77 & 60,31 & 123,33 \\
\hline \begin{tabular}{|l} 
Bufo spinosus \\
\end{tabular} & 30 SWJ32 & 100,00 & 133,69 & 123,08 & 38,00 & 6622,39 & 319,42 & 0,57 & 318,85 & 115,71 & 222,40 & 223,21 & 54,51 & 446,43 & 54,08 & 10,01 & 34,77 & 152,31 & 55,09 & 57,58 & 115,66 \\
\hline Bufo spinosus & 30SWJ37 & 100,00 & 133,45 & 122,78 & 38,00 & 6609,44 & 317,97 & 0,34 & 317,63 & 116,86 & 221,53 & 222,51 & 53,91 & 443,59 & 51,77 & 10,97 & 32,66 & 147,23 & 58,21 & 60,83 & 113,94 \\
\hline Bufo spinosus & 30SWJ38 & 100,00 & 130,96 & 122,67 & 38,00 & 6614,49 & 315,76 & $-1,69$ & 317,45 & 114,22 & 219,05 & 220,07 & 51,27 & 454,29 & 53,23 & 11,78 & 32,05 & 150,22 & 60,60 & 63,53 & 116,78 \\
\hline Bufo spinosus & 30SWJ39 & 100,00 & 129,38 & 122,36 & 38,00 & 6612,27 & 313,97 & $-2,93$ & 316,90 & 112,62 & 217,27 & 218,53 & 49,86 & \begin{tabular}{|l|l|}
460,68 \\
\end{tabular} & 54,08 & 12,45 & 31,42 & 151,54 & 62,56 & 65,56 & 118,38 \\
\hline Bufo spinosus & 30 SWJ50 & 100,00 & 127,69 & 122,77 & 38,37 & 6551,86 & 311,55 & $-3,77$ & 315,32 & 108,62 & 215,92 & 216,22 & 49,68 & 467,37 & 58,79 & 11,88 & 33,73 & 159,86 & 60,48 & 64,90 & 116,82 \\
\hline Bufo spinosus & 30SWJ51 & 100,00 & 128,77 & 122,86 & 38,44 & 6557,40 & 312,57 & $-2,92$ & 315,49 & 109,92 & 216,97 & 217,32 & 50,64 & 460,01 & 57,16 & 11,66 & 33,52 & 156,84 & 59,95 & 64,64 & 114,24 \\
\hline Bufo spinosus & 30 SWJ52 & 100,00 & 133,79 & 122,73 & 38,44 & 6540,52 & 316,21 & 1,21 & 315,00 & 115,63 & 221,32 & 221,88 & 55,37 & 436,92 & 53,67 & 10,58 & 33,69 & 148,18 & 56,80 & 61,01 & 107,97 \\
\hline Bufo spinosus & 30SWJ62 & 100,00 & 138,03 & 121,89 & 38,58 & 6483,92 & 317,54 & 5,41 & 312,13 & 120,22 & 224,68 & 225,21 & 60,16 & 413,27 & 51,48 & 9,97 & 33,99 & 139,39 & 54,32 & 58,86 & 99,42 \\
\hline Bufo spinosus & 30 SWJ76 & 100,00 & 134,61 & 121,55 & 38,82 & 6462,91 & 313,02 & 2,20 & 310,82 & 117,55 & 220,68 & 221,38 & 56,69 & 428,03 & 50,88 & 12,09 & 31,03 & 141,85 & 61,89 & 66,78 & 100,57 \\
\hline Bufo spinosus & 30SWJ77 & 100,00 & 128,87 & 122,03 & 38,82 & 6483,01 & 308,72 & $-3,01$ & 311,73 & 111,45 & 215,26 & 215,97 & 50,74 & 454,88 & 54,52 & 13,78 & 29,97 & 150,85 & 67,42 & 73,20 & 107,28 \\
\hline Bufo spinosus & 30SWJ99 & 100,00 & 118,33 & 119,86 & 38,51 & 6436,01 & 295,44 & $-11,94$ & 307,38 & 100,21 & 204,26 & 205,12 & 41,34 & 494,68 & 61,08 & 18,13 & 27,68 & 162,79 & 81,62 & 88,84 & 111,42 \\
\hline Bufo spinosus & 30SWK11 & 100,00 & 127,21 & 119,86 & 37,71 & 6654,59 & 311,46 & $-3,37$ & 314,83 & 110,91 & 215,81 & 216,84 & 47,49 & 464,80 & 53,60 & 12,60 & 31,68 & 149,25 & 62,02 & 63,58 & 122,94 \\
\hline Bufo spinosus & 305WK12 & 100,00 & 124,11 & 119,03 & 37,44 & 6643,19 & 307,64 & $-5,88$ & 313,52 & 107.91 & 212.52 & 213,62 & 44,65 & 474,90 & 54,89 & 13,53 & 31,11 & $\mid 151,70$ & 64.56 & $\begin{array}{l}66,55 \\
\end{array}$ & 125,21 \\
\hline Bufo spinosus & 30SWK22 & 100,00 & 125,56 & 119,97 & 37,98 & 6623,30 & 308,77 & $-5,27$ & 314,04 & 109,49 & 213,51 & 214,71 & 45,99 & 469,67 & 54,92 & 13,59 & 30,66 & 151,05 & 65,05 & 67,47 & 122,26 \\
\hline Bufo spinosus & 30SWK30 & 100,00 & 128,39 & 122,10 & 38,00 & 6612,87 & 312,56 & $-3,83$ & 316,39 & 111,76 & 216,24 & 217,35 & 48,82 & 463,96 & 54,65 & 12,93 & 31,00 & 151,84 & 63,84 & \begin{tabular}{|l|}
66,83 \\
\end{tabular} & 119,37 \\
\hline Bufo spinosus & 30SWK71 & 100,00 & 113,51 & 123,53 & \begin{tabular}{|l|l|}
38,84 \\
\end{tabular} & $\begin{array}{ll}6510,86 \\
\end{array}$ & 296,77 & $-19,11$ & 315,88 & 95,81 & 200,28 & 201,36 & 35,75 & 531,54 & 65,52 & 19,14 & 27,77 & \begin{tabular}{|l|l|}
176,37 \\
\end{tabular} & 84,38 & $\begin{array}{l}92,16 \\
\end{array}$ & 127,66 \\
\hline Bufo spinosus & 30SWK72 & 100,00 & 114,84 & 123,94 & 38,78 & 6504,07 & 298,22 & $-18,23$ & 316,45 & 97,64 & 201,27 & 202,55 & 36,71 & 529,12 & 65,56 & 19,03 & 27,95 & 175,45 & 84,35 & 91,78 & 128,03 \\
\hline Bufo spinosus & 30SWK80 & 100,00 & 113,99 & 121,85 & 38,65 & 6483,76 & 294,69 & $-17,24$ & 311,93 & 95,93 & 200,63 & 201,60 & 36,80 & 520,77 & 64,36 & 19,13 & 27,34 & 172,34 & 84,60 & 92,57 & 121,23 \\
\hline Bufo spinosus & 30SWK82 & 100,00 & 110,53 & 121,79 & 38,60 & 6481,56 & 291,16 & $-21,05$ & 312,21 & 92,89 & 196,90 & 198,10 & 33,16 & 535,29 & 67,2 & 20,84 & 27,04 & 176,77 & 89,48 & 98,00 & 124,87 \\
\hline Bufo spinosus & 30SWK90 & 100,00 & 116,58 & 119,88 & 38,45 & 6443,29 & 293,81 & $-13,81$ & $\begin{array}{l}307,62 \\
302\end{array}$ & \begin{tabular}{|l|l|}
98,66 \\
\end{tabular} & 202,56 & 203,46 & 39,53 & 501,62 & $\begin{array}{l}62,54 \\
\end{array}$ & 18,95 & 27,31 & 165,01 & $\begin{array}{l}3,40 \\
84,10\end{array}$ & $\begin{array}{l}91,51 \\
91\end{array}$ & 113,06 \\
\hline Bufo spinosus & $305 \times 601$ & 50,00 & 180,97 & 91,21 & 38,06 & 4995,75 & 306,45 & 71,09 & 235,36 & 156,82 & 245,13 & 248,81 & 120,57 & 250,03 & 37,21 & 2,03 & 49,72 & 98,54 & 15,19 & 23,28 & 79,87 \\
\hline Bufo spinosus & 30 XG13 & 77,00 & 177,22 & 98,53 & 39,01 & 5218,30 & 310,74 & 61,50 & 249,24 & 150,96 & 244,65 & 247,50 & 113,88 & 271,97 & 40,23 & 2,32 & 47,83 & 104,89 & 18,07 & 27,37 & 82,33 \\
\hline Bufo spinosus & 30 XG14 & 100,00 & 169,89 & 102,74 & 39,03 & 5405,75 & 310,13 & 51,13 & 259,00 & 142,17 & 240,30 & 242,78 & 104,59 & 298,53 & 42,45 & 3,26 & 45,36 & 110,75 & 22,45 & 31,53 & 87,54 \\
\hline Bufo spinosus & $30 \mathrm{SXG17}$ & 100,00 & 160,87 & 110,77 & 39,68 & 5727,21 & 312,77 & 36,10 & 276,67 & 130,43 & 236,43 & 237,94 & 91,78 & 336,38 & 45,67 & 4,90 & 42,20 & 117,44 & 30,48 & 39,09 & 92,01 \\
\hline Bufo spinosus & 30SXG24 & 92,00 & 174,82 & 102,19 & 39,44 & 5312,10 & 312,18 & 56,31 & 255,86 & $\begin{array}{l}147,92 \\
14,4\end{array}$ & 243,68 & \begin{tabular}{|l|}
246,19 \\
\end{tabular} & $\mid \begin{array}{r}11,24 \\
110,24\end{array}$ & | & 42,23 & 2,73 & $\begin{array}{l}4,2,11 \\
7,11\end{array}$ & 109,56 & $\begin{array}{l}0,40 \\
20,19\end{array}$ & 30,23 & 84,23 \\
\hline Bufo spinosus & 30SXG27 & 100,00 & 165,69 & 110,98 & 39,92 & 5649,69 & 315,10 & 40,62 & 274,48 & 135,95 & 239,87 & 241,26 & 97,10 & 322,84 & 45,60 & 4,13 & 43,86 & 115,58 & 27,64 & 37,69 & 88,31 \\
\hline Bufo spinosus & $30 S X G 28$ & 100,00 & 150,61 & 113,57 & 39,63 & 5862,45 & 308,13 & 24,37 & 283,76 & 120,82 & 228,34 & 229,78 & 80,49 & 383,29 & 50,60 & 7,32 & 39,63 & 129,49 & 40,27 & 48,06 & 100,86 \\
\hline Bufo spinosus & $30 S \times G 29$ & 100,00 & 135,25 & 115,02 & 39,09 & 6045,20 & 299,51 & 8,79 & 290,73 & 110,42 & 215,94 & 217,42 & 63,70 & 455,83 & 58,89 & 11,65 & 35,79 & 149,59 & 56,40 & 61,37 & 116,24 \\
\hline \begin{tabular}{|l} 
Bufo spinosus \\
\end{tabular} & 30 SXG38 & 100,00 & 169,85 & 113,70 & 40,50 & 5651,02 & 319,95 & 42,49 & 277,46 & 139,68 & 243,88 & 245,08 & 100,80 & 313,13 & 45,82 & 3,62 & 45,34 & 113,96 & 25,87 & 37,57 & 84,12 \\
\hline Bufo spinosus & $30 \mathrm{SXG39}$ & 100,00 & 159,56 & 115,53 & 40,17 & 5803,77 & 315,15 & 31,25 & 283,89 & 128,48 & 236,18 & 237,14 & 89,25 & 351,11 & 48,74 & 5,53 & 42,01 & 122,20 & 34,09 & 44,18 & 91,23 \\
\hline Bufo spinosus & $305 \times 665$ & & & & & & & & & & & & & & & & & & & & \\
\hline Bufo spinosus & $305 \times G 69$ & 100,00 & 167,66 & 116,15 & 41,02 & 5638,52 & 318,49 & 38,72 & 279,77 & 138,34 & 241,47 & 242,52 & 98,66 & 335,36 & 51,44 & 4,60 & 45,19 & 124,75 & 29,79 & 43,90 & 86,18 \\
\hline Bufo spinosus & $30 S \times 689$ & 100,00 & 175,98 & 112,19 & 41,00 & 5420,67 & 319,54 & 50,03 & 269,52 & 148,85 & 246,34 & 247,80 & 109,30 & 312,98 & 53,91 & 4,10 & 48,99 & 126,43 & 26,48 & 42,01 & 79,49 \\
\hline Bufo spinosus & 30 XX99 & 79,00 & 180,58 & 109,37 & 41,00 & 5288,47 & 319,70 & 56,83 & 262,87 & 155,03 & 248,88 & 250,73 & 115,47 & 298,50 & 54,94 & 4,00 & 52,17 & 126,64 & 24,59 & 40,65 & 75,11 \\
\hline \begin{tabular}{|l} 
Bufo spinosus \\
\end{tabular} & $30 \mathrm{SXH10}$ & 100,00 & 143,76 & 116,03 & 39,24 & 6040,71 & 307,85 & $\begin{array}{l}0,0 \\
15,79 \\
\end{array}$ & 292,06 & 120,10 & 224,36 & 225,40 & 71,79 & 408,06 & 53,51 & 8,69 & 37,64 & 134,36 & 47,08 & 52,55 & 104,28 \\
\hline Bufo spinosus & $30 \mathrm{~S} \times \mathrm{H} 12$ & 100,00 & 160,97 & 117,42 & 40,00 & 5947,23 & 321,29 & 31,01 & 290,28 & 128,20 & 239,56 & 240,31 & 88,66 & 337,19 & 46,14 & 5,14 & 41,70 & 114,03 & 34,47 & 42,27 & 84,77 \\
\hline Bufo spinosus & $30 \mathrm{SXH13}$ & 100,00 & 163,85 & 117,87 & 40,00 & 5951,82 & 323,92 & 33,54 & 290,38 & 131,48 & 242,43 & 243,01 & 91,25 & 326,75 & 45,59 & 4,71 & 42,19 & 111,07 & 33,41 & 40,68 & 80,99 \\
\hline Bufo spinosus & $30 \mathrm{SXH15}$ & 100,00 & 157,33 & 118,67 & 39,99 & 6041,73 & 320,72 & 26,74 & 293,99 & 130,91 & 237,50 & 237,97 & 83,89 & 347,87 & $47, \mathrm{C}$ & 6,10 & 39,93 & 114,83 & 40,63 & 44,60 & 82,83 \\
\hline \begin{tabular}{|l} 
Bufo spinosus \\
\end{tabular} & $30 \mathrm{~S} \times \mathrm{H} 2 \mathrm{O}$ & 100,00 & 160,52 & 116,36 & 40,07 & 5859,28 & 318,01 & 31,53 & 286,48 & 128,67 & 237,89 & 238,85 & 89,54 & 342,41 & 47 & 5,10 & 42,01 & 117,74 & 33,39 & 42,79 & 88,05 \\
\hline \begin{tabular}{|l} 
Bufo spinosus \\
\end{tabular} & $30 \mathrm{SXH} 23$ & 100,00 & 166,99 & 118,20 & 40,32 & 5891,20 & 325,24 & 36,20 & 289,04 & 134,37 & 244,73 & 245,19 & 95,04 & 320,00 & 46,28 & 4,33 & 43,28 & 110,82 & 31,59 & 40,88 & 78,78 \\
\hline Bufo spinosus & $30 \mathrm{~S} \times \mathrm{H} 31$ & 100,00 & 163,71 & 118,16 & 40,51 & 5851,48 & 320,97 & 33,14 & 287,83 & 131,87 & 240,82 & 241,51 & 92,36 & 335,63 & 48,00 & 4,85 & 43,15 & 116,94 & 32.51 & 42,78 & 84,45 \\
\hline Bufo spinosus & $30 \mathrm{~S} \times \mathrm{H3} 3$ & 100,00 & 168,96 & 118,92 & 40,94 & 5848,79 & 325,87 & 37,70 & 288,17 & 137,05 & 246,03 & 246,49 & 97,40 & 317,30 & 47,37 & 4,12 & 44,38 & 111,85 & 30,50 & 41,24 & 77,54 \\
\hline Bufo spinosus & $30 \mathrm{~S} \times \mathrm{H} 36$ & 100,00 & 146,88 & 117,98 & 40,00 & 6050,49 & 310,16 & 17,26 & 292,90 & 125,80 & 227,36 & 228,03 & 74,01 & 395,32 & 51,84 & 9,04 & 36,91 & 127,41 & 52,43 & 56,84 & 90,37 \\
\hline Bufo spinosus & $\begin{array}{l}30 \mathrm{~S} \times \mathrm{H} 442 \\
\end{array}$ & 100,00 & $\begin{array}{l}14,00 \\
169,81\end{array}$ & $\begin{array}{l}11,50 \\
119,50\end{array}$ & 41 & $\begin{array}{l}5003,49,55 \\
5795\end{array}$ & 325,57 & $\begin{array}{ll}1,20 \\
37,98\end{array}$ & 287,59 & \begin{tabular}{|l|}
138,33 \\
130
\end{tabular} & \begin{tabular}{|l|}
245,83 \\
\end{tabular} & \begin{tabular}{|l|}
246,50 \\
240
\end{tabular} & $\begin{array}{l}98,54 \\
98,5\end{array}$ & | & $\begin{array}{l}1,04 \\
48,45\end{array}$ & 3,94 & $\begin{array}{l}30,53 \\
453\end{array}$ & $\begin{array}{l}114,22 \\
114,\end{array}$ & $\begin{array}{l}2,4,29 \\
29,29\end{array}$ & $\begin{array}{l}30,04 \\
42,20\end{array}$ & 78,85 \\
\hline Bufo spinosus & $30 \mathrm{SXH} 43$ & 100,00 & 164,89 & 118,93 & 40,86 & 5849,01 & 322,05 & 33,71 & 288,34 & 133,06 & 241,92 & 242,58 & 93,44 & 336,60 & 49,91 & 5,00 & 43,68 & 117,83 & 34,13 & 45,94 & 81,16 \\
\hline Bufo spinosus & $30 \mathrm{~S} \times \mathrm{H} 45$ & 100,00 & 153,31 & 117,88 & 40,10 & 5951,01 & 313,14 & 23,56 & 289.58 & $\mid 127,44$ & 232.03 & 232.93 & 81,24 & 378,31 & 52.56 & 7,68 & 38,99 & $\mid 126,14$ & 46,28 & F4,47 & 87,53 \\
\hline Bufo spinosus & $30 \mathrm{~S} \times \mathrm{H} 46$ & 100,00 & 148,49 & 117,36 & 39,99 & 5991,87 & 309,28 & 19,41 & 289,87 & 148,49 & 227,92 & 228,73 & 76,22 & 396,39 & 53,53 & 9,01 & 37,29 & 129,54 & 51,91 & 58,53 & 90,28 \\
\hline Bufo spinosus & $30 \mathrm{~S} \times \mathrm{H} 47$ & 100,00 & 139,29 & 116,61 & 39,69 & 6063,79 & 302,22 & 11,19 & 291,03 & 128,43 & 220,07 & 220,89 & 66 & 433,17 & 55,26 & 11,52 & 34,49 & 137,38 & 62,04 & 65,94 & 97,5 \\
\hline \begin{tabular}{|l} 
Bufo spinosus \\
\end{tabular} & |305XH4 & $\begin{array}{l}100,00 \\
100\end{array}$ & $\begin{array}{l}137,49 \\
137,41\end{array}$ & $\begin{array}{l}11,0,01 \\
116,19\end{array}$ & $\begin{array}{l}3,09 \\
39,42\end{array}$ & $\mid 6007,15$ & 30,24 & $\begin{array}{r}r 1,15 \\
9,62\end{array}$ & 290, & 130,16 & 218,48 & 219,18 & 64,59 & 439,88 & 55,64 & 12,19 & 33,73 & $\begin{array}{l}139,74 \\
\end{array}$ & 65,08 & 68,10 & 97,91 \\
\hline Bufo spinosus & $30 \mathrm{~S} \times \mathrm{H} 50$ & 100,00 & 177,76 & 120,11 & 41,70 & 5681,36 & 330,25 & 45,01 & 285,24 & 147,28 & 252,02 & 252,39 & 107,44 & 299,05 & 47,22 & 2,59 & 49,04 & 112,32 & 22,37 & 35,57 & 77,64 \\
\hline Bufo spinosus & $30 \mathrm{SXH51}$ & 100,00 & 176,58 & 120,63 & 41,65 & 5711,35 & 330,13 & 43,54 & 286,59 & 145,69 & 251,24 & 251.56 & 105.99 & 302.26 & 47.95 & 298 & 48.54 & 112.50 & 23.96 & 36,14 & 76.50 \\
\hline Bufo spinosus & 30SXH53 & 100,00 & 152,10 & 117,47 & 40,34 & 5896,20 & 310,52 & 22,78 & 287,74 & 120,85 & 230,4 & 230 & 80, & 391,85 & 54,71 & 8,12 & 39,48 & 132,68 & 46,29 & 56,29 & 93,03 \\
\hline Bufo spinosus & 30 XH56 & 100,00 & 146,71 & 116,34 & 40,01 & 5950,56 & 305,92 & 18,71 & 287,21 & 155,11 & 225,60 & 226,49 & 75,18 & 411,71 & 56,05 & 9,79 & 36,74 & 135,81 & 54,56 & 62,28 & 93,67 \\
\hline
\end{tabular}




\begin{tabular}{|c|c|c|c|c|c|c|c|c|c|c|c|c|c|c|c|c|c|c|c|c|c|}
\hline TAXON & UTM & $\mathrm{km2}$ & B101 & $\mathrm{B1O2}$ & $\mathrm{BIO3}$ & $\mathrm{B104}$ & B105 & B106 & B107 & B108 & B109 & 81010 & B1011 & B1012 & BIO13 & BIO14 & BIO15 & BIO16 & B1017 & BIO18 & BIO19 \\
\hline Bufo spinosus & 30SXH57 & 100,00 & 141,69 & 115,62 & 39,89 & 5984,79 & 301,64 & 14,37 & 287,27 & 151,79 & 221,27 & 222,22 & 69,91 & 432,56 & 57,13 & 11,32 & 34,87 & 140,41 & 60,76 & 66,92 & 97,39 \\
\hline Bufo spinosus & 30 XXH58 & 100,00 & 142,56 & 115,13 & $\begin{array}{l}39,85 \\
\end{array}$ & 5982,00 & 301,74 & 15,49 & 286,25 & 152,41 & 222,02 & 222,81 & 70,77 & 428,47 & 56,95 & 11,25 & 34,88 & 140,04 & 61,05 & 67,12 & 95,49 \\
\hline Bufo spinosus & $30 \mathrm{SXH60}$ & 100,00 & 179,11 & 119,22 & 41,82 & 5622,63 & 329,72 & 47,06 & 282,67 & 149,38 & 252,55 & 252,93 & 109,56 & 298,01 & 48,85 & 2,73 & 49,87 & 114,67 & 22,28 & 37,67 & 76,57 \\
\hline Bufo spinosus & 30 XXH64 & 100,00 & 151,17 & 116,24 & 40,11 & 5860,56 & 307,67 & 23,06 & 284,61 & 137,29 & 228,65 & 229,75 & 80,54 & 401,33 & 57,18 & 8,61 & 38,69 & \begin{tabular}{|l|l|}
137,03 \\
\end{tabular} & 48,79 & 59,51 & 93,54 \\
\hline Bufo spinosus & 30SXH65 & 100,00 & 144,24 & 115,33 & 39,92 & 5911,52 & 302,10 & 17,10 & 285,01 & \begin{tabular}{|l|}
139,66 \\
\end{tabular} & 222,62 & 223,77 & 73,39 & 432,05 & 58,99 & 10,63 & 36,29 & \begin{tabular}{|l|l|}
143,74 \\
\end{tabular} & 56,97 & 65,91 & 99,61 \\
\hline Bufo spinosus & $30 \mathrm{SXH66}$ & 100,00 & 149,38 & 115,34 & 40,01 & 5874,64 & 305,55 & 22,10 & 283,45 & 159,56 & 227,07 & 228,18 & 78,64 & 410,53 & 58,13 & 9,49 & 37,49 & 139,62 & 53,10 & 63,02 & 93,43 \\
\hline Bufo spinosus & 30SXH67 & 100,00 & 149,41 & 114,73 & 40,00 & 5872,88 & 305,05 & 22,55 & 282,49 & 159,75 & 227,07 & 228,20 & 78,63 & 411,25 & 58,21 & 9,72 & 37,14 & 140,16 & 54,33 & 63,98 & 92,81 \\
\hline \begin{tabular}{|l} 
Bufo spinosus \\
\end{tabular} & 30 SXH68 & 100,00 & 142,02 & 113,82 & 39,87 & 5933,72 & 298,99 & 16,03 & 282,95 & 152,27 & 220,73 & 221,85 & 70,98 & 441,90 & 59,60 & 11,88 & 34,58 & 146,62 & $\begin{array}{ll}62,88 \\
\end{array}$ & 70,57 & 98,86 \\
\hline Bufo spinosus & $30 \mathrm{SXH71}$ & 100,00 & 178,63 & 116,88 & 41,76 & 5550,24 & 326,59 & 48,83 & 277,76 & 150,00 & 250,95 & 251,82 & 110,09 & 298,88 & 51,72 & 3,32 & 49,93 & \begin{tabular}{|l|l|}
117,47 \\
\end{tabular} & 24,25 & 41,11 & 73,47 \\
\hline Bufo spinosus & $30 \mathrm{SXH72}$ & 100,00 & 177,32 & 117,13 & \begin{tabular}{|l|l|}
41,63 \\
\end{tabular} & 5578,35 & 325,76 & 47,36 & 278,40 & 163,10 & 250,02 & 250,90 & 108,56 & 303,84 & 52,70 & 3,46 & 49,61 & 117,92 & 26,08 & 43,02 & 72,70 \\
\hline Bufo spinosus & $30 \mathrm{SXH75}$ & 100,00 & 149,40 & 114,43 & 40,08 & 5814,46 & 303,77 & 22,72 & 281,06 & 156,23 & 226,13 & 227,51 & 79,30 & 419,80 & 60,28 & 9,59 & 37,78 & 144,82 & 52,92 & 64,41 & 96,90 \\
\hline Bufo spinosus & $30 \mathrm{SXH78}$ & 100,00 & 149,39 & 112,52 & 40,00 & 5810,07 & 302,00 & 24,32 & 277,68 & 160,09 & 226,17 & 227,48 & 79,46 & 425,31 & 61,31 & 10,38 & 37,02 & \begin{tabular}{|l|l|}
148,14 \\
\end{tabular} & 56,93 & 68,25 & 95,77 \\
\hline Bufo spinosus & $30 \mathrm{SXH} 81$ & 100,00 & 179,97 & 113,99 & 41,46 & 5444,26 & 324,12 & 52,53 & 271,60 & 159,36 & 250,52 & 251,79 & 112,64 & 292,76 & 53,77 & 3,42 & 52,47 & 119,63 & 24,24 & 41,31 & 70,22 \\
\hline Bufo spinosus & $30 \mathrm{SXH83}$ & 100,00 & 168,56 & 114,31 & 41,02 & 5579,27 & 316,39 & 41,38 & 275,01 & 175,92 & 241,35 & 242,81 & 100,41 & 344,30 & 57,59 & 5,64 & 46,19 & 131,40 & 35,20 & 51,27 & 80,19 \\
\hline Bufo spinosus & $30 \mathrm{SXH89}$ & 100,00 & 148,21 & 110,09 & 39,95 & 5750,68 & 298,07 & 25,22 & 272,85 & 159,33 & 223,96 & 225,60 & 79,03 & 446,46 & 64,77 & 11,42 & 36,43 & 157,67 & 60,70 & 73,58 & 101,23 \\
\hline Bufo spinosus & $30 \mathrm{SXH91}$ & 100,00 & 180,85 & 111,16 & 41,18 & 5349,22 & 321,50 & 55,73 & 265,77 & 189,96 & 249,89 & 251,66 & 114,82 & 288,62 & 55,62 & 3,80 & 54,55 & 122,54 & 24,43 & 42,02 & 67,75 \\
\hline Bufo spinosus & $30 \mathrm{~S} \times \mathrm{H} 92$ & 100,00 & 182,93 & 111,19 & 41,27 & 5337,78 & 322,79 & 57,58 & 265,22 & 195,09 & 251,56 & 253,29 & 116,55 & 288,90 & 56,03 & 3,51 & 54,63 & 123,30 & 24,35 & 42,49 & 67,24 \\
\hline Bufo spinosus & 30SXH93 & 100,00 & 178,78 & 111,72 & 41,09 & 5400,40 & 320,62 & 53,39 & 267,23 & 191,18 & 248,55 & 250,44 & 112,20 & 309,93 & 57,72 & 4,22 & 51,72 & 128,54 & 28,58 & 46,75 & 71,09 \\
\hline Bufo spinosus & 30SXH94 & 100,00 & 170,06 & 112,04 & 41,00 & 5492,12 & 314,73 & 44,80 & 269,93 & 182,25 & 241,54 & 243,40 & 103,08 & 350,82 & 60,63 & 5,69 & 46,96 & \begin{tabular}{|l|l|}
138,28 \\
\end{tabular} & 36,41 & 53,73 & 80,22 \\
\hline Bufo spinosus & 30 SXH95 & 100,00 & 162,30 & 111,57 & $\mid 40,77$ | & 5574,44 & 308,95 & 37,72 & 271,23 & $\mid 172,71$ & 235,08 & 237,00 & 94,60 & 389,55 & 62.99 & 7.53 & 43,21 & $\mid 147,42$ & 44,34 & 60,79 & 89,86 \\
\hline Bufo spinosus & 30SXH98 & 100,00 & 144,32 & 109,36 & 39,72 & \begin{tabular}{|l|l|}
5737,64 \\
\end{tabular} & 294,20 & 22,01 & 272,20 & 155,50 & 219,91 & 221,75 & 75,75 & 475,68 & 67,75 & 12,47 & 35,70 & 166,80 & 64,63 & 78,26 & 110,11 \\
\hline Bufo spinosus & 30SXJ08 & 100,00 & 122,13 & 117,97 & 38,70 & 6381,62 & 295,58 & $-6,56$ & 302,14 & 104,82 & 207,47 & 208,10 & 45,69 & 473,02 & 57,98 & 17,31 & 28,02 & 154,30 & 79,13 & 85,51 & 103,34 \\
\hline Bufo spinosus & 30SXJ09 & 100,00 & 120,42 & 117,75 & \begin{tabular}{|l|l|}
38,44 \\
\end{tabular} & 6394,95 & 293,89 & $-8,44$ & 302,32 & 102,88 & 205,79 & 206,61 & 43,75 & 479,12 & 59,40 & 18,10 & 27,64 & \begin{tabular}{|l|l|}
156,27 \\
\end{tabular} & 81,62 & 88,12 & $\begin{array}{ll}104,53 \\
\end{array}$ \\
\hline Bufo spinosus & $30 \mathrm{~S} \times \mathrm{J19}$ & 100,00 & 123,78 & 115,25 & 38,13 & 6342,05 & 292,98 & $-3,72$ & 296,70 & 135,69 & 208,34 & 209,01 & 47,72 & 460,06 & 57,08 & 17,71 & 27,87 & 149,62 & 80,81 & 85,97 & 97,18 \\
\hline Bufo spinosus & $305 \times J 27$ & 100,00 & 135,49 & 113,62 & 38,55 & 6222,47 & 299,38 & 8,49 & 290,89 & 153,20 & 218,48 & 218,69 & 60,57 & 418,58 & 49,97 & 14,38 & 29,99 & \begin{tabular}{|l|l|}
134,59 \\
\end{tabular} & 71,86 & 73,58 & 87,35 \\
\hline Bufo spinosus & $305 \times 129$ & 100,00 & 126,43 & 112,75 & 38,00 & 6289,60 & 291,53 & 0,37 & 291,16 & 144,61 & 210,27 & 210,82 & 51,06 & 446,32 & 55,21 & 17,49 & 28,18 & 145,12 & 80,79 & 84,38 & 91,66 \\
\hline Bufo spinosus & $305 \times 136$ & 100,00 & 141,98 & 111,71 & 38,92 & 6101,21 & 301,05 & $\begin{array}{ll}16,47 \\
\end{array}$ & 284,58 & \begin{tabular}{|l|}
154,50 \\
\end{tabular} & 223,22 & 223,39 & 68,34 & \begin{tabular}{|l|}
402,47 \\
\end{tabular} & \begin{tabular}{|l|l|}
50,05 \\
\end{tabular} & 12,97 & 31,48 & $\begin{array}{l}428,76 \\
128,\end{array}$ & $\begin{array}{l}\mid 60,75 \\
67,55\end{array}$ & $\begin{array}{l}4,40161 \\
681\end{array}$ & 83,69 \\
\hline Bufo spinosus & $305 \times 137$ & 100,00 & 129,43 & 112,05 & 38,30 & 6210,37 & 291,93 & 4,19 & 287,74 & 146,47 & 212,47 & 212,64 & 55,10 & 445,05 & 52,90 & 16,54 & 28,95 & 142,84 & 79,29 & 80,87 & 91,56 \\
\hline Bufo spinosus & $305 \times 146$ & 100,00 & 140,77 & 109,92 & 38,90 & 6050,06 & 297,10 & 16,81 & 280,29 & 150,23 & 221,32 & 221,66 & 67,97 & 413,15 & 52,03 & 13,81 & 31,29 & $\mid 132,51$ & 70,02 & 72,27 & 85,21 \\
\hline Bufo spinosus & $305 \times 149$ & 100,00 & 122,53 & 108,38 & 37,99 & 6213,33 & 282,04 & $-0,13$ & 282,17 & 139,53 & 202,60 & 205,97 & 48,61 & 465,00 & 56,91 & 19,70 & 27,76 & 150,18 & 89,13 & 90,91 & 92,11 \\
\hline Bufo spinosus & $305 \times 151$ & 100,00 & 133,18 & 112,97 & 39,00 & 6048,94 & 293,03 & 8,12 & 284,91 & 139,41 & 213,86 & 214,76 & 61,01 & 463,61 & 57,82 & 14,67 & 31,29 & \begin{tabular}{|l|l|}
146,88 \\
\end{tabular} & 74,18 & 77,11 & 100,44 \\
\hline Bufo spinosus & $305 \times 152$ & 100,00 & 129,60 & 112,21 & 38,96 & $\begin{array}{l}6071,79 \\
6071,4\end{array}$ & 289,74 & $\begin{array}{l}, 1+25 \\
5,25 \\
\end{array}$ & 284,49 & \begin{tabular}{|l|}
131,89 \\
\end{tabular} & \begin{tabular}{|l|}
210,860 \\
\end{tabular} & 211,45 & 57,43 & \begin{tabular}{|l|}
478,03 \\
4703
\end{tabular} & $\begin{array}{l}1,306 \\
58,38\end{array}$ & 16,09 & $\begin{array}{l}1,25 \\
30,25\end{array}$ & $\begin{array}{l}40,00 \\
151,48 \\
\end{array}$ & $\begin{array}{l}74,109 \\
78,93\end{array}$ & $\begin{array}{ll}1,1126 \\
\end{array}$ & 102,80 \\
\hline Bufo spinosus & $305 \times 153$ & 100,00 & 132,83 & 111,44 & 38,99 & 6054,51 & 291,36 & 8,81 & 282,55 & 143,03 & 213,66 & 214,39 & 60,61 & 461,08 & 57,05 & 15,37 & 30,49 & \begin{tabular}{|l|l|}
146,18 \\
\end{tabular} & 76,52 & 79,16 & 98,14 \\
\hline Bufo spinosus & $305 \times 154$ & 100,00 & 138,76 & 110,19 & 39,02 & 6004,92 & 294,48 & 15,13 & 279,34 & 147,93 & 218,64 & 219,31 & 66,72 & 435,97 & 55,88 & 14,11 & 31,42 & 141,36 & 71,40 & 75,39 & 91,89 \\
\hline Bufo spinosus & $305 \times 155$ & 100,00 & 148,64 & 108,27 & 39,01 & 5905,81 & 299,69 & 25,99 & 273,70 & 157,78 & 226,81 & 227,51 & 77,32 & 400,95 & 55,10 & 12,10 & 33,61 & 136,10 & 62,95 & 69,85 & 84,22 \\
\hline Bufo spinosus & $305 \times 158$ & 100,00 & 127,50 & 106,93 & 37,98 & 6110,70 & 283,45 & 5,91 & 277,54 & 142,05 & 209,36 & 209,55 & 54,73 & 458,52 & 54,60 & 18,52 & 28,35 & 144,68 & 85,95 & 86,95 & 91,62 \\
\hline \begin{tabular}{|l} 
Bufo spinosus \\
\end{tabular} & $305 \times 159$ & 100,00 & 120,95 & 106,30 & 37,90 & 6167,78 & 277,81 & $-0,17$ & 277,97 & 137,32 & 163,31 & 203,76 & 47,78 & 477,04 & 57,77 & 20,75 & 27,53 & 152,52 & 92,88 & 93,98 & 93,77 \\
\hline Bufo spinosus & 30SXJ61 & 100,00 & 137,99 & 111,40 & 39,21 & 5952,97 & 293,82 & 13,92 & 279,90 & 147,24 & 217,15 & 218,16 & 66,81 & 456,65 & 59,88 & 13,80 & 32,50 & 149,99 & 70,42 & 76,63 & 99,55 \\
\hline Bufo spinosus & $305 \times 162$ & 100,00 & 140,55 & 110,31 & 39,25 & 5927,19 & 294,52 & 17,05 & 277,47 & 150,31 & 219,21 & 220,26 & 69,46 & 446,74 & 59,58 & 13,52 & 32,87 & $\mid 148,61$ & 69,04 & 75,92 & 96,71 \\
\hline Bufo spinosus & $305 \times 163$ & 100,00 & 144,75 & 109,03 & 39,27 & 5877,77 & 296,22 & 22,16 & 274,06 & 154,58 & 222,55 & 223,61 & 74,08 & 430,61 & 59,06 & 12,83 & 33,59 & \begin{tabular}{|l|l|}
146,08 \\
\end{tabular} & 66,01 & 74,06 & 92,64 \\
\hline Bufo spinosus & $305 \times 164$ & 100,00 & 149,53 & 107,54 & 39,27 & 5826,07 & 298,32 & 27,84 & 270,48 & 159,32 & 226,47 & 227,62 & 79,22 & 412,81 & 58,55 & 12,10 & 34,66 & 143,23 & 62,50 & 71,75 & 88,25 \\
\hline \begin{tabular}{|l} 
Bufo spinosus \\
\end{tabular} & $305 \times 165$ & 100,00 & 140,37 & 107,06 & 38,91 & 5923,89 & 291,50 & 19,09 & 272,41 & \begin{tabular}{|l|l|}
149,81 \\
\end{tabular} & 218,99 & 219,93 & 69,25 & \begin{tabular}{|l|l|}
438,99 \\
\end{tabular} & 58,03 & 14,58 & 31,61 & 146,35 & 71,97 & 78,82 & 92,03 \\
\hline Bufo spinosus & $305 \times 166$ & 100,00 & 137,73 & 106,27 & 38,63 & 5952,26 & 288,87 & 16,69 & 272,18 & 146,89 & 216,82 & 217,55 & 66,32 & 444,08 & 57,30 & 15,64 & 30,68 & 146,17 & 75,42 & 81,56 & 91,85 \\
\hline Bufo spinosus & $305 \times 167$ & 100,00 & 134,58 & 105,47 & 38,08 & 5986,80 & 286,09 & 14,12 & 271,97 & 143,41 & 214,29 & 214,93 & 63,03 & 449,14 & 56,28 & 16,73 & 29,75 & $\begin{array}{l}145,65 \\
\end{array}$ & 79,29 & 84,23 & 91,38 \\
\hline Bufo spinosus & $305 \times 168$ & 100,00 & 122,35 & 105,18 & 37,93 & 6098,75 & 276,92 & 2,28 & 274,63 & 136,46 & 203,99 & 204,38 & 50,08 & 487,44 & 57,57 & 20,50 & 27,48 & 153,17 & 92,86 & 94,41 & 97,42 \\
\hline Bufo spinosus & $305 \times 169$ & 100,00 & 130,08 & 103,49 & 37,92 & 6039,47 & 281, & $\begin{array}{l}, 26 \\
10,47 \\
\end{array}$ & 270,84 & 141,93 & 203,62 & 210,93 & 58,12 & 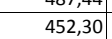 & 55,16 & 18,70 & 29,05 & | & 85,51 & 88,67 & 88,76 \\
\hline \begin{tabular}{|l} 
Bufo spinosus \\
\end{tabular} & $305 \times J 71$ & 100,00 & 129,27 & 109,91 & 39,00 & 5973,05 & 285,19 & 6,64 & 278,55 & 139,33 & 208,87 & 210,05 & 58,50 & 504,70 & 63,75 & 16,71 & 30,28 & 162,69 & 80,68 & 86,76 & 111,01 \\
\hline Bufo spinosus & $30 \mathrm{~S} \times \mathrm{J72}$ & 100,00 & 135,05 & 108,85 & 39,00 & 5916,15 & 288,28 & 13,03 & 275,26 & 145,11 & 213,66 & 214,93 & 64,58 & 480,25 & 62,86 & 15,44 & 31,38 & 158,73 & 75,77 & 83,35 & 104,77 \\
\hline Bufo spinosus & $305 \times 173$ & 100,00 & 134,74 & 107,78 & 38,92 & 5912,92 & 287,08 & 13,31 & 273,78 & 144,68 & 213,34 & 214,45 & 64,27 & 479,66 & 62,49 & 15,88 & 30,90 & 158,43 & 77,23 & 84,66 & 103,68 \\
\hline Bufo spinosus & $305 \times 174$ & 100,00 & 144,64 & 106,00 & 38,97 & 5808,97 & 292,51 & 24,30 & 268,21 & 154,66 & 221,46 & 222,71 & 74,91 & 443,42 & 61,79 & 13,75 & 33,54 & 153,08 & 68,48 & 78,70 & 95,51 \\
\hline Bufo spinosus & $305 \times 175$ & 100,00 & 139 & 105,26 & 38,74 & 5863,84 & 288,17 & $\begin{array}{l}4,30 \\
19,44 \\
\end{array}$ & \begin{tabular}{|l|}
268,74 \\
268,74
\end{tabular} & \begin{tabular}{|l|}
149,050 \\
140
\end{tabular} & \begin{tabular}{|l|}
217,05 \\
2170
\end{tabular} & \begin{tabular}{|l|}
218,16 \\
216
\end{tabular} & 69,21 & \begin{tabular}{|l|}
$4437,4<$ \\
457,30
\end{tabular} & $\mid \begin{array}{ll}61,21 \\
\end{array}$ & $\begin{array}{ll}15,15 \\
15,39\end{array}$ & $\begin{array}{l}3,, 43 \\
31,63\end{array}$ & $\begin{array}{l}\mid 53,00 \\
154,40\end{array}$ & $\begin{array}{l}\mid c 0,40 \\
74,34\end{array}$ & 83,16 & $\begin{array}{l}90,15 \\
96,96\end{array}$ \\
\hline Bufo spinosus & $305 \times 176$ & 100,00 & 136,34 & 104,40 & 38,32 & 5894,38 & 285,41 & 16,88 & 268,53 & 145,73 & 214,62 & 215,66 & 65,99 & 462,44 & 60,29 & 16,51 & 30,46 & 154,06 & 78,14 & 86,10 & 96,48 \\
\hline Bufo spinosus & $305 \times J 77$ & 100,00 & 129,46 & 103,84 & $\begin{array}{l}38,05 \\
\end{array}$ & 5965,21 & 280,00 & 10,43 & 269.57 & $\mid 138,84$ & 208,95 & $\mid 209,79$ & 58,54 & 479,80 & 59,22 & 18,64 & 28,75 & 155,00 & 85.94 & 91,66 & 98,22 \\
\hline Bufo spinosus & $305 \times 178$ & 100,00 & 134,17 & 102,25 & 37,95 & 5919,14 & 282,15 & 16,04 & 266,11 & 144,01 & 212,92 & 213,66 & 63,56 & 458,25 & 58,45 & 17,81 & 29,83 & 151,35 & 81,92 & 88,97 & 92,58 \\
\hline Bufo spinosus & $305 \times 179$ & 100,00 & 145,16 & 100,16 & 37,99 & 5811,26 & 288,28 & 27,86 & 260,41 & 154,01 & 221,87 & 222,82 & 75,13 & 417,16 & 56,96 & 15,33 & 32,41 & 144,09 & 71,62 & 81,59 & 83, \\
\hline \begin{tabular}{|l} 
Bufo spinosus \\
\end{tabular} & $305 \times 181$ & 100,00 & 139,38 & 108,16 & 39,12 & 5823,71 & 290,00 & 17,87 & 272,13 & 150,14 & 216,53 & 217,97 & 69,86 & 480,55 & 65,73 & 14,34 & 32,98 & \begin{tabular}{|l|l|}
164,05 \\
\end{tabular} & 71,62 & 82,44 & 107,25 \\
\hline Bufo spinosus & $305 \times 182$ & 100,00 & 142,61 & 106,86 & 39,12 & 5781,11 & 291,03 & 22,04 & 268,99 & 153,31 & 219,00 & 220,57 & 73,45 & 468,84 & 65,57 & 13,90 & 33,69 & 162,69 & 69,65 & 81,45 & 104,05 \\
\hline Bufo spinosus & $305 \times 183$ & 100,00 & 143,86 & 105,54 & 39,10 & 5758.33 & 29070 & 24,10 & 266,60 & $\mid 154,37$ & 219.85 & 221,39 & 74,88 & 464.10 & 65.49 & 1398 & 33.84 & 162.18 & 69,61 & 81,77 & 102,29 \\
\hline Bufo spinosus & $305 \times 184$ & 100,00 & 143,71 & 104,29 & 39,00 & 5747,43 & 289,46 & 24,87 & 264,59 & 154,15 & 219,55 & 221, & 75, & 462,29 & 65,19 & 14,37 & 33,59 & 161,71 & 70,50 & 82,78 & 100,98 \\
\hline Bufo spinosus & $305 \times 185$ & 100,00 & 151,95 & 102,27 & 38,99 & 5649,61 & 293,41 & 34,26 & 259,15 & 162,57 & 226,08 & 227,78 & 83,80 & 435,08 & 65,18 & 12,88 & 35,90 & 158,16 & 63,79 & 78,46 & 94,93 \\
\hline
\end{tabular}




\begin{tabular}{|c|c|c|c|c|c|c|c|c|c|c|c|c|c|c|c|c|c|c|c|c|c|}
\hline TAXON & UTM & $\mathrm{km} 2$ & B101 & B102 & $\mathrm{BIO3}$ & B104 & BIO5 & B106 & B107 & B108 & B109 & B1010 & B1011 & BIO12 & BIO13 & BIO14 & BIO15 & B1016 & B1017 & BIO18 & B1019 \\
\hline Bufo spinosus & $305 \times 186$ & 100,00 & 143,03 & 101,81 & 38,50 & 5747,54 & 286,85 & 25,65 & 261,20 & 153,06 & 218,83 & 220,32 & 74,19 & 457,23 & 63,92 & 15,32 & 32,73 & 159,77 & 72,87 & 85,12 & 97,37 \\
\hline Bufo spinosus & $305 \times 188$ & 100,00 & 150,47 & 98,58 & 38,21 & 5662,01 & 289,49 & 34,89 & 254,60 & 160,34 & 224,78 & 226,36 & 82,20 & 425,20 & 62,30 & 14,31 & 34,76 & 153,35 & 67,35 & 81,33 & 88,84 \\
\hline Bufo spinosus & $305 \times 189$ & 100,00 & 151,22 & 97,45 & 38,00 & 5660,88 & 289,16 & 36,08 & 253,09 & 160,92 & 225,42 & 226,98 & 82,86 & 416,22 & 60,92 & 14,41 & 34,58 & 150,62 & 67,12 & 81,19 & 85,54 \\
\hline Bufo spinosus & $305 \times 190$ & 100,00 & 153,25 & 107,17 & 39,81 & 5630,23 & 298,25 & 32,30 & 265,95 & 164,95 & 227,01 & 228,96 & 85,40 & 449,15 & 68,17 & 11,03 & 38,19 & 164,83 & 58,95 & 75,35 & 103,51 \\
\hline Bufo spinosus & $305 \times 191$ & 100,00 & 154,65 & 105,88 & 39,80 & 5600,81 & 298,09 & \begin{tabular}{|l|l|}
34,84 \\
\end{tabular} & 263,25 & 166,33 & 227,97 & 230,00 & 87,14 & 446,79 & 68,62 & 11,06 & 38,44 & 165,52 & 58,81 & 75,95 & 102,75 \\
\hline Bufo spinosus & $305 \times 192$ & 100,00 & 157,11 & 104,43 & 39,78 & 5563,59 & 298,29 & 38,17 & 260,11 & 168,70 & 229,72 & 231,88 & 89,87 & 440,43 & 69,03 & 10,91 & 39,15 & 165,36 & 57,65 & 75,60 & 101,15 \\
\hline Bufo spinosus & $305 \times 193$ & 100,00 & 161,82 & 102,37 & 39,76 & 5482,65 & 299,51 & 44,50 & 255,01 & 173,54 & 233,14 & 235,41 & 95,32 & 428,66 & 69,86 & 10,31 & 40,90 & 165,05 & 54,69 & 74,34 & 98,67 \\
\hline \begin{tabular}{|l} 
Bufo spinosus \\
\end{tabular} & $305 \times 194$ & 100,00 & 154,36 & 101,60 & 39,15 & 5556,76 & 293,62 & 37,51 & 256,10 & 165,70 & 227,05 & 229,12 & 87,33 & 448,82 & 69,43 & 12,38 & 37,73 & 167,25 & 62,05 & 79,83 & 101,26 \\
\hline Bufo spinosus & $305 \times 195$ & 100,00 & 154,12 & 100,07 & \begin{tabular}{l|l|}
38,95 \\
\end{tabular} & 5546,10 & 291,99 & 38,17 & 253,82 & 165,20 & 226,60 & 228,75 & 87,31 & 447,85 & 69,32 & 12,82 & 37,47 & 166,93 & 63,14 & 81,01 & 100,04 \\
\hline Bufo spinosus & $305 \times 197$ & 100,00 & 157,92 & 96,72 & 38,69 & 5480,10 & 291,59 & 44,24 & 247,35 & 168,84 & 229,31 & 231,46 & 91,61 & 430,08 & 68,64 & 12,78 & 38,43 & 163,54 & 61,12 & 80,02 & 94,32 \\
\hline Bufo spinosus & $30 S \times K 00$ & 100,00 & 117,03 & 117,58 & 38,22 & 6405,90 & 290,68 & $-11,81$ & 302,48 & 99,08 & 202,55 & 203,36 & 40,19 & 491,68 & 61,76 & 19,42 & 27,18 & 160,49 & 85,47 & 92,59 & 107,13 \\
\hline Bufo spinosus & 30SXK02 & 100,00 & 112,02 & 116,72 & 38,00 & 6418,30 & 285,11 & $-16,89$ & 302,01 & 102,91 & 197,50 & 198,48 & 35,11 & 505,36 & 65,11 & 21,51 & 26,86 & 165,13 & 91,23 & 99,35 & 109,06 \\
\hline Bufo spinosus & 30SXK10 & 100,00 & 119,41 & 114,96 & 38,03 & 6364,99 & 289,05 & \begin{tabular}{|c|}
$-7,86$ \\
-10
\end{tabular} & \begin{tabular}{|l|}
296,91 \\
\end{tabular} & 134,11 & 204,31 & 205,06 & $\begin{array}{l}\mid 3,111 \\
43,17\end{array}$ & 474,57 & 59,86 & $\begin{array}{l}\mid 1,1,29 \\
19,\end{array}$ & 27,44 & $\begin{array}{l}154,89 \\
\end{array}$ & 85,25 & 91,36 & 99,81 \\
\hline Bufo spinosus & 30SXK12 & 100,00 & 107,80 & 113,86 & 37,99 & 6396,03 & 277,60 & $-18,99$ & 296,59 & 126,32 & 193,10 & 194,14 & 31,64 & 514,64 & 66,77 & 23,34 & 26,70 & 169,85 & 96,73 & 105,32 & 107,11 \\
\hline Bufo spinosus & $305 \times K 22$ & 100,00 & 105,08 & 111,26 & 37,82 & 6372,31 & 272,03 & $-19,79$ & 291,83 & 123,10 & 188,12 & 191,08 & 29,40 & 520,37 & 67,76 & 24,79 & 26,65 & 173,16 & 101,24 & 109,76 & 104,98 \\
\hline Bufo spinosus & $305 \times K 30$ & 100,00 & 117,71 & 110,05 & 37,95 & 6293,58 & 280,91 & $-6,02$ & 286,93 & 135,21 & 201,84 & 202,31 & 42,81 & 476,10 & 60,00 & 20,90 & 27,42 & 156,32 & 91,20 & 95,71 & 94,79 \\
\hline Bufo spinosus & $30 \mathrm{~S} \times \mathrm{K} 31$ & 100,00 & 113,36 & 109,34 & 37,76 & 6319,51 & 276,69 & $-10,14$ & 286,82 & 131,17 & 140,04 & 198,55 & 38,41 & 486,33 & 62,48 & 22,50 & 27,36 & 161,19 & 94,60 & 101,05 & 95,69 \\
\hline Bufo spinosus & $305 \times K 32$ & 100,00 & 108,52 & 108,46 & 37,33 & 6339,29 & 271,47 & $-14,69$ & 286,15 & 126,45 & 58,98 & 194,06 & 33,24 & 499,43 & 65,36 & 24,27 & 27,34 & 167,26 & 97,03 & 107,17 & 97,07 \\
\hline Bufo spinosus & $305 \times K 40$ & 100,00 & 116,01 & 107,73 & \begin{tabular}{|l|l|}
37,78 \\
\end{tabular} & \begin{tabular}{ll|l}
6252,44 \\
\end{tabular} & 276,27 & $-6,16$ & 282,43 & 133,03 & 123,01 & 200,16 & 41,92 & 485,12 & 60,79 & 22,01 & 27,28 & 158,67 & 94,35 & 98,94 & 95,01 \\
\hline Bufo spinosus & $305 \times K 41$ & 100,00 & 113,97 & 106,82 & $|37,28|$ & 6276,32 & 273,90 & $-7,82$ & 281,73 & $\mid \begin{array}{l}131,38 \\
\end{array}$ & 40,80 & $\mid 198,58$ & 39,77 & 483,34 & 61,95 & 22.85 & 27,58 & 159,95 & 92,75 & 101,60 & 92,75 \\
\hline Bufo spinosus & $305 \times K 42$ & 100,00 & 116,05 & 105,51 & 37,03 & 6277,06 & 274,28 & $-5,51$ & 279,79 & 133,90 & 41,45 & 200,47 & 41,45 & 464,69 & 60,71 & 22,55 & 28,61 & 155,38 & 86,90 & 99,96 & 86,90 \\
\hline Bufo spinosus & 30 SXK50 & 100,00 & 127,65 & 104,81 & 37,71 & 6135,18 & 281,71 & 6,70 & 275,01 & 142,82 & 92,14 & 209,82 & 54,41 & 442,77 & 54,53 & 19,12 & 28,90 & 142,62 & 84,56 & 87,90 & 84,95 \\
\hline Bufo spinosus & 30SXK51 & 100,00 & 121,03 & 104,12 & 37,22 & 6191,15 & 276,05 & 0,70 & 275,35 & 137,93 & 48,32 & 204,10 & 47,33 & 458,95 & 57,95 & 21,34 & 28,56 & 149,92 & 86,45 & 95,23 & 86,45 \\
\hline Bufo spinosus & 30 XKK52 & 100,00 & 116,95 & 103,14 & 37,03 & 6232,40 & 272,18 & $-2,82$ & 275,00 & 134,51 & 42,97 & 200,73 & 42,97 & 464,15 & 60,12 & 22,83 & 28,82 & 154,08 & 85,43 & 100,12 & 85,43 \\
\hline Bufo spinosus & $305 \times K 60$ & 100,00 & 133,08 & 102,24 & $\begin{array}{l}37,55 \\
\end{array}$ & 6028,01 & 282,71 & 13,90 & 268,81 & 144,14 & 135,44 & 213,70 & 61,01 & 432,27 & 53,45 & 18,14 & 29,76 & 139,75 & 81,08 & 85,84 & 82,95 \\
\hline Bufo spinosus & 30SXK61 & 100,00 & 121,73 & 102,01 & 37,02 & 6146,47 & 274,28 & 2,65 & 271,63 & 138,39 & 48,60 & 204,06 & 48,60 & 461,33 & 57,58 & 21,59 & 28,58 & 148,96 & 86,06 & 95,50 & 86,06 \\
\hline Bufo spinosus & 305XK62 & 100,00 & 106,15 & 101,78 & 36,92 & 6218,09 & 261,26 & $\begin{array}{l}-12,13 \\
-12\end{array}$ & 273,40 & $\begin{array}{l}122,72 \\
\end{array}$ & 32,84 & $\begin{array}{l}190,04 \\
\end{array}$ & 32,84 & 520,18 & 66,47 & 26,72 & 27,06 & $\begin{array}{l}171,32 \\
\end{array}$ & $\begin{array}{l}0,31,31 \\
\end{array}$ & 113,83 & $\begin{array}{ll}97,31 \\
\end{array}$ \\
\hline Bufo spinosus & $305 \times K 70$ & 100,00 & 129,53 & 100,59 & \begin{tabular}{|l|l|}
37,27 \\
\end{tabular} & 5995,70 & 277,80 & 11,79 & 266,01 & 140,13 & 119,53 & 209,80 & 58,06 & 456,08 & 56,17 & 19,62 & 29,24 & 147,22 & 85,81 & 92,48 & 88,02 \\
\hline Bufo spinosus & $305 \times K 71$ & 100,00 & 116,02 & 100,53 & 36,95 & 6112,56 & 267,73 & $-1,27$ & 269,01 & 131,13 & 43,85 & 198,16 & 43,85 & 495,53 & 61,02 & 23,65 & 27,54 & 158,38 & 93,56 & 103,52 & 93,56 \\
\hline Bufo spinosus & $30 \mathrm{~S} \times \mathrm{K} 80$ & 100,00 & 133,40 & 98,33 & 37,20 & 5881,55 & 277,88 & 17,42 & 260,45 & 142,60 & 180,96 & 212,31 & 63,21 & 457,53 & 58,17 & 18,99 & 29,97 & 152,34 & 84,32 & 93,37 & 89,68 \\
\hline Bufo spinosus & $30 \mathrm{SXK81}$ & 100,00 & 107,43 & 99,34 & 36,75 & 6087,26 & 258,74 & $-8,79$ & 267,52 & 121,45 & 36,15 & 189,55 & 36,15 & 548,46 & 66,48 & 26,89 & 25,90 & 173,45 & 106,31 & 115,03 & 106,31 \\
\hline \begin{tabular}{|l} 
Bufo spinosus \\
\end{tabular} & 30 SXK82 & 100,00 & 95,14 & 99,06 & 36,21 & 6135,27 & 247,94 & $-20,86$ & 268,79 & 110,04 & 23,55 & 178,07 & 23,55 & 600,15 & 73,97 & 31,18 & 24,62 & 192,01 & 117,01 & 128,30 & 117,01 \\
\hline Bufo spinosus & 30SXK90 & 100,00 & 137,15 & 96,17 & 37,23 & 5766,21 & 277,84 & 22,66 & 255,19 & 146,16 & 210,50 & 214,60 & 68,34 & 461,90 & 60,83 & 18,45 & 30,90 & 158,33 & 82,55 & 94,14 & 92,39 \\
\hline Bufo spinosus & 30SXK91 & 100,00 & 118,16 & 97,05 & 36,70 & 5962,03 & 264,77 & 3,03 & 261,74 & 128,88 & 86,00 & 198,45 & 47,94 & 516,47 & 61,85 & 23,82 & 27,32 & 164,19 & 99,90 & 108,37 & 100,35 \\
\hline Bufo spinosus & 30SXK92 & 100,00 & 118,22 & 96,24 & 36,31 & 5976,35 & 264,32 & 3,29 & 261,02 & 129,84 & 58,95 & 198,64 & 47,90 & 505,18 & 61,45 & 23,95 & 27,82 & 160,42 & 95,62 & 107,63 & 95,73 \\
\hline Bufo spinosus & 30SYG06 & 10,00 & 181,91 & 102,00 & 40,91 & 5058,64 & 312,73 & 64,45 & 248,27 & 158,64 & 246,73 & 249,27 & 119,73 & 311,55 & 53,73 & 3,82 & 52,45 & 135,18 & 23,00 & 37,91 & 87,09 \\
\hline Bufo spinosus & $\begin{array}{l}30 \mathrm{SYHO1} \\
3\end{array}$ & 62,00 & 182,16 & 108,79 & 年 41,00 & $\begin{array}{l}5030,044 \\
5270,48\end{array}$ & 320,05 & $\begin{array}{l}4,45 \\
58,99 \\
\end{array}$ & \begin{tabular}{|l|}
260,06 \\
261,06
\end{tabular} & \begin{tabular}{|l|}
$194,93,93$ \\
\end{tabular} & \begin{tabular}{|l|}
249,9915 \\
\end{tabular} & \begin{tabular}{|l|}
252,12 \\
\end{tabular} & \begin{tabular}{|l|}
117,15 \\
115
\end{tabular} & \begin{tabular}{|l|}
286,90 \\
26,0
\end{tabular} & 56,79 & $\begin{array}{l}3,02 \\
4,00\end{array}$ & $\begin{array}{ll}25,45 \\
55,98\end{array}$ & $\begin{array}{l}125,45 \\
125 \\
\end{array}$ & 24,32 & $\begin{array}{ll}2,31 \\
42,38\end{array}$ & $\begin{array}{l}0,07,05 \\
67,0\end{array}$ \\
\hline Bufo spinosus & 30SYHO2 & 80,00 & 182,46 & 108,92 & 41,00 & 5276,77 & 320,21 & 59,09 & 261,13 & 195,28 & 250,29 & 252,49 & 117,35 & 297,04 & 58,03 & 4,00 & 54,71 & 128,71 & 26,03 & 44,69 & 68,70 \\
\hline Bufo spinosus & 30SYHO3 & 100,00 & 181,04 & 109,05 & 41,01 & 5301,23 & 319,32 & 57,70 & 261,62 & 194,00 & 249,20 & 251,55 & 115,75 & 311,40 & 59,62 & 4,00 & 53,46 & 133,19 & 28,22 & 47,27 & 71,40 \\
\hline Bufo spinosus & 30SYH05 & 100,00 & 166,77 & 109,71 & 40,85 & 5465,29 & 309,83 & $\begin{array}{ll}43,67 \\
\end{array}$ & 266,15 & 179,36 & 237,69 & 240,01 & 100,20 & 384,95 & 64,88 & 6,78 & 45,22 & 151,15 & 41,97 & 60,32 & 89,22 \\
\hline Bufo spinosus & 30SYHOG & 100,00 & 144,42 & 108,84 & 39,61 & 5689,09 & 293,55 & 22,42 & 271,13 & 144,48 & 219,20 & 221,28 & 76,49 & 486,58 & 69,47 & 12,40 & 36,53 & 172,01 & 63,57 & 78,33 & 115,60 \\
\hline \begin{tabular}{|l} 
Bufo spinosus \\
\end{tabular} & 30SYHO8 & 100,00 & 133,87 & 107,45 & 39,09 & 5786,82 & 284,80 & 13,19 & 271,61 & \begin{tabular}{l|l}
144,48 \\
\end{tabular} & 210,39 & 212,43 & 65,38 & 534,69 & 71,73 & 15,72 & 32,70 & 181,60 & 76,45 & 89,32 & 125,78 \\
\hline Bufo spinosus & 30SYHO9 & 100,00 & 148,30 & 106,84 & 39,64 & 5640,08 & 294,15 & 27,77 & 266,38 & 160,23 & 222,30 & 224,45 & 80,64 & 481,97 & 70,89 & 12,15 & 37,05 & 174,40 & 63,64 & 80,44 & 113,50 \\
\hline Bufo spinosus & 30SYH15 & 100,00 & 175,28 & 107,31 & 40,93 & 5313,91 & 313,30 & 53,72 & 259,57 & 188,76 & 243,76 & 246,37 & 110,37 & 366,35 & 65,66 & 5,46 & 49,10 & 151,58 & 37,05 & 57,48 & 84,94 \\
\hline Bufo spinosus & 30SYH16 & 100,00 & 159,20 & $\begin{array}{ll}107,47 \\
\end{array}$ & 40,10 & 5490,83 & 302,30 & 37,95 & 264,34 & 169,42 & 230,56 & 233, & 92, & 442,74 & 69,8 & 8,99 & 41,99 & 68,76 & 51,36 & 70,57 & 106,53 \\
\hline Bufo spinosus & 30SYH17 & 100,00 & 137,58 & 106,62 & 39,14 & 5704,24 & 286,43 & 17,54 & 268,89 & \begin{tabular}{|l|}
126,61 \\
\end{tabular} & 212,69 & 215,01 & $\begin{array}{ll}69,98 \\
69\end{array}$ & 534,91 & 73,4 & \begin{tabular}{|l|}
$0,4,70$ \\
14
\end{tabular} & 34,32 & 186,51 & 72,75 & 87,84 & 129,03 \\
\hline \begin{tabular}{|l} 
Bufo spinosus \\
\end{tabular} & 30SYH18 & 100,00 & 135,72 & 105,93 & 39,01 & 5715,70 & 284,32 & 16,26 & 268,07 & 135,22 & 211,13 & 213,36 & 68,11 & 545,95 & 74,34 & 15,54 & 33,65 & 189,00 & 76,09 & 91,16 & 130,99 \\
\hline Bufo spinosus & 30SYH19 & 100,00 & 140,82 & 105,29 & 39,20 & 5663,73 & 287,27 & 21,68 & 265,59 & 149,01 & 215,32 & 217,56 & 73,55 & 529,39 & 74,34 & 14,42 & 35,07 & 187,23 & 72,32 & 89,16 & 126,96 \\
\hline Bufo spinosus & 30 SYH 25 & 77,00 & 180,16 & 105,37 & 41,00 & 5215,02 & 314,92 & 60,07 & 254,85 & 194,17 & 247,07 & 250,04 & 116,15 & 369,19 & 67,10 & 4,91 & 51,03 & 156,33 & 34,86 & 57,50 & 89,25 \\
\hline Bufo spinosus & 30 SYH26 & 100,00 & 162,06 & 105,68 & 40,10 & 5418,68 & 302,65 & 42,09 & 260,56 & 164,62 & 232,30 & 235,03 & 96,54 & 452,93 & 72,10 & 8,67 & 43,43 & 176,14 & 50,53 & 71,93 & 112,25 \\
\hline Bufo spinosus & $\begin{array}{l}305 \mathrm{~S} Y \mathrm{n} 28 \\
\end{array}$ & 100,00 & $\begin{array}{l}10,03,83 \\
143,83\end{array}$ & $\begin{array}{l}104,60 \\
104,61\end{array}$ & 39 & $\begin{array}{l}541,000 \\
5600,58\end{array}$ & 288,71 & $\begin{array}{l}42,030 \\
25,05 \\
\end{array}$ & \begin{tabular}{|l|}
263,66 \\
\end{tabular} & \begin{tabular}{|l|}
$129,31,31$ \\
\end{tabular} & $\begin{array}{l}252,30 \\
217,22\end{array}$ & $\mid \begin{array}{l}\mid 53,035 \\
219,66\end{array}$ & 77,15 & \begin{tabular}{|l|l|}
534,83 \\
\end{tabular} & 76,21 & $\mid \begin{array}{l}0,0 \\
13,50\end{array}$ & $\begin{array}{l}43,45 \\
36,49\end{array}$ & $\begin{array}{l}193,59 \\
\end{array}$ & $\begin{array}{ll}69,20 \\
69,\end{array}$ & $\begin{array}{ll}1,150 \\
88,25\end{array}$ & $\begin{array}{l}11,2,28 \\
132,28\end{array}$ \\
\hline Bufo spinosus & $30 \mathrm{SYH} 29$ & 100,00 & 157,11 & 103,99 & 39,83 & 5462,54 & 297,39 & 38,60 & 258,79 & 160,71 & 228,11 & 230,76 & 91,36 & 495,67 & 76,34 & 10,57 & 41,07 & 189,27 & 58,63 & 81,85 & 124,46 \\
\hline Bufo spinosus & 30SYH36 & 76,00 & 172,53 & 104,27 & 40,29 & 5282,72 & 308,81 & 53,31 & 255,50 & $\mid 157,76$ & 240,39 & 243,27 & 108,08 & 439,99 & 73,14 & 6,73 & 47,77 & 180,04 & 43,50 & 68.74 & 114,51 \\
\hline Bufo spinosus & 30SYH37 & 100,00 & 156,46 & 103,95 & 39,66 & 5443,78 & 297,10 & 37,91 & 259,19 & 131,88 & 227,12 & 229,92 & 90,96 & 507,02 & 76,68 & 10,34 & 41,72 & 195,70 & 57,87 & 81,19 & 130,93 \\
\hline Bufo spinosus & 30SYH38 & 100,00 & 130,60 & 102,73 & 38,43 & 5683,61 & 277,40 & 13,50 & 263,90 & 103,87 & 205,45 & 208,02 & 63,76 & 603,69 & 79,85 & 17,44 & 33,08 & 211,11 & 83,60 & 100,75 & 150,39 \\
\hline Bufo spinosus & \begin{tabular}{|c|}
$305 Y H 39$ \\
$305 \%$
\end{tabular} & 100,00 & 144,33 & 102,50 & | 30,45 & $\begin{array}{l}500,34,15 \\
555,15\end{array}$ & 286,91 & $\frac{10,00}{27,00}$ & \begin{tabular}{|l|}
259,91 \\
250
\end{tabular} & \begin{tabular}{|l|}
118,71 \\
11,7
\end{tabular} & \begin{tabular}{|l|}
216,85 \\
21,85
\end{tabular} & \begin{tabular}{|l|}
$219,56<$ \\
210
\end{tabular} & $\begin{array}{l}\mid 25,10 \\
78,26\end{array}$ & \begin{tabular}{|l|}
557,31 \\
57,
\end{tabular} & $\begin{array}{l}75,000 \\
79,22\end{array}$ & $\begin{array}{l}1,1,49 \\
13,79\end{array}$ & $\begin{array}{l}3,00 \\
36,98\end{array}$ & $\begin{array}{l}204,92 \\
20,1\end{array}$ & $\begin{array}{l}3,1,13 \\
713\end{array}$ & $\begin{array}{r}0,15 \\
92,80\end{array}$ & $\begin{array}{l}140,35 \\
141,15\end{array}$ \\
\hline Bufo spinosus & 30 SYH 46 & 30,00 & 180,65 & 102,84 & 40,40 & 5191,81 & 313,65 & 62,23 & 251,42 & 158,72 & 246,81 & 249,93 & 116,88 & 444,02 & 74,65 & 5,37 & 51,47 & 191,30 & 39,09 & 67,95 & 123,14 \\
\hline Bufo spinosus & 30SYH47 & 100,00 & 161,13 & 102,73 & 39,57 & 5376,77 & 299,46 & 43,28 & 256,17 & 137,70 & 230,58 & 233,57 & 96,22 & 517,59 & 78,54 & 9,54 & 44,19 & 206,86 & 55,42 & 81,62 & 139,68 \\
\hline Bufo spinosus & 30SYH48 & 100,00 & 147,95 & 101,86 & 39,00 & 5496,58 & 289,23 & 30,96 & 258,2 & 123,39 & 219,55 & 222,47 & 82, & 565,97 & 80,80 & 12,82 & 39,29 & 214,74 & 68,09 & 92,00 & $\begin{array}{ll}148,93 \\
\end{array}$ \\
\hline Bufo spinosus & 30SYH49 & 100,00 & 147,75 & 101,29 & 38,85 & 5494,05 & 288,34 & 31,16 & 257,18 & 123,03 & 219,25 & 222,17 & 82,22 & 568,60 & 81,47 & 13,02 & 38,90 & 215,42 & 69,06 & 93,62 & 149,08 \\
\hline
\end{tabular}




\begin{tabular}{|c|c|c|c|c|c|c|c|c|c|c|c|c|c|c|c|c|c|c|c|c|c|}
\hline TAXON & UTM & $\mathrm{km} 2$ & BIO1 & B102 & $\mathrm{BIO3}$ & B104 & B105 & B106 & B107 & B108 & 8109 & B1010 & BIO11 & B1012 & BIO13 & B1014 & BIO15 & B1016 & B1017 & B1018 & B1019 \\
\hline Bufo spinosus & 30SYH57| & 71,00 & 178,86 & 101,94 & 40,00 & 5217,23 & 312,31 & 60,79 & 251,52 & 157,38 & 245,42 & 248,61 & 114,68 & 492,36 & 78,70 & 6,12 & 51,98 & 214,95 & 42,95 & 75,21 & 143,88 \\
\hline Bufo spinosus & 30SYH58 & 100,00 & 160,29 & 101,03 & 39,26 & 5370,17 & 297,63 & 43,41 & 254,21 & 137,30 & 229,64 & 232,68 & 95,54 & 554,42 & 82,17 & 9,95 & 44,69 & 224,76 & 58,50 & 87,69 & 155,10 \\
\hline \begin{tabular}{|l} 
Bufo spinosus \\
\end{tabular} & $\begin{array}{l}30 \text { SYH59 } \\
\end{array}$ & 100,00 & 165,68 & 101,14 & 39,39 & 5336,27 & 301,81 & 48,57 & 253,24 & $\begin{array}{l}143,14 \\
\end{array}$ & 234,28 & 237,34 & 100,95 & 555,96 & 83,49 & 9,23 & 46,88 & 230,87 & 56,25 & 88,41 & 159,20 \\
\hline Bufo spinosus & 30SYH68 & 10,00 & 169,94 & 101,12 & \begin{tabular}{|l|l|}
39,47 \\
\end{tabular} & 5283,29 & 305,35 & 52,71 & 252,65 & 148,12 & 237,71 & 240,76 & 105,71 & 546,24 & 82,59 & 8,06 & 49,12 & 232,47 & 51,65 & 84,59 & 160,47 \\
\hline Bufo spinosus & 30SYH69 & 10,00 & 170,18 & 100,91 & \begin{tabular}{l|l|}
39,45 \\
\end{tabular} & 5303,91 & 305,36 & 52,82 & 252,55 & \begin{tabular}{|l|l|}
148,27 \\
\end{tabular} & 238,09 & 241,09 & 105,45 & 562,73 & 84,45 & 8,55 & 49,09 & 239,91 & 53,73 & 88,45 & 166,55 \\
\hline Bufo spinosus & 30SYJO0 & 100,00 & 155,61 & 105,66 & 39,80 & 5555,91 & 298,20 & 35,92 & 262,28 & 167,72 & 228,19 & 230,44 & 88,69 & 460,32 & 71,19 & 10,76 & 39,49 & 172,56 & 58,32 & 77,35 & 108,73 \\
\hline Bufo spinosus & 30SYJO2 & 100,00 & 169,80 & 101,78 & 40,00 & 5352,22 & 304,00 & 52,88 & 251,12 & 182,31 & 238,94 & 241,55 & 104,55 & 424,42 & 72,88 & 8,66 & 44,99 & 170,37 & 48,57 & 72,18 & 101,98 \\
\hline Bufo spinosus & 30SYJO3 & 100,00 & 168,71 & 100,05 & 39,94 & 5337,45 & 301,39 & 53,23 & 248,16 & 181,09 & 237,61 & 240,26 & 103,62 & 429,98 & 73,90 & 9,23 & 44,47 & 172,31 & 50,47 & 74,18 & 102,75 \\
\hline Bufo spinosus & 30 SYJO5 & 100,00 & 166,41 & 96,64 & 39,28 & 5302,08 & 296,17 & 53,60 & 242,58 & 178,57 & 234,92 & 237,66 & 102,14 & 436,16 & 75,19 & 10,58 & 43,50 & 174,36 & 53,81 & 77,63 & 102,01 \\
\hline Bufo spinosus & 30SYJO6 & 100,00 & 165,44 & 95,01 & 39,01 & 5293,51 & 293,86 & 53,87 & 239,99 & 177,42 & 233,86 & 236,68 & 101,27 & 438,06 & 75,39 & 11,25 & 42,87 & 174,73 & 55,44 & 79,30 & 101,17 \\
\hline Bufo spinosus & 30SYJ07 & 100,00 & 166,40 & 93,37 & \begin{tabular}{l|l|}
38,95 \\
\end{tabular} & 5267,47 & 293,03 & 55,71 & 237,33 & 178,25 & 234,31 & 237,26 & 102,52 & \begin{tabular}{|l|l|}
431,58 \\
\end{tabular} & 74,97 & 11,56 & 43,03 & 173,01 & 55,33 & 79,25 & 98,46 \\
\hline Bufo spinosus & 30SYJ08 & 100,00 & 167,01 & 92,15 & 38,61 & 5261,87 & 292,83 & 56,86 & 235,97 & 178,53 & 234,81 & 237,69 & 103,18 & 421,74 & 73,28 & 11,57 & 42,99 & 169,44 & 55,16 & 78,88 & 94,67 \\
\hline Bufo spinosus & 30SYJO9 & 100,00 & 160,41 & $\begin{array}{l}2,08 \\
\end{array}$ & 37,99 & 5362,79 & 288,70 & 49,75 & 238,95 & 171,34 & 230,00 & 232,42 & 95,51 & 428,82 & 69,92 & 13,27 & 39,42 & 166,71 & 61,35 & 82,93 & 93,31 \\
\hline Bufo spinosus & 30SYJ11 & 100,00 & 169,64 & 102,15 & 40,01 & 5328,99 & 304,21 & 52,64 & 251,57 & 182,70 & 238,42 & 241,24 & 104,81 & 445,22 & 75,33 & 8,56 & 45,40 & 179,08 & 49,42 & 74,85 & 110,63 \\
\hline Bufo spinosus & $30 \mathrm{SYJ12}$ & 100,00 & 175,42 & 99,84 & 40,01 & 5239,15 & 305,98 & 59,97 & 246,01 & 188,69 & 242,74 & 245,67 & 111,35 & 431,18 & 76,26 & 8,03 & 47,87 & 178,21 & 46,04 & 73,26 & 107,94 \\
\hline Bufo spinosus & 30SYJ13 & 100,00 & 176,74 & 97,73 & 40,00 & 5188,13 & 304,63 & 63,16 & 241,47 & $\begin{array}{ll}189,93 \\
\end{array}$ & 243,33 & 246,34 & 113,46 & 427,88 & 77,39 & 8,01 & 48,83 & 178,87 & 45,33 & 73,54 & 106,88 \\
\hline \begin{tabular}{|l|} 
Bufo spinosus \\
\end{tabular} & $30 \mathrm{SYJ14}$ & 100,00 & 175,11 & 95,80 & 39,95 & 5162,86 & 301,05 & 63,02 & 238,03 & 188,26 & 241,27 & 244,49 & 112,14 & 434,26 & 78,86 & 8,61 & 48,27 & 181,00 & 47,58 & 75,66 & 107,15 \\
\hline Bufo spinosus & 30SYI15 & 100,00 & 170,39 & 94,29 & 39,39 & 5182,47 & 295,91 & 59,55 & 236,36 & 183,27 & 236,85 & 240,14 & 107,42 & 446,90 & 79,84 & 10,05 & 46,41 & 183,66 & 51,78 & 79,39 & 108,19 \\
\hline Bufo spinosus & 30SYJ17 & 100,00 & $\begin{array}{ll}170,87 \\
\end{array}$ & 90,37 & 39,00 & 5111,14 & 292,25 & 62,94 & 229,31 & 183,49 & 236,36 & 239,79 & 108,94 & 441,61 & 80,99 & 10,95 & 46,75 & 183,14 & 52,74 & 80,69 & 104,02 \\
\hline Bufo spinosus & 30SYJ18 & 100,00 & 167,99 & 89,79 & 38,51 & 5159,09 & 290,30 & 59,94 & 230,36 & 180,15 & 234,19 & 237,46 & 105,51 & 438,38 & 77,94 & 11,82 & 44,56 & 179,09 & 55,45 & 82,12 & 100,81 \\
\hline Bufo spinosus & 30SYJ19 & 100,00 & 155,37 & 90,99 & 37,79 & 5357,42 & 283,63 & 45,56 & 238,07 & 166,40 & 224,88 & 227,57 & 90,93 & 458,99 & 72,35 & 14,63 & 38,07 & 175,92 & 67,17 & 89,65 & 100,94 \\
\hline \begin{tabular}{|l} 
Bufo spinosus \\
\end{tabular} & $30 \mathrm{SYJ} 20$ & 100,00 & 161,27 & $\begin{array}{r}102,76 \\
\end{array}$ & 39,77 & 5409,64 & 299,06 & 43,64 & 255,43 & 169,00 & 231,37 & 234,10 & 95,89 & 489,92 & 77,30 & 10,09 & 42,53 & 190,19 & 56,71 & 81,62 & 124,09 \\
\hline Bufo spinosus & 30SYJ21 & 100,00 & 165,65 & 101,30 & \begin{tabular}{|l|l|}
39,79 \\
\end{tabular} & 5339,22 & 300,55 & 49,14 & 251,41 & 176,73 & 234,67 & 237,43 & 100,84 & 481,21 & 78,40 & 9,51 & 44,28 & 190,88 & 54,07 & 80,95 & 122,79 \\
\hline Bufo spinosus & 30SYJ22 & 100,00 & 168,81 & $\begin{array}{l}99,36 \\
\end{array}$ & 39,81 & 5279,18 & 300,68 & 53,71 & 246,97 & 182,04 & 236,77 & 239,79 & 104,65 & 475,11 & 79,52 & 9,31 & 45,55 & 191,42 & 52,57 & 80,87 & 121,54 \\
\hline Bufo spinosus & $30 \mathrm{SYJ} 23$ & 100,00 & 173,90 & 97,01 & 39,91 & 5186,52 & 301,71 & 60,73 & 240,98 & 187,31 & 240,30 & 243,48 & 110,50 & \begin{tabular}{|l|l|}
460,88 \\
\end{tabular} & 80,59 & 8,63 & 48,03 & 190,34 & 49,35 & 79,16 & 118,22 \\
\hline Bufo spinosus & 30 SYJ 25 & 100,00 & 176,56 & 92,18 & 39,57 & 5054,61 & 297,92 & 67,46 & 230,45 & 190,01 & 240,95 & 244,55 & 115,05 & 446,92 & 82,85 & 8,90 & 49,95 & 189,43 & 48,38 & 79,53 & 112,10 \\
\hline Bufo spinosus & 30SYJ26 & 99,00 & 175,54 & 89,83 & 39,25 & 5005,52 & 294,31 & 68,41 & 225,90 & \begin{tabular}{ll|}
188,86 \\
\end{tabular} & 239,28 & 243,17 & 114,93 & 444,15 & 83,98 & 9,09 & 50,35 & 189,34 & 49,09 & 80,34 & 109,50 \\
\hline Bufo spinosus & 30SYJ27 & 100,00 & 173,96 & 87,97 & 39,00 & 4986,04 & 290,95 & 68,09 & 222,85 & 187,11 & 237,27 & 241,28 & 113,45 & 441,73 & 84,26 & 9,91 & 50,22 & 188,59 & 50,72 & 82,28 & 106,80 \\
\hline Bufo spinosus & $30 \mathrm{SYJ} 29$ & 100,00 & 160,16 & 88,68 & 37,70 & 5226,04 & 284,34 & 52,04 & 232,30 & 171,93 & 227,54 & 230,65 & 97,17 & 462,29 & 75,74 & 13,71 & 40,62 & 182,64 & 63,83 & 90,03 & 104,77 \\
\hline Bufo spinosus & $30 \mathrm{SYJ30}$ & 100,00 & 157,99 & 101,69 & 39,41 & 5412,07 & 295,78 & 41,07 & 254,72 & 133,98 & 228,08 & 230,92 & 92,74 & 524,14 & 80,05 & 10,99 & 41,91 & 203,56 & $\begin{array}{ll}60,87 \\
\end{array}$ & \begin{tabular}{ll|}
87,18 \\
\end{tabular} & 136,38 \\
\hline Bufo spinosus & 30SYJ31 & 100,00 & 165,65 & 100,49 & 39,72 & 5323,01 & 300,06 & 49,58 & 250,49 & 150,78 & 234,32 & 237,24 & 101,08 & 508,10 & 80,91 & 9,80 & 44,84 & 203,56 & 55,90 & 85,08 & 134,45 \\
\hline Bufo spinosus & $30 \mathrm{SYJ32}$ & 100,00 & 168,37 & 98,61 & \begin{tabular}{ll|}
39,62 \\
\end{tabular} & 5263,81 & 299,92 & 53,56 & 246,36 & \begin{tabular}{|l|l|}
155,07 \\
\end{tabular} & 236,04 & 239,10 & 104,44 & 501,73 & 81,88 & 9,56 & 46,00 & 202,90 & 54,54 & 85,01 & 132,77 \\
\hline Bufo spinosus & 30SYJ33 & 94,00 & 175,58 & 96,19 & 39,77 & 5151,25 & 302,46 & 62,88 & 239,58 & 175,71 & 241,48 & 244,84 & 112,74 & 478,48 & 82,56 & 8,56 & 49,07 & 199,01 & 49,47 & 81,90 & 127,13 \\
\hline Bufo spinosus & 30 SYJ34 & 83,00 & 177,99 & 93,86 & 39,78 & 5079,17 & 301,41 & 67,27 & 234,14 & 191,76 & 242,68 & 246,17 & 115,93 & 465,64 & 83,37 & 8,01 & 50,42 & 196,55 & 47,74 & 80,94 & 122,39 \\
\hline Bufo spinosus & 30SYJ39 & 93,00 & 171,91 & 85,77 & \begin{tabular}{|l|l|}
37,67 \\
\end{tabular} & 5036,25 & 289,90 & 65,66 & 224,24 & \begin{tabular}{ll|l}
184,57 \\
\end{tabular} & 236,06 & 239,78 & 110,72 & 440,55 & 77,82 & 11,16 & 46,32 & 184,18 & 54,45 & 85,56 & 103,47 \\
\hline \begin{tabular}{|l} 
Bufo spinosus \\
\end{tabular} & $30 \mathrm{SY} Y 40$ & 100,00 & 167,35 & 101,01 & 39,65 & 5315,62 & 302,27 & 50,52 & 251,75 & 144,27 & 235,75 & 238,78 & 102,67 & 530,74 & 82,46 & 9,23 & 46,43 & 218,19 & 55,11 & 86,49 & 147,33 \\
\hline Bufo spinosus & 30SYJ41 & 92,00 & 178,72 & 99,65 & \begin{tabular}{|l|l}
39,99 \\
\end{tabular} & 5194,28 & 309,11 & 62,64 & 246,47 & 156,51 & 244,90 & 248,08 & 114,94 & 503,61 & 82,83 & 7,26 & 51,03 & 216,47 & 47,22 & 82,13 & 143,56 \\
\hline Bufo spinosus & $30 \mathrm{SYJ42}$ & 37,00 & 179,44 & 97,85 & \begin{tabular}{|l|l|}
39,97 \\
\end{tabular} & 5155,15 & 307,64 & 64,85 & 242,79 & 156,95 & 245,13 & 248,38 & 116,18 & 491,85 & 82,98 & 7,20 & 51,16 & 210,54 & 46,64 & 81,48 & 137,85 \\
\hline Bufo spinosus & $30 \mathrm{SYJ43}$ & 2,00 & 179,67 & 96,50 & 40,00 & 5101,33 & 306,00 & 66,83 & 239,17 & 157,33 & 244,83 & 248,00 & 117,33 & 484,17 & 83,00 & 8,00 & 50,67 & 205,50 & 47,00 & 82,00 & 133,33 \\
\hline Bufo spinosus & 30SYJ50 & 91,00 & 178,28 & 100,93 & 39,94 & 5233,66 & 310,87 & 60,86 & 250,01 & 156,53 & 245,10 & 248,07 & 113,90 & 537,55 & 84,02 & 7,42 & 51,87 & 234,68 & 48,71 & 85,38 & 160,51 \\
\hline Bufo spinosus & 30SYJ51 & 15,00 & 181,67 & 99,90 & 40,00 & 5192,90 & 312,10 & 64,86 & 247,24 & 159,90 & 247,57 & 250,81 & 117,71 & 518,95 & 83,95 & 7,00 & 52,95 & 228,43 & 46,00 & 83,29 & 154,05 \\
\hline Bufo spinosus & $30 \mathrm{SYJ60}$ & 0,00 & 181,57 & 101,00 & 40,00 & 5224,86 & 314,43 & 63,71 & 250,71 & 160,14 & 248,00 & 251,14 & 116,86 & 554,14 & 85,57 & 7,00 & 54,00 & 247,14 & 48,00 & 87,00 & 171,57 \\
\hline Bufo spinosus & 30SYKOO & 100,00 & 139,41 & \begin{tabular}{ll|}
94,26 \\
\end{tabular} & \begin{tabular}{|l|l|}
37,13 \\
\end{tabular} & 5666,42 & 277,01 & 26,49 & 250,53 & 148,94 & 214,20 & 215,70 & 71,98 & 472,11 & 64,15 & 18,16 & 31,70 & 165,66 & 81,42 & 95,94 & 96,76 \\
\hline Bufo spinosus & 30SYK01 & 100,00 & 134,56 & \begin{tabular}{ll|}
94,06 \\
\end{tabular} & 36,96 & 5741,43 & 273,68 & 21,12 & 252,56 & 143,61 & 209,48 & 211,81 & 66,34 & 477,33 & 61,79 & 19,63 & 30,41 & 163,17 & 86,90 & 99,28 & 95,21 \\
\hline Bufo spinosus & 30SYKO2 & 100,00 & 133,17 & 93,51 & 36,64 & 5766,06 & 272,32 & 19,80 & 252,52 & \begin{tabular}{|l|l|}
141,83 \\
\end{tabular} & 170,55 & 210,65 & 64,64 & 472,90 & 60,31 & 20,15 & 30,38 & 160,07 & 87,72 & 100,21 & 92,38 \\
\hline \begin{tabular}{|l} 
Bufo spinosus \\
\end{tabular} & 30SYK10 & 100,00 & 143,46 & 92,15 & 37,02 & 5547,72 & 277,29 & 31,91 & 245,38 & 153,64 & 216,17 & 218,25 & 77,29 & 479,42 & 67,76 & 17,51 & 33,16 & 173,14 & 78,71 & 96,77 & 101,15 \\
\hline Bufo spinosus & 30SYK11 & 100,00 & 149,50 & 90,61 & 36,97 & 5478,63 & 280,43 & 38,69 & 241,74 & 159,46 & 221,06 & 223,19 & 83,84 & 453,34 & 66,30 & 16,24 & 34,97 & 167,62 & 73,26 & 92,60 & 94,66 \\
\hline Bufo spinosus & 30SYK 12 & 100,00 & 134,80 & 92,09 & 36,45 & 5682,40 & 271.49 & 22,29 & 249,21 & $\mid 143,69$ & 208,88 & 211,21 & 67,34 & 486,30 & 63,02 & 19,95 & 30,71 & $\mid 167,47$ & 88.44 & 102,36 & 97,31 \\
\hline Bufo spinosus & 30SYK20 & 100,00 & 160,35 & 87,92 & 37,24 & 5238,23 & 284,38 & 52,25 & 232,14 & 171,66 & 227,90 & 230,92 & 97,21 & 451,01 & 72,79 & 13,91 & 39,85 & 177,48 & 64,00 & 89,53 & 100,12 \\
\hline \begin{tabular}{|l} 
Bufo spinosus \\
\end{tabular} & 30SYK21 & 100,00 & 145,32 & 89,86 & 36,76 & 5470,59 & 276,20 & 34,98 & 241,22 & 155,35 & 216,84 & 21 & 80,06 & 483,17 & 68,68 & 17 & 33,96 & 176,54 & 78,74 & 98,83 & 102,43 \\
\hline Bufo spinosus & 30SYK22 & 100,00 & 141,91 & 89,99 & \begin{tabular}{|l|}
36,38 \\
\end{tabular} & 5542,24 & 274,33 & 30,88 & 243,45 & 151,30 & 214,58 & 216,54 & 75,93 & 483,39 & 66,07 & 18,39 & 32,69 & 172,99 & 82,58 & \begin{tabular}{|l|l|}
100,81 \\
\end{tabular} & 99,84 \\
\hline \begin{tabular}{|l|} 
Bufo spinosus \\
\end{tabular} & 30SYK31 & 100,00 & 156,25 & 86,80 & 36,88 & 5275,68 & 281,12 & 48,02 & 233,10 & 167,22 & 224,50 & 227,43 & 93,01 & 466,86 & 71,02 & 15,19 & 37,94 & 179,61 & 69,63 & 94,88 & 102,45 \\
\hline Bufo spinosus & 30SYK32 & 100,00 & 160,29 & 85,89 & 36,64 & 5244,68 & 283,74 & 51,95 & 231,79 & \begin{tabular}{ll|l|}
170,88 \\
\end{tabular} & \begin{tabular}{|l|l|}
227,87 & \\
\end{tabular} & 230,75 & 97,07 & 446,44 & 68,37 & 14,57 & 38,74 & 173,66 & 66,49 & 91,97 & 96,40 \\
\hline Bufo spinosus & 30SYK41 & 86,00 & 171,83 & 83,56 & 36,8 & 5049,79 & 289,73 & 65,27 & 224,45 & 183,75 & 236,14 & 23 & 110,35 & 432,37 & 71,21 & 12,03 & 43,70 & 177,79 & 56,71 & 87,44 & 98,35 \\
\hline Bufo spinosus & 30SYK42 & 100,00 & 168,88 & 83,31 & 36, & 5093,37 & 287,97 & 61,97 & 226,00 & 180,32 & 233,98 & 237 & 107,00 & 432,64 & 68,52 & 13,02 & 41,82 & 174,65 & 59,97 & 89,27 & 95,79 \\
\hline Bufo spinosus & 30SYK51 & 6,00 & 172,20 & 83,00 & 36,90 & 5063,60 & 290,00 & 65,90 & 224,10 & 184,20 & 236,90 & 240,90 & 111,00 & 436,90 & 70,60 & 12,00 & 43,40 & 179,00 & 57,90 & 89,00 & 99,20 \\
\hline Bufo spinosus & 30SYK52 & 57,00 & 171,46 & 82,73 & 36,02 & 5099,43 & 289,46 & 63,70 & 225,76 & \begin{tabular}{|l|l|}
182,67 \\
\end{tabular} & 236,61 & 239,70 & \begin{tabular}{|l|l|}
109,33 \\
\end{tabular} & $\mid 435,60$ & 69,07 & 12,52 & 42,66 & \begin{tabular}{|l|l|}
177,43 \\
\end{tabular} & 58,92 & 89,85 & 97,71 \\
\hline Bufo spinosus & 30TTK48 & 40,00 & 134,10 & 111,33 & 37,38 & 6306,80 & 307,13 & 13,61 & 293,52 & 64,43 & 218,56 & 218,64 & 57,33 & 483,51 & 59,92 & 8,43 & 40,90 & 171,39 & 46,87 & 46,92 & 156,69 \\
\hline Bufo spinosus & 30TTK49 & 40,00 & 115,98 & 109,66 & 37,2 & 6252,05 & 288,25 & $-1,39$ & 289,64 & 47,76 & 199 & 200 & 4 & 562,68 & $69, / 3$ & 11,05 & 39,69 & 198,97| & 57,68 & 58,81 & 182 \\
\hline \begin{tabular}{|l} 
Bufo spinosus \\
\end{tabular} & 30TTK56 & 100,00 & 125,09 & 110,34 & 36,99 & 6336,47 & 299,69 & 5,54 & 294,16 & 55,85 & 209,65 & 210,40 & 48,89 & 532,56 & 65,03 & 9,79 & 40,50 & 186,53 & 52,18 & 52,97 & 171,06 \\
\hline
\end{tabular}




\begin{tabular}{|c|c|c|c|c|c|c|c|c|c|c|c|c|c|c|c|c|c|c|c|c|c|}
\hline TAXON & UTM & $\mathrm{km} 2$ & BIO1 & B102 & $B 103$ & BIO4 & B105 & B106 & B107 & B108 & B109 & B1010 & BIO11 & BIO12 & BIO13 & B1014 & BIO15 & B1016 & B1017 & B1018 & 81019 \\
\hline Bufo spinosus & 30TTK57 & 100,00 & 125,48 & 111,03 & 37,08 & 6317,04 & 299,69 & 5,65 & 294,04 & 56,32 & 209,99 & 210,54 & 49,34 & 515,12 & 63,05 & 9,67 & 39,93 & 180,10 & 51,77 & 52,14 & 164,56 \\
\hline Bufo spinosus & 30TTK58 & 100,00 & 125,15 & 111,64 & 37,57 & 6296,49 & 298,85 & 5,27 & 293,58 & 56,00 & 209,26 & 209,81 & 49,13 & 503,89 & 61,86 & 9,69 & 39,55 & $\begin{array}{l}175,86 \\
\end{array}$ & 51,83 & 52,15 & 159,95 \\
\hline Bufo spinosus & 30TTK59 & 100,00 & 118,74 & 111,53 & 37,89 & 6264,91 & 292,03 & 0,06 & 291,97 & 50,05 & 202,19 & 203,01 & 43,41 & 522,27 & 64,35 & 10,65 & 38,81 & 182,02 & 55,69 & 56,28 & 164,96 \\
\hline Bufo spinosus & 30TTK65 & 100,00 & 113,49 & 109,94 & 36,78 & 6341,39 & 289,57 & $-5,24$ & 294,81 & 45,07 & $\begin{array}{l}198,60 \\
\end{array}$ & $\begin{array}{l}199,43 \\
\end{array}$ & 38,40 & 586,38 & 70,42 & 12,04 & 39,20 & 201,93 & 59,78 & 61,71 & 185,52 \\
\hline Bufo spinosus & 30TTK66 & 100,00 & 79,21 & 106,14 & 36,41 & 6224,39 & 253,47 & $-34,09$ & 287,56 & 14,25 & 163,83 & 164,57 & 7,95 & 803,94 & 95,97 & 19,66 & 37,45 & 276,18 & 86,49 & 92,45 & 257,79 \\
\hline Bufo spinosus & 30TTK67 & 100,00 & 109,14 & 110,24 & 37,07 & 6281,82 & 283,90 & $-8,71$ & 292,61 & 41,20 & $\mid 192,97$ & $\mid 194,39$ & 34,75 & 578,51 & 69,88 & $\mid 12,63$ & 37,97 & $\mid$\begin{tabular}{|l|l|}
198,20 \\
\end{tabular} & 62,04 & 64,14 & $\begin{array}{ll}180,73 \\
\end{array}$ \\
\hline Bufo spinosus & 30TTK68 & 100,00 & 121,72 & 112,60 & 37,88 & 6290,36 & 296,40 & 1,58 & 294,82 & 52,69 & 205,55 & 206,38 & 46,00 & 494,14 & 59,95 & 10,43 & 38,06 & 168,79 & 53,79 & 54,29 & 152,38 \\
\hline Bufo spinosus & 30TTK69 & 100,00 & 116,55 & 112,76 & 38,00 & 6255,50 & 290,74 & $-2,36$ & 293,10 & 54,45 & 199,44 & 200,97 & 41,45 & $\begin{array}{l}504,86 \\
\end{array}$ & 61,34 & 11,15 & 37,32 & \begin{tabular}{|l|l|}
171,90 \\
\end{tabular} & 56,85 & 57,70 & 154,59 \\
\hline Bufo spinosus & 30TTK74 & 100,00 & 134,76 & 112,76 & 36,99 & 6418,78 & 312,39 & $\begin{array}{ll}11,83 \\
\end{array}$ & 300,57 & 68,51 & 220,79 & 221,21 & 57,26 & $\begin{array}{l}470,09 \\
\end{array}$ & 55,91 & 8,45 & 40,06 & 159,85 & 46,18 & $\begin{array}{l}46,69 \\
\end{array}$ & 145,14 \\
\hline Bufo spinosus & 30TTK75 & 100,00 & 81,44 & 107,65 & 36,44 & 6263,92 & 257,81 & $-33,16$ & 290,97 & \begin{tabular}{|l|l|}
16,03 \\
\end{tabular} & \begin{tabular}{ll|}
166,67 \\
\end{tabular} & 167,38 & 9,72 & 767,13 & $\begin{array}{l}90,58 \\
\end{array}$ & 19,21 & 36,84 & 259,87 & 83,75 & 88,86 & 241,18 \\
\hline Bufo spinosus & 30TTK76 & 100,00 & 91,53 & 108,77 & 36,79 & $\begin{array}{ll}6260,14 \\
\end{array}$ & 267,27 & $-24,49$ & 291,75 & 25,18 & 175,92 & \begin{tabular}{ll|}
177,06 \\
\end{tabular} & 18,91 & \begin{tabular}{ll|l}
680,86 \\
\end{tabular} & 80,72 & \begin{tabular}{ll|}
16,69 \\
\end{tabular} & 36,68 & 229,91 & 75,34 & \begin{tabular}{ll|}
79,58 \\
\end{tabular} & 211,18 \\
\hline Bufo spinosus & 30TTK77 & 100,00 & 97,20 & 109,86 & 37,13 & 6246,57 & 272,49 & $-19,59$ & \begin{tabular}{|l|}
292,07 \\
\end{tabular} & 30,34 & 180,93 & \begin{tabular}{|l|l|}
182,39 \\
\end{tabular} & 24,13 & 626,00 & 74,51 & 15,30 & 36,35 & 210,42 & 70,67 & 74,09 & 191,65 \\
\hline Bufo spinosus & 30TTK78 & 100,00 & 114,63 & 112,80 & 37,91 & 6271,61 & 289,86 & $-4,61$ & 294,47 & 55,68 & 197,59 & $\begin{array}{l}199,56 \\
\end{array}$ & 39,69 & 504,84 & 60,39 & 11,68 & 36,46 & 168,65 & 57,96 & 59,24 & 151,39 \\
\hline Bufo spinosus & 30TTK84 & 100,00 & 134,41 & 113,27 & 37,00 & 6425,82 & 312,65 & 10,59 & 302,07 & 81,47 & 220,52 & 220,95 & 56,82 & 456,62 & 53,71 & 8,67 & 39,33 & 153,00 & 46,50 & 47,06 & 137,83 \\
\hline Bufo spinosus & 30TTK85 & 100,00 & 78,37 & 108,42 & 36,60 & $\begin{array}{ll}6264,29 \\
\end{array}$ & 255,69 & $-36,63$ & 292,32 & 13,03 & 163,74 & 164,41 & 6,90 & \begin{tabular}{ll|}
760,19 \\
\end{tabular} & 88,73 & 20,16 & 35,67 & 253,42 & 86,09 & \begin{tabular}{|c|}
91,79 \\
\end{tabular} & 233,99 \\
\hline Bufo spinosus & 30TTK86 & 100,00 & 104,01 & 111,33 & 37,03 & $\begin{array}{ll}6298,99 \\
\end{array}$ & 281,10 & $-14,76$ & 295,86 & 38,62 & 188,25 & 189,81 & 30,01 & $\begin{array}{l}569,76 \\
\end{array}$ & 66,99 & 14,01 & 36,09 & 188,25 & 65,19 & 67,68 & 169,77 \\
\hline Bufo spinosus & 30TTK87 & 100,00 & 112,29 & 112,73 & 37,60 & $\begin{array}{ll}6295,44 \\
\end{array}$ & 288,80 & \begin{tabular}{|l|l|}
$-7,63$ \\
\end{tabular} & 296,43 & 62,51 & 195,94 & $\begin{array}{l}197,81 \\
\end{array}$ & 37,44 & 507,78 & 59,81 & 12,44 & 35,86 & \begin{tabular}{ll|}
166,60 \\
\end{tabular} & 59,43 & 61,05 & 148,84 \\
\hline Bufo spinosus & 30TTK88 & 100,00 & 115,08 & 113,70 & 37,98 & 6268,39 & 290,92 & $-5,17$ & 296,09 & 72,80 & 197,78 & 200,01 & 40,13 & 480,61 & 56,77 & 11,78 & 35,36 & 157,37 & 57,66 & 58,97 & 139,60 \\
\hline Bufo spinosus & 30ТтK94 & 100,00 & 150,38 & 114,48 & 37,00 & 6451,97 & 328,03 & 24,12 & 303,91 & 108,28 & 236,77 & 236,78 & 71,27 & 381,23 & 44,71 & 6,37 & 39,86 & 128,30 & 37,38 & 37,38 & 113,13 \\
\hline Bufo spinosus & 30тTK95 & 100,00 & 94,42 & 110,80 & 36,89 & 6314,75 & 272,60 & $-23,77$ & 296,37 & 36,90 & 179,93 & 180,69 & 21,05 & 643,16 & 74,43 & 17,05 & 35,56 & 210,75 & 74,63 & 78,42 & 191,89 \\
\hline Bufo spinosus & 30TTK96 & 100,00 & 91,54 & 110,67 & 37,01 & 6268,13 & 268,93 & $-26,01$ & 294,93 & 33,22 & 176,05 & 177,31 & 18,89 & 629,13 & 73,17 & 17,20 & 34,74 & 204,69 & 75,06 & 79,02 & 184,84 \\
\hline \begin{tabular}{|l|} 
Bufo spinosus \\
\end{tabular} & 30TTK97 & 100,00 & $\begin{array}{ll}99,04 \\
\end{array}$ & 111,70 & 37,34 & 6257,05 & 275,69 & $-19,61$ & 295,30 & 48,24 & 182,84 & 184,34 & 25,79 & $\begin{array}{l}565,46 \\
\end{array}$ & 66,21 & 15,39 & 34,41 & 182,77 & 69,10 & 72,18 & 162,84 \\
\hline Bufo spinosus & 30TTL40 & 39,00 & 117,22 & 110,80 & 37,98 & 6241,55 & 289,36 & $-0,44$ & 289,80 & 48,96 & 200,42 & 201,29 & 42,09 & 537,40 & 66,89 & 10,84 & 39,51 & $\begin{array}{l}189,65 \\
\end{array}$ & 56,73 & 57,22 & 172,22 \\
\hline Bufo spinosus & 30TTL57 & 100,00 & 115,39 & 114,42 & 39,00 & $\begin{array}{ll}6158,74 \\
\end{array}$ & 287,28 & $-3,76$ & 291,04 & 75,66 & 197,18 & $\begin{array}{l}197,42 \\
\end{array}$ & 40,06 & \begin{tabular}{|l|l|}
444,03 \\
\end{tabular} & 56,61 & 11,27 & 37,08 & 157,38 & 55,33 & 55,47 & 133,44 \\
\hline Bufo spinosus & 30TTL58 & 100,00 & 118,25 & 114,45 & 39,00 & 6157,61 & 289,66 & $-1,44$ & 291,09 & 78,51 & 199,50 & 199,90 & 42,43 & 426,35 & 54,25 & 10,94 & 36,63 & 150,60 & 53,39 & 53,63 & 128,16 \\
\hline Bufo spinosus & 30TTL63 & 100,00 & 119,51 & 116,51 & 39,01 & 6228,66 & 293,60 & $-0,62$ & 294,22 & 79,06 & 202,72 & 202,72 & 43,67 & 431,98 & 54,71 & 10,97 & 37,70 & 153,08 & 53,65 & 53,65 & 125,65 \\
\hline Bufo spinosus & 30TTL65 & 100,00 & 118,88 & 116,50 & 39,01 & 6191,56 & 292,08 & $-1,21$ & 293,29 & 78,72 & 201,26 & 201,26 & 43,07 & 410,75 & 52,21 & 10,97 & 37,74 & 146,54 & 53,00 & 53,00 & 116,99 \\
\hline Bufo spinosus & 30TTL66 & 100,00 & 114,36 & 115,74 & 39,00 & \begin{tabular}{|l|l|}
6172,04 \\
\end{tabular} & 287,32 & $-5,11$ & 292,43 & 74,34 & 196,24 & 196,68 & 39,04 & 426,80 & 53,56 & 11,65 & 36,71 & 150,57 & 56,11 & 56,36 & 122,45 \\
\hline Bufo spinosus & 30TTL67 & 100,00 & 115,36 & 115,55 & 39,00 & 6155,89 & 287,85 & $-4,08$ & 291,93 & 75,61 & 196,41 & $\begin{array}{l}197,42 \\
\end{array}$ & 40,03 & $\begin{array}{l}417,49 \\
\end{array}$ & 52,16 & 11,57 & 36,18 & $\begin{array}{l}146,45 \\
\end{array}$ & 55,03 & 55,53 & 119,99 \\
\hline Bufo spinosus & 30TTL73 & 100,00 & 120,48 & 118,22 & 39,59 & 6217,77 & 295,16 & $-0,53$ & 295,68 & 79,94 & 203,51 & \begin{tabular}{|l|l|}
203,67 \\
\end{tabular} & 44,79 & 414,32 & 50,82 & $\begin{array}{l}10,99 \\
\end{array}$ & 35,68 & 142,51 & 53,90 & 53,97 & 118,64 \\
\hline Bufo spinosus & 30TTL75 & 100,00 & 118,36 & $\begin{array}{ll}117,62 \\
\end{array}$ & 39,62 & $\begin{array}{ll}6170,04 \\
\end{array}$ & 292,09 & $-1,89$ & 293,97 & 78,08 & 200,76 & 200,92 & 43,20 & 394,29 & 49,00 & 11,00 & 36,49 & \begin{tabular}{ll|}
137,82 \\
\end{tabular} & 53,90 & 53,96 & 108,48 \\
\hline Bufo spinosus & 30TTL76 & 100,00 & 115,98 & 116,93 & 39,04 & 6154,60 & 289,42 & $-4,00$ & 293,42 & 75,96 & \begin{tabular}{|l|l|}
197,03 \\
\end{tabular} & 198,15 & 40,83 & 399,35 & $\begin{array}{lll}49,00 \\
\end{array}$ & \begin{tabular}{|l|l|}
11,38 \\
\end{tabular} & 35,69 & 138,35 & 54,94 & 55,48 & 110,35 \\
\hline Bufo spinosus & 30TTL80 & 100,00 & 116,94 & 115,38 & 38,70 & 6194,59 & 291,30 & $-3,28$ & 294,58 & 76,48 & 198,09 & 200,76 & 42,40 & 447,38 & 53,07 & 11,43 & 34,27 & 146,34 & 56,69 & 57,84 & 127,78 \\
\hline Bufo spinosus & 30TTL81 & 100,00 & 119,77 & 116,53 & 39,00 & 6165,85 & 293,85 & $-0,93$ & 294,78 & 79,18 & 200,16 & 202,99 & 45,29 & 424,89 & 50,31 & 11,05 & 33,65 & \begin{tabular}{|l|l|}
138,73 \\
\end{tabular} & 55,23 & 56,31 & 120,59 \\
\hline Bufo spinosus & 30TTL84 & 100,00 & 118,22 & 118,05 & 40,00 & 6094,94 & 291,11 & $-2,11$ & 293,22 & 77,77 & $\begin{array}{l}197,44 \\
\end{array}$ & 200,09 & 44,13 & $\begin{array}{l}395,58 \\
\end{array}$ & 47,83 & 11,05 & 33,18 & 130,74 & 55,48 & 56,54 & 108,39 \\
\hline Bufo spinosus & 30TTL87 & 100,00 & 1117,45 & 1117,01 & 39,01 & 6128,10 & 290,28 & $-3,02$ & 293,30 & 77,47 & 196,72 & 199,04 & 42,31 & 381,31 & 46,22 & 11,59 & 33,62 & 128,43 & 54,19 & 55,82 & 103,11 \\
\hline Bufo spinosus & 30TTL88 & 100,00 & 120,04 & $\begin{array}{l}116,87 \\
\end{array}$ & 39,00 & $\begin{array}{lll}6129,04 \\
\end{array}$ & 292,54 & $-0,96$ & 293,50 & 80,56 & 199,23 & 201,35 & 44,43 & 369,22 & 44,14 & $\begin{array}{l}11,29 \\
\end{array}$ & 33,43 & 124,61 & 52,34 & 54,01 & 99,94 \\
\hline Bufo spinosus & 30TTL89 & 100,00 & 123,24 & 116,25 & 39,00 & $\begin{array}{ll}6124,41 \\
\end{array}$ & 295,14 & 1,65 & 293,49 & 83,91 & 202,13 & 204,34 & 47,36 & 358,89 & 42,33 & 10,93 & 33,26 & 121,55 & 50,74 & 52,56 & 97,16 \\
\hline Bufo spinosus & 30TTL91 & 100,00 & 117,60 & 116,18 & 39,00 & 6136,11 & 291,29 & $-2,71$ & 294,00 & 77,22 & 197,47 & 200,64 & 43,65 & 418,35 & 50,18 & 11,39 & 32,73 & 133,71 & 56,42 & 58,07 & 115,02 \\
\hline Bufo spinosus & 30TTL92 & 100,00 & 119,23 & 117,02 & 39,26 & 6087,00 & 291,85 & $-1,21$ & 293,05 & 78,44 & 197,85 & 201,35 & 45,51 & 402,74 & 48,03 & 11,02 & 31,95 & 127,79 & 55,75 & 57,51 & 110,08 \\
\hline Bufo spinosus & 30TTL93 & 100,00 & 119,44 & 117,50 & 39,96 & 6030,78 & 291,30 & $-0,79$ & 292,09 & 78,96 & 197,04 & 200,89 & 46,37 & 391,78 & 46,69 & 11,02 & 31,25 & $\mid 123,57$ & 55,69 & 57,79 & 106,13 \\
\hline Bufo spinosus & 30TTL96 & 100,00 & 117,16 & 1117,26 & 39,36 & $\begin{array}{l}6097,63 \\
\end{array}$ & 290,05 & $-3,19$ & 293,24 & 77,09 & 196,05 & 198,89 & 42,75 & 382,61 & 46,59 & 11,75 & 32,22 & \begin{tabular}{ll|}
124,92 \\
\end{tabular} & 55,61 & 57,70 & 102,01 \\
\hline Bufo spinosus & 30TTL97 & 100,00 & 120,42 & $\begin{array}{ll}117,03 \\
\end{array}$ & 39,03 & 6113,75 & 293,03 & $-0,62$ & 293,66 & 80,65 & 199,27 & 201,87 & 45,18 & 368,74 & 44,48 & 11,30 & 32,49 & 121,59 & 53,13 & 55,11 & 98,48 \\
\hline Bufo spinosus & 30TTL98 & 100,00 & 120,71 & 117,00 & 39,00 & 6116,87 & 293,11 & $-0,66$ & 293,78 & 81,40 & $\begin{array}{l}199,52 \\
\end{array}$ & 202,03 & 45,15 & 367,73 & 43,89 & 11,57 & 32,38 & 121,95 & 53,17 & 55,27 & 98,40 \\
\hline Bufo spinosus & 30TTL99 & 100,00 & 123,40 & 116,79 & 39,00 & 6113,62 & 295,29 & 1,44 & 293,85 & 84,35 & 202,00 & 204,42 & 47,40 & 361,10 & 42,50 & 11,65 & 32,23 & 120,58 & 52,20 & 54,24 & 97,04 \\
\hline Bufo spinosus & 30TTM53 & 90,00 & 116,54 & 114,76 & 39,00 & 6052,98 & 286,48 & $-3,53$ & 290,01 & 77,97 & 196,54 & 196,54 & 41,24 & 461,58 & 58,57 & 13,78 & 34,71 & 164,57 & 62,22 & 62,22 & 141,87 \\
\hline Bufo spinosus & 30TTM62 & 100,00 & 120,20 & 115,04 & 39,00 & 6087,90 & 290,52 & $-0,55$ & 291,06 & 81,15 & 200,17 & 200,39 & 44,52 & 413,72 & 51,54 & 12,11 & 34,03 & 145,85 & 57,31 & 57,43 & 121,43 \\
\hline Bufo spinosus & 30тTM64 & 100,00 & 118,42 & 115,20 & 39,00 & 6033,58 & 288,30 & $-2,81$ & 291,11 & 80,39 & 198,16 & 198,16 & 43,04 & 445,7 & 55,58 & 14,38 & 33,53 & 159,09 & 63,73 & 63,73 & 132,16 \\
\hline Bufo spinosus & 30TTM & 100,00 & $\begin{array}{l}116,47 \\
\end{array}$ & 115,28 & 39,09 & 5983, & 285 & $-4,31$ & 289,88 & 78,71 & 195,43 & 195,43 & 41,65 & 479,97 & 60,65 & 17,05 & 33,31 & $\mid 173,27$ & 71,19 & 71,19 & 142,10 \\
\hline Bufo spinosus & 30TTM68 & 100,00 & 115,66 & \begin{tabular}{ll|}
115,14 \\
\end{tabular} & 39,30 & 5920,82 & 283,44 & $-4,84$ & 288,27 & 78,75 & $\begin{array}{l}193,59 \\
\end{array}$ & $\begin{array}{l}193,59 \\
\end{array}$ & 41,14 & 510,51 & 65,92 & 19,61 & 33,18 & $\begin{array}{l}186,15 \\
\end{array}$ & 78,70 & 78,70 & 149,35 \\
\hline Bufo spinosus & 30TTM69 & 100,00 & 114,35 & $\begin{array}{l}114,99 \\
\end{array}$ & 39,66 & 5869,97 & 281,20 & $-6,07$ & 287,28 & 77,94 & $\begin{array}{l}191,56 \\
\end{array}$ & $\begin{array}{l}191,56 \\
\end{array}$ & 40,43 & 531,65 & 69,26 & 21,31 & 33,10 & 194,55 & 83,77 & 83,77 & 154,35 \\
\hline Bufo spinosus & 30TTM72 & 100,00 & 121,22 & 115,76 & 39,00 & $\begin{array}{ll}6085,42 \\
\end{array}$ & 292,07 & $-0,26$ & 292,33 & 82,42 & 200,30 & 201,51 & 45,26 & 396,00 & 48,23 & 12,26 & 33,17 & 138,25 & 56,89 & 57,44 & 112,25 \\
\hline Bufo spinosus & 30TTM73 & 100,00 & 119,93 & 115,98 & 39,00 & 6054,20 & 290,56 & $-1,70$ & 292,26 & 81,61 & 199,49 & 199,75 & 44,16 & 413,48 & 50,49 & 13,51 & 32,68 & 145,36 & 60,75 & 60,88 & 118,08 \\
\hline Bufo spinosus & 30TTN & 100,00 & $\begin{array}{l}114,03 \\
\end{array}$ & 115,95 & 39,95 & 5900,76 & 282,31 & $-7,13$ & 289,43 & 77,75 & $\begin{array}{l}191,87 \\
\end{array}$ & \begin{tabular}{|l|l|}
191,87 \\
\end{tabular} & 39,68 & 517,01 & 67,13 & 21,75 & 32,80 & \begin{tabular}{|l|l|}
188,87 \\
\end{tabular} & 84,68 & 84,68 & 145,62 \\
\hline Bufo spinosus & 30TTM85 & 100,00 & 119,63 & 116,05 & 39,03 & 5984,16 & 289,65 & $-1,88$ & 291,53 & 82,89 & 198,59 & 198,59 & 44,51 & $\begin{array}{l}431,66 \\
\end{array}$ & 53,50 & 15,91 & 31,95 & 152,64 & 67,61 & 67,61 & 120,59 \\
\hline Bufo spinosus & 30TTM90 & 100,00 & 120,98 & \begin{tabular}{ll|}
116,89 \\
\end{tabular} & 39,01 & 6105,73 & 292,91 & $-0,66$ & 293,57 & 82,10 & 199,48 & 201,74 & 45,03 & $\begin{array}{l}373,56 \\
\end{array}$ & 43,81 & 12,30 & 31,86 & \begin{tabular}{ll|}
125,32 \\
\end{tabular} & 54,53 & 56,83 & 100,95 \\
\hline Bufo spinosus & 30TTM98 & 100,00 & 115,31 & 115,94 & 39,65 & 5873,47 & 283,65 & $-6,28$ & 289,93 & 80,58 & 192,79 & $\begin{array}{l}192,79 \\
\end{array}$ & 41,40 & 486,16 & 61,73 & 21,00 & 31 & 173 & 82,64 & 82,64 & 131,60 \\
\hline Bufo spinosus & $30 \pi T$ & 58,00 & $\begin{array}{ll}93,44 \\
\end{array}$ & 109,66 & 39,99 & & & $-19,50$ & & 60,25 & 16 & 16 & 25,44 & 749,48 & 97,07 & 33,26 & 30,23 & 266,40 & 122,49 & 122,49 & 220,42 \\
\hline Bufo spinosus & 30TTN54 & 50,00 & 85,92 & 107,32 & 39,96 & 5432,77 & 240,95 & $-24,42$ & 265,37 & 54,00 & 157,99 & 157,99 & 19,85 & 827,83 & 105,94 & 37,45 & 29,26 & 289,86 & 136,27 & 136,33 & 244,65 \\
\hline Bufo spinosus & 30TTN56 & 47,00 & 65,31 & 101,61 & 39,72 & 5231,31 & 214,28 & $-38,83$ & 253,11 & 31,13 & 135,35 & 135,42 & 3,28 & 1038,97 & 128,89 & 48,32 & 27,40 & 352,92 & 172,06 & 172,99 & 312,22 \\
\hline
\end{tabular}




\begin{tabular}{|c|c|c|c|c|c|c|c|c|c|c|c|c|c|c|c|c|c|c|c|c|c|}
\hline TAXON & UTM & $\mathrm{km} 2$ & B101 & B102 & $\mathrm{BIO3}$ & B104 & B105 & B106 & B107 & B108 & 8109 & BIO10 & BIO11 & BIO12 & B1013 & BIO14 & BIO15 & B1016 & B1017 & B1018 & B1019 \\
\hline Bufo spinosus & 30TTN60 & 100,00 & 112,30 & 114,63 & 39,92 & 5825,36 & 278,29 & $-7,38$ & 285,67 & 76,30 & 189,01 & 189,01 & 39,02 & 557,37 & 73,12 & 23,30 & 32,92 & 204,20 & 89,71 & 89,71 & 160,39 \\
\hline Bufo spinosus & 30TTN62 & 100,00 & 104,34 & 112,87 & 40,00 & 5683,40 & 266,90 & $-12,56$ & 279,46 & 69,82 & 179,35 & 179,35 & 33,50 & 640,29 & 84,06 & 28,65 & 31,66 & 232,06 & 106,62 & 106,62 & 182,98 \\
\hline Bufo spinosus & 30TTN63 & 100,00 & 97,88 & 110,95 & 40,00 & 5567,66 & 257,41 & $-16,42$ & 273,84 & 64,54 & 171,46 & 171,46 & 28,97 & 704,86 & 91,85 & 32,32 & 30,37 & 252,02 & 118,46 & 118,46 & 202,02 \\
\hline Bufo spinosus & 30TTN64 & 100,00 & 88,79 & 108,26 & 40,01 & 5445,67 & 244,62 & $-22,48$ & 267,11 & 56,85 & 160,94 & 160,94 & 22,20 & 795,50 & 102,14 & 37,00 & 28,97 & 279,16 & 134,13 & 134,13 & 230,18 \\
\hline Bufo spinosus & 30TTN65 & 100,00 & 79,02 & 105,37 & 39,96 & 5328,69 & 231,28 & $-29,09$ & 260,37 & 48,33 & \begin{tabular}{|l|l|}
149,91 \\
\end{tabular} & 149,92 & 14,66 & 894,13 & 113,10 & 42,03 & 27,92 & 308,30 & 150,90 & \begin{tabular}{|l|l|}
151,08 \\
\end{tabular} & 261,42 \\
\hline Bufo spinosus & 30TTN66 & 100,00 & 75,87 & 102,94 & 40,22 & 5193,28 & 223,88 & $-29,61$ & 253,49 & 46,30 & \begin{tabular}{|l|l}
144,83 \\
\end{tabular} & 144,96 & 13,51 & 955,68 & 120,26 & 45,30 & 27,28 & 325,99 & 161,73 & 162,86 & 279,55 \\
\hline Bufo spinosus & 30TTN70 & 100,00 & 111,83 & 115,86 & 39,87 & 5876,95 & 279,96 & $-8,85$ & 288,81 & 76,08 & 189,31 & 189,31 & 37,82 & 541,07 & 70,76 & 23,03 & 32,95 & 198,52 & $\begin{array}{l}90,65 \\
\end{array}$ & 90,65 & 151,22 \\
\hline \begin{tabular}{|l} 
Bufo spinosus \\
\end{tabular} & 30TTN71 & 100,00 & 108,29 & 115,51 & 39,98 & 5833,44 & 275,83 & $-11,51$ & 287,33 & 72,84 & 185,29 & 185,29 & 35,15 & 574,51 & 75,41 & 23,60 & 32,70 & 210,81 & 98,28 & 98,28 & 159,69 \\
\hline Bufo spinosus & 30TTN75 & 100,00 & 78,74 & 105,74 & 39,91 & 5340,06 & 231,84 & $-29,75$ & 261,59 & 48,48 & 149,70 & 149,71 & 14,15 & 879,32 & 110,85 & 42,46 & 27,29 & 302,26 & 151,78 & 151,81 & 252,92 \\
\hline Bufo spinosus & 30TTN76 & 100,00 & 78,15 & 103,75 & 40,21 & 5204,15 & 227,04 & $-28,09$ & 255,13 & 49,18 & 147,27 & 147,36 & 15,44 & 919,81 & 115,94 & 44,84 & 26,84 & 313,84 & 159,43 & 160,50 & 263,60 \\
\hline Bufo spinosus & 30TTN81 & 100,00 & 112,09 & 115,44 & 39,99 & 5801,20 & 278,79 & $-8,02$ & 286,81 & 77,48 & 188,47 & 188,47 & 38,95 & 549,74 & 72,17 & 22,12 & 32,53 & 201,18 & 96,41 & 96,41 & 148,43 \\
\hline Bufo spinosus & 30TTN82 & 100,00 & 108,29 & 114,24 & 40,00 & 5713,11 & 272,77 & $-10,27$ & 283,04 & 74,53 & 183,56 & 183,56 & 36,55 & 591,44 & 77,61 & 24,31 & 31,73 & 214,95 & 104,96 & 104,96 & 159,59 \\
\hline \begin{tabular}{|l} 
Bufo spinosus \\
\end{tabular} & 30TTN83 & 100,00 & 100,81 & 111,97 & 40,01 & 5578,91 & 261,61 & $-14,78$ & 276,39 & 68,47 & 174,49 & 174,49 & 31,46 & 662,58 & 86,12 & 30,41 & 30,02 & 236,55 & 117,88 & 117,88 & 180,73 \\
\hline Bufo spinosus & 30TTN84 & 100,00 & 93,04 & 109,27 & 40,02 & 5449,02 & 249,85 & $-19,49$ & 269,34 & 62,02 & 165,11 & 165,11 & 25,95 & 741,51 & 95,24 & 36,19 & 28,41 & 259,91 & 131,66 & 131,66 & 204,84 \\
\hline Bufo spinosus & 30TTN85 & 100,00 & 81,85 & 106,21 & 39,96 & 5333,53 & 235,12 & $-27,29$ & 262,41 & 52,04 & \begin{tabular}{|l|l|}
152,64 \\
\end{tabular} & 152,66 & 17,04 & 846,14 & 106,77 & 41,86 & 27,03 & 290,70 & 149,41 & 149,46 & 238,33 \\
\hline Bufo spinosus & 30TTN88 & 100,00 & 110,02 & 98,86 & 42,09 & \begin{tabular}{|l|l|}
4609,07 \\
\end{tabular} & 240,93 & 8,93 & 232,00 & 86,32 & \begin{tabular}{|c|c|}
169,63 \\
\end{tabular} & \begin{tabular}{|l|l|}
170,88 \\
\end{tabular} & 53,76 & 820,57 & 109,09 & $\mid 41,97$ & 27,09 & 279,84 & 148,35 & \begin{tabular}{|l|l|}
155,84 \\
\end{tabular} & 213,51 \\
\hline Bufo spinosus & 30TTN90 & 100,00 & 115,60 & 114,52 & 39,93 & 5754,04 & 280,47 & $-4,69$ & 285,16 & 82,10 & 191,30 & 191,30 & 42,93 & 521,09 & 67,51 & 23,59 & 31,24 & 187,63 & 91,22 & 91,22 & 139,00 \\
\hline Bufo spinosus & 30TTN91 & 100,00 & 112,42 & 114,10 & 39,99 & 5708,68 & 276,63 & $-6,76$ & 283,39 & 79,24 & 187,61 & 187,61 & 40,64 & 551,70 & 71,77 & 24,11 & 31,20 & 198,91 & 98,15 & 98,15 & 146,58 \\
\hline Bufo spinosus & 30TTN92 & 100,00 & 107,67 & 113,09 & 40,00 & 5642,44 & 270,31 & $-10,03$ & 280,35 & 75,30 & 182,14 & 182,14 & 36,94 & 595,94 & 77,47 & 26,22 & 30,55 & 213,70 & 107,31 & 107,31 & 158,62 \\
\hline Bufo spinosus & 30TTN93 & 100,00 & 101,07 & 111,23 & 40,01 & 5538,27 & 260,69 & $-14,21$ & 274,90 & 69,69 & 174,09 & 174,09 & 32,15 & 658,48 & 84,97 & 31,07 & 29,28 & 233,02 & 119,10 & 119,10 & 176,86 \\
\hline Bufo spinosus & 30TTN94 & 100,00 & 93,59 & 108,77 & 40,01 & 5418,02 & 249,74 & $-18,79$ & 268,53 & 63,35 & 165,26 & 165,26 & 26,95 & 733,11 & 93,67 & 36,51 & 27,87 & 255,42 & 132,52 & 132,52 & 199,38 \\
\hline Bufo spinosus & 30TTN95 & 100,00 & 76,79 & 105,17 & 39,78 & 5315,46 & 229,65 & $-31,55$ & 261,19 & 47,66 & 147,52 & 147,55 & 12,59 & 876,14 & | 108,91 & $\begin{array}{l}44,02 \\
4\end{array}$ & 26,10 & \begin{tabular}{|l|}
296,94 \\
\end{tabular} & $\begin{array}{l}156,47 \\
\end{array}$ & 156,71 & 245,86 \\
\hline Bufo spinosus & 30TTN96 & 100,00 & 67,08 & 102,48 & 39,64 & 5231,01 & 217,01 & $-38,30$ & 255,30 & 38,78 & 136,90 & 137,01 & 4,63 & 974,58 & 119,49 & 49,01 & 25,20 & 325,77 & 172,95 & 173,32 & 277,70 \\
\hline Bufo spinosus & 30TTN97 & 100,00 & 91,15 & 101,79 & 40,74 & 4985,50 & 233,21 & $-13,42$ & 246,64 & 64,77 & 156,72 & 157,24 & 30,60 & 860,57 & 110,01 & 44,04 & 26,18 & 292,84 & \begin{tabular}{ll|}
155,83 \\
\end{tabular} & 160,33 & 233,59 \\
\hline Bufo spinosus & 30TTP60 & 100,00 & 129,66 & 89,93 & 43,73 & 3918,14 & 241,79 & 38,42 & 203,37 & 111,05 & 178,84 & 181,95 & 82,53 & 850,03 & 116,32 & 42,40 & 28,38 & 284,03 & 149,06 & 158,09 & 214,18 \\
\hline \begin{tabular}{|l|} 
Bufo spinosus \\
\end{tabular} & 30TTP62 & 99,00 & 135,89 & 79,64 & 42,56 & 3713,09 & 235,61 & 50,83 & 184,78 & 118,95 & 182,44 & 185,98 & 91,25 & 853,17 & 117,04 & 41,15 & 28,65 & 288,29 & 146,45 & 158,71 & 219,36 \\
\hline Bufo spinosus & 30TTP73 & & & & & & & & & & & & & & & & & & & & \\
\hline Bufo spinosus & 30TTP82 & 60,00 & 138,75 & 71,62 & 40,72 & 3679,04 & 230,37 & 56,65 & 173,71 & 122,63 & 185,16 & 188,74 & 94,25 & 829,42 & 113,76 & 40,20 & 28,83 & 282,16 & 143,90 & 157,39 & 211,51 \\
\hline \begin{tabular}{|l} 
Bufo spinosus \\
\end{tabular} & 30TUK04 & 100,00 & 152,48 & 114,92 & 37,00 & 6473,37 & 330,21 & 25,06 & 305,15 & 110,58 & 239,14 & 239,14 & 72,90 & 365,59 & 42,55 & $\begin{array}{l}6,31 \\
6,31 \\
\end{array}$ & 39,21 & 122,56 & 36,52 & 36,52 & 106,51 \\
\hline Bufo spinosus & 30TUK05 & 100,00 & 91,60 & 111,19 & 36,98 & 6312,57 & 270,40 & $-26,92$ & 297,31 & 37,66 & 177,25 & 178,03 & 18,63 & 640,32 & 74,19 & 17,84 & 34,65 & 206,66 & 76,97 & 80,68 & 186,89 \\
\hline Bufo spinosus & 30TUK06 & 100,00 & 80,47 & 110,13 & 36,98 & 6240,22 & 258,27 & $-35,89$ & 294,16 & 23,13 & 165,30 & 166,20 & 9,04 & 683,23 & 79,23 & 20,24 & 33,51 & 219,28 & 84,51 & 89,35 & 198,20 \\
\hline \begin{tabular}{|l} 
Bufo spinosus \\
\end{tabular} & 30TUK07 & 100,00 & 76,67 & 109,66 & 37,02 & 6199,42 & 253,59 & $-38,70$ & 292,29 & 15,36 & 161,19 & 161,95 & 5,96 & 693,74 & 80,34 & 21,14 & 32,93 & 222,01 & 87,41 & 93,44 & 200,16 \\
\hline Bufo spinosus & 30TUK08 & 100,00 & 105,93 & 113,03 & 37,83 & 6234,50 & 282,07 & $-14,19$ & 296,26 & 64,14 & 188,86 & 190,86 & 32,37 & 495,59 & 60,24 & 14,20 & 33,61 & 157,74 & 64,29 & 66,78 & 136,18 \\
\hline Bufo spinosus & 30TUK13 & 100,00 & 153,80 & 115,00 & 37,00 & 6529,68 & 332,82 & 25,31 & 307,51 & 111,49 & 241,18 & 241,18 & 73,63 & 362,19 & 41,65 & 5,97 & 39,65 & 121,37 & 35,44 & 35,44 & 104,84 \\
\hline Bufo spinosus & 30TUK14 & 100,00 & 151,35 & 114,68 & 37,00 & 6499,67 & 329,40 & 23,35 & 306,06 & 109,40 & 238,49 & 238,49 & 71,49 & 361,03 & 41,78 & 6,41 & 38,95 & 120,26 & 36,98 & 36,98 & 103,24 \\
\hline Bufo spinosus & 30TUK15 & 100,00 & 107,17 & 112,56 & 37,00 & 6357,38 & 286,19 & $-14,32$ & 300,52 & 71,97 & 192,81 & 193,76 & 32,42 & 526,62 & 62,91 & 14,19 & 34,84 & 168,06 & 64,68 & 66,84 & 147,18 \\
\hline \begin{tabular}{|l} 
Bufo spinosus \\
\end{tabular} & 30TUK16 & 100,00 & 82,40 & 110,78 & 37,00 & 6241,99 & 260,71 & $-34,80$ & 295,51 & 35,77 & 167,32 & 168,13 & 10,85 & 646,15 & 76,49 & 19,65 & 32,89 & 203,86 & 82,49 & 87,53 & 181,66 \\
\hline Bufo spinosus & 30TUK17 & 100,00 & 79,97 & 110,37 & 37,01 & 6204,22 & 257,10 & $-36,50$ & 293,60 & 31,32 & 164,45 & 165,12 & 9,03 & 648,18 & 77,16 & 20,45 & 32,38 & 203,69 & 84,44 & 89,93 & 181,01 \\
\hline Bufo spinosus & 30TUK23 & 100,00 & 151,83 & 114,95 & 37,00 & 6558,41 & 331,25 & 23,05 & 308,19 & 109,52 & 239,88 & 239,88 & 71,45 & 361,57 & 41,58 & 6,19 & 39,18 & 120,32 & 36,54 & 36,54 & 102,94 \\
\hline Bufo spinosus & 30TUK24 & 100,00 & 148,45 & 114,23 & 37,00 & 6501,82 & 326,70 & 20,22 & 306,48 & 106,40 & 235,77 & 235,77 & 68,69 & 362,49 & 42,4 & 6,90 & 38,08 & 119,71 & 38,77 & 38,77 & 101,54 \\
\hline Bufo spinosus & 30 TUK 25 & 100,00 & 135,47 & 113,90 & 37,00 & 6441,15 & 313,42 & 9,08 & 304,35 & 104,99 & 222,13 & 222,33 & 57,18 & 389,31 & 47,34 & 8,90 & 36,26 & 126,13 & 46,22 & 46,31 & 105,63 \\
\hline \begin{tabular}{|l} 
Bufo spinosus \\
\end{tabular} & 30 TUK26 & 100,00 & 94,91 & 111,68 & 37,00 & 6277,75 & 272,94 & $-24,75$ & 297,69 & 72,72 & 179,80 & 180,69 & 21,95 & 555,93 & 68,55 & 0 & 33,22 & 175,91 & 73,17 & $\begin{array}{l}76,48 \\
76,48\end{array}$ & 149,86 \\
\hline Bufo spinosus & 30TUK27 & 100,00 & 89,82 & 111,24 & 37,00 & 6224,85 & 266,71 & $-28,78$ & 295,48 & 70,00 & 173,92 & 174,90 & 17,89 & 566,20 & 70,59 & 18,04 & 32,43 & 178,04 & 76,65 & 80,72 & 150,68 \\
\hline Bufo spinosus & 30TUK29 & 100,00 & 97,39 & 111,69 & 37,25 & 6172,59 & 272,32 & $-22,07$ & 294,39 & 77,13 & 179,98 & 181,63 & 24,99 & 497,97 & 64,06 & 16,68 & 32,32 & 155,57 & 71,03 & 74,46 & 127,42 \\
\hline Bufo spinosus & 30TUK33 & 100,00 & 148,26 & 114,36 & 36,68 & 6573,51 & 328,10 & 19,23 & 308,86 & 110,18 & 236,68 & 236,68 & 67,90 & 366,73 & 43,08 & 6,69 & 38,38 & 20,75 & 38,74 & 38,74 & 102,31 \\
\hline Bufo spinosus & 30TUK34 & 100,00 & $\begin{array}{l}146,20 \\
146,30\end{array}$ & 113,97 & 36,92 & 6520,96 & 324,74 & 17,80 & \begin{tabular}{|l|}
306,94 \\
\end{tabular} & 108,63 & 233,89 & 233,89 & 66,48 & 363,94 & $\begin{array}{l}43,27 \\
43,2\end{array}$ & 7,34 & 37,36 & 119,40 & 40,36 & 40,36 & 99,86 \\
\hline \begin{tabular}{|l} 
Bufo spinosus \\
\end{tabular} & 30TUK3 & 100,00 & 129,37 & 113,05 & 36,90 & 6435,29 & 307,23 & 3,53 & 303,71 & 102,52 & 215,81 & 216,31 & 51,82 & 408,73 & 50,69 & 10,20 & 35,68 & 132,82 & 50,62 & 51,16 & 108,39 \\
\hline Bufo spinosus & 30TUK36 & 100,00 & 90,23 & 111,35 & 37,00 & 6263,98 & 268,25 & $-29,08$ & 297,34 & 71,25 & 175,15 & 175,99 & 18,05 & 568,18 & 71,19 & $\mid 17,99$ & 32.66 & 180,80 & 77,02 & 80,79 & 149,91 \\
\hline Bufo spinosus & 30TUK37 & 100,00 & 95,44 & 111,44 & 37,00 & 6240,27 & 272,10 & $-24,57$ & 296,67 & 77,51 & 179,49 & 180,74 & 22,86 & 520,51 & 67,05 & 16,80 & 32,78 & 165,76 & 72,71 & 76,01 & 133,20 \\
\hline Bufo spinosus & 30TUK38 & 100,00 & 85,05 & 110,75 & 37,00 & 6175,64 & 261,01 & $-32,71$ & 293,72 & 65,94 & 168,71 & 169,68 & 13,97 & 576,70 & 72,81 & 19,77 & 31,65 & 181,17 & 81,46 & 86,51 & 149,94 \\
\hline \begin{tabular}{|l} 
Bufo spinosus \\
\end{tabular} & 30TUK & 100,00 & $\begin{array}{l}0,04,10 \\
104\end{array}$ & $\begin{array}{ll}11,11,62 \\
11,62\end{array}$ & 37,10 & $\begin{array}{ll}617,04,29 \\
6184,\end{array}$ & 27,01 & $\begin{array}{l}-3, / 14 \\
-17,14 \\
\end{array}$ & $\begin{array}{l}30,1 / 2 \\
295,22 \\
\end{array}$ & 97,69 & 186,34 & 188,11 & 30,71 & 449,96 & 60,10 & 15,34 & 32,89 & 142,87 & 66,47 & 69,05 & 109,53 \\
\hline \begin{tabular}{|l|} 
Bufo spinosus \\
\end{tabular} & 30TUK44 & 100,00 & 137,53 & 113,39 & 36,27 & 6544,31 & 316,55 & 9,15 & 307,40 & 116,17 & 225,59 & 225,62 & 57,96 & 384,04 & 47,22 & 8,61 & 36,50 & 125,24 & 45,59 & 45,61 & 102,26 \\
\hline Bufo spinosus & 30TUK45 & 100,00 & 146,31 & 112,88 & 36,51 & 6512,57 & 323,18 & \begin{tabular}{ll|}
17,87 \\
\end{tabular} & 305,31 & 107,34 & 233,69 & 233,69 & 66,26 & 353,29 & 42,51 & 7,55 & 37,12 & 115,64 & 40,71 & 40,71 & 94,95 \\
\hline Bufo spinosus & 30TUK46 & 100,00 & 100,93 & 111,37 & 36,83 & 6305,77 & 278,33 & $-20,28$ & 298,61 & 82,70 & 186,21 & 186,97 & 27,26 & 508,86 & 65,08 & 15,92 & 33,13 & 163,43 & 70,14 & 72,82 & 130,45 \\
\hline Bufo spinosus & 30TUK48 & 100,00 & 88,76 & 110,42 & 37,00 & 6176,06 & 264,24 & $-29,81$ & 294,05 & 71,09 & 172,36 & 173,36 & 17,44 & 539,78 & 70,30 & 18,85 & 31,91 & 171,63 & 78,73 & 83,12 & 134,92 \\
\hline \begin{tabular}{|l} 
Bufo spinosus \\
\end{tabular} & 30TUK53 & 100,00 & 150,74 & 113,37 & 36,00 & 6632,21 & 330,08 & 20,54 & 309,54 & \begin{tabular}{|l|}
109,54 \\
\end{tabular} & 239,77 & 239,77 & 69,22 & 357,35 & 42,01 & 6,85 & 38,16 & 117,52 & 38,30 & 38,30 & 98,42 \\
\hline Bufo spinosus & 30TUK54 & 100,00 & 131,14 & 112,60 & 36,09 & 6545,57 & 310,48 & 3,62 & 306,87 & 113,72 & 219,40 & 219,58 & 52,15 & 401,54 & 50,23 & 9,73 & 35,69 & 130,93 & 49,81 & 49,99 & 104,96 \\
\hline Bufo spinosus & 30TUK55 & 100,00 & 140,85 & 112,00 & 36,01 & 6541,56 & 318,01 & 12,68 & 305,33 & 110,79 & 228,88 & 228,88 & 60,92 & 365,31 & 44,80 & 8,45 & 35,97 & 118,38 & 44,29 & 44,29 & 96,25 \\
\hline Bufo spinosus & 30TUK56 & 100,00 & 118,29 & 111,17 & 36,41 & \begin{tabular}{ll|}
6398,64 \\
\end{tabular} & 294,72 & $-5,92$ & 300,64 & 92,11 & 204,53 & 204 & 41 & 438,19 & 55,93 & 12,85 & 34,18 & 141,45 & 59,34 & 60,68 & 111,31 \\
\hline Bufo spinosus & 30TUK58 & 100,00 & 96,35 & 109,92 & 36,98 & 6196,46 & 270,65 & $-23,76$ & 294,41 & 85,99 & 179,84 & 180,83 & 24,11 & 484,28 & 65,80 & 16,94 & 32,88 & 156,43 & 73,19 & 76,41 & 114,71 \\
\hline
\end{tabular}




\begin{tabular}{|c|c|c|c|c|c|c|c|c|c|c|c|c|c|c|c|c|c|c|c|c|c|}
\hline TAXON & UTM & $\mathrm{km2}$ & BIO1 & B102 & $\mathrm{BIO3}$ & B104 & B105 & B106 & B107 & B108 & B109 & BIO10 & BIO11 & BIO12 & BIO13 & BIO14 & BIO15 & BIO16 & BIO17 & B1018 & BlO19 \\
\hline Bufo spinosus & 30TUK59| & 100,00 & 103,59 & 109,52 & 36,96 & 6183,07 & 275,94 & $-17,90$ & 293,85 & 121,31 & 186,10 & 187,49 & 30,31 & 432,48 & 60,85 & 15,26 & 34,09 & 142,54 & 67,51 & 69,93 & 97,73 \\
\hline Bufo spinosus & 30TUK63 & 100,00 & 151,11 & 112,77 & 36,00 & 6661,99 & \begin{tabular}{|l|l|}
330,47 \\
\end{tabular} & 20,64 & 309,84 & \begin{tabular}{|l|l|}
108,24 \\
\end{tabular} & $\begin{array}{l}240,56 \\
2\end{array}$ & 240,56 & 69,26 & \begin{tabular}{|l|l|}
357,44 \\
\end{tabular} & 41,84 & 7,00 & 37,62 & $\begin{array}{l}117,66 \\
117\end{array}$ & 38,88 & 38,88 & 98,11 \\
\hline Bufo spinosus & 30TUK64 & 100,00 & $\begin{array}{l}143,47 \\
\end{array}$ & 111,86 & 36,00 & 6613,83 & 321,64 & 14,24 & 307,40 & $\begin{array}{ll}113,18 \\
\end{array}$ & 232,51 & 232,51 & 62,66 & $\begin{array}{ll}368,43 \\
\end{array}$ & 44,41 & 8,08 & 36,43 & \begin{tabular}{l|l|}
120,08 \\
\end{tabular} & 43,36 & 43,36 & 98,32 \\
\hline Bufo spinosus & 30TUK65 & 100,00 & $\begin{array}{ll}132,66 \\
\end{array}$ & 111,17 & 36,00 & 6534,47 & 309,78 & 5,08 & 304,70 & \begin{tabular}{l|l}
113,12 \\
\end{tabular} & 220,75 & 220,75 & 53,25 & 387,33 & 48,71 & 9,88 & 35,14 & \begin{tabular}{|l|l|}
125,27 \\
\end{tabular} & 49,91 & 49,91 & 99,34 \\
\hline Bufo spinosus & 30TUK66 & 100,00 & 113,97 & 110,31 & 36,34 & 6387,97 & 290,11 & $-9,62$ & 299,73 & $\begin{array}{l}93,62 \\
\end{array}$ & 200,12 & 200,66 & 38,09 & 443,80 & 57,94 & 13,48 & \begin{tabular}{l|l}
33,95 \\
\end{tabular} & \begin{tabular}{|l|l|}
143,79 \\
\end{tabular} & \begin{tabular}{|c|}
62,19 \\
\end{tabular} & \begin{tabular}{|c|}
63,67 \\
\end{tabular} & 109,62 \\
\hline Bufo spinosus & 30TUK67 & 100,00 & 115,18 & 109,57 & 36,26 & 6353,57 & 289,42 & $-8,52$ & 297,94 & 99,45 & 200,54 & 201,23 & 39,29 & 424,64 & 56,42 & 13,34 & 33,94 & 137,14 & \begin{tabular}{|c|}
61,37 \\
\end{tabular} & 62,58 & 102,34 \\
\hline Bufo spinosus & 30TUK69 & 100,00 & 100,89 & 108,38 & 36,53 & 6170,98 & 272,44 & $-20,11$ & 292,55 & 118,39 & $\begin{array}{l}183,75 \\
\end{array}$ & \begin{tabular}{|l|l|}
184,77 \\
\end{tabular} & 28,19 & 441,47 & 62,70 & 16,10 & 34,16 & 146,82 & 70,40 & 73,12 & 97,69 \\
\hline Bufo spinosus & 30TUK74 & 100,00 & 148,29 & 111,08 & 35,77 & 6661,16 & 326,08 & 18,42 & \begin{tabular}{|l|l|}
307,66 \\
\end{tabular} & \begin{tabular}{l|l|}
106,53 \\
\end{tabular} & 237,77 & 237,77 & \begin{tabular}{ll|}
66,49 \\
\end{tabular} & \begin{tabular}{|l|l|}
360,88 \\
\end{tabular} & 42,33 & 7,73 & 36,76 & \begin{tabular}{|l|}
118,60 \\
\end{tabular} & 41,34 & 41,34 & 97,94 \\
\hline Bufo spinosus & 30TUK75 & 100,00 & 136,04 & 110,17 & \begin{tabular}{|l|l|}
35,75 \\
\end{tabular} & 6585,37 & 312,70 & 8,06 & 304,64 & \begin{tabular}{|l|l|l|l}
107,44 \\
\end{tabular} & \begin{tabular}{|l|l|}
224,68 \\
\end{tabular} & 224,68 & 55,91 & 383,44 & 47,17 & 9,64 & \begin{tabular}{|l|l|}
35,07 \\
\end{tabular} & \begin{tabular}{l|l|}
123,98 \\
\end{tabular} & 48,72 & 48,72 & 99,62 \\
\hline Bufo spinosus & 30TUK76 & 100,00 & 126,44 & 109,29 & 35,91 & 6486,12 & 301,51 & 0,41 & \begin{tabular}{|l|l|}
301,10 \\
\end{tabular} & \begin{tabular}{|l|}
104,01 \\
\end{tabular} & 213,75 & \begin{tabular}{|l|l|}
214,03 \\
\end{tabular} & 48,02 & \begin{tabular}{|c|}
399,10 \\
\end{tabular} & 51,13 & \begin{tabular}{l|l}
11,25 \\
\end{tabular} & 34,41 & \begin{tabular}{|l|l|}
128,63 \\
\end{tabular} & 54,68 & 54,91 & 99,41 \\
\hline Bufo spinosus & 30TUK77 & 100,00 & 128,57 & 108,45 & \begin{tabular}{|l|l|}
35,97 \\
\end{tabular} & \begin{tabular}{ll|l|}
6458,48 \\
\end{tabular} & 301,79 & 2,79 & 299,00 & $\begin{array}{l}98,53 \\
\end{array}$ & \begin{tabular}{|l|l|}
215,16 \\
\end{tabular} & 215,53 & 50,03 & 387,77 & 49,53 & 11,21 & 34,19 & $\begin{array}{ll}124,92 \\
\end{array}$ & 53,75 & \begin{tabular}{l|l}
54,05 \\
\end{tabular} & 96,10 \\
\hline Bufo spinosus & 30TUK78 & 100,00 & 110,91 & 107,58 & 35,99 & 6295,12 & 282,65 & $-11,84$ & 294,49 & \begin{tabular}{l|l|l|}
120,68 \\
\end{tabular} & \begin{tabular}{|l|l|}
194,87 \\
\end{tabular} & \begin{tabular}{l|l|}
196,09 \\
\end{tabular} & 35,86 & \begin{tabular}{|l|l|}
419,20 \\
\end{tabular} & 58,01 & 14,20 & 34,27 & \begin{tabular}{l|l|}
137,62 \\
\end{tabular} & \begin{tabular}{l|l}
64,45 \\
\end{tabular} & 66,14 & 95,07 \\
\hline Bufo spinosus & 30TUK79 & 100,00 & 95,53 & 107,68 & 36,53 & 6167,27 & 267,01 & $-23,95$ & 290,96 & \begin{tabular}{ll|}
111,88 \\
\end{tabular} & \begin{tabular}{l|l|}
178,89 \\
\end{tabular} & \begin{tabular}{|l|l|}
179,49 \\
\end{tabular} & 23,83 & 475,36 & 65,91 & \begin{tabular}{ll|}
17,76 \\
\end{tabular} & 32,92 & 156,51 & 75,28 & 79,14 & 107,48 \\
\hline Bufo spinosus & 30TUK84 & 100,00 & 147,45 & 110,31 & 35,23 & 6700,32 & 325,16 & 17,49 & \begin{tabular}{|l|l|}
307,68 \\
\end{tabular} & \begin{tabular}{ll|}
104,51 \\
\end{tabular} & \begin{tabular}{|l|l|}
237,42 \\
\end{tabular} & 237,42 & \begin{tabular}{l|l|l}
65,15 \\
\end{tabular} & 368,48 & 42,69 & 8,10 & 36,39 & \begin{tabular}{l|l|}
121,08 \\
\end{tabular} & \begin{tabular}{l|l}
42,55 \\
\end{tabular} & \begin{tabular}{l|l}
42,55 \\
\end{tabular} & 100,48 \\
\hline Bufo spinosus & 30TUK85 & 100,00 & 145,18 & 109,17 & 35,10 & 6648,13 & 321,11 & 16,44 & 304,68 & 102,51 & 234,40 & 234,40 & 63,61 & 368,66 & 42,96 & 8,57 & 35,7 & \begin{tabular}{|l|l|l|}
121,13 \\
\end{tabular} & 43,99 & 43,99 & 99,45 \\
\hline Bufo spinosus & 30TUK86 & 100,00 & 133,66 & 108,22 & 35,36 & 6561,83 & 308,14 & 6,79 & 301,35 & 98,74 & 221,89 & 222,00 & 53,67 & 390,65 & 47,58 & 10,50 & \begin{tabular}{l|l}
34,35 \\
\end{tabular} & \begin{tabular}{l|l}
125,95 \\
\end{tabular} & 51,28 & 51,34 & 101,24 \\
\hline Bufo spinosus & 30TUK87 & 100,00 & 133,51 & 107,34 & 35,38 & 6530,87 & 306,06 & 7,06 & 299,00 & 93,52 & 220,89 & 221,09 & 53,58 & \begin{tabular}{ll|}
385,86 \\
\end{tabular} & 47,13 & 10,80 & 34,08 & \begin{tabular}{|l|}
124,41 \\
\end{tabular} & 51,68 & 51,78 & 99,15 \\
\hline Bufo spinosus & 30TUK88 & 100,00 & 120,92 & 106,42 & 35,70 & 6408,92 & 291,84 & $-2,97$ & 294,81 & $\begin{array}{ll}109,49 \\
\end{array}$ & \begin{tabular}{|l|l|}
205,88 \\
\end{tabular} & 207,34 & 43,50 & \begin{tabular}{ll|l}
407,06 \\
\end{tabular} & 52,75 & 12,92 & 33,55 & 130,32 & \begin{tabular}{|l|l|}
59,09 \\
\end{tabular} & 60,40 & 98,12 \\
\hline Bufo spinosus & 30TUK89 & 100,00 & 98,05 & 106,76 & 36,38 & 6211,20 & 268,70 & $-21,19$ & 289,90 & 113,77 & \begin{tabular}{ll|}
181,84 \\
\end{tabular} & \begin{tabular}{ll|}
182,58 \\
\end{tabular} & 25,62 & \begin{tabular}{ll|l}
478,86 \\
\end{tabular} & 64,70 & 17,80 & 32,27 & \begin{tabular}{|l|l|}
155,90 \\
\end{tabular} & 74,58 & 78,62 & 110,54 \\
\hline Bufo spinosus & 30TUK96 & 100,00 & 142,41 & 107,19 & 35,01 & 6629,52 & 316,24 & 14,88 & 301,36 & \begin{tabular}{ll|}
100,00 \\
\end{tabular} & 231,30 & 231,30 & 60,84 & 380,83 & \begin{tabular}{ll|}
44,26 \\
\end{tabular} & 9,53 & 35,10 & 125,81 & 46,72 & 46,72 & 103,71 \\
\hline Bufo spinosus & 30TUK97 & 100,00 & 130,01 & 106,23 & 35,08 & 6535,23 & 302,11 & 4,72 & 297,39 & 91,01 & 217,24 & 217,90 & 50,46 & 406,46 & 48,70 & \begin{tabular}{l|l}
11,65 \\
\end{tabular} & 33,54 & \begin{tabular}{|l|l|}
131,35 \\
\end{tabular} & \begin{tabular}{|l|l}
54,53 \\
\end{tabular} & 54,97 & 105,93 \\
\hline Bufo spinosus & 30TUK98 & 100,00 & 117,08 & 105,55 & 35,46 & 6424,03 & 287,68 & $-5,43$ & 293,11 & 92,36 & 202,24 & \begin{tabular}{|l|l|}
203,76 \\
\end{tabular} & 39,80 & 433,53 & 54,70 & \begin{tabular}{l|l|}
14,08 \\
\end{tabular} & \begin{tabular}{|c|}
32,57 \\
\end{tabular} & $\begin{array}{l}137,60 \\
\end{array}$ & \begin{tabular}{ll|}
62,24 \\
\end{tabular} & 64,39 & 106,93 \\
\hline Bufo spinosus & 30TUK99 & 100,00 & 96,32 & 106,41 & 36,45 & 6227,65 & \begin{tabular}{|l|l|}
266,97 \\
\end{tabular} & $-21,79$ & 288,76 & \begin{tabular}{ll|l}
105,56 \\
\end{tabular} & \begin{tabular}{|l|l|}
180,69 \\
\end{tabular} & 181,32 & 24,05 & 503,34 & 65,66 & 18,77 & 31,15 & \begin{tabular}{ll|}
161,06 \\
\end{tabular} & 76,80 & 81,29 & 120,12 \\
\hline Bufo spinosus & 30TUL01 & 100,00 & 116,99 & 115,61 & 38,79 & 6125,72 & 290,26 & $-4,01$ & 294,27 & 76,75 & \begin{tabular}{ll|l}
196,66 \\
\end{tabular} & \begin{tabular}{|l|l|}
199,79 \\
\end{tabular} & 43,19 & 409,76 & 50,29 & 11,94 & 32,06 & 129,01 & 57,22 & 59,14 & 109,13 \\
\hline Bufo spinosus & 30TUL03 & 100,00 & 118,01 & 116,63 & 39,36 & 6071,70 & 290,22 & $-2,33$ & 292,55 & \begin{tabular}{ll|}
77,63 \\
\end{tabular} & $\begin{array}{l}196,35 \\
\end{array}$ & \begin{tabular}{l|l|l|}
199,95 \\
\end{tabular} & \begin{tabular}{ll|}
44,42 \\
\end{tabular} & 390,95 & 47,67 & \begin{tabular}{|l|l|}
11,58 \\
\end{tabular} & 31,22 & \begin{tabular}{|l|l|}
122,40 \\
\end{tabular} & 56,58 & 58,81 & 103,35 \\
\hline Bufo spinosus & \begin{tabular}{|l|l|}
$30 T U L O 5$ \\
\end{tabular} & 100,00 & 119,92 & 117,01 & 39,21 & 6073,97 & 292,05 & $-0,88$ & 292,92 & 79,81 & 198,15 & 201,49 & 45,87 & 374,10 & 45,45 & 11,11 & 31,60 & 119,13 & 54,34 & 56,68 & 98,92 \\
\hline Bufo spinosus & 30TULO9 & 100,00 & 124,48 & 117,00 & 39,01 & 6110,66 & 296,34 & 1,98 & 294,37 & 85,50 & 202,91 & 205,33 & 48,39 & 362,45 & 42,43 & \begin{tabular}{ll|}
11,87 \\
\end{tabular} & 31,51 & 119,34 & 53,11 & 55,39 & 96,87 \\
\hline Bufo spinosus & 30TUL15 & 100,00 & 120,68 & 116,36 & 39,02 & 6096,79 & 292,68 & $-0,61$ & 293,29 & 80,60 & \begin{tabular}{|l|l|}
199,20 \\
\end{tabular} & \begin{tabular}{|l|}
202,54 \\
\end{tabular} & $\begin{array}{l}46,05 \\
\end{array}$ & 373,62 & 45,62 & $\begin{array}{l}11,35 \\
\end{array}$ & 31,03 & \begin{tabular}{|l|l|}
117,61 \\
\end{tabular} & 54,56 & 57,46 & 97,78 \\
\hline Bufo spinosus & 30TUL18 & 100,00 & 123,31 & 116,90 & 39,00 & 6114,50 & 295,28 & 1,28 & \begin{tabular}{|l|l|}
293,99 \\
\end{tabular} & \begin{tabular}{ll|}
83,96 \\
\end{tabular} & \begin{tabular}{|l|l|}
201,97 \\
\end{tabular} & \begin{tabular}{|l|l|}
204,40 \\
\end{tabular} & 47,29 & 368,44 & 43,48 & $11, \varepsilon$ & 31, & \begin{tabular}{|l|l|}
118,60 \\
\end{tabular} & 53,89 & 56,66 & 98,44 \\
\hline Bufo spinosus & 30TUL24 & 100,00 & 119,42 & 114,94 & 38,87 & 6127,27 & 291,15 & $-1,90$ & 293,05 & \begin{tabular}{l|l}
93,05 \\
\end{tabular} & \begin{tabular}{|l|l|}
198,64 \\
\end{tabular} & 201,77 & 44,47 & 379,32 & \begin{tabular}{l|l|}
47,25 \\
\end{tabular} & 12,00 & 31,03 & 118,09 & 56,54 & 59,31 & 97,02 \\
\hline Bufo spinosus & 30TUL29 & 100,00 & 124,35 & $\begin{array}{ll}116,46 \\
\end{array}$ & 39,00 & 6110,26 & 295,87 & 1,75 & \begin{tabular}{|l|l|}
294,12 \\
\end{tabular} & 85,78 & 202,97 & 205,22 & 47,91 & \begin{tabular}{l|l|}
377,03 \\
\end{tabular} & 44,03 & 12,18 & 30,50 & \begin{tabular}{l|l|}
120,93 \\
\end{tabular} & 54,84 & 58,46 & 101,84 \\
\hline Bufo spinosus & 30TUL30 & 100,00 & 95,80 & 111,23 & 37,54 & 6133,05 & 269,38 & $-23,46$ & 292,84 & 103,81 & \begin{tabular}{|l|l|}
177,94 \\
\end{tabular} & \begin{tabular}{|l|l|}
179,37 \\
\end{tabular} & 23,76 & 485,58 & $\begin{array}{l}64,25 \\
\end{array}$ & 17,28 & 32,02 & $\begin{array}{ll}153,65 \\
\end{array}$ & 72,46 & 76,43 & 119,35 \\
\hline Bufo spinosus & 30TUL39 & 100,00 & 124,29 & 115,97 & 39,00 & 6127,98 & 295,91 & 2,29 & 293,62 & 85,70 & \begin{tabular}{|l|l|}
203,32 \\
\end{tabular} & 205,50 & 47,89 & 385,62 & 44,94 & \begin{tabular}{l|l}
12,25 \\
\end{tabular} & 30,20 & 122,30 & 55,58 & 59,60 & 105,06 \\
\hline Bufo spinosus & 30TUL45 & 100,00 & 121,37 & 112,94 & 38,00 & 6173,82 & 291,62 & $-0,67$ & 292,29 & 121,33 & 201,36 & 203,87 & 45,39 & 380,49 & $\begin{array}{l}47,15 \\
\end{array}$ & 12,10 & \begin{tabular}{l|l}
30,85 \\
\end{tabular} & \begin{tabular}{|l|}
118,29 \\
\end{tabular} & 56,43 & \begin{tabular}{l|l}
60,15 \\
\end{tabular} & 96,74 \\
\hline Bufo spinosus & 30TUL48 & 100,00 & 121,62 & 114,72 & 38,82 & 6148,09 & 292,76 & $-0,10$ & 292,86 & 82,72 & 201,16 & 203,36 & 45,36 & $\begin{array}{l}396,06 \\
\end{array}$ & 46,36 & 12,66 & 29,93 & 123,46 & 57,60 & 62,23 & 106,48 \\
\hline Bufo spinosus & 30TUL50 & 100,00 & 106,06 & 109,31 & 36,96 & 6168,92 & 277,19 & $-15,90$ & \begin{tabular}{|l|l|}
293,08 \\
\end{tabular} & \begin{tabular}{ll|l}
124,70 \\
\end{tabular} & $\begin{array}{l}188,09 \\
\end{array}$ & \begin{tabular}{l|l|}
189,54 \\
\end{tabular} & 32,53 & \begin{tabular}{|l|l|l}
414,73 \\
\end{tabular} & 58,77 & 15,01 & 34,32 & \begin{tabular}{|l|l|}
137,72 \\
\end{tabular} & 65,86 & 68,31 & 92,25 \\
\hline Bufo spinosus & 30TUL51 & 100,00 & 111,96 & 109,47 & 36,99 & 6186,67 & 282,21 & $-10,26$ & 292,47 & 131,75 & 193,70 & 195,51 & 37,53 & 397,01 & 54,77 & 14,28 & 33,63 & 130,34 & \begin{tabular}{ll|}
62,25 \\
\end{tabular} & 64,91 & 90,30 \\
\hline Bufo spinosus & 30TUL57 & 100,00 & 123,07 & 112,78 & 38,02 & 6181,97 & 293,06 & 0,34 & 292,72 & 84,41 & 203,18 & 205,50 & 46,37 & 391,90 & 46,43 & 12,03 & 30,66 & \begin{tabular}{|l|l|}
121,94 \\
\end{tabular} & 56,41 & 61,21 & 103,59 \\
\hline Bufo spinosus & 30TUL58 & 100,00 & 123,85 & 113,52 & 38,29 & 6158,24 & 294,08 & 1,67 & 292,41 & 85,56 & \begin{tabular}{|l|l|}
203,82 \\
\end{tabular} & 205,75 & 47,39 & 397,03 & 46,06 & \begin{tabular}{|l|l|}
12,08 \\
\end{tabular} & 30,10 & \begin{tabular}{l|l}
123,65 \\
\end{tabular} & \begin{tabular}{|l|l|}
56,97 \\
\end{tabular} & 61,73 & 106,99 \\
\hline Bufo spinosus & 30TUL59 & 100,00 & 124,59 & 114,18 & 38,41 & 6141,55 & 294,91 & 2,19 & 292,73 & 86,62 & 203,97 & 205,89 & 47,84 & 403,19 & 46,57 & 12,84 & 29,82 & 125,94 & 57,73 & 62,66 & 110,59 \\
\hline Bufo spinosus & \begin{tabular}{|l|l|}
$30 T U L 70$ \\
\end{tabular} & 100,00 & 95,84 & 107,16 & 36,46 & 6136,64 & 265,89 & $-23,49$ & 289,38 & \begin{tabular}{ll|}
112,59 \\
\end{tabular} & $\begin{array}{l}178,64 \\
1\end{array}$ & \begin{tabular}{|l|l|}
179,37 \\
\end{tabular} & 24,13 & 465,38 & 65,18 & 17,91 & 33,21 & $\begin{array}{ll}154,68 \\
\end{array}$ & 75,01 & 79,26 & 103,41 \\
\hline Bufo spinosus & 30TUL71 & 100,00 & 106,17 & 106,36 & $\begin{array}{ll}36,08 \\
\end{array}$ & 6191,89 & 274,05 & $-15,29$ & 289,34 & $\begin{array}{ll}124,98 \\
\end{array}$ & \begin{tabular}{|l|l|}
188,57 \\
\end{tabular} & \begin{tabular}{l|l|}
189,81 \\
\end{tabular} & 32,22 & $\begin{array}{l}418,26 \\
\end{array}$ & 58,89 & $\begin{array}{l}15,86 \\
\end{array}$ & \begin{tabular}{l|l|}
34,05 \\
\end{tabular} & \begin{tabular}{|l|l|}
140,14 \\
\end{tabular} & 67,73 & \begin{tabular}{|l|l|}
71,37 \\
\end{tabular} & 91,20 \\
\hline Bufo spinosus & 30TUL78 & 100,00 & 120,36 & 110,48 & 37,54 & 6159,98 & 288,13 & $-2,19$ & 290,31 & 96,41 & \begin{tabular}{|l|l|}
200,69 \\
\end{tabular} & 202,44 & 44,06 & 417,91 & 48,99 & 13, & 29,8 & \begin{tabular}{ll|}
129,16 \\
\end{tabular} & 59,82 & 67,49 & 109,73 \\
\hline Bufo spinosus & 30TUL79 & 100,00 & 116,90 & 111,40 & 37,96 & 6113,09 & 285,53 & $-5,35$ & 290,88 & \begin{tabular}{|l|l|}
86,07 \\
\end{tabular} & \begin{tabular}{|l|l|}
196,91 \\
\end{tabular} & \begin{tabular}{|l|l|l|}
198,48 \\
\end{tabular} & 41,60 & 432,60 & 50,56 & 14,06 & 29,12 & 133,23 & 61,81 & 70,69 & 114,12 \\
\hline Bufo spinosus & 30TUL80 & 100,00 & 92,66 & 106,66 & 36,56 & 6150,71 & 262,51 & $-25,10$ & 287,61 & 107,84 & \begin{tabular}{l|l|}
176,05 \\
\end{tabular} & $\begin{array}{ll}176,55 \\
\end{array}$ & 21,48 & 499,76 & 67,25 & 19,42 & 31,58 & 162,96 & 78,63 & 83,80 & 115,60 \\
\hline Bufo spinosus & 30TUL81 & 100,00 & 105,88 & 104,96 & 35,99 & 6242,37 & 272,87 & $-14,65$ & 287,52 & 124,39 & \begin{tabular}{|l|l|}
189,19 \\
\end{tabular} & $\begin{array}{l}190,15 \\
\end{array}$ & 31,43 & 440,81 & 59,41 & 16,20 & \begin{tabular}{l|l}
32,55 \\
\end{tabular} & 144,80 & 69,11 & 73,87 & 100,32 \\
\hline Bufo spinosus & 30TUL88 & 100,00 & 118,28 & 108,75 & \begin{tabular}{ll|}
37,06 \\
\end{tabular} & 6172,89 & 284,97 & $-3,97$ & 288,95 & $\begin{array}{ll}106,98 \\
\end{array}$ & $\begin{array}{l}199,23 \\
19\end{array}$ & 200,66 & 42,14 & \begin{tabular}{l|l}
430,05 \\
\end{tabular} & 50,49 & \begin{tabular}{l|l|l|}
13,62 \\
\end{tabular} & 29,58 & \begin{tabular}{|l|l|}
132,71 \\
\end{tabular} & 61,48 & 70,13 & 111,92 \\
\hline Bufo spinosus & 30TUL89 & 100,00 & 115,78 & 109,77 & 37,20 & 6117,25 & 282,95 & $-6,84$ & \begin{tabular}{|l|l|}
289,78 \\
\end{tabular} & \begin{tabular}{|l|l|}
126,76 \\
\end{tabular} & \begin{tabular}{|l|l|}
196,10 \\
\end{tabular} & \begin{tabular}{|l|l|l|}
197,42 \\
\end{tabular} & \begin{tabular}{|l|l|}
40,47 \\
\end{tabular} & \begin{tabular}{ll|}
440,64 \\
\end{tabular} & 51,64 & 14, & 28,99 & \begin{tabular}{|l|l|}
135,42 \\
\end{tabular} & \begin{tabular}{l|l}
63,55 \\
\end{tabular} & 73,62 & 114,46 \\
\hline Bufo spinosus & \begin{tabular}{|l|l|}
30 TUL90 \\
\end{tabular} & 100,00 & 88,55 & 106,60 & 36,78 & 6147,86 & 258,66 & $-27,33$ & 285,99 & 96,43 & \begin{tabular}{|l|l|}
172,41 \\
\end{tabular} & 172,71 & 18, & 541,27 & $\begin{array}{l}69,75 \\
\end{array}$ & 20,88 & 30,08 & 172,62 & \begin{tabular}{|l|l|}
83,43 \\
\end{tabular} & 88,12 & 130,46 \\
\hline Bufo spinosus & 30TUL91 & 100,00 & 103,04 & 104,20 & 36,11 & 6268,38 & 269,75 & $-15,97$ & 285,72 & \begin{tabular}{l|l|}
120,93 \\
\end{tabular} & \begin{tabular}{|l|l|}
187,10 \\
\end{tabular} & $\begin{array}{l}187,99 \\
1\end{array}$ & 28,96 & \begin{tabular}{ll|}
474,41 \\
\end{tabular} & \begin{tabular}{ll|}
61,07 \\
\end{tabular} & 16,82 & 31,16 & \begin{tabular}{ll|}
152,40 \\
\end{tabular} & 72,34 & 78,09 & 112,79 \\
\hline Bufo spinosus & 30TUL99 & 100,00 & 114,38 & 108,18 & 37,00 & 6126,71 & 280,60 & \begin{tabular}{|c|}
$-7,34$ \\
\end{tabular} & 287,94 & 126,71 & $\begin{array}{l}195,19 \\
19\end{array}$ & $\begin{array}{l}196,37 \\
\end{array}$ & 39,34 & \begin{tabular}{ll|l}
449,90 \\
\end{tabular} & 52,73 & \begin{tabular}{l|l}
15,02 \\
\end{tabular} & 28,89 & \begin{tabular}{ll|}
138,42 \\
\end{tabular} & 65,21 & 75,53 & 115,86 \\
\hline Bufo spinosus & 30TUM00 & 100,00 & 121,52 & 117,00 & 39,00 & 6099,22 & 293,63 & $-0,48$ & 294,12 & 82,95 & $\begin{array}{l}199,86 \\
\end{array}$ & 202,31 & 45,59 & 376,10 & 44,12 & 12,70 & 31,45 & \begin{tabular}{ll|}
124,40 \\
\end{tabular} & 55,38 & 58,17 & 101,02 \\
\hline Bufo spinosus & \begin{tabular}{|l|l|} 
30TUM06 \\
\end{tabular} & 100,00 & 118,18 & 115,99 & 39,44 & 5893,34 & 287,03 & $-3,74$ & 290,76 & 83,73 & 194, & 196, & 44,2 & 448, & 55,47 & 18,38 & 30,2 & \begin{tabular}{ll|}
155,69 \\
\end{tabular} & 73,56 & 74,99 & 120,66 \\
\hline Bufo spinosus & 30TUM11 & 100,00 & 118,37 & 117,00 & 39,00 & 6073,24 & 290,72 & $-3,53$ & 294,26 & 80, & 196,67 & 199,01 & 42,72 & 399,96 & 47,04 & 14,32 & 30,24 & 131,10 & 59,76 & 63,84 & 108,02 \\
\hline Bufo spinosus & \begin{tabular}{|l|l|} 
30TUM14 \\
\end{tabular} & 100,00 & 119,74 & 116,61 & 39,38 & 5942,53 & 289,71 & $-2,67$ & 292,38 & 85,06 & \begin{tabular}{l|l|}
196,49 \\
\end{tabular} & \begin{tabular}{ll|}
198,33 \\
\end{tabular} & 45,33 & 421,78 & 50,84 & \begin{tabular}{ll|}
16,58 \\
\end{tabular} & 29,67 & \begin{tabular}{|l|l|}
142,10 \\
\end{tabular} & \begin{tabular}{|l|l|}
65,79 \\
\end{tabular} & 69,43 & 113,40 \\
\hline Bufo spinosus & 30TUM17 & 100,00 & 117,29 & 115,08 & 39,24 & 5806,82 & 284,13 & $-4,69$ & \begin{tabular}{l|l|}
288,82 \\
\end{tabular} & 84,79 & \begin{tabular}{l|l|}
192,30 \\
\end{tabular} & \begin{tabular}{|l|l|}
194,02 \\
\end{tabular} & 44,52 & \begin{tabular}{|l|l|}
469,07 \\
\end{tabular} & 58,02 & 20,24 & 29,21 & $\begin{array}{l}161,68 \\
\end{array}$ & 78,54 & 80,92 & 124,26 \\
\hline Bufo spinosus & \begin{tabular}{|l|} 
30TUM18 \\
\end{tabular} & 100,00 & 114,87 & 114,51 & \begin{tabular}{|c|}
39,26 \\
\end{tabular} & 5750,62 & 280,61 & $-6,58$ & 287,19 & \begin{tabular}{|l|l|}
83,02 \\
\end{tabular} & \begin{tabular}{ll|}
189,36 \\
\end{tabular} & \begin{tabular}{|l|l|}
190,87 \\
\end{tabular} & 42,83 & 493,50 & 61,48 & 22,02 & 29,04 & 170,85 & 84,79 & 86,58 & 130,20 \\
\hline Bufo spinosus & $30 \mathrm{~T}$ & 100 & & 111 & 39, & 6060 & 290 & $-4,0$ & 294 & 80, & 196 & 198, & 42, & 409, & 47, & 14 & 29,68 & 132 & \begin{tabular}{ll|}
60,86 \\
\end{tabular} & $6 s, / 2$ & \\
\hline Bufo spinosus & 30TUM22 & 100,00 & 116,34 & 117,00 & 39,00 & 6033,32 & 288,63 & $-5,76$ & 294,39 & 80,11 & \begin{tabular}{|l|l|l|l|l}
194,44 \\
\end{tabular} & \begin{tabular}{|l|l|}
196,61 \\
\end{tabular} & \begin{tabular}{l|l|l}
41,35 \\
\end{tabular} & \begin{tabular}{ll|}
421,60 \\
\end{tabular} & $\begin{array}{l}9,58 \\
\end{array}$ & 15,54 & 29,37 & \begin{tabular}{|l|l|}
136,94 \\
\end{tabular} & 63,37 & 68,72 & 114,20 \\
\hline Bufo spinosus & 30TUM25 & 100,00 & 118,05 & 116,00 & 39,00 & 5875,11 & 286,80 & $-5,09$ & 291,90 & 85,13 & \begin{tabular}{|l|l|}
194,26 \\
\end{tabular} & \begin{tabular}{|l|l|}
195,84 \\
\end{tabular} & 44,66 & 443,61 & 53,41 & 18,29 & 28,99 & \begin{tabular}{|l|l|}
148,39 \\
\end{tabular} & 69,82 & 75,11 & 118,03 \\
\hline
\end{tabular}




\begin{tabular}{|c|c|c|c|c|c|c|c|c|c|c|c|c|c|c|c|c|c|c|c|c|c|}
\hline TAXON & UTM & $\mathrm{km} 2$ & BIO1 & B102 & $B 103$ & BIO4 & B105 & B106 & B107 & B108 & B109 & B1010 & BIO11 & BIO12 & BIO13 & B1014 & BIO15 & B1016 & B1017 & B1018 & 81019 \\
\hline Bufo spinosus & 30TUM26 & 100,00 & 117,05 & 115,38 & 39,03 & 5819,70 & 284,64 & $-5,93$ & 290,57 & 85,09 & 192,47 & 194,16 & 44,41 & 459,45 & 55,68 & 19,51 & 28,57 & 154,73 & 74,14 & 79,14 & 121,54 \\
\hline Bufo spinosus & 30TUM27 & 100,00 & 117,38 & 114,55 & 39,09 & 5749,96 & 282,96 & $-4,90$ & 287,87 & 86,52 & 191,98 & $\begin{array}{l}193,45 \\
\end{array}$ & 45,56 & 473,03 & 57,88 & 20,51 & 28,42 & 160,59 & 78,11 & 82,48 & 124,39 \\
\hline Bufo spinosus & 30TUM28 & 100,00 & 116,00 & 113,62 & 39,21 & 5688,18 & 279,92 & $-5,54$ & 285,46 & 85,75 & 189,75 & \begin{tabular}{|l|l|}
191,17 \\
\end{tabular} & 44,94 & $\begin{array}{l}494,83 \\
\end{array}$ & 61,05 & 22,19 & 28,15 & 169,00 & 83,81 & 87,49 & 129,43 \\
\hline Bufo spinosus & 30TUM29 & 100,00 & 112,78 & 112,65 & 39,19 & 5631,06 & 275,25 & $-7,28$ & 282,52 & 83,09 & 185,99 & 187,28 & 42,63 & 525,30 & 65,14 & 24,28 & 27,92 & 179,86 & 91,29 & $\begin{array}{l}94,23 \\
\end{array}$ & 137,08 \\
\hline Bufo spinosus & 30TUM32 & 100,00 & 116,04 & 117,00 & 39,00 & 6025,13 & 288,00 & $-6,39$ & 294,39 & 79,98 & 194,07 & 196,12 & 41,03 & 430,89 & 50,41 & 15,72 & 29,08 & 138,06 & 63,74 & 70,54 & 117,22 \\
\hline Bufo spinosus & 30TUM34 & 100,00 & 120,10 & 116,06 & 39,00 & 5897,92 & 289,35 & $-3,58$ & 292,93 & 87,40 & $\mid \begin{array}{l}196,63 \\
\end{array}$ & $\mid \begin{array}{l}198,19 \\
\end{array}$ & 46,40 & \begin{tabular}{|l|l|}
432,74 \\
\end{tabular} & 51,34 & \begin{tabular}{|c|c|}
17,12 \\
\end{tabular} & 28,79 & $\mid 141,74$ & 65,51 & 72,43 & 115,91 \\
\hline Bufo spinosus & 30TUM35 & 100,00 & 119,29 & 115,69 & 39,01 & 5833,60 & 287,07 & $-4,72$ & 291,80 & 87,83 & 194,83 & 196,56 & 46,54 & 445,27 & 53,14 & 18,44 & 28,56 & 146,99 & 68,80 & 76,01 & 117,87 \\
\hline Bufo spinosus & 30TUM38 & 100,00 & 114,84 & 112,86 & 39,01 & 5647,56 & 277,71 & $-6,86$ & 284,57 & 86,00 & 188,38 & $\begin{array}{l}189,59 \\
\end{array}$ & $\begin{array}{ll}44,63 \\
\end{array}$ & 503,23 & 61,25 & 22,71 & 27,38 & 169,15 & 83,95 & 89,87 & 130,77 \\
\hline Bufo spinosus & 30TUM41 & 100,00 & 116,48 & 116,22 & 39,00 & $\begin{array}{ll}6077,18 \\
\end{array}$ & 289,07 & $-5,09$ & 294,16 & 77,72 & $\begin{array}{l}195,67 \\
\end{array}$ & $\begin{array}{l}197,33 \\
\end{array}$ & 41,18 & $\begin{array}{l}432,19 \\
\end{array}$ & 50,04 & \begin{tabular}{ll|}
14,91 \\
\end{tabular} & 29,02 & $\begin{array}{l}135,79 \\
\end{array}$ & 62,79 & 69,55 & 119,23 \\
\hline Bufo spinosus & 30TUM43 & 100,00 & 115,33 & \begin{tabular}{ll|}
116,54 \\
\end{tabular} & 39,00 & \begin{tabular}{|l|l|l|}
5937,94 \\
\end{tabular} & 286,39 & \begin{tabular}{|l|l|}
$-7,99$ \\
\end{tabular} & 294,38 & 82,39 & 192,84 & 194,41 & 41,83 & 445,14 & 51,89 & 16,70 & 28,48 & 142,24 & 65,52 & 74,47 & 119,81 \\
\hline Bufo spinosus & 30TUM44 & 100,00 & 119,96 & 115,96 & 39,00 & 5873,55 & 288,56 & $-4,79$ & 293,35 & $\begin{array}{ll}88,68 \\
\end{array}$ & $\begin{array}{l}196,36 \\
\end{array}$ & $\begin{array}{l}197,90 \\
\end{array}$ & 46,86 & $\begin{array}{l}437,99 \\
\end{array}$ & 51,36 & 17,04 & 28,47 & 141,45 & 64,96 & 74,22 & 116,53 \\
\hline Bufo spinosus & 30TUM47 & 100,00 & 115,94 & 113,37 & 39,00 & 5664,99 & 279,62 & $-7,53$ & 287,15 & 88,30 & 189,80 & $\begin{array}{l}191,02 \\
\end{array}$ & 45,72 & 487,52 & 58,13 & 21,51 & 27,29 & 160,58 & 77,79 & 86,99 & 126,13 \\
\hline Bufo spinosus & 30TUM49 & 100,00 & 109,31 & 110,90 & 39,00 & 5549,84 & 269,61 & $-10,74$ & 280,35 & 82,26 & 181,95 & 182,82 & 40,77 & 548,23 & 65,97 & 25,72 & 26,17 & $\mid 181,77$ & 92,73 & 100,16 & 141,59 \\
\hline Bufo spinosus & 30TUM50 & 100,00 & 124,34 & 114,90 & 38,89 & 6106,90 & 295,01 & 2,06 & 292,94 & 62,07 & 203,37 & 205,14 & 47,94 & 412,16 & 47,90 & 13,03 & 29,88 & 130,10 & 58,24 & 63,54 & 115,23 \\
\hline Bufo spinosus & 30TUM53 & 100,00 & 115,88 & 116,02 & 39,00 & $\begin{array}{l}5919,29 \\
\end{array}$ & 285,99 & $-9,34$ & 295,32 & \begin{tabular}{|l|l|}
84,67 \\
\end{tabular} & 193,06 & $\begin{array}{l}194,61 \\
\end{array}$ & 42,60 & $\begin{array}{l}448,14 \\
\end{array}$ & 51,67 & \begin{tabular}{ll|}
16,64 \\
\end{tabular} & 28,66 & $\begin{array}{ll}141,64 \\
\end{array}$ & $\begin{array}{l}64,66 \\
\end{array}$ & 75,90 & 119,57 \\
\hline Bufo spinosus & 30TUM54 & 100,00 & 118,23 & 115,84 & 38,94 & $\begin{array}{ll}5842,82 \\
\end{array}$ & 286,59 & $-7,87$ & 294,45 & 89,16 & $\begin{array}{l}194,26 \\
\end{array}$ & $\begin{array}{l}195,91 \\
\end{array}$ & 45,86 & $\begin{array}{l}446,61 \\
\end{array}$ & 51,50 & 17,21 & 28,76 & 142,14 & 64,70 & 76,95 & 117,39 \\
\hline Bufo spinosus & 30TUM55 & 100,00 & 120,99 & 114,95 & 38,98 & 5756,24 & 287,11 & $-5,64$ & 292,75 & $\begin{array}{ll}93,99 \\
\end{array}$ & 195,90 & $\begin{array}{l}197,43 \\
\end{array}$ & \begin{tabular}{ll|}
49,67 \\
\end{tabular} & 446,02 & 51,90 & $\begin{array}{ll}18,06 \\
\end{array}$ & 28,31 & $\begin{array}{l}143,43 \\
\end{array}$ & 65,46 & 77,75 & 115,77 \\
\hline Bufo spinosus & 30TUM56 & 100,00 & $\begin{array}{l}119,70 \\
\end{array}$ & 113,90 & 38,97 & 5683,32 & 283,72 & $-5,96$ & 289,69 & 93,62 & 193,73 & $\begin{array}{l}194,98 \\
\end{array}$ & 49,34 & 462,42 & 54,10 & $\begin{array}{l}19,69 \\
\end{array}$ & 27,77 & $\begin{array}{l}149,64 \\
\end{array}$ & 69,88 & 82,09 & 118,81 \\
\hline Bufo spinosus & 30TUM59 & 100,00 & 110,88 & 109,56 & 39,00 & 5495,01 & 268,95 & $-9,26$ & 278,22 & 85,30 & 182,86 & 183,40 & 43,01 & 548,82 & 65,37 & 25,64 & 25,81 & 180,01 & 91,50 & 100,58 & 140,82 \\
\hline Bufo spinosus & 30TUM61 & 100,00 & 120,32 & 114,40 & 38,47 & 6036,22 & 290,06 & $-3,31$ & 293,37 & 85,23 & 198,96 & 200,41 & 45,18 & 431,13 & 49,61 & 14,44 & 29,26 & 134,87 & 60,73 & 69,65 & 117,55 \\
\hline Bufo spinosus & 30TUM63 & 100,00 & 119,17 & 115,22 & 38,41 & 5885,32 & 287,68 & $-7,44$ & 295,12 & 89,93 & 195,93 & 197,41 & 46,32 & 439,86 & 50,41 & 16,09 & 29,01 & 138,04 & 62,10 & 75,25 & 115,75 \\
\hline \begin{tabular}{|l|} 
Bufo spinosus \\
\end{tabular} & 30TUM64 & 100,00 & 116,19 & 115,26 & 38,27 & 5815,91 & 283,91 & $-11,75$ & 295,66 & 89,12 & 192,21 & 193,42 & 44,57 & 454,02 & 52,14 & 17,58 & 28,65 & $\begin{array}{l}142,29 \\
\end{array}$ & 64,78 & 80,12 & 117,01 \\
\hline Bufo spinosus & 30TUM65 & 100,00 & 120,56 & $\begin{array}{ll}114,66 \\
\end{array}$ & 38,52 & 5723,75 & 285,82 & $-8,01$ & \begin{tabular}{|l|l|}
293,82 \\
\end{tabular} & $\begin{array}{ll}95,88 \\
\end{array}$ & $\begin{array}{l}194,97 \\
\end{array}$ & 196,42 & 50,15 & $\begin{array}{l}447,48 \\
\end{array}$ & 51,29 & \begin{tabular}{ll|}
18,07 \\
\end{tabular} & 28,54 & $\begin{array}{ll}141,68 \\
\end{array}$ & 64,24 & 79,89 & 113,66 \\
\hline Bufo spinosus & 30TUM68 & 100,00 & 114,51 & 110,01 & 38,80 & 5524,72 & 273,23 & $-8,14$ & 281,38 & 90,16 & 186,78 & 187,56 & 46,52 & 518,49 & 60,62 & 23,53 & 26,12 & 167,51 & 82,83 & 94,81 & 131,75 \\
\hline Bufo spinosus & 30TUM70 & 100,00 & 120,65 & 112,09 & 38,00 & 6069,25 & 288,93 & $-2,75$ & 291,68 & 88,68 & 199,90 & 201,46 & 45,47 & 426,42 & 49,18 & 14,18 & 29,31 & 132,47 & 60,36 & 69,57 & 113,54 \\
\hline Bufo spinosus & 30TUM71 & 100,00 & 119,13 & 112,84 & 38,00 & 6011,37 & 287,38 & $-5,33$ & 292,71 & 86,99 & 197,57 & 199,08 & 44,55 & 434,87 & 49,93 & 14,78 & 28,91 & 134,93 & 61,43 & 72,25 & 115,50 \\
\hline Bufo spinosus & 30TUM72 & 100,00 & 118,17 & 113,46 & 38,02 & 5946,90 & 286,29 & $-7,18$ & 293,47 & 94,90 & 195,99 & 197,31 & 44,71 & 440,20 & 50,73 & 15,58 & 28,85 & 136,36 & 62,00 & 74,74 & 115,50 \\
\hline Bufo spinosus & 30TUM73 & 100,00 & 120,60 & 113,79 & 38,01 & 5866,47 & 287,42 & $-6,64$ & 294,06 & 99,05 & 197,23 & 198,49 & 48,18 & 436,93 & 50,23 & 15,99 & 28,97 & 136,12 & 61,21 & 75,53 & 113,04 \\
\hline Bufo spinosus & 30TUM74 & 100,00 & 121,31 & 113,99 & 38,00 & 5780,65 & 286,95 & $-7,65$ & 294,60 & 103,09 & 196,71 & 197,91 & 50,21 & $\begin{array}{l}438,37 \\
\end{array}$ & 50,55 & \begin{tabular}{ll|}
16,69 \\
\end{tabular} & 29,02 & $\begin{array}{l}136,96 \\
\end{array}$ & 61,24 & 77,77 & 111,05 \\
\hline Bufo spinosus & 30TUM75 & 100,00 & 118,92 & $\begin{array}{l}113,79 \\
\end{array}$ & 38,02 & 5711,37 & 283,52 & $\begin{array}{l}-10,29 \\
\end{array}$ & \begin{tabular}{|l|l|}
293,81 \\
\end{tabular} & \begin{tabular}{|l|l|}
104,70 \\
\end{tabular} & 193,40 & 194,54 & $\begin{array}{ll}49,02 \\
\end{array}$ & 454,39 & 52,15 & 18,33 & 28,52 & 141,93 & 64,84 & 82,43 & 113,56 \\
\hline Bufo spinosus & 30TUM77 & 100,00 & 117,27 & 110,45 & 38,12 & 5576,35 & 277,07 & $-7,69$ & 284,76 & 93,87 & 190,12 & $\begin{array}{l}190,76 \\
\end{array}$ & 48,83 & $\begin{array}{l}492,67 \\
4\end{array}$ & 56,39 & 21,82 & 26,74 & 156,50 & 75,42 & 90,09 & 123,93 \\
\hline Bufo spinosus & 30TUM79 & 100,00 & $\mid 111,89$ & \begin{tabular}{|l|l|}
106,71 \\
\end{tabular} & 38,25 & 5428,82 & 266,68 & $-7,42$ & 274,10 & 87,91 & 183,20 & 183,58 & 45,18 & 555,44 & 64,72 & 25,89 & 25,01 & \begin{tabular}{|l|l|}
178,71 \\
\end{tabular} & 91,41 & $\mid 102,15$ & 141,46 \\
\hline Bufo spinosus & 30TUM80 & 100,00 & 118,00 & 110,56 & 37,59 & 6067,71 & 284,98 & $-5,22$ & 290,20 & 105,01 & 197,54 & 198,71 & 43,04 & 437,78 & 50,68 & 14,66 & 28,99 & 135,09 & 62,41 & 72,84 & 114,67 \\
\hline Bufo spinosus & 30TUM81 & 100,00 & 116,95 & 111,21 & 37,90 & 6006,65 & 284,05 & $-7,19$ & 291,23 & 108,06 & 195,69 & 196,92 & 42,89 & 443,65 & 51,36 & 15,47 & 28,75 & 136,57 & 63,39 & 75,42 & 115,59 \\
\hline Bufo spinosus & 30TUM82 & 100,00 & 117,95 & 111,66 & 38,00 & \begin{tabular}{|l|l}
5940,03 \\
\end{tabular} & 284,48 & $-7,22$ & 291,70 & $\begin{array}{l}106,45 \\
\end{array}$ & 195,72 & 196,94 & 44,73 & 443,83 & 51,25 & 15,91 & 28,60 & $\begin{array}{l}136,89 \\
\end{array}$ & 63,27 & 76,37 & 114,72 \\
\hline \begin{tabular}{|l|} 
Bufo spinosus \\
\end{tabular} & 30TUM83 & 100,00 & \begin{tabular}{ll|}
117,61 \\
\end{tabular} & 112,01 & 38,00 & $\begin{array}{ll}5866,48 \\
\end{array}$ & 283,38 & $-8,45$ & \begin{tabular}{|l|l|}
291,84 \\
\end{tabular} & $\begin{array}{ll}111,42 \\
\end{array}$ & $\begin{array}{l}194,47 \\
\end{array}$ & $\begin{array}{l}195,61 \\
\end{array}$ & 45,32 & \begin{tabular}{ll|l}
449,42 \\
\end{tabular} & 51,88 & 16,78 & 28,39 & $\begin{array}{ll}138,73 \\
\end{array}$ & 64,22 & 78,93 & 114,93 \\
\hline Bufo spinosus & 30TUM85 & 100,00 & 117,19 & $\begin{array}{l}111,39 \\
\end{array}$ & 38,00 & 5721,58 & 280,28 & $-9,41$ & 289,69 & 94,97 & 192,09 & $\begin{array}{l}192,98 \\
\end{array}$ & 47,09 & \begin{tabular}{ll|l}
466,69 \\
\end{tabular} & 53,01 & $\begin{array}{l}19,09 \\
\end{array}$ & 27,68 & $\begin{array}{l}144,82 \\
\end{array}$ & 68,30 & 84,67 & 117,12 \\
\hline Bufo spinosus & 30TUM86 & 100,00 & 112,63 & 110,45 & 38,00 & $\begin{array}{ll}5660,24 \\
\end{array}$ & 274,55 & $-12,10$ & 286,66 & 87,77 & 186,88 & \begin{tabular}{ll|}
187,64 \\
\end{tabular} & 43,37 & \begin{tabular}{ll|}
496,62 \\
\end{tabular} & 55,80 & 21,52 & 26,70 & 154,33 & 75,32 & 91,19 & 124,66 \\
\hline Bufo spinosus & 30TUM87 & 100,00 & 116,17 & 108,59 & 38,00 & 5572,34 & 274,58 & $-7,01$ & 281,59 & 92,07 & 189,17 & 189,63 & 47,62 & 501,96 & 56,91 & 22,37 & 26,03 & 158,15 & 77,71 & 91,85 & 126,35 \\
\hline Bufo spinosus & 30TUM93 & 100,00 & 114,63 & 110,05 & 37,68 & 5881,85 & 279,41 & $-9,63$ & 289,04 & 116,75 & 191,84 & 192,75 & 42,29 & 463,51 & 53,42 & 17,71 & 27,62 & 142,29 & 68,02 & 82,04 & 117,94 \\
\hline Bufo spinosus & 30TUM95 & 100,00 & 117,54 & 108,95 & 37,89 & 5730,65 & 278,82 & $-6,41$ & 285,23 & 92,02 & 192,58 & 193,36 & 46,88 & 472,01 & 52,98 & 19,47 & 26,93 & 146,03 & 70,81 & 84,98 & 119,02 \\
\hline Bufo spinosus & 30TUM & 100,00 & 113,27 & 108,10 & 37,92 & 5665,31 & 273,44 & $-9,11$ & 282,55 & 87,18 & 187,76 & 188,23 & 43,72 & $\begin{array}{l}500,03 \\
\end{array}$ & 55,74 & 21,76 & 25,99 & 154,71 & 77,24 & 91,33 & 126,07 \\
\hline Bufo spinosus & 30TUM99 & 100,00 & 112,43 & 102,95 & 38,00 & 5414,49 & 264,02 & $-3,80$ & 267,82 & 87,41 & \begin{tabular}{ll|}
183,62 \\
\end{tabular} & $\begin{array}{l}183,69 \\
\end{array}$ & 45,63 & 564,68 & 64,61 & 26,34 & 24,06 & 179,09 & \begin{tabular}{|l|l|}
93,83 \\
\end{tabular} & 101,38 & 144,31 \\
\hline Bufo spinosus & 30TUNOO & 100,00 & 113,28 & $\begin{array}{l}113,74 \\
\end{array}$ & 39,77 & 5700,10 & 277,23 & $-6,27$ & 283,50 & 81,03 & 188,47 & $\begin{array}{l}188,47 \\
\end{array}$ & 41,84 & 531,77 & 67,99 & 24,85 & 30,01 & $\begin{array}{l}188,38 \\
\end{array}$ & 94,56 & 94,56 & 140,40 \\
\hline Bufo spinosus & 30TUN01 & 100,00 & 111,04 & 112,70 & 39,98 & 5628,60 & 272,93 & $-7,22$ & 280,16 & 79,47 & 185,17 & 185,17 & 40,30 & 563,92 & 72,45 & 26,71 & 29,77 & 199,85 & 101,55 & 101,55 & 148,49 \\
\hline Bufo spinosus & 30TUN02 & 100,00 & 106,83 & 111,48 & 40,00 & 5549,11 & 266,75 & $-9,47$ & 276,22 & 76,01 & 180,08 & 180,08 & 37,55 & 606,52 & 77,94 & 29,18 & 29,16 & 213,89 & 110,31 & 110,31 & 159,96 \\
\hline Bufo spinosus & 30TUNO3 & 100,00 & 103,34 & 109,88 & 40,00 & 5459,93 & 260,54 & $-11,11 \mid$ & 271,66 & $73,21 \mid$ & 175,34 & 175,34 & 35,38 & 650,41 & 83,54 & 32,09 & 28,48 & 228,09 & 118,83 & 118,83 & 172,09 \\
\hline Bufo spinosus & 30TUN04 & 100,00 & 96,16 & 107,92 & 39,99 & 5364,44 & 250,54 & $-16,02$ & 666,56 & 66,93 & 167,02 & 167,02 & 30,00 & 718 & 91,48 & 36,42 & 27,36 & 75 & 131,44 & 31,44 _ & 192,26 \\
\hline Bufo spinosus & 30TUN05 & 100,00 & 80 & 105,08 & 39,8 & 529 & 233,09 & $-27,70$ & 26 & 52,43 & 151,28 & 151,33 & 16,81 & 841 & $\begin{array}{l}104,65 \\
\end{array}$ & 42,91 & 25,69 & 284,91 & 152,84 & 153,09 & 231,68 \\
\hline Bufo spinosus & 30TUN06 & 100,00 & 67,79 & 102,16 & 39,56 & 5215,84 & 217,31 & $-37,60$ & \begin{tabular}{|l|l|}
254,91 \\
\end{tabular} & 40,02 & 137,45 & 137,62 & 5,61 & \begin{tabular}{|c|}
963,07 \\
\end{tabular} & \begin{tabular}{|l|l|}
117,60 \\
\end{tabular} & 49,21 & 24,66 & 320,48 & $\begin{array}{l}173,26 \\
\end{array}$ & \begin{tabular}{|l|l|}
173,77 \\
\end{tabular} & 271,29 \\
\hline Bufo spinosus & 30TUN07 & 100,00 & 74,75 & 100,90 & 39,99 & 5084,37 & 219,96 & $-29,25$ & 249,21 & \begin{tabular}{ll|l}
48,05 \\
\end{tabular} & 142,29 & \begin{tabular}{ll|}
142,70 \\
\end{tabular} & 13,83 & 947,55 & 117,25 & 48,74 & 24,89 & 316,92 & 171,84 & 174,25 & 263,42 \\
\hline Bufo spinosus & 30TUN11 & 100,00 & 109,07 & 111,48 & 39,88 & 5567,29 & 269,32 & $-8,31$ & 277,63 & 78,70 & 182,48 & 182,55 & 39,53 & \begin{tabular}{|l|l|}
576,87 \\
\end{tabular} & 73,10 & 27,93 & 28,45 & 201,05 & 104,75 & 104,80 & 151,04 \\
\hline Bufo spinosus & 30TUN12 & 100,00 & 105,21 & 110,09 & 39,98 & 5484,01 & 263,13 & $-10,52$ & 273,65 & 75,65 & 177,55 & 177,55 & 36,96 & 619,48 & 78,58 & 30,70 & 27,93 & 215,26 & 113,46 & 113,46 & 162,66 \\
\hline Bufo spinosus & 30TUN16 & 100,00 & 78,12 & 102,39 & 39,84 & 5167,15 & 226,15 & $-28,03$ & 254,18 & 51,17 & 146,75 & 147,05 & \begin{tabular}{ll|}
15,97 \\
\end{tabular} & 888,69 & 109,61 & 45,98 & 24,75 & 297,35 & 162,91 & $\begin{array}{l}163,98 \\
\end{array}$ & 243,87 \\
\hline Bufo spinosus & 30TUN17 & 100,00 & 79,01 & 100,01 & 39,96 & 5033,41 & 222,44 & $-24,72$ & 247,16 & 53,18 & 145,73 & 146,35 & 18,47 & 921,48 & 114,09 & 47,83 & 24,58 & 307,72 & 168,94 & 171,41 & 252,54 \\
\hline Bufo spinosus & 30TUN21 & 100,00 & 105,70 & 110,34 & 39,43 & 5519,19 & 264,80 & $-11,34$ & 276,14 & 76,67 & 177,90 & 178,71 & 37,20 & 596,61 & 74,41 & 29,11 & 27,19 & 204,42 & 107,89 & 109,29 & 155,92 \\
\hline Bufo spinosus & 30TUN22 & 100,00 & 103,05 & 108,81 & 39,66 & 5432,62 & 259,46 & $-12,24$ & 271,70 & 74,61 & $\begin{array}{l}174,47 \\
\end{array}$ & $\begin{array}{l}174,79 \\
\end{array}$ & 35,75 & 634 & 79,38 & 31,56 & 26,73 & 217,08 & 116,31 & 116,92 & 16 \\
\hline Bufo spinosus & $30 \mathrm{TL}$ & 100,00 & $\begin{array}{ll}90,07 \\
\end{array}$ & 10 & 39,77 & & & $-20,16$ & 261,97 & 62,69 & 160,11 & 160,14 & & 760,14 & 94,15 & 38,96 & 25,36 & 256,25 & & \begin{tabular}{|l|}
140,77 \\
\end{tabular} & 20 \\
\hline Bufo spinosus & 30TUN25 & 100,00 & 83,33 & 103,26 & 39,81 & 5209,53 & 232,64 & $-24,53$ & 257,17 & 56,47 & 152,47 & 152,62 & 20,19 & 828,77 & 101,93 & 42,87 & 24,62 & 277,06 & 152,97 & 153,39 & 224,02 \\
\hline Bufo spinosus & 30TUN26 & 100,00 & 73,81 & $\mid 101,07$ & 39,60 & 5150,06 & 221,03 & $-31,47$ & 252,51 & 47,44 & 142,43 & 142,67 & 12,10 & 917,93 & $\mid 111,60$ & 47,71 & 23,88 & 303,48 & 168,51 & 169,33 & 252,25 \\
\hline
\end{tabular}




\begin{tabular}{|c|c|c|c|c|c|c|c|c|c|c|c|c|c|c|c|c|c|c|c|c|c|}
\hline TAXON & UTM & $\mathrm{km} 2$ & BIO1 & BIO2 & $\mathrm{BIO3}$ & B104 & B105 & B106 & B107 & B108 & 8109 & B1010 & BIO11 & B1012 & BIO13 & B1014 & BIO15 & B1016 & B1017 & B1018 & B1019 \\
\hline Bufo spinosus & 30TUN32 & 100,00 & 103,38 & 107,30 & 39,40 & 5369,91 & 257,61 & $-11,11$ & 268,72 & 76,31 & 173,92 & 174,31 & 37,19 & 640,16 & 79,22 & 31,81 & 25,89 & 216,41 & 116,32 & 118,36 & 166,88 \\
\hline Bufo spinosus & 30TUN33 & 100,00 & 99,10 & 105,73 & 39,69 & 5295,84 & 250,86 & $-13,18$ & 264,04 & 72,29 & 168,86 & 169,11 & 33,99 & 687,41 & 85,03 & 34,75 & 25,42 & 231,73 & 126,50 & 127,49 & 180,19 \\
\hline Bufo spinosus & 30TUN35 & 100,00 & 83,84 & 102,02 & 39,59 & 5166,43 & 231,60 & $-23,32$ & 254,91 & 57,79 & 152,46 & 152,70 & 21,45 & 828,77 & \begin{tabular}{|l|l|}
101,18 \\
\end{tabular} & 42,98 & 24,12 & 275,09 & 153,42 & 153,77 & 222,86 \\
\hline Bufo spinosus & 30TUN36 & 100,00 & 81,83 & 100,10 & 39,74 & 5077,09 & 226,35 & $-23,31$ & 249,66 & 56,39 & 149,19 & 149,59 & 20,72 & 872,92 & 106,65 & 45,55 & 23,93 & 289,19 & 161,93 & 162,79 & 235,85 \\
\hline Bufo spinosus & 30TUN37 & 100,00 & 79,28 & 97,90 & 39,70 & 4982,78 & 220,31 & $-23,47$ & 243,78 & 54,46 & 145,36 & 145,99 & 19,53 & 923,41 & 112,72 & 48,30 & 23,67 & 304,85 & 171,00 & 172,65 & 251,05 \\
\hline Bufo spinosus & 30TUN38 & 100,00 & 77,77 & 95,54 & \begin{tabular}{|l|l|}
39,75 \\
\end{tabular} & $\begin{array}{ll}4880,97 \\
\end{array}$ & 215,01 & $-22,60$ & 237,61 & 52,92 & 142,35 & 143,25 & 19,38 & 971,99 & 118,52 & 50,96 & 23,61 & 319,81 & 179,35 & 182,11 & 265,67 \\
\hline Bufo spinosus & 30TUN39 & 100,00 & 107,75 & 88,69 & 40,18 & 4470,70 & 229,18 & 11,69 & 217,48 & 87,06 & 165,69 & 167,45 & 53,23 & 867,20 & 111,23 & 44,20 & 25,51 & 293,17 & 158,73 & 167,19 & 228,33 \\
\hline Bufo spinosus & 30TUN41 & 100,00 & 101,74 & 107,86 & 39,02 & 5420,32 & 257,66 & $-14,34$ & 271,99 & 75,09 & \begin{tabular}{|l|l|}
173,02 \\
\end{tabular} & 173,41 & 35,02 & 627,36 & 76,11 & 30,86 & 25,24 & 208,63 & 1111,03 & 1116,13 & 163,18 \\
\hline Bufo spinosus & 30TUN44 & 100,00 & 83,80 & 102,75 & 39,18 & 5232,73 & 233,68 & $-24,74$ & 258,42 & 57,72 & 153,55 & 153,56 & 20,65 & $\begin{array}{l}801,07 \\
\end{array}$ & 96,52 & 41,34 & 23,69 & 263,35 & 146,87 & 147,75 & 214,32 \\
\hline Bufo spinosus & 30TUN46 & 100,00 & 72,65 & 99,05 & 39,24 & 5099,93 & 217,71 & $-31,28$ & 248,99 & 47,16 & 140,96 & 141,15 & 11,77 & 929,34 & 111,11 & 48,75 & 22,86 & 302,76 & 171,73 & 171,79 & 253,64 \\
\hline Bufo spinosus & 30TUN47 & 100,00 & 66,54 & 97,04 & 39,20 & 5034,80 & 209,15 & $-35,25$ & 244,41 & 40,70 & 134,10 & 134,40 & 6,82 & \begin{tabular}{ll|}
1002,78 \\
\end{tabular} & \begin{tabular}{|l|l|}
119,17 \\
\end{tabular} & 52,86 & 22,54 & 324,81 & 184,95 & 185,50 & 276,72 \\
\hline Bufo spinosus & 30TUN48 & 100,00 & 67,51 & 94,53 & 39,34 & 4919,88 & 205,76 & $-31,83$ & 237,59 & 39,98 & 133,37 & 134,05 & 9,35 & 1040,16 & 123,97 & 54,86 & 22,76 & 337,29 & 191,38 & 193,21 & 288,05 \\
\hline Bufo spinosus & 30TUN49 & 100,00 & 100,95 & 88,36 & \begin{tabular}{l|l|}
39,92 \\
\end{tabular} & 4525,81 & 223,92 & 5,10 & 218,82 & 80,02 & 159,82 & 161,59 & 46,13 & 905,04 & $\begin{array}{l}113,95 \\
\end{array}$ & 46,21 & 24,80 & 303,52 & 165,79 & 173,43 & 241,78 \\
\hline Bufo spinosus & 30TUN50 & 100,00 & 108,18 & 107,94 & 39,00 & 5427,27 & 264,00 & $-9,95$ & 273,95 & 82,67 & 179,40 & 179,86 & 41,34 & 581,56 & 69,70 & 27,79 & 25,18 & 191,44 & 99,60 & 107,21 & 149,70 \\
\hline Bufo spinosus & 30TUN54 & 100,00 & 75,20 & 101,38 & 39,01 & 5232,19 & 224,77 & $-31,92$ & 256,68 & 49,17 & 145,45 & 145,45 & 12,64 & 858,34 & 101,26 & 44,68 & 22,65 & 277,25 & 156,33 & 156,65 & 231,81 \\
\hline Bufo spinosus & 30TUN55 & 100,00 & 67,09 & 99,61 & 38,96 & 5184,02 & 214,98 & $-37,53$ & 252,51 & 40,85 & \begin{tabular}{|l|l|}
137,07 \\
\end{tabular} & 137,07 & 5,56 & 938,72 & 109,96 & 49,34 & 22,30 & 301,20 & 171,41 & 171,43 & 256,99 \\
\hline Bufo spinosus & 30TUN56 & 100,00 & 54,14 & 97,61 & \begin{tabular}{|l|l|}
38,77 \\
\end{tabular} & 5154,62 & 200,68 & $-47,84$ & 248,52 & 24,53 & 124,04 & 124,04 & $-6,25$ & \begin{tabular}{|l|}
1057,32 \\
\end{tabular} & 122,17 & 56,16 & 21,65 & 335,88 & 192,65 & 192,66 & 294,61 \\
\hline Bufo spinosus & 30TUN57 & 100,00 & 76,96 & 95,17 & \begin{tabular}{l|l|}
39,27 \\
\end{tabular} & 4934,79 & 215,46 & $-24,06$ & 239,52 & 52,90 & 142,68 & 143,37 & 18,05 & 952,74 & 114,06 & 49,92 & 22,76 & 310,09 & 176,30 & 177,79 & 259,61 \\
\hline Bufo spinosus & 30TUN58 & 100,00 & 64,12 & 93,81 & $\begin{array}{l}39,15 \\
\end{array}$ & 4927,86 & 202,28 & $\mid-34,64$ & 236,92 & 36,02 & 130,13 & 130,90 & 6,13 & 1062,61 & 125,24 & 56,25 & 22,12 & 342,21 & 195,97 & 197,36 & 294,85 \\
\hline Bufo spinosus & 30TUN59 & 100,00 & 114,75 & 83,58 & 39,86 & 4343,91 & 229,66 & 21,50 & 208,16 & 95,38 & 170,75 & 172,82 & 61,66 & 863,78 & 110,35 & 42,60 & 25,75 & 293,55 & 155,75 & 166,59 & 229,39 \\
\hline Bufo spinosus & 30TUN60 & 100,00 & 107,78 & 106,52 & 38,92 & 5388,48 & 261,99 & $-9,53$ & 271,52 & 83,11 & \begin{tabular}{|l|l|}
178,64 \\
\end{tabular} & 178,98 & 41,52 & 589,75 & 69,89 & 28,18 & 24,79 & 192,11 & 100,31 & 108,56 & 151,41 \\
\hline Bufo spinosus & 30TUN61 & 100,00 & 103,72 & 104,85 & 38,99 & 5328,17 & 255,71 & $-11,23$ & 266,94 & 79,01 & 174,02 & 174,09 & 38,44 & 631,21 & 75,10 & 30,81 & 24,13 & 205,94 & 109,97 & 115,17 & 163,11 \\
\hline Bufo spinosus & 30TUN62 & 100,00 & 100,53 & 103,01 & 39,00 & 5256,10 & 249,99 & $-11,71$ & 261,70 & 75,86 & \begin{tabular}{|l|l|}
170,14 \\
\end{tabular} & 170,17 & 36,28 & 672,64 & 80,35 & 33,38 & 23,89 & 219,87 & 119,62 & 122,53 & $\begin{array}{l}174,97 \\
\end{array}$ \\
\hline Bufo spinosus & 30TUN63 & 100,00 & 95,59 & 101,35 & $39,00 \mid$ & 5191,21 & 242,75 & $-14,30$ & 257,06 & 70,87 & 164,51 & $\mid \begin{array}{l}164,51 \\
\end{array}$ & 32,34 & 724,91 & 86,66 & 36,61 & 23,41 & 236,82 & 131,10 & 132,35 & 190,20 \\
\hline Bufo spinosus & 30TUN64 & 100,00 & 80,02 & 100,06 & 38,98 & 5184,33 & 227,28 & $-26,53$ & 253,81 & 54,72 & 149,56 & 149,56 & 17,97 & 837,02 & 98,52 & 43,42 & 22,52 & 269,66 & 152,69 & 152,69 & 224,50 \\
\hline \begin{tabular}{|l|} 
Bufo spinosus \\
\end{tabular} & 30TUN65 & 100,00 & 69,90 & 98,53 & 38,94 & 5144,39 & 215,94 & $-34,28$ & 250,22 & 43,91 & 139,24 & 139,24 & 8,80 & \begin{tabular}{|l|l|}
926,83 \\
\end{tabular} & \begin{tabular}{|l|l|}
108,09 \\
\end{tabular} & 48,77 & 21,90 & 296,21 & 169,89 & 169,89 & 252,41 \\
\hline Bufo spinosus & 30TUN66 & 100,00 & 64,93 & 96,69 & \begin{tabular}{|l|}
38,92 \\
\end{tabular} & 5085,61 & 208,57 & $-37,11$ & 245,68 & 39,03 & 133,55 & 133,73 & 4,92 & $\begin{array}{l}990,62 \\
\end{array}$ & \begin{tabular}{|l|l|}
115,28 \\
\end{tabular} & 52,41 & 21,68 & 315,93 & \begin{tabular}{|l|l|}
182,13 \\
\end{tabular} & 182,35 & 272,32 \\
\hline Bufo spinosus & 30TUN68 & 100,00 & 96,86 & 88,38 & 39,26 & 4626,31 & 222,21 & 0,02 & 222,19 & 75,25 & 157,31 & 158,81 & 40,88 & \begin{tabular}{|c|}
912,28 \\
\end{tabular} & 112,01 & 46,25 & 23,97 & 302,74 & 166,82 & 173,13 & 246,33 \\
\hline Bufo spinosus & 30TUN69 & 100,00 & 117,26 & 81,33 & 39,36 & 4297,31 & 229,34 & 25,31 & 204,04 & 98,33 & 172,43 & 174,63 & 64,57 & 870,67 & 1110,78 & 42,19 & 25,82 & 296,73 & 155,49 & 167,92 & 233,20 \\
\hline Bufo spinosus & 30TUN70 & 100,00 & 108,62 & 104,73 & \begin{tabular}{|l|}
38,47 \\
\end{tabular} & 5357,18 & 260,88 & $-7,79$ & 268,68 & 84,45 & \begin{tabular}{|l|l|}
179,17 \\
\end{tabular} & 179,25 & 42,87 & 593,01 & 69,56 & 28,22 & 24,35 & 191,54 & 100,47 & 108,47 & 152,06 \\
\hline \begin{tabular}{|l|} 
Bufo spinosus \\
\end{tabular} & 30TUN72 & 100,00 & 99,99 & 101,48 & 38,67 & 5232,63 & 248,00 & $-11,38$ & 259,38 & 75,58 & 169,40 & 169,40 & 36,08 & 682,09 & 80,68 & 33,80 & 23,22 & 221,05 & 120,96 & 123,15 & 177,63 \\
\hline Bufo spinosus & 30TUN74 & 100,00 & 89,82 & 98,09 & 38,98 & 5102,09 & 233,30 & $-16,41$ & 249,71 & 65,46 & 157,94 & 157,94 & 28,13 & 792,77 & 93,82 & 40,51 & 22,65 & 256,46 & 144,87 & 144,87 & 210,52 \\
\hline Bufo spinosus & 30TUN75 & 100,00 & 83,51 & 96,70 & 38,99 & 5049,08 & 225,18 & $-20,38$ & 245,56 & 59,29 & 151,16 & 151,18 & 22,95 & 856,41 & 101,02 & 44,38 & 22,20 & 276,21 & 158,04 & 158,04 & 229,83 \\
\hline Bufo spinosus & 30TUN76 & 100,00 & 80,56 & 94,80 & 38,99 & 4971,70 & 219,32 & $-21,07$ & 240,39 & 56,74 & \begin{tabular}{|l|l|}
147,03 \\
\end{tabular} & 147,40 & 21,09 & 907,74 & 107,14 & 47,28 & 22,14 & 292,77 & 168,25 & 168,85 & 245,53 \\
\hline Bufo spinosus & 30TUN83 & 100,00 & 97,92 & 97,97 & 38,61 & 5124,45 & 241,13 & $-9,80$ & 250,94 & 73,74 & 166,08 & 166,08 & 35,36 & 729,99 & 85,87 & 36,48 & 22,68 & 235,61 & 131,57 & 131,59 & 192,01 \\
\hline \begin{tabular}{|l} 
Bufo spinosus \\
\end{tabular} & 30TUN84 & 100,00 & 95,87 & 95,97 & 38,78 & 5037,41 & 235,94 & $-9,26$ & 245,21 & 72,10 & 163,01 & 163,01 & 34,63 & 773,53 & 91,48 & 38,99 & 22,55 & 250,52 & 141,46 & 141,46 & 205,00 \\
\hline Bufo spinosus & 30TUN85 & 100,00 & 75,40 & 95,93 & \begin{tabular}{ll|}
38,82 \\
\end{tabular} & 5077,38 & 217,77 & $-27,32$ & 245,09 & 50,12 & \begin{tabular}{|l|l|}
143,84 \\
\end{tabular} & 143,85 & 14,98 & $\begin{array}{l}908,83 \\
\end{array}$ & \begin{tabular}{|l|l|}
105,03 \\
\end{tabular} & 47,62 & 21,45 & 288,47 & 167,41 & 167,41 & 246,18 \\
\hline Bufo spinosus & 30TUN86 & 100,00 & 66,77 & 94,64 & \begin{tabular}{|l|l|}
38,78 \\
\end{tabular} & 5038,34 & 207,94 & $-33,90$ & 241,84 & 40,28 & 134,84 & 135,01 & 7,35 & 990,20 & 113,64 & 52,54 & 21,05 & 312,65 & 183,28 & 183,33 & 271,50 \\
\hline Bufo spinosus & 30TUN88 & 100,00 & 112,28 & 82,25 & 38,92 & 4422,59 & 227,97 & 18,89 & 209,08 & 92,69 & \begin{tabular}{|l|l|}
169,27 \\
\end{tabular} & 171,39 & 58,07 & 878,46 & 108,95 & 42,39 & 24,85 & 296,31 & 157,07 & 168,16 & 237,92 \\
\hline Bufo spinosus & 30TUN90 & 100,00 & 109,22 & 101,28 & 38,00 & 5337,25 & 258,43 & $-4,49$ & 262,92 & 84,31 & \begin{tabular}{|l|l|}
179,54 \\
\end{tabular} & 179,57 & 43,42 & 602,44 & 69,40 & 28,63 & 23,47 & 191,90 & 102,63 & 104,81 & 155,11 \\
\hline Bufo spinosus & 30TUN93 & 100,00 & 101,05 & 95,72 & 38,19 & 5085,48 & 241,52 & $-4,99$ & 246,51 & 76,96 & 168,68 & 168,68 & 38,88 & 728,04 & 85,35 & 35,99 & 22,53 & 234,67 & 131,51 & 131,51 & 192,18 \\
\hline Bufo spinosus & 30TUN94 & 100,00 & 97,51 & 94,17 & 38,50 & 5005,21 & 235,48 & $-6,21$ & 241,69 & 73,75 & 164,15 & 164,25 & 36,64 & 776,04 & 91,17 & 38,84 & 22,19 & 250,43 & 142,05 & 142,05 & 206,47 \\
\hline Bufo spinosus & 30TUN95 & 100,00 & 78,28 & 94,44 & \begin{tabular}{|l|l|}
38,47 \\
\end{tabular} & 5046,53 & 218,68 & $-23,58$ & 242,26 & 53,54 & 146,15 & 146,33 & 18,04 & 901,17 & 103,65 & 46,95 & 21,24 & 285,22 & 166,28 & 166,34 & 244,29 \\
\hline Bufo spinosus & 30TUN96 & 100,00 & 78,44 & 92,35 & 38,73 & 4948,25 & 215,06 & $-21,10$ & 236,15 & 54,41 & 144,41 & 145,20 & 19,49 & 937,75 & 108,48 & 48,88 & 21,28 & 298,43 & 173,79 & 174,56 & 255,77 \\
\hline \begin{tabular}{|l} 
Bufo spinosus \\
\end{tabular} & 30TUN97 & 100,00 & 96,77 & 86,74 & 38,7 & 4674,80 & 222,08 & 0,53 & 221,54 & 75,08 & 157,79 & 159,46 & 40,07 & 905,34 & 108,19 & 45,29 & 22,97 & 296,79 & 165,17 & 171,07 & 246,67 \\
\hline \begin{tabular}{|l} 
Bufo spinosus \\
\end{tabular} & 30TUPOO & 100,00 & 126,74 & 83,46 & 41,44 & 4057,12 & 235,08 & 36,23 & 198,85 & 108,39 & 178,43 & 181,14 & 77,34 & 829,34 & 111,57 & 41,76 & 27,54 & 281,62 & 149,04 & 159,96 & 210,49 \\
\hline \begin{tabular}{|l|} 
Bufo spinosusus \\
\end{tabular} & \begin{tabular}{|l|}
$30 T U P 01$ \\
\end{tabular} & 98,00 & 132,84 & 77,05 & \begin{tabular}{l|l}
40,95 \\
\end{tabular} & 3870,73 & 232,49 & 46,63 & 185,86 & 115,81 & 181,85 & 184,96 & 85,62 & 834,29 & \begin{tabular}{|l|l|}
112,99 \\
\end{tabular} & 41,12 & 27,93 & 284,33 & 147,81 & 160,77 & 212,72 \\
\hline Bufo spinosus & 30TUP02 & 40,00 & 136,08 & 73,30 & \begin{tabular}{l|l|l}
40,65 \\
\end{tabular} & 3764,03 & 230,71 & 52,45 & 178,26 & 119,80 & 183,68 & 186,80 & 90,21 & 839,39 & 114,00 & 40,95 & 28,24 & 286,77 & 147,48 & 161,79 & 215,03 \\
\hline Bufo spinosus & 30TUP11 & 96,00 & 128,99 & 78,27 & 40,69 & 3961,70 & 231,50 & 41,54 & 89,96 & 111,36 & 179,31 & 182,19 & 4 & 46,18 & 13,34 & 41 & 27,45 & 11 & 50 & 53,76 & 218,27 \\
\hline \begin{tabular}{|l} 
Bufo spinosus \\
\end{tabular} & 30TUP20 & 100,00 & 134 & 77,88 & 40,29 & 3995,93 & 237,12 & 46,48 & \begin{tabular}{|l|}
190,63 \\
\end{tabular} & & 185,62 & & 85,65 & 802,19 & 107,72 & 38 & 27,90 & 276,54 & 141,34 & 155,20 & 206,81 \\
\hline Bufo spinosus & 30TUP21 & 65,00 & 132,62 & 76,72 & 40,33 & 3942,74 & 233,28 & 45,64 & 187,64 & 115,31 & 182,62 & 185,54 & 84,31 & \begin{tabular}{|l|l|}
833,38 \\
\end{tabular} & 111,64 & 40,50 & 27,68 & 286,53 & 147,33 & 161,81 & 215,78 \\
\hline Bufo spinosus & 30TUP30 & 100,00 & 126,56 & 80,18 & 40,24 & 4107,21 & 233,28 & 36,55 & \begin{tabular}{|l|l|}
196,73 \\
\end{tabular} & $\mid 108,50$ & \begin{tabular}{|l|}
178,94 \\
\end{tabular} & 181,48 & 76,06 & 836,94 & $\mid 110,50$ & 40,98 & 27,01 & 287,16 & $\mid 149,31$ & $\mid 162,56$ & 217,93 \\
\hline Bufo spinosus & 30TUP40 & 100,00 & 125,65 & 79,37 & \begin{tabular}{|l|}
39,98 \\
\end{tabular} & 4126,27 & 232,18 & 35,84 & \begin{tabular}{|l|l|}
196,34 \\
\end{tabular} & $\begin{array}{ll}107,63 \\
\end{array}$ & 178,33 & 180,71 & 74,97 & 848,13 & 111,03 & 41,13 & 26,89 & 291,40 & 150,82 & 164,76 & 223,18 \\
\hline Bufo spinosus & 30TUP60 & 75,00 & 129,85 & 75,75 & 39,1 & 4064,14 & 232,53 & 42,05 & \begin{tabular}{ll|}
190,47 \\
\end{tabular} & 112,40 & 181 & 18 & 79,68 & 859,68 & 111,71 & 40,19 & 27,31 & 76 & 149,96 & 167,00 & 230,73 \\
\hline Bufo spinosus & 30TUP70 & 60,00 & 138,51 & 71,72 & 38,94 & 3944,71 & 235,56 & 53,15 & 182,42 & 121,71 & 188,22 & 190,99 & 89,35 & 851,58 & 111,16 & 38,07 & 28,35 & 298,79 & 145,09 & 165,69 & 231,25 \\
\hline Bufo spinosus & 30TVK06 & 100,00 & 142,47 & 106,21 & 35,00 & 6653,52 & 315,94 & 15,49 & 300,45 & 99,92 & 231,60 & 231,60 & 60,65 & 393,55 & 45,92 & 9,78 & 35,14 & 131,53 & 47,31 & 47,31 & 110,19 \\
\hline Bufo spinosus & 30TVK07 & 100,00 & 138,22 & $\mid 105,19$ & 35,00 & 6599,22 & 309,76 & 12,52 & 297,24 & 95,99 & 226,14 & 226,46 & 57,02 & 400,96 & $\mid 47,07$ & $\mid \begin{array}{ll}10,68 \\
\end{array}$ & 34,48 & $\mid 133,24$ & 50,14 & 50,30 & 110,73 \\
\hline Bufo spinosus & 30TVK08 & 100,00 & 124,39 & 104,41 & 35,06 & 6501,56 & 294,21 & 1,24 & 92,97 & 83,41 & 209,89 & 211,86 & 45,44 & 432,64 & 51,12 & 13,14 & 32,69 & 139,51 & 58,66 & 60,32 & 113,69 \\
\hline Bufo spinosus & 30TVK09 & 100,00 & 113,60 & 104,19 & 35,3 & 6407,64 & 282,44 & $-7,6$ & 289, & 85, & 198, & 200, & 36,88 & 464 & 56,18 & 15,15 & 31,66 & & 65,86 & 69,08 & 118 \\
\hline \begin{tabular}{|l} 
Bufo spinosus \\
\end{tabular} & 30TVK17 & 100,00 & 138,91 & 104,25 & 34,96 & 6616,96 & 310,09 & 13,86 & 296,23 & 96,55 & 227,31 & 227,31 & 57,37 & 414,99 & 49,71 & 10,90 & 35,08 & 140,19 & 50,32 & 50,32 & 118,99 \\
\hline
\end{tabular}




\begin{tabular}{|c|c|c|c|c|c|c|c|c|c|c|c|c|c|c|c|c|c|c|c|c|c|}
\hline TAXON & UTM & $\mathrm{km2}$ & B101 & $\mathrm{B1O2}$ & $\mathrm{BIO3}$ & $\mathrm{B104}$ & B105 & B106 & B107 & B108 & B109 & 81010 & B1011 & BIO12 & B1013 & 81014 & BIO15 & BIO16 & B1017 & BIO18 & B1019 \\
\hline Bufo spinosus & 30TVK18 & 100,00 & 131,85 & 103,41 & 34,97 & 6562,13 & 301,39 & 8,21 & 293,18 & 90,01 & 218,54 & 219,79 & 51,45 & 430,06 & 51,12 & 11,99 & 33,87 & 143,24 & 54,72 & 55,46 & 120,27 \\
\hline Bufo spinosus & 30TVK19 & 100,00 & 122,10 & 103,03 & 35,01 & 6504,33 & 290,27 & 0,24 & 290,03 & 80,60 & 207,63 & 209,40 & 43,13 & 452,22 & 52,58 & 13,31 & 32,24 & 146,66 & 60,58 & 63,19 & 121,45 \\
\hline Bufo spinosus & 30 TVK26 & 100,00 & 138,25 & 104,76 & 34,99 & 6657,59 & 311,19 & 13,42 & 297,77 & 95,62 & 227,21 & 227,21 & 56,31 & 433,86 & 52,36 & 10,97 & 35,88 & 147,81 & 50,58 & 50,58 & 128,45 \\
\hline Bufo spinosus & 30TVK27 & 100,00 & 135,36 & 103,56 & \begin{tabular}{|l|l|}
34,97 \\
\end{tabular} & 6603,25 & 306,28 & 11,89 & 294,39 & 93,05 & 223,48 & 223,52 & 54,19 & 441,59 & 53,65 & 11,71 & 35,26 & 150,21 & 52,99 & 53,01 & 130,36 \\
\hline Bufo spinosus & 30TVK28 & 100,00 & 134,52 & 102,71 & 34,77 & 6590,42 & 303,93 & 11,24 & 292,69 & 92,35 & 222,28 & 222,54 & 53,49 & 438,63 & 53,81 & 11,70 & 34,89 & $\begin{array}{l}149,35 \\
\end{array}$ & 53,68 & 53,80 & 127,92 \\
\hline Bufo spinosus & 30TVK29 & 100,00 & 123,83 & 102,72 & 35,00 & 6522,81 & 292,25 & 2,43 & 289,82 & 82,35 & 209,81 & 211,40 & 44,65 & 461,17 & 55,11 & 13,13 & 33,00 & \begin{tabular}{|l|l|}
152,18 \\
\end{tabular} & 60,21 & 62,15 & 128,16 \\
\hline Bufo spinosus & 30 TVK36 & 100,00 & 139,30 & 104,45 & 34,74 & 6663,92 & 312,32 & 14,42 & 297,90 & 96,29 & 228,15 & 228,15 & 57,02 & 441,51 & 54,98 & 10,73 & 37,02 & \begin{tabular}{|l|l|}
153,39 \\
\end{tabular} & 49,58 & 49,58 & 133,44 \\
\hline \begin{tabular}{|l} 
Bufo spinosus \\
\end{tabular} & $\begin{array}{l}\text { 30TVK37 } \\
\end{array}$ & 100,00 & 138,10 & 102,94 & 34,50 & 6626,82 & 309,23 & 14,46 & 294,77 & 95,56 & 226,59 & 226,59 & 56,19 & 444,80 & 56,12 & 11,12 & 36,95 & 155,32 & 50,47 & 50,47 & 134,92 \\
\hline Bufo spinosus & 30TVK38 & 100,00 & 136,31 & 102,21 & 34,23 & 6602,03 & 306,29 & 13,06 & 293,23 & 93,77 & 224,52 & 224,52 & 54,94 & 443,90 & 56,36 & 11,18 & 36,47 & \begin{tabular}{|l|l|}
154,53 \\
\end{tabular} & 51,94 & 51,94 & 132,50 \\
\hline Bufo spinosus & 30TVK39 & 100,00 & 132,33 & 102,09 & \begin{tabular}{|c|}
34,58 \\
\end{tabular} & 6564,50 & 301,02 & 9,65 & 291,37 & 90,28 & 219,68 & 220,00 & 51,72 & 447,13 & 56,23 & 11,54 & 35,06 & 153,56 & 55,03 & 55,22 & 130,17 \\
\hline Bufo spinosus & 30TVK43 & 100,00 & 146,90 & 110,28 & 35,02 & 6784,14 & 326,59 & 17,10 & 309,49 & 103,19 & 237,63 & 237,63 & 63,67 & 408,17 & 49,26 & 8,35 & 37,78 & 140,62 & 42,91 & 42,91 & 120,14 \\
\hline Bufo spinosus & 30TVK49 & 100,00 & 134,81 & 102,96 & 34,73 & 6603,20 & 305,15 & 11,37 & 293,78 & 92,12 & 222,82 & 222,82 & 53,66 & 442,82 & 58,10 & 10,74 & 36,60 & 155,84 & 52,14 & 52,14 & 130,55 \\
\hline \begin{tabular}{|l} 
Bufo spinosus \\
\end{tabular} & 30TVK53 & 100,00 & 144,53 & 111,16 & 35,28 & 6768,78 & 324,73 & 14,94 & 309,79 & \begin{tabular}{|l|l|}
100,76 \\
\end{tabular} & 235,02 & 235,02 & 61,71 & 415,71 & 50,65 & 8,66 & 37,63 & 143,47 & 44,26 & 44,26 & 121,99 \\
\hline Bufo spinosus & 30TVK54 & 100,00 & 143,67 & 109,71 & 35,11 & 6755,05 & 322,69 & 15,08 & 307,61 & 99,94 & 233,95 & 233,95 & 60,92 & 420,95 & 52,77 & 9,08 & 37,83 & \begin{tabular}{|l|l|}
147,14 \\
\end{tabular} & 44,87 & 44,87 & 124,71 \\
\hline Bufo spinosus & 30TVK55 & 100,00 & 141,85 & 108,40 & 34,99 & 6738,40 & 319,77 & 14,16 & 305,61 & 98,29 & 231,79 & 231,79 & 59,30 & 429,84 & 55,43 & 9,63 & 38,22 & \begin{tabular}{l|l|}
152,05 \\
\end{tabular} & 45,89 & 45,89 & 128,52 \\
\hline Bufo spinosus & 30TVK56 & 100,00 & 142,59 & 107,10 & 34,73 & 6737,97 & 319,71 & 15,12 & 304,59 & 99,05 & 232,33 & 232,33 & 59,72 & 429,50 & 57,37 & 9,44 & 39,30 & 154,57 & 44,76 & 44,76 & 129,99 \\
\hline Bufo spinosus & 30TVK58 & 100,00 & 137,29 & 105,89 & $\begin{array}{l}34,75 \\
\end{array}$ & 6671,55 & 312,08 & 12,03 & 300,05 & 93,89 & 225,91 & 225,91 & 55,51 & 441,80 & 60,58 & 10,14 & 38,73 & 159,91 & 48,39 & 48,39 & 132,82 \\
\hline Bufo spinosus & 30TVK63 & 100,00 & 141,18 & 112,37 & 36,00 & 6743,88 & 321,63 & 11,90 & 309,73 & 97,42 & 231,27 & 231,27 & 58,88 & 423,68 & 51,31 & 9,18 & 36,88 & 144,92 & 46,64 & 46,64 & 122,68 \\
\hline Bufo spinosus & 30TVK67 & 100,00 & 137,19 & 109,24 & \begin{tabular}{|l|}
35,68 \\
\end{tabular} & 6661,03 & 313,95 & 11,86 & 302,08 & 93,44 & 225,66 & 225,66 & 56,13 & 436,79 & 59,65 & 9,84 & 39,03 & 158,62 & 47,44 & 47,44 & 130,13 \\
\hline Bufo spinosus & 30TVK68 & 100,00 & 136,47 & 108,46 & 35,96 & 6623,71 & 311,34 & 12,18 & 299,16 & 92,69 & 224,35 & 224,35 & 55,92 & 432,86 & 59,86 & 9,67 & 39,16 & \begin{tabular}{|l|l|}
158,13 \\
\end{tabular} & 47,77 & 47,77 & 128,14 \\
\hline Bufo spinosus & 30TVK69 & 100,00 & 130,82 & 105,62 & 35,28 & 6593,60 & 302,23 & 8,04 & 294,19 & 87,81 & 218,64 & 218,64 & 50,92 & 440,21 & 58,48 & 10,84 & 36,21 & 155,32 & 53,21 & 53,21 & 125,62 \\
\hline \begin{tabular}{|l} 
Bufo spinosus \\
\end{tabular} & $\begin{array}{l}\text { 30TVK73 } \\
\end{array}$ & 100,00 & 141,02 & 113,14 & 36,00 & 6727,66 & 321,23 & 11,60 & 309,64 & 97,50 & 230,97 & 230,97 & 59,09 & \begin{tabular}{|l|l|}
419,19 \\
\end{tabular} & 50,42 & 9,30 & 36,39 & 142,58 & 47,14 & 47,14 & 119,64 \\
\hline Bufo spinosus & 30TVK74 & 100,00 & 132,79 & 112,49 & 36,00 & 6702,53 & 312,62 & 5,07 & 307,55 & 89,18 & 222,58 & 222,58 & 51,62 & 446,31 & 53,93 & 10,94 & 35,29 & \begin{tabular}{ll|}
150,76 \\
\end{tabular} & 52,65 & 52,65 & 126,82 \\
\hline Bufo spinosus & 30TVK76 & 100,00 & 127,98 & 110,16 & 36,00 & 6648,33 & 304,79 & 2,62 & 302,17 & 84,65 & 216,96 & 216,96 & 47,77 & 456,99 & 56,81 & 12,23 & 34,59 & 155,52 & 55,91 & 55,91 & 129,05 \\
\hline Bufo spinosus & 30TVK77 & 100,00 & 127,52 & 108,89 & 36,00 & 6620,45 & 302,52 & 3,27 & 299,25 & 84,27 & 215,94 & 215,94 & 47,71 & 453,90 & 57,35 & 12,08 & 34,72 & \begin{tabular}{|l|l|}
155,45 \\
\end{tabular} & 56,17 & 56,17 & 127,52 \\
\hline Bufo spinosus & 30TVK78 & 100,00 & 132,00 & 107,07 & 35,82 & 6613,92 & 304,40 & 8,54 & 295,86 & 88,89 & 220,03 & 220,03 & 52,04 & 431,48 & 56,53 & 10,85 & 35,91 & 151,10 & 52,36 & 52,36 & 120,87 \\
\hline Bufo spinosus & 30TVK79 & 100,00 & 130,23 & 104,81 & 35,19 & 6592,21 & 299,79 & $\frac{0,340}{7,80}$ & 291,99 & $\mid 80,36$ & 218,03 & 218,03 & 50,57 & $\begin{array}{l}328,29 \\
\end{array}$ & 55,77 & $\begin{array}{l}10,909 \\
10,\end{array}$ & 34,90 & 148,50 & 54,04 & 54,04 & 117,38 \\
\hline Bufo spinosus & 30TVK83 & 100,00 & 138,79 & 113,98 & 36,19 & 6701,32 & 318,91 & 9,42 & 309,49 & 95,62 & 228,52 & 228,52 & 57,55 & 421,78 & 49,56 & 9,79 & 35,27 & \begin{tabular}{|l|l|}
141,03 \\
\end{tabular} & 49,49 & 49,49 & 118,06 \\
\hline Bufo spinosus & 30TVK86 & 100,00 & 129,06 & 110,40 & 36,00 & 6643,83 & 305,12 & 3,24 & 301,89 & 85,92 & 217,78 & 217,78 & 48,93 & 445,04 & 54,00 & 12,35 & 33,79 & 149,01 & 56,37 & 56,37 & 122,41 \\
\hline Bufo spinosus & 30TVK87 & 100,00 & 125,00 & 109,19 & 36,00 & 6611,96 & 299,33 & 1,01 & 298,32 & 82,09 & 213,40 & 213,40 & 45,56 & 453,26 & 54,74 & 12,95 & 32,86 & 150,36 & 59,67 & 59,67 & 123,08 \\
\hline Bufo spinosus & 30TVK88 & 100,00 & 121,64 & 107,84 & 35,95 & 6583,24 & 294,27 & $-0,88$ & 295,15 & 79,05 & 209,83 & 209,84 & 42,75 & 458,95 & 54,87 & 13,65 & 32,03 & 150,42 & 62,90 & 62,91 & 122,69 \\
\hline Bufo spinosus & $\begin{array}{l}\text { 30TVK89 } \\
\end{array}$ & 100,00 & 126,58 & 104,72 & 35,36 & $\begin{array}{l}6508,24 \\
658,39 \\
\end{array}$ & 295,38 & $\begin{array}{l}-0,00 \\
4,42 \\
\end{array}$ & 290,96 & 84,21 & 20 & \begin{tabular}{|l|}
214,50 \\
\end{tabular} & $\begin{array}{ll}42,38 \\
47,38\end{array}$ & | & 53,18 & $\begin{array}{l}12,27 \\
12,27\end{array}$ & 32,92 & \begin{tabular}{l|l}
143,65 \\
143
\end{tabular} & 58,45 & 58,59 & 113,28 \\
\hline Bufo spinosus & 30TVK98 & 100,00 & 124,56 & 108,02 & \begin{tabular}{|l|l|}
36,03 \\
\end{tabular} & 6591,40 & 296,51 & 0,65 & 295,86 & 82,17 & 212,64 & 212,74 & 45,40 & 441,87 & 51,74 & 13,47 & 31,56 & \begin{tabular}{|l|l|}
143,03 \\
\end{tabular} & 61,68 & 61,82 & 115,46 \\
\hline Bufo spinosus & 30TVK99 & 100,00 & 120,32 & 107,32 & 36,00 & 6555,77 & 291,08 & $-2,42$ & 293,49 & 78,23 & 207,61 & 208,11 & 41,79 & 453,08 & 52,21 & 14,56 & 30,42 & 143,92 & 65,75 & 66,43 & 116,97 \\
\hline Bufo spinosus & 30TVLOO & 100,00 & 103,47 & 104,36 & 35,96 & 6315,89 & 271,61 & $-14,89$ & 286,50 & 97,34 & 188,25 & 189,18 & 29,18 & 495,14 & 61,23 & 17,16 & 30,66 & 156,36 & 73,01 & 77,93 & 122,97 \\
\hline Bufo spinosus & 30TVL01 & 100,00 & 80,62 & 106,71 & 37,19 & 6073,35 & 250,45 & $-32,06$ & 282,52 & 83,05 & 164,19 & 164,30 & 12,32 & 595,66 & 74,22 & 23,49 & 28,36 & 187,09 & 91,97 & 95,44 & 147,75 \\
\hline \begin{tabular}{|l} 
Bufo spinosus \\
\end{tabular} & \begin{tabular}{|l|} 
30TVL03 \\
\end{tabular} & 100,00 & 111,68 & 101,23 & 35,18 & 6409,99 & 274,44 & $\begin{array}{ll}-7,84 \\
\end{array}$ & 282,27 & \begin{tabular}{|l|l|}
123,56 \\
\end{tabular} & 196,60 & 198,14 & 34,33 & 477,20 & 56,09 & 14,21 & 30,30 & 148,11 & 68,19 & 76,25 & 121,31 \\
\hline Bufo spinosus & 30TVL04 & 100,00 & 113,19 & 101,99 & 35,75 & 6386,37 & 276,05 & $-6,75$ & 282,80 & 116,68 & 197,64 & 198,95 & 35,67 & 469,46 & 54,85 & 14,00 & 30,08 & \begin{tabular}{|l|l|}
145,44 \\
\end{tabular} & 67,00 & 75,35 & 120,02 \\
\hline Bufo spinosus & 30TVL10 & 100,00 & 112,46 & 102,96 & 35,38 & $\begin{array}{lll}6427,44 \\
\end{array}$ & 279,75 & $-7,11$ & 286,86 & 80,22 & 197,93 & 199,25 & 35,60 & 478,21 & 56,21 & 15,01 & 30,94 & 150,99 & 67,21 & 71,88 & 123,97 \\
\hline Bufo spinosus & 30TVL11 & 100,00 & 77,29 & 106,95 & 37,36 & 6068,16 & 247,71 & $-34,23$ & 281,95 & 70,78 & 161,14 & 161,28 & 9,66 & 626,03 & 76,40 & 24,97 & 27,68 & 194,81 & 96,49 & 99,25 & 157,99 \\
\hline \begin{tabular}{|l} 
Bufo spinosus \\
\end{tabular} & 30TVL12 & 100,00 & 82,73 & 105,64 & 37,0 & 6128,99 & 251,27 & $-30,42$ & 281,69 & 86,58 & 166,66 & 167,03 & 13,17 & 603,08 & 72,94 & 23,32 & 27,85 & \begin{tabular}{|l|l|}
187,35 \\
\end{tabular} & 92,53 & 97,16 & 152,35 \\
\hline Bufo spinosus & 30TVL14 & 100,00 & 107,35 & 102,19 & 35,99 & 6359,05 & 271,21 & $-11,09$ & 282,30 & 116,53 & 192,19 & 193,14 & 31,24 & 496,32 & 57,82 & 15,51 & 29,34 & 152,82 & 71,83 & 80,63 & 127,33 \\
\hline Bufo spinosus & 30TVL19 & 100,00 & 115,14 & 105,68 & 36,66 & 6155,45 & 279,34 & $-5,68$ & 285,02 & 107,13 & 196,25 & 197,19 & 39,82 & 457,84 & 52,77 & 15,62 & 27,99 & 140,09 & 67,60 & 77,27 & 117,99 \\
\hline Bufo spinosus & 30TVL20 & 100,00 & 116,65 & 102,55 & 35,13 & 6465,02 & 284,01 & $-3,38$ & 287,39 & 75,82 & 202,20 & 203,73 & 38,82 & 477,18 & 55,71 & 14,20 & 31,40 & \begin{tabular}{|c|}
153,59 \\
\end{tabular} & 64,93 & 68,63 & 128,32 \\
\hline Bufo spinosus & 30TVL21 & 100,00 & 84,19 & 106,10 & 36,89 & 6169,99 & 254,29 & $-29,16$ & 283,45 & 61,23 & 168,71 & 16 & 14,22 & 607,58 & 72,58 & 23,35 & 27,95 & 88,62 & 92,03 & 95,29 & 156,05 \\
\hline Bufo spinosus & 30TVL22 & 100,00 & 89,15 & 105,22 & 30,05 & 6195,81 & 257,50 & $-25,31$ & \begin{tabular}{|l|}
282,81 \\
\end{tabular} & $\begin{array}{l}81,25 \\
82,82\end{array}$ & 173,58 & 17 & \begin{tabular}{|l|l|}
18,03 \\
\end{tabular} & 575,22 & 68,69 & 21,29 & 27,97 & $\begin{array}{l}170,02 \\
177,58 \\
\end{array}$ & 86,99 & 92,20 & 146,47 \\
\hline \begin{tabular}{|l} 
Bufo spinosus \\
\end{tabular} & 30TVL23 & 100,00 & 72,79 & 106,73 & 37,51 & 6045,02 & 242,56 & $-38,25$ & 280,81 & 68,29 & 156,35 & 156,48 & 5,44 & 658,42 & 78,70 & 27,16 & 26,32 & 202,81 & 103,42 & 105,63 & 167,97 \\
\hline \begin{tabular}{|l} 
Bufo spinosus \\
\end{tabular} & 30TVL24 & 100,00 & 93,79 & 104,32 & 36,48 & 6221,50 & 260,20 & \begin{tabular}{|l|l|l|}
$-21,89$ \\
\end{tabular} & 282,09 & \begin{tabular}{|l|}
103,11 \\
\end{tabular} & 177,89 & 178,38 & 21,18 & 554,28 & 65,42 & 19,96 & 27,84 & 170,44 & $\begin{array}{l}83,91 \\
83,9\end{array}$ & 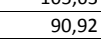 & 141,50 \\
\hline Bufo spinosus & 30TVL27 & 100,00 & 112,87 & 103,91 & 36,01 & 6262,71 & 276,90 & $-6,79$ & 283,69 & 86,03 & 195,63 & 196,50 & 36,60 & 471,66 & 54,16 & 15,43 & 28,28 & 144,47 & 69,39 & 77,94 & 122,11 \\
\hline Bufo spinosus & 30TVL30 & 100,00 & 119,57 & 102,73 & 35,07 & 6498,95 & 287,51 & $-0,85$ & 288,36 & 77,69 & 205,32 & 206,90 & 41,19 & 476,05 & 56,83 & 13,65 & 32,14 & 156,14 & 63,41 & 66,05 & 131,37 \\
\hline \begin{tabular}{|l} 
Bufo spinosus \\
\end{tabular} & 30TVL31 & 100,00 & $\frac{11}{11}$ & 103,04 & 35,52 & $\begin{array}{l}04528,78 \\
6428\end{array}$ & 279,39 & $\begin{array}{l}-0,05 \\
-6,72 \\
\end{array}$ & \begin{tabular}{|l|}
286,11 \\
286,1
\end{tabular} & 73,78 & 197,50 & 198,75 & 35,20 & 496,87 & 58,38 & 15,25 & 30,58 & 158,92 & $\begin{array}{ll}69,08 \\
\end{array}$ & 73,27 & 133,32 \\
\hline Bufo spinosus & 30TVL32 & 100,00 & 89,33 & 105,67 & 36,72 & 6214,66 & 258,42 & $-25,45$ & 283,86 & 76,32 & 173,92 & 174,25 & 17,79 & 578,12 & 68,50 & 21,47 & 27,60 & 177,52 & 87,52 & 92,90 & 148,19 \\
\hline Bufo spinosus & 30TVL33 & 100,00 & 93,59 & 104,76 & 36,51 & 6246,76 & 261,29 & $-22,01$ & 283,30 & 79,89 & 178,09 & 178,63 & 20,99 & 562,40 & 65,76 & 20,43 & 27,73 & 172.92 & $84,79 \mid$ & 90,65 & 145,03 \\
\hline Bufo spinosus & 30TVL34 & 100,00 & 86,44 & 105,55 & 36,82 & 6168,71 & 254,56 & $-27,94$ & 282,50 & 96,85 & 170,42 & 170,66 & 15,35 & 591,88 & 69,86 & 22,81 & 26,76 & 181,19 & 91,63 & 97,38 & 151,49 \\
\hline Bufo spinosus & 30TVL40 & 100,00 & 127,79 & 102,91 & 35,01 & 6550,89 & 296,39 & 5,74 & 290,64 & 85,55 & 214,56 & 215,24 & 47,88 & 454,56 & 57,17 & 12,01 & 34,19 & 154,78 & 57,89 & 58,64 & 129 \\
\hline \begin{tabular}{|l} 
Bufo spinosus \\
\end{tabular} & 30TVL41 & 100,00 & 120,84 & 102,69 & 35,08 & 6501,78 & 288,23 & 0,27 & 287,97 & 79,02 & 206,51 & 207,87 & 42,13 & 468,87 & 56,71 & 13,27 & 31,97 & 154,61 & 63,08 & 65,25 & 129,18 \\
\hline Bufo spinosus & 30TVL43 & 100,00 & 109,23 & 103,29 & 36,00 & 6385,04 & 275,66 & $-9,20$ & 284,86 & 68,98 & 194,21 & 195,12 & 32,98 & 499,32 & 56,90 & 15,97 & 29,15 & 155,92 & 72,09 & 77,84 & 131,74 \\
\hline Bufo spinosus & 30TVL44 & 100,00 & 95,01 & 105,03 & 36,40 & 6252,22 & 262,72 & $-21,24$ & 283,96 & 86,56 & 179,36 & 179,79 & 21,82 & 555,86 & 64,66 & 20,44 & 27,23 & \begin{tabular}{|c|}
170,18 \\
\end{tabular} & 84,87 & 90,53 & 143,55 \\
\hline Bufo spinosus & 30TVL45 & 100,00 & 94,63 & 105,17 & 36,48 & 6228,27 & 262,01 & $-21,67$ & 283,68 & 89,50 & 178,54 & 178 & 21,54 & 555,45 & 64,78 & 20,73 & 26,73 & \begin{tabular}{|l|}
169,10 \\
\end{tabular} & 85,71 & 92,87 & 143,01 \\
\hline Bufo spinosus & 30TVL47 & 100,00 & 110,21 & 104,01 & 36,01 & 6266,56 & 275,21 & $-8,54$ & 283,75 & 80,04 & 193,46 & 194,19 & 34,55 & 485,09 & 55,48 & 16,84 & 27,36 & 147,43 & 73,57 & 80,99 & 125,80 \\
\hline
\end{tabular}




\begin{tabular}{|c|c|c|c|c|c|c|c|c|c|c|c|c|c|c|c|c|c|c|c|c|c|}
\hline TAXON & UTM & $\mathrm{km2}$ & BIO1 & $\begin{array}{l}\mathrm{BIO2} \\
\end{array}$ & $\mathrm{BIO3}$ & B104 & B105 & B106 & B107 & B108 & B109 & BIO10 & BIO11 & B1012 & BIO13 & BIO14 & BIO15 & BIO16 & BIO17 & B1018 & BlO19 \\
\hline Bufo spinosus & 30TVL48 & 100,00 & 104,54 & 104,90 & 36,47 & 6204,16 & 270,09 & $-13,47$ & 283,56 & 117,58 & 187,43 & 187,73 & 29,86 & 506,53 & 58,59 & 18,77 & 26,41 & 153,38 & 78,77 & 87,40 & 130,42 \\
\hline Bufo spinosus & 30TVL49 & 100,00 & 103,11 & 105,19 & 36,68 & 6153,76 & 268,55 & $-14,83$ & 283,38 & \begin{tabular}{l|l|l|}
119,62 \\
\end{tabular} & \begin{tabular}{|l|l|}
185,19 \\
\end{tabular} & $\begin{array}{l}185,55 \\
\end{array}$ & 29,06 & 512,73 & 59,46 & 19,73 & 25,87 & $\begin{array}{l}155,59 \\
1\end{array}$ & \begin{tabular}{|l|l|}
80,97 \\
\end{tabular} & 90,08 & 131,61 \\
\hline Bufo spinosus & 30TVL50 & 100,00 & 133,14 & 103,39 & 35,00 & 6579,67 & 302,35 & 10,41 & 291,94 & 90,44 & 220,66 & 220,69 & 52,75 & 434,01 & 57,10 & 10,67 & 35,80 & \begin{tabular}{l|l|}
152,12 \\
\end{tabular} & 53,20 & 53,21 & 124,29 \\
\hline Bufo spinosus & 30TVL51 & 100,00 & 128,43 & 102,74 & 35,00 & 6538,75 & 296,04 & 6,70 & 289,35 & 86,38 & 215,28 & 215,54 & 48,77 & 440,69 & 55,86 & 11,65 & 33,64 & \begin{tabular}{|l|l|}
149,99 \\
\end{tabular} & 57,75 & 58,04 & 122,79 \\
\hline Bufo spinosus & 30TVL52 & 100,00 & 119,14 & 103,05 & 35,49 & 6471,71 & 286,06 & $-0,94$ & \begin{tabular}{|l|l|}
286,99 \\
\end{tabular} & 77,81 & 204,90 & 205,77 & 40,94 & \begin{tabular}{ll|}
466,92 \\
\end{tabular} & 55,77 & 13,73 & 31,05 & \begin{tabular}{|l|l|}
151,94 \\
\end{tabular} & \begin{tabular}{|l|l|}
65,03 \\
\end{tabular} & 67,44 & 126,10 \\
\hline Bufo spinosus & 30 TVL54 & 100,00 & 97,28 & 105,44 & 36,44 & 6285,75 & 265,47 & $-19,77$ & 285,24 & 84,53 & 181,84 & 182,24 & 23,39 & 546,22 & 63,27 & 20,09 & 26,97 & 166,33 & 83,72 & 89,91 & 141,45 \\
\hline Bufo spinosus & 30TVL55 & 100,00 & 76,54 & 107,27 & 37,39 & 6122,88 & 246,61 & $-37,30$ & 283,90 & \begin{tabular}{l|l|}
87,02 \\
\end{tabular} & 160,33 & 160,37 & 6,47 & 648,73 & 76,29 & 27,79 & 24,67 & $\begin{array}{l}197,61 \\
\end{array}$ & \begin{tabular}{ll|}
105,10 \\
\end{tabular} & \begin{tabular}{ll|}
107,78 \\
\end{tabular} & 166,35 \\
\hline Bufo spinosus & 30TVL56 & 100,00 & 98,65 & 105,45 & \begin{tabular}{|l|l|}
36,47 \\
\end{tabular} & 6247,34 & 265,84 & $-18,73$ & 284,57 & \begin{tabular}{|l|l|}
108,90 \\
\end{tabular} & \begin{tabular}{ll|}
182,44 \\
\end{tabular} & \begin{tabular}{|l|l|}
182,74 \\
\end{tabular} & 24,61 & 536,54 & 62,27 & 20,27 & 26,21 & $\begin{array}{l}162,15 \\
\end{array}$ & 83,91 & \begin{tabular}{l|l}
91,55 \\
\end{tabular} & 138,26 \\
\hline Bufo spinosus & 30TVL58 & 100,00 & 109,69 & 104,92 & \begin{tabular}{|l|}
36,27 \\
\end{tabular} & 6237,29 & 274,93 & $-8,82$ & 283,75 & \begin{tabular}{l|l}
114,42 \\
\end{tabular} & $\begin{array}{l}192,60 \\
1\end{array}$ & \begin{tabular}{|l|l|}
193,04 \\
\end{tabular} & 34,23 & 486,60 & 55,97 & 17,97 & 26,23 & \begin{tabular}{|l|l|}
146,29 \\
\end{tabular} & 76,12 & 83,23 & 125,49 \\
\hline Bufo spinosus & 30TVL59 & 100,00 & 108,00 & 105,03 & 36,61 & 6185,94 & 273,14 & $-10,25$ & \begin{tabular}{|l|l|}
283,39 \\
\end{tabular} & \begin{tabular}{ll|}
124,27 \\
\end{tabular} & $\begin{array}{ll}190,18 \\
\end{array}$ & \begin{tabular}{l|l|}
190,51 \\
\end{tabular} & 33,01 & \begin{tabular}{ll|l}
493,92 \\
\end{tabular} & 57,00 & 18,96 & 25,70 & \begin{tabular}{|l|l|}
148,62 \\
\end{tabular} & $\begin{array}{l}78,66 \\
\end{array}$ & 86,02 & 127,11 \\
\hline Bufo spinosus & 30TVL60 & 100,00 & 126,06 & 104,05 & 35,02 & 6558,47 & 295,12 & 4,32 & 290,81 & 83,61 & 213,47 & 213,51 & \begin{tabular}{ll|}
46,63 \\
\end{tabular} & 447,94 & 57,04 & 11,99 & 33,66 & 152,69 & 58,60 & 58,63 & 124,06 \\
\hline Bufo spinosus & 30TVL61 & 100,00 & 121,44 & 103,71 & 35,33 & 6520,14 & 289,47 & 0,86 & 288,61 & 79,56 & 208,07 & \begin{tabular}{|l|}
208,63 \\
\end{tabular} & 42,72 & 457,78 & 56,02 & 13,16 & 31,80 & \begin{tabular}{|l|l|}
151,47 \\
\end{tabular} & 63,16 & 63,89 & 124,21 \\
\hline Bufo spinosus & 30TVL62 & 100,00 & 122,19 & 103,14 & 35,32 & 6491,62 & 288,90 & 1,52 & 287,38 & 80,64 & \begin{tabular}{|l|l|}
208,18 \\
\end{tabular} & 208,88 & 43,69 & \begin{tabular}{l|l}
450,45 \\
\end{tabular} & 54,49 & 13,15 & 31,25 & $\begin{array}{ll}147,72 \\
\end{array}$ & \begin{tabular}{|c|}
63,30 \\
\end{tabular} & 64,48 & 120,74 \\
\hline Bufo spinosus & 30TVL63 & 100,00 & 103,22 & 105,44 & 36,24 & 6361,51 & 272,07 & $-14,94$ & 287,01 & $\begin{array}{ll}70,18 \\
\end{array}$ & \begin{tabular}{l|l|l}
188,55 \\
\end{tabular} & \begin{tabular}{|l|l|l|}
189,08 \\
\end{tabular} & 28,16 & 522,84 & \begin{tabular}{l|l}
60,45 \\
\end{tabular} & 18,56 & 27,81 & \begin{tabular}{ll|}
161,01 \\
\end{tabular} & \begin{tabular}{ll|}
79,09 \\
\end{tabular} & 84,01 & 136,24 \\
\hline Bufo spinosus & 30TVL64 & 100,00 & 94,16 & 106,62 & 36,72 & 6278,11 & 263,56 & $-23,05$ & \begin{tabular}{|l|l|}
286,62 \\
\end{tabular} & 85,77 & $\begin{array}{ll}178,82 \\
\end{array}$ & \begin{tabular}{l|l|l|}
179,12 \\
\end{tabular} & 20,69 & 560,23 & 65,27 & 21,5 & 26,17 & 169,19 & 87,76 & 93,92 & 144,27 \\
\hline Bufo spinosus & 30TVL66 & 100,00 & 76,30 & 107,84 & 37,44 & 6119,81 & 246,56 & $-38,21$ & 284,77 & $\begin{array}{l}90,68 \\
\end{array}$ & \begin{tabular}{|l|l|}
159,88 \\
\end{tabular} & \begin{tabular}{|l|l|}
159,89 \\
\end{tabular} & 5,98 & 651,92 & 76,56 & 28,84 & 23,88 & \begin{tabular}{|l|l|}
198,39 \\
\end{tabular} & \begin{tabular}{|l|l|}
107,84 \\
\end{tabular} & \begin{tabular}{|l|}
110,04 \\
\end{tabular} & 166,99 \\
\hline Bufo spinosus & 30TVL68 & 100,00 & 108,25 & 105,39 & 36,51 & 6236,98 & 274,38 & $-10,43$ & 284,81 & 125,95 & \begin{tabular}{l|l|}
191,41 \\
\end{tabular} & \begin{tabular}{ll|}
191,62 \\
\end{tabular} & 33,21 & 493,10 & 56,96 & 18,96 & 25,61 & \begin{tabular}{ll|l}
147,88 \\
\end{tabular} & 78,89 & 85,53 & 126,82 \\
\hline Bufo spinosus & 30TVL70 & 100,00 & 124,57 & 103,99 & 35,16 & 6556,40 & 292,94 & 3,20 & 289,73 & 82,36 & \begin{tabular}{|l|l|}
212,23 \\
\end{tabular} & 212,23 & 45,64 & 442,06 & 55,17 & 12,34 & 32,79 & \begin{tabular}{ll|}
148,33 \\
\end{tabular} & 59,95 & 59,96 & 118,65 \\
\hline Bufo spinosus & 30TVL71 & 100,00 & 120,88 & 103,79 & 35,43 & 6518,66 & 288,58 & 0,21 & 288,37 & 79,19 & \begin{tabular}{ll|}
207,66 \\
\end{tabular} & 208,00 & 42,49 & 451,60 & 54,44 & 13,41 & 31,27 & \begin{tabular}{ll|}
147,68 \\
\end{tabular} & \begin{tabular}{ll|l}
64,06 \\
\end{tabular} & 64,58 & 119,43 \\
\hline Bufo spinosus & 30TVL73 & 100,00 & 112,34 & 104,94 & 36,00 & 6424,94 & 280,08 & $-7,36$ & 287,45 & 72,50 & \begin{tabular}{ll|}
197,80 \\
\end{tabular} & 198,45 & 35,42 & 480,68 & 55,10 & 16,20 & 28,44 & \begin{tabular}{l|l}
149,45 \\
\end{tabular} & 72,21 & 75,72 & 125,06 \\
\hline Bufo spinosus & 30TVL74 & 100,00 & 103,10 & 106,20 & 36,32 & 6343,56 & 271,86 & $-15,71$ & 287,56 & 76,53 & \begin{tabular}{|l|l|}
188,08 \\
\end{tabular} & 188,45 & 27,75 & 519,66 & 60,06 & 19,41 & 26,66 & $\begin{array}{ll}157,63 \\
\end{array}$ & 81,13 & 86,61 & 133,97 \\
\hline Bufo spinosus & 30TVL76 & 100,00 & 84,50 & 108,12 & \begin{tabular}{l|l|}
37,05 \\
\end{tabular} & 6186,52 & 254,92 & \begin{tabular}{|l|l|}
$-32,07$ \\
\end{tabular} & 286,99 & \begin{tabular}{l|l|}
100,32 \\
\end{tabular} & $\begin{array}{l}168,44 \\
1\end{array}$ & \begin{tabular}{l|l|}
168,50 \\
\end{tabular} & \begin{tabular}{l|l}
12,55 \\
\end{tabular} & 608,11 & 71,52 & 26,34 & 23,99 & \begin{tabular}{|l|l}
184,73 \\
\end{tabular} & 100,57 & \begin{tabular}{ll|}
106,50 \\
\end{tabular} & 155,64 \\
\hline Bufo spinosus & 30TVL77 & 100,00 & 97,54 & 107,18 & 36,97 & 6228,79 & 266,13 & $-20,66$ & 286,78 & 115,05 & $\begin{array}{ll}181,13 \\
\end{array}$ & \begin{tabular}{ll|}
181,36 \\
\end{tabular} & 23,63 & \begin{tabular}{|l|l|}
543,17 \\
\end{tabular} & 63,46 & 22,25 & 24,68 & \begin{tabular}{ll|}
163,89 \\
\end{tabular} & 88,89 & 95,62 & 139,32 \\
\hline Bufo spinosus & 30TVL78 & 100,00 & 104,81 & 106,58 & 36,97 & 6231,13 & 272,08 & $-13,99$ & 286,08 & 123,26 & \begin{tabular}{|l|l|}
187,92 \\
\end{tabular} & \begin{tabular}{|l|l|l|}
188,19 \\
\end{tabular} & 30,10 & 509,49 & 59,28 & 20,53 & 24,84 & \begin{tabular}{|l|l|}
153,19 \\
\end{tabular} & 83,48 & 89,84 & 130,68 \\
\hline Bufo spinosus & 30TVL79 & 100,00 & 109,26 & 106,14 & 37,00 & 6203,81 & 275,37 & $-9,81$ & 285,18 & 128,27 & 191,55 & \begin{tabular}{|l|l|l|}
191,93 \\
\end{tabular} & 34,18 & 491,62 & 57,06 & 19,99 & 24,75 & 147,52 & 81,13 & 87,21 & 126,18 \\
\hline Bufo spinosus & 30TVL80 & 100,00 & 128,46 & 102,32 & 35,07 & 6577,84 & 294,21 & 6,89 & 287,32 & $\begin{array}{l}86,39 \\
\end{array}$ & 216,18 & 216,18 & 49,14 & 414,96 & 51,50 & 11,70 & 32,79 & 138,37 & 57,21 & 57,21 & 106,89 \\
\hline Bufo spinosus & 30TVL81 & 100,00 & 125,82 & 102,84 & 35,13 & 6542,43 & 291,63 & 4,37 & 287,25 & 84,01 & \begin{tabular}{|l|l|}
213,03 \\
\end{tabular} & \begin{tabular}{|l|l|}
213,07 \\
\end{tabular} & \begin{tabular}{|l|l|}
46,97 \\
\end{tabular} & \begin{tabular}{ll|}
423,35 \\
\end{tabular} & 51,04 & 12,59 & 31,28 & \begin{tabular}{|l|l|}
138,47 \\
\end{tabular} & \begin{tabular}{l|l}
60,82 \\
\end{tabular} & \begin{tabular}{ll|l}
60,87 \\
\end{tabular} & 108,85 \\
\hline Bufo spinosus & 30TVL82 & 100,00 & 121,66 & 103,83 & 35,64 & 6497,10 & 288,13 & 0,42 & 287,70 & 80,32 & 207,91 & 208,36 & 43,33 & 438,88 & 51,11 & 13,93 & 29,88 & \begin{tabular}{|l|l}
140,13 \\
\end{tabular} & 65,12 & 66,08 & 112,81 \\
\hline Bufo spinosus & 30TVL84 & 100,00 & 101,52 & \begin{tabular}{ll|}
107,48 \\
\end{tabular} & 36,76 & 6345,08 & 271,39 & $-18,01$ & 289,41 & 86,21 & \begin{tabular}{|l|l|l|}
186,58 \\
\end{tabular} & \begin{tabular}{|l|l|}
186,88 \\
\end{tabular} & 26,30 & 524,94 & 61,32 & 20,44 & 25,87 & \begin{tabular}{|l|l|}
157,71 \\
\end{tabular} & \begin{tabular}{l|l|}
83,85 \\
\end{tabular} & 89,76 & 134,30 \\
\hline Bufo spinosus & 30TVL87 & 100,00 & 94,49 & 108,47 & 37,00 & 6223,54 & 264,29 & $-24,13$ & 288,42 & 111,81 & $\begin{array}{l}178,15 \\
\end{array}$ & \begin{tabular}{|l|l|}
178,29 \\
\end{tabular} & 20,81 & 559,91 & 65,81 & 24,12 & 23,88 & \begin{tabular}{|l|l|}
169,43 \\
\end{tabular} & 93,76 & \begin{tabular}{|l|l}
100,73 \\
\end{tabular} & 143,13 \\
\hline Bufo spinosus & 30TVL88 & 100,00 & 102,05 & 107,89 & 37,00 & 6222,84 & 270,60 & $-17,08$ & 287,69 & 120,28 & \begin{tabular}{l|l|}
185,22 \\
\end{tabular} & 185,51 & 27,69 & 523,70 & 61,33 & 22,14 & 24,10 & \begin{tabular}{ll|l}
157,90 \\
\end{tabular} & 87,73 & 94,40 & 133,97 \\
\hline Bufo spinosus & 30TVL89 & 100,00 & 110,14 & 107,13 & 37,00 & 6215,73 & 276,77 & $-9,44$ & 286,21 & 129,18 & $\begin{array}{l}192,51 \\
\end{array}$ & 192,81 & 34,86 & \begin{tabular}{|l|l|}
489,47 \\
\end{tabular} & 57,12 & 20,56 & 24,16 & 146,90 & 82,44 & 87,78 & 125,10 \\
\hline Bufo spinosus & 30TVL91 & 100,00 & 121,90 & 104,96 & 35,73 & 6522,61 & 289,31 & $-0,26$ & 289,56 & 80,44 & 208,64 & \begin{tabular}{|l|l|}
208,92 \\
\end{tabular} & 43,39 & 436,13 & 50,64 & 14,20 & 29,76 & $\begin{array}{l}137,75 \\
\end{array}$ & \begin{tabular}{l|l}
65,45 \\
\end{tabular} & 66,21 & 110,47 \\
\hline Bufo spinosus & 30TVL92 & 100,00 & 120,83 & 105,11 & 35,93 & 6492,10 & 287,99 & $-1,00$ & \begin{tabular}{|l|l|}
288,99 \\
\end{tabular} & 79,70 & \begin{tabular}{|l|l|}
206,94 \\
\end{tabular} & 207,49 & \begin{tabular}{ll|}
42,66 \\
\end{tabular} & 438,51 & $\begin{array}{l}50,65 \\
\end{array}$ & 14,73 & 28,94 & \begin{tabular}{ll|}
136,86 \\
\end{tabular} & 67,03 & \begin{tabular}{ll|l}
68,37 \\
\end{tabular} & 110,90 \\
\hline Bufo spinosus & \begin{tabular}{|c|} 
30TVL93 \\
\end{tabular} & 100,00 & 115,93 & 106,16 & 36,04 & 6443,86 & 283,94 & $-5,49$ & 289,42 & 76,12 & 201,56 & 202,12 & 38,45 & \begin{tabular}{|l|l|}
458,06 \\
\end{tabular} & 53,33 & 16,36 & 27,60 & 139,58 & 71,74 & 74,50 & 115,90 \\
\hline Bufo spinosus & 30TVL94 & 100,00 & 109,13 & 107,41 & 36,51 & 6384,33 & 278,25 & $-11,94$ & \begin{tabular}{|l|l|l|}
290,19 \\
\end{tabular} & $\begin{array}{l}4,15 \\
\end{array}$ & \begin{tabular}{l|l|l|l|}
194,22 \\
\end{tabular} & $\begin{array}{l}194,69 \\
\end{array}$ & 32,82 & 488,23 & 57,34 & 18,77 & 26,21 & \begin{tabular}{|l|l|l|}
146,03 \\
\end{tabular} & 78,52 & $\begin{array}{l}83,07 \\
\end{array}$ & 123,73 \\
\hline Bufo spinosus & 30TVL96 & 100,00 & 91,51 & 109,60 & 37,08 & 6245,60 & 262,68 & $-27,70$ & 290,38 & \begin{tabular}{|l|l|}
108,68 \\
\end{tabular} & \begin{tabular}{|l|l|}
175,71 \\
\end{tabular} & $\begin{array}{l}175,85 \\
\end{array}$ & \begin{tabular}{|l|l|}
17,98 \\
\end{tabular} & 575,53 & 68,11 & 25,49 & 23,55 & 174,62 & \begin{tabular}{|l|l|}
97,43 \\
\end{tabular} & 103,34 & 146,49 \\
\hline Bufo spinosus & 30TVL97 & 100,00 & 95,54 & 109,50 & 37,04 & 6239,01 & 266,14 & $-24,09$ & 290,22 & 113,26 & \begin{tabular}{|l|l|}
179,30 \\
\end{tabular} & \begin{tabular}{|l|l|}
179,44 \\
\end{tabular} & 21,46 & 556,16 & 65,73 & 24,58 & 23,43 & 168,52 & 94,61 & \begin{tabular}{|l|l|}
101,49 \\
\end{tabular} & 141,73 \\
\hline Bufo spinosus & 30TVL99 & 100,00 & 112,22 & 108,10 & 37,00 & 6224,92 & 279,54 & $-8,33$ & 287,87 & \begin{tabular}{ll|}
131,68 \\
\end{tabular} & $\begin{array}{l}194,76 \\
\end{array}$ & \begin{tabular}{|l|l|l|}
194,99 \\
\end{tabular} & 36,66 & 480,92 & $\begin{array}{l}56,55 \\
\end{array}$ & 20,60 & 23,92 & 144,70 & 82,34 & \begin{tabular}{l|l}
87,35 \\
\end{tabular} & 122,43 \\
\hline Bufo spinosus & \begin{tabular}{|l|l|}
$30 T V M 05$ \\
\end{tabular} & 100,00 & 112,95 & 107,09 & 37,28 & 5760,54 & 274,08 & $-8,37$ & 282,45 & 90,29 & 188,68 & 189,24 & 42,01 & \begin{tabular}{|l|l|}
491,35 \\
\end{tabular} & 55,07 & 20,69 & 25,91 & 150,16 & 76,06 & \begin{tabular}{|l|}
88,95 \\
\end{tabular} & 124,25 \\
\hline Bufo spinosus & 30TVM06 & 100,00 & & 105,86 & 37,31 & 5681,69 & 272,60 & $-6,31$ & \begin{tabular}{|l|l|}
278,90 \\
\end{tabular} & 86,09 & $\begin{array}{l}188,46 \\
1\end{array}$ & \begin{tabular}{l|l|}
188,94 \\
\end{tabular} & \begin{tabular}{l|l|l}
43,75 \\
\end{tabular} & 502,32 & 55,56 & 21,98 & 25,36 & \begin{tabular}{ll|l}
154,82 \\
\end{tabular} & 79,12 & 91,04 & 127,23 \\
\hline Bufo spinosus & \begin{tabular}{|l|l|} 
30TVM07 \\
\end{tabular} & 100,00 & 109,41 & 104,96 & \begin{tabular}{ll|}
37,58 \\
\end{tabular} & 5617,43 & 266,83 & $-9,09$ & \begin{tabular}{|l|l|}
275,92 \\
\end{tabular} & 81,92 & $\begin{array}{l}183,45 \\
\end{array}$ & \begin{tabular}{l|l|}
183,60 \\
\end{tabular} & 40,16 & 534,38 & 59,16 & 24,54 & 24,48 & $\begin{array}{l}164,72 \\
\end{array}$ & 86,46 & 96,09 & 135,46 \\
\hline Bufo spinosus & 30TVM08 & 100,00 & 111,80 & 102,96 & 37,8 & 5518,87 & 265,60 & $-4,60$ & 270,20 & $85, \mathrm{C}$ & \begin{tabular}{|l|l|l|l|}
184,38 \\
\end{tabular} & \begin{tabular}{|l|l|l|l}
184,43 & \\
\end{tabular} & 43, & 547,60 & 61,40 & 25,5 & 23,94 & $\begin{array}{l}170,85 \\
\end{array}$ & 90,28 & 97,61 & 139,69 \\
\hline Bufo spinosus & 30TVM09 & 100,00 & 111,43 & 101,12 & 37,86 & 5430,86 & 262,16 & $-2,76$ & 264,92 & 85,14 & \begin{tabular}{|l|l|}
182,99 \\
\end{tabular} & 183 & & 572,90 & 64,84 & 26,9 & 23,45 & 180,18 & $\begin{array}{l}96,46 \\
\end{array}$ & 100,11 & 147,05 \\
\hline Bufo spinosus & $\begin{array}{l}\text { 30TVM10 } \\
\end{array}$ & 100,00 & 116,10 & 106,11 & 36,93 & 6097,96 & 280,07 & $-4,93$ & 285,01 & 107,70 & $\begin{array}{ll}196,38 \\
\end{array}$ & 197,21 & 41,09 & 455,39 & 52,32 & 15,94 & 27,82 & \begin{tabular}{|l|l|}
139,40 \\
\end{tabular} & 67,54 & 77,48 & 117,18 \\
\hline Bufo spinosus & 30TVM11 & 100,00 & 114,51 & 106,49 & 37,00 & 6042,88 & 278,37 & $-6,55$ & \begin{tabular}{|l|}
284,92 \\
\end{tabular} & 115,84 & \begin{tabular}{|l|l|}
194,09 \\
\end{tabular} & \begin{tabular}{ll|l}
194,96 \\
\end{tabular} & $\begin{array}{l}40,25 \\
\end{array}$ & 462,86 & 53,24 & 16,96 & 27,29 & \begin{tabular}{|l|l|}
141,17 \\
\end{tabular} & 69,51 & 80,18 & 118,63 \\
\hline Bufo spinosus & 30TVM12 & 100,00 & 112,73 & 106,63 & 37,00 & 5981,48 & 276,42 & $-8,06$ & \begin{tabular}{|l|l|l|l}
284,48 \\
\end{tabular} & 123,04 & $\begin{array}{l}191,60 \\
1\end{array}$ & \begin{tabular}{ll|l}
192,36 \\
\end{tabular} & 39,31 & $\begin{array}{l}472,45 \\
\end{array}$ & 54,27 & 18,01 & 26,84 & \begin{tabular}{|l|l|}
143,71 \\
\end{tabular} & \begin{tabular}{ll|}
71,90 \\
\end{tabular} & 83,22 & 120,59 \\
\hline Bufo spinosus & $\begin{array}{l}\text { 30TVM15 } \\
\end{array}$ & 100,00 & 111,19 & 105,43 & 37,01 & 5789,24 & 271,59 & $-7,88$ & 279,47 & 82,72 & 187,42 & \begin{tabular}{l|l|}
187,72 \\
\end{tabular} & 39,7 & 500,25 & 55,85 & 21,35 & 25,09 & \begin{tabular}{ll|l}
151,78 \\
\end{tabular} & 79,31 & 90,31 & 126,99 \\
\hline Bufo spinosus & 30TVM16 & 100,00 & 111,97 & 104,21 & 37,01 & 5715,59 & 270 & $-6,01$ & 276,18 & 82,35 & \begin{tabular}{|l|l|}
186,99 \\
\end{tabular} & 187,33 & 41,24 & 511,24 & 56,15 & 22,66 & 24,54 & 155,95 & 82,46 & \begin{tabular}{|l|}
92,47 \\
\end{tabular} & 129,83 \\
\hline Bufo spinosus & 30TVM17 & 100,00 & 110 & 103,01 & 37,13 & 5638,93 & 266,86 & $-5,55$ & 272,42 & 81,7 & \begin{tabular}{|l|l|}
184,87 \\
\end{tabular} & \begin{tabular}{|l|l|}
185,04 \\
\end{tabular} & \begin{tabular}{|l|l|}
40,97 \\
\end{tabular} & 532,14 & 58,37 & 24,53 & 23,95 & \begin{tabular}{ll|}
163,16 \\
\end{tabular} & 87,60 & 94,81 & 135,47 \\
\hline Bufo spinosus & \begin{tabular}{|l|}
30 TVM19 \\
\end{tabular} & 100,00 & 106,62 & 100,06 & 37,50 & 5472,88 & 257,88 & $-5,60$ & 263,48 & \begin{tabular}{l|l|}
78,68 \\
\end{tabular} & 178,90 & 178,90 & 39,00 & 591,22 & 65,97 & 28,41 & 22,67 & \begin{tabular}{|l|l|}
183,39 \\
\end{tabular} & \begin{tabular}{|l|}
101,23 \\
\end{tabular} & \begin{tabular}{|l|}
103,29 \\
\end{tabular} & 152,37 \\
\hline Bufo spinosus & 30TVM21 & 100,00 & 117,80 & 105,10 & 36,95 & 6058,18 & 280,57 & $-2,33$ & 282,90 & 86,66 & \begin{tabular}{|l|l|l|}
197,29 \\
\end{tabular} & \begin{tabular}{|l|l|}
198,23 \\
\end{tabular} & 43,08 & 454,72 & 51,80 & 16,72 & 26,99 & \begin{tabular}{|l|l|}
138,47 \\
\end{tabular} & $\begin{array}{l}69,05 \\
\end{array}$ & 78,04 & 116,95 \\
\hline Bufo spinosus & 30TVM22 & 100,00 & 113,55 & 105,43 & 37,00 & 6006,30 & 276,36 & $-6,03$ & 282,39 & 118,28 & \begin{tabular}{ll|}
192,68 \\
\end{tabular} & 193, & 39,70 & 472,53 & 53,98 & 18,31 & 26,17 & \begin{tabular}{ll|}
142,92 \\
\end{tabular} & \begin{tabular}{|l|}
73,27 \\
\end{tabular} & 83,16 & 120,81 \\
\hline Bufo spinosus & \begin{tabular}{|l|l|}
$30 T V M 23$ \\
\end{tabular} & 100,00 & 109,67 & 105,44 & 37,00 & 5941 & 272,32 & $-9,19$ & 281,50 & 125,40 & \begin{tabular}{|l|l|}
188,09 \\
\end{tabular} & \begin{tabular}{|l|l|}
188,45 \\
\end{tabular} & 36,70 & 491,21 & 56,07 & 20,01 & 25,35 & 148,21 & 77,60 & 87,96 & 125,23 \\
\hline Bufo spinosus & $\begin{array}{l}\text { 30TVM24 } \\
\end{array}$ & 100,00 & 109,50 & 104,90 & 37,00 & 5880,93 & 271,14 & $-8,71$ & 279,85 & \begin{tabular}{l|l|}
106,82 \\
\end{tabular} & \begin{tabular}{|l|l|}
187,10 \\
\end{tabular} & $\begin{array}{ll}187,48 \\
\end{array}$ & \begin{tabular}{|l|l|}
37,17 \\
\end{tabular} & 498,61 & 56,35 & 20,91 & 25,01 & $\begin{array}{l}149,86 \\
\end{array}$ & $\begin{array}{ll}79,75 \\
\end{array}$ & 89,26 & 126,97 \\
\hline Bufo spinosus & $\begin{array}{l}30 T V M 25 \\
\end{array}$ & 100,00 & 111,49 & 103,89 & 37,00 & 5813,87 & 271,12 & $-5,72$ & 276,84 & 79,86 & \begin{tabular}{|l|l|}
187,97 \\
\end{tabular} & $\begin{array}{ll}188,22 \\
\end{array}$ & 39,69 & 501,24 & 55,78 & 21,67 & 24,59 & $\begin{array}{l}151,04 \\
1\end{array}$ & 81,29 & \begin{tabular}{l|l}
90,25 \\
\end{tabular} & 127,60 \\
\hline Bufo spinosus & 30TVM26 & 100,00 & 111,23 & 102,81 & 37,00 & 5753,47 & 269,03 & $-4,78$ & 273,81 & \begin{tabular}{|l|l|}
79,89 \\
\end{tabular} & \begin{tabular}{ll|l}
186,86 \\
\end{tabular} & \begin{tabular}{|l|l|}
186,97 \\
\end{tabular} & 39,92 & 514,61 & 56,32 & 23,10 & 23,89 & \begin{tabular}{ll|}
155,56 \\
\end{tabular} & \begin{tabular}{l|l}
84,85 \\
\end{tabular} & 92,01 & 131,14 \\
\hline Bufo spinosus & 30 & & 109 & 101, & 37,6 & 0 & 20 & $-5,01$ & 270 & 78, & 100 & 184 & 38, & 536,70 & 58,1 & 25,04 & 23,22 & 162, & $90,19 \mid$ & 95,39 & 137 \\
\hline Bufo spinosus & 30TVM28 & 100,00 & 106,77 & 100,34 & 37,02 & 5602,76 & 260,64 & $-5,78$ & \begin{tabular}{|l|l|}
266,42 \\
\end{tabular} & 76,42 & \begin{tabular}{ll|}
180,51 \\
\end{tabular} & 180,51 & 37,33 & 565,93 & 61,75 & 27,25 & 22,64 & \begin{tabular}{|l|l|}
172,47 \\
\end{tabular} & 96,81 & 98,44 & 145,12 \\
\hline Bufo spinosus & 30TVM29 & 100,00 & 103,68 & 98,99 & 37,13 & 5518,38 & 255,18 & $-6,58$ & 261,75 & 74,01 & \begin{tabular}{|l|l|}
176,60 \\
\end{tabular} & \begin{tabular}{|l|l|}
176,60 \\
\end{tabular} & 35,58 & 601,44 & 66,36 & 29,42 & 22,04 & $\begin{array}{l}184,45 \\
\end{array}$ & 104,62 & \begin{tabular}{|l|l|}
105,03 \\
\end{tabular} & 155,32 \\
\hline
\end{tabular}




\begin{tabular}{|c|c|c|c|c|c|c|c|c|c|c|c|c|c|c|c|c|c|c|c|c|c|}
\hline TAXON & UTM & $\mathrm{km} 2$ & B101 & B102 & $\mathrm{BIO3}$ & BIO4 & BIO5 & B106 & B107 & B108 & B109 & B1010 & BIO11 & BIO12 & B1013 & BIO14 & BIO15 & B1016 & B1017 & B1018 & B1019 \\
\hline Bufo spinosus & 30TVM30 & 100,00 & 113,54 & 104,84 & 36,68 & 6124,35 & 277,16 & $-5,93$ & 283,09 & 117,41 & 194,40 & 195,11 & 38,66 & 470,29 & 53,89 & 17,29 & 26,70 & 142,25 & 72,34 & 80,95 & 121,05 \\
\hline Bufo spinosus & 30TVM31 & 100,00 & 116,31 & 104,60 & \begin{tabular}{|l|}
36,68 \\
\end{tabular} & 6072,02 & 278,74 & $-3,36$ & 282,10 & 103,63 & 196,28 & 196,77 & 41,52 & 463,01 & 52,81 & 17,39 & 26,34 & 140,08 & 71,91 & 80,16 & 118,98 \\
\hline Bufo spinosus & 30TVM32 & 100,00 & 112,25 & 104,83 & \begin{tabular}{|l|l|}
36,97 \\
\end{tabular} & 6015,64 & 274,71 & $-6,50$ & 281,21 & 123,59 & 191,55 & 191,91 & 38,29 & 479,94 & 54,83 & 19,08 & 25,51 & 144,56 & 76,05 & 84,79 & 123,00 \\
\hline Bufo spinosus & 30TVM33 & 100,00 & 108,27 & 104,77 & 37,00 & 5964,49 & 270,72 & $-9,20$ & 279,92 & 126,45 & 187,12 & 187,39 & 35,21 & 498,45 & 56,83 & 20,76 & 24,88 & 149,79 & 80,56 & 89,25 & 127,45 \\
\hline Bufo spinosus & 30TVM34 & 100,00 & $\begin{array}{ll}106,97 \\
\end{array}$ & 104,04 & 37,00 & 5908,60 & 268,39 & $-9,57$ & 277,97 & \begin{tabular}{|l|}
121,96 \\
\end{tabular} & \begin{tabular}{|l|}
185,07 \\
\end{tabular} & 185,15 & 34,46 & 511,04 & 57,86 & 22,09 & 24,09 & 152,90 & 83,91 & 91,86 & 130,41 \\
\hline Bufo spinosus & 30TVM35 & 100,00 & 109,45 & 103,08 & 37,00 & 5851,53 & 269,04 & $-6,22$ & 275,25 & 91,42 & 186,56 & 186,61 & 37,19 & 509,54 & 56,90 & 22,61 & 23,77 & 151,84 & 84,68 & 91,23 & 130,31 \\
\hline Bufo spinosus & 30 TVM36 & 100,00 & 107,53 & 102,06 & 37,00 & 5790,03 & 265,81 & $-6,63$ & 272,44 & 79,54 & 183,78 & 183,81 & 35,90 & 526,94 & 58,12 & 24,18 & 23,20 & 157,04 & 88,99 & 92,82 & 134,78 \\
\hline \begin{tabular}{|l} 
Bufo spinosus \\
\end{tabular} & 30TVM37 & 100,00 & 106,62 & 100,78 & 37,00 & 5733,36 & 263,24 & $-6,06$ & 269,30 & 74,05 & 182,03 & 182,05 & 35,59 & 543,52 & 58,96 & 25,78 & 22,52 & 162,43 & $\begin{array}{l}03,38 \\
93\end{array}$ & 95,74 & 139,28 \\
\hline Bufo spinosus & 30TVM38 & 100,00 & 106,07 & 99,22 & 37,00 & 5654,97 & 260,06 & $-4,72$ & 264,78 & 73,92 & 180,35 & 180,35 & 35,83 & 565,09 & 60,68 & 27,50 & 22,06 & 170,20 & 98,48 & 99,15 & 145,37 \\
\hline Bufo spinosus & 30TVM39 & 100,00 & 102,91 & 97,88 & 37,01 & 5555,62 & 254,18 & $-5,56$ & 259,75 & 71,68 & 176,22 & 176,22 & 34,31 & 602,44 & 65,96 & 29,75 & 21,75 & 183,21 & 106,31 & 106,31 & 156,24 \\
\hline Bufo spinosus & 30TVM 40 & 100,00 & 113,46 & 104,42 & 36,52 & 6135,33 & 276,98 & $-5,46$ & 282,45 & 122,49 & 194,55 & 195,09 & 38,56 & 472,12 & 54,16 & 17,76 & 26,23 & 142,26 & 74,12 & 81,77 & 121,43 \\
\hline Bufo spinosus & 30TVM41 & 100,00 & 115,39 & 104,04 & 36,71 & 6081,07 & 277,89 & $-3,05$ & 280,94 & 108,31 & 195,63 & 195,91 & 40,63 & 467,45 & 53,33 & 18,07 & 25,81 & 140,75 & 74,19 & 81,43 & 120,23 \\
\hline \begin{tabular}{|l} 
Bufo spinosus \\
\end{tabular} & 30TVM42 & 100,00 & 111,55 & 104,21 & 36,99 & 6041,66 & 274,06 & $-6,11$ & 280,17 & 129,77 & 191,33 & 191,65 & 37,41 & 484,68 & 55,41 & 19,70 & 24,98 & 145,36 & 78,42 & 84,94 & 124,35 \\
\hline Bufo spinosus & 30 TVM 43 & 100,00 & 107,22 & 104,07 & 37,00 & 5987,94 & 269,58 & $-9,39$ & 278,97 & 125,28 & 186,45 & 186,49 & 33,98 & 506,27 & 57,85 & 21,60 & 24,22 & 151,88 & 83,48 & 90,24 & 129,68 \\
\hline Bufo spinosus & 30TVM44 & 100,00 & 105,16 & 103,69 & 37,00 & 5929,56 & 266,49 & $-10,45$ & 276,94 & 122,79 & 183,57 & 183,60 & 32,48 & 520,90 & 59,21 & 23,12 & 23,55 & 155,71 & 87,36 & 93,38 & 133,58 \\
\hline Bufo spinosus & 30TVM 45 & 100,00 & 106,31 & 102,81 & 37,00 & 5873,44 & 266,03 & $-8,04$ & 274,06 & 121,05 & 183,90 & 183,92 & 34,19 & 523,97 & 58,84 & 23,95 & 23,05 & 155,33 & 89,15 & 92,81 & 134,59 \\
\hline Bufo spinosus & 30TVM46 & 100,00 & 102,56 & 102,01 & 37,00 & 5811,44 & 261,32 & $-10,13$ & 271,45 & 111,71 & 179,48 & 179,48 & 31,14 & 548,59 & 61,10 & 26,01 & 22,41 & 161,84 & 94,85 & 95,70 & 141,36 \\
\hline Bufo spinosus & 30TVM47 & 100,00 & 103,58 & 100,47 & 37,00 & 5754,95 & 260,05 & $-7,40$ & 267,45 & 78,16 & 179,56 & 179,56 & 32,73 & 555,10 & 60,95 & 27,10 & 22,00 & 163,67 & 97,40 & 97,87 & 143,66 \\
\hline Bufo spinosus & 30TVM48 & 100,00 & 101,72 & 99,07 & \begin{tabular}{|l|l|}
37,07 \\
\end{tabular} & 5679,72 & 255,82 & $-7,16$ & 262,98 & 68,78 & 176,82 & 176,82 & 31,73 & 578,09 & 62,43 & 28,77 & 21,59 & 171,22 & 102,78 & 102,78 & 150,41 \\
\hline Bufo spinosus & 30TVM49 & 100,00 & 102,13 & 97,24 & 37,12 & 5571,20 & 252,62 & $-4,45$ & 257,07 & 69,98 & 175,98 & 175,98 & 33,61 & 602,61 & 65,54 & 29,99 & 21,43 & 181,30 & 108,10 & 108,10 & 158,06 \\
\hline Bufo spinosus & 30TVM50 & 100,00 & 110,55 & 104,77 & 36,84 & 6143,94 & 274,70 & $-7,78$ & 282,48 & 122,81 & 191,94 & 192,25 & 35,78 & 485,23 & 55,82 & 19,06 & 25,37 & 145,75 & 78,05 & 85,01 & 124,84 \\
\hline \begin{tabular}{|l} 
Bufo spinosus \\
\end{tabular} & 30TVM51 & 100,00 & 113,26 & 104,34 & 36,74 & 6101,44 & 276,36 & $-4,91$ & 281,27 & 126,94 & 193,83 & \begin{tabular}{|l|l|}
194,16 \\
\end{tabular} & 38,61 & \begin{tabular}{|l|l|}
476,93 \\
\end{tabular} & 54,66 & 19,11 & 25,11 & 142,94 & 77,42 & 84,06 & 122,55 \\
\hline Bufo spinosus & 30TVM52 & 100,00 & 110,15 & 104,31 & 37,00 & 6051,09 & 272,95 & $-7,05$ & 280,00 & 128,69 & 190,22 & 190,32 & 36,14 & 492,55 & 56,49 & 20,68 & 24,27 & 147,56 & 81,44 & 87,01 & 126,53 \\
\hline Bufo spinosus & 30TVM53 & 100,00 & 104,78 & 104,49 & 37,00 & 5998,73 & 267,37 & $-11,24$ & 278,61 & 122,68 & 184,23 & 184,25 & 31,62 & 519,89 & 59,55 & 22,90 & 23,56 & 155,87 & 87,63 & 93,27 & 133,73 \\
\hline Bufo spinosus & 30TVM54 & 100,00 & 99,64 & 104,28 & 37,01 & 5928,96 & 261,78 & $-14,93$ & 276,71 & 116,67 & 178,42 & 178,42 & 27,65 & 550,25 & 62,66 & 25,36 & 22,82 & 164,55 & 94,37 & 96,50 & 141,87 \\
\hline Bufo spinosus & 30TVM55 & 100,00 & 101,93 & 103,01 & 37,03 & 5877,10 & 262,16 & $-11,48$ & 273,65 & 118,18 & 179,87 & 179,87 & 30,22 & 547,68 & 61,75 & 25,84 & 22,42 & 162,52 & 95,08 & 96,40 & 141,54 \\
\hline Bufo spinosus & 30TVM56 & 100,00 & 97,36 & 102,37 & 37,11 & 5809,75 & 256,47 & $\begin{array}{l}-1,140 \\
-14,40\end{array}$ & 270,87 & $\mid \begin{array}{l}\mid 113,70 \\
113\end{array}$ & $\begin{array}{l}174,64 \\
170\end{array}$ & $\begin{array}{l}174,64 \\
170\end{array}$ & 26,77 & 579,32 & $\begin{array}{l}64,67 \\
6\end{array}$ & 28,43 & 21,82 & \begin{tabular}{|l|}
170,90 \\
\end{tabular} & \begin{tabular}{|l|}
102,09 \\
\end{tabular} & \begin{tabular}{r|}
102,18 \\
\end{tabular} & 150,45 \\
\hline Bufo spinosus & 30TVM57 & 100,00 & 98,61 & 100,84 & 37,11 & 5748,41 & 255,27 & $-11,40$ & 266,66 & 106,82 & 175,03 & 175,03 & 28,49 & 584,84 & 64,45 & 29,29 & 21,51 & 171,20 & 104,24 & 104,24 & 152,75 \\
\hline Bufo spinosus & 30TVM58 & 100,00 & 98,86 & 99,24 & 37,44 & 5667,41 & 252,48 & $-9,10$ & 261,58 & 69,68 & 174,25 & 174,25 & 29,75 & 600,95 & 65,14 & 30,32 & 21,19 & 176,48 & 108,41 & 108,41 & 158,28 \\
\hline Bufo spinosus & 30TVM59 & 100,00 & 99,00 & 97,41 & 37,52 & 5574,17 & 249,40 & $-6,82$ & 256,22 & 66,52 & 173,22 & 173,22 & 31,22 & 624,74 & 66,83 & 31,49 & 21,03 & 185,39 & 113,75 & 113,75 & 166,05 \\
\hline Bufo spinosus & 30TVM60 & 100,00 & 111,15 & 105,20 & 36,93 & 6157,40 & 275,67 & $-7,15$ & 282,81 & 129,52 & 192,69 & 192,96 & 36,12 & 484,53 & 55,92 & 19,53 & 24,88 & 145,21 & 79,38 & 85,17 & 124,46 \\
\hline Bufo spinosus & 30TVM61 & 100,00 & 110,19 & 105,12 & 37,00 & 6111,20 & 274,16 & $-7,155$ & \begin{tabular}{|l|}
281,71 \\
281
\end{tabular} & \begin{tabular}{|l|l|}
128,98 \\
\end{tabular} & 191,00 & $\begin{array}{l}191,29 \\
\end{array}$ & $\begin{array}{ll}30,12 \\
35,64\end{array}$ & \begin{tabular}{|l|}
494,30 \\
491,30
\end{tabular} & $\begin{array}{l}56,61 \\
56,6\end{array}$ & 20,54 & 24,34 & $\begin{array}{l}147,28 \\
147\end{array}$ & 81,72 & $\begin{array}{l}0,11 \\
86,87 \\
\end{array}$ & 126,25 \\
\hline Bufo spinosus & 30TVM62 & 100,00 & 108,38 & 105,01 & 37,00 & 6062,17 & 271,86 & $-8,63$ & 280,49 & 126,90 & 188,79 & 188,91 & 34,46 & 502,86 & 57,81 & 21,81 & 23,59 & 150,64 & 84,96 & 91,00 & 129,31 \\
\hline Bufo spinosus & 30TVM63 & 100,00 & 101,94 & 105,06 & 37,04 & 5997,43 & 265,26 & $-13,73$ & 278,99 & 119,57 & 181,64 & 181,66 & 29,21 & 537,35 & 61,60 & 24,48 & 22,84 & 161,06 & 92,35 & 96,47 & 138,56 \\
\hline Bufo spinosus & 30TVM64 & 100,00 & 95,36 & 104,86 & 37,20 & 5925,16 & 258,21 & $-18,69$ & 276,90 & 111,96 & 174,48 & 174,49 & 24,00 & 577,95 & 65,75 & 27,61 & 22,01 & 172,62 & 101,03 & 102,07 & 149,71 \\
\hline Bufo spinosus & 30TVM65 & 100,00 & 99,66 & 103,47 & 37,19 & 5877,67 & 260,07 & $-13,36$ & 273,44 & 116,60 & 177,81 & 177,81 & 28,24 & 565,63 & 63,77 & 27,44 & 21,85 & 167,67 & 99,91 & 100,37 & 146,89 \\
\hline Bufo spinosus & 30TVM66 & 100,00 & $\begin{array}{l}96,00 \\
96,82\end{array}$ & 102,54 & 37,51 & 5810,34 & 255,69 & $\begin{array}{l}-14,50 \\
-14,68 \\
\end{array}$ & \begin{tabular}{|l|}
270,37 \\
\end{tabular} & \begin{tabular}{|l|}
112,97 \\
120
\end{tabular} & $\begin{array}{l}174,30 \\
174\end{array}$ & $\begin{array}{l}174,30 \\
174\end{array}$ & $\begin{array}{l}20,44 \\
26,32\end{array}$ & $\begin{array}{l}030,05 \\
592,52\end{array}$ & $\begin{array}{ll}65,98 \\
65\end{array}$ & $\mid 29,71$ & $\begin{array}{ll}21,05 \\
21,25\end{array}$ & $\begin{array}{l}174,32 \\
\end{array}$ & \begin{tabular}{|c|}
105,92 \\
105
\end{tabular} & $\begin{array}{l}105,92 \\
10,9\end{array}$ & 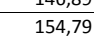 \\
\hline Bufo spinosus & 30TVM67 & 100,00 & 85,73 & 102,20 & 37,72 & 5724,80 & 243,80 & $-23,75$ & 267,55 & 100,12 & 162,63 & 162,63 & 17,15 & 672,44 & 73,45 & 35,13 & 20,31 & 195,63 & 121,75 & 121,75 & 177,26 \\
\hline Bufo spinosus & 30TVM68 & 100,00 & 93,86 & 100,04 & 37,83 & 5660,56 & 248,30 & $-14,12$ & 262,42 & 72,58 & 169,56 & 169,56 & 25,44 & 641,77 & 69,19 & 33,05 & 20,53 & 186,60 & 117,08 & 117,08 & 170,02 \\
\hline Bufo spinosus & 30TVM69 & 100,00 & 98,16 & 97,64 & 37,81 & 5565,22 & 248,23 & $-7,76$ & 255,99 & 65,35 & 172,37 & 172,37 & 30,50 & 646,26 & 68,22 & 32,82 & 20,34 & 190,43 & 118,83 & 118,83 & 172,83 \\
\hline Bufo spinosus & 30TVM72 & 100,00 & 106,10 & 105,89 & 37,01 & 6061,74 & 270,43 & $-10,91$ & 281,34 & 124,35 & 186,61 & 186,65 & 32,47 & 516,80 & 59,62 & 23,21 & 23,02 & 154,97 & 89,04 & 93,36 & 133,00 \\
\hline \begin{tabular}{|l} 
Bufo spinosus \\
\end{tabular} & 30TVM73 & 100,00 & 98,56 & 105,98 & 37,12 & 5997,22 & 262,84 & $-17,20$ & 280,04 & 115,77 & 178,54 & 178,56 & 26,25 & 559,55 & 64,18 & 26,39 & 22,13 & 167,59 & 98,07 & 99,80 & 144,61 \\
\hline Bufo spinosus & 30TVM74 & 100,00 & 100,22 & 105,01 & 37,27 & 5943,49 & 262,73 & $-14,36$ & 277,09 & 117,38 & 179,39 & 179,40 & 28,16 & 559,96 & 63,73 & 26,99 & 21,78 & 166,78 & 99,11 & 100,65 & 145,18 \\
\hline Bufo spinosus & 30TVM75 & 100,00 & 100,45 & 103,88 & 37,25 & 5882,88 & 261,01 & $-12,85$ & 273,87 & 117,54 & 178,77 & 178,77 & 28,93 & 569,77 & 64,18 & 28,18 & 21,36 & 168,50 & 102,01 & 102,59 & 148,42 \\
\hline Bufo spinosus & 30TVM76 & 100,00 & 87,60 & 103,64 & 37,9 & 5792,22 & 247,70 & $-23,53$ & 271,22 & 102,96 & 165,40 & 165,40 & 18,18 & 656,62 & 72,67 & 34,2 & 20,29 & 192,43 & 119,18 & 19,18 & 172,73 \\
\hline Bufo spinosus & 30TVM77 & 100,00 & 77,65 & 102,83 & 37,99 & 5712,01 & 236,49 & \begin{tabular}{|l|l|}
$-31,63$ \\
\end{tabular} & 268,12 & \begin{tabular}{|l|l|}
91,60 \\
90
\end{tabular} & 154,71 & 154,71 & \begin{tabular}{|l|l|}
9,76 \\
9
\end{tabular} & \begin{tabular}{|l|l|}
735,33 \\
\end{tabular} & 79,78 & 39,36 & 19,46 & 213,12 & $\begin{array}{l}134,59 \\
\end{array}$ & 134,59 & 195,12 \\
\hline \begin{tabular}{|l} 
Bufo spinosus \\
\end{tabular} & 30TVM78 & 100,00 & 88,24 & 101,01 & 38,00 & 5655,53 & 243,54 & $-19,99$ & 263,53 & 69,76 & 164,02 & 164,02 & 20,13 & 687,79 & 73,85 & 36,12 & 19,78 & 198,62 & 126,73 & 126,73 & $\begin{array}{l}183,08 \\
\end{array}$ \\
\hline Bufo spinosus & 30TVM79 & 100,00 & 98,67 & 98,00 & 37,93 & 5559,87 & 248,47 & $-7,68$ & 256,15 & 64,45 & 172,70 & 172,72 & 31,04 & 659,48 & 69,32 & 33,73 & 19,95 & 193,11 & $\mid 122,43$ & 122,43 & 177,13 \\
\hline Bufo spinosus & 30TVM80 & 100,00 & 110,79 & 107,04 & 37,00 & 6174,34 & 276,78 & $-8,55$ & 285,32 & 129,90 & 192,57 & 192,73 & 35,75 & 489,78 & 57,03 & 21,07 & 23,77 & 146,94 & 83,42 & 88,50 & 125,37 \\
\hline Bufo spinosus & 30TVM81 & 100,00 & 107,37 & 107,21 & 37,07 & 6121,69 & 273,23 & $-11,05$ & 284,28 & 125,88 & 188,52 & 188,66 & 33,26 & 509,37 & 59,19 & 22,79 & 23,06 & 152,96 & 88,11 & 93,40 & 130,80 \\
\hline Bufo spinosus & 30TVM8 & 100,00 & 101 & 107,39 & 37,35 & \begin{tabular}{|l}
6056,29 \\
606
\end{tabular} & 267,30 & $-15,85$ & \begin{tabular}{|l|}
283,15 \\
283,15
\end{tabular} & \begin{tabular}{|l|}
119,08 \\
119,0
\end{tabular} & $\begin{array}{l}100,32,2 \\
182,21\end{array}$ & $\begin{array}{l}180,000 \\
182,22 \\
\end{array}$ & $\begin{array}{l}30,26 \\
28,29\end{array}$ & \begin{tabular}{|l|l|}
543,64 \\
\end{tabular} & | & 25,53 & 22,24 & $\begin{array}{l}163,19 \\
163\end{array}$ & $\begin{array}{l}\mid 0,11 \\
95,59 \\
\end{array}$ & $\begin{array}{l}30,404 \\
99,04\end{array}$ & $\begin{array}{l}140,00 \\
140,21\end{array}$ \\
\hline Bufo spinosus & 30TVM83 & 100,00 & 98,03 & 106,97 & 37,55 & 6000,19 & 263,21 & $-18,06$ & 281,27 & 115,23 & 178,17 & 178,18 & 25,65 & 568,01 & 65,21 & 27,55 & 21,58 & 169,93 & 101,13 & 104,28 & 147,14 \\
\hline Bufo spinosus & 30TVM84 & 100,00 & 97,05 & 106,23 & \begin{tabular}{|l|l|}
37,68 \\
\end{tabular} & 5944,40 & 260,66 & $-17,95$ & 278,60 & 114,03 & 176,37 & 176,37 & 25,10 & 583,63 & 66,38 & 29,07 & 21,05 & $\begin{array}{l}173,67 \\
\end{array}$ & 105,01 & 107,08 & 151,81 \\
\hline Bufo spinosus & 30TVM 85 & 100,00 & 87,08 & 105,51 & 37,98 & 5859,40 & 249,67 & $-25,81$ & 275,48 & 102,62 & 165,79 & 165,79 & 16,95 & 654,34 & 73,23 & 34,11 & 20,19 & 193,01 & 119,14 & 119,61 & 171,68 \\
\hline Bufo spinosus & 30TVM86 & 100,00 & 88,57 & 104,39 & 38,00 & 5798,97 & 249,07 & $-23,21$ & 272,28 & 103,98 & 166,36 & 166,36 & 18,99 & 659,17 & 72,95 & 34,65 & 19,81 & 193,02 & 120,91 & 120,91 & 173 \\
\hline Bufo spinosus & \begin{tabular}{|c|}
30 TVM 87 \\
\end{tabular} & $\begin{array}{l}100,00 \\
\end{array}$ & $\begin{array}{l}0,59,26 \\
69,2\end{array}$ & $\begin{array}{l}103,39 \\
103,39\end{array}$ & 38,00 & 5696,11 & 228,73 & $\begin{array}{l}-29,21 \\
-39,70 \\
\end{array}$ & \begin{tabular}{|l|}
268,43 \\
\end{tabular} & $\begin{array}{l}2,350 \\
82,56\end{array}$ & \begin{tabular}{|l|l}
146,46 \\
146
\end{tabular} & \begin{tabular}{|l|l}
146,46 \\
146
\end{tabular} & $\mid \frac{\mid 0,39}{2,19}$ & \begin{tabular}{|l|}
800,97 \\
\end{tabular} & $\begin{array}{l}2,35 \\
86,39 \\
\end{array}$ & \begin{tabular}{|l|l|}
43,730 \\
43
\end{tabular} & $\begin{array}{l}11,01 \\
18,76\end{array}$ & $\begin{array}{l}150,0<4 \\
231,33 \\
\end{array}$ & \begin{tabular}{|l|}
148,06 \\
140
\end{tabular} & \begin{tabular}{|l|}
148,06 \\
140,
\end{tabular} & 213,46 \\
\hline Bufo spinosus & 30TVM88 & 100,00 & 90,20 & 101,26 & 37,99 & 5654,98 & 245,08 & $-18,43$ & 263,51 & 76,82 & 165,95 & 165,95 & 22,02 & 690,99 & 74,06 & 36,42 & 19,29 & 199,16 & 128,53 & 128,53 & 184,51 \\
\hline Bufo spinosus & 30TVM89 & 100,00 & 103,03 & 97,94 & 37,92 & 5556,56 & 251,82 & $-4,12$ & 255,95 & 65,56 & 176,62 & 176,79 & 35,10 & 653,00 & 68,64 & 33,29 & 19,55 & 191,01 & 122,43 & 122,43 & 175,85 \\
\hline Bufo spinosus & 30TVM90 & 100,00 & 109,67 & 108,41 & 37,01 & 6175,28 & 276,93 & $-10,38$ & 287,30 & 128,80 & 191, & 191 & 34,72 & 497,12 & 58,27 & 22,23 & 23,19 & 149,60 & 86,38 & 91,22 & $\begin{array}{ll}127,03 \\
\end{array}$ \\
\hline Bufo spinosus & 30TVM91 & 100,00 & 105,88 & 108,52 & 37,18 & 6119,48 & 273,03 & $-13,45$ & 286,48 & 124,41 & 187,18 & 187,24 & 31,70 & 520,76 & 60,75 & 24,19 & 22,38 & 156,58 & 91,88 & 96,24 & 133,75 \\
\hline
\end{tabular}




\begin{tabular}{|c|c|c|c|c|c|c|c|c|c|c|c|c|c|c|c|c|c|c|c|c|c|}
\hline TAXON & UTM & $\mathrm{km} 2$ & B101 & B102 & $\mathrm{BIO3}$ & B104 & B105 & B106 & B107 & B108 & 8109 & BIO10 & BIO11 & BIO12 & B1013 & BIO14 & BIO15 & B1016 & B1017 & B1018 & B1019 \\
\hline Bufo spinosus & 30TVM92 & 100,00 & 100,07 & 108,72 & 37,73 & 6058,65 & 267,23 & $-17,95$ & 285,18 & 117,93 & 180,93 & 180,94 & 27,00 & 556,12 & 64,39 & 26,95 & 21,52 & 166,86 & 99,45 & 103,55 & 143,63 \\
\hline Bufo spinosus & 30TVM93 & 100,00 & 95,84 & 108,37 & \begin{tabular}{|l|l|}
37,98 \\
\end{tabular} & 6002,07 & 262,09 & $-20,98$ & 283,07 & 112,94 & 176,07 & $\begin{array}{l}176,09 \\
\end{array}$ & 23,52 & 587,12 & 67,38 & 29,36 & 20,87 & 175,48 & 106,11 & 108,37 & 152,44 \\
\hline Bufo spinosus & 30TVM94 & 100,00 & 93,69 & 107,52 & 37,99 & 5940,38 & 258,53 & $-21,79$ & 280,32 & \begin{tabular}{|l|l|}
110,41 \\
\end{tabular} & \begin{tabular}{|l|}
173,17 \\
\end{tabular} & 173,17 & 22,16 & 609,52 & 69,25 & 31,33 & 20,35 & 181,15 & 111,26 & 112,79 & 159,04 \\
\hline Bufo spinosus & 30TVM95 & 100,00 & 73,65 & 106,18 & 38,00 & 5824,96 & 237,28 & $-38,38$ & 275,67 & 87,98 & 152,53 & 152,53 & 4,92 & 747,79 & 82,90 & 40,55 & 19,10 & 219,58 & 137,90 & 137,99 & 197,28 \\
\hline Bufo spinosus & 30TVM96 & 100,00 & 83,40 & 105,32 & 38,00 & 5793,34 & 244,72 & $-28,48$ & 273,21 & 98,52 & 161,39 & 161,39 & 14,36 & 701,13 & 77,27 & 37,58 & 19,15 & 204,79 & 129,98 & 129,98 & 185,41 \\
\hline Bufo spinosus & 30TVM97 & 100,00 & 71,52 & 103,63 & 38,00 & 5701,55 & 230,87 & $-37,93$ & 268,80 & 85,05 & 148,69 & 148,69 & 4,16 & 797,59 & 86,10 & 43,69 & 18,42 & 230,23 & 148,77 & 148,77 & 212,75 \\
\hline Bufo spinosus & 30TVM98 & 100,00 & 91,12 & 101,98 & 38,00 & 5661,91 & 246,27 & $-18,21$ & \begin{tabular}{ll|l}
264,47 \\
\end{tabular} & 84,41 & $\begin{array}{ll}166,85 \\
\end{array}$ & 166,85 & 22,79 & 696,98 & 74,72 & 36,97 & 18,87 & 200,20 & 130,80 & 130,80 & 186,20 \\
\hline \begin{tabular}{|l} 
Bufo spinosus \\
\end{tabular} & 30TVM99 & 100,00 & 102,76 & 98,85 & 37,97 & 5568,33 & 252,12 & $\begin{array}{r}4,5,18 \\
-5,\end{array}$ & 257,30 & 60,80 & $\begin{array}{l}176,65 \\
\end{array}$ & \begin{tabular}{|l|}
176,71 \\
\end{tabular} & 34,77 & 662,93 & 69,71 & 34,25 & 19,01 & $\begin{array}{l}192,52 \\
\end{array}$ & 125,39 & 125,39 & 178,41 \\
\hline Bufo spinosus & 30TVNOO & 100,00 & 108,50 & 99,59 & 37,93 & 5349,25 & 256,73 & $-3,32$ & 260,05 & 82,66 & 179,20 & 179,20 & 42,52 & 609,08 & 69,48 & 29,05 & 23,06 & 192,55 & 104,69 & 105,56 & 157,47 \\
\hline Bufo spinosus & 30TVN02 & 100,00 & 94,93 & 97,31 & 38,01 & 5225,65 & 240,01 & $-12,12$ & 252,13 & 69,28 & 164,63 & 164,63 & 31,41 & 724,43 & 82,86 & 36,32 & 21,84 & 228,54 & 129,62 & 129,62 & 191,08 \\
\hline Bufo spinosus & 30TVN03 & 100,00 & 98,08 & 94,63 & 38,07 & 5091,35 & 238,07 & $-6,49$ & 244,56 & 73,30 & 165,73 & 165,91 & 36,01 & 748,90 & 86,70 & 37,29 & 21,95 & 239,08 & 135,73 & 135,79 & 199,06 \\
\hline Bufo spinosus & 30TVN06 & 100,00 & 93,48 & 88,85 & 38,40 & 4816,21 & 223,41 & $-4,68$ & 228,10 & 70,61 & 156,37 & 158,01 & 35,10 & 882,73 & 103,43 & 44,41 & 22,11 & 285,17 & 162,07 & 165,37 & 240,34 \\
\hline \begin{tabular}{|l} 
Bufo spinosus \\
\end{tabular} & 30TVN12 & 100,00 & 97,30 & 95,50 & 38,00 & 5209,78 & 240,46 & $-8,07$ & 248,53 & 71,01 & 166,72 & 166,72 & 33,68 & 720,35 & 81,96 & 35,95 & 21,62 & 226,56 & 129,66 & 129,66 & 190,89 \\
\hline Bufo spinosus & 30TVN13 & 100,00 & 100,03 & 92,71 & 37,99 & 5074,66 & 237,86 & $-3,24$ & 241,09 & 74,87 & 167,07 & 167,61 & 37,92 & 750,81 & 86,35 & 37,08 & 21,81 & 239,05 & 136,11 & 136,80 & 200,91 \\
\hline Bufo spinosus & 30TVN14 & 100,00 & 98,48 & 90,81 & 38,00 & 4978,57 & 232,98 & $-2,46$ & 235,44 & 73,93 & 163,50 & 164,93 & 37,72 & 795,52 & 91,84 & 39,50 & 21,81 & 254,44 & 145,48 & 146,70 & 214,80 \\
\hline Bufo spinosus & 30TVN15 & 100,00 & 96,76 & 89,05 & 38,07 & 4883,89 & 227,97 & $-2,11$ & 230,09 & 73,03 & 160,45 & 162,12 & 37,23 & 841,59 & 97,63 & 41,88 & 21,90 & 270,43 & 153,84 & 156,64 & 228,98 \\
\hline Bufo spinosus & 30TVN17 & 100,00 & 113,51 & 79,24 & 38,01 & 4450,67 & 227,75 & 21,95 & 205,80 & 93,08 & 170,64 & 172,86 & 58,77 & 894,42 & 107,47 & 41,87 & 24,48 & 299,30 & 157,15 & 170,29 & 248,74 \\
\hline Bufo spinosus & 30TVN22 & 100,00 & 98,18 & 94,05 & \begin{tabular}{|l|l|}
37,97 \\
\end{tabular} & 5211,92 & 239,98 & $-5,71$ & 245,69 & 71,22 & \begin{tabular}{ll|l}
167,44 \\
\end{tabular} & 167,58 & 34,47 & 722,47 & 81,64 & 35,99 & 21,27 & 226,16 & 130,84 & 130,90 & 192,53 \\
\hline Bufo spinosus & 30TVN23 & 100,00 & 97,04 & 91,99 & \begin{tabular}{|l|l|}
37,98 \\
\end{tabular} & 5098,92 & 234,97 & $-4,75$ & 239,73 & 70,94 & 164,45 & 165,11 & 34,86 & 768,87 & 87,30 & 38,34 & 21,30 & 242,35 & 140,32 & 140,99 & 207,25 \\
\hline Bufo spinosus & 30TVN24 & 100,00 & 101,35 & 88,78 & 37,93 & 4946,85 & 233,22 & 1,82 & 231,41 & 76,64 & 165,72 & 167,33 & 40,81 & 798,72 & 91,63 & 39,16 & 21,85 & 255,50 & 144,76 & 147,93 & 217,80 \\
\hline Bufo spinosus & 30TVN25 & 100,00 & 99,07 & 87,23 & 38,01 & 4861,28 & 227,97 & 1,48 & 226,50 & 75,07 & 162,11 & 163,98 & 39,72 & 847,18 & 97,49 & 41,77 & 21,85 & 271,79 & 153,74 & 158,29 & 232,81 \\
\hline Bufo spinosus & 30 TVN26 & 100,00 & 99,52 & 84,82 & 38,02 & 4741,43 & 224,38 & 4,32 & 220,06 & 76,76 & 160,99 & 163,08 & 41,78 & 890,45 & 103,09 & 43,70 & 22,14 & 287,85 & 160,75 & 167,71 & 246,91 \\
\hline Bufo spinosus & 30TVN27 & 100,00 & 107,99 & 79,62 & $\begin{array}{l}37,86 \\
\end{array}$ & 4511,05 & 224,35 & 16,62 & 207,73 & 86,80 & 166,03 & 168,27 & 52,73 & 923,58 & 108,73 & 43,79 & 23,61 & 305,11 & 163,16 & 175,73 & 259,52 \\
\hline Bufo spinosus & 30TVN28 & 100,00 & $\begin{array}{lll}122,87 \\
\end{array}$ & 72,20 & 37,51 & 4186,08 & 226,96 & 37,08 & 189,88 & 104,00 & 175,99 & 178,64 & 71,12 & 948,32 & 114,92 & 42,33 & 26,21 & 323,75 & 161,69 & 182,72 & 270,20 \\
\hline Bufo spinosus & 30TVN30 & 100,00 & 99,40 & 96,63 & 37,33 & 5448,19 & 247,74 & $-7,01$ & 254,75 & 69,27 & 171,72 & 171,72 & 32,52 & 648,39 & 71,83 & 32,34 & 21,29 & 198,45 & 115,93 & 115,93 & 170,14 \\
\hline Bufo spinosus & 30TVN31 & 100,00 & 96,78 & 95,23 & 37,79 & 5345,47 & 242,09 & $-7,86$ & 249,95 & 67,83 & 167,90 & 167,90 & 31,47 & 694,26 & 77,24 & 34,87 & 21,03 & 213,68 & 125,51 & 125,51 & 184,37 \\
\hline Bufo spinosus & 30TVN32 & 100,00 & 98,01 & 93,01 & 37,90 & 5220,81 & 238,88 & $-4,56$ & 243,45 & 70,10 & $\begin{array}{l}167,05 \\
\end{array}$ & 167,62 & 34,19 & 729,61 & 81,65 & 36,42 & 21,10 & 226,93 & 132,83 & 133,19 & 196,12 \\
\hline Bufo spinosus & 30TVN33 & 100,00 & 99,88 & 90,41 & 37,83 & 5087,54 & 235,72 & $-0,61$ & 236,32 & 73,30 & 166,10 & 167,68 & 37,62 & 768,08 & 86,51 & 37,99 & 21,23 & 241,69 & 139,82 & 141,61 & 209,01 \\
\hline Bufo spinosus & 30TVN34 & 100,00 & 102,11 & 87,56 & 37,89 & 4943,68 & 232,54 & 3,78 & 228,76 & 76,89 & 166,15 & 168,01 & 41,55 & 807,40 & 91,67 & 39,47 & 21,58 & 257,15 & 145,83 & 150,27 & 222,41 \\
\hline Bufo spinosus & 30 TVN35 & 100,00 & 100,09 & 85,70 & 37,99 & 4839,53 & 227,32 & 3,92 & 223,40 & 75,82 & 162,73 & 164,78 & 41,04 & 860,57 & 98,02 & 42,14 & 21,75 & 275,25 & 155,33 & 161,40 & 239,24 \\
\hline Bufo spinosus & 30 TVN36 & 100,00 & 98,50 & 83,98 & 37,94 & 4741,51 & 222,92 & 4,39 & 218,54 & 75,08 & 159,90 & 161,99 & 40,86 & 910,65 & 104,03 & 44,72 & 21,92 & 292,47 & 164,27 & 171,98 & 255,13 \\
\hline Bufo spinosus & $\begin{array}{l}30 \text { TVN37 } \\
\end{array}$ & 100,00 & 106,25 & 78,95 & 37,64 & - 4519,87 & 222,60 & \begin{tabular}{|c|}
4,351 \\
15,81
\end{tabular} & 206,80 & 83,86 & 164,41 & \begin{tabular}{|l|l|}
166,69 \\
\end{tabular} & $\begin{array}{ll}51,04 \\
51,04\end{array}$ & $\begin{array}{l}948,49 \\
\end{array}$ & 110,55 & 45,01 & 23,36 & 311,21 & 167,55 & $\begin{array}{l}180,65 \\
180\end{array}$ & 269,49 \\
\hline Bufo spinosus & 30TVN40 & 100,00 & 100,81 & 95,65 & \begin{tabular}{|l|l|l|l}
37,49 \\
\end{tabular} & 5453,55 & 247,77 & $-3,97$ & 251,74 & 69,92 & 173,08 & 173,21 & 33,90 & 645,41 & 70,98 & 32,20 & 21,06 & 196,42 & 116,78 & 116,78 & $\begin{array}{ll}171,18 \\
\end{array}$ \\
\hline Bufo spinosus & 30TVN41 & 100,00 & 97,97 & 94,24 & 37,84 & 5348,75 & 242,03 & $-5,08$ & 247,11 & 68,22 & 168,75 & 169,27 & 32,69 & 695,17 & 76,59 & 34,88 & 20,91 & 212,73 & 126,85 & 126,95 & 186,38 \\
\hline Bufo spinosus & 30 TVN42 & 100,00 & 94,73 & 92,92 & 37,97 & 5248,90 & 235,92 & $-6,76$ & 242,68 & 66,10 & 163,77 & 164,82 & 30,91 & 748,93 & 82,50 & 37,81 & 20,56 & 230,02 & 137,79 & 137,95 & 202,92 \\
\hline Bufo spinosus & 30TVN43 & 100,00 & 94,96 & 90,73 & 37,93 & 5126,11 & 232,01 & $-4,57$ & 236,57 & 67,53 & 161,78 & 163,49 & 32,63 & 793,42 & 87,77 & 39,94 & 20,51 & 245,95 & 145,83 & 147,30 & 217,37 \\
\hline \begin{tabular}{|l} 
Bufo spinosus \\
\end{tabular} & 30TVN44 & 100,00 & 99,73 & 87,26 & 37,82 & 4960,01 & 230,43 & 2,49 & 227,94 & 73,85 & 164,09 & 165,94 & 39,32 & 829,36 & 92,90 & 40,81 & 21,28 & 261,53 & 150,31 & 155,01 & 230,64 \\
\hline Bufo spinosus & 30TVN45 & 100,00 & 103,27 & 83,95 & 37,82 & 4805,38 & 228,38 & 8,55 & 219,83 & 78,79 & 165,41 & 167,48 & 44,52 & 868,29 & 98,77 & 41,92 & 21,89 & 277,71 & 155,42 & 163,40 & 244,62 \\
\hline Bufo spinosus & 30TVN46 & 100,00 & 101,68 & 82.19 & $37,70 \mid$ & 4705,55 & 224,07 & 8,78 & 215,30 & 78,10 & 162,36 & \begin{tabular}{|l|l|}
164,63 \\
\end{tabular} & 44,20 & 919,65 & 105,53 & 44,48 & 22.03 & 295,47 & 164,43 & \begin{tabular}{|l|l|}
174,03 \\
\end{tabular} & 261,18 \\
\hline Bufo spinosus & 30TVN47 & 100,00 & 84,44 & 84,65 & \begin{tabular}{|l|l|}
37,98 \\
\end{tabular} & 4773,45 & 211,57 & $-8,16$ & 219,73 & 50,17 & 146,53 & 148,96 & 27,38 & 1012,71 & 114,26 & 51,64 & 20,71 & 319,08 & 186,35 & 192,27 & 286,46 \\
\hline Bufo spinosus & 30TVN48 & 100,00 & 94,57 & 79,63 & 37,77 & 4553,22 & 213,35 & 5,26 & 208,09 & 65,35 & 153,28 & 155,92 & 39,71 & 1037,07 & 120,07 & 50,90 & 22,20 & 334,28 & 186,41 & 198,12 & 297,73 \\
\hline \begin{tabular}{|l} 
Bufo spinosus \\
\end{tabular} & 30TVN49 & 100,00 & 121,90 & 67,96 & 36,93 & 4068,85 & 221,70 & 40,18 & 181,52 & 103,62 & 173,25 & 176,26 & 71,89 & 1048,45 & 128,75 & 46,1 & 26,42 & 356,67 & \begin{tabular}{|l|l|}
176,45 \\
\end{tabular} & 202,64 & 309,96 \\
\hline Bufo spinosus & 30TVN50 & 100,00 & 100,50 & 95,25 & \begin{tabular}{|c|}
37,68 \\
\end{tabular} & 5447,36 & 246,48 & $-3,64$ & 250,12 & 69,33 & 172,36 & 172,86 & 33,82 & 656,37 & 70,75 & 32,93 & 20,83 & 197,61 & 120,26 & 120,34 & 176,11 \\
\hline Bufo spinosus & 30TVN53 & 100,00 & 99,65 & 89,08 & 37,80 & 5092,41 & 234,07 & 0,99 & 233,08 & 71,91 & 165,73 & 167,58 & 37,53 & 792,05 & 87,44 & 39,24 & 20,59 & 245,68 & 144,52 & 147,93 & 219,92 \\
\hline Bufo spinosus & 30 TVN54 & 100,00 & 106,21 & 84,98 & 37,53 & 4905,19 & 233,44 & 10,21 & 223,23 & 80,17 & 169,55 & 171,56 & 46,08 & 826,97 & 93,60 & 39,72 & 21,58 & 261,92 & 148,03 & 155,24 & 233,76 \\
\hline Bufo spinosus & 30TVN55 & 100,00 & 113,55 & 80,20 & 37,16 & 4 & 233,01 & $\begin{array}{l}20,75 \\
20\end{array}$ & 212,25 & 89,81 & 173,80 & $\begin{array}{l}171,9,99 \\
\end{array}$ & 55,64 & 865,90 & \begin{tabular}{|c|}
100,81 \\
\end{tabular} & $\begin{array}{ll}40,08 \\
\end{array}$ & 22,87 & 280,37 & $\begin{array}{l}151,47 \\
150\end{array}$ & $\begin{array}{l}163,42 \\
\end{array}$ & 249,80 \\
\hline Bufo spinosus & $30 \mathrm{TVN} 5$ & 100,00 & 106,14 & 80,16 & 37,35 & 4654,46 & 225,83 & 14,56 & 211,27 & 82,72 & 165,90 & 168,30 & 49,16 & 930,85 & 108,16 & 44,22 & 22,41 & 299,67 & 164,75 & \begin{tabular}{ll|}
176,64 \\
\end{tabular} & 268,72 \\
\hline Bufo spinosus & 30TVN57 & 100,00 & 90,49 & 82,57 & $\begin{array}{l}37,85 \\
\end{array}$ & 4709,62 & 214,55 & $-0,90$ & 215,45 & 52,83 & 151,43 & 153,93 & 33,92 & \begin{tabular}{|l|}
1014,97 \\
\end{tabular} & 115,98 & 50,75 & 21,14 & 321,54 & 184,65 & 193,13 & 291,03 \\
\hline Bufo spinosus & 30TVN58 & 100,00 & 108,37 & 74,56 & 37,25 & 4385,44 & 219,45 & 21,93 & 197,52 & 82,71 & 164,34 & 167,09 & 54,88 & 1034,62 & 123,48 & 48,07 & 23,87 & 339,52 & 179,88 & 197,78 & 305,10 \\
\hline Bufo spinosus & 30TVN59 & 100,00 & 126,02 & 66,15 & 36,59 & 4031,09 & 223,35 & 45,27 & 178,07 & \begin{tabular}{ll|l}
107,64 & \\
\end{tabular} & 176,66 & 179,72 & 76,24 & 1066,38 & 132,93 & 45,83 & 27,00 & 23 & 176,75 & 205,10 & 322,81 \\
\hline \begin{tabular}{|l} 
Bufo spinosus \\
\end{tabular} & $30 \mathrm{TVNG}$ & 100,00 & $\begin{array}{l}12,02 \\
99,87 \\
\end{array}$ & $\begin{array}{l}0,1 \\
95,39\end{array}$ & 37, & $\begin{array}{l}403,109 \\
5454,15\end{array}$ & 245 & \begin{tabular}{|c|}
43,22 \\
$-4,22$
\end{tabular} & 250,03 & 68,44 & 172,01 & 172,54 & 33,22 & 672,87 & 71,24 & 33,95 & 20,19 & 200,78 & 124,47 & 124,56 & 181,88 \\
\hline Bufo spinosus & 30TVN61 & 100,00 & 109,10 & 91,23 & 37,38 & 5275,72 & 247,20 & 6,92 & 240,28 & 79,42 & 177,51 & 178,99 & 44,13 & 687,76 & 74,70 & 33,49 & 20,67 & 210,78 & 125,36 & 128,02 & 189,41 \\
\hline Bufo spinosus & 30TVN62 & 100,00 & 111,51 & 88,30 & 37,32 & 5124,11 & 244,29 & 11,61 & 232,68 & 81,37 & 177,68 & 179,32 & 48,27 & 728,47 & 80,75 & 34,84 & 21,01 & 226,71 & 131,29 & 136,11 & 203,84 \\
\hline Bufo spinosus & 30TVN63 & 100,00 & 107,20 & 87,07 & 37,60 & 5038,53 & 238,05 & 9,28 & 228,77 & 79,07 & 172,23 & 174,21 & 45,30 & 785,92 & 87,87 & 38,01 & 20,95 & 245,04 & 141,95 & 147,61 & 221,72 \\
\hline Bufo spinosus & 30TVN64 & 100,00 & 110,67 & 83,52 & 37,36 & 4865,24 & 235,67 & 15,42 & 220,24 & 84,28 & 173,25 & 175,36 & 50,84 & 832,07 & 95,12 & 39,33 & 21,70 & 263,67 & 147,92 & 156,78 & 238 \\
\hline \begin{tabular}{|l} 
Bufo spinosus \\
\end{tabular} & 30TVN66 & 100,00 & 105,04 & 80,32 & 37,39 & 4675,92 & 225,36 & $\begin{array}{ll}13,67 \\
13\end{array}$ & 211,68 & 74,50 & 164,97 & 167,42 & 47,88 & 950,00 & $\mid$ & 45,36 & 22,03 & 303,34 & 168,65 & 180,39 & 276,88 \\
\hline Bufo spinosus & 30TVN67 & 100,00 & 101,25 & 79,16 & 37,55 & 4599,45 & 219,84 & 11,59 & 208,25 & 65,66 & 160,21 & 162,83 & 45,37 & 1010,80 & 117,99 & 48,59 & 22,10 & 323,75 & 179,86 & 192,51 & 296,21 \\
\hline Bufo spinosus & 30TVN68 & 100,00 & 120,69 & 69.95 & 36,74 & 4232.60 & 224.58 & 36,79 & 187,79 & 100,07 & 174,13 & 177.02 & 68.49 & 104282 & 128,30 & 45,78 & 25.59 & 347.40 & 175,27 & 198,70 & 317,65 \\
\hline Bufo spinosus & 30TVN70 & 100,00 & 104,58 & 94,92 & 37,86 & 5438,01 & 248,84 & 0,10 & 248,7 & 73,09 & 175 , & 176,68 & 37,92 & 669,04 & 70,87 & 33,55 & 19,95 & 199,48 & 124,75 & 125,08 & 182,08 \\
\hline Bufo spinosus & 30TVN71 & 100,00 & 109,94 & 91,44 & 37,53 & 5283,77 & 247,82 & 7,43 & 240,39 & 79,87 & 178,32 & 179,88 & 44,84 & 695,56 & 75,50 & 33,96 & 20,25 & 211,65 & 127,88 & 130,55 & 192,67 \\
\hline
\end{tabular}




\begin{tabular}{|c|c|c|c|c|c|c|c|c|c|c|c|c|c|c|c|c|c|c|c|c|c|}
\hline TAXON & UTM & $\mathrm{km} 2$ & BIO1 & BIO2 & $\mathrm{BIO3}$ & B104 & B105 & B106 & B107 & B108 & 8109 & B1010 & BIO11 & B1012 & BIO13 & B1014 & BIO15 & B1016 & B1017 & B1018 & B1019 \\
\hline Bufo spinosus & 30TVN72 & 100,00 & 106,97 & 89,83 & 37,74 & 5181,20 & 242,08 & 6,58 & 235,50 & 73,49 & 174,00 & 175,75 & 43,37 & 749,71 & 82,34 & 36,79 & 20,27 & 229,53 & 137,57 & 141,17 & 209,90 \\
\hline Bufo spinosus & 30TVN73 & 100,00 & 112,44 & 85,79 & 37,43 & 5006,60 & 241,04 & 14,90 & 226,15 & 83,56 & 176,85 & 178,75 & 50,72 & 786,61 & 88,77 & 37,40 & 21,15 & 245,54 & 141,27 & 148,32 & 225,13 \\
\hline Bufo spinosus & 30TVN74 & 100,00 & 107,62 & 84,58 & 37,51 & 4912,95 & 234,44 & 12,03 & 222,40 & 74,75 & 170,82 & 172,86 & 47,35 & \begin{tabular}{|l|l|}
851,06 \\
\end{tabular} & 96,70 & 40,89 & 21,06 & 266,57 & 153,21 & 160,98 & 245,17 \\
\hline Bufo spinosus & 30TVN75 & 100,00 & 105,31 & 82,77 & 37,50 & 4807,18 & 229,48 & 11,75 & 217,73 & 67,09 & 167,05 & 169,38 & 46,57 & $\begin{array}{l}910,55 \\
\end{array}$ & 104,51 & 43,79 & 21,23 & 286,82 & 163,32 & 172,66 & 264,81 \\
\hline Bufo spinosus & 30TVN76 & 100,00 & 107,88 & 79,40 & $\begin{array}{l}37,36 \\
\end{array}$ & $\begin{array}{lll}4649,58 \\
\end{array}$ & 226,83 & 17,28 & 209,55 & 67,34 & 167,40 & 169,86 & 51,09 & 964,32 & 112,88 & 45,46 & 22,21 & 308,11 & 170,29 & 183,10 & 285,22 \\
\hline Bufo spinosus & 30TVN77 & 100,00 & 122,34 & 71,61 & 36,73 & 4342,73 & 229,04 & 36,54 & 192,50 & 98,41 & 177,24 & 179,90 & 68,68 & 1009,67 & 123,94 & 44,06 & 25,19 & 332,97 & 169,58 & 190,88 & 310,96 \\
\hline Bufo spinosus & 30TVN78 & 100,00 & 120,92 & 69,74 & \begin{tabular}{|l|}
36,68 \\
\end{tabular} & 4244,12 & 224,77 & 37,20 & 187,57 & 91,57 & \begin{tabular}{|l|l|l}
174,43 \\
\end{tabular} & 177,29 & 68,58 & $\begin{array}{l}1066,48 \\
\end{array}$ & 131,83 & 46,55 & 25,63 & 353,54 & 178,62 & 202,15 & 330,37 \\
\hline Bufo spinosus & 30TVN79 & 100,00 & 123,75 & 66,45 & 36,40 & 4096,70 & 222,63 & 42,77 & 179,86 & 95,72 & 175,16 & 178,28 & 73,33 & \begin{tabular}{|l|}
1118,18 \\
\end{tabular} & 140,30 & 47,95 & 26,70 & 374,65 & $\begin{array}{ll}184,63 \\
\end{array}$ & 212,21 & 350,73 \\
\hline Bufo spinosus & 30TVN82 & 100,00 & 103,17 & 91,27 & 37,89 & 5220,71 & 240,35 & 2,42 & 237,93 & 60,00 & \begin{tabular}{|l|l|}
170,94 \\
\end{tabular} & 172,61 & 39,31 & 771,66 & 84,04 & 38,65 & 19,54 & 233,49 & 143,87 & 146,24 & 215,95 \\
\hline Bufo spinosus & 30TVN83 & 100,00 & 104,94 & 88,13 & 37,73 & 5072,27 & 237,26 & 6,80 & 230,46 & 63,63 & 170,70 & 172,44 & 42,99 & 820,28 & 91,21 & 40,44 & 20,14 & 252,12 & 150,79 & 155,49 & 233,70 \\
\hline Bufo spinosus & 30TVN84 & 100,00 & 103,96 & 86,15 & \begin{tabular}{l|l|}
37,85 \\
\end{tabular} & 4963,33 & 233,21 & 7,87 & 225,33 & 55,78 & 167,96 & 170,04 & 43,42 & 871,21 & 98,06 & 42,76 & 20,30 & 269,96 & 159,22 & 165,50 & 250,88 \\
\hline Bufo spinosus & 30TVN85 & 100,00 & 104,85 & 83,38 & 37,74 & 4828,90 & 229,94 & 11,22 & 218,72 & 54,11 & 166,92 & 169,21 & 45,99 & 924,90 & 105,84 & 44,83 & 20,84 & 290,18 & 167,04 & 175,80 & 270,28 \\
\hline Bufo spinosus & 30TVN86 & 100,00 & 105,44 & 80,40 & 37,56 & 4686,24 & \begin{tabular}{|l|}
225,87 \\
\end{tabular} & 14,56 & 211,31 & 57,21 & 165,48 & 167,92 & 48,38 & 987,13 & \begin{tabular}{|l|l|}
114,97 \\
\end{tabular} & 47,12 & 21,75 & 313,49 & 175,99 & 187,50 & 293,23 \\
\hline Bufo spinosus & 30TVN87 & 100,00 & 124,55 & 70,93 & 36,59 & 4335,24 & 230,32 & 39,18 & \begin{tabular}{|l|l|}
191,14 \\
\end{tabular} & 88,84 & 179,24 & 181,90 & 70,99 & $\begin{array}{l}1029,46 \\
\end{array}$ & 127,20 & 44,41 & 25,55 & 338,75 & 171,69 & 193,69 & 322,91 \\
\hline Bufo spinosus & 30TVN88 & 100,00 & 126,70 & 67,62 & 36,38 & 4189,88 & 227,43 & 44,06 & 183,37 & 89,67 & \begin{tabular}{|l|l|}
179,27 \\
\end{tabular} & 182,15 & 74,93 & 1088,14 & 136,91 & 45,96 & 26,80 & 362,44 & 178,49 & 204,42 & 347,08 \\
\hline Bufo spinosus & 30TVN89 & 100,00 & 128,19 & 64,79 & 36,19 & 4057,18 & 224,63 & 47,99 & \begin{tabular}{|l|l|}
176,64 \\
\end{tabular} & 90,41 & 178,88 & 181,96 & 78,10 & 1143,30 & 145,65 & 47,71 & 27,72 & 384,24 & 185,29 & 214,87 & 368,93 \\
\hline \begin{tabular}{|l|} 
Bufo spinosus \\
\end{tabular} & 30TVN92 & 100,00 & 117,27 & 88,59 & 37,62 & 5141,02 & 249,09 & 16,71 & 232,37 & 86,20 & 183,32 & 184,93 & 53,60 & 738,05 & 81,65 & 35,49 & 20,21 & 225,82 & 135,85 & 140,65 & 209,57 \\
\hline Bufo spinosus & 30TVN93 & 100,00 & 115,36 & 86,42 & \begin{tabular}{l|l|l}
37,65 \\
\end{tabular} & 5019,65 & 244,13 & 17,40 & 226,73 & 80,67 & 179,86 & 181,60 & 53,52 & 797,27 & 89,48 & 38,23 & 20,47 & 246,02 & 145,48 & 151,88 & 229,88 \\
\hline Bufo spinosus & 30TVN94 & 100,00 & 108,73 & 85,55 & 37,76 & 4938,92 & 236,51 & 12,67 & 223,84 & 62,07 & 172,20 & 174,24 & 48,30 & 872,13 & 98,54 & 42,44 & 20,30 & 270,24 & 159,39 & 166,11 & 253,37 \\
\hline Bufo spinosus & 30TVN95 & 100,00 & 106,38 & 83,55 & 37,77 & 4828,87 & 231,28 & 12,65 & 218,63 & 56,30 & 168,32 & 170,60 & 47,55 & 938,21 & 107,38 & 45,50 & 20,76 & 293,76 & 170,03 & 178,55 & 276,05 \\
\hline Bufo spinosus & 30TVN96 & 100,00 & 119,40 & 76,09 & \begin{tabular}{|l|}
37,08 \\
\end{tabular} & 4543,25 & 232,90 & 30,66 & 202,24 & 72,38 & \begin{tabular}{|l|l|}
177,02 \\
\end{tabular} & 179,58 & 63,58 & 990,60 & 118,93 & 44,53 & 23,73 & 319,32 & 170,56 & 186,73 & 305,49 \\
\hline Bufo spinosus & 30TVN97 & 100,00 & 127,89 & 70,10 & 36,50 & 4311,79 & 232,34 & 43,09 & 189,25 & 84,19 & 182,03 & 184,80 & 74,59 & $\begin{array}{l}1051,79 \\
\end{array}$ & 130,99 & 44,68 & 26,18 & \begin{tabular}{|l|l|}
346,75 \\
\end{tabular} & 173,91 & 196,73 & 336,28 \\
\hline Bufo spinosus & 30TVN98 & 100,00 & 127,89 & 67,50 & \begin{tabular}{|l|}
36,38 \\
\end{tabular} & 4192,74 & 228,50 & 45,43 & 183,07 & 84,73 & 180,31 & 183,21 & 76,13 & $\begin{array}{ll}1115,08 \\
\end{array}$ & 140,70 & 46,87 & 27,06 & 370,99 & 182,25 & 208,23 & 361,25 \\
\hline Bufo spinosus & 30TVN99 & 92,00 & 132,29 & 63,55 & $\begin{array}{l}35,85 \\
\end{array}$ & 4036,25 & 226,96 & 52,44 & 174,52 & 89,47 & 182,50 & 185,60 & 82,34 & 1168,21 & 150,77 & 47,53 & 28,83 & 394,26 & 186,08 & 217,14 & 387,18 \\
\hline Bufo spinosus & 30TVP10 & 91,00 & 140,29 & 63,68 & 37,35 & 3761,53 & 229,76 & 61,62 & 168,14 & 124,53 & 180,70 & 190,41 & 93,41 & 969,80 & 123,50 & 40,83 & 29,56 & 344,03 & 159,72 & 190,60 & 276,50 \\
\hline Bufo spinosus & 30TVP21 & 27,00 & 140,55 & 60,16 & 37,02 & 3639,68 & 225,79 & 65,43 & 160,36 & 125,52 & 168,52 & 189,21 & 95,34 & 1037,54 & 131,59 & 43,05 & 30,11 & 369,63 & 167,59 & 205,20 & 300,34 \\
\hline Bufo spinosus & 30TVP31 & 33,00 & $\begin{array}{lll}141,27 \\
\end{array}$ & 58,56 & 36,50 & 3605,85 & 224,90 & 67,10 & 157,79 & 126,46 & 168,79 & 189,33 & 96,25 & \begin{tabular}{|l|}
1070,27 \\
\end{tabular} & 135,50 & 43,90 & 30,44 & 381,94 & 170,77 & 211,92 & 313,67 \\
\hline Bufo spinosus & 30TVP50 & 100,00 & 135,87 & 60,90 & \begin{tabular}{|l|l|}
36,17 \\
\end{tabular} & 3806,96 & 224,75 & 58,97 & 165,78 & 119,22 & \begin{tabular}{|l|l|}
183,13 \\
\end{tabular} & 186,40 & 88,57 & 1097,40 & 139,97 & 45,10 & 29,04 & 382,13 & 177,06 & 212,35 & 336,43 \\
\hline Bufo spinosus & 30TVP60 & 70,00 & 135,37 & 61,27 & 36,10 & 3860,41 & 225,37 & 57,86 & 167,51 & 118,11 & 183,29 & 186,66 & 87,44 & $\begin{array}{l}1113,97 \\
\end{array}$ & 142,87 & 45,54 & 28,87 & 384,38 & 178,76 & 213,35 & 349,47 \\
\hline Bufo spinosus & 30TWK04 & 100,00 & 130,37 & 114,95 & 36,94 & 6642,86 & 309,52 & 1,63 & 307,89 & 92,86 & 219,20 & 219,43 & 50,21 & 441,77 & 49,99 & 12,28 & 32,11 & 140,49 & 58,70 & 58,93 & 117,95 \\
\hline Bufo spinosus & 30TWK06 & 100,00 & 132,45 & 111,60 & 36,29 & 6620,05 & 307,21 & 4,89 & 302,31 & 90,06 & 220,83 & 220,83 & 52,19 & 422,20 & 48,04 & 12,28 & 32,21 & 136,34 & 57,04 & 57,04 & 111,09 \\
\hline Bufo spinosus & 30TWK13 & 100,00 & 123,29 & 117,98 & \begin{tabular}{|l|l|}
37,19 \\
\end{tabular} & 6629,14 & 305,54 & $-6,08$ & 311,62 & \begin{tabular}{|l|l|}
107,24 \\
\end{tabular} & 211,53 & 212,54 & 43,97 & 474,44 & 54,90 & 13,98 & 30,69 & 150,29 & 65,49 & 67,36 & $\begin{array}{ll}124,68 \\
\end{array}$ \\
\hline Bufo spinosus & 30TWK16 & 100,00 & 127,79 & 113,26 & \begin{tabular}{|l|l|}
36,87 \\
\end{tabular} & 6594,18 & 303,69 & 0,04 & 303,65 & 99,34 & 215,59 & 216,07 & 48,31 & 438,84 & 50,71 & 13,74 & 30,57 & 137,36 & 62,54 & 63,34 & 113,30 \\
\hline Bufo spinosus & 30TWK17 & 100,00 & 126,06 & 112,16 & 36,89 & 6577,82 & 300,33 & $-1,06$ & 301,40 & 93,71 & 213,49 & 213,97 & 46,62 & 440,05 & 51,25 & 14,45 & 30,10 & 136,90 & 64,18 & 65,06 & 112,45 \\
\hline Bufo spinosus & 30TWK18 & 100,00 & 120,12 & 111,49 & 36,94 & 6549,52 & 294,01 & $-5,69$ & 299,71 & 99,00 & 207,06 & 207,89 & 41,36 & 457,38 & 53,90 & 16,17 & 28,94 & 141,10 & 68,84 & 70,79 & 115,82 \\
\hline \begin{tabular}{|l} 
Bufo spinosus \\
\end{tabular} & 30TWK24 & 100,00 & 124,19 & 117,79 & 37,38 & 6596,71 & 304,64 & $-5,54$ & 310,18 & 108,39 & 211,75 & 212,77 & 44,76 & 466,35 & 54,82 & 14,50 & 29,86 & 147,90 & 66,71 & 69,05 & 120,30 \\
\hline Bufo spinosus & 30TWK25 & 100,00 & 125,32 & 116,25 & \begin{tabular}{|l|l|}
37,10 \\
\end{tabular} & 6590,00 & 303,86 & $-3,68$ & 307,55 & 110,08 & 212,66 & 213,78 & 45,93 & 454,83 & 53,64 & 14,42 & 29,77 & 143,11 & 65,92 & 67,82 & 116,49 \\
\hline Bufo spinosus & 30TWK26 & 100,00 & 128,90 & 114,41 & $\begin{array}{ll}37,02 \\
\end{array}$ & 6576,52 & 304,81 & 0,05 & 304,76 & 114,28 & 215,90 & 216,89 & 49,34 & \begin{tabular}{|l|l|}
433,33 \\
\end{tabular} & 51,13 & 13,79 & 29,99 & 134,91 & 63,40 & 64,64 & 110,08 \\
\hline Bufo spinosus & 30TWK28 & 100,00 & 122,64 & 112,57 & 37,00 & 6538,77 & 296,27 & $-4,50$ & 300,77 & \begin{tabular}{|l|l|}
107,37 \\
\end{tabular} & 209,05 & 210,05 & 43,69 & 446,70 & 53,55 & 15,97 & 28,56 & 138,34 & 68,56 & 70,90 & 111,56 \\
\hline Bufo spinosus & 30TWK29 & 100,00 & 120,61 & 111,60 & \begin{tabular}{|l|l|}
36,97 \\
\end{tabular} & 6519,43 & 293,10 & $-5,77$ & \begin{tabular}{|l|l|}
298,87 & \\
\end{tabular} & 105,81 & 206,94 & 207,78 & 42,03 & 449,01 & 54,25 & 16,81 & 28,10 & 138,53 & 70,50 & 73,21 & 111,14 \\
\hline \begin{tabular}{|l} 
Bufo spinosus \\
\end{tabular} & 30TWK33 & 100,00 & 116,66 & 120,74 & 38,00 & 6585,14 & 300,33 & $-14,06$ & 314,40 & 100,01 & 204,55 & 205,58 & 38,06 & 505,99 & 60,53 & \begin{tabular}{l|l|l|}
16,58 \\
\end{tabular} & 29,01 & 163,99 & 74,23 & 78,88 & 129,05 \\
\hline Bufo spinosus & 30TWK34 & 100,00 & 119,18 & 119,33 & \begin{tabular}{|l|l|}
37,97 \\
\end{tabular} & 6573,64 & 300,76 & $-11,16$ & 311,92 & 102,91 & 206,62 & 207,67 & 40,36 & 489,62 & 58,69 & 16,23 & 28,90 & 157,40 & 72,49 & 76,48 & 124,41 \\
\hline Bufo spinosus & 30TWK35 & 100,00 & 121,19 & 117,90 & \begin{tabular}{|l|l|}
37,73 \\
\end{tabular} & $\begin{array}{lll}6561,97 \\
\end{array}$ & 300,68 & $-8,71$ & 309,39 & 105,44 & 208,23 & 209,28 & 42,12 & 474,27 & 57,05 & 15,95 & 28,80 & 151,19 & 71,10 & 74,64 & 119,71 \\
\hline Bufo spinosus & 30TWK43 & 100,00 & 115,33 & 121,93 & 38,00 & 6564,51 & 299,45 & $-16,16$ & 315,60 & 98,45 & 202,97 & 204,06 & 36,84 & 515,11 & 62,31 & 17,43 & 28,55 & 168,05 & 77,36 & 82,94 & 129,92 \\
\hline Bufo spinosus & 30TWK45 & 100,00 & 121,44 & 119,10 & 38,00 & 6541,49 & 300,99 & $-9,46$ & 310,45 & \begin{tabular}{|l|l|}
105,64 \\
\end{tabular} & 208,11 & 209,25 & 42,46 & 475,39 & 58,11 & 16,37 & 28,55 & 152,80 & 72,86 & 77,12 & 118,42 \\
\hline \begin{tabular}{|l} 
Bufo spinosus \\
\end{tabular} & 30TWK46 & 100,00 & 120,01 & 117,84 & 37,90 & 6528,19 & 297,99 & $-10,22$ & 308,21 & 104,49 & 206,46 & 207,61 & 41,21 & 473,49 & 58,31 & 17,00 & 27,97 & 151,43 & 74,06 & 78,60 & 116,90 \\
\hline Bufo spinosus & 30TWK49 & 100,00 & 106,46 & 115,14 & \begin{tabular}{|c|}
37,57 \\
\end{tabular} & 6454,86 & 281,33 & $-21,36$ & 302,69 & 90,44 & 192,08 & 193,16 & 28,95 & 510,99 & 64,31 & 21,77 & 25,87 & 161,34 & 86,29 & 93,58 & 123,12 \\
\hline Bufo spinosus & 30TWK53 & 100,00 & 111,27 & 122.96 & 38,14 & 6545,77 & 295,52 & $-20,88$ & 316,40 & 94,02 & 198,63 & \begin{tabular}{|l|l|}
199,73 \\
\end{tabular} & 33,01 & 537.06 & 65,77 & 19,21 & 27,92 & 176,51 & 83,23 & 90,26 & 133,53 \\
\hline Bufo spinosus & 30TWK57 & 100,00 & 119,51 & 117,14 & 37,99 & 6488,75 & 295,10 & $-10,90$ & 306,00 & 104,30 & 205,19 & 206,31 & 40,91 & 466,33 & 58,95 & 86 & 57 & 10 & 76,57 & 81,97 & 111,85 \\
\hline \begin{tabular}{|l} 
Bufo spinosus \\
\end{tabular} & 30TWK58 & 100,00 & 118,81 & 115,73 & 37 & 6474,79 & 292,47 & $-11,08$ & 303,55 & 103,83 & 204,13 & 20 & 40,08 & 460,90 & 58,77 & 18,36 & 27,27 & 146,40 & 77,21 & 82,94 & 109,38 \\
\hline Bufo spinosus & 30TWK59 & 100,00 & 105,42 & 115,33 & \begin{tabular}{|l|l|}
37,69 \\
\end{tabular} & $\begin{array}{lll}6438,03 \\
\end{array}$ & 279,56 & $-23,01$ & \begin{tabular}{|l|l|}
302,57 \\
\end{tabular} & 91,42 & \begin{tabular}{|l|l|}
190,73 \\
\end{tabular} & 191,80 & 28,00 & 513,53 & 65,75 & 22,56 & 25,86 & 162,88 & 89,14 & 97,38 & 121,44 \\
\hline \begin{tabular}{|l|} 
Bufo spinosus \\
\end{tabular} & 30TWK66 & 100,00 & 114,23 & 119,39 & 38,00 & 6481,22 & 292,02 & $-17,12$ & 309,14 & 98,42 & 200,04 & 201,21 & 36,14 & 498,53 & 63,48 & 19,64 & 27,18 & 161,69 & 83,12 & 90,30 & 118,71 \\
\hline Bufo spinosus & 30TWK67 & 100,00 & 110,23 & 117,68 & 38,00 & 6460,58 & 286,09 & $-20,18$ & 306,27 & 94,21 & 195,76 & 196,93 & 32,25 & 505,56 & 64,96 & 21,13 & 26,69 & 162,87 & 86,71 & 94,60 & 118,85 \\
\hline Bufo spinosus & 30TWK68 & 100,00 & 106,73 & 116,36 & \begin{tabular}{|l|l|}
37,98 \\
\end{tabular} & 6444,07 & 281,06 & $-22,78$ & 303,84 & 92,12 & 192,05 & 19 & 29,05 & 511,24 & 66,21 & 22,38 & 26,24 & 163,79 & 89,62 & 98,37 & 119 \\
\hline \begin{tabular}{|l} 
Bufo spinosus \\
\end{tabular} & 30TWK69 & 100,00 & 100,23 & 115,12 & 37,98 & 6406,54 & 273,40 & $-27,95$ & 301,35 & 108,35 & 185,25 & 186,29 & 23,23 & 534,06 & \begin{tabular}{|c|c|}
69,36 \\
\end{tabular} & 24,75 & 25,53 & 171,11 & 95,85 & 105,88 & 123,69 \\
\hline Bufo spinosus & 30TWK74 & 100,00 & 110,37 & 122,18 & \begin{tabular}{l|l}
38,55 \\
\end{tabular} & 6485,66 & 291,48 & $-22,01$ & 313,48 & $\begin{array}{ll}93,44 \\
\end{array}$ & 196,49 & 197,79 & 32,30 & 534,96 & 67,54 & 20,89 & 27,25 & \begin{tabular}{|l|l|}
175,98 \\
\end{tabular} & 88,80 & 97,18 & 127,60 \\
\hline Bufo spinosus & 30TWK75 & 100,00 & 109,20 & 120,60 & 38,14 & 6473,89 & 288,21 & $\mid-22,43$ & 310,64 & 92,58 & $\mid 195,14$ & $\mid$\begin{tabular}{|c|c|}
196,34 \\
\end{tabular} & 31,22 & 528,06 & 67,51 & 21,41 & 26,89 & $\mid 172,83$ & 89,73 & 98,27 & 124,22 \\
\hline Bufo spinosus & 30TWK77 & 100,00 & 100,86 & 116,83 & 38,00 & 6434,42 & 275,74 & $-28,48$ & 304,22 & 90,25 & 186,35 & 187,48 & 23,63 & 542,34 & 70,55 & 24,52 & 25,95 & 175,27 & 97,08 & 107,42 & 124,29 \\
\hline Bufo spinosus & 30TWK 7 & 100,00 & 97,08 & 115,41 & \begin{tabular}{|l|l|}
37,98 \\
\end{tabular} & 6407,53 & 270,31 & $-31,59$ & 301,90 & \begin{tabular}{|l|l|}
109,17 \\
\end{tabular} & 182,16 & 183 & 20 & 550,90 & 72,06 & 26,03 & 25,54 & $1 / 8$, & 100,62 & 111,84 & 125 \\
\hline \begin{tabular}{|l} 
Bufo spinosus \\
\end{tabular} & 30TWK79 & 100,00 & 93,35 & 114,29 & 37,94 & 6378,58 & 265,36 & $-34,21$ & 299,57 & 112,60 & 178,20 & 179,19 & 16,96 & 562,22 & 73,74 & 27,55 & 25,18 & 182,72 & 104,53 & 116,45 & 127,31 \\
\hline
\end{tabular}




\begin{tabular}{|c|c|c|c|c|c|c|c|c|c|c|c|c|c|c|c|c|c|c|c|c|c|}
\hline TAXON & UTM & $\mathrm{km2}$ & B101 & $\mathrm{B1O2}$ & $\mathrm{BIO3}$ & B104 & B105 & B106 & B107 & B108 & B109 & 81010 & B1011 & BIO12 & BIO13 & 81014 & B1015 & B1016 & B1017 & BIO18 & B1019 \\
\hline Bufo spinosus & 30TWK83 & 100,00 & 102,58 & 120,26 & 38,17 & 6476,73 & 282,14 & $-27,89$ & 310,03 & 84,56 & 189,01 & 190,08 & 25,43 & 562,12 & 71,36 & 23,60 & 26,19 & 184,82 & 96,95 & 106,93 & 129,77 \\
\hline Bufo spinosus & 30TWK84 & 100,00 & 96,47 & 118,36 & 38,01 & 6457,47 & 274,20 & $-32,79$ & 306,99 & 78,13 & 182,81 & 183,78 & 19,61 & 580,26 & 74,21 & 25,90 & 25,51 & 189,63 & 102,94 & 114,16 & 132,22 \\
\hline Bufo spinosus & 30TWK85 & 100,00 & 95,13 & 117,38 & 38,00 & 6441,05 & 271,36 & $-33,71$ & 305,07 & 78,52 & 181,13 & 182,19 & 18,36 & 578,71 & 74,69 & 26,55 & 25,51 & 188,32 & 104,36 & 115,87 & 131,04 \\
\hline Bufo spinosus & 30TWK88 & 100,00 & 86,30 & 113,60 & 37,80 & 6367,38 & 257,78 & $-40,42$ & 298,21 & 104,73 & 171,25 & 172,19 & 10,56 & 599,53 & 78,42 & 30,40 & 24,72 & 196,11 & 113,56 & 127,13 & 133,66 \\
\hline Bufo spinosus & 30TWK89 & 100,00 & 87,80 & 112,80 & \begin{tabular}{ll|}
37,62 \\
\end{tabular} & $\begin{array}{ll}6350,86 \\
\end{array}$ & 257,53 & \begin{tabular}{|l|l|}
$-39,03$ \\
\end{tabular} & 296,56 & 106,71 & 172,23 & \begin{tabular}{|l|}
173,13 \\
\end{tabular} & 11,91 & 584,62 & 77,23 & 30,11 & 25,07 & 192,41 & 112,14 & 125,67 & 129,43 \\
\hline Bufo spinosus & 30TWK94 & 100,00 & 92,23 & 116,03 & 38,00 & 6430,56 & 267,20 & $-35,36$ & 302,56 & 88,19 & 178,35 & 179,33 & 16,06 & 590,88 & 76,23 & 27,84 & 25,12 & 192,64 & 108,68 & 120,74 & 130,77 \\
\hline Bufo spinosus & 30TWK95 & 100,00 & 92,36 & 115,23 & 38,00 & 6416,55 & 265,77 & $-35,26$ & 301,03 & 104,81 & 178,05 & 179,08 & 16,05 & 583,27 & 75,98 & 28,08 & 25,35 & 190,72 & 108,82 & 121,12 & 128,16 \\
\hline \begin{tabular}{|l} 
Bufo spinosus \\
\end{tabular} & 30TWK96 & 100,00 & 85,48 & 113,66 & 37,82 & 6392,18 & 257,51 & $-40,91$ & 298,42 & 103,58 & 170,97 & 171,90 & \begin{tabular}{|l|l|}
9,68 \\
\end{tabular} & 610,64 & 79,62 & 30,81 & 24,78 & 200,34 & 116,10 & 129,69 & 133,84 \\
\hline Bufo spinosus & 30TWK97 & 100,00 & 80,60 & 112,32 & 37,32 & 6361,69 & 251,36 & $-44,86$ & 296,22 & 98,38 & 165,82 & 166,64 & 5,25 & 630,88 & 82,18 & 32,84 & 24,31 & 207,19 & 121,55 & 136,08 & 138,47 \\
\hline Bufo spinosus & 30TWK98 & 100,00 & 80,94 & 111,58 & 37,14 & 6340,80 & 250,10 & $\begin{array}{l}-44,57 \\
\end{array}$ & 294,66 & 98,89 & 165,63 & 166,52 & 5,51 & 622,34 & 81,77 & 32,99 & 24,56 & 205,50 & 121,34 & 136,15 & 135,74 \\
\hline Bufo spinosus & 30TWK99 & 100,00 & 85,59 & 111,09 & 37,27 & 6324,33 & 252,81 & $-40,40$ & 293,21 & 104,34 & 169,66 & 170,64 & 9,83 & 589,39 & 78,67 & 31,47 & 25,33 & 196,45 & 116,27 & 130,66 & 127,00 \\
\hline Bufo spinosus & 30TWLOO & 100,00 & 116,08 & 108,45 & 36,33 & 6509,48 & 287,06 & $-7,05$ & 294,12 & 84,66 & 202,66 & 203,28 & 37,98 & 464,71 & 54,42 & 16,51 & 28,29 & 142,27 & 71,14 & 73,34 & 117,52 \\
\hline \begin{tabular}{|l} 
Bufo spinosus \\
\end{tabular} & 30TWL04 & 100,00 & 111,49 & 108,35 & 36,71 & 6393,51 & 280,81 & $-10,72$ & 291,53 & 108,95 & 196,57 & 196,98 & 34,78 & 476,03 & 56,68 & 18,80 & 25,92 & 142,80 & 77,88 & 82,26 & 119,36 \\
\hline Bufo spinosus & 30TWL07 & 100,00 & 97,13 & 110,66 & \begin{tabular}{|l|l|}
37,37 \\
\end{tabular} & 6252,88 & 268,36 & $-23,79$ & 292,15 & 115,05 & 180,97 & 181,10 & 22,64 & 549,99 & 65,41 & 24,94 & 23,07 & 167,04 & 95,15 & 102,44 & 139,62 \\
\hline Bufo spinosus & 30TWL10 & 100,00 & 111,09 & 110,77 & \begin{tabular}{|l|l|}
36,97 \\
\end{tabular} & 6485,27 & 283,86 & $-13,21$ & 297,06 & 94,90 & 197,40 & 198,20 & 33,63 & 486,73 & 58,25 & 18,92 & 27,01 & 149,32 & 76,94 & 80,93 & 121,82 \\
\hline Bufo spinosus & 30TWL11 & 100,00 & 111,94 & 110,05 & 36,88 & 6467,81 & 283,48 & $-12,04$ & 295,51 & 95,51 & 197,93 & 198,69 & 34,63 & 478,39 & 57,52 & 18,76 & 26,85 & 146,10 & 76,74 & 80,79 & 118,94 \\
\hline Bufo spinosus & 30TWL13 & 100,00 & 114,15 & 109,12 & 36,77 & 6428,10 & 283,77 & $-9,39$ & 293,16 & 102,65 & 199,37 & 200,05 & 36,77 & 463,86 & 55,97 & 18,51 & 26,19 & 140,01 & 76,30 & 80,35 & 114,78 \\
\hline Bufo spinosus & 30TWL16 & 100,00 & 103,25 & 111,04 & 37,11 & 6304,82 & 274,36 & $-19,40$ & 293,76 & 122,31 & 187,32 & 187,66 & 27,77 & 517,06 & 62,34 & 23,22 & 23,60 & 157,68 & 89,63 & 96,24 & 129,67 \\
\hline Bufo spinosus & 30TWL17 & 100,00 & 103,53 & 111,29 & \begin{tabular}{|l|l|}
37,17 \\
\end{tabular} & 6279,43 & 274,65 & $-19,02$ & 293,67 & 122,61 & 187,15 & 187,58 & 28,16 & 519,04 & 62,40 & 23,79 & 23,10 & 158,25 & 91,01 & 97,74 & 130,71 \\
\hline Bufo spinosus & \begin{tabular}{|l|} 
30TWL19 \\
\end{tabular} & 100,00 & 110,87 & 111,19 & 37.55 . & $\mid 6229,64$ & 280,75 & -11.81 & 292.56 & 130,53 & 193,55 & $\mid 193,84$ & 35,34 & 490,44 & 58,62 & 22.78 & 22.84 & 148,93 & 87,42 & 93,05 & 124,01 \\
\hline Bufo spinosus & 30 TWL23 & 100,00 & 107,73 & 111,14 & 37,00 & 6395,07 & 279,09 & \begin{tabular}{ll|}
$-16,64$ \\
\end{tabular} & 295,73 & 117,25 & 192,73 & 193,40 & 30,99 & 492,52 & 60,48 & 21,39 & 25,13 & 150,85 & 83,67 & 89,55 & 120,92 \\
\hline Bufo spinosus & 30TWL24 & 100,00 & 107,67 & 111,21 & 37,00 & 6371,25 & 278,73 & $-16,60$ & 295,33 & 127,47 & 192,42 & 192,95 & 31,09 & 491,85 & 60,39 & 21,70 & 24,67 & 150,90 & 84,58 & 90,68 & 121,06 \\
\hline Bufo spinosus & 30TWL26 & 100,00 & 105,36 & 111,83 & \begin{tabular}{|l|l|}
37,18 \\
\end{tabular} & $\begin{array}{ll}6306,08 \\
\end{array}$ & 276,62 & \begin{tabular}{|l|l|}
$-18,44$ \\
\end{tabular} & 295,06 & 124,83 & 189,21 & 189,83 & 29,54 & 506,69 & \begin{tabular}{ll|}
61,87 \\
\end{tabular} & 23,41 & 23,57 & 155,68 & 89,50 & 96,17 & 125,79 \\
\hline Bufo spinosus & 30TWL27 & 100,00 & 103,26 & 112,48 & 37,56 & 6274,36 & 274,86 & $-20,32$ & 295,18 & 122,43 & 186,79 & 187,23 & 27,83 & 520,87 & 63,32 & 24,73 & 22,91 & 159,92 & 93,13 & 100,17 & 130,19 \\
\hline Bufo spinosus & 30TWL28 & 100,00 & 104,37 & 112,80 & 37,86 & 6240,78 & 276,01 & $-19,05$ & 295,06 & 123,50 & 187,44 & 187,69 & 29,20 & 519,80 & 62,82 & 25,08 & 22,39 & 159,21 & 93,81 & 100,57 & 130,73 \\
\hline Bufo spinosus & 30TWL30 & 100,00 & 120,48 & 111,99 & 37,01 & 6479,73 & 291,73 & $-6,48$ & 298,21 & 106,04 & 205,97 & 206,87 & 41,95 & 442,85 & 54,92 & 17,53 & 27,35 & 137,01 & 72,47 & 76,33 & 107,34 \\
\hline Bufo spinosus & 30TWL34 & 100,00 & 103,25 & $\mid 112,50$ & 37,45 & 6352,49 & 274,90 & \begin{tabular}{|l|l|}
$-21,79$ \\
-2.0
\end{tabular} & \begin{tabular}{|l|l|}
296,68 \\
\end{tabular} & 122,84 & $\begin{array}{l}187,75 \\
\end{array}$ & 188,19 & 26,94 & 512,13 & $\begin{array}{l}4,3,82 \\
63,2\end{array}$ & 24,03 & 24,14 & $\begin{array}{l}159,32 \\
152\end{array}$ & $\begin{array}{l}90,44 \\
90\end{array}$ & 98,01 & 124,74 \\
\hline Bufo spinosus & 30 TWL35 & 100,00 & 101,26 & 112,75 & 37,71 & 6319,27 & 272,95 & $-23,49$ & 296,44 & 120,55 & 185,24 & 185,87 & 25,27 & 523,95 & 65,03 & 25,26 & 23,49 & 162,96 & 93,88 & 101,78 & 128,29 \\
\hline Bufo spinosus & 30TWL36 & 100,00 & 100,93 & 113,00 & 37,98 & 6291,45 & 272,63 & $-23,75$ & 296,38 & 120,11 & 184,61 & 185,22 & 25,24 & 528,39 & 65,26 & 25,80 & 23,01 & 164,10 & 95,48 & 103,54 & 130,21 \\
\hline Bufo spinosus & 30TWL37 & 100,00 & 103,16 & 113,23 & 37,99 & 6272,93 & 274,97 & $-21,53$ & 296,50 & 122,53 & 186,64 & 186,98 & 27,49 & 520,99 & 64,03 & 25,62 & 22,73 & 161,25 & 94,88 & 102,47 & 129,11 \\
\hline Bufo spinosus & 30TWL38 & 100,00 & 107,05 & 113,55 & 38,00 & 6243,97 & 278,66 & $-17,82$ & 296,47 & 126,84 & 189,90 & 190,27 & 31,47 & 506,42 & 62,06 & 24,94 & 22,58 & 156,39 & 92,73 & 99,67 & 126,17 \\
\hline Bufo spinosus & 30TWL39 & 100,00 & 109,03 & |113,99 & 38,00 & 6221,73 & 280,64 & \begin{tabular}{|l|l|l|l|l|}
$-15,73$ \\
\end{tabular} & \begin{tabular}{|l|}
296,38 \\
\end{tabular} & \begin{tabular}{|l|}
128,99 \\
\end{tabular} & \begin{tabular}{|l|}
191,51 \\
\end{tabular} & 191,92 & 33,55 & \begin{tabular}{|l|l|}
503,57 \\
\end{tabular} & $\begin{array}{l}61,23 \\
61\end{array}$ & $\mid 25,10$ & 22,12 & $\begin{array}{l}154,73 \\
150\end{array}$ & $\begin{array}{ll}2,119 \\
92,94\end{array}$ & $\begin{array}{ll}99,47 \\
\end{array}$ & 126,49 \\
\hline Bufo spinosus & 30TWL45 & 100,00 & 101,42 & 113,01 & 37,96 & 6313,14 & 272,55 & $-24,05$ & 296,60 & 120,94 & 185,25 & 185,75 & 25,16 & 521,14 & 65,67 & 25,74 & 23,55 & 163,99 & 95,18 & 103,92 & 125,89 \\
\hline Bufo spinosus & 30TWL46 & 100,00 & 101,78 & 113,18 & 38,00 & 6287,87 & 272,96 & $-23,51$ & 296,47 & 121,38 & 185,08 & 185,94 & 25,77 & 522,12 & 65,52 & 26,11 & 23,19 & 163,97 & 96,14 & 104,76 & 126,84 \\
\hline Bufo spinosus & 30 TWL48 & 100,00 & 107,87 & 114,02 & 38,00 & 6247,87 & 279,03 & $-17,74$ & 296,77 & 128,00 & 190,51 & 191,08 & 31,85 & 501,45 & 62,41 & 25,29 & 22,61 & 156,52 & 93,48 & 101,12 & 123,39 \\
\hline \begin{tabular}{|l} 
Bufo spinosus \\
\end{tabular} & 30TWL49 & 100,00 & 106,99 & 114,69 & 38,00 & 6217,22 & 278,67 & $-18,62$ & 297,29 & 126,85 & 189,35 & 189,79 & 31,42 & 514,24 & 63,20 & 26,27 & 22,00 & 159,39 & 96,54 & 104,10 & 128,16 \\
\hline Bufo spinosus & 30TWL51 & 100,00 & 106,28 & \begin{tabular}{|l|}
113,61 \\
113,61
\end{tabular} & 37,56 & 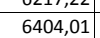 & 277,77 & $\begin{array}{l}-1,0,04 \\
-21,32\end{array}$ & $\mid 299,08$ & \begin{tabular}{|l|}
126,6303 \\
\end{tabular} & \begin{tabular}{|l|}
190,97 \\
190,97
\end{tabular} & \begin{tabular}{|l|}
191,94 \\
109
\end{tabular} & $\begin{array}{l}\frac{31,424}{28,86} \\
\end{array}$ & \begin{tabular}{|l|}
497,92 \\
497
\end{tabular} & $\begin{array}{l}3,20 \\
64,29 \\
\end{array}$ & 22,93 & 25,53 & \begin{tabular}{|l|}
158,24 \\
15,25
\end{tabular} & $\begin{array}{l}\mid 80,74 \\
88,77 \\
\end{array}$ & $\begin{array}{r}97,15 \\
97,15\end{array}$ & $\begin{array}{l}120,10 \\
116,70\end{array}$ \\
\hline Bufo spinosus & 30TWL54 & 100,00 & 98,00 & 113,00 & 37,85 & 6319,16 & 268,42 & $-28,34$ & 296,76 & 117,66 & 181,79 & 182,50 & 21,83 & 533,39 & 68,43 & 26,86 & 23,96 & 170,27 & 99,07 & 109,13 & 126,11 \\
\hline Bufo spinosus & 30TWL55 & 100,00 & 100,28 & 113,00 & 38,00 & 6305,38 & 270,42 & $-25,85$ & 296,27 & 120,17 & 183,82 & 184,44 & 24,16 & 523,34 & 67,03 & 26,47 & 23,74 & 166,91 & 97,78 & 107,47 & 124,24 \\
\hline Bufo spinosus & 30TWL57 & 100,00 & 109,50 & 113,14 & 37,89 & 6275,19 & 278,71 & $-17,05$ & 295,76 & 130,26 & 192,22 & 192,81 & 32,96 & 484,23 & 62,01 & 24,46 & 23,93 & 154,03 & 91,11 & 99,48 & 115,77 \\
\hline \begin{tabular}{|l} 
Bufo spinosus \\
\end{tabular} & 30TWL59 & 100,00 & 101,72 & 114,83 & 38,00 & 6195,27 & 272,78 & $-24,05$ & 296,83 & 121,25 & 183,77 & 184,08 & 26,56 & 541,03 & 67,11 & 28,44 & 21,87 & 169,30 & \begin{tabular}{|r|r|r|}
103,28 \\
\end{tabular} & 112,47 & 133,71 \\
\hline Bufo spinosus & 30TWL61 & 100,00 & 101,79 & 113,57 & 37,77 & 6377,40 & 272,29 & $-25,99$ & 298,28 & 122,08 & 186,20 & 187,18 & 24,97 & 514,26 & $\begin{array}{l}67,48 \\
67\end{array}$ & 24,75 & 25,52 & 166,23 & 94,57 & 104,59 & 118,06 \\
\hline Bufo spinosus & 30TWL62 & 100,00 & 101,37 & 113,01 & 37,79 & 6352,98 & 271,03 & $-25,93$ & 296,96 & 121,79 & 185,60 & 186,39 & 24,84 & 512,22 & 67,35 & 25,23 & 25,26 & 166,09 & 95,40 & 105,62 & 117,44 \\
\hline Bufo spinosus & 30TWL64 & 100,00 & 92,52 & 112,46 & 37,63 & 6276,63 & 261,53 & $-33,62$ & 295,15 & 111,91 & 175,77 & 176,50 & 17,02 & 558,12 & 72,37 & 29,19 & 23,85 & 180,46 & 106,31 & 118,18 & 129,79 \\
\hline Bufo spinosus & 30TWL67 & 100,00 & 115,46 & 112,12 & 37,8 & 6277,88 & 282,14 & $-11,88$ & 294,02 & 137,19 & 197,70 & 198,35 & 38,25 & 450,56 & 59,37 & 22,72 & 25,38 & 146,03 & 85,86 & 94,40 & 104,77 \\
\hline Bufo spinosus & 30TWL68 & 100,00 & 112,19 & 112 & 38,6 & 6249,84 & $\frac{20,1}{279,7}$ & $\begin{array}{l}-14,71 \\
-14,\end{array}$ & 294,50 & 133,40 & 194,21 & \begin{tabular}{|l|}
194,71 \\
\end{tabular} & 35,50 & $\begin{array}{l}472,48 \\
472,4\end{array}$ & $\begin{array}{l}61,37 \\
6\end{array}$ & 24,37 & 24,31 & $\begin{array}{l}152,06 \\
\end{array}$ & $\begin{array}{l}30,60 \\
00\end{array}$ & 999,71 & 111,62 \\
\hline \begin{tabular}{|l} 
Bufo spinosus \\
\end{tabular} & 30TWL70 & 100,00 & 91,25 & 113,37 & 37,78 & 6353,50 & 261,86 & $-35,97$ & 297,83 & 110,50 & 175,78 & 176,58 & 15,10 & 567,06 & 74,54 & 28,58 & 25,04 & 185,02 & 106,81 & 119,27 & 128,13 \\
\hline Bufo spinosus & 30TWL71 & 100,00 & 100,38 & 112,73 & 37,64 & 6345,85 & 268,58 & $-27,65$ & 296,23 & 120,78 & 184,12 & 185,14 & 23,60 & 515,33 & 68,84 & 25,71 & 25,99 & 169,48 & 97,71 & 108,87 & 115,26 \\
\hline Bufo spinosus & 30TWL74 & 100,00 & 94,44 & 111,69 & 37,69 & 6269,73 & 261,15 & $-32,36$ & 293,51 & 114,28 & 177,20 & 177,95 & 18,48 & 541,81 & 71,72 & 28,85 & 24,78 & 178,10 & 105,54 & 118,04 & 122,80 \\
\hline Bufo spinosus & 30TWL79 & 100,00 & 104,45 & 112,51 & 38,00 & 6188,75 & 271,01 & $-21,80$ & 292,81 & 124,98 & 185,71 & 186,24 & 28,54 & 515,73 & 66,75 & 27,82 & 23,61 & 166,43 & 101,02 & 112,18 & 122,07 \\
\hline Bufo spinosus & 30 TWLI & 100,00 & $\begin{array}{r}90,43 \\
93,70\end{array}$ & $\frac{112}{112}$ & 37,43 & $\mid \begin{array}{ll}\mid c 10,1 / 1 \\
6338,13\end{array}$ & 261,37 & $\begin{array}{l}-2,00 \\
-33,88 \\
\end{array}$ & \begin{tabular}{|l|}
295,25 \\
25,2
\end{tabular} & \begin{tabular}{|l|}
113,39 \\
1130
\end{tabular} & \begin{tabular}{|l|}
$\mid 170,1,1$ \\
177,54
\end{tabular} & $\begin{array}{l}170,24 \\
178,62 \\
\end{array}$ & $\begin{array}{l}\mid 0,044 \\
17,14\end{array}$ & $\mid 547,11$ & $\begin{array}{l}\mid 73,1 / 40 \\
730\end{array}$ & 28,23 & 25,82 & $\begin{array}{l}181,65 \\
180\end{array}$ & \begin{tabular}{|l|}
106,07 \\
\end{tabular} & $\begin{array}{l}11,10,79 \\
11,79\end{array}$ & 119,77 \\
\hline Bufo spinosus & 30TWL98 & 100,00 & 113,05 & 109,24 & 37,46 & 6207,38 & 273,55 & $-14,03$ & 287,58 & 135,14 & 193,65 & 194,38 & 36,22 & 453,66 & 62,75 & 24,44 & 27,61 & 153,12 & 90,73 & 102,77 & 100,08 \\
\hline Bufo spinosus & 30TWM02 & 100,00 & 97.86 & $\mid 110,42$ & 37,99 & 6061,51 & 266,39 & -21.04 & 287,44 & 115,60 & $\mid 178,84$ & $\mid 178,89$ & 24,96 & 574,46 & 66.58 & 28,80 & 20,96 & 172,38 & $\mid 104,40$ & 107,16 & 148,76 \\
\hline Bufo spinosus & 30TWMO3 & 100,00 & 93,98 & 109,78 & 38,00 & 6001,04 & 261,56 & $-23,63$ & 285,19 & 110,94 & 174,33 & 174,36 & 21,81 & 605,37 & 69,45 & 31,18 & 20,27 & 180,79 & 110,97 & 113,23 & 157,66 \\
\hline Bufo spinosus & 30TWMO4 & 100,00 & 85,75 & 108, & 38,00 & 5923,26 & 251,68 & $-29,78$ & 281,46 & 101,73 & 165,23 & 165,23 & 14,97 & 666,40 & 75,31 & 35,51 & 19,49 & 197,55 & 123,31 & 124,57 & 17 \\
\hline \begin{tabular}{|l} 
Bufo spinosus \\
\end{tabular} & 30TWM05 & 100,00 & 70,14 & $\begin{array}{l}106,53 \\
\end{array}$ & 38,00 & 5815,45 & 233,82 & $-42,16$ & 275,98 & 84,29 & 148,92 & 148,92 & 1,64 & 779,62 & 86,31 & 42,85 & 18,61 & 228,66 & 145,29 & 145,29 & 205,86 \\
\hline Bufo spinosus & 30TWM06 & 100,00 & 91,56 & 106,05 & 38,00 & 5817,45 & 252,79 & $-21,79$ & 274,57 & 107,69 & 169,41 & 169,41 & 21,56 & 661,18 & 73,31 & 35,29 & 19,10 & 193,37 & 124,01 & 124,21 & 174,34 \\
\hline Bufo spinosus & 30TWM07 & 100,00 & 70,76 & 104,27 & 38,01 & 5708,69 & 230,51 & $-39,31$ & 269,82 & 84,63 & 148,01 & 148,01 & 3,28 & 811,61 & 87,62 & 44,84 & 18,14 & 234,22 & 152,54 & 152,54 & 216,71 \\
\hline Bufo spinosus & 30TWM08 & 100,00 & 89,97 & 103,04 & 38,06 & 5672,90 & 245,93 & $-20,14$ & 266,06 & 100,88 & 165,91 & 165, & 21, & 712,04 & 76,42 & 38,20 & 18,40 & 204,14 & 134,80 & 134,80 & 190, \\
\hline \begin{tabular}{|l} 
Bufo spinosus \\
\end{tabular} & 30TWM11 & 100,00 & 103,61 & 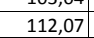 & 38,00 & 6125,34 & 273,87 & $-17,73$ & 291,61 & 122,12 & 185,23 & 185,33 & 29,68 & 541,47 & 63,54 & 26,93 & 21,18 & 163,32 & $\begin{array}{l}8,87 \\
9\end{array}$ & 104,65 & 139,26 \\
\hline
\end{tabular}




\begin{tabular}{|c|c|c|c|c|c|c|c|c|c|c|c|c|c|c|c|c|c|c|c|c|c|}
\hline TAXON & UTM & $\mathrm{km} 2$ & B101 & B102 & $\mathrm{BIO3}$ & BIO4 & B105 & B106 & B107 & B108 & B109 & B1010 & BIO11 & BIO12 & 81013 & BIO14 & BIO15 & BIO16 & B1017 & BIO18 & B1019 \\
\hline Bufo spinosus & 30TWM12 & 100,00 & 97,65 & 111,98 & 38,00 & 6063,67 & 267,47 & $-22,53$ & 290,01 & 115,41 & 178,63 & 178,69 & 24,68 & 582,73 & 67,62 & 30,02 & 20,29 & 174,84 & 107,47 & 111,59 & 151,12 \\
\hline Bufo spinosus & 30TWM13 & 100,00 & 96,87 & 111,31 & 38,04 & 6017,11 & 265,36 & $-22,23$ & 287,59 & 114,39 & 177,16 & 177,21 & 24,34 & 596,68 & 68,64 & 31,22 & 19,93 & 178,25 & 110,88 & 114,29 & 155,30 \\
\hline Bufo spinosus & 30TWM14 & 100,00 & 79,04 & 109,12 & 38,02 & 5905,41 & 245,44 & $-36,45$ & 281,89 & 94,44 & 158,69 & 158,69 & 9,01 & 716,27 & 80,58 & 38,98 & 18,83 & 211,92 & 133,97 & 134,53 & 188,09 \\
\hline Bufo spinosus & 30TWM15 & 100,00 & 68,97 & 107,08 & 38,02 & 5817,98 & 232,96 & $-43,81$ & 276,77 & 83,09 & 147,78 & 147,78 & 0,49 & 794,58 & 87,97 & 44,08 & 18,21 & 233,03 & 149,38 & 149,38 & 209,87 \\
\hline Bufo spinosus & 30TWM16 & 100,00 & 80,61 & 106,79 & 38,04 & 5796,00 & 242,94 & $-32,60$ & 275,54 & 95,78 & 158,64 & 158,64 & 11,50 & 737,33 & 81,18 & 40,38 & 18,32 & 215,15 & 139,25 & 139,33 & 195,45 \\
\hline Bufo spinosus & 30TWM17 & 100,00 & 93,83 & 105,35 & 38,08 & 5763,45 & 252,61 & $-19,24$ & 271,85 & 110,11 & 170,63 & 170,63 & 24,09 & 674,93 & 74,07 & 36,31 & 18,55 & 196,01 & 128,47 & 128,65 & 178,33 \\
\hline Bufo spinosus & 30TWM18 & 100,00 & 110,04 & 102,28 & \begin{tabular}{|l|l|}
38,03 \\
\end{tabular} & 5706,21 & 262,98 & $-2,26$ & 265,24 & 124,43 & 185,29 & 185,29 & 39,92 & 602,75 & 65,87 & 31,60 & 18,93 & 173,77 & 116,27 & 116,44 & 157,84 \\
\hline \begin{tabular}{|l} 
Bufo spinosus \\
\end{tabular} & 30TWM19 & 100,00 & 120,28 & 98,44 & 37,98 & 5591,73 & 266,30 & 9,67 & 256,62 & 88,06 & $\begin{array}{l}193,38 \\
\end{array}$ & 193,38 & 50,78 & 581,66 & 62,07 & 29,70 & 19,11 & 168,78 & 113,38 & 113,42 & 152,68 \\
\hline Bufo spinosus & 30TWM22 & 100,00 & 96,86 & 113,61 & 38,16 & 6066,54 & 268,07 & $-24,41$ & 292,48 & 114,77 & 177,89 & 177,97 & 24,04 & 594,34 & 68,98 & 31,16 & 19,96 & 178,36 & 111,02 & 115,83 & 154,58 \\
\hline Bufo spinosus & 30TWM23 & 100,00 & 100,11 & 113,02 & 38,18 & 6033,19 & 269,86 & $-20,79$ & 290,66 & 118,09 & 180,38 & 180,43 & 27,22 & 585,53 & 67,66 & 30,79 & 19,88 & 175,20 & 110,05 & 114,06 & 152,42 \\
\hline Bufo spinosus & 30TWM24 & 100,00 & 76,56 & 109,64 & 38,18 & 5900,86 & 243,23 & $-39,27$ & 282,50 & 91,92 & 156,19 & 156,19 & 6,65 & 738,56 & 83,14 & 40,72 & 18,55 & 218,56 & 139,47 & 140,34 & 193,94 \\
\hline Bufo spinosus & 30TWM25 & 100,00 & 68,24 & 107,45 & 38,15 & 5819,86 & 232,22 & $-45,10$ & 277,32 & 82,59 & 147,03 & 147,03 & $-0,29$ & 807,14 & 89,42 & 45,16 & 17,94 & 236,86 & 153,03 & 153,23 & 212,90 \\
\hline \begin{tabular}{|l} 
Bufo spinosus \\
\end{tabular} & 30TWM26 & 100,00 & 88,12 & 108,23 & 38,21 & 5828,86 & 251,09 & $-27,02$ & 278,11 & 104,26 & 166,05 & 166,05 & 18,05 & 698,10 & 77,51 & 38,12 & 18,28 & 204,48 & 132,99 & 133,36 & $\begin{array}{ll}184,37 \\
\end{array}$ \\
\hline Bufo spinosus & 30TWM27 & 100,00 & 91,55 & 106,67 & 38,27 & 5774,84 & 251,68 & $-22,38$ & 274,06 & 107,79 & 168,63 & 168,63 & 21,84 & 694,45 & 76,45 & 37,87 & 18,18 & 202,16 & 133,02 & 133,16 & 183,65 \\
\hline Bufo spinosus & 30TWM28 & 100,00 & 99,88 & 104,49 & 38,32 & 5719,76 & 255,82 & $-12,94$ & 268,76 & 116,42 & 175,71 & 175,71 & 30,24 & 666,60 & 72,70 & 36,00 & 18,18 & 192,58 & 128,78 & 128,95 & 175,86 \\
\hline Bufo spinosus & 30TWM29 & 100,00 & 120,41 & 100,10 & 38,02 & 5642,81 & 268,08 & 8,30 & 259,78 & 117,56 & 194,07 & 194,07 & 50,30 & 572,70 & 62,49 & 29,95 & 18,94 & 165,38 & 113,07 & 113,23 & 147,71 \\
\hline Bufo spinosus & 30TWM30 & 100,00 & 104,56 & 115,04 & 38,02 & 6178,03 & 277,30 & $-19,92$ & 297,21 & 123,75 & 186,70 & 186,90 & 29,64 & 537,74 & 64,31 & 27,47 & 21,05 & 163,83 & 100,23 & 106,71 & 137,27 \\
\hline Bufo spinosus & 30TWM31 & 100,00 & 103,45 & 115,62 & 38,23 & 6134,85 & 276,37 & $-20,69$ & 297,06 & 122,47 & 184,84 & 185,21 & 29,02 & 554,93 & 65,48 & 28,72 & 20,44 & 167,84 & 104,20 & 110,61 & 143,26 \\
\hline Bufo spinosus & 30TWM32 & 100,00 & 100,33 & 115,52 & 38,74 & 6085,66 & 272,95 & $-22,71$ & 295,66 & 118,86 & 181,43 & 181,54 & 26,86 & 582,24 & 67,90 & 30,58 & 19,91 & 175,02 & 110,07 & 115,38 & 151,54 \\
\hline Bufo spinosus & 30TWM33 & 100,00 & 99,18 & 114,38 & 38,68 | & 6035,13 & 269,98 & -22.77 & 292,75 & 117,33 & $\mid 179,49$ & $\mid 179,60$ & 26,17 & 597,93 & 69,21 & 31.78 & 19,53 & 179,08 & $|113,60|$ & 119,15 & 155,93 \\
\hline Bufo spinosus & 30TWM34 & 100,00 & 85,60 & 111,58 & 38,56 & 5936,16 & 253,40 & $-32,75$ & 286,15 & 102,03 & 165,18 & 165,19 & 14,49 & 689,98 & 78,33 & 37,81 & 18,55 & 204,94 & 131,59 & 133,87 & 180,82 \\
\hline Bufo spinosus & 30TWM 35 & 100,00 & 73,56 & 108,60 & 38,32 & 5840,88 & 238,10 & $-41,36$ & 279,45 & 88,67 & 152,30 & 152,30 & 4,19 & 778,78 & 86,81 & 43,56 & 17,84 & 229,28 & 148,81 & 149,08 & 205,05 \\
\hline Bufo spinosus & 30TWM36 & 100,00 & 86,13 & 108,96 & \begin{tabular}{|l|l|}
38,61 \\
\end{tabular} & 5831,72 & 249,59 & $-29,72$ & 279,31 & 102,28 & 164,16 & 164,16 & 16,16 & 717,70 & 79,76 & 39,59 & 18,01 & 210,42 & 137,64 & 138,29 & 189,70 \\
\hline Bufo spinosus & 30TWM37 & 100,00 & 96,07 & 107,64 & 38,54 & 5802,31 & 256,53 & $-19,25$ & 275,78 & 113,14 & 173,14 & 173,14 & 25,69 & 672,42 & 74,59 & 36,74 & 18,16 & 196,71 & 129,78 & 130,72 & 176,85 \\
\hline Bufo spinosus & 30TWM40 & 100,00 & 106,05 & 115,52 & 38,05 & 6179,69 & 278,45 & $-19,45$ & 297,90 & 125,65 & 187,90 & 188,35 & 30,78 & 530,34 & 64,28 & 27,42 & 21,32 & 162,98 & 100,19 & 107,63 & 134,11 \\
\hline Bufo spinosus & 30TWM41 & 100,00 & 105,43 & 116,28 & 38,43 & 6140,06 & 278,34 & $-19,78$ & 298,12 & 124,92 & 186,82 & 187,18 & 30,50 & 546,13 & 65,2 & 28,45 & 20,74 & 166,35 & 103,75 & 110,58 & 140,07 \\
\hline Bufo spinosus & 30TWM42 & 100,00 & 103,64 & 116,72 & 38,95 & 6096,81 & 276,75 & $-20,97$ & \begin{tabular}{|l|}
297,71 \\
\end{tabular} & \begin{tabular}{|l|}
122,70 \\
\end{tabular} & $\begin{array}{l}180,0262 \\
184,6\end{array}$ & $\begin{array}{l}184,78 \\
\end{array}$ & 29,42 & 568,59 & $\begin{array}{l}6,24,79 \\
\end{array}$ & 29,94 & 19,90 & 171,65 & 108,52 & 115,21 & 147,62 \\
\hline Bufo spinosus & 30TWM43 & 100,00 & 101,79 & 115,45 & 38,91 & 6050,05 & 273,08 & $-21,62$ & 294,71 & 120,42 & 182,06 & 182,21 & 28,19 & 586,40 & 68,46 & 31,32 & 19,54 & 176,49 & 112,42 & 119,54 & 152,32 \\
\hline Bufo spinosus & 30TWM44 & 100,00 & 91,01 & 112,88 & 38,79 & 5964,44 & 259,40 & $-29,18$ & 288,57 & 108,27 & 170,54 & 170,55 & 19,05 & 662,31 & 75,82 & 36,30 & 18,65 & 197,60 & 127,36 & 131,80 & 173,05 \\
\hline Bufo spinosus & 30TWM45 & 100,00 & 82,08 & 110,24 & 38,58 & 5878,70 & 247,42 & $-35,12$ & 282,54 & 98,21 & 160,86 & 160,86 & 11,45 & 731,03 & 82,29 & 40,77 & 17,89 & 216,24 & 140,76 & 141,49 & 191,97 \\
\hline Bufo spinosus & 30TWM46 & 100,00 & 80,56 & 108,70 & 38,54 & 5819,04 & 243,60 & $-34,96$ & 278,56 & 96,40 & 158,60 & 158,60 & 10,80 & 757,90 & 84,18 & 42,44 & 17,65 & 222,38 & 146,11 & 146,57 & 200,06 \\
\hline Bufo spinosus & 30TWM48 & 100,00 & 105,81 & 106,21 & 38,58 & 5790,45 & 262,59 & $\begin{array}{l}3,0,79 \\
-9,9\end{array}$ & 272,38 & $\begin{array}{r}124,10 \\
\end{array}$ & $\begin{array}{l}181,99 \\
189\end{array}$ & 181,99 & $\begin{array}{ll}34,73 \\
34,7\end{array}$ & \begin{tabular}{|l|l|}
631,48 \\
\end{tabular} & $\begin{array}{l}34,10 \\
70,85\end{array}$ & $\begin{array}{l}42,440 \\
34,70\end{array}$ & $\begin{array}{l}18,56 \\
18,5\end{array}$ & 185,93 & \begin{tabular}{|l|}
123,74 \\
123,4
\end{tabular} & 124,95 & 162,81 \\
\hline Bufo spinosus & 30TWM49 & 100,00 & 126,24 & 102,65 & 38,02 & 5775,38 & 276,19 & 10,47 & 265,72 & 146,67 & 195,92 & 200,91 & 54,01 & 508,37 & 59,42 & 27,88 & 20,34 & 153,06 & 104,01 & 107,40 & 122,04 \\
\hline Bufo spinosus & 30TWM50 & 100,00 & 107,07 & 115,01 & 38,01 & 6181,32 & 278,07 & $-18,90$ & 296,97 & 127,18 & 188,72 & 189,23 & 31,86 & 520,60 & 64,27 & 27,27 & 21,79 & 162,18 & 99,62 & 107,97 & 129,36 \\
\hline Bufo spinosus & 30TWM51 & 100,00 & 106,51 & 115,54 & 38,41 & 6147,29 & 277,73 & $-19,11$ & 296,84 & 126,08 & 187,71 & 187,97 & 31,51 & 535,59 & 65,18 & 28,19 & 21,02 & 165,40 & 102,76 & 110,74 & 134,96 \\
\hline Bufo spinosus & 30TWM52 & 100,00 & 101,71 & 115,63 & 38,63 & 6093,30 & 273,15 & $-22,72$ & 295,87 & 120,85 & 182,51 & 182,69 & 27,64 & 574,92 & 68,56 & 30,83 & 20,09 & 175,47 & 110,84 & 118,72 & 147,09 \\
\hline Bufo spinosus & $\begin{array}{l}30 \text { TWM53 } \\
\end{array}$ & 100,00 & 99,08 & $\begin{array}{l}111,05 \\
114,75\end{array}$ & 38,75 & |6046,90 & 269,09 & $\begin{array}{l}-24,129 \\
-24,29\end{array}$ & \begin{tabular}{|l|}
293,38 \\
293
\end{tabular} & 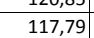 & \begin{tabular}{|l|}
$179,3,33$ \\
179,3
\end{tabular} & \begin{tabular}{|l|}
$179,43,43$ \\
\end{tabular} & 25,55 & \begin{tabular}{|l|l|}
601,88 \\
60
\end{tabular} & $\begin{array}{l}\mid c 0,00 \\
70,87\end{array}$ & $\begin{array}{l}30,030 \\
32,60\end{array}$ & $\begin{array}{l}2,0,51 \\
19,0\end{array}$ & 182,47 & \begin{tabular}{|l|}
116,30 \\
11,3
\end{tabular} & 123,77 & $\begin{array}{l}147,05 \\
54,95\end{array}$ \\
\hline Bufo spinosus & 30TWM54 & 100,00 & 84,73 & 111,67 & 38,62 & 5938,56 & 251,56 & $\begin{array}{l}-34,74 \\
\end{array}$ & 286,30 & 101,62 & 164,07 & 164,10 & 13,18 & 701,31 & 80,52 & 39,10 & 18,36 & 210,06 & 135,73 & 139,05 & 182,08 \\
\hline Bufo spinosus & 30TWM55 & 100,00 & 88,05 & 110,97 & 38,73 & 5908,63 & 253,33 & $-30,57$ & 283,90 & 105,21 & 166,83 & 166,84 & 16,68 & 696,33 & 79,36 & 38,76 & 18,22 & 207,43 & 134,85 & 136,98 & 181,61 \\
\hline Bufo spinosus & 30TWM56 & 100,00 & 92,81 & 109,93 & 38,73 & 5880,87 & 255,93 & $-25,41$ & 281,34 & 110,30 & 170,93 & 170,93 & 21,33 & 683,68 & 77,52 & 37,95 & 18,29 & 202,97 & 132,50 & 134,67 & 178,30 \\
\hline Bufo spinosus & 30TWM60 & 100,00 & 104,44 & 114,17 & 38,01 & 6169,92 & 273,68 & $-21,68$ & 295,36 & 124,74 & 185,87 & 186,26 & 29,28 & 530,32 & 66,51 & 28,30 & 22,01 & 167,25 & 102,72 & 112,54 & 129,82 \\
\hline \begin{tabular}{|l} 
Bufo spinoususus \\
Bufo spinos
\end{tabular} & $\begin{array}{l}30 \mathrm{TWM} 63 \\
3\end{array}$ & 100,00 & $\begin{array}{r}01,44 \\
91,97 \\
\end{array}$ & $\begin{array}{ll}114,17 \\
112,84\end{array}$ & $\begin{array}{l}38,01 \\
38,32\end{array}$ & \begin{tabular}{|l|}
6010,92 \\
601894
\end{tabular} & 259,63 & $\begin{array}{l}-2,00 \\
-30,03 \\
\end{array}$ & \begin{tabular}{|l|}
289,66 \\
289,6
\end{tabular} & \begin{tabular}{|l|l|l|l|l|l|}
110,27 \\
\end{tabular} & \begin{tabular}{|l|}
$173,01,93$ \\
171,93
\end{tabular} & \begin{tabular}{|l|}
172,204 \\
172,04
\end{tabular} & \begin{tabular}{|l|}
19,11 \\
19,1
\end{tabular} & \begin{tabular}{|l|}
$640,32,81$ \\
640.
\end{tabular} & $\begin{array}{l}\mid c 0,51 \\
75,90\end{array}$ & 28,4 & $\begin{array}{l}2,014 \\
19,41 \\
\end{array}$ & $\begin{array}{l}10,23 \\
195,60\end{array}$ & $\begin{array}{l}124,7,2 \\
124,72\end{array}$ & 1131,51 & $\begin{array}{l}12,8,82 \\
163,30\end{array}$ \\
\hline Bufo spinosus & 30TWM64 & 100,00 & 91,17 & 111,90 & 38,49 & 5971,71 & 257,24 & $-29,86$ & 287,10 & 109,08 & 170,47 & 170,52 & 18,71 & 661,68 & 77,32 & 36,82 & 18,96 & 200,35 & 128,66 & 132,58 & 169,82 \\
\hline Bufo spinosus & 30TWM65 & 100,00 & 91,99 & 111,00 & 38,69 & 5931,07 & 256,52 & $-27,79$ & 284,32 & 109,95 & 170,67 & 170,70 & 19,94 & 673,25 & 77,72 & 37,49 & 18,67 & 202,23 & 130,87 & 134,42 & 173,94 \\
\hline Bufo spinosus & 30TWM66 & 100,00 & 97,99 & 110,15 & 38,76 & 5916,93 & 260,65 & $-21,48$ & 282,12 & 116,42 & 176,20 & 176,23 & 25,69 & 653,75 & 75,19 & 36,20 & 18,76 & 80 & 126,85 & 30,21 & 168,89 \\
\hline Bufo spinosus & 30TWM67 & 100,00 & 105,56 & 108,59 & 38,47 & 5898,47 & 265,38 & $-13,16$ & 278,54 & $\begin{array}{l}124,65 \\
12,42\end{array}$ & 183,04 & 183,08 & 32,92 & \begin{tabular}{|l|l|}
625,73 \\
\end{tabular} & 71,84 & 34, & 19,22 & 187,22 & $\begin{array}{l}121,40 \\
\end{array}$ & 124,74 & 160,55 \\
\hline \begin{tabular}{|l} 
Bufo spinosus \\
\end{tabular} & 30TWM & 100,00 & 130,87 & 103,68 & 38,11 & 5811,44 & 280,87 & 13,60 & 267,27 & 151,81 & 205,82 & 205,84 & 57,84 & 516,60 & 59,99 & 28,08 & 20,37 & 156,31 & 103,10 & 106,02 & 123,92 \\
\hline \begin{tabular}{|l} 
Bufo spinosus \\
\end{tabular} & 30TWM72 & 100,00 & 99,36 & 112,68 & 38,05 & 6087,58 & 266,03 & $\begin{array}{l}-24,67 \\
\end{array}$ & 290,70 & 119,00 & $\begin{array}{l}179,66 \\
\end{array}$ & 179,81 & 25,04 & 578,93 & 71,36 & 31,90 & 21,09 & 181,13 & 113,30 & 123,71 & 143,23 \\
\hline Bufo spinosus & 30TWM73 & 100,00 & 98,35 & 112,10 & 38,12 & 6048,86 & 264,16 & $-24,80$ & 288,95 & 117,78 & 178,12 & 178,32 & 24,46 & 600,17 & 72,80 & 33,19 & 20,39 & 185,91 & 117,19 & 126,24 & 150,12 \\
\hline Bufo spinosus & 30TWM74 & 100,00 & 104,64 & 111,38 & 38,15 & 6037,67 & 268,88 & $-18,07$ & 286,95 & 124,35 & 183,90 & 184,07 & 30,39 & 579,31 & 70,04 & 31,70 & 20,70 & 178,88 & 112,50 & 119,76 & 145,13 \\
\hline Bufo spinosus & 30TWM & 100,00 & 131,83 & $\begin{array}{l}111,50 \\
103,92\end{array}$ & $\frac{00}{38}$ & \begin{tabular}{|l}
5807,65 \\
\end{tabular} & $\begin{array}{l}20,00 \\
281,63\end{array}$ & $\begin{array}{l}-14,0,43 \\
14,43 \\
\end{array}$ & \begin{tabular}{|l|}
267,20 \\
267
\end{tabular} & \begin{tabular}{|l|}
148,30 \\
140
\end{tabular} & $\begin{array}{l}\mid 03,50 \\
206,70\end{array}$ & \begin{tabular}{|l|}
206,71 \\
20,71
\end{tabular} & \begin{tabular}{|l|l|}
58,81 \\
\end{tabular} & $\mid \begin{array}{l}\mid 7,59,05 \\
559\end{array}$ & $\mid 0,0,46$ & $\begin{array}{ll}29,22 \\
29\end{array}$ & 20,09 & 164,46 & $\begin{array}{l}107,43 \\
107\end{array}$ & 108,30 & $\begin{array}{l}14,15 \\
141,47\end{array}$ \\
\hline Bufo spinosus & 30TWM81 & 100,00 & 95,19 & 111,13 & 38,00 & 6093,47 & 259,76 & $-28,84$ & 288,61 & 114,84 & 175,50 & 175,73 & 20,67 & 584,71 & 73,75 & 32,71 & 21,90 & 186,25 & 115,83 & 127,53 & 140,88 \\
\hline Bufo spinosus & 30TWM82 & 100,00 & 93,96 & 110,92 & $38,00 \mid$ & 6058,28 & 258,25 & $-29,35$ & $287,60 \mid$ & $\mid 113,12$ & $\mid 173,90$ & $\mid 173,96$ & 19,82 & 607,35 & 75,29 & 34,08 & 21,12 & 191,30 & 119,85 & 131,13 & 148,50 \\
\hline Bufo spinosus & 30TWM83 & 100,00 & 102,29 & 111,08 & 38,01 & 6063,83 & 266,08 & $-21,32$ & 287,40 & 122,23 & 181,75 & 182,01 & 27,54 & 575,06 & 71,24 & 31,73 & 21,45 & 180,48 & 112,34 & 123,17 & 141,63 \\
\hline Bufo spinosus & 30TWM & 100,00 & 112,56 & 110,32 & 38,00 & 6074,30 & 274,85 & $-10,78$ & 285,63 & 133,44 & 191,83 & 191,95 & 37,15 & 536,46 & 66,46 & 28,88 & 22,09 & 167,91 & 103,46 & 111,82 & 132 \\
\hline \begin{tabular}{|l} 
Bufo spinosus \\
\end{tabular} & 30TWM88 & 100,00 & 134,35 & 105,10 & 38,04 & 5889,37 & 286,21 & 14,87 & 271,33 & 132,12 & 210,31 & 210,31 & 60,31 & 546,65 & 61,38 & 27,62 & 21,02 & 160,87 & 102,44 & 104,23 & 141,00 \\
\hline Bufo spinosus & 30TWM89 & 100,00 & 131,38 & 104,44 & 38,28 & 5824,87 & 281,87 & 13,37 & 268,50 & 108,01 & 206,61 & 206,61 & 58,00 & 599,62 & 65,11 & 30,34 & 20,55 & 175,85 & 111,50 & 111,85 & 158,52 \\
\hline Bufo spinosus & 30TWM91 & 100,00 & 8784 & 108,99 & 37,95 & 6050,08 & 249,71 & -35.05 & 284.76 & 106,85 & 167,60 & $\mid 167,79$ & 13.94 & 624.44 & 78,82 & 35.82 & 21.71 & 199,61 & 125,27 & 139,48 & 148,70 \\
\hline Bufo spinosus & 30TWM92 & 100,00 & 72,64 & 106,71 & 37,77 & 5954,64 & 233,16 & $-46,25$ & 279,41 & 89,69 & 152,01 & 152, & 0,86 & 739,71 & 89,38 & 43,41 & 19,55 & 230,16 & 148,20 & 155,56 & 180,58 \\
\hline Bufo spinosus & 30TWM93 & 100,00 & 108,87 & 109,70 & 38,00 & 6087,02 & 270,50 & $-15,03$ & 285,53 & 129,85 & 188,27 & 188,40 & 33,36 & 539,83 & 68,31 & 29,30 & 22,86 & 171,31 & 104,81 & 115,50 & 130, \\
\hline
\end{tabular}




\begin{tabular}{|c|c|c|c|c|c|c|c|c|c|c|c|c|c|c|c|c|c|c|c|c|c|}
\hline TAXON & UTM & $\mathrm{km} 2$ & BIO1 & B102 & $B 103$ & BIO4 & B105 & B106 & B107 & B108 & B109 & B1010 & BIO11 & B1012 & BIO13 & B1014 & BIO15 & B1016 & B1017 & B1018 & 81019 \\
\hline Bufo spinosus & 30TWM94 & 100,00 & 116,65 & 109,32 & 38,00 & 6088,93 & 277,28 & $-6,85$ & 284,12 & 138,12 & 195,80 & 195,84 & 40,77 & 518,92 & 65,08 & 27,44 & 23,06 & 163,27 & 99,03 & 108,04 & 127,24 \\
\hline Bufo spinosus & 30TWM98 & 100,00 & 132,69 & 105,57 & 38,03 & 5901,17 & 285,19 & 12,88 & 272,31 & 98,97 & 208,86 & 208,86 & 58,47 & 581,45 & 64,16 & 28,73 & 21,48 & 171,39 & 106,18 & 106,63 & 155,19 \\
\hline Bufo spinosus & 30TWM99 & 100,00 & 131,07 & 104,91 & 38,25 & 5841,19 & 282,14 & 12,33 & 269,81 & 95,75 & 206,50 & 206,50 & 57,70 & \begin{tabular}{ll|l}
635,06 \\
\end{tabular} & 70,00 & 31,24 & 21,29 & $\begin{array}{l}189,54 \\
\end{array}$ & $\begin{array}{ll}114,88 \\
\end{array}$ & 115,15 & 174,14 \\
\hline Bufo spinosus & 30TWNO0 & 100,00 & 120,38 & $\begin{array}{ll}94,44 \\
\end{array}$ & 37,97 & 5419,18 & 260,53 & 13,68 & 246,85 & 88,49 & 190,40 & $\begin{array}{l}191,40 \\
\end{array}$ & 53,06 & 629,12 & 66,32 & 31,18 & 19,25 & 187,06 & 120,44 & 121,28 & 170,86 \\
\hline Bufo spinosus & 30TWN02 & 100,00 & 122,30 & 88,59 & 37,80 & 5134,56 & 253,13 & 21,27 & 231,85 & 92,57 & 188,13 & 189,59 & 58,65 & 725,80 & 80,04 & 34,78 & 20,01 & 221,58 & 134,57 & 139,36 & 206,13 \\
\hline Bufo spinosus & 30TWN03 & 100,00 & 116,25 & 87,55 & 37,88 & 5049,03 & 246,02 & 17,38 & 228,64 & 76,28 & $\mid 181,08$ & \begin{tabular}{|l|l|}
182,81 \\
\end{tabular} & 54,08 & 797,32 & 88,72 & 38,69 & 19,84 & 243,94 & $\mid \begin{array}{l}147,58 \\
\end{array}$ & $\mid 152,84$ & 229,04 \\
\hline Bufo spinosus & 30TWN04 & 100,00 & 108,15 & 86,93 & 37,99 & 4972,08 & 237,41 & 11,42 & 225,99 & 55,08 & 172,15 & 174,14 & 47,45 & 881,71 & 98,74 & 43,52 & 19,67 & 271,41 & 163,24 & 168,67 & 255,44 \\
\hline Bufo spinosus & 30TWN05 & 100,00 & 111,15 & 83,25 & 37,86 & 4804,25 & 234,88 & 17,47 & 217,42 & 60,22 & 172,58 & 174,81 & 52,45 & 940,18 & 107,73 & 45,27 & 20,77 & 294,35 & 170,42 & 179,21 & 278,61 \\
\hline Bufo spinosus & 30TWN06 & 100,00 & 120,93 & 76,99 & 37,38 & 4558,16 & 235,22 & 31,95 & 203,28 & 72,35 & 178,65 & $\begin{array}{l}181,13 \\
\end{array}$ & 65,04 & $\begin{array}{l}998,87 \\
\end{array}$ & \begin{tabular}{|l|l|}
119,07 \\
\end{tabular} & 45,23 & 23,21 & 320,68 & $\begin{array}{l}173,37 \\
\end{array}$ & \begin{tabular}{|l|l|}
188,61 \\
\end{tabular} & 308,02 \\
\hline Bufo spinosus & 30TWN08 & 100,00 & 130,79 & 67,22 & 36,46 & 4178,09 & 230,99 & \begin{tabular}{|l|l|}
49,14 \\
\end{tabular} & \begin{tabular}{ll|}
181,86 \\
\end{tabular} & 84,61 & 182,80 & 185,90 & 79,44 & 1139,08 & \begin{tabular}{|l|l|}
144,30 \\
\end{tabular} & 47,36 & 27,59 & 380,12 & 184,84 & 211,30 & 374,92 \\
\hline Bufo spinosus & 30TWN09 & 99,00 & 138,12 & 61,59 & 35,64 & 3978,81 & 229,93 & 59,82 & 170,11 & 90,52 & 187,26 & 190,50 & 88,95 & 1202,85 & 157,78 & 47,29 & 30,38 & 411,24 & 187,22 & 220,79 & 410,73 \\
\hline Bufo spinosus & 30TWN11 & 100,00 & 121,17 & 92,97 & 38,03 & 5325,25 & 258,05 & 16,19 & 241,87 & 87,30 & $\begin{array}{l}189,92 \\
\end{array}$ & $\begin{array}{l}190,83 \\
\end{array}$ & 55,10 & 671,24 & 71,31 & 33,48 & 19,01 & 200,12 & 129,18 & $\begin{array}{l}130,57 \\
\end{array}$ & 183,99 \\
\hline Bufo spinosus & 30TWN12 & 100,00 & 116,42 & 91,61 & 38,06 & 5218,73 & 251,37 & 13,86 & 237,50 & 78,65 & $\mid 183,78$ & 185,01 & 51,99 & 741,39 & 80,05 & 37,07 & 18,90 & 222,10 & 141,43 & 143,53 & 207,29 \\
\hline Bufo spinosus & 30TWN13 & 100,00 & 117,52 & 88,77 & 38,00 & 5076,73 & 248,27 & 17,84 & 230,43 & 75,49 & 182,56 & 184,25 & 54,99 & 795,94 & 87,64 & 39,16 & 19,33 & 241,68 & 149,44 & 153,49 & 227,16 \\
\hline Bufo spinosus & 30TWN14 & 100,00 & 114,06 & 86,70 & 38,04 & 4951,83 & 242,09 & 17,31 & 224,79 & \begin{tabular}{ll|}
60,66 \\
\end{tabular} & \begin{tabular}{ll|}
177,48 \\
\end{tabular} & $\begin{array}{l}179,45 \\
\end{array}$ & 53,44 & 873,38 & 97,76 & 42,79 & 19,69 & 268,69 & 161,95 & 167,58 & 253,84 \\
\hline Bufo spinosus & 30TWN15 & 100,00 & 110,09 & 85,02 & 38,03 & 4845,20 & 235,85 & 15,60 & 220,25 & 58,25 & $\begin{array}{l}172,10 \\
\end{array}$ & $\begin{array}{l}174,23 \\
\end{array}$ & 51,07 & $\begin{array}{l}950,45 \\
\end{array}$ & $\begin{array}{l}107,55 \\
\end{array}$ & 46,56 & 19,95 & 295,50 & $\begin{array}{l}174,82 \\
\end{array}$ & 181,79 & 279,59 \\
\hline Bufo spinosus & 30TWN16 & 100,00 & $\begin{array}{ll}98,64 \\
\end{array}$ & 85,16 & 38,28 & 4807,67 & 225,03 & 5,69 & 219,33 & 47,92 & 160,34 & 162,73 & 40,71 & 1045,75 & $\begin{array}{l}118,43 \\
\end{array}$ & 52,56 & 19,70 & 326,01 & $\begin{array}{l}193,81 \\
\end{array}$ & $\begin{array}{ll}199,88 \\
\end{array}$ & 307,97 \\
\hline Bufo spinosus & 30TWN17 & 100,00 & 128,64 & 72,98 & 37,36 & 4354,73 & 236,46 & 43,81 & 192,65 & 82,11 & 183,14 & 186,01 & 75,52 & $\begin{array}{l}1079,46 \\
\end{array}$ & \begin{tabular}{|l|l|}
131,80 \\
\end{tabular} & 47,04 & 24,96 & 352,18 & 181,94 & 201,95 & 344,04 \\
\hline Bufo spinosus & 30TWN18 & 100,00 & 134,32 & 68,06 & 36,94 & 4171,27 & 235,38 & 53,62 & 181,75 & 89,29 & 186,00 & 189,16 & 83,60 & 1148,38 & 144,51 & 47,86 & 27,29 & 381,57 & 186,91 & 212,95 & 377,88 \\
\hline Bufo spinosus & 30TWN19 & 100,00 & 136,81 & 64,62 & 36,64 & 4030,81 & 233,08 & 59,18 & 173,91 & 91,57 & 186,35 & 189,85 & 88,01 & 1213,41 & 155,48 & 49,45 & 28,69 & 408,53 & 193,61 & 224,12 & 406,77 \\
\hline Bufo spinosus & 30TWN20 & 100,00 & 126,10 & 96,62 & 38,00 & 5507,50 & 267,48 & 16,71 & 250,77 & 94,30 & 197,64 & 197,75 & 57,42 & 585,64 & 61,84 & 29,96 & 18,98 & 170,90 & 116,21 & 116,25 & 153,13 \\
\hline \begin{tabular}{|l|} 
Bufo spinosus \\
\end{tabular} & 30TWN21 & 100,00 & 110,79 & 96,77 & 38,36 & 5416,85 & 252,98 & 4,19 & 248,79 & 66,36 & 182,05 & 182,15 & 44,22 & $\begin{array}{l}711,86 \\
\end{array}$ & 74,31 & 37,25 & 17,99 & 207,94 & 138,90 & 138,90 & 192,77 \\
\hline Bufo spinosus & 30TWN22 & 100,00 & 111,72 & 94,34 & 38,29 & 5288,91 & 250,19 & 7,67 & 242,52 & \begin{tabular}{ll|}
61,67 \\
\end{tabular} & 180,75 & 181,31 & 46,66 & $\begin{array}{l}758,46 \\
\end{array}$ & 80,55 & 39,13 & 18,04 & 223,91 & $\begin{array}{l}147,33 \\
\end{array}$ & $\begin{array}{ll}147,51 \\
\end{array}$ & 209,39 \\
\hline Bufo spinosus & 30TWN23 & 100,00 & 112,54 & 91,62 & 38,28 & 5147,34 & 246,88 & 11,33 & 235,56 & 60,18 & 178,85 & 180,25 & 49,36 & 813,72 & 88,10 & 41,36 & 18,36 & 244,33 & 156,34 & 157,56 & 229,17 \\
\hline Bufo spinosus & 30TWN24 & 100,00 & 119,93 & 86,90 & 38,16 & 4940,64 & 247,10 & 22,81 & 224,29 & 66,12 & 182,88 & 184,78 & 59,15 & 862,41 & 95,99 & 42,06 & 19,59 & 264,73 & 160,61 & 165,94 & 250,16 \\
\hline Bufo spinosus & 30TWN25 & 100,00 & 117,45 & 84,69 & 38,13 & 4802,05 & 241,38 & 23,20 & 218,18 & 65,44 & 178,44 & 180,66 & 58,75 & 945,48 & 107,01 & 45,75 & 20,05 & 294,32 & 173,45 & 180,86 & 279,21 \\
\hline Bufo spinosus & 30TWN26 & 100,00 & 113,08 & 82,98 & 38,30 & 4690,10 & 234,81 & 21,53 & 213,27 & 62,92 & 172,61 & 175,10 & 56,11 & 1031,02 & 118,07 & $\begin{array}{ll}49,92 \\
\end{array}$ & 20,60 & 324,36 & 187,44 & 196,33 & 308,42 \\
\hline Bufo spinosus & 30TWN27 & 100,00 & 120,50 & 77,90 & 38,17 & 4471,05 & 234,66 & 33,45 & 201,21 & 72,74 & 176,71 & \begin{tabular}{ll|}
179,56 \\
\end{tabular} & \begin{tabular}{ll|}
66,37 \\
\end{tabular} & $\begin{array}{l}1097,43 \\
\end{array}$ & 129,37 & 50,81 & 22,51 & 352,25 & 192,55 & 207,20 & 338,87 \\
\hline Bufo spinosus & 30TWN28 & 100,00 & 132,12 & 71,51 & 37,82 & 4217,71 & 237,05 & 50,52 & 186,53 & 86,93 & 184,41 & \begin{tabular}{|l|}
187,61 \\
\end{tabular} & 81,19 & 1160,03 & \begin{tabular}{ll|}
142,02 \\
\end{tabular} & 50,33 & 25,43 & 381,14 & 194,15 & 216,73 & 372,79 \\
\hline Bufo spinosus & 30TWN29 & 100,00 & 136,55 & 67,88 & 37,67 & 4062,26 & 236,21 & 58,40 & $\begin{array}{l}177,81 \\
\end{array}$ & 93,08 & $\begin{array}{l}186,50 \\
\end{array}$ & 190,04 & 87,82 & $\begin{array}{l}1216,98 \\
\end{array}$ & 151,89 & 51,40 & 26,91 & 405,01 & $\begin{array}{l}199,13 \\
\end{array}$ & 226,79 & 398,51 \\
\hline Bufo spinosus & 30TWN30 & 100,00 & 127,14 & $\begin{array}{l}98,39 \\
\end{array}$ & 38,01 & 5580,14 & 270,47 & 15,84 & 254,63 & \begin{tabular}{ll|}
115,86 \\
\end{tabular} & 199,45 & $\begin{array}{l}199,45 \\
\end{array}$ & 57,31 & 562,21 & 61,32 & 29,66 & 19,05 & 162,42 & $\begin{array}{l}113,49 \\
\end{array}$ & 113,76 & 142,64 \\
\hline Bufo spinosus & 30TWN31 & 100,00 & 112,62 & 98,18 & 38,56 & 5463,45 & 255,92 & 4,41 & 251,51 & 69,11 & 184,18 & 184,18 & 45,19 & 698,07 & 73,03 & 37,09 & 17,75 & 201,94 & $\mid 137,27$ & 137,27 & 186,42 \\
\hline Bufo spinosus & 30TWN33 & 100,00 & 103,56 & 94,58 & 38,90 & 5221,61 & 242,10 & 1,07 & 241,03 & 47,20 & 172,36 & 172,57 & 39,87 & 862,93 & 92,57 & 45,23 & 17,73 & 257,56 & 166,55 & 166,66 & 241,63 \\
\hline Bufo spinosus & 30TWN34 & 100,00 & 118,90 & 89,15 & 38,76 & 4985,27 & 248,45 & 20,54 & 227,91 & 64,53 & 182,50 & 184,28 & 57,72 & 871,82 & 95,63 & 43,42 & 18,82 & 265,85 & 165,05 & 168,09 & 249,88 \\
\hline Bufo spinosus & 30TWN35 & 100,00 & 112,87 & 87,58 & 38,92 & 4872,46 & 240,42 & 17,16 & 223,26 & 60,24 & 175,05 & 177,12 & 53,48 & 969,30 & $\begin{array}{l}108,05 \\
\end{array}$ & 48,34 & 19,18 & 299,53 & 181,38 & $\begin{array}{ll}185,61 \\
\end{array}$ & 282,65 \\
\hline \begin{tabular}{|l|} 
Bufo spinosus \\
\end{tabular} & 30TWN36 & 100,00 & 118,93 & 83,30 & 38,89 & 4648,14 & 239,72 & 27,74 & 211,98 & 68,82 & $\begin{array}{l}177,68 \\
\end{array}$ & 180,22 & 62,58 & 1040,38 & $\begin{array}{l}118,56 \\
\end{array}$ & 50,06 & 20,62 & $\begin{array}{l}327,62 \\
\end{array}$ & $\begin{array}{ll}188,78 \\
\end{array}$ & $\begin{array}{l}197,71 \\
\end{array}$ & 311,32 \\
\hline Bufo spinosus & 30TWN37 & 100,00 & $\begin{array}{l}126,97 \\
\end{array}$ & 78,23 & 38,76 & 4416,47 & 240,09 & 40,70 & 199,39 & 79,37 & 182,17 & 185,09 & 73,65 & 1110,02 & $\begin{array}{l}130,25 \\
\end{array}$ & 51,03 & 22,59 & $\begin{array}{l}356,79 \\
\end{array}$ & $\begin{array}{l}194,15 \\
\end{array}$ & 209,22 & 342,71 \\
\hline Bufo spinosus & 30TWN38 & 100,00 & 125,53 & 76,22 & 38,88 & 4295,56 & 235,67 & \begin{tabular}{|l|l}
41,87 \\
\end{tabular} & 193,80 & 79,55 & \begin{tabular}{|l|l|}
178,97 \\
\end{tabular} & 182,14 & 73,98 & 1184,68 & \begin{tabular}{|l|l|}
140,08 \\
\end{tabular} & 54,29 & 23,10 & 383,79 & 205,43 & 223,01 & 368,89 \\
\hline Bufo spinosus & 30TWN39 & 100,00 & 130,98 & 72,34 & 38,82 & 4113,23 & 235,15 & 51,13 & 184,02 & 87,08 & 181,70 & 185,18 & 81,85 & 1246,81 & 150,37 & 55,51 & 24,49 & 409,47 & 211,22 & 234,16 & 396,09 \\
\hline Bufo spinosus & 30TWN40 & 100,00 & 128,64 & 100,21 & 38,06 & 5669,25 & 273,99 & 15,27 & 258,73 & 148,38 & 191,98 & 201,80 & 57,55 & 533,26 & 60,36 & 29,04 & 19,70 & 156,83 & 109,49 & 112,01 & 130,23 \\
\hline Bufo spinosus & 30TWN41 & 100,00 & 113,05 & 99,65 & 38,75 & 5511,61 & 257,95 & 3,55 & 254,40 & 78,84 & 185,14 & 185,14 & 44,99 & 697,21 & 73,21 & 37,48 & 17,57 & 200,54 & 137,18 & 137,18 & 184,62 \\
\hline Bufo spinosus & 30TWN42 & 100,00 & 111,66 & 97,48 & 38,97 & 5372,17 & 253,22 & 4,92 & 248,30 & 55,80 & 182,10 & 182,10 & 45,54 & \begin{tabular}{ll|}
765,08 \\
\end{tabular} & 79,88 & 40,51 & 17,51 & 223,68 & \begin{tabular}{|l|l|}
149,08 \\
\end{tabular} & 499,08 & 207,95 \\
\hline Bufo spinosus & 30TWN43 & 100,00 & 104,69 & 95,80 & 39,00 & 5253,68 & 244,22 & 1,10 & 243,12 & 47,78 & $\begin{array}{l}173,98 \\
\end{array}$ & \begin{tabular}{ll|}
173,98 \\
\end{tabular} & 40 & 867,38 & 92,76 & 45,79 & 17,66 & 43 & $\begin{array}{l}167,34 \\
\end{array}$ & $\begin{array}{ll}167,34 \\
\end{array}$ & 241,97 \\
\hline Bufo spinosus & 30TWN44 & 100,00 & 116,32 & 91,52 & 39,00 & 5041,25 & 248,65 & 16,52 & 232,13 & 61,40 & 180,99 & 182,51 & 54,49 & 893,15 & 97,14 & 45,32 & 18,33 & 271,42 & $\begin{array}{l}170,94 \\
\end{array}$ & $\begin{array}{l}171,69 \\
\end{array}$ & 254,05 \\
\hline Bufo spinosus & 30TWN45 & 100,00 & 108,38 & 90,08 & 39,01 & 4932,58 & 239,01 & 11,27 & 227,75 & 55,25 & 171,85 & 173,45 & 48,43 & 998,88 & 110,42 & 50,92 & 18,72 & 307,34 & 189,19 & 190,92 & 289,05 \\
\hline Bufo spinosus & 30TWN46 & 100,00 & 123,61 & 83,98 & 39,18 & 4612,31 & 243,96 & 32,62 & 211,34 & 73,60 & 181,61 & 184,19 & 67,65 & 1057,52 & 120,02 & 50,76 & 20,66 & 333,64 & 191,58 & 200,33 & 315,99 \\
\hline Bufo spinosus & 30TWN47 & 100,00 & 127,37 & 80,59 & 39,48 & 4414,46 & 242,24 & 40,45 & 201,79 & 79,66 & 182,45 & 185,32 & 74,13 & 1134,07 & 130,68 & 53,16 & 21,75 & 362,79 & 200,85 & 13,87 & 344,92 \\
\hline Bufo spinosus & 30TWN48 & 100,00 & 130,0 & 77,45 & 39, & 4246,62 & 240,0 & 46,70 & 193,35 & 84,39 & 182,71 & 185,86 & 79,20 & 1204,46 & 140 & 55,47 & 22,78 & 389,75 & , 58 & 82 & 372,07 \\
\hline Bufo spinosus & $30 \mathrm{TWI}$ & 83,00 & 135,59 & 73,79 & 39 & 4081 & 239 & 55,56 & 18 & 91,69 & 185,64 & 189,10 & 86,91 & 1255,69 & 149,38 & 56,31 & 24,10 & 411,33 & 213,84 & 236,38 & 394,56 \\
\hline Bufo spinosus & 30TWN50 & 100,00 & 128,81 & 101,63 & 38,17 & 5707,35 & 275,59 & 14,16 & 261,43 & 149,29 & 178,54 & 202,48 & 57,20 & 531,73 & 60,97 & 29,42 & 19,74 & 159,20 & 108,66 & 111,32 & 127,16 \\
\hline Bufo spinosus & 30TWN51 & 100,00 & 117,27 & 100,71 & 38,83 & 5560,53 & 262,85 & 6,08 & 256,77 & 96,97 & $\begin{array}{l}189,70 \\
\end{array}$ & $\begin{array}{l}189,70 \\
\end{array}$ & 48,22 & 677,80 & 71,69 & 36,57 & 17,82 & 194,92 & $\begin{array}{l}133,18 \\
\end{array}$ & \begin{tabular}{|l|l}
133,23 \\
\end{tabular} & 177,28 \\
\hline Bufo spinosus & 30TWN52 & 100,00 & 111,01 & 98,69 & 38,99 & 5410,56 & 253,88 & 3,30 & 250,58 & 54,19 & 181,92 & 181,92 & 44,35 & 784,16 & 81,97 & 41,74 & 17,60 & 29,51 & 151,86 & 151,86 & 213,21 \\
\hline Bufo spinosus & 30TWN53 & 100,00 & 99,05 & 97,23 & 39,00 & 5289,83 & 240,71 & $-5,51$ & 246,22 & 42,19 & 169,02 & 169,02 & 34,61 & 912,83 & 98,09 & 48,79 & 17,47 & 272,35 & 174,91 & 174,91 & 255,66 \\
\hline Bufo spinosus & 30TWN54 & 100,00 & 108,16 & 93,91 & 39,01 & 5109,92 & 243,98 & 6,90 & 237,08 & 52,94 & 175,02 & 175,43 & 45,78 & $\begin{array}{l}945,86 \\
\end{array}$ & \begin{tabular}{|l|l|}
103,08 \\
\end{tabular} & \begin{tabular}{ll|}
49,09 \\
\end{tabular} & 18,18 & 287,36 & 180,52 & 180,55 & 269,18 \\
\hline Bufo spinosus & 30TWN55 & 100,00 & 101,96 & 91,96 & 39,17 & 4992,10 & 235,34 & 3,58 & 231,76 & 48,52 & 167,24 & 168,02 & 41,50 & 1042,61 & 115,05 & 54,16 & 18,39 & 320,16 & 197,85 & 198,55 & 300,92 \\
\hline Bufo spinosus & 30TWN56 & 100,00 & 121,30 & 86,70 & 39,73 & 4667,95 & 244,58 & 28,76 & 215,83 & 70,68 & 180,08 & 182,54 & 64,62 & 1082,56 & \begin{tabular}{ll|l}
121,58 \\
\end{tabular} & \begin{tabular}{ll|}
52,97 \\
\end{tabular} & 20,11 & 340,60 & $\begin{array}{l}198,55 \\
\end{array}$ & \begin{tabular}{|l|l|}
204,39 \\
\end{tabular} & 320,05 \\
\hline Bufo spinosus & 30TWN57 & 100,00 & 121,94 & 84,15 & 40,03 & 4490,28 & 240,93 & 32,96 & 207,97 & 73,57 & 178,16 & $\begin{array}{l}180,97 \\
\end{array}$ & 67,85 & 1167,68 & 132,45 & 56,49 & 20 & 371,32 & 210,95 & 220,01 & 345 \\
\hline Bufo spinosus & & 100,00 & 128 & 80 & 40 & & & 50 & 196,79 & 82 & 180,89 & 184,14 & 77,08 & $\begin{array}{l}1240,29 \\
\end{array}$ & 142,68 & 58,48 & 21,94 & 399,49 & 218,99 & 233,70 & 377,46 \\
\hline Bufo spinosus & 30TWN59 & 44,00 & 139,91 & 75,83 & 40,32 & 4069,49 & 244,87 & 58,97 & 185,90 & 95,91 & 189,63 & 193,12 & 91,12 & \begin{tabular}{|l|}
1259,76 \\
\end{tabular} & 147,65 & 57,21 & 23,51 & 411,15 & 216,65 & 238,33 & 390,14 \\
\hline Bufo spinosus & 30TWN60 & 100,00 & 128,49 & 102,42 & 38,65 & 5712,74 & 275,91 & 13,51 & 262,40 & 148,66 & 202,28 & 202,28 & 56,78 & 570,93 & 63,70 & 30,87 & 19,23 & 168,39 & 113,13 & 114,32 & 141,37 \\
\hline
\end{tabular}




\begin{tabular}{|c|c|c|c|c|c|c|c|c|c|c|c|c|c|c|c|c|c|c|c|c|c|}
\hline TAXON & UTM & $\mathrm{km} 2$ & BIO1 & B102 & $B 103$ & BIO4 & B105 & B106 & B107 & B108 & 8109 & B1010 & BIO11 & B1012 & BIO13 & B1014 & BIO15 & B1016 & B1017 & B1018 & B1019 \\
\hline Bufo spinosus & 30TWN61 & 100,00 & 123,57 & 101,06 & 38,90 & 5586,07 & 268,85 & 11,30 & 257,55 & 97,75 & 195,97 & 195,97 & 53,90 & 664,02 & 70,13 & 35,35 & 18,29 & 191,84 & 129,09 & 129,09 & 173,33 \\
\hline Bufo spinosus & 30TWN62 & 100,00 & 116,46 & 99,48 & 39,00 & 5443,10 & 259,68 & 7,43 & 252,25 & 61,06 & 187,44 & 187,44 & 49,16 & 775,19 & 81,60 & 40,88 & 18,03 & 228,47 & $\begin{array}{l}148,49 \\
\end{array}$ & 148,49 & 211,26 \\
\hline Bufo spinosus & 30TWN63 & 100,00 & 103,32 & $\begin{array}{ll}97,94 \\
\end{array}$ & 39,01 & 5316,96 & 245,23 & $-2,27$ & 247,50 & 45,76 & $\begin{array}{l}173,31 \\
\end{array}$ & $\begin{array}{l}173,31 \\
\end{array}$ & 38,25 & 914,81 & 99,12 & 48,44 & 17,94 & 274,80 & 173,71 & 173,71 & 257,41 \\
\hline Bufo spinosus & 30TWN64 & 100,00 & 104,07 & 95,58 & 39,10 & 5166,61 & 242,19 & 1,56 & 240,63 & 48,36 & 172,21 & 172,21 & 41,03 & $\begin{array}{l}984,99 \\
\end{array}$ & 108,32 & 51,52 & 18,30 & 300,55 & 186,36 & $\begin{array}{l}186,36 \\
\end{array}$ & 281,81 \\
\hline Bufo spinosus & 30TWN65 & 100,00 & 114,75 & 92,10 & 39,59 & 4941,28 & 246,34 & 16,24 & 230,10 & 61,12 & 178,84 & 179,67 & 54,48 & 1037,83 & 115,65 & 52,42 & 19,30 & 323,01 & 194,30 & 195,10 & 302,10 \\
\hline Bufo spinosus & 30TWN66 & 100,00 & 130,98 & 86,46 & 40,11 & 4575,07 & 251,84 & 39,33 & 212,51 & 81,00 & 188,09 & $\mid$ & 75,39 & $\mid 1103,43$ & \begin{tabular}{|l|l|}
124,59 \\
\end{tabular} & 52,88 & 20,87 & 350,55 & 199,35 & 206,77 & 327,82 \\
\hline Bufo spinosus & 30TWN67 & 100,00 & 123,06 & 85,63 & 40,39 & 4495,82 & 243,12 & 33,38 & 209,73 & 74,62 & 179,28 & 182,14 & 68,95 & 1199,36 & 135,85 & 58,32 & 20,85 & 382,33 & 217,09 & 225,01 & 358,30 \\
\hline Bufo spinosus & 30TWN68 & 100,00 & 128,29 & 82,14 & \begin{tabular}{ll|}
40,94 \\
\end{tabular} & 4248,49 & 241,72 & 43,40 & $\begin{array}{l}198,32 \\
\end{array}$ & \begin{tabular}{ll|}
82,67 \\
\end{tabular} & \begin{tabular}{|l|l|}
180,87 \\
\end{tabular} & \begin{tabular}{ll|}
184,08 \\
\end{tabular} & 77,57 & \begin{tabular}{|l|}
1282,11 \\
\end{tabular} & 145,99 & 61,18 & 21,70 & $\begin{array}{l}412,56 \\
\end{array}$ & 227,80 & 241,07 & 386,77 \\
\hline Bufo spinosus & 30TWN69 & 47,00 & 142,35 & 77,38 & $\begin{array}{l}40,97 \\
4\end{array}$ & 4040,34 & $\begin{array}{l}247,61 \\
\end{array}$ & \begin{tabular}{|l|l|}
61,04 \\
\end{tabular} & $\begin{array}{l}186,56 \\
\end{array}$ & 98,65 & 191,69 & \begin{tabular}{ll|}
195,08 \\
\end{tabular} & $\begin{array}{ll}93,94 \\
\end{array}$ & \begin{tabular}{|l|}
1284,21 \\
\end{tabular} & \begin{tabular}{|l|l|}
149,00 \\
\end{tabular} & 59,06 & 23,20 & $\begin{array}{l}418,49 \\
\end{array}$ & 222,79 & 243,99 & 393,32 \\
\hline Bufo spinosus & 30TWN71 & 100,00 & 122,45 & 101,95 & 38,96 & 5618,81 & 269,19 & 9,36 & 259,82 & 75,45 & \begin{tabular}{|l|l|}
195,46 \\
\end{tabular} & \begin{tabular}{|l|}
195,46 \\
\end{tabular} & 52,41 & 709,88 & 75,19 & 37,01 & 18,93 & 208,65 & 134,01 & 134,01 & 191,71 \\
\hline Bufo spinosus & \begin{tabular}{|l|} 
30TWN72 \\
\end{tabular} & 100,00 & 120,18 & 100,16 & 39,00 & 5473,56 & 264,10 & $\begin{array}{ll}10,08 \\
\end{array}$ & 254,02 & \begin{tabular}{|l|l|l|}
59,92 & \\
\end{tabular} & 191,43 & $\mid$\begin{tabular}{|l}
191,43 \\
\end{tabular} & 52,22 & 795,65 & 86,12 & \begin{tabular}{|l|l|l|}
40,98 \\
\end{tabular} & 18,93 & 239,09 & \begin{tabular}{|l|l|}
148,78 \\
\end{tabular} & \begin{tabular}{|c|c|}
148,78 \\
\end{tabular} & 221,42 \\
\hline Bufo spinosus & 30TWN73 & 100,00 & 103,41 & 98,80 & 39,01 & 5350,09 & 246,23 & $-3,39$ & 249,61 & 45,57 & $\begin{array}{l}173,73 \\
\end{array}$ & \begin{tabular}{|l|}
173,73 \\
\end{tabular} & 37,87 & $\begin{array}{l}936,65 \\
\end{array}$ & 102,89 & 49,35 & 18,41 & 283,47 & 175,99 & 175,99 & 265,79 \\
\hline Bufo spinosus & 30TWN74 & 100,00 & 100,62 & 96,62 & 39,21 & 5208,45 & 240,12 & $-2,82$ & 242,94 & 44,68 & 169,38 & 169,38 & 37,17 & 1021,25 & $\mid 113,47$ & 53,57 & 18,56 & 312,86 & 191,86 & 191,86 & 293,94 \\
\hline Bufo spinosus & 30TWN75 & 100,00 & 108,49 & 94,04 & 39,53 & 5036,57 & 243,08 & 7,88 & 235,20 & 54,16 & $\begin{array}{ll}174,61 \\
\end{array}$ & $\begin{array}{l}174,66 \\
\end{array}$ & \begin{tabular}{ll|}
46,97 \\
\end{tabular} & $\begin{array}{l}1073,28 \\
\end{array}$ & 120,82 & 54,95 & 19,36 & 334,82 & 200,40 & 200,40 & 313,61 \\
\hline Bufo spinosus & 30TWN76 & 100,00 & 111,01 & 90,73 & 39,88 & $\begin{array}{lll}4809,98 \\
\end{array}$ & 239,75 & 14,90 & 224,85 & 59,29 & \begin{tabular}{l|l|l|}
172,92 \\
\end{tabular} & \begin{tabular}{ll|}
174,38 \\
\end{tabular} & \begin{tabular}{ll|}
52,67 \\
\end{tabular} & $\begin{array}{l}1155,76 \\
\end{array}$ & \begin{tabular}{|l|l|}
130,57 \\
\end{tabular} & 58,44 & 19,83 & 363,66 & 213,91 & 216,84 & 340,62 \\
\hline Bufo spinosus & 30TWN77 & 100,00 & 129,54 & 85,98 & \begin{tabular}{ll|}
40,78 \\
\end{tabular} & $\begin{array}{l}4449,01 \\
\end{array}$ & 248,19 & 39,74 & 208,45 & 81,29 & $\begin{array}{ll}184,82 \\
\end{array}$ & 187,75 & 75,75 & $\begin{array}{l}1224,90 \\
\end{array}$ & $\begin{array}{l}139,65 \\
\end{array}$ & 59,02 & 21,43 & 393,34 & 220,21 & 229,16 & 366,76 \\
\hline Bufo spinosus & 30TWN78 & 100,00 & 136,02 & 82,26 & 41,51 & 4169,84 & 247,28 & 51,34 & $\begin{array}{l}195,95 \\
\end{array}$ & 90,94 & \begin{tabular}{|l|l|}
187,18 \\
\end{tabular} & 190,48 & 86,04 & $\begin{array}{l}1306,41 \\
\end{array}$ & \begin{tabular}{|l|l|}
148,74 \\
\end{tabular} & 62,01 & 22,07 & 422,21 & 231,31 & 246,37 & 393,01 \\
\hline Bufo spinosus & 30TWN79 & 55,00 & 142,54 & 79,19 & $\begin{array}{lll}41,49 \\
\end{array}$ & 4050,54 & 248,44 & 59,70 & $\mid 188,74$ & 98,79 & 191,96 & 195,32 & 93,85 & 1318,53 & 152,11 & 61,78 & 22,71 & \begin{tabular}{|l|l|}
428,98 \\
\end{tabular} & 231,91 & 252,33 & 399,74 \\
\hline Bufo spinosus & 30TWN81 & 100,00 & 127,08 & 102,29 & 38,90 & $5634,65[$ & 274,04 & 12,96 & 261,09 & 69,60 & 200,10 & 200,10 & 56,46 & 736,82 & 81,42 & 36,91 & 20,25 & 222,85 & 134,50 & 134,50 & 206,27 \\
\hline Bufo spinosus & 30TWN82 & 100,00 & 122,08 & 101,03 & 38,99 & 5523,64 & 267,28 & 10,41 & 256,87 & \begin{tabular}{ll|}
61,07 \\
\end{tabular} & $\begin{array}{ll}193,86 \\
\end{array}$ & 193,86 & 53,14 & $\begin{array}{l}830,67 \\
\end{array}$ & $\begin{array}{l}93,74 \\
\end{array}$ & 41,59 & 20,33 & 255,99 & 150,78 & \begin{tabular}{ll|}
150,78 \\
\end{tabular} & 238,30 \\
\hline Bufo spinosus & 30TWN83 & 100,00 & 110,64 & 99,59 & 39,01 & 5397,98 & 254,13 & 2,25 & 251,88 & 51,75 & 181,21 & 181,21 & 43,90 & $\begin{array}{l}943,14 \\
\end{array}$ & \begin{tabular}{ll|}
106,92 \\
\end{tabular} & 48,21 & 19,84 & 291,81 & $\begin{array}{l}172,73 \\
\end{array}$ & \begin{tabular}{ll|}
172,73 \\
\end{tabular} & 273,47 \\
\hline \begin{tabular}{|l|} 
Bufo spinosus \\
\end{tabular} & 30TWN84 & 100,00 & 91,57 & 97,49 & 39,01 & 5276,41 & 233,10 & $-13,28$ & $\begin{array}{ll}246,38 \\
\end{array}$ & 35,46 & \begin{tabular}{|l|l|}
161,44 \\
\end{tabular} & $\begin{array}{l}161,44 \\
\end{array}$ & 27,57 & 1060,01 & \begin{tabular}{|l|}
118,21 \\
\end{tabular} & 56,62 & 18,24 & 323,42 & 199,51 & 199,51 & 305,06 \\
\hline Bufo spinosus & 30TWN85 & 100,00 & 106,58 & 95,36 & 39,43 & 5114,41 & $\mid 243,07$ & 4,09 & 238,99 & 51,34 & \begin{tabular}{|l|l|}
173,73 \\
\end{tabular} & $\mid \begin{array}{l}173,73 \\
\end{array}$ & 43,91 & \begin{tabular}{|l|}
1099,31 \\
\end{tabular} & $\mid 125,91$ & 56,20 & 19,88 & $\mid 345,57$ & 203,27 & 203,27 & 324,35 \\
\hline Bufo spinosus & 30TWN86 & 100,00 & 113,46 & 92,50 & 39,91 & 4893,48 & 244,21 & 14,93 & 229,28 & 60,58 & 176,77 & 177,71 & 53,68 & 1171,81 & 135,21 & 58,72 & 20,63 & 373,55 & 215,77 & 216,84 & 349,65 \\
\hline Bufo spinosus & 30TWN87 & 100,00 & 114,38 & 90,20 & 40,28 & \begin{tabular}{|l|l|}
4714,87 \\
\end{tabular} & 240,70 & 19,19 & 221,50 & 63,64 & 174,15 & 176,25 & 57,07 & $\begin{array}{l}1253,24 \\
\end{array}$ & 144,73 & 62,59 & 20,78 & $\begin{array}{l}401,85 \\
\end{array}$ & 230,62 & 233,34 & 375,75 \\
\hline Bufo spinosus & 30TWN88 & 100,00 & 129,64 & 84,99 & 41,19 & 4340,68 & 245,11 & 41,00 & 204,11 & 82,85 & 183,45 & 186,52 & 77,15 & $\begin{array}{l}1323,19 \\
\end{array}$ & 152,53 & 64,33 & 21,75 & 428,25 & 238,60 & 250,17 & 398,13 \\
\hline Bufo spinosus & 30TWN89 & 84,00 & 141,98 & 80,34 & \begin{tabular}{l|l}
41,12 \\
\end{tabular} & \begin{tabular}{ll|l|}
4147,07 \\
\end{tabular} & \begin{tabular}{|l|}
249,07 \\
\end{tabular} & 56,16 & 192,91 & $\begin{array}{l}97,07 \\
\end{array}$ & \begin{tabular}{|l|l|}
192,83 \\
\end{tabular} & 196,01 & 91,49 & \begin{tabular}{|l|}
1324,87 \\
\end{tabular} & 154,41 & 63,41 & 22,63 & 431,54 & 237,27 & 257,20 & 400,51 \\
\hline Bufo spinosus & 30TWN90 & 100,00 & 130,41 & 103,87 & 38,51 & 5766,03 & 279,85 & 13,29 & 266,56 & 90,01 & 204,94 & 204,94 & 57,74 & 694,81 & 78,47 & 33,90 & 21,38 & 210,72 & $\begin{array}{l}124,39 \\
\end{array}$ & 124,39 & 195,88 \\
\hline Bufo spinosus & 30TWN92 & 100,00 & 124,90 & 101,77 & \begin{tabular}{|l|l|}
38,94 \\
\end{tabular} & \begin{tabular}{|l|l|}
5574,60 \\
\end{tabular} & \begin{tabular}{|l|}
271,25 \\
\end{tabular} & 11,91 & 259,34 & 63,38 & \begin{tabular}{|l|l|}
197,29 \\
\end{tabular} & 197,29 & 55,07 & 861,72 & \begin{tabular}{|l|l|}
101,88 \\
\end{tabular} & 41,69 & 22,23 & 272,79 & 151,59 & 151,59 & 255,62 \\
\hline Bufo spinosus & 30TWN93 & 100,00 & 114,54 & 100,49 & 39,01 & $\begin{array}{l}5454,66 \\
\end{array}$ & 259,17 & 4,41 & 254,76 & 54,88 & 185,74 & 185,74 & 46,83 & $\begin{array}{l}966,57 \\
9\end{array}$ & \begin{tabular}{|l|l|}
113,87 \\
\end{tabular} & 48,01 & 21,46 & $\begin{array}{l}306,26 \\
\end{array}$ & $\begin{array}{l}172,27 \\
\end{array}$ & $\begin{array}{l}172,27 \\
\end{array}$ & 287,92 \\
\hline Bufo spinosus & 30TWN94 & 100,00 & 112,33 & $\begin{array}{ll}98,54 \\
\end{array}$ & 39,03 & 5324,67 & 253,68 & 5,05 & \begin{tabular}{|l|l|}
248,64 \\
\end{tabular} & 54,25 & 181,91 & 181,91 & 46,41 & $\begin{array}{l}1044,64 \\
\end{array}$ & \begin{tabular}{|l|}
123,47 \\
\end{tabular} & 52,04 & 21,45 & 333,16 & $\begin{array}{l}187,74 \\
\end{array}$ & 187,74 & 313,34 \\
\hline Bufo spinosus & 30TWN95 & 100,00 & 112,46 & 96,45 & 39,30 & 5169,92 & 249,99 & 7,99 & 242,00 & 56,38 & \begin{tabular}{|l|l|l|}
180,13 \\
\end{tabular} & 180,13 & 48,65 & 1115,28 & 131,91 & 55,58 & 21,42 & 357,89 & 201,88 & 201,88 & 336,12 \\
\hline Bufo spinosus & 30TWN96 & 100,00 & 104,13 & 94,60 & 39,59 & 5054,56 & 238,99 & 2,51 & 236,48 & 49,88 & 170,57 & 170,57 & 42,31 & $\begin{array}{l}1187,49 \\
\end{array}$ & 138,57 & 60,62 & 20,39 & 378,00 & 219,52 & 219,52 & 355,21 \\
\hline Bufo spinosus & 30TWN97 & 100,00 & 110,60 & 91,78 & 40,00 & 4839,21 & 239,44 & 12,53 & 226,92 & 58,56 & 172,80 & 174,20 & 51,36 & $\begin{array}{l}1259,47 \\
\end{array}$ & $\begin{array}{l}147,50 \\
\end{array}$ & 63,49 & 20,90 & 404,84 & 233,16 & 234,64 & 379,23 \\
\hline Bufo spinosus & 30TWN98 & 100,00 & 120,70 & 87,94 & \begin{tabular}{|l|l|}
40,59 \\
\end{tabular} & \begin{tabular}{|l|l|}
4563,81 \\
\end{tabular} & \begin{tabular}{|l|}
241,46 \\
\end{tabular} & 27,30 & 214,15 & 71,55 & \begin{tabular}{|l|l|}
177,77 \\
\end{tabular} & 180,49 & 64,91 & $\begin{array}{l}1332,12 \\
\end{array}$ & $\begin{array}{l}156,15 \\
\end{array}$ & 66,26 & 21,49 & 431,84 & 244,48 & 251,74 & 402,44 \\
\hline Bufo spinosus & 30TWN99 & 100,00 & 133,51 & 83,01 & \begin{tabular}{l|l|}
40,83 \\
\end{tabular} & 4317,29 & \begin{tabular}{|l|l|}
244,87 \\
\end{tabular} & $\begin{array}{ll}43,87 \\
\end{array}$ & 201,01 & 90,02 & \begin{tabular}{ll|l|}
186,91 \\
\end{tabular} & 189,84 & 80,53 & 1355,71 & $\begin{array}{l}159,45 \\
\end{array}$ & $\begin{array}{ll}66,82 \\
\end{array}$ & 22,10 & 441,31 & 248,15 & 264,33 & 409,19 \\
\hline Bufo spinosus & 30TWP00 & 79,00 & 137,74 & 60,59 & 35,91 & 3895,53 & 227,82 & 61,13 & 166,69 & 93,62 & 185,65 & 189,02 & 89,81 & $\begin{array}{l}1245,64 \\
\end{array}$ & 163,35 & 49,35 & 30,33 & 425,02 & $\begin{array}{l}194,31 \\
\end{array}$ & 229,77 & 424,19 \\
\hline Bufo spinosus & 30TWP10 & 94,00 & 132,38 & 64,68 & 36,92 & 3975,66 & 228,22 & 55,49 & 172,72 & 89,86 & 181,32 & 184,84 & 84,41 & 1266,20 & 160,96 & 52,91 & 27,98 & $425,57]$ & 204,62 & 235,59 & 420,02 \\
\hline Bufo spinosus & 30TWP20 & 75,00 & 136,08 & 66,31 & 37,61 & 3978,94 & 233,33 & 59,44 & 173,89 & 93,78 & 184,80 & 188,46 & 88,51 & 1263,98 & 158,65 & 53,35 & 27,25 & 422,90 & 205,95 & 236,04 & 415,55 \\
\hline Bufo spinosus & 30TWP30 & 40,00 & 137,65 & 69,00 & 38,61 & 3995,39 & 236,84 & 60,23 & 176,61 & 94,85 & 186,32 & 190,00 & 89,87 & 1267,71 & 155,84 & 54,73 & 26,05 & 421,16 & 210,02 & 237,97 & 409,79 \\
\hline Bufo spinosus & 30TWP40 & & & & & & & & & & & & & & & & & & & & \\
\hline Bufo spinosus & 30TWP90 & 28,00 & 138,83 & 80,55 & 40,75 & 4220,05 & 245,72 & 50,41 & 195,31 & $\mid 105,70$ & 190,86 & \begin{tabular}{|l|l|}
193,91 \\
\end{tabular} & 86,75 & 1355,98 & 160,34 & $\mid 66,73$ & 22,59 & 442,94 & 248,83 & 269,58 & 409,41 \\
\hline Bufo spinosus & 30ТХK05 & 100,00 & 85,42 & 112,53 & 37,48 . & $6386,84]$ & 256,24 & $-40,19$ & 296,44 & 103,25 & 170,92 & 171,92 & 9,99| & 611,81 & 79,73 & 31,25 & 24,81 & 201,77 & 117,99 & 131,47 & 131,33 \\
\hline Bufo spinosus & 30TXK06 & 100,00 & 79,90 & 111,37 & 37,1 & \begin{tabular}{|l|l|}
6361,73 \\
\end{tabular} & 249,61 & $-44,79$ & 94,40 & 97,32 & \begin{tabular}{|l|l|}
165,13 \\
\end{tabular} & 165,92 & 4,81 & 636,51 & 82,84 & 33,56 & 24,36 & 09,90 & 124,25 & 38,84 & 136,99 \\
\hline Bufo spinosus & 30TXK07 & 100,00 & 76,83 & 110,40 & 37, & 6336 & 24 & $-47,18$ & 292,56 & 94,26 & 161,80 & $\begin{array}{l}162,60 \\
\end{array}$ & 1,99 & \begin{tabular}{ll|}
646,58 \\
\end{tabular} & 84,44 & 34,85 & 24,10 & 213,76 & 127,65 & \begin{tabular}{|l|l|}
142,93 \\
\end{tabular} & 139,03 \\
\hline Bufo spinosus & 30TXK08 & 100,00 & 77,03 & 109,66 & 37,08 & 6312,45 & 243,99 & $-46,97$ & 290,96 & 94,68 & 161,59 & 162,30 & 2,12 & 639,09 & 84,13 & 35,02 & 24,46 & 212,45 & 127,62 & 143,21 & 136,57 \\
\hline Bufo spinosus & 30TXK13 & 100,00 & 103,18 & 112,92 & \begin{tabular}{l|l|l|}
37,95 \\
\end{tabular} & $\begin{array}{ll}6398,18 \\
\end{array}$ & $\begin{array}{l}272,30 \\
\end{array}$ & $-23,34$ & \begin{tabular}{|l|l|}
295,64 \\
\end{tabular} & 121,64 & 188,49 & $\begin{array}{l}189,50 \\
\end{array}$ & 27,14 & 528,20 & 69,37 & 25,15 & 26,55 & $\begin{array}{l}175,43 \\
\end{array}$ & 101,53 & 1111,21 & 109,10 \\
\hline Bufo spinosus & 30TXK14 & 100,00 & 94,15 & 1111,73 & 37,50 & \begin{tabular}{|l|l|}
6385,23 \\
\end{tabular} & 262,70 & $-31,40$ & 294,10 & 112,38 & $\begin{array}{ll}179,48 \\
\end{array}$ & 180,45 & 18,54 & $\begin{array}{l}565,25 \\
\end{array}$ & 74,42 & 28,39 & 25,88 & \begin{tabular}{l|l}
8,35 \\
\end{tabular} & 1110,60 & 22,19 & 117,06 \\
\hline Bufo spinosus & 30TXK16 & 100,00 & 80,38 & 109,45 & 37,00 & \begin{tabular}{|l|}
6342,31 \\
\end{tabular} & 247,30 & $-43,47$ & 290,77 & 97,85 & $\begin{array}{ll}161,94 \\
\end{array}$ & 166,18 & 5,42 & \begin{tabular}{ll|l}
626,66 \\
\end{tabular} & 82,40 & 33,88 & 24,82 & 208,97 & 125,47 & 140,04 & 131,01 \\
\hline Bufo spinosus & $30 \mathrm{TXK}$ & 100,00 & 81,07 & 108,66 & $37, \mathrm{C}$ & \begin{tabular}{ll|}
6320,35 \\
\end{tabular} & $246,23 \mid$ & $-42,92$ & 289,15 & 98,94 & \begin{tabular}{|l|l|}
129,53 \\
\end{tabular} & \begin{tabular}{|l|}
166,37 \\
\end{tabular} & 6,01 & 614,81 & 81,79 & 33,82 & 25,33 & 206,54 & 124,02 & 139,62 & 127,34 \\
\hline Bufo spinosus & 30TXK18 & 100,00 & 75,69 & 107,67 & 37,00 & \begin{tabular}{|l|l|}
6288,67 \\
\end{tabular} & 239,92 & $-47,22$ & 287,14 & 93,29 & 120,62 & 160,59 & 1,25 & 642,11 & 84,96 & $\mid 36,08$ & 24,72 & 215,03 & \begin{tabular}{|l|}
130,37 \\
\end{tabular} & $\mid 147,04$ & 134,20 \\
\hline Bufo spinosus & 30TXK19 & 100,00 & 83,36 & 107,15 & 37,00 & \begin{tabular}{ll|}
6276,76 \\
\end{tabular} & 244,69 & $-41,06$ & 285,75 & 102,17 & 44,08 & 167,57 & 8,08 & 586,94 & 80,05 & 33,30 & 26,64 & 200,45 & 118,56 & 137,53 & 119,29 \\
\hline Bufo spinosus & 30 TXK26 & 100,00 & 87,08 & 107,41 & 37,00 & 6329,36 & 250,13 & $-36,45$ & 86,58 & 105,25 & \begin{tabular}{|l|l}
49,88 \\
\end{tabular} & 172,45 & 11,81 & 580,7 & 78, & 31,95 & 26,41 & 197,09 & 115,44 & 133,34 & 11 \\
\hline Bufo spinosus & $30 \mathrm{TX}$ & 100 & $\begin{array}{ll}90,92 \\
\end{array}$ & 106,46 & 36, & & 251,44 & $-33,16$ & 28 & $\begin{array}{l}109,82 \\
\end{array}$ & 15,49 & 17 & 15,49 & 549 & 75,58 & 30,67 & 27,89 & 189,27 & 106,92 & 128,99 & 106,92 \\
\hline Bufo spinosus & 30TXK28 & 100,00 & 84,80 & 105,77 & 36,99 & \begin{tabular}{ll|}
6281,25 \\
\end{tabular} & 244,63 & $-38,76$ & 283,39 & 103,45 & 18,02 & 169,19 & 9,79 & 578,01 & 79,11 & 32,97 & 27,26 & $\begin{array}{l}198,66 \\
19\end{array}$ & $\begin{array}{ll}113,88 \\
\end{array}$ & $\begin{array}{l}137,05 \\
\end{array}$ & 113,97 \\
\hline Bufo spinosus & 30TXK29 & 100,00 & 85,15 & 105,01 & 36,99 & \begin{tabular}{ll|l}
6255,66 \\
\end{tabular} & 243,10 & $-38,75$ & 281,85 & 104,12 & 9,82 & 168,88 & 9,82 & 569,58 & 78,84 & 32,90 & 27,86 & $\begin{array}{l}197,32 \\
\end{array}$ & 1111,47 & \begin{tabular}{|l|l|}
137,19 \\
\end{tabular} & 111,47 \\
\hline Bufo spinosus & 30TXK34 & 100,00 & 96,54 & 106,77 & 37,00 & 6341,71 & 258,65 & $-26,12$ & 284,78 & 114,40 & 23,29 & 182,16 & 21,10 & 541,29 & 72,33 & 28,84 & 27,11 & \begin{tabular}{ll|}
183,53 \\
\end{tabular} & 104,59 & \begin{tabular}{|l|}
122,41 \\
\end{tabular} & 104,6 \\
\hline Bufo spinos & $30 \mathrm{TX}$ & 100, & & 105,96 & 37,00 & 229,52 & 252 & -31, & 83,59 & 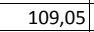 & 34 & 17 & 16,12 & 562,28 & 75 & 30 & 2 & & 109,01 & & 10 \\
\hline Bufo spinosus & 30TXK3 & 100,00 & 89,36 & 105,15 & 36,96 & 6310,23 & 249,32 & $-33,01$ & 282,33 & 107,46 & 14,43 & 174,49 & 14,43 & 562,61 & 76,48 & 31,49 & 27,46 & $\begin{array}{l}192,96 \\
\end{array}$ & 108,06 & \begin{tabular}{|l|l|}
132,04 \\
\end{tabular} & 108,06 \\
\hline Bufo spinosus & 30TXK37 & 100,00 & 96,51 & 103,75 & 36,84 & 6301,96 & 252,85 & $-26,35$ & 279,20 & 115,90 & 21,12 & 181,14 & 21,12 & 510,25 & 71,81 & 27,73 & 30,17 & 179,23 & 93,54 & 123,62 & 93,54 \\
\hline
\end{tabular}




\begin{tabular}{|c|c|c|c|c|c|c|c|c|c|c|c|c|c|c|c|c|c|c|c|c|c|}
\hline TAXON & UTM & $\mathrm{km} 2$ & B101 & B102 & $\mathrm{BIO3}$ & BIO4 & BIO5 & B106 & B107 & B108 & B109 & BIO10 & BIO11 & BIO12 & B1013 & BIO14 & BIO15 & B1016 & B1017 & BIO18 & B1019 \\
\hline Bufo spinosus & 30TХK38 & 100,00 & 95,22 & 102,94 & 36,59 & 6273,83 & 249,72 & $-28,17$ & 277,89 & 115,05 & 19,50 & 179,20 & 19,50 & 508,38 & 72,46 & 27,36 & 30,95 & 180,26 & 92,49 & 125,50 & 92,49 \\
\hline Bufo spinosus & 30TXK39 & 100,00 & 96,64 & 102,03 & 36,50 & 6237,25 & 248,21 & $-27,50$ & 275,72 & 117,08 & 20,75 & 179,66 & 20,75 & 493,07 & 71,48 & 25,97 & 32,38 & 177,07 & 88,36 & 124,17 & 88,36 \\
\hline Bufo spinosus & 30 TXK43 & 100,00 & 118,27 & 104,35 & 37,00 & 6282,53 & 274,74 & $-3,33$ & 278,07 & 136,69 & 43,12 & 202,61 & 43,12 & 444,88 & 59,51 & 22,17 & 29,90 & 150,68 & 80,74 & 97,98 & 80,74 \\
\hline Bufo spinosus & 30TXK44 & 100,00 & 115,99 & 103,29 & $\begin{array}{l}36,95 \\
\end{array}$ & 6304,84 & 271,75 & $-5,23$ & 276,98 & 134,93 & 40,46 & 200,65 & 40,46 & 442,88 & 60,61 & 22,91 & 30,87 & 152,32 & 78,36 & 100,94 & 78,36 \\
\hline Bufo spinosus & 30TXK45 & 100,00 & 100,83 & 103,15 & 36,74 & 6318,85 & 257,94 & $-20,10$ & 278,04 & 119,41 & 25,62 & 186,08 & 25,62 & 503,32 & 69,24 & 27,13 & 29,50 & 174,30 & $\begin{array}{ll}91,03 \\
\end{array}$ & $\begin{array}{ll}118,84 \\
\end{array}$ & 91,03 \\
\hline Bufo spinosus & 30TXK46 & 100,00 & 100,39 & 102,03 & 36,38 & 6310,30 & 255,61 & $-20,58$ & 276,19 & 119,41 & 25,17 & 185,30 & 25,17 & 494,29 & 69,28 & 26,03 & 30,70 & 173,50 & 87,49 & 119,83 & 87,49 \\
\hline Bufo spinosus & 30TXK47 & 100,00 & 105,58 & 100,56 & 36,06 & 6302,53 & 257,69 & $-15,92$ & 273,61 & 125,56 & 29,86 & 189,98 & 29,86 & 456,05 & 66,08 & 22,62 & 33,51 & 163,82 & 76,81 & 114,08 & 76,81 \\
\hline \begin{tabular}{|l} 
Bufo spinosus \\
\end{tabular} & 30TXK48 & 100,00 & 106,64 & 99,68 & 36,05 & 6268,44 & 255,85 & $-15,66$ & 271,51 & 127,33 & 30,49 & 190,24 & 30,49 & 442,42 & 65,35 & 21,40 & 35,04 & $\begin{array}{l}161,32 \\
\end{array}$ & 73,19 & 113,16 & 73,19 \\
\hline Bufo spinosus & 30TXK49 & 100,00 & 105,09 & 99,04 & \begin{tabular}{l|l|l}
36,05 \\
\end{tabular} & 6222,95 & 251,72 & $-18,01$ & 269,73 & 126,24 & 29,09 & 187,64 & 29,09 & 443,49 & 66,29 & 21,18 & 35,94 & 163,25 & 73,09 & 115,32 & 73,09 \\
\hline Bufo spinosus & 30TXK53 & 100,00 & 104,61 & 102,85 & 36,96 & 6278,89 & 261,26 & $-14,89$ & 276,15 & 122,03 & 30,58 & 189,31 & 30,58 & 509,56 & 67,23 & 26,95 & 28,05 & 171,62 & 93,89 & 114,91 & 93,89 \\
\hline Bufo spinosus & 30TXK54 & 100,00 & 110,14 & 101,39 & 36,45 & 6285,68 & 264,95 & $-9,05$ & 274,00 & 128,37 & 35,58 & 194,76 & 35,58 & 469,38 & 63,75 & 24,51 & 30,30 & 161,03 & 82,34 & 108,75 & 82,34 \\
\hline Bufo spinosus & 30TXK55 & 100,00 & 113,78 & 99,76 & 36,03 & 6306,82 & 267,17 & $-5,13$ & 272,30 & 132,75 & 38,54 & 198,56 & 38,54 & 438,72 & 61,46 & 21,63 & 32,73 & 153,64 & 73,11 & 104,93 & 73,11 \\
\hline \begin{tabular}{|l} 
Bufo spinosus \\
\end{tabular} & 30TXK56 & 100,00 & 112,06 & 98,56 & 35,93 & 6318,25 & 264,44 & $-6,62$ & 271,06 & 131,48 & 36,42 & 196,96 & 36,42 & 432,95 & 62,20 & 20,58 & 34,39 & 154,45 & 69,78 & 107,29 & 69,78 \\
\hline Bufo spinosus & 30TXK59 & 100,00 & 94,94 & 98,25 & 36,00 & 6198,18 & 243,00 & $-25,97$ & 268,97 & 114,45 & 20,13 & 177,62 & 20,13 & 503,23 & 72,60 & 25,45 & 32,69 & 180,55 & 86,46 & 128,89 & 86,46 \\
\hline \begin{tabular}{|l|} 
Bufo spinosus \\
\end{tabular} & 30TXK63 & 100,00 & 82,82 & 102,00 & 36,40 & 6236,43 & 241,01 & $-35,06$ & 276,07 & 98,15 & 38,77 & $\mid 167,37$ & 10,31 & 644,46 & 81,18 & 35,28 & 24,06 & 210,51 & $\mid 127,79$ & 140,53 & 127,99 \\
\hline Bufo spinosus & 30TXK64 & 100,00 & 87,24 & 100,95 & 36,13 & 6239,38 & 243,50 & $-30,71$ & 274,21 & 103,31 & 23,44 & 171,63 & 14,31 & 605,14 & 78,26 & 33,42 & 25,65 & \begin{tabular}{|l|}
201,08 \\
\end{tabular} & 116,08 & 137,66 & 116,18 \\
\hline Bufo spinosus & 30TXK65 & 100,00 & 101,19 & 98,94 & 36,00 & 6251,87 & 254,13 & $-16,56$ & 270,68 & 118,92 & 27,25 & 185,38 & 27,25 & 510,44 & 69,27 & 26,68 & 29,66 & 174,93 & 89,85 & 121,25 & 89,85 \\
\hline Bufo spinosus & 30TXK66 & 100,00 & 108,23 & 97,32 & 35,94 & 6269,53 & 259,48 & $-9,12$ & 268,61 & 126,95 & 33,81 & 192,60 & 33,81 & 458,11 & 64,67 & 22,13 & 33,10 & 161,26 & 74,98 & 112,78 & 74,98 \\
\hline Bufo spinosus & 30TXK67 & 100,00 & 104,56 & 96,94 & 35,79 & 6246,24 & 254,15 & $\begin{array}{l}-13,47 \\
\end{array}$ & 267,62 & 123,62 & 30,08 & 188,43 & 30,08 & 469,72 & 66,91 & 22,78 & 33,33 & 166,56 & 77,30 & 117,66 & 77,30 \\
\hline Bufo spinosus & 30TXK69 & 100,00 & 100,38 & 96,35 & \begin{tabular}{|l|l|}
35,97 \\
\end{tabular} & 6177,58 & 245,97 & $-19,36$ & 265,34 & 120,29 & 25,86 & 182,75 & 25,86 & 478,58 & 69,53 & 23,12 & 34,12 & 172,34 & 79,11 & 123,21 & 79,11 \\
\hline Bufo spinosus & 30TXK73 & 100,00 & 90,47 & 99,95 & 36,11 & 6192,30 & 245,25 & $-26,30$ & 271,55 & 106,12 & 20,42 & 174,21 & 18,38 & 604,95 & 76,52 & 32,69 & 25,01 & $\begin{array}{ll}197,56 \\
\end{array}$ & 116,88 & 134,35 & 116,88 \\
\hline Bufo spinosus & 30TXK77 & 100,00 & 88,03 & 97,19 & 36,00 & 6165,48 & 238,27 & $-29,22$ & 267,50 & 105,11 & 15,14 & 170,92 & 15,14 & 579,55 & 77,91 & 31,66 & 27,76 & $\begin{array}{l}197,02 \\
\end{array}$ & $\begin{array}{l}105,96 \\
\end{array}$ & 139,66 & 105,96 \\
\hline Bufo spinosus & 30TXK78 & 100,00 & 86,79 & 96,62 & 35,98 & 6147,74 & 235,81 & $-30,66$ & 266,47 & 104,22 & 13,87 & 169,33 & 13,87 & 581,24 & 78,81 & 31,64 & 28,28 & 198,74 & 105,94 & 141,88 & 105,94 \\
\hline Bufo spinosus & 30TXK79 & 100,00 & 90,39 & 96,06 & 35,95 & 6131,76 & 237,29 & $-27,62$ & 264,91 & 108,73 & 17,29 & 172,42 & 17,29 & 551,11 & 76,38 & 28,97 & 30,00 & 191,40 & 97,79 & 137,19 & 97,79 \\
\hline Bufo spinosus & 30TXK83 & 100,00 & 106,31 & 97,56 & 36,03 & 6113,81 & 256,51 & $-9,25$ & 265,75 & 122,37 & 34,74 & 188,70 & 34,74 & 529,97 & 67,17 & 27,57 & 27,21 & 171,99 & 98,04 & 116,27 & 98,04 \\
\hline Bufo spinosus & 30TXK85 & 100,00 & 113,47 & 95,37 & 35,96 & 6117,38 & 260,95 & $-1,89$ & 262,84 & 130,88 & 41,07 & 195,58 & 41,07 & 474,12 & 63,06 & 23,84 & 30,62 & 158,27 & 81,69 & 108,52 & 81,69 \\
\hline Bufo spinosus & 30TXK86 & 100,00 & 102,09 & 95,56 & 35,84 & 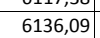 & 250,16 & \begin{tabular}{|c|}
$-13,05$ \\
$-13,75$
\end{tabular} & 263,91 & \begin{tabular}{|l|}
119,14 \\
19
\end{tabular} & 29,49 & $\begin{array}{l}184,51 \\
\end{array}$ & 29,49 & 519,94 & $\begin{array}{l}69,72 \\
69\end{array}$ & 26,87 & 29,38 & $\mid 175,49$ & $\begin{array}{l}\mid 1,205 \\
91,25\end{array}$ & 122,76 & $\begin{array}{l}91,25 \\
9\end{array}$ \\
\hline Bufo spinosus & 30TXK87 & 100,00 & 86,28 & 96,04 & 35,94 & 6125,23 & 235,37 & $-29,68$ & 265,04 & 102,63 & 14,27 & 168,73 & 14,27 & 603,92 & 79,63 & 33,52 & 26,50 & 202,00 & 112,33 & 142,80 & 112,33 \\
\hline Bufo spinosus & 30TXK88 & 100,00 & 86,99 & 95,60 & 35,78 & 6107,93 & 234,77 & $-29,32$ & 264,09 & 103,80 & 14,83 & 168,97 & 14,83 & 591,79 & 79,21 & 32,33 & 27,40 & 199,92 & 108,56 & 142,45 & 108,56 \\
\hline Bufo spinosus & 30TXK89 & 100,00 & 89,89 & 95,19 & 35,86 & 6094,73 & 236,24 & $-26,91$ & 263,15 & 107,44 & 17,72 & 171,58 & 17,72 & 566,46 & 77,28 & 30,17 & 28,85 & 193,84 & 101,71 & 138,72 & 101,71 \\
\hline Bufo spinosus & 30TXK93 & 100,00 & 115,89 & 95,69 & 36,00 & 6010,63 & 262,18 & 1,05 & 261,12 & 130,54 & 45,08 & 196,67 & 45,08 & 502,89 & 62,32 & 24,72 & 28,11 & 159,14 & 93,18 & 108,58 & 93,18 \\
\hline Bufo spinosus & 30TXK94 & 100,00 & 119,28 & 94,74 & 36,00 & 6011,05 & 264,14 & $\begin{array}{l}4,03 \\
4,4\end{array}$ & \begin{tabular}{|l|}
260,11 \\
\end{tabular} & \begin{tabular}{|l|}
134,87 \\
\end{tabular} & 48,01 & \begin{tabular}{|l|}
199,74 \\
\end{tabular} & 48,01 & \begin{tabular}{|l|}
479,71 \\
49,
\end{tabular} & $\begin{array}{l}60,69 \\
60,\end{array}$ & 23,89 & $\begin{array}{l}29,11 \\
29,46\end{array}$ & \begin{tabular}{|l|}
153,64 \\
15,4
\end{tabular} & $\begin{array}{l}0,10 \\
86,55 \\
\end{array}$ & 104,66 & 86,55 \\
\hline Bufo spinosus & 30TXK95 & 100,00 & 108,05 & 94,79 & 35,99 & 6058,85 & 254,35 & $-6,84$ & 261,19 & 124,64 & 36,56 & 189,29 & 36,56 & 518,90 & 67,10 & 27,16 & 28,55 & 169,40 & 93,58 & 116,73 & 93,58 \\
\hline Bufo spinosus & 30TXK97 & 100,00 & 76,32 & 95,25 & 35,61 & 6078,79 & 225,79 & $-38,10$ & 263,89 & 91,31 & 5,56 & 158,37 & 5,56 & 684,15 & 86,82 & 39,06 & 23,75 & 222,42 & 133,91 & 155,19 & 133,91 \\
\hline Bufo spinosus & 30TXK98 & 100,00 & 82,76 & 94,76 & 35,80 & 6063,78 & 230,25 & $-32,22$ & 262,47 & 98,75 & 11,65 & 164,31 & 11,65 & 634,63 & 82,64 & 35,73 & 25,51 & 209,67 & 120,22 & 148,25 & 120,22 \\
\hline Bufo spinosus & 30TXL03 & 100,00 & 98,95 & 106,91 & 37,00 & 6224,39 & 255,57 & $-28,46$ & 284,03 & 120,35 & 32,00 & 181,13 & 22,49 & 490,08 & 69,96 & 27,81 & 29,75 & 171,77 & 97,98 & 117,53 & 98,94 \\
\hline \begin{tabular}{|l} 
Bufo spinosus \\
\end{tabular} & 30TXL04 & 100,00 & 99,64 & 106,82 & 37,01 & 6202,40 & 255,97 & $-27,78$ & 283,75 & 121,25 & 33,08 & 181,40 & 23,17 & 487,85 & 69,53 & 27,75 & 29,61 & 170,67 & 97,46 & 117,16 & 99,37 \\
\hline Bufo spinosus & 30TXL06 & 100,00 & 114,08 & 106,94 & 37,01 & 6214,52 & 270,16 & $-13,74$ & 283,90 & 136,69 & 47,45 & 195,19 & 36,60 & 429,45 & 62,00 & 23,40 & 30,77 & 150,01 & 84,97 & 100,88 & 88,75 \\
\hline Bufo spinosus & 30TXL12 & 100,00 & 95,85 & 105,01 & 37,00 & 6202,83 & 249,54 & $-31,10$ & 280,64 & 117,09 & 26,91 & 177,72 & 19,57 & 497,81 & 71,90 & 28,04 & 30,91 & 176,99 & 96,26 & 122,93 & 96,50 \\
\hline Bufo spinosus & 30TXL13 & 100,00 & 98,47 & 104,71 & 37,00 & 6186,85 & 251,01 & $-28,75$ & 279,77 & 120,31 & 31,71 & 179,94 & 22,29 & 482,34 & 70,19 & 26,68 & 31,63 & 172,32 & 92,00 & 119,73 & 93,40 \\
\hline \begin{tabular}{|l} 
Bufo spinosus \\
\end{tabular} & $\begin{array}{l}\text { 30TXL18 } \\
\end{array}$ & 100,00 & 120,30 & 106,30 & 37,00 & 6192,00 & 275,99 & $-6,49$ & 282,48 & 143,19 & 64,53 & 200,77 & 42,88 & 415,63 & 60,05 & 22,16 & 30,99 & 144,16 & 82,69 & 96,31 & 87,34 \\
\hline Bufo spinosus & 30TXL19 & 100,00 & 114,54 & 106,66 & 37,01 & 6165,47 & 271,34 & $-11,31$ & 282,65 & 136,73 & 157,51 & 194,75 & 37,77 & 451,84 & 63,56 & 24,54 & 28,89 & 154,08 & 90,97 & 104,31 & 97,97 \\
\hline Bufo spinosus & 30TXL20 & 100,00 & 90,82 & 103,97 & 36,94 & 6227,62 & 245,18 & $-34,25$ & 279,44 & 110,87 & 15,03 & 173,66 & 15,03 & 527,99 & 75,08 & 29,67 & 30,20 & 186,55 & 100,45 & 130,35 & 100,45 \\
\hline Bufo spinosus & 30TXL21 & 100,00 & 97,52 & 102,87 & 36,87 & 6191,58 & 247,66 & $-28,73$ & 276,39 & 119,02 & 26,43 & 179,32 & 21,33 & 482,29 & 70,89 & 25,56 & 33,13 & 174,63 & 88,47 & 122,35 & 88,61 \\
\hline Bufo spinosus & 30TXL22 & 100,00 & 99,03 & 102,34 & 36,82 & 6166,32 & 247,45 & $-27,74$ & 275,19 & 121,14 & 32,12 & 180,13 & 22,89 & 470,05 & 69,89 & 24,30 & 33,92 & 171,59 & 84,86 & 120,63 & 85,96 \\
\hline \begin{tabular}{|l} 
Bufo spinosus \\
\end{tabular} & \begin{tabular}{|l}
$30 T X L 23$ \\
\end{tabular} & 100,00 & $\begin{array}{l}101,91 \\
101\end{array}$ & 102,08 & $\begin{array}{l}30,02 \\
36,85\end{array}$ & $\begin{array}{l}010,139,68 \\
6130\end{array}$ & 248,97 & $-25,49$ & 274,47 & 124,33 & 35,14 & 182,20 & 25,52 & 455,18 & 68,36 & 23,12 & 34,76 & 167,11 & 80,94 & 117,21 & 83,37 \\
\hline Bufo spinosus & 30TXL24 & 100,00 & 96,83 & 102,61 & 36,90 & 6129,49 & 245,92 & $-29,65$ & 275,58 & 118,51 & 30,43 & 177,20 & 20,92 & 487,09 & 71,41 & 26,08 & 32,53 & 175,48 & 90,18 & 123,84 & 92,75 \\
\hline Bufo spinosus & 30TXL31 & 100,00 & 104,71 & 99,65 & 36,29 & 6145,01 & 248,19 & $-21,79$ & 269,98 & 127,27 & 37,75 & 185,23 & 28,40 & 435,22 & 66,48 & 20,53 & 37,38 & $\mid 162.89$ & 72,70 & 115,31 & 73,72 \\
\hline Bufo spinosus & 30TXL32 & 100,00 & 102,32 & 99,48 & 36,27 & 6111,27 & 244,66 & $-24,75$ & 269,41 & 124,86 & 35,49 & 182,03 & 26,05 & 444,99 & 67,97 & 20,99 & 37,29 & 166,56 & 74,21 & 118,63 & 76,57 \\
\hline Bufo spinosus & 30TXL33 & 100,00 & 100,56 & 99,81 & 36,35 & 6097,72 & 243,69 & $-26,50$ & 270,19 & 122,92 & 33,88 & 180,03 & 24,34 & 455,56 & 69,13 & 21,99 & 36,32 & 169,37 & 77,45 & 120,71 & 80,36 \\
\hline Bufo spinosus & $30 T X$ & 100,00 & 106,06 & $\begin{array}{r}30,01 \\
100,24\end{array}$ & 30,30 & 6100,01 & $\begin{array}{l}24,05 \\
249,72\end{array}$ & $\begin{array}{l}-21,32 \\
-21,32\end{array}$ & $\mid$\begin{tabular}{|l|}
271,04 \\
\end{tabular} & \begin{tabular}{|l|}
128,83 \\
128,
\end{tabular} & \begin{tabular}{|l|l|}
39,46 \\
396
\end{tabular} & $\begin{array}{l}185,23 \\
185,23\end{array}$ & 29,41 & \begin{tabular}{|l|}
435,01 \\
43501
\end{tabular} & $\begin{array}{l}\mid c 5,113 \\
66,35 \\
\end{array}$ & \begin{tabular}{|l|}
21,07 \\
21,0
\end{tabular} & $\frac{0,52}{36,42}$ & \begin{tabular}{|l|}
161,47 \\
167
\end{tabular} & 74,15 & 113,91 & $\begin{array}{l}0,0,61 \\
77,61\end{array}$ \\
\hline Bufo spinosus & 30TXL35 & 100,00 & 106,74 & 100,94 & 36,57 & 6099,30 & 252,09 & $-20,23$ & 272,32 & 129,56 & 40,47 & 185,94 & 30,32 & 436,62 & 66,18 & 21,77 & 35,22 & 160,59 & 76,35 & 112,66 & 79,99 \\
\hline Bufo spinosus & 30TXL40 & 100,00 & 98,19 & 99,03 & 36,00 & 6177,33 & 244,29 & $-25,42$ & 269,70 & $\mid$\begin{tabular}{|l|}
119,08 \\
\end{tabular} & 23,32 & $\mid 179,94$ & 22,66 & 477,14 & 70,56 & 23,76 & 34,72 & $\mid 174,42$ & 81,71 & 124,25 & 81,71 \\
\hline Bufo spinosus & 30TXL41 & 100,00 & 97,45 & 98,44 & 36,00 & 6130,43 & 241,32 & $-27,00$ & 268,32 & 118,89 & 27,51 & 178,22 & 21,91 & 474,47 & 70,94 & 23,18 & 35,55 & 175,01 & 80,73 & 125,40 & 81,19 \\
\hline Bufo spinosus & $30 T \times L$ & 100,00 & 103,06 & 97,26 & 36,00 & 6075,59 & 241,99 & $-23,24$ & 265,22 & 125,75 & 36,52 & 18 & 27,15 & 437,31 & 67,55 & 19,54 & 38,94 & 165,59 & 69,53 & 118,96 & 72,10 \\
\hline \begin{tabular}{|l} 
Bufo spinosus \\
\end{tabular} & 30TXL43 & 100,00 & 103,52 & 97,70 & 36,03 & 6064,31 & 242,87 & $-22,97$ & 265,83 & 126,45 & 37,18 & 182,36 & 27,64 & 437,57 & $\mid 67,50$ & 19,82 & 38,29 & 165,04 & 70,36 & 118,27 & 73,68 \\
\hline Bufo spinosus & 30TXL44 & 100,00 & 99,57 & 98,60 & 36,16 & 6063,16 & 241,76 & $-26,03$ & 267,80 & 121,83 & 33,31 & 178,59 & 23,97 & 462,21 & 69,90 & 22,22 & 35,83 & 171,22 & 78,36 & 122,62 & 81,31 \\
\hline Bufo spinosus & 30 TXL45 & 100,00 & 103,29 & 99,36 & 36,30 & 6071.57 & 246.90 & -22.48 & 269,38 & 125.80 & 37,30 & 182,32 & 27.53 & 450.06 & 68.11 & 22.12 & 35.47 & 165.82 & 77.56 & 117.56 & 80.82 \\
\hline Bufo spinosus & 30TXL50 & 100,00 & 91,90 & 98,01 & 36,01 & 6162,41 & 238,94 & $-29,51$ & 268,45 & 111,65 & 17,40 & 173 & 17 & 515,99 & 74,51 & 26,49 & 32,53 & 185,27 & 89,94 & 132,90 & 89,94 \\
\hline Bufo spinosus & 30TXL51 & 100,00 & 87,73 & 98,07 & 36,00 & 6124,77 & 234,65 & $-33,71$ & 268,35 & 107,34 & 13,52 & 169,11 & 13,46 & 539,12 & 77,24 & 28,50 & 31,44 & 192,34 & 96,55 & 138,61 & 96,55 \\
\hline
\end{tabular}




\begin{tabular}{|c|c|c|c|c|c|c|c|c|c|c|c|c|c|c|c|c|c|c|c|c|c|}
\hline TAXON & UTM & $\mathrm{km} 2$ & B101 & B102 & $\mathrm{BIO3}$ & BIO4 & B105 & B106 & B107 & B108 & B109 & BIO10 & BIO11 & BIO12 & B1013 & BIO14 & BIO15 & B1016 & B1017 & B1018 & B1019 \\
\hline Bufo spinosus & 30TXL52 & 100,00 & 95,48 & 97,20 & 36,00 & 6089,01 & 238,10 & $-27,74$ & 265,83 & 116,36 & 26,76 & 175,60 & 20,49 & 487,24 & 72,39 & 23,87 & 34,90 & 178,61 & 83,15 & 128,89 & 83,55 \\
\hline Bufo spinosus & 30TXL53 & 100,00 & 93,34 & 97,36 & 36,00 & 6066,05 & 236,19 & $-29,89$ & 266,08 & 114,21 & 26,24 & 173,12 & 18,58 & 500,72 & 73,83 & 25,11 & 34,01 & 182,28 & 87,26 & 131,60 & 88,09 \\
\hline Bufo spinosus & 30TXL54 & 100,00 & 90,49 & 97,91 & 36,00 & 6048,23 & 234,72 & $-32,40$ & 267,12 & 111,02 & 24,29 & 169,99 & 16,06 & 520,93 & 75,81 & 27,03 & 32,34 & 187,29 & 93,71 & 135,29 & 94,70 \\
\hline Bufo spinosus & 30TXL55 & 100,00 & 99,63 & 98,26 & 36,01 & 6049,87 & 242,98 & $-24,70$ & 267,68 & 121,47 & 33,74 & 178,65 & 24,53 & 472,58 & 70,42 & 23,61 & 34,13 & 172,20 & 82,48 & 122,96 & 84,61 \\
\hline Bufo spinosus & 30 XTL56 & 100,00 & 108,24 & 99,50 & 36,17 & \begin{tabular}{|l|l|}
6072,37 \\
\end{tabular} & 253,65 & \begin{tabular}{|l|l|}
$-16,47$ \\
\end{tabular} & \begin{tabular}{|l|l|}
270,12 \\
\end{tabular} & 130,62 & 42,57 & 187,26 & 32,59 & 438,60 & 65,96 & 22,22 & 34,36 & 159,44 & 77,44 & 111,43 & 79,67 \\
\hline Bufo spinosus & 30TXL57 & 100,00 & 117,97 & 101,20 & 36,25 & 6124,89 & 266,89 & $-7,00$ & 273,89 & 140,69 & 52,13 & 197,44 & 41,42 & 406,46 & 61,17 & 21,35 & 33,91 & 146,15 & 74,08 & 99,27 & 76,03 \\
\hline Bufo spinosus & 30TXL60 & 100,00 & 94,83 & 96,48 & 36,00 & 6139,80 & 239,94 & $-25,42$ & 265,35 & $\begin{array}{lll}114,68 \\
\end{array}$ & 20,78 & 176,50 & 20,78 & 505,03 & 73,01 & 25,25 & 33,01 & 181,19 & 86,05 & 130,33 & 86,05 \\
\hline \begin{tabular}{|l} 
Bufo spinosus \\
\end{tabular} & 30TXL61 & 100,00 & 90,23 & 96,60 & 35,99 & 6104,58 & 235,41 & $-30,41$ & 265,82 & $\begin{array}{l}109,78 \\
\end{array}$ & 16,47 & 171,37 & 16,47 & 529,44 & 75,96 & 27,37 & 31,93 & 188,81 & 92,93 & 136,23 & 92,93 \\
\hline Bufo spinosus & 30TXL62 & 100,00 & 93,88 & 96,39 & 36,00 & 6076,15 & 237,07 & $-27,70$ & 264,77 & 114,11 & 21,47 & 174,17 & 19,72 & 505,76 & 73,78 & 25,51 & 33,43 & 182,48 & 87,48 & 131,67 & 87,48 \\
\hline Bufo spinosus & 30TXL63 & 100,00 & 90,23 & 96,66 & 36,00 & 6052,86 & 234,09 & $-31,12$ & 265,21 & 110,10 & 19,00 & 170,15 & 16,26 & 527,51 & 76,18 & 27,39 & 31,97 & 188,53 & 94,05 & 136,34 & 94,05 \\
\hline Bufo spinosus & 30TXL64 & 100,00 & 97,19 & 96,94 & 36,00 & 6042,81 & 240,17 & $-25,19$ & 265,35 & 118,09 & 31,02 & 176,54 & 22,75 & 489,91 & 72,06 & 24,70 & 33,49 & 176,98 & 85,80 & 126,94 & 86,37 \\
\hline Bufo spinosus & 30TXL65 & 100,00 & 107,50 & 97,78 & 36,00 & 6055,16 & 250,82 & $-16,10$ & 266,92 & \begin{tabular}{ll|l}
129,47 \\
\end{tabular} & 41,66 & 186,47 & 32,33 & 441,42 & 66,32 & 21,81 & 34,95 & 160,91 & 75,92 & 113,19 & 77,19 \\
\hline Bufo spinosus & 30TXL67 & 100,00 & 117,43 & 100,42 & 36,10 & 6102,58 & 265,95 & $-6,52$ & 272,46 & 139,90 & 51,90 & 196,82 & 41,34 & 411,37 & 61,44 & 21,69 & 33,30 & 147,14 & 74,86 & 99,97 & 75,70 \\
\hline Bufo spinosus & 30TXL68 & 100,00 & 123,29 & 101,80 & 36,25 & 6140,66 & 274,94 & $-0,96$ & 275,90 & 145,87 & 57,65 & 203,00 & 46,66 & 396,42 & 58,78 & 21,01 & 32,39 & 139,89 & 74,69 & 93,15 & 75,25 \\
\hline Bufo spinosus & 30TXL69 & 100,00 & 131,13 & 103,27 & 36,36 & 6188,04 & 286,48 & 6,68 & 279,80 & 154,08 & 105,36 & 211,40 & 53,98 & 377,27 & 55,39 & 18,90 & 31,50 & 130,90 & 73,64 & 84,45 & 74,45 \\
\hline Bufo spinosus & 30TXL70 & 100,00 & 91,62 & 95,82 & 35,95 & 6104,33 & 237,03 & $-26,92$ & 263,95 & 110,41 & 18,39 & 173,10 & 18,39 & 535,96 & 75,51 & 27,64 & 30,93 & 188,29 & 93,76 & 135,37 & 93,76 \\
\hline Bufo spinosus & 30TXL71 & 100,00 & 88,97 & 95,70 & 35,92 & 6076,17 & 234,03 & $-29,79$ & 263,82 & 107,70 & 15,86 & 169,95 & 15,86 & 549,70 & 77,34 & 28,97 & 30,47 & 192,75 & 97,80 & 139,05 & 97,80 \\
\hline Bufo spinosus & 30TXL72 & 100,00 & 101,13 & 95,36 & 35,98 & 6059,70 & 243,06 & $-19,58$ & 262,65 & 121,64 & 27,75 & 181,10 & 27,18 & 478,34 & 70,08 & 23,47 & 34,08 & 172,16 & 80,84 & 123,14 & 80,84 \\
\hline Bufo spinosus & 30TXL74 & 100,00 & 109,47 & 96,76 & 36,00 & 6044,27 & 252,24 & $-13,11$ & 265,36 & 131,08 & 42,85 & 188,66 & 34,88 & 439,68 & 65,54 & 21,57 & 34,89 & 158,99 & 74,79 & 111,64 & 74,89 \\
\hline Bufo spinosus & 30TXL75 & 100,00 & 114,92 & 97,98 & 36,00 & 6066,83 & 259,62 & $-8,03$ & 267,65 & 136,97 & 48,13 & 194,08 & 39,80 & 419,59 & 62,66 & 20,99 & 34,60 & 151,11 & 72,50 & 104,34 & 72,64 \\
\hline Bufo spinosus & 30TXL79 & 100,00 & 127,20 & 102,48 & 36,18 & 6146,71 & 281,60 & 3,56 & 278,04 & 149,99 & 54,67 & 207,17 & 50,63 & 391,98 & 56,46 & 20,06 & 30,52 & 135,25 & 75,40 & 88,81 & 75,40 \\
\hline \begin{tabular}{|l} 
Bufo spinosus \\
\end{tabular} & 30TXL80 & 100,00 & 92,12 & 94,93 & 35,88 & 6074,91 & 237,01 & $-25,42$ & 262,43 & 110,20 & 19,59 & 173,29 & 19,59 & 548,33 & 75,97 & 28,70 & 29,87 & 189,62 & 97,12 & \begin{tabular}{|l|l|}
135,95 \\
\end{tabular} & 97,12 \\
\hline Bufo spinosus & 30TXL81 & 100,00 & 90,67 & 94,95 & 35,90 & \begin{tabular}{|c|}
6049,47 \\
\end{tabular} & 235,18 & $-27,06$ & 262,24 & 109,03 & 18,25 & 171,36 & 18,25 & 555,37 & 77,05 & 29,46 & 29,80 & 191,96 & 99,52 & 138,05 & 99,52 \\
\hline Bufo spinosus & 30TXL82 & 100,00 & 105,61 & 95,06 & 36,00 & 6036,24 & 247,85 & $-14,08$ & 261,93 & 125,84 & 32,08 & 185,38 & 32,08 & 471,49 & 68,23 & 23,19 & 33,44 & 167,17 & 79,96 & \begin{tabular}{|l|l|}
118,27 \\
\end{tabular} & 79,96 \\
\hline Bufo spinosus & 30TXL83 & 100,00 & 109,49 & 95,77 & 35,97 & 6035,23 & 252,01 & $-11,32$ & 263,33 & 130,29 & 36,04 & 188,90 & 35,78 & 452,96 & 66,15 & 22,27 & 33,96 & 161,12 & 76,89 & 112,97 & 76,89 \\
\hline Bufo spinosus & 30TXL84 & 100,00 & 115,72 & 96,93 & 36,00 & 6040,90 & 259,44 & $-6,17$ & 265,62 & 137,23 & 43,16 & 194,89 & 41,48 & 427,11 & 62,83 & 21,12 & 34,23 & 151,85 & 72,94 & 104,76 & 72,94 \\
\hline Bufo spinosus & 30TXL85 & 100,00 & 116,66 & 97,82 & 36,00 & 6051,52 & 261,97 & $-5,50$ & $\begin{array}{l}267,48 \\
267\end{array}$ & 138,31 & 43,75 & \begin{tabular}{|l|}
195,76 \\
\end{tabular} & 42,05 & |424,05 & $\begin{array}{l}62,31 \\
62,31\end{array}$ & 21,52 & 33,57 & 150,21 & 73,66 & 102,92 & 73,66 \\
\hline Bufo spinosus & 30TXL86 & 100,00 & 126,49 & 99,79 & 36,01 & 6088,22 & 275,16 & 2,99 & 272,17 & 148,82 & 52,40 & 205,93 & 51,04 & 391,26 & 57,25 & 20,01 & 33,19 & 137,14 & 69,25 & 91,28 & 69,25 \\
\hline Bufo spinosus & 30TXL87 & 100,00 & 132,95 & 101,34 & 36,00 & 6120,77 & 284,55 & 8,68 & 275,87 & 155,74 & 56,94 & 212,68 & 56,86 & 373,65 & 53,97 & 18,64 & 32,14 & 129,19 & 67,90 & 84,27 & 67,90 \\
\hline Bufo spinosus & 30TXL88 & 100,00 & 134,58 & 102,23 & 36,03 & 6145,04 & 288,41 & $\begin{array}{ll}10,24 \\
\end{array}$ & 278,17 & 157,57 & 58,01 & 214,51 & 58,01 & 370,96 & 52,88 & 18,25 & 31,04 & 127,03 & 68,71 & 82,26 & 68,71 \\
\hline Bufo spinosus & 30TXL90 & 100,00 & 93,26 & 94,10 & 35,88 & 6037,54 & 237,51 & $-23,38$ & 260,88 & 110,95 & 21,41 & 173,85 & 21,41 & 560,38 & 76,22 & 29,78 & 28,83 & 190,28 & 100,83 & 135,84 & 100,83 \\
\hline Bufo spinosus & 30TXL91 & 100,00 & $\begin{array}{l}92,79 \\
92,79\end{array}$ & 94,06 & $\begin{array}{l}35,90 \\
55,91\end{array}$ & 6024,18 & 236,62 & $\begin{array}{l}-24,29 \\
-24,\end{array}$ & \begin{tabular}{|l|}
260,90 \\
\end{tabular} & 110,82 & $\begin{array}{l}\mid 20,82 \\
20,82\end{array}$ & $\begin{array}{l}173,14 \\
173\end{array}$ & $\begin{array}{ll}20,82 \\
20\end{array}$ & 558,18 & 76,49 & 29,75 & $\begin{array}{ll}29,18 \\
29,18\end{array}$ & \begin{tabular}{|l|}
190,50 \\
\end{tabular} & \begin{tabular}{|l|l|}
100,44 \\
\end{tabular} & $\begin{array}{l}136,29 \\
13,4\end{array}$ & 100,44 \\
\hline Bufo spinosus & 30TXL92 & 100,00 & 108,34 & 94,90 & 35,97 & 6013,94 & 250,88 & $-10,67$ & 261,55 & 128,18 & 35,46 & 187,89 & 35,46 & 475,73 & 67,67 & 23,81 & 32,43 & 165,47 & 81,84 & 115,82 & 81,84 \\
\hline Bufo spinosus & 30TXL93 & 100,00 & 119,24 & 96,28 & 35,99 & 6024,23 & 262,65 & $-1,61$ & 264,25 & 140,10 & 45,57 & 198,47 & 45,57 & 430,39 & 61,95 & 21,19 & 33,56 & 149,75 & 73,45 & 102,24 & 73,45 \\
\hline Bufo spinosus & 30TXL94 & 100,00 & 121,76 & 97,31 & 36,00 & 6022,52 & 266,54 & 0,07 & 266,46 & 143,10 & 48,05 & 200,89 & 48,05 & 420,08 & 60,59 & 21,03 & 33,48 & 146,01 & 72,48 & 98,88 & 72,48 \\
\hline Bufo spinosus & 30TXL95 & 100,00 & 119,29 & 97,91 & 36,00 & 6025,98 & 265,34 & $-2,58$ & 267,92 & $\begin{array}{ll}140,63 \\
\end{array}$ & 45,32 & 198,40 & 45,32 & 428,44 & 61,70 & 21,84 & 32,63 & 148,84 & 75,02 & 101,15 & 75,02 \\
\hline \begin{tabular}{|l} 
Bufo spinosus \\
\end{tabular} & 30TXL96 & 100,00 & 134,56 & 100,49 & 36,02 & 6076,06 & 284,31 & 10,75 & 273,56 & 157,00 & 59,40 & 213,91 & 59,40 & 377,88 & 53,95 & 18,37 & 32,59 & 129,18 & 67,32 & $\frac{11}{84,10}$ & 67,32 \\
\hline Bufo spinosus & 30TXL97 & 100,00 & 139,50 & 101,88 & 36,10 & 6104,79 & 291,85 & $\begin{array}{ll}15,07 \\
\end{array}$ & 276,78 & 162,47 & 63,90 & 219,12 & 63,90 & 364,50 & 51,29 & 17,19 & 31,80 & 123,17 & 66,23 & 79,08 & 66,23 \\
\hline Bufo spinosus & 30TXL98 & 100,00 & 142,43 & 102,88 & 36,18 & 6118,22 & 296,53 & 17,65 & 278,88 & 165,50 & 66,35 & 222,14 & 66,35 & 358,47 & 49,68 & 16,66 & 30,96 & 119,94 & 66,09 & 76,27 & 66,09 \\
\hline Bufo spinosus & 30TXL99 & 100,00 & 143,05 & 103,63 & 36,55 & 6128,25 & 298,72 & 18,23 & 280,49 & 166,48 & 66,65 & 222,90 & 66,65 & 358,56 & 48,94 & 16,63 & 29,89 & 118,88 & 66,91 & 75,70 & 66,91 \\
\hline \begin{tabular}{|l} 
Bufo spinosus \\
\end{tabular} & 30TXM01 & 100,00 & 95,38 & 108,00 & 37,85 & \begin{tabular}{|l|}
6071,08 \\
\end{tabular} & 255,01 & $-28,10$ & 283,11 & 115,35 & $\begin{array}{l}174,92 \\
\end{array}$ & 175,13 & 20,77 & 577,34 & 74,88 & 32,82 & 23,46 & 187,54 & \begin{tabular}{|c|}
116,08 \\
\end{tabular} & 129,63 & 134,59 \\
\hline \begin{tabular}{|l} 
Bufo spinosus \\
\end{tabular} & 30TXM04 & 100,00 & 128,32 & 108,00 & 37,95 & 6113,23 & 286,81 & 4,12 & 282,69 & 150,56 & 207,32 & 207,38 & 51,53 & 475,79 & 60,21 & 23,86 & 24,52 & 149,16 & 88,55 & 94,31 & 116,81 \\
\hline Bufo spinosus & 30TXM05 & 100,00 & 133,34 & 107,29 & 37,99 & 6057,35 & 290,14 & 10,14 & 279,99 & 155,39 & 211,64 & 211,64 & 57,25 & 485,86 & 59,23 & 23,80 & 23,70 & 148,22 & 89,40 & 92,39 & 122,30 \\
\hline Bufo spinosus & 30TXM06 & 100,00 & 134,37 & 106,67 & 37,99 & 6021,66 & 289,83 & 12,23 & 277,60 & 155,06 & 212,27 & 212,27 & 58,71 & 513,80 & 60,26 & 25,03 & 22,90 & 152,93 & 93,81 & 95,71 & 132,79 \\
\hline Bufo spinosus & 30TXM07 & 100,00 & 136,85 & 105,91 & 38,00 & 5960,25 & 290,10 & 15,45 & 274,65 & \begin{tabular}{|l|l|}
102,64 \\
\end{tabular} & 213,73 & 213,73 & 61,61 & 545,48 & 61,27 & 26,12 & 22,41 & 47 & 98,66 & 98,93 & 144,92 \\
\hline Bufo spinosus & 30TXM08 & 100,00 & 134,51 & 105,33 & 38,00 & 5906,84 & 286,6 & 14,23 & 272,43 & $\begin{array}{r}02,34 \\
98,32\end{array}$ & 210,73 & 210,73 & $\begin{array}{l}1,0,05 \\
60\end{array}$ & $\begin{array}{l}595,02 \\
\end{array}$ & 66,05 & 28,54 & 22,00 & $\begin{array}{l}178,07 \\
\end{array}$ & $\begin{array}{r}0,06,76 \\
106\end{array}$ & \begin{tabular}{|c|}
106,98 \\
10,9
\end{tabular} & 162,32 \\
\hline \begin{tabular}{|l} 
Bufo spinosus \\
\end{tabular} & 30TXM09 & 100,00 & 131,31 & 105,03 & 38,08 & 5861,17 & 282,84 & 12,12 & 270,72 & 94,86 & 207,03 & 207,03 & 57,59 & 657,07 & 74,70 & 31,62 & 21,99 & 198,86 & 116,63 & 116,63 & 184,39 \\
\hline Bufo spinosus & 30TXM14 & 100,00 & 132,42 & 107,17 & 37,69 & 6099,90 & 289,75 & 8,56 & 281,19 & \begin{tabular}{ll|}
154,72 \\
\end{tabular} & 211,33 & 211,37 & 55,81 & 466,15 & 59,06 & 22,67 & 24,96 & 145,23 & 85,77 & 88,68 & 114,99 \\
\hline Bufo spinosus & 30TXM15 & 100,00 & 137,34 & 106,54 & 37,96 & 6040,20 & 292,78 & 14,55 & 278,22 & 159,61 & 215,33 & 215,33 & 61,35 & 480,36 & 58,18 & 22,85 & 24,02 & 145,01 & 87,32 & 89,54 & 122,01 \\
\hline Bufo spinosus & 30TXM17 & 100,00 & 132,53 & 106,19 & 38,00 & 5976,67 & 286,65 & 11,06 & 275,59 & 102,39 & 209,63 & 209,63 & 57,17 & 567,05 & 63,84 & 27,16 & 22,45 & 167,42 & 101,85 & 102,41 & 152,02 \\
\hline Bufo spinosus & $30 \mathrm{TX}$ & 100,00 & 130,54 & 105,84 & 38,00 & 5931,66 & 283 & $\begin{array}{r}1,000 \\
9,80\end{array}$ & \begin{tabular}{|l|}
273,94 \\
27
\end{tabular} & \begin{tabular}{|l|l|}
94,21 \\
94,
\end{tabular} & \begin{tabular}{|l|}
207,13 \\
\end{tabular} & \begin{tabular}{|l|}
207,13 \\
\end{tabular} & 55,90 & \begin{tabular}{|l|l|}
618,58 \\
\end{tabular} & $\begin{array}{l}3,, 404 \\
69,70\end{array}$ & 29,63 & 22,02 & $\begin{array}{l}185,17 \\
184\end{array}$ & $\begin{array}{l}110,020 \\
110\end{array}$ & $\begin{array}{l}110,09 \\
11,1\end{array}$ & 170,60 \\
\hline Bufo spinosus & 30TXM19 & 100,00 & 130,52 & 105,12 & 38,01 & 5871,83 & 282,08 & 10,50 & 271,58 & 94,28 & 206,24 & 206,24 & 56,29 & 673,35 & 77,95 & 31,95 & 22,21 & 205,12 & 118,55 & 118,55 & 191,28 \\
\hline Bufo spinosus & 30TXM20 & 100,00 & 120,56 & 106,08 & 37,00 & 6164,38 & 276,99 & $-4,47$ & 281,46 & 143,08 & $\mid 196,55$ & 200,55 & 43,73 & 431,75 & 61,31 & 22,69 & 29,33 & $\mid 146,86$ & 85,24 & 97,42 & 94,21 \\
\hline Bufo spinosus & 30TXM24 & 100,00 & 138,28 & 106,28 & 37,48 & 6087,83 & 294,44 & 15,01 & 279,43 & 160,78 & 216,96 & 216,96 & 61,71 & 449,59 & 56,90 & 21,03 & 25,46 & 138,72 & 81,65 & 82,90 & 111,29 \\
\hline Bufo spinosus & 30TXM25 & 100,00 & 135,71 & 106,21 & 37,74 & 6045,86 & 291,28 & 12,96 & 278,32 & 157,97 & 213,74 & 213,74 & 59,53 & 487,17 & 59,36 & 23,02 & 24,15 & 147,02 & 88,34 & 90,45 & 123,8 \\
\hline Bufo spinosus & $\begin{array}{l}30 \mathrm{TXM} 26 \\
30\end{array}$ & $\begin{array}{l}100,00 \\
\end{array}$ & 132,34 & $\begin{array}{l}10,21 \\
106,18\end{array}$ & 37,95 & $\begin{array}{l}\mid 6004,000 \\
6011,91\end{array}$ & 287,35 & $\begin{array}{l}10,14 \\
10,\end{array}$ & $\begin{array}{l}27,, 25 \\
277,21 \\
\end{array}$ & $\begin{array}{ll}140,20 \\
\end{array}$ & \begin{tabular}{|l|}
209,87 \\
20
\end{tabular} & \begin{tabular}{|l|}
209,87 \\
20
\end{tabular} & $\begin{array}{l}50,56 \\
56,56\end{array}$ & $\mid \begin{array}{l}\mid l 01,11 \\
530,36\end{array}$ & $\begin{array}{l}3,20 \\
62,22 \\
\end{array}$ & $\begin{array}{l}25,35 \\
25,3\end{array}$ & $\begin{array}{l}24,1109 \\
23,09\end{array}$ & $\begin{array}{l}157,15< \\
157,15\end{array}$ & $\begin{array}{l}0,344 \\
95,82\end{array}$ & \begin{tabular}{|l|}
0,495 \\
99,69
\end{tabular} & $\begin{array}{l}12,05 \\
138,38\end{array}$ \\
\hline Bufo spinosus & 30TXM27 & 100,00 & 133,69 & 105,99 & 38,00 & 5966,34 & 287,39 & 12,47 & 274,92 & 96,91 & 210,66 & 210,66 & 58,58 & 564,81 & 63,52 & 26,71 & 22,52 & 167,48 & 101,29 & 102,42 & 151,60 \\
\hline Bufo spinosus & 30TXM28 & 100,00 & 127,85 & 105,90 & 38,00 & 5923,58 & 280,96 & 7,13 & 273,82 & 91,65 & 204,24 & 204,24 & 53,19 & 630,60 & 71,13 & 30,23 & 21,98 & 188,22 & 112,42 & 112,42 & 173,84 \\
\hline Bufo spinosus & 30TXM29 & 100,00 & 126,49 & 105,21 & 38,02 & 5856,42 & 278,16 & 6,71 & 271,46 & 87,33 & 202,15 & 202 & 52, & 689,63 & 79,75 & 32,97 & 21,94 & 209,18 & 122,07 & 122,07 & 195, \\
\hline Bufo spinosus & 30TXM33 & 100,00 & 138,50 & 106,01 & 37,01 & 6139,19 & 295,47 & 14,89 & 280,58 & 161,23 & 217,79 & 217,79 & 61,48 & 421,05 & 55,96 & 19,55 & 27,19 & 133,53 & 76,64 & 78,88 & 100,73 \\
\hline
\end{tabular}




\begin{tabular}{|c|c|c|c|c|c|c|c|c|c|c|c|c|c|c|c|c|c|c|c|c|c|}
\hline TAXON & UTM & $\mathrm{km} 2$ & B101 & B102 & $\mathrm{BIO3}$ & B104 & B105 & B106 & B107 & B108 & B109 & BIO10 & BIO11 & BIO12 & B1013 & BIO14 & BIO15 & B1016 & B1017 & B1018 & B1019 \\
\hline Bufo spinosus & 30TXM36 & 100,00 & 129,18 & 106,00 & 37,92 & 6005,93 & 284,30 & 7,06 & 277,23 & 147,96 & 206,79 & 206,79 & 53,67 & 535,59 & 63,38 & 25,68 & 22,83 & 158,98 & 97,45 & 99,31 & 138,33 \\
\hline Bufo spinosus & 30TXM37 & 100,00 & 129,39 & 105,94 & 38,00 & 5959,24 & 283,29 & 8,04 & 275,24 & 95,12 & 206,40 & 206,40 & 54,34 & 575,10 & 65,06 & 27,44 & 22,10 & 168,96 & 103,88 & 104,77 & 153,17 \\
\hline Bufo spinosus & 30TXM38 & 100,00 & 127,53 & 105,31 & 38,00 & 5906,47 & 279,88 & 6,84 & 273,04 & 91,61 & 203,72 & 203,72 & 52,95 & 626,84 & 70,12 & 29,96 & 21,65 & 186,67 & 112,73 & 113,19 & 171,50 \\
\hline Bufo spinosus & 30TXM39 & 100,00 & 124,96 & 104,99 & 38,09 & 5850,36 & 275,92 & 5,17 & 270,75 & 89,49 & 200,52 & 200,52 & 51,20 & 687,19 & 78,48 & 32,94 & 21,50 & 207,19 & 123,07 & 123,44 & 192,83 \\
\hline Bufo spinosus & 30TXM40 & 100,00 & 136,26 & 105,00 & 36,99 & \begin{tabular}{|l|l|}
6209,37 \\
\end{tabular} & 292,96 & 11,42 & \begin{tabular}{|l|l|}
281,54 \\
\end{tabular} & 159,41 & 216,57 & 216,58 & 58,69 & 372,54 & 54,78 & 17,63 & 32,07 & 126,86 & 70,29 & 75,02 & 80,25 \\
\hline Bufo spinosus & 30TXM41 & 100,00 & 138,05 & 105,43 & 37,00 & 6186,51 & 295,37 & 13,80 & 281,57 & 160,80 & 218,13 & 218,13 & 60,69 & 379,92 & 54,90 & 17,58 & 31,18 & 126,83 & 69,95 & 70,45 & 84,77 \\
\hline Bufo spinosus & 30TXM44 & 100,00 & 138,46 & 105,95 & 37,08 & 6090,79 & 294,70 & 15,47 & 279,23 & 160,71 & 217,24 & 217,24 & 61,92 & 439,31 & 56,51 & 20,22 & 25,72 & 136,14 & 79,98 & 80,42 & 106,61 \\
\hline \begin{tabular}{|l} 
Bufo spinosus \\
\end{tabular} & $30 \mathrm{TXM} 45$ & 100,00 & 134,59 & 105,80 & 37,72 & 6029,52 & 290,12 & 12,27 & 277,86 & 156,46 & 212,67 & 212,67 & 58,95 & 477,71 & 59,03 & 22,36 & 24,01 & 144,83 & 87,31 & 89,01 & 118,78 \\
\hline Bufo spinosus & 30TXM46 & 100,00 & 132,77 & 105,54 & 37,91 & 5971,76 & 287,08 & 10,98 & 276,10 & 154,50 & 209,96 & 209,96 & 57,60 & 516,95 & 61,24 & 24,34 & 22,70 & 152,71 & 94,45 & 94,96 & 132,09 \\
\hline Bufo spinosus & 30TXM48 & 100,00 & 120,32 & 104,88 & 38,03 & 5861,92 & 272,18 & 0,66 & 271,51 & 84,90 & 196,10 & 196,10 & 46,53 & 641,09 & 70,74 & 31,44 & 20,65 & 187,44 & 117,89 & 119,70 & 171,65 \\
\hline Bufo spinosus & 30TXM49 & 100,00 & 111,52 & 104,06 & 38,12 & 5778,43 & 261,90 & $-6,27$ & 268,17 & 76,92 & 186,52 & 186,52 & 39,16 & 720,40 & 78,95 & 36,34 & 19,71 & 210,17 & 133,69 & 136,21 & 195,68 \\
\hline Bufo spinosus & 30TXM55 & 100,00 & 130,65 & 105,09 & 37,32 & 6008,16 & 285,82 & 8,62 & 277,20 & 152,32 & 208,28 & 208,36 & 55,40 & 481,03 & 59,89 & 22,92 & 23,46 & 146,85 & 89,62 & 92,53 & 116,77 \\
\hline \begin{tabular}{|l} 
Bufo spinosus \\
\end{tabular} & 30TXM57 & 100,00 & 124,80 & 104,84 & 38,00 & 5881,56 & 277,18 & 4,57 & 272,62 & 137,31 & 200,75 & 200,76 & 50,84 & 569,34 & 65,41 & 27,60 & 20,89 & 165,63 & \begin{tabular}{l|l|}
106,48 \\
\end{tabular} & 109,27 & 145,84 \\
\hline Bufo spinosus & 30TXM58 & 100,00 & 113,90 & 103,95 & 38,00 & 5797,35 & 264,50 & $-4,35$ & 268,85 & 116,61 & 188,90 & 188,90 & 41,18 & 649,11 & 72,57 & 32,71 & 19,63 & 186,95 & 122,80 & 126,16 & 168,81 \\
\hline Bufo spinosus & 30TXM59 & 100,00 & 103,55 & 102,68 & 38,04 & 5708,48 & 252,07 & $-12,97$ & 265,04 & 93,71 & 177,73 & 177,74 & 32,32 & 734,06 & 79,99 & 38,29 & 18,39 & 209,68 & 140,80 & 144,08 & 193,00 \\
\hline Bufo spinosus & 30TXM60 & 100,00 & 135,65 & 104,38 & 36,44 & 6225,17 & 293,69 & 11,31 & 282,38 & 158,78 & 207,07 & 216,32 & 58,02 & 371,20 & 53,65 & 17,91 & 30,35 & 126,58 & 71,97 & 79,83 & 7009 \\
\hline Bufo spinosus & 30TXM64 & 100,00 & 119,33 & 104,01 & $\begin{array}{ll}37,06 \\
\end{array}$ & 5984,79 & 273,83 & $-1,61$ & 275,44 & 140,75 & 196,83 & 196,96 & 44,60 & 484,83 & 62,92 & 24,45 & 23,75 & 153,50 & 94,64 & 102,13 & 110,14 \\
\hline Bufo spinosus & 30TXM65 & 100,00 & 121,25 & 104,19 & 37,42 & 5940,58 & 275,03 & 0,62 & 274,40 & 142,57 & 198,01 & 198,11 & 46,95 & 503,56 & 63,01 & 25,09 & 22,43 & 155,19 & 97,32 & 103,62 & 118,05 \\
\hline Bufo spinosus & 30TXM66 & 100,00 & 128,08 & 104,69 & 37,91 & 5906,69 & 281,10 & 7,36 & 273,74 & 149,54 & 204,25 & 204,33 & 53,87 & 508,92 & 60,97 & 24,51 & 21,57 & 151,79 & 97,01 & 100,58 & 123,64 \\
\hline Bufo spinosus & 30TXM67 & 100,00 & 118,97 & 103,90 & 38,00 & 5817,41 & 270,15 & 0.01 & 270,13 & 139,65 & $\mid$\begin{tabular}{|l|l|}
194,19 \\
\end{tabular} & 194,25 & 46,15 & 572,81 & 66,77 & 28.48 & 20,11 & $\mid 168,26$ & 110,30 & $\mid 114.96$ & 141,91 \\
\hline Bufo spinosus & 30TXM68 & 100,00 & 109,32 & 102,91 & 38,01 & 5729,41 & 258,29 & $-7,86$ & 266,14 & 129,00 & 183,44 & 183,52 & 37,62 & 649,78 & 73,60 & 33,38 & 18,82 & 188,19 & 126,30 & 131,44 & 164,01 \\
\hline \begin{tabular}{|l} 
Bufo spinosus \\
\end{tabular} & 30TXM69 & 100,00 & 96,15 & 101,10 & 38,05 & 5631,87 & 242,63 & \begin{tabular}{|l|l|}
$-18,79$ \\
\end{tabular} & 261,42 & 113,00 & 169,56 & 169,58 & 26,19 & 753,18 & 83,07 & 40,55 & 17,42 & 215,76 & 148,84 & 152,24 & 192,26 \\
\hline Bufo spinosus & 30TXM70 & 100,00 & 139,91 & 104,45 & $\begin{array}{l}36,05 \\
\end{array}$ & 6233,91 & 299,11 & 15,36 & 283,75 & 163,46 & 148,13 & 220,96 & 62,00 & 362,75 & 50,22 & 17,38 & 28,79 & 122,03 & 71,01 & 77,63 & 71,93 \\
\hline Bufo spinosus & 30TXM71 & 100,00 & 146,76 & 105,24 & 36,17 & 6257,39 & 307,56 & 21,90 & 285,66 & 170,51 & 227,09 & 227,87 & 68,17 & 356,92 & 46,94 & 16,56 & 26,97 & 116,55 & 69,08 & 73,65 & 72,93 \\
\hline Bufo spinosus & 30TXM72 & 100,00 & 139,49 & 105,01 & 36,78 & 6172,47 & 298,75 & 15,87 & 282,87 & 162,73 & 218,90 & 219,44 & 62,19 & 380,41 & 50,38 & 17,99 & 26,22 & 123,59 & 73,79 & 79,24 & 79,60 \\
\hline Bufo spinosus & 30TXM74 & 100,00 & 123,39 & 103,77 & 37,03 & 5963,16 & 277,90 & 2,33 & 275,57 & 145,01 & 200,31 & 200,54 & 48,69 & 461,11 & 59,48 & 22,87 & 23,54 & 145,45 & 91,31 & 97,31 & 101,83 \\
\hline Bufo spinosus & 30 TXM75 & 100,00 & 122,42 & 103,73 & 37,22 & 5894,58 & 275,50 & 2,08 & 273,42 & \begin{tabular}{|l|l|}
143,58 \\
\end{tabular} & \begin{tabular}{|l|}
198,42 \\
\end{tabular} & 198,74 & 48,47 & $\mid 487,62$ & $\begin{array}{l}0,1,03 \\
61,03\end{array}$ & 24,21 & 22,26 & $\begin{array}{l}150,28 \\
150,4\end{array}$ & $\begin{array}{l}\mid 1,11 \\
96,39 \\
\end{array}$ & $\mid$ & $\begin{array}{l}11,0,87 \\
110\end{array}$ \\
\hline Bufo spinosus & 30TXM76 & 100,00 & 124,55 & 103,96 & 37,89 & 5840,31 & 276,45 & 4,49 & 271,96 & 145,76 & 199,77 & 200,03 & 51,17 & 504,72 & 61,06 & 24,69 & 21,14 & 151,66 & 99,13 & 103,45 & 118,15 \\
\hline Bufo spinosus & 30TXM77 & 100,00 & 114,39 & 102,89 & 38,00 & 5741,08 & 263,99 & $-3,34$ & 267,33 & 134,57 & 188,62 & 188,75 & 42,53 & 574,25 & 67,66 & 29,05 & 19,62 & 169,91 & 113,86 & 118,68 & 137,66 \\
\hline Bufo spinosus & 30TXM78 & 100,00 & 105,11 & 101,80 & 38,00 & 5660,68 & 252,52 & $-11,02$ & 263,54 & 124,45 & 178,48 & 178,66 & 34,44 & 651,86 & 74,57 & 34,13 & 18,21 & 189,92 & 130,24 & 135,19 & 159,73 \\
\hline Bufo spinosus & 30TXM79 & 100,00 & 94,27 & 100,14 & 38,01 & 5578,12 & 239,18 & $-20,06$ & 259,24 & 112,36 & 166,83 & 166,86 & 24,87 & 748,31 & 83,20 & 40,77 & 16,95 & 215,23 & 151,02 & 156,15 & 186,56 \\
\hline Bufo spinosus & 30TXM80 & 100,00 & 145,28 & 104,63 & 36,21 & 6190,31 & 303,61 & 20,15 & \begin{tabular}{|l|}
283,46 \\
\end{tabular} & $\begin{array}{l}168,93 \\
160\end{array}$ & $\begin{array}{l}79,03 \\
79,03\end{array}$ & 225,67 & $\begin{array}{ll}67,72 \\
672\end{array}$ & \begin{tabular}{|l|}
$355,22,2$ \\
\end{tabular} & $\begin{array}{l}0,20 \\
47,42\end{array}$ & 416,52 & 28,16 & $\begin{array}{l}116,99 \\
11,0\end{array}$ & $\mid$ & $\begin{array}{l}74,27 \\
74,\end{array}$ & $\begin{array}{l}0,09 \\
69,08 \\
\end{array}$ \\
\hline Bufo spinosus & 30TXM81 & 100,00 & 144,28 & 104,85 & 36,36 & 6169,93 & 303,16 & 19,72 & 283,44 & 167,74 & 140,13 & 224,41 & 66,73 & 363,76 & 47,59 & 16,95 & 26,93 & 118,23 & 71,85 & 75,41 & 72,28 \\
\hline Bufo spinosus & 30TXM82 & 100,00 & 139,35 & 104,73 & 36,89 & 6112,10 & 297,35 & $\begin{array}{ll}15,57 \\
\end{array}$ & 281,78 & 162,46 & 174,81 & 218,70 & 62,77 & 381,90 & 49,74 & 18,05 & 25,86 & 122,92 & 76,19 & 79,36 & 77,58 \\
\hline Bufo spinosus & 30TXM83 & 100,00 & 136,28 & 104,68 & 37,00 & 6036,82 & 292,76 & 13,48 & 279,28 & 159,10 & 210,90 & 214,44 & 60,58 & 400,59 & 51,58 & 19,03 & 24,70 & 126,96 & 80,25 & 82,88 & 83,63 \\
\hline Bufo spinosus & 30TXM84 & 100,00 & 133,34 & 104,30 & 37,08 & 5953,49 & 288,14 & 11,68 & 276,45 & 155,49 & 209,82 & 210,30 & 58,63 & 422,34 & 53,57 & 20,11 & 23,76 & 131,74 & 84,71 & 86,98 & 90,53 \\
\hline \begin{tabular}{|l} 
Bufo spinosus \\
\end{tabular} & 30TXM85 & 100,00 & 129,53 & 103,97 & 37,52 & 5870,70 & 282,41 & 8,86 & 273,55 & 151,40 & 204,97 & 205,53 & 55,79 & 451,78 & 56,16 & 21,72 & 22,41 & 138,37 & 90,90 & 92,84 & 99,45 \\
\hline Bufo spinosus & 30TXM86 & 100,00 & 124,99 & 103,48 & 37,99 & 5784,12 & 275,87 & 5,21 & 270,66 & 146,09 & 199,47 & 199,92 & 52,24 & 488,99 & 59,35 & 23,81 & 21,27 & 147,01 & 98,59 & 100,42 & 110,74 \\
\hline Bufo spinosus & 30TXM88 & 100,00 & 112,24 & 102,10 & 38,10 & 5625,63 & 258,76 & $-4,53$ & 263,29 & 132,04 & 184,71 & 185,06 & 41,42 & 601,19 & 69,05 & 30,72 & 18,49 & 174,65 & 122,07 & 124,87 & 143,51 \\
\hline Bufo spinosus & 30TXM89 & 100,00 & 102,23 & 100,74 & 38,23 & 5560,33 & 246,57 & $-12,78$ & 259,35 & 120,78 & 174,27 & 174,50 & 32,76 & 687,58 & 76,95 & 36,54 & 17,18 & 197,48 & 140,41 & 144,25 & 167,70 \\
\hline Bufo spinosus & 30TXM94 & 100,00 & 125,42 & 103,15 & 37,16 & 5845,85 & 277,79 & 5,00 & 272,79 & 146,96 & 109,87 & 201,35 & 52,13 & 434,80 & 56,04 & 21,21 & 24,10 & 136,59 & 88,95 & 91,20 & 89,39 \\
\hline \begin{tabular}{|l} 
Bufo spinosus \\
\end{tabular} & 30TXM98 & 100,00 & 103,57 & 100,42 & 37,97 & 5556,27 & 248,27 & $-11,52$ & 259,79 & 122,65 & 175,53 & 175,85 & 34,14 & 625,63 & 72,82 & 33,18 & 18,16 & $\begin{array}{l}183,75 \\
\end{array}$ & \begin{tabular}{|l|}
131,05 \\
50
\end{tabular} & $\begin{array}{r}133,33 \\
\end{array}$ & 144,31 \\
\hline Bufo spinosus & $30 T \times N O 0$ & 100,00 & 127,58 & 104,76 & 38,30 & 5801,83 & 278,61 & 9,32 & 269,29 & 70,78 & 202,65 & 202,65 & 54,66 & 733,37 & 85,78 & 35,25 & 22,26 & 226,05 & 128,43 & 128,43 & 212,22 \\
\hline Bufo spinosus & 30TXN01 & 100,00 & 122,08 & 104,38 & 38,45 & 5749,16 & 272,88 & 5,07 & 267,82 & 58,33 & 196,59 & 196,59 & 49,94 & 823,10 & 98,48 & 39,67 & 22,73 & 259,36 & 142,68 & 142,68 & 244,35 \\
\hline Bufo spinosus & $30 \mathrm{TXN02}$ & 100,00 & 118,55 & 103,34 & 38,71 & 5664,61 & 267,93 & 3,58 & 264,35 & 56,29 & 192,16 & 192,16 & 47,55 & 908,59 & 110,43 & 43,78 & 23,08 & 15 & 56,75 & 156,75 & 274,93 \\
\hline Bufo spinosus & 30TXNO3 & 100,00 & 117,28 & 101,84 & 38,87 & 5563,0 & 264,31 & $\begin{array}{l}4,46 \\
4,4\end{array}$ & 259,85 & 56,19 & 189,71 & 189,71 & 47,87 & 987,76 & \begin{tabular}{|l|l|}
121,64 \\
\end{tabular} & $\begin{array}{l}45,10 \\
47,40\end{array}$ & 23,51 & 321,10 & 170,42 & 170,42 & 303,38 \\
\hline \begin{tabular}{|l} 
Bufo spinosus \\
\end{tabular} & 30TXN04 & 100,00 & 120,11 & 99,69 & 38,96 & 5424,70 & 263,16 & 9,95 & 253,21 & 60,57 & 190,76 & 190,76 & 52,43 & 1054,55 & 130,95 & 50,27 & 23,93 & 346,91 & 182,97 & 182,97 & 327,25 \\
\hline \begin{tabular}{|l} 
Bufo spinosus \\
\end{tabular} & 30TXN05 & 100,00 & 110,26 & 97,76 & 39,07 & 5256,90 & 249,72 & 3,59 & $\begin{array}{l}246,12 \\
24,12\end{array}$ & 53,32 & 179,04 & 179,04 & 45,21 & 1130,85 & 136,25 & 56,18 & 21,96 & 365,42 & 203,32 & 203,32 & 344,20 \\
\hline Bufo spinosus & 30 TXN06 & 100,00 & 106,18 & 95,55 & 39,43 & 5116,10 & 241,79 & 2,54 & 239,25 & 50,97 & 173,27 & 173,27 & 43,10 & 1195,82 & 142,30 & 60,52 & 21,15 & 384,30 & 219,61 & 219,61 & 361,55 \\
\hline Bufo spinosus & 30TXN07 & 100,00 & 120,29 & 91,28 & 39,95 & 4846,52 & 246,87 & 20,70 & 226,18 & 68,22 & 181,79 & 183,66 & 60,27 & 1249,93 & 149 & 62,11 & 21,78 & 06,52 & 230,56 & 234,53 & 379,90 \\
\hline \begin{tabular}{|l} 
Bufo spinosus \\
\end{tabular} & $\begin{array}{l}30 \text { TXN08 } \\
3\end{array}$ & 100,00 & 12 & $\begin{array}{l}1,1,20 \\
87,62\end{array}$ & | & $\begin{array}{l}404,52,20 \\
4626,20\end{array}$ & 246, & 31,30 & \begin{tabular}{|l|}
215,33 \\
215
\end{tabular} & 79,84 & 185,25 & 187,69 & 69,99 & 1304,00 & 156,08 & 64,90 & 21,99 & 425,17 & 241,37 & 251,01 & 395,35 \\
\hline Bufo spinosus & 30TXN09 & 67,00 & 131,10 & 84,45 & 40,21 & 4476,51 & 244,47 & 37,44 & 207,04 & 90,90 & 186,80 & 189,40 & 75,49 & \begin{tabular}{|l|}
1344,08 \\
\end{tabular} & 160,62 & 67,51 & 22,10 & 438,57 & 250,79 & 265,82 & 405,86 \\
\hline Bufo spinosus & 30TXN10 & 100,00 & 123,99 & 105,02 & 38,19 & 5829,79 & 275,63 & 5,13 & 270,50 & 65,01 & $\mid 199,39$ & $\mid 199,39$ & 50,54 & 757,65 & 89,75 & 36,32 & 22.51 & $234,27 \mid$ & $\mid 132.08$ & $\mid 132.08$ & 221,01 \\
\hline Bufo spinosus & 30 XN11 & 100,00 & 112,57 & 104,39 & 38,63 & 5739,69 & 263,64 & $-3,90$ & 267,55 & 49,56 & 187,27 & 187,27 & 40,99 & 859,66 & 101,79 & 42,53 & 2017 & 267,27 & 151,36 & 151,36 & 252,99 \\
\hline Bufo spinosus & $30 T \times N$ & 100,00 & 104,16 & 102,64 & 38,87 & 5612,40 & 252,62 & $-9,53$ & 262,15 & 43,29 & 177,51 & 177 & 34,44 & 941,64 & 110,28 & 47,85 & 20,74 & 291,98 & 169,21 & 169,21 & 27 \\
\hline \begin{tabular}{|l} 
Bufo spinosus \\
\end{tabular} & \begin{tabular}{|c|}
$30 T X N 13$ \\
30
\end{tabular} & $\begin{array}{l}100,00 \\
100\end{array}$ & $\begin{array}{l}104,10 \\
118,26\end{array}$ & $\begin{array}{l}102,04 \\
102,80\end{array}$ & $\begin{array}{l}30,01 \\
38,63\end{array}$ & $\begin{array}{l}501,440 \\
5631,79\end{array}$ & $26,02,64$ & $\begin{array}{l}-3,50 \\
3,42 \\
\end{array}$ & \begin{tabular}{|l|}
263,22 \\
263,
\end{tabular} & 56,39 & 191,36 & 191,36 & 47,70 & 996,28 & 125,80 & 47,05 & 24,63 & 327,85 & $\begin{array}{l}169,48 \\
\end{array}$ & $\begin{array}{l}169,48 \\
\end{array}$ & 310,93 \\
\hline Bufo spinosus & 30TXN14 & 100,00 & 114,75 & 100,62 & 38,90 & 5484,35 & 259,12 & 3,13 & 255,99 & 54,69 & $\mid 186,16$ & $\mid$\begin{tabular}{|l|l|}
186,16 \\
\end{tabular} & 46,05 & 1064,60 & $\mid$\begin{tabular}{|l|l|}
132,53 \\
\end{tabular} & 51,37 & 23,62 & 348,62 & $\mid 185,86$ & $\mid 185,86$ & 329,79 \\
\hline Bufo spinosus & 30TXN15 & 100,00 & 107,71 & 98.34 & 39,02 & 5316.13 & 247.88 & -0.46 & 248.34 & 50,04 & $\mid 177,17$ & $\mid 177,17$ & 41.58 & 1130.84 & 136.92 & 56.58 & 21.81 & 364,65 & 204.42 & 204.42 & 344,08 \\
\hline Bufo spinosus & 30TXN16 & 100,00 & 94,84 & 95,87 & 39,18 & 5175,51 & 231,62 & $-9,67$ & 241,29 & 39,67 & 162 & 162 & 31, & 1194,21 & 139,45 & 62,56 & 19 & 376,12 & 224,05 & 224,05 & 354,54 \\
\hline Bufo spinosus & 30 XN17 & 100,00 & 121,06 & 92,23 & 39,79 & 4938,64 & 248,44 & 18,70 & 229,73 & 67,68 & 183,71 & 185,35 & 59,33 & 1233,22 & 149,93 & 61,36 & 22,18 & 402,18 & 228,79 & 233,11 & 376,19 \\
\hline
\end{tabular}




\begin{tabular}{|c|c|c|c|c|c|c|c|c|c|c|c|c|c|c|c|c|c|c|c|c|c|}
\hline TAXON & UTM & $\mathrm{km} 2$ & B101 & B102 & $\mathrm{BIO3}$ & B104 & BIO5 & B106 & B107 & B108 & B109 & B1010 & BIO11 & B1012 & B1013 & BIO14 & BIO15 & BIO16 & BIO17 & B1018 & B1019 \\
\hline Bufo spinosus & 30TXN18 & 100,00 & 117,03 & 90,82 & 39,96 & 4835,37 & 241,98 & 16,72 & 225,26 & 65,70 & 178,11 & 180,21 & 56,93 & 1297,17 & 156,49 & 65,53 & 21,61 & 421,85 & 243,14 & 248,53 & 394,30 \\
\hline Bufo spinosus & 30TXN19 & 26,00 & 129,97 & 85,70 & 39,96 & 4614,73 & 244,82 & 32,49 & 212,33 & 96,22 & 187,60 & 189,94 & 71,90 & 1314,87 & 159,18 & $\begin{array}{l}66,88 \\
\end{array}$ & 22,29 & 431,17 & 249,34 & 264,29 & 396,94 \\
\hline Bufo spinosus & $30 T X N 20$ & 100,00 & 116,12 & 104,93 & 38,45 & 5801,88 & 267,64 & $-1,72$ & 269,35 & 55,99 & 191,37 & 191,37 & 43,40 & 782,81 & 91,30 & 38,45 & 21,42 & 238,41 & 138,98 & 138,98 & 225,49 \\
\hline Bufo spinosus & $30 T X N 21$ & 100,00 & 110,77 & 103,97 & 38,69 & 5720,06 & 260,75 & $-5,38$ & 266,14 & 48,12 & 185,19 & 185,19 & 39,23 & 858,42 & 100,73 & 42,72 & 21,16 & 264,27 & 153,29 & 153,29 & 250,21 \\
\hline Bufo spinosus & $30 T X N 22$ & 100,00 & $\begin{array}{ll}103,37 \\
\end{array}$ & 102,39 & 38,82 & 5608,17 & 251,24 & $-10,44$ & 261,68 & 42,50 & \begin{tabular}{ll|}
176,68 \\
\end{tabular} & $\begin{array}{ll}176,68 \\
\end{array}$ & 33,57 & 936,79 & 109,38 & \begin{tabular}{|l|l|}
47,68 \\
\end{tabular} & 20,38 & 288,82 & 169,79 & 169,79 & 273,40 \\
\hline Bufo spinosus & $30 \mathrm{TXN} 23$ & 100,00 & 111,31 & 102,05 & 38,93 & 5571,81 & 257,65 & $-2,50$ & 260,15 & 50,36 & 183,84 & 183,84 & 41,60 & 988,25 & 120,37 & 48,46 & 22,30 & 315,84 & 175,14 & 175,14 & 299,01 \\
\hline Bufo spinosus & 30 TXN24 & 100,00 & 105,82 & 100,25 & \begin{tabular}{|l|l|}
38,97 \\
\end{tabular} & 5446,53 & 249,11 & $-5,28$ & 254,39 & 46,76 & 176,99 & 176,99 & 37,91 & \begin{tabular}{|l|l|}
1056,73 \\
\end{tabular} & 127,07 & 53,08 & 21,29 & 336,13 & 191,33 & 191,33 & 317,75 \\
\hline \begin{tabular}{|l} 
Bufo spinosus \\
\end{tabular} & 30 TXN25 & 100,00 & 100,82 & 98,30 & 39,01 & 5322,00 & 240,78 & $\begin{array}{l}-7,48 \\
-1,40 \\
\end{array}$ & 248,25 & 43,32 & 170,44 & 170,44 & 34,87 & 1122,83 & 133,32 & 57,64 & 20,37 & 355,39 & 207,64 & 207,64 & 335,49 \\
\hline Bufo spinosus & 30 TXN26 & 89,00 & 93,17 & 96,25 & 39,11 & 5206,27 & 230,03 & $-12,54$ & 242,57 & 37,57 & 161,61 & 161,63 & 28,95 & 1181,31 & 137,49 & \begin{tabular}{|c|}
62,37 \\
\end{tabular} & 19,12 & 369,64 & 223,78 & 223,78 & 348,52 \\
\hline \begin{tabular}{|l|} 
Bufo spinosus \\
\end{tabular} & 30TXN27 & 72,00 & 109,27 & 94,73 & 39,63 & 5078,57 & 241,06 & 4,33 & 236,72 & 54,34 & \begin{tabular}{|l|l|}
174,58 \\
\end{tabular} & \begin{tabular}{|l|l|}
175,53 \\
\end{tabular} & 45,96 & $\mid 1221,24$ & $\mid 147,16$ & \begin{tabular}{|c|c|}
62,18 \\
\end{tabular} & 21,02 & 393,30 & 230,13 & 231,38 & 369,47 \\
\hline Bufo spinosus & $30 \mathrm{TXN28}$ & 100,00 & 112,90 & 92,41 & 39,88 & 4942,30 & 239,95 & 9,99 & 229,95 & 59,69 & 175,67 & 177,35 & 51,08 & 1269,48 & 153,18 & 64,76 & 21,08 & 410,29 & 240,76 & 245,22 & 384,35 \\
\hline Bufo spinosus & 30 TXN29 & 28,00 & 124,35 & 88,39 & 39,99 & 4757,15 & 243,02 & 23,58 & 219,44 & 85,54 & 184,21 & 186,09 & 64,29 & 1294,07 & 157,29 & 66,15 & 21,94 & 422,26 & 247,30 & 260,13 & 391,01 \\
\hline \begin{tabular}{|l} 
Bufo spinosus \\
\end{tabular} & 30 TXN30 & 100,00 & 115,90 & 104,45 & 38,38 & 5773,08 & 266,18 & $-2,04$ & 268,22 & 67,10 & 190,80 & 190,80 & 43,46 & 772,37 & 88,94 & 38,00 & 20,84 & 232,83 & 139,04 & 139,04 & 219,86 \\
\hline Bufo spinosus & 30 TXN31 & 100,00 & 120,59 & 103,87 & 38,52 & 5721,66 & 268,99 & 2,92 & 266,06 & 65,57 & 194,55 & 194,55 & 48,45 & 814,16 & 96,60 & 39,15 & 21,72 & 252,33 & 145,09 & 145,09 & 238,28 \\
\hline Bufo spinosus & 30 TXN32 & 100,00 & 113,49 & 102,85 & 38,92 & 5636,46 & 260,48 & $-2,03$ & 262,51 & 51,78 & 186,71 & 186,71 & 42,65 & 896,38 & 106,61 & 44,13 & 21,28 & 279,60 & 161,46 & 161,46 & 264,25 \\
\hline Bufo spinosus & 30TXN33 & 100,00 & $\begin{array}{lll}113,11 \\
\end{array}$ & 101,81 & 38,94 & 5557,36 & 257,84 & $-1,08$ & 258,92 & 52,09 & $\mid 185,17$ & $\mid$\begin{tabular}{|l}
185,17 \\
\end{tabular} & \begin{tabular}{|l|l|}
43,17 \\
\end{tabular} & \begin{tabular}{|c|c|}
960,76 \\
\end{tabular} & \begin{tabular}{|l|l|}
115,81 \\
\end{tabular} & $\mid 47,24$ & 21,58 & 303,97 & 173,33 & 173,33 & 287,33 \\
\hline Bufo spinosus & 30 TXN34 & 100,00 & 102,45 & 99,88 & 39,00 & 5425,73 & 244,40 & $-8,52$ & 252,92 & 43,64 & 173,20 & 173,20 & 34,78 & 1043,23 & 122,97 & 53,41 & 20,09 & 326,28 & 193,20 & 193,20 & 308,08 \\
\hline Bufo spinosus & 30TXN35 & 100,00 & 91,78 & 97,76 & 38,99 & 5311,18 & 231,03 & $-16,31$ & 247,34 & 35,01 & 161,50 & 161,50 & 26,25 & 1113,44 & 128,04 & 59,14 & 18,53 & 343,19 & 211,70 & 211,70 & 323,82 \\
\hline Bufo spinosus & 30 TXN36 & 81,00 & 90,19 & 96,37 & 39,05 & 5227,71 & 226,97 & $-16,30$ & 243,27 & 34,44 & 158,80 & 158,81 & 25,69 & 1166,10 & 134,19 & 62,39 & 18,37 & 360,71 & 223,80 & 223,80 & 340,07 \\
\hline Bufo spinosus & 30TXN37 & & & & & & & & & & & & & & & & & & & & \\
\hline Bufo spinosus & 30TXN38 & 10,00 & 120,55 & 92,86 & \begin{tabular}{|l|}
39,97 \\
\end{tabular} & 4970,73 & 245,95 & 15,35 & 230,60 & 73,98 & 183,47 & 184,90 & 57,65 & 1211,15 & 147,21 & 61,21 & 21,39 & 391,34 & 230,73 & 239,12 & 366,19 \\
\hline Bufo spinosus & 30TXN39 & & & & & & & & & & & & & & & & & & & & \\
\hline Bufo spinosus & 30TXN40 & 100,00 & 108,21 & 103,44 & \begin{tabular}{|l|l|}
38,47 \\
\end{tabular} & 5707,76 & 256,78 & $-8,56$ & 265,34 & 71,64 & 182,34 & 182,34 & 36,77 & 781,12 & 86,62 & \begin{tabular}{|l|l|}
39,74 \\
\end{tabular} & 19,31 & 229,63 & 145,28 & 146,48 & 215,80 \\
\hline Bufo spinosus & 30 TXN41 & 100,00 & 119,31 & 103,47 & 38,94 & 5672,28 & 266,17 & 1,97 & 264,20 & 81,03 & 192,59 & 192,59 & 47,78 & 796,64 & 92,31 & 38,74 & 20,62 & 243,00 & 145,39 & 145,78 & 228,46 \\
\hline Bufo spinosus & $30 \mathrm{TXN} 42$ & 100,00 & 107,87 & 101,97 & 38,86 & 5576,71 & 252,92 & $-6,84$ & 259,76 & 48,18 & 180,30 & 180,30 & 37,93 & 892,28 & 102,53 & 45,19 & 19,58 & 271,23 & 165,82 & 165,88 & 255,72 \\
\hline Bufo spinosus & 30TXN43 & 100,00 & 105,35 & 101,11 & 39,00 & 5500,27 & 248,66 & $-7,84$ & 256,50 & 45,35 & 176,90 & 176,90 & 36,38 & 954,67 & 110,75 & 48,62 & 19,55 & 293,38 & 178,09 & 178,09 & 276,66 \\
\hline Bufo spinosus & 30TXN44 & 100,00 & 88,07 & 98,23 & 38,93 & 5375,46 & 228,34 & $-21,44$ & 249,78 & 30,71 & 158,55 & 158,55 & 21,58 & \begin{tabular}{|l|}
1053,74 \\
\end{tabular} & 117,87 & 56,95 & 17,45 & 316,51 & 203,15 & 203,15 & 298,49 \\
\hline Bufo spinosus & 30 TXN45 & 100,00 & 85,92 & 97,14 & \begin{tabular}{|l|l|}
38,97 \\
\end{tabular} & 5304,76 & 224,21 & $-21,97$ & 246,18 & 29,51 & 155,51 & 155,51 & 20,47 & 1105,56 & 123,97 & 60,19 & 17,23 & 333,86 & 214,72 & 214,72 & 314,68 \\
\hline Bufo spinosus & 30 TXN46 & 75,00 & 86,27 & 96,27 & 39,05 & 5234,26 & 222,50 & $-20,60$ & 243,10 & 30,64 & 154,88 & 154,91 & 21,63 & 1150,02 & 129,98 & 62,58 & 17,33 & 350,31 & 224,32 & 224,35 & 329,99 \\
\hline Bufo spinosus & 30 TXN47 & & & & & & & & & & & & & & & & & & & & \\
\hline Bufo spinosus & 30 TXN50 & 100,00 & 104,72 & 102,40 & 38,53 & 5650,83 & 251,56 & $-11,08$ & 262,63 & 76,05 & 178,11 & 178,11 & 34,09 & 777,70 & 84,18 & 40,27 & 18,30 & 225,41 & 148,41 & 150,99 & 209,58 \\
\hline Bufo spinosus & 30TXN51 & 100,00 & 108,88 & 102,45 & 38,88 & 5601,82 & 254,21 & $\begin{array}{l}1,00 \\
-6,87 \\
\end{array}$ & \begin{tabular}{|l|}
261,08 \\
\end{tabular} & 73,79 & \begin{tabular}{|l|l|}
181,44 \\
\end{tabular} & 181,44 & 38,63 & 810,39 & $\begin{array}{l}4,10 \\
89,62\end{array}$ & 41,22 & 18,58 & 239,75 & 153,41 & \begin{tabular}{|l|l|}
154,05 \\
\end{tabular} & 224,22 \\
\hline Bufo spinosus & 30 TXN52 & 100,00 & 94,12 & 100,09 & 38,71 & 5497,32 & 237,15 & $-18,39$ & 255,54 & 40,05 & 165,93 & 165,93 & 25,84 & 916,59 & 99,80 & \begin{tabular}{|l|l|l|}
49,03 \\
\end{tabular} & 17,30 & 267,96 & $\begin{array}{ll}177,47 \\
\end{array}$ & 177,65 & 251,91 \\
\hline Bufo spinosus & 30 TXN53 & 100,00 & 99,49 & 100,32 & 38,99 & 5455,79 & 241,25 & $-12,97$ & 254,22 & 40,27 & 170,50 & 170,50 & 31,29 & 945,43 & 105,78 & 49,59 & 17,88 & 282,90 & 181,64 & 181,64 & 266,11 \\
\hline Bufo spinosus & 30 TXN54 & 100,00 & 91,52 & 98,72 & 38,99 & 5372,49 & 231,15 & $-18,93$ & 250,08 & 33,87 & 161,74 & 161,74 & 24,79 & 1018,51 & 113,14 & 54,83 & 17,13 & 304,08 & 198,37 & 198,37 & 286,13 \\
\hline Bufo spinosus & 30 TXN55 & 100,00 & 83,60 & 96,82 & 38,95 & 5296,25 & 221,06 & $-24,57$ & 245,62 & 27,39 & 153,08 & 153,08 & 18,14 & 1091,06 & 120,27 & 60,17 & 16,46 & 324,97 & 215,11 & 215,11 & 305,78 \\
\hline \begin{tabular}{|l} 
Bufo spinosus \\
\end{tabular} & 30 TXN56 & 37,00 & 79,52 & 95,46 & 38,96 & 5231,69 & 215,01 & $-27,01$ & 242,02 & 24,21 & 148,19 & 148,19 & 14,99 & 1149,13 & 126,64 & 64,19 & 16,15 & 343,11 & 228,41 & 228,41 & 322,84 \\
\hline Bufo spinosus & $30 T \times N 60$ & 100,00 & 96,16 & 100,88 & 38,29 & 5581,02 & 241,26 & $-18,22$ & 259,48 & 85,60 & 168,81 & 168,82 & 26,77 & 795,91 & 85,27 & 42,70 & 17,05 & 226,86 & 156,68 & 159,86 & 207,69 \\
\hline Bufo spinosus & 30TXN61 & 100,00 & 103,46 & 101,43 & 38,79 & 5547,82 & 247,30 & $-11,17$ & 258,47 & 72,57 & 175,39 & 175,41 & 34,01 & 809,72 & 86,63 & 42,30 & 17,41 & 234,79 & 157,77 & 159,76 & 217,41 \\
\hline Bufo spinosus & 30 TXN62 & 100,00 & 102,55 & 100,90 & 38,94 & 5489,47 & 244,74 & $-11,35$ & 256,10 & 66,79 & 173,81 & 173,82 & 33,73 & 857,75 & 92,71 & 44,94 & 17,23 & 250,88 & 167,34 & 168,63 & 233,86 \\
\hline \begin{tabular}{|l} 
Bufo spinosus \\
\end{tabular} & 30TXN63 & 100,00 & 94,94 & 99,57 & 38,5 & 5416,45 & 235,38 & $-17,14$ & 252,52 & 42,68 & 165,40 & 165,40 & 27,29 & 934,84 & 101,29 & 50,20 & 16,66 & 273,25 & 183,96 & 184,22 & 256,22 \\
\hline \begin{tabular}{|l} 
Bufo spinosus \\
\end{tabular} & 30 TXN64 & 100,00 & 83,53 & 97,27 & 38,80 & 5341,30 & 221,56 & $-25,87$ & 247,43 & 26,82 & 153,35 & 153,35 & 17,30 & 1027,09 & 110,20 & 57,1 & 15,75 & 298,96 & 204,99 & \begin{tabular}{|l|}
205,07 \\
\end{tabular} & 280,60 \\
\hline Bufo spinosus & $30 \mathrm{TXN} 65$ & 92,00 & 75,72 & 95,36 & 38,75 & 5277,87 & 211,78 & $-31,52$ & 243,30 & 20,16 & 145,08 & 145,08 & 10,64 & 1101,25 & 117,80 & 62,58 & 15,22 & 320,67 & 221,68 & 221,68 & 301,24 \\
\hline Bufo spinosus & 30 TXN66 & 6,00 & 87,25 & 96,60 & 39,35 & 5232,89 & 221,79 & $-20,99$ & 242,79 & 31,36 & 155,43 & 155,50 & 22,10 & 1101,02 & 121,46 & 60,74 & 16,26 & 328,58 & 220,57 & 220,71 & 308,65 \\
\hline Bufo spinosus & 30 TXN70 & 100,00 & 93,34 & 99,94 & 38,1 & 5532,25 & 236,91 & $-20,37$ & 257,28 & 102,67 & 165,38 & 165,39 & 24,60 & 791,18 & 85,56 & 43,09 & 16,42 & 24,03 & 59,32 & 63,03 & 201,26 \\
\hline Bufo spinosus & 30TXN71 & 100,00 & 106,47 & 101,52 & 38,6 & 5516,39 & 249,32 & $-8,36$ & 257,68 & 73,80 & $\begin{array}{l}177,73 \\
\end{array}$ & 177,85 & 37,28 & 768,70 & $\begin{array}{l}80,66 \\
80\end{array}$ & 40,01 & 16,93 & 221,67 & 152,48 & 155,23 & 201,94 \\
\hline \begin{tabular}{|l} 
Bufo spinosus \\
\end{tabular} & 30TXN72 & 100,00 & 99,76 & 100,32 & 38,92 & 5452,55 & 240,74 & $-13,67$ & 254,42 & 68,84 & 170,46 & 170,51 & 31,48 & 845,69 & 88,74 & 45,10 & 16,26 & 243,56 & 168,79 & 170,71 & 224,78 \\
\hline Bufo spinosus & 30TXN73 & 100,00 & 85,05 & 97,78 & 38,79 & 5374,32 & 223,78 & $-25,52$ & 249,30 & 41,20 & 155,22 & 155,22 & 18,37 & 957,36 & 99,77 & 53,41 & 15,22 & 272,27 & 193,53 & $\mid 194.56$ & 254,34 \\
\hline Bufo spinosus & 30 TXN74 & 100,00 & 67,09 & 93,69 & 38,16 & 5304,14 & 202,82 & $-39,59$ & 242,41 & 15,92 & 136,99 & 136,99 & 2,03 & 1089,61 & 112,52 & 63,81 & 14,30 & 307,78 & 223,36 & 223,49 & 288,38 \\
\hline Bufo spinosus & 30 TXN75 & 83,00 & 65,57 & 93,03 & 38,28 & 5259,30 & 199,91 & $-40,09$ & 240,00 & 10,91 & 134,93 & 134,93 & 1,10 & 1131,74 & 117,47 & 66,48 & 14,20 & 322,24 & 232,28 & 232,28 & 302,19 \\
\hline \begin{tabular}{|l} 
Bufo spinosus \\
\end{tabular} & $\begin{array}{l}30 T X N 80 \\
30\end{array}$ & $\begin{array}{l}0,00,00 \\
100,0\end{array}$ & $\begin{array}{l}5,71 \\
95,74\end{array}$ & $\begin{array}{l}59,77 \\
99,7\end{array}$ & 38 & 5501 & 238,35 & $\begin{array}{l}-48,12 \\
-18,12\end{array}$ & \begin{tabular}{|l|}
256,46 \\
25,4
\end{tabular} & $\mid 111,46$ & 167,05 & 167,16 & 27,15 & 759,75 & 82,89 & 41,34 & 16,27 & 215,49 & 155,52 & 160,27 & 188,89 \\
\hline Bufo spinosus & 30TXN81 & 100,00 & 100,32 & 100,29 & 38,84 & 5463,93 & 241,77 & $-13,60$ & 255,36 & 77,98 & 171,12 & 171,20 & 31,85 & 777,44 & 82,15 & 41,64 & 16,02 & 220,54 & 158,28 & 161,55 & 198,11 \\
\hline Bufo spinosus & 30 TXN82 & 100,00 & 89,62 & 98,52 & 38,72 & 5404,83 & 229,01 & $-22,31$ & 251,32 & 68,85 & 159,91 & 159,98 & 22,28 & 875,33 & 91,00 & 48,59 & 15,18 & 246,25 & 179,37 & 182,28 & 225,52 \\
\hline Bufo spinosus & 30 TXN83 & 100,00 & 75,68 & 95,40 & 38,34 & 5342,54 & 212,55 & $-33,13$ & 245,68 & 55,34 & 145,72 & 145,72 & 9,74 & 993,85 & 102,26 & 57,44 & 14,39 & 278,46 & 205,26 & 206,54 & 257,5 \\
\hline Bufo spinosus & 30 TXN84 & 100,00 & 50,41 & 89,26 & 37,13 & 5272,72 & 183,66 & $-53,41$ & 237,07 & 35,53 & 120,55 & 120 & $-13,35$ & 1171,25 & 119,66 & 71,5 & 13,39 & 325,22 & 244,61 & 244,93 & 302 \\
\hline \begin{tabular}{|l} 
Bufo spinosus \\
\end{tabular} & 30 XN85 & 53,00 & 42,17 & 86,92 & 36,71 & 5231,16 & 173,46 & \begin{tabular}{|c|c|}
$-60,17$ \\
\end{tabular} & 233,62 & 9,99 & 112,02 & 112,02 & $-20,73$ & 1248,27 & 126,53 & $\begin{array}{l}77,25 \\
7\end{array}$ & 13,13 & 346,39 & 261,15 & 261,15 & 324,94 \\
\hline Bufo spinosus & $30 \mathrm{TXN} 90$ & 100,00 & 93,84 & 99,07 & 38,37 & 5463,30 & 235,24 & $-19,39$ & 254,62 & 111,83 & 164,67 & 164,93 & 25,66 & 755,96 & 83,18 & 41,68 & 15,97 & 215,56 & 158,02 & 162,15 & 183,27 \\
\hline Bufo spinosus & 30TXN91 & 100,00 & 94.57 & 99,19 & 38,74 & 5424,62 & 234,78 & -18.37 & 253,15 & 100,32 & 164.88 & 165.09 & 26,64 & 790,45 & 84,67 & 43.56 & 15.38 & 222,04 & 164,76 & 169,02 & 195,90 \\
\hline Bufo spinosus & 30TXN92 & 100,00 & 80,76 & 96,43 & 38,33 & 5376,12 & 218,68 & $-29,57$ & 248,24 & 91,78 & 150,89 & 150,93 & 14,14 & 911,97 & 95,94 & 52,47 & 14,39 & 254,73 & 190,97 & 194,87 & 229,06 \\
\hline Bufo spinosus & 30TXN94 & 50,00 & 49,03 & 88,31 & 36,92 & 5266,55 & 181,26 & $-54,64$ & 235,91 & 53,19 & 119,07 & 119,07 & $-14,66$ & 1173,98 & 120,41 & 72,41 & 13,14 & 326,20 & 247,68 & 248,08 & 300,06 \\
\hline
\end{tabular}




\begin{tabular}{|c|c|c|c|c|c|c|c|c|c|c|c|c|c|c|c|c|c|c|c|c|c|}
\hline TAXON & UTM & $\mathrm{km} 2$ & B101 & B102 & $\mathrm{BIO3}$ & B104 & B105 & B106 & B107 & B108 & B109 & BIO10 & BIO11 & BIO12 & B1013 & BIO14 & BIO15 & B1016 & B1017 & BIO18 & B1019 \\
\hline Bufo spinosus & 30TYК03 & 100,00 & 121,97 & 93,96 & 36,01 & 5896,13 & 264,49 & 7,97 & 256,52 & 131,42 & 70,05 & 201,18 & 52,27 & 500,34 & 61,01 & 23,30 & 28,63 & 161,39 & 94,81 & 108,03 & 95,10 \\
\hline Bufo spinosus & 30TYK04 & 100,00 & 123,28 & 93,37 & 36,00 & 5899,78 & 264,98 & 9,00 & 255,98 & 132,69 & 57,10 & 202,31 & 53,42 & 485,57 & 60,07 & 22,98 & 29,46 & 156,54 & 90,19 & 105,87 & 90,23 \\
\hline Bufo spinosus & 30TYK05 & 100,00 & 100,61 & 94,21 & 35,98 & \begin{tabular}{|l|l|}
6014,84 \\
\end{tabular} & 246,59 & $-13,39$ & 259,98 & 116,11 & 30,21 & 181,51 & 30,21 & 575,43 & 72,34 & 30,21 & 26,24 & 183,80 & 108,59 & 126,76 & 108,59 \\
\hline Bufo spinosus & 30TYK06 & 100,00 & 82,51 & 94,53 & 35,76 & 6042,75 & 230,55 & $-31,23$ & 261,78 & 97,21 & 12,21 & 164,17 & 12,21 & 668,16 & 83,47 & 36,83 & 23,72 & 213,93 & 130,97 & 147,32 & 130,97 \\
\hline Bufo spinosus & 30TYK07 & 100,00 & 68,33 & 94,32 & 35,40 & 6042,30 & 217,98 & $-44,36$ & 262,34 & 82,14 & $-1,25$ & 150,22 & $-1,25$ & 753,29 & 92,79 & 42,78 & 21,72 & 239,41 & 152,74 & 163,50 & 152,74 \\
\hline Bufo spinosus & 30TYK08 & 100,00 & 75,69 & 93,84 & 35,46 & 6025,71 & 223,34 & $-37,81$ & 261,16 & 90,59 & 5,51 & 156,97 & 5,51 & 697,84 & 87,99 & 39,66 & 23,44 & 224,99 & 137,49 & 155,86 & 137,49 \\
\hline Bufo spinosus & 30TYK09 & 100,00 & 86,99 & 93,51 & 35,51 & 6011,49 & 232,11 & $-27,88$ & 259,99 & 103,30 & 16,13 & 167,61 & 16,13 & 620,20 & 80,92 & 34,51 & 26,07 & 204,10 & 116,77 & 143,94 & 116,77 \\
\hline Bufo spinosus & 30TYK13 & 100,00 & 133,52 & 91,90 & 36,12 & 5720,51 & 270,72 & 20,66 & 250,06 & 141,93 & 190,10 & 210,40 & 65,70 & 480,60 & 60,84 & 20,39 & 30,59 & 163,49 & 89,91 & 102,94 & 94,05 \\
\hline Bufo spinosus & 30TYK14 & 100,00 & 123,12 & 92,46 & 36,00 & 5828,78 & 263,21 & 9,57 & 253,64 & 131,23 & 74,62 & 201,51 & 54,37 & 506,39 & 61,50 & 23,19 & 28,91 & 164,30 & 96,57 & 110,36 & 96,83 \\
\hline Bufo spinosus & 30TYK15 & 100,00 & 107,86 & 92,99 & 35,94 & 5930,00 & 251,03 & $-5,59$ & 256,62 & 121,00 & 39,34 & 187,61 & 38,37 & 561,84 & 69,31 & 27,93 & 26,82 & 177,01 & 107,34 & 122,82 & 107,34 \\
\hline Bufo spinosus & 30TYK16 & 100,00 & 89,12 & 93,38 & 35,75 & 5989,60 & 234,93 & $-23,77$ & 258,70 & 103,82 & 19,38 & 169,94 & 19,38 & 647,59 & 80,16 & 34,49 & 24,11 & 204,66 & 126,70 & 141,65 & 126,70 \\
\hline Bufo spinosus & 30TYK17 & 100,00 & 79,80 & 93,19 & 35,45 & 5998,27 & 226,32 & $-32,95$ & 259,27 & 94,19 & 10,12 & 160,93 & 10,12 & 696,13 & 86,12 & 38,19 & 23,01 & 220,55 & 138,31 & 152,19 & 138,31 \\
\hline \begin{tabular}{|l} 
Bufo spinosus \\
\end{tabular} & 30TYK18 & 100,00 & 82,81 & 92,92 & 35,28 & 5984,08 & 228,21 & $-30,54$ & 258,75 & 97,72 & 12,92 & 163,42 & 12,92 & 670,47 & 84,31 & 37,02 & 23,94 & 214,57 & \begin{tabular}{|l|}
131,01 \\
\end{tabular} & 148,71 & 131,01 \\
\hline Bufo spinosus & 30TYK19 & 100,00 & 84,04 & 92,84 & 35,36 & 5973,25 & 228,81 & $-29,69$ & 258,50 & 99,50 & 14,15 & 164,42 & 14,15 & 658,21 & 83,72 & 36,58 & 24,62 & 212,06 & 127,53 & 148,67 & 127,53 \\
\hline Bufo spinosus & 30TYK23 & 100,00 & 144,56 & 89,52 & 36,22 & 5531,22 & 276,12 & 33,26 & 242,86 & 153,56 & 217,08 & 218,90 & 78,57 & 466,90 & 64,05 & 17,85 & 33,37 & 167,93 & 80,47 & 98,66 & 94,84 \\
\hline Bufo spinosus & 30TYK24 & 100,00 & 128,92 & 91,07 & 36,01 & 5715,12 & 265,81 & 16,21 & 249,60 & 137,03 & 174,89 & 205,76 & 61,53 & 508,72 & 62,90 & 21,82 & 29,73 & 170,49 & 96,40 & 109,53 & 100,30 \\
\hline Bufo spinosus & 30TYK25 & 100,00 & 107,68 & 92,12 & 35,88 & 5869,38 & 249,48 & $-5,07$ & 254,55 & 118,68 & 48,43 & 186,86 & 39,12 & 584,87 & 70,64 & 28,20 & 26,23 & 183,42 & 114,63 & 126,74 & 114,80 \\
\hline Bufo spinosus & 30TYK26 & 100,00 & 100,24 & 92,26 & 35,75 & 5912,12 & 243,11 & $-12,43$ & 255,55 & 114,83 & 31,38 & 179,99 & 31,38 & 609,25 & 74,69 & 30,53 & 25,43 & 189,27 & 118,88 & 132,87 & 118,88 \\
\hline Bufo spinosus & 30TYK27 & 100,00 & 94,48 & 92,16 & 35,46 & 5924,91 & 237,75 & $-18,30$ & 256,05 & 108,97 & 25,47 & 174,32 & 25,47 & 632,28 & 78,20 & 32,69 & 24,78 & 198,42 & 123,46 & 138,70 & 123,46 \\
\hline Bufo spinosus & 30TYK28 & 100,00 & 91,93 & 92,03 & 35,40 & 5929,76 & 235,15 & $-21,11$ & 256,26 & 107,05 & 22,75 & 171,87 & 22,75 & 639,74 & 79,87 & 33,69 & 24,73 & 202,01 & 124,61 & $\begin{array}{ll}141,07 \\
\end{array}$ & 124,61 \\
\hline Bufo spinosus & 30TYK29 & 100,00 & 106,46 & 92,37 & 35,61 & 5904,93 & 247,78 & $-7,97$ & 255,75 & 123,05 & 37,10 & 185,51 & 37,10 & 561,23 & 72,01 & 28,34 & 27,61 & 178,99 & 105,47 & 124,78 & 105,47 \\
\hline \begin{tabular}{|l} 
Bufo spinosus \\
\end{tabular} & $\begin{array}{l}\text { 30TYK33 } \\
\end{array}$ & 100,00 & 157,83 & 86,51 & 36,28 & 5315,71 & 282,90 & 48,26 & 234,65 & 167,63 & 226,74 & 229,22 & 93,87 & 445,78 & 66,24 & 15,17 & 37,56 & 170,38 & 69,38 & 93,29 & 93,96 \\
\hline Bufo spinosus & 30TYK34 & 100,00 & 142,37 & 88,91 & 36,01 & 5524,07 & 273,70 & 30,99 & 242,71 & 150,77 & 214,97 & 216,80 & 76,91 & 486,08 & 65,09 & 18,55 & 32,92 & 173,11 & 84,74 & 103,44 & 99,05 \\
\hline Bufo spinosus & 30TYK36 & 100,00 & 120,48 & 90,97 & 35,82 & 5759,56 & 258,38 & 7,41 & 250,97 & 128,45 & 105,86 & 197,99 & 52,83 & 546,76 & 66,65 & 24,28 & 28,53 & 176,65 & 105,75 & 118,76 & 107,49 \\
\hline Bufo spinosus & 30TYK37 & 100,00 & 114,97 & 91,26 & 35,73 & 5801,89 & 254,09 & 1,70 & 252,38 & 124,68 & 54,33 & 193,03 & 46,97 & 560,99 & 68,52 & 25,89 & 27,74 & 177,86 & 109,10 & 122,68 & 109,30 \\
\hline Bufo spinosus & 30TYK38 & 100,00 & 105,05 & 91,56 & 35,64 & 5850,46 & 245,73 & $-7,82$ & 253,55 & 119,73 & 36,66 & 183,72 & 36,64 & 594,96 & 73,63 & 28,94 & 26,24 & 184,55 & 115,64 & 129,85 & 115,64 \\
\hline Bufo spinosus & $\begin{array}{l}\text { 30TYK39 } \\
\end{array}$ & 100,00 & 113,69 & 92,18 & 35,97 & 5842,47 & 253,56 & $-0,02$ & 254,55 & 125,77 & 46,14 & \begin{tabular}{|l|}
191,87 \\
\end{tabular} & 44,99 & 552,52 & $\begin{array}{l}69,58 \\
69,5\end{array}$ & 26,05 & 28,10 & \begin{tabular}{|l|}
173,67 \\
\end{tabular} & 105,55 & 120,14 & 105,55 \\
\hline Bufo spinosus & 30TYK43 & 100,00 & 160,71 & 85,01 & 36,01 & 5244,10 & 283,73 & 51,85 & 231,88 & 170,75 & 228,53 & 231,13 & 97,66 & 453,06 & 67,77 & 14,71 & 38,72 & 175,56 & 68,20 & 94,68 & 97,40 \\
\hline Bufo spinosus & 30TYK47 & 100,00 & 121,71 & 90,79 & 35,97 & 5728,22 & 258,75 & 8,35 & 250,40 & 128,71 & 137,52 & 198,86 & 54,79 & 557,17 & 67,35 & 23,85 & 28,58 & 180,73 & 108,31 & 120,55 & 110,92 \\
\hline Bufo spinosus & 30TYK48 & 100,00 & 108,78 & 91,05 & 35,78 & 5802,24 & 248,13 & $-3,89$ & 252,02 & 117,16 & 45,72 & 186,98 & 41,16 & 602,38 & 72,99 & 27,83 & 26,31 & 186,16 & 119,52 & 130,85 & 119,58 \\
\hline Bufo spinosus & 30TYK49 & 100,00 & 112,81 & 91,67 & 35,87 & 5799,99 & 252,14 & $-1,10$ & 253,24 & 120,85 & 46,74 & 190,63 & 44,90 & 578,67 & 71,28 & 26,39 & 27,33 & 179,76 & 113,38 & 125,70 & 113,40 \\
\hline \begin{tabular}{|l} 
Bufo spinosus \\
\end{tabular} & 30TYK53 & 60,00 & 165,35 & 83,90 & 36,00 & 5208,10 & 286,17 & 56,26 & 229,91 & 175,53 & 232,55 & 235,01 & 102,42 & 451,74 & 68,84 & 13,92 & 40,39 & 178,36 & 65,44 & 94,38 & 98,85 \\
\hline Bufo spinosus & 30TYK54 & 60,00 & 153,71 & 86,33 & 36,02 & 5332,60 & 279,54 & 43,44 & 236,10 & 162,32 & 223,34 & 225,66 & 90,49 & 486,86 & 69,44 & 16,11 & 36,36 & 182,61 & 77,08 & $\begin{array}{ll}102,47 \\
\end{array}$ & 103,82 \\
\hline Bufo spinosus & 30TYK59 & 40,00 & 112,86 & 91,12 & 35,82 & 5774,23 & 251,69 & $-0,48$ & 252,17 & 119,95 & 59,28 & 190,71 & 45,66 & 595,51 & 72,06 & 26,45 & 26,98 & 185,86 & 118,42 & 128,97 & 118,77 \\
\hline Bufo spinosus & 30TYLOO & 100,00 & 100,68 & 93,65 & 35,72 & 5991,09 & 243,55 & $-15,63$ & 259,18 & 118,49 & 29,31 & 180,54 & 29,31 & 540,35 & 72,88 & 28,51 & 29,16 & 180,99 & 97,22 & 127,50 & 97,22 \\
\hline Bufo spinosus & 30TYL01 & 100,00 & 95,05 & 93,76 & 35,76 & 5986,23 & 238,47 & $-21,30$ & 259,77 & 112,71 & 23,67 & 174,78 & 23,67 & 564,13 & 76,12 & 30,37 & 28,37 & 189,44 & 102,78 & 134,63 & 102,78 \\
\hline \begin{tabular}{|l} 
Bufo spinosus \\
\end{tabular} & $\begin{array}{l}\text { 30TYL03 } \\
\end{array}$ & 100,00 & 120,38 & 96,21 & 36,00 & 5988,00 & 264,03 & 0,13 & 263,90 & 140,84 & 47,60 & 199,38 & 47,60 & 442,49 & 62,33 & 22,27 & 32,47 & 150,72 & 77,01 & 102,17 & 77,01 \\
\hline Bufo spinosus & 30TYL04 & 100,00 & 128,06 & 97,86 & 36,00 & 6000,80 & 273,61 & 6,32 & 267,29 & 149,40 & 54,93 & 206,99 & 54,88 & 414,35 & 58,48 & 20,44 & 32,87 & 140,48 & 72,46 & 93,32 & 72,46 \\
\hline Bufo spinosus & 30TYL05 & 100,00 & 135,72 & 99,61 & 36,04 & 6025,13 & 283,62 & 12,59 & 271,03 & 157,66 & 61,97 & 214,66 & 61,74 & 388,46 & 54,65 & 18,39 & 32,93 & 130,68 & 68,50 & 85,03 & 68,50 \\
\hline Bufo spinosus & 30TYL07 & 100,00 & 144,08 & 102,25 & 36,37 & 6057,12 & 296,00 & 19,68 & 276,32 & 167,03 & 69,18 & 223,23 & 69,18 & 362,62 & 50,07 & 16,34 & 31,95 & 120,05 & 65,58 & 76,32 & 65,58 \\
\hline Bufo spinosus & 30TYL08 & 100,00 & 147,00 & 103,29 & 36,7 & 6075,08 & 300,51 & 22,25 & 278,27 & 170,25 & 71,66 & 226,18 & 71,66 & 355,77 & 48,37 & 15,92 & 31,24 & 116,53 & 65,40 & 73,91 & 65,40 \\
\hline Bufo spinosus & 30TYLO9 & 100,00 & 148,51 & 104,01 & 36,99 & 6077,60 & 303,15 & 23,56 & 279,59 & 171,91 & 72,67 & 227,53 & 72,67 & 353,00 & 47,32 & 15,67 & 30,28 & 114,69 & 65,39 & 72,80 & 65,39 \\
\hline Bufo spinosus & 30TYL10 & 100,00 & 102,54 & 93,13 & 35,82 & 5950,25 & 244,84 & $-13,08$ & 257,92 & 120,08 & 32,05 & 181,99 & 32,05 & 552,67 & 72,99 & 29,41 & 28,32 & 181,29 & 101,44 & 126,59 & 101,44 \\
\hline Bufo spinosus & 30TYL11 & 100,00 & 106,53 & 93,56 & 35,70 & 5941,94 & 248,77 & $-10,01$ & 258,77 & 124,49 & 35,74 & 185,55 & 35,74 & 528,69 & 70,90 & 27,69 & 29,27 & 174,84 & 95,94 & 121,62 & 95,94 \\
\hline Bufo spinosus & 30TYL12 & 100,00 & 114,35 & 94,74 & 35,98 & 5948,82 & 256,97 & $-3,66$ & 260,62 & 133,53 & 42,95 & 193,27 & 42,95 & 488,99 & 66,7 & 25,01 & 30,69 & 162,80 & 87,40 & 111,36 & 87,40 \\
\hline Bufo spinosus & 30TYL13 & 100,00 & 120,96 & 96,19 & 36,00 & 5955,15 & 264,72 & $\begin{array}{ll}3,18 \\
1,18\end{array}$ & 263,54 & \begin{tabular}{|l|l|}
140,97 \\
\end{tabular} & $\begin{array}{l}49,06 \\
49,0\end{array}$ & $\begin{array}{l}199,65 \\
\end{array}$ & \begin{tabular}{|l|l|}
49,06 \\
42,0
\end{tabular} & | 458,44 & $60,1,2$ & 22,79 & 31,53 & $\begin{array}{l}153,08 \\
15,00\end{array}$ & $\begin{array}{l}1,1,40 \\
81,40\end{array}$ & 103,08 & 81,40 \\
\hline \begin{tabular}{|l} 
Bufo spinosus \\
\end{tabular} & 30TYL14 & 100,00 & 127,50 & 97,79 & 36,00 & 5971,89 & 273,09 & 6,11 & 266,98 & 148,28 & 55,17 & 206,20 & 55,06 & 431,76 & 59,89 & 20,81 & 32,13 & 143,95 & 76,56 & 95,36 & 76,56 \\
\hline Bufo spinosus & 30TYL15 & 100,00 & 137,35 & 99,78 & 36,18 & 5990,26 & 285,10 & 14,33 & 270,77 & 159,05 & 65,33 & 215,87 & 64,22 & 398,05 & 55,03 & $\mid 18,12$ & 32.69 & 131,48 & 70,89 & 84.97 & 70,89 \\
\hline Bufo spinosus & 30TYL16 & 100,00 & 146,32 & 101,65 & 36,68 & 6010,72 & 296,19 & 22,16 & 274,02 & 168,23 & 78,09 & 224,96 & 72,52 & 370,77 & 50,68 & 16,07 & 32,89 & 120,83 & 66,73 & 76,48 & 66,73 \\
\hline Bufo spinosus & 30TYL17 & 100,00 & 148,10 & 102,69 & 36,80 & 6032,76 & 299,68 & $\begin{array}{ll}23,34 \\
\end{array}$ & 276,34 & 168,94 & 75,64 & 226,92 & 73,75 & 363,62 & 49,38 & 15,61 & 32,39 & 118,29 & 65,78 & 74,51 & 65,78 \\
\hline Bufo spinosus & $30 \mathrm{TYL}$ & 100,00 & $\begin{array}{l}14,10 \\
110,80\end{array}$ & $\begin{array}{r}02,05 \\
92,95 \\
\end{array}$ & 35 & 5895,90 & \begin{tabular}{|l|}
251,75 \\
\end{tabular} & $\mid$\begin{tabular}{|l|l|}
$-4,60$ \\
\end{tabular} & \begin{tabular}{|l|}
256,35 \\
\end{tabular} & \begin{tabular}{|l|}
$128,26,26$ \\
\end{tabular} & $\begin{array}{l}40,94 \\
40,93\end{array}$ & $\begin{array}{l}20,32,4 \\
189,42 \\
\end{array}$ & 40,93 & \begin{tabular}{|l|}
$535,13<2$ \\
\end{tabular} & $\begin{array}{l}35,70 \\
69,78 \\
\end{array}$ & $\begin{array}{l}\mid 0,010 \\
26,77\end{array}$ & $\begin{array}{l}28,731 \\
28,71\end{array}$ & $\begin{array}{l}172,13 \\
172,1 \\
\end{array}$ & $\begin{array}{l}59,11 \\
99,11\end{array}$ & 118,94 & $\begin{array}{l}99,11 \\
99,\end{array}$ \\
\hline Bufo spinosus & 30TYL21 & 100,00 & 123,69 & 94,50 & 36,00 & 5880,54 & 264,86 & 5,84 & 259,02 & 140,88 & 55,55 & 201,77 & 53,63 & 480,97 & 63,68 & 22,64 & 30,88 & 154,82 & 87,78 & 104,53 & 87,79 \\
\hline Bufo spinosus & 30TYL22 & 100,00 & 121,20 & 95,16 & 36,00 & 5905,73 & 263,52 & 2,64 & 260,88 & 139,69 & 51.91 & 199,39 & 50,53 & 484,13 & $64,79 \mid$ & 23,21 & 30,65 & $\mid 157,38$ & 88.16 & 105,77 & 88,17 \\
\hline Bufo spinosus & 30TYL23 & 100,00 & 129,53 & 96,95 & 36,01 & 5917,39 & 273,45 & 9,05 & 264,40 & 149,44 & 60,86 & 207,72 & 58,37 & 449,66 & 60,72 & 20,57 & 31,81 & 146,05 & 81,33 & 96,20 & 81,34 \\
\hline Bufo spinosus & 30TYL24 & 100,00 & 134,76 & 98,59 & 36,18 & 5938,88 & 280,62 & 12,99 & 267,63 & 155,68 & 67,53 & 213,03 & 63,11 & 427,03 & 57,93 & 19,04 & 32,34 & 138,71 & 77,01 & 90,07 & 77 \\
\hline \begin{tabular}{|l} 
Bufo spinosus \\
\end{tabular} & 30TYL25 & 100,00 & 142,00 & 100,52 & 36,74 & 5961,88 & 289,83 & 18,81 & 271,02 & $\begin{array}{ll}161,28 \\
\end{array}$ & 75,85 & 220,33 & 69,60 & 400,61 & 54,32 & 17,21 & 32,90 & 129,56 & 72,24 & 82,60 & 72,25 \\
\hline Bufo spinosus & 30TYL26 & 100,00 & 147,16 & 102,06 & 36,92 & 5984,36 & 296,88 & 22,70 & 274,18 & 160,48 & 82,08 & 225,53 & 73,97 & 381,64 & 51,51 & 16,00 & 33,10 & 123,42 & 68,83 & 77,54 & 68,86 \\
\hline Bufo spinosus & 30TYL27 & 100,00 & 150,22 & 103,28 & $37.00 \mid$ & 6004.46 & 301.46 & 25,15 & 276,31 & 159.53 & 83.54 & 228,75 & 76,40 & 369.90 & 49.51 & 15,42 & 32.65 & 119.92 & 67,10 & 74.68 & 67.15 \\
\hline Bufo spinosus & 30TYL28 & 100,00 & 141,27 & 103,36 & 37,00 & 6026,76 & 293,91 & 16,48 & 277,43 & 163,92 & 67,06 & 220,09 & 66,99 & 387,27 & 52,42 & 17,14 & 31,11 & 125,88 & 70,01 & 80,77 & 70,01 \\
\hline \begin{tabular}{|l} 
Bufo spinosus \\
\end{tabular} & 30TYL30 & 100,00 & 118,61 & 93,06 & 35,99 & 5838,37 & 258,66 & 2,61 & 256,04 & 131,25 & 51,76 & 196,54 & 49,72 & 527,06 & 67,34 & 24,41 & 29,16 & 166,63 & 99,49 & 115,73 & 99,57 \\
\hline
\end{tabular}




\begin{tabular}{|c|c|c|c|c|c|c|c|c|c|c|c|c|c|c|c|c|c|c|c|c|c|}
\hline TAXON & UTM & $\mathrm{km} 2$ & BIO1 & BIO2 & $B 103$ & BIO4 & B105 & B106 & B107 & B108 & B109 & B1010 & BIO11 & BIO12 & BIO13 & B1014 & BIO15 & B1016 & B1017 & B1018 & B1019 \\
\hline Bufo spinosus & 30TYL31 & 100,00 & 122,49 & 94,09 & 36,00 & 5848,88 & 263,37 & 5,04 & 258,33 & 136,73 & 55,75 & 200,25 & 53,10 & 507,43 & 65,71 & 23,12 & 29,93 & 161,32 & 94,97 & 109,91 & 95,10 \\
\hline Bufo spinosus & 30TYL32 & 100,00 & 133,59 & 96,09 & 36,10 & 5848,65 & 275,59 & 13,99 & 261,60 & 140,98 & 69,86 & 210,97 & 63,95 & $\begin{array}{l}464,46 \\
\end{array}$ & 60,79 & 19,82 & 31,84 & $\begin{array}{l}149,59 \\
\end{array}$ & 85,77 & $\begin{array}{l}97,49 \\
\end{array}$ & 86,31 \\
\hline Bufo spinosus & 30TYL33 & 100,00 & 136,96 & 97,60 & 36,23 & 5872,92 & 280,81 & 16,10 & 264,72 & 144,41 & 73,30 & 214,55 & 66,74 & 447,91 & 59,08 & 18,85 & 32,32 & $\begin{array}{l}144,72 \\
\end{array}$ & 82,19 & 92,25 & 82,85 \\
\hline Bufo spinosus & 30TYL34 & 100,00 & 142,34 & 99,50 & 36,76 & 5901,58 & 288,19 & 19,92 & 268,27 & 146,99 & 78,78 & 220,24 & 71,52 & \begin{tabular}{ll|}
423,89 \\
\end{tabular} & 56,32 & $\begin{array}{l}17,36 \\
\end{array}$ & 32,97 & 137,90 & 76,94 & 85,89 & 77,94 \\
\hline Bufo spinosus & 30TYL35 & 100,00 & 143,02 & 100,82 & 36,70 & 5940,71 & 290,94 & 19,49 & 271,45 & 150,37 & 78,90 & 221,16 & 71,21 & 414,94 & 55,39 & 17,11 & 32,87 & 134,25 & 75,32 & 83,91 & 75,83 \\
\hline Bufo spinosus & 30TYL36 & 100,00 & 149,20 & 102,61 & 36,94 & 5967,16 & 298,83 & 24,44 & 274,39 & 153,92 & 85,32 & 227,44 & 76,60 & 390,97 & 52,10 & $\mid 15,74$ & 33,37 & 128,10 & 70,41 & 78,03 & 71,10 \\
\hline Bufo spinosus & 30TYL37 & 100,00 & 151,31 & 103,91 & 37,00 & 5995,37 & 302,51 & 25,69 & 276,82 & 157,30 & 86,81 & 229,77 & 77,99 & 379,98 & 50,51 & 15,35 & 33,08 & 124,24 & 68,44 & 75,90 & 68,99 \\
\hline Bufo spinosus & 30TYL38 & 100,00 & 140,16 & 103,91 & 37,00 & 6023,04 & 292,97 & 15,12 & 277,85 & 162,99 & 66,52 & 219,07 & 66,27 & 402,41 & 54,10 & 17,74 & 31,13 & $\begin{array}{ll}129,98 \\
\end{array}$ & 72,69 & 83,93 & 72,69 \\
\hline Bufo spinosus & 30TYL40 & 100,00 & 109,39 & $\begin{array}{ll}91,87 \\
\end{array}$ & 35,70 & 5823,57 & 249,52 & $-4,65$ & 254,17 & 122,61 & 42,23 & $\begin{array}{l}187,43 \\
\end{array}$ & 41,16 & $\begin{array}{l}589,35 \\
\end{array}$ & 73,23 & 27,54 & 26,94 & $\begin{array}{ll}182,63 \\
\end{array}$ & 115,19 & 128,43 & 115,21 \\
\hline Bufo spinosus & 30TYL41 & 100,00 & 119,24 & 93,51 & 35,97 & 5819,53 & 259,90 & 2,94 & 256,97 & 129,11 & 54,79 & 196,99 & 50,72 & 543,12 & 68,61 & 24,24 & 28,79 & 170,06 & 104,42 & 117,63 & 104,67 \\
\hline Bufo spinosus & 30TYL42 & 100,00 & 123,81 & $\begin{array}{ll}94,93 \\
\end{array}$ & 36,01 & 5838,01 & 265,70 & 5,77 & 259,93 & $\begin{array}{l}134,76 \\
\end{array}$ & 59,92 & 201,50 & 54,81 & 520,60 & 66,62 & 22,74 & 29,64 & 163,75 & $\begin{array}{ll}99,13 \\
\end{array}$ & 111,31 & 99,43 \\
\hline Bufo spinosus & 30TYL43 & 100,00 & 133,19 & 97,27 & 36,27 & 5854,53 & 276,90 & 12,92 & 263,97 & 138,21 & 69,69 & 210,85 & 63,74 & \begin{tabular}{|l|l|}
481,13 \\
\end{tabular} & 62,31 & $\begin{array}{l}19,97 \\
\end{array}$ & 31,23 & 154,15 & 89,95 & 99,95 & 90,99 \\
\hline Bufo spinosus & 30TYL44 & 100,00 & 140,32 & 99,42 & 36,68 & 5888,21 & 286,16 & 18,08 & 268,09 & 143,57 & 76,69 & 218,13 & 70,13 & 450,49 & 58,86 & 18,01 & 32,39 & 146,43 & 82,97 & 90,82 & 84,47 \\
\hline Bufo spinosus & 30TYL45 & 100,00 & 145,58 & 101,43 & 36,95 & 5916,80 & 293,39 & 21,75 & 271,64 & 149,00 & 81,82 & 223,47 & 74,58 & 426,60 & 56,07 & 16,75 & 33,06 & 139,95 & 77,66 & 84,61 & 79,26 \\
\hline Bufo spinosus & 30TYL46 & 100,00 & 150,73 & 103,24 & 37,00 & $\begin{array}{l}5957,93 \\
\end{array}$ & 300,52 & 25,43 & 275,08 & 153,39 & 86,88 & 228,96 & 78,75 & 402,34 & 52,94 & $\begin{array}{l}15,59 \\
\end{array}$ & 33,55 & $\begin{array}{l}133,19 \\
\end{array}$ & 72,40 & 78,88 & 74,04 \\
\hline Bufo spinosus & 30TYL47 & 100,00 & 152,55 & 104,68 & 37,01 & 6001,37 & $\begin{array}{l}304,22 \\
\end{array}$ & 26,26 & 277,96 & 155,34 & 88,44 & 231,15 & 79,55 & 388,64 & 51,21 & 15,34 & 33,43 & 128,15 & 69,58 & 76,82 & 70,90 \\
\hline Bufo spinosus & 30TYL48 & 100,00 & 140,81 & $\begin{array}{l}104,68 \\
\end{array}$ & 37,00 & 6037,27 & 294,13 & 14,99 & 279,14 & \begin{tabular}{ll|}
162,67 \\
\end{tabular} & 69,21 & 219,93 & 66,72 & 414,60 & 55,17 & \begin{tabular}{ll|}
17,81 \\
\end{tabular} & 30,88 & $\begin{array}{l}133,07 \\
\end{array}$ & 75,60 & 85,93 & 75,63 \\
\hline Bufo spinosus & 30TYL50 & 39,00 & 110,93 & 91,70 & 35,70 & 5798,36 & 250,68 & $-2,77$ & 253,45 & 120,29 & 45,79 & $\mid 188,80$ & 43,29 & 598,38 & 73,23 & 27,07 & 26,75 & $\mid 184,88$ & 118,50 & $\mid$ & 118,63 \\
\hline Bufo spinosus & 30TYL51 & 30,00 & 120,18 & 93,35 & 36,00 & 5791,27 & 260,47 & 4,02 & 256,45 & 127,02 & 56,69 & 197,64 & 52,31 & $556,07]$ & 69,22 & 23,95 & 28,58 & 174,89 & 108,18 & 121,33 & 108,84 \\
\hline Bufo spinosus & 30TYL53 & 28,00 & 128,54 & $\begin{array}{ll}96,54 \\
\end{array}$ & 36,07 & 5848,34 & 271,93 & 9,02 & 262,90 & 132,63 & 65,00 & 206,22 & 59,39 & \begin{tabular}{|l|l|}
511,17 \\
\end{tabular} & 65,32 & 21,34 & 30,10 & 161,73 & $\begin{array}{ll}97,24 \\
\end{array}$ & $\begin{array}{l}106,76 \\
\end{array}$ & 98,34 \\
\hline Bufo spinosus & 30TYL54 & 20,00 & 136,03 & 98,91 & 36,57 & 5875,89 & 281,49 & 14,34 & 267,14 & 139,37 & 72,29 & 213,83 & 66,17 & $\begin{array}{l}478,94 \\
\end{array}$ & 61,80 & \begin{tabular}{ll|}
19,17 \\
\end{tabular} & 31,37 & $\begin{array}{l}153,89 \\
\end{array}$ & 89,77 & $\begin{array}{l}98,31 \\
\end{array}$ & 91,17 \\
\hline \begin{tabular}{|l|} 
Bufo spinosus \\
\end{tabular} & 30TYL55 & 20,00 & 147,33 & 101,73 & 37,00 & 5906,85 & 295,18 & 23,21 & 271,97 & $\begin{array}{l}149,97 \\
\end{array}$ & 83,45 & 225,12 & 76,67 & \begin{tabular}{|l|l|}
432,97 \\
\end{tabular} & 56,36 & 16,42 & 33,30 & $\begin{array}{l}143,39 \\
\end{array}$ & 78,88 & 85,85 & 81,06 \\
\hline Bufo spinosus & 30TYM02 & 100,00 & 119,04 & $\begin{array}{l}101,79 \\
\end{array}$ & 37,00 & 5880,27 & $\begin{array}{l}270,87 \\
\end{array}$ & $-1,21$ & $\begin{array}{l}272,07 \\
\end{array}$ & 140,31 & 45,86 & $\begin{array}{l}195,83 \\
\end{array}$ & 45,86 & \begin{tabular}{ll|l}
436,98 \\
\end{tabular} & 58,78 & 22,03 & 26,51 & 142,13 & 83,77 & 95,42 & 83,77 \\
\hline Bufo spinosus & 30TYM03 & 100,00 & 121,30 & 102,29 & 37,03 & 5829,62 & 272,96 & 1,40 & 271,56 & 142,63 & 48,45 & 197,35 & 48,45 & \begin{tabular}{|l|l|}
432,10 \\
\end{tabular} & 57,20 & 21,41 & 25,71 & 138,24 & 84,15 & 92,54 & 84,15 \\
\hline Bufo spinosus & 30TYM08 & 100,00 & 88,36 & $\begin{array}{l}97,26 \\
\end{array}$ & 37,60 & 5508,18 & 230,50 & $-24,23$ & 254,73 & 105,88 & 160,23 & 160,39 & 20,16 & 720,99 & 83,39 & 40,79 & 17,43 & 213,13 & 154,64 & 158,41 & 164,13 \\
\hline Bufo spinosus & 30TYM15 & 100,00 & 125,70 & 102,99 & 37,97 & 5700,40 & 274,90 & 5,97 & 268,92 & 147,01 & 53,81 & 199,82 & 53,81 & 433,63 & 55,17 & 20,96 & 24,46 & 133,81 & 85,59 & 90,75 & 85,59 \\
\hline Bufo spinosus & 30TYM16 & 100,00 & 120,28 & 102,10 & 38,00 & 5599,41 & 267,16 & 2,13 & 265,03 & 140,79 & 50,66 & \begin{tabular}{ll|}
193,06 \\
\end{tabular} & 49,74 & $\begin{array}{l}460,89 \\
\end{array}$ & 57,81 & 22,69 & 23,24 & 140,17 & 92,80 & 96,65 & 92,80 \\
\hline Bufo spinosus & 30TYM18 & 100,00 & 84,91 & $\begin{array}{ll}96,38 \\
\end{array}$ & 37,59 & 5494,60 & 226,17 & $-27,16$ & 253,33 & 102,28 & 141,59 & 156,87 & $\begin{array}{ll}17,03 \\
\end{array}$ & \begin{tabular}{|l|l|}
744,17 \\
\end{tabular} & 86,03 & 42,78 & 17,13 & 220,64 & 161,93 & \begin{tabular}{ll|l}
167,48 \\
\end{tabular} & 166,72 \\
\hline Bufo spinosus & 30TYM19 & 100,00 & 88,36 & $\begin{array}{l}97,19 \\
\end{array}$ & 37,89 & 5459,20 & 228,76 & $-23,99$ & 252,76 & $\begin{array}{l}105,96 \\
\end{array}$ & 159,32 & 159,69 & 20,57 & \begin{tabular}{|l|l|}
748,71 \\
\end{tabular} & 84,95 & \begin{tabular}{ll|}
42,66 \\
\end{tabular} & 16,45 & 218,88 & 162,66 & \begin{tabular}{ll|}
166,63 \\
\end{tabular} & 170,54 \\
\hline \begin{tabular}{|l|} 
Bufo spinosus \\
\end{tabular} & 30TYM23 & 100,00 & 133,82 & 104,75 & 37,54 & $\begin{array}{ll}5886,82 \\
\end{array}$ & 286,82 & $\begin{array}{ll}10,93 \\
\end{array}$ & 275,89 & 156,65 & 59,92 & 210,54 & 59,92 & $\begin{array}{l}404,49 \\
4\end{array}$ & 52,69 & 19,04 & 27,00 & $\begin{array}{ll}127,86 \\
\end{array}$ & 75,98 & 85,29 & 75,98 \\
\hline Bufo spinosus & 30TYM24 & 100,00 & 128,66 & 103,96 & 37,82 & 5790,78 & 279,75 & 7,34 & 272,41 & 150,75 & 55,90 & 204,04 & 55,90 & 422,33 & 54,45 & 20,46 & 25,78 & 132,25 & 80,26 & 89,67 & 80,26 \\
\hline Bufo spinosus & 30TYM25 & 100,00 & 120,68 & $\mid 102,38$ & 37,99 & 5658,50 & 268,98 & $\mid 1,79$ & 267,19 & 141,72 & 49,54 & 194,45 & 49,54 & \begin{tabular}{|l|l|}
446,03 \\
\end{tabular} & 57,28 & 22,05 & 24,90 & $\mid 138,37$ & 85,43 & 95,15 & 85,43 \\
\hline Bufo spinosus & 30TYM26 & 100,00 & 114,57 & 101,09 & 38,00 & 5542,32 & 260,48 & $-1,73$ & 262,21 & 134,72 & 45,07 & 186,83 & 45,07 & $\begin{array}{l}477,26 \\
\end{array}$ & 60,33 & 24,09 & 23,59 & 146,04 & \begin{tabular}{|l|l}
93,28 \\
\end{tabular} & 102,42 & 93,28 \\
\hline Bufo spinosus & 30TYM27 & 100,00 & 104,51 & $\begin{array}{ll}99,64 \\
\end{array}$ & 37,96 & 5510,83 & 248,36 & $\begin{array}{l}-10,49 \\
\end{array}$ & 258,85 & 123,77 & 35,49 & 176,45 & 35,49 & 568,04 & 69,02 & 30,34 & 20,63 & 171,32 & 117,18 & 125,31 & 117,18 \\
\hline Bufo spinosus & 30TYM28 & 100,00 & 80,47 & 94,96 & 37,23 & $\begin{array}{ll}5496,64 \\
\end{array}$ & 220,75 & $-30,73$ & 251,48 & 97,38 & 95,71 & 152,59 & 12,68 & \begin{tabular}{|l|l|}
787,18 \\
\end{tabular} & 90,38 & 46,20 & 16,86 & 233,47 & $\begin{array}{l}172,16 \\
\end{array}$ & $\begin{array}{l}178,97 \\
\end{array}$ & $\begin{array}{l}174,81 \\
\end{array}$ \\
\hline \begin{tabular}{|l|} 
Bufo spinosus \\
\end{tabular} & 30TYM30 & 100,00 & 133,48 & 104,51 & 37,00 & 6012,76 & 287,51 & 8,84 & 278,67 & 156,45 & 58,93 & 211,93 & 58,93 & $\begin{array}{l}413,99 \\
4\end{array}$ & 55,36 & 19,37 & 29,03 & 134,10 & 75,30 & 88,75 & 75,30 \\
\hline Bufo spinosus & 30TYM33 & 100,00 & 134,14 & $\begin{array}{l}105,67 \\
\end{array}$ & 37,61 & 5933,01 & 287,56 & 10,00 & 277,56 & 157,45 & 59,48 & 211,13 & 59,48 & 414,51 & 53,65 & $\begin{array}{ll}19,94 \\
\end{array}$ & 26,74 & 131,27 & 76,99 & 89,01 & 76,99 \\
\hline Bufo spinosus & 30TYM38 & 100,00 & 78,61 & $\begin{array}{ll}94,14 \\
\end{array}$ & 36,99 & 5512,26 & 218,56 & $-32,14$ & 250,70 & 95,54 & 56,50 & $\begin{array}{ll}151,07 \\
\end{array}$ & 10,81 & 816,36 & 93,06 & 48,68 & 16,69 & 242,03 & 1777,78 & 186,64 & 179,85 \\
\hline Bufo spinosus & 30TYM39 & 100,00 & 80,08 & 94,72 & 37,34 & 5482,13 & 219,26 & $-30,90$ & 250,15 & $\begin{array}{l}97,07 \\
\end{array}$ & 71,04 & 151,82 & 12,33 & 831,24 & 93,34 & 49,55 & 15,96 & 244,17 & 184,12 & 192,69 & 185,37 \\
\hline Bufo spinosus & 30TYM43 & 90,00 & 130,45 & 105,99 & 37,41 & 5970,19 & 284,57 & 5,68 & 278,89 & 153,76 & 55,27 & 207,92 & 55,27 & 439,32 & 56,62 & 21,78 & 26,46 & $\begin{array}{l}139,74 \\
\end{array}$ & 81,06 & 96,76 & 81,06 \\
\hline Bufo spinosus & 30TYM46 & 80,00 & 116,98 & 103,20 & 38,00 & $\begin{array}{ll}5734,44 \\
\end{array}$ & 265,45 & $-2,60$ & 268,05 & 138,54 & 44,49 & $\begin{array}{l}191,44 \\
\end{array}$ & \begin{tabular}{ll|}
44,49 \\
\end{tabular} & 520,43 & 63,95 & 27,64 & 22,29 & 160,19 & 101,33 & $\begin{array}{l}117,36 \\
\end{array}$ & 101,33 \\
\hline Bufo spinosus & 30TYM47 & 80,00 & 103,99 & 100,19 & 37,82 & 5630,26 & 248,97 & $-12,48$ & 261,45 & 123,89 & 33,43 & 177,30 & 33,43 & $\begin{array}{l}621,35 \\
\end{array}$ & 73,81 & 34,77 & 19,80 & $\begin{array}{ll}188,02 \\
\end{array}$ & 126,75 & $\begin{array}{l}143,15 \\
\end{array}$ & 126,75 \\
\hline Bufo spinosus & 30TYM48 & 72,00 & 85,12 & 95,56 & 37,28 & 5544,62 & 225,99 & $-27,19$ & 253,18 & 102,81 & 19,26 & $\begin{array}{l}157,72 \\
\end{array}$ & 16,49 & 784,91 & 89,55 & 46,55 & 17,06 & 233,23 & 169,40 & 83,31 & 169,44 \\
\hline Bufo spinosus & 30TYM49 & 70,00 & 81,19 & 94,76 & 37,22 & 5508,15 & 220,63 & $-30,19$ & 250,82 & 98,42 & 23,08 & 153,32 & 13,07 & 838,58 & 93,89 & 50,40 & 15,92 & 246,55 & 184,52 & \begin{tabular}{|l|l|}
197,08 \\
\end{tabular} & 184,86 \\
\hline Bufo spinosus & 30TYNOO & 100,00 & 89,01 & 97,77 & 38,10 & 5436,31 & 229,17 & $-23,37$ & 252,54 & 106,64 & 159,62 & 159,92 & 21,38 & \begin{tabular}{|l|l|}
777,07 \\
\end{tabular} & 85,95 & 43,85 & 15,60 & 223,04 & 165,59 & 170,13 & 184,36 \\
\hline Bufo spinosus & 30TYN01 & 100,00 & 87,26 & 97,46 & 38,44 & 5402,29 & 226,07 & $-24,44$ & 250,51 & 104,60 & 157,51 & 157,71 & 20,01 & 824,62 & 89,14 & 46,93 & 14,90 & 233,53 & 175,42 & 179,88 & 199,54 \\
\hline Bufo spinosus & 30TYN02 & 100,00 & 68,75 & $\begin{array}{ll}93,02 \\
\end{array}$ & 37,67 & 5353,69 & 204,51 & $-39,25$ & 243,76 & 84,01 & \begin{tabular}{|l|l|}
139,07 \\
\end{tabular} & \begin{tabular}{ll|}
139,08 \\
\end{tabular} & 2,90 & $\begin{array}{l}982,46 \\
\end{array}$ & $\begin{array}{l}104,07 \\
\end{array}$ & $\begin{array}{l}58,76 \\
\end{array}$ & 13,90 & 276,88 & 209,18 & 212,16 & 242,29 \\
\hline Bufo spinosus & 30TYNO3 & 99,00 & 36,88 & 84,36 & 35,64 & 5266,47 & 167,53 & $-65,62$ & 233,15 & 48,42 & 107,42 & 107,42 & $-25,95$ & 1224,93 & 127,53 & 77,30 & 13,04 & 70 & 600,60 & 60,76 & 307,40 \\
\hline Bufo spinosus & 30TYN04 & 24,00 & 37,92 & 84,46 & 35, & 5244,13 & 168,00 & $-64,05$ & 232,05 & 49,61 & 108,08 & 108,08 & $-24,88$ & 1240,59 & 127,92 & 78,29 & 12,91 & 345,81 & 264,09 & 264,09 & 313,63 \\
\hline Bufo spinosus & 30TYN11 & 100,00 & $\begin{array}{ll}88,63 \\
\end{array}$ & $\begin{array}{ll}97,46 \\
\end{array}$ & 38,54 & 5397,75 & 226,94 & $-23,45$ & 250,39 & 106,24 & $\begin{array}{l}158,62 \\
\end{array}$ & $\begin{array}{l}158,93 \\
\end{array}$ & 21,25 & 810,72 & 88,09 & 46,50 & 14,91 & 230,73 & 175,15 & $\begin{array}{l}179,47 \\
\end{array}$ & 192,09 \\
\hline Bufo spinosus & 30TYN13 & 100,00 & 47,94 & 86,82 & 36,42 & 5292,12 & $\mid \begin{array}{l}179,49 \\
\end{array}$ & $\mid-55,73$ & 235,22 & 60,84 & $\mid 118,25$ & $\mid 118,25$ & $-16,06$ & $\mid 1150,14$ & 120,31 & 72,13 & 13,03 & 323,51 & 247,41 & 248,28 & 284,42 \\
\hline Bufo spinosus & 30TYN14 & 42,00 & 31,99 & 81,89 & 35,16 & 5231,31 & 160,33 & $-69,29$ & 229,62 & 42,90 & 102,19 & 102,19 & $-30,23$ & 1279,76 & 132,24 & 81,80 & 12,62 & 357,57 & 274,11 & 274,11 & 321,20 \\
\hline Bufo spinosus & 30TYN21 & 100,00 & 66,17 & 91,41 & 37,11 & 5384,10 & 201,54 & $-41,29$ & 242,83 & 81,39 & 137,00 & 137,03 & 0,17 & \begin{tabular}{|l|l|}
975,38 \\
\end{tabular} & $\begin{array}{l}105,45 \\
\end{array}$ & 59,65 & 14,11 & 279,86 & 212,92 & 216,61 & 230,55 \\
\hline Bufo spinosus & 30TYN22 & 100,00 & 50,84 & 86,83 & 36, & 5324,42 & 183,01 & $-53,86$ & 236,86 & 64,18 & 121,53 & 121,54 & $-13,60$ & $\begin{array}{l}1107,97 \\
\end{array}$ & $\begin{array}{l}117,49 \\
\end{array}$ & 69,53 & 13,33 & 314,53 & 240,49 & 242,34 & 268,20 \\
\hline Bufo spinosus & 30TYN23 & 100,00 & 31,49 & 80,98 & 34,68 & 5249,75 & 159,70 & $-70,20$ & 229,90 & 42,31 & 101,95 & 101,95 & $-30,77$ & $\begin{array}{l}1263,16 \\
\end{array}$ & \begin{tabular}{|l|l|}
131,94 \\
\end{tabular} & 81,12 & 12,65 & 355,52 & 272,37 & 273,15 & 312,09 \\
\hline Bufo spinosus & 30TYN24 & 45,00 & 12,23 & 75,01 & 33,06 & 5179,52 & $\begin{array}{l}136,49 \\
\end{array}$ & $\begin{array}{l}-86,88 \\
\end{array}$ & 223,37 & 20,55 & 82,48 & 82,48 & $-47,96$ & $\begin{array}{l}1414,76 \\
\end{array}$ & \begin{tabular}{|l|l|}
146,01 \\
\end{tabular} & 92,52 & 12,06 & $\begin{array}{l}395,43 \\
\end{array}$ & $\begin{array}{l}303,44 \\
\end{array}$ & 303,44 & 355,09 \\
\hline Bufo spinosus & 30TYN31 & 100,00 & 70,22 & 92,07 & 37,21 & $\begin{array}{l}5403,92 \\
\end{array}$ & 205,96 & $-38,19$ & 244,15 & 85,95 & 140,27 & 141,19 & 3,76 & 955,42 & \begin{tabular}{|l|l|}
103,40 \\
\end{tabular} & 58,53 & 14,31 & 274 & 210,92 & 216,40 & 222,30 \\
\hline Bufo spinosus & $30 \mathrm{TY}$ & 100,00 & 53 & 87 & 36,17 & 5 & 18 & $-51,45$ & & 67,34 & 12 & & $-11,23$ & 10 & \begin{tabular}{|l|l|}
116,32 \\
\end{tabular} & 69 & 13,39 & 311,69 & 239,92 & 243,42 & 261,42 \\
\hline Bufo spinosus & 30TYN33 & 73,00 & 24,93 & 78,12 & 33,91 & 5242,21 & 151,45 & $-75,58$ & 227,03 & 34,83 & 95,59 & 95,59 & $-36,74$ & 1312,23 & 137,11 & 85,36 & 12,44 & 369,86 & 284,55 & 284,55 & 322,51 \\
\hline Bufo spinosus & 30TYN41 & 60,00 & 68,64 & 91,25 & 36,95 & 5417,10 & 204,09 & $-39,29$ & 243,38 & 84,25 & 128,36 & 139,81 & 2,00 & 977,54 & 105,69 & 60,61 & 14,23 & 281,73 & 217,47 & 223,80 & 225,39 \\
\hline
\end{tabular}




\begin{tabular}{|c|c|c|c|c|c|c|c|c|c|c|c|c|c|c|c|c|c|c|c|c|c|}
\hline TAXON & UTM & $\mathrm{km2}$ & BIO1 & B102 & $\mathrm{BIO3}$ & B104 & B105 & B106 & B107 & B108 & B109 & BIO10 & BIO11 & BIO12 & BIO13 & BIO14 & BIO15 & BIO16 & BIO17 & BIO18 & BlO19 \\
\hline Bufo spinosus & 30TYN42 & 60,00 & 32,27 & 79,78 & 34,22 & 5289,33 & 160,47 & $-69,20$ & 229,68 & 43,05 & 103,33 & 103,33 & $-30,38$ & 1247,89 & 131,84 & 80,87 & 12,80 & 354,47 & 272,80 & 273,09 & 300,99 \\
\hline Bufo spinosus & 30TYN43 & 7,00 & 32,10 & 79,82 & 34,30 & 5264,38 & 159,53 & $-69,34$ & $\begin{array}{ll}228,88 \\
\end{array}$ & \begin{tabular}{ll|l}
42,99 \\
\end{tabular} & $\begin{array}{l}102,71 \\
\end{array}$ & 102,71 & $-30,40$ & 1270,33 & 132,88 & 82,49 & \begin{tabular}{ll|}
12,58 \\
\end{tabular} & 358,52 & 277,48 & 278,31 & 309,23 \\
\hline Bufo spinosus & 31SBC38 & 10,00 & 169,55 & 100,91 & 39,45 & 5288,55 & 304,82 & 52,45 & 252,36 & 147,91 & 237,36 & 240,55 & 105,09 & 551,09 & 83,00 & 8,00 & 49,18 & $\begin{array}{ll}234,82 \\
\end{array}$ & 51,82 & 85,27 & 162,64 \\
\hline Bufo spinosus & 31 SBC39 & 2,00 & 171,09 & 101,09 & 39,64 & 5302,18 & 305,91 & 53,73 & 252,18 & \begin{tabular}{|l|l|}
149,27 \\
\end{tabular} & \begin{tabular}{|l|l|}
239,09 \\
\end{tabular} & 242,18 & \begin{tabular}{ll|}
106,36 \\
\end{tabular} & 563,55 & 84,73 & 8,18 & 49,91 & 241,36 & 53,09 & 88,27 & 168,18 \\
\hline Bufo spinosus & $31 \mathrm{SBC} 48$ & & & & & & & & & & & & & & & & & & & & \\
\hline Bufo spinosus & $31 \mathrm{SBC} 49$ & 100,00 & 174,19 & 100,95 & 39,64 & 5282,85 & 308,67 & 56,60 & 252,07 & 152,84 & 241,82 & 244,76 & 109,48 & 573,36 & 87,54 & 7,64 & 51,85 & 250,76 & 51,53 & 88,73 & 176,00 \\
\hline Bufo spinosus & 31SBC59 & 73,00 & 178,30 & 99,98 & 39,52 & 5248,02 & 311,31 & $\begin{array}{ll}60,82 \\
\end{array}$ & 250,49 & \begin{tabular}{ll|}
157,60 \\
\end{tabular} & \begin{tabular}{|l|l|}
245,06 \\
\end{tabular} & 248,11 & 113,73 & \begin{tabular}{|l|l|}
578,22 \\
\end{tabular} & 91,41 & 6,83 & 54,31 & 258,70 & $\begin{array}{l}48,95 \\
\end{array}$ & 88,32 & 182,77 \\
\hline Bufo spinosus & 31 SBD30 & 7,00 & 181,00 & 101,00 & 40,00 & 5247,00 & 314,00 & 63,00 & 251,00 & \begin{tabular}{ll|}
159,00 \\
\end{tabular} & 248,00 & 251,00 & 116,00 & 557,00 & 86,00 & 7,00 & 54,00 & 248,00 & 48,00 & 87,00 & 173,00 \\
\hline Bufo spinosus & 31 SBD40 & 51,00 & 180,61 & 101,19 & \begin{tabular}{l|l}
39,92 \\
\end{tabular} & 5239,28 & 313,91 & 62,61 & 251,30 & 159,51 & 247,30 & 250,34 & \begin{tabular}{l|l|l|}
115,92 \\
\end{tabular} & \begin{tabular}{|l|l|}
572,82 \\
\end{tabular} & 90,86 & 7,14 & 54,59 & 256,71 & 48,90 & 88,87 & 180,37 \\
\hline Bufo spinosus & 31SBD50 & 7,00 & 178,80 & 100,60 & 39,73 & 5254,93 & 312,27 & 61,20 & \begin{tabular}{|l|l|}
251,07 \\
\end{tabular} & \begin{tabular}{ll|}
157,80 \\
\end{tabular} & 245,80 & 248,67 & \begin{tabular}{|l|l|}
114,13 \\
\end{tabular} & 586,67 & 93,67 & 7,00 & \begin{tabular}{|l|l|}
54,47 \\
\end{tabular} & 262,87 & \begin{tabular}{|l|l|}
50,07 \\
\end{tabular} & 90,33 & 186,27 \\
\hline Bufo spinosus & 31SBE42 & 6,00 & 171,25 & 83,00 & 36,00 & 5146,13 & 289,75 & 62,75 & 227,00 & \begin{tabular}{ll|}
181,88 \\
\end{tabular} & 237,38 & 240,13 & 108,75 & \begin{tabular}{|l|l|l|}
440,88 \\
\end{tabular} & 69,88 & 12,38 & 42,88 & 179,25 & \begin{tabular}{|l|l|l|}
60,13 \\
\end{tabular} & 91,38 & 98,25 \\
\hline Bufo spinosus & 31TBE43 & 42,00 & 168,69 & 83,80 & 36,00 & 5191,27 & 288,73 & 59,20 & 229,53 & \begin{tabular}{ll|}
178,49 \\
\end{tabular} & \begin{tabular}{|l|l|}
235,78 \\
\end{tabular} & 238,10 & $\begin{array}{ll}105,92 \\
\end{array}$ & \begin{tabular}{|l|l|l|}
450,08 \\
\end{tabular} & 69,67 & 13,00 & 41,61 & \begin{tabular}{|l|l|}
180,04 \\
\end{tabular} & 63,59 & 94,02 & 98,96 \\
\hline Bufo spinosus & 31TBE44 & 53,00 & 153,70 & 86,17 & 36,00 & 5322,66 & 279,40 & 43,45 & 235,94 & \begin{tabular}{ll|}
162,33 \\
\end{tabular} & \begin{tabular}{|l|l|}
223,42 \\
\end{tabular} & 225,59 & 90,90 & \begin{tabular}{|l|l|}
497,59 \\
\end{tabular} & 71,08 & 16,06 & 36,24 & \begin{tabular}{ll|}
186,84 \\
\end{tabular} & \begin{tabular}{|l|l|}
77,97 \\
\end{tabular} & \begin{tabular}{l|l}
104,35 \\
\end{tabular} & 107,06 \\
\hline Bufo spinosus & 31TBE46 & 50,00 & 137,70 & 89,03 & 36,00 & 5531,17 & 269,65 & 25,35 & 244,30 & 144,77 & 210,79 & 212,35 & 73,30 & 538,71 & 69,70 & 19,68 & 31,86 & $\begin{array}{l}187,75 \\
\end{array}$ & \begin{tabular}{l|l|l|}
94,87 \\
\end{tabular} & \begin{tabular}{ll|}
114,51 \\
\end{tabular} & 111,69 \\
\hline Bufo spinosus & 31TBE49 & 40,00 & 119,56 & 91,25 & 35,92 & 5731,29 & 257,22 & 5,59 & 251,63 & 125,81 & $\begin{array}{l}145,69 \\
14\end{array}$ & 196,73 & 52,88 & 581,34 & \begin{tabular}{ll|}
69,86 \\
\end{tabular} & 24,46 & 28,17 & 185,85 & \begin{tabular}{|l|l|}
113,97 \\
\end{tabular} & 125,36 & 116,83 \\
\hline Bufo spinosus & 31ТВЕ53 & & & & & & & & & & & & & & & & & & & & \\
\hline Bufo spinosus & 31TBE54 & 80,00 & 164,95 & 85,25 & 36,02 & 5226,37 & 287,26 & 54,61 & 232,65 & 173,45 & 233,00 & 235,31 & 103,00 & \begin{tabular}{l|l|}
473,82 \\
\end{tabular} & 71,71 & 13,63 & 39,91 & \begin{tabular}{|l|l|}
185,67 \\
\end{tabular} & \begin{tabular}{ll|}
69,66 \\
\end{tabular} & \begin{tabular}{l|l}
99,72 \\
\end{tabular} & 103,14 \\
\hline Bufo spinosus & 31TBE55 & 100,00 & 159,40 & 86,61 & 36,07 & 5294,17 & 284,20 & 48,04 & 236,16 & 166,89 & 228,64 & 230,73 & $\begin{array}{l}97,16 \\
\end{array}$ & \begin{tabular}{l|l|}
490,98 \\
\end{tabular} & 71,74 & 14,86 & 37,91 & 187,11 & 75,92 & $\begin{array}{ll}104,02 \\
\end{array}$ & 105,02 \\
\hline Bufo spinosus & 31TBE59 & 100,00 & 126,75 & 91,35 & 36,00 & 5672,10 & 263,16 & 12,45 & 250,71 & \begin{tabular}{ll|}
132,39 \\
\end{tabular} & \begin{tabular}{ll|}
198,51 \\
\end{tabular} & 203,30 & 61,11 & 573,99 & 69,69 & 22,45 & 29,45 & $\begin{array}{ll}188,32 \\
\end{array}$ & $\begin{array}{ll}108,58 \\
\end{array}$ & $\begin{array}{ll}122,88 \\
\end{array}$ & 117,01 \\
\hline Bufo spinosus & 31TBE65 & 61,00 & 169,18 & 86,34 & 36,36 & 5208,07 & 291,59 & 57,66 & 233,93 & \begin{tabular}{ll|}
176,24 \\
\end{tabular} & 237,21 & 239,49 & $\begin{array}{ll}108,25 \\
\end{array}$ & 475,79 & 73,4 & 12,71 & 41, & 188,24 & 69,84 & \begin{tabular}{ll|}
101,51 \\
\end{tabular} & 102,36 \\
\hline Bufo spinosus & 31TBE66 & 101,00 & 159,37 & 87,61 & 36,12 & 5304,93 & 285,12 & \begin{tabular}{ll|}
47,15 \\
\end{tabular} & 237,97 & 165,57 & \begin{tabular}{|l|l|}
229,12 \\
\end{tabular} & 231,24 & 98,10 & 510,59 & 74,43 & 14,72 & 37,96 & 193,39 & 79,62 & 108,70 & 108,96 \\
\hline Bufo spinosus & 31ТВE67 & 99,00 & 151,74 & 89,09 & 36,22 & 5395,38 & 280,51 & 38,61 & 241,91 & \begin{tabular}{l|l|l|l|}
157,12 \\
\end{tabular} & 223,05 & $\begin{array}{l}224,85 \\
\end{array}$ & 89,94 & 532,20 & 74,02 & 16,31 & 35,63 & $\begin{array}{l}194,55 \\
1\end{array}$ & 87,19 & $\begin{array}{l}113,19 \\
13\end{array}$ & 112,28 \\
\hline Bufo spinosus & 31TВE68 & 100,00 & 152,41 & 90,56 & 36,46 & 5433,54 & 282,66 & 37,89 & 244,77 & 156,81 & 224,30 & 225,90 & 90,42 & 528,33 & $\begin{array}{l}3,07 \\
\end{array}$ & 16,16 & 35,71 & \begin{tabular}{|l|l|}
191,94 \\
\end{tabular} & 87,81 & $\begin{array}{l}112,87 \\
\end{array}$ & 110,21 \\
\hline Bufo spinosus & 31тВE69 & 101,00 & 148,92 & 92,00 & 36,53 & 5502,09 & 281,72 & 33,28 & 248,44 & \begin{tabular}{ll|}
152,69 \\
\end{tabular} & 221,81 & 223,33 & \begin{tabular}{l|l|l}
86,35 \\
\end{tabular} & 535,42 & 71,96 & 16,89 & 34,60 & 190,29 & \begin{tabular}{l|l}
91,55 \\
\end{tabular} & \begin{tabular}{|l|l|}
114,38 \\
\end{tabular} & 110,82 \\
\hline Bufo spinosus & 31TBE76 & 47,00 & 160,62 & 87,60 & 36,32 & 5279,43 & 285,97 & 48,37 & 237,60 & \begin{tabular}{ll|}
166,48 \\
\end{tabular} & 230,10 & 232,30 & 100,23 & 522,03 & 76,90 & 14,48 & 38,40 & $\begin{array}{l}198,53 \\
\end{array}$ & 80,72 & \begin{tabular}{|l|}
111,20 \\
\end{tabular} & 112,05 \\
\hline Bufo spinosus & 31TBE77 & 99,00 & 164,72 & 88,66 & 36,73 & 5260,90 & 290,13 & 51,68 & 238,45 & 169,45 & 234,01 & 236,08 & 105,05 & 515,23 & 77,21 & 13,70 & 39,55 & 197,66 & 79,70 & 111,03 & 108,34 \\
\hline Bufo spinosus & 31ТВE87 & 15,00 & 170,22 & 89,00 & 37,00 & 5213,22 & 294,56 & 57,11 & 237,44 & 174,44 & 239,00 & 241,00 & \begin{tabular}{|l|}
111,67 \\
\end{tabular} & 509,44 & 79,00 & 12,89 & 41,22 & $\begin{array}{l}199,00 \\
\end{array}$ & \begin{tabular}{ll|}
77,56 \\
\end{tabular} & 111,11 & 96,56 \\
\hline Bufo spinosus & 31ТВE88 & 74,00 & 168,71 & 89,88 & 37,00 & 5244,22 & 294,39 & 54,71 & 239,69 & 172,01 & \begin{tabular}{ll|}
237,96 \\
\end{tabular} & 240,06 & 109,76 & 520,70 & 79,70 & 13,07 & \begin{tabular}{ll|l}
41,03 \\
\end{tabular} & 201,58 & 80,84 & \begin{tabular}{|l|l|}
114,04 \\
\end{tabular} & 97,06 \\
\hline Bufo spinosus & 31TBF40 & 33,00 & 108,69 & 91,31 & 35,60 & 5789,89 & 248,31 & $-4,47$ & 252,78 & \begin{tabular}{|l|l|}
118,67 \\
\end{tabular} & 43,71 & \begin{tabular}{|l|l|}
186,73 \\
\end{tabular} & 41,31 & \begin{tabular}{|c|}
616,76 \\
\end{tabular} & 74,91 & 27,93 & 26, & \begin{tabular}{|l|l|}
189,78 \\
\end{tabular} & 123,22 & \begin{tabular}{|l|}
133,71 \\
\end{tabular} & 123,42 \\
\hline Bufo spinosus & 31TBF41 & 36,00 & 122,72 & 93,48 & 36,00 & 5776,44 & 262,82 & 6,48 & 256,34 & 128,44 & 59,78 & 200,06 & 55,10 & 555,26 & 68,62 & 23,24 & 28,84 & 176,24 & 108,32 & 120,42 & 109,58 \\
\hline Bufo spinosus & 31TBF43 & 23,00 & 130,70 & 96,81 & 36,14 & 5835,59 & 274,08 & 10,97 & 263,11 & 134,95 & \begin{tabular}{|l|l|l|}
67,38 \\
\end{tabular} & 208,35 & \begin{tabular}{|c|}
61,97 \\
\end{tabular} & \begin{tabular}{ll|}
511,16 \\
\end{tabular} & \begin{tabular}{ll|}
64,92 \\
\end{tabular} & 20,78 & 30,35 & \begin{tabular}{|l|l|}
163,16 \\
\end{tabular} & \begin{tabular}{|l|}
97,27 \\
\end{tabular} & \begin{tabular}{|l|l|}
106,70 \\
\end{tabular} & 98,78 \\
\hline Bufo spinosus & 31TBF50 & 100,00 & 111,46 & 91,01 & 35,60 & 5761,27 & 250,48 & $-1,84$ & 252,32 & \begin{tabular}{|l|l|}
119,02 \\
\end{tabular} & 112,78 & 189,19 & 44,59 & 622,24 & 74,61 & 27,16 & 26,54 & \begin{tabular}{|l|l|}
193,39 \\
\end{tabular} & \begin{tabular}{|l|l|}
124,08 \\
\end{tabular} & \begin{tabular}{ll|}
133,86 \\
\end{tabular} & 126,29 \\
\hline Bufo spinosus & 31TBF51 & 100,00 & 112,71 & 92,11 & 35,72 & 5780,48 & 252,82 & $-1,59$ & 254,41 & 120,27 & 57,08 & $\begin{array}{l}190,44 \\
\end{array}$ & 45,43 & \begin{tabular}{|l|l|l|}
610,58 \\
\end{tabular} & 74,07 & 26,67 & 26,86 & \begin{tabular}{ll|}
188,91 \\
\end{tabular} & \begin{tabular}{ll|}
122,06 \\
\end{tabular} & \begin{tabular}{ll|}
131,81 \\
\end{tabular} & 122,89 \\
\hline Bufo spinosus & 31TBF59 & 100,00 & 143,56 & 107,13 & 37,00 & 6127,80 & 299,68 & 15,58 & 284,10 & \begin{tabular}{|l|l|}
167,14 \\
\end{tabular} & 74,32 & 223,41 & 67,83 & 414,24 & $\begin{array}{l}54,45 \\
\end{array}$ & 17,95 & 30,49 & \begin{tabular}{ll|}
132,41 \\
\end{tabular} & 75,43 & 86,64 & 75,47 \\
\hline Bufo spinosus & 31 TBF60 & 100,00 & 131,81 & 92,23 & 36,17 & 5648,64 & 268,52 & 16,45 & 252,08 & 136,55 & 206,01 & 207,95 & 66,86 & 576,26 & 70,87 & 21,04 & 30,52 & 191,29 & \begin{tabular}{|l|l|}
106,43 \\
\end{tabular} & \begin{tabular}{|l|l|}
122,69 \\
\end{tabular} & 118,72 \\
\hline Bufo spinosus & 31TBF61 & 99,00 & 109,30 & 90,92 & 35,52 & 5755,61 & 248,77 & $-3,78$ & 252,55 & $\begin{array}{ll}116,48 \\
\end{array}$ & $\begin{array}{l}146,49 \\
1\end{array}$ & \begin{tabular}{ll|l}
186,98 \\
\end{tabular} & 42,61 & \begin{tabular}{ll|l}
648,49 \\
\end{tabular} & \begin{tabular}{ll|l}
76,95 \\
\end{tabular} & 28,02 & 25,89 & \begin{tabular}{|l|l|}
199,39 \\
\end{tabular} & \begin{tabular}{|l|l|}
130,34 \\
\end{tabular} & \begin{tabular}{|l|}
138,81 \\
\end{tabular} & 133,36 \\
\hline Bufo spinosus & 31 TBF62 & 101,00 & 126,41 & 94,24 & 36,04 & 5757,05 & 267,19 & 9,53 & 257,66 & 130,90 & $\begin{array}{ll}188,52 \\
\end{array}$ & 203,58 & \begin{tabular}{|l|l}
59,55 \\
\end{tabular} & 576,00 & 69,50 & 22,39 & 29,10 & 184,31 & 111,21 & 123,23 & 116,88 \\
\hline Bufo spinosus & 31TBF63 & 100,00 & 136,87 & 97,23 & 36,51 & 5786,36 & 279,66 & 16,86 & 262,80 & 139,95 & \begin{tabular}{|l|l|}
196,36 \\
\end{tabular} & 214,02 & 69,52 & \begin{tabular}{|l|l|}
531,63 \\
\end{tabular} & 65,19 & 19,19 & 31,10 & $\begin{array}{ll}174,12 \\
\end{array}$ & \begin{tabular}{|l|l|}
100,18 \\
\end{tabular} & \begin{tabular}{|l|l|}
113,19 \\
\end{tabular} & 106,70 \\
\hline Bufo spinosus & 31ТВF66 & 100,00 & 151,15 & 104,38 & 37,00 & 5977,35 & 301,79 & 24,80 & 276,99 & 153,03 & 86,90 & 229,76 & 79,66 & 436,73 & \begin{tabular}{l|l|}
55,95 \\
\end{tabular} & 15,89 & 33,54 & \begin{tabular}{ll|}
145,56 \\
\end{tabular} & 78,73 & 85,18 & 82,56 \\
\hline Bufo spinosus & 31TBF67 & 100,00 & 147,35 & 105,65 & 37,01 & 6064,38 & 300,56 & 20,03 & 280,53 & 151,48 & 82,53 & 226,74 & 73,87 & 435,17 & 56,25 & 16,97 & 32,07 & 140,70 & 79,07 & 86,45 & 81,33 \\
\hline Bufo spinosus & 31TBF68 & 100,00 & 147,14 & 107,15 & 37,09 & 6135,96 & 302,66 & 18,54 & \begin{tabular}{|l|l|}
284,12 \\
\end{tabular} & $\begin{array}{ll}159,99 \\
\end{array}$ & 81,97 & 227,28 & 71,9 & 423,67 & 54,92 & 17,47 & 31,34 & \begin{tabular}{|l|l|}
135,17 \\
\end{tabular} & \begin{tabular}{ll|}
76,65 \\
\end{tabular} & 86,63 & 78,02 \\
\hline Bufo spinosus & 31TBF70 & 100,00 & 150,82 & 93,17 & 36,79 & 5497,04 & 284,54 & 34,28 & 250,26 & 153,43 & 223,81 & 225,19 & 89,03 & 552,58 & 74,84 & 16,49 & \begin{tabular}{|l|}
35,08 \\
\end{tabular} & \begin{tabular}{|l|l|}
196,49 \\
\end{tabular} & \begin{tabular}{|l|l|}
93,63 \\
\end{tabular} & \begin{tabular}{|l|l|}
117,83 \\
\end{tabular} & 111,35 \\
\hline Bufo spinosus & 31TBF71 & 101,00 & 132,77 & 92,82 & 36,20 & 5636,99 & 270,10 & \begin{tabular}{|l|}
17,10 \\
\end{tabular} & \begin{tabular}{|l|}
252,99 \\
\end{tabular} & 136 , & \begin{tabular}{|l|l|}
207,72 \\
\end{tabular} & 208,94 & 68 & \begin{tabular}{|l|l|}
596,72 \\
\end{tabular} & 74,31 & 21,1 & 30, & \begin{tabular}{|l|l|}
197,60 \\
\end{tabular} & \begin{tabular}{|l|l|}
109,47 \\
\end{tabular} & $\begin{array}{l}126,59 \\
\end{array}$ & 123,37 \\
\hline Bufo spinosus & 31TBF72 & 100,00 & 120,88 & 92,66 & 35,83 & 5726,96 & 260,58 & 5,80 & 254,78 & 126,04 & \begin{tabular}{|l|l|}
194,37 \\
\end{tabular} & 197,99 & 54 & 625,55 & 75,00 & 24,6 & 27, & 197,57 & 121,08 & \begin{tabular}{|l|l|}
132,97 \\
\end{tabular} & 129,80 \\
\hline Bufo spinosus & 31TBF73 & 100,00 & 136,20 & 96,45 & 36,51 & 5760,37 & 278,20 & 16,94 & 261,26 & 139,32 & 212,64 & 213,25 & 69,49 & 559,53 & 67,84 & 19,63 & 30,87 & 183,26 & 103,73 & 118,88 & 114,94 \\
\hline Bufo spinosus & 31TBF76 & 100,00 & 151,21 & 104,35 & $\begin{array}{l}37,05 \\
\end{array}$ & 5991,01 & 301,78 & 24,64 & 277,14 & 153,10 & 86,74 & 229,97 & 79,66 & 451,58 & 57,12 & 15,97 & 33,44 & 150,71 & 81,91 & 88,18 & 86,67 \\
\hline Bufo spinosus & 31TBF80 & 99,00 & 161,91 & 93,13 & 37,04 & 5377,75 & 292,75 & 45,29 & 247,46 & 163,14 & 233,20 & 234,91 & $\begin{array}{l}101,67 \\
\end{array}$ & \begin{tabular}{l|l|}
550,62 \\
\end{tabular} & 80,09 & 14,42 & 38,54 & 204,72 & 89,35 & \begin{tabular}{l|l}
119,45 \\
\end{tabular} & 103,11 \\
\hline Bufo spinosus & 31TBF81 & 100,00 & 164,48 & 95,48 & 37,50 & 5414,10 & 297,55 & $\begin{array}{l}46,15 \\
\end{array}$ & 251,40 & \begin{tabular}{|l|l|}
164,37 \\
\end{tabular} & 236,30 & 237,81 & 103, & \begin{tabular}{|l|l|}
542,19 \\
\end{tabular} & \begin{tabular}{ll|}
79,46 \\
\end{tabular} & 14, & 39, & 202,26 & 88,71 & $\begin{array}{l}118,75 \\
12\end{array}$ & 100,01 \\
\hline Bufo spinosus & 31TBF82 & 100,00 & 162,39 & 97,16 & 37,52 & 5505,06 & 298,44 & 42,41 & 256,03 & 161,91 & 235,44 & 236,63 & 100, & 534,86 & 76,70 & 14,34 & 38, & \begin{tabular}{|l|l|}
196,78 \\
\end{tabular} & \begin{tabular}{|l|}
88,67 \\
\end{tabular} & 116,74 & 100,34 \\
\hline Bufo spinosus & 31ТВF83 & 101,00 & 154,13 & 97,79 & 37,09 & 5636,11 & 293,67 & 33,58 & 260,09 & \begin{tabular}{ll|l}
155,13 \\
\end{tabular} & 228,81 & 229,75 & $\begin{array}{l}90,46 \\
\end{array}$ & 533,66 & 71,59 & 15,66 & $\begin{array}{l}35,76 \\
\end{array}$ & \begin{tabular}{|l|l|}
188,14 \\
\end{tabular} & $\begin{array}{l}91,76 \\
\end{array}$ & \begin{tabular}{|l|l|}
115,07 \\
\end{tabular} & 106,59 \\
\hline Bufo spinosus & 31TBF88 & 100,00 & 147,34 & 108,04 & 37,01 & 6253,64 & 304,80 & \begin{tabular}{l|l}
17,25 \\
\end{tabular} & 287,55 & 165,05 & \begin{tabular}{|l|}
81,18 \\
\end{tabular} & 228,70 & $\begin{array}{l}0,27 \\
\end{array}$ & \begin{tabular}{|l|l|}
447,09 \\
\end{tabular} & 56,39 & 18,29 & 30,66 & \begin{tabular}{ll|}
140,92 \\
\end{tabular} & 81,15 & 92,29 & 83,36 \\
\hline Bufo spinosus & 31TBF90 & 101,00 & 166,11 & 91,45 & 36,95 & 5296,97 & 294,19 & 50,89 & 243,29 & 167,91 & 236,18 & 238,11 & 106,50 & 549,27 & 82,41 & 13,79 & 40,63 & 208,34 & 88,54 & \begin{tabular}{|l|l|}
121,87 \\
\end{tabular} & 101,14 \\
\hline Bufo spinosus & 31TBF91 & 99,00 & 167,58 & 93,52 & 37,26 & 5338,64 & 297,71 & 50,72 & 246,99 & \begin{tabular}{|l|l|l|}
168,19 \\
\end{tabular} & 238,26 & 240,07 & 107,74 & 544,71 & 82,29 & 13,61 & 40, & 207,22 & 88,10 & \begin{tabular}{|l|l|}
121,40 \\
\end{tabular} & 98,81 \\
\hline Bufo spinosus & $31 \mathrm{TBF92}$ & 100,00 & 154,42 & 94,27 & 36,87 & 5503,33 & 289,07 & \begin{tabular}{|c|c|}
36,95 \\
\end{tabular} & 252,12 & 156,01 & 227,38 & 228,80 & 92,66 & 574,65 & 78,97 & 15,66 & 36,24 & \begin{tabular}{|l|l|}
204,95 \\
\end{tabular} & 95,11 & 121,81 & 114,87 \\
\hline Bufo spinosus & 31TBF93 & 100,00 & 149,18 & 95,28 & \begin{tabular}{|c|}
36,69 \\
\end{tabular} & 5614,96 & 286,96 & 30,72 & \begin{tabular}{|l|l|}
256,24 \\
\end{tabular} & 151,58 & 223,56 & 224,74 & 85,42 & $\begin{array}{ll}572,98 \\
\end{array}$ & 74,83 & 16,53 & 34,38 & $\begin{array}{l}197,79 \\
\end{array}$ & 97,31 & \begin{tabular}{|l|}
120,03 \\
\end{tabular} & 120,59 \\
\hline Bufo spinosus & 31TBF96 & 100,00 & 157,82 & 102,20 & 36,99 & 5922,54 & 304,71 & 32,44 & 272,26 & 160,45 & \begin{tabular}{|l|l|}
108,67 \\
\end{tabular} & \begin{tabular}{|l|l|}
235,67 \\
\end{tabular} & 87,02 & \begin{tabular}{l|l}
455,63 \\
\end{tabular} & 59,54 & 14,90 & 35,59 & \begin{tabular}{|l|l|}
158,33 \\
\end{tabular} & 80,41 & 99,20 & 87,44 \\
\hline Bufo spinosus & 31TBG54 & 87,00 & 133,04 & 107,32 & \begin{tabular}{l|l|}
37,95 \\
\end{tabular} & 6022,70 & 287,83 & 7,08 & 280,74 & \begin{tabular}{|l|l|}
157,12 \\
\end{tabular} & 56,73 & 211,02 & 56,73 & 454,14 & 57,03 & 23,13 & 24,92 & $\begin{array}{l}143,35 \\
\end{array}$ & 84,73 & \begin{tabular}{|l|l|}
102,08 \\
\end{tabular} & 84,73 \\
\hline Bufo spinosus & טוס & 80,6 & & & 38,00 & 5838 & $2 \pi$ & $-1,19$ & & 145 & 46, & 196, & 46, & 528,42 & 64,16 & 28,48 & 21, & 162,98 & 102,72 & 121,12 & 102 \\
\hline Bufo spinosus & 31TBG57 & 75,00 & 106,03 & 100,90 & 37,82 & 5693,90 & 251,97 & $-11,65$ & 263,62 & 126,45 & 34,42 & 180,16 & 34,42 & 632,45 & 74,49 & 35,77 & \begin{tabular}{|l|l|}
19,60 \\
\end{tabular} & 191,70 & 128,20 & 147,83 & 128,20 \\
\hline Bufo spinosus & 31TBG59 & 71,00 & 95,19 & 98,30 & 37,86 & 5571,13 & 236,89 & $-19,53$ & 256,42 & \begin{tabular}{|l|l|}
114,42 \\
\end{tabular} & 25,60 & \begin{tabular}{|l|l|}
167,87 \\
\end{tabular} & 25,51 & 753,62 & 84,71 & 44,39 & 16,72 & 222,37 & 161,80 & \begin{tabular}{l|l|}
177,92 \\
\end{tabular} & 161,80 \\
\hline
\end{tabular}




\begin{tabular}{|c|c|c|c|c|c|c|c|c|c|c|c|c|c|c|c|c|c|c|c|c|c|}
\hline TAXON & UTM & $\mathrm{km} 2$ & BIO1 & B1O2 & $\mathrm{BIO3}$ & B104 & BIO5 & B106 & B107 & B108 & 8109 & B1010 & BIO11 & B1012 & BIO13 & B1014 & BIO15 & B1016 & B1017 & B1018 & B1019 \\
\hline Bufo spinosus & 31TBG60 & 99,00 & 142,24 & 109,03 & 37,06 & 6230,79 & 300,97 & 12,59 & 288,37 & 167,32 & 65,65 & 223,13 & 64,47 & 425,82 & 55,24 & 19,53 & 29,18 & 136,97 & 77,25 & 92,28 & 77,25 \\
\hline \begin{tabular}{|l|} 
Bufo spinosus \\
\end{tabular} & 31TBG61 & 99,00 & 145,58 & 109,98 & 37,30 & 6252,72 & 304,86 & 14,82 & 290,04 & 171,28 & 67,70 & 226,38 & 66,72 & \begin{tabular}{|l|l|}
412,88 \\
\end{tabular} & 53,18 & 19,44 & 28,93 & 132,63 & 74,38 & 90,48 & 74,38 \\
\hline \begin{tabular}{|l} 
Bufo spinosus \\
\end{tabular} & \begin{tabular}{|l|l|} 
31TBG63 \\
\end{tabular} & 100,00 & 138,13 & 109,30 & 37,45 & 6190,12 & 296,38 & $\begin{array}{l}9,06 \\
9,6\end{array}$ & 287,32 & $\begin{array}{l}163,46 \\
\end{array}$ & 59,56 & 218,05 & 59,56 & $\begin{array}{l}444,79 \\
\end{array}$ & 56,09 & 22,57 & 26,18 & $\begin{array}{l}142,27 \\
\end{array}$ & 81,40 & \begin{tabular}{r|}
101,05 \\
\end{tabular} & 81,40 \\
\hline Bufo spinosus & 31TBG64 & 100,00 & 135,08 & 108,65 & 37,80 & 6121,91 & 291,72 & 7,18 & 284,54 & 160,03 & 57,18 & 214,06 & 57,18 & 464,06 & 57,65 & 24,18 & 24,68 & 147,08 & 86,22 & 106,54 & 86,22 \\
\hline Bufo spinosus & 31TBG69 & 100,00 & 108,25 & 101,56 & $\begin{array}{l}38,18 \\
\end{array}$ & 5675,63 & 252,42 & $-9,89$ & 262,31 & 129,11 & 36,32 & 181,76 & 36,32 & $\begin{array}{l}690,46 \\
\end{array}$ & 77,56 & 40,20 & 17,42 & 204,72 & $\begin{array}{ll}144,83 \\
\end{array}$ & 163,83 & 144,83 \\
\hline Bufo spinosus & 31TBG70 & 100,00 & 148,52 & 110,90 & 37,29 & 6343,37 & 309,34 & 16,40 & 292,94 & 174,56 & 79,91 & 230,50 & 68,86 & 414,38 & 53,14 & 18,95 & 29,71 & 133,12 & 74,25 & 90,12 & 74,59 \\
\hline Bufo spinosus & 31TBG74 & 99,00 & 130,29 & 108,41 & 37,46 & 6184,54 & 287,63 & 2,37 & 285,26 & 155,17 & 51,54 & 210,03 & 51,54 & 504,80 & 62,03 & 27,39 & 24,00 & 160,76 & 93,78 & 119,62 & 93,78 \\
\hline Bufo spinosus & 31TBG75 & 101,00 & 119,74 & 105,02 & \begin{tabular}{|l|l|}
37,42 \\
\end{tabular} & $\begin{array}{ll}6025,83 \\
\end{array}$ & 272,88 & $-4,03$ & 276,91 & 142,89 & 43,39 & 197,82 & 43,39 & 577,21 & 69,13 & 32,48 & 21,95 & 180,38 & 110,56 & 138,61 & 110,56 \\
\hline Bufo spinosus & 31TBG76 & 100,00 & 114,29 & 103,19 & $\begin{array}{l}37,55 \\
\end{array}$ & 5925,61 & 264,62 & $-7,12$ & 271,74 & 136,52 & 39,39 & 191,15 & 39,39 & 626,68 & 73,45 & 36,04 & 20,47 & 192,91 & 123,16 & 151,35 & 123,16 \\
\hline Bufo spinosus & 31TBG77 & 101,00 & 112,32 & 102,68 & 37,74 & 5863,95 & 260,96 & $-8,14$ & 269,10 & 134,25 & 38,04 & 188,24 & 38,04 & 656,09 & 75,50 & 38,25 & 19,38 & 199,58 & 131,22 & 158,97 & 131,22 \\
\hline Bufo spinosus & 31TBG81 & 99,00 & 144,13 & 112,80 & 37,06 & 6500,57 & 308,62 & 10,08 & 298,54 & \begin{tabular}{|l|l|}
171,27 \\
\end{tabular} & 61,88 & 227,81 & 61,49 & 438,79 & 55,56 & 21,46 & 27,92 & 143,53 & 78,34 & 101,32 & 78,34 \\
\hline \begin{tabular}{|l|} 
Bufo spinosus \\
\end{tabular} & 31TBG84 & 100,00 & 122,59 & 105,93 & 37,01 & 6166,65 & 278,31 & $-2,91$ & 281,22 & 146,39 & 44,41 & 202,31 & 44,41 & 573,46 & 68,98 & 31,92 & 22,78 & 181,56 & 107,77 & 139,78 & 107,77 \\
\hline Bufo spinosus & 31TBG89 & 100,00 & 93,12 & 96,45 & 37,06 & 5683,73 & 235,14 & $-21,42$ & 256,56 & 112,22 & 22,11 & 167,15 & 22,11 & 865,35 & 94,12 & 53,61 & 16,39 & 254,89 & 183,38 & 214,32 & 183,38 \\
\hline Bufo spinosus & 31TBH50 & 62,00 & 91,60 & 97,31 & 37,83 & 5526,61 & 231,46 & $-22,06$ & 253,51 & 110,18 & 36,34 & 163,54 & 22,51 & 803,95 & 88,68 & 48,01 & 15,84 & 234,57 & 176,23 & 188,76 & 176,83 \\
\hline Bufo spinosus & 31TBH51 & 66,00 & 72,18 & 91,90 & \begin{tabular}{|l|}
37,08 \\
\end{tabular} & 5440,33 & 208,14 & $-36,69$ & 244,83 & 88,29 & 81,93 & 143,57 & 5,17 & \begin{tabular}{|l|l|}
963,17 \\
\end{tabular} & 103,96 & 59,76 & 14,44 & 277,84 & 214,91 & 223,19 & 220,08 \\
\hline Bufo spinosus & 31TBH52 & 61,00 & 26,09 & 77,48 & 33,53 & 5281,27 & 152,94 & $-74,49$ & 227,43 & 36,03 & 97,28 & 97,28 & $-36,08$ & 1296,34 & 136,53 & 84,57 & 12,68 & 367,71 & 283,47 & 283,64 & 313,16 \\
\hline \begin{tabular}{|l|} 
Bufo spinosus \\
\end{tabular} & 31твH60 & 101,00 & 97,64 & 98,63 & 37,98 & 5582,82 & 238,54 & $-17,64$ & 256,18 & 117,12 & 34,65 & 170,18 & 27,44 & 786,31 & 86,23 & 47,05 & 15,98 & 229,72 & 170,56 & 186,30 & 170,95 \\
\hline Bufo spinosus & 31TBH61 & 101,00 & 86,55 & 95,72 & 37,64 & 5505,15 & 224,68 & $-25,87$ & 250,55 & 104,58 & 39,33 & 158,31 & 17,86 & 884,59 & 95,35 & 54,24 & 14,83 & 255,72 & 196,21 & 209,57 & 197,68 \\
\hline Bufo spinosus & 31TBH62 & 100,00 & 46,28 & 83,24 & 35,06 & 5349,68 & 176,70 & $-57,15$ & 233,85 & 58,97 & \begin{tabular}{|l|l|}
105,13 \\
\end{tabular} & 117,52 & $-18,02$ & 1169,48 & 123,92 & 75,53 & 13,20 & 333,57 & 259,65 & 262,50 & 275,92 \\
\hline Bufo spinosus & 31TBH63 & 36,00 & 21,95 & 75,16 & 32,93 & 5248,28 & 146,94 & $-77,73$ & 224,67 & 31,48 & 92,89 & 92,89 & $-39,50$ & $\begin{array}{l}1345,64 \\
\end{array}$ & 140,64 & 88,57 & 12,28 & 379,52 & 294,93 & 294,93 & 327,05 \\
\hline Bufo spinosus & 31TBH71 & 99,00 & 55,15 & 85,39 & 35,34 & 5420,49 & 187,79 & $-50,20$ & 237,99 & 69,03 & 58,75 & 127,11 & $-10,36$ & $\begin{array}{l}1111,69 \\
\end{array}$ & 118,50 & 71,49 & 13,75 & 319,11 & 247,34 & 254,56 & 256,27 \\
\hline Bufo spinosus & 31TBH82 & 99,00 & 23,05 & 74,61 & 32,54 & 5307,09 & 149,13 & $-76,48$ & 225,61 & 32,80 & 82,46 & 94,82 & $-38,87$ & \begin{tabular}{|l|}
1343,39 \\
\end{tabular} & 141,01 & 88,87 & 12,47 & 380,00 & 296,94 & 297,26 & 321,47 \\
\hline Bufo spinosus & 31TBH83 & 16,00 & 26,35 & 75,46 & \begin{tabular}{|l|l|l|}
32,88 \\
\end{tabular} & 5295,10 & 152,16 & $-73,70$ & 225,86 & 36,54 & 82,50 & 97,70 & $-35,85$ & 1336,59 & \begin{tabular}{|l|l|}
139,58 \\
\end{tabular} & 88,68 & 12,36 & 377,22 & 296,10 & 297,43 & 320,87 \\
\hline Bufo spinosus & 31TBH90 & 100,00 & 67,45 & 87,70 & 35,65 & 5529,86 & 203,16 & $-39,40$ & 242,56 & 82,86 & 11,64 & 140,52 & 0,07 & 1058,72 & 113,45 & 68,57 & 14,69 & 307,44 & 233,12 & 251,45 & 233,86 \\
\hline Bufo spinosus & 31TBH91 & 100,00 & 57,69 & 84,80 & 35,00 & 5466,00 & 190,84 & $-47,45$ & 238,29 & 71,85 & 34,21 & 130,24 & $-8,32$ & 1130,54 & 119,98 & 73,84 & 13,92 & 325,03 & 251,39 & 264,91 & 256,33 \\
\hline \begin{tabular}{|l|} 
Bufo spinosus \\
\end{tabular} & 31твH92 & 100,00 & 27,92 & 75,45 & 32,68 & 5333,73 & 154,78 & $-72,13$ & 226,91 & 38,21 & 69,40 & $\begin{array}{l}99,83 \\
\end{array}$ & $-34,58$ & 1322,21 & 138,87 & 87,78 & 12,61 & 374,57 & 293,48 & 295,91 & 313,36 \\
\hline Bufo spinosus & 31TCF00 & 91,00 & 170,15 & 88,95 & 36,96 & 5216,73 & 294,89 & 56,82 & 238,07 & $\mid 173,18$ & 239,02 & 241,14 & 111,33 & 542,26 & 85,01 & 13,00 & 42,55 & 211,58 & 85,65 & 122,43 & 97,56 \\
\hline Bufo spinosus & 31TCF01 & 91,00 & 169,24 & 90,59 & 37,01 & 5270,78 & 295,88 & 54,37 & 241,51 & \begin{tabular}{|l|l|}
171,44 \\
\end{tabular} & 238,53 & 240,62 & 109,85 & 544,22 & 84,76 & 13,71 & 42,07 & 211,19 & 87,53 & 123,63 & 97,33 \\
\hline Bufo spinosus & 31TCF05 & 100,00 & 159,51 & 96,97 & 36,84 & 5707,16 & 298,92 & 38,62 & 260,29 & 162,82 & 205,02 & 235,38 & 92,45 & \begin{tabular}{|l|l|}
502,93 \\
\end{tabular} & 68,89 & 14,89 & 36,64 & 179,87 & 87,99 & 112,60 & 99,25 \\
\hline Bufo spinosus & 31TCF06 & 100,00 & 146,94 & 98,80 & 36,36 & 5915,29 & 292,01 & 24,43 & 267,58 & 151,15 & 177,38 & 224,94 & 75,96 & 530,69 & 64,09 & 17,86 & 31,50 & 173,85 & 99,04 & 112,21 & 107,57 \\
\hline Bufo spinosus & 31TCF07 & 101,00 & 142,31 & 100,70 & 36,31 & 6051,46 & 291,38 & 18,27 & 273,10 & 147,80 & 78,59 & 221,51 & 68,61 & 528,52 & 62,41 & 19,92 & 29,48 & 166,29 & 101,07 & 111,62 & 104,64 \\
\hline Bufo spinosus & 31TCF08 & 100,00 & 138,00 & 102,41 & 36,24 & 6171,55 & 290,48 & 12,48 & 278,00 & \begin{tabular}{|l|l|}
159,87 \\
\end{tabular} & 72,58 & 218,37 & 61,91 & 530,82 & 63,45 & 22,11 & 27,82 & 163,49 & 101,44 & 113,67 & 102,71 \\
\hline Bufo spinosus & 31TCF09 & 100,00 & 146,17 & 107,88 & \begin{tabular}{|l|}
36,88 \\
\end{tabular} & 6403,92 & 305,28 & 15,33 & 289,95 & 171,55 & 78,90 & 228,72 & 65,59 & 471,30 & 57,43 & 21,07 & 28,69 & 149,71 & 85,98 & 103,90 & 86,57 \\
\hline Bufo spinosus & 31TCF15 & 101,00 & 145,84 & 92,56 & 35,91 & 5691,94 & 282,92 & 28,81 & 254,11 & 151,16 & 220,48 & 221,73 & 78,41 & 579,26 & 72,72 & 18,21 & 32,13 & 193,91 & 104,29 & 123,97 & 121,18 \\
\hline Bufo spinosus & 31TCF16 & 100,00 & 144,25 & 94,60 & 35,96 & 5815,44 & 284,88 & 25,33 & 259,55 & 149,85 & $\begin{array}{ll}199,48 \\
\end{array}$ & 221,21 & 74,36 & 562,22 & 68,15 & 19,17 & 30,79 & 183,79 & 106,39 & 122,69 & 114,40 \\
\hline \begin{tabular}{|l} 
Bufo spinosus \\
\end{tabular} & $\begin{array}{l}\text { 31TCF17 } \\
\end{array}$ & 99,00 & 125,28 & 93,84 & 35,53 & 5901,09 & 268,66 & 7,94 & 260,72 & 133,01 & 61,14 & 203,30 & 54,08 & 630,37 & 72,59 & 26,30 & 25,89 & 190,87 & 126,36 & 138,57 & 127,53 \\
\hline Bufo spinosus & 31TCF18 & 101,00 & 134,27 & 98,05 & \begin{tabular}{l|l|l}
35,95 \\
\end{tabular} & 6053,09 & 282,00 & 12,50 & 269,50 & 150,27 & 69,86 & 213,36 & 59,84 & 569,94 & 66,61 & 23,90 & 26,82 & 173,44 & 110,70 & 125,38 & 111,34 \\
\hline \begin{tabular}{|l|} 
Bufo spinosus \\
\end{tabular} & \begin{tabular}{|l|}
31 TCF19 \\
\end{tabular} & 100,00 & 141,51 & 102,39 & 36,10 & 6233,94 & 294,30 & 15,42 & 278,88 & 164,79 & 74,35 & 222,12 & 63,49 & 517,98 & 61,49 & 22,94 & 27,60 & 161,22 & 96,77 & $\begin{array}{l}114,76 \\
\end{array}$ & 96,87 \\
\hline Bufo spinosus & 31TCF24 & 91,00 & 156,86 & 86,37 & 35,72 & 5403,86 & 284,08 & 44,77 & 239,31 & 163,53 & \begin{tabular}{|l|l|}
189,87 & \\
\end{tabular} & 229,39 & 93,31 & 568,38 & 81,03 & 16,61 & 36,80 & 206,02 & 99,29 & 128,08 & 113,84 \\
\hline Bufo spinosus & 31TCF25 & 99,00 & 145,13 & 87,91 & 35,27 & 5575,42 & 277,06 & 31,92 & 245,14 & 152,12 & 204,07 & 219,64 & 78,86 & 593,26 & 75,52 & 19,18 & 31,89 & 200,03 & 108,90 & 130,00 & 122,54 \\
\hline Bufo spinosus & 31TCF26 & 101,00 & 134,25 & 89,96 & 35,21 & 5736,76 & 271,14 & 19,53 & 251,61 & 141,36 & 186,22 & 210,50 & 65,48 & 618,71 & 72,03 & 22,63 & 28,15 & 196,75 & 120,61 & 135,04 & 127,73 \\
\hline Bufo spinosus & 31TCF27 & 100,00 & 120,60 & 89,93 & 35,00 & 5805,41 & 260,19 & 6,82 & 253,36 & 128,42 & 57,11 & 197,84 & 50,98 & 670,91 & 76,09 & 28,75 & 24,87 & 202,60 & 135,85 & 149,16 & 136,49 \\
\hline Bufo spinosus & 31TCF28 & 100,00 & 129,82 & 93,38 & 35,30 & 5923,63 & 272,63 & 12,25 & 260,38 & 138,93 & 64,02 & 207,74 & 57,47 & 610,76 & 70,25 & 26,00 & 25,96 & 184,97 & 120,04 & 137,98 & 120,13 \\
\hline Bufo spinosus & 31 TCF36 & 100,00 & 136,20 & 85,52 & 34,7 & 5605,32 & 267,82 & 25,11 & 242,71 & 144,68 & 167,76 & 210,99 & 68,99 & 624,55 & 74,92 & 22,99 & 28,69 & 202,11 & 121,90 & 39,31 & 128,05 \\
\hline Bufo spinosus & 31TCF37 & 100,00 & 114,28 & 86,34 & 34,4 & 5723,86 & 250,82 & 4,11 & 246,72 & \begin{tabular}{|l|l|}
122,64 \\
\end{tabular} & 48,59 & 190,80 & 46,14 & 718,90 & 80,58 & 32,16 & 23,49 & 215,68 & 146,96 & 160,95 & 147,02 \\
\hline \begin{tabular}{|l} 
Bufo spinosus \\
\end{tabular} & 31TCF38 & 101,00 & 130,78 & 89,58 & \begin{tabular}{l|l}
34,95 \\
\end{tabular} & 5816,48 & 269,14 & 16,21 & 252,92 & 138,87 & 64,10 & 207,49 & 59,81 & 621,44 & 70,68 & 26,14 & 26,05 & 190,56 & 122,19 & 141,97 & 122,21 \\
\hline Bufo spinosus & 31TCF39 & 100,00 & 133,43 & 91,90 & 35,08 & 5911,36 & 274,57 & 16,60 & 257,97 & 145,94 & 60,67 & 210,86 & 60,54 & 597,88 & 68,80 & 26,49 & 26,11 & 181,22 & 114,03 & 139,69 & 114,03 \\
\hline Bufo spinosus & 31TCF45 & 98.00 & 160,62 & 75,79 & 33,81 & 5147,51 & 277,23 & 56,59 & 220,64 & $\mid 171,42$ & 103,96 & 229,48 & 98,64 & 553,08 & 77,58 & $\mid 17,17$ & 36,42 & 201,01 & 97.92 & $\mid 132,79$ & 113,60 \\
\hline Bufo spinosus & 31TCF55 & 69,00 & 160,04 & 71,70 & 33,01 & 5056,42 & 272,84 & 59,35 & 213,49 & 172,27 & 199,78 & 227,65 & 99,01 & 559,29 & 75,85 & 17,51 & 35,78 & 200,36 & 98,77 & 33,98 & 122,29 \\
\hline \begin{tabular}{|l} 
Bufo spinosus \\
\end{tabular} & $\begin{array}{l}\text { 31TCF56 } \\
\end{array}$ & 101,00 & 155,31 & 74,55 & 33 & 5207,45 & 272,43 & 52,23 & 22 & 166,81 & 167,68 & 22 & 92,09 & 566,00 & 74,3 & 19,01 & 32,80 & $\begin{array}{ll}197,41 \\
\end{array}$ & 104,13 & 134,60 & 119,22 \\
\hline Bufo spinosus & 31TCF57 & 99,00 & 147,41 & 78,90 & \begin{tabular}{|l|}
33,88 \\
\end{tabular} & 5423,19 & 270,97 & 40,84 & 230,14 & 157,99 & 100,81 & 219,44 & 81,40 & 581,84 & 72,51 & 21,21 & 29,63 & \begin{tabular}{|l|l|}
194,63 \\
\end{tabular} & 112,55 & \begin{tabular}{|l|}
136,12 \\
\end{tabular} & 117,33 \\
\hline \begin{tabular}{|l|} 
Bufo spinosus \\
\end{tabular} & 31TCF65 & 46,00 & 162,50 & 71,04 & 33,00 & 5050,68 & 274,52 & 62,36 & 212,16 & 175,04 & 227,02 & 230,05 & 101,48 & 558,36 & 77,79 & 18,38 & 34,71 & 201,48 & 99,46 & 134,50 & 120,18 \\
\hline Bufo spinosus & 31TCF66 & 100,00 & 154,23 & 73,09 & 33,01 & 5191,91 & 270,40 & 52,41 & 217,99 & 165,97 & 220,92 & 223,55 & 91,57 & 583,63 & 76,96 & 20,63 & 31,16 & 202,41 & 108,47 & 138,47 & 122,70 \\
\hline Bufo spinosus & \begin{tabular}{|l|}
31 TCF67 \\
\end{tabular} & 101,00 & 145,25 & 76,66 & 33,25 & 5386,18 & 267,13 & 40,66 & \begin{tabular}{l|l|l|}
226,47 & \\
\end{tabular} & \begin{tabular}{ll|l}
156,07 \\
\end{tabular} & 176,01 & 217,00 & 80,06 & 608,72 & 75,16 & 23,26 & 28,20 & 90 & 119,23 & 142,62 & 123,55 \\
\hline \begin{tabular}{|l} 
Bufo spinosus \\
\end{tabular} & 31TCF68 & 99,00 & 131,15 & 79,81 & 33,66 & 5559,16 & 259,21 & 24,77 & 234,45 & 141,26 & $\begin{array}{ll}64,97 \\
\end{array}$ & 205,27 & 64,24 & 666,55 & 75,62 & 29,08 & 25,12 & 208,11 & 131,83 & $\begin{array}{l}156,38 \\
\end{array}$ & 131,86 \\
\hline Bufo spinosus & 31TCF69 & 101,00 & 126,00 & 81,38 & 33,80 & 5630,80 & 256,95 & 18,44 & 238,52 & 135,73 & 58,01 & 200,83 & 58,01 & 688,63 & 77,25 & 32,79 & 23,99 & 208,25 & 132,74 & 164,76 & 132,74 \\
\hline Bufo spinosus & 31TCF76 & 100,00 & 158,41 & 71,91 & 32,99 & 5151,24 & 272,81 & 57,54 & 215,27 & 170,21 & 224,63 & 227,14 & 96,04 & 582,02 & 79,99 & 21,60 & 31,08 & 204,76 & $\mid 108,70$ & $\mid 139,79$ & 120,42 \\
\hline Bufo spinosus & 31TCF77 & 101,00 & 145,54 & 74,80 & 33,01 & 5344,03 & 265,69 & 42,47 & 223,23 & 156,52 & 193,43 & 216,74 & 81,12 & 627,43 & 78,06 & 25,09 & 27,47 & 208,00 & 123,24 & 148,06 & 127,46 \\
\hline Bufo spinosus & 31TCF78 & 101 & 130,54 & 77,56 & $33, \mathrm{C}$ & 5504,74 & 256,71 & 26, & 230,66 & $14 \mathrm{C}$ & 72, & 20 & 64 & 687,65 & 77,12 & 30,22 & 24,46 & 214,64 & 136,78 & 162,16 & 136 \\
\hline \begin{tabular}{|l} 
Bufo spinosus \\
\end{tabular} & $\begin{array}{l}\text { 31TCF79 } \\
\end{array}$ & 100,00 & 128,91 & 78,91 & 33,06 & 5569,67 & 257,32 & 23,18 & 234,14 & 138,99 & 61,92 & 203,09 & 61,92 & 687,95 & 76,92 & 32,81 & 24,03 & 210,20 & 132,79 & 165,84 & 132,79 \\
\hline
\end{tabular}




\begin{tabular}{|c|c|c|c|c|c|c|c|c|c|c|c|c|c|c|c|c|c|c|c|c|c|}
\hline TAXON & UTM & $\mathrm{km2}$ & B101 & $\mathrm{B1O2}$ & $\mathrm{BIO3}$ & $\mathrm{B104}$ & $\mathrm{B105}$ & B106 & 8107 & B108 & B109 & 81010 & B1011 & BIO12 & B1013 & 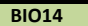 & BIO15 & B1O16 & B1017 & B1018 & B1019 \\
\hline Bufo spinosus & 31 TCF86 & 91,00 & 159,65 & 71,41 & 32,97 & 5147,19 & 273,63 & 59,16 & 214,47 & 171,28 & 226,06 & 228,23 & 97,46 & 592,90 & 83,01 & 22,78 & 30,74 & 209,33 & 111,23 & 142,36 & 121,67 \\
\hline Bufo spinosus & 31TCF87 & 99,00 & 154,53 & 72,64 & 32,94 & 5250,76 & 271,23 & 52,83 & 218,40 & 165,66 & 222,41 & 224,40 & 90,97 & 606,20 & 80,03 & 24,43 & 28,57 & 207,34 & 117,39 & 145,62 & 122,55 \\
\hline Bufo spinosus & 31TCF88 & 101,00 & 146,61 & 74,55 & 32,95 & 5379,89 & 267,30 & 43,24 & 224,06 & 157,43 & 124,63 & 218,17 & 81,53 & 630,24 & 76,94 & 26,90 & 26,52 & 206,60 & 124,75 & 151,34 & 125,14 \\
\hline Bufo spinosus & 31TCF89 & 101,00 & 139,33 & 76,38 & \begin{tabular}{|l|l|}
32,97 \\
\end{tabular} & 5485,22 & 263,93 & 34,78 & 229,15 & 149,73 & 72,92 & 212,16 & 72,92 & 652,83 & 74,95 & 30,19 & 25,02 & 205,62 & 126,21 & 158,68 & 126,21 \\
\hline Bufo spinosus & 31TCF96 & 63,00 & 162,17 & 71,02 & 32,93 & 5135,33 & 275,55 & 61,89 & 213,65 & \begin{tabular}{|l|l|}
173,63 \\
\end{tabular} & 228,45 & 230,55 & 100,06 & 597,04 & 85,61 & 22,81 & 31,43 & 213,67 & 111,73 & 143,07 & 122,33 \\
\hline Bufo spinosus & \begin{tabular}{|l|} 
31TCF97 \\
\end{tabular} & 101,00 & 155,44 & 71,73 & 32,62 & 5239,23 & 271,63 & 54,42 & 217,21 & 166,41 & 223,38 & 225,25 & 92,23 & 620,28 & 82,75 & 25,01 & 28,58 & 213,10 & 119,15 & 148,12 & 126,26 \\
\hline Bufo spinosus & 31TCF99 & 100,00 & 150,56 & 74,29 & 32,61 & 5400,68 & 271,62 & 46,79 & \begin{tabular}{|l|l|}
224,84 \\
\end{tabular} & 161,05 & 84,77 & 222,03 & 84,77 & 616,26 & 74,95 & 28,32 & 26,30 & 201,81 & 118,82 & 152,44 & 118,82 \\
\hline \begin{tabular}{|l} 
Bufo spinosus \\
\end{tabular} & 31TCG00 & 101,00 & 150,62 & 112,15 & 37,00 & 6602,27 & 315,20 & 15,70 & 299,50 & 178,15 & 76,80 & 235,19 & 66,23 & 437,61 & 53,96 & 20,16 & 29,04 & 142,76 & 77,21 & 101,21 & 77,22 \\
\hline Bufo spinosus & 31TCG01 & 100,00 & 149,52 & 113,44 & 37,00 & 6668,43 & 315,83 & 13,52 & 302,31 & 177,81 & 64,06 & 234,61 & 63,75 & 440,78 & 54,38 & 20,69 & 28,24 & 145,22 & 77,05 & 105,55 & 77,05 \\
\hline Bufo spinosus & 31TCG03 & 100,00 & 131,63 & 107,10 & 36,88 & $\begin{array}{lll}6366,07 \\
\end{array}$ & 290,37 & 2,88 & 287,50 & 156,82 & 50,46 & 213,46 & 50,46 & 551,20 & 66,24 & 28,90 & 24,44 & 177,22 & 100,41 & 137,19 & 100,41 \\
\hline Bufo spinosus & 31TCG05 & 101,00 & 113,19 & 100,43 & 36,55 & 6053,24 & 263,76 & $-7,62$ & 271,38 & 135,18 & 37,09 & 191,81 & 37,09 & 700,20 & 80,56 & 40,33 & 20,96 & 217,23 & 134,33 & 177,91 & 134,33 \\
\hline Bufo spinosus & 31TCG06 & 100,00 & 107,47 & 98,54 & 36,54 & 5951,47 & 255,26 & $-11,17$ & 266,43 & 128,46 & 32,85 & 184,80 & 32,85 & 762,64 & 85,91 & 45,06 & 19,62 & 233,25 & 149,42 & 195,38 & 149,42 \\
\hline \begin{tabular}{|l} 
Bufo spinosus \\
\end{tabular} & 31TCG10 & 100,00 & 148,09 & 106,57 & 36,55 & 6410,78 & 305,75 & 17,94 & 287,81 & 173,48 & 74,81 & 230,39 & 66,60 & 474,01 & 56,88 & 22,27 & 28,30 & 150,99 & 84,91 & 108,93 & 84,92 \\
\hline Bufo spinosus & 31TCG11 & 100,00 & 148,88 & 108,25 & 36,80 & 6481,73 & 308,54 & 17,17 & 291,36 & 175,20 & 66,22 & 231,77 & 65,83 & 466,93 & 56,24 & 22,36 & 27,81 & 150,37 & 82,35 & 110,83 & 82,35 \\
\hline Bufo spinosus & 31TCG12 & 101,00 & 145,60 & 108,07 & 36,81 & 6466,74 & 305,13 & 14,48 & 290,65 & 171,97 & 62,63 & 228,31 & 62,63 & 485,26 & 58,42 & 23,85 & 26,74 & 156,84 & 85,61 & 118,50 & 85,61 \\
\hline Bufo spinosus & 31TCG13 & 100,00 & 134,26 & 104,94 & 36,54 & 6324,92 & 290,34 & 6,70 & 283,64 & 158,86 & 53,53 & 215,44 & 53,53 & 557,00 & 66,26 & 29,01 & 24,74 & 178,38 & 100,51 & 139,94 & 100,51 \\
\hline Bufo spinosus & 31TCG14 & 100,00 & 119,22 & 100,30 & 36,13 & 6123,16 & 270,38 & $-2,44$ & 272,82 & 141,63 & 42,18 & 198,48 & 42,18 & 663,98 & 77,33 & 36,82 & 22,38 & 208,67 & 123,72 & 170,29 & 123,72 \\
\hline Bufo spinosus & 31TCG15 & 99,00 & 101,89 & 95,01 & 35,75 & 5921,92 & 247,70 & $-13,87$ & 261,58 & 121,46 & 28,49 & 179,32 & 28,49 & 793,30 & 90,01 & 46,81 & 19,97 & 242,68 & 155,53 & 200,06 & 155,53 \\
\hline Bufo spinosus & 31TCG16 & 101,00 & 105,52 & 96,40 & 36,16 & 5926,78 & 251,74 & $-11,38$ & 263,12 & 125,83 & 31,49 & 182,73 & 31,49 & 796,46 & 89,31 & 46,46 & 19,72 & 243,61 & 154,88 & 207,47 & 154,88 \\
\hline Bufo spinosus & 31TCG19 & 100,00 & 85,20 & 91,00 & 35,91 & 5684,82 & 224,70 & $-25,41$ & 250,11 & \begin{tabular}{ll|}
102,57 \\
\end{tabular} & 15,24 & 159,72 & 15,13 & 991,70 & 106,40 & 62,57 & 16,37 & 292,01 & 207,85 & 250,60 & 207,85 \\
\hline Bufo spinosus & 31TCG24 & 100,00 & 119,50 & 97,78 & 35,88 & 6070,98 & 268,10 & $-0,65$ & 268,75 & 140,95 & 43,20 & 198,17 & 43,20 & 679,44 & 78,79 & 37,49 & 22,68 & 212,84 & 125,75 & 175,27 & 125,75 \\
\hline \begin{tabular}{|l} 
Bufo spinosus \\
\end{tabular} & 31TCG25 & 101,00 & 113,46 & 96,40 & 35,79 & 6002,89 & 260,44 & $-4,72$ & 265,17 & 134,30 & 38,32 & 191,44 & 38,32 & 731,19 & 83,64 & 41,37 & 21,60 & 226,89 & 137,85 & 190,11 & 137,85 \\
\hline Bufo spinosus & 31TCG27 & 100,00 & 110,40 & 96,15 & \begin{tabular}{|l|l|}
36,03 \\
\end{tabular} & 5934,42 & 255,86 & $-6,91$ & 262,77 & 131,10 & 35,86 & 187,36 & 35,86 & 790,05 & 88,08 & 45,32 & 20,25 & 242,42 & 151,64 & 211,22 & 151,64 \\
\hline Bufo spinosus & 31TCG28 & 99,00 & 85,87 & 89,44 & 35,39 & 5711,95 & 225,33 & $-23,97$ & 249,30 & 102,84 & 15,88 & 160,93 & 15,79 & 965,62 & 105,61 & 59,56 & 17,35 & 287,94 & 197,62 & 245,02 & 197,62 \\
\hline Bufo spinosus & 31TCG29 & 101,00 & 72,96 & 86,12 & 34,95 & 5607,02 & 209,42 & $-33,45$ & 242,88 & 88,30 & 7,88 & 147,16 & 4,98 & 1052,25 & 113,75 & 67,49 & 15,78 & 309,17 & 223,17 & 259,37 & 223,46 \\
\hline Bufo spinosus & 31TCG31 & 101,00 & 144,05 & 96,82 & 35,74 & 6086,38 & 289,93 & 21,95 & 267,99 & 166,11 & 67,02 & 222,39 & 67,02 & 533,50 & 62,27 & 26,14 & 26,87 & 165,44 & 95,64 & 127,96 & 95,64 \\
\hline Bufo spinosus & 31TCG33 & 100,00 & 136,32 & 97,96 & 35,89 & 6125,76 & $\mid \begin{array}{l}284,35 \\
\end{array}$ & $\begin{array}{l}14,07 \\
14\end{array}$ & 270,28 & $\begin{array}{l}158,88 \\
\end{array}$ & 58,65 & 215,15 & 58,65 & 578,41 & $\begin{array}{l}67,94 \\
67\end{array}$ & 30,14 & 25,21 & $\begin{array}{l}182,78 \\
\end{array}$ & \begin{tabular}{|l|}
102,51 \\
\end{tabular} & 146,70 & 102,51 \\
\hline Bufo spinosus & 31TCG34 & 100,00 & 126,66 & 96,48 & 35,73 & 6057,52 & 273,47 & 6,68 & 266,79 & 148,22 & 50,25 & 204,90 & 50,25 & 646,01 & 75,22 & 34,60 & 23,94 & 203,36 & 116,24 & 168,70 & 116,24 \\
\hline Bufo spinosus & 31TCG36 & 100,00 & 117,81 & 95,62 & 35,85 & $\begin{array}{ll}5979,94 \\
\end{array}$ & 263,39 & $-0,18$ & 263,56 & 138,88 & 42,61 & 195,41 & 42,61 & 723,82 & 82,78 & 39,32 & 22,59 & 226,92 & 131,99 & $\mid \begin{array}{l}198,32 \\
\end{array}$ & 131,99 \\
\hline Bufo spinosus & 31TCG37 & 101,00 & 105,48 & 92,90 & 35,55 & 5864,52 & 248,53 & $-8,86$ & 257,39 & 124,87 & 32,59 & 181,90 & 32,59 & 822,30 & 92,24 & 46,80 & 20,57 & 252,73 & 156,84 & 221,14 & 156,84 \\
\hline Bufo spinosus & 31TCG38 & 101,00 & 100,74 & 92,05 & 35,65 & 5808,73 & 242,40 & $-12,33$ & 254,73 & 119,60 & 28,60 & 176,52 & 28,60 & 875,04 & 97,42 & 50,57 & 19,64 & 266,84 & 169,90 & 237,59 & 169,90 \\
\hline Bufo spinosus & 31TCG39 & 100,00 & 72,43 & 84,84 & 34,63 & 5608,18 & \begin{tabular}{|l|l|}
208,53 \\
\end{tabular} & $\begin{array}{l}-1,1,30 \\
-33,39 \\
\end{array}$ & 241,93 & $\begin{aligned} 87,47 \\
\end{aligned}$ & $\begin{array}{l}\mid 0,000 \\
13,71\end{array}$ & 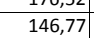 & \begin{tabular}{|l|l|}
4,76 \\
4
\end{tabular} & $\begin{array}{l}1056,72 \\
1056\end{array}$ & $\mid$ & 60,88 & $\begin{array}{l}16,13 \\
16,\end{array}$ & \begin{tabular}{|l|}
$310,90,9$ \\
\end{tabular} & 222,37 & \begin{tabular}{|l|l|}
261,89 \\
\end{tabular} & 223,34 \\
\hline Bufo spinosus & 31TCG40 & 100,00 & 134,28 & 89,61 & \begin{tabular}{|l|l|}
34,87 \\
\end{tabular} & 5866,07 & 273,02 & 19,04 & 253,98 & 153,05 & 61,62 & 210,99 & 61,62 & 604,61 & 69,64 & 28,48 & 25,80 & 182,92 & 112,33 & 145,81 & 112,33 \\
\hline Bufo spinosus & 31TCG43 & 101,00 & 134,01 & 93,72 & 35,06 & 6002,69 & 277,59 & 15,22 & 262,37 & 155,12 & 58,41 & 211,45 & 58,41 & 607,39 & 71,19 & 31,74 & 25,31 & 190,79 & 106,90 & 155,82 & 106,90 \\
\hline Bufo spinosus & 31TCG48 & 99,00 & 74,03 & 83,61 & 34,23 & 5611,50 & 209,89 & $-30,57$ & 240,46 & 88,63 & 8,95 & 148,70 & 6,73 & 1029,71 & 113,12 & 64,84 & 16,74 & 304,54 & 213,65 & 254,52 & 213,88 \\
\hline Bufo spinosus & 31TCG49 & 101,00 & 83,04 & 86,28 & 34,86 & 5660,96 & 220,30 & $-24,22$ & 244,53 & 99,18 & 16,94 & 157,79 & 14,22 & 986,01 & 108,81 & 60,63 & 17,82 & 294,88 & 200,65 & 253,99 & 200,96 \\
\hline Bufo spinosus & 31TCG50 & $\begin{array}{l}100,00 \\
100\end{array}$ & $\begin{array}{l}0.0,04 \\
125,20\end{array}$ & $\begin{array}{l}80,200 \\
85,47\end{array}$ & $\begin{array}{l}34,00 \\
34,08\end{array}$ & 5757,16 & \begin{tabular}{|l|}
260,77 \\
260
\end{tabular} & $\begin{aligned}-24,22 \\
14,22\end{aligned}$ & 246,55 & 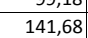 & $\begin{array}{l}\mid 0,34,95 \\
54,4\end{array}$ & 201,17 & $\begin{array}{l}14,2<4 \\
54,95\end{array}$ & \begin{tabular}{|l|}
672,70 \\
672,0
\end{tabular} & $\begin{array}{l}0,01 \\
77,02\end{array}$ & $\begin{array}{l}0,030 \\
33,49\end{array}$ & $\begin{array}{l}1,02 \\
24,15\end{array}$ & \begin{tabular}{|l|}
$201,27,0$ \\
\end{tabular} & \begin{tabular}{|l|}
126,60 \\
120
\end{tabular} & \begin{tabular}{|l|}
163,08 \\
16,0
\end{tabular} & 126,60 \\
\hline Bufo spinosus & 31TCG52 & 101,00 & 133,87 & 88,88 & \begin{tabular}{|l|l|}
34,67 \\
\end{tabular} & 5867,08 & 272,45 & 19,13 & 253,33 & 153,15 & 60,71 & 210,23 & 60,71 & 621,01 & 72,45 & 32,35 & 25,55 & 191,85 & 109,86 & 157,58 & 109,86 \\
\hline Bufo spinosus & 31TCG54 & 100,00 & 128,47 & 90,52 & 34,94 & 5904,12 & 269,06 & 12,75 & 256,31 & 148,32 & 54,50 & 204,86 & 54,50 & 656,86 & 77,26 & 33,38 & 25,45 & 207,43 & 113,50 & 175,72 & 113,50 \\
\hline Bufo spinosus & 31TCG59 & 101,00 & 53,42 & 77,91 & 33,18 & 5480,81 & 185,19 & $-46,43$ & 231,62 & 65,12 & 6,63 & 127,25 & $-10,71$ & 1162,71 & 125,42 & 76,56 & 14,33 & 334,58 & 253,12 & 273,89 & 255,58 \\
\hline Bufo spinosus & 31TCG60 & 101,00 & 123,97 & 82,54 & 33,89 & 5682,52 & 256,82 & 15,55 & 241,28 & 151,45 & 55,06 & 199,25 & 55,06 & 695,57 & 79,27 & 35,38 & 23,78 & 206,99 & 130,82 & 170,18 & 130,82 \\
\hline \begin{tabular}{|l} 
Bufo spinosus \\
\end{tabular} & 31TCG61 & 99,00 & 125,74 & 83,80 & 33,97 & 5727,71 & 259,95 & 15,87 & 244,08 & 143,41 & 55,75 & 201,19 & 55,75 & 683,17 & 78,92 & 35,98 & 24,29 & 206,36 & 124,60 & 171,33 & 124,60 \\
\hline Bufo spinosus & 31TCG62 & 100,00 & 128,55 & 85,27 & 34,02 & 5765,80 & 263,99 & 17,17 & 246,82 & 146,21 & 57,46 & 204,06 & 57,46 & 667,49 & 77,95 & 34,40 & 25,03 & 205,20 & 118,07 & 171,74 & 118,07 \\
\hline Bufo spinosus & 31TCG63 & 100,00 & 128,65 & 86,51 & 34,10 & 5808,17 & 265,45 & 16,13 & 249,32 & \begin{tabular}{|l|l|}
147,04 \\
\end{tabular} & 56,57 & 204,41 & 56,57 & 667,53 & 78,55 & 33,57 & 25,63 & 208,33 & 115,35 & 175,76 & 115,35 \\
\hline Bufo spinosus & 31TCG64 & 101,00 & 120,85 & 86,78 & 34,10 & 5815,49 & 258,77 & 8,88 & 249,89 & 139,11 & 48,99 & 196,76 & 48,99 & 712,98 & 84,27 & 35,55 & 25,45 & 224,98 & 122,59 & 192,38 & 122,59 \\
\hline Bufo spinosus & 31TCG66 & 100,00 & 100,32 & 85,03 & 34, & 5725,60 & 237,58 & 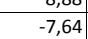 & $\begin{array}{l}245,22 \\
245\end{array}$ & \begin{tabular}{|l|}
116,90 \\
\end{tabular} & $\begin{array}{l}30,95 \\
30,95\end{array}$ & 175,84 & \begin{tabular}{|l|l|}
30,66 \\
\end{tabular} & 843,93 & 97,14 & $\begin{array}{l}46,30 \\
46,\end{array}$ & 22,37 & 260,39 & 155,95 & 225,38 & 155,97 \\
\hline \begin{tabular}{|l} 
Bufo spinosus \\
\end{tabular} & 31TCG67 & 100,00 & 99,70 & 85,67 & 34,39 & 5726,07 & 237,23 & $-8,64$ & $\begin{array}{ll}245,87 \\
\end{array}$ & 116,54 & 30,30 & 175,10 & 29,84 & 851,07 & 97,52 & 47,29 & 22,18 & 262,35 & 158,57 & 229,13 & 158,57 \\
\hline Bufo spinosus & 31TCG70 & 100,00 & 134,73 & 80,03 & 33,31 & 5606,56 & 263,71 & 27,21 & 236,49 & 179,06 & 66,32 & 208,80 & 66,32 & 653,16 & 74,56 & 32,30 & 24,83 & 199,86 & 121,51 & 162,07 & 121,51 \\
\hline Bufo spinosus & 31TCG71 & 101,00 & 127,45 & 81,27 & 33,46 & 5665,09 & 259,12 & 19,54 & 239,58 & 161,52 & 58,44 & 202,31 & 58,44 & 687,89 & 79,31 & 35,96 & 24,35 & 207,74 & 124,61 & 174,50 & 124,61 \\
\hline Bufo spinosus & 31 TCG72 & 101,00 & 126,24 & 82,42 & 33,64 & 5699,56 & 259,27 & 17,33 & 241,95 & 142,78 & 56,45 & 201,25 & 56,45 & 694,37 & 81,27 & 35,29 & 24,88 & 212,50 & 122,24 & 180,40 & 122,24 \\
\hline \begin{tabular}{|l} 
Bufo spinosus \\
\end{tabular} & \begin{tabular}{|l|l|l|l|l|l|}
31 TCG6 \\
\end{tabular} & $\begin{array}{l}101,00 \\
101\end{array}$ & $\frac{120}{82}$ & $\begin{array}{l}8,424 \\
80,14\end{array}$ & 33,4 & 5598,00 & $\begin{array}{l}25,216 \\
216,28 \\
\end{array}$ & \begin{tabular}{|c|c|c|}
$-20,41$ \\
\end{tabular} & \begin{tabular}{|l|}
236,68 \\
236
\end{tabular} & 95,78 & 19,20 & 157,11 & 15,95 & 964,72 & 108,32 & 56,96 & 19,15 & 286,27 & 192,24 & 241,99 & 192,74 \\
\hline Bufo spinosus & 31TCG77 & 100,00 & 69,87 & 78,66 & 33,21 & 5544,47 & 203,01 & $\begin{array}{l}-30,74 \\
\end{array}$ & 233,75 & 82,42 & 22,81 & 144,45 & 4,99 & 1048,60 & 115,51 & 64,47 & 17,03 & 305,64 & 217,30 & 255,84 & 219,13 \\
\hline Bufo spinosus & 31TCG78 & 101,00 & 85,85 & 82,15 & 33,85 & 5619,35 & 220,94 & $-18,18$ & 239,12 & 100,67 & 23,43 & 160,50 & 18,55 & \begin{tabular}{|l|l|}
949,62 \\
\end{tabular} & 106,95 & 56,21 & $\mid 19,49$ & 285,60 & 186,85 & 246,24 & 187,27 \\
\hline Bufo spinosus & 31TCG79 & 93,00 & 84,65 & 82,50 & 33,99 & 5614,10 & 219,73 & $-19,88$ & 239,61 & 99,70 & 26,61 & 159,09 & 17,16 & 961,84 & 107,81 & 57,50 & 19,35 & 288,82 & 191,07 & 250,67 & 192,28 \\
\hline Bufo spinosus & 31 TCG80 & 100,00 & 142,39 & 77,58 & 33,01 & 5522,76 & 268,04 & 36,43 & 231,61 & 182,38 & 74,93 & 215,34 & 74,93 & 629,71 & 73,18 & 30,88 & 25,36 & 197,39 & 117,18 & 157,80 & 117 \\
\hline \begin{tabular}{|l} 
Bufo spinosus \\
\end{tabular} & \begin{tabular}{|l|l|l|l|l}
31 TCG81 \\
\end{tabular} & $\begin{array}{l}100,00 \\
100\end{array}$ & $\begin{array}{l}14,59 \\
127,46\end{array}$ & $\begin{array}{l}71,00 \\
79,08\end{array}$ & $\begin{array}{l}3,01 \\
33,01\end{array}$ & 5607,84 & $\begin{array}{l}20,0404 \\
257,22\end{array}$ & $20,43 \mid$ & \begin{tabular}{|l|}
235,91 \\
235
\end{tabular} & 169,23 & 59,53 & 201,81 & 59,53 & 699,47 & 80,66 & 36,45 & 24,19 & 211,40 & 126,42 & $\begin{array}{ll}179,08 \\
\end{array}$ & 126,42 \\
\hline Bufo spinosus & 31TCG84 & 101,00 & 127,57 & 82,38 & 33,35 & 5708,55 & 260,98 & 18,27 & 242,71 & 144,95 & 57,26 & 202,28 & 57,26 & 702,92 & 84,28 & 32,92 & 27,02 & 222,55 & $\mid 115,79$ & $\mid$\begin{tabular}{|l|l|}
193,19 \\
\end{tabular} & 1115,79 \\
\hline Bufo spinosus & 31TCG86 & 101,00 & 95,66 & 80,92 & 33,60 & 5627,15 & 229,94 & $-8,22$ & 238,16 & 110,43 & 29,12 & 170,56 & 28,44 & 882,62 & 101,85 & 48,92 & 21,74 & 269,03 & 164,82 & 231,88 & 164,88 \\
\hline Bufo spinosus & 31TCG87 & 99,00 & 67,24 & 77,10 & 32,93 & 5503,48 & 199,44 & $-31,32$ & 230,76 & 78,97 & $13, \mathrm{c}$ & 141, & 3, & 1068,36 & 117,04 & 67,59 & 16 & 307,45 & 224,74 & 256,98 & 226 \\
\hline Bufo spinosus & 31TCG88 & 100,00 & 63,33 & 76,98 & 32,89 & 5497,30 & 195,29 & $-35,57$ & 230,86 & 73,67 & 28,23 & 137,52 & $-0,41$ & 1098,87 & 119,62 & 68,98 & 15,87 & 316,04 & 231,11 & 263,61 & 235,88 \\
\hline
\end{tabular}




\begin{tabular}{|c|c|c|c|c|c|c|c|c|c|c|c|c|c|c|c|c|c|c|c|c|c|}
\hline TAXON & UTM & $\mathrm{km} 2$ & B101 & B1O2 & BIO3 & B104 & BIO5 & B106 & B107 & B108 & 8109 & B1010 & BIO11 & BIO12 & BIO13 & BIO14 & BIO15 & B1016 & B1017 & B1018 & B1019 \\
\hline Bufo spinosus & 31TCG89 & 99,00 & 66,22 & 77,80 & 33,05 & 5506,40 & 198,47 & $-33,72$ & 232,19 & 78,52 & 20,48 & 140,17 & 1,86 & 1083,69 & 118,31 & 67,99 & 16,35 & 313,94 & 227,60 & 264,52 & 231,28 \\
\hline \begin{tabular}{|l|} 
Bufo spinosus \\
\end{tabular} & 31TCG90 & 101,00 & 136,36 & 75,89 & 32,62 & 5509,64 & 261,97 & 32,01 & 229,96 & 171,63 & 69,87 & 209,50 & 69,87 & 671,94 & 76,56 & 34,14 & 24,21 & 207,62 & 126,49 & 167,94 & 126,49 \\
\hline \begin{tabular}{|l} 
Bufo spinosus \\
\end{tabular} & 31TCG95 & 101,00 & 111,81 & 80,22 & 33,02 & 5654,02 & 244,94 & $\begin{array}{l}2,04 \\
6,04\end{array}$ & 238,90 & 127,50 & 43,42 & 186,65 & 43,42 & 788,95 & 94,18 & 39,23 & 25,53 & 246,95 & 135,20 & 217,09 & 135,20 \\
\hline Bufo spinosus & 31TCG96 & 101,00 & 83,33 & 77,80 & 32,93 & 5542,42 & 215,76 & $-16,57$ & 232,33 & 95,44 & 20,50 & 157,85 & 18,52 & \begin{tabular}{|l|l|}
965,67 \\
\end{tabular} & 108,47 & 57,35 & 18,90 & 283,52 & 192,36 & 241,41 & 193,01 \\
\hline Bufo spinosus & 31TCG97 & 100,00 & 71,85 & 76,80 & \begin{tabular}{|l|l|}
32,78 \\
\end{tabular} & 5500,74 & 203,82 & $-26,53$ & 230,35 & 81,58 & 21,96 & 146,11 & 8,09 & 1042,29 & $\begin{array}{l}114,65 \\
\end{array}$ & 64,51 & 16,80 & 300,67 & 216,33 & 253,16 & 218,34 \\
\hline Bufo spinosus & 31TCG98 & 101,00 & 64,66 & 76,27 & 32,77 & 5478,46 & 196,19 & $-33,27$ & 229,46 & 73,71 & 26,64 & 138,66 & 1,43 & 1092,72 & 118,86 & 68,90 & 15,71 & 312,52 & 231,01 & 261,60 & 235,04 \\
\hline Bufo spinosus & 31TCG99 & 99,00 & 73,05 & 78,05 & 33,11 & 5513,07 & 205,46 & $-26,95$ & 232,41 & 85,52 & 20,57 & 146,93 & 8,37 & 1043,01 & 114,88 & 64,81 & 16,92 & 303,95 & 215,59 & 257,31 & 218,58 \\
\hline Bufo spinosus & 31TCH02 & 95,00 & 16,76 & 72,03 & 31,69 & 5314,50 & 142,11 & $-81,48$ & 223,59 & 25,51 & 72,44 & 88,96 & $-44,56$ & 1402,13 & 146,60 & 93,52 & 12,24 & 394,75 & 310,47 & 310,92 & 335,91 \\
\hline Bufo spinosus & $31 \mathrm{TCH} 10$ & 101,00 & 70,82 & 86,96 & 35,20 & 5577,10 & 206,95 & $-36,13$ & 243,08 & 86,42 & 10,36 & 144,48 & 2,97 & 1077,72 & 114,90 & 70,09 & 15,04 & 313,38 & 233,40 & 262,96 & 234,27 \\
\hline Bufo spinosus & 31TCH11 & 99,00 & 40,14 & 78,04 & 33,24 & 5413,46 & 169,87 & $-60,88$ & 230,75 & 51,68 & 42,97 & 112,88 & $-23,66$ & 1250,71 & 132,46 & 83,15 & 13,13 & 357,02 & 278,78 & 286,50 & 287,67 \\
\hline $\begin{array}{l}\text { Bufo spinosus } \\
\end{array}$ & 31TCH12 & 99,00 & 35,17 & 76,66 & 32,96 & 5377,96 & 163,51 & $-65,17$ & 228,68 & 46,14 & 49,97 & 107,55 & $-28,01$ & 1292,35 & 136,01 & 86,41 & 12,75 & 367,07 & 288,25 & 293,91 & 301,36 \\
\hline \begin{tabular}{|l|} 
Bufo spinosus \\
\end{tabular} & 31TCH13 & & & & & & & & & & & & & & & & & & & & \\
\hline Bufo spinosus & $31 \mathrm{TCH} 20$ & 99,00 & 29,54 & 74,46 & 32,24 & 5393,53 & $\begin{array}{ll}158,03 \\
\end{array}$ & $-69,34$ & 227,37 & 39,43 & 54,78 & 102,71 & $-32,76$ & \begin{tabular}{|l|}
1309,39 \\
\end{tabular} & \begin{tabular}{|l|l|}
138,61 \\
\end{tabular} & 86,76 & 12,76 & 371,32 & 291,52 & 295,71 & 303,96 \\
\hline Bufo spinosus & 31TCH21 & 100,00 & 28,59 & 74,34 & 32,22 & 5380,76 & 156,52 & $-70,36$ & 226,89 & 38,52 & 49,77 & 101,43 & $-33,76$ & 1327,84 & 139,92 & 88,51 & 12,64 & 375,89 & 294,86 & 300,09 & 310,24 \\
\hline Bufo spinosus & $31 \mathrm{TCH} 22$ & 100,00 & 36,77 & 76,64 & 32,94 & 5390,09 & 165,55 & $-63,34$ & 228,89 & 47,95 & 40,53 & 109,38 & $-26,45$ & 1286,02 & 135,51 & 86,24 & 12,79 & \begin{tabular}{|l|l|}
365,47 \\
\end{tabular} & 286,99 & 294,17 & 298,24 \\
\hline Bufo spinosus & $31 \mathrm{TCH} 23$ & 101,00 & 39,35 & 77,48 & 33,21 & 5379,69 & 168,15 & $-61,19$ & 229,34 & 50,94 & 43,30 & 111,59 & $-24,16$ & $\begin{array}{ll}1278,98 \\
\end{array}$ & 134,37 & 86,22 & 12,74 & 363,34 & 286,52 & 294,29 & 297,12 \\
\hline \begin{tabular}{|l|} 
Bufo spinosus \\
\end{tabular} & $31 \mathrm{TCH} 30$ & 101,00 & 34,97 & 75,26 & 32,50 & 5415,06 & 164,19 & $-64,10$ & 228,29 & 45,33 & 41,12 & 108,31 & $-27,73$ & 1280,86 & 135,90 & 84,92 & 13,07 & 364,04 & 284,49 & 292,27 & 294,25 \\
\hline Bufo spinosus & 31TCH31 & 101,00 & 16,34 & 70,81 & 31,23 & 5342,24 & 142,52 & $-80,45$ & 222,97 & 24,73 & 73,74 & 89,29 & $-44,29$ & $\begin{array}{l}1407,13 \\
\end{array}$ & 147,27 & 93,70 & 12,09 & 394,26 & 312,75 & 313,65 & 334,46 \\
\hline Bufo spinosus & 31TCH32 & 100,00 & 30,59 & 74,37 & 32,30 & 5365,39 & 158,33 & $-67,99$ & 226,33 & 40,75 & 55,22 & 103,22 & $-31,65$ & \begin{tabular}{|l|}
1322,80 \\
\end{tabular} & 139,29 & 88,89 & 12,41 & $\mid 374,10$ & 296,83 & 300,48 & 308,79 \\
\hline Bufo spinosus & 31TCH33 & 94,00 & 28,42 & 73,96 & 32,25 & 5346,24 & 155,51 & $-70,03$ & 225,54 & 38,52 & 56,33 & 100,74 & $-33,62$ & \begin{tabular}{|l|}
1344,27 \\
\end{tabular} & 140,94 & 90,78 & 12,19 & 379,09 & 302,24 & 304,95 & 316,39 \\
\hline Bufo spinosus & $31 \mathrm{TCH} 41$ & 100,00 & 63,26 & 81,99 & 34,13 & 5523,37 & 196,65 & $-40,04$ & 236,68 & 77,13 & 9,88 & 136,79 & $-2,89$ & 1124,23 & 120,96 & 73,64 & 14,88 & 327,29 & 242,00 & 272,27 & 244,91 \\
\hline \begin{tabular}{|l} 
Bufo spinosus \\
\end{tabular} & 31TCH42 & 100,00 & 53,73 & 80,04 & 33,75 & 5467,77 & 185,45 & $-48,06$ & 233,50 & 66,64 & 18,61 & 126,77 & $-11,23$ & 1190,48 & 126,61 & 79,35 & 13,87 & 342,55 & 260,50 & 283,88 & 266,82 \\
\hline Bufo spinosus & 31TCH51 & 101,00 & 67,54 & 82,16 & 34,13 & 5539,02 & 201,42 & $-35,78$ & 237,21 & 81,70 & 15,01 & 141,19 & 1,18 & 1094,70 & 118,56 & 70,96 & 15,47 & 320,44 & 232,44 & 270,99 & 235,29 \\
\hline Bufo spinosus & 31TCH53 & 13,00 & 58,38 & 80,89 & \begin{tabular}{|l|l|}
33,87 \\
\end{tabular} & 5485,23 & $\begin{array}{l}190,67 \\
\end{array}$ & $-44,20$ & 234,88 & 71,88 & 29,31 & 131,43 & $-7,10$ & \begin{tabular}{|l|}
1166,48 \\
\end{tabular} & 124,06 & 77,42 & 14,06 & 336,38 & 253,41 & 282,39 & 261,69 \\
\hline Bufo spinosus & $31 \mathrm{TCH} 61$ & 101,00 & 43,72 & 75,90 & 32,65 & 5428,46 & 173,92 & $-55,01$ & 228,93 & 54,61 & 25,73 & 117,07 & $-19,20$ & 1239,91 & 131,77 & 82,07 & 13,39 & 352,25 & 272,38 & 289,12 & 281,41 \\
\hline \begin{tabular}{|l|} 
Bufo spinosus \\
\end{tabular} & 31TCH62 & 86,00 & 25,43 & 72,18 & 31,67 & 5356,26 & 153,02 & $\begin{array}{l}-71,17 \\
\end{array}$ & 224,19 & 34,47 & 52,42 & 98,35 & $-35,47$ & \begin{tabular}{l|}
1362,91 \\
\end{tabular} & 142,62 & 91,10 & 12,01 & 380,74 & 303,49 & 308,27 & 321,17 \\
\hline Bufo spinosus & 31TCH71 & 16,00 & 42,06 & 74,86 & 32,44 & 5413,72 & 171,80 & $-55,63$ & 227,43 & 52,47 & 31,98 & 115,36 & $-20,23$ & \begin{tabular}{|l|}
1250,03 \\
\end{tabular} & $\mid 132,67$ & 82,76 & 13,23 & 353,38 & 273,94 & 289,90 & 285,08 \\
\hline Bufo spinosus & $31 \mathrm{TCH72}$ & 2,00 & 31,13 & 72,90 & 31,93 & 5365,65 & 159,33 & $-65,51$ & 224,84 & 40,46 & 47,63 & 104,04 & $-30,04$ & $\begin{array}{l}1324,96 \\
\end{array}$ & 139,04 & 88,49 & 12,24 & 370,43 & 295,28 & 301,96 & 309,85 \\
\hline Bufo spinosus & 31TCH9O & 57,00 & 22,38 & 69,87 & 31,00 & 5348,90 & 149,96 & $-71,69$ & 221,65 & 20,28 & 76,64 & 95,73 & $-36,89$ & $\begin{array}{l}1376,73 \\
\end{array}$ & 142,64 & 89,22 & 12,14 & 377,34 & 303,91 & 305,72 & 327,94 \\
\hline Bufo spinosus & 31TDF06 & 37,00 & 157,68 & 70,70 & \begin{tabular}{|l|l|}
32,57 \\
\end{tabular} & 5176,48 & 272,55 & 58,09 & 214,45 & 168,68 & 224,93 & 226,84 & 95,61 & 632,00 & 88,07 & 24,34 & 30,05 & 222,25 & 117,84 & 148,61 & 131,50 \\
\hline Bufo spinosus & 31TDF07 & 100,00 & 148,43 & 71,25 & 32,08 & 5291,64 & 266,58 & 48,21 & 218,37 & 159,33 & 217,47 & 219,19 & 85,31 & 668,64 & 85,49 & 27,15 & 27,00 & 223,53 & 127,41 & 155,86 & 139,43 \\
\hline Bufo spinosus & 31TDF08 & 101,00 & 149,24 & 72,06 & 32,09 & 5339,18 & 268,69 & 47,90 & 220,79 & 159,90 & 173,09 & 220,30 & 85,04 & 650,99 & 81,38 & 28,46 & 26,38 & 215,60 & 128,65 & 156,33 & 131,18 \\
\hline Bufo spinosus & 31TDF09 & 100,00 & 157,57 & 73,07 & 32,23 & 5337,48 & 276,76 & 54,45 & 222,32 & 168,05 & 93,54 & 228,09 & 92,38 & 597,40 & 76,89 & 27,83 & 27,82 & 201,93 & 114,38 & 150,33 & 114,39 \\
\hline Bufo spinosus & 31TDF16 & & & & & & & & & & & & & & & & & & & & \\
\hline Bufo spinosus & 31TDF17 & 101,00 & 160,92 & 70,50 & 32,28 & 5174,62 & 276,34 & 61,01 & 215,33 & 171,39 & 221,88 & 229,63 & 98,42 & $\begin{array}{l}629,25 \\
\end{array}$ & 90,08 & 24,99 & 31,01 & 224,52 & 120,14 & 150,01 & 129,05 \\
\hline \begin{tabular}{|l} 
Bufo spinosus \\
\end{tabular} & 31TDF18 & 99,00 & 160,91 & 71,10 & 32,03 & 5239,75 & 277,92 & 59,79 & 218,13 & 171,23 & 130,82 & 230,38 & 97,46 & 609,35 & 84,18 & 26,58 & 29,69 & 213,79 & 118,71 & 150,19 & 120,98 \\
\hline Bufo spinosus & 31TDF27 & 85,00 & 166,22 & 70,16 & \begin{tabular}{|l|l|}
32,17 \\
\end{tabular} & 5089,19 & 280,30 & 66,64 & 213,66 & 176,56 & 218,22 & 233,41 & 104,49 & 618,62 & 94,89 & 23,92 & 33,86 & 229,10 & 117,70 & 148,27 & 125,51 \\
\hline Bufo spinosus & 31TDF28 & 101,00 & 158,99 & 70,16 & 31,69 & 5227,88 & 276,22 & 58,85 & 217,37 & 169,24 & 158,51 & 228,43 & 95,97 & 626,99 & 86,51 & 27,97 & 28,92 & 218,95 & 124,19 & 154,23 & 126,40 \\
\hline Bufo spinosus & 31TDF29 & 101,00 & 159,89 & 70,96 & 31,86 & 5280,03 & 278,34 & 58,46 & 219,88 & 175,16 & 99,82 & 229,64 & 95,80 & \begin{tabular}{|l|l|}
601,07 \\
\end{tabular} & 80,09 & 29,35 & 28,43 & 206,58 & 115,70 & 153,82 & $\begin{array}{ll}116,03 \\
\end{array}$ \\
\hline Bufo spinosus & 31TDF38 & 52,00 & 163,90 & 70,18 & \begin{tabular}{|l|l|}
32,17 \\
\end{tabular} & 5079,68 & 278,78 & 64,25 & 214,53 & 174,00 & \begin{tabular}{|l|l|}
199,54 \\
\end{tabular} & 230,92 & 102,04 & 607,25 & 90,54 & 25,82 & 32,14 & 220,47 & 117,99 & 149,53 & 122,51 \\
\hline \begin{tabular}{|l} 
Bufo spinosus \\
\end{tabular} & \begin{tabular}{|l|l|}
$31 T D F 39$ \\
\end{tabular} & 99,00 & 159,05 & 70,45 & 31,72 & 5221,53 & 276,62 & 58,24 & 218,38 & 169,22 & 122,48 & 227,97 & 年 & 625,82 & 85,89 & 29,41 & 28,45 & 215,99 & 124,66 & 157,10 & 125,50 \\
\hline Bufo spinosus & 31TDF49 & 74,00 & 155,34 & 69,84 & 31,34 & 5248,01 & 273,44 & 54,54 & 218,91 & 166,02 & 191,46 & 224,66 & 91,70 & 669,03 & 91,23 & 31,05 & 27,32 & 226,69 & 133,39 & 164,11 & 139,00 \\
\hline Bufo spinosus & 31TDF59 & 14,00 & 161,65 & 69,94 & 31,41 & 5210,88 & 278,76 & \begin{tabular}{|c|}
60,24 \\
\end{tabular} & 218,53 & 171,76 & 216,00 & 230,12 & 98,29 & 649,65 & 96,41 & 27,29 & 30,94 & 228,76 & 121,53 & 155,41 & 138,59 \\
\hline Bufo spinosus & 31TDG01 & 101,00 & 148,37 & 75,39 & 32,3 & 5488,51 & 272,64 & 43,17 & 22 & 196,91 & 81,18 & 220,65 & 81,18 & 613,92 & 72,77 & 32,55 & 25,69 & 197,42 & 109,00 & 62,21 & 109,00 \\
\hline Bufo spinosus & 31TDG02 & 101,00 & 146,68 & 76,64 & 32,4 & 5543,49 & 272,71 & 40,25 & 232,46 & $\begin{array}{ll}195,43 \\
\end{array}$ & 78,39 & 219,41 & 78,39 & 612,12 & 72,23 & 31,38 & 26,17 & $\mid 196,17$ & 103,62 & 166,15 & 103,62 \\
\hline \begin{tabular}{|l} 
Bufo spinosus \\
\end{tabular} & 31TDG03 & 100,00 & 138,99 & 77,70 & 32,62 & 5595,96 & 267,33 & 32,06 & 235,27 & 185,64 & 70,21 & 212,47 & 70,21 & \begin{tabular}{|l|l|}
646,98 \\
\end{tabular} & 76,68 & 31,46 & 26,92 & 203,51 & $\begin{array}{l}105,68 \\
\end{array}$ & $\begin{array}{l}179,85 \\
\end{array}$ & 105,68 \\
\hline Bufo spinosus & 31TDG04 & 100,00 & 133,54 & 78,74 & 32,86 & 5641,89 & 263,69 & 26,12 & 237,57 & 158,12 & 64,30 & 207,59 & 64,30 & 674,76 & 81,50 & 31,44 & 27,99 & 212,37 & 107,54 & 190,92 & 107,54 \\
\hline Bufo spinosus & 31TDG05 & 100,00 & 127,55 & 79,61 & $|32.97|$ & 5659,60 & 259,13 & 19,95 & 239,18 & 144,45 & 58,10 & $\mid 201,78$ & 58,10 & 706,09 & 86,06 & 32,36 & 28,71 & 225,31 & 111,86 & 203,49 & 111,86 \\
\hline Bufo spinosus & 31TDG06 & 100,00 & 106,21 & 79,00 & 32,99 & 5609,13 & 238,65 & 2,26 & 236,39 & 121,23 & 39,69 & 180,73 & 38,92 & 829,94 & 97,73 & 43,36 & 24,43 & 55,93 & 47,61 & 25,40 & 147,75 \\
\hline Bufo spinosus & 31TDG07 & $101, \mathrm{C}$ & 97,75 & 79,2 & $33, \mathrm{C}$ & 5585,81 & 230,65 & $-4,96$ & 235,61 & 112,18 & 32,50 & 17 & 31,12 & 884,39 & 102,25 & 48, & 21,83 & 99 & 165,19 & 234,06 & 165,33 \\
\hline Bufo spinosus & 31TDG08 & 101,00 & 67,80 & 75,83 & $\begin{array}{l}32,65 \\
\end{array}$ & 5466,88 & 199,08 & $-29,52$ & 228,60 & 74,25 & 25,33 & 141,74 & 4,84 & \begin{tabular}{|l|}
1075,86 \\
\end{tabular} & 116,99 & 67,49 & 15,94 & 307,24 & 226,72 & 258,04 & 230,88 \\
\hline \begin{tabular}{|l|} 
Bufo spinosus \\
\end{tabular} & 31TDG09 & 101,00 & 88,07 & 79,57 & 33,42 & 5552,21 & 221,40 & $-13,35$ & 234,75 & 102,11 & 28,74 & 162,03 & 22,14 & 952,05 & 107,28 & 56,50 & 18,73 & 284,35 & 188,33 & 243,10 & 189,54 \\
\hline Bufo spinosus & 31TDG10 & 100,00 & 143,65 & 72,82 & 31,99 & 5436,23 & 266,45 & 41,19 & 225,27 & 191,40 & 78,13 & 215,81 & 78,13 & \begin{tabular}{|c|}
661,58 \\
\end{tabular} & 76,92 & 35,13 & 24,44 & 210,32 & 124,08 & 170,04 & 124,08 \\
\hline Bufo spinosus & 31TDG11 & 100,00 & 130,92 & 73,96 & 32,00 & 5506,36 & 256,72 & 28,36 & 228,36 & 179,89 & 64,96 & 20 & 64,96 & 711,82 & 81,20 & 37,69 & 23,64 & 30 & 129,34 & 87,13 & 129,34 \\
\hline \begin{tabular}{|l} 
Bufo spinosus \\
\end{tabular} & 31TDG12 & 101,00 & 138,82 & 74,97 & 31,99 & 5534,36 & 264,97 & 34,06 & 230,90 & 187,60 & 71,46 & 211,89 & 71,46 & 664,54 & 77,32 & 33,73 & 25,52 & 209,84 & 113,45 & 180,96 & 113,45 \\
\hline Bufo spinosus & 31TDG14 & 101,00 & 129,63 & 76,99 & 32,13 & 5603,61 & 258,87 & 23,76 & 235,10 & 155,03 & 61,35 & 203,38 & 61,35 & 702,44 & 85,59 & 32,35 & 28,71 & 221,47 & 111,01 & 202,88 & 111,01 \\
\hline Bufo spinosus & 31TDG15 & 101,00 & $\mid 123,04$ & 77,90 & 32,41 & 5614,28 & 253,69 & 17,34 & 236,35 & 138,98 & 54,84 & \begin{tabular}{|l|l|}
197,03 \\
\end{tabular} & 54,84 & \begin{tabular}{|l|l|}
734,72 \\
\end{tabular} & 89,87 & 33,72 & 28,82 & 233,69 & \begin{tabular}{|l|l|}
116,68 \\
\end{tabular} & 213,33 & 116,68 \\
\hline Bufo spinosus & 31TDG16 & 100,00 & 109,61 & 78,14 & 32,94 & 5594,27 & 241,39 & 5,90 & 35,49 & 124,73 & 42,68 & 183,93 & 42,52 & 816,30 & 97,07 & 41,02 & 25,05 & 253,79 & 141,82 & 225,21 & 141,82 \\
\hline Bufo spinosus & 31TDG17 & 100,00 & 92,30 & 77,43 & 32, & 5530,63 & 224,15 & $-7,93$ & 232 & 105,48 & 30,03 & 166 & 27,32 & 927,47 & 105,12 & 53,59 & 19,78 & & 180,58 & 237,38 & 18 \\
\hline \begin{tabular}{|l} 
Bufo spinosus \\
\end{tabular} & 31TDG18 & 98,00 & 62,33 & 74,21 & 32,38 & 5421,81 & $\begin{array}{l}292,68 \\
\end{array}$ & $-33,11$ & 225,79 & $\begin{array}{l}60,52 \\
60,40\end{array}$ & 21,32 & $\begin{array}{l}135,92 \\
\end{array}$ & 0,71 & 1113,96 & 119,15 & 70,54 & 14,95 & 312,34 & 240,85 & 260,57 & 245,94 \\
\hline
\end{tabular}




\begin{tabular}{|c|c|c|c|c|c|c|c|c|c|c|c|c|c|c|c|c|c|c|c|c|c|}
\hline TAXON & UTM & $\mathrm{km} 2$ & B101 & B102 & $\mathrm{BIO3}$ & B104 & BIO5 & B106 & B107 & B108 & B109 & BIO10 & BIO11 & BIO12 & B1013 & BIO14 & BIO15 & BIO16 & B1017 & BIO18 & B1019 \\
\hline Bufo spinosus & 31TDG19 & 44,00 & 74,09 & 76,62 & 32,84 & 5468,72 & 205,63 & $-23,84$ & 229,47 & 82,36 & 21,98 & 147,66 & 10,64 & 1044,01 & 113,79 & 65,48 & 16,03 & 299,40 & 218,83 & 252,53 & 222,53 \\
\hline Bufo spinosus & 31TDG20 & 100,00 & 152,94 & 71,68 & 31,71 & 5379,99 & 273,79 & 50,50 & 223,29 & 200,40 & 87,61 & 223,95 & 87,61 & 634,60 & 77,02 & 33,88 & 25,47 & 208,06 & 119,64 & 165,13 & 119,64 \\
\hline Bufo spinosus & 31TDG21 & 101,00 & 134,01 & 72,64 & 31,69 & 5474,85 & 258,67 & 31,96 & 226,71 & 182,80 & 68,49 & 206,92 & 68,49 & 718,32 & 81,31 & 38,66 & 23,28 & 224,13 & 132,51 & 188,93 & 132,51 \\
\hline Bufo spinosus & 31TDG22 & 99,00 & 125,49 & 73,69 & 31,92 & 5511,67 & 252,13 & 23,39 & 228,73 & 174,44 & 59,73 & 198,87 & 59,73 & 746,68 & 87,10 & 38,10 & 23,96 & 229,79 & 133,40 & 201,19 & 133,40 \\
\hline Bufo spinosus & 31TDG23 & 101,00 & 120,63 & 74,58 & 32,00 & 5523,95 & 248,55 & 18,30 & 230,24 & 167,35 & 54,73 & 194,10 & 54,73 & 769,68 & 90,82 & \begin{tabular}{|l|}
38,58 \\
\end{tabular} & 24,64 & 234,97 & 134,90 & 209,82 & 134,90 \\
\hline Bufo spinosus & 31TDG24 & 100,00 & 126,73 & 75,58 & 32,00 & 5574,07 & 255,26 & 22,19 & 233,07 & 149,77 & 59,32 & 200,34 & 59,32 & 739,43 & 89,01 & 34,71 & 27,42 & 230,37 & 121,26 & 210,88 & 121,26 \\
\hline Bufo spinosus & 31TDG25 & 100,00 & 120,53 & 76,48 & 32,00 & 5584,37 & 250,26 & 15,99 & 234,26 & 135,76 & 53,10 & 194,30 & 53,10 & 770,56 & 92,84 & 36,19 & 27,23 & 241,75 & 127,33 & 219,72 & 127,33 \\
\hline \begin{tabular}{|l} 
Bufo spinosus \\
\end{tabular} & 31TDG26 & 101,00 & 110,29 & 77,01 & 32,33 & 5569,27 & 241,08 & $\begin{array}{l}7,03 \\
7,5\end{array}$ & 234,05 & 124,80 & 43,82 & 184,24 & 43,67 & 832,47 & 97,84 & 42,19 & 24,08 & 256,10 & 147,86 & 225,80 & 147,86 \\
\hline Bufo spinosus & 31TDG27 & 101,00 & 99,41 & 77,17 & 32,82 & 5532,74 & 230,85 & $-1,67$ & 232,51 & 113,10 & 36,06 & 173,24 & 34,05 & 897,92 & 102,41 & 49,96 & 20,58 & 268,64 & 171,64 & 232,58 & 171,86 \\
\hline Bufo spinosus & 31TDG28 & 100,00 & 71,10 & 74,64 & 32,52 & 5429,70 & 201,55 & $-24,87$ & 226,41 & 71,42 & 28,10 & 144,59 & 9,08 & 1066,16 & 114,64 & 66,61 & 15,65 & 301,19 & 226,87 & 252,25 & 231,73 \\
\hline Bufo spinosus & 31TDG30 & 100,00 & 157,83 & 71,01 & 31,53 & 5300,33 & 277,10 & 55,68 & 221,42 & 197,57 & 96,21 & 227,47 & 93,06 & 632,38 & 82,25 & 31,86 & 26,59 & 212,42 & 124,07 & 160,28 & 124,09 \\
\hline Bufo spinosus & 31TDG31 & 101,00 & 144,71 & 71,51 & 31,09 & 5430,91 & 267,32 & 42,09 & 225,23 & 192,77 & 78,92 & 216,44 & 78,92 & 701,68 & 81,71 & 38,45 & 23,28 & 223,49 & 133,61 & 182,06 & 133,61 \\
\hline \begin{tabular}{|l} 
Bufo spinosus \\
\end{tabular} & 31TDG32 & 101,00 & 126,55 & 72,56 & 31,49 & 5485,82 & 252,29 & 24,87 & 227,42 & 175,21 & 61,18 & 199,62 & 61,18 & 777,76 & 87,68 & 41,15 & 22,50 & 238,41 & 144,73 & 204,14 & 144,73 \\
\hline Bufo spinosus & 31TDG33 & 100,00 & 127,01 & 73,42 & 31,53 & 5519,44 & 253,66 & 24,32 & 229,34 & 175,75 & 60,87 & 200,29 & 60,87 & 774,75 & 89,25 & 39,24 & 23,82 & 237,88 & 138,84 & 209,39 & 138,84 \\
\hline Bufo spinosus & 31TDG34 & 101,00 & 129,94 & 74,44 & 31,72 & 5552,03 & 257,43 & 25,65 & 231,78 & 165,59 & 62,72 & 203,31 & 62,72 & 768,28 & 89,48 & \begin{tabular}{|l|l|}
36,97 \\
\end{tabular} & 25,35 & 236,62 & 132,24 & 212,86 & 132,24 \\
\hline Bufo spinosus & 31TDG35 & 100,00 & 124,92 & 75,47 & 31,97 & 5577,89 & 253,79 & 20,32 & 233,47 & 140,55 & 57,43 & 198,57 & 57,43 & 794,52 & 92,92 & 37,77 & 25,36 & 245,58 & 137,07 & 218,86 & 137,07 \\
\hline Bufo spinosus & 31TDG36 & 100,00 & 114,79 & 76,19 & 32,08 & 5563,09 & 244,76 & 11,45 & 233,31 & 130,09 & 48,35 & 188,44 & 48,04 & 837,99 & 96,99 & 42,20 & 23,51 & 256,19 & 151,28 & 225,56 & 151,35 \\
\hline Bufo spinosus & 31TDG37 & 101,00 & 107,25 & 76,76 & 32,33 & 5546,01 & 238,00 & 4,78 & 233,22 & 121,53 & 42,10 & 180,97 & 41,12 & 876,42 & 99,70 & 46,81 & 21,35 & 263,89 & 165,67 & 227,95 & 165,95 \\
\hline Bufo spinosus & 31TDG38 & 101,00 & 73,34 & 74,25 & 32,47 & 5414,20 & 203,41 & $-22,12$ & 225,52 & 68,72 & 37,31 & 146,73 & 11,69 & 1057,84 & 112,89 & \begin{tabular}{|c|}
64,87 \\
\end{tabular} & 15,93 & 300,44 & 226,13 & 248,49 & 231,54 \\
\hline Bufo spinosus & 31TDG39 & 75,00 & 30,22 & 69,10 & 30,97 & 5326,44 & 157,92 & $-61,66$ & 219,58 & 7,90 & 87,34 & 103,49 & $-27,81$ & 1327,69 & 135,14 & \begin{tabular}{|l|l|}
82,08 \\
\end{tabular} & 13,05 & 373,45 & 287,85 & 289,66 & 317,77 \\
\hline Bufo spinosus & 31TDG40 & 101,00 & 153,92 & 70,08 & 31,02 & 5322,70 & 273,35 & 51,94 & 221,41 & 184,27 & 153,09 & 224,08 & 89,16 & 686,11 & 89,72 & 33,67 & 25,24 & 226,52 & 139,44 & 169,65 & 141,06 \\
\hline \begin{tabular}{|l} 
Bufo spinosus \\
\end{tabular} & 31TDG41 & 100,00 & 143,57 & 70,61 & 31,01 & 5418,05 & 265,73 & 41,25 & 224,47 & 191,17 & 83,61 & 215,19 & 78,09 & 744,65 & 88,99 & 40,05 & 22,43 & 234,86 & 148,77 & 186,25 & 148,81 \\
\hline Bufo spinosus & 31TDG42 & 100,00 & 113,04 & 71,73 & 31,59 & 5434,21 & 238,94 & 14,74 & 224,20 & 152,19 & 57,00 & 186,19 & 49,79 & 869,95 & 97,70 & \begin{tabular}{|l|l}
48,67 \\
\end{tabular} & 20,16 & 260,21 & 174,95 & 213,02 & $\begin{array}{ll}175,78 \\
\end{array}$ \\
\hline Bufo spinosus & 31TDG43 & 101,00 & 120,79 & 72,53 & 31,36 & 5480,88 & 247,16 & 19,81 & 227,36 & 168,24 & 56,24 & 193,96 & 55,80 & 841,38 & 93,61 & 44,30 & 21,43 & 251,91 & 161,19 & 215,44 & 161,25 \\
\hline Bufo spinosus & 31TDG44 & 101,00 & 130,89 & 73,43 & 31,21 & 5539,31 & 257,59 & 26,91 & 230,68 & 168,05 & 63,87 & 204,03 & 63,87 & 819,11 & 91,15 & 40,15 & 22,82 & 246,08 & 151,03 & 214,89 & 151,03 \\
\hline Bufo spinosus & 31TDG45 & 100,00 & 123,43 & 74,48 & 31,81 & 5541,19 & 251,55 & 19,82 & 231,73 & 138,59 & 56,68 & 196,77 & 56,65 & 844,31 & 94,95 & 41,38 & 22,77 & 254,73 & 155,64 & 222,07 & 155,64 \\
\hline Bufo spinosus & 31TDG46 & 101,00 & $\begin{aligned} 98,81 \\
\end{aligned}$ & 74,53 & 32,16 & 5461,29 & 227,98 & $\begin{array}{l}0,296 \\
0,29\end{array}$ & 227,69 & $\begin{array}{l}123,23 \\
\end{array}$ & 38,16 & 172,11 & 35,25 & \begin{tabular}{|l|l|}
935,05 \\
\end{tabular} & \begin{tabular}{|l|}
102,41 \\
\end{tabular} & 54,20 & 18,70 & 269,63 & 188,71 & 229,59 & 189,68 \\
\hline Bufo spinosus & \begin{tabular}{|l|}
$31 T D G 47$ \\
\end{tabular} & 100,00 & 107,07 & 76,01 & 32,18 & 5516,90 & 237,20 & 5,42 & 231,79 & 122,12 & 43,70 & 180,49 & 41,55 & 899,99 & 99,75 & \begin{tabular}{|l|l|}
49,27 \\
\end{tabular} & 19,80 & 265,71 & 176,79 & 226,44 & 177,02 \\
\hline Bufo spinosus & 31TDG48 & 99,00 & 90,22 & 75,53 & 32,75 & 5453,60 & 220,57 & $-7,82$ & 228,39 & 99,62 & 32,26 & 163,59 & 26,84 & 975,65 & 105,37 & 59,03 & 17,02 & 278,09 & 203,11 & 234,79 & 205,54 \\
\hline Bufo spinosus & 31TDG49 & 61,00 & 55,44 & 71,98 & 31,95 & 5347,45 & 184,37 & $-37,63$ & 222,00 & 36,75 & 62,02 & 128,52 & $-4,12$ & 1168,61 & 120,65 & 72,21 & 14,13 & 328,65 & 255,93 & 262,42 & 270,85 \\
\hline Bufo spinosus & 31TDG50 & 100,00 & 149,07 & 69,41 & 30,93 & 5340,44 & 268,83 & 47,51 & 221,32 & 172,34 & 184,93 & 219,62 & 84,45 & 739,98 & 97,36 & 35,59 & 24,90 & 240,67 & 149,22 & 177,14 & 156,74 \\
\hline Bufo spinosus & 31TDG51 & 100,00 & 150,52 & $\begin{array}{l}0,149 \\
69,89\end{array}$ & 30,82 & $54+12,19$ & 271,39 & \begin{tabular}{|l|l|}
47,10 \\
\end{tabular} & \begin{tabular}{|l|l|}
224,29 \\
\end{tabular} & $\begin{array}{l}175,65 \\
172,4\end{array}$ & \begin{tabular}{|l|}
190,74 \\
\end{tabular} & \begin{tabular}{|l|}
221,70 \\
2
\end{tabular} & $\begin{array}{l}4,4,58 \\
84,5\end{array}$ & 751,99 & $\begin{array}{l}1,13 \\
97,13\end{array}$ & 37,05 & 23,69 & 241,22 & \begin{tabular}{|l|}
152,85 \\
152,5
\end{tabular} & 178,44 & 159,64 \\
\hline Bufo spinosus & 31TDG52 & 100,00 & 121,05 & 70,84 & 31,14 & 5416,66 & 245,56 & 21,77 & 223,79 & 158,67 & 73,56 & 193,60 & 57,38 & 871,94 & 101,31 & 48,10 & 20,27 & 261,90 & 179,63 & 207,94 & 181,17 \\
\hline Bufo spinosus & 31TDG53 & 101,00 & 120,29 & 71,75 & 31,31 & 5454,72 & 245,94 & 19,90 & 226,03 & 168,79 & 56,34 & 193,21 & 55,81 & 879,46 & 97,58 & 47,86 & 20,11 & 259,23 & 176,63 & 214,88 & 176,63 \\
\hline Bufo spinosus & 31TDG54 & 100,00 & 125,16 & 72,61 & 31,28 & 5493,16 & 251,46 & 22,80 & 228,67 & 159,72 & 59,79 & 198,10 & 59,49 & 882,49 & 96,36 & 45,17 & 20,85 & 259,02 & 173,86 & 217,20 & 173,90 \\
\hline Bufo spinosus & 31TDG55 & 101,00 & 112,93 & 73,61 & 31,78 & 5470,40 & 240,58 & 12,28 & 228,29 & 146,27 & 49,85 & 185,97 & 48,41 & 911,09 & 98,75 & 49,15 & 19,85 & 264,80 & 182,35 & 222,98 & 182,41 \\
\hline Bufo spinosus & 31TDG56 & 101,00 & 126,48 & 74,94 & $\frac{1,1,70}{31,73}$ & $\begin{array}{l}541,42,87 \\
5552,\end{array}$ & $\begin{array}{l}24,50 \\
254,68 \\
\end{array}$ & $\begin{array}{l}\mid L, 200 \\
21,49 \\
\end{array}$ & \begin{tabular}{|l|}
233,19 \\
23,19
\end{tabular} & \begin{tabular}{|l|}
140,273 \\
\end{tabular} & $\begin{array}{l}45,30 \\
59,32\end{array}$ & \begin{tabular}{|l|}
199,65 \\
199,5
\end{tabular} & $\begin{array}{l}40,411 \\
59,17\end{array}$ & \begin{tabular}{|l|l|}
878,35 \\
175
\end{tabular} & $\begin{array}{l}0,15 \\
94,59 \\
\end{array}$ & 年5, & $\begin{array}{l}21,03 \\
21,32\end{array}$ & 261,01 & \begin{tabular}{|l|l|}
171,38 \\
17,3
\end{tabular} & 218,56 & $\begin{array}{l}010<, 41 \\
171,39\end{array}$ \\
\hline Bufo spinosus & 31TDG57 & 100,00 & 129,29 & 76,38 & 31,96 & 5582,05 & 258,48 & 22,78 & 235,70 & 147,30 & 61,07 & 202,62 & 61,07 & 845,98 & 92,13 & 42,93 & 20,88 & 250,54 & 166,34 & 210,12 & 166,34 \\
\hline Bufo spinosus & 31TDG58 & 94,00 & 108,42 & 76,50 & 32,40 & 5508,44 & 238,70 & 6,27 & 232,44 & 122,51 & 45,63 & 181,73 & 42,94 & 909,93 & 97,99 & 51,44 & 18,50 & 263,54 & 186,08 & 220,40 & 187,06 \\
\hline Bufo spinosus & 31TDG59 & 18,00 & 90,81 & 75,95 & 32,85 & 5439,71 & 221,28 & $-7,67$ & 228,96 & 94,19 & 36,19 & 163,85 & 27,56 & 980,58 & 103,82 & 59,57 & 16,30 & 277,15 & 209,02 & 230,66 & 212,69 \\
\hline Bufo spinosus & 31TDG60 & 61,00 & 154,39 & 69,16 & 30,85 & 5341,51 & 273,27 & 51,57 & 221,70 & 165,06 & 219,98 & 224,61 & 89,12 & 727,44 & 103,91 & 31,62 & 28,39 & 244,78 & 137,27 & 168,24 & 159,08 \\
\hline Bufo spinosus & 31TDG61 & 101,00 & 146,85 & 69,27 & 30,42 & 5401,26 & 267,46 & $\begin{array}{ll}44,08 \\
\end{array}$ & 223,38 & 169,79 & 194,63 & 218,05 & 81,26 & 781,72 & 103,63 & 37,41 & 24,57 & 249,46 & \begin{tabular}{|l|}
157,06 \\
\end{tabular} & 180,94 & 168,79 \\
\hline Bufo spinosus & 31TDG62 & 101,00 & 149,18 & 69,89 & 30,11 & 5469,89 & 270,71 & 44,27 & 226,44 & 175,51 & 190,11 & 220,84 & 82,05 & 782,31 & 103,47 & 38,13 & 24,38 & 247,74 & 157,19 & 178,56 & 168,20 \\
\hline Bufo spinosus & 31TDG63 & 100,00 & 134,37 & 70,82 & 30,71 & 5472,86 & 258,25 & 31,14 & 227,11 & 182,29 & 82,49 & 206,82 & 68,42 & 864,54 & 102,08 & 45,97 & 21,14 & 257,04 & 178,28 & 202,84 & 178,94 \\
\hline Bufo spinosus & 31TDG64 & 100,00 & 133,71 & 71,88 & 30,84 & 5515,80 & 258,82 & 29,58 & 229,23 & 177,28 & 81,89 & 206,53 & 66,99 & 870,25 & 101,28 & 45,16 & 21,27 & 255,94 & 178,43 & 203,14 & 178,73 \\
\hline \begin{tabular}{|l} 
Bufo spinosus \\
\end{tabular} & 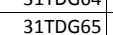 & 100,00 & $\begin{array}{ll}130, / 61 \\
134,61\end{array}$ & $\begin{array}{l}1,100 \\
73,08\end{array}$ & $\frac{30,}{31,}$ & 5543,73 & 2600,82 & 29,16 & 231,66 & 171,21 & 67,05 & 207,58 & 67,05 & 869,24 & 99,53 & 44,63 & 21,17 & 253,62 & 177,00 & 205,04 & 177,00 \\
\hline \begin{tabular}{|l} 
Bufo spinosus \\
\end{tabular} & 31TDG66 & 101,00 & 128,84 & 74,49 & 31,64 & 5531,15 & 256,26 & 23,76 & 232,50 & 153,06 & 61,83 & 201,77 & 61,83 & 877,56 & 97,45 & 45,15 & 20,81 & 255,27 & 177,86 & 209,00 & 177,86 \\
\hline Bufo spinosus & 31TDG67 & 100,00 & 137,40 & 76,11 & 31,80 & 5580,44 & 265,66 & 29,24 & 236,41 & 175,68 & 68,76 & 210,45 & 68,73 & 808,42 & 94,24 & $|42,97|$ & 21,05 & 236,38 & 165,84 & 188,53 & 165,85 \\
\hline Bufo spinosus & 31TDG68 & 86,00 & 114,42 & 76,43 & 32,34 & 5500,76 & 243,88 & 11,05 & 232,83 & 134,60 & 51,47 & 187,37 & 48,63 & 893,25 & 96,76 & 50,69 & 18,58 & 255,03 & 186,61 & 211,05 & 187,34 \\
\hline Bufo spinosus & 31TDG70 & & & & & & & & & & & & & & & & & & & & \\
\hline Bufo spinosus & 31TDG71 & 99,00 & 15 & 69,51 & 30, & 5364,56 & 275 & 52,56 & 223,14 & 167,35 & 224,72 & 227,13 & 90,86 & 711,45 & 107,54 & 29,23 & 30,94 & 243,24 & 129,62 & 160,29 & 156,59 \\
\hline Bufo spinosus & 31TDG72 & 101,00 & 154,90 & 69,47 & 30,09 & 5459,06 & 275,20 & 48,78 & 226,42 & 165,21 & 225,52 & 226,12 & 87,35 & 736,21 & 108,20 & 31,73 & 28,88 & 244,81 & 137,61 & 161,82 & 162,07 \\
\hline Bufo spinosus & 31TDG73 & 100,00 & 151,59 & 69,54 & 29,97 & 5553,31 & 273,66 & 44,30 & 229,36 & $\mid 165,46$ & 222.68 & 223,75 & 82,63 & 769,42 & 108,47 & 35,29 & 26,44 & 246,62 & 149,64 & 161,79 & 168,62 \\
\hline Bufo spinosus & 31TDG74 & 101,00 & 148,67 & 70,75 & 30,06 & 5587,62 & 272,30 & 40,82 & 231,48 & 177,15 & 209,99 & 221,44 & 79,36 & 785,67 & 106,68 & 38,35 & 24,72 & 244,16 & 159,67 & 167,53 & 169,2 \\
\hline Bufo spinosus & 31TDG75 & 101,00 & 138,71 & 72,55 & 30,92 & 5523,73 & 263,75 & 32,51 & 231,24 & 182,50 & 104 & 21 & 71,13 & 832,95 & 103,27 & 43,47 & 22,28 & 247,40 & 173,37 & 186,58 & 17 \\
\hline \begin{tabular}{|l} 
Bufo spinosus \\
\end{tabular} & 31TDG76 & 100,00 & 143,13 & 74,41 & 31,20 & 5552,16 & 269,17 & $\begin{array}{l}35,16 \\
35,\end{array}$ & 234,01 & $\begin{array}{l}185,68 \\
\end{array}$ & $\begin{array}{l}111,35 \\
\end{array}$ & 215,67 & 74,65 & 784,79 & $\begin{array}{l}99,79 \\
9\end{array}$ & \begin{tabular}{|l|l|}
41,08 \\
\end{tabular} & 22,69 & 235,03 & 163,83 & 173,85 & 164,27 \\
\hline Bufo spinosus & 31TDG77 & 100,00 & 138,85 & 75,89 & 31,95 & 5538,66 & 266,13 & 30,97 & 235,15 & 177,79 & 103,96 & 211,36 & 70,83 & 782,67 & 97,23 & 41,56 & 21,97 & 231,89 & 164,30 & 174,28 & 164,77 \\
\hline Bufo spinosus & 31TDG78 & 93,00 & 127.93 & 77,01 & 32,06 & 551400 & 256,73 & 21,64 & 235,10 & 166,72 & 73,70 & 200,46 & 60.95 & 827.53 & 96,41 & 45,54 & 20,13 & 238.31 & 175,62 & 187,78 & 175,90 \\
\hline Bufo spinosus & 31TDG79 & 46,00 & 113,70 & 77,44 & 32,85 & 5476,17 & 243,58 & 10,14 & 233,44 & 142,50 & 62,03 & 186,30 & 48, & 879,16 & 98,03 & 50,52 & 18,20 & 248,55 & 189,73 & 200,52 & 191,48 \\
\hline Bufo spinosus & 31TDG81 & 58,00 & 156,33 & 69,67 & 30,77 & 5324,65 & 274,68 & 52,23 & 222,45 & 166,76 & 221,85 & 226,11 & 91,01 & 700,06 & 108,38 & 27,85 & 32,13 & 241,39 & 125,74 & 155,80 & 153,82 \\
\hline
\end{tabular}




\begin{tabular}{|c|c|c|c|c|c|c|c|c|c|c|c|c|c|c|c|c|c|c|c|c|c|}
\hline TAXON & UTM & $\mathrm{km} 2$ & BIO1 & B102 & $B 103$ & BIO4 & B105 & B106 & B107 & B108 & B109 & B1010 & BIO11 & BIO12 & BIO13 & BIO14 & BIO15 & B1016 & B1017 & B1018 & 81019 \\
\hline Bufo spinosus & 31TDG82 & 99,00 & 151,01 & 69,29 & 30,32 & 5396,79 & 270,51 & 46,31 & 224,20 & 161,54 & 221,06 & 221,71 & 84,91 & 744,17 & 109,39 & 31,64 & 28,92 & 246,43 & 139,20 & 164,30 & 163,79 \\
\hline Bufo spinosus & 31TDG83 & 101,00 & 152,89 & 69,74 & 30,10 & 5483,13 & 273,79 & 46,21 & 227,58 & 163,03 & 223,94 & 224,33 & 85,14 & 738,58 & 109,55 & 31,46 & 29,01 & 243,75 & 137,25 & 159,43 & 163,03 \\
\hline Bufo spinosus & 31TDG84 & 101,00 & 151,60 & 71,06 & 30,56 & 5502,87 & 273,56 & 44,03 & 229,53 & 161,75 & 222,87 & 223,26 & 83,40 & 745,99 & 107,99 & 33,42 & 27,63 & 240,70 & 143,15 & $\begin{array}{l}156,73 \\
\end{array}$ & 162,27 \\
\hline Bufo spinosus & 31TDG85 & 101,00 & 151,47 & 73,02 & 31,16 & 5489,76 & 274,51 & 43,28 & 231,23 & 163,92 & 222,63 & 222,94 & 83,53 & $\begin{array}{l}727,58 \\
\end{array}$ & $\begin{array}{l}104,06 \\
\end{array}$ & 33,71 & 26,96 & 232,38 & 143,45 & \begin{tabular}{|l|l|}
154,74 \\
\end{tabular} & 155,45 \\
\hline Bufo spinosus & 31TDG86 & 100,00 & 150,17 & 74,92 & 31,76 & 5484,51 & 274,44 & 41,47 & 232,96 & 160,93 & 221,32 & 221,62 & 82,25 & 708,14 & 99,79 & 33,60 & 26,14 & 224,22 & 142,91 & 150,56 & 149,80 \\
\hline Bufo spinosus & 31TDG87 & 101,00 & 149,24 & 76,75 & 32,16 & 5487,27 & 274,86 & 39,84 & 235,02 & 160,05 & 216,56 & 220,80 & 81,28 & \begin{tabular}{|c|c|}
69,46 \\
\end{tabular} & 96,19 & \begin{tabular}{|l|l|}
32,82 \\
\end{tabular} & 25,71 & 217,65 & \begin{tabular}{|l|l|}
140,02 \\
\end{tabular} & $\mid$ & \begin{tabular}{ll|l}
146,16 \\
\end{tabular} \\
\hline Bufo spinosus & 31TDG88 & 100,00 & 145,31 & 78,30 & 32,55 & 5499,28 & 272,62 & 35,72 & 236,90 & 157,99 & 205,09 & 217,05 & 77,44 & 700,65 & 94,38 & 33,65 & 24,44 & 217,15 & 142,92 & 147,29 & 151,21 \\
\hline Bufo spinosus & 31TDG89 & 82,00 & 138,88 & 79,63 & 32,99 & 5506,15 & 267,94 & 29,75 & 238,19 & 152,98 & $\begin{array}{l}186,80 \\
\end{array}$ & 211,01 & 71,29 & $\begin{array}{l}724,75 \\
\end{array}$ & 93,55 & 35,45 & 22,99 & 219,97 & 148,58 & \begin{tabular}{ll|}
152,88 \\
\end{tabular} & 159,90 \\
\hline Bufo spinosus & 31TDG91 & & & & & & & & & & & & & & & & & & & & \\
\hline Bufo spinosus & 31TDG92 & 90,00 & $\begin{array}{lll}150,89 \\
\end{array}$ & 70,44 & 31,30 & 5265,40 & 268,98 & 47,70 & 221,29 & \begin{tabular}{ll|}
161,82 \\
\end{tabular} & 218,54 & 220,26 & 86,91 & $\begin{array}{l}712,95 \\
\end{array}$ & $\begin{array}{l}106,85 \\
\end{array}$ & 28,68 & 30,50 & 240,38 & 130,56 & $\begin{array}{l}156,86 \\
\end{array}$ & 156,52 \\
\hline Bufo spinosus & 31TDG93 & 101,00 & 149,48 & 71,06 & 31,22 & 5302,24 & 268,45 & 45,39 & 223,06 & 160,19 & 218,27 & 219,19 & 84,88 & 722,41 & $\begin{array}{l}106,15 \\
\end{array}$ & 30,10 & 29,09 & 238,99 & 135,13 & 158,25 & 157,90 \\
\hline Bufo spinosus & 31TDG94 & 101,00 & 148,97 & 72,30 & 31,68 & 5318,50 & 269,01 & 43,99 & 225,02 & 159,60 & 218,08 & 218,93 & 84,16 & $\begin{array}{l}721,56 \\
\end{array}$ & 104,28 & 31,32 & 28,05 & 234,82 & 138,13 & 157,69 & 156,27 \\
\hline Bufo spinosus & 31TDG95 & 100,00 & 155,34 & 74,30 & 32,15 & 5331,84 & 276,12 & 48,17 & 227,95 & 165,50 & 224,38 & 224,95 & 89,64 & 666,18 & $\begin{array}{l}100,65 \\
\end{array}$ & 28,02 & 29,82 & 222,45 & 124,31 & 143,50 & 143,07 \\
\hline Bufo spinosus & 31TDG96 & 101,00 & 154,32 & 76,03 & 32,57 & 5354,37 & 276,69 & 46,32 & 230,38 & $\begin{array}{l}164,47 \\
\end{array}$ & 223,78 & 224,28 & 88,29 & \begin{tabular}{ll|}
645,72 \\
\end{tabular} & $\begin{array}{l}96,88 \\
\end{array}$ & 27,87 & 29,30 & 214,89 & 123,38 & 138,33 & 136,76 \\
\hline Bufo spinosus & 31TDG97 & 101,00 & 154,91 & 77,94 & 32,98 & 5376,61 & 278,77 & 45,78 & 232,99 & 164,75 & 224,66 & 225,07 & 88,52 & $\begin{array}{l}620,55 \\
\end{array}$ & $\begin{array}{l}93,45 \\
\end{array}$ & 26,50 & 29,39 & 207,71 & 118,15 & \begin{tabular}{l|l|}
129,83 \\
\end{tabular} & 131,77 \\
\hline Bufo spinosus & 31TDG98 & 101,00 & 154,16 & 79,68 & 33,31 & 5404,67 & 279,85 & $\begin{array}{ll}43,98 \\
\end{array}$ & 235,87 & 163,77 & 224,38 & 224,69 & 87,42 & \begin{tabular}{ll|l|}
614,88 \\
\end{tabular} & 91,59 & 25,70 & 28,95 & 205,24 & $\begin{array}{ll}114,78 \\
\end{array}$ & \begin{tabular}{l|l|}
123,02 \\
\end{tabular} & 133,82 \\
\hline Bufo spinosus & 31TDG99 & 101,00 & 144,56 & 80,52 & 33,46 & 5443,28 & 272,35 & 34,86 & 237,48 & 151,97 & 215,52 & 215,81 & 77,70 & 669,90 & 92,67 & 29,61 & 25,82 & 213,72 & $\begin{array}{ll}128,84 \\
\end{array}$ & 135,24 & 149,82 \\
\hline Bufo spinosus & 31TDHOO & 28,00 & 50,10 & 74,04 & 32,22 & 5406,83 & 179,99 & $-45,96$ & 225,95 & 54,34 & 38,71 & $\mid 123,44$ & $-11,53$ & $\mid 1195,66$ & 126,85 & 77,40 & 13,68 & 334,47 & 260,85 & 277,01 & 270,95 \\
\hline Bufo spinosus & 31TDH10 & 1,00 & 66,35 & 76,06 & 32,71 & 5443,68 & 197,47 & $-31,08$ & 228,54 & 73,65 & 28,11 & 139,74 & 3,46 & $\begin{array}{l}1094,46 \\
\end{array}$ & $\begin{array}{l}117,96 \\
\end{array}$ & 69,86 & 14,97 & 310,84 & 233,85 & 260,63 & 239,64 \\
\hline Bufo spinosus & 31TDH80 & 1,00 & 143,90 & 82,12 & 33,46 & 5540,21 & 274,54 & 32,40 & 242,14 & 151,89 & 212,72 & 216,18 & 75,45 & 677,58 & $\begin{array}{l}90,55 \\
\end{array}$ & 30,60 & 24,48 & 211,47 & 130,48 & \begin{tabular}{ll|}
131,98 \\
\end{tabular} & 154,59 \\
\hline Bufo spinosus & 31TDH90 & 17,00 & 130,04 & 80,65 & 33,43 & 5452,04 & 259,87 & 22,49 & 237,38 & 1119,93 & 201,55 & 201,87 & 63,90 & $\begin{array}{l}750,58 \\
\end{array}$ & 95,23 & 35,71 & 22,82 & 229,15 & $\begin{array}{ll}150,32 \\
\end{array}$ & $\begin{array}{l}154,35 \\
\end{array}$ & 172,62 \\
\hline Bufo spinosus & 31TEG02 & 28,00 & 159,86 & 72,57 & 32,57 & 5126,33 & 275,57 & 56,43 & 219,14 & 170,95 & 218,33 & 227,33 & 97,29 & $\begin{array}{l}631,48 \\
\end{array}$ & 102,14 & 21,71 & 35,33 & 225,67 & 106,76 & \begin{tabular}{ll|}
137,62 \\
\end{tabular} & 139,43 \\
\hline Bufo spinosus & 31TEG03 & 93,00 & 153,07 & 72,72 & 32,65 & 5129,58 & 269,70 & 50,30 & 219,40 & $\mid$\begin{tabular}{|l|l|}
164,14 \\
\end{tabular} & 219,05 & 220,85 & 91,19 & 659,64 & $\mid$\begin{tabular}{|l|l|}
100,74 \\
\end{tabular} & 24,89 & 31,94 & 226,71 & $\mid 118,30$ & $\mid$\begin{tabular}{|l|l|}
144,85 \\
\end{tabular} & 143,42 \\
\hline Bufo spinosus & 31TEG04 & 100,00 & 156,39 & 74,26 & 33,10 & 5126,21 & 273,53 & 52,28 & 221,25 & 167,27 & 222,84 & 223,95 & 94,16 & 632,72 & 98,18 & 23,59 & 32,44 & 219,16 & 112,16 & 137,79 & 137,12 \\
\hline Bufo spinosus & 31TEG05 & 101,00 & 159,00 & 76,01 & 33,36 & 5156,94 & 277,61 & 53,28 & 224,33 & 169,69 & 225,81 & 226,69 & 95,95 & \begin{tabular}{ll|}
606,38 \\
\end{tabular} & 95,44 & 22,60 & 32,90 & 211,53 & 107,01 & $\begin{array}{l}130,96 \\
\end{array}$ & 130,71 \\
\hline Bufo spinosus & 31TEG06 & 97,00 & 158,23 & 77,35 & 33,63 & 5215,84 & 278,52 & 51,12 & 227,39 & 168,48 & 225,83 & 226,54 & 94,18 & 597,79 & 93,37 & 22,87 & 32,11 & 207,20 & 107,21 & 128,67 & 128,37 \\
\hline Bufo spinosus & 31TEG07 & 99,00 & 158,76 & 79,15 & 33,82 & 5266,93 & 280,93 & 50,05 & 230,89 & $\begin{array}{ll}168,66 \\
\end{array}$ & 227,07 & 227,46 & \begin{tabular}{ll|}
93,87 \\
\end{tabular} & $\begin{array}{l}582,46 \\
\end{array}$ & 91,29 & 22,05 & 32,32 & 202,72 & 103,44 & 119,33 & 126,14 \\
\hline Bufo spinosus & 31TEG08 & 101,00 & 156,38 & 80,48 & 33,99 & 5305,64 & 280,52 & 46,90 & 233,62 & 166,31 & 225,23 & 225,66 & 90,90 & $\begin{array}{l}587,55 \\
5\end{array}$ & 90,46 & 22,33 & 31,40 & 202,46 & 103,81 & $\begin{array}{l}119,66 \\
\end{array}$ & 129,73 \\
\hline Bufo spinosus & 31TEG09 & 90,00 & 144,42 & 80,68 & 33,90 & 5361,71 & 271,10 & 35,65 & 235,45 & 153,62 & 214,34 & 214,71 & 78,84 & $\begin{array}{l}656,66 \\
\end{array}$ & 92,80 & 27,31 & 27,12 & 213,79 & 121,92 & \begin{tabular}{|l|l|}
133,07 \\
\end{tabular} & 148,59 \\
\hline Bufo spinosus & 31TEG13 & 37,00 & 159,26 & 74,63 & 33,92 & 4974,95 & 273,68 & 56,92 & 216,76 & 170,61 & 210,58 & 225,08 & 99,42 & 587,89 & 94,26 & 19,53 & 35,63 & 211,92 & 100,21 & 130,21 & 126,39 \\
\hline Bufo spinosus & 31TEG14 & 82,00 & 158,10 & 75,46 & 34,12 & 4968,86 & 273,17 & 55,60 & 217,57 & $\begin{array}{l}169,46 \\
\end{array}$ & 218,00 & 223,94 & 98,45 & \begin{tabular}{|l|l|}
581,97 \\
\end{tabular} & 92,08 & 19,95 & 34,63 & 207,98 & 101,27 & 129,57 & 123,84 \\
\hline Bufo spinosus & 31TEG16 & 17,00 & 158,85 & 77,65 & 34,00 & 5097,04 & 277,38 & 53,23 & 224,15 & 169,54 & 224,85 & 225,92 & 96,69 & 576,65 & 91,23 & 20,46 & 33,62 & 204,23 & 100,58 & 125,35 & 123,88 \\
\hline Bufo spinosus & 31TEG17 & 27,00 & 152,47 & 79,42 & 34,11 & 5163,58 & 274,11 & 45,63 & 228,47 & 162,74 & 219,58 & 220,32 & 89,89 & 597,79 & 91,05 & 21,89 & 31,53 & 206,53 & 105,05 & 127,42 & 132,21 \\
\hline Bufo spinosus & 31TEG18 & 92,00 & 150,02 & 80,18 & 34,19 & 5227,00 & 273,39 & 42,56 & 230,83 & 160,23 & 218,03 & 218,70 & 86,39 & 614,06 & 91,62 & 23,13 & 30,37 & 208,97 & 108,82 & 128,38 & 137,49 \\
\hline \begin{tabular}{|l} 
Bufo spinosus \\
\end{tabular} & 31TEG19 & 30,00 & 151,89 & 82,00 & 34,39 & 5309,02 & 277,59 & 42,27 & 235,32 & 161,70 & 220,98 & 221,36 & 86,77 & 602,16 & 90,39 & 22,30 & 30,66 & 205,52 & $\begin{array}{ll}104,05 \\
\end{array}$ & 120,39 & 137,52 \\
\hline Bufo spinosus & 31TEG27 & & & & & & & & & & & & & & & & & & & & \\
\hline Bufo spinosus & 31TEG28 & 31,00 & 152,98 & \begin{tabular}{l|l}
80,93 \\
\end{tabular} & 34,83 & 5170,83 & 275,50 & 45,63 & 229,88 & 163,23 & 220,27 & 220,98 & 90,05 & 588,20 & 90,30 & 20,48 & 32,55 & 205,35 & 99,82 & 120,45 & 132,93 \\
\hline Bufo spinosus & 31TEHOO & 8,00 & 143,60 & 82,49 & 34,11 & 5406,03 & 272,29 & 33,72 & 238,57 & 147,51 & 214,13 & 214,46 & 77,38 & 656,68 & 91,94 & 26,81 & 27,44 & 213,72 & 119,09 & 27,74 & 152,85 \\
\hline Calotriton arnoldi & 31TDG52 & 100,00 & 121,05 & 70,84 & 31 & 5416,66 & 245,56 & 21,77 & 79 & 158,67 & 73,56 & 193,60 & 57,38 & 871,94 & 101,31 & 48,10 & 20,27 & 61,90 & 79,63 & 07,94 & 181,17 \\
\hline Calotriton asper & 30TWN87 & 100,00 & 114,38 & 90,20 & 40,28 & \begin{tabular}{ll|l}
4714,87 \\
\end{tabular} & 240,70 & 19,19 & 221,50 & 63,64 & 174,15 & 176,25 & 57,07 & 1253,24 & 144,73 & 62,59 & 20,78 & 401,85 & 230,62 & 233,34 & 375,75 \\
\hline Calotriton asper & 30TWN96 & 100,00 & 104,13 & 94,60 & 39,59 & 5054,56 & 238,99 & 2,51 & 236,48 & 49,88 & 1770,57 & $\begin{array}{l}170,57 \\
\end{array}$ & 42,31 & $\begin{array}{l}1187,49 \\
\end{array}$ & \begin{tabular}{|l|l|}
138,57 \\
\end{tabular} & \begin{tabular}{ll|}
60,62 \\
\end{tabular} & 20,39 & 378,00 & 219,52 & 219,52 & 355,21 \\
\hline Calotriton asper & 30TWN97 & 100,00 & 110,60 & 91,78 & 40,00 & $\begin{array}{ll}4839,21 \\
\end{array}$ & 239,44 & 12,53 & 226,92 & 58,56 & 172,80 & 174,20 & 51,36 & $\begin{array}{l}1259,47 \\
\end{array}$ & 147,50 & 63,49 & 20,90 & 404,84 & 233,16 & 234,64 & 379,23 \\
\hline Calotriton asper & 30TWN99 & 100,00 & 133,51 & 83,01 & 40,83 & 4317,29 & 244,87 & 43,87 & 201,01 & 90,02 & 186,91 & 189,84 & 80,53 & 1355,71 & 159,45 & 66,82 & 22,10 & 441,31 & 248,15 & 264,33 & 409,19 \\
\hline Calotriton asper & 30TXM69 & 100,00 & 96,15 & 101,10 & 38,05 & 5631,87 & 242,63 & $-18,79$ & 261,42 & 113,00 & 169,56 & 169,58 & 26,19 & 753,18 & 83,07 & 40,55 & 17,42 & 215,76 & \begin{tabular}{ll|l|l|}
148,84 \\
\end{tabular} & 52,24 & 192,26 \\
\hline Calotriton asper & 30TXM7 & 100,00 & 94 & 100,14 & 38,01 & 5578,12 & 239,18 & $-20,06$ & 259,24 & 112,36 & 166,83 & 166,86 & 24,87 & 748,31 & 83,20 & 40,77 & 16,95 & 215,23 & 151,02 & 156,15 & 186,56 \\
\hline Calotriton asper & 30TXM89 & 100,00 & 102,23 & 100,74 & 38,23 & 5560,33 & 246,57 & $-12,78$ & 259,35 & 120,78 & 174,27 & 174,50 & 32,76 & $\begin{array}{l}687,58 \\
\end{array}$ & 76,95 & 36,54 & 17,18 & $\begin{array}{ll}197,48 \\
\end{array}$ & 140,41 & $\begin{array}{l}144,25 \\
\end{array}$ & 167,70 \\
\hline Calotriton asper & 30TXM99 & 100,00 & 94,60 & $\begin{array}{ll}99,09 \\
\end{array}$ & 38,08 & 5505,17 & 237,16 & $-18,87$ & 256,03 & 112,80 & $\begin{array}{l}166,07 \\
\end{array}$ & $\begin{array}{l}166,36 \\
\end{array}$ & 26,08 & \begin{tabular}{|l|l|}
718,17 \\
\end{tabular} & 81,02 & 39,44 & 16,76 & 208,06 & 150,51 & 154,57 & 170,46 \\
\hline Calotriton asper & 30TXN06 & 100,00 & 106,18 & 95,55 & 39,43 & 5116,10 & 241,79 & 2,54 & 239,25 & 50,97 & 173,27 & 173,27 & 43,10 & 1195,82 & 142,30 & 60,52 & 21,15 & 384,30 & 219,61 & 19,61 & 361, \\
\hline Calotriton asper & 30TXN07 & 100,00 & 120,29 & 91,28 & 39,95 & 4846,52 & 246,87 & 20,70 & 226,18 & 68,22 & 181,79 & 183,66 & 60,27 & \begin{tabular}{|l|}
1249,93 \\
\end{tabular} & 149,77 & 62,11 & 21,78 & 406,52 & 230,56 & 234,53 & 379,90 \\
\hline Calotriton asper & $30 \mathrm{TXN}$ & 100,00 & 107,71 & 98,34 & 39, & 5316,13 & 247,88 & $-0,46$ & 248,34 & 50,04 & 177,17 & 177,17 & 41,58 & 1130,84 & 136,92 & 56,58 & 21,81 & 364,65 & 204,42 & 204,42 & 344,08 \\
\hline Calotriton asper & 30TXN16 & 100,00 & 94,84 & 95,87 & 39,18 & 5175,51 & 231,62 & $-9,67$ & 241,29 & 39,67 & 162,94 & 162,95 & 31,27 & 1194,21 & $\begin{array}{l}139,45 \\
\end{array}$ & 62,56 & 19,60 & 376,12 & 224,05 & 224,05 & 354,54 \\
\hline Calotriton asper & 30TXN17 & 100,00 & 121,06 & 92,23 & 39,79 & 4938,64 & 248,44 & 18,70 & 229,73 & 67,68 & 183,71 & 185,35 & 59,33 & 1233,22 & \begin{tabular}{|l|l|}
149,93 \\
\end{tabular} & 61,36 & 22,18 & 402,18 & 228,79 & 233,11 & 376,19 \\
\hline Calotriton asper & 30TXN18 & 100,00 & 117,03 & 90,82 & 39,96 & 4835,3 & 241,98 & 16,72 & 26 & 65,70 & $17 \varepsilon$ & 18 & 56 & 1297 & \begin{tabular}{|l|l|}
156,49 \\
\end{tabular} & 65, & 21,61 & 421,85 & 243,14 & 248,53 & 39 \\
\hline Calotriton asper & $30 \mathrm{TXN}$ & 89,00 & 93 & 96, & 39, & 5206,27 & 230,03 & $-12,54$ & 24 & 37,57 & 161 & $\begin{array}{ll}161,63 \\
\end{array}$ & 28 & 1181,31 & $\begin{array}{l}137,49 \\
\end{array}$ & 62, & 19,12 & 369,64 & 223,78 & 223,78 & 34 \\
\hline Calotriton asper & 30 TXN27 & 72,00 & 109,27 & 94,73 & 39,63 & 5078,57 & 241,06 & 4,33 & 236,72 & 54,34 & 174,58 & 175,53 & 45,96 & \begin{tabular}{|l|}
1221,24 \\
\end{tabular} & $\begin{array}{l}147,16 \\
\end{array}$ & 62,18 & 21,02 & 393,30 & 230,13 & 231,38 & 369,47 \\
\hline Calotriton asper & 30TXN28 & 100,00 & 112,90 & 92,41 & 39,88 & 4942,30 & 239,95 & 9,99 & 229,95 & 59,69 & $\begin{array}{l}175,67 \\
\end{array}$ & $\begin{array}{l}177,35 \\
\end{array}$ & 51,08 & 1269,48 & \begin{tabular}{|l|l|}
153,18 \\
\end{tabular} & $\begin{array}{l}64,76 \\
\end{array}$ & 21,08 & 410,29 & 240,76 & 245,22 & 384,35 \\
\hline Calotriton asper & 30 TXN29 & 28,00 & 124,35 & 88,39 & 39,99 & 4757,15 & 243,02 & 23,58 & 219,44 & 85,54 & 184,21 & 186,09 & 64,29 & $\begin{array}{l}1294,07 \\
\end{array}$ & 157,29 & 66,15 & 21,94 & 422,26 & 247,30 & 260,13 & 391,01 \\
\hline Calotrit & $30 T \times n$ & 100,00 & 102 & 99, & $39, \mathrm{C}$ & 5425, & 0 & $-8,52$ & & $\mid 43,64$ & 173,20 & & 34 & 1043,23 & 122 & 53,41 & 20,09 & 32 & 193,20 & \begin{tabular}{|l|l|}
193,20 \\
\end{tabular} & 30 \\
\hline Calotriton asper & 30TXN35 & 100,00 & 91,78 & 97,76 & 38,99 & 5311,18 & 231,03 & $-16,31$ & 247,34 & 35,01 & 161,50 & 161,50 & 26,25 & \begin{tabular}{|l|}
1113,44 \\
\end{tabular} & 128,04 & 59,14 & 18,53 & 343,19 & 211,70 & 211,70 & 323,8 \\
\hline Calotriton asper & 30TXN36 & 81,00 & 90,19 & 96,37 & 39,05 & 5227,71 & 226,97 & $-16,30$ & 243,27 & 34,44 & 158,80 & 158,81 & 25,69 & 1166,10 & 134,19 & 62,39 & 18,37 & 360,71 & 223,80 & 223,80 & 340,07 \\
\hline
\end{tabular}




\begin{tabular}{|c|c|c|c|c|c|c|c|c|c|c|c|c|c|c|c|c|c|c|c|c|c|}
\hline TAXON & UTM & $\mathrm{km2}$ & BIO1 & B1O2 & $\mathrm{BIO3}$ & B104 & B105 & B106 & B107 & B108 & B109 & 81010 & B1011 & BIO12 & B1013 & 81014 & B1015 & B1016 & B1017 & B1018 & B1019 \\
\hline Calotriton asper & 30TXN37 & & & & & & & & & & & & & & & & & & & & \\
\hline Calotriton asper & 30 TXN38 & 10,00 & 120,55 & 92,86 & 39,97 & \begin{tabular}{|l|l|}
4970,73 \\
\end{tabular} & 245,95 & 15,35 & 230,60 & 73,98 & 183,47 & 184,90 & 57,65 & 1211,15 & 147,21 & 61,21 & 21,39 & 391,34 & 230,73 & 239,12 & 366,19 \\
\hline Calotriton asper & 30TXN43 & 100,00 & 105,35 & 101,11 & 39,00 & 5500,27 & 248,66 & \begin{tabular}{|c|}
$-7,84$ \\
\end{tabular} & 256,50 & 45,35 & 176,90 & 176,90 & 36,38 & 954,67 & \begin{tabular}{|l|l|}
110,75 \\
\end{tabular} & 48,62 & 19,55 & 293,38 & 178,09 & $\begin{array}{l}178,09 \\
\end{array}$ & 276,66 \\
\hline Calotriton asper & 30 TXN44 & 100,00 & 88,07 & 98,23 & 38,93 & 5375,46 & 228,34 & $-21,44$ & 249,78 & 30,71 & 158,55 & 158,55 & 21,58 & 1053,74 & 117,87 & 56,95 & 17,45 & 316,51 & 203,15 & 203,15 & 298,49 \\
\hline Calotriton asper & 30TXN45 & 100,00 & 85,92 & \begin{tabular}{|c|}
97,14 \\
\end{tabular} & 38,97 & 5304,76 & 224,21 & \begin{tabular}{|l|l|}
$-21,97$ \\
\end{tabular} & 246,18 & 29,51 & 155,51 & 155,51 & 20,47 & 1105,56 & $\mid 123,97$ & 60,19 & 17,23 & 333,86 & 214,72 & 214,72 & 314,68 \\
\hline Calotriton asper & 30 TXN46 & 75,00 & 86,27 & 96,27 & 39,05 & 5234,26 & 222,50 & $-20,60$ & 243,10 & 30,64 & 154,88 & 154,91 & 21,63 & 1150,02 & 129,98 & 62,58 & 17,33 & 350,31 & 224,32 & 224,35 & 329,99 \\
\hline Calotriton asper & 30TXN47 & & & & & & & & & & & & & & & & & & & & \\
\hline Calotriton asper & 30TXN52 & 100,00 & 94,12 & 100,09 & 38,71 & 5497,32 & 237,15 & $-18,39$ & 255,54 & 40,05 & 165,93 & 165,93 & 25,84 & \begin{tabular}{|c|}
916,59 \\
\end{tabular} & 99,80 & 49,03 & 17,30 & 267,96 & 177,47 & 177,65 & 251,91 \\
\hline Calotriton asper & 30TXN53 & 100,00 & 99,49 & 100,32 & 38,99 & 5455,79 & 241,25 & $-12,97$ & 254,22 & 40,27 & 170,50 & 170,50 & 31,29 & 945,43 & $\begin{array}{r}105,78 \\
\end{array}$ & 49,59 & 17,88 & 282,90 & 181,64 & 181,64 & 266,11 \\
\hline Calotriton asper & 30TXN54 & 100,00 & 91,52 & 98,72 & 38,99 & 5372,49 & 231,15 & $-18,93$ & 250,08 & 33,87 & 161,74 & 161,74 & 24,79 & 1018,51 & 113,14 & 54,83 & 17,13 & 304,08 & 198,37 & 198,37 & 286,13 \\
\hline Calotriton asper & 30 TXN55 & 100,00 & 83,60 & 96,82 & 38,95 & 5296,25 & 221,06 & $-24,57$ & 245,62 & 27,39 & 153,08 & 153,08 & 18,14 & \begin{tabular}{|l|}
1091,06 \\
\end{tabular} & 120,27 & 60,17 & 16,46 & 324,97 & 215,11 & 215,11 & 305,78 \\
\hline Calotriton asper & 30 TXN56 & 37,00 & 79,52 & 95,46 & 38,96 & 5231,69 & 215,01 & $-27,01$ & 242,02 & 24,21 & 148,19 & 148,19 & 14,99 & 1149,13 & 126,64 & 64,19 & 16,15 & 343,11 & 228,41 & 228,41 & 322,84 \\
\hline Calotriton asper & 30TXN60 & 100,00 & 96,16 & $\begin{array}{l}100,88 \\
100\end{array}$ & 38,29 & 5581,02 & 241,26 & $-18,22$ & $\begin{array}{l}259,48 \\
259\end{array}$ & 85,60 & $\begin{array}{l}168,81 \\
\end{array}$ & 168,82 & 26,77 & 795,91 & \begin{tabular}{|l|}
85,27 \\
\end{tabular} & 42,70 & 17,05 & \begin{tabular}{|l|}
226,86 \\
\end{tabular} & $\begin{array}{l}25,4,1 \\
156,68 \\
\end{array}$ & $\begin{array}{l}259,86 \\
159,8\end{array}$ & 207,69 \\
\hline Calotriton asper & 30 TXN61 & 100,00 & 103,46 & 101,43 & 38,79 & 5547,82 & 247,30 & $-11,17$ & 258,47 & 72,57 & 175,39 & 175,41 & 34,01 & 809,72 & 86,63 & 42,30 & 17,41 & 234,79 & 157,77 & 159,76 & 217,41 \\
\hline Calotriton asper & 30TXN62 & 100,00 & 102,55 & 100,90 & 38,94 & 5489,47 & 244,74 & $-11,35$ & 256,10 & 66,79 & 173,81 & 173,82 & 33,73 & 857,75 & 92,71 & 44,94 & 17,23 & 250,88 & 167,34 & 168,63 & 233,86 \\
\hline Calotriton asper & 30TXN63 & 100,00 & 94,94 & 99,57 & 38,95 & 5416,45 & 235,38 & $-17,14$ & 252,52 & 42,68 & 165,40 & 165,40 & 27,29 & 934,84 & 101,29 & 50,20 & 16,66 & 273,25 & 183,96 & 184,22 & 256,22 \\
\hline Calotriton asper & $30 \mathrm{TXN64}$ & 100,00 & 83,53 & 97,27 & 38,80 & 5341,30 & 221,56 & $-25,87$ & 247,43 & 26,82 & 153,35 & 153,35 & 17,30 & 1027,09 & 110,20 & 57,12 & 15,75 & 298,96 & 204,99 & 205,07 & 280,60 \\
\hline Calotriton asper & 30 TXN65 & 92,00 & 75,72 & 95,36 & 38,75 & 5277,87 & 211,78 & $-31,52$ & 243,30 & 20,16 & 145,08 & 145,08 & 10,64 & 1101,25 & 117,80 & 62,58 & 15,22 & 320,67 & 221,68 & 221,68 & 301,24 \\
\hline Calotriton asper & 30 TXN66 & 6,00 & 87,25 & 96,60 & 39,35 & 5232,89 & 221,79 & $-20,99$ & 242,79 & 31,36 & 155,43 & 155,50 & 22,10 & 1101,02 & 121,46 & 60,74 & 16,26 & 328,58 & 220,57 & 220,71 & 308,65 \\
\hline Calotriton asper & 30 TXN70 & 100,00 & 93,34 & 99,94 & 38,19 & 5532,25 & 236,91 & $-20,37$ & 257,28 & \begin{tabular}{ll|}
102,67 \\
\end{tabular} & 165,38 & 165,39 & 24,60 & 791,18 & 85,56 & 43,09 & 16,42 & 224,03 & 159,32 & 163,03 & 201,26 \\
\hline Calotriton asper & 30TXN74 & 100,00 & 67,09 & 93,69 & 38,16 & 5304,14 & 202,82 & $-39,59$ & 242,41 & 15,92 & 136,99 & 136,99 & 2,03 & \begin{tabular}{|l|}
1089,61 \\
\end{tabular} & 112,52 & 63,8 & 14,30 & 307,78 & 223,36 & 223,49 & 288,38 \\
\hline Calotriton asper & 30TXN75 & 83,00 & 65,57 & 93,03 & 38,28 & 5259,30 & \begin{tabular}{|l|l|}
199,91 \\
\end{tabular} & $-40,09$ & 240,00 & 10,91 & 134,93 & 134,93 & 1,10 & $\begin{array}{l}1131,74 \\
1131\end{array}$ & \begin{tabular}{|l|l|}
117,47 \\
\end{tabular} & $\begin{array}{ll}66,48 \\
\end{array}$ & 14,20 & 322,24 & 232,28 & 232,28 & 302,19 \\
\hline Calotriton asper & 30TXN80 & 100,00 & 95,74 & 99,77 & 38,26 & 5501,36 & 238,35 & \begin{tabular}{|c|}
$-18,12$ \\
\end{tabular} & 256,46 & \begin{tabular}{|l|l|}
111,46 \\
\end{tabular} & 167,05 & 167,16 & 27,15 & 759,75 & $\begin{array}{l}82,89 \\
\end{array}$ & 41,34 & 16,27 & 215,49 & 155,52 & 160,27 & 188,89 \\
\hline Calotriton asper & 30 TXN82 & 100,00 & 89,62 & 98,52 & 38,72 & 5404,83 & 229,01 & $-22,31$ & 251,32 & 68,85 & 159,91 & 159,98 & 22,28 & 875,33 & 91,00 & 48,59 & 15,18 & 246,25 & 179,37 & 182,28 & 225,52 \\
\hline Calotriton asper & 30 TXN83 & 100,00 & 75,68 & 95,40 & 38,34 & 5342,54 & 212,55 & $-33,13$ & 245,68 & 55,34 & 145,72 & 145,72 & 9,74 & 993,85 & 102,26 & 57,44 & 14,39 & 278,46 & 205,26 & 206,54 & 257,59 \\
\hline Calotriton asper & 30TXN84 & 100,00 & 50,41 & 89,26 & 37,13 & 5272,72 & 183,66 & $-53,41$ & 237,07 & 35,53 & 120,55 & 120,55 & $-13,35$ & 1171,25 & 119,66 & 71,51 & 13,39 & 325,22 & 244,61 & 244,93 & 302,94 \\
\hline Calotriton asper & 30TXN85 & 53,00 & $\mid \begin{array}{l}0,, 14 \\
42,17\end{array}$ & $\begin{array}{l}80,920 \\
86,92\end{array}$ & 36,71 & 5231,16 & $\begin{array}{l}173,46 \\
\end{array}$ & $\begin{array}{l}-50,41 \\
-60,17 \\
\end{array}$ & 233,62 & \begin{tabular}{|c|}
9,99 \\
9,95
\end{tabular} & $\begin{array}{l}112,02 \\
1120\end{array}$ & 112,02 & $\begin{array}{l}-20,73 \\
-20,5\end{array}$ & 1248,27 & $\begin{array}{l}126,53 \\
\end{array}$ & 77,25 & 13,13 & 346,39 & $\begin{array}{l}261,15 \\
\end{array}$ & 261,15 & 324,94 \\
\hline Calotriton asper & 30TXN90 & 100,00 & 93,84 & 99,07 & 38,37 & 5463,30 & 235,24 & $-19,39$ & 254,62 & 111,83 & 164,67 & 164,93 & 25,66 & 755,96 & 83,18 & 41,68 & 15,97 & 215,56 & 158,02 & 162,15 & 183,27 \\
\hline Calotriton asper & 30 TXN91 & 100,00 & 94,57 & 99,19 & 38,74 & 5424,62 & 234,78 & $-18,37$ & 253,15 & 100,32 & 164,88 & 165,09 & 26,64 & 790,45 & 84,67 & 43,56 & 15,38 & 222,04 & 164,76 & 169,02 & 195,90 \\
\hline Calotriton asper & 30 TXN92 & 100,00 & 80,76 & 96,43 & 38,33 & 5376,12 & 218,68 & $-29,57$ & 248,24 & 91,78 & 150,89 & 150,93 & 14,14 & 911,97 & 95,94 & 52,47 & 14,39 & 254,73 & 190,97 & \begin{tabular}{|l|}
194,87 \\
\end{tabular} & 229,06 \\
\hline Calotriton asper & $\begin{array}{l}\text { 30TXN93 } \\
\end{array}$ & 100,00 & 48,20 & 88,18 & 36,68 & 5295,76 & 181,29 & $-55,86$ & 237,16 & 58,64 & 118,67 & 118,67 & $-15,74$ & 1150,99 & \begin{tabular}{|c|}
119,68 \\
\end{tabular} & 71,05 & 13,38 & 322,05 & 242,88 & 243,18 & 291,27 \\
\hline Calotriton asper & 30TXN94 & 50,00 & $\begin{array}{l}49,03 \\
49,2\end{array}$ & $\mid 80,31$ & 36,92 & 5266,55 & $\begin{array}{l}181,26 \\
\end{array}$ & $\begin{array}{l}-54,64 \\
-54,64\end{array}$ & 235,91 & 53,19 & 119,07 & $\begin{array}{l}119,07 \\
\end{array}$ & $-14,66$ & \begin{tabular}{|l|l|}
1173,98 \\
1
\end{tabular} & 120,41 & 72,41 & $\begin{array}{ll}13,14 \\
13\end{array}$ & 326,20 & \begin{tabular}{|l|}
247,68 \\
248
\end{tabular} & \begin{tabular}{|l|}
248,08 \\
240
\end{tabular} & 300,06 \\
\hline Calotriton asper & 30TXN95 & & & & & & & & & & & & & & & & & & & & \\
\hline Calotriton asper & 30TYM09 & 100,00 & 93,51 & 98,46 & 38,09 & 5475,67 & 235,12 & $-19,66$ & 254,78 & 111,59 & $\begin{array}{ll}164,52 \\
\end{array}$ & 164,91 & 25,38 & 714,28 & 81,03 & 39,71 & 16,65 & 207,72 & $\mid 152,62$ & 155,93 & 165,51 \\
\hline Calotriton asper & 30TYM18 & 100,00 & 84,91 & 96,38 & 37,59 & 5494,60 & 226,17 & $-27,16$ & 253,33 & 102,28 & 141,59 & 156,87 & 17,03 & 744,17 & 86,03 & 42,78 & 17,13 & 220,64 & 161,93 & 167,48 & 166,72 \\
\hline Calotriton asper & 30TYM19 & 100,00 & 88,36 & 97,19 & 37,89 & 5459,20 & 228,76 & $-23,99$ & 252,76 & 105,96 & 159,32 & 159,69 & 20,57 & 748,71 & 84,95 & 42,66 & 16,45 & 218,88 & 162,66 & 166,63 & 170,54 \\
\hline Calotriton asper & 30TYM28 & $\begin{array}{l}100,00 \\
100\end{array}$ & $\begin{array}{l}0,00,47 \\
80,\end{array}$ & $\begin{array}{l}1,119 \\
94,96\end{array}$ & $\frac{37,03}{37,23}$ & 54596,64 & $\begin{array}{l}220,75 \\
220\end{array}$ & $\begin{array}{l}-20,39 \\
-30,73 \\
\end{array}$ & $\begin{array}{ll}251,48 \\
2510\end{array}$ & $\begin{array}{r}0,50 \\
97,38 \\
\end{array}$ & $\begin{aligned} & 35,52,71 \\
& 95,1\end{aligned}$ & $\begin{array}{l}152,59 \\
1529\end{array}$ & $\begin{array}{ll}12,68 \\
127\end{array}$ & $\begin{array}{l}\mid 480,11 \\
787,18\end{array}$ & $\begin{array}{l}4,50 \\
90,38\end{array}$ & $\begin{array}{l}42,00 \\
46,20\end{array}$ & $\begin{array}{l}10,45 \\
16,86\end{array}$ & $\begin{array}{l}233,47 \\
233 \\
\end{array}$ & $\begin{array}{l}172,16 \\
\end{array}$ & $\begin{array}{l}178,97 \\
170\end{array}$ & 174,81 \\
\hline Calotriton asper & 30TYM31 & 100,00 & 131,14 & 104,62 & 37,01 & 5981,44 & 285,08 & 6,98 & 278,10 & 154,00 & 56,63 & 209,23 & 56,63 & 419,51 & 55,75 & 20,03 & 28,22 & 135,46 & 76,51 & 90,58 & 76,51 \\
\hline Calotriton asper & 30TYM38 & 100,00 & 78,61 & 94,14 & 36,99 & 5512,26 & 218,56 & \begin{tabular}{|l|l|}
$-32,14$ \\
\end{tabular} & 250,70 & 95,54 & 56,50 & 151,07 & 10,81 & 816,36 & 93,06 & 48,68 & 16,69 & 242,03 & 177,78 & 186,64 & 179,85 \\
\hline Calotriton asper & 30TYM39 & 100,00 & 80,08 & 94,72 & 37,34 & 5482,13 & 219,26 & $-30,90$ & 250,15 & 97,07 & 71,04 & 151,82 & 12,33 & 831,24 & 93,34 & 49,55 & 15,96 & 244,17 & 184,12 & 192,69 & 185,37 \\
\hline Calotriton asper & 30TYM 48 & 72,00 & 85,12 & 95,56 & 37,28 & 5544,62 & 225,99 & $-27,19$ & 253,18 & 102,81 & 19,26 & 157,72 & 16,49 & 784,91 & 89,55 & 46,55 & 17,06 & 233,23 & 169,40 & 183,31 & 169,44 \\
\hline Calotriton asper & 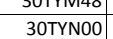 & $\frac{1}{100,00}$ & \begin{tabular}{|l|}
89,11 \\
89,01
\end{tabular} & \begin{tabular}{|l|}
97,77 \\
97,
\end{tabular} & $\begin{array}{ll}3 r, 4 \\
38,1\end{array}$ & \begin{tabular}{|l|}
54446,02 \\
5436,31
\end{tabular} & \begin{tabular}{|l|}
229,17 \\
229
\end{tabular} & $\begin{array}{l}-23,19 \\
-23,37\end{array}$ & $\begin{array}{l}253,54 \\
252,54\end{array}$ & $\begin{array}{l}102,0164 \\
106,64\end{array}$ & \begin{tabular}{r|r|r|}
159,60 \\
159,62
\end{tabular} & $\begin{array}{l}\mid 31,1 / 2 \\
159,92\end{array}$ & $\begin{array}{l}\mid 0,45 \\
21,38\end{array}$ & \begin{tabular}{|l|}
774,01 \\
777,07
\end{tabular} & 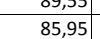 & \begin{tabular}{|l|}
40,33 \\
43,85 \\
\end{tabular} & $\begin{array}{l}11,00 \\
15,60\end{array}$ & \begin{tabular}{|l|}
223,04 \\
223
\end{tabular} & $\begin{array}{l}169,40 \\
165,59 \\
\end{array}$ & $\begin{array}{l}170,311 \\
170,13 \\
\end{array}$ & $\begin{array}{l}109,44 \\
184,36\end{array}$ \\
\hline Calotriton asper & 30TYN01 & 100,00 & 87,26 & 97,46 & 38,44 & 5402,29 & 226,07 & $-24,44$ & 250,51 & 104,60 & 157,51 & 157,71 & 20,01 & 824,62 & 89,14 & 46,93 & 14,90 & 233,53 & 175,42 & 179,88 & 199,54 \\
\hline Calotriton asper & 30TYNO2 & 100,00 & 68,75 & 93,02 & 37,67 & 5353,69 & 204,51 & $-39,25$ & 243,76 & 84,01 & 139,07 & 139,08 & 2,90 & 982,46 & 104,07 & 58,76 & 13,90 & 276,88 & 209,18 & 212,16 & 242,29 \\
\hline Calotriton asper & 30TYN03 & 99,00 & 36,88 & 84,36 & 35,64 & 5266,47 & 167,53 & $-65,62$ & 233,15 & 48,42 & $\begin{array}{ll}107,42 \\
\end{array}$ & 107,42 & $-25,95$ & 1224,93 & 127,53 & 77,30 & 13,04 & 43,70 & 60,60 & 60,76 & 307,40 \\
\hline Calotriton asper & 30TYN04 & 24,00 & $\begin{array}{l}30,00 \\
37,92\end{array}$ & \begin{tabular}{|l|l|}
84,46 \\
\end{tabular} & 35,90 & 5244,13 & 168,00 & $\begin{array}{l}-04,05 \\
-64,05 \\
\end{array}$ & 232,05 & \begin{tabular}{|l|l|}
49,461 \\
49
\end{tabular} & 108,08 & \begin{tabular}{|l|l|}
108,08 \\
\end{tabular} & $\begin{array}{l}-24,88 \\
-24,\end{array}$ & \begin{tabular}{|l|l|}
1240,59 \\
124,
\end{tabular} & $\begin{array}{l}127,92 \\
\end{array}$ & 78,29 & 12,91 & 345,81 & 264,09 & 264,09 & 313,63 \\
\hline Calotriton asper & 30 TYN & 100,00 & 88,63 & 97,46 & 38,54 & 5397,75 & 226,94 & $-23,45$ & 250,39 & 106,24 & 158,62 & 158,93 & 21,25 & 810,72 & 88,09 & 46,50 & 14,91 & 230,73 & 175,15 & \begin{tabular}{ll|}
179,47 \\
\end{tabular} & 192,09 \\
\hline Calotriton asper & $\begin{array}{l}\text { 30TYN12 } \\
\end{array}$ & 100,00 & 59,95 & 90,18 & 37,03 & 5337,92 & $\begin{array}{l}193,96 \\
\end{array}$ & $-46,36$ & 240,32 & 74,31 & 130,37 & 130,42 & $-5,22$ & $\begin{array}{l}1041,24 \\
1\end{array}$ & 110,51 & 63,90 & 13,66 & 294,87 & 224,28 & 227,15 & 253,79 \\
\hline Calotriton asper & 30TYN13 & 100,00 & 47,94 & 86,82 & 36,42 & 5292,12 & 179,49 & $-55,73$ & 235,22 & 60,84 & 118,25 & 118,25 & $-16,06$ & 1150,14 & 120,31 & 72,13 & 13,03 & 323,51 & 247,41 & 248,28 & 284,42 \\
\hline Calotriton asper & 30TYN14 & 42,00 & 31,99 & 81,89 & 35,16 & 5231,31 & 160,33 & $-69,29$ & 229,62 & 42,90 & 102,19 & 102,19 & $-30,23$ & 1279,76 & 132,24 & 81,80 & 12,62 & 57,57 & 274,11 & 274,11 & 321,20 \\
\hline Calotriton asper & 30 TYN2 & $\begin{array}{l}400,00 \\
100\end{array}$ & $\begin{array}{l}1,3917 \\
66,17\end{array}$ & $\begin{array}{l}\mid l 1,05 \\
91,41 \\
\end{array}$ & $\frac{3,10}{37,11}$ & 538 & $\begin{array}{l}100,53 \\
201,54\end{array}$ & $\begin{array}{l}-0.31,29 \\
-41,29\end{array}$ & $\begin{array}{l}242,83 \\
242,83\end{array}$ & $\begin{array}{l}2,30 \\
81,39 \\
\end{array}$ & \begin{tabular}{|l|}
137,00 \\
\end{tabular} & \begin{tabular}{|l|}
137,03 \\
17,03
\end{tabular} & $\mid \begin{array}{r}\mid-10,25 \\
0,17\end{array}$ & \begin{tabular}{|l|l|}
975,38 \\
\end{tabular} & $\mid \begin{array}{l}32,24 \\
105,45\end{array}$ & $\begin{array}{l}\mid c 1,00 \\
59,65\end{array}$ & $\begin{array}{ll}14,11 \\
\end{array}$ & \begin{tabular}{|l|}
279,86 \\
273
\end{tabular} & \begin{tabular}{|l|}
212,92 \\
212
\end{tabular} & 216,61 & 230,55 \\
\hline Calotriton asper & 30TYN22 & 100,00 & 50,84 & 86,83 & 36,13 & 5324,42 & 183,01 & $-53,86$ & 236,86 & 64,18 & 121,53 & 121,54 & $-13,60$ & \begin{tabular}{|l|}
1107,97 \\
\end{tabular} & 117,49 & 69,53 & 13,33 & 314,53 & 240,49 & 242,34 & 268,20 \\
\hline Calotriton asper & 30TYN23 & 100,00 & 31,49 & $\begin{array}{l}0,00 \\
80,98\end{array}$ & 34,68 & 5249,75 & $\begin{array}{l}159,70 \\
15,0\end{array}$ & $\begin{array}{l}-70,20 \\
-70,0\end{array}$ & 229,90 & $\mid 42,31$ & 101,95 & $\begin{array}{l}101,95 \\
\end{array}$ & $-30,77$ & | & $\mid \begin{array}{l}\mid 131,94 \\
131,94\end{array}$ & 81,12 & 12,65 & 355,52 & \begin{tabular}{|l|}
272,37 \\
\end{tabular} & $\begin{array}{l}273,15 \\
27,4\end{array}$ & 312,09 \\
\hline Calotriton asper & 30TYN24 & 45,00 & 12,23 & 75,01 & 33,06 & 5179,52 & 136,49 & $-86,88$ & 223,37 & 20,55 & 82,48 & 82,48 & $-47,96$ & 1414,76 & 146,01 & 92,52 & 12,06 & 395,43 & 303,44 & 303,44 & 355,09 \\
\hline Calotriton asper & 30 TYN30 & 100,00 & 73,98 & 93,03 & 37,18 & 5439,41 & 211,19 & $-35,42$ & 246,60 & 90,23 & 120,12 & 145 & 7,01 & 902,70 & 99,28 & 54,75 & 14,94 & 262,06 & 199,63 & 205,61 & 206 \\
\hline Calotriton asper & 30TYN31 & $\begin{array}{l}100,00 \\
100\end{array}$ & $\begin{array}{l}70,20 \\
70,22\end{array}$ & $\begin{array}{l}3,00 \\
92,07 \\
\end{array}$ & $\begin{array}{l}37,10 \\
37,21\end{array}$ & $\begin{array}{l}5450,41 \\
5403,92\end{array}$ & $\begin{array}{l}205,96 \\
2015\end{array}$ & $\begin{array}{l}-38,42 \\
-38,19 \\
\end{array}$ & $\begin{array}{l}244,15 \\
244\end{array}$ & 85,95 & \begin{tabular}{l|}
140,27 \\
\end{tabular} & 141,19 & 3,76 & 955,42 & 103,40 & 58,53 & 14,31 & 274,77 & 210,92 & 216,40 & 222,30 \\
\hline Calotriton asper & 30TYN32 & 100,00 & 53,61 & 87,07 & 36,17 & 5340,93 & $\mid 185,78$ & $\mid-51,45$ & 237,22 & 67,34 & $\mid 124,30$ & $\mid 124,31$ & $-11,23$ & \begin{tabular}{|l|l|}
1094,52 \\
\end{tabular} & \begin{tabular}{|l|l|}
116,32 \\
\end{tabular} & 69,00 & 13,39 & 311,69 & 239,92 & 243,42 & 261,42 \\
\hline Calotriton asper & 30TYN33 & 73,00 & 24,93 & 78,12 & 33,91 & 5242,21 & 151,45 & $-75,58$ & 227,03 & 34,83 & 95,59 & 95,59 & $-36,74$ & \begin{tabular}{|l|}
1312,23 \\
\end{tabular} & 137,11 & 85,36 & 12,44 & 369,86 & 284,55 & 284,55 & 322,51 \\
\hline Calotriton asper & 30TYN41 & 60,00 & 68,64 & 91,25 & 36,95 & 5417,10 & 204,09 & $-39,29$ & 243,38 & 84,25 & 128,36 & 139,8 & 2,00 & 977,54 & 105,69 & 60,61 & 14,23 & 281,73 & 217,47 & 223,80 & 225 \\
\hline Calotriton asper & 30TYN42 & 60,00 & 32,27 & 79,78 & 34,22 & 5289,33 & 160,47 & $-69,20$ & 229,68 & 43,05 & 103,33 & 103,33 & $-30,38$ & 1247,89 & 131,84 & 80,87 & 12,80 & 354,47 & 272,80 & 73,09 & 300,99 \\
\hline
\end{tabular}




\begin{tabular}{|c|c|c|c|c|c|c|c|c|c|c|c|c|c|c|c|c|c|c|c|c|c|}
\hline TAXON & UTM & $\mathrm{km} 2$ & BIO1 & BIO2 & BIO3 & B104 & BIO5 & B106 & B107 & B108 & 8109 & B1010 & BIO11 & B1012 & BIO13 & BIO14 & BIO15 & B1016 & B1017 & B1018 & B1019 \\
\hline Calotriton asper & 30TYN43 & 7,00 & 32,10 & 79,82 & 34,30 & 5264,38 & 159,53 & $-69,34$ & 228,88 & 42,99 & 102,71 & 102,71 & $-30,40$ & 1270,33 & 132,88 & 82,49 & 12,58 & 358,52 & 277,48 & 278,31 & 309,23 \\
\hline Calotriton asper & \begin{tabular}{|l|}
31 TBG57 \\
\end{tabular} & 75,00 & 106,03 & 100,90 & 37,82 & 5693,90 & 251,97 & $-11,65$ & 263,62 & 126,45 & 34,42 & \begin{tabular}{ll|}
180,16 \\
\end{tabular} & 34,42 & 632,45 & 74,49 & 35,77 & 19,60 & 191,70 & 128,20 & 147,83 & 128,20 \\
\hline Calotriton asper & 31твH50 & 62,00 & 91,60 & 97,31 & 37,83 & 5526,61 & 231,46 & $-22,06$ & 253,51 & 110,18 & 36,34 & 163,54 & 22,51 & 803,95 & 88,68 & 48,01 & 15,84 & 234,57 & $\begin{array}{l}176,23 \\
\end{array}$ & \begin{tabular}{|l|l|}
188,76 \\
\end{tabular} & 176,83 \\
\hline Calotriton asper & 31TBH51 & 66,00 & 72,18 & 91,90 & 37,08 & 5440,33 & 208,14 & $-36,69$ & 244,83 & 88,29 & 81,93 & 143,57 & 5,17 & 963,17 & 103,96 & 59,76 & 14,44 & 277,84 & 214,91 & 223,19 & 220,08 \\
\hline Calotriton asper & 31TBH52 & 61,00 & 26,09 & 77,48 & 33,53 & 5281,27 & 152,94 & $-74,49$ & 227,43 & 36,03 & 97,28 & 97,28 & $-36,08$ & \begin{tabular}{|l|}
1296,34 \\
\end{tabular} & 136,53 & 84,57 & 12,68 & 367,71 & 283,47 & 283,64 & 313,16 \\
\hline Calotriton asper & 31TBH53 & 9,00 & 24,26 & 76,73 & 33,41 & 5245,24 & 149,97 & $-75,92$ & 225,89 & 34,01 & 95,03 & 95,03 & $-37,42$ & \begin{tabular}{|l|}
1326,48 \\
\end{tabular} & 138,59 & 86,93 & 12,39 & 374,03 & 289,73 & 290,09 & 323,49 \\
\hline Calotriton asper & 31TBH61 & 101,00 & 86,55 & 95,72 & 37,64 & 5505,15 & 224,68 & $-25,87$ & 250,55 & 104,58 & 39,33 & 158,31 & 17,86 & 884,59 & 95,35 & 54,24 & 14,83 & 255,72 & 196,21 & 209,57 & 197,68 \\
\hline Calotriton asper & 31TBH62 & 100,00 & 46,28 & 83,24 & 35,06 & 5349,68 & 176,70 & $-57,15$ & 233,85 & 58,97 & \begin{tabular}{|l|l|}
105,13 \\
\end{tabular} & 117,52 & $-18,02$ & 1169,48 & 123,92 & 75,53 & 13,20 & 333,57 & \begin{tabular}{|l|l|}
259,65 \\
\end{tabular} & 262,50 & 275,92 \\
\hline Calotriton asper & 31TBH63 & 36,00 & 21,95 & 75,16 & 32,93 & 5248,28 & 146,94 & $-77,73$ & 224,67 & 31,48 & 92,89 & 92,89 & $-39,50$ & $\begin{array}{l}1345,64 \\
\end{array}$ & 140,64 & 88,57 & 12,28 & 379,52 & 294,93 & 294,93 & 327,05 \\
\hline Calotriton asper & 31TBH71 & 99,00 & 55,15 & 85,39 & 35,34 & 5420,49 & 187,79 & $-50,20$ & 237,99 & 69,03 & 58,75 & 127,11 & $-10,36$ & $\begin{array}{l}1111,69 \\
\end{array}$ & 118,50 & 71,49 & 13,75 & 319,11 & 247,34 & 254,56 & 256,27 \\
\hline Calotriton asper & 31TBH72 & 96,00 & 38,68 & 80,03 & 34,10 & 5337,34 & 167,37 & $-63,47$ & 230,84 & 50,35 & 85,49 & 110,15 & $-24,84$ & 1231,11 & 129,94 & 80,44 & 12,89 & 350,21 & 273,33 & 276,04 & 291,12 \\
\hline Calotriton asper & 31тВH80 & 101,00 & 73,62 & 90,47 & 36,17 & 5549,55 & 210,64 & $-35,65$ & 246,29 & 89,95 & 23,21 & 146,50 & 5,41 & $\begin{array}{l}1002,25 \\
\end{array}$ & 107,72 & 63,82 & 14,97 & 291,28 & 219,81 & 239,59 & 221,43 \\
\hline 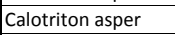 & 31TBH81 & 100,00 & 45,16 & 81,45 & 34,30 & \begin{tabular}{|l|l|}
5396,87 \\
\end{tabular} & 175,81 & $-57,61$ & 233,42 & 57,61 & 57,27 & 117,18 & $-19,32$ & 1187,21 & 126,34 & 77,62 & 13,40 & 340,32 & 265,22 & 269,45 & 274,49 \\
\hline Calotriton asper & 31TBH82 & 99,00 & 23,05 & 74,61 & 32,54 & 5307,09 & 149,13 & $-76,48$ & 225,61 & 32,80 & 82,46 & 94,82 & $-38,87$ & \begin{tabular}{|l|}
1343,39 \\
\end{tabular} & 141,01 & 88,87 & 12,47 & 380,00 & 296,94 & 297,26 & 321,47 \\
\hline Calotriton asper & 31TBH91 & 100,00 & 57,69 & 84,80 & 35,00 & 5466,00 & 190,84 & $-47,45$ & 238,29 & 71,85 & 34,21 & 130,24 & $-8,32$ & 1130,54 & \begin{tabular}{|l|l|}
119,98 \\
\end{tabular} & 73,84 & 13,92 & 325,03 & 251,39 & 264,91 & 256,33 \\
\hline Calotriton asper & 31TBH92 & 100,00 & 27,92 & 75,45 & 32,68 & 5333,73 & 154,78 & $-72,13$ & 226,91 & 38,21 & 69,40 & 99,83 & $-34,58$ & 1322,21 & 138,87 & 87,78 & 12,61 & 374,57 & 293,48 & 295,91 & 313,36 \\
\hline Calotriton asper & 31TCG17 & 100,00 & 101,83 & 95,57 & 36,21 & 5870,22 & 246,60 & $-13,95$ & 260,55 & \begin{tabular}{|l|l|}
121,63 \\
\end{tabular} & 28,55 & 178,34 & 28,55 & $\begin{array}{l}844,18 \\
\end{array}$ & 93,05 & 50,19 & 18,67 & 255,17 & 167,57 & 219,47 & 167,57 \\
\hline Calotriton asper & 31TCG18 & 101,00 & 95,11 & 93,72 & 36,10 & 5789,82 & 237,62 & $-18,57$ & 256,19 & 114,02 & 23,29 & 170,75 & 23,17 & \begin{tabular}{|l|l|}
912,47 \\
\end{tabular} & 98,85 & 55,75 & 17,54 & 271,84 & \begin{tabular}{|l|l|}
186,17 \\
\end{tabular} & 234,07 & 186,17 \\
\hline Calotriton asper & 31TCG19 & 100,00 & 85,20 & 91,00 & 35,91 & 5684,82 & 224,70 & $-25,41$ & 250,11 & 102,57 & 15,24 & 159,72 & 15,13 & 991,70 & 106,40 & 62,57 & 16,37 & 292,01 & 207,85 & 250,60 & 207,85 \\
\hline Calotriton asper & 31TCG27 & 100,00 & 110,40 & 96,15 & 36,03 & 5934,42 & 255,86 & $-6,91$ & 262,77 & 131,10 & 35,86 & 187,36 & 35,86 & 790,05 & 88,08 & 45,32 & 20,25 & 242,42 & 151,64 & 211,22 & 151,64 \\
\hline Calotriton asper & 31TCG29 & 101,00 & 72,96 & 86,12 & \begin{tabular}{l|l}
34,95 \\
\end{tabular} & 5607,02 & 209,42 & $-33,45$ & 242,88 & 88,30 & 7,88 & 147,16 & 4,98 & 1052,25 & \begin{tabular}{|l|l|}
113,75 \\
\end{tabular} & 67,49 & 15,78 & 309,17 & 223,17 & 259,37 & 223,46 \\
\hline Calotriton asper & 31TCG35 & 100,00 & 102,56 & 91,07 & 35,19 & 5855,30 & 244,94 & \begin{tabular}{|l|l|}
$-10,29$ \\
$-10,7$
\end{tabular} & 255,23 & 120,90 & 30,50 & 179,28 & 30,50 & 813,86 & 92,62 & 46,27 & 20,91 & 250,31 & 154,85 & 211,10 & 154,85 \\
\hline Calotriton asper & 31TCG37 & 101,00 & 105,48 & 92,90 & \begin{tabular}{l|l|}
35,55 \\
\end{tabular} & 5864,52 & 248,53 & $-8,86$ & 257,39 & 124,87 & 32,59 & 181,90 & 32,59 & 822,30 & 92,24 & 46,80 & 20,57 & 252,73 & 156,84 & 221,14 & 156,84 \\
\hline Calotriton asper & 31TCG38 & 101,00 & 100,74 & 92,05 & 35,65 & 5808,73 & 242,40 & $-12,33$ & 254,73 & 119,60 & 28,60 & 176,52 & 28,60 & 875,04 & 97,42 & 50,57 & 19,64 & 266,84 & 169,90 & 237,59 & 169,90 \\
\hline Calotriton asper & 31TCG39 & 100,00 & 72,43 & 84,84 & 34,63 & 5608,18 & 208,53 & $-33,39$ & 241,93 & 87,47 & 13,71 & 146,77 & 4,76 & 1056,72 & 114,67 & 66,88 & 16,13 & 310,90 & 222,37 & 261,89 & 223,34 \\
\hline Calotriton asper & 31TCG46 & 100,00 & 97,35 & 88,30 & 34,84 & 5776,11 & 237,24 & $-12,70$ & 249,94 & 114,72 & 26,74 & 173,27 & 26,74 & 863,40 & 97,85 & 49,07 & 20,60 & 264,79 & \begin{tabular}{|l|l|}
164,38 \\
\end{tabular} & 227,18 & 164,38 \\
\hline 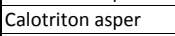 & 31TCG47 & 100,00 & 73,25 & 83,05 & 34,10 & 5610,93 & 209,02 & $-30,90$ & 239,92 & 87,44 & 7,54 & 148,02 & 6,28 & \begin{tabular}{r|}
1023,62 \\
\end{tabular} & 112,84 & 64,09 & 16,84 & 302,60 & 211,83 & 249,96 & 211,91 \\
\hline Calotriton asper & 31TCG48 & 99,00 & 74,03 & 83,61 & 34,23 & 5611,50 & 209,89 & $-30,57$ & 240,46 & 88,63 & 8,95 & 148,70 & 6,73 & 1029,71 & 113,12 & 64,84 & 16,74 & 304,54 & 213,65 & 254,52 & 213,88 \\
\hline Calotriton asper & 31TCG49 & 101,00 & 83,04 & 86,28 & 34,86 & 5660,96 & 220,30 & $-24,22$ & 244,53 & 99,18 & 16,94 & 157,79 & 14,22 & 986,01 & 108,81 & 60,63 & 17,82 & 294,88 & 200,65 & 253,99 & 200,96 \\
\hline Calotriton asper & 31TCG55 & 100,00 & 122,96 & 90,48 & 34,96 & 5889,88 & 263,85 & 7,80 & 256,05 & 142,53 & 49,29 & 199,42 & 49,29 & 693,17 & 81,14 & 35,47 & 25,08 & 219,27 & 120,52 & 189,14 & 120,52 \\
\hline Calotriton asper & 31TCG56 & 100,00 & 101,21 & 87,01 & 34,60 & 5759,90 & 239,94 & $-8,37$ & 248,31 & 118,44 & 30,82 & 177,04 & 30,82 & 836,70 & 95,76 & 46,51 & 21,94 & 258,07 & 156,10 & 221,74 & 156,10 \\
\hline Calotriton asper & 31TCG57 & 101,00 & 93,94 & 86,16 & 34,51 & 5718,43 & 231,94 & $-14,21$ & 246,15 & 110,49 & 24,77 & 169,36 & 24,33 & 890,55 & 100,86 & 51,10 & 20,70 & 272,21 & 170,57 & 235,88 & 170,58 \\
\hline Calotriton asper & 31TCG59 & 101,00 & 53,42 & 77,91 & \begin{tabular}{|l|}
33,18 \\
\end{tabular} & 5480,81 & 185,19 & $-46,43$ & 231,62 & 65,12 & 6,63 & 127,25 & $-10,71$ & 1162,71 & 125,42 & 76,56 & 14,33 & 334,58 & 253,12 & 273,89 & 255,58 \\
\hline Calotriton asper & 31TCG68 & 100,00 & 102,52 & 86,83 & 34,61 & 5742,15 & 240,55 & $-6,99$ & 247,55 & $\begin{array}{lll}120,07 \\
\end{array}$ & 35,21 & 177,77 & 31,88 & 835,53 & 96,50 & 45,65 & 22,99 & 260,03 & 153,37 & 233,65 & 153,48 \\
\hline Calotriton asper & 31TCG76 & 101,00 & 82,16 & 80,14 & 33,41 & 5598,00 & 216,28 & $-20,41$ & 236,68 & 95,78 & 19,20 & 157,11 & 15,95 & 964,72 & 108,32 & 56,96 & 19,15 & 286,27 & 192,24 & 241,99 & 192,74 \\
\hline Calotriton asper & 31TCG77 & 100,00 & 69,87 & 78,66 & 33,21 & 5544,47 & 203,01 & $-30,74$ & 233,75 & 82,42 & 22,81 & 144,45 & 4,99 & $\begin{array}{r}1048,60 \\
\end{array}$ & 115,51 & 64,47 & 17,03 & 305,64 & 217,30 & 255,84 & 219,13 \\
\hline Calotriton asper & 31TCG78 & 101,00 & 85,85 & 82,15 & 33,85 & 5619,35 & 220,94 & $-18,18$ & 239,12 & 100,67 & 23,43 & 160,50 & 18,55 & 949,62 & \begin{tabular}{l|l|}
106,95 \\
\end{tabular} & 56,21 & 19,49 & 285,60 & 186,85 & 246,24 & 187,27 \\
\hline Calotriton asper & 31TCG79 & 93,00 & 84,65 & 82,50 & 33,99 & 5614,10 & 219,73 & $-19,88$ & 239,61 & 99,70 & 26,61 & 159,09 & 17,16 & 961,84 & 107,81 & 57,50 & 19,35 & 288,82 & \begin{tabular}{|l|l|}
191,07 \\
\end{tabular} & 250,67 & 192,28 \\
\hline Calotriton asper & 31TCG86 & 101,00 & 95,66 & 80,92 & 33,60 & 5627,15 & 229,94 & $-8,22$ & 238,16 & $\begin{array}{lll}110,43 & \\
\end{array}$ & 29,12 & 170,56 & 28,44 & 882,62 & 101,85 & 48,92 & 21,74 & 269,03 & 164,82 & 231,88 & 164,88 \\
\hline Calotriton asper & 31TCG87 & 99,00 & 67,24 & 77,10 & 32,93 & 5503,48 & 199,44 & $-31,32$ & 230,76 & 78,97 & 13,91 & 141,54 & 3,51 & 1068,36 & 117,04 & 67,59 & 16,05 & 307,45 & 224,74 & 256,98 & 226,27 \\
\hline Calotriton asper & 31TCG88 & 100,00 & 63,33 & 76,98 & 32,89 & 5497,30 & 195,29 & $-35,57$ & 230,86 & 73,67 & 28,23 & 137,52 & $-0,41$ & 1098,87 & 119,62 & 68,98 & 15,87 & 316,04 & 231,11 & 263,61 & 235,88 \\
\hline Calotriton asper & 31TCG94 & 100,00 & 127,57 & 80,26 & 33,00 & 5672,18 & 259,42 & 19,64 & 239,77 & 145,23 & 57,99 & 202,01 & 57,99 & 702,18 & 84,92 & 32,64 & 27,54 & 221,86 & 113,81 & 196,36 & 113,81 \\
\hline Calotriton asper & 31TCG95 & 101,00 & 111,81 & 80,22 & 33,02 & 5654,02 & 244,94 & 6,04 & 238,90 & 127,50 & 43,42 & 186,65 & 43,42 & 788,95 & 94,18 & 39,23 & 25,53 & 246,95 & 135,20 & 217,09 & 135,20 \\
\hline Calotriton asper & 31TCG96 & 101,00 & 83,33 & 77,80 & 32,5 & 5542,42 & 215,76 & $-16,57$ & 232,33 & 95,44 & 20,50 & 157,85 & 18,52 & 965,67 & 108,47 & 57,35 & 18,90 & 283,52 & 192,36 & 241,41 & 193,01 \\
\hline Calotriton asper & 31TCG97 & 100,00 & 71,85 & 76,80 & 32,7 & 5500,74 & 203,82 & $-26,53$ & 230,35 & 81,58 & 21,96 & 146,11 & 8,09 & $\begin{array}{l}1042,29 \\
\end{array}$ & 114,65 & 64,51 & 16,80 & 300,67 & 216,33 & 253,16 & 218,34 \\
\hline Calotriton asper & 31TCG98 & 101,00 & 64,66 & 76,27 & 32,77 & 5478,46 & 196,19 & $-33,27$ & 229,46 & 73,71 & 26,64 & 138,66 & 1,43 & 1092,72 & 118,86 & 68,90 & 15,71 & 312,52 & 231,01 & 261,60 & 235,04 \\
\hline Calotriton asper & 31TCG99 & 99,00 & 73,05 & 78,05 & 33,11 & 5513,07 & 205,46 & $-26,95$ & 232,41 & 85,52 & 20,57 & 146,93 & 8,37 & 1043,01 & \begin{tabular}{ll|}
114,88 \\
\end{tabular} & 64,81 & 16,92 & 303,95 & 215,59 & 257,31 & 218,58 \\
\hline Calotriton asper & $31 \mathrm{TCH} 02$ & 95,00 & 16,76 & 72,03 & 31,69 & 5314,50 & 142,11 & $-81,48$ & 223,59 & 25,51 & 72,44 & 88,96 & $-44,56$ & 1402,13 & 146,60 & 93,52 & 12,24 & 394,75 & 310,47 & 310,92 & 335,91 \\
\hline Calotriton asper & 31TCH03 & 12,00 & 56,29 & 83,90 & 34,95 & 5433,32 & 187,96 & $-48,19$ & 236,15 & 70,27 & 32,02 & 128,30 & $-9,55$ & \begin{tabular}{|l|}
1176,73 \\
\end{tabular} & 123,28 & 78,25 & 13,22 & 336,01 & 262,95 & 275,64 & 270,55 \\
\hline Calotriton asper & 31TCH10 & 101,00 & 70,82 & 86,96 & 35,2 & 5577 & 206,95 & $-36,13$ & 243,08 & 86,42 & 10,36 & 144,48 & 2,97 & 1077,72 & 114,90 & 70,09 & 15,04 & 313,38 & 233,40 & 262,96 & 234,27 \\
\hline Calotriton asper & 31TCH11 & 99,00 & 40,14 & 78,04 & 33,24 & 5413,46 & 169,87 & $-60,88$ & 230,75 & 51,68 & 42,97 & 112,88 & $-23,66$ & 1250,71 & 132,46 & 83,15 & 13,13 & 357,02 & 278,78 & 286,50 & 287,67 \\
\hline Calotriton asper & 31TCH12 & 99,00 & 35,17 & 76,66 & 32,96 & 5377,96 & 163,51 & $-65,17$ & 228,68 & 46,14 & 49,97 & 107,55 & $-28,01$ & \begin{tabular}{l|l}
1292,35 \\
\end{tabular} & 136,01 & 86,41 & 12,75 & 367,07 & 288,25 & 293,91 & 301,36 \\
\hline Calotriton asper & $31 \mathrm{TCH} 13$ & & & & & & & & & & & & & & & & & & & & \\
\hline Calotriton asper & $31 \mathrm{TCH} 20$ & 99,00 & 9,54 & 74,46 & 32,24 & 93,53 & 158,03 & $-69,34$ & 7 & 39,43 & 54,78 & 102 & $-32,76$ & $\begin{array}{l}1309,39 \\
\end{array}$ & 138,61 & 86,76 & 12,76 & 371,32 & 291,52 & 295,71 & 303,96 \\
\hline Calotriton asper & 31TCH21 & 100,00 & 28,59 & 74,34 & 32 & 5380,76 & 156,52 & $-70,36$ & 226,89 & 38,52 & 49,77 & 101,43 & $-33,76$ & | 1327,84 & 139,92 & 88,51 & 12,64 & 375,89 & 294,86 & 300,09 & 310,24 \\
\hline Calotriton asper & $31 \mathrm{TCH} 22$ & 100,00 & 36,77 & 76,64 & 32,94 & 5390,09 & 165,55 & $-63,34$ & 228,89 & 47,95 & 40,53 & 109,38 & $-26,45$ & $\begin{array}{l}1286,02 \\
\end{array}$ & 135,51 & 86,24 & 12,79 & 365,47 & 286,99 & 294,17 & 298,24 \\
\hline Calotriton asper & $31 \mathrm{TCH} 23$ & 101,00 & 39,35 & 77,48 & 33,21 & 5379,69 & 168,15 & $-61,19$ & 229,34 & 50,94 & 43,30 & 111,59 & $-24,16$ & 1278,98 & 134,37 & 86,22 & 12,74 & 363,34 & 286,52 & 294,29 & 297,12 \\
\hline Calotriton asper & $31 \mathrm{TCH} 24$ & & & & & & & & & & & & & & & & & & & & \\
\hline Calotriton asper & $31 \mathrm{TCH} 30$ & 101,00 & 34,97 & 75 & 32,50 & 5415,06 & 164,19 & -64 & 228,29 & 4 & 41 & 10 & -2 & 1280,86 & 13 & 84,92 & 7 & 36 & 284,49 & 292,27 & 294 \\
\hline Calotriton asper & 31TCH31 & 101,00 & 16,34 & 70,81 & 31,23 & 5342,24 & 142,52 & $-80,45$ & 222,97 & 24,73 & 73,74 & 89,29 & $-44,29$ & 1407,13 & 147,27 & 93,70 & 12,09 & 394,26 & 312,75 & 313,65 & 334,46 \\
\hline
\end{tabular}




\begin{tabular}{|c|c|c|c|c|c|c|c|c|c|c|c|c|c|c|c|c|c|c|c|c|c|}
\hline TAXON & UTM & $\mathrm{km} 2$ & B101 & B1O2 & BIO3 & B104 & BIO5 & B106 & B107 & B108 & 8109 & B1010 & BIO11 & BIO12 & BIO13 & B1014 & BIO15 & B1016 & B1017 & B1018 & B1019 \\
\hline Calotriton asper & $31 \mathrm{TCH} 32$ & 100,00 & 30,59 & 74,37 & 32,30 & 5365,39 & 158,33 & $-67,99$ & 226,33 & 40,75 & 55,22 & 103,22 & $-31,65$ & 1322,80 & 139,29 & 88,89 & 12,41 & 374,10 & 296,83 & 300,48 & 308,79 \\
\hline Calotriton asper & 31TCH33 & 94,00 & 28,42 & 73,96 & 32,25 & 5346,24 & 155,51 & $-70,03$ & 225,54 & 38,52 & 56,33 & 100,74 & $-33,62$ & $\begin{array}{l}1344,27 \\
\end{array}$ & 140,94 & 90,78 & 12,19 & 379,09 & 302,24 & 304,95 & 316,39 \\
\hline Calotriton asper & 31TCH34 & 2,00 & 66,65 & 85,02 & 34,99 & 5504,73 & 200,11 & $-38,88$ & 238,99 & \begin{tabular}{|l|l|}
81,76 \\
\end{tabular} & 24,92 & 139,35 & $-0,33$ & 1134,10 & 119,36 & 76,22 & 13,78 & 327,18 & 248,53 & 278,37 & 255,48 \\
\hline Calotriton asper & $31 \mathrm{TCH} 40$ & 99,00 & 67,52 & 82,72 & 34,24 & 5557,99 & 201,88 & $-36,39$ & 238,27 & 81,69 & 12,90 & 141,48 & 0,85 & 1089,40 & \begin{tabular}{|l|l|}
118,08 \\
\end{tabular} & 70,05 & 15,66 & 319,18 & 231,33 & 268,49 & 233,07 \\
\hline Calotriton asper & 31TCH41 & 100,00 & 63,26 & 81,99 & \begin{tabular}{|l|l|}
34,13 \\
\end{tabular} & 5523,37 & $\begin{array}{l}196,65 \\
\end{array}$ & \begin{tabular}{|l|l|}
$-40,04$ \\
\end{tabular} & 236,68 & 77,13 & 9,88 & 136,79 & $-2,89$ & 1124,23 & 120,96 & 73,64 & 14,88 & 327,29 & 242,00 & 272,27 & 244,91 \\
\hline Calotriton asper & $31 \mathrm{TCH} 42$ & 100,00 & 53,73 & 80,04 & 33,75 & 5467,77 & 185,45 & $-48,06$ & 233,50 & 66,64 & 18,61 & 126,77 & $-11,23$ & \begin{tabular}{|l|}
1190,48 \\
\end{tabular} & 126,61 & 79,35 & 13,87 & 342,55 & 260,50 & 283,88 & 266,82 \\
\hline Calotriton asper & $31 \mathrm{TCH} 43$ & 60,00 & 43,68 & 77,61 & 33,20 & 5405,50 & 173,36 & $-56,52$ & 229,88 & 55,53 & 26,16 & 116,18 & $-20,01$ & $\begin{array}{l}1253,39 \\
\end{array}$ & 132,37 & 84,77 & 12,95 & 357,19 & 279,18 & 291,92 & 287,73 \\
\hline Calotriton asper & $31 \mathrm{TCH} 50$ & 100,00 & 71,39 & 82,70 & 34,26 & 5567,46 & 205,94 & $-32,33$ & 238,27 & 85,79 & 11,74 & 145,40 & 4,63 & 1063,64 & 116,05 & 67,96 & 16,14 & 313,12 & 222,89 & 264,81 & 224,47 \\
\hline Calotriton asper & 31TCH51 & 101,00 & 67,54 & 82,16 & 34,13 & 5539,02 & 201,42 & $-35,78$ & 237,21 & 81,70 & 15,01 & 141,19 & 1,18 & 1094,70 & 118,56 & 70,96 & 15,47 & 320,44 & 232,44 & 270,99 & 235,29 \\
\hline Calotriton asper & 31TCH52 & 99,00 & 38,21 & 75,38 & 32,56 & 5400,44 & 167,34 & $-60,59$ & 227,93 & 48,91 & 33,73 & 111,10 & $-24,56$ & $\begin{array}{l}1280,87 \\
\end{array}$ & 135,31 & 85,82 & 12,83 & 362,94 & 284,53 & 296,30 & 295,04 \\
\hline Calotriton asper & 31TCH53 & 13,00 & 58,38 & 80,89 & 33,87 & 5485,23 & 190,67 & $-44,20$ & 234,88 & 71,88 & 29,31 & \begin{tabular}{|l|}
131,43 \\
\end{tabular} & $-7,10$ & $\begin{array}{ll}1166,48 \\
\end{array}$ & $\begin{array}{l}124,06 \\
\end{array}$ & 77,42 & 14,06 & 336,38 & 253,41 & 282,39 & 261,69 \\
\hline Calotriton asper & $31 \mathrm{TCH} 60$ & 100,00 & 43,75 & 75,39 & 32,54 & 5429,16 & 173,81 & $-54,41$ & 228,22 & 54,28 & 15,13 & 117,26 & $-18,95$ & 1231,44 & 131,27 & 81,77 & 13,31 & 349,41 & 271,67 & 285,63 & 278,23 \\
\hline 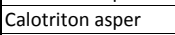 & 31TCH61 & 101,00 & 43,72 & 75,90 & 32,65 & 5428,46 & 173,92 & $-55,01$ & 228,93 & 54,61 & 25,73 & \begin{tabular}{|l|}
117,07 \\
\end{tabular} & $-19,20$ & 1239,91 & $\mid 131,77$ & 82,07 & 13,39 & 352,25 & 272,38 & 289,12 & 281,41 \\
\hline Calotriton asper & $31 \mathrm{TCH} 62$ & 86,00 & 25,43 & 72,18 & \begin{tabular}{|l|l|}
31,67 \\
\end{tabular} & 5356,26 & 153,02 & $-71,17$ & 224,19 & 34,47 & 52,42 & 98,35 & $-35,47$ & 1362,91 & 142,62 & 91,10 & 12,01 & 380,74 & 303,49 & 308,27 & 321,17 \\
\hline Calotriton asper & 31TCH63 & 7,00 & 50,29 & 78,24 & 33,31 & 5437,28 & 181,18 & $-50,06$ & 231,24 & 62,46 & 26,72 & 123,17 & $-13,72$ & 1210,88 & 128,52 & 81,17 & 13,41 & 346,10 & 266,16 & 287,18 & 275,01 \\
\hline Calotriton asper & 31TCH70 & 25,00 & 63,07 & 78,72 & 33,28 & 5501,75 & 195,50 & $-37,42$ & 232,93 & 75,62 & 13,79 & 136,87 & $-1,66$ & 1110,05 & 120,56 & 71,60 & 15,38 & 321,86 & 235,70 & 269,98 & 239,61 \\
\hline Calotriton asper & 31TCH71 & 16,00 & 42,06 & 74,86 & 32,44 & 5413,72 & 171,80 & $-55,63$ & 227,43 & 52,47 & 31,98 & 115,36 & $-20,23$ & 1250,03 & 132,67 & 82,76 & 13,23 & 353,38 & 273,94 & 289,90 & 285,08 \\
\hline Calotriton asper & 31TCH72 & 2,00 & 31,13 & 72,90 & $\begin{array}{ll}31,93 \\
\end{array}$ & 5365,65 & 159,33 & $-65,51$ & 224,84 & 40,46 & 47,63 & 104,04 & $-30,04$ & $\begin{array}{l}1324,96 \\
\end{array}$ & 139,04 & 88,49 & 12,24 & 370,43 & 295,28 & 301,96 & 309,85 \\
\hline Calotriton asper & 31TCH80 & 17,00 & 26,86 & 71,15 & 31,32 & 5368,95 & 154,94 & $-68,27$ & 223,21 & 34,06 & 68,62 & 100,29 & $-33,26$ & $\begin{array}{l}1345,76 \\
\end{array}$ & 140,51 & 87,68 & 12,45 & 371,94 & 296,81 & 302,25 & 316,72 \\
\hline Calotriton asper & 31TCH90 & 57,00 & 22,38 & 69,87 & 31,00 & 5348,90 & 149,96 & $-71,69$ & 221,65 & 20,28 & 76,64 & 95,73 & $-36,89$ & \begin{tabular}{|l|}
1376,73 \\
\end{tabular} & 142,64 & 89,22 & 12,14 & 377,34 & 303,91 & 305,72 & 327,94 \\
\hline Calotriton asper & 31TDG06 & 100,00 & 106,21 & 79,00 & 32,99 & 5609,13 & 238,65 & 2,26 & 236,39 & \begin{tabular}{|l|l|}
121,23 \\
\end{tabular} & 39,69 & 180,73 & 38,92 & 829,94 & 97,73 & 43,36 & 24,43 & 255,93 & 147,61 & 225,40 & 147,75 \\
\hline Calotriton asper & 31TDG07 & 101,00 & 97,75 & 79,20 & 33,01 & 5585,81 & 230,65 & $-4,96$ & 235,61 & $\begin{array}{ll}112,18 \\
\end{array}$ & 32,50 & 172,05 & 31,12 & 884,39 & 102,25 & 48,81 & 21,83 & 268,99 & 165,19 & 234,06 & 165,33 \\
\hline Calotriton asper & 31TDG08 & 101,00 & 67,80 & 75,83 & \begin{tabular}{l|l|}
32,65 \\
\end{tabular} & 5466,88 & 199,08 & $-29,52$ & 228,60 & 74,25 & 25,33 & 141,74 & 4,84 & 1075,86 & 116,99 & 67,49 & 15,94 & 307,24 & 226,72 & 258,04 & 230,88 \\
\hline Calotriton asper & 31TDG09 & 101,00 & 88,07 & 79,57 & 33,42 & 5552,21 & 221,40 & $-13,35$ & 234,75 & 102,11 & 28,74 & 162,03 & 22,14 & 952,05 & 107,28 & 56,50 & 18,73 & 284,35 & 188,33 & 243,10 & 189,54 \\
\hline Calotriton asper & 31TDG15 & 101,00 & 123,04 & 77,90 & 32,41 & 5614,28 & 253,69 & 17,34 & 236,35 & 138,98 & 54,84 & 197,03 & 54,84 & 734,72 & 89,87 & 33,72 & 28,82 & 233,69 & 116,68 & 213,33 & 116,68 \\
\hline Calotriton asper & 31TDG16 & 100,00 & 109,61 & 78,14 & 32,94 & 5594,27 & 241,39 & 5,90 & 235,49 & 124,73 & 42,68 & 183,93 & 42,52 & 816,30 & \begin{tabular}{|l|}
97,07 \\
\end{tabular} & 41,02 & 25,05 & 253,79 & 141,82 & 225,21 & 141,82 \\
\hline 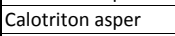 & 31TDG17 & 100,00 & 92,30 & 77,43 & 32,98 & 5530,63 & 224,15 & $-7,93$ & 232,07 & $\begin{array}{ll}105,48 \\
\end{array}$ & 30,03 & 166,30 & 27,32 & \begin{tabular}{|l|l|}
927,47 \\
\end{tabular} & 105,12 & 53,59 & 19,78 & 274,98 & 180,58 & 237,38 & $\begin{array}{ll}181,09 \\
\end{array}$ \\
\hline Calotriton asper & 31TDG18 & 98,00 & 62,33 & 74,21 & \begin{tabular}{|l|l|}
32,38 \\
\end{tabular} & 5421,81 & 192,68 & $-33,11$ & 225,79 & 60,52 & 21,32 & 135,92 & 0,71 & 1113,96 & 119,15 & 70,54 & 14,95 & 312,34 & 240,85 & 260,57 & 245,94 \\
\hline Calotriton asper & 31TDG19 & 44,00 & 74,09 & 76,62 & 32,84 & 5468,72 & 205,63 & $-23,84$ & 229,47 & 82,36 & 21,98 & 147,66 & 10,64 & 1044,01 & 113,79 & 65,48 & 16,03 & 299,40 & 218,83 & 252,53 & 222,53 \\
\hline Calotriton asper & 31TDG20 & 100,00 & 152,94 & 71,68 & 31,71 & 5379,99 & 273,79 & 50,50 & 223,29 & 200,40 & 87,61 & 223,95 & 87,61 & 634,60 & 77,02 & 33,88 & 25,47 & 208,06 & 119,64 & 165,13 & 119,64 \\
\hline Calotriton asper & 31TDG26 & 101,00 & 110,29 & 77,01 & 32,33 & 5569,27 & 241,08 & 7,03 & 234,05 & 124,80 & 43,82 & 184,24 & 43,67 & 832,47 & 97,84 & 42,19 & 24,08 & 256,10 & 147,86 & 225,80 & 147,86 \\
\hline Calotriton asper & 31TDG27 & 101,00 & 99,41 & 77,17 & 32,82 & 5532,74 & 230,85 & $-1,67$ & 232,51 & 113,10 & 36,06 & 173,24 & 34,05 & 897,92 & 102,41 & 49,96 & 20,58 & 268,64 & 171,64 & 232,58 & 171,86 \\
\hline Calotriton asper & 31TDG28 & 100,00 & 71,10 & 74,64 & 32,52 & 5429,70 & 201,55 & $-24,87$ & 226,41 & 71,42 & 28,10 & 144,59 & 9,08 & 1066,16 & 114,64 & 66,61 & 15,65 & 301,19 & 226,87 & 252,25 & 231,73 \\
\hline Calotriton asper & 31TDG34 & 101,00 & 129,94 & 74,44 & 31,72 & 5552,03 & 257,43 & 25,65 & 231,78 & \begin{tabular}{|l|l|}
165,59 \\
\end{tabular} & 62,72 & 203,31 & 62,72 & 768,28 & 89,48 & 36,97 & 25,35 & 236,62 & 132,24 & 212,86 & 132,24 \\
\hline Calotriton asper & 31TDG35 & 100,00 & 124,92 & 75,47 & \begin{tabular}{|l|}
31,97 \\
\end{tabular} & 5577,89 & 253,79 & 20,32 & 233,47 & $\begin{array}{l}140,55 \\
\end{array}$ & 57,43 & 198,57 & 57,43 & 794,52 & 92,92 & 37,77 & 25,36 & 245,58 & 137,07 & 218,86 & 137,07 \\
\hline Calotriton asper & 31TDG36 & 100,00 & 114,79 & 76,19 & 32,08 & 5563,09 & 244,76 & 11,45 & 233,31 & 130,09 & 48,35 & 188,44 & 48,04 & 837,99 & 96,99 & 42,20 & 23,51 & 256,19 & 151,28 & 225,56 & 151,35 \\
\hline Calotriton asper & 31TDG37 & 101,00 & 107,25 & 76,76 & 32,33 & 5546,01 & 238,00 & 4,78 & 233,22 & \begin{tabular}{|l|l|}
121,53 \\
\end{tabular} & 42,10 & 180,97 & 41,12 & 876,42 & 99,70 & 46,81 & 21,35 & 263,89 & 165,67 & 227,95 & 165,95 \\
\hline Calotriton asper & 31TDG38 & 101,00 & 73,34 & 74,25 & \begin{tabular}{|l|l|}
32,47 \\
\end{tabular} & 5414,20 & 203,41 & $-22,12$ & 225,52 & 68,72 & 37,31 & 146,73 & 11,69 & 1057,84 & 112,89 & 64,87 & 15,93 & 300,44 & 226,13 & 248,49 & 231,54 \\
\hline Calotriton asper & 31TDG39 & 75,00 & 30,22 & 69,10 & \begin{tabular}{|l|l|}
30,97 \\
\end{tabular} & 5326,44 & 157,92 & $-61,66$ & 219,58 & 7,90 & 87,34 & 103,49 & $-27,81$ & $\begin{array}{l}1327,69 \\
\end{array}$ & 135,14 & 82,08 & 13,05 & 373,45 & 287,85 & 289,66 & 317,77 \\
\hline Calotriton asper & 31TDG42 & 100,00 & 113,04 & 71,73 & 31,59 & 5434,21 & 238,94 & 14,74 & 224,20 & \begin{tabular}{|l|l|}
152,19 \\
\end{tabular} & 57,00 & 186,19 & 49,79 & 869,95 & 97,70 & 48,67 & 20,16 & 260,21 & 174,95 & 213,02 & 175,78 \\
\hline Calotriton asper & 31TDG43 & 101,00 & 120,79 & 72,53 & 31,36 & 5480,88 & 247,16 & 19,81 & 227,36 & 168,24 & 56,24 & 193,96 & 55,80 & 841,38 & 93,61 & 44,30 & 21,43 & 251,91 & $\begin{array}{l}161,19 \\
\end{array}$ & 215,44 & 161,25 \\
\hline Calotriton asper & 31TDG45 & 100,00 & 123,43 & 74,48 & 31,81 & 5541,19 & 251,55 & 19,82 & 231,73 & \begin{tabular}{|l|l|}
138,59 \\
\end{tabular} & 56,68 & 196,77 & 56,65 & 844,31 & 94,95 & 41,38 & 22,77 & 254,73 & 155,64 & 222,07 & 155,64 \\
\hline Calotriton asper & 31TDG46 & 101,00 & 98,81 & 74,53 & 32,16 & 5461,29 & 227,98 & 0,29 & 227,69 & \begin{tabular}{|l|l|}
123,23 \\
\end{tabular} & 38,16 & 172,11 & 35,25 & 935,05 & 102,41 & 54,20 & 18,70 & 269,63 & $\mid 188,71$ & 229,59 & 189,68 \\
\hline Calotriton asper & 31TDG47 & 100,00 & \begin{tabular}{|l|l|}
107,07 \\
\end{tabular} & 76,01 & 32, & 5516,90 & 237,20 & 5,42 & 231,79 & \begin{tabular}{|l|l|}
122,12 \\
\end{tabular} & 43,70 & 180,49 & 41,55 & 899,99 & $\begin{array}{l}99,75 \\
\end{array}$ & 49,27 & 19,80 & 65,71 & \begin{tabular}{|l|l|}
176,79 \\
\end{tabular} & 226,44 & 177,02 \\
\hline Calotriton asper & 31TDG48 & 99,00 & 90,22 & 75,53 & 32, & 5453,60 & 220,57 & $-7,82$ & 228,39 & \begin{tabular}{|l|}
99,62 \\
\end{tabular} & 32,26 & 163,59 & 26,84 & 975,65 & 105,37 & 59,03 & 17,02 & 278,09 & 203,11 & 234,79 & 205,54 \\
\hline Calotriton asper & 31TDG49 & 61,00 & 55,44 & 71,98 & 31, & 5347,45 & \begin{tabular}{|l|}
184,37 \\
\end{tabular} & $-37,63 \mid$ & 222,00 & $\begin{array}{l}36,75 \\
36,0\end{array}$ & $\begin{array}{ll}62,02 \\
62\end{array}$ & 128,52 & $\begin{array}{l}-4,04,12 \\
\end{array}$ & 1168,61 & 120,65 & 72,21 & 14,13 & 328,65 & 255,93 & 262,42 & 270,85 \\
\hline Calotriton asper & 31TDG52 & 100,00 & 121,05 & 70,84 & 31,14 & 5416,66 & 245,56 & 21,77 & 223,79 & \begin{tabular}{|l|l|}
158,67 \\
\end{tabular} & 73,56 & 193,60 & 57,38 & 871,94 & 101,31 & 48,10 & 20,27 & 261,90 & 179,63 & 207,94 & 181,17 \\
\hline Calotriton asper & 31TDG53 & 101,00 & 120,29 & 71,75 & 31,31 & 5454,72 & 245,94 & 19,90 & 226,03 & $\mid 168,79$ & 56,34 & $\mid 193,21$ & 55,81 & 879,46 & 97,58 & 47,86 & 20,11 & 259,23 & 176,63 & 214,88 & 176,63 \\
\hline Calotriton asper & 31TDG54 & 100,00 & 125,16 & 72,61 & 31,2 & 5493,16 & 251,46 & 22,80 & 228,67 & 159,72 & 59,79 & 198,10 & 59,49 & 882,49 & 96,36 & 45,17 & 20,85 & 259,02 & 173,86 & 217,20 & 173,90 \\
\hline Calotriton asper & 31TDG55 & 101,00 & 11 & 73 & 31 & 5470,40 & 240,58 & 12,28 & 22 & 146,27 & 49,85 & 185 & 48,41 & 911,09 & 98,75 & & 19,85 & 264,80 & 182,35 & 222,98 & 182,41 \\
\hline Calotriton asper & 31TDG56 & 101,00 & 126,48 & 74,94 & 31,7 & 5552,87 & 254,68 & 21,49 & 233,19 & \begin{tabular}{|l|l|}
143,13 \\
\end{tabular} & 59,32 & 199,65 & 59,17 & 878,35 & 94,59 & 43,36 & 21,32 & 261,01 & 171,38 & 218,56 & $\begin{array}{ll}171,39 \\
\end{array}$ \\
\hline Calotriton asper & 31TDG57 & 100,00 & 129,29 & 76,38 & 31,96 & 5582,05 & 258,48 & 22,78 & 235,70 & 147,30 & 61,07 & 202,62 & 61,07 & 845,98 & 92,13 & 42,93 & 20,88 & 250,54 & 166,34 & 210,12 & 166,34 \\
\hline Calotriton asper & 31TDG58 & 94,00 & 108,42 & 76,50 & 32,40 & 5508,44 & 238,70 & 6,27 & 232,44 & 122,51 & 45,63 & 181,73 & 42,94 & 909,93 & 97,99 & 51,44 & 18,50 & 263,54 & 186,08 & 220,40 & 187,06 \\
\hline Calotriton asper & 31TDG59 & 18,00 & 90 & 75,95 & 32,8 & 5439,71 & 221,28 & $-7,67$ & 6 & 94 & 36,19 & 163 & 27,56 & \begin{tabular}{|c|}
980,58 \\
\end{tabular} & 103,82 & 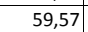 & 16,30 & 277,15 & 02 & 230,66 & 212,69 \\
\hline Calotriton asper & 31TDG64 & 100,00 & \begin{tabular}{|l|}
133,71 \\
\end{tabular} & 71,88 & 30,84 & 5515,80 & 258,82 & 29,58 & 229,23 & \begin{tabular}{|l|l|l|}
177,28 \\
\end{tabular} & 81,89 & 206,53 & 66,99 & 870,25 & \begin{tabular}{|l|l|}
101,28 \\
\end{tabular} & 45,16 & 21,27 & 255,94 & $\begin{array}{l}178,43 \\
\end{array}$ & 203,14 & 178,73 \\
\hline Calotriton asper & 31TDG65 & 100,00 & 134,61 & 73,08 & 31,10 & 5543,73 & 260,82 & 29,16 & 231,66 & \begin{tabular}{|l|l|}
171,21 \\
\end{tabular} & 67,05 & 207,58 & 67,05 & 869,24 & 99,53 & 44,63 & 21,17 & 253,62 & 177,00 & 205,04 & 177,00 \\
\hline Calotriton asper & 31TDG68 & 86,00 & 114,42 & 76,43 & 32,34 & 5500,76 & 243,88 & 11,05 & 232,83 & \begin{tabular}{|l|l|}
134,60 \\
\end{tabular} & 51,47 & 187,37 & 48,63 & 893,25 & 96,76 & 50,69 & 18,58 & 255,03 & $\mid 186,61$ & 211,05 & 187,34 \\
\hline Calotriton asper & 31TDG76 & 100,00 & 143,13 & 74,41 & 31,20 & 5552,16 & 269,17 & 35,16 & 234,01 & \begin{tabular}{|l|l|}
185,68 \\
\end{tabular} & 111,35 & 215,67 & 74,65 & 784,79 & 99,79 & 41,08 & 22,69 & 235,03 & 163,83 & 173,85 & 164,27 \\
\hline Calotriton asper & 31TDG77 & 100,00 & 138,85 & 75,89 & 31, & 5538,66 & 266,13 & 30,97 & 23 & \begin{tabular}{|l|l|}
177,79 \\
\end{tabular} & 103,96 & & 70,83 & \begin{tabular}{|l|l|}
782,67 \\
\end{tabular} & 97,23 & 41,56 & 21,97 & 231,89 & 164,30 & 174,28 & 164 \\
\hline Calotriton asper & 31TDG78 & 93,00 & 127,93 & 77,01 & 32,06 & 5514,09 & 256,73 & 21,64 & 235,10 & 166,72 & 73,70 & 200,46 & 60,95 & 827,53 & 96,41 & 45,54 & 20,13 & 238,31 & 175,62 & 187,78 & 175,90 \\
\hline
\end{tabular}




\begin{tabular}{|c|c|c|c|c|c|c|c|c|c|c|c|c|c|c|c|c|c|c|c|c|c|}
\hline TAXON & UTM & $\mathrm{km} 2$ & BIO1 & B102 & $\mathrm{BIO3}$ & B104 & BIO5 & B106 & B107 & B108 & B109 & BIO10 & BIO11 & B1012 & BIO13 & 81014 & B1015 & B1016 & B1017 & B1018 & B1019 \\
\hline Calotriton asper & 31TDG79 & 46,00 & 113,70 & 77,44 & 32,85 & 5476,17 & 243,58 & 10,14 & 233,44 & 142,50 & 62,03 & 186,30 & 48,28 & 879,16 & 98,03 & 50,52 & 18,20 & 248,55 & 189,73 & 200,52 & 191,48 \\
\hline Calotriton asper & 31TDG89 & 82,00 & 138,88 & 79,63 & 32,99 & 5506,15 & 267,94 & 29,75 & 238,19 & 152,98 & 186,80 & 211,01 & 71,29 & 724,75 & 93,55 & 35,45 & 22,99 & 219,97 & \begin{tabular}{ll|}
148,58 \\
\end{tabular} & 152,88 & 159,90 \\
\hline Chioglossa lusitanica & 29SND69 & 100,00 & 156,26 & 94,39 & 39,99 & 4724,42 & 292,26 & 58,78 & 233,49 & 98,11 & 216,29 & 219,20 & 98,11 & $\begin{array}{l}888,65 \\
\end{array}$ & 129,02 & 7,71 & 55,92 & 364,47 & 53,76 & 54,91 & 364,47 \\
\hline Chioglossa lusitanica & 29SND78 & 100,00 & 156,18 & 94,27 & 39,20 & 4899,09 & 295,88 & 58,04 & 237,84 & 96,54 & 218,78 & 221,83 & 96,54 & 877,66 & 127,63 & 7,38 & 56,02 & 360,54 & 52,64 & 53,34 & 360,54 \\
\hline Chioglossa lusitanica & 29SND79 & 101,00 & 153,58 & 94,51 & 39,06 & 4917,92 & 293,90 & 55,02 & 238,88 & 93,68 & 216,89 & 219,49 & 93,68 & \begin{tabular}{|l|l}
919,63 \\
\end{tabular} & \begin{tabular}{|c|}
133,97 \\
\end{tabular} & 8,12 & 55,83 & 377,20 & 56,25 & 56,71 & 377,20 \\
\hline Chioglossa lusitanica & 29SND88 & 99,00 & 154,56 & 94,24 & 38,52 & 5066,11 & 297,74 & 55,48 & 242,26 & 93,30 & 220,01 & 222,74 & 93,30 & 894,16 & 130,22 & 7,64 & 55,91 & 366,97 & 54,09 & 54,49 & 366,97 \\
\hline Chioglossa lusitanica & 29SNE50 & 101,00 & 152,49 & 93,64 & 40,52 & 4559,42 & 284,73 & 56,28 & 228,45 & 96,01 & 210,15 & 213,00 & 96,01 & 936,03 & 135,86 & 8,58 & 55,59 & 383,17 & 57,83 & 59,04 & 383,17 \\
\hline \begin{tabular}{|c} 
Chioglossa lusitanica \\
\end{tabular} & 29SNE51 & 101,00 & 150,79 & 94,81 & 40,71 & 4567,43 & 283,90 & 53,75 & 230,15 & 94,13 & 208,58 & 211,30 & 94,13 & $\begin{array}{l}971,58 \\
\end{array}$ & 140,67 & 9,29 & 54,97 & 396,61 & 61,51 & 62,51 & 396,61 \\
\hline Chioglossa lusitanica & 29SNE52 & 100,00 & 145,71 & 94,36 & $\begin{array}{l}40,55 \\
\end{array}$ & 4572,50 & 278,62 & 48,77 & 229,86 & 89,08 & 204,36 & 206,28 & 89,08 & 1042,81 & 151,36 & 10,45 & 54,69 & 424,94 & 67,24 & 68,03 & 424,94 \\
\hline \begin{tabular}{|l|} 
Chioglossa Iusitanica \\
\end{tabular} & 29SNE60 & 100,00 & 156,03 & 95,70 & 40,18 | & 4727,17 & 292,76 & 57,48 & 235,28 & 97,60 & 216,06 & 218,82 & 97,60 & \begin{tabular}{|l|l|l|}
909,29 \\
\end{tabular} & $\mid 131,69$ & 8,14 & 55,40 & 371,90 & 56,08 & 57,23 & 371,90 \\
\hline Chioglossa lusitanica & 29SNE61 & 100,00 & 151,40 & 95,90 & 40,15 & 4750,56 & 289,01 & 52,56 & 236,45 & 92,84 & 211,99 & 214,58 & 92,84 & 973,54 & 141,32 & 9,16 & 55,04 & 397,64 & 61,64 & 62,21 & 397,64 \\
\hline Chioglossa lusitanica & 29SNE62 & 100,00 & 141,47 & 93,16 & 39,39 & 4773,60 & 277,94 & 44,03 & 233,92 & 83,16 & 204,14 & 205,27 & 83,16 & 1091,31 & 160,04 & 10,87 & 54,99 & 445,90 & 69,95 & 70,01 & 445,90 \\
\hline Chioglossa lusitanica & 29SNE71 & 100,00 & 147,42 & 94,63 & 38,97 & 4938,86 & 288,14 & 48,14 & 240,01 & 87,19 & 211,97 & 213,50 & 87,19 & 1016,43 & 148,84 & 9,58 & 55,22 & 415,88 & 63,99 & 64,14 & 415,88 \\
\hline Chioglossa lusitanica & 29SNE72 & 101,00 & 147,01 & 95,68 & 39,19 & 4934,79 & 287,99 & 46,80 & 241,19 & 86,58 & 211,29 & 212,84 & 86,58 & 1037,05 & 151,67 & 10,03 & 55,00 & 423,37 & 66,27 & 66,45 & 423,37 \\
\hline Chioglossa lusitanica & 29SNE80 & 101,00 & 147,36 & 93,38 & 38,00 & 5105,65 & 290,68 & 48,02 & 242,66 & 85,73 & 214,97 & 216,08 & 85,73 & \begin{tabular}{|c|}
999,48 \\
\end{tabular} & 146,99 & 9,09 & 55,62 & 409,81 & 61,75 & 61,78 & 409,81 \\
\hline Chioglossa lusitanica & 29SNE81 & 100,00 & 139,59 & 91,18 & 37,40 & 5112,34 & 281,58 & 41,21 & 240,36 & 78,28 & 208,20 & 208,53 & 78,28 & 1095,12 & 162,51 & 10,33 & 55,64 & 449,06 & 67,73 & 67,73 & 449,06 \\
\hline \begin{tabular}{|l} 
Chioglossa lusitanica \\
\end{tabular} & 29SNE82 & 101,00 & 142,45 & 93,26 & \begin{tabular}{l|l}
37,95 \\
\end{tabular} & 5101,60 & 285,13 & 42,50 & 242,63 & 80,70 & 210,18 & 210,85 & 80,70 & 1080,88 & 159,84 & 10,28 & 55,32 & 442,08 & 67,84 & 67,92 & 442,08 \\
\hline Chioglossa lusitanica & 29SNE90 & 100,00 & 144,25 & 91,88 & 37,01 & 5263,55 & 289,66 & 44,62 & 245,03 & 81,28 & 214,68 & 215,34 & 81,28 & 1026,81 & 151,79 & 9,32 & 55,69 & 420,93 & 63,00 & 63,03 & 420,93 \\
\hline Chioglossa lusitanica & 29SNE91 & 100,00 & 133,40 & 88,25 & 36,15 & 5252,89 & 276,32 & 35,82 & 240,49 & 71,19 & 204,67 & 204,67 & 71,19 & 1151,78 & 172,48 & 10,85 & 55,87 & 472,69 & 70,36 & 70,36 & 472,69 \\
\hline Chioglossa lusitanica & 29SNE92 & 100,00 & 141,13 & 92,11 & 37,01 & 5261,34 & 286,09 & 40,61 & 245,48 & 77,82 & 211,52 & 211,83 & 77,82 & 1085,70 & 161,39 & 10,10 & 55,59 & 444,37 & 67,32 & 67,38 & 444,37 \\
\hline \begin{tabular}{|c} 
Chioglossa lusitanica \\
\end{tabular} & 29SPEO0 & 100,00 & 156,61 & 96,31 & 37,36 & 5412,16 & 306,87 & 52,65 & 254,22 & 91,06 & 227,34 & 229,15 & 91,06 & 892,60 & 129,81 & 7,50 & 55,12 & 363,46 & 55,07 & 55,67 & 363,46 \\
\hline Chioglossa lusitanica & 29SPE01 & 101,00 & 148,83 & 94,02 & 36,76 & 5429,34 & 298,03 & 45,95 & 252,07 & 83,36 & 220,92 & 221,77 & 83,36 & 983,23 & \begin{tabular}{|l|l|l|l|l|}
144,85 \\
\end{tabular} & 8,69 & 55,36 & 401,42 & 60,77 & 60,98 & 401,42 \\
\hline Chioglossa lusitanica & 29SPE02 & 101,00 & 138,63 & 90,45 & 36,04 & 5409,04 & 285,24 & 37,94 & 247,30 & 73,95 & 211,46 & 211,53 & 73,95 & 1097,44 & 163,97 & 10,08 & 55,76 & 449,22 & 67,41 & 67,41 & 449,22 \\
\hline Chioglossa lusitanica & 29SPE12 & 100,00 & 151,78 & 95,52 & 36,56 & 5580,80 & 303,98 & 46,12 & 257,86 & 84,14 & 225,44 & 226,36 & 84,14 & 943,37 & 138,41 & 8,12 & 55,08 & 383,08 & 58,69 & 59,05 & 383,08 \\
\hline Chioglossa lusitanica & 29TMH76 & 18,00 & 142,36 & 59,45 & 39,14 & 3130,50 & 224,05 & 74,18 & 149,86 & 112,64 & 180,45 & 184,00 & 103,45 & 970,82 & 140,59 & 26,09 & 42,05 & 384,09 & 112,86 & 138,27 & 322,23 \\
\hline Chioglossa lusitanica & 29TMH86 & 101,00 & 140,88 & 60,43 & 39,01 & 3189,41 & 224,79 & 71,89 & 152,90 & 110,68 & 179,94 & 183,48 & 101,52 & \begin{tabular}{r|}
1001,25 \\
\end{tabular} & 143,27 & 27,08 & 41,99 & 395,29 & 115,62 & 140,68 & 334,91 \\
\hline Chioglossa lusitanica & 29TMH94 & 96,00 & 134,43 & 62,32 & 38,30 & 3383,03 & 224,15 & 63,56 & 160,59 & 101,66 & 176,79 & 179,88 & 92,99 & 1163,86 & 165,96 & 30,57 & 43,29 & 460,44 & 125,92 & 149,26 & 407,56 \\
\hline Chioglossa lusitanica & 29TMH95 & 101,00 & 132,06 & 62,84 & 38,29 & 3379,81 & 222,68 & 60,82 & 161,87 & 99,50 & 174,35 & 177,58 & 90,84 & 1161,49 & 163,83 & 31,54 & 42,44 & 457,27 & 129,28 & 152,73 & 403,12 \\
\hline Chioglossa lusitanica & 29TMH96 & 101,00 & 132,67 & 62,76 & 38,41 & 3336,99 & 222,47 & 61,55 & 160,92 & 100,76 & 174,14 & 177,72 & 91,95 & 1134,29 & 158,51 & 31,50 & 41,88 & 444,68 & 129,01 & 152,87 & 389,79 \\
\hline Chioglossa lusitanica & 29TNE44 & 101,00 & 157,36 & 99,73 & 43,31 & 4271,78 & 286,11 & 58,28 & 227,83 & 102,93 & 210,29 & 212,65 & 102,55 & 952,53 & 133,76 & 10,00 & 53,12 & 382,72 & 63,82 & 67,21 & 382,71 \\
\hline \begin{tabular}{|l|l} 
Chioglossa lusitanica \\
\end{tabular} & 29TNE45 & 101,00 & 159,50 & 98,46 & 43,90 & 4164,52 & 283,32 & 60,82 & 222,49 & 108,75 & 210,58 & 212,78 & 105,32 & 936,35 & 130,70 & 9,70 & 52,90 & 374,25 & 62,54 & 67,44 & 374,14 \\
\hline Chioglossa lusitanica & 29TNE46 & 100,00 & 155,75 & 96,92 & 43,75 & 4129,05 & 276,81 & 57,49 & 219,32 & 107,60 & 206,33 & 208,40 & 101,84 & 981,31 & 136,99 & 10,65 & 52,63 & 391,48 & 66,27 & 71,75 & 391,01 \\
\hline Chioglossa lusitanica & 29TNE49 & 100,00 & 151,63 & 89,81 & \begin{tabular}{|c|}
43,97 \\
\end{tabular} & 3905,53 & 258,44 & 56,55 & 201,90 & 107,68 & 198,79 & 200,54 & 99,55 & 1025,40 & 142,39 & 11,30 & 52,40 & 412,01 & 68,11 & 78,33 & 403,22 \\
\hline Chioglossa lusitanica & 29TNE53 & 101,00 & 151,81 & 98,81 & \begin{tabular}{|c|}
41,57 \\
\end{tabular} & 4545,58 & 286,84 & 52,19 & 234,65 & 94,84 & 209,36 & 211,64 & 94,84 & 1002,83 & 143,49 & 10,28 & 53,94 & 406,24 & 66,25 & 67,75 & 406,24 \\
\hline Chioglossa lusitanica & 29TNE54 & 101,00 & 156,27 & 102,18 & 42,50 & 4514,23 & 292,22 & 54,61 & 237,61 & 99,02 & 212,75 & 215,25 & 99,02 & 975,79 & 137,69 & 10,19 & 53,13 & 392,97 & 65,87 & 68,08 & 392,97 \\
\hline \begin{tabular}{|l} 
Chioglossa lusitanica \\
\end{tabular} & 29TNE55 & 99,00 & 150,55 & 100,13 & 42,22 & 4497,70 & 284,29 & 49,83 & 234,45 & 93,64 & 207,01 & 209,27 & 93,64 & 1043,22 & 148,06 & 11,27 & 53,18 & 419,77 & 70,97 & 73,17 & 419,77 \\
\hline Chioglossa lusitanica & 29TNE56 & 101,00 & 150,10 & 99,40 & 42,36 & 4444,24 & 281,01 & 49,47 & 231,54 & 93,55 & 205,67 & 207,82 & 93,41 & 1053,40 & 149,12 & 11,4 & 52,88 & 422,23 & 71,75 & 75,15 & 422,23 \\
\hline Chioglossa lusitanica & 29TNE57 & 101,00 & 148,69 & 97,64 & 42,53 & 4378,99 & 275,62 & 48,79 & 226,84 & 97,88 & 203,34 & 205,27 & 92,45 & 1070,57 & 151,49 & 11,72 & 52,86 & 428,03 & 72,49 & 77,32 & 427,56 \\
\hline Chioglossa lusitanica & 29TNE58 & 100,00 & 146,09 & 95,18 & \begin{tabular}{|l|l|l|}
42,45 & \\
\end{tabular} & 4321,16 & 268,92 & 47,29 & 221,63 & 98,02 & $\begin{array}{ll}199,92 \\
\end{array}$ & 201,72 & 90,42 & 1099,79 & 155,99 & 12,10 & 52,83 & 440,82 & 74,02 & 80,08 & 438,16 \\
\hline Chioglossa lusitanica & 29TNE59 & 101,00 & 145,60 & 94,24 & 42,64 & 4275,39 & 265,54 & 47,09 & 218,45 & 98,05 & 198,66 & 200,38 & 90,22 & 1107,62 & 156,50 & 12,31 & 52,68 & 444,74 & 74,34 & 82,05 & 439,23 \\
\hline Chioglossa lusitanica & 29TNE63 & 101,00 & 130,56 & 89,14 & 38,42 & 4769,88 & 264,01 & 35,22 & 228,79 & 72,92 & 194,23 & 194,62 & 72,92 & 1221,84 & 181,18 & $\begin{array}{l}12,82 \\
12\end{array}$ & 55,21 & 499,16 & 78,16 & 78,31 & 499,16 \\
\hline Chioglossa lusitanica & 29TNE64 & 100,00 & 155 & 101,81 & 41,50 & 4683,46 & 294,72 & 53,07 & 241,64 & 96,83 & 215,14 & 217,20 & 96,83 & 978,93 & 139,33 & 9,92 & 53,46 & 394,96 & 65,10 & 67,15 & 394,96 \\
\hline Chioglossa lusitanica & 29TNE65 & 101,00 & 154,92 & 102,10 & 41,75 & 4672,85 & 292,96 & 51,79 & 241,18 & 95,81 & 213,88 & 216,01 & 95,81 & 997,15 & 141,65 & 10,31 & 53,17 & 401,08 & 66,87 & 69,43 & 401,08 \\
\hline Chioglossa lusitanica & 29TNE66 & 100,00 & 156,09 & 101,84 & 42,1 & 4606,32 & 291,36 & 52,82 & 238,53 & 97,33 & 213,92 & 215,92 & 97,29 & 989,81 & 139,97 & 10,23 & 52,97 & 396,23 & 66,28 & 70,18 & 396,23 \\
\hline \begin{tabular}{|l} 
Chioglossa lusitanica \\
\end{tabular} & 29TNE67 & 100,00 & 151,69 & $\begin{array}{l}99,91 \\
99\end{array}$ & 42,6 & 4573,47 & 284,14 & 49,24 & 234,90 & 97,01 & 209,18 & 210,97 & 93,25 & \begin{tabular}{l|l}
1039,96 \\
\end{tabular} & 147,79 & 10,93 & 53,01 & 415,86 & 69,58 & 74,15 & 415,82 \\
\hline Chioglossa lusitanica & 29TNE68 & 101,00 & 134,72 & 93 & 40,4 & 4632,53 & 264,80 & 36,08 & 228,72 & 80,31 & 194,14 & 195,64 & 76,89 & 1229,75 & 179,29 & 13,54 & 53,76 & 495,74 & 82,40 & 85,19 & 495,61 \\
\hline Chioglossa lusitanica & 29TNE69 & 101,00 & 128,02 & 91,01 & 39,86 & 4638,69 & 256,21 & 30,75 & 225,47 & 73,66 & 187,77 & 189,16 & 70,46 & 1311,34 & 192,53 & 14,74 & 54,03 & 529,92 & 88,13 & 90,71 & 529,25 \\
\hline Chioglossa lusitanica & 29TNE73 & 100,00 & 130,48 & 89,04 & 37,71 & 4935,42 & 267,29 & 34,12 & 233,17 & 71,19 & 196,84 & 196,95 & 71,19 & 1223,43 & $\mid 182.48$ & $\mid 12,47$ & 55,44 & 500,58 & 77,23 & 77,23 & 500,58 \\
\hline Chioglossa lusitanica & 29TNE74 & 100,00 & 144,66 & 96,62 & 39,51 & 4909,73 & 284,97 & 43,52 & 241,46 & 84,22 & 208,62 & 209,88 & 84,22 & 1088,21 & 159,07 & 10,86 & 54,50 & 42,33 & 70,82 & 71,38 & 442,33 \\
\hline \begin{tabular}{|l} 
Chioglossa lusitanica \\
\end{tabular} & 29TNE75 & 101 & 15 & 101 & 40 & & 295,17 & 49,96 & 24 & 93,12 & 4 & & 93 & 998 & 143,36 & 9, & 53,72 & 402,78 & 65,75 & 68,01 & 402,78 \\
\hline Chioglossa lusitanica & 29TNE76 & 101,00 & 154,06 & 101,53 & 41,08 & 4813,66 & 293,38 & 49,62 & 243,76 & 93,18 & 215,14 & 216,88 & 93,18 & 1005,56 & 143,97 & 9,99 & 53,47 & 404,01 & 66,34 & 69,56 & 404,01 \\
\hline Chioglossa lusitanica & 29TNE77 & 100,00 & 151,71 & 100,66 & 41,18 & 4778,52 & 288,89 & 47,59 & 241,30 & 91,92 & 212,30 & 213,84 & 91,08 & 1035,22 & 148,55 & 10,42 & 53,45 & 415,23 & 68,17 & 72,12 & 415,23 \\
\hline Chioglossa lusitanica & 29TNE78 & 100,00 & 148,15 & 99,57 & \begin{tabular}{ll|l}
41,25 & \\
\end{tabular} & 4758,31 & 283,45 & 44,56 & 238,88 & 92,48 & 208,55 & 209,97 & 87,76 & \begin{tabular}{|l|}
1076,81 \\
\end{tabular} & 155,12 & 11,07 & 53,44 & 431,68 & 70,90 & 75,54 & 431,42 \\
\hline Chioglossa lusitanica & 29TNE79 & 101,00 & 134 & 94,47 & 39,9 & 300,60 & 267,62 & 33,70 & 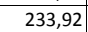 & 76,77 & & & 74,32 & 123 & 181,96 & 13,33 & 13 & 57 & 81,97 & 84,94 & 499,52 \\
\hline Chioglossa lusitanica & 29TNE83 & 100,00 & 136,83 & 91,53 & 37, & & 278,06 & 37,73 & 240,33 & 75,38 & 204,90 & 205,18 & 75,38 & 1153,36 & 171,78 & 11,27 & 55,46 & 471,89 & 72,49 & 72,49 & 471,89 \\
\hline Chioglossa lusitanica & 29TNE84 & 101,00 & 133,66 & 90,79 & \begin{tabular}{|c|}
37,47 \\
\end{tabular} & 5087,30 & 273,82 & 34,71 & 239,11 & 72,27 & 201,61 & 201,88 & 72,27 & 1197,70 & 179,06 & 11,86 & 55,43 & 489,74 & 75,49 & 75,49 & 489,74 \\
\hline \begin{tabular}{|l|} 
Chioglossa Iusitanica \\
\end{tabular} & 29TNE85 & 100,00 & 147,50 & 97,92 & 39,26 & 5042,36 & 289,99 & 44,08 & 245,90 & 85,04 & 212,90 & 214,17 & 85,04 & 1059,06 & 155,04 & 10,29 & 54,51 & 429,45 & 68,30 & 69,66 & 429,45 \\
\hline Chioglossa lusitanica & 29TNE86 & 100,00 & 150,11 & 99,94 & 39,99 & 5010,48 & 292,48 & 45,38 & 247,10 & 87,50 & 214,40 & 215,94 & 87,50 & 1037,19 & 150,83 & 10,03 & 54,12 & 418,79 & 67,60 & 69,74 & 418,79 \\
\hline Chioglossa lu & 29TNE87 & 101,00 & 151 & 1007 & 40,36 & 9,05 & 292,32 & 46,06 & & 88,92 & 21 & 216 & 88 & & 148,92 & 9,93 & 53,91 & 413,26 & 66,69 & 70,08 & 413 \\
\hline Chioglossa lusitanica & 29TNE88 & 101,00 & 149,07 & 100,28 & 40,46 & 4943,27 & 288,54 & 43,95 & 244,59 & 88,11 & 212,25 & 213,54 & 86,67 & 1056,45 & 153,52 & 10,50 & 53,85 & 424,47 & 68,67 & 72,72 & 424,47 \\
\hline
\end{tabular}




\begin{tabular}{|c|c|c|c|c|c|c|c|c|c|c|c|c|c|c|c|c|c|c|c|c|c|}
\hline TAXON & UTM & $\mathrm{km} 2$ & BIO1 & $\mathrm{B1O2}$ & $\mathrm{BIO3}$ & B104 & B105 & B106 & B107 & B108 & B109 & 81010 & B1011 & BIO12 & B1013 & B1014 & 81015 & B1016 & BIO17 & B1018 & \begin{tabular}{|l|}
$B 1019$ \\
\end{tabular} \\
\hline Chioglossa lusitanica & 29TNE89 & 99,00 & 143,28 & 98,96 & 40,16 & 4954,20 & 281,94 & 38,90 & 243,03 & 81,35 & 206,81 & 207,99 & 80,99 & 1124,35 & 164,80 & 11,31 & 54,06 & 452,74 & 73,25 & 77,10 & 452,74 \\
\hline $\begin{array}{l}\text { Chioglossa lusitanica } \\
\end{array}$ & 29TNE93 & 101,00 & 140,56 & 92,62 & 37,11 & 5261,71 & 285,37 & 39,35 & 246,03 & 77,01 & 210,76 & 211,08 & 77,01 & 1102,34 & 164,09 & 10,29 & 55,49 & 450,73 & 68,82 & 68,84 & 450,73 \\
\hline Chioglossa lusitanica & 29TNE94 & 100,00 & $\begin{array}{l}125,53 \\
125\end{array}$ & 86,11 & 35,79 & 5217,44 & 265,27 & 28,23 & 237,05 & 63,45 & 195,88 & 195,88 & 63,45 & 1276,51 & 193,59 & 12,38 & 56,13 & 523,51 & \begin{tabular}{|c|c|c|}
78,29 \\
\end{tabular} & 78,29 & 523,51 \\
\hline Chioglossa lusitanica & 29TNE95 & 101,00 & 127,45 & 87,81 & 36,31 & 5197,31 & 267,32 & 28,99 & 238,32 & 65,12 & \begin{tabular}{|l|l|}
196,99 \\
\end{tabular} & 197,21 & 65,12 & 1266,14 & 191,66 & 12,29 & 55,95 & 518,23 & 78,40 & 78,48 & 518,23 \\
\hline Chioglossa lusitanica & 29TNE96 & 100,00 & 144,25 & 96,90 & 38,48 & 5194,21 & 288,55 & 39,98 & 248,56 & 80,12 & 211,84 & 212,90 & 80,12 & 1084,89 & 160,45 & 10,32 & 54,88 & 440,40 & 69,82 & 70,58 & 440,40 \\
\hline Chioglossa lusitanica & 29TNE99 & 101,00 & 143,90 & 99,38 & 39,62 & 5127,85 & 286,19 & 38,18 & 248,01 & 79,91 & 210,06 & 211,01 & 79,71 & 1097,89 & 162,19 & 10,71 & 54,52 & 443,23 & 70,70 & 73,80 & 443,23 \\
\hline Chioglossa lusitanica & 29TNF26 & 68,00 & 143,71 & 84,72 & 45,01 & 3658,17 & 241,52 & 55,50 & 186,02 & 99,99 & 188,56 & 190,46 & 97,07 & 1215,52 & 165,55 & 15,08 & 51,03 & 482,21 & 83,56 & 100,72 & 480,78 \\
\hline Chioglossa lusitanica & 29TNF32 & 101,00 & 145,57 & 84,92 & 44,51 & 3682,73 & 242,81 & 53,91 & 188,90 & 104,71 & 189,77 & 191,53 & 96,39 & 1108,58 & 151,23 & 13,26 & 51,97 & 448,35 & 74,67 & 90,24 & 429,45 \\
\hline Chioglossa lusitanica & 29TNF33 & 100,00 & 143,08 & 86,64 & 44,26 & 3769,42 & 244,08 & 50,32 & \begin{tabular}{|c|}
193,75 \\
\end{tabular} & \begin{tabular}{|c|}
101,57 \\
\end{tabular} & 188,84 & 190,75 & 93,44 & 1153,38 & 156,89 & 14,21 & 51,96 & 467,44 & 78,42 & 95,49 & 444,94 \\
\hline Chioglossa lusitanica & 29TNF35 & 101,00 & 143,79 & 89,17 & 44,34 & 3853,99 & 248,86 & 50,08 & \begin{tabular}{|c|}
198,78 \\
\end{tabular} & $\begin{array}{ll}101,82 \\
\end{array}$ & \begin{tabular}{|c|}
191,19 \\
\end{tabular} & 193,23 & 93,92 & 1176,16 & 162,85 & 15,00 & 51,60 & 476,56 & 80,52 & 100,90 & 450,62 \\
\hline Chioglossa lusitanica & 29TNF36 & 100,00 & 142,72 & 88,75 & 44,37 & 3874,54 & 248,10 & 50,30 & 197,80 & 100,59 & 190,60 & 192,54 & 93,19 & 1208,89 & 165,64 & 15,18 & 51,16 & 484,74 & 82,84 & 101,99 & 470,16 \\
\hline Chioglossa lusitanica & 29TNF37 & 101,00 & 143,27 & 87,78 & 44,23 & 3880,42 & 248,43 & 52,12 & 196,31 & 100,95 & 191,39 & 193,10 & 93,98 & 1219,17 & 165,45 & 15,05 & 51,07 & 485,64 & 82,94 & 101,87 & 478,73 \\
\hline \begin{tabular}{|c} 
Chioglossa lusitanica \\
\end{tabular} & 29TNF38 & 101,00 & 142,52 & 86,87 & 43,81 & 3905,18 & 248,58 & 52,35 & 196,23 & 99,41 & 191,21 & 192,75 & 93,25 & 1241,90 & 168,32 & 15,31 & 51,18 & 493,36 & 84,21 & 103,44 & 490,86 \\
\hline Chioglossa lusitanica & 29TNF39 & 100,00 & 142,67 & 85,68 & 43,22 & 3921,25 & 249,19 & 53,49 & \begin{tabular}{|c|}
195,69 \\
\end{tabular} & $\begin{array}{l}97,62 \\
\end{array}$ & 191,73 & 193,13 & 93,16 & 1252,93 & 169,96 & 15,41 & 51,40 & 497,59 & 84,71 & 104,50 & 496,90 \\
\hline Chioglossa lusitanica & 29TNF40 & 100,00 & 147,44 & 89,30 & 43,83 & 3923,90 & 254,03 & 52,39 & 201,63 & \begin{tabular}{ll|}
103,46 \\
\end{tabular} & $\begin{array}{l}195,05 \\
\end{array}$ & 196,67 & 95,31 & 1079,18 & 149,73 & 12,26 & 52,06 & 434,59 & 72,22 & 83,50 & 423,05 \\
\hline Chioglossa lusitanica & 29TNF41 & 101,00 & 142,38 & 89,36 & 43,37 & 3991,40 & 250,94 & 47,24 & 203,70 & 98,11 & \begin{tabular}{|l|l|}
191,25 \\
\end{tabular} & 193,01 & 90,04 & 1145,99 & 159,30 & 13,48 & 52,06 & 462,52 & 77,32 & 89,31 & 448,96 \\
\hline Chioglossa lusitanica & 29TNF42 & 100,00 & 139,86 & 89,98 & 43,29 & 4039,26 & 249,99 & 44,34 & 205,65 & 95,41 & 189,66 & 191,42 & 87,24 & 1184,27 & 164,08 & 14,18 & 52,01 & 478,82 & \begin{tabular}{l|l}
80,25 \\
\end{tabular} & 93,42 & 462,77 \\
\hline Chioglossa lusitanica & 29TNF43 & 100,00 & 139,21 & 90,71 & 43,30 & 4069,14 & 250,59 & 43,39 & 207,20 & \begin{tabular}{|c|}
94,59 \\
\end{tabular} & 189,62 & 191,44 & 86,51 & 1202,18 & 165,41 & 14,71 & 52,01 & 486,77 & 81,77 & 96,65 & 467,70 \\
\hline Chioglossa lusitanica & 29TNF44 & 101,00 & 145,19 & 91,73 & 43,95 & 4024,80 & 255,19 & 48,47 & 206,73 & 100,89 & 194,71 & 196,60 & 92,76 & 1143,15 & 155,45 & 13,92 & 51,95 & 463,79 & 77,06 & 95,12 & 439,23 \\
\hline Chioglossa lusitanica & 29TNF45 & 100,00 & 143,60 & 92,24 & 43,84 & 4070,49 & 255,27 & 46,97 & 208,31 & 98,94 & 194,03 & 195,90 & 91,10 & \begin{tabular}{ll|}
1174,73 \\
\end{tabular} & 159,85 & 14,55 & 51,68 & 475,51 & 79,77 & 98,42 & 452,40 \\
\hline Chioglossa lusitanica & 29TNF46 & 101,00 & 139,99 & 92,04 & 43,5 & 4124,76 & 253,26 & 44,26 & 208,99 & 94,91 & 191,59 & 193,29 & 87,44 & 1229,65 & 167,21 & 15,41 & 51,34 & \begin{tabular}{|c|}
495,06 \\
\end{tabular} & 84,11 & \begin{tabular}{|c|}
101,93 \\
\end{tabular} & 478,38 \\
\hline Chioglossa lusitanica & 29TNF47 & 100,00 & 139,14 & 91,24 & 43,32 & 4147,14 & 252,84 & 44,35 & 208,48 & 93,89 & 191,25 & 192,76 & 86,61 & 1253,11 & $\mid 169,91$ & $\begin{array}{l}25,41+1 \\
5,81\end{array}$ & 51,14 & 501,37 & $\begin{array}{l}84,1+32 \\
86,\end{array}$ & \begin{tabular}{|l|l|l}
103,48 \\
\end{tabular} & 491,26 \\
\hline Chioglossa lusitanica & 29TNF48 & 100,00 & 142,13 & 90,79 & 43,15 & 4135,87 & 255,81 & 47,93 & \begin{tabular}{|l|}
207,87 \\
\end{tabular} & $\begin{array}{l}96,82 \\
\end{array}$ & \begin{tabular}{ll|}
194,12 \\
\end{tabular} & 195,50 & 89,72 & 1230,59 & 165,88 & 15,35 & 51,02 & 490,29 & 84,29 & 102,44 & 483,04 \\
\hline Chioglossa lusitanica & 29TNF49 & 101,00 & 139,80 & 89,86 & 42,66 & 4175,54 & 254,55 & 46,33 & 208,22 & 94,19 & 192,55 & 193,76 & 87,19 & 1270,24 & 171,95 & 16,30 & 51,01 & 504,73 & 88,23 & 105,84 & 500,86 \\
\hline Chioglossa lusitanica & 29TNF50 & 101,00 & 139,58 & 92,61 & 42,17 & 4304,23 & 258,99 & 41,99 & 217,01 & 92,04 & 193,36 & 195,11 & 84,30 & 1181,11 & 167,89 & 13,43 & 52,76 & 475,58 & 79,54 & 87,48 & 468,92 \\
\hline \begin{tabular}{|l} 
Chioglossa lusitanica \\
\end{tabular} & 29TNF51 & 101,00 & 130,68 & 90,91 & 41,39 & 4383,84 & 251,56 & 34,36 & 217,20 & 83,11 & 186,06 & 187,79 & 75,27 & 1291,53 & 185,22 & 15,29 & 52,99 & 520,41 & 88,04 & 94,96 & 515,26 \\
\hline Chioglossa lusitanica & 29TNF52 & 100,00 & $\begin{array}{l}5,06 \\
128,82\end{array}$ & 90,79 & $\begin{array}{l}41,35 \\
41,34 \\
\end{array}$ & $\begin{array}{ll}4305,204 \\
4388,35\end{array}$ & $\mid 249,56$ & 32,56 & 217,00 & \begin{tabular}{l|l}
03,11 \\
80,65
\end{tabular} & $\begin{array}{l}10,040 \\
184,49\end{array}$ & $\mid \frac{\mid 0,1,13}{186,10}$ & 73,51 & \begin{tabular}{|l|}
1319,05 \\
1319
\end{tabular} & \begin{tabular}{|l|l|l|l|l|l|}
188,56 \\
\end{tabular} & $\mid 15,87$ & \begin{tabular}{|c|}
52,82 \\
5
\end{tabular} & $\mid \begin{array}{ll}52,41,86 \\
531\end{array}$ & $\begin{array}{l}00,04 \\
90,28\end{array}$ & $\begin{array}{l}34,50 \\
98,23\end{array}$ & 525,29 \\
\hline Chioglossa lusitanica & 29TNF53 & 101,00 & 139,12 & 93,95 & 42,65 & 4304,01 & 258,06 & 40,55 & 217,52 & \begin{tabular}{|c|c|}
91,75 \\
\end{tabular} & \begin{tabular}{|c|}
192,97 \\
\end{tabular} & 194,65 & 83,83 & 1206,82 & 168,46 & 14,26 & 52,14 & 487,19 & 81,32 & 94,06 & 473,32 \\
\hline Chioglossa lusitanica & 29TNF54 & 101,00 & 143,24 & 94,76 & 43,14 & 4278,36 & 261,19 & 44,06 & 217,13 & 96,03 & 196,62 & 198,24 & 88,15 & 1165,91 & 160,49 & 13,81 & 51,97 & 470,68 & 78,26 & 93,43 & 453,65 \\
\hline Chioglossa lusitanica & 29TNF55 & 100,00 & 140,87 & 95,08 & 42,9 & 4326,04 & 260,24 & 41,73 & 218,51 & 93,30 & 195,21 & 196,68 & 85,53 & 1202,49 & 165,11 & 14,53 & 51,85 & 484,56 & 81,28 & 96,84 & 468,84 \\
\hline Chioglossa lusitanica & 29TNF56 & 101,00 & 139,94 & 95,13 & 42,95 & 4354,26 & 260,13 & 41,13 & 219,00 & 92,16 & 194,79 & 196,27 & 84,56 & 1221,82 & $\mid 166,99$ & 14,97 & 51,64 & 490,56 & 83,17 & 98,86 & 477,69 \\
\hline Chioglossa lusitanica & 29TNF57 & $\begin{array}{l}101,00 \\
100\end{array}$ & 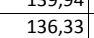 & 94,43 & $\begin{array}{ll}42,53 \\
42,54\end{array}$ & $\begin{array}{ll}4353,4200 \\
4395,62\end{array}$ & \begin{tabular}{|l|l|}
257,89 \\
257
\end{tabular} & 38,43 & 219,46 & 88,25 & $\begin{array}{l}\mid 97,13 \\
192,09\end{array}$ & \begin{tabular}{|l|}
193,38 \\
193
\end{tabular} & $\begin{array}{l}04,00 \\
80,76 \\
\end{array}$ & $\begin{array}{l}1271,82 \\
1271,83 \\
\end{array}$ & 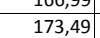 & $\begin{array}{l}\mid 4,5,97 \\
15,9\end{array}$ & \begin{tabular}{|c|c|}
51,45 \\
5
\end{tabular} & $\begin{array}{l}4508,53 \\
508\end{array}$ & 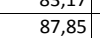 & \begin{tabular}{|c|}
502,60 \\
102,68
\end{tabular} & 500,28 \\
\hline \begin{tabular}{|l} 
Chioglossa lusitanica \\
\end{tabular} & 29TNF58 & 100,00 & 142,10 & 94,36 & 42,68 & 4362,30 & 262,89 & 44,19 & 218,70 & \begin{tabular}{l|l}
94,05 \\
\end{tabular} & 197,22 & 198,42 & 86,75 & 1212,75 & 162,86 & 15,06 & 51,03 & 482,85 & 83,48 & 99,97 & 474,72 \\
\hline Chioglossa lusitanica & 29TNF59 & 101,00 & 139,94 & 93,48 & 42,1 & 4393,00 & 261,73 & 42,6 & 219,10 & \begin{tabular}{|c|}
91,63 \\
\end{tabular} & 195,73 & 196,85 & 84,56 & 1243,58 & 167,10 & 16,12 & 50,99 & 493,44 & 87,40 & 103,38 & 487,78 \\
\hline Chioglossa lusitanica & 29TNF60 & 100,00 & & 94,39 & 41, & 4585,71 & 262,88 & 35, & 227,30 & 84,4 & 193,27 & 194,86 & 77,17 & 1237,64 & 179,24 & 13, & 53,37 & 498,24 & 82,88 & 88,33 & 495,79 \\
\hline Chioglossa lusitanica & 29TNF61 & 100,00 & 135,59 & 94,12 & 41,30 & 4545,64 & 261,58 & 36,27 & 225,31 & 84,47 & 193,36 & 194,77 & 78,12 & 1233,48 & 177,66 & 13,94 & 53,23 & 497,11 & 82,71 & 89,56 & 492,25 \\
\hline Chioglossa lusitanica & 29TNFG2 & 101,00 & 119,24 & 89,37 & 39,56 & 4648,32 & 246,04 & 23,36 & 222,68 & 65,19 & 179,50 & 180,74 & 62,13 & 1421,55 & 207,84 & 17,24 & 53,69 & 573,99 & 97,86 & 101,46 & 572,57 \\
\hline \begin{tabular}{|l} 
Chioglossa lusitanica \\
\end{tabular} & 29TNF63 & 100,00 & 137,18 & 96,37 & 41,92 & 4552,30 & 263,63 & 36,45 & 227,18 & 87,09 & 194,87 & 196,22 & 79,29 & 1227,80 & 174,69 & 14,04 & 52,72 & 494,00 & 82,05 & 92,22 & 486,62 \\
\hline Chioglossa lusitanica & 29TNF64 & 100,00 & 139,87 & 96,89 & 42,25 & 4533,38 & 265,28 & 38 & 226,47 & 89,13 & 197,19 & 198,52 & 82,13 & 1200,42 & 169,04 & 13,86 & 52,38 & 482,70 & 80,33 & 92,20 & 473,27 \\
\hline Chioglossa lusitanica & 29TNF65 & 101,00 & & 97,96 & 42,5 & 4548,34 & 267,19 & 39 & 227,70 & 90,7 & 198,67 & 199,98 & 83,18 & 1191,76 & 166,29 & 13, & 52,13 & 478,12 & 9,78 & 93,05 & 468,42 \\
\hline Chioglossa lusitanica & 29TNFG6 & 100,00 & 55 & 98,10 & 42,5 & 4557,92 & 267,53 & 39,38 & 228,15 & $\begin{array}{l}90,49 \\
90,40\end{array}$ & 198,65 & 199,92 & $\mid 82,92$ & 1198,66 & 165,92 & 14, & 51,88 & 479,50 & 80,88 & 94,69 & 470,84 \\
\hline Chioglossa lusitanica & 29TNF67 & 100,00 & 13 & 97,85 & 42,15 & 4589,24 & 266,73 & 37, & 229,06 & 88 & 197,36 & 198,49 & 80,91 & 1225,60 & 168,33 & 14,86 & 51,72 & 488,61 & 83,77 & 97,47 & 482,14 \\
\hline Chioglossa lusitanica & 29TNF68 & 101,00 & 137,90 & 97,23 & $\begin{array}{l}42,15 \\
41,97 \\
\end{array}$ & 4606,79 & 266,17 & 37,05 & 229,12 & 87,12 & 196,63 & 197,66 & 79,77 & 1240,93 & 168,44 & 15,51 & 51,33 & 492,91 & 86,19 & 99,84 & 488,19 \\
\hline Chioglossa lusitanica & 29TNF69 & 100,00 & 31 & 96,15 & 41,53 & 4630,85 & 264,13 & 35,32 & 228,80 & \begin{tabular}{|l|l}
83,85 \\
\end{tabular} & 194,67 & 195,62 & 77,28 & \begin{tabular}{|l|}
1267,98 \\
\end{tabular} & 170,11 & 16,66 & 50,99 & \begin{tabular}{|c|}
502,08 \\
\end{tabular} & 90,32 & 103,32 & 498,82 \\
\hline Chioglossa lusitanica & 29TNF70 & 100,00 & 2 & 93,82 & 39,84 & 4794,23 & 263,60 & 31,18 & 232,42 & 74,29 & 193,10 & 194,21 & 71,49 & 1276,03 & $\mid 187,97$ & 13,92 & 54,17 & 515,51 & 84,71 & $\begin{array}{l}38,05 \\
8,50\end{array}$ & 514,91 \\
\hline Chioglossa lusitanica & 29TNF71 & $\begin{array}{l}101,00 \\
100\end{array}$ & 13 & $\begin{array}{l}30,02 \\
97,23 \\
\end{array}$ & 431,0 & 4748,50 & $\begin{array}{l}203,00 \\
270,65\end{array}$ & 36,33 & 234,42 & \begin{tabular}{l|l}
44,96 \\
84,
\end{tabular} & $\begin{array}{l}199,28 \\
\end{array}$ & 200,42 & 78,59 & $\begin{array}{l}1219,303 \\
1195,33 \\
\end{array}$ & | & $\begin{array}{l}20,32,9 \\
12,1\end{array}$ & 53,50 & $\mid \begin{array}{l}\mid c 1,31 \\
480,83\end{array}$ & $\begin{array}{l}78,99 \\
78,99\end{array}$ & 85,21 & 478,45 \\
\hline Chioglossa lusitanica & 29TNF72 & 100,00 & 12 & 93,12 & 39,79 & 4811,33 & 256,79 & 25,56 & 231,23 & 67,5 & 187,14 & 188,20 & 65,25 & 1354,86 & 199,64 & 15,47 & 54,07 & 547,42 & 91,22 & 94,88 & 546,90 \\
\hline Chioglossa lusitanica & 29TNF73 & 100,00 & 97 & 94,19 & 40,16 & 4798,34 & 257,82 & 26 , & 231,62 & 69,9 & \begin{tabular}{|l|l|l|}
188,03 \\
\end{tabular} & 189,07 & 66,37 & 1340,38 & 195,83 & 15,66 & 53,65 & 540,51 & 90,73 & 95,98 & 538,99 \\
\hline Chioglossa lusitanica & 29TNF74 & 101,00 & 8,99 & 95,57 & 40,63 & 4783,60 & 260,6 & & 232 & & 190 & 191,63 & 69,36 & 1309 & 189 & 15, & 53, & 527,26 & 88,82 & 95,55 & 524,72 \\
\hline Chioglossa lusitanica & 29TNF75 & 100,00 & 13 & 99 , & 41 & $477 !$ & 270,14 & & 236 & & 198 & 199,50 & 77,09 & & 174,59 & 13,90 & 52,80 & 489,74 & 81,78 & 91,80 & 486,31 \\
\hline Chioglossa lusitanica & 29TNF76 & 101,00 & 141,79 & 100,39 & 41,96 & 4748,21 & 274,06 & 37,90 & 236,17 & 87,98 & 202,21 & 203,32 & 81,53 & 1172,75 & 164,56 & 13,40 & 52,24 & 467,99 & 78,52 & 90,37 & 462,94 \\
\hline \begin{tabular}{|l} 
Chioglossa lusitanica \\
\end{tabular} & 29TNF77 & 100,00 & 139,96 & 100,63 & 41,82 & 4786,69 & 273,79 & 35,96 & 237,83 & 85,58 & 201,14 & 201,93 & 79,40 & 1195,50 & 166,38 & 14,04 & 52,04 & 475,06 & 81,10 & 92,96 & 472,06 \\
\hline Chioglossa lusitanica & 29TNF78 & 101,00 & 126,95 & 97,32 & 40,78 & 4844,60 & 261,42 & 25,75 & 235,68 & 68,04 & 189,60 & 190,52 & 66,83 & 1333,31 & 185,94 & 17,30 & 52,04 & 531,44 & 94,53 & 103,38 & 531,32 \\
\hline Chioglossa lusitani & 29TNF79 & 101,00 & & 95,81 & 40,47 & 841,80 & 258,19 & & 233 & $65,5 \varepsilon$ & 187,19 & 188 & 64,62 & 1349 & 185 & 18 & & 536,28 & 98,47 & 107,09 & 536,16 \\
\hline Chioglossa lusitanica & 29TNF80 & & & & 39, & & 275 & 33,90 & 241,22 & 75,65 & 201,18 & 202,29 & 75,13 & 119 & 176,73 & 12, & 54,37 & 482,82 & 78,28 & 81,81 & 482,81 \\
\hline Chioglossa lusitanica & 29TNF81 & 101,00 & 138,58 & 98,97 & 40,41 & 4957,04 & 276,29 & 34,33 & 241,95 & 78,33 & 202,15 & 203,23 & 76,25 & 1184,88 & 174,47 & 12,24 & 54,20 & 477,17 & 77,25 & 82,20 & 477,00 \\
\hline Chioglossa lusitanica & 29TNF82 & 100,00 & 133,58 & 98,23 & 40,21 & 4971,25 & 271,19 & 30,14 & 241,06 & 73,00 & 197,70 & 198,66 & 71,47 & 1244,51 & 184,08 & 13,26 & 54,36 & 502,42 & 81,71 & 86,36 & 502,12 \\
\hline Chioglossa lusitanica & 29TNF83 & 101,00 & 109,14 & 87,77 & 37,62 & 4975,93 & 242,62 & 12,70 & 229,92 & 49,47 & 175,17 & 175,58 & 49,22 & 493,52 & 222,19 & 18,53 & 54,42 & 606,03 & 102,49 & 103,59 & 606,01 \\
\hline Chioglossa lusitanica & $29 \mathrm{TNF}$ & $101, \mathrm{C}$ & & & 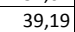 & 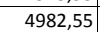 & & 19, & 235,79 & 58,2 & 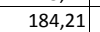 & 184 & 57,85 & 139 & 206 & 16 & 54,06 & 565,62 & 95,33 & 98,47 & 565,51 \\
\hline Chioglossa lusitanica & 29TNF85 & 100,00 & \begin{tabular}{|l|l|}
136,01 \\
\end{tabular} & $\mid$ & 41,17 & 4 & 274,28 & 30,99 & 243,29 & 75,89 & \begin{tabular}{|l|l|l|l|l|l|}
199,76 \\
\end{tabular} & $\mid$ & $\begin{array}{l}73,051 \\
73,51\end{array}$ & $\begin{array}{l}1222,05 \\
\end{array}$ & \begin{tabular}{|l|l|}
177,54 \\
\end{tabular} & $\begin{array}{l}13,546 \\
\end{array}$ & 53,63 & \begin{tabular}{|l|l|l|l|}
490,55 \\
\end{tabular} & 81,16 & 89,01 & 489,57 \\
\hline
\end{tabular}




\begin{tabular}{|c|c|c|c|c|c|c|c|c|c|c|c|c|c|c|c|c|c|c|c|c|c|}
\hline TAXON & UTM & $\mathrm{km} 2$ & BIO1 & B102 & $\mathrm{BIO3}$ & 8104 & B105 & B106 & B107 & B108 & B109 & BIO10 & B1011 & BIO12 & B1013 & B1014 & 81015 & B1016 & BIO17 & B1018 & B1019 \\
\hline Chioglossa lusitanica & 29TNF86 & 101,00 & 125,67 & 98,43 & 40,38 & 4998,73 & 264,11 & 23,07 & 241,04 & 64,83 & 190,54 & 191,36 & 63,74 & 1325,58 & 192,39 & 15,93 & 53,57 & 533,46 & 91,11 & 96,93 & 533,22 \\
\hline $\begin{array}{l}\text { Chioglossa lusitanica } \\
\end{array}$ & 29TNF87 & 101,00 & 135,01 & 101,65 & 41,07 & 4987,46 & 274,44 & 29,83 & 244,61 & 74,73 & 199,17 & 199,92 & 72,50 & 1223,35 & 174,13 & 14,38 & 52,84 & 488,05 & 83,36 & 92,32 & 487,44 \\
\hline Chioglossa lusitanica & 29TNF88 & 99,00 & $\begin{array}{l}141,71 \\
140\end{array}$ & 103,14 & 41,42 & 4974,24 & 281,45 & 35,06 & 246,39 & 83,10 & 205,58 & 206,22 & 78,92 & 1144,18 & 158,88 & 13,41 & 52,08 & 4 & 78,01 & 89,11 & 451,23 \\
\hline Chioglossa lusitanica & 29TNF89 & 101,00 & 138,03 & 102,06 & 40,95 & 4999,15 & 277,95 & 31,91 & 246,04 & 78,21 & 202,41 & 202,92 & 75,17 & 1176,14 & 161,05 & 14,66 & 51,68 & 463,52 & 82,57 & 92,81 & 463,14 \\
\hline Chioglossa lusitanica & 29TNF90 & 100,00 & 135,74 & 97,24 & 39,11 & 5140,79 & 277,09 & 31,58 & 245,51 & \begin{tabular}{|l|l|}
71,87 \\
\end{tabular} & 202,41 & 203,33 & 71,87 & 1192,29 & 178,24 & 11,99 & 54,96 & 483,60 & 77,32 & 79,46 & 483,60 \\
\hline Chioglossa lusitanica & 29TNF91 & 100,00 & 132,75 & 97,32 & 39,23 & 5137,78 & 273,84 & 28,79 & 245,06 & 68,99 & 199,50 & 200,32 & 68,99 & 1228,40 & 184,01 & 12,60 & 55,01 & 498,40 & 79,94 & 82,35 & 498,40 \\
\hline Chioglossa lusitanica & 29TNF92 & 101,00 & 126,83 & 96,14 & 39,03 & 5143,95 & 267,40 & 23,92 & 243,48 & 63,31 & 193,92 & 194,57 & 63,31 & 1295,64 & 194,83 & 13,75 & 55,18 & 526,94 & 85,17 & 87,05 & 526,94 \\
\hline Chioglossa lusitanica & 29TNF93 & 100,00 & 112,22 & 89,85 & 37,50 & 5123,48 & 249,76 & 13,62 & 236,13 & 50,27 & 180,26 & 180,45 & 50,27 & 1440,64 & 216,60 & 16,93 & 55,02 & 587,21 & 97,41 & 97,51 & 587,21 \\
\hline Chioglossa lusitanica & 29TNF94 & 100,00 & 117,18 & 94,18 & 38,63 & 5143,77 & 257,13 & 16,22 & 240,91 & 54,41 & 184,94 & 185,37 & 54,41 & 1388,86 & 207,75 & 16,25 & 54,85 & 564,88 & 94,28 & 95,58 & 564,88 \\
\hline Chioglossa lusitanica & 29TNF95 & 101,00 & 138,40 & 103,35 & 40,82 & 5122,49 & 281,31 & 31,16 & 250,14 & 75,40 & 204,41 & 205,04 & 74,01 & 1168,52 & 171,57 & 12,46 & 54,07 & 469,70 & 76,62 & 82,85 & 469,33 \\
\hline Chioglossa lusitanica & 29TNF96 & 100,00 & 122,41 & 99,04 & 39,60 & 5160,22 & 265,41 & 18,77 & 246,64 & 58,88 & 189,82 & 190,40 & 58,88 & 1327,04 & 195,32 & 16,05 & 54,19 & 536,19 & 91,36 & 95,12 & 536,19 \\
\hline Chioglossa lusitanica & 29TNF97 & 100,00 & 115,88 & 95,90 & 39,03 & 5136,17 & 257,03 & 14,56 & 242,47 & 53,35 & 183,44 & 183,91 & 53,35 & 1372,61 & 199,44 & 17,95 & 53,49 & 553,49 & 98,06 & 101,01 & 553,49 \\
\hline \begin{tabular}{|c} 
Chioglossa lusitanica \\
\end{tabular} & 29TNF98 & 101,00 & 121,02 & 98,41 & 39,61 & 5139,73 & 263,22 & 17,96 & 245,26 & 57,91 & 188,29 & 188,76 & 57,91 & 1316,53 & 188,74 & 17,26 & 53,01 & 528,34 & 94,25 & 98,83 & 528,34 \\
\hline Chioglossa lusitanica & 29TNF99 & 100,00 & 135,05 & 103,43 & 40,67 & 5161,06 & 279,51 & 27,52 & 251,99 & 71,37 & 201,96 & 202,26 & 70,61 & 1168,49 & 163,49 & 14,49 & 52,32 & 463,38 & 81,88 & 88,21 & 463,32 \\
\hline Chioglossa lusitanica & 29TNG11 & 68,00 & 142,97 & 75,17 & 42,97 & 3566,09 & 236,70 & 63,82 & \begin{tabular}{|c|}
172,88 \\
\end{tabular} & 98,36 & \begin{tabular}{|l|l|}
187,37 \\
\end{tabular} & 188,68 & 98,36 & 1288,24 & 180,59 & 15,17 & 52,45 & 518,55 & 83,56 & 108,22 & 518,55 \\
\hline Chioglossa lusitanica & 29TNG12 & 87,00 & 137,29 & 73,96 & 42,06 & 3627,14 & 232,43 & 58,62 & 173,81 & $\begin{array}{l}92,83 \\
\end{array}$ & \begin{tabular}{|l|l|}
182,87 \\
\end{tabular} & 184,29 & 92,14 & 1378,35 & 191,82 & 19,18 & 51,61 & 553,01 & 96,64 & 118,57 & 552,97 \\
\hline Chioglossa lusitanica & 29TNG13 & 86,00 & 140,49 & 72,13 & 41,64 & 3603,62 & 234,13 & 62,90 & 171,23 & 100,04 & 185,70 & 187,01 & 95,30 & 1358,91 & $\mid 189,08$ & 19,68 & 51,07 & 544,43 & 96,92 & 119,11 & 541,84 \\
\hline Chioglossa lusitanica & 29TNG14 & 99,00 & 141,35 & 69,97 & 41,01 & 3592,14 & 233,55 & 65,01 & 168,54 & 103,58 & 186,44 & 187,73 & 96,16 & 1368,59 & 193,12 & 21,54 & 50,70 & 549,61 & 101,51 & 122,99 & 542,04 \\
\hline Chioglossa lusitanica & 29TNG15 & 101,00 & 132,16 & 69,72 & 40,14 & 3685,33 & 227,32 & 55,75 & 171,56 & 93,81 & 178,93 & 180,33 & 86,39 & 1509,91 & 227,25 & 27,33 & 50,50 & 609,48 & 119,62 & 138,03 & 604,19 \\
\hline Chioglossa lusitanica & 29TNG16 & 63,00 & 144,91 & 65,38 & 39,81 & 3554,55 & 233,48 & 71,05 & 162,43 & 107,66 & 189,68 & 190,80 & 99,84 & \begin{tabular}{|l|}
1361,27 \\
\end{tabular} & 195,80 & 24,69 & 49,54 & 549,03 & 108,17 & 128,84 & 528,42 \\
\hline Chioglossa lusitanica & 29TNG17 & 33,00 & 149,14 & 62,22 & 38,97 & 3510,00 & 234,61 & 76,97 & 157,64 & 112 & 193,11 & 194,33 & 104,31 & 1294,33 & 179,89 & 25,03 & 48,31 & 519,61 & 107,44 & 128,50 & 486,56 \\
\hline Chioglossa lusitanica & 29TNG18 & 45,00 & 144,43 & $\begin{array}{ll}61,74 \\
61,7\end{array}$ & 38,37 & 3541,20 & 231,42 & 73,05 & 158,37 & 107,44 & \begin{tabular}{|l|l|l|}
189,24 \\
\end{tabular} & 190,36 & \begin{tabular}{|c|}
99,57 \\
94,5
\end{tabular} & $\begin{array}{l}1364,63 \\
134,\end{array}$ & 199,30 & 28,12 & $\begin{array}{l}48,315 \\
48,48\end{array}$ & 549,64 & 116,34 & 136,83 & 520,34 \\
\hline Chioglossa lusitanica & 29TNG20 & 101,00 & 138,63 & 80,62 & 42,90 & 3774,84 & 239,93 & 54,36 & 185,56 & 91,40 & 185,97 & 187,32 & 91,40 & 1326,01 & 182,29 & 16,74 & 51,84 & 531,55 & 89,82 & 110,74 & 531,55 \\
\hline \begin{tabular}{|l} 
Chioglossa lusitanica \\
\end{tabular} & 29TNG21 & 100,00 & 140,46 & 79,05 & 42,58 & 3766,11 & 241,19 & 57,32 & 183,88 & 93,37 & 187,78 & 188,95 & 93,37 & 1319,70 & 182,44 & 16,80 & 51,79 & 528,80 & 89,38 & 111,32 & 528,80 \\
\hline Chioglossa lusitanica & 29TNG22 & 101,00 & 137,87 & 77,71 & 41,84 & 3802,67 & 239,14 & 55,51 & 183,63 & 92,15 & 185,93 & 187,09 & 90,40 & 1364,18 & 189,74 & 19,11 & 51,39 & 545,54 & 96,55 & \begin{tabular}{|c|}
117,25 \\
\end{tabular} & 545,41 \\
\hline \begin{tabular}{|l} 
Chioglossa lusitanica \\
\end{tabular} & 29TNG23 & 100,00 & 133,12 & 76,64 & 41,04 & 3855,64 & 235,53 & 51,17 & 184,36 & 88,49 & 182,12 & 183,32 & 85,21 & 1450,79 & 209,92 & 22,81 & 50,88 & 581,76 & 108,37 & 126,68 & 581,25 \\
\hline Chioglossa lusitanica & $\begin{array}{l}\text { 29TNG24 } \\
291\end{array}$ & 99,00 & 142,72 & 73,68 & $\begin{array}{l}41,04 \\
40,92 \\
\end{array}$ & $\begin{array}{l}303,204 \\
3762,67\end{array}$ & $\mid \begin{array}{l}240,83 \\
240,82\end{array}$ & 62,56 & $\begin{array}{l}104,50 \\
178,27\end{array}$ & \begin{tabular}{|l|}
0,45 \\
101,27
\end{tabular} & $\begin{array}{l}\mid l 0,14 \\
190,16\end{array}$ & $\begin{array}{l}\mid 0,31,21 \\
191,21\end{array}$ & o5,21 & $\begin{array}{l}140,15 \\
1360,54\end{array}$ & $\mid \begin{array}{l}\mid 195,29 \\
195\end{array}$ & $\begin{array}{ll}21,41 \\
21,41\end{array}$ & $\begin{array}{l}50,56 \\
50,56\end{array}$ & 545,50 & \begin{tabular}{|l|l|}
101,24 \\
\end{tabular} & $\begin{array}{l}\mid 2,06 \\
121,49\end{array}$ & 538,25 \\
\hline Chioglossa lusitanica & 29TNG25 & 101,00 & 142,44 & 71,61 & 40,21 & 3755,29 & 239,25 & 63,49 & 175,77 & 101,68 & 189,94 & 190,94 & 95,01 & \begin{tabular}{|l|}
1394,60 \\
\end{tabular} & 206,60 & 23,94 & 50,39 & 561,40 & $\begin{array}{ll}107,55 \\
\end{array}$ & 126,99 & 552,19 \\
\hline Chioglossa lusitanica & 29TNG26 & 100,00 & 137,42 & 70,38 & 39,69 & 3792,18 & 234,78 & | 59,26 & 175,52 & \begin{tabular}{r|}
95,03 \\
\end{tabular} & 185,76 & 186,73 & 89,89 & 1494,19 & 233,27 & 28,30 & 50,67 & 605,16 & 120,03 & $\mid 137,69$ & 598,49 \\
\hline Chioglossa lusitanica & 29TNG27 & 80,00 & 142,23 & 66,90 & 39,02 & 3729,91 & 235,55 & 66,17 & 169,38 & 100,94 & 189,67 & 190,59 & 95,20 & 1456,53 & 226,75 & 28,89 & 50,29 & 590,88 & 119,23 & 137,56 & 576,63 \\
\hline Chioglossa lusitanica & 29TNG28 & 86,00 & 139,17 & 65,44 & 38,37 & 3735,36 & 232,63 & 64,36 & 168,28 & 99,83 & 186,87 & 187,97 & 92,44 & $\begin{array}{l}1463,59 \\
140\end{array}$ & 227,46 & 31,15 & 49,23 & 589,78 & 125,44 & 144,09 & 572,35 \\
\hline Chioglossa lusitanica & $\begin{array}{l}\text { 29TNG30 } \\
290\end{array}$ & $\begin{array}{l}0,0000 \\
100,00\end{array}$ & 142,44 & \begin{tabular}{|c|c|}
84,53 \\
84
\end{tabular} & $\begin{array}{l}30,37 \\
42,87 \\
\end{array}$ & $\begin{array}{l}3933,87 \\
3938\end{array}$ & \begin{tabular}{|l|l|}
252,03 \\
249,38
\end{tabular} & 54 & $\begin{array}{l}100,20 \\
195,22\end{array}$ & 95, 95 & $\begin{array}{l}\mid l 0,0 \\
191,86\end{array}$ & | & $\begin{array}{ll}32,44 \\
92,81\end{array}$ & $\begin{array}{l}140,390 \\
1270,66\end{array}$ & \begin{tabular}{|l|l|}
172,69 \\
172,
\end{tabular} & | & $\begin{array}{l}45,25 \\
51,41 \\
\end{array}$ & $\mid$ & $\begin{array}{r}\mid 22,44 \\
86,42 \\
\end{array}$ & \begin{tabular}{|l|}
106,61 \\
106,
\end{tabular} & 504,88 \\
\hline Chioglossa lusitanica & 29TNG31 & 101,00 & 138,13 & 83,65 & 42,12 & 3997,59 & 246,81 & 50,50 & 196,31 & 90,32 & 188,70 & 189,82 & 88,05 & 1338,81 & 185,48 & 18,15 & 51,15 & 533,35 & $\begin{array}{l}94,35 \\
\end{array}$ & 113,34 & 533,25 \\
\hline Chioglossa lusitanica & 29TNG32 & 101,00 & 142,57 & 82,02 & 41,8 & 3972,07 & 249,88 & 55,81 & 194,06 & 98,7 & 192,74 & 193,71 & 92,50 & 1300,19 & 180,92 & 17,88 & 51,01 & 516,76 & 92,01 & 111,91 & 515,34 \\
\hline Chioglossa lusitanica & 29TNG33 & 100,00 & & 80,92 & 40,7 & 4087,55 & 238,12 & & 196,20 & 79,68 & 180,45 & 181 & 77,3 & 1483 & 217,87 & 24,4 & 50,58 & 592,61 & \begin{tabular}{|c|}
114,75 \\
\end{tabular} & 129,94 & 592,45 \\
\hline Chioglossa lusitanica & 29TNG34 & 100,00 & 130,47 & 79,59 & 40,55 & 4068,19 & 239,44 & 45,08 & 194,36 & 84,61 & 182,58 & 183,56 & 79,95 & 1482,56 & 223,25 & 25,55 & 50,53 & 593,07 & 116,73 & 132,15 & 591,82 \\
\hline Chioglossa lusitanica & 29TNG35 & 100,00 & 145,15 & 76,03 & 40,07 & 3941,12 & 248,67 & 61,79 & 186,88 & \begin{tabular}{|l|}
101,87 \\
\end{tabular} & 195,09 & 195,83 & 95,17 & 1342,05 & 200,47 & 22,86 & 50,10 & 537,04 & 104,42 & 122,88 & 526,61 \\
\hline \begin{tabular}{|l} 
Chioglossa lusitanica \\
\end{tabular} & 29TNG36 & 101,00 & 144,76 & 73,61 & 39,76 & 3928,62 & 246,38 & 62,98 & 183,40 & 101,35 & 194,70 & 195,47 & 95,00 & 1380,58 & 213,07 & 25,50 & 50,08 & 554,99 & 110,69 & 128,51 & 543,54 \\
\hline Chioglossa lusitanica & 29TNG37 & 100,00 & 139,44 & 72,37 & 39,17 & 3952,22 & 241,01 & 58 & 182,39 & 95,37 & 190,05 & 190,83 & 89,86 & 1472,17 & 236,44 & 29,55 & 50,39 & 593,97 & 122,06 & 138,70 & 586,24 \\
\hline Chioglossa lusitanica & 29TNG38 & 88,00 & 9,79 & 70,11 & 38,7 & 5,64 & ,20 & 60 & \begin{tabular}{|l|l|}
178,77 \\
\end{tabular} & $\begin{array}{l}97,45 \\
\end{array}$ & 190,29 & 191,03 & 90,4 & 1461,61 & 233,79 & 31,05 & 49,66 & 586,56 & 124,93 & 141,71 & 575,20 \\
\hline Chioglossa lusitanica & 29TNG39 & 101,00 & 136,77 & 68,86 & 38,12 & 3933,53 & 236,40 & 58,27 & 178,13 & 94,66 & 187,42 & 188,34 & 87,9 & 1478,41 & 235,28 & 33,27 & 48,80 & 590,26 & 130,99 & $\mid 148,84$ & 576,22 \\
\hline Chioglossa lusitanica & 29TNG40 & 10 & 14 & 88,48 & 42,53 & 4128,39 & 258,94 & 53,25 & 205,69 & 100, & 197,76 & 198,85 & 93 & 1208,74 & 163,53 & 15,25 & 50,98 & 478,58 & 83,25 & 102,33 & 474,61 \\
\hline Chioglossa lusitanica & 29TNG41 & 100,00 & $\begin{array}{l}138,67 \\
13,0\end{array}$ & 87,77 & 41,79 & 4212,47 & 254,27 & 46,55 & 207,72 & \begin{tabular}{|l|l|}
92,38 \\
\end{tabular} & 192,13 & 193,18 & 85,67 & 1304,64 & 181,44 & 18,13 & 50,77 & $\begin{array}{l}417,18 \\
517,\end{array}$ & $\frac{93,25}{94,26}$ & 111,32 & 514,42 \\
\hline Chioglossa lusitanica & 29TNG42 & 100,00 & 73 & 86,50 & 41,29 & 4229,46 & 25 & 46 & 206,99 & 90 & 191,60 & 192,52 & 84,68 & 1324,39 & 187,27 & 19,51 & 50,38 & 524,80 & 98,47 & 114,94 & 521,03 \\
\hline Chioglossa lusitanica & 29TNG43 & 101,00 & 51 & 85,64 & 40,8 & 235,56 & 253,34 & 46,66 & 206,68 & 91,15 & 191,53 & 192,29 & 84,30 & 1342,99 & 195,19 & 21,10 & 50,03 & 532,19 & $\mid$ & 118,92 & 527,01 \\
\hline Chioglossa lusitanica & 29TNG44 & 100,00 & 13 & $\begin{array}{l}30,24 \\
84,27 \\
\end{array}$ & 40,4 & 4270,75 & $\mid \begin{array}{l}\mid 24,54,88 \\
246\end{array}$ & 40,75 & $\begin{array}{l}206,00 \\
206,14\end{array}$ & 84,49 & $\begin{array}{l}185,44 \\
185\end{array}$ & $\begin{array}{l}186,28 \\
186,25\end{array}$ & 77, 74 & \begin{tabular}{|l|}
1431,34 \\
143,
\end{tabular} & $\mid \frac{214,47}{214,4}$ & $\begin{array}{l}21,10 \\
24,88\end{array}$ & $\begin{array}{l}0,035 \\
49,83 \\
\end{array}$ & 567,90 & 1115,32 & $\begin{array}{l}129,11 \\
129,11\end{array}$ & 563,75 \\
\hline \begin{tabular}{|l} 
Chioglossa lusitanica \\
\end{tabular} & 29TNG45 & 101,00 & 142,30 & 82,14 & 40,13 & 4197,28 & 255,32 & 53,36 & 201,9 & 96,35 & 195,81 & 196,38 & 89,24 & 1323,49 & 199,84 & 23,13 & 49,47 & 524,75 & 106,82 & 122,21 & 513,46 \\
\hline Chioglossa lusitanica & 29TNG50 & 101,00 & 140,38 & 92,44 & 41,82 & 4400,09 & 262,18 & 43, & 218,44 & 91,96 & 196,36 & 197,28 & 84,8 & 1243,80 & 168,81 & 16,54 & 50,69 & 492,03 & 88,82 & 104,69 & 487,03 \\
\hline Chioglossa lusitanica & 29TNG51 & 100,00 & 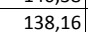 & 010 & 41 & 4425,39 & 26 & 42, & 218 & 89,5 & 194,64 & 195,49 & 82,5 & 1274,66 & 176,06 & 17 & 50,29 & 503,34 & 93,86 & 109,01 & 498,60 \\
\hline Chioglossa lusitanica & $29 T N$ & 10 & & & 40 & 446 & & & 217 & 81 & 188 & 5 & 75 & & 19 & 21 & 49,95 & 535,88 & 104,88 & 117,86 & 532,10 \\
\hline Chioglossa lusitanica & 29TNG53 & 101,00 & 131,96 & 89,04 & 40,50 & 4465,45 & 254,88 & 37,47 & 217,42 & 83,37 & 189,44 & 190,19 & 76,41 & 1345,19 & 193,52 & 21,98 & 49,53 & 529,65 & 106,91 & 119,50 & 523,62 \\
\hline \begin{tabular}{|l} 
Chioglossa lusitanica \\
\end{tabular} & 29TNG54 & 101,00 & 107,50 & 82,47 & 38,62 & 4465,10 & 228,68 & 18,35 & 210,33 & 60,80 & 166,06 & 167,06 & 54,06 & 1555,27 & 221,33 & 30,16 & 48,53 & 611,15 & 134,21 & 142,65 & 608,70 \\
\hline Chioglossa lusitanica & 29TNG55 & 100,00 & 132,57 & 86,93 & 39,88 & 4446,63 & 254,36 & 39,24 & 215,13 & 84,11 & 189,82 & 190,56 & 77,19 & 1347,31 & 201,06 & 24,82 & 48,65 & 528,58 & 114,33 & 126,30 & 517,21 \\
\hline Chioglossa lusitan & 29TNG59 & 100,00 & & & 38,72 & 4310,81 & & 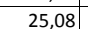 & 206,7 & 67,71 & 170,02 & I & 62,24 & 1500 & 226 , & & 46,38 & 586,61 & 144,05 & 155,97 & 575,97 \\
\hline Chioglossa lusitanica & 29TN & & & & 41 & 64 & & 35,02 & 228,66 & 83,36 & 194,34 & 195 & 76,56 & & 170 & 17, & 50,72 & 502,46 & 92,99 & 105,74 & 499 \\
\hline Chioglossa lusitanica & 29TNG61 & 101,00 & 129,52 & 92,96 & 40,52 & 4652,63 & 257,84 & 31,49 & 226,34 & 76,71 & 189,55 & 190,32 & 71,80 & 1320,79 & 179,13 & 19,68 & 50,09 & 520,45 & 100,31 & 111,37 & 517,43 \\
\hline Chioglossa lusitanica & 29TNG62 & 101,00 & 115,32 & 87,95 & 39,30 & 4647,57 & 241,85 & 21,15 & 220,70 & 62,37 & 176,03 & 176,82 & 58,84 & 1450,71 & 198,80 & 24,52 & 49,68 & 571,37 & 116,97 & 125,53 & 570,44 \\
\hline Chioglossa lusitanica & 29TNG63 & 100,00 & 123,83 & 90,23 & 39,73 & 4660,90 & 51,54 & 27,50 & 224,04 & 72,50 & 184,36 & 185,01 & 66,47 & $\begin{array}{ll}1369,05 \\
\end{array}$ & 192,82 & 23,31 & 49,05 & 536,57 & 111,71 & 121,10 & 531,94 \\
\hline Chioglossa lusitar & 29TN & 10101 & & & 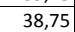 & 618 & & 18, & 217,7 & 61, & 171,38 & 172 & 55,2 & & & 28 & 48,52 & 57 & 12 & 135,08 & \\
\hline Chioglossa lusitanica & 29TNG65 & 100,00 & 104,96 & 83,10 & 38,21 & 4573,78 & $\mid 228,97$ & $\begin{array}{l}14,215 \\
14,35\end{array}$ & 214,62 & 57,06 & $\mid 165,27$ & 166,23 & $\begin{array}{l}50,52 \\
50,5\end{array}$ & $\begin{array}{l}1523,45 \\
\end{array}$ & $\mid$ & 31,05 & \begin{tabular}{|l|l|}
47,71 \\
47
\end{tabular} & 594,87 & \begin{tabular}{|l|}
135,51 \\
\end{tabular} & \begin{tabular}{|l|}
143,03 \\
\end{tabular} & 591,62 \\
\hline
\end{tabular}




\begin{tabular}{|c|c|c|c|c|c|c|c|c|c|c|c|c|c|c|c|c|c|c|c|c|c|}
\hline TAXON & UTM & $\mathrm{km} 2$ & $\mathrm{BIO1}$ & $\mathrm{B1O2}$ & $\mathrm{BIO3}$ & $\mathrm{B104}$ & B105 & $\mathrm{B106}$ & $\mathrm{B107}$ & B108 & $\mathrm{BIO9}$ & 81010 & B1011 & BIO12 & $\mathrm{B1O13}$ & 81014 & B1015 & B1016 & B1017 & $\mathrm{BIO18}$ & B1019 \\
\hline Chioglossa lusitanica & 29TNG66 & 100,00 & 132,97 & 90,07 & 39,70 & 4650,79 & 259,97 & 35,22 & 224,75 & 81,72 & 193,13 & 193,56 & 75,17 & 1269,36 & 188,81 & 24,75 & 47,50 & 491,39 & 112,81 & 122,05 & 476,26 \\
\hline Chioglossa lusitanica & 29TNG67 & 101,00 & 131,55 & 88,09 & 39,38 & 4616,44 & 255,96 & 34,71 & 221,25 & 80,76 & 191,40 & 191,92 & 74,53 & 1285,02 & 193,17 & 26,55 & 47,19 & 496,80 & 116,35 & 126,10 & 482,80 \\
\hline Chioglossa lusitanica & 29TNG70 & 100,00 & 125,96 & 95,39 & 40,34 & 4836,55 & 259,46 & 25,65 & 233,80 & 69,04 & 188,61 & 189,35 & 66,06 & 1323,33 & 177,65 & 18,87 & 50,92 & 523,00 & 98,51 & 107,73 & 522,32 \\
\hline Chioglossa lusitanica & 29TNG71 & 101,00 & 123,47 & 93,49 & $\begin{array}{l}39,85 \\
\end{array}$ & 4824,53 & 255,95 & 24,26 & 231,69 & 67,47 & 186,21 & 186,93 & 64,12 & 1335,23 & 178,47 & 20,38 & 50,23 & 525,75 & 102,88 & 111,40 & 524,43 \\
\hline Chioglossa lusitanica & 29TNG72 & 100,00 & 97,65 & 83,12 & 37,48 & 4745,83 & 225,53 & 6,75 & 218,78 & 42,20 & 160,59 & 161,38 & 41,58 & 1545,54 & 206,22 & 28,51 & 49,13 & 607,76 & 130,75 & 134,74 & 607,72 \\
\hline Chioglossa lusitanica & 29TNG73 & 100,00 & 115,12 & 89,06 & 38,83 & 4792,36 & 245,33 & 18,81 & 226,53 & 61,56 & 177,89 & 178,53 & 57,06 & 1389,96 & 190,55 & 24,75 & 48,83 & 543,13 & 116,06 & 122,88 & 540,40 \\
\hline Chioglossa lusitanica & 29TNG74 & 100,00 & 118,22 & 89,85 & 39,04 & 4792,53 & 248,44 & 20,96 & 227,47 & 66,63 & 181,05 & 181,57 & 60,02 & 1355,98 & 189,64 & 24,99 & 48,16 & 527,67 & 115,35 & 123,03 & 523,51 \\
\hline Chioglossa lusitanica & 29TNG75 & 100,00 & 95,31 & 81,82 & 37,30 & 4670,94 & 221,61 & 5,29 & 216,32 & 47,01 & 157,29 & 158,27 & 40,48 & 1539,21 & 211,15 & 32,58 & 47,17 & 598,54 & 140,23 & 145,68 & 596,07 \\
\hline Chioglossa lusitanica & 29TNG76 & 101,00 & 119,59 & 88,52 & 38,71 & 4750,27 & 247,99 & 22,54 & 225,45 & 68,06 & 181,81 & 182,36 & 61,94 & 1331,79 & \begin{tabular}{|c|}
191,78 \\
\end{tabular} & 27,01 & 47,14 & 514,88 & 119,36 & 127,88 & 506,72 \\
\hline Chioglossa lusitanica & 29TNG77 & 101,00 & 133,18 & 91,21 & 39,10 & 4819,46 & 261,81 & 31,66 & 230,15 & 79,49 & 195,82 & 196,10 & 73,70 & 1193,18 & 176,81 & 24,51 & 46,56 & 456,50 & 108,58 & 116,42 & 442,62 \\
\hline Chioglossa lusitanica & 29TNG80 & 101,00 & 112,87 & 91,32 & 38,75 & 4947,97 & 247,61 & 15,16 & 232,45 & 53,01 & 177,90 & 178,60 & 53,01 & 1400,14 & 192,11 & 21,42 & 51,11 & 556,51 & 107,68 & 112,99 & 556,51 \\
\hline Chioglossa lusitanica & 29TNG81 & 99,00 & 115,24 & 91,50 & 38,82 & 4947,70 & 249,65 & 16,98 & 232,68 & 55,94 & 180,29 & 180,76 & 55,18 & 1364,75 & 183,45 & 21,60 & 50,37 & 539,13 & 106,90 & 111,89 & 538,88 \\
\hline Chioglossa lusitanica & 29TNG82 & 101,00 & 108,29 & 87,72 & 38,01 & 4896,41 & 240,41 & 12,73 & 227,68 & 49,93 & 172,98 & 173,49 & 49,60 & 1410,36 & 187,29 & 24,39 & 49,53 & 554,55 & 115,56 & 120,32 & 554,48 \\
\hline Chioglossa lusitanica & 29TNG83 & 100,00 & 95,35 & 82,54 & 36,89 & 4825,88 & 224,96 & 4,18 & 220,77 & 39,97 & 159,66 & 160,33 & 38,78 & 1502,75 & 199,67 & 29,19 & 48,38 & 587,88 & 130,81 & 134,52 & 587,87 \\
\hline Chioglossa lusitanica & 29TNG84 & 101,00 & 115,06 & 89,61 & 38,44 & 4900,82 & 247,18 & 17,13 & 230,05 & 62,29 & 179,62 & 180,01 & 55,89 & 1330,30 & 182,38 & 24,65 & 48,11 & 516,80 & 113,30 & 119,51 & 514,85 \\
\hline Chioglossa lusitanica & 29TNG85 & 101,00 & 110,38 & 87,58 & 38,09 & 4847,86 & 241,14 & 14,13 & 227,01 & 58,55 & 174,38 & 174,95 & 52,32 & 1362,59 & 188,53 & 27,05 & 47,48 & 528,30 & 120,16 & 126,83 & 525,43 \\
\hline Chioglossa lusitanica & 29TNG86 & 100,00 & 118,55 & 89,98 & 38,52 & 4887,39 & 249,84 & 19,15 & 230,69 & 65,38 & 182,86 & 183,30 & 59,50 & 1277,69 & 180,86 & 25,94 & 46,84 & 491,94 & 114,51 & 120,97 & 485,73 \\
\hline Chioglossa lusitanica & 29TNG90 & 100,00 & 120,45 & 96,51 & 39,18 & 5118,80 & 260,85 & 17,93 & 242,93 & 57,81 & 187,52 & 187,92 & 57,81 & 1287,23 & 177,84 & 18,68 & 51,39 & 510,95 & 96,68 & 101,54 & 510,95 \\
\hline Chioglossa lusitanica & 29TNG91 & 101,00 & 106,49 & 88,55 & \begin{tabular}{|l|l|l|}
37,63 \\
\end{tabular} & 5026,95 & 242,03 & 9,90 & 232,12 & 46,30 & 173,06 & 173,50 & 46,30 & 1386,53 & 188,86 & 23,03 & 50,32 & 548,86 & 111,20 & 114,51 & 548,86 \\
\hline Chioglossa lusitanica & 29TNG92 & 101,00 & 104,70 & 86,50 & 37,29 & 4987,78 & 238,55 & 9,44 & 229,12 & 45,29 & 170,90 & 171,31 & 45,29 & 1385,85 & 185,38 & 24,36 & 49,44 & 545,62 & 114,51 & 117,69 & 545,62 \\
\hline Chioglossa lusitanica & 29TNG93 & 100,00 & 96,32 & 83,47 & 36,63 & 4929,91 & 228,39 & 3,62 & 224,77 & 39,17 & 162,07 & 162,53 & 38,30 & 1441,20 & 190,75 & 27,84 & 48,34 & 563,31 & 125,34 & 128,21 & 563,31 \\
\hline \begin{tabular}{|l} 
Chioglossa lusitanica \\
\end{tabular} & 29TNG94 & 100,00 & 104,76 & 86,30 & 37,24 & 4947,62 & 237,78 & 9,36 & 228,42 & 50,88 & 170,56 & 170,87 & 45,91 & 1358,63 & 181,85 & 26,28 & 47,98 & 528,21 & 118,26 & 122,51 & 528,04 \\
\hline Chioglossa lusitanica & 29TNG98 & 101,00 & 137,22 & 92,45 & \begin{tabular}{|c|}
37,87 \\
\end{tabular} & 5162,84 & 269,37 & 28,60 & 240,77 & 79,01 & 204,71 & 204,75 & 73,95 & 989,93 & 142,03 & 21,46 & 44,79 & 370,10 & 91,71 & 93,81 & 359,00 \\
\hline Chioglossa lusitanica & 29TNHOO & 16,00 & 147,29 & 59,00 & 38,48 & 3400,52 & 230,67 & 78,95 & 151,71 & 112,29 & 190,24 & 191,67 & 104,38 & 1225,90 & 174,48 & 26,95 & 46,81 & 491,57 & 111,81 & 134,71 & 450,57 \\
\hline Chioglossa lusitanica & 29TNHO2 & 97,00 & 132,26 & 63,14 & 37,98 & 3521,94 & 224,76 & 60,48 & 164,28 & 97,19 & 177,01 & 179,36 & 89,11 & 1311,65 & 191,91 & 32,75 & 44,97 & 520,73 & 131,71 & 153,40 & 479,06 \\
\hline Chioglossa lusitanica & 29TNH03 & 72,00 & 140,28 & 62,04 & 38,15 & 3441,65 & 229,47 & 68,97 & 160,50 & 106,00 & 183,51 & 186,10 & 97,60 & 1187,87 & 170,53 & 29,84 & 44,38 & 70,94 & 121,46 & 144,58 & 424,12 \\
\hline Chioglossa lusitanica & 29TNH04 & 98,00 & $\begin{array}{l}137,01 \\
137,01\end{array}$ & 62,14 & 38,09 & 3452,36 & 228,38 & 64,98 & 163,40 & 103,02 & 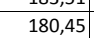 & 183,28 & 94,56 & 1187,81 & 169,67 & 31,04 & 43,51 & 468,51 & 125,83 & 148,93 & 420,04 \\
\hline Chioglossa lusitanica & 29TNH05 & 99,00 & 130,21 & 64,82 & $\begin{array}{l}38,15 \\
\end{array}$ & 3496,92 & 225,11 & 57,22 & 167,89 & 96,18 & 174,38 & 177,55 & 87,89 & 1236,42 & 176,17 & 33,76 & 42,70 & 484,35 & 135,19 & 157,82 & 436,14 \\
\hline Chioglossa lusitanica & 29TNH08 & 81,00 & 139,86 & 62,83 & 39,45 & 3245,91 & 226,50 & 68,94 & 157,55 & 108,65 & 179,71 & 183,68 & 99,93 & 1066,54 & 146,17 & 30,11 & 40,82 & 414,13 & 122,84 & 147,26 & 363,35 \\
\hline Chioglossa lusitanica & 29TNHO9 & 36,00 & 140,84 & 62,53 & 39,81 & 3197,92 & 225,89 & 70,47 & 155,42 & 110,27 & 179,88 & 184,00 & 101,47 & 1046,33 & 142,86 & 29,83 & 40,06 & 404,94 & 121,86 & 146,55 & 354,73 \\
\hline Chioglossa lusitanica & 29TNH10 & 61,00 & 146,39 & 60,06 & 37,91 & 3519,36 & 232,27 & 76,11 & 156,16 & 109,72 & 190,75 & 192,23 & 101,94 & 1275,06 & 185,37 & 28,73 & 46,99 & 509,45 & 116,28 & 138,47 & 472,93 \\
\hline Chioglossa lusitanica & 29TNH11 & 40,00 & 146,34 & 60,45 & 37,82 & 3518,47 & 233,20 & 75,68 & 157,53 & $\begin{array}{l}109,97 \\
\end{array}$ & 190,80 & 192,50 & $\begin{array}{l}102,30 \\
102\end{array}$ & 1241,93 & \begin{tabular}{|l|l|}
180,28 \\
\end{tabular} & 28,89 & $\begin{array}{ll}46,24 \\
46,24\end{array}$ & \begin{tabular}{|l|l|}
494,43 \\
\end{tabular} & $\begin{array}{l}116,57 \\
116,5\end{array}$ & 139,20 & 455,66 \\
\hline Chioglossa lusitanica & 29TNH14 & 100,00 & 133,17 & 66,01 & \begin{tabular}{|c|}
37,97 \\
\end{tabular} & 3607,29 & 230,45 & 58,59 & 171,85 & 97,29 & 178,97 & 181,81 & 89,22 & 1284,45 & 186,08 & 34,10 & 43,76 & 503,35 & 134,48 & 156,51 & 461,63 \\
\hline Chioglossa lusitanica & 29TNH15 & 101,00 & 131,49 & 66,60 & 38,05 & 3585,35 & 229,44 & 56,70 & 172,74 & 96,06 & 176,92 & 180,04 & 88,01 & 1269,31 & 181,60 & 34,69 & 42,87 & 494,86 & 136,62 & 158,82 & 451,55 \\
\hline Chioglossa lusitanica & 29TNH16 & 100,00 & 129,53 & 66,99 & 38,23 & 3553,02 & 227,55 & 54,86 & 172,69 & 94,82 & 174,47 & 177,92 & 86,69 & 1258,25 & 177,72 & 35,39 & 41,99 & 487,99 & 139,03 & 161,37 & 443,71 \\
\hline Chioglossa lusitanica & 29TNH17 & 101,00 & 129,68 & 66,59 & 38,59 & 3486,06 & 225,87 & 55,66 & 170,21 & 95,86 & 173,47 & 177,07 & 87,56 & 1227,19 & 170,96 & 35,16 & 41,07 & 474,12 & 138,50 & 161,14 & 429,01 \\
\hline Chioglossa lusitanica & 29TNH19 & 64,00 & $\begin{array}{l}12,00 \\
140,89\end{array}$ & $\begin{array}{l}80,35 \\
63,56\end{array}$ & 年, 39,93 & $\begin{array}{ll}340,0,00 \\
322,95\end{array}$ & 227,11 & $\begin{array}{l}0,700 \\
69,77 \\
\end{array}$ & \begin{tabular}{|l|l|l|l|l|}
157,34 \\
\end{tabular} & \begin{tabular}{|c|}
50,000 \\
109,84 \\
\end{tabular} & \begin{tabular}{|l|}
180,43 \\
180,
\end{tabular} & 184,43 & \begin{tabular}{|l|}
101,17 \\
10
\end{tabular} & $\begin{array}{l}124,19 \\
1059,58\end{array}$ & \begin{tabular}{|l|l|l|l|l}
143,29 \\
\end{tabular} & $\begin{array}{ll}30,28 \\
30,2\end{array}$ & $\begin{array}{ll}40,01 \\
40,01\end{array}$ & | & $\begin{array}{ll}122,48 \\
12,4\end{array}$ & 140,75 & 361,63 \\
\hline Chioglossa lusitanica & $29 \mathrm{TNH} 20$ & 100,00 & 140,04 & 63,04 & 37,60 & 3718,64 & 232,42 & \begin{tabular}{ll|}
66,87 \\
\end{tabular} & 165,55 & 101,01 & 187,74 & 188,88 & 93,81 & 1395,50 & 212,46 & 32,47 & 47,52 & 556,28 & 127,28 & 147,77 & 529,68 \\
\hline Chioglossa lusitanica & 29TNH21 & 101,00 & 143,07 & 62,99 & 37,73 & 3680,33 & 234,96 & 69,79 & 165,16 & 104,60 & 190,07 & 191,50 & 97,21 & 1313,98 & 195,41 & 31,39 & 46,36 & 520,5 & $\mid 123,46$ & 145,06 & 488,04 \\
\hline Chioglossa lusitanica & 29TNH22 & 98,00 & 142,56 & 64,37 & 37,83 & 3673,06 & 236,45 & 68,27 & 168,18 & 104,48 & 189,39 & 191,20 & 97,00 & 1282,23 & 189,18 & 31,60 & 45,59 & 505,62 & 124,06 & 145,95 & 470,89 \\
\hline Chioglossa lusitanica & 29TNH23 & 100,00 & 140,69 & 65,81 & 37 & 3675,02 & 236,85 & 65,44 & 171,42 & 102,96 & 187,49 & 189,76 & 95,38 & 1268,02 & 185,23 & 32,23 & 44,81 & 28 & 126,63 & 148,60 & 460,75 \\
\hline 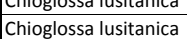 & $\frac{291 \mathrm{NTH} 24}{29 \mathrm{TNH}}$ & 101,00 & $\begin{array}{l}14,099 \\
139,46\end{array}$ & $\begin{array}{l}\frac{63,01}{66,85} \\
\end{array}$ & 38 & $\begin{array}{l}30 / 7,04 \\
3657,53\end{array}$ & 237,04 & $\begin{array}{l}03,44 \\
63,64 \\
\end{array}$ & \begin{tabular}{|l|}
173,40 \\
173
\end{tabular} & $\begin{array}{l}102,90 \\
102,32 \\
\end{array}$ & $\mid$\begin{tabular}{|l|l|l|l|}
185,96 \\
\end{tabular} & \begin{tabular}{|l|l|}
188,60 \\
\end{tabular} & \begin{tabular}{|c|}
93,50 \\
94,54
\end{tabular} & $\begin{array}{l}120,04 \\
1247,55\end{array}$ & \begin{tabular}{|l|}
180,25 \\
180,10
\end{tabular} & 32,7 & $\begin{array}{ll}43,01 \\
43,93\end{array}$ & \begin{tabular}{|l|}
486,78 \\
486,8
\end{tabular} & $\begin{array}{l}128,03 \\
128,3 \\
\end{array}$ & $\begin{array}{l}148,00 \\
150,59\end{array}$ & $\begin{array}{l}400,15 \\
448,39 \\
\end{array}$ \\
\hline Chioglossa lusitanica & 29TNH25 & 101,00 & 134,22 & 68,49 & 38,02 & 3679,17 & 235,07 & 57,13 & 177,94 & 97,31 & 180,95 & 184,04 & 89,61 & 1277,87 & 182,81 & 34,92 & 42,98 & 495,32 & 135,80 & 157,76 & 456,50 \\
\hline Chioglossa lusitanica & $29 \mathrm{TNH} 26$ & 101,00 & 129,38 & 69,40 & 38,11 & 3658,94 & 231,39 & 52,28 & 179,10 & 93,09 & 175,81 & 179,24 & 85,42 & 1295,09 & 183,16 & 36,61 & 42,07 & 499,18 & 141,72 & 163,38 & 459,85 \\
\hline Chioglossa lusitanica & 29TNH29 & 39,00 & 138,94 & 65,60 & 40,1 & 3300,89 & 227,96 & 66,33 & 161,63 & 106,78 & 179,56 & 183,64 & 98,28 & 1096,42 & 147,44 & 31,46 & 39,97 & 20,50 & 51 & 49,00 & 378,18 \\
\hline Chioglossa lusitanica & 29TNH30 & 101,00 & 136 & 68,31 & 37, & 3916,51 & 236,40 & 58,16 & 178,24 & \begin{tabular}{r|r|}
94,75 \\
96
\end{tabular} & 186,93 & $\begin{array}{l}188,06 \\
188,06\end{array}$ & 88,14 & 1444,96 & 225,06 & 34,07 & 47,76 & 572,47 & $\begin{array}{l}132,50 \\
\end{array}$ & 151,25 & 553,08 \\
\hline Chioglossa lusitanica & $29 \mathrm{TNH}^{3}$ & 100,00 & 135 & 69,05 & 37,66 & 3905,13 & 237,49 & 56,52 & 180,97 & 94,42 & 186,07 & 187,56 & 87,79 & 1419,43 & 217,60 & 34,7 & 46,73 & 558,64 & 134,36 & 153,66 & 535,47 \\
\hline Chioglossa lusitanica & 29TNH34 & 100,00 & 137,98 & 70,61 & 37,67 & 3829,36 & 242,21 & 57,25 & 184,96 & 98,68 & 186,96 & 189,58 & 91,35 & 1297,37 & 188,15 & 34,52 & 43,99 & 501,72 & 132,89 & 154,22 & 468,82 \\
\hline Chioglossa lusitanica & 29TNH35 & 101,00 & 132,84 & 72,28 & 37,68 & 3838,58 & 240,40 & 50,95 & 189,45 & 94,15 & 182,04 & 185,10 & 86,75 & 1326,75 & 190,10 & 36,64 & 43,10 & 509,81 & 140,19 & 161,30 & 476,37 \\
\hline Chioglossa lusitanica & 29 TNH 40 & 101,00 & 124,43 & 76,64 & 38,4 & 26,21 & 236,23 & 39,22 & 197,01 & 80,58 & 178,19 & 179,63 & 74,68 & 1499,32 & 232,05 & 36,10 & 47,05 & 15 & 41,93 & 157,16 & 573,21 \\
\hline Chioglossa lusitanica & 29 TNH43 & $\begin{array}{l}101,00 \\
100\end{array}$ & $\frac{144}{140}$ & $\begin{array}{ll}72,84 \\
72,87\end{array}$ & $\begin{array}{l}30, \\
37,\end{array}$ & $\frac{44}{3}$ & 246,17 & \begin{tabular}{|c|c|c|}
56,53 \\
5
\end{tabular} & \begin{tabular}{|l|}
189,64 \\
18,1
\end{tabular} & $\begin{array}{l}00,30 \\
98,34 \\
\end{array}$ & \begin{tabular}{|l|}
190,91 \\
190,
\end{tabular} & \begin{tabular}{|l|l|}
193,06 \\
\end{tabular} & \begin{tabular}{r|r}
4,80 \\
91,84
\end{tabular} & \begin{tabular}{|l|}
14593,54 \\
1293,19
\end{tabular} & \begin{tabular}{|l|}
190,16 \\
190,16
\end{tabular} & $\begin{array}{l}30,10 \\
33,42\end{array}$ & 44,74 & \begin{tabular}{|l|}
499,02 \\
49,0
\end{tabular} & \begin{tabular}{l|l}
128,68 \\
12,0
\end{tabular} & 149,06 & 471,50 \\
\hline Chioglossa lusitanica & 29TNH44 & 99,00 & 134,34 & 75,62 & 37,50 & 4016,51 & 247,01 & 47,82 & 199,18 & 92,76 & 186,25 & 188,81 & 86,23 & 1354,82 & 196,79 & 36,70 & 43,95 & 518,70 & 139,25 & 159,31 & 490,94 \\
\hline Chioglossa lusitanica & 29TNH45 & 100,00 & 133,85 & 75,41 & 37,71 & 3948,35 & 245,54 & 48,08 & 197,45 & 93,39 & 184,49 & 187,60 & 86,62 & 1327,24 & 189,42 & 36,86 & 42,92 & 505,97 & 139,84 & 160,39 & 476,27 \\
\hline Chioglossa lusitanica & 29TNH47 & 101,00 & 129,79 & 73,67 & 39,01 & 3726,10 & 235,43 & 48,83 & 186,61 & 92,02 & 177,26 & 180,80 & 85,29 & 1276,81 & 177,09 & 37,02 & 41,03 & 484,24 & 141,41 & 162,11 & 451,80 \\
\hline Chioglossa lusitanica & 29 TNH 48 & 99,00 & 130,64 & 71,90 & 39,94 & 3580,81 & 231,16 & 52,91 & 178 & 94,65 & 175,87 & 179,58 & 87,62 & 1222,47 & 166,76 & 35,87 & 40,09 & 463,07 & 138,08 & 159,15 & 42 \\
\hline Chioglossa lusitanica & $\begin{array}{l}29 \text { TNH49 } \\
29140\end{array}$ & $\begin{array}{ll}59,00 \\
99,\end{array}$ & 138,44 & 68,49 & 41,26 & $\begin{array}{l}330,01 \\
3334,69\end{array}$ & 228,73 & \begin{tabular}{|c|c|}
64,79 \\
64
\end{tabular} & \begin{tabular}{|l|l|}
163,94 \\
\end{tabular} & \begin{tabular}{|r|r|}
105,25 \\
10,5
\end{tabular} & \begin{tabular}{|l|l|l|l|l|}
179,57 \\
\end{tabular} & \begin{tabular}{|l|}
183,74 \\
18,0
\end{tabular} & \begin{tabular}{l|l}
91,402 \\
97,48
\end{tabular} & $\begin{array}{l}12<, 41 \\
1091,49\end{array}$ & \begin{tabular}{|l|l|}
144,730 \\
\end{tabular} & $\begin{array}{l}30,59 \\
31,59 \\
\end{array}$ & $\begin{array}{ll}30,203 \\
39,26\end{array}$ & $\mid \begin{array}{l}\mid 403,013,86 \\
413,\end{array}$ & $\begin{array}{l}124,400 \\
124,45\end{array}$ & $\begin{array}{l}14,15 \\
146,72\end{array}$ & $\begin{array}{l}42,30 \\
379,25\end{array}$ \\
\hline Chioglossa lusitanica & 29TNH50 & 101,00 & 115,81 & 80,39 & 38,78 & 4246,05 & 232,99 & 27,72 & 205,27 & 70,53 & 171,45 & 172,95 & 65,34 & 1493,95 & 224,52 & 36,57 & 45,84 & 578,78 & 145,19 & 158,22 & 565,92 \\
\hline Chioglossa lusitanica & 29TNH51 & 100,00 & 117,26 & 79,99 & 38,79 & 4189,91 & 233,81 & 29,61 & 204,20 & 72,66 & 172,18 & 173,85 & 67,67 & 1479,02 & 221,39 & 37,47 & 45,33 & 570,71 & 146,62 & 600,59 & 555,60 \\
\hline Chioglossa lusitanica & 29TNH53 & 101,00 & 136,65 & 77,41 & 38,54 & 49,65 & 247,69 & 49,24 & 198,45 & 93,7 & 188 & 191 & 87 & 1301,01 & 191,18 & 34,07 & 44,30 & 497,36 & 130,92 & 149,73 & 47 \\
\hline Chioglossa lusitanica & 29TNH55 & 101,00 & 132,55 & 77,84 & 38,55 & 3952,98 & 244,93 & 45,58 & 199,35 & 91,08 & 183,42 & 186,37 & 85,47 & 1311,62 & 86,78 & 36,64 & 42,66 & 96,98 & 138,85 & 158,30 & 470, \\
\hline
\end{tabular}




\begin{tabular}{|c|c|c|c|c|c|c|c|c|c|c|c|c|c|c|c|c|c|c|c|c|c|}
\hline TAXON & UTM & $\mathrm{km} 2$ & BIO1 & $\mathrm{BIO2}$ & $\mathrm{BIO3}$ & B104 & B105 & B106 & B107 & B108 & B109 & 81010 & B1011 & B1012 & B1013 & B1014 & BIO15 & BIO16 & B1017 & B1018 & B1019 \\
\hline Chioglossa lusitanica & 29TNH57 & 100,00 & 129,49 & 75,79 & 39,47 & 3760,92 & 236,42 & 46,84 & 189,58 & 90,69 & 177,58 & 181,00 & 84,70 & 1264,25 & 174,91 & 36,84 & 40,79 & 476,82 & 140,23 & 160,14 & 447,24 \\
\hline Chioglossa lusitanica & 29TNH58 & 101,00 & 136,43 & 72,36 & 40,72 & 3553,90 & 234,25 & 58,55 & 175,70 & 100,03 & 181,02 & 184,78 & 93,25 & 1141,24 & 154,04 & 33,02 & 39,87 & 430,70 & 128,01 & 149,16 & 399,31 \\
\hline Chioglossa Iusitanica & 29TNH59 & 98,00 & $\begin{array}{lll}140,77 \\
\end{array}$ & 69,91 & 41,80 & 3381,91 & 231,80 & 66,23 & $\mid \begin{array}{l}165,56 \\
\end{array}$ & 106,31 & 182,51 & $\mid 186,54$ & $\mid 99,09$ & $\mid 1058,70$ & 139,63 & 30,57 & 39,04 & 399,41 & 120,42 & 142,28 & 367,09 \\
\hline Chioglossa lusitanica & 29TNH60 & 100,00 & 118,94 & 83,20 & 38,98 & 4353,18 & 238,48 & 27,84 & 210,64 & 71,76 & 175,90 & 177,36 & 67,11 & 1409,20 & 210,16 & 34,42 & 45,45 & 541,88 & 137,56 & 150,38 & 528,85 \\
\hline Chioglossa lusitanica & 29TNH61 & 101,00 & 119,95 & 82,67 & 39,13 & 4262,34 & 238,07 & 29,73 & 208,34 & 73,64 & 175,70 & 177,29 & 69,46 & 1400,04 & 207,77 & 35,43 & 44,95 & 536,38 & 139,36 & 153,01 & 521,48 \\
\hline Chioglossa lusitanica & 29TNH63 & 100,00 & 127,69 & 81,29 & 39,80 & 4046,96 & 241,44 & 39,35 & 202,09 & 83,45 & 180,25 & 182,44 & 79,89 & 1331,88 & 194,42 & 35,67 & 43,65 & 505,65 & 137,02 & 153,53 & 485,67 \\
\hline Chioglossa lusitanica & 29TNH67 & 100,00 & 126,03 & 77,79 & 40,01 & 3800,28 & 234,24 & 42,32 & 191,92 & 86,01 & 174,86 & 178,03 & 81,18 & 1264,47 & 174,59 & 37,33 & 40,38 & 474,41 & 141,64 & 160,31 & 446,85 \\
\hline \begin{tabular}{|l} 
Chioglossa Iusitanica \\
\end{tabular} & 29TNH68 & 101,00 & 134,85 & 74,68 & 40,77 & 3631,25 & 235,43 & 54,60 & 180,83 & 96,81 & 180,73 & $\mid 184,20$ & 90,95 | & $\mid 1139,74$ & $\mid 153,76$ & 33,40 & 39,51 & 427,46 & $\mid \begin{array}{ll}128,78 \\
\end{array}$ & $\mid 149,04$ & 397,92 \\
\hline Chioglossa lusitanica & 29TNH69 & 95,00 & 138,76 & 72,50 & 41,54 & 3500,36 & 233,97 & 61,39 & 172,57 & 102,55 & 182,52 & $\begin{array}{l}186,15 \\
\end{array}$ & 95,99 & 1070,00 & 141,51 & 31,45 & 38,83 & 401,11 & 122,61 & 143,65 & 370,04 \\
\hline Chioglossa lusitanica & 29TNH70 & 101,00 & 121,99 & 85,74 & 39,01 & 4488,05 & 244,15 & 27,49 & 216,65 & 72,54 & 180,79 & \begin{tabular}{|c|}
181,86 \\
\end{tabular} & 68,41 & 1311,15 & 193,43 & 31,86 & 44,90 & 500,27 & 128,43 & \begin{tabular}{|c|}
141,17 \\
\end{tabular} & 487,17 \\
\hline Chioglossa lusitanica & 29TNH73 & 101,00 & 126,68 & 83,29 & 40,45 & 4067,70 & 240,51 & 37,36 & 203,15 & 81,38 & 179,54 & 181,47 & 78,91 & 1275,06 & 184,29 & 34,28 & 43,04 & 481,31 & 132,43 & 148,01 & 462,41 \\
\hline Chioglossa lusitanica & 29TNH76 & 100,00 & 123,45 & 80,75 & 40,48 & 3913,96 & 234,63 & 37,28 & 197,35 & 81,06 & 174,02 & 176,74 & 77,42 & 1263,07 & 175,84 & 36,85 & 40,71 & 472,81 & 140,15 & 157,23 & 448,44 \\
\hline Chioglossa lusitanica & 29TNH77 & 100,00 & 122,67 & 79,66 & 40,36 & 3855,55 & 232,35 & 37,61 & 194,73 & 81,38 & 172,28 & 175,29 & 77,27 & 1252,18 & 172,13 & 37,44 & 39,90 & 467,53 & \begin{tabular}{|c|}
142,08 \\
\end{tabular} & 159,52 & 441,33 \\
\hline Chioglossa lusitanica & 29TNH78 & 100,00 & 125,41 & 78,00 & 40,75 & 3774,11 & 231,87 & 42,35 & 189,52 & 85,45 & 173,73 & 176,95 & 80,70 & 1203,79 & 163,01 & 36,49 & 39,10 & 444,58 & 138,77 & 157,20 & 420,48 \\
\hline Chioglossa lusitanica & 29TNH79 & 101,00 & 127,95 & 76,35 & 40,99 & 3677,10 & 230,73 & 46,82 & 183,90 & 89,37 & 174,66 & 178,06 & 84,01 & 1160,08 & 154,75 & 35,67 & 38,39 & 431,51 & 135,97 & 155,20 & 401,73 \\
\hline Chioglossa lusitanica & 29TNH85 & 101,00 & 121,53 & 83,23 & 40,44 & 4063,13 & 235,80 & 32,57 & 203,23 & 76,88 & 174,31 & 176,45 & 73,91. & 1235,25 & 172,50 & 35,55 & 40,89 & 461,64 & 135,93 & 151,63 & 439,92 \\
\hline Chioglossa lusitanica & 29TNH86 & 101,00 & 115,94 & 82,36 & 40,29 & 4041,46 & 230,32 & 28,34 & 201,98 & 72,10 & 168,44 & 170,87 & 68,70 & 1270,44 & 175,37 & 37,83 & 39,99 & 73,87 & 143,78 & 159,12 & 450,46 \\
\hline Chioglossa lusitanica & 29TNH88 & 101,00 & 120,39 & 79,96 & 40,75 & 3879,56 & 229,84 & 35,39 & 194,45 & 78,82 & 170,37 & 173,09 & 74,51 & $\begin{array}{l}1209,88 \\
\end{array}$ & 163,08 & 37,42 & 38,62 & 448,59 & 141,75 & 158,84 & 421,24 \\
\hline Chioglossa lusitanica & 29TNH89 & 100,00 & 118,54 & 78,92 & 40,75 & 3828,43 & 226,61 & 34,99 & $\begin{array}{l}191,62 \\
\end{array}$ & 77,91 & 167,77 & 170,85 & 73,56 & $\begin{array}{l}1211,67 \\
\end{array}$ & \begin{tabular}{c|c|}
161,56 \\
\end{tabular} & 38,36 & 37,93 & 448,19 & 144,90 & 162,40 & 419,19 \\
\hline \begin{tabular}{|l} 
Chioglossa lusitanica \\
\end{tabular} & 29TNH91 & 101,00 & 118,31 & 88,03 & 39,00 & $\mid 4616,37$ & 244,04 & 21,27 & 222,77 & 67,07 & 178,96 & 179,91 & $\mid 63,44$ & 1205,83 & 171,39 & 30,83 & 43,10 & 454,83 & $\mid 123,06$ & 135,26 & 441,25 \\
\hline Chioglossa lusitanica & 29TNI40 & 18,00 & 140,90 & 67,00 & 41,90 & 3225,38 & 226,97 & 68,62 & 158,34 & 109,17 & 180,34 & 184,66 & 101,00 & 1040,24 & 135,86 & 30,03 & 39,00 & 394,31 . & 119,52 & 142,10 & 359,59 \\
\hline Chioglossa lusitanica & 29TNJ60 & 66,00 & 138,42 & 71,58 & 41,92 & 3427,75 & 231,34 & 62,74 & 168,59 & 103,12 & 181,05 & 184,86 & 96,42 & 1051,61 & 137,08 & 31,55 & 38,09 & 393,14 & 123,14 & 144,39 & 360,99 \\
\hline Chioglossa lusitanica & 29TNJ61 & 82,00 & 138,78 & 70,46 & 42,23 & 3350,75 & 229,34 & 64,74 & 164,60 & 104,63 & 180,27 & 184,22 & 97,70 & \begin{tabular}{|l|}
1035,07 \\
\end{tabular} & 133,93 & 31,48 & 37,61 & 386,40 & 123,21 & 144,96 & 352,94 \\
\hline Chioglossa lusitanica & 29TNJ70 & 100,00 & 127,38 & 75,21 & 41,21 & 3607,29 & 228,03 & 47,99 & 180,04 & 89,86 & 172,98 & 176,58 & 84,18 & 1147,25 & 151,21 & 35,90 & 37,79 & 425,82 & 137,08 & 156,62 & 394,60 \\
\hline Chioglossa lusitanica & 29TNJ71 & 101,00 & 129,37 & 73,82 & 41,56 & 3531,06 & 227,00 & 51,70 & 175,30 & 92,88 & 173,72 & 177,51 & 86,87 & 1112,83 & 144,77 & 35,26 & 37,04 & 412,33 & 135,00 & 155,22 & 379,66 \\
\hline Chioglossa lusitanica & 29TNJ72 & 101,00 & 133,10 & 72,15 & 42,08 & 3432,01 & 226,92 & 57,35 & 169,57 & 97,92 & 175,90 & 179,71 & 91,45 & 1067,50 & 137,07 & 34,02 & 36,65 & 394,97 & 131,15 & 152,16 & 360,88 \\
\hline Chioglossa lusitanica & 29TNJ73 & 59,00 & 136,04 & 70,98 & 42,29 & 3368,61 & 227,33 & 61,57 & 165,76 & 101,66 & 177,81 & 181,81 & 95,03 & 1033,72 & 133,07 & 33,30 & 36,18 & $\begin{array}{l}381,82 \\
\end{array}$ & 128,65 & 150,28 & 346,35 \\
\hline Chioglossa lusitanica & 29TNJ80 & 100,00 & 122,17 & 77,45 & 40,97 & 3732,97 & 226,80 & \begin{tabular}{l|l}
40,28 \\
\end{tabular} & 186,52 & 82,75 & 169,73 & 173,01 & 77,78 & 1168,66 & 153,90 & 37,45 & 37,24 & 431,41 & 141,75 & 160,10 & 400,68 \\
\hline Chioglossa lusitanica & 29TNJ81 & 100,00 & 123,92 & 76,14 & 41,25 & 3653,63 & 225,79 & 43,65 & 182,14 & 85,62 & 170,26 & 173,78 & 80,28 & 1142,11 & 148,61 & 37,10 & 36,76 & 420,70 & 140,61 & 159,65 & 388,46 \\
\hline Chioglossa lusitanica & 29TNJ82 & 100,00 & 130,16 & 74,18 & 41,87 & 3535,37 & 227,38 & 52,20 & 175,18 & 93,44 & 174,59 & 178,24 & 87,60 & 1077,42 & 138,13 & 35,11 & 36,12 & 396,33 & 134,04 & 154,27 & 362,51 \\
\hline Chioglossa lusitanica & 29TNJ83 & 101,00 & 130,18 & 72,98 & 41,98 & 3479,40 & 225,55 & 53,48 & 172,07 & 94,38 & 173,69 & 177,47 & 88,12 & 1072,64 & 137,44 & 35,55 & 35,79 & 393,85 & 135,68 & 156,29 & 358,51 \\
\hline Chioglossa lusitanica & 29TNJ84 & 31,00 & 128,75 & 72,62 & 42,07 & 3463,58 & 223,64 & 52,51 & 171,13 & 93,16 & 172,00 & 175,75 & 86,98 & 1079,11 & 138,18 & 36,49 & 35,25 & 395,05 & 138,64 & 159,35 & 358,69 \\
\hline Chioglossa lusitanica & 29TNJ90 & 101,00 & 120,50 & 79,13 & 40,94 & 3826,89 & 227,57 & 36,78 & 190,79 & 79,70 & 169,58 & 172,59 & 75,19 & 1151,81 & 150,82 & 37,43 & 36,92 & 423,15 & 141,40 & 158,99 & 392,64 \\
\hline \begin{tabular}{|l} 
Chioglossa lusitanica \\
\end{tabular} & 29TNJ91 & 101,00 & 119,44 & 78,01 & 41,06 & 3765,45 & 224,70 & 37,15 & 187,55 & 79,81 & 167,50 & $\mid 170,67$ & 74,70 & $\mid 1154,74$ & $\mid 149,70$ & 38,31 & 36,17 & 423,15 & 144,50 & 162,42 & 391,05 \\
\hline Chioglossa lusitanica & 29TPE03 & 99,00 & 143,31 & 93,20 & 36,73 & 5412,20 & 291,02 & 40,40 & 250,62 & 77,86 & 215,25 & 215,73 & 77,86 & 1056,32 & 156,96 & 9,67 & 55,29 & 430,96 & 65,84 & 65,92 & 430,96 \\
\hline Chioglossa lusitanica & 29TPE04 & 101,00 & 133,29 & 89,19 & 35,94 & 5376,00 & 277,60 & 32,75 & 244,84 & 68,79 & 205,28 & 205,44 & 68,79 & 1173,62 & 176,92 & 10,95 & 55,84 & 80,06 & 72,32 & 72,34 & 480,06 \\
\hline Chioglossa lusitanica & 29TPE05 & 101,00 & 126,58 & 86,64 & 35,51 & 5336,17 & 268,16 & 27,58 & 240,57 & 62,81 & 198,19 & 198,24 & 62,81 & 1256,14 & 190,94 & 11,95 & 56,14 & 514,50 & 76,92 & 76,93 & 514,50 \\
\hline Chioglossa lusitanica & 29TPE06 & 100,00 & 135,12 & 91,66 & 36,74 & 5328,00 & 278,88 & 32,86 & 246,03 & 70,31 & 205,51 & 205,99 & 70,31 & 1164,94 & 175,36 & 11,03 & 55,58 & 475,27 & 73,03 & 73,29 & 475,27 \\
\hline Chioglossa lusitanica & 29TPE07 & 101,00 & 141,90 & 96,20 & 37,94 & 5321,55 & 287,46 & 36,82 & 250,64 & 76,22 & 211,36 & 212,15 & 76,22 & 1091,34 & 162,71 & 10,26 & 55,15 & 443,22 & $\begin{array}{l}69,66 \\
\end{array}$ & 70,37 & 443,22 \\
\hline Chioglossa lusitanica & 29TPE13 & 101,00 & 138,06 & 90,21 & 35,47 & 5541,54 & 286,28 & 35,83 & 250,45 & 71,63 & 212,30 & 212,50 & \begin{tabular}{ll|}
71,63 \\
\end{tabular} & 1089,64 & 163,14 & 9,87 & 55,65 & 44,77 & 66,97 & 66,98 & 444,77 \\
\hline Chioglossa lusitanica & 29TPE14 & 101,00 & 143,73 & 93,64 & 36,32 & 5535,10 & 293,33 & 39,08 & 254,25 & 76,45 & 217,15 & 217,53 & 76,45 & 1033,99 & 153,73 & 9,37 & 55,26 & 20,45 & 64,75 & 64,79 & 420,45 \\
\hline Chioglossa lusitanica & 29TPE15 & 99,00 & 129,26 & 87,30 & 35,12 & 5467,14 & 273,53 & 28,66 & 244,87 & 63,75 & 202,52 & 202,53 & 63,75 & 1199,32 & 181,90 & 11,09 & 55,96 & 490,30 & 73,40 & 73,40 & 490,30 \\
\hline Chioglossa lusitanica & 29TPE16 & 100,00 & 89,37 & 73,79 & 32,38 & 5308,01 & 222,81 & $-1,45$ & 224,25 & 29,35 & 162,23 & 162,23 & 29,35 & 1627,76 & 249,32 & 17,25 & 56,10 & 663,37 & 100,90 & 100,90 & 663,37 \\
\hline Chioglossa lusitanica & 29TPE17 & 100,00 & 105,52 & 77,94 & 33,30 & 5333,84 & 240,87 & 11,12 & 229,75 & 43,46 & 177,77 & 177,83 & 43,46 & 1488,39 & 230,10 & 14,23 & 56,81 & 610,46 & 89,59 & 89,68 & 610,46 \\
\hline Chioglossa lusitanica & 29TPE23 & 100,00 & 136,93 & 89,41 & 34,98 & 5655,55 & 286,47 & 34,08 & 252,39 & 69,31 & 212,77 & 212,88 & 69, & 1072,25 & 160,25 & 9,60 & 55,52 & 33 & 65,86 & 65,86 & 436,33 \\
\hline Chioglossa lusitanica & 29TPE24 & 100,00 & 142,68 & 92,77 & 35,65 & 5654,12 & 293,58 & 37,45 & 256,12 & 74,19 & 217,73 & 218,05 & 74,19 & 1014,30 & 150,67 & 8,95 & 55,21 & 411,38 & 63,29 & 63,31 & 411,38 \\
\hline Chioglossa lusitanica & 29TPE25 & 101,00 & 13 & 90,80 & 35,35 & 5606,22 & 285,74 & 33,34 & 252,40 & 69,51 & 211,78 & 212,03 & 69,51 & 1075,73 & 161,29 & 9,71 & 55,46 & 437,30 & 66,83 & $\begin{array}{l}66,87 \\
\end{array}$ & 437,30 \\
\hline Chioglossa lusitanica & 29TPE26 & 101,00 & 103,49 & 76,74 & 32,49 & 5450,47 & 240,55 & 9,06 & 231,49 & 40,44 & 177,45 & $\begin{array}{l}177,47 \\
\end{array}$ & 40,44 & 1460,65 & 224,47 & 13,97 & 56,51 & 598,38 & 87,92 & 88,13 & 598,38 \\
\hline Chioglossa lusitanica & 29TPE27 & 100,00 & 106,99 & 77,23 & 32,68 & 5450,44 & 243,96 & 11,69 & 232,27 & 43,10 & 180,52 & 180,54 & 43,10 & 1421,80 & 219,17 & 13,32 & 56,76 & 83,80 & 85,34 & 86,46 & 583,80 \\
\hline Chioglossa Iusitanica & 29TPE36 & 101,00 & 139,74 & $\begin{array}{l}92,73 \\
\end{array}$ & 35,6 & 5699,14 & 290, & 33,56 & 256,6 & 70,2 & 215,06 & 2 & 70 & 1004,28 & 49,39 & $\begin{array}{ll}9,13 \\
\end{array}$ & 54,98 & 405 & 63,55 & \begin{tabular}{|c|c|c|}
64 \\
\end{tabular} & \begin{tabular}{|l|l|l}
405,67 \\
\end{tabular} \\
\hline Chioglossa lusitanica & 29TP & 100,00 & 126,44 & 86,62 & 34,39 & 5632,12 & 27 & 24,14 & 247,98 & 58,40 & 201,32 & & 58 & $\begin{array}{l}1136,45 \\
\end{array}$ & 171,51 & 10,64 & 55,48 & 461,98 & 70,81 & 73,01 & 461,98 \\
\hline Chioglossa lusitanica & 29TPE38 & 101,00 & 108,42 & 77,78 & 32,55 & 5536,88 & 247,27 & 11,75 & 235,51 & 42,64 & 182,53 & 182,68 & 42,64 & 1323,69 & 202,22 & 12,65 & 56,09 & 541,51 & 81,32 & 87,37 & 541,51 \\
\hline Chioglossa lusitanica & 29TPF01 & 100,00 & 128,78 & 95,58 & 38,14 & 5282,38 & 272,01 & 24,88 & 247,14 & 63,64 & $\begin{array}{l}197,92 \\
\end{array}$ & 198,34 & 63,64 & $\begin{array}{l}1241,40 \\
\end{array}$ & 187,92 & 12,69 & 55,62 & 505,95 & 80,76 & 81,46 & 505,95 \\
\hline Chioglossa Iusitanica & 29TPF02 & 100,00 & 120,33 & 92,91 & 37,62 & 5265,34 & 262,17 & 18,53 & 243,64 & 55,99 & 189,91 & 190,07 & 55,99 & 1328,52 & 201,64 & 14,36 & 55,81 & 542,65 & 87,32 & 87,58 & 542,65 \\
\hline Chioglossa Iusitanica & 29TPF03 & 101,00 & 113, & 90,97 & 37,23 & 258,84 & 254,54 & 13,4 & 41,10 & 50,04 & 18 & 18 & 50 & 1387,50 & 209,98 & 89 & 55,33 & 60 & \begin{tabular}{|c|c|c|}
99 \\
\end{tabular} & $\begin{array}{ll}92,91 \\
\end{array}$ & 566 \\
\hline Chioglossa lusitanica & 29TPF04 & 100,00 & 128,77 & & 39, & 5306,69 & 275,19 & 22,47 & 252,72 & 62,85 & 197,94 & 198 & 62,85 & 1242,10 & 187,23 & 13,26 & 55,32 & 505,25 & 81,75 & 84,25 & 505,25 \\
\hline \begin{tabular}{|c} 
Chioglossa lusitanica \\
\end{tabular} & \begin{tabular}{l|l} 
29TPF06 \\
\end{tabular} & 100,00 & 141,31 & 108,38 & 40,93 & 5312,79 & 291,76 & 30,46 & 261,30 & 79,60 & 209,92 & 210,29 & 74,38 & 1113,87 & 165,33 & 11,38 & 54,92 & 449,72 & 71,98 & 77,73 & 448,75 \\
\hline Chioglossa lusitanica & 29TPF07 & 101,00 & 129,25 & 104,96 & 40,17 & 5320,59 & 279,02 & 21,27 & 257,75 & 69,15 & 198,58 & 198,93 & 63,25 & 1223,92 & 181,16 & 14,12 & 54,73 & 496,20 & 82,95 & 87,13 & 494,7 \\
\hline Chioglossa lusitanica & 29TPF08 & 100,00 & 108,66 & 93,52 & 38,00 & 5223,34 & 250,90 & 8,30 & 242,61 & 45,75 & 178,02 & 178,18 & 45 & $\begin{array}{l}1370,44 \\
\end{array}$ & 97,65 & 19,63 & 52,80 & 55 & 101,85 & 103,26 & 551,12 \\
\hline Chioglossa lusitanica & 29TPF09 & 100,00 & 111,77 & 94,08 & 38,18 & 5213,47 & 253,83 & 10,63 & 243,20 & 48,68 & 180,74 & 180,98 & 48,68 & 1325,43 & 188,43 & 19,36 & 52,06 & 530,87 & 99,87 & 101,47 & 530,87 \\
\hline
\end{tabular}




\begin{tabular}{|c|c|c|c|c|c|c|c|c|c|c|c|c|c|c|c|c|c|c|c|c|c|}
\hline TAXON & UTM & $\mathrm{km} 2$ & $\mathrm{BIO1}$ & $\mathrm{B1O2}$ & $\mathrm{BIO3}$ & B104 & B105 & $\mathrm{B106}$ & $\mathrm{B107}$ & B108 & 8109 & 81010 & B1011 & $\mathrm{BIO12}$ & $\mathrm{B1O13}$ & 81014 & B1015 & 81016 & B1017 & B1018 & B1019 \\
\hline Chioglossa lusitanica & 29TPF16 & 101,00 & 133,02 & 106,93 & 40,08 & 5451,47 & 286,04 & 22,66 & 263,38 & 70,80 & 203,93 & 204,22 & 65,01 & 1150,71 & 172,83 & 12,42 & 55,22 & 467,60 & 76,12 & 78,60 & 466,91 \\
\hline Chioglossa lusitanica & 29TPF17 & 99,00 & 124,80 & 103,41 & 39,44 & 5430,11 & 275,66 & 16,91 & 258,75 & 60,08 & 195,94 & 196,20 & 57,73 & 1205,82 & 179,03 & 14,42 & 54,47 & 488,74 & 83,17 & 84,79 & 488,54 \\
\hline Chioglossa lusitanica & 29TPF18 & 101,00 & 116,77 & 98,81 & 38,68 & 5375,05 & 264,19 & 11,86 & 252,33 & 51,10 & 187,58 & 187,81 & 51,10 & 1252,20 & 182,52 & 16,84 & 53,27 & 505,01 & 90,84 & 91,97 & 505,01 \\
\hline Chioglossa lusitanica & 29TPF26 & 100,00 & 140,98 & 107,60 & 39,89 & 5514,54 & 294,66 & 28,42 & 266,25 & 73,20 & 212,58 & 212,65 & 71,78 & 1005,65 & 149,08 & 10,67 & 54,36 & 404,49 & 66,37 & 67,06 & 404,46 \\
\hline Chioglossa lusitanica & 29TPG00 & 101,00 & 128,55 & 101,51 & 39,68 & 5268,55 & 274,20 & 21,32 & 252,88 & 63,34 & 197,31 & 197,49 & 63,30 & 1164,34 & 161,88 & 15,93 & 51,68 & 461,28 & 85,32 & 88,02 & 461,28 \\
\hline Chioglossa lusitanica & 29TPG01 & 100,00 & 111,76 & 92,42 & 37,99 & 5168,72 & 251,69 & 11,49 & 240,20 & 49,41 & 180,21 & 180,35 & 49,41 & 1289,31 & 176,79 & 20,77 & 50,47 & 510,67 & 101,87 & 103,85 & 510,67 \\
\hline Chioglossa lusitanica & 29TPG02 & 100,00 & 106,85 & 88,80 & 37,21 & 5111,32 & 244,26 & 9,02 & 235,24 & 45,71 & 174,80 & 174,99 & 45,71 & 1310,86 & 176,48 & 22,83 & 49,52 & 516,13 & 107,83 & 110,31 & 516,13 \\
\hline Chioglossa lusitanica & 29TPG03 & 101,00 & 100,34 & 86,02 & 36,70 & 5053,09 & 235,86 & 4,79 & 231,07 & 40,97 & 167,75 & 168,01 & 40,55 & 1349,43 & 178,69 & 25,66 & 48,45 & 527,55 & 116,37 & 118,48 & 527,53 \\
\hline Chioglossa lusitanica & 29TPG10 & 100,00 & 126,91 & 102,29 & 39,40 & 5384,67 & 275,27 & 18,51 & 256,76 & 60,43 & 197,61 & 197,66 & 60,43 & 1124,66 & 158,03 & 15,63 & 51,73 & 446,89 & 82,92 & 83,49 & 446,89 \\
\hline Chioglossa lusitanica & 29TPG11 & 100,00 & 130,59 & 102,55 & 39,37 & 5379,72 & 278,26 & 21,08 & 257,18 & 63,94 & 201,00 & 201,04 & 63,94 & 1069,72 & 146,26 & 15,45 & 50,64 & 420,48 & 80,50 & 80,87 & 420,48 \\
\hline Chioglossa lusitanica & 29TPG12 & 100,00 & 115,84 & 95,37 & 38,04 & 5283,63 & 259,08 & 11,91 & 247,16 & 51,65 & 185,68 & 185,71 & 51,65 & 1176,26 & 158,86 & 19,73 & 49,55 & 462,11 & 95,00 & 95,45 & 462,11 \\
\hline Chioglossa lusitanica & 29TPG23 & 100,00 & 128,44 & 100,89 & 38,75 & 5426,73 & 275,36 & 18,16 & 257,20 & 64,68 & 199,68 & 199,68 & 61,42 & 993,49 & 130,73 & 16,78 & 48,38 & 385,02 & 80,62 & 80,62 & 384,57 \\
\hline Chioglossa lusitanica & 29TPG33 & 100,00 & 121,95 & 100,70 & 38,33 & 5475,42 & 271,29 & 12,10 & 259,19 & 57,53 & 194,34 & 194,34 & 54,80 & 986,87 & 131,60 & 17,61 & 48,16 & 384,05 & 82,26 & 82,26 & 383,95 \\
\hline Chioglossa lusitanica & 29TPG34 & 101,00 & 119,10 & 99,36 & $\begin{array}{l}38,15 \\
\end{array}$ & 5438,35 & 267,03 & 10,11 & 256,92 & 58,52 & 191,03 & 191,03 & 52,56 & 996,47 & 130,92 & 19,09 & 47,19 & 385,91 & 86,18 & 86,18 & 385,02 \\
\hline Chioglossa lusitanica & 29TPG79 & 101,00 & 115,29 & 102,23 & 38,71 & 5504,49 & 264,82 & 3,55 & 261,28 & 52,63 & 187,88 & 187,88 & 47,61 & 798,91 & 105,84 & 21,01 & 40,71 & 302,25 & 87,53 & 87,53 & 288,56 \\
\hline Chioglossa lusitanica & 29TPG88 & 101,00 & 75,96 & 99,19 & 37,83 & 5498,03 & 229,16 & $-29,65$ & 258,81 & 16,66 & 149,91 & 149,95 & 10,69 & 1056,83 & 135,57 & 32,94 & 38,18 & 389,90 & 128,19 & 128,45 & 374,70 \\
\hline Chioglossa lusitanica & 29TPHO3 & 101,00 & 122,39 & 88,14 & 39,68 & 4526,51 & 245,68 & 25,57 & 220,12 & 71,62 & 181,60 & 182,66 & 68,41 & 1110,45 & 154,52 & 30,34 & 41,20 & 414,15 & 119,09 & 132,83 & 396,58 \\
\hline Chioglossa lusitanica & 29TPH32 & 101,00 & 111,82 & 93,24 & 38,93 & 4954,82 & 246,85 & 9,55 & 237,30 & 56,42 & 177,15 & 177,45 & 52,28 & 1029,96 & 138,71 & 28,51 & 40,24 & 384,92 & 113,70 & 120,04 & 368,31 \\
\hline Chioglossa lusitanica & 29TPH49 & 100,00 & 124,12 & 86,46 & 40,94 & 4260,85 & 240,72 & 31,49 & 209,23 & 77,22 & 179,05 & 180,94 & 72,71 & 962,06 & 123,51 & 32,72 & 34,54 & 345,94 & 124,92 & 139,97 & 313,62 \\
\hline Chioglossa lusitanica & 29TPH51 & 100,00 & 92,45 & 95,33 & 38,24 & 5173,82 & 235,67 & $-10,10$ & 245,76 & 35,76 & 161,46 & 161,51 & 30,84 & 1078,35 & 141,86 & 31,88 & 39,27 & 402,52 & 125,19 & 125,91 & 386,28 \\
\hline Chioglossa lusitanica & 29TPH54 & 100,00 & 115,34 & 94,76 & 39,46 & 4935,88 & 249,56 & 12,04 & 237,52 & 59,65 & 179,89 & 180,24 & 55,34 & 926,28 & 120,82 & 27,95 & 37,42 & 19 & 110,92 & 118,09 & 318,13 \\
\hline \begin{tabular}{|l} 
Chioglossa lusitanica \\
\end{tabular} & 29TPH55 & 101,00 & 115,59 & 93,60 & 39,80 & 4824,02 & 247,23 & 14,03 & 233,20 & 61,30 & 178,62 & 179,20 & 57,08 & 937,10 & 121,15 & 29,23 & 36,63 & 342,96 & 114,97 & 125,70 & 317,72 \\
\hline Chioglossa lusitanica & 29TPH56 & 100,00 & 112,59 & 92,57 & \begin{tabular}{l|l|}
39,92 & \\
\end{tabular} & 4721,95 & 242,36 & 12,91 & 229,45 & 59,88 & 174,30 & 175,10 & 55,56 & 969,45 & 124,37 & 31,62 & 35,72 & 352,59 & 122,46 & 134,51 & 325,18 \\
\hline Chioglossa lusitanica & 29TPH57 & 101,00 & 108,53 & 91,48 & 39,99 & 4634,93 & 236,83 & 10,77 & 226,06 & 57,27 & 169,01 & 170,10 & 52,83 & 1012,28 & 129,34 & 34,45 & 34,89 & 366,04 & 131,43 & 143,40 & 336,67 \\
\hline Chioglossa lusitanica & 29TPH58 & 99,00 & 111,89 & 90,21 & 40,17 & 4511,60 & 236,79 & 15,61 & 221,18 & 62,19 & 170,64 & 171,93 & 57,57 & 1001,05 & 128,05 & 34,69 & 34,26 & 360,09 & 131,93 & 144,69 & 328,66 \\
\hline Chioglossa lusitanica & 29TPH63 & 100,00 & 96,65 & 96,45 & 38,91 & 5119,07 & 238,28 & $-6,57$ & 244,86 & 39,94 & 164,49 & 164,55 & 35,18 & 1010,04 & 131,23 & 31,90 & 37,11 & 372,28 & 124,46 & 125,75 & 350,78 \\
\hline Chioglossa lusitanica & 29TPH64 & 100,00 & 101,18 & 95,94 & 39,16 & 5028,11 & 240,07 & $-1,63$ & 241,70 & 45,30 & 167,53 & 167,73 & $\begin{array}{ll}40,68 \\
406\end{array}$ & 986,45 & $\mid 127,35$ & 31,77 & 36,41 & 361,41 & $\begin{array}{l}123,68 \\
123,4\end{array}$ & 127,55 & 337,53 \\
\hline Chioglossa lusitanica & 29TPH68 & 100,00 & 112,91 & 91,50 & $\begin{array}{l}40,35 \\
\end{array}$ & 4561,33 & 239,10 & 15,52 & 223,58 & 62,99 & 172,22 & 173,42 & 57,89 & 963,04 & 124,25 & 34,13 & 33,53 & 344,15 & 129,85 & 142,22 & 311,33 \\
\hline Chioglossa lusitanica & 29TPH74 & 100,00 & 79,80 & 95,67 & 38,76 & 5085,43 & 222,37 & $-21,16$ & 243,53 & 24,80 & 147,66 & 147,86 & 19,67 & 1114,89 & 141,35 & 39,34 & 34,79 & 402,99 & 148,23 & 150,17 & 377,98 \\
\hline Chioglossa lusitanica & 29TPH76 & 100,00 & 110,21 & 95,48 & 40,02 & 4853,39 & 243,99 & 8,24 & 235,75 & 55,87 & 173,58 & 174,10 & 51,26 & 916,31 & 118,62 & 31,57 & 34,05 & 329,48 & 121,99 & 131,67 & 299,50 \\
\hline Chioglossa lusitanica & 29TPH78 & 100,00 & 114,42 & 92,48 & 40,65 & 4583,52 & 241,15 & 16,33 & 224,81 & 67,71 & 173,87 & 175,05 & 58,89 & 927,82 & 120,75 & 33,81 & 32,65 & 328,82 & 128,45 & 140,50 & 294,39 \\
\hline Chioglossa lusitanica & 29TPH80 & 101,00 & 115,40 & $\begin{aligned} 5,43,38 \\
103,38\end{aligned}$ & 38,97 & 5547,08 & 265,72 & $\frac{2,60}{200}$ & \begin{tabular}{|l|l|}
263,12 \\
\end{tabular} & $\begin{array}{l}51,78 \\
51,1\end{array}$ & 188,51 & 188,51 & $\begin{array}{l}0,000 \\
46,90 \\
\end{array}$ & \begin{tabular}{|l|l|}
754,35 \\
\end{tabular} & \begin{tabular}{|l|l|}
99,32 \\
\end{tabular} & \begin{tabular}{|l|l|}
20,75 \\
\end{tabular} & 39,45 & 283,55 & 87,01 & $\begin{array}{r}4,01 \\
87,01 \\
\end{array}$ & 266,77 \\
\hline Chioglossa lusitanica & 29TPH96 & 100,00 & 95,13 & 98,32 & 40,01 & 4996,45 & 234,96 & $-7,69$ & 242,65 & 43,34 & 160,89 & 161,15 & 34,80 & 956,82 & 123,38 & 36,55 & 32,03 & 337,68 & 137,32 & 142,85 & 305,49 \\
\hline Chioglossa lusitanica & 29TPH98 & 100,00 & 111,66 & 95,51 & 41,04 & 4661,68 & 241,84 & 11,66 & 230,17 & 80,23 & 172,05 & 173,17 & 54,95 & 896,42 & 118,15 & 35,10 & 30,95 & 313,24 & 131,72 & 142,51 & 274,12 \\
\hline Chioglossa lusitanica & 29TPJ01 & 101,00 & 112,48 & 79,91 & 40,93 & 3893,99 & 221,85 & 28,54 & 193,32 & 71,38 & 162,61 & 165,58 & 66,65 & 1180,63 & 152,27 & 40,25 & 35,61 & 430,41 & 150,73 & 167,32 & 398,02 \\
\hline Chioglossa lusitanica & 29TPJ02 & 101,00 & 123,80 & 77,64 & 41,36 & 3730,50 & 226,94 & 41,71 & 185,24 & 84,33 & 171,23 & 174,39 & 79,08 & 1089,72 & 138,96 & 36,99 & 35,12 & 396,56 & 139,64 & 158,09 & 362,56 \\
\hline Chioglossa lusitanica & \begin{tabular}{|l|} 
29TPJ03 \\
\end{tabular} & 101,00 & 127,49 & 76,06 & 41,66 & 3640,31 & 227,42 & 47,19 & 180,23 & 89,29 & 173,45 & 176,91 & 83,71 & 1057,71 & 135,04 & 36,25 & 34,85 & 384,15 & 137,13 & 156,45 & 348,63 \\
\hline Chioglossa lusitanica & 29TPJ11 & 99,00 & 107,59 & 81,49 & \begin{tabular}{|c|}
40,67 \\
\end{tabular} & 4002,55 & 220,11 & 21,82 & 198,28 & 65,15 & 159,35 & 162,08 & 60,56 & 1187,50 & 151,90 & 41,50 & 34,98 & 430,71 & 154,62 & 170,05 & 397,96 \\
\hline Chioglossa lusitanica & 29TPJ12 & 100,00 & 123,46 & 78,92 & 41,39 & 3807,52 & 228,45 & 39,93 & 188,52 & 82,91 & 171,92 & 174,97 & 77,90 & 1067,06 & 135,81 & 36,83 & 34,70 & 386,28 & 138,65 & 156,57 & 351,79 \\
\hline Chioglossa lusitanica & 29TPJ13 & 90,00 & 132,24 & 76,74 & 41,84 & 3674,46 & 232,24 & 50,79 & 181,45 & 93,37 & 178,62 & 181,91 & 87,82 & 1000,76 & 128,78 & 34,41 & 34,42 & 361,84 & 130,66 & 149,97 & 325,86 \\
\hline Chioglossa lusitanica & 29TPJ20 & 101,00 & 115,98 & 83,44 & 40,8 & 4089,90 & 229,6 & 27,49 & 202,15 & 71,75 & 168,76 & 171,14 & 67,24 & 1089,15 & 138,99 & 37,26 & 35,04 & 394,35 & 140,28 & 155,81 & 362,46 \\
\hline Chioglossa lusitanica & 29TPJ42 & 53,00 & 137,48 & 80,69 & 41, & 3889,44 & 242,19 & 50,71 & \begin{tabular}{|l|l|l|l|l|}
191,48 \\
\end{tabular} & 96,05 & 186,59 & 189,31 & 89,93 & $\begin{array}{l}902,47 \\
\end{array}$ & 118,12 & 31,6 & 33,45 & 321,57 & $\begin{array}{l}120,77 \\
\end{array}$ & 138,51 & 284,69 \\
\hline Chioglossa lusitanica & \begin{tabular}{l|l} 
29TPJ71 \\
\end{tabular} & 100,00 & 120,92 & 87,16 & 41,43 & 4187,18 & 236,81 & 29,09 & 207,72 & 87,25 & 174,57 & $\begin{array}{l}176,78 \\
\end{array}$ & 70,42 & 941,81 & 123,60 & 36,55 & 31,16 & 328,99 & 136,06 & 150,07 & 288,43 \\
\hline Chioglossa lusitanica & 29TPJ81 & 101,00 & 126,36 & 87,08 & 41,82 & 4144,52 & 240,59 & 34,49 & 206,10 & 102,20 & 179,16 & 181,45 & 75,99 & 896,35 & 118,96 & 35,47 & 30,70 & 311,92 & 132,18 & 146,10 & 267,74 \\
\hline Chioglossa lusitanica & 29TPJ82 & 58,00 & 138,31 & 83,19 & 42,02 & 3938,42 & 244,93 & 49,47 & 195,46 & 117,08 & 188,16 & 190,77 & 90,12 & 844,71 & 13,54 & 33,05 & 30,98 & 95,40 & 123,81 & 139,59 & 248,57 \\
\hline Chioglossa lusitanica & $\begin{array}{l}\text { 29TPJ90 } \\
\text { 29T3 }\end{array}$ & 100,00 & 114,77 & $\begin{array}{l}91,12 \\
91,70\end{array}$ & $\begin{array}{ll}42,0<6 \\
41,64\end{array}$ & 4366,20 & 237,3 & $\begin{array}{l}19,38 \\
19,38 \\
\end{array}$ & 218,00 & 87,72 & $\begin{array}{l}170,1,05 \\
171,05\end{array}$ & 172,75 & $\begin{array}{ll}0,012 \\
62,01\end{array}$ & \begin{tabular}{|l|l|}
927,64 \\
\end{tabular} & $\mid \begin{array}{l}\mid 122,50 \\
120\end{array}$ & 38,00 & 30,01 & 15 & $\begin{array}{ll}140,21 \\
\end{array}$ & $\begin{array}{ll}151,97 \\
\end{array}$ & 276,80 \\
\hline Chioglossa lusitanica & 29TPJ91 & 99,00 & 119,93 & 88,97 & $41, \varepsilon$ & 419 & 237,16 & 27,14 & 210,02 & 96,71 & 173,61 & 175,77 & 69,22 & 921,04 & 122,25 & 38,30 & 29,70 & 317,98 & 140,67 & 153,30 & 270,80 \\
\hline Chioglossa lusitanica & $\begin{array}{l}\text { 29TPJ92 } \\
\end{array}$ & 60,00 & 135,50 & 84,06 & 42,06 & 3954,26 & 243,15 & 46,30 & 196,86 & $\mid \begin{array}{r}114,32 \\
\end{array}$ & 185,50 & 188,13 & 87,30 & 853,51 & 114,98 & 34,70 & 30,12 & 296,43 & 128,88 & 143,72 & 246,58 \\
\hline Chioglossa lusitanica & 29TQJ00 & 100,00 & 113,08 & 92,84 & 41,78 & 4381,67 & 236,87 & 17,31 & 219,56 & 88,49 & 169,52 & 171,28 & 60,21 & 922,77 & 122,26 & 39,35 & 29,15 & 317,84 & 143,82 & 154,93 & 269,66 \\
\hline Chioglossa lusitanica & 29TQJ02 & 55,00 & 134,41 & 84,61 & 42,4 & 3939,63 & 242,38 & 45,21 & 197,17 & 113,77 & 184,19 & 186,89 & 86,64 & 853,56 & 115,54 & t & 29,65 & 62 & 132,68 & 146,74 & 240,90 \\
\hline Chioglossa lusitanica & 29TQJ11 & $\begin{array}{l}5,00 \\
99,00\end{array}$ & $\begin{array}{l}134,41 \\
116,27\end{array}$ & $\begin{array}{l}4,014 \\
91,42\end{array}$ & $\frac{42}{42}$ & & 235 & $\frac{43}{22}$ & 212,93 & 93, & $\begin{array}{l}10,193 \\
169,88\end{array}$ & $\begin{array}{l}100,09 \\
172,19 \\
\end{array}$ & $\frac{60,044}{65,80}$ & \begin{tabular}{|l|l|}
923,49 \\
923,4
\end{tabular} & $\mid$\begin{tabular}{|l|}
$\mid 123,345$ \\
123,3
\end{tabular} & $\frac{30,}{41,}$ & 28,29 & $\begin{array}{ll}34,0<2 \\
15,14\end{array}$ & $\begin{array}{l}149,59 \\
149\end{array}$ & $\begin{array}{l}160,4,54 \\
\end{array}$ & 260,00 \\
\hline Chioglossa lusitanica & 29TQJ 20 & 100,00 & 124,77 & 91,78 & 42,81 & 4161,25 & 242,74 & 30,59 & 212,15 & 102,85 & 177,63 & 180,01 & 74,43 & 857,62 & 116,19 & 39,08 & 28,52 & 292,47 & 140,78 & 151,30 & 233,71 \\
\hline Chioglossa lusitanica & 29TQJ21 & 99,00 & 125,99 & 89,26 & 42,98 & 4019,27 & 239,73 & 34,48 & 205,25 & 105,42 & 176,76 & 179,55 & 77,59 & 879,09 & 119,14 & 40,58 & 28,35 & 298,48 & 145,41 & 156,50 & 237,74 \\
\hline Chioglossa lusitanica & 29TQJ32 & 74,00 & 134,23 & 83,35 & 43,00 & 3796,84 & 238,70 & 46,89 & 191,82 & 116,10 & 181,84 & 185,14 & 88,38 & 858,30 & 117,33 & 40,27 & 28,58 & 290,85 & 144,00 & 156,31 & 226,00 \\
\hline Chioglossa lusitanica & 30TTN69 & 100,00 & 119,03 & 95,86 & 43,2 & 4250,99 & 241 & 22,63 & 219,26 & 97,51 & 173,16 & 175,43 & 67,69 & 853,09 & 115,27 & 42,55 & 27,79 & 287,22 & 149,88 & 157,86 & $22 C$ \\
\hline Chioglossa lusitanica & $\begin{array}{l}\text { 30TTN77 } \\
\end{array}$ & $\begin{array}{l}100,00 \\
\end{array}$ & 98,10 & $\begin{array}{r}3,02,69 \\
102,69\end{array}$ & 年51,47 & 年42024,04 & 238,58 & \begin{tabular}{|c|c|}
22,50 \\
$-6,54$
\end{tabular} & \begin{tabular}{|l|}
245,21 \\
245
\end{tabular} & 71,23 & 162,47 & 163,09 & 38,12 & 840,56 & 109,74 & 41,76 & 27,21 & 288,74 & 148,36 & 153,87 & 229,47 \\
\hline Chioglossa lusitanica & 30TTN98 & 100,00 & 104,51 & 97,99 & 41,50 & 4682,67 & 236,71 & 3,26 & 233,45 & 80,60 & 165,31 & 166,57 & 47,39 & 836,88 & 109,55 & 43,05 & 26,60 & 284,92 & 152,31 & 159,29 & 219,97 \\
\hline Chioglossa lusitanica & 30TTP60 & 100,00 & 129,66 & 89,93 & 43,73 & 3918,14 & 241,79 & 38,42 & 203,37 & 111,05 & 178,84 & 181,95 & 82,53 & 850,03 & 116,32 & 42,40 & 28,38 & 284,03 & 149,06 & 158,09 & 214,18 \\
\hline Chioglossa lusitanica & 30TTP62 & 99,00 & 135,89 & 79,64 & 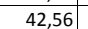 & 713,09 & 235,61 & 50,8 & 84,78 & 118,95 & 182 & 185 & 91, & 853,17 & 117,04 & 41 & 28 & 288,29 & 146,45 & 158,71 & 219 \\
\hline Chioglossa lusitanica & 30TTP80 & 100,00 & 126,93 & 86,91 & 42,80 & 3981,43 & 237,32 & 36,17 & 201,14 & 108,64 & 177,37 & 180,30 & 78,91 & 843,78 & 114,67 & 42,99 & 27,94 & 283,30 & 151,37 & 160,74 & 211,27 \\
\hline
\end{tabular}




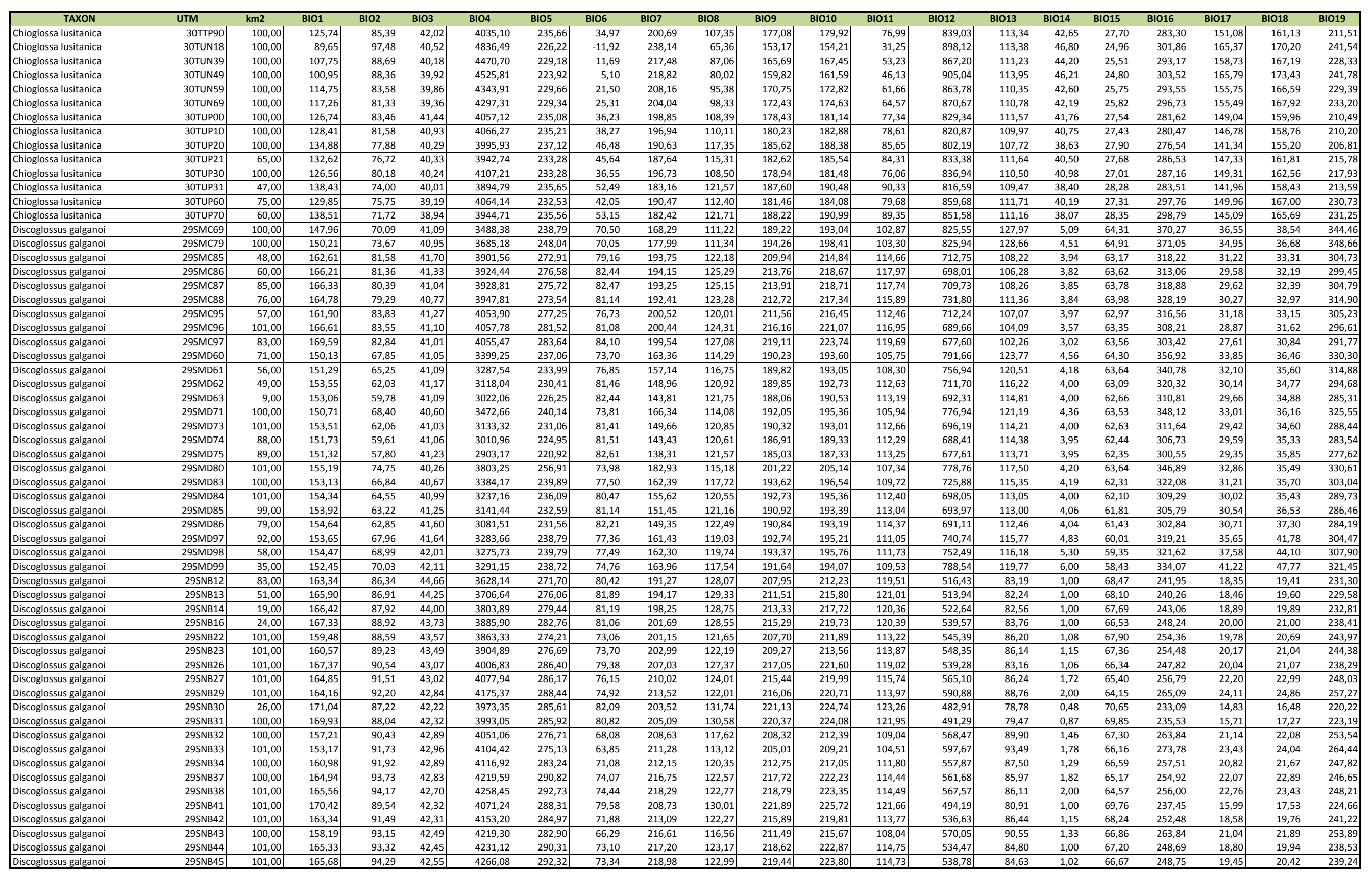




\begin{tabular}{|c|c|c|c|c|c|c|c|c|c|c|c|c|c|c|c|c|c|c|c|c|c|}
\hline TAXON & UTM & $\mathrm{km} 2$ & BIO1 & $\mathrm{BIO2}$ & $\mathrm{BIO3}$ & B104 & B105 & B106 & BI07 & B108 & B109 & 81010 & B1011 & B1012 & B1013 & BI014 & B1015 & BIO16 & B1017 & B1018 & B1019 \\
\hline Discoglossus galganoi & 29SNB47 & 100,00 & 163,18 & 96,28 & 42,48 & 4369,40 & 293,99 & 70,04 & 223,95 & 119,40 & 218,06 & 222,73 & 111,14 & 569,30 & 87,22 & 2,00 & 64,67 & 257,01 & 22,82 & 23,42 & 249,30 \\
\hline Discoglossus galganoi & 29SNB48 & 101,00 & 167,66 & 96,33 & 42,62 & 4369,44 & 298,26 & 74,38 & 223,87 & 123,46 & 222,40 & 226,92 & 115,25 & 551,81 & 83,96 & 2,00 & 64,54 & 248,81 & 21,95 & 22,84 & 241,24 \\
\hline Discoglossus galganoi & 29SNB49 & 101,00 & 168,13 & 96,77 & 42,39 & 4402,72 & 299,73 & 74,62 & 225,11 & 123,45 & 223,21 & 227,86 & 115,34 & 557,31 & 84,01 & 2,00 & 64,01 & 249,32 & 22,72 & 23,49 & 242,42 \\
\hline Discoglossus galganoi & 29SNB52 & 101,00 & 164,37 & 92,97 & 42,21 & 4241,13 & 288,17 & 71,28 & 216,89 & 122,52 & 218,10 & 222,13 & 1113,81 & 533,03 & 86,93 & 1,00 & 68,19 & 251,74 & 17,99 & 19,46 & 240,04 \\
\hline Discoglossus galganoi & 29SNB68 & 101,00 & 164,04 & 101,89 & 42,18 & 4647,18 & 304,28 & 66,41 & 237,87 & 117,29 & 222,77 & 227,32 & 108,81 & 564,32 & 85,29 & 2,00 & 63,15 & 250,55 & 23,05 & 23,58 & 244,48 \\
\hline Discoglossus galganoi & 29SNB72 & 101,00 & 158,56 & 95,96 & 42,03 & 4413,77 & 287,27 & 62,45 & 224,82 & 114,93 & 214,69 & 218,96 & 106,39 & $\begin{array}{l}571,05 \\
\end{array}$ & 92,86 & 1,49 & 66,85 & 265,98 & 20,14 & 21,88 & 254,31 \\
\hline Discoglossus galganoi & 295NB74 & 100,00 & 155,46 & 98,99 & 42,00 & 4582,57 & 290,88 & 57,98 & 232,90 & 109,87 & 213,81 & 218,20 & 101,36 & 595,08 & 93,54 & 2,00 & 64,75 & 269,91 & 23,20 & 24,36 & 260,62 \\
\hline Discoglossus galganoi & 29SNB75 & 101,00 & 159,78 & 100,28 & 42,00 & 4621,93 & 297,04 & 61,54 & 235,50 & 113,35 & 218,43 & 222,83 & 105,05 & $\begin{array}{l}572,95 \\
\end{array}$ & 89,41 & 2,00 & 64,65 & 259,20 & 22,04 & 23,10 & 250,47 \\
\hline Discoglossus galganoi & 29SNB79 & 100,00 & 166,09 & 105,06 & 42,25 & 4779,42 & 311,19 & 66,12 & 245,07 & 1117,61 & 226,48 & 231,18 & 109,12 & 553,21 & 83,07 & 2,00 & 62,53 & 242,47 & 22,90 & 23,34 & 237,38 \\
\hline Discoglossus galganoi & 29SNB80 & 97,00 & 169,36 & 92,45 & 42,75 & 4192,89 & 288,39 & 74,36 & 214,03 & 128,18 & 222,39 & 226,50 & 119,50 & 515,13 & 88,79 & 1,00 & 69,74 & 249,99 & 15,82 & 18,36 & 234,58 \\
\hline Discoglossus galganoi & 29SNB82 & 101,00 & 157,12 & \begin{tabular}{l|l}
96,63 \\
\end{tabular} & 41,94 & 4496,11 & 287,34 & 59,58 & 227,76 & 112,64 & 214,29 & 218,59 & 103,89 & 581,80 & $\begin{array}{l}93,91 \\
\end{array}$ & 1,63 & 66,26 & 269,03 & 20,85 & 22,90 & 257,09 \\
\hline Discoglossus galganoi & 29SNB83 & 99,00 & 153,72 & 98,40 & 41,99 & 4596,25 & 288,04 & 55,56 & 232,47 & 108,30 & 212,29 & 216,57 & 99,42 & $\begin{array}{l}603,65 \\
\end{array}$ & 95,34 & 2,03 & 64,86 & 274,47 & 22,96 & 24,69 & 264,03 \\
\hline Discoglossus galganoi & 29SNB84 & 101,00 & 156,82 & 99,72 & 41,99 & 4649,05 & 293,62 & 58,02 & 235,60 & 110,58 & 215,99 & 220,47 & \begin{tabular}{|c|}
101,90 \\
\end{tabular} & 587,33 & 91,97 & 2,00 & 64,52 & 265,77 & 22,60 & 24,20 & 255,97 \\
\hline Discoglossus galganoi & 29SNB85 & 101,00 & 160,15 & 101,33 & 42,00 & 4701,10 & 299,33 & $\begin{array}{ll}60,68 \\
\end{array}$ & 238,64 & \begin{tabular}{ll|}
113,07 \\
\end{tabular} & $\begin{array}{ll}219,98 \\
\end{array}$ & 224,36 & 104,50 & $\begin{array}{l}569,56 \\
\end{array}$ & 88,36 & 2,00 & 64,34 & 256,54 & 21,87 & 23,07 & 247,50 \\
\hline Discoglossus galganoi & 295NB87 & 101,00 & 164,19 & 104,66 & 42,02 & $\mid 4802,14$ & 308,43 & 63,30 & 245,14 & 115,60 & 225,09 & 229,45 & $\mid 107,14$ & 552,20 & 83,83 & 2,00 & 63,11 & 244,63 & 22,16 & 23,00 & 237,50 \\
\hline Discoglossus galganoi & 295NB89 & 100,00 & 165,90 & 107,83 & 42,29 & 4898,78 & 315,21 & 63,79 & 251,42 & 115,99 & 227,84 & 232,60 & 107,52 & 549,89 & 82,33 & 2,00 & 61,86 & 238,70 & 23,05 & 23,82 & 233,98 \\
\hline Discoglossus galganoi & 29SNB91 & 101,00 & 158,51 & 95,20 & 41,90 & 4472,75 & 285,95 & 60,85 & 225,10 & 114,12 & 215,32 & 219,49 & \begin{tabular}{|c|}
105,46 \\
\end{tabular} & 573,59 & 93,32 & 1,59 & 66,76 & 267,24 & 19,59 & 22,46 & 253,81 \\
\hline Discoglossus galganoi & 29SNB92 & 100,00 & 150,90 & 97,38 & 41,39 & 4624,20 & 284,06 & 52,19 & 231,87 & 105,03 & 209,76 & 213,97 & 96,25 & 620,53 & 97,73 & 1,99 & 64,87 & 281,73 & 23,16 & 25,60 & 270,38 \\
\hline Discoglossus galganoi & 29SNB94 & 100,00 & 159,33 & \begin{tabular}{l|l}
99,98 \\
\end{tabular} & 41,80 & 4709,88 & 296,68 & 59,39 & 237,29 & 112,16 & \begin{tabular}{|l|l|}
219,24 \\
\end{tabular} & 223,63 & 103,63 & 571,80 & 89,02 & 2,00 & 64,30 & 258,27 & 21,49 & 23,73 & 247,61 \\
\hline Discoglossus galganoi & 29SNB97 & 100,00 & 164,92 & 105,55 & 42,00 & 4874,85 & 310,72 & 62,35 & 248,37 & 115,44 & 226,73 & 231,23 & 106,64 & 545,94 & 82,66 & 2,00 & 62,55 & 240,46 & 21,97 & 23,29 & 232,84 \\
\hline Discoglossus galganoi & 295NB98 & 100,00 & 166,44 & 107,51 & 42,05 & 4933,26 & 315,14 & 63,07 & 252,06 & 116,25 & 228,91 & 233,37 & 107,37 & 539,69 & $81,21$. & 2,00 & 61,85 & 235,36 & 22,26 & 23,41 & 228,93 \\
\hline Discoglossus galganoi & 29SNB99 & 101,00 & 165,62 & 110,00 & 42,07 & 5015,02 & 318,32 & 61,18 & 257,14 & 114,36 & 229,15 & 233,73 & 105,83 & 547,67 & 81,68 & 2,00 & 61,23 & 235,78 & 23,44 & 23,94 & 231,03 \\
\hline Discoglossus galganoi & 29SNC06 & 92,00 & 166,43 & 85,60 & 41,05 & 4169,39 & 285,32 & 79,35 & 205,97 & 122,99 & 217,60 & 222,47 & 115,64 & 681,47 & 101,62 & 3,41 & 63,05 & 302,61 & 28,84 & 31,25 & 293,11 \\
\hline Discoglossus galganoi & 29SNC07 & 101,00 & 169,51 & 84,83 & 40,99 & 4161,27 & 287,38 & 82,44 & 204,94 & 125,92 & 220,59 & 225,31 & $\begin{array}{l}118,66 \\
\end{array}$ & 667,01 & 99,49 & 3,01 & 63,32 & 296,84 & 27,18 & 30,14 & 287,32 \\
\hline Discoglossus galganoi & 29SNC08 & 88,00 & 170,53 & 83,66 & 40,89 & 4135,33 & 286,57 & 83,89 & 202,68 & 127,01 & 221,21 & 225,76 & 119,78 & 664,00 & 99,33 & 3,00 & 63,24 & 295,24 & 26,97 & 30,01 & 285,61 \\
\hline Discoglossus galganoi & 29SNC09 & 44,00 & 169,96 & 82,41 & 40,92 & 4094,55 & 283,96 & 83,82 & 200,14 & 126,75 & 220,06 & 224,33 & 119,35 & \begin{tabular}{|c|}
666,27 \\
\end{tabular} & 99,81 & 3,00 & 63,11 & 295,30 & 27,00 & 30,45 & 285,77 \\
\hline Discoglossus galganoi & 29SNC17 & 101,00 & 170,53 & 86,68 & 41,03 & 4232,24 & 291,12 & 82,37 & 208,75 & 126,37 & 222,68 & 227,27 & 118,88 & 648,25 & 95,83 & 3,00 & 62,78 & 286,50 & 27,00 & 29,86 & 278,50 \\
\hline Discoglossus galganoi & 29SNC18 & 101,00 & 170,36 & 85,57 & 40,95 & 4216,61 & 289,75 & 82,38 & 207,36 & 126,20 & 222,34 & 226,68 & 118,63 & 654,34 & 96,99 & 3,00 & 62,89 & 288,89 & 27,13 & 30,05 & 280,95 \\
\hline Discoglossus galganoi & 29SNC21 & 101,00 & 164,38 & 92,12 & 42,16 & 4247,06 & 290,22 & 74,66 & 215,56 & 121,27 & 217,10 & 221,97 & 113,42 & 612,68 & 91,38 & 2,49 & 63,49 & 272,22 & 25,95 & 26,81 & 265,08 \\
\hline Discoglossus galganoi & 29SNC22 & 99,00 & 166,10 & 91,82 & 42,02 & 4275,52 & 292,11 & 76,33 & 215,78 & 122,47 & 219,16 & 224,04 & 114,58 & 614,17 & 91,45 & 2,67 & 63,12 & 272,23 & 26,19 & 27,32 & 265,21 \\
\hline Discoglossus galganoi & 29SNC23 & 101,00 & 168,86 & 91,32 & 42,00 & 4281,82 & 294,32 & 78,88 & 215,44 & 124,77 & 221,79 & 226,66 & 116,93 & 608,71 & 90,47 & 2,99 & 63,12 & 269,53 & 25,78 & 27,64 & 262,48 \\
\hline \begin{tabular}{|l} 
Discoglossus galganoi \\
\end{tabular} & $295 N C 30$ & 100,00 & 164,80 & 94,76 & 42,16 & 4339,40 & 294,27 & 73,09 & 221,18 & 120,82 & 218,96 & 223,73 & 112,79 & 591,55 & 88,55 & 2,06 & 63,69 & 263,40 & 24,27 & 24,90 & 256,82 \\
\hline Discoglossus galganoi & 29SNC31 & 101,00 & 161,27 & 94,95 & 42,00 & 4402,58 & 292,56 & \begin{tabular}{ll|}
69,61 \\
\end{tabular} & 222,95 & 116,77 & 216,36 & 221,20 & 108,72 & $\begin{array}{l}624,36 \\
\end{array}$ & 92,71 & 2,89 & 62,71 & 274,96 & 27,25 & 27,68 & 269,36 \\
\hline Discoglossus galganoi & 29SNC32 & 101,00 & 164,58 & 94,37 & 41,92 & 4412,68 & 295,47 & 72,80 & 222,67 & 119,62 & 219,70 & 224,62 & 111,69 & 614,58 & 90,98 & 2,73 & 62,64 & 270,49 & 26,43 & 27,17 & 264,92 \\
\hline Discoglossus galganoi & 29SNC33 & 100,00 & 167,77 & 93,79 & 41,93 & 4408,51 & 297,79 & 76,01 & 221,78 & 122,43 & 222,68 & 227,53 & 114,64 & $\begin{array}{l}605,45 \\
\end{array}$ & 89,46 & 2,95 & 62,79 & 266,27 & 25,92 & 26,94 & 260,68 \\
\hline Discoglossus galganoi & 29SNC39 & 100,00 & 168,15 & 88,67 & 40,81 & 4385,91 & 293,38 & 77,73 & 215,65 & 122,21 & 222,70 & 227,00 & 114,55 & 657,82 & 96,56 & 3,71 & 61,08 & 283,95 & 29,97 & 32,20 & 279,29 \\
\hline Discoglossus galganoi & 29SNC41 & 101,00 & 166,46 & 97,10 & 42,00 & 4485,43 & 300,43 & 72,71 & 227,71 & 120,71 & 222,62 & 227,24 & 112,62 & 584,59 & 86,96 & 2,10 & 63,03 & 257,83 & 24,48 & 25,09 & 252,44 \\
\hline Discoglossus galganoi & 29SNC44 & 101,00 & 169,99 & 95,22 & 41,79 & 4509,82 & 302,72 & 76,65 & 226,07 & 123,49 & 226,24 & 231,00 & \begin{tabular}{|c|}
115,48 \\
\end{tabular} & 591,50 & 86,65 & 2,87 & 61,89 & 257,60 & 25,84 & 27,04 & 253,18 \\
\hline Discoglossus galganoi & 29SNC45 & 101,00 & 169,94 & 94,46 & 41,41 & 4514,58 & 302,27 & 76,89 & 225,38 & 123,17 & 226,18 & 230,97 & 115,35 & 601,31 & 87,88 & 3,00 & 61,71 & 260,69 & 26,58 & 27,74 & 256,66 \\
\hline Discoglossus galganoi & 295NC52 & 101,00 & 169,67 & 98,88 & 42,01 & 4587,13 & 306,68 & 74,25 & 232,43 & 122,60 & 227,16 & 231,83 & 114,48 & 566,97 & 83,56 & 2,08 & 62,27 & 247,49 & 24,29 & 24,99 & 243,05 \\
\hline Discoglossus galganoi & 29SNC55 & 100,00 & 168,90 & 96,51 & 41,20 & 4621,95 & 304,91 & 74,40 & 230,51 & 121,21 & 226,82 & 231,37 & 113,07 & 597,31 & 86,69 & 3,00 & 60,85 & 256,22 & 27,24 & 28,15 & 253,45 \\
\hline \begin{tabular}{|l} 
Discoglossus galganoi \\
\end{tabular} & 29SNC57 & 100,00 & 163,63 & 94,28 & 40,87 & 4652,67 & 298,97 & 70,09 & 228,88 & 115,47 & 221,89 & 226,65 & 107,55 & 653,05 & 94,55 & 4,00 & 59,70 & 276,30 & 32,10 & 32,64 & 275,18 \\
\hline Discoglossus galganoi & 29SNC58 & 101,00 & 166,18 & 93,38 & 40,73 & 4621,51 & 299,98 & 72,89 & 227,09 & 118,19 & 224,19 & 228,68 & 110,35 & 646,13 & $\begin{array}{l}93,50 \\
\end{array}$ & 4,00 & 59,70 & 273,34 & 31,76 & 32,74 & 271,86 \\
\hline Discoglossus galganoi & 29SNC59 & 101,00 & 166,11 & 92,51 & 40, & 4606,06 & 298,89 & 73,02 & 225,86 & 118,06 & 223,91 & 228,27 & 110,24 & 657,11 & $\begin{array}{c}95,19 \\
\end{array}$ & 4,00 & 59,58 & 277,46 & 32,31 & 33,59 & 275,99 \\
\hline Discoglossus galganoi & 29SNC66 & 100,00 & 163,32 & 96,95 & 40,96 & 4748,38 & 302,52 & 68,20 & 234,32 & 113,71 & 223,07 & 22 & 10 & 633,58 & 90,95 & 3,66 & 59,27 & 266,10 & 31,68 & 31,91 & 265,71 \\
\hline Discoglossus galganoi & 29SNC70 & 101,00 & 166,79 & 105,49 & 42,09 & 4809,92 & 312,99 & 66,70 & 246,29 & 1117,83 & 227,47 & 232,23 & 109,28 & 554,83 & 82,57 & 2,00 & 61,93 & 2 & 23,42 & 23,73 & 236,96 \\
\hline Discoglossus galganoi & 29SNC71 & 100,00 & 167,97 & 105,13 & 42,01 & 4818,71 & 314,16 & $\begin{array}{l}68,10 \\
\end{array}$ & 246,06 & 118,71 & 228,77 & 233,40 & 110,28 & 553,44 & 81,62 & 2,00 & 61,39 & 238,80 & 23,73 & 24,02 & 235,39 \\
\hline Discoglossus galganoi & 29SNC76 & 101,00 & 160,29 & 98,06 & 40,77 & 4851,99 & 302,55 & \begin{tabular}{|l|l}
64,27 \\
\end{tabular} & 238,27 & 104,42 & 223,43 & 226,39 & 102,36 & 641,73 & 91,18 & 3,81 & 58,25 & 266,81 & 33,29 & 33,29 & 266,81 \\
\hline Discoglossus galganoi & 29SNC77 & 101,00 & 158,54 & 96,49 & 40,18 & 4855,58 & 299,73 & 63,38 & 236,35 & 100,76 & 222,23 & 224,66 & 100,60 & 666,05 & 94,64 & 4,08 & 57,82 & 276,19 & 35,39 & 35,39 & 276,19 \\
\hline Discoglossus galganoi & 29SNC79 & 101,00 & 163,50 & 95,29 & 40,00 & 4822,36 & 302,59 & 68,15 & 34,43 & 06,34 & 224,34 & & 105, & 59,75 & 93 & 4,00 & 57,83 & 273,29 & 35,38 & 35,75 & 273,29 \\
\hline \begin{tabular}{|l} 
Discoglossus galganoi \\
\end{tabular} & $295 N C 81$ & 101, & 165,59 & 108 & 42 & 4 & 317,28 & 63,29 & 253,99 & 114 & 228,42 & 23 & 10 & 561,88 & 82 & 2,18 & 60,46 & 239,21 & 25,24 & 25,36 & 236,65 \\
\hline Discoglossus galganoi & 29SNC83 & 101,00 & 165,01 & 105,72 & 41,89 & 4963,12 & 314,42 & 64,19 & 250,23 & 113,99 & 228,62 & 232,37 & 105,65 & 577,32 & 82,20 & 3,00 & 59,25 & 241,88 & 28,08 & 28,08 & 240,77 \\
\hline Discoglossus galganoi & 29SNC85 & 100,00 & 163,64 & 101,55 & 41,01 & 4935,13 & 309,45 & 65,10 & 244,36 & 108,31 & 227,21 & 230,59 & 104,60 & $\begin{array}{l}598,99 \\
\end{array}$ & 84,16 & 3,00 & 58,12 & 247,69 & $\begin{array}{l}30,76 \\
\end{array}$ & 30,76 & 247,69 \\
\hline Discoglossus galganoi & 29SNC87 & 100,00 & 157,48 & 97,19 & 40,03 & 4938,52 & 300,59 & 61,44 & 239,15 & 98,67 & 223,75 & 224,75 & 98,67 & 661,51 & 92,89 & 4,07 & 57,07 & 271,88 & 36,14 & 36,14 & 271,88 \\
\hline Discoglossus galganoi & 29SNC89 & 100,00 & 163,08 & 96,52 & 40,01 & 4922,84 & 304,76 & 66,54 & 238,22 & 104,04 & 225,79 & 22 & 103 & 654,01 & 92,12 & 4,03 & 57,18 & 268,90 & 36,06 & 36,14 & 268,90 \\
\hline Discoglossus galganoi & 29SNC91 & 100,00 & 164,76 & 111,73 & 42,12 & 5095,89 & 321,09 & 60,14 & 260,95 & 112,42 & 229,47 & 233,99 & 103,97 & 560,86 & 81,73 & 2,19 & 59,75 & 236,43 & 26,09 & 26,09 & 234,05 \\
\hline Discoglossus galganoi & 29SNC92 & 101,00 & 165,37 & 109,80 & 42,00 & 5080,16 & 319,78 & 61,63 & 258,15 & 113,12 & 230,16 & 234,41 & 104,70 & 562,89 & 80,75 & 2,80 & 59,01 & 235,45 & 27,29 & 27,30 & 233,49 \\
\hline \begin{tabular}{|l|} 
Discoglossus galganoi \\
\end{tabular} & 295NC94 & 100,00 & 161,65 & 105,11 & 41,13 & 5062,79 & 312,44 & 60,52 & 251,92 & 107,12 & 228,18 & 230,52 & $\mid \begin{array}{l}101,29 \\
\end{array}$ & 597,04 & 83,31 & $\mid 3,19$ & 57,84 & 245,71 & 30,75 & 30,75 & 245,55 \\
\hline Discoglossus : & 29SNC99 & 100,00 & 162,60 & 97,82 & 39,99 & 5028,22 & 307,13 & 64,41 & 242,72 & 102,16 & 226,96 & 230, & 102, & 649,82 & 90,50 & 4,00 & 56,37 & 264,99 & 36,64 & 36,65 & 264,99 \\
\hline Discoglossus galganoi & 29SND02 & 101,00 & 164,16 & 76,69 & 40,82 & 3826,01 & 267,79 & 81,53 & 186,27 & 123,76 & 210,72 & 214,20 & 116,05 & 686,86 & 105,02 & 3,44 & 62,06 & 302,33 & 29,19 & 33,27 & 290,53 \\
\hline
\end{tabular}




\begin{tabular}{|c|c|c|c|c|c|c|c|c|c|c|c|c|c|c|c|c|c|c|c|c|c|}
\hline TAXON & UTM & $\mathrm{km} 2$ & $\mathrm{BIO1}$ & B1O2 & $\mathrm{BIO3}$ & B104 & B105 & $\mathrm{B106}$ & $\mathrm{B107}$ & B108 & 8109 & 81010 & B1011 & B1012 & 81013 & 81014 & B1015 & 81016 & B1017 & $\mathrm{BIO18}$ & B1019 \\
\hline Discoglossus galganoi & 29SND05 & 101,00 & 155,97 & 73,29 & 40,97 & 3622,09 & 252,84 & 75,74 & 177,10 & 117,80 & 199,97 & 202,88 & 109,98 & 738,07 & 113,12 & 4,51 & 60,61 & 319,44 & 34,41 & 39,11 & 307,22 \\
\hline Discoglossus galganoi & 29SND09 & 101,00 & 152,42 & 73,80 & \begin{tabular}{l|l|l}
42,05 \\
\end{tabular} & 3457,76 & 245,39 & 72,05 & 173,34 & 115,68 & 193,97 & 196,45 & 107,71 & 810,14 & 120,76 & 6,13 & 57,97 & 341,25 & 43,40 & 49,26 & 330,91 \\
\hline \begin{tabular}{|l} 
Discoglossus galganoi \\
\end{tabular} & 29 SND12 & 101,00 & 166,69 & 80,13 & 40,82 & 3974,29 & 276,01 & 81,52 & 194,50 & 124,59 & 215,32 & 218,92 & 117,01 & 675,43 & 101,78 & 3,45 & 61,80 & 295,13 & 29,08 & 32,92 & 285,80 \\
\hline Discoglossus galganoi & 29SND24 & 100,00 & 164,81 & 81,94 & 40,97 & 4020,68 & 276,34 & 78,16 & 198,18 & 122,04 & 214,24 & 217,55 & 114,29 & 700,91 & 103,93 & 4,00 & 60,20 & 300,66 & 33,15 & 36,90 & 293,36 \\
\hline Discoglossus galganoi & 29 SND25 & 101,00 & 161,26 & 81,61 & 40,91 & 3997,80 & 272,25 & 74,87 & 197,38 & 118,84 & 210,46 & 213,58 & 111,06 & 735,20 & 108,67 & 4,79 & 59,47 & 313,26 & 36,15 & 39,89 & 306,39 \\
\hline Discoglossus galganoi & 29SND40 & 100,00 & 168,20 & 89,94 & 40,42 & 4473,58 & 295,80 & 76,41 & 219,39 & 121,14 & 223,95 & 228,03 & 113,50 & 657,81 & 96,03 & 4,00 & 60,04 & 280,67 & 31,31 & 33,32 & 277,32 \\
\hline Discoglossus galganoi & 29SND43 & 101,00 & 165,55 & 88,08 & 40,38 & 4386,48 & 289,87 & 74,40 & 215,47 & 119,04 & 220,25 & 223,94 & 111,32 & 704,16 & 103,05 & 4,47 & 59,20 & 297,69 & 35,20 & 37,73 & 294,37 \\
\hline Discoglossus galganoi & $29 S N D 45$ & 101,00 & 165,76 & 88,03 & 40,78 & 4321,19 & 288,15 & 74,32 & 213,82 & 119,42 & 219,42 & 222,85 & $\begin{array}{ll}111,97 \\
\end{array}$ & 723,74 & \begin{tabular}{|l|l|}
105,79 \\
\end{tabular} & 4,87 & 58,48 & 304,00 & 37,37 & 40,32 & 300,70 \\
\hline Discoglossus galganoi & 29SND46 & 101,00 & 166,58 & 88,53 & 40,98 & 4293,35 & 288,52 & 74,46 & 214,05 & 120,34 & 219,92 & 223,14 & 112,81 & 727,41 & 106,05 & 5,03 & 58,10 & 304,27 & 38,17 & 41,38 & 301,09 \\
\hline Discoglossus galganoi & 29SND47 & 101,00 & 163,11 & 89,05 & 40,96 & 4309,41 & 285,90 & 70,68 & 215,21 & 116,77 & 216,77 & 219,84 & 109,16 & 770,68 & 112,25 & 5,77 & 57,55 & 320,32 & 42,06 & 45,06 & 318,06 \\
\hline Discoglossus galganoi & 29SND51 & 100,00 & 168,79 & 91,31 & 40,28 & 4550,32 & 298,81 & 75,55 & 223,27 & 120,76 & 225,68 & 229,68 & 112,94 & 660,12 & 95,85 & 4,00 & 59,32 & 278,45 & 32,50 & 34,38 & 276,43 \\
\hline Discoglossus galganoi & 29SND55 & 100,00 & 162,59 & 90,29 & 40,09 & 4516,73 & 291,27 & 69,36 & 221,91 & 114,68 & 219,35 & 222,82 & 107,06 & 757,73 & 110,34 & 5,54 & 57,69 & 315,09 & 41,03 & 43,10 & 314,16 \\
\hline \begin{tabular}{|l} 
Discoglossus galganoi \\
\end{tabular} & 29SND56 & 100,00 & 164,14 & 90,99 & 40,28 & 4499,20 & 292,42 & 70,03 & 222,39 & 115,91 & 220,46 & 223,79 & 108,37 & 758,66 & 110,26 & 5,55 & 57,46 & 314,56 & 41,55 & 43,99 & 313,51 \\
\hline Discoglossus galganoi & 29SND61 & 100,00 & 168,42 & 93,18 & 40,17 & 4677,65 & 302,26 & 73,77 & 228,49 & 119,18 & 227,10 & 231,18 & 111,43 & 659,02 & 94,87 & 4,00 & 58,62 & 275,31 & 33,64 & 35,16 & 274,36 \\
\hline Discoglossus galganoi & 29SND62 & 100,00 & 166,34 & 92,62 & 40,02 & 4682,53 & 300,06 & 71,66 & 228,40 & 116,55 & 225,23 & 229,08 & 109,13 & $\begin{array}{l}689,45 \\
\end{array}$ & 99,47 & 4,62 & 58,18 & 287,12 & 36,23 & 37,75 & 286,52 \\
\hline Discoglossus galganoi & 29 SND65 & 101,00 & 162,54 & 92,21 & 39,99 & 4676,03 & 296,03 & 67,49 & 228,53 & 110,27 & 221,56 & 225,14 & 105,29 & 763,63 & 110,71 & 5,94 & 57,23 & 315,68 & 42,68 & 44,36 & 315,62 \\
\hline Discoglossus galganoi & 29 SND70 & 101,00 & 166,85 & 95,14 & 40,07 & 4804,47 & 305,03 & 70,95 & 234,08 & 113,76 & 227,38 & 231,65 & 108,60 & 651,19 & 92,75 & 4,00 & 57,94 & 269,61 & 34,63 & 35,48 & 269,59 \\
\hline \begin{tabular}{|l} 
Discoglossus galganoi \\
\end{tabular} & 29 SND73 & 101,00 & 166,31 & 94,13 & 39,99 & 4803,72 & 303,41 & 70,01 & 233,40 & 113,13 & 226,98 & 230,79 & 107,78 & 701,93 & 100,70 & 4,97 & 57,44 & 289,84 & 38,35 & 39,74 & 289,81 \\
\hline Discoglossus galganoi & 29SND74 & 101,00 & 163,90 & 93,73 & 39,83 & 4823,81 & 301,46 & 67,69 & 233,77 & 106,79 & 225,15 & 228,75 & 105,49 & 737,46 & 106,23 & 5,32 & 57,22 & 304,37 & 41,04 & 42,31 & 304,37 \\
\hline Discoglossus galganoi & 29SND76 & 101,00 & 166,34 & 94,80 & 39,87 & 4805,36 & 303,58 & 68,38 & 235,21 & 111,06 & 227,19 & 230,44 & 107,33 & 748,79 & 107,79 & 5,66 & 56,58 & 307,78 & 42,49 & 44,37 & 307,73 \\
\hline Discoglossus galganoi & 29SND80 & 101,00 & 166,63 & 96,48 & 40,00 & 4914,35 & 307,64 & 69,17 & 238,47 & 107,97 & 228,70 & 232,91 & 107,09 & 646,56 & 91,14 & 4,00 & 57,21 & 265,65 & 35,67 & 36,13 & 265,65 \\
\hline \begin{tabular}{|l} 
Discoglossus galganoi \\
\end{tabular} & 29 SND85 & 99,00 & 163,36 & 95,07 & 39,14 & 4975,53 & 304,82 & 65,19 & 239,63 & 103,05 & 226,75 & 230,31 & 103,01 & 759,23 & 109,09 & 5,89 & 56,40 & 311,86 & 43,72 & 44,89 & 311,86 \\
\hline \begin{tabular}{|l} 
Discoglossus galganoi \\
\end{tabular} & 29SND86 & 100,00 & 164,90 & 95,70 & \begin{tabular}{|c|}
39,27 \\
\end{tabular} & 4975,12 & 306,28 & 65,64 & 240,64 & \begin{tabular}{|l|}
105,07 \\
\end{tabular} & 228,30 & 231,51 & 104,17 & 762,81 & 109,64 & 5,84 & 56,31 & 312,88 & 43,97 & 45,47 & 312,88 \\
\hline Discoglossus galganoi & 29SND87 & 101,00 & 163,28 & 95,93 & 39,23 & 5002,83 & 305,49 & 63,42 & 242,07 & 102,54 & 227,23 & 230,24 & 102,16 & 794,42 & 114,52 & 6,29 & 56,04 & 325,44 & 46,72 & 48,10 & 325,44 \\
\hline Discoglossus galganoi & 29SND90 & 100,00 & 165,34 & 97,75 & 39,97 & 5033,34 & 309,49 & 66,49 & 243,01 & 104,96 & 229,23 & 233,44 & 104,66 & 649,04 & 90,68 & 4,01 & 56,50 & 264,87 & 36,60 & 36,92 & 264,87 \\
\hline Discoglossus galganoi & 29SND91 & 100,00 & 165,52 & 97,41 & 39,74 & 5042,61 & 309,69 & 66,78 & 242,92 & 105,51 & 229,67 & 233,77 & 104,78 & 666,33 & 93,51 & 4,71 & 56,51 & 272,06 & 38,02 & 38,47 & 272,06 \\
\hline Discoglossus galganoi & $29 \mathrm{SND92}$ & 100,00 & 167,01 & $\begin{array}{l}97,38 \\
97,38\end{array}$ & 39,53 & 5049,72 & 311,14 & $\begin{array}{ll}67,58 \\
\end{array}$ & 243,55 & 108,42 & 231,32 & 235,16 & 105,97 & 672,80 & 94,69 & 4,91 & 56,41 & 274,65 & $\begin{array}{l}30,037 \\
38,37\end{array}$ & 39,36 & 274,65 \\
\hline Discoglossus galganoi & 29SND93 & 100,00 & 166,58 & 97,03 & 39,23 & 5067,16 & 310,69 & 67,06 & 243,63 & 107,18 & 231,19 & 234,92 & 105,31 & 693,44 & 98,05 & 5,00 & 56,36 & 283,46 & 39,40 & 40,47 & 283,46 \\
\hline Discoglossus galganoi & 29 SND96 & 101,00 & 161,90 & 95,79 & 38,71 & 5140,64 & 307,12 & 61,99 & 245,13 & 99,61 & 227,89 & 231,10 & 99,61 & 788,45 & 113,31 & 6,03 & 55,97 & 322,89 & 46,10 & 47,06 & 322,89 \\
\hline Discoglossus galganoi & 29SNE01 & 71,00 & 155,54 & 75,36 & 43,04 & 3391,56 & 246,96 & 73,98 & 172,98 & 118,78 & 195,81 & 198,16 & 110,94 & 820,20 & 120,06 & 6,99 & 56,68 & 341,42 & 46,29 & 53,10 & 331,97 \\
\hline Discoglossus galganoi & 29SNE10 & 101,00 & 155,98 & 79,34 & 42,57 & 3622,00 & 256,06 & 71,49 & 184,58 & 116,98 & 199,76 & 202,30 & 109,14 & 821,60 & 119,97 & 6,60 & 56,95 & 341,94 & 45,99 & 51,55 & 334,68 \\
\hline \begin{tabular}{|l} 
Discoglossus galganoi \\
\end{tabular} & 29SNE12 & 101,00 & 154,19 & 80,64 & 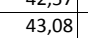 & 3581,21 & 253,36 & 68,70 & \begin{tabular}{|l|l|}
184,66 \\
\end{tabular} & $\begin{array}{ll}115,14 \\
\end{array}$ & 197,19 & \begin{tabular}{|l|l|}
199,53 \\
\end{tabular} & \begin{tabular}{|l|}
107,27 \\
\end{tabular} & 874,10 & 125,94 & 0,004 & 55,56 & 359,32 & 52,16 & 58,23 & 353,13 \\
\hline Discoglossus galganoi & 29SNE20 & 101,00 & 152,52 & 84,09 & 41,92 & 3904,09 & 262,92 & 64,42 & 198,50 & 110,37 & 200,48 & 203,16 & 102,82 & 879,72 & 128,01 & 7,63 & 56,25 & 363,10 & 51,42 & 55,46 & 359,14 \\
\hline Discoglossus galganoi & 29SNE21 & 100,00 & 154,41 & 85,30 & 42,49 & 3858,25 & 264,11 & 65,67 & 198,45 & 112,57 & 201,62 & 204,18 & 104,94 & 879,25 & 127,02 & 7,92 & 55,83 & 361,05 & 52,38 & 56,89 & 357,44 \\
\hline Discoglossus galganoi & 29SNE22 & 101,00 & 156,45 & 86,16 & 43,06 & 3801,99 & 264,73 & 66,96 & 197,77 & 114,81 & 202,60 & 205,01 & 107,05 & 877,24 & 125,73 & 8,03 & 55,11 & 358,35 & 53,36 & 58,58 & 354,81 \\
\hline Discoglossus galganoi & 29SNE32 & 100,00 & 153,67 & 90,88 & 42,44 & 4083,90 & 272,45 & 60,72 & 211,73 & 106,56 & 204,07 & 206,71 & 101,62 & 929,17 & 133,19 & 8,90 & 54,84 & 377,49 & 58,40 & 61,82 & 376,70 \\
\hline \begin{tabular}{|l} 
Discoglossus galganoi \\
\end{tabular} & 29SPBO1 & 101,00 & $\begin{array}{l}13,02,03 \\
162,03\end{array}$ & \begin{tabular}{|c|c|}
94,36 \\
94
\end{tabular} & 年41,61 & 4497,07 & 288,29 & $\begin{array}{ll}63,89 \\
63,1\end{array}$ & 224,40 & \begin{tabular}{|l|}
117,19 \\
119
\end{tabular} & 218,91 & 223,10 & \begin{tabular}{|l|}
108,31 \\
108,
\end{tabular} & |555,68 & \begin{tabular}{|l|} 
\\
89,50
\end{tabular} & $\frac{0,300}{1,30}$ & $\begin{array}{ll}4,04 \\
66,64\end{array}$ & \begin{tabular}{|l|l|}
258,63 \\
\end{tabular} & $\begin{array}{l}0,4,44 \\
18,44 \\
\end{array}$ & \begin{tabular}{l|l|l|l|l|}
21,93 \\
\end{tabular} & 244,09 \\
\hline Discoglossus galganoi & 29SPB02 & 100,00 & 156,21 & 96,72 & 41,06 & 4645,49 & 288,15 & 56,77 & 231,38 & 109,81 & 215,06 & 219,32 & 100,94 & 589,35 & 92,50 & 1,92 & 64,92 & 268,40 & 21,17 & 24,40 & 255,58 \\
\hline Discoglossus galganoi & 29SPB05 & 100,00 & 163,97 & 101,37 & 41,34 & 4816,27 & 303,75 & 62,08 & 241,66 & 115,01 & 224,98 & 229,16 & 106,18 & 546,64 & 83,50 & 2,0 & 63,37 & 244,04 & 20,84 & 23,48 & 233,34 \\
\hline Discoglossus galganoi & 29SPB06 & 101,00 & 166,78 & 103,09 & 41,77 & 4864,45 & 308,96 & 64,24 & 244,73 & 117,18 & 228,35 & 232,62 & 10 & 531,27 & 80,81 & 1,99 & 62,92 & 35,55 & 20,77 & 23,04 & 225,63 \\
\hline Discoglossus galganoi & 29SPB07 & 101,0 & 166,32 & 105,44 & 41,88 & 4943,26 & 312,49 & 62,73 & 249,76 & 115,83 & 229,00 & 23 & 107 & 535,87 & 80,73 & 2,00 & 62,05 & 234,58 & 21,63 & 23,64 & 226,01 \\
\hline 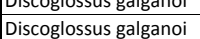 & $\begin{array}{l}295 \mathrm{PBO} \\
29 \mathrm{SBO8}\end{array}$ & 100,00 & $\begin{array}{l}10,52 \\
167,55\end{array}$ & $\begin{array}{l}107,44 \\
107,56\end{array}$ & 41 & \begin{tabular}{|l}
5043,20 \\
5003,47
\end{tabular} & $31,46,84$ & $\begin{array}{ll}62,159 \\
62,99 \\
\end{array}$ & \begin{tabular}{|l|}
253,84 \\
25,0
\end{tabular} & \begin{tabular}{|l|}
116,34 \\
116,1
\end{tabular} & 230,05 & $\mid \frac{233,25}{235,25}$ & \begin{tabular}{|l|l|l|l}
107,44 \\
\end{tabular} & | & $\mid \begin{array}{ll}60,15 \\
79,44\end{array}$ & $\frac{2,0}{2,0}$ & $\begin{array}{l}02,205 \\
61,50\end{array}$ & \begin{tabular}{|l|}
234,009 \\
230,09
\end{tabular} & $\begin{array}{l}1,100 \\
21,97 \\
\end{array}$ & $\frac{23,84}{23,82}$ & $\begin{array}{l}220,01 \\
222,77\end{array}$ \\
\hline Discoglossus galganoi & 29SPB11 & 99,00 & 168,63 & 92,33 & 41,09 & 4481,92 & 291,86 & 70,19 & 221,67 & 123,23 & 224,88 & 228,95 & 114,35 & 520,10 & 83,18 & 1,01 & 66,93 & 242,62 & 16,15 & 20,50 & 226,66 \\
\hline Discoglossus galganoi & 29SPB15 & 101,00 & 166,02 & 100,20 & 41,00 & 4869,35 & 304,94 & 63,33 & 61 & 115,96 & 227,46 & 231,61 & 107,26 & 532,74 & 81,03 & 1,9 & 63,12 & 36,72 & 20,00 & 23,43 & 224,84 \\
\hline Discoglossus galganoi & 29SPB16 & 100,00 & 169,62 & 101,78 & 1,1 & 4908,01 & 310,38 & 66,19 & 19 & 118,84 & 231,52 & 235,58 & 110 & 27 & 77,93 & 1,7 & 62,67 & 227,15 & 19,65 & 22,79 & 215,99 \\
\hline Discoglossus galganoi & 29SPB20 & 11,00 & 174,00 & 89,13 & $\begin{array}{l}41,120 \\
41,00\end{array}$ & 4376,00 & 292,25 & 77,00 & 21 & 129,75 & 228,88 & 232,88 & 12 & $\begin{array}{l}490,25 \\
490,2\end{array}$ & 79,25 & 1,0 & 68,00 & 231,00 & 14,00 & 19,00 & 213,38 \\
\hline Discoglossus galganoi & 29SPB25 & 100,00 & 169,33 & 98,40 & 40,57 & 4894,24 & 306,29 & 66,31 & 239,97 & 118,59 & 231,09 & 234,90 & 110,06 & 513,84 & 77,78 & 1,6 & 62,78 & 227,38 & 18,76 & 23,11 & 214,10 \\
\hline Discoglossus galganoi & 29SPB26 & 101,00 & 169,08 & 100,77 & 40,72 & 4972,45 & 309,87 & 64,94 & 244,93 & 117,62 & 231,85 & 235,79 & 108,74 & 516,25 & 77,31 & 1,88 & 61,94 & 225,79 & 19,77 & 23,69 & 213,66 \\
\hline Discoglossus galganoi & 29SPB31 & 58,00 & 174,81 & 88,67 & 40,00 & 4559,20 & 295,23 & 75,87 & 219,36 & 127,54 & 231,51 & 235,26 & 118,59 & 486,49 & 76,64 & 1,00 & 65,94 & 222,86 & 14,03 & 19,99 & 205,03 \\
\hline Discoglossus galganoi & 29SPB32 & 101,00 & 173,23 & 90,13 & 39,87 & 4653,86 & 296,81 & 73,27 & 223,54 & 124,94 & 231,23 & 234,90 & 115,92 & 493,39 & 76,86 & 1,00 & 65,25 & 21 & 14,76 & 20,66 & 206,99 \\
\hline \begin{tabular}{|l} 
Discoglossus galganoi \\
\end{tabular} & 29SPB33 & 100,00 & 172 & $\frac{\pi 2}{92}-3 x-1$ & 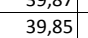 & 22 & 299,82 & $\begin{array}{ll}31,13 \\
713\end{array}$ & \begin{tabular}{|l|}
228,69 \\
\end{tabular} & \begin{tabular}{|l|l|l|l|l|l|}
122,83 \\
\end{tabular} & $\begin{array}{l}231,25 \\
231,68\end{array}$ & \begin{tabular}{|l|}
235,45 \\
\end{tabular} & \begin{tabular}{|l|l|l|l|l|}
113,82 \\
\end{tabular} & $\begin{array}{l}453,23 \\
497,26\end{array}$ & $\begin{array}{l}70,000 \\
76,39\end{array}$ & $\frac{1,00}{1,00}$ & $\frac{00,25}{64,32}$ & $\begin{aligned} 223,32 \\
223\end{aligned}$ & $\begin{array}{l}4,15 \\
15,71\end{array}$ & $\frac{20,00}{21,49}$ & 206,86 \\
\hline Discoglossus galganoi & 29SPB35 & 101,00 & 169,60 & 96,90 & 39,96 & 4957,53 & 305,73 & 65,96 & 239,77 & 117,77 & 231,96 & 235,63 & 109,06 & 511,72 & 76,62 & 1,60 & 62,32 & 224,38 & 18,45 & 23,57 & 210,04 \\
\hline Discoglossus galganoi & 29SPB36 & 99,00 & 171,07 & 98,97 & 40,02 & 5027,06 & 310,27 & 66,23 & 244,03 & 118,48 & 234,36 & 238,01 & 109,54 & 504,43 & 74,85 & 1,80 & 61,47 & 219,22 & 19,03 & 23,80 & 205,73 \\
\hline Discoglossus galganoi & 29SPB37 & 101,00 & 168,89 & 101,83 & 40,13 & 5123,45 & 312,79 & 62,74 & 250,05 & 115,32 & 233,65 & 237,34 & 106,44 & 517,24 & 75,86 & 2,00 & 60,68 & 222 & 20,43 & 24,79 & 209,98 \\
\hline Discoglossus galganoi & 29SPB38 & 100,00 & 165,74 & 104,48 & 40,26 & 5217,51 & 314,11 & 58,52 & 255,59 & 111,43 & 231,94 & 235 & 102 & 536,33 & 77,76 & 2,00 & 60,14 & 227,63 & 22,05 & 25,60 & 217 \\
\hline \begin{tabular}{|l|l|} 
Discoglossus galganoi \\
\end{tabular} & $\begin{array}{l}295 \mathrm{~PB} 30 \\
29 P B 42\end{array}$ & $\begin{array}{l}100,00 \\
100\end{array}$ & $\begin{array}{l}10,14 \\
174,39\end{array}$ & $\begin{array}{r}10,4,40 \\
87,81 \\
\end{array}$ & $\begin{array}{l}40,20 \\
39,07\end{array}$ & $\mid \begin{array}{ll}321,1,1 \\
4705,30\end{array}$ & 2914,11 & \begin{tabular}{|l|l}
30,252 \\
74,27
\end{tabular} & \begin{tabular}{|l|}
222,13 \\
22,1
\end{tabular} & 125,04 & 232,76 & 236,31 & 116,11 & 486,66 & 74,96 & 1,00 & 65,00 & 218,79 & 14,07 & 21,01 & 200,46 \\
\hline \begin{tabular}{|l} 
Discoglossus galganoi \\
\end{tabular} & 29SPB43 & 100,00 & 171,07 & 90,36 & 39,05 & 4835,05 & 298,26 & 69,46 & 228,80 & 120,41 & 231,39 & 234,94 & $\mid 111,54$ & 503,00 & 76,14 & 1,00 & 63,58 & 223,05 | & 15,97 & 22,78 & 205,61 \\
\hline Discoglossus galganoi & 29SPB44 & 100,00 & 168,94 & 93,08 & 39,08 & 4953,04 & 301,00 & 65,92 & 235,08 & 116,97 & 230,92 & 234,64 & 108,21 & 514,36 & 76,65 & 1,65 & 62,62 & 225,14 & 17,70 & 24,14 & 208,76 \\
\hline Discoglossus & 29SPB45 & 101,00 & 167,17 & 95,93 & 39,15 & 5057,97 & 303,87 & 62,46 & 41, & 114 & 230 & 234 & 105 & 524,81 & 77,31 & 1,95 & 61 & 227,20 & 19,13 & 25,01 & 212,03 \\
\hline |Discoglossus galganoi & 29SPB46 & 101,00 & 170,38 & 97,69 & 39,49 & 5097,67 & 309,21 & 64,66 & 244,55 & 116,60 & 234,40 & 237,99 & 107,66 & 508,40 & 74,47 & 2,00 & 61,12 & 218,77 & 19,17 & 24,74 & 204, \\
\hline
\end{tabular}




\begin{tabular}{|c|c|c|c|c|c|c|c|c|c|c|c|c|c|c|c|c|c|c|c|c|c|}
\hline TAXON & UTM & $\overline{\mathrm{km} 2}$ & BIO1 & $\overline{B 102}$ & $\mathrm{BIO3}$ & $\begin{array}{ll}B 104 \\
\end{array}$ & B105 & B106 & B107 & B108 & B109 & BIO10 & BI011 & $\overline{B 1012}$ & BIO13 & B1014 & BIO15 & BIO16 & BIO17 & B1018 & BlO19 \\
\hline Discoglossus galganoi & 29SPB47 & 100,00 & 168,88 & 100,49 & 39,82 & 5191,89 & 311,99 & 61,96 & 250,03 & 114,28 & 234,42 & 237,89 & 105,12 & 517,01 & 75,01 & 2,00 & 60,66 & 220,39 & 20,28 & 25,11 & 207,22 \\
\hline Discoglossus galganoi & 295 PB48 & 100,00 & 167,76 & 102,78 & 39,96 & 5275,35 & 314,51 & 59,57 & 254,94 & 112,04 & 234,53 & 238,02 & 103,20 & 523,92 & 75,31 & 2,00 & \begin{tabular}{|l|l|}
59,87 \\
\end{tabular} & 221,33 & 21,22 & 25,76 & 209,24 \\
\hline Discoglossus galganoi & 29SPB52 & 100,00 & 175,19 & 85,50 & 38,19 & 4763,32 & 295,72 & 74,92 & 220,80 & \begin{tabular}{ll|l}
124,69 \\
\end{tabular} & 233,97 & 237,43 & 115,81 & 482,36 & 73,92 & 1,00 & 64,48 & 214,43 & 13,55 & 21,57 & 194,99 \\
\hline Discoglossus galganoi & 29SPB53 & 101,00 & 172,90 & 87,90 & 38,16 & 4887,35 & 298,20 & 71,02 & 227,18 & \begin{tabular}{|l|l|}
121,10 \\
\end{tabular} & 233,55 & 236,92 & 112,13 & $\begin{array}{l}493,46 \\
\end{array}$ & 74,73 & 1,01 & 63,42 & 216,54 & 15,33 & 23,12 & 197,79 \\
\hline Discoglossus galganoi & 29SPB54 & 101,00 & 170,45 & 90,94 & 38,30 & 5007,82 & 300,94 & 66,97 & 233,97 & 117,41 & \begin{tabular}{|l|l|}
232,94 \\
\end{tabular} & 236,36 & 108,48 & \begin{tabular}{|l|}
506,42 \\
\end{tabular} & 75,65 & 1,51 & 62,28 & 219,73 & 17,00 & 24,36 & 202,13 \\
\hline Discoglossus galganoi & 29SPB55 & 99,00 & 166,69 & 94,61 & 38,71 & 5134,48 & 303,20 & 61,36 & 241,84 & 112,48 & 231,25 & 234,60 & 103,59 & 528,04 & 77,56 & 2,00 & 61,28 & 226,42 & 19,01 & 25,85 & 210,22 \\
\hline Discoglossus galganoi & 29SPB56 & 100,00 & 168,05 & 96,89 & 38,95 & 5204,47 & $\begin{array}{l}307,65 \\
\end{array}$ & 61,30 & 246,35 & \begin{tabular}{|l|l|}
112,94 \\
\end{tabular} & 233,58 & 236,92 & 103,94 & \begin{tabular}{l|l}
520,95 \\
\end{tabular} & 76,11 & 2,00 & 60,74 & 221,98 & 19,40 & 25,68 & 206,68 \\
\hline Discoglossus galganoi & 29SPB57 & 100,00 & 168,52 & 99,30 & \begin{tabular}{l|l|}
39,05 \\
\end{tabular} & 5265,48 & $\begin{array}{l}311,35 \\
\end{array}$ & 60,62 & 250,73 & 112,74 & 235,06 & 238,25 & 103,76 & \begin{tabular}{|l|}
519,26 \\
\end{tabular} & 75,34 & 2,00 & 60,09 & 219,62 & 20,12 & 25,82 & 205,28 \\
\hline Discoglossus galganoi & 29SPB62 & 100,00 & 176,32 & 82,94 & 37,30 & 4827,46 & 295,47 & 75,96 & 219,51 & \begin{tabular}{|l|l|}
124,72 \\
\end{tabular} & 235,65 & 238,97 & 115,88 & 476,06 & 73,79 & 1,00 & 64,06 & 209,23 & 13,14 & 22,10 & 188,61 \\
\hline Discoglossus galganoi & 29SPB63 & 100,00 & 173,50 & 85,69 & 37,29 & 4955,21 & 297,65 & 71,32 & 226,33 & \begin{tabular}{|l|l|l|}
120,63 \\
\end{tabular} & 234,78 & 237,93 & 111,59 & 490,51 & 75,08 & 1,01 & \begin{tabular}{|c|}
62,88 \\
\end{tabular} & 213,02 & 14,88 & 23,59 & 193,09 \\
\hline Discoglossus galganoi & 29SPB64 & 100,00 & 171,35 & 89,14 & 37,69 & 5074,96 & 300,92 & 67,29 & 233,63 & \begin{tabular}{|l|l|}
117,19 \\
\end{tabular} & \begin{tabular}{|l|l|l}
234,48 \\
\end{tabular} & 237,69 & 108,34 & \begin{tabular}{l|l}
502,45 \\
\end{tabular} & 75,84 & 1,52 & \begin{tabular}{|c|}
62,03 \\
\end{tabular} & 215,97 & 16,64 & 24,62 & 197,18 \\
\hline Discoglossus galganoi & $29 \mathrm{SPB} 65$ & 101,00 & 170,61 & 92,24 & 37,94 & 5171,80 & 304,69 & 64,81 & 239,88 & 115,30 & 235,21 & 238,42 & 106,43 & 507,57 & 75,85 & 1,94 & 61,13 & 216,36 & \begin{tabular}{l|l}
17,85 \\
\end{tabular} & 25,54 & 198,55 \\
\hline Discoglossus galganoi & 29SPB66 & 100,00 & 167,46 & 96,09 & 38,26 & 5281,79 & 307,19 & 59,68 & 247,51 & \begin{tabular}{l|l}
111,22 \\
\end{tabular} & 233,90 & 237,04 & \begin{tabular}{|c|}
102,17 \\
\end{tabular} & $\begin{array}{l}526,75 \\
\end{array}$ & 77,38 & 2,00 & 60,41 & 222,67 & \begin{tabular}{l|l}
19,45 \\
\end{tabular} & 26,22 & 206,49 \\
\hline Discoglossus galganoi & 29SPB68 & 99,00 & 161,51 & 102,50 & 38,98 & 5475,86 & \begin{tabular}{|c|}
310,95 \\
\end{tabular} & 50,86 & 260,09 & \begin{tabular}{|l|l|l}
103,49 \\
\end{tabular} & 231,21 & 234,26 & 94,64 & 565,09 & 80,49 & 2,59 & 58,77 & 234,47 & 24,03 & 29,36 & 221,11 \\
\hline Discoglossus galganoi & 29SPB72 & 100,00 & 177,28 & 80,30 & 36,32 & 4889,62 & 294,83 & 76,74 & 218,10 & \begin{tabular}{|l|l|l|}
124,96 \\
\end{tabular} & 237,14 & 240,23 & 115,76 & 471,86 & $\begin{array}{l}74,05 \\
\end{array}$ & 1,0 & 63,8 & 205,10 & \begin{tabular}{l|l|}
12,65 \\
\end{tabular} & 22,54 & 183,14 \\
\hline Discoglossus galganoi & 29SPB73 & 101,00 & 176,50 & 82,76 & \begin{tabular}{l|l|}
36,45 \\
\end{tabular} & 5001,32 & 298,23 & 74,25 & 223,98 & 123,65 & 237,87 & 240,98 & 113,67 & 476,04 & 74,01 & 1,00 & 63,01 & 204,82 & 13,89 & 23,71 & 183,47 \\
\hline Discoglossus galganoi & 29SPB74 & 100,00 & 174,51 & 86,77 & 36,99 & 5116,97 & $\begin{array}{l}301,96 \\
\end{array}$ & 70,11 & 231,86 & \begin{tabular}{|l|l|l|}
119,42 \\
\end{tabular} & 237,91 & 240,89 & \begin{tabular}{l|l|}
110,45 \\
\end{tabular} & $\begin{array}{l}487,26 \\
\end{array}$ & 74,79 & 1,03 & 62,14 & 208,15 & 15,20 & 24,17 & 187,95 \\
\hline Discoglossus galganoi & 29 SPB75 & 100,00 & 173,17 & 90,78 & 37,35 & 5223,84 & 306,17 & 66,62 & 239,55 & 116,95 & 238,22 & 241,18 & \begin{tabular}{|l|l|}
108,03 \\
\end{tabular} & 497,01 & 75,20 & 1,71 & 61,08 & 210,63 & 16,92 & 25,31 & 191,71 \\
\hline Discoglossus galganoi & 29SPB76 & 101,00 & 172,13 & 94,68 & \begin{tabular}{|c|}
37,97 \\
\end{tabular} & 5322,15 & 310,30 & 63,59 & 246,72 & \begin{tabular}{l|l|}
115,01 \\
\end{tabular} & 238,91 & 241,79 & 105,99 & 504,11 & 75,30 & 1,99 & 60,38 & 212,14 & 18,20 & 25,85 & 194,57 \\
\hline Discoglossus galganoi & 29SPB77 & 100,00 & 169,75 & 98,39 & 38,1 & 5425,29 & 313,11 & 59,47 & 253,64 & \begin{tabular}{|l|l|l}
111,36 \\
\end{tabular} & 238,29 & 241,06 & 102,6 & 517,79 & 76,19 & 2,01 & 59, & 216,32 & 19,64 & 26,46 & 200,12 \\
\hline Discoglossus galganoi & 29SPB78 & 101,00 & 163,20 & 102,44 & 38,68 & 5548,81 & 313,16 & 51,22 & 261,94 & 104,07 & 233,97 & 236,76 & 95,18 & 557,05 & 79,98 & 2,45 & 58,67 & 230,14 & 23,44 & 29,16 & 215,80 \\
\hline Discoglossus galganoi & 29SPB79 & 100,00 & 158,60 & 105,26 & 38,94 & 5641,23 & 313,68 & 45,54 & 268,14 & $\begin{array}{l}98,76 \\
\end{array}$ & 231,00 & 233,69 & 89,80 & 585,79 & 82,62 & 3,10 & 57,73 & 239,91 & 26,44 & 31,26 & 227,16 \\
\hline Discoglossus galganoi & 29SPB81 & 49,00 & 177,89 & 79,56 & 36,00 & 4901,23 & 294,59 & 76,90 & 217,69 & \begin{tabular}{|c|}
136,93 \\
\end{tabular} & \begin{tabular}{|l|l|}
238,02 & \\
\end{tabular} & 241,00 & 116,18 & 476,69 & 75,25 & 1,00 & 63,82 & 206,57 & 12,51 & 22,87 & \begin{tabular}{ll|l}
183,93 \\
\end{tabular} \\
\hline Discoglossus galganoi & 29SPB82 & 101,00 & 177,98 & 79,33 & 35,82 & 4964,47 & 295,56 & 76,60 & 218,96 & 144,32 & \begin{tabular}{|l|l|}
238,62 \\
\end{tabular} & 241,52 & 115,22 & 472,48 & 74,62 & 1,00 & 63,57 & 203,23 & 12,62 & 23,47 & 180,27 \\
\hline Discoglossus galganoi & $295 \mathrm{SB} 83$ & 99,00 & 177,82 & 81,79 & 35,97 & 5067,99 & 299,41 & 74,67 & 224,73 & 146,24 & 239,98 & 242,83 & 113,7 & 473,24 & 74,27 & 1,00 & 62,87 & 202,07 & 13,64 & 23,87 & 179,64 \\
\hline Discoglossus galganoi & 29SPB84 & 101,00 & 174,38 & 87,23 & 36,64 & 5210,35 & 303,54 & 68,52 & 235,02 & 120,05 & 239,13 & 241,89 & 109,09 & 493,86 & 76,00 & 1,26 & 61,76 & 209,21 & 15,46 & 24,91 & 188,50 \\
\hline Discoglossus galganoi & 29SPB85 & 100,00 & 172,92 & 91,72 & 37,08 & 5321,27 & \begin{tabular}{|c|}
307,98 \\
\end{tabular} & \begin{tabular}{ll|}
64,69 \\
\end{tabular} & 243,29 & \begin{tabular}{ll|}
115,49 \\
\end{tabular} & 239,49 & 242,16 & $\begin{array}{l}106,45 \\
\end{array}$ & \begin{tabular}{|l|l}
504,88 \\
\end{tabular} & 76,49 & 1,83 & 61,00 & 212,53 & \begin{tabular}{|l|l|l|}
17,19 \\
\end{tabular} & 25,68 & 193,27 \\
\hline Discoglossus galganoi & 29SPB86 & 100,00 & 169,77 & 96,12 & 37,83 & 5442,40 & 311,10 & 59,32 & 251,78 & \begin{tabular}{|l|l|l|}
111,16 \\
\end{tabular} & \begin{tabular}{|l|l|}
238,45 \\
\end{tabular} & 241,03 & 102,23 & 523,43 & 77,89 & 2,00 & 60,25 & 218,73 & \begin{tabular}{|l|}
18,97 \\
\end{tabular} & 26,66 & 201,01 \\
\hline Discoglossus galganoi & 29SPB88 & 100,00 & 162,84 & 103,31 & 38,20 & 5644,99 & 314,91 & 48,97 & 265,94 & 102,43 & 235,01 & 237,46 & 93,42 & 564,64 & 81,17 & 2,69 & 58,47 & 232,19 & 23,76 & 29,72 & 217,38 \\
\hline Discoglossus galganoi & 29SPB89 & 100,00 & 153,82 & 106,46 & 38,23 & 5757,84 & 312,54 & 38,85 & 273,69 & 92,73 & 228,07 & 230,59 & 83,71 & 620,39 & 86,93 & 3,43 & 57,47 & 252,59 & \begin{tabular}{|l|l}
28,53 \\
\end{tabular} & 33,33 & 239,85 \\
\hline Discoglossus galganoi & 29SPB90 & & & & & & & & & & & & & & & & & & & & \\
\hline Discoglossus galganoi & 29SPB91 & 91,00 & 176,63 & 82,44 & 36,29 & 4991,09 & 297,27 & 73,43 & 223,85 & 129,05 & 238,21 & 241,18 & 113,96 & 495,43 & 77,43 & 1,00 & 63,73 & 213,67 & 13,84 & 23,77 & $\begin{array}{ll}191,63 \\
\end{array}$ \\
\hline Discoglossus galganoi & 29SPB92 & 101,00 & 176,34 & 83,35 & 36,08 & 5092,33 & 299,59 & 72,02 & 227,57 & \begin{tabular}{ll|}
134,69 \\
\end{tabular} & 239,17 & 242,06 & 112,29 & \begin{tabular}{l|l}
493,55 \\
\end{tabular} & \begin{tabular}{l|l|}
77,15 \\
\end{tabular} & 1,00 & 63,20 & 211,19 & \begin{tabular}{l|l}
14,05 \\
\end{tabular} & 24,00 & 189,05 \\
\hline Discoglossus galganoi & 29SPB93 & 100,00 & 178,35 & 85,09 & 36,17 & 5167,99 & 304,21 & 72,76 & 231,45 & \begin{tabular}{|l|l|l|l|}
147,42 \\
\end{tabular} & 242,25 & 244,99 & 113,29 & 482,24 & 75,46 & 1,00 & 62,70 & 205,42 & \begin{tabular}{|l|l|l|}
14,09 \\
\end{tabular} & 24,00 & 183,32 \\
\hline Discoglossus galganoi & 29SPB94 & 101,00 & 174,68 & 89,65 & 36,78 & 5315,18 & 307,38 & 66,53 & 240,84 & 122,55 & 241,05 & 243,73 & \begin{tabular}{ll|}
108,15 \\
\end{tabular} & 502,46 & 77,16 & 1,28 & \begin{tabular}{l|l|l}
61,65 \\
\end{tabular} & 212,05 & 15,74 & 24,94 & 191,58 \\
\hline Discoglossus galganoi & 29SPB95 & 99,00 & 169,82 & 94,92 & 37,18 & 5462,90 & 310,08 & 58,89 & 251,19 & \begin{tabular}{|l|l|}
110,79 \\
\end{tabular} & 238,72 & 241,25 & $\begin{array}{l}101,85 \\
\end{array}$ & 531,43 & 79,77 & 2,00 & 60,74 & 222,38 & 18,52 & 26,68 & 203,61 \\
\hline Discoglossus galganoi & 29SPB96 & 100,00 & 169,28 & 98,16 & 37,82 & 5549,99 & 313,89 & 56,72 & 257,17 & 109,34 & 239,57 & 242,12 & 100,46 & 534,59 & 79,41 & 2,00 & 60,10 & 222,36 & 19,56 & 27,16 & 204,72 \\
\hline Discoglossus galganoi & 29SPB97 & 100,00 & 170,11 & 100,77 & 38,00 & 5609,81 & 317,98 & 56,11 & 261,87 & 109,56 & 241,47 & 243,77 & \begin{tabular}{|c|}
100,57 \\
\end{tabular} & 529,92 & 78,18 & 2,00 & \begin{tabular}{|l|l|}
59,68 \\
\end{tabular} & 219,39 & 20,10 & 27,11 & 202,56 \\
\hline Discoglossus galganoi & 29SPB99 & 100,00 & 15 & 107,69 & 38,00 & 5848,46 & & 35,78 & 278,14 & 90,23 & 227,96 & 230,29 & 81, & 635,97 & 88,77 & 3,60 & 57,37 & 257,79 & F & t & 245,06 \\
\hline Discoglossus galganoi & $295 \mathrm{SCOO}$ & 101,00 & 165,29 & 112,18 & 42,05 & 5145,05 & 5 & 59,05 & 263,01 & 112,51 & 230,68 & 235,07 & 103,90 & 548,8 & 80,47 & 2,00 & 59,99 & 232,29 & 24,28 & 25,03 & 228,07 \\
\hline Discoglossus galganoi & $29 \mathrm{SPCO4}$ & 100,00 & 161,82 & 106,48 & 41,04 & 5164,14 & 314,94 & 58,80 & 256,14 & 108,27 & 229,01 & 231,91 & 100,14 & 589,98 & 81,44 & 3,02 & 57,23 & 241,04 & \begin{tabular}{|l|}
30,93 \\
\end{tabular} & 30,93 & 240,44 \\
\hline Discoglossus galganoi & $295 \mathrm{SCO5}$ & 101,00 & 163,99 & 104,51 & 40,97 & 5131,42 & 314,60 & 61,82 & 252,78 & 109,97 & 230,79 & 233,51 & 102,35 & 583,41 & 80,05 & 3,00 & $\begin{array}{l}57,05 \\
\end{array}$ & 237,34 & 31,10 & 31,10 & 236,97 \\
\hline Discoglossus galganoi & 29SPC08 & 100,00 & 160,69 & 99,94 & 39,98 & 5139,34 & 308,49 & 60,77 & 247,72 & \begin{tabular}{|c|}
99,37 \\
\end{tabular} & \begin{tabular}{|l|l|}
228,08 \\
\end{tabular} & 230,42 & \begin{tabular}{|c|}
99,08 \\
\end{tabular} & 640,14 & 87,99 & 4,12 & 55,88 & 258,78 & 36,81 & 36,81 & 258,78 \\
\hline Discoglossus galganoi & 29SPC10 & 101,00 & 168,64 & 109,86 & 41,74 & 66,21 & 322. & 61, & 260,56 & \begin{tabular}{|c|c|}
115,16 \\
\end{tabular} & 4,22 & 8,31 & 106,2 & 527,4 & 76,84 & 2,00 & 59, & 222,91 & I & 4,74 & 216,76 \\
\hline Discoglossus galganoi & $295 P C 12$ & 99,00 & 16 & 109,94 & 41,19 & 522 & 32 & 60,97 & 262,05 & 113,38 & 234,04 & 238,20 & 104, & 540, & 76,70 & 2,27 & 58, & 224,17 & 26,18 & 27,20 & 219,97 \\
\hline Discoglossus galganoi & 29SPC13 & 101,00 & 160,51 & 10 & 41,00 & 5282,23 & & 54,79 & 262,31 & \begin{tabular}{|l|l|l|l}
105,93 \\
\end{tabular} & 228,42 & 232,21 & 97, & 589,14 & 81,72 & 3,00 & 57,24 & 240,98 & 30,63 & 30,77 & 238,69 \\
\hline Discoglossus galganoi & \begin{tabular}{|l|l|}
$295 P C 18$ \\
\end{tabular} & 101,00 & 160,60 & 102,15 & 39,90 & 5255,88 & 311,74 & 58,30 & 253,45 & 102,59 & 228,97 & 231,89 & 97,68 & 638,67 & \begin{tabular}{|l|l|}
86,96 \\
\end{tabular} & 4,34 & 55,44 & 256,29 & 37,43 & 37,43 & 256,26 \\
\hline Discoglossus galganoi & $29 \mathrm{SPC} 23$ & 100,00 & 165,26 & 109,13 & 40,97 & 5331,75 & 321,37 & 57,58 & 263,80 & 109,62 & 233,19 & 237,03 & 100,88 & 556,98 & 77,25 & 3,00 & 57,18 & 227,79 & 28,54 & 29,44 & 223,46 \\
\hline Discoglossus galganoi & $29 \mathrm{SPC} 34$ & 101,00 & 167,87 & 109,05 & 40,35 & 5414,99 & 324 & 58,33 & 266,15 & \begin{tabular}{|c|}
110,67 \\
\end{tabular} & 236,92 & 240,31 & 102, & 542,35 & 74,31 & 3,00 & 56,4 & 220,05 & 47 & 29,80 & 214,46 \\
\hline Discoglossus galganoi & $295 \mathrm{SC} 35$ & 100 & 167,02 & 108,80 & 40,12 & 5433 & 323,99 & $\begin{array}{l}57,58 \\
\end{array}$ & 266,41 & 109,55 & 236,34 & 239,79 & 101,03 & 553,34 & 75,23 & 3,16 & \begin{tabular}{|l|l|l|}
55,95 \\
\end{tabular} & 223,18 & 30,26 & 31,26 & 218,25 \\
\hline \begin{tabular}{|l} 
Discoglossus galganoi \\
\end{tabular} & $295 P C 40$ & 101,00 & 164,01 & 106,92 & 40,01 & 5409,63 & 317,65 & 54,14 & 263,51 & 107,14 & \begin{tabular}{l|l|}
233,05 \\
\end{tabular} & 236,42 & 98,43 & 550,22 & 77,29 & 2,92 & \begin{tabular}{c|c}
57,95 \\
\end{tabular} & 227,62 & \begin{tabular}{|l|l|}
25,75 \\
\end{tabular} & 28,88 & 218,07 \\
\hline Discoglossus galganoi & 29SPC41 & 100,00 & 166,05 & 108,00 & 40,01 & 5437,09 & 321,08 & 55,40 & 265,69 & 108,56 & 235,40 & 238,69 & 99,84 & 540,63 & 75,50 & 3,00 & 57,42 & 222,30 & 26,20 & 29,02 & 213,41 \\
\hline Discoglossus galganoi & 29SPC44 & 100,00 & 168,91 & 109,81 & 40,04 & 5516,29 & 327,01 & 57,07 & 269,94 & 110,10 & 239,67 & 242,44 & 101,4 & 531,63 & 73,28 & 3,00 & 56,19 & 215,10 & 27,82 & 29,73 & 207,85 \\
\hline Discoglossus galganoi & 29SPC45 & & 168 & 109,90 & 40, & 5520 & 327. & 56, & 270 & 109 & 23,59 & 242 & 101, & 536,43 & 73,75 & 3,02 & 55,77 & 215,92 & 28,96 & 30,40 & 209 \\
\hline Discoglossus galganoi & 29SPC46 & 100,00 & 168,21 & 110,05 & 40,00 & 5541,22 & 327,67 & 56,19 & 271,48 & 108,93 & 239,34 & 242,04 & 100,49 & 546,01 & 74,72 & 3,51 & 55,06 & 218,49 & \begin{tabular}{|l|l|}
31,15 \\
\end{tabular} & 32,31 & 212,21 \\
\hline Discoglossus galganoi & 29SPC50 & 100,00 & 165,21 & 106,32 & 39,84 & 5479,81 & 318,78 & 54,19 & 264,59 & \begin{tabular}{|l|}
107,29 \\
\end{tabular} & 235,18 & 238,30 & $\begin{array}{l}98,45 \\
\end{array}$ & 542,76 & 76,27 & 2,73 & 57,73 & 223,62 & 25,01 & 28,78 & 212,74 \\
\hline Discoglossus galganoi & 29SPC51 & 101,00 & 167,10 & 107,59 & 39,88 & 5507,90 & 322,31 & 55,03 & 267,28 & $\begin{array}{l}108,55 \\
\end{array}$ & 237,41 & 240,46 & 99,80 & 533,46 & 74,70 & 3,00 & 57,20 & 218,51 & 25,75 & 29,11 & 208,22 \\
\hline Discoglos & $29 \mathrm{SPC52}$ & 100,00 & 168,43 & 108,65 & 39,5 & & & 55,7 & 265 & & 9,34 & & 100,59 & 526, & 73,52 & 3,00 & 56,66 & 214 & & 2 & 204, \\
\hline Discoglossus galganoi & 29SPC56 & 100,00 & 166,97 & 111,41 & 39,97 & 5663,5 & 329 & 52,7 & 276,63 & $106,25[$ & 240,07 & 242,45 & 97,86 & 546,35 & 75,01 & 3,92 & 54,31 & 217,49 & 31,92 & 33,19 & 209 \\
\hline Discoglossus galganoi & 29SPC57 & 100,00 & 168,13 & 111,79 & 39,96 & 5684,87 & 331,09 & 53,09 & 278,00 & 106,93 & 241,54 & 243,71 & 98,65 & 543,91 & \begin{tabular}{|l|l}
74,76 \\
\end{tabular} & 3,99 & 53,94 & 215,79 & 32,57 & 33,71 & 208,22 \\
\hline
\end{tabular}




\begin{tabular}{|c|c|c|c|c|c|c|c|c|c|c|c|c|c|c|c|c|c|c|c|c|c|}
\hline TAXON & UTM & $\mathrm{km} 2$ & B101 & $\mathrm{B1O2}$ & $\mathrm{BIO3}$ & B104 & B105 & B106 & B107 & B108 & B109 & B1010 & BIO11 & BIO12 & 81013 & B1014 & B1015 & B1016 & $\begin{array}{ll}1017 \\
17\end{array}$ & $\mathrm{BIO18}$ & B1019 \\
\hline Discoglossus galganoi & 29SPC60 & 100,00 & 163,18 & 106,26 & 39,15 & 5569,55 & 317,99 & 50,66 & 267,33 & 104,12 & 234,43 & 237,22 & 95,19 & 556,04 & 78,26 & 2,98 & 57,41 & 227,75 & 25,89 & 29,93 & 216,04 \\
\hline Discoglossus galganoi & 29SPC61 & 100,00 & 162,79 & 107,89 & \begin{tabular}{|c|}
39,17 \\
\end{tabular} & 5622,32 & 320,55 & 49,19 & 271,36 & 103,19 & 234,95 & 237,86 & 94,22 & 558,30 & 78,06 & 3,08 & 56,97 & 227,34 & 26,79 & 30,50 & 216,45 \\
\hline Discoglossus galganoi & 29SPC62 & 100,00 & 167,16 & 108,97 & 39,37 & 5633,15 & 325,76 & 52,92 & 272,84 & 107,02 & 239,42 & 241,86 & 98,14 & 532,84 & 74,71 & 3,00 & 56,49 & 216,13 & 26,27 & 29,60 & 205,40 \\
\hline Discoglossus galganoi & 29SPC68 & 101,00 & 165,88 & 113,77 & 39,39 & 5827,84 & 333,01 & 48,04 & 284,97 & 102,98 & 241,62 & 243,26 & 94,45 & 550,29 & 75,81 & 4,00 & 53,27 & 216,66 & 33,90 & 34,73 & 207,97 \\
\hline Discoglossus galganoi & 29SPC69 & 100,00 & 168,82 & 114,62 & \begin{tabular}{|c|}
39,47 \\
\end{tabular} & 5851,69 & 336,48 & 49,70 & 286,78 & \begin{tabular}{|c|c|}
105,11 \\
\end{tabular} & 244,84 & 246,10 & 96,77 & 535,56 & 74,10 & 4,00 & 52,84 & 210,37 & 33,94 & 34,49 & 201,39 \\
\hline Discoglossus galganoi & $29 S P C 70$ & 100,00 & 161,09 & 106,73 & 38,95 & 5675,07 & 318,19 & 46,80 & 271,38 & 100,66 & 233,89 & 236,54 & 91,70 & 571,07 & 80,41 & 3,15 & 57,24 & 232,70 & 26,59 & 31,03 & 220,35 \\
\hline Discoglossus galganoi & 29SPC71 & 101,00 & 158,40 & 108,44 & 38,92 & 5732,58 & 318,87 & 43,40 & 275,47 & 97,48 & 232,29 & 234,86 & 88,52 & 587,30 & 81,78 & 3,33 & 56,56 & 237,71 & 28,70 & 32,39 & 226,39 \\
\hline Discoglossus galganoi & $295 P C 72$ & 100,00 & 165,22 & 109,58 & 39,03 & 5735,12 & 326,20 & 49,42 & 276,78 & 103,68 & 239,04 & 241,32 & 95,01 & 543,63 & 76,32 & 3,01 & 56,35 & 219,52 & 26,65 & 30,28 & 208,00 \\
\hline Discoglossus galganoi & $29 S P C 74$ & 100,00 & 162,33 & 111,87 & 39,01 & 5819,58 & 327,60 & 45,12 & 282,49 & 99,79 & 237,63 & 239,69 & 91,24 & 560,86 & 77,53 & 3,71 & 54,81 & 223,50 & 30,66 & 33,10 & 213,25 \\
\hline Discoglossus galganoi & 29SPC75 & 100,00 & 160,62 & 112,54 & 38,99 & 5859,96 & 327,79 & 43,08 & 284,70 & 97,82 & 236,75 & 238,66 & 89,31 & 570,99 & 78,47 & 4,01 & 54,31 & 226,36 & 32,31 & 34,26 & 216,50 \\
\hline Discoglossus galganoi & $295 P C 80$ & 101,00 & 154,66 & 107,93 & 38,41 & 5795,37 & 315,84 & 39,03 & 276,81 & 93,23 & 229,63 & 232,06 & 84,21 & 614,21 & 85,61 & 3,64 & 56,86 & 248,62 & 29,24 & 33,59 & 236,45 \\
\hline Discoglossus galganoi & $295 P C 82$ & 101,00 & 160,19 & 110,52 & 38,84 & 5854,69 & 324,58 & 42,86 & 281,71 & 97,50 & 235,97 & 238,01 & 88,63 & 575,40 & 80,09 & 3,43 & 55,90 & 230,86 & 28,88 & 32,50 & 219,15 \\
\hline \begin{tabular}{|l} 
Discoglossus galganoi \\
\end{tabular} & 29SPC83 & 100,00 & 162,91 & 111,65 & 38,96 & 5873,63 & 328,54 & 44,51 & 284,04 & 99,78 & 238,88 & 240,86 & 91,00 & 557,23 & 77,57 & 3,32 & 55,43 & 222,59 & 28,81 & 32,01 & 210,99 \\
\hline Discoglossus galganoi & $295 P C 84$ & 101,00 & 157,50 & 112,40 & 38,91 & 5936,03 & 326,01 & 39,01 & 286,99 & 93,97 & 234,75 & 236,48 & 85,22 & 589,00 & 80,89 & 4,03 & 54,68 & 233,65 & 32,11 & 34,68 & 222,91 \\
\hline Discoglossus galganoi & $295 P C 85$ & 100,00 & 154,08 & 112,77 & 38,61 & 5968,82 & 324,12 & 35,77 & 288,36 & 90,35 & 231,94 & 233,88 & 81,75 & 611,60 & 83,11 & 4,36 & 53,93 & 241,21 & 34,97 & 36,92 & 231,16 \\
\hline Discoglossus galganoi & 29SPC90 & 100,00 & 155,39 & 109,04 & 38,17 & 5882,69 & 318,88 & 38,08 & 280,80 & 92,63 & 231,65 & 233,82 & 83,79 & 613,37 & 85,57 & 3,45 & 56,86 & 247,51 & 28,96 & 33,52 & 234,93 \\
\hline Discoglossus galganoi & 29SPC91 & 101,00 & 158,57 & 110,27 & 38,30 & 5915,33 & 323,67 & 40,32 & 283,35 & 95,27 & 235,23 & 237,27 & 86,32 & 589,82 & 82,32 & 3,35 & 56,42 & 237,01 & 28,48 & 32,65 & 224,46 \\
\hline \begin{tabular}{|l} 
Discoglossus galganoi \\
\end{tabular} & 29SPC92 & 99,00 & 153,35 & 111,44 & 38,22 & 5977,65 & 321,58 & 34,63 & 286,95 & 89,59 & 231,15 & 233,13 & 80,78 & 621,02 & 85,31 & 3,99 & 55,51 & 247,66 & 31,83 & 35,31 & 236,26 \\
\hline Discoglossus galganoi & 29SPC95 & 101,00 & 153,03 & 113,44 & 38,21 & 6051,86 & 325,26 & 33,25 & 292,01 & 88,29 & 232,23 & 233,77 & 79,68 & 615,80 & 83,41 & 4,51 & 53,75 & 241,99 & 35,09 & 37,22 & 231,30 \\
\hline Discoglossus galganoi & 29SPD00 & 101,00 & 164,58 & 99,37 & 39,79 & 5146,66 & 311,81 & 64,14 & 247,67 & 103,56 & 230,05 & 234,15 & 102,51 & 650,04 & 89,94 & 4,54 & 55,90 & 263,25 & 37,71 & 38,10 & 263,25 \\
\hline Discoglossus galganoi & 29SPD01 & 101,00 & 164,77 & 98,75 & 39,30 & 5155,83 & 311,99 & \begin{tabular}{|c|}
64,27 \\
\end{tabular} & 247,72 & 104,12 & 230,51 & 234,52 & 102,75 & 667,05 & 92, & 5,00 & 55,91 & 270,59 & 38,92 & 39,36 & 270,59 \\
\hline Discoglossus galganoi & 29SPD02 & 100,00 & 167,21 & 98,91 & 39,28 & 5169,43 & 314,35 & 66,14 & 248,21 & 109,00 & 233,19 & 236,94 & 104,65 & 665,74 & 92,82 & 4,97 & 55,84 & 270,11 & 38,65 & 39,55 & 270,11 \\
\hline \begin{tabular}{|l} 
Discoglossus galganoi \\
\end{tabular} & 29SPD06 & 101,00 & 162,42 & 96,54 & \begin{tabular}{|c|}
38,07 \\
\end{tabular} & 5278,41 & 310,58 & \begin{tabular}{|c|}
61,03 \\
\end{tabular} & 249,54 & 98,67 & 230,34 & 233,67 & 98,67 & 781,05 & 111,75 & 6,01 & 55,70 & 318,61 & 46,15 & 47,22 & 318,61 \\
\hline Discoglossus galganoi & $29 S P D 13$ & 100,00 & 165,32 & 99,37 & 38,84 & 5312,71 & 315,68 & 63,01 & 252,67 & 107,43 & 233,46 & 237,16 & 101,29 & 694,89 & 96,87 & 5,21 & 55,44 & 280,93 & 41,01 & 42,06 & 280,87 \\
\hline Discoglossus galganoi & 29SPD14 & 101,00 & 165,21 & 98,75 & 38,55 & 5330,92 & 315,60 & 62,83 & 252,77 & 106,32 & 233,90 & 237,29 & 101,11 & 714,56 & 100,17 & 5,54 & 55,28 & 289,08 & 42,56 & 43,73 & 289,07 \\
\hline Discoglossus galganoi & 29SPD16 & 100,00 & 161,78 & 96,94 & 37,96 & 5407,71 & 312,48 & 59,44 & 253,04 & 96,84 & 231,64 & 234,87 & 96,84 & 780,17 & 111,29 & 6,00 & 55,41 & 317,28 & 46,43 & 47,58 & 317,28 \\
\hline Discoglossus galganoi & 29SPD17 & 100,00 & 162,40 & 97,18 & 37,83 & 5441,73 & 313,80 & 59,03 & \begin{tabular}{|l|}
254,77 \\
25,4
\end{tabular} & 97,30 & 232,95 & 235,84 & 90,87 & 787,81 & $\frac{111,25}{112,55}$ & 6,00 & 55,10 & 319,82 & $\begin{array}{l}40,45 \\
47,48\end{array}$ & 48,64 & 319,82 \\
\hline Discoglossus galganoi & 29SPD24 & 100,00 & 163,64 & 99,38 & 38,08 & 5448,06 & 316,78 & 60,27 & 256,51 & 106,05 & 234,11 & 237,44 & 98,42 & 720,95 & 100,47 & 5,90 & 54,74 & 290,40 & 43,93 & 45,10 & 290,08 \\
\hline Discoglossus galganoi & $29 S P D 25$ & 101,00 & 160,69 & 97,33 & 37,76 & 5474,17 & 313,32 & 58,49 & 254,84 & 98,78 & 231,64 & 235,06 & 95,46 & 766,08 & 108,18 & 6,11 & 55,04 & 309,96 & 46,21 & 47,49 & 309,96 \\
\hline Discoglossus galganoi & $29 S P D 26$ & 101,00 & 160,01 & 96,71 & 37,40 & 5512,44 & 312,78 & 57,41 & 255,37 & 95,55 & 231,52 & 234,88 & 94,22 & 787,61 & 111,94 & 6,14 & 55,06 & 319,04 & 47,62 & 48,89 & 319,04 \\
\hline Discoglossus galganoi & $29 S P D 29$ & 101,00 & 165,74 & 99,41 & 37,31 & 5638,23 & 320,90 & 57,92 & 262,98 & 103,96 & 239,38 & 240,89 & 97,06 & 762,84 & 108,38 & 5,99 & 54,66 & 306,90 & 46,46 & 48,16 & 306,55 \\
\hline \begin{tabular}{|l} 
Discoglossus galganoi \\
\end{tabular} & 29SPD30 & 100,00 & 161,50 & 105,37 & 39,15 & 5515,50 & 318,91 & 54,19 & 264,71 & $\begin{array}{l}103,47 \\
\end{array}$ & \begin{tabular}{|l|l|}
232,66 \\
\end{tabular} & \begin{tabular}{|l|}
236,00 \\
\end{tabular} & 95,16 & $\mid 042,40$ & \begin{tabular}{|l|}
87,17 \\
\end{tabular} & 5,00 & 54,22 & 259,03 & 39,70 & $\begin{array}{ll}40,00 \\
40,00\end{array}$ & 256,64 \\
\hline Discoglossus galganoi & 29SPD34 & 101,00 & 160,24 & 99,30 & \begin{tabular}{ll|l}
37,85 & \\
\end{tabular} & 5550,93 & 315,39 & 56,72 & 258,67 & 102,24 & 232,29 & 235,74 & 94,27 & 740,95 & 103,04 & 6,14 & 54,40 & 298,01 & 45,47 & 46,65 & 297,21 \\
\hline Discoglossus galganoi & $29 S P D 35$ & 100,00 & 150,96 & 93,90 & 36,71 & 5549,48 & 303,30 & 51,48 & 251,82 & 87,76 & 223,30 & 227,27 & 86,22 & 847,69 & 120,82 & 7,24 & 54,84 & 343,56 & 52,06 & 53,06 & 343,56 \\
\hline Discoglossus galganoi & $29 S P D 36$ & 101,00 & 153,98 & 94,90 & 36,77 & 5604,19 & 307,60 & 52,43 & 255,18 & 91,66 & 227,18 & 230,49 & 87,92 & 831,12 & 118,49 & 6,95 & 54,64 & 336,25 & 51,13 & 52,08 & 336,14 \\
\hline Discoglossus galganoi & $295 P D 37$ & 100,00 & 162,36 & 98,66 & 37,05 & 5674,95 & 318,45 & 56,13 & 262,32 & 101,76 & 236,42 & 238,79 & 94,20 & 758,86 & 106,97 & 5,99 & 54,36 & 305,26 & 46,45 & 47,80 & 304,45 \\
\hline \begin{tabular}{|l} 
Discoglossus galganoi \\
\end{tabular} & 29SPD38 & 101,00 & $\begin{array}{ll}10,30,82 \\
162,82\end{array}$ & $\begin{array}{ll}0,000 \\
98,87\end{array}$ & 36,98 & 5732,46 & \begin{tabular}{|l|}
31,494 \\
319,80
\end{tabular} & $\begin{array}{l}50,139 \\
55,39\end{array}$ & $\begin{array}{ll}264,42 \\
\end{array}$ & $\begin{array}{l}101,39 \\
101,39\end{array}$ & 237,89 & 239,77 & $\begin{array}{l}34,20 \\
93,75 \\
\end{array}$ & \begin{tabular}{|l|}
761,730 \\
\end{tabular} & $\mid 107,66$ & 5, 593 & 54,35 & \begin{tabular}{|l|l|}
305,98 \\
302
\end{tabular} & $\begin{array}{l}0,45 \\
46,83 \\
\end{array}$ & $\begin{array}{l}44,00 \\
48,18\end{array}$ & 305,15 \\
\hline Discoglossus galganoi & 29SPD43 & 99,00 & 163,16 & 104,89 & \begin{tabular}{|c|}
38,67 \\
\end{tabular} & 5647,58 & 323,13 & 54,71 & 268,42 & 103,38 & 236,58 & 239,30 & 95,26 & 675,98 & 91,26 & 5,35 & 53,69 & 269,65 & 42,25 & 43,30 & 266,46 \\
\hline Discoglossus galganoi & 29SPD44 & 101,00 & 155,18 & 99,28 & \begin{tabular}{|c|}
37,57 \\
\end{tabular} & 5640,11 & 312,16 & 51,31 & 260,85 & 96,60 & 228,72 & 232,15 & 88,58 & 767,07 & 106,42 & 6,42 & 54,01 & 307,69 & 47,74 & 48,74 & 306,19 \\
\hline Discoglossus galganoi & $29 S P D 45$ & 99,00 & 145,56 & 94,44 & 36,50 & 5659,10 & 300,09 & 44,74 & 255,35 & 86,12 & 220,27 & 223,39 & 79,69 & 866,89 & 122, & 7,64 & 54,20 & 348,96 & 54,20 & 54,73 & 348,51 \\
\hline Discoglossus galganoi & $29 S P D 46$ & 100,00 & 156,64 & 97,92 & 36,98 & 5715,55 & 313,60 & 51,85 & 261,75 & 96,79 & 231,46 & 234,36 & 88,84 & 779,71 & 109,38 & 6,38 & 54,05 & 313,09 & 48,41 & 49,55 & 311,72 \\
\hline \begin{tabular}{|l|} 
Discoglossus galganoi \\
\end{tabular} & 29SPD49 & 99,00 & 164,02 & 100,39 & $36, \varepsilon$ & 5853,23 & 323,01 & 53,88 & 269,13 & 100,56 & 240,91 & 242,15 & 93,07 & 730,46 & 102,34 & 5,7 & 53,71 & 291,92 & 45,35 & 46,81 & 289,43 \\
\hline Discoglossus galganoi & 29SPD52 & 101,00 & 166,26 & 111,13 & 39,15 & 5767,16 & 331,38 & 51,92 & 279,45 & 104,00 & 241,34 & 243,14 & 96,06 & 610,44 & 82,21 & 4,99 & 52,86 & 241,30 & 38,96 & 39,79 & 235,35 \\
\hline Discoglossus galganoi & 29SPD53 & 101,00 & 162,51 & 107,88 & 38,71 & 5768,06 & 326,25 & 50,88 & 275,37 & 100,99 & 237,82 & 239,95 & 92,98 & 656,75 & 87,85 & 5,19 & 52,99 & 260,40 & 41,79 & 42,66 & 255,47 \\
\hline Discoglossus galganoi & 29SPD54 & 100,00 & 159,58 & 104,37 & 37,9 & 5772,25 & 321,21 & 50,21 & 271,00 & 98,48 & 235,00 & 237,44 & 90,46 & 698,68 & 94,3 & 5,69 & 53,15 & 277,95 & 44,20 & 45,22 & 273,87 \\
\hline Discoglossus galganoi & 29SPD56 & 101,00 & 157,86 & 100,85 & 37,0 & 5829,21 & \begin{tabular}{|l|}
317,95 \\
317,
\end{tabular} & $\begin{array}{l}0,2167 \\
49,1\end{array}$ & 268,29 & $\begin{array}{l}0,46,27 \\
96\end{array}$ & 234,37 & 236,51 & 88,25 & $\begin{array}{l}735,80 \\
\end{array}$ & 101,2 & $\begin{array}{l}6,006 \\
6,06 \\
\end{array}$ & 53,23 & 293,24 & $\begin{array}{lll}46,52 \\
\end{array}$ & $\begin{array}{ll}47,25 \\
47,58\end{array}$ & 289,84 \\
\hline Discoglossus galganoi & 29SPD58 & 101,00 & 160,07 & 100,45 & 36,7 & 5897,48 & 320,11 & 50,25 & 269,86 & 96,85 & 237,75 & 239,16 & 89,13 & 729,97 & 101,25 & 5,8 & 53,19 & 290,69 & 45,96 & 47,07 & 287,24 \\
\hline Discoglossus galganoi & $29 S P D 60$ & 100,00 & 168,81 & 115,08 & 39,66 & 5867,40 & 337,01 & 49,50 & 287,52 & 104,80 & 245,21 & 246,19 & 96,54 & 544,56 & 75,00 & 4,03 & 52,36 & 213,40 & 35,45 & 35,99 & 204,68 \\
\hline Discoglossus galganoi & $29 S P D 61$ & 100,00 & 167,71 & 115,31 & 39,86 & 5882,00 & 336,11 & 48,61 & 287,49 & 103,42 & 244,34 & 245,41 & 95,43 & 563,84 & 77,06 & 4,32 & 52,19 & 220,94 & 36,92 & 37,50 & 212,62 \\
\hline Discoglossus galganoi & 29SPD62 & 100,00 & 165,88 & 114,38 & 39,3 & 5882,08 & 334,61 & 48,07 & 286,54 & 101,80 & 242,73 & 243,80 & 93,97 & 590,70 & 79,85 & 4,86 & 52,16 & 85 & 38,45 & 39,20 & 224,20 \\
\hline \begin{tabular}{|l} 
Discoglossus galganoi \\
\end{tabular} & $\begin{array}{l}25 \mathrm{PSPOL} \\
29 \mathrm{PD} 64\end{array}$ & 101,00 & 163 & $\frac{11}{10}$ & 38 & 5 & \begin{tabular}{|l|}
329,000 \\
329,05
\end{tabular} & $\begin{array}{l}40,39 \\
49,39 \\
\end{array}$ & \begin{tabular}{|l|}
279,646 \\
\end{tabular} & $\begin{array}{l}100,14 \\
\end{array}$ & \begin{tabular}{|l|}
240,79 \\
240
\end{tabular} & \begin{tabular}{|l|}
242,18 \\
\end{tabular} & $\begin{array}{ll}0,22 \\
92,22\end{array}$ & $\begin{array}{l}\mid 930,05 \\
634,25\end{array}$ & $\begin{array}{l}\mid 7,000 \\
84,37\end{array}$ & $\begin{array}{l}4,000 \\
5,02\end{array}$ & $\frac{2,10}{52,28}$ & \begin{tabular}{|l|l|l|l|l|}
249,93 \\
\end{tabular} & $\begin{array}{l}0,435 \\
40,92 \\
\end{array}$ & $\begin{array}{l}\frac{35,20}{41,94} \\
\end{array}$ & 243,47 \\
\hline Discoglossus galganoi & 29SPD65 & 99,00 & 159,07 & 105,07 & 37,66 & 5905,09 & 322,77 & 47,30 & 275,47 & 96,15 & 236,66 & 238,35 & 88,16 & 682,61 & 91,35 & 5,51 & 52,42 & 269,79 & 43,77 & 44,68 & 264,17 \\
\hline \begin{tabular}{|l} 
Discoglossus galganoi \\
\end{tabular} & 29SPD69 & 99,00 & 163,36 & 102,63 & 36,88 & 5985,69 & 325,23 & 50,46 & \begin{tabular}{|l|}
274,77 \\
\end{tabular} & 98,32 & 242,23 & 242,91 & $\begin{array}{l}90,104 \\
90,58\end{array}$ & $\mid 672,44$ & 91,76 & 5,20 & 52,53 & 265,70 & 42,64 & 44,03 & 260,42 \\
\hline Discoglossus galganoi & $29 S P D 70$ & 101,00 & 168,47 & 116,41 & 39,00 & 5985,76 & 339,92 & 46,32 & 293,60 & 102,76 & 246,63 & 247,24 & 94,58 & 521,55 & 72,42 & 4,00 & 51,71 & 202,79 & 34,94 & 35,31 & 192,28 \\
\hline Discoglossus galganoi & $29 S P D 71$ & 100,00 & 168,40 & 116,38 & 39,0 & 5976,06 & 339,55 & 46,77 & 292,79 & 102,82 & 246 & 247 & 94,75 & 533,62 & 73,51 & 4,00 & 51,58 & 207,55 & 35,67 & 36,27 & 197 \\
\hline \begin{tabular}{|l|} 
Discoglossus galganoi \\
\end{tabular} & $\begin{array}{l}25 \mathrm{PSD} 1 \\
29 \mathrm{SPD} 2\end{array}$ & $\begin{array}{l}101,00 \\
100\end{array}$ & $\begin{array}{l}100,40 \\
167,95\end{array}$ & $\begin{array}{l}110,50 \\
115,53 \\
\end{array}$ & | 39,09 & 5969,52 & \begin{tabular}{|c|c|}
338,12 \\
338,12
\end{tabular} & $\begin{array}{l}40,113 \\
47,37 \\
\end{array}$ & \begin{tabular}{|l|}
290,75 \\
\end{tabular} & $\begin{array}{l}102,45 \\
102\end{array}$ & \begin{tabular}{|l|l|}
245,99 \\
\end{tabular} & \begin{tabular}{|l|}
246,49 \\
240
\end{tabular} & \begin{tabular}{|c|}
44,50 \\
94,5
\end{tabular} & \begin{tabular}{|c|}
$549,0<09$ \\
549
\end{tabular} & 74,84 & $\begin{array}{l}4,00 \\
4,03 \\
\end{array}$ & $\begin{array}{l}1,1,60 \\
51,63\end{array}$ & \begin{tabular}{|l|}
214,01 \\
\end{tabular} & $\begin{array}{l}3,00 \\
36,08 \\
\end{array}$ & $\begin{array}{ll}30,21 \\
36,81\end{array}$ & $\begin{array}{l}201,40 \\
204,42\end{array}$ \\
\hline Discoglossus galganoi & 29SPD79 & 100,00 & 164,08 & 103,93 & 36,99 & 6046,74 & 328,12 & 49,56 & 278,56 & 98,21 & 243,88 & 244,25 & 90,47 & 634,59 & 85,11 & 4,96 & 51,67 & 248,84 & 40,90 & 42,10 & 242,06 \\
\hline Discoglossus galganoi & 29SPD83 & 100,00 & 164.86 & 113,41 & 38,41 & 6057.4 & 336.19 & 44,88 & 291.31 & 98.84 & 244,34 & 244,99 & 90,78 & 559,73 & 75,01 & 4,28 & 51,20 & 21,95 & 36.56 & 37,66 & 206,87 \\
\hline Discoglossus & 29SPE12 & 100,00 & 151,78 & 95,52 & 36,56 & 5580,80 & 303,98 & 46,12 & $257, \varepsilon$ & 84,14 & 225,44 & 226 & 84 & 943,37 & 138,41 & 4 & 55,08 & 383,08 & 58,69 & 59,05 & 383,08 \\
\hline \begin{tabular}{|l} 
Discoglossus galganoi \\
\end{tabular} & 29SPE21 & 100,00 & 157,59 & 97,04 & 36,15 & 5765,61 & 13,94 & 49,60 & 264,34 & 88,08 & 233,56 & 234,55 & 87,85 & 858,44 & 124,23 & 7,02 & 54,74 & 346,39 & 53,52 & 54,15 & 346,39 \\
\hline
\end{tabular}




\begin{tabular}{|c|c|c|c|c|c|c|c|c|c|c|c|c|c|c|c|c|c|c|c|c|c|}
\hline TAXON & UTM & km2 & BIO1 & $\mathrm{BIO2}$ & $\mathrm{B1O3}$ & $\mathrm{B1O4}$ & B105 & B106 & B107 & B108 & B109 & B1010 & BIO11 & B1012 & BIO13 & B1014 & B1015 & BIO16 & B1017 & B1018 & \begin{tabular}{|c|} 
BIO19 \\
301,33
\end{tabular} \\
\hline Discoglossus galganoi & 29SPE30 & 100,00 & 165,01 & 99,91| & 36,85 & 5785,91 & 322,58 & 55,11 & 267,47 & 101,66 & 240,95 & 241,99 & 94,62 & 754,97 & 106,97 & 6,00 & 54,14 & 302,59 & 46,47 & 48,13 & 301,33 \\
\hline Discoglossus galganoi & 29SPE31 & 101,00 & 157,49 & 97,29 & 36,01 & 5870,90 & 315,45 & $\begin{array}{l}48,45 \\
\end{array}$ & 267,00 & 91,57 & 234,94 & 235,83 & 86,60 & 833,36 & 120,00 & 6,90 & 54,25 & 334,68 & 52,14 & 52,80 & 334,45 \\
\hline Discoglossus galganoi & 29SPE32 & 100,00 & 155,12 & 96,91 & 36,01 & 5844,35 & 312,09 & 46,21 & 265,88 & 88,22 & 232,29 & \begin{tabular}{l|l|}
232,95 \\
\end{tabular} & 84,38 & 856,54 & 123,96 & 7,15 & 54,26 & 343,94 & 53,86 & 54,35 & 343,80 \\
\hline Discoglossus galganoi & 29SPE42 & 99,00 & 156,54 & 97,94 & 36,04 & 5903,14 & 314,45 & 46,30 & 268,15 & 92,15 & 234,38 & 234,94 & 84,72 & 808,24 & 115,72 & 6,78 & 53,88 & 322,90 & 50,98 & 51,71 & 321,60 \\
\hline Discoglossus galganoi & 29SPE51 & 101,00 & 162,83 & 100,88 & 36,68 & 5941,95 & 322,45 & 50,59 & 271,86 & \begin{tabular}{|c|}
97,88 \\
\end{tabular} & 241,23 & 241,63 & 90,42 & \begin{tabular}{|c|}
716,97 \\
\end{tabular} & 100,21 & 5,86 & 53,12 & 284,78 & 45,20 & 46,64 & 281,24 \\
\hline Discoglossus galganoi & 29SPE52 & 101,00 & 157,55 & 99,13 & 36,10 & 5958,68 & 316,43 & 46,10 & 270,33 & 92,54 & 236,26 & 236,52 & \begin{tabular}{l|l}
84,95 \\
\end{tabular} & 761,84 & 107,67 & 6,19 & 53,17 & 302,85 & 48,50 & 49,19 & 300,00 \\
\hline Discoglossus galganoi & 29SPE60 & 101,00 & 160,83 & 101,30 & 36,43 & 6005,53 & 322,03 & 48,31 & $273,71 \mid$ & 95,56 . & $240,07 \mid$ & 240,54 & 87,79 & 697,13 & 96,08 & 5,66 & 52,50 & 275,62 & 44,60 & 45,66 & 270,71 \\
\hline Discoglossus galganoi & 29SPE61 & 99,00 & 159,52 & 100,65 & 36,13 & 6011,88 & 320,19 & 46,94 & 273,24 & 94,04 & 238,99 & 239,26 & 86,33 & 709,88 & 98,39 & 5,94 & 52,45 & 280,56 & \begin{tabular}{|c|}
45,79 \\
\end{tabular} & 46,52 & 275,97 \\
\hline Discoglossus galganoi & 29SPE70 & 101,00 & 160,68 & 102,50 & 36,39 & 6061,68 & 323,93 & 46,84 & 277,09 & 94,72 & 240,89 & 241,08 & 86,94 & 661,91 & 89,78 & 5,25 & 51,91 & 259,85 & 42,67 & 43,48 & 253,48 \\
\hline Discoglossus galganoi & 29SPE71 & 100,00 & 159,82 & 101,92 & 36,35 & 6065,58 & 322,31 & 45,97 & 276,34 & 93,66 & \begin{tabular}{|l|l}
240,05 \\
\end{tabular} & 240,17 & 85,82 & $\begin{array}{l}670,65 \\
\end{array}$ & 91,49 & 5,45 & 51,84 & 263,29 & 43,56 & 44,06 & 257,20 \\
\hline Discoglossus galganoi & 29SPE72 & 101,00 & 157,64 & 101,21 & 36,08 & 6065,15 & 319,49 & 44,06 & 275,43 & 91,42 & 237,94 & 238,00 & 83,62 & \begin{tabular}{ll|}
684,95 \\
\end{tabular} & 93,96 & 5,83 & 51,77 & 268,81 & \begin{tabular}{ll|}
45,03 \\
\end{tabular} & 45,28 & 262,93 \\
\hline Discoglossus galganoi & 29SPE80 & 100,00 & 161,60 & 103,86 & 36,56 & 6119,63 & 326,96 & 46,28 & 280,68 & 94,92 & 242,58 & 242,65 & 87,03 & 621,49 & 82,74 & 5,02 & 51,02 & 241,96 & 40,81 & 41,16 & 234,20 \\
\hline Discoglossus galganoi & 29SQA19 & 10,00 & 178,00 & 87,00 & 37,00 & 4992,64 & 302,64 & 72,00 & 230,64 & \begin{tabular}{|c|}
136,73 \\
\end{tabular} & 240,55 & 243,45 & \begin{tabular}{|c|}
115,64 \\
\end{tabular} & 523,27 & 80,91 & 1,00 & 64,91 & 227,91 & 14,00 & 22,00 & 207,55 \\
\hline Discoglossus galganoi & 29SQA29 & 85,00 & 178,83 & 87,79 & 37,13 & 5027,68 & 304,23 & 72,22 & \begin{tabular}{|l|l|}
232,02 \\
\end{tabular} & \begin{tabular}{l|l}
143,22 \\
\end{tabular} & \begin{tabular}{|l|l|l|}
241,99 \\
\end{tabular} & 245,02 & 116,11 & $\begin{array}{l}528,25 \\
\end{array}$ & 81,26 & 1,00 & 64,74 & 230,03 & \begin{tabular}{ll|l}
14,15 \\
\end{tabular} & 22,00 & 210,30 \\
\hline Discoglossus galganoi & 29SQA39 & 100,00 & 178,93 & 88,43 & 37,01 & 5120,94 & 306,79 & 71,23 & 235,55 & \begin{tabular}{l|l|l}
143,96 \\
\end{tabular} & 243,43 & 246,48 & \begin{tabular}{|l|l|}
115,26 \\
\end{tabular} & 540,45 & 82,58 & 1,00 & 64,61 & 233,88 & \begin{tabular}{ll|l}
14,96 \\
\end{tabular} & 22,00 & 214,68 \\
\hline Discoglossus galganoi & 29SQBO00 & 46,00 & 176,74 & 85,34 & 37,00 & 5008,82 & 299,92 & 71,94 & 227,98 & 123,20 & 239,08 & 242,08 & 114,04 & 511,26 & 79,38 & 1,00 & 64,36 & 221,58 & 14,00 & 23,00 & 200,42 \\
\hline Discoglossus galganoi & 29SQB01 & 100,00 & 177,03 & 85,80 & 36,91 & 5086,65 & 301,93 & 71,36 & 230,57 & \begin{tabular}{ll|}
128,89 \\
\end{tabular} & 240,26 & 243,19 & 113,3 & 505,93 & 78,73 & 1,00 & 63,83 & 218,10 & 14,01 & 23,13 & 196,75 \\
\hline Discoglossus galganoi & 295QBO2 & 100,00 & 175,71 & 87,83 & 36,78 & 5211,77 & 304,69 & 68,22 & 236,47 & 121,68 & 240,67 & 243,42 & 110,32 & 511,72 & 79,20 & 1,00 & 63,09 & 218,53 & 14,72 & 23,99 & 197,38 \\
\hline Discoglossus galganoi & 29SQB03 & 100,00 & 176,62 & 90,04 & \begin{tabular}{l|l}
36,92 \\
\end{tabular} & 5313,06 & 309,19 & 67,62 & 241,57 & \begin{tabular}{|l|l|}
130,20 \\
\end{tabular} & 243,06 & 245,67 & \begin{tabular}{ll|}
110,08 \\
\end{tabular} & $\begin{array}{l}505,56 \\
\end{array}$ & 78,12 & 1,00 & 62,66 & 214,59 & \begin{tabular}{ll|}
15,01 \\
\end{tabular} & 23,97 & 193,80 \\
\hline Discoglossus galganoi & 29SQB04 & 100,00 & 175,53 & 93,32 & 37,02 & 5425,44 & 312,93 & 64,53 & 248,41 & 120,14 & 243,71 & 246,19 & 107,63 & $\begin{array}{ll}511,63 \\
\end{array}$ & 78,33 & 1,29 & \begin{tabular}{ll|}
61,96 \\
\end{tabular} & 215,68 & 16,04 & 24,62 & 195,76 \\
\hline Discoglossus galganoi & 29SQB06 & 101,00 & 165,53 & 101,65 & 37,97 ] & 5683,37 . & 315,98 & 50,49 & 265,49 & 104,53 & $238,24 \mid$ & $240,44[$ & 95,45 & 566,49 _ & 83,17 . & 2,01 & 59,96 & 234,53 & $21,17 \mid$ & 28,32 & 217,67 \\
\hline Discoglossus galganoi & 29SQB07 & 100,00 & 164,82 & 104,21 & 38,00 & 5762,46 & 319,25 & 48,34 & 270,91 & 102,79 & 238,75 & \begin{tabular}{|l|}
240,87 \\
\end{tabular} & 93,82 & 569,38 & 82,77 & 2,29 & 59,36 & 234,26 & 22,28 & 28,82 & 218,29 \\
\hline Discoglossus galganoi & 29SQB08 & 100,00 & 163,17 & 106,56 & 38,00 & 5835,67 & 321,68 & 45,53 & 276,15 & 100,43 & \begin{tabular}{|l|l|}
238,34 \\
\end{tabular} & 240,40 & 91,52 & 576,80 & 82,82 & 2,68 & 58,52 & 235,69 & 23,96 & 29,93 & 220,70 \\
\hline Discoglossus galganoi & 29SQB09 & 101,00 & 149,98 & 109,34 & 38,00 & 5955,40 & 315,23 & 31,79 & 283,43 & 86,71 & 227,37 & 229,53 & \begin{tabular}{ll|l}
77,75 \\
\end{tabular} & 655,52 & $\begin{array}{l}90,98 \\
\end{array}$ & 3,83 & 57,21 & 264,65 & 30,41 & 35,23 & 252,11 \\
\hline Discoglossus galganoi & 29SQB10 & 96,00 & 177,80 & 87,58 & 37,01 & 5066,93 & 303,78 & 71,44 & 232,34 & \begin{tabular}{l|l|l|l|l}
130,63 \\
\end{tabular} & 241,16 & 244,08 & 114,66 & 518,74 & 80,20 & 1,00 & 64,27 & 224,79 & 14,00 & 22,93 & 204,25 \\
\hline Discoglossus galganoi & 29SQB11 & 100,00 & 178,60 & 89,13 & 37,01 & 5175,99 & 307,72 & 70,57 & 237,15 & 130,95 & 243,40 & 246,23 & 113,90 & 513,12 & 79,52 & 1,00 & 63,83 & 220,93 & 14,38 & 23,00 & 200,28 \\
\hline Discoglossus galganoi & 29SQB14 & 100,00 & 177,04 & 97,18 & 37,40 & 5528,40 & 319,21 & 63,27 & 255,94 & \begin{tabular}{|l|l|}
117,12 \\
\end{tabular} & \begin{tabular}{|l|l|}
247,02 \\
\end{tabular} & 249,25 & 108,02 & 518,64 & 79,16 & 1,11 & 62,08 & 218,60 & 16,14 & 24,15 & 199,43 \\
\hline Discoglossus galganoi & 29SQB16 & 99,00 & 168,83 & 104,02 & 38,00 & 5771,93 & 322,70 & 51,44 & 271,26 & \begin{tabular}{|c|}
106,39 \\
\end{tabular} & 242,73 & \begin{tabular}{|l|l|l|}
244,82 \\
\end{tabular} & \begin{tabular}{|c|}
97,38 \\
\end{tabular} & 560,74 & 82,61 & 2,01 & 60,17 & 232,12 & 20,69 & 27,51 & 215,31 \\
\hline Discoglossus galganoi & 29SQB17 & 101,00 & 163,36 & 107,06 & 38,00 & 5877,79 & 322,84 & 44,57 & 278,27 & 99,97 & 239,10 & 241,08 & 90,98 & 589,06 & 85,03 & 2,50 & 59,22 & 241,64 & 23,35 & 29,53 & 226,20 \\
\hline Discoglossus galganoi & 29SQB18 & 100,00 & 159,01 & 109,34 & 38,00 & 5957,20 & 322,97 & 39,38 & 283,59 & 95,16 & 236,25 & \begin{tabular}{|l|}
238,07 \\
\end{tabular} & $\begin{array}{l}86,15 \\
\end{array}$ & 610,38 & 86,62 & 2,97 & 58,25 & 248,23 & 25,93 & 31,53 & 233,97 \\
\hline Discoglossus galganoi & 29SQB19 & 99,00 & 151,81 & 111,03 & 38,00 & 6028,69 & 319,92 & 31,80 & 288,13 & 87,58 & 230,39 & 232,23 & 78,6 & 649,94 & 90,32 & 3. & 57, & 262,00 & 29,59 & 34,50 & 249,20 \\
\hline Discoglossus galganoi & $29 \mathrm{SQB} 20$ & 100,00 & 179,04 & 89,73 & 37,08 & 5151,40 & 308,35 & 70,87 & 237,48 & 134,68 & 243,99 & 246,81 & 114,96 & 524,89 & 80,86 & 1,00 & 64,52 & 227,17 & 14,90 & 22,01 & 207,32 \\
\hline Discoglossus galganoi & 29SQB21 & 101,00 & 179,80 & 92,42 & 37,20 & 5285,69 & 313,51 & 69,27 & 244,24 & \begin{tabular}{|l|l|}
131,97 \\
\end{tabular} & 246,44 & 249,12 & 113,76 & 522,48 & 80,46 & 1,00 & 63,68 & 224,48 & 15,00 & 22,31 & 204,82 \\
\hline Discoglossus galganoi & 29SQB22 & 100,00 & 178,30 & 95,58 & 37,40 & 5428,78 & 317,33 & 65,47 & 251,87 & \begin{tabular}{l|l}
119,33 \\
\end{tabular} & 247,04 & 249,51 & \begin{tabular}{l|l|l}
110,55 \\
\end{tabular} & \begin{tabular}{|c|}
529,87 \\
\end{tabular} & 81,28 & 1,00 & 63,28 & 226,09 & 15,47 & 22,99 & 206,78 \\
\hline Discoglossus galganoi & 29SQB24 & 100,00 & 175,60 & 101,94 & \begin{tabular}{l|l|}
37,95 \\
\end{tabular} & 5673,27 & 325,06 & 58,67 & 266,40 & \begin{tabular}{|l|l|l}
114,06 \\
\end{tabular} & 248,11 & $\begin{array}{l}250,25 \\
\end{array}$ & 104,99 & 543,60 & 81,97 & 1,36 & 61,76 & 228,44 & 18,02 & 24,99 & 210,41 \\
\hline Discoglossus galganoi & $29 S Q B 25$ & 99,00 & 170,63 & 105,14 & 37,99 & 5800,16 & 325,97 & 51,97 & 274,00 & 107,85 & \begin{tabular}{|l|l|}
245,09 \\
\end{tabular} & 247,13 & 98,82 & 567,97 & 84,15 & 1,98 & 60,84 & 236,44 & 0,20 & 26,87 & 219,51 \\
\hline Discoglossus galganoi & $295 Q B 28$ & 100,00 & 158,95 & 111,69 & 38,00 & 6054,53 & 326,96 & 37,32 & 289,64 & 94,01 & 237,72 & 239,36 & 85,00 & \begin{tabular}{ll|}
619,95 \\
\end{tabular} & 87,61 & 2,99 & 58,42 & 251,77 & 26,12 & 31,53 & 237,91 \\
\hline Discoglossus galganoi & $295 Q B 29$ & 100,00 & 158,47 & 112,97 & 38,00 & 6098,34 & 328,68 & 36,09 & 292,59 & 92,97 & 237,91 & 239,45 & 83, & $\begin{array}{l}619,05 \\
\end{array}$ & 86,71 & 3,20 & 57,68 & 249,70 & 27,20 & 32,28 & 236,40 \\
\hline Discoglossus galganoi & 29SQB31 & 100,00 & 180,39 & 95,44 & 37,43 & 5399,35 & 319,24 & 67,63 & 251,61 & 121,85 & \begin{tabular}{|l|l|}
248,92 \\
\end{tabular} & 251,55 & 113,18 & 535,35 & 82,11 & 1,00 & 63,83 & 229,68 & 15,20 & 22,00 & 210,79 \\
\hline Discoglossus galganoi & 29SQB34 & 100,00 & 179,52 & 106,17 & 38,01 & 5772,33 & 334,80 & 59,57 & 275,24 & \begin{tabular}{|c|}
116,62 \\
\end{tabular} & 253,47 & 255,43 & \begin{tabular}{|c|}
107,67 \\
\end{tabular} & 542,43 & 81,89 & 1,01 & 62,08 & 228,52 & 18,01 & 23,92 & 211,26 \\
\hline Discoglossus galganoi & $29 S Q B 35$ & 101,00 & 175,74 & 109,07 & \begin{tabular}{l|l}
38,05 \\
\end{tabular} & 5890,17 & 336,24 & 54,13 & 282,11 & 111,61 & 251,58 & 253,33 & 102,63 & \begin{tabular}{l|l}
558,45 \\
\end{tabular} & 83,11 & 1,74 & 61,18 & 233,21 & \begin{tabular}{l|l|l|}
19,53 \\
\end{tabular} & 5,44 & 216,83 \\
\hline Discoglossus galganoi & $29 \mathrm{SQBB38}$ & 101,00 & 165,25 & 114,19 & 38,03 & 6120,83 & 336,06 & \begin{tabular}{|l|l|}
41,25 \\
\end{tabular} & 294,81 & 99,12 & 244,91 & 246,42 & 90,10 & 596,49 & 84,86 & 2,55 & 58,82 & 242,79 & 24,17 & 29,42 & 228,80 \\
\hline Discoglossus galganoi & 29SQB39 & 100,00 & 163,07 & 115,24 & 38,00 & 6172,04 & 336,21 & 38,54 & 297,66 & 96,41 & 243,54 & 244,97 & 87,38 & 601,53 & 84,57 & 2,78 & 58,19 & 242,94 & 25,49 & 30,41 & 229,54 \\
\hline Discoglossus galganoi & $29 \mathrm{SQB} 43$ & 100,00 & 180,23 & 108,01 & $\begin{array}{l}38,05 \\
\end{array}$ & 5804,21 & 22 & 59,06 & 279,16 & \begin{tabular}{|l|l|}
117,10 \\
\end{tabular} & \begin{tabular}{|l|l|}
254,92 \\
\end{tabular} & 256,92 & 108,11 & 558,84 & 84,54 & 1,00 & 62,92 & 237,05 & 17,80 & 23,23 & 220,29 \\
\hline Discoglossus galganoi & 29SQB44 & 101,00 & 180,49 & 1,05 & 38,36 & 5900,58 & 342 & 57, & 285,55 & 116,18 & $256,64 \mid$ & 258,40 & 107: & 556,03 & 83,69 & 1,1 & 62, & 234,70 & 24 & 3,4 & 218,49 \\
\hline Discoglossus galganoi & $29 \mathrm{SQB} 45$ & 99,00 & 179,99 & 113,45 & 38,61 & 5980,75 & 34 & 55,51 & 290,71 & \begin{tabular}{|l|l|}
114,92 \\
\end{tabular} & 257,41 & 259,01 & 105,74 & 555,42 & 82,92 & 1,41 & 61,79 & 232,99 & 18,81 & 24,00 & 217,38 \\
\hline Discoglossus galganoi & 29SQB48 & 99,00 & 165,34 & 116,84 & 38,20 & 6207,25 & 340,24 & 39,51 & 300,73 & 98,16 & 246,41 & 247,64 & 89,31 & 606,48 & 85,72 & 2,53 & 58,92 & 246,50 & 24,30 & 29,31 & 233,16 \\
\hline Discoglossus galganoi & 29SQB49 & 99,00 & 160,27 & 117,41 & \begin{tabular}{|c|}
38,07 \\
\end{tabular} & 6265,76 & 337,49 & 34,39 & 303,10 & 92,76 & 242,46 & 243,63 & 83,80 & \begin{tabular}{|c|}
624,67 \\
\end{tabular} & 86,79 & 3,01 & 58,13 & 251,52 & 26,41 & 31,25 & 238,92 \\
\hline Discoglossus galganoi & 29SQB53 & 100,00 & 181,30 & 113,02 & 38,63 & 5927,42 & 346,34 & 57,17 & 289,17 & \begin{tabular}{|c|c|}
116,76 \\
\end{tabular} & 258,02 & 259,85 & \begin{tabular}{l|l}
107,85 \\
\end{tabular} & 573,75 & 86,57 & 1,00 & 63,24 & 243,96 & 18,11 & 22,87 & 228,30 \\
\hline Discoglossus galganoi & 29SQB54 & 100,00 & 17 & & 38,8 & 34,62 & 349 & 53,49 & 296,01 & \begin{tabular}{|l|l|}
113,93 \\
\end{tabular} & 257,94 & 259,54 & 104, & \begin{tabular}{|l|}
580,19 \\
\end{tabular} & 86,72 & T. & 62, & 245,06 & 19, & 3,63 & 230,07 \\
\hline Discoglossus galganoi & $29 \mathrm{SQBB5}$ & 100,00 & 182 & & 38, & 6077,18 & 35 & 55 & 299,36 & 116,50 & 261,79 & 263,16 & 107,47 & 559,71 & 83,53 & 1,13 & 62,24 & 235,80 & 18,43 & 23,01 & 221,17 \\
\hline Discoglossus galganoi & 29 SQB56 & 100,00 & 176,11 & 118,63 & 38,93 & 6163,05 & 350,68 & 48,61 & 302,07 & 109,00 & 256,31 & 257,66 & \begin{tabular}{|l|}
100,02 \\
\end{tabular} & \begin{tabular}{l|l}
582,65 \\
\end{tabular} & 85,06 & 1,97 & 61,03 & 242,14 & 20,77 & 25,32 & 228,14 \\
\hline Discoglossus galganoi & 29SQB58 & 100,00 & 164,45 & 119,16 & \begin{tabular}{l|l}
38,45 \\
\end{tabular} & 6288,16 & 342,96 & 37,21 & 305,74 & 96,54 & 246,97 & 248,00 & \begin{tabular}{l|l}
87,55 \\
\end{tabular} & 621,15 & 87,10 & 2,57 & 59,09 & 252,23 & 24,62 & 29,52 & 239,62 \\
\hline Discoglossus galganoi & 29SQB63 & 57,00 & 184,32 & 116,90 & 39,00 & 5995,94 & 353,94 & 58,03 & 295,91 & \begin{tabular}{|l|l|}
119,06 \\
\end{tabular} & 262,14 & 263,82 & 110,10 & 574,31 & 86,98 & 1,00 & 63,84 & 245,33 & \begin{tabular}{l|l|l}
18,05 \\
\end{tabular} & 22,11 & 230,18 \\
\hline Discoglossus galganoi & 29SQB64 & 54,00 & 184,91 & 120,33 & 39,0 & 6101,45 & 355 & 55,90 & 303,44 & 118,35 & 264, & 265,64 & 109,23 & 571,64 & 86,08 & 1,00 & 63,33 & 243,27 & 18,19 & 22,17 & 228 \\
\hline Discoglossus galganoi & 29SQB66 & 49,00 & 179,39 & 121,08 & 39,00 & 6213,04 & 356,69 & 50,47 & 306,22 & 111,55 & 260,39 & 261,53 & 102,69 & $\begin{array}{l}576,55 \\
\end{array}$ & 84,32 & 1,69 & 61,45 & 240,57 & 19,96 & 24,26 & 226,99 \\
\hline Discoglossus galganoi & $295 Q C 00$ & 100,00 & 152,57 & 110,61 & 38,01 & 5987,54 & 319,70 & 33,50 & 286,20 & 88,75 & 230,46 & 232,42 & $\begin{array}{l}79,85 \\
\end{array}$ & \begin{tabular}{ll|}
634,96 \\
\end{tabular} & 88,02 & 3,70 & 56,71 & 255,20 & 30,10 & 34,59 & 242,76 \\
\hline Discoglossus galganoi & $295 Q C 01$ & 100,00 & 150,73 & 111,68 & 38,02 & 6030,24 & 320,13 & 31,31 & 288,82 & 86,57 & 229,46 & 231,34 & 77,71 & 643,26 & 88,33 & 4,06 & 56,03 & 256,93 & 31,92 & $\begin{array}{l}35,85 \\
\end{array}$ & 245,11 \\
\hline Discoglossus ga & $295 Q C 02$ & 101,00 & 150,90 & 112,55 & 38,00 & 6064,71 & 322,05 & \begin{tabular}{l|l}
30,95 \\
\end{tabular} & 291,10 & 86,38 & 230,08 & 231,97 & 77,51 & 638,97 & \begin{tabular}{l|l}
87,25 \\
\end{tabular} & 4,11 & 55,41 & 253,83 & 32,80 & 36,32 & 242, \\
\hline Discoglossus galganoi & $295 Q C 10$ & 101,00 & 157,87 & 112,11 & 38,00 & 6052,92 & 326,94 & 36,77 & 290,16 & 92,90 & 236,66 & 238,34 & 84,15 & 608,89 & 85,03 & 3,21 [ & 57,12 & 244,71 & 27,85 & 32,59 & 231, \\
\hline
\end{tabular}




\begin{tabular}{|c|c|c|c|c|c|c|c|c|c|c|c|c|c|c|c|c|c|c|c|c|c|}
\hline TAXON & UTM & $\mathrm{km} 2$ & $\mathrm{BIO1}$ & $\mathrm{B1O2}$ & $\mathrm{BIO3}$ & B104 & B105 & $\mathrm{B106}$ & 8107 & B108 & $\mathrm{BIO9}$ & $\mathrm{B1010}$ & B1011 & $\mathrm{BIO12}$ & 81013 & 81014 & B1015 & BIO16 & BIO17 & B1018 & B1019 \\
\hline Discoglossus galganoi & 29SQC11 & 100,00 & 148,36 & 113,07 & 38,00 & 6121,03 & 320,93 & 27,46 & 293,47 & 83,27 & 228,53 & 230,22 & 74,29 & 662,73 & 90,34 & 4,26 & 56,03 & 263,69 & 32,92 & 36,88 & 252,11 \\
\hline Discoglossus galganoi & 29SQC12 & 100,00 & 150,30 & 113,83 & 38,00 & 6146,70 & 324,17 & 28,77 & 295,39 & 84,84 & 230,91 & 232,48 & 75,97 & 644,97 & 87,74 & 4,05 & 55,47 & 255,49 & 32,72 & 36,30 & 243,86 \\
\hline \begin{tabular}{|l} 
Discoglossus galganoi \\
\end{tabular} & $295 Q C 14$ & 101,00 & 159,23 & 115,59 & 38,01 & 6171,35 & 334,37 & 35,95 & 298,41 & 92,41 & 239,95 & 241,13 & 83,86 & 579,12 & 79,00 & 3,69 & 54,64 & 227,61 & 30,38 & 33,67 & 215,52 \\
\hline Discoglossus galganoi & 29SQC16 & 100,00 & 158,39 & 116,15 & 38,01 & 6218,94 & 335,43 & 34,82 & 300,61 & 91,30 & 240,07 & 241,02 & 82,66 & 573,53 & 77,26 & 4,05 & 53,32 & 222,97 & 32,25 & 34,93 & 211,15 \\
\hline Discoglossus galganoi & 29SQC20 & 100,00 & 158,69 & 114,03 & 38,00 & 6141,20 & 330,86 & 35,80 & 295,06 & 92,59 & 238,82 & 240,27 & 83,67 & 610,75 & 84,96 & 3,20 & 57,20 & 244,88 & 27,67 & 32,37 & 231,93 \\
\hline Discoglossus galganoi & $29 \mathrm{SQC21}$ & 100,00 & 145,29 & 114,35 & 38,00 & 6208,92 & 321,02 & 23,04 & 297,98 & 79,29 & 227,01 & 228,47 & 70,48 & 684,79 & 92,50 & 4,51 & 55,84 & 271,28 & 34,24 & 38,10 & 260,10 \\
\hline Discoglossus galganoi & $295 Q C 22$ & 100,00 & 152,88 & 115,44 & 38,00 & 6225,07 & 329,21 & 29,54 & 299,66 & 86,07 & 234,56 & 235,86 & 77,28 & 632,78 & 85,95 & 3,97 & 55,60 & 250,05 & 31,60 & 35,43 & 238,19 \\
\hline Discoglossus galganoi & $295 \mathrm{SQC23}$ & 101,00 & 156,44 & 116,22 & 38,00 & 6236,16 & 333,51 & 32,47 & 301,04 & 89,36 & 238,35 & 239,41 & 80,62 & 605,30 & 82,13 & 3,85 & 55,16 & 238,15 & 30,84 & 34,48 & 226,19 \\
\hline Discoglossus galganoi & $2950 C 25$ & 100,00 & 154,87 & 116,72 & 38,00 & 6296,31 & 333,94 & 30,57 & 303,37 & 86,94 & 237,62 & 238,51 & 78,50 & 601,18 & 80,36 & 4,00 & 53,84 & 233,81 & 32,68 & 35,64 & 222,19 \\
\hline Discoglossus galganoi & 29SQC30 & 100,00 & 153,54 & 115,83 & 38,00 & 6238,75 & 329,83 & 29,25 & 300,58 & 86,61 & 235,49 & 236,64 & 77,72 & 646,89 & 88,68 & 3,60 & 56,96 & 258,16 & 29,81 & 34,28 & 246,06 \\
\hline Discoglossus galganoi & $29 \mathrm{SQC31}$ & 101,00 & 143,35 & 115,71 & 37,99 & 6285,63 & 321,80 & 20,01 & 301,79 & 76,51 & 226,30 & 227,65 & 67,74 & 700,80 & 93,93 & 4,65 & 55,87 & 276,69 & 34,98 & 38,88 & 265,89 \\
\hline Discoglossus galganoi & $29 \mathrm{SQC} 32$ & 100,00 & 150,07 & 116,82 & 38,00 & 6311,19 & 329,47 & 25,56 & 303,92 & 82,63 & 233,28 & 234,30 & 73,90 & 652,92 & 87,76 & 4,06 & 55,58 & 257,04 & 32,41 & 36,21 & 245,72 \\
\hline \begin{tabular}{|l} 
Discoglossus galganoi \\
\end{tabular} & $29 \mathrm{SQC35}$ & 100,00 & 153,54 & 117,59 & 38,00 & 6363,24 & 335,03 & 28,24 & 306,79 & 85,10 & 237,65 & 238,31 & 76,50 & 609,65 & 80,58 & 4,00 & 54,00 & 236,09 & 32,50 & 35,71 & 224,86 \\
\hline Discoglossus galganoi & $295 Q C 36$ & 100,00 & 157,07 & 117,85 & 38,00 & 6360,65 & 338,56 & 31,38 & 307,18 & 88,35 & 241,04 & 241,64 & 79,81 & 581,93 & 76,87 & 4,00 & 53,48 & 224,35 & 31,94 & 34,76 & 212,76 \\
\hline Discoglossus galganoi & 29SQC38 & 100,00 & 163,23 & 117,86 & 38,00 & 6367,95 & 344,36 & 36,86 & 307,50 & 93,88 & 247,29 & 247,38 & 85,35 & 532,76 & 70,17 & 3,44 & 52,54 & 203,66 & 30,08 & 31,66 & 191,64 \\
\hline Discoglossus galganoi & $295 Q C 40$ & 101,00 & 158,58 & 118,01 & 38,01 & 6304,75 & 337,41 & 32,34 & 305,07 & 90,67 & 241,28 & 242,38 & 81,72 & 626,43 & 86,06 & 3,03 & 57,45 & 250,37 & 27,34 & 32,01 & 238,25 \\
\hline Discoglossus galganoi & $29 S Q C 41$ & 99,00 & 150,44 & 117,83 & 38,00 & 6353,23 & 331,26 & 24,82 & 306,44 & 82,53 & 234,27 & 235,31 & 73,66 & 662,91 & 89,17 & 3,90 & 56,33 & 261,88 & 31,52 & 35,70 & 250,75 \\
\hline \begin{tabular}{|l} 
Discoglossus galganoi \\
\end{tabular} & $29 \mathrm{SQC47}$ & 99,00 & 162,97 & 118,88 & 37,99 & 6437,15 & 345,94 & 35,39 & 310,55 & 92,87 & 248,00 & 248,04 & 84,26 & 542,14 & 71,52 & 3,23 & 53,43 & 207,59 & 29,09 & 30,04 & 195,96 \\
\hline Discoglossus galganoi & $29 S Q C 48$ & 101,00 & 164,45 & 118,63 & \begin{tabular}{|c|}
37,97 \\
\end{tabular} & 6434,42 & 347,13 & 37,04 & 310,09 & 94,36 & 249,40 & 249,46 & 85,73 & 525,70 & 69,10 & 3,06 & 52,98 & 200,26 & 28,72 & 29,29 & 188,50 \\
\hline Discoglossus galganoi & 29SQC49 & 99,00 & 163,25 & 117,95 & 37,60 & 6448,65 & 346,10 & 36,12 & 309,98 & 92,98 & 248,56 & 248,66 & 84,46 & 523,97 & 68,46 & 3,31 & 52,23 & 198,42 & 29,73 & 30,41 & 186,63 \\
\hline Discoglossus galganoi & 29SQC50 & 100,00 & 154,05 & 119,27 & 38,01 & 6389,85 & 336,10 & 27,00 & 309,10 & 85,45 & 238,34 & 239,30 & 76,60 & 656,46 & 88, & 3,43 & 57,26 & 260,95 & 29,22 & 33,80 & 249,81 \\
\hline \begin{tabular}{|l} 
Discoglossus galganoi \\
\end{tabular} & $29 S Q C 51$ & 100,00 & 157,25 & 120,01 & 38,00 & 6413,78 & 340,24 & 29,40 & 310,84 & 88,09 & 241,84 & 242,56 & 79,16 & 631,14 & 85,14 & 3,27 & 56,81 & 249,59 & 28,48 & 32,89 & 238,35 \\
\hline \begin{tabular}{|l} 
Discoglossus galganoi \\
\end{tabular} & 29SQC52 & 100,00 & 158,74 & 120,32 & 38,00 & \begin{tabular}{ll|l}
6435,63 \\
\end{tabular} & 342,47 & 30,48 & 311,99 & 89,27 & 243,72 & 244,24 & 80,33 & 613,54 & 82,38 & 3,19 & 56,22 & 241,10 & 28,37 & 32,57 & 229,94 \\
\hline Discoglossus galganoi & $29 \mathrm{SQC53}$ & 100,00 & 152,34 & 119,87 & 38,00 & 6469,16 & 337,34 & 24,95 & 312,39 & 82,86 & 237,97 & 238,62 & 74,10 & 638,24 & 84,75 & 3,94 & 55,30 & 248,30 & 31,58 & 35,35 & 237,69 \\
\hline Discoglossus galganoi & $29 \mathrm{SQC57}$ & 101,00 & 157,18 & 119,37 & 37,73 & 6509,74 & 342,79 & 29,19 & 313,61 & 86,55 & 243,60 & 243,67 & 77,96 & 573,23 & 74,97 & 3,87 & 53,01 & 217,74 & 31,36 & 32,25 & 206,81 \\
\hline Discoglossus galganoi & $29 S Q C 59$ & 100,00 & 160,74 & 118,62 & 37,32 & 6523,95 & 345,77 & 32,92 & 312,85 & 90,06 & 247,48 & 247,51 & 81,41 & 535,84 & 69,69 & 3,57 & 52,03 & 201,52 & 30,46 & 30,61 & 190,22 \\
\hline Discoglossus galganoi & $29 S Q D 21$ & 101,00 & 167,54 & 115,88 & 37,93 & 6306,67 & 345,66 & $\frac{\mid 2,2,66}{42,66}$ & 302,99 & 98,62 & 250,56 & 250,69 & $\begin{array}{l}91,41 \pm \\
90,15\end{array}$ & 493,85 & 65,03 & 3,03 & 51,52 & 187,80 & 29,46 & $\begin{array}{l}0,01 \\
30,62\end{array}$ & 175,35 \\
\hline Discoglossus galganoi & 29SQD22 & 99,00 & 166,10 & 114,86 & 37,35 & 6329,11 & 344,38 & 41,63 & 302,75 & 96,99 & 249,73 & 249,83 & 88,67 & 500,07 & 65,06 & 3,38 & 50,77 & 189,08 & 31,18 & 31,49 & 176,83 \\
\hline Discoglossus galganoi & 29 SQD26 & 101,00 & 159,38 & 108,83 & 36,05 & 6397,50 & 335,77 & 38,95 & 296,82 & 90,23 & 244,69 & 244,69 & 82,14 & 526,93 & 67,03 & 4,02 & 49,63 & 196,72 & 35,47 & 35,47 & 184,62 \\
\hline Discoglossus galganoi & 29SQD31 & 100,00 & 165,92 & 116,10 & 37,53 & 6383,78 & 346,06 & 40,36 & 305,70 & 96,25 & 250,19 & 250,23 & 87,68 & 499,24 & 64,97 & 3,08 & 51,30 & 188,50 & 29,97 & 30,39 & 176,32 \\
\hline Discoglossus galganoi & 29SQD40 & 100,00 & 167,71 & 117,67 & 37,59 & 6440,08 & 349,40 & 40,25 & 309,15 & 97,20 & 252,73 & 252,73 & 88,58 & 494,36 & 64,55 & 3,00 & 52,06 & 186,50 & 28,03 & 28,13 & 174,54 \\
\hline \begin{tabular}{|l} 
Discoglossus galganoi \\
\end{tabular} & $29 S Q D 41$ & 100,00 & 167,40 & 116,77 & 37,13 & $\begin{array}{l}6444,, 88 \\
648\end{array}$ & 349,11 & $\begin{array}{l}40,70 \\
40,70\end{array}$ & 308,41 & $\begin{array}{ll}1,202 \\
96,92\end{array}$ & 252,81 & 252,81 & 88,49 & \begin{tabular}{|l|l|}
488,53 \\
\end{tabular} & $\begin{array}{l}4,4,47 \\
63,\end{array}$ & 3,01 & 51,48 & 183,45 & 28,49 & 28,51 & 171,45 \\
\hline Discoglossus galganoi & 29SQD51 & 100,00 & 168,69 & 117,58 & 37,14 & 6495,95 & 351,42 & 40,79 & 310,63 & 97,43 & 254,64 & 254,64 & 88,89 & 478,98 & 62,25 & 3,00 & 51,94 & 179,24 & 27,14 & 27,14 & 167,53 \\
\hline Discoglossus galganoi & 29SQD54 & 90,00 & 156,13 & 113,97 & 36,59 & 6540,17 & 338,76 & 31,17 & 307,59 & 85,11 & 243,50 & 243,50 & 76,94 & 517,89 & 66,59 & 4,21 & 49,36 & 189,84 & 34,20 & 34,20 & 177,86 \\
\hline Discoglossus galganoi & 29 SQD58 & 72,00 & 159,68 & 111,35 & 36,05 & 6490,86 & 338,59 & 36,23 & 302,36 & 89,04 & 246,51 & 246,51 & 80,72 & 470,35 & 59,39 & 4,00 & 47,57 & 170,54 & 33,51 & 33,51 & 158,14 \\
\hline Discoglossus galganoi & 29SQE51 & 63,00 & 158,98 & 110,69 & 36,68 & 6427,51 & 334,89 & 36,06 & 298,83 & 88,21 & 244,68 & 244,68 & 80,34 & 454,36 & 55,83 & 4,50 & 46,13 & 164,21 & 34,23 & 34,23 & 151,88 \\
\hline \begin{tabular}{|l} 
Discoglossus galganoi \\
\end{tabular} & 29TMH75 & $\frac{23,00}{22,00}$ & $\begin{array}{ll}13,50,72 \\
144,72\end{array}$ & $\begin{array}{r}59,03 \\
59,38\end{array}$ & $\begin{array}{l}30,0 \\
39,38\end{array}$ & | $312,32,36$ & 225,90 & $\begin{array}{l}0,00 \\
76,72 \\
\end{array}$ & \begin{tabular}{|l|l|}
149,18 \\
149
\end{tabular} & \begin{tabular}{|l|l|}
115,10 \\
\end{tabular} & \begin{tabular}{|l|}
182,95 \\
182,
\end{tabular} & $\begin{array}{l}24,00 \\
186,33\end{array}$ & \begin{tabular}{|l|}
105,72 \\
105,
\end{tabular} & \begin{tabular}{|l|}
951,31 \\
951
\end{tabular} & \begin{tabular}{|c|c|}
139,23 \\
139,23
\end{tabular} & \begin{tabular}{|c|}
4,30 \\
24,79
\end{tabular} & $\begin{array}{ll}4,11 \\
42,82\end{array}$ & 378,46 & 108,46 & \begin{tabular}{|l|}
133,97 \\
13,97
\end{tabular} & $\begin{array}{l}31,100 \\
315,95\end{array}$ \\
\hline Discoglossus galganoi & 29TMH76 & 18,00 & 142,36 & 59,45 & 39,14 & 3130,50 & 224,05 & 74,18 & 149,86 & 112,64 & 180,45 & 184,00 & 103,45 & 970,82 & 140,59 & 26,09 & 42,05 & 384,09 & 112,86 & 138,27 & 322,23 \\
\hline Discoglossus galganoi & 29TMH83 & & & & & & & & & & & & & & & & & & & & \\
\hline Discoglossus galganoi & 29TMH84 & 11,00 & 13 & 60,94 & 38,7 & 73,38 & 225,63 & 70,25 & 155,38 & 108,50 & 180,31 & 183, & 99, & 055,56 & 150,25 & 27,56 & 43,06 & 419,00 & 116,56 & 40,94 & 361,06 \\
\hline \begin{tabular}{|l|l|l} 
Discoglossus galganoi \\
\end{tabular} & 29TMH85 & 76,00 & 139,86 & 60,66 & 38,86 & 3227,67 & 224,58 & 70,50 & 154,08 & 109,07 & 179,49 & 182,91 & 99,89 & 1022,70 & 146,27 & 27,14 & 42,50 & 405,09 & 116,07 & 140,82 & 344,98 \\
\hline \begin{tabular}{|l|} 
Discoglossus galganoi \\
\end{tabular} & 29TMH86 & 101,00 & 140,88 & 60,43 & 39,01 & 3189,41 & 224,79 & 71,89 & 152,90 & 110,68 & 179,94 & 183,48 & 101,52 & 1001,25 & 143,27 & 27,08 & 41,99 & 395,29 & 115,62 & \begin{tabular}{|l|l}
140,68 \\
\end{tabular} & 334,91 \\
\hline Discoglossus galganoi & 29TMH87 & 60,00 & 143,94 & 60,09 & 39,43 & 3139,24 & 225,93 & 75,29 & 150,63 & 114,11 & 182,18 & 185,88 & 104,93 & \begin{tabular}{|c|}
980,60 \\
\end{tabular} & \begin{tabular}{|l|l|}
139,88 \\
\end{tabular} & 26,78 & 41,41 & 385,48 & 113,95 & 139,40 & 326,89 \\
\hline Discoglossus galganoi & 29тMH90 & 6,00 & 148,43 & 58,79 & 38,79 & 3288,93 & 229,93 & 80,50 & 149,43 & 115,14 & 189,36 & 191,43 & 106,64 & 1150,64 & 161,21 & 25,29 & 46,07 & 461,43 & 107,86 & 131,50 & 415,43 \\
\hline Discoglossus galganoi & 29тMH91 & 46,00 & 146 & 59,04 & 38,62 & 3311,15 & 229,18 & 78,01 & 151,16 & 113,22 & 187,59 & 189,99 & 104,65 & 1143,04 & 1,42 & 26,2 & 45,56 & 00 & 67 & 134,49 & 409,85 \\
\hline Discoglossus galganoi & 29TMH93 & 45,00 & 142 & 60,38 & 38 & 3303 & 228 & 73,36 & 154,65 & 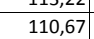 & $\mid 183,91$ & 186,81 & 101,71 & 1081,97 & 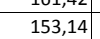 & 26,94 & 44,01 & 12 & 113,87 & $\begin{array}{l}34,4,10 \\
\end{array}$ & 376,59 \\
\hline Discoglossus galganoi & 29TMH94 & 96,00 & 134 & 62,32 & 38,30 & 3383,03 & 224,15 & 63,56 & 160,59 & 101,66 & 176,79 & 179,88 & 92,99 & 1163,86 & 165,96 & 30,57 & 43,29 & 460,44 & 125,92 & 149,26 & 407,56 \\
\hline Discoglossus galganoi & 29TMH95 & $\begin{array}{r}101,00 \\
100\end{array}$ & 132,06 & 62,84 & 38,29 & 3379,81 & 222,68 & 60,82 & $\begin{array}{l}161,87 \\
\end{array}$ & 99,50 & 174,35 & 177,58 & 90,84 & 1161,49 & 163,83 & 31,54 & 42,44 & 457,27 & 129,28 & 152,73 & 403,12 \\
\hline Discoglossus galganoi & 29TMH96 & 101,00 & 132,67 & 62,76 & 38,41 & 3336,99 & 222,47 & 61,55 & 160,92 & 100,76 & 174,14 & 177,72 & 91,95 & 1134,29 & 158,51 & 31,50 & 41,88 & 444,68 & 129,01 & 152,87 & 389,79 \\
\hline Discoglossus galganoi & 29TMH98 & 28,00 & 142,80 & 61,16 & 39,53 & 3177,18 & 226,53 & 73,42 & 153,11 & 112,60 & 181,80 & 185,62 & 103,67 & 1013,53 & 141,49 & 28,18 & 41,00 & 395,73 & 117,49 & 142,60 & 341,07 \\
\hline \begin{tabular}{|l} 
Discoglossus galganoi \\
\end{tabular} & \begin{tabular}{|l|} 
29TNE14 \\
\end{tabular} & $\frac{20}{94} \cdot 3 x-3$ & 15 & $80,1,69$ & $\frac{43}{43}$ & 3489 & 249 & $\frac{\mid 3,44}{67,60}$ & \begin{tabular}{|l|l|}
181,44 \\
\end{tabular} & \begin{tabular}{|l|l}
114,96 \\
\end{tabular} & $\begin{array}{l}\mid 101,00 \\
194,89 \\
\end{array}$ & $\begin{array}{l}10,02,96 \\
196,96\end{array}$ & \begin{tabular}{|l|l|}
106,94 \\
\end{tabular} & \begin{tabular}{|l|l|}
15,43 \\
9153
\end{tabular} & $\begin{array}{l}\mid 41,43 \\
130,14\end{array}$ & 告0,10 & 54,31 & 372,73 & $\begin{aligned} 51,43 \\
57,22\end{aligned}$ & $\begin{array}{c}\frac{14,20}{64,43} \\
\end{array}$ & 366,66 \\
\hline \begin{tabular}{|l} 
Discoglossus galganoi \\
\end{tabular} & 29TNE15 & 95,00 & 152,10 & 79,87 & 44,23 & 3433,91 & 244,94 & 66,57 & 178,37 & 114,04 & 192,57 & 194,69 & 106,07 & 940,82 & 132,95 & 9,80 & 53,87 & 381,66 & 60,01 & 67,97 & 375,23 \\
\hline Discoglossus galganoi & 29TNE17 & 40,00 & 151,00 & 77,70 & \begin{tabular}{|c|}
44,97 \\
\end{tabular} & 3321,38 & 237,20 & 65,97 & 171,23 & 113,99 & 189,58 & 191,34 & 105,62 & 973,01 & 136,21 & 10,34 & 53,00 & 393,07 & 63,24 & 72,89 & 385,45 \\
\hline Discoglossus galganoi & 29TNE24 & 101,00 & 157,05 & 86,34 & 43,98 & 3694,57 & 261,43 & 67,16 & 194,27 & 116,16 & 201,40 & 203,60 & 108,25 & 901,97 & 127,53 & 8,99 & 53,98 & 365,32 & 57,08 & 63,58 & 361,36 \\
\hline Discoglossus galganoi & 29TNE26 & 100,00 & 152,32 & 84,16 & 44,45 & 3581,52 & 250,69 & 63,32 & 187,37 & 112,44 & 194 & 196 & 10 & 969,56 & 136,02 & 10,03 & 53,09 & 390,74 & 63,01 & 70,94 & 385 \\
\hline \begin{tabular}{|l|l|} 
Discoglossus galganoi \\
\end{tabular} & 29TNE27 & $\begin{array}{l}100,00 \\
100\end{array}$ & $\begin{array}{l}15,32,94 \\
150,94\end{array}$ & $\begin{array}{l}4,10 \\
81,77 \\
\end{array}$ & 444,7 & $\begin{array}{ll}3501,125 \\
3491,93 \\
\end{array}$ & 244,10 & $\begin{array}{l}5,32 \\
63,03 \\
\end{array}$ & \begin{tabular}{|l|}
181,07 \\
181,
\end{tabular} & 111,95 & 191,99 & 193,90 & 103,76 & 988,28 & 138,04 & 10,85 & 52,79 & 397,95 & 65,18 & 74,10 & 391,49 \\
\hline \begin{tabular}{|l} 
Discoglossus galganoi \\
\end{tabular} & 29TNE28 & 101,00 & 149,73 & 78,91 & 45,04 & 3384,36 & 236,65 & 63,11 & $\mid 173,54$ & 111,73 & $\mid 189,05$ & 190,76 & $\mid 103,37$ & 1002,72 & $\mid 139,53$ & $\mid 11,00$ & 52,55 & 403,88 & 66,14 & 76,54 & 395,56 \\
\hline Discoglossus galganoi & 29TNE29 & 91,00 & 148,62 & 76,34 & 45,23 & 3286,96 & 230,02 & 63,25 & 166,77 & 111,66 & 186,35 & 187,93 & 103,07 & 1017,60 & 140,94 & 11,13 & 52,35 & 410,05 & 67,19 & 78,96 & 399,81 \\
\hline Discoglossu & 29TNE34 & 100,00 & 158,71 & 92,86 & 43,79 & 3959,58 & 274,19 & 64,23 & 209, & 114 & 206 & 209 & 106,97 & 911,58 & 128,28 & 9,09 & 53,73 & 366,69 & 58,88 & 64,19 & 365, \\
\hline \begin{tabular}{|l} 
Discoglossus galganoi \\
\end{tabular} & 29TNE37 & 100,00 & 151,92 & 8,12 & 44,21 & 760,17 & 256,36 & 59,47 & 196,88 & 109,94 & 196,99 & 198,97 & 101,90 & 999,56 & 139,38 & 11,00 & 52,72 & 00,87 & 66,00 & 74,56 & 396,25 \\
\hline
\end{tabular}




\begin{tabular}{|c|c|c|c|c|c|c|c|c|c|c|c|c|c|c|c|c|c|c|c|c|c|}
\hline TAXON & UTM & $\mathrm{km} 2$ & $\mathrm{BIO1}$ & B1O2 & $\mathrm{BIO3}$ & B104 & B105 & $\mathrm{B106}$ & 8107 & B108 & B109 & 81010 & B1011 & $\mathrm{BIO12}$ & $\mathrm{B1O13}$ & 81014 & BIO15 & B1016 & B1017 & B1018 & B1019 \\
\hline Discoglossus galganoi & 29TNE38 & 100,00 & 151,17 & 85,28 & 44,48 & 3655,62 & 249,50 & 59,88 & 189,62 & 110,04 & 194,48 & 196,30 & 101,87 & 1009,27 & 140,22 & 11,01 & 52,38 & 405,38 & 67,20 & 76,61 & 398,25 \\
\hline Discoglossus galganoi & 29TNE39 & 101,00 & 149,99 & 83,28 & 44,75 & 3590,40 & 244,10 & 59,58 & 184,53 & 109,52 & 192,36 & 194,02 & 101,25 & 1023,95 & 141,72 & 11,49 & 52,18 & 411,92 & 68,18 & 79,27 & 402,06 \\
\hline \begin{tabular}{|l|l} 
Discoglossus galganoi \\
\end{tabular} & 29TNE44 & 101,00 & 157,36 & 99,73 & 43,31 & 4271,78 & 286,11 & 58,28 & 227,83 & 102,93 & 210,29 & 212,65 & 102,55 & 952,53 & 133,76 & 10,00 & 53,12 & 382,72 & 63,82 & 67,21 & 382,71 \\
\hline Discoglossus galganoi & 29TNE45 & 101,00 & 159,50 & 98,46 & 43,90 & 4164,52 & 283,32 & 60,82 & 222,49 & 108,75 & 210,58 & 212,78 & 105,32 & 936,35 & 130,70 & 9,70 & 52,90 & 374,25 & 62,54 & 67,44 & 374,14 \\
\hline Discoglossus galganoi & 29TNE46 & 100,00 & 155,75 & 96,92 & 43,75 & 4129,05 & 276,81 & 57,49 & 219,32 & 107,60 & 206,33 & 208,40 & 101,84 & 981,31 & 136,99 & 10,65 & 52,63 & 391,48 & 66,27 & 71,75 & 391,01 \\
\hline Discoglossus galganoi & 29TNE56 & 101,00 & 150,10 & 99,40 & 42,36 & 4444,24 & 281,01 & 49,47 & 231,54 & 93,55 & 205,67 & 207,82 & 93,41 & 1053,40 & 149,12 & 11,49 & 52,88 & 422,23 & 71,75 & 75,15 & 422,23 \\
\hline Discoglossus galganoi & 29TNE57 & 101,00 & 148,69 & 97,64 & 42,53 & 4378,99 & 275,62 & 48,79 & 226,84 & 97,88 & 203,34 & 205,27 & 92,45 & 1070,57 & 151,49 & 11,72 & 52,86 & 428,03 & 72,49 & 77,32 & 427,56 \\
\hline Discoglossus galganoi & 29TNE58 & 100,00 & 146,09 & 95,18 & 42,45 & 4321,16 & 268,92 & 47,29 & 221,63 & 98,02 & 199,92 & 201,72 & 90,42 & 1099,79 & 155,99 & 12,10 & 52,83 & 440,82 & 74,02 & 80,08 & 438,16 \\
\hline Discoglossus galganoi & 29TNE76 & 101,00 & 154,06 & 101,53 & 41,08 & 4813,66 & 293,38 & 49,62 & 243,76 & 93,18 & 215,14 & 216,88 & 93,18 & 1005,56 & 143,97 & 9,99 & 53,47 & 404,01 & 66,34 & 69,56 & 404,01 \\
\hline Discoglossus galganoi & 29TNE77 & 100,00 & 151,71 & 100,66 & 41,18 & 4778,52 & 288,89 & 47,59 & 241,30 & 91,92 & 212,30 & 213,84 & 91,08 & 1035,22 & 148,55 & 10,42 & 53,45 & 415,23 & 68,17 & 72,12 & 415,23 \\
\hline Discoglossus galganoi & 29TNE78 & 100,00 & 148,15 & 99,57 & 41,25 & 4758,31 & 283,45 & 44,56 & 238,88 & 92,48 & 208,55 & 209,97 & 87,76 & 1076,81 & 155,12 & 11,07 & 53,44 & 431,68 & 70,90 & 75,54 & 431,42 \\
\hline Discoglossus galganoi & 29TNE85 & 100,00 & 147,50 & 97,92 & 39,26 & 5042,36 & 289,99 & 44,08 & 245,90 & 85,04 & 212,90 & 214,17 & 85,04 & 1059,06 & 155,04 & 10,29 & 54,51 & 429,45 & 68,30 & 69,66 & 429,45 \\
\hline \begin{tabular}{|l} 
Discoglossus galganoi \\
\end{tabular} & 29TNE95 & 101,00 & 127,45 & 87,81 & 36,31 & 5197,31 & 267,32 & 28,99 & 238,32 & 65,12 & 196,99 & 197,21 & 65,12 & 1266,14 & 191,66 & 12,29 & 55,95 & 518,23 & 78,40 & 78,48 & 518,23 \\
\hline Discoglossus galganoi & 29TNE96 & 100,00 & 144,25 & 96,90 & 38,48 & 5194,21 & 288,55 & 39,98 & 248,56 & 80,12 & 211,84 & 212,90 & 80,12 & 1084,89 & 160,45 & 10,32 & 54,88 & 440,40 & 69,82 & 70,58 & 440,40 \\
\hline Discoglossus galganoi & 29TNF20 & 39,00 & 148,11 & 75,99 & 45,39 & 3278,87 & 228,40 & 62,72 & 165,68 & 111,24 & 185,74 & 187,30 & 102,70 & 1033,57 & 142,44 & 11,91 & 52,02 & 416,51 & 68,59 & 81,88 & 404,38 \\
\hline Discoglossus galganoi & 29TNF25 & 28,00 & 144,51 & 85,81 & 44,94 & 3674,23 & 243,21 & 54,34 & 188,87 & 104,47 & 189,36 & 191,38 & 97,09 & 1183,21 & 162,30 & 14,83 & 51,15 & 472,75 & 81,40 & 99,72 & 460,91 \\
\hline Discoglossus galganoi & 29TNF26 & 68,00 & 143,71 & 84,72 & 45,01 & 3658,17 & 241,52 & 55,50 & 186,02 & 99,99 & 188,56 & 190,46 & 97,07 & 1215,52 & 165,55 & 15,08 & 51,03 & 482,21 & 83,56 & 100,72 & 480,78 \\
\hline \begin{tabular}{|l} 
Discoglossus galganoi \\
\end{tabular} & 29TNF27 & 83,00 & 143,39 & 83,67 & 44,84 & 3665,84 & 241,48 & 56,50 & \begin{tabular}{l|l}
184,98 \\
\end{tabular} & 98,16 & 188,60 & 190,35 & 96,94 & 1229,74 & 168,04 & 15,06 & 51,32 & 488,82 & 83,48 & 101,82 & 488,58 \\
\hline Discoglossus galganoi & 29TNF28 & 101,00 & 142,97 & 82,67 & 44,28 & 3688,89 & 241,72 & 57,07 & 184,65 & 96,45 & 188,66 & 190,33 & 96,40 & 1246,49 & 171,06 & 15,08 & 51,64 & 496,82 & 83,70 & 103,29 & 496,82 \\
\hline \begin{tabular}{|l|} 
Discoglossus galganoi \\
\end{tabular} & 29TNF29 & 100,00 & 143,40 & 81,55 & 43,81 & 3705,16 & 242,68 & 58,44 & 184,24 & 96,74 & 189,45 & $\mid 190,99$ & 96,74 & $\mid 1253,60$ & $\mid 172.57$ & 14,95 & 51,94 & 500,80 & 83,10 & 104,21 & 500,80 \\
\hline Discoglossus galganoi & 29TNF31 & 101,00 & 148,07 & 83,26 & 44,69 & 3597,97 & 241,68 & 57,46 & 184,22 & 107,87 & 190,73 & 192,50 & 99,47 & 1065,36 & 146,05 & 12,2 & 52,00 & 429,98 & 71,06 & 85,21 & 414,46 \\
\hline \begin{tabular}{|l|} 
Discoglossus galganoi \\
\end{tabular} & 29TNF32 & 101,00 & 145,57 & 84,92 & 44,51 & 3682,73 & 242,81 & 53,91 & 188,90 & 104,71 & 189,77 & 191,53 & 96,39 & 1108,58 & 151,23 & 13,26 & 51,97 & 448,35 & 74,67 & 90,24 & 429,45 \\
\hline \begin{tabular}{|l} 
Discoglossus galganoi \\
\end{tabular} & 29TNF33 & 100,00 & 143,08 & 86,64 & 44,26 & 3769,42 & 244,08 & 50,32 & \begin{tabular}{|c|}
193,75 \\
\end{tabular} & \begin{tabular}{|c|}
101,57 \\
\end{tabular} & 188,84 & 190,75 & 93,44 & 1153,38 & 156,89 & 14,21 & 51,96 & 467,44 & 78,42 & 95,49 & 444,94 \\
\hline Discoglossus galganoi & 29TNF35 & 101,00 & 143,79 & 89,17 & 44,34 & 3853,99 & 248,86 & 50,08 & 198,78 & 101,82 & 191,19 & 193,23 & 93,92 & 1176,16 & 162,85 & 15,00 & 51,60 & 476,56 & 80,52 & 100,90 & 450,62 \\
\hline Discoglossus galganoi & 29TNF36 & 100,00 & 142,72 & 88,75 & 44,37 & 3874,54 & 248,10 & 50,30 & 197,80 & 100,59 & 190,60 & 192,54 & 93,19 & 1208,89 & 165,64 & 15,18 & 51,16 & 484,74 & 82,84 & 101,99 & 470,16 \\
\hline Discoglossus galganoi & 29TNF37 & 101,00 & 143,27 & 87,78 & 44,23 & 3880,42 & 248,43 & 52,12 & 196,31 & 100,95 & 191,39 & 193,10 & 93,98 & 1219,17 & 165,45 & 15,05 & 51,07 & 485,64 & 82,94 & 101,87 & 478,73 \\
\hline Discoglossus galganoi & 29TNF38 & 101,00 & $\begin{array}{l}142,27 \\
142,52\end{array}$ & 86,87 & 43,81 & 3905,18 & 248,58 & $\frac{52,35}{52,35}$ & 196,23 & $\begin{array}{c}99,41 \\
99\end{array}$ & 191,21 & 192,75 & 93,25 & $\mid 1241,90$ & 168,32 & 15,31 & 51,18 & \begin{tabular}{|l|l|}
493,36 \\
\end{tabular} & $\begin{array}{l}82,24,21 \\
\end{array}$ & 103,44 & 490,86 \\
\hline \begin{tabular}{|l} 
Discoglossus galganoi \\
\end{tabular} & 29TNF45 & 100,00 & 143,60 & 92,24 & 43,84 & 4070,49 & 255,27 & 46,97 & 208,31 & 98,94 & $\begin{array}{ll}194,03 \\
\end{array}$ & 195,90 & 91,10 & 1174,73 & 159,85 & 14,55 & 51,68 & 475,51 & 79,77 & 98,42 & 452,40 \\
\hline \begin{tabular}{|l|} 
Discoglossus galganoi \\
\end{tabular} & 29TNF46 & 101,00 & 139,99 & 92,04 & 43,58 & 4124,76 & 253,26 & 44,26 & 208,99 & 94,91 & 191,59 & 193,29 & 87,44 & 1229,65 & 167,21 & 15,41 & 51,34 & 495,06 & 84,11 & 101,93 & 478,38 \\
\hline Discoglossus galganoi & 29TNF47 & 100,00 & 139,14 & 91,24 & 43,32 & 4147,14 & 252,84 & 44,35 & 208,48 & 93,89 & 191,25 & 192,76 & 86,61 & 1253,11 & 169,91 & 15,81 & 51,14 & 501,37 & 86,32 & 103,48 & 491,26 \\
\hline Discoglossus galganoi & 29TNF49 & 101,00 & 139,80 & 89,86 & 42,66 & 4175,54 & 254,55 & 46,33 & 208,22 & 94,19 & 192,55 & 193,76 & 87,19 & 1270,24 & 171,95 & 16,30 & 51,01 & 504,73 & 88,23 & 105,84 & 500,86 \\
\hline Discoglossus galganoi & 29TNF55 & 100,00 & 140,87 & $\begin{array}{l}55,08 \\
95,\end{array}$ & $\frac{42,94}{42,94}$ & 4326,04 & 260,24 & $\begin{array}{l}41,73 \\
41,5\end{array}$ & 218,51 & \begin{tabular}{|l|l|}
93,30 \\
3
\end{tabular} & \begin{tabular}{|l|l|}
195,21 \\
\end{tabular} & $\begin{array}{ll}196,68 \\
\end{array}$ & 85,53 & $\begin{array}{l}1202,49 \\
1202,49\end{array}$ & $\mid 165,11$ & $\begin{array}{ll}14,53 \\
140\end{array}$ & $\begin{array}{l}1,101 \\
51,85\end{array}$ & 484,56 & \begin{tabular}{l|l}
81,28 \\
\end{tabular} & $\begin{array}{r}\mid 01,04 \\
96,84 \\
\end{array}$ & 468,84 \\
\hline Discoglossus galganoi & 29TNF56 & 101,00 & 139,94 & 95,13 & 42,95 & 4354,26 & 260,13 & 41,13 & 219,00 & 92,16 & 194,79 & 196,27 & 84,56 & 1221,82 & 166,99 & 14,97 & 51,64 & 490,56 & 83,17 & 98,86 & 477,69 \\
\hline \begin{tabular}{|l|} 
Discoglossus galganoi \\
\end{tabular} & 29TNF58 & 100,00 & 142,10 & 94,36 & 42,68 & 4362,30 & 262,89 & 44,19 & 218,70 & 94,05 & 197,22 & 198,42 & 86,75 & 1212,75 & 162,86 & 15,06 & 51,03 & 482,85 & 83,48 & 99,97 & 474,72 \\
\hline \begin{tabular}{|l|} 
Discoglossus galganoi \\
\end{tabular} & 29TNF59 & 101,00 & 139,94 & 93,48 & 42,13 & 4393,00 & 261,73 & 42,64 & 219,10 & 91,63 & 195,73 & 196,85 & 84,56 & 1243,58 & 167,10 & 16,12 & 50,99 & 493,44 & 87,40 & 103,38 & 487,78 \\
\hline Discoglossus galganoi & 29TNF60 & 100,00 & 135,03 & 94,39 & 41,03 & 4585,71 & 262,88 & 35,58 & 227,30 & 84,44 & 193,27 & 194,86 & 77,17 & 1237,64 & 179,24 & 13,79 & 53,37 & 498,24 & 82,88 & 88,33 & 495,79 \\
\hline Discoglossus galganoi & 29TNF61 & 100,00 & $\begin{array}{l}135,05 \\
135,59\end{array}$ & \begin{tabular}{|c|}
44,12 \\
94,12
\end{tabular} & $\frac{4,103}{41,30}$ & 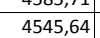 & $\begin{array}{l}20,00 \\
261,58\end{array}$ & $\begin{array}{l}3,20 \\
36,27 \\
\end{array}$ & 225,31 & $\begin{array}{l}44,44 \\
84,47 \\
\end{array}$ & \begin{tabular}{|l|l|l|l|l|}
193,36 \\
\end{tabular} & \begin{tabular}{|l|l|l}
194,77 \\
\end{tabular} & 78,12 & $\begin{array}{l}1253,04 \\
123,48\end{array}$ & 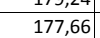 & $\begin{array}{l}\mid 3,179 \\
13,94\end{array}$ & \begin{tabular}{|l|l|}
53,23 \\
53
\end{tabular} & $\mid$\begin{tabular}{|l|}
$490,24,11$ \\
\end{tabular} & $\begin{array}{l}\mid c, 200 \\
82,71\end{array}$ & \begin{tabular}{l|l}
0,035 \\
89,56
\end{tabular} & 492,25 \\
\hline Discoglossus galganoi & 29TNF67 & 100,00 & 139,03 & 97,85 & 42,15 & 4589,24 & 266,73 & 37,67 & 229,06 & 88,29 & 197,36 & 198,49 & 80,91 & 1225,60 & 168,33 & 14,86 & 51,72 & 488,61 & 83,77 & 97,47 & 482,14 \\
\hline Discoglossus galganoi & 29TNF70 & 100,00 & 131,12 & 93,82 & 39,84 & 4794,23 & 263,60 & 31,18 & 232,42 & 74,29 & 193,10 & 194,21 & 71,49 & 1276,03 & 187,97 & 13,92 & 54,17 & 515,51 & 84,71 & 88,05 & 514,91 \\
\hline Discoglossus galganoi & 29TNF71 & 101,00 & 138,55 & 97,23 & 41,02 & 4748,50 & 270,65 & 36,33 & 234,32 & 84,96 & 199,28 & 200,42 & 78,59 & 1195,33 & 173,64 & 12,91 & 53,50 & 480,83 & 78,99 & 85,21 & 478,45 \\
\hline \begin{tabular}{|l|} 
Discoglossus galganoi \\
\end{tabular} & 29TNF72 & 100, & 124,75 & 93,12 & 39 & 4811,33 & 256,79 & 25,56 & 231,23 & 67,57 & 187,14 & 188,20 & 65,25 & 1354,86 & 199,64 & 15,47 & 54,07 & 547,42 & 91,22 & 94,88 & 546,90 \\
\hline \begin{tabular}{|l|} 
Discoglossusus galganoi \\
\end{tabular} & $\begin{array}{l}\text { 291NF/ } \\
\text { 29TNF73 }\end{array}$ & 100,00 & $\begin{array}{l}125,15 \\
125,97\end{array}$ & $\begin{array}{l}93,12 \\
94,19 \\
\end{array}$ & $\begin{array}{l}35, \\
40,\end{array}$ & $\begin{array}{l}481,335 \\
4798,34\end{array}$ & 257,82 & \begin{tabular}{|l|}
26,19 \\
260
\end{tabular} & $\begin{array}{l}231,23 \\
231,62 \\
\end{array}$ & 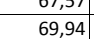 & $\mid$\begin{tabular}{|l|}
188,03 \\
\end{tabular} & $\begin{array}{l}180,20,07 \\
189,0\end{array}$ & \begin{tabular}{|c|}
63,353 \\
66,37
\end{tabular} & \begin{tabular}{|l|}
1334,00 \\
1340,38
\end{tabular} & \begin{tabular}{|l|}
1959,83 \\
\end{tabular} & \begin{tabular}{|l|l|}
15,66 \\
15
\end{tabular} & $\begin{array}{l}4,301 \\
53,65 \\
\end{array}$ & \begin{tabular}{|l|}
$441,42,51$ \\
540
\end{tabular} & $\begin{array}{l}1,2< \\
90,73 \\
\end{array}$ & $\begin{array}{ll}4,600 \\
95,98 \\
\end{array}$ & $\begin{array}{l}340,90 \\
538,99\end{array}$ \\
\hline Discoglossus galganoi & 29TNF75 & 100,00 & 137,44 & 99,71 & 41,73 & 4775,34 & 270,14 & 34,08 & 236,05 & 82,59 & 198,39 & 199,50 & 77,09 & 1223,22 & 174,59 & 13,90 & 52,80 & 489,74 & 81,78 & 91,80 & 486,31 \\
\hline Discoglossus galganoi & 29TNF77 & 100,00 & 139,96 & 100,63 & 41,82 & 4786,69 & 273,79 & 35,96 & 237,83 & 85,58 & 201,14 & 201,93 & 79,40 & 1195,50 & 166,38 & 14,04 & 52,04 & 475,06 & 81,10 & 92,96 & 472,06 \\
\hline Discoglossus galganoi & 29TNF79 & 101,00 & 124,43 & 95,81 & $4 c$ & 4841,80 & 258,1 & 24,30 & 233,89 & 65,58 & 187,19 & 188,09 & 64,62 & 1349,39 & 185,11 & 18,55 & 51,51 & 36,28 & 98,47 & 107,09 & 536,16 \\
\hline \begin{tabular}{|l|} 
Discoglossus galganoi \\
\end{tabular} & 29TNF80 & 101,00 & 137,26 & 9 & 3 & 4966,71 & 275, & 33,90 & 241,22 & 75,65 & 201,18 & 202,29 & 75,13 & 1195,95 & 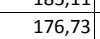 & $\frac{10}{12}$ & 54 & $\begin{array}{ll}482,82 \\
\end{array}$ & 78,28 & $\begin{array}{l}81,81 \\
81\end{array}$ & 482,81 \\
\hline \begin{tabular}{|l} 
Discoglossus galganoi \\
\end{tabular} & 29TNFE & 101,00 & 138 & 98,97 & 40,41 & 4957,04 & 276 & 34,33 & 241,95 & 78,33 & 202,15 & 203,23 & 76,25 & 1184,88 & 174,47 & 12,24 & 54,20 & 477,17 & 77,25 & 82,20 & 477,00 \\
\hline \begin{tabular}{|l|} 
Discoglossus galganoi \\
\end{tabular} & 29TNF84 & 101,00 & 118,90 & 93,61 & 39,19 & 4982,55 & 254,88 & 19,09 & 235,79 & 58,28 & 184,21 & 184,84 & 57,85 & 1397,56 & 206,45 & 16,64 & 54,06 & 565,62 & 95,33 & 98,47 & 565,51 \\
\hline \begin{tabular}{|l|} 
Discoglossus galganoi \\
\end{tabular} & 29TNF85 & 100,00 & 136,01 & 101,39 & 41,17 & 4965,90 & 274,28 & 30,99 & 243,29 & 75,89 & 199,76 & 200,67 & 73,51 & 1222,05 & 177,54 & 13,56 & 53,63 & 490,55 & 81,16 & 89,01 & 489,57 \\
\hline Discoglossus galganoi & 29TNF89 & 101,00 & 138,03 & 102,06 & 40,95 & 4999,15 & 277,95 & 31,91 & 246,04 & 78,21 & 202,41 & 202,92 & 75 & 1176,14 & 161,05 & 14,66 & 51 & 463,52 & 82,57 & 92,81 & 463,14 \\
\hline Discoglossus galganoi & 29TNF93 & 100,00 & $\begin{array}{ll}13,0,03 \\
112,22\end{array}$ & $\begin{array}{r}80,20 \\
89,85 \\
\end{array}$ & $\frac{40}{37}$ & \begin{tabular}{ll|l}
45323,48 \\
5123
\end{tabular} & 249 & \begin{tabular}{|c|c|}
13,62 \\
13
\end{tabular} & $\begin{array}{l}236,13 \\
236,13\end{array}$ & \begin{tabular}{l|l}
50,27 \\
5
\end{tabular} & \begin{tabular}{|l|}
180,26 \\
\end{tabular} & \begin{tabular}{|l|l|}
180,45 \\
\end{tabular} & 50,27 & $|1470,64|$ & \begin{tabular}{|l|}
216,60 \\
2160
\end{tabular} & $\begin{array}{l}4,009 \\
16,93\end{array}$ & $\begin{array}{l}1,100 \\
55,02\end{array}$ & \begin{tabular}{|l|l|}
587,21 \\
\end{tabular} & $\begin{array}{ll}97,41 \\
97,41\end{array}$ & $\begin{array}{l}20,101 \\
97,51\end{array}$ & $\begin{array}{ll}403,14 \\
587,21\end{array}$ \\
\hline Discoglossus galganoi & 29TNF96 & 100,00 & 122,41 & 99,04 & 39,60 & 5160,22 & 265,41 & 18,77 & 246,64 & 58,88 & 189,82 & 190,40 & 58,88 & 1327,04 & 195,32 & 16,05 & 54,19 & 536,19 & 91,36 & 95,12 & 536,19 \\
\hline Discoglossus galganoi & 29TNF98 & 101,00 & $\begin{array}{ll}121,01 \\
121,02\end{array}$ & 98,41 & 39,61 & 5139,73 & 263,22 & 17,96 & 245,26 & 57,901 & $\begin{array}{l}188,29 \\
\end{array}$ & 188,76 & 57,91 & 1316,53 & $\mid 188,74$ & $\begin{array}{ll}17,26 \\
\end{array}$ & 53,01 & 528,34 & $\begin{array}{l}1,104 \\
94,25 \\
\end{array}$ & $\begin{array}{ll}0,12 \\
98,83\end{array}$ & 528,34 \\
\hline \begin{tabular}{|l|} 
Discoglossus galganoi \\
\end{tabular} & 29TNG07 & & & & & & & & & & & & & & & & & & & & \\
\hline \begin{tabular}{|l|} 
Discoglossus galganoi \\
\end{tabular} & 29TNG09 & & & & & & & & & & & & & & & & & & & & \\
\hline \begin{tabular}{|l} 
Discoglossus galganoi \\
\end{tabular} & 29TNG10 & 39,00 & 142,01 & 77,27 & 43 & 3598,76 & 237,07 & 61,08 & 175,99 & 96,92 & 186,80 & 188 & 96 & 1285,85 & 179,44 & 15,17 & 52,20 & 517,23 & 84,00 & 107,13 & 517,23 \\
\hline Discoglossus galganoi & 29TNG11 & 68,00 & 142,97 & 75,17 & 42,97 & 3566,09 & 236,70 & 63,82 & 172,88 & 98,36 & 187,37 & 188,68 & 98,36 & 1288,24 & 180,59 & 15,17 & 52,45 & 518,55 & 83,56 & 108,22 & 518,55 \\
\hline Discoglossus galganoi & 29TNG12 & 87,00 & 137.29 & 73,96 & 4206 & 3627,14 & 232.43 & 58,62 & 173,81 & 92.83 & $\mid 182.87$ & $\mid 184,29$ & 92,14 & 1378.35 & 191.82 & 19,18 & 51,61 & 553.01 & 96,64 & 118.57 & 552.97 \\
\hline Discoglossu & 29TNG13 & 86,00 & 140,49 & 72,13 & 41,64 & 3603,62 & 234,13 & 62,90 & 171. & 100,04 & 185,7 & 187 & 95, & 1358,91 & 189,08 & 19,68 & 51 & 544,43 & 96,92 & 119,11 & 541,84 \\
\hline Discoglossus galganoi & 29TNG14 & 99,00 & 141,35 & 69,97 & 41,01 & 3592,14 & 233,55 & 65,01 & 168,54 & 103,58 & 186,44 & 187,73 & 96,16 & 1368,59 & 93,12 & 21,54 & 50,70 & 549,61 & 101,51 & 122,99 & 542,04 \\
\hline
\end{tabular}




\begin{tabular}{|c|c|c|c|c|c|c|c|c|c|c|c|c|c|c|c|c|c|c|c|c|c|}
\hline TAXON & UTM & $\mathrm{km} 2$ & $\mathrm{BIO1}$ & $\mathrm{B1O2}$ & $\mathrm{BIO3}$ & $\mathrm{B104}$ & B105 & $\mathrm{B106}$ & $\mathrm{B107}$ & B108 & $\mathrm{BIO9}$ & 81010 & B1011 & $\mathrm{B1012}$ & $\mathrm{B1O13}$ & BIO14 & B1015 & BIO16 & B1017 & $\mathrm{BIO18}$ & B1019 \\
\hline Discoglossus galganoi & 29TNG15 & 101,00 & 132,16 & 69,72 & 40,14 & 3685,33 & 227,32 & 55,75 & 171,56 & 93,81 & 178,93 & 180,33 & 86,39 & 1509,91 & 227,25 & 27,33 & 50,50 & 609,48 & 119,62 & 138,03 & 604,19 \\
\hline Discoglossus galganoi & 29TNG16 & 63,00 & 144,91 & 65,38 & 39,81 & 3554,55 & 233,48 & 71,05 & 162,43 & 107,66 & 189,68 & 190,80 & 99,84 & 1361,27 & 195,80 & 24,69 & 49,54 & 549,03 & 108,17 & 128,84 & 528,42 \\
\hline \begin{tabular}{|l} 
Discoglossus galganoi \\
\end{tabular} & 29TNG17 & 33,00 & 149,14 & 62,22 & 38,97 & 3510,00 & 234,61 & 76,97 & 157,64 & 112,28 & 193,11 & 194,33 & 104,31 & 1294,33 & 179,89 & 25,03 & 48,31 & 519,61 & 107,44 & 128,50 & 486,56 \\
\hline Discoglossus galganoi & 29TNG18 & 45,00 & 144,43 & 61,74 & 38,37 & 3541,20 & 231,42 & 73,05 & 158,37 & 107,44 & 189,24 & 190,36 & 99,57 & 1364,63 & 199,30 & 28,12 & 48,48 & 549,64 & 116,34 & 136,83 & 520,34 \\
\hline Discoglossus galganoi & 29TNG19 & 57,00 & 145,12 & 59,99 & \begin{tabular}{|c|}
37,97 \\
\end{tabular} & 3519,84 & 230,93 & 75,11 & 155,82 & 108,43 & 189,61 & 191,00 & 100,84 & 1316,97 & 192,33 & 28,91 & 47,32 & 528,09 & 117,50 & 139,10 & 493,80 \\
\hline Discoglossus galganoi & 29TNG22 & 101,00 & 137,87 & 77,71 & 41,84 & 3802,67 & 239,14 & 55,51 & 183,63 & 92,15 & 185,93 & 187,09 & 90,40 & 1364,18 & 189,74 & 19,11 & 51,39 & 545,54 & 96,55 & 117,25 & 545,41 \\
\hline Discoglossus galganoi & 29TNG23 & 100,00 & 133,12 & 76,64 & \begin{tabular}{|l|l|}
41,04 \\
\end{tabular} & 3855,64 & 235,53 & 51,17 & 184,36 & 88,49 & 182,12 & 183,32 & 85,21 & 1450,79 & 209,92 & 22,81 & 50,88 & 581,76 & 108,37 & 126,68 & 581,25 \\
\hline Discoglossus galganoi & 29TNG24 & 99,00 & 142,72 & 73,68 & 40,92 & 3762,67 & 240,82 & 62,56 & 178,27 & 101,27 & $\begin{array}{l}190,16 \\
\end{array}$ & 191,21 & 95,21 & 1360,54 & 195,29 & 21,41 & 50,56 & 545,50 & 101,24 & 121,49 & 538,65 \\
\hline Discoglossus galganoi & 29TNG25 & 101,00 & 142,44 & 71,61 & 40,21 & 3755,29 & 239,25 & 63,49 & 175,77 & 101,68 & 189,94 & 190,94 & 95,01 & 1394,60 & 206,60 & 23,94 & 50,39 & 561,40 & 107,55 & 126,99 & 552,19 \\
\hline Discoglossus galganoi & 29TNG26 & 100,00 & 137,42 & 70,38 & 39,69 & 3792,18 & 234,78 & 59,26 & 175,52 & 95,03 & 185,76 & 186,73 & 89,89 & 1494,19 & 233,27 & 28,30 & 50,67 & 605,16 & 120,03 & 137,69 & 598,49 \\
\hline Discoglossus galganoi & 29TNG27 & 80,00 & 142,23 & 66,90 & 39,02 & 3729,91 & 235,55 & 66,17 & 169,38 & 100,94 & 189,67 & 190,59 & 95,20 & 1456,53 & 226,75 & 28,89 & 50,29 & \begin{tabular}{|c|}
590,88 \\
\end{tabular} & 119,23 & 137,56 & 576,63 \\
\hline Discoglossus galganoi & 29TNG28 & 86,00 & 139,17 & 65,44 & 38,37 & 3735,36 & 232,63 & 64,36 & 168,28 & 99,83 & 186,87 & 187,97 & 92,44 & 1463,59 & 227,46 & 31,15 & 49,23 & 589,78 & 125,44 & 144,09 & 572,35 \\
\hline \begin{tabular}{|l} 
Discoglossus galganoi \\
\end{tabular} & 29TNG29 & 72,00 & 142,90 & 62,57 & 37,89 & 3707,49 & 233,27 & 70,12 & 163,15 & 103,57 & 190,24 & 191,12 & 96,35 & 1394,43 & 212,13 & 30,94 & 48,26 & 558,48 & 122,62 & 142,96 & 533,75 \\
\hline Discoglossus galganoi & 29TNG33 & 100,00 & 128,02 & 80,92 & 40,79 & 4087,55 & 238,12 & 41,92 & 196,20 & 79,68 & 180,45 & 181,48 & 77,39 & 1483,19 & 217,87 & 24,47 & 50,58 & 592,61 & 114,75 & 129,94 & 592,45 \\
\hline Discoglossus galganoi & 29TNG36 & 101,00 & 144,76 & 73,61 & 39,76 & 3928,62 & 246,38 & 62,98 & 183,40 & 101,35 & 194,70 & 195,47 & 95,00 & 1380,58 & 213,07 & 25,50 & 50,08 & 554,99 & 110,69 & 128,51 & 543,54 \\
\hline Discoglossus galganoi & 29TNG37 & 100,00 & 139,44 & 72,37 & 39,17 & 3952,22 & 241,01 & 58,61 & 182,39 & 95,37 & 190,05 & 190,83 & 89,86 & 1472,17 & 236,44 & 29,55 & 50,39 & 593,97 & 122,06 & 138,70 & 586,24 \\
\hline Discoglossus galganoi & 29TNG38 & 88,00 & 139,79 & 70,11 & 38,73 & 3935,64 & 239,20 & 60,43 & 178,77 & 97,45 & 190,29 & 191,03 & 90,49 & 1461,61 & 233,79 & 31,05 & 49,66 & 586,56 & 124,93 & 141,71 & 575,20 \\
\hline \begin{tabular}{|l} 
Discoglossus galganoi \\
\end{tabular} & 29TNG39 & 101,00 & 136,77 & 68,86 & 38,12 & 3933,53 & 236,40 & 58,27 & 178,13 & 94,66 & 187,42 & 188,34 & 87,94 & 1478,41 & 235,28 & 33,27 & 48,80 & 590,26 & 130,99 & 148,84 & 576,22 \\
\hline Discoglossus galganoi & 29TNG40 & 101,00 & 145,85 & 88,48 & \begin{tabular}{|l|l|}
42,53 & \\
\end{tabular} & 4128,39 & 258,94 & 53,25 & 205,69 & 100,52 & 197,76 & 198,85 & 93,45 & 1208,74 & 163,53 & $\begin{array}{l}15,25 \\
\end{array}$ & 50,98 & \begin{tabular}{|c|}
478,58 \\
\end{tabular} & 83,25 & 102,33 & 474,61 \\
\hline Discoglossus galganoi & 29TNG41 & 100,00 & 138,67 & 87,77 & 41,79 & 4212,47 & 254,27 & 46,55 & 207,72 & 92,38 & 192,13 & 193,18 & 85,67 & 1304,64 & 181,44 & 18,13 & 50,77 & 517,18 & 94,26 & 111,32 & 514,42 \\
\hline Discoglossus galganoi & 29TNG42 & 100,00 & 137,73 & 86,50 & 41,29 & 4229,46 & 253,40 & 46,41 & 206,99 & 90,97 & 191,60 & 192,52 & 84,68 & 1324,39 & 187,27 & 19,51 & 50,38 & 524,80 & 98,47 & 114,94 & 521,03 \\
\hline Discoglossus galganoi & 29TNG43 & 101,00 & 137,51 & 85,64 & 40,89 & 4235,56 & 253,34 & \begin{tabular}{|c|}
46,66 \\
\end{tabular} & 206,68 & 91,15 & 191,53 & 192,29 & 84,30 & 1342,99 & 195,19 & 21,10 & 50,03 & 532,19 & 103,16 & 118,92 & 527,01 \\
\hline \begin{tabular}{|l} 
Discoglossus galganoi \\
\end{tabular} & 29TNG46 & 101,00 & 143,29 & 80,28 & 39,91 & 4175,75 & 254,49 & 55,52 & 198,96 & 97,62 & \begin{tabular}{|c|}
196,56 \\
\end{tabular} & \begin{tabular}{|c|}
197,13 \\
\end{tabular} & 90,47 & 1332,85 & 205,65 & 24,82 & 49,20 & 528,98 & 110,47 & 125,52 & 515,79 \\
\hline Discoglossus galganoi & 29TNG48 & 100,00 & 128,16 & 78,41 & 39,08 & 4198,61 & 239,79 & 41,84 & 197,95 & 83,04 & 182,58 & 183,64 & 76,66 & 1502,07 & 239,28 & 32,79 & 48,85 & \begin{tabular}{|l|l}
595,05 \\
\end{tabular} & 133,86 & 147,87 & 587,57 \\
\hline Discoglossus galganoi & 29TNG49 & 101,00 & 125,64 & 77,56 & 38,85 & 4165,73 & 237,61 & 39,97 & 197,64 & 81,13 & 179,86 & 181,09 & 75,07 & 1508,88 & 237,59 & 34,66 & 47,92 & \begin{tabular}{r|r}
594,55 \\
\end{tabular} & 138,65 & 153,11 & 584,39 \\
\hline Discoglossus galganoi & 29TNG51 & 100,00 & 138,16 & 91,40 & 41,41 & 4425,39 & 260,50 & 42,19 & 218,31 & 89,59 & 194,64 & 195,49 & 82,54 & 1274,66 & 176,06 & 17,98 & 50,29 & 503,34 & 93,86 & 109,01 & 498,60 \\
\hline Discoglossus galganoi & 29TNG57 & 100,00 & 121,78 & 83,80 & 39,37 & 4411,63 & 241,26 & 30,73 & 210,53 & 74,30 & 179,22 & 180,18 & $\mid 67,99$ & 1462,85 & 223,46 & 30,92 & 47,97 & 573,14 & 131,38 & 142,73 & 565,07 \\
\hline Discoglossus galganoi & 29TNG58 & 99,00 & 113,23 & 81,48 & 38,81 & 4356,27 & 232,03 & 24,34 & 207,69 & 66,96 & 170,34 & 171,53 & 61,18 & 1517,29 & 227,58 & 34,32 & 47,03 & 591,85 & 141,42 & 152,52 & 583,34 \\
\hline Discoglossus galganoi & 29TNG59 & 100,00 & 113,55 & 80,92 & 38,72 & 4310,81 & 231,79 & 25,08 & 206,71 & 67,71 & 170,02 & 171,45 & 62,24 & 1509,61 & 226,36 & 35,67 & 46,38 & 586,61 & 144,05 & 155,97 & 575,97 \\
\hline Discoglossus galganoi & 29TNG61 & 101,00 & 129,52 & 92,96 & 40,52 & 4652,63 & 257,84 & 31,49 & 226,34 & 76,71 & 189,55 & 190,32 & 71,80 & 1320,79 & 179,13 & 19,68 & 50,09 & 520,45 & 100,31 & 111,37 & 517,43 \\
\hline Discoglossus galganoi & 29TNG62 & 101,00 & 115,32 & 87,95 & 39,30 & 4647,57 & 241,85 & 21,15 & 220,70 & 62,37 & 176,03 & 176,82 & 58,84 & 1450,71 & 198,80 & 24,52 & 49,68 & 571,37 & 116,97 & 125,53 & 570,44 \\
\hline \begin{tabular}{|l} 
Discoglossus galganoi \\
\end{tabular} & 29TNG64 & 101,00 & 110,77 & 85,49 & 38,75 & 4618,93 & 235,05 & $\mid 18,21$ & 217,71 & $\mid 61,90$ & $\begin{array}{ll}171,38 \\
\end{array}$ & $\begin{array}{l}172,25 \\
1725\end{array}$ & 55,21 & $\mid \begin{array}{l}1401,37 \\
1481,37\end{array}$ & 208,95 & 28,14 & 48,52 & 579,94 & 126,96 & 135,08 & 577,66 \\
\hline Discoglossus galganoi & 29TNG66 & 100,00 & 132,97 & 90,07 & 39,70 & 4650,79 & 259,97 & 35,22 & 224,75 & 81,72 & 193,13 & 193,56 & 75,17 & 1269,36 & 188,81 & 24,75 & 47,50 & 491,39 & 112,81 & 122,05 & 476,26 \\
\hline Discoglossus galganoi & 29TNG67 & 101,00 & 131,55 & 88,09 & 39,38 & 4616,44 & 255,96 & 34,71 & 221,25 & 80,76 & 191,40 & 191,92 & 74,53 & 1285,02 & 193,17 & 26,55 & 47,19 & 496,80 & 116,35 & 126,10 & 482,80 \\
\hline Discoglossus galganoi & 29TNG69 & 101,00 & 130,59 & 84,99 & 39,07 & 4480,68 & 250,32 & 36,18 & 214,14 & 81,15 & 188,92 & 189,76 & 75,99 & 1312,73 & 200,11 & 30,08 & 46,38 & 505,62 & 123,59 & 137,23 & 491,56 \\
\hline Discoglossus galganoi & 29TNG72 & 100,00 & 97,65 & 83,12 & 37,48 & 4745,83 & 225,53 & 6,75 & 218,78 & 42,20 & 160,59 & 161,38 & 41,58 & 1545,54 & 206,22 & 28,51 & 49,13 & 607,76 & 130,75 & 134,74 & 607,72 \\
\hline \begin{tabular}{|l} 
Discoglossus galganoi \\
\end{tabular} & 29TNG73 & 100,00 & $\begin{aligned} 315,03 \\
115,12\end{aligned}$ & $\begin{array}{ll}83,11 \\
89,06\end{array}$ & $\begin{array}{l}3,40 \\
38,83\end{array}$ & $\begin{array}{l}474,32,36 \\
4792,\end{array}$ & 245,33 & \begin{tabular}{|c|c|}
18,81 \\
\end{tabular} & \begin{tabular}{|l|l|}
226,53 \\
\end{tabular} & $\begin{array}{ll}42,1,56 \\
61\end{array}$ & \begin{tabular}{|l|l|}
177,89 \\
\end{tabular} & 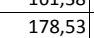 & $\begin{array}{l}41,00 \\
57,06\end{array}$ & $\begin{array}{l}134,394 \\
1389,96\end{array}$ & \begin{tabular}{|l|l|}
190,55 \\
\end{tabular} & 24,75 & $\begin{array}{ll}4,15 \\
48,83\end{array}$ & 543,13 & 116,06 & 122,88 & 540,40 \\
\hline Discoglossus galganoi & 29TNG75 & 100,00 & 95,31 & 81,82 & 37,30 & 4670,94 & 221,61 & 5,29 & 216,32 & 47,01 & 157,29 & 158,27 & 40,48 & 1539,21 & 211,15 & 32,58 & 47,17 & 598,54 & 140,23 & 145,68 & 596,07 \\
\hline Discoglossus galganoi & 29TNG81 & 99,00 & 115,24 & 91,50 & 38,82 & 4947,70 & 249,65 & 16,98 & 232,68 & 55,94 & 180,29 & 180,76 & 55,18 & \begin{tabular}{|l|}
1364,75 \\
\end{tabular} & 183,45 & 21,60 & 50,37 & 539,13 & 106,90 & 111,89 & 538,88 \\
\hline Discoglossus galganoi & 29TNG83 & 100,00 & 95,35 & 82,54 & $36, \varepsilon$ & 4825,88 & 224,96 & 4,18 & 220,77 & 39,97 & 159,66 & 160,33 & 38,78 & 1502,75 & 199,67 & 29,19 & 48,38 & 587,88 & 130,81 & 134,52 & 587,87 \\
\hline Discoglossus galganoi & 29TNG84 & 101,00 & 115,06 & 89, & 38, & 4900,82 & 247,18 & 17,13 & 230,05 & 62,29 & 179,62 & 180,01 & 55,89 & 1330,30 & 182,38 & 24,65 & 48,11 & 516,80 & 113,30 & 119,51 & 514,85 \\
\hline Discoglossus galganoi & 29TNG85 & 101,00 & 110,38 & 87,58 & 38, & 4847,86 & 241,14 & 14,13 & 227,01 & 58,55 & 174,38 & 174,95 & 52,32 & 1362,59 & 188,53 & 27,0 & 47,48 & 528,30 & 120,16 & 126,83 & 525,43 \\
\hline Discoglossus galganoi & 29TNG86 & 100,00 & 118,55 & 89,98 & 38,52 & 4887,39 & 249,84 & 19,15 & 230,69 & 65,38 & 182,86 & 183,30 & 59,50 & 1277,69 & 180,86 & 25,94 & 46,84 & 491,94 & 114,51 & 120,97 & 485,73 \\
\hline Discoglossus galganoi & 29TNG87 & 100,00 & 131,52 & 92,63 & 38,90 & 4978,81 & 263,13 & 27,19 & 235,94 & 75,96 & 196,55 & 196,79 & 70,46 & 1135,81 & 164,80 & 23,53 & 46,00 & 431,70 & 03,51 & 109,38 & 420,30 \\
\hline Discoglossus galganoi & 29TNG88 & 100,00 & 134,92 & 90,86 & 38,50 & 4962,84 & 263,7 & 30,42 & 36 & 79,33 & 199,65 & 199,84 & 74,12 & 1091,09 & 159,33 & 23,6 & 45,35 & 411,98 & 101,28 & 06,87 & 399,33 \\
\hline Discoglossus galganoi & 29TNG92 & 101,00 & 104 & 86,5 & 37, & 49887,78 & 238,55 & $\begin{array}{c}3,4,44 \\
9,44 \\
\end{array}$ & 22 & 45,29 & 170,90 & 171,31 & 45,29 & 1385,85 & \begin{tabular}{|l|l|}
185,38 \\
\end{tabular} & 24, & 49,44 & $\begin{array}{l}4+1,30 \\
545,62\end{array}$ & ,51 & 117,69 & 545,62 \\
\hline Discoglossus galganoi & 29TNG & 100,00 & 96 & 83 & 36,63 & 4929,91 & 228,39 & 3,62 & 224,77 & 39,17 & 162,07 & 162,53 & 38,30 & 1441,20 & 190,75 & 27,84 & 48,34 & 563,31 & 125,34 & 128,21 & 563,31 \\
\hline Discoglossus galganoi & 29TNG94 & 100,00 & 104,76 & 86,30 & 37,24 & 4947,62 & 237,78 & 9,36 & 228,42 & 50,88 & 170,56 & 170,87 & 45,91 & 1358,63 & 181,85 & 26,28 & 47,98 & 528,21 & 118,26 & 122,51 & 528,04 \\
\hline Discoglossus galganoi & 29TNG98 & 101,00 & 137,22 & 92,45 & 37,87 & 5162,84 & 269,37 & 28,60 & 240,77 & 79,01 & 204,71 & 204,75 & 73,95 & 989,93 & 142,03 & 21,46 & 44,79 & 370,10 & 91,71 & 93,81 & 359,00 \\
\hline Discoglossus galganoi & 29TNHOO & 16,00 & 147,29 & 59,00 & 38, & 3400,52 & 230,67 & 78,95 & 151,71 & 112,29 & $19 \mathrm{C}$ & 191,67 & 104,38 & 1225,90 & 174,48 & sor & 46,81 & 57 & 111,81 & 134,71 & 450,57 \\
\hline \begin{tabular}{|l} 
Discoglossus galganoi \\
\end{tabular} & 29TNHC & 40,00 & $\frac{14}{14}$ & 59 & 38 & 3389,01 & 229,52 & $\begin{array}{l}0,55,00 \\
75\end{array}$ & $\begin{array}{l}154,52 \\
154\end{array}$ & \begin{tabular}{|l|l|l|l|l|}
110,27 \\
\end{tabular} & 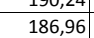 & 189,12 & \begin{tabular}{|l|}
101,96 \\
101,9
\end{tabular} & $\begin{array}{l}12290,85 \\
1190,\end{array}$ & \begin{tabular}{|l|}
170,30 \\
170
\end{tabular} & $27,27,81$ & $\begin{array}{ll}40,01 \\
45,66\end{array}$ & | & 111,01 & 138,49 & 430,70 \\
\hline Discoglossus galganoi & 29TNH02 & 97,00 & 132,26 & 63,14 & 37,98 & 3521,94 & 224,76 & 60,48 & 164,28 & 97,19 & 177,01 & 179,36 & 89,11 & 1311,65 & 191,91 & 32,75 & 44,97 & 520,73 & 131,71 & 153,40 & 479,06 \\
\hline Discoglossus galganoi & 29TNHO3 & 72,00 & 140,28 & 62,04 & 38,15 & 3441,65 & 229,47 & 68,97 & 160,50 & 106,00 & 183,51 & 186,10 & 97,60 & 1187,87 & 170,53 & 29,84 & 44,38 & 470,94 & 121,46 & 144,58 & 424,12 \\
\hline Discoglossus galganoi & 29TNHO4 & 98,00 & 137,01 & 63,14 & 38,09 & 3452,36 & 228,38 & 64,98 & 163,40 & 103,02 & 180, & 183,28 & 94,56 & 1187,81 & 169,67 & 31,04 & 43,51 & 468,51 & 125,83 & 148,93 & 420,04 \\
\hline Discoglossus galganoi & 29TNHO & 99,00 & 130 & 64,82 & 38 & 3496,92 & 225,11 & 57,22 & 167 & $\begin{array}{ll}96,18 \\
96,\end{array}$ & 174 & 17 & 87,89 & $\frac{110,123,42}{123}$ & 176,17 & 33,76 & 42,70 & 484,35 & 135,19 & 157,82 & 436 \\
\hline \begin{tabular}{|l|} 
Discoglossus galganoi \\
\end{tabular} & 29TNHOG & $\begin{aligned} 501,00 \\
101\end{aligned}$ & $\begin{array}{l}130,21 \\
130,82\end{array}$ & $\begin{array}{ll}64,73 \\
64,73\end{array}$ & 38,44 & $\begin{array}{l}3454,54 \\
344,75\end{array}$ & 224,58 & $\begin{array}{ll}1,2<2 \\
58,12\end{array}$ & \begin{tabular}{|l|}
166,45 \\
16,5
\end{tabular} & $\begin{array}{l}\mid c 0,10 \\
97,50 \\
\end{array}$ & \begin{tabular}{|l|}
174,06 \\
174,
\end{tabular} & \begin{tabular}{|l|l|l}
177,48 \\
\end{tabular} & \begin{tabular}{l|l}
81,05 \\
89,05
\end{tabular} & $\begin{array}{l}120,44 \\
1201,01\end{array}$ & \begin{tabular}{|l|}
168,81 \\
180
\end{tabular} & 33,56 & $\begin{array}{ll}41,93 \\
41,\end{array}$ & $\begin{array}{l}404,53 \\
468,53 \\
\end{array}$ & 134,43 & 157,02 & 4418,84 \\
\hline Discoglossus galganoi & 29TNH08 & 81,00 & 139,86 & 62,83 & 39,45 & 3245,91 & 226,50 & 68,94 & 157,55 & 108,65 & 179,71 & 183,68 & 99,93 & 1066,54 & 146,17 & 30,11 & 40,82 & 414,13 & 122,84 & 147,26 & 363,35 \\
\hline Discoglossus galganoi & 29TNHO9 & 36,00 & 140,84 & 62.53 & 39,81 & 319792 & 225.89 & 70,47 & 155.42 & 110,27 & 179.88 & 184,00 & $\mid 101.47$ & 1046,33 & 142.86 & 29.83 & 40,06 & 404.94 & 121.86 & 146.55 & 354,73 \\
\hline Discoglossu & 29TNH10 & 61,00 & 146,39 & 60,06 & 37,91 & 3519,36 & 232,27 & 76,1 & 156,1 & 109,72 & 190 & 192,23 & 101 & 1275,06 & 185,37 & 28,73 & 46,99 & 509 & 116,28 & 138,47 & 472,93 \\
\hline \begin{tabular}{|l} 
Discoglossus galganoi \\
\end{tabular} & 29TNH11 & 40,00 & 146,34 & 60,45 & 37,82 & 518,47 & 233,20 & 75,68 & 157,53 & 109,97 & 190,80 & 192,50 & 102,30 & 1241,93 & $\begin{array}{l}0,28 \\
80,2\end{array}$ & 28,89 & 46,24 & 494,43 & 116,57 & 139,20 & 455,66 \\
\hline
\end{tabular}




\begin{tabular}{|c|c|c|c|c|c|c|c|c|c|c|c|c|c|c|c|c|c|c|c|c|c|}
\hline TAXON & UTM & $\mathrm{km} 2$ & B101 & $\mathrm{B1O2}$ & $\mathrm{BIO3}$ & B104 & B105 & B106 & B107 & $\mathrm{B108}$ & B109 & 81010 & BIO11 & BIO12 & B1013 & B1014 & B1015 & B1016 & $\begin{array}{ll}1017 \\
17\end{array}$ & BIO18 & B1019 \\
\hline Discoglossus galganoi & 29TNH12 & 80,00 & 143,85 & 61,84 & 37,90 & 3527,18 & 233,33 & 72,06 & 161,27 & 107,84 & 188,46 & 190,54 & 99,85 & 1225,40 & 177,83 & 29,87 & 45,22 & 485,94 & 119,86 & 142,71 & 444,59 \\
\hline Discoglossus galganoi & 29TNH15 & 101,00 & 131,49 & 66,60 & \begin{tabular}{ll|l}
38,05 \\
\end{tabular} & 3585,35 & 229,44 & 56,70 & 172,74 & 96,06 & 176,92 & 180,04 & 88,01 & 1269,31 & 181,60 & 34,69 & 42,87 & 494,86 & 136,62 & 158,82 & 451,55 \\
\hline \begin{tabular}{|l} 
Discoglossus galganoi \\
\end{tabular} & 29TNH16 & 100,00 & 129,53 & 66,99 & 38,23 & 3553,02 & 227,55 & 54,86 & 172,69 & 94,82 & 174,47 & 177,92 & 86,69 & 1258,25 & 177,72 & 35,39 & 41,99 & 487,99 & 139,03 & 161,37 & 443,71 \\
\hline Discoglossus galganoi & 29TNH19 & 64,00 & 140,89 & 63,56 & 39,93 & 3223,95 & 227,11 & 69,77 & 157,34 & 109,84 & 180,43 & 184,43 & 101,17 & 1059,58 & 143,29 & 30,28 & 40,01 & 408,67 & 122,48 & 146,75 & 361,63 \\
\hline Discoglossus galganoi & 29TNH20 & 100,00 & 140,04 & 63,04 & 37,60 & 3718,64 & 232,42 & \begin{tabular}{|c|}
66,87 \\
\end{tabular} & 165,55 & 101,01 & 187,74 & 188,88 & 93,81 & 1395,50 & 212,46 & 32,47 & 47,52 & 556,28 & 127,28 & 147,77 & 529,68 \\
\hline Discoglossus galganoi & 29TNH21 & 101,00 & 143,07 & 62,99 & 37,73 & 3680,33 & 234,96 & 69,79 & 165,16 & 104,60 & 190,07 & 191,50 & 97,21 & 1313,98 & 195,41 & 31,39 & 46,36 & 520,52 & 123,46 & 145,06 & 488,04 \\
\hline Discoglossus galganoi & 29TNH22 & 98,00 & 142,56 & 64,37 & 37,83 & 3673,06 & 236,45 & 68,27 & 168,18 & 104,48 & 189,39 & 191,20 & 97,00 & 1282,23 & 189,18 & 31,60 & 45,59 & 505,62 & 124,06 & 145,95 & 470,89 \\
\hline Discoglossus galganoi & 29TNH23 & 100,00 & 140,69 & 65,81 & 37,91 & 3675,02 & 236,85 & 65,44 & 171,42 & 102,96 & 187,49 & 189,76 & 95,38 & 1268,02 & 185,23 & 32,23 & 44,81 & 497,28 & 126,63 & 148,60 & 460,75 \\
\hline Discoglossus galganoi & 29TNH24 & 101,00 & 139,46 & 66,85 & 38,14 & 3657,53 & 237,04 & 63,64 & 173,40 & 102,32 & 185,96 & 188,60 & 94,54 & 1247,55 & 180,10 & 32,75 & 43,93 & 486,78 & 128,33 & 150,59 & 448,39 \\
\hline Discoglossus galganoi & 29TNH25 & 101,00 & 134,22 & 68,49 & 38,02 & 3679,17 & 235,07 & 57,13 & 177,94 & 97,31 & 180,95 & 184,04 & 89,61 & 1277,87 & 182,81 & 34,92 & 42,98 & 495,32 & 135,80 & 157,76 & 456,50 \\
\hline Discoglossus galganoi & 29TNH26 & 101,00 & 129,38 & 69,40 & 38,11 & 3658,94 & 231,39 & 52,28 & 179,10 & 93,09 & 175,81 & 179,24 & 85,42 & 1295,09 & 183,16 & 36,61 & 42,07 & 499,18 & 141,72 & 163,38 & 459,85 \\
\hline Discoglossus galganoi & 29TNH27 & 100,00 & 129,17 & 68,83 & 38,77 & 3574,89 & 228,79 & 53,35 & 175,45 & 94,07 & 174,25 & 178,02 & 86,21 & 1259,95 & 175,62 & 36,27 & 41,11 & 484,03 & 140,94 & 162,85 & 443,55 \\
\hline \begin{tabular}{|l} 
Discoglossus galganoi \\
\end{tabular} & 29TNH28 & 101,00 & 138,15 & 66,22 & 39,76 & 3371,93 & 229,55 & 64,80 & 164,75 & 105,12 & 179,97 & 183,87 & 96,86 & 1124,24 & 152,92 & 32,00 & 40,55 & 432,17 & 126,98 & 150,29 & 389,89 \\
\hline Discoglossus galganoi & 29TNH29 & 39,00 & 138,94 & 65,60 & 40,11 & 3300,89 & 227,96 & 66,33 & 161,63 & 106,78 & 179,56 & 183,64 & 98,28 & 1096,42 & 147,44 & 31,46 & 39,97 & 420,50 & 125,51 & 149,00 & 378,18 \\
\hline Discoglossus galganoi & 29TNH30 & 101,00 & 136,38 & 68,31 & 37,86 & 3916,51 & 236,40 & 58,16 & 178,24 & 94,75 & 186,93 & 188,06 & 88,14 & \begin{tabular}{ll|l}
1444,96 \\
\end{tabular} & 225,06 & 34,07 & 47,76 & 572,47 & 132,50 & 151,25 & 553,08 \\
\hline Discoglossus galganoi & 29TNH33 & 101,00 & 140,89 & 68,88 & 37,78 & 3814,67 & 241,68 & 61,72 & 179,97 & 101,09 & 189,69 & 191,86 & 94,03 & 1286,69 & 188,93 & 32,96 & 44,87 & 500,80 & 127,77 & 149,09 & 469,14 \\
\hline Discoglossus galganoi & 29TNH34 & 100,00 & 137,98 & 70,61 & \begin{tabular}{|c|}
37,67 \\
\end{tabular} & 3829,36 & 242,21 & 57,25 & 184,96 & 98,68 & 186,96 & 189,58 & 91,35 & 1297,37 & 188,15 & 34,52 & 43,99 & 501,72 & 132,89 & 154,22 & 468,82 \\
\hline \begin{tabular}{|l} 
Discoglossus galganoi \\
\end{tabular} & 29TNH35 & 101,00 & 132,84 & 72,28 & 37,68 & 3838,58 & 240,40 & 50,95 & 189,45 & 94,15 & 182,04 & 185,10 & 86,75 & 1326,75 & 190,10 & 36,64 & 43,10 & 509,81 & 140,19 & 161,30 & 476,37 \\
\hline Discoglossus galganoi & 29TNH36 & 101,00 & 129,84 & 72,27 & 38,05 & 3774,65 & 236,38 & 49,07 & 187,31 & 92,04 & 178,03 & 181,37 & 84,62 & 1317,82 & 186,12 & 37,45 & 42,10 & 504,27 & 143,19 & 164,27 & 469,58 \\
\hline Discoglossus galganoi & 29 29TH37 & 101,00 & 127.82 & 71,68 & 38,69 & 3685,61 & 231,99 & 48,85 & $\mid 183,14$ & 91,12 & $\mid 174,58$ & 178,31 & 83,80 & 1296,43 & 180,66 & 37,63 & 41,15 & 494.57 & $\mid 144,29$ & 165,38 & 458,65 \\
\hline Discoglossus galganoi & 29TNH39 & 66,00 & 137,72 & 67,21 & 40,50 & 3335,65 & 228,27 & \begin{tabular}{l|l|}
64,37 \\
\end{tabular} & 163,90 & 104,80 & 178,85 & 182,93 & 96,84 & 1111,28 & 148,76 & 32,07 & 39,82 & 423,65 & 126,76 & 149,62 & 385,50 \\
\hline \begin{tabular}{|l} 
Discoglossus galganoi \\
\end{tabular} & 29TNH43 & 101,00 & 140,12 & 72,87 & 37,98 & 3953,22 & 246,17 & 56,53 & \begin{tabular}{|l|l|}
189,64 \\
\end{tabular} & 98,34 & 190,91 & 193,06 & 91,84 & 1293,19 & 190,16 & 33,42 & 44,74 & 499,02 & 128,68 & 149,06 & 471,50 \\
\hline \begin{tabular}{|l} 
Discoglossus galganoi \\
\end{tabular} & 29TNH44 & 99,00 & 134,34 & 75,62 & 37,50 & 4016,51 & 247,01 & 47,82 & \begin{tabular}{|l|l|}
199,18 \\
\end{tabular} & 92,76 & 186,25 & 188,81 & 86,23 & 1354,82 & $\mid 196,79$ & 36,70 & 43,95 & 518,70 & 139,25 & 159,31 & 490,94 \\
\hline Discoglossus galganoi & 29 TNH 45 & 100,00 & 133,85 & 75,41 & 37,71 & 3948,35 & 245,54 & 48,08 & 197,45 & 93,39 & 184,49 & 187,60 & 86,62 & 1327,24 & 189,42 & 36,86 & 42,92 & 505,97 & 139,84 & 160,39 & 476,27 \\
\hline Discoglossus galganoi & 29TNH46 & 100,00 & 133,61 & 74,17 & 38,49 & 3807,22 & 241,03 & 50,75 & 190,27 & 94,78 & 182,11 & 185,54 & 87,87 & 1277,88 & 179,38 & 36,11 & 41,96 & 486,11 & 137,91 & 158,76 & 454,57 \\
\hline Discoglossus galganoi & 29TNH47 & 101,00 & 129,79 & 73,67 & 39,01 & 3726,10 & 235,43 & 48,83 & 186,61 & 92,02 & 177,26 & 180,80 & 85,29 & 1276,81 & 177,09 & 37,02 & 41,03 & 484,24 & 141,41 & 162,11 & 451,80 \\
\hline Discoglossus galganoi & 29TNH48 & 99,00 & 130,64 & 71,90 & 39,94 & 3580,81 & 231,16 & $\begin{array}{l}40,031 \\
52,91\end{array}$ & $\begin{array}{l}178,25 \\
\end{array}$ & \begin{tabular}{|c|c|}
94,65 \\
\end{tabular} & 175,87 & 179,58 & 87 & $\mid \begin{array}{l}122,01 \\
122,47\end{array}$ & 166,76 & 35,87 & $\begin{array}{l}1,00 \\
40,09\end{array}$ & $\mid \begin{array}{l}\mid 463,07 \\
463,0\end{array}$ & $\begin{array}{l}138,08 \\
138,1\end{array}$ & 159,15 & 429,36 \\
\hline Discoglossus galganoi & 29TNH49 & 99,00 & 138,44 & 68,49 & 41,26 & 3334,69 & 228,73 & 64,79 & 163,94 & 105,25 & 179,57 & 183,74 & 97,48 & 1091,49 & 144,73 & 31,59 & 39,26 & 413,86 & 124,45 & 146,72 & 379,25 \\
\hline Discoglossus galganoi & 29TNH50 & 101,00 & 115,81 & 80,39 & 38,78 & 4246,05 & 232,99 & 27,72 & 205,27 & 70,53 & 171,45 & 172,95 & 65,34 & 1493,95 & 224,52 & 36,57 & 45,84 & 578,78 & 145,19 & 158,22 & 565,92 \\
\hline Discoglossus galganoi & 29TNH52 & 101,00 & 121,80 & 79,71 & 38,86 & 4121,18 & 237,20 & 34,24 & 202,96 & 77,75 & 175,64 & 177,56 & 73,05 & 1442,01 & 214,66 & 37,59 & 44,81 & 553,96 & 145,11 & 160,61 & 535,85 \\
\hline Discoglossus galganoi & 29TNH53 & 101,00 & 136,65 & 77,41 & 38,54 & 4049,65 & 247,69 & 49,24 & 198,45 & 93,11 & 188,96 & 191,10 & 87,81 & 1301,01 & 191,18 & 34,07 & 44,30 & 497,36 & $\begin{array}{l}130,92 \\
\end{array}$ & 149,73 & 473,88 \\
\hline \begin{tabular}{|l} 
Discoglossus galganoi \\
\end{tabular} & 29TNH55 & 101,00 & 132,55 & 77,84 & 38,55 & 3952,98 & 244,93 & $\begin{array}{ll}4,24,58 \\
458\end{array}$ & \begin{tabular}{|l|}
199,35 \\
\end{tabular} & \begin{tabular}{|c|c|}
91,08 \\
9,1
\end{tabular} & $\begin{array}{l}183,42 \\
183\end{array}$ & 186,37 & $\begin{array}{l}80,014 \\
85,47\end{array}$ & $\begin{array}{l}13011,62 \\
131,\end{array}$ & 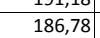 & 36,64 & \begin{tabular}{|c|c|}
42,66 \\
40
\end{tabular} & \begin{tabular}{|l|l|}
496,98 \\
40,
\end{tabular} & $\begin{array}{ll}138,85 \\
\end{array}$ & 158,30 & $\begin{array}{l}47,00 \\
470,35\end{array}$ \\
\hline Discoglossus galganoi & 29TNH56 & 101,00 & 131,83 & 76,71 & 38,90 & 3858,57 & 241,48 & 46,94 & 194,54 & 91,76 & 181,28 & 184,54 & 85,86 & 1281,64 & 179,77 & 36,54 & 41,76 & 484,46 & 138,73 & 158,58 & 456,12 \\
\hline Discoglossus galganoi & 29TNH57 & 100,00 & 129,49 & 75,79 & 39,47 & 3760,92 & 236,42 & 46,84 & 189,58 & 90,69 & 177,58 & 181,00 & 84,70 & 1264,25 & 174,91 & 36,84 & 40,79 & 476,82 & 140,23 & 160,14 & 447,24 \\
\hline Discoglossus galganoi & 29TNH58 & 101,00 & 136,43 & 72,36 & 40,72 & 3553,90 & 234,25 & 58,55 & 175,70 & 100,03 & 181,02 & 184,78 & 93,25 & 1141,24 & 154,04 & 33,02 & 39,87 & 430,70 & 128,01 & 149,16 & 399,31 \\
\hline Discoglossus galganoi & 29TNH59 & 98,00 & 140,77 & 69,91 & 41,80 & 3381,91 & 231,80 & 66,23 & 165,56 & 106,31 & 182,51 & 186,54 & 99,09 & 1058,70 & 139,63 & 30,57 & 39,04 & 399,41 & 120,42 & 142,28 & 367,09 \\
\hline \begin{tabular}{|l} 
Discoglossus galganoi \\
\end{tabular} & 29TNH60 & $\begin{array}{l}30,000 \\
100,00\end{array}$ & $\begin{array}{ll}14,17 \\
118,94\end{array}$ & 83,20 & 年1,00 & 4353,18 & 238,48 & $\begin{array}{l}27,84 \\
27\end{array}$ & $\begin{array}{l}10,640 \\
210,\end{array}$ & \begin{tabular}{|c|}
11,76 \\
71,7
\end{tabular} & \begin{tabular}{|l|l|l|l|l|l}
175,90 \\
\end{tabular} & 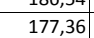 & $\frac{35,031}{67,11}$ & 1409,20 & $\mid$\begin{tabular}{|l|l|}
210,16 \\
216
\end{tabular} & $\begin{array}{ll}30,47 \\
34,42\end{array}$ & $\begin{array}{l}3,044 \\
45,45\end{array}$ & \begin{tabular}{|l|}
$543,41,88$ \\
\end{tabular} & $\begin{array}{l}130,425 \\
137,56\end{array}$ & $\begin{array}{l}14,20 \\
150,38\end{array}$ & 528,85 \\
\hline Discoglossus galganoi & 29TNH61 & 101,00 & 119,95 & 82,67 & 39,1 & 4262,34 & 238,07 & 29,73 & 208,34 & 73,64 & 175,70 & 177,29 & 69,46 & 1400,04 & 207,77 & 35,43 & 44,95 & 536,38 & 139,36 & 153,01 & 521,48 \\
\hline Discoglossus galganoi & 29TNH62 & 101,00 & 126,70 & 82,14 & 39,66 & 4142,87 & 242,07 & 37,06 & 205,01 & 81,27 & 180,62 & 182,46 & 77,59 & 1348,88 & 199,73 & 34,98 & 44,38 & 514,25 & 135,83 & 151,36 & 496,63 \\
\hline Discoglossus galganoi & 29TNH63 & 100,00 & 127,69 & 81, & 39,80 & 4046,96 & 241,44 & 39,35 & 202,09 & 83,45 & 180,25 & 182,44 & 79,89 & 1331,88 & 194,42 & 35,67 & 43,65 & 505,65 & 137,02 & 153,53 & 485,67 \\
\hline Discoglossus galganoi & 29TNH64 & 101,00 & 133,27 & 80,09 & 39,73 & 3986,03 & 244,84 & 45,28 & 199,56 & 89,76 & 184,79 & 187,14 & 85,81 & 1267,58 & 182,28 & 34,57 & 42,88 & 79,13 & 132,16 & 150,26 & 456,27 \\
\hline 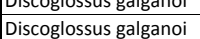 & $\begin{array}{l}29 \text { TNNH67 } \\
297\end{array}$ & 100,00 & $\begin{array}{l}13,26,03 \\
126,03\end{array}$ & $\begin{array}{l}\frac{80,059}{77,79} \\
\end{array}$ & $\begin{array}{l}35, \\
40,\end{array}$ & $\begin{array}{l}3580,05 \\
3800,28\end{array}$ & 2344,24 & $\begin{array}{l}4,20 \\
42,32 \\
\end{array}$ & $\begin{array}{l}199,, 90 \\
191,92 \\
\end{array}$ & \begin{tabular}{|c|}
85,0 \\
86,01
\end{tabular} & $\mid \frac{\mid 184,19}{174,86}$ & \begin{tabular}{|l|l|l|l|l|}
178,03 \\
\end{tabular} & $\begin{array}{l}83,18 \\
81,1\end{array}$ & \begin{tabular}{|l|}
120,50 \\
1264,47
\end{tabular} & \begin{tabular}{|l|l|l|l|l|l}
174,59 \\
\end{tabular} & $34,3,3$ & $\begin{array}{l}4,300 \\
40,38 \\
\end{array}$ & | & \begin{tabular}{|l|}
142,106 \\
141,64
\end{tabular} & $\begin{array}{l}150,20 \\
160,31\end{array}$ & $\begin{array}{l}450,27 \\
446,85 \\
\end{array}$ \\
\hline Discoglossus galganoi & 29TNH68 & 101,00 & 134,85 & 74,68 & 40,77 & 3631,25 & 235,43 & 54,60 & 180,83 & 96,81 & 180,73 & 184,20 & 90,95 & 1139,74 & 153,76 & 33,40 & 39,51 & 427,46 & 128,78 & 149,04 & 397,92 \\
\hline Discoglossus galganoi & 29TNH69 & 95,00 & 138,76 & 72,50 & 41,54 & 3500,36 & 233,97 & 61,39 & 172,57 & 102,55 & 182,52 & 186,15 & 95,99 & 1070,00 & 141,51 & 31,45 & 38,83 & 01,11 & 22,61 & 143,65 & 370,04 \\
\hline Discoglossus galganoi & 29TNH70 & 101,00 & 121,99 & 85,74 & 39,0 & 4488,05 & 244 & 27,49 & 216,65 & 272,54 & 180,79 & 181,86 & 68,41 & 1311,15 & 193,43 & 31,86 & 44 & 27 & 43 & 17 & 487,17 \\
\hline Discoglossus galganoi & 29TNH72 & 100,00 & 120,88 & 84,11 & 39,92 & 4229,67 & 23 & 30,06 & 208,68 & 74,28 & 176,17 & $\begin{array}{ll}171,80 \\
\end{array}$ & $\begin{array}{l}20,111 \\
71,15\end{array}$ & 1325,34 & \begin{tabular}{|l|l|}
192,94 \\
\end{tabular} & & $\begin{array}{ll}43,67 \\
43,\end{array}$ & 72 & 75 & 149,76 & 486,41 \\
\hline Discoglossus galganoi & 29TNH73 & 101,00 & 126 & 83,29 & 40 & 4067,70 & 240,51 & 37,36 & 203,15 & 81,38 & 179,54 & 181,47 & 78,91 & 1275,06 & 184,29 & 34,2 & 43,04 & 481,31 & 132,43 & 148,01 & 462,41 \\
\hline Discoglossus galganoi & 29TNH75 & 100,00 & 126,05 & 81,54 & 40,60 & 3942,56 & 237,71 & 38,92 & 198,78 & 82,92 & 177,11 & 179,57 & 79,78 & 1257,87 & 177,32 & 35,75 & 41,48 & 472,00 & 136,39 & 153,28 & 449,29 \\
\hline Discoglossus galganoi & 29TNH77 & 100,00 & 122,67 & 79,66 & 40,36 & 3855,55 & 232,35 & 37,61 & 194,73 & 81,38 & 172,28 & 175,29 & 77,27 & 1252,18 & 172,13 & 37,44 & 39,90 & 467,53 & 142,08 & 159,52 & 441,33 \\
\hline Discoglossus galganoi & 29TNH78 & 100,00 & 125,41 & 78,00 & 40,7 & 3774,11 & 231,87 & 42,35 & & 85,45 & 173,73 & 176,95 & 80,70 & 1203,79 & 163,01 & 49 & 39,10 & 58 & 77 & 157,20 & 420,48 \\
\hline \begin{tabular}{|l} 
Discoglossus galganoi \\
\end{tabular} & 29TNH79 & 101,00 & $\frac{12}{12}$ & 76 & $\frac{40}{40}-3 x-3$ & $\frac{5}{3}$ & $\frac{23}{23}$ & $\begin{array}{ll}42,3,82 \\
46,2\end{array}$ & \begin{tabular}{|l|l|}
183,90 \\
\end{tabular} & $\begin{array}{l}03,43 \\
89,37 \\
\end{array}$ & \begin{tabular}{|l|l|}
174,66 \\
\end{tabular} & 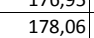 & 84,01 & $\begin{array}{l}120,1,08 \\
1160,08\end{array}$ & \begin{tabular}{|c|}
$\mid 035,01$ \\
154,75
\end{tabular} & $\begin{array}{l}30,45 \\
35,67 \\
\end{array}$ & $\frac{35,10}{38,39}$ & \begin{tabular}{|l|}
$430,1,51$ \\
431
\end{tabular} & \begin{tabular}{|l|l|}
135,97 \\
\end{tabular} & 155,20 & $\begin{array}{l}42,40 \\
401,73\end{array}$ \\
\hline Discoglossus galganoi & 29TNH82 & 100,00 & 116,25 & 85,54 & 39,56 & 4367,94 & 237,33 & 23,49 & 213,84 & 68,15 & 173,50 & 175,03 & 64,72 & \begin{tabular}{|l|}
1291,08 \\
\end{tabular} & 184,62 & 34,22 & 42,98 & 487,78 & 134,11 & 147,04 & 472,19 \\
\hline Discoglossus galganoi & 29TNH84 & 100,00 & 127,03 & 83,97 & 40,56 & 4104,26 & 241,13 & 36,61 & 204,52 & 81,13 & 180,29 & 182,31 & 78,65 & 1198,23 & 169,39 & 33,26 & 41,66 & 448,57 & 128,19 & 144,12 & 428,34 \\
\hline Discoglossus galganoi & 29TNH86 & 101,00 & 115,94 & 82,36 & 40,29 & 4041,46 & 230,32 & 28,34 & 201,98 & 72,10 & 168,44 & 170,87 & 68,70 & 1270,44 & 175,37 & 37,83 & 39,99 & 473,87 & 143,78 & 159,12 & 450,46 \\
\hline Discoglossus galganoi & 29TNH88 & 101,00 & 120,39 & 79,96 & 40,7 & 3879,56 & 229,84 & 35,39 & 194,45 & 78,82 & 170,37 & 17 & 74,51 & 1209,88 & 163,08 & 37,42 & 38,62 & 448,59 & 141,75 & 158,84 & 42 \\
\hline \begin{tabular}{|l|} 
Discoglossus galganoi \\
\end{tabular} & $\begin{array}{l}\text { 29TNH89 } \\
\text { 2910 }\end{array}$ & $\begin{array}{l}100,00 \\
100\end{array}$ & $\begin{array}{l}12,55 \\
118,54\end{array}$ & 78,92 & 40,75 & 3828,43 & 226,61 & \begin{tabular}{|c|c|}
34,999 \\
34,
\end{tabular} & $\begin{array}{l}194,45 \\
191,62 \\
\end{array}$ & $\begin{array}{l}70,021 \\
77,91\end{array}$ & \begin{tabular}{|l|l|l|l|l|}
167,77 \\
\end{tabular} & \begin{tabular}{|l|l|}
170,85 \\
\end{tabular} & \begin{tabular}{l|}
43,56 \\
73,5
\end{tabular} & \begin{tabular}{|l|l|}
1211,67 \\
121,
\end{tabular} & \begin{tabular}{|l|}
161,56 \\
161
\end{tabular} & \begin{tabular}{|l|l|}
38,36 \\
38
\end{tabular} & $\begin{array}{l}30,024 \\
37,93\end{array}$ & \begin{tabular}{|l|l|}
$448,0,19$ \\
\end{tabular} & \begin{tabular}{l|l|l|l|l|l|}
144,90 \\
\end{tabular} & 162,40 & 4419,19 \\
\hline Discoglossus galganoi & 29TNH90 & 100,00 & 122,24 & 89,38 & 38,96 & 4753,56 & 249,93 & 22,45 & 227,48 & 69,16 & 184,61 & 185,24 & 65,15 & 1166,68 & 166,79 & 28,45 & 43,87 & 440,45 & 115,60 & 126,20 & 428,22 \\
\hline Discoglossus galganoi & 29TNH91 & 101,00 & 118,31 & 88,03 & 39,00 & 4616,37 & 244,04 & 21,27 & 222,77 & 67,07 & 178,96 & 179,91 & 63,44 & 1205,83 & 171,39 & 30,83 & 43,10 & 454,83 & 123,06 & 135,26 & 441,25 \\
\hline Discoglosst & 29TNH93 & 100,00 & 120,09 & 86,50 & 39,86 & 80,79 & 240,84 & 26,0 & 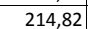 & 71,3 & 177 & 178 & 68 & 1192,53 & 167,75 & 32,62 & & 446 & 127,21 & 141,04 & 429 \\
\hline \begin{tabular}{|l} 
Discoglossus galganoi \\
\end{tabular} & 29TNH95 & 101,00 & 120,38 & 84,72 & 40,10 & 199,03 & 37,33 & 29,28 & 208,05 & 73,99 & 175,04 & 176,95 & 70,86 & 118,55 & 64,11 & 34,36 & 40,28 & 441,78 & 132,04 & 446,98 & 420, \\
\hline
\end{tabular}




\begin{tabular}{|c|c|c|c|c|c|c|c|c|c|c|c|c|c|c|c|c|c|c|c|c|c|}
\hline TAXON & UTM & $\mathrm{km} 2$ & BI01 & B102 & $B 103$ & BIO4 & B105 & B106 & 8107 & B108 & $B 109$ & B1010 & BIO11 & B1012 & BIO13 & BIO14 & B1015 & B1016 & B1017 & B1018 & B1019 \\
\hline Discoglossus galganoi & 29TNH96 & 101,00 & 121,63 & 83,64 & 40,42 & 4105,72 & 236,21 & 32,01 & 204,20 & 76,47 & 174,88 & 177,02 & 73,10 & 1172,85 & 160,54 & 34,80 & 39,63 & 435,42 & 133,02 & 148,72 & 411,98 \\
\hline Discoglossus galganoi & 29TNH97 & 100,00 & 122,66 & 82,42 & 40,76 & 4034,11 & 235,08 & 34,51 & 200,57 & 78,55 & $\begin{array}{l}174,71 \\
\end{array}$ & 177,24 & 74,77 & 1155,42 & 156,30 & 35,05 & 38,88 & 427,68 & 133,61 & \begin{tabular}{l|l|}
150,03 \\
\end{tabular} & 402,29 \\
\hline Discoglossus galganoi & 29TNH98 & 101,00 & 121,27 & 81,36 & 40,79 & 3959,32 & 232,09 & 34,47 & $\begin{array}{l}197,61 \\
\end{array}$ & 78,34 & 172,28 & 174,98 & 74,29 & 1159,91 & 155,18 & 36,09 & 38,11 & 428,21 & 137,12 & 153,85 & 401,04 \\
\hline Discoglossus galganoi & 29TNH99 & 100,00 & 121,31 & 80,24 & 40,97 & 3889,75 & 230,11 & 36,08 & 194,03 & 79,50 & 171,34 & \begin{tabular}{ll|}
174,06 \\
\end{tabular} & 75,10 & 1152,55 & 152,47 & 36,63 & 37,43 & 424,45 & 138,80 & 156,01 & 395,57 \\
\hline Discoglossus galganoi & 29TNJ40 & 18,00 & 140,90 & 67,00 & 41,90 & 3225,38 & 226,97 & 68,62 & 158,34 & 109,17 & 180,34 & 184,66 & 101,00 & 1040,24 & 135,86 & 30,03 & 39,00 & 394,31 & 119,52 & 142,10 & 359,59 \\
\hline Discoglossus galganoi & 29TNJ50 & 35,00 & 140,32 & 69,33 & \begin{tabular}{l|l}
42,05 \\
\end{tabular} & 3314,98 & 229,41 & 66,90 & 162,51 & 106,79 & 181,08 & 185,25 & $\begin{array}{l}99,56 \\
\end{array}$ & 1041,52 & 135,65 & 30,56 & 38,54 & 392,02 & 120,49 & 142,51 & 359,29 \\
\hline Discoglossus galganoi & 29TNJ51 & 48,00 & 137,32 & 69,06 & 42,18 & 3289,25 & 226,38 & 64,58 & 161,79 & 104,32 & 177,74 & 182,08 & 96,99 & 1053,97 & 136,43 & 32,00 & 37,81 & 395,00 & 125,51 & 147,40 & 360,88 \\
\hline Discoglossus galganoi & 29TNJ52 & 12,00 & 139,57 & 68,29 & 42,50 & 3239,32 & 226,61 & 67,61 & 159,00 & $\begin{array}{l}107,07 \\
\end{array}$ & 179,29 & 183,57 & $\begin{array}{l}99,82 \\
\end{array}$ & $\begin{array}{l}1024,82 \\
\end{array}$ & $\begin{array}{l}132,75 \\
\end{array}$ & 31,04 & 37,57 & 383,82 & $\begin{array}{l}122,86 \\
\end{array}$ & 145,32 & 348,71 \\
\hline Discoglossus galganoi & 29TNJ60 & 66,00 & 138,42 & 71,58 & \begin{tabular}{l|l}
41,92 \\
\end{tabular} & 3427,75 & 231,34 & \begin{tabular}{|c|}
62,74 \\
\end{tabular} & 168,59 & 103,12 & 181,05 & 184,86 & 96,42 & 1051,61 & \begin{tabular}{|c|}
137,08 \\
\end{tabular} & 31,55 & 38,09 & 393,14 & 123,14 & 144,39 & 360,99 \\
\hline Discoglossus galganoi & 29TNJ61 & 82,00 & 138,78 & 70,46 & 42,23 & 3350,75 & 229,34 & \begin{tabular}{|c|}
64,74 \\
\end{tabular} & 164,60 & 104,63 & 180,27 & 184,22 & 97,70 & 1035,07 & \begin{tabular}{|c|}
133,93 \\
\end{tabular} & 31,48 & 37,61 & 386,40 & 123,21 & $\begin{array}{l}144,96 \\
\end{array}$ & 352,94 \\
\hline Discoglossus galganoi & 29TNJ62 & 77,00 & 138,50 & 69,71 & \begin{tabular}{ll|}
42,42 \\
\end{tabular} & 3311,98 & 227,83 & 65,35 & 162,48 & 104,89 & 179,31 & 183,41 & 97,82 & 1028,44 & 132,74 & 31,91 & 37,02 & 383,10 & 124,55 & 146,55 & 348,41 \\
\hline Discoglossus galganoi & 29TNJ70 & 100,00 & 127,38 & 75,21 & 41,21 & 3607,29 & 228,03 & 47,99 & 180,04 & 89,86 & 172,98 & 176,58 & 84,18 & 1147,25 & 151,21 & 35,90 & 37,79 & 425,82 & \begin{tabular}{|l|l|}
137,08 \\
\end{tabular} & 156,62 & 394,60 \\
\hline Discoglossus galganoi & 29TNJ71 & 101,00 & 129,37 & 73,82 & \begin{tabular}{ll|l}
41,56 & \\
\end{tabular} & 3531,06 & 227,00 & 51,70 & 175,30 & 92,88 & $\begin{array}{l}173,72 \\
\end{array}$ & 177,51 & 86,87 & 1112,83 & 144,77 & 35,26 & 37,04 & 412,33 & 135,00 & 155,22 & 379,66 \\
\hline Discoglossus galganoi & 29TNJ72 & 101,00 & 133,10 & 72,15 & \begin{tabular}{|l|l}
42,08 \\
\end{tabular} & 3432,01 & 226,92 & 57,35 & 169,57 & $\begin{array}{l}97,92 \\
\end{array}$ & 175,90 & \begin{tabular}{|l|}
179,71 \\
\end{tabular} & 91,45 & 1067,50 & \begin{tabular}{|l|l|}
137,07 \\
\end{tabular} & 34,02 & 36,65 & 394,97 & $\begin{array}{l}131,15 \\
\end{array}$ & $\begin{array}{l}152,16 \\
\end{array}$ & 360,88 \\
\hline Discoglossus galganoi & 29TNJ80 & 100,00 & 122,17 & 77,45 & \begin{tabular}{l|l|l|}
40,97 \\
\end{tabular} & \begin{tabular}{|c|}
3732,97 \\
\end{tabular} & 226,80 & \begin{tabular}{l|l}
40,28 \\
\end{tabular} & 186,52 & 82,75 & 169,73 & \begin{tabular}{|l|}
173,01 \\
\end{tabular} & 77,78 & 1168,66 & \begin{tabular}{|c|}
153,90 \\
\end{tabular} & 37,45 & 37,24 & 431,41 & $\begin{array}{l}141,75 \\
\end{array}$ & 160,10 & 400,68 \\
\hline Discoglossus galganoi & 29TNJ81 & 100,00 & 123,92 & 76,14 & \begin{tabular}{l|l}
41,25 \\
\end{tabular} & 3653,63 & 225,79 & 43,65 & 182,14 & 85,62 & 170,26 & 173,78 & 80,28 & 1142,11 & 148,61 & 37,10 & 36,76 & 420,70 & 140,61 & 159,65 & 388,46 \\
\hline Discoglossus galganoi & 29TNJ82 & 100,00 & 130,16 & 74,18 & \begin{tabular}{|c|}
41,87 \\
\end{tabular} & 3535,37 & 227,38 & 52,20 & 175,18 & 93,44 & 174,59 & 178,24 & 87,60 & 1077,42 & 138,13 & 35,11 & 36,12 & 396,33 & 134,04 & 154,27 & 362,51 \\
\hline Discoglossus galganoi & 29TNJ83 & 101,00 & 130,18 & 72,98 & 41,98 & 3479,40 & 225,55 & 53,48 & $\begin{array}{l}172,07 \\
\end{array}$ & 94,38 & 173,69 & 177,47 & 88,12 & 1072,64 & 137,44 & 35,55 & 35,79 & 393,85 & \begin{tabular}{|c|}
135,68 \\
\end{tabular} & 156,29 & 358,51 \\
\hline Discoglossus galganoi & 29TNJ84 & 31,00 & 128,75 & 72,62 & \begin{tabular}{|l|l|}
42,07 & \\
\end{tabular} & 3463,58 & 223,64 & 52,51 & 171,13 & 93,16 & 172,00 & 175,75 & 86,98 & 1079,11 & \begin{tabular}{|c|}
138,18 \\
\end{tabular} & 36,49 & 35,25 & 395,05 & 138,64 & 159,35 & 358,69 \\
\hline Discoglossus galganoi & 29TNJ90 & 101,00 & 120,50 & 79,13 & 40,94 & 3826,89 & 227,57 & 36,78 & 190,79 & 79,70 & 169,58 & 172,59 & 75,19 & 1151,81 & $150, \varepsilon$ & 37,43 & 36,92 & \begin{tabular}{l|l}
423,15 \\
\end{tabular} & 141,40 & 158,99 & 392,64 \\
\hline Discoglossus galganoi & 29TNJ91 & 101,00 & 119,44 & 78,01 & \begin{tabular}{ll|l}
41,06 \\
\end{tabular} & 3765,45 & 224,70 & 37,15 & 187,55 & 79,81 & 167,50 & 170,67 & 74,70 & 1154,74 & 149,70 & 38,31 & 36,17 & 423,15 & 144,50 & 162,42 & 391,05 \\
\hline Discoglossus galganoi & 29TNJ93 & 92,00 & 133,74 & 73,98 & $\begin{array}{l}41,97 \\
\end{array}$ & 3525,79 & 229,64 & 55,54 & 174,11 & 96,84 & $\begin{array}{l}177,87 \\
\end{array}$ & 181,48 & 91,05 & 1025,37 & \begin{tabular}{ll|}
131,62 \\
\end{tabular} & 34,11 & 35,33 & $\begin{array}{l}374,76 \\
\end{array}$ & 130,39 & $\begin{array}{l}150,86 \\
\end{array}$ & 339,41 \\
\hline Discoglossus galganoi & 29TNJ94 & 26,00 & 139,35 & 72,33 & 42,44 & 3429,44 & 231,53 & 63,05 & 168,49 & 103,72 & 181,98 & 185,72 & 97,65 & 980,72 & 127,09 & 32,65 & 35,09 & 358,56 & 125,33 & $\mid 146,77$ & 322,12 \\
\hline Discoglossus galganoi & 29TPE13 & 101,00 & 138,06 & 90,21 & \begin{tabular}{|c|}
35,47 \\
\end{tabular} & 5541,54 & 286,28 & 35,83 & 250,45 & 71,63 & 212,30 & 212,50 & 71,63 & 1089,64 & 163,14 & 9,87 & 55,65 & 444,77 & 66,97 & 66,98 & 444,77 \\
\hline Discoglossus galganoi & 29TPE17 & 100,00 & 105,52 & 77,94 & 33,30 & 5333,84 & \begin{tabular}{r|r}
240,87 \\
\end{tabular} & 11,12 & 229,75 & 43,46 & 177,77 & 177,83 & 43,46 & 1488,39 & 230,10 & 14,23 & 56,81 & 610,46 & 89,59 & 89,68 & 610,46 \\
\hline \begin{tabular}{|l|} 
Discoglossus galganoi \\
\end{tabular} & 29TPE18 & 101,00 & 138,06 & 94,81 & 37,17 & 5436,40 & 284,38 & 32,78 & 251,60 & 71,02 & 209,38 & 209,73 & 71,02 & $\begin{array}{l}1101,46 \\
\end{array}$ & 165,42 & 10,36 & 55,31 & 447,47 & 70,05 & 70,65 & 447,47 \\
\hline Discoglossus galganoi & 29TPE23 & 100,00 & 136,93 & 89,41 & 34,98 & 5655,55 & 286,47 & 34,08 & 252,39 & 69,31 & 212,77 & 212,88 & 69,31 & 1072,25 & $\begin{array}{l}160,25 \\
\end{array}$ & 9,60 & 55,52 & 436,33 & 65,86 & 65,86 & 436,33 \\
\hline Discoglossus galganoi & 29TPE24 & 100,00 & 142,68 & 92,77 & 35,65 & 5654,12 & 293,58 & 37,45 & 256,12 & 74,19 & 217,73 & 218,05 & 74,19 & 1014,30 & 150,67 & 8,95 & 55,21 & 411,38 & 63,29 & 63,31 & 411,38 \\
\hline Discoglossus galganoi & 29TPE33 & 101,00 & 151,94 & 96,18 & \begin{tabular}{|c|}
35,97 \\
\end{tabular} & 5812,66 & 307,44 & 43,36 & 264,08 & 84,32 & 228,71 & 229,21 & 81,34 & 887,47 & 129,32 & 7,58 & 54,42 & 356,64 & 56,06 & 56,28 & 356,61 \\
\hline Discoglossus galganoi & 29TPE34 & 100,00 & 144,07 & 93,37 & \begin{tabular}{|c|}
35,58 \\
\end{tabular} & 5763,97 & 297,00 & 37,53 & 259,47 & 74,25 & 220,63 & 220,80 & 74,25 & 963,29 & \begin{tabular}{|c|}
142,08 \\
\end{tabular} & 8,48 & 54,82 & 388,56 & 60,65 & 60,78 & 388,56 \\
\hline \begin{tabular}{|l} 
Discoglossus galganoi \\
\end{tabular} & 29TPE36 & 101,00 & 139,74 & 92,73 & 35,61 & 5699,14 & 290,19 & 33,56 & 256,64 & 70,23 & 215,06 & 215,18 & 70,23 & 1004,28 & 149,39 & 9,13 & 54,98 & 405,67 & 63,55 & 64,08 & 405,67 \\
\hline Discoglossus galganoi & 29TPE44 & 100,00 & 149,48 & 96,03 & 35,86 & 5860,33 & 304,97 & 40,37 & 264,60 & 84,59 & 226,95 & 227,18 & 78,09 & 871,44 & \begin{tabular}{|c|}
126,58 \\
\end{tabular} & 7,52 & 54,06 & 348,36 & 55,63 & 55,78 & 347,93 \\
\hline Discoglossus galganoi & 29TPE46 & 99,00 & 140,79 & 93,71 & 35,62 & \begin{tabular}{rl|}
5799,87 \\
\end{tabular} & 293,41 & 33,34 & 260,08 & 71,02 & 217,52 & 217,64 & 70,04 & $\begin{array}{l}944,75 \\
\end{array}$ & \begin{tabular}{|c|}
139,10 \\
\end{tabular} & 8,62 & 54,33 & 378,87 & 60,64 & 61,32 & 378,87 \\
\hline Discoglossus galganoi & 29TPE47 & 101,00 & 132,53 & 90,33 & 34,91 & 5754,58 & 282,24 & 27,16 & 255,08 & 62,33 & 208,59 & 208,83 & 62,33 & 1017,71 & 151,31 & $\begin{array}{l}9,63 \\
\end{array}$ & 54,73 & 409,90 & \begin{tabular}{|c|c|}
64,86 \\
\end{tabular} & 66,79 & 409,90 \\
\hline Discoglossus galganoi & 29TPE53 & 100,00 & 151,91 & 97,36 & \begin{tabular}{c|c}
35,85 \\
\end{tabular} & 5953,50 & 309,70 & 41,55 & 268,15 & 87,23 & 230,81 & 231,01 & 79,58 & 808,77 & 115,52 & 6,97 & 53,33 & 321,81 & 52,04 & 52,23 & 319,62 \\
\hline Discoglossus galganoi & 29TPE54 & 100,00 & 147,75 & 95,98 & 35,62 & 5933,51 & 304,19 & 38,06 & 266,13 & 83,16 & 226,32 & 226,50 & 75,69 & 844,05 & 121,51 & 7,38 & 53,61 & 335,96 & 54,66 & 54,79 & 334,47 \\
\hline Discoglossus galganoi & 29TPE55 & 100,00 & 139,99 & 93,16 & 35,09 & 5892,53 & 294,01 & 32,20 & 261,81 & 76,16 & 218,11 & 218,19 & 68,40 & 909,11 & 132,39 & 8,41 & 53,90 & 362,66 & 58,54 & 59,38 & 361,92 \\
\hline Discoglossus galganoi & 29TPE56 & 101,00 & 128,25 & 88,22 & 34,20 & 5835,14 & 278,60 & 23,79 & 254,82 & 62,95 & 205,80 & 206,08 & 57,84 & 1007,41 & 148,40 & 9,62 & 54,15 & 403,27 & 64,49 & 67,35 & 403,21 \\
\hline Discoglossus galganoi & 29TPE57 & 100,00 & 122, & 85,75 & 33,73 & 5797,0 & 270,2 & 19,26 & 250,98 & 53,93 & 199,19 & 199,57 & 52,20 & 1057,68 & 156,75 & 10,24 & 54,34 & 424 & 67,76 & \begin{tabular}{|c|}
71,56 \\
\end{tabular} & 424,64 \\
\hline Discoglossus galganoi & \begin{tabular}{|l|} 
29TPE63 \\
\end{tabular} & 100,00 & 147,31 & 96,56 & 35,56 & 6005,60 & 305,4 & 37,25 & 268,21 & 82,40 & 227,14 & 227,18 & 74,60 & 805,58 & 114,23 & 7,23 & 52,82 & 319,18 & 52,55 & 52,87 & 315,84 \\
\hline Discoglossus galganoi & 29TPE65 & 100,00 & 129,91 & 90,14 & \begin{tabular}{ll|l}
34,26 \\
\end{tabular} & 5929,70 & 283,01 & 23,91 & 259,10 & $\begin{array}{l}66,46 \\
\end{array}$ & 208,92 & 209,16 & 58,67 & 944,84 & 136,77 & 9,21 & 53,25 & \begin{tabular}{|c|}
375,78 \\
\end{tabular} & 61,54 & 63,95 & 373,87 \\
\hline Discoglossus galganoi & 29TPE67 & 101,00 & 125,29 & 89,10 & 34,18 & 5888,96 & 276,66 & 19,84 & 256,83 & 61,99 & 203,34 & 203,90 & 54,13 & \begin{tabular}{|c|}
971,07 \\
\end{tabular} & 141,31 & 9,83 & 53,26 & 386,21 & 64,13 & 66,99 & 385,15 \\
\hline Discoglossus galganoi & 29TPE73 & 100,00 & 150,30 & 98,84 & 35, & 6062,09 & 310,71 & 38,27 & 272,44 & 84,43 & 230,77 & 230,80 & 76,58 & $\begin{array}{l}739,65 \\
\end{array}$ & \begin{tabular}{|c|}
102,88 \\
\end{tabular} & 6,62 & 51,89 & 290,90 & 49,06 & 49,23 & 285,78 \\
\hline Discoglossus galganoi & 29TPE75 & 99,00 & 135,54 & 4,15 & 34, & 6008,58 & $292, \mathrm{C}$ & 26,54 & 265,49 & 70,70 & 215,39 & 215,63 & 62,83 & 847,52 & 119,95 & 8,43 & 52,10 & 334,35 & 56,87 & 58,58 & 330,22 \\
\hline \begin{tabular}{|l|} 
Discoglossus galganoi \\
\end{tabular} & 29TPE77 & 100,00 & 122,37 & 90 & 34 & 5945,4 & 275, & 16,19 & 259,07 & 58,62 & 201,30 & 201,94 & 50,77 & 938,22 & 134,22 & 9,98 & 52,23 & 370,92 & 63,72 & 66,87 & 367,88 \\
\hline Discoglossus galganoi & 29TPE84 & 101,00 & 14 & 99,36 & 35,82 & $\begin{array}{l}6104,88 \\
\end{array}$ & 308,4 & 33,98 & 274,42 & 80,31 & 227,97 & 228,03 & 72,56 & 717,78 & $\begin{array}{l}98,46 \\
\end{array}$ & \begin{tabular}{ll|}
6,86 \\
\end{tabular} & 51,03 & 280,18 & 49,20 & 49,35 & 273,80 \\
\hline Discoglossus galganoi & 29TPE85 & 101,00 & 126,42 & 93,40 & 34,64 & 6044,36 & 283,86 & 18,13 & 265,73 & 61,90 & 207,17 & 207,49 & 54,01 & 867,71 & $\mid 120,90$ & 9,38 & 51,16 & 339,84 & \begin{tabular}{|c|}
60,08 \\
\end{tabular} & \begin{tabular}{|c|}
62,81 \\
\end{tabular} & 334,06 \\
\hline Discoglossus galganoi & 29TPE86 & 100,00 & 117,60 & 90,52 & 34,02 & 6008,49 & 272,64 & 11,27 & 261,36 & 53,76 & 197,92 & 198,45 & 45,95 & 928,26 & 130,25 & 10,32 & 51,22 & 364,31 & 64,53 & 68,45 & 358,97 \\
\hline Discoglossus galganoi & 29TPE95 & 100,00 & 133,71 & 97,47 & 35, & 6122,54 & 294,97 & 22,26 & 272,71 & 67,52 & 215,21 & 215,54 & 59,77 & 762,82 & \begin{tabular}{|c|}
103,58 \\
\end{tabular} & 8,34 & 49,95 & 295,84 & 54,36 & 55,87 & 288,21 \\
\hline Discoglossus galganoi & 29TPE96 & 100,00 & 121,66 & 94,40 & 34, & 6085 & 280 & 12,66 & 267,88 & 56,49 & 202,72 & 203,40 & 48,71 & 839,86 & 114,81 & 9,92 & 49,81 & 326,27 & 60,70 & 63,49 & 318,88 \\
\hline \begin{tabular}{|l} 
Discoglossus galganoi \\
\end{tabular} & $\begin{array}{l}\text { 29TPE97 } \\
\end{array}$ & 101,00 & 123,33 & 95,54 & 35,03 & $\begin{array}{l}6081,09 \\
\end{array}$ & 282,39 & 13,56 & 268,83 & 57,85 & 204,07 & 204,93 & 50,15 & 815,68 & 111,21 & 9,77 & 49,60 & 316,66 & 59,75 & 62,02 & 309,32 \\
\hline Discoglossus galganoi & 29TPF07 & 101,00 & 129,25 & 104,96 & \begin{tabular}{|l|l|}
40,17 \\
\end{tabular} & 5320,59 & 279,02 & 21,27 & 257,75 & 69,15 & 198,58 & 198,93 & 63,25 & $\begin{array}{l}1223,92 \\
\end{array}$ & 181,16 & 14,12 & 54,73 & 496,20 & 82,95 & 87,13 & 494,77 \\
\hline Discoglossus galganoi & 29TPF08 & 100,00 & 108,66 & 93,52 & 38,00 & 5223,34 & 250,90 & 8,30 & 242,61 & 45,75 & 178,02 & 178,18 & 45,68 & 1370,44 & $\begin{array}{l}197,65 \\
\end{array}$ & \begin{tabular}{ll|}
19,63 \\
\end{tabular} & 52,80 & 551,13 & $\begin{array}{l}101,85 \\
\end{array}$ & \begin{tabular}{|c|}
103,26 \\
\end{tabular} & 551,12 \\
\hline Discoglossus galganoi & 29TPF09 & 100 & 111 & 94 & 38 & 2 & 253 & 10,63 & 243 & 48,68 & 180 & $18 \mathrm{C}$ & 48,68 & 1325 & 188 & 19,36 & 52,06 & 530 & 99,87 & 101,47 & $53 c$ \\
\hline Discoglossus galganoi & 29TPF32 & 101,00 & 118,52 & 91,48 & 35,98 & 5579,90 & 265,56 & 14,68 & 250,89 & 50,49 & 192,24 & 192,61 & 50,49 & 1181,51 & 178,55 & 12,66 & 55,06 & 480,60 & 78,06 & 80,25 & 480,60 \\
\hline Discoglossus galganoi & 29TPF43 & 100,00 & 128,47 & 98,78 & 37,29 & 5690,11 & 281,10 & \begin{tabular}{l|l}
19,51 \\
\end{tabular} & 261,59 & 58,25 & 203,40 & 203,53 & 58,25 & 1018,61 & 151,77 & 11,11 & 54,11 & 410,75 & 69,20 & 69,37 & 410,75 \\
\hline Discoglossus galganoi & 29TPF49 & 100,00 & 137,42 & 106,91 & 39,23 & 5629,61 & 292,32 & 23,10 & 269,23 & 67,23 & 211,12 & 211,12 & 66,99 & 873,61 & 123,63 & $\begin{array}{l}11,76 \\
\end{array}$ & 51,03 & 345,28 & 63,87 & 63,87 & 345,28 \\
\hline Discog| & 29TPF & 101, & & & 35 & ? & & 17, & & 61 & & & 54 & & 50 & 9 & & 34 & & 63,13 & 342 \\
\hline Discoglossus galganoi & 29TPF72 & 100, & 127 & 99,08 & 36,53 & 5904,58 & 284,36 & 16,5 & 267,84 & 62, & 205,84 & 205,9 & $55, \mathrm{C}$ & 843,94 & $119, / 3$ & 9,89 & 51, & 331,56 & $61,64]$ & 61,79 & 330,1 \\
\hline Discoglossus galganoi & 29TPF81 & 100,00 & 126,60 & 98,86 & 36,16 & 5977,64 & 284,65 & 15,28 & 269,37 & 60,96 & 205,60 & 206,19 & 53,50 & 801,99 & 111,22 & 9,53 & 50,05 & 313,21 & 59,84 & 60,40 & 308,99 \\
\hline
\end{tabular}




\begin{tabular}{|c|c|c|c|c|c|c|c|c|c|c|c|c|c|c|c|c|c|c|c|c|c|}
\hline TAXON & UTM & $\mathrm{km} 2$ & $\mathrm{BIO1}$ & $\mathrm{B1O2}$ & $\mathrm{BIO3}$ & B104 & B105 & $\mathrm{B106}$ & $\mathrm{B107}$ & B108 & $\mathrm{BIO9}$ & 81010 & B1011 & $\mathrm{BIO12}$ & $\mathrm{B1O13}$ & BIO14 & B1015 & B1016 & B1017 & $\mathrm{BIO18}$ & B1019 \\
\hline Discoglossus galganoi & 29TPF86 & 100,00 & 126,57 & 105,56 & 37,85 & 5900,58 & 287,13 & 11,93 & 275,19 & 60,90 & 204,84 & 204,84 & 53,61 & 744,61 & 101,80 & 10,30 & 48,49 & 289,46 & 59,65 & 59,65 & 287,21 \\
\hline Discoglossus galganoi & 29TPF92 & 100,00 & 125,21 & 101,71 & 36,70 & 6019,31 & 285,83 & 12,23 & 273,60 & 58,92 & 205,25 & 205,49 & 51,56 & 742,40 & 99,73 & 9,73 & 48,30 & 287,10 & 58,92 & 59,10 & 280,79 \\
\hline \begin{tabular}{|l} 
Discoglossus galganoi \\
\end{tabular} & 29TPF95 & 100,00 & 123,98 & 105,18 & 37,72 & 5972,06 & 285,81 & 9,47 & 276,34 & 57,90 & 203,57 & 203,57 & 50,66 & 712,27 & 94,80 & 9,98 & 47,46 & 274,87 & 58,80 & 58,80 & 269,70 \\
\hline Discoglossus galganoi & 29TPF96 & 100,00 & 125,79 & 106,55 & 38,02 & 5947,17 & 287,79 & 10,27 & 277,52 & 59,50 & 204,76 & 204,76 & 52,34 & 691,95 & 91,70 & \begin{tabular}{l|l|l|}
10,15 \\
\end{tabular} & 47,00 & 266,69 & 57,95 & 57,95 & 261,99 \\
\hline Discoglossus galganoi & 29TPF98 & 100,00 & 120,57 & 107,46 & 38,12 & 5908,98 & 283,11 & 5,07 & 278,03 & 54,57 & 199,09 & 199,09 & 47,67 & 701,41 & 92,47 & 11,18 & 46,30 & 270,26 & 61,39 & 61,39 & 266,71 \\
\hline Discoglossus galganoi & 29TPG03 & 101,00 & 100,34 & 86,02 & 36,70 & 5053,09 & 235,86 & 4,79 & 231,07 & 40,97 & 167,75 & 168,01 & 40,55 & 1349,43 & 178,69 & 25,66 & 48,45 & 527,55 & 116,37 & 118,48 & 527,53 \\
\hline Discoglossus galganoi & 29TPG05 & 101,00 & 119,89 & 93,96 & 38,26 & 5155,67 & 258,22 & 15,84 & 242,38 & 63,14 & 187,92 & 188,01 & 57,21 & 1153,20 & 156,06 & 22,16 & 47,08 & 443,66 & 100,34 & 101,71 & 440,77 \\
\hline Discoglossus galganoi & 29TPG06 & 101,00 & 120,72 & 93,71 & 38,19 & 5132,34 & 258,02 & 16,47 & 241,55 & 63,99 & 188,26 & 188,35 & 58,39 & 1133,64 & 155,70 & 22,98 & 46,17 & 434,04 & 101,53 & 103,93 & 429,13 \\
\hline Discoglossus galganoi & 29TPG07 & 100,00 & 123,10 & 93,56 & 38,15 & 5116,46 & 259,22 & 18,05 & 241,17 & 66,16 & 190,42 & 190,56 & 60,93 & 1099,61 & 152,97 & 23,37 & 45,42 & 418,36 & 101,12 & 104,45 & 411,31 \\
\hline Discoglossus galganoi & 29TPG09 & 99,00 & 123,31 & 91,60 & 38,18 & 4991,49 & 255,79 & 19,62 & 236,17 & 67,51 & 188,94 & 189,15 & 63,01 & 1087,23 & 152,76 & 25,49 & 43,95 & 410,21 & 105,63 & 112,58 & 399,86 \\
\hline Discoglossus galganoi & 29TPG10 & 100,00 & 126,91 & 102,29 & 39,40 & 5384,67 & 275,27 & 18,51 & 256,76 & 60,43 & 197,61 & 197,66 & 60,43 & 1124,66 & 158,03 & 15,63 & 51,73 & 446,89 & 82,92 & 83,49 & 446,89 \\
\hline Discoglossus galganoi & 29TPG13 & 101,00 & 114,59 & 94,29 & 37,88 & 5258,16 & 256,75 & 11,16 & 245,59 & 51,08 & 184,25 & 184,28 & 50,83 & 1171,31 & 155,10 & 20,77 & 48,71 & 457,27 & 97,45 & 97,95 & 457,27 \\
\hline \begin{tabular}{|l} 
Discoglossus galganoi \\
\end{tabular} & 29TPG14 & 101,00 & 113,99 & 93,88 & 37,92 & 5231,74 & 255,38 & 10,69 & 244,69 & 55,23 & 183,38 & 183,44 & 50,77 & 1159,41 & 152,44 & 21,83 & 47,73 & 449,20 & 99,54 & 100,49 & 449,09 \\
\hline Discoglossus galganoi & 29TPG15 & 99,00 & 117,40 & 94,81 & 38,05 & 5235,88 & 258,51 & 12,64 & 245,87 & 59,84 & 186,75 & 186,77 & 53,92 & 1115,37 & 149,09 & 21,82 & 46,89 & 429,50 & 97,90 & 99,06 & 427,21 \\
\hline Discoglossus galganoi & 29TPG18 & 100,00 & 110,04 & 91,71 & 37,90 & 5063,02 & 246,93 & 8,24 & 238,69 & 54,47 & 177,24 & 177,33 & 49,44 & 1155,09 & 158,04 & 26,98 & 44,29 & 440,11 & 112,45 & 115,47 & 432,49 \\
\hline Discoglossus galganoi & 29TPG22 & 101,00 & 133,16 & 103,27 & 39,01 & 5460,32 & 282,04 & 21,44 & 260,59 & 66,48 & 204,71 & 204,71 & 65,46 & 970,41 & 130,05 & 15,04 & 49,31 & 377,52 & 75,53 & 75,53 & 377,52 \\
\hline Discoglossus galganoi & 29TPG23 & 100,00 & 128,44 & 100,89 & 38,75 & 5426,73 & 275,36 & 18,16 & 257,20 & 64,68 & 199,68 & 199,68 & 61,42 & 993,49 & 130,73 & 16,78 & 48,38 & 385,02 & 80,62 & 80,62 & 384,57 \\
\hline \begin{tabular}{|l} 
Discoglossus galganoi \\
\end{tabular} & 29TPG24 & 100,00 & 128,78 & 100,20 & 38,64 & 5413,35 & 274,57 & 18,36 & 256,21 & 68,08 & 199,94 & 199,94 & 62,10 & 972,87 & 127,05 & 17,39 & 47,39 & 374,59 & 81,45 & 81,45 & 372,83 \\
\hline Discoglossus galganoi & 29TPG26 & 101,00 & 105,01 & 92,90 & 37,58 & 5216,32 & 246,69 & 2,59 & 244,09 & 48,25 & 174,52 & 174,57 & 42,60 & 1153,25 & 153,62 & 25,51 & 45,44 & 443,06 & 108,79 & 109,53 & 438,97 \\
\hline Discoglossus galganoi & 29TPG28 & 101,00 & 102,96 & 91,96 & 37,86 & 5109,11 & 242,32 & 1,67 & 240,65 & 47,18 & 170,96 & 171,02 & 42,07 & 1159,66 & 156,59 & 27,99 & 43,84 & 442,53 & 115,48 & 117,44 & 435,04 \\
\hline Discoglossus galganoi & 29TPG33 & 100,00 & 121,95 & 100,70 & 38,33 & 5475,42 & 271,29 & 12,10 & 259,19 & 57,53 & 194,34 & 194,34 & 54,80 & 986,87 & 131,60 & 17,6 & 48,16 & 384,05 & 82,26 & 82,26 & 383,95 \\
\hline Discoglossus galganoi & 29TPG34 & 101,00 & 119,10 & 99,36 & 38,15 & 5438,35 & 267,03 & 10,11 & 256,92 & 58,52 & $\mid 191,03$ & 191,03 & 52,56 & 996,47 & 130,92 & 19,09 & 47,19 & 385,91 & 86,18 & 86,18 & 385,02 \\
\hline \begin{tabular}{|l} 
Discoglossus galganoi \\
\end{tabular} & 29TPG35 & 101,00 & 108,30 & 95,95 & 37,66 & 5353,04 & 254,26 & 3,04 & 251,22 & 49,68 & 179,55 & 179,55 & 43,77 & \begin{tabular}{|c|c|}
1075,13 \\
\end{tabular} & 141,59 & 22,76 & 46,07 & 415,19 & 98,62 & 98,63 & 412,73 \\
\hline Discoglossus galganoi & 29TPG42 & 101,00 & 119,50 & 102,14 & 38,32 & 5551,84 & 272,26 & 8,95 & 263,32 & 51,70 & 193,03 & 193,03 & 51,39 & 962,54 & 131,89 & 16,71 & 48,75 & 378,48 & 79,34 & 79,34 & 378,47 \\
\hline Discoglossus galganoi & 29TPG48 & 100,00 & 108,67 & 96,86 & 37,97 & 5314,99 & 253,42 & 2,25 & 251,18 & 49,64 & 179,27 & 179,29 & 44,47 & 997,65 & 133,38 & 24,48 & 42,97 & 380,02 & 101,32 & 101,38 & 371,02 \\
\hline Discoglossus galganoi & 29TPG49 & 101,00 & 118,67 & 97,49 & 38,41 & 5283,64 & 261,09 & 10,54 & 250,55 & 58,99 & 188,28 & 188,28 & 54,20 & 919,91 & 123,69 & 22,59 & 42,35 & 348,53 & 93,97 & 93,97 & 337,24 \\
\hline Discoglossus galganoi & 29TPG54 & 100,00 & 112,14 & 101,49 & 37,99 & 5549,06 & 265,44 & 2,10 & 263,34 & 50,57 & $\begin{array}{l}180,0100 \\
\end{array}$ & 186,01 & 44,43 & \begin{tabular}{|l|l|}
933,69 \\
\end{tabular} & \begin{tabular}{|l|l|l|l}
123,73 \\
\end{tabular} & 19,01 & 46,45 & 363,30 & 84,68 & 84,68 & 361,72 \\
\hline Discoglossus galganoi & 29TPG59 & 101,00 & 120,87 & 99,39 & 38,56 & 5362,54 & 265,42 & 10,95 & 254,47 & 59,95 & 191,56 & 191,56 & 55,12 & 854,10 & 114,17 & 21,06 & 41,95 & 323,58 & 88,29 & 88,29 & 311,47 \\
\hline Discoglossus galganoi & 29TPG63 & 100,00 & 112,97 & 103,74 & 38,15 & 5628,42 & 269,69 & 1,35 & 268,34 & 50,38 & 187,93 & 187,93 & 44,10 & 878,27 & 118,15 & 16,94 & 46,75 & 343,20 & 79,00 & 79,00 & 342,17 \\
\hline Discoglossus galganoi & 29TPG64 & 100,00 & 104,22 & 101,47 & 37,91 & 5587,04 & 259,60 & $-4,87$ & 264,47 & 42,66 & 178,99 & 178,99 & 36,56 & 935,40 & 123,39 & 19,90 & 45,50 & 363,13 & 88,84 & 88,84 & 360,58 \\
\hline Discoglossus galganoi & 29TPG65 & 100,00 & 91,21 & 98,25 & 37,45 & 5510,92 & 244,11 & $-14,60$ & 258,71 & 31,40 & 165,31 & 165,32 & 25,41 & 1036,29 & 135,29 & 25,12 & 43,62 & 396,79 & 105,96 & 106,01 & 391,05 \\
\hline \begin{tabular}{|l} 
Discoglossus galganoi \\
\end{tabular} & 29TPG67 & 101,00 & $\begin{array}{l}1,121 \\
90,62\end{array}$ & 90,13 & 37,76 & 5449,74 & 241,65 & $-15,01$ & 256,66 & $\begin{array}{ll}31,1418 \\
31\end{array}$ & \begin{tabular}{|l|l|}
163,81 \\
\end{tabular} & $\begin{array}{l}163,81 \\
163\end{array}$ & 25,53 & 1033,16 & \begin{tabular}{|l|l|}
135,57 \\
\end{tabular} & 27,56 & $\begin{array}{ll}43,1,95 \\
41,15\end{array}$ & 391,99 & 111,28 & 111,28 & 382,79 \\
\hline Discoglossus galganoi & 29TPG68 & 101,00 & 95,38 & 98,77 & 37,99 & 5429,41 & 245,36 & $-11,17$ & 256,53 & 35,56 & 168,01 & 168,01 & 30,21 & 994,16 & 131,08 & 26,93 & 41,40 & 376,34 & 108,56 & 108,56 & 365,59 \\
\hline Discoglossus galganoi & 29TPG72 & 100,00 & 104,66 & 103,39 & 37,88 & 5685,59 & 263,66 & $-5,85$ & 269,52 & 42,04 & 180,79 & 180,80 & 35,52 & 889,11 & 119,21 & 17,01 & 46,29 & 346,30 & 82,30 & 82,30 & 345,29 \\
\hline Discoglossus galganoi & 29TPG74 & 100,00 & 102,89 & 103,19 & 37,94 & 5639,26 & 260,53 & $-7,56$ & 268,10 & 40,61 & 178,40 & 178,40 & 34,42 & 888,01 & 117,14 & 19,58 & 44,67 & 343,11 & 87,15 & 87,15 & 339,61 \\
\hline Discoglossus galganoi & 29TPG77 & 100,00 & 72,02 & 96,50 & 37,33 & 5454,39 & 223,74 & $-31,34$ & 255,08 & 13,92 & 145,64 & 145,74 & 7,94 & 1141,30 & 146,33 & 33,84 & 39,61 & 424,73 & 132,61 & 133,18 & 411,98 \\
\hline \begin{tabular}{|l} 
Discoglossus galganoi \\
\end{tabular} & 29TPG78 & 99,00 & 84,24 & $\begin{array}{ll}0,030 \\
98,73\end{array}$ & $\frac{37,53}{37,94}$ & 54561,01 & 235,92 & $\begin{array}{ll}-3,21,51 \\
-21,51\end{array}$ & \begin{tabular}{|l|}
257,42 \\
25
\end{tabular} & $\begin{array}{l}24,82 \\
24,81\end{array}$ & \begin{tabular}{|l|}
157,045 \\
157,5
\end{tabular} & $\begin{array}{l}\mid 43,7,45 \\
157,55\end{array}$ & \begin{tabular}{|c|}
19,16 \\
19
\end{tabular} & $\mid \frac{114,103}{1035,81}$ & \begin{tabular}{|l|}
134,6354 \\
134,
\end{tabular} & 30,25 & $\frac{35,016}{39,76}$ & 387,35 & 119,01 & 13,10 & $\begin{array}{l}41,90 \\
374,39\end{array}$ \\
\hline Discoglossus galganoi & 29TPG83 & 100,00 & 114,34 & 107,76 & 38,57 & 5717,94 & 275,96 & $-0,14$ & 276,10 & 49,76 & 190,63 & 190,63 & 43,99 & 756,43 & 100,89 & 14,92 & 45,71 & 294,30 & 71,12 & 71,12 & 293,56 \\
\hline Discoglossus galganoi & 29TPG84 & 100,00 & 101,08 & 104,58 & 38,04 & 5694,84 & 260,62 & $-10,39$ & 271,01 & 38,15 & 177,42 & 177,42 & 31,99 & 848,62 & 111,77 & 19,55 & 43,67 & 325,23 & 86,52 & 86,52 & 320,86 \\
\hline Discoglossus galganoi & 29TPG85 & 99,00 & 90,22 & 102,10 & 37,74 & 5649,05 & 247,58 & $-18,81$ & 266,39 & 28,47 & 166,10 & 166,16 & 22,38 & 931,97 & 121,43 & 24,22 & 41,70 & 352,40 & 101,25 & 101,38 & 344,17 \\
\hline Discoglossus galganoi & 29TPG87 & 100,00 & 60,76 & 96,29 & 37,14 & 5479,39 & 213,40 & $-41,90$ & 255,30 & 3,18 & 134,78 & 135,09 & $-3,08$ & 1192,08 & 150,36 & 37,89 & 37,67 & 436,76 & 145,06 & 146,84 & 421,17 \\
\hline Discoglossus galganoi & 29TPG93 & 100,00 & 114,11 & 109,10 & $38, \varepsilon$ & 5783,44 & 276,86 & $-1,48$ & 278,34 & 48,78 & 191,09 & 191,09 & 42,76 & 707,57 & 93,88 & 14,70 & 44,40 & 271,75 & 69,24 & 69,24 & 270,03 \\
\hline Discoglossus galganoi & 29TPG94 & 101,00 & 110,64 & 108,34 & 38,65 & 5772,11 & 272,62 & $-4,27$ & 276,90 & 45,99 & 187,51 & 187,51 & 39,68 & 726,49 & 96,60 & 16,51 & 43,40 & 277,94 & 73,92 & 73,92 & 274,29 \\
\hline Discoglossus galganoi & 29TPG95 & 101,00 & 102,24 & 106,49 & 38,29 & 5749,81 & 262,78 & $-11,04$ & 273,82 & 38,15 & 179,12 & 179,12 & 32,12 & 781,86 & 103,44 & 20,04 & 41,76 & 296,35 & 84,39 & 84,39 & 288,95 \\
\hline Discoglossus galganoi & 29TPG96 & 100,00 & 97,20 & 105,45 & 38,22 & 5715,20 & 256,35 & $-15,01$ & 4 & 33,71 & 173,68 & 173,68 & 27,75 & 820,67 & 07,87 & 22 & 53 & 33 & 92,64 & 92,64 & 298,22 \\
\hline Discoglossus galganoi & 29TPHO1 & 100,00 & 124 & $\begin{array}{r}90,02 \\
90,02\end{array}$ & 38 & 4776,79 & 252,75 & $\begin{array}{r}24,07 \\
24 \\
\end{array}$ & 22 & $\mid 71,31$ & \begin{tabular}{|l|}
187,58 \\
\end{tabular} & & 67,60 & $\mid$ & 51,59 & $\frac{22}{27}$ & & 403,69 & 109,82 & 122,46 & 389,66 \\
\hline Discoglossus galganoi & 29TPH02 & 99,00 & 126,84 & & 39, & 4652,13 & 251,70 & 27,49 & 224 & 74,29 & 187,64 & 188,44 & 70,94 & 1066,92 & 149,59 & 27,5 & 41,88 & 398,26 & 111,13 & 125,05 & 382,20 \\
\hline Discoglossus galganoi & 29TPH06 & 100,00 & 122,37 & 85,04 & 40,24 & 4221,63 & 238,92 & 30,56 & 208,36 & 75,70 & 177,15 & 178,95 & 72,04 & 1114,61 & 150,96 & 33,28 & 38,97 & 412,09 & 127.86 & 143,18 & 388,61 \\
\hline Discoglossus galganoi & 29TPH07 & 100,00 & 123,13 & 83,78 & 40,52 & 4121,32 & 237,34 & 33,13 & 204,21 & 77,79 & 176,53 & 178,70 & 74,12 & 1106,65 & 148,29 & 33,80 & 38,24 & 408,04 & 129,36 & 145,35 & 382,48 \\
\hline Discoglossus galganoi & 29TPH08 & 100,00 & 50 & 82,49 & 40,5 & 4047,40 & 236,24 & 36,13 & 1 & 80,26 & 176,78 & 179,07 & 76 & 1090,69 & 44,51 & 34 & 37,66 & 400,97 & 129,85 & 146,52 & 373,57 \\
\hline \begin{tabular}{|l} 
Discoglossus galganoi \\
\end{tabular} & 29TPHO9 & 100,00 & $\frac{12}{12}$ & 81 & 40 & 3966,66 & 232,24 & $\begin{array}{ll}30,15 \\
35,86\end{array}$ & & $\begin{array}{ll}\mid 70,73 \\
79,73\end{array}$ & $\mid 173,76$ & 17 & 75,50 & 1103,86 & \begin{tabular}{|c|}
$144,31,75$ \\
144
\end{tabular} & 35,37 & 36,96 & 404,69 & 134,34 & $\begin{array}{ll}140,32 \\
151,17\end{array}$ & 375,61 \\
\hline \begin{tabular}{|l} 
Discoglossus galganoi \\
\end{tabular} & 29TPH14 & 100,00 & 127,77 & 88,45 & 39,92 & 4530,25 & 250,04 & 30,10 & 219,94 & 76,72 & 186,71 & 187,88 & 73,19 & 1014,92 & 138,48 & 28,44 & 39,90 & 375,81 & 111,82 & 126,42 & 355,63 \\
\hline Discoglossus galganoi & 29TPH16 & 101,00 & 125,04 & 86,30 & 40,07 & 4330,92 & 243,26 & 31,13 & 212,13 & 76,77 & 181,15 & 182,83 & 73,01 & 1042,90 & 139,56 & 31,21 & 38,41 & 383,96 & 120,74 & 136,01 & 359,84 \\
\hline Discoglossus galganoi & 29TPH17 & 100,00 & 126,18 & 84,96 & 40,36 & 4216,44 & 241,65 & 34,25 & 207,40 & 79,44 & 180,65 & 182,65 & 75, & 1038,06 & 137,45 & 31,90 & 37,78 & 381,03 & 122,60 & 138,47 & 354,94 \\
\hline Discoglossus galganoi & 29TPH18 & 101,00 & 12 & 83,80 & 40,68 & 4123,85 & 238,95 & 35,24 & 203 & 80,25 & 178,80 & 180 & 76,07 & 1044,09 & 136,94 & 32,81 & 37,04 & 382,20 & 125,76 & 142,04 & 35 \\
\hline \begin{tabular}{|l|l|} 
Discoglossus galganoi \\
\end{tabular} & 29TPH2O & $\begin{array}{l}100,00 \\
100\end{array}$ & $\begin{array}{l}12,00 \\
128,59\end{array}$ & $\begin{array}{l}3,00 \\
94,28 \\
\end{array}$ & $\begin{array}{l}34,00 \\
38,67\end{array}$ & $\begin{array}{l}412,00 \\
5087,38\end{array}$ & 263,24 & $\begin{array}{l}3,24 \\
21,88 \\
\end{array}$ & $\begin{array}{l}243,1 / 3 \\
241,35\end{array}$ & 70,80 & 195,16 & 195,28 & 66,58 & 936,27 & 128,52 & 22,83 & 42,26 & 350,85 & 94,21 & 97,52 & 337,98 \\
\hline Discoglossus galganoi & 29TPH21 & 100,00 & 131,78 & 93,25 & 38,97 & 4996,08 & 263,61 & 26,14 & 237,47 & 75,01 & 196,99 & 197,21 & 70,90 & 914,56 & 125,36 & 22,94 & 41,58 & 340,74 & 94,05 & 100,10 & 325,66 \\
\hline Discoglossus galganoi & 29TPH23 & 101,00 & 119,56 & 91,15 & 39,07 & 4762,91 & 248,70 & 19,16 & 229,53 & 66,02 & 181,97 & 182,57 & 62,19 & 1024,94 & 139,16 & 28,49 & 40,09 & 381,25 & 112,89 & 125,25 & 363,04 \\
\hline Discoglossu & 29TPH25 & 100,00 & 126,69 & 88,78 & 40,00 & 25,55 & 249,07 & 29,25 & 10 & $75, \varepsilon$ & 185 & 186 & 72 & 981,64 & 131,10 & 28,68 & 38,56 & 361 & 112,42 & 126,98 & 338,67 \\
\hline \begin{tabular}{|l} 
Discoglossus galganoi \\
\end{tabular} & 29TPH27 & 100,00 & 123,01 & 86,66 & 40,23 & 337,90 & 41,68 & 29,27 & 212,41 & 74,82 & 179,25 & 180,94 & 70,80 & .019,81 & 33,69 & 31,80 & 37,10 & 373,07 & 122,70 & 137,63 & 346,56 \\
\hline
\end{tabular}




\begin{tabular}{|c|c|c|c|c|c|c|c|c|c|c|c|c|c|c|c|c|c|c|c|c|c|}
\hline TAXON & UTM & $\mathrm{km} 2$ & BIO1 & BIO2 & $\mathrm{BIO3}$ & B104 & BIO5 & B106 & B107 & B108 & B109 & B1010 & B1011 & B1012 & $\begin{array}{lll}B 1013 \\
\end{array}$ & $\begin{array}{lll}B 1014 \\
\end{array}$ & B1015 & B1016 & $\begin{array}{lll}\text { B1017 } & \\
\end{array}$ & $\begin{array}{lll}B 1018 & \end{array}$ & B1019 \\
\hline Discoglossus galganoi & 29TPH31 & 101,00 & 119,04 & 94,44 & 38,82 & 5059,74 & 255,30 & 14,04 & 241,25 & 62,01 & 185,63 & 185,73 & 57,79 & 967,60 & 131,02 & 25,32 & 41,14 & 362,64 & 102,89 & 105,66 & 347,87 \\
\hline Discoglossus galganoi & 29TPH35 & 101,00 & 118,79 & 90,60 & 39,82 & 4643,16 & 245,49 & 20,12 & 225,38 & 66,82 & 179,40 & 180,40 & 62,86 & \begin{tabular}{|c|}
996,47 \\
\end{tabular} & 131,71 & 30,01 & 37,94 & \begin{tabular}{|l|l|}
366,67 \\
\end{tabular} & 117,26 & 130,42 & 343,40 \\
\hline Discoglossus galganoi & 29TPH43 & 101,00 & 100,48 & 93,27 & 38,81 & 4951,50 & 237,13 & $\frac{-2,22}{-0,22}$ & 237,35 & 45,75 & 166,10 & 166,39 & 41,46 & $\begin{array}{r}\mid 1075,10 \\
\end{array}$ & $\mid 142,03$ & 32,36 & 38,51 & 398,95 & 126,43 & $\begin{array}{l}132,82 \\
\end{array}$ & 379,34 \\
\hline Discoglossus galganoi & 29TPH45 & 100,00 & 111,85 & 92,25 & 39,68 & 4763,05 & 242,47 & 11,89 & 230,58 & 58,62 & 174,21 & 174,95 & 54,51 & 1003,77 & 131,25 & 31,17 & 37,17 & 368,70 & 121,41 & 132,90 & 344,71 \\
\hline Discoglossus galganoi & 29TPH50 & 99,00 & 103,52 & 97,16 & 38,31 & 5267,63 & 247,89 & $-2,19$ & 250,08 & 44,77 & 173,39 & 173,39 & 40,01 & 986,10 & 131,01 & 27,03 & 40,63 & 371,34 & 108,83 & 108,87 & 357,52 \\
\hline Discoglossus galganoi & 29TPH51 & 100,00 & 92,45 & 95,33 & 38,24 & 5173,82 & 235,67 & $-10,10$ & 245,76 & 35,76 & 161,46 & 161,51 & 30,84 & $\begin{array}{l}1078,35 \\
\end{array}$ & 141,86 & 31,88 & 39,27 & 402,52 & 125,19 & 125,91 & 386,28 \\
\hline Discoglossus galganoi & 29TPH52 & 100,00 & 95,85 & 95,19 & 38,70 & 5107,97 & 237,01 & $-6,60$ & 243,60 & 39,57 & 163,73 & 163,78 & 34,81 & $\mid 1057,17$ & 138,92 & 31,84 & 38,58 & 392,95 & 124,87 & 126,52 & 374,61 \\
\hline Discoglossus galganoi & 29TPH54 & 100,00 & 115,34 & 94,76 & 39,46 & 4935,88 & 249,56 & 12,04 & 237,52 & 59,65 & 179,89 & 180,24 & 55,34 & 926,28 & 120,82 & 27,95 & 37,42 & 341,19 & 110,92 & 118,09 & 318,13 \\
\hline Discoglossus galganoi & 29TPH55 & 101,00 & 115,59 & 93,60 & 39,80 & 4824,02 & 247,23 & 14,03 & 233,20 & 61,30 & 178,62 & 179,20 & 57,08 & 937,10 & $\begin{array}{l}121,15 \\
\end{array}$ & 29,23 & 36,63 & 342,96 & 114,97 & 125,70 & 317,72 \\
\hline Discoglossus galganoi & 29TPH56 & 100,00 & 112,59 & 92,57 & 39,92 & 4721,95 & 242,36 & 12,91 & 229,45 & 59,88 & 174,30 & 175,10 & 55,56 & $\begin{array}{l}969,45 \\
\end{array}$ & 124,37 & 31,62 & 35,72 & 352,59 & 122,46 & 134,51 & 325,18 \\
\hline Discoglossus galganoi & 29TPH57 & 101,00 & 108,53 & 91,48 & 39,99 & \begin{tabular}{|l|l|}
4634,93 \\
\end{tabular} & 236,83 & 10,77 & 226,06 & 57,27 & 169,01 & 170,10 & 52,83 & 1012,28 & 129,34 & 34,45 & 34,89 & 366,04 & 131,43 & 143,40 & 336,67 \\
\hline Discoglossus galganoi & 29TPH58 & 99,00 & 111,89 & 90,21 & 40,17 & 4511,60 & 236,79 & 15,61 & 221,18 & 62,19 & 170,64 & 171,93 & 57,57 & 1001,05 & 128,05 & 34,69 & 34,26 & 360,09 & 131,93 & 144,69 & 328,66 \\
\hline Discoglossus galganoi & 29TPH60 & 101,00 & 104,75 & 99,05 & 38,49 & 5352,43 & 251,30 & $-2,77$ & 254,06 & 44,83 & 175,79 & 175,79 & 39,85 & 926,98 & 122,54 & 25,86 & 40,07 & 348,48 & 104,41 & 104,43 & 333,57 \\
\hline Discoglossus galganoi & 29TPH63 & 100,00 & 96,65 & 96,45 & 38,91 & 5119,07 & 238,28 & $-6,57$ & 244,86 & 39,94 & 164,49 & 164,55 & 35,18 & 1010,04 & 131,23 & 31,90 & 37,11 & 372,28 & 124,46 & 125,75 & 350,78 \\
\hline Discoglossus galganoi & 29TPH64 & 100,00 & 101,18 & 95,94 & 39,16 & 5028,11 & 240,07 & $-1,63$ & 241,70 & 45,30 & 167,53 & 167,73 & 40,68 & $\begin{array}{l}986,45 \\
\end{array}$ & 127,35 & 31,77 & 36,41 & 361,41 & 123,68 & 127,55 & 337,53 \\
\hline Discoglossus galganoi & 29TPH67 & 100,00 & 111,40 & 92,64 & 40,16 & 4672,44 & 240,37 & 12,48 & 227,89 & 59,48 & 172,27 & 173,21 & 54,89 & 959,28 & 123,40 & 33,20 & 34,14 & 344,70 & 127,14 & 138,91 & 313,97 \\
\hline Discoglossus galganoi & 29TPH68 & 100,00 & 112,91 & 91,50 & 40,35 & 4561,33 & 239,10 & 15,52 & 223,58 & 62,99 & 172,22 & 173,42 & 57,89 & 963,04 & 124,25 & 34,13 & 33,53 & 344,15 & 129,85 & 142,22 & 311,33 \\
\hline Discoglossus galganoi & 29TPH70 & 99,00 & 120,04 & 101,98 & 38,92 & 5464,69 & 267,27 & 7,93 & 259,34 & 57,30 & 191,79 & 191,79 & 52,47 & 768,84 & 101,73 & 20,23 & 40,17 & 290,06 & 85,34 & 85,34 & 274,12 \\
\hline Discoglossus galganoi & 29TPH73 & 101,00 & 86,82 & 97,28 & 38,88 & 5179,44 & 231,19 & $-16,28$ & 247,47 & 30,10 & 155,82 & 155,92 & 25,01 & \begin{tabular}{|l|}
1044,37 \\
\end{tabular} & 133,86 & 35,11 & 35,84 & 381,04 & 134,58 & 135,46 & 358,23 \\
\hline Discoglossus galganoi & 29TPH74 & 100,00 & 79,80 & 95,67 & 38,76 & 5085,43 & 222,37 & $-21,16$ & 243,53 & 24,80 & 147,66 & 147,86 & 19,67 & 1114,89 & 141,35 & 39,34 & 34,79 & 402,99 & 148,23 & 150,17 & 377,98 \\
\hline Discoglossus galganoi & 29TPH75 & 101,00 & 94,02 & 96,11 & 39,45 & 4995,44 & 233,21 & $\begin{array}{r}-7,67 \\
\end{array}$ & 240,88 & 39,08 & 160,11 & 160,38 & 34,17 & 1015,93 & 129,58 & 35,50 & 34,52 & 366,79 & 135,23 & 139,76 & 339,58 \\
\hline Discoglossus galganoi & 29TPH78 & 100,00 & 114,42 & 92,48 & 40,65 & 4583,52 & 241,15 & 16,33 & 224,81 & 67,71 & 173,87 & 175,05 & 58,89 & 927,82 & 120,75 & 33,81 & 32,65 & 328,82 & 128,45 & 140,50 & 294,39 \\
\hline Discoglossus galganoi & 29TPH84 & 99,00 & 84,45 & 98,01 & 39,11 & 5161,57 & 228,83 & $-18,65$ & 247,48 & 28,14 & 153,10 & 153,23 & 22,80 & \begin{tabular}{|l|}
1035,10 \\
\end{tabular} & 131,26 & 37,17 & 34,15 & 372,30 & 140,47 & 142,00 & 346,19 \\
\hline Discoglossus galganoi & 29TPJ04 & 56,00 & 137,36 & 73,90 & 42,15 & 3514,50 & 232,05 & 58,87 & 173,18 & 100,53 & 181,14 & 184,83 & 94,53 & 981,99 & 127,14 & 33,35 & 34,81 & 356,73 & 127,39 & 148,12 & 319,92 \\
\hline Discoglossus galganoi & 29TPJ10 & 101,00 & 112,25 & 82,44 & 40,65 & 4047,22 & 225,37 & 25,05 & 200,32 & 68,87 & 164,45 & 167,13 & 64,32 & $\begin{array}{l}1150,58 \\
\end{array}$ & 148,39 & 39,02 & 35,57 & 418,62 & 146,55 & 162,06 & 387,48 \\
\hline Discoglossus galganoi & 29TPJ11 & 99,00 & 107,59 & 81,49 & 40,67 & 4002,55 & 220,11 & 21,82 & 198,28 & 65,15 & 159,35 & 162,08 & 60,56 & 1187,50 & 151,90 & 41,50 & 34,98 & 430,71 & 154,62 & 170,05 & 397,96 \\
\hline Discoglossus galganoi & 29TPJ12 & 100,00 & 123,46 & $\frac{\mid 1,4,9}{78,92}$ & 41,39 & 3807,52 & 228,45 & 39,93 & 188,52 & 82,91 & 171,92 & 174,97 & 77,90 & 1067,06 & 135,81 & 36,83 & 34,70 & $\begin{array}{l}350,1+28 \\
386,\end{array}$ & 138,65 & 156,57 & 351,79 \\
\hline Discoglossus galganoi & 29TPJ13 & 90,00 & 132,24 & 76,74 & 41,84 & 3674,46 & 232,24 & 50,79 & 181,45 & 93,37 & 178,62 & 181,91 & 87,82 & 1000,76 & 128,78 & 34,41 & 34,42 & 361,84 & 130,66 & 149,97 & 325,86 \\
\hline Discoglossus galganoi & 29TPJ20 & 101,00 & 115,98 & 83,44 & 40,87 & 4089,90 & 229,64 & 27,49 & 202,15 & 71,75 & 168,76 & 171,14 & 67,24 & 1089,15 & 138,99 & 37,26 & 35,04 & 394,35 & 140,28 & 155,81 & 362,46 \\
\hline Discoglossus galganoi & 29TPJ24 & & & & & & & & & & & & & & & & & & & & \\
\hline Discoglossus galganoi & 29TPJ30 & 100,00 & 121,04 & 84,16 & 40,86 & 4126,23 & 234,68 & 31,21 & 203,47 & 76,08 & 174,03 & 176,41 & 71,45 & 1022,14 & 130,45 & 35,14 & 34,61 & 368,39 & 133,01 & 148,65 & 335,45 \\
\hline Discoglossus galganoi & 29TPJ40 & 101,00 & 128,17 & 84,57 & 41,07 & 4134,92 & 240,82 & 37,28 & 203,54 & 82,84 & 181,01 & 183,25 & 77,93 & 945,88 & 122,14 & 32,70 & 34,02 & 338,76 & 124,47 & 140,34 & 304,66 \\
\hline Discoglossus galganoi & 29TPJ41 & 100,00 & 129,11 & 83,08 & 41,29 & 4026,54 & 238,90 & 40,38 & 198,52 & 85,34 & 180,45 & 182,99 & 80,33 & 948,94 & 122,89 & 33,48 & 33,49 & 338,62 & 126,88 & 143,42 & 302,84 \\
\hline Discoglossus galganoi & 29TPJ42 & 53,00 & 137,48 & 80,69 & 41,72 & 3889,44 & 242,19 & 50,71 & 191,48 & 96,05 & 186,59 & 189,31 & 89,93 & \begin{tabular}{|c|c|}
902,47 \\
\end{tabular} & 118,12 & 31,63 & 33,45 & 321,57 & 120,77 & 138,51 & 284,69 \\
\hline Discoglossus galganoi & 29TPJ52 & 41,00 & 139,23 & 81,22 & 41,72 & 3912,25 & 244,14 & 51,68 & 192,46 & 111,51 & 188,72 & 191,29 & 91,29 & 874,91 & 115,40 & 31,32 & 32,94 & 309,83 & 119,20 & 136,62 & 271,68 \\
\hline Discoglossus galganoi & 29TPJ60 & 100,00 & 108,41 & 88,88 & 40,73 & 4367,70 & 230,35 & 15,04 & 215,32 & 61,15 & 165,12 & 166,80 & 56,09 & \begin{tabular}{r|}
1025,98 \\
\end{tabular} & 132,00 & 38,71 & 32,21 & 362,76 & 144,13 & 156,86 & 326,34 \\
\hline Discoglossus galganoi & 29TPJ61 & 101,00 & 128,73 & 85,00 & 41,49 & 4095,14 & 240,69 & 38,16 & 202,54 & 93,10 & 180,98 & 183,27 & 79,05 & 912,44 & 119,82 & 33,86 & 32,17 & 321,09 & 127,55 & 142,96 & 282,41 \\
\hline Discoglossus galganoi & 29TPJ62 & 54,00 & 139,54 & 81,85 & 41,87 & 3920,14 & 244,99 & 51,45 & 193,54 & 117,69 & 189,06 & 191,73 & 91,50 & 858,44 & 114,06 & 31,57 & 32,26 & 302,67 & 119,81 & 136,55 & 261,82 \\
\hline Discoglossus galganoi & 29TPJ71 & 100,00 & 120,92 & 87,16 & 41,43 & 4187,18 & 236,81 & 29,09 & 207,72 & 87,25 & \begin{tabular}{|l|l|}
174,57 \\
\end{tabular} & 176,78 & 70,42 & 941,81 & 123,60 & 36,55 & 31,16 & 328,99 & 136,06 & 150,07 & 288,43 \\
\hline Discoglossus galganoi & 29TQE04 & 100,00 & 154,81 & 104,37 & 36,24 & 6192,69 & 321,03 & 38,01 & 283,02 & 86,55 & 237,01 & 237,01 & 78,85 & 586,07 & 76,24 & 5,54 & 48,99 & 224,24 & 41,44 & 41,44 & 214,93 \\
\hline Discoglossus galganoi & 29TQE06 & 100,00 & 119,30 & 96,47 & 34,97 & 6132,22 & 280,84 & $\begin{array}{r}0,10 \\
9,10\end{array}$ & 271,74 & 53,72 & 201,13 & 201,82 & 46,16 & 805,73 & \begin{tabular}{|c|}
107,34 \\
\end{tabular} & 10,19 & 48,41 & 309,67 & 60,69 & 63,48 & 300,38 \\
\hline Discoglossus galganoi & 29TQE09 & 100,00 & 13 & 101 & 36, & 6116,52 & 294,27 & 17,42 & 276,85 & 64,19 & 212,74 & 212,94 & 56,78 & 685,57 & 89,87 & 8,81 & 47,62 & 262,67 & 54,02 & 54,22 & 253,71 \\
\hline Discoglossus galganoi & 29TQE14 & 100,00 & 151,00 & 105,03 & 36,02 & 6245,07 & 319,05 & 33,85 & 285,20 & 82,28 & 234,02 & 234,02 & 74,70 & 573,23 & 73,34 & 6,00 & 47,74 & 216,81 & 42,50 & 42,50 & 206,36 \\
\hline Discoglossus galganoi & 29TQE16 & 100,00 & 126,83 & 100,71 & 35,60 & +4 & 292,02 & 13,50 & 278,52 & 59,89 & 209,38 & 209,97 & 52,39 & 705 & 90,99 & 9,18 & 47,08 & 62 & 55,30 & 56,81 & 256,77 \\
\hline Discoglossus galganoi & 29TQE18 & 101,00 & 125,54 & 101,80 & 36,00 & 6169,60 & 290,29 & 11,75 & 278,54 & 58,30 & 207,24 & 208 & 51,04 & 686,06 & 88,32 & 9,12 & 46,56 & 260,12 & 55,46 & 56,49 & 249,12 \\
\hline Discoglossus galganoi & 29TQE19 & 100,00 & 127,25 & 103,00 & 36,19 & 6162,70 & 292,13 & 12,80 & 279,33 & 59,83 & 209,15 & 209,75 & 52,47 & 6601,92 & $\begin{array}{l}80,32,14 \\
85,\end{array}$ & $\begin{array}{ll}9,124 \\
9,13\end{array}$ & 46,17 & 250,62 & 54,62 & 55,15 & 239,65 \\
\hline Discoglossus galganoi & 29TQE24 & 99,00 & 149,99 & 106,28 & 36,22 & 6291,31 & 319,92 & 31,59 & 288,33 & 80,97 & 233,87 & 233,87 & 73,29 & 545,39 & 69,12 & 5,95 & 46,76 & 203,85 & 41,63 & 41,63 & 192,54 \\
\hline Discoglossus & 29TQE27 & 100,00 & 115,21 & 101,46 & 35,89 & 6193,50 & 281,50 & 2,46 & 279,03 & 48,61 & 197,91 & 198,74 & 41,40 & 724,32 & 92,23 & 10,95 & 45,11 & 270,80 & 61.14 & 63,60 & 257,91 \\
\hline Discoglossus galganoi & 29TQE28 & 100,00 & 119,46 & 102,97 & 36,06 & 6199,91 & 286,09 & 5,50 & 280,59 & 52,27 & 20 & 20 & 44,99 & 678,62 & 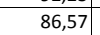 & 10,04 & Fe & 53,79 & 57,87 & 59,40 & 240,81 \\
\hline Discoglossus galganoi & 29TQE44 & 100 & 15 & 109, & 36 & 4 & 32 & 31,54 & 29 & 82 & & & 74,89 & 477 & 59,45 & 5,67 & 45,00 & 173,76 & & 38,39 & 161,35 \\
\hline Discoglossus galganoi & 29TQE45 & 100,00 & 151,61 & 109,59 & 37,00 & 6324,97 & 323,68 & 30,62 & 293,06 & 81,56 & 235,82 & 235,82 & 74,03 & 473,99 & 59,14 & 5,99 & 44,33 & 172,29 & 39,09 & 39,09 & 159,80 \\
\hline \begin{tabular}{|l} 
Discoglossus galganoi \\
\end{tabular} & 29TQE48 & 99,00 & 117,99 & 107,09 & 36,82 & 6247,59 & 288,57 & 1,73 & 286,85 & 50,00 & 201,22 & 202,15 & 43,11 & 606,94 & 75,98 & 10,64 & 41,83 & 219,55 & 57,39 & 58,73 & 204,08 \\
\hline Discoglossus galganoi & 29TQE49 & 100,00 & 111,13 & 106,74 & 36,98 & 6218,89 & 281,23 & $-3,86$ & 285,09 & 43,78 & 193,70 & 195,11 & 36,90 & 629,64 & 78,99 & 11,61 & 41,15 & 227,45 & 61,36 & 63,11 & 210,94 \\
\hline Discoglossus galgan & 29TQE54 & 53,00 & 143,79 & 109,60 & 36,76 & 6381,46 & 318,09 & 22,92 & 295,17 & 73,69 & 229,20 & & 66,36 & 499,15 & 61,49 & 6,79 & 43,84 & 41 & 42,44 & 42,54 & 16 \\
\hline Discoglossus galganoi & 29TQF05 & 99,00 & 12 & 10 & 37, & 6018,77 & 285,45 & 6,53 & 278,92 & 55,32 & 202,18 & 202,18 & 48,14 & 667,94 & 85,85 & 10,00 & 45,79 & 255,06 & 58,03 & 58,03 & 247,19 \\
\hline Discoglossus galganoi & 29TQF07 & 100,00 & 124,47 & 108,48 & 38,15 & 5975,92 & 288,21 & 7,85 & 280,36 & 57,62 & 203,80 & 203,80 & 50,69 & 634,57 & 81,31 & 10,33 & 45,02 & 241,67 & 56,70 & 56,70 & 235,01 \\
\hline \begin{tabular}{|l} 
Discoglossus galganoi \\
\end{tabular} & 29TQF08 & 100,00 & 119,33 & 108,56 & 38,17 & 5959,95 & 283,31 & 3,05 & 280,26 & 52,92 & 198,65 & 198,65 & 45,99 & 654,23 & 84,20 & 11,16 & 44,66 & 249,16 & 60,21 & 60,21 & 243,12 \\
\hline Discoglossus galganoi & 29TQF11 & 100,00 & 123,25 & 104,14 & 36,98 & 6128,57 & 287,91 & 8,57 & 279,33 & 55,96 & 204,75 & 205,19 & 48,69 & 659,94 & 84,82 & 9,63 & 45,38 & (1) & $5655,4-2$ & 56,89 & 238,38 \\
\hline Discoglossus galgan & 29TQF14 & 99,00 & 120,89 & 106 & 37,4 & 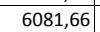 & 286,01 & 5,07 & 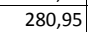 & 53,65 & 201,93 & & 46 & (3) & 80,74 & & & 230,09 & 57,48 & 57,48 & 227 \\
\hline \begin{tabular}{|l} 
Discoglossus galganoi \\
\end{tabular} & 29TQF15 & \begin{tabular}{rl|}
101,00 \\
\end{tabular} & 120,75 & 107,73 & 37,95 & 6071,48 & 286,05 & 4,44 & 281,61 & 53,44 & 201,50 & 201,50 & 46,21 & 621,94 & 79,17 & 10,14 & 43,99 & 234,15 & 57,15 & 57,15 & 223,71 \\
\hline
\end{tabular}




\begin{tabular}{|c|c|c|c|c|c|c|c|c|c|c|c|c|c|c|c|c|c|c|c|c|c|}
\hline TAXON & UTM & $\mathrm{km} 2$ & BIO1 & $\mathrm{BIO2}$ & BIO3 & B104 & B105 & B106 & BIO7 & B108 & B109 & 81010 & B1011 & B1012 & B1013 & BI014 & B1015 & B1016 & B1017 & B1018 & B1019 \\
\hline Discoglossus galganoi & 29TQF17 & 99,00 & 126,84 & 110,00 & 38,23 & 6022,16 & 292,13 & 8,85 & 283,28 & 59,28 & 206,62 & 206,62 & 52,31 & 571,63 & 73,31 & 9,92 & 43,27 & 214,56 & 53,54 & 53,54 & 205,38 \\
\hline Discoglossus galganoi & 29TQF18 & 100,00 & 122,60 & 110,21 & 38,40 & 6005,49 & 287,87 & 4,76 & 283,11 & 55,36 & 202,28 & 202,28 & 48,48 & 585,02 & 75,58 & 10,69 & 43,04 & 219,49 & 56,23 & 56,23 & 210,90 \\
\hline Discoglossus galganoi & 29TQF19 & 100,00 & 118,95 & 110,37 & 38,70 & 5982,06 & 284,32 & 1,44 & 282,88 & 52,01 & 198,36 & 198,36 & 45,22 & 596,50 & 77,51 & 11,53 & 42,49 & 223,55 & 59,05 & 59,05 & 215,39 \\
\hline Discoglossus galganoi & 29TQF22 & 100,00 & 122,91 & 107,17 & 37,21 & 6155,81 & 289,87 & 6,40 & 283,47 & 54,95 & 205,13 & 205,15 & \begin{tabular}{ll|}
47,82 \\
\end{tabular} & $\begin{array}{l}599,66 \\
\end{array}$ & 76,48 & $\begin{array}{l}9,97 \\
\end{array}$ & 43,38 & 223,26 & 55,36 & 55,37 & 209,93 \\
\hline Discoglossus galganoi & 29TQF28 & 100,00 & 120,82 & 111,21 & 38,30 & 6056,09 & 287,94 & 2,60 & 285,34 & 53,22 & 201,28 & 201,28 & 46,19 & 543,86 & 70,42 & \begin{tabular}{ll|}
10,86 \\
\end{tabular} & 41,16 & 200,26 & 55,77 & 55,77 & 188,94 \\
\hline Discoglossus galganoi & 29TQF29 & 100,00 & 120,33 & 111,61 & 38,78 & 6032,92 & 287,25 & 1,88 & 285,36 & \begin{tabular}{c|c|}
52,66 \\
\end{tabular} & 200,29 & 200,29 & 45,80 & $\begin{array}{l}541,55 \\
\end{array}$ & 70,40 & 11,25 & 40,85 & 199,19 & 56,50 & 56,50 & 188,40 \\
\hline Discoglossus galganoi & 29TQF35 & 100,00 & 118,97 & 110,87 & 38,08 & 6142,17 & 287,85 & 0,92 & 286,92 & 50,75 & 200,85 & 200,85 & 43,79 & 533,91 & 68,62 & 10,49 & 40,59 & 194,06 & 55,55 & 55,55 & 178,62 \\
\hline Discoglossus galganoi & 29TQF36 & 100,00 & 120,24 & 111,54 & 38,22 & 6129,71 & 289,00 & 1,76 & 287,24 & 52,16 & 201,72 & 201,72 & 45,03 & 517,40 & 66,80 & 10,28 & 40,33 & \begin{tabular}{|c|}
187,67 \\
\end{tabular} & 54,43 & 54,43 & 172,97 \\
\hline Discoglossus galganoi & 29TQF45 & 99,00 & 120,27 & 112,72 & 38,18 & 6173,60 & 290,70 & 1,01 & 289,68 & 74,07 & 202,34 & 202,34 & 44,59 & $\begin{array}{l}485,16 \\
\end{array}$ & 62,58 & 10,14 & 39,43 & 173,62 & 53,39 & 53,39 & 155,40 \\
\hline Discoglossus galganoi & 29TQF55 & 20,00 & 120,39 & 113,85 & 38,85 & 6201,03 & 291,73 & 0,48 & 291,24 & 80,33 & 202,91 & 202,91 & 44,55 & $\begin{array}{l}462,15 \\
\end{array}$ & 59,55 & 10,12 & 38,76 & 165,27 & 52,79 & 52,79 & 143,82 \\
\hline Discoglossus galganoi & 29TQG02 & 100,00 & 118,31 & 110,55 & 39,00 & 5867,35 & 282,03 & 1,14 & 280,89 & 52,36 & 196,31 & 196,31 & 45,68 & 636,56 & 84,01 & 13,14 & 43,33 & 241,71 & 63,07 & 63,07 & 237,84 \\
\hline Discoglossus galganoi & 29TQG03 & 100,00 & 114,88 & 110,19 & 38,98 & 5844,04 & 278,26 & $-1,66$ & 279,92 & 49,20 & 192,60 & 192,60 & 42,71 & 654,32 & 86,67 & 14,58 & 42,81 & 247,97 & 66,98 & 66,98 & 243,35 \\
\hline Discoglossus galganoi & 29TQG04 & 99,00 & 107,72 & 109,04 & 38,75 & 5831,01 & 270,54 & $-7,80$ & 278,34 & 42,36 & 185,45 & 185,45 & 36,15 & \begin{tabular}{|c|c|}
697,38 \\
\end{tabular} & 92,22 & 17,25 & 41,55 & 262,69 & 75,26 & 75,26 & 255,74 \\
\hline Discoglossus galganoi & 29TQG05 & 99,00 & 104,21 & 108,35 & 38,61 & 5812,30 & 266,16 & $-10,78$ & $\begin{array}{ll}276,93 \\
\end{array}$ & 39,18 & $\begin{array}{l}181,82 \\
\end{array}$ & 181,82 & 33,12 & 720,31 & 95,06 & 19,42 & 40,52 & 270,01 & 80,76 & 80,76 & 260,84 \\
\hline Discoglossus galganoi & 29TQG13 & 101,00 & 111,71 & 110,86 & 39,00 & 5909,07 & 276,33 & $-5,18$ & 281,51 & $\mid 45,45$ & $\mid 190,29$ & 190,29 & $\mid 38,81$. & 625,53 & 82,37 & $\mid 15,30$ & 40,67 & 232,93 & 68,39 & 68,39 & 224,64 \\
\hline Discoglossus galganoi & 29TQG21 & 101,00 & 113,17 & 111,51 & 38,93 & 6004,49 & 280,10 & $-4,34$ & 284,44 & 46,17 & 193,10 & 193,10 & 39,30 & 572,97 & 74,83 & 13,54 & 39,72 & 210,03 & 63,41 & 63,41 & 199,39 \\
\hline Discoglossus galganoi & 29TQG22 & 100,00 & 112,56 & 111,70 & 38,98 & 5985,53 & 279,23 & $-5,25$ & 284,47 & 45,37 & 192,16 & 192,16 & 38,74 & 576,92 & 75,50 & 14,41 & 39,31 & 211,27 & 65,18 & 65,18 & 200,58 \\
\hline Discoglossus galganoi & 29TQG26 & 100,00 & 107,80 & 111,40 & 39,00 & 5903,09 & 272,74 & $-9,90$ & 282,63 & 53,23 & 186,34 & 186,34 & 34,78 & 619,73 & 80,76 & 18,88 & 37,12 & 224,81 & 77,87 & 77,87 & 209,72 \\
\hline Discoglossus galganoi & 29TQG30 & 99,00 & 118,24 & 112,71 & 38,98 & 6054,24 & 286,54 & $-0,55$ & 287,09 & 58,13 & $\begin{array}{l}198,47 \\
\end{array}$ & $\begin{array}{l}198,47 \\
\end{array}$ & 43,35 & $\begin{array}{l}504,83 \\
\end{array}$ & 65,56 & 12,00 & 38,70 & 181,38 & 57,28 & 57,28 & 168,57 \\
\hline Discoglossus galganoi & 29TQG32 & 101,00 & 115,15 & 112,95 & 39,00 & $\mid 6022,04$ & 283,26 & $-3,62$ & 286,87 & 62,35 & 194,93 & $\begin{array}{l}194,93 \\
\end{array}$ & 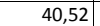 & 521,67 & 67,79 & $\mid \frac{\mid 13,77}{\mid}$ & 37,72 & $\mid 187,15$ & 62,19 & 62,19 & 173,83 \\
\hline Discoglossus galganoi & 29TQG36 & 100,00 & 111,99 & 112,95 & 39,00 & 5944,72 & 278,49 & $-7,13$ & 285,62 & 73,74 & 190,64 & 190,64 & 38,05 & 562,72 & 72,66 & 17,69 & 36,04 & 203,73 & 73,84 & 73,84 & 183,80 \\
\hline Discoglossus galganoi & 29TQG41 & 98,00 & 116,63 & 113,70 & 39,00 & 6077,83 & 286,10 & $-2,87$ & 288,97 & 77,60 & 197,19 & 197,19 & 41,35 & 474,35 & 61,05 & 12,53 & 36,55 & 168,65 & 58,62 & 58,62 & 151,31 \\
\hline Discoglossus galganoi & 29TQG43 & 91,00 & 109,68 & 113,67 & 39,00 & 6041,99 & 279,31 & $-9,32$ & 288,63 & 71,14 & 189,93 & 189,93 & 34,99 & 522,63 & 67,10 & 15,60 & 35,67 & 186,39 & 68,06 & 68,06 & 167,33 \\
\hline Discoglossus galganoi & 29TQG46 & 80,00 & 114,57 & 113,95 & 39,00 & 5963,28 & 282,04 & $-5,28$ & 287,32 & 76,54 & $\begin{array}{l}193,27 \\
\end{array}$ & 193,27 & 40,03 & $\begin{array}{l}523,95 \\
\end{array}$ & 66,95 & 17,08 & 34,98 & 189,85 & 71,64 & 71,64 & 165,34 \\
\hline Discoglossus galganoi & 29TQG47 & 75,00 & 110,56 & 113,81 & 39,00 & 5933,95 & 278,12 & $-8,62$ & 286,74 & 72,76 & 189,15 & 189,15 & 36,70 & 553,25 & 70,70 & 19,14 & 34,52 & 200,81 & 77,97 & 77,97 & 173,41 \\
\hline Discoglossus galganoi & 29тQH12 & 101,00 & 109,52 & 106,53 & 39,84 & 5511,58 & 262,08 & $-3,35$ & 265,42 & 74,24 & 182,02 & 182,02 & 41,22 & 714,61 & 94,32 & 24,98 & 34,18 & 257,79 & 99,18 & 99,18 & 229,73 \\
\hline Discoglossus galganoi & 29TQH21 & 99,00 & 90,49 & 107,60 & 39,20 & 5617,95 & 248,60 & $-21,87$ & 270,47 & 53,99 & 165,27 & 165,27 & 21,89 & 794,80 & \begin{tabular}{|l|l|}
101,78 \\
\end{tabular} & 30,23 & 32,91 & 282,67 & 115,17 & 115,17 & 254,36 \\
\hline Discoglossus galganoi & $29 \mathrm{TQH} 40$ & 62,00 & 109,52 & 112,79 & 39,82 & 5784,23 & 273,06 & $-8,42$ & 281,48 & 73,07 & 185,82 & 185,82 & 37,25 & 601,74 & 78,75 & 23,27 & 33,20 & 219,38 & \begin{tabular}{l|l}
90,83 \\
\end{tabular} & 90,83 & 182,55 \\
\hline Discoglossus galganoi & 29TQJ00 & 100,00 & 113,08 & 92,84 & 41,78 & 4381,67 & 236,87 & 17,31 & 219,56 & 88,49 & 169,52 & 171,28 & 60,21 & 922,77 & 122,26 & 39,35 & 29,15 & 317,84 & 143,82 & 154,93 & 269,66 \\
\hline Discoglossus galganoi & 29TQJ01 & 101,00 & 126,22 & 88,44 & 42,23 & 4110,48 & 240,86 & 34,05 & 206,81 & 104,11 & 178,50 & 180,95 & 76,45 & 878,86 & 118,09 & 37,42 & 29,36 & 302,72 & 137,04 & 149,67 & 250,74 \\
\hline Discoglossus galganoi & 29TQJ02 & 55,00 & 134,41 & 84,61 & 42,41 & 3939,63 & 242,38 & 45,21 & 197,17 & 113,77 & 184,19 & 186,89 & 86,64 & 853,56 & 115,54 & 36,12 & 29,65 & 294,62 & 132,68 & 146,74 & 240,90 \\
\hline Discoglossus galganoi & 29TQJ11 & 99,00 & 116,27 & 91,42 & \begin{tabular}{|c|}
42,38 \\
\end{tabular} & 4195,11 & 235,68 & 22,75 & 212,93 & 93,97 & 169,88 & 172,19 & 65,80 & 923,49 & 123,35 & 41,56 & 28,29 & 315,14 & 149,59 & 160,54 & 260,00 \\
\hline Discoglossus galganoi & 29TQJ20 & 100,00 & 124,77 & 91,78 & 42,81 & 4161,25 & 242,74 & 30,59 & 212,15 & 102,85 & 177,63 & 180,01 & 74,43 & 857,62 & \begin{tabular}{|c|}
116,19 \\
\end{tabular} & 39,08 & 28,52 & 292,47 & 140,78 & 151,30 & 233,71 \\
\hline Discoglossus galganoi & 29TQJ21 & 99,00 & 125,99 & 89,26 & \begin{tabular}{ll|}
42,98 \\
\end{tabular} & 4019,27 & 239,73 & 34,48 & 205,25 & 105,42 & 176,76 & 179,55 & 77,59 & $\begin{array}{l}879,09 \\
\end{array}$ & 119,14 & 40,58 & 28,35 & 298,48 & 145,41 & 156,50 & 237,74 \\
\hline Discoglossus galganoi & 30STG36 & 50,00 & 179,75 & 122,09 & 39,04 & 6222,42 & 358,25 & 50,54 & 307,72 & 111,81 & 261,12 & 262,19 & 103,03 & 579,31 & 84,54 & 1,48 & 61,61 & 241,93 & 19,79 & 23,93 & 228,63 \\
\hline Discoglossus galganoi & 30STG39 & 40,00 & 170,22 & 122,02 & 38,84 & 6377,82 & 352,44 & 40,78 & 311,65 & 100,87 & 253,89 & 254,67 & 91,93 & 593,58 & 82,44 & 2,22 & 59,20 & 239,95 & 22,91 & 27,60 & 228,11 \\
\hline Discoglossus galganoi & 30STG43 & 100,00 & 181,69 & 119,12 & 39,88 & 6025,71 & 352,62 & 56,32 & 296,30 & 116,07 & 260,01 & 261,71 & 107,65 & 592,01 & 89,27 & 1,00 & 64,06 & 253,86 & 18,01 & 22,01 & 238,95 \\
\hline Discoglossus galganoi & 30STG44 & 100,00 & 183,53 & 121,81 & 39,90 & 6117,17 & 358,86 & 55,53 & 303,33 & 116,78 & 263,25 & 264,59 & 108,12 & 581,99 & 87,18 & 1,00 & 63,46 & 248,29 & 18,00 & 22,00 & 234,10 \\
\hline Discoglossus galganoi & 30STG48 & 100,00 & 174,66 & 123,03 & 39,00 & 6355,98 & 356,75 & 44,67 & 312,08 & 105,38 & 258,06 & 258,77 & 96,49 & 588,01 & 82,80 & 2,04 & 60,20 & 240,29 & 21,39 & 25,70 & 228,30 \\
\hline Discoglossus galganoi & 30STG49 & 100,00 & 165,69 & 122,71 & 38,70 & 6434,94 & 349,90 & 35,92 & 313,99 & 95,88 & 250,41 & 251,07 & 87,03 & 620,24 & 85,77 & 2,65 & 58,86 & 49,59 & 24,31 & 29,03 & 238,44 \\
\hline Discoglossus galganoi & 30STG53 & 100,00 & 180,32 & 119,61 & 40,01 & 6004,94 & 350,80 & 56,53 & 294,27 & 114,99 & 258,30 & 259,98 & 106,86 & 598,05 & 90,15 & 1,00 & 64,34 & 257,19 & 18,00 & 22,09 & 242,00 \\
\hline Discoglossus galganoi & 30STG54 & 100,00 & 178,92 & 122,02 & 40,00 & 6132,48 & 353,85 & 52,36 & 301,49 & 112,07 & 258,86 & 260,17 & 103,72 & 603,02 & 89,54 & 1,00 & 63,51 & 256,85 & 18,41 & 22,61 & 242,78 \\
\hline Discoglossus galganoi & 30STG57 & 100,00 & 178,89 & 124,02 & 39,27 & 6320,81 & 360,30 & 48,86 & 311,45 & 110,09 & 261,71 & 262,37 & 100,99 & 584,72 & 83,77 & 1,46 & 61,38 & 241,95 & 19,40 & 23,80 & 229,87 \\
\hline Discoglossus galganoi & 30STG59 & 100,00 & 162,75 & 123,58 & 38,4 & 6489,78 & 349,12 & 32,60 & 316,52 & 92,60 & 248,53 & 249,06 & 83,68 & 639,22 & 88,46 & 2,57 & 58,97 & 255,99 & 24,94 & 29,09 & 245,75 \\
\hline Discoglossus galganoi & 30STG64 & 100,00 & 178,90 & 121,65 & 40,04 & 6099,63 & 352,74 & 53,57 & 299,16 & 112,38 & 258,36 & 259,7 & 104 & 603,89 & 90,72 & 1,00 & 63,89 & 257,81 & 18,23 & 22,30 & 243,60 \\
\hline Discoglossus galganoi & 30STG67 & 100,00 & 175,46 & 124,19 & 39,23 & 6358,80 & 357,91 & 45,78 & 312,14 & 106,27 & 259,13 & 259,64 & 97,48 & 605,06 & 87,20 & 1,63 & 61,45 & 249,46 & 19,86 & 24,03 & 238,20 \\
\hline Discoglossus galganoi & 30STG68 & 100,00 & 168,27 & 124,46 & $\begin{array}{ll}38,92 \\
\end{array}$ & 6463,01 & 353,97 & 37,80 & \begin{tabular}{|l|l|}
316,17 \\
\end{tabular} & 98,27 & 253,63 & 253,86 & 89,14 & 629,00 & 88,82 & 2,00 & 60,12 & 254,86 & 22,39 & 25,94 & 244,62 \\
\hline Discoglossus galganoi & 30STG69 & 100,00 & 158,30 & 123,72 & 38,13 & 6543,04 & 346,16 & 27,98 & \begin{tabular}{|l|l}
318,18 \\
\end{tabular} & 87,73 & 245,06 & 245,34 & 78,92 & 664,30 & 91,73 & 2,86 & 58,72 & 264,30 & 26,15 & 28,46 & 255,15 \\
\hline Discoglossus galganoi & 30STG79 & 100,00 & 158,45 & 124,13 & $\begin{array}{l}38,25 \\
\end{array}$ & 6569,95 & 347,11 & 27,77 & 319,34 & 87,62 & 245,74 & 245,83 & 78,66 & 668,05 & $\begin{array}{c}92,56 \\
\end{array}$ & 2,95 & 58,80 & 264,92 & 25,84 & 27,06 & 256,60 \\
\hline Discoglossus galganoi & 30STG84 & 100,00 & 178,47 & 119,55 & 40,00 & 6065,93 & 349,58 & 54,61 & 294,97 & 112,69 & 257,68 & 258,66 & 104,36 & 71 & 93,91 & 1,00 & 64,34 & 69 & 17,10 & 22,24 & 249,12 \\
\hline Discoglossus galganoi & 30STH40 & 100,00 & 160 & 12 & 38, & 6479,99 & 3 & 31,07 & 31 & 90,63 & 246,38 & 246,83 & 81,72 & $\begin{array}{l}633,15 \\
\end{array}$ & 86,42 & 2,97 & 58,00 & 251,74 & 26,43 & 30,23 & 241,17 \\
\hline Discoglossus galganoi & 30STH42 & 100,00 & 151,34 & 121,54 & 37,99 & 6546,37 & 339,06 & 22,35 & 316,71 & 81,06 & 238,43 & 238,74 & 72,14 & $\begin{array}{l}658,05 \\
\end{array}$ & 87,87 & 3,93 & 55,88 & 256,05 & 31,06 & 34,19 & 246,37 \\
\hline Discoglossus galganoi & 30STH46 & 100,00 & 155,29 & 120,92 & \begin{tabular}{l|l|}
37,69 \\
\end{tabular} & $\begin{array}{ll}6598,03 \\
\end{array}$ & 343,72 & 26,13 & 317,59 & 83,97 & 243,16 & 243,18 & 75,32 & $\begin{array}{l}593,16 \\
\end{array}$ & 77,76 & 3,99 & 53,64 & 225,08 & 30,95 & 31,10 & 214,95 \\
\hline Discoglossus galganoi & 30STH48 & 100,00 & 157,44 & 119,95 & \begin{tabular}{|c|}
37,17 \\
\end{tabular} & 6597,95 & 344,99 & 28,26 & 316,73 & 85,84 & 245,26 & 245,27 & 77,32 & 561,16 & 72,90 & 3,99 & 52,53 & 210,48 & 31,05 & 31,16 & 199,90 \\
\hline Discoglossus galganoi & 30STH50 & 100,00 & 154,55 & 122,76 & 38,00 & 6541,03 & 342,21 & 24,70 & 317,51 & 84,12 & 241,26 & 241,71 & 75 & $\begin{array}{l}667,25 \\
\end{array}$ & $\begin{array}{l}90,76 \\
\end{array}$ & 3,32 & 57,67 & 263,34 & 28,34 & 32,51 & 253 \\
\hline Discoglossus galganoi & 30STH53 & 100,00 & 154,90 & 122,75 & 38,00 & 6617,85 & 344,73 & 24,51 & 320,22 & 83,45 & 243,01 & 243,06 & 74,60 & 631,86 & 84,23 & 3,78 & 55,64 & 243,45 & 29,58 & 30,37 & 234,31 \\
\hline Discoglossus galganoi & 30STH54 & 100,00 & 154,50 & 122,49 & \begin{tabular}{|c|}
37,96 \\
\end{tabular} & 6634,03 & 344,70 & 23,91 & 320,79 & 82,82 & 243,02 & 243,02 & 74,04 & 621,54 & 82,39 & 4,00 & 55,00 & 237,79 & 30,11 & 30,11 & 228,58 \\
\hline \begin{tabular}{|l|} 
Discoglossus galganoi \\
\end{tabular} & 305TH56 & 100,00 & 156,51 & $\begin{array}{lll}121,87 \\
\end{array}$ & 37,81 & 6632,01 & 346,29 & 26,18 & 320,11 & 84,64 & 244,90 & 244,91 & $\mid 76,15$ & 588,28 & 77,20 & 3,90 & 53,72 & 222,09 & 30,26 & 30,38 & 212,54 \\
\hline Discoglossus galganoi & 30STH59 & 100,00 & 158,08 & 120,01 & 37,01 & 6644,11 & 346,61 & 28,50 & 318,1 & 85,85 & 246,69 & 246, & 77, & 543,94 & 70,90 & 3,76 & 51,89 & 201,49 & 30,76 & 30,76 & 191,24 \\
\hline Discoglossus galganoi & 30STH60 & 100,00 & 154,76 & 123,63 & 38,00 & 6584,50 & 343,96 & 24,34 & 319,62 & 83,79 & 242,28 & 242,47 & 74,96 & 669,32 & 91,24 & 3,44 & 57,66 & 63,09 & 28,16 & 29,76 & 254, \\
\hline
\end{tabular}




\begin{tabular}{|c|c|c|c|c|c|c|c|c|c|c|c|c|c|c|c|c|c|c|c|c|c|}
\hline TAXON & UTM & $\mathrm{km} 2$ & $\mathrm{BIO1}$ & $\mathrm{B1O2}$ & $\mathrm{BIO3}$ & B104 & $\mathrm{B105}$ & $\mathrm{B106}$ & B107 & B108 & $\mathrm{BIO9}$ & 81010 & B1011 & B1O12 & B1O13 & 81014 & B1015 & B1016 & B1017 & $\mathrm{BIO18}$ & B1019 \\
\hline Discoglossus galganoi & 30STH61 & 100,00 & 152,05 & 123,47 & 38,00 & 6622,53 & 342,36 & 21,54 & 320,82 & 80,86 & 240,30 & 240,46 & 72,04 & 670,25 & 90,40 & 3,68 & 56,78 & 260,80 & 29,55 & 31,25 & 252,50 \\
\hline Discoglossus galganoi & 30STH63 & 100,00 & 157,68 & 123,72 & 38,00 & 6652,56 & 348,56 & 26,31 & 322,26 & 85,60 & 246,30 & 246,33 & 76,89 & 621,23 & 83,23 & 3,33 & 56,03 & 238,75 & 28,07 & 28,60 & 230,16 \\
\hline \begin{tabular}{|l} 
Discoglossus galganoi \\
\end{tabular} & 30STH70 & 100,00 & 151,81 & 123,86 & 38,00 & 6621,13 & 342,24 & 21,17 & 321,08 & 80,58 & 240,03 & 240,17 & 71,88 & 685,67 & 93,23 & 3,73 & 57,39 & 267,92 & 29,08 & 30,53 & 260,25 \\
\hline Discoglossus galganoi & 30STH77 & 100,00 & 153,77 & 122,52 & $\begin{array}{l}37,05 \\
\end{array}$ & 6741,82 & 346,30 & 22,12 & 324,18 & 80,67 & 243,93 & 243,93 & 72,03 & 585,37 & 78,13 & 4,07 & 52,76 & 216,22 & 31,41 & 31,41 & 207,88 \\
\hline Discoglossus galganoi & 30STH89 & 100,00 & 160,79 & 122,07 & 37,01 & 6751,70 & 352,34 & 28,51 & 323,83 & 87,16 & 251,17 & 251,17 & 78,56 & 523,03 & 69,94 & 3,46 & 52,02 & 189,93 & 28,30 & 28,30 & 181,55 \\
\hline Discoglossus galganoi & 30STJ41 & 100,00 & 168,00 & 118,16 & 37,00 & 6540,08 & 352,32 & 39,14 & 313,18 & 96,26 & 254,77 & 254,77 & 87,71 & 479,60 & 61,97 & 3,00 & 51,34 & 177,79 & 27,78 & 27,78 & 166,52 \\
\hline Discoglossus galganoi & 30STJ42 & 100,00 & 167,78 & 117,33 & 37,00 & 6552,41 & 351,55 & 39,67 & 311,88 & 95,93 & 254,79 & 254,79 & 87,54 & 471,53 & 60,81 & 3,00 & 50,65 & 173,96 & 28,00 & 28,00 & 162,49 \\
\hline Discoglossus galganoi & $30 \mathrm{STT} 49$ & 71,00 & 156,13 & 111,76 & 36,26 & 6505,03 & 335,34 & 32,39 & 302,95 & 85,06 & 243,28 & 243,28 & 77,19 & 468,44 & $\begin{array}{l}57,95 \\
\end{array}$ & 4,65 & 46,47 & 168,19 & 34,86 & 34,86 & 155,72 \\
\hline Discoglossus galganoi & 30STIS0 & 100,00 & 163,18 & 119,64 & 37,01 & 6621,01 & 350,36 & 33,55 & 316,80 & 90,76 & 251,32 & 251,32 & 82,37 & 509,18 & 66,27 & 3,17 & 51,72 & 188,16 & 28,62 & 28,62 & 177,60 \\
\hline Discoglossus galganoi & 30STJ60 & 100,00 & 162,60 & 120,19 & 37,01 & 6670,16 & 351,09 & 32,07 & 319,02 & 89,56 & 251,53 & 251,53 & 81,13 & 507,73 & 66,73 & 3,06 & 51,73 & 186,28 & 28,21 & 28,21 & 176,27 \\
\hline Discoglossus galganoi & 30STJ77 & 100,00 & 147,64 & 115,50 & 36,43 & 6635,54 & 332,56 & 20,52 & 312,04 & 75,32 & 236,87 & 236,87 & 67,48 & 485,83 & 60,11 & 5,42 & 45,44 & 169,46 & 37,52 & 37,52 & 157,28 \\
\hline Discoglossus galganoi & 30STJ81 & 100,00 & 163,48 & 120,86 & 37,00 & 6732,77 & 353,18 & 31,55 & 321,62 & 89,64 & 253,32 & 253,32 & 81,22 & 484,17 & 63,95 & 3,17 & 50,84 & 173,96 & 27,62 & 27,62 & 164,79 \\
\hline \begin{tabular}{|l} 
Discoglossus galganoi \\
\end{tabular} & 30STJ93 & 100,00 & 161,94 & 119,95 & 37,00 & 6733,40 & 350,90 & 30,21 & 320,68 & 92,86 & 252,06 & 252,06 & 79,61 & 459,79 & 59,58 & 3,71 & 48,80 & 161,48 & 29,06 & 29,06 & 152,00 \\
\hline Discoglossus galganoi & 30STJ95 & 100,00 & 151,63 & 118,54 & 36,72 & 6729,74 & 340,22 & 21,33 & 318,89 & 78,04 & 242,05 & 242,05 & 69,90 & 472,72 & 59,57 & 4,74 & 46,27 & 163,10 & 34,22 & 34,22 & 152,54 \\
\hline Discoglossus galganoi & 30STK41 & 70,00 & 160,83 & 111,62 & 36,88 & 6438,31 & 337,22 & 37,00 & 300,22 & 89,67 & 246,68 & 246,68 & 81,92 & 435,49 & 53,34 & 4,25 & 45,75 & 156,26 & 32,98 & 32,98 & 143,93 \\
\hline Discoglossus galganoi & 30STK51 & 100,00 & 161,28 & 112,52 & 36,93 & 6469,97 & 338,53 & 36,40 & 302,13 & 89,56 & 247,40 & 247,40 & 81,93 & 420,85 & 51,29 & 4,13 & 45,34 & 149,64 & 32,44 & 32,44 & 137,23 \\
\hline Discoglossus galganoi & 30STK61 & 100,00 & 161,41 & 113,45 & 37,00 & 6464,10 & 339,30 & 35,73 & 303,57 & 89,90 & 247,71 & 247,71 & 82,00 & 405,86 & 49,08 & 4,07 & 44,62 & 142,62 & 31,97 & 31,97 & 130,32 \\
\hline \begin{tabular}{|l} 
Discoglossus galganoi \\
\end{tabular} & 30STK92 & 100,00 & 158,97 & 115,00 & 37,00 & 6517,41 & 337,92 & 31,26 & 306,66 & 116,95 & 246,07 & 246,07 & 78,94 & 372,09 & 43,72 & 5,00 & 42,38 & 127,20 & 32,20 & 32,20 & 113,03 \\
\hline Discoglossus galganoi & 30SUG19 & 100,00 & 170,83 & 123,41 & 38,00 & 6637,60 & 358,88 & 38,45 & 320,44 & 98,80 & 259,16 & 259,16 & 89,47 & 637,10 & 91,01 & 2,26 & 60,45 & 249,29 & 20,32 & 20,32 & 245,07 \\
\hline Discoglossus galganoi & 30SUHO2 & 100,00 & 151,15 & 124,70 & 37,43 & 6797,93 & 346,13 & 18,10 & 328,02 & 79,88 & 242,27 & $242,27 \mid$ & 68,97 & 665.09 & $\mid 92,69$ & 3,96 & 56,19 & 250,52 & 29,42 & 29,42 & 245,90 \\
\hline Discoglossus galganoi & 30SUHO3 & 100,00 & 156,72 & 124,97 & 37,22 & 6812,88 & 351,83 & 22,94 & 328,90 & 84,97 & 248,16 & 248,16 & 73,96 & 629,18 & 88,10 & 3,4 & 56,14 & 235,71 & 27,18 & 27,18 & 231,01 \\
\hline Discoglossus galganoi & 30SUH05 & 100,00 & 154,29 & 124,77 & 37,14 & 6832,25 & 350,07 & 20,79 & 329,28 & 83,11 & 246,08 & 246,08 & 71,36 & 606,60 & 84,11 & 4,00 & 54,17 & 222,77 & 29,59 & 29,59 & 217,47 \\
\hline \begin{tabular}{|l} 
Discoglossus galganoi \\
\end{tabular} & 30SUHO6 & 100,00 & 156,69 & 124,19 & 37,01 & \begin{tabular}{ll|}
6840,76 \\
\end{tabular} & 351,82 & 22,84 & 328,98 & 84,58 & 248,40 & 248,40 & 73,47 & 581,11 & 80,24 & 3,99 & 53,46 & 211,54 & 29,10 & 29,10 & 206,06 \\
\hline Discoglossus galganoi & 30SUHO7 & 100,00 & 159,41 & 124,00 & 37,00 & 6836,97 & 353,94 & 25,40 & 328,54 & 85,75 & 251,04 & 251,04 & 76,13 & 553,36 & 76,10 & 3,42 & 53,17 & 200,52 & 27,60 & 27,60 & 194,65 \\
\hline Discoglossus galganoi & 30SUH10 & 100,00 & 160,43 & 124,05 & 37,94 & 6743,60 & 352,50 & 27,41 & 325,09 & 89,12 & 250,70 & 250,70 & 78,31 & 659,05 & 93,60 & 3,05 & 58,55 & 253,14 & 24,49 & 24,49 & 249,34 \\
\hline Discoglossus galganoi & 30SUH17 & 100,00 & 159,76 & 124,03 & 37,00 & 6852,95 & 354,63 & 25,22 & 329,41 & 88,66 & 251,68 & 251,68 & 76,34 & 548,21 & 75, & 3,42 & 53,12 & 197,20 & 27,31 & 27,31 & 191,87 \\
\hline Discoglossus galganoi & 30 SUH20 & 100,00 & 164,69 & 123,62 & 37,62 & 6753,70 & 356,12 & 31,21 & \begin{tabular}{|l|l|}
324,91 \\
\end{tabular} & 94,63 & 255,00 & 255,00 & 82,13 & $\mid 645,91$ & 93,62 & 2,866 & 59,03 & 248,81 & 22,74 & 22,74 & 244,30 \\
\hline Discoglossus galganoi & $30 \mathrm{SUH} 22$ & 100,00 & 157,27 & 124,38 & \begin{tabular}{|c|}
37,08 \\
\end{tabular} & 6836,77 & 352,36 & 23,58 & 328,78 & 86,77 & 249,13 & 249,13 & 74,42 & 638,21 & 91,70 & 3,51 & 56,67 & 241,62 & 26,43 & 26,43 & 235,18 \\
\hline Discoglossus galganoi & $30 \mathrm{SUH} 23$ & 100,00 & 149,64 & 124,64 & 37,01 & 6867,08 & 346,31 & 16,29 & 330,03 & 79,18 & 242,11 & 242,11 & 66,75 & \begin{tabular}{|c|c|}
647,95 \\
\end{tabular} & 91,83 & 4,34 & 54,98 & 242,28 & 30,37 & 30,37 & 235,08 \\
\hline Discoglossus galganoi & $30 \mathrm{SUH} 24$ & 100,00 & 152,59 & 124,99 & 37,00 & 6879,76 & 349,49 & 18,78 & 330,70 & 82,04 & 245,28 & 245,28 & 69,63 & 621,17 & 88,01 & 4,03 & 54,46 & 230,47 & 29,16 & 29,16 & 223,26 \\
\hline Discoglossus galganoi & $30 \mathrm{SUH} 26$ & 100,00 & 157,27 & 124,76 & 37,00 & 6887,23 & 353,44 & 22,57 & 330,86 & 86,49 & 249,83 & 249,83 & 73,66 & 571,73 & 80,10 & 3,89 & 53,37 & 207,64 & 28,53 & 28,53 & 201,17 \\
\hline \begin{tabular}{|l} 
Discoglossus galganoi \\
\end{tabular} & $30 \mathrm{SUH} 30$ & 100,00 & 162,30 & 122,87 & 37,04 & 6771,33 & 354,04 & 29,24 & \begin{tabular}{|l|l|l}
324,80 \\
\end{tabular} & $\mid 92,31$ & \begin{tabular}{|l|}
253,16 \\
\end{tabular} & \begin{tabular}{|l|l}
253,16 \\
\end{tabular} & 80,00 & 647,49 & $\begin{array}{l}0,10 \\
94,59 \\
\end{array}$ & 3,26 & 58,61 & \begin{tabular}{|l|}
249,89 \\
\end{tabular} & 23,69 & 23,69 & 243,64 \\
\hline Discoglossus galganoi & 30 SUH32 & 100,00 & 156,88 & 123,97 & 37,00 & 6859,15 & 351,87 & 22,99 & 328,88 & 86,10 & 249,13 & 249,13 & 73,61 & 635,38 & 92,01 & 3,77 & 56,51 & 240,96 & 26,70 & 26,70 & 233,23 \\
\hline Discoglossus galganoi & 30SUH33 & 100,00 & 155,03 & 124,15 & 37,00 & 6882,36 & 351,03 & 20,96 & 330,08 & 84,19 & 247,63 & 247,63 & 71,67 & 625,04 & 89,89 & 3,97 & 55,43 & 234,58 & 27,97 & 27,97 & 226,59 \\
\hline Discoglossus galganoi & 30SUH34 & 100,00 & 152,05 & 124,73 & 37,00 & 6907,64 & 348,98 & 17,85 & 331,13 & 81,11 & 245,16 & 245,16 & 68,66 & 617,62 & 87,99 & 4,11 & 54,31 & 229,10 & 29,42 & 29,42 & 220,93 \\
\hline Discoglossus galganoi & 30SUH37 & 100,00 & 158,19 & 124,25 & 37,00 & 6893,18 & 353,98 & 23,16 & 330,82 & 87,52 & 250,85 & 250,85 & 74,40 & 543,75 & 75,72 & 3,51 & 52,56 & 194,90 & 27,77 & 27,77 & 188,42 \\
\hline \begin{tabular}{|l} 
Discoglossus galganoi \\
\end{tabular} & 30SUH38 & 100,00 & $\begin{array}{ll}130,13 \\
160,64\end{array}$ & $\begin{array}{l}124,25 \\
124,02\end{array}$ & 37,00 & 6858, 6 & 355,60 & $\begin{array}{l}25,47 \\
25\end{array}$ & 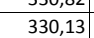 & $\begin{array}{l}1,325 \\
89,97 \\
\end{array}$ & 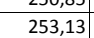 & \begin{tabular}{|l|l|}
253,13 \\
\end{tabular} & 76,72 & $\begin{array}{l}543,13 \\
517,02\end{array}$ & 71,21 & \begin{tabular}{l|l|l|}
, 28 \\
3,28
\end{tabular} & 52,03 & \begin{tabular}{|l|}
182,91 \\
182
\end{tabular} & 26,94 & 26,94 & $\begin{array}{l}100,42 \\
177,24\end{array}$ \\
\hline Discoglossus galganoi & $30 \mathrm{SUH} 40$ & 100,00 & 166,59 & 121,69 & 37,01 & 6766,19 & 356,73 & 33,38 & 323,35 & 96,41 & 257,32 & 257,32 & 83,97 & 627,45 & 92,90 & 3,00 & 58,99 & 243,12 & 22,05 & 22,05 & 235,93 \\
\hline Discoglossus galganoi & $30 \mathrm{SUH} 41$ & 100,00 & 163,68 & 122,52 & 37,00 & 6815,77 & 355,97 & 29,91 & 326,06 & 93,17 & 255,18 & 255,18 & 80,68 & 621,48 & 91,61 & 3,31 & 57,85 & 238,69 & 23,62 & 23,62 & 230,69 \\
\hline Discoglossus galganoi & $30 \mathrm{SUH} 42$ & 100,00 & 159,93 & 123,20 & 37,00 & 6866,91 & 354 & 25,70 & 328,43 & 88,95 & 252,18 & 252,18 & 76,42 & 618,63 & 90,50 & 3,56 & 56,64 & 235,22 & 25,44 & 25,44 & 226,66 \\
\hline Discoglossus galganoi & $30 \mathrm{SUH} 44$ & 100,00 & 151,10 & 124,14 & 37,00 & 6935,14 & 348, & 16,70 & 331,71 & 79,95 & 244,71 & 244,71 & 67,39 & 613,34 & 87,6 & 4,1 & 53,95 & 227,34 & 29,66 & 29,66 & 218,34 \\
\hline 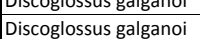 & $\begin{array}{l}3050 \mathrm{n} 44 \\
30 \mathrm{SUH} 4\end{array}$ & 100,00 & $\begin{array}{l}13,10 \\
156,62\end{array}$ & $\begin{array}{l}124,14 \\
124,50\end{array}$ & 37,00 & $\begin{array}{ll}69512,74 \\
6912,72\end{array}$ & 3452,90 & $\frac{10,0}{21,42}$ & \begin{tabular}{|l|l|}
331,48 \\
331,4
\end{tabular} & \begin{tabular}{|l|}
55,87 \\
5
\end{tabular} & \begin{tabular}{|l|}
249,65 \\
\end{tabular} & $\frac{244,11}{249,65}$ & $\begin{array}{l}\mid l, 59 \\
72,71\end{array}$ & $\mid \begin{array}{l}\mid 51,34,91 \\
541\end{array}$ & $\frac{8,6}{75,4}$ & $\begin{array}{l}4,1 \\
3,7\end{array}$ & $\begin{array}{l}32,03 \\
52,08\end{array}$ & \begin{tabular}{|l|l|}
193,57 \\
\end{tabular} & $\begin{array}{l}28,44 \\
28,44\end{array}$ & $\begin{array}{l}28,00 \\
28,44\end{array}$ & $\begin{array}{l}218,54 \\
186,43\end{array}$ \\
\hline Discoglossus galganoi & $30 \mathrm{SUH} 49$ & 100,00 & 156,20 & 124,03 & 37,00 & 6904,72 & 351,85 & 21,02 & 330,83 & 85,84 & 249,25 & 249,25 & 72,32 & 508,38 & 68,64 & 3,86 & 50,16 & 176,05 & 29,40 & 29,40 & 170,30 \\
\hline Discoglossus galganoi & 30SUH54 & 100,00 & 150,88 & 123,99 & 37,00 & 6938,76 & 347,95 & 16,38 & 331,58 & 79,54 & 244,46 & 244,46 & 67,07 & 605,83 & 86,74 & 4,39 & 53,43 & 224,08 & 30,25 & 30,25 & 214,33 \\
\hline Discoglossus galganoi & 30SUH57 & 100,00 & 151,04 & 124,89 & 37,00 & 6933,85 & 348,32 & 15,91 & 332,42 & 80,23 & 244,52 & 244,52 & 67 & 52,66 & 76,2 & 4,3 & 50,95 & 195,91 & 31,15 & 31,15 & 188,14 \\
\hline Discoglossus galganoi & 30SUH62 & 100,00 & 159,36 & 121,62 & 36,99 & 6883,64 & 352, & 26,08 & \begin{tabular}{|l|l|}
326,81 \\
\end{tabular} & $\begin{array}{l}80,25 \\
88,66\end{array}$ & 252,18 & 252,18 & 76,03 & 598,82 & 88 & $\frac{4,}{3,}$ & 55,69 & 227,40 & 26,00 & $\frac{1,110}{26,00}$ & 217,16 \\
\hline Discoglossus galganoi & $30 \mathrm{SUH}$ & 100,00 & 151,72 & 122,97 & 37,00 & 6927,43 & 347 & 18,08 & 329,83 & 80,69 & 245,28 & 245,28 & 68,30 & 609,03 & 88,09 & 4,5 & 53,90 & 227,54 & 29,81 & 29,81 & 216,79 \\
\hline Discoglossus galganoi & $30 \mathrm{SUH} 65$ & 100,00 & 153,88 & 123,98 & 37,00 & 6938,73 & 350,60 & 19,02 & 331,58 & 82,97 & 247,51 & 247,51 & 69,97 & 568,39 & 80,88 & 4,03 & 52,71 & 207,44 & 29,00 & 29,00 & 198,00 \\
\hline Discoglossus galganoi & 30 SUH66 & 100,00 & 147,75 & 124,62 & 37,00 & 6951,08 & 345,61 & 13,05 & 332,56 & 78,56 & 241,74 & 241,74 & 64,00 & 573,10 & 79,68 & 4,80 & 50,88 & 204,96 & 32,71 & 32,71 & 195,86 \\
\hline Discoglossus galganoi & 30SUH67 & 100,00 & 149,16 & 124,99 & 37,00 & 6940,01 & 346,73 & 13,99 & 332,74 & 88,94 & 242,86 & 242,86 & 65,36 & 549,43 & 75,42 & 4,36 & 50,23 & 17 & 32,05 & 32,05 & 185,56 \\
\hline \begin{tabular}{|l} 
Discoglossus galganoi \\
\end{tabular} & $30 \mathrm{SUH}$ & 100,00 & $\begin{array}{l}1433,25 \\
153,25\end{array}$ & $\begin{array}{ll}124,53 \\
124,97\end{array}$ & 37,00 & $\begin{array}{ll}\mid 65428,40 \\
6920\end{array}$ & 350 & \begin{tabular}{|l|l}
17,89 \\
17,5
\end{tabular} & $\mid$\begin{tabular}{|l|l|l|l|l|}
332,15 \\
\end{tabular} & \begin{tabular}{|l|}
$00,34,5$ \\
104,50
\end{tabular} & \begin{tabular}{|l|}
246,76 \\
\end{tabular} & \begin{tabular}{|l|}
246,76 \\
\end{tabular} & $\begin{array}{l}\mid c 0,30 \\
69,48\end{array}$ & $\begin{array}{l}343,43 \\
517,11\end{array}$ & $\begin{array}{l}7,4,42 \\
70,02\end{array}$ & $\begin{array}{l}4,00 \\
4,09\end{array}$ & $\begin{array}{ll}0,25 \\
49,73\end{array}$ & $\mid \begin{array}{l}\mid, 44,11 \\
180,85\end{array}$ & $\begin{array}{l}2,0,47 \\
30,7\end{array}$ & $\begin{array}{ll}32,0,47 \\
30,\end{array}$ & $\begin{array}{l}10,30, \\
172,72\end{array}$ \\
\hline \begin{tabular}{|l} 
Discoglossus galganoi \\
\end{tabular} & 30SUH69 & 100,00 & 148,55 & 125,02 & 37,00 & 6936,00 & 345,94 & 13,06 & 332,88 & 116,64 & 242,25 & 242,25 & 64,80 & 517,39 & 68,56 & 4,43 & 48,32 & 179,27 & 32,96 & 32,96 & 169,88 \\
\hline \begin{tabular}{|l} 
Discoglossus galganoi \\
\end{tabular} & 30SUH74 & 100,00 & 151,78 & 123,02 & 37,00 & 6941,81 & 348,19 & $\begin{array}{l}17,94 \\
17,\end{array}$ & \begin{tabular}{|l|l|}
330,25 \\
\end{tabular} & \begin{tabular}{|l|l|l|l|l|l|}
80,72 \\
\end{tabular} & \begin{tabular}{|l|l|}
245,66 \\
\end{tabular} & 245,66 & 68,25 & 582,21 & 83,49 & $4,4,44$ & 52,59 & 214,36 & 30,20 & 30,20 & 203,55 \\
\hline Discoglossus galganoi & 30 SUH75 & 100,00 & 148,38 & 123,98 & 37,00 & 6945,49 & 345,76 & 14,17 & 331,59 & 81,12 & 242,28 & 242,28 & 64,94 & 577,95 & 81,45 & 4,75 & 51,44 & 209,36 & 32,20 & 32,20 & 198,97 \\
\hline Discoglossus galganoi & $30 \mathrm{SUH7}$ & 100,00 & 147,51 & 125,44 & 37,00 & 6943,53 & 345,35 & 11,86 & 333,49 & 101,89 & 241,28 & 24 & 63 & 527,11 & 70,51 & 4,52 & 48,64 & 184,42 & 33,20 & 33,20 & 174,00 \\
\hline \begin{tabular}{|l|} 
Discoglossus galganoi \\
\end{tabular} & $\begin{array}{l}3050 \mathrm{n} / \mathrm{O} \\
30 \mathrm{SU} 85\end{array}$ & $\begin{array}{l}100,00 \\
\end{array}$ & $\begin{array}{l}14 r, 51 \\
141,49\end{array}$ & $\begin{array}{ll}124,44 \\
124,08\end{array}$ & 37,00 & |6956, 61 & 339,93 & \begin{tabular}{|l|l|}
7,609 \\
7,69
\end{tabular} & \begin{tabular}{|c|}
330,4324 \\
332,1
\end{tabular} & \begin{tabular}{|c|c|}
$1,1,04$ \\
91
\end{tabular} & \begin{tabular}{|l|}
235,90 \\
235
\end{tabular} & \begin{tabular}{|l|}
235,90 \\
235
\end{tabular} & $\begin{array}{ll}58,33 \\
58\end{array}$ & |591,33 & \begin{tabular}{|c|c|}
82,19 \\
8
\end{tabular} & $\begin{array}{l}4,256 \\
5,76\end{array}$ & $\begin{array}{ll}40,044 \\
49,85\end{array}$ & \begin{tabular}{|l|}
213,17 \\
21,4
\end{tabular} & $\begin{array}{l}3,21 \\
36,21 \\
\end{array}$ & $\begin{array}{l}30,20 \\
36,21\end{array}$ & 200,69 \\
\hline Discoglossus galganoi & 30SUH95 & 100,00 & 140,41 & 124,03 & 37,00 & 6966,58 & 338,94 & 6,78 & 332,16 & 92,96 & 235,03 & 235,03 & 57,38 & 584,27 & 80,83 & 5,92 & 49,15 & 211,03 & 37,01 & 37,01 & 196,48 \\
\hline Discoglossus galganoi & 30SUH96 & 100,00 & 146,94 & 124,51 & 37,00 & 6950,51 & 344,40 & 12,19 & 332,21 & 100,02 & 240,92 & 240,92 & 63,40 & 542,94 & 74,48 & 4,81 & 49,26 & 195,16 & 33,37 & 33,37 & 181,33 \\
\hline Discoglossus & 30SUH99 & 100,00 & 146,58 & 126,61 & 37,44 & 6909,73 & 344,29 & 10,52 & 20 & 129,35 & 239, & 239, & 63,37 & 489,23 & 62,42 & 4,24 & 46,61 & 171,92 & 33,88 & 33,88 & 156,1 \\
\hline \begin{tabular}{|l} 
Discoglossus galganoi \\
\end{tabular} & 30 SUJO & 100,00 & 159,36 & 121,10 & 37,00 & 6790,35 & 350,59 & 26,64 & 323,95 & $\begin{array}{r}89,07 \\
\end{array}$ & 250,54 & 250,54 & 76,72 & 476,07 & 62,28 & 3,92 & 49,00 & 166,33 & 29,72 & 29,72 & 157,84 \\
\hline
\end{tabular}




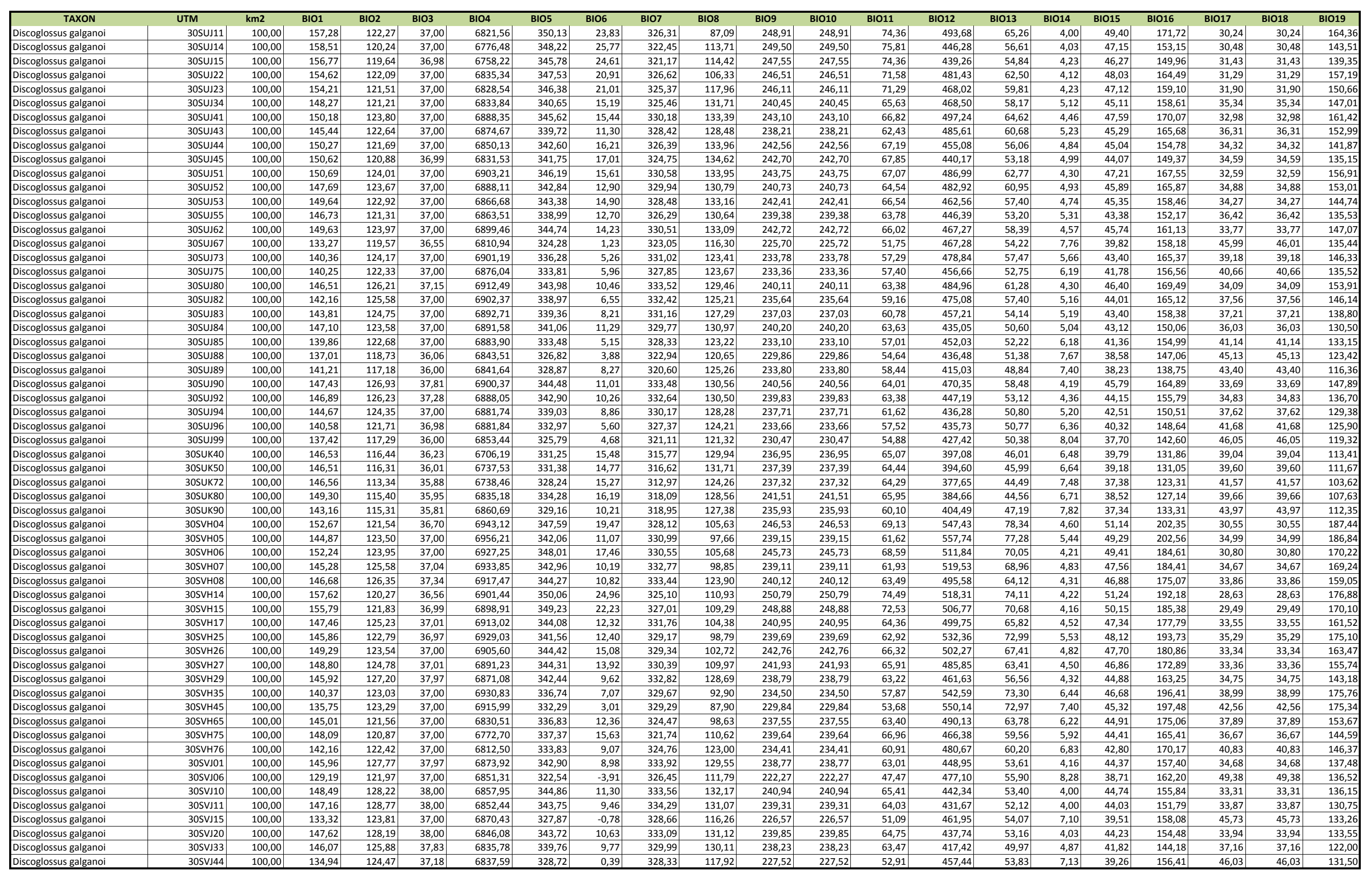




\begin{tabular}{|c|c|c|c|c|c|c|c|c|c|c|c|c|c|c|c|c|c|c|c|c|c|}
\hline TAXON & UTM & $\mathrm{km} 2$ & B101 & $\mathrm{B1O2}$ & $\mathrm{BIO3}$ & BIO4 & B105 & B106 & B107 & $\mathrm{B108}$ & B109 & B1010 & BIO11 & BIO12 & B1013 & B1014 & BIO15 & B1016 & B1017 & $\mathrm{BIO18}$ & B1019 \\
\hline Discoglossus galganoi & $30 \mathrm{SVJ} 45$ & 100,00 & 128,65 & 123,56 & 37,03 & 6835,67 & 322,47 & $-4,44$ & 326,91 & 111,14 & 221,50 & 221,50 & 47,35 & 478,31 & 55,59 & 8,50 & 37,84 & 162,32 & 50,98 & 50,98 & 136,15 \\
\hline Discoglossus galganoi & 30 SVJ50 & 100,00 & 143,14 & 125,34 & 37,59 & 6834,76 & 336,97 & 7,78 & 329,18 & 125,91 & 235,43 & 235,43 & 60,97 & 450,52 & 54,61 & 5,57 & 42,19 & 157,93 & 39,32 & 39,32 & 134,14 \\
\hline Discoglossus galganoi & 30 SVJ55 & 100,00 & 138,96 & 123,14 & 37,03 & 6822,71 & 330,55 & 4,48 & 326,07 & 122,39 & 231,19 & 231,19 & 56,86 & 436,58 & 50,83 & 7,02 & 38,73 & 147,13 & 44,65 & 44,65 & 124,51 \\
\hline Discoglossus galganoi & 30SVK01 & 100,00 & 149,04 & 113,12 & 35,00 & 6882,69 & 332,72 & 15,98 & 316,74 & 117,76 & 242,08 & 242,08 & 65,22 & 385,81 & 43,97 & 7,68 & 36,92 & 125,51 & 42,08 & 42,08 & 107,56 \\
\hline Discoglossus galganoi & 30SVK10 & 100,00 & 139,54 & 115,28 & 35,74 & \begin{tabular}{ll|}
6879,58 \\
\end{tabular} & 326,16 & 7,09 & 319,07 & \begin{tabular}{|l|l|}
121,73 \\
\end{tabular} & 232,81 & 232,81 & 56,51 & 420,94 & 48,24 & 8,56 & 36,62 & 136,80 & 46,77 & 46,77 & 117,76 \\
\hline Discoglossus galganoi & 30SVK11 & 100,00 & 148,71 & 112,90 & 35,00 & 6894,10 & 332,38 & 15,75 & 316,62 & 106,71 & 241,81 & 241,81 & 64,72 & 390,78 & 44,25 & 7,80 & 37,00 & 127,62 & 42,60 & 42,60 & 109,72 \\
\hline Discoglossus galganoi & 30 SVK32 & 100,00 & 148,20 & 111,54 & 35,01 & 6826,51 & 329,53 & 17,08 & 312,45 & 104,25 & 239,90 & 239,90 & 64,68 & 399,91 & 46,23 & 8,15 & 37,33 & 134,99 & 42,58 & 42,58 & 115,87 \\
\hline Discoglossus galganoi & 30SVK41 & 100,00 & 142,28 & 113,99 & 35,88 & 6815,05 & 326,08 & 11,25 & 314,82 & \begin{tabular}{|l|}
98,38 \\
\end{tabular} & 234,01 & 234,01 & 59,56 & 419,66 & 47,72 & 8,47 & 36,83 & 139,45 & 45,42 & 45,42 & 120,79 \\
\hline Discoglossus galganoi & 30SWH28 & 100,00 & 130,82 & 122,95 & 38,00 & 6646,01 & 318,52 & $-1,10$ & 319,62 & 111,49 & 220,70 & 220,86 & 51,95 & 476,01 & 59,69 & 9,92 & 36,66 & 165,36 & 54,88 & 55,57 & 128,99 \\
\hline Discoglossus galganoi & 30SWH33 & 100,00 & 115,28 & 121,64 & 37,99 & 6624,59 & 303,36 & $-14,60$ & 317,95 & 93,55 & 205,45 & 205,58 & 37,90 & 563,74 & 71,58 & 14,55 & 35,49 & 195,09 & 67,78 & 68,03 & 155,56 \\
\hline Discoglossus galganoi & 30SWH54 & 100,00 & 131,29 & 120,31 & 38,04 & 6476,47 & 312,01 & 1,13 & 310,89 & 110,88 & 218,81 & 218,99 & 54,62 & 468,32 & 60,97 & 10,81 & 36,17 & 161,00 & 56,14 & 56,56 & 124,16 \\
\hline Discoglossus galganoi & 30SWJ11 & 100,00 & 132,95 & 123,77 & 38,00 & 6688,70 & 321,48 & $-0,02$ & 321,50 & 114,59 & 222,89 & 223,38 & 53,13 & 461,69 & 56,23 & 9,45 & 36,06 & 159,09 & 53,73 & 54,64 & 124,72 \\
\hline \begin{tabular}{|l} 
Discoglossus galganoi \\
\end{tabular} & 30TTK44 & 60,00 & 132,45 & 109,16 & 36,60 & 6377,70 & 307,43 & 12,65 & 294,78 & 62,97 & 217,85 & 218,38 & 55,81 & 543,52 & 66,52 & 8,45 & 42,58 & 193,49 & 48,58 & 49,33 & 179,36 \\
\hline Discoglossus galganoi & 30TTK57 & 100,00 & 125,48 & 111,03 & \begin{tabular}{|c|}
37,08 \\
\end{tabular} & 6317,04 & 299,69 & 5,65 & 294,04 & 56,32 & 209,99 & 210,54 & 49,34 & 515,12 & 63,05 & 9,67 & 39,93 & 180,10 & 51,77 & 52,14 & 164,56 \\
\hline Discoglossus galganoi & 30TTK59 & 100,00 & 118,74 & 111,53 & 37,89 & 6264,91 & 292,03 & 0,06 & 291,97 & 50,05 & 202,19 & 203,01 & 43,41 & 522,27 & 64,35 & 10,65 & 38,81 & 182,02 & 55,69 & 56,28 & 164,96 \\
\hline Discoglossus galganoi & 30TTK66 & 100,00 & 79,21 & 106,14 & 36,41 & 6224,39 & 253,47 & $-34,09$ & 287,56 & 14,25 & 163,83 & 164,57 & 7,95 & 803,94 & 95,97 & 19,66 & 37,45 & 276,18 & 86,49 & 92,45 & 257,79 \\
\hline Discoglossus galganoi & 30TTK67 & 100,00 & 109,14 & 110,24 & \begin{tabular}{|c|}
37,07 \\
\end{tabular} & 6281,82 & 283,90 & $-8,71$ & 292,61 & 41,20 & 192,97 & 194,39 & 34,75 & 578,51 & 69,88 & 12,63 & 37,97 & 198,20 & 62,04 & 64,14 & 180,73 \\
\hline \begin{tabular}{|l} 
Discoglossus galganoi \\
\end{tabular} & 30TTK74 & 100,00 & 134,76 & 112,76 & 36,99 & 6418,78 & 312,39 & 11,83 & 300,57 & 68,51 & 220,79 & 221,21 & 57,26 & 470,09 & 55,91 & 8,45 & 40,06 & 159,85 & 46,18 & 46,69 & 145,14 \\
\hline Discoglossus galganoi & 30TTK75 & 100,00 & 81,44 & 107,65 & 36,44 & 6263,92 & 257,81 & $-33,16$ & 290,97 & 16,03 & 166,67 & 167,38 & 9,72 & 767,13 & 90,58 & 19,21 & 36,84 & 259,87 & 83,75 & 88,86 & 241,18 \\
\hline Discoglossus galganoi & 30TTK76 & 100,00 & 91,53 & 108,77 & 36,79 & 6260,14 & 267,27 & $-24,49$ & 291,75 & 25,18 & 175,92 & 177,06 & 18,91 & 680,86 & 80,72 & 16,69 & 36,68 & 229,91 & 75,34 & 79,58 & 211,18 \\
\hline Discoglossus galganoi & 30TTK77 & 100,00 & 97,20 & 109,86 & 37,13 & 6246,57 & 272,49 & $-19,59$ & 292,07 & 30,34 & 180,93 & 182,39 & 24,13 & 626,00 & 74,51 & 15,30 & 36,35 & 210,42 & 70,67 & 74,09 & 191,65 \\
\hline \begin{tabular}{|l} 
Discoglossus galganoi \\
\end{tabular} & 30TTK78 & 100,00 & 114,63 & 112,80 & 37,91 & 6271,61 & 289,86 & $-4,61$ & 294,47 & 55,68 & 197,59 & 199,56 & 39,69 & 504,84 & 60,39 & 11,68 & 36,46 & 168,65 & 57,96 & 59,24 & 151,39 \\
\hline \begin{tabular}{|l} 
Discoglossus galganoi \\
\end{tabular} & 30TTK84 & 100,00 & 134,41 & 113,27 & 37,00 & 6425,82 & 312,65 & 10,59 & 302,07 & 81,47 & 220,52 & 220,95 & 56,82 & 456,62 & 53,71 & 8,67 & 39,33 & 153,00 & 46,50 & 47,06 & 137,83 \\
\hline Discoglossus galganoi & 30TTK86 & 100,00 & 104,01 & 111,33 & 37,03 & 6298,99 & 281,10 & $-14,76$ & 295,86 & 38,62 & 188,25 & 189,81 & 30,01 & 569,76 & 66,99 & 14,01 & 36,09 & 188,25 & 65,19 & 67,68 & 169,77 \\
\hline Discoglossus galganoi & 30TTK87 & 100,00 & 112,29 & 112,73 & 37,60 & 6295,44 & 288,80 & $-7,63$ & 296,43 & 62,51 & 195,94 & 197,81 & 37,44 & 507,78 & 59,81 & 12,44 & 35,86 & 166,60 & 59,43 & 61,05 & 148,84 \\
\hline Discoglossus galganoi & 30TTK89 & 100,00 & 114,12 & 114,19 & 38,01 & 6219,95 & 289,16 & $-5,91$ & 295,07 & 73,80 & 195,95 & 198,39 & 39,77 & 472,86 & 55,95 & 11,97 & 34,69 & 154,65 & 58,43 & 59,90 & 136,11 \\
\hline Discoglossus galganoi & 30TाK94 & 100,00 & 150,38 & 114,48 & 37,00 & $\mid 6451,97$ & 328,03 & 24,12 & 303,91 & \begin{tabular}{rl|}
108,28 \\
\end{tabular} & 236,77 & 236,78 & 71,27 & 381,23 & $\begin{array}{l}4,71 \\
44,\end{array}$ & 6 & 39,86 & 128,30 & $\begin{array}{l}30,45 \\
37,38 \\
\end{array}$ & 37,38 & 113,13 \\
\hline Discoglossus galganoi & 30TTK95 & 100,00 & 94,42 & 110,80 & 36,89 & 6314,75 & 272,60 & $-23,77$ & 296,37 & 36,90 & 179,93 & 180,69 & 21,05 & 643,16 & 74,43 & 17,05 & 35,56 & 210,75 & 74,63 & 78,42 & 191,89 \\
\hline Discoglossus galganoi & 30TTK96 & 100,00 & 91,54 & 110,67 & 37,01 & 6268,13 & 268,93 & $-26,01$ & 294,93 & 33,22 & 176,05 & 177,31 & 18,89 & 629,13 & 73,17 & 17,20 & 34,74 & 204,69 & 75,06 & 79,02 & 184,84 \\
\hline Discoglossus galganoi & 30TTL56 & 100,00 & 115,04 & 114,44 & 39,00 & 6165,01 & 287,15 & $-3,84$ & 290,99 & 75,32 & 197,15 & 197,26 & 39,83 & 452,74 & 57,87 & 11,27 & 37,59 & 161,16 & 55,84 & 55,92 & 135,98 \\
\hline Discoglossus galganoi & 30TTL61 & 100,00 & 113,50 & 113,97 & 38,46 & 6218,07 & 287,22 & $-5,21$ & 292,44 & 72,68 & 196,09 & 197,31 & 38,71 & 492,07 & 60,22 & 11,71 & 36,64 & 168,50 & 58,69 & 59,31 & 148,05 \\
\hline \begin{tabular}{|l} 
Discoglossus galganoi \\
\end{tabular} & 30TTL63 & 100,00 & 119,51 & 116,51 & 39,01 & 6228,66 & 293,60 & 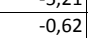 & 294,22 & 79,06 & 202,72 & 202,72 & \begin{tabular}{|l|l|}
43,67 \\
43
\end{tabular} & \begin{tabular}{|l|l|}
431,98 \\
43
\end{tabular} & 54,71 & $\begin{array}{l}11,1 / 9 \\
10,97\end{array}$ & 37,70 & \begin{tabular}{|l|l|}
153,08 \\
\end{tabular} & $\begin{array}{l}53,650 \\
53,65\end{array}$ & 53,65 & 125,65 \\
\hline Discoglossus galganoi & 30TTL64 & 100,00 & 120,29 & 116,82 & $\begin{array}{ll}39,05 \\
\end{array}$ & 6221,36 & 294,10 & $-0,18$ & 294,27 & 80,06 & 203,19 & 203,19 & 44,14 & 413,41 & 52,97 & 10,68 & 38,41 & 148,23 & 52,13 & 52,13 & 118,31 \\
\hline Discoglossus galganoi & 30TTL69 & 100,00 & 122,06 & 115,03 & 39,00 & 6155,46 & 293,29 & 0,89 & 292,40 & 82,50 & 201,72 & 203,25 & 45,71 & 378,28 & 47,02 & 9,83 & 35,32 & 131,58 & 49,88 & 50,85 & 107,96 \\
\hline Discoglossus galganoi & 30TTL77 & 100,00 & 115,30 & 116,42 & 39,02 & 6142,99 & 288,43 & $-4,77$ & 293,20 & 75,46 & 195,38 & 197,22 & 40,21 & 399,37 & 48,49 & 11,80 & 34,90 & 137,61 & 55,20 & 56,19 & 110,71 \\
\hline Discoglossus galganoi & 30TTL78 & 100,00 & 119,71 & 116,10 & 39,00 & 6150,08 & 292,16 & $-0,90$ & 293,06 & 79,96 & 199,21 & 201,27 & 43,98 & 375,74 & 45,45 & 10,79 & 34,65 & 129,17 & 51,47 & 52,77 & 103,77 \\
\hline \begin{tabular}{|l} 
Discoglossus galganoi \\
\end{tabular} & $\begin{array}{l}30 T T L 80 \\
30\end{array}$ & 100,00 & 116,94 & $\begin{array}{ll}1115,10 \\
115,38\end{array}$ & 38,70 & $\begin{array}{l}010,00 \\
6194,59\end{array}$ & 291,30 & $\begin{array}{l}-3,28 \\
-3,28\end{array}$ & \begin{tabular}{|l|}
294,58 \\
298
\end{tabular} & 76,48 & 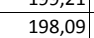 & 200,76 & $\begin{array}{l}45,30 \\
42,40\end{array}$ & $\mid$\begin{tabular}{|l|l}
447,38 \\
\end{tabular} & $\begin{array}{l}5,, 45 \\
53,07 \\
\end{array}$ & $\begin{array}{ll}11,43 \\
11,4\end{array}$ & $\begin{array}{l}34,20 \\
34,27 \\
\end{array}$ & \begin{tabular}{|l|l|}
146,34 \\
140
\end{tabular} & $\begin{array}{l}31,474 \\
56,69\end{array}$ & 57,84 & 127,78 \\
\hline Discoglossus galganoi & 30TTL84 & 100,00 & 118,22 & 118,05 & 40,00 & 6094,94 & 291,11 & $-2,11$ & 293,22 & 77,77 & 197,44 & 200,09 & 44,13 & 395,58 & 47,83 & 11,05 & 33,18 & 130,74 & 55,48 & 56,54 & 108,39 \\
\hline Discoglossus galganoi & 30TTL86 & 100,00 & 114,99 & 117,17 & 39,21 & 6118,82 & 288,09 & $-5,01$ & 293,10 & 74,80 & 194,29 & 196,82 & 40,29 & 395,85 & 48,46 & 11,95 & 33,60 & 132,92 & 56,56 & 57,97 & 107,10 \\
\hline Discoglossus galganoi & 30TTL87 & 100,00 & 117,45 & 117,01 & 39,01 & 6128,10 & 290,28 & $-3,02$ & 293,30 & 77,47 & 196,72 & 199,04 & 42,31 & 381, & 46,22 & 11,59 & 33,62 & 128,43 & 54,19 & 55,82 & 103,11 \\
\hline Discoglossus galganoi & 30TTL88 & 100,00 & 120,04 & 116,87 & 39,00 & 6129,04 & 292,54 & $-0,96$ & 293,50 & 80,56 & 199,23 & 201,35 & 44,43 & 369,22 & 44,14 & 11,29 & 33,43 & 124,61 & 52,34 & 54,01 & 99,94 \\
\hline Discoglossus galganoi & 30TTM52 & 95,00 & 116,33 & 114,59 & 39,00 & 6081,45 & 286,63 & $-3,58$ & 290,21 & 77,34 & 196,83 & 196,83 & 40,68 & 452,17 & 57,37 & $13, \mathrm{C}$ & 34,89 & 160,40 & 60,13 & 60,13 & 138,52 \\
\hline Discoglossus galganoi & 30TTM55 & 84,00 & 117,11 & 114,77 & 39,00 & 6000,72 & 285,95 & $-3,43$ & 289,39 & 78,98 & 196,27 & 196,27 & 42,17 & 481,39 & 60,98 & 15,51 & 34,29 & 173,54 & 66,96 & 66,96 & 147,86 \\
\hline Discoglossus galganoi & 30TTM60 & 100,00 & 120,34 & 115,00 & 39,00 & 6131,49 & 291,38 & $-0,43$ & 291,81 & 80,93 & 199,72 & 201,24 & 44,30 & 389,94 & 48,50 & 10,63 & 34,65 & 135,93 & 52,24 & 53,13 & 112,21 \\
\hline Discoglossus galganoi & 30TTM83 & 100,00 & 121,46 & 116,04 & 39,00 & 6028,39 & 292,09 & $-0,39$ & 292,48 & 84,00 & 199,86 & 200,99 & 46,17 & 400,38 & 48,43 & 13,59 & 31,92 & 41 & 60,23 & 60,83 & 111,39 \\
\hline Discoglossus galganoi & 30TTM84 & 100,00 & 119 & 116,05 & 39,03 & 6009,51 & 290,27 & $\begin{array}{ll}-2,04 \\
-2,50\end{array}$ & 29 & 82,80 & 198,69 & $\frac{219}{19}$ & $\begin{array}{l}44,115 \\
44,65 \\
\end{array}$ & 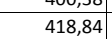 & 51, & 14,8 & 31,77 & 78 & $\begin{array}{l}64,48 \\
64,\end{array}$ & 64,70 & 116,88 \\
\hline Discoglossus galganoi & 30TTM92 & 100,00 & 120,89 & 116 & 39,00 & 6061,87 & 292,44 & $-1,17$ & 293,61 & 83,17 & 198,99 & 201,06 & 45,29 & 389 & 46,3 & 13, & 31,44 & 132,64 & 58,42 & 60,35 & 106,25 \\
\hline Discoglossus galganoi & 30TTN53 & 58,00 & 93,44 & 109,66 & 39,99 & 5543,63 & 251,73 & $-19,50$ & 271,23 & 60,25 & 166,97 & 166,97 & 25,44 & \begin{tabular}{|l|l|}
749,48 \\
\end{tabular} & 97,07 & 33,26 & 30,23 & 266,40 & \begin{tabular}{|l|l|}
122,49 \\
\end{tabular} & 122,49 & 220,42 \\
\hline Discoglossus galganoi & 30TTN54 & 50,00 & 85,92 & 107,32 & 39,96 & 5432,77 & 240,95 & $-24,42$ & 265,37 & 54,00 & 157,99 & 157,99 & 19,85 & 827,83 & 105,94 & 37,45 & 29,26 & 289,86 & 136,27 & 136,33 & 244,65 \\
\hline Discoglossus galganoi & 30TTN63 & 100,00 & 97,88 & 110, & 40,00 & 5567,66 & 257,41 & $-16,42$ & 273,84 & 64,54 & 171,46 & 171,46 & 28,97 & 704,86 & 91,85 & 32,32 & 30 & 02 & 118,46 & 118,46 & 202,02 \\
\hline \begin{tabular}{|l} 
Discoglossus galganoi \\
\end{tabular} & $30 T T N 6$ & 100,00 & 88 & 108 & 40,01 & 5445,67 & 244,62 & $-22,48$ & 267,11 & 56,85 & 160,94 & 160,94 & 22,20 & 795,50 & $\mid \begin{array}{l}102,14 \\
\end{array}$ & 37,00 & 28,97 & 279,16 & 134,13 & 134,13 & 230,18 \\
\hline Discoglossus galganoi & 30TTN70 & 100,00 & 111,83 & 115,86 & 39,87 & 5876,95 & 279,96 & $-8,85$ & 288,81 & 76,08 & 189,31 & 189,31 & 37,82 & 541,07 & 70,76 & 23,03 & 32,95 & 198,52 & 90,65 & 90,65 & 151,22 \\
\hline \begin{tabular}{|l} 
Discoglossus galganoi \\
\end{tabular} & 30TTN71 & 100,00 & 108,29 & 115,51 & 39,98 & 5833,44 & 275,83 & \begin{tabular}{|c|c|}
$-0,01$ \\
$-11,51$ \\
\end{tabular} & \begin{tabular}{|l|l|}
287,33 \\
\end{tabular} & 72,84 & $\begin{array}{l}185,29 \\
\end{array}$ & $\begin{array}{l}185,29 \\
\end{array}$ & 35,15 & 574,51 & 75,41 & 23,60 & 32,70 & 210,81 & $\begin{array}{l}0,00 \\
98,28 \\
\end{array}$ & 98,28 & 159,69 \\
\hline Discoglossus galganoi & 30TTN73 & 100,00 & 96,86 & 111,50 & 40,00 & 5591,34 & 257,71 & $-18,05$ & 275,76 & 63,91 & 170,84 & 170,84 & 27,56 & 694,81 & 90,14 & 32,83 & 29,98 & 247,84 & 120,24 & 120,24 & 195,0 \\
\hline Discoglossus galganoi & 30TTN76 & 100,00 & 78,15 & 103,75 & 40,21 & 5204,15 & 227,04 & $-28,09$ & 255,13 & 49,18 & 147 & 147 & 15,44 & 919,81 & 115,94 & 44,84 & 26,84 & 313,84 & 159,43 & 160,50 & 26 \\
\hline \begin{tabular}{|l|} 
Discoglossus galganoi \\
\end{tabular} & 30TTN81 & $\begin{array}{l}100,00 \\
\end{array}$ & $\begin{array}{r}112,109 \\
112,09\end{array}$ & 115,44 & 年 39,91 & $\mid \begin{array}{ll}524,11 \\
5801,20\end{array}$ & 278,79 & \begin{tabular}{|c|c|}
$-8,0202$ \\
-10
\end{tabular} & \begin{tabular}{|l|}
286,81 \\
286,
\end{tabular} & $\begin{array}{l}\mid c 5,10 \\
77,48\end{array}$ & $\begin{array}{l}181,27 \\
188,47 \\
\end{array}$ & \begin{tabular}{|l|}
188,47 \\
188,
\end{tabular} & \begin{tabular}{l|}
$0,44,95$ \\
38,95
\end{tabular} & \begin{tabular}{|c|}
$\mid 19,01$ \\
549,74
\end{tabular} & $\mid$\begin{tabular}{|l|l|}
72,17 \\
724
\end{tabular} & $\begin{array}{ll}22,124 \\
22\end{array}$ & \begin{tabular}{|l|l|}
32,53 \\
3
\end{tabular} & \begin{tabular}{|l|}
13,04 \\
201,18 \\
\end{tabular} & \begin{tabular}{|c|}
56,45 \\
96,41
\end{tabular} & $\begin{array}{r}90,50 \\
96,41 \\
\end{array}$ & $\begin{array}{l}203,00 \\
148,43\end{array}$ \\
\hline Discoglossus galganoi & 30TTN82 & 100,00 & 108,29 & 114,24 & 40,00 & 5713,11 & 272,77 & $-10,27$ & 283,04 & 74,53 & 183,56 & 183,56 & 36,55 & 591,44 & 77,61 & 24,31 & 31,73 & 214,95 & 104,96 & 104,96 & 159,59 \\
\hline Discogolossus & 30TाN83 & 100,00 & 100,81 & 111.97 & 40,01 & 5578.91 & 261,61 & $-14,78$ & 276,39 & 68.47 & $\mid 174,49$ & $\mid 174,49$ & 31.46 & 662.58 & 86,12 & 30,41 & 30.02 & 236.55 & 117.88 & 117.88 & 180,73 \\
\hline Discoglossus & 30TTN90 & 100,00 & 115,60 & 114,52 & 39,93 & 5754,04 & 280,47 & $-4,69$ & 285,16 & 82,10 & 191,30 & 191, & 42, & 521,09 & 67,51 & 23,59 & 31 & 187 & 91,22 & 91,22 & 139,00 \\
\hline \begin{tabular}{|l} 
Discoglossus galganoi \\
\end{tabular} & 30TTN92 & 100,00 & 107,67 & 113,09 & 40,00 & 5642,44 & 270,31 & $-10,03$ & 280,35 & 75,30 & 182,14 & 182,14 & 36,94 & 595,94 & 77,47 & 26,22 & 30,55 & 213,70 & $\mid 107,31$ & 107,31 & 158,62 \\
\hline
\end{tabular}




\begin{tabular}{|c|c|c|c|c|c|c|c|c|c|c|c|c|c|c|c|c|c|c|c|c|c|}
\hline TAXON & UTM & $\mathrm{km} 2$ & B101 & $\mathrm{B1O2}$ & $\mathrm{BIO3}$ & BIO4 & B105 & B106 & B107 & B108 & B109 & BIO10 & BIO11 & B1012 & 81013 & B1014 & B1015 & B1016 & $\begin{array}{ll}1017 \\
17\end{array}$ & B1018 & B1019 \\
\hline Discoglossus galganoi & 30TTN93 & 100,00 & 101,07 & 111,23 & 40,01 & 5538,27 & 260,69 & $-14,21$ & 274,90 & 69,69 & 174,09 & 174,09 & 32,15 & 658,48 & 84,97 & 31,07 & 29,28 & 233,02 & 119,10 & 119,10 & 176,86 \\
\hline Discoglossus galganoi & 30TTN95 & 100,00 & 76,79 & 105,17 & 39,78 & 5315,46 & 229,65 & $-31,55$ & 261,19 & 47,66 & 147,52 & 147,55 & 12,59 & 876,14 & 108,91 & 44,02 & 26,10 & 296,94 & 156,47 & 156,71 & 245,86 \\
\hline Discoglossus galganoi & $\begin{array}{l}30 \text { TTP50 } \\
\end{array}$ & 30,00 & 132,53 & 89,02 & 43,47 & 3951,38 & 244,09 & 41,30 & 202,79 & 113,38 & 182,32 & 185,32 & 84,91 & 827,68 & \begin{tabular}{|c|c|c|}
113,53 \\
\end{tabular} & 39,98 & 28,60 & 278,89 & 142,02 & $\begin{array}{ll}151,87 \\
\end{array}$ & 212,13 \\
\hline Discoglossus galganoi & 30TTP60 & 100,00 & 129,66 & 89,93 & 43,73 & 3918,14 & 241,79 & 38,42 & 203,37 & 111,05 & 178,84 & 181,95 & 82,53 & 850,03 & 116,32 & 42,40 & 28,38 & 284,03 & 149,06 & 158,09 & 214,18 \\
\hline Discoglossus galganoi & 30TTP63 & 31,00 & 138,23 & 75,91 & 42,15 & 3643,91 & 233,54 & 55,32 & \begin{tabular}{|l|l|}
178,22 \\
\end{tabular} & 121,89 & 183,98 & 187,49 & 94,31 & 852,65 & 117,02 & 40,69 & 28,85 & 289,35 & 145,51 & 159,12 & 220,78 \\
\hline Discoglossus galganoi & 30TTP80 & 100,00 & 126,93 & 86,91 & 42,80 & 3981,43 & 237,32 & 36,17 & 201,14 & 108,64 & 177,37 & 180,30 & 78,91 & 843,78 & 114,67 & 42,99 & 27,94 & 283,30 & 151,37 & 160,74 & 211,27 \\
\hline Discoglossus galganoi & 30TTP82 & 60,00 & 138,75 & 71,62 & 40,72 & 3679,04 & 230,37 & 56,65 & 173,71 & 122,63 & 185,16 & 188,74 & 94,25 & 829,42 & 113,76 & 40,20 & 28,83 & 282,16 & 143,90 & 157,39 & 211,51 \\
\hline Discoglossus galganoi & 30TाP91 & 100,00 & 126,39 & 81,66 & 41,69 & 3926,47 & 231,46 & 38,29 & 193,18 & 108,81 & 176,19 & 179,21 & 78,95 & 863,94 & 116,71 & 43,76 & 27,58 & 291,58 & 154,86 & 165,97 & 219,20 \\
\hline Discoglossus galganoi & 30TUK04 & 100,00 & 152,48 & 114,92 & 37,00 & 6473,37 & 330,21 & 25,06 & 305,15 & 110,58 & 239,14 & 239,14 & 72,90 & 365,59 & 42,55 & 6,31 & 39,21 & 122,56 & 36,52 & 36,52 & 106,51 \\
\hline Discoglossus galganoi & 30TUK05 & 100,00 & 91,60 & 111,19 & 36,98 & 6312,57 & 270,40 & $-26,92$ & 297,31 & 37,66 & 177,25 & 178,03 & 18,63 & 640,32 & 74,19 & 17,84 & 34,65 & 206,66 & 76,97 & 80,68 & 186,89 \\
\hline Discoglossus galganoi & 30TUK06 & 100,00 & 80,47 & 110,13 & 36,98 & 6240,22 & 258,27 & $-35,89$ & 294,16 & 23,13 & 165,30 & 166,20 & 9,04 & 683,23 & 79,23 & 20,24 & 33,51 & 219,28 & 84,51 & 89,35 & 198,20 \\
\hline Discoglossus galganoi & 30TUK07 & 100,00 & 76,67 & 109,66 & 37,02 & 6199,42 & 253,59 & $-38,70$ & 292,29 & 15,36 & 161,19 & 161,95 & 5,96 & 693,74 & 80,34 & 21,14 & 32,93 & 222,01 & 87,41 & 93,44 & 200,16 \\
\hline \begin{tabular}{|l} 
Discoglossus galganoi \\
\end{tabular} & 30TUK08 & 100,00 & 105,93 & 113,03 & 37,83 & 6234,50 & 282,07 & $-14,19$ & 296,26 & 64,14 & 188,86 & 190,86 & 32,37 & 495,59 & 60,24 & 14,20 & 33,61 & 157,74 & 64,29 & 66,78 & 136,18 \\
\hline Discoglossus galganoi & 30TUK13 & 100,00 & 153,80 & 115,00 & 37,00 & 6529,68 & 332,82 & 25,31 & 307,51 & 111,49 & 241,18 & 241,18 & 73,63 & 362,19 & 41,65 & 5,97 & 39,65 & 121,37 & 35,44 & 35,44 & 104,84 \\
\hline Discoglossus galganoi & 30TUK14 & 100,00 & 151,35 & 114,68 & 37,00 & $\begin{array}{l}6499,67 \\
\end{array}$ & 329,40 & 23,35 & 306,06 & 109,40 & 238,49 & 238,49 & 71,49 & 361,03 & 41,78 & 6,41 & 38,95 & 120,26 & 36,98 & 36,98 & 103,24 \\
\hline Discoglossus galganoi & 30TUK16 & 100,00 & 82,40 & 110,78 & 37,00 & 6241,99 & 260,71 & $-34,80$ & 295,51 & 35,77 & 167,32 & 168,13 & 10,85 & 646,15 & 76,49 & 19,65 & 32,89 & 203,86 & 82,49 & 87,53 & 181,66 \\
\hline Discoglossus galganoi & 30TUK18 & 100,00 & 85,68 & 110,95 & 37,17 & 6184,79 & 261,81 & $-31,63$ & 293,44 & 40,94 & 169,28 & 170,44 & 14,40 & 600,66 & 72,73 & 19,18 & 32,23 & 188,44 & 80,13 & 85,09 & 164,78 \\
\hline \begin{tabular}{|l} 
Discoglossus galganoi \\
\end{tabular} & 30TUK19 & 100,00 & 92,96 & 111,70 & 37,53 & 6162,45 & 268,20 & $-25,55$ & 293,75 & 55,26 & 175,56 & 177,18 & 21,10 & 536,76 & 66,86 & 17,20 & 32,19 & 168,07 & 73,77 & 77,81 & 143,09 \\
\hline Discoglossus galganoi & 30 TUK24 & 100,00 & 148,45 & 114,23 & 37,00 & 6501,82 & 326,70 & 20,22 & 306,48 & 106,40 & 235,77 & 235,77 & 68,69 & 362,49 & 42,40 & 6,90 & 38,08 & 119,71 & 38,77 & 38,77 & 101,54 \\
\hline Discoglossus galganoi & 30 TUK25 & 100,00 & 135,47 & 113,90 & 37,00 & 6441,15 & 313,42 & 9,08 & 304,35 & 104,99 & 222,13 & 222,33 & 57,18 & 389,31 & 47,34 & 8,90 & 36,26 & 126,13 & 46,22 & 46,31 & 105,63 \\
\hline Discoglossus galganoi & 30 TUK26 & 100,00 & 94,91 & 111,68 & 37,00 & 6277,75 & 272,94 & $-24,75$ & 297,69 & 72,72 & 179,80 & 180,69 & 21,95 & 555,93 & 68,55 & 16,80 & 33,22 & 175,91 & 73,17 & 76,48 & 149,86 \\
\hline Discoglossus galganoi & 30TUK28 & 100,00 & 80,02 & 110,48 & 37,01 & 6176,16 & 256,19 & $-36,62$ & 292,81 & 47,95 & 163,94 & 164,79 & 9,42 & 625,94 & 76,25 & 21,04 & 31,64 & 195,47 & 85,60 & 91,35 & 169,35 \\
\hline \begin{tabular}{|l} 
Discoglossus galganoi \\
\end{tabular} & 30TUK34 & 100,00 & 146,30 & 113,97 & 36,92 & 6520,96 & 324,74 & 17,80 & 306,94 & 108,63 & 233,89 & 233,89 & 66,48 & 363,94 & 43,27 & 7,34 & 37,36 & 119,40 & 40,36 & 40,36 & 99,86 \\
\hline Discoglossus galganoi & 30TUK35 & 100,00 & 129,37 & 113,05 & 36,90 & 6435,29 & 307,23 & 3,53 & 303,71 & 102,52 & 215,81 & 216,31 & 51,82 & 408,73 & 50,69 & 10,20 & 35,68 & 132,82 & 50,62 & 51,16 & 108,39 \\
\hline Discoglossus galganoi & 30 TUK36 & 100,00 & 90,23 & 111,35 & 37,00 & 6263,98 & 268,25 & $-29,08$ & 297,34 & 71,25 & 175,15 & 175,99 & 18,05 & 568,18 & 71,19 & 17,99 & 32,66 & 180,80 & 77,02 & 80,79 & 149,91 \\
\hline Discoglossus galganoi & 30TUK38 & 100,00 & 85,05 & 110,75 & 37,00 & 6175,64 & 261,01 & $-32,71$ & 293,72 & 65,94 & 168,71 & 169,68 & 13,97 & 576,70 & 72,81 & 19,77 & 31,65 & 181,17 & 81,46 & 86,51 & 149,94 \\
\hline Discoglossus galganoi & 30TUK39 & 100,00 & $\begin{array}{l}0,04,10 \\
104,1\end{array}$ & 111,62 & 37,10 & 6184,29 & 278,08 & $\begin{array}{ll}-17,14 \\
-17,14\end{array}$ & 295,22 & \begin{tabular}{|l|l|}
97,69 \\
\end{tabular} & 186,34 & 188,11 & 30,71 & 449,96 & 60,10 & 15,34 & 32,89 & 142,87 & $\begin{array}{l}1,4,47 \\
66,47\end{array}$ & $\begin{array}{l}69,05 \\
69\end{array}$ & 109,53 \\
\hline \begin{tabular}{|l} 
Discoglossus galganoi \\
\end{tabular} & 30TUK43 & 100,00 & 145,94 & 114,02 & 36,11 & 6601,61 & 326,07 & 16,37 & 309,70 & 117,03 & 234,62 & 234,62 & 65,32 & 370,04 & 44,08 & 7,20 & 37,97 & 121,24 & 40,37 & 40,37 & 101,62 \\
\hline \begin{tabular}{|l|} 
Discoglossus galganoi \\
\end{tabular} & 30TUK45 & 100,00 & 146,31 & 112,88 & 36,51 & 6512,57 & 323,18 & 17,87 & 305,31 & 107,34 & 233,69 & 233,69 & 66,26 & 353,29 & 42,51 & 7,55 & 37,12 & 115,64 & 40,71 & 40,71 & 94,95 \\
\hline Discoglossus galganoi & 30 TUK46 & 100,00 & 100,93 & 111,37 & 36,83 & 6305,77 & 278,33 & $-20,28$ & 298,61 & 82,70 & 186,21 & 186,97 & 27,26 & 508,86 & 65,08 & 15,92 & 33,13 & 163,43 & 70,14 & 72,82 & 130,45 \\
\hline Discoglossus galganoi & 30TUK49 & 100,00 & 106,49 & 110,67 & 37,00 & 6192,96 & 279,53 & $-15,58$ & 295,10 & 120,31 & 188,72 & 190,49 & 32,85 & 428,51 & 58,98 & 14,66 & 33,71 & 138,90 & 64,95 & 67,18 & 100,21 \\
\hline Discoglossus galganoi & $\begin{array}{l} \\
30 \text { TUK5 } 53 \\
\end{array}$ & 100,00 & 150,74 & 113,37 & 36,00 & 6632,21 & 330,08 & 20,54 & 309,54 & $\begin{array}{l}109,54 \\
\end{array}$ & 239,77 & 239,77 & $\frac{32,00}{69,22}$ & | 350,35 & 42,01 & 年, & 38,16 & $\begin{array}{ll}117,52 \\
\end{array}$ & \begin{tabular}{|l|l|}
38,30 \\
\end{tabular} & 38,30 & 98,42 \\
\hline Discoglossus galganoi & 30 TUK54 & 100,00 & 131,14 & 112,60 & 36,09 & 6545,57 & 310,48 & 3,62 & 306,87 & 113,72 & 219,40 & 219,58 & 52,15 & 401,54 & 50,23 & 9,73 & 35,69 & 130,93 & 49,81 & 49,99 & 104,96 \\
\hline Discoglossus galganoi & 30 TUK55 & 100,00 & 140,85 & 112,00 & 36,01 & 6541,56 & 318,01 & 12,68 & 305,33 & 110,79 & 228,88 & 228,88 & 60,92 & 365,31 & 44,80 & 8,45 & 35,97 & 118,38 & 44,29 & 44,29 & 96,25 \\
\hline \begin{tabular}{|l|} 
Discoglossus galganoi \\
\end{tabular} & 30 TUK56 & 100,00 & 118,29 & 111,17 & 36,41 & 6398,64 & 294,72 & $-5,92$ & 300,64 & 92,11 & 204,53 & 204,95 & 41,94 & 438,19 & 55,93 & 12,85 & 34,18 & 141,45 & 59,34 & 60,68 & 111,31 \\
\hline Discoglossus galganoi & $\begin{array}{l}\text { 30TUK59 } \\
\end{array}$ & 100,00 & 103,59 & 109,52 & 36,96 & 6183,07 & 275,94 & $-17,90$ & 293,85 & 121,31 & 186,10 & 187,49 & 30,31 & 432,48 & 60,85 & 15,26 & 34,09 & 142,54 & 67,51 & 69,93 & 97,73 \\
\hline \begin{tabular}{|l} 
Discoglossus galganoi \\
\end{tabular} & 30TUK63 & 100,00 & 151,11 & 112,77 & 36,00 & 6661,99 & 330,47 & 20,64 & 309,84 & $\begin{array}{l}108,24 \\
\end{array}$ & 240,56 & 240,56 & 69,26 & 357,44 & 41,84 & 7,00 & 37,62 & 117,66 & 38,88 & 38,88 & 98,11 \\
\hline Discoglossus galganoi & 30TUK64 & 100,00 & 143,47 & 111,86 & 36,00 & 6613,83 & 321,64 & 14,24 & 307,40 & 113,18 & 232,51 & 232,51 & 62,66 & 368,43 & 44,41 & 8,08 & 36,43 & 120,08 & 43,36 & 43,36 & 98,32 \\
\hline Discoglossus galganoi & 30TUK65 & 100,00 & 132,66 & 111,17 & 36,00 & 6534,47 & 309,78 & 5,08 & 304,70 & 113,12 & 220,75 & 220,75 & 53,25 & 387,33 & 48,71 & 9,88 & 35,14 & 125,27 & 49,91 & 49,91 & 99,34 \\
\hline Discoglossus galganoi & 30TUK66 & 100,00 & 113,97 & 110,31 & 36,34 & 6387,97 & 290,11 & $-9,62$ & 299,73 & 93,62 & 200,12 & 200,66 & 38,09 & 443,80 & 57,94 & 13,48 & 33,95 & 143,79 & 62,19 & 63,67 & 109,62 \\
\hline Discoglossus galganoi & $\begin{array}{l}\text { 30TUK68 } \\
\end{array}$ & 100,00 & 112,38 & 108,73 & 36 & 6287,41 & 284,87 & $-10,69$ & 295,57 & 119,11 & 196,26 & 197,41 & 37,17 & 413,36 & 57,04 & 13,77 & 34,30 & 134,88 & 62,91 & 64,32 & 94,84 \\
\hline Discoglossus galganoi & 30TUK69 & 100,00 & 100,89 & 108,38 & 36 & 6170,98 & 272,44 & $-20,11$ & 292,55 & 118,39 & 183,75 & 184,77 & 28,19 & 441,47 & 62,70 & 16,10 & 34,16 & 146,82 & 70,40 & 73,12 & 97,69 \\
\hline Discoglossus galganoi & 30TUK74 & 100,00 & 148,29 & 111,08 & 35,77 & 6661,16 & 326,08 & 18,42 & 307,66 & 106,53 & 237,77 & 237,77 & 66,49 & 360,88 & 42,33 & 7,73 & 36,76 & 118,60 & 41,34 & 41,34 & 97,94 \\
\hline Discoglossus galganoi & 30TUK75 & 100,00 & 136,04 & 110,17 & 35 & 6585,37 & 312,70 & 8,06 & 304,64 & 107,44 & 224,68 & 224,68 & 55,91 & 383,44 & 47,17 & 9,64 & 35,07 & 123,98 & 48,72 & 48,72 & 99,62 \\
\hline Discoglossus galganoi & 30TUK76 & 100,00 & 126,44 & 109,29 & 35 & 6486,12 & 301, & 0,41 & 301,10 & 104,01 & 75 & 2 & 48,02 & 399,10 & 13 & 11,25 & 34,41 & 63 & 54,68 & 54,91 & 99,41 \\
\hline \begin{tabular}{|l} 
Discoglossus galganoi \\
\end{tabular} & 30TUK77 & 100,00 & 128,57 & 108,45 & 3 & 6458,48 & 301,79 & 2,79 & 299,00 & $\begin{array}{r}\mid c 0,01 \\
98,53 \\
\end{array}$ & 215,16 & 21 & $\begin{array}{ll}50,024 \\
503\end{array}$ & 年 & \begin{tabular}{|l|l|l|l|}
49,53 \\
\end{tabular} & $\frac{11,}{11,}$ & $\begin{array}{l}34,419 \\
34,19\end{array}$ & $\begin{array}{ll}124,92 \\
\end{array}$ & $\begin{array}{ll}43,00 \\
53,75\end{array}$ & 54,05 & 96,10 \\
\hline Discoglossus galganoi & 30TUK & 100,00 & 95 & 107,68 & 36,53 & 6167,27 & 267,01 & $-23,95$ & 290,96 & 111,88 & 178,89 & 179,49 & 23,83 & 475,36 & 65,91 & 17,76 & 32,92 & 156,51 & 75,28 & 79,14 & 107,48 \\
\hline Discoglossus galganoi & 30TUK85 & 100,00 & 145,18 & 109,17 & 35,10 & 6648,13 & 321,11 & 16,44 & 304,68 & 102,51 & 234,40 & 234,40 & 63,61 & 368,66 & 42,96 & 8,57 & 35,71 & 121,13 & 43,99 & 43,99 & 99,45 \\
\hline \begin{tabular}{|l|} 
Discoglossus galganoi \\
\end{tabular} & 30 TUK86 & 100,00 & 133,66 & 108,22 & 35,36 & 6561,83 & 308,14 & 6,79 & 301,35 & 98,74 & 221,89 & 222,00 & 53,67 & 390,65 & 47,58 & 10,50 & 34,35 & 125,95 & 51,28 & 51,34 & 101,24 \\
\hline Discoglossus galganoi & 30TUK87 & 100,00 & 133,51 & 107,34 & 35 , & 6530,87 & 306,06 & 7,06 & 299,00 & 93,52 & 220,89 & 221,09 & 53,58 & 385,86 & 47,13 & 10,80 & 34,08 & 41 & 51,68 & 51,78 & 99,15 \\
\hline Discoglossus galganoi & 30TUKद & 100,00 & 12 & 106,42 & 35 & $\begin{array}{ll}6530,08 \\
6402\end{array}$ & 291,84 & $\begin{array}{l}-2,97 \\
-2,97 \\
\end{array}$ & 294,81 & $\begin{aligned} 109,49 \\
109\end{aligned}$ & 205,05 & \begin{tabular}{|l|}
207,34 \\
\end{tabular} & $\begin{array}{l}3,50 \\
43,50\end{array}$ & \begin{tabular}{|l|l|}
303,00 \\
407,06
\end{tabular} & 年, & $\begin{array}{ll}12,90 \\
12,92\end{array}$ & 33,55 & \begin{tabular}{|l|}
130,32 \\
\end{tabular} & $\begin{array}{l}1,00 \\
59,09\end{array}$ & $\begin{array}{ll}1,100 \\
60,40\end{array}$ & $\begin{array}{ll}98,12 \\
98,12\end{array}$ \\
\hline Discoglossus galganoi & 30TUK89 & 100,00 & 98,05 & 106,76 & 36,38 & 6211,20 & 268,70 & $-21,19$ & 289,90 & 113,77 & 181,84 & 182,58 & 25,62 & 478,86 & 64,70 & 17,80 & 32,27 & 155,90 & 74,58 & 78,62 & 110,54 \\
\hline Discoglossus galganoi & 30TUK95 & 100,00 & 145,68 & 108,31 & 35,00 & 6683,45 & 321,35 & 16,88 & 304,47 & 102,77 & 235,29 & 235,29 & 63,46 & 376,91 & 43,02 & 8,79 & 35,68 & 124,77 & 44,47 & 44,47 & 103,72 \\
\hline \begin{tabular}{|l|} 
Discoglossus galganoi \\
\end{tabular} & 30 TUK96 & 100,00 & 142,41 & 107,19 & 35,01 & 6629,52 & 316,24 & 14,88 & 301,36 & 100,00 & 231,30 & 231,30 & 60,84 & 380,83 & 44,26 & 9,53 & 35,10 & 125,81 & 46,72 & 46,72 & 103,71 \\
\hline \begin{tabular}{|l|} 
Discoglossus galganoi \\
\end{tabular} & 30TUK97 & 100,00 & 130,01 & 106,23 & 35,08 & 6535,23 & 302,11 & 4,72 & 297,39 & 91,01 & 217,24 & 217,90 & 50,46 & 406,46 & 48,70 & 11,65 & 33,54 & 131,35 & 54,53 & 54,97 & 105,93 \\
\hline Discoglossus galganoi & $\begin{array}{l}\text { 30TUK99 } \\
30\end{array}$ & $\begin{array}{l}100,00 \\
\end{array}$ & 90,01 & $\begin{array}{l}10,25 \\
106,41\end{array}$ & $\begin{array}{l}30,00 \\
36,45 \\
\end{array}$ & | & 260,11 & \begin{tabular}{|c|c|}
$-21,79$ \\
$-21,4$
\end{tabular} & \begin{tabular}{|l|}
288,76 \\
\end{tabular} & \begin{tabular}{r|r}
105,56 \\
100
\end{tabular} & $\begin{array}{ll}21,24 \\
180,69\end{array}$ & $\begin{array}{l}181,32 \\
182\end{array}$ & \begin{tabular}{l|l}
24,05 \\
24,0
\end{tabular} & $\begin{array}{l}503,40 \\
503,34\end{array}$ & $\begin{array}{ll}40,10 \\
65,66\end{array}$ & $\begin{array}{l}1,003 \\
18,77 \\
\end{array}$ & $\begin{array}{l}30,44 \\
31,15\end{array}$ & \begin{tabular}{l|l}
161,06 \\
161
\end{tabular} & $\begin{array}{l}4,350 \\
76,80\end{array}$ & \begin{tabular}{|l|l|l|}
81,29 \\
\end{tabular} & $\begin{array}{l}120,12 \\
120,12\end{array}$ \\
\hline Discoglossus galganoi & 30TUL04 & 100,00 & 118,51 & 116,89 & 39,44 & 6066,89 & 290,54 & $-2,02$ & 292,56 & 78,15 & 196,72 & 200,28 & 44,73 & 384,11 & 46,77 & 11,48 & 31,17 & 120,88 & 56,10 & 58,44 & 101,31 \\
\hline Discoglossus galganoi & 30TULO9 & 100,00 & 124,48 & 117,00 & 39,01 & 6110,66 & 296,34 & 1,98 & 294,37 & 85,50 & 202,91 & 205,33 & 48,39 & 362,45 & 42,43 & 11,87 & 31,51 & 119,34 & 53,11 & 55,39 & 96,87 \\
\hline Discoglossus & 30TUL18 & 100,00 & 123,31 & 116,90 & 39,00 & 6114,50 & 295,28 & 1,28 & 293,99 & 83,96 & 201, & 204 & 47, & 368,44 & 43,48 & 11,85 & 31,01 & 118,60 & 53,89 & 56,66 & 98,44 \\
\hline Discoglossus galganoi & 30TUL21 & 100,00 & 108,61 & 113,21 & 38,00 & 6144,71 & 281,79 & $-12,28$ & 294,07 & $\begin{array}{ll}127,77 \\
19\end{array}$ & 189,54 & 191,95 & 35,27 & 426,13 & 55,39 & 13,99 & 32,14 & 133,37 & 62,80 & 65,65 & 106,39 \\
\hline
\end{tabular}




\begin{tabular}{|c|c|c|c|c|c|c|c|c|c|c|c|c|c|c|c|c|c|c|c|c|c|}
\hline TAXON & UTM & $\mathrm{km} 2$ & B101 & $\mathrm{B1O2}$ & $\mathrm{BIO3}$ & BIO4 & B105 & B106 & B107 & $\mathrm{B108}$ & B109 & B1010 & B1011 & B1012 & B1013 & B1014 & B1015 & B1016 & B1017 & B1018 & B1019 \\
\hline Discoglossus galganoi & 30TUL29 & 100,00 & 124,35 & 116,46 & 39,00 & 6110,26 & 295,87 & 1,75 & 294,12 & 85,78 & 202,97 & 205,22 & 47,91 & 377,03 & 44,03 & 12,18 & 30,50 & 120,93 & 54,84 & 58,46 & 101,84 \\
\hline Discoglossus galganoi & 30TUL30 & 100,00 & 95,80 & 111,23 & 37,54 & 6133,05 & 269,38 & $-23,46$ & 292,84 & 103,81 & 177,94 & 179,37 & 23,76 & 485,58 & 64,25 & 17,28 & 32,02 & 153,65 & 72,46 & 76,43 & 119,35 \\
\hline \begin{tabular}{|l} 
Discoglossus galganoi \\
\end{tabular} & 30TUL32 & 100,00 & 114,95 & 112,78 & 38,00 & 6158,72 & 286,66 & $-6,86$ & 293,52 & 135,48 & 195,63 & 197,95 & 40,37 & 393,73 & 51,45 & 13,05 & 32,16 & 124,57 & 59,27 & 61,92 & 96,10 \\
\hline Discoglossus galganoi & 30TUL38 & 100,00 & 122,01 & 115,66 & 39,00 & 6139,48 & 293,63 & 0,19 & 293,44 & 82,82 & 201,31 & 203,60 & 45,82 & \begin{tabular}{|c|}
386,17 \\
\end{tabular} & 45,38 & 12,31 & 30,30 & 121,43 & 56,31 & 60,28 & 103,48 \\
\hline Discoglossus galganoi & 30TUL39 & 100,00 & 124,29 & 115,97 & 39,00 & 6127,98 & 295,91 & 2,29 & 293,62 & 85,70 & 203,32 & 205,50 & 47,89 & 385,62 & 44,94 & 12,25 & 30,20 & 122,30 & 55,58 & 59,60 & 105,06 \\
\hline Discoglossus galganoi & 30TUL50 & 100,00 & 106,06 & 109,31 & 36,96 & 6168,92 & 277,19 & $-15,90$ & 293,08 & 124,70 & 188,09 & 189,54 & 32,53 & 414,73 & 58,77 & 15,01 & 34,32 & 137,72 & 65,86 & 68,31 & 92,25 \\
\hline Discoglossus galganoi & 30TUL51 & 100,00 & 111,96 & 109,47 & 36,99 & \begin{tabular}{ll|}
6186,67 \\
\end{tabular} & 282,21 & $-10,26$ & 292,47 & 131,75 & 193,70 & 195,51 & 37,53 & 397,01 & 54,77 & 14,28 & 33,63 & 130,34 & 62,25 & 64,91 & 90,30 \\
\hline Discoglossus galganoi & $\begin{array}{l}\text { 30TUL55 } \\
\end{array}$ & 100,00 & 120,87 & 111,34 & 37,96 & 6203,96 & 290,23 & \begin{tabular}{|l|l|}
$-1,04$ \\
\end{tabular} & 291,27 & 139,61 & 201,57 & 203,75 & 44,41 & 386,99 & 48,02 & 12,09 & 31,04 & 120,80 & 56,94 & 61,18 & 97,56 \\
\hline Discoglossus galganoi & 30TUL56 & 100,00 & 122,10 & 112,07 & 38,00 & 6182,96 & 291,54 & $-0,10$ & 291,64 & 108,31 & 202,33 & 204,53 & 45,69 & 388,29 & 47,19 & 12,05 & 30,90 & 120,47 & 56,23 & 61,05 & 100,49 \\
\hline Discoglossus galganoi & 30TUL57 & 100,00 & 123,07 & 112,78 & 38,02 & 6181,97 & 293,06 & 0,34 & 292,72 & 84,41 & 203,18 & 205,50 & 46,37 & 391,90 & 46,43 & 12,03 & 30,66 & 121,94 & 56,41 & 61,21 & 103,59 \\
\hline Discoglossus galganoi & 30TUL58 & 100,00 & 123,85 & 113,52 & 38,29 & 6158,24 & 294,08 & 1,67 & 292,41 & 85,56 & 203,82 & 205,75 & 47,39 & 397,03 & 46,06 & 12,08 & 30,10 & 123,65 & 56,97 & 61,73 & 106,99 \\
\hline Discoglossus galganoi & 30TUL59 & 100,00 & 124,59 & 114,18 & 38,41 & 6141,55 & 294,91 & 2,19 & 292,73 & 86,62 & 203,97 & 205,89 & 47,84 & 403,19 & 46,57 & 12,84 & 29,82 & 125,94 & 57,73 & 62,66 & 110,59 \\
\hline \begin{tabular}{|l} 
Discoglossus galganoi \\
\end{tabular} & 30TUL69 & 100,00 & 122,60 & 112,92 & 38,06 & 6127,94 & 292,03 & $-0,01$ & 292,04 & 85,78 & 202,30 & 203,99 & 46,31 & 412,80 & 47,56 & 13,17 & 29,66 & 128,49 & 58,56 & 65,24 & 111,82 \\
\hline Discoglossus galganoi & 30TUL70 & 100,00 & 95,84 & 107,16 & 36,46 & 6136,64 & 265,89 & $-23,49$ & 289,38 & 112,59 & 178,64 & 179,37 & 24,13 & 465,38 & 65,18 & 17,91 & 33,21 & 154,68 & 75,01 & 79,26 & 103,41 \\
\hline Discoglossus galganoi & 30TUL71 & 100,00 & 106,17 & 106,36 & 36,08 & 6191,89 & 274,05 & $-15,29$ & 289,34 & 124,98 & 188,57 & 189,81 & 32,22 & 418,26 & 58,89 & 15,86 & 34,05 & 140,14 & 67,73 & 71,37 & 91,20 \\
\hline Discoglossus galganoi & 30TUL72 & 100,00 & 110,81 & 106,15 & 36,19 & 6232,58 & 277,81 & $-10,92$ & 288,72 & 130,18 & 193,23 & 194,73 & 35,67 & 414,40 & 55,85 & 14,89 & 32,81 & 136,22 & 65,05 & 69,51 & 94,27 \\
\hline Discoglossus galganoi & $\begin{array}{l}\text { 30TUL73 } \\
\end{array}$ & 100,00 & 114,46 & 106,51 & 36,45 & 6257,94 & 281,22 & \begin{tabular}{c|c|}
$-7,24$ \\
\end{tabular} & 288,46 & 134,77 & 196,88 & 198,54 & 38,53 & 411,88 & 53,39 & 13,91 & 31,75 & 132,72 & 62,76 & 67,76 & 97,63 \\
\hline \begin{tabular}{|l} 
Discoglossus galganoi \\
\end{tabular} & 30TUL78 & 100,00 & 120,36 & 110,48 & 37,54 & 6159,98 & 288,13 & $-2,19$ & 290,31 & 96,41 & 200,69 & 202,44 & 44,06 & 417,91 & 48,99 & 13,38 & 29,81 & 129,16 & 59,82 & 67,49 & 109,73 \\
\hline Discoglossus galganoi & 30TUL83 & 100,00 & 116,33 & 104,58 & 36,00 & 6316,88 & 281,53 & $-5,29$ & 286,81 & 137,03 & 199,51 & 201,18 & 39,40 & 422,53 & 52,92 & 13,46 & 31,27 & 134,14 & 62,60 & 68,32 & 102,75 \\
\hline Discoglossus galganoi & 30TUL89 & 100,00 & 115,78 & 109,77 & 37,20 & 6117,25 & 282,95 & $-6,84$ & 289,78 & 126,76 & 196,10 & 197,42 & 40,47 & 440,64 & 51,64 & 14,72 & 28.99 & 135,42 & 63,55 & 73,62 & 114,46 \\
\hline Discoglossus galganoi & 30TUL90 & 100,00 & 88,55 & 106,60 & 36,78 & 6147,86 & 258,66 & $-27,33$ & 285,99 & 96,43 & 172,41 & 172,71 & 18,22 & 541,27 & 69,7 & 20,88 & 30,08 & 172,62 & 83,43 & 88,12 & 130,46 \\
\hline \begin{tabular}{|l} 
Discoglossus galganoi \\
\end{tabular} & 30TUL91 & 100,00 & 103,04 & 104,20 & 36,11 & 6268,38 & 269,75 & $-15,97$ & 285,72 & 120,93 & 187,10 & 187,99 & 28,96 & 474,41 & 61,07 & 16,82 & 31,16 & 152,40 & 72,34 & 78,09 & 112,79 \\
\hline \begin{tabular}{|l} 
Discoglossus galganoi \\
\end{tabular} & 30TUL92 & 100,00 & 112,51 & 102,63 & 35,62 & \begin{tabular}{|c|c|}
6364,53 \\
\end{tabular} & 276,80 & $-8,16$ & 284,96 & 131,29 & \begin{tabular}{|l|}
196,61 \\
\end{tabular} & 198,26 & 35,66 & 449,85 & 55,77 & 14,37 & 31,18 & 142,48 & 66,20 & 72,41 & 109,86 \\
\hline Discoglossus galganoi & 30TUL97 & 100,00 & 119,23 & 106,41 & 36,72 & 6233,07 & 284,23 & $-2,50$ & 286,73 & 91,11 & 200,99 & 202,45 & 42,55 & 432,63 & 50,53 & 13,55 & 29,47 & 133,64 & 62,01 & 70,22 & 111,88 \\
\hline Discoglossus galganoi & 30TUM06 & 100,00 & 118,18 & 115,99 & 39,44 & 5893,34 & 287,03 & $-3,74$ & 290,76 & 83,73 & 194,35 & 196,05 & 44,21 & 448,20 & 55,47 & 18,38 & 30,23 & 155,69 & 73,56 & 74,99 & 120,66 \\
\hline Discoglossus galganoi & 30TUM17 & 100,00 & 117,29 & 115,08 & 39,24 & 5806,82 & 284,13 & $-4,69$ & 288,82 & 84,79 & 192,30 & 194,02 & 44,52 & 469,07 & 58,02 & 20,24 & 29,21 & 161,68 & 78,54 & 80,92 & 124,26 \\
\hline Discoglossus galganoi & 30TUM22 & 100,00 & 116,34 & 117,00 & 39,00 & 60033,32 & 288,63 & $-5,76$ & \begin{tabular}{|l|l|}
294,39 \\
\end{tabular} & 80,11 & $\begin{array}{l}194,44 \\
\end{array}$ & $\begin{array}{l}194,626 \\
\end{array}$ & 41,35 & 421,60 & $\begin{array}{l}40,562 \\
49,5\end{array}$ & 15,54 & 29,37 & 136,94 & 63,37 & $\begin{array}{l}00,327 \\
68,72\end{array}$ & 114,20 \\
\hline Discoglossus galganoi & 30TUM23 & 100,00 & 120,17 & 116,92 & 39,15 & 5964,66 & 290,75 & $-2,26$ & 293,01 & 85,50 & 197,48 & 199,12 & 45,63 & 417,02 & 49,59 & 15,83 & 29,43 & 137,30 & 63,17 & 68,10 & 112,54 \\
\hline Discoglossus galganoi & 30TUM25 & 100,00 & 118,05 & 116,00 & 39,00 & 5875,11 & 286,80 & $-5,09$ & 291,90 & 85,13 & 194,26 & 195,84 & 44,66 & 443,61 & 53,41 & 18,29 & 28,99 & 148,39 & 69,82 & 75,11 & 118,03 \\
\hline Discoglossus galganoi & 30TUM33 & 100,00 & 116,86 & 116,91 & 39,00 & 5964,17 & 287,89 & $-6,16$ & 294,05 & 82,65 & 194,20 & 196,15 & 42,60 & 435,02 & 51,10 & 16,41 & 28,95 & 140,78 & 65,07 & 72,13 & 117,56 \\
\hline Discoglossus galganoi & 30TUM36 & 100,00 & 117,71 & 114,89 & 39,00 & 5767,21 & 284,04 & $-5,85$ & 289,89 & 87,57 & 192,61 & 194,06 & 45,82 & 462,38 & 55,49 & 19,68 & 28,04 & 153,60 & 73,11 & 80,41 & 121,46 \\
\hline \begin{tabular}{|l} 
Discoglossus galganoi \\
\end{tabular} & 30TUM38 & 100,00 & 114,84 & 112,86 & 39,01 & 5647,56 & 277,71 & 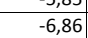 & \begin{tabular}{|l|}
284,57 \\
\end{tabular} & 86,00 & $\begin{array}{l}188,38 \\
\end{array}$ & $\begin{array}{l}189,59 \\
\end{array}$ & $\begin{array}{l}43,02 \\
44,63 \\
\end{array}$ & $\begin{array}{l}402,30 \\
503,23\end{array}$ & $\begin{array}{l}0,4+25 \\
61,2\end{array}$ & 22,71 & $\begin{array}{l}27,34 \\
27,38\end{array}$ & $\begin{array}{ll}169,15 \\
\end{array}$ & $\begin{array}{l}3,11 \\
83,95 \\
\end{array}$ & \begin{tabular}{l|l}
$89,87+87$ \\
\end{tabular} & 130,77 \\
\hline Discoglossus galganoi & 30TUM39 & 100,00 & 112,70 & 111,60 & 39,02 & 5574,34 & 273,58 & $-7,33$ & 280,91 & 84,59 & 185,41 & 186,47 & 43,48 & 530,67 & 64,97 & 24,63 & 27,08 & 179,08 & 90,80 & 95,92 & 137,57 \\
\hline Discoglossus galganoi & 30TUM47 & 100,00 & 115,94 & 113,37 & 39,00 & 5664,99 & 279,62 & $-7,53$ & 287,15 & 88,30 & 189,80 & 191,02 & 45,72 & 487,52 & 58,13 & 21,51 & 27,29 & 160,58 & 77,79 & 86,99 & 126,13 \\
\hline Discoglossus galganoi & 30TUM48 & 100,00 & 113,35 & 112,18 & 39,00 & 5604,36 & 275,24 & $-8,78$ & 284,02 & 86,09 & 186,47 & 187,52 & 43,78 & 513,62 & 61,56 & 23,37 & 26,75 & 169,87 & 84,42 & 92,81 & 132,54 \\
\hline Discoglossus galganoi & 30TUM49 & 100,00 & 109,31 & 110,90 & 39,00 & 5549,84 & 269,61 & $-10,74$ & 280,35 & 82,26 & 181,95 & 182,82 & 40,77 & 548,23 & 65,97 & 25,72 & 26,17 & 181,77 & 92,73 & 100,16 & 141,59 \\
\hline Discoglossus galganoi & 30TUM51 & 100,00 & 122,95 & 115,51 & 38,98 & 6066,38 & 293,71 & 0,46 & 293,25 & 63,90 & 201,60 & 203,15 & 46,92 & 423,85 & 49,38 & 13,88 & 29,50 & 134,49 & 59,79 & 66,21 & 119,16 \\
\hline Discoglossus galganoi & 30TUM54 & 100,00 & 118,23 & 115,84 & 38,94 & 5842,82 & 286,59 & $-7,87$ & 294,45 & 89,16 & 194,26 & 195,91 & 45,86 & 446,61 & 51,50 & 17,21 & 28,76 & 142,14 & 64,70 & 76,95 & 117,39 \\
\hline Discoglossus galganoi & 30TUM57 & 100,00 & 115,86 & 112,71 & 39,00 & 5627,80 & 278,45 & $-8,25$ & 286,70 & 90,00 & 189,36 & 190,38 & 46,43 & 490,84 & 57,69 & 21,75 & 26,95 & 159,46 & 76,90 & 88,51 & 125,72 \\
\hline Discoglossus galganoi & 30TUM59 & 100,00 & 110,88 & 109,56 & 39,00 & 5495,01 & 268,95 & $-9,26$ & 278,22 & 85,30 & 182,86 & 183,40 & 43,01 & 548,82 & 65,37 & 25,64 & 25,81 & 180,01 & 91,50 & 100,58 & 140,82 \\
\hline Discoglossus galganoi & 30TUM60 & 100,00 & 122,48 & 113,60 & 38,7 & 6089,17 & 292,07 & $-0,49$ & 292,56 & 86,07 & 201,70 & 203,24 & 46,55 & 419,17 & 48,36 & 13,4 & 29,68 & 131,25 & 58,86 & 66,41 & 114,57 \\
\hline Discoglossus galganoi & 30TUM61 & 100,00 & 120,32 & 114,40 & 38,47 & 6036,22 & 290,06 & $-3,31$ & 293,37 & 85,23 & 198,96 & 200,41 & 45,18 & 431,13 & 49,61 & 14,2 & 29,26 & 134,87 & 60,73 & 69,65 & 117,55 \\
\hline Discoglossus galganoi & $\begin{array}{l} \\
\text { 30TUM63 } \\
\end{array}$ & 100,00 & 119,17 & 115,22 & 38,41 & 5885,32 & 287,68 & $-7,44$ & 295,12 & 89,93 & 195,93 & $\begin{array}{ll}2197,41 \\
\end{array}$ & 46,32 & 439,86 & 50,41 & 16,09 & 29,01 & 138,04 & 62,10 & 75,25 & 115,75 \\
\hline Discoglossus galganoi & 30TUM65 & 100,00 & 120,56 & 114,66 & 38,52 & 5723,75 & 285,82 & $-8,01$ & 293,82 & 95,88 & $\begin{array}{l}194,97 \\
\end{array}$ & 196,42 & 50,15 & 447,48 & 51,29 & 18,07 & 28,54 & 141,68 & 64,24 & 79,89 & 113,66 \\
\hline Discoglossus galganoi & 30TUM71 & 100,00 & 119,13 & 112,84 & 38,00 & 6011,37 & 287,38 & $-5,33$ & 92,71 & 86,99 & 197,57 & 199,08 & 44 & 434,87 & 49,9 & 14,78 & 28,91 & 93 & 61,43 & 72,25 & 115,50 \\
\hline Discoglossus galganoi & 30TUM75 & 100,00 & 118 & 113 & 38 & 5711,37 & 283,52 & \begin{tabular}{|c|c|}
$-10,29$ \\
$-1,5$
\end{tabular} & 293,81 & \begin{tabular}{|l|}
104,70 \\
60
\end{tabular} & 193,40 & $\begin{array}{l}194,54 \\
1940\end{array}$ & 49,02 & 454,39 & $\frac{43}{52}-13 x$ & & 28,52 & & $\begin{array}{l}64,84 \\
64\end{array}$ & 82,43 & 113,56 \\
\hline Discoglossus galganoi & 30TUM? & 100,00 & 118 & 11 & 38,03 & 5644,23 & 280,66 & $-9,05$ & 289,70 & 95,17 & 192,05 & 193,00 & 49,30 & 471,03 & 53,46 & $20, \mathrm{C}$ & 27,54 & 148,38 & 69,53 & 85,92 & 117,91 \\
\hline Discoglossus galganoi & 30TUM89 & 100,00 & 112,65 & 104,88 & 38,02 & 5418,04 & 265,75 & $-5,36$ & 271,10 & 88,43 & 183,75 & 184,00 & 45,94 & 558,20 & 64,41 & 25,91 & 24,59 & 178,22 & 91,90 & 102,24 & 142,23 \\
\hline Discoglossus galganoi & 30TUM99 & 100,00 & 112,43 & 102,95 & 38,00 & 5414,49 & 264,02 & $-3,80$ & 267,82 & 87,41 & 183,62 & 183,69 & 45,63 & 564,68 & 64,61 & 26,34 & 24,06 & 179,09 & 93,83 & 101,38 & 144,31 \\
\hline Discoglossus galganoi & 30TUNOO & 100,00 & 113,28 & 113,74 & 39,77 & 5700,10 & 277,23 & $-6,27$ & 28 & 81,03 & 188,47 & 188,47 & 41 & 531,77 & 67,99 & 24,85 & 30,01 & 38 & 94,56 & 94,56 & 140,40 \\
\hline \begin{tabular}{|l} 
Discoglossus galganoi \\
\end{tabular} & 30TUN01 & 100,00 & 11 & 112 & $\begin{array}{l}35, \\
39,\end{array}$ & 5628,60 & 272,93 & $\begin{array}{l}-0,27 \\
-7,22\end{array}$ & 280,16 & $\begin{array}{l}\mid l, 1,3 \\
79,47\end{array}$ & $\begin{array}{l}10,41 \\
185,17\end{array}$ & \begin{tabular}{|l|}
$185,4,17$ \\
185
\end{tabular} & $\begin{array}{l}41,04 \\
40,30\end{array}$ & 563,92 & $\mid \begin{array}{l}\mid 7,2,45 \\
72\end{array}$ & $\begin{array}{ll}24,03 \\
26,71\end{array}$ & 29,77 & $\begin{array}{l}190,80 \\
199,85 \\
\end{array}$ & \begin{tabular}{|c|}
401,55 \\
105
\end{tabular} & \begin{tabular}{|l|l|}
101,55 \\
10,0
\end{tabular} & $\begin{array}{r}44,40 \\
148,49\end{array}$ \\
\hline Discoglossus galganoi & 30TUN12 & 100,00 & 105,21 & 110,09 & 39,98 & 5484,01 & 263,13 & $-10,52$ & 273,65 & 75,65 & 177,55 & 177,55 & 36,96 & 619,48 & 78,58 & 30,70 & 27,93 & 215,26 & 113,46 & 113,46 & 162,66 \\
\hline Discoglossus galganoi & 30 TUN24 & 100,00 & 90,07 & 105,16 & 39,77 & 5281,60 & 241,81 & $-20,16$ & 261,97 & 62,69 & 160,11 & 160,14 & 25,69 & 760,14 & 94,15 & 38,96 & 25,36 & 256,25 & $\mid 140,39$ & $\mid 140,77$ & 203,05 \\
\hline Discoglossus galganoi & 30TUN41 & 100,00 & 101,74 & 107,86 & 39,02 & 5420,32 & 257,66 & $-14,34$ & 271,99 & 75,09 & 173,02 & 173,41 & 35,02 & 627,36 & 76,11 & 30,86 & 25,24 & 208,63 & 111,03 & 116,13 & 163,18 \\
\hline Discoglossus galganoi & 30TUN42 & 100,00 & 97,22 & 106,17 & 39,05 & 5354,13 & 250,99 & $-16,26$ & 267,24 & 70,70 & 167,87 & 16 & 31 & 674,79 & 81,94 & 33 & 24,87 & 224,17 & 121,51 & 124,96 & 176 \\
\hline \begin{tabular}{|l|} 
Discoglossus galganoi \\
\end{tabular} & $\begin{array}{l}30 \text { UN } 43 \\
30\end{array}$ & 100,00 & $\begin{array}{l}91,2<2 \\
93,60\end{array}$ & 104,56 & $\begin{array}{ll}39,16 \\
39,16\end{array}$ & $\mid 5282,69$ & 244,86 & $\begin{array}{l}-17,20 \\
-17,88\end{array}$ & \begin{tabular}{|l|}
262,73 \\
\end{tabular} & 60,0 & $\begin{array}{l}163,50 \\
163\end{array}$ & \begin{tabular}{|l|}
160,535 \\
163,5
\end{tabular} & $\begin{array}{l}31,00 \\
29,04 \\
\end{array}$ & 719,69 & $\begin{array}{l}1,344 \\
87,54\end{array}$ & $\begin{array}{l}30,1 \\
36,59 \\
\end{array}$ & 24,015 & $\begin{array}{l}234,11 \\
238,82 \\
\end{array}$ & \begin{tabular}{|l|}
131,28 \\
131
\end{tabular} & \begin{tabular}{|l|}
133,60 \\
\end{tabular} & $\begin{array}{l}1 / 10,00 \\
189,55\end{array}$ \\
\hline Discoglossus galganoi & 30TUN50 & 100,00 & 108,18 & 107,94 & 39,00 & 5427,27 & 264,00 & $-9,95$ & 273,95 & 82,67 & 179,40 & 179,86 & 41,34 & 581,56 & 69,70 & 27,79 & 25,18 & 191,44 & 99,60 & 107,21 & 149,70 \\
\hline Discoglossus galganoi & 30TUN51 & 100,00 & 102,94 & 106,35 & 39,00 & 5369,64 & 256,83 & $-12,45$ & 269,28 & 77,30 & 173,72 & 173,89 & 37,00 & 628,56 & 75,55 & 30,81 & 24,62 & 206,99 & 110,28 & 115,75 & 162,79 \\
\hline Discoglossus & 30TUN62 & 100,00 & 100,53 & 103,01 & 39,00 & 5256,10 & 249,99 & $-11,71$ & 261,70 & 75,86 & 170,14 & 170,17 & 36,28 & 672,64 & 80,35 & 33,38 & 23,89 & 219 & 119,62 & 122,53 & 174,97 \\
\hline \begin{tabular}{|l} 
Discoglossus galganoi \\
\end{tabular} & 30TUN66 & 100,00 & 64,93 & 96,69 & 38,92 & 085,61 & 208,57 & \begin{tabular}{|c|c|}
$-37,11$ \\
\end{tabular} & 245,68 & 39,03 & 133,55 & 133,73 & \begin{tabular}{|c|}
4,202 \\
4
\end{tabular} & 90,62 & $\begin{array}{l}15,28 \\
15,0\end{array}$ & 52,41 & 21,68 & 315,93 & 182,13 & 182,35 & 272,32 \\
\hline
\end{tabular}




\begin{tabular}{|c|c|c|c|c|c|c|c|c|c|c|c|c|c|c|c|c|c|c|c|c|c|}
\hline TAXON & UTM & $\overline{\mathrm{km} 2}$ & BIO1 & $\overline{B 102}$ & $\mathrm{BIO3}$ & $\begin{array}{ll}B 104 \\
\end{array}$ & B105 & B106 & B107 & B108 & B109 & BIO10 & BIO11 & $\overline{B 1012}$ & BIO13 & BIO14 & BIO15 & B1016 & BIO17 & BIO18 & B1019 \\
\hline Discoglossus galganoi & 30TUN71 & 100,00 & 103,74 & 103,20 & 38,69 & 5300,40 & 254,09 & $-10,03$ & 264,13 & 79,26 & 173,72 & 173,73 & 38,92 & 638,52 & 75,21 & 31,10 & 23,84 & 206,53 & 110,94 & 114,36 & 165,02 \\
\hline Discoglossus galganoi & 30TUN73 & 100,00 & 95,15 & 99,90 & 38,93 & 5169,28 & 240,88 & $-13,69$ & 254,58 & $\begin{array}{l}70,69 \\
\end{array}$ & $\begin{array}{l}163,85 \\
\end{array}$ & $\begin{array}{l}163,85 \\
\end{array}$ & \begin{tabular}{|c|}
32,27 \\
\end{tabular} & 733,92 & 86,87 & 37,00 & 22,96 & 237,79 & \begin{tabular}{ll|l}
132,46 \\
\end{tabular} & 132,82 & 192,86 \\
\hline Discoglossus galganoi & 30TUN76 & 100,00 & 80,56 & 94,80 & 38,99 & 4971,70 & 219,32 & $-21,07$ & 240,39 & 56,74 & \begin{tabular}{l|l|l|l|l}
147,03 \\
\end{tabular} & 147,40 & 21,09 & 907,74 & 107,14 & 47,28 & 22,14 & 292,77 & $\begin{array}{l}168,25 \\
\end{array}$ & \begin{tabular}{l|l}
168,85 \\
\end{tabular} & 245,53 \\
\hline Discoglossus galganoi & 30TUN79 & 100,00 & 123,58 & 78,04 & 39,04 & 4201,48 & 231,11 & 33,69 & \begin{tabular}{l|l|l|l|}
197,42 \\
\end{tabular} & \begin{tabular}{l|l}
105,42 \\
\end{tabular} & \begin{tabular}{l|l|l}
177,32 \\
\end{tabular} & 179,72 & 71,90 & 867,25 & 110,66 & 40,79 & 26,48 & 298,05 & \begin{tabular}{|l|l|}
152,39 \\
\end{tabular} & $\begin{array}{l}167,59 \\
\end{array}$ & 234,12 \\
\hline Discoglossus galganoi & 30TUN81 & 100,00 & 106,50 & 101,19 & 38,20 & 5260,10 & 254,22 & $-6,16$ & 260,38 & 82,25 & \begin{tabular}{|c|}
175,87 \\
\end{tabular} & \begin{tabular}{|c|}
175,88 \\
\end{tabular} & 41,89 & \begin{tabular}{l|l}
635,95 \\
\end{tabular} & 74,48 & 30,76 & 23,36 & 204,92 & \begin{tabular}{l|l|l|}
110,45 \\
\end{tabular} & \begin{tabular}{|c|}
112,24 \\
\end{tabular} & 164,48 \\
\hline Discoglossus galganoi & 30TUN84 & 100,00 & 95,87 & 95,97 & 38,78 & 5037,41 & 235,94 & $-9,26$ & 245,21 & 72,10 & 163,01 & 163,01 & 34,63 & 773,53 & 91,48 & 38,99 & 22,55 & 250,52 & 141,46 & \begin{tabular}{|l|l}
141,46 \\
\end{tabular} & 205,00 \\
\hline Discoglossus galganoi & 30TUN97 & 100,00 & 96,77 & 86,74 & 38,76 & 4674,80 & 222,08 & 0,53 & 221,54 & 75,08 & \begin{tabular}{|l|l|l|}
157,79 \\
\end{tabular} & 159,46 & \begin{tabular}{ll|l}
40,07 \\
\end{tabular} & 905,34 & 108,19 & 45,29 & 22,97 & 296,79 & 165,17 & $\begin{array}{ll}171,07 \\
\end{array}$ & 246,67 \\
\hline Discoglossus galganoi & 30TUN99 & 100,00 & 129,86 & 72,59 & 38,23 & 4062,29 & 231,07 & 43,82 & 187,25 & 112,45 & \begin{tabular}{|l|l|}
181,34 \\
\end{tabular} & \begin{tabular}{ll|}
183,99 \\
\end{tabular} & 79,52 & 896,31 & 113,76 & 40,26 & 27,29 & 311,29 & \begin{tabular}{|c|}
153,49 \\
\end{tabular} & \begin{tabular}{ll|}
173,86 \\
\end{tabular} & 247,30 \\
\hline Discoglossus galganoi & 30TUP00 & 100,00 & 126,74 & 83,46 & 41,44 & 4057,12 & 235,08 & 36,23 & 198,85 & \begin{tabular}{|l|l|l|l|l}
108,39 \\
\end{tabular} & \begin{tabular}{l|l}
178,43 \\
\end{tabular} & 181,14 & 77,34 & 829,34 & 111,57 & 41,76 & 27,54 & 281,62 & \begin{tabular}{|c|}
149,04 \\
\end{tabular} & \begin{tabular}{l|l|l|}
159,96 \\
\end{tabular} & 210,49 \\
\hline Discoglossus galganoi & 30TUP01 & 98,00 & 132,84 & 77,05 & \begin{tabular}{l|l}
40,95 \\
\end{tabular} & 3870,73 & 232,49 & 46,63 & \begin{tabular}{|c|}
185,86 \\
\end{tabular} & 115,81 & \begin{tabular}{|c|}
181,85 \\
\end{tabular} & 184,96 & 85,62 & 834,29 & 112,99 & 41,12 & 27,93 & 284,33 & 147,81 & \begin{tabular}{|c|}
160,77 \\
\end{tabular} & 212,72 \\
\hline Discoglossus galganoi & 30TUP02 & 40,00 & 136,08 & 73,30 & \begin{tabular}{l|l|}
40,65 \\
\end{tabular} & 3764,03 & 230,71 & $\begin{array}{l}52,45 \\
\end{array}$ & 178,26 & 119,80 & 183,68 & 186,80 & 90,21 & 839,39 & 114,00 & 40,95 & 28,24 & 286,77 & \begin{tabular}{|l|l|}
147,48 \\
\end{tabular} & \begin{tabular}{|c|}
161,79 \\
\end{tabular} & 215,03 \\
\hline Discoglossus galganoi & 30TUP10 & 100,00 & 128,41 & 81,58 & 40,93 & 4066,27 & 235,21 & 38,27 & 196,94 & 110,11 & 180,23 & \begin{tabular}{|c|}
182,88 \\
\end{tabular} & 78,61 & 820,87 & 109,97 & 40,75 & 27,43 & \begin{tabular}{|l|l|}
280,47 \\
\end{tabular} & \begin{tabular}{|l|l|}
146,78 \\
\end{tabular} & 158,76 & 210,20 \\
\hline Discoglossus galganoi & 30TUP11 & 96,00 & 128,99 & 78,27 & 40,69 & 3961,70 & 231,50 & 41,54 & \begin{tabular}{ll|}
189,96 \\
\end{tabular} & \begin{tabular}{ll|l}
111,36 \\
\end{tabular} & \begin{tabular}{|l|l|}
179,31 \\
\end{tabular} & 182,19 & 80,64 & 846,18 & 113,34 & 41,76 & 27,45 & 289,11 & \begin{tabular}{|c|}
150,50 \\
\end{tabular} & \begin{tabular}{|l|l}
163,76 \\
\end{tabular} & 218,27 \\
\hline Discoglossus galganoi & 30TUP12 & 20,00 & 136,32 & 73,40 & 40,36 & 3793,60 & 231,56 & 52,20 & \begin{tabular}{|c|}
179,36 \\
\end{tabular} & 120,20 & \begin{tabular}{|l|l|l|}
184,20 \\
\end{tabular} & \begin{tabular}{|c|}
187,40 \\
\end{tabular} & 90,04 & 836,84 & 113,28 & 40,60 & 28,04 & 287,08 & \begin{tabular}{l|l}
147,12 \\
\end{tabular} & \begin{tabular}{l|l}
161,92 \\
\end{tabular} & 215,56 \\
\hline Discoglossus galganoi & 30TUP20 & 100,00 & 134,88 & 77,88 & 40,29 & 3995,93 & 237,12 & 46,48 & \begin{tabular}{|l|l|l|}
190,63 \\
\end{tabular} & \begin{tabular}{|c|}
117,35 \\
\end{tabular} & \begin{tabular}{|l|l|}
185,62 \\
\end{tabular} & 188,38 & 85,6 & 802,19 & 107,72 & 38,63 & 27,9 & 276,54 & 141,34 & 155,20 & 206,81 \\
\hline Discoglossus galganoi & 30TUP21 & 65,00 & 132,62 & 76,72 & 40,33 & 3942,74 & 233,28 & 45,64 & 187,64 & 115,31 & \begin{tabular}{ll|}
182,62 \\
\end{tabular} & 185,54 & 84,31 & 833,38 & 111,64 & 40,50 & 27,68 & 286,53 & 147,33 & 161,81 & 215,78 \\
\hline Discoglossus galganoi & 30TUP30 & 100,00 & 126,56 & 80,18 & 40,24 & 4107,21 & 233,28 & 36,55 & \begin{tabular}{|c|}
196,73 \\
\end{tabular} & \begin{tabular}{|l|l|}
108,50 \\
\end{tabular} & \begin{tabular}{|c|}
178,94 \\
\end{tabular} & $\begin{array}{l}181,48 \\
\end{array}$ & 76,06 & 836,94 & 110,50 & 40,98 & 27,01 & 287,16 & \begin{tabular}{|c|}
149,31 \\
\end{tabular} & $\begin{array}{l}162,56 \\
\end{array}$ & 217,93 \\
\hline Discoglossus galganoi & 30TUP31 & 47,00 & 138,43 & 74,00 & 40,01 & 3894,79 & 235,65 & 52,49 & 183,16 & 121,57 & 187,60 & 190,48 & 90,33 & 816,59 & \begin{tabular}{|l|l|}
109,47 \\
\end{tabular} & 38,40 & 28,28 & 283,51 & $\begin{array}{ll}141,96 \\
\end{array}$ & 158,43 & 213,59 \\
\hline Discoglossus galganoi & 30TUP40 & 100,00 & 125,65 & 79,37 & 39,98 & 4126,27 & 232,18 & 35,84 & \begin{tabular}{|l|l|}
196,34 \\
\end{tabular} & \begin{tabular}{l|l}
107,63 \\
\end{tabular} & \begin{tabular}{|l|l}
178,33 \\
\end{tabular} & 180,71 & \begin{tabular}{|c|}
74,97 \\
\end{tabular} & 848,13 & 111,03 & 41,13 & 26,89 & 291,40 & \begin{tabular}{l|l}
150,82 \\
\end{tabular} & \begin{tabular}{ll|}
164,76 \\
\end{tabular} & 223,18 \\
\hline Discoglossus galganoi & 30TUP90 & 55,00 & 139,28 & 68,17 & 38,0 & 3876,10 & 233,27 & 56,65 & \begin{tabular}{l|l|l|}
176,62 \\
\end{tabular} & \begin{tabular}{l|l|l|l|}
123,02 \\
\end{tabular} & \begin{tabular}{|l|l|l|l}
187,99 \\
\end{tabular} & \begin{tabular}{ll|}
190,92 \\
\end{tabular} & 91,0 & 899,9 & 116,01 & $39, \mathrm{C}$ & 28,8 & 317,35 & 150,91 & \begin{tabular}{|c|}
175,76 \\
\end{tabular} & 250,17 \\
\hline Discoglossus galganoi & 30TVK06 & 100,00 & 142,47 & 106,21 & 35,00 & 6653,52 & 315,94 & 15,49 & 300,45 & 99,92 & 231,60 & 231,60 & 60,65 & \begin{tabular}{|l|l|}
393,55 \\
\end{tabular} & 45,92 & 9,78 & 35,14 & 131,53 & 47,31 & 47,31 & 110,19 \\
\hline Discoglossus galganoi & 30TVK07 & 100,00 & 138,22 & 105,19 & 35,00 & 6599,22 & 309,76 & 12,52 & 297,24 & \begin{tabular}{|c|}
95,99 \\
\end{tabular} & 226,14 & 226,46 & 57,02 & \begin{tabular}{ll|}
400,96 \\
\end{tabular} & 47,07 & 10,68 & \begin{tabular}{|c|}
34,48 \\
\end{tabular} & \begin{tabular}{|c|}
133,24 \\
\end{tabular} & 50,14 & 50,30 & 110,73 \\
\hline Discoglossus galganoi & 30TVK14 & 100,00 & 143,95 & 108,34 & 35,00 & 6764,50 & 321,63 & \begin{tabular}{ll|l}
15,06 \\
\end{tabular} & 306,57 & \begin{tabular}{|c|}
100,59 \\
\end{tabular} & 234,79 & 234,79 & 61,20 & \begin{tabular}{l|l}
403,45 \\
\end{tabular} & 46,28 & 9,30 & \begin{tabular}{l|l|}
35,95 \\
\end{tabular} & \begin{tabular}{|c|}
134,67 \\
\end{tabular} & 46,24 & 46,24 & 115,13 \\
\hline Discoglossus galganoi & 30 TVK29 & 100,00 & 123,83 & 102,72 & 35,00 & 6522,81 & 292,25 & 2,43 & 289,82 & 82,35 & 209,81 & 211,40 & \begin{tabular}{l|l}
44,65 \\
\end{tabular} & 461,17 & 55,11 & 13,13 & 33,00 & 152,18 & 60,21 & \begin{tabular}{l|l}
62,15 \\
\end{tabular} & 128,16 \\
\hline Discoglossus galganoi & 30TVK43 & 100,00 & 146,90 & 110,28 & 35,02 & 6784,14 & 326,59 & 17,10 & 309,49 & 103,19 & 237,63 & 237,63 & 63,67 & 408,17 & 49,26 & 8,35 & 37, & 140,62 & 42,91 & 42,91 & 120,14 \\
\hline Discoglossus galganoi & 30TVL02 & 100,00 & 104,18 & 102,76 & 35,80 & 6328,72 & 269,13 & $-14,21$ & 283,34 & 120,89 & 188,74 & 189,91 & 29,02 & 496,09 & 60,40 & 16,33 & 30,06 & 155,61 & 73,06 & 80,28 & 123,40 \\
\hline Discoglossus galganoi & 30TVLO3 & 100,00 & 111,68 & 101,23 & 35,18 & 6409,99 & 274,44 & $-7,84$ & 282,27 & 123,56 & $\begin{array}{l}196,60 \\
1\end{array}$ & \begin{tabular}{|c|}
198,14 \\
\end{tabular} & 34,33 & 477,20 & 56,09 & 14,21 & 30,30 & 148,11 & 68,19 & \begin{tabular}{l|l}
76,25 \\
\end{tabular} & 121,31 \\
\hline Discoglossus galganoi & 30TVL10 & 100,00 & 112,46 & 102,96 & 35,38 & 6427,44 & 279,75 & $-7,11$ & 286,86 & 80,22 & \begin{tabular}{|l|l|}
197,93 \\
\end{tabular} & 199,25 & 35,60 & 478,21 & 56,21 & 15,01 & 30,94 & \begin{tabular}{|l|l|}
150,99 \\
\end{tabular} & 67,21 & 71,88 & 123,97 \\
\hline Discoglossus galganoi & 30TVL11 & 100,00 & 77,29 & 106,95 & 37,36 & 6068,16 & 247,71 & $-34,23$ & 281,95 & \begin{tabular}{|c|}
70,78 \\
\end{tabular} & \begin{tabular}{|c|}
161,14 \\
\end{tabular} & 161,28 & 9,66 & 626,03 & 76,40 & 24,97 & 27,68 & 194,81 & \begin{tabular}{|c|}
96,49 \\
\end{tabular} & \begin{tabular}{l|l}
99,25 \\
\end{tabular} & 157,99 \\
\hline Discoglossus galganoi & 30TVL12 & 100,00 & 82,73 & 105,64 & 37,01 & 6128,99 & 251,27 & $-30,42$ & \begin{tabular}{|l|}
281,69 \\
\end{tabular} & 86,58 & \begin{tabular}{|l|l|}
166,66 \\
\end{tabular} & 167,03 & \begin{tabular}{|l|}
13,17 \\
\end{tabular} & 603,08 & 72,94 & 23,32 & 27,85 & \begin{tabular}{|c|}
187,35 \\
\end{tabular} & \begin{tabular}{|c|}
92,53 \\
\end{tabular} & 97,16 & 152,35 \\
\hline Discoglossus galganoi & 30TVL19 & 100,00 & 115,14 & 105,68 & 36,66 & 6155,45 & 279,34 & $-5,68$ & 285,02 & 107,13 & 196,25 & 197,19 & 39,82 & 457,84 & 52,77 & 15,62 & 27,99 & 140,09 & 67,60 & 77,27 & 117,99 \\
\hline Discoglossus galganoi & 30TVL31 & 100,00 & 112,12 & 103,04 & 35,52 & 6428,78 & 279,39 & $-6,72$ & 286,11 & 73,78 & $\begin{array}{l}197,50 \\
\end{array}$ & 198,75 & 35,20 & \begin{tabular}{|l|l|}
496,87 \\
\end{tabular} & 58,38 & 15,25 & 30,58 & 158,92 & 69,08 & 73,27 & 133,32 \\
\hline Discoglossus galganoi & 30TVL34 & 100,00 & 86,44 & 105,55 & 36,82 & 6168,71 & 254,56 & $-27,94$ & 282,50 & 96,85 & \begin{tabular}{l|l}
170,42 \\
\end{tabular} & 170,66 & \begin{tabular}{l|l|l}
15,35 \\
\end{tabular} & \begin{tabular}{|l|l|}
591,88 \\
\end{tabular} & \begin{tabular}{ll|}
69,86 \\
\end{tabular} & 22,81 & 26,76 & 181,19 & 91,63 & 97,38 & 151,49 \\
\hline Discoglossus galganoi & 30TVL52 & 100,00 & 119,14 & 103,05 & 35,49 & 6471,71 & 286,06 & $-0,94$ & 286,99 & 77,81 & 204,90 & 205,77 & 40,94 & 466,92 & 55,77 & 13,7 & 31,05 & 151,94 & \begin{tabular}{|c|}
65,03 \\
\end{tabular} & 67,44 & 126,10 \\
\hline Discoglossus galganoi & 30TVM12 & 100,00 & 112,73 & 106,63 & 37,00 & 5981,48 & 276,42 & $-8,06$ & 284,48 & 123,04 & \begin{tabular}{|c|}
191,60 \\
\end{tabular} & 192,36 & 39,31 & \begin{tabular}{ll|}
472,45 \\
\end{tabular} & 54,27 & 18,01 & 26,84 & 143,71 & \begin{tabular}{|c|}
71,90 \\
\end{tabular} & 83,22 & 120,59 \\
\hline Discoglossus galganoi & 30 TVN24 & 100,00 & 101,35 & 88,78 & 37,93 & 4946,85 & 233,22 & 1,82 & 231,41 & 76,64 & \begin{tabular}{|l|l|}
165,72 \\
\end{tabular} & 167,33 & 40,81 & 798,72 & 91,63 & 39,16 & 21,85 & 255,50 & \begin{tabular}{|l|l}
144,76 \\
\end{tabular} & \begin{tabular}{|l|l|}
147,93 \\
\end{tabular} & 217,80 \\
\hline Discoglossus galganoi & 30 TVN25 & 100,00 & 99,07 & 87,23 & 38,01 & 4861,28 & 227,97 & 1,48 & 226,50 & 75,07 & \begin{tabular}{|l|l|}
162,11 \\
\end{tabular} & 163,98 & 39,72 & 847,18 & 97,49 & 41,77 & \begin{tabular}{|l|l}
21,85 \\
\end{tabular} & 271,79 & 153,74 & 158,29 & 232,81 \\
\hline Discoglossus galganoi & 30 TVN26 & 100,00 & 99,52 & 84,82 & 38,02 & 4741,43 & 224,38 & 4,32 & 220,06 & 76,76 & \begin{tabular}{|l|l|l|}
160,99 \\
\end{tabular} & \begin{tabular}{|c|}
163,08 \\
\end{tabular} & & \begin{tabular}{l|l}
890,45 \\
\end{tabular} & 103,09 & 43,70 & 22,14 & 287,85 & $\begin{array}{l}160,75 \\
\end{array}$ & 167,71 & 246,91 \\
\hline Discoglossus galganoi & 30TVN35 & 100,00 & 100,09 & 85,70 & 37,99 & 4839, & 27 & 3,9 & 223,4 & 75,82 & 162,73 & 164 & 41,6 & 860,57 & 98,02 & 42, & 21, & 275 & 155,33 & 161,40 & 239,24 \\
\hline Discoglossus galganoi & 30TVP11 & 3,00 & 142,42 & 61,75 & 37,17 & 3685,50 & 75 & \begin{tabular}{|c|c|}
65,08 \\
\end{tabular} & 163,67 & 126,75 & \begin{tabular}{|l|l|}
171,08 \\
\end{tabular} & 191,25 & 96 & \begin{tabular}{|c|}
988,92 \\
\end{tabular} & \begin{tabular}{|l|}
126,33 \\
\end{tabular} & 41,25 & 30,00 & 352,42 & 161,17 & 195,08 & 283,42 \\
\hline Discoglossus galganoi & 30TVP21 & 27,00 & 140,55 & 60,16 & 37,02 & 3639,68 & 225,79 & 65,43 & \begin{tabular}{|l|l|}
160,36 \\
\end{tabular} & 125,52 & \begin{tabular}{|c|}
168,52 \\
\end{tabular} & 189,21 & 95,34 & 1037,54 & 131,59 & 43,05 & 30,11 & 369,63 & \begin{tabular}{|c|}
167,59 \\
\end{tabular} & 205,20 & 300,34 \\
\hline Discoglossus galganoi & 30TVP30 & 86,00 & 138,58 & 60,93 & $\begin{array}{l}36,75 \\
\end{array}$ & 3722,42 & 226,02 & 62,32 & 163,70 & 122,92 & 174,77 & 188,31 & 92,36 & 1043,38 & 131,23 & 43,16 & 29,64 & 369,18 & 169,38 & 204,99 & 306,25 \\
\hline Discoglossus galganoi & 30TVP51 & 62,00 & 139,49 & 58,70 & 36,04 & 3704,47 & 224,75 & \begin{tabular}{|c|}
64,47 \\
\end{tabular} & 160,28 & 123,59 & $\begin{array}{l}181,65 \\
\end{array}$ & 188,60 & 93,16 & 1118,94 & 143,78 & 45,42 & 29,88 & $\begin{array}{l}393,06 \\
\end{array}$ & \begin{tabular}{|c|}
179,04 \\
\end{tabular} & 217,62 & 343,98 \\
\hline Discoglossus galganoi & 30TWM08 & 100,00 & 89,97 & 103,04 & $38, \mathrm{C}$ & 672,90 & 245 & $-20,14$ & 266, & 100,88 & 5,91 & 165,91 & 21,5 & 712,04 & 76,42 & 38,20 & 18,40 & 204,14 & 134,80 & 134,80 & 190,31 \\
\hline Discoglossus galganoi & 30TWM34 & 100,00 & 85 & 58 & 38,5 & 5936,16 & 25 & $-32,75$ & 286 & 102,03 & \begin{tabular}{|l|l|}
165,18 \\
\end{tabular} & 165,19 & 14 & 689,98 & 78,33 & 37,81 & 18, & 204,94 & 131,59 & 133,87 & 180,82 \\
\hline Discoglossus galganoi & 30TWM37 & 100 & 96,07 & & 38,54 & 5802,31 & & $-19,2$ & 275,78 & 113,14 & 173,14 & 173,14 & 25,6 & 672,42 & 74,59 & 36,74 & 18, & 196,71 & 129,78 & 130,72 & 176,85 \\
\hline Discoglossus galganoi & 30TWM48 & 100,00 & 105,81 & 106,21 & 38,58 & 5790,45 & 262,59 & $-9,79$ & 272,38 & \begin{tabular}{|l|l|}
124,10 \\
\end{tabular} & $\begin{array}{l}181,99 \\
1\end{array}$ & $\begin{array}{l}181,99 \\
\end{array}$ & 34,73 & 631,48 & $\begin{array}{l}70,85 \\
\end{array}$ & 34,70 & \begin{tabular}{ll|}
18,56 \\
\end{tabular} & \begin{tabular}{l|l|l|}
185,93 \\
\end{tabular} & \begin{tabular}{|c|}
123,74 \\
\end{tabular} & \begin{tabular}{l|l}
124,95 \\
\end{tabular} & 162,81 \\
\hline Discoglossus galganoi & 30TWM49 & 100,00 & 126,24 & 102,65 & 38,02 & 5775,38 & 276,19 & \begin{tabular}{|l|}
10,47 \\
\end{tabular} & 265,72 & 146,67 & \begin{tabular}{|c|}
195,92 \\
\end{tabular} & 200,91 & 54, & 508,37 & 59,42 & 27,88 & 20,34 & 153,06 & 104,01 & 107,40 & 122,04 \\
\hline Discoglossus galganoi & 30TWM67 & 100,00 & 105,56 & 108,59 & \begin{tabular}{|c|}
38,47 \\
\end{tabular} & 5898,47 & 265 & $-13,16$ & 278,54 & 124,65 & 183,04 & 183,08 & 32,9 & 625,73 & 71,84 & 34,36 & 19, & 187,22 & 121,40 & 124,74 & 160,55 \\
\hline Discoglossus galganoi & 30TWM76 & 100,00 & & 109,80 & 38,40 & 5979,02 & 269 & $-12,52$ & 282,15 & 128,21 & 186,54 & 186,61 & 34,49 & 593,73 & 69,97 & 32,39 & 20,06 & 180,44 & 114,66 & 121,32 & 150,67 \\
\hline \begin{tabular}{|l} 
Discoglossus galganoi \\
\end{tabular} & 30TWM77 & 100,00 & 122,10 & 107,81 & 38,04 & 5973,97 & 279,65 & 1,33 & 278,32 & 143,23 & \begin{tabular}{l|l|}
199,55 \\
\end{tabular} & $\begin{array}{l}199,65 \\
\end{array}$ & 47,51 & 536,37 & 63,52 & 28,69 & 20,92 & \begin{tabular}{l|l|}
163,45 \\
\end{tabular} & 103,33 & \begin{tabular}{ll|}
108,63 \\
\end{tabular} & 133,39 \\
\hline Discoglossus galganoi & 30TWN02 & 100,00 & 122,30 & 88,59 & 37,80 & 5134,56 & 253,13 & 21,27 & 231,85 & 92,57 & \begin{tabular}{|l|l|l|}
188,13 \\
\end{tabular} & 189,59 & $\begin{array}{l}58,65 \\
\end{array}$ & 725,80 & 80,04 & 34,78 & 20,01 & 221,58 & \begin{tabular}{|c|}
134,57 \\
\end{tabular} & \begin{tabular}{ll|}
139,36 \\
\end{tabular} & 206,13 \\
\hline Discoglossus galganoi & 30TWN21 & 100,00 & 110,79 & 96,77 & 38,36 & 5416,85 & 252,98 & 4,19 & 248,79 & \begin{tabular}{|c|c|}
66,36 \\
\end{tabular} & \begin{tabular}{ll|}
182,05 \\
\end{tabular} & 182, & 44,2 & 711,86 & 74,31 & 37,2 & 17,9 & 207,94 & 138,90 & 138,90 & 192,77 \\
\hline Discoglossus galganoi & $30 \mathrm{TW}$ & 100, & 118 & 89,1 & 38, & 498 & 248 & 20,5 & & 64 & 182. & 184 & $5 /$ & 871 & 95, & 43,42 & & 265,85 & \begin{tabular}{l|l|}
165,05 \\
\end{tabular} & \begin{tabular}{|l|}
168,09 \\
\end{tabular} & 249 \\
\hline Discoglossus galganoi & 30TXM15 & 100,00 & 137,34 & 106,54 & 37,96 & 6040,20 & 292,78 & 14,55 & 278,22 & 159,61 & 215,33 & 215,33 & 61,35 & 480,36 & 58,18 & 22,85 & 24,02 & 145,01 & 87,32 & 89,54 & 122,01 \\
\hline Discoglossus jeanneae & 29SQA35 & 24,00 & 177,69 & 83,83 & 38,69 & 4534,21 & 291,17 & 77,52 & \begin{tabular}{|l|l|}
213,66 \\
\end{tabular} & $\begin{array}{l}155,45 \\
\end{array}$ & 234,41 & 238,17 & 122,10 & 557,24 & 92,62 & 0,00 & \begin{tabular}{|c|}
67,28 \\
\end{tabular} & 248,90 & \begin{tabular}{|c|}
12,69 \\
\end{tabular} & 20,00 & 230,62 \\
\hline Discoglossus jeanneae & 29SQA36 & 95,00 & 177,07 & 84,66 & 38,31 & 4649,30 & 293,27 & 75,19 & \begin{tabular}{|l|l|}
218,08 \\
\end{tabular} & \begin{tabular}{l|l|l|}
153,02 \\
\end{tabular} & 235,24 & 238,90 & \begin{tabular}{|c|}
119,87 \\
\end{tabular} & 554,28 & 90,71 & 0,00 & $\begin{array}{l}66,75 \\
\end{array}$ & 246,68 & 13,00 & 20,40 & 228,02 \\
\hline Discoglo & $2950 A 3$ & 70,00 & & & & 587 & & 74,1 & & 152, & 237,56 & 241, & & 551 & 87,79 & & 65, & & & 21,43 & 223 \\
\hline Discoglossus jeanneae & 295QA44 & 26,00 & 179,26 & 71,10 & 35,90 & 4487, & 281, & 85,62 & 195,4 & 157,85 & 234,28 & 238,97 & 123,28 & 601,9 & 100,23 & 0,38 & 68,10 & 258,90 & 11,90 & 21,03 & 243, \\
\hline Discoglossus jeanneae & 29SQA45 & 69,00 & 176,93 & 76,35 & 36,36 & 4649,63 & 286,27 & 79,15 & 207,12 & 153,94 & 234,81 & 238,93 & 119,44 & 587,01 & 95,92 & 0,38 & \begin{tabular}{|c|}
66,81 \\
\end{tabular} & 255,15 & \begin{tabular}{|l|}
13,02 \\
\end{tabular} & 21,31 & 237,94 \\
\hline
\end{tabular}




\begin{tabular}{|c|c|c|c|c|c|c|c|c|c|c|c|c|c|c|c|c|c|c|c|c|c|}
\hline TAXON & UTM & $\overline{\mathrm{km} 2}$ & $\begin{array}{ll}\mathrm{BIO1} \\
\end{array}$ & $\begin{array}{c}\mathrm{BIO2} \\
\end{array}$ & B103 & B104 & B105 & BIO6 & B107 & B108 & B109 & BIO10 & BIO11 & $\overline{B 1012}$ & BIO13 & BIO14 & BIO15 & B1016 & BIO17 & BIO18 & B1019 \\
\hline Discoglossus jeanneae & 29SOA52 & & & & & & & & & & & & & & & & & & & & \\
\hline \begin{tabular}{|l} 
Discoglossus jeanneae \\
\end{tabular} & 29SQA53 & 100,00 & 177,64 & 70,43 & 35,65 & 4493,07 & 279,11 & 84,29 & 194,82 & 143,26 & 232,93 & 237,52 & 121,50 & 635,77 & 110,43 & 1,00 & 69,06 & 277,45 & 13,16 & 23,23 & 262,34 \\
\hline Discoglossus jeanneae & 29SQA54 & 93,00 & $\begin{array}{ll}177,06 \\
\end{array}$ & 70,42 & 34,92 & 4627,92 & 281,23 & 82,24 & 198,99 & \begin{tabular}{|l|l|l|}
449,73 \\
\end{tabular} & 234,27 & 238,95 & \begin{tabular}{l|l|l|}
119,38 \\
\end{tabular} & 623,61 & \begin{tabular}{ll|}
105,06 \\
\end{tabular} & 1,00 & 68,15 & 269,05 & 13,48 & 23,19 & 253,37 \\
\hline Discoglossus jeanneae & 29SQA55 & 100,00 & 176,14 & 71,50 & 34,46 & 4748,96 & 283,85 & 79,40 & 204,45 & \begin{tabular}{l|l|l|l|l|}
150,89 \\
\end{tabular} & 235,24 & 239,52 & \begin{tabular}{|l|l|}
117,14 \\
\end{tabular} & 611,03 & \begin{tabular}{|c|}
99,24 \\
\end{tabular} & 1,00 & 67,15 & 261,72 & 14,25 & 22,82 & 245,79 \\
\hline Discoglossus jeanneae & 295QA56 & 100,00 & 173,87 . & 72,93 & 33,94 & 4924,18 & 286,72 & 74,69 & 212,03 . & 144,30 | & 235,60 | & 239,56 | & $112,85[$ & 606,72 & 95,02 & 1,00 & 65,93 & 257,52 & 15,55 [ & 23,43 & 241,52 \\
\hline Discoglossus jeanneae & 29SQA57 & 100,00 & 174,19 & 75,94 & 34,00 & 5074,94 & 292,53 & 72,25 & 220,28 & 137,56 & 238,01 & 241,78 & 111,32 & \begin{tabular}{l|l}
594,55 \\
\end{tabular} & 90,93 & 1,00 & 65,47 & 252,01 & 16,14 & 23,23 & 235,14 \\
\hline Discoglossus jeanneae & 29SQA58 & 101,00 & 175,78 & 81,62 & 34,94 & 5197,06 & 300,87 & 70,73 & 230,14 & 126,74 & 241,48 & 244,90 & 111,45 & 585,37 & 88,62 & 1,00 & 65,05 & 248,94 & 16,59 & 22,96 & 231,55 \\
\hline Discoglossus jeanneae & 29SQA61 & 69,00 & 173,72 & 74,04 & 37,77 & 4251,75 & 275,40 & 81,89 & \begin{tabular}{|c|}
193,51 \\
\end{tabular} & 129,78 & 226,25 & 230,55 & \begin{tabular}{l|l}
120,81 \\
\end{tabular} & $\begin{array}{l}723,45 \\
\end{array}$ & 126,98 & 0,92 & 71,45 & \begin{tabular}{|c|}
326,94 \\
\end{tabular} & \begin{tabular}{ll|}
14,62 \\
\end{tabular} & 23,06 & 313,23 \\
\hline Discoglossus jeanneae & 29SQA62 & 96,00 & 173,91 & 72,69 & 36,69 & 4381,85 & 276,29 & 80,88 & \begin{tabular}{l|l}
195,42 \\
\end{tabular} & 128,33 & 228,08 & 232,35 & \begin{tabular}{l|l}
119,18 \\
\end{tabular} & 703,15 & 122,12 & 1,00 & 70,45 & \begin{tabular}{|c|}
313,64 \\
\end{tabular} & 14,39 & 23,54 & 299,47 \\
\hline Discoglossus jeanneae & 29SQA63 & 91,00 & 174,26 & 71,55 & 35,73 & 4530,08 & 278,14 & 80,13 & \begin{tabular}{|l|l|l|}
198,02 \\
\end{tabular} & 127,05 & \begin{tabular}{|l|l|l|}
230,42 \\
\end{tabular} & 234,79 & \begin{tabular}{|c|}
117,85 \\
\end{tabular} & 680,79 & 116,33 & 1,00 & 69,49 & 299,66 & 14,39 & 23,80 & 284,77 \\
\hline Discoglossus jeanneae & 29SQA64 & 82,00 & 173,11 & 71,60 & 34,77 & 4697,90 & 280,25 & 77,27 & 202,98 & 123,76 & 231,64 & \begin{tabular}{|l|l|}
235,93 \\
\end{tabular} & \begin{tabular}{ll|}
114,68 \\
\end{tabular} & 667,31 & \begin{tabular}{|l|l|}
111,07 \\
\end{tabular} & 1,00 & 68,47 & 289,70 & \begin{tabular}{|l|l|l|}
14,79 & \\
\end{tabular} & 24,00 & 274,71 \\
\hline Discoglossus jeanneae & 29SQA65 & 87,00 & 173,45 & 71,17 & 33,89 & 4832,19 & 282,94 & 76,20 & 206,74 & 123,52 & 233,76 & 237,93 & \begin{tabular}{|l|l|}
113,34 \\
\end{tabular} & 646,16 & 104,12 & 1,00 & 67,41 & 276,87 & 15,43 & 23,97 & 261,60 \\
\hline Discoglossus jeanneae & 29SQA66 & 81,00 & 172,10 & 71,69 & 33,18 & 5004,39 & 285,84 & 72,94 & 212,90 & 120,75 & 234,93 & 238,95 & \begin{tabular}{ll|}
110,16 \\
\end{tabular} & 634,60 & $\begin{array}{l}98,66 \\
\end{array}$ & 1,00 & 66,61 & 268,96 & \begin{tabular}{|l|l|}
16,27 \\
\end{tabular} & 24,00 & 253,05 \\
\hline Discoglossus jeanneae & 30STE69 & 90,00 & 166,92 & 83,47 & 39,98 & 4208,93 & 277,68 & 71,14 & 206,55 & 123,23 & 220,05 & 223,59 & \begin{tabular}{l|l}
115,12 \\
\end{tabular} & 848,89 & 146,18 & 0,58 & 76,41 & 404,67 & 13,56 & 22,34 & 401,74 \\
\hline Discoglossus jeanneae & 30STE79 & 80,00 & 165,85 & 86,17 & 40,60 & 4236,28 & 280,03 & 69,61 & 210,41 & 121,75 & 219,52 & 223,38 & 114,45 & 815,53 & 141,61 & 0,9 & 76,6 & 396,23 & 13,03 & 22,71 & 390,32 \\
\hline Discoglossus jeanneae & 30STF30 & 17,00 & 172,45 & 75,41 & 38,41 & 4164,14 & 274,41 & 81,00 & 193,41 & 129,27 & \begin{tabular}{|l|l|l|}
224,23 \\
\end{tabular} & \begin{tabular}{|l|l|}
228,09 \\
\end{tabular} & \begin{tabular}{|l|l|l|}
120,68 \\
\end{tabular} & 769,41 & \begin{tabular}{|c|}
134,77 \\
\end{tabular} & 0,41 & 72,95 & \begin{tabular}{|c|}
352,82 \\
\end{tabular} & 14,77 & 22,41 & 340,09 \\
\hline Discoglossus jeanneae & 30STF31 & 98,00 & 172,86 & 74,49 & 37,92 & 4225,17 & 274,71 & 80,89 & \begin{tabular}{l|l|l|l|}
193,82 \\
\end{tabular} & \begin{tabular}{|l|l|}
129,00 \\
\end{tabular} & 225,26 & 229,20 & \begin{tabular}{|l|l|}
120,17 \\
\end{tabular} & 756,80 & 131,74 & 0,44 & 72,26 & 344,73 & \begin{tabular}{l|l|l}
14,59 \\
\end{tabular} & 22,62 & 331,52 \\
\hline Discoglossus jeanneae & 30STF32 & 90,00 & 172,06 & 73,73 & 36,93 & 4378,73 & 275,79 & 78,71 & \begin{tabular}{ll|l}
197,08 \\
\end{tabular} & 126,41 & 226,50 & 230,49 & 117,51 & 741,70 & 127,34 & 1,00 & 71,14 & \begin{tabular}{|c|}
333,93 \\
\end{tabular} & 15,08 & 23,50 & 320,08 \\
\hline Discoglossus jeanneae & 30STF33 & 90,00 & 171,30 & 73,63 & 35,99 & 4544,89 & 278,05 & 76,28 & 201,77 & 123,77 & \begin{tabular}{|l|l|}
228,06 \\
\end{tabular} & 232,17 & \begin{tabular}{ll|}
114,86 \\
\end{tabular} & 724,33 & 122,30 & 1,00 & 70,20 & 322,57 & 15,14 & 23,99 & 307,85 \\
\hline Discoglossus jeanneae & 30 STF34 & 90,00 & 171,41 & 73,47 & \begin{tabular}{|c|}
35,17 \\
\end{tabular} & 4698,44 & 280,66 & 74,99 & 205,66 & 122,05 & 230,19 & 234,29 & 113, & 700,70 & 115,90 & 1, & 69, & 308,26 & \begin{tabular}{|c|}
15,67 \\
\end{tabular} & 24,01 & 292,74 \\
\hline Discoglossus jeanneae & 30STF35 & 81,00 & 172,92 & 73,12 & 34,53 & 4830,34 & 284,27 & 75,48 & 208,79 & \begin{tabular}{l|l}
121,93 \\
\end{tabular} & 233,49 & 237,52 & \begin{tabular}{|c|}
113,13 \\
\end{tabular} & 668,82 & 108,03 & 1,00 & 68,07 & 290,48 & 15,98 & 23,88 & 274,22 \\
\hline Discoglossus jeanneae & 30 STF36 & 80,00 & 171,69 & 75,24 & 34,32 & 5009,00 & 288,16 & 71,81 & 216,35 & \begin{tabular}{|c|}
118,67 \\
\end{tabular} & 234,80 & 238,68 & \begin{tabular}{ll|}
109,86 \\
\end{tabular} & 657,79 & 103,48 & 1,00 & 67,23 & 283,17 & \begin{tabular}{l|l|l|}
16,55 \\
\end{tabular} & 23,91 & 266,49 \\
\hline Discoglossus jeanneae & 30STF38 & 72,00 & 171,74 & 86,27 & 35,82 & 5325,61 & 303,23 & 65,21 & \begin{tabular}{|l|l|}
238,02 \\
\end{tabular} & \begin{tabular}{ll|}
114,89 \\
\end{tabular} & 239,46 & 242,79 & $\begin{array}{l}106,25 \\
\end{array}$ & 637,94 & 97,45 & 1,00 & 65,84 & 273,76 & 17,25 & 23,73 & 256,61 \\
\hline Discoglossus jeanneae & 30STF40 & 79,00 & 170,05 & 77,24 & 38,86 & 4149,76 & 273,55 & $77,47 \mid$ & 196,08 & 127,19 & 221,86 & 225,45 & 118,45 & 822,55 & 142,23 & 0,24 & 73,99 & 380,45 & $15,04[$ & 22,30 & 370,92 \\
\hline Discoglossus jeanneae & 30STF41 & 100,00 & 172,72 & 74,78 & 38,32 & 4162,68 & 273,71 & 80,79 & \begin{tabular}{l|l|l|l|}
192,92 \\
\end{tabular} & \begin{tabular}{ll|}
129,06 \\
\end{tabular} & 224,63 & 228,16 & 120,80 & $\begin{array}{l}787,68 \\
\end{array}$ & 135,86 & 0,05 & 73,02 & 361,95 & \begin{tabular}{l|l}
15,05 \\
\end{tabular} & 22,06 & 349,54 \\
\hline Discoglossus jeanneae & 30STF42 & 100,00 & 172,28 & 74,59 & 37,45 & 4314,16 & 275,88 & 79,09 & 196,79 & 127,13 & 226,17 & 229,93 & \begin{tabular}{|c|}
118,57 \\
\end{tabular} & 768,15 & 131,09 & 0,67 & 71,80 & \begin{tabular}{ll|}
349,92 \\
\end{tabular} & \begin{tabular}{|c|}
15,67 \\
\end{tabular} & 22,89 & 335,87 \\
\hline Discoglossus jeanneae & 30STF43 & 100,00 & 171,37 & 75,07 & 36,61 & 4494,42 & 278,71 & 76,42 & 202,28 & 124,26 & 227,63 & 231,55 & \begin{tabular}{|c|}
115,70 \\
\end{tabular} & 748,11 & 125,94 & 1,00 & 70,66 & \begin{tabular}{|c|}
337,59 \\
\end{tabular} & \begin{tabular}{l|l|l}
15,96 \\
\end{tabular} & 23,63 & 322,29 \\
\hline Discoglossus jeanneae & 30 STF44 & 100,00 & 170,27 & 76,41 & 36,06 & 4680,85 & 282,25 & 73,23 & \begin{tabular}{|l|l|}
209,02 \\
\end{tabular} & 121,12 & 229,12 & 233,04 & 112,49 & 729,53 & 120,67 & 1,00 & 69,77 & 326,03 & 16,01 & 24,01 & 309,93 \\
\hline Discoglossus jeanneae & 30STF45 & 100,00 & 169,68 & 78,14 & 35,66 & 4861,25 & 286,50 & 70,68 & 215,82 & \begin{tabular}{|l|l|l|l|}
118,62 \\
\end{tabular} & 231,10 & \begin{tabular}{|l|l|}
234,95 \\
\end{tabular} & \begin{tabular}{|l|l|}
109,92 \\
\end{tabular} & 708,52 & $\begin{array}{l}114,95 \\
\end{array}$ & 1,00 & 68,80 & \begin{tabular}{|c|}
313,47 \\
\end{tabular} & 16,20 & 24,13 & 296,85 \\
\hline Discoglossus jeanneae & 30STF46 & 100,00 & 172,40 & 79,32 & 35,49 & 4987,73 & 292,23 & 71,79 & 220,45 & 119,53 & 235,35 & 239,11 & \begin{tabular}{l|l}
110,95 \\
\end{tabular} & \begin{tabular}{|c|c|}
673,38 \\
\end{tabular} & $\begin{array}{l}107,45 \\
\end{array}$ & 1,00 & 67,82 & 295,25 & \begin{tabular}{|l|l|l|}
16,53 \\
\end{tabular} & 23,51 & 277,60 \\
\hline Discoglossus jeanneae & 30STF47 & 100,00 & $\begin{array}{ll}171,66 \\
\end{array}$ & 83,90 & 35,81 & 5167,62 & 298,66 & 68,02 & 230,64 & \begin{tabular}{l|l}
116,63 \\
\end{tabular} & 237,20 & 240,68 & \begin{tabular}{|c|}
108,14 \\
\end{tabular} & 662,66 & 103,91 & 1,00 & 66,96 & 288,72 & 17,01 & 23,58 & 271,04 \\
\hline Discoglossus jeanneae & 30STF50 & 100,00 & 168,95 & 78,27 & 39,21 & 4103,92 & 272,40 & 75,62 & \begin{tabular}{ll|}
196,79 \\
\end{tabular} & \begin{tabular}{l|l|l|}
126,26 \\
\end{tabular} & 220,38 & 223,74 & \begin{tabular}{|c|}
117,77 \\
\end{tabular} & 855,68 & 146,48 & 0,21 & 74,96 & 398,75 & 15,01 & 22,30 & 392,21 \\
\hline Discoglossus jeanneae & 30STF51 & 100,00 & 167,76 & 78,74 & 38,64 & 4257,40 & 274,60 & 73,17 & 201,43 & 123,72 & 221,33 & 224,81 & \begin{tabular}{ll|}
114,96 \\
\end{tabular} & 835,94 & 142,24 & 0,58 & 73,81 & $\begin{array}{ll}388,02 \\
\end{array}$ & 15,32 & 23,08 & 378,19 \\
\hline Discoglossus jeanneae & 30STF52 & 100,00 & 169,60 & 77,73 & 38,01 & 4336,43 & 276,87 & 74,98 & 201,89 & 124,45 & 224,16 & 227,73 & \begin{tabular}{|l|l}
116,00 \\
\end{tabular} & 802,55 & 136,23 & 0,8 & 72, & 371,01 & 15,89 & 3,25 & 357,32 \\
\hline Discoglossus jeanneae & 30STF53 & 100,00 & 171,09 & 77,64 & 37,41 & 4455,91 & 280,34 & 75,76 & 204,58 & \begin{tabular}{|l|l|}
124,36 \\
\end{tabular} & 227,16 & 230,82 & \begin{tabular}{|l|l|l|}
116,13 \\
\end{tabular} & 768,19 & 129,70 & 1,00 & 71,54 & \begin{tabular}{|l|l|}
353,12 \\
\end{tabular} & 16,00 & 23,21 & 336,74 \\
\hline Discoglossus jeanneae & 30STF54 & 100,00 & 167,50 & 81,14 & 37,10 & 4709,99 & 284,60 & \begin{tabular}{l|l}
68,95 \\
\end{tabular} & 215,66 & 118,41 & 227,11 & 230,79 & \begin{tabular}{l|l}
109,68 \\
\end{tabular} & 760,61 & 125,99 & 1,00 & 70,60 & \begin{tabular}{|c|}
346,04 \\
\end{tabular} & 16,13 & 24,07 & 329,51 \\
\hline Discoglossus jeanneae & 30STF55 & 100,00 & 165,22 & 84,72 & \begin{tabular}{l|l|l|}
37,05 \\
\end{tabular} & 4918,91 & 289,35 & 63,82 & 225,53 & 113,95 & 227,76 & 231,43 & \begin{tabular}{ll|l}
105,18 \\
\end{tabular} & 749,39 & 121,80 & 1,00 & 69,44 & 337,26 & 17,08 & 24,59 & 320,86 \\
\hline Discoglossus jeanneae & 30STF57 & 100,00 & 169,81 & 89,57 . & 37,21 & 5177,85 & 302,29 & 64,88 . & $237,41 \mid$ & 114,88 & 235,72 & 239,06 & 106, & $688,84[$ & 109,76 & 1, & 67, & 305,73 & 10 & 3,52 & 287,59 \\
\hline Discoglossus jeanneae & 30STF58 & 100,00 & 08 & 94,41 & 37,7 & $\begin{array}{l}328,45 \\
\end{array}$ & 310, & 63,4 & 246,89 & 114,27 & 239,19 & . & 10 & 667,79 & 105,33 & 1, & 66,5 & 294,63 & the & 促 & 276,42 \\
\hline Discoglossus jeanneae & 30STF59 & 100,00 & 17 & 99,87 & 38,3 & 5464,44 & 31 & 63 & 256,55 & \begin{tabular}{l|l|l|l|}
115,02 \\
\end{tabular} & 243,65 & 246,45 & 107 & \begin{tabular}{|c|c|}
643,67 \\
\end{tabular} & 100,88 & 1,00 & 66,33 & 282,79 & 17,21 & 22,81 & 264,69 \\
\hline Discoglossus jeanneae & 30STF60 & 100,00 & 163,12 & 85,08 & 39,39 & 4376,18 & 278,43 & 65,18 & 213,25 & \begin{tabular}{|l|l|l|l}
118,40 \\
\end{tabular} & 218,60 & 222,23 & \begin{tabular}{l|l|l|l|}
109,53 \\
\end{tabular} & 853,79 & 144,88 & 0,93 & 75,37 & \begin{tabular}{l|l}
403,55 \\
\end{tabular} & 14,45 & 23,76 & 398,62 \\
\hline Discoglossus jeanneae & 30STF61 & 100,00 & 164,61 & 83,27 & 39,14 & 4365,90 & 278,12 & 67,86 & 210,26 & 120,64 & 219,93 & 223,56 & \begin{tabular}{ll|l}
111,16 \\
\end{tabular} & 840,99 & \begin{tabular}{|l|l|}
143,07 \\
\end{tabular} & 0 & 74,27 & \begin{tabular}{|c|}
396,99 \\
\end{tabular} & 15,20 & 23,82 & 386,95 \\
\hline Discoglossus jeanneae & 30STF62 & 100,00 & 165,14 & 82,93 & 38,78 & 4449,51 & 279,79 & 68,0 & $211,77 \mid$ & 119,86 & $221,57 \mid$ & 225,24 _ & 110,77 & 820,39 | & 138,76 & 1, & 73,24 & 384,86 & 5,59 ] & 3,91 . & 371,59 \\
\hline Discoglossus jeanneae & 30STF63 & 100,00 & 16 & 84,68 & 38,34 & 621,54 & 283, & 65,09 & 218,12 & \begin{tabular}{ll|}
116,82 \\
\end{tabular} & 222,88 & 226,50 & 107, & 800,63 & 133,64 & 1, & 71,88 & 371,84 & 1 & 4,50 & 356,97 \\
\hline Discoglossus jeanneae & 30STF64 & 100,00 & 15 & 92,74 & 38,40 & 5017,22 & 28 & 48,51 & 238,58 & \begin{tabular}{ll|}
102,94 \\
\end{tabular} & 218,40 & 221,77 & 93 & 819,93 & \begin{tabular}{ll|}
131,07 \\
\end{tabular} & 1,40 & 70,22 & 371,48 & 18,62 & 27,59 & 360,28 \\
\hline Discoglossus jeanneae & 30STF65 & 100,00 & 165 & 87,84 & 37,91 & & 291,96 & 63,35 & 228,62 & 114,42 & 227,81 & 231,30 & 105 & 754,59 & 123,63 & 1,03 & 69,99 & \begin{tabular}{|l|}
344,99 \\
\end{tabular} & 16,89 & 24,36 & 327,48 \\
\hline Discoglossus jeanneae & 30STF66 & 100,00 & 165,34 & 90,67 & \begin{tabular}{ll|}
37,88 \\
\end{tabular} & 5056,80 & 297,25 & 61,18 & 236,06 & 112,45 & \begin{tabular}{|l|l|}
230,04 \\
\end{tabular} & 233,33 & \begin{tabular}{l|l|l|l|l|}
103,99 \\
\end{tabular} & 737,02 & 119,37 & 1,00 & 69,04 & \begin{tabular}{|c|}
333,87 \\
\end{tabular} & 17,22 & 4,32 & 315,92 \\
\hline Discoglossus jeanneae & 30STF67 & 100,00 & 168,90 & 93,03 & 38,08 & 5159,38 & 304,42 & 63, & 240,91 & \begin{tabular}{|l|l|l}
114,46 \\
\end{tabular} & 234,91 & 238 & 106 & \begin{tabular}{l|l}
702,95 \\
\end{tabular} & 113,37 & 1, & 68, & 61 & 9 & 3,46 & 297,82 \\
\hline Discoglossus jeanneae & 30STF68 & 100,00 & $\mid 171,47$ & 97,29 & 38,64 & 5297,85 & 312 & 63,87 | & 249,01 & 115,13 & 239,32 & 242,31 & \begin{tabular}{|l|l|l|}
107,15 \\
\end{tabular} & 674,89 | & 108,22 & 1,00 & 67,69 & 302,13 & 17,01 & 33,00 & 283,13 \\
\hline Discoglossus jeanneae & 30STF69 & 100,00 & 172,93 & 102,83 & 39,14 & 5452 & \begin{tabular}{|c|}
321,68 \\
\end{tabular} & 62,42 & 259,26 & 114,55 & \begin{tabular}{|l|l|l|}
242,83 \\
\end{tabular} & 245,58 & 106, & 654,38 & \begin{tabular}{|c|}
104,17 \\
\end{tabular} & 1,00 & 67,05 & 291,10 & 16,96 & 22,61 & 272,50 \\
\hline Discoglossus jeanneae & \begin{tabular}{|l|}
30 STF70 \\
\end{tabular} & 100,00 & 170,76 & 82,27 & \begin{tabular}{ll|}
40,56 \\
\end{tabular} & 4070,03 & 278,45 & 77,89 & 200,57 & 129,87 & 222,10 & 225,97 & 121,34 & 806,82 & $\begin{array}{l}143,07 \\
\end{array}$ & 1,00 & 76,03 & 396,34 & 13,86 & 22,01 & 381,87 \\
\hline Discoglossus jeanneae & 30STF71 & 100,00 & 168,40 & 83,23 & 40,00 & 4224,27 & 279,62 & 73,68 & 205,94 & 126,16 & 221,77 & 225,72 & \begin{tabular}{|l|l|}
117,17 \\
\end{tabular} & 808,52 & 141,14 & 1, & 75,01 & 393,01 & 14,41 & 2,69 & 376,83 \\
\hline Discoglossus jeanneae & 30STF72 & 100,00 & 166,30 & 84,93 & 39,37 & 77 & 282,35 & 69,2 & 213,06 & \begin{tabular}{|l|l|l|l}
121,98 \\
\end{tabular} & 222,38 & 226 & 112 & 800,83 & \begin{tabular}{|c|}
137,35 \\
\end{tabular} & 1, & 73,74 & 383,87 & 15, & 23,45 & 367 \\
\hline Discoglossus jeanneae & $30 \mathrm{ST}$ & 100 & & 87 & 39 & 462 & 28 & 63,84 & 221,63 & \begin{tabular}{|l|l|}
116,84 \\
\end{tabular} & 222,47 & 226,19 & $\begin{array}{l}107,54 \\
\end{array}$ & \begin{tabular}{|c|}
793,29 \\
\end{tabular} & 133,20 & 1,00 & 72,50 & 374,14 & \begin{tabular}{|l|l|}
15,97 \\
\end{tabular} & 24,37 & 357 \\
\hline Discoglossus jeanneae & 30STF74 & 100,00 & 158,09 & 92,03 & \begin{tabular}{|c|}
38,87 \\
\end{tabular} & 4898,94 & 288,79 & 54,41 & 234,38 & $\begin{array}{ll}108,48 \\
\end{array}$ & 221,05 & 224,46 & \begin{tabular}{|c|}
98,97 \\
\end{tabular} & $\begin{array}{l}797,05 \\
\end{array}$ & 129,72 & 1,23 & 70,83 & \begin{tabular}{|c|}
367,79 \\
\end{tabular} & \begin{tabular}{l|l|l|l|}
17,65 \\
\end{tabular} & 26,06 & 353,45 \\
\hline Discoglossus jeanneae & 30STF75 & 100,00 & 157,73 & 94,24 & 38,77 & 5045,92 & 292,93 & 52,28 & 240,65 & \begin{tabular}{|c|}
106,20 \\
\end{tabular} & 222,78 & 226,04 & 96,92 & 784,05 & 126,18 & 1,29 & 69,82 & \begin{tabular}{l|l|}
358,35 \\
\end{tabular} & 18,22 & 26,35 & 343,30 \\
\hline Discoglossus jeanneae & 30STF76 & 100,00 & 162,57 & 94,47 & 38,71 & 5093,79 & 298,56 & 57,03 & 241,52 & 109,78 & \begin{tabular}{|l|l|}
228,15 \\
\end{tabular} & 231,24 & \begin{tabular}{|l|l|}
101,07 \\
\end{tabular} & 750,01 & 121,26 & 1,13 & 69,25 & 342,29 & \begin{tabular}{l|l}
7,83 \\
\end{tabular} & 5,01 & 324,72 \\
\hline Discoglos & 30 & 10 & & & 38, & & & 49, & 25 & 103,6 & 22 & 30,04 & 94 & 756, & & 1,35 & 67,90 & 33 & & 20,55 & \\
\hline Discoglossus jeanneae & 30STF78 & 100,00 & 164,69 & 100,93 & 38,99 & 5369,9 & 310 & $55, \mathrm{C}$ & 255,80 & \begin{tabular}{|l|l|}
108,20 \\
\end{tabular} & 233,97 & 236,78 & 99,91 & 714,16 & 113,74 & 1,04 & 67,65 & 320,81 & 18,01 & 24,51 & 302, \\
\hline Discoglossus jeanneae & 30STF80 & 43,00 & 175,91 & 82,28 & 41,56 & 3927,69 & 281,94 & 86,09 & 195,84 & 137,66 & 225,39 & 229,80 & 129,36 & 749,14 & 138,61 & 1,00 & 76,92 & 382,69 & 13,02 & 20,77 & 358,81 \\
\hline
\end{tabular}




\begin{tabular}{|c|c|c|c|c|c|c|c|c|c|c|c|c|c|c|c|c|c|c|c|c|c|}
\hline TAXON & UTM & $\overline{\mathrm{km} 2}$ & BIO1 & $\mathrm{B1O2}$ & $\mathrm{BIO3}$ & B104 & B105 & B106 & B107 & B108 & B109 & BIO10 & BIO11 & $\overline{B 1012}$ & BIO13 & B1014 & BIO15 & B1016 & BIO17 & B1018 & BlO19 \\
\hline Discoglossus jeanneae & 30STF81 & 100,00 & 173,15 & 83,09 & 40,87 & 4074,54 & 282,17 & 81,16 & 201,01 & 133,03 & 224,64 & 228,83 & 124,45 & 760,43 & 137,52 & 1,00 & 75,86 & 382,20 & 13,55 & 21,39 & 358,96 \\
\hline Discoglossus jeanneae & 30STF82 & 100,00 & 173,59 & 83,40 & 40,32 & 4196,64 & 284,72 & 80,30 & 204,42 & \begin{tabular}{|l|l|}
131,67 \\
\end{tabular} & 226,76 & 230,81 & 123,30 & 749,50 & \begin{tabular}{ll|l}
133,75 \\
\end{tabular} & 1,00 & 74,76 & $\begin{array}{l}371,99 \\
3\end{array}$ & 14,12 & 21,54 & 348,06 \\
\hline Discoglossus jeanneae & 30STF83 & 100,00 & 173,10 & 84,66 & 39,84 & 4358,86 & 287,95 & 77,71 & 210,25 & \begin{tabular}{|l|l|}
129,07 \\
\end{tabular} & 228,36 & 232,25 & 120,63 & 739,53 & 129,64 & 1,00 & 73,58 & 361,28 & 14,88 & 21,88 & 337,73 \\
\hline Discoglossus jeanneae & 30STF84 & 100,00 & 159,27 & 93,11 & 39,21 & 4853,83 & 290,15 & 55,91 & 234,24 & \begin{tabular}{ll|l}
110,40 \\
\end{tabular} & 221,77 & 225,12 & 100,94 & 779,16 & 127,61 & 1,32 & 71,04 & 363,68 & 17,39 & 25,77 & 347,73 \\
\hline Discoglossus jeanneae & 30STF85 & 100,00 & 147,33 & 100,24 & 39,00 . & 5242,53 & 291,33 & 37,85 [ & $253,47 \mid$ & 94,49 & $215,79 \mid$ & $218,57]$ & 84,58 & 816,53 & 126,63 & 2,14 & $68,67 \mid$ & $367,17 \mid$ & 21,33 & 30,02 & 356,10 \\
\hline Discoglossus jeanneae & 30STF86 & 100,00 & 139,97 & 104,57 & 39,00 & 5481,88 & 291,96 & 26,83 & 265,13 & 84,45 & 212,01 & 214,44 & 74,54 & 840,73 & 126,14 & 2,85 & 66,86 & 369,18 & 24,63 & 33,24 & 359,97 \\
\hline Discoglossus jeanneae & 30STF87 & 100,00 & 144,08 & 105,08 & 39,00 & 5527,88 & 297,17 & 30,56 & 266,61 & 87,53 & 216,61 & 219,03 & 77,99 & 815,38 & 123,04 & 2,60 & 66,53 & 358,10 & 23,87 & 31,97 & 346,90 \\
\hline Discoglossus jeanneae & 30STF88 & 100,00 & 159,18 & 103,34 & 39,01 & 5441,13 & 308,69 & 47,81 & 260,88 & \begin{tabular}{|l|l|}
102,47 \\
\end{tabular} & 229,94 & 232,45 & $\begin{array}{l}93,75 \\
\end{array}$ & 739,03 & \begin{tabular}{ll|l}
116,06 \\
\end{tabular} & 1,46 & \begin{tabular}{|c|}
67,26 \\
\end{tabular} & \begin{tabular}{|l|}
330,99 \\
\end{tabular} & 19,64 & 26,47 & 314,51 \\
\hline Discoglossus jeanneae & 30STF89 & 100,00 & 164,97 & 105,62 & \begin{tabular}{|c|}
39,37 \\
\end{tabular} & 5509,10 & 317,27 & 52,51 & 264,76 & 106,85 & 236,40 & 238,74 & 98,66 & 703,42 & 111,41 & 1,05 & 67,10 & \begin{tabular}{|c|}
314,99 \\
\end{tabular} & 18,34 & 24,40 & 297,42 \\
\hline Discoglossus jeanneae & 30STF91 & 39,00 & 176,17 & 83,33 & 41,17 & 4017,94 & 284,50 & 85,06 & 199,44 & 137,06 & 226,75 | & 231,21 . & 128,54 & 719,27 . & 131,94 & 1,00 & 76,06 . & 365,92 & 13,00 & 20,62 & 341,06 \\
\hline Discoglossus jeanneae & 30STF92 & 93,00 & 174,60 & 84,83 & 40,84 & 4174,83 & 286,67 & 81,19 & 205,48 & 133,55 & \begin{tabular}{|l|l|l|l|l}
227,43 \\
\end{tabular} & 231,57 & 124,91 & \begin{tabular}{ll|}
713,66 \\
\end{tabular} & 128,04 & 1,00 & 74,88 & 357,33 & \begin{tabular}{|l|l|}
13,87 & \\
\end{tabular} & 21,17 & 333,13 \\
\hline Discoglossus jeanneae & 30STF93 & 100,00 & 166,98 & 89,40 & 40,09 & 4514,49 & 288,77 & 68,36 & 220,41 & 122,21 & 224,76 & 228,44 & \begin{tabular}{l|l|}
113,05 \\
\end{tabular} & $\begin{array}{l}735,55 \\
\end{array}$ & 125,81 & 1,13 & 72,92 & 356,18 & 15,45 & 23,38 & 336,01 \\
\hline Discoglossus jeanneae & 30STF94 & 100,00 & 159,15 & 94,59 & 39,62 & 4860,97 & 291,42 & 55,28 & 236,14 & \begin{tabular}{ll|}
110,56 \\
\end{tabular} & 221,89 & 225,26 & 100,99 & 759,01 & 124,04 & 1,38 & \begin{tabular}{l|l}
70,95 \\
\end{tabular} & 355,90 & 17,41 & 25,68 & 339,61 \\
\hline Discoglossus jeanneae & 30STF95 & 100,00 & 151,72 & 99,36 & 39,19 & 5148,58 & 293,22 & 43,49 & 249,72 & $\begin{array}{ll}99,93 \\
\end{array}$ & 218,81 & 221,64 & 90,19 & 783,50 & 123,22 & 1,91 & 69,12 & 357,32 & \begin{tabular}{l|l}
19,93 \\
\end{tabular} & 28,33 & 343,75 \\
\hline Discoglossus jeanneae & 30STF96 & 100,00 & 140,76 & 105,24 & 39,02 & 5472,22 & 292,95 & 27,36 & 265,59 & 85,59 & 212,85 & 215,11 & 75,5 & 823,41 & 123,36 & 2,90 & 66, & 362,83 & 24,15 & 32,79 & 353,24 \\
\hline Discoglossus jeanneae & 30STF97 & 100,00 & 150,34 & 103,86 & 39,00 & 5436,48 & 300,43 & 38,15 & 262,28 & 94,78 & \begin{tabular}{|l|l|l|}
221,63 \\
\end{tabular} & 223,92 & 85,39 & 776,73 & 119,36 & 2,20 & \begin{tabular}{l|l|}
67,05 \\
\end{tabular} & 346,44 & 21,62 & 29,46 & 332,90 \\
\hline Discoglossus jeanneae & 30STF98 & 100,00 & 156,77 & 104,40 & 39,06 & 5475,32 & 307,66 & 44,50 & 263,16 & 100,01 & 228,30 & 230,60 & 91,14 & 743,66 & 115,82 & 1,85 & 67,04 & 332,79 & 20,44 & 27,36 & 317,06 \\
\hline Discoglossus jeanneae & 30STF99 & 100,00 & 162,62 & 106,09 & 39,23 & 5534,61 & 315,61 & 49,36 & 266,25 & \begin{tabular}{l|l|l|l|l}
104,63 \\
\end{tabular} & 234,77 & 236,86 & 96,04 & 712,37 & 111,81 & 1,42 & 66,75 & 318,54 & 19,35 & 25,61 & 301,63 \\
\hline Discoglossus jeanneae & 30STG34 & 56,00 & 185,45 & 121,81 & \begin{tabular}{l|l}
39,35 \\
\end{tabular} & 6122,18 & 361,35 & 56,06 & 305,29 & \begin{tabular}{l|l|l|}
118,62 \\
\end{tabular} & 264,96 & 266,55 & \begin{tabular}{ll|l}
109,75 \\
\end{tabular} & 574,53 & 86,42 & 1,00 & 63,36 & 244,78 & 18,00 & 22,00 & 230,79 \\
\hline Discoglossus jeanneae & 30STG50 & 100,00 & 177,03 & 105,44 & 39,7 & 5583,52 & 329,56 & 63,59 & 265,97 & \begin{tabular}{ll|}
116,68 \\
\end{tabular} & 248,59 & 251,21 & $108, \mathrm{~s}$ & 618, & 96,50 & 1,00 & 66, & 271,26 & 16,58 & 21,61 & 253,39 \\
\hline Discoglossus jeanneae & 30STG60 & 100,00 & 174,76 & 108,79 & 39,92 & 5594,85 & 330,94 & 61,34 & 269,60 & 114,40 & 246,56 & 249,06 & 106,93 & 634,01 & 100,54 & 1,00 & 66,62 & 280,69 & 16,59 & 21,63 & 262,52 \\
\hline Discoglossus jeanneae & 30STG61 & 100,00 & 176,62 & 114,36 & 40,43 & 5730,71 & 339,71 & 60,30 & 279,41 & \begin{tabular}{l|l}
114,43 \\
\end{tabular} & 250,25 & 252,50 & 107,10 & 615,43 & 97,20 & 1,00 & 66,46 & 271,11 & \begin{tabular}{|c|}
16,10 \\
\end{tabular} & 21,01 & 253,67 \\
\hline Discoglossus jeanneae & 30STG71 & 100,00 & 175,13 & 113,89 & \begin{tabular}{|l|}
40,27 \\
\end{tabular} & 5719,97 & 337,59 & 58,99 & 278,60 & 113,35 & \begin{tabular}{|l|l|}
248,85 \\
\end{tabular} & 251,01 & 105,91 & $\begin{array}{l}629,15 \\
\end{array}$ & \begin{tabular}{l|l|}
100,05 \\
\end{tabular} & 1,00 & 66,39 & 278,57 & \begin{tabular}{|c|}
16,39 \\
\end{tabular} & 21,41 & 261,01 \\
\hline Discoglossus jeanneae & 30STG72 & 100,00 & 177,07 & 116,95 & 40,28 & 5847,54 & 343,72 & 58,04 & 285,68 & 113,66 & 252,76 & 254,48 & $\begin{array}{l}106,05 \\
\end{array}$ & 615,68 & 96,88 & 1,00 & \begin{tabular}{l|l}
65,85 \\
\end{tabular} & 269,98 & 16,13 & 21,12 & 253,51 \\
\hline Discoglossus jeanneae & 30STG81 & 100,00 & 170,50 & 112,65 & 39,99 & 5754,78 & 332,39 & 53,71 & 278,68 & 108,88 & 245,23 & 247,12 & \begin{tabular}{|c|}
100,98 \\
\end{tabular} & $\begin{array}{l}660,95 \\
\end{array}$ & \begin{tabular}{l|l}
103,85 \\
\end{tabular} & 1,00 & $65, \mathrm{c}$ & 291,38 & 17,70 & 23,10 & 274,78 \\
\hline \begin{tabular}{|l|l|l|l} 
Discoglossus jeanneae \\
\end{tabular} & 30 SUF03 & 82,00 & 169,39 & 89,49 & 40,47 & 4467,10 & 290,21 & 71,31 & 218,90 & 125,21 & 226,56 & 230,21 & 116,17 & 700,22 & 120,39 & 1,22 & \begin{tabular}{|c|}
73,03 \\
\end{tabular} & 341,09 & 15,43 & 22,72 & 320,33 \\
\hline Discoglossus jeanneae & 30SUF06 & 100,00 & 141,85 & 105,55 & 39,09 & 5464,68 & 294,05 & 28,43 & 265,62 & 86,67 & 213,94 & 216,01 & 76,81 & 802,06 & 120,23 & 3,02 & 66,62 & 354,21 & 24,06 & 32,49 & 343,76 \\
\hline Discoglossus jeanneae & 30SUF07 & 100,00 & 148,85 & 104,70 & 39,04 & 5460,91 & 299,82 & 35,93 & 263,89 & 93,13 & 220,67 & 222,81 & 83,66 & 769,43 & 117,27 & 2,48 & 66,68 & 342,70 & 22,23 & 30,04 & 329,43 \\
\hline Discoglossus jeanneae & 30SUF08 & 100,00 & 151,01 & 106,04 & 39,03 & 5559,36 & 304,70 & 37,09 & 267,61 & 93,84 & 224,24 & 226,11 & 84,63 & 756,68 & 115,23 & 2,43 & 66,08 & 335,16 & 22,23 & 29,63 & 321,26 \\
\hline Discoglossus jeanneae & 30SUF09 & 100,00 & 153,81 & 107,61 & 39,00 & 5651,03 & 310,21 & 38,57 & 271,64 & 95,21 & 228,32 & 229,94 & 86,20 & 742,10 & 112,92 & 2,29 & 65,64 & 326,77 & 22,01 & 28,98 & 312,48 \\
\hline Discoglossus jeanneae & 30SUF13 & 41,00 & 177,76 & 86,60 & \begin{tabular}{l|l}
40,55 \\
\end{tabular} & 4321,56 & 293,13 & 81,98 & 211,15 & 135,25 & 232,73 & 236,49 & 126,22 & 639,44 & 112,78 & 1,00 & 73,62 & \begin{tabular}{l|l|}
317,35 \\
\end{tabular} & 14,11 & 20,27 & 294,35 \\
\hline Discoglossus jeanneae & 30SUF15 & 100,00 & 137,05 & 106,49 & 39,38 & 5453,24 & 289,99 & 23,00 & 266,99 & 82,54 & 209,28 & 211,17 & 72,27 & \begin{tabular}{l|l}
805,45 \\
\end{tabular} & 119,46 & 3,47 & 66,20 & 353,64 & 25,29 & 34,08 & 345,22 \\
\hline Discoglossus jeanneae & 30SUF25 & 100,00 & 151,94 & 100,82 & 39,72 & 5156,42 & 294,15 & 42,55 & 251,60 & 100,47 & 219,74 & 221,94 & 90,62 & 720,34 & 111,42 & 2,52 & 67,90 & 328,08 & 20,82 & 28,60 & 314,10 \\
\hline Discoglossus jeanneae & 30SUF27 & 100,00 & 147,31 & 105,57 & 39,00 & 5509,06 & 299,63 & 33,14 & 266,49 & 91,15 & 220,22 & 221,83 & 81,75 & 740,6 & 110,76 & 3,10 & 65,66 & 327,50 & 23,41 & 30,92 & 314,60 \\
\hline Discoglossus jeanneae & 30SUF34 & 86,00 & 168,50 & 91,96 & 39,99 & 4679,37 & 294,07 & 66,24 & 227,83 & 122,48 & 229,17 & 232,01 & 113,01 & 630,40 & \begin{tabular}{|c|}
103,78 \\
\end{tabular} & 1,59 & 70,51 & 301,26 & \begin{tabular}{|l|l|}
16,97 \\
\end{tabular} & 23,19 & 282,53 \\
\hline Discoglossus jeanneae & 30SUF35 & 100,00 & 158,75 & 97,82 & 39,57 & 5031,04 & 295,61 & 51,20 & 244,41 & 108,57 & 224,73 & 226,96 & $\begin{array}{l}88,93 \\
\end{array}$ & 671,78 & $\begin{array}{l}105,65 \\
\end{array}$ & 2,26 & 68,27 & \begin{tabular}{|c|}
310,74 \\
\end{tabular} & 19,50 & 26,30 & 294,46 \\
\hline Discoglossus jeanneae & 30SUF44 & 99,00 & 175,94 & 87,81 & 39,80 & 4528,52 & 294,53 & \begin{tabular}{c|}
75,85 \\
\end{tabular} & 218,68 & 131,70 & 234,36 & 237,40 & \begin{tabular}{|l|l|}
122,17 \\
\end{tabular} & 584,84 & 98,22 & 1,33 & 71,14 & 283,83 & 16,13 & 21,07 & 263,71 \\
\hline Discoglossus jeanneae & 30SUF48 & 100,00 & 164,32 & 99,91 & 38,79 & 5356,79 & 307,45 & 52,37 & 255,08 & \begin{tabular}{|c|}
109,16 \\
\end{tabular} & 235,01 & 236,27 & 100,19 & \begin{tabular}{|c|c|}
643,47 \\
\end{tabular} & 100,51 & 2,44 & 66,3 & 291,23 & 20,14 & 25,76 & 273,91 \\
\hline Discoglossus jeanneae & 30SUF56 & 100,00 & $3+$ & 87,59 & 38, &, 36 & & 76 & 224,60 & 131,76 & 241,54 & 243,85 & 122, & 574,2 & 97,38 & 1,6 & 70,0 & 275,22 & 1,46] & $1,11[$ & 253,32 \\
\hline Discoglossus jeanneae & 30SUF67 & 100,00 & 170,32 & 93,93 & 38,2 & 5138,18 & 30 & 61,14 & 242,35 & 117,80 & 238,01 & 239,35 & 108,82 & 573,92 & 93,08 & 2,34 & 66,71 & \begin{tabular}{|l|l|}
264,25 \\
\end{tabular} & 18,82 & 23,33 & 245,63 \\
\hline Discoglossus jeanneae & 30SUF68 & 100,00 & 160,01 & 101,65 & 38,30 & 5489,69 & 306,78 & 45,54 & 261,24 & \begin{tabular}{|l|l|}
103,07 \\
\end{tabular} & 233,11 & 233,63 & \begin{tabular}{|c|}
94,37 \\
\end{tabular} & 604,52 & 93,12 & 3,17 & 64,03 & 268,35 & 21,43 & 25,48 & 252,56 \\
\hline Discoglossus jeanneae & 30 SUF76 & 60,00 & 178,71 & 86,90 & \begin{tabular}{l|l|}
37,95 \\
\end{tabular} & 4863,15 & 300,02 & 73,37 & 226,66 & 129,82 & 242,24 & 244,01 & 120,51 & 525,85 & 87,91 & 2,07 & 67,84 & 246,26 & 17,54 & 21,09 & 227,32 \\
\hline Discoglossus jeanneae & 30SUF77 & 100,00 & 159,55 & 100,20 & 38,38 & 5393,29 & 303,62 & 46,13 & 257,50 & \begin{tabular}{|l|l|}
104,07 \\
\end{tabular} & 231,38 & 231,93 & 95,20 & $\begin{array}{l}575,35 \\
\end{array}$ & 88,88 & 3,26 & \begin{tabular}{ll|}
63,66 \\
\end{tabular} & 255,70 & 21,20 & 24,50 & 240,32 \\
\hline Discoglossus jeanneae & 30SUF79 & 100,00 & 45 & 68 & $38, \mathrm{C}$ & 52 & 309, & 每 & 283,45 & 84,89 & 225, & 225 & $77+7+3$ & 629,21 & 90,48 & 4,67 & 60,1 & 64,72 & 6,09 & 6,35 & 253,12 \\
\hline \begin{tabular}{|l} 
Discoglossus jeanneae \\
\end{tabular} & 30 SUF89 & 10 & 13 & 1 & 38,6 & 6037,40 & 308 & 15,46 & 293,00 & 75,24 & 219,99 & 21 & 66 & 639,85 & 88,60 & 5,89 & 57, & 261,41 & 29,57 & 29,63 & 252,07 \\
\hline Discoglossus jeanneae & 30SUF98 & 100 & 164,71 & 100,24 & 38,00 & 5490,06 & & 49,53 & 260,20 & \begin{tabular}{|l|l|}
107,06 \\
\end{tabular} & 238,20 & 238,29 & 98,9 & 499,38 & 77,35 & 3,34 & 61,9 & 218,94 & 19,81 & 20,69 & 203,59 \\
\hline Discoglossus jeanneae & 30SUF99 & 100,00 & 131,28 & 115,92 & 38,00 & 6159,14 & 307,14 & 6,72 & 300,42 & \begin{tabular}{ll|l}
67,43 \\
\end{tabular} & 214,93 & 214,93 & \begin{tabular}{l|l|l}
58,55 \\
\end{tabular} & $\begin{array}{l}651,95 \\
\end{array}$ & 87,41 & 7,08 & 55,91 & 259,09 & 33,13 & 33,13 & 251,82 \\
\hline Discoglossus jeanneae & 30 SUG30 & 100,00 & 161,39 & 106,38 & 38,92 & 5693,89 & 316,09 & 44,78 & 271,31 & 101,95 & 236,83 & 237,75 & 93,1 & 674,11 & 101,81 & 2,51 & \begin{tabular}{|c|}
64,53 \\
\end{tabular} & 295,99 & 21,35 & 27,45 & 281,19 \\
\hline Discoglossus jeanneae & 30SUG37 & 100,00 & 173,29 & 119,06 & 37,97 & 6501,13 & 354,58 & 43,41 & 311,17 & \begin{tabular}{|l|l|l|l}
103,03 \\
\end{tabular} & 259,91 & 259 & 93,5 & 642,11 & 92,83 & 2,01 & \begin{tabular}{|c|}
61,93 \\
\end{tabular} & 255,04 & 18,79 & 18,79 & 251,26 \\
\hline Discoglossus jeanneae & 30 SUG45 & 100 & 173 & 113,65 & 37,96 & 6261 & 345 & 48,10 & 297,14 & 106, & 257,18 & 257,18 & \begin{tabular}{|c|}
97,48 \\
\end{tabular} & \begin{tabular}{|c|c|}
624,27 \\
\end{tabular} & 91,20 & 2,05 & 62,30 & 255,65 & 18,35 & $\begin{array}{l}18,35 \\
\end{array}$ & 248,82 \\
\hline Discoglossus jeanneae & $30 S U G 46$ & 100,00 & 173,01 & 115,77 & 37,69 & 6390,71 & 349,22 & 45,24 & 303,99 & 104,06 & 258,29 & 258,29 & 94,97 & \begin{tabular}{ll|}
629,66 \\
\end{tabular} & 90,83 & 2,29 & \begin{tabular}{|c|}
61,69 \\
\end{tabular} & 253,01 & 18,80 & 18,80 & 248,18 \\
\hline Discoglossus jeanneae & 30SUG47 & 100,00 & 172,30 & 117,66 & 37,30 & 6512,78 & 352,83 & 42,70 & \begin{tabular}{|l|l|}
310,13 \\
\end{tabular} & 102,23 & 259,24 & 259,24 & 92,72 & 633,68 & 91,18 & 2,39 & 61,22 & 250,11 & 19,36 & 19,36 & 247,05 \\
\hline Discoglossus jeanneae & 30SUG48 & 100,00 & 176,47 & 118,81 & 37,23 & 6575,07 & 359,06 & 45,1 & 313,91 & 107,69 & 264,08 & 264,08 & 95, & 620,2 & 91,78 & 2,0 & 61 & 243, & 17,5 & 17,58 & 239,9 \\
\hline Discoglossus jeanneae & 30 SUG & & 166 & & 37, & 618. & & & 291, & 103 & & & 94, & 619 & 89,40 & $2, \infty>$ & 61, & 255,64 & 20, & 20,03 & 247 \\
\hline Discoglossus jeanneae & 30 SUG56 & 100,00 & 172,76 & 114,40 & 37,12 & 6397,20 & 348,01 & 45,56 & 302,45 & \begin{tabular}{|l|l|l|l}
103,79 \\
\end{tabular} & 258,24 & 258,24 & 94,82 & 614,39 & 87,47 & 2,53 & \begin{tabular}{|l|l|l|}
61,03 \\
\end{tabular} & 245,24 & 19,16 & 19,16 & 241,01 \\
\hline Discoglossus jeanneae & 30 SUG57 & 100,00 & 176,82 & 115,35 & \begin{tabular}{|c|}
37,08 \\
\end{tabular} & 6451,29 & 353,91 & 48,21 & 305,70 & \begin{tabular}{|l|l|}
107,37 \\
\end{tabular} & 262,91 & 262,91 & 97,94 & 600,80 & 86,33 & 2,02 & 61,42 & 236,98 & 17,28 & 17,28 & 234,25 \\
\hline Discoglossus jeanneae & 30SUG65 & 100,00 & 163,63 & 113,17 & 37,00 & 6389,03 & 338,84 & $\begin{array}{ll}37,62 \\
\end{array}$ & 301,22 & 95,10 & 249,51 & 249,51 & 86,51 & 621,64 & 86,47 & 3,48 & 59,73 & 247,99 & 2,27 & 22,27 & 243,27 \\
\hline Discoglos. & $3054 G 67$ ( & 10 & & & 37,0 & 477,71 & & 46 , & 305,04 & 106, & 261 & & & 588, & 83,95 & 2,59 & 60, & 230 & & & 22 \\
\hline Discoglossus jeanneae & 30SUG73 & 100,00 & 160,62 & 110,39 & 37,03 & 6209,9 & 329, & 37,22 & 292,52 & 94,11 & 244,16 & 244,1 & 86,08 & 598,01 & 82,75 & 3,88 & 59,53 & 244,13 & 22,91 & 22,91 & 235,89 \\
\hline Discoglossus jeanneae & 30SUG74 & 100,00 & 155,15 & 113,29 & 37,00 & 6391,20 & 331,46 & 29,64 & 301,81 & 86,90 & 241,43 & 241,43 & 78,57 & 624,57 & 84,86 & 4,55 & 58,31 & 247,93 & 25,42 & 25,42 & 242,53 \\
\hline
\end{tabular}




\begin{tabular}{|c|c|c|c|c|c|c|c|c|c|c|c|c|c|c|c|c|c|c|c|c|c|}
\hline TAXON & UTM & $\mathrm{km} 2$ & B101 & $\mathrm{B1O2}$ & $\mathrm{BIO3}$ & BIO4 & B105 & B106 & B107 & $\mathrm{B108}$ & B109 & B1010 & BIO11 & B1012 & B1013 & B1014 & B1015 & B1016 & $\begin{array}{ll}1017 \\
17\end{array}$ & BIO18 & B1019 \\
\hline Discoglossus jeanneae & 30SUG75 & 100,00 & 155,82 & 114,23 & 37,00 & 6483,09 & 334,95 & 29,28 & 305,67 & 86,84 & 243,34 & 243,34 & 78,06 & 628,75 & 85,66 & 4,59 & 57,93 & 245,89 & 25,79 & 25,79 & 242,22 \\
\hline Discoglossus jeanneae & 30SUG76 & 100,00 & 167,93 & 112,70 & 36,94 & 6465,81 & 344,27 & 41,35 & 302,92 & 98,95 & 254,88 & 254,88 & 89,66 & 591,31 & 81,95 & 3,36 & 59,12 & 230,97 & 21,26 & 21,26 & 228,66 \\
\hline Discoglossus jeanneae & 30SUG77 & 100,00 & 172,85 & 113,05 & 36,76 & 6504,26 & 349,80 & 45,24 & 304,56 & 104,92 & 260,04 & 260,04 & 93,80 & \begin{tabular}{|c|}
576,88 \\
\end{tabular} & 81,82 & 3,05 & 59,29 & 224,69 & 19,93 & 19,93 & 221,81 \\
\hline Discoglossus jeanneae & 30SUG79 & 100,00 & 174,32 & 115,61 & 36,68 & 6642,51 & 356,23 & 44,43 & 311,80 & 105,50 & 263,37 & 263,37 & 93,36 & 566,28 & 83,23 & 2,84 & 58,80 & 220,16 & 19,61 & 19,61 & 213,69 \\
\hline Discoglossus jeanneae & 30SUG81 & 100,00 & 153,52 & 110,27 & 37,74 & 6081,48 & 320,52 & 31,07 & 289,45 & 88,59 & 235,66 & 235,66 & 80,89 & 579,69 & 82,66 & 4,74 & 58,76 & 239,96 & 24,57 & 24,57 & 228,61 \\
\hline Discoglossus jeanneae & 30SUG82 & 100,00 & 160,03 & 108,95 & 37,09 & 6113,47 & 325,95 & 37,62 & 288,34 & 94,39 & 242,38 & 242,38 & 86,69 & 565,50 & 80,03 & 4,05 & 59,18 & 233,26 & 22,71 & 22,71 & 222,88 \\
\hline Discoglossus jeanneae & 30SUG83 & 100,00 & 146,88 & 114,40 & 37,01 & 6387,08 & 324,88 & 21,16 & 303,71 & 78,95 & 233,39 & 233,39 & 70,75 & 626,14 & 83,73 & 5,68 & 56,84 & 246,76 & 28,60 & 28,60 & 240,65 \\
\hline Discoglossus jeanneae & 30 SUG84 & 100,00 & 153,59 & 113,48 & 36,98 & 6436,52 & 331,44 & 27,62 & 303,83 & 84,82 & 240,74 & 240,74 & 76,60 & 607,21 & 80,98 & 4,97 & 57,11 & 237,89 & 26,17 & 26,17 & 233,38 \\
\hline Discoglossus jeanneae & 30SUG85 & 100,00 & 148,31 & 115,62 & 36,83 & 6568,63 & 331,42 & 20,96 & 310,46 & 80,28 & 237,43 & 237,43 & 69,99 & 636,94 & 86,21 & 5,68 & 56,18 & 244,56 & 29,24 & 29,24 & 241,33 \\
\hline Discoglossus jeanneae & 30SUG86 & 100,00 & 166,49 & 112,03 & 36,32 & 6502,36 & 343,51 & 40,11 & 303,40 & 98,99 & 254,17 & 254,17 & 87,96 & 578,36 & 80,01 & 3,79 & 58,17 & 224,45 & 22,03 & 22,03 & 221,88 \\
\hline Discoglossus jeanneae & 30SUG90 & 100,00 & 124,09 & 117,99 & 37,99 & 6306,11 & 305,62 & $-1,53$ & 307,15 & 58,80 & 210,03 & 210,03 & 49,98 & 696,79 & 91,66 & 8,28 & 54,52 & 269,74 & 38,04 & 38,04 & 264,54 \\
\hline Discoglossus jeanneae & 30SUG91 & 100,00 & 154,26 & 110,16 & 37,51 & 6085,34 & 321,24 & 31,49 & 289,75 & 89,03 & 236,53 & 236,53 & 81,49 & 549,58 & 78,58 & 4,79 & 58,01 & 226,02 & 24,42 & 24,42 & 214,44 \\
\hline \begin{tabular}{|l} 
Discoglossus jeanneae \\
\end{tabular} & 30SUG92 & 100,00 & 153,51 & 111,81 & 37,11 & 6234,93 & 325,26 & 29,25 & 296,01 & 86,55 & 237,92 & 237,92 & 78,91 & 561,34 & 77,69 & 5,05 & 57,17 & 226,44 & 25,16 & 25,16 & 217,01 \\
\hline Discoglossus jeanneae & 30SUG93 & 100,00 & 149,08 & 114,18 & 37,00 & 6403,34 & 327,12 & 23,01 & 304,10 & 80,62 & 235,97 & 235,97 & 72,76 & 592,08 & 78,83 & 5,62 & 56,10 & 232,11 & 27,61 & 27,61 & 225,90 \\
\hline Discoglossus jeanneae & 30SUH91 & 100,00 & 173,91 & 115,37 & 36,04 & 6737,19 & 357,76 & 43,66 & 314,10 & 104,35 & 264,36 & 264,36 & 91,91 & 522,34 & 77,31 & 3,08 & 56,38 & 200,06 & 20,91 & 20,91 & 190,64 \\
\hline Discoglossus jeanneae & 30SUJ99 & 100,00 & 137,42 & 117,29 & 36,00 & 6853,44 & 325,79 & 4,68 & 321,11 & 121,32 & 230,47 & 230,47 & 54,88 & 427,42 & 50,38 & 8,04 & 37,70 & 142,60 & 46,05 & 46,05 & 119,32 \\
\hline Discoglossus jeanneae & 30SVF08 & 100,00 & 133,56 & 113,95 & 38,03 & 6023,94 & 304,68 & 10,38 & 294,30 & 71,01 & 215,36 & 215,38 & 62,47 & 616,68 & 84,16 & 7,03 & 55,93 & 246,27 & 32,40 & 32,95 & 237,63 \\
\hline \begin{tabular}{|l} 
Discoglossus jeanneae \\
\end{tabular} & 30SVF09 & 100,00 & 136,99 & 115,65 & 38,00 & 6143,62 & 311,83 & 11,90 & 299,92 & 72,73 & 220,46 & 220,46 & 64,20 & 596,54 & 80,01 & 6,42 & 55,62 & 238,08 & 29,95 & 29,95 & 229,69 \\
\hline Discoglossus jeanneae & 30SVF17 & 100,00 & 159,46 & 103,53 & 38,19 & 5540,32 & 309,17 & 42,39 & 266,78 & 101,41 & 233,86 & 233,92 & 93,12 & 458,48 & 67,69 & 3,80 & 59,34 & 196,04 & 19,99 & 20,58 & 183,33 \\
\hline Discoglossus jeanneae & 30SVF18 & 100,00 & 126,82 & 117,46 & 38,02 & 6171,08 & 304,79 & 1,30 & 303,49 & 63,14 & 210,80 & 210,83 & 54,17 & 631,64 & 82,95 & 7,90 & 53,93 & 245,10 & 35,22 & 35,73 & 239,22 \\
\hline Discoglossus jeanneae & 30SVF19 & 100,00 & 139,25 & 116,15 & 38,00 & 6168,30 & 314,74 & 13,34 & 301,40 & 74,45 & 223,03 & 223,03 & 65,97 & 561,14 & 75,10 & 6,36 & 54,89 & 222,64 & 28,74 & 28,74 & 214,12 \\
\hline Discoglossus jeanneae & 30SVF26 & & & & & & & & & & & & & & & & & & & & \\
\hline Discoglossus jeanneae & 30SVF27 & 100,00 & 141,26 & 111,30 & 38,16 & 5870,76 & 306,13 & 19,53 & 286,61 & 80,52 & 220,65 & 220,71 & 71,64 & 534,35 & 72,65 & 6,17 & 55,57 & 213,17 & 28,24 & 29,07 & 205,17 \\
\hline Discoglossus jeanneae & 30SVF28 & 100,00 & 132,77 & 117,33 & 38,04 & 6163,82 & 309,87 & 6,88 & 302,99 & 69,12 & 216,59 & 216,59 & 59,94 & 577,46 & 76,14 & 7,13 & 53,57 & 224,27 & 31,52 & 31,52 & 218,23 \\
\hline Discoglossus jeanneae & 30SVF38 & 100,00 & 127,31 & 118,64 & 38,00 & 6235,23 & 307,54 & 0,59 & 306,95 & 63,47 & 212,11 & 212,11 & 53,92 & 596,31 & 77,20 & 8,08 & 52,06 & 225,13 & 35,01 & 35,01 & 221,38 \\
\hline Discoglossus jeanneae & 30SVF39 & 100,00 & 131,54 & 119,18 & 38,00 & 6302,90 & 313,32 & 3,82 & 309,50 & 66,47 & 217,44 & 217,44 & 57,15 & 576,55 & 75, & 7,64 & 52,13 & 217,65 & 33,15 & 33,15 & 213,27 \\
\hline Discoglossus jeanneae & 30SVF46 & 39,00 & 176,27 & 94,16 & 38,00 & 5177,69 & 309,59 & 64,71 & 244,88 & \begin{tabular}{r|r|}
122,35 \\
\end{tabular} & 244,45 & 245,33 & 113,53 & 341,96 & 49,25 & 2,31 & 59,10 & 146,37 & $\begin{array}{l}3,13 \\
13,47\end{array}$ & $\begin{array}{l}17,37 \\
17, \quad l\end{array}$ & 137,31 \\
\hline Discoglossus jeanneae & 30 SVF 47 & 100,00 & 159,54 & 105,76 & 38,09 & 5649,02 & 313,34 & 40,31 & 273,04 & 100,56 & 235,24 & 235,39 & 91,74 & 405,70 & 56,34 & 3,81 & 56,20 & 165,65 & 18,68 & 20,10 & 157,14 \\
\hline Discoglossus jeanneae & 30SVF48 & 100,00 & 144,43 & 115,47 & 38,02 & 6075,72 & 316,82 & 18,45 & 298,38 & 81,20 & 226,66 & 226,66 & 72,07 & 482,90 & 65,27 & 5,73 & 53,36 & 187,41 & 25,48 & 25,48 & 181,11 \\
\hline Discoglossus jeanneae & 30SVF49 & 100,00 & 144,52 & 117,92 & 38,00 & 6222,36 & 322,06 & 16,38 & 305,67 & 79,48 & 228,90 & 228,90 & 70,24 & 488,69 & 66,22 & 5,89 & 52,86 & 187,38 & 25,87 & 25,87 & 181,41 \\
\hline Discoglossus jeanneae & 30SVF56 & 72,00 & 177,14 & 92,92 & 37,97 & 5138,75 & 308,87 & 66,64 & 242,23 & 124,12 & 244,73 & 245,98 & 115,02 & 323,99 & 46,75 & 2,07 & 58,29 & 137,38 & 12,52 & 17,56 & 129,49 \\
\hline \begin{tabular}{|l} 
Discoglossus jeanneae \\
\end{tabular} & $\begin{array}{l}30 \text { SVF57 } \\
305\end{array}$ & 100,00 & 159,37 & 105,05 & 38,01 & 5647,74 & 312,63 & \begin{tabular}{|l|}
40,51 \\
\end{tabular} & 272,12 & \begin{tabular}{|l|l|}
100,78 \\
124,2
\end{tabular} & 234,96 & 235,27 & \begin{tabular}{|c|c|}
91,68 \\
91
\end{tabular} & 398,57 & 54,91 & 3,90 & 55,24 & \begin{tabular}{|l|l|}
159,44 \\
\end{tabular} & \begin{tabular}{|l|l|}
19,14 \\
\end{tabular} & 22,90 & 152,46 \\
\hline Discoglossus jeanneae & 30SVF58 & 100,00 & 151,65 & 111,24 & 38,00 & 5928,96 & 316,66 & 28,35 & 288,31 & 89,96 & 231,53 & 231,60 & 80,85 & 437,84 & 59,44 & 5,03 & 53,48 & 169,94 & 22,82 & 24,13 & 163,64 \\
\hline Discoglossus jeanneae & 30SVF59 & 100,00 & 104,01 & 121,17 & 37,92 & 6446,90 & 292,30 & $-23,95$ & 316,25 & 45,38 & 192,09 & 192,42 & 29,21 & 717,51 & 89,99 & 14,93 & 46,53 & 256,12 & 59,06 & 62,18 & 247,05 \\
\hline Discoglossus jeanneae & 30SVF68 & 100,00 & 145,95 & 111,88 & 38,00 & 5986,90 & 313,21 & 22,53 & 290,68 & 85,22 & 226,68 & 226,92 & 74,84 & 459,45 & 61,02 & 5,88 & 51,92 & 172,95 & 26,35 & 31,35 & 168,28 \\
\hline Discoglossus jeanneae & 30SVF69 & 100,00 & 72,97 & 122,82 & 37,61 & 6587,29 & 267,50 & $-54,97$ & 322,48 & 21,67 & 163,66 & 164,27 & $-2,03$ & 900,79 & 109,13 & 25,20 & 41,06 & 314,29 & 93,63 & 97,06 & 292,93 \\
\hline \begin{tabular}{|l} 
Discoglossus jeanneae \\
\end{tabular} & $\begin{array}{l}30 \text { SVF79 } \\
3\end{array}$ & 100,00 & 84,24 & $\begin{array}{l}12,02 \\
121,90\end{array}$ & 37,75 & 6536,23 & 276,12 & - $-43,49$ & \begin{tabular}{|l|l|}
319,61 \\
\end{tabular} & $\begin{array}{ll}1,3,94 \\
33\end{array}$ & $\begin{array}{l}173,840 \\
173,84\end{array}$ & \begin{tabular}{|l|}
174,6768 \\
\end{tabular} & $\begin{array}{c}-2,03 \\
9,40\end{array}$ & 800,169 & $\mid$\begin{tabular}{|c|c|}
99,13 \\
99,13
\end{tabular} & 21,72 & $\begin{array}{l}41,00 \\
41,68\end{array}$ & \begin{tabular}{|l|}
285,37 \\
28,3
\end{tabular} & $\begin{array}{l}3,003 \\
81,84\end{array}$ & 86,32 & 266,44 \\
\hline Discoglossus jeanneae & 30 SVG00 & 100,00 & 140,34 & 115,24 & 37,99 & 6202,73 & 315,66 & 15,01 & 300,65 & 74,86 & 224,61 & 224,61 & 66,69 & 582,23 & 79,01 & 6,38 & 55,46 & 231,74 & 29,46 & 29,46 & 222,61 \\
\hline Discoglossus jeanneae & 30SVG01 & 100,00 & 158,93 & 109,21 & 37,43 & 6048,53 & 323,79 & 36,26 & 287,53 & 93,18 & 240,85 & 240,85 & 86,47 & 493,41 & 72,84 & 4,5 & 57,51 & 204,53 & 22,43 & 22,43 & 190,89 \\
\hline Discoglossus jeanneae & 30SVG02 & 100,00 & 150,38 & 113,64 & 37,05 & 6307,82 & 325 , & 24,74 & 300,86 & 82,49 & 236,10 & 236,10 & 75,05 & 546,70 & 74,73 & 5,65 & 55,64 & 217,00 & 26,42 & 26,42 & 207,91 \\
\hline Discoglossus jeanneae & 30SVG03 & 100 & 144,25 & 116,31 & 37,0 & 6493,53 & 326,55 & 16,71 & 309,84 & 75,08 & 232,55 & 23 & 66,95 & 591,22 & 77 & 6,4 & 54,50 & 226,69 & 29,73 & 29,73 & 221,93 \\
\hline \begin{tabular}{|l} 
Discoglossus jus jeanneae \\
\end{tabular} & \begin{tabular}{|l|}
$305 \mathrm{VG} 04$ \\
\end{tabular} & 100,00 & $\begin{array}{l}1443,14 \\
153,14\end{array}$ & $\begin{array}{ll}1110,31 \\
113,90\end{array}$ & 36,66 & $\begin{array}{l}049,303 \\
6516,42\end{array}$ & 3233,25 & $\frac{\mid 0,1 / 35}{26,35}$ & $\begin{array}{l}305,64,90 \\
306,90\end{array}$ & \begin{tabular}{|c|}
83,34 \\
83
\end{tabular} & \begin{tabular}{|l|}
241,63 \\
241
\end{tabular} & \begin{tabular}{|l|}
241,63 \\
241,63
\end{tabular} & \begin{tabular}{|c|}
70,353 \\
75,1
\end{tabular} & | & 73,6 & $\frac{0,4}{5,6}$ & 55,34 & \begin{tabular}{|l|l|l}
216,96 \\
216
\end{tabular} & $\frac{\mid 2,1 / 1}{26,66}$ & 26,15 & $\begin{array}{l}221,93 \\
213,60\end{array}$ \\
\hline Discoglossus jeanneae & 30SVG05 & 100,00 & 160,37 & 111,84 & 36,06 & 6553,34 & 339,08 & 34,10 & 304,97 & 92,30 & 249,14 & 249,14 & 81,81 & 554,87 & 74,29 & 4,92 & 55,97 & 212,51 & 24,45 & 24,45 & 209,51 \\
\hline Discoglossus jeanneae & 30SVG06 & 100,00 & 159,20 & 112,65 & 36,05 & 6647,09 & 340,97 & 32,25 & 308,72 & 91,17 & 249,27 & 249,27 & 79,61 & 574,35 & 80,27 & 5,09 & 55,89 & 221,47 & 25,64 & 25,64 & 215,16 \\
\hline Discoglossus jeanneae & 30SVG08 & 100,00 & 171,91 & 110,63 & 35,73 & 6666,36 & 351,30 & 45,10 & 306,20 & 103,21 & 261,64 & 261,64 & 91,40 & 539,60 & 79,5 & 3,6 & 57,24 & 11,39 & 21,10 & 21,10 & 201,90 \\
\hline Discoglossus jeanneae & 30SVG09 & 100, & 173,32 & 111,54 & 35,9 & 6694,79 & 353,79 & $\begin{array}{l}45,67 \\
45,10\end{array}$ & 308,12 & $\mid \begin{array}{l}\mid 104,30 \\
104\end{array}$ & 26 & 26 & 92,20 & 530,16 & 78,9 & $\frac{3,}{3,}$ & 56,99 & 206,95 & 20,62 & 20,62 & 196,72 \\
\hline \begin{tabular}{|l} 
Discoglossus jeanneae \\
\end{tabular} & 30SVG10 & 100,00 & 146,56 & 114,97 & 37,99 & 6181,29 & 320,53 & 20,79 & 299,74 & 80,53 & 230,58 & 230,58 & 72,92 & 519,77 & 71,88 & 5,83 & 55,21 & 208,73 & 26,13 & 26,13 & 197,66 \\
\hline Discoglossus jeanneae & 30 SVG12 & 100,00 & 149,03 & 114,67 & 37,13 & 6337,57 & 325,89 & 22,51 & 303,38 & 80,62 & 235,18 & 235,18 & 73,41 & 525,07 & 72,16 & 5,99 & 54,51 & 205,95 & 27,16 & 27,16 & 196,40 \\
\hline Discoglossus jeanneae & 30SVG13 & 100,00 & 138,03 & 118,49 & 37,01 & 6573,18 & 324,53 & 9,28 & 315,26 & 68,87 & 227,57 & 227,57 & 60,05 & 604,05 & 78,08 & 7,40 & 53,03 & 225,93 & 32,95 & 32,95 & 222,81 \\
\hline Discoglossus jeanneae & 30SVG14 & 100,00 & 143,62 & 117,40 & 36,8 & 6630,32 & 330,15 & 14,90 & 315,25 & 75,28 & 233,90 & 233 & 64,83 & 589,65 & 77,39 & 6,85 & 53,37 & 12 & 31,00 & 31,00 & 217,41 \\
\hline \begin{tabular}{|l} 
Discoglossus jeanneae \\
\end{tabular} & 30SVG15 & 100,00 & $\frac{14}{15}$ & $\begin{array}{lll}1114,40 \\
11,31\end{array}$ & 36,15 & $\begin{array}{l}6005,027 \\
6658,71\end{array}$ & 33 & 25,51 & 31 & $\begin{array}{l}\mid 5,26 \\
85,32\end{array}$ & 243,65 & 243,65 & $\begin{array}{l}4,305 \\
73,77 \\
\end{array}$ & $\begin{array}{l}503,03 \\
567,08\end{array}$ & $\begin{array}{l}71,3,80 \\
76,1\end{array}$ & $\begin{array}{l}0,000 \\
5,90\end{array}$ & 54,41 & $\mid$\begin{tabular}{|l|}
214,94 \\
212
\end{tabular} & $\begin{array}{l}27,50 \\
27,50\end{array}$ & $\frac{1,100}{27,50}$ & 2121,41 \\
\hline Discoglossus jeanneae & 30 SVG20 & 100,00 & 145,69 & 116,98 & 38,00 & 6252,42 & 322,93 & 18,24 & 304,69 & 78,98 & 230,76 & 230,76 & 71,08 & 505,76 & 68,07 & 6,06 & 53,89 & 199,54 & 26,34 & 26,34 & 189,76 \\
\hline Discoglossus jeanneae & 30 SVG21 & 100,00 & 156,34 & 113,11 & \begin{tabular}{ll|l}
37,95 & \\
\end{tabular} & 6152,04 & 326,59 & 30,64 & 295,95 & 88,38 & 239,92 & 239,92 & 82,50 & $\begin{array}{l}432,45 \\
\end{array}$ & 64,77 & 4,80 & 55,33 & 176,44 & 22,57 & 22,57 & 160,84 \\
\hline \begin{tabular}{|l} 
Discoglossus jeanneae \\
\end{tabular} & 30 SVG 22 & 100,00 & 153,52 & 114,99 & 37,21 & 6338,62 & 330,23 & 26,31 & 303,92 & 84,42 & 239,78 & 239,78 & 77,80 & 473,18 & 65,41 & 5,45 & 54,03 & 185,84 & 24,53 & 24,53 & 175,09 \\
\hline Discoglossus jeanneae & 30 SVG23 & 100,00 & 143,48 & 118,29 & 37,0 & 6569,32 & 329,22 & 14,20 & 315 & 73,80 & 232,93 & 233 & 65,32 & 558,01 & 71,9 & 6,87 & 52,63 & 208,01 & 30,10 & 30,10 & 204 \\
\hline \begin{tabular}{|l|l|l} 
Discoglossus jeanneae \\
\end{tabular} & \begin{tabular}{|l|}
$305 V G 25$ \\
30 VG 24
\end{tabular} & 100,00 & $\begin{array}{l}14,40 \\
144,54\end{array}$ & $\begin{array}{l}11,0,25 \\
117,80\end{array}$ & 36,96 & $\begin{array}{ll}0504,52,62 \\
664,62\end{array}$ & $\begin{array}{ll}32,24 \\
331,67\end{array}$ & $\begin{array}{l}14,20 \\
15,37 \\
\end{array}$ & \begin{tabular}{|l|l|}
316,30 \\
316
\end{tabular} & 75,56 & 235,03 & 235,03 & 65,56 & 568,15 & 74,36 & 6,89 & 52,60 & 210,27 & 30,69 & 30,69 & 207,29 \\
\hline Discoglossus jeanneae & 30 SVG25 & 100,00 & 130,21 & 120,26 & 36,87 & 6743,06 & 322,75 & 0,62 & 322,12 & 61,14 & 222,23 & 222,23 & 50,70 & 642,81 & 86,59 & 8,94 & 50,67 & 236,40 & 39,79 & 39,79 & 228,93 \\
\hline Discoglossus jeanneae & 30SVG27 & 100,00 & 149,35 & 114,96 & 35,68 & 6835,44 & 338,37 & 21,04 & 317,34 & 80,48 & 242,35 & 242,35 & 68,20 & 594,90 & 86,50 & 6,71 & 53,41 & 227,54 & 31,52 & 31,52 & 214,6 \\
\hline Discoglossus jeanneae & 30 SVG28 & 100,00 & 167,47 & 109,58 & 35,04 & 6784,30 & 349,56 & 41,31 & 308,25 & 97,45 & 259, & 259 & 86, & 545,37 & 83,71 & 4,61 & 56 & 215,71 & 23,85 & 23,85 & 20 \\
\hline Discoglossus jeanneae & 30 SVG30 & 100,00 & 148,16 & 118,29 & 38,00 & 6278,06 & 26,89 & 19,56 & 307,33 & 81,36 & 233,53 & 233,53 & 73,22 & 479,05 & 64,55 & 5,64 & 53,49 & 187,07 & 24,65 & 24,65 & 178,29 \\
\hline
\end{tabular}




\begin{tabular}{|c|c|c|c|c|c|c|c|c|c|c|c|c|c|c|c|c|c|c|c|c|c|}
\hline TAXON & UTM & $\mathrm{km} 2$ & $\mathrm{BIO1}$ & $\mathrm{B1O2}$ & $\mathrm{BIO3}$ & B104 & B105 & $\mathrm{B106}$ & 8107 & B108 & $\mathrm{BIO9}$ & 81010 & B1011 & BIO12 & B1O13 & 81014 & B1015 & 81016 & B1017 & $\mathrm{BIO18}$ & B1019 \\
\hline Discoglossus jeanneae & 30SVG31 & 100,00 & 156,21 & 115,40 & 37,99 & 6220,19 & 330,04 & 28,66 & 301,38 & 87,92 & 240,69 & 240,69 & 81,49 & 421,63 & 60,03 & 5,01 & 54,07 & 168,55 & 21,97 & 21,97 & 155,25 \\
\hline Discoglossus jeanneae & 30 SVG32 & 100,00 & 155,35 & 116,17 & \begin{tabular}{|l|l|}
37,27 \\
\end{tabular} & 6367,30 & 333,48 & 27,03 & 306,45 & 86,06 & 241,90 & 241,90 & 79,03 & 449,20 & 60,94 & 5,31 & 53,20 & 174,40 & 23,25 & 23,25 & 164,69 \\
\hline Discoglossus jeanneae & 30SVG33 & 100,00 & 145,52 & 118,63 & 37,00 & 6567,88 & 331,36 & 15,78 & 315,57 & 76,20 & 235,00 & 235,00 & 67,37 & 530,49 & 68,97 & 6,75 & 52,08 & 196,18 & 29,18 & 29,18 & 192,47 \\
\hline Discoglossus jeanneae & 30SVG34 & 100,00 & 139,93 & 119,43 & 36,99 & 6683,69 & 329,45 & 9,99 & 319,46 & 71,39 & 231,01 & 231,01 & 60,73 & 574,29 & 75,90 & 7,53 & 51,31 & 209,78 & 33,08 & 33,08 & 206,13 \\
\hline Discoglossus jeanneae & 30SVG36 & 100,00 & 132,62 & 119,55 & 36,53 & 6795,28 & 325,48 & 2,86 & 322,62 & 75,23 & 225,41 & 225,41 & 52,59 & 626,85 & 85,85 & 9,01 & 50,08 & 230,35 & 40,13 & 40,13 & 219,61 \\
\hline Discoglossus jeanneae & 30SVG37 & 100,00 & 162,55 & 110,80 & 35,25 & 6759,06 & 345,47 & 36,00 & 309,47 & 95,21 & 254,03 & 254,03 & 81,78 & 537,45 & 80,05 & 5,21 & 54,72 & 208,61 & 25,54 & 25,54 & 195,53 \\
\hline Discoglossus jeanneae & 30SVG38 & 100,00 & 172,59 & 108,24 & 35,04 & 6691,36 & 350,72 & 47,06 & 303,66 & 103,34 & 262,76 & 262,76 & 92,04 & 500,91 & 75,67 & 3,99 & 55,81 & 195,89 & 21,58 & 21,58 & 183,27 \\
\hline Discoglossus jeanneae & 30 SVG40 & 100,00 & 145,38 & 119,73 & 38,00 & 6347,76 & 327,09 & 15,72 & 311,37 & 78,74 & 231,55 & 231,55 & 69,68 & 491,34 & 66,55 & 5,95 & 52,60 & 186,27 & 25,97 & 25,97 & 180,81 \\
\hline Discoglossus jeanneae & 30SVG41 & 100,00 & 153,30 & 119,43 & 37,94 & 6373,83 & 334,49 & 23,04 & 311,45 & 85,31 & 239,83 & 239,83 & 76,87 & 453,80 & 62,06 & 5,21 & 53,01 & 173,27 & 22,75 & 22,75 & 166,64 \\
\hline Discoglossus jeanneae & 30 SVG42 & 100,00 & 148,23 & 119,59 & 37,30 & 6503,29 & 333,06 & 17,69 & 315,37 & 79,29 & 236,58 & 236,58 & 70,59 & 494,17 & 65,33 & 6,06 & 52,03 & 182,97 & 26,45 & 26,45 & 179,08 \\
\hline Discoglossus jeanneae & 30SVG43 & 100,00 & 147,47 & 119,11 & 37,00 & 6579,18 & 333,78 & 17,30 & 316,48 & 78,58 & 237,05 & 237,05 & 69,25 & 511,75 & 66,96 & 6,32 & 51,82 & 186,44 & 27,85 & 27,85 & 184,32 \\
\hline Discoglossus jeanneae & 30SVG44 & 100,00 & 139,33 & 119,77 & 37,00 & 6682,62 & 329,05 & 9,07 & 319,98 & 79,28 & 230,30 & 230,30 & 60,18 & 564,60 & 74,91 & 7,68 & 50,60 & 204,73 & 33,72 & 33,72 & 200,23 \\
\hline Discoglossus jeanneae & 30 SVG45 & 100,00 & 136,11 & 119,86 & 36,88 & 6743,93 & 327,60 & 5,93 & 321,68 & 83,75 & 228,09 & 228,09 & 56,45 & 587,08 & $\begin{array}{ll}79,14 \\
\end{array}$ & 8,34 & 49,90 & 214,21 & \begin{tabular}{l|l}
36,75 \\
36
\end{tabular} & 36,75 & 205,80 \\
\hline Discoglossus jeanneae & 30 SVG46 & 100,00 & 143,98 & 117,51 & 36,36 & 6768,92 & 333,58 & 14,49 & 319,08 & 91,27 & 236,06 & 236,06 & 63,70 & 566,46 & 78,63 & 7,38 & 50,98 & 209,87 & 33,53 & 33,53 & 199,33 \\
\hline Discoglossus jeanneae & 30SVG48 & 100,00 & 160,46 & 112,17 & 35,26 & 6796,60 & 345,24 & 32,91 & 312,34 & 105,88 & 252,39 & 252,39 & 79,30 & 527,44 & 78,75 & 5,40 & 53,53 & 202,94 & 26,89 & 26,89 & 187,64 \\
\hline Discoglossus jeanneae & 30 SVG50 & 100,00 & 111,64 & 121,25 & $\begin{array}{l}37,95 \\
\end{array}$ & 6483,53 & 300,34 & $-16,90$ & 317,23 & 53,95 & 200,07 & 200,32 & 36,09 & 673,94 & 85,04 & 12,65 & 47,20 & 240,43 & 51,48 & 55,05 & 233,93 \\
\hline Discoglossus jeanneae & 30SVG51 & 100,00 & 137,77 & 120,31 & 37,80 & 6468,57 & 323,32 & 7,91 & 315,41 & 72,75 & 225,69 & 225,71 & 61,08 & 533,14 & 69,61 & 7,34 & 50,53 & 192,97 & 31,75 & 32,01 & 190,72 \\
\hline \begin{tabular}{|l} 
Discoglossus jeanneae \\
\end{tabular} & 30SVG52 & 100,00 & 121,04 & 121,37 & 37,53 & 6577,65 & 311,27 & $-8,14$ & 319,41 & 69,02 & 210,81 & 210,84 & 44,02 & 627,20 & 80,32 & 10,60 & 47,88 & 223,75 & 44,60 & 45,24 & 217,73 \\
\hline Discoglossus jeanneae & 30SVG53 & 100,00 & 132,54 & 120,41 & 37,09 & 6610,03 & 321,70 & 2,59 & 319,11 & 79,42 & 222,59 & 222,61 & 54,58 & 576,19 & 74,64 & 8,94 & 49,04 & 206,32 & 38,22 & 38,56 & 200,98 \\
\hline Discoglossus jeanneae & 30 SVG54 & 100,00 & 143,99 & 119,14 & 37,00 & 6641,52 & 332,01 & 13,67 & 318,34 & 94,65 & 234,34 & 234,34 & 65,17 & 527,69 & 69,98 & 6,98 & 50,44 & 190,85 & 31,01 & 31,01 & 186,00 \\
\hline Discoglossus jeanneae & 30SVG55 & 100,00 & 134,70 & 120,19 & 37,00 & 6727,44 & 325,86 & 4,20 & 321,66 & 86,12 & 226,34 & 226,34 & 55,16 & 576,79 & 77,1 & 8, & 48,93 & 209,65 & 37,73 & 37,73 & 199,31 \\
\hline Discoglossus jeanneae & 30SVG56 & 100,00 & 135,86 & 119,61 & 36,73 & 6767,58 & 327,38 & 5,70 & 321,69 & 87,11 & 227,97 & 227,97 & 55,90 & 579,11 & 78,55 & 8,52 & 48,84 & 211,90 & 38,31 & 38,31 & 198,88 \\
\hline Discoglossus jeanneae & 30SVG57 & 100,00 & 119,51 & 121,43 & \begin{tabular}{|c|}
36,87 \\
\end{tabular} & 6806,40 & 314,62 & $-10,48$ & 325,10 & 69,97 & 212,57 & 212,58 & 40,06 & 653,93 & 86,56 & 11,92 & 45,99 & 235,78 & 51,76 & 51,94 & 217,53 \\
\hline Discoglossus jeanneae & 30SVG58 & 100,00 & 148,94 & 115,90 & 36,12 & 6782,17 & 336,74 & 19,89 & 316,85 & 100,73 & 240,96 & 240,96 & 68,35 & 539,85 & 76,30 & 6,80 & 50,24 & 201,74 & 32,99 & 32,99 & 185,82 \\
\hline Discoglossus jeanneae & 30SVG61 & 100,00 & 112,41 & 121,28 & 37,86 & 6532,90 & 301,90 & $-16,22$ & 318,13 & 62,72 & 201,56 & 201,79 & 36,41 & 659,49 & 82,80 & 12,84 & 46,09 & 233,59 & 52,19 & 55,75 & 224,71 \\
\hline Discoglossus jeanneae & 30 SVG62 & 100,00 & 122,76 & 120,85 & 37,48 & 6557,57 & 311,71 & $-6,24$ & 317,96 & 74,06 & 212,14 & 212,21 & 45,92 & 605,29 & 77 & 10,4 & 47,20 & 215,44 & 43,91 & 45,90 & 207,94 \\
\hline Discoglossus jeanneae & 30SVG63 & 100,00 & 122,08 & 121,11 & 37,19 & 6612,23 & 312,55 & $\begin{array}{l}-7,240 \\
-7,40 \\
\end{array}$ & 319,95 & 73,26 & 212,25 & $\frac{212,1}{212,32}$ & 44,72 & 613,89 & 78,69 & $\begin{array}{l}\mid 0,414 \\
10,86\end{array}$ & $\begin{array}{l}4,2,73 \\
46,73\end{array}$ & 218,94 & \begin{tabular}{|l|l|}
45,77 \\
45
\end{tabular} & 47,06 & 208,89 \\
\hline Discoglossus jeanneae & 30 SVG65 & 100,00 & 135,93 & 119,71 & 37,00 & 6691,84 & 325,60 & 5,58 & 320,03 & 87,42 & 226,97 & 226,97 & 56,80 & 556,57 & 73,86 & 8,38 & 48,16 & 201,59 & 37,38 & 37,38 & 190,13 \\
\hline Discoglossus jeanneae & 30 SVG66 & 100,00 & 137,12 & 119,37 & 36,88 & 6732,43 & 327,30 & 6,80 & 320,50 & 88,49 & 228,65 & 228,65 & 57,50 & 556,55 & 74,74 & 8,29 & 48,10 & 202,79 & 37,60 & 37,60 & 189,02 \\
\hline Discoglossus jeanneae & 30SVG67 & 100,00 & 132,71 & 119,32 & 36,68 & 6757,97 & 323,71 & 2,81 & 320,90 & 83,86 & 224,71 & 224,71 & 53,13 & 581,53 & 77,70 & 9,48 & 47,01 & 211,09 & 42,71 & 42,82 & 194,21 \\
\hline Discoglossus jeanneae & 30SVG74 & 100,00 & 139,94 & 118,44 & 37,00 & 6572,61 & 325,67 & 10,28 & 315,39 & 92,14 & 229,21 & 229,23 & 62,07 & 516,92 & 67,15 & 7,63 & 47,99 & 185,14 & 34,32 & 35,44 & 176,46 \\
\hline \begin{tabular}{|l} 
Discoglossus jeanneae \\
\end{tabular} & 30 SVG 85 & 100,00 & 140,54 & 117,37 & 37,00 & 6548,81 & 324,38 & $\begin{array}{l}0,202 \\
11,65 \\
\end{array}$ & 312,73 & $\begin{array}{ll}2,2,73 \\
22\end{array}$ & \begin{tabular}{|l|l|}
229,30 \\
\end{tabular} & 229,42 & 63,09 & 503,91 & $\begin{array}{l}64,87 \\
64,1\end{array}$ & $\begin{array}{l}7,607 \\
7,67\end{array}$ & 46,85 & $\begin{array}{l}179,86 \\
\end{array}$ & 35,31 & 37,92 & 168,24 \\
\hline Discoglossus jeanneae & 30SVG88 & 100,00 & 163,67 & 111,76 & 36,80 & 6443,26 & 338,13 & 36,77 & 301,36 & 117,71 & 250,17 & 250,25 & 86,18 & 414,98 & 54,20 & 4,38 & 48,68 & 149,10 & 24,87 & 26,67 & 139,02 \\
\hline Discoglossus jeanneae & 30SVG91 & 100,00 & 123,64 & 117,72 & 37,63 & 6400,30 & 305,85 & $-3,53$ & 309,38 & 75,38 & 210,51 & 211,27 & 48,91 & 561,19 & 69,47 & 10,75 & 44,90 & 196,42 & 44,97 & 52,32 & 186,69 \\
\hline Discoglossus jeanneae & 30SVG98 & 100,00 & 138,54 & 117,48 & 37,01 & 6605,31 & 323,07 & 9,57 & 313,50 & 90,52 & 227,97 & 228,16 & 60,40 & 507,78 & 64,38 & 8,58 & 44,35 & 179,71 & 41,02 & 43,36 & 161,53 \\
\hline Discoglossus jeanneae & 30SVG99 & 100,00 & 148,60 & 115,92 & 37,00 & 6562,74 & 329,82 & 20,00 & 309,82 & $\mid \begin{array}{r}101,51 \\
\end{array}$ & 237,17 & 237,29 & 70,40 & 463,21 & 59,05 & 6,64 & 45,31 & 164,47 & 34,75 & 36,81 & 148,06 \\
\hline \begin{tabular}{|l} 
Discoglossus jeanneae \\
\end{tabular} & 30SVHO4 & 100,00 & $\begin{array}{l}14,00 \\
152,67\end{array}$ & 121,54 & 36,70 & 69043,12 & 347,59 & $\begin{array}{ll}19,47 \\
\end{array}$ & 328,12 & \begin{tabular}{|l|l|l|l|l|}
105,63 \\
\end{tabular} & | 246,53 & $\mid 246,53$ & $\begin{array}{ll}0,404 \\
69,13\end{array}$ & 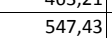 & $\begin{array}{l}30,03 \\
78,34 \\
\end{array}$ & $\frac{0,044}{4,60}$ & $\begin{array}{ll}43,114 \\
51,14\end{array}$ & 202,35 & 30,55 & 30,01 & $\begin{array}{l}140,00 \\
187,44\end{array}$ \\
\hline Discoglossus jeanneae & $30 \mathrm{SVH} 12$ & 100,00 & 165,95 & 116,11 & 36,00 & 6846,00 & 353,68 & 35,44 & 318,24 & 105,58 & 258,18 & 258,18 & 83,22 & 519,72 & 77, & 3,74 & 53,92 & 197,10 & 24,62 & 24,62 & 183,63 \\
\hline Discoglossus jeanneae & 30SVH13 & 100,00 & 163,29 & 117,95 & 36,05 & 6870,86 & 352,93 & 31,71 & 321,22 & 115,03 & 255,89 & 255,89 & 80,25 & 515,05 & 75,36 & 3,79 & 52,75 & 193,19 & 25,86 & 25,86 & 179,25 \\
\hline Discoglossus jeanneae & 30SVH14 & 100,00 & 157,62 & 120,27 & 36,56 & 6901,44 & 350,06 & 24,96 & 325,10 & 110,93 & 250,79 & 250,79 & 74,49 & 518,31 & 74,11 & 4,22 & 51,24 & 192,18 & 28,63 & 28,63 & 176,88 \\
\hline Discoglossus jeanneae & 30 SVH 21 & 100 & 175,23 & 112,19 & 36,0 & 6708,16 & 355,88 & 46,71 & 309,18 & 107,21 & 265,28 & 265,28 & 93,80 & 478,04 & 70, & 3,0 & 54,79 & 181,60 & 20,69 & 20,69 & 170,99 \\
\hline \begin{tabular}{|l} 
Discoglossus jus jeanneae \\
\end{tabular} & 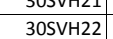 & 100,00 & $\begin{array}{l}1 / 7,25 \\
167,66\end{array}$ & $\begin{array}{l}111,19 \\
115,08\end{array}$ & 30,00 & 6811,41 & 353,80 & $\begin{array}{l}\mid 4,1 / 1 \\
37,68\end{array}$ & 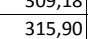 & $\mid \begin{array}{l}\mid 11,21 \\
117,58\end{array}$ & $\mid \frac{\mid 203,20}{259,44}$ & \begin{tabular}{|l|}
259,44 \\
259
\end{tabular} & $\begin{array}{l}5,30 \\
85,38 \\
\end{array}$ & \begin{tabular}{|l|}
498,74 \\
49,74
\end{tabular} & $\frac{1, i}{73,}$ & $\frac{3,0}{3,6}$ & 53,34 & $\begin{array}{l}181,00 \\
188,84 \\
\end{array}$ & \begin{tabular}{|l|l|}
24,08 \\
24
\end{tabular} & $\begin{array}{l}24,08 \\
24,0\end{array}$ & $\begin{array}{l}11,99 \\
174,98\end{array}$ \\
\hline Discoglossus jeanneae & 30SVH33 & 100,00 & 163,99 & 116,79 & 36,00 & 6826,59 & 351,34 & 33,03 & 318,31 & 117,36 & 255,90 & 255,90 & 81,46 & 484,88 & 69,84 & 3,89 & 51,35 & 181,73 & 26,11 & 26,11 & 165,59 \\
\hline Discoglossus jeanneae & 30 SVH34 & 100,00 & 153,79 & 120,08 & 36,59 & 6892,22 & 345,85 & 21,45 & 324,40 & 106,64 & 246,91 & 246,91 & 71,05 & 508,68 & 71,43 & 4,8 & 49,44 & 88,17 & 31,19 & 31,19 & 169,55 \\
\hline Discoglossus jeanneae & $30 \mathrm{SVH} 41$ & 100,00 & 172,06 & 112,09 & 36,00 & 6687,70 & 352,28 & 43,94 & 308,34 & 125,90 & 261,96 & 261 & 91,14 & 58,41 & 66, & 3,4 & 52,76 & 03 & 22,34 & 22,34 & 160,08 \\
\hline Discoglossus jeanneae & 30 SVH42 & 100,00 & 168,91 & 114,17 & 36,00 & 6738,83 & 351,87 & 39,52 & 312,34 & 122,59 & 259,43 & 255 & 87,43 & $\begin{array}{l}\mid 450,41,65 \\
461\end{array}$ & 66, & $\frac{3,4}{3,6}$ & 51,84 & $\begin{array}{ll}173,28 \\
\end{array}$ & 24,00 & 24,00 & 158,57 \\
\hline \begin{tabular}{|l} 
Discoglossus jeanneae \\
\end{tabular} & $30 \mathrm{SVH}$ & 100,00 & 163 & 116,73 & 36,05 & 6798,84 & 349,91 & 32,62 & 317,29 & 116,79 & 254,96 & 254,96 & 81,34 & 471,24 & 66,79 & 4,03 & 50,53 & 175,58 & 26,70 & 26,70 & 158,96 \\
\hline Discoglossus jeanneae & 30 SVH44 & 100,00 & 148,33 & 120,66 & 36,76 & 6890,83 & 341,28 & 15,92 & 325,37 & 100,84 & 241,58 & 241,58 & 65,94 & 515,72 & 70,99 & 5,67 & 47,88 & 189,17 & 34,67 & 34,67 & 168,88 \\
\hline Discoglossus jeanneae & 30 SVH50 & 100,00 & 164,82 & 112,77 & 36,00 & 6714,47 & 346,88 & 36,63 & 310,25 & 117,82 & 255,25 & 255,25 & 84,05 & 475,58 & 68,54 & 4,43 & 51,68 & 179,36 & 25,53 & 25,53 & 164,36 \\
\hline Discoglossus jeanneae & 30SVH52 & 100,00 & 170,28 & 113,68 & 36,0 & 6664,14 & 350,71 & 41,16 & 55 & 124,24 & 259,68 & 259,68 & 89,45 & 436,84 & 61,1 & 3,31 & 50,87 & 84 & 23,39 & 23,39 & 148,33 \\
\hline \begin{tabular}{|l} 
Discoglossus jeanneae \\
\end{tabular} & $30 \mathrm{SVH}$ & 100,00 & 163 & $\begin{array}{l}111,00 \\
116,49\end{array}$ & 36, & 60052,17 & 348,31 & $\begin{array}{l}41,10 \\
32,62\end{array}$ & \begin{tabular}{|c|c|}
315,69 \\
31,50
\end{tabular} & \begin{tabular}{|l|}
$116,77,7$ \\
\end{tabular} & \begin{tabular}{|l|}
254,13 \\
250
\end{tabular} & \begin{tabular}{|l|}
254,13 \\
\end{tabular} & $\begin{array}{l}3,43 \\
81,79 \\
\end{array}$ & \begin{tabular}{|l|}
450,045 \\
455,50
\end{tabular} & $\frac{x_{1,}}{63,}$ & $\frac{1,4}{4,6}$ & $\begin{array}{ll}4,0,48 \\
49,1\end{array}$ & $\begin{array}{l}168,26 \\
\end{array}$ & | 26,90 & $\frac{20,350}{26,90}$ & $\begin{array}{l}140,03 \\
151,61\end{array}$ \\
\hline \begin{tabular}{|l|l} 
Discoglossus jeanneae \\
\end{tabular} & 30 SVH54 & 100,00 & 152,54 & 119,68 & 36,80 & 6830,84 & 342,73 & 20,42 & 322,31 & 105,50 & 244,79 & 244,79 & 70,64 & 485,61 & 65,96 & 5,25 & 47,56 & 177,26 & 32,77 & 32,77 & 157,69 \\
\hline Discoglossus jeanneae & 30 SVH62 & 100,00 & 164,73 & 114,86 & 36,16 & 6674,53 & 346,68 & 35,18 & 311,50 & 118,38 & 254,51 & 254,51 & 84,26 & 441,02 & 60,50 & 4,08 & 49,19 & 162,05 & 26,24 & 26,24 & 146,58 \\
\hline \begin{tabular}{|l} 
Discoglossus jeanneae \\
\end{tabular} & 30SVH63 & 100,00 & 164,47 & 116,01 & 36,64 & 6684,56 & 347,21 & 34,17 & 313,04 & 118,42 & 254,30 & 254,30 & 83,66 & 433,40 & 58,56 & 3,93 & 48,54 & 157,97 & 26,50 & 26,50 & 142,27 \\
\hline Discoglossus jeanneae & $30 \mathrm{SVH} 64$ & 100,00 & 154 & 119,16 & 36,95 & 6780,69 & 342,24 & 22,47 & 319,76 & 107,34 & 245,70 & 245 & 72,69 & 464,67 & 61,84 & 5,05 & 46,69 & 168,01 & 32,31 & 32,31 & $14 \varepsilon$ \\
\hline \begin{tabular}{|l} 
Discoglossus jeanneae \\
\end{tabular} & 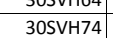 & 100,00 & 156,35 & $\begin{array}{l}1118,10 \\
118,46\end{array}$ & 37,00 & 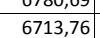 & 341,24 & \begin{tabular}{|l|l|}
24,83 \\
\end{tabular} & \begin{tabular}{|l|l|}
317,06 \\
\end{tabular} & \begin{tabular}{|l|}
109,79 \\
\end{tabular} & \begin{tabular}{|l|}
246,80 \\
\end{tabular} & \begin{tabular}{|l|}
246,80 \\
\end{tabular} & $\begin{array}{l}72,505 \\
75,59\end{array}$ & \begin{tabular}{|l|l|}
442,10 \\
442
\end{tabular} & $\begin{array}{l}1,044 \\
57,42\end{array}$ & $\begin{array}{l}3,8057 \\
4,87\end{array}$ & $\begin{array}{l}40,009 \\
45,98\end{array}$ & $\begin{array}{l}158,07 \\
158\end{array}$ & $\begin{array}{l}2,1,52 \\
31,52 \\
\end{array}$ & $\begin{array}{l}20,51,52 \\
31,5\end{array}$ & $\begin{array}{l}140,51 \\
139,85\end{array}$ \\
\hline Discoglossus jeanneae & 30 SVH75 & 100,00 & 148,09 & 120,87 & 37,00 & 6772,70 & 337,37 & 15,63 & 321,74 & 110,62 & 239,64 & 239,64 & 66,96 & 466,38 & 59,56 & 5,92 & 44,41 & 165,41 & 36,67 & 36,67 & 144,59 \\
\hline Discoglossus jeanneae & 30SVH90 & 100,00 & 157,60 & 114,58 & 37,00 & 6514,66 & 335,62 & 29,21 & 306,41 & 111,28 & 245,21 & 245,31 & 79,36 & 423,56 & 53,86 & 5,10 & 46,10 & 150,25 & 29,61 & 31,51 & 135,57 \\
\hline Discoglossus jeanneae & 30SVH92 & 100,00 & 154,5 & 116,88 & 37,00 & 6587,96 & 336,01 & 24,5 & 311,47 & 108,27 & 243,29 & 243 & 75, & 431,61 & 54,32 & 5,40 & 44,88 & 152,25 & 32,54 & 33,10 & 134 \\
\hline |Discoglossus jeanneae & 30SVH94 & 100,00 & 149,32 & 119,44 & 37,01 & 6665,62 & 334,43 & 17,92 & 316,51 & 125,98 & 239,23 & 239,23 & 69,49 & 442,82 & 55,28 & 6,04 & 43,18 & 155,66 & 36,73 & 36,77 & 134,33 \\
\hline
\end{tabular}




\begin{tabular}{|c|c|c|c|c|c|c|c|c|c|c|c|c|c|c|c|c|c|c|c|c|c|}
\hline TAXON & UTM & $\mathrm{km} 2$ & $\mathrm{BIO1}$ & $\mathrm{B1O2}$ & $\mathrm{BIO3}$ & B104 & B105 & $\mathrm{B106}$ & $\mathrm{B107}$ & B108 & $\mathrm{BIO9}$ & 81010 & B1011 & B1O12 & $\mathrm{B1O13}$ & 81014 & B1015 & B1016 & B1017 & $\mathrm{BIO18}$ & B1019 \\
\hline Discoglossus jeanneae & 30SVH95 & 100,00 & 143,64 & 121,02 & 37,12 & 6708,19 & 331,32 & 11,41 & 319,91 & 124,45 & 234,24 & 234,24 & 63,41 & 460,92 & 57,49 & 6,88 & 41,94 & 162,34 & 40,95 & 40,95 & 137,51 \\
\hline Discoglossus jeanneae & 30SVH98 & 100,00 & 139,86 & 122,99 & 37,83 & 6736,23 & 329,23 & 6,42 & 322,81 & 121,03 & 230,88 & 230,88 & 59,26 & 458,89 & 56,75 & 7,38 & 39,95 & 160,64 & 45,17 & 45,17 & 132,16 \\
\hline Discoglossus jeanneae & 30SWG06 & 100,00 & 146,83 & 114,45 & 37,00 & 6411,38 & 323,90 & \begin{tabular}{|c|}
19,77 \\
\end{tabular} & 304,13 & 99,96 & 233,36 & 233,69 & 70,77 & 448,55 & 55,63 & 6,58 & 45,28 & 156,92 & 33,01 & 38,71 & 145,03 \\
\hline Discoglossus jeanneae & 30SWG09 & 100,00 & 121,09 & 120,41 & 37,09 & 6669,44 & 310,41 & $-8,41$ & 318,82 & 79,84 & 211,79 & 212,10 & 43,19 & 574,48 & 71,75 & 12,40 & 40,50 & 199,80 & 56,02 & 58,31 & 174,50 \\
\hline Discoglossus jeanneae & 30SWG12 & 100,00 & 101,44 & 119,38 & 37,42 & 6512,31 & 288,48 & $-25,79$ & 314,27 & 51,48 & 190,12 & 191,34 & 26,44 & 673,90 & 84,83 & 18,07 & 39,16 & 232,05 & 70,73 & 75,03 & 208,34 \\
\hline Discoglossus jeanneae & 30SWG16 & 100,00 & 149,42 & 112,81 & 37,04 & 6306,94 & 321,98 & 23,26 & 298,72 & 103,02 & 234,14 & 234,83 & 74,31 & 423,79 & 52,47 & 6,21 & 44,50 & 145,99 & 31,96 & 38,55 & 135,13 \\
\hline Discoglossus jeanneae & 30SWG19 & 100,00 & 102,99 & 121,55 & 37,25 & 6684,30 & 294,93 & $-25,91$ & 320,84 & 79,69 & 194,39 & 194,80 & 25,85 & 658,50 & 82,24 & 17,84 & 37,02 & 226,52 & 74,95 & 76,55 & 192,90 \\
\hline Discoglossus jeanneae & 30 SWG25 & 100,00 & 148,54 & 111,22 & 37,23 & 6192,77 & 317,25 & 23,82 & 293,44 & 102,47 & 231,48 & 232,64 & 74,95 & 412,52 & 51,19 & 6,22 & 43,74 & \begin{tabular}{|l|l|}
139,83 \\
\end{tabular} & 32,02 & 38,50 & 130,54 \\
\hline Discoglossus jeanneae & 30 SWG28 & 100,00 & 130,69 & 117,71 & 37,32 & 6494,73 & 312,40 & 2,30 & 310,10 & 107,79 & 218,55 & 219,21 & 54,36 & 504,53 & 64,02 & 10,30 & 40,24 & 173,95 & 48,59 & 52,84 & 151,06 \\
\hline Discoglossus jeanneae & 30SWG29 & 100,00 & 110,30 & 120,44 & 37,52 & 6619,50 & 298,79 & $-18,26$ & 317,05 & 87,32 & 200,58 & 201,02 & 33,63 & 610,67 & 77,00 & 16,02 & 37,12 & 210,14 & 68,94 & 70,97 & 177,13 \\
\hline Discoglossus jeanneae & 30SWG35 & 100,00 & 137,91 & 113,41 & 37,73 & 6255,02 & 310,44 & 12,36 & 298,08 & 104,23 & 222,05 & 223,26 & 64,15 & 455,59 & 57,55 & 8,47 & 41,45 & 154,03 & 40,45 & 46,23 & 139,74 \\
\hline Discoglossus jeanneae & 30SWG37 & 100,00 & 142,67 & 114,20 & 37,86 & 6298,67 & 315,76 & 15,97 & 299,80 & 120,83 & 227,31 & 228,16 & 67,95 & 435,64 & 55,24 & 7,52 & 41,38 & 148,18 & 38,60 & 44,01 & 131,43 \\
\hline \begin{tabular}{|l} 
Discoglossus jeanneae \\
\end{tabular} & 30SWG39 & 100,00 & 122,08 & 119,02 & 37,76 & 6531,97 & 305,88 & $-6,37$ & 312,25 & 99,95 & 210,69 & 211,26 & 45,77 & 538,32 & 68,69 & 12,72 & 37,90 & 185,42 & 58,18 & \begin{tabular}{|l|l|}
61,05 \\
\end{tabular} & 155,37 \\
\hline Discoglossus jeanneae & 30SWG43 & 100,00 & 143,50 & 108,73 & 37,84 & 6021,64 & 306,44 & 21,31 & 285,14 & 105,51 & 223,97 & 225,81 & 72,36 & 4415,18 & 51,79 & 7,17 & 42,11 & 137,89 & 35,13 & 41,23 & 129,15 \\
\hline Discoglossus jeanneae & 30SWG48 & 100,00 & 133,42 & 116,38 & \begin{tabular}{|c|}
37,97 \\
\end{tabular} & 6375,05 & 310,23 & 5,79 & 304,44 & 112,25 & 219,40 & 220,26 & 58,35 & 472,79 & 60,70 & 9,84 & 38,89 & 161,44 & 47,91 & 51,92 & 137,14 \\
\hline Discoglossus jeanneae & 30SWG49 & 100,00 & 122,95 & 118,41 & 37,96 & 6475,62 & 304,59 & $-5,06$ & 309,65 & 100,98 & 210,68 & 211,39 & 47,27 & 526,21 & 67,58 & 12,72 & 37,10 & 180,48 & 58,56 & 61,17 & 149,34 \\
\hline \begin{tabular}{|l} 
Discoglossus jeanneae \\
\end{tabular} & 30SWG52 & 100,00 & 118,74 & 113,35 & 37,86 & 6231,44 & 291,99 & $-5,15$ & 297,14 & 94,74 & 202,79 & 204,69 & 46,57 & 548,09 & 70,14 & 14,23 & 38,14 & 183,59 & 58,63 & 62,94 & 163,17 \\
\hline \begin{tabular}{|l} 
Discoglossus jeanneae \\
\end{tabular} & 30SWG57 & 100,00 & 135,03 & 114,82 & 38,00 & 6267,46 & 307,81 & 8,50 & 299,31 & 113,81 & 219,26 & 220,45 & 61,03 & 458,12 & 58,86 & 9,54 & 38,80 & 154,95 & 46,52 & 50,82 & 132,23 \\
\hline Discoglossus jeanneae & 30SWG59 & 100,00 & 132,38 & 117,02 & 38,00 & 6359,18 & 308,74 & 4,14 & 304,60 & 111,25 & 217,97 & 218,96 & 57,32 & 470,81 & 60,97 & 10,31 & 37,72 & 160,66 & 50,57 & 53,86 & 132,38 \\
\hline Discoglossus jeanneae & 30SWG63 & 100,00 & 156,89 & 102,82 & 38,00 & 5690,49 & 305,92 & 38,53 & 267,39 & 127,10 & 232,02 & 234,47 & 89,07 & 341,99 & 42,68 & 4,76 & 42,92 & 116,86 & 27,22 & 33,63 & 105,29 \\
\hline Discoglossus jeanneae & 30SWHOO & 100,00 & 135,70 & 118,81 & 37,07 & 6620,45 & 321,12 & 5,99 & 315,12 & 97,55 & 225,36 & 225,55 & 57,45 & 503,33 & 63, & 9,04 & 42,12 & 176,09 & 44,77 & 46,68 & 153,98 \\
\hline \begin{tabular}{|l} 
Discoglossus jeanneae \\
\end{tabular} & 30SWHO1 & 100,00 & 131,25 & 119,80 & 37,08 & 6658,89 & 318,57 & 1,16 & 317,42 & 100,95 & 221,56 & 221,69 & 52,66 & 522,87 & 65,45 & 10,09 & 41,08 & 182,81 & 49,46 & 50,68 & 157,44 \\
\hline Discoglossus jeanneae & 30SWHO2 & 100,00 & 144,42 & 118,63 & 37,09 & 6611,24 & 328,17 & 14,06 & 314,11 & 115,59 & 233,70 & 233,81 & 65,58 & 459,73 & 57,65 & 7,20 & 42,47 & 160,87 & 39,82 & \begin{tabular}{|c|}
40,88 \\
\end{tabular} & 139,07 \\
\hline Discoglossus jeanneae & 30SWHO5 & 100,00 & 146,81 & 120,28 & 37,49 & 6636,79 & 331,49 & 14,79 & 316,69 & 128,08 & 236,24 & 236,24 & 67,31 & 437,31 & 54,96 & 6,57 & 41,47 & 153,16 & 39,79 & 39,86 & 128,39 \\
\hline Discoglossus jeanneae & 30SWH10 & 100,00 & 119,81 & 120,31 & 37,38 & 6638,95 & 308,01 & $-9,60$ & 317,61 & 94,93 & 210,08 & 210,42 & 42,17 & 569,87 & 71,55 & 13,20 & 38,99 & 197,38 & 59,80 & 61,74 & 168,19 \\
\hline Discoglossus jeanneae & 30SWH11 & 100,00 & 134,09 & 119,02 & 37,29 & 6587,66 & 318,37 & 4,40 & 313,97 & 111,43 & 223,24 & 223,42 & 56,20 & 498,22 & 62,81 & 9,64 & 40,51 & 173,14 & 48,17 & 50,10 & 147,80 \\
\hline Discoglossus jeanneae & 30SWH12 & 100,00 & 134,78 & 119,67 & 37,38 & 6609,19 & 319,85 & 4,54 & 315,31 & 114,20 & 224,19 & 224,34 & 56,55 & 年 & $\begin{array}{l}2,010 \\
62,07\end{array}$ & 9,38 & 40,19 & 171,31 & 48,13 & 49,49 & 144,39 \\
\hline Discoglossus jeanneae & 30SWH16 & 100,00 & 143,69 & 121,04 & 37,97 & 6623,49 & 328,40 & 11,49 & 316,91 & 124,80 & 233,03 & 233,03 & 64,38 & 435,98 & 55,13 & 7,22 & 39,76 & 152,02 & 43,33 & 43,33 & 123,95 \\
\hline Discoglossus jeanneae & 30 SWH20 & 100,00 & 97,98 & 121,82 & 37,70 & 6678,92 & 289,86 & $-30,73$ & 320,59 & 74,45 & 189,41 & 189,81 & 21,11 & 674,38 & 84,46 & 19,71 & 35,07 & 231,49 & 82,36 & 82,62 & 191,90 \\
\hline Discoglossus jeanneae & 30SWH21 & 100,00 & 108,66 & 121,42 & 37,75 & 6662,13 & 298,65 & $-20,64$ & 319,29 & 85,88 & 199,53 & 199,80 & 31,31 & 615,27 & 77,37 & 16,50 & 36,18 & 212,34 & 72,30 & 72,93 & 175,07 \\
\hline Discoglossus jeanneae & 30SWH24 & 100,00 & 144,52 & 119,50 & 37,97 & 6537,57 & 326,10 & 13,49 & 312,61 & 125,46 & 232,60 & 232,66 & 66,33 & 431,48 & 55,08 & 7,33 & 39,93 & 149,76 & 42,48 & 42,80 & 123,02 \\
\hline \begin{tabular}{|l} 
Discoglossus jeanneae \\
\end{tabular} & $30 \mathrm{SWH} 30$ & 100,00 & 102,13 & 120,83 & 37,45 & 6632,01 & 291,64 & $-26,36$ & 318,00 & 78,76 & 192,94 & 193,40 & 25,83 & 644,83 & 81,33 & 18,94 & 34,79 & 221,03 & 79,58 & 80,12 & 181,02 \\
\hline Discoglossus jeanneae & 30SWH34 & 100,00 & 127,64 & 121,06 & 37,99 & 6585,76 & 312,86 & $-2,88$ & 315,74 & 107,04 & 216,92 & 217,02 & 50,06 & 499,64 & 63,86 & 11,34 & 36,86 & 173,19 & 57,30 & 57,69 & 137,60 \\
\hline Discoglossus jeanneae & 30 SWH35 & 100,00 & 135,10 & 120,94 & 38,00 & 6562,45 & 318,66 & 3,99 & 314,68 & 115,32 & 223,75 & 223,83 & 57,18 & 461,17 & 59,19 & 9,41 & 37,62 & 159,92 & 51,44 & 51,82 & 126,39 \\
\hline Discoglossus jeanneae & $30 S W H 36$ & 100,00 & 126,54 & 122,05 & 38,00 & 6610,75 & 312,94 & $-4,77$ & 317,70 & 106,23 & 216,08 & 216,18 & 48,37 & 497,56 & 63,25 & 11,47 & 36,08 & 172,49 & 58,95 & 59,70 & 134,27 \\
\hline Discoglossus jeanneae & $30 \mathrm{SWH} 40$ & 100,00 & 111,35 & 119,94 & 37,86 & 6555,71 & 296,98 & $-17,14$ & 314,12 & 88,53 & 200,57 & 201,16 & 35,33 & 587,22 & 74,95 & 16,23 & 35,18 & 201,40 & 71,21 & 72,18 & 163,32 \\
\hline \begin{tabular}{|l} 
Discoglossus jeanneae \\
\end{tabular} & 30 SWH41 & 100,00 & 104,01 & 120,89 & 37,87 & $\mid \begin{array}{ll}\mid 65007,13 \\
6607\end{array}$ & 292,17 & $-24,69$ & \begin{tabular}{|l|}
316,87 \\
312
\end{tabular} & $\begin{array}{l}0,035 \\
80,68 \\
\end{array}$ & \begin{tabular}{|l|}
194,50 \\
\end{tabular} & \begin{tabular}{|l|l|l|l|l|l}
194,73 \\
\end{tabular} & 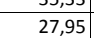 & $\begin{array}{l}301,24 \\
624,24\end{array}$ & $\begin{array}{l}74,20 \\
79,20\end{array}$ & \begin{tabular}{l|l}
18,58 \\
18,5
\end{tabular} & 33,10 & \begin{tabular}{|l|l|}
213,93 \\
\end{tabular} & $\begin{array}{l}\mid 1,42 \\
79,32\end{array}$ & $\begin{array}{l}79,40 \\
79,43\end{array}$ & 171,15 \\
\hline Discoglossus jeanneae & $30 \mathrm{SWH} 42$ & 100,00 & 117,07 & 120,59 & 37,6 & 6569,31 & 302,61 & $-12,38$ & 314,99 & 94,95 & 206,40 & 206,77 & 40,55 & 550,65 & 70,50 & 14,42 & 35,34 & 189,73 & 66,72 & 67,18 & 150,78 \\
\hline Discoglossus jeanneae & 30 SWH43 & 100,00 & 126,58 & 120,40 & 37,99 & 6533,06 & 309,88 & $-3,61$ & 313,49 & 105,78 & 215,07 & 215,37 & 49,71 & 500,56 & 64,43 & 11,81 & 36,40 & 172,66 & 58,66 & 59,34 & 136,50 \\
\hline Discoglossus jeanneae & 30 SWH44 & 100,00 & 120,14 & 121,30 & 38,0 & 6578,54 & 305,68 & $-10,05$ & 315,73 & 98,81 & 209,57 & 20 & 42,99 & 529,28 & 67,71 & 13,5 & 35,21 & 182,61 & 64,91 & 65,25 & 142,30 \\
\hline Discoglossus jeanneae & $30 S W H 45$ & 100 & 122,26 & 121,51 & $38, \mathrm{C}$ & 6578,14 & 307,64 & $-8,31$ & 315,95 & 101,38 & 211,55 & 21 & 44,91 & 515,95 & 65, & 13, & 35,23 & 178,04 & 63,34 & 64,24 & 137,55 \\
\hline \begin{tabular}{|l} 
Discoglossus jus jeanneae \\
\end{tabular} & \begin{tabular}{|l|}
$305 W H 446$ \\
305
\end{tabular} & 100,00 & $\begin{array}{ll}112,20 \\
115,51\end{array}$ & $\begin{array}{l}12,51 \\
122,13 \\
\end{array}$ & 38,00 & $\begin{array}{ll}03710,44 \\
6610,28\end{array}$ & $\begin{array}{l}30,04 \\
302,89\end{array}$ & \begin{tabular}{|c|c|}
$-0,51,96$ \\
$-14,6$
\end{tabular} & \begin{tabular}{|c|}
13,95 \\
317,85 \\
\end{tabular} & \begin{tabular}{|l|}
101,30 \\
94,21
\end{tabular} & $\mid \frac{\mid 11,30}{205,38}$ & \begin{tabular}{|l|}
205,49 \\
\end{tabular} & \begin{tabular}{|c|}
$34,3,10$ \\
38
\end{tabular} & $\mid \begin{array}{l}31,95 \\
545,61\end{array}$ & $\begin{array}{ll}0.3,-4 \\
69, \mathrm{C}\end{array}$ & $14, \varepsilon$ & $\begin{array}{l}33,25 \\
3,92\end{array}$ & \begin{tabular}{|l|}
188,01 \\
1884
\end{tabular} & $\begin{array}{l}3,394 \\
69,40\end{array}$ & $\begin{array}{l}0,24 \\
70,86\end{array}$ & $\begin{array}{l}131,53 \\
143,76\end{array}$ \\
\hline Discoglossus jeanneae & 30SWH50 & 100,00 & 120,56 & 118,94 & 38,00 & 6466,86 & 302,08 & $-7,79$ & 309,87 & 98,62 & 208,15 & 208,87 & 44,98 & 530,73 & 68,54 & 13,60 & 35,69 & 181,69 & 62,95 & 64,42 & 146,11 \\
\hline Discoglossus jeanneae & 30SWH53 & 100,00 & 123,01 & 120,28 & 38,00 & 6502,48 & 305,49 & $-6,56$ & 312,05 & 101,84 & 211,27 & 211,45 & 46,66 & 513,34 & 66,25 & 13,13 & 35,28 & 176,21 & 63,08 & 63,49 & 137,18 \\
\hline Discoglossus jeanneae & 30SWH55 & 100,00 & 121,66 & 121,17 & 38,03 & 6532,07 & 305,32 & $-8,37$ & 313,69 & 100,71 & 210,34 & 210,44 & 44,90 & 514,17 & 65,99 & 13,5 & 34,55 & 47 & 65,08 & 66,08 & 134,49 \\
\hline Discoglossus jeanneae & 30 SWH56 & 100,00 & 117,42 & 121,80 & 38,0 & 6568,34 & 302,79 & $-12,63$ & 315,42 & \begin{tabular}{|c|}
96,35 \\
96
\end{tabular} & 206,74 & 206,80 & 40,53 & 530,40 & 67,58 & 14,6 & 33,55 & 182,10 & 68,66 & 70,37 & 137,23 \\
\hline \begin{tabular}{|l} 
Discoglossus jeanneae \\
\end{tabular} & $30 \mathrm{SWh}$ & 100,00 & 129 & 12 & 38,3 & 6539,40 & 312,89 & $-1,79$ & 314,68 & 110,51 & 217,68 & 218,04 & 51,72 & 460,34 & 58,64 & 11,2 & 34,25 & 157,76 & 58,58 & 62,27 & 115,81 \\
\hline \begin{tabular}{|l} 
Discoglossus jeanneae \\
\end{tabular} & 30SWH62 & 100,00 & 122,64 & 119,54 & 38,00 & 6448,83 & 303,26 & $-6,08$ & 309,34 & 101,19 & 210,08 & 210,48 & 47,03 & 510,83 & 66,39 & 13,34 & 34,84 & 174,56 & 63,86 & 64,27 & 135,26 \\
\hline Discoglossus jeanneae & 30SWH67 & 100,00 & 121,15 & 121,71 & 38,09 & 6519,50 & 304,16 & $-9,30$ & 313,46 & 100,49 & 209,50 & 209,64 & 44,39 & 503,36 & 64,59 & 13,88 & 33,23 & 172,13 & 66,52 & 69,38 & 126,38 \\
\hline Discoglossus jeanneae & 30SWH72 & 100,00 & 116,62 & 119,38 & 38,00 & 6439,80 & 297,18 & $-11,63$ & 1 & 94,75 & 204,30 & 204,62 & 41,43 & 539,06 & tor & 15,50 & 33,44 & 02 & 71,05 & 71,07 & 140,00 \\
\hline \begin{tabular}{|l} 
Discoglossus jeanneae \\
\end{tabular} & $30 \mathrm{SWH}$ & 100,00 & $\frac{1}{12}$ & $\begin{array}{l}111,50 \\
118,79\end{array}$ & 38 & 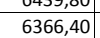 & 300,15 & \begin{tabular}{|c|c|}
$-1,5,17$ \\
-5,
\end{tabular} & \begin{tabular}{|l|}
300,301 \\
305
\end{tabular} & \begin{tabular}{|c|}
$24,1 / 10$ \\
101,86
\end{tabular} & \begin{tabular}{|l|}
209,27 \\
\end{tabular} & \begin{tabular}{|l|l|}
209,862 \\
\end{tabular} & \begin{tabular}{l|l|}
48,48 \\
48,
\end{tabular} & $\begin{array}{l}502,02,28 \\
502\end{array}$ & $\begin{array}{l}3,005 \\
65,59 \\
\end{array}$ & $\frac{11,0}{13,7}$ & 33,91 & \begin{tabular}{|l|l|}
$169,65<5$ \\
\end{tabular} & $\begin{array}{l}1,100 \\
65,89 \\
\end{array}$ & $\begin{array}{l}6,1,19 \\
66,19\end{array}$ & $\begin{array}{l}140,06 \\
128,66\end{array}$ \\
\hline Discoglossus jeanneae & 30 SWJ21 & 100,00 & 130,26 & 123,61 & 38,00 & 6663,32 & 318,20 & $-2,24$ & 320,43 & 111,63 & 219,78 & 220,45 & 50,70 & 468,59 & 57,16 & 10,34 & 35,35 & 161,11 & 56,33 & 58,31 & 124,34 \\
\hline Discoglossus jeanneae & 30 SWJ59 & 100,00 & 127,01 & 123,13 & 38,41 & 6551.42 & 310,42 & $-5,79$ & 316,21 & 110,01 & 214,11 & 215,17 & 48,17 & 471,94 & 56,39 & 13,88 & 30,06 & 156,34 & 67,69 & 72,37 & 117,24 \\
\hline \begin{tabular}{|l} 
Discoglossus jeanneae \\
\end{tabular} & 30SWJ78 & 100,00 & 128,24 & 122,09 & 38,76 & 6484,87 & 308,30 & $-3,78$ & 312,08 & 111,22 & 214,59 & 215,53 & 50,03 & 459,34 & (5) & 14,16 & 29,56 & 151,98 & 68,91 & 74,51 & 108,72 \\
\hline Discoglossus jeanneae & 30 SWJg & 100,00 & 118,33 & 119,86 & 38, & 6436 & 295,44 & $-11,94$ & 307,38 & 10 & 204,26 & & 41,34 & 494,68 & 61,08 & 18, & 27,68 & 162,79 & 81,62 & 88,84 & 111,42 \\
\hline \begin{tabular}{|l} 
Discoglossus jeanneae \\
\end{tabular} & $\begin{array}{l}305 \times G 76 \\
3\end{array}$ & 86,00 & $\begin{array}{ll}1170,53 \\
179,86\end{array}$ & $\begin{array}{l}111,00 \\
106,64\end{array}$ & 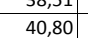 & $\begin{array}{l}-5452,2,99 \\
525 \mid\end{array}$ & $\begin{array}{l}293,44 \\
317,07\end{array}$ & $\begin{array}{c}-1,1,84 \\
57,88\end{array}$ & \begin{tabular}{|c|}
259,19 \\
250
\end{tabular} & \begin{tabular}{|l|l|}
153,89 \\
\end{tabular} & \begin{tabular}{|l|}
247,61 \\
\end{tabular} & \begin{tabular}{|l|}
249,56 \\
242
\end{tabular} & \begin{tabular}{|l|l|}
115,17 \\
\end{tabular} & \begin{tabular}{|l} 
\\
300,50
\end{tabular} & $\begin{array}{l}4,1,00 \\
49,40 \\
\end{array}$ & $\mid \frac{\mid 0,15}{3,09}$ & 50,35 & \begin{tabular}{|l|}
123,67 \\
12,1
\end{tabular} & $\begin{array}{ll}21,62 \\
21,62\end{array}$ & 石, 35,51 & $\begin{array}{r}41,42,13 \\
84,1\end{array}$ \\
\hline Discoglossus jeanneae & $30 \mathrm{~S} \times \mathrm{H} 26$ & 100,00 & 152,54 & 118,53 & 40,00 & 6042,06 & 315,78 & 22,14 & 293,64 & 126,31 & 232,79 & 233,29 & 79,33 & 368,38 & 48,94 & 7,50 & 38,25 & 119,71 & 46,63 & \begin{tabular}{|l|}
51,08 \\
\end{tabular} & 84,98 \\
\hline \begin{tabular}{|l} 
Discoglossus je. \\
\end{tabular} & $305 \times H 36$ & 100,00 & 146.88 & 117.98 & $40,00 \mid$ & 6050,49 & 310,16 & 17,26 & 292.90 & 125.80 & 227.36 & 228.03 & 74,01 & 395,32 & 51.84 & 9,04 & 36.91 & 127.41 & 52.43 & 56,84 & 90.37 \\
\hline Discoglossus jeanneae & $30 \mathrm{SXH45}$ & 100,00 & 153,31 & 117,88 & 40,10 & 5951,01 & 313,14 & 23,56 & 289,58 & 127, & $232, \mathrm{C}$ & 232, & 81, & 378 & 52,56 & 7,68 & 38 & 126,14 & 46,28 & 54,47 & 87,53 \\
\hline Discoglossus jeanneae & $30 \mathrm{SXH46}$ & 100,00 & 148,49 & 117,36 & 39,99 & 5991,87 & 09,28 & 19,41 & 899,87 & 148,49 & 227,92 & 228,73 & 76,22 & 96,39 & 53,53 & 9,01 & 37,29 & 129,54 & 51,91 & 58,53 & 90,28 \\
\hline
\end{tabular}




\begin{tabular}{|c|c|c|c|c|c|c|c|c|c|c|c|c|c|c|c|c|c|c|c|c|c|}
\hline TAXON & UTM & $\mathrm{km} 2$ & B101 & $\mathrm{B1O2}$ & $\mathrm{BIO3}$ & B104 & B105 & B106 & B107 & $\mathrm{B108}$ & B109 & B1010 & BIO11 & BIO12 & B1013 & B1014 & B1015 & B1016 & $\begin{array}{ll}1017 \\
17\end{array}$ & B1018 & B1019 \\
\hline Discoglossus jeanneae & $30 \mathrm{SXH} 65$ & 100,00 & 144,24 & 115,33 & 39,92 & 5911,52 & 302,10 & 17,10 & 285,01 & 139,66 & 222,62 & 223,77 & 73,39 & 432,05 & 58,99 & 10,63 & 36,29 & 143,74 & 56,97 & 65,91 & 99,61 \\
\hline Discoglossus jeanneae & $30 \mathrm{SXH66}$ & 100,00 & 149,38 & 115,34 & 40,01 & 5874,64 & 305,55 & 22,10 & 283,45 & 159,56 & 227,07 & 228,18 & 78,64 & 410,53 & 58,13 & 9,49 & 37,49 & 139,62 & 53,10 & 63,02 & 93,43 \\
\hline Discoglossus jeanneae & $30 \mathrm{~S} \times \mathrm{H} 67$ & 100,00 & 149,41 & 114,73 & 40,00 & 5872,88 & 305,05 & 22,55 & 282,49 & 159,75 & 227,07 & 228,20 & 78,63 & 411,25 & 58,21 & 9,72 & 37,14 & 140,16 & 54,33 & 63,98 & 92,81 \\
\hline Discoglossus jeanneae & $30 \mathrm{SXH68}$ & 100,00 & 142,02 & 113,82 & 39,87 & 5933,72 & 298,99 & 16,03 & 282,95 & 152,27 & 220,73 & 221,85 & 70,98 & 441,90 & 59,60 & 11,88 & 34,58 & 146,62 & 62,88 & 70,57 & 98,86 \\
\hline Discoglossus jeanneae & $305 \times 349$ & 100,00 & 122,53 & 108,38 & 37,99 & 6213,33 & 282,04 & $-0,13$ & 282,17 & 139,53 & 202,60 & 205,97 & 48,61 & 465,00 & 56,91 & 19,70 & 27,76 & 150,18 & 89,13 & 90,91 & 92,11 \\
\hline Discoglossus jeanneae & $305 \times 157$ & 100,00 & 135,43 & 107,41 & 38,28 & 6046,96 & 289,62 & 13,45 & 276,17 & 144,99 & 215,97 & 216,39 & 62,89 & 435,39 & 53,66 & 15,97 & 29,95 & 139,20 & 77,11 & 80,02 & 88,35 \\
\hline Discoglossus jeanneae & $305 \times 165$ & 100,00 & 140,37 & 107,06 & 38,91 & 5923,89 & 291,50 & 19,09 & 272,41 & 149,81 & 218,99 & 219,93 & 69,25 & 438,99 & 58,03 & 14,58 & 31,61 & 146,35 & 71,97 & 78,82 & 92,03 \\
\hline Discoglossus jeanneae & $305 \times 166$ & 100,00 & 137,73 & 106,27 & 38,63 & 5952,26 & 288,87 & 16,69 & 272,18 & 146,89 & 216,82 & 217,55 & 66,32 & 444,08 & 57,30 & 15,64 & 30,68 & 146,17 & 75,42 & 81,56 & 91,85 \\
\hline Discoglossus jeanneae & 305XJ67 & 100,00 & 134,58 & 105,47 & 38,08 & 5986,80 & 286,09 & 14,12 & 271,97 & 143,41 & 214,29 & 214,93 & 63,03 & 449,14 & 56,28 & 16,73 & 29,75 & 145,65 & 79,29 & 84,23 & 91,38 \\
\hline Discoglossus jeanneae & $305 \times 168$ & 100,00 & 122,35 & 105,18 & 37,93 & 6098,75 & 276,92 & 2,28 & 274,63 & 136,46 & 203,99 & 204,38 & 50,08 & 487,44 & 57,57 & 20,50 & 27,48 & 153,17 & 92,86 & 94,41 & 97,42 \\
\hline Discoglossus jeanneae & 30SXJ77 & 100,00 & 129,46 & 103,84 & 38,05 & 5965,21 & 280,00 & 10,43 & 269,57 & 138,84 & 208,95 & 209,79 & 58,54 & 479,80 & 59,22 & 18,64 & 28,75 & 155,00 & 85,94 & 91,66 & 98,22 \\
\hline Discoglossus jeanneae & 30SXK11 & 100,00 & 112,66 & 114,56 & 38,00 & 6389,70 & 282,94 & $-14,45$ & 297,39 & 129,78 & 197,94 & 198,83 & 36,42 & 499,21 & 63,90 & 21,56 & 26,85 & 163,73 & 91,80 & 99,37 & 104,68 \\
\hline \begin{tabular}{|l} 
Discoglossus jeanneae \\
\end{tabular} & $305 \times K 40$ & 100,00 & 116,01 & 107,73 & 37,78 & 6252,44 & 276,27 & $-6,16$ & 282,43 & 133,03 & 123,01 & 200,16 & 41,92 & 485,12 & 60,79 & 22,01 & 27,28 & 158,67 & 94,35 & 98,94 & 95,01 \\
\hline Discoglossus jeanneae & $305 \times K 50$ & 100,00 & 127,65 & 104,81 & 37,71 & 6135,18 & 281,71 & 6,70 & 275,01 & 142,82 & 92,14 & 209,82 & 54,41 & 442,77 & 54,53 & 19,12 & 28,90 & 142,62 & 84,56 & 87,90 & 84,95 \\
\hline Discoglossus jeanneae & $305 \times 552$ & 100,00 & 116,95 & 103,14 & 37,03 & 6232,40 & 272,18 & $-2,82$ & 275,00 & 134,51 & 42,97 & 200,73 & 42,97 & 464,15 & 60,12 & 22,83 & 28,82 & 154,08 & 85,43 & 100,12 & 85,43 \\
\hline Discoglossus jeanneae & 30SYK52 & 57,00 & 171,46 & 82,73 & 36,02 & 5099,43 & 289,46 & 63,70 & 225,76 & 182,67 & 236,61 & 239,70 & 109,33 & 435,60 & 69,07 & 12,52 & 42,66 & 177,43 & 58,92 & 89,85 & (1) \\
\hline Discoglossus jeanneae & 30TTK44 & 60,00 & 132,45 & 109,16 & 36,60 & 6377,70 & 307,43 & 12,65 & 294,78 & 62,97 & 217,85 & 218,38 & 55,81 & 543,52 & 66,52 & 8,45 & 42,58 & 193,49 & 48,58 & 49,33 & 179,36 \\
\hline \begin{tabular}{|l} 
Discoglossus jeanneae \\
\end{tabular} & 30TVK46 & 100,00 & 142,44 & 105,04 & 34,08 & 6722,08 & 317,54 & 15,72 & 301,82 & 99,19 & 232,04 & 232,04 & 59,47 & 433,65 & 56,45 & 9,89 & 38,66 & 154,29 & 46,01 & 46,01 & 131,79 \\
\hline Discoglossus jeanneae & 30TVK54 & 100,00 & 143,67 & 109,71 & 35,11 & 6755,05 & 322,69 & 15,08 & 307,61 & 99,94 & 233,95 & 233,95 & 60,92 & 420,95 & 52,77 & 9,08 & 37,83 & 147,14 & 44,87 & $\begin{array}{l}4,87 \\
\end{array}$ & 124,71 \\
\hline \begin{tabular}{|l} 
Discogosssus jeanneae \\
\end{tabular} & $30 T V K 55$ & 100,00 & 141,85 & 108,40 & 34,99 & 6738.40 & 319,77 & 14,16 & 305,61 & 98,29 & $\mid 231,79$ & 231,79 & 59,30 & 429,84 & 55,43 & 9,63 & 38,22 & 152.05 & 45,89 & 45,89 & 128,52 \\
\hline Discoglossus jeanneae & 30 TVK56 & 100,00 & 142,59 & 107,10 & 34,73 & 6737,97 & 319,71 & 15,12 & 304,59 & 99,05 & 232,33 & 232,33 & 59,72 & 429,50 & 57,37 & 9,44 & 39,30 & 154,57 & 44,76 & 44,76 & 129,99 \\
\hline \begin{tabular}{|l} 
Discoglossus jeanneae \\
\end{tabular} & 30TVK57 & 100,00 & 140,80 & 106,21 & 34,44 & 6736,18 & 317,72 & 13,90 & 303,82 & 97,37 & 230,36 & 230,36 & 58,05 & 437,08 & 60,00 & 9,60 & 39,76 & 158,71 & 45,75 & 45,75 & 132,97 \\
\hline Discoglossus jeanneae & 30TVK64 & 100,00 & 135,64 & 111,39 & 35,88 & 6717,81 & 315,40 & 7,72 & 307,68 & 91,90 & 225,52 & 225,52 & 54,00 & 443,15 & 54,57 & 10,44 & 36,41 & 151,81 & 50,33 & 50,33 & 128,69 \\
\hline Discoglossus jeanneae & 30TVK65 & 100,00 & 136,33 & 110,13 & 35,57 & 6706,47 & 314,83 & 9,29 & 305,54 & 92,67 & 225,97 & 225,97 & 54,79 & 441,00 & 56,15 & 10,42 & 37,09 & 154,02 & 49,42 & 49,42 & 129,26 \\
\hline Discoglossus jeanneae & 30TVK69 & 100,00 & 130,82 & 105,62 & 35,28 & 6593,60 & 302,23 & 8,04 & 294,19 & 87,81 & 218,64 & 218,64 & 50,92 & 440,21 & 58,48 & 10,84 & 36,21 & 155,32 & 53,21 & 53,21 & 125,62 \\
\hline Discoglossus jeanneae & 30TVK74 & 100,00 & 132,79 & 112,49 & 36,00 & 6702,53 & 312,62 & 5,07 & 307,55 & 89,18 & 222,58 & 222,58 & 51,62 & 446,31 & 53,93 & 10,94 & 35,29 & 150,76 & 52,65 & 52,65 & 126,82 \\
\hline Discoglossus jeanneae & 30TVK75 & 100,00 & 133,78 & 111,15 & 36,00 & 6683,05 & 311,94 & 6,99 & 304,95 & $\begin{array}{l}90,26 \\
90,26\end{array}$ & 223,04 & 223,04 & 52,85 & 4440,63 & $\begin{array}{l}54,90 \\
540\end{array}$ & 11,08 & 35,72 & 151,22 & 51,74 & 51,74 & 125,60 \\
\hline Discoglossus jeanneae & 30TVK76 & 100,00 & 127,98 & 110,16 & 36,00 & 6648,33 & 304,79 & 2,62 & 302,17 & 84,65 & 216,96 & 216,96 & 47,77 & 456,99 & 56,81 & 12,23 & 34,59 & 155,52 & 55,91 & 55,91 & 129,05 \\
\hline Discoglossus jeanneae & 30TVK77 & 100,00 & 127,52 & 108,89 & 36,00 & 6620,45 & 302,52 & 3,27 & 299,25 & 84,27 & 215,94 & 215,94 & 47,71 & 453,90 & 57,35 & 12,08 & 34,72 & 155,45 & 56,17 & 56,17 & 127,52 \\
\hline Discoglossus jeanneae & 30TVK78 & 100,00 & 132,00 & 107,07 & 35,82 & 6613,92 & 304,40 & 8,54 & 295,86 & 88,89 & 220,03 & 220,03 & 52,04 & 431,48 & 56,53 & 10,85 & 35,91 & 151,10 & 52,36 & 52,36 & 120,87 \\
\hline Discoglossus jeanneae & 30TVK79 & 100,00 & 130,23 & 104,81 & 35,19 & 6592,21 & 299,79 & 7,80 & 291,99 & 87,36 & 218,03 & 218,03 & 50,57 & 428,29 & 55,77 & 10,97 & 34,90 & 148,50 & 54,04 & 54,04 & 117,38 \\
\hline \begin{tabular}{|l} 
Discoglossus jeanneae \\
\end{tabular} & 30TVK84 & 100,00 & 136,38 & 112,93 & 36,00 & 6688,14 & 315,22 & 8,16 & 307,06 & $\begin{array}{l}93,16 \\
93,10\end{array}$ & $\begin{array}{ll}225,78 \\
220\end{array}$ & \begin{tabular}{|l|l|}
225,78 \\
\end{tabular} & 55,40 & $\mid \begin{array}{ll}\mid 27,27,51 \\
4\end{array}$ & 51,14 & $\begin{array}{l}\mid 0,4) \\
10,45\end{array}$ & 35,06 & \begin{tabular}{|l|}
143,71 \\
143
\end{tabular} & 50,99 & $\begin{array}{l}4,40,99 \\
50\end{array}$ & 119,44 \\
\hline Discoglossus jeanneae & 30TVK85 & 100,00 & 130,92 & 111,85 & 36,04 & 6663,29 & 308,86 & 3,97 & 304,89 & 87,80 & 220,08 & 220,08 & 50,55 & 442,93 & 53,19 & 11,81 & 34,14 & 148,08 & 54,91 & 54,91 & 122,79 \\
\hline Discoglossus jeanneae & 30TVK86 & 100,00 & 129,06 & 110,40 & 36,00 & 6643,83 & 305,12 & 3,24 & 301,89 & 85,92 & 217,78 & 217,78 & 48,93 & 445,04 & 54,00 & 12,35 & 33,79 & 149,01 & 56,37 & 56,37 & 122,41 \\
\hline Discoglossus jeanneae & 30TVK87 & 100,00 & 125,00 & 109,19 & 36,00 & 6611,96 & 299,33 & 1,01 & 298,32 & 82,09 & 213,40 & 213,40 & 45,56 & 453,26 & 54,74 & 12,95 & 32,86 & 150,36 & 59,67 & 59,67 & 123,08 \\
\hline Discoglossus jeanneae & 30TVK89 & 100,00 & 126,58 & 104,72 & 35,36 & 6585,39 & 295,38 & 4,42 & 290,96 & 84,21 & 214,39 & 214,50 & 47,38 & 431,15 & 53,18 & 12,27 & 32,92 & 143,65 & 58,45 & 58,59 & 113,28 \\
\hline \begin{tabular}{|l} 
Discoglossus jeanneae \\
\end{tabular} & $\begin{array}{l}\text { SOTVK93 } \\
30 \text { To }\end{array}$ & 100,00 & $\begin{array}{l}12,50 \\
133,88 \\
\end{array}$ & 115,16 & $\begin{array}{l}3,30 \\
36,72\end{array}$ & 6682,34 & 314,40 & $\begin{array}{ll}4,43 \\
4,33\end{array}$ & 310,06 & $\begin{array}{ll}04,1,02 \\
91,02\end{array}$ & $\mid$\begin{tabular}{|l|}
223,35 \\
\end{tabular} & 223,35 & $\begin{array}{l}41,30 \\
53,06\end{array}$ & | & | & $\begin{array}{l}11,01 \\
11,0 \\
\end{array}$ & 33,60 & \begin{tabular}{|l|}
1431,44 \\
144
\end{tabular} & $\begin{array}{l}30,45 \\
54,57\end{array}$ & $\begin{array}{l}54,57 \\
54,57\end{array}$ & $\begin{array}{l}11,2,20 \\
119,15\end{array}$ \\
\hline Discoglossus jeanneae & $30 \mathrm{TVK}$ & 100,00 & 138,49 & 113,19 & 36,39 & 6662,75 & 316,37 & 9,55 & 306,82 & 95,65 & 227,41 & 227,41 & 57,56 & 415,14 & 48,55 & 10,29 & 34,43 & 137,83 & 50,81 & 50,81 & 113,59 \\
\hline Discoglossus jeanneae & 30TVK95 & 100,00 & 132,32 & 112,24 & 36,18 & 6644,92 & 309,54 & 4,81 & 304,73 & 89,54 & 221,22 & 221,22 & 52,02 & 432,00 & 50,47 & 11,76 & 33,33 & 142,08 & 55,31 & 55,31 & 117,16 \\
\hline \begin{tabular}{|l} 
Discoglossus jeanneae \\
\end{tabular} & 30TVL25 & 100,00 & 108,37 & 102,99 & 35,99 & 6326,98 & 272,63 & $-10,23$ & 282,85 & 93,76 & 192,45 & 193,55 & 32,51 & 493,86 & 56,84 & 15,78 & 28,86 & 151,52 & 71,94 & 80,44 & 127,86 \\
\hline Discoglossus jeanneae & 30 TVL26 & 100 & 112,70 & 103,07 & 36,00 & 6315,11 & 276,66 & $-6,85$ & 283,51 & 74,65 & 196,25 & 197,43 & 36,25 & 475,34 & 54, & 15,05 & 28,77 & 146,19 & 69,14 & 77,29 & 123,50 \\
\hline \begin{tabular}{|l} 
Discoglossus jus jeanneae \\
\end{tabular} & 30TVL27 & 100,00 & $\begin{array}{ll}112,12,87 \\
112,\end{array}$ & $\begin{array}{l}10,03,91 \\
103,91\end{array}$ & $\frac{30,00}{36,01}$ & $\begin{array}{l}\mid l 11,11 \\
6262,71\end{array}$ & $\begin{array}{l}27,00 \\
276,90\end{array}$ & $\begin{array}{l}-2,05 \\
-6,79\end{array}$ & $\begin{array}{l}283,51 \\
289 \\
\end{array}$ & \begin{tabular}{|c|}
4,03 \\
86,03
\end{tabular} & \begin{tabular}{|l|l|}
$190,25,63$ \\
\end{tabular} & $\begin{array}{l}197,45 \\
196,50\end{array}$ & | 30,230 & $\mid$\begin{tabular}{|l}
$\mid 43,34,66$ \\
471,66
\end{tabular} & \begin{tabular}{r|r}
54,16 \\
54
\end{tabular} & 15,4 & $\frac{28,111}{28,28}$ & \begin{tabular}{|l|}
$140,19,47$ \\
144
\end{tabular} & $\begin{array}{l}\mid 69,14 \\
69,39\end{array}$ & $\begin{array}{l}1,25 \\
77,94 \\
\end{array}$ & $\begin{array}{l}12,30,11 \\
122,1\end{array}$ \\
\hline Discoglossus jeanneae & 30TVL32 & 100,00 & 89,33 & 105,67 & 36,72 & 6214,66 & 258,42 & $-25,45$ & 283,86 & 76,32 & 173,92 & 174,25 & 17,79 & 578,12 & 68,50 & 21,47 & 27,60 & 177,52 & 87,52 & 92,90 & 148,19 \\
\hline Discoglossus jeanneae & 30TVL35 & 100,00 & 104,34 & 103,59 & 36,00 & 6301,34 & 269,84 & $-13,51$ & 283,36 & 89,26 & 188,49 & 189,34 & 29,28 & 510,81 & 58,92 & 17,23 & 28,11 & 155,47 & 75,87 & 84,21 & 132,27 \\
\hline Discoglossus jeanneae & 30TVL37 & 100,00 & 107,35 & 104,11 & 36,1 & 6255,96 & 272,44 & $-11,06$ & 283,50 & 105,80 & 190,72 & 191,32 & 32,04 & 494,47 & 56,99 & 17,06 & 27,40 & 150,43 & 74,52 & 83,17 & 127,57 \\
\hline Discoglossus jeanneae & 30TVL38 & 100,00 & 100,34 & 105 & 36, & 6175,1 & 266,04 & $-17,38$ & 283,42 & 117,67 & 182,90 & & 26,50 & 522,24 & 60,83 & 19,44 & 26,54 & 159,43 & 80,88 & $\begin{array}{l}90,116 \\
90,76\end{array}$ & 133,88 \\
\hline \begin{tabular}{|l} 
Discoglossus jeanneae \\
\end{tabular} & $30 \mathrm{TVL}$ & 100,00 & 120 & 102,69 & 35,08 & 6501,78 & 288,23 & 0,27 & 287,97 & 79,02 & 206,51 & 207,87 & 42,13 & 468,87 & 56, & 13, & 31,97 & 154,61 & 63,08 & 65,25 & 129,18 \\
\hline Discoglossus jeanneae & 30TVL43 & 100,00 & 109,23 & 103,29 & 36,00 & 6385,04 & 275,66 & $-9,20$ & 284,86 & 68,98 & 194,21 & 195,12 & 32,98 & 499,32 & 56,90 & 15,97 & 29,15 & 155,92 & 72,09 & 77,84 & 131,74 \\
\hline Discoglossus jeanneae & 30TVL44 & 100,00 & 95,01 & 105,03 & 36,40 & 6252,22 & 262,72 & $-21,24$ & 283,96 & 86,56 & 179,36 & 179,79 & 21,82 & 555,86 & 64,66 & 20,44 & 27,23 & 170,18 & 84,87 & 90,53 & 143,55 \\
\hline Discoglossus jeanneae & 30TVL47 & 100,00 & 110,21 & 104,01 & 36,01 & 6266,56 & 275,21 & $-8,54$ & 283,75 & 80,04 & 193,46 & 19 & 34,55 & 485,09 & 55,48 & 16,84 & 27,36 & 43 & 73,57 & 80,99 & 125,80 \\
\hline \begin{tabular}{|l} 
Discoglossus jeanneae \\
\end{tabular} & 30TVL & 100,00 & 10 & 10 & 36 & 6 & 268,55 & \begin{tabular}{|c|c|c|c|}
$-0,34$ \\
$-14,83$
\end{tabular} & \begin{tabular}{|l|l|}
283,38 \\
\end{tabular} & $\begin{array}{l}00,04 \\
119,62 \\
\end{array}$ & $\begin{array}{l}185,40 \\
185,19\end{array}$ & \begin{tabular}{|l|}
185,55 \\
18,5
\end{tabular} & \begin{tabular}{|c|}
29,06 \\
29,0
\end{tabular} & $\begin{array}{l}\mid c 0,039 \\
512,73\end{array}$ & $\begin{array}{l}30,406 \\
59,46\end{array}$ & $\begin{array}{l}10,0 \\
19,7 \\
\end{array}$ & 25,87 & \begin{tabular}{|l|}
151,4559 \\
\end{tabular} & 80,97 & $\begin{array}{l}0,08 \\
90,08 \\
\end{array}$ & $\begin{array}{l}12,00 \\
131,61\end{array}$ \\
\hline Discoglossus jeanneae & 30TVL51 & 100,00 & 128,43 & 102,74 & 35,00 & 6538,75 & 296,04 & 6,70 & 289,35 & 86,38 & 215,28 & 215,54 & 48,77 & 440,69 & 55,86 & 11,65 & 33,64 & 149,99 & 57,75 & 58,04 & 122,79 \\
\hline Discoglossus jeanneae & 30TVL52 & 100,00 & 119,14 & 103,05 & 35,49 & 6471,71 & 286,06 & $-0,94$ & 286,99 & 77,81 & 204,90 & 205,77 & 40,94 & 466,92 & 55,77 & $\mid 13,73$ & 31.05 & 151,94 & 65,03 & 67,44 & 126,10 \\
\hline \begin{tabular}{|l} 
Discoglossus jeanneae \\
\end{tabular} & 30TVL54 & 100,00 & 97,28 & 105,44 & 36,44 & 6285,75 & 265,47 & $-19,77$ & 285,24 & 84,53 & 181,84 & 182,24 & 23,39 & 546,22 & 63,27 & 20,09 & 26,97 & 166,33 & 83,72 & 89,91 & 141,45 \\
\hline Discoglossus jeanneae & 30 TVLL & 100,00 & 76,54 & 107,27 & 37,3 & 6122,88 & 246,61 & $-37,30$ & 283,90 & 87,02 & 160,33 & 160 & 6,47 & 648,73 & 76,29 & 27,79 & 24,67 & 197,61 & 105,10 & 107,78 & 166 \\
\hline Discoglossus jeanneae & 30TVL56 & 100,00 & 98,65 & 105,45 & 36,47 & 6247,34 & 265,84 & $-18,73$ & 284,57 & 108,90 & 182,44 & 182,74 & 24,61 & 536,54 & 62,27 & 20,27 & 26,21 & 162,15 & 83,91 & 91,55 & 138,26 \\
\hline Discoglossus jeanneae & 30TVL58 & 100,00 & 109,69 & 104,92 & 36,27 & 6237,29 & 274,93 & $-8,82$ & 283,75 & 114,42 & 192,60 & 193,04 & 34,23 & 486,60 & 55,97 & 17,97 & 26,23 & 146,29 & 76,12 & 83,23 & 125,49 \\
\hline Discoglossus jeanneae & 30TVL60 & 100,00 & 126,06 & 104,05 & 35,02 & 6558,47 & 295,12 & 4,32 & 290,81 & 83,61 & 213,47 & 213,51 & 46,63 & 447,94 & 57,04 & 11,99 & 33,66 & 152,69 & 58,60 & 58,63 & 124,06 \\
\hline Discoglossus jeanneae & 30TVL61 & 100,00 & 121,44 & 103,71 & 35,33 & 6520,14 & 289,47 & 0,86 & 288,6 & 79,56 & 208 & 208 & 42, & 457,78 & 56,02 & 13,16 & 31,80 & 15 & 63,16 & 63,89 & 124 \\
\hline |Discoglossus jeanneae & 30TVL62 & 100,00 & 122,19 & 103,14 & 35,32 & 6491,62 & 288,90 & 1,52 & 287,38 & 80,64 & 208,18 & 208,88 & 43,69 & 450,45 & 54,49 & 13,15 & 31,25 & 147,72 & 63,30 & 64,48 & 120,74 \\
\hline
\end{tabular}




\begin{tabular}{|c|c|c|c|c|c|c|c|c|c|c|c|c|c|c|c|c|c|c|c|c|c|}
\hline TAXON & UTM & $\overline{\mathrm{km} 2}$ & BIO1 & $\mathrm{B1O2}$ & $\mathrm{BIO3}$ & $\begin{array}{ll}B 104 \\
\end{array}$ & B105 & B106 & B107 & B108 & B109 & BIO10 & BI011 & BIO12 & BIO13 & BIO14 & BIO15 & BIO16 & BIO17 & BIO18 & BlO19 \\
\hline Discoglossus jeanneae & 30TVL63 & 100,00 & 103,22 & 105,44 & 36,24 & 6361,51 & 272,07 & $-14,94$ & 287,01 & 70,18 & 188,55 & 189,08 & 28,16 & 522,84 & 60,45 & 18,56 & 27,81 & 161,01 & 79,09 & 84,01 & 136,24 \\
\hline Discoglossus jeanneae & 30TVL64 & 100,00 & 94,16 & 106,62 & 36,72 & 6278,11 & 263,56 & $-23,05$ & 286,62 & 85,77 & 178,82 & 179,12 & 20,69 & 560,23 & 65,27 & 21,59 & 26,17 & 169,19 & 87,76 & 93,92 & 144,27 \\
\hline Discoglossus jeanneae & 30TVL71 & 100,00 & 120,88 & 103,79 & 35,43 & 6518,66 & 288,58 & 0,21 & 288,37 & 79,19 & 207,66 & 208,00 & 42,49 & $\begin{array}{l}451,60 \\
\end{array}$ & 54,44 & 13,41 & 31,27 & \begin{tabular}{ll|}
147,68 \\
\end{tabular} & 64,06 & 64,58 & 119,43 \\
\hline Discoglossus jeanneae & 30TVL80 & 100,00 & $\begin{array}{ll}128,46 \\
\end{array}$ & 102,32 & 35,07 & 6577,84 & 294,21 & 6,89 & 287,32 & 86,39 & 216,18 & 216,18 & 49,14 & 414,96 & 51,50 & 11,70 & 32,79 & 138,37 & 57,21 & 57,21 & 106,89 \\
\hline Discoglossus jeanneae & 30TVL86 & 100,00 & 88,62 & 108,83 & 37,01 & 6219,83 & 259,37 & $-29,34$ & 288,71 & 105,40 & \begin{tabular}{|c|}
172,68 \\
\end{tabular} & 172,75 & 15,67 & 588,72 & 69,34 & 25,68 & 23,87 & 178,59 & 98,32 & \begin{tabular}{|l|l|}
104,12 \\
\end{tabular} & 150,35 \\
\hline Discoglossus jeanneae & 30TVL91 & 100,00 & 121,90 & 104,96 & 35,73 & 6522,61 & 289,31 & $-0,26$ & 289,56 & 80,44 & 208,64 & 208,92 & 43,39 & 436,13 & 50,64 & 14,20 & 29,76 & 137,75 & \begin{tabular}{l|l|}
65,45 \\
\end{tabular} & 66,21 & 110,47 \\
\hline Discoglossus jeanneae & 30TVL93 & 100,00 & 115,93 & 106,16 & 36,04 & 6443,86 & 283,94 & $-5,49$ & 289,42 & 76,12 & 201,56 & 202,12 & \begin{tabular}{l|l}
38,45 \\
\end{tabular} & \begin{tabular}{ll|}
458,06 \\
\end{tabular} & 53,33 & \begin{tabular}{|c|}
16,36 \\
\end{tabular} & 27,60 & \begin{tabular}{|c|}
139,58 \\
\end{tabular} & 71,74 & 74,50 & 115,90 \\
\hline Discoglossus jeanneae & 30TVL96 & 100,00 & 91,51 & 109,60 & 37,08 & 6245,60 & 262,68 & $-27,70$ & 290,38 & \begin{tabular}{|l|l|l|l}
108,68 \\
\end{tabular} & \begin{tabular}{|l|l|}
175,71 \\
\end{tabular} & $\begin{array}{l}175,85 \\
\end{array}$ & \begin{tabular}{ll|l}
17,98 \\
\end{tabular} & 575,53 & 68,11 & 25,49 & 23,55 & \begin{tabular}{ll|}
174,62 \\
\end{tabular} & 97,43 & 103,34 & 146,49 \\
\hline Discoglossus jeanneae & 30TVL97 & 100,00 & 95,54 & 109,50 & 37,04 & 6239,01 & 266,14 & $-24,09$ & \begin{tabular}{|l|l|}
290,22 \\
\end{tabular} & \begin{tabular}{|l|l|l}
113,26 \\
\end{tabular} & $\begin{array}{l}179,30 \\
1\end{array}$ & \begin{tabular}{|c|}
179,44 \\
\end{tabular} & 21,46 & 556,16 & 65,73 & 24,58 & 23,43 & 168,52 & 94,61 & \begin{tabular}{|c|}
101,49 \\
\end{tabular} & 141,73 \\
\hline Discoglossus jeanneae & 30TVM05 & 100,00 & 112,95 & 107,09 & 37,28 & 5760,54 & 274,08 & $-8,37 \mid$ & 282,45 & 90,29 , & 188,68 & 189,24 & 42,01 & 491,35 [ & 55,07 & 20,69 & 25,91 & 150,16 & 76,06 & 88,95 & 124,25 \\
\hline Discoglossus jeanneae & $\begin{array}{l}30 T V M 15 \\
\end{array}$ & 100,00 & 111,19 & 105,43 & 37,01 & 5789,24 & 271,59 & $-7,88$ & 279,47 & 82,72 & \begin{tabular}{|l|l|l}
187,42 & \\
\end{tabular} & 187,72 & 39,77 & 500,25 & 55,85 & 21,35 & 25,09 & 151,78 & 79,31 & 90,31 & 126,99 \\
\hline Discoglossus jeanneae & 30TVM17 & 100,00 & 110,73 & 103,01 & 37,13 & 5638,93 & 266,86 & $-5,55$ & 272,42 & 81,73 & \begin{tabular}{|l|l|}
184,87 \\
\end{tabular} & 185,04 & \begin{tabular}{|l|l|}
40,97 \\
\end{tabular} & 532,14 & 58,37 & 24,53 & 23,95 & \begin{tabular}{ll|}
163,16 \\
\end{tabular} & 87,60 & 94,81 & 135,47 \\
\hline Discoglossus jeanneae & 30TVM22 & 100,00 & 113,55 & 105,43 & 37,00 & 6006,30 & 276,36 & $-6,03$ & 282,39 & 118,28 & 192,68 & 193,21 & 39,70 & 472,53 & 53,98 & 18,31 & 26,17 & \begin{tabular}{ll|}
142,92 \\
\end{tabular} & 73,27 & 83,16 & 120,81 \\
\hline Discoglossus jeanneae & 30TVM23 & 100,00 & 109,67 & 105,44 & 37,00 & 5941,56 & 272,32 & $-9,19$ & 281,50 & 125,40 & \begin{tabular}{l|l|}
188,09 \\
\end{tabular} & $\begin{array}{l}188,45 \\
\end{array}$ & 36,70 & 491,21 & 56,07 & 20,01 & 25,35 & 148,21 & 77,60 & 87,96 & 125,23 \\
\hline Discoglossus jeanneae & $\begin{array}{l}30 T V M 25 \\
\end{array}$ & 100,00 & 111,49 & 103,89 & 37,00 & 5813,87 & 271,12 & $-5,72$ & 276,84 & 79,86 & $\mid 187,97$ & 188,22 & 39,6 & 501,24 & 55,78 & 21,6 & 24,59 & \begin{tabular}{|l|l|}
151,04 \\
\end{tabular} & 81,29 & 90,25 & 127,60 \\
\hline Discoglossus jeanneae & 30TVM32 & 100,00 & 112,25 & 104,83 & 36,97 & 6015,64 & 274,71 & $-6,50$ & 281,21 & 123,59 & $\begin{array}{l}191,55 \\
\end{array}$ & 191,91 & 38,29 & \begin{tabular}{|l|l|}
479,94 \\
\end{tabular} & 54,83 & \begin{tabular}{|c|}
19,08 \\
\end{tabular} & 25,51 & \begin{tabular}{|c|}
144,56 \\
\end{tabular} & \begin{tabular}{ll|}
76,05 \\
\end{tabular} & 84,79 & 123,00 \\
\hline Discoglossus jeanneae & 30TVM34 & 100,00 & $\begin{array}{ll}106,97 \\
\end{array}$ & 104,04 & 37,00 & 5908,60 & 268,39 & $-9,57$ & 277,97 & \begin{tabular}{ll|l}
121,96 \\
\end{tabular} & \begin{tabular}{|l|l|}
185,07 \\
\end{tabular} & $\begin{array}{l}185,15 \\
\end{array}$ & 34,46 & \begin{tabular}{|l|l|}
511,04 \\
\end{tabular} & 57,86 & 22,09 & 24,09 & \begin{tabular}{|l|l|}
152,90 \\
\end{tabular} & 83,91 & 91,86 & 130,41 \\
\hline Discoglossus jeanneae & 30TVM38 & 100,00 & 106,07 & 99,22 & 37,00 & 5654,97 & 260,06 & $-4,72$ & 264,78 & 73,92 & 180,35 & 180,35 & 35,83 & \begin{tabular}{|l|l|}
565,09 \\
\end{tabular} & 60,68 & 27,50 & 22,06 & \begin{tabular}{|l|l}
170,20 \\
\end{tabular} & 98,48 & $\begin{array}{l}9,15 \\
\end{array}$ & 145,37 \\
\hline Discoglossus jeanneae & 30TVM39 & 100,00 & 102,91 & 97,88 & 37,01 & 5555,62 & 254,18 & $-5,56$ & 259,75 & 71,68 & \begin{tabular}{l|l|l|}
176,22 \\
\end{tabular} & \begin{tabular}{ll|}
176,22 \\
\end{tabular} & 34,31 & 602,44 & \begin{tabular}{c|c|}
65,96 \\
\end{tabular} & 29,75 & 21,75 & 183,21 & 106,31 & 106,31 & 156,24 \\
\hline Discoglossus jeanneae & $\begin{array}{l}30 \text { TVM40 } \\
\end{array}$ & 100,00 & 113,46 & 104,42 & 36,52 & 6135,33 & 276,98 & $-5,46$ & 282,45 & \begin{tabular}{ll|l}
122,49 \\
\end{tabular} & 194,55 & 195,09 & 38,5 & 472,12 & 54,16 & 17,7 & 26, & \begin{tabular}{|l|l|}
142,26 \\
\end{tabular} & 74,12 & 81,77 & 121,43 \\
\hline Discoglossus jeanneae & 30TVM41 & 100,00 & 115,39 & 104,04 & 36,71 & 6081,07 & 277,89 & $-3,05$ & 280,94 & 108,31 & \begin{tabular}{|l|l|l|}
195,63 \\
\end{tabular} & 195,91 & 40,63 & \begin{tabular}{ll|}
467,45 \\
\end{tabular} & 53,33 & 18,07 & 25,81 & \begin{tabular}{l|l}
140,75 \\
\end{tabular} & 74,19 & 81,43 & 120,23 \\
\hline Discoglossus jeanneae & 30TVM42 & 100,00 & 111,55 & 104,21 & 36,99 & 6041,66 & 274,06 & $-6,11$ & 280,17 & 129,77 & \begin{tabular}{|l|l|l|l|}
191,33 \\
\end{tabular} & $\begin{array}{l}191,65 \\
\end{array}$ & 37,41 & \begin{tabular}{ll|l}
484,68 \\
\end{tabular} & 55,41 & \begin{tabular}{|c|}
19,70 \\
\end{tabular} & 24,98 & \begin{tabular}{ll|}
145,36 \\
\end{tabular} & 78,42 & 84,94 & 124,35 \\
\hline Discoglossus jeanneae & 30TVM43 & 100,00 & 107,22 & 104,07 & 37,00 & 5987,94 & 269,58 & $-9,39$ & 278,97 & 125,28 & $\begin{array}{l}186,45 \\
\end{array}$ & \begin{tabular}{|c|}
186,49 \\
\end{tabular} & 33,98 & 506,27 & 57,85 & 21,60 & 24,22 & \begin{tabular}{|c|}
151,88 \\
\end{tabular} & 83,48 & 90,24 & 129,68 \\
\hline Discoglossus jeanneae & 30TVM44 & 100,00 & 105,16 & 103,69 & 37,00 & 5929,56 & 266,49 & $-10,45$ & 276,94 & 122,79 & \begin{tabular}{|l|l|}
183,57 \\
\end{tabular} & 183,60 & 32,4 & 520,90 & 59,21 & 23,12 & 23,55 & 155,71 & 87,36 & 93,38 & 133,58 \\
\hline Discoglossus jeanneae & 30TVM45 & 100,00 & 106,31 & 102,81 & 37,00 & 5873,44 & 266,03 & $-8,04$ & 274,06 & 121,05 & \begin{tabular}{ll|}
183,90 \\
\end{tabular} & 183,92 & 34,1 & 523,97 & 58,84 & 23,5 & 23, & 155,33 & \begin{tabular}{l|l}
89,15 \\
\end{tabular} & 92,81 & 134,59 \\
\hline \begin{tabular}{|l|l|l|l} 
Discoglossus jeanneae \\
\end{tabular} & $\begin{array}{l}30 \text { TVM } 46 \\
\end{array}$ & 100,00 & 102,56 & 102,01 & 37,00 & 5811,44 & 261,32 & $-10,13$ & 271,45 & 111,71 & 179,48 & 179,48 & 31,14 & 548,59 & 61,10 & 26,01 & 22,41 & 161,84 & \begin{tabular}{|c|}
94,85 \\
\end{tabular} & 95,70 & 141,36 \\
\hline Discoglossus jeanneae & $\begin{array}{l}30 T V M 48 \\
\end{array}$ & 100,00 & 101,72 & 99,07 & \begin{tabular}{|c|}
37,07 \\
\end{tabular} & 5679,72 & 255,82 & $-7,16$ & 262,98 & 68,78 & \begin{tabular}{l|l|l|}
176,82 \\
\end{tabular} & \begin{tabular}{ll|}
176,82 \\
\end{tabular} & 31,73 & \begin{tabular}{|l|l|}
578,09 \\
\end{tabular} & 62,43 & 28,77 & 21,59 & \begin{tabular}{|c|}
171,22 \\
\end{tabular} & 102,78 & \begin{tabular}{|c|}
102,78 \\
\end{tabular} & 150,41 \\
\hline Discoglossus jeanneae & 30TVM55 & 100,00 & 101,93 & 103,01 & 37,03 & 5877,10 & 262,16 & $-11,48$ & 273,65 & 118,18 & \begin{tabular}{|l|}
179,87 \\
\end{tabular} & 179,87 & 30,22 & \begin{tabular}{|l|l|}
547,68 \\
\end{tabular} & 61,75 & 25,84 & 22,42 & 162,52 & \begin{tabular}{|c|}
95,08 \\
\end{tabular} & 96,40 & 141,54 \\
\hline Discoglossus jeanneae & 30TVM58 & 100,00 & 98,86 & 99,24 & 37,44 & 5667,41 & 252,48 & $-9,10$ & 261,58 & 69,68 & \begin{tabular}{|l|l|l|}
174,25 \\
\end{tabular} & 174,25 & 29,75 & \begin{tabular}{ll|}
600,95 \\
\end{tabular} & 65,14 & 30,32 & 21,19 & 176,48 & 108,41 & 108,41 & 158,28 \\
\hline Discoglossus jeanneae & 30TVM59 & 100,00 & 99,00 & 97,41 & 37,52 & 5574,17 & 249,40 & $-6,82$ & 256,22 & 66,52 & 173,22 & 173,22 & 31,22 & 624,74 & 66,83 & 31,49 & 21,03 & \begin{tabular}{|c|}
185,39 \\
\end{tabular} & \begin{tabular}{|c|}
113,75 \\
\end{tabular} & \begin{tabular}{ll|l}
113,75 \\
\end{tabular} & 166,05 \\
\hline Discoglossus jeanneae & 30TVM64 & 100,00 & 95,36 & 104,86 & 37,20 & 5925,16 & 258,21 & $-18,69$ & 276,90 & \begin{tabular}{|c|}
111,96 \\
\end{tabular} & \begin{tabular}{|l|l|l|l|}
174,48 \\
\end{tabular} & \begin{tabular}{|c|}
174,49 \\
\end{tabular} & 24,00 & $\begin{array}{l}577,95 \\
\end{array}$ & 65,75 & 27,61 & 22,01 & \begin{tabular}{ll|}
172,62 \\
\end{tabular} & \begin{tabular}{|l|l|l}
101,03 \\
\end{tabular} & \begin{tabular}{|c|}
102,07 \\
\end{tabular} & 149,71 \\
\hline Discoglossus jeanneae & 30TVM65 & 100,00 & 99,66 & 103,47 & 37,19 & 5877,67 & 260,07 & $-13,36$ & 273,44 & 116,60 & \begin{tabular}{|c|}
177,81 \\
\end{tabular} & 177,81 & 28,24 & 565,63 & 63,77 & 27,44 & 21,85 & 167,67 & 99,91 & 100,37 & 146,89 \\
\hline Discoglossus jeanneae & 30TVM66 & 100,00 & 96,82 & 102,54 & 37,51 & 5810,34 & 255,69 & $-14,68$ & 270,37 & \begin{tabular}{|l|l|}
112,97 \\
\end{tabular} & \begin{tabular}{ll|}
174,30 \\
\end{tabular} & 174,30 & 26,32 & $\begin{array}{l}592,52 \\
\end{array}$ & 65,98 & 29,71 & 21,25 & \begin{tabular}{ll|}
174,32 \\
\end{tabular} & \begin{tabular}{l|l}
105,92 \\
\end{tabular} & \begin{tabular}{l|l}
105,92 \\
\end{tabular} & 154,79 \\
\hline Discoglossus jeanneae & & 100,00 & 85,73 & 102,20 & 37,72 & 5724,80 & 243,80 & $-23,75$ & 267,55 & 100,12 & $\begin{array}{ll}162,63 \\
\end{array}$ & 162,63 & 17 & 672,44 & 73,45 & 35,13 & 20,31 & \begin{tabular}{|l|l|}
195,63 \\
\end{tabular} & 121,75 & 121,75 & 177,26 \\
\hline Discoglossus jeanneae & 30TVM72 & 100,00 & 106,10 & 105,89 & 37,01 & 6061,74 & 270,43 & $-10,91$ & 281,34 & 124,35 & 186,61 & 186,65 & 32,47 & 516,80 & 59,62 & 23,21 & 23,02 & \begin{tabular}{|l|l|}
154,97 \\
\end{tabular} & 89,04 & 93,36 & 133,00 \\
\hline Discoglossus jeanneae & 30TVM74 & 100,00 & 100,22 & 105,01 & 37,27 & 5943,49 & 262,73 & $-14,36$ & 277,09 & \begin{tabular}{|c|}
117,38 \\
\end{tabular} & \begin{tabular}{|c|}
179,39 \\
\end{tabular} & 179,40 & 28,16 & 559,96 & 63,73 & 26,99 & 21,78 & \begin{tabular}{|c|}
166,78 \\
\end{tabular} & 99,11 & \begin{tabular}{l|l}
100,65 \\
\end{tabular} & 145,18 \\
\hline Discoglossus jeanneae & $\begin{array}{l}30 T V M 75 \\
\end{array}$ & 100,00 & 100,45 & 103,88 & $\begin{array}{l}37,25 \\
\end{array}$ & 5882,88 & 261,01 & $-12,85$ & 273,87 & 117,54 & 178,77 & 178,77 & 28,93 & 569,77 & 64,18 & 28,18 & 21,36 & 168,50 & \begin{tabular}{|l|l|}
102,01 \\
\end{tabular} & \begin{tabular}{|l|l|}
102,59 \\
\end{tabular} & 148,42 \\
\hline Discoglossus jeanneae & $\begin{array}{l}30 T V M 76 \\
\end{array}$ & 100,00 & 87,60 & 103,64 & 37,90 & 5792,22 & 247,70 & $-23,5$ & 271,22 & \begin{tabular}{ll|}
102,96 \\
\end{tabular} & \begin{tabular}{|c|}
165,40 \\
\end{tabular} & 165,40 & 18, & 656,62 & 72,67 & 34,2 & 20, & \begin{tabular}{|l|l|}
192,43 \\
\end{tabular} & \begin{tabular}{|c|}
119,18 \\
\end{tabular} & \begin{tabular}{|l|l|}
119,18 \\
\end{tabular} & 172,73 \\
\hline Discoglossus jeanneae & $\begin{array}{l}30 T V M 78 \\
\end{array}$ & 100,00 & 88,24 & 101,01 & 38,00 & 555,53 & 243, & $-19,9$ & 263,53 & 69,7 & 164,02 & 16 & $2 x+2+3$ & 687, & 73,85 & 36, & 19, & 198 & 126,73 & \begin{tabular}{|l|l}
126,73 \\
\end{tabular} & 183,08 \\
\hline Discoglossus jeanneae & 30TVM81 & 100,00 & 107,37 & 107,21 & 37,07 & 6121,69 & 27 & $-11,05$ & 284,28 & 125,88 & \begin{tabular}{|l|l|}
188,52 \\
\end{tabular} & 188,66 & 33, & 509,37 & 59,19 & 22,79 & 23, & 152,96 & 88,11 & 93,40 & 130,80 \\
\hline Discoglossus jeanneae & 30TVM83 & 100,00 & 98,03 & 106,97 & \begin{tabular}{l|l|l}
37,55 \\
\end{tabular} & 6000,19 & 263,21 & $-18,06$ & 281,27 & \begin{tabular}{l|l}
115,23 \\
\end{tabular} & $17 \varepsilon$ & $\begin{array}{l}178,18 \\
\end{array}$ & 25,6 & 568,01 & 65,21 & 27,55 & 21,58 & \begin{tabular}{ll|}
169,93 \\
\end{tabular} & 101,13 & \begin{tabular}{|c|}
104,28 \\
\end{tabular} & 147,14 \\
\hline Discoglossus jeanneae & 30TVM84 & 100,00 & 97,05 & 106,23 & 37,68 & 5944,40 & 260,66 & $-17,95$ & 278,60 & 114,03 & 176,37 & 176,37 & 25,1 & 583,63 & 66,38 & 29,07 & 21,05 & 173,67 & 105,01 & \begin{tabular}{|l|l|}
107,08 \\
\end{tabular} & 151,81 \\
\hline Discoglossus jeanneae & 30TVM91 & 100,00 & 105,88 & 108,52 & 37,18 & 6119,48 & 273,03 & $-13,45$ & 286,48 & 124,41 & \begin{tabular}{|l|l|}
187,18 \\
\end{tabular} & 187,24 & 31, & 520,76 & 60,75 & 24,19 & 22,38 & \begin{tabular}{|c|}
156,58 \\
\end{tabular} & \begin{tabular}{|c|}
91,88 \\
\end{tabular} & 96,24 & 133,75 \\
\hline Discoglossus jeanneae & $\begin{array}{l}30 T V M 93 \\
\end{array}$ & 10 & 95 & 37 & 37,9 & 7f & to & $-20,9$ & 283,07 & 112,94 & 17 & $17 \epsilon$ & 23,5 & 587, & 67,38 & 29,3 & 20,8 & 175,48 & 106,11 & 108,37 & 152,44 \\
\hline \begin{tabular}{|l} 
Discoglossus jeanneae \\
\end{tabular} & 30TVM94 & 10 & 93 & 107,52 & 37,99 & 594 & 25 & $-21,79$ & 280,32 & 110,41 & 173,17 & 173 & 22, & 609,52 & 69,25 & 31, & 20, & \begin{tabular}{|l|l|}
181,15 \\
\end{tabular} & \begin{tabular}{|l|l|}
111,26 \\
\end{tabular} & 112,79 & 159,04 \\
\hline Discoglossus jeanneae & 30TVM99 & 100,00 & 102,76 & 98,85 & 37,97 & 5568,33 & 252,12 & $-5,18$ & 257,30 & 60, & 176,6 & 176, & & \begin{tabular}{|c|}
662,93 \\
\end{tabular} & 69,71 & 34,2 & 19, & $\begin{array}{l}192,52 \\
\end{array}$ & \begin{tabular}{|l|l|}
125,39 \\
\end{tabular} & 125,39 & 178,41 \\
\hline Discoglossus jeanneae & $\begin{array}{l}30 T V N 00 \\
\end{array}$ & 100,00 & 108,50 & 99,59 & 37,93 & 5349,25 & 256,73 & $-3,32$ & 260,05 & 82,66 & $\begin{array}{l}179,20 \\
1\end{array}$ & \begin{tabular}{|c|}
179,20 \\
\end{tabular} & 42,52 & \begin{tabular}{l|l|}
609,08 \\
\end{tabular} & 69,48 & \begin{tabular}{l|l|}
29,05 \\
\end{tabular} & 23,06 & \begin{tabular}{l|l}
192,55 \\
\end{tabular} & $\begin{array}{l}104,69 \\
\end{array}$ & $\begin{array}{l}105,56 \\
\end{array}$ & 157,47 \\
\hline Discoglossus jeanneae & 30TVN03 & 100,00 & 98,08 & 94,63 & 38,07 & 5091,35 & 238,07 & $-6,49$ & 244,56 & 73,30 & 165,73 & 165,91 & 36,01 & 748,90 & 86,70 & 37,29 & 21,95 & 239,08 & \begin{tabular}{|l|l|}
135,73 \\
\end{tabular} & \begin{tabular}{|c|}
135,79 \\
\end{tabular} & 199,06 \\
\hline Discoglossus jeanneae & 30TVN22 & 100,00 & 98,18 & 94,05 & 37,97 & 5211,92 & 239,98 & $-5,71$ & 245,69 & 71,22 & \begin{tabular}{|c|c|}
167,44 \\
\end{tabular} & 167,58 & 34,4 & 722,47 & 81,64 & 35,99 & 21,2 & 226,16 & 130,84 & 130,90 & 192,53 \\
\hline Discoglossus jeanneae & 30TVN42 & 100,00 & 94,73 & 92,92 & 37,97 & 5248,90 & 235 & $-6,76$ & 242,68 & 66 , & 163,7 & 164,82 & 30,91 & \begin{tabular}{|l|l}
748,93 \\
\end{tabular} & 82,50 & 37,81 & 20,56 & 230,02 & \begin{tabular}{|c|}
137,79 \\
\end{tabular} & \begin{tabular}{ll|l}
137,95 \\
\end{tabular} & 202,92 \\
\hline Discoglossus jeanneae & 30TVN43 & 100,00 & 94,96 & 90,73 & 37,93 & 5126,11 & 232,01 & $-4,57$ & 236,57 & \begin{tabular}{ll|l}
67,53 \\
\end{tabular} & \begin{tabular}{|l|l|}
161,78 \\
\end{tabular} & \begin{tabular}{|l|l|}
163,49 \\
\end{tabular} & 32,63 & \begin{tabular}{|c|}
793,42 \\
\end{tabular} & 87,77 & 39,94 & 20,51 & \begin{tabular}{|l|l|}
245,95 \\
\end{tabular} & \begin{tabular}{|l|l|}
145,83 \\
\end{tabular} & 147,30 & 217,37 \\
\hline Discoglossus jeanneae & 30TVN44 & 100,00 & 99,73 & 87,26 & 37,82 & 4960,01 & 230,43 & 2,49 & 227,94 & 73,85 & \begin{tabular}{|l|l|l|}
164,09 \\
\end{tabular} & 165,94 & 39,32 & $\begin{array}{l}829,36 \\
\end{array}$ & 92,90 & 40,81 & 21,28 & 261,53 & 150,31 & 155,01 & 230,64 \\
\hline Discoglossus jeanneae & 30TVN46 & 100,00 & 101,68 & 82,19 & 37,70 & 4705,55 & 224,07 & 8,7 & 215,30 & 78,1 & 162,36 & 164, & 44 & 919,6 & 105,53 & 44, & 22, & 295, & 164 & 174,03 & 261,18 \\
\hline Discoglossus jeanneae & $30 \mathrm{TVI}$ & 100, & 98,9 & 91, & 37, & 522 & 237 & $-1,86$ & & 70, & 167 & 168 & 35, & 749 & 81, & 37 & 20, & 229 & 137,40 & \begin{tabular}{|l|l|}
139,13 \\
\end{tabular} & 205 \\
\hline Discoglossus jeanneae & 30TVN54 & 100,00 & 106,21 & 84,98 & 37,53 & 4905,19 & 233,44 & 10,21 & 223,23 & 80,17 & \begin{tabular}{|c|c|}
169,55 \\
\end{tabular} & 171,56 & 46,08 & 826,97 & 93,60 & 39,72 & 21,58 & 261,92 & \begin{tabular}{|l|l|l|}
148,03 \\
\end{tabular} & 155,24 & 233,76 \\
\hline Discoglossus jeanneae & 30TVN55 & 100,00 & 113,55 & 80,20 & 37,16 & 4694,17 & 233,01 & 20,75 & 212,25 & 89,81 & 173,80 & 175,99 & 55,64 & 865,90 & 100,81 & \begin{tabular}{|l|l|}
40,08 \\
\end{tabular} & 22,87 & 280,37 & \begin{tabular}{|l|l|}
151,47 \\
\end{tabular} & \begin{tabular}{ll|}
163,42 \\
\end{tabular} & 249,80 \\
\hline Discoglossus jeanneae & 30 TVN56 & 100,00 & 106,14 & 80,16 & \begin{tabular}{l|l}
37,35 \\
\end{tabular} & 4654,46 & 225,83 & 14,56 & 211,27 & 82,72 & \begin{tabular}{|c|}
165,90 \\
\end{tabular} & 168,30 & 49,16 & $\begin{array}{l}930,85 \\
\end{array}$ & \begin{tabular}{|l|}
108,16 \\
\end{tabular} & 44,22 & 22,41 & \begin{tabular}{|l|}
299,67 \\
\end{tabular} & \begin{tabular}{ll|l}
164,75 \\
\end{tabular} & \begin{tabular}{|c|}
176,64 \\
\end{tabular} & 268,72 \\
\hline Discoglos & $30 \mathrm{TVNG}$ & & & & 37,3 & & & & 25 & & & & & 728 & 80 & & & 226 & 131,29 & \begin{tabular}{|c|}
136,11 \\
\end{tabular} & 20 \\
\hline Discoglossus jeanneae & 30TVN64 & 100,00 & \begin{tabular}{|c|}
110,67 \\
\end{tabular} & 83,52 & 37,36 & 4865,24 & 235,6 & \begin{tabular}{|l|l|l|}
15,42 \\
\end{tabular} & 220,24 & 84,28 & \begin{tabular}{|c|}
173,25 \\
\end{tabular} & \begin{tabular}{|c|}
175,36 \\
\end{tabular} & 50,84 & 832,0 & 95,12 & 39,33 & 21,70 & $263,67 \mid$ & \begin{tabular}{ll|}
147,92 \\
\end{tabular} & \begin{tabular}{|c|}
156,78 \\
\end{tabular} & 238, \\
\hline Discoglossus jeanneae & 30TVN65 & 100,00 & 108,42 & 81,64 & 37,37 & 4761,87 & 230,73 & 15,28 & 215,45 & 82,29 & \begin{tabular}{ll|}
169,62 \\
\end{tabular} & 171,90 & 50,06 & 889,65 & 102,73 & 42,10 & 21,96 & 283,26 & 157,77 & 168,31 & 257,69 \\
\hline
\end{tabular}




\begin{tabular}{|c|c|c|c|c|c|c|c|c|c|c|c|c|c|c|c|c|c|c|c|c|c|}
\hline TAXON & UTM & $\overline{\mathrm{km} 2}$ & BIO1 & $\mathrm{B1O2}$ & $\mathrm{BIO3}$ & B104 & B105 & B106 & B107 & B108 & B109 & B1010 & BIO11 & $\overline{B 1012}$ & BIO13 & BIO14 & BIO15 & B1016 & BIO17 & BIO18 & BlO19 \\
\hline Discoglossus jeanneae & 30TVN66 & 100,00 & 105,04 & 80,32 & 37,39 & 4675,92 & 225,36 & 13,67 & 211,68 & 74,50 & 164,97 & 167,42 & 47,88 & 950,00 & 110,36 & 45,36 & 22,03 & 303,34 & 168,65 & 180,39 & 276,88 \\
\hline Discoglossus jeanneae & 30TVN73 & 100,00 & 112,44 & 85,79 & 37,43 & 5006,60 & 241,04 & 14,90 & 226,15 & 83,56 & $\begin{array}{l}176,85 \\
1\end{array}$ & 178,75 & 50,72 & 786,61 & 88,77 & 37,40 & 21,15 & 245,54 & \begin{tabular}{|l|l|}
141,27 \\
\end{tabular} & 148,32 & 225,13 \\
\hline Discoglossus jeanneae & 30TVN74 & 100,00 & 107,62 & 84,58 & 37,51 & 4912,95 & 234,44 & 12,03 & 222,40 & 74,75 & \begin{tabular}{l|l}
170,82 \\
\end{tabular} & \begin{tabular}{ll|}
172,86 \\
\end{tabular} & \begin{tabular}{ll|l}
47,35 \\
\end{tabular} & 851,06 & 96,70 & 40,89 & 21,06 & 266,57 & \begin{tabular}{|l|}
153,21 \\
\end{tabular} & \begin{tabular}{ll|}
160,98 \\
\end{tabular} & 245,17 \\
\hline Discoglossus jeanneae & 30TVN75 & 100,00 & 105,31 & 82,77 & 37,50 & 4807,18 & 229,48 & 11,75 & 217,73 & 67,09 & $\begin{array}{l}167,05 \\
\end{array}$ & 169,38 & 46,57 & $\begin{array}{l}910,55 \\
\end{array}$ & 104,51 & 43,79 & 21,23 & 286,82 & 163,32 & \begin{tabular}{ll|}
172,66 \\
\end{tabular} & 264,81 \\
\hline Discoglossus jeanneae & 30TVN77 & 100,00 & 122,34 & 71,61 & 36,73 & 4342,73 & 229,04 & 36,54 & 192,50 & 98,41 & \begin{tabular}{|l|l|}
177,24 \\
\end{tabular} & 179,90 & 68,68 & 1009,67 & 123,94 & 44,06 & 25,19 & 332,97 & 169,58 & \begin{tabular}{|c|}
190,88 \\
\end{tabular} & 310,96 \\
\hline Discoglossus jeanneae & 30TVN82 & 100,00 & 103,17 & 91,27 & 37,89 & 5220,71 & 240,35 & 2,42 & 237,93 & 60,00 & 170,94 & 172,61 & 39,31 & 771,66 & 84,04 & 38,65 & 19,54 & 233,49 & 143,87 & 146,24 & 215,95 \\
\hline Discoglossus jeanneae & 30TVN83 & 100,00 & 104,94 & 88,13 & 37,73 & 5072,27 & 237,26 & 6,80 & 230,46 & 63,63 & \begin{tabular}{|l|l|}
170,70 \\
\end{tabular} & 172,44 & 42,99 & 820,28 & 91,21 & 40,44 & 20,14 & 252,12 & \begin{tabular}{|l|l|}
150,79 \\
\end{tabular} & \begin{tabular}{|l|}
155,49 \\
\end{tabular} & 233,70 \\
\hline Discoglossus jeanneae & 30TVN84 & 100,00 & 103,96 & 86,15 & \begin{tabular}{l|l|}
37,85 \\
\end{tabular} & 4963,33 & 233,21 & 7,87 & 225,33 & 55,78 & $\begin{array}{l}167,96 \\
\end{array}$ & $\begin{array}{l}170,04 \\
\end{array}$ & 43,42 & 871,21 & $\begin{array}{l}98,06 \\
\end{array}$ & 42,76 & 20,30 & 269,96 & \begin{tabular}{l|l}
159,22 \\
\end{tabular} & $\begin{array}{l}165,50 \\
\end{array}$ & 250,88 \\
\hline Discoglossus jeanneae & 30TVN85 & 100,00 & 104,85 & 83,38 & 37,74 & 4828,90 & 229,94 & 11,22 & 218,72 & 54,11 & \begin{tabular}{l|l|l|}
166,92 \\
\end{tabular} & 169,21 & $\begin{array}{l}45,99 \\
\end{array}$ & 924,90 & 105,84 & 44,83 & 20,84 & 290,18 & $\begin{array}{l}167,04 \\
\end{array}$ & \begin{tabular}{|c|}
175,80 \\
\end{tabular} & 270,28 \\
\hline Discoglossus jeanneae & 30TVN87 & 100,00 & 124,55 & 70,93 & 36,59 & 4335,24 & 230,32 & 39,18 & 191,14 & $88,84[$ & 179,24 & 181,90 & 70,99 & 1029,46 & 127,20 & 44,41 & 25,55 & 338,75 _ & 171,69 & 193,69 & 322,91] \\
\hline Discoglossus jeanneae & \begin{tabular}{|l|l|}
$30 T V N 93$ \\
\end{tabular} & 100,00 & 115,36 & 86,42 & \begin{tabular}{l|l}
37,65 \\
\end{tabular} & 5019,65 & 244,13 & 17,40 & 226,73 & \begin{tabular}{|l|}
80,67 \\
\end{tabular} & \begin{tabular}{|c|c|}
179,86 \\
\end{tabular} & \begin{tabular}{|c|}
181,60 \\
\end{tabular} & 53,52 & \begin{tabular}{|c|}
797,27 \\
\end{tabular} & 89,48 & 38,23 & 20,47 & 246,02 & 145,48 & \begin{tabular}{|c|}
151,88 \\
\end{tabular} & 229,88 \\
\hline Discoglossus jeanneae & \begin{tabular}{|l|}
$30 T V N 94$ \\
\end{tabular} & 100,00 & 108,73 & 85,55 & 37,76 & 4938,92 & 236,51 & \begin{tabular}{|c|}
12,67 \\
\end{tabular} & 223,84 & 62,07 & \begin{tabular}{|l|l|}
172,20 \\
\end{tabular} & 174,24 & 48,30 & 872,13 & 98,54 & 42,44 & 20,30 & 270,24 & \begin{tabular}{|c|}
159,39 \\
\end{tabular} & 166,11 & 253,37 \\
\hline Discoglossus jeanneae & 30TWK13 & 100,00 & 123,29 & 117,98 & 37,19 & 6629,14 & 305,54 & $-6,08$ & 311,62 & \begin{tabular}{|l|l|l|}
107,24 \\
\end{tabular} & 211,53 & 212,54 & 43,97 & 474,44 & 54,90 & 13,98 & 30,69 & \begin{tabular}{|l|}
150,29 \\
\end{tabular} & 65,49 & $\begin{array}{l}67,36 \\
\end{array}$ & 124,68 \\
\hline Discoglossus jeanneae & 30TWK14 & 100,00 & 120,81 & 116,91 & 37,10 & 6612,59 & 301,81 & $-7,68$ & 309,48 & \begin{tabular}{ll|}
104,56 \\
\end{tabular} & 208,88 & 209,86 & $\begin{array}{l}1,75 \\
\end{array}$ & 479,51 & 55,68 & 14,85 & \begin{tabular}{l|l}
30,15 \\
\end{tabular} & \begin{tabular}{|l|l|}
151,01 \\
\end{tabular} & 67,53 & 69,73 & 125,27 \\
\hline Discoglossus jeanneae & $\begin{array}{l}\text { 30TWK18 } \\
\end{array}$ & 100,00 & 120,12 & 111,49 & 36,94 & 6549,52 & 294,01 & $-5,69$ & 299,71 & \begin{tabular}{ll|}
99,00 \\
\end{tabular} & 207,06 & 207,89 & 41,3 & \begin{tabular}{|l|l}
457,38 \\
\end{tabular} & 53, & 16,7 & 28, & 141, & 68,84 & \begin{tabular}{|c|}
70,79 \\
\end{tabular} & 115,82 \\
\hline Discoglossus jeanneae & \begin{tabular}{|l|} 
30TWK19 \\
\end{tabular} & 100,00 & 112,36 & 111,47 & 37,00 & 6508,24 & 286,23 & $-12,49$ & 298,72 & 96,21 & \begin{tabular}{|c|}
199,07 \\
\end{tabular} & \begin{tabular}{|c|}
199,68 \\
\end{tabular} & 34,50 & 485,32 & 57,84 & 18,46 & 27,66 & 149,55 & 75,38 & 78,99 & 122,06 \\
\hline Discoglossus jeanneae & 30TWK29 & 100,00 & 120,61 & 111,60 & 36,97 & 6519,43 & 293,10 & $-5,77$ & 298,87 & 105,81 & 206,94 & 207,78 & 42,03 & 449,01 & 54,25 & 16,81 & 28,10 & 138,53 & 70,50 & 73,21 & 111,14 \\
\hline Discoglossus jeanneae & 30TWK38 & 100,00 & 118,60 & 114,31 & 37,01 & 6511,69 & 293,20 & $-9,39$ & 302,60 & 103,35 & 204,84 & 205,76 & 40,13 & 463,81 & 56,89 & 17,48 & \begin{tabular}{|l|l|l|}
27,65 & \\
\end{tabular} & 145,43 & 73,58 & 77,58 & 114,14 \\
\hline Discoglossus jeanneae & $\begin{array}{l}\text { 30TWK39 } \\
\end{array}$ & 100,00 & 112,12 & 113,88 & 37,09 & 6487,24 & 286,54 & $-14,96$ & 301,50 & 96,33 & \begin{tabular}{|c|}
198,19 \\
\end{tabular} & \begin{tabular}{l|l|}
199,15 \\
\end{tabular} & 34,28 & 486,07 & 60,07 & 19,58 & 26,61 & 152,13 & 79,28 & 84,59 & 118,92 \\
\hline Discoglossus jeanneae & $\begin{array}{l}30 T W K 43 \\
\end{array}$ & 100,00 & 115,33 & 121,93 & 38,00 & 6564,51 & 299,45 & $-16,16$ & 315,60 & 98,45 & 202,97 & 204,06 & 36,8 & 515,11 & 62,3 & 17, & 28, & 168, & 77,36 & 82,94 & 129,92 \\
\hline Discoglossus jeanneae & 30TWK48 & 100,00 & 118,36 & 115,32 & 37,49 & 6495,22 & 292,94 & $-10,56$ & 303,49 & 103,10 & 204,25 & 205,29 & 39,91 & 464,03 & 58,03 & 17,97 & 27,41 & 146,60 & 75,60 & 80,51 & 112,32 \\
\hline Discoglossus jeanneae & 30TWK49 & 100,00 & 106,46 & 115,14 & \begin{tabular}{|c|}
37,57 \\
\end{tabular} & 6454,86 & 281,33 & $-21,36$ & 302,69 & 90,44 & \begin{tabular}{l|l|}
192,08 \\
\end{tabular} & $\begin{array}{l}193,16 \\
\end{array}$ & 28,95 & 510,99 & 64,31 & 21,77 & 25,87 & \begin{tabular}{|c|}
161,34 \\
\end{tabular} & 86,29 & 93,58 & 123,12 \\
\hline Discoglossus jeanneae & 30TWK57 & 100,00 & 119,51 & 117,14 & \begin{tabular}{|c|}
37,99 \\
\end{tabular} & 6488,75 & 295,10 & $-10,90$ & 306,00 & 104,30 & \begin{tabular}{|l|l|}
205,19 \\
\end{tabular} & 206,31 & 40,91 & 466,33 & 58,95 & 17,86 & 27,57 & \begin{tabular}{l|l}
149,15 \\
\end{tabular} & 76,57 & \begin{tabular}{|l|l|}
81,97 \\
\end{tabular} & 111,85 \\
\hline Discoglossus jeanneae & 30TWK58 & 100,00 & 118,81 & 115,73 & 37,71 & 6474,79 & 292,47 & $-11,08$ & 303,55 & 103,83 & 204,13 & 205,10 & 40,08 & 460,90 & 58,77 & 18,36 & 27,27 & \begin{tabular}{|c|}
146,40 \\
\end{tabular} & 77,21 & 82,94 & 109,38 \\
\hline Discoglossus jeanneae & $\begin{array}{l}\text { 30TWK67 } \\
\end{array}$ & 100,00 & 110,23 & 117,68 & 38,00 & 6460,58 & 286,09 & $-20,18$ & 306,27 & 94,21 & $\begin{array}{l}195,76 \\
\end{array}$ & \begin{tabular}{ll|}
196,93 \\
\end{tabular} & 32,2 & 505,56 & $\begin{array}{l}64,96 \\
\end{array}$ & 21,1 & 26, & 162,87 & 86,71 & 94,60 & 118,85 \\
\hline \begin{tabular}{|l|l|l|l} 
Discoglossus jeanneae \\
\end{tabular} & 30TWK83 & 100,00 & 102,58 & 120,26 & 38,17 & 6476,73 & 282,14 & $-27,89$ & 310,03 & 84,56 & 189,01 & 190,08 & 25,43 & 562,12 & 71,36 & 23,60 & 26,19 & 184,82 & \begin{tabular}{|l|l|}
96,95 \\
\end{tabular} & \begin{tabular}{|l|}
106,93 \\
\end{tabular} & 129,77 \\
\hline Discoglossus jeanneae & $\begin{array}{l}30 T W K 84 \\
\end{array}$ & 100,00 & 96,47 & 118,36 & 38,01 & 6457,47 & 274,20 & $-32,79$ & 306,99 & 78,13 & \begin{tabular}{|l|l|}
182,81 \\
\end{tabular} & \begin{tabular}{ll|}
183,78 \\
\end{tabular} & 19,61 & \begin{tabular}{|l|}
580,26 \\
\end{tabular} & 74,21 & 25,90 & 25,51 & \begin{tabular}{ll|}
189,63 \\
\end{tabular} & \begin{tabular}{|c|}
102,94 \\
\end{tabular} & \begin{tabular}{ll|}
114,16 \\
\end{tabular} & 132,22 \\
\hline Discoglossus jeanneae & 30TWK85 & 100,00 & 95,13 & 117,38 & 38,00 & 6441,05 & 271,36 & $-33,71$ & 305,07 & 78,52 & \begin{tabular}{|l|l|l|l|}
181,13 \\
\end{tabular} & \begin{tabular}{|c|}
182,19 \\
\end{tabular} & \begin{tabular}{ll|}
18,36 \\
\end{tabular} & 578,71 & 74,69 & 26,55 & 25,51 & 188,32 & 104,36 & \begin{tabular}{|c|}
115,87 \\
\end{tabular} & 131,04 \\
\hline Discoglossus jeanneae & $\begin{array}{l}\text { 30TWL03 } \\
\end{array}$ & 100,00 & 118,13 & 107,04 & 36,16 & 6446,04 & 286,24 & $-4,34$ & 290,58 & 86,60 & \begin{tabular}{|l|l|}
203,59 \\
\end{tabular} & 204,21 & 40,31 & 446,77 & 52,88 & 16,51 & \begin{tabular}{|l|l|}
27,15 & \\
\end{tabular} & \begin{tabular}{|l|l|}
134,88 \\
\end{tabular} & 71,42 & \begin{tabular}{|c|}
74,17 \\
\end{tabular} & 111,64 \\
\hline Discoglossus jeanneae & \begin{tabular}{|l|}
$30 T W L 07$ \\
\end{tabular} & 100,00 & 97,13 & 110,66 & 37,37 & 6252,88 & 268,36 & $-23,79$ & 292,15 & \begin{tabular}{ll|}
115,05 \\
\end{tabular} & \begin{tabular}{|l|}
180,97 \\
\end{tabular} & 181,10 & 22,64 & 549,99 & 65,41 & 24,94 & 23,07 & 167,04 & \begin{tabular}{l|l}
95,15 \\
\end{tabular} & 102,44 & 139,62 \\
\hline Discoglossus jeanneae & \begin{tabular}{|l|l|}
$30 T W L 13$ \\
\end{tabular} & 100,00 & 114,15 & 109,12 & 36,77 & 6428,10 & 283,77 & $-9,39$ & 293,16 & 102,65 & \begin{tabular}{|c|}
199,37 \\
\end{tabular} & $\begin{array}{l}200,05 \\
\end{array}$ & 36,77 & \begin{tabular}{ll|}
463,86 \\
\end{tabular} & 55,97 & 18,51 & 26,19 & \begin{tabular}{|l|}
140,01 \\
\end{tabular} & 76,30 & 80,35 & 114,78 \\
\hline Discoglossus jeanneae & 30TWL14 & 100,00 & 111,38 & 109,54 & 37,00 & 6393,14 & 281,39 & $-11,82$ & 293,21 & 127,34 & \begin{tabular}{|c|}
196,38 \\
\end{tabular} & 196,90 & 34,62 & 475,03 & 57,42 & 19,64 & 25,46 & 143,82 & 79,57 & 84,34 & 117,86 \\
\hline Discoglossus jeanneae & $\begin{array}{l}30 T W L 17 \\
\end{array}$ & 100,00 & 103,53 & 111,29 & \begin{tabular}{|c|}
37,17 \\
\end{tabular} & 6279,43 & 274,65 & $-19,02$ & 293,67 & 122,61 & 187,15 & 187,58 & 28,16 & 519,04 & 62,40 & 23,79 & 23,10 & \begin{tabular}{l|l}
158,25 \\
\end{tabular} & 91,01 & 97,74 & 130,71 \\
\hline Discoglossus jeanneae & \begin{tabular}{|l|}
$30 T W L 19$ \\
\end{tabular} & 100,00 & 110,87 & 111,19 & $\begin{array}{l}37,55 \\
\end{array}$ & & 280,75 & $-11,81$ & 292,56 & 130,53 & $\begin{array}{l}193,55 \\
\end{array}$ & 193,84 & 35,34 & 490,44 & 58,62 & 22,78 & 22,84 & \begin{tabular}{|l|l|}
148,93 \\
\end{tabular} & 87,42 & 93,05 & 124,01 \\
\hline Discoglossus jeanneae & \begin{tabular}{|l|}
$30 T W L 20$ \\
\end{tabular} & 100,00 & 117,97 & 111,08 & 36,99 & 6495,60 & 289,61 & $-7,80$ & 297,41 & \begin{tabular}{|l|}
103,08 \\
\end{tabular} & 203,95 & 204,80 & 39,76 & 454,84 & 55,32 & 17,71 & 27,43 & \begin{tabular}{|c|}
139,94 \\
\end{tabular} & 72,83 & 76,21 & 112,00 \\
\hline Discoglossus jeanneae & 30TWL23 & 100,00 & 107,73 & 111,14 & 37,00 & 6395,07 & 279,09 & $-16,64$ & 295,73 & 117,25 & \begin{tabular}{|l|l|}
192,73 \\
\end{tabular} & \begin{tabular}{|c|}
193,40 \\
\end{tabular} & 30,99 & 492,52 & 60,48 & 21,39 & 25,13 & \begin{tabular}{l|l}
150,85 \\
1
\end{tabular} & 83,67 & 89,55 & 120,92 \\
\hline Discoglossus jeanneae & 30TWL24 & 100,00 & 107,67 & 111,21 & 37,00 & 6371,25 & 278,73 & $-16,60$ & 295,33 & 127,47 & \begin{tabular}{|l|l|}
192,42 \\
\end{tabular} & 192,95 & 31,09 & \begin{tabular}{l|l|}
491,85 \\
\end{tabular} & 60,39 & 21,70 & 24,67 & 150,90 & 84,58 & 90,68 & 121,06 \\
\hline Discoglossus jeanneae & $\begin{array}{l}30 T W L 27 \\
\end{array}$ & 100,00 & 103,26 & 112,48 & 37,56 & 6274,36 & 274,86 & $-20,32$ & 295,18 & 122,43 & \begin{tabular}{|c|}
186,79 \\
\end{tabular} & 187,23 & 27, & 520,87 & 63,32 & 24,73 & 22,9 & $\begin{array}{l}159,92 \\
\end{array}$ & 93,13 & \begin{tabular}{|c|}
100,17 \\
\end{tabular} & 130,19 \\
\hline Discoglossus jeanneae & $\begin{array}{l}30 T W L 34 \\
\end{array}$ & 100,00 & 103,25 &, 50 & 37,45 & 2,49 & 274, & $-21,79$ & 296 & 122,84 & 187,75 & $18 \varepsilon$ & 26 & 512,13 & 63,82 & $4,0,0,0$ & 24, & 159 & 0,44 & 98,01 & 124,74 \\
\hline Discoglossus jeanneae & 30TWL35 & 100,00 & 101,26 & 112,75 & 37,71 & 9,27 & 27. & $-23,49$ & 29 & 120,55 & 185,24 & 18 & 25, & 523,95 & \begin{tabular}{|c|}
65,03 \\
\end{tabular} & 25,26 & 23,49 & 162,96 & 93,88 & \begin{tabular}{|c|c|}
101,78 \\
\end{tabular} & 128,29 \\
\hline Discoglossus jeanneae & $\begin{array}{l}30 T W L 36 \\
\end{array}$ & 100,00 & 100 & 113,00 & \begin{tabular}{|c|}
37,98 \\
\end{tabular} & 6291,45 & 272,63 & $-23,75$ & 296,38 & 120 & \begin{tabular}{|l|}
184,61 \\
\end{tabular} & 185,22 & 25,2 & 528,39 & 65,26 & 25,80 & 23, & \begin{tabular}{|c|}
164,10 \\
\end{tabular} & 95,48 & \begin{tabular}{|c|}
103,54 \\
\end{tabular} & 130,21 \\
\hline Discoglossus jeanneae & 30TWL38 & 100,00 & 107,05 & 113,55 & 38,00 & 6243,97 & 278,66 & $-17,82$ & 296,47 & 126,84 & 189,90 & 190,27 & 31, & 506,42 & 62,06 & 24,94 & 22,58 & 156,39 & \begin{tabular}{|l|l}
92,73 \\
\end{tabular} & 99,67 & 126,17 \\
\hline Discoglossus jeanneae & $\begin{array}{l}30 T W L 39 \\
\end{array}$ & 100,00 & 109,03 & 113,99 & 38,00 & ,73 & 280,64 & $-15,73$ & 296,38 & 128,99 & \begin{tabular}{|c|}
191,51 \\
\end{tabular} & $\begin{array}{l}191,92 \\
\end{array}$ & 33 & 503,57 & 61,23 & 25,1 & 22,12 & \begin{tabular}{|l|l|l}
154,73 \\
\end{tabular} & \begin{tabular}{|c|}
92,94 \\
\end{tabular} & \begin{tabular}{l|l|}
99,47 \\
\end{tabular} & 126,49 \\
\hline Discoglossus jeanneae & $\begin{array}{l}30 T W L 49 \\
\end{array}$ & 10 & 106,99 & 9 & 38,0 & t & & $-18,62$ & 297 & 126,85 & 189,35 & 18 & 31,4 & 514,24 & 63,20 & 26,2 & 22,0 & 159, & 6,54 & 104,10 & 128,16 \\
\hline \begin{tabular}{|l} 
Discoglossus jeanneae \\
\end{tabular} & \begin{tabular}{l|l|}
$30 T W L 55$ \\
\end{tabular} & 10 & 100,28 & 1 & 38,00 & 630 & 27 & $-25,85$ & 296 & $12 c$ & 183,82 & 184,44 & 24 & 523,34 & 67,03 & 26,47 & 23,74 & 166,91 & 97,78 & 107,47 & 124,24 \\
\hline Discoglossus jeanneae & \begin{tabular}{l|l}
$30 T W L 65$ \\
\end{tabular} & 100 & 99,31 & & 37,70 & 6279,44 & 267 & $-27,34$ & 294,95 & 119,48 & \begin{tabular}{|l|}
182,29 \\
\end{tabular} & 182,98 & 23,38 & 523,26 & 68,26 & 27,16 & 24,29 & 169,50 & $\begin{array}{ll}99,93 \\
\end{array}$ & \begin{tabular}{|l|l|}
110,74 \\
\end{tabular} & 121,65 \\
\hline Discoglossus jeanneae & 30TWM07 & 100,00 & 70,76 & 104,27 & 38,01 & 5708,69 & 230,51 & $-39,31$ & \begin{tabular}{|l|l|}
269,82 \\
\end{tabular} & 84,63 & \begin{tabular}{|l|l|l|}
148,01 \\
\end{tabular} & 148,01 & 3,28 & 811,61 & 87,62 & 44,84 & \begin{tabular}{|l|l|}
18,14 \\
\end{tabular} & 234,22 & 152,54 & \begin{tabular}{|c|}
152,54 \\
\end{tabular} & 216,71 \\
\hline Discoglossus jeanneae & 30TWM11 & 100,00 & 103,61 & 112,07 & 38,00 & 6125,34 & 273,87 & $-17,73$ & 291,61 & 122,12 & \begin{tabular}{|l|l|}
185,23 \\
\end{tabular} & 185,33 & 29,68 & 541,47 & 63,54 & 26,93 & 21,18 & 163,32 & \begin{tabular}{|l|}
98,87 \\
\end{tabular} & \begin{tabular}{l|l|}
104,65 \\
\end{tabular} & 139,26 \\
\hline Discoglossus jeanneae & 30TWM32 & 100,00 & 100,33 & 115,52 & 38,74 & 885,66 & 272 & $-22,71$ & 295,66 & \begin{tabular}{|c|}
118,86 \\
\end{tabular} & \begin{tabular}{|l|l|l|}
181,43 \\
\end{tabular} & 181,54 & 26,8 & 582,24 & 67,90 & 30,58 & 19, & \begin{tabular}{|l|l|}
175,02 \\
\end{tabular} & \begin{tabular}{|c|}
110,07 \\
\end{tabular} & \begin{tabular}{|c|}
115,38 \\
\end{tabular} & 151,54 \\
\hline Discoglossus jeanneae & 30TWM33 & 100 & 99,18 & 114,38 & 38,68 & 6035,13 & 269 & $-22,77$ & 292,75 & 117, & \begin{tabular}{|c|}
179,49 \\
\end{tabular} & 179,6 & 26,17 & 597,93 & 69,21 & 31,78 & $\begin{array}{l}19,53 \\
\end{array}$ & \begin{tabular}{|c|}
179,08 \\
\end{tabular} & 113,60 & \begin{tabular}{|c|c|}
119,15 \\
\end{tabular} & 155,93 \\
\hline Discoglossus jeanneae & 30TWM36 & 100,00 & 86,13 & 108,96 & 38,61 & 5831,72 & 249,59 & $-29,72$ & 279,31 & 102,28 & \begin{tabular}{ll|}
164,16 \\
\end{tabular} & \begin{tabular}{ll|}
164,16 \\
\end{tabular} & 16,16 & 717,70 & 79,76 & 39,59 & 18,01 & 210,42 & 137,64 & 138,29 & 189,70 \\
\hline Discoglossus jeanneae & 30TWM37 & 100,00 & 96,07 & 107,64 & 38,54 & 5802,31 & 256,53 & $-19,25$ & 275,78 & 113,14 & \begin{tabular}{|l|l|}
173,14 \\
\end{tabular} & 173,14 & 25,69 & 672,42 & 74,59 & 36,74 & 18,16 & 196,71 & 129,78 & 130,72 & 176,85 \\
\hline Discoglossus jeanneae & 30TWM40 & 100,00 & 106,05 & 115,52 & 38,05 & 6179,69 & 278,4 & $-19,45$ & 297,90 & 125,65 & 187, & 188, & 30, & 530,3 & 64,2 & 27, & 21, & 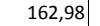 & 100,19 & 107,63 & 134,11] \\
\hline Discoglossus jeanneae & 30TWM42 & & 103,64 & 116 & 38, & 609 & & $-20,97$ & 291 & 122 & 184 & & 29 & 568,59 & 66,79 & $29,94[$ & 19, & 171 & $\begin{array}{l}108,52 \\
\end{array}$ & 115,21 & 147 \\
\hline Discoglossus jeanneae & 30TWM43 & 100,00 & 101,79 & 115,45 & 38,91 & 6050,05 & 273,08 & $-21,62$ & 294,71 & 120,42 & \begin{tabular}{|l|l|}
182,06 \\
\end{tabular} & 182,21 & 28,19 & 586,40 & 68,46 & 31,32 & 19,54 & \begin{tabular}{|l|l|}
176,49 \\
\end{tabular} & \begin{tabular}{|l|l|}
112,42 \\
\end{tabular} & 119,54 & 152,32 \\
\hline Discoglossus jeanneae & 30TWM46 & 100,00 & 80,56 & 108,70 & 38,54 & 5819,04 & 243,60 & $-34,96$ & 278,56 & 96,40 & 158,60 & 158,60 & 10,80 & 757,90 & 84,18 & 42,44 & \begin{tabular}{l|l}
17,65 \\
\end{tabular} & 222,38 & 146,11 & \begin{tabular}{|l|l|}
146,57 \\
\end{tabular} & 200,06 \\
\hline Discoglossus jeanneae & 30TWM47 & 100,00 & 97,51 & 108,40 & 38,58 & 5830,24 & 258,38 & $-19,01$ & 277,40 & 115,15 & \begin{tabular}{|c|}
174,78 \\
\end{tabular} & \begin{tabular}{|c|}
174,78 \\
\end{tabular} & 26,59 & 667,01 & 74,69 & 36,66 & 18,24 & 196,31 & 129,31 & 130,20 & 174,48 \\
\hline Discoglos & Th & & 105,81 & & & & & $-9,79$ & & & & 18 & & 631,4 & 70, & & & & & 124 & 162 \\
\hline Discoglossus jeanneae & 30TWM49 & 100,00 & 126,24 & 102, & 38,02 & 5775,3 & 276 & 10,47 & 265,72 & \begin{tabular}{|l|l|}
146,67 \\
\end{tabular} & 195,92 & 200,91 & 54,01 & 508,37 & 59,42 & 27,88 | & 20,34 & 153,06 - & $104,01 \mid$ & 107,40 & 122 \\
\hline Discoglossus jeanneae & 30TWM52 & 100,00 & 101,71 & 115,63 & 38,63 & 6093,30 & 273,15 & $-22,72$ & 295,87 & 120,85 & 182,51 & 182,69 & 27,64 & 574,92 & 68,56 & 30,83 & 20,09 & \begin{tabular}{|c|}
175,47 \\
\end{tabular} & 110,84 & 118,72 & 147,09 \\
\hline
\end{tabular}




\begin{tabular}{|c|c|c|c|c|c|c|c|c|c|c|c|c|c|c|c|c|c|c|c|c|c|}
\hline TAXON & UTM & $\mathrm{km} 2$ & B101 & $\mathrm{B1O2}$ & $\mathrm{BIO3}$ & BIO4 & B105 & B106 & B107 & $\mathrm{B108}$ & B109 & B1010 & BIO11 & BIO12 & 81013 & B1014 & B1015 & B1016 & $\begin{array}{ll}1017 \\
17\end{array}$ & B1018 & B1019 \\
\hline Discoglossus jeanneae & 30TWM62 & 100,00 & 99,40 & 114,24 & 38,26 & 6087,27 & 268,43 & $-25,07$ & 293,51 & 118,60 & 179,88 & 180,16 & 25,34 & 583,53 & 70,72 & 31,80 & 20,43 & 180,39 & 113,42 & 123,01 & 146,80 \\
\hline Discoglossus jeanneae & 30TWM66 & 100,00 & 97,99 & 110,15 & 38,76 & 5916,93 & 260,65 & $-21,48$ & 282,12 & 116,42 & 176,20 & 176,23 & 25,69 & 653,75 & 75,19 & 36,20 & 18,76 & 195,80 & 126,85 & 130,21 & 168,89 \\
\hline Discoglossus jeanneae & 30TWM73 & 100,00 & 98,35 & 112,10 & 38,12 & 6048,86 & 264,16 & $-24,80$ & 288,95 & 117,78 & 178,12 & 178,32 & 24,46 & 600,17 & 72,80 & 33,19 & 20,39 & 185,91 & 117,19 & 126,24 & 150,12 \\
\hline Discoglossus jeanneae & 30TWM75 & 100,00 & 105,81 & 110,60 & 38,19 & 6005,52 & 268,75 & $-15,87$ & 284,62 & 125,63 & 184,67 & 184,71 & 31,91 & 589,35 & 70,32 & 32,27 & 20,32 & 180,49 & 114,13 & 120,21 & 148,72 \\
\hline Discoglossus jeanneae & 30TWM76 & 100,00 & 108,27 & 109,80 & 38,40 & 5979,02 & 269,63 & $-12,52$ & 282,15 & 128,21 & 186,54 & 186,61 & 34,49 & 593,73 & 69,97 & 32,39 & 20,06 & 180,44 & 114,66 & 121,32 & 150,67 \\
\hline Discoglossus jeanneae & 30TWM83 & 100,00 & 102,29 & 111,08 & 38,01 & 6063,83 & 266,08 & $-21,32$ & 287,40 & 122,23 & 181,75 & 182,01 & 27,54 & 575,06 & 71,24 & 31,73 & 21,45 & 180,48 & 112,34 & 123,17 & 141,63 \\
\hline Discoglossus jeanneae & 30TWN01 & 100,00 & 120,28 & 91,73 & 37,94 & 5288,90 & 256,13 & 16,42 & 239,71 & 88,03 & 188,49 & 189,70 & 54,88 & 677,58 & 72,94 & 33,23 & 19,58 & 203,86 & 128,09 & 130,50 & 187,86 \\
\hline Discoglossus jeanneae & 30TWNO3 & 100,00 & 116,25 & 87,55 & 37,88 & 5049,03 & 246,02 & 17,38 & 228,64 & 76,28 & 181,08 & 182,81 & 54,08 & 797,32 & 88,72 & 38,69 & 19,84 & 243,94 & 147,58 & 152,84 & 229,04 \\
\hline Discoglossus jeanneae & 30 TWN20 & 100,00 & 126,10 & 96,62 & 38,00 & 5507,50 & 267,48 & 16,71 & 250,77 & 94,30 & 197,64 & 197,75 & 57,42 & 585,64 & 61,84 & 29,96 & 18,98 & 170,90 & 116,21 & 116,25 & 153,13 \\
\hline Discoglossus jeanneae & 30TWN23 & 100,00 & 112,54 & 91,62 & 38,28 & 5147,34 & 246,88 & 11,33 & 235,56 & 60,18 & 178,85 & 180,25 & 49,36 & 813,72 & 88,10 & 41,36 & 18,36 & 244,33 & 156,34 & 157,56 & 229,17 \\
\hline Discoglossus jeanneae & 30TWN24 & 100,00 & 119,93 & 86,90 & 38,16 & 4940,64 & 247,10 & 22,81 & 224,29 & 66,12 & 182,88 & 184,78 & 59,15 & 862,41 & 95,99 & 42,06 & 19,59 & 264,73 & 160,61 & 165,94 & 250,16 \\
\hline Discoglossus jeanneae & 30TWN33 & 100,00 & 103,56 & 94,58 & 38,90 & 5221,61 & 242,10 & 1,07 & 241,03 & 47,20 & 172,36 & 172,57 & 39,87 & 862,93 & 92,57 & 45,23 & 17,73 & 257,56 & 166,55 & 166,66 & 241,63 \\
\hline \begin{tabular}{|l} 
Discoglossus jeanneae \\
\end{tabular} & 30TWN41 & 100,00 & 113,05 & 99,65 & 38,75 & 5511,61 & 257,95 & 3,55 & 254,40 & 78,84 & 185,14 & 185,14 & 44,99 & 697,21 & 73,21 & 37,48 & 17,57 & 200,54 & 137,18 & 137,18 & 184,62 \\
\hline Discoglossus jeanneae & 30TWN42 & 100,00 & 111,66 & 97,48 & 38,97 & 5372,17 & 253,22 & 4,92 & 248,30 & 55,80 & 182,10 & 182,10 & 45,54 & 765,08 & 79,88 & 40,51 & 17,51 & 223,68 & 149,08 & 149,08 & 207,95 \\
\hline Discoglossus jeanneae & 30 TWN70 & 100,00 & 128,26 & 103,05 & 38,81 & 5722,17 & 276,35 & 12,53 & 263,82 & 117,08 & 202,17 & 202,17 & 56,39 & 621,40 & 66,86 & 32,47 & 19,35 & 180,75 & 118,47 & 118,66 & 161,95 \\
\hline Discoglossus jeanneae & 30TWN81 & 100,00 & 127,08 & 102,29 & 38,90 & 5634,65 & 274,04 & 12,96 & 261,09 & 69,60 & 200,10 & 200,10 & 56,46 & 736,82 & 81,42 & 36,91 & 20,25 & 222,85 & 134,50 & 134,50 & 206,27 \\
\hline Discoglossus jeanneae & 30TWN91 & 100,00 & 129,65 & 102,72 & 38,78 & 5672,55 & 277,29 & 14,55 & 262,73 & 67,71 & 202,99 & 202,99 & 58,42 & 767,09 & 88,85 & 37,06 & 21,72 & 238,28 & 135,92 & 135,92 & 222,37 \\
\hline \begin{tabular}{|l} 
Discoglossus jeanneae \\
\end{tabular} & 30TXK06 & 100,00 & 79,90 & 111,37 & 37,18 & 6361,73 & 249,61 & $-44,79$ & 294,40 & 97,32 & 165,13 & 165,92 & 4,81 & 636,51 & 82,84 & 33,56 & 24,36 & 209,90 & 124,25 & 138,84 & 136,99 \\
\hline Discoglossus jeanneae & 30TXK07 & 100,00 & 76,83 & 110,40 & \begin{tabular}{|l|l|l|l|}
37,03 & \\
\end{tabular} & 6336,85 & 245,38 & $-47,18$ & 292,56 & 94,26 & 161,80 & 162,60 & 1,99 & 646,58 & 84,44 & 34,85 & 24,10 & 213,76 & 127,65 & 142,93 & 139,03 \\
\hline Discoglossus jeanneae & 30TXK19 & 100,00 & 83,36 & 107,15 & 37,00 & 6276,76 & 244,69 & $-41,06$ & 285,75 & 102,17 & 44,08 & 167,57 & 8,08 & 586,94 & 80,05 & 33,30 & 26,64 & 200,45 & 118,56 & 137,53 & 119,29 \\
\hline Discoglossus jeanneae & $30 \mathrm{TXK26}$ & 100,00 & 87,08 & 107,41 & 37,00 & 6329,36 & 250,13 & $-36,45$ & 286,58 & 105,25 & 49,88 & 172,45 & 11,81 & 580,73 & 78,1 & 31,6 & 26,41 & 197,09 & 115,44 & 133,34 & 115,90 \\
\hline Discoglossus jeanneae & $\begin{array}{l}30 \text { TXK27 } \\
\end{array}$ & 100,00 & 90,92 & 106,46 & 36,99 & 6310,71 & 251,44 & $\frac{-33,16}{-33}$ & 284,60 & 109,82 & 15,49 & 175,78 & 15,49 & 549,27 & 75,58 & 30,67 & 27,89 & 189,27 & 106,92 & 128,99 & 106,92 \\
\hline Discoglossus jeanneae & 30 TXK29 & 100,00 & 85,15 & 105,01 & 36,99 & \begin{tabular}{ll|}
6255,66 \\
\end{tabular} & 243,10 & $-38,75$ & 281,85 & 104,12 & \begin{tabular}{|c|}
9,82 \\
\end{tabular} & 168,88 & 9,82 & 569,58 & 78,84 & 32,90 & 27,86 & 197,32 & 111,47 & 137,19 & 111,47 \\
\hline Discoglossus jeanneae & 30TXK34 & 100,00 & 96,54 & 106,77 & 37,00 & 6341,71 & 258,65 & $-26,12$ & 284,78 & 114,40 & 23,29 & 182,16 & 21,10 & 541,29 & 72,33 & 28,84 & 27,11 & 183,53 & 104,59 & 122,41 & 104,60 \\
\hline Discoglossus jeanneae & 30TXK35 & 100,00 & 91,11 & 105,96 & 37,00 & 6329,52 & 252,52 & $-31,06$ & 283,59 & 109,05 & 34,57 & 176,71 & 16,12 & 562,28 & 75,46 & 30,82 & 26,95 & 191,22 & 109,01 & 129,35 & 109,10 \\
\hline Discoglossus jeanneae & 30TXK36 & 100,00 & 89,36 & 105,15 & 36,96 & 6310,23 & 249,32 & $-33,01$ & 282,33 & 107,46 & 14,43 & 174,49 & 14,43 & 562,61 & 76,48 & 31,49 & 27,46 & 192,96 & 108,06 & 132,04 & 108,06 \\
\hline Discoglossus jeanneae & 30TXK43 & 100,00 & 118,27 & 104,35 & 37,00 & 6282,53 & 274,74 & \begin{tabular}{r|r|r|r|}
$-3,33$ \\
\end{tabular} & \begin{tabular}{|l|l|}
278,07 \\
\end{tabular} & 136,69 & 43,12 & 202,61 & 43,12 & $\mid 444,88$ & 59,51 & 22,17 & 29,90 & 150,68 & \begin{tabular}{|l|}
80,74 \\
\end{tabular} & \begin{tabular}{|l|l|}
97,98 \\
97
\end{tabular} & $\begin{array}{r}80,74 \\
80,0\end{array}$ \\
\hline Discoglossus jeanneae & 30TXK44 & 100,00 & 115,99 & 103,29 & 36,95 & 6304,84 & 271,75 & $-5,23$ & 276,98 & 134,93 & 40,46 & 200,65 & 40,46 & 442,88 & 60,61 & 22,91 & 30,87 & 152,32 & 78,36 & 100,94 & 78,36 \\
\hline Discoglossus jeanneae & 30 TXK48 & 100,00 & 106,64 & 99,68 & 36,05 & 6268,44 & 255,85 & $-15,66$ & 271,51 & 127,33 & 30,49 & 190,24 & 30,49 & 442,42 & 65,35 & 21,40 & 35,04 & 161,32 & 73,19 & 113,16 & 73,19 \\
\hline Discoglossus jeanneae & 30TXK56 & 100,00 & 112,06 & 98,56 & 35,93 & 6318,25 & 264,44 & $-6,62$ & 271,06 & 131,48 & 36,42 & 196,96 & 36,42 & 432,95 & 62,20 & 20,58 & 34,39 & 154,45 & 69,78 & 107,29 & 69,78 \\
\hline Discoglossus jeanneae & 30TXK63 & 100,00 & 82,82 & 102,00 & 36,40 & 6236,43 & 241,01 & $-35,06$ & 276,07 & 98,15 & 38,77 & 167,37 & 10,31 & 644,46 & 81,18 & 35,28 & 24,06 & 210,51 & 127,79 & 140,53 & 127,99 \\
\hline \begin{tabular}{|l} 
Discoglossus jeanneae \\
\end{tabular} & 30TXK64 & 100,00 & 82,24 & 100,95 & 36,13 & $\begin{array}{ll}6239,38 \\
6239\end{array}$ & 243,50 & $\begin{array}{l}-30,71 \\
-30\end{array}$ & 274,21 & $\mid$\begin{tabular}{r|r|}
103,31 \\
\end{tabular} & 23,44 & 171,63 & 14,31 & $\begin{array}{l}605,14 \\
\end{array}$ & $\begin{array}{l}31,10 \\
78,26\end{array}$ & $\begin{array}{ll}33,42 \\
33,42\end{array}$ & 25,65 & \begin{tabular}{|l|l|}
201,08 \\
\end{tabular} & $\begin{array}{ll}116,08 \\
\end{array}$ & \begin{tabular}{|l|l|l|l|l|l}
137,66 \\
\end{tabular} & 116,18 \\
\hline Discoglossus jeanneae & 30TXK73 & 100,00 & 90,47 & 99,95 & 36,11 & 6192,30 & 245,25 & $-26,30$ & 271,55 & 106,12 & 20,42 & 174,21 & 18,38 & 604,95 & 76,52 & 32,69 & 25,01 & 197,56 & 116,88 & 134,35 & 116,88 \\
\hline \begin{tabular}{|l} 
Discoglossus jeanneae \\
\end{tabular} & 30TXK79 & 100,00 & 90,39 & 96,06 & 35,95 & 6131,76 & 237,29 & $-27,62$ & 264,91 & 108,73 & 17,29 & 172,42 & 17,29 & 551,11 & 76,38 & 28,97 & 30,00 & 191,40 & 97,79 & 137,19 & 97,79 \\
\hline Discoglossus jeanneae & 30TXK88 & 100,00 & 86,99 & 95,60 & 35,78 & 6107,93 & 234,77 & $-29,32$ & 264,09 & 103,80 & 14,83 & 168,97 & 14,83 & 591,79 & 79,21 & 32,33 & 27,40 & 199,92 & 108,56 & 142,45 & 108,56 \\
\hline Discoglossus jeanneae & 30TXK95 & 100,00 & 108,05 & 94,79 & 35,99 & 6058,85 & 254,35 & \begin{tabular}{r|}
$-6,84$ \\
\end{tabular} & 261,19 & 124,64 & 36,56 & 189,29 & 36,56 & 518,90 & 67,10 & 27,16 & 28,55 & 169,40 & 93,58 & 116,73 & 93,58 \\
\hline Discoglossus jeanneae & 30TXL04 & 100,00 & 99,64 & 106,82 & 37,01 & 6202,40 & 255,97 & $-27,78$ & 283,75 & 121,25 & 33,08 & 181,40 & 23,17 & 487,85 & 69,53 & 27,75 & 29,61 & 170,67 & 97,46 & 117,16 & 99,37 \\
\hline Discoglossus jeanneae & $30 \mathrm{TXL}$ & 100,00 & 95,85 & 105,01 & 37,00 & 6202,83 & 249,54 & $-31,10$ & 280,64 & 117,09 & 26,91 & 177,72 & 19,57 & 497,81 & 71,90 & 28,04 & 30,91 & 176,99 & 96,26 & 122,93 & 96,50 \\
\hline Discoglossus jeanneae & 30TXL20 & 100,00 & 90,82 & 103,97 & 36,94 & 6227,62 & 245,18 & $-34,25$ & 279,44 & 110,87 & 15,03 & 173,66 & 15,03 & 527,99 & 75,08 & 29,67 & 30,20 & 186,55 & 100,45 & 130,35 & 100,45 \\
\hline Discoglossus jeanneae & 30TXL21 & 100,00 & 97,52 & 102,87 & 36,8 & 6191,58 & 247,66 & $-28,73$ & 276,39 & 119,02 & 26,43 & 179,32 & 21,33 & 482,29 & 70,8 & 25,56 & 33,13 & 174,63 & 88,47 & 122,35 & 88,61 \\
\hline Discoglossus jeanneae & 30TXL22 & 100 & 99,03 & 102,34 & 36,82 & 6166,32 & 247,45 & $-27,74$ & 275,19 & 121,14 & 32,12 & 180,13 & 22,89 & 470,05 & 69,8 & 24 & 33,92 & 171,59 & 84,86 & 120,63 & 85,96 \\
\hline \begin{tabular}{|l} 
Discoglossus jus jeanneae \\
\end{tabular} & $30 T \times 23$ & 100,00 & $\begin{aligned} 9,02,32 \\
102,32\end{aligned}$ & $\begin{aligned} 90,54 \\
99,48\end{aligned}$ & 30, & $\begin{array}{l}010,025 \\
6111,27 \\
\end{array}$ & 244,45 & $\begin{array}{l}-24,74 \\
-24,75\end{array}$ & \begin{tabular}{|l|}
269,41 \\
21
\end{tabular} & $\mid \frac{\mid 11,14}{124,86}$ & \begin{tabular}{|c|c|c|}
35,49 \\
\end{tabular} & \begin{tabular}{|l|l|l|l|}
182,03 \\
\end{tabular} & \begin{tabular}{|l|}
22,05 \\
26,05
\end{tabular} & \begin{tabular}{|l|l|}
444,99 \\
440
\end{tabular} & $\begin{array}{l}69, \text {, } \\
67,\end{array}$ & 20,5 & 37,29 & \begin{tabular}{|l|}
11,39 \\
166,56 \\
\end{tabular} & $\begin{array}{l}4,, 00 \\
74,21 \\
\end{array}$ & $\begin{array}{l}110,03 \\
118,63 \\
\end{array}$ & $\begin{array}{l}0,50 \\
76,57 \\
\end{array}$ \\
\hline Discoglossus jeanneae & 30TXL42 & 100,00 & 103,06 & 97,26 & 36,00 & 6075,59 & 241,99 & $-23,24$ & 265,22 & 125,75 & 36,52 & 182,22 & 27,15 & 437,31 & 67,55 & 19,54 & 38,94 & 165,59 & 69,53 & 118,96 & 72,10 \\
\hline Discoglossus jeanneae & 30TXL43 & 100,00 & 103,52 & 97,70 & 36,03 & 6064,31 & 242,87 & $-22,97$ & 265,83 & 126,45 & 37,18 & 182,36 & 27,64 & 437,57 & 67,50 & 19,82 & 38,29 & 165,04 & 70,36 & 118,27 & 73,68 \\
\hline Discoglossus jeanneae & 30TXL45 & 100,00 & 103,29 & 99,36 & 36,3 & 6071,57 & 246,90 & $-22,48$ & 269,38 & 125,80 & 37,30 & 182,32 & 27,53 & 450,06 & 68, & 22 & 35,47 & 165,82 & 77,56 & 117,56 & 80,82 \\
\hline Discoglossus jeanneae & $\begin{array}{l}30 \mathrm{TXL52} \\
\end{array}$ & 100,00 & 95, & 97,20 & 36,0 & 6089,01 & 238,10 & $\begin{array}{l}-27,74 \\
-27,4 \\
\end{array}$ & 265,83 & 116,36 & 26,76 & 17 & 20,49 & $\begin{array}{l}487,24 \\
487\end{array}$ & $\begin{array}{l}72, \\
72,\end{array}$ & & 34,90 & 61 & 83,15 & 128,89 & 83,55 \\
\hline \begin{tabular}{|l} 
Discoglossus jeanneae \\
\end{tabular} & $30 \mathrm{TX}$ & 100,00 & & 97,36 & 36,00 & 6066,05 & 236,19 & $-29,89$ & 266,08 & 114,21 & 26,24 & 173,12 & 18,58 & 500,72 & 73, & 25, & 34,01 & 182,28 & 87,26 & 131,60 & 88,09 \\
\hline \begin{tabular}{|l} 
Discoglossus jeanneae \\
\end{tabular} & 30TXL61 & 100,00 & 90,23 & 96,60 & 35,99 & 6104,58 & 235,41 & $-30,41$ & 265,82 & 109,78 & 16,47 & 171,37 & 16,47 & 529,44 & 75,96 & 27,37 & 31,93 & 188,81 & 92,93 & 136,23 & 92,93 \\
\hline Discoglossus jeanneae & 30TXL70 & 100,00 & 91,62 & 95,82 & 35,95 & 6104,33 & 237,03 & $-26,92$ & 263,95 & 110,41 & 18,39 & 173,10 & 18,39 & 535,96 & 75,51 & 27,64 & 30,93 & 88,29 & 93,76 & 135,37 & 93,76 \\
\hline Discoglossus jeanneae & 30TXL80 & 100,00 & 92,12 & 94,93 & $35, \varepsilon$ & 6074,91 & 237,01 & $-25,42$ & 3 & 110,20 & 19,59 & 17 & 19,59 & 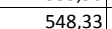 & 75 & 28,70 & 29,87 & 62 & 97,12 & 135,95 & 97,12 \\
\hline Discoglossus jeanneae & $30 T X M$ & 100,00 & 95 & 108,00 & 37, & 6071 & 255,01 & $-28,10$ & 28 & 115 & 174,92 & 17 & 20,77 & 577,34 & 74, & 32,8 & 23,46 & 187,54 & 116,08 & 129,63 & 134,59 \\
\hline \begin{tabular}{|l|l} 
Discoglossus jeanneae \\
\end{tabular} & 30TXM05 & 100,00 & 133,34 & 107,29 & 37,99 & 6057,35 & 290,14 & 10,14 & 279,99 & 155,39 & 211,64 & 211,64 & 57,25 & 485,86 & 59,23 & 23,80 & 23,70 & 148,22 & 89,40 & 92,39 & 122,30 \\
\hline Discoglossus jeanneae & 30TXM15 & 100,00 & 137,34 & 106,54 & 37,96 & 6040,20 & 292,78 & 14,55 & 278,22 & 159,61 & 215,33 & 215,33 & 61,35 & 480,36 & 58,18 & 22,85 & 24,02 & 145,01 & 87,32 & 89,54 & 122,01 \\
\hline \begin{tabular}{|l} 
Discoglossus jeanneae \\
\end{tabular} & 30TXM27 & 100,00 & 133,69 & 105,99 & 38,00 & 5966,34 & 287,39 & 12,47 & 274,92 & 96,91 & 210,66 & 210,66 & 58,58 & 564,81 & 63,52 & 207 & 22,52 & 167,48 & 101,29 & 102,42 & 151,60 \\
\hline Discoglossus jeanneae & $30 \mathrm{TXN}$ & 100,00 & 12 & 104,76 & 38, & 5801,83 & 278,61 & 9,32 & 269 & 70,78 & 202,65 & 202 & 54,66 & 733,37 & 85 & 35,25 & 22,26 & 226,05 & 128,43 & 128,43 & 212 \\
\hline \begin{tabular}{|l|l|l} 
Discoglossus jeanneae \\
\end{tabular} & 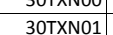 & 100,00 & $\begin{array}{ll}122,08 \\
122,08\end{array}$ & $\begin{array}{l}104,10 \\
104,38 \\
\end{array}$ & 30,45 & $\begin{array}{l}2001,00 \\
5749,16\end{array}$ & 272,01 & $\begin{array}{ll}3,32 \\
5,07\end{array}$ & \begin{tabular}{|l|l|}
267,82 \\
\end{tabular} & 58,33 & 196,59 & 196,59 & 49,94 & 823,10 & 98,48 & 39,67 & 22,73 & 259,36 & 142,68 & 142,68 & 244,35 \\
\hline Discoglossus jeanneae & 30TXN03 & 100,00 & 117,28 & 101,84 & 38,87 & 5563,04 & 264,31 & 4,46 & 259,85 & 56,19 & 189,71 & 189,71 & 47,87 & 987,76 & 121,64 & 47,40 & 23,51 & 321,10 & 170,42 & 170,42 & 303,38 \\
\hline Discoglossus jeanneae & $30 \mathrm{TXN04}$ & 100,00 & 120,11 & 99,69 & 38,96 & 5424,70 & 263,16 & 9,95 & 253,21 & 60,57 & 190,76 & 190,76 & 52,43 & 1054,55 & 130,95 & 50,27 & 23,93 & 346,91 & 182,97 & 182,97 & 327,25 \\
\hline Discoglossus jeanneae & 30TXN12 & 100,00 & 104,1 & 102,64 & 38,87 & 5612,40 & 252,62 & $-9,53$ & 262 & 43, & 177,51 & 177 & 34 & 941,64 & 110,28 & 47 & 20,74 & 291 & 165 & 169,21 & 276,37 \\
\hline Discoglossus jeanneae & 30TXN13 & 100,00 & 118,26 & 102,80 & 38,63 & 5631,79 & 266,64 & 3,42 & 263,22 & 56,39 & 191,36 & 191,36 & 47,70 & 996,28 & 125,80 & 47,05 & 24,63 & 327,85 & 169,48 & 609,48 & 310,93 \\
\hline
\end{tabular}




\begin{tabular}{|c|c|c|c|c|c|c|c|c|c|c|c|c|c|c|c|c|c|c|c|c|c|}
\hline TAXON & UTM & $\mathrm{km} 2$ & BIO1 & B102 & $\mathrm{BIO3}$ & 8104 & B105 & B106 & B107 & B108 & B109 & 81010 & B1011 & BIO12 & B1013 & B1014 & 81015 & B1016 & 81017 & B1018 & B1019 \\
\hline Discoglossus jeanneae & 30TXN14 & 100,00 & 114,75 & 100,62 & 38,90 & 5484,35 & 259,12 & 3,13 & 255,99 & 54,69 & 186,16 & 186,16 & 46,05 & 1064,60 & 132,53 & 51,37 & 23,62 & 348,62 & 185,86 & 185,86 & 329,79 \\
\hline Discoglossus jeanneae & 30 TXN23 & 100,00 & 111,31 & 102,05 & 38,93 & 5571,81 & 257,65 & $-2,50$ & 260,15 & 50,36 & 183,84 & 183,84 & 41,60 & 988,25 & 120,37 & 48,46 & 22,30 & 315,84 & 175,14 & 175,14 & 299,01 \\
\hline Discoglossus jeanneae & 30TXN31 & 100,00 & 120,59 & \begin{tabular}{|l|l|}
103,87 \\
\end{tabular} & 38,52 & 5721,66 & 268,99 & 2,92 & 266,06 & \begin{tabular}{|c|c|}
65,57 \\
\end{tabular} & $\begin{array}{l}194,55 \\
\end{array}$ & $\begin{array}{l}194,55 \\
\end{array}$ & 48,45 & 814,16 & 96,60 & 39,15 & 21,72 & 252,33 & 145,09 & 145,09 & 238,28 \\
\hline Discoglossus jeanneae & 30TXN33 & 100,00 & 113,11 & 101,81 & 38,94 & 5557,36 & 257,84 & $-1,08$ & 258,92 & 52,09 & \begin{tabular}{|c|}
185,17 \\
\end{tabular} & \begin{tabular}{|c|}
185,17 \\
\end{tabular} & 43,17 & 960,76 & 115,81 & 47,24 & 21,58 & 303,97 & 173,33 & 173,33 & 287,33 \\
\hline Discoglossus jeanneae & 30TXN43 & 100,00 & 105,35 & 101,11 & 39,00 & 5500,27 & 248,66 & $-7,84$ & 256,50 & $\begin{array}{l}45,35 \\
\end{array}$ & 176,90 & 176,90 & 36,38 & \begin{tabular}{|c|}
954,67 \\
\end{tabular} & 110,75 & 48,62 & 19,55 & 293,38 & 178,09 & 178,09 & 276,66 \\
\hline Discoglossus jeanneae & 30 TXN90 & 100,00 & 93,84 & 99,07 & 38,37 & 5463,30 & 235,24 & $-19,39$ & 254,62 & 111,83 & 164,67 & 164,93 & 25,66 & 755,96 & 83,18 & 41,68 & 15,97 & 215,56 & 158,02 & 162,15 & 183,27 \\
\hline Discoglossus jeanneae & 30TYN01 & 100,00 & 87,26 & 97,46 & 38,44 & 5402,29 & 226,07 & $-24,44$ & 250,51 & 104,60 & 157,51 & 157,71 & 20,01 & 824,62 & 89,14 & 46,93 & 14,90 & 233,53 & 175,42 & 179,88 & 199,54 \\
\hline Discoglossus jeanneae & 31SBE42 & 6,00 & 171,25 & 83,00 & 36,00 & 5146,13 & 289,75 & 62,75 & 227,00 & 181,88 & 237,38 & 240,13 & 108,75 & 440,88 & 69,88 & 12,38 & 42,88 & 179,25 & 60,13 & 91,38 & 98,25 \\
\hline Discoglossus jeanneae & 31TBE65 & 61,00 & 169,18 & 86,34 & 36,36 & 5208,07 & 291,59 & 57,66 & 233,93 & \begin{tabular}{|c|}
176,24 \\
\end{tabular} & 237,21 & 239,49 & 108,25 & 475,79 & 73,49 & 12,71 & 41,21 & 188,24 & 69,84 & 101,51 & 102,36 \\
\hline Discoglossus jeanneae & 31TBE66 & 101,00 & \begin{tabular}{ll|l}
159,37 \\
\end{tabular} & 87,61 & 36,12 & 5304,93 & 285,12 & 47,15 & 237,97 & \begin{tabular}{|c|}
165,57 \\
\end{tabular} & 229,12 & 231,24 & 98,10 & 510,59 & 74,43 & 14,72 & 37,96 & 193,39 & 79,62 & 108,70 & 108,96 \\
\hline Discoglossus jeanneae & 31TBF64 & 100,00 & 142,25 & 99,74 & 36,88 & 5840,12 & 287,64 & 19,92 & 267,72 & \begin{tabular}{ll|}
144,62 \\
\end{tabular} & 139,80 & 219,75 & 73,86 & 500,73 & 62,41 & 17,86 & 32,10 & 165,21 & 93,88 & 102,80 & 99,04 \\
\hline Epidalea calamita & $295 \mathrm{MC} 77$ & 7,00 & 165,36 & 77,64 & 41,14 & 3779,50 & 268,86 & 83,14 & 185,71 & 125,50 & 210,64 & 215,21 & 118,00 & 717,43 & 110,43 & 4,00 & 64,07 & 323,64 & 30,07 & 32,79 & 306,79 \\
\hline Epidalea calamita & 29SMC86 & 60,00 & 166,21 & 81,36 & 41,33 & 3924,44 & 276,58 & 82,44 & \begin{tabular}{|c|}
194,15 \\
\end{tabular} & \begin{tabular}{|c|}
125,29 \\
\end{tabular} & 213,76 & \begin{tabular}{|l|l|}
218,67 \\
\end{tabular} & \begin{tabular}{|c|}
117,97 \\
\end{tabular} & 698,01 & 106,28 & 3,82 & 63,62 & 313,06 & 29,58 & 32,19 & 299,45 \\
\hline Epidalea calamita & 29SMC87 & 85,00 & 166,33 & 80,39 & 41,04 & 3928,81 & 275,72 & 82,47 & 193,25 & \begin{tabular}{|c|}
125,15 \\
\end{tabular} & 213,91 & 218,71 & 117,74 & 709,73 & 108,26 & 3,85 & 63,78 & 318,88 & 29,62 & 32,39 & 304,79 \\
\hline Epidalea calamita & 29SMC88 & 76,00 & 164,78 & 79,29 & 40,77 & 3947,81 & 273,54 & 81,14 & 192,41 & 123,28 & 212,72 & 217,34 & 115,89 & 731,80 & 111,36 & 3,84 & 63,98 & 328,19 & 30,27 & 32,97 & 314,90 \\
\hline Epidalea calamita & 29SMC96 & 101,00 & 166,61 & 83,55 & 41,10 & 4057,78 & 281,52 & 81,08 & 200,44 & 124,31 & 216,16 & 221,07 & 116,95 & 689,66 & 104,09 & 3,57 & 63,35 & 308,21 & 28,87 & 31,62 & 296,61 \\
\hline Epidalea calamita & $295 M C 97$ & 83,00 & 169,59 & 82,84 & 41,01 & 4055,47 & 283,64 & 84,10 & 199,54 & \begin{tabular}{|l|l|l|l|l|}
127,08 \\
\end{tabular} & 219,11 & 223,74 & 119,69 & 677,60 & 102,26 & 3,02 & 63,56 & 303,42 & 27,61 & 30,84 & 291,77 \\
\hline Epidalea calamita & 29SMD63 & 9,00 & 153,06 & 59,78 & 41,09 & 3022,06 & 226,25 & 82,44 & 143,81 & \begin{tabular}{|l|l|}
121,75 \\
\end{tabular} & 188,06 & \begin{tabular}{|l|l|}
190,53 \\
\end{tabular} & \begin{tabular}{|l|l|}
113,19 \\
\end{tabular} & 692,31 & 114,81 & 4,00 & 62,66 & 310,81 & 29,66 & 34,88 & 285,31 \\
\hline Epidalea calamita & 29SMD65 & 11,00 & 152,83 & 53,46 & 41,63 & 2683,38 & 214,13 & 87,29 & 126,83 & 125,54 & 183,25 & 185,29 & 117,13 & 638,17 & 110,50 & 3,42 & 63,04 & 284,83 & 26,96 & 34,38 & 259,42 \\
\hline Epidalea calamita & 29SMD75 & 89,00 & 151,32 & 57,80 & 41,23 & 2903,17 & 220,92 & 82,61 & 138,31 & 121,57 & 185,03 & 187,33 & 113,25 & 677,61 & 113,71 & 3,95 & 62,35 & 300,55 & 29,35 & 35,85 & 277,62 \\
\hline Epidalea calamita & 29SMD85 & 99,00 & 153,92 & 63,22 & 41,25 & 3141,44 & 232,59 & 81,14 & \begin{tabular}{|l|l|}
151,45 \\
\end{tabular} & 121,16 & 190,92 & 193,39 & 113,04 & 693,97 & 113,00 & 4,06 & 61,81 & 305,79 & 30,54 & 36,53 & 286,46 \\
\hline Epidalea calamita & $295 \mathrm{SM} 86$ & 79,00 & 154,64 & $\begin{array}{l}62,22 \\
62,85 \\
\end{array}$ & 41,60 & 3081,51 & 231,56 & 82,21 & 149,35 & 122,49 & 190,84 & 193,19 & $\mid 114,37$ & 691,11 & 112,46 & $\begin{array}{l}4,004 \\
4,04\end{array}$ & $\begin{array}{l}1,114 \\
61,43 \\
\end{array}$ & 302,84 & 30,71 & 37,30 & 284,19 \\
\hline Epidalea calamita & 29SMD94 & 100,00 & 154,66 & 69,63 & 40,84 & 3484,84 & 245,83 & 77,01 & $\begin{array}{ll}168,82 \\
\end{array}$ & \begin{tabular}{|l|l|}
118,17 \\
\end{tabular} & 196,54 & 199,51 & 110,10 & 725,66 & 113,71 & 4,11 & 61,57 & 318,32 & 32,08 & 36,79 & 302,73 \\
\hline Epidalea calamita & 29SMD99 & 35,00 & 152,45 & 70,03 & 42,11 & 3291,15 & 238,72 & 74,76 & 163,96 & 117,54 & 191,64 & 194,07 & 109,53 & 788,54 & 119,77 & 6,00 & 58,43 & 334,07 & 41,22 & 47,77 & 321,45 \\
\hline Epidalea calamita & 29 SNB12 & 83,00 & 163,34 & 86,34 & 44,66 & 3628,14 & 271,70 & 80,42 & 191,27 & 128,07 & 207,95 & 212,23 & 119,51 & 516,43 & 83,19 & 1,00 & 68,47 & 241,95 & 18,35 & 19,41 & 231,30 \\
\hline Epidalea calamita & 29SNB13 & 51,00 & 165,90 & 86,91 & 44,25 & 3706,64 & 276,06 & 81,89 & 194,17 & 129,33 & 211,51 & 215,80 & 121,01 & 513,94 & 82,24 & 1,00 & 68,10 & 240,26 & 18,46 & 19,60 & 229,58 \\
\hline Epidalea calamita & $\mid$ & $\begin{array}{ll}19,00 \\
19,0\end{array}$ & $\begin{array}{l}10,56,42 \\
166,4\end{array}$ & 87,90 & 44,00 & 3803,89 & 279,44 & 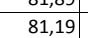 & 198,25 & 128,75 & 213,33 & 217,72 & $\begin{array}{l}120,01 \\
120,36\end{array}$ & $\mid 522,64$ & $\begin{array}{l}\mid \frac{\mid 0,24}{82,56} \\
\end{array}$ & $\frac{1,00}{1,00}$ & $\mid \frac{\mid 0,10}{67,69}$ & $\begin{array}{l}243,20 \\
243,06\end{array}$ & $\begin{array}{l}10,40 \\
18,89\end{array}$ & $\begin{array}{l}19,00 \\
19,89\end{array}$ & 232,81 \\
\hline Epidalea calamita & 29SNB19 & 31,00 & 168,49 & 90,07 & 43,00 & 4041,32 & 288,02 & 80,83 & 207,20 & 127,34 & 218,22 & 222,93 & 119,46 & 569,29 & 86,15 & 2,00 & 64,95 & 257,37 & 22,49 & 23,78 & 248,22 \\
\hline Epidalea calamita & $295 N B 21$ & 101,00 & 166,71 & 86,81 & 43,34 & 3809,92 & 278,55 & 80,58 & \begin{tabular}{|l|l|}
197,97 \\
\end{tabular} & 129,16 & 214,36 & 218,16 & 120,69 & \begin{tabular}{|l|l|}
498,75 \\
\end{tabular} & 80,82 & 0,90 & 69,59 & 237,30 & 16,71 & 17,97 & 225,62 \\
\hline Epidalea calamita & 29 SNB23 & 101,00 & 160,57 & 89,23 & 43,49 & 3904,89 & 276,69 & 73,70 & 202,99 & 122,19 & 209,27 & 213,56 & 113,87 & 548,35 & 86,14 & 1,15 & 67,36 & 254,48 & 20,17 & 21,04 & 244,38 \\
\hline Epidalea calamita & 29SNB25 & 100,00 & 164,72 & 90,25 & 43,24 & 3981,16 & 283,08 & 77,15 & 205,94 & 125,25 & 214,24 & 218,62 & 116,82 & 543,22 & 84,29 & 1,00 & 66,73 & 250,47 & 20,04 & 20,94 & 240,79 \\
\hline Epidalea calamita & $29 \mathrm{SNB} 26$ & 101,00 & 167,37 & 90,54 & 43,07 & 4006,83 & 286,40 & 79,38 & 207,03 & 127,37 & 217,05 & 221,60 & 119,02 & 539,28 & 83,16 & 1,06 & 66,34 & 247,82 & 20,04 & 21,07 & 238,29 \\
\hline Epidalea calamita & 29SNB27 & 101,00 & 164,85 & 91,51 & 43,02 & 4077,94 & 286,17 & 76,15 & 210,02 & 124,01 & 215,44 & 219,99 & 115,74 & 565,10 & 86,24 & 1,72 & 65,40 & 256,79 & 22,20 & 22,99 & 248,03 \\
\hline Epidalea calamita & 29SNB29 & 101,00 & 164,16 & 92,20 & 42,84 & 4175,37 & 288,44 & 74,92 & 213,52 & 122,01 & 216,06 & 220,71 & 113,97 & 590,88 & 88,76 & 2,00 & 64,15 & 265,09 & 24,11 & 24,86 & 257,27 \\
\hline Epidalea calamita & 29SNB36 & 101,00 & 165,93 & 92,97 & 42,95 & 4165,94 & 289,95 & 75,3 & 214,58 & \begin{tabular}{|l|l|}
124,09 \\
\end{tabular} & 217,99 & 222,40 & 115,90 & 546,52 & 84,50 & 1,23 & 66,02 & 250,43 & 20,62 & 21,50 & 241,41 \\
\hline Epidalea calamita & 29 SNB37 & 100,00 & 164,94 & 93,73 & 42,83 & 4219,59 & 290,82 & 74,07 & 216,75 & 122,57 & 217,72 & 222,23 & 114,44 & 561,68 & 85,97 & 1,82 & 65,17 & 254,92 & 22,07 & 22,89 & 246,65 \\
\hline Epidalea calamita & $295 N B 38$ & 101,00 & 165,56 & 94,17 & 42,70 & 4258,45 & 292,73 & 74,44 & 218,29 & 122,77 & 218,79 & 223,35 & 114,49 & 567,57 & 86,11 & 2,00 & 64,57 & 256,00 & 22,76 & 23,43 & 248,21 \\
\hline Epidalea calamita & 295NB39 & 100,00 & 165,48 & 94,48 & 42,38 & 4301,43 & 293,85 & 74,15 & 219,70 & 122,07 & 219,27 & 223,98 & 114,02 & 576,49 & 86,88 & 2,00 & 64,22 & 258,47 & 23,19 & 24,02 & 251,19 \\
\hline Epidalea calamita & 29 SNB40 & 40,00 & 169,94 & 88,87 & 42,02 & 4031,70 & 286,43 & 79,40 & 207,02 & 130,30 & 221,06 & 224,83 & 121,79 & 494,32 & 81,45 & 1,00 & 69,98 & 238,64 & 15,89 & 17,36 & 225,43 \\
\hline Epidalea calamita & 29SNB47 & 100,00 & 163,18 & 8 & 42,48 & 4369,40 & 293,99 & 70,04 & 223,95 & 119,40 & 218,06 & 222,73 & 111,14 & 569,36 & 87,22 & 2,00 & 64,67 & 257,01 & 22,82 & 23,42 & 249,30 \\
\hline Epidalea calamita & 29 NNB48 & 101,00 & 167,66 & , 33 & 42,62 & 4369,44 & 298,26 & 74,38 & 223,87 & 123,46 & 222,40 & 226,92 & 115,25 & 551,81 & $\begin{array}{l}\mid 83,96 \\
83,2\end{array}$ & 2,00 & 64,54 & 248,81 & 21,95 & 22,84 & 241,24 \\
\hline Epidalea calamita & $295 N B 49$ & 10 & 16 & 96,77 & 42,39 & 4402,72 & 299,73 & 74,62 & 225,11 & 123,45 & 223,21 & 227,86 & 115,34 & 557,31 & 84,01 & 2,00 & 64,01 & 249,32 & 22,72 & 23,49 & 242,42 \\
\hline Epidalea calamita & 29SNB51 & 100,00 & 169,62 & 90,95 & 42,34 & 4135,12 & 289,13 & 77,28 & 211,85 & 128,81 & 221,94 & 225,75 & 120,05 & 502,62 & 83,26 & 1,00 & 69,36 & 241,57 & 16,27 & 18,05 & 228,53 \\
\hline Epidalea calamita & $29 \mathrm{SNB} 52$ & 101,00 & 16 & 92,97 & 42,21 & 4241,13 & 288,17 & 71,28 & 216,89 & 122,52 & 218,10 & 222,13 & 113,81 & 533,03 & 86,93 & 1,00 & 68,19 & 251,74 & 17,99 & 19,46 & 240,04 \\
\hline Epidalea calamita & 29 SNB56 & 101,00 & 159,93 & 97,96 & 42,07 & 4473,81 & 293,72 & 64,86 & 228,86 & 115,26 & 216,56 & 221,03 & 106,94 & 579,15 & 89,53 & 2,00 & 64,59 & 261,53 & 23,14 & 23,72 & 253,80 \\
\hline Epidalea calamita & 295NB57 & $\begin{array}{l}101,00 \\
100\end{array}$ & 165,13 & $\begin{array}{l}98,47 \\
98,4\end{array}$ & 42,25 & 4481,33 & 299, & $\begin{array}{l}34,00 \\
69,77\end{array}$ & $\begin{array}{l}229,00 \\
229,64\end{array}$ & \begin{tabular}{l|l}
119,205 \\
\end{tabular} & $\begin{array}{l}221,66 \\
221,66\end{array}$ & $\begin{array}{l}226,03 \\
226,18\end{array}$ & $\begin{array}{l}111,69 \\
111,69\end{array}$ & $\begin{array}{l}554,76 \\
554,\end{array}$ & $\begin{array}{l}85,12 \\
85,12\end{array}$ & 2,009 & $\begin{array}{l}4,35,53 \\
64,\end{array}$ & $\begin{array}{l}\mid 251,30 \\
250,30\end{array}$ & 21,91 & 22,56 & $\begin{array}{l}\mid 243,00 \\
242,74\end{array}$ \\
\hline Epidalea calamita & 29SNB58 & 100,00 & 167,38 & 98,91 & 42,36 & 4491,59 & 302,26 & 72,00 & 230,26 & 121,99 & 223,90 & 228,48 & 113,80 & 548,53 & 83,37 & 2,00 & 64,49 & 246,13 & 21,50 & 22,24 & 239,15 \\
\hline Epidalea calamita & 29SNB59 & 100,00 & 168,86 & 99,21 & 42,32 & 4520,42 & 304,48 & 73,29 & 231,19 & 122,86 & 225,62 & 230,19 & 114,75 & 547,27 & 82,53 & 2,00 & 63,86 & 244,05 & 22,02 & 22,64 & 237,48 \\
\hline Epidalea calamita & $29 \mathrm{SNB} 61$ & 101,00 & 168,60 & 92,44 & 42,55 & 4200,03 & 289,83 & 74,99 & 214 & 127,13 & 221,86 & 225 & 118,45 & 511,8 & 85,67 & 1, & 69,11 & 245,74 & 16,66 & 18,50 & 232,36 \\
\hline Epidalea calamita & 29 SNB62 & 100,00 & 164 & & 42, & 1 & 290 & 70, & 219,91 & 122 & 219 & 223,56 & 113 & 533,42 & 87,70 & 1,01 & 68,11 & 252,20 & 17,90 & 19,49 & 240,04 \\
\hline Epidalea calamita & 29 SNB64 & 100,00 & 158,55 & 97,46 & 42,01 & 4485,71 & 291,07 & 62,47 & 228,60 & 114,12 & 215,45 & 219,80 & 105,29 & 576,21 & 91,25 & 1,79 & 65,55 & 263,75 & 21,95 & 23,02 & 254,29 \\
\hline Epidalea calamita & 29 SNB66 & 101,00 & 162,98 & 99,69 & 42,06 & 4555,55 & 299,11 & 66,03 & 233,08 & 117,41 & 220,63 & 225,06 & 108,82 & 559,86 & 86,75 & 1,99 & 64,56 & 253,15 & 21,71 & 22,47 & 245,11 \\
\hline Epidalea calamita & 29 SNB67 & 100,00 & 165,05 & 100,68 & 42,10 & 4589,97 & 302,86 & 67,74 & 235,12 & 118,94 & 223,03 & 227,53 & 110,40 & 553,32 & 84,75 & 2,00 & 64,32 & 248,44 & 21,63 & 22,47 & 241,14 \\
\hline Epidalea calam & 29SNB68 & 101,00 & 164,04 & 101,89 & 42,1 & 4647,18 & 304 & 66,41 & 237,87 & 117,29 & 222,77 & 227,32 & 108,81 & & 85,29 & 2,00 & 63,15 & 250,55 & 23,05 & 23,58 & 244,48 \\
\hline Epidalea calamita & 29 SNB71 & & & & 42 & 428 & 288 & 70,12 & 218,62 & 123,08 & 219,68 & 223,82 & 114,3 & 532,25 & 89,16 & 1,00 & 68,54 & 253,83 & 17,50 & 19,48 & 240,31 \\
\hline Epidalea calamita & 29SNB72 & 101,00 & 158,56 & 95,96 & 42,03 & 4413,77 & 287,27 & 62,45 & 224,82 & 114,93 & 214,69 & 218,96 & 106,39 & $\begin{array}{l}571,05 \\
\end{array}$ & 92,86 & 1,49 & 66,85 & 265,98 & 20,14 & 21,88 & 254,31 \\
\hline Epidalea calamita & \begin{tabular}{|l|}
$29 S N B 75$ \\
\end{tabular} & 101,00 & 159,78 & 100,28 & 42,00 & 4621,93 & 297,04 & 61,54 & 235,50 & 113,35 & 218,43 & 222,83 & 105,05 & 572,95 & 89,41 & 2,00 & 64,65 & 259,20 & 22,04 & 23,10 & 250,47 \\
\hline Epidalea calamita & 29 SNB77 & 101,00 & 162,11 & 103,12 & 42,01 & 4726,24 & 304,26 & 62,65 & 241,60 & 114,45 & 221,96 & 226,48 & 106,06 & 566,85 & 86,19 & 2,00 & 63,50 & 252,11 & 22,82 & 23,23 & 245,35 \\
\hline Epidalea calan & $29 \mathrm{SNB}$ & 97,00 & & & 42,7 & 4192 & 288 & 74 & 214,03 & 128, & 222,39 & 226 & 119 & 515 & 88,79 & 1,00 & 69,74 & 249,99 & 15,82 & 18,36 & 234 \\
\hline Epidalea calamita & $295 \mathrm{NB} 81$ & 101,00 & 162,83 & 94,57 & 42,07 & 4366,06 & \begin{tabular}{|l|}
287,94 \\
\end{tabular} & 66,33 & 221,61 & \begin{tabular}{l|l}
119,65 \\
119,6
\end{tabular} & 218,25 & 222,48 & 111,04 & 548,10 & $\begin{array}{ll}91,22 \\
19\end{array}$ & $\begin{array}{l}, 009 \\
1,09\end{array}$ & \begin{tabular}{|l|l|}
67,97 \\
\end{tabular} & 259,42 & $\begin{array}{l}18,02 \\
18,0\end{array}$ & 20,46 & 245,71 \\
\hline
\end{tabular}




\begin{tabular}{|c|c|c|c|c|c|c|c|c|c|c|c|c|c|c|c|c|c|c|c|c|c|}
\hline TAXON & UTM & $\mathrm{km} 2$ & B101 & B102 & $\mathrm{BIO3}$ & BIO4 & B105 & B106 & B107 & B108 & B109 & B1010 & B1011 & BIO12 & 81013 & BIO14 & BIO15 & B1016 & B1017 & BIO18 & B1019 \\
\hline Epidalea calamita & 29SNB82 & 101,00 & 157,12 & 96,63 & 41,94 & 4496,11 & 287,34 & 59,58 & 227,76 & 112,64 & 214,29 & 218,59 & 103,89 & 581,80 & 93,91 & 1,63 & 66,26 & 269,03 & 20,85 & 22,90 & 257,09 \\
\hline Epidalea calamita & 29SNB84 & 101,00 & 156,82 & 99,72 & 41,99 & 4649,05 & 293,62 & 58,02 & 235,60 & 110,58 & 215,99 & 220,47 & 101,90 & 587,33 & 91,97 & 2,00 & 64,52 & 265,77 & 22,60 & 24,20 & 255,97 \\
\hline Epidalea calamita & 29 SNB85 & 101,00 & 160,15 & 101,33 & 42,00 & 4701,10 & 299,33 & 60,68 & 238,64 & 113,07 & 219,98 & 224,36 & 104,50 & 569,56 & 88,36 & 2,00 & 64,34 & 256,54 & 21,87 & 23,07 & 247,50 \\
\hline Epidalea calamita & 29SNB89 & 100,00 & 165,90 & 107,83 & 42,29 & 4898,78 & 315,21 & 63,79 & 251,42 & 115,99 & 227,84 & 232,60 & 107,52 & 549,89 & 82,33 & 2,00 & 61,86 & 238,70 & 23,05 & 23,82 & 233,98 \\
\hline Epidalea calamita & 29SNB90 & 101,00 & 167,65 & 92,61 & 42,31 & 4268,22 & 287,80 & 71,63 & 216,17 & 125,45 & 221,67 & 225,81 & \begin{tabular}{|l|}
116,87 \\
\end{tabular} & 525,16 & 88,98 & 1,00 & 69,10 & 252,34 & 16,11 & 19,09 & 236,77 \\
\hline Epidalea calamita & 29SNB91 & 101,00 & 158,51 & 95,20 & 41,90 & 4472,75 & 285,95 & 60,85 & 225,10 & 114,12 & 215,32 & 219,49 & 105,46 & 573,59 & 93,32 & 1,59 & 66,76 & 267,24 & 19,59 & 22,46 & 253,81 \\
\hline Epidalea calamita & 29SNB94 & 100,00 & 159,33 & 99,98 & 41,80 & 4709,88 & 296,68 & 59,39 & 237,29 & 112,16 & 219,24 & 223,63 & 103,63 & 571,80 & 89,02 & 2,00 & 64,30 & 258,27 & 21,49 & 23,73 & 247,61 \\
\hline Epidalea calamita & 29 SNB95 & 100,00 & 162,10 & 101,68 & 41,85 & 4764,64 & 301,97 & 61,28 & 240,69 & 114,21 & 222,62 & 226,94 & 105,44 & 557,84 & 85,81 & 2,00 & 63,79 & 250,25 & 21,36 & 23,25 & 240,45 \\
\hline Epidalea calamita & 29SNB97 & 100,00 & 164,92 & 105,55 & 42,00 & 4874,85 & 310,72 & 62,35 & 248,37 & 115,44 & 226,73 & 231,23 & 106,64 & 545,94 & 82,66 & 2,00 & 62,55 & 240,46 & 21,97 & 23,29 & 232,84 \\
\hline Epidalea calamita & 29SNB98 & 100,00 & 166,44 & 107,51 & $\begin{array}{l}42,05 \\
\end{array}$ & 4933,26 & 315,14 & 63,07 & 252,06 & 116,25 & 228,91 & 233,37 & 107,37 & 539,69 & 81,21 & 2,00 & 61,85 & 235,36 & 22,26 & 23,41 & 228,93 \\
\hline Epidalea calamita & 29SNB99 & 101,00 & 165,62 & 110,00 & 42,07 & 5015,02 & 318,32 & 61,18 & 257,14 & 114,36 & 229,15 & 233,73 & 105,83 & 547,67 & 81,68 & 2,00 & 61,23 & 235,78 & 23,44 & 23,94 & 231,03 \\
\hline Epidalea calamita & 29SNC08 & 88,00 & 170,53 & 83,66 & 40,89 & 4135,33 & 286,57 & 83,89 & 202,68 & 127,01 & 221,21 & 225,76 & 119,78 & 664,00 & 99,33 & 3,00 & 63,24 & 295,24 & 26,97 & 30,01 & 285,61 \\
\hline Epidalea calamita & 29SNC09 & 44,00 & 169,96 & 82,41 & 40,92 & 4094,55 & 283,96 & 83,82 & 200,14 & 126,75 & 220,06 & 224,33 & 119,35 & 666,27 & 99,81 & 3,00 & 63,11 & 295,30 & 27,00 & 30,45 & 285,77 \\
\hline Epidalea calamita & 29SNC17 & 101,00 & 170,53 & 86,68 & \begin{tabular}{|l|l|l|}
41,03 \\
\end{tabular} & 4232,24 & 291,12 & 82,37 & 208,75 & 126,37 & 222,68 & 227,27 & 118,88 & 648,25 & 95,83 & 3,00 & 62,78 & 286,50 & 27,00 & 29,86 & 278,50 \\
\hline Epidalea calamita & $295 N C 20$ & 100,00 & 163,43 & 92,33 & 42,46 & 4224,95 & 288,91 & 73,92 & 214,99 & 120,64 & 215,90 & 220,69 & 112,66 & 606,74 & 90,73 & 2,30 & 63,70 & 270,56 & 25,52 & 26,30 & 263,18 \\
\hline Epidalea calamita & 29 SNC21 & 101,00 & 164,38 & 92,12 & 42,16 & 4247,06 & 290,22 & 74,66 & 215,56 & 121,27 & 217,10 & 221,97 & 113,42 & 612,68 & 91,38 & 2,49 & 63,49 & 272,22 & 25,95 & 26,81 & 265,08 \\
\hline Epidalea calamita & $29 \mathrm{SNC} 22$ & 99,00 & 166,10 & 91,82 & 42,02 & 4275,52 & 292,11 & 76,33 & 215,78 & 122,47 & 219,16 & 224,04 & 114,58 & 614,17 & 91,45 & 2,67 & 63,12 & 272,23 & 26,19 & 27,32 & 265,21 \\
\hline Epidalea calamita & 29 SNC23 & 101,00 & 168,86 & 91,32 & 42,00 & 4281,82 & 294,32 & 78,88 & 215,44 & 124,77 & 221,79 & 226,66 & 116,93 & 608,71 & 90,47 & 2,99 & 63,12 & 269,53 & 25,78 & 27,64 & 262,48 \\
\hline Epidalea calamita & 29SNC27 & 101,00 & 170,20 & 88,60 & 40,99 & 4323,06 & 294,15 & 80,47 & 213,68 & 125,06 & 223,61 & 228,18 & 117,38 & 639,31 & 94,12 & 3,00 & 62,43 & 280,42 & 27,36 & 29,82 & 274,05 \\
\hline Epidalea calamita & 295NC28 & 101,00 & 169,01 & 87,66 & 40,97 & 4313,12 & 291,96 & 79,80 & 212,16 & $\mid 123,92$ & 222,42 & 226,85 & \begin{tabular}{|l|l|}
116,38 \\
\end{tabular} & 654,50 & 96,47 & 3,00 & 62.12 & 286,12 & 28,15 & 30,59 & 279,97 \\
\hline Epidalea calamita & 29SNC29 & 100,00 & 169,06 & 86,49 & 40,86 & 4278,31 & 290,27 & 80,32 & 209,94 & 124,19 & 222,01 & 226,24 & 116,70 & 658,33 & 97,10 & 3,03 & 61,99 & 287,19 & 28,26 & 31,05 & 280,91 \\
\hline Epidalea calamita & $29 \mathrm{SNC} 30$ & 100,00 & 164,80 & 94,76 & 42,16 & 4339,40 & 294,27 & 73,09 & 221,18 & 120,82 & 218,96 & 223,73 & 112,79 & 591,55 & 88,55 & 2,06 & 63,69 & 263,40 & 24,27 & 24,90 & 256,82 \\
\hline Epidalea calamita & 29SNC31 & 101,00 & 161,27 & 94,95 & 42,00 & \begin{tabular}{ll|l|}
4402,58 \\
\end{tabular} & 292,56 & 69,61 & 222,95 & 116,77 & 216,36 & 221,20 & 108,72 & 624,36 & 92,71 & 2,89 & 62,71 & 274,96 & 27,25 & 27,68 & 269,36 \\
\hline Epidalea calamita & 29 SNC32 & 101,00 & 164,58 & 94,37 & 41,92 & 4412,68 & 295,47 & 72,80 & 222,67 & 119,62 & 219,70 & 224,62 & 111,69 & \begin{tabular}{|c|}
614,58 \\
\end{tabular} & 90,98 & 2,73 & 62,64 & 270,49 & 26,43 & 27,17 & 264,92 \\
\hline Epidalea calamita & 29 SNC33 & 100,00 & 167,77 & 93,79 & 41,93 & 4408,51 & 297,79 & 76,01 & 221,78 & 122,43 & 222,68 & 227,53 & 114,64 & 605,45 & 89,46 & 2,95 & 62,79 & 266,27 & 25,92 & 26,94 & 260,68 \\
\hline Epidalea calamita & 29SNC34 & 101,00 & 169,72 & 93,09 & 41,86 & 4404,57 & 299,00 & 78,24 & 220,76 & 124,28 & 224,49 & 229,21 & 116,51 & 603,04 & 88,7 & 2,98 & 62,63 & 264,73 & 25,86 & 26,98 & 259,18 \\
\hline Epidalea calamita & 29 SNC39 & 100,00 & 168,15 & 88,67 & 40,81 & 4385,91 & 293,38 & 77,73 & 215,65 & $\begin{array}{l}122,21 \\
121\end{array}$ & 222,70 & 227,00 & 114,55 & 657,82 & $90,1 / 26$ & 3,71 & $\begin{array}{ll}61,08 \\
6\end{array}$ & 283,95 & 29,97 & 32,20 & 279,29 \\
\hline Epidalea calamita & 29 SNC41 & 101,00 & 166,46 & 97,10 & 42,00 & 4485,43 & 300,43 & 72,71 & 227,71 & 120,71 & 222,62 & 227,24 & 112,62 & 584,59 & 86,96 & 2,10 & 63,03 & 257,83 & 24,48 & 25,09 & 252,44 \\
\hline Epidalea calamita & 29 SNC42 & 99,00 & 168,70 & 96,55 & 42,00 & 4483,66 & 302,16 & 75,09 & 227,07 & 122,67 & 224,64 & 229,38 & 114,78 & 580,33 & 85,94 & 2,06 & 62,96 & 255,20 & 24,26 & 25,13 & 250,04 \\
\hline Epidalea calamita & 29 SNC45 & 101,00 & 169,94 & 94,46 & 41,41 & 4514,58 & 302,27 & 76,89 & 225,38 & 123,17 & 226,18 & 230,97 & 115,35 & 601,31 & $87, \varepsilon$ & 3,00 & 61,71 & 260,69 & 26,58 & 27,74 & 256,66 \\
\hline Epidalea calamita & $295 N C 46$ & 100,00 & 168,48 & 93,61 & 41,02 & 4534,77 & 300,59 & 75,62 & 224,97 & 121,42 & 225,07 & 229,66 & 113,51 & 619,70 & 90,45 & 3,03 & 61,34 & 267,23 & 27,81 & 29,05 & 263,86 \\
\hline Epidalea calamita & 295NC49 & 101,00 & 167,49 & \begin{tabular}{|l|l|}
90,72 \\
9
\end{tabular} & $\begin{array}{l}41,0< \\
40,48\end{array}$ & 4504,72 & 296,56 & 75,55 & \begin{tabular}{|l|}
221,01 \\
\end{tabular} & $\begin{array}{l}120,28 \\
120,2\end{array}$ & \begin{tabular}{|l|}
223,71 \\
\end{tabular} & 227,97 & \begin{tabular}{|l|}
112,67 \\
112
\end{tabular} & 655,11 & 90,453 & 3,96 & $60,1,30$ & 279,75 & 31,13 & 32,90 & 276,80 \\
\hline Epidalea calamita & 29SNC50 & 101,00 & 169,36 & 99,40 & 42,16 & 4546,86 & 305,86 & 73,78 & 232,08 & 122,96 & 226,42 & 231,14 & 114,82 & 551,54 & 82,71 & 2,00 & 63,51 & 244,19 & 22,46 & 23,32 & 238,44 \\
\hline Epidalea calamita & 29 SNC51 & 101,00 & 169,44 & 99,28 & 42,04 & 4569,18 & 306,46 & 73,87 & 232,59 & 122,67 & 226,81 & 231,38 & 114,65 & 560,00 & 83,21 & 2,00 & 62,58 & 245,94 & 23,75 & 24,40 & 240,90 \\
\hline Epidalea calamita & 29 SNC52 & 101,00 & 169,67 & 98,88 & 42,01 & 4587,13 & 306,68 & 74,25 & 232,43 & 122,60 & 227,16 & 231,83 & 114,48 & 566,97 & 83,56 & 2,08 & 62,27 & 247,49 & 24,29 & 24,99 & 243,05 \\
\hline Epidalea calamita & 29 SNC53 & 100,00 & 170,04 & 98,17 & 41,97 & 4596,44 & 306,70 & 74,80 & 231,89 & 122,87 & 227,55 & 232,26 & 114,58 & 573,44 & 83,86 & 2,58 & 61,79 & 248,75 & 25,34 & 26,21 & 244,83 \\
\hline Epidalea calamita & 29SNC54 & 101,00 & 168,58 & \begin{tabular}{|c|c|}
97,49 \\
97
\end{tabular} & 年 41,65 & $\begin{array}{l}450,0,49 \\
4619,20\end{array}$ & 305,30 & $\begin{array}{l}74,00 \\
73,76\end{array}$ & \begin{tabular}{|l|}
231,54 \\
231
\end{tabular} & \begin{tabular}{|l|}
121,07 \\
12,0
\end{tabular} & $\mid 226,41$ & \begin{tabular}{|l|}
$32,1,19$ \\
231
\end{tabular} & \begin{tabular}{|l|}
113,01 \\
113,01
\end{tabular} & 590,22 & $\begin{array}{l}80,00 \\
85,94\end{array}$ & $2,2,99$ & $\begin{array}{l}1,1,12 \\
61,2\end{array}$ & \begin{tabular}{|l|}
254,271 \\
\end{tabular} & $\begin{array}{l}26,74 \\
26,74\end{array}$ & $\begin{array}{l}27,45 \\
27,45\end{array}$ & $\begin{array}{l}244,03 \\
251,14\end{array}$ \\
\hline Epidalea calamita & 29SNC55 & 100,00 & 168,90 & 96,51 & 41,20 & 4621,95 & 304,91 & 74,40 & 230,51 & 121,21 & 226,82 & 231,37 & 113,07 & 597,31 & 86,69 & 3,00 & 60,85 & 256,22 & 27,24 & 28,15 & 253,45 \\
\hline Epidalea calamita & $295 N C 56$ & 101,00 & 164,47 & 95,36 & 40,94 & 4653,64 & 300,76 & 70,51 & 230,25 & 116,51 & 222,78 & 227,54 & 108,55 & 636,12 & 92,18 & 3,69 & 60,01 & 270,33 & 30,59 & 31,18 & 268,80 \\
\hline Epidalea calamita & 29SNC59 & 101,00 & 166,11 & 92,51 & 40,3 & 4606,06 & 298,89 & 73,02 & 225,86 & 118,06 & 223,91 & 228,27 & 110,24 & 657,11 & 95,19 & 4,00 & 59,58 & 277,46 & 32,31 & 33,59 & 275,99 \\
\hline Epidalea calamita & 29 SNC60 & 100,00 & 168,91 & 102,19 & 42, & 4666,86 & 309,80 & 71,14 & 238,66 & 121,42 & 227,67 & 232,32 & 113,08 & 548,16 & 81, & 2,00 & 62,98 & 240,78 & 22,67 & 23,01 & 235,76 \\
\hline Epidalea calamita & 295NC61 & 100,00 & $\begin{array}{l}10,91 \\
169,39\end{array}$ & $\begin{array}{l}102,199 \\
102,09\end{array}$ & $\begin{array}{l}42,14 \\
42,06\end{array}$ & $\begin{array}{l}400,000 \\
4689,62\end{array}$ & 30,80 & \begin{tabular}{|l|l|l|l|}
71,73 \\
\end{tabular} & \begin{tabular}{|l|}
239,000 \\
239,0
\end{tabular} & $\begin{array}{l}121,42 \\
121,44 \\
\end{array}$ & $\mid \begin{array}{l}\mid 228,44 \\
22,4\end{array}$ & \begin{tabular}{|l|}
$232,32,05$ \\
233
\end{tabular} & \begin{tabular}{|l|}
113,19 \\
113,19
\end{tabular} & $\begin{array}{l}40,10 \\
552,32\end{array}$ & $\begin{array}{l}81,- \\
81, \varepsilon\end{array}$ & 2,00 & $\begin{array}{l}0,250 \\
62,34 \\
\end{array}$ & \begin{tabular}{|l|}
240,81 \\
240
\end{tabular} & $\begin{array}{l}2,201 \\
23,25 \\
\end{array}$ & $\frac{23,01}{23,92}$ & $\begin{array}{l}23,10 \\
236,45\end{array}$ \\
\hline Epidalea calamita & 29 SNC63 & 100,00 & 169,43 & 100,65 & 41,97 & 4709,57 & 310,18 & 72,45 & 237,73 & 120,91 & 228,61 & 233,21 & 112,84 & 567,75 & 82,31 & 2,86 & 60,67 & 243,66 & 26,02 & 26,75 & 240,76 \\
\hline Epidalea calamita & 29SNC65 & 101,00 & 165,21 & 98,42 & 41,09 & 4744,75 & 305,35 & 69,42 & 235,94 & 116,34 & 224,94 & 229,67 & 108,29 & 609,86 & 87,75 & 3,01 & 60,04 & 257,88 & 29,32 & 29,53 & 256,77 \\
\hline Epidalea calamita & 29SNC66 & 100,00 & 163,32 & 96,95 & 40,96 & 4748,38 & 302,52 & 68,20 & 234,32 & 113,71 & 223,07 & 227,75 & 106,26 & \begin{tabular}{|c|}
633,58 \\
\end{tabular} & 90,95 & 3,66 & 59,27 & 266,10 & 31,68 & 31,91 & 265,71 \\
\hline Epidalea calamita & $295 N C 69$ & 100,00 & 165,62 & $\begin{array}{l}0,16 \\
94,16\end{array}$ & 40,24 & 4717,41 & 301,6 & 71,25 & 230,38 & 115,59 & \begin{tabular}{|l|}
224,87 \\
\end{tabular} & 229 & $\begin{array}{l}108,58 \\
\end{array}$ & 652,73 & 93,69 & 4,00 & 58,75 & 272,66 & $\begin{array}{ll}3,34 \\
33,\end{array}$ & 34,18 & 272,37 \\
\hline Epidalea calamita & $295 N C 70$ & 101,00 & 166,79 & 105,49 & 42,09 & 4809,92 & 312,99 & 66,70 & 246,29 & 117,83 & 227,47 & 232,23 & 109,28 & 554,83 & 82, & 2,00 & 61,93 & 241,11 & 23,42 & 23,73 & 236,96 \\
\hline Epidalea calamita & $295 N C 71$ & 100,00 & 167,97 & 105,13 & 42,01 & 4818,71 & 314,16 & 68,10 & 246,06 & 118,71 & 228,77 & 233,40 & 110,28 & 553,44 & 81,62 & 2,00 & 61,39 & 238,80 & 23,73 & 24,02 & 235,39 \\
\hline Epidalea calamita & 29 SNC72 & 101,00 & 168,99 & 104,16 & 42,00 & 4819,09 & 314,36 & 69,59 & 244,77 & 119,59 & 229,74 & 234,33 & 111,15 & 554,55 & 80,84 & 2,28 & 61,04 & 237,65 & 24,72 & 25,06 & 234,67 \\
\hline Epidalea calamita & 29 SNC73 & 101,00 & 167,30 & 103,29 & 41,94 & 4840,16 & 312,68 & 68,40 & 244,28 & 117,58 & 228,25 & 233 & 109 & 571,18 & 81,99 & 3,00 & 59,96 & 242,07 & 27,26 & 27,38 & 240,14 \\
\hline Epidalea calamita & $29 \mathrm{NNC7}$ & 101,00 & 164,58 & 101,83 & 47 & 4 & 309 & 66,51 & 242,84 & $\begin{array}{ll}114,73 \\
\end{array}$ & 226,27 & 230 & 106,55 & 594,93 & 84,9 & 3,00 & 59,55 & 250,03 & 28,86 & 28,86 & 249,31 \\
\hline Epidalea calamita & 29 SNC75 & 100,00 & 164,53 & 100,09 & \begin{tabular}{|l|l|}
41,03 \\
\end{tabular} & 4838,18 & 307,66 & 67,28 & 240,38 & 114,29 & 226,21 & 230,19 & 106,54 & 604,28 & 86,00 & 3,00 & 59,13 & 252,46 & 30,18 & 30,18 & 252,28 \\
\hline Epidalea calamita & 29 SNC76 & 101,00 & 160,29 & 98,06 & 40,77 & 4 & 302,55 & $\begin{array}{l}64,27 \\
642\end{array}$ & 238,27 & 104,42 & \begin{tabular}{|l|}
223,43 \\
221
\end{tabular} & 226,39 & 102,36 & $\begin{array}{l}641,73 \\
\end{array}$ & 90,18 & 3,81 & 58,25 & 266,81 & 33,29 & 33,29 & 266,81 \\
\hline Epidalea calamita & 29 SNC77 & 101,00 & 158,54 & 96,49 & 40,18 & 4855,58 & 299,73 & 63,38 & 236,35 & 100,76 & 222,23 & 224,66 & 100,60 & $\begin{array}{l}666,05 \\
\end{array}$ & 94,64 & 4,08 & 57,82 & 276,19 & 35,39 & 35,39 & 276,19 \\
\hline Epidalea calamita & 29 SNC78 & 99,00 & 160,21 & 95,62 & 40,11 & 4836,39 & 300,15 & 65,21 & 234,94 & 102,41 & 222,25 & 225 & 102,35 & 669,04 & 95,14 & 4,02 & 57,86 & 277,31 & 35,75 & 35,75 & 277 \\
\hline Epidalea calamita & 29SNC80 & \begin{tabular}{|l|}
101,00 \\
100
\end{tabular} & $\frac{10,21}{165,24}$ & \begin{tabular}{|r|r|r|r|}
108,90 \\
\end{tabular} & $\begin{array}{ll}40, \\
42,\end{array}$ & $\begin{array}{l}4050,33 \\
4951,82\end{array}$ & 316,80 & \begin{tabular}{|l|l|}
62,73 \\
62.0
\end{tabular} & \begin{tabular}{|l|}
254,06 \\
25,0
\end{tabular} & \begin{tabular}{|l|}
114,69 \\
114,6
\end{tabular} & \begin{tabular}{|l|}
227,97 \\
227
\end{tabular} & \begin{tabular}{|l|}
232,64 \\
23,04
\end{tabular} & \begin{tabular}{|l|}
106,17 \\
106,17
\end{tabular} & 50038,11 & $\mid \begin{array}{l}\mid 52,74 \\
82,\end{array}$ & $\begin{array}{ll}2,064 \\
2,06\end{array}$ & $\begin{array}{l}3,1,00 \\
61,14\end{array}$ & \begin{tabular}{|l|}
239,67 \\
\end{tabular} & $\begin{array}{l}3,112 \\
24,29 \\
\end{array}$ & $\begin{array}{l}3,1,41 \\
24,4\end{array}$ & 236,34 \\
\hline Epidalea calamita & $295 N C 81$ & 101,00 & 165,59 & 108,62 & 42,09 & 4964,21 & 317,28 & 63,29 & 253,99 & 114,89 & 228,42 & 233,08 & 106,27 & \begin{tabular}{|c|}
561,88 \\
\end{tabular} & 82,25 & 2,18 & 60,46 & 239,21 & 25,24 & 25,36 & 236,65 \\
\hline Epidalea calamita & $295 N C 82$ & 99,00 & 167.03 & 107.19 & 42.01 & 4950,75 & 317.14 & 65.50 & 251.64 & 116,11 & 229,61 & 234,29 & $\mid 107,79$ & 559.42 & 80.96 & 2.64 & 60.02 & 236,69 & 26,40 & 26.50 & 234,41 \\
\hline Epidalea calamita & 29SNC83 & 101,00 & 165,01 & 105,72 & 41,89 & 4963,12 & 314,42 & 64,19 & 250,23 & 113, & 228,62 & 232,37 & 105,65 & 577,32 & 82,20 & 3,00 & 59,25 & 241,88 & 28,08 & 28,08 & 240,77 \\
\hline Epidalea calamita & 29 SNC84 & 101,00 & 163,50 & 103,66 & 41,22 & 4958,27 & 311,40 & 63,87 & 247,52 & 112,01 & 227,62 & 230,76 & 104,36 & 593,24 & 83,70 & 3,01 & 58,59 & 246,40 & 29,81 & 29,81 & 246,24 \\
\hline
\end{tabular}




\begin{tabular}{|c|c|c|c|c|c|c|c|c|c|c|c|c|c|c|c|c|c|c|c|c|c|}
\hline TAXON & UTM & $\mathrm{km} 2$ & B101 & B102 & $\mathrm{BIO3}$ & BIO4 & B105 & B106 & B107 & B108 & B109 & B1010 & BIO11 & BIO12 & 81013 & BIO14 & BIO15 & B1016 & B1017 & B1018 & B1019 \\
\hline Epidalea calamita & 29SNC85 & 100,00 & 163,64 & 101,55 & 41,01 & 4935,13 & 309,45 & 65,10 & 244,36 & 108,31 & 227,21 & 230,59 & 104,60 & 598,99 & 84,16 & 3,00 & 58,12 & 247,69 & 30,76 & 30,76 & 247,69 \\
\hline Epidalea calamita & $295 N C 86$ & 100,00 & 161,19 & 99,26 & 40,70 & 4930,57 & 305,38 & 63,90 & 241,49 & 102,56 & 226,06 & 228,18 & 102,29 & 624,39 & 87,51 & 3,77 & 57,59 & 257,09 & 33,38 & 33,38 & 257,09 \\
\hline Epidalea calamita & 29 SNC87 & 100,00 & 157,48 & 97,19 & 40,03 & 4938,52 & 300,59 & 61,44 & 239,15 & 98,67 & 223,75 & 224,75 & 98,67 & 661,51 & 92,89 & 4,07 & 57,07 & 271,88 & 36,14 & 36,14 & 271,88 \\
\hline Epidalea calamita & 29SNC89 & 100,00 & 163,08 & 96,52 & 40,01 & 4922,84 & 304,76 & 66,54 & 238,22 & 104,04 & 225,79 & 229,75 & 103,99 & 654,01 & 92,12 & 4,03 & 57,18 & 268,90 & 36,06 & 36,14 & 268,90 \\
\hline Epidalea calamita & 29SNC91 & 100,00 & 164,76 & 111,73 & 42,12 & 5095,89 & 321,09 & 60,14 & 260,95 & \begin{tabular}{ll|}
112,42 \\
\end{tabular} & 229,47 & 233,99 & 103,97 & 560,86 & 81,73 & 2,19 & 59,75 & 236,43 & 26,09 & 26,09 & 234,05 \\
\hline Epidalea calamita & 29SNC93 & 100,00 & 163,36 & 107,68 & 41,78 & 5076,10 & 316,32 & 60,82 & 255,49 & 111,17 & 228,91 & 232,37 & 102,78 & 580,06 & 81,76 & 3,00 & 58,43 & 240,55 & 28,79 & 28,79 & 239,58 \\
\hline Epidalea calamita & 29SNC94 & 100,00 & 161,65 & 105,11 & 41,13 & 5062,79 & 312,44 & 60,52 & 251,92 & \begin{tabular}{ll|}
107,12 \\
\end{tabular} & 228,18 & 230,52 & 101,29 & 597,04 & 83,31 & 3,19 & 57,84 & 245,71 & 30,75 & 30,75 & 245,55 \\
\hline Epidalea calamita & $295 \mathrm{NC} C 6$ & 100,00 & 161,72 & 100,41 & 40,40 & 5014,36 & 307,90 & 63,07 & 244,83 & 101,64 & 227,53 & 229,77 & 101,64 & 610,86 & 84,42 & 3,90 & 56,55 & 248,98 & 33,86 & 33,86 & 248,98 \\
\hline Epidalea calamita & 29SNC97 & 101,00 & 160,32 & 98,67 & 40,00 & 5013,92 & 305,33 & 62,47 & 242,87 & 100,35 & 227,13 & 228,47 & 100,35 & 630,48 & 87,14 & 4,00 & 56,21 & 256,55 & 35,39 & 35,39 & 256,55 \\
\hline Epidalea calamita & 29SNC98 & 101,00 & 160,41 & 97,95 & 40,00 & 5019,94 & 305,06 & 62,60 & 242,46 & 100,33 & 226,64 & 228,62 & 100,33 & 646,31 & 89,76 & 4,01 & 56,42 & 263,36 & 36,37 & 36,37 & 263,36 \\
\hline Epidalea calamita & 29SNC99 & 100,00 & 162,60 & 97,82 & 39,99 & 5028,22 & 307,13 & 64,41 & 242,72 & 102,16 & 226,96 & 230,84 & 102,16 & 649,82 & 90,50 & 4,00 & 56,37 & 264,99 & 36,64 & 36,65 & 264,99 \\
\hline Epidalea calamita & 29SND03 & 101,00 & 160,54 & 75,24 & 40,72 & 3756,82 & 261,73 & 78,79 & 182,94 & 120,86 & 206,23 & 209,56 & 113,18 & 707,24 & 108,25 & 3,99 & 61,58 & 309,55 & 31,18 & 35,44 & 297,42 \\
\hline Epidalea calamita & 29SND19 & 100,00 & 155,32 & 78,63 & 41,99 & \begin{tabular}{|l|}
3664,69 \\
\end{tabular} & 256,27 & 71,28 & 184,99 & 116,06 & 199,79 & 202,38 & 108,15 & 810,80 & 119,14 & 6,25 & 57,62 & 339,55 & 44,17 & 49,25 & 331,81 \\
\hline Epidalea calamita & 29SND23 & 101,00 & 166,88 & 82,44 & 40,89 & 4062,76 & 279,72 & 79,88 & 199,84 & 123,67 & 216,86 & 220,34 & 116,05 & 680,99 & 101,13 & 4,00 & 60,87 & 293,59 & 31,14 & 34,84 & 286,27 \\
\hline Epidalea calamita & 29SND25 & 101,00 & 161,26 & 81,61 & 40,91 & 3997,80 & 272,25 & 74,87 & 197,38 & 118,84 & 210,46 & 213,58 & 111,06 & 735,20 & \begin{tabular}{|l|l|}
108,67 \\
\end{tabular} & 4,79 & 59,47 & 313,26 & 36,15 & 39,89 & 306,39 \\
\hline Epidalea calamita & 29 SND26 & 101,00 & 159,71 & 81,56 & 41,01 & 3964,80 & 269,88 & 73,31 & 196,58 & 117,48 & 208,47 & 211,54 & 109,77 & 756,41 & 111,66 & 5,06 & 58,96 & 320,51 & 38,33 & 42,25 & 313,91 \\
\hline Epidalea calamita & 29SND28 & 101,00 & 144,18 & 81,60 & 40,51 & 4038,77 & 257,03 & 57,77 & 199,26 & 101,73 & 194,40 & 197,49 & 93,99 & \begin{tabular}{|c|c|}
927,78 \\
\end{tabular} & 136,62 & 7,98 & 57,12 & 385,76 & 53,21 & 55,56 & 381,90 \\
\hline Epidalea calamita & 29SND34 & 100,00 & 166,83 & 85,17 & 40,92 & 4174,14 & 283,97 & 77,71 & 206,26 & 122,48 & 218,47 & 221,85 & 114,71 & 695,73 & 102,21 & 4,03 & 59,65 & 296,03 & 33,76 & 37,29 & 290,63 \\
\hline Epidalea calamita & 29SND36 & 101,00 & 163,01 & 85,30 & 40,99 & 4139,85 & 279,47 & 73,62 & 205,86 & 118,69 & 214,20 & 217,29 & 110,95 & 745,59 & 109,38 & 5,01 & 58,52 & 313,82 & 38,47 & 41,99 & 309,20 \\
\hline Epidalea calamita & 295ND38 & 101,00 & 154,11 & 86,06 & 40,92 & 4160,23 & 272,22 & 64,23 & 207.99 & 109,68 & 205,85 & 208,84 & $\mid$\begin{tabular}{|c|}
101.98 \\
\end{tabular} & 852,33 & $\mid 124,75$ & 6,88 & 57,12 & 353,53 & 48,20 & 50,95 & 350,97 \\
\hline Epidalea calamita & 29SND40 & 100,00 & 168,20 & 89,94 & 40,42 & 4473,58 & 295,80 & 76,41 & 219,39 & 121,14 & 223,95 & 228,03 & 113,50 & 657,81 & 96,03 & 4,00 & 60,04 & 280,67 & 31,31 & 33,32 & 277,32 \\
\hline Epidalea calamita & $29 \mathrm{SND} 42$ & 101,00 & 165,60 & 88,53 & 40,27 & 4423,03 & 291,14 & 74,42 & 216,71 & 118,99 & 220,79 & 224,66 & 111,24 & \begin{tabular}{|l|l|}
694,78 \\
\end{tabular} & $\begin{array}{r}101,68 \\
\end{array}$ & 4,13 & 59,47 & 294,52 & 33,99 & 36,29 & 291,45 \\
\hline Epidalea calamita & 29SND44 & 100,00 & 163,98 & 87,84 & 40,42 & 4365,45 & 287,47 & 72,59 & 214,88 & 117,42 & 218,27 & 221,88 & 109,75 & 727,36 & 106,51 & 4,88 & 58,87 & 306,26 & 37,05 & 39,69 & 303,29 \\
\hline Epidalea calamita & 29 SND45 & 101,00 & 165,76 & 88,03 & 40,78 & 4321,19 & 288,15 & 74,32 & 213,82 & 119,42 & 219,42 & 222,85 & 111,97 & 723,74 & 105,79 & 4,87 & 58,48 & 304,00 & 37,37 & 40,32 & 300,70 \\
\hline Epidalea calamita & 29SND46 & 101,00 & 166,58 & 88,53 & 40,98 & 4293,35 & 288,52 & 74,46 & 214,05 & 120,34 & 219,92 & 223,14 & 112,81 & 727,41 & 106,05 & 5,03 & 58,10 & 304,27 & 38,17 & 41,38 & 301,09 \\
\hline Epidalea calamita & 29SND50 & 101,00 & 167,79 & 91,83 & 40,21 & 4577,92 & 299,08 & 74,61 & $\begin{array}{lll}224,47 & \end{array}$ & 119,69 & 225,07 & 229,25 & 111,94 & 656,23 & 95,12 & 4,00 & 59,42 & 277,02 & 32,25 & 33,94 & 275,19 \\
\hline Epidalea calamita & 29SND53 & 100,00 & 164,97 & $\begin{array}{l}10,36 \\
90,36\end{array}$ & 40,04 & 4544,14 & 294,20 & 71,92 & 222,29 & \begin{tabular}{|l|l|}
116,87 \\
\end{tabular} & 221,92 & 225,62 & $\mid 109,24$ & 712,40 & \begin{tabular}{|c|}
103,62 \\
\end{tabular} & 4,94 & 58,43 & 298,19 & 37,14 & 39,10 & 296,69 \\
\hline Epidalea calamita & 29SND54 & 100,00 & 163,62 & 90,20 & 40,02 & 4533,12 & 292,51 & 70,56 & 221,95 & 115,70 & 220,47 & 224,08 & 107,92 & 735,01 & 107,10 & 5,02 & 58,32 & 306,96 & 38,58 & 40,59 & 305,63 \\
\hline Epidalea calamita & 29 SND55 & 100,00 & 162,59 & 90,29 & 40,09 & 4516,73 & 291,27 & 69,36 & 221,91 & 114,68 & 219,35 & 222,82 & 107,06 & 757,73 & 110,34 & 5,54 & 57,69 & 315,09 & 41,03 & 43,10 & 314,16 \\
\hline Epidalea calamita & 29 SND56 & 100,00 & 164,14 & 90,99 & 40,28 & 4499,20 & 292,42 & 70,03 & 222,39 & 115,91 & 220,46 & 223,79 & 108,37 & 758,66 & 110,26 & 5,55 & 57,46 & 314,56 & 41,55 & 43,99 & 313,51 \\
\hline Epidalea calamita & 29SND57 & 101,00 & 163,58 & 91,65 & 40,52 & 4487,99 & 292,20 & 68,96 & 223,24 & 114,77 & 219,93 & 223,01 & 107,82 & 778,36 & 112,98 & 5,93 & 57,09 & 321,51 & 43,46 & 45,93 & 320,79 \\
\hline Epidalea calamita & 29SND59 & 101,00 & 155,63 & 92,85 & 40,48 & 4542,00 & 286,69 & $\begin{array}{l}60,08 \\
60,\end{array}$ & 226,61 & 100,20 & \begin{tabular}{|l|l|}
212,94 \\
\end{tabular} & \begin{tabular}{|l|}
215,92 \\
210
\end{tabular} & \begin{tabular}{|l|}
99,49 \\
99
\end{tabular} & 886,67 & 128,71 & 7,65 & 56,03 & \begin{tabular}{|l|l|l|l|l|l|}
363,69 \\
\end{tabular} & 53,16 & 54,72 & 363,69 \\
\hline Epidalea calamita & 29SND60 & 100,00 & 167,56 & 93,60 & 40,16 & 4693,55 & 302,33 & 73,11 & 229,22 & 118,44 & 226,51 & 230,75 & 110,51 & \begin{tabular}{|l|l|}
652,08 \\
\end{tabular} & 93,74 & 4,00 & 58,75 & 272,51 & 33,19 & 34,41 & 271,85 \\
\hline Epidalea calamita & 29 SND62 & 100,00 & 166,34 & 92,62 & 40,02 & 4682,53 & 300,06 & 71,66 & 228,40 & 116,55 & 225,23 & 229,08 & 109,13 & 689,45 & 99,47 & 4,62 & 58,18 & 287,12 & 36,23 & 37,75 & 286,52 \\
\hline Epidalea calamita & 29 SND63 & 101,00 & 164,31 & 92,28 & 39,99 & 4680,84 & 298,07 & 69,76 & 228,31 & 114,41 & 223,45 & 227,20 & 107,21 & 718,88 & 103,97 & 5,00 & 57,95 & 298,56 & 38,39 & 39,92 & 298,32 \\
\hline Epidalea calamita & 29 SND64 & 100,00 & 163,53 & 92,14 & 39,99 & 4671,31 & 296,93 & 68,86 & 228,06 & 112,76 & 222,46 & 226,16 & 106,44 & 739,71 & \begin{tabular}{|l|l|}
107,19 \\
\end{tabular} & 5,24 & 57,64 & 306,74 & 40,06 & 41,67 & 306,59 \\
\hline Epidalea calamita & 29SND65 & 101,00 & $\begin{array}{l}10,53,54 \\
162,54\end{array}$ & $\begin{array}{l}92,44 \\
92,21\end{array}$ & $\begin{array}{ll}39,99 \\
39,93\end{array}$ & 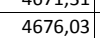 & 296,03 & $\begin{array}{l}0,00 \\
67,49 \\
\end{array}$ & $\begin{array}{l}228,53 \\
\end{array}$ & $\begin{array}{l}1110,27 \\
\end{array}$ & $\mid 221,56$ & 225,14 & $\begin{array}{l}105,29 \\
105,4\end{array}$ & 763,63 & $\mid$ & $\frac{3,44}{5,94}$ & 57,23 & \begin{tabular}{|l|}
315,68 \\
314
\end{tabular} & $\begin{array}{l}40,00 \\
42,68\end{array}$ & $\begin{array}{l}4,106 \\
44,36\end{array}$ & 315,62 \\
\hline Epidalea calamita & 29SND66 & 101,00 & 165,61 & 93,09 & 40,11 & 4654,14 & 298,53 & 69,45 & 229,09 & 114,68 & 224,13 & 227,40 & 108,00 & 751,99 & 108,81 & 5,59 & 57,07 & 310,31 & 41,83 & 44,10 & 310,05 \\
\hline Epidalea calamita & 29SND70 & 101,00 & 166,85 & 95,14 & 40,07 & 4804,47 & 305,03 & 70,95 & 234,08 & 113,76 & 227,38 & 231,65 & 108,60 & 651,19 & 92,75 & 4,00 & 57,94 & 269,61 & 34,63 & 35,48 & 269,59 \\
\hline Epidalea calamita & 29SND71 & 100,00 & 168,11 & 94,80 & 40,01 & 4798,65 & 305,51 & 71,85 & 233,66 & 116,48 & 228,52 & 232, & 109,66 & 657,29 & 93,77 & 4,01 & 57,93 & 271,99 & 34,92 & 36,13 & 271,84 \\
\hline Epidalea calamita & 29SND72 & 101,00 & 167,56 & 94,45 & 40,00 & 4800,62 & 304,86 & 71,40 & 233,45 & 115,69 & 228,11 & 232 & 109,13 & 676,64 & 96,79 & 4,4 & 57,64 & 279,63 & 36,56 & 37,84 & 279,55 \\
\hline Epidalea calamita & 29SND73 & $\begin{array}{l}101,00 \\
101,00\end{array}$ & $\begin{array}{l}10,50 \\
166,31\end{array}$ & $\begin{array}{l}4,45 \\
94,13\end{array}$ & $\begin{array}{l}49,99 \\
39,9\end{array}$ & $\begin{array}{l}4800,026 \\
4803,72\end{array}$ & $\begin{array}{l}304,80 \\
303,41\end{array}$ & $\begin{array}{l}1,40 \\
70,01\end{array}$ & $\begin{array}{l}233,45 \\
233,40 \\
\end{array}$ & $\begin{array}{l}113,13 \\
113,13\end{array}$ & $\mid \frac{\mid 20,11}{226,98}$ & $\mid$\begin{tabular}{|l|l|}
230,79 \\
230
\end{tabular} & \begin{tabular}{|l|}
107,78 \\
107,78
\end{tabular} & 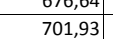 & \begin{tabular}{|l}
50,19 \\
100,70
\end{tabular} & $\begin{array}{ll}4,4 \\
4,9\end{array}$ & 57,44 & $\begin{array}{l}289,85 \\
289 \\
\end{array}$ & $\begin{array}{l}30,30 \\
38,35\end{array}$ & $\begin{array}{l}1,144 \\
39,74 \\
\end{array}$ & $\begin{array}{l}27,593 \\
289,81\end{array}$ \\
\hline Epidalea calamita & 29SND74 & 101,00 & 163,90 & 93,73 & 39,83 & 4823,81 & 301,46 & 67,69 & 233,77 & 106,79 & 225,15 & 228,75 & 105,49 & 737,46 & 106,23 & 5,32 & 57,22 & 304,37 & 41,04 & 42,31 & 304,37 \\
\hline Epidalea calamita & 29SND75 & 100,00 & 164,11 & 93,99 & 39,71 & 4828,13 & 301,70 & 67,27 & 234,44 & 106,90 & 225,40 & 228,76 & 105,26 & 751,74 & 108,35 & 5,77 & 56,91 & 309,75 & 42,51 & 43,99 & 309,75 \\
\hline Epidalea calamita & 29SND80 & 101,00 & 166,63 & 96,48 & 40,00 & 4914,35 & 307,64 & 69,17 & 238,47 & 107,97 & 228,70 & 232,91 & 107,09 & 646,56 & 91,1 & 4,00 & 57,21 & 265,65 & 35,67 & 36,13 & 265,65 \\
\hline Epidalea calamita & $29 \mathrm{SND} 82$ & 100,00 & 166,25 & 95,78 & 39,86 & 4933,50 & 307,14 & 68,68 & 238,46 & 107,86 & 228,73 & 232 & 106,37 & 683,16 & 97,0 & 4,9 & 56,91 & 280,67 & 38,24 & 39,23 & 280,67 \\
\hline Epidalea calamita & 29SND83 & 101,00 & 165 & 95,47 & 39,54 & 494 & 306,57 & 67,94 & 238,62 & 106,90 & 228,45 & 232,34 & 105,62 & 704,76 & 100,50 & 5,00 & 56,88 & 289,71 & 39,38 & 40,52 & 289,71 \\
\hline Epidalea calamita & 29 SND84 & 101,00 & 166,20 & 95,57 & 39,56 & 4949,48 & 307,08 & 67,86 & 239,22 & 107,46 & 229,05 & 232,68 & 105,90 & 717,25 & 102,55 & 5,08 & 56,79 & 294,66 & 40,21 & 41,54 & 294,66 \\
\hline Epidalea calamita & 29 SND86 & 100,00 & 164,90 & 95,70 & 39,27 & 4975,12 & 306,28 & 65,64 & 240,64 & 105,07 & 228,30 & 231,51 & 104,17 & 762,81 & 109,64 & 5,84 & 56,31 & 312,88 & 43,97 & 45,47 & 312,88 \\
\hline Epidalea calamita & 29 SND90 & 100,00 & 165,34 & 97,75 & 39,97 & 5033,34 & 309,49 & 66,49 & 243,01 & 104,96 & 229,23 & 233,44 & 104,66 & 649,04 & 90,68 & 4,01 & 56,50 & 264,87 & 36,60 & 36,92 & 264,87 \\
\hline Epidalea calamita & 29SND91 & 100,00 & $\begin{array}{l}10,54 \\
165,52\end{array}$ & 97,41 & $\begin{array}{ll}39,74 \\
39,4\end{array}$ & 5042,61 & 309,69 & $\begin{array}{l}60,74 \\
66,78 \\
\end{array}$ & \begin{tabular}{|l|}
242,92 \\
242
\end{tabular} & 105,51 & \begin{tabular}{|l|}
229,67 \\
225
\end{tabular} & \begin{tabular}{|l|}
233,77 \\
23,7
\end{tabular} & \begin{tabular}{|l|l}
104,780 \\
\end{tabular} & $\begin{array}{l}64,06,33 \\
66,33\end{array}$ & $\begin{array}{l}90,00 \\
93,51\end{array}$ & $\frac{4,0}{4,7}$ & 50,51 & \begin{tabular}{|l|}
272,06 \\
\end{tabular} & $\begin{array}{l}30,002 \\
38,02\end{array}$ & $\begin{array}{l}30,424 \\
38,47\end{array}$ & $\begin{array}{l}204,01 \\
272,06\end{array}$ \\
\hline Epidalea calamita & 29SND92 & 100,00 & 167,01 & 97,38 & 39,53 & 5049,72 & 311,14 & 67,58 & 243,55 & 108,42 & 231,32 & 235,16 & 105,97 & 672,80 & 94,69 & 4,91 & 56,41 & 274,65 & 38,37 & 39,36 & 274,65 \\
\hline Epidalea calamita & $29 \mathrm{SND93}$ & 100,00 & 166,58 & 97,03 & 39,23 & 5067,16 & 310,69 & |67,06 & 243,63 & $\begin{array}{l}107,18 \\
\end{array}$ & $\begin{array}{l}231,19 \\
\end{array}$ & 234,92 & 105,31 & 693,44 & \begin{tabular}{|l|l|}
98,05 \\
\end{tabular} & 5,00 & 56,36 & 283,46 & 39,40 & $\begin{array}{l}0,47 \\
40,40\end{array}$ & 283,46 \\
\hline Epidalea calamita & 29 SND94 & 100,00 & 164,63 & 96,36 & 39,00 & 5094,30 & 309,10 & 65,31 & 243,79 & 103,10 & 229,80 & 233,27 & 103,05 & 729,34 & 103,74 & 5,38 & 56,13 & 298,24 & 42,26 & 43,34 & 298,24 \\
\hline Epidalea calamita & 29 SND95 & 101,00 & 164,40 & 96,29 & 38,97 & 5107,33 & 308,97 & 64,56 & 244,41 & 102,61 & 229,69 & 233 & 102,46 & 749,64 & 107,05 & 5,86 & 56,03 & 306,62 & 43,75 & 44,92 & 306 \\
\hline Epidalea calamita & 29SND96 & $\begin{array}{l}101,00 \\
100\end{array}$ & $\begin{array}{l}104,40 \\
161,90\end{array}$ & $\begin{array}{l}0,25 \\
95,79\end{array}$ & $\begin{array}{ll}38,71 \\
38,71\end{array}$ & | 5140,64 & 307,12 & $\begin{array}{l}4,30 \\
61,99 \\
\end{array}$ & $\begin{array}{l}245,13 \\
24,\end{array}$ & \begin{tabular}{r|}
99,01 \\
99,61
\end{tabular} & \begin{tabular}{|l|}
227,89 \\
229
\end{tabular} & \begin{tabular}{|l|}
231,10 \\
231
\end{tabular} & \begin{tabular}{|l|}
99,61 \\
99,01
\end{tabular} & $\begin{array}{l}743,04 \\
788,45\end{array}$ & $\mid$ & $\begin{array}{l}3,00 \\
6,03 \\
\end{array}$ & $\begin{array}{l}5,0,97 \\
5,9\end{array}$ & $\begin{array}{l}322,89 \\
322 \\
\end{array}$ & 46,10 & $\begin{array}{ll}44,05 \\
47,06\end{array}$ & $\begin{array}{l}30,02 \\
322,89\end{array}$ \\
\hline Epidalea calamita & 29SND98 & 101,00 & 159,65 & 96,07 & 38,20 & 5204,60 & 306,12 & 58,25 & 247,87 & 96,60 & 226,80 & 229,56 & 96,60 & 842,70 & 121,84 & 6,97 & 55,70 & 344,44 & 50,83 & 51,66 & 344,44 \\
\hline Epidalea calamita & 29SNE11 & 101,00 & 155,21 & 80,06 & 42,88 & 3601,97 & 254,96 & 70,29 & 184,66 & 116,16 & 198,65 & 201,09 & 108,34 & 845,97 & 122,64 & 7,29 & 56,16 & 349,90 & 48,92 & 54,74 & 343,15 \\
\hline Epidalea calamita & 29SPB00 & 100,00 & 168,65 & 91,91 & 41,97 & 323,17 & 288,65 & 71,93 & 216,7 & 125,49 & 223,02 & 227,16 & 116,65 & 520,02 & 86,18 & 1,01 & 68,52 & 247,88 & 15,63 & 19,26 & 231,80 \\
\hline Epidalea calamita & 29SPB01 & 101,00 & 162,03 & 94,36 & 41,61 & 4497,07 & 288,29 & 63,89 & 224,40 & 117,19 & 218,91 & 223,10 & 108,31 & 555,68 & 89,50 & 1,30 & 66,64 & 258,63 & 18,44 & 21,93 & 244,09 \\
\hline
\end{tabular}




\begin{tabular}{|c|c|c|c|c|c|c|c|c|c|c|c|c|c|c|c|c|c|c|c|c|c|}
\hline TAXON & UTM & $\mathrm{km} 2$ & B101 & B102 & $\mathrm{BIO3}$ & BIO4 & B105 & B106 & B107 & B108 & B109 & B1010 & BIO11 & BIO12 & B1013 & BIO14 & BIO15 & B1016 & B1017 & BIO18 & B1019 \\
\hline Epidalea calamita & 29SPB02 & 100,00 & 156,21 & 96,72 & 41,06 & 4645,49 & 288,15 & 56,77 & 231,38 & 109,81 & 215,06 & 219,32 & 100,94 & 589,35 & 92,50 & 1,92 & 64,92 & 268,40 & 21,17 & 24,40 & 255,58 \\
\hline Epidalea calamita & 29SPB04 & 101,00 & 162,26 & 99,50 & 41,29 & 4747,51 & 299,03 & 61,25 & 237,78 & 114,29 & 222,41 & 226,65 & 105,52 & 555,11 & 85,60 & 1,98 & 64,07 & 250,12 & 20,58 & 23,46 & 238,41 \\
\hline Epidalea calamita & 29SPB05 & 100,00 & 163,97 & 101,37 & 41,34 & 4816,27 & 303,75 & 62,08 & 241,66 & 115,01 & 224,98 & 229,16 & 106,18 & 546,64 & 83,50 & 2,00 & 63,37 & 244,04 & 20,84 & 23,48 & 233,34 \\
\hline Epidalea calamita & 29SPB06 & 101,00 & 166,78 & 103,09 & 41,77 & 4864,45 & 308,96 & 64,24 & 244,73 & 117,18 & 228,35 & 232,62 & 108,45 & 531,27 & 80,81 & 1,99 & 62,92 & 235,55 & 20,77 & 23,04 & 225,63 \\
\hline Epidalea calamita & 29SPB07 & 101,00 & 166,32 & 105,44 & \begin{tabular}{|l|l|}
41,88 \\
\end{tabular} & $\begin{array}{ll}4943,26 \\
\end{array}$ & 312,49 & \begin{tabular}{|l|l|}
62,73 \\
\end{tabular} & 249,76 & 115,83 & 229,00 & 233,25 & \begin{tabular}{|l|}
107,03 \\
\end{tabular} & 535,87 & 80,73 & 2,00 & 62,05 & 234,58 & 21,63 & 23,64 & 226,01 \\
\hline Epidalea calamita & 29SPB08 & 100,00 & 167,55 & 107,56 & 41,97 & 5003,47 & 316,84 & 62,99 & 253,84 & 116,34 & 230,95 & 235,25 & 107,44 & 530,96 & 79,44 & 2,00 & 61,50 & 230,09 & 21,97 & 23,82 & 222,77 \\
\hline Epidalea calamita & 29SPB09 & 100,00 & 166,65 & 110,11 & 42,02 & 5078,42 & 319,97 & 61,01 & 258,96 & 114,61 & 231,07 & 235,43 & 105,78 & 538,22 & 79,76 & 2,00 & 60,83 & 230,49 & 23,08 & 24,19 & 224,76 \\
\hline Epidalea calamita & 29SPB10 & 83,00 & 172,73 & 90,49 & 41,49 & 4345,16 & 291,22 & 75,65 & 215,57 & 128,91 & 227,13 & 231,16 & 120,17 & 499,02 & 81,41 & 1,00 & 68,00 & 236,81 & 14,28 & 18,78 & 220,00 \\
\hline Epidalea calamita & 29SPB11 & 99,00 & 168,63 & 92,33 & 41,09 & 4481,92 & 291,86 & 70,19 & 221,67 & 123,23 & 224,88 & 228,95 & 114,35 & 520,10 & 83,18 & 1,01 & 66,93 & 242,62 & 16,15 & 20,50 & 226,66 \\
\hline Epidalea calamita & 29SPB14 & 100,00 & 164,15 & 98,47 & 40,99 & 4808,23 & 300,24 & 62,28 & 237,96 & 114,95 & 224,83 & 228,98 & 106,16 & 543,03 & 83,13 & 1,86 & 63,62 & 243,27 & 19,80 & 23,49 & 230,58 \\
\hline Epidalea calamita & 29SPB15 & 101,00 & 166,02 & 100,20 & 41,00 & 4869,35 & 304,94 & 63,33 & 241,61 & 115,96 & 227,46 & 231,61 & 107,26 & 532,74 & 81,03 & 1,93 & 63,12 & 236,72 & 20,00 & 23,43 & 224,84 \\
\hline Epidalea calamita & 29SPB16 & 100,00 & 169,62 & 101,78 & 41,12 & 4908,01 & 310,38 & 66,19 & 244,19 & 118,84 & 231,52 & 235,58 & 110,12 & 514,27 & 77,93 & 1,73 & 62,67 & 227,15 & 19,65 & 22,79 & 215,99 \\
\hline Epidalea calamita & 29SPB17 & 100,00 & 168,05 & 104,46 & 年11,20 & 5005,48 & 313,51 & 63,50 & 250,01 & $\begin{array}{l}116,38 \\
110,4\end{array}$ & $\begin{array}{l}231,39 \\
\end{array}$ & $\begin{array}{l}235,43 \\
230\end{array}$ & 107,52 & 524,31 & 78,49 & 1,98 & 61,72 & 228,42 & 21,01 & 23,75 & 218,70 \\
\hline Epidalea calamita & 29SPB20 & 11,00 & 174,00 & 89,13 & 41,00 & 4376,00 & 292,25 & 77,00 & 215,25 & 129,75 & 228,88 & 232,88 & 121,00 & 490,25 & 79,25 & 1,00 & 68,00 & 231,00 & 14,00 & 19,00 & 213,38 \\
\hline Epidalea calamita & 29SPB21 & 97,00 & 172,04 & 90,53 & 40,61 & 4512,68 & 293,65 & 73,35 & 220,30 & 125,89 & 228,34 & 232,29 & 116,95 & 501,29 & 79,80 & 1,00 & 66,59 & 232,37 & 14,78 & 20,05 & 215,44 \\
\hline Epidalea calamita & 29SPB23 & 101,00 & 168,25 & 94,56 & 40,32 & 4735,29 & 298,46 & 67,19 & 231,27 & 119,61 & 227,77 & 231,71 & 110,66 & 519,73 & 80,23 & 1,19 & 64,47 & 234,68 & 17,37 & 22,16 & 219,59 \\
\hline Epidalea calamita & 29SPB24 & 100,00 & 165,69 & 97,05 & 40,46 & 4849,47 & 300,64 & 63,40 & 237,24 & 115,70 & 226,89 & 230,83 & 107,08 & 533,69 & 81,11 & 1,86 & 63,31 & 237,35 & 19,21 & 23,72 & 223,55 \\
\hline Epidalea calamita & 29SPB25 & 100,00 & 169,33 & 98,40 & 40,57 & 4894,24 & 306,29 & 66,31 & 239,97 & 118,59 & 231,09 & 234,90 & 110,06 & 513,84 & 77,78 & 1,62 & 62,78 & 227,38 & 18,76 & 23,11 & 214,10 \\
\hline Epidalea calamita & 29SPB26 & 101,00 & 169,08 & 100,77 & 40,72 & 4972,45 & 309,87 & 64,94 & 244,93 & 117,62 & 231,85 & 235,79 & 108,74 & 516,25 & 77,31 & 1,88 & 61,94 & 225,79 & 19,77 & 23,69 & 213,66 \\
\hline Epidalea calamita & 29SPB27 & 100,00 & 167,14 & 103,45 & 40,86 & 5076,86 & 312,47 & 61,61 & 250,86 & 114,53 & 231,33 & 235,27 & 105,58 & 528,04 & 78,16 & 2,00 & 61,08 & 228,12 & 21,14 & 24,51 & 217,42 \\
\hline Epidalea calamita & 29SPB28 & 100,00 & 167,52 & 105,62 & 40,98 & 5143,11 & 316,07 & 60,92 & 255,16 & 113,99 & 232,69 & 236,56 & $\begin{array}{ll}105,07 \\
\end{array}$ & 527,53 & 77, & 2,00 & 60,50 & 225,69 & 21,84 & 24,69 & 216,24 \\
\hline Epidalea calamita & 29SPB31 & 58,00 & 174,81 & 88,67 & 40,00 & 4559,20 & 295,23 & 75,87 & 219,36 & 127,54 & 231,51 & 235,26 & 118,59 & 486,49 & 76,64 & 1,00 & 65,94 & 222,86 & 14,03 & 19,99 & 205,03 \\
\hline Epidalea calamita & 29SPB32 & 101,00 & 173,23 & 90,13 & \begin{tabular}{|l|l|}
39,87 \\
\end{tabular} & $\begin{array}{ll}4653,86 \\
\end{array}$ & 296,81 & 73,27 & 223,54 & 124,94 & 231,23 & 234,90 & 115,92 & 4993,39 & 76,86 & 1,00 & 65,25 & 224,21 & 14,76 & 20,66 & 206,99 \\
\hline Epidalea calamita & 29SPB33 & 100,00 & 172,24 & 92,08 & 39,85 & 4756,22 & 299,82 & 71,13 & 228,69 & 122,83 & 231,68 & 235,45 & 113,82 & 497,26 & 76,39 & 1,00 & 64,32 & 223,32 & 15,71 & 21,49 & 206,86 \\
\hline Epidalea calamita & 29SPB34 & 101,00 & 170,86 & 94,32 & 39,90 & 4859,98 & 302,54 & 68,46 & 234,07 & 120,14 & 231,78 & 235,50 & 111,38 & 504,14 & 76,40 & 1,15 & 63,32 & 223,70 & 16,99 & 22,58 & 208,22 \\
\hline Epidalea calamita & 29SPB35 & 101,00 & 169,60 & 96,90 & 39,96 & 4957,53 & 305,73 & 65,96 & 239,77 & 117,77 & 231,96 & 235,63 & 109,06 & 511,72 & 76,6 & 1,60 & 62,32 & 224,38 & 18,45 & 23,57 & 210,04 \\
\hline Epidalea calamita & 29SPB36 & 99,00 & 171,07 & 98,97 & 40,02 & 5027,06 & 310,27 & 66,23 & 244,03 & 118,48 & 234,36 & 238,01 & 109,54 & 504,43 & 74,85 & $\begin{array}{l}1,000 \\
1,80\end{array}$ & $\begin{array}{ll}61,47 \\
61,4\end{array}$ & 219,22 & $\begin{array}{l}19,43 \\
19,03\end{array}$ & 23,80 & 205,73 \\
\hline Epidalea calamita & 29SPB37 & 101,00 & 168,89 & 101,83 & 40,13 & 5123,45 & 312,79 & 62,74 & 250,05 & 115,32 & 233,65 & 237,34 & 106,44 & 517,24 & 75,86 & 2,00 & 60,68 & 222,11 & 20,43 & 24,79 & 209,98 \\
\hline Epidalea calamita & 29SPB38 & 100,00 & 165,74 & 104,48 & 40,26 & 5217,51 & 314,11 & 58,52 & 255,59 & 111,43 & 231,94 & 235,57 & 102,43 & 536,33 & 77,76 & 2,00 & 60,14 & 227,63 & 22,05 & 25,60 & 217,14 \\
\hline Epidalea calamita & 29SPB39 & 100,00 & 165,47 & 106,32 & 40,48 & 5275,48 & 316,66 & 57,26 & 259,40 & 110,34 & 232,63 & 236,23 & 101,60 & 539,62 & 77,46 & 2,16 & 59,39 & 226,96 & 23,19 & 26,27 & 217,56 \\
\hline Epidalea calamita & 29SPB42 & 100,00 & 174,39 & 87,81 & 39,07 & 4705,30 & 296,40 & 74,27 & 222,13 & 125,04 & 232,76 & 236,31 & 116,11 & 486,66 & 74,96 & 1,00 & 65,00 & 218,79 & 14,07 & 21,01 & 200,46 \\
\hline Epidalea calamita & 29SPB43 & 100,00 & 171,07 & $\begin{array}{l}90,36 \\
90,36\end{array}$ & 39,05 & 4835,05 & 298,26 & $\begin{array}{l}4,21,46 \\
69,\end{array}$ & 228,80 & $\begin{array}{l}120,41 \\
\end{array}$ & 231,39 & \begin{tabular}{|l|}
234,94 \\
\end{tabular} & $\begin{array}{l}111,54 \\
111,54\end{array}$ & $\begin{array}{l}4003,00 \\
503\end{array}$ & 76,14 & $\begin{array}{l}1,000 \\
1,00\end{array}$ & $\begin{array}{ll}63,58 \\
63\end{array}$ & 223,05 & $\begin{array}{l}4,96 \\
15,97 \\
\end{array}$ & 22,78 & 205,61 \\
\hline Epidalea calamita & 29SPB44 & 100,00 & 168,94 & 93,08 & \begin{tabular}{|l|}
39,08 \\
\end{tabular} & 4953,04 & 301,00 & 65,92 & 235,08 & 116,97 & 230,92 & 234,64 & 108,21 & 514,36 & 76,65 & 1,65 & 62,62 & 225,14 & 17,70 & 24,14 & 208,76 \\
\hline Epidalea calamita & 29SPB45 & 101,00 & 167,17 & 95,93 & $\begin{array}{l}39,15 \\
\end{array}$ & 5057,97 & 303,87 & 62,46 & 241,41 & 114,03 & 230,75 & 234,29 & 105,23 & 524,81 & 77,31 & 1,95 & 61,65 & 227,20 & 19,13 & 25,01 & 212,03 \\
\hline Epidalea calamita & 29SPB46 & 101,00 & 170,38 & 97,69 & 39,49 & 5097,67 & 309,21 & 64,66 & 244,55 & 116,60 & 234,40 & 237,99 & 107,66 & 508,40 & 74,47 & 2,00 & 61,12 & 218,77 & 19,17 & 24,74 & 204,27 \\
\hline Epidalea calamita & 29SPB47 & 100,00 & 168,88 & 100,49 & 39,82 & 5191,89 & 311,99 & 61,96 & 250,03 & 114,28 & 234,42 & 237,89 & 105,12 & 517,01 & 75,01 & 2,00 & 60,66 & 220,39 & 20,28 & 25,11 & 207,22 \\
\hline Epidalea calamita & 29SPB48 & 100,00 & 167,76 & 102,78 & 39,96 & 5275,35 & 314,51 & 59,57 & 254,94 & 112,04 & 234,53 & 238,02 & 103,20 & 523,92 & 75,31 & 2,00 & 59,87 & 221,33 & 21,22 & 25,76 & 209,24 \\
\hline Epidalea calamita & 29SPB49 & 100,00 & 166,50 & 105,08 & 40,00 & 5340,31 & 316,69 & 57,41 & 259,28 & 110,07 & 234,41 & 237,71 & 101,40 & 532,89 & 75,91 & 2,06 & 59,35 & 223,19 & 22,59 & 26,21 & 212,30 \\
\hline Epidalea calamita & 29SPB51 & & & & & & & & & & & & & & & & & & & & \\
\hline Epidalea calamita & 29SPB52 & 100,00 & 175,19 & 85,50 & 38,19 & 763,32 & 295,72 & 74,92 & 220,80 & 124,69 & 233,97 & 237,43 & 115,81 & 482,36 & 73,92 & 1,00 & 64,48 & 214,43 & 13,55 & 21,57 & 194,99 \\
\hline Epidalea calamita & $29 \mathrm{SPB53}$ & 101,00 & 172,90 & 87,90 & 38,16 & 4887,35 & 298,20 & 71,02 & 227,18 & 121,10 & 233,55 & 236,92 & 112,13 & 493,46 & 74,73 & 1,01 & 63,42 & 216,54 & 15,33 & 23,12 & 197,79 \\
\hline Epidalea calamita & 29SPB54 & 101,00 & 170,45 & 90,94 & 38,30 & 5007,82 & 300,94 & $\begin{array}{ll}66,97 \\
6\end{array}$ & 233,97 & 117,41 & 232,94 & 236,36 & $\begin{array}{ll}108,48 \\
\end{array}$ & 506,42 & 75,65 & 1,51 & 62,28 & 219,73 & 17,00 & 24,36 & 202,13 \\
\hline Epidalea calamita & 29SPB55 & 99,00 & 166,69 & 94,61 & 38,71 & 5134,48 & 303,20 & 61,36 & 241,84 & 112,48 & 231,25 & 234,60 & 103,59 & 528,04 & 77,56 & 2,00 & 61,28 & 226,42 & 19,01 & 25,85 & 210,22 \\
\hline Epidalea calamita & 29SPB56 & 100,00 & 168,05 & 96,89 & 38,95 & 5204,47 & 307,65 & 61,30 & 246,35 & 112,94 & 233,58 & 236,92 & 103,94 & 520,95 & 76,11 & 2,00 & 60,74 & 221,98 & 19,40 & 25,68 & 206,68 \\
\hline Epidalea calamita & 29SPB57 & 100,00 & 168,52 & 99,30 & 39,05 & 5265,48 & 311,35 & 60,62 & 250,73 & 112,74 & 235,06 & 238,25 & 103,76 & 519,26 & 75, & 2,00 & 60,09 & 219,62 & 20,12 & 25,82 & 205,28 \\
\hline Epidalea calamita & 29SPB58 & 101,00 & 165,17 & 102,30 & 39,26 & 5365,91 & 312,87 & $\begin{array}{l}0,0602 \\
56,02\end{array}$ & 256,85 & 108,46 & 233,42 & $\begin{array}{ll}236,58 \\
\end{array}$ & 年 & 539,10 & 77,02 & 2,18 & 59,31 & 225,79 & 22,22 & 27,10 & 212,91 \\
\hline Epidalea calamita & 29SPB62 & 100,00 & 176,32 & 82,94 & 37,30 & 4827,46 & 295,47 & 75,96 & 219,51 & 124,72 & 235,65 & 238,97 & 115,88 & 476,06 & 73,79 & 1,00 & 64,06 & 209,23 & 13,14 & 22,10 & 188,61 \\
\hline Epidalea calamita & 29SPB63 & 100,00 & 173,50 & 85,69 & 37,29 & 4955,21 & 297,65 & 71,32 & 226,33 & 120,63 & 234,78 & 237,93 & 111,59 & 490,51 & 75,08 & 1,01 & 62,88 & 213,02 & 14,88 & 23,59 & 193,09 \\
\hline Epidalea calamita & 29SPB64 & 100,00 & 171,35 & 89,14 & 37,69 & 5074,96 & 300,92 & 67,29 & 233,63 & 117,19 & 234,48 & 237,69 & 108,34 & \begin{tabular}{|c|}
502,45 \\
\end{tabular} & 75,84 & 1,52 & 62,03 & 215,97 & 16,64 & 24,62 & 197,18 \\
\hline Epidalea calamita & 29SPB65 & 101,00 & 170,61 & 92,24 & 37,94 & 5171,80 & 304,69 & 64,81 & 239,88 & 115,30 & 235 & 238,42 & 106,43 & 507,57 & 75, & 1,94 & 61,13 & 216,36 & 17,85 & 25,54 & 198,55 \\
\hline Epidalea calamita & 29SPB66 & 100,00 & 167,46 & 96 & 38 & 5281,79 & 307 & 59,68 & 247,51 & 111,22 & 233,90 & 237,04 & 102,17 & 526,75 & 77,38 & 2,00 & 60,41 & 222,67 & 19,45 & 26,22 & 206,49 \\
\hline Epidalea calamita & 29SPB68 & 99,00 & 161,51 & 102,50 & 38,98 & 5475,86 & 310,95 & 50,86 & 260,09 & 103,49 & 231,21 & 234,26 & 94,64 & 565,09 & 80,49 & 2,59 & 58,77 & 234,47 & 24,03 & 29,36 & 221,11 \\
\hline Epidalea calamita & 29SPB69 & 101,00 & 160,85 & 104,80 & 39,03 & 5543,35 & 313,78 & $\begin{array}{l}0,17 \\
49,17\end{array}$ & 264,61 & \begin{tabular}{|l|l|}
102,18 \\
\end{tabular} & $\begin{array}{l}231,74 \\
231\end{array}$ & 234,69 & $\begin{array}{l}4,3404 \\
30\end{array}$ & 569,54 & $\begin{array}{l}0,45 \\
80,36 \\
\end{array}$ & 2,99 & 57,97 & 234,49 & 25,62 & 30,24 & 222,24 \\
\hline Epidalea calamita & 29SPB71 & 11,00 & 178,00 & 79,38 & 36,38 & 4854,08 & 293,31 & 77,85 & 215,46 & 125,85 & 236,69 & 240,08 & 116,31 & 471,38 & 74,15 & 1,00 & 64,08 & 205,62 & 12,00 & 22,00 & 183,46 \\
\hline Epidalea calamita & $29 S P B 72$ & 100,00 & 177,28 & 80,30 & 36,32 & 4889,62 & 294,83 & 76,74 & 218,10 & 124,96 & 237,14 & 240 & 115,76 & 471,86 & 74,05 & 1,00 & 63,85 & 205,10 & 12,65 & 22,54 & 183 \\
\hline Epidalea calamita & $295 P B 73$ & 101,00 & 176,50 & 82,76 & 36,45 & 5001,32 & 298,23 & 74,25 & 223,98 & 123,65 & 237,87 & 240,98 & 113,67 & 476,04 & 74,01 & 1,00 & 63,01 & 204,82 & 13,89 & 23,71 & 183,47 \\
\hline Epidalea calamita & 29SPB74 & 100,00 & 174,51 & 86,77 & 36,99 & 5116,97 & 301,96 & 70,11 & 231,86 & 119,42 & 237,91 & 240,89 & 110,45 & 487,26 & 74,79 & 1,03 & 62,14 & 208,15 & 15,20 & 24,17 & 187,95 \\
\hline Epidalea calamita & 29SPB75 & 100,00 & 173,17 & 90,78 & 37,35 & 5223,84 & 306,17 & 66,62 & 239,55 & 116,95 & 238,22 & 241,18 & 108,03 & 497,01 & 75,20 & 1,71 & 61,08 & 210,63 & 16,92 & 25,31 & 191,71 \\
\hline Epidalea calamita & 29SPB76 & 101,00 & 172,13 & 94,68 & 37,97 & 5322,15 & 310,30 & 63,59 & 246 , & 115,01 & 238, & 241, & 105, & 504,11 & 75,30 & 1,99 & 60,38 & 212,14 & 18,20 & 25,85 & 194,57 \\
\hline Epidalea calamita & 29SPB77 & 100,00 & 169,75 & 98,39 & 38,18 & 5425,29 & 313,11 & 59,47 & 253,64 & \begin{tabular}{|l|l|}
111,36 \\
\end{tabular} & 238,29 & 241,06 & 102,64 & 517,79 & 76,19 & 2,01 & 59,74 & 216,32 & \begin{tabular}{|l|l|l|l|l}
19,64 \\
\end{tabular} & 26,46 & 200,12 \\
\hline
\end{tabular}




\begin{tabular}{|c|c|c|c|c|c|c|c|c|c|c|c|c|c|c|c|c|c|c|c|c|c|}
\hline TAXON & UTM & $\mathrm{km} 2$ & B101 & B102 & $\mathrm{BIO3}$ & B104 & B105 & B106 & B107 & B108 & B109 & B1010 & B1011 & BIO12 & B1013 & BIO14 & BIO15 & B1016 & B1017 & B1018 & B1019 \\
\hline Epidalea calamita & 29SPB78 & 101,00 & 163,20 & 102,44 & 38,68 & 5548,81 & 313,16 & 51,22 & 261,94 & 104,07 & 233,97 & 236,76 & 95,18 & 557,05 & 79,98 & 2,45 & 58,67 & 230,14 & 23,44 & 29,16 & 215,80 \\
\hline Epidalea calamita & 29SPB79 & 100,00 & 158,60 & 105,26 & 38,94 & 5641,23 & 313,68 & 45,54 & 268,14 & 98,76 & 231,00 & 233,69 & 89,80 & 585,79 & 82,62 & 3,10 & 57,73 & 239,91 & 26,44 & 31,26 & 227,16 \\
\hline Epidalea calamita & 29SPB81 & 49,00 & 177,89 & 79,56 & 36,00 & 4901,23 & 294,59 & 76,90 & 217,69 & 136,93 & 238,02 & 241,00 & $\begin{array}{r}116,18 \\
\end{array}$ & 476,69 & 75,25 & 1,00 & 63,82 & 206,57 & 12,51 & 22,87 & 183,93 \\
\hline Epidalea calamita & 29SPB82 & 101,00 & 177,98 & 79,33 & 35,82 & 4964,47 & 295,56 & 76,60 & 218,96 & 144,32 & 238,62 & 241,52 & 115,22 & 472,48 & 74,62 & 1,00 & 63,57 & 203,23 & 12,62 & 23,47 & 180,27 \\
\hline Epidalea calamita & 29SPB83 & 99,00 & 177,82 & 81,79 & \begin{tabular}{|c|}
35,97 \\
\end{tabular} & 5067,99 & 299,41 & 74,67 & 224,73 & 146,24 & 239,98 & 242,83 & 113,78 & 473,24 & 74,27 & 1,00 & 62,87 & 202,07 & 13,64 & 23,87 & 179,64 \\
\hline Epidalea calamita & 29SPB84 & 101,00 & 174,38 & 87,23 & 36,64 & 5210,35 & 303,54 & 68,52 & 235,02 & 120,05 & 239,13 & 241,89 & 109,09 & 493,86 & 76,00 & 1,26 & 61,76 & 209,21 & 15,46 & 24,91 & 188,50 \\
\hline Epidalea calamita & 29SPB85 & 100,00 & 172,92 & 91,72 & 37,08 & 5321,27 & 307,98 & 64,69 & 243,29 & 115,49 & 239,49 & 242,16 & 106,45 & 504,88 & 76,49 & 1,83 & 61,00 & 212,53 & 17,19 & 25,68 & 193,27 \\
\hline Epidalea calamita & 29SPB86 & 100,00 & 169,77 & 96,12 & 37,83 & 5442,40 & 311,10 & 59,32 & 251,78 & 111,16 & 238,45 & 241,03 & 102,23 & 523,43 & 77,89 & 2,00 & 60,25 & 218,73 & 18,97 & 26,66 & 201,01 \\
\hline Epidalea calamita & 29SPB87 & 100,00 & 168,34 & 99,61 & 38,00 & 5531,28 & 314,37 & 56,26 & 258,11 & 108,81 & 238,52 & 241,06 & 99,98 & 531,65 & 78,12 & 2,02 & 59,57 & 220,72 & 20,46 & 27,36 & 204,23 \\
\hline Epidalea calamita & 29SPB88 & 100,00 & 162,84 & 103,31 & 38,20 & 5644,99 & 314,91 & 48,97 & 265,94 & 102,43 & 235,01 & 237,46 & 93,42 & 564,64 & 81,17 & 2,69 & 58,47 & 232,19 & 23,76 & 29,72 & 217,38 \\
\hline Epidalea calamita & 29SPB89 & 100,00 & 153,82 & 106,46 & 38,23 & 5757,84 & 312,54 & 38,85 & 273,69 & 92,73 & 228,07 & 230,59 & 83,71 & 620,39 & 86,93 & 3,43 & 57,47 & 252,59 & 28,53 & 33,33 & 239,85 \\
\hline Epidalea calamita & 29SPB90 & & & & & & & & & & & & & & & & & & & & \\
\hline Epidalea calamita & 29SPB91 & 91,00 & 176,63 & 82,44 & 36,29 & 4991,09 & 297,27 & 73,43 & 223,85 & 129,05 & 238,21 & 241,18 & 113,96 & 495,43 & 77,43 & 1,00 & 63,73 & 213,67 & 13,84 & 23,77 & 191,63 \\
\hline Epidalea calamita & 29SPB92 & 101,00 & 176,34 & 83,35 & \begin{tabular}{|l|}
36,08 \\
\end{tabular} & 5092,33 & 299,59 & 72,02 & 227,57 & 134,69 & 239,17 & 242,06 & 112,29 & 493,55 & 77,15 & 1,00 & 63,20 & 211,19 & 14,05 & 24,00 & 189,05 \\
\hline Epidalea calamita & 29SPB93 & 100,00 & 178,35 & 85,09 & \begin{tabular}{|l|l|}
36,17 \\
\end{tabular} & 5167,99 & 304,21 & 72,76 & 231,45 & 147,42 & 242,25 & 244,99 & 113,29 & 482,24 & 75,46 & 1,00 & 62,70 & 205,42 & 14,09 & 24,00 & 183,32 \\
\hline Epidalea calamita & 29SPB94 & 101,00 & 174,68 & 89,65 & 36,78 & 5315,18 & 307,38 & 66,53 & 240,84 & 122,55 & 241,05 & 243,73 & 108,15 & 502,46 & 77,16 & 1,28 & 61,65 & 212,05 & 15,74 & 24,94 & 191,58 \\
\hline Epidalea calamita & 29SPB95 & 99,00 & 169,82 & 94,92 & 37,18 & 5462,90 & 310,08 & 58,89 & 251,19 & 110,79 & 238,72 & 241,25 & 101,85 & 531,43 & 79,77 & 2,00 & 60,74 & 222,38 & 18,52 & 26,68 & 203,61 \\
\hline Epidalea calamita & 29SPB96 & 100,00 & 169,28 & 98,16 & 37,82 & 5549,99 & 313,89 & 56,72 & 257,17 & 109,34 & 239,57 & 242,12 & 100,46 & 534,59 & 79,41 & 2,00 & 60,10 & 222,36 & 19,56 & 27,16 & 204,72 \\
\hline Epidalea calamita & 29SPB97 & 100,00 & 170,11 & 100,77 & 38,00 & 5609,81 & 317,98 & 56,11 & 261,87 & 109,56 & 241,47 & 243,77 & 100,57 & 529,92 & 78,18 & 2,00 & 59,68 & 219,39 & 20,10 & 27,11 & 202,56 \\
\hline Epidalea calamita & 29SPB98 & 100,00 & 164,84 & 104,28 & 38,01 & 5721,95 & 318,91 & 49,21 & 269,70 & $\mid 103,34$ & 238,19 & 240,41 & 94,44 & 558,94 & 80,74 & 2.51 & 58,66 & 229,30 & 23,06 & 29,22 & 214,00 \\
\hline Epidalea calamita & 29SPB99 & 100,00 & 152,23 & 107,69 & 38,00 & 5848,46 & 313,92 & 35,78 & 278,14 & 90,23 & 227,96 & 230,29 & 81,17 & 635,97 & 88,77 & 3,60 & 57,37 & 257,79 & 29,35 & 34,22 & 245,06 \\
\hline Epidalea calamita & $295 P C 00$ & 101,00 & 165,29 & 112,18 & 42,05 & 5145,05 & 322,05 & 59,05 & 263,01 & $\mid \begin{array}{r}\mid 12,51 \\
1121\end{array}$ & 230,68 & 235,07 & $\mid$\begin{tabular}{|l|l|}
103,90 \\
\end{tabular} & 548,84 & 80,47 & 2,00 & 59,99 & 232,29 & 24,28 & 25,03 & 228,07 \\
\hline Epidalea calamita & 29SPC01 & 100,00 & 165,98 & 111,91 & 42,01 & 5165,10 & 322,97 & 59,96 & 263,01 & 112,77 & 231,50 & 236,05 & \begin{tabular}{|l|l|}
104,19 \\
\end{tabular} & 549,03 & 79,49 & 2,02 & 59,40 & 230,39 & 25,61 & 25,86 & 226,94 \\
\hline Epidalea calamita & 29SPC02 & 101,00 & 166,33 & 110,50 & 41,87 & 5160,53 & 322,00 & 60,85 & 261,15 & 112,99 & 231,84 & 236,18 & 104,34 & 552,50 & 78,82 & 2,58 & 58,68 & 229,86 & 26,91 & 27,28 & 227,05 \\
\hline Epidalea calamita & 29SPC03 & 101,00 & 160,69 & 108,62 & 41,23 & 5185,48 & 316,10 & 56,55 & 259,55 & 107,39 & 227,90 & 231,14 & 98,85 & 592,32 & 82,64 & 3,04 & 57,66 & 243,29 & 30,44 & 30,45 & 242,18 \\
\hline Epidalea calamita & 29SPC04 & 100,00 & 161,82 & 106,48 & 41,04 & 5164,14 & 314,94 & 58,80 & 256,14 & 108,27 & 229,01 & 231,91 & 100,14 & 589,98 & 81, & 3,02 & 57,23 & 241,04 & 30,93 & 30,93 & 240,44 \\
\hline Epidalea calamita & $295 P C 05$ & 101,00 & 163,99 & 104,51 & 40,97 & 5131,42 & 314,60 & $\begin{array}{ll}61,82 \\
61\end{array}$ & 252,78 & \begin{tabular}{|l|}
109,97 \\
\end{tabular} & 230,79 & 233,51 & 102,35 & 583,41 & $\begin{array}{l}1,440 \\
80,05\end{array}$ & 3,00 & 57,05 & 237,34 & $\begin{array}{l}31,10 \\
31\end{array}$ & 31,10 & 236,97 \\
\hline Epidalea calamita & 29SPC06 & 100,00 & 163,16 & 102,61 & 40,53 & 5122,15 & 312,29 & 62,04 & 250,25 & 105,59 & 229,36 & 232,55 & 101,71 & 596,58 & 81,61 & 3,75 & 56,34 & 241,45 & 33,24 & 33,24 & 241,42 \\
\hline Epidalea calamita & 29SPC08 & 100,00 & 160,69 & 99,94 & 39,98 & 5139,34 & 308,49 & 60,77 & 247,72 & 99,37 & 228,08 & 230,42 & 99,08 & 640,14 & 87,99 & 4,12 & 55,88 & 258,78 & 36,81 & 36,81 & 258,78 \\
\hline Epidalea calamita & $29 \mathrm{SPC} 10$ & 101,00 & 168,64 & 109,86 & 41,74 & 5166,21 & 322,54 & 61,98 & 260,56 & 115,16 & 234,22 & 238,31 & 106,22 & 527,47 & 76,84 & 2,00 & 59,79 & 222,91 & 23,19 & 24,74 & 216,76 \\
\hline Epidalea calamita & 29SPC11 & 101,00 & 167,94 & 110,49 & 41,60 & 5210,14 & 323,28 & 61,00 & 262,28 & 113,82 & 234,09 & 238,19 & 105,04 & 534,53 & 76,94 & 2,02 & 59,23 & 223,80 & 24,49 & 25,59 & 218,77 \\
\hline Epidalea calamita & 29SPC12 & 99,00 & 167,73 & 109,94 & 411,19 & 5225,10 & 323,02 & $\begin{array}{l}1,00,97 \\
60\end{array}$ & 262,05 & \begin{tabular}{|l|l|}
113,38 \\
11
\end{tabular} & \begin{tabular}{|l|}
234,04 \\
\end{tabular} & \begin{tabular}{|l|}
238,20 \\
\end{tabular} & \begin{tabular}{|l|}
104,57 \\
104
\end{tabular} & 540,49 & 76,70 & 2,27 & 58,39 & 224,17 & $\begin{array}{l}24,4518 \\
26,18\end{array}$ & 27,20 & 219,97 \\
\hline Epidalea calamita & 29SPC13 & 101,00 & 160,51 & 109,02 & 41,00 & 5282,23 & 317,10 & 54,79 & 262,31 & 105,93 & 228,42 & 232,21 & 97,33 & 589,14 & 81,72 & 3,00 & 57,24 & 240,98 & 30,63 & 30,77 & 238,69 \\
\hline Epidalea calamita & 29SPC18 & 101,00 & 160,60 & 102,15 & 39,90 & 5255,88 & 311,74 & 58,30 & 253,45 & 102,59 & 228,97 & 231,89 & 97,68 & 638,67 & 86,96 & 4,34 & 55,44 & 256,29 & 37,43 & 37,43 & 256,26 \\
\hline Epidalea calamita & 29SPC19 & 101,00 & 161,79 & 101,60 & 39,82 & 5264,89 & 312,60 & 59,40 & 253,21 & 104,32 & 229,51 & 233,04 & 98,68 & 646,77 & 88,31 & 4,52 & 55,33 & 259,77 & 38,18 & 38,21 & 259,71 \\
\hline Epidalea calamita & 29SPC21 & 100,00 & 168,08 & 109,25 & 41,01 & 5274,95 & 322,74 & 60,09 & 262,65 & 113,04 & 235,19 & 238,98 & $\begin{array}{r}104,03 \\
\end{array}$ & 530,51 & 75,64 & 2,06 & 58,64 & 220,93 & 24,62 & 26,39 & 214,45 \\
\hline Epidalea calamita & $295 P C 22$ & $\begin{array}{l}101,00 \\
100\end{array}$ & $\begin{array}{l}10,080 \\
168,42\end{array}$ & 109,29 & 年1 40,91 & 5297,34 & 323,47 & $\begin{array}{l}60,32 \\
60,32\end{array}$ & \begin{tabular}{|l|}
263,15 \\
263
\end{tabular} & $\begin{array}{l}113,02 \\
113,0\end{array}$ & $\mid$ & \begin{tabular}{|l|}
239,61 \\
2396
\end{tabular} & \begin{tabular}{|l|}
104,16 \\
104,
\end{tabular} & $\mid$\begin{tabular}{|l|l|l}
533,19 \\
\end{tabular} & 75,13 & 2,37 & $\begin{array}{l}0,0,04 \\
58,07\end{array}$ & \begin{tabular}{|l|}
220,33 \\
22,3
\end{tabular} & $\begin{array}{l}24,024 \\
25,82\end{array}$ & $\mid \begin{array}{l}\mid 2,335 \\
27,36\end{array}$ & $\begin{array}{l}214,45 \\
214,65\end{array}$ \\
\hline Epidalea calamita & 29SPC23 & 100,00 & 165,26 & 109,13 & 40,97 & 5331,75 & 321,37 & 57,58 & 263,80 & 109,62 & 233,19 & 237,03 & 100,88 & 556,98 & 77,25 & 3,00 & 57,18 & 227,79 & 28,54 & 29,44 & 223,46 \\
\hline Epidalea calamita & 29SPC25 & 101,00 & 165,01 & 107,59 & 40,39 & 5344,68 & 320,41 & 58,02 & 262,39 & 109,00 & 233,26 & 236,94 & 100,45 & 569,88 & 77,21 & 3,12 & 55,98 & 230,09 & 31,34 & 31,72 & 227,01 \\
\hline Epidalea calamita & $29 S P C 26$ & 100,00 & 163,38 & 106,58 & 40,03 & 5357,52 & 318,45 & 57,03 & 261,42 & 107,29 & 231,94 & 235,68 & 98,68 & 588,79 & 78,97 & 3,99 & 55,43 & 236,50 & 33,58 & 33,74 & 234,22 \\
\hline Epidalea calamita & 29SPC27 & 101,00 & 163,06 & 105,66 & 40,00 & 5364,20 & 317,54 & 57,23 & 260,31 & 106,79 & 231,86 & 235,42 & 98,44 & 602,02 & 80,68 & 4,00 & 55,12 & 240,99 & 35,23 & 35,36 & 239,16 \\
\hline Epidalea calamita & 295PC30 & $\begin{array}{l}101,00 \\
101,00\end{array}$ & $\begin{array}{l}100,00 \\
166,07\end{array}$ & $\begin{array}{l}1007,00 \\
107,70\end{array}$ & $\begin{array}{l}40,00 \\
40,62\end{array}$ & 5320,27, & 31,24 & $\begin{array}{l}\mid l, 25 \\
57,17 \\
\end{array}$ & \begin{tabular}{|l|}
262,14 \\
262,14
\end{tabular} & \begin{tabular}{|l|l|}
110,25 \\
11,5
\end{tabular} & \begin{tabular}{|l|}
233,87 \\
23,80
\end{tabular} & \begin{tabular}{|l|}
237,42 \\
237,53
\end{tabular} & \begin{tabular}{|l|}
90,44 \\
101,40
\end{tabular} & \begin{tabular}{|l|}
538,07 \\
538,07
\end{tabular} & $\begin{array}{l}0,06 \\
76,59 \\
\end{array}$ & $\frac{4,6}{2,3}$ & 58,12 & \begin{tabular}{|l|}
224,42 \\
22,4
\end{tabular} & $\begin{array}{l}3,25 \\
24,33 \\
\end{array}$ & $\begin{array}{l}3,30 \\
27,07 \\
\end{array}$ & $\begin{array}{l}23,10 \\
215,93\end{array}$ \\
\hline Epidalea calamita & 29SPC31 & 100,00 & 166,25 & 108,74 & 40,75 & 5373,15 & 321,21 & 56,92 & 264,29 & 109,87 & 234,71 & 238,28 & 101,01 & 540,34 & 75,98 & 2,89 & 57,64 & 223,15 & 26,13 & 28,48 & 215,62 \\
\hline Epidalea calamita & $29 S P C 32$ & 10000 & 168,44 & 108.99 & 40.68 & 537766 & 32378 & 58.78 & 26500 & 111,72 & 236.88 & 240.46 & 103.10 & 530.80 & 74,13 & 280 & 57.45 & 218.09 & 26,20 & 28,24 & 21101 \\
\hline Epidalea calamita & 29SPC33 & 100,00 & 168,65 & 109,01 & 40,4 & 5392,90 & 324,63 & 58,97 & 265,66 & 111,64 & 237,36 & 240,86 & 103,12 & 533,38 & 73,8 & 2,9 & 56,89 & 217,75 & 27,26 & 28,95 & 211,42 \\
\hline Epidalea calamita & $295 P C 34$ & 101,00 & $\begin{array}{l}167,87 \\
167\end{array}$ & 109,05 & 4 & 5414,99 & 324,4 & 58,33 & 266,15 & $\begin{array}{l}110,67 \\
110\end{array}$ & 236,92 & 240,31 & $\mid$ & 542,35 & 74,31 & 3,00 & 56,41 & 220,05 & 28,47 & 29,80 & 214,46 \\
\hline Epidalea calamita & 29SPC35 & 100,00 & 167,02 & 108,80 & 40, & 5433,43 & 323,99 & 57,58 & 266,41 & 109,55 & 236,34 & 239,79 & 101,03 & 553,34 & 75,23 & 3,16 & 55,95 & 223,18 & 30,26 & 31,26 & 218,25 \\
\hline Epidalea calamita & 29SPC36 & 101,00 & 164,36 & 108,31 & 40,00 & 5467,16 & 321,97 & 55,28 & 266,69 & 106,72 & 234,42 & 237,79 & 98,15 & 577,66 & 77,96 & 3,98 & 55,18 & 231,45 & 33,13 & 33,78 & 227,34 \\
\hline Epidalea calamita & 29SPC37 & 100,00 & 165,27 & 107,92 & 40,00 & 5472,45 & 322,58 & 56,23 & 266,34 & 107,39 & 235,64 & 238,79 & 98,97 & 581,16 & 78,36 & 4,00 & 54,85 & 232,22 & 34,01 & 34,58 & 228,44 \\
\hline Epidalea calamita & $29 S P C 38$ & 100,00 & 162,29 & 106,91 & 39,89 & 5492,93 & 319,66 & 54,09 & 265,57 & 104,35 & 233,02 & 236,21 & 95 & 614,36 & 82,31 & 4,41 & 54,57 & 89 & 36,96 & 37,18 & 241,92 \\
\hline Epidalea calamita & $295 \mathrm{PC} 39$ & $\begin{array}{l}101,00 \\
100\end{array}$ & $\frac{10,25}{158,32}$ & 105,42 & 39 & 5511,46 & 315 & 54,43 & \begin{tabular}{|l|}
264,37 \\
264
\end{tabular} & \begin{tabular}{|l|}
$100,70,0$ \\
\end{tabular} & $\begin{array}{l}229,73< \\
229\end{array}$ & \begin{tabular}{|l|}
232,91 \\
232
\end{tabular} & $\begin{array}{l}30,00 \\
92,33\end{array}$ & \begin{tabular}{|l|l|}
658,86 \\
\end{tabular} & $\begin{array}{l}\mid 20,11 \\
88,45 \\
\end{array}$ & $\begin{array}{l}4,44 \\
5,04\end{array}$ & 54,28 & \begin{tabular}{|l|}
262,54 \\
262
\end{tabular} & $\begin{array}{l}30,31 \\
40,31\end{array}$ & $\begin{array}{l}1,100 \\
40,40\end{array}$ & $\begin{array}{l}241,52 \\
260,37\end{array}$ \\
\hline Epidalea calamita & 29SPC40 & 101,00 & 164,01 & 106,92 & 40,01 & 5409,63 & 317,65 & 54,14 & 263,51 & 107,14 & 233,05 & 236,42 & 98,43 & 550,22 & 77,29 & 2,92 & 57,95 & 227,62 & 25,75 & 28,88 & 218,07 \\
\hline Epidalea calamita & $295 P C 41$ & 100,00 & 166,05 & 108,00 & 40,01 & 5437,09 & 321,08 & 55,40 & 265,69 & 108,56 & 235,40 & 238,69 & $\begin{array}{l}99,84 \\
9\end{array}$ & 540,63 & 75,50 & 3,00 & 57,42 & 222,30 & 26,20 & 29,02 & 213,41 \\
\hline Epidalea calamita & 29SPC42 & 100,00 & 168,63 & 108,80 & 40,06 & 5456,22 & 324,43 & 57,49 & 266,93 & 110,51 & 238,29 & 241,35 & 102,19 & 527,43 & 73,36 & 2,99 & 56,99 & 215,81 & 26,20 & 28,86 & 207,36 \\
\hline Epidalea calamita & $29 S P C 44$ & 100,00 & 168,91 & 109,81 & 40,04 & 5516,29 & 327,01 & 57,07 & 269,94 & 110,10 & 239,67 & 242 & 101 & 531,63 & 73,28 & 3,00 & 56,19 & 215,10 & 27,82 & 29,73 & 207 \\
\hline Epidalea calamita & $\begin{array}{l}295 \mathrm{PSC} 45 \\
\end{array}$ & $\begin{array}{l}100,00 \\
\end{array}$ & $\begin{array}{l}100,51 \\
168,72\end{array}$ & $\begin{array}{l}109,01 \\
109,90\end{array}$ & 40,02 & 5520,70 & 327,46 & 56,84 & \begin{tabular}{|l|}
270,62 \\
27
\end{tabular} & \begin{tabular}{|l|}
109,73 \\
10,0
\end{tabular} & \begin{tabular}{|l|}
239,59 \\
230
\end{tabular} & \begin{tabular}{|l|}
242,28 \\
\end{tabular} & $\begin{array}{l}101,23 \\
101,23\end{array}$ & \begin{tabular}{|l|}
536,43 \\
56,3
\end{tabular} & $\begin{array}{l}\mid 5,20 \\
73,75\end{array}$ & $\begin{array}{l}3,002 \\
3,02\end{array}$ & $\begin{array}{l}5,110 \\
5,77\end{array}$ & \begin{tabular}{|l|}
215,92 \\
210
\end{tabular} & $\begin{array}{l}\mid l 1,026 \\
28,96 \\
\end{array}$ & \begin{tabular}{|l|l|}
30,40 \\
3
\end{tabular} & 2009,14 \\
\hline Epidalea calamita & $29 \mathrm{SPC} 46$ & 100,00 & 168,21 & 110,05 & 40,00 & 5541,22 & 327,67 & 56,19 & 271,48 & 108,93 & 239,34 & 242,04 & 100,49 & 546,01 & 74,72 & 3,51 & 55,06 & 218,49 & 31,15 & 32,31 & 212,21 \\
\hline Epidalea calamita & 29SPC48 & 100,00 & 166,22 & 109,81 & 39,98 & 5599,39 & 326,71 & 54,12 & 272,59 & 106,36 & 238,41 & 241,00 & 98,04 & 575,10 & 78,17 & 4,08 & 54,29 & 228,73 & 34,55 & 35,15 & 223,27 \\
\hline Epidalea calamita & $29 S P C 50$ & 100,00 & 165,21 & 106,32 & 39,84 & 5479,81 & 318,78 & 54,19 & 264,59 & 107,29 & 235, & 238, & 98, & 542,76 & 76,27 & 2,73 & 57,73 & 223,62 & 25,01 & 28,78 & 212,74 \\
\hline Epidalea calamita & $29 S P C 51$ & 101,00 & 167,10 & 107,59 & 39,88 & 5507,90 & 322,31 & 55,03 & 267,28 & 108,55 & 237,41 & 240,46 & 99,80 & 533,46 & 74,70 & 3,00 & 57,20 & 218,51 & 25,75 & 29,11 & 208,22 \\
\hline
\end{tabular}




\begin{tabular}{|c|c|c|c|c|c|c|c|c|c|c|c|c|c|c|c|c|c|c|c|c|c|}
\hline TAXON & UTM & $\mathrm{km} 2$ & B101 & B102 & $\mathrm{BIO3}$ & B104 & B105 & B106 & B107 & B108 & B109 & BIO10 & B1011 & BIO12 & B1013 & BIO14 & BIO15 & BIO16 & B1017 & B1018 & B1019 \\
\hline Epidalea calamita & 29SPC52 & 100,00 & 168,43 & 108,65 & 39,99 & 5543,99 & 325,30 & 55,72 & 269,58 & 109,37 & 239,34 & 242,17 & 100,59 & 526,22 & 73,52 & 3,00 & 56,66 & 214,39 & 26,14 & 29,12 & 204,65 \\
\hline Epidalea calamita & 29SPC53 & 100,00 & 166,86 & 109,71 & 39,99 & 5586,67 & 325,93 & 53,65 & 272,28 & 107,14 & 238,44 & 241,20 & 98,53 & 537,68 & 74,58 & 3,00 & 56,35 & \begin{tabular}{|l|l|}
217,67 \\
\end{tabular} & 27,47 & 29,91 & 208,80 \\
\hline Epidalea calamita & 29SPC54 & 100,00 & 167,86 & 110,35 & 40,00 & 5602,91 & 327,94 & 54,27 & 273,67 & 107,78 & 239,81 & 242,30 & 99,23 & 534,37 & 73,98 & 3,03 & 55,77 & 215,26 & 28,15 & 30,24 & 206,77 \\
\hline Epidalea calamita & 29SPC55 & 101,00 & 166,82 & 111,02 & \begin{tabular}{l|l}
39,95 \\
\end{tabular} & 5639,14 & 328,46 & 52,88 & 275,58 & 106,43 & 239,38 & 241,86 & 97,84 & 543,21 & 74,81 & 3,39 & 54,97 & 217,40 & 30,10 & 31,80 & 209,48 \\
\hline Epidalea calamita & 29SPC57 & 100,00 & 168,13 & 111,79 & 39,96 & $\begin{array}{lll}5684,87 \\
\end{array}$ & 331,09 & 53,09 & 278,00 & 106,93 & 241,54 & 243,71 & 98,65 & 543,91 & 74,76 & 3,99 & 53,94 & \begin{tabular}{|l|l|}
215,79 \\
\end{tabular} & 32,57 & 33,71 & 208,22 \\
\hline Epidalea calamita & 29SPC58 & 100,00 & 168,60 & 112,24 & 39,97 & 5700,35 & 332,14 & 53,08 & 279,07 & 107,03 & 242,20 & 244,23 & 98,73 & 546,20 & 75,06 & 4,00 & 53,57 & 216,33 & 33,25 & 34,09 & 208,90 \\
\hline Epidalea calamita & 29SPC59 & 100,00 & 167,52 & 112,36 & 39,84 & 5728,25 & 331,77 & 51,96 & 279,81 & 105,68 & 241,69 & 243,64 & 97,36 & 562,54 & 76,98 & 4,17 & 53,42 & 222,29 & 35,05 & 35,62 & 215,23 \\
\hline Epidalea calamita & 295PC60 & 100,00 & 163,18 & 106,26 & 39,15 & 5569,55 & 317,99 & 50,66 & 267,33 & 104,12 & 234,43 & 237,22 & 95,19 & 556,04 & 78,26 & 2,98 & 57,41 & 227,75 & 25,89 & 29,93 & 216,04 \\
\hline Epidalea calamita & 29SPC61 & 100,00 & 162,79 & 107,89 & \begin{tabular}{|c|}
39,17 \\
\end{tabular} & 5622,32 & 320,55 & 49,19 & 271,36 & 103,19 & 234,95 & 237,86 & 94,22 & 558,30 & 78,06 & 3,08 & 56,97 & 227,34 & 26,79 & 30,50 & 216,45 \\
\hline Epidalea calamita & 29SPC62 & 100,00 & 167,16 & 108,97 & \begin{tabular}{|l|l|}
39,37 \\
\end{tabular} & 5633,15 & 325,76 & 52,92 & 272,84 & 107,02 & 239,42 & 241,86 & 98,14 & 532,84 & 74,71 & 3,00 & 56,49 & \begin{tabular}{|l|l|}
216,13 \\
\end{tabular} & 26,27 & 29,60 & 205,40 \\
\hline Epidalea calamita & 29SPC63 & 101,00 & 165,10 & 110,21 & 39,51 & 5678,03 & 326,27 & 50,42 & 275,85 & 104,51 & 238,20 & 240,63 & 95,64 & 545,39 & 75,90 & 3,00 & 56,10 & 219,89 & 27,74 & 30,49 & 209,94 \\
\hline Epidalea calamita & 29SPC64 & 101,00 & 165,09 & 111,09 & 39,43 & 5713,22 & 327,85 & 49,66 & 278,20 & 104,05 & 238,78 & 241,18 & 95,33 & 546,52 & 75,67 & 3,30 & 55,16 & 218,88 & 29,32 & 31,59 & 209,42 \\
\hline Epidalea calamita & 29SPC65 & 99,00 & 164,63 & 111,94 & 39,49 & 5746,92 & 328,91 & 48,54 & 280,37 & 103,08 & 238,90 & 241,08 & 94,49 & 551,15 & 75,98 & 3,93 & 54,29 & 219,39 & 31,55 & 33,24 & 210,27 \\
\hline Epidalea calamita & 29SPC67 & 100,00 & 163,22 & 112,86 & 39,25 & 5799,65 & 329,68 & 46,44 & 283,24 & 101,10 & 238,40 & 240,30 & 92,42 & 565,42 & 77,51 & 4,10 & 53,61 & 223,34 & 34,08 & 35,10 & 214,86 \\
\hline Epidalea calamita & 29SPC68 & 101,00 & 165,88 & 113,77 & 39,39 & 5827,84 & 333,01 & 48,04 & 284,97 & 102,98 & 241,62 & 243,26 & 94,45 & 550,29 & 75,81 & 4,00 & 53,27 & 216,66 & 33,90 & 34,73 & 207,97 \\
\hline Epidalea calamita & 29SPC69 & 100,00 & 168,82 & 114,62 & 39,47 & 5851,69 & 336,48 & 49,70 & 286,78 & 105,11 & 244,84 & 246,10 & 96,77 & 535,56 & 74,10 & 4,00 & 52,84 & 210,37 & 33,94 & 34,49 & 201,39 \\
\hline Epidalea calamita & $29 S P C 70$ & 100,00 & 161,09 & 106,73 & 38,95 & 5675,07 & 318,19 & 46,80 & 271,38 & 100,66 & 233,89 & 236,54 & 91,70 & 571,07 & 80,41 & 3,15 & 57,24 & 232,70 & 26,59 & 31,03 & 220,35 \\
\hline Epidalea calamita & 29SPC71 & 101,00 & 158,40 & 108,44 & 38,92 & 5732,58 & 318,87 & 43,40 & 275,47 & 97,48 & 232,29 & 234,86 & 88,52 & 587,30 & 81,78 & 3,33 & 56,56 & 237,71 & 28,70 & 32,39 & 226,39 \\
\hline Epidalea calamita & 29SPC72 & 100,00 & 165,22 & 109,58 & \begin{tabular}{|l|l|}
39,03 \\
\end{tabular} & 5735,12 & 326,20 & 49,42 & 276,78 & 103,68 & 239,04 & 241,32 & 95,01 & 543,63 & 76,32 & 3,01 & 56,35 & 219,52 & 26,65 & 30,28 & 208,00 \\
\hline Epidalea calamita & 29SPC73 & 100,00 & 164,62 & 110,88 & 39,01 & 5774,34 & 327,87 & 47,88 & 279,99 & 102,55 & 239,21 & 241,35 & 94,00 & 546,35 & 76,21 & 3,05 & 55,68 & 219,18 & 27,99 & 31,12 & 208,24 \\
\hline Epidalea calamita & 29SPC74 & 100,00 & 162,33 & 111,87 & 39,01 & 5819,58 & 327,60 & 45,12 & 282,49 & 99,79 & 237,63 & 239,69 & 91,24 & 560,86 & 77,5 & 3,71 & 54,81 & 223,50 & 30,66 & 33,10 & 213,25 \\
\hline Epidalea calamita & 29SPC75 & 100,00 & 160,62 & 112,54 & 38,99 & 5859,96 & 327,79 & 43,08 & 284,70 & 97,82 & 236,75 & 238,66 & 89,31 & 570,99 & 78,47 & 4,01 & 54,31 & 226,36 & 32,31 & 34,26 & 216,50 \\
\hline Epidalea calamita & 29SPC79 & 99,00 & $\begin{array}{ll}166,67 \\
\end{array}$ & 115,78 & 39,06 & 5948,78 & 337,34 & 45,49 & 291,85 & 101,73 & 244,35 & 245,09 & 93,47 & 531,21 & 73,60 & 4,00 & 52,15 & \begin{tabular}{|l|}
207,08 \\
\end{tabular} & 34,50 & 35,24 & 196,76 \\
\hline Epidalea calamita & $295 \mathrm{SC} 80$ & 101,00 & 154,66 & 107,93 & 38,41 & 5795,37 & 315,84 & 39,03 & 276,81 & 93,23 & 229,63 & 232,06 & 84,21 & 614,21 & 85,61 & 3,64 & 56,86 & 248,62 & 29,24 & 33,59 & 236,45 \\
\hline Epidalea calamita & $29 \mathrm{SPC} 81$ & 99,00 & 159,18 & 109,25 & 38,81 & 5818,30 & 321,64 & 42,67 & 278,97 & 97,08 & 234,43 & 236,60 & 88,26 & 583,86 & 81,56 & 3,29 & 56,41 & 235,44 & 28,32 & 32,34 & 223,32 \\
\hline Epidalea calamita & 29SPC82 & 101,00 & 160,19 & 110,52 & 38,84 & 5854,69 & 324,58 & 42,86 & 281,71 & 97,50 & 235,97 & 238,01 & 88,63 & 575,40 & 80,09 & 3,43 & 55,90 & 230,86 & 28,88 & 32,50 & 219,15 \\
\hline Epidalea calamita & 29SPC83 & 100,00 & 162,91 & 111,65 & 38,96 & 5873,63 & 328,54 & $\begin{array}{l}42,50 \\
44,51 \\
\end{array}$ & \begin{tabular}{|l|l|}
284,04 \\
\end{tabular} & 99,78 & 238,88 & \begin{tabular}{|l|}
240,86 \\
\end{tabular} & $\begin{array}{l}90,000 \\
91,00\end{array}$ & 557,23 & $\begin{array}{l}77,57 \\
7,5\end{array}$ & $\begin{array}{l}3,45 \\
3,32\end{array}$ & 55,43 & 222,59 & $\begin{array}{l}28,80 \\
281\end{array}$ & 32,01 & 210,99 \\
\hline Epidalea calamita & 29SPC84 & 101,00 & 157,50 & 112,40 & 38,91 & 5936,03 & 326,01 & 39,01 & 286,99 & 93,97 & 234,75 & 236,48 & 85,22 & 589,00 & 80,89 & 4,03 & 54,68 & 233,65 & 32,11 & 34,68 & 222,91 \\
\hline Epidalea calamita & $29 S P C 85$ & 100,00 & 154,08 & 112,77 & 38,61 & 5968,82 & 324,12 & 35,77 & 288,36 & 90,35 & 231,94 & 233,88 & 81,75 & 611,60 & 83,11 & 4,36 & 53,93 & 241,21 & 34,97 & 36,92 & 231,16 \\
\hline Epidalea calamita & $295 \mathrm{SC} 86$ & 100,00 & 156,27 & 113,57 & 38,80 & 5976,05 & 326,95 & 37,27 & 289,67 & 92,08 & 234,28 & 235,96 & 83,77 & 595,57 & 81,03 & 4,27 & 53,38 & 233,99 & 35,05 & 36,73 & 223,79 \\
\hline Epidalea calamita & 29SPC87 & 101,00 & 159,43 & 114,49 & 38,96 & 6000,35 & 331,08 & 39,33 & 291,75 & 94,80 & 237,95 & 239,14 & 86,38 & 570,55 & 78,01 & 4,14 & 52,95 & 223,31 & 34,51 & 36,02 & 212,68 \\
\hline Epidalea calamita & $295 P C 88$ & 100,00 & 163,88 & 115,66 & 39,00 & 5993,57 & 335,55 & $\begin{array}{l}42,50 \\
42,5\end{array}$ & 293,05 & $\begin{array}{l}4,000 \\
98,77\end{array}$ & 242,25 & \begin{tabular}{|l|}
243,16 \\
\end{tabular} & $\begin{array}{l}90,00 \\
90,53 \\
\end{array}$ & 537,45 & $\begin{array}{l}0,131 \\
74,13\end{array}$ & 4,00 & 52,71 & 209,84 & $\begin{array}{l}4,1,1 \\
33,10\end{array}$ & $\begin{array}{l}30,404 \\
34,49\end{array}$ & 198,71 \\
\hline Epidalea calamita & 29SPC89 & 101,00 & 164,90 & 116,08 & 39,00 & 6008,93 & 337,25 & 42,91 & 294,34 & 99,43 & 243,26 & 244,31 & 91,08 & 526,22 & 72,82 & 4,00 & 52,14 & 204,59 & 33,36 & 34,51 & 193,08 \\
\hline Epidalea calamita & 29SPC90 & 100,00 & 155,39 & 109,04 & \begin{tabular}{|l|}
38,17 \\
\end{tabular} & 5882,69 & 318,88 & 38,08 & 280,80 & 92,63 & 231,65 & 233,82 & 83,79 & 613,37 & 85,57 & 3,45 & 56,86 & 247,51 & 28,96 & 33,52 & 234,93 \\
\hline Epidalea calamita & 29SPC91 & 101,00 & 158,57 & 110,27 & 38,30 & 5915,33 & 323,67 & 40,32 & 283,35 & 95,27 & 235,23 & 237,27 & 86,32 & 589,82 & 82,32 & 3,35 & 56,42 & 237,01 & 28,48 & 32,65 & 224,46 \\
\hline Epidalea calamita & 29SPC92 & 99,00 & 153,35 & 111,44 & 38,22 & 5977,65 & 321,58 & 34,63 & 286,95 & 89,59 & 231,15 & 233,13 & 80,78 & 621,02 & 85,31 & 3,99 & 55,51 & 247,66 & 31,83 & 35,31 & 236,26 \\
\hline Epidalea calamita & 29SPC93 & 101,00 & 159,94 & 112,53 & 38,63 & 5969,28 & 328,46 & 40,33 & 288,14 & 95,84 & 237,50 & 239,16 & 87,01 & 576,55 & 79,75 & 3,52 & 55,27 & 229,36 & 29,91 & 33,20 & 217,51 \\
\hline Epidalea calamita & 29SPC94 & 99,00 & 158,64 & 113,32 & 38,53 & 6010,83 & 329,04 & 38,53 & 290,51 & 93,99 & 236,90 & 238,53 & 85,32 & 581,60 & 79,89 & 3,74 & 54,58 & 230,01 & 31,40 & 34,26 & 218,55 \\
\hline Epidalea calamita & 29SPC95 & 101,00 & 153,03 & 113,44 & 38,21 & 6051,86 & 325,26 & 33,25 & 292,01 & 88,29 & 232,23 & 233,77 & 79,68 & 615,80 & 83,41 & 4,51 & 53,75 & 241,99 & 35,09 & 37,22 & 231,30 \\
\hline Epidalea calamita & 29SPC99 & 100,00 & 165,35 & 116,18 & 38,94 & 6062,52 & 338,82 & 42,56 & 296,26 & 99,26 & 244,25 & 245,25 & 90,75 & 516,90 & 71,06 & 4,00 & 51,87 & 200,16 & 32,14 & 34,00 & 187,97 \\
\hline Epidalea calamita & $29 S P D 00$ & 101,00 & 164,58 & 99,37 & 39,79 & 5146,66 & 311,81 & 64,14 & 247,67 & 103,56 & 230,05 & 234,15 & 102,51 & 650,04 & 89,94 & 4,54 & 55,90 & 263,25 & 37,71 & 38,10 & 263,25 \\
\hline Epidalea calamita & $\begin{array}{l}\text { 25SPDO0 } \\
\text { 29SPD01 }\end{array}$ & $\begin{array}{l}101,00 \\
101,00\end{array}$ & $\begin{array}{l}104,50 \\
164,77\end{array}$ & $\begin{array}{l}99,31 \\
98,75 \\
\end{array}$ & 39,30 & $\begin{array}{l}114,0,00 \\
5155,83\end{array}$ & $\begin{array}{l}31,61 \\
311,99\end{array}$ & $\begin{array}{l}64,44 \\
64,27 \\
\end{array}$ & \begin{tabular}{|l|}
247,72 \\
247
\end{tabular} & \begin{tabular}{|l|}
104,12 \\
104,
\end{tabular} & $\mid \frac{\mid 30,03}{230,51}$ & \begin{tabular}{|l|}
234,52 \\
2345
\end{tabular} & \begin{tabular}{|l|}
102,51 \\
102,75
\end{tabular} & $\begin{array}{l}\mid 350,04 \\
667,05 \\
\end{array}$ & \begin{tabular}{|l|l|}
$92,34,81$ \\
92
\end{tabular} & 5,00 & 55,91 & $\begin{array}{l}\mid 203,25 \\
270,59\end{array}$ & $\begin{array}{l}1,1 / 1 \\
38,92\end{array}$ & | & $\begin{array}{l}203,25 \\
270,59\end{array}$ \\
\hline Epidalea calamita & $29 S P D 02$ & 100,00 & 167,21 & 98,91 & 39,28 & 5169,43 & 314,35 & 66,14 & 248,21 & 109,00 & 233,19 & 236,94 & 104,65 & 665,74 & 92,82 & 4,97 & 55,84 & 270,11 & 38,65 & 39,55 & 270,11 \\
\hline Epidalea calamita & 29SPD03 & 101,00 & 167,25 & 98,55 & 39,03 & 5191,98 & 314,55 & 65,88 & 248,68 & 109,20 & 233,68 & 237,16 & 104,42 & 682,99 & 95,73 & 5,00 & 55,90 & 277,45 & 39,46 & 40,56 & 277,45 \\
\hline Epidalea calamita & 29SPD04 & 101,00 & 167,18 & 98,12 & 39,00 & 5207,99 & 314,58 & 65,51 & 249,07 & 108,01 & 233,88 & 237,27 & 104,14 & 701,80 & 98,94 & 5,02 & 55,98 & 285,48 & 40,41 & 41,68 & 285,48 \\
\hline Epidalea calamita & 29SPD05 & 100,00 & 164,19 & 97,09 & 38,45 & 5241,36 & 311,9 & $\begin{array}{l}53,09 \\
63\end{array}$ & 248,88 & \begin{tabular}{|l|l|}
101,06 \\
\end{tabular} & 231,63 & 234,92 & \begin{tabular}{|l|l|}
100,91 \\
\end{tabular} & $\begin{array}{l}747,79 \\
\end{array}$ & \begin{tabular}{|r|}
106,27 \\
\end{tabular} & 5,02 & $\begin{array}{ll}55,64 \\
55\end{array}$ & $\begin{array}{l}0,4,40 \\
304,62 \\
\end{array}$ & $\begin{array}{l}44,26 \\
44,2 \\
\end{array}$ & $\begin{array}{l}41,06 \\
45,40\end{array}$ & $\begin{array}{l}20.04,40 \\
304,62 \\
\end{array}$ \\
\hline Epidalea calamita & 29SPD06 & 101,00 & 162,42 & 96,54 & \begin{tabular}{|l|l|}
38,07 \\
\end{tabular} & 5278,41 & 310,58 & 61,03 & 249,54 & 98,67 & 230,34 & 233,67 & 98,67 & 781,05 & 111,75 & 6,0 & 55,70 & 318,61 & 46,15 & 47,22 & 318,61 \\
\hline Epidalea calamita & 29SPD10 & 100,00 & 161,34 & 100,52 & 39,30 & 5273,02 & 312,03 & 59,57 & 252,46 & $\begin{array}{r}102,42 \\
\end{array}$ & 228,95 & 232,85 & 98,11 & 669,64 & 92,03 & 4,97 & 55,26 & 269,45 & $\begin{array}{l}39,96 \\
39,96\end{array}$ & 40,06 & 269,45 \\
\hline Epidalea calamita & 29SPD11 & 101,00 & 164,59 & 100,59 & 39,14 & 5276,51 & 314,93 & 62,16 & 252,77 & 107,17 & 232,23 & 235,88 & \begin{tabular}{|l|l|}
101,03 \\
\end{tabular} & 662,80 & 91,24 & 5,00 & 55,36 & 266,99 & 39,18 & 39,92 & 266,87 \\
\hline Epidalea calamita & $29 S P D 12$ & 100,00 & 166,36 & 100,31 & 39,03 & 5282,65 & 316,66 & 63,77 & 252,89 & 110,21 & 234,10 & 237,65 & 102,66 & 666,77 & 92,14 & 5,00 & 55,42 & 268,94 & 39,34 & 40,14 & 268,71 \\
\hline Epidalea calamita & 29SPD13 & 100,00 & 165 & $\begin{array}{l}0,51 \\
99,37\end{array}$ & 38,84 & 5312,71 & $\frac{115}{315}$ & $\begin{array}{ll}63,01 \\
63\end{array}$ & \begin{tabular}{|l|}
252,67 \\
25,6
\end{tabular} & \begin{tabular}{|l|}
107,43 \\
10,4
\end{tabular} & 233,46 & \begin{tabular}{|l|}
237,16 \\
237
\end{tabular} & $\begin{array}{l}101,290 \\
101\end{array}$ & $\mid \begin{array}{ll}6904,89 \\
\end{array}$ & $\begin{array}{l}2,14 \\
96,87 \\
\end{array}$ & 5,21 & 55,44 & 280,94 & $\begin{array}{l}35,04 \\
41,01\end{array}$ & $\begin{array}{l}42,06 \\
42,06\end{array}$ & $\begin{array}{l}200,11 \\
280,87\end{array}$ \\
\hline Epidalea calamita & 29SPD14 & 101,00 & 165,21 & 98,75 & 38,55 & 5330,92 & 315,60 & 62,83 & 252,77 & 106,32 & 233,90 & 237,29 & 101,11 & 714,56 & 100,17 & 5,54 & 55,28 & 289,08 & 42,56 & 43,73 & 289,07 \\
\hline Epidalea calamita & 29SPD15 & 99,00 & 162,46 & 97,29 & 38,02 & 5371,46 & 312,91 & 60,64 & $252,27 \mid$ & 98,53 & 231,79 & 235,15 & | & 757.44 & 107,32 & 5,99 & 55,27 & $307,5 \mid$ & 45,20 & 46,33 & 307,57 \\
\hline Epidalea calamita & $29 S P D 16$ & 100,00 & 161,78 & 96,94 & 37,96 & 5407,71 & 312,48 & 59,44 & 253,04 & 96,84 & 231,64 & 234,87 & 96,84 & 780,17 & 111,29 & 6,00 & 55,41 & 317,28 & 46,43 & 47,58 & 317,28 \\
\hline Epidalea calamita & 29SPD17 & 100,00 & 162,40 & 97,18 & 37,83 & 5441,73 & 313,80 & 59,03 & 254,77 & 97,30 & 232,95 & 235,84 & 96 & 787,81 & 112,55 & 6,00 & 55,10 & 319,82 & 47,48 & 48,64 & 315 \\
\hline Epidalea calamita & $29 S P D 20$ & 100,00 & 159,85 & 102,48 & 39,07 & 5401,49 & 313,94 & 55,83 & 258,10 & \begin{tabular}{|c|}
103,21 \\
\end{tabular} & 229,40 & 233,08 & 95,22 & $\begin{array}{l}674,09 \\
\end{array}$ & \begin{tabular}{|c|c|}
91,73 \\
93
\end{tabular} & 5,03 & 54,81 & 269,90 & 40,77 & 40,90 & 269,22 \\
\hline Epidalea calamita & 29SPD21 & 100,00 & 164,55 & 102,79 & 39,06 & 5396,16 & 318,34 & 59,78 & 258,56 & 107,75 & 233,89 & 237,44 & 99,64 & 654,05 & 88,96 & 5,00 & 54,91 & 262,27 & 39,32 & 39,95 & 261,14 \\
\hline Epidalea calamita & 29SPD22 & 100,00 & 166,06 & 102,14 & 39,02 & 5404,88 & 319,60 & 61,34 & 258,25 & 109,06 & 235,63 & 238,95 & 100,95 & 661,05 & 90,44 & 5,06 & 54,90 & 265,60 & 39,65 & 40,57 & 264,47 \\
\hline Epidalea calamita & 29SPD23 & 101,00 & 162,56 & 99,87 & 38,44 & 5420,56 & 315,60 & 59,50 & 256,09 & 105,28 & 232,51 & 236,07 & 97,74 & 712,61 & 98,85 & 5,84 & 54,81 & 286,88 & 43,34 & 44,26 & 286,62 \\
\hline Epidalea calamita & 29SPD24 & 100,00 & 163,64 & 99,38 & 38,08 & 5448,06 & $\frac{1,00}{16,78}$ & 60,27 & 256,51 & 106,05 & 234,11 & 237,44 & 98,42 & 720,95 & 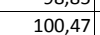 & 5,90 & 54,74 & 290,40 & 43,93 & 45,10 & 290,08 \\
\hline
\end{tabular}




\begin{tabular}{|c|c|c|c|c|c|c|c|c|c|c|c|c|c|c|c|c|c|c|c|c|c|}
\hline TAXON & UTM & $\mathrm{km} 2$ & B101 & B102 & $\mathrm{BIO3}$ & B104 & B105 & B106 & B107 & B108 & B109 & BIO10 & BIO11 & BIO12 & B1013 & BIO14 & BIO15 & B1016 & B1017 & B1018 & B1019 \\
\hline Epidalea calamita & 29SPD25 & 101,00 & 160,69 & 97,33 & 37,76 & 5474,17 & 313,32 & 58,49 & 254,84 & 98,78 & 231,64 & 235,06 & 95,46 & 766,08 & 108,18 & 6,11 & 55,04 & 309,96 & 46,21 & 47,49 & 309,96 \\
\hline Epidalea calamita & 29SPD26 & 101,00 & 160,01 & 96,71 & 37,40 & 5512,44 & 312,78 & 57,41 & 255,37 & 95,55 & 231,52 & 234,88 & 94,22 & 787,61 & 111,94 & 6,14 & 55,06 & 319,04 & 47,62 & 48,89 & 319,04 \\
\hline Epidalea calamita & 29SPD27 & 100,00 & 161,47 & 97,40 & 37,06 & 5567,78 & 315,33 & 57,12 & 258,21 & 98,03 & 233,97 & 236,64 & 94,68 & 784,94 & 111,68 & 6,06 & 54,87 & 317,36 & 47,71 & 48,92 & 317,33 \\
\hline Epidalea calamita & 29SPD28 & 101,00 & 163,53 & 98,34 & 37,12 & 5619,06 & 318,43 & 57,26 & 261,16 & 101,12 & 236,92 & 238,95 & 95,64 & 774,94 & 110,22 & 5,99 & 54,79 & 312,52 & 47,14 & 48,58 & 312,37 \\
\hline Epidalea calamita & 29SPD29 & 101,00 & 165,74 & 99,41 & 37,31 & 5638,23 & 320,90 & 57,92 & 262,98 & \begin{tabular}{|l|}
103,96 \\
\end{tabular} & 239,38 & 240,89 & 97,06 & 762,84 & 108,38 & 5,99 & 54,66 & 306,90 & $\begin{array}{ll}46,46 \\
\end{array}$ & 48,16 & 306,55 \\
\hline Epidalea calamita & 29SPD30 & 100,00 & 161,50 & 105,37 & 39,15 & 5515,50 & 318,91 & 54,19 & 264,71 & 103,47 & 232,66 & 236,00 & 95,16 & 649,40 & 87,17 & 5,00 & 54,22 & 259,03 & 39,70 & 40,00 & 256,64 \\
\hline Epidalea calamita & 29SPD31 & 101,00 & 164,08 & 105,16 & 39,06 & 5516,52 & 321,40 & 56,66 & 264,73 & 105,84 & 235,25 & 238,34 & 97,68 & 647,09 & 86,94 & 5,00 & 54,20 & 258,42 & 39,55 & 40,13 & 255,93 \\
\hline Epidalea calamita & 29SPD32 & 101,00 & 164,90 & 104,14 & 38,99 & 5524,03 & 321,94 & 57,97 & 263,97 & 106,51 & 236,26 & 239,30 & 98,44 & 659,01 & 89,18 & 5,07 & 54,34 & 263,67 & 40,15 & 41,02 & 261,42 \\
\hline Epidalea calamita & 29SPD34 & 101,00 & 160,24 & 99,30 & $\begin{array}{l}37,85 \\
\end{array}$ & 5550,93 & 315,39 & 56,72 & 258,67 & 102,24 & 232,29 & 235,74 & 94,27 & 740,95 & 103,04 & 6,14 & 54,40 & 298,01 & 45,47 & 46,65 & 297,21 \\
\hline Epidalea calamita & 29SPD35 & 100,00 & 150,96 & 93,90 & 36,71 & 5549,48 & 303,30 & 51,48 & 251,82 & 87,76 & 223,30 & 227,27 & 86,22 & 847,69 & 120,82 & 7,24 & 54,84 & 343,56 & 52,06 & 53,06 & 343,56 \\
\hline Epidalea calamita & 29SPD36 & 101,00 & 153,98 & 94,90 & 36,77 & 5604,19 & 307,60 & 52,43 & 255,18 & 91,66 & 227,18 & 230,49 & 87,92 & 831,12 & 118,49 & 6,95 & 54,64 & 336,25 & 51,13 & 52,08 & 336,14 \\
\hline Epidalea calamita & 29SPD37 & 100,00 & 162,36 & 98,66 & $\begin{array}{l}37,05 \\
\end{array}$ & 5674,95 & 318,45 & 56,13 & 262,32 & 101,76 & 236,42 & 238,79 & 94,20 & 758,86 & 106,97 & 5,99 & 54,36 & 305,26 & 46,45 & 47,80 & 304,45 \\
\hline Epidalea calamita & 29SPD38 & 101,00 & 162,82 & 98,87 & 36,98 & 5732,46 & 319,80 & 55,39 & 264,41 & 101,39 & 237,89 & 239,77 & 93,75 & 761,73 & 107,66 & 5,93 & 54,35 & 305,98 & 46,83 & 48,18 & 305,15 \\
\hline Epidalea calamita & 29SPD40 & 100,00 & 160,85 & 107,88 & 39,32 & 5634,39 & 321,61 & 50,65 & 270,96 & 101,18 & 233,86 & 236,68 & 93,03 & 641,53 & 85,81 & 5,19 & 53,71 & 254,70 & 40,13 & 40,43 & 250,73 \\
\hline Epidalea calamita & 29SPD41 & 100,00 & 162,43 & 107,64 & 39,01 & 5644,46 & 323,51 & 52,29 & 271,22 & 102,49 & 235,74 & 238,27 & 94,25 & 645,10 & 86,31 & 5,02 & 53,74 & 256,50 & 40,14 & 40,61 & 252,58 \\
\hline Epidalea calamita & $29 S P D 42$ & 100,00 & 164,73 & 107,12 & 39,01 & 5646,44 & 325,62 & 54,64 & 270,98 & 104,53 & 238,01 & 240,52 & 96,53 & 643,72 & 86,33 & 5,01 & 53,71 & 256,23 & 39,98 & 40,80 & 252,39 \\
\hline Epidalea calamita & $29 \mathrm{SPD} 43$ & 99,00 & 163,16 & 104,89 & 38,67 & 5647,58 & 323,13 & 54,71 & 268,42 & 103,38 & 236,58 & 239,30 & 95,26 & 675,98 & 91,26 & 5,35 & 53,69 & 269,65 & 42,25 & 43,30 & 266,46 \\
\hline Epidalea calamita & 29SPD44 & 101,00 & 155,18 & 99,28 & 37,57 & 5640,11 & 312,16 & 51,31 & 260,85 & 96,60 & 228,72 & 232,15 & 88,58 & 767,07 & 106,42 & 6,42 & 54,01 & 307,69 & 47,74 & 48,74 & 306,19 \\
\hline Epidalea calamita & 29SPD45 & 99,00 & 145,56 & 94,44 & 36,50 & 5659,10 & 300,09 & 44,74 & 255,35 & 86,12 & 220,27 & 223,39 & 79,69 & 866,89 & 122,89 & 7,64 & 54,20 & 348,96 & 54,20 & 54,73 & 348,51 \\
\hline Epidalea calamita & 29SPD46 & 100,00 & 156,64 & 97,92 & 36,98 & 5715,55 & 313,60 & 51,85 & 261,75 & 96,79 & 231,46 & 234,36 & 88,84 & 779,71 & 109,38 & 6,38 & 54,05 & 313,09 & 48,41 & 49,55 & 311,72 \\
\hline Epidalea calamita & 29SPD47 & 100,00 & 161,78 & 99,90 & 37,00 & 5777,09 & 320,23 & 53,95 & 266,28 & 100,13 & 237,49 & 239,55 & 92,44 & 738,82 & 103 & 5,96 & 53,79 & 295,82 & 45,84 & 47,24 & 293,69 \\
\hline Epidalea calamita & 29SPD49 & 99,00 & 164,02 & 100,39 & 36,89 & 5853,23 & 323,01 & 53,88 & 269,13 & 100,56 & 240,91 & 242,15 & 93,07 & 730,46 & 102,34 & 5,78 & 53,71 & 291,92 & 45,35 & 46,81 & 289,43 \\
\hline Epidalea calamita & 29SPD50 & 101,00 & 161,35 & 110,94 & 39,34 & 5753,36 & 325,81 & 47,58 & 278,22 & 99,84 & 236,19 & 238,25 & 91,60 & 621,37 & 83,68 & 5,08 & 53,01 & 245,32 & 39,71 & 39,97 & 239,52 \\
\hline Epidalea calamita & 29SPD51 & 100,00 & 164,01 & 111,44 & 39,36 & 5761,51 & 328,97 & 49,73 & 279,23 & 102,11 & 239,04 & 240,87 & 93,99 & 614,70 & 82,82 & 4,99 & 52,89 & 242,76 & 39,40 & 39,88 & 236,78 \\
\hline Epidalea calamita & 29SPD52 & 101,00 & 166,26 & 111,13 & 39,15 & 5767,16 & 331,38 & 51,92 & 279,45 & 104,00 & 241,34 & 243,14 & 96,06 & 610,44 & 82,21 & 4,99 & 52,86 & 241,30 & 38,96 & 39,79 & 235,35 \\
\hline Epidalea calamita & 29SPD53 & 101,00 & 162,51 & 107,88 & 38,71 & 5768,06 & 326,25 & 50,88 & 275,37 & 100,99 & 237,82 & 239,95 & 92,98 & 656,75 & 87,85 & 5,19 & 52,99 & 260,40 & 41,79 & 42,66 & 255,47 \\
\hline Epidalea calamita & 29SPD54 & 100,00 & 159,58 & 104,37 & 37,96 & 5772,25 & 321,21 & 50,21 & 271,00 & $\begin{array}{l}98,48 \\
98,\end{array}$ & $\begin{array}{l}235,00 \\
23\end{array}$ & 237,44 & $\begin{array}{l}90,46 \\
90\end{array}$ & 698,68 & $\begin{array}{l}1,100 \\
94,38 \\
\end{array}$ & 5,69 & 53,15 & 277,95 & 44,20 & 45,22 & 273,87 \\
\hline Epidalea calamita & 29SPD55 & 101,00 & 155,24 & 100,88 & 37,30 & 5793,53 & 315,14 & 48,08 & 267,07 & 94,52 & 231,21 & 233,80 & 86,40 & 749,56 & 103,06 & 6,22 & 53,30 & 298,95 & 47,35 & 48,26 & 295,74 \\
\hline Epidalea calamita & $29 S P D 56$ & 101,00 & 157,86 & 100,85 & 37,00 & 5829,21 & 317,95 & 49,67 & 268,29 & 96,27 & 234,37 & 236,51 & 88,25 & 735,80 & 101,26 & 6,06 & 53,23 & 293,24 & 46,52 & 47,58 & 289,84 \\
\hline Epidalea calamita & 29SPD59 & 101,00 & 163,90 & 101,51 & 36,84 & 5918,49 & 324,06 & 52,29 & 271,77 & 99,59 & 241,73 & 242,68 & 92,03 & 700,88 & 96,96 & 5,47 & 53,10 & 278,58 & 43,96 & 45,45 & 274,74 \\
\hline Epidalea calamita & $29 S P D 60$ & 100,00 & 168,81 & 115,08 & 39,66 & 5867,40 & 337,01 & 49,50 & 287,52 & \begin{tabular}{|l|}
104,80 \\
\end{tabular} & 245,21 & 246,19 & 96,54 & 544,56 & 75,00 & 4,03 & 52,36 & 213,40 & 35,45 & 35,99 & 204,68 \\
\hline Epidalea calamita & 29SPD61 & 100,00 & 167,71 & 115,31 & 39,86 & 5882,00 & 336,11 & |48,61 & \begin{tabular}{|l|l|}
287,49 \\
\end{tabular} & $\begin{array}{l}103,42 \\
100\end{array}$ & \begin{tabular}{|l|}
244,34 \\
242
\end{tabular} & \begin{tabular}{|l|}
245,41 \\
\end{tabular} & $\begin{array}{l}00,4,43 \\
95,4\end{array}$ & 563,84 & 77,06 & 4,32 & 52,19 & 220,94 & 36,92 & $\begin{array}{l}37,50 \\
37,5\end{array}$ & 212,62 \\
\hline Epidalea calamita & 29SPD62 & 100,00 & 165,88 & 114,38 & 39,38 & 5882,08 & 334,61 & 48,07 & 286,54 & 101,80 & 242,73 & 243,80 & 93,97 & 590,70 & 79,85 & 4,86 & 52,16 & 231,85 & 38,45 & 39,20 & 224,20 \\
\hline Epidalea calamita & 29SPD63 & 99,00 & 165,28 & 111,71 & 39,01 & 5881,51 & 332,24 & 49,14 & 283,10 & 101,48 & 242,15 & 243,45 & 93,61 & 608,40 & 81,64 & 4,91 & 52,16 & 239,24 & 39,44 & 40,35 & 232,05 \\
\hline Epidalea calamita & 29SPD64 & 101,00 & 163,57 & 108,86 & 38,40 & 5889,68 & 329,05 & 49,39 & 279,66 & 100,14 & 240,79 & 242,18 & 92,22 & 634,25 & 84,37 & 5,02 & 52,28 & 249,93 & 40,92 & 41,94 & 243,47 \\
\hline Epidalea calamita & 29SPD67 & 100,00 & 160,17 & 102,90 & 37,00 & 5953,39 & 322,70 & 48,59 & 274,10 & 96,39 & 238,64 & 239,99 & 88,50 & 689,63 & 93,57 & 5,52 & 52,62 & 272,83 & 43,92 & 45,00 & 267,58 \\
\hline Epidalea calamita & 29SPD68 & 100,00 & $\frac{10,11}{162,31}$ & 102,78 & 37,01 & 5974,32 & 324,56 & \begin{tabular}{|l|l}
49,86 \\
49,86
\end{tabular} & 274,70 & \begin{tabular}{|l|l|}
97,69 \\
97
\end{tabular} & \begin{tabular}{|l|}
240,94 \\
\end{tabular} & \begin{tabular}{|l|}
242,01 \\
245
\end{tabular} & $\begin{array}{l}0,00 \\
89,96\end{array}$ & \begin{tabular}{|l|l|}
677,68 \\
67,08
\end{tabular} & $\begin{array}{l}\mid 30,17 \\
92,17 \\
\end{array}$ & $\begin{array}{l}5,34 \\
5,34 \\
\end{array}$ & $\begin{array}{ll}52,48 \\
52\end{array}$ & \begin{tabular}{|l|}
267,94 \\
269
\end{tabular} & $\begin{array}{l}43,52 \\
43,03\end{array}$ & $\begin{array}{ll}43,000 \\
44,25\end{array}$ & 262,65 \\
\hline Epidalea calamita & 29SPD69 & 99,00 & 163,36 & 102,63 & 36,88 & 5985,69 & 325,23 & 50,46 & 274,77 & 98,32 & 242,23 & 242,91 & 90,58 & 672,44 & 91,76 & 5,20 & 52,53 & 265,70 & 42,64 & 44,03 & 260,42 \\
\hline Epidalea calamita & 29SPD70 & 101,00 & 168,47 & 116,41 & 39,00 & 5985,76 & 339,92 & 46,32 & 293,60 & \begin{tabular}{r|}
102,76 \\
\end{tabular} & 246,63 & 247,24 & 94,58 & 521,55 & 72,42 & 4,00 & 51,71 & 202,79 & 34,94 & 35,31 & 192,28 \\
\hline Epidalea calamita & 29SPD71 & 100,00 & 168,40 & 116,38 & 39,05 & 5976,06 & 339,55 & 46,77 & 292,79 & 102,82 & 246,31 & 247,10 & 94,75 & 533,62 & 73,51 & 4,00 & 51,58 & 207,55 & 35,67 & 36,27 & 197,40 \\
\hline Epidalea calamita & $29 S P D 72$ & 101,00 & 167,95 & 115,53 & 39,09 & 5969,52 & 338,12 & 47,37 & 290,75 & 102,45 & 245,99 & 246,49 & 94,50 & 549,09 & 74,84 & 4,03 & 51,63 & 214,01 & 36,08 & 36,81 & 204,42 \\
\hline Epidalea calamita & $\begin{array}{l}\text { 25SPDI } \\
29 S P D 73\end{array}$ & $\begin{array}{l}100,00 \\
100,0\end{array}$ & $\begin{array}{l}10,95 \\
164,64\end{array}$ & $\begin{array}{l}111,53 \\
112,88\end{array}$ & 39,09| & $\begin{array}{l}390,50,29 \\
5980,29\end{array}$ & 333,12 & $\begin{array}{l}4,313 \\
46,27 \\
\end{array}$ & \begin{tabular}{|l|}
287,60 \\
287
\end{tabular} & \begin{tabular}{|l|}
$10<, 45$ \\
99,49
\end{tabular} & \begin{tabular}{|l|}
242,99 \\
242,
\end{tabular} & $\begin{array}{l}240,45 \\
243,82 \\
\end{array}$ & $\begin{array}{l}4,50 \\
91,55 \\
\end{array}$ & \begin{tabular}{|l|l|}
586,46 \\
586,
\end{tabular} & \begin{tabular}{|l|}
$4,, 84,71$ \\
781
\end{tabular} & 4,05 & $\begin{array}{l}1,150 \\
51,56\end{array}$ & \begin{tabular}{|l|}
228,94 \\
224
\end{tabular} & $\begin{array}{l}30,00 \\
38,45\end{array}$ & \begin{tabular}{|l|}
30,01 \\
39,36
\end{tabular} & $\begin{array}{l}204,42 \\
220,19\end{array}$ \\
\hline Epidalea calamita & \begin{tabular}{|l|}
$29 S P D 75$ \\
\end{tabular} & 100,00 & 160,41 & 107,47 & 37,79 & 6004,66 & 327,26 & 45,64 & 281,61 & 95,76 & 239,45 & 240,56 & 87,78 & 640,06 & 84,48 & 5,02 & 51,79 & 250,86 & 41,51 & 42,46 & 243,36 \\
\hline Epidalea calamita & 29SPD77 & 100,00 & 163,55 & 105,60 & 37,01 & 6029,43 & 328,94 & 49,05 & 279,88 & 98,36 & 243,08 & 243,80 & 90,37 & 630,06 & 83,43 & 4,99 & 51,70 & 246,92 & 40,79 & 42,02 & 239,72 \\
\hline Epidalea calamita & 29SPD78 & 101,00 & 163,18 & 104,46 & 36,98 & 6042,43 & 327,73 & 48,82 & 278,91 & 97,58 & 242,86 & 243,48 & 89,67 & 638,86 & 85,3 & 4,99 & 51,72 & 250,58 & 41,22 & 42,48 & 243,70 \\
\hline Epidalea calamita & 29SPD79 & 100,00 & 164,08 & 103,93 & 36,99 & $\begin{array}{l}6046,74 \\
6046\end{array}$ & 328,1 & $\begin{array}{l}40,06 \\
49,56 \\
\end{array}$ & 278,56 & 98,21 & \begin{tabular}{|l|}
243,88 \\
\end{tabular} & 244,25 & $\begin{array}{ll}0,47 \\
0,0\end{array}$ & $\begin{array}{l}634,59 \\
\end{array}$ & 85,1 & $\frac{4, i}{4,-3}$ & 51,67 & 248,84 & 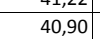 & $\begin{array}{l}42,460 \\
42,10 \\
\end{array}$ & 242,06 \\
\hline Epidalea calamita & $29 S P D 80$ & 100,00 & 166,48 & 116,63 & 39,00 & 6016,54 & 338,82 & 43,80 & 295,03 & \begin{tabular}{|l|}
101,63 \\
\end{tabular} & 244,73 & 245,60 & 92,25 & 515,78 & 71,39 & 4,6 & 51,66 & 200,01 & 33,50 & 34,65 & 188,28 \\
\hline Epidalea calamita & $29 S P D 82$ & 100,00 & 167,14 & 115,38 & 38,95 & 6039,30 & 339,05 & 45,73 & 293,31 & 101,06 & 246,31 & 246,66 & 93,00 & 532,86 & 72,48 & 4,00 & 51,25 & 206,41 & 35,04 & 35,95 & 195,55 \\
\hline Epidalea calamita & 29SPD83 & 100,00 & 164,86 & 113,41 & 38,41 & 6057,41 & 336,19 & 44,88 & 291,31 & 98,84 & 244,34 & 244,99 & 90,78 & 559,73 & 75,01 & 4,28 & 51,20 & 216,95 & 36,56 & 37,66 & 206,87 \\
\hline Epidalea calamita & 29SPD84 & 100,00 & 164,51 & 111,56 & 38,02 & 6072,79 & 334,88 & 45,70 & 289,18 & 98,41 & 244,35 & 244,90 & 90,37 & 571,99 & 76,07 & 4,41 & 51,20 & 222,03 & 37,21 & 38,09 & 212,37 \\
\hline Epidalea calamita & $\begin{array}{l}\text { 29SPDD84 } \\
\end{array}$ & 100,00 & 100,31 & 104,91 & 30,02 & 6114,80 & 327,59 & $\begin{array}{ll}4,1,66 \\
456\end{array}$ & \begin{tabular}{|l|}
$\mid 281,93$ \\
281
\end{tabular} & $\begin{array}{ll}90,414 \\
94,69\end{array}$ & \begin{tabular}{|l|}
241,76 \\
240
\end{tabular} & \begin{tabular}{|l|}
242,15 \\
\end{tabular} & $\begin{array}{ll}0,376 \\
86,66\end{array}$ & 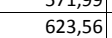 & 82,11 & $\frac{4,41}{5,00}$ & $\frac{1,20}{51,16}$ & \begin{tabular}{|l|}
242,62 \\
242
\end{tabular} & $\begin{array}{l}3 r, 21 \\
40,83\end{array}$ & $\begin{array}{ll}30,035 \\
41,62\end{array}$ & 234,50 \\
\hline Epidalea calamita & 29SPD89 & 100,00 & 160,42 & 104,07 & 36,61 & 6124,59 & 326,65 & 45,32 & 281,34 & 93,82 & 241,47 & 241,73 & 86,14 & 627,26 & 83,17 & 5,00 & 51,11 & 244,16 & 41,07 & 41,74 & 236,20 \\
\hline Epidalea calamita & 29SPD94 & 101,00 & 162,61 & 111,41 & 37,79 & 6154,11 & 335,04 & 43,05 & 291.99 & 95,77 & 243,83 & 244,16 & 87,60 & 563,05 & 74,21 & 4,31 & 50,71 & 216,84 & 36,79 & 37,66 & 206,23 \\
\hline Epidalea calamita & 29SPD97 & 100,00 & 162,45 & 107,19 & 36,97 & 6180,94 & 332,20 & 45,06 & 287,14 & 95,38 & 244,22 & 244,52 & 87,40 & 580,10 & 75,34 & 4,52 & 50,45 & 223,50 & 38,32 & 39,01 & 213,86 \\
\hline Epidalea calamita & 29SPE10 & 100,00 & 159,18 & 97,18 & 36,9 & 5576,36 & 312,60 & 53,12 & 259,48 & 91,49 & 232,06 & 233,77 & 91,49 & 854,46 & 123,62 & 6,97 & 54 & 346,49 & 52,60 & 53,47 & 346,49 \\
\hline Epidalea calamita & 29SPE12 & 100,00 & 151,78 & 95,52 & 36,56 & 5580,80 & 303,98 & 46,12 & 257,86 & 84,14 & 225,44 & 226,36 & 84,14 & 943,37 & 138,41 & 8,12 & 55,08 & 383,08 & 58,69 & 59,05 & 383,08 \\
\hline Epidalea calamita & 29SPE21 & 100,00 & 157,59 & 97,04 & 36,15 & 5765,61 & 313,94 & 49,60 & 264,34 & 88,08 & 233,56 & 234,55 & 87,85 & 858,44 & 124,23 & 7,02 & 54,74 & 346,39 & 53,52 & 54,15 & 346,39 \\
\hline Epidalea calamita & 29SPE22 & 100,00 & 153,76 & 96,17 & 36,13 & 5741,76 & 308,91 & 46,21 & 262,70 & 84,23 & 229,40 & 230,39 & 84,23 & 900,23 & 131,32 & 7,73 & 54,81 & 363,70 & 56,48 & 56,78 & 363,70 \\
\hline Epidalea calamita & 29SPE30 & 100,00 & 165,01 & 99,91 & 36,85 & 5785,91 & 322,58 & 55,11 & 267,47 & 101,66 & 240,95 & 241, & 94, & 754,97 & 106,97 & 6,00 & 54,14 & 302,59 & 46,47 & 48,13 & 301,33 \\
\hline Epidalea calamita & 29SPE31 & 101,00 & 157,49 & 97,29 & 36,01 & 5870,90 & 315,45 & 48,45 & 267,00 & 91,57 & 234,94 & 235,83 & 86,60 & 833,36 & 120,00 & 6,90 & 54,25 & 334,68 & 52,14 & 52,80 & 334,45 \\
\hline
\end{tabular}




\begin{tabular}{|c|c|c|c|c|c|c|c|c|c|c|c|c|c|c|c|c|c|c|c|c|c|}
\hline TAXON & UTM & $\mathrm{km} 2$ & B101 & B102 & $\mathrm{BIO3}$ & 8104 & B105 & B106 & B107 & B108 & 8109 & BIO10 & BIO11 & BIO12 & 81013 & BIO14 & BIO15 & B1016 & B1017 & BIO18 & B1019 \\
\hline Epidalea calamita & 29SPE32 & 100,00 & 155,12 & 96,91 & 36,01 & 5844,35 & 312,09 & 46,21 & 265,88 & 88,22 & 232,29 & 232,95 & 84,38 & 856,54 & 123,96 & 7,15 & 54,26 & 343,94 & 53,86 & 54,35 & 343,80 \\
\hline Epidalea calamita & 29SPE40 & 101,00 & 164,31 & 100,45 & 36,85 & 5868,35 & 323,23 & 53,36 & 269,86 & 100,41 & 241,48 & 242,36 & 92,96 & 733,33 & 103,07 & 5,98 & 53,64 & 292,77 & 45,60 & 47,25 & 290,38 \\
\hline Epidalea calamita & 29SPE41 & 100,00 & 163,53 & 100,25 & 36,75 & 5876,42 & 322,10 & 52,19 & 269,90 & 99,20 & 240,77 & 241,49 & 91,83 & 744,16 & 105,12 & 6,05 & 53,53 & 296,93 & 46,41 & 48,04 & 294,75 \\
\hline Epidalea calamita & 29SPE42 & 99,00 & 156,54 & 97,94 & 36,04 & 5903,14 & 314,45 & 46,30 & 268,15 & 92,15 & 234,38 & 234,94 & 84,72 & 808,24 & 115,72 & 6,78 & 53,88 & 322,90 & 50,98 & 51,71 & 321,60 \\
\hline Epidalea calamita & 29SPE50 & 100,00 & 163,77 & \begin{tabular}{|l|l|}
101,27 \\
\end{tabular} & 36,87 & 5932,29 & 323,69 & 51,76 & 271,94 & $\begin{array}{l}99,08 \\
\end{array}$ & 241,85 & 242,54 & 91,55 & \begin{tabular}{|c|}
705,68 \\
\end{tabular} & 98,12 & 5,53 & 53,11 & 280,54 & 44,12 & 45,66 & 276,80 \\
\hline Epidalea calamita & 29SPE51 & 101,00 & 162,83 & 100,88 & 36,68 & 5941,95 & 322,45 & 50,59 & 271,86 & 97,88 & 241,23 & 241,63 & 90,42 & 716,97 & 100,21 & 5,86 & 53,12 & 284,78 & 45,20 & 46,64 & 281,24 \\
\hline Epidalea calamita & 29SPE52 & 101,00 & 157,55 & 99,13 & 36,10 & 5958,68 & 316,43 & 46,10 & 270,33 & 92,54 & 236,26 & 236,52 & 84,95 & 761,84 & \begin{tabular}{|l|l|}
107,67 \\
\end{tabular} & 6,19 & 53,17 & 302,85 & 48,50 & 49,19 & 300,00 \\
\hline Epidalea calamita & 29SPE60 & 101,00 & 160,83 & 101,30 & 36,43 & 6005,53 & 322,03 & 48,31 & 273,71 & 95,56 & 240,07 & 240,54 & 87,79 & 697,13 & $\begin{array}{l}96,08 \\
\end{array}$ & 5,66 & 52,50 & 275,62 & 44,60 & 45,66 & 270,71 \\
\hline Epidalea calamita & 29SPE61 & 99,00 & 159,52 & 100,65 & 36,13 & 6011,88 & 320,19 & 46,94 & 273,24 & 94,04 & 238,99 & 239,26 & 86,33 & 709,88 & 98,39 & 5,94 & 52,45 & 280,56 & 45,79 & 46,52 & 275,97 \\
\hline Epidalea calamita & 29SPE62 & 100,00 & 155,44 & 99,42 & 36,04 & 6016,15 & 315,34 & 43,59 & 271,75 & 90,01 & 235,19 & 235,31 & 82,29 & 739,68 & 103,40 & 6,29 & 52,52 & 292,50 & 48,01 & 48,30 & 288,25 \\
\hline Epidalea calamita & 29SPE70 & 101,00 & 160,68 & 102,50 & 36,39 & 6061,68 & 323,93 & 46,84 & 277,09 & 94,72 & 240,89 & 241,08 & 86,94 & 661,91 & 89,78 & 5,25 & 51,91 & 259,85 & 42,67 & 43,48 & 253,48 \\
\hline Epidalea calamita & 29SPE71 & 100,00 & 159,82 & 101,92 & 36,35 & 6065,58 & 322,31 & 45,97 & 276,34 & 93,66 & 240,05 & 240,17 & 85,82 & 670,65 & 91,49 & 5,45 & 51,84 & 263,29 & 43,56 & 44,06 & 257,20 \\
\hline Epidalea calamita & 29SPE72 & 101,00 & 157,64 & 101,21 & 36,08 & 6065,15 & 319,49 & 44,06 & 275,43 & 91,42 & 237,94 & 238,00 & 83,62 & 684,95 & 93,96 & 5,83 & 51,77 & 268,81 & 45,03 & 45,28 & 262,93 \\
\hline Epidalea calamita & 29SPE81 & 100,00 & 160,04 & 103,15 & 36,37 & 6120,16 & 324,52 & 44,95 & 279,57 & 93,18 & 240,99 & 241,01 & 85,30 & 632,97 & 84,87 & 5,11 & 51,11 & 246,61 & 41,57 & 41,67 & 239,18 \\
\hline Epidalea calamita & 29SPE90 & 101,00 & 161,53 & 104,82 & 36,31 & 6179,27 & 328,69 & 45,03 & 283,66 & 94,00 & 243,44 & 243,47 & 86,17 & 590,59 & 77,21 & 4,79 & 50,34 & 227,83 & 39,41 & 39,47 & 218,83 \\
\hline Epidalea calamita & 29SPE91 & 100,00 & 158,95 & 103,88 & 36,13 & 6177,81 & 325,38 & 42,89 & 282,49 & 91,39 & 240,88 & 240,89 & 83,55 & 606,26 & 79,87 & 5,05 & 50,38 & 234,12 & 40,67 & 40,69 & 225,45 \\
\hline Epidalea calamita & 29SQA19 & 10,00 & 178,00 & 87,00 & 37,00 & 4992,64 & 302,64 & 72,00 & 230,64 & 136,73 & 240,55 & 243,45 & 115,64 & 523,27 & 80,91 & 1,00 & 64,91 & 227,91 & 14,00 & 22,00 & 207,55 \\
\hline Epidalea calamita & 29SQA26 & & & & & & & & & & & & & & & & & & & & \\
\hline Epidalea calamita & 29SQA28 & 14,00 & 178,46 & 86,77 & 37,23 & 4954,31 & 301,69 & 73,00 & 228,69 & 152,23 & 240,62 & 243,69 & 116,85 & 536,15 & 83,08 & 1,00 & 65,62 & 234,08 & 14,00 & 22,00 & 214,69 \\
\hline Epidalea calamita & 29SQA29 & 85,00 & 178,83 & 87,79 & 37,13 & 5027,68 & 304,23 & 72,22 & 232,02 & 143,22 & 241,99 & 245,02 & 116,11 & 528,25 & 81,26 & 1,00 & 64,74 & 230,03 & 14,15 & 22,00 & 210,30 \\
\hline Epidalea calamita & 29SQA35 & 24,00 & 177,69 & 83,83 & 38,69 & 4534,21 & 291,17 & 77,52 & 213,66 & 155,45 & 234,41 & 238,17 & 122,10 & 557,24 & 92,62 & 0,00 & 67,28 & 248,90 & 12,69 & 20,00 & 230,62 \\
\hline Epidalea calamita & 29SQA36 & 95,00 & 177,07 & 84,66 & 38,31 & 4649,30 & 293,27 & 75,19 & 218,08 & 153,02 & 235,24 & 238,90 & 119,87 & 554,28 & 90,71 & 0,00 & 66,75 & 246,68 & 13,00 & 20,40 & 228,02 \\
\hline Epidalea calamita & 29SQA37 & 70,00 & 177,22 & 84,36 & 37,45 & \begin{tabular}{|l|l|}
4807,11 \\
\end{tabular} & 296,27 & 74,12 & 222,15 & 152,46 & 237,56 & 241,03 & 117,86 & 551,16 & 87,79 & 0,53 & 65,83 & 242,48 & 13,59 & 21,43 & 223,57 \\
\hline Epidalea calamita & 29SQA38 & 99,00 & 178,11 & 85,82 & 37,06 & 4961,88 & 301,15 & 73,00 & 228,15 & 152,06 & 240,71 & 243,84 & 116,70 & 544,02 & 84,41 & 1,00 & 65,20 & 236,98 & 14,46 & 22,00 & 217,83 \\
\hline Epidalea calamita & 29SQA43 & 19,00 & 179,33 & 70,04 & 35,96 & 4462,26 & 279,67 & 86,48 & 193,19 & 158,41 & 234,30 & 238,67 & 123,78 & 609,26 & 105,11 & 0,93 & 68,96 & 264,70 & 11,96 & 22,00 & 248,44 \\
\hline Epidalea calamita & 29SQA44 & 26,00 & 179,26 & 71,10 & 35,90 & 4487,74 & 281,03 & 85,62 & 195,41 & 157,85 & 234,28 & 238,97 & 123,28 & 601,95 & 100,23 & 0,38 & 68,10 & 258,90 & 11,90 & 21,03 & 243,23 \\
\hline Epidalea calamita & $29 \mathrm{SQA45}$ & 69,00 & 176,93 & 76,35 & 36,36 & 4649,63 & 286,27 & $\frac{79,15}{79,15}$ & \begin{tabular}{|l|}
207,12 \\
\end{tabular} & $\begin{array}{l}153,94 \\
\end{array}$ & 234,81 & 238,93 & 119,44 & 587,01 & $\begin{array}{l}95,92 \\
\end{array}$ & o, & 60,101 & 255,15 & 13,02 & 21,31 & 237,94 \\
\hline Epidalea calamita & 29SQA46 & 101,00 & 175,51 & 79,22 & 36,27 & 4778,15 & 290,15 & 74,90 & 215,25 & 151,44 & 235,35 & 239,28 & 116,57 & 579,61 & 92,91 & 0,65 & 66,18 & 252,08 & 13,88 & 21,77 & 234,53 \\
\hline Epidalea calamita & 29SQA47 & 99,00 & 176,25 & 80,88 & 35,97 & 4931,20 & 295,24 & 73,49 & 221,75 & 150,49 & 238,23 & 241,92 & 115,29 & 568,75 & 88,95 & 0,97 & 65,60 & 246,05 & 14,79 & 21,97 & 227,88 \\
\hline Epidalea calamita & 29SQA48 & 99,00 & 177,43 & 83,96 & 36,08 & 5077,41 & 301,60 & 72,08 & 229,52 & 148,23 & 241,44 & 244,77 & 114,47 & 561,33 & 86,13 & 1,00 & 65,01 & 241,91 & 15,03 & 22,02 & 223,48 \\
\hline Epidalea calamita & 29SQA52 & & & & & & & & & & & & & & & & & & & & \\
\hline Epidalea calamita & 29SQA53 & 100,00 & 177,64 & 70,43 & 35,65 & 4493,07 & 279,11 & 84,29 & 194,82 & 143,26 & 232,93 & 237,52 & 121,50 & 635,77 & 110,43 & 1,00 & 69,06 & 277,45 & 13,16 & 23,23 & 262,34 \\
\hline Epidalea calamita & 29SQA54 & 93,00 & 177,06 & 70,42 & 34,92 & 4627,92 & 281,23 & 82,24 & 198,99 & 149,73 & 234,27 & 238,95 & 119,38 & 623,61 & 105,06 & 1,00 & 68,15 & 269,05 & 13,48 & 23,19 & 253,37 \\
\hline Epidalea calamita & 29SQA56 & 100,00 & 173,87 & 72,93 & 33,94 & 4924,18 & 286,72 & 74,69 & 212,03 & 144,30 & 235,60 & 239,56 & 112,85 & 606,72 & 95,02 & 1,00 & 65,93 & 257,52 & 15,55 & 23,43 & 241,52 \\
\hline Epidalea calamita & 29SQA57 & 100,00 & 174,19 & 75,94 & 34,00 & 5074,94 & 292,53 & 72,25 & 220,28 & 137,56 & 238,01 & 241,78 & 111,32 & 594,55 & 90,93 & 1,00 & 65,47 & 252,01 & 16,14 & 23,23 & 235,14 \\
\hline Epidalea calamita & 29SQA58 & 101,00 & 175,78 & 81,62 & 34,94 & 5197,06 & 300,87 & 70,73 & 230,14 & 126,74 & 241,48 & 244,90 & 111,45 & 585,37 & 88,62 & 1,00 & 65,05 & 248,94 & 16,59 & 22,96 & 231,55 \\
\hline Epidalea calamita & 29SQA60 & & & & & & & & & & & & & & & & & & & & \\
\hline Epidalea calamita & 29SQA61 & 69,00 & 173,72 & 74,04 & 37,77 & 4251,75 & 275,40 & 81,89 & 193,51 & 129,78 & 226,25 & 230,55 & 120,81 & 723,45 & \begin{tabular}{|l|l|}
126,98 \\
\end{tabular} & 0,92 & 71,45 & 326,94 & 14,62 & 23,06 & 313,23 \\
\hline Epidalea calamita & 29SQA62 & 96,00 & 173,91 & 72,69 & 36,69 & 4381,85 & 276,29 & 80,88 & 195,42 & 128,33 & 228,08 & 232,35 & 119,18 & 703,15 & 122,12 & 1,00 & 70,45 & 313,64 & 14,39 & 23,54 & 299,47 \\
\hline Epidalea calamita & 29SQA63 & 91,00 & 174,26 & 71,55 & 35,73 & 4530,08 & 278,14 & 80,13 & 198,02 & 127,05 & 230,42 & 234,79 & 117,85 & 680,79 & 116,33 & 1,00 & 69,49 & 299,66 & 14,39 & 23,80 & 284,77 \\
\hline Epidalea calamita & 29SQA65 & 87,00 & 173,45 & 71,17 & 33,89 & 4832,19 & 282,94 & 76,20 & 206,74 & 123,52 & 233,76 & 237 & 113,34 & 646,16 & 104,12 & 1,00 & 67,41 & 276,87 & 15,43 & 23,97 & 261,60 \\
\hline Epidalea calamita & 29SQA66 & 81,00 & 172,10 & 71,69 & 33,18 & 5004,39 & 285,84 & 72,94 & 212,90 & 120,75 & 234,93 & 238,95 & 110,16 & 634,60 & $\begin{array}{l}98,66 \\
\end{array}$ & 1,00 & 66,61 & 268,96 & 16,27 & 24,00 & 253,05 \\
\hline Epidalea calamita & 29SQBOO & 46,00 & 176,74 & 85,34 & 37,00 & 5008,82 & 299,92 & 71,94 & 227,98 & 123,20 & \begin{tabular}{|l|l|}
239,08 \\
\end{tabular} & 242,08 & 114,04 & 511,26 & 79,38 & 1,00 & 64,36 & 221,58 & 14,00 & 23,00 & 200,42 \\
\hline Epidalea calamita & 29SQB01 & 100,00 & 177,03 & 85,80 & 36,91 & 5086,65 & 301,93 & 71,36 & 230,57 & 128,89 & 240,26 & 243,19 & 113,39 & 505,93 & 78,73 & 1,00 & 63,83 & 218,10 & 14,01 & 23,13 & 196,75 \\
\hline Epidalea calamita & 29SQB02 & 100,00 & 175,71 & 87,83 & 36,78 & 5211,77 & 304,69 & 68,22 & \begin{tabular}{ll|}
236,47 \\
\end{tabular} & $\begin{array}{lll}121,68 \\
\end{array}$ & 240,67 & 243,42 & 110,32 & 511,72 & 79,20 & 1,00 & 63,09 & 18,53 & 14,72 & 23,99 & 197,38 \\
\hline Epidalea calamita & 29SQB03 & 100,00 & 176,62 & $\begin{array}{l}10,030 \\
90,04\end{array}$ & 36,92 & 5313,06 & 309,19 & $\begin{array}{ll}67,62 \\
67\end{array}$ & 241,57 & 130,20 & \begin{tabular}{|l|}
243,06 \\
\end{tabular} & \begin{tabular}{|l|}
245,67 \\
245
\end{tabular} & \begin{tabular}{|l|l|}
110,08 \\
10,
\end{tabular} & 505,56 & 78,12 & 1,00 & 62,66 & 214,59 & 15,01 & 23,97 & 193,80 \\
\hline Epidalea calamita & $295 Q B O$ & 100,00 & 175 & 93,32 & 37,02 & 5425,44 & 312,93 & 64,53 & 248,41 & 120,14 & 243,71 & 246,19 & 107,63 & 511,63 & 78 & 1,29 & 61,96 & 215,68 & 16,04 & 24,62 & 195,76 \\
\hline Epidalea calamita & 29SQB05 & 101,00 & 169,79 & 97,85 & 37,29 & 5573,42 & 314,27 & 56,43 & 257,84 & 109,60 & 240,50 & 242,85 & 100,61 & 543,49 & 81,20 & 2,00 & 60,59 & 226,67 & 19,23 & 27,11 & 208,41 \\
\hline Epidalea calamita & 29SQB06 & 101,00 & 165,53 & 101,65 & 37,97 & 5683,37 & 315,98 & 50,49 & 265,49 & 104,53 & 238,24 & 240,44 & 95,45 & 566,49 & 83,17 & 2,01 & 59,96 & 234,53 & 21,17 & 28,32 & 217,67 \\
\hline Epidalea calamita & 29SQB07 & 100,00 & 164,82 & 104,21 & 38,00 & 5762,46 & 319,25 & 48,34 & 270,91 & 102,79 & 238,75 & 240,87 & 93,82 & 569,38 & 82, & 2,29 & 59,36 & 26 & 22,28 & 28,82 & 218,29 \\
\hline Epidalea calamita & 29SQBOB & 100,00 & 16 & $\begin{array}{l}104,21 \\
106,56 \\
\end{array}$ & 38 & 5835 & 321,68 & $\begin{array}{l}40,35 \\
45,53 \\
\end{array}$ & $\begin{array}{l}27,115 \\
276,15\end{array}$ & 100,43 & $\begin{array}{l}230,13 \\
238,34\end{array}$ & \begin{tabular}{|l|}
240,40 \\
240
\end{tabular} & $\begin{array}{ll}3,0<2 \\
91,52\end{array}$ & | & $\begin{array}{ll}82,17 \\
82,82\end{array}$ & $2,2,68$ & 58,52 & \begin{tabular}{|l|}
235,69 \\
23,6
\end{tabular} & $\begin{array}{l}\mid 2,206 \\
23,96\end{array}$ & \begin{tabular}{|l|l}
29,93 \\
29,93
\end{tabular} & $\begin{array}{l}210,23 \\
220,70\end{array}$ \\
\hline Epidalea calamita & $295 \mathrm{SQB09}$ & 101,00 & 149,98 & 109,34 & 38,00 & 5955,40 & 315,23 & 31,79 & 283,43 & 86,71 & 227,37 & 229,53 & 77,75 & 655,52 & 90,98 & 3,83 & 57,21 & 264,65 & 30,41 & 35,23 & 252,11 \\
\hline Epidalea calamita & 29SQB10 & 96,00 & 177,80 & 87,58 & 37,01 & 5066,93 & 303,78 & 71,44 & $\begin{array}{l}232,34 \\
232\end{array}$ & \begin{tabular}{|l|}
130,63 \\
\end{tabular} & 241,16 & \begin{tabular}{|l|l|}
244,08 \\
\end{tabular} & $\mid 114,66$ & 518,74 & 80,20 & $\begin{array}{l}3,000 \\
1,00\end{array}$ & $\begin{array}{ll}64,27 \\
64,\end{array}$ & 224,79 & $\begin{array}{l}\mid 0,4,0 \\
14,00\end{array}$ & 22,93 & 204,25 \\
\hline Epidalea calamita & 29SQB11 & 100,00 & 178,60 & 89,13 & 37,01 & 5175,99 & 307,72 & 70,57 & 237,15 & 130,95 & 243,40 & 246,23 & 113,90 & 513,12 & 79,52 & 1,00 & 63,83 & 220,93 & 14,38 & 23,00 & 200,28 \\
\hline Epidalea calamita & 29SQB12 & 99,00 & 177,09 & 91,82 & 37,01 & 5318,58 & 311,16 & 67,03 & 244,13 & 119,89 & 244,00 & 246 & 110,55 & 519,52 & 80,10 & 1,00 & 63,16 & 221,75 & 15,04 & 23,39 & 20 \\
\hline Epidalea calamita & $\begin{array}{l}\text { 29SQBD13 } \\
\end{array}$ & \begin{tabular}{|l|}
101,00 \\
100
\end{tabular} & 175,23 & $\begin{array}{l}1,0<2 \\
94,79 \\
\end{array}$ & 37,05 & 5452,54 & $\begin{array}{l}31,10 \\
314,19\end{array}$ & $\begin{array}{l}62,94 \\
62, \\
\end{array}$ & $\begin{array}{l}251,25 \\
2513\end{array}$ & \begin{tabular}{|l|l|}
116,11 \\
\end{tabular} & \begin{tabular}{|l|}
244,04 \\
\end{tabular} & \begin{tabular}{|l|}
246,46 \\
246
\end{tabular} & \begin{tabular}{|l|}
107,10 \\
107
\end{tabular} & | & $\begin{array}{l}00,80 \\
80,87\end{array}$ & $\begin{array}{l}, 001 \\
1,01\end{array}$ & $\begin{array}{l}3,10 \\
62,52\end{array}$ & \begin{tabular}{|l|}
224,05 \\
220
\end{tabular} & $\begin{array}{l}0,04 \\
15,94 \\
\end{array}$ & $\begin{array}{l}24,02 \\
24,02\end{array}$ & 204,34 \\
\hline Epidalea calamita & 29SQB14 & 100,00 & 177,04 & 97,18 & 37,40 & 5528,40 & 319,21 & 63,27 & 255,94 & 117,12 & 247,02 & 249,25 & 108,02 & 518,64 & 79,16 & 1,11 & 62,08 & 218,60 & 16,14 & 24,15 & 199,43 \\
\hline Epidalea calamita & 29SQB15 & 100,00 & 171,39 & 101,11 & 37,85 & 5671,57 & 320,33 & 55,58 & 264,75 & 110,05 & 243,75 & 245,90 & 101,01 & 548,55 & 81,87 & 1,99 & 60,71 & 228,67 & 19,41 & 26,72 & 210,85 \\
\hline Epidalea calamita & 29SQB16 & 99,00 & 168,83 & 104,02 & 38,00 & 5771,93 & 322,70 & 51,44 & 271,26 & 106,39 & 242,73 & 244,82 & 97,38 & 560,74 & 82,61 & 2,01 & 60,17 & 232,12 & 20,69 & 27,51 & 215,31 \\
\hline Epidalea calamita & 29SQB17 & 101,00 & 163,36 & 107,06 & 38,00 & 5877,79 & 322,84 & 44,57 & 278,27 & 99,97 & 239,10 & 241,08 & 90,98 & 589,06 & 85,03 & 2,50 & 59,22 & 241,64 & 23,35 & 29,53 & 226,20 \\
\hline
\end{tabular}




\begin{tabular}{|c|c|c|c|c|c|c|c|c|c|c|c|c|c|c|c|c|c|c|c|c|c|}
\hline TAXON & UTM & $\mathrm{km} 2$ & B101 & B102 & $\mathrm{BIO3}$ & B104 & B105 & B106 & B107 & B108 & B109 & BIO10 & BIO11 & BIO12 & B1013 & BIO14 & BIO15 & B1016 & B1017 & BIO18 & B1019 \\
\hline Epidalea calamita & 29SQB18 & 100,00 & 159,01 & 109,34 & 38,00 & 5957,20 & 322,97 & 39,38 & 283,59 & 95,16 & 236,25 & 238,07 & 86,15 & 610,38 & 86,62 & 2,97 & 58,25 & 248,23 & 25,93 & 31,53 & 233,97 \\
\hline Epidalea calamita & 29SQB19 & 99,00 & 151,81 & 111,03 & 38,00 & 6028,69 & 319,92 & 31,80 & 288,13 & 87,58 & 230,39 & 232,23 & 78,65 & 649,94 & 90,32 & 3,61 & 57,35 & 262,00 & 29,59 & 34,50 & 249,20 \\
\hline Epidalea calamita & 29SQB20 & 100,00 & 179,04 & 89,73 & 37,08 & 5151,40 & 308,35 & 70,87 & 237,48 & 134,68 & 243,99 & 246,81 & 114,96 & 524,89 & 80,86 & 1,00 & 64,52 & 227,17 & 14,90 & 22,01 & 207,32 \\
\hline Epidalea calamita & 29SQB21 & 101,00 & 179,80 & 92,42 & 37,20 & 5285,69 & 313,51 & 69,27 & 244,24 & 131,97 & 246,44 & 249,12 & 113,76 & 522,48 & 80,46 & 1,00 & 63,68 & 224,48 & 15,00 & 22,31 & 204,82 \\
\hline Epidalea calamita & 29SQB22 & 100,00 & 178,30 & 95,58 & $\begin{array}{l}37,40 \\
\end{array}$ & 5428,78 & 317,33 & \begin{tabular}{|c|}
65,47 \\
\end{tabular} & 251,87 & 119,33 & 247,04 & 249,51 & 110,55 & 529,87 & 81,28 & 1,00 & 63,28 & 226,09 & 15,47 & 22,99 & 206,78 \\
\hline Epidalea calamita & 29SQB24 & 100,00 & 175,60 & 101,94 & 37,95 & 5673,27 & 325,06 & 58,67 & 266,40 & 114,06 & 248,11 & 250,25 & 104,99 & 543,60 & 81,97 & 1,36 & 61,76 & 228,44 & 18,02 & 24,99 & 210,41 \\
\hline Epidalea calamita & 29SQB25 & 99,00 & 170,63 & 105,14 & 37,99 & 5800,16 & 325,97 & 51,97 & 274,00 & 107,85 & 245,09 & 247,13 & 98,82 & 567,97 & 84,15 & 1,98 & 60,84 & 236,44 & 20,20 & 26,87 & 219,51 \\
\hline Epidalea calamita & $29 S Q B 26$ & 101,00 & 165,03 & 108,10 & 38,00 & 5908,15 & 325,85 & 45,03 & 280,81 & 101,40 & 241,28 & 243,17 & $\begin{array}{ll}90,2626 \\
\end{array}$ & 594,59 & 86,44 & 2,06 & 60,03 & 245,36 & 22,21 & 28,46 & 229,72 \\
\hline Epidalea calamita & 29SQB27 & 100,00 & 162,82 & 109,90 & 38,00 & 5980,37 & 327,18 & 41,83 & 285,35 & 98,45 & 240,34 & 242,12 & 89,41 & 602,57 & 86,51 & 2,57 & 59,20 & 246,70 & 24,01 & 29,90 & 231,84 \\
\hline Epidalea calamita & 29SQB28 & 100,00 & 158,95 & 111,69 & 38,00 & 6054,53 & 326,96 & 37,32 & 289,64 & 94,01 & 237,72 & 239,36 & 85,00 & 619,95 & 87,61 & 2,99 & 58,42 & 251,77 & 26,12 & 31,53 & 237,91 \\
\hline Epidalea calamita & 29SQB29 & 100,00 & 158,47 & 112,97 & 38,00 & 6098,34 & 328,68 & 36,09 & 292,59 & 92,97 & 237,91 & 239,45 & 83,95 & 619,05 & 86,71 & 3,20 & 57,68 & 249,70 & 27,20 & 32,28 & 236,40 \\
\hline Epidalea calamita & 29SQB32 & 100,00 & 179,88 & 99,43 & 37,81 & 5541,95 & 324,76 & 64,30 & 260,46 & 119,66 & 250,41 & 252,84 & 110,82 & 540,01 & 82,50 & 1,00 & 63,43 & 230,37 & 16,01 & 22,43 & 212,05 \\
\hline Epidalea calamita & 29SQB33 & 100,00 & 178,05 & 103,27 & 37,99 & 5681,46 & 329,20 & $\begin{array}{l}40,05 \\
60,\end{array}$ & 269,14 & 116,39 & $\begin{array}{l}250,78 \\
25,7\end{array}$ & 252,92 & $\begin{array}{l}107,42 \\
107\end{array}$ & 549,83 & $\begin{array}{l}2,3,33 \\
83\end{array}$ & 1,00 & $\begin{array}{l}62,64 \\
62,5\end{array}$ & 232,79 & $\frac{10,10}{17,50}$ & $\begin{array}{l}23,45 \\
23,88\end{array}$ & 215,05 \\
\hline Epidalea calamita & 29SQB34 & 100,00 & 179,52 & 106,17 & 38,01 & 5772,33 & 334,80 & 59,57 & 275,24 & 116,62 & 253,47 & 255,43 & 107,67 & 542,43 & 81,89 & 1,01 & 62,08 & 228,52 & 18,01 & 23,92 & 211,26 \\
\hline Epidalea calamita & 29SQB35 & 101,00 & 175,74 & 109,07 & \begin{tabular}{l|l|}
38,05 \\
\end{tabular} & 5890,17 & 336,24 & 54,13 & 282,11 & 111,61 & 251,58 & 253,33 & 102,63 & 558,45 & 83,11 & 1,74 & 61,18 & 233,21 & 19,53 & 25,44 & 216,83 \\
\hline Epidalea calamita & 29SQB36 & 100,00 & 170,21 & 111,26 & 38,03 & 5991,56 & 335,15 & 47,61 & 287,54 & 105,24 & 247,70 & 249,40 & 96,23 & 581,49 & 85,01 & 2,00 & 60,50 & 240,69 & 21,21 & 26,95 & 225,24 \\
\hline Epidalea calamita & 29SQB37 & 100,00 & 165,23 & 112,90 & 38,01 & 6067,55 & 333,76 & 42,02 & 291,74 & 99,63 & 243,99 & 245,63 & 90,71 & 602,17 & 86,41 & 2,31 & 59,48 & 246,70 & 23,48 & 28,98 & 232,27 \\
\hline Epidalea calamita & 29SQB38 & 101,00 & 165,25 & 114,19 & 38,03 & 6120,83 & 336,06 & 41,25 & 294,81 & 99,12 & 244,91 & 246,42 & 90,10 & 596,49 & 84,86 & 2,55 & 58,82 & 242,79 & 24,17 & 29,42 & 228,80 \\
\hline Epidalea calamita & 29SQB39 & 100,00 & 163,07 & 115,24 & 38,00 & 6172,04 & 336,21 & 38,54 & 297,66 & 96,41 & 243,54 & 244,97 & 87,38 & 601,53 & 84,57 & 2,78 & 58,19 & 242,94 & 25,49 & 30,41 & 229,54 \\
\hline Epidalea calamita & 29SQB42 & 101,00 & 181,47 & 103,41 & 37,99 & 5658,01 & 332,43 & 63,26 & 269,18 & 119,88 & 253,93 & 256,14 & 110,99 & 551,11 & 83,89 & 1,00 & 63,41 & 235,04 & 16,67 & 22,57 & 217,58 \\
\hline Epidalea calamita & 29SQB43 & 100,00 & 180,23 & 108,01 & 38,05 & 5804,21 & 338,22 & 59,06 & 279,16 & 117,10 & 254,92 & 256,92 & 108,11 & 558,84 & 84, & 1,00 & 62,92 & 237,05 & 17,80 & 23,23 & 220,29 \\
\hline Epidalea calamita & 29SQB44 & 101,00 & 180,49 & 111,05 & 38,36 & 5900,58 & 342,96 & 57,41 & 285,55 & 116,18 & 256,64 & 258,40 & 107,23 & 556,03 & 83,69 & 1,12 & 62,60 & 234,70 & 18,32 & 23,41 & 218,49 \\
\hline Epidalea calamita & 29SQB45 & 99,00 & 179,99 & 113,45 & 38,61 & 5980,75 & 346,22 & 55,51 & 290,71 & 114,92 & 257,41 & 259,01 & 105,74 & 555,42 & 82,92 & 1,41 & 61,79 & 232,99 & 18,81 & 24,00 & 217,38 \\
\hline Epidalea calamita & 29SQB48 & 99,00 & 165,34 & 116,84 & 38,20 & 6207,25 & 340,24 & 39,51 & 300,73 & 98,16 & 246,41 & 247,64 & 89,31 & 606,48 & 85,72 & 2,53 & 58,92 & 246,50 & 24,30 & 29,31 & 233,16 \\
\hline Epidalea calamita & 29SQB49 & 99,00 & 160,27 & 117,41 & 38,07 & 6265,76 & 337,49 & 34,39 & 303,10 & 92,76 & 242,46 & 243,63 & 83,80 & 624,67 & 86,79 & 3,01 & 58,13 & 251,52 & 26,41 & 31,25 & 238,92 \\
\hline Epidalea calamita & 29SQB52 & 100,00 & 182,30 & 107,75 & 38,14 & 5772,57 & 339,60 & 61,60 & 278,00 & 119,54 & 256,69 & 258,72 & 110,67 & 565,41 & 85,81 & 1,00 & 63,65 & 241,42 & 17,54 & 22,50 & 224,85 \\
\hline Epidalea calamita & $29 \mathrm{SQB5} 5$ & 100,00 & 179,52 & 116,15 & 38,86 & 6034,62 & 349,50 & 53,49 & 296,01 & 113,93 & 257,94 & 259,54 & 104,97 & \begin{tabular}{|l|l|}
580,19 \\
\end{tabular} & $\begin{array}{l}0,101 \\
86,72 \\
\end{array}$ & $\begin{array}{l}1,003 \\
1,33\end{array}$ & 62,52 & \begin{tabular}{|l|}
245,06 \\
\end{tabular} & 19,19 & 23,63 & $\begin{array}{l}234,05 \\
230,07\end{array}$ \\
\hline Epidalea calamita & 29SQB55 & 100,00 & 182,80 & 117,92 & \begin{tabular}{|l|}
38,98 \\
\end{tabular} & 6077,18 & 354,84 & 55,47 & 299,36 & 116,50 & 261,79 & 263,16 & 107,47 & 559,71 & 83,53 & 1,13 & 62,24 & 235,80 & 18,43 & 23,01 & 221,17 \\
\hline Epidalea calamita & 29SQB56 & 100,00 & 176,11 & 118,63 & 38,93 & 6163,05 & 350,68 & 48,61 & 302,07 & 109,00 & 256,31 & 257,66 & 100,02 & 582,65 & 85,06 & 1,97 & 61,03 & 242,14 & 20,77 & 25,32 & 228,14 \\
\hline Epidalea calamita & 29SQB57 & 100,00 & 171,79 & 119,16 & 38,85 & 6226,66 & 348,23 & 44,11 & 304,11 & 104,11 & 253,04 & 254,23 & 95,11 & 594,15 & 85,23 & 2,00 & 60,20 & 244,31 & 22,15 & 26,90 & 230,84 \\
\hline Epidalea calamita & $29 \mathrm{SQB58}$ & 100,00 & 164,45 & 119,16 & 38,45 & 6288,16 & 342,96 & 37,21 & 305,74 & 96,54 & 246,97 & 248,00 & 87,55 & 621,15 & 87,10 & 2,57 & 59,09 & 252,23 & 24,62 & 29,52 & 239,62 \\
\hline Epidalea calamita & 29SQB559 & 100,00 & 161,72 & 119,53 & 38,08 & 6337,03 & 341,97 & 34,20 & \begin{tabular}{|l|}
307,77 \\
\end{tabular} & $\begin{array}{l}0,3,37 \\
93\end{array}$ & 244,95 & 245,92 & $\begin{array}{l}1,36 \\
84,36\end{array}$ & 626,22 & $\begin{array}{l}8,57 \\
86,5\end{array}$ & 2,97 & 58,34 & \begin{tabular}{|l|}
251,97 \\
\end{tabular} & $\begin{array}{l}24,069 \\
25,99\end{array}$ & 30,74 & 239,89 \\
\hline Epidalea calamita & 29SQB62 & 62,00 & 182,98 & 110,49 & 38,71 & 5832,79 & 343,73 & 61,26 & 282,48 & 119,58 & 258,21 & 260,28 & 110,66 & 575,13 & 87,33 & 1,00 & 63,97 & 246,17 & 17,90 & 22,00 & 229,97 \\
\hline Epidalea calamita & 29SQB64 & 54,00 & 184,91 & 120,33 & 39,01 & 6101,45 & 359,34 & 55,90 & 303,44 & 118,35 & 264,13 & 265,64 & 109,23 & 571,64 & 86,08 & 1,00 & 63,33 & 243,27 & 18,19 & 22,17 & 228,95 \\
\hline Epidalea calamita & 29SQB66 & 49,00 & 179,39 & 121,08 & 39,00 & 6213,04 & 356,69 & 50,47 & 306,22 & 111,55 & 260,39 & 261,53 & 102,69 & 576,55 & 84,32 & 1,69 & 61,45 & 240,57 & 19,96 & 24,26 & 226,99 \\
\hline Epidalea calamita & $295 \mathrm{SQB67}$ & 43,00 & 170,53 & 120,97 & 38,97 & 6280,84 & 349,67 & 42,23 & 307,44 & 102,34 & 252,81 & 253,81 & 93,31 & 608,03 & 86,59 & 2,00 & 60,22 & 249,81 & 22,67 & 27,20 & 236,97 \\
\hline Epidalea calamita & 29SQB69 & $\begin{array}{l}5,000 \\
40,00\end{array}$ & 164,02 & 121,00 & 38,38 & $\begin{array}{l}020,0.04 \\
6377,10\end{array}$ & 346,10 & $\begin{array}{l}42,25 \\
35,40\end{array}$ & \begin{tabular}{|l|}
310,70 \\
31,4
\end{tabular} & \begin{tabular}{|l|}
05,05 \\
95,05
\end{tabular} & \begin{tabular}{|l|}
242,01 \\
247,85
\end{tabular} & \begin{tabular}{|l|}
248,63 \\
2481
\end{tabular} & $\begin{array}{l}3,01,07 \\
86,\end{array}$ & \begin{tabular}{|l|l|}
620,57 \\
\end{tabular} & $\mid \begin{array}{l}\mid 0,03,65 \\
85,65\end{array}$ & 2,72 & 58,25 & \begin{tabular}{|l|}
249,95 \\
2490
\end{tabular} & $\begin{array}{l}2,0 \\
25,08\end{array}$ & $\begin{array}{l}29,20 \\
29,77\end{array}$ & 238,12 \\
\hline Epidalea calamita & $29 S Q C 00$ & 100,00 & 152,57 & 110,61 & 38,01 & $\begin{array}{ll}5987,54 \\
\end{array}$ & 319,70 & 33,50 & 286,20 & 88,75 & 230,46 & 232,42 & 79,85 & 634,96 & 88,02 & 3,70 & 56,71 & 255,20 & 30,10 & 34,59 & 242,76 \\
\hline Epidalea calamita & 29SQC01 & 100,00 & 150,73 & 111,68 & 38,02 & 6030,24 & 320,13 & 31,31 & 288,82 & 86,57 & 229,46 & 231,34 & 77,71 & 643,26 & 88,33 & 4,06 & 56,03 & 256,93 & 31,92 & 35,85 & 245,11 \\
\hline Epidalea calamita & 29SQC02 & 101,00 & 150,90 & 112,55 & 38,00 & 6064,71 & 322,05 & 30,95 & 291,10 & 86,38 & 230,08 & 231,97 & 77,51 & 638,97 & 87,25 & 4,11 & 55,41 & 253,83 & 32,80 & 36,32 & 242,32 \\
\hline Epidalea calamita & $295 Q C 03$ & 100,00 & 153,97 & 113,52 & 38,06 & 6079,14 & 326,21 & 33,28 & 292,93 & 88,97 & 233,47 & 235,12 & 80,25 & 615,00 & 83,9 & 3,99 & 54,92 & 243,32 & 32,25 & 35,44 & 231,67 \\
\hline Epidalea calamita & $295 \mathrm{SQC04}$ & 100,00 & 162,19 & 114,61 & 38,27 & 6086,43 & 334,44 & 40,11 & 294,33 & 96,37 & 241,55 & 242,96 & 87,75 & 558,28 & 76,98 & 3,34 & 54,69 & 220,37 & 29,30 & 32,56 & 208,18 \\
\hline Epidalea calamita & $29 \mathrm{SQC05}$ & 100,00 & 151,69 & 114,27 & 38,05 & 6140,97 & 326,38 & 30,66 & 295,72 & 85,99 & 232,26 & 233,59 & 77,36 & 622,94 & 83,87 & 4,57 & 53,71 & 243,87 & 35,20 & 37,55 & 232,90 \\
\hline Epidalea calamita & $295 Q C 06$ & 100,00 & 151,43 & 114,50 & 38,00 & 6152,60 & 326,90 & 30,33 & 296,57 & 85,56 & 232,32 & 233,59 & 77,10 & 619,90 & 83,06 & 4,68 & 53,24 & 241,60 & 36,05 & 38,10 & 230,70 \\
\hline Epidalea calamita & 29SQC09 & 101,00 & 165,31 & 116,39 & 38,40 & 6139,80 & 340,59 & 41,61 & 298,98 & 98,23 & 245,51 & 246,18 & 89,80 & 516,38 & 70,23 & 3,88 & 51,95 & 199,27 & 31,38 & 33,42 & 186,85 \\
\hline Epidalea calamita & $29 S Q C 10$ & 101,00 & 157,87 & 112,11 & 38,00 & 6052,92 & 326,94 & 36,77 & 290,16 & $\begin{array}{ll}0,200 \\
92,90\end{array}$ & \begin{tabular}{|l|l|}
236,66 \\
236,
\end{tabular} & $\begin{array}{l}40,10 \\
238,34\end{array}$ & $\begin{array}{l}3,150 \\
84,15 \\
\end{array}$ & \begin{tabular}{|l|}
608,89 \\
60,0
\end{tabular} & 85,6 & $\begin{array}{l}3,4 \\
3,2\end{array}$ & 57,12 & 244,71 & $\begin{array}{l}1,1,00 \\
27,85 \\
\end{array}$ & $\begin{array}{l}3,42 \\
32,59\end{array}$ & $\begin{array}{l}230,05 \\
231,55\end{array}$ \\
\hline Epidalea calamita & $29 \mathrm{SQC11}$ & 100,00 & 148 & 113,07 & 38,00 & 6121,03 & 320,93 & 27,46 & 293,47 & 83,27 & 228,53 & 230,22 & 74,29 & 662,73 & 90,34 & 4,26 & 56,03 & 263,69 & 32,92 & 36,88 & 252,11 \\
\hline Epidalea calamita & $295 Q C 12$ & 100,00 & 150,30 & 113,83 & 38,00 & 6146,70 & 324,17 & 28,77 & 295,39 & 84,84 & 230,91 & 232,48 & 75,97 & 644,97 & 87,74 & 4,05 & 55,47 & 255,49 & 32,72 & 36,30 & 243,86 \\
\hline Epidalea calamita & $29 \mathrm{SQC13}$ & 100,00 & 157,54 & 114,97 & 38,01 & 6161,86 & 331,80 & 34,74 & 297,06 & 91,12 & 238,20 & 239,41 & 82,41 & 594,93 & 81,35 & 3,71 & 55,09 & 234,82 & 30,46 & 33,99 & 222,73 \\
\hline Epidalea calamita & $295 Q C 14$ & 101,00 & 159,23 & 115,59 & 38,01 & 6171,35 & 334,37 & 35,95 & 298,41 & 92,41 & 239,95 & 241,13 & 83,86 & 579,12 & 79,00 & 3,69 & 54,64 & 227,61 & 30,38 & 33,67 & 215,52 \\
\hline Epidalea calamita & $2950 C 15$ & 100,00 & 153 & $\frac{11}{11}$ & 38,00 & $\begin{array}{l}\mid 61 / 1,30 \\
6216,08\end{array}$ & 330,77 & $\begin{array}{l}3,05 \\
31,06\end{array}$ & \begin{tabular}{|l|}
$299,71,71$ \\
\end{tabular} & $\begin{array}{l}2,414 \\
87,03\end{array}$ & $\mid$ & \begin{tabular}{|l|}
236,60 \\
2315
\end{tabular} & $\begin{array}{l}\mid 23,00 \\
78,50\end{array}$ & 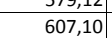 & 81,63 & $\begin{array}{l}3,009 \\
4,19\end{array}$ & 53,79 & \begin{tabular}{|l|}
236,94 \\
230
\end{tabular} & $\begin{array}{l}0,50 \\
33,57 \\
\end{array}$ & $\begin{array}{l}30,28 \\
36,28\end{array}$ & 225,45 \\
\hline Epidalea calamita & $295 \mathrm{SQC16}$ & 100,00 & 158,39 & 116,15 & 38,01 & 6218,94 & 335,43 & 34,82 & 300,61 & 91,30 & 240,07 & 241,02 & 82,66 & 573,53 & 77,26 & 4,05 & 53,32 & 222,97 & 32,25 & 34,93 & 211,15 \\
\hline Epidalea calamita & 29SQC18 & 100,00 & 164,18 & 116,89 & $\begin{array}{l}38,05 \\
\end{array}$ & 6215,49 & 341,29 & 39,71 & 301,58 & 96,36 & 245,84 & 246,14 & 88,03 & 526,17 & 71,00 & 3,69 & 52,55 & 203,06 & 30,51 & 32,19 & 190,74 \\
\hline Epidalea calamita & $295 Q C 20$ & 100,00 & 158,69 & 114,03 & 38,00 & 6141,20 & 330,86 & 35,80 & 295,06 & 92,59 & 238,82 & 240,27 & 83,67 & 610,75 & 84,96 & 3,20 & 57,20 & 244,88 & 27,67 & 32,37 & 231,93 \\
\hline Epidalea calamita & $29 S Q C 21$ & 100,00 & 145,29 & 114,35 & 38,00 & 6208,92 & 321,02 & 23,04 & 297,98 & 79,29 & 227,01 & 228,47 & 70,48 & 684,79 & 92,50 & 4,51 & 55,84 & 271,28 & 34,24 & 38,10 & 260 \\
\hline Epidalea calamita & 29SQC23 & $\begin{array}{l}101,00 \\
100\end{array}$ & $\begin{array}{l}14,25 \\
156,44 \\
\end{array}$ & $\begin{array}{ll}114,53 \\
116,22\end{array}$ & 38,00 & $\begin{array}{l}020,56,16 \\
6236,16\end{array}$ & 333,51 & $\begin{array}{l}3,44 \\
32,47 \\
\end{array}$ & \begin{tabular}{|l|} 
\\
301,04
\end{tabular} & \begin{tabular}{|l|l|}
89,36 \\
8
\end{tabular} & \begin{tabular}{|l|}
238,35 \\
235
\end{tabular} & \begin{tabular}{|l|}
239,41 \\
23,1
\end{tabular} & $\begin{array}{l}0,40 \\
80,62\end{array}$ & \begin{tabular}{|l|l|}
605,30 \\
605
\end{tabular} & $\begin{array}{l}2,30 \\
82,13\end{array}$ & $\begin{array}{l}4,11 \\
3,85 \\
\end{array}$ & $\begin{array}{l}55,04 \\
5,16\end{array}$ & \begin{tabular}{|l|}
238,15 \\
23,0
\end{tabular} & $\begin{array}{l}4,424 \\
30,84\end{array}$ & $\begin{array}{l}0,1+48 \\
34,48\end{array}$ & $\begin{array}{l}200,10 \\
226,19\end{array}$ \\
\hline Epidalea calamita & $295 Q C 24$ & 99,00 & 155,97 & 116,59 & 38,00 & 6269,81 & 334,19 & 31,82 & 302,37 & 88,53 & 238,37 & 239,35 & 79,85 & 601,12 & 80,98 & 3,94 & 54,55 & 235,10 & 31,61 & 34,93 & 223,33 \\
\hline Epidalea calamita & $29 \mathrm{SQC25}$ & 100,00 & 154,87 & 116,72 & 38,00 & 6296,31 & 333,94 & 30,57 & 303,37 & 86,94 & 237,62 & 238,51 & 78,50 & 601,18 & 80,36 & 4,00 & 53,84 & 233,81 & 32,68 & 35,64 & 222,19 \\
\hline Epidalea calamita & $295 Q C 26$ & 100,00 & 157,30 & 117,01 & 38,00 & 6306,67 & 336,74 & 32,57 & 304,1 & 89,24 & 240,27 & 241, & 80, & 579,70 & 77,33 & 4,01 & 53,38 & 224 & 32,31 & 35,03 & 212,53 \\
\hline Epidalea calamita & $295 \mathrm{SQC27}$ & 100,00 & 160,26 & 117,09 & 38,00 & 6298,64 & 339,64 & 35,21 & 304,44 & 92,04 & 243,19 & 243,81 & 83,50 & 555,99 & 74,05 & 4,00 & 52,60 & 214,13 & 31,88 & 34,19 & 202,09 \\
\hline
\end{tabular}




\begin{tabular}{|c|c|c|c|c|c|c|c|c|c|c|c|c|c|c|c|c|c|c|c|c|c|}
\hline TAXON & UTM & $\mathrm{km} 2$ & B101 & B102 & $\mathrm{BIO3}$ & BIO4 & B105 & B106 & B107 & B108 & B109 & B1010 & BIO11 & BIO12 & B1013 & BIO14 & BIO15 & BIO16 & BIO17 & BIO18 & B1019 \\
\hline Epidalea calamita & 29SQC28 & 101,00 & 162,42 & 117,04 & 38,00 & 6296,73 & 341,58 & 37,15 & 304,44 & 93,96 & 245,39 & 245,72 & 85,55 & 537,24 & 71,40 & 3,97 & 52,31 & 206,15 & 31,56 & 33,13 & 193,92 \\
\hline Epidalea calamita & 2950 C30 & 100,00 & 153,54 & 115,83 & 38,00 & 6238,75 & 329,83 & 29,25 & 300,58 & 86,61 & 235,49 & 236,64 & 77,72 & 646,89 & 88,68 & 3,60 & 56,96 & 258,16 & 29,81 & 34,28 & 246,06 \\
\hline Epidalea calamita & $295 Q C 31$ & 101,00 & 143,35 & 115,71 & 37,99 & 6285,63 & 321,80 & 20,01 & 301,79 & 76,51 & 226,30 & 227,65 & 67,74 & 700,80 & 93,93 & 4,65 & 55,87 & 276,69 & 34,98 & 38,88 & 265,89 \\
\hline Epidalea calamita & 29SQC32 & 100,00 & 150,07 & 116,82 & 38,00 & 6311,19 & 329,47 & 25,56 & 303,92 & 82,63 & 233,28 & 234,30 & 73,90 & 652,92 & 87,76 & 4,06 & 55,58 & 257,04 & 32,41 & 36,21 & 245,72 \\
\hline Epidalea calamita & 29SQC33 & 100,00 & 153,02 & 117,28 & 38,00 & 6330,62 & 333,25 & 27,94 & 305,31 & 85,31 & 236,62 & 237,48 & 76,49 & 627,71 & 84,15 & 4,00 & 55,13 & 245,93 & 31,71 & 35,48 & 234,45 \\
\hline Epidalea calamita & $29 \mathrm{SQC} 36$ & 100,00 & 157,07 & 117,85 & 38,00 & 6360,65 & 338,56 & 31,38 & 307,18 & 88,35 & 241,04 & 241,64 & 79,81 & 581,93 & 76,87 & 4,00 & 53,48 & 224,35 & 31,94 & 34,76 & 212,76 \\
\hline Epidalea calamita & 29SQC38 & 100,00 & 163,23 & 117,86 & 38,00 & 6367,95 & 344,36 & 36,86 & 307,50 & 93,88 & 247,29 & 247,38 & 85,35 & 532,76 & 70,17 & 3,44 & 52,54 & 203,66 & 30,08 & 31,66 & 191,64 \\
\hline Epidalea calamita & $295 \mathrm{SC} 39$ & 101,00 & 165,75 & 117,51 & 37,97 & 6367,88 & 346,27 & 39,30 & 306,97 & 96,22 & 249,75 & 249,85 & 87,54 & 511,19 & 67,20 & 3,08 & 52,34 & 194,91 & 28,83 & 30,27 & 182,78 \\
\hline Epidalea calamita & $2950 C 40$ & 101,00 & 158,58 & 118,01 & 38,01 & 6304,75 & 337,41 & 32,34 & 305,07 & 90,67 & 241,28 & 242,38 & 81,72 & 626,43 & 86,06 & 3,03 & 57,45 & 250,37 & 27,34 & 32,01 & 238,25 \\
\hline Epidalea calamita & 29SQC41 & 99,00 & 150,44 & 117,83 & 38,00 & 6353,23 & 331,26 & 24,82 & 306,44 & 82,53 & 234,27 & 235,31 & 73,66 & 662,91 & 89,17 & 3,90 & 56,33 & 261,88 & 31,52 & 35,70 & 250,75 \\
\hline Epidalea calamita & $29 \mathrm{SQC42}$ & 101,00 & 152,95 & 118,39 & 38,00 & 6376,73 & 334,71 & 26,75 & 307,97 & 84,57 & 237,21 & 237,92 & 75,77 & 640,44 & 85,79 & 3,86 & 55,69 & 251,67 & 31,08 & 35,10 & 240,44 \\
\hline Epidalea calamita & $29 S Q C 46$ & 100,00 & 159,70 & 119,06 & 37,99 & 6443,91 & 343,06 & 32,26 & 310,81 & 89,84 & 244,80 & 244,96 & 81,12 & 569,21 & 75,04 & 3,69 & 53,64 & 218,71 & 30,47 & 32,42 & 207,26 \\
\hline Epidalea calamita & $295 \mathrm{SQC48}$ & 101,00 & 164,45 & 118,63 & 37,97 & $\begin{array}{l}6434,42 \\
6434\end{array}$ & 347,13 & $\begin{array}{l}37,04 \\
37,2\end{array}$ & \begin{tabular}{|l|l|}
310,09 \\
\end{tabular} & $\begin{array}{l}94,36 \\
94,36\end{array}$ & 249,40 & 249,46 & 85,73 & 525,70 & 69,10 & 3,06 & 52,98 & 200,26 & 28,72 & 29,29 & 188,50 \\
\hline Epidalea calamita & 29SQC49 & 99,00 & 163,25 & 117,95 & 37,60 & 6448,65 & 346,10 & 36,12 & 309,98 & 92,98 & 248,56 & 248,66 & 84,46 & 523,97 & 68,46 & 3,31 & 52,23 & 198,42 & 29,73 & 30,41 & 186,63 \\
\hline Epidalea calamita & $29 \mathrm{SQC50}$ & 100,00 & 154,05 & 119,27 & 38,01 & 6389,85 & 336,10 & 27,00 & 309,10 & 85,45 & 238,34 & 239,30 & 76,60 & 656,46 & 88,95 & 3,43 & 57,26 & 260,95 & 29,22 & 33,80 & 249,81 \\
\hline Epidalea calamita & $29 S Q C 52$ & 100,00 & 158,74 & 120,32 & 38,00 & 6435,63 & 342,47 & 30,48 & 311,99 & 89,27 & 243,72 & 244,24 & 80,33 & 613,54 & 82,38 & 3,19 & 56,22 & 241,10 & 28,37 & 32,57 & 229,94 \\
\hline Epidalea calamita & $295 \mathrm{SaC53}$ & 100,00 & 152,34 & 119,87 & 38,00 & 6469,16 & 337,34 & 24,95 & 312,39 & 82,86 & 237,97 & 238,62 & 74,10 & 638,24 & 84,75 & 3,94 & 55,30 & 248,30 & 31,58 & 35,35 & 237,69 \\
\hline Epidalea calamita & $29 \mathrm{SQC54}$ & 100,00 & 153,33 & 119,90 & 38,00 & 6489,27 & 338,89 & 25,67 & 313,23 & 83,50 & 239,37 & 239,85 & 74,71 & 623,19 & 82,50 & 4,00 & 54,77 & 241,07 & 31,37 & 34,32 & 230,40 \\
\hline Epidalea calamita & 29 SQC57 & 101,00 & 157,18 & 119,37 & 37,73 & 6509,74 & 342,79 & 29,19 & 313,61 & 86,55 & 243,60 & 243,67 & 77,96 & 573,23 & 74,97 & 3,87 & 53,01 & 217,74 & 31,36 & 32,25 & 206,81 \\
\hline Epidalea calamita & $2950 \mathrm{c} 63$ & 22,00 & 148,95 & 120,27 & 37,98 | & 6508,00 & 335,43 & 21,27 & 314.16 & 79,09 & 235,43 & 235,86 & 70,36 & 658,91 & 87,20 & 4,20 & 55,09 & 255,39 & 32.91 & 35,98 & 245,32 \\
\hline Epidalea calamita & 29SQD02 & 99,00 & 165,92 & 114,71 & 38,00 & 6184,23 & 340,88 & 43,15 & 297,73 & 98,20 & 247,12 & 247,40 & 90,08 & 515,70 & 68,77 & 4,00 & 50,75 & 197,38 & 33,19 & 34,14 & 185,29 \\
\hline Epidalea calamita & 29SQD03 & 99,00 & 162,05 & 112,89 & 37,65 & 6217,30 & 336,97 & 40,74 & 296,23 & 94,54 & 244,16 & 244,37 & 86,30 & 543,79 & 71,43 & 4,07 & 50,64 & 207,91 & 35,20 & 35,89 & 196,42 \\
\hline Epidalea calamita & 29SQD06 & 100,00 & 162,13 & 108,65 & \begin{tabular}{|l|l|}
36,89 \\
\end{tabular} & 6249,81 & 334,75 & 43,05 & 291,70 & 94,37 & 244,94 & 245,01 & 86,27 & 553,42 & 71,32 & 4,17 & 50,11 & 211,10 & 36,57 & 36,87 & 200,20 \\
\hline Epidalea calamita & 29SQD07 & 100,00 & 160,93 & 107,44 & 36,60 & 6257,25 & 332,73 & 42,59 & 290,13 & 93,20 & 243,99 & 244,13 & 85,12 & 562,46 & 72,17 & 4,35 & 49,91 & 214,50 & 37,65 & 37,91 & 203,80 \\
\hline Epidalea calamita & 29SQD08 & 100,00 & 157,66 & 105,80 & 36,10 & 6268,10 & 328,62 & 40,38 & 288,23 & 89,93 & 241,04 & 241,07 & 81,84 & 585,14 & 75,05 & 4,93 & 49,95 & 223,42 & 39,58 & 39,63 & 213,04 \\
\hline Epidalea calamita & 29SQD11 & 100,00 & 167,48 & 115,79 & 38,00 & 6236,47 & 344,04 & 43,37 & 300,67 & 99,24 & 249,51 & 249,55 & 90,87 & 497,77 & 66,39 & 3,17 & 51,52 & 190,39 & 30,01 & 30,95 & 177,96 \\
\hline Epidalea calamita & $29 S Q D 12$ & 101,00 & 165,75 & 114,65 & 37,94 & 6258,15 & 342,40 & 42,12 & 300,29 & 97,21 & \begin{tabular}{|l|}
248,07 \\
\end{tabular} & 248,14 & 89,01 & 509,34 & $\begin{array}{l}0,00 \\
67,00\end{array}$ & 3,90 & 50,63 & 193,64 & 32,47 & 33,34 & 181,47 \\
\hline Epidalea calamita & 29SQD13 & 101,00 & 161,91 & 112,93 & \begin{tabular}{|l|l|}
37,27 \\
\end{tabular} & 6289,60 & 338,44 & 39,80 & 298,64 & 93,62 & 245,15 & 245,26 & 85,32 & 532,07 & 69,11 & 4,03 & 50,50 & 201,98 & 34,28 & 34,72 & 190,05 \\
\hline Epidalea calamita & 29SQD17 & 100,00 & 159,88 & 107,54 & 36,00 & 6335,02 & 333,55 & 40,64 & 292,92 & 91,31 & 244,13 & 244,13 & 83,15 & 544,58 & 68,94 & 4,05 & 49,74 & 205,57 & 36,49 & 36,51 & 194,10 \\
\hline Epidalea calamita & 29SQD18 & 100,00 & 158,95 & 106,70 & 36,00 & 6328,08 & 331,75 & 40,47 & 291,28 & 90,38 & 243,22 & 243,22 & 82,34 & 550,14 & 69,56 & 4,51 & 49,38 & 207,69 & 37,51 & 37,51 & 196,47 \\
\hline Epidalea calamita & 29SQD19 & 101,00 & 162,86 & 107,15 & 36,24 & 6303,35 & 334,62 & 43,71 & 290,90 & 94,08 & 246,61 & 246,61 & 86,02 & 526,36 & 66,90 & 4,10 & 49,34 & 198,82 & 35,70 & 35,70 & 187,74 \\
\hline Epidalea calamita & $29 S Q D 20$ & 99,00 & 165,92 & \begin{tabular}{|l|l|}
116,54 \\
104
\end{tabular} & 37,249 & 6306,84 & 344,73 & \begin{tabular}{|l|l|}
40,70 \\
\end{tabular} & 304,03 & \begin{tabular}{|l|l|}
47,01 \\
\end{tabular} & \begin{tabular}{|l|}
249,04 \\
240
\end{tabular} & \begin{tabular}{|l|}
249,12 \\
\end{tabular} & $\begin{array}{l}80,66 \\
88,66\end{array}$ & 506,59 & $\begin{array}{l}00,90 \\
66,95\end{array}$ & 3,20 & $\begin{array}{ll}51,86 \\
51,4\end{array}$ & 193,22 & 29,84 & 30,62 & 180,89 \\
\hline Epidalea calamita & 29SQD21 & 101,00 & 167,54 & 115,88 & \begin{tabular}{|l|l|}
37,93 \\
\end{tabular} & 6306,67 & 345,66 & 42,66 & 302,99 & 98,62 & 250,56 & 250,69 & 90,15 & 493,85 & 65,03 & 3,03 & 51,52 & 187,80 & 29,46 & 30,62 & 175,35 \\
\hline Epidalea calamita & 29SQD22 & 99,00 & 166,10 & 114,86 & 37,35 & 6329,11 & 344,38 & 41,63 & 302,75 & 96,99 & 249,73 & 249,83 & 88,67 & 500,07 & 65,06 & 3,38 & 50,77 & 189,08 & 31,18 & 31.49 & 176,83 \\
\hline Epidalea calamita & 29SQD23 & 100,00 & 162,78 & 113,37 & 37,00 & 6357,80 & 341,02 & 39,52 & 301,50 & 93,64 & 247,12 & 247,14 & 85,36 & 515,75 & 66,36 & 4,00 & 50,40 & 194,20 & 32,93 & 33,12 & 182,06 \\
\hline Epidalea calamita & 29SQD26 & 101,00 & 159,38 & 108,83 & 36,05 & 6397,50 & 335,77 & 38,95 & 296,82 & 90,23 & 244,69 & 244,69 & 82,14 & 526,93 & 67,03 & 4,02 & 49,63 & 196,72 & 35,47 & 35,47 & 184,62 \\
\hline Epidalea calamita & 29SQD27 & $\begin{array}{l}100,00 \\
100\end{array}$ & $\begin{array}{l}13,30,06 \\
160,06\end{array}$ & \begin{tabular}{|l|}
107,97 \\
107,97
\end{tabular} & 30,0 & | 6397,26 & 335,49 & $\begin{array}{l}30,395 \\
39,85 \\
\end{array}$ & \begin{tabular}{|l|}
295,604 \\
254
\end{tabular} & $\begin{array}{l}\mid 0,23 \\
90,75\end{array}$ & $\begin{array}{l}245,32 \\
2450\end{array}$ & $\begin{array}{l}445,32 \\
245\end{array}$ & $\begin{array}{l}2,, 44 \\
82,60\end{array}$ & \begin{tabular}{|l|l|}
521,58 \\
21
\end{tabular} & $\begin{array}{l}66,06 \\
66,0\end{array}$ & $\begin{array}{ll}4,07 \\
, 07\end{array}$ & $\begin{array}{l}4,303 \\
49,38\end{array}$ & 194,52 & $\begin{array}{ll}35,41 \\
35,48\end{array}$ & $\begin{array}{l}35,41 \\
35,48\end{array}$ & $\begin{array}{l}104,02 \\
182,45\end{array}$ \\
\hline Epidalea calamita & 29SQD31 & 100,00 & 165,92 & 116,10 & 37,53 & 6383,78 & 346,06 & 40,36 & 305,70 & 96,25 & 250,19 & 250,23 & 87,68 & 499,24 & 64,97 & 3,08 & 51,30 & 188,50 & 29,97 & 30,39 & 176,32 \\
\hline Epidalea calamita & 29SQD32 & 99,00 & 163,79 & 115,06 & $\begin{array}{l}37,05 \\
\end{array}$ & 6406,58 & 344,01 & 38,80 & 305,22 & 94,02 & 248,83 & 248,84 & 85,67 & 506,41 & 65,30 & 3,67 & 50,66 & 190,02 & 31,50 & 31,52 & 177,81 \\
\hline Epidalea calamita & 29SQD35 & 99,00 & 158,47 & 110,82 & 36,14 & 6450,33 & 337,36 & 36,26 & 301,10 & 88,72 & 244,43 & 244,43 & 80,42 & 519,96 & 66,67 & 4,00 & 49,57 & 192,81 & 34,79 & 34,79 & 180,51 \\
\hline Epidalea calamita & 29SQD36 & 100,00 & 158,56 & 109,69 & 36,00 & 6453,55 & 336,64 & 37,03 & 299,60 & 88,73 & 244,68 & 244,68 & 80,45 & 515,19 & 66,6 & 4,06 & 49,25 & 190,48 & 34,98 & 34,98 & 178,10 \\
\hline Epidalea calamita & $\begin{array}{l}295 \text { Q } 290037 \\
\end{array}$ & 100,00 & $\begin{array}{l}13,50,05 \\
159,95\end{array}$ & \begin{tabular}{|l|}
109,03 \\
109,03
\end{tabular} & 30,00 & 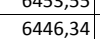 & $\begin{array}{l}330,04 \\
337,11\end{array}$ & $\begin{array}{l}3,05 \\
38,68 \\
\end{array}$ & \begin{tabular}{|l|}
$298,40,43$ \\
\end{tabular} & \begin{tabular}{|l|l|}
80,15 \\
90,07
\end{tabular} & \begin{tabular}{|l|}
246,00 \\
246,03
\end{tabular} & \begin{tabular}{|l|}
246,00 \\
246,
\end{tabular} & \begin{tabular}{|l|l|}
80,45 \\
81,86
\end{tabular} & $\mid$\begin{tabular}{|l|l|l|l|}
502,86 \\
\end{tabular} & $\begin{array}{l}0,026 \\
64,88\end{array}$ & $\begin{array}{l}4,00 \\
4,01\end{array}$ & \begin{tabular}{|l|}
48,25 \\
48,87 \\
\end{tabular} & $\begin{array}{l}190,48 \\
185,48\end{array}$ & 34,50 & 34,50 & $\begin{array}{l}1 / 10,10 \\
173,13\end{array}$ \\
\hline Epidalea calamita & $295 Q D 3$ & 100,00 & 162,23 & 109,03 & 36,06 & 6418,17 & 338,20 & 40,89 & 297,31 & 92,29 & 247,74 & 247,74 & 84,08 & 488,93 & 61,73 & 4,00 & 48,59 & 180,47 & 33,92 & 33,92 & 168,29 \\
\hline Epidalea calamita & 29SQD41 & 100,00 & 167,40 & 116,77 & 37,13 & 6444,88 & 349,11 & 40,70 & 308,41 & 96,92 & 252,81 & 252,81 & 88,49 & 488,53 & 63,47 & 3,01 & 51,48 & 183,45 & 28,49 & 28,51 & 171,45 \\
\hline Epidalea calamita & 29SQD42 & 101,00 & 163,45 & 115,65 & 37,00 & 6467,77 & 345,24 & 37,56 & 307,68 & 92,97 & 249,25 & 249,25 & 84,56 & 501,69 & 64,52 & 3,59 & 50,63 & 187,05 & 30,86 & 30,86 & 175,00 \\
\hline Epidalea calamita & $295 Q D 46$ & 101,00 & 158,61 & 111,09 & 36,02 & 6493,81 & 338,0 & 35,56 & 302,51 & 88,12 & 245,17 & 245,17 & 79,77 & 501,75 & 64,84 & 4,00 & 48,76 & 184,06 & 34,20 & 34,20 & 171,66 \\
\hline Epidalea calamita & 29SQD47 & 100,00 & 160,86 & 110,70 & \begin{tabular}{|l|l|}
36,07 \\
\end{tabular} & 6477,91 & 339,36 & 37,98 & 301,38 & 90,34 & 247,32 & 247,32 & 82,02 & 484,05 & 62,15 & 4,00 & 48,47 & 177,12 & 33,49 & 33,49 & 164,73 \\
\hline Epidalea calamita & 29SQD52 & 92,00 & 167,44 & 116,65 & 37,00 & 6497,98 & 349,78 & 40,09 & 309,69 & 96,03 & 253,58 & 253,58 & 87,75 & 477,86 & 61,55 & 3,01 & 50,82 & 177,33 & 28,63 & 28,63 & 165,58 \\
\hline Epidalea calamita & 29SQD53 & 97,00 & 165,47 & 115,63 & 37,00 & 6512,83 & 347,79 & 38,87 & 308,92 & 94,19 & 252,03 & 252,03 & 85,84 & 479,56 & 61,44 & 3,16 & 50,23 & 176,96 & 29,56 & 29,56 & 165,02 \\
\hline Epidalea calamita & 29SQD55 & 82,00 & 156,69 & 113,12 & 36,23 & 6542,17 & 338,71 & 32,22 & 306,49 & 85,59 & 244,25 & 244,25 & 77,52 & 505,80 & 65,25 & 4,08 & 48,90 & 184,66 & 34,11 & 34,11 & 172,52 \\
\hline Epidalea calamita & $\frac{29 S Q D 56}{2956}$ & 82,0 & $\begin{array}{l}150,03 \\
157,94\end{array}$ & \begin{tabular}{|l|}
112,30 \\
112,3
\end{tabular} & 36,01 & 6536,19| & 338 & \begin{tabular}{|l|l|l|l|}
33,71 \\
\end{tabular} & \begin{tabular}{|l|}
305,27 \\
30,27
\end{tabular} & $\begin{array}{l}\mid l, 39 \\
86,92 \\
\end{array}$ & \begin{tabular}{|l|}
245,25 \\
245
\end{tabular} & \begin{tabular}{|l|}
245,25 \\
\end{tabular} & 78,64 & \begin{tabular}{|l|}
402,20 \\
492,20
\end{tabular} & $\begin{array}{l}\mid 20,20 \\
63,35 \\
\end{array}$ & $\begin{array}{l}4,00 \\
4,02\end{array}$ & $\begin{array}{ll}40,50 \\
483\end{array}$ & $\begin{array}{l}104,00 \\
179,17\end{array}$ & 33,79 & $\begin{array}{l}34,11 \\
33,79\end{array}$ & 166,85 \\
\hline Epidalea calamita & 29SQD57 & 80,00 & 160,28 & 111,88 & 36,03 & 6511,11 & 340,08 & 36,26 & 303,83 & 89,31 & 247,30 & 247,30 & 81,00 & 474,24 & 60,62 & 4,00 & 48,02 & 172,21 & 33,12 & 33,12 & 159,87 \\
\hline Epidalea calamita & 29SQE12 & 101,00 & 159,51 & $\begin{array}{l}106,20 \\
106\end{array}$ & 36,38 & 6265,51 & 328,80 & $\begin{array}{l}0,209 \\
40,89\end{array}$ & \begin{tabular}{|l|}
287,91 \\
\end{tabular} & $\begin{array}{l}\mid 90,55 \\
90,5\end{array}$ & 242,56 & 242,56 & 82,76 & 537,63 & $\begin{array}{l}68,69 \\
68,\end{array}$ & 4,94 & $\begin{array}{l}48,43 \\
48,\end{array}$ & 203,31 & 37,95 & 37,95 & 192,75 \\
\hline Epidalea calamita & 29SQE22 & 99,00 & 161,24 & 107,65 & 36,48 & 6301,11 & 332,08 & 41,32 & 290,76 & 91,85 & 245,08 & 245,08 & 83,98 & 500,32 & 63,38 & 4,59 & 47,75 & 187,07 & 35,98 & 35,98 & 175,85 \\
\hline Epidalea calamita & 29SQE30 & 100,00 & 160,68 & 108,58 & 36,06 & 6384,78 & 334,81 & 39,60 & 295,20 & 90,75 & 245,78 & 245,78 & 82,71 & 488,52 & 60,88 & 4,24 & 47,79 & 180,53 & 34,82 & 34,82 & 168 \\
\hline Epidalea calamita & 29SQEL41 & $\begin{array}{l}101,00 \\
100\end{array}$ & $\begin{array}{l}10,00 \\
154,90\end{array}$ & \begin{tabular}{|l|}
109,12 \\
109,12
\end{tabular} & $\begin{array}{l}30,0 \\
36,13\end{array}$ & $\begin{array}{l}\mid 25019,10 \\
6419,67\end{array}$ & 330,21 & $\begin{array}{l}3,00 \\
33,53 \\
\end{array}$ & \begin{tabular}{|l|}
296,68 \\
290
\end{tabular} & \begin{tabular}{|c|c|}
84,60 \\
0,6
\end{tabular} & \begin{tabular}{|l|}
240,72 \\
242
\end{tabular} & \begin{tabular}{|l|}
240,72 \\
240
\end{tabular} & $\begin{array}{l}20,1 / 2 \\
76,87\end{array}$ & \begin{tabular}{|l|}
$480,3<2$ \\
489,60
\end{tabular} & $\begin{array}{l}0,00 \\
60,49 \\
\end{array}$ & $\begin{array}{l}, 24 \\
4,99 \\
\end{array}$ & $\begin{array}{l}4,, 13 \\
46,49 \\
\end{array}$ & $\begin{array}{l}10,50,5 \\
178,67\end{array}$ & $\begin{array}{l}4,02 \\
36,92 \\
\end{array}$ & $\begin{array}{l}4,02 \\
36,92 \\
\end{array}$ & $\begin{array}{l}100,00 \\
166,26\end{array}$ \\
\hline Epidalea calamita & 29SQE42 & 100,00 & 153,12 & 109,16 & 36,26 & 6395,85 & 327,66 & 32,03 & 295,63 & 82,96 & 238,64 & 238,64 & 75,36 & 489,82 & 60,62 & 5,12 & 46,01 & 178,57 & 37,77 & 37,77 & 166,24 \\
\hline Epidalea calamita & 29SQE50 & 70,00 & 159,94 & 110,91 & 36,59 & 6450,74 & 336,84 & 36,84 & 300,00 & 89,39 & 246,15 & 246,15 & 81,11 & 456,27 & 56,13 & 4,02 & 46,66 & 165,05 & 33,50 & 33,50 & 152,85 \\
\hline Epidalea calamita & 29SQE51 & 63,00 & 158,98 & 110,69 & 36,68 & 6427,51 & 334,89 & 36,06 & 298,83 & 88,21 & 244,68 & 244, & 80, & 454,36 & 55,83 & 4,50 & 46,13 & 164,21 & 34,23 & 34,23 & 151,88 \\
\hline Epidalea calamita & 29SQE552 & 66,00 & 155,05 & 110,34 & 36,55 & 6425,27 & 330,51 & 32,56 & 297,95 & $\mid$ & 240,69 & 240,69 & 76,57 & 463,73 & 57,01 & 5,01 & 45,64 & 167,40 & 36,06 & 36,06 & 154,87 \\
\hline
\end{tabular}




\begin{tabular}{|c|c|c|c|c|c|c|c|c|c|c|c|c|c|c|c|c|c|c|c|c|c|}
\hline TAXON & UTM & $\mathrm{km} 2$ & BIO1 & BIO2 & $\mathrm{BIO3}$ & B104 & BIO5 & B106 & B107 & B108 & 8109 & BIO10 & BIO11 & BIO12 & 81013 & BIO14 & BIO15 & B1016 & B1017 & B1018 & 81019 \\
\hline Epidalea calamita & 29TMH74 & & & & & & & & & & & & & & & & & & & & \\
\hline Epidalea calamita & 29TMH75 & 22,00 & 144,72 & 59,38 & 39,38 & 3132,36 & 225,90 & 76,72 & 149,18 & 115,10 & 182,95 & 186,33 & 105,72 & 951,31 & 139,23 & 24,79 & 42,82 & 378,46 & 108,46 & 133,97 & 315,95 \\
\hline Epidalea calamita & 29TMH76 & 18,00 & 142,36 & 59,45 & 39,14 & 3130,50 & 224,05 & 74,18 & 149,86 & $\begin{array}{ll}112,64 \\
\end{array}$ & $\begin{array}{l}180,45 \\
\end{array}$ & 184,00 & $\begin{array}{l}103,45 \\
\end{array}$ & \begin{tabular}{ll|}
970,82 \\
\end{tabular} & 140,59 & 26,09 & 42,05 & 384,09 & 112,86 & $\begin{array}{l}138,27 \\
\end{array}$ & 322,23 \\
\hline Epidalea calamita & 29TMH84 & 11,00 & 139,81 & $\begin{array}{ll}60,94 \\
\end{array}$ & 38,75 & 3273,38 & 225,63 & 70,25 & 155,38 & 108,50 & 180,31 & $\begin{array}{l}183,69 \\
\end{array}$ & \begin{tabular}{ll|}
99,50 \\
\end{tabular} & 1055,56 & \begin{tabular}{l|l|}
150,25 \\
\end{tabular} & 27,56 & 43,06 & 419,00 & 116,56 & $\begin{array}{ll}140,94 \\
\end{array}$ & 361,06 \\
\hline Epidalea calamita & 29тMH87 & 60,00 & 143,94 & 60,09 & 39,43 & 3139,24 & 225,93 & 75,29 & 150,63 & $114,11 \mid$ & 182,18 | & 185,88 & 104,93 & 980,60 & 139,88 & 26,78 & 41,41 & 385,48 & 113,95 & 139,40 & 326,89 \\
\hline Epidalea calamita & 29TMH91 & 46,00 & 146,53 & 59,04 & 38,62 & 3311,15 & 229,18 & 78,01 & 151,16 & 113,22 & 187,59 & 189,99 & 104,65 & 1143,04 & 161,42 & 26,24 & 45,56 & 458,00 & 110,67 & 134,49 & 409,85 \\
\hline Epidalea calamita & 29TMH92 & 25,00 & 141,23 & 60,49 & 38,14 & 3378,23 & 227,51 & 71,47 & 156,05 & 107,72 & 183,44 & 185,91 & 99,12 & 1175,86 & 168,47 & 28,44 & 44,98 & 469,60 & 117,91 & 141,35 & 420,91 \\
\hline Epidalea calamita & 29TMH93 & 45,00 & 142,97 & 60,38 & 38,58 & 3303,65 & 228,01 & 73,36 & 154,65 & 110,67 & 183,91 & 186,81 & \begin{tabular}{|l|}
101,71 \\
\end{tabular} & $\begin{array}{l}1081,97 \\
\end{array}$ & 153,14 & 26,94 & 44,01 & 431,12 & $\begin{array}{ll}113,87 \\
\end{array}$ & 138,10 & 376,59 \\
\hline Epidalea calamita & 29TMH94 & 96,00 & 134,43 & 62,32 & 38,30 & 3383,03 & 224,15 & 63,56 & 160,59 & $\begin{array}{ll}101,66 \\
\end{array}$ & 176,79 & \begin{tabular}{ll|}
179,88 \\
\end{tabular} & $\begin{array}{ll}92,99 \\
\end{array}$ & $\begin{array}{l}1163,86 \\
\end{array}$ & $\begin{array}{l}165,96 \\
\end{array}$ & 30,57 & 43,29 & 460,44 & $\begin{array}{l}125,92 \\
\end{array}$ & \begin{tabular}{|l|l|}
149,26 \\
\end{tabular} & 407,56 \\
\hline Epidalea calamita & 29TMH98 & 28,00 & 142,80 & 61,16 & 39,53 & 3177,18 & 226,53 & 73,42 & \begin{tabular}{|l|l|}
153,11 \\
\end{tabular} & \begin{tabular}{|l|l|}
112,60 \\
\end{tabular} & \begin{tabular}{|l|l|}
181,80 \\
\end{tabular} & \begin{tabular}{ll|}
185,62 \\
\end{tabular} & \begin{tabular}{|l|}
103,67 \\
\end{tabular} & 1013,53 & $\begin{array}{l}141,49 \\
\end{array}$ & 28,18 & 41,00 & \begin{tabular}{|l|l|}
395,73 \\
\end{tabular} & 117,49 & 142,60 & 341,07 \\
\hline Epidalea calamita & 29TNE14 & 94,00 & 153,37 & 80,69 & 43,99 & 3489,40 & 249,04 & 67,60 & 181,44 & 114,96 & $\begin{array}{ll}194,89 \\
\end{array}$ & 196,96 & 106,94 & \begin{tabular}{|l|l|}
915,43 \\
\end{tabular} & 130,14 & 8,93 & 54,31 & 372,73 & 57,22 & 64,43 & 366,66 \\
\hline Epidalea calamita & 29TNE15 & 95,00 & 152,10 & 79,87 & 44,23 & 3433,91 & 244,94 & 66,57 & $\begin{array}{l}178,37 \\
\end{array}$ & \begin{tabular}{|l|l|}
114,04 \\
\end{tabular} & $\begin{array}{l}192,57 \\
\end{array}$ & $\begin{array}{l}194,69 \\
\end{array}$ & \begin{tabular}{|l|}
106,07 \\
\end{tabular} & 940,82 & 132,95 & 9,80 & 53,87 & $\begin{array}{l}381,66 \\
\end{array}$ & 60,01 & 67,97 & 375,23 \\
\hline Epidalea calamita & 29TNE17 & 40,00 & 151,00 & 77,70 & 44,97 & 3321,38 & 237,20 & 65,97 & 171,23 & 113,99 & 189,58 & 191,34 & 105,62 & 973,01 & 136,21 & 10,34 & 53,00 & 393,07 & 63,24 & 72,89 & 385,45 \\
\hline Epidalea calamita & 29TNE26 & 100,00 & 152,32 & 84,16 & 44,45 & 3581,52 & 250,69 & 63,32 & 187,37 & 112,44 & $\begin{array}{ll}194,77 \\
\end{array}$ & 196,81 & 104,39 & $\begin{array}{l}969,56 \\
\end{array}$ & \begin{tabular}{ll|}
136,02 \\
\end{tabular} & \begin{tabular}{l|l|}
10,03 \\
\end{tabular} & 53,09 & 390,74 & 63,01 & 70,94 & 385,71 \\
\hline Epidalea calamita & 29TNE27 & 100,00 & 150,94 & 81,77 & 44,72 & 3491,93 & 244,10 & $\begin{array}{ll}63,03 \\
\end{array}$ & \begin{tabular}{|l|l|}
181,07 \\
\end{tabular} & 111,95 & 191,99 & 193,90 & $\begin{array}{l}103,76 \\
\end{array}$ & $\begin{array}{l}988,28 \\
\end{array}$ & 138,04 & 10,85 & 52,79 & $\begin{array}{l}397,95 \\
\end{array}$ & 65,18 & 74,10 & 391,49 \\
\hline Epidalea calamita & 29TNE28 & 101,00 & 149,73 & 78,91 & 45,04 & 3384,36 & 236,65 & 63,11 & $\begin{array}{ll}173,54 \\
\end{array}$ & $\begin{array}{ll}111,73 \\
\end{array}$ & 189,05 & $\begin{array}{l}190,76 \\
\end{array}$ & 103,37 & 1002,72 & $\begin{array}{l}139,53 \\
\end{array}$ & 11,00 & 52,55 & $\begin{array}{l}403,88 \\
\end{array}$ & $\begin{array}{l}66,14 \\
\end{array}$ & 76,54 & 395,56 \\
\hline Epidalea calamita & 29TNE29 & 91,00 & 148,62 & 76,34 & 45,23 & 3286,96 & 230,02 & 63,25 & 166,77 & 111,66 & 186,35 & \begin{tabular}{ll|}
187,93 \\
\end{tabular} & $\begin{array}{l}103,07 \\
\end{array}$ & $\begin{array}{l}1017,60 \\
\end{array}$ & 140,94 & 11,13 & 52,35 & 410,05 & 67,19 & 78,96 & 399,81 \\
\hline Epidalea calamita & 29TNE37 & 100,00 & 151,92 & 88,12 & 44,21 & 3760,17 & 256,36 & 59,47 & 196,88 & 109,94 & $\begin{array}{ll}196,99 \\
\end{array}$ & $\mid 198,97$ & $\mid \begin{array}{l}101,90 \\
\end{array}$ & \begin{tabular}{|l|l|}
999,56 \\
\end{tabular} & \begin{tabular}{|l|l|}
139,38 \\
\end{tabular} & \begin{tabular}{|l|l|}
11,00 \\
\end{tabular} & 52,72 & $\mid 400,87$ & 66,69 & 74,56 & 396,25 \\
\hline Epidalea calamita & 29TNE38 & 100,00 & 151,17 & 85,28 & 44,48 & 3655,62 & 249,50 & 59,88 & 189,62 & 110,04 & \begin{tabular}{|l|l|l|l}
194,48 \\
\end{tabular} & 196,30 & \begin{tabular}{|l|}
101,87 \\
\end{tabular} & 1009,27 & 140,22 & 11,01 & 52,38 & 405,38 & 67,20 & 76,61 & 398,25 \\
\hline Epidalea calamita & 29TNE39 & 101,00 & 149,99 & 83,28 & 44,75 & 3590,40 & 244,10 & 59,58 & 184,53 & 109,52 & 192,36 & 194,02 & 101,25 & 1023,95 & \begin{tabular}{ll|}
141,72 \\
\end{tabular} & 11,49 & 52,18 & 411,92 & 68,18 & 79,27 & 402,06 \\
\hline Epidalea calamita & 29TNE43 & 100,00 & 152,01 & 96,88 & 42,29 & 4334,80 & 280,95 & 54,54 & $\begin{array}{ll}226,42 \\
\end{array}$ & $\begin{array}{ll}97,23 \\
\end{array}$ & 206,12 & 208,63 & \begin{tabular}{ll|l}
97,14 \\
\end{tabular} & 988,34 & \begin{tabular}{ll|}
140,82 \\
\end{tabular} & 10,21 & 53,90 & 399,77 & 65,27 & 67,43 & 399,77 \\
\hline Epidalea calamita & 29TNE44 & 101,00 & 157,36 & 99,73 & 43,31 & 4271,78 & 286,11 & 58,28 & $\begin{array}{ll}227,83 \\
\end{array}$ & $\begin{array}{ll}102,93 \\
\end{array}$ & 210,29 & 212,65 & 102,55 & $\begin{array}{l}952,53 \\
\end{array}$ & $\begin{array}{l}133,76 \\
\end{array}$ & 10,00 & 53,12 & 382,72 & 63,82 & 67,21 & 382,71 \\
\hline Epidalea calamita & 29TNE45 & 101,00 & 159,50 & 98,46 & 43,90 & $\begin{array}{lll}4164,52 \\
\end{array}$ & 283,32 & 60,82 & 222,49 & 108,75 & 210,58 & 212,78 & 105,32 & 936,35 & $\mid$\begin{tabular}{|l|}
130,70 \\
\end{tabular} & 9,70 & 52,90 & 374,25 & 62,54 & 67,44 & 374,14 \\
\hline Epidalea calamita & 29TNE53 & 101,00 & 151,81 & 98,81 & 41,57 & 4545,58 & 286,84 & 52,19 & 234,65 & 94,84 & 209,36 & 211,64 & 94,84 & 1002,83 & 143,49 & 10,28 & 53,94 & 406,24 & 66,25 & 67,75 & 406,24 \\
\hline Epidalea calamita & 29TNE56 & 101,00 & 150,10 & 99,40 & 42,36 & 4444,24 & 281,01 & \begin{tabular}{|l|l}
49,47 \\
\end{tabular} & 231,54 & 93,55 & 205,67 & 207,82 & 93,41 & 1053,40 & 149,12 & 11,49 & 52,88 & 422,23 & 71,75 & 75,15 & 422,23 \\
\hline Epidalea calamita & 29TNE78 & 100,00 & 148,15 & 99,57 & 41,25 & 4758,31 & 283,45 & 44,56 & 238,88 & 92,48 & 208,55 & 209,97 & 87,76 & 1076,81 & 155,12 & \begin{tabular}{ll|}
11,07 \\
\end{tabular} & 53,44 & 431,68 & 70,90 & 75,54 & 431,42 \\
\hline Epidalea calamita & 29TNE87 & 101,00 & 151,38 & 100,69 & 40,36 & 4969,05 & 292,32 & 46,06 & 246,27 & 88,92 & 214,94 & 216,39 & 88,82 & 1027,25 & \begin{tabular}{ll|}
148,92 \\
\end{tabular} & $\begin{array}{ll}9,93 \\
\end{array}$ & 53,91 & $\begin{array}{l}413,26 \\
\end{array}$ & 66,69 & 70,08 & 413,26 \\
\hline Epidalea calamita & 29TNE89 & 99,00 & 143,28 & $\begin{array}{lll}98,96 \\
\end{array}$ & 40,16 & 4954,20 & 281,94 & 38,90 & 243,03 & 81,35 & 206,81 & 207,99 & 80,99 & 1124,35 & 164,80 & 11,31 & 54,06 & 452,74 & 73,25 & 77,10 & 452,74 \\
\hline Epidalea calamita & 29TNE98 & 100,00 & 146,38 & 99,49 & 39,50 & 5130,69 & 289,32 & 40,54 & 248,78 & 82,20 & 212,43 & 213,62 & 82,20 & 1069,29 & \begin{tabular}{l|l|}
157,42 \\
\end{tabular} & 10,31 & 54,43 & $\begin{array}{l}431,66 \\
\end{array}$ & 68,89 & 71,63 & 431,66 \\
\hline Epidalea calamita & 29TNF20 & 39,00 & 148,11 & 75,99 & 45,39 & 3278,87 & 228,40 & 62,72 & 165,68 & 111,24 & \begin{tabular}{|l|l|}
185,74 \\
\end{tabular} & 187,30 & 102,70 & $\begin{array}{l}1033,57 \\
\end{array}$ & 142,44 & 11,91 & 52,02 & 416,51 & 68,59 & 81,88 & 404,38 \\
\hline Epidalea calamita & 29TNF21 & 42,00 & 147,88 & 78,33 & 45,13 & 3371,42 & 232,38 & 61,15 & $\begin{array}{l}171,23 \\
\end{array}$ & 110,42 & 187,18 & \begin{tabular}{ll|}
188,83 \\
\end{tabular} & 101,85 & $\begin{array}{l}1056,40 \\
\end{array}$ & \begin{tabular}{|l|l|}
144,77 \\
\end{tabular} & 12,05 & 52,00 & 425,88 & 70,18 & 84,85 & 411,62 \\
\hline Epidalea calamita & 29TNF26 & 68,00 & 143,71 & 84,72 & 45,01 & 3658,17 & 241,52 & 55,50 & 186,02 & 99,99 & 188,56 & 190,46 & 97,07 & 1215,52 & 165,55 & 15,08 & 51,03 & 482,21 & 83,56 & 100,72 & 480,78 \\
\hline Epidalea calamita & 29TNF27 & 83,00 & 143,39 & 83,67 & 44,84 & 3665,84 & 241,48 & 56,50 & \begin{tabular}{|l|l|}
184,98 \\
\end{tabular} & \begin{tabular}{|l|l}
98,16 \\
\end{tabular} & 188,60 & 190,35 & 96,94 & 1229,74 & 168,04 & \begin{tabular}{ll|}
15,06 \\
\end{tabular} & 51,32 & 488,82 & 83,48 & 101,82 & 488,58 \\
\hline Epidalea calamita & 29TNF28 & 101,00 & 142,97 & 82,67 & 44,28 & 3688,89 & 241,72 & 57,07 & 184,65 & $\begin{array}{l}96,45 \\
\end{array}$ & 188,66 & 190,33 & 96,40 & $\begin{array}{l}1246,49 \\
\end{array}$ & $\begin{array}{l}171,06 \\
\end{array}$ & 15,08 & 51,64 & 496,82 & 83,70 & 103,29 & 496,82 \\
\hline Epidalea calamita & 29TNF31 & 101,00 & \begin{tabular}{ll|l|}
148,07 \\
\end{tabular} & 83,26 & 44,69 & 3597,97 & 241,68 & 57,46 & 184,22 & \begin{tabular}{|l|l|}
107,87 \\
\end{tabular} & \begin{tabular}{|l|l|}
190,73 \\
\end{tabular} & 192,50 & $\begin{array}{l}99,47 \\
\end{array}$ & 1065,36 & $\begin{array}{l}146,05 \\
\end{array}$ & 12,24 & 52,00 & \begin{tabular}{|l|l|}
429,98 \\
\end{tabular} & 71,06 & 85,21 & 414,46 \\
\hline Epidalea calamita & 29TNF32 & 101,00 & 145,57 & 84,92 & 44,51 & 3682,73 & 242,81 & 53,91 & $\begin{array}{l}188,90 \\
\end{array}$ & 104,71 & 189,77 & $\begin{array}{l}191,53 \\
\end{array}$ & 96,39 & 1108,58 & \begin{tabular}{ll|}
151,23 \\
\end{tabular} & $\begin{array}{l}13,26 \\
\end{array}$ & 51,97 & $\begin{array}{l}448,35 \\
\end{array}$ & 74,67 & $\begin{array}{ll}90,24 \\
\end{array}$ & 429,45 \\
\hline Epidalea calamita & 29TNF34 & 101,00 & 142,93 & 88,24 & 44,24 & 3832,79 & 246,60 & 49,26 & 197,34 & 100,95 & 189,74 & 191,72 & 92,80 & 1169,53 & 160,71 & 14,84 & 51,92 & 475,06 & 79,95 & 99,15 & 447,97 \\
\hline Epidalea calamita & 29TNF35 & 101,00 & 143,79 & 89,17 & 44,34 & 3853,99 & 248,86 & 50,08 & $\begin{array}{ll}198,78 \\
\end{array}$ & 101,82 & 191,19 & 193,23 & 93,92 & 1176,16 & 162,85 & 15,00 & 51,60 & 476,56 & 80,52 & 100,90 & 450,62 \\
\hline Epidalea calamita & 29TNF45 & 100,00 & 143,60 & 92,24 & 43,84 & 4070,49 & 255,27 & 46,97 & 208,31 & $\begin{array}{ll}98,94 \\
\end{array}$ & \begin{tabular}{|l|l|}
194,03 \\
\end{tabular} & 195,90 & 91,10 & 1174,73 & 159,85 & 14,55 & 51,68 & 75,51 & 79,77 & 98,42 & 452,40 \\
\hline Epidalea calamita & 29TNF50 & 101,00 & 139,58 & 92,61 & 42,17 & 4304,23 & 258,99 & 41,99 & 217,01 & 92,04 & 193,36 & 195,11 & 84,30 & \begin{tabular}{|l|}
1181,11 \\
\end{tabular} & 167,89 & \begin{tabular}{|l|l|}
13,43 \\
\end{tabular} & 52,76 & \begin{tabular}{|l|l|}
475,58 \\
\end{tabular} & 79,54 & 87,48 & 468,92 \\
\hline Epidalea calamita & 29TNF60 & 100,00 & 135,03 & 94,39 & $41, \mathrm{C}$ & 4585,71 & 262,88 & 35,58 & 227,30 & 84,44 & \begin{tabular}{|l|l|}
193,27 \\
\end{tabular} & \begin{tabular}{ll|}
194,86 \\
\end{tabular} & 77,17 & \begin{tabular}{ll|}
1237,64 \\
\end{tabular} & \begin{tabular}{|l|l|}
179,24 \\
\end{tabular} & $\begin{array}{l}13,79 \\
\end{array}$ & 53,37 & 498,24 & 82,88 & $\begin{array}{l}88,33 \\
\end{array}$ & 495,79 \\
\hline Epidalea calamita & 29TNF61 & 100,00 & 135,59 & 94,12 & 41,30 & 4545,64 & 261,58 & $\begin{array}{ll}36,27 \\
\end{array}$ & $\begin{array}{ll}225,31 \\
\end{array}$ & \begin{tabular}{ll|l}
84,47 \\
\end{tabular} & $\begin{array}{ll}193,36 \\
\end{array}$ & 194,77 & 78,12 & 1233,48 & $\begin{array}{l}177,66 \\
\end{array}$ & 13,94 & 53,23 & 497,11 & 82,71 & 89,56 & 492,25 \\
\hline Epidalea calamita & 29TNF62 & 101,00 & 119,24 & 89,37 & 39,56 & 4648,32 & 246,04 & 23,36 & 222,68 & 65,19 & $179,50 \mid$ & $\mid 180,74$ & 62,13 & 1421,55 & 207,84 & 17,24 & 53,69 & 573,99 & 97,86 & 101,46 & 572,57 \\
\hline Epidalea calamita & 29TNF63 & 100,00 & 137,18 & 96,37 & 41,92 & 4552,30 & 263,63 & 36,45 & 227,18 & 87,09 & $\begin{array}{ll}194,87 \\
\end{array}$ & 196,22 & 79,29 & 1227,80 & 174,69 & 14,04 & 52,72 & 94,00 & 82,05 & 92,22 & 486,62 \\
\hline Epidalea calamita & 29TNF66 & 100,00 & 140,95 & 98,10 & 42 & 4557,92 & 267,53 & 39,38 & 228,15 & 90,49 & 198,65 & 199,92 & 82,92 & $\begin{array}{l}1198,66 \\
\end{array}$ & \begin{tabular}{|l|l|}
165,92 \\
\end{tabular} & \begin{tabular}{ll|}
14,16 \\
\end{tabular} & 51,88 & 479,50 & 80,88 & $\begin{array}{l}94,69 \\
\end{array}$ & 470,84 \\
\hline Epidalea calamita & 29TNF70 & 100,00 & 131,12 & 93,82 & 39,84 & 4794,23 & 263,60 & 31,18 & 232,42 & 74,29 & 193,10 & 194,21 & 71,49 & \begin{tabular}{|l|}
1276,03 \\
\end{tabular} & $\mid 187,97$ & 13,92 & 54,17 & 515,51 & 84,71 & 88,05 & 514,91 \\
\hline Epidalea calamita & 29TNF71 & 101,00 & 138,55 & 97,23 & 41,02 & 4748,50 & 270,65 & 36,33 & 234,32 & 84,96 & \begin{tabular}{|l|l|}
199,28 \\
\end{tabular} & 200,42 & \begin{tabular}{|c|c|}
78,59 \\
\end{tabular} & \begin{tabular}{|l|l|}
1195,33 \\
\end{tabular} & $\mid$\begin{tabular}{|l|l|}
173,64 \\
\end{tabular} & 12,91 & 53,50 & \begin{tabular}{|l|l|}
480,83 \\
\end{tabular} & \begin{tabular}{|c|}
78,99 \\
\end{tabular} & 85,21 & $\begin{array}{ll}478,45 \\
\end{array}$ \\
\hline Epidalea calamita & 29TNF72 & 100,00 & 124,75 & 93,12 & 39,79 & 4811,33 & 256,79 & 25,56 & 231,23 & $\begin{array}{ll}67,57 \\
\end{array}$ & 187,14 & 188,20 & 65,25 & $\begin{array}{l}1354,86 \\
\end{array}$ & 199,64 & $\begin{array}{l}15,47 \\
\end{array}$ & 54,07 & $\begin{array}{l}547,42 \\
\end{array}$ & 91,22 & $\begin{array}{ll}94,88 \\
\end{array}$ & 546,90 \\
\hline Epidalea calamita & 29TNF78 & 101,00 & 126,95 & 97,32 & 40,78 & 4844,60 & 261,42 & 25,75 & 235,68 & 68,04 & 189,60 & 190,52 & 66,83 & 1333,31 & 185,94 & 17,30 & 52,04 & 531,44 & 94,53 & 103,38 & 531,32 \\
\hline Epidalea calamita & 29TNFT & 101,00 & 124,43 & 95,81 & 40, & 4841,80 & 258,19 & 24,30 & 233,89 & 65,58 & 187,19 & 188,09 & 64,62 & $\begin{array}{l}1349,39 \\
\end{array}$ & 185,11 & 18,55 & 51,51 & 536,28 & 98,47 & 107,09 & 536,16 \\
\hline Epidalea calamita & 29TNF82 & 100,00 & 133,58 & 98,23 & 40,21 & 4971,25 & 271,19 & 30,14 & 241,06 & 73,00 & 197,70 & 198,66 & 71,47 & $\begin{array}{l}1244,51 \\
\end{array}$ & \begin{tabular}{|l|l|}
184,08 \\
\end{tabular} & 13,26 & 54,36 & 502,42 & 81,71 & 86,36 & 502,12 \\
\hline Epidalea calamita & 29TNF83 & 101,00 & 109,14 & 87,77 & 37,62 & 4975,93 & 242,62 & 12,70 & 229,92 & 49,47 & \begin{tabular}{|l|l|}
175,17 \\
\end{tabular} & 175,58 & 49,22 & 1493,52 & 222,19 & 18,53 & 54,42 & 606,03 & 102,49 & 103,59 & 606,01 \\
\hline Epidalea calamita & 29TNF84 & 101,00 & 118,90 & 93,61 & 39,19 & 982,55 & 254,88 & 19,09 & 35,79 & 58,28 & 18 & 18 & 5 & $\begin{array}{l}1397,56 \\
\end{array}$ & 206,45 & 16,6 & 54,06 & 62 & 95,33 & 98,47 & 56 \\
\hline Epidalea calamita & $29 \mathrm{TN}$ & 101,00 & 138 & 102,06 & 40 & 4 & 277,95 & 31,91 & 246,04 & 78,21 & 202,41 & 202 & 75,17 & 1176,14 & $\begin{array}{l}161,05 \\
\end{array}$ & 14,6 & 51,68 & 403,52 & 82,57 & \begin{tabular}{|l|l}
92,81 \\
\end{tabular} & 463 \\
\hline Epidalea calamita & 29TNF97 & 100,00 & \begin{tabular}{ll|}
115,88 \\
\end{tabular} & 95,90 & 39,03 & 5136,17 & 257,03 & 14,56 & 242,47 & 53,35 & 183,44 & 183,91 & 53,35 & \begin{tabular}{|l|}
1372,61 \\
\end{tabular} & 199,44 & 17,95 & 53,49 & 553,49 & 98,06 & 101,01 & 553,49 \\
\hline Epidalea calamita & 29TNF98 & 101,00 & $\begin{array}{ll}121,02 \\
\end{array}$ & $\begin{array}{ll}98,41 \\
\end{array}$ & 39,61 & 5139,73 & 263,22 & 17,96 & 245,26 & 57,91 & $\begin{array}{ll}188,29 \\
\end{array}$ & $\begin{array}{l}188,76 \\
\end{array}$ & 57,91 & 1316,53 & 188,74 & $\begin{array}{l}17,26 \\
\end{array}$ & 53,01 & 528,34 & $\begin{array}{ll}94,25 \\
\end{array}$ & $\begin{array}{ll}98,83 \\
\end{array}$ & 528,34 \\
\hline Epidalea calamita & 29TNG11 & 68,00 & 142,97 & 75,17 & 42,97 & 3566,09 & 236,70 & 63,82 & \begin{tabular}{|l|l|}
172,88 \\
\end{tabular} & 98,36 & \begin{tabular}{|l|l|}
187,37 \\
\end{tabular} & 188,68 & 98,36 & 1288,24 & 180,59 & $\begin{array}{ll}15,17 \\
\end{array}$ & 52,45 & 518,55 & 83,56 & 108,22 & 518,55 \\
\hline Epidale & $29 \mathrm{TNC}$ & 86, & 140 & 72,13 & 4151 & 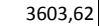 & 3 & 62,90 & 3 & $.00,04$ & 185,70 & 187 & 95 & 358 & \begin{tabular}{|l|l|}
189,08 \\
\end{tabular} & 19 & & 54 & 92 & & 54 \\
\hline Epidalea calamita & 29TNG14 & 99,00 & 141,35 & 69,97 & 41,01 & \begin{tabular}{|l|l|}
3592,14 \\
\end{tabular} & 233,55 & 65,01 & 168,54 & 103,58 & \begin{tabular}{|l|l|}
186,44 \\
\end{tabular} & 187,73 & 96,16 & $\begin{array}{l}1368,59 \\
\end{array}$ & \begin{tabular}{|l|l|}
193,12 \\
\end{tabular} & 21,54 & 50,70 & 549,61 & 101,51 & 122,99 & 542,04 \\
\hline Epidalea calamita & 29TNG15 & 101,00 & 132,16 & 69,72 & 40,14 & 3685,33 & 227,32 & 55,75 & 171,56 & 93,81 & 178,93 & 180,33 & 86,39 & 1509,91 & 227,25 & 27,33 & 50,50 & 609,48 & 119,62 & 138,03 & 604,19 \\
\hline
\end{tabular}




\begin{tabular}{|c|c|c|c|c|c|c|c|c|c|c|c|c|c|c|c|c|c|c|c|c|c|}
\hline TAXON & UTM & $\mathrm{km} 2$ & B101 & B102 & $\mathrm{BIO3}$ & BIO4 & B105 & B106 & B107 & B108 & B109 & B1010 & BIO11 & BIO12 & B1013 & BIO14 & BIO15 & BIO16 & BIO17 & B1018 & B1019 \\
\hline Epidalea calamita & 29TNG17 & 33,00 & 149,14 & 62,22 & 38,97 & 3510,00 & 234,61 & 76,97 & 157,64 & 112,28 & 193,11 & 194,33 & 104,31 & 1294,33 & 179,89 & 25,03 & 48,31 & 519,61 & 107,44 & 128,50 & 486,56 \\
\hline Epidalea calamita & 29TNG18 & 45,00 & 144,43 & 61,74 & 38,37 & 3541,20 & 231,42 & 73,05 & 158,37 & 107,44 & 189,24 & 190,36 & 99,57 & $\begin{array}{l}1364,63 \\
\end{array}$ & 199,30 & 28,12 & 48,48 & 549,64 & 116,34 & 136,83 & 520,34 \\
\hline Epidalea calamita & 29TNG22 & 101,00 & 137,87 & 77,71 & 41,84 & 3802,67 & 239,14 & 55,51 & 183,63 & 92,15 & 185,93 & 187,09 & 90,40 & 1364,18 & 189,74 & 19,11 & 51,39 & 545,54 & 96,55 & 117,25 & 545,41 \\
\hline Epidalea calamita & 29TNG23 & 100,00 & 133,12 & 76,64 & 41,04 & 3855,64 & 235,53 & 51,17 & 184,36 & 88,49 & 182,12 & 183,32 & 85,21 & 1450,79 & 209,92 & 22,81 & 50,88 & 581,76 & 108,37 & 126,68 & 581,25 \\
\hline Epidalea calamita & 29TNG25 & 101,00 & 142,44 & 71,61 & 40,21 & 3755,29 & 239,25 & 63,49 & 175,77 & \begin{tabular}{|l|l|}
101,68 \\
\end{tabular} & 189,94 & 190,94 & 95,01 & $\begin{array}{ll}1394,60 \\
\end{array}$ & 206,60 & 23,94 & 50,39 & 561,40 & 107,55 & 126,99 & 552,19 \\
\hline Epidalea calamita & 29TNG26 & 100,00 & 137,42 & 70,38 & 39,69 & 3792,18 & 234,78 & 59,26 & 175,52 & 95,03 & 185,76 & 186,73 & 89,89 & 1494,19 & 233,27 & 28,30 & 50,67 & 605,16 & 120,03 & 137,69 & 598,49 \\
\hline Epidalea calamita & 29TNG28 & 86,00 & 139,17 & 65,44 & 38,37 & 3735,36 & 232,63 & 64,36 & 168,28 & 99,83 & 186,87 & 187,97 & 92,44 & 1463,59 & 227,46 & 31,15 & 49,23 & 589,78 & 125,44 & 144,09 & 572,35 \\
\hline Epidalea calamita & 29TNG29 & 72,00 & 142,90 & 62,57 & 37,89 & 3707,49 & 233,27 & 70,12 & 163,15 & \begin{tabular}{|l|}
103,57 \\
\end{tabular} & 190,24 & 191,12 & 96,35 & \begin{tabular}{|l|l|}
1394,43 \\
\end{tabular} & 212,13 & 30,94 & 48,26 & 558,48 & 122,62 & 142,96 & 533,75 \\
\hline Epidalea calamita & 29TNG32 & 101,00 & 142,57 & 82,02 & 41,84 & 3972,07 & 249,88 & 55,81 & 194,06 & 98,75 & 192,74 & 193,71 & 92,50 & 1300,19 & 180,92 & 17,88 & 51,01 & 516,76 & 92,01 & 111,91 & 515,34 \\
\hline Epidalea calamita & 29TNG33 & 100,00 & 128,02 & 80,92 & 40,79 & 4087,55 & 238,12 & 41,92 & 196,20 & 79,68 & 180,45 & 181,48 & 77,39 & 1483,19 & 217,87 & 24,47 & 50,58 & 592,61 & 114,75 & 129,94 & 592,45 \\
\hline Epidalea calamita & 29TNG34 & 100,00 & 130,47 & 79,59 & 40,55 & 4068,19 & 239,44 & 45,08 & 194,36 & 84,61 & 182,58 & 183,56 & 79,95 & 1482,56 & 223,25 & 25,55 & 50,53 & 593,07 & 116,73 & 132,15 & 591,82 \\
\hline Epidalea calamita & 29TNG35 & 100,00 & 145,15 & 76,03 & 40,07 & 3941,12 & 248,67 & 61,79 & 186,88 & 101,87 & 195,09 & 195,83 & 95,17 & 1342,05 & 200,47 & 22,86 & 50,10 & 537,04 & 104,42 & 122,88 & 526,61 \\
\hline Epidalea calamita & 29TNG41 & 100,00 & 138,67 & 87,77 & 41,79 & 4212,47 & 254,27 & 46,55 & 207,72 & 92,38 & 192,13 & 193,18 & 85,67 & 1304,64 & 181,44 & 18,13 & 50,77 & 517,18 & 94,26 & 111,32 & 514,42 \\
\hline Epidalea calamita & 29TNG43 & 101,00 & 137,51 & 85,64 & 40,89 & 4235,56 & 253,34 & 46,66 & 206,68 & 91,15 & 191,53 & 192,29 & 84,30 & 1342,99 & 195,19 & 21,10 & 50,03 & 532,19 & 103,16 & 118,92 & 527,01 \\
\hline Epidalea calamita & 29TNG45 & 101,00 & 142,30 & 82,14 & 40,13 & 4197,28 & 255,32 & 53,36 & 201,96 & 96,35 & 195,81 & 196,38 & 89,24 & 1323,49 & 199,84 & 23,13 & 49,47 & 524,75 & 106,82 & 122,21 & 513,46 \\
\hline Epidalea calamita & 29TNG47 & 101,00 & 140,40 & 78,74 & 39,58 & 4179,19 & 250,40 & 53,58 & 196,82 & 94,83 & 193,98 & 194,52 & 87,86 & 1391,06 & 221,47 & 27,84 & 49,40 & 553,23 & 118,50 & 132,59 & 542,12 \\
\hline Epidalea calamita & 29TNG48 & 100,00 & 128,16 & 78,41 & 39,08 & 4198,61 & 239,79 & 41,84 & 197,95 & 83,04 & 182,58 & 183,64 & 76,66 & 1502,07 & 239,28 & 32,79 & 48,85 & 595,05 & 133,86 & 147,87 & 587,57 \\
\hline Epidalea calamita & 29TNG49 & 101,00 & 125,64 & 77,56 & 38,85 & 4165,73 & 237,61 & 39,97 & 197,64 & 81,13 & 179,86 & 181,09 & 75,07 & \begin{tabular}{|l|}
1508,88 \\
\end{tabular} & 237,59 & 34,66 & 47,92 & 594,55 & 138,65 & 153,11 & 584,39 \\
\hline Epidalea calamita & 29TNG50 & 101,00 & 140,38 & 92,44 & 41,82 & 4400,09 & 262,18 & 43,75 & 218,44 & 91,96 & 196,36 & 197,28 & 84,86 & 1243,80 & 168,81 & 16,54 & 50,69 & 492,03 & 88,82 & 104,69 & 487,03 \\
\hline Epidalea calamita & 29TNG52 & 100,00 & 130,71 & 89,65 & 40,70 & 4468,95 & 253,57 & 35,99 & 217.57 & 81,64 & $\mid 188,20$ & 188,95 & 75,02 & $\mid 1357,70$ & $\mid$\begin{tabular}{|l|l|}
191.48 \\
\end{tabular} & 21,14 & 49,95 & 535,88 & 104,88 & 117,86 & 532,10 \\
\hline Epidalea calamita & 29TNG53 & 101,00 & 131,96 & 89,04 & 40,50 & 4465,45 & 254,88 & $\begin{array}{ll}37,47 \\
\end{array}$ & 217,42 & 83,37 & 189,44 & 190,19 & 76,41 & 1345,19 & 193,52 & 21,98 & 49,53 & 529,65 & 106,91 & 119,50 & 523,62 \\
\hline Epidalea calamita & 29TNG54 & 101,00 & 107,50 & 82,47 & 38,62 & 4465,10 & 228,68 & 18,35 & 210,33 & 60,80 & 166,06 & 167,06 & 54,06 & 1555,27 & 221,33 & 30,16 & 48,53 & 611,15 & 134,21 & 142,65 & 608,70 \\
\hline Epidalea calamita & 29TNG56 & 101,00 & 134,95 & 86,64 & 39,84 & $\begin{array}{ll}4443,65 \\
\end{array}$ & 256,33 & 41,37 & 214,96 & 86,19 & 192,04 & \begin{tabular}{ll|}
192,69 \\
\end{tabular} & 79,37 & 1329,41 & 202,14 & 25,73 & 48,28 & 520,27 & 115,85 & 126,77 & 506,14 \\
\hline Epidalea calamita & 29TNG58 & 99,00 & 113,23 & 81,48 & 38,81 & 4356,27 & 232,03 & 24,34 & 207,69 & 66,96 & 170,34 & 171,53 & 61,18 & 1517,29 & 227,58 & 34,32 & 47,03 & 591,85 & 141,42 & 152,52 & 583,34 \\
\hline Epidalea calamita & 29TNG59 & 100,00 & 113,55 & 80,92 & 38,72 & 4310,81 & 231,79 & 25,08 & 206,71 & 67,71 & 170,02 & 171,45 & 62,24 & 1509,61 & 226,36 & 35,67 & 46,38 & 586,61 & 144,05 & 155,97 & 575,97 \\
\hline Epidalea calamita & 29TNG60 & 100,00 & 134,74 & 95,32 & 41,24 & 4644,93 & 263,68 & 35,02 & 228,66 & 83,36 & 194,34 & 195,08 & 76,56 & 1273,15 & 170,29 & 17,49 & 50,72 & 502,46 & 92,99 & 105,74 & 499,23 \\
\hline Epidalea calamita & 29TNG61 & 101,00 & 129,52 & 92,96 & $\begin{array}{l}40,52 \\
40,5\end{array}$ & 4652,63 & 257,84 & 31,49 & 226,34 & 76,71 & 189,55 & 190,32 & 71,80 & $\mid \begin{array}{l}1320,79 \\
\end{array}$ & 179,13 & \begin{tabular}{l|}
19,68 \\
19
\end{tabular} & 50,09 & 520,45 & 100,31 & 111,37 & 517,43 \\
\hline Epidalea calamita & 29TNG62 & 101,00 & 115,32 & 87,95 & 39,30 & 4647,57 & 241,85 & 21,15 & 220,70 & 62,37 & 176,03 & 176,82 & 58,84 & 1450,71 & 198,80 & 24,52 & 49,68 & 571,37 & 116,97 & 125,53 & 570,44 \\
\hline Epidalea calamita & 29TNG63 & 100,00 & 123,83 & 90,23 & 39,73 & 4660,90 & 251,54 & 27,50 & 224,04 & 72,50 & 184,36 & 185,01 & 66,47 & 1369,05 & 192,82 & 23,31 & 49,05 & 536,57 & 111,71 & 121,10 & 531,94 \\
\hline Epidalea calamita & 29TNG64 & 101,00 & 110,77 & 85,49 & 38,75 & 4618,93 & 235,92 & 18,21 & 217,71 & 61,90 & 171,38 & 172,25 & 55,21 & 1481,37 & 208,95 & 28,14 & 48,52 & 579,94 & 126,96 & 135,08 & 577,66 \\
\hline Epidalea calamita & 29TNG65 & 100,00 & 104,96 & 83,10 & 38,21 & 4573,78 & 228,97 & 14,35 & 214,62 & 57,06 & 165,27 & 166,23 & 50,52 & 1523,45 & 215,64 & 31,05 & 47,71 & 594,87 & 135,51 & 143,03 & 591,62 \\
\hline Epidalea calamita & 29TNG66 & 100,00 & 132,97 & $\begin{array}{l}0,07 \\
90,07\end{array}$ & 39,70 & 4650,79 & 259,97 & 35,22 & \begin{tabular}{|l|}
224,75 \\
\end{tabular} & 81,72 & \begin{tabular}{|l|l|}
193,13 \\
\end{tabular} & 193,56 & 75,17 & $\begin{array}{l}1269,36 \\
\end{array}$ & \begin{tabular}{|l|}
188,81 \\
\end{tabular} & $\begin{array}{l}24,75 \\
24,7\end{array}$ & 47,50 & 491,39 & 112,81 & 122,05 & 476,26 \\
\hline Epidalea calamita & 29TNG70 & 100,00 & 125,96 & 95,39 & 40,34 & 4836,55 & 259,46 & 25,65 & 233,80 & 69,04 & 188,61 & 189,35 & 66,06 & 1323,33 & 177,65 & 18,87 & 50,92 & 523,00 & 98,51 & 107,73 & 522,32 \\
\hline Epidalea calamita & 29TNG71 & 101,00 & 123,47 & 93,49 & 39,85 & 4824,53 & 255,95 & 24,26 & 231,69 & 67,47 & 186,21 & 186,93 & 64,12 & 1335,23 & 178,47 & 20,38 & 50,23 & 525,75 & 102,88 & 111,40 & 524,43 \\
\hline Epidalea calamita & 29TNG72 & 100,00 & 97,65 & 83,12 & 37,48 & 4745,83 & 225,53 & 6,75 & 218,78 & 42,20 & 160,59 & 161,38 & 41,58 & 1545,54 & 206,22 & 28,51 & 49,13 & 607,76 & 130,75 & 134,74 & 607,72 \\
\hline Epidalea calamita & 29TNG73 & 100,00 & 115,12 & 89,06 & 38,83 & 4792,36 & 245,33 & 18,81 & 226,53 & 61,56 & 177,89 & 178,53 & 57,06 & 1389,96 & 190,55 & 24,75 & 48,83 & 543,13 & 116,06 & 122,88 & 540,40 \\
\hline Epidalea calamita & 29TNG74 & 100,00 & 118,22 & $\begin{array}{l}89,00 \\
89,85\end{array}$ & $\begin{array}{l}30,03 \\
39,04\end{array}$ & 4792,53 & 248,44 & $\begin{array}{l}\frac{10,01}{20,96} \\
\end{array}$ & \begin{tabular}{|l|}
227,47 \\
22,4
\end{tabular} & $\begin{array}{l}1,0,63 \\
66,63\end{array}$ & \begin{tabular}{|l|l|}
181,05 \\
181
\end{tabular} & \begin{tabular}{|l|l|}
181,57 \\
\end{tabular} & $\begin{array}{ll}1,0,02 \\
60,\end{array}$ & $\begin{array}{l}130,505 \\
1355,98\end{array}$ & \begin{tabular}{|l|l|}
189,64 \\
1994
\end{tabular} & $\begin{array}{l}\mid 24,139 \\
24,99\end{array}$ & $\begin{array}{l}40,035 \\
48,16\end{array}$ & $\begin{array}{l}527,15 \\
527\end{array}$ & 115,35 & $\begin{array}{l}12,00 \\
123,03\end{array}$ & $\begin{array}{l}523,40 \\
523,51\end{array}$ \\
\hline Epidalea calamita & 29TNG75 & 100,00 & 95,31 & 81,82 & 37,30 & 4670,94 & 221,61 & 5,29 & 216,32 & 47,01 & 157,29 & 158,27 & 40,48 & 1539,21 & 211,15 & 32,58 & 47,17 & 598,54 & 140,23 & 145,68 & 596,07 \\
\hline Epidalea calamita & 29TNG80 & 101,00 & 112,87 & 91,32 & 38,75 & 4947,97 & 247,61 & 15,16 & 232,45 & 53,01 & 177,90 & 178,60 & 53,01 & \begin{tabular}{|l|}
1400,14 \\
\end{tabular} & 192,11 & 21,42 & 51,11 & 556,51 & 107,68 & 112,99 & 556,51 \\
\hline Epidalea calamita & 29TNG81 & 99,00 & 115,24 & 91,50 & 38,8 & 4947,70 & 249,65 & 16,98 & 232,68 & 55,94 & 180,29 & 180,76 & 55,18 & 1364,75 & 183,45 & 21,60 & 50,37 & 539,13 & 106,90 & 111,89 & 538,88 \\
\hline Epidalea calamita & 29TNG82 & 101,00 & 108,29 & 87,72 & 38 & 4896,41 & 240,41 & 12,73 & 227,68 & 49,93 & 172,98 & 173,49 & 49,60 & 1410,36 & 187,29 & 24,39 & 49,53 & 554,55 & 115,56 & 120,32 & 554,48 \\
\hline Epidalea calamita & 29TNG83 & $\begin{array}{l}100,00 \\
100,0\end{array}$ & $\begin{array}{r}0,25 \\
95,35\end{array}$ & $\frac{81,1 / 24}{82,54}$ & $\begin{array}{l}30, \\
36,\end{array}$ & $\begin{array}{l}4899,44 \mid \\
4825,88\end{array}$ & $\begin{array}{l}24,41 \\
224,96\end{array}$ & $\begin{array}{r}2,15 \\
4,18 \\
\end{array}$ & \begin{tabular}{|l|}
220,77 \\
220
\end{tabular} & \begin{tabular}{|l|}
39,95 \\
39,97
\end{tabular} & \begin{tabular}{|l|}
159,66 \\
159,66
\end{tabular} & \begin{tabular}{|l|l}
160,33 \\
\end{tabular} & $\begin{array}{l}59,70 \\
38,78 \\
\end{array}$ & $\begin{array}{l}141,02,75 \\
1502,75\end{array}$ & \begin{tabular}{|l|l|}
199,67 \\
199
\end{tabular} & $\begin{array}{l}24,19 \\
29,19\end{array}$ & \begin{tabular}{|l|l|}
48,38 \\
48,38
\end{tabular} & 587,88 & $\begin{array}{l}1130,30 \\
130,81\end{array}$ & $\begin{array}{l}12,52 \\
134,52\end{array}$ & $\begin{array}{l}354,48 \\
587,87\end{array}$ \\
\hline Epidalea calamita & 29TNG87 & 100,00 & 131,52 & 92,63 & 38,90 & 4978,81 & 263,13 & 27,19 & 235,94 & 75,96 & 196,55 & 196,79 & 70,46 & 1135,81 & 164,80 & 23,53 & 46,00 & 431,70 & 103,51 & 109,38 & 420,30 \\
\hline Epidalea calamita & 29TNG91 & 101.00 & 106,49 & 88.55 & 37.63 & 502695 & 24203 & 990 & 232.12 & 46,30 & 173.06 & 173.50 & 46,30 & 1386.53 & 188.86 & 23.03 & 50,32 & 54886 & 111,20 & 114.51 & 548.86 \\
\hline Epidalea calamita & 29TNG92 & 101,00 & 104,70 & 86,50 & 37,29 & 4987,78 & 238,55 & 9,44 & 229,12 & 45,29 & 170,90 & 171,31 & 45,29 & 1385,85 & 185,38 & 24,36 & 49,44 & 545,62 & 14,51 & 117,69 & 545,62 \\
\hline Epidalea calamita & 29TNG93 & 100,00 & 96,32 & 83,47 & 36, & 4929,91 & 228 & $\begin{array}{l}3,44 \\
3,62 \\
\end{array}$ & 224,77 & $\begin{array}{l}39,17 \\
39,1 \\
\end{array}$ & 162,07 & 162,53 & 38,30 & $\begin{array}{l}3041,20 \\
144,\end{array}$ & $\begin{array}{l}190,75 \\
190,0\end{array}$ & 27 & 48,34 & 563,31 & 125,34 & 128,21 & 563,31 \\
\hline Epidalea calamita & 29TNG94 & 100,00 & 104,76 & 86,30 & 37,24 & 4947,62 & 237 & 9,36 & 228,42 & 50,88 & 170,56 & 170,87 & 45,91 & 1358,63 & 181,85 & 26,28 & 47,98 & 528,21 & 118,26 & 122,51 & 528,04 \\
\hline Epidalea calamita & 29TNG96 & 100,00 & 116,26 & 90,73 & 38,15 & 4979,74 & 250,19 & 15,81 & 234,38 & 62,01 & 181,98 & 182,26 & 56,26 & 1238,14 & 172,01 & 25,34 & 46,58 & 475,99 & 111,39 & 116,99 & 471,15 \\
\hline Epidalea calamita & 29TNG98 & 101,00 & 137,22 & 92,45 & 37,87 & 5162,84 & 269,37 & 28,60 & 240,77 & 79,01 & 204,71 & 204,75 & 73,95 & 989,93 & 142,03 & 21,46 & 44,79 & 370,10 & 91,71 & 93,81 & 359,00 \\
\hline Epidalea calamita & 29TNG99 & 101,00 & 134,39 & 91,03 & 38,14 & 5016,64 & 264,07 & 28,52 & 235,55 & 77,88 & 199,94 & 200,11 & 73,24 & 1026,37 & 147,59 & 23,51 & 44,20 & 384,14 & 97,82 & 102,91 & 372,22 \\
\hline Epidalea calamita & 29TNHC & 16,00 & 14 & 59,00 & 38, & 3400,52 & 230,67 & 78,95 & 151,71 & 112,29 & 190,24 & 191,67 & 104,38 & 1225,90 & $\begin{array}{ll}174,48 \\
\end{array}$ & 26,9 & 46,81 & 491,57 & 111,81 & 134,71 & 450,57 \\
\hline Epidalea calamita & 29TNHO1 & 40,00 & 144,58 & 59,91 & 38,18 & 3389,01 & 229,52 & 75,00 & 154,52 & 110,27 & 186,96 & 189,12 & 101,96 & 1190,85 & 170,30 & 27,81 & 45,66 & 475,97 & 115,04 & 138,49 & 430,70 \\
\hline Epidalea calamita & 29TNHO2 & 97,00 & 132,26 & 63,14 & 37,98 & 3521,94 & 224,76 & 60,48 & 164,28 & 97,19 & 177,01 & 179,36 & 89,11 & 1311,65 & 191,91 & 32,75 & 44,97 & 520,73 & 131,71 & 153,40 & 479,06 \\
\hline Epidalea calamita & 29TNHO3 & 72,00 & 140,28 & 62,04 & 38,15 & 3441,65 & 229,47 & 68,97 & 160,50 & 106,00 & 183,51 & 186,10 & 97,60 & 1187,87 & 170,53 & 29,84 & 44,38 & 470,94 & 121,46 & 144,58 & 424,12 \\
\hline Epidalea calamita & 29TNH06 & 101,00 & 130,82 & 64, & 38,44 & 3443,75 & 224,58 & 58,12 & 166,45 & 97,50 & 174,06 & 177,48 & 89,05 & 1201,01 & 168,81 & 33,56 & 41,93 & 468,53 & 134,43 & 157,51 & $41 \varepsilon$ \\
\hline Epidalea calamita & 29TNH08 & 81,00 & 139,86 & 62,83 & 39,45 & 3245,91 & 226,50 & $\begin{array}{l}68,94 \\
68\end{array}$ & 157,55 & \begin{tabular}{|c|}
108,65 \\
\end{tabular} & 179,71 & 183,68 & 99,93 & \begin{tabular}{|l|l|}
1066,54 \\
\end{tabular} & $\begin{array}{l}146,17 \\
\end{array}$ & 30,11 & 40,82 & 414,13 & 122,84 & 147,26 & 363,35 \\
\hline Epidalea calamita & 29TNH10 & 61,00 & 146,39 & 60,06 & 37,91 & 3519,36 & 232,27 & 76,11 & 156,16 & 109,72 & 190,75 & 192,23 & 101,94 & 1275,06 & 185,37 & 28,73 & 46,99 & 509,45 & 116,28 & 138,47 & 472,93 \\
\hline Epidalea calamita & 29TNH11 & 40,00 & 146,34 & 60.45 & 37,82 & 3518.47 & 233,20 & 75,68 & 157.53 & $\mid 109.97$ & 190,80 & 192.50 & 102,30 & 1241.93 & 180,28 & 28.89 & 46,24 & 494,43 & 116,57 & 139,20 & 455,66 \\
\hline Epidalea calamita & 29TNH13 & 101,00 & 134,2 & 65,16 & 37,83 & 3618,45 & 230,51 & 60,17 & 170,34 & 97,99 & 180, & 182, & 90 & 1306,88 & 191,55 & 33,69 & 44,61 & 514,94 & 132,93 & 154,63 & 475,23 \\
\hline Epidalea calamita & 29TNH14 & 100,00 & 133,17 & 66,01 & 37,97 & 3607,29 & 230,45 & 58,59 & 171,85 & 97,29 & 178,97 & 181,81 & 89,22 & 1284,45 & 186,08 & 34,10 & 43,76 & 3,35 & 134,48 & 156,51 & 461, \\
\hline
\end{tabular}




\begin{tabular}{|c|c|c|c|c|c|c|c|c|c|c|c|c|c|c|c|c|c|c|c|c|c|}
\hline TAXON & UTM & $\mathrm{km} 2$ & B101 & B102 & $\mathrm{BIO3}$ & B104 & B105 & B106 & B107 & B108 & B109 & B1010 & BIO11 & BIO12 & B1013 & BIO14 & BIO15 & BIO16 & BIO17 & B1018 & B1019 \\
\hline Epidalea calamita & 29TNH22 & 98,00 & 142,56 & 64,37 & 37,83 & 3673,06 & 236,45 & 68,27 & 168,18 & 104,48 & 189,39 & 191,20 & 97,00 & 1282,23 & 189,18 & 31,60 & 45,59 & 505,62 & 124,06 & 145,95 & 470,89 \\
\hline Epidalea calamita & 29TNH23 & 100,00 & 140,69 & 65,81 & 37,91 & 3675,02 & 236,85 & 65,44 & 171,42 & 102,96 & 187,49 & 189,76 & 95,38 & 1268,02 & 185,23 & 32,23 & 44,81 & 497,28 & 126,63 & 148,60 & 460,75 \\
\hline Epidalea calamita & 29TNH24 & 101,00 & 139,46 & 66,85 & 38,14 & 3657,53 & 237,04 & 63,64 & 173,40 & 102,32 & 185,96 & 188,60 & 94,54 & 1247,55 & 180,10 & 32,75 & 43,93 & 486,78 & 128,33 & 150,59 & 448,39 \\
\hline Epidalea calamita & 29TNH27 & 100,00 & 129,17 & 68,83 & 38,77 & 3574,89 & 228,79 & 53,35 & 175,45 & 94,07 & 174,25 & 178,02 & 86,21 & 1259,95 & 175,62 & 36,27 & 41,11 & 484,03 & 140,94 & 162,85 & 443,55 \\
\hline Epidalea calamita & 29TNH29 & 39,00 & 138,94 & 65,60 & 40,11 & 3300,89 & 227,96 & $\begin{array}{ll}66,33 \\
\end{array}$ & \begin{tabular}{|l|}
161,63 \\
\end{tabular} & 106,78 & \begin{tabular}{ll|}
179,56 \\
\end{tabular} & 183,64 & 98,28 & $\begin{array}{ll}1096,42 \\
\end{array}$ & 147,44 & 31,46 & 39,97 & 420,50 & 125,51 & 149,00 & 378,18 \\
\hline Epidalea calamita & 29TNH30 & 101,00 & 136,38 & 68,31 & 37,86 & 3916,51 & 236,40 & 58,16 & 178,24 & 94,75 & 186,93 & 188,06 & 88,14 & 1444,96 & 225,06 & 34,07 & 47,76 & 572,47 & 132,50 & 151,25 & 553,08 \\
\hline Epidalea calamita & 29TNH34 & 100,00 & 137,98 & 70,61 & \begin{tabular}{|l|l|}
37,67 \\
\end{tabular} & 3829,36 & 242,21 & 57,25 & 184,96 & 98,68 & 186,96 & 189,58 & 91,35 & \begin{tabular}{|l|l|}
1297,37 \\
\end{tabular} & 188,15 & 34,52 & 43,99 & 501,72 & 132,89 & 154,22 & 468,82 \\
\hline Epidalea calamita & 29TNH35 & 101,00 & 132,84 & 72,28 & 37,68 & 3838,58 & 240,40 & 50,95 & 189,45 & 94,15 & 182,04 & 185,10 & 86,75 & 1326,75 & 190,10 & 36,64 & 43,10 & 509,81 & 140,19 & 161,30 & 476,37 \\
\hline Epidalea calamita & 29TNH37 & 101,00 & 127,82 & 71,68 & 38,69 & 3685,61 & 231,99 & 48,85 & 183,14 & 91,12 & 174,58 & 178,31 & 83,80 & 1296,43 & 180,66 & 37,63 & 41,15 & 494,57 & 144,29 & 165,38 & 458,65 \\
\hline Epidalea calamita & 29TNH38 & 100,00 & 130,25 & 69,90 & \begin{tabular}{|c|}
39,58 \\
\end{tabular} & 3529,25 & 228,82 & 54,21 & 174,62 & 95,40 & 174,66 & 178,55 & 87,84 & 1225,75 & 167,86 & 35,84 & 40,29 & 467,01 & 138,82 & 160,53 & 429,77 \\
\hline Epidalea calamita & 29TNH39 & 66,00 & 137,72 & 67,21 & 40,50 & 3335,65 & 228,27 & 64,37 & 163,90 & 104,80 & 178,85 & 182,93 & 96,84 & 1111,28 & 148,76 & 32,07 & 39,82 & 423,65 & 126,76 & 149,62 & 385,50 \\
\hline Epidalea calamita & $29 \mathrm{TNH} 40$ & 101,00 & 124,43 & 76,64 & 38,40 & 4126,21 & 236,23 & 39,22 & 197,01 & 80,58 & 178,19 & 179,63 & 74,68 & 1499,32 & 232,05 & 36,10 & 47,05 & 587,15 & 141,93 & 157,16 & 573,21 \\
\hline Epidalea calamita & $29 \mathrm{TNH} 42$ & 100,00 & 132,13 & 74,96 & 37,98 & 4042,12 & 242,29 & 47,15 & 195,13 & 89,34 & 184,54 & 186,42 & 83,32 & \begin{tabular}{|l|}
1407,67 \\
\end{tabular} & 212,28 & 35,99 & 45,57 & 545,52 & 138,23 & 156,49 & 523,46 \\
\hline Epidalea calamita & 29TNH43 & 101,00 & 140,12 & 72,87 & \begin{tabular}{|l|l|}
37,98 \\
\end{tabular} & 3953,22 & 246,17 & 56,53 & 189,64 & 98,34 & 190,91 & 193,06 & 91,84 & 1293,19 & 190,16 & 33,42 & 44,74 & 499,02 & 128,68 & 149,06 & 471,50 \\
\hline Epidalea calamita & 29TNH44 & 99,00 & 134,34 & 75,62 & 37,50 & 4016,51 & 247,01 & 47,82 & 199,18 & 92,76 & 186,25 & 188,81 & 86,23 & 1354,82 & 196,79 & 36,70 & 43,95 & 518,70 & 139,25 & 159,31 & 490,94 \\
\hline Epidalea calamita & 29TNH45 & 100,00 & 133,85 & 75,41 & 37,71 & 3948,35 & 245,54 & 48,08 & 197,45 & 93,39 & 184,49 & 187,60 & 86,62 & 1327,24 & 189,42 & 36,86 & 42,92 & 505,97 & 139,84 & 160,39 & 476,27 \\
\hline Epidalea calamita & 29TNH46 & 100,00 & 133,61 & 74,17 & 38,49 & 3807,22 & 241,03 & 50,75 & 190,27 & 94,78 & 182,11 & 185,54 & 87,87 & 1277,88 & 179,38 & 36,11 & 41,96 & 486,11 & 137,91 & 158,76 & 454,57 \\
\hline Epidalea calamita & 29TNH47 & 101,00 & 129,79 & 73,67 & 39,01 & 3726,10 & 235,43 & 48,83 & 186,61 & 92,02 & 177,26 & 180,80 & 85,29 & 1276,81 & 177,09 & 37,02 & 41,03 & 484,24 & 141,41 & 162,11 & 451,80 \\
\hline Epidalea calamita & 29TNH48 & 99,00 & 130,64 & 71,90 & 39,94 & 3580,81 & 231,16 & 52,91 & 178,25 & 94,65 & 175,87 & 179,58 & 87,62 & \begin{tabular}{|l|}
1222,47 \\
\end{tabular} & 166,76 & 35,87 & 40,09 & 463,07 & 138,08 & 159,15 & 429,36 \\
\hline Epidalea calamita & 29TNH49 & 99,00 & 138,44 & 68.49 & 41,26 & 3334,69 & 228,73 & 64,79 & $\mid 163,94$ & 105,25 & $\mid 179,57$ & $\mid 183,74$ & 97.48 & $\mid 1091,49$ & $\mid 144,73$ & 31,59 & 39,26 & 413,86 & 124,45 & $\mid 146,72$ & 379,25 \\
\hline Epidalea calamita & 29TNH50 & 101,00 & 115,81 & 80,39 & 38,78 & 4246,05 & 232,99 & 27,72 & 205,27 & 70,53 & 171,45 & 172,95 & 65,34 & 1493,95 & 224,52 & 36,57 & 45,84 & 578,78 & 145,19 & 158,22 & 565,92 \\
\hline Epidalea calamita & 29TNH55 & 101,00 & 132,55 & 77,84 & 38,55 & 3952,98 & 244,93 & 45,58 & 199,35 & $\begin{array}{ll}91,08 \\
0,0\end{array}$ & 183,42 & 186,37 & 85,47 & 1311,62 & $\begin{array}{l}186,78 \\
186,\end{array}$ & 36,64 & 42,66 & 496,98 & 138,85 & 158,30 & 470,35 \\
\hline Epidalea calamita & 29TNH56 & 101,00 & 131,83 & 76,71 & $\begin{array}{l}38,90 \\
\end{array}$ & $\begin{array}{l}3858,57 \\
\end{array}$ & 241,48 & 46,94 & 194,54 & 91,76 & 181,28 & 184,54 & 85,86 & 1281,64 & 179,77 & 36,54 & 41,76 & 484,46 & 138,73 & 158,58 & 456,12 \\
\hline Epidalea calamita & 29TNH57 & 100,00 & 129,49 & 75,79 & 39,47 & 3760,92 & 236,42 & 46,84 & 189,58 & 90,69 & $\begin{array}{l}177,58 \\
\end{array}$ & 181,00 & 84,70 & 1264,25 & 174,91 & 36,84 & 40,79 & 476,82 & 140,23 & 160,14 & 447,24 \\
\hline Epidalea calamita & 29TNH59 & 98,00 & 140,77 & 69,91 & 41,80 & 3381,91 & 231,80 & 66,23 & 165,56 & 106,31 & 182,51 & 186,54 & 99,09 & 1058,70 & 139,63 & 30,57 & 39,04 & 399,41 & 120,42 & 142,28 & 367,09 \\
\hline Epidalea calamita & 29TNH60 & 100,00 & 118,94 & 83,20 & 38,98 & 4353,18 & 238,48 & 27,84 & 210,64 & 71,76 & 175,90 & 177,36 & 67,11 & 1409,20 & 210,16 & 34,42 & 45,45 & 541,88 & 137,56 & 150,38 & 528,85 \\
\hline Epidalea calamita & 29TNH61 & 101,00 & 119,95 & 82,67 & 39,13 & 4262,34 & 238,07 & 29,73 & 208,34 & 73,64 & $\begin{array}{l}175,70 \\
\end{array}$ & 177,29 & 69,46 & 1400,04 & 207,77 & $\begin{array}{l}35,43 \\
35,43\end{array}$ & 44,95 & 536,38 & 139,36 & 153,01 & 521,48 \\
\hline Epidalea calamita & 29TNH63 & 100,00 & 127,69 & 81,29 & 39,80 & 4046,96 & 241,44 & 39,35 & 202,09 & 83,45 & 180,25 & 182,44 & 79,89 & 1331,88 & 194,42 & 35,67 & 43,65 & 505,65 & 137,02 & 153,53 & 485,67 \\
\hline Epidalea calamita & 29TNH64 & 101,00 & 133,27 & 80,09 & 39,73 & 3986,03 & 244,84 & 45,28 & 199,56 & 89,76 & 184,79 & 187,14 & 85,81 & 1267,58 & 182,28 & 34,57 & 42,88 & 479,13 & 132,16 & 150,26 & 456,27 \\
\hline Epidalea calamita & 29TNH65 & 101,00 & 130,40 & 79,78 & 39,77 & 3917,78 & 241,68 & 43,59 & 198,09 & 88,21 & 181,02 & 183,65 & 84,03 & 1279,46 & 181,47 & 35,99 & 42,05 & 482,16 & 136,82 & 155,12 & 457,82 \\
\hline Epidalea calamita & 29TNH68 & 101,00 & 134,85 & 74,68 & 40,77 & 3631,25 & 235,43 & 54,60 & 180,83 & 96,81 & $\begin{array}{l}180,73 \\
\end{array}$ & 184,20 & 90,95 & 1139,74 & 153,76 & 33,40 & 39,51 & 427,46 & 128,78 & $\begin{array}{l}149,04 \\
\end{array}$ & 397,92 \\
\hline Epidalea calamita & 29TNH70 & 101,00 & 121,99 & 85,74 & 39,01 & 4488,05 & 244,15 & 27,49 & \begin{tabular}{|l|l|}
216,65 \\
\end{tabular} & $\begin{array}{l}30,015 \\
72,54\end{array}$ & \begin{tabular}{|l|l|}
180,79 \\
\end{tabular} & 181,86 & 60,41 & \begin{tabular}{|l|l|l|l|}
1311,15 \\
\end{tabular} & $\begin{array}{l}193,43 \\
\end{array}$ & 31,86 & 44,90 & 500,27 & 128,43 & $\begin{array}{l}141,17 \\
1404\end{array}$ & 487,17 \\
\hline Epidalea calamita & 29TNH72 & 100,00 & 120,88 & 84,11 & 39,92 & 4229,67 & 238,74 & 30,06 & 208,68 & 74,28 & 176,17 & 177,82 & 71,15 & 1325,34 & 192,94 & 34,76 & 43,67 & 502,72 & 135,75 & 149,76 & 486,41 \\
\hline Epidalea calamita & 29TNH73 & 101,00 & 126,68 & 83,29 & $\begin{array}{l}40,45 \\
\end{array}$ & 4067,70 & 240,51 & 37,36 & 203,15 & 81,38 & 179,54 & 181,47 & 78,91 & 1275,06 & 184,29 & 34,28 & 43,04 & 481,31 & 132,43 & 148,01 & 462,41 \\
\hline Epidalea calamita & 29TNH77 & 100,00 & 122,67 & 79,66 & 40,36 & 3855,55 & 232,35 & 37,61 & 194,73 & 81,38 & 172,28 & 175,29 & 77,27 & 1252,18 & 172,13 & 37,44 & 39,90 & 467,53 & 142,08 & 159,52 & 441,33 \\
\hline Epidalea calamita & 29TNH78 & 100,00 & 125,41 & 78,00 & 40,75 & 3774,11 & 231,87 & 42,35 & 189,52 & 85,45 & 173,73 & 176,95 & 80,70 & 1203,79 & 163,01 & 36,49 & 39,10 & 448,58 & 138,77 & 157,20 & 420,48 \\
\hline Epidalea calamita & 29TNH86 & 101,00 & $\begin{array}{l}1215,41 \\
115,94\end{array}$ & 82,36 & 40,29 & 4041,46 & 230,32 & $\begin{array}{l}42,3,34 \\
28,4\end{array}$ & \begin{tabular}{|l|}
201,92 \\
201,98
\end{tabular} & $\mid \frac{\mid 0,43}{72,10}$ & \begin{tabular}{|l|l|}
168,44 \\
\end{tabular} & 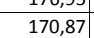 & $\frac{60,10}{68,70}$ & $\mid \begin{array}{l}\mid 120, r \\
1270,44\end{array}$ & \begin{tabular}{|l|}
175,37 \\
175
\end{tabular} & $\begin{array}{l}30,49 \\
37,83 \\
\end{array}$ & $\begin{array}{l}39,10 \\
39,99\end{array}$ & $\begin{array}{l}440,50 \\
473,87\end{array}$ & 143,78 & $\begin{array}{l}159,12 \\
150\end{array}$ & $\begin{array}{l}42,40 \\
450,46\end{array}$ \\
\hline Epidalea calamita & 29TNH91 & 101,00 & 118,31 & 88,03 & 39,00 & 4616,37 & 244,04 & 21,27 & 222,77 & 67,07 & 178,96 & 179,91 & 63,44 & 1205,83 & 171,39 & 30,83 & 43,10 & 454,83 & 123,06 & 135,26 & 441,25 \\
\hline Epidalea calamita & 29TNH92 & 101,00 & 117,40 & 87,18 & 39,25 & 4506,35 & 240,98 & 22,00 & 218,98 & 67,39 & 176,50 & 177,65 & 64,03 & 1213,36 & 171,45 & 32,25 & 42,41 & 456,32 & 126,99 & $\begin{array}{l}139,71 \\
\end{array}$ & 440,75 \\
\hline Epidalea calamita & 29TNH97 & 100,00 & 122,66 & 82,42 & 40,76 & 4034,11 & 235,08 & 34,51 & 200,57 & 78,55 & 174,71 & 177,24 & 74,77 & 1155,42 & 156,30 & 35,05 & 38,88 & 427,68 & 133,61 & 150,03 & 402,29 \\
\hline Epidalea calamita & 29TNH98 & 101,00 & 121,27 & 81,36 & 40,79 & 3959,32 & 232,09 & 34,47 & 197,61 & 78,34 & 172,28 & 174,98 & 74,29 & 1159,91 & 155,18 & 36,09 & 38,11 & 428,21 & 137,12 & 153,85 & 401,04 \\
\hline Epidalea calamita & $\begin{array}{l}29 T N J 40 \\
29100\end{array}$ & 18,00 & $\begin{array}{l}12,21 \\
140,90\end{array}$ & $\frac{61,30}{67,00}$ & $\begin{array}{l}40, \\
41,\end{array}$ & 32525,38 & $\begin{array}{l}23,09 \\
226,97\end{array}$ & $\begin{array}{ll}4,484 \\
68,62\end{array}$ & \begin{tabular}{|l|}
158,34 \\
15,4
\end{tabular} & \begin{tabular}{|}
$\mid \begin{array}{r}\mid 0,34 \\
109,17\end{array}$ \\
\end{tabular} & \begin{tabular}{|l|}
180,34 \\
180,
\end{tabular} & \begin{tabular}{|l|l|}
184,66 \\
186
\end{tabular} & \begin{tabular}{|l|}
14,29 \\
101,00
\end{tabular} & $\mid$\begin{tabular}{|l|}
1040,24 \\
1040,24
\end{tabular} & $\mid$\begin{tabular}{|l}
$\mid 530,16$ \\
135,86
\end{tabular} & $\begin{array}{l}30,09 \\
30,03\end{array}$ & $\begin{array}{l}30,11 \\
39,00\end{array}$ & $\begin{array}{l}428,21 \\
394,31\end{array}$ & 113,12 & $\begin{array}{l}143,103 \\
142,10 \\
\end{array}$ & $\begin{array}{l}401,04 \\
359,59\end{array}$ \\
\hline Epidalea calamita & 29TNJ51 & 48,00 & 137,32 & 69,06 & 42,18 & 3289,25 & 226,38 & 64,58 & $\begin{array}{l}161,79 \\
\end{array}$ & 104,32 & 177,74 & 182,08 & $\begin{array}{l}96,99 \\
96,\end{array}$ & 1053,97 & 136,43 & 32,00 & 37,81 & 395,00 & 125,51 & 147,40 & 360,88 \\
\hline Epidalea calamita & 29TNJ62 & 77,00 & 138,50 & 69,71 & 42,42 & 3311,98 & 227,83 & 65,35 & 162,48 & 104,89 & 179,31 & 183,41 & 97,82 & 1028,44 & 132,74 & 31,91 & 37,02 & 383,10 & 124,55 & 46,55 & 348,41 \\
\hline Epidalea calamita & 29TNJ70 & 100,00 & 127,38 & 75,21 & 41 & 3607,29 & 228,03 & 47,99 & 180,04 & 89,86 & 172,98 & 176,58 & 84,18 & 1147,25 & 151,21 & 35,90 & 37,79 & 425,82 & 137,08 & 156,62 & 394,60 \\
\hline Epidalea calamita & 29TNJ72 & 101,00 & 133 & 72,15 & $\frac{41}{42}$ & 3432,01 & 226,92 & 57,35 & \begin{tabular}{|l|}
$169,57,5$ \\
\end{tabular} & $\begin{array}{l}\mid 93,009 \\
97,92\end{array}$ & 175,90 & \begin{tabular}{|l|}
179,71 \\
\end{tabular} & $\begin{array}{l}\mid 94,40 \\
91,45 \\
\end{array}$ & 1067,50 & |137,07 & 34,02 & 36,65 & $\begin{array}{l}4294,02 \\
394,97\end{array}$ & 131,15 & $\begin{array}{l}152,16 \\
\end{array}$ & 360,88 \\
\hline Epidalea calamita & \begin{tabular}{|l|} 
29TNJ83 \\
\end{tabular} & 101,00 & 13 & 72,98 & 41, & 3479,40 & 225,55 & 53,48 & 172,07 & 94,38 & 173,69 & 177,47 & 88,12 & 1072,64 & 137,44 & 35,55 & 35,79 & 393,85 & 135,68 & 156,29 & 358,51 \\
\hline Epidalea calamita & 29TNJ84 & 31,00 & 128,75 & 72,62 & 42,07 & 3463,58 & 223,64 & 52,51 & 171,13 & 93,16 & 172,00 & 175,75 & $\begin{array}{l}86,98 \\
86,9\end{array}$ & 1079,11 & 138,18 & 36,49 & 35,25 & 395,05 & 138,64 & 159,35 & 358,69 \\
\hline Epidalea calamita & 29TNJ91 & 101,00 & 119,44 & 78,01 & 41,06 & 3765,45 & 224,70 & 37,15 & 187,55 & 79,81 & 167,50 & 170,67 & 74,70 & 1154,74 & 149,70 & 38,31 & 36,17 & 423,15 & 144,50 & 162,42 & 391,05 \\
\hline Epidalea calamita & 29TNJ92 & 99,00 & 122,03 & 76,58 & 41,3 & 3678,40 & 224,31 & 41,38 & 182,93 & 83,46 & 168,71 & 172,09 & 78,17 & 1126,56 & 144,34 & 37,91 & 35,67 & 11,83 & 143,04 & 161,75 & 378,12 \\
\hline Epidalea calamita & 29TPE13 & $\begin{array}{l}501,00 \\
101\end{array}$ & 138 & $\begin{array}{l}90,21 \\
90,21\end{array}$ & 35 & 55 & 286,28 & $\begin{array}{l}1,00 \\
35,83 \\
\end{array}$ & \begin{tabular}{|l|}
250,45 \\
25,5
\end{tabular} & $\begin{array}{l}03,406 \\
71,63\end{array}$ & $\mid \begin{array}{l}212,301 \\
212,3\end{array}$ & 212,50 & 71,63 & $\mid$ & \begin{tabular}{|l|}
$144,3,14$ \\
163
\end{tabular} & \begin{tabular}{|c|}
9,87 \\
9,8
\end{tabular} & 55,65 & $\begin{array}{l}41,05 \\
444,77\end{array}$ & $\begin{array}{r}44,04 \\
66,97\end{array}$ & 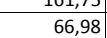 & $\begin{array}{l}3 /, 12 \\
444,77\end{array}$ \\
\hline Epidalea calamita & 29TPE16 & 100,00 & 89,37 & 73,79 & 32,38 & 5308,01 & 222,81 & $-1,45$ & 224,25 & 29,35 & 162,23 & 162,23 & 29,35 & 1627,76 & 249,32 & 17,25 & 56,10 & 663,37 & 100,90 & 100,90 & 663,37 \\
\hline Epidalea calamita & 29TPE17 & 100,00 & 105,52 & 77,94 & 33,30 & 5333,84 & 240,87 & 11,12 & 229,75 & 43,46 & $\begin{array}{l}177,77 \\
\end{array}$ & 177,83 & 43,46 & 1488,39 & $\mid 230,10$ & 14,23 & 56,81 & 610,46 & 89,59 & $\begin{array}{ll}89,68 \\
808\end{array}$ & 610,46 \\
\hline Epidalea calamita & 29TPE23 & 100,00 & 136,93 & 89,41 & 34,98 & 5655,55 & 286,47 & 34,08 & 252,39 & 69,31 & 212,77 & 212,88 & 69,31 & 1072,25 & 160,25 & 9,60 & 55,52 & 436,33 & 65,86 & 65,86 & 436,33 \\
\hline Epidalea calamita & 29TPE24 & 100,00 & 142 & 92,77 & 35, & 5654,12 & 293,58 & 37,45 & 256 & 74,19 & 217,73 & $21 \varepsilon$ & 74,19 & 1014,30 & 150,67 & 8,95 & 55,21 & 411,38 & 63,29 & 63,31 & 41 \\
\hline Epidalea calamita & $\begin{array}{l}\text { 29TPE25 } \\
\text { 29TL }\end{array}$ & $\begin{array}{l}101,00 \\
100\end{array}$ & $\begin{array}{l}14,00 \\
137,34\end{array}$ & 90,80 & 年, 35,35 & 56006,22 & $\begin{array}{l}2935,70 \\
285,74\end{array}$ & $\begin{array}{l}1,434 \\
33,34 \\
\end{array}$ & \begin{tabular}{|l|}
252,40 \\
250
\end{tabular} & $\begin{array}{l}\mid 4,15 \\
69,51 \\
\end{array}$ & \begin{tabular}{|l|l|}
211,78 \\
\end{tabular} & \begin{tabular}{|l|}
212,03 \\
\end{tabular} & $\begin{array}{l}4,15 \\
69,51 \\
\end{array}$ & $\begin{array}{l}1075,73 \\
\end{array}$ & \begin{tabular}{|l|l|}
161,29 \\
151
\end{tabular} & $0,0,71$ & $\begin{array}{l}35,21 \\
55,46\end{array}$ & $\begin{array}{l}41,50 \\
437,30\end{array}$ & $\begin{array}{l}3,20 \\
66,83\end{array}$ & $\begin{array}{l}6,31.87 \\
66,\end{array}$ & $\begin{array}{l}41,50 \\
437,30\end{array}$ \\
\hline Epidalea calamita & 29TPE26 & 101,00 & 103,49 & 76,74 & 32,49 & 5450,47 & 240,55 & 9,06 & 231,49 & 40,44 & 177,45 & 177,47 & 40,44 & 1460,65 & 224,47 & 13,97 & 56,51 & 598,38 & 87,92 & 88,13 & 598,38 \\
\hline Epidalea calamita & 29TPE28 & 100,00 & 115,82 & 82,63 & 34,00 & 5469,42 & 255,98 & 17,15 & 238,83 & 50,50 & 188,84 & 188,97 & 50,50 & 1311,44 & 200,81 & 12,45 & 56,23 & 537,03 & 80,49 & 82,35 & 537,03 \\
\hline Epidalea calamita & 29TPE33 & 101,00 & 151,94 & 96,18 & 35,97 & 5812,66 & 307,44 & 43,3 & 264,08 & 84,3 & 228 & 229 & 81, & 887,47 & 129,32 & 7,58 & 54,42 & 356,64 & 56,06 & 56,28 & 356,61 \\
\hline Epidalea calamita & 29TPE34 & 100,00 & 144,07 & 93,37 & 35,58 & 5763,97 & 297,00 & 37,53 & 259,47 & 74,25 & 220,63 & 220,80 & 74,25 & 963,29 & 142,08 & 8,48 & 54,82 & 88,56 & 60,65 & 60,78 & 388, \\
\hline
\end{tabular}




\begin{tabular}{|c|c|c|c|c|c|c|c|c|c|c|c|c|c|c|c|c|c|c|c|c|c|}
\hline TAXON & UTM & $\mathrm{km} 2$ & B101 & B102 & $\mathrm{BIO3}$ & B104 & B105 & B106 & B107 & B108 & B109 & B1010 & BIO11 & BIO12 & B1013 & BIO14 & BIO15 & BIO16 & BIO17 & B1018 & B1019 \\
\hline Epidalea calamita & 29TPE43 & 101,00 & 153,35 & 97,14 & 35,97 & 5887,56 & 310,18 & 43,60 & 266,59 & 89,12 & 231,20 & 231,48 & 81,69 & 837,38 & 120,72 & 7,00 & 53,85 & 334,35 & 53,38 & 53,65 & 333,63 \\
\hline Epidalea calamita & 29TPE44 & 100,00 & 149,48 & 96,03 & 35,86 & 5860,33 & 304,97 & 40,37 & 264,60 & 84,59 & 226,95 & 227,18 & 78,09 & 871,44 & 126,58 & 7,52 & 54,06 & 348,36 & 55,63 & 55,78 & 347,93 \\
\hline Epidalea calamita & 29TPE46 & 99,00 & 140,79 & 93,71 & 35,62 & 5799,87 & 293,41 & 33,34 & 260,08 & 71,02 & 217,52 & 217,64 & 70,04 & 944,75 & 139,10 & 8,62 & 54,33 & 378,87 & 60,64 & 61,32 & 378,87 \\
\hline Epidalea calamita & 29TPE48 & 99,00 & 117,54 & 82,71 & 33,32 & 5674,60 & 261,50 & 16,91 & 244,60 & 48,96 & 192,78 & 193,24 & 48,96 & 1155,77 & 173,94 & \begin{tabular}{|l|l|}
11,18 \\
\end{tabular} & 55,15 & 468,54 & 73,04 & 77,68 & 468,54 \\
\hline Epidalea calamita & 29TPE49 & 101,00 & 125,55 & 88,94 & 34,86 & 5693,66 & 273,09 & 21,39 & 251,70 & 56,06 & 200,71 & 201,07 & 56,06 & 1071,7 & 160,32 & \begin{tabular}{|l|l|}
10,53 \\
\end{tabular} & 54,81 & 432,91 & $\begin{array}{ll}69,15 \\
\end{array}$ & 71,71 & 432,91 \\
\hline Epidalea calamita & 29TPE53 & 100,00 & 151,91 & 97,36 & 35,85 & 5953,50 & 309,70 & 41,55 & 268,15 & 87,23 & 230,81 & 231,01 & 79,58 & 808,77 & 115,52 & 6,97 & 53,33 & 321,81 & 52,04 & 52,23 & 319,62 \\
\hline Epidalea calamita & 29TPE54 & 100,00 & 147,75 & 95,98 & 35,62 & 5933,51 & 304,19 & 38,06 & 266,13 & 83,16 & 226,32 & 226,50 & 75,69 & 844,05 & 121,51 & 7,38 & 53,61 & 335,96 & 54,66 & 54,79 & 334,47 \\
\hline Epidalea calamita & 29TPE55 & 100,00 & 139,99 & 93,16 & 35,09 & 5892,53 & 294,01 & 32,20 & 261,81 & 76,16 & 218,11 & 218,19 & 68,40 & 909,11 & 132,39 & 8,41 & 53,90 & 362,66 & 58,54 & 59,38 & 361,92 \\
\hline Epidalea calamita & 29TPE56 & 101,00 & 128,25 & 88,22 & 34,20 & 5835,14 & 278,60 & 23,79 & 254,82 & 62,95 & 205,80 & 206,08 & 57,84 & 1007,41 & 148,40 & 9,62 & 54,15 & 403,27 & $\begin{array}{l}64,49 \\
\end{array}$ & 67,35 & 403,21 \\
\hline Epidalea calamita & 29TPE59 & 100,00 & 119,76 & 86,90 & 34,11 & 5766,20 & 267,68 & 16,35 & 251,34 & 49,78 & 196,01 & 196,68 & 49,78 & 1061,22 & 157,39 & 10,70 & 54,14 & 426,26 & 69,47 & 72,85 & 426,26 \\
\hline Epidalea calamita & 29TPE63 & 100,00 & 147,31 & 96,56 & 35,56 & 6005,60 & 305,46 & 37,25 & 268,21 & 82,40 & 227,14 & 227,18 & 74,60 & 805,58 & 114,23 & 7,23 & 52,82 & 319,18 & 52,55 & 52,87 & 315,84 \\
\hline Epidalea calamita & 29TPE64 & 101,00 & 148,18 & 97,18 & 35,78 & 5989,67 & 305,84 & 37,38 & 268,45 & 82,93 & 227,58 & 227,62 & 75,21 & 797,19 & 113,21 & 7,17 & 52,86 & 315,68 & 52,29 & 52,49 & 312,48 \\
\hline Epidalea calamita & 29TPE65 & 100,00 & 129,91 & 90,14 & 34,26 & 5929,70 & 283,01 & 23,91 & 259,10 & 66,46 & 208,92 & 209,16 & 58,67 & 944,84 & 136,77 & 9,21 & 53,25 & 375,78 & 61,54 & 63,95 & 373,87 \\
\hline Epidalea calamita & 29TPE66 & 100,00 & 121,79 & 86,97 & 33,72 & 5881,62 & 272,26 & 17,83 & 254,43 & 59,20 & 200,18 & 200,57 & 51,21 & 1009,52 & 147,16 & 10,10 & 53,46 & 402,21 & 65,82 & 69,68 & 400,97 \\
\hline Epidalea calamita & 29TPE67 & 101,00 & 125,29 & 89,10 & 34,18 & 5888,96 & 276,66 & 19,84 & 256,83 & 61,99 & 203,34 & 203,90 & 54,13 & $\begin{array}{l}971,07 \\
\end{array}$ & 141,31 & 9,83 & 53,26 & 386,21 & 64,13 & 66,99 & 385,15 \\
\hline Epidalea calamita & 29TPE69 & 101,00 & 123,25 & 90,59 & 34,72 & 5856,27 & 274,74 & 17,18 & 257,56 & 58,81 & 200,55 & 201,39 & 52,01 & 969,08 & 141,09 & 10,03 & 53,06 & 385,06 & 65,36 & 67,80 & 384,65 \\
\hline Epidalea calamita & 29TPE73 & 100,00 & 150,30 & 98,84 & 35,77 & 6062,09 & 310,71 & 38,27 & 272,44 & 84,43 & 230,77 & 230,80 & 76,58 & 739,65 & 102,88 & 6,62 & 51,89 & 290,90 & 49,06 & 49,23 & 285,78 \\
\hline Epidalea calamita & 29TPE76 & 101,00 & 116,20 & 87,38 & 33,60 & 5936,45 & 267,97 & 12,02 & 255,95 & 53,37 & 195,55 & 196,01 & 45,46 & 998,94 & 143,22 & 10,53 & 52,42 & 395,43 & 67,06 & 71,63 & 392,21 \\
\hline Epidalea calamita & \begin{tabular}{|l|} 
29TPE77 \\
\end{tabular} & 100,00 & 122,37 & 90,04 & 34,30 & 5945,46 & 275,26 & 16,19 & 259,07 & 58,62 & 201,30 & 201,94 & 50,77 & 938,22 & 134,22 & 9,98 & 52,23 & 370,92 & 63,72 & 66,87 & 367,88 \\
\hline Epidalea calamita & 29TPE78 & 101,00 & 123,45 & 91,55 & 34,80 & 5941,90 & 276,94 & 16,45 & 260,49 & 59,43 & 202,15 & 202,87 & 51,50 & 917,39 & 131,03 & 9,84 & 52,04 & 362,22 & 63,19 & 65,75 & 359,37 \\
\hline Epidalea calamita & 29TPE83 & 100,00 & 155,39 & 101,75 & 36,05 & 6107,25 & 318,29 & 40,92 & 277,37 & 88,51 & 236,29 & 236,29 & 80,65 & 662,07 & 89,77 & 5,86 & 50,92 & 258,07 & 44,53 & 44,53 & 251,09 \\
\hline Epidalea calamita & 29TPE85 & 101,00 & 126,42 & 93,40 & 34,64 & 6044,36 & 283,86 & 18,13 & 265,73 & 61,90 & 207,17 & 207,49 & 54,01 & 867,71 & 120,90 & 9,38 & 51,16 & 339,84 & 60,08 & 62,81 & 334,06 \\
\hline Epidalea calamita & 29TPE86 & 100,00 & 117,60 & 90,52 & 34,02 & 6008,49 & 272,64 & \begin{tabular}{|l|l|}
11,27 \\
\end{tabular} & 261,36 & 53,76 & 197,92 & 198,45 & 45,95 & 928,26 & 130,25 & \begin{tabular}{ll|}
10,32 \\
\end{tabular} & 51,22 & 364,31 & 64,53 & 68,45 & 358,97 \\
\hline Epidalea calamita & \begin{tabular}{|l|} 
29TPE88 \\
\end{tabular} & 100,00 & 124,78 & 94,46 & 35,08 & 6008,36 & 281,25 & 15,80 & 265,45 & 59,89 & 204,33 & 205,17 & 52,01 & 849,17 & 118,51 & 9,48 & 50,67 & 332,56 & 60,52 & 62,53 & 327,54 \\
\hline Epidalea calamita & 29TPE89 & 101,00 & 124,13 & 95,26 & 35,25 & 5995,30 & 280,81 & 14,85 & 265,97 & 59,14 & 203,39 & 204,31 & 51,43 & 843,46 & 117,63 & 9,60 & 50,67 & 330,28 & 60,83 & 62,57 & 325,45 \\
\hline Epidalea calamita & 29TPE95 & 100,00 & 133,71 & 97,47 & 35,24 & 6122,54 & 294,97 & 22,26 & 272,71 & 67,52 & 215,21 & 215,54 & 59,77 & 762,82 & 103,58 & 8,34 & 49,95 & 295,84 & 54,36 & 55,87 & 288,21 \\
\hline Epidalea calamita & 29TPE96 & 100,00 & 121,66 & 94,40 & $\begin{array}{l}34,49 \\
34,79\end{array}$ & 6085,22 & 280,54 & 12,66 & 267,88 & 56,49 & 202,72 & 203,40 & 48,71 & \begin{tabular}{|l|l|l|l|l|}
839,86 \\
\end{tabular} & 114,81 & $\begin{array}{l}9,34 \\
9,92\end{array}$ & 49,81 & 326,27 & 60,70 & $\begin{array}{l}0,014 \\
63,49\end{array}$ & 318,88 \\
\hline Epidalea calamita & \begin{tabular}{|l|} 
29TPE97 \\
\end{tabular} & 101,00 & 123,33 & 95,54 & 35,03 & 6081,09 & 282,39 & 13,56 & 268,83 & 57,85 & 204,07 & 204,93 & 50,15 & 815,68 & 111,21 & 9,77 & 49,60 & 316,66 & 59,75 & 62,02 & 309,32 \\
\hline Epidalea calamita & 29TPE98 & 100,00 & 128,77 & 98,03 & 35,72 & 6080,10 & 288,79 & 17,22 & 271,56 & 62,50 & 209,12 & 209,95 & 54,96 & 765,26 & 103,76 & 9,16 & 49,35 & 296,62 & 56,86 & 57,99 & 289,48 \\
\hline Epidalea calamita & 29TPF02 & 100,00 & 120,33 & 92,91 & 37,62 & 5265,34 & 262,17 & 18,53 & 243,64 & 55,99 & 189,91 & 190,07 & 55,99 & 1328,52 & 201,64 & 14,36 & 55,81 & 542,65 & 87,32 & 87,58 & 542,65 \\
\hline Epidalea calamita & \begin{tabular}{|l|} 
29TPF03 \\
\end{tabular} & 101,00 & 113,74 & 90,97 & 37,23 & 5258,84 & 254,54 & 13,44 & 241,10 & 50,04 & 183,61 & 183,69 & 50,04 & 1387,50 & 209,98 & 15,89 & 55,33 & 566,60 & \begin{tabular}{|l|l|}
92,49 \\
\end{tabular} & 92,91 & 566,60 \\
\hline Epidalea calamita & 29TPF04 & 100,00 & 128,77 & 101,16 & 39,55 & 5306,69 & 275,19 & 22,47 & 252,72 & $\frac{0,045}{62,85}$ & \begin{tabular}{|l|}
197,94 \\
197
\end{tabular} & \begin{tabular}{|l|l|}
198,38 \\
\end{tabular} & $\begin{array}{ll}0,0485 \\
62,85\end{array}$ & 1242,10 & \begin{tabular}{|l|}
187,23 \\
\end{tabular} & 13,26 & 55,32 & 505,25 & 81,75 & \begin{tabular}{l|l}
84,25 \\
\end{tabular} & 505,25 \\
\hline Epidalea calamita & $\begin{array}{l}\text { 29TPF07 } \\
\end{array}$ & 101,00 & 129,25 & 104,96 & 40,17 & 5320,59 & 279,02 & 21,27 & 257,75 & 69,15 & 198,58 & 198,93 & 63,25 & 1223,92 & 181,16 & 14,12 & 54,73 & 496,20 & 82,95 & 87,13 & 494,77 \\
\hline Epidalea calamita & 29TPF08 & 100,00 & 108,66 & 93,52 & 38,00 & 5223,34 & 250,90 & 8,30 & 242,61 & 45,75 & 178,02 & 178,18 & 45,68 & \begin{tabular}{|l|}
1370,44 \\
\end{tabular} & 197,65 & 19,63 & 52,80 & 551,13 & 101,85 & 103,26 & 551,12 \\
\hline Epidalea calamita & 29TPF09 & 100,00 & 111,77 & 94,08 & 38,18 & 5213,47 & 253,83 & 10,63 & 243,20 & 48,68 & 180,74 & 180,98 & 48,68 & 1325,43 & 188,43 & 19,36 & 52,06 & 530,87 & 99,87 & 101,47 & 530,87 \\
\hline Epidalea calamita & 29TPF11 & 100,00 & 128,63 & 95,37 & 37,60 & 5404,76 & 274,24 & 23,95 & 250,29 & 62,05 & 199,63 & 199,88 & 62,05 & 1200,90 & 182,25 & 12,14 & 55,80 & 489,67 & 77,94 & 78,26 & 489,67 \\
\hline Epidalea calamita & 29TPF12 & 100,00 & $\begin{array}{l}12,03 \\
118,88 \\
\end{array}$ & $\begin{array}{ll}0,31,96 \\
91,96\end{array}$ & $\begin{array}{l}36,84 \\
36,0\end{array}$ & 5385,78 & 262,58 & \begin{tabular}{|l|l|}
16,65 \\
16,
\end{tabular} & \begin{tabular}{|l|}
245,93 \\
\end{tabular} & $\begin{array}{l}53,27 \\
53\end{array}$ & $\begin{array}{l}190,27 \\
190,0\end{array}$ & $\begin{array}{l}190,32 \\
190, \\
\end{array}$ & $\begin{array}{l}53,27 \\
53\end{array}$ & $\begin{array}{l}1295,22 \\
1295\end{array}$ & \begin{tabular}{|l|l|}
192,19 \\
197,19
\end{tabular} & $\mid \frac{12,14}{13,90}$ & 55,05 & $\begin{array}{l}40,01 \\
529,52\end{array}$ & 84,37 & 85,12 & $\begin{array}{l}40,09 \\
529,52\end{array}$ \\
\hline Epidalea calamita & 29TPF13 & 101,00 & 121,03 & 95,23 & 37,65 & 5397,58 & 266,55 & 17,10 & 249,45 & 54,91 & 192,27 & 192,40 & 54,91 & 1270,64 & 192,82 & 13,83 & 55,64 & 518,67 & 83,82 & 84,37 & 518,67 \\
\hline Epidalea calamita & \begin{tabular}{|l|} 
29TPF17 \\
\end{tabular} & 99,00 & 124,80 & 103,41 & 39,44 & 5430,11 & 275,66 & 16,91 & 258,75 & 60,08 & 195,94 & 196,20 & 57,73 & 1205,82 & 179,03 & 14,42 & 54,47 & 488,74 & 83,17 & 84,79 & 488,54 \\
\hline Epidalea calamita & 29TPF19 & 101,00 & 113,80 & 96,73 & 38,31 & 5336,32 & 259,53 & 10,18 & 249,36 & 48,93 & 184,38 & 184,52 & 48,93 & 1255,75 & 179,85 & 18,12 & 52,30 & 503,68 & \begin{tabular}{|l|l|}
94,08 \\
\end{tabular} & 94,80 & 503,68 \\
\hline Epidalea calamita & 29TPF20 & 100,00 & 131,99 & 94,76 & 36,96 & 5520,84 & 279,47 & 26,29 & 253,18 & 63,93 & 204,61 & 204,73 & 63,93 & 1119,52 & 169,25 & 10,95 & 55,43 & 455,27 & 72,09 & 72,60 & 455,27 \\
\hline Epidalea calamita & 29TPF21 & 101,00 & $\begin{array}{l}13,95 \\
126,21\end{array}$ & $\begin{array}{l}4,16 \\
93,56 \\
\end{array}$ & $\begin{array}{l}30,050 \\
36,68\end{array}$ & 53213,84 & 272,97 & \begin{tabular}{|l|l|}
21,53 \\
2,5
\end{tabular} & $\begin{array}{l}251,40 \\
251,44 \\
\end{array}$ & $\begin{array}{l}53,55 \\
58,52\end{array}$ & \begin{tabular}{|l|}
$198,01,83$ \\
\end{tabular} & \begin{tabular}{|l|}
$198,97 / 57$ \\
\end{tabular} & $\begin{array}{l}53,53 \\
58,52\end{array}$ & \begin{tabular}{|l|l|l|l|l|}
1172,13 \\
\end{tabular} & \begin{tabular}{|l|}
177,25 \\
177,94
\end{tabular} & $\begin{array}{l}0,95 \\
11,92\end{array}$ & 55,70 & $\begin{array}{l}453,27 \\
477,64\end{array}$ & 75,95 & $\begin{array}{l}\mid 2,00 \\
76,74\end{array}$ & $\begin{array}{l}453,27 \\
477,64 \\
\end{array}$ \\
\hline Epidalea calamita & 29TPF22 & 100,00 & 123,09 & 94,03 & 36,88 & 5506,71 & 269,90 & 18,45 & 251,45 & 55,53 & 195,71 & 195,79 & 55,53 & 1199,46 & 182,05 & 12,66 & 55,60 & 488,99 & 78,61 & 79,60 & 488,99 \\
\hline Epidalea calamita & 29TPF30 & 101,00 & 138,54 & 97,73 & 37,13 & 5630,05 & 289,25 & 30,10 & 259,15 & 68,92 & 212,42 & 212,50 & 68,92 & 1001,01 & 149,52 & 9,60 & 54,78 & 403,99 & 64,84 & 65,10 & 403,99 \\
\hline Epidalea calamita & 29TPF34 & 100,00 & 123,76 & 98,46 & 37,58 & 5598,62 & 274,87 & 16,29 & 258,58 & 54,90 & 197,58 & 197,69 & 54,90 & 1117,24 & 167,71 & 12,54 & 54,69 & 453,09 & 75,71 & 76,31 & 453,09 \\
\hline Epidalea calamita & 29TPF35 & 101,00 & 137, & 105,49 & 39 & 5607,72 & 292 & 25,79 & 266,52 & 67,82 & 211,25 & 211,27 & 67,82 & 982,27 & 146,01 & 10,54 & 54,18 & 49 & 65,43 & 65,51 & 395,49 \\
\hline Epidalea calamita & 29TPF37 & 101,00 & 136 & 106,85 & 39,44 & 5597,15 & 291 & 23,96 & 267,78 & 66,93 & 209,96 & 209,98 & 66,93 & 970,32 & 142,26 & 11,30 & 53,38 & 388,98 & 66,55 & 66,61 & 388,98 \\
\hline Epidalea calamita & 29TPF39 & 101,00 & 128,98 & 104,90 & 39,08 & 5570,40 & 282,66 & 17,49 & 265,18 & 60,08 & 202,29 & 202,29 & 60,08 & \begin{tabular}{|l|}
1002,01 \\
\end{tabular} & 143,85 & 13,58 & 51,97 & 400,05 & 73,12 & 73,12 & 400,05 \\
\hline Epidalea calamita & 29TPF40 & 100,00 & 133,53 & 95,41 & 36,31 & 5720,40 & 284,69 & 25,68 & 259,01 & 63,05 & 208,84 & 209,07 & 63,05 & 991,53 & 147,47 & 9,75 & 54,42 & 398,90 & 65,13 & 65,67 & 398,90 \\
\hline Epidalea calamita & 29TPF41 & 100,00 & 130,09 & 95,51 & 36,44 & 5704,54 & 281,07 & 22,43 & 258,64 & 59,81 & 205,16 & 205,40 & 59,81 & \begin{tabular}{|l|}
1019,40 \\
\end{tabular} & 152,10 & 10,51 & 54,47 & 410,99 & \begin{tabular}{|l|l}
67,65 \\
\end{tabular} & 68,26 & 410,99 \\
\hline Epidalea calamita & 29TPF43 & 100,00 & 128 & 98 & $\begin{array}{l}30,44 \\
37,29\end{array}$ & 5690,11 & 281 & \begin{tabular}{|l|l|}
19,51 \\
\end{tabular} & $\begin{array}{l}261,54 \\
261\end{array}$ & $\begin{array}{l}5,101 \\
58,25\end{array}$ & $\mid$\begin{tabular}{|l|}
203,40 \\
\end{tabular} & \begin{tabular}{|l|}
203,53 \\
\end{tabular} & $\begin{array}{l}5,21 \\
58,25\end{array}$ & $\begin{array}{l}1018,61 \\
101,0\end{array}$ & \begin{tabular}{|l|}
151,77 \\
151,7
\end{tabular} & 11,11 & 54,11 & 4410,75 & \begin{tabular}{|l|l|}
69,20 \\
\end{tabular} & $\begin{array}{l}\mid c 0,20 \\
69,37 \\
\end{array}$ & 4410,75 \\
\hline Epidalea calamita & 29TPF44 & 100,00 & 132,75 & 102,47 & 38,08 & 5697,92 & 287,24 & 21,71 & 265,53 & 62,03 & 207,71 & 207,71 & 62,03 & 972,21 & 144,25 & 10,68 & 53,94 & 391,00 & 66,10 & 66,10 & 391,00 \\
\hline Epidalea calamita & 29TPF45 & 100,00 & 140,70 & $\begin{array}{l}105,77 \\
\end{array}$ & 38,89 & 5667,42 & 295,95 & 27,37 & $\begin{array}{l}268,58 \\
\end{array}$ & 70,06 & \begin{tabular}{|l|}
214,86 \\
\end{tabular} & 214,86 & 69,73 & 898,03 & 131,61 & $\begin{array}{r}9,06 \\
9,86\end{array}$ & 53,24 & 358,68 & 60 & 60,80 & 358,68 \\
\hline Epidalea calamita & 29TPF47 & 99,00 & 132,70 & 105,43 & 38,83 & 5659,92 & 288,25 & 20,00 & 268,25 & 62,32 & 207,06 & 207,06 & 62,32 & 938,61 & 136,65 & 11,66 & 52,49 & 375,35 & 66,55 & 66,55 & 375,35 \\
\hline Epidalea calamita & 29TPF48 & 101,00 & 140,12 & 107,65 & 39,32 & 5646,39 & 295,76 & 25,48 & 270,27 & 69,34 & 214,06 & 214,06 & 69,34 & 865,86 & 123,90 & 10,87 & 51,73 & 343,18 & 61,50 & 61,50 & 34 \\
\hline Epidalea calamita & $\begin{array}{l}\text { 29TPF49 } \\
\end{array}$ & $\begin{array}{l}100,00 \\
100\end{array}$ & $\begin{array}{l}14,14 \\
137,42 \\
\end{array}$ & \begin{tabular}{|l|}
106,91 \\
10,9
\end{tabular} & $\begin{array}{l}39,23 \\
39,4\end{array}$ & $\begin{array}{l}564,93,61 \\
562,\end{array}$ & $\begin{array}{l}2932,30 \\
292,32\end{array}$ & \begin{tabular}{|l|l|}
23,10 \\
23
\end{tabular} & 269,23 & $\begin{array}{l}53,24 \\
67,23 \\
\end{array}$ & $\begin{array}{l}211,120 \\
211\end{array}$ & $\begin{array}{l}14,00 \\
211,12\end{array}$ & $\begin{array}{l}35,34 \\
66,99 \\
\end{array}$ & \begin{tabular}{|l|}
873,001 \\
873,61
\end{tabular} & \begin{tabular}{|l|l|}
123,63 \\
123
\end{tabular} & 11,76 & $\begin{array}{l}11,1,03 \\
51,03\end{array}$ & $\begin{array}{l}34,10 \\
345,28 \\
\end{array}$ & \begin{tabular}{|l|}
03,87 \\
63,87
\end{tabular} & $\begin{array}{l}1,100 \\
63,87 \\
\end{array}$ & $\begin{array}{l}34,10 \\
345,28 \\
\end{array}$ \\
\hline Epidalea calamita & 29TPF50 & 100,00 & 126,65 & 92,55 & 35,46 & 5783,08 & 277,61 & 19,91 & 257,70 & 55,85 & 202,85 & 203,38 & 55,85 & 993,74 & 146,73 & 10,17 & 53,88 & 398,03 & 66,35 & 67,84 & 398,03 \\
\hline Epidalea calamita & 29TPF51 & 101,00 & 131,64 & 96,88 & 36,43 & 578281 & 284,82 & 22.60 & 262,23 & 60,43 & 20801 & 208.14 & 60,43 & 944,00 & 138.90 & 9.93 & 53.56 & 377.33 & 64,01 & 64,23 & 377.33 \\
\hline Epidalea calamita & 29TPF52 & 100,00 & 137,54 & 101,08 & 37,46 & 5779,03 & 292,46 & 25,97 & 266,49 & 65,88 & 213,69 & 213, & 65, & 888,20 & 129,97 & 9,39 & 53,19 & 353,77 & 60 & 60,27 & 353,77 \\
\hline Epidalea calamita & 29TPF53 & 100,00 & 141,10 & 103,66 & 38,12 & 5763,83 & 296,81 & 28,05 & 268,76 & 69,62 & 216,60 & 216,60 & 69,12 & 850,97 & 23,81 & 9,14 & 52,78 & 337,87 & 57,88 & 57,88 & 337,83 \\
\hline
\end{tabular}




\begin{tabular}{|c|c|c|c|c|c|c|c|c|c|c|c|c|c|c|c|c|c|c|c|c|c|}
\hline TAXON & UTM & $\mathrm{km2}$ & BIO1 & B102 & $\mathrm{BIO3}$ & BIO4 & B105 & B106 & B107 & B108 & B109 & BIO10 & BIO11 & BIO12 & BIO13 & BIO14 & BIO15 & BIO16 & BIO17 & BIO18 & BIO19 \\
\hline Epidalea calamita & 29TPF55 & 100,00 & 143,81 & 106,25 & 38,74 & 5720,69 & 300,02 & 29,27 & 270,76 & 74,26 & 218,64 & 218,64 & 72,02 & 814,43 & 117,22 & 9,14 & 52,12 & 322,14 & 56,22 & 56,22 & 321,98 \\
\hline Epidalea calamita & 29TPF56 & 100,00 & 139,49 & 105,69 & 38,59 & 5705,64 & 295,63 & 25,55 & $\begin{array}{ll}270,08 \\
2\end{array}$ & 70,99 & 214,41 & 214,41 & 68,22 & 837,54 & 120,32 & 9,97 & 51,84 & 331,83 & 59,22 & 59,22 & 331,53 \\
\hline Epidalea calamita & 29TPF57 & 101,00 & $\begin{array}{l}134,38 \\
\end{array}$ & 105,98 & 38,67 & 5715,32 & 291,15 & 20,48 & \begin{tabular}{ll|}
270,66 \\
\end{tabular} & 63,93 & $\begin{array}{l}209,56 \\
2\end{array}$ & 209,56 & 63,28 & 863,64 & 124,24 & 11,01 & 51,61 & 343,18 & 62,44 & 62,44 & 343,14 \\
\hline Epidalea calamita & 29TPF58 & 99,00 & 136,87 & 107,07 & 38,82 & 5702,16 & 293,58 & 22,00 & 271,58 & 65,83 & $\begin{array}{l}211,69 \\
2\end{array}$ & 211,69 & 65,64 & 829,85 & 117,91 & 11,02 & 50,93 & 327,95 & 60,81 & 60,81 & 327,95 \\
\hline Epidalea calamita & 29TPF59 & 101,00 & 140,06 & 107,68 & 39,02 & 5679,65 & 296,10 & 24,35 & 271,75 & 70,61 & 214,39 & 214,39 & 68,77 & \begin{tabular}{|l|l|}
794,76 \\
\end{tabular} & 111,26 & 10,91 & 50,28 & 312,01 & 58,91 & 58,91 & 312,01 \\
\hline Epidalea calamita & 29TPF60 & 100,00 & 126,95 & 93,99 & 35,55 & 5856,68 & 279,99 & \begin{tabular}{l|l}
18,95 \\
\end{tabular} & 261,04 & \begin{tabular}{|l|l|l|}
60,23 \\
\end{tabular} & 204,05 & 204,72 & 55,29 & 931,01 & 135,27 & 9,88 & 52,80 & 369,36 & \begin{tabular}{ll|}
63,92 \\
\end{tabular} & 65,18 & 369,14 \\
\hline Epidalea calamita & 29TPF61 & 100,00 & 132,16 & 97,93 & 36,39 & 5855,03 & 287,09 & 21,78 & 265,31 & \begin{tabular}{ll|}
64,63 \\
\end{tabular} & 209,47 & 209,65 & \begin{tabular}{l|l|}
59,93 \\
\end{tabular} & 881,01 & 127,52 & 9,52 & 52,48 & 348,64 & \begin{tabular}{ll|l}
61,25 \\
\end{tabular} & 61,44 & 348,50 \\
\hline Epidalea calamita & 29TPF62 & 100,00 & 131,94 & 99,50 & 36,82 & 5846,01 & 287,62 & 20,89 & 266,74 & 63,30 & \begin{tabular}{|l|l|}
209,20 \\
\end{tabular} & 209,32 & \begin{tabular}{l|l|l}
59,75 \\
\end{tabular} & \begin{tabular}{l|l|}
870,22 \\
\end{tabular} & 125,57 & 9,66 & 52,26 & \begin{tabular}{|l|l|}
344,02 \\
\end{tabular} & \begin{tabular}{ll|l}
61,16 \\
\end{tabular} & \begin{tabular}{l|l}
61,35 \\
\end{tabular} & 343,96 \\
\hline Epidalea calamita & 29TPF63 & 101,00 & 134,25 & 101,94 & 37,38 & 5835,98 & 290,96 & 21,88 & 269,08 & 63,60 & 211,38 & 211,38 & \begin{tabular}{|l|l|}
61,97 \\
\end{tabular} & 844,73 & 121,62 & 9,68 & 52,03 & \begin{tabular}{|l|l|}
333,64 \\
\end{tabular} & 59,71 & 59,71 & 333,62 \\
\hline Epidalea calamita & 29TPF64 & 99,00 & 141,58 & 105,17 & 38,20 & 5807,07| & 298,94 & 27,17 & 271,77 & 72,58 . & 217,82 & 217,82 & 69,07 _ & 782,20 & 111,55 & 8,88 & 51,52 & 307,77 & 55,02 & 55,02 & 307,29 \\
\hline Epidalea calamita & 29TPF66 & 100,00 & 138,95 & 106,55 & 38,53 & 5783,69 & 296,75 & 23,90 & 272,85 & \begin{tabular}{|l|l|l|}
68,93 \\
\end{tabular} & \begin{tabular}{|l|l|}
214,97 \\
\end{tabular} & \begin{tabular}{|l|l|}
214,97 \\
\end{tabular} & 66,74 & \begin{tabular}{ll|}
780,99 \\
\end{tabular} & 110,72 & 9,66 & 50,94 & 307,18 & 56,57 & 56,57 & 306,92 \\
\hline Epidalea calamita & 29TPF67 & 100,00 & 138,89 & 107,36 & 38,83 & 5764,51 & 296,72 & 23,36 & 273,36 & \begin{tabular}{|l|l|}
69,09 \\
\end{tabular} & 214,57 & 214,57 & \begin{tabular}{|c|}
66,78 \\
\end{tabular} & 768,30 & 108,26 & 9,93 & 50,41 & \begin{tabular}{|l|l|}
301,58 \\
\end{tabular} & 56,62 & 56,62 & 301,41 \\
\hline Epidalea calamita & 29TPF68 & 101,00 & 125,92 & 105,07 & 38,24 & 5746,97 & 283,86 & 12,69 & 271,17 & 55,71 & \begin{tabular}{|l|l|}
201,92 \\
\end{tabular} & 201,94 & 54,87 & $\begin{array}{l}847,90 \\
\end{array}$ & 119,58 & 11,95 & 50,01 & \begin{tabular}{|l|l|}
334,57 \\
\end{tabular} & \begin{tabular}{ll|}
65,86 \\
\end{tabular} & 65,90 & 334,55 \\
\hline Epidalea calamita & 29TPF69 & 100,00 & 124,72 & 105,60 & 38,38 & 5737,43 & 282,95 & 11,12 & \begin{tabular}{|l|l|}
271,83 \\
\end{tabular} & 53,84 & 200,67 & 200,69 & 53,80 & \begin{tabular}{l|l|}
842,56 \\
\end{tabular} & 118,37 & 12,49 & 49,51 & 332,58 & \begin{tabular}{ll|}
66,68 \\
\end{tabular} & 66,71 & 332,58 \\
\hline Epidalea calamita & 29TPF70 & 101,00 & 126,52 & 95,46 & 35,48 & 5924,88 & 281,66 & 17,39 & 264,27 & 61,88 & 204,75 & 205,50 & 54,21 & 874,26 & 124,50 & 9,71 & 51,57 & 344,34 & \begin{tabular}{l|l|l}
61,95 \\
\end{tabular} & 63,13 & 342,25 \\
\hline Epidalea calamita & 29TPF71 & 100,00 & 127,17 & 97,36 & 36,08 & 5919,39 & 283,19 & \begin{tabular}{l|l|l}
17,05 \\
\end{tabular} & 266,14 & 62,28 & 205,32 & 205,96 & 54,80 & 856,38 & 121,62 & 9,80 & 51,38 & 336,79 & 61,71 & \begin{tabular}{l|l}
62,35 \\
\end{tabular} & 334,93 \\
\hline Epidalea calamita & 29TPF72 & 100,00 & 127,59 & 99,08 & 36,53 & 5904,58 & 284,36 & 16,52 & 267,84 & 62,55 & 205,84 & \begin{tabular}{|l|}
205,97 \\
\end{tabular} & \begin{tabular}{l|l|}
55,05 \\
\end{tabular} & \begin{tabular}{|l|l|}
843,94 & \\
\end{tabular} & 119,73 & 9,89 & 51,16 & $\begin{array}{l}331,56 \\
\end{array}$ & 61,64 & \begin{tabular}{ll|}
61,79 \\
\end{tabular} & 330,15 \\
\hline Epidalea calamita & 29TPF73 & 100,00 & 133,46 & 102,44 & 37,27 & 5891,66 & 291,47 & 20,37 & 271,10 & $\begin{array}{ll}67,96 \\
\end{array}$ & 211,44 & 211,44 & 60,61 & 792,11 & 111,81 & 9,37 & 50,82 & \begin{tabular}{|l|l|}
310,49 \\
\end{tabular} & 57,83 & 57,83 & 309,20 \\
\hline Epidalea calamita & 29TPF75 & 99,00 & 134,33 & 105,26 & 37,99 & 5864,59 & 293,29 & \begin{tabular}{ll|}
19,66 \\
\end{tabular} & 273,63 & 67,46 & 211,71 & 211,71 & \begin{tabular}{ll|l}
61,42 \\
\end{tabular} & \begin{tabular}{|l|l|}
765,39 \\
\end{tabular} & 107,37 & 9,63 & 50,20 & 299,43 & 57,12 & 57,12 & 298,61 \\
\hline Epidalea calamita & 29TPF76 & 101,00 & 133,84 & 105,95 & 38,20 & 5841,09 & 292,79 & 18,91 & 273,88 & 66,99 & 210,85 & 210,86 & 61,2 & 757,77 & 105,79 & 9,82 & 49,8 & 296,32 & 57,40 & 57,40 & 295,41 \\
\hline Epidalea calamita & 29TPF77 & 100,00 & 137,67 & 107,68 & 38,62 & 5820,77 & 296,98 & 21,54 & 275,44 & 71,36 & 214,26 & 214,26 & 64,96 & 721,04 & 99,86 & 9,74 & 49,31 & 281,24 & 54,96 & 54,96 & 280,28 \\
\hline Epidalea calamita & 29TPF78 & 100,00 & 129,88 & 107,05 & 38,40 & 5809,03 & 289,73 & 14,60 & 275,14 & 62,27 & $\begin{array}{l}206,69 \\
\end{array}$ & 206,69 & 57,73 & \begin{tabular}{|l|l|}
759,94 \\
\end{tabular} & \begin{tabular}{ll|l}
105,55 \\
\end{tabular} & 10,85 & $\begin{array}{l}49,07 \\
\end{array}$ & 297,53 & \begin{tabular}{l|l|l|}
59,92 \\
\end{tabular} & $\begin{array}{ll}5,92 \\
\end{array}$ & 297,20 \\
\hline Epidalea calamita & 29TPF81 & 100,00 & 126,60 & 98,86 & 36,16 & 5977,64 & 284,65 & 15,28 & 269,37 & $\begin{array}{ll}60,96 \\
\end{array}$ & 205,60 & 206,19 & 53,50 & \begin{tabular}{|l|l|}
801,99 \\
\end{tabular} & 111,22 & 9,53 & \begin{tabular}{l|l|l|}
50,05 \\
\end{tabular} & 313,21 & 59,84 & 60,40 & 308,99 \\
\hline Epidalea calamita & 29TPF82 & 100,00 & 131,03 & 101,63 & 36,88 & 5965,24 & 290,16 & 18,01 & 272,15 & 64,99 & \begin{tabular}{|l|}
210,07 \\
\end{tabular} & 210,10 & 57,57 & 761,25 & 105,14 & 9,16 & \begin{tabular}{l|l}
49,85 \\
\end{tabular} & 296,71 & 57,24 & 57,26 & 292,83 \\
\hline Epidalea calamita & 29TPF83 & 101,00 & 129,88 & 102,77 & 37,09 & 5951,56 & 289,35 & 16,37 & 272,99 & 63,97 & 208,81 & 208,81 & 56,52 & 756,55 & $\begin{array}{ll}104,25 \\
\end{array}$ & 9,48 & 49,5 & 294,66 & 57,70 & 57,70 & 291,10 \\
\hline Epidalea calamita & 29TPF84 & 99,00 & 136,85 & 105,53 & 37,81 & 5927,83 & 296,95 & 21,49 & 275,46 & 70,53 & 215,16 & 215,16 & 63,22 & \begin{tabular}{|l|}
702,12 \\
\end{tabular} & $\begin{array}{l}96,03 \\
\end{array}$ & 8,77 & 49,13 & 272,78 & 53,29 & 53,29 & 269,14 \\
\hline Epidalea calamita & 29TPF85 & 101,00 & 133,76 & 105,84 & 37,90 & 5913,94 & 294,04 & 18,42 & \begin{tabular}{|l|l}
275,63 \\
\end{tabular} & 67,60 & 211,91 & 211,91 & 60,34 & \begin{tabular}{|l|l|}
713,10 \\
\end{tabular} & 97,54 & 9,38 & \begin{tabular}{l|l|}
48,85 \\
\end{tabular} & 277,16 & 55,33 & 55,33 & 274,08 \\
\hline Epidalea calamita & 29TPF86 & 100,00 & 126,57 & 105,56 & $\begin{array}{l}37,85 \\
\end{array}$ & 5900,58 & 287,13 & \begin{tabular}{|l|l|l|}
11,93 \\
\end{tabular} & 275,19 & \begin{tabular}{|c|}
60,90 \\
\end{tabular} & \begin{tabular}{|l|l|}
204,84 \\
\end{tabular} & 204,84 & 53,61 & 744,61 & 101,80 & 10,30 & \begin{tabular}{|l|l|}
48,49 \\
\end{tabular} & 289,46 & 59,65 & 59,65 & 287,21 \\
\hline Epidalea calamita & 29TPF87 & 99,00 & 128,44 & 106,95 & 38,07 & 5880,29 & 289,34 & 12,93 & 276,42 & 62,64 & 206,21 & 206,21 & 55,45 & $\begin{array}{l}721,95 \\
\end{array}$ & 98,36 & 10,32 & 48,11 & 280,52 & 58,36 & 58,36 & 278,59 \\
\hline Epidalea calamita & 29TPF88 & 101,00 & 131,27 & 108,01 & 38,51 & 5851,74 & 291,97 & 14,96 & 277,01 & 65,44 & \begin{tabular}{|l|}
208,61 \\
\end{tabular} & 208,61 & 58,38 & \begin{tabular}{|l|l|}
695,99 \\
\end{tabular} & 94,18 & 10,34 & \begin{tabular}{|l|l|}
47,79 \\
\end{tabular} & 270,13 & \begin{tabular}{l|l}
56,85 \\
\end{tabular} & 56,85 & 268,09 \\
\hline Epidalea calamita & 29TPF91 & 101,00 & 127,38 & 101,04 & 36,35 & 6036,27 & 287,82 & 14,43 & 273,39 & 60,91 & 207,49 & 207,84 & 53,55 & 739,90 & 99,64 & 9,21 & 48,60 & 286,37 & \begin{tabular}{|l|l}
57,43 \\
\end{tabular} & 57,71 & 279,78 \\
\hline Epidalea calamita & 29TPF93 & 100,00 & 125,30 & 103,03 & 37,01 & 6001,13 & 286,26 & 11,60 & 274,66 & \begin{tabular}{|l|l|}
59,07 \\
\end{tabular} & 205,17 & 205,17 & 51,65 & 728,21 & 97,39 & 9,94 & 47,86 & 281,22 & 58,88 & 58,88 & 275,19 \\
\hline Epidalea calamita & 29TPF94 & 100,00 & 127,14 & 104,70 & 37,31 & 5992,22 & 288,67 & \begin{tabular}{l|l}
12,45 \\
\end{tabular} & 276,22 & 60,62 & 206,74 & 206,74 & 53,35 & 706,35 & 94,23 & 9,63 & 47,70 & 272,59 & 57,28 & 57,28 & 267,10 \\
\hline Epidalea calamita & \begin{tabular}{|l|} 
29TPF95 \\
\end{tabular} & 100,00 & 123,98 & 105,18 & 37,72 & 5972,06 & 285,81 & 9,47 & 276,34 & 57,90 & 203,57 & 203,57 & 50,66 & 712,27 & 94,80 & 9,98 & 47,46 & 274,87 & 58,80 & 58,80 & 269,70 \\
\hline Epidalea calamita & 29TPF96 & 100,00 & 125,79 & 106,55 & 38,02 & 5947,17 & 287,79 & 10,27 & 277,52 & 59,50 & 204,76 & 204,76 & 52,34 & \begin{tabular}{ll|l}
691,95 \\
\end{tabular} & 91,70 & 10,15 & 47,00 & 266,69 & \begin{tabular}{l|l|}
57,95 \\
\end{tabular} & 57,95 & 261,99 \\
\hline Epidalea calamita & 29TPF97 & 101,00 & 119,67 & 106,41 & 37,99 & 5930,73 & 282,07 & 4,67 & 277,39 & 53,80 & 198,61 & 198,61 & 46,65 & 718,31 & 95,14 & 11,02 & 46,70 & 276,97 & \begin{tabular}{|l|l|}
61,95 \\
\end{tabular} & \begin{tabular}{|l|l|}
61,95 \\
\end{tabular} & 272,98 \\
\hline Epidalea calamita & \begin{tabular}{|l|l|} 
29TPF98 \\
\end{tabular} & 100,00 & 120,57 & 107,46 & 38,12 & 5908,98 & 283,11 & \begin{tabular}{l|l}
, 07 \\
\end{tabular} & 278,03 & 54,57 & \begin{tabular}{|l|l|}
199,09 \\
\end{tabular} & 199,09 & 47,67 & $\begin{array}{l}701,41 \\
\end{array}$ & 92,47 & 11,18 & 46,30 & 270,26 & \begin{tabular}{|l|l|}
61,39 \\
\end{tabular} & 61,39 & 266,71 \\
\hline Epidalea calamita & 29TPF99 & 100,00 & 130,68 & 109,56 & 38,84 & 5876,27 & 292,54 & 13,18 & 279,36 & 64,36 & 208,23 & 208,23 & 57,49 & 638,01 & 83,60 & 10,49 & \begin{tabular}{|l|l|}
46,07 \\
\end{tabular} & 245,56 & 55,23 & 55,23 & 241,94 \\
\hline Epidalea calamita & 29TPG00 & 101,00 & 128,55 & 101,51 & 39,68 & 5268,55 & 274,20 & 21,32 & 252,88 & 63,34 & 197,31 & \begin{tabular}{|l|l|l|}
197,49 \\
\end{tabular} & 63,30 & 1164,34 & 161,88 & 15,93 & 51,68 & 461,28 & 85,32 & 88,02 & 461,28 \\
\hline Epidalea calamita & 29TPG01 & 100,00 & 111,76 & 92,42 & 37,99 & 5168,72 & 251,69 & 11,49 & 240,20 & 49,41 & 180,21 & 180,35 & 49,41 & 1289,31 & \begin{tabular}{|l|}
176,79 \\
\end{tabular} & 20,77 & 50,47 & 510,67 & \begin{tabular}{|l|}
101,87 \\
\end{tabular} & \begin{tabular}{|l|l|}
103,85 \\
\end{tabular} & 510,67 \\
\hline Epidalea calamita & 29TPG03 & 101,00 & 100,34 & 86,02 & 36,70 & 5053,09 & 235,86 & 4,79 & 231,07 & \begin{tabular}{|l|l|}
40,97 \\
\end{tabular} & \begin{tabular}{|l|l|}
167,75 \\
\end{tabular} & \begin{tabular}{|l|}
168,01 \\
\end{tabular} & \begin{tabular}{l|l|}
40,55 \\
\end{tabular} & 1349,43 & 178,69 & 25,66 & $\begin{array}{l}48,45 \\
\end{array}$ & 527,55 & \begin{tabular}{|l|l|}
116,37 \\
\end{tabular} & \begin{tabular}{|l|l|}
118,48 \\
\end{tabular} & 527,53 \\
\hline Epidalea calamita & 29TPG05 & 101,00 & 119,89 & 93,96 & 38,26 & 5155,67 & 258,22 & 15,84 & 242,38 & 63,14 & \begin{tabular}{ll|}
187,92 \\
\end{tabular} & 188,01 & 57,21 & 1153,20 & 156,06 & 22,16 & \begin{tabular}{|l|l|}
47,08 \\
\end{tabular} & 443,66 & 100,34 & 101,71 & 440,77 \\
\hline Epidalea calamita & 29TPG06 & 101,00 & 120,72 & 93,71 & 38,19 & 5132,34 & 258,02 & \begin{tabular}{|l|l|}
16,47 \\
\end{tabular} & 241,55 & \begin{tabular}{|l|l|}
63,99 \\
\end{tabular} & \begin{tabular}{ll|}
188,26 \\
\end{tabular} & $\begin{array}{l}188,35 \\
\end{array}$ & 58,39 & 1133,64 & 155,70 & 22,98 & \begin{tabular}{|l|l|}
46,17 \\
\end{tabular} & \begin{tabular}{|l|}
434,04 \\
\end{tabular} & 101,53 & $\begin{array}{ll}103,93 \\
\end{array}$ & 429,13 \\
\hline Epidalea calamita & 29TPG10 & 100,00 & 126,91 & 102,29 & 39,40 & 884,67 & 275,27 & 18,51 & 256,76 & 60,43 & \begin{tabular}{|l|l|}
197,61 \\
\end{tabular} & 197,66 & 60,4 & $1124, \epsilon$ & 158,03 & 15,6 & 51,7 & \begin{tabular}{|l|}
446,89 \\
\end{tabular} & \begin{tabular}{l|l|}
82,92 \\
\end{tabular} & 83,49 & 446,89 \\
\hline Epidalea calamita & 29TPG13 & 101,00 & 114,59 & 94,29 & 37,88 & 5258,16 & 256,75 & 11,16 & 245,59 & 51,08 & 184,25 & 184,28 & 50,8 & 1171,31 & 155,10 & 20,77 & 48,71 & 457,27 & \begin{tabular}{|l|l|}
97,45 \\
\end{tabular} & \begin{tabular}{|l|l}
97,95 \\
\end{tabular} & 457,27 \\
\hline Epidalea calamita & 29TPG15 & 99,00 & 117,40 & 94,81 & 38,05 & 5235,88 & 258,51 & 12,64 & 245,87 & \begin{tabular}{|l|l|l|}
59,84 \\
\end{tabular} & $\begin{array}{l}186,75 \\
\end{array}$ & \begin{tabular}{|l|}
186,77 \\
\end{tabular} & 53,9 & 1115,37 & \begin{tabular}{|l|}
149,09 \\
\end{tabular} & 21,82 & 46,89 & 429,50 & 97,90 & 99,06 & 427,21 \\
\hline Epidalea calamita & 29TPG18 & 100,00 & 110,04 & 91,71 & 37,90 & 5063,02 & 246,93 & \begin{tabular}{l|l|}
8,24 \\
8
\end{tabular} & 238,69 & 54,47 & $\begin{array}{l}177,24 \\
1\end{array}$ & \begin{tabular}{ll|l}
177,33 \\
\end{tabular} & 49,44 & 1155,09 & 158,04 & 26,98 & \begin{tabular}{l|l|}
44,29 \\
\end{tabular} & \begin{tabular}{l|l|}
440,11 \\
\end{tabular} & $\begin{array}{l}112,45 \\
\end{array}$ & $\begin{array}{l}115,47 \\
115\end{array}$ & 432,49 \\
\hline Epidalea calamita & 29TPG20 & 100,00 & 116,55 & 98,57 & 38,25 & 5422,90 & 264,90 & 10,39 & 254,51 & 50,42 & $\begin{array}{l}188,25 \\
\end{array}$ & 188,27 & 50,42 & \begin{tabular}{|l|l|}
1146,33 \\
\end{tabular} & 161,59 & 17,49 & 51,15 & 456,30 & 88,32 & 88,41 & 456,30 \\
\hline Epidalea calamita & 29TPG22 & 101,00 & 133,16 & 103,27 & 39,01 & 5460,32 & 282,0 & 21,44 & 260,59 & 66,48 & 204,71 & 204,71 & 65,4 & 970,41 & 130,05 & 15,04 & 49,31 & \begin{tabular}{|l|}
377,52 \\
\end{tabular} & \begin{tabular}{|l|l|}
75,53 \\
\end{tabular} & 75,53 & 377,52 \\
\hline Epidalea calamita & \begin{tabular}{|l|l|l|l|}
$29 T P G 23$ \\
\end{tabular} & 100,00 & 128,44 & 100,89 & 38,75 & 5426,73 & 275,36 & 18,16 & 257,20 & 64,68 & 199,68 & 199,68 & 61,4 & \begin{tabular}{|l|l|}
993,49 \\
\end{tabular} & 130,73 & 16,78 & 48,38 & 385,02 & 80,62 & 80,62 & 384,57 \\
\hline Epidalea calamita & 29TPG24 & 100,00 & 128,78 & 100,20 & 38,64 & 5413,35 & 274,57 & 18,36 & 256,21 & \begin{tabular}{|l|l|}
68,08 \\
\end{tabular} & \begin{tabular}{|l|l|}
199,94 \\
\end{tabular} & 199,94 & 62,10 & $\begin{array}{l}972,87 \\
\end{array}$ & $\begin{array}{ll}127,05 \\
\end{array}$ & 17,39 & 47,39 & \begin{tabular}{|l|l|}
374,59 \\
\end{tabular} & \begin{tabular}{l|l}
81,45 \\
\end{tabular} & \begin{tabular}{l|l|}
81,45 \\
\end{tabular} & 372,83 \\
\hline Epidalea calamita & 29TPG27 & 100,00 & 92,11 & 89,78 & 37,22 & 5108,96 & 231,86 & $-6,13$ & 237,99 & 37,64 & \begin{tabular}{ll|}
160,60 \\
\end{tabular} & 160,72 & 31,96 & 1256,74 & 167,10 & 30,40 & 44,18 & 481,01 & \begin{tabular}{|l|l|}
125,38 \\
\end{tabular} & $\begin{array}{l}126,75 \\
\end{array}$ & 474,89 \\
\hline Epidalea calamita & 29TPG30 & 101,00 & 129,20 & 104,36 & 38,86 & 5549,78 & 281,83 & 17,57 & 264,26 & \begin{tabular}{|l|l|}
60,49 \\
\end{tabular} & \begin{tabular}{|l|}
202,10 \\
\end{tabular} & 202,10 & 60,49 & 983,61 & 138,69 & 14,19 & $51, \mathrm{C}$ & 390,06 & 73,76 & 73,76 & 390,06 \\
\hline Epidalea calamita & $29 \mathrm{TPG} 3$ & 99,00 & 119 & 101,17 & 38,4 & 5507 & 270 & 10, & 260, & 52, & 192. & 192 & 52, & \begin{tabular}{|l|l|}
1040,03 \\
\end{tabular} & 144 & 16,75 & 50, & 412 & \begin{tabular}{|l|l|}
81,99 \\
\end{tabular} & 81,99 & 412 \\
\hline Epidalea calamita & 29TPG33 & 100,00 & 121,95 & 100,70 & 38,33 & 5475,42 & 271,29 & 12,10 & \begin{tabular}{|l|l|}
259,19 \\
\end{tabular} & 57,53 & \begin{tabular}{|l|l|}
194,34 \\
\end{tabular} & 194,34 & 54,80 & \begin{tabular}{|l|}
986,87 \\
\end{tabular} & 131,60 & 17,61 & 48,16 & 384,05 & 82,26 & 82,26 & 383,95 \\
\hline Epidalea calamita & 29TPG34 & 101,00 & 119,10 & 99,36 & 38,15 & 5438,35 & 267,03 & 10,11 & \begin{tabular}{|l|l|}
256,92 \\
\end{tabular} & 58,52 & \begin{tabular}{|l|l|}
191,03 \\
\end{tabular} & 191,03 & 52,56 & \begin{tabular}{|l|l|}
996,47 \\
\end{tabular} & 130,92 & 19,09 & 47,19 & 385,91 & 86,18 & 86,18 & 385,02 \\
\hline Epidalea calamita & 29TPG37 & 100,00 & 81,18 & 89,85 & 36,97 & 5161,60 & 223,24 & $-16,66$ & 239,90 & 26,61 & \begin{tabular}{ll|l}
150,66 \\
\end{tabular} & \begin{tabular}{|l|}
150,77 \\
\end{tabular} & 20,92 & 1289,79 & 168,92 & 33,27 & 43,10 & \begin{tabular}{|l|l}
490,73 \\
\end{tabular} & \begin{tabular}{|l|l|}
134,79 \\
\end{tabular} & \begin{tabular}{ll|}
135,32 \\
\end{tabular} & 482,99 \\
\hline Epidalea & 29TPG38 & 100,00 & & & 37,72 & 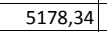 & & $-4,64$ & 243,39 & 40,4 & 165, & 165,96 & 35,20 & 1152,50 & 153 & 28,99 & 43,10 & 438 & 118,41 & \begin{tabular}{|l|l|}
119,17 \\
\end{tabular} & \\
\hline Epidalea calamita & 29TPG40 & 100,00 & 139,68 & 107,25 & 39,28 & 5619,8 & 294,6 & 24,54 & 269,48 & $69,90[$ & 213,18 & 213,18 & 69,41 & 839,87 & 116,78 & 11,78 & 50,19 & $329,39 \mid$ & 62,42 & 62,42 & 329, \\
\hline Epidalea calamita & 29TPG41 & 100,00 & 132,24 & 105,64 & 38,95 & 5603,97 & 286,01 & 18,46 & 267,55 & 63,01 & 205,82 & 205,82 & 62,58 & 880,38 & 121,57 & 13,71 & 49,58 & 345,71 & 68 & 68 & 345,69 \\
\hline
\end{tabular}




\begin{tabular}{|c|c|c|c|c|c|c|c|c|c|c|c|c|c|c|c|c|c|c|c|c|c|}
\hline TAXON & UTM & $\mathrm{km2}$ & B101 & $\mathrm{B1O2}$ & $\mathrm{BIO3}$ & $\mathrm{B104}$ & B105 & B106 & B107 & B108 & B109 & 81010 & B1011 & BIO12 & BIO13 & 81014 & B1015 & B1016 & B1017 & BIO18 & B1019 \\
\hline Epidalea calamita & 29TPG42 & 101,00 & 119,50 & 102,14 & 38,32 & 5551,84 & 272,26 & 8,95 & 263,32 & 51,70 & 193,03 & 193,03 & 51,39 & 962,54 & 131,89 & 16,71 & 48,75 & 378,48 & 79,34 & 79,34 & 378,47 \\
\hline Epidalea calamita & 29TPG44 & 100,00 & 113,68 & 99,82 & 38,01 & 5485,88 & 264,16 & 4,66 & 259,50 & 52,80 & 186,67 & 186,67 & 46,81 & 981,93 & 129,95 & 19,66 & 46,90 & 381,73 & 87,10 & 87,10 & 380,84 \\
\hline Epidalea calamita & 29TPG47 & 101,00 & 87,27 & 93,12 & 37,28 & 5272,05 & 232,57 & $-13,80$ & 246,38 & 30,69 & 158,08 & 158,12 & 25,08 & 1178,80 & 154,82 & 30,25 & 43,01 & 449,01 & 123,01 & 123,16 & 441,24 \\
\hline Epidalea calamita & 29TPG48 & 100,00 & 108,67 & 96,86 & 37,97 & 5314,99 & 253,42 & 2,25 & 251,18 & 49,64 & 179,27 & 179,29 & 44,47 & 997,65 & 133,38 & 24,48 & 42,97 & 380,02 & 101,32 & 101,38 & 371,02 \\
\hline Epidalea calamita & 29TPG49 & 101,00 & 118,67 & 97,49 & 38,41 & 5283,64 & 261,09 & 10,54 & 250,55 & 58,99 & 188,28 & 188,28 & 54,20 & 919,91 & 123,69 & 22,59 & 42,35 & 348,53 & 93,97 & 93,97 & 337,24 \\
\hline Epidalea calamita & 29TPG50 & 100,00 & 137,60 & 107,47 & 39,01 & 5663,99 & 293,42 & 22,08 & 271,34 & 69,40 & 211,95 & 211,95 & 66,82 & 797,61 & 110,60 & 11,75 & 49,53 & 312,43 & 60,95 & 60,95 & 312,37 \\
\hline Epidalea calamita & 29TPG51 & 100,00 & 135,10 & 106,82 & 38,97 & 5652,70 & 290,36 & 19,93 & 270,43 & 68,85 & 209,35 & 209,35 & 64,65 & 802,20 & 109,94 & 12,67 & 48,85 & 313,40 & 63,25 & 63,25 & 313,23 \\
\hline Epidalea calamita & 29TPG52 & 99,00 & 126,28 & 105,19 & 38,73 & 5629,65 & 281,48 & 12,63 & 268,85 & 59,49 & 200,62 & 200,62 & 56,60 & 851,88 & 116,31 & 14,69 & 48,20 & 333,63 & 70,27 & 70,27 & 333,50 \\
\hline Epidalea calamita & 29TPG54 & 100,00 & 112,14 & 101,49 & 37,99 & 5549,06 & 265,44 & 2,10 & 263,34 & 50,57 & 186,01 & 186,01 & 44,43 & 933,69 & 123,73 & 19,01 & 46,45 & 363,30 & 84,68 & 84,68 & 361,72 \\
\hline Epidalea calamita & 29TPG58 & 99,00 & 113,24 & 99,55 & 38,22 & 5409,77 & 260,71 & 4,08 & 256,63 & 52,44 & 184,97 & 184,97 & 47,33 & 906,05 & \begin{tabular}{ll|}
121,16 \\
\end{tabular} & 22,17 & 42,81 & 345,63 & 92,32 & 92,32 & 336,18 \\
\hline Epidalea calamita & 29TPG59 & 101,00 & 120,87 & 99,39 & 38,56 & 5362,54 & 265,42 & 10,95 & 254,47 & 59,95 & 191,56 & 191,56 & 55,12 & 854,10 & 114,17 & 21,06 & 41,95 & 323,58 & 88,29 & 88,29 & 311,47 \\
\hline Epidalea calamita & 29TPG67 & 101,00 & 90,62 & 98,13 & 37,76 & 5449,74 & 241,65 & $-15,01$ & 256,66 & 31,18 & 163,81 & 163,81 & 25,53 & 1033,16 & 135,57 & 27,56 & 41,95 & 391,99 & 111,28 & 111,28 & 382,79 \\
\hline Epidalea calamita & 29TPG70 & 101,00 & 120,49 & 106,61 & 38,23 & 5758,56 & 281,01 & 6,19 & 274,81 & 50,93 & 197,05 & 197,05 & 49,40 & 797,41 & 110,24 & 12,70 & 48,25 & 313,45 & 66,84 & 66,84 & 313,45 \\
\hline Epidalea calamita & 29TPG71 & 99,00 & 106,29 & 103,38 & 37,79 & 5709,64 & 265,63 & $-4,35$ & 269,98 & 41,02 & 182,72 & 182,73 & 36,85 & 887,24 & 120,34 & 15,88 & 47,03 & 346,53 & 79,77 & 79,77 & 346,12 \\
\hline Epidalea calamita & 29TPG76 & 100,00 & 69,20 & 95,75 & 37,03 & 5474,24 & 221,21 & $-33,69$ & 254,90 & 11,21 & 143,07 & 143,32 & 5,10 & 1166,78 & 148,91 & 33,61 & 40,03 & 435,09 & 133,11 & 134,16 & 423,21 \\
\hline Epidalea calamita & 29TPG79 & 101,00 & 115,29 & 102,23 & 38,71 & 5504,49 & 264,82 & 3,55 & 261,28 & 52,63 & 187,88 & 187,88 & 47,61 & 798,91 & 105,84 & 21,01 & 40,71 & 302,25 & 87,53 & 87,53 & 288,56 \\
\hline Epidalea calamita & 29TPG80 & 100,00 & 121,05 & 107,95 & 38,31 & 5805,80 & 283,05 & 5,75 & 277,30 & 55,69 & 198,22 & 198,22 & 49,43 & 736,72 & 99,75 & 12,07 & 47,20 & 287,01 & 63,76 & 63,76 & 286,57 \\
\hline Epidalea calamita & 29TPG81 & 100,00 & 112,63 & 106,89 & 38,07 & 5769,69 & 274,83 & $-0,95$ & 275,78 & 47,70 & $\begin{array}{ll}189,63 \\
\end{array}$ & 189,63 & 41,79 & 781,52 & 105,21 & 13,80 & 46,54 & 304,45 & 70,73 & 70,73 & 304,31 \\
\hline Epidalea calamita & 29TPG82 & 101,00 & 115,92 & 108,05 & 38,48 & 5741,87 & 278,21 & 1,19 & 277,01 & 49,20 & 192,39 & 192,39 & 45,23 & 751,50 & 101,08 & 13,75 & 46,42 & 293,71 & 68,50 & 68,50 & 293,50 \\
\hline Epidalea calamita & 29TPG83 & 100,00 & 114,34 & 107,76 & 38,57 & 5717,94 & 275,96 & $-0,14$ & 276,10 & 49,76 & \begin{tabular}{|l|l|}
190,63 \\
\end{tabular} & \begin{tabular}{|l|l|}
190,63 \\
\end{tabular} & 43,99 & 756,43 & $\mid 100,89$ & 14,92 & 45,71 & 294,30 & 71,12 & 71.12 & 293,56 \\
\hline Epidalea calamita & 29TPG84 & 100,00 & 101,08 & 104,58 & 38,04 & 5694,84 & 260,62 & $-10,39$ & 271,01 & 38,15 & 177,42 & 177,42 & 31,99 & 848,62 & 111,77 & 19,55 & 43,67 & 325,23 & 86,52 & 86,52 & 320,86 \\
\hline Epidalea calamita & 29TPG85 & 99,00 & 90,22 & 102,10 & 37,74 & 5649,05 & 247,58 & $-18,81$ & 266,39 & 28,47 & 166,10 & 166,16 & 22,38 & 931,97 & 121,43 & 24,22 & 41,70 & 352,40 & 101,25 & 101,38 & 344,17 \\
\hline Epidalea calamita & 29TPG86 & 101,00 & 80,34 & 100,06 & 37,57 & 5586,05 & 235,83 & $-26,54$ & 262,37 & 19,98 & 155,48 & 155,64 & 13,90 & 1015,72 & 130,94 & 29,10 & 40,06 & 379,28 & 116,18 & 116,72 & 367,84 \\
\hline Epidalea calamita & 29TPG87 & 100,00 & 60,76 & 96,29 & 37,14 & 5479,39 & 213,40 & $-41,90$ & 255,30 & 3,18 & 134,78 & 135,09 & $-3,08$ & 1192,08 & 150,36 & 37,89 & 37,67 & 436,76 & 145,06 & 146,84 & 421,17 \\
\hline Epidalea calamita & 29TPG88 & 101,00 & 75,96 & 99,19 & 37,83 & 5498,03 & 229,16 & $-29,65$ & 258,81 & 16,66 & 149,91 & 149,95 & 10,69 & 1056,83 & 135,57 & 32,94 & 38,18 & 389,90 & 128,19 & 128,45 & 374,70 \\
\hline Epidalea calamita & 29TPG90 & 101,00 & 125,92 & 109,62 & 38,77 & 5856,70 & 288,50 & 8,71 & 279,79 & 60,02 & 203,44 & 203,44 & 53,20 & 655,17 & 85,95 & 11,25 & 45,79 & 252,45 & 58,32 & 58,32 & 249,87 \\
\hline Epidalea calamita & 29TPG91 & 100,00 & 118,94 & 109,38 & 38,64 & 5827,16 & 282,27 & $\frac{0,1 / 2}{2,54}$ & 279,73 & 53,38 & 196,21 & 196,21 & 46,87 & $\mid 687,62$ & $\begin{array}{l}0,57 \\
90,5 \\
\end{array}$ & $\frac{1,26}{12,47}$ & 45,58 & 265,21 & $\begin{array}{l}0,324 \\
63,42\end{array}$ & 63,42 & $\begin{array}{l}24,04,07 \\
264\end{array}$ \\
\hline Epidalea calamita & 29TPG93 & 100,00 & 114,11 & 109,10 & 38,82 & 5783,44 & 276,86 & $-1,48$ & 278,34 & 48,78 & 191,09 & 191,09 & 42,76 & 707,57 & 93,88 & 14,70 & 44,40 & 271,75 & 69,24 & 69,24 & 270,03 \\
\hline Epidalea calamita & 29TPG94 & 101,00 & 110,64 & 108,34 & 38,65 & 5772,11 & 272,62 & $-4,27$ & 276,90 & 45,99 & 187,51 & 187,51 & 39,68 & 726,49 & 96,60 & 16,51 & 43,40 & 277,94 & 73,92 & 73,92 & 274,29 \\
\hline Epidalea calamita & 29TPG95 & 101,00 & 102,24 & 106,49 & 38,29 & 5749,81 & 262,78 & $-11,04$ & 273,82 & 38,15 & 179,12 & 179,12 & 32,12 & 781,86 & 103,44 & 20,04 & 41,76 & 296,35 & 84,39 & 84,39 & 288,95 \\
\hline Epidalea calamita & 29TPG96 & 100,00 & 97,20 & 105,45 & 38,22 & 5715,20 & 256,35 & $-15,01$ & 271,35 & 33,71 & $\begin{array}{ll}173,68 \\
\end{array}$ & 173,68 & 27,75 & 820,67 & 107,87 & 22,87 & 40,53 & 308,33 & 92,64 & 92,64 & 298,22 \\
\hline Epidalea calamita & 29TPG97 & 100,00 & 73,90 & 100,69 & 37,78 & 5591,12 & 229,81 & $\begin{array}{l}-1,01 \\
-32,99 \\
\end{array}$ & 262,80 & \begin{tabular}{|l|l|}
13,84 \\
13
\end{tabular} & $\begin{array}{l}149,23 \\
\end{array}$ & 149,36 & 7,62 & 1021,92 & \begin{tabular}{|l|l|}
130,38 \\
\end{tabular} & 32,26 & $\begin{array}{l}37,71 \\
37,\end{array}$ & \begin{tabular}{|l|l|}
374,88 \\
\end{tabular} & \begin{tabular}{|c|}
125,27 \\
127
\end{tabular} & 125,90 & 359,55 \\
\hline Epidalea calamita & \begin{tabular}{|l|} 
29TPG98 \\
\end{tabular} & 100,00 & 85,79 & 102,94 & 38,30 & 5606,91 & 241,86 & $-23,44$ & 265,30 & 24,33 & 161,06 & 161,06 & 18,38 & 920,26 & 118,99 & 28,64 & 37,98 & 339,37 & 112,59 & 112,59 & 324,04 \\
\hline Epidalea calamita & 29TPHO4 & 99,00 & 121,42 & 87,18 & 39,96 & 4424,42 & 242,69 & 26,47 & 216,22 & 72,14 & 179,22 & 180,64 & 68,82 & \begin{tabular}{|l|}
1120,45 \\
\end{tabular} & 154,66 & 31,63 & 40,43 & 416,81 & 123,06 & 137,21 & 397,36 \\
\hline Epidalea calamita & 29TPH07 & 100,00 & 123,13 & 83,78 & 40,52 & 4121,32 & 237,34 & 33,13 & 204,21 & 77,79 & 176,53 & 178,70 & 74,12 & 1106,65 & 148,29 & 33,80 & 38,24 & 408,04 & 129,36 & 145,35 & 382,48 \\
\hline Epidalea calamita & 29TPH18 & 101,00 & 125,68 & 83,80 & 40,68 & 4123,85 & 238,95 & 35,24 & 203,71 & 80,25 & 178,80 & 180,96 & 76,07 & 1044,09 & 136,94 & 32,81 & 37,04 & 382,20 & 125,76 & 142,04 & 354,40 \\
\hline Epidalea calamita & 29TPH2O & 100,00 & $\begin{array}{l}128,00 \\
128,59\end{array}$ & $\begin{array}{l}3,00 \\
94,28\end{array}$ & $\begin{array}{l}4,00 \\
38,67\end{array}$ & $\begin{array}{l}412,03 \\
5087,38\end{array}$ & 263,24 & $\begin{array}{l}3,24 \\
21,88 \\
\end{array}$ & \begin{tabular}{|l|}
241,35 \\
245
\end{tabular} & $\mid \frac{\mid 0,23}{70,80}$ & $\begin{array}{l}195,16 \\
195,0\end{array}$ & $\begin{array}{l}195,28 \\
195,\end{array}$ & 60,58 & \begin{tabular}{|l|}
044,203 \\
936,27
\end{tabular} & \begin{tabular}{|l|}
$128,52,5$ \\
128
\end{tabular} & $\begin{array}{l}32,01 \\
22,83\end{array}$ & $\begin{array}{l}3,240 \\
42,26\end{array}$ & \begin{tabular}{|l|}
350,85 \\
35,8
\end{tabular} & | & $\begin{aligned} 14,04 \\
97,52\end{aligned}$ & 337,98 \\
\hline Epidalea calamita & 29TPH35 & 101,00 & 118,79 & 90,60 & 39,82 & 4643,16 & 245,49 & 20,12 & 225,38 & 66,82 & 179,40 & 180,40 & 62,86 & 996,47 & 131,71 & 30,01 & 37,94 & 366,67 & 117,26 & 130,42 & 343,40 \\
\hline Epidalea calamita & 29TPH50 & 99,00 & 103,52 & 97,16 & 38,31 & 5267,63 & 247,89 & $-2,19$ & 250,08 & 44,77 & 173,39 & 173,39 & 40,01 & 986,10 & 131,01 & 27,03 & 40,63 & 371,34 & 108,83 & 108,87 & 357,52 \\
\hline Epidalea calamita & 29TPH55 & 101,00 & 115,59 & 93,60 & 39,80 & 4824,02 & 247,23 & 14,03 & 233,20 & 61,30 & 178,62 & 179,20 & 57,08 & 937,10 & 121,15 & 29,23 & 36,63 & 342,96 & 114,97 & 125,70 & 317,72 \\
\hline Epidalea calamita & 29TPH56 & 100,00 & 112,59 & 92,57 & 39,92 & 4721,95 & 242,36 & 12,91 & 229,45 & 59,88 & 174,30 & 175,10 & 55,56 & 969,45 & 124,37 & 31,62 & 35,72 & 352,59 & 122,46 & 134,51 & 325,18 \\
\hline Epidalea calamita & $\begin{array}{l}29 T P H 58 \\
29 T 2\end{array}$ & $\begin{array}{l}10,00 \\
99,00\end{array}$ & $\begin{array}{l}11,599 \\
111,89\end{array}$ & $\begin{array}{l}2,3 / 1 \\
90,21\end{array}$ & $\begin{array}{l}35, \\
40,\end{array}$ & 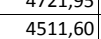 & $\begin{array}{l}24,50 \\
236,79\end{array}$ & $\begin{array}{l}15,61 \\
15,61\end{array}$ & \begin{tabular}{|l|}
221,18 \\
2218
\end{tabular} & \begin{tabular}{|l|l}
35,190 \\
62,19
\end{tabular} & $\begin{array}{l}14,50 \\
170,64 \\
\end{array}$ & $\begin{array}{l}17,10 \\
171,93 \\
\end{array}$ & $\begin{array}{l}3,50 \\
57,57 \\
\end{array}$ & 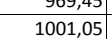 & \begin{tabular}{|l|l|}
128,05 \\
\end{tabular} & $\begin{array}{l}1,02 \\
34,69 \\
\end{array}$ & $\begin{array}{l}33,1 / 26 \\
34,26\end{array}$ & \begin{tabular}{|l}
$36,59,09$ \\
360
\end{tabular} & \begin{tabular}{|l|}
131,930 \\
131
\end{tabular} & $\begin{array}{l}134,51 \\
144,69\end{array}$ & $\begin{array}{l}32,18 \\
328,66\end{array}$ \\
\hline Epidalea calamita & 29TPH60 & 101,00 & 104,75 & 99,05 & 38,49 & 5352,43 & 251,30 & $-2,77$ & 254,06 & 44,83 & 175,79 & 175,79 & 39,85 & 926,98 & 122,54 & 25,86 & 40,07 & 348,48 & 104,41 & 104,43 & 333,57 \\
\hline Epidalea calamita & 29TPH63 & 100,00 & 96,65 & 96,45 & 38,91 & 5119,07 & 238,28 & $-6,57$ & 244,86 & 39,94 & 164,49 & 164,55 & 35,18 & 1010,04 & 131,23 & 31,90 & 37,11 & 372,28 & 124,46 & 125,75 & 350,78 \\
\hline Epidalea calamita & 29TPH64 & 100,00 & 101,18 & 95,94 & 39,16 & 5028,11 & 240,07 & $-1,63$ & 241,70 & 45,30 & 167,53 & 167,73 & 40,68 & 986,45 & 127,35 & 31,77 & 36,41 & 361,41 & 123,68 & 127,55 & 337,53 \\
\hline Epidalea calamita & 29TPH68 & 100,00 & 112,91 & 91,50 & $\begin{array}{l}40, \\
40,\end{array}$ & 4562,1133 & 239,1 & $\begin{array}{l}1,05,52 \\
15\end{array}$ & 223,58 & 62,99 & 172,22 & 173,42 & $\begin{array}{l}40,80 \\
57,89\end{array}$ & $\begin{array}{l}563,04 \\
963,4\end{array}$ & 124,25 & 34,13 & \begin{tabular}{|l|l|}
33,53 \\
3
\end{tabular} & \begin{tabular}{|l|}
344,15 \\
\end{tabular} & $\begin{array}{l}129,85 \\
\end{array}$ & 142,22 & 311,33 \\
\hline Epidalea calamita & 29TPH7 & 99,00 & 120,04 & 101,98 & 38,92 & 5464,69 & 267,27 & 7,93 & 259,34 & 57,30 & 191,79 & 191,79 & 52,47 & 768,84 & 101,73 & 20,23 & 40,17 & 290,06 & 85,34 & 85,34 & 274,12 \\
\hline Epidalea calamita & 29TPH73 & 101,00 & 86,82 & 97,28 & 38,88 & 5179,44 & 231,19 & $-16,28$ & 247,47 & 30,10 & 155,82 & 155,92 & 25,01 & 1044,37 & 133,86 & 35,11 & 35,84 & 381,04 & \begin{tabular}{r|}
134,58 \\
\end{tabular} & 135,46 & 358,23 \\
\hline Epidalea calamita & 29TPH74 & 100,00 & 79,80 & 95,67 & 38,76 & 5085,43 & 222,37 & $-21,16$ & 243,53 & 24,80 & 147,66 & 147,86 & 19,67 & 1114,89 & 141,35 & 39,34 & 34,79 & 402,99 & 148,23 & 150,17 & 377,98 \\
\hline Epidalea calamita & 29TPH75 & 101,00 & 94,02 & 96,11 & 39,45 & 4995,44 & 233,21 & $-7,67$ & 240,88 & 39,08 & 160,11 & 160,38 & 34,17 & 1015,93 & 129,58 & 35,50 & 34,52 & 79 & 135,23 & 139,76 & 339,58 \\
\hline Epidalea calamita & 29TPH78 & 100,00 & $\begin{array}{l}314,42 \\
114,42\end{array}$ & $\begin{array}{l}0,11 \\
92,48\end{array}$ & 40 & 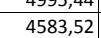 & 24 & \begin{tabular}{|l|l|}
16,33 \\
1,0
\end{tabular} & \begin{tabular}{|l|}
224,81 \\
22,0
\end{tabular} & $\mid \begin{array}{l}\mid c 5,00 \\
67,71\end{array}$ & \begin{tabular}{|l|}
173,87 \\
13
\end{tabular} & \begin{tabular}{|l|l|}
175,0505 \\
\end{tabular} & 58,89 & \begin{tabular}{|l|l|}
927,82 \\
\end{tabular} & \begin{tabular}{|l|}
$\mid$ \\
120,75 \\
\end{tabular} & $\begin{array}{ll}33,81 \\
33,81\end{array}$ & 32,65 & \begin{tabular}{|l|}
$328,82,5$ \\
\end{tabular} & \begin{tabular}{|l|}
128,45 \\
12,4
\end{tabular} & 140,50 & $\begin{array}{l}294,39 \\
294,39\end{array}$ \\
\hline Epidalea calamita & 29TPH81 & 99,00 & 126,87 & 102,37 & 39,00 & 5448,44 & 272,65 & 13,83 & 258,82 & 63,77 & 197,98 & 197,98 & 59,01 & 694,68 & 91,52 & 18,59 & 38,74 & 259,96 & 80,41 & 80,41 & 239,84 \\
\hline Epidalea calamita & 29TPH83 & 101,00 & 103,10 & 100,38 & 39,18 & 5272,73 & 248,04 & $-4,25$ & 252,29 & 43,77 & 172,58 & 172,58 & 38,79 & 876,14 & 113,19 & 28,54 & 35,80 & 320,06 & $\mid$\begin{tabular}{|l|l|}
112,79 \\
\end{tabular} & 112,79 & 295,79 \\
\hline Epidalea calamita & 29TPH84 & 99,00 & 84,45 & 98,01 & 39,11 & 5161,57 & 228,83 & $-18,65$ & 247,48 & 28,14 & 153,10 & 153,23 & 22,80 & 1035,10 & 131,26 & 37,17 & 34,15 & 372,30 & 140,47 & 142,00 & 346,19 \\
\hline Epidalea calamita & 29TPH85 & 100,00 & 86,49 & 97,08 & 39,39 & 5063,74 & 228,23 & $-15,52$ & 243 & 31,32 & 153,68 & 153,93 & 26,09 & 1038,17 & 131,85 & 38,02 & 33,43 & 371,23 & 143,15 & 146,55 & 342 \\
\hline Epidalea calamita & 29TPH95 & 101,00 & 82,12 & 98,49 & 39,41 & 5119,52 & 226,07 & $-20,73$ & 246,80 & 26,62 & 150,14 & 150,32 & 21,01 & 1033,23 & 130,99 & 39,47 & 32,41 & 366,08 & 147,11 & 149,18 & 336,68 \\
\hline Epidalea calamita & 29TPJ01 & 101,00 & 112,48 & 79,91 & 40,93 & 3893,99 & 221,85 & 28,54 & 193,32 & 71,38 & 162,61 & 165,58 & 66,65 & 1180,63 & 152,27 & 40,25 & 35,61 & 430,41 & 150,73 & 167,32 & 398,02 \\
\hline Epidalea calamita & 29TPJ20 & 101,00 & 115.98 & 83,44 & 40.87 & 4089.90 & 229,64 & 27,49 & 202.15 & 71,75 & 168.76 & 171.14 & 67,24 & 1089.15 & 138.99 & 37,26 & 35.04 & 394.35 & 140,28 & 155,81 & 362.46 \\
\hline Epidalea calamita & 29TPJ23 & 94,00 & 133,06 & 77,66 & 41,9 & 3722,46 & 234,09 & 50,4 & 183,68 & 93, & 180,09 & 183 & 88 & 977,56 & 126,37 & 34,11 & 33,99 & 351,59 & 129,36 & 148,23 & 314,92 \\
\hline Epidalea calamita & 29TPJ31 & 100,00 & 135,22 & 81,16 & 41,29 & 3932,80 & 241,41 & 47,83 & 193,58 & 92,40 & 185,17 & 187,79 & 87,18 & 929,59 & 120,41 & 31,68 & 34,24 & 333,90 & 121,13 & 138,70 & 299,17 \\
\hline
\end{tabular}




\begin{tabular}{|c|c|c|c|c|c|c|c|c|c|c|c|c|c|c|c|c|c|c|c|c|c|}
\hline TAXON & UTM & $\mathrm{km} 2$ & B101 & B102 & $\mathrm{BIO3}$ & 8104 & B105 & B106 & B107 & B108 & B109 & BIO10 & BIO11 & BIO12 & 81013 & BIO14 & BIO15 & B1016 & B1017 & B1018 & B1019 \\
\hline Epidalea calamita & 29TPJ41 & 100,00 & 129,11 & 83,08 & 41,29 & 4026,54 & 238,90 & 40,38 & 198,52 & 85,34 & 180,45 & 182,99 & 80,33 & 948,94 & 122,89 & 33,48 & 33,49 & 338,62 & 126,88 & 143,42 & 302,84 \\
\hline Epidalea calamita & 29TPJ60 & 100,00 & 108,41 & 88,88 & 40,73 & 4367,70 & 230,35 & 15,04 & 215,32 & 61,15 & 165,12 & 166,80 & 56,09 & 1025,98 & 132,00 & 38,71 & 32,21 & 362,76 & 144,13 & 156,86 & 326,34 \\
\hline Epidalea calamita & 29TQE04 & 100,00 & 154,81 & 104,37 & 36,24 & 6192,69 & 321,03 & 38,01 & 283,02 & 86,55 & 237,01 & 237,01 & 78,85 & 586,07 & 76,24 & 5,54 & 48,99 & 224,24 & 41,44 & 41,44 & 214,93 \\
\hline Epidalea calamita & 29TQE05 & 101,00 & 138,92 & 100,86 & 35,66 & 6179,17 & 303,34 & 24,93 & 278,40 & 71,73 & 221,24 & 221,47 & 63,98 & 681,18 & 89,82 & 7,55 & 48,70 & 261,17 & 50,10 & 50,85 & 251,98 \\
\hline Epidalea calamita & 29TQE06 & 100,00 & 119,30 & 96,47 & \begin{tabular}{|l|l|}
34,97 \\
\end{tabular} & 6132,22 & 280,84 & 9,10 & 271,74 & 53,72 & 201,13 & 201,82 & 46,16 & \begin{tabular}{|l|l|}
805,73 \\
\end{tabular} & 107,34 & 10,19 & 48,41 & \begin{tabular}{|l|l|}
309,67 \\
\end{tabular} & 60,69 & 63,48 & 300,38 \\
\hline Epidalea calamita & 29TQE07 & 100,00 & 123,62 & 98,16 & 35,33 & 6135,20 & 285,67 & 12,02 & 273,65 & 57,43 & 204,98 & 205,92 & 49,78 & 759,97 & 100,67 & 9,58 & 48,27 & 291,79 & 57,97 & 59,88 & 282,52 \\
\hline Epidalea calamita & 29TQE08 & 99,00 & 125,47 & 99,36 & 35,85 & 6122,78 & 287,60 & 13,15 & 274,45 & 58,98 & 206,49 & 207,47 & 51,45 & 736,57 & 97,22 & 9,29 & 48,01 & 282,68 & 56,92 & 58,27 & 273,55 \\
\hline Epidalea calamita & 29TQE14 & 100,00 & 151,00 & 105,03 & 36,02 & 6245,07 & 319,05 & 33,85 & 285,20 & 82,28 & 234,02 & 234,02 & 74,70 & 573,23 & 73,34 & 6,00 & 47,74 & 216,81 & 42,50 & 42,50 & 206,36 \\
\hline Epidalea calamita & 29TQE17 & 100,00 & 116,90 & 99,27 & 35,58 & 6162,49 & 280,77 & 5,20 & 275,57 & 50,61 & 198,90 & 199,93 & 43,24 & 757,81 & 97,69 & 10,55 & 46,63 & 287,30 & 60,86 & 63,32 & 276,08 \\
\hline Epidalea calamita & 29TQE18 & 101,00 & 125,54 & 101,80 & 36,00 & 6169,60 & 290,29 & 11,75 & 278,54 & 58,30 & 207,24 & 208,30 & 51,04 & 686,06 & 88,32 & 9,12 & 46,56 & 260,12 & 55,46 & 56,49 & 249,12 \\
\hline Epidalea calamita & 29TQE19 & 100,00 & 127,25 & 103,00 & 36,19 & 6162,70 & 292,13 & 12,80 & 279,33 & 59,83 & 209,15 & 209,75 & 52,47 & 661,92 & 85,14 & 9,13 & 46,17 & 250,62 & 54,62 & 55,15 & 239,65 \\
\hline Epidalea calamita & 29TQE24 & 99,00 & 149,99 & 106,28 & 36,22 & 6291,31 & 319,92 & 31,59 & 288,33 & 80,97 & 233,87 & 233,87 & 73,29 & 545,39 & 69,12 & 5,95 & 46,76 & 203,85 & 41,63 & 41,63 & 192,54 \\
\hline Epidalea calamita & 29TQE26 & 101,00 & 136,78 & 104,80 & 36,17 & $\mid 6252,37$ & 305,10 & $\frac{20,15}{20,15}$ & \begin{tabular}{|l|}
284,95 \\
285
\end{tabular} & 68,32 & 220,21 & 220,43 & 60,87 & 600,82 & 76,44 & 7,80 & 46,06 & 224,75 & 48,41 & $\begin{array}{l}48,75 \\
48,7\end{array}$ & 212,96 \\
\hline Epidalea calamita & 29TQE27 & 100,00 & 115,21 & 101,46 & 35,89 & 6193,50 & 281,50 & 2,46 & 279,03 & 48,61 & 197,91 & 198,74 & 41,40 & 724,32 & 92,23 & 10,95 & 45,11 & 270,80 & 61,14 & 63,60 & 257,91 \\
\hline Epidalea calamita & 29TQE28 & 100,00 & 119,46 & 102,97 & 36,06 & 6199,91 & 286,09 & 5,50 & 280,59 & 52,27 & 201,76 & 202,81 & 44,99 & 678,62 & 86,57 & 10,04 & 44,90 & 253,79 & 57,87 & 59,40 & 240,81 \\
\hline Epidalea calamita & 29TQE29 & 100,00 & 116,36 & 103,20 & 36,24 & 6180,34 & 282,62 & 2,50 & 280,12 & 49,27 & 198,36 & 199,41 & 42,10 & 682,64 & 87,11 & 10,50 & 44,39 & 254,87 & 59,63 & 61,24 & 241,53 \\
\hline Epidalea calamita & 29TQE33 & 100,00 & 159,17 & 108,60 & 36,74 & 6323,18 & 330,81 & 38,28 & 292,54 & 89,22 & 243,18 & 243,18 & 81,60 & 480,89 & 60,47 & 5,00 & 46,54 & 177,64 & 36,23 & 36,23 & 165,88 \\
\hline Epidalea calamita & 29TQE34 & 101,00 & 153,85 & 108,24 & 36,66 & 6322,03 & 325,13 & 33,56 & 291,56 & 83,90 & 238,00 & 238,00 & 76,40 & 497,22 & 62,53 & 5,55 & 46,01 & 183,51 & 38,52 & 38,52 & 171,69 \\
\hline Epidalea calamita & 29TQE35 & 99,00 & 149,72 & 108,06 & 36,90 & 6304,32 & 320,61 & 30,16 & 290,45 & 80,12 & 233,76 & 233,76 & 72,64 & 508,86 & 64,10 & 6,03 & 45,44 & 187,75 & 40,64 & 40,64 & 175,75 \\
\hline Epidalea calamita & 29TQE37 & 99,00 & 132,68 & 106,64 & 36,72 & 6260,68 & 302,26 & 15,30 & 286,96 & 64,04 & 216,10 & 216,41 & 56,71 & 576,18 & 72,79 & 8,43 & 44,17 & 212,34 & 49,52 & 49,99 & 199,15 \\
\hline Epidalea calamita & 29TQE38 & 100,00 & 110,46 & 103,62 & 36,32 & \begin{tabular}{|l|l|}
6198,67 \\
\end{tabular} & 278,44 & $-3,04$ & 281,49 & 43,78 & 193,30 & 194,22 & 36,73 & 697,16 & 88,05 & 11,78 & 43,03 & 256,34 & 63,16 & 65,78 & 241,57 \\
\hline Epidalea calamita & 29TQE39 & 101,00 & 109,91 & 104,34 & 36,66 & 6188,14 & 277,81 & $-3,78$ & 281,59 & 43,16 & 192,28 & 193,47 & 36,11 & 681,21 & 86,15 & 11,77 & 42,58 & 250,19 & 63,12 & 65,34 & 234,95 \\
\hline Epidalea calamita & 29TQE44 & 100,00 & 152,58 & 109,43 & \begin{tabular}{|l|}
36,98 \\
\end{tabular} & \begin{tabular}{|l|l|}
6344,64 \\
\end{tabular} & 325,43 & 31,54 & 293,89 & 82,55 & 237,27 & 237,27 & 74,89 & \begin{tabular}{|l|l|}
477,37 \\
\end{tabular} & 59,45 & 5,67 & 45,00 & $\begin{array}{l}173,76 \\
\end{array}$ & 38,39 & 38,39 & 161,35 \\
\hline Epidalea calamita & 29TQE45 & 100,00 & 151,61 & 109,59 & 37,00 & 6324,97 & 323,68 & 30,62 & 293,06 & 81,56 & 235,82 & 235,82 & 74,03 & 473,99 & 59,14 & 5,99 & 44,33 & 172,29 & 39,09 & 39,09 & 159,80 \\
\hline Epidalea calamita & 29TQE47 & 101,00 & 140,64 & 109,38 & 37,03 & 6294,98 & 312,04 & 20,83 & 291,21 & 71,06 & 224,69 & 224,75 & 63,78 & 502,05 & 62,86 & 7,40 & 43,31 & 182,16 & 44,17 & 44,21 & 168,79 \\
\hline Epidalea calamita & 29TQE48 & 99,00 & 117,99 & 107,09 & 36,82 & 6247,59 & 288,57 & 1,73 & 286,85 & 50,00 & 201,22 & 202,15 & 43,11 & 606,94 & 75,98 & 10,64 & 41,83 & 219,55 & 57,39 & 58,73 & 204,08 \\
\hline Epidalea calamita & 29TQE49 & 100,00 & 111,13 & 106,74 & 36,98 & $\mid 6218,89$ & 281,23 & $\begin{array}{c}-3,86 \\
-3,86 \\
\end{array}$ & \begin{tabular}{|l|}
285,09 \\
\end{tabular} & 43,78 & \begin{tabular}{|l|}
193,70 \\
\end{tabular} & \begin{tabular}{|l|}
195,11 \\
\end{tabular} & 36,90 & 629,64 & 78,99 & 11,61 & 41,15 & 227,45 & 61,36 & 63,11 & 210,94 \\
\hline Epidalea calamita & 29TQE53 & 60,00 & 149,80 & 109,92 & 36,70 & 6408,64 & 324,57 & $\begin{array}{ll}27,94 \\
\end{array}$ & 296,63 & 79,16 & 235,42 & 235,42 & 71,58 & 480,32 & 59,08 & 5,85 & 44,56 & 173,02 & 39,20 & 39,20 & 160,24 \\
\hline Epidalea calamita & 29TQE54 & 53,00 & 143,79 & 109,60 & 36,76 & 6381,46 & 318,09 & 22,92 & 295,17 & 73,69 & 229,20 & 229,32 & 66,36 & \begin{tabular}{|l|l|}
499,15 \\
\end{tabular} & 61,49 & 6,79 & 43,84 & 179,41 & 42,44 & 42,54 & 166,18 \\
\hline Epidalea calamita & 29TQE56 & 50,00 & 137,16 & 109,69 & 36,99 & 6325,01 & 310,13 & 17,17 & 292,96 & 67,55 & 221,57 & 221,77 & 60,39 & 507,69 & 62,88 & 7,87 & 42,52 & 181,96 & 45,81 & 46,01 & 168,04 \\
\hline Epidalea calamita & 29TQE57 & 42,00 & 139,19 & 110,38 & 37,06 & 6308,52 & 311,71 & 18,79 & 292,92 & 69,40 & 223,40 & 223,47 & 62,26 & 486,51 & 60,44 & 7,65 & 42,35 & 174,30 & 44,42 & 44,45 & 160,43 \\
\hline Epidalea calamita & 29TQE58 & $\begin{array}{ll}42,00 \\
47,00\end{array}$ & 134,90 & 110,69 & 37,23 & 6298,43 & 307,31 & $\begin{array}{l}14,87 \\
14,1\end{array}$ & 292,44 & 65,49 & \begin{tabular}{|l|}
219,16 \\
\end{tabular} & \begin{tabular}{|l|}
219,25 \\
\end{tabular} & 58,23 & \begin{tabular}{|l|l|}
493,18 \\
493,18
\end{tabular} & $60,1,34$ & 8,28 & $\begin{array}{ll}42,53 \\
41,59\end{array}$ & $\begin{array}{l}176,15 \\
176,\end{array}$ & $\begin{array}{l}44,46,67 \\
46,\end{array}$ & $\begin{array}{l}44,45 \\
46,74 \\
\end{array}$ & 161,74 \\
\hline Epidalea calamita & 29TQF05 & 99,00 & 122,03 & 106,32 & \begin{tabular}{|l|l|}
37,58 \\
\end{tabular} & 6018,77 & 285,45 & 6,53 & 278,92 & 55,32 & 202,18 & 202,18 & 48,14 & 667,94 & 85,85 & 10,00 & 45,79 & 255,06 & 58,03 & 58,03 & 247,19 \\
\hline Epidalea calamita & 29TQF06 & 100,00 & 125,29 & 107,78 & 38,01 & 6002,93 & 288,91 & 8,85 & 280,05 & 58,28 & 204,97 & 204,97 & 51,21 & 640,23 & 82,02 & 9,97 & 45,41 & 244,05 & 56,19 & 56,19 & 236,84 \\
\hline Epidalea calamita & 29TQF07 & 100,00 & 124,47 & 108,48 & 38,15 & 5975,92 & 288,21 & 7,85 & 280,36 & 57,62 & 203,80 & 203,80 & 50,69 & 634,57 & 81,31 & 10,33 & 45,02 & 241,67 & 56,70 & 56,70 & 235,01 \\
\hline Epidalea calamita & 29TQF08 & 100,00 & 119,33 & 108,56 & 38,17 & 5959,95 & 283,31 & 3,05 & 280,26 & 52,92 & 198,65 & 198,65 & 45,99 & 654,23 & 84,20 & 11,16 & 44,66 & 249,16 & 60,21 & 60,21 & 243,12 \\
\hline Epidalea calamita & 29TQF11 & $\begin{array}{l}100,00 \\
100\end{array}$ & 123,25 & 104,14 & 36,98 & 6128,57 & $\begin{array}{l}20,51 \\
287,91\end{array}$ & $\begin{array}{l}3,07 \\
8,57 \\
\end{array}$ & \begin{tabular}{|l|}
279,33 \\
20
\end{tabular} & $\begin{array}{ll}55,96 \\
55\end{array}$ & 204,75 & \begin{tabular}{|l|}
205,1900 \\
\end{tabular} & \begin{tabular}{|l|l|}
48,69 \\
489
\end{tabular} & $\begin{array}{l}\mid 534,25 \\
659,94\end{array}$ & $\begin{array}{l}84,262 \\
84,82\end{array}$ & $\begin{array}{l}1,10 \\
9,63\end{array}$ & 445,38 & $\begin{array}{l}\mid 439,10 \\
249,59\end{array}$ & $\begin{array}{l}00,11 \\
56,55\end{array}$ & \begin{tabular}{l|l}
56,89 \\
56
\end{tabular} & 238,38 \\
\hline Epidalea calamita & 29TQF14 & 99,00 & 120,89 & 106,77 & 37,49 & 6081,66 & 286,01 & 5,07 & 280,95 & 53,65 & 201,93 & 201,93 & 46,56 & 633,33 & 80,74 & 10,00 & 44,27 & 238,69 & 57,48 & 57,48 & 227,90 \\
\hline Epidalea calamita & 29TQF15 & 101,00 & 120,75 & 107,73 & $\begin{array}{l}37,95 \\
\end{array}$ & 6071,48 & 286,05 & 4,44 & 281,61 & 53,44 & 201,50 & 201,50 & 46,21 & 621,94 & 79,17 & 10,14 & 43,99 & 234,15 & 57,15 & 57,15 & 223,71 \\
\hline Epidalea calamita & 29TQF16 & 100,00 & 119,86 & 108,46 & 38,00 & 6049,59 & 285,22 & 3,36 & 281,85 & 52,53 & 200,33 & 200,33 & 45,51 & 616,45 & 78,70 & 10,64 & 43,43 & 231,63 & 58,12 & 58,12 & 221,61 \\
\hline Epidalea calamita & 29TQF17 & 99,00 & 126,84 & 110,00 & 38,23 & 6022,16 & 292,13 & 8,85 & 283,28 & 59,28 & 206,62 & 206,62 & 52,31 & 571,63 & 73,31 & 9,92 & 43,27 & 214,56 & 53,54 & 53,54 & 205,38 \\
\hline Epidalea calamita & 29TQF18 & 100,00 & 122,60 & 110,21 & 38,40 & 6005,49 & 287,87 & 4,76 & 283,11 & 55,36 & 202,28 & 202,28 & 48,48 & 585,02 & 75,58 & 10,69 & 43,04 & 219,49 & 56,23 & 56,23 & 210,90 \\
\hline Epidalea calamita & 29TQF19 & 100,00 & 118,95 & 110,37 & 38,70 & 5982,06 & 284,32 & 1,44 & 282,88 & 52,01 & 198,36 & 198,36 & 45,22 & 596,50 & 77,51 & 11,53 & 42,49 & 223,55 & 59,05 & 59,05 & 215,39 \\
\hline Epidalea calamita & 29TQF24 & 101,00 & 119,11 & 108,31 & 37,93 & 6126,72 & 286,04 & 2,39 & 283,64 & 51,25 & 200,62 & 200,65 & 44,23 & 592,82 & 75,47 & 10,10 & 42,64 & 220,00 & 56,88 & 56,90 & 206,55 \\
\hline Epidalea calamita & 29TQF25 & 100,00 & 118,78 & 109,07 & 38,00 & 6103,65 & 285,76 & 1,81 & 283,94 & 51,01 & 200,04 & 200,04 & 44,07 & 582,67 & 74,56 & 10,5 & 42,24 & 215,88 & 56,95 & 56,95 & 202,80 \\
\hline Epidalea calamita & 29TQF26 & 100,00 & 119,46 & 109,95 & 38,00 & 6093,24 & 286,7 & $\begin{array}{l}, 1,91 \\
1,91\end{array}$ & 284,88 & 51,71 & 200,57 & 200,57 & 44,79 & 566,95 & 72,83 & $\frac{10}{10}$ & $\begin{array}{l}42,49 \\
41,69\end{array}$ & 209,51 & 56,51 & 56,51 & 196,92 \\
\hline Epidalea calamita & 29TQF27 & 101,00 & 120,53 & 110,64 & 38,04 & 6077 & 287,51 & 2,25 & 285,26 & 52,64 & 201,23 & 201,23 & 45,72 & 554,07 & 71,52 & 10, & 41,49 & 204,46 & 55,79 & 55,79 & 192,65 \\
\hline Epidalea calamita & 29TQF28 & 100,00 & 120,82 & 111,21 & 38,30 & 6056,09 & 287,94 & 2,60 & 285,34 & 53,22 & 201,28 & 201,28 & 46,19 & 543,86 & 70,42 & 10,86 & 41,16 & 200,26 & 55,77 & 55,77 & 188,94 \\
\hline Epidalea calamita & 29TQF29 & 100,00 & 120,33 & 111,61 & 38,78 & 6032,92 & 287,25 & 1,88 & 285,36 & 52,66 & 200,29 & 200,29 & 45,80 & 541,55 & 70,40 & 11,25 & 40,85 & 199,19 & 56,50 & 56,50 & 188,40 \\
\hline Epidalea calamita & 29TQF34 & 100,00 & 118,35 & 110,22 & 38,01 & 6155,54 & 287,30 & 0,83 & 286,47 & 50,35 & 200,59 & 200,59 & 43,27 & 549,21 & 70,31 & 10,36 & 41,10 & 200,35 & 56,01 & 56,01 & 184,51 \\
\hline Epidalea calamita & 29TQF35 & 100,00 & $\frac{11}{118}$ & $\begin{array}{ll}1110,22 \\
110,87\end{array}$ & 38,08 & $\mid 6132,17$ & 287,85 & $\begin{array}{l}0,05 \\
0,92 \\
\end{array}$ & $\begin{array}{l}286,94 \\
286,\end{array}$ & \begin{tabular}{|c|}
50,75 \\
50
\end{tabular} & \begin{tabular}{|l|}
200,85 \\
200
\end{tabular} & \begin{tabular}{|l|}
200,85 \\
20
\end{tabular} & $\begin{array}{l}3,21 \\
43,79 \\
\end{array}$ & $\mid \begin{array}{l}\mid 433,21 \\
533,91\end{array}$ & $\begin{array}{l}0,51 \\
68,62\end{array}$ & $\begin{array}{l}10,00 \\
10,49 \\
\end{array}$ & $\begin{array}{ll}41,11 \\
40,59\end{array}$ & \begin{tabular}{|l|l|}
194,06 \\
\end{tabular} & 50,51 & $\begin{array}{l}0,010 \\
55,55\end{array}$ & $\begin{array}{l}104,51 \\
178,62\end{array}$ \\
\hline Epidalea calamita & 29TQF36 & 100,00 & 120,24 & 111,54 & 38,22 & 6129,71 & 289,00 & 1,76 & 287,24 & 52,16 & 201,72 & 201,72 & 45,03 & 517,40 & 66,80 & 10,28 & 40,33 & \begin{tabular}{|l|}
187,67 \\
\end{tabular} & 54,43 & 54,43 & 172,97 \\
\hline Epidalea calamita & 29TQF37 & 100,00 & 118,55 & 111,76 & 38,46 & 6114,85 & 287,34 & 0,26 & 287,08 & 51,81 & 199,80 & 199,80 & 43,42 & 515,96 & 66,72 & 10,98 & 39,88 & \begin{tabular}{|l|l|}
186,47 \\
\end{tabular} & 55,52 & 55,52 & 172,01 \\
\hline Epidalea calamita & 29TQF38 & 100,00 & 117,16 & 112,03 & 38,93 & 6097,53 & 285,87 & $-0,68$ & 286,55 & 50,01 & 198,18 & 198,18 & 42,05 & 517,13 & 66,94 & 11,24 & 39,33 & 186,47 & 57,05 & 57,05 & 172,52 \\
\hline Epidalea calamita & 29TQF39 & 101,00 & 117,53 & 112,34 & 38,95 & 6073,13 & 286,20 & $-0,80$ & 287,00 & 54,47 & 198,29 & 198,29 & 42,66 & 509,77 & 66,10 & 11,77 & 38,87 & 183,34 & 57,22 & 57,22 & 169 \\
\hline Epidalea calamita & 29TQF40 & 100,00 & 116,70 & 108,66 & 37,23 & 6227,32 & 287,15 & $-0,06$ & 287,21 & 48,54 & 199,46 & 200,47 & 41,83 & 578,11 & 72,63 & 10,60 & 40,89 & 208,46 & 57,44 & 58,19 & 191,94 \\
\hline Epidalea calamita & 29TQF44 & 99,00 & 118,41 & 112,01 & 38,09 & 6184,50 & 288,97 & 0,23 & 288,74 & 65,45 & 200,91 & 200,91 & 42,97 & 506,69 & 65,08 & 10,55 & 39,66 & 181,50 & 54,95 & 54,95 & 163,34 \\
\hline Epidalea calamita & 29TQF45 & 99,00 & 120,27 & 112,72 & 38,18 & 6173,60 & 290,70 & 1,01 & 289,68 & 74,07 & 202,34 & 202,34 & 44,59 & 485,16 & 62,58 & 10,14 & 39,43 & 173,62 & 53,39 & 53,39 & 155,40 \\
\hline Epidalea calamita & 29TQF46 & 101,00 & 118,96 & 112,92 & 38,60 & 6153,76 & 289,35 & 0,24 & 289,11 & 76,52 & 200,76 & 200, & 43, & 481,04 & 62,11 & 10,63 & 38 & 171,84 & 54,16 & 54,16 & 153,67 \\
\hline Epidalea calamita & 29TQF47 & 100,00 & 116,77 & 112,93 & 38,80 & 6141,71 & 287,25 & $\begin{array}{l}-1,44 \\
-1,44 \\
\end{array}$ & 288,68 & 76,17 & 198,53 & 198,53 & 41,46 & 481,72 & 62,16 & 11,00 & 38,46 & 171,64 & 55,31 & 55,31 & 153,66 \\
\hline
\end{tabular}




\begin{tabular}{|c|c|c|c|c|c|c|c|c|c|c|c|c|c|c|c|c|c|c|c|c|c|}
\hline TAXON & UTM & $\mathrm{km2}$ & B101 & $\mathrm{B1O2}$ & $\mathrm{BIO3}$ & B104 & B105 & B106 & B107 & B108 & B109 & 81010 & B1011 & B1O12 & B1013 & 81014 & B1015 & B1016 & B1017 & B1018 & B1019 \\
\hline Epidalea calamita & 29TQF48 & 100,00 & 116,89 & 113,23 & 38,97 & 6130,25 & 286,98 & $-1,75$ & 288,73 & 76,96 & 198,25 & 198,25 & 41,58 & 475,93 & 61,37 & 11,24 & 37,99 & 169,20 & 55,66 & 55,66 & 151,72 \\
\hline Epidalea calamita & 29TQF49 & 100,00 & 119,58 & 113,50 & 38,97 & 6115,42 & 289,29 & 0,01 & 289,29 & 80,05 & 200,47 & 200,48 & 43,96 & 459,76 & 59,24 & 11,05 & 37,64 & 163,38 & 54,36 & 54,37 & 146,34 \\
\hline Epidalea calamita & 29TQF50 & 33,00 & 117,20 & 110,11 & 37,63 & 6238,59 & 288,82 & $-0,27$ & 289,09 & 48,91 & 200,27 & 201,05 & 42,04 & 550,61 & 68,77 & 10,71 & 39,96 & 195,89 & 56,96 & 57,45 & 178,63 \\
\hline Epidalea calamita & 29TQF51 & 36,00 & 117,76 & 111,09 & 38,00 & 6228,51 & 289,45 & $-0,02$ & 289,47 & 49,35 & 200,98 & 201,33 & 42,56 & 530,89 & 66,45 & 10,80 & 39,60 & 188,53 & 56,38 & 56,60 & 170,73 \\
\hline Epidalea calamita & 29TQF55 & 20,00 & 120,39 & 113,85 & 38,85 & \begin{tabular}{|l|l|}
6201,03 \\
\end{tabular} & 291,73 & 0,48 & 291,24 & 80,33 & 202,91 & 202,91 & 44,55 & \begin{tabular}{ll|}
462,15 \\
\end{tabular} & 59,55 & 10,12 & 38,76 & 165,27 & 52,79 & 52,79 & 143,82 \\
\hline Epidalea calamita & 29TQF57 & 14,00 & 116,18 & 113,95 & 38,95 & 6147,14 & 287,14 & $-2,68$ & 289,82 & 76,45 & 198,00 & 198,00 & 40,59 & 463,73 & 59,59 & 11,00 & 37,95 & 164,86 & 55,27 & 55,27 & 143,95 \\
\hline Epidalea calamita & 29TQG00 & 99,00 & 123,09 & 110,27 & 38,96 & 5918,68 & 286,88 & 5,41 & \begin{tabular}{|l|l|}
281,47 \\
\end{tabular} & 56,58 & 201,70 & 201,70 & 49,72 & 619,22 & 80,70 & 11,43 & 44,19 & 235,64 & 58,29 & 58,29 & 230,85 \\
\hline Epidalea calamita & 29TQG02 & 100,00 & 118,31 & 110,55 & 39,00 & 5867,35 & 282,03 & $\begin{array}{ll}, 1,14 \\
1,4\end{array}$ & 280,89 & 52,36 & 196,31 & 196,31 & 45,68 & 636,56 & 84,01 & 13,14 & 43,33 & 241,71 & 63,07 & 63,07 & 237,84 \\
\hline Epidalea calamita & 29TQG03 & 100,00 & 114,88 & 110,19 & 38,98 & 5844,04 & 278,26 & $-1,66$ & 279,92 & 49,20 & 192,60 & 192,60 & 42,71 & 654,32 & 86,67 & 14,58 & 42,81 & 247,97 & 66,98 & 66,98 & 243,35 \\
\hline Epidalea calamita & 29TQG04 & 99,00 & 107,72 & 109,04 & 38,75 & 5831,01 & 270,54 & $-7,80$ & 278,34 & 42,36 & 185,45 & 185,45 & 36,15 & 697,38 & 92,22 & 17,25 & 41,55 & 262,69 & 75,26 & 75,26 & 255,74 \\
\hline Epidalea calamita & 29TQG06 & 101,00 & 97,59 & 107,19 & 38,63 & 5777,70 & 258,37 & $-16,03$ & 274,40 & 33,35 & 174,90 & 174,90 & 27,26 & 770,14 & 100,90 & 22,35 & 39,27 & 286,20 & 90,40 & 90,40 & 274,29 \\
\hline Epidalea calamita & 29TQG07 & 100,00 & 75,27 & 102,87 & 38,12 & 5659,24 & 233,23 & $-33,33$ & 266,56 & 14,21 & 151,42 & 151,61 & 7,86 & 961,33 & 122,26 & 31,36 & 36,71 & 349,51 & 121,47 & 122,08 & 332,88 \\
\hline Epidalea calamita & 29TQG10 & 101,00 & 116,77 & 110,67 & 39,00 & 5974,82 & 282,16 & $-0,12$ & 282,28 & 50,13 & 196,21 & 196,21 & 43,23 & 602,56 & 78,66 & 12,23 & 42,09 & 225,51 & 61,11 & 61,11 & 217,74 \\
\hline Epidalea calamita & 29TQG13 & 101,00 & 111,71 & 110,86 & 39,00 & 5909,07 & 276,33 & $-5,18$ & 281,51 & 45,45 & 190,29 & 190,29 & 38,81 & 625,53 & 82,37 & 15,30 & 40,67 & 232,93 & 68,39 & 68,39 & 224,64 \\
\hline Epidalea calamita & 29TQG14 & 100,00 & 106,12 & 110,05 & 38,93 & 5890,84 & 270,36 & $-10,14$ & 280,50 & 40,21 & 184,73 & 184,73 & 33,77 & 662,20 & 87,05 & 17,70 & 39,73 & 245,46 & 75,48 & 75,48 & 235,49 \\
\hline Epidalea calamita & 29TQG16 & 100,00 & 100,74 & 109,21 & 38,89 & 5841,69 & 263,66 & $-14,63$ & 278,29 & 35,43 & 178,66 & 178,66 & 29,22 & 704,69 & 92,02 & 21,13 & 38,13 & 258,67 & 85,76 & 85,76 & 245,22 \\
\hline Epidalea calamita & 29TQG20 & 100,00 & 116,37 & 111,62 & 38,94 & 6018,44 & 283,37 & $-1,28$ & 284,65 & 49,07 & 196,27 & 196,27 & 42,19 & 557,49 & 72,66 & 12,32 & 40,29 & 204,73 & 59,88 & 59,88 & 194,08 \\
\hline Epidalea calamita & 29TQG21 & 101,00 & 113,17 & 111,51 & 38,93 & 6004,49 & 280,10 & $-4,34$ & 284,44 & 46,17 & 193,10 & 193,10 & 39,30 & 572,97 & 74,83 & 13,54 & 39,72 & 210,03 & 63,41 & 63,41 & 199,39 \\
\hline Epidalea calamita & 29TQG22 & 100,00 & 112,56 & 111,70 & 38,98 & 5985,53 & 279,23 & $-5,25$ & 284,47 & 45,37 & 192,16 & 192,16 & 38,74 & 576,92 & 75,50 & 14,41 & 39,31 & 211,27 & 65,18 & 65,18 & 200,58 \\
\hline Epidalea calamita & 29TQG24 & 99,00 & 106,53 & 111,31 & 38,98 & 5942,33 & 272,67 & $-10,62$ & 283,29 & 40,28 & 185,74 & 185,74 & 33,40 & 617,64 & 80,63 & 17,53 & 38,15 & 224,86 & 74,17 & 74,17 & 212,30 \\
\hline Epidalea calamita & 29TQG25 & 101,00 & 110,34 & 111,69 & 39,00 & 5924,36 & 275,84 & $-7,58$ & 283,42 & 47,51 & 189,06 & 189,06 & 36,88 & 598,86 & 78,31 & 17,36 & 37,81 & 217,92 & 72,90 & 72,90 & 204,71 \\
\hline Epidalea calamita & 29 TQG26 & 100,00 & 107,80 & 111,40 & 39,00 & 5903,09 & 272,74 & $-9,90$ & 282,63 & 53,23 & 186,34 & 186,34 & 34,78 & 619,73 & 80,76 & 18,88 & 37,12 & 224,81 & 77,87 & 77,87 & 209,72 \\
\hline Epidalea calamita & 29TQG28 & 99,00 & 90,53 & 108,82 & 38,88 & 5790,17 & 253,27 & \begin{tabular}{|l|l|}
$-23,63$ \\
\end{tabular} & 276,91 & 40,68 & 167,92 & 167,93 & 20,00 & 757,65 & 96,61 & 26,40 & 34,76 & 270,71 & 103,29 & 103,30 & 250,27 \\
\hline Epidalea calamita & 29TQG30 & 99,00 & 118,24 & 112,71 & 38,98 & 6054,24 & 286,54 & $-0,55$ & 287,09 & 58,13 & 198,47 & 198,47 & 43,35 & 504,83 & 65,56 & 12,00 & 38,70 & 181,38 & 57,28 & 57,28 & 168,57 \\
\hline Epidalea calamita & 29TQG32 & 101,00 & 115,15 & 112,95 & 39,00 & 6022,04 & 283,26 & $-3,62$ & 286,87 & 62,35 & 194,93 & 194,93 & 40,52 & 521,67 & 67,79 & 13,77 & 37,72 & 187,15 & 62,19 & 62,19 & 173,83 \\
\hline Epidalea calamita & 29TQG33 & 100,00 & 109,75 & 112,69 & 38,99 & 6005,46 & 277,86 & $-8,55$ & 286,41 & 60,00 & 189,58 & 189,58 & 35,59 & 555,71 & 72,08 & 15,75 & 37,15 & 199,17 & 68,57 & 68,57 & 184,91 \\
\hline Epidalea calamita & 29TQG34 & 100,00 & 109,08 & 112,74 & 38,97 & 5982,61 & 276,92 & $\begin{array}{l}-9,39 \\
-9,39 \\
\end{array}$ & \begin{tabular}{|l|}
286,31 \\
\end{tabular} & 65,83 & $\begin{array}{l}188,59 \\
\end{array}$ & $\begin{array}{l}188,59 \\
\end{array}$ & 35,17 & 564,89 & 73,18 & 16,72 & 36,65 & 202,73 & 71,26 & 71,26 & 187,20 \\
\hline Epidalea calamita & 29TQG35 & 100,00 & 113,57 & 113,09 & 39,00 & 5964,48 & 280,43 & $-5,71$ & 286,14 & 74,89 & 192,48 & 192,48 & 39,41 & 547,40 & 70,94 & 16,45 & 36,42 & 197,66 & 69,83 & 69,83 & 180,30 \\
\hline Epidalea calamita & 29TQG36 & 100,00 & 111,99 & 112,95 & 39,00 & 5944,72 & 278,49 & $-7,13$ & 285,62 & 73,74 & 190,64 & 190,64 & 38,05 & 562,72 & 72,66 & 17,69 & 36,04 & 203,73 & 73,84 & 73,84 & 183,80 \\
\hline Epidalea calamita & 29TQG37 & 100,00 & 107,03 & 112,53 & 39,00 & 5911,25 & 273,25 & $-11,47$ & 284,72 & 69,31 & 185,40 & 185,40 & 33,77 & 599,10 & 77,00 & 20,05 & 35,24 & 216,74 & 81,45 & 81,45 & 193,97 \\
\hline Epidalea calamita & 29TQG38 & 101,00 & 106,13 & 112,22 & 39,00 & 5872,46 & 271,28 & $-11,75$ & 283,03 & 68,77 & 184,03 & 184,03 & 33,35 & 615,72 & 79,11 & 21,37 & 34,82 & 223,15 & 85,66 & 85,66 & 197,37 \\
\hline Epidalea calamita & 29TQG40 & 100,00 & 116,85 & 113,49 & 38,97 & 6098,32 & 286,63 & $-2,42$ & \begin{tabular}{|l|}
289,050 \\
\end{tabular} & 77,78 & \begin{tabular}{|l|l|}
197,83 \\
\end{tabular} & \begin{tabular}{|l|l|}
197,83 \\
\end{tabular} & 年, & 470,69 & 60,57 & $\begin{array}{ll}1,1196 \\
11,96\end{array}$ & 37,01 & $\begin{array}{l}25,113 \\
167,12\end{array}$ & $\begin{array}{l}35,16 \\
57,16\end{array}$ & $\begin{array}{l}35,00 \\
57,16\end{array}$ & 149,90 \\
\hline Epidalea calamita & 29TQG41 & 98,00 & 116,63 & 113,70 & 39,00 & 6077,83 & 286,10 & $-2,87$ & 288,97 & 77,60 & 197,19 & 197,19 & 41,35 & 474,35 & 61,05 & 12,53 & 36,55 & 168,65 & 58,62 & 58,62 & 151,31 \\
\hline Epidalea calamita & 29TQG45 & 86,00 & 116,09 & 114,02 & 39,00 & 5989,02 & 284,02 & $-4,08$ & 288,09 & 78,02 & 195,22 & 195,22 & 41,51 & 506,24 & 64,85 & 15,65 & 35,28 & 182,75 & 67,67 & 67,67 & 160,55 \\
\hline Epidalea calamita & 29TQG46 & 80,00 & 114,57 & 113,95 & 39,00 & 5963,28 & 282,04 & $-5,28$ & 287,32 & 76,54 & 193,27 & 193,27 & 40,03 & 523,95 & 66,95 & 17,08 & 34,98 & 189,85 & 71,64 & 71,64 & 165,34 \\
\hline Epidalea calamita & 29TQHO5 & 100,00 & 74,91 & 99,24 & 39,39 & 5169,66 & 220,93 & $-28,05$ & 248,98 & 21,71 & 143,89 & 143,99 & 13,48 & 1055,92 & 132,96 & 42,27 & 31,32 & 370,01 & 155,47 & 156,53 & 339,66 \\
\hline Epidalea calamita & 29TQH27 & 100,00 & 82,73 & $\begin{array}{r}30,24 \\
100,29\end{array}$ & $\frac{15,30}{40,40}$ & $\begin{array}{l}5101,700 \\
504\end{array}$ & 225,37 & $\begin{array}{l}-20,01 \\
-20,01\end{array}$ & 245,38 & $\mid \begin{array}{l}\mid 1,1 / 2 \\
50,25\end{array}$ & \begin{tabular}{|l|}
149,06 \\
149,06
\end{tabular} & \begin{tabular}{|l|}
149,50 \\
149,5
\end{tabular} & $\begin{array}{l}23,40 \\
22,69\end{array}$ & \begin{tabular}{|r} 
\\
987,79 \\
\end{tabular} & $\begin{array}{l}\mid 5,26,24 \\
126\end{array}$ & $\begin{array}{l}42,2 ! \\
43,63\end{array}$ & $\frac{21,53}{28,73}$ & \begin{tabular}{|l|}
340,24 \\
3
\end{tabular} & $\begin{array}{l}157,60 \\
157\end{array}$ & $\begin{array}{l}15,302,62 \\
162,\end{array}$ & $\begin{array}{l}293,00 \\
298,65\end{array}$ \\
\hline Epidalea calamita & 30STF32 & 90,00 & 172,06 & 73,73 & 36,93 & 4378,73 & 275,79 & 78,71 & 197,08 & 126,41 & 226,50 & 230,49 & 117,51 & 741,70 & 127,34 & 1,00 & 71,14 & 333,93 & 15,08 & 23,50 & 320,08 \\
\hline Epidalea calamita & 30STF33 & 90,00 & 171,30 & 73,63 & 35,99 & 4544,89 & 278,05 & 76,28 & 201,77 & 123,77 & 228,06 & 232,17 & 114,86 & 724,33 & 122,30 & 1,00 & 70,20 & 322,57 & 15,14 & 23,99 & 307,85 \\
\hline Epidalea calamita & 30STF34 & 90,00 & 171,41 & 73,47 & 35,17 & 4698,44 & 280,66 & 74,99 & 205,66 & 122,05 & 230,19 & 234,29 & 113,12 & 700,70 & 115,90 & 1,00 & 69,12 & 308,26 & 15,67 & 24,01 & 292,74 \\
\hline Epidalea calamita & 30STF35 & 81,00 & 172,92 & 73,12 & 34,53 & 4830,34 & 284,27 & 75,48 & 208,79 & 121,93 & 233,49 & 237 & 113,13 & 668,82 & 108,03 & 1,00 & 68,07 & 290,48 & 15,98 & 23,88 & 274,22 \\
\hline Epidalea calamita & 30STF36 & 80,00 & 171,69 & 75,24 & 34, & 5009,00 & 288,16 & 71,81 & 216,35 & \begin{tabular}{|l|l|}
118,67 \\
\end{tabular} & 234,80 & 238,68 & 109,86 & 657,79 & \begin{tabular}{|l|l|}
103,48 \\
\end{tabular} & 1,00 & 67,23 & 283,17 & 16,55 & 23,91 & 266,49 \\
\hline Epidalea calamita & 30STF40 & 79,00 & 170,05 & 77,24 & 38,86 & 4149,76 & 273,55 & 77,47 & 196,08 & 127,19 & 221,86 & 225,45 & 118,45 & 822,55 & 142,23 & 0,24 & 73,99 & 380,45 & 15,04 & 22,30 & 370,92 \\
\hline Epidalea calamita & 30STF41 & 100,00 & 172,72 & 74,78 & 38,32 & 4162,68 & 273,71 & 80,79 & 192,92 & 129,06 & 224,63 & 228,16 & 120,80 & \begin{tabular}{|l|l|}
787,68 \\
\end{tabular} & 135,86 & 0,05 & 73,02 & 361,95 & 15,05 & 22,06 & 349,54 \\
\hline Epidalea calamita & 30STF42 & 100,00 & 172,28 & 74,59 & 37,45 & 4314,16 & 275,88 & 79,09 & 196,79 & 127,13 & 226,17 & 229,93 & 118,57 & 768,15 & 131,09 & 0,67 & 71,80 & 349,92 & 15,67 & 22,89 & 335,87 \\
\hline Epidalea calamita & 30STF45 & 100,00 & 169,68 & 78,14 & 35 & 4861,25 & 286,5 & 70,68 & 215,82 & 118,62 & 231,10 & 234,95 & $\begin{array}{l}109,92 \\
\end{array}$ & 708,52 & 114,95 & 1,00 & 68,80 & \begin{tabular}{|l|l|}
313,47 \\
\end{tabular} & 16,20 & 24,13 & 296,85 \\
\hline Epidalea calamita & 30STF46 & 100,00 & 172,40 & 79,32 & 35,49 & 4987 & 292, & 71,79 & 220,45 & 119,53 & 235,35 & 239,11 & 110,95 & 673,38 & 107,45 & 1,00 & 67,82 & 295,25 & 16,53 & 23,51 & 277,60 \\
\hline Epidalea calamita & $\begin{array}{l}\text { 30STF47 } \\
\end{array}$ & 100,00 & 171,66 & 83,90 & 35,81 & 5167,62 & 298,66 & 68,02 & 230,64 & 116,63 & 237,20 & 240,68 & 108,14 & 662,66 & 103,91 & 1,00 & 66,96 & 288,72 & 17,01 & 23,58 & 271,04 \\
\hline Epidalea calamita & 30STF48 & 100,00 & 171,85 & 89,53 & 36,60 & 5327,55 & 306,51 & 64,98 & 241,53 & 114,99 & 239,74 & 242,99 & 106,50 & 650,58 & 100,83 & 1,00 & 66,49 & 282,57 & 17,13 & 23,46 & 264,93 \\
\hline Epidalea calamita & 30STF52 & 100,00 & 169,60 & 77,73 & 38,01 & 4336,43 & 276,87 & 74,98 & 201,89 & 124,45 & 224,16 & 227, & 116,00 & 802,55 & 136,23 & 0,89 & 72,62 & 371,01 & 15,89 & 23,25 & 357,32 \\
\hline Epidalea calamita & \begin{tabular}{|l} 
30STF53 \\
30ST
\end{tabular} & 100,00 & 17 & 77,64 & $\begin{array}{l}30, \\
37,\end{array}$ & $\frac{4}{4}$ & 280,3 & $\begin{array}{l}75,76 \\
75,76\end{array}$ & $\begin{array}{l}204,58 \\
204\end{array}$ & \begin{tabular}{|l|}
124,463 \\
\end{tabular} & \begin{tabular}{|l|}
227,16 \\
227
\end{tabular} & \begin{tabular}{|l|}
230,82 \\
\end{tabular} & \begin{tabular}{|l|}
116,13 \\
113
\end{tabular} & $\mid$ & \begin{tabular}{|l|}
129,70 \\
\end{tabular} & $\begin{array}{l}0,00 \\
1,00\end{array}$ & 71,54 & \begin{tabular}{|l|}
353,12 \\
35
\end{tabular} & $\begin{array}{l}0,00 \\
16,00 \\
\end{array}$ & 23,21 & 336,74 \\
\hline Epidalea calamita & 30STF55 & 100,00 & 165,22 & 84,72 & 37,05 & 4918,91 & 289,35 & 63,82 & 225,53 & 113,95 & 227,76 & 231,43 & 105,18 & 749,39 & 121,80 & 1,00 & 69,44 & 337,26 & 17,08 & 24,59 & 320,86 \\
\hline Epidalea calamita & 30STF56 & 100,00 & 169,24 & 85,20 & 36,86 & 5007,16 & 295,14 & $\begin{array}{l}67,15 \\
67\end{array}$ & \begin{tabular}{|l|}
227,99 \\
22,5
\end{tabular} & 116,47 & 232,86 & 236,40 & 108,03 & 708,52 & $\begin{array}{l}114,43 \\
\end{array}$ & 1,00 & 68,59 & 316,82 & $\begin{array}{ll}16,82 \\
16,8\end{array}$ & 23,70 & 298,76 \\
\hline Epidalea calamita & 30STF57 & 100,00 & 169,81 & 89,57 & 37,21 & 5177,85 & 302,29 & 64,88 & 237,41 & 114,88 & 235,72 & 239,06 & 106,60 & 688,84 & 109,76 & 1,00 & 67,71 & 305,73 & 17,10 & 23,52 & 287,59 \\
\hline Epidalea calamita & 30STF58 & 100,00 & 171,08 & 94,41 & 37,79 & 5328,45 & 310,34 & 63,45 & 246,89 & 114,27 & 239,19 & 242 & 106,05 & 667,79 & 105,33 & 1,00 & 66,99 & 294,63 & 17,19 & 23,25 & 27 \\
\hline Epidalea calamita & \begin{tabular}{|l|}
$305 T F 59$ \\
30
\end{tabular} & $\begin{array}{l}100,00 \\
\end{array}$ & $\begin{array}{l}1 / 1,00 \\
173,72\end{array}$ & $\begin{array}{l}4,44 \\
99,87\end{array}$ & $\begin{array}{l}38,37 \\
38,37\end{array}$ & $\begin{array}{l}5326,44,44 \\
5464\end{array}$ & 319,76 & $\begin{array}{l}5,, 21 \\
63,21 \\
\end{array}$ & $\begin{array}{l}256,55 \\
256\end{array}$ & $\begin{array}{l}114,27 \\
115,02 \\
\end{array}$ & \begin{tabular}{|l|}
243,65 \\
243
\end{tabular} & $\begin{array}{l}42,2< \\
246,45 \\
\end{array}$ & $\begin{array}{l}107,12 \\
10,03\end{array}$ & | & \begin{tabular}{|l|}
100,88 \\
100,53
\end{tabular} & $\begin{array}{l}, 000 \\
1,00\end{array}$ & $\begin{array}{l}0,353 \\
66,33\end{array}$ & \begin{tabular}{|l|}
282,790 \\
282
\end{tabular} & $\begin{array}{l}1,1,21 \\
17,4\end{array}$ & \begin{tabular}{|l|}
22,81 \\
22,8
\end{tabular} & $\begin{array}{l}270,42 \\
264,69\end{array}$ \\
\hline Epidalea calamita & 30STF61 & 100,00 & 164,61 & 83,27 & 39,14 & 4365,90 & 278,12 & 67,86 & 210,26 & 120,64 & 219,93 & 223,56 & 111,16 & 840,99 & 143,07 & 1,00 & 74,27 & 396,99 & 15,20 & 23,82 & 386,95 \\
\hline Epidalea c & 30STF63 & 100,00 & 164,08 & 84,68 & 38,34 & 4621.54 & 283,21 & 65.09 & 218,12 & 116,82 & 22288 & 226.50 & 107.76 & 800,63 & 133,64 & 1,01 & 71.88 & 371.8 & 16,41 & 24.50 & 356.97 \\
\hline Epidalea calamita & 30STF64 & 100,00 & 153,75 & 92,74 & 38,40 & 5017,22 & 287,09 & 48,51 & 238,58 & 102,94 & 218,40 & 221,77 & 93, & 819,93 & 131,07 & 1,40 & 70,22 & 371,48 & 18,62 & 27,59 & 360,28 \\
\hline Epidalea calamita & 30STF65 & 100,00 & 165,30 & 87,84 & 37,91 & 4897,96 & 291,96 & 63,35 & 228,62 & 114,42 & 227,81 & 231,30 & \begin{tabular}{|r|}
105,79 \\
\end{tabular} & 754,59 & 123,63 & 1,03 & 69,99 & 344,99 & 16,89 & 24,36 & 327,48 \\
\hline
\end{tabular}




\begin{tabular}{|c|c|c|c|c|c|c|c|c|c|c|c|c|c|c|c|c|c|c|c|c|c|}
\hline TAXON & UTM & $\mathrm{km2}$ & BIO1 & B102 & $\mathrm{BIO3}$ & B104 & B105 & B106 & B107 & B108 & B109 & BIO10 & BIO11 & B1012 & BIO13 & BIO14 & BIO15 & BIO16 & BIO17 & B1018 & BlO19 \\
\hline Epidalea calamita & 30STF66 & 100,00 & 165,34 & 90,67 & 37,88 & 5056,80 & 297,25 & 61,18 & 236,06 & 112,45 & 230,04 & 233,33 & 103,99 & 737,02 & 119,37 & 1,00 & 69,04 & 333,87 & 17,22 & 24,32 & 315,92 \\
\hline Epidalea calamita & 30STF67 & 100,00 & 168,90 & 93,03 & 38,08 & 5159,38 & 304,42 & 63,52 & 240,91 & \begin{tabular}{ll|l}
114,46 \\
\end{tabular} & 234,91 & \begin{tabular}{|l|l|}
238,07 \\
\end{tabular} & $\begin{array}{l}106,27 \\
1\end{array}$ & $\begin{array}{l}702,95 \\
7\end{array}$ & 113,37 & 1,00 & 68,34 & 316,61 & \begin{tabular}{|l|l|}
17,09 \\
\end{tabular} & 23,46 & 297,82 \\
\hline Epidalea calamita & 30STF68 & 100,00 & $\begin{array}{l}171,47 \\
\end{array}$ & 97,29 & 38,64 & 5297,85 & 312,87 & 63,87 & 249,01 & \begin{tabular}{l|l|l|l|}
115,13 \\
\end{tabular} & 239,32 & 242,31 & \begin{tabular}{ll|}
107,15 \\
\end{tabular} & \begin{tabular}{ll|}
674,89 \\
\end{tabular} & 108,22 & 1,00 & 67,69 & 302,13 & 17,01 & 23,00 & 283,13 \\
\hline Epidalea calamita & 30STF69 & 100,00 & 172,93 & 102,83 & 39,14 & 5452,05 & 321,68 & 62,42 & 259,26 & 114,55 & 242,83 & 245,58 & 106,81 & 654,38 & \begin{tabular}{|l|l|}
104,17 \\
\end{tabular} & 1,00 & 67,05 & 291,10 & \begin{tabular}{l|l|l|l|}
16,96 \\
\end{tabular} & 22,61 & 272,50 \\
\hline Epidalea calamita & 30STF70 & 100,00 & 170,76 & 82,27 & 40,56 & 4070,03 & \begin{tabular}{|l|l|}
278,45 \\
\end{tabular} & 77,89 & 200,57 & 129,87 & 222,10 & 225,97 & 121,34 & 806,82 & 143,07 & 1,00 & \begin{tabular}{|l|l|l|}
76,03 \\
\end{tabular} & 396,34 & 13,86 & 22,01 & 381,87 \\
\hline Epidalea calamita & 30STF71 & 100,00 & 168,40 & 83,23 & 40,00 & 4224,27 & 279,62 & 73,68 & 205,94 & 126,16 & 221,77 & 225,72 & \begin{tabular}{|l|l|}
117,17 \\
\end{tabular} & 808,52 & 141,14 & 1,00 & 75,01 & 393,01 & 14,41 & 22,69 & 376,83 \\
\hline Epidalea calamita & 30STF75 & 100,00 & 157,73 & 94,24 & 38,77 & 5045,92 & 292,93 & 52,28 & 240,65 & \begin{tabular}{ll|}
106,20 \\
\end{tabular} & 222,78 & 226,04 & \begin{tabular}{ll|}
96,92 \\
\end{tabular} & $\begin{array}{l}784,05 \\
\end{array}$ & 126,18 & 1,29 & \begin{tabular}{l|l}
69,82 \\
\end{tabular} & 358,35 & 18,22 & 26,35 & 343,30 \\
\hline Epidalea calamita & 30STF76 & 100,00 & 162,57 & 94,47 & 38,71 & 5093,79 & 298,56 & 57,03 & 241,52 & \begin{tabular}{|l|l|}
109,78 \\
\end{tabular} & 228,15 & 231,24 & \begin{tabular}{|l|l|}
101,07 \\
\end{tabular} & 750,01 & 121,26 & 1,13 & \begin{tabular}{l|l}
69,25 \\
\end{tabular} & 342,29 & \begin{tabular}{l|l}
17,83 \\
\end{tabular} & 25,01 & 324,72 \\
\hline Epidalea calamita & 30STF77 & 100,00 & 158,26 & 99,27 & \begin{tabular}{ll|}
38,87 \\
\end{tabular} & 5321,01 & 302,43 & 49,17 & 253,27 & \begin{tabular}{|l|l|}
103,04 \\
\end{tabular} & \begin{tabular}{l|l|}
227,22 \\
\end{tabular} & 230,04 & 94,22 & 756,27 & 119,35 & 1,35 & 67,90 & 339,33 & 19,30 & 26,55 & 323,32 \\
\hline Epidalea calamita & 30STF78 & 100,00 & 164,69 & 100,93 & $38,99[$ & 5369,97 & 310,85 & 55,05 & 255,80 & 108,20 & $233,97 \mid$ & 236,78 & 99,91 & 714,16 & 113,74 & 1,04 & 67,65 . & 320,81 & $18,01 \mid$ & 24,51 & 302,89 \\
\hline Epidalea calamita & 30STF80 & 43,00 & 175,91 & 82,28 & 41,56 & 3927,69 & 281,94 & 86,09 & \begin{tabular}{|l|l|}
195,84 \\
\end{tabular} & \begin{tabular}{ll|}
137,66 \\
\end{tabular} & \begin{tabular}{|l|l|}
225,39 \\
\end{tabular} & 229,80 & 129,36 & 749,14 & 138,61 & 1,00 & \begin{tabular}{ll|}
76,92 \\
\end{tabular} & 382,69 & 13,02 & 20,77 & 358,81 \\
\hline Epidalea calamita & 30STF81 & 100,00 & 173,15 & 83,09 & \begin{tabular}{ll|}
40,87 \\
\end{tabular} & 4074,54 & 282,17 & 81,16 & 201,01 & \begin{tabular}{|l|l|}
133,03 \\
\end{tabular} & 224,64 & 228,83 & \begin{tabular}{l|l|}
124,45 \\
\end{tabular} & 760,43 & 137,52 & 1,00 & 75,86 & 382,20 & 13,55 & 21,39 & 358,96 \\
\hline Epidalea calamita & 30 STF84 & 100,00 & 159,27 & 93,11 & 39,21 & 4853,83 & 290,15 & 55,91 & 234,24 & \begin{tabular}{ll|}
110,40 \\
\end{tabular} & 221,77 & 225,12 & \begin{tabular}{ll|}
100,94 \\
\end{tabular} & \begin{tabular}{ll|}
779,16 \\
\end{tabular} & 127,61 & 1,32 & \begin{tabular}{|l|}
71,04 \\
\end{tabular} & 363,68 & 17,39 & 25,77 & 347,73 \\
\hline Epidalea calamita & 30STF85 & 100,00 & 147,33 & 100,24 & 39,00 & 5242,53 & 291,33 & 37,85 & 253,47 & \begin{tabular}{ll|}
94,49 \\
\end{tabular} & 215,79 & \begin{tabular}{|l|l|}
218,57 \\
\end{tabular} & 84,58 & 816,53 & 126,63 & 2,14 & \begin{tabular}{ll|}
68,67 \\
\end{tabular} & \begin{tabular}{|l|l|}
367,17 \\
\end{tabular} & 21,33 & 30,02 & 356,10 \\
\hline Epidalea calamita & 30STF86 & 100,00 & 139,97 & 104,57 & 39,00 & 5481,88 & 291,96 & 26,83 & 265,13 & 84,45 & 212,01 & 214,44 & 74,5 & 840,73 & 126,14 & 2,85 & \begin{tabular}{ll|}
66,86 \\
\end{tabular} & 369,18 & $24,63 \mid$ & 33,24 & 359,97 \\
\hline Epidalea calamita & 30STF87 & 100,00 & 144,08 & 105,08 & 39,00 & 5527,88 & 297,17 & 30,56 & 266,61 & 87,53 & 216,61 & 219,03 & 77,99 & 815,38 & 123,04 & 2,60 & 66,53 & 358,10 & 23,87 & 31,97 & 346,90 \\
\hline Epidalea calamita & 30STF88 & 100,00 & 159,18 & 103,34 & 39,01 & 5441,13 & 308,69 & 47,81 & \begin{tabular}{|l|l|}
260,88 \\
\end{tabular} & \begin{tabular}{|l|l|}
102,47 \\
\end{tabular} & \begin{tabular}{|l|l|}
229,94 \\
\end{tabular} & 232,45 & \begin{tabular}{l|l}
93,75 \\
\end{tabular} & \begin{tabular}{|l|l|}
739,03 \\
\end{tabular} & \begin{tabular}{ll|l}
116,06 \\
\end{tabular} & 1,46 & \begin{tabular}{|c|}
67,26 \\
\end{tabular} & \begin{tabular}{|l|l|}
330,99 \\
\end{tabular} & 19,64 & 26,47 & 314,51 \\
\hline Epidalea calamita & 30STF91 & 39,00 & 176,17 & 83,33 & 41,17 & 4017,94 & 284,50 & 85,06 & 199,44 & 137,06 & 226,75 & 231,21 & 128,54 & \begin{tabular}{|l|}
719,27 \\
\end{tabular} & 131,94 & 1,00 & 76,06 & 365,92 & 13,00 & 20,62 & 341,06 \\
\hline Epidalea calamita & 30STF93 & 100,00 & 166,98 & 89,40 & 40,09 & 4514,49 & 288,77 & 68,36 & 220,41 & 122,21 & 224,76 & 228,44 & \begin{tabular}{l|l|}
113,05 \\
\end{tabular} & $\begin{array}{l}735,55 \\
\end{array}$ & 125,81 & 1,13 & $\begin{array}{ll}72,92 \\
\end{array}$ & 356,18 & \begin{tabular}{l|l}
15,45 \\
\end{tabular} & 23,38 & 336,01 \\
\hline Epidalea calamita & 30STF95 & 100,00 & 151,72 & 99,36 & 39,19 & 5148,58 & 293,22 & 43,49 & 249,72 & \begin{tabular}{l|l|}
99,93 \\
\end{tabular} & 218,81 & 221,64 & 90,19 & 783,5 & 123,22 & 1,91 & 69,1 & 357,32 & \begin{tabular}{l|l}
19,93 \\
\end{tabular} & 28,33 & 343,75 \\
\hline Epidalea calamita & 30STF96 & 100,00 & 140,76 & 105,24 & 39,02 & 5472,22 & 292,95 & 27,36 & 265,59 & 85,59 & \begin{tabular}{|l|l|}
212,85 \\
\end{tabular} & 215,11 & 75,54 & 823,41 & 123,36 & 2,90 & \begin{tabular}{|l|l|}
66,79 \\
\end{tabular} & \begin{tabular}{|l|l|}
362,83 \\
\end{tabular} & 24,15 & 32,79 & 353,24 \\
\hline Epidalea calamita & 30STF97 & 100,00 & 150,34 & 103,86 & 39,00 & 5436,48 & 300,43 & 38,15 & 262,28 & $\begin{array}{l}94,78 \\
\end{array}$ & $\begin{array}{ll}221,63 \\
\end{array}$ & 223,92 & 85,39 & \begin{tabular}{ll|}
776,73 \\
\end{tabular} & 119,36 & 2,20 & $\begin{array}{l}67,05 \\
6\end{array}$ & \begin{tabular}{|l|l|}
346,44 \\
\end{tabular} & 21,62 & 29,46 & 332,90 \\
\hline Epidalea calamita & 30STF98 & 100,00 & 156,77 & 104,40 & \begin{tabular}{ll|}
39,06 \\
\end{tabular} & 5475,32 & 307,66 & 44,50 & 263,16 & 100,01 & 228,30 & 230,60 & 91,14 & \begin{tabular}{ll|}
743,66 \\
\end{tabular} & 115,82 & 1,85 & \begin{tabular}{|l|l|}
67,04 \\
\end{tabular} & 332,79 & 20,44 & 27,36 & 317,06 \\
\hline Epidalea calamita & 30STF99 & 100,00 & 162,62 & 106,09 & 39,23 & 5534,61 & 315,61 & 49,36 & 266,25 & $\begin{array}{ll}104,63 \\
\end{array}$ & 234,77 & 236,86 & 96,04 & 712,37 & 111,81 & 1,42 & $\begin{array}{ll}66,75 \\
\end{array}$ & 318,54 & \begin{tabular}{l|l}
19,35 \\
\end{tabular} & 25,61 & 301,63 \\
\hline Epidalea calamita & 30STG34 & 56,00 & 185,45 & 121,81 & 39,35 & 6122,18 & 361,35 & 56,06 & 305,29 & \begin{tabular}{ll|}
118,62 \\
\end{tabular} & 264,96 & 266,55 & \begin{tabular}{ll|}
109,75 \\
\end{tabular} & 574,53 & 86,42 & 1,00 & 63,36 & 244,78 & 18,00 & 22,00 & 230,79 \\
\hline Epidalea calamita & 30STG36 & 50,00 & 179,75 & 122,09 & 39,04 & 6222,42 & 358,25 & 50,54 & 307,72 & 111,81 & 261,12 & 262,19 & 103,03 & 579,31 & 84,54 & 1,48 & 61,61 & 241,93 & 19,79 & 23,93 & 228,63 \\
\hline Epidalea calamita & 30STG39 & 40,00 & 170,22 & 122,02 & 38,84 & 6377,82 & 352,44 & 40,78 & 311,65 & \begin{tabular}{ll|}
100,87 \\
\end{tabular} & \begin{tabular}{|l|l|}
253,89 \\
\end{tabular} & \begin{tabular}{|l|l|}
254,67 \\
\end{tabular} & 91,93 & \begin{tabular}{|l|l|}
593,58 \\
\end{tabular} & 82,44 & 2,22 & 59,20 & \begin{tabular}{l|l|}
239,95 \\
\end{tabular} & 22,91 & 27,60 & 228,11 \\
\hline Epidalea calamita & \begin{tabular}{|l|l|}
30 STG40 \\
\end{tabular} & 100,00 & 178,80 & \begin{tabular}{|l|l|}
101,57 \\
\end{tabular} & 38,31 & 5567,91 & 327,09 & \begin{tabular}{|c|}
65,27 \\
\end{tabular} & 261,82 & $\begin{array}{ll}118,66 \\
\end{array}$ & \begin{tabular}{|l|l|}
250,12 \\
\end{tabular} & 252,82 & 110,41 & 603,77 & 92,50 & 1,00 & 65,52 & 261,87 & 17,00 & 22,04 & 244,38 \\
\hline Epidalea calamita & 30STG43 & 100,00 & 181,69 & 119,12 & 39,88 & 6025,71 & 352,62 & 56,32 & 296,30 & 116,07 & 260,01 & 261,71 & \begin{tabular}{ll|}
107,65 \\
\end{tabular} & 592,01 & 89,27 & 1,00 & \begin{tabular}{ll|}
64,06 \\
\end{tabular} & 253,86 & 18,01 & 22,01 & 238,95 \\
\hline Epidalea calamita & 30STG48 & 100,00 & 174,66 & 123,03 & 39,00 & 6355,98 & 356,75 & 44,67 & 312,08 & \begin{tabular}{|l|}
105,38 \\
\end{tabular} & \begin{tabular}{|l|l|}
258,06 \\
\end{tabular} & 258,77 & 96,49 & 588,01 & 82,80 & 2,04 & 60,20 & 240,29 & 21,39 & 25,70 & 228,30 \\
\hline Epidalea calamita & 30STG49 & 100,00 & 165,69 & 122,71 & 38,70 & 6434,94 & 349,90 & 35,92 & 313,99 & \begin{tabular}{ll|}
95,88 \\
\end{tabular} & 250,41 & \begin{tabular}{|l|}
251,07 \\
\end{tabular} & 87,03 & 620,24 & 85,77 & 2,65 & 58,86 & 249,59 & 24,31 & 29,03 & 238,44 \\
\hline Epidalea calamita & \begin{tabular}{|l|l|}
30 STG50 \\
\end{tabular} & 100,00 & 177,03 & 105,44 & 39,14 & 5583,52 & 329,56 & 63,59 & 265,97 & 116,68 & 248,59 & 251,21 & 108,93 & \begin{tabular}{ll|}
618,46 \\
\end{tabular} & 96,50 & 1,00 & 66,22 & 271,26 & 16,58 & 21,61 & 253,39 \\
\hline Epidalea calamita & 30STG51 & 100,00 & 178,28 & 111,45 & 39,81 & 5734,61 & 338,11 & 61,29 & \begin{tabular}{|l|}
276,82 \\
\end{tabular} & 116,05 & 252,01 & 254,32 & \begin{tabular}{ll|}
108,26 \\
\end{tabular} & 608,31 & $\begin{array}{l}94,08 \\
\end{array}$ & 1,00 & \begin{tabular}{l|l}
65,75 \\
\end{tabular} & 265,59 & \begin{tabular}{|l|l|}
16,77 \\
\end{tabular} & 21,31 & 248,46 \\
\hline Epidalea calamita & 30STG57 & 100,00 & 178,89 & 124,02 & \begin{tabular}{|l|}
39,27 \\
\end{tabular} & 6320,81 & 360,30 & 48,86 & 311,45 & \begin{tabular}{l|l|l|l|l}
110,09 \\
\end{tabular} & 261,71 & 262,37 & \begin{tabular}{ll|}
100,99 \\
\end{tabular} & 584,72 & 83,77 & 1,46 & 61,38 & 241,95 & 19,40 & 23,80 & 229,87 \\
\hline Epidalea calamita & 30STG58 & 100,00 & 168,71 & 123,92 & 39,00 & 6427,23 & 353,35 & 38,44 & \begin{tabular}{|l|}
314,92 \\
\end{tabular} & $\begin{array}{l}99,08 \\
\end{array}$ & 253,38 & 254,00 & 90,12 & 621,32 & 87,25 & 2,01 & 59,98 & 252,34 & 22,64 & 27,19 & 241,33 \\
\hline Epidalea calamita & 30STG59 & 100,00 & 162,75 & 123,58 & 38,49 & 6489,78 & 349,12 & 32,60 & 316,52 & 92,60 & 248,53 & 249,06 & 83,68 & 639,22 & 88,46 & 2,57 & 58,97 & 255,99 & 24,94 & 29,09 & 245,75 \\
\hline Epidalea calamita & 30STG60 & 100,00 & 174,76 & 108,79 & 39,92 & 5594,85 & 330,94 & 61,34 & 269,60 & 114,40 & 246,56 & 249,06 & \begin{tabular}{|l|l|}
106,93 \\
\end{tabular} & 634,01 & 100,54 & 1,00 & 66,62 & 280,69 & 16,59 & 21,63 & 262,52 \\
\hline Epidalea calamita & 30STG61 & 100,00 & 176,62 & 114,36 & 40,43 & 5730,71 & 339,71 & 60,30 & 279,41 & 114,43 & 250,25 & 252,50 & 107,10 & 615,43 & 97,20 & 1,00 & \begin{tabular}{ll|}
66,46 \\
\end{tabular} & 271,11 & 16,10 & 21,01 & 253,67 \\
\hline Epidalea calamita & 30STG67 & 100,00 & 175,46 & 124,19 & 39,23 & 6358,80 & 357,91 & 45,78 & 312,14 & \begin{tabular}{|l|}
106,27 \\
\end{tabular} & 259,13 & 259,6 & \begin{tabular}{|l|l|}
97,48 \\
\end{tabular} & 605,0 & 87,20 & 1,63 & \begin{tabular}{l|l}
61,45 \\
\end{tabular} & 249,46 & $\begin{array}{l}9,86 \\
\end{array}$ & 4,03 & 238,20 \\
\hline Epidalea calamita & 30STG69 & 100,00 & 158,30 & 123,72 & 38,13 & 6543,04 & \begin{tabular}{|l|l|}
346,16 \\
\end{tabular} & 27,98 & 318,18 & 87,73 & 245,06 & 245,34 & 78,92 & 664,30 & 91,73 & 2,86 & 58,72 & 264,30 & 26,15 & 28,46 & 255,15 \\
\hline Epidalea calamita & 30STG70 & 100,00 & 171,25 & 109,52 & 39,94 & 5615,85 & 328,45 & 57,40 & 271,05 & \begin{tabular}{|l|l|}
111,07 \\
\end{tabular} & \begin{tabular}{|l|l|}
243,65 \\
\end{tabular} & $\begin{array}{l}245,95 \\
\end{array}$ & \begin{tabular}{|l|l|}
103,34 \\
\end{tabular} & 659,12 & 104,64 & 1,01 & \begin{tabular}{l|l|}
66,65 \\
\end{tabular} & 292,77 & \begin{tabular}{|l|l|}
17,48 \\
\end{tabular} & 22,87 & 274,92 \\
\hline Epidalea calamita & 30STG71 & 100,00 & 175,13 & 113,89 & 40,27 & 5719,97 & 337,59 & 58,99 & 278,60 & 113,35 & \begin{tabular}{|l|l|}
248,85 \\
\end{tabular} & 251,01 & 105,91 & \begin{tabular}{|l|l|}
629,15 \\
\end{tabular} & 100,05 & 1,00 & 66,39 & 278,57 & 16,39 & 21,41 & 261,01 \\
\hline Epidalea calamita & 30STG72 & 100,00 & 177,07 & 116,95 & 40,28 & 5847,54 & 343,72 & 58,04 & 285,68 & 113,66 & 252,76 & 254,48 & \begin{tabular}{l|l}
106,05 \\
\end{tabular} & 615,68 & 96,88 & 1,00 & \begin{tabular}{l|l}
65,85 \\
\end{tabular} & 269,98 & \begin{tabular}{|l|l|}
16,13 \\
\end{tabular} & 21,12 & 253,51 \\
\hline Epidalea calamita & 30STG74 & 100,00 & 179,84 & 120,65 & $\begin{array}{l}40,05 \\
\end{array}$ & 56,41 & $351, \varepsilon$ & 55,69 & 296,15 & 113,80 & 258,72 & 259,93 & 105,75 & \begin{tabular}{|l|l|}
603,07 \\
\end{tabular} & 91,89 & 1,00 & 64,22 & 258,35 & 19 & 22,00 & 244,27 \\
\hline Epidalea calamita & 30STG75 & 100,00 & 17 & 122,20 & 40,00 & 6187,95 & 354,3 & 52,27 & 302,10 & 111,36 & 259,58 & 260,49 & 103,01 & 605,46 & 90,63 & 1,00 & 63,20 & 255,82 & 18,00 & 22,63 & 243,01 \\
\hline Epidalea calamita & 30STG79 & 100,00 & 158,45 & 124,13 & 38,25 & 6569,95 & 347,11 & 27,77 & 319,34 & 87,6 & 245,74 & 245,83 & $\begin{array}{ll}78,66 \\
\end{array}$ & 668,05 & 92,56 & 2,95 & 58,80 & 264,92 & 25,84 & 27,06 & 256,60 \\
\hline Epidalea calamita & 30STG81 & 100,00 & 170,50 & 112,65 & \begin{tabular}{|l|l}
39,99 \\
\end{tabular} & 5754,78 & 332,39 & 53,71 & \begin{tabular}{|l|l|}
278,68 \\
\end{tabular} & $\begin{array}{ll}108,88 \\
\end{array}$ & 245,23 & 247,12 & $\begin{array}{ll}100,98 \\
\end{array}$ & 660,95 & 103,85 & 1,00 & 65,99 & 291,38 & \begin{tabular}{|l|l|}
17,70 \\
\end{tabular} & 23,10 & 274,78 \\
\hline Epidalea calamita & 30STG82 & 100,00 & 174,71 & 115,52 & 40,01 & 5849,26 & 340,04 & 55,75 & 284,29 & 111,67 & 250,75 & 252,36 & 103,77 & 635,29 & 99,57 & 1,00 & 65,56 & 278,16 & 17,04 & 22,36 & 262,19 \\
\hline Epidalea calamita & 30STG83 & 100,00 & 177,47 & 117,67 & 40,01 & 5958,16 & 345,79 & 55,99 & 289,79 & \begin{tabular}{|l|l|}
112,87 \\
\end{tabular} & 255,04 & 256,45 & 105,00 & \begin{tabular}{|l|l|}
619,63 \\
\end{tabular} & 96,17 & 1,00 & \begin{tabular}{|l|l|l|}
64,89 \\
\end{tabular} & 268,61 & 17,01 & 22,04 & 253,77 \\
\hline Epidalea calamita & $\begin{array}{l}\text { 30STG85 } \\
\end{array}$ & 100,00 & 176,23 & 121,39 & 39,94 & 6199,54 & 351,67 & 50,30 & 301,37 & 108,99 & 257,54 & 258,30 & 100,60 & 621,77 & 93,35 & 1,00 & 63,29 & 261,99 & 18,00 & 22,97 & 249,97 \\
\hline Epidalea calamita & 30STG88 & 100,00 & 171,70 & 124,24 & 38,91 & 6496,07 & 357,21 & 40,91 & 316,29 & 101,11 & \begin{tabular}{|l|l|}
257,59 \\
\end{tabular} & 257,70 & 92,28 & 624,53 & 89,52 & 2,00 & 60,71 & 252,07 & 20,61 & 22,20 & 243,36 \\
\hline Epidalea calamita & 30STG89 & 100,00 & 165,30 & 124,77 & \begin{tabular}{l|l|}
38,45 \\
\end{tabular} & 6580,47 & 353,79 & 33,74 & 320,05 & \begin{tabular}{ll|}
93,88 \\
\end{tabular} & 252,60 & 252,63 & 85,04 & 643,30 & 90,31 & 2,47 & 59,56 & 255,34 & \begin{tabular}{|l|l|}
23,07 \\
\end{tabular} & 23,72 & 247,64 \\
\hline Epidalea calamita & 30STG93 & 100,00 & 177,00 & 116,03 & 39,99 & 5944,39 & 343,43 & 55,99 & 287,44 & \begin{tabular}{|l|l|}
112,67 \\
\end{tabular} & 254,63 & 255,78 & \begin{tabular}{ll|}
104,59 \\
\end{tabular} & \begin{tabular}{ll|}
626,95 \\
\end{tabular} & $\begin{array}{l}97,35 \\
\end{array}$ & 1,00 & \begin{tabular}{|l|l|}
64,88 \\
\end{tabular} & 271,58 & 17,00 & 22,10 & 257,21 \\
\hline Epidalea calamita & 30ST & 100,00 & 17 & 123 & 38,8 & 6501 & 358 & & 315 & 103, & 260 & 260, & 94 & 621,06 & 89,58 & 1,93 & 61,14 & 250,08 & \begin{tabular}{|l|}
19,47 \\
\end{tabular} & 20,25 & 242 \\
\hline Epidalea calamita & 30STH40 & 100,00 & 160,71 & 122,37 & 38,23 & 6479,99 & 346,34 & 31,07 & 315,27 & 90,63 & 246,38 & 246,83 & 81,72 & 633,15 & 86,42 & 2,97 & 58,00 & 251,74 & 26,43 & 30,23 & 241,17 \\
\hline Epidalea calamita & 30STH41 & 100,00 & 160,59 & 122,44 & 38,03 & 6501,08 & 346,94 & 30,69 & 316,24 & 90,13 & 246,60 & 246,97 & 81,27 & 623,32 & 84,59 & 3,05 & 57,23 & 245,85 & 26,93 & 30,72 & 235,46 \\
\hline Epidalea calamita & 30STH42 & 100,00 & 151,34 & 121,54 & 37,99 & \begin{tabular}{ll|}
6546,37 \\
\end{tabular} & 339,06 & 22,35 & 316,71 & \begin{tabular}{ll|}
81,06 \\
\end{tabular} & \begin{tabular}{|l|l|l|}
238,43 \\
\end{tabular} & 238,74 & 72,14 & \begin{tabular}{ll|}
658,05 \\
\end{tabular} & 87,87 & 3,93 & 55,88 & \begin{tabular}{|l|l|}
256,05 \\
\end{tabular} & 31,06 & 34,19 & 246,37 \\
\hline Epidale & 30STH43 & 100,00 & 152,44 & & 38,0 & 6564,90 & & 23, & 317 & 81 & 239 & 240,03 & 72, & 641, & 85,26 & 4,01 & 55,4 & 247,99 & & 34,01 & \\
\hline Epidalea calamita & 30STH44 & 100,00 & 153,94 & 121,57 & 38,00 & 6575,7 & 342, & 24,53 & 317,83 & 83,12 & 241,33 & 241,64 & 74,22 & \begin{tabular}{|l|l|}
622,99 \\
\end{tabular} & 82,48 & 4,00 & 54,88 & 239,42 & 30,12 & 33,11 & 229, \\
\hline Epidalea calamita & \begin{tabular}{|l|l|}
$30 S T H 46$ \\
\end{tabular} & 100,00 & 155,29 & 120,92 & 37,69 & 6598,03 & 343,72 & 26,13 & \begin{tabular}{|l|l|}
317,59 \\
\end{tabular} & 83,97 & 243,16 & 243,18 & 75,32 & 593,16 & 77,76 & 3,99 & 53,64 & 225,08 & 30,95 & 31,10 & 214,95 \\
\hline
\end{tabular}




\begin{tabular}{|c|c|c|c|c|c|c|c|c|c|c|c|c|c|c|c|c|c|c|c|c|c|}
\hline TAXON & UTM & $\mathrm{km} 2$ & B101 & B102 & $\mathrm{BIO3}$ & BIO4 & B105 & B106 & B107 & B108 & B109 & B1010 & BIO11 & BIO12 & B1013 & BIO14 & BIO15 & BIO16 & B1017 & BIO18 & B1019 \\
\hline Epidalea calamita & 30STH47 & 100,00 & 155,30 & 120,33 & 37,30 & 6604,54 & 343,48 & 26,08 & 317,40 & 83,89 & 243,26 & 243,27 & 75,19 & 581,81 & 75,87 & 4,00 & 53,02 & 219,34 & 31,45 & 31,55 & 209,07 \\
\hline Epidalea calamita & 30STH50 & 100,00 & 154,55 & 122,76 & 38,00 & 6541,03 & 342,21 & 24,70 & 317,51 & 84,12 & 241,26 & 241,71 & 75,17 & 667,25 & 90,76 & 3,32 & 57,67 & 263,34 & 28,34 & 32,51 & 253,95 \\
\hline Epidalea calamita & 30STH51 & 100,00 & 153,72 & 122,75 & 38,00 & 6576,28 & 342,43 & 23,63 & 318,80 & 82,89 & 241,05 & 241,33 & 74,09 & 661,33 & 89,25 & 3,54 & 56,83 & 258,68 & 29,39 & 32,99 & 249,47 \\
\hline Epidalea calamita & 30STH52 & 100,00 & 154,26 & 122,84 & 38,00 & 6601,11 & 343,57 & 24,05 & 319,52 & 83,09 & 242,07 & 242,18 & 74,22 & 646,74 & 86,74 & 3,61 & 56,34 & 251,10 & 29,43 & 31,63 & 241,95 \\
\hline Epidalea calamita & 30STH53 & 100,00 & 154,90 & 122,75 & 38,00 & 6617,85 & 344,73 & 24,51 & 320,22 & 83,45 & 243,01 & 243,06 & 74,60 & 631,86 & 84,23 & 3,78 & 55,64 & 243,45 & 29,58 & 30,37 & 234,31 \\
\hline Epidalea calamita & 30STH58 & 100,00 & 160,03 & 120,83 & 37,06 & 6641,15 & 348,80 & 29,68 & 319,12 & 87,60 & 248,34 & 248,34 & 79,01 & 546,29 & 71,27 & 3,55 & 52,77 & 203,87 & 29,41 & 29,41 & 193,80 \\
\hline Epidalea calamita & 30STH59 & 100,00 & 158,08 & 120,01 & 37,01 & 6644,11 & 346,61 & 28,50 & 318,10 & 85,85 & 246,69 & 246,69 & 77,37 & 543,94 & 70,90 & 3,76 & 51,89 & 201,49 & 30,76 & 30,76 & 191,24 \\
\hline Epidalea calamita & 30STH60 & 100,00 & 154,76 & 123,63 & 38,00 & 6584,50 & 343,96 & 24,34 & 319,62 & 83,79 & 242,28 & 242,47 & 74,96 & 669,32 & 91,24 & 3,44 & 57,66 & 263,09 & 28,16 & 29,76 & 254,51 \\
\hline Epidalea calamita & 30STH61 & 100,00 & 152,05 & 123,47 & 38,00 & 6622,53 & 342,36 & 21,54 & 320,82 & 80,86 & 240,30 & 240,46 & 72,04 & 670,25 & 90,40 & 3,68 & 56,78 & 260,80 & 29,55 & 31,25 & 252,50 \\
\hline Epidalea calamita & 30STH63 & 100,00 & 157,68 & 123,72 & 38,00 & 6652,56 & 348,56 & 26,31 & 322,26 & 85,60 & 246,30 & 246,33 & 76,89 & 621,23 & 83,23 & 3,33 & 56,03 & 238,75 & 28,07 & 28,60 & 230,16 \\
\hline Epidalea calamita & 30STH68 & 100,00 & 158,55 & 121,57 & 37,19 & 6686,85 & 349,00 & 27,63 & 321,37 & 85,77 & 247,87 & 247,87 & 77,34 & 551,79 & 72,81 & 3,78 & 52,64 & 204,48 & 29,63 & 29,63 & 195,11 \\
\hline Epidalea calamita & 30STH69 & 100,00 & 160,45 & 120,86 & 37,00 & 6684,73 & 350,04 & 29,56 & 320,48 & 87,46 & 249,60 & 249,60 & 79,00 & 529,86 & 69,74 & 3,37 & 52,25 & 195,47 & 28,90 & 28,90 & 185,73 \\
\hline Epidalea calamita & 30STH70 & 100,00 & 151,81 & 123,86 & 38,00 & 6621,13 & 342,24 & 21,17 & 321,08 & 80,58 & 240,03 & 240,17 & 71,88 & 685,67 & 93,23 & 3,73 & 57,39 & 267,92 & 29,08 & 30,53 & 260,25 \\
\hline Epidalea calamita & 30STH71 & 100,00 & 159,14 & 124,55 & 38,00 & 6644,97 & 350,01 & 27,44 & 322,57 & 87,29 & 247,66 & 247,69 & 78,43 & 642,25 & 87,52 & 3,21 & 57,40 & 249,90 & 26,60 & 26,83 & 242,09 \\
\hline Epidalea calamita & 30STH72 & 100,00 & 161,12 & 124,65 & 38,00 & 6671,75 & 352,56 & 28,79 & 323,77 & 88,78 & 249,95 & 249,95 & 79,81 & 621,28 & 84,23 & 3,12 & 57,01 & 239,88 & 26,17 & 26,17 & 232,06 \\
\hline Epidalea calamita & 30STH73 & 100,00 & 157,96 & 124,19 & 38,00 & 6695,41 & 350,16 & 25,70 & 324,46 & 85,29 & 247,26 & 247,26 & 76,62 & 621,96 & 83,71 & 3,38 & 55,96 & 237,66 & 27,83 & 27,83 & 229,96 \\
\hline Epidalea calamita & 30STH74 & 100,00 & 154,56 & 123,97 & \begin{tabular}{|c|}
37,97 \\
\end{tabular} & 6724,35 & 347,42 & 22,71 & 324,71 & 81,68 & 244,42 & 244,42 & 73,12 & 623,88 & 83,69 & 3,98 & 54,97 & 235,97 & 29,66 & 29,66 & 228,38 \\
\hline Epidalea calamita & 30STH75 & 100,00 & 155,29 & 123,65 & 37,63 & 6738,76 & 348,04 & 23,29 & 324,75 & 82,23 & 245,27 & 245,27 & 73,59 & 606,42 & 81,36 & 4,00 & 54,31 & 227,60 & 29,78 & 29,78 & 219,78 \\
\hline Epidalea calamita & 30STH76 & 100,00 & 152,99 & 122,95 & \begin{tabular}{|l|}
37,08 \\
\end{tabular} & 6744,62 & 346,10 & 21,23 & 324,86 & 80,04 & 243,23 & 243,23 & 71,27 & 602,77 & 80,62 & 4,09 & 53,45 & 224,19 & 31,37 & 31,37 & 216,19 \\
\hline Epidalea calamita & 30STH77 & 100,00 & 153,77 & 122,52 & $\begin{array}{l}37,05 \\
\end{array}$ & 6741,82 & 346,30 & 22,12 & 324,18 & 80,67 & 243,93 & 243,93 & 72,03 & 585,37 & 78,13 & 4,07 & 52,76 & 216,22 & 31,41 & 31,41 & 207,88 \\
\hline Epidalea calamita & 30STH78 & 100,00 & 158,94 & 122,04 & \begin{tabular}{|l|l|}
37,07 \\
\end{tabular} & 6726,54 & 350,29 & 27,17 & 323,12 & 85,86 & 248,81 & 248,81 & 77,15 & 548,75 & 73, & 3,6 & 52,59 & 201,97 & 29,17 & 29,17 & 193,23 \\
\hline Epidalea calamita & 30STH79 & 100,00 & 161,64 & 121,60 & $\begin{array}{l}37,05 \\
\end{array}$ & 6709,72 & 352,14 & 29,99 & 322,15 & 88,46 & $\begin{array}{l}251,24 \\
\end{array}$ & 251,24 & 79,87 & 522,23 & 69,38 & 3,30 & 52,32 & \begin{tabular}{|l|}
191,36 \\
\end{tabular} & 28,09 & 28,09 & 182,27 \\
\hline Epidalea calamita & 30STH80 & 100,00 & 159,47 & 124,72 & 38,00 & 6639,36 & 350,07 & 27,82 & 322,25 & 87,76 & 247,96 & 247,97 & 78,89 & 656,20 & 90,41 & 3,03 & 58,29 & 256,68 & 25,59 & 25,70 & 249,59 \\
\hline Epidalea calamita & 30STH82 & 100,00 & 160,47 & 124,88 & 37,99 & 6717,64 & 353,05 & 27,63 & 325,43 & 87,61 & 250,08 & 250,08 & 78,63 & 626,84 & 85,41 & 3,14 & 57,05 & 240,49 & 26,13 & 26,13 & 233,82 \\
\hline Epidalea calamita & 30STH83 & 100,00 & 152,89 & 124,35 & 37,89 & 6749,92 & 346,89 & 20,61 & 326,28 & 79,97 & 243,25 & 243,25 & 71,38 & 644,83 & 87,63 & 3,99 & 55,49 & 243,88 & 29,88 & 29,88 & 237,43 \\
\hline Epidalea calamita & 30STH85 & 100,00 & 153,88 & 124,01 & 37,63 & 6775,67 & 347,84 & 21,45 & 326,39 & 80,45 & 244,69 & 244,69 & 72,05 & 611,90 & 83,02 & 4,00 & 54,14 & 227,90 & 30,21 & 30,21 & 221,07 \\
\hline Epidalea calamita & 30STH86 & 100,00 & $\begin{array}{l}156,00 \\
156,58\end{array}$ & 123,79 & 37,37 & 6782,16 & 350,26 & 23,82 & 326,44 & $80,4,86$ & $\begin{array}{l}247,33 \\
\end{array}$ & 247,33 & 74,38 & 585,63 & $\begin{array}{l}0,0<1 \\
79,31\end{array}$ & 3,89 & 53,74 & 216,73 & $\begin{array}{l}29,32 \\
29,32\end{array}$ & 29,32 & 209,48 \\
\hline Epidalea calamita & 30STH90 & 100,00 & 165,87 & 124,90 & 38,01 & 6649,20 & 356,02 & 33,41 & 322,61 & 93,65 & 254,33 & 254,33 & 84,77 & 634,47 & 88,36 & 2,52 & 59,05 & 247,76 & 22,97 & 22,97 & 241,61 \\
\hline Epidalea calamita & 30STH91 & 100,00 & 163,51 & 124,97 & 37,99 & 6701,95 & 355,13 & 30,47 & 324,66 & 90,71 & 252,71 & 252,71 & 81,61 & 631,52 & 87,42 & 2,86 & 58,05 & 243,73 & 24,30 & 24,30 & 237,81 \\
\hline Epidalea calamita & 30STH92 & 100,00 & 154,90 & 124,82 & 37,90 & 6763,98 & 348,95 & 22,06 & 326,90 & 81,84 & 245,55 & 245,55 & 72,92 & 651,22 & 89,77 & 3,59 & 56,58 & 247,49 & 28,03 & 28,03 & 241,99 \\
\hline Epidalea calamita & 30STH93 & 100,00 & 152,65 & 124,72 & \begin{tabular}{|c|}
37,68 \\
\end{tabular} & 6786,90 & 347,49 & 19,87 & 327,63 & 79,39 & 243,60 & 243,60 & 70,57 & 645,78 & 88,98 & 3,84 & 55,60 & 242,73 & 29,33 & 29,33 & 237,29 \\
\hline Epidalea calamita & 30STH94 & 100,00 & 155,75 & 124,84 & 37,59 & 6791,60 & 350,71 & 22,55 & 328,16 & 82,34 & \begin{tabular}{|l|}
246,94 \\
\end{tabular} & \begin{tabular}{|l|}
246,94 \\
\end{tabular} & 73,25 & $\begin{array}{l}617,97 \\
\end{array}$ & $\begin{array}{l}80,30 \\
85,14 \\
\end{array}$ & $\begin{array}{l}3,404 \\
3,79\end{array}$ & 55,09 & $\begin{array}{l}230,59 \\
\end{array}$ & 28,66 & 28,66 & 224,83 \\
\hline Epidalea calamita & 30STH95 & 100,00 & 154,11 & 124,24 & 37,09 & $\begin{array}{ll}6804,66 \\
\end{array}$ & 349,13 & 21,09 & 328,03 & 80,45 & 245,41 & 245,41 & 71,63 & 609,40 & 83,61 & 4,01 & 54,18 & 225,23 & 29,96 & 29,96 & 219,28 \\
\hline Epidalea calamita & 30STH97 & 100,00 & 159,33 & 123,80 & 37,09 & 6807,79 & 353,41 & 25,99 & 327,42 & 85,22 & 250,69 & 250,69 & 76,50 & 555,60 & 75,74 & 3,37 & 53,54 & 203,08 & 27,64 & 27,64 & 196,31 \\
\hline Epidalea calamita & 30STH99 & 100,00 & 157,95 & 122,70 & 37,00 & 6791,74 & 350,87 & 24,91 & 325,97 & 83,74 & 248,87 & 248,87 & 75,27 & 532,52 & 71,53 & 3,95 & 51,32 & 191,25 & 29,83 & 29,83 & 183,63 \\
\hline Epidalea calamita & 30STJ44 & 90,00 & 162,42 & 115,44 & 36,93 & 6560,68 & 345,72 & 35,69 & 310,02 & 90,72 & 249,89 & 249,89 & 82,45 & 479,24 & 61,85 & 3,79 & 49,47 & 174,85 & 30,70 & 30,70 & 163,08 \\
\hline Epidalea calamita & $305 T$ T45 & $\begin{array}{l}0,00 \\
90,00\end{array}$ & $\frac{10,42}{155,14}$ & $\begin{array}{l}1114,44 \\
114,11\end{array}$ & 30,53 & 650,000 & 338,12 & $\begin{array}{l}3,003 \\
29,58 \\
\end{array}$ & \begin{tabular}{|l|}
308,71 \\
308
\end{tabular} & 83,58 & \begin{tabular}{|l|}
243,04 \\
243,04
\end{tabular} & \begin{tabular}{|l|}
243,04 \\
243,04
\end{tabular} & 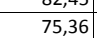 & \begin{tabular}{|l|}
505,07 \\
\end{tabular} & $\begin{array}{l}1,000 \\
65,06 \\
\end{array}$ & $\frac{3,1 / 28}{4,28}$ & 48,41 & \begin{tabular}{|l|}
183,0202 \\
\end{tabular} & 34,39 & 34,79 & $\begin{array}{l}103,00 \\
171,02\end{array}$ \\
\hline Epidalea calamita & 30STJ48 & 80,00 & 157,30 & 112,20 & 36,16 & 6532,43 & 337,47 & 32,83 & 304,64 & 85,80 & 244,71 & 244,71 & 77,88 & 470,31 & 59,10 & 4,17 & 47,10 & 169,25 & 33,86 & 33,86 & 156,80 \\
\hline Epidalea calamita & 30STJ55 & 100,00 & 158,09 & 115,29 & 36,66 & 6600,31 & 342,14 & 31,33 & 310,82 & 86,12 & 246,40 & 246,40 & 77,93 & 481,99 & 61,95 & 4,14 & 48,14 & 173,26 & 32,86 & 32,86 & 161,53 \\
\hline Epidalea calamita & 30STJ57 & 100,00 & 153,24 & 113,56 & 36,34 & 6576,88 & 335,72 & 27,88 & 307,84 & 81,56 & 241,36 & 241,36 & 73,40 & 485,68 & 61,27 & 4,99 & 46,87 & 173,18 & 35,75 & 35,75 & 160,91 \\
\hline Epidalea calamita & 30STJ58 & 100,00 & 155,40 & 113,15 & 36,29 & 6552,72 & 336,67 & 30,22 & 306,45 & 83,61 & 243,05 & 243,05 & 75,49 & 467,24 & 58,29 & 4,7 & 46,49 & 166,39 & 34,67 & 34,67 & 153,99 \\
\hline Epidalea calamita & 30STJ60 & 100,00 & 162,60 & 120,19 & 37,01 & 6670,16 & 351,09 & $\begin{array}{l}0,2,07 \\
32,0\end{array}$ & $\begin{array}{l}319,02 \\
\end{array}$ & 89,56 & 251,53 & 251,53 & 81,13 & 507,73 & $\begin{array}{ll}66,73 \\
\end{array}$ & 3,06 & 51,73 & 186,28 & 28,21 & 28,21 & 176,27 \\
\hline Epidalea calamita & 30STJ61 & 100,00 & 165,51 & 119,52 & 37,00 & 6647,77 & 352,82 & 35,38 & 317,43 & 92,67 & 254,06 & 254,06 & 84,17 & 483,15 & 63,18 & 3,00 & 51,24 & 176,44 & 27,62 & 27,62 & 166,13 \\
\hline Epidalea calamita & 30STJ62 & 100,00 & 166,71 & 118,79 & 37,00 & 6630,30 & 352,93 & 36,76 & 316,17 & 93,99 & 255,07 & 255,07 & 85,52 & 466,96 & 60,83 & 3,00 & 50,72 & 169,80 & 27,38 & 27,38 & 159,24 \\
\hline Epidalea calamita & $30 \mathrm{STJ65}$ & 100,00 & 155,29 & 116,12 & 36,70 & 6632,08 & 340,62 & 27,62 & 313,01 & 83,03 & 244,19 & 244,19 & 74,88 & 484,69 & 61, & 4, & 47,61 & 172,52 & 33,67 & 33,67 & 161,03 \\
\hline Epidalea calamita & 30STJ67 & 100,00 & 146,09 & 114,28 & 36,10 & 6615,83 & 330,29 & 20,18 & 310,11 & 74,11 & 235,11 & 235,11 & 66,36 & 505,77 & $\begin{array}{l}62,89 \\
62\end{array}$ & $5,-5$ & 45,92 & $\begin{array}{l}178,34 \\
\end{array}$ & 38,77 & 38,77 & 165,94 \\
\hline Epidalea calamita & 30STJ68 & 100,00 & 152,12 & 114,12 & 36,43 & 6587,83 & 334,79 & 26,04 & 308,75 & 80,00 & 240,53 & 240,53 & 72,31 & 468,32 & 57,84 & 4,9 & 45,61 & 164,79 & 35,90 & 35,90 & 152,42 \\
\hline Epidalea calamita & 30STJ69 & 100,00 & 148,10 & 113,43 & 36,43 & 6562,40 & 329,99 & 22,97 & 307,02 & 76,38 & 236,27 & 236,27 & 68,73 & \begin{tabular}{|l|l|}
475,96 \\
\end{tabular} & 57,61 & 5,61 & 44,69 & 166,87 & 38,15 & 38,15 & 154,07 \\
\hline Epidalea calamita & 30STJ70 & 100,00 & 162,94 & 120,93 & 37,00 & 6711,61 & 352,53 & 31,34 & 321,19 & 89,45 & 252,49 & 252,49 & 80,99 & 503,63 & 66,61 & 3,16 & 51,62 & 183,48 & 27,84 & 27,84 & 174,04 \\
\hline Epidalea calamita & 30STJ71 & 100,00 & 164,95 & 120,14 & 37,00 & 6683,93 & 353,31 & 33,90 & 319,41 & 91,52 & 254,01 & 254,01 & 83,24 & 482,22 & 63,35 & 3,01 & 51,07 & $\begin{array}{l}174,78 \\
\end{array}$ & 27,49 & 27,49 & 164,96 \\
\hline Epidalea calamita & 30STJ73 & 100,00 & $\begin{array}{l}104,53 \\
165,03\end{array}$ & $\begin{array}{l}12,14 \\
118,73 \\
\end{array}$ & 37,00 & | & 351 & $\begin{array}{l}35,70 \\
34,71 \\
\end{array}$ & \begin{tabular}{|l|}
317,04 \\
317,0
\end{tabular} & 91,92 & 253,87 & 253,87 & 83,65 & 457,19 & 59,44 & 3,02 & 49,79 & 163,93 & 27,85 & 27,85 & 153,66 \\
\hline Epidalea calamita & 30STJ74 & 100,00 & 162,17 & 117,93 & 37,00 & 6665,46 & 348,56 & 32,45 & 316,11 & 89,02 & 251,31 & 251,31 & 80,81 & 458,88 & 59,24 & 3,78 & 48,81 & 163,27 & 29,70 & 29,70 & 152,46 \\
\hline Epidalea calamita & 30STJ75 & 100,00 & 156,64 & 117,10 & 36,93 & 6659,80 & 342,72 & 27,78 & 314,95 & 83,69 & 245,82 & 245,82 & 75,59 & 470,78 & 60,01 & 4,24 & 47,59 & $\mid 166,20$ & 32.63 & 32.63 & 154,99 \\
\hline Epidalea calamita & 30STJ76 & 100,00 & 140,27 & 115,77 & 36,36 & 6661,01 & 326,81 & 13,58 & 313,23 & 68,12 & 230,10 & 230,10 & 60,34 & 531,60 & 65,98 & 6,25 & 45,55 & 185,83 & 41,36 & 41,36 & 173,77 \\
\hline Epidalea calamita & 30STJ78 & 100,00 & 149,32 & 115,03 & 36,47 & 6607,44 & 332,96 & 22,44 & 310,52 & 77,11 & 238,01 & 238,01 & 69,21 & 468,16 & 57,26 & 5,28 & 44,98 & 162,83 & 36,89 & 36,89 & 150 \\
\hline Epidalea calamita & 30STJ80 & $\begin{array}{l}100,00 \\
\end{array}$ & $\begin{array}{l}14,52 \\
162,30\end{array}$ & 121,46 & $\begin{array}{l}30,41 \\
37,00\end{array}$ & $\begin{array}{l}6000,494 \\
6739,35\end{array}$ & 352,98 & $\begin{array}{l}2,44 \\
30,08 \\
\end{array}$ & \begin{tabular}{|l|}
322,90 \\
320
\end{tabular} & $\begin{array}{l}11,11 \\
88,63\end{array}$ & \begin{tabular}{|l|}
252,38 \\
258
\end{tabular} & \begin{tabular}{|l|}
252,38 \\
258
\end{tabular} & $\begin{array}{l}\mid c 5,12 \\
79,85\end{array}$ & $\begin{array}{l}500,70 \\
502,74\end{array}$ & $\begin{array}{l}1,26 \\
66,85 \\
\end{array}$ & 3,20 & 51,45 & \begin{tabular}{|l|}
181,60 \\
181,68 \\
\end{tabular} & $\begin{array}{l}0,099 \\
27,79 \\
\end{array}$ & $\begin{array}{l}0,010 \\
27,79\end{array}$ & $\begin{array}{l}350,40 \\
172,88\end{array}$ \\
\hline Epidalea calamita & 30STI82 & 100,00 & 159,71 & 120,06 & 37,00 & 6722,78 & 349,14 & 28,61 & 320,54 & 86,01 & 249,70 & 249,70 & 77,87 & 486,66 & 63,75 & 3,78 & 49,62 & 173,27 & 29,86 & 29,86 & 163,70 \\
\hline Epidalea calamita & 30STI83 & 100,00 & 164,26 & 119,30 & 37,00 & 6693,97 & 351,82 & 33,32 & 318,50 & 91,13 & 253,90 & 253,90 & 82,54 & 454,95 & 59,16 & 3,09 & 49,66 & 161,80 & 27,59 & 27,59 & 151,82 \\
\hline Epidalea calamita & 30STJ85 & 100,00 & 156,96 & 117,95 & 36,97 & 6694,57 & 344,17 & 27,14 & 317,03 & 83,64 & 246,83 & 246,83 & 75, & 460,36 & 58,52 & 4,14 & 47,29 & 161,05 & 31,85 & 31,85 & 150,23 \\
\hline Epidalea calamita & 30STJ90 & 100,00 & 160,49 & 121,98 & 37,00 & 6771,17 & 352,25 & 27,84 & 324,41 & 86,45 & 251,27 & 251,27 & 78,05 & 506,21 & 67,55 & 3,66 & 50,97 & 181,01 & 28,85 & 28,85 & 172,84 \\
\hline
\end{tabular}




\begin{tabular}{|c|c|c|c|c|c|c|c|c|c|c|c|c|c|c|c|c|c|c|c|c|c|}
\hline TAXON & UTM & $\mathrm{km} 2$ & B101 & B102 & $\mathrm{BIO3}$ & BIO4 & B105 & B106 & B107 & B108 & B109 & B1010 & BIO11 & BIO12 & 81013 & BIO14 & BIO15 & B1016 & B1017 & BIO18 & B1019 \\
\hline Epidalea calamita & 30STJ91 | & 100,00 & 160,67 & 121,29 & 37,00 & 6770,12 & 351,61 & 28,18 & 323,43 & 86,43 & 251,34 & 251,34 & 78,01 & 491,08 & 64,97 & 3,69 & 50,11 & 174,53 & 29,03 & 29,03 & 165,92 \\
\hline Epidalea calamita & 30STJ92 & 100,00 & 162,71 & 120,71 & 37,00 & 6751,35 & 352,47 & 30,39 & 322,09 & 91,52 & 253,05 & 253,05 & 80,01 & 468,96 & 61,53 & 3,40 & 49,86 & 165,95 & 28,06 & 28,06 & 156,97 \\
\hline Epidalea calamita & 30STJ96 & 100,00 & 141,01 & 117,50 & 36,58 & 6708,53 & 329,46 & 12,15 & 317,31 & 68,05 & 231,51 & 231,51 & 60,23 & 505,65 & 62,12 & 6,26 & 44,46 & 172,77 & 40,59 & 40,59 & 161,21 \\
\hline Epidalea calamita & 30STJ97 & 100,00 & 127,72 & 116,23 & 36,51 & 6662,72 & 315,44 & 1,45 & 313,99 & 55,93 & 218,06 & 218,12 & 48,59 & 552,82 & 65,80 & 8,28 & 42,71 & 187,37 & 48,65 & 48,73 & 174,55 \\
\hline Epidalea calamita & 30STJ98 & 100,00 & 132,35 & 115,84 & 36,44 & $\begin{array}{ll}6643,61 \\
\end{array}$ & 318,84 & 5,84 & 313,00 & 60,65 & 222,37 & 222,40 & 53,04 & 517,27 & 60,93 & 7,73 & 42,39 & 174,55 & 46,10 & 46,14 & 161,46 \\
\hline Epidalea calamita & 30STK41 & 70,00 & 160,83 & 111,62 & 36,88 & 6438,31 & 337,22 & 37,00 & 300,22 & 89,67 & 246,68 & 246,68 & 81,92 & 435,49 & 53,34 & 4,25 & 45,75 & 156,26 & 32,98 & 32,98 & 143,93 \\
\hline Epidalea calamita & 30STK42 & 61,00 & 159,72 & $\begin{array}{lll}111,47 \\
\end{array}$ & 37,00 & 6405,93 & 335,10 & 36,22 & 298,88 & 88,79 & 244,95 & 244,95 & 80,91 & 433,38 & 53,14 & 4,72 & 45,05 & 155,24 & 33,98 & 33,98 & 142,80 \\
\hline Epidalea calamita & 30STK51 & 100,00 & 161,28 & 112,52 & 36,93 & 6469,97 & 338,53 & 36,40 & 302,13 & 89,56 & 247,40 & 247,40 & 81,93 & 420,85 & 51,29 & 4,13 & 45,34 & 149,64 & 32,44 & 32,44 & 137,23 \\
\hline Epidalea calamita & 30STK52 & 100,00 & 161,90 & 112,44 & 37,00 & 6442,02 & 338,05 & 37,23 & 300,82 & 90,26 & 247,52 & 247,52 & 82,78 & 411,27 & 50,17 & 4,20 & 44,75 & 146,01 & 32,27 & 32,27 & 133,61 \\
\hline Epidalea calamita & 30STK71 & 100,00 & 159,49 & 114,03 & 37,00 & 6506,11 & 338,62 & 32,78 & 305,84 & 94,35 & 246,32 & 246,32 & 79,77 & 400,66 & 47,97 & 4,71 & 43,70 & 138,88 & 32,83 & 32,83 & 126,42 \\
\hline Epidalea calamita & 30STK81 & 100,00 & 157,36 & 114,90 & 37,00 & 6538,47 & 337,27 & 30,14 & 307,14 & 109,29 & 244,77 & 244,77 & 77,19 & 397,06 & 46,97 & 5,00 & 43,09 & 135,98 & 33,42 & 33,42 & 123,21 \\
\hline Epidalea calamita & 30STK82 & 100,00 & 159,99 & 114,49 & 37,00 & 6497,45 & 338,29 & 33,01 & 305,28 & 118,40 & 246,75 & 246,75 & 80,04 & 379,04 & 44,91 & 5,00 & 42,66 & 130,14 & 32,23 & 32,23 & 117,00 \\
\hline Epidalea calamita & $\begin{array}{l}\text { SOSTK92 } \\
\text { 30ST }\end{array}$ & 100,00 & 158,97 & 115,00 & 37,00 & 6517,41 & 337,92 & 31,26 & $\begin{array}{l}306,66 \\
\end{array}$ & 116,95 & $\begin{array}{l}246,07 \\
\end{array}$ & 246,07 & 78,94 & 372,09 & 43,72 & 5,00 & 42,38 & 127,20 & 32,20 & 32,20 & 113,03 \\
\hline Epidalea calamita & 30SUF03 & 82,00 & 169,39 & 89,49 & \begin{tabular}{|l|l|}
40,47 \\
\end{tabular} & 4467,10 & 290,21 & 71,31 & 218,90 & 125,21 & 226,56 & 230,21 & 116,17 & 700,22 & 120,39 & 1,22 & 73,03 & 341,09 & 15,43 & 22,72 & 320,33 \\
\hline Epidalea calamita & 30SUF06 & 100,00 & 141,85 & 105,55 & 39,09 & 5464,68 & 294,05 & 28,43 & 265,62 & 86,67 & 213,94 & 216,01 & 76,81 & 802,06 & 120,23 & 3,02 & 66,62 & 354,21 & 24,06 & 32,49 & 343,76 \\
\hline Epidalea calamita & 30SUF07 & 100,00 & 148,85 & 104,70 & 39,04 & 5460,91 & 299,82 & 35,93 & 263,89 & 93,13 & 220,67 & 222,81 & 83,66 & 769,43 & 117,27 & 2,48 & 66,68 & 342,70 & 22,23 & 30,04 & 329,43 \\
\hline Epidalea calamita & $\begin{array}{l}\text { 30SUF09 } \\
\end{array}$ & 100,00 & 153,81 & 107,61 & 39,00 & 5651,03 & 310,21 & 38,57 & 271,64 & 95,21 & 228,32 & 229,94 & 86,20 & 742,10 & 112,92 & 2,29 & 65,64 & 326,77 & 22,01 & 28,98 & 312,48 \\
\hline Epidalea calamita & 30SUF15 & 100,00 & 137,05 & 106,49 & 39,38 & 5453,24 & 289,99 & 23,00 & 266,99 & 82,54 & 209,28 & 211,17 & 72,27 & 805,45 & 119,46 & 3,47 & 66,20 & 353,64 & 25,29 & 34,08 & 345,22 \\
\hline Epidalea calamita & 30SUF16 & 100,00 & 129,29 & 109,97 & 39,02 & 5681,03 & 290,17 & 12,23 & 277,94 & 71,73 & 205,11 & 206,59 & 61,96 & 839,94 & 121,57 & 4,46 & 64,32 & 360,19 & 29,42 & 38,14 & 352,82 \\
\hline Epidalea calamita & 30SUF17 & 100,00 & 139,45 & 108,08 & 39,01 & 5631,49 & 296,76 & 23,59 & 273,17 & 82,19 & 214,24 & 215,90 & 72,48 & 790,95 & 116,12 & 3,52 & 64,97 & 344,10 & 25,83 & 33,99 & 333,83 \\
\hline Epidalea calamita & 30SUF18 & 100,00 & 145,50 & 107,76 & 39,00 & 5650,69 & 302,14 & 29,69 & 272,45 & 87,59 & 220,36 & 221,86 & 78,06 & 764,70 & 113, & 3,0 & 65,04 & 334,29 & 24,24 & 31,91 & 322,21 \\
\hline Epidalea calamita & 30SUF19 & 100,00 & 153,66 & 107,43 & 39,00 & 5652,85 & 309,79 & 38,03 & 271,76 & 95,08 & 228,48 & 229,80 & 86,25 & 731,08 & 110,58 & 2,50 & 65,31 & 321,66 & 22,23 & 29,17 & 307,50 \\
\hline Epidalea calamita & 30SUF24 & 94,00 & 168,45 & 92,06 & \begin{tabular}{l|l}
40,05 \\
\end{tabular} & 4652,58 & 293,99 & 66,92 & 227,07 & 122,51 & 228,58 & 231,67 & 113,12 & 654,52 & 109,13 & 1,48 & 71,20 & 313,71 & 16,63 & 23,23 & 294,45 \\
\hline Epidalea calamita & 30SUF25 & 100,00 & 151,94 & 100,82 & 39,72 & 5156,42 & 294,15 & 42,55 & 251,60 & 100,47 & 219,74 & 221,94 & 90,62 & 720,34 & 111,42 & 2,52 & 67,90 & 328,08 & 20,82 & 28,60 & 314,10 \\
\hline Epidalea calamita & 30 SUF 26 & 100,00 & 139,10 & 106,50 & 39,10 & 5504,40 & 293,23 & 24,74 & 268,49 & 83,18 & 212,23 & 213,84 & 73,82 & 778,80 & 115,34 & 3,84 & 65,27 & 341,04 & 26,48 & 34,36 & 329,79 \\
\hline Epidalea calamita & 30SUF28 & 100,00 & 154,73 & 104,85 & 39,00 & 5515,90 & 306,01 & 40,84 & 265,16 & 98,07 & 227,66 & 229,06 & 88,86 & 712,38 & 108 & 2,53 & 65,93 & 317,38 & 21,69 & 28,53 & 302,36 \\
\hline Epidalea calamita & 30SUF29 & 100,00 & 159,16 & 105,45 & 39,00 & 5574,05 & 311,62 & $\begin{array}{l}44,54 \\
44,54\end{array}$ & 267,08 & \begin{tabular}{|c|}
101,34 \\
\end{tabular} & 232,83 & 234,14 & 92,55 & 696,91 & $\mid 106,71$ & 2,18 & 65,71 & 309,96 & 20,84 & 27,23 & 294,31 \\
\hline Epidalea calamita & 30SUF34 & 86,00 & 168,50 & 91,96 & 39,99 & 4679,37 & 294,07 & 66,24 & 227,83 & 122,48 & 229,17 & 232,01 & 113,01 & 630,40 & \begin{tabular}{|l|}
103,78 \\
\end{tabular} & 1,59 & 70,51 & 301,26 & 16,97 & 23,19 & 282,53 \\
\hline Epidalea calamita & 30SUF35 & 100,00 & 158,75 & 97,82 & 39,57 & 5031,04 & 295,61 & 51,20 & 244,41 & 108,57 & 224,73 & 226,96 & 98,93 & 671,78 & 105,65 & 2,26 & 68,27 & 310,74 & 19,50 & 26,30 & 294,46 \\
\hline Epidalea calamita & 30SUF36 & 100,00 & 168,44 & 94,62 & 39,09 & 4960,52 & 300,68 & 62,44 & 238,24 & 118,42 & 233,11 & 235,40 & 109,13 & 645,01 & 104,60 & 1,90 & 69,21 & 303,24 & 18,20 & 23,92 & 283,39 \\
\hline Epidalea calamita & 30SUF37 & 100,00 & 154,78 & 102,31 & 39,00 & 5375,08 & 301,58 & 42,60 & 258,97 & 100,04 & 225,88 & 227,42 & 90,71 & 694,24 & 106,26 & 2,77 & 66,19 & 311,65 & 21,86 & 28,57 & 296,34 \\
\hline Epidalea calamita & 30SUF39 & 100,00 & 163,16 & 103,55 & 38,99 & 5526,19 & 312,55 & $\begin{array}{l}42,03 \\
49,03\end{array}$ & 263,52 & $\begin{array}{l}105,89 \\
150\end{array}$ & \begin{tabular}{|l|}
236,23 \\
\end{tabular} & \begin{tabular}{|l|}
237,36 \\
\end{tabular} & $\begin{array}{ll}0,11 \\
97,02\end{array}$ & 666,41 & $\begin{array}{l}102,47 \\
\end{array}$ & 2,11 & 65,86 & 298,11 & $\begin{array}{l}1,00 \\
20,08\end{array}$ & 26,09 & 281,61 \\
\hline Epidalea calamita & 30SUF44 & 99,00 & 175,94 & 87,81 & 39,80 & 4528,52 & 294,53 & 75,85 & 218,68 & 131,70 & 234,36 & 237,40 & 122,17 & 584,84 & 98,22 & 1,33 & 71,14 & 283,83 & 16,13 & 21,07 & 263,71 \\
\hline Epidalea calamita & 30SUF 45 & 100,00 & 168,58 & 92,63 & 39,20 & 4834,96 & 296,72 & 63,92 & 232,80 & 120,46 & 231,56 & 233,94 & 111,00 & 617,16 & 100,64 & 2,04 & 69,42 & 291,88 & 17,94 & 23,56 & 272,80 \\
\hline Epidalea calamita & 30SUF46 & 100,00 & 178,09 & 89,38 & 39,01 & 4774,36 & 301,57 & 74,88 & 226,69 & 130,14 & 240,01 & 242,55 & 121,06 & 595,38 & 100,12 & 1,28 & 70,45 & 285,75 & 16,65 & 21,29 & 263,75 \\
\hline Epidalea calamita & $\begin{array}{l}30 \text { SUF } 47 \\
\end{array}$ & 100,00 & 173,28 & 93,60 & 38,83 & 5034,15 & 304,91 & 66,24 & 238,67 & 121,99 & 239,05 & 241,00 & 112,97 & 613,31 & \begin{tabular}{|l|l}
100,35 \\
\end{tabular} & 1,92 & 68,59 & 287,44 & 18,10 & 22,93 & 267,01 \\
\hline Epidalea calamita & 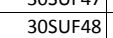 & 100,00 & 164,32 & $\begin{array}{l}59,91 \\
99,\end{array}$ & 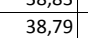 & | & 307,45 & $\begin{array}{l}52,37 \\
52,\end{array}$ & 255,08 & \begin{tabular}{|l|}
109,16 \\
109
\end{tabular} & $\mid \begin{array}{l}235,01 \\
235,0\end{array}$ & 236,27 & \begin{tabular}{|l|}
100,19 \\
10
\end{tabular} & | & 100,51 & $\frac{1,254}{2,44}$ & $\begin{array}{l}0,0,35 \\
66,35\end{array}$ & \begin{tabular}{|l|}
291,23 \\
\end{tabular} & $\begin{array}{l}\mid 0,14 \\
20,14\end{array}$ & $\begin{array}{l}25,75 \\
25,76\end{array}$ & 273,91 \\
\hline Epidalea calamita & 30SUF49 & 100,00 & 161,69 & 103,47 & 38,72 & 5564,11 & 311,51 & 46,74 & 264,78 & 103,90 & 235,49 & 236,38 & 95,11 & 651,43 & 99,29 & 2,53 & 65,11 & 289,43 & 20,62 & 26,60 & 273,68 \\
\hline Epidalea calamita & 30SUF54 & 49,00 & 180,49 & 85,28 & 39,21 & 4478,44 & 295,30 & 80,95 & 214,34 & 136,74 & 238,13 & 241,05 & 127,16 & 556,48 & 94,54 & 1,1 & 71,26 & 271,38 & 15,97 & 20,07 & 250,74 \\
\hline Epidalea calamita & 30SUF55 & 100,00 & 166,07 & 93,57 & 39,03 & 4922,22 & 296,25 & 59,76 & 236,49 & 117,03 & 230,54 & 232,58 & 107,47 & 602,98 & 97,23 & 2,34 & 68,10 & 281,26 & 19,05 & 24,29 & 263,55 \\
\hline Epidalea calamita & $\begin{array}{l}30 \text { SUF56 } \\
\end{array}$ & 100,00 & 179,54 & 87,59 & 38,50 & 4770,36 & 300,70 & 76,10 & 224,60 & 131,76 & 241,54 & 243,85 & 122,45 & 574,20 & 97,38 & 1,66 & 70,02 & 275,22 & 17,46 & 21,11 & 253,32 \\
\hline Epidalea calamita & 30SUF57 & 100,00 & 167,71 & 95,80 & 38,66 & 5165,28 & 303,53 & 58,40 & 245,13 & 115,01 & 235,71 & 237,16 & 105,96 & 606,67 & 97,54 & 2,2 & 67,11 & 279,59 & 19,05 & 24,16 & 260,99 \\
\hline Epidalea calamita & $\begin{array}{l}30 \text { SUF58 } \\
\end{array}$ & 100,00 & 161,08 & 101,12 & 38,52 & 5442,92 & 306,77 & 47,73 & 259,03 & 105,01 & 233,33 & 234,19 & 96,07 & 628,19 & 97,20 & 2,85 & 65,08 & 281,10 & 21,02 & 26,19 & 264,78 \\
\hline Epidalea calamita & 30SUF59 & 100,00 & 151,96 & 107,04 & 38,38 & 5743,58 & 309,15 & 34,31 & 274,84 & 92,37 & 228,85 & 229,23 & 83,52 & 661,30 & 97,48 & 3,74 & 62,77 & 285,63 & 23,96 & 28,66 & 272,52 \\
\hline Epidalea calamita & 30SUF66 & 100,00 & 181,38 & 85,40 & 38,01 & 4749,54 & 299,71 & 78,08 & \begin{tabular}{|l|l|}
221,63 \\
\end{tabular} & 134,01 & 243,11 & 245,35 & 124,52 & 550,63 & 94, & 1, & 69,57 & 63,32 & 17,94 & 21,02 & 241,76 \\
\hline Epidalea calamita & 30SUF67 & 100,00 & 170,32 & 93,93 & 38,20 & 5138,18 & 303,49 & 61,14 & 242,35 & \begin{tabular}{|l|}
117,80 \\
11,0
\end{tabular} & \begin{tabular}{|l|}
238,01 \\
238
\end{tabular} & \begin{tabular}{|l|}
239,35 \\
235
\end{tabular} & $\begin{array}{l}104,4<2 \\
108,82 \\
\end{array}$ & 573,92 & $\begin{array}{l}93, \\
93, \\
\end{array}$ & 2,3 & 66,71 & $\begin{array}{l}26,25 \\
264,25 \\
\end{array}$ & $\begin{array}{ll}18,82 \\
18,82\end{array}$ & $\begin{array}{l}1,02 \\
23,33\end{array}$ & 245,63 \\
\hline Epidalea calamita & 30SUF68 & 100,00 & 160,01 & 101,65 & 38,30 & 5489,69 & 306,78 & 45,54 & 261,24 & 103,07 & 233,11 & 233,63 & 94,37 & 604,52 & 93,12 & 3,1 & 64,03 & 268,35 & 21,43 & 25,48 & 252,56 \\
\hline Epidalea calamita & $\begin{array}{l}30 \text { SUF69 } \\
\end{array}$ & 100,00 & 148,18 & 108,52 & 38,10 & 5824,46 & 308,79 & 29,03 & $\begin{array}{l}279,76 \\
\end{array}$ & 87,60 & 226,42 & 226,51 & 78,91 & 649,50 & 94,31 & 4,30 & 61,40 & 276,40 & 25,32 & 26,83 & 264,26 \\
\hline Epidalea calamita & 30SUF76 & 60,00 & 178,71 & 86,90 & \begin{tabular}{l|l}
37,95 \\
\end{tabular} & 4863,15 & 300,02 & 73,37 & 226,66 & 129,82 & 242,24 & 244,01 & 120,51 & 525,85 & 87,91 & 2,07 & 67,84 & 246,26 & 17,54 & 21,09 & 227,32 \\
\hline Epidalea calamita & 30SUF77 & 100,00 & 159,55 & 100,20 & 38,38 & 5393,29 & 303,62 & 46,13 & 257,50 & 104,07 & 231,38 & 231,93 & 95,20 & 575,35 & 88,88 & 3,26 & 63,66 & 255,70 & 21,20 & 24,50 & 240,32 \\
\hline Epidalea calamita & 30SUF78 & $\begin{array}{l}100,00 \\
100\end{array}$ & 15 & 105,24 & 38,18 & \begin{tabular}{|l|}
5646,55 \\
5646
\end{tabular} & $\begin{array}{l}303,1 \\
307,\end{array}$ & $\begin{array}{l}40,159 \\
36,49 \\
\end{array}$ & \begin{tabular}{|l|}
270,67 \\
\end{tabular} & $\begin{array}{l}44,46 \\
94,86\end{array}$ & \begin{tabular}{|l|}
229,24 \\
224
\end{tabular} & \begin{tabular}{|l|}
229,34 \\
22,3
\end{tabular} & $\begin{array}{l}30,25 \\
86,25\end{array}$ & 595,17 & $\begin{array}{l}80,00 \\
89,12\end{array}$ & $\begin{array}{l}3,200 \\
3,87\end{array}$ & $\begin{array}{l}3,000 \\
61,92\end{array}$ & $\begin{array}{l}258,15 \\
258,1\end{array}$ & 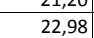 & 24,53 & $\begin{array}{l}24,34,17 \\
244\end{array}$ \\
\hline Epidalea calamita & 30SUF86 & 60,00 & 174,85 & 90,24 & 38,04 & 4988,76 & 301,67 & 67,22 & 234,45 & 124,08 & 240,53 & 241,71 & 115,09 & 496,94 & 80,94 & 2,22 & 65,88 & 228,36 & 17,27 & 20,95 & 211,64 \\
\hline Epidalea calamita & 30SUF88 & 100,00 & 161,41 & 101,54 & 38,05 & 5530,29 & 308,63 & 45,94 & 262,69 & 103,62 & 235,46 & 235,54 & 95,27 & 539,06 & 83,10 & 3,43 & 62,29 & 236,67 & 20,83 & 21,66 & 221,22 \\
\hline Epidalea calamita & 30SUF89 & 100,00 & 138,18 & 113,21 & 38,01 & 6037,40 & 308,46 & 15,46 & 293,00 & 75,24 & 219,99 & 219,99 & 66,65 & 639,85 & 88,60 & 5,89 & 57,88 & 261,41 & 29,57 & 29,63 & 252,07 \\
\hline Epidalea calamita & 30SUF96 & 57,00 & 178,52 & 89,16 & 38,00 & 4952,90 & 303,42 & 71,34 & 232,08 & 127,89 & 243,63 & 244 & 119,07 & 456,51 & 73,92 & 2,04 & 65,26 & 209,08 & 15,84 & 19,48 & 193 \\
\hline Epidalea calamita & 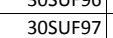 & \begin{tabular}{|l|}
100,00 \\
100
\end{tabular} & $\begin{array}{ll}170,52 \\
175,94\end{array}$ & $\begin{array}{l}9,100 \\
91,94\end{array}$ & 37,94 & | 55314,45 & 306,17 & $\begin{array}{l}1,43 \\
66,45 \\
\end{array}$ & $\begin{array}{l}23,00,72 \\
239\end{array}$ & \begin{tabular}{|l|}
123,09 \\
1209
\end{tabular} & \begin{tabular}{|l|}
243,525 \\
243
\end{tabular} & \begin{tabular}{|l|}
244,291 \\
24
\end{tabular} & $\begin{array}{l}114,42 \\
114\end{array}$ & | & 74,74 & 2,264 & $\begin{array}{l}03,20 \\
64,55\end{array}$ & \begin{tabular}{|l|}
210,690 \\
210
\end{tabular} & $\begin{array}{l}1,04 \\
16,53 \\
\end{array}$ & $\begin{array}{l}1,40 \\
20,02\end{array}$ & $\begin{array}{l}50,03 \\
194,90\end{array}$ \\
\hline Epidalea calamita & 30SUF98 & 100,00 & 164,71 & 100,24 & 38,00 & 5490,06 & 309,73 & 49,53 & 260,20 & 107,06 & 238,20 & 238,29 & 98,92 & 499,38 & 77,35 & 3,34 & 61,90 & 218,94 & 19,81 & 20,69 & 203,59 \\
\hline Epidalea calamita & 30SUF99 & 100,00 & 131,28 & 115,92 & 38,00 & 6159,14 & 307,14 & 6,72 & 300,42 & 67,43 & 214,93 & 214,93 & 58,55 & 651,95 & 87,41 & 7,08 & 55,91 & 259,09 & 33,13 & 33,13 & 251,82 \\
\hline Epidalea calamita & 30SUG04 & 100,00 & 174,68 & 117,00 & 39,43 & 6094,71 & 344,37 & 51,05 & 293,3 & 109,03 & 254 & 255, & 100 & 639,99 & 97,29 & 1,29 & 64,03 & 271,75 & 17,62 & 22,87 & 259 \\
\hline Epidalea calamita & 30 SUG05 & 100,00 & 174,83 & 118,95 & 39,03 & 6223,51 & 349,01 & 49,08 & 299,93 & 107,51 & 256,89 & 257,21 & 98,96 & 636,42 & 95,56 & 1,52 & 63,53 & 266,32 & 17,58 & 22,12 & 255,99 \\
\hline
\end{tabular}




\begin{tabular}{|c|c|c|c|c|c|c|c|c|c|c|c|c|c|c|c|c|c|c|c|c|c|}
\hline TAXON & UTM & $\mathrm{km} 2$ & B101 & B102 & $\mathrm{BIO3}$ & 8104 & B105 & B106 & B107 & B108 & B109 & B1010 & BIO11 & BIO12 & 81013 & BIO14 & BIO15 & B1016 & B1017 & B1018 & B1019 \\
\hline Epidalea calamita & 30SUG06 & 100,00 & 177,07 & 120,20 & 39,00 & 6308,46 & 354,11 & 49,54 & 304,57 & 108,70 & 260,46 & 260,56 & 100,03 & 624,19 & 92,89 & 1,40 & 62,82 & 257,88 & 17,40 & 18,85 & 248,75 \\
\hline Epidalea calamita & 30SUG09 & 100,00 & 171,41 & 123,90 & 38,02 & 6601,14 & 359,11 & 39,39 & 319,72 & 99,62 & 259,17 & 259,17 & 90,60 & 629,89 & 89,50 & 2,11 & 60,41 & 248,30 & 20,38 & 20,38 & 242,66 \\
\hline Epidalea calamita & 30SUG13 & 100,00 & 174,70 & 113,11 & 39,04 & 5956,19 & 338,53 & 53,39 & 285,14 & 110,82 & 253,09 & 253,78 & $\begin{array}{r}102,18 \\
\end{array}$ & 640,77 & 98,39 & 1,38 & 64,44 & 275,81 & 17,38 & 23,21 & 262,82 \\
\hline Epidalea calamita & 30SUG14 & 100,00 & 175,94 & 115,21 & 39,00 & 6080,95 & 343,77 & 52,44 & 291,33 & 110,44 & 256,08 & 256,56 & 101,84 & 635,34 & 96,55 & 1,40 & 64,10 & 269,43 & 17,41 & 22,06 & 258,12 \\
\hline Epidalea calamita & 30SUG15 & 100,00 & 176,83 & 117,18 & \begin{tabular}{|l|}
38,98 \\
\end{tabular} & 6195,92 & 349,00 & 51,24 & 297,76 & 109,89 & 258,59 & 258,86 & 101,00 & 631,30 & 94,82 & 1,59 & 63,29 & 263,54 & \begin{tabular}{ll|}
17,38 \\
\end{tabular} & 20,48 & 253,87 \\
\hline Epidalea calamita & 30SUG16 & 100,00 & 177,14 & 119,05 & 38,87 & 6319,29 & 353,65 & 49,57 & 304,07 & 108,73 & 260,71 & 260,80 & 99,67 & 628,85 & 93,36 & 1,74 & 62,61 & 258,14 & 17,54 & 19,01 & 250,19 \\
\hline Epidalea calamita & 30SUG19 & 100,00 & 170,83 & 123,41 & 38,00 & 6637,60 & 358,88 & 38,45 & \begin{tabular}{|l|l|}
320,44 \\
\end{tabular} & 98,80 & 259,16 & 259,16 & 89,47 & 637,10 & 91,01 & 2,26 & 60,45 & 249,29 & 20,32 & 20,32 & 245,07 \\
\hline Epidalea calamita & 30SUG20 & 100,00 & 158,31 & 108,00 & 38,99 & 5733,43 & 315,49 & 41,41 & 274,08 & $\begin{array}{l}0,607 \\
98,67\end{array}$ & 234,24 & 235,27 & 89,62 & 699,48 & \begin{tabular}{|l|r|}
105,59 \\
\end{tabular} & 2,70 & 64,63 & 306,20 & 21,86 & 28,20 & 291,83 \\
\hline Epidalea calamita & 30SUG24 & 100,00 & 175,65 & 113,80 & 38,80 & 6090,45 & 342,76 & 52,23 & 290,52 & 109,98 & 256,11 & 256,36 & 101,49 & 634,57 & 95,71 & 2,00 & 63,62 & 267,67 & 17,95 & 21,50 & 257,17 \\
\hline Epidalea calamita & 30SUG25 & 100,00 & 177,11 & 115,70 & \begin{tabular}{|l|l|}
38,47 \\
\end{tabular} & 6197,34 & 348,18 & 51,59 & 296,60 & 110,24 & 259,11 & 259,20 & 101,24 & 629,42 & 94,16 & 1,99 & 63,18 & 261,45 & $\mid 17,47$ & $\mid 18,83$ & 252,76 \\
\hline Epidalea calamita & 30 SUG26 & 100,00 & 174,32 & 118,30 & 38,05 & 6364,71 & 351,55 & 46,19 & 305,35 & 105,34 & 258,78 & 258,78 & 96,44 & 641,77 & 94,36 & 2,00 & 62,40 & 261,26 & 18,11 & 18,20 & 254,61 \\
\hline Epidalea calamita & 30SUG29 & 100,00 & 171,23 & 122,66 & 37,88 & 6667,74 & 359,38 & 38,34 & 321,03 & 100,62 & 260,12 & 260,12 & 89,40 & 638,74 & 92,99 & 2,38 & 60,78 & 248,38 & 19,95 & 19,95 & 244,96 \\
\hline Epidalea calamita & 30SUG30 & 100,00 & 161,39 & 106,38 & 38,92 & 5693,89 & 316,09 & 44,78 & 271,31 & $\begin{array}{l}101,95 \\
\end{array}$ & $\begin{array}{l}236,83 \\
236\end{array}$ & 237,75 & 93,14 & $\mid 674,11$ & $\mid$ & 2,51 & 60,153 & \begin{tabular}{|l|}
295,99 \\
\end{tabular} & 21,35 & 27,45 & 281,19 \\
\hline Epidalea calamita & 30SUG33 & 100,00 & 170,43 & 111,18 & 38,29 & $\begin{array}{ll}6014,66 \\
\end{array}$ & 334,47 & 48,73 & 285,74 & 106,37 & 250,28 & 250,43 & 97,68 & 644,45 & 96,44 & 2,01 & 63,51 & 273,78 & 19,10 & 22,07 & 262,59 \\
\hline Epidalea calamita & 30SUG34 & 100,00 & 175,81 & 112,36 & 38,18 & 6089,49 & 341,99 & 52,48 & 289,51 & 110,43 & 256,49 & 256,55 & 101,55 & 626,32 & 93,86 & 2,00 & 63,44 & 263,17 & 17,58 & 19,36 & 253,45 \\
\hline Epidalea calamita & 30 SUG36 & 100,00 & 174,02 & 116,99 & 37,99 & 6375,32 & 350,62 & 46,18 & 304,44 & 105,03 & 258,75 & 258,75 & 96,00 & 637,83 & 93,10 & 2,00 & 62,23 & 258,14 & 18,25 & 18,25 & 252,49 \\
\hline Epidalea calamita & 30SUG39 & 100,00 & 172,72 & 121,66 & 37,46 & 6673,92 & 360,28 & 39,74 & 320,55 & 103,10 & 261,75 & 261,75 & 90,77 & 634,97 & 94,36 & 2,40 & 60,84 & 247,91 & 19,40 & 19,40 & 242,96 \\
\hline Epidalea calamita & 30 SUG 40 & 100,00 & 164,62 & 104,62 & 38,48 & 5666,15 & 316,75 & 48,21 & 268,55 & 105,23 & 239,72 & 240,42 & 96,60 & 643,79 & 97,35 & 2,44 & 64,83 & 283,87 & 20,00 & 25,60 & 268,63 \\
\hline Epidalea calamita & 30SUG41 & 100,00 & 163,92 & 107,10 & \begin{tabular}{|l|}
38,08 \\
\end{tabular} & 5819,24 & 321,13 & 45,30 & 275,83 & 102,48 & 241,36 & 241,74 & 94,05 & 648,59 & 96,53 & 2,91 & 63,63 & 280,68 & 21,20 & 25,07 & 267,16 \\
\hline Epidalea calamita & 30SUG49 & 100,00 & 177,84 & 119,92 & $37,05 \mid$ & 6641,07 & 362,81 & 45,38 & 317,43 & $\mid \begin{array}{l}108,48 \\
\end{array}$ & $\mid 266,49$ & 266,49 & 96,15 & 608,36 & 91,39 & 2,03 & 61,38 & 238,32 & 17,34 & 17,34 & 233,03 \\
\hline Epidalea calamita & 30SUG50 & 100,00 & 164,66 & 103,90 & 38,05 & 5680,63 & 316,29 & 47,89 & 268,40 & 105,03 & 240,25 & 240,61 & 96,56 & 622,40 & 93,90 & 2,99 & 63,95 & 273,02 & 20,50 & 25,05 & 257,99 \\
\hline Epidalea calamita & 30SUG51 & 100,00 & 162,12 & 107,03 & 38,00 & 5867,14 & 320,73 & 42,83 & 277,90 & 100,31 & 240,56 & 240,65 & 91,79 & 632,73 & 92,63 & 3,03 & 62,66 & 271,50 & 21,88 & 24,04 & 258,61 \\
\hline Epidalea calamita & 30SUG53 & 100,00 & 170,54 & 108,60 & $\begin{array}{l}37,96 \\
\end{array}$ & 6023,41 & 332,88 & 49,09 & 283,79 & 106,23 & 250,80 & 250,83 & 97,62 & 612,15 & 89,50 & 2,55 & 62,47 & 257,70 & 19,62 & 20,08 & 247,41 \\
\hline Epidalea calamita & 30SUG54 & 100,00 & 169,43 & 111,11 & 37,68 & 6182,19 & 337,53 & 45,85 & 291,68 & 103,08 & 251,95 & 251,95 & 94,54 & 619,52 & 89,40 & 2,85 & 61,66 & 255,64 & 20,03 & 20,03 & 247,58 \\
\hline Epidalea calamita & 30SUG55 & 100,00 & 170,56 & 112,87 & 37,33 & 6300,87 & 342,64 & 45,02 & 297,62 & 102,83 & 254,71 & 254,71 & 94,03 & 619,35 & 88,62 & 2,86 & 61,12 & 251,06 & 20,03 & 20,03 & 245,03 \\
\hline Epidalea calamita & 30SUG56 & 100,00 & 172,76 & 114,40 & 37,12 & 6397,20 & 348,01 & 45,56 & 302,45 & 103,79 & 258,24 & 258,24 & 94,82 & 614,39 & 87,47 & 2,53 & 61,03 & 245,24 & 19,16 & 19,16 & 241,01 \\
\hline Epidalea calamita & 30SUG58 & 100,00 & 174,33 & 117,37 & 37,00 & 6577,87 & 356,15 & 44,03 & 312,11 & 105,81 & 262,29 & 262,29 & $\begin{array}{ll}93,83 \\
3,83\end{array}$ & \begin{tabular}{|l|l|}
609,07 \\
\end{tabular} & 89,21 & 2,52 & 60,53 & \begin{tabular}{|l|}
238,13 \\
\end{tabular} & 19,02 & 19,02 & 234,34 \\
\hline Epidalea calamita & 30 SUG60 & 100,00 & 161,05 & 105,06 & 38,00 & 5764,34 & 315,83 & 43,04 & 272,78 & 100,34 & 238,06 & 238,18 & 91,94 & 607,87 & 90,73 & 3,27 & 62,49 & 263,13 & 21,77 & 23,36 & 249,10 \\
\hline Epidalea calamita & 30SUG61 & 100,00 & 160,85 & 107,15 & 37,99 & 5906,79 & 320,53 & 41,13 & 279,40 & 98,45 & 240,06 & 240,08 & 90,04 & 611,66 & 89,09 & 3,27 & 61,66 & 260,49 & 22,17 & 22,45 & 247,99 \\
\hline Epidalea calamita & 30SUG63 & 100,00 & 165,01 & 109,44 & 37,39 & 6115,90 & 330,89 & 42,56 & 288,33 & 99,67 & 247,00 & 247,00 & 91,44 & 608,08 & 86,41 & 3,27 & 60,98 & 252,16 & 21,25 & 21,25 & 242,99 \\
\hline Epidalea calamita & 30SUG64 & 100,00 & 166,05 & 110,95 & \begin{tabular}{|c|}
37,07 \\
\end{tabular} & 6241,95 & 335,71 & 41,93 & 293,78 & 99,02 & 249,73 & 249,73 & 90,74 & 609,53 & 85,97 & 3,18 & 60,58 & 248,72 & 21,10 & 21,10 & 241,49 \\
\hline Epidalea calamita & 30SUG66 & 100,00 & 168,88 & 113,75 & 37,00 & $\mid 6442,65$ & 345,35 & $\begin{array}{l}1,35 \\
41,78 \\
\end{array}$ & 303,57 & $\begin{array}{l}0,0,54 \\
99\end{array}$ & 255,26 & 255,26 & $\begin{array}{l}0,73 \\
90,73\end{array}$ & \begin{tabular}{|l|l|}
608,13 \\
\end{tabular} & 85,05 & $\begin{array}{ll}3,106 \\
3,13\end{array}$ & 59,89 & \begin{tabular}{|l|}
239,79 \\
\end{tabular} & 20,77 & 20,77 & 236,57 \\
\hline Epidalea calamita & 30SUG70 & 100,00 & 153,02 & 108,60 & 38,00 & 5919,84 & 315,12 & 32,55 & 282,56 & 90,59 & 232,64 & 232,64 & 82,25 & 606,43 & 88,06 & 4,36 & 60,45 & 256,18 & 24,30 & 24,34 & 243,79 \\
\hline Epidalea calamita & 30SUG71 & 100,00 & 151,62 & 110,58 & \begin{tabular}{|c|}
37,88 \\
\end{tabular} & 6072,57 & 318,97 & 29,47 & 289,50 & 87,29 & 233,57 & 233,57 & 79,09 & 616,86 & 87,21 & 4,57 & 59,53 & 255,86 & 25,25 & 25,25 & 245,22 \\
\hline Epidalea calamita & 30SUG73 & 100,00 & 160,62 & 110,39 & 37,03 & 6209,98 & 329,74 & 37,22 & 292,52 & 94,11 & 244,16 & 244,16 & 86,08 & 598,01 & 82,75 & 3,88 & 59,53 & 244,13 & 22,91 & 22,91 & 235,89 \\
\hline Epidalea calamita & 30SUG74 & 100,00 & 155,15 & 113,29 & 37,00 & 6391,20 & 331,46 & 29,64 & 301,81 & 86,90 & 241,43 & 241,43 & 78,57 & 624,57 & 84,86 & 4,55 & 58,31 & 247,93 & 25,42 & 25,42 & 242,53 \\
\hline Epidalea calamita & 30SUG75 & 100,00 & $\begin{array}{l}135,135 \\
155,82\end{array}$ & $\begin{array}{l}111,25 \\
114,23\end{array}$ & 37,00 & |6483,09| & 334,95 & 29,28 & \begin{tabular}{|l|}
305,67 \\
30
\end{tabular} & $\begin{array}{l}80,0,84 \\
86,8\end{array}$ & \begin{tabular}{|l|}
243,34 \\
2434
\end{tabular} & \begin{tabular}{|l|}
241,4334 \\
\end{tabular} & 78,06 & $\mid \begin{array}{l}\mid 28,3,75 \\
628,7\end{array}$ & $\begin{array}{l}84,00 \\
85,66\end{array}$ & 4 & $\begin{array}{ll}0 ., 51 \\
57,93\end{array}$ & \begin{tabular}{|l|}
245,89 \\
248
\end{tabular} & $\begin{array}{l}25,44 \\
25,79\end{array}$ & $\begin{array}{l}25,449 \\
25,79\end{array}$ & $\begin{array}{l}242,23 \\
242,22\end{array}$ \\
\hline Epidalea calamita & 30SUG79 & 100,00 & 174,32 & 115,61 & 36,68 & 6642,51 & 356,23 & 44,43 & 311,80 & 105,50 & 263,37 & 263,37 & 93,36 & 566,28 & 83,2 & 2,84 & 58,80 & 220,16 & 19,61 & 19,61 & 213,69 \\
\hline Epidalea calamita & 30SUG80 & 100,00 & 145,86 & 111,84 & 38,00 & 6057,58 & 314,52 & 23,17 & 291,35 & 81,99 & 227,83 & 227,83 & 73,82 & 607,50 & 85,53 & 5,29 & 58,42 & 250,28 & 26,89 & 26,89 & 239,62 \\
\hline Epidalea calamita & 30SUG81 & 100,00 & 153,52 & 110,27 & 37,74 & 6081,48 & 320,52 & 31,07 & 289,45 & 88,59 & 235,66 & 235,66 & 80,89 & 579,69 & 82,66 & 4,74 & 58,76 & 239,96 & 24,57 & 24,57 & 228,61 \\
\hline Epidalea calamita & 30SUG83 & 100,00 & 146,88 & 114,40 & 37,01 & 6387,08 & 324,88 & 21,16 & 303,71 & 78,95 & 233,39 & 233,39 & 70,75 & 626,14 & 83, & 5,6 & 56,84 & 246,76 & 28,60 & 28,60 & 240,65 \\
\hline Epidalea calamita & \begin{tabular}{|l|}
050005 \\
30 UG 84
\end{tabular} & 100,00 & $\begin{array}{l}14,00 \\
153,59\end{array}$ & $\begin{array}{l}1114,40 \\
113,48\end{array}$ & 36,01 & 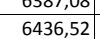 & 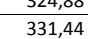 & $\begin{array}{l}27,1,62 \\
27,62\end{array}$ & \begin{tabular}{|l|}
303,83 \\
303
\end{tabular} & $\begin{array}{l}0,35 \\
84,82 \\
\end{array}$ & \begin{tabular}{|l|}
240,74 \\
240
\end{tabular} & \begin{tabular}{|l|}
240,74 \\
240
\end{tabular} & $\mid \begin{array}{l}\mid 0,15 \\
76,60\end{array}$ & \begin{tabular}{|l|}
$600,14,21$ \\
607
\end{tabular} & $\begin{array}{l}83,15 \\
80,98\end{array}$ & $\frac{3,0}{4,9}$ & $\begin{array}{l}00,04 \\
57,11\end{array}$ & \begin{tabular}{|l|}
$237,89,0$ \\
237
\end{tabular} & $\begin{array}{l}20,00 \\
26,17\end{array}$ & $\begin{array}{l}26,17 \\
26, \\
\end{array}$ & $\begin{array}{l}24,05 \\
233,38 \\
\end{array}$ \\
\hline Epidalea calamita & 30SUG85 & 100,00 & 148,31 & 115,62 & 36,83 & 6568,63 & 331,42 & 20,96 & 310,46 & 80,28 & 237,43 & 237,43 & 69,99 & 636,94 & 86,21 & 5,68 & 56,18 & 244,56 & 29,24 & 29,24 & 241,33 \\
\hline Epidalea calamita & 30SUG90 & 100,00 & 124,09 & 117,99 & 37,99 & 6306,11 & 305,62 & $-1,53$ & 307,15 & 58,80 & 210,03 & 210,03 & 49,98 & 696,79 & 91,66 & 8,28 & 54,52 & 269,74 & 38,04 & 38,04 & 264,54 \\
\hline Epidalea calamita & 30SUG91 & 100,00 & 154,26 & 110,16 & 37,51 & 6085,34 & 321,24 & 31,49 & 289,75 & 89,03 & 236,53 & 236,53 & 81,49 & 549,58 & 78,58 & 4,7 & 58,01 & 226,02 & 24,42 & 24,42 & 214,44 \\
\hline Epidalea calamita & 30SUG92 & 100,00 & 153,51 & 111,81 & 37,1 & 6234,93 & 325, & 29,25 & 296,01 & 86,55 & 237,92 & 237,92 & 78,91 & 561,34 & 77,6 & 5,0 & 57,17 & 226,44 & 25,16 & 25,16 & 217,01 \\
\hline Epidalea calamita & 30SUG93 & 100,00 & 149,08 & 114,18 & 37,00 & 6403,34 & 327,12 & 23,01 & 304,10 & 80,62 & 235,97 & 235,97 & 72,76 & 592,08 & 78,83 & 5,6 & 56,10 & 232,11 & 27,61 & 27,61 & 225,90 \\
\hline Epidalea calamita & 30SUG94 & 100,00 & 154,81 & 113,20 & 36,90 & 6460,44 & 332,98 & 28,65 & 304,33 & 85,55 & 242,41 & 242,41 & 77,56 & 581,53 & 76,64 & 5,13 & 56,41 & 225,90 & 25,89 & 25,89 & 221,69 \\
\hline Epidalea calamita & 30 SUG96 & 100,00 & 169,14 & 110,37 & 36,00 & 6498,94 & 344,60 & 43,37 & 301,23 & 102,06 & 256,68 & 256,68 & 90,79 & 550,85 & 76,01 & 3,79 & 57,74 & 213,36 & 21,20 & 21,20 & 210,45 \\
\hline Epidalea calamita & 30SUG98 & 100,00 & 174,07 & 111,48 & 36,00 & 6596,45 & 352,12 & 46,86 & 305,26 & 105,95 & 262,70 & 262,70 & 94,11 & 539,69 & 78,25 & 3,07 & 57,72 & 10,20 & 20,13 & 20,13 & 203,50 \\
\hline Epidalea calamita & 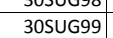 & 100,00 & 174,24 & $\begin{array}{l}111,40 \\
112,71\end{array}$ & 36,00 & | 65057,41 & 354 & $\begin{array}{l}40,00 \\
45,97 \\
\end{array}$ & 308,58 & \begin{tabular}{|l|l|}
105,44 \\
100
\end{tabular} & $\mid \begin{array}{l}262,10 \\
263,70\end{array}$ & \begin{tabular}{|l|}
263,70 \\
\end{tabular} & \begin{tabular}{l|l}
43,38 \\
93,3
\end{tabular} & $\mid$ & $\begin{array}{l}\mid 0,20 \\
79,08\end{array}$ & 3,06 & 57,43 & 208,75 & $\frac{20,15}{20,22}$ & $\frac{20,15}{20,22}$ & 200,42 \\
\hline Epidalea calamita & 30SUHOO & 100,00 & 165,63 & 124,63 & 38,00 & 6680,67 & 356,48 & 32,82 & 323,66 & 93,24 & 254,76 & 254,76 & 84,18 & 638,97 & 89,64 & 2,68 & 59,13 & 247,83 & 22,80 & 22,80 & 242,89 \\
\hline Epidalea calamita & 30SUHO2 & 100,00 & 151,15 & 124,70 & \begin{tabular}{|l|l|}
37,43 \\
\end{tabular} & \begin{tabular}{|l|l|}
6797,93 \\
\end{tabular} & 346,13 & 18,10 & 328,02 & 79,88 & 242,27 & 242,27 & 68,97 & 665,09 & 92,69 & 3,96 & 56,19 & 250,52 & 29,42 & 29,42 & 245,90 \\
\hline Epidalea calamita & 30SUHO3 & 100,00 & 156,72 & 124,97 & 37,22 & 6812,88 & 351,83 & 22,94 & 328,90 & 84,97 & 248,16 & 248,16 & 73,96 & 629,18 & 88,10 & 3,43 & 56,14 & 235,71 & 27,18 & 27,18 & 231,01 \\
\hline Epidalea calamita & 30SUHO4 & 100,00 & 152,84 & 124,93 & \begin{tabular}{|l|l|}
37,05 \\
\end{tabular} & 6831,90 & 348,81 & 19,41 & 329,40 & 81,84 & 244,76 & 244,76 & 70,04 & 628,36 & 87,41 & 3,9 & 54,82 & 232,80 & 29,55 & 29,55 & 227 \\
\hline Epidalea calamita & 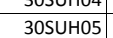 & 100,00 & $\begin{array}{l}13,04 \\
154,29\end{array}$ & $\begin{array}{l}124,53 \\
124,77\end{array}$ & 37, & $\begin{array}{l}\mid 001,100 \\
6832,25 \\
\end{array}$ & $\begin{array}{l}340,01 \\
350,07\end{array}$ & \begin{tabular}{|l|l|}
20,79 \\
20
\end{tabular} & $\begin{array}{l}329,28 \\
329\end{array}$ & $\begin{array}{l}81,04 \\
83,11 \\
\end{array}$ & \begin{tabular}{|l|}
246,08 \\
240
\end{tabular} & \begin{tabular}{|l|}
246,08 \\
240
\end{tabular} & $\begin{array}{l}0,04 \\
71,36\end{array}$ & \begin{tabular}{|l|l|}
606,60 \\
60,00
\end{tabular} & $\begin{array}{l}1,41 \\
84,11\end{array}$ & | 3,00 & $\begin{array}{ll}4,02 \\
54,17\end{array}$ & \begin{tabular}{|l|}
222,770 \\
222
\end{tabular} & | & \begin{tabular}{|l|l|}
29,59 \\
293
\end{tabular} & $\begin{array}{l}217,04 \\
217,47\end{array}$ \\
\hline Epidalea calamita & 30SUHO6 & 100,00 & 156,69 & 124,19 & 37,01 & 6840,76 & 351,82 & 22,84 & 328,98 & 84,58 & 248,40 & 248,40 & 73,47 & 581,11 & 80,24 & 3,99 & 53,46 & 211,54 & 29,10 & 29,10 & 206,06 \\
\hline Epidalea calamita & 30SUH08 & 100,00 & 156,61 & 123,59 & 37,00 & 6837,61 & 350,97 & 22,84 & 328,13 & 81,95 & 248,43 & 248,43 & 73,45 & 549,13 & 74,76 & 3,80 & 52,03 & 197,04 & 29,49 & 29,49 & 190,72 \\
\hline Epidalea calamita & 30SUHO9 & 100,00 & 156,29 & 123,05 & 37,00 & 6827,99 & 350,39 & 22,76 & 327,6 & 81,7 & 247,94 & 247, & 73, & 533,95 & 72,05 & 4,00 & 51,27 & 190,05 & 30,05 & 30,05 & 183,17 \\
\hline Epidalea calamita & $30 \mathrm{SUH} 10$ & 100,00 & 160,43 & 124,05 & 37,94 & 6743,60 & 352,50 & 27,41 & 325,09 & 89,12 & 250,70 & 250,70 & 78,31 & 659,05 & 93,60 & 3,05 & 58,55 & 253,14 & 24,49 & 24,49 & 249,34 \\
\hline
\end{tabular}




\begin{tabular}{|c|c|c|c|c|c|c|c|c|c|c|c|c|c|c|c|c|c|c|c|c|c|}
\hline TAXON & UTM & $\mathrm{km} 2$ & B101 & B102 & $\mathrm{BIO3}$ & 8104 & B105 & B106 & B107 & B108 & B109 & B1010 & BIO11 & BIO12 & B1013 & BIO14 & BIO15 & B1016 & B1017 & BIO18 & B1019 \\
\hline Epidalea calamita & 30SUH11 & 100,00 & 153,44 & 124,32 & 37,41 & 6790,20 & 347,48 & 20,28 & 327,20 & 82,93 & 244,46 & 244,46 & 71,11 & 668,52 & 94,50 & 3,88 & 56,90 & 253,99 & 27,99 & 27,99 & 249,24 \\
\hline Epidalea calamita & $30 \mathrm{SUH} 12$ & 100,00 & 152,39 & 124,68 & 37,23 & 6821,05 & 347,75 & 19,14 & 328,61 & 81,93 & 243,99 & 243,99 & 69,83 & 657,64 & 92,90 & 3,98 & 56,20 & 247,94 & 28,79 & 28,79 & 242,44 \\
\hline Epidalea calamita & 30SUH13 & 100,00 & 154,20 & 124,93 & 37,09 & 6841,54 & 350,06 & 20,50 & 329,56 & 83,68 & 246,18 & 246,18 & 71,38 & 636,21 & 89,85 & 3,75 & 55,83 & 238,13 & 28,24 & 28,24 & 232,44 \\
\hline Epidalea calamita & 30SUH14 & 100,00 & 150,81 & 124,97 & 37,02 & 6860,81 & 347,49 & 17,34 & 330,15 & 80,42 & 243,28 & 243,28 & 67,93 & 632,93 & 88,78 & 4,17 & 54,50 & 234,54 & 30,24 & 30,24 & 228,31 \\
\hline Epidalea calamita & 30SUH15 & 100,00 & 154,26 & 124,99 & 37,00 & 6858,90 & 350,54 & 20,44 & 330,10 & 83,81 & 246,70 & 246,70 & 71,17 & 603,60 & 84,48 & 4,00 & 54,14 & 221,67 & 29,30 & 29,30 & 215,70 \\
\hline Epidalea calamita & 30SUH17 & 100,00 & 159,76 & 124,03 & 37,00 & 6852,95 & 354,63 & 25,22 & 329,41 & 88,66 & 251,68 & 251,68 & 76,34 & 548,21 & 75,84 & 3,42 & 53,12 & 197,20 & 27,31 & 27,31 & 191,87 \\
\hline Epidalea calamita & 30SUH18 & 100,00 & 160,50 & 123,94 & 37,00 & 6853,55 & 354,88 & 26,04 & 328,84 & 87,45 & 252,51 & 252,51 & 76,96 & 528,38 & 72,45 & 3,32 & 52,48 & 188,55 & 27,29 & 27,29 & 183,01 \\
\hline Epidalea calamita & 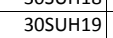 & 100,00 & 156,72 & 123,25 & 37,00 & 6850,13 & 351,13 & 22,66 & 328,47 & 82,51 & 248,74 & 248,74 & 73,43 & 527,22 & 71,32 & 3,82 & 51,09 & 186,22 & 29,49 & 29,49 & 180,06 \\
\hline Epidalea calamita & $30 \mathrm{SUH} 20$ & 100,00 & 164,69 & 123,62 & 37,62 & 6753,70 & 356,12 & 31,21 & 324,91 & 94,63 & 255,00 & 255,00 & 82,13 & 645,91 & 93,62 & 2,86 & 59,03 & 248,81 & 22,74 & 22,74 & 244,30 \\
\hline Epidalea calamita & $30 \mathrm{SUH} 21$ & 100,00 & 155,18 & 124,01 & 37,13 & 6815,08 & 349,27 & 21,83 & 327,44 & 84,73 & 246,69 & 246,69 & 72,49 & 660,60 & 94,63 & 3,78 & 57,17 & 251,76 & 27,13 & 27,13 & 245,69 \\
\hline Epidalea calamita & $30 \mathrm{SUH} 22$ & 100,00 & 157,27 & 124,38 & 37,08 & 6836,77 & 352,36 & 23,58 & 328,78 & 86,77 & 249,13 & 249,13 & 74,42 & 638,21 & 91,70 & 3,51 & 56,67 & 241,62 & 26,43 & 26,43 & 235,18 \\
\hline Epidalea calamita & $30 \mathrm{SUH} 23$ & 100,00 & 149,64 & 124,64 & 37,01 & 6867,08 & 346,31 & 16,29 & 330,03 & 79,18 & 242,11 & 242,11 & 66,75 & 647,95 & 91,83 & 4,34 & 54,98 & 242,28 & 30,37 & 30,37 & 235,08 \\
\hline Epidalea calamita & 30SUH24 & 100,00 & 152,59 & 124,99 & 37,00 & 6879,76 & 349,49 & 18,78 & 330,70 & 82,04 & \begin{tabular}{|l|}
245,28 \\
\end{tabular} & \begin{tabular}{|l|}
245,28 \\
\end{tabular} & 69,63 & 621,17 & $\begin{array}{l}11,00 \\
88,01 \\
\end{array}$ & 4, 4,03 & 54,46 & \begin{tabular}{|l|}
230,47 \\
\end{tabular} & 29,16 & 29,16 & 223,26 \\
\hline Epidalea calamita & $30 \mathrm{SUH} 25$ & 100,00 & 155,16 & 124,99 & 37,00 & 6879,92 & 351,62 & 20,82 & 330,80 & 84,49 & 247,76 & 247,76 & 71,97 & 596,25 & 84,09 & 3,99 & 54,09 & 219,10 & 28,85 & 28,85 & 212,30 \\
\hline Epidalea calamita & 30 SUH26 & 100,00 & 157,27 & 124,76 & 37,00 & 6887,23 & 353,44 & 22,57 & 330,86 & 86,49 & 249,83 & 249,83 & 73,66 & 571,73 & 80,10 & 3,89 & 53,37 & 207,64 & 28,53 & 28,53 & 201,17 \\
\hline Epidalea calamita & $30 \mathrm{SUH} 29$ & 100,00 & 159,68 & 123,59 & 37,00 & 6866,72 & 354,01 & 24,97 & 329,04 & 89,87 & 251,91 & 251,91 & 76,03 & 509,45 & 69,12 & 3,47 & 51,26 & 178,71 & 27,92 & 27,92 & 173,23 \\
\hline Epidalea calamita & 30SUH30 & 100,00 & 162,30 & 122,87 & 37,04 & 6771,33 & 354,04 & 29,24 & 324,80 & 92,31 & 253,16 & 253,16 & 80,00 & 647,49 & 94,59 & 3,26 & 58,61 & 249,89 & 23,69 & 23,69 & 243,64 \\
\hline Epidalea calamita & 30SUH31 & 100,00 & 159,11 & 123,50 & 37,05 & 6820,64 & 352,68 & 25,53 & 327,15 & 88,65 & 250,72 & 250,72 & 76,22 & 643,77 & 93,65 & 3,54 & 57,47 & 246,45 & 25,46 & 25,46 & 239,30 \\
\hline Epidalea calamita & 30SUH32 & 100,00 & 156,88 & 123,97 & 37,00 & 6859,15 & 351,87 & 22,99 & 328,88 & 86,10 & 249,13 & 249,13 & 73,61 & 635,38 & 92,01 & 3,77 & 56,51 & 240,96 & 26,70 & 26,70 & 233,23 \\
\hline Epidalea calamita & 30SUH33 & 100,00 & 155,03 & 124,15 & 37,00 & 6882,36 & 351,03 & 20,96 & 330,08 & 84,19 & 247,63 & 247,63 & 71,67 & 625,04 & 89,89 & 3,97 & 55,43 & 234.58 & 27,97 & 27,97 & 226,59 \\
\hline Epidalea calamita & 30SUH34 & 100,00 & 152,05 & 124,73 & 37,00 & 6907,64 & 348,98 & 17,85 & 331,13 & 81,11 & 245,16 & 245,16 & 68,66 & 617,62 & 87,99 & 4,11 & 54,31 & 229,10 & 29,42 & 29,42 & 220,93 \\
\hline Epidalea calamita & 30SUH35 & 100,00 & 153,47 & 124,96 & 37,00 & 6914,82 & 350,41 & 18,82 & 331,59 & $\begin{array}{l}82,61 \\
82,1\end{array}$ & 246,64 & 246,64 & 69,85 & 595,47 & 84,36 & 4,00 & 53,71 & 218,63 & 29,03 & 29,03 & 210,82 \\
\hline Epidalea calamita & 30SUH36 & 100,00 & 156,80 & 124,81 & 37,00 & 6903,97 & 353,21 & 21,85 & 331,37 & 86,01 & 249,63 & 249,63 & 72,98 & 566,97 & 79,78 & 3,86 & 53,20 & 205,78 & 28,44 & 28,44 & 198,61 \\
\hline Epidalea calamita & 30SUH37 & 100,00 & 158,19 & 124,25 & 37,00 & 6893,18 & 353,98 & 23,16 & 330,82 & 87,52 & 250,85 & 250,85 & 74,40 & 543,75 & 75,72 & 3,51 & 52,56 & 194,90 & 27,77 & 27,77 & 188,42 \\
\hline Epidalea calamita & 30SUH38 & 100,00 & 160,64 & 124,02 & 37,00 & 6885,64 & 355,60 & 25,47 & 330,13 & 89,97 & 253,13 & 253,13 & 76,72 & 517,02 & 71,21 & 3,28 & 52,03 & 182,91 & 26,94 & 26,94 & 177,24 \\
\hline Epidalea calamita & $30 \mathrm{SUH} 40$ & 100,00 & 166,59 & 121,69 & 37,01 & 6766,19 & 356,73 & 33,38 & 323,35 & 96,41 & 257,32 & 257,32 & 83,97 & 627,45 & 92,90 & 3,00 & 58,99 & 243,12 & 22,05 & 22,05 & 235,93 \\
\hline Epidalea calamita & 30SUH41 & 100,00 & 163,68 & 122,52 & 37,00 & 6815,77 & 355,97 & $\begin{array}{l}3,90 \\
29,91 \\
\end{array}$ & 326,06 & $\begin{array}{l}00,111 \\
93,17\end{array}$ & 255,18 & 255,18 & 80,68 & \begin{tabular}{|l|l|}
621,48 \\
\end{tabular} & $\begin{array}{l}2,1,61 \\
91\end{array}$ & 3,31 & 57,85 & $\mid$\begin{tabular}{|l|}
238,69 \\
\end{tabular} & 23,62 & 23,62 & 230,69 \\
\hline Epidalea calamita & $30 \mathrm{SUH} 42$ & 100,00 & 159,93 & 123,20 & 37,00 & 6866,91 & 354,13 & 25,70 & 328,43 & 88,95 & 252,18 & 252,18 & 76,42 & 618,63 & 90,50 & 3,56 & 56,64 & 235,22 & 25,44 & 25,44 & 226,66 \\
\hline Epidalea calamita & $30 \mathrm{SUH} 43$ & 100,00 & 154,47 & 123,89 & 37,00 & 6906,66 & 350,66 & 20,31 & 330,36 & 83,37 & 247,52 & 247,52 & 70,86 & 619,21 & 89,46 & 3,99 & 55,09 & 232,34 & 28,04 & 28,04 & 223,41 \\
\hline Epidalea calamita & $30 \mathrm{SUH} 44$ & 100,00 & 151,10 & 124,14 & 37,00 & 6935,14 & 348,41 & 16,70 & 331,71 & 79,95 & 244,71 & 244,71 & 67,39 & 613,34 & 87,64 & 4,10 & 53,95 & 227,34 & 29,66 & 29,66 & 218,34 \\
\hline Epidalea calamita & $30 \mathrm{SUH} 46$ & 100,00 & 157,91 & 124,35 & 37,00 & 6911,92 & 354,04 & 22,60 & 331,45 & 87,01 & 250,81 & 250,81 & 73,84 & 555,28 & 78,31 & 3,76 & 52,91 & 201,13 & 27,90 & 27,90 & 193,54 \\
\hline Epidalea calamita & 30SUH47 & 100,00 & 156,62 & 124,50 & 37,00 & 6912,72 & 352,90 & 21,42 & \begin{tabular}{|l|}
331,48 \\
331,4
\end{tabular} & $\begin{array}{l}85,87 \\
8\end{array}$ & \begin{tabular}{|l|}
249,65 \\
240
\end{tabular} & \begin{tabular}{|l|}
249,65 \\
240
\end{tabular} & 72,71 & 541,91 & $\begin{array}{l}70,11 \\
75,45\end{array}$ & 3,73 & 52,08 & \begin{tabular}{|l|l|}
193,57 \\
\end{tabular} & 28,44 & 28,44 & 186,43 \\
\hline Epidalea calamita & $30 \mathrm{SUH} 48$ & 100,00 & 158,87 & 124,11 & 37,00 & 6901,36 & 354,40 & 23,56 & 330,84 & 88,28 & 251,73 & 251,73 & 75,01 & 516,26 & 70,91 & 3,53 & 51,42 & 181,79 & 27,87 & 27,87 & 175,64 \\
\hline Epidalea calamita & $30 \mathrm{SUH} 49$ & 100,00 & 156,20 & 124,03 & 37,00 & 6904,72 & 351,85 & 21,02 & 330,83 & 85,84 & 249,25 & 249,25 & 72,32 & 508,38 & 68,64 & 3,86 & 50,16 & 176,05 & 29,40 & 29,40 & 170,30 \\
\hline Epidalea calamita & 30SUH50 & 100,00 & 175,19 & 119,49 & 37,00 & 6695,72 & 361,25 & 42,80 & 318,44 & 105,48 & 264,70 & 264,70 & 93,00 & 587,42 & 87,73 & 2,28 & 59,74 & 228,21 & 18,78 & 18,78 & 221,46 \\
\hline Epidalea calamita & 30SUH51 & 100,00 & 167,94 & 121,13 & 37,00 & 6800,02 & 358,36 & 34,78 & 323,58 & 97,66 & 259,20 & 259,20 & 84,95 & 597,88 & 88,85 & 2,99 & 58,12 & 230,16 & 22,01 & 22,01 & 221,71 \\
\hline Epidalea calamita & 30SUH52 & 100,00 & 156,27 & $\begin{array}{l}121,15 \\
122,73\end{array}$ & 37,00 & 6808,54 & 350,98 & $\begin{array}{l}4,10 \\
22,63 \\
\end{array}$ & \begin{tabular}{|l|l|}
328,35 \\
325
\end{tabular} & $\begin{array}{l}31,400 \\
85,45\end{array}$ & \begin{tabular}{|l|}
249,04 \\
240
\end{tabular} & \begin{tabular}{|l|}
249,04 \\
240
\end{tabular} & $\begin{array}{l}4,, 25 \\
72,88\end{array}$ & $\begin{array}{l}\mid 619,82 \\
619,0\end{array}$ & $\begin{array}{l}0,00 \\
90,50 \\
\end{array}$ & 3, 396 & 55,71 & $\mid$ & $\frac{\mid 2,10}{27,16}$ & $\begin{array}{l}27,01 \\
27,16\end{array}$ & 225,29 \\
\hline Epidalea calamita & 30SUH53 & 100,00 & 151,46 & 123,55 & 37,00 & 6923,90 & 347,84 & 17,35 & 330,49 & 80,16 & 244,83 & 244,83 & 67,78 & 620,32 & 89,50 & 4,44 & 54,35 & 232,18 & 29,65 & 29,65 & 222,21 \\
\hline Epidalea calamita & 30SUH54 & 100,00 & 150,88 & 123,99 & 37,00 & 6938,76 & 347,95 & 16,38 & 331,58 & 79,54 & 244,46 & 244,46 & 67,07 & 605,83 & 86,74 & 4,39 & 53,43 & 224,08 & 30,25 & 30,25 & 214,33 \\
\hline Epidalea calamita & 30SUH55 & 100,00 & 154,13 & 124,04 & 37,00 & 6932,63 & 350,89 & 19,13 & 331,76 & 83,23 & 247,52 & 247,52 & 70,19 & 577,22 & 82,19 & 4,02 & 53,10 & 211,24 & 28,82 & 28,82 & 202,25 \\
\hline Epidalea calamita & $\begin{array}{l}30 \text { SUH56 } \\
\end{array}$ & 100,00 & 156,92 & 124,19 & 37,00 & 6927,64 & 353,20 & 21,55 & 331,65 & 85,88 & 250,18 & 250,18 & 72,80 & 550,41 & 77,5 & 3,89 & 52,44 & 198,71 & 28,34 & 28,34 & 190,68 \\
\hline Epidalea calamita & 30SUH57 & 100,00 & 151,04 & 124,89 & 37,00 & 6933,85 & 348,32 & 15,91 & 332,42 & 80,23 & 244,52 & 244,52 & 67,21 & 552,66 & 76,26 & 4,34 & 50,95 & \begin{tabular}{|l|}
195,91 \\
\end{tabular} & 31,15 & 31,15 & 188,14 \\
\hline Epidalea calamita & 30SUH58 & 100,00 & 155,92 & 124,62 & 37,00 & 6916,51 & 352,13 & 20,50 & 331,63 & 87,59 & 249,11 & 249,11 & 72,13 & 518,13 & 70,77 & 3,93 & 50,58 & 181,39 & 29,22 & 29,22 & 174,72 \\
\hline Epidalea calamita & 30SUH61 & 100,00 & 168,19 & 119,91 & 36,98 & 6799,46 & 357,62 & 35,53 & 322,10 & 98,02 & 259,55 & 259,55 & 85,31 & 583,79 & 86,68 & 3,14 & 57,68 & 224,48 & 22,09 & 22,09 & 215,60 \\
\hline Epidalea calamita & 30SUH62 & 100,00 & 159,36 & 121,62 & 36,99 & 6883,64 & 352,88 & 26,08 & 326,81 & 88,66 & 252,18 & 252,18 & 76,03 & 598,82 & $88, \mathrm{C}$ & 3,2 & 55,69 & 227,40 & 26,00 & 26,00 & 217,16 \\
\hline Epidalea calamita & 30SUH63 & 100,00 & 151,72 & 122,97 & 37,00 & 6927,43 & 347,90 & 18,08 & 329,83 & $\begin{array}{l}0,000 \\
80,69 \\
\end{array}$ & \begin{tabular}{|l|}
245,28 \\
\end{tabular} & \begin{tabular}{|l|}
245,28 \\
\end{tabular} & $60,0,30$ & $\begin{array}{l}509,03 \\
6090 \\
\end{array}$ & $\begin{array}{l}80, \\
88, \\
\end{array}$ & $\frac{3,}{4,}$ & 53,90 & 227,54 & 29,81 & 29,81 & $\begin{array}{l}21,16,79 \\
216,79\end{array}$ \\
\hline Epidalea calamita & $30 \mathrm{SUHG}$ & 100,00 & 150,72 & 123,71 & 37,00 & 6944,50 & 347,86 & 16,61 & 331,26 & 79,53 & 244,57 & 244,57 & 67,15 & 596,67 & 85,45 & 4,58 & 52,90 & 220,07 & 30,67 & 30,67 & 209,74 \\
\hline Epidalea calamita & 30 SUH65 & 100,00 & 153,88 & 123,98 & 37,00 & 6938,73 & 350,60 & 19,02 & 331,58 & 82,97 & 247,51 & 247,51 & 69,97 & 568,39 & 80,88 & 4,03 & 52,71 & 207,44 & 29,00 & 29,00 & 198,00 \\
\hline Epidalea calamita & 30SUH67 & 100,00 & 149,16 & 124,99 & 37,00 & 6940,01 & 346,73 & 13,99 & 332,74 & 88,94 & 242,86 & 242,86 & 65,36 & 549,43 & 75,42 & 4,36 & 50,23 & 194,17 & 32,05 & 32,05 & 185,56 \\
\hline Epidalea calamita & 30SUH69 & 100,00 & 148,55 & 125,02 & 37,00 & 6936,00 & 345,94 & 13,06 & 332,88 & 116,64 & 242,25 & 242,25 & 64,80 & 517,39 & 68,56 & 4,43 & 48,32 & 27 & 32,96 & 32,96 & 169,88 \\
\hline Epidalea calamita & 30SUH72 & 100,00 & $\frac{140}{164}$ & 120,13 & 36,78 & $\mid 6853,19$ & $35,54,20$ & $\begin{array}{l}3,, 00 \\
31,22\end{array}$ & \begin{tabular}{|l|l|}
323,98 \\
323,9
\end{tabular} & \begin{tabular}{|c|c|c|c|c|}
93,39 \\
93
\end{tabular} & \begin{tabular}{|l|}
256,33 \\
\end{tabular} & \begin{tabular}{|l|}
256,33 \\
\end{tabular} & $\begin{array}{l}4,00 \\
80,81\end{array}$ & $\mid 571,80$ & $\begin{array}{l}0,30 \\
84,39 \\
\end{array}$ & $\begin{array}{l}4,45 \\
3,52\end{array}$ & $\begin{array}{l}40,52 \\
55,76\end{array}$ & $\mid \begin{array}{l}\mid 17,217 \\
217,34\end{array}$ & $\begin{array}{l}24,27 \\
24\end{array}$ & $\begin{array}{l}24,27 \\
24,\end{array}$ & $\begin{array}{l}207,00 \\
207,05\end{array}$ \\
\hline Epidalea calamita & 30SUH73 & 100,00 & 150,43 & 122,52 & 36,84 & 6938,53 & 346,58 & 16,95 & 329,64 & 79,37 & 244,26 & 244,26 & 66,90 & 603,05 & 87,12 & 4,85 & 53,18 & 224,50 & 30,80 & 30,80 & 213,05 \\
\hline Epidalea calamita & 30SUH74 & 100,00 & 151,78 & 123,02 & 37,00 & 6941,81 & 348,19 & 17,94 & 330,25 & 80,72 & \begin{tabular}{|l|}
245,66 \\
\end{tabular} & 245,66 & 68,25 & 582,21 & $\begin{array}{l}1,124 \\
83,49\end{array}$ & 年, 44 & 52,59 & 214,36 & 30,20 & 30,20 & 203,55 \\
\hline Epidalea calamita & 30 SUH75 & 100,00 & 148,38 & 123,98 & 37,00 & 6945,49 & 345,76 & 14,17 & 331,59 & 81,12 & 242,28 & 242,28 & 64,94 & 577,95 & 81,45 & 4,75 & 51,44 & 209,36 & 32,20 & 32,20 & 198,97 \\
\hline Epidalea calamita & 30SUH77 & 100,00 & 147,90 & 125,00 & 37,00 & 6946,68 & 345,71 & 12,77 & 332,94 & 101,20 & 241,78 & 241,78 & 64,02 & 543,49 & 74,16 & 4,66 & 49,51 & 192,43 & 32,81 & 32,81 & 181,97 \\
\hline Epidalea calamita & 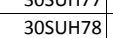 & $\begin{array}{l}100,00 \\
\end{array}$ & $\begin{array}{l}147,50 \\
147,51\end{array}$ & 125,44 & 37,00 & $\begin{array}{l}\mid 634,000 \\
6943,53\end{array}$ & $345,1,35$ & $\begin{array}{ll}11,86 \\
117\end{array}$ & \begin{tabular}{|l|}
333,49 \\
333,4
\end{tabular} & \begin{tabular}{|l|}
101,89 \\
100
\end{tabular} & \begin{tabular}{|l|}
241,28 \\
241
\end{tabular} & \begin{tabular}{|l|}
241,28 \\
241
\end{tabular} & $\begin{array}{l}4,, 0<4 \\
63,78 \\
\end{array}$ & \begin{tabular}{|l|}
$527,4,11$ \\
5
\end{tabular} & 70,51 & $\begin{array}{l}4,400 \\
4,52 \\
\end{array}$ & $\begin{array}{l}48,11 \\
48,64\end{array}$ & \begin{tabular}{|l|}
184,42 \\
18,4
\end{tabular} & $\begin{array}{l}2,01 \\
33,20 \\
\end{array}$ & $\begin{array}{ll}20,01 \\
33,20\end{array}$ & $\begin{array}{l}101,51 \\
174,00\end{array}$ \\
\hline Epidalea calamita & 30SUH79 & 100,00 & 146,89 & 125,74 & 37,00 & 6936,43 & 344,63 & 10,99 & 333,64 & 126,48 & 240,77 & 240,77 & 63,22 & 511,78 & 67,01 & 4,52 & 47,64 & 178,23 & 33,67 & 33,67 & 166,41 \\
\hline Epidalea calamita & 30SUH81 & 100,00 & 173,46 & 116,62 & 36,23 & 6739,70 & 358,49 & 42,42 & 316,07 & 103,77 & 263,92 & 263,92 & 91,24 & 537,50 & 79,71 & 2,97 & 57,01 & 206,38 & 20,59 & 20,59 & 197,35 \\
\hline Epidalea calamita & 30SUH82 & 100,00 & 158,93 & 119,88 & 36,38 & 6896,57 & 351,39 & 26,70 & 324,69 & 88,28 & 252, & 252, & 75, & 578,24 & 85,17 & 4,16 & 54,55 & 218,97 & 26,85 & 26,85 & 207 \\
\hline Epidalea calamita & 30SUH83 & 100,00 & 150,42 & 121,94 & 36,52 & 6952,54 & 346,31 & 17,11 & 329,19 & $\mid 79,19$ & 244,50 & 244,50 & 66,77 & 593,26 & 85,86 & $4,4,98$ & 52,75 & 220,49 & 31,11 & 31,11 & 208,25 \\
\hline
\end{tabular}




\begin{tabular}{|c|c|c|c|c|c|c|c|c|c|c|c|c|c|c|c|c|c|c|c|c|c|}
\hline TAXON & UTM & $\mathrm{km2}$ & B101 & $\mathrm{B1O2}$ & $\mathrm{BIO3}$ & B104 & B105 & B106 & B107 & B108 & B109 & 81010 & B1011 & BIO12 & BIO13 & 81014 & B1015 & BIO16 & BIO17 & BIO18 & B1019 \\
\hline Epidalea calamita & $30 \mathrm{SUH} 84$ & 100,00 & 154,04 & 122,48 & 36,91 & 6943,70 & 349,56 & 20,06 & 329,49 & 83,92 & 247,77 & 247,77 & 70,27 & 563,59 & 80,97 & 4,26 & 52,42 & 207,25 & 29,19 & 29,19 & 196,12 \\
\hline Epidalea calamita & $30 \mathrm{SUH} 85$ & 100,00 & 141,49 & 124,08 & 37,00 & 6965,81 & 339,93 & 7,69 & 332,24 & 91,04 & 235,90 & 235,90 & 58,33 & 591,33 & 82,19 & 5,76 & 49,85 & 213,17 & 36,21 & 36,21 & 200,69 \\
\hline Epidalea calamita & 30SUH86 & 100,00 & 145,59 & 124,74 & 37,00 & 6964,43 & 343,72 & 10,73 & 332,99 & 98,61 & 239,85 & 239,85 & 61,92 & 559,53 & 77,06 & 5,04 & 49,66 & 200,49 & 33,95 & 33,95 & 188,22 \\
\hline Epidalea calamita & 30SUH87 & 100,00 & 146,01 & 125,26 & 37,00 & 6949,86 & 344,13 & 10,88 & 333,25 & 99,38 & 240,03 & 240,03 & 62,22 & 539,66 & 72,92 & 4,84 & 48,75 & 191,20 & 33,88 & 33,88 & 179,09 \\
\hline Epidalea calamita & 30SUH88 & 100,00 & 144,92 & 125,94 & 37,00 & $\begin{array}{ll}6940,05 \\
\end{array}$ & 343,28 & \begin{tabular}{|l|l|}
9,27 \\
\end{tabular} & 334,01 & 107,70 & 238,79 & 238,79 & 61,38 & 525,05 & 69,43 & 4,77 & 47,69 & 184,06 & 34,63 & 34,63 & 171,40 \\
\hline Epidalea calamita & 30SUH89 & 100,00 & 148,44 & 126,05 & 37,05 & 6923,10 & 345,99 & 12,38 & 333,61 & 131,37 & 242,10 & 242,10 & 64,94 & 493,66 & 63,99 & 4,09 & 47,51 & 172,80 & 32,73 & 32,73 & 159,31 \\
\hline Epidalea calamita & 30SUH91 & 100,00 & 173,91 & 115,37 & 36,04 & 6737,19 & 357,76 & 43,66 & 314,10 & 104,35 & 264,36 & 264,36 & 91,91 & 522,34 & 77,31 & 3,08 & 56,38 & 200,06 & 20,91 & 20,91 & 190,64 \\
\hline Epidalea calamita & 30SUH92 & 100,00 & 163,76 & 118,20 & 36,05 & 6865,54 & 353,73 & 32,17 & 321,56 & \begin{tabular}{|l|}
93,18 \\
\end{tabular} & 256,31 & 256,31 & 80,76 & 550,32 & 81,49 & 3,78 & 54,71 & 208,74 & 24,99 & 24,99 & 196,92 \\
\hline Epidalea calamita & 30SUH93 & 100,00 & 157,60 & 120,31 & 36,39 & 6920,18 & 350,89 & 25,01 & 325,88 & 91,03 & 251,12 & 251,12 & 74,21 & 557,10 & 81,35 & 4,24 & 53,21 & 207,95 & 27,88 & 27,88 & 195,62 \\
\hline Epidalea calamita & 30SUH95 & 100,00 & 140,41 & 124,03 & 37,00 & 6966,58 & 338,94 & 6,78 & 332,16 & 92,96 & 235,03 & 235,03 & 57,38 & 584,27 & 80,83 & 5,92 & 49,15 & 211,03 & 37,01 & 37,01 & 196,48 \\
\hline Epidalea calamita & 30SUH97 & 100,00 & 146,86 & 125,39 & 37,00 & 6938,87 & 344,56 & 11,62 & 332,94 & 100,52 & 240,75 & 240,75 & 63,27 & 525,40 & 70,56 & 4,64 & 48,40 & 186,60 & 33,58 & 33,58 & 173,00 \\
\hline Epidalea calamita & 30SUH98 & 100,00 & 147,00 & 125,99 & 37,00 & 6930,67 & 344,96 & 11,24 & 333,72 & 118,62 & 240,77 & 240,77 & 63,63 & 505,15 & 66,19 & 4,32 & 47,51 & 177,79 & 33,52 & 33,52 & 163,80 \\
\hline Epidalea calamita & 30SUH99 & 100,00 & 146,58 & 126,61 & 37,44 & 6909,73 & 344,29 & 10,52 & 333,77 & 129,35 & 239,97 & 239,97 & 63,37 & 489,23 & 62,42 & 4,24 & 46,61 & 171,92 & 33,88 & 33,88 & 156,11 \\
\hline Epidalea calamita & 30SUJO1 & 100,00 & 160,82 & 121,92 & 37,00 & 6783,25 & 352,34 & 27,82 & 324,52 & 89,92 & 251,71 & 251,71 & 78,15 & 485,01 & 64,20 & 3,49 & 50,32 & 170,88 & 28,56 & 28,56 & 162,91 \\
\hline Epidalea calamita & 30SUJ02 & 100,00 & 159,36 & 121,10 & 37,00 & 6790,35 & 350,59 & 26,64 & 323,95 & 89,07 & 250,54 & 250,54 & 76,72 & 476,07 & 62,28 & 3,92 & 49,00 & 166,33 & 29,72 & 29,72 & 157,84 \\
\hline Epidalea calamita & 30SUJO3 & 100,00 & 158,62 & 120,52 & 37,00 & 6769,54 & 348,91 & 26,27 & 322,64 & 99,67 & 249,47 & 249,47 & 76,11 & 465,44 & 60,16 & 3,94 & 48,21 & 161,70 & 30,25 & 30,25 & 152,66 \\
\hline Epidalea calamita & 30SUJO4 & 100,00 & 156,92 & 119,92 & 37,00 & 6755,07 & 346,35 & 25,01 & 321,34 & 102,60 & 247,57 & 247,57 & 74,59 & 458,75 & 58,51 & 4,14 & 47,32 & 158,13 & 31,29 & 31,29 & 148,60 \\
\hline Epidalea calamita & 30SUJ08 & 100,00 & 137,04 & 116,82 & 36,70 & 6673,35 & 323,89 & 8,81 & 315,09 & 77,53 & 227,21 & 227,23 & 56,81 & 486,26 & 57,10 & 7,11 & 42,11 & 162,30 & 43,28 & 43,30 & 149,61 \\
\hline Epidalea calamita & 30SUJ10 & 100,00 & 160,25 & 122,95 & 37,00 & 6834,18 & 353,38 & 26,25 & 327,13 & 88,09 & 251,96 & 251,96 & 76,84 & 497,58 & 66,73 & 3,46 & 50,66 & 174,90 & 28,12 & 28,12 & 168,17 \\
\hline Epidalea calamita & 30SUJ11 & 100,00 & 157,28 & 122,27 & $37,00 \mid$ & 6821,56 & 350,13 & 23,83 & 326,31 & 87,09 & 248,91 & 248,91 & 74,36 & 493,68 & 65,26 & 4,00 & 49,40 & 171,72 & 30,24 & 30,24 & 164,36 \\
\hline Epidalea calamita & 30SUJ12 & 100,00 & 158,19 & 121,74 & 37,00 & 6812,73 & 350,10 & 25,05 & 325,05 & 103,86 & 249,71 & 249,71 & 75,26 & 474,85 & 61,96 & 3,89 & 48,81 & 164,18 & 29,88 & 29,88 & 156,28 \\
\hline Epidalea calamita & \begin{tabular}{|l|l}
30 SUJ13 \\
\end{tabular} & 100,00 & 156,64 & 121,00 & 37,00 & 6801,50 & 347,80 & 23,78 & 324,02 & $\begin{array}{l}105,67 \\
\end{array}$ & 248,01 & 248,01 & 73,92 & 465,89 & 59,87 & 4,12 & 47,67 & 160,01 & 31,00 & 31,00 & 151,35 \\
\hline Epidalea calamita & 30SUJ14 & 100,00 & 158,51 & 120,24 & 37,00 & \begin{tabular}{ll|l|}
6776,48 \\
\end{tabular} & 348,22 & 25,77 & 322,45 & 113,71 & 249,50 & 249,50 & 75,81 & 446,28 & 56,61 & 4,03 & 47,15 & 153,15 & 30,48 & 30,48 & 143,51 \\
\hline Epidalea calamita & 30SUJ15 & 100,00 & 156,77 & 119,64 & 36,98 & 6758,22 & 345,78 & 24,61 & 321,17 & 114,42 & 247,55 & 247,55 & 74,36 & 439,26 & 54,84 & 4,23 & 46,27 & 149,96 & 31,43 & 31,43 & 139,35 \\
\hline Epidalea calamita & 30SUJ16 & 100,00 & 150,71 & 118,95 & 36,93 & 6750,22 & 339,48 & 19,53 & 319,95 & 112,31 & 241,65 & 241,65 & 68,87 & 447,62 & 54,79 & 4,97 & 44,69 & 150,97 & 34,73 & 34,73 & 139,90 \\
\hline Epidalea calamita & 30SUJ18 & 100,00 & 139,00 & 117,31 & 36,77 & 6694,77 & 326,16 & 9,66 & 316,50 & 112,17 & 229,44 & 229,45 & 58,38 & 467,38 & 54,50 & 6,79 & 41,90 & 155,04 & 41,88 & 41,89 & 141,82 \\
\hline Epidalea calamita & 30 SUJ22 & 100,00 & 154,62 & 122,09 & 37,00 & 6835,34 & 347,53 & 20,91 & 326,62 & \begin{tabular}{|l|l|}
106,33 \\
\end{tabular} & 246,51 & 246,51 & $\begin{array}{l}71,58 \\
71,58\end{array}$ & 481,43 & $\begin{array}{l}4,50 \\
62,50\end{array}$ & 4,12 & 48,03 & 164,49 & 31,29 & 31,29 & 157,19 \\
\hline Epidalea calamita & 30SUJ23 & 100,00 & 154,21 & 121,51 & 37,00 & 6828,54 & 346,38 & 21,01 & 325,37 & 117,96 & 246,11 & 246,11 & 71,29 & 468,02 & 59,81 & 4,23 & 47,12 & 159,10 & 31,90 & 31,90 & 150,66 \\
\hline Epidalea calamita & 30SUJ24 & 100,00 & 155,18 & 120,80 & 37,00 & 6806,05 & 346,03 & 22,25 & 323,78 & 119,90 & 246,76 & 246,76 & 72,42 & 450,64 & 56,65 & 4,29 & 46,35 & 153,20 & 31,85 & 31,85 & 143,24 \\
\hline Epidalea calamita & 30 SUJ 25 & 100,00 & 154,72 & 120,04 & 36,99 & 6787,16 & 344,53 & 21,95 & 322,58 & 120,57 & 246,02 & 246,02 & 72,17 & 439,75 & 54,41 & 4,44 & 45,49 & 148,96 & 32,50 & 32,50 & 138,06 \\
\hline Epidalea calamita & 30SUJ26 & 100,00 & 152,32 & 119,27 & 36,81 & 6771,48 & 341,38 & 20,07 & 321,31 & 122,77 & 243,51 & 243,51 & 70,08 & 435,45 & 52,76 & 4,90 & 44,36 & 146,68 & 34,10 & 34,10 & 134,77 \\
\hline Epidalea calamita & 30SUJ27 & 100,00 & 144,30 & 118,69 & 36,73 & 6749,11 & 333,08 & 13,26 & \begin{tabular}{|l|}
319,82 \\
31,1
\end{tabular} & 127,03 & \begin{tabular}{|l|}
235,39 \\
239
\end{tabular} & \begin{tabular}{|l|}
235,39 \\
239
\end{tabular} & 62,75 & \begin{tabular}{|l|}
450,37 \\
40,45
\end{tabular} & 53,29 & 5,94 & 42,70 & 150,73 & 38,40 & 38,40 & 136,93 \\
\hline Epidalea calamita & 30SUJ31 & 100,00 & 150,96 & 123,14 & 37,00 & 6882,02 & 345,94 & 16,56 & 329,38 & 115,15 & 243,83 & 243,83 & 67,74 & 502,99 & 65,85 & 4,31 & 48,20 & 171,38 & 32,64 & 32,64 & 164,81 \\
\hline Epidalea calamita & 30SUJ32 & 100,00 & 151,82 & 122,74 & 37,00 & 6864,87 & 345,74 & 17,56 & 328,18 & 132,25 & 244,36 & 244,36 & 68,72 & 484,56 & 62,45 & 4,38 & 47,40 & 164,73 & 32,69 & 32.69 & 156,66 \\
\hline Epidalea calamita & 30SUJ34 & 100,00 & 148,27 & 121,21 & 37,00 & 6833,84 & 340,65 & 15,19 & 325,46 & 131,71 & 240,45 & 240,45 & 65,63 & 468,50 & 58,17 & 5,12 & 45,11 & 158,61 & 35,34 & 35,34 & 147,01 \\
\hline Epidalea calamita & 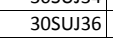 & 100,00 & 152,20 & 119,78 & 36,92 & 6784,40 & 341,57 & 19,43 & 322,15 & 134,07 & 243,51 & 243,51 & 69,69 & 428,59 & 51,38 & 4,99 & 43,87 & 144,37 & 34,22 & 34,22 & 131,29 \\
\hline Epidalea calamita & 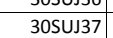 & 100,00 & 144,70 & $\begin{array}{l}119,100 \\
119,00\end{array}$ & 30,75 & 67775,17 & 333,91 & $\begin{array}{l}0,43 \\
12,81 \\
\end{array}$ & \begin{tabular}{|l|}
321,10 \\
3210
\end{tabular} & \begin{tabular}{|l|}
128,67 \\
128
\end{tabular} & \begin{tabular}{|l|}
236,24 \\
236,2
\end{tabular} & \begin{tabular}{|l|}
236,24 \\
236,2
\end{tabular} & $\begin{array}{l}62,83 \\
62,8\end{array}$ & \begin{tabular}{|l|l|}
$440,1,99$ \\
441
\end{tabular} & $\begin{array}{l}\mid 1,100 \\
51,74\end{array}$ & $\begin{array}{l}4,459 \\
5,98\end{array}$ & $\begin{array}{l}43,01 \\
42,35\end{array}$ & 148,48 & 38,34 & $\begin{array}{ll}38,34 \\
38,4\end{array}$ & $\begin{array}{l}131,29 \\
132,89\end{array}$ \\
\hline Epidalea calamita & 30SUJ38 & 100,00 & 131,12 & 117,91 & 36,48 & 6727,14 & 319,99 & 1,57 & 318,42 & 114,04 & 222,45 & 222,45 & 50,72 & 480,95 & 55,18 & 8,10 & 40,09 & 160,68 & 46,89 & 46,89 & 141,54 \\
\hline Epidalea calamita & 30SUJ39 & 100,00 & 138,86 & 117,22 & 36,46 & 6705,00 & 325,71 & 8,61 & 317,10 & 122,84 & 229,62 & 229,62 & 58,14 & 437,96 & 50,32 & 7,14 & 40,21 & 146,02 & 42,50 & 42,50 & 127,45 \\
\hline Epidalea calamita & 30SUJ42 & 100,00 & 146,07 & 123,11 & 37,00 & 6891,55 & 341,34 & 11,74 & 329,60 & 129,14 & 239,19 & 239,19 & 62,95 & 497,35 & 63,27 & 5,08 & 46,15 & 169,92 & 35,59 & 35,59 & 158,83 \\
\hline Epidalea calamita & 30SUJ43 & 100,00 & 145,44 & 122,64 & 37,00 & 6874,67 & 339,72 & 11,30 & 328,42 & 128,48 & 238,21 & 238,21 & 62,43 & 485,61 & 60,68 & 5,23 & 45,29 & 165,68 & 36,31 & 36,31 & 152,99 \\
\hline Epidalea calamita & \begin{tabular}{|l|}
$305 U J 46$ \\
\end{tabular} & 100,00 & 149,38 & 120,01 & 36,91 & 6803,76 & 339,39 & 16,32 & \begin{tabular}{|l|}
323,06 \\
\end{tabular} & 133,49 & 241,15 & 241,15 & 66,78 & \begin{tabular}{|l|l|}
431,73 \\
\end{tabular} & 51,15 & 5,34 & 43,24 & 146,16 & 35,74 & 35,74 & 130,47 \\
\hline Epidalea calamita & 30SUJ47 & 100,00 & 139,20 & 119,04 & 36,58 & 6777,43 & 328,92 & 7,78 & 321,14 & 122,71 & 231,06 & 231,06 & 57,63 & 456,81 & 52,81 & 6,85 & 41,34 & 153,92 & 41,97 & 41,97 & 135,41 \\
\hline Epidalea calamita & 30SUJ48 & 100,00 & 128,70 & 118,21 & 36,60 & 6735,84 & 318,01 & $-0,92$ & 318,93 & 111,44 & 220,25 & 220,25 & 48,31 & 482,80 & 55,92 & 8,52 & 39,42 & 161,99 & 48,59 & 48,59 & 140,19 \\
\hline Epidalea calamita & 30SUJ49 & 100,00 & 140,21 & 117,42 & 36,08 & 6738,94 & 327,38 & 9,10 & 318,27 & 124,44 & 231,39 & 231,39 & 58,99 & 427,31 & 49,60 & 6,9 & 39,94 & 142,94 & 41,89 & 41,89 & 123,03 \\
\hline Epidalea calamita & 30 SUJ50 & 100,00 & 148,90 & 124,47 & 37,00 & 6917,34 & 345,44 & \begin{tabular}{|c|}
$, 13,79$ \\
13
\end{tabular} & 331,64 & $\begin{array}{ll}128,63 \\
\end{array}$ & 242,25 & 242,25 & 65,34 & 509,58 & $\begin{array}{l}66,83 \\
663\end{array}$ & 4,47 & 47,94 & 175,40 & $\begin{array}{l}31,00 \\
33,10\end{array}$ & $\begin{array}{l}43,10 \\
3,10 \\
\end{array}$ & 166,39 \\
\hline Epidalea calamita & 30SUJ51 & 100,00 & 150,69 & 124,01 & 37,00 & 6903,21 & 346,19 & 15,61 & 330,58 & 133,95 & 243,75 & 243,75 & 67,07 & 486,99 & 62, & 4,30 & 47,21 & 167,55 & 32,59 & 32,59 & 156,91 \\
\hline Epidalea calamita & 30SUJ52 & 100,00 & 147,69 & 123,67 & 37,00 & 6888,11 & 342,84 & 12,90 & 329,94 & 130,79 & 240,73 & 240,73 & 64,54 & 482,92 & 60,95 & 4,93 & 45,89 & 165,87 & 34.88 & 34,88 & 153,01 \\
\hline Epidalea calamita & 30SUJ53 & 100,00 & 149,64 & 122,92 & 37,00 & 6866,68 & 343,38 & 14,90 & 328,48 & 133,16 & 242,41 & 242,41 & 66,54 & 462,56 & 57,40 & 4,74 & 45,35 & 158,46 & 34,27 & 34,27 & 144,74 \\
\hline Epidalea calamita & 30SUJ54 & 100,00 & 147,92 & 122,07 & 37,00 & 6864,75 & 340,99 & 13,44 & 327,55 & 131,67 & 240,57 & 240,57 & 64,81 & 455,88 & 55,47 & 5,07 & 44,39 & 155,87 & 35,52 & 35,52 & 140,57 \\
\hline Epidalea calamita & \begin{tabular}{|l}
3050355 \\
3050
\end{tabular} & 100,00 & 146 & 121,31 & 37,00 & | $60006,1 / 51$ & 338,99 & $\begin{array}{l}1,44 \\
12,70 \\
\end{array}$ & \begin{tabular}{|l|l|}
326,29 \\
\end{tabular} & \begin{tabular}{|l|}
130,64 \\
1304
\end{tabular} & \begin{tabular}{|l|}
239,38 \\
2317
\end{tabular} & \begin{tabular}{|l|}
239,38 \\
238
\end{tabular} & $\begin{array}{l}4,101 \\
63,78 \\
\end{array}$ & \begin{tabular}{|l|}
4456,39 \\
446
\end{tabular} & $\begin{array}{l}53,24 \\
53,20\end{array}$ & 5,31 & $\begin{array}{ll}43,38 \\
43,38\end{array}$ & 152,17 & $\frac{30,32}{36,42}$ & $\begin{array}{l}30,32 \\
36,42\end{array}$ & $\begin{array}{l}140,513 \\
35,53\end{array}$ \\
\hline Epidalea calamita & 30SUJ56 & 100,00 & 144,03 & 120,42 & 36,71 & 6835,28 & 335,41 & 10,61 & 324,80 & 127,69 & 236,51 & 236,51 & 61,60 & 443,45 & 51,75 & 5,95 & 42,22 & 150,82 & 38,71 & 38,71 & 132,20 \\
\hline Epidalea calamita & 30SUJ57 & 100,00 & 132,87 & 119,36 & 36,71 & 6787,24 & 323,47 & 1,64 & 321,84 & 115,81 & 224,95 & 224,97 & 51,61 & $|473,97|$ & 54,74 & $7,79 \mid$ & 40,19 & 160,11 & 46,02 & 46,03 & 138,46 \\
\hline Epidalea calamita & 30SUJ58 & 100,00 & 131,10 & 118,38 & 36,48 & 6761,15 & 320,51 & 0,67 & 319,85 & 114,06 & 222,93 & 222,93 & 50,26 & 467,69 & 54,66 & 8,25 & 39,29 & 157,42 & 47,50 & 47,50 & 134,38 \\
\hline Epidalea calamita & 30SUJ59 & 100,00 & 139,33 & 117,47 & 36,02 & 6758,71 & 326,81 & 7,85 & 318,96 & 123,33 & 230,97 & 230,97 & 57,93 & 426,18 & 49,96 & 7,13 & 39,41 & 142,91 & 42,85 & 42,85 & 12 \\
\hline Epidalea calamita & 30 SUJ61 & 100,00 & 147,49 & 124,72 & 37,00 & 6918,40 & 343,85 & 11,91 & 331,94 & \begin{tabular}{|l|}
130,79 \\
\end{tabular} & 240,96 & 240,96 & 63,70 & 489,01 & 62,27 & 4,62 & 46,51 & 169,13 & 34,19 & 34,19 & 155,95 \\
\hline Epidalea calamita & 30SUJ62 & 100,00 & 149,63 & 123,97 & 37,00 & 6899,46 & 344,74 & 14,23 & 330,51 & 133,09 & 242,72 & 242,72 & 66,02 & 467,27 & 58,39 & 4,57 & 45,74 & 161,13 & 33,77 & 33,77 & 147,07 \\
\hline Epidalea calamita & 30SUJ63 & 100,00 & 145,25 & 123,52 & 37,00 & 6890,92 & 340,28 & 10,49 & 329,79 & 128,27 & 238,45 & 238,45 & 62,09 & 469,25 & 57,34 & 5,25 & 44,38 & 161,49 & 36,57 & 36,57 & 145,12 \\
\hline Epidalea calamita & 30 SUJ64 & 100,00 & 145,08 & 122,74 & 37,00 & 6870,34 & 338,94 & 10,49 & 328,45 & 128,49 & 238,01 & 238,01 & 62,12 & 457,61 & 54,77 & 5,32 & 43,57 & 157,08 & 37,04 & 37,04 & 139 \\
\hline Epidalea calamita & 30 SUJ65 & 100,00 & 141,45 & 121,91 & 36,99 & 6863,46 & 334,63 & $\begin{array}{l}70,48 \\
7,4\end{array}$ & 327,16 & 124,84 & 234,37 & 234,37 & 58,69 & 459,14 & 53,75 & 5,96 & 42,35 & 157,07 & 39,61 & 39,61 & 137,65 \\
\hline
\end{tabular}




\begin{tabular}{|c|c|c|c|c|c|c|c|c|c|c|c|c|c|c|c|c|c|c|c|c|c|}
\hline TAXON & UTM & $\mathrm{km2}$ & B101 & $\mathrm{B1O2}$ & $\mathrm{BIO3}$ & B104 & B105 & B106 & B107 & B108 & $\mathrm{BIO9}$ & 81010 & B1011 & B1012 & BIO13 & 81014 & BIO15 & B1O16 & B1017 & B1018 & B1019 \\
\hline Epidalea calamita & 30SUJ66 & 100,00 & 138,87 & 120,82 & 36,84 & 6853,41 & 330,98 & 5,46 & 325,52 & 122,02 & 231,64 & 231,64 & 56,39 & 456,53 & 52,59 & 6,61 & 41,24 & 155,54 & 41,78 & 41,78 & 134,68 \\
\hline Epidalea calamita & 30SUJ67 & 100,00 & 133,27 & 119,57 & $\begin{array}{l}36,55 \\
\end{array}$ & 6810,94 & 324,28 & 1,23 & 323,05 & 116,30 & 225,70 & 225,72 & 51,75 & 467,28 & 54,22 & 7,76 & 39,82 & 158,18 & 45,99 & 46,01 & 135,44 \\
\hline Epidalea calamita & 30SUJ68 & 100,00 & 127,92 & 118,44 & 36,46 & 6771,95 & 317,75 & $-2,49$ & 320,25 & 110,53 & 220,03 & 220,03 & 47,24 & 475,21 & 56,03 & 8,85 & 38,49 & 160,12 & 49,94 & 49,94 & 135,27 \\
\hline Epidalea calamita & 30SUJ69 & 100,00 & 138,46 & 117,39 & 36,06 & 6776,79 & 326,03 & 6,79 & 319,24 & 122,33 & 230,29 & 230,29 & 56,83 & 426,07 & 50,24 & 7,51 & 38,77 & 142,88 & 43,81 & 43,81 & 120,28 \\
\hline Epidalea calamita & 30SUJ70 & 100,00 & 149,86 & 125,35 & 37,00 & 6926,91 & 346,50 & 13,57 & 332,92 & 133,03 & 243,32 & 243,32 & 66,07 & \begin{tabular}{|l|l|}
485,27 \\
\end{tabular} & 62,41 & 4,04 & 47,35 & 168,93 & 32,20 & 32,20 & 156,07 \\
\hline Epidalea calamita & 30SUJ71 & 100,00 & 150,08 & 125,08 & 37,00 & 6909,14 & 346,05 & 13,92 & 332,12 & 133,77 & 243,34 & 243,34 & 66,37 & 469,68 & 59,18 & 4,21 & 46,36 & 163,15 & 32,79 & 32,79 & 148,78 \\
\hline Epidalea calamita & 30SUJ72 & 100,00 & 144,93 & 124,86 & 37,00 & 6910,35 & 341,01 & 9,19 & 331,82 & 128,45 & 238,29 & 238,29 & 61,42 & 474,52 & 58,32 & 4,97 & 44,83 & 164,41 & 36,07 & 36,07 & 147,54 \\
\hline Epidalea calamita & \begin{tabular}{|l|}
$305 U J 73$ \\
\end{tabular} & 100,00 & 140,36 & 124,17 & 37,00 & 6901,19 & 336,28 & 5,26 & 331,02 & 123,41 & 233,78 & 233,78 & 57,29 & 478,84 & 57,47 & 5,66 & 43,40 & \begin{tabular}{|l|l|}
165,37 \\
\end{tabular} & 39,18 & 39,18 & 146,33 \\
\hline Epidalea calamita & 30SUJ74 & 100,00 & 143,51 & 123,26 & 37,00 & 6884,85 & 337,84 & 8,47 & 329,36 & 126,77 & 236,64 & 236,64 & 60,49 & 455,14 & 53,60 & 5,38 & 42,92 & 156,66 & 37,91 & 37,91 & 137,36 \\
\hline Epidalea calamita & 30SUJ75 & 100,00 & 140,25 & 122,33 & 37,00 & 6876,04 & 333,81 & 5,96 & 327,85 & \begin{tabular}{|l|}
123,67 \\
\end{tabular} & 233,36 & 233,36 & 57,40 & 456,66 & 52,75 & 6,19 & 41,78 & $\mid 156,56$ & 40,66 & 40,66 & 135,52 \\
\hline Epidalea calamita & 30SUJ76 & 100,00 & 131,62 & 121,11 & 36,99 & 6845,36 & 324,71 & $-0,64$ & 325,36 & 114,22 & 224,64 & 224,64 & 49,95 & 478,72 & 55,45 & 7,72 & 40,05 & 163,20 & 46,50 & 46,50 & 139,57 \\
\hline Epidalea calamita & 30SUJ77 & 100,00 & 129,08 & 119,84 & 36,69 & 6811,62 & 320,59 & $-2,58$ & 323,17 & 111,64 & 221,71 & 221,73 & 47,82 & 479,38 & 56,10 & 8,50 & 38,99 & 162,42 & 49,09 & 49,11 & 137,63 \\
\hline Epidalea calamita & 30SUJ78 & 100,00 & 129,47 & 118,53 & 36,27 & 6797,85 & 319,50 & $-1,77$ & 321,27 & 112,44 & 221,84 & 221,86 & 48,38 & 467,19 & 55,19 & 8,76 & 38,21 & 157,42 & 49,51 & 49,52 & 132,25 \\
\hline Epidalea calamita & 30SUJ79 & 100,00 & 140,64 & 117,26 & 36,00 & 6813,01 & 328,23 & 8,23 & 319,99 & 124,71 & 232,97 & 232,97 & 58,34 & 417,31 & 49,25 & 7,44 & 38,68 & 139,88 & 43,10 & 43,10 & 117,30 \\
\hline Epidalea calamita & 30SUJ80 & 100,00 & 146,51 & 126,21 & $\begin{array}{l}37,15 \\
\end{array}$ & 6912,49 & 343,98 & 10,46 & 333,52 & 129,46 & 240,11 & 240,11 & 63,38 & 484,96 & 61,28 & 4,30 & 46,40 & 169,49 & 34,09 & 34,09 & 153,91 \\
\hline Epidalea calamita & 30 SUJ 81 & 100,00 & 146,86 & 125,88 & 37,04 & 6901,70 & 343,59 & 10,77 & 332,83 & 130,04 & 240,18 & 240,18 & 63,61 & 470,88 & 58,30 & 4,47 & 45,48 & 164,25 & 34,40 & 34,40 & 147,42 \\
\hline Epidalea calamita & 30SUJ82 & 100,00 & 142,16 & 125,58 & 37,00 & 6902,37 & 338,97 & 6,55 & 332,42 & 125,21 & 235,64 & 235,64 & 59,16 & 475,08 & 57,40 & 5,16 & 44,01 & 165,12 & 37,56 & 37,56 & 146,14 \\
\hline Epidalea calamita & 30SUJ83 & 100,00 & 143,81 & 124,75 & 37,00 & 6892,71 & 339,36 & 8,21 & 331,16 & 127,29 & 237,03 & 237,03 & 60,78 & 457,21 & 54,14 & 5,19 & 43,40 & 158,38 & 37,21 & 37,21 & 138,80 \\
\hline Epidalea calamita & 30SUJ84 & 100,00 & 147,10 & 123,58 & 37,00 & 6891,58 & 341,06 & 11,29 & 329,77 & 130,97 & 240,20 & 240,20 & 63,63 & 435,05 & 50,60 & 5,04 & 43,12 & 150,06 & 36,03 & 36,03 & 130,50 \\
\hline Epidalea calamita & 30 SUJ85 & 100,00 & 139,86 & 122.68 & $37,00 \mid$ & 6883,90 & 333,48 & 5,15 & 328,33 & $\mid 123,22$ & 233,10 & 233,10 & 57,01 & 452,03 & 52,22 & 6,18 & 41,36 & $\mid 154.99$ & 41,14 & 41,14 & 133,15 \\
\hline Epidalea calamita & 30SUJ86 & 100,00 & 139,18 & 121,51 & 37,00 & 6872,99 & 331,72 & 5,03 & 326,69 & 122,69 & 232,32 & 232,32 & 56,42 & 445,18 & 51,66 & 6,5 & 40,38 & 151,85 & 42,23 & 42,23 & 129,33 \\
\hline Epidalea calamita & 30SUJ87 & 100,00 & 128,53 & 120,22 & 36,90 & 6825,34 & 320,44 & $-3,11$ & 323,55 & 111,06 & 221,42 & 221,42 & 47,25 & 476,95 & 56,08 & 8,54 & 38,63 & $\begin{array}{l}161,68 \\
\end{array}$ & 49,58 & 49,58 & 136,07 \\
\hline Epidalea calamita & 30SUJ88 & 100,00 & 137,01 & 118,73 & $\begin{array}{ll}36,06 \\
\end{array}$ & $\begin{array}{ll}6843,51 \\
\end{array}$ & 326,82 & 3,88 & 322,94 & 120,65 & 229,86 & 229,86 & 54,64 & \begin{tabular}{|l|l|}
436,48 \\
\end{tabular} & 51,38 & 7,67 & 38,58 & 147,06 & 45,13 & 45,13 & 123,42 \\
\hline Epidalea calamita & 30SUJ89 & 100,00 & 141,21 & 117,18 & 36,00 & 6841,64 & 328,87 & 8,27 & 320,60 & 125,26 & 233,80 & 233,80 & 58,44 & 415,03 & 48,84 & 7,40 & 38,23 & 138,75 & 43,40 & 43,40 & 116,36 \\
\hline Epidalea calamita & 30SUJ90 & 100,00 & 147,43 & 126,93 & 37,81 & 6900,37 & 344,48 & 11,01 & 333,48 & 130,56 & 240,56 & 240,56 & 64,01 & 470,35 & 58,48 & 4,19 & 45,79 & 164,89 & 33,69 & 33,69 & 147,89 \\
\hline Epidalea calamita & 30SUJ91 & 100,00 & 147,66 & 126,60 & 37,53 & 6892,61 & 344,21 & 11,08 & 333,13 & 131,09 & 240,71 & 240,71 & 64,23 & 455,62 & 55,2 & 4,2 & 45,06 & 159,29 & 33,96 & 33,96 & 141,21 \\
\hline Epidalea calamita & 30SUJ92 & 100,00 & 146,89 & 126,23 & 37,28 & 6888,05 & 342,90 & $\begin{array}{l}10,26 \\
10,4\end{array}$ & \begin{tabular}{|l|l|}
332,64 \\
\end{tabular} & 130,50 & \begin{tabular}{|l|}
239,83 \\
\end{tabular} & \begin{tabular}{|l|}
239,83 \\
\end{tabular} & 63,38 & 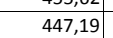 & $\begin{array}{l}53,12 \\
53,12\end{array}$ & 年, 4,36 & 44,15 & 155,79 & 34,83 & 34,83 & 136,70 \\
\hline Epidalea calamita & 30SUJ93 & 100,00 & 145,83 & 125,46 & 37,05 & 6882,95 & 341,08 & 9,45 & 331,63 & 129,68 & 238,78 & 238,78 & 62,57 & 441,07 & 51,63 & 4,78 & 43,28 & 153,05 & 36,04 & 36,04 & 132,92 \\
\hline Epidalea calamita & 30SUJ94 & 100,00 & 144,67 & 124,35 & 37,00 & 6881,74 & 339,03 & 8,86 & 330,17 & 128,28 & 237,71 & 237,71 & 61,62 & 436,28 & 50,80 & 5,20 & 42,51 & 150,51 & 37,62 & 37,62 & 129,38 \\
\hline Epidalea calamita & 30SUJ95 & 100,00 & 136,17 & 123,12 & 37,00 & 6876,93 & 330,38 & 1,78 & 328,60 & 119,18 & 229,47 & 229,47 & 53,59 & 460,05 & 53,51 & 6,70 & 40,60 & 157,81 & 43,56 & 43,56 & 134,31 \\
\hline Epidalea calamita & 30SUJ96 & 100,00 & 140,58 & 121,71 & 36,98 & 6881,84 & 332,97 & 5,60 & 327,37 & 124,21 & 233,66 & 233,66 & 57,52 & 435,73 & 50,77 & 6,36 & 40,32 & 148,64 & 41,68 & 41,68 & 125,90 \\
\hline Epidalea calamita & 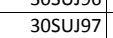 & 100,00 & 132,15 & 120,44 & 36,84 & $\begin{array}{l}60051,94 \\
6851,92\end{array}$ & 324,03 & $\begin{array}{c}-0,53 \\
-0,53 \\
\end{array}$ & 324,56 & \begin{tabular}{|l|}
115,20 \\
15,2
\end{tabular} & \begin{tabular}{|l|}
225,31 \\
\end{tabular} & 225,31 & 50,23 & \begin{tabular}{|l|l|}
460,33 \\
400
\end{tabular} & 54,11 & 8,08 & \begin{tabular}{|l|l|}
38,49 \\
\end{tabular} & \begin{tabular}{|l|}
$150,8,84$ \\
155
\end{tabular} & 47,81 & $\begin{array}{l}41,06 \\
47,81\end{array}$ & 130,91 \\
\hline Epidalea calamita & 30SUJ98 & 100,00 & 131,73 & 118,86 & 36,18 & 6842,66 & 322,13 & $-0,47$ & 322,60 & 114,83 & 224,72 & 224,73 & 49,97 & $\begin{array}{l}454,45 \\
\end{array}$ & 53,69 & 8,53 & 37,87 & 152,77 & 48,75 & 48,75 & 127,88 \\
\hline Epidalea calamita & 30SUJ99 & 100,00 & 137,42 & 117,29 & 36,00 & 6853,44 & 325,79 & 4,68 & 321,11 & 121,32 & 230,47 & 230,47 & 54,88 & 427,42 & 50,38 & 8,04 & 37,70 & 142,60 & 46,05 & 46,05 & 119,32 \\
\hline Epidalea calamita & 30SUKO1 & 100,00 & 154,70 & 115,56 & 37,00 & 6570,73 & 335,95 & 26,02 & 309,94 & 112,48 & 242,89 & 242,89 & 74,18 & 386,27 & 44,60 & 5,27 & 41,76 & 130,38 & 34,47 & 34,47 & 115,88 \\
\hline Epidalea calamita & 30SUKO2 & 100,00 & 157,32 & 115,00 & 37,00 & 6535,01 & 336,74 & 28,77 & 307,97 & 115,01 & 244,70 & 244,70 & 76,95 & 368,51 & 42,81 & 5,00 & 41,51 & 125,01 & 33,47 & 33,47 & 109,88 \\
\hline Epidalea calamita & $\begin{array}{l}\text { SOSUK12 } \\
30 \text { S }\end{array}$ & 100,00 & 155,81 & 115,07 & 37,00 & $\begin{array}{ll}65356,55 \\
6556,\end{array}$ & 335,75 & 26,94 & $\begin{array}{l}308,82 \\
30,\end{array}$ & $\begin{array}{l}113,23 \\
113,\end{array}$ & 243,57 & 243,57 & 75,22 & | & $\begin{array}{l}4,201 \\
42,02\end{array}$ & $\begin{array}{l}3,00 \\
5,35\end{array}$ & \begin{tabular}{|c|}
40,46 \\
40,
\end{tabular} & \begin{tabular}{|l|}
123,19 \\
\end{tabular} & $\begin{array}{l}30,47 \mid \\
34,38\end{array}$ & $\begin{array}{l}34,44 \\
34,38\end{array}$ & $\begin{array}{l}100,00 \\
107,31\end{array}$ \\
\hline Epidalea calamita & 30 SUK22 & 100,00 & 153,51 & 115,03 & 36,75 & 6590,10 & 334,04 & 24,14 & 309,90 & 110,88 & 241,71 & 241,71 & 72,60 & 366,62 & 41,84 & 6,00 & 40,20 & 122,49 & 35,40 & 35,40 & 105,70 \\
\hline Epidalea calamita & 30SUK32 & 100,00 & 151,96 & 115,00 & 36,26 & 6621,24 & 332,95 & 22,09 & 310,85 & 111,36 & 240,81 & 240,81 & 70,95 & 366,31 & 42,20 & 6,19 & 39,38 & 121,68 & 36,48 & 36,48 & 104,07 \\
\hline Epidalea calamita & 30SUK41 & 100,00 & 148,86 & 115,56 & 36,17 & 6671,69 & 331,60 & 18,05 & 313,56 & 126,31 & 238,56 & 238,56 & 67,48 & 380,72 & 44,31 & 6,51 & 39,38 & 125,79 & 38,29 & 38,29 & 107,69 \\
\hline Epidalea calamita & 30 SUK42 & 100,00 & 153,17 & 114,75 & 36,09 & 6644,08 & 333,95 & 22,73 & 311,21 & 112,53 & 242,41 & 242,41 & 71,86 & 359,77 & 41,62 & 6,1 & 39,30 & 119,29 & 36,19 & 36,19 & 101,33 \\
\hline Epidalea calamita & $\begin{array}{l}3050 \mathrm{~N} 442 \\
30 \mathrm{U} 50\end{array}$ & 100,00 & $\begin{array}{l}\frac{13,11}{146,51} \\
\end{array}$ & $\begin{array}{l}1114,13 \\
116,31\end{array}$ & 36,09 & $\begin{array}{l}0043,400 \\
673,53\end{array}$ & 331,38 & $\begin{array}{l}2,15 \\
14,77 \\
\end{array}$ & \begin{tabular}{|l|}
31,21 \\
316,62
\end{tabular} & \begin{tabular}{|l|}
131,71 \\
131
\end{tabular} & $\mid$\begin{tabular}{|l|}
237,41 \\
237,39
\end{tabular} & \begin{tabular}{|l|}
237,391 \\
237
\end{tabular} & $\begin{array}{l}1,000 \\
64,44 \\
\end{array}$ & | & $\begin{array}{l}1,026 \\
45,99 \\
\end{array}$ & $\begin{array}{l}0,14 \\
6,64 \\
\end{array}$ & $\begin{array}{l}39,18 \\
39,18\end{array}$ & \begin{tabular}{|l|l|l|l|l|}
131,05 \\
\end{tabular} & 年0, & | 30,690 & $\begin{array}{l}101,33 \\
111,67\end{array}$ \\
\hline Epidalea calamita & 30SUK60 & 100,00 & 145,95 & 116,11 & 36,00 & 6769,99 & 331,10 & 13,71 & 317,39 & 130,61 & 237,25 & 237,25 & 63,46 & 394,45 & 46,21 & 6,86 & 38,87 & 131,01 & 40,37 & 40,37 & 110,80 \\
\hline Epidalea calamita & 30SUK81 & 100,00 & 150,23 & 113,89 & 35,75 & 6808,46 & 333,32 & $\begin{array}{ll}17,67 \\
\end{array}$ & 315,65 & 128,81 & 241,94 & 241,94 & 67,01 & 376,61 & 43,63 & 6,93 & 38,01 & 123,27 & 39,85 & 39,85 & 104,72 \\
\hline Epidalea calamita & 30SUK90 & 100,00 & 143,16 & 115,31 & 35,81 & 6860,69 & 329,16 & 10,21 & 318,95 & 127,38 & 235,93 & 235,93 & 60,10 & $\begin{array}{l}404,49 \\
\end{array}$ & 47,19 & 7,82 & 37,34 & 133,31 & 43,97 & 43,97 & 112,35 \\
\hline Epidalea calamita & 30SUK91 & 100,00 & 150,90 & 113,42 & 35,24 & 6847,36 & 334,12 & 17,96 & 316,15 & 119,18 & 243,29 & 243 & 67,14 & 377,12 & 43,17 & 7,2 & 37,55 & 123,31 & 40,33 & 40,33 & 105,06 \\
\hline Epidalea calamita & 30SVF07 & 100,00 & 167,91 & 97,84 & 38,12 & 5325,12 & 307,58 & 54,66 & 252,93 & 112,35 & 238,92 & 239,17 & 103,99 & \begin{tabular}{|l|l|}
454,88 \\
\end{tabular} & 70,73 & 2,9 & 61,86 & 201,03 & 17,95 & 19,37 & 186,34 \\
\hline Epidalea calamita & 30SVF08 & 100,00 & 133,56 & 113,95 & 38,03 & 6023,94 & 304,68 & 10,38 & 294,30 & 71,01 & 215,36 & 215,38 & 62,47 & 616,68 & 84,16 & 7,03 & 55,93 & 246,27 & 32,40 & 32,95 & 237,63 \\
\hline Epidalea calamita & 30SVF09 & 100,00 & 136,99 & 115,65 & 38,00 & 6143,62 & 311,83 & 11,90 & 299,92 & 72,73 & 220,46 & 220,46 & 64,20 & 596,54 & 80,01 & 6,42 & 55,62 & 238,08 & 29,95 & 29,95 & 229,69 \\
\hline Epidalea calamita & 30SVF17 & 100,00 & 159,46 & 103,53 & 38,19 & 5540,32 & 309,17 & 42,39 & 266,78 & 101,41 & 233,86 & 233,92 & 93,12 & 458,48 & 67,69 & 3,80 & 59,34 & 196,04 & 19,99 & 20,58 & 183,33 \\
\hline Epidalea calamita & 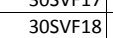 & 100,00 & $\begin{array}{l}13,40 \\
126,82\end{array}$ & 117,46 & 38,02 & $\begin{array}{l}30471,08 \\
6171\end{array}$ & 304,79 & $\begin{array}{c}4,2,30 \\
1,30\end{array}$ & \begin{tabular}{|l|}
303,49 \\
30,10
\end{tabular} & $\mid \begin{array}{l}\mid c 1,41 \\
63,14\end{array}$ & \begin{tabular}{|l|}
210,80 \\
210,80
\end{tabular} & \begin{tabular}{|l|}
210,83 \\
21,2
\end{tabular} & $\begin{array}{l}3,12 \\
54,17\end{array}$ & $\begin{array}{l}530,40 \\
631,64\end{array}$ & \begin{tabular}{|l|}
82,95 \\
82,95
\end{tabular} & $\frac{3,000}{7,90}$ & $\begin{array}{l}53,93 \\
53,\end{array}$ & $\mid$\begin{tabular}{|l|}
$245,10,1$ \\
\end{tabular} & 35,22 & $\begin{array}{l}\mid 0,50 \\
35,73\end{array}$ & $\begin{array}{l}20,03,22 \\
239,22\end{array}$ \\
\hline Epidalea calamita & 30SVF19 & 100,00 & 139,25 & 116,15 & 38,00 & 6168,30 & 314,74 & 13,34 & 301,40 & 74,45 & 223,03 & 223,03 & 65,97 & 561,14 & 75,10 & 6,36 & 54,89 & 222,64 & 28,74 & 28,74 & 214,12 \\
\hline Epidalea calamita & 30SVF26 & & & & & & & & & & & & & & & & & & & & \\
\hline Epidalea calamita & 30SVF28 & 100,00 & 132,77 & 117,33 & 38,04 & 6163,82 & 309,87 & 6,88 & 302,99 & 69,12 & 216,59 & 216,59 & 59,94 & 577,46 & 76,14 & 7,13 & 53,57 & 24,27 & 31,52 & 31,52 & 218,23 \\
\hline Epidalea calamita & 30 SVF29 & 100,00 & 135,92 & 117,76 & 38,00 & 6238,52 & 314,48 & 9,06 & 305,41 & 70,73 & 220,70 & 220 & 62,00 & 564,20 & 74,42 & 6,97 & 53,54 & 218,67 & 30,59 & 30,59 & 211,99 \\
\hline Epidalea calamita & 30 SVF 36 & 46,00 & 174,84 & 94,82 & 38,02 & 5184,26 & 309,11 & 63,31 & \begin{tabular}{|l|}
245,80 \\
\end{tabular} & 120,82 & 243,44 & 244,08 & 112,26 & 362,41 & 53,00 & 2,33 & 60,03 & 157,21 & 14,16 & 17,56 & 146,72 \\
\hline Epidalea calamita & 30SVF37 & 100,00 & 154,58 & 107,92 & 38,13 & 5726,31 & 312,32 & 34,15 & 278,18 & 94,73 & 231,64 & 231,68 & 86,07 & 441,92 & 61,35 & 4,36 & 56,31 & 180,91 & 21,02 & 21,48 & 171,45 \\
\hline Epidalea calamita & 30SVF38 & 100,00 & 127.31 & 118,64 & $38,00 \mid$ & 6235,23 & 307,54 & 0.59 & 306.95 & 63,47 & 212,11 & 212,11 & 53.92 & 596,31 & 77,20 & 8.08 & 5206 & 225,13 & 35.01 & 35.01 & 221.38 \\
\hline Epidalea calamita & 30SVF39 & 100,00 & 131,54 & 119,18 & 38,00 & 6302,90 & 313,32 & 3,82 & 309,50 & 66,47 & 217, & 217 & 57 & 576,55 & 75,14 & 7,64 & 52 & 217 & 33,15 & 33,15 & 213,27 \\
\hline Epidalea calamita & 30 SVF46 & 39,00 & 176,27 & 94,16 & 38,00 & 5177,69 & 309,59 & 64,71 & 244,88 & 122,35 & 244,45 & 245,33 & 113,53 & 341,96 & 49,25 & 2,31 & 59,10 & 146,37 & 13,47 & 17,37 & 137,31 \\
\hline
\end{tabular}




\begin{tabular}{|c|c|c|c|c|c|c|c|c|c|c|c|c|c|c|c|c|c|c|c|c|c|}
\hline TAXON & UTM & $\mathrm{km} 2$ & B101 & B102 & $\mathrm{BIO3}$ & B104 & B105 & B106 & B107 & B108 & B109 & BIO10 & BIO11 & BIO12 & B1013 & BIO14 & BIO15 & BIO16 & B1017 & B1018 & B1019 \\
\hline Epidalea calamita & 30SVF47 & 100,00 & 159,54 & 105,76 & 38,09 & 5649,02 & 313,34 & 40,31 & 273,04 & 100,56 & 235,24 & 235,39 & 91,74 & 405,70 & 56,34 & 3,81 & 56,20 & 165,65 & 18,68 & 20,10 & 157,14 \\
\hline Epidalea calamita & 30SVF48 & 100,00 & 144,43 & 115,47 & 38,02 & 6075,72 & 316,82 & 18,45 & 298,38 & 81,20 & 226,66 & 226,66 & 72,07 & 482,90 & 65,27 & 5,73 & 53,36 & 187,41 & 25,48 & 25,48 & 181,11 \\
\hline Epidalea calamita & 30SVF49 & 100,00 & 144,52 & 117,92 & 38,00 & 6222,36 & 322,06 & 16,38 & 305,67 & 79,48 & 228,90 & 228,90 & 70,24 & 488,69 & 66,22 & 5,89 & 52,86 & 187,38 & 25,87 & 25,87 & 181,41 \\
\hline Epidalea calamita & 30 SVF56 & 72,00 & 177,14 & 92,92 & \begin{tabular}{|l|l|}
37,97 \\
\end{tabular} & 5138,75 & 308,87 & 66,64 & 242,23 & 124,12 & 244,73 & 245,98 & 115,02 & 323,99 & 46,75 & 2,07 & 58,29 & \begin{tabular}{|l|l|}
137,38 \\
\end{tabular} & 12,52 & 17,56 & 129,49 \\
\hline Epidalea calamita & 30SVF57 & 100,00 & 159,37 & 105,05 & 38,01 & 5647,74 & 312,63 & 40,51 & 272,12 & 100,78 & 234,96 & 235,27 & 91,68 & 398,57 & 54,91 & 3,90 & 55,24 & \begin{tabular}{|l|l|}
159,44 \\
\end{tabular} & 19,14 & 22,90 & 152,46 \\
\hline Epidalea calamita & 30SVF58 & 100,00 & 151,65 & 111,24 & 38,00 & 5928,96 & 316,66 & 28,35 & 288,31 & 89,96 & 231,53 & 231,60 & 80,85 & 437,84 & 59,44 & 5,03 & 53,48 & 169,94 & 22,82 & 24,13 & 163,64 \\
\hline Epidalea calamita & 30SVF59 & 100,00 & 104,01 & 121,17 & 37,92 & 6446,90 & 292,30 & $-23,95$ & 316,25 & 45,38 & 192,09 & 192,42 & 29,21 & 717,51 & 89,99 & 14,93 & 46,53 & 256,12 & 59,06 & 62,18 & 247,05 \\
\hline Epidalea calamita & 30SVF66 & & & & & & & & & & & & & & & & & & & & \\
\hline Epidalea calamita & 30SVF67 & 100,00 & 138,51 & 113,04 & 38,00 & 6002,14 & 307,75 & 14,95 & 292,80 & 77,56 & 219,50 & 220,01 & 67,56 & 494,65 & 64,81 & 6,81 & 51,52 & 184,87 & 29,65 & 36,48 & 181,19 \\
\hline Epidalea calamita & 30SVF68 & 100,00 & 145,95 & 111,88 & 38,00 & 5986,90 & 313,21 & 22,53 & 290,68 & 85,22 & 226,68 & 226,92 & 74,84 & 459,45 & 61,02 & 5,88 & 51,92 & \begin{tabular}{l|l|}
172,95 \\
\end{tabular} & 26,35 & 31,35 & 168,28 \\
\hline Epidalea calamita & 30SVF69 & 100,00 & 72,97 & 122,82 & 37,61 & 6587,29 & 267,50 & $-54,97$ & 322,48 & 21,67 & 163,66 & 164,27 & $-2,03$ & 900,79 & 109,13 & 25,20 & 41,06 & 314,29 & 93,63 & 97,06 & 292,93 \\
\hline Epidalea calamita & 30SVF76 & & & & & & & & & & & & & & & & & & & & \\
\hline Epidalea calamita & 30SVF77 & 100,00 & 141,47 & 111,78 & 38,00 & 5970,81 & 308,71 & 18,41 & 290,30 & 80,95 & 221,84 & 222,72 & 70,96 & 465,72 & 60,90 & 6,16 & 51,14 & 172,79 & 27,34 & 35,47 & 169,90 \\
\hline Epidalea calamita & 30SVF86 & 30,00 & 171,17 & 93,81 & 37,69 & 5251,89 & 306,11 & 59,75 & 246,36 & 117,72 & 240,14 & 242,11 & 107,92 & 311,67 & 43,47 & 2,33 & 55,06 & $\begin{array}{l}124,75 \\
\end{array}$ & 13,64 & 19,44 & 119,36 \\
\hline Epidalea calamita & 30SVF87 & 100,00 & 148,05 & 107,66 & 37,99 & 5823,31 & 308,04 & 27,55 & 280,49 & 89,11 & 226,04 & 227,34 & 79,09 & 421,66 & 55,24 & 5,26 & 51,20 & 156,62 & 24,17 & 31,90 & 153,55 \\
\hline Epidalea calamita & 30SVF89 & 100,00 & 112,96 & 118,39 & 37,97 & 6356,66 & 295,94 & $-13,57$ & 309,51 & 60,76 & 199,37 & 200,30 & 39,15 & 628,47 & 77,78 & 13,18 & 45,06 & 221,29 & 52,71 & 59,65 & 211,40 \\
\hline Epidalea calamita & 30SVF96 & 31,00 & 172,63 & 91,29 & 37,20 & 5181,34 & 304,29 & 62,76 & 241,54 & 120,05 & 240,20 & 242,66 & 110,12 & 296,85 & 41,29 & 2,17 & 54,78 & \begin{tabular}{|l|l|}
117,63 \\
\end{tabular} & 13,05 & 18,63 & 112,80 \\
\hline Epidalea calamita & 30SVF97 & 100,00 & 157,29 & 101,36 & 37,74 & 5594,42 & 306,41 & 40,82 & 265,58 & 100,68 & 231,47 & 233,33 & 90,53 & 366,20 & 48,44 & 3,94 & 51,79 & 137,63 & 19,61 & 26,57 & 134,02 \\
\hline Epidalea calamita & 30SVF98 & 100,00 & 154,21 & 104,91 & \begin{tabular}{|l|l|}
37,83 \\
\end{tabular} & 5767,85 & 309,91 & 35,00 & 274,91 & 95,56 & 231,09 & 232,62 & 85,49 & 383,14 & 50,11 & 4,41 & 50,69 & \begin{tabular}{|l|l|}
141,25 \\
\end{tabular} & 21,40 & 28,81 & 138,01 \\
\hline Epidalea calamita & 30SVG00 & 100,00 & 140,34 & 115,24 & 37,99 & 6202,73 & 315,66 & 15,01 & 300,65 & 74,86 & 224,61 & 224,61 & 66,69 & 582,23 & 79,01 & 6,38 & 55,46 & 231,74 & 29,46 & 29,46 & 222,61 \\
\hline Epidalea calamita & 30SVG01 & 100,00 & 158,93 & 109,21 & 37,43 & 6048,53 & 323,79 & 36,26 & 287,53 & 93,18 & 240,85 & 240,85 & 86,47 & 493,41 & $72, \varepsilon$ & 4,53 & 57,51 & 204,53 & 22,43 & 22,43 & 190,89 \\
\hline Epidalea calamita & 30SVG02 & 100,00 & 150,38 & 113,64 & 37,05 & 6307,82 & 325,61 & 24,74 & 300,86 & 82,49 & 236,10 & 236,10 & 75,05 & 546,70 & 74,73 & 5,65 & 55,64 & 217,00 & 26,42 & 26,42 & 207,91 \\
\hline Epidalea calamita & 30SVG03 & 100,00 & 144,25 & 116,31 & $\begin{array}{l}37,00 \\
\end{array}$ & \begin{tabular}{|l|l|l|}
6493,53 \\
\end{tabular} & 326,55 & 16,71 & 309,84 & 75,08 & 232,55 & 232,55 & 66,95 & 591,22 & 77,10 & 6,41 & 54,50 & \begin{tabular}{|l|l|}
226,69 \\
\end{tabular} & 29,73 & 29,73 & 221,93 \\
\hline Epidalea calamita & 30SVG04 & 100,00 & 153,14 & 113,90 & 36,66 & 6516,42 & 333,25 & 26,35 & 306,90 & 83,34 & 241,63 & 241,63 & 75,37 & 567,18 & 73,69 & 5,63 & 55,34 & 216,96 & 26,66 & 26,66 & 213,60 \\
\hline Epidalea calamita & 30SVG05 & 100,00 & 160,37 & 111,84 & 36,06 & 6553,34 & 339,08 & 34,10 & 304,97 & 92,30 & 249,14 & 249,14 & 81,81 & 554,87 & 74,29 & 4,92 & 55,97 & 212,51 & 24,45 & 24,45 & 209,51 \\
\hline Epidalea calamita & 30SVG06 & 100,00 & 159,20 & 112,65 & 36,05 & 6647,09 & 340,97 & 32,25 & 308,72 & 91,17 & 249,27 & 249,27 & 79,61 & 574,35 & 80,27 & 5,09 & 55,89 & 221,47 & 25,64 & 25,64 & 215,16 \\
\hline Epidalea calamita & 30SVG07 & 100,00 & 168,36 & 110,49 & 35,88 & 6646,22 & 347,64 & $\begin{array}{ll}41,99 \\
41,\end{array}$ & 305,65 & \begin{tabular}{|c|}
100,01 \\
\end{tabular} & 258,01 & 258,01 & 88,29 & 551,40 & $\begin{array}{l}79,78 \\
79,78\end{array}$ & 4,04 & 57,01 & 215,75 & 22,23 & 22,23 & 207,42 \\
\hline Epidalea calamita & 30SVG08 & 100,00 & 171,91 & 110,63 & 35,73 & 6666,36 & 351,30 & 45,10 & 306,20 & 103,21 & 261,64 & 261,64 & 91,40 & 539,60 & 79,57 & 3,61 & 57,24 & 211,39 & 21,10 & 21,10 & 201,90 \\
\hline Epidalea calamita & 30SVG09 & 100,00 & 173,32 & 111,54 & 35,91 & 6694,79 & 353,79 & 45,67 & 308,12 & 104,30 & 263,36 & 263,36 & 92,20 & 530,16 & 78,97 & 3,19 & 56,99 & 206,95 & 20,62 & 20,62 & 196,72 \\
\hline Epidalea calamita & 30SVG10 & 100,00 & 146,56 & 114,97 & 37,99 & 6181,29 & 320,53 & 20,79 & 299,74 & 80,53 & 230,58 & 230,58 & 72,92 & 519,77 & 71,88 & 5,83 & 55,21 & 208,73 & 26,13 & 26,13 & 197,66 \\
\hline Epidalea calamita & 30SVG11 & 100,00 & 156,80 & 111,43 & 37,70 & 6116,14 & 325,09 & 32,39 & 292,70 & 89,82 & 239,79 & 239,79 & 83,49 & 465,79 & 69,00 & 4,91 & 56,07 & 191,06 & 22,99 & 22,99 & 176,59 \\
\hline Epidalea calamita & 30SVG12 & 100,00 & 149,03 & \begin{tabular}{|l|}
114,67 \\
14,5
\end{tabular} & 37,13 & 6337,57 & 325,89 & 22,51 & 303,38 & $\begin{array}{ll}80,62 \\
802\end{array}$ & \begin{tabular}{|l|l|}
235,18 \\
\end{tabular} & \begin{tabular}{|l|}
235,18 \\
\end{tabular} & 73,41 & 525,07 & 72,16 & 5,99 & 54,51 & 205,95 & 27,16 & 27,16 & 196,40 \\
\hline Epidalea calamita & 30SVG13 & 100,00 & 138,03 & 118,49 & 37,01 & 6573,18 & 324,53 & 9,28 & 315,26 & 68,87 & 227,57 & 227,57 & 60,05 & 604,05 & 78,08 & 7,40 & 53,03 & 225,93 & 32,95 & 32,95 & 222,81 \\
\hline Epidalea calamita & 30SVG14 & 100,00 & 143,62 & 117,40 & 36,89 & 6630,32 & 330,15 & 14,90 & 315,25 & 75,28 & 233,90 & 233,90 & 64,83 & 589,65 & 77,39 & 6,85 & 53,37 & 220,12 & 31,00 & 31,00 & 217,41 \\
\hline Epidalea calamita & 30SVG15 & 100,00 & 153,21 & 114,31 & 36,15 & 6658,71 & 337,18 & 25,51 & 311,67 & 85,32 & 243,65 & 243,65 & 73,77 & 567,08 & 76,80 & 5,90 & 54,41 & 214,94 & 27,50 & 27,50 & 210,31 \\
\hline Epidalea calamita & 30SVG17 & 100,00 & 157,83 & 112,85 & 35,48 & 6784,96 & 343,38 & 30,41 & 312,97 & 88,40 & 249,78 & 249,78 & 76,82 & 581,42 & 85,36 & 5,54 & 55,32 & 226,36 & 27,17 & 27,17 & 214,31 \\
\hline Epidalea calamita & 30SVG18 & 100,00 & 169,51 & 109,81 & 35,04 & 6741,25 & 350,59 & 43,18 & 307,41 & 100,09 & 260,53 & 260,53 & 88,44 & 545,42 & 82,57 & 4,19 & 56,62 & 215,55 & 22,63 & 22,63 & 202,51 \\
\hline Epidalea calamita & 30SVG19 & 100,00 & 176,16 & 109,95 & 35,71 & 6650,96 & 354,20 & 49,42 & 304,78 & 107,47 & 265,52 & 265,52 & 95,54 & 504,54 & 74,97 & 3,16 & 56,46 & \begin{tabular}{|l|l|}
196,19 \\
\end{tabular} & 20,22 & 20,22 & 186,13 \\
\hline Epidalea calamita & 30 SVG20 & 100,00 & 145,69 & 116,98 & 38,00 & 6252,42 & 322,93 & 18,24 & 304,69 & 78,98 & $\begin{array}{l}230,76 \\
\end{array}$ & 230,76 & 71,08 & 505,76 & 68,07 & 6,06 & 53,89 & 199,54 & 26,34 & 26,34 & 189,76 \\
\hline Epidalea calamita & 30 SVG21 & 100,00 & 156,34 & 113,11 & $\begin{array}{l}37,95 \\
\end{array}$ & 6152,04 & 326,59 & 30,64 & 295,95 & 88,38 & 239,92 & 239,92 & 82,50 & 432,45 & 64,77 & 4,80 & 55,33 & \begin{tabular}{|l|l|}
176,44 \\
\end{tabular} & 22,57 & 22,57 & 160,84 \\
\hline Epidalea calamita & 30 SVG22 & 100,00 & 153,52 & $\mid 114,99$ & 37,2 & 6338,62 & 330,23 & 26,31 & 303,92 & 84,42 & 239,78 & 239,78 & 77,80 & 473,18 & 65,41 & 5,45 & 54,03 & 185,84 & 24,53 & 24,53 & 175,09 \\
\hline Epidalea calamita & 30 SVG23 & 100,00 & 143,48 & 118,29 & 37,00 & 6569,32 & 329,22 & 14,20 & 315,02 & 73,80 & 232,93 & 232,93 & 65,32 & 558,01 & $\begin{array}{l}0,11+92 \\
71,9\end{array}$ & 6,87 & 52,63 & 208,01 & 30,10 & 30,10 & 204,63 \\
\hline Epidalea calamita & 30SVG24 & 100,00 & 144,54 & 117,80 & 36,96 & 6647,62 & 331,67 & 15,37 & 316,30 & 75,56 & 235,03 & 235,03 & 65,56 & 568,15 & 74,36 & 6,89 & 52,60 & 210,27 & 30,69 & 30,69 & 207,29 \\
\hline Epidalea calamita & 30SVG25 & 100,00 & 130,21 & 120,26 & 36,87 & 6743,06 & 322,75 & 0,62 & 322,12 & 61,14 & 222,23 & 222,23 & 50,70 & 642,81 & 86,59 & 8,94 & 50,67 & 236,40 & 39,79 & 39,79 & 228,93 \\
\hline Epidalea calamita & 30 SVG26 & 100,00 & 138,11 & 118,47 & 36,35 & 6793,43 & 329,70 & 8,59 & 321,11 & 69,51 & 230,62 & 230,62 & 57,78 & 620,03 & 85,5 & 8,01 & 51,60 & 30,96 & 36,29 & 36,29 & 221,40 \\
\hline Epidalea calamita & 30SVG27 & 100,00 & 149 & \begin{tabular}{|l|l|}
114,96 \\
\end{tabular} & 35,68 & 6835,44 & 338,37 & \begin{tabular}{|l|l|}
21,04 \\
\end{tabular} & 317,34 & 80,48 & 242,35 & 242,35 & 68,20 & 594,90 & 86,50 & 6,01 & 53,41 & 227,54 & 31,52 & $\begin{array}{l}30,52 \\
31,52\end{array}$ & 214,63 \\
\hline Epidalea calamita & 30SVG28 & 100,00 & 167,47 & 109,58 & 35,04 & 6784,30 & 349,56 & 41,31 & 308,25 & 97,45 & 259,05 & 259,05 & 86,04 & 545,37 & 83,7 & 4,61 & 56,18 & 215,71 & 23,85 & 23,85 & 200,56 \\
\hline Epidalea calamita & 30 SVG30 & 100,00 & 148,16 & 118,29 & 38,00 & 6278,06 & 326,89 & 19,56 & 307,33 & 81,36 & 233,53 & 233,53 & 73,22 & 479,05 & 64,55 & 5,64 & 53,49 & 187,07 & 24,65 & 24,65 & 178,29 \\
\hline Epidalea calamita & 30SVG31 & 100,00 & 156,21 & 115,40 & 37,99 & 6220,19 & 330,04 & 28,66 & 301,38 & 87,92 & 240,69 & 240,69 & 81,49 & 421,63 & 60,03 & 5,01 & 54,07 & 168,55 & 21,97 & 21,97 & 155,25 \\
\hline Epidalea calamita & 30 SVG32 & 100,00 & 155,35 & 116,17 & 37,27 & 6367,30 & 333,48 & 27,03 & 306,45 & 86,06 & 241,90 & 241,90 & 79,03 & 449,20 & 60,94 & 5,31 & 53,20 & 174,40 & 23,25 & 23,25 & 164,69 \\
\hline Epidalea calamita & \begin{tabular}{|l|}
$30 \mathrm{NVG} 33$ \\
\end{tabular} & 100,00 & 14 & $\frac{11}{11 \zeta}$ & 37,00 & $\begin{array}{l}05067,88 \\
6567\end{array}$ & 331 & $\begin{array}{l}1,3,78 \\
15,8\end{array}$ & \begin{tabular}{|l|}
315,575 \\
\end{tabular} & $\frac{\mid 00,00}{76,20}$ & $\begin{array}{l}235,00 \\
23,0\end{array}$ & $\begin{array}{l}235,00 \\
23,0\end{array}$ & $\begin{array}{l}6,303 \\
67,37\end{array}$ & $\begin{array}{l}\mid 443,20,49 \\
530\end{array}$ & $\begin{array}{l}60,349 \\
68,97\end{array}$ & 6,515 & $\begin{array}{l}52,08 \\
52,08\end{array}$ & $\begin{array}{l}196,18 \\
\end{array}$ & \begin{tabular}{|l|l|}
29,18 \\
\end{tabular} & $\begin{array}{ll}29,23 \\
29,18\end{array}$ & $\begin{array}{l}104,05 \\
192,47\end{array}$ \\
\hline Epidalea calamita & 30 SVG 34 & 100,00 & 139,93 & 119,43 & 36,99 & 6683,69 & 329,45 & 9,99 & 319,46 & 71,39 & 231,01 & 231,01 & 60,73 & 574,29 & 75,90 & 7,53 & 51,31 & 209,78 & 33,08 & 33,08 & 206,13 \\
\hline Epidalea calamita & 30SVG37 & 100,00 & 162,55 & $\mid$ & 35,25 & 6759,06 & 345,47 & 36,00 & 309,47 & 95,21 & $\begin{array}{l}254,03 \\
\end{array}$ & 254,03 & 81,78 & 537,45 & 80,05 & 5,21 & 54,72 & 208,61 & 25,54 & 25,54 & 195,53 \\
\hline Epidalea calamita & 30SVG38 & 100,00 & 172,59 & 108,24 & 35,04 & 6691,36 & 350,72 & 47,06 & 303,66 & 103,34 & 262,76 & 262,76 & 92,04 & 500,91 & 75,67 & 3,99 & 55,81 & 195,89 & 21,58 & 21,58 & 183,27 \\
\hline Epidalea calamita & 30SVG39 & 100,00 & 174,79 & 108,88 & 35,10 & 6664,34 & 352,41 & 48,55 & 303,86 & 105,84 & 264,30 & 264 & 94,21 & 482,79 & 72,16 & 3,47 & 55,40 & 186,60 & 20,73 & 20,73 & 179 \\
\hline Epidalea calamita & \begin{tabular}{|l|}
$30 \mathrm{NVG} 40$ \\
\end{tabular} & $\begin{array}{l}100,00 \\
\end{array}$ & $\begin{array}{l}1 / 14,13 \\
145,38\end{array}$ & \begin{tabular}{|l|}
$119,73,0$ \\
\end{tabular} & 38,00 & $\begin{array}{l}6000,434 \\
6347,76\end{array}$ & 327,09 & $\begin{array}{l}40,35 \\
15,72 \\
\end{array}$ & \begin{tabular}{|l|}
311,370 \\
310
\end{tabular} & $\begin{array}{c}0,044 \\
78,74 \\
\end{array}$ & \begin{tabular}{|l|}
231,55 \\
230
\end{tabular} & \begin{tabular}{|l|}
231,55 \\
230
\end{tabular} & $\begin{array}{l}4,212 \\
69,68\end{array}$ & \begin{tabular}{|l|l|}
491,34 \\
491,
\end{tabular} & $\begin{array}{l}2,10 \\
66,55 \\
\end{array}$ & $\begin{array}{l}5,41 \\
5,95 \\
\end{array}$ & $\begin{array}{l}52,40 \\
52,60\end{array}$ & $\begin{array}{l}100,00 \\
186,27\end{array}$ & \begin{tabular}{|l|}
25,97 \\
25
\end{tabular} & \begin{tabular}{|l|}
25,717 \\
257
\end{tabular} & $\begin{array}{l}1 / 1,10 \\
180,81\end{array}$ \\
\hline Epidalea calamita & 30SVG41 & 100,00 & 153,30 & 119,43 & 37,94 & 6373,83 & 334,49 & 23,04 & 311,45 & 85,31 & 239,83 & 239,83 & 76,87 & 453,80 & 62,06 & 5,21 & 53,01 & 173,27 & 22,75 & 22,75 & 166,64 \\
\hline Epidalea calamita & 30SVG42 & 100,00 & 148,23 & 119.59 & 37,30 & 6503,29 & 33306 & 17,69 & 315,37 & 79,29 & 236.58 & 236.58 & 70,59 & 494,17 & 65,33 & 6.06 & 5203 & 182.90 & 26,45 & 26.45 & 179,08 \\
\hline Epidalea calamita & 30SVG43 & 100,00 & 147,47 & 119,11 & 37,00 & 6579,18 & 333,78 & 17,30 & 316,48 & 78,58 & $237, \mathrm{C}$ & 237,05 & 69, & 511,75 & 66,96 & 6,32 & 51 & 186,44 & 27,85 & 27,85 & 184,32 \\
\hline Epidalea calamita & 30SVG44 & 100,00 & 139,33 & 119,77 & 37,00 & 6682,62 & 329,05 & 9,07 & 319,98 & 79,28 & 230,30 & 230,30 & 60,18 & 564,60 & 74,91 & 7,68 & 50,60 & 204,73 & 33,72 & 33,72 & 200,23 \\
\hline
\end{tabular}




\begin{tabular}{|c|c|c|c|c|c|c|c|c|c|c|c|c|c|c|c|c|c|c|c|c|c|}
\hline TAXON & UTM & $\mathrm{km} 2$ & B101 & B102 & $\mathrm{BIO3}$ & BIO4 & B105 & B106 & B107 & B108 & B109 & BIO10 & BIO11 & BIO12 & B1013 & BIO14 & BIO15 & BIO16 & B1017 & BIO18 & B1019 \\
\hline Epidalea calamita & 30SVG45 & 100,00 & 136,11 & 119,86 & 36,88 & 6743,93 & 327,60 & 5,93 & 321,68 & 83,75 & 228,09 & 228,09 & 56,45 & 587,08 & 79,14 & 8,34 & 49,90 & 214,21 & 36,75 & 36,75 & 205,80 \\
\hline Epidalea calamita & 30SVG47 & 100,00 & 147,62 & 116,10 & 35,98 & 6802,55 & 336,55 & \begin{tabular}{ll|}
18,67 \\
\end{tabular} & 317,88 & 93,94 & 239,99 & 239,99 & 66,83 & 562,77 & 80,08 & 6,99 & 51,40 & 211,26 & 32,76 & 32,76 & 197,56 \\
\hline Epidalea calamita & 30SVG48 & 100,00 & 160,46 & 112,17 & 35,26 & 6796,60 & 345,24 & 32,91 & 312,34 & 105,88 & 252,39 & 252,39 & 79,30 & 527,44 & 78,75 & 5,40 & 53,53 & 202,94 & 26,89 & 26,89 & 187,64 \\
\hline Epidalea calamita & 30SVG50 & 100,00 & 111,64 & 121,25 & \begin{tabular}{l|l|l}
37,95 \\
\end{tabular} & 6483,53 & 300,34 & $-16,90$ & 317,23 & 53,95 & 200,07 & 200,32 & 36,09 & 673,94 & 85,04 & 12,65 & 47,20 & 240,43 & 51,48 & 55,05 & 233,93 \\
\hline Epidalea calamita & 30SVG51 & 100,00 & 137,77 & 120,31 & $\begin{array}{l}37,80 \\
\end{array}$ & 6468,57 & 323,32 & 7,91 & 315,41 & 72,75 & 225,69 & 225,71 & 61,08 & 533,14 & 69,61 & 7,34 & 50,53 & \begin{tabular}{|l|l|}
192,97 \\
\end{tabular} & 31,75 & 32,01 & 190,72 \\
\hline Epidalea calamita & 30SVG52 & 100,00 & 121,04 & 121,37 & 37,53 & 6577,65 & 311,27 & $-8,14$ & 319,41 & 69,02 & 210,81 & 210,84 & 44,02 & 627,20 & 80,32 & 10,60 & 47,88 & 223,75 & 44,60 & 45,24 & 217,73 \\
\hline Epidalea calamita & 30SVG53 & 100,00 & 132,54 & 120,41 & 37,09 & 6610,03 & 321,70 & 2,59 & 319,11 & 79,42 & 222,59 & 222,61 & 54,58 & 576,19 & 74,64 & 8,94 & 49,04 & 206,32 & 38,22 & 38,56 & 200,98 \\
\hline Epidalea calamita & 30SVG54 & 100,00 & 143,99 & 119,14 & 37,00 & 6641,52 & 332,01 & 13,67 & 318,34 & 94,65 & 234,34 & 234,34 & 65,17 & 527,69 & 69,98 & 6,98 & 50,44 & 190,85 & 31,01 & 31,01 & 186,00 \\
\hline Epidalea calamita & 30SVG55 & 100,00 & 134,70 & 120,19 & 37,00 & 6727,44 & 325,86 & 4,20 & 321,66 & 86,12 & 226,34 & 226,34 & 55,16 & 576,79 & 77,16 & 8,54 & 48,93 & 209,65 & 37,73 & 37,73 & 199,31 \\
\hline Epidalea calamita & 30SVG56 & 100,00 & 135,86 & 119,61 & 36,73 & 6767,58 & 327,38 & 5,70 & 321,69 & 87,11 & 227,97 & 227,97 & 55,90 & 579,11 & 78,55 & 8,52 & 48,84 & 211,90 & 38,31 & 38,31 & 198,88 \\
\hline Epidalea calamita & 30SVG58 & 100,00 & 148,94 & 115,90 & 36,12 & 6782,17 & 336,74 & 19,89 & 316,85 & 100,73 & 240,96 & 240,96 & 68,35 & 539,85 & 76,30 & 6,80 & 50,24 & 201,74 & 32,99 & 32,99 & 185,82 \\
\hline Epidalea calamita & 30SVG59 & 100,00 & 171,17 & 110,18 & 35,92 & 6609,16 & 348,34 & 44,54 & 303,81 & 124,97 & 259,99 & 259,99 & 91,48 & 451,57 & 64,77 & 3,78 & 52,74 & 169,93 & 22,11 & 22,11 & 158,86 \\
\hline Epidalea calamita & 30 SVG60 & 100,00 & 71,10 & 123,12 & $\begin{array}{l}37,55 \\
\end{array}$ & 6632,43 & 267,01 & $-57,13$ & 324,14 & 20,08 & 162,51 & 163,00 & $-4,30$ & 913,97 & 110,84 & 26,09 & 40,48 & 318,17 & 96,84 & 99,76 & 294,48 \\
\hline Epidalea calamita & 30SVG61 & 100,00 & 112,41 & 121,28 & 37,86 & 6532,90 & 301,90 & $-16,22$ & 318,13 & 62,72 & 201,56 & 201,79 & 36,41 & 659,49 & 82,80 & 12,84 & 46,09 & 233,59 & 52,19 & 55,75 & 224,71 \\
\hline Epidalea calamita & 30SVG62 & 100,00 & 122,76 & 120,85 & 37,48 & 6557,57 & 311,71 & $-6,24$ & 317,96 & 74,06 & 212,14 & 212,21 & 45,92 & 605,29 & 77,14 & 10,41 & 47,20 & 215,44 & 43,91 & 45,90 & 207,94 \\
\hline Epidalea calamita & 30SVG63 & 100,00 & 122,08 & 121,11 & 37,19 & 6612,23 & 312,55 & $-7,40$ & 319,95 & 73,26 & 212,25 & 212,32 & 44,72 & 613,89 & 78,69 & 10,86 & 46,73 & 218,94 & 45,77 & 47,06 & 208,89 \\
\hline Epidalea calamita & 30SVG64 & 100,00 & 136,36 & 119,84 & 37,00 & 6636,61 & 325,11 & 6,08 & 319,03 & 88,25 & 226,72 & 226,73 & 57,94 & 547,77 & 71,86 & 8,15 & 48,48 & 197,16 & 35,97 & 36,09 & 188,69 \\
\hline Epidalea calamita & 30SVG65 & 100,00 & 135,93 & 119,71 & 37,00 & 6691,84 & 325,60 & 5,58 & 320,03 & 87,42 & 226,97 & 226,97 & 56,80 & 556,57 & 73,86 & 8,38 & 48,16 & 201,59 & 37,38 & 37,38 & 190,13 \\
\hline Epidalea calamita & 30SVG67 & 100,00 & 132,71 & 119,32 & \begin{tabular}{|l|}
36,68 \\
\end{tabular} & 6757,97 & 323,71 & 2,81 & 320,90 & 83,86 & 224,71 & 224,71 & 53,13 & 581,53 & 77,70 & 9,48 & 47,01 & 211,09 & 42,71 & 42,82 & 194,21 \\
\hline Epidalea calamita & 30SVG72 & 100,00 & 131,32 & 119,24 & \begin{tabular}{|l|l|}
37,27 \\
\end{tabular} & 6501,60 & 316,88 & 2,31 & 314,58 & 83,27 & 219,66 & 219,80 & 54,84 & 548,03 & 69,45 & 8,87 & 47,55 & \begin{tabular}{|l|l|}
194,36 \\
\end{tabular} & 38,15 & 40,92 & 187,99 \\
\hline Epidalea calamita & 30SVG74 & 100,00 & 139,94 & 118,44 & 37,00 & 6572,61 & 325,67 & 10,28 & 315,39 & 92,14 & 229,21 & 229,23 & 62,07 & 516,92 & 67, & 7,63 & 47,99 & \begin{tabular}{|l|l|}
185,14 \\
\end{tabular} & 34,32 & 35,44 & 176,46 \\
\hline Epidalea calamita & 30SVG75 & 100,00 & 137,38 & 118,94 & 37,00 & 6634,40 & 324,88 & 7,42 & 317,47 & 89,10 & 227,53 & 227,55 & 58,95 & 534,26 & 69,94 & 8,20 & 47,38 & $\mid 192,19$ & 36,90 & 37,68 & 180,31 \\
\hline Epidalea calamita & 30SVG76 & 100,00 & 139,21 & 118,62 & 37,00 & $\begin{array}{ll}6671,63 \\
\end{array}$ & 326,99 & 9,16 & 317,82 & 90,94 & 229,79 & 229,79 & 60,30 & 530,29 & 70,12 & 7,98 & 47,31 & \begin{tabular}{|c|}
191,77 \\
\end{tabular} & 36,68 & 36,73 & 177,96 \\
\hline Epidalea calamita & 30SVG77 & 100,00 & 145,97 & 116,83 & 36,66 & 6663,67 & 331,46 & 16,71 & 314,75 & 98,09 & 236,19 & 236,21 & 66,75 & 506,15 & 67,71 & 7,02 & 47,99 & \begin{tabular}{|l|l|}
184,15 \\
\end{tabular} & 33,73 & 34,28 & 169,86 \\
\hline Epidalea calamita & 30SVG79 & 100,00 & 168,21 & 111,19 & 36,14 & 6497,86 & 343,14 & 41,24 & 301,89 & 122,41 & 255,39 & 255,42 & 89,80 & 416,60 & 56,08 & 3,86 & 49,86 & 151,84 & 23,30 & 23,59 & 141,36 \\
\hline Epidalea calamita & 30SVG82 & 100,00 & 137,17 & 117,37 & 37,33 & 6421,42 & 318,57 & 9,05 & 309,52 & 89,62 & 224,11 & 224,44 & 61,34 & 504,70 & 63,27 & 7,80 & 47,40 & 177,97 & 34,45 & 40,80 & 172,27 \\
\hline Epidalea calamita & 30SVG83 & 100,00 & 144,03 & 116,31 & 37,00 & $\begin{array}{l}0424,42 \\
6424,32\end{array}$ & 324,13 & $\begin{array}{l}, 009 \\
15,93 \\
\end{array}$ & 308,20 & \begin{tabular}{l|l|l|}
96,98 \\
\end{tabular} & \begin{tabular}{|l|}
230,86 \\
23
\end{tabular} & 231,19 & 67,69 & 476,49 & $\begin{array}{l}0,27 \\
60,29 \\
\end{array}$ & 6,071 & 48,16 & 168,45 & 30,90 & 35,47 & 162,76 \\
\hline Epidalea calamita & 30SVG85 & 100,00 & 140,54 & 117,37 & 37,00 & 6548,81 & 324,38 & 11,65 & 312,73 & 92,73 & 229,30 & 229,42 & 63,09 & 503,91 & 64,87 & 7,67 & 46,85 & 179,86 & 35,31 & 37,92 & 168,24 \\
\hline Epidalea calamita & 30 SVG86 & 100,00 & 147,12 & 116,06 & 37,00 & 6551,86 & 329,27 & 18,45 & 310,82 & 99,57 & 235,67 & 235,73 & 69,33 & 479,10 & 62,33 & 6,66 & 47,36 & 171,90 & 32,13 & 33,97 & 160,06 \\
\hline Epidalea calamita & 30SVG87 & 100,00 & 151,08 & 115,10 & 36,94 & 6555,31 & 332,01 & 22,66 & 309,36 & 103,88 & 239,61 & 239,64 & 72,95 & 465,92 & 60,94 & 6,13 & 47,49 & 167,68 & 30,89 & 32,69 & 154,99 \\
\hline Epidalea calamita & 30SVG88 & 100,00 & 163,67 & 111,76 & 36,80 & 6443,26 & 338,13 & 36,77 & 301,36 & 117,71 & 250,17 & 250,25 & 86,18 & 414,98 & 54,20 & 4,38 & 48,68 & 149,10 & 24,87 & 26,67 & 139,02 \\
\hline Epidalea calamita & 30SVG89 & 100,00 & 164,75 & 112,11 & 36,78 & 6463,34 & 339,70 & 37,53 & $\begin{array}{l}02,17 \\
302\end{array}$ & |118,98 & $\begin{array}{l}251,51 \\
251\end{array}$ & 251,55 & $\begin{array}{l}30,109 \\
86,95\end{array}$ & \begin{tabular}{|l|l|}
411,70 \\
\end{tabular} & $\begin{array}{ll}4,267 \\
53,87\end{array}$ & 4,17 & $\begin{array}{l}40,06 \\
48,48 \\
\end{array}$ & $\begin{array}{l}448,10 \\
148\end{array}$ & 24,91 & 25,92 & 136,85 \\
\hline Epidalea calamita & 30SVG91 & 100,00 & 123,64 & 117,72 & \begin{tabular}{|l|l|}
37,63 \\
\end{tabular} & 6400,30 & 305,85 & $-3,53$ & 309,38 & 75,38 & 210,51 & 211,27 & 48,91 & 561,19 & 69,47 & 10,75 & 44,90 & \begin{tabular}{|l|l|}
196,42 \\
\end{tabular} & 44,97 & 52,32 & 186,69 \\
\hline Epidalea calamita & 30SVG92 & 100,00 & 131,97 & 117,07 & 37,32 & 6407,26 & 312,95 & 4,42 & 308,53 & 84,12 & 218,78 & 219,35 & 56,67 & 518,62 & 64,18 & 8,86 & 45,68 & 181,84 & 38,77 & 46,37 & 173,32 \\
\hline Epidalea calamita & 30SVG93 & 100,00 & 129,06 & 118,02 & 37,19 & 6480,29 & 312,71 & 1,07 & 311,64 & 80,73 & 216,99 & 217,51 & 53,18 & 538,44 & 66,96 & 9,71 & 44,88 & 189,25 & 42,22 & 48,92 & 177,36 \\
\hline Epidalea calamita & 30SVG94 & 100,00 & 137,81 & 116,80 & 37,03 & 6468,53 & 319,42 & 9,71 & 309,71 & 90,09 & 225,38 & 225,91 & 61,62 & 497,66 & 62,30 & 8,00 & 45,82 & 175,46 & 36,53 & 43,52 & 164,63 \\
\hline Epidalea calamita & 30SVG95 & 100,00 & 151,79 & 113,35 & 37,00 & 6370,99 & 327,12 & 25,09 & 302,03 & \begin{tabular}{|l|}
105,32 \\
\end{tabular} & 237,60 & 237,94 & 75,87 & 436,68 & 54,84 & 5,77 & 47,27 & 153,81 & 28,69 & 34,02 & 145,86 \\
\hline Epidalea calamita & 30SVG96 & 100,00 & 153,87 & 113,10 & 37,00 & 6394,29 & 329,22 & 27,06 & 302,16 & 107,45 & 239,94 & 240,28 & 77,50 & 432,02 & 54,56 & 5,47 & 47,16 & 152,66 & 28,46 & 33,47 & 143,34 \\
\hline Epidalea calamita & 30SVG98 & 100,00 & 138,54 & 117,48 & 37,01 & 6605,31 & 323,07 & 9,57 & 313,50 & 90,52 & 227,97 & 228,16 & 60,40 & 507,78 & 64,38 & 8,58 & 44,35 & 179,71 & 41,02 & 43,36 & 161,53 \\
\hline Epidalea calamita & 30SVHO1 & 100,00 & 173,25 & 114,34 & 36,00 & 6739,98 & 356,56 & 43,78 & 312,78 & 103,74 & 263,86 & 263,86 & 91,44 & 511,77 & 75,83 & 3,23 & 55,60 & \begin{tabular}{|l|l|}
195,58 \\
\end{tabular} & 21,62 & 21,62 & 185,27 \\
\hline Epidalea calamita & 30SVHO2 & 100,00 & 166,13 & 116,79 & 36,00 & 6846,37 & 354,41 & 35,08 & 319,33 & 96,84 & 258,37 & 258,37 & 83,31 & 530,30 & 78, & 3,62 & 54,44 & 201,04 & 24,27 & 24,27 & 188,86 \\
\hline Epidalea calamita & 30SVHO3 & 100,00 & 155,87 & 119,93 & 36,17 & 6936,06 & 349,27 & 23,47 & 325,80 & $\begin{array}{r}103,94 \\
\end{array}$ & 249,62 & 249,62 & 72,41 & 553,67 & 80,94 & 4,54 & 52,48 & 207,08 & 29,00 & 29,00 & 192,78 \\
\hline Epidalea calamita & 30SVHO4 & 100,00 & 152,67 & 121,54 & 36,70 & 6943,12 & 347,59 & 19,47 & 328,12 & 105,63 & 246,53 & 246,53 & 69,13 & 547,43 & 78,34 & 4,60 & 51,14 & 202,35 & 30,55 & 30,55 & 187,44 \\
\hline Epidalea calamita & 30SVH05 & 100,00 & 144,87 & 123,50 & 37,00 & 6956,21 & 342,06 & 11,07 & 330,99 & 97,66 & 239,15 & 239,15 & 61,62 & 557,74 & 77,28 & 5,44 & 49,29 & 202,56 & 34,99 & 34,99 & 186,84 \\
\hline Epidalea calamita & 30SVH06 & 100,00 & 152,24 & 123,95 & 37,00 & 6927,25 & 348,01 & 17,46 & 330,55 & 105,68 & 245,73 & 245,73 & 68,59 & 511,84 & 70,05 & 4 & 49,41 & 84,61 & 30,80 & 30,80 & 170,22 \\
\hline Epidalea calamita & 30SVHO7 & 100,00 & 145,28 & 125,58 & 37,04 & 6933,85 & 342,96 & 10,19 & 332,77 & 98,85 & 239,11 & 239,11 & 61,93 & 519,53 & 68,96 & $4, \varepsilon$ & 47,56 & 184,41 & 34,67 & 34,67 & 169,24 \\
\hline Epidalea calamita & 30 SVHO8 & 100,00 & 146,68 & 126,35 & 37,34 & 6917,47 & 344,27 & 10,82 & 333,44 & 123,90 & 240,12 & 240,12 & 63,49 & 495,58 & 64,12 & 4,3 & 46,88 & \begin{tabular}{|l|l|}
175,07 \\
\end{tabular} & 33,86 & 33,86 & 159,05 \\
\hline Epidalea calamita & $\begin{array}{l}30 \text { SVHOO } \\
\end{array}$ & 100,00 & 146,35 & 127,13 & 37,87 & 6903,11 & 343,78 & $\begin{array}{ll}9,0,97 \\
9,\end{array}$ & 333,81 & 129,14 & 239,60 & 239,60 & 63,14 & 478,40 & $\begin{array}{l}60,09 \\
6\end{array}$ & 4,12 & 46,07 & 168,82 & 33,85 & 33,85 & 151,16 \\
\hline Epidalea calamita & 30SVH10 & 100,00 & 177,28 & 111,16 & 35,96 & 6661,47 & 356,09 & 49,61 & 306,48 & 108,35 & 266,54 & 266,54 & 96,29 & 491,86 & 72,84 & 3,00 & 55,99 & 189,31 & 20,07 & 20,07 & 179,62 \\
\hline Epidalea calamita & 30SVH12 & 100,00 & 165,95 & 116,11 & 36,00 & 6846,00 & 353,68 & 35,44 & 318,24 & 105,58 & 258,18 & 258,18 & 83,22 & 519,72 & 77,25 & 3,74 & 53,92 & 197,10 & 24,62 & 24,62 & 183,63 \\
\hline Epidalea calamita & $\begin{array}{l}30 \mathrm{SVH} 13 \\
\end{array}$ & 100,00 & 163 & $\begin{array}{l}1110,14 \\
117,95\end{array}$ & 36,05 & $\begin{array}{l}0040,00 \\
6870,86\end{array}$ & 352,93 & $\begin{array}{l}\mid 0,44 \\
31,71 \\
\end{array}$ & \begin{tabular}{|l|}
321,22 \\
32,
\end{tabular} & \begin{tabular}{|l|}
115,03 \\
11,03
\end{tabular} & \begin{tabular}{|l|}
255,890 \\
250
\end{tabular} & \begin{tabular}{|l|}
255,890 \\
250
\end{tabular} & $\begin{array}{l}30,24 \\
80,25\end{array}$ & $\mid \begin{array}{l}\mid 1,, 15,05 \\
515\end{array}$ & 75,36 & $\begin{array}{l}3,17 \\
3,79\end{array}$ & \begin{tabular}{|l|l}
52,75 \\
52
\end{tabular} & $\begin{array}{l}193,19 \\
193\end{array}$ & $\begin{array}{ll}25,86 \\
25,\end{array}$ & 25,86 & $\begin{array}{l}103,05 \\
179,25\end{array}$ \\
\hline Epidalea calamita & 30SVH15 & 100,00 & 155,79 & 121,83 & 36,99 & 6898,91 & 349,23 & 22,23 & 327,01 & 109,29 & 248,88 & 248,88 & 72,53 & 506,77 & 70,68 & 4,16 & 50,15 & \begin{tabular}{|c|}
185,38 \\
\end{tabular} & 29,49 & 29,49 & 170,10 \\
\hline Epidalea calamita & 30 SVH 16 & 100,00 & 151,04 & 123,69 & 37,00 & 6916,59 & 346,40 & 16,60 & 329,79 & $\mid 104,47$ & 244,47 & 244,47 & 67,67 & 505,62 & 68.55 & 4,41 & 48,62 & $\mid 182,34$ & 31,85 & 31.85 & 166,40 \\
\hline Epidalea calamita & 30SVH17 & 100,00 & 147,46 & 125,23 & 37,01 & 6913,02 & 344,08 & 12,32 & 331,76 & 104,38 & 240,95 & 240,95 & 64,36 & 499,75 & 65,82 & 4,52 & 47,34 & 177,79 & 33,55 & 33,55 & 161,52 \\
\hline Epidalea calamita & 30SVH18 & 100,00 & 141,26 & 126,56 & 37,49 & 6920,60 & 339,46 & 5,81 & 333,64 & 122,40 & 234,95 & 234 & 58,32 & 507,36 & 64,76 & 5,18 & 45,75 & 179,45 & 37,25 & 37,25 & 160 \\
\hline Epidalea calamita & \begin{tabular}{|c|}
$30 \mathrm{SVH} 19$ \\
\end{tabular} & $\begin{array}{l}100,00 \\
\end{array}$ & $\begin{array}{l}141,20 \\
143,09\end{array}$ & $\begin{array}{l}127,50 \\
127,54\end{array}$ & 37, 37,95 & 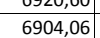 & $\begin{array}{l}330,40 \\
340,91\end{array}$ & $\begin{array}{l}0,01 \\
6,75 \\
\end{array}$ & \begin{tabular}{|l|}
$333,04,16$ \\
334
\end{tabular} & \begin{tabular}{|l|}
125,67 \\
125
\end{tabular} & \begin{tabular}{|l|}
236,47 \\
230
\end{tabular} & \begin{tabular}{|l|}
236,47 \\
230
\end{tabular} & $\begin{array}{l}0,025 \\
60,09 \\
\end{array}$ & \begin{tabular}{|l|l|}
480,86 \\
\end{tabular} & $\begin{array}{l}59,16 \\
594\end{array}$ & $\begin{array}{l}, 10 \\
4,61 \\
\end{array}$ & $\begin{array}{l}3,15 \\
45,19\end{array}$ & \begin{tabular}{|l|l|}
169,93 \\
\end{tabular} & $\begin{array}{l}1,25 \\
35,97 \\
\end{array}$ & $\begin{array}{l}3,25 \\
35,97\end{array}$ & $\begin{array}{l}100,12 \\
150,17\end{array}$ \\
\hline Epidalea calamita & 30 SVH21 & 100,00 & 175,23 & 112,19 & 36,00 & 6708,16 & 355,88 & 46,71 & 309,18 & 107,21 & 265,28 & 265,28 & 93,80 & 478,04 & 70,70 & 3,01 & 54,79 & 181,60 & 20,69 & 20,69 & 170,99 \\
\hline Epidalea calamita & $30 \mathrm{SVH} 22$ & 100,00 & 167,66 & 115,08 & 36,00 & 6811,41 & 353,58 & 37,68 & 315,90 & 117,58 & 259,44 & 259,44 & 85,38 & 498,74 & 73,72 & 3,62 & 53,34 & 188,84 & 24,08 & 24,08 & 174,98 \\
\hline Epidalea calamita & $30 \mathrm{SVH} 24$ & 100,00 & 155,16 & 120,19 & 36,47 & 6904,58 & 347,68 & 22,64 & 325,04 & 108,23 & 248 & 248, & 72,14 & 515,62 & 73,10 & 4,60 & 50 & \begin{tabular}{|l|l|}
191,16 \\
\end{tabular} & 30,13 & 30,13 & 173,88 \\
\hline Epidalea calamita & 30 SVH 25 & 100,00 & 145,86 & 122,79 & 36,97 & 6929,03 & 341,56 & 12,40 & 329,17 & 98,79 & 239,69 & 239,69 & 62,92 & 532,36 & 72,99 & 5,53 & 48,12 & 193,73 & 35,29 & 35,29 & 175,10 \\
\hline
\end{tabular}




\begin{tabular}{|c|c|c|c|c|c|c|c|c|c|c|c|c|c|c|c|c|c|c|c|c|c|}
\hline TAXON & UTM & $\mathrm{km2}$ & B101 & $\mathrm{B1O2}$ & $\mathrm{BIO3}$ & B104 & B105 & B106 & B107 & B108 & $\mathrm{BIO9}$ & 81010 & B1011 & BIO12 & BIO13 & 81014 & B1015 & B1O16 & B1017 & B1018 & B1019 \\
\hline Epidalea calamita & $30 \mathrm{SVH} 26$ & 100,00 & 149,29 & 123,54 & 37,00 & 6905,60 & 344,42 & 15,08 & 329,34 & 102,72 & 242,76 & 242,76 & 66,32 & 502,27 & 67,41 & 4,82 & 47,70 & 180,86 & 33,34 & 33,34 & 163,47 \\
\hline Epidalea calamita & 30 SVH27 & 100,00 & 148,80 & 124,78 & 37,01 & 6891,23 & 344,31 & 13,92 & 330,39 & 109,97 & 241,93 & 241,93 & 65,91 & 485,85 & 63,41 & 4,50 & 46,86 & 172,89 & 33,36 & 33,36 & 155,74 \\
\hline Epidalea calamita & 30 SVH28 & 100,00 & 144,50 & 126,24 & 37,59 & 6887,54 & 341,26 & 9,10 & 332,16 & 126,84 & 237,76 & 237,76 & 61,79 & 484,93 & 61,33 & 4,74 & 45,53 & 171,86 & 35,68 & 35,68 & 152,64 \\
\hline Epidalea calamita & $30 \mathrm{SVH} 29$ & 100,00 & 145,92 & 127,20 & \begin{tabular}{|l|l|}
37,97 \\
\end{tabular} & 6871,08 & 342,44 & 9,62 & 332,82 & 128,69 & 238,79 & 238,79 & 63,22 & 461,63 & 56,56 & 4,32 & 44,88 & 163,25 & 34,75 & 34,75 & 143,18 \\
\hline Epidalea calamita & 30SVH31 & 100,00 & 174,42 & 111,81 & \begin{tabular}{|c|}
35,97 \\
\end{tabular} & $\begin{array}{ll}6694,98 \\
\end{array}$ & 354,43 & 46,19 & 308,23 & 120,97 & 264,31 & 264,31 & 93,27 & 464,98 & 68,30 & 3,05 & 54,04 & 176,06 & 21,03 & 21,03 & 164,68 \\
\hline Epidalea calamita & 30SVH33 & 100,00 & 163,99 & 116,79 & 36,00 & 6826,59 & 351,34 & 33,03 & 318,31 & 117,36 & 255,90 & 255,90 & 81,46 & 484,88 & 69,84 & 3,89 & 51,35 & 181,73 & 26,11 & 26,11 & 165,59 \\
\hline Epidalea calamita & 30SVH35 & 100,00 & 140,37 & 123,03 & 37,00 & 6930,83 & 336,74 & 7,07 & 329,67 & 92,90 & 234,50 & 234,50 & 57,87 & 542,59 & 73,30 & 6,44 & 46,68 & 196,41 & 38,99 & 38,99 & 175,76 \\
\hline Epidalea calamita & \begin{tabular}{|l|}
$30 \mathrm{SVH} 36$ \\
\end{tabular} & 100,00 & 147,72 & 123,40 & 37,00 & 6898,34 & 342,58 & 13,64 & 328,94 & 101,11 & 241,08 & 241,08 & 64,94 & 497,93 & 66,21 & 5,07 & 46,86 & 178,98 & 34,49 & 34,49 & 160,34 \\
\hline Epidalea calamita & 30SVH37 & 100,00 & 147,75 & 124,45 & 37,01 & 6881,14 & 342,70 & 13,11 & 329,59 & 114,63 & 240,86 & 240,86 & 65,12 & 481,28 & 62,21 & 4,71 & 46,21 & $\begin{array}{ll}171,07 \\
\end{array}$ & 34,39 & 34,39 & 152,79 \\
\hline Epidalea calamita & 30SVH38 & 100,00 & 148,85 & 125,41 & 37,41 & 6858,53 & 343,64 & 13,66 & 329,98 & $\begin{array}{l}131,73 \\
\end{array}$ & 241,52 & 241,52 & 66,19 & 460,18 & 57,72 & 4,16 & 45,48 & 163,18 & 33,46 & 33,46 & 143,98 \\
\hline Epidalea calamita & 30SVH39 & 100,00 & 146,88 & 126,43 & \begin{tabular}{|c|}
37,87 \\
\end{tabular} & 6853,03 & 342,19 & 10,88 & 331,31 & 129,72 & 239,51 & 239,51 & 64,41 & 452,64 & 55,16 & 4,27 & 44,49 & 159,99 & 34,66 & 34,66 & 139,43 \\
\hline Epidalea calamita & $30 \mathrm{SVH} 41$ & 100,00 & 172,06 & 112,09 & 36,00 & 6687,70 & 352,28 & 43,94 & 308,34 & 125,90 & 261,96 & 261,96 & 91,14 & 458,41 & 66,63 & 3,46 & 52,76 & 173,03 & 22,34 & 22,34 & 160,08 \\
\hline Epidalea calamita & $30 \mathrm{SVH} 42$ & 100,00 & 168,91 & 114,17 & 36,00 & 6738,83 & 351,87 & 39,52 & 312,34 & 122,59 & 259,43 & 259,43 & 87,43 & 461,65 & 66,40 & 3,64 & 51,84 & 173,28 & 24,00 & 24,00 & 158,57 \\
\hline Epidalea calamita & $30 \mathrm{SVH} 43$ & 100,00 & 163,33 & 116,73 & $\begin{array}{l}36,05 \\
\end{array}$ & 6798,84 & 349,91 & 32,62 & 317,29 & 116,79 & 254,96 & 254,96 & 81,34 & 471,24 & 66,79 & 4,03 & 50,53 & 175,58 & 26,70 & 26,70 & 158,96 \\
\hline Epidalea calamita & $30 \mathrm{SVH} 44$ & 100,00 & 148,33 & 120,66 & 36,76 & 6890,83 & 341,28 & 15,92 & 325,37 & 100,84 & 241,58 & 241,58 & 65,94 & 515,72 & 70,99 & 5,67 & 47,88 & 189,17 & 34,67 & 34,67 & 168,88 \\
\hline Epidalea calamita & $30 \mathrm{SVH} 46$ & 100,00 & 146,07 & 123,18 & 37,00 & 6878,33 & 340,31 & 12,33 & 327,98 & 99,86 & 239,18 & 239,18 & 63,76 & 494,85 & 65,02 & 5,43 & 45,99 & 177,10 & 36,01 & 36,01 & 157,28 \\
\hline Epidalea calamita & $30 \mathrm{SVH} 47$ & 100,00 & 145,99 & 124,14 & 37,00 & 6870,11 & 340,45 & 11,56 & 328,90 & 119,88 & 238,96 & 238,96 & 63,64 & 480,10 & 61,46 & 5,12 & 45,32 & 170,58 & 36,08 & 36,08 & 150,46 \\
\hline Epidalea calamita & $30 \mathrm{SVH} 48$ & 100,00 & 146,49 & 124,96 & 37,16 & 6857,76 & 340,81 & 11,58 & 329,23 & 128,84 & 239,18 & 239,18 & 63,97 & 464,11 & 57,69 & 5,01 & 44,44 & 164,26 & 35,99 & 35,99 & 143,41 \\
\hline Epidalea calamita & 30SVH49 & 100,00 & 147,50 & 125,45 & 37,46 & 6835,61 & 341,49 & 11,92 & 329,56 & 130,52 & 239,71 & 239,71 & 65,16 & 447,70 & 54,38 & 4,81 & 43,65 & 157,62 & 35,58 & 35,58 & 136,44 \\
\hline Epidalea calamita & 30SVH50 & 100,00 & 164,82 & $\mid 112,77$ & 36,00 & 6714,47 & 346,88 & 36,63 & 310,25 & 1117,82 & 255,25 & 255,25 & 84,05 & 475,58 & 68.54 & 4,43 & 51,68 & $\mid 179,36$ & 25,53 & 25,53 & 164,36 \\
\hline Epidalea calamita & 30SVH52 & 100,00 & 170,28 & 113,68 & 36,05 & 6664,14 & 350,71 & 41,16 & 309,55 & 124,24 & 259,68 & 259,68 & 89,45 & 436,84 & 61, & 3,31 & 50,87 & 161,84 & 23,39 & 23,39 & 148,33 \\
\hline Epidalea calamita & 30SVH53 & 100,00 & 163,20 & 116,49 & 36,24 & 6752,17 & 348,31 & 32,62 & 315,69 & $\begin{array}{l}116,77 \\
\end{array}$ & 254,13 & 254,13 & 81,79 & 455,50 & 63,27 & 4,01 & 49,48 & 168,26 & 26,90 & 26,90 & 151,61 \\
\hline Epidalea calamita & 30SVH54 & 100,00 & 152,54 & 119,68 & 36,80 & 6830,84 & 342,73 & 20,42 & 322,31 & 105,50 & 244,79 & 244,79 & 70,64 & 485,61 & 65,96 & 5,25 & 47,56 & 177,26 & 32,77 & 32,77 & 157,69 \\
\hline Epidalea calamita & 30 SVH56 & 100,00 & 144,76 & 122,97 & 37,00 & 6864,75 & 338,35 & 11,25 & 327,10 & 104,27 & 237,83 & 237,83 & 62,92 & 490,56 & 63,53 & 5,96 & 45,01 & 174,62 & 37,62 & 37,62 & 153,92 \\
\hline Epidalea calamita & 30SVH57 & 100,00 & 146,16 & 123,48 & 37,01 & 6850,53 & 339,36 & 11,95 & 327,41 & 127,02 & 238,77 & 238,77 & 63,90 & 471,66 & 59,66 & 5,38 & 44,42 & 167,22 & 36,88 & 36,88 & 146,25 \\
\hline Epidalea calamita & 30SVH58 & 100,00 & 146,40 & 124,25 & 37,12 & 6837,86 & 339,53 & 11,86 & 327,67 & 128,63 & 238,77 & 238,77 & 64,06 & 458,37 & 56,5 & 5,1 & 43,79 & 162,01 & 36,71 & 36,71 & 140,19 \\
\hline Epidalea calamita & $\begin{array}{l}30 \text { SVH59 } \\
\end{array}$ & 100,00 & 144,79 & $\mid 124,84$ & 37,39 & $\begin{array}{l}68525,02 \\
6825\end{array}$ & 338,13 & \begin{tabular}{|l|l|}
9,79 \\
9
\end{tabular} & 328,35 & $\begin{array}{l}127,27 \\
127\end{array}$ & 236,96 & 236,96 & 62,84 & 454,60 & 55,18 & 5,40 & 42,85 & \begin{tabular}{|l|l|}
160,04 \\
\end{tabular} & 38,25 & 38,25 & 136,98 \\
\hline Epidalea calamita & $30 \mathrm{SVH} 62$ & 100,00 & 164,73 & 114,86 & 36,16 & 6674,53 & 346,68 & 35,18 & 311,50 & 118,38 & 254,51 & 254,51 & 84,26 & 441,02 & 60,50 & 4,08 & 49,19 & 162,05 & 26,24 & 26,24 & 146,58 \\
\hline Epidalea calamita & 30SVH63 & 100,00 & 164,47 & 116,01 & 36,64 & 6684,56 & 347,21 & 34,17 & 313,04 & 118,42 & 254,30 & 254,30 & 83,66 & 433,40 & 58,56 & 3,93 & 48,54 & 157,97 & 26,50 & 26,50 & 142,27 \\
\hline Epidalea calamita & $30 \mathrm{SVH} 64$ & 100,00 & 154,19 & 119,16 & 36,95 & 6780,69 & 342,24 & 22,47 & 319,76 & 107,34 & 245,70 & 245,70 & 72,69 & 464,67 & 61,84 & 5,05 & 46,69 & 168,01 & 32,31 & 32,31 & 148,91 \\
\hline Epidalea calamita & $30 \mathrm{SVH} 65$ & 100,00 & 145,01 & 121,56 & 37,00 & 6830,51 & 336,83 & 12,36 & 324,47 & 98,63 & 237,55 & 237,55 & 63,40 & 490,13 & 63,78 & 6,22 & 44,91 & 175,06 & 37,89 & 37,89 & 153,67 \\
\hline Epidalea calamita & $\begin{array}{l}30 \mathrm{SVH} 69 \\
\end{array}$ & 100,00 & 146,29 & \begin{tabular}{|l|l|}
124,01 \\
\end{tabular} & 37,65 & |6792,17 & 337,92 & \begin{tabular}{|l|l|}
11,67 \\
12,0
\end{tabular} & \begin{tabular}{|l|}
326,24 \\
\end{tabular} & \begin{tabular}{|c|}
128,97 \\
\end{tabular} & 237,93 & 237,93 & $\begin{array}{ll}64,61 \\
640\end{array}$ & |442,55 & 53,97 & 5,37 & 42,74 & $\begin{array}{l}155,66 \\
150\end{array}$ & 37,81 & 37,81 & 132,21 \\
\hline Epidalea calamita & 30SVH71 & 100,00 & 158,31 & 115,52 & 36,50 & 6665,09 & 341,10 & 28,90 & 312,20 & 111,62 & 248,20 & 248,20 & 78,44 & 454,27 & 61,34 & 5,01 & 48,06 & 165,90 & 29,30 & 29,35 & 149,21 \\
\hline Epidalea calamita & $30 \mathrm{SVH} 72$ & 100,00 & 159,66 & 115,97 & 36,73 & 6665,73 & 342,40 & 29,73 & 312,66 & 113,17 & 249,38 & 249,38 & 79,49 & 443,50 & 59,31 & 4,74 & 47,62 & 161,06 & 29,03 & 29,03 & 144,19 \\
\hline Epidalea calamita & 30SVH73 & 100,00 & 158,57 & 117,19 & 36,92 & 6693,90 & 342,66 & 27,94 & 314,72 & 112,08 & 248,70 & 248,70 & 78,07 & 440,84 & 58,22 & 4,71 & 46,95 & 159,03 & 29,90 & 29,90 & 141,52 \\
\hline Epidalea calamita & 30 SVH74 & 100,00 & 156,35 & 118,46 & 37,00 & 6713,76 & 341,89 & 24,83 & 317,06 & 109,79 & 246,80 & 246,80 & 75,59 & 442,10 & 57,42 & 4,87 & 45,98 & 158,07 & 31,52 & 31,52 & 139,85 \\
\hline Epidalea calamita & 30SVH75 & 100,00 & $\begin{array}{l}130,50,09 \\
148,\end{array}$ & \begin{tabular}{|l|}
120,87 \\
120,0
\end{tabular} & 37,00 & 6772,70 & $\begin{array}{l}34,05 \\
337,37\end{array}$ & $\begin{array}{l}4,03 \\
15,63 \\
\end{array}$ & $\begin{array}{l}\mid 11,00 \\
321,74\end{array}$ & $\begin{array}{l}110,62 \\
10,5\end{array}$ & $\begin{array}{l}239,60 \\
239,64\end{array}$ & \begin{tabular}{|l|}
239,64 \\
230
\end{tabular} & $\begin{array}{l}\mid 3,35 \\
66,96\end{array}$ & $\begin{array}{l}\mid 442,10 \\
466,38 \\
\end{array}$ & $\begin{array}{l}30,446 \\
59,56\end{array}$ & $\begin{array}{ll}4,019 \\
5,92\end{array}$ & $\begin{array}{l}43,40 \\
44,41\end{array}$ & \begin{tabular}{|l|}
165,41 \\
16,1
\end{tabular} & $\begin{array}{l}31,024 \\
36,67\end{array}$ & $\begin{array}{l}1,25 \\
36,67\end{array}$ & $\begin{array}{l}13,05 \\
144,59\end{array}$ \\
\hline Epidalea calamita & 30SVH76 & 100,00 & 142,16 & 122,42 & 37,00 & 6812,50 & 333,83 & 9,07 & 324,76 & 123,00 & 234,41 & 234,41 & 60,91 & 480,67 & 60,20 & 6,83 & 42,80 & 170,17 & 40,83 & 40,83 & 146,37 \\
\hline Epidalea calamita & 30SVH77 & 100,00 & 142,68 & 123,08 & \begin{tabular}{|l|l|}
37,03 \\
\end{tabular} & 6806,49 & 334,28 & 9,16 & 325,12 & 124,01 & 234,77 & 234,77 & 61,13 & 469,75 & 57,91 & 6,51 & 42,44 & 165,86 & 40,73 & 40,73 & 141,46 \\
\hline Epidalea calamita & 30SVH78 & 100,00 & 143,55 & 123,34 & 37,31 & 6789,82 & 334,83 & 9,47 & 325,36 & 125,28 & 235,28 & 235,28 & 62,08 & 457,77 & 56,10 & 6,16 & 41,93 & 161,07 & 40,42 & 40,42 & 136,31 \\
\hline Epidalea calamita & 30SVH81 & 100,00 & 159,91 & 114,97 & 36,5 & 6589,05 & 339,97 & 30,88 & 309,10 & 113,51 & 248,51 & 248,56 & 80,65 & 429,66 & 56, & 4,7 & 47,06 & 154,55 & 28,56 & 29,46 & 139,10 \\
\hline Epidalea calamita & 30 SVH 82 & 100,00 & 160,16 & 115,77 & 36,99 & 6603,46 & 340,81 & $\begin{array}{l}0,47 \\
30,47\end{array}$ & 310,34 & \begin{tabular}{|l|l|}
113,89 \\
\end{tabular} & \begin{tabular}{|l|l|}
248,95 \\
\end{tabular} & 248,96 & 80,58 & 424,64 & 55,04 & 4,6 & 46,62 & $\begin{array}{l}151,94 \\
15,\end{array}$ & 28,97 & 29,23 & 135,88 \\
\hline Epidalea calamita & $30 \mathrm{SVH} 84$ & 100,00 & 151,55 & 119,32 & 37,00 & 6704,51 & 337,58 & 19,89 & 317,69 & 108,82 & 241,97 & 241,97 & 71,14 & 447,91 & 56,74 & 5,63 & 44,35 & 158,38 & 34,87 & 34,87 & 138,63 \\
\hline Epidalea calamita & 30SVH85 & 100,00 & 146,29 & 120,92 & 37,01 & 6742,36 & 334,64 & 13,91 & 320,72 & 123,55 & 237,31 & 237,31 & 65,56 & 461,99 & 57,69 & 6,39 & 43,18 & 163,03 & 38,59 & 38,59 & 140,59 \\
\hline Epidalea calamita & 30 SVH86 & 100,00 & 141,92 & 122,06 & 37,06 & 6764,19 & 332,12 & 9,23 & 322,88 & 122,99 & 233,60 & 233,60 & 61,22 & 471,71 & 58,5 & 6,9 & 42,31 & 166,75 & 41,62 & 41,62 & 141,42 \\
\hline Epidalea calamita & 30SVH87 & 100,00 & 139,49 & 123,06 & 37,12 & 6786,70 & 330,69 & $\frac{6,201}{6,01}$ & $\begin{array}{l}22,006 \\
324,68\end{array}$ & 120,62 & 231,38 & 231,38 & 58,45 & 474,48 & 58,5 & 7, & 41,23 & $\begin{array}{l}167,08 \\
\end{array}$ & 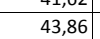 & $\begin{array}{l}41,0<2 \\
43,86 \\
\end{array}$ & 140,26 \\
\hline Epidalea calamita & 30SVH88 & 100,00 & 141 & 123,04 & 37,28 & 6771,16 & 332,17 & 7,86 & 324,31 & 123,02 & 233,21 & 233,21 & 60,82 & 458,14 & 56,45 & 6,96 & 41,01 & 160,90 & 42,93 & 42,93 & 134,25 \\
\hline Epidalea calamita & 30 SVH89 & 100,00 & 140,90 & 123,53 & 37,70 & 6775,70 & 331,73 & 7,22 & 324,51 & 122,73 & 232,59 & 232,59 & 59,84 & 453,45 & 55,56 & 7,05 & 40,45 & 158,53 & 43,93 & 43,93 & 131,40 \\
\hline Epidalea calamita & 30SVH91 & 100,00 & 157,54 & 115,40 & 37,00 & 6535,99 & 336,60 & 28,51 & 308,10 & 111,21 & 245,42 & 245,54 & 79,16 & 422,17 & 53,42 & 5,06 & 45,63 & 149,34 & 30,23 & 31,69 & 133,69 \\
\hline Epidalea calamita & 30SVH93 & 100,00 & 154,94 & 117,56 & 37,00 & 6602,10 & 336,82 & 24,36 & 312,46 & 111,42 & 243,77 & 243,82 & 75,61 & 425,90 & 53,23 & 5,27 & 44,41 & 49,47 & 32,83 & 33,28 & 131,48 \\
\hline Epidalea calamita & \begin{tabular}{|c|}
$30 \mathrm{SVH} 95$ \\
\end{tabular} & 100,00 & 143,64 & $\frac{1}{12}$ & 37,12 & $\mid 6708,19$ & 330,02 & $\begin{array}{l}4,30 \\
11,41 \\
\end{array}$ & \begin{tabular}{|l|}
319,91 \\
319
\end{tabular} & \begin{tabular}{|l|l|l|l|l|}
124,45 \\
\end{tabular} & \begin{tabular}{|l|}
234,24 \\
\end{tabular} & \begin{tabular}{|l|}
234,24 \\
234
\end{tabular} & 63,41 & $\begin{array}{l}42,, 00,92 \\
460\end{array}$ & $\begin{array}{l}\mid 5,25 \\
57,49 \\
\end{array}$ & $\frac{3,27}{6,88}$ & $\begin{array}{ll}4,, 44 \\
41,94\end{array}$ & \begin{tabular}{|l|}
1452,34 \\
162,
\end{tabular} & 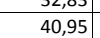 & $\begin{array}{l}30,20 \\
40,95\end{array}$ & $\begin{array}{l}131,40 \\
137,51\end{array}$ \\
\hline Epidalea calamita & 30SVH97 & 100,00 & 139,67 & 122,69 & 37,56 & 6736,95 & 329,12 & 6,52 & 322,60 & 120,83 & 230,82 & 230,82 & 59,15 & 465,53 & 57,73 & 7,51 & 40,27 & 163,32 & 44,75 & 44,75 & 135,38 \\
\hline Epidalea calamita & 30SVH98 & 100,00 & 139,86 & 122,99 & 37,83 & 6736,23 & 329,23 & 6,42 & 322,81 & 121,03 & 230,88 & 230,88 & 59,26 & 458,89 & 56,75 & 7,38 & 39,95 & 160,64 & 45,17 & 45,17 & 132,16 \\
\hline Epidalea calamita & 30SVH99 & 100,00 & 139,69 & 123,08 & 37,79 & 6748,69 & 329,19 & 6,02 & 323,17 & 121,15 & 230,91 & 230,91 & 58,94 & 453,36 & 55,73 & 7,39 & 39,36 & 158,10 & 45,71 & 45,71 & 129,19 \\
\hline Epidalea calamita & 30 SVJo0 & 100,00 & 148,87 & 127,44 & 38,00 & 6881,30 & 345,65 & 11,99 & 333,65 & 132,29 & 241,78 & 24 & 65,87 & 452,13 & 55,12 & 4,00 & 45,43 & 158,93 & 32,90 & 32,90 & 140 \\
\hline Epidalea calamita & 30svJ01 & $\begin{array}{l}100,00 \\
\end{array}$ & $\begin{array}{l}140,01 \\
145,96\end{array}$ & \begin{tabular}{|l|}
127,77 \\
127,7
\end{tabular} & 30,00 & $\begin{array}{l}0001,100 \\
6873,92\end{array}$ & 342,03 & \begin{tabular}{|c|c|}
1,95 \\
8,98
\end{tabular} & \begin{tabular}{|l|}
333,92 \\
333,92
\end{tabular} & \begin{tabular}{|l|}
129,55 \\
12,55
\end{tabular} & \begin{tabular}{|l|}
238,77 \\
238
\end{tabular} & \begin{tabular}{|l|}
238,77 \\
231
\end{tabular} & $\begin{array}{l}3,010 \\
63,01 \\
\end{array}$ & | & $\begin{array}{l}30,12 \\
53,61\end{array}$ & $\begin{array}{l}4,40 \\
4,16 \\
\end{array}$ & $\begin{array}{l}4,45 \\
44,37 \\
\end{array}$ & \begin{tabular}{|l|}
157,40 \\
150
\end{tabular} & $\begin{array}{l}32,50 \\
34,68\end{array}$ & $\begin{array}{l}34,68 \\
34,68 \\
\end{array}$ & $\begin{array}{l}140,13 \\
137,48\end{array}$ \\
\hline Epidalea calamita & 30SVJO2 & 100,00 & 143,81 & 127,26 & 38,00 & 6880,20 & 340,49 & 7,06 & 333,44 & 127,11 & 236,74 & 236,74 & 60,84 & 446,77 & 53,00 & 4,54 & 43,43 & 156,01 & 36,44 & 36,44 & 134,77 \\
\hline Epidalea calamita & 30SVJO3 & 100,00 & 142,10 & 126,30 & 37,46 & 6881,69 & 338,09 & 5,64 & 332,45 & 125,62 & 235,12 & 235,12 & 59,01 & 445,49 & 52,57 & 5,19 & 42,22 & 154,66 & 38,37 & 38,37 & 132,61 \\
\hline Epidalea calamita & 30SVJO4 & 100,00 & 135,10 & 124,96 & 37,05 & 6881,69 & 330,80 & 0,21 & 330,58 & 118,0 & 228, & 228,37 & 52, & 466,01 & 54,44 & 6,42 & 40,85 & 160,88 & & 43,42 & 136,69 \\
\hline Epidalea calamita & $\begin{array}{l}30 \text { SVJ } 05 \\
\end{array}$ & 100,00 & 130,97 & 123,47 & 37,00 & 6870,26 & 325,77 & $\begin{array}{l}-2,56 \\
-2,56 \\
\end{array}$ & 328,33 & 113,57 & 224,31 & 224,31 & 48,85 & 475,61 & 55,56 & $\frac{2,47}{7,50}$ & 39,55 & 162,95 & 47,10 & 47,10 & 137,71 \\
\hline
\end{tabular}




\begin{tabular}{|c|c|c|c|c|c|c|c|c|c|c|c|c|c|c|c|c|c|c|c|c|c|}
\hline TAXON & UTM & $\mathrm{km} 2$ & B101 & B102 & $\mathrm{BIO3}$ & B104 & B105 & B106 & B107 & B108 & B109 & BIO10 & BIO11 & BIO12 & B1013 & BIO14 & BIO15 & B1016 & B1017 & B1018 & B1019 \\
\hline Epidalea calamita & 30SVJ06 & 100,00 & 129,19 & 121,97 & 37,00 & 6851,31 & 322,54 & $-3,91$ & 326,45 & 111,79 & 222,27 & 222,27 & 47,47 & 477,10 & 55,90 & 8,28 & 38,71 & 162,20 & 49,38 & 49,38 & 136,52 \\
\hline Epidalea calamita & 30SVJ07 & 100,00 & 131,62 & 120,57 & 36,83 & 6862,95 & 323,58 & $-1,03$ & 324,61 & 114,59 & 224,92 & 224,92 & 49,54 & 460,03 & 54,08 & 8,21 & 38,10 & 155,29 & 48,46 & 48,46 & 130,47 \\
\hline Epidalea calamita & 30SVJ08 & 100,00 & 128,99 & 118,95 & 36,32 & 6836,28 & 319,54 & $-2,78$ & 322,32 & 111,71 & 221,98 & 222,00 & 47,55 & 465,26 & 54,82 & 9,07 & 37,28 & 155,83 & 51,08 & 51,10 & 130,69 \\
\hline Epidalea calamita & 305VJ09 & 100,00 & 139,00 & 117,17 & 36,00 & 6873,60 & 327,36 & 5,94 & 321,43 & 123,10 & 232,25 & 232,25 & 56,13 & 423,66 & 49,44 & 8,03 & 37,47 & 140,40 & 45,81 & 45,81 & 118,53 \\
\hline Epidalea calamita & $30 \mathrm{SVJ10}$ & 100,00 & 148,49 & 128,22 & 38,00 & 6857,95 & 344,86 & 11,30 & 333,56 & \begin{tabular}{|l|}
132,17 \\
\end{tabular} & 240,94 & 240,94 & 65,41 & 442,34 & 53,40 & 4,00 & 44,74 & 155,84 & 33,31 & 33,31 & 136,15 \\
\hline Epidalea calamita & 30SVJ11 & 100,00 & 147,16 & 128,77 & 38,00 & 6852,44 & 343,75 & 9,46 & 334,29 & 131,07 & 239,31 & 239,31 & 64,03 & 431,67 & 52,12 & 4,00 & 44,03 & 151,79 & 33,87 & 33,87 & 130,75 \\
\hline Epidalea calamita & 30SVJ12 & 100,00 & 145,34 & 127,97 & 38,00 & 6855,16 & 341,47 & 8,08 & 333,38 & 129,08 & 237,77 & 237,77 & 62,36 & 430,18 & 51,64 & 4,23 & 43,15 & 150,32 & 35,40 & 35,40 & 128,68 \\
\hline Epidalea calamita & $\begin{array}{l}0 \text { osv } 13 \\
\end{array}$ & 100,00 & 143,91 & 126,68 & 37,89 & 6858,15 & 339,39 & 7,36 & 332,03 & 127,80 & 236,59 & 236,59 & 61,18 & 430,37 & 51,26 & 4,76 & 42,04 & 149,31 & 37,37 & 37,37 & 127,06 \\
\hline Epidalea calamita & 30SVJ14 & 100,00 & 138,22 & 125,37 & 37,23 & 6874,87 & 333,56 & 2,55 & 331,01 & 121,61 & 231,30 & 231,30 & 55,50 & 448,08 & 52,82 & 5,88 & 40,84 & 154,54 & 41,71 & 41,71 & 130,77 \\
\hline Epidalea calamita & 30SVJ15 & 100,00 & 133,32 & 123,81 & 37,00 & 6870,43 & 327,87 & $-0,78$ & 328,66 & 116,26 & 226,57 & 226,57 & 51,09 & 461,95 & 54,07 & 7,10 & 39,51 & 158,08 & 45,73 & 45,73 & 133,26 \\
\hline Epidalea calamita & 30SVJ17 & 100,00 & 131,07 & 120,62 & 36,84 & 6857,65 & 322,85 & $-1,81$ & 324,66 & 114,03 & 224,17 & 224,17 & 49,04 & 461,86 & 54,09 & 8,49 & 37,81 & 155,32 & 49,35 & 49,35 & 130,82 \\
\hline Epidalea calamita & 30SVJ18 & 100,00 & 131,14 & 119,15 & 36,31 & 6845,13 & 321,53 & $-1,08$ & 322,61 & 114,18 & 224,04 & 224,04 & 49,31 & 457,24 & 53,43 & 8,76 & 37,21 & 152,28 & 50,13 & 50,13 & 128,56 \\
\hline Epidalea calamita & 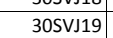 & 100,00 & 136,40 & 117,32 & 36,00 & 6863,28 & 324,79 & 3,71 & \begin{tabular}{|l|}
321,08 \\
\end{tabular} & $\mid 120,36$ & 229,45 & 229,45 & 53,82 & 434,31 & $\begin{array}{l}0,343 \\
50,33\end{array}$ & 8,44 & $\frac{37,0}{37,00}$ & 142,90 & $\begin{array}{l}40,154 \\
47,74\end{array}$ & 47,74 & 121,74 \\
\hline Epidalea calamita & 30 SVJ20 & 100,00 & 147,62 & 128,19 & 38,00 & 6846,08 & 343,72 & 10,63 & 333,09 & 131,12 & 239,85 & 239,85 & 64,75 & 437,74 & 53,16 & 4,03 & 44,23 & 154,48 & 33,94 & 33,94 & 133,55 \\
\hline Epidalea calamita & $305 \mathrm{~V} J 22$ & 100,00 & 146,95 & 127,78 & 38,00 & 6837,73 & 342,15 & 9,75 & 332,40 & 130,93 & 239,15 & 239,15 & 64,08 & 418,04 & 50,58 & 4,00 & 43,23 & 146,07 & 34,69 & 34,69 & 124,21 \\
\hline Epidalea calamita & $305 \mathrm{SV} 23$ & 100,00 & 145,52 & 126,56 & 37,99 & 6840,83 & 340,04 & 8,74 & 331,30 & 129,61 & 237,74 & 237,74 & 62,74 & 420,08 & 50,24 & 4,60 & 42,20 & 145,53 & 36,85 & 36,85 & 123,39 \\
\hline Epidalea calamita & 30 SVJ27 & 100,00 & 138,01 & 120,68 & 36,75 & 6871,08 & 329,10 & 3,85 & 325,25 & 121,88 & 230,97 & 230,97 & 55,32 & 434,99 & 50,34 & 7,21 & 38,25 & 145,27 & 44,89 & 44,89 & 123,82 \\
\hline Epidalea calamita & 30 SVJ28 & 100,00 & 135,25 & 119,14 & 36,33 & 6859,47 & 325,16 & 2,30 & 322,87 & 118,86 & 228,19 & 228,19 & 52,80 & 442,13 & 51,11 & 8,18 & 37,29 & 146,24 & 47,59 & 47,59 & 124,93 \\
\hline Epidalea calamita & $305 \mathrm{~V} J 29$ & 100,00 & 137,95 & 117,35 & 36,00 & 6861,37 & 325,99 & 5,17 & 320,82 & 122,23 & 230,87 & 230,87 & 55,37 & 430,23 & 49,26 & 8,04 & 37,27 & 140,51 & 46,49 & 46,49 & 121,50 \\
\hline Epidalea calamita & $305 \mathrm{~V} J 32$ & 100,00 & 147,26 & 126,73 & 38,00 & 6819,47 & 341,26 & 10,77 & 330,49 & 131,51 & 239,21 & 239,21 & 64,75 & 418,02 & 50,40 & 4,12 & 42,60 & 145,18 & 35,91 & 35,91 & 123,62 \\
\hline Epidalea calamita & $305 \mathrm{VJ} 33$ & 100,00 & 146,07 & 125,88 & 37,83 & 6835,78 & 339,76 & 9,77 & 329,99 & 130,11 & 238,23 & 238,23 & 63,47 & 417,42 & 49, & $4, \varepsilon$ & 41,82 & 144,18 & 37,16 & 37,16 & 122,00 \\
\hline Epidalea calamita & $305 \mathrm{~S} J 34$ & 100,00 & 136,18 & 125,01 & 37,16 & 6853,50 & 330,64 & 1,10 & 329,54 & 119,39 & 229,01 & 229,01 & 53,96 & 451,78 & 53,40 & 6,54 & 39,76 & 154,97 & 44,15 & 44,15 & 130,48 \\
\hline Epidalea calamita & 30SVJ37 & 100,00 & 139,10 & 120,68 & \begin{tabular}{|l|l}
36,88 \\
\end{tabular} & 6864,69 & 329,58 & 4,81 & 324,77 & 123,21 & 231,79 & 231,79 & 56,30 & 431,93 & 49,58 & 7,11 & 38,28 & 143,32 & 44,71 & 44,71 & 122,90 \\
\hline Epidalea calamita & 30 SVJ38 & 100,00 & 137,88 & 119,14 & 36,31 & 6851,14 & 327,05 & 4,58 & 322,47 & 121,71 & 230,52 & 230,52 & 55,31 & 434,18 & 49,52 & 7,94 & 37,38 & 142,45 & 46,40 & 46,40 & 123,18 \\
\hline Epidalea calamita & $305 \mathrm{SV} 39$ & 100,00 & 138,51 & 117,42 & 36,01 & 6854,10 & 326,20 & 5,83 & 320,37 & 115,19 & 231,10 & 231,10 & 55,77 & 430,66 & 48,64 & 8,14 & 37,09 & 139,81 & 46,55 & 46,55 & 122,17 \\
\hline Epidalea calamita & 30 SVJ40 & 100,00 & 146,12 & 126,05 & \begin{tabular}{|l|l|}
37,97 \\
\end{tabular} & 6835,88 & 340,31 & 10,31 & 330,00 & 129,36 & 238,40 & 238,40 & 63,86 & 440,99 & 53,4 & 4,86 & 42,94 & 154,66 & 36,81 & 36,81 & 132,48 \\
\hline Epidalea calamita & 30 SVJ42 & 100,00 & 147,07 & 125,73 & 37,80 & 68524,05 & 340,22 & 11,03 & $\begin{array}{ll}329,18 \\
\end{array}$ & 130,93 & $\begin{array}{l}239,08 \\
239\end{array}$ & 239,08 & $\begin{array}{l}64,71 \\
640\end{array}$ & 419,65 & $\begin{array}{l}50,444 \\
50,44\end{array}$ & $\begin{array}{l}4,004 \\
4,93\end{array}$ & 41,76 & 145,29 & $\begin{array}{l}0,01 \\
36,93 \\
\end{array}$ & $\begin{array}{l}30,010 \\
6,93\end{array}$ & 123,44 \\
\hline Epidalea calamita & $305 \mathrm{SV} 43$ & 100,00 & 146,62 & 125,01 & $\begin{array}{l}37,45 \\
\end{array}$ & 6823,15 & 339,09 & 10,59 & 328,50 & 130,47 & 238,72 & 238,72 & 64,20 & 415,36 & 49,60 & 5,00 & 41,53 & 142,82 & 37,42 & 37,42 & 121,07 \\
\hline Epidalea calamita & $30 \mathrm{SVJ} 44$ & 100,00 & 134,94 & 124,47 & 37,18 & 6837,59 & 328,72 & 0,39 & 328,33 & 117,92 & 227,52 & 227,52 & 52,91 & 457,44 & 53,83 & 7,13 & 39,26 & 156,41 & 46,03 & 46,03 & 131,50 \\
\hline Epidalea calamita & 30 SVJ45 & 100,00 & 128,65 & 123,56 & 37,03 & 6835,67 & 322,47 & $-4,44$ & 326,91 & 111,14 & 221,50 & 221,50 & 47,35 & 478,31 & 55,59 & 8,50 & 37,84 & 162,32 & 50,98 & 50,98 & 136,15 \\
\hline Epidalea calamita & 30SVJ46 & 100,00 & 138,17 & 122,27 & 37,00 & 6842,14 & 329,49 & 3,76 & 325,73 & 121,55 & 230,58 & 230,58 & 55,69 & 437,42 & 50,53 & 7,14 & 38,40 & 146,42 & 45,07 & 45,07 & 124,66 \\
\hline Epidalea calamita & $305 \mathrm{~S} 449$ & 100,00 & 140,49 & 117,41 & 36,00 & 6837,43 & 327,53 & 7,189 & 319,64 & \begin{tabular}{|l|l}
105,80 \\
\end{tabular} & $\begin{array}{l}232,76 \\
232\end{array}$ & \begin{tabular}{|l|}
232,76 \\
\end{tabular} & 57,93 & \begin{tabular}{|l|l|}
425,16 \\
425,
\end{tabular} & $\begin{array}{l}0,43 \\
47,43\end{array}$ & 8,03 & $\begin{array}{l}30,404 \\
37,04\end{array}$ & \begin{tabular}{|l|}
138,04 \\
138,04
\end{tabular} & 45,75 & $\begin{array}{ll}45,75 \\
45,75\end{array}$ & 121,16 \\
\hline Epidalea calamita & $305 \mathrm{~V} J 50$ & 100,00 & 143,14 & 125,34 & 37,59 & 6834,76 & 336,97 & 7,78 & 329,18 & 125,91 & 235,43 & 235,43 & 60,97 & 450,52 & 54,61 & 5,57 & 42,19 & 157,93 & 39,32 & 39,32 & 134,14 \\
\hline Epidalea calamita & 30SVJ51 & 100,00 & 146,97 & 125,01 & 37,74 & 6819,39 & 339,39 & 11,22 & 328,17 & 130,10 & 238,76 & 238,76 & 64,74 & 426,66 & 51,64 & 5,00 & 42,08 & 148,41 & $\mid 37,15$ & 37,15 & 126,10 \\
\hline Epidalea calamita & 30 SVJ52 & 100,00 & 146,53 & 124,87 & 37,88 & 6810,31 & 338,57 & 11,10 & 327,47 & 130,18 & 238,37 & 238,37 & 64,26 & 420,59 & 50,62 & 5,00 & 41,29 & 145,68 & 37,72 & 37,72 & 123,19 \\
\hline Epidalea calamita & $30 \mathrm{SVJJ3}$ & 100,00 & 146,14 & 124,31 & 37,35 & 6814,92 & 337,58 & 10,36 & 327,22 & 130,06 & 238,08 & 238,08 & 63,67 & 416,54 & 49,82 & 5,19 & 41,49 & 143,32 & 38,29 & 38,29 & 120,92 \\
\hline Epidalea calamita & $305 \mathrm{~s} v 54$ & 100,00 & $\begin{array}{l}14,14 \\
144,27\end{array}$ & $\begin{array}{l}124,51 \\
123,68 \\
\end{array}$ & 37,15 & $\begin{array}{ll}0.142,25 \\
6812,25\end{array}$ & 335,56 & \begin{tabular}{|l|}
0,90 \\
8,92
\end{tabular} & \begin{tabular}{|l|l|}
326,64 \\
326
\end{tabular} & $\begin{array}{l}128,22 \\
128,0\end{array}$ & $\begin{array}{l}50,000 \\
236,22\end{array}$ & $\begin{array}{l}236,220 \\
236,2\end{array}$ & $\begin{array}{l}61,91 \\
61\end{array}$ & \begin{tabular}{|l|}
420,01 \\
42,01
\end{tabular} & $\begin{array}{l}43,024 \\
49,45 \\
\end{array}$ & $\begin{array}{l}3,194 \\
5,94\end{array}$ & $\begin{array}{l}1,49 \\
39,88 \\
\end{array}$ & \begin{tabular}{|l|}
142,702 \\
142,0
\end{tabular} & $\begin{array}{l}0,34 \\
40,63 \\
\end{array}$ & \begin{tabular}{|l|}
0,25 \\
40,63
\end{tabular} & $\begin{array}{l}121,02 \\
121,01\end{array}$ \\
\hline Epidalea calamita & 30SVI55 & 100,00 & 138,96 & 123,14 & 37,03 & 6822,71 & 330,55 & 4,48 & 326,07 & 122,39 & 231,19 & 231,19 & 56,86 & 436,58 & 50,83 & 7,02 & 38,73 & 147,13 & 44,65 & 44,65 & 124,51 \\
\hline Epidalea calamita & 30 SVJ56 & 100,00 & 141,14 & 121,81 & 37,00 & 6824,03 & 331,22 & 6,81 & 324,42 & 124,94 & 233,10 & 233,10 & 58,76 & 426,60 & 49,15 & 7,00 & 38,18 & 142,00 & 43,97 & 43,97 & 121,56 \\
\hline Epidalea calamita & 30SVJ60 & 100,00 & 146,60 & 124,06 & 37,64 & 6791,43 & 337,84 & 11,36 & 326,48 & 129,55 & 237,93 & 237,93 & 64,54 & 433,45 & 52,76 & 5,24 & 41,85 & 151,32 & 37,87 & 37,87 & 128,27 \\
\hline Epidalea calamita & $305 \mathrm{SV} 63$ & 100,00 & 145,56 & 123,84 & 37,56 & 6793,06 & 336,41 & 10,36 & 326,05 & 129,08 & 237,10 & 237,10 & 63,46 & 418,47 & $49, \varepsilon$ & 5,9 & 40,10 & 143,10 & 40,69 & 40,69 & 120,32 \\
\hline Epidalea calamita & $305 \mathrm{~s} J 64$ & 100,00 & $\begin{array}{l}14,50 \\
145,46\end{array}$ & $\begin{array}{l}123,04 \\
123,06\end{array}$ & 年, 37,06 & $\begin{array}{l}0 / 97,060 \\
6786,10\end{array}$ & $\begin{array}{l}330,41 \\
335,44\end{array}$ & $\begin{array}{l}10,40 \\
10,40 \\
\end{array}$ & \begin{tabular}{|l|}
325,05 \\
325,05
\end{tabular} & $\begin{array}{l}129,290 \\
129,29\end{array}$ & \begin{tabular}{|l|}
236,99 \\
236,9
\end{tabular} & \begin{tabular}{|l|}
236,99 \\
236,9
\end{tabular} & $\begin{array}{l}63,40 \\
63,45 \\
\end{array}$ & \begin{tabular}{|l|}
$415,4,23$ \\
415,
\end{tabular} & $\begin{array}{ll}48, c, \varepsilon \\
48,8\end{array}$ & $\begin{array}{l}3,990 \\
6,00 \\
\end{array}$ & $\begin{array}{l}0,10 \\
39,58 \\
\end{array}$ & $\begin{array}{l}435,10 \\
140,40\end{array}$ & $\begin{array}{l}40,95 \\
40,97 \\
\end{array}$ & $\begin{array}{l}40,99 \\
40,97\end{array}$ & $\begin{array}{l}120,32 \\
118,88 \\
\end{array}$ \\
\hline Epidalea calamita & 30 SVJ65 & 100,00 & 142,53 & 122,46 & 37,01 & 6797,50 & 332,62 & 8,01 & 324,61 & 126,37 & 234,29 & 234,29 & 60,49 & 422,73 & 49,10 & 6,82 & 38,56 & 141,88 & 43,16 & 43,16 & 120,14 \\
\hline Epidalea calamita & 30SVJ67 & 100,00 & 141,23 & 120,51 & 37,00 & 6800,68 & 329,50 & 7,49 & 322,01 & 125,39 & 232,94 & 232,94 & 59,03 & 423,83 & 47,80 & 7,35 & 37,40 & 138,80 & 45,29 & 45,29 & 119,79 \\
\hline Epidalea calamita & 30 SVJ68 & 100,00 & 139,38 & 119,45 & 36,99 & 6792,24 & 326,91 & 6,43 & 320,48 & 121,76 & 230,94 & 230,94 & 57,30 & 429,52 & 48,12 & 8,10 & 36,96 & 139,14 & 46,72 & 46,72 & 121,38 \\
\hline Epidalea calamita & $305 \mathrm{~V} J 70$ & 100,00 & 145,14 & 123,99 & 37,99 & 6779,11 & 335,9 & $\begin{array}{l}0,45 \\
10,46 \\
\end{array}$ & 325,44 & 127,62 & 236,54 & 236,54 & 63,40 & | 436,02 & $53, \mathrm{C}$ & $\frac{6,00}{6,00}$ & 40,94 & 151,82 & 40,34 & 40,34 & 127,27 \\
\hline Epidalea calamita & $305 \mathrm{SVJ3}$ & 100,00 & 145,29 & 123,21 & 37,25 & 6768,91 & 334,90 & 10,55 & 324,35 & 128,87 & 236,44 & 236,44 & 63,49 & 417,83 & 49,6 & 6,00 & 39,88 & 142,34 & 41,16 & 41,16 & 119,35 \\
\hline Epidalea calamita & $305 \mathrm{~V} v 74$ & 100,00 & 144,82 & 122,80 & 37,18 & 6770,99 & 333,99 & 10,20 & 323,79 & 128,72 & 236,08 & 236,08 & 63,02 & 415,01 & 48,65 & 6,14 & 39,17 & 140,27 & 41,79 & 41,79 & 117,90 \\
\hline Epidalea calamita & $30 \mathrm{SVJ75}$ & 100,00 & 144,96 & 122,00 & 37,01 & 6776,05 & 333,15 & 10,24 & 322,91 & 129,05 & 236,03 & 236,03 & 62,79 & 414,24 & 48,00 & 6,75 & 38,26 & 138,93 & 42,70 & 42,70 & 116,81 \\
\hline Epidalea calamita & $305 \mathrm{SVJ7}$ & 100,00 & 143,29 & 121,29 & 37,03 & 6768,62 & 331,36 & 9,25 & 322,12 & 127,52 & 234,38 & 234,38 & 61,47 & 416,98 & 47,55 & 7,05 & 37,74 & 137,95 & 44,09 & 44,09 & 117,32 \\
\hline Epidalea calamita & 30 SVJ77 & 100,00 & $\frac{142}{142}$ & $\begin{array}{l}121,23 \\
120,53\end{array}$ & 37,00 & $\begin{array}{l}670,020 \\
6778,90\end{array}$ & 329,51 & $\begin{array}{l}3,250 \\
8,49\end{array}$ & \begin{tabular}{|l|}
321,02 \\
3212
\end{tabular} & \begin{tabular}{|l|}
126,27 \\
\end{tabular} & \begin{tabular}{|l|}
233,47 \\
237
\end{tabular} & \begin{tabular}{|l|}
233,47 \\
230
\end{tabular} & $\begin{array}{l}60,07 \\
60,\end{array}$ & \begin{tabular}{|l|l|}
419,88 \\
419,88
\end{tabular} & $\mid$\begin{tabular}{|l|}
47,05 \\
47
\end{tabular} & $\frac{7,000}{7,60}$ & \begin{tabular}{|l|l|}
36,94 \\
36
\end{tabular} & \begin{tabular}{|l|}
137,13 \\
13,13
\end{tabular} & $\begin{array}{l}44,03 \\
45,58\end{array}$ & $\begin{array}{l}44,05 \\
45,58\end{array}$ & 1117,90 \\
\hline Epidalea calamita & 30SVJ78 & 100,00 & 141,08 & 119,51 & 37,00 & \begin{tabular}{ll|}
6769,87 \\
\end{tabular} & 327,47 & 7,95 & 319,52 & 121,23 & 232,09 & 232,09 & 58,94 & 422,44 & 47,01 & 8,00 & 36,31 & 136,81 & 46,45 & 46,45 & 118,64 \\
\hline Epidalea calamita & 30 SVJ80 & 100,00 & 140,69 & 123,88 & 37,93 & 6766.96 & 331,26 & 6.62 & 324,64 & $|122,67|$ & 231,94 & 231,94 & 59,36 & 449,30 & 54,72 & 7,00 & 39.91 & 156,44 & 44,36 & 44,36 & 129,07 \\
\hline Epidalea calamita & $305 \mathrm{~S} / 83$ & 100,00 & 144,75 & 122,99 & 37,67 & 6738,62 & 333,31 & 10,16 & 323,15 & 128,24 & 235,38 & 235,38 & 63,21 & 417,82 & 49,56 & 6,62 & 39,22 & 142,08 & 42,68 & 42,68 & 118,05 \\
\hline Epidalea calamita & $305 \mathrm{SV} 85$ & 100,00 & 143,96 & 122,00 & 37,15 & 6750,31 & 331,81 & 9,66 & 322,16 & 128,12 & 234,82 & 234 & 62,24 & 415,35 & 48,00 & 7,00 & 37,99 & 139,01 & 44,36 & 44,36 & 116 \\
\hline Epidalea calamita & $305 v \sqrt{3} 6$ & 100,00 & 140,81 & 121,76 & 37,16 & 6746,40 & 328,68 & 6,90 & 321,79 & $\begin{array}{ll}124,73 \\
\end{array}$ & 231,79 & 231,79 & 59,32 & 4 & 48,34 & 7,76 & 37,00 & 140,92 & 46,98 & 46,98 & 118,40 \\
\hline Epidalea calamita & 30 SVJ87 & 100,00 & 141,18 & 120,79 & 37,01 & 6743,01 & 327,89 & 7,84 & 320,05 & 124,94 & 231,94 & 231,94 & 59,87 & 421,58 & 47,50 & 8,00 & 36,32 & 138,12 & 47,05 & 47,05 & 117,12 \\
\hline Epidalea calamita & 30 SVJ88 & 100,00 & 140,10 & 119,89 & 37,00 & 6747,06 & 326,07 & 6,97 & 319,10 & 123,77 & 230,75 & 230,75 & 58,24 & 424,99 & 47,57 & 8,29 & 35,82 & 137,26 & 48,16 & 48,16 & 118,49 \\
\hline Epidalea calamita & 30SVJ90 & 100,00 & 137,31 & 123,81 & 37,97 & 6755,60 & 327,59 & 3,46 & 324,12 & 119,08 & 228,68 & 228,68 & 56, & 457,68 & 55,81 & 7,90 & 38 & 158,96 & 47,99 & 47,99 & 129,13 \\
\hline Epidalea calamita & 30SVJ91 & 100,00 & 137,54 & 123,87 & 37,99 & 6745,77 & 327,53 & 3,47 & 324,06 & 119,60 & 228,68 & 228,68 & 56,69 & 452,03 & 54,69 & 7,90 & 38,25 & 156,15 & 48,22 & 48,22 & 126,74 \\
\hline
\end{tabular}




\begin{tabular}{|c|c|c|c|c|c|c|c|c|c|c|c|c|c|c|c|c|c|c|c|c|c|}
\hline TAXON & UTM & $\mathrm{km2}$ & BIO1 & B102 & $\mathrm{BIO3}$ & B104 & B105 & B106 & B107 & B108 & B109 & BIO10 & BIO11 & B1012 & BIO13 & BIO14 & BIO15 & BIO16 & BIO17 & BIO18 & BIO19 \\
\hline Epidalea calamita & 30SVJ92 & 100,00 & 142,75 & 123,03 & 37,95 & 6712,64 & 331,08 & 8,64 & 322,45 & 125,73 & 233,26 & 233,26 & 61,86 & 426,77 & 51,09 & 7,06 & 38,14 & 146,14 & 45,13 & 45,13 & 119,23 \\
\hline Epidalea calamita & 30SVJ95 & 100,00 & 143,69 & 122,00 & $\begin{array}{ll}37,86 \\
\end{array}$ & 6707,67 & 330,29 & 9,75 & 320,54 & $\begin{array}{l}127,69 \\
\end{array}$ & 233,91 & 233,91 & 62,46 & 414,76 & 47,81 & 7,21 & 37,31 & \begin{tabular}{|l|l|}
138,81 \\
\end{tabular} & 45,64 & 45,64 & 114,32 \\
\hline Epidalea calamita & 30SVJ96 & 100,00 & 140,72 & 121,75 & 37,59 & 6723,46 & 327,53 & 6,95 & 320,58 & \begin{tabular}{|l|l|}
124,70 \\
\end{tabular} & 231,31 & 231,31 & 59,56 & 423,62 & 48,05 & 8,03 & 36,39 & 140,24 & 48,18 & 48,18 & 116,52 \\
\hline Epidalea calamita & 30SVJ97 & 100,00 & 140,27 & 120,99 & 37,04 & 6723,97 & 326,42 & 6,76 & \begin{tabular}{l|l|}
319,66 \\
\end{tabular} & 124,05 & 230,68 & 230,68 & 58,99 & 424,32 & 48,05 & 8,25 & 35,79 & \begin{tabular}{l|l|}
139,12 \\
13
\end{tabular} & 49,18 & 49,18 & 116,06 \\
\hline Epidalea calamita & 30SVJ98 & 100,00 & 138,31 & 120,23 & 37,03 & 6714,53 & 324,20 & 5,57 & 318,63 & 122,34 & 228,71 & 228,71 & 57,38 & 429,36 & 48,37 & 8,98 & 35,36 & $\begin{array}{l}139,45 \\
\end{array}$ & 50,64 & 50,64 & 117,79 \\
\hline Epidalea calamita & 30SVKO0 & 100,00 & 142,08 & 115,15 & 35,59 & 6885,85 & 328,40 & 8,99 & 319,41 & 126,45 & 235,29 & 235,29 & $\begin{array}{l}58,85 \\
\end{array}$ & 410,00 & 47,49 & 8,07 & 36,99 & \begin{tabular}{|l|l|}
134,34 \\
\end{tabular} & 45,10 & 45,10 & 114,06 \\
\hline Epidalea calamita & 30SVK01 & 100,00 & 149,04 & 113,12 & 35,00 & 6882,69 & 332,72 & 15,98 & 316,74 & 117,76 & \begin{tabular}{|l|l|}
242,08 \\
\end{tabular} & 242,08 & 65,22 & 385,81 & 43,97 & 7,68 & 36,92 & 125,51 & 42,08 & 42,08 & 107,56 \\
\hline Epidalea calamita & 30SVK10 & 100,00 & 139,54 & 115,28 & 35,74 & 6879,58 & 326,16 & 7,09 & 319,07 & \begin{tabular}{|l|l|}
121,73 \\
\end{tabular} & 232,81 & 232,81 & 56,51 & 420,94 & 48,24 & 8,56 & 36,62 & \begin{tabular}{|l|l|}
136,80 \\
\end{tabular} & 46,77 & 46,77 & 117,76 \\
\hline Epidalea calamita & 30SVK11 & 100,00 & 148,71 & 112,90 & 35,00 & 6894,10 & 332,38 & 15,75 & 316,62 & 106,71 & 241,81 & 241,81 & \begin{tabular}{ll|}
64,72 \\
\end{tabular} & 390,78 & \begin{tabular}{l|l}
44,25 \\
\end{tabular} & 7,80 & 37,00 & $\begin{array}{ll}127,62 \\
\end{array}$ & 42,60 & 42,60 & 109,72 \\
\hline Epidalea calamita & 30SVK20 & 100,00 & 141,35 & 115,29 & 35,82 & 6871,42 & 327,40 & 8,79 & 318,62 & 109,46 & 234,14 & 234,14 & 58,06 _ & 418,41 & 47,17 & 8,19 & 36,83 & 135,77 & 45,66 & 45,66 & 118,28 \\
\hline Epidalea calamita & 30 SVK21 & 100,00 & 149,35 & 112,96 & 35,06 & 6871,38 & 332,62 & 16,78 & 315,84 & \begin{tabular}{|l|l|}
105,12 \\
\end{tabular} & \begin{tabular}{|l|l|}
241,92 \\
\end{tabular} & \begin{tabular}{|l|l|}
241,92 \\
\end{tabular} & \begin{tabular}{l|l|}
65,45 \\
\end{tabular} & 392,59 & 44,66 & 7,59 & 37,04 & \begin{tabular}{|l|l|}
129,84 \\
\end{tabular} & \begin{tabular}{l|l}
41,85 \\
\end{tabular} & \begin{tabular}{l|l}
41,85 \\
\end{tabular} & 111,98 \\
\hline Epidalea calamita & 30SVK22 & 100,00 & 149,90 & 111,27 & 35,00 & 6847,68 & 331,14 & 18,29 & 312,85 & \begin{tabular}{|l|}
105,72 \\
\end{tabular} & 241,91 & 241,91 & \begin{tabular}{|c|}
65,97 \\
\end{tabular} & 390,97 & 44,78 & 7,99 & 36,77 & \begin{tabular}{|l|l|}
130,69 \\
\end{tabular} & \begin{tabular}{l|l}
42,15 \\
\end{tabular} & \begin{tabular}{l|l}
42,15 \\
\end{tabular} & 112,01 \\
\hline Epidalea calamita & 30SVK31 & 100,00 & 146,79 & 113,32 & 35,32 & 6849,82 & 330,11 & 14,84 & 315,27 & 102,71 & 238,96 & 238,96 & 63,23 & 403,49 & 45,93 & 7,89 & 37,22 & \begin{tabular}{|l|l|}
134,38 \\
\end{tabular} & 42,99 & 42,99 & 115,95 \\
\hline Epidalea calamita & 30SVK32 & 100,00 & 148,20 & 111,54 & 35,01 & 6826,51 & 329,53 & \begin{tabular}{|l|l|}
17,08 \\
\end{tabular} & 312,45 & 104,25 & 239,90 & 239,90 & \begin{tabular}{ll|l}
64,68 \\
\end{tabular} & 399,91 & 46,23 & 8,15 & 37,33 & \begin{tabular}{|l|l|l|l|}
134,99 \\
\end{tabular} & 42,58 & 42,58 & 115,87 \\
\hline Epidalea calamita & $30 \mathrm{SVK} 40$ & 100,00 & 143,46 & 115,60 & 36,00 & 6829,75 & 328,63 & 11,20 & 317,43 & 99,51 & 235,32 & 235,32 & 60,50 & 415,52 & 46,59 & 8,0 & 37,1 & \begin{tabular}{|l|l|}
136,82 \\
\end{tabular} & \begin{tabular}{ll|}
44,46 \\
\end{tabular} & \begin{tabular}{ll|}
44,46 \\
\end{tabular} & 118,98 \\
\hline Epidalea calamita & $30 \mathrm{SVK} 42$ & 100,00 & 143,69 & 112,19 & 35,34 & 6798,35 & \begin{tabular}{|l|l|}
325,53 \\
\end{tabular} & 13,30 & 312,22 & 99,84 & 234,97 & 234,97 & $\begin{array}{ll}60,75 \\
\end{array}$ & \begin{tabular}{|l|l|}
416,79 \\
\end{tabular} & 48,69 & 8,62 & 37,00 & 140,71 & 44,87 & 44,87 & 121,01 \\
\hline Epidalea calamita & 30SVK50 & 100,00 & 141,80 & 116,19 & 36,00 & 6809,98 & 326,92 & 9,91 & 317,01 & \begin{tabular}{|l|l|}
98,08 \\
\end{tabular} & \begin{tabular}{|l|l|}
233,49 \\
\end{tabular} & \begin{tabular}{|l|l|}
233,49 \\
\end{tabular} & \begin{tabular}{l|l|}
59,15 \\
\end{tabular} & 420,79 & 47,14 & 8,24 & 36,94 & \begin{tabular}{|l|l|}
138,66 \\
\end{tabular} & \begin{tabular}{ll|}
45,49 \\
\end{tabular} & 45,49 & 120,36 \\
\hline Epidalea calamita & 30 SWF06 & 31,00 & 178,38 & 85,78 & 36,97 & 4976,35 & 301,83 & 72,30 & 229,52 & 128,25 & 242,68 & \begin{tabular}{|l|l|}
245,75 \\
\end{tabular} & \begin{tabular}{|l|l|}
118,15 \\
\end{tabular} & 266,20 & 37,42 & 1,63 & 55,30 & $\begin{array}{ll}106,15 \\
\end{array}$ & 11,02 & 16,27 & 100,95 \\
\hline Epidalea calamita & $\begin{array}{l}\text { 30SWF07 } \\
\end{array}$ & 100,00 & 162,90 & 96,33 & 37,43 & 5421,05 & 303,66 & 49,63 & \begin{tabular}{|l|}
254,03 \\
\end{tabular} & $\begin{array}{ll}108,33 \\
\end{array}$ & 234,18 & 236,65 & $\begin{array}{l}98,06 \\
\end{array}$ & 329,34 & 43,60 & 3,15 & 51,93 & \begin{tabular}{ll|}
124,36 \\
\end{tabular} & \begin{tabular}{ll|}
17,06 \\
\end{tabular} & 23,40 & 120,34 \\
\hline Epidalea calamita & $\begin{array}{l}\text { 30SWF08 } \\
\end{array}$ & 100,00 & 137,34 & 109,31 & \begin{tabular}{|l|}
37,88 \\
\end{tabular} & 5970,86 & 302,06 & 15,92 & 286,14 & 82,48 & 217,38 & 219,10 & \begin{tabular}{ll|l}
67,16 \\
\end{tabular} & 467,47 & 59,30 & 7,89 & 47,3 & $\begin{array}{l}165,75 \\
\end{array}$ & 33,92 & 41,08 & 160,40 \\
\hline Epidalea calamita & \begin{tabular}{|l|}
30 SWF17 \\
\end{tabular} & 100,00 & 151,18 & 99,22 & 37,40 & 5556,79 & 298,51 & \begin{tabular}{|l|l|}
36,55 \\
\end{tabular} & 261,96 & 98,95 & \begin{tabular}{|l|l|}
224,63 \\
\end{tabular} & 227,24 & 85,36 & 387,70 & 50,30 & 5,71 & 49,20 & 140,50 & 26,11 & 32,34 & 135,14 \\
\hline Epidalea calamita & $\begin{array}{l}\text { 30SWF18 } \\
\end{array}$ & 100,00 & 96,85 & 118,61 & \begin{tabular}{l|l|}
37,85 \\
\end{tabular} & 6405,28 & 281,46 & $-29,14$ & 310,60 & \begin{tabular}{ll|}
46,89 \\
\end{tabular} & $\begin{array}{l}184,04 \\
184\end{array}$ & \begin{tabular}{|l|l}
185,72 \\
\end{tabular} & 23,59 & \begin{tabular}{ll|}
700,28 \\
\end{tabular} & 88,84 & 19,01 & \begin{tabular}{ll|}
40,02 \\
\end{tabular} & 242,45 & 72,24 & 77,01 & 221,70 \\
\hline Epidalea calamita & 30SWF19 & 100,00 & $\begin{array}{l}130,46 \\
\end{array}$ & 111,75 & 37,81 & 6109,05 & 300,50 & 7,40 & 293,10 & 78,34 & \begin{tabular}{l|l|}
212,63 \\
\end{tabular} & 214,39 & \begin{tabular}{|l|l|}
58,97 \\
\end{tabular} & 498,17 & 62,45 & 9,34 & 44,82 & \begin{tabular}{ll|}
172,25 \\
\end{tabular} & 39,73 & 46,65 & 165,68 \\
\hline Epidalea calamita & $\begin{array}{l}30 S W F 26 \\
\end{array}$ & 98,00 & 179,60 & 80,83 & 36,15 & 4808,28 & 296,48 & 76,88 & 219,60 & 131,95 & \begin{tabular}{|l|}
240,91 \\
\end{tabular} & \begin{tabular}{|l|}
245,09 \\
\end{tabular} & 121,53 & 242,97 & 34,06 & 1,00 & 54,81 & \begin{tabular}{|l|}
95,87 \\
\end{tabular} & \begin{tabular}{l|l|l|}
10,02 \\
\end{tabular} & 15,00 & 90,52 \\
\hline Epidalea calamita & $\begin{array}{l}30 S W F 27 \\
\end{array}$ & 100,00 & 160,94 & 93,17 & 37,06 & 5331,03 & 298,14 & 50,03 & 248,11 & \begin{tabular}{ll|}
108,69 \\
\end{tabular} & 230,70 & 233,95 & 97,54 & 326,73 & 42,43 & 3,73 & 50,09 & 119,54 & 19,59 & 25,41 & 115,17 \\
\hline Epidalea calamita & $\begin{array}{l}30 \text { SWF28 } \\
\end{array}$ & 100,00 & 122,55 & 112,38 & 37,97 & 6127,31 & 293,78 & $-0,15$ & 293,94 & \begin{tabular}{l|}
72,78 \\
\end{tabular} & 205,08 & 207,13 & 51,35 & 534,98 & 68,02 & 11,34 & 43,20 & 184,09 & \begin{tabular}{l|l|l|}
46,45 \\
\end{tabular} & 52,93 & 174,92 \\
\hline Epidalea calamita & $\begin{array}{l}30 S W F 29 \\
\end{array}$ & 100,00 & 145,65 & 104,86 & 37,57 & 5826,32 & \begin{tabular}{|l|l|}
302,48 \\
\end{tabular} & 26,71 & 275,76 & 91,43 & 223,29 & 225,54 & $\begin{array}{l}76,95 \\
\end{array}$ & \begin{tabular}{ll|}
406,06 \\
\end{tabular} & 50,43 & 6,11 & \begin{tabular}{|l|l|}
46,27 \\
\end{tabular} & \begin{tabular}{l|l|}
140,37 \\
\end{tabular} & 28,82 & 35,61 & 136,85 \\
\hline Epidalea calamita & $\begin{array}{l}30 S W F 36 \\
\end{array}$ & 34,00 & 180,41 & 79,20 & \begin{tabular}{l|l}
36,05 \\
\end{tabular} & 4752,23 & 294,80 & $\begin{array}{ll}79,02 \\
\end{array}$ & 215,77 & 133,45 & \begin{tabular}{|l|l|}
240,84 \\
\end{tabular} & 245,05 & \begin{tabular}{|l|l|}
123,07 \\
\end{tabular} & 234,66 & 32,57 & 1,00 & 54,66 & 91,84 & 10,00 & 15,00 & 86,34 \\
\hline Epidalea calamita & \begin{tabular}{|l|}
$305 W F 37$ \\
\end{tabular} & 87,00 & 167,73 & 88,00 & 36,67 & 5132,04 & 296,56 & 60,19 & 236,36 & \begin{tabular}{|l|l|}
116,87 \\
\end{tabular} & 234,14 & 237,92 & 106,30 & 287,17 & 37,22 & 2,64 & 50,52 & \begin{tabular}{|l|l|}
105,88 \\
\end{tabular} & 16,01 & 21,44 & 101,28 \\
\hline Epidalea calamita & $\begin{array}{l}30 S W F 38 \\
\end{array}$ & 100,00 & 142,22 & 104,11 & 37,77 & 5781,32 & 297,62 & 24,26 & 273,36 & 88,74 & \begin{tabular}{|l|l|}
219,12 \\
\end{tabular} & 221,81 & 74,32 & 415,66 & 51,95 & 6,74 & \begin{tabular}{|l|}
45,49 \\
\end{tabular} & \begin{tabular}{|l|l|}
142,97 \\
\end{tabular} & 30,94 & 37,60 & 139,01 \\
\hline Epidalea calamita & $\begin{array}{l}30 S W F 39 \\
\end{array}$ & 100,00 & 160,39 & 95,69 & 37,13 & 5459,98 & 301,24 & \begin{tabular}{l|l|l}
47,45 \\
\end{tabular} & 253,79 & \begin{tabular}{ll|}
119,38 \\
\end{tabular} & \begin{tabular}{|l|l|}
232,06 \\
\end{tabular} & 235,10 & \begin{tabular}{l|l}
95,45 \\
\end{tabular} & 323,93 & 39,69 & 3,71 & \begin{tabular}{|l|l|}
47,44 \\
\end{tabular} & 114,23 & 20,68 & 26,78 & 110,24 \\
\hline Epidalea calamita & $\begin{array}{l}30 S W F 47 \\
\end{array}$ & 40,00 & 171,80 & 84,11 & 36,39 & 4984,22 & 295,09 & 67,17 & 227,93 & 139,22 & 235,78 & 240,20 & 112,19 & 260,81 & 34,20 & 2,11 & \begin{tabular}{l|l}
49,87 \\
\end{tabular} & 96,44 & 14,78 & 19,85 & 90,93 \\
\hline Epidalea calamita & $\begin{array}{l}30 \text { SWF49 } \\
\end{array}$ & 100,00 & 168,05 & 90,03 & 36,93 & 5222,22 & 299,62 & 59,06 & 240,56 & 142,15 & 235,85 & 239,51 & 105,63 & 281,36 & 35,90 & 2,58 & \begin{tabular}{ll|l}
47,82 & \\
\end{tabular} & \begin{tabular}{ll|l}
101,46 \\
\end{tabular} & 17,24 & 22,94 & 95,53 \\
\hline Epidalea calamita & \begin{tabular}{|l|}
$30 S W F 57$ \\
\end{tabular} & 35,00 & 180,43 & 78,35 & 36,03 & 4722,03 & 294,35 & $\begin{array}{l}80,46 \\
\end{array}$ & 213,89 & 158,62 & 240,24 & 245,16 & 123,86 & 220,24 & 31,65 & 1,00 & 51,08 & 85,03 & \begin{tabular}{l|l}
11,95 \\
\end{tabular} & \begin{tabular}{ll|}
16,97 \\
\end{tabular} & 76,14 \\
\hline Epidalea calamita & $\begin{array}{l}30 S W F 58 \\
\end{array}$ & 100,00 & 172,02 & 84,87 & 36,67 & 4991,31 & 295,91 & \begin{tabular}{|l|l|}
67,38 \\
\end{tabular} & 228,53 & \begin{tabular}{|l|l|}
147,44 \\
\end{tabular} & 236,24 & 240,65 & 112,60 & 257,20 & 34,58 & 2,17 & 49,02 & \begin{tabular}{|l|}
5,14 \\
\end{tabular} & 15,54 & 21,12 & 87,52 \\
\hline Epidalea calamita & $\begin{array}{l}30 \text { SWF59 } \\
\end{array}$ & 100,00 & 147,86 & 100,32 & 37,53 & 5634,95 & 296,31 & 32,21 & 264,09 & \begin{tabular}{|l|l|}
106,88 \\
\end{tabular} & 222,25 & 225,46 & 81,54 & 380,63 & 47,31 & 6,18 & 44,01 & 129,35 & \begin{tabular}{|l|}
29,97 \\
\end{tabular} & 36,03 & 123,23 \\
\hline Epidalea calamita & $\begin{array}{l}30 \text { SWF67 } \\
\end{array}$ & 65,00 & 179,98 & 79,82 & 36,63 & 4714,35 & 294,94 & 79,64 & 215,30 & 158,40 & \begin{tabular}{|l|l|}
239,82 \\
\end{tabular} & \begin{tabular}{|l|l}
244,83 \\
\end{tabular} & 123,90 & 225,80 & 32,51 & 1,07 & 51,71 & 87,95 & 12,02 & 18,04 & 77,76 \\
\hline Epidalea calamita & $\begin{array}{l}30 S W F 68 \\
\end{array}$ & 100,00 & 171,50 & 85,66 & 36,96 & 4987,16 & 295,83 & 66,57 & 229,26 & 147,73 & 235,65 & \begin{tabular}{|l|}
240,14 \\
\end{tabular} & 112,24 & 260,08 & 35,26 & 2,2 & 48,56 & 96,64 & 16,01 & 22,06 & 87,50 \\
\hline Epidalea calamita & $\begin{array}{l}30 \text { SWF69 } \\
\end{array}$ & 100,00 & 144,29 & 101,58 & 37,77 & 5675,91 & 294,55 & 27,91 & 266,64 & \begin{tabular}{ll|}
107,48 \\
\end{tabular} & 219,46 & 222,52 & 77,7 & 397,01 & $\begin{array}{l}49,25 \\
\end{array}$ & 6,94 & 42,90 & 132,95 & 2,81 & 38,94 & 126,45 \\
\hline Epidalea calamita & \begin{tabular}{|l|l|}
30 SWF76 \\
\end{tabular} & 41,00 & 175,49 & 81,61 & 36,94 & 4769,35 & 292,80 & 73,86 & 218,94 & 153,98 & 236,18 & 241,18 & 118,8 & \begin{tabular}{|l|l|}
247,45 \\
\end{tabular} & 33,71 & 1,67 & 50,75 & 94,73 & \begin{tabular}{|l|l|}
13,35 \\
\end{tabular} & 19,71 & 85,75 \\
\hline Epidalea calamita & 30SWF77 & 100,00 & 176,22 & 82,23 & \begin{tabular}{ll|}
36,96 \\
\end{tabular} & 4798,15 & 294,35 & 74,02 & 220,33 & \begin{tabular}{|l|l|}
154,27 \\
\end{tabular} & \begin{tabular}{l|l|l}
237,42 \\
\end{tabular} & 242,31 & \begin{tabular}{|l|l|}
119,29 \\
\end{tabular} & 244,06 & 34,03 & 1,71 & \begin{tabular}{l|l|}
50,29 \\
\end{tabular} & \begin{tabular}{l|l}
93,95 \\
\end{tabular} & \begin{tabular}{ll|}
3,52 \\
\end{tabular} & \begin{tabular}{l|l}
19,92 \\
\end{tabular} & 83,53 \\
\hline Epidalea calamita & 30SWF78 & 100,00 & 175,00 & 84,50 & 37,00 & 4891,20 & 296,34 & \begin{tabular}{ll|l}
71,05 \\
\end{tabular} & 225,29 & 152,16 & 237,72 & 242,35 & 116,86 & 249,27 & 34,99 & 2,00 & 49,12 & 95,04 & 14,89 & 21,39 & 83,71 \\
\hline Epidalea calamita & $\begin{array}{l}30 \text { SWF79 } \\
\end{array}$ & 100,00 & 163,15 & 92,40 & 37,41 & 5242,14 & 297,03 & 53,20 & 243,83 & 137,36 & 231,33 & 235,22 & 101,06 & 302,16 & 39,06 & 3,46 & 46,01 & 108,60 & \begin{tabular}{|l|l|}
21,05 \\
\end{tabular} & 27,49 & 98,20 \\
\hline Epidalea calamita & $\begin{array}{l}30 \text { SWF87 } \\
\end{array}$ & 57,00 & 175,68 & 83,45 & 37,00 & 821,32 & 4,8 & 72,54 & 222,29 & 153,54 & 237,12 & 242,00 & 118,3 & 251,78 & 34,87 & 1,79 & 0,59 & \begin{tabular}{|l|}
97,13 \\
\end{tabular} & 3,96 & 0,78 & 85,87 \\
\hline Epidalea calamita & $\begin{array}{l}30 \text { SWF88 } \\
\end{array}$ & 97,00 & 173,50 & 86,06 & 37,04 & 4928,89 & 296 & 68,35 & 228,00 & 150,29 & 236,65 & 241,17 & 114,74 & 260,41 & 36,10 & 2,00 & 49,24 & 99,37 & 15,50 & 22,37 & 86,88 \\
\hline Epidalea calamita & 30SWF89 & 100,00 & 171,15 & 89,01 & 37,33 & 5051,64 & 298,24 & 63,49 & 234,75 & 146,85 & 236,22 & 240,4 & $\begin{array}{l}110,95 \\
\end{array}$ & 270,72 & 37,31 & 2,34 & \begin{tabular}{|l|l|}
47,94 \\
\end{tabular} & \begin{tabular}{|l|l|}
101,80 \\
\end{tabular} & 17,16 & 24,09 & 88,43 \\
\hline Epidalea calamita & 30SWF99 & 88,00 & 176,42 & 87,67 & \begin{tabular}{l|l|}
37,69 \\
\end{tabular} & 4938,62 & 299,72 & \begin{tabular}{|l|l|}
69,77 \\
\end{tabular} & 229,94 & 153,11 & \begin{tabular}{|l|l|}
239,69 \\
\end{tabular} & \begin{tabular}{|l|l|}
243,92 \\
\end{tabular} & 117,31 & 256,69 & $\begin{array}{l}36,65 \\
\end{array}$ & 2,07 & \begin{tabular}{l|l}
49,15 \\
\end{tabular} & \begin{tabular}{l|l|}
99,56 \\
\end{tabular} & $\begin{array}{ll}15,48 \\
\end{array}$ & 22,94 & 84,13 \\
\hline Epidalea calamita & 30SWG00 & 100,00 & 91,45 & 120,29 & 37,60 & 6517,73 & 280,53 & $-35,74$ & 316,27 & \begin{tabular}{|l|l|}
41,14 \\
\end{tabular} & \begin{tabular}{|l|}
180,47 \\
\end{tabular} & \begin{tabular}{|l|l|}
181,69 \\
\end{tabular} & 16,76 & 743,27 & 92,87 & 20,85 & 39,38 & 257,27 & \begin{tabular}{|l|l|}
78,97 \\
\end{tabular} & 83,08 & 233,23 \\
\hline Epidalea calamita & 30SWG03 & 100,00 & 112,13 & 119,29 & 37,38 & 6521,42 & 298,87 & $-15,51$ & 314,38 & 62,80 & 200,97 & 201,69 & 36,7 & 620,72 & 77,48 & \begin{tabular}{ll|}
14,42 \\
\end{tabular} & 41,36 & 215,71 & 58,83 & \begin{tabular}{ll|}
64,42 \\
\end{tabular} & 196,34 \\
\hline Epidalea calamita & 30SWG04 & 100,00 & 131,75 & 117,00 & 37,11 & 6454 & 313 & \begin{tabular}{|l|l|}
4,08 \\
\end{tabular} & 309,18 & 83,71 & 219,19 & 219,85 & 56,02 & 515,82 & 64,16 & 9,37 & 43,94 & 180,12 & 41,83 & 48,92 & 166,51 \\
\hline Epidalea calamita & 30SWG05 & 100,00 & 150,64 & 112,52 & 37,01 & 6310,40 & 323,64 & 24,64 & 298,99 & 104,28 & \begin{tabular}{|l|l|}
235,48 \\
\end{tabular} & $\begin{array}{l}236,06 \\
\end{array}$ & 75,49 & 427,50 & 52,55 & 5,91 & 46,10 & \begin{tabular}{l|l|}
148,82 \\
\end{tabular} & 29,76 & 36,66 & 140,36 \\
\hline Epidalea calamita & 30SWG09 & 100,00 & 121,09 & 120,41 & 37,09 & 6669,44 & 310,41 & $-8,41$ & 318,82 & 79,84 & 211,79 & 212,10 & 43,19 & 574,48 & 71,75 & 12,40 & 40,50 & $\begin{array}{l}199,80 \\
\end{array}$ & 56,02 & 58,31 & 174,50 \\
\hline Epidalea calamita & 30SWG11 & 100,00 & 132,95 & 113,16 & 37,64 & 6208,22 & 305,95 & 8,40 & 297,55 & 85,38 & 216,56 & 218,04 & 60,2 & 489,86 & 61,16 & 8,98 & 44,23 & 168,36 & 39,18 & 46,19 & 160,45 \\
\hline Epidalea calamita & $30 S W G$ & 100,00 & 101,44 & 11 & 37,4 & 512 & 288 & $-25,79$ & 314 & 51,48 & 190 & 191 & 26,4 & 673,90 & 84,83 & 18, & 39, & 232,05 & No, & 75,03 & 208 \\
\hline Epidalea calamita & \begin{tabular}{|l|l|}
$30 S W G 13$ \\
\end{tabular} & 100,00 & 99,91 & 119,76 & 37,30 & 6547,08 & 288,19 & $-27,56$ & 315,75 & \begin{tabular}{|l|l|l|}
49,82 \\
\end{tabular} & \begin{tabular}{|l|l|}
189,21 \\
\end{tabular} & \begin{tabular}{|l|l|}
190,23 \\
\end{tabular} & 24,62 & 683,86 & 85,86 & 18,71 & 38,55 & 234,97 & 73,59 & 77,43 & 209,17 \\
\hline Epidalea calamita & $\begin{array}{l}30 \text { SWG15 } \\
\end{array}$ & 100,00 & 143,41 & 113,58 & 37,11 & 6319,60 & 317,77 & \begin{tabular}{ll|}
17,28 \\
\end{tabular} & 300,49 & \begin{tabular}{|l|l|}
96,60 \\
\end{tabular} & 228,55 & 229,30 & 68,56 & 448,80 & 55,77 & 7,20 & 44,06 & \begin{tabular}{|l|l|}
154,73 \\
\end{tabular} & 35,01 & 41,78 & 143,45 \\
\hline Epidalea calamita & 30SWG16 & 100,00 & 149,42 & 112,81 & 37,04 & 6306,94 & 321,98 & 23,26 & \begin{tabular}{|l|l|}
298,72 \\
\end{tabular} & \begin{tabular}{|l|l|}
103,02 \\
\end{tabular} & 234,14 & \begin{tabular}{|l|l|}
234,83 \\
\end{tabular} & 74,31 & 423,79 & 52,47 & 6,21 & 44,50 & \begin{tabular}{|l|l|}
145,99 \\
\end{tabular} & 31,96 & \begin{tabular}{l|l}
38,55 \\
\end{tabular} & 135,13 \\
\hline Epidale & 30SWG19 & 100,00 & 1020 & & 37, & & & $-25,91$ & 320,84 & 79,69 & 194 & 194 & 25, & 658,50 & 82,24 & 17,84 & $3702+2$ & 226 & & 55 & 192 \\
\hline Epidalea calamita & 30SWG21 & 100,00 & 126,21 & 112,80 & 37,52 & 6201,71 & 298,98 & 2,32 & 296,66 & 76,06 & 209,87 & 211,48 & 53,91 & 521,88 & 65,50 & 11,33 & 42,31 & $177,94[$ & 47,53 & 53,39 & 165,77 \\
\hline Epidalea calamita & 30SWG22 & 100,00 & 101,21 & 118,70 & 37,38 & 6485,48 & 286,99 & $-25,45$ & 312,44 & 51,23 & \begin{tabular}{|l|l|}
189,61 \\
\end{tabular} & \begin{tabular}{|l|l|}
190,87 \\
\end{tabular} & 26,50 & 668,34 & 84,71 & 18,64 & \begin{tabular}{|c|}
38,13 \\
\end{tabular} & 228,60 & 72,73 & 76,59 & 203,33 \\
\hline
\end{tabular}




\begin{tabular}{|c|c|c|c|c|c|c|c|c|c|c|c|c|c|c|c|c|c|c|c|c|c|}
\hline TAXON & UTM & $\mathrm{km} 2$ & B101 & B102 & $\mathrm{BIO3}$ & BIO4 & B105 & B106 & B107 & B108 & B109 & B1010 & BIO11 & BIO12 & 81013 & BIO14 & BIO15 & B1016 & B1017 & BIO18 & B1019 \\
\hline Epidalea calamita & 30SWG23 & 100,00 & 128,17 & 115,04 & 37,61 & 6322,85 & 304,92 & 2,49 & 302,43 & 80,31 & 213,63 & 214,81 & 54,24 & 511,63 & 64,55 & 10,46 & 41,77 & 174,92 & 45,77 & 51,87 & 160,67 \\
\hline Epidalea calamita & 30SWG24 & 100,00 & 141,87 & 112,34 & 37,29 & 6229,59 & 312,96 & 16,88 & 296,08 & 95,09 & 225,51 & 226,74 & 68,09 & 441,81 & 55,15 & 7,41 & 43,24 & 150,25 & 35,69 & 42,24 & 140,01 \\
\hline Epidalea calamita & 30SWG25 & 100,00 & 148,54 & 111,22 & 37,23 & 6192,77 & 317,25 & 23,82 & 293,44 & 102,47 & 231,48 & 232,64 & 74,95 & 412,52 & 51,19 & 6,22 & 43,74 & 139,83 & 32,02 & 38,50 & 130,54 \\
\hline Epidalea calamita & 30 SWG26 & 100,00 & 150,31 & 111,76 & \begin{tabular}{|l|}
37,27 \\
\end{tabular} & 6217,77 & 319,74 & 24,91 & 294,83 & 104,48 & 233,65 & 234,60 & 76,27 & $\begin{array}{l}407,45 \\
\end{array}$ & 50,71 & 5,99 & 43,55 & 138,21 & 31,82 & 38,17 & 127,79 \\
\hline Epidalea calamita & 30SWG28 & 100,00 & 130,69 & 117,71 & 37,32 & \begin{tabular}{|l|l|}
6494,73 \\
\end{tabular} & 312,40 & 2,30 & 310,10 & \begin{tabular}{|l|l|}
107,79 \\
\end{tabular} & 218,55 & 219,21 & 54,36 & 504,53 & 64,02 & 10,30 & 40,24 & 173,95 & 48,59 & 52,84 & 151,06 \\
\hline Epidalea calamita & 30SWG29 & 100,00 & 110,30 & 120,44 & 37,52 & 6619,50 & 298,79 & $-18,26$ & 317,05 & 87,32 & 200,58 & 201,02 & 33,63 & 610,67 & 77,00 & 16,02 & 37,12 & 210,14 & 68,94 & 70,97 & 177,13 \\
\hline Epidalea calamita & 30SWG30 & 100,00 & 150,26 & 103,06 & 37,42 & 5769,05 & 303,53 & 32,27 & 271,25 & 95,54 & 226,81 & 229,25 & 81,95 & 377,09 & 45,99 & 5,37 & 45,40 & 128,24 & 26,90 & 33,41 & $\begin{array}{ll}124,89 \\
\end{array}$ \\
\hline Epidalea calamita & 30SWG31 & 100,00 & 116,82 & 114,07 & 37,57 & 6265,03 & 292,50 & $-7,49$ & 299,99 & 67,82 & \begin{tabular}{|l|}
201,51 \\
\end{tabular} & 203,23 & 44,28 & 570,07 & 72,29 & 14,36 & 40,05 & 193,01 & 57,89 & 62,74 & 175,77 \\
\hline Epidalea calamita & 30SWG32 & 100,00 & 108,31 & 116,88 & 37,58 & 6403,72 & 289,88 & $-17,44$ & 307,32 & 58,95 & 195,25 & 196,76 & 34,38 & 619,90 & 78,99 & 16,83 & 38,24 & 210,41 & 66,78 & 70,91 & 187,42 \\
\hline Epidalea calamita & 30SWG33 & 100,00 & 135,56 & 112,17 & \begin{tabular}{|l|l|}
37,69 \\
\end{tabular} & \begin{tabular}{|l|l|}
6190,07 \\
\end{tabular} & 306,04 & 11,34 & 294,70 & 88,76 & 218,78 & 220,29 & 62,79 & 463,58 & 58,39 & 8,76 & 41,95 & 156,30 & 40,33 & 46,45 & 144,90 \\
\hline Epidalea calamita & 30SWG35 & 100,00 & 137,91 & 113,41 & 37,73 & 6255,02 & 310,44 & 12,36 & 298,08 & 104,23 & 222,05 & 223,26 & 64,15 & 455,59 & 57,55 & 8,47 & 41,45 & 154,03 & 40,45 & 46,23 & 139,74 \\
\hline Epidalea calamita & 30SWG37 & 100,00 & 142,67 & 114,20 & 37,86 & 6298,67 & 315,76 & 15,97 & 299,80 & $\begin{array}{ll}120,83 \\
\end{array}$ & 227,31 & 228,16 & 67,95 & 435,64 & 55,24 & 7,52 & 41,38 & 148,18 & 38,60 & 44,01 & 131,43 \\
\hline Epidalea calamita & 30SWG38 & 100,00 & 134,64 & 116,67 & 37,80 & 6414,44 & 312,78 & 6,73 & 306,05 & 113,44 & 221,11 & 221,89 & 58,84 & 474,94 & 60,64 & 9,41 & 39,96 & 162,93 & 45,98 & 50,41 & 140,35 \\
\hline Epidalea calamita & 30SWG39 & 100,00 & 122,08 & 119,02 & 37,76 & 6531,97 & 305,88 & $-6,37$ & 312,25 & 99,95 & 210,69 & 211,26 & 45,77 & 538,32 & 68,69 & 12,72 & 37,90 & 185,42 & 58,18 & 61,05 & 155,37 \\
\hline Epidalea calamita & 30SWG40 & 100,00 & 152,15 & 100,91 & 37,54 & 5671,06 & 301,24 & 35,71 & 265,53 & \begin{tabular}{|l|l|}
115,63 \\
\end{tabular} & 227,13 & 229,90 & 85,04 & 362,27 & 44,10 & 5,15 & 44,74 & 122,92 & 26,55 & 32,86 & 118,51 \\
\hline Epidalea calamita & 30SWG41 & 100,00 & 121,78 & 112,29 & 37,66 & 6180,22 & 293,31 & $-1,59$ & 294,90 & 74,71 & 204,99 & 206,92 & 50,00 & 535,18 & 67,99 & 13,07 & 39,90 & 179,45 & 53,83 & 58,79 & 163,96 \\
\hline Epidalea calamita & 30SWG42 & 100,00 & 108,77 & 116,04 & 37,70 & 6363,33 & 288,35 & $-16,43$ & 304,78 & 69,62 & 194,99 & 196,67 & 35,45 & 611,50 & 78,24 & 17,09 & 37,39 & 206,11 & 67,97 & 71,68 & 182,05 \\
\hline Epidalea calamita & 30SWG43 & 100,00 & 143,50 & 108,73 & 37,84 & 6021,64 & 306,44 & 21,31 & 285,14 & \begin{tabular}{|l|}
105,51 \\
\end{tabular} & 223,97 & 225,81 & 72,36 & 415,18 & 51,79 & 7,17 & 42,11 & 137,89 & 35,13 & 41,23 & 129,15 \\
\hline Epidalea calamita & 30SWG44 & 100,00 & 125,28 & 114,48 & \begin{tabular}{|l|l|}
37,88 \\
\end{tabular} & 6292,01 & 300,34 & 0,19 & 300,14 & 101,58 & 210,23 & 211,67 & 51,86 & 514,18 & 65,61 & 11,80 & 39,21 & 173,75 & 51,62 & 56,37 & 154,16 \\
\hline Epidalea calamita & 30SWG48 & 100,00 & 133,42 & 116,38 & 37,97 & 6375,05 & 310,23 & 5,79 & 304,44 & 112,25 & 219,40 & 220,26 & 58,35 & 472,79 & 60,70 & 9,84 & 38,89 & 161,44 & 47,91 & 51,92 & 137,14 \\
\hline Epidalea calamita & 30SWG49 & 100,00 & 122,95 & 118,41 & 37,96 & 6475,62 & 304,59 & $-5,06$ & 309,65 & 100,98 & 210,68 & 211,39 & 47,27 & 526,21 & 67,58 & 12,72 & 37,10 & 180,48 & 58,56 & 61,17 & 149,34 \\
\hline Epidalea calamita & 30SWG50 & 100,00 & 157,90 & 97,31 & 37,46 & 5502,16 & 300,28 & 43,97 & 256,31 & 129,80 & 230,17 & 233,28 & 92,68 & \begin{tabular}{|c|}
329,08 \\
\end{tabular} & 40,29 & 4,23 & 45,03 & 114,02 & 23,50 & 29,72 & 107,16 \\
\hline Epidalea calamita & 30SWG51 & 100,00 & 135,59 & 107,66 & 37,92 & 5960,92 & 297,10 & \begin{tabular}{|l|l|}
14,97 \\
\end{tabular} & 282,13 & 101,08 & 215,22 & 217,60 & 65,88 & 450,66 & 56,53 & 9,29 & 41,14 & 149,65 & 41,48 & 47,14 & 139,36 \\
\hline Epidalea calamita & 30SWG52 & 100,00 & 118,74 & 113,35 & 37,86 & 6231,44 & 291,99 & $-5,15$ & 297,14 & 94,74 & 202,79 & 204,69 & 46,57 & 548,09 & 70,14 & 14,23 & 38,14 & 183,59 & 58,63 & 62,94 & 163,17 \\
\hline Epidalea calamita & 30SWG53 & 100,00 & 151,59 & 105,21 & 37,97 & 5832,13 & 306,55 & 31,64 & 274,91 & 121,75 & 229,11 & 231,27 & 82,44 & 370,07 & 45,47 & 5,61 & 42,53 & 123,97 & 30,08 & 36,27 & 114,67 \\
\hline Epidalea calamita & 30SWG56 & 100,00 & 121,43 & 116,06 & 37,92 & 6350,07 & 298,60 & $-4,86$ & 303,46 & 98,91 & 207,23 & 208,45 & 47,40 & 531,51 & 68,21 & 13,40 & 37,08 & 179,99 & 58,83 & 62,27 & 152,71 \\
\hline Epidalea calamita & 30SWG59 & 100,00 & 132,38 & 117,02 & 38,00 & 6359,18 & 308,74 & $\begin{array}{ll}-3,14 \\
4,14\end{array}$ & 304,60 & \begin{tabular}{r|}
111,25 \\
\end{tabular} & 217,97 & 218,96 & 57,32 & 470,81 & $\begin{array}{l}60,97 \\
60,47\end{array}$ & 10,31 & 37,72 & 160,66 & $\begin{array}{l}0,0,57 \\
50,\end{array}$ & 53,86 & 132,38 \\
\hline Epidalea calamita & 30SWG60 & 100,00 & 156,21 & 97,80 & 37,75 & 5499,91 & 298,91 & 42,09 & 256,82 & 128,22 & 228,41 & 231,70 & 91,19 & 335,54 & 40,97 & 4,48 & 44,29 & 116,20 & 24,87 & 31,24 & 107,69 \\
\hline Epidalea calamita & 30SWG61 & 100,00 & 143,49 & 104,67 & 37,99 & 5807,31 & 298,15 & 24,66 & 273,49 & 116,26 & 220,59 & 223,24 & 75,18 & 403,63 & 49,97 & 7,29 & 41,69 & 134,36 & 35,11 & 41,08 & 124,97 \\
\hline Epidalea calamita & 30SWG62 & 100,00 & 141,01 & 106,89 & 37,97 & 5903,09 & 299,60 & 20,50 & 279,10 & 115,58 & 219,66 & 222,04 & 71,64 & 418,46 & 52,33 & 7,97 & 40,81 & 138,42 & 37,92 & 43,70 & 127,56 \\
\hline Epidalea calamita & 30SWG63 & 100,00 & 156,89 & 102,82 & 38,00 & 5690,49 & 305,92 & 38,53 & 267,39 & 127,10 & 232,02 & 234,47 & 89,07 & 341,99 & 42,68 & 4,76 & 42,92 & 116,86 & 27,22 & 33,63 & 105,29 \\
\hline Epidalea calamita & 30 SWG64 & 100,00 & 143,89 & 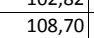 & 37,99 & 5968,45 & 304,53 & $\begin{array}{ll}21,56 \\
21,56\end{array}$ & \begin{tabular}{|l|}
282,97 \\
\end{tabular} & 119,22 & \begin{tabular}{|l|}
223,44 \\
22,4
\end{tabular} & \begin{tabular}{|l|}
225,39 \\
\end{tabular} & 73,30 & \begin{tabular}{|l|l|}
406,44 \\
\end{tabular} & $\begin{array}{l}42,000 \\
51,05\end{array}$ & $\begin{array}{ll}4,110 \\
7,40\end{array}$ & 40,52 & \begin{tabular}{|l|}
134,69 \\
130
\end{tabular} & 37,31 & $\begin{array}{l}3,00 \\
42,92\end{array}$ & 121,16 \\
\hline Epidalea calamita & 30SWG65 & 100,00 & 129,95 & 113,35 & 38,00 & 6193,44 & 300,41 & 5,10 & 295,31 & 108,03 & 213,16 & 214,82 & 57,55 & 479,40 & 61,47 & 10,97 & 37,88 & 160,57 & 50,27 & 54,67 & 138,60 \\
\hline Epidalea calamita & 30SWG66 & 100,00 & 119,94 & 115,46 & 37,88 & 6316,01 & 295,73 & $-5,88$ & 301,61 & 97,31 & 205,27 & 206,60 & 46,37 & 536,43 & 68,96 & 14,37 & 36,18 & 180,68 & 62,16 & 65,17 & 151,16 \\
\hline Epidalea calamita & 30SWG68 & 100,00 & 129,05 & 116,26 & 38,00 & 6309,61 & 303,79 & 1,58 & 302,21 & 107,38 & 214,05 & 215,21 & 54,92 & 483,47 & 62,64 & 11,28 & 36,86 & 163,72 & 53,81 & 56,95 & 134,88 \\
\hline Epidalea calamita & 30SWG69 & 100,00 & 125,43 & 117,41 & 38,00 & 6367,87 & 302,64 & $-2,10$ & 304,74 & 103,67 & 211,35 & 212,27 & 50,73 & 501,81 & 65,10 & 12,45 & 36,06 & 170,50 & 58,49 & 60,77 & 137,84 \\
\hline Epidalea calamita & 30SWG70 & 100,00 & $\begin{array}{l}125,45 \\
159,69\end{array}$ & $\mid$ & 37,87 & | 53093,61 & 2908,73 & \begin{tabular}{|l|l|}
47,05 \\
47
\end{tabular} & $\mid 251,69$ & $\begin{array}{l}132,57 \\
\end{array}$ & 230,19 & \begin{tabular}{|l|}
233,77 \\
\end{tabular} & \begin{tabular}{l|l|}
05,87 \\
95
\end{tabular} & $\begin{array}{l}301,01 \\
318,72\end{array}$ & $\begin{array}{l}50,32 \\
40,\end{array}$ & \begin{tabular}{|l|}
$4,, 403$ \\
4
\end{tabular} & $\begin{array}{ll}40,50 \\
44,51\end{array}$ & $\begin{array}{l}112,52 \\
1120\end{array}$ & $\begin{array}{l}0,43 \\
23,47 \\
\end{array}$ & 29,96 & 101,64 \\
\hline Epidalea calamita & 30SWG71 & 100,00 & 152,69 & 100,67 & 37,9 & 5599,65 & 299,15 & 36,47 & 262,69 & 124,80 & 226,48 & 229,51 & 86,54 & 355,43 & 44,14 & 5,45 & 42,76 & 121,56 & 28,99 & 35,29 & 110,29 \\
\hline Epidalea calamita & 30SWG72 & 100,00 & 151,10 & 103,10 & 38,00 & 5694,17 & 300,88 & 32,95 & 267,92 & 122,01 & 226,39 & 229,08 & 83,76 & 365,64 & 45,43 & 5,86 & 41,93 & 123,62 & 30,96 & 37,22 & 111,62 \\
\hline Epidalea calamita & 30SWG73 & 100,00 & 162,92 & 100,54 & 38,01 & 5537,90 & 306,48 & 46,31 & 260,16 & 134,02 & 235,66 & 238,38 & 96,78 & 313,27 & 40,85 & 3,78 & 43,80 & 110,31 & 23,94 & 30,75 & 95,97 \\
\hline Epidalea calamita & 30SWG74 & 100,00 & 151,97 & 106,00 & 38,0 & 5797,69 & 305,59 & 31,41 & 274,17 & 122,64 & 228,80 & 231,01 & 83,10 & 364,66 & 45,64 & 5,83 & 41,41 & 122,48 & 31,96 & 38,14 & 108,35 \\
\hline Epidalea calamita & 30SWG75 & 100,00 & 131,21 & 112,51 & 38,00 & 6137,04 & 299,15 & 6,73 & 292,42 & 109,45 & 213,48 & 215,27 & 59,23 & 470,07 & 60,27 & \begin{tabular}{|c|}
10,93 \\
\end{tabular} & 37,49 & 156,36 & 50,31 & 54,71 & 133,99 \\
\hline Epidalea calamita & 30SWG77 & 100,00 & 125,93 & 115,18 & 37,97 & 6262,87 & 298,96 & \begin{tabular}{|c|c|c|}
$-0,24$ \\
\end{tabular} & 299,21 & $\begin{array}{l}103,99 \\
\end{array}$ & 210,25 & 211,69 & 52,67 & 498,77 & $\begin{array}{l}64,43 \\
\end{array}$ & 12,68 & 36,12 & 167,36 & 57,72 & 60,85 & 137,99 \\
\hline Epidalea calamita & 30SWG78 & 100,00 & 131,36 & 115,47 & 38,00 & 6238,93 & 303,27 & 4,73 & 298,54 & 110,07 & 215,20 & 216,39 & 57,86 & 468,90 & 60,81 & 11,01 & 36,76 & 157,61 & 52,91 & 56,30 & 128,90 \\
\hline Epidalea calamita & 30SWG79 & 100,00 & 128,27 & 116,74 & 38,01 & 6304,95 & 302,71 & 1,07 & 301,64 & \begin{tabular}{ll|l}
106,82 \\
\end{tabular} & 213,16 & 21 & 54,13 & \begin{tabular}{|l|l|}
483,07 \\
\end{tabular} & 62,92 & 11,8 & 36,05 & 21 & 56,64 & 59,17 & 130,85 \\
\hline Epidalea calamita & 30 SWG80 & 100,00 & 165,59 & \begin{tabular}{|l|} 
\\
93,54 \\
\end{tabular} & 37,8 & 5247,23 & 290,58 & 54,39 & 245,19 & $\begin{array}{l}139,68 \\
130\end{array}$ & 233,77 & 237,46 & $\mid \begin{array}{r}4,13 \\
103,20\end{array}$ & | 295,56 & 39,35 & 3,2 & 45,72 & \begin{tabular}{|l|l|}
107,79 \\
\end{tabular} & 20,76 & 27,63 & 94,16 \\
\hline Epidalea calamita & 30SWG & 100,00 & 160,25 & 97,70 & 37,99 & 5419,57 & 300,41 & 46,09 & 254,32 & 132,88 & 231,18 & 234,46 & 95,96 & 321,14 & 41,36 & 4,22 & 43,86 & 113,80 & 24,71 & 31,51 & 99,92 \\
\hline Epidalea calamita & 30SWG82 & 100,00 & 161,55 & 99,23 & 38,00 & 5469,05 & 303,05 & 46,01 & 257,04 & 133,45 & 233,16 & 236,22 & 96,45 & 317,63 & 41,41 & 4,06 & 43,88 & 112,54 & 24,57 & 31,51 & 97,51 \\
\hline Epidalea calamita & 30SWG83 & 100,00 & 167,74 & 99,16 & 38,06 & 5423,78 & 307,43 & 51,92 & 255,51 & 139,93 & 238,62 & 241,43 & 102,65 & 294,92 & 40,18 & 3,23 & 44,63 & 106,63 & 21,77 & 29,06 & 90,01 \\
\hline Epidalea calamita & 30SWG87 & 100,00 & 134,92 & 113,63 & 38,14 & 6122,39 & 302,26 & 9,58 & 292,68 & 113,04 & 216,92 & 218 & 62,80 & 449,87 & 58,10 & 10,33 & 37,11 & 45 & 49,95 & 54,15 & 123,74 \\
\hline Epidalea calamita & 30 SWG88 & 100,00 & 139 & 114,28 & 38 & 6118,37 & 306,33 & 13,00 & 293,33 & 118,91 & 221,25 & 22 & 66,99 & 427,34 & 55,49 & $\begin{array}{ll}9,14 \\
9,4\end{array}$ & 37,66 & 142,09 & 46,64 & 50,95 & 116,48 \\
\hline Epidalea calamita & 30SWG90 & 100,00 & 162,44 & 95,17 & 37,99 & 5294,62 & 298,41 & 50,19 & 248,22 & 136,31 & 231,38 & 235,03 & 99,61 & 314,14 & 41,14 & 3,89 & 45,13 & 113,73 & 23,25 & 30,41 & 98,76 \\
\hline Epidalea calamita & 30SWG91 & 100,00 & 176,51 & 92,11 & 38,00 & 5085,30 & 304,70 & $\begin{array}{ll}6,04 \\
66,04\end{array}$ & $\begin{array}{l}238,67 \\
238,\end{array}$ & $\begin{array}{l}151,54 \\
\end{array}$ & 242,00 & $\begin{array}{l}245,68 \\
\end{array}$ & \begin{tabular}{|l|}
115,30 \\
\end{tabular} & 260,83 & 37,75 & 2, & 48,35 & 100,20 & $\frac{15,25}{16,46}$ & $\begin{array}{ll}04,27 \\
24,4\end{array}$ & 82,80 \\
\hline Epidalea calamita & 30SWG92 & 100,00 & 175,27 & 94,86 & 38,15 & 5187,80 & 307,08 & 62,62 & 244,47 & 149,29 & 242,43 & 245,73 & 112,84 & 267,15 & 38,55 & 2,25 & 47,30 & 101,38 & 17,62 & 25,55 & 83,10 \\
\hline Epidalea calamita & 30SWG93 & 100,00 & 168,13 & 99,49 & 38,34 & 5395,51 & 307,27 & 52,05 & 255,22 & 140,55 & 238,50 & 24 & 103,29 & 295,93 & 40,79 & 3,30 & 44,89 & 107,88 & 21,99 & 29,78 & 85 \\
\hline Epidalea calamita & 30SWG95 & 100,00 & $\begin{array}{l}100,15 \\
144,93 \\
\end{array}$ & \begin{tabular}{|l|}
$5,49,42$ \\
109,42
\end{tabular} & 38,49 & $\mid 5887,40$ & 302,58 & $\begin{array}{ll}21,95 \\
21,95\end{array}$ & $\begin{array}{l}280,62 \\
280,62\end{array}$ & \begin{tabular}{|l|}
117,33 \\
1173
\end{tabular} & \begin{tabular}{|l|}
223,080 \\
223
\end{tabular} & \begin{tabular}{|l|}
225,153 \\
225
\end{tabular} & \begin{tabular}{|l|}
75,07 \\
75
\end{tabular} & | & $\begin{array}{l}\mid 20,15 \\
50,58\end{array}$ & $\begin{array}{l}3,00 \\
7,75 \\
\end{array}$ & $\begin{array}{l}34,030 \\
39,07\end{array}$ & \begin{tabular}{|l|}
132,26 \\
132
\end{tabular} & \begin{tabular}{|l|l|}
39,84 \\
3
\end{tabular} & $\begin{array}{l}5,10 \\
45,79\end{array}$ & $\begin{array}{r}0,45 \\
112,91 \\
\end{array}$ \\
\hline Epidalea calamita & 30SWG96 & 100,00 & 144,29 & 110,90 & 38,65 & 5940,80 & 304,21 & 20,36 & 283,85 & 118,84 & 223,43 & 225,23 & 74,01 & 402,57 & 51,29 & 7,93 & 38,69 & 132,37 & 41,16 & 46,88 & 112,11 \\
\hline Epidalea calamita & 30SWG97 & 100,00 & 151,15 & 111,36 & 38,95 & 5907,51 & 309,48 & 26,44 & 283,05 & 121,44 & 229,52 & 231,13 & 80,52 & 372,18 & 47,73 & 6,42 & 39,93 & 124,09 & 36,34 & 42,69 & 103,01 \\
\hline Epidalea calamita & 30SWG98 & 100,00 & 148,92 & 113,06 & 38,88 & 5976,33 & 310,19 & 23,00 & 287,19 & 120,97 & 228 & 229, & 77, & 382,85 & 49,54 & 7,04 & 39,39 & 127,28 & 39,17 & 45,08 & 103, \\
\hline Epidalea calamita & 30SWG99 & 100,00 & 141,93 & 115,04 & 38,85 & 6098,75 & 307,93 & 14,80 & 293,13 & 121,79 & 223,39 & 224,51 & 69,38 & 413,51 & 54,08 & 8,66 & 37,59 & 137,00 & 45,97 & 50,49 & 109,85 \\
\hline
\end{tabular}




\begin{tabular}{|c|c|c|c|c|c|c|c|c|c|c|c|c|c|c|c|c|c|c|c|c|c|}
\hline TAXON & UTM & $\mathrm{km} 2$ & B101 & B102 & $\mathrm{BIO3}$ & 8104 & B105 & B106 & B107 & B108 & B109 & B1010 & BIO11 & BIO12 & B1013 & BIO14 & BIO15 & B1016 & B1017 & BIO18 & B1019 \\
\hline Epidalea calamita & 30SWHOO & 100,00 & 135,70 & 118,81 & 37,07 & 6620,45 & 321,12 & 5,99 & 315,12 & 97,55 & 225,36 & 225,55 & 57,45 & 503,33 & 63,04 & 9,04 & 42,12 & 176,09 & 44,77 & 46,68 & 153,98 \\
\hline Epidalea calamita & 30SWHO1 & 100,00 & 131,25 & 119,80 & \begin{tabular}{|l|l|}
37,08 \\
\end{tabular} & 6658,89 & 318,57 & 1,16 & 317,42 & 100,95 & 221,56 & 221,69 & 52,66 & 522,87 & 65,45 & 10,09 & 41,08 & 182,81 & 49,46 & 50,68 & 157,44 \\
\hline Epidalea calamita & 30SWHO2 & 100,00 & 144,42 & 118,63 & 37,09 & 6611,24 & 328,17 & 14,06 & 314,11 & 115,59 & 233,70 & 233,81 & 65,58 & 459,73 & 57,65 & 7,20 & 42,47 & 160,87 & 39,82 & 40,88 & 139,07 \\
\hline Epidalea calamita & 30SWHO3 & 100,00 & 152,16 & 117,87 & 37,10 & 6566,44 & 333,27 & 21,56 & 311,71 & 127,42 & 240,51 & 240,57 & 73,34 & 424,25 & 53,19 & 5,88 & 43,00 & 147,95 & 35,37 & 36,05 & 127,97 \\
\hline Epidalea calamita & 30SWHO4 & 100,00 & 153,38 & 118,44 & 37,31 & 6570,38 & 334,75 & 22,41 & 312,34 & 134,77 & 241,78 & 241,81 & 74,35 & 415,06 & 52,06 & 5,56 & 42,79 & 144,82 & 34,95 & 35,32 & 123,95 \\
\hline Epidalea calamita & 30SWHO5 & 100,00 & 146,81 & 120,28 & 37,49 & 6636,79 & 331,49 & 14,79 & 316,69 & 128,08 & 236,24 & 236,24 & 67,31 & 437,31 & 54,96 & 6,57 & 41,47 & 153,16 & 39,79 & 39,86 & 128,39 \\
\hline Epidalea calamita & 30SWHO7 & 100,00 & 136,94 & 122,64 & $\begin{array}{l}37,95 \\
\end{array}$ & 6703,97 & 325,61 & 4,01 & 321,60 & 117,94 & 227,56 & 227,56 & 56,86 & 468,29 & 58,47 & 8,23 & 39,13 & 163,95 & 47,88 & 47,88 & 133,54 \\
\hline Epidalea calamita & 30SWHO9 & 100,00 & 134,57 & 123,45 & 37,88 & 6738,96 & 324,19 & 1,06 & 323,14 & 115,69 & 225,62 & 225,62 & 54,10 & 468,23 & 57,77 & 8,75 & 38,11 & 163,12 & 50,86 & 50,86 & 130,85 \\
\hline Epidalea calamita & 30SWH10 & 100,00 & 119,81 & 120,31 & 37,38 & 6638,95 & 308,01 & $-9,60$ & 317,61 & 94,93 & 210,08 & 210,42 & 42,17 & 569,87 & 71,55 & 13,20 & 38,99 & 197,38 & 59,80 & 61,74 & 168,19 \\
\hline Epidalea calamita & 30SWH11 & 100,00 & 134,09 & 119,02 & \begin{tabular}{|l|l|}
37,29 \\
\end{tabular} & 6587,66 & 318,37 & 4,40 & 313,97 & 111,43 & 223,24 & 223,42 & 56,20 & 498,22 & 62,81 & 9,64 & 40,51 & 173,14 & 48,17 & 50,10 & 147,80 \\
\hline Epidalea calamita & 30SWH12 & 100,00 & 134,78 & 119,67 & \begin{tabular}{|c|}
37,38 \\
\end{tabular} & 6609,19 & 319,85 & 4,54 & 315,31 & 114,20 & 224,19 & 224,34 & 56,55 & 491,51 & 62,07 & 9,38 & 40,19 & 171,31 & 48,13 & 49,49 & 144,39 \\
\hline Epidalea calamita & 30SWH14 & 100,00 & 148,97 & 119,01 & 37,71 & 6557,42 & 330,43 & 17,86 & 312,57 & 130,21 & 237,24 & 237,24 & 70,45 & 422,51 & 53,51 & 6,37 & 41,31 & 147,08 & 38,62 & 38,94 & 123,22 \\
\hline Epidalea calamita & 30SWH16 & 100,00 & 143,69 & 121,04 & \begin{tabular}{|l|l|}
37,97 \\
\end{tabular} & 6623,49 & 328,40 & 11,49 & 316,91 & 124,80 & 233,03 & 233,03 & 64,38 & 435,98 & 55,13 & 7,22 & 39,76 & 152,02 & 43,33 & 43,33 & 123,95 \\
\hline Epidalea calamita & 30SWH17 & 100,00 & 134,64 & 122,57 & 38,00 & 6673,81 & 322,48 & 2,36 & 320,11 & 115,32 & 224,87 & 224,87 & 55,14 & 470,69 & 59,10 & 9,06 & 38,14 & 164,29 & 51,01 & 51,01 & 131,44 \\
\hline Epidalea calamita & 30SWH20 & 100,00 & 97,98 & 121,82 & 37,70 & 6678,92 & 289,86 & $-30,73$ & 320,59 & 74,45 & 189,41 & 189,81 & 21,11 & 674,38 & 84,46 & 19,71 & 35,07 & 231,49 & 82,36 & 82,62 & 191,90 \\
\hline Epidalea calamita & 30SWH21 & 100,00 & 108,66 & 121,42 & 37,75 & 6662,13 & 298,65 & $-20,64$ & 319,29 & 85,88 & 199,53 & 199,80 & 31,31 & 615,27 & 77,37 & 16,50 & 36,18 & 212,34 & 72,30 & 72,93 & 175,07 \\
\hline Epidalea calamita & 30 SWH22 & 100,00 & 129,43 & 120,05 & 37,79 & 6589,29 & 314,54 & $-0,47$ & 315,01 & 108,49 & 218,69 & 218,97 & 51,83 & 507,32 & 64,45 & 10,86 & 38,66 & 176,13 & 53,73 & 54,77 & 145,49 \\
\hline Epidalea calamita & 30SWH23 & 100,00 & 135,81 & 119,95 & 37,88 & 6573,86 & 319,58 & 5,31 & \begin{tabular}{|l|}
314,27 \\
\end{tabular} & $\begin{array}{l}115,67 \\
\end{array}$ & 224,68 & 224,79 & 57,81 & 473,78 & 60,36 & 9,25 & 39,12 & $\begin{array}{l}164,77 \\
\end{array}$ & 48,83 & 49,47 & 135,25 \\
\hline Epidalea calamita & 30SWH24 & 100,00 & 144,52 & 119,50 & \begin{tabular}{|l|l|}
37,97 \\
\end{tabular} & 6537,57 & 326,10 & 13,49 & 312,61 & 125,46 & 232,60 & 232,66 & 66,33 & 431,48 & 55,08 & 7,33 & 39,93 & 149,76 & 42,48 & 42,80 & 123,02 \\
\hline Epidalea calamita & 30SWH25 & 100,00 & 140,51 & 120,64 & 38,00 & 6580,19 & 324,05 & 8.96 & 315,09 & $\mid 121,21$ & 229,27 & 229,33 & 61.99 & 444,95 & 56,81 & 7,98 & 39,07 & 154,85 & 46,07 & 46,40 & 125,01 \\
\hline Epidalea calamita & 30SWH26 & 100,00 & 142,96 & 120,98 & 38,00 & 6576,61 & 326,16 & 10,95 & 315,21 & 123,99 & 231,54 & 231,55 & 64,16 & 431,01 & 54,96 & 7,51 & 39,07 & 149,84 & 44,83 & 44,90 & 120,01 \\
\hline Epidalea calamita & 30 SWH27 & 100,00 & 136,53 & 122,09 & 38,00 & 6621,28 & 322,34 & 4,31 & 318,03 & 117,43 & 226,03 & 226,05 & 57,70 & 455,02 & 57,62 & 8,86 & 37,61 & $\begin{array}{l}158,18 \\
\end{array}$ & 50,57 & 50,66 & 124,84 \\
\hline Epidalea calamita & 30SWH30 & 100,00 & 102,13 & 120,83 & $\begin{array}{l}37,45 \\
\end{array}$ & 6632,01 & 291,64 & $-26,36$ & 318,00 & 78,76 & 192,94 & 193,40 & 25,83 & 644,83 & 81,33 & 18,94 & 34,79 & 221,03 & 79,58 & 80,12 & 181,02 \\
\hline Epidalea calamita & 30SWH31 & 100,00 & 108,29 & 121,08 & 37,73 & 6625,97 & 297,12 & $-20,70$ & 317,82 & 85,36 & 198,76 & 199,10 & 31,57 & 606,90 & 76,87 & 16,75 & 35,28 & 209,08 & 73,52 & 73,98 & 169,73 \\
\hline Epidalea calamita & 30SWH32 & 100,00 & 114,08 & 121,17 & 37,90 & 6616,64 & 301,82 & $-15,40$ & 317,22 & 91,90 & 204,23 & 204,44 & 36,99 & 573,92 & 72,88 & 15,03 & 35,73 & 198,20 & 68,40 & 68,88 & 159,72 \\
\hline Epidalea calamita & 30SWH33 & 100,00 & 115,28 & 121,64 & 37,99 & 6624,59 & 303,36 & $-14,60$ & 317,95 & 93,55 & 205,45 & 205,58 & 37,90 & 563,74 & 71,58 & 14,55 & 35,49 & 195,09 & 67,78 & 68,03 & 155,56 \\
\hline Epidalea calamita & 30 SWH34 & 100,00 & 127,64 & 121,06 & 37,99 & 6585,76 & 312,86 & $\begin{array}{l}-2,88 \\
-2,0\end{array}$ & 315,74 & \begin{tabular}{|c|}
107,04 \\
\end{tabular} & $\begin{array}{l}216,92 \\
21,9\end{array}$ & 217,02 & 50,06 & $\mid 499,64$ & $\begin{array}{l}1,1,06 \\
63,86 \\
\end{array}$ & 11,34 & $\begin{array}{l}3,4,86 \\
36,86\end{array}$ & 173,19 & 57,30 & 57,69 & 137,60 \\
\hline Epidalea calamita & 30 SWH37 & 100,00 & 137,60 & 121,74 & 38,00 & 6574,66 & 321,26 & 5,33 & 315,93 & 118,44 & 226,15 & 226,18 & 58,94 & 443,36 & 56,69 & 8,84 & 37,12 & 153,45 & 50,73 & 51,05 & 119,20 \\
\hline Epidalea calamita & 30 SWH40 & 100,00 & 111,35 & 119,94 & 37,86 & 6555,71 & 296,98 & \begin{tabular}{|l|l|}
$-17,14$ \\
\end{tabular} & 314,12 & 88,53 & 200,57 & 201,16 & 35,33 & 587,22 & 74,95 & 16,23 & 35,18 & 201,40 & 71,21 & 72,18 & 163,32 \\
\hline Epidalea calamita & 30SWH41 & 100,00 & 104,01 & 120,89 & 37,87 & 6607,13 & 292,17 & $-24,69$ & 316,87 & 80,68 & 194,50 & 194,73 & 27,95 & 624,24 & 79,20 & 18,58 & 33,92 & 213,93 & 79,32 & 79,43 & 171,15 \\
\hline Epidalea calamita & 30 SWH42 & 100,00 & 117,07 & 120,59 & 37,97 & 6569,31 & 302,61 & $-12,38$ & 314,99 & 94,95 & 206,40 & 206,77 & 40,55 & 550,65 & 70,50 & 14,42 & 35,34 & 189,73 & 66,72 & 67,18 & 150,78 \\
\hline Epidalea calamita & 30 SWH43 & 100,00 & 126,58 & 120,40 & 37,99 & 6533,06 & 309,88 & $\begin{array}{r}1,300 \\
-3,61 \\
\end{array}$ & \begin{tabular}{|l|l|}
313,49 \\
\end{tabular} & \begin{tabular}{|l|}
105,78 \\
145
\end{tabular} & 215,07 & 215,37 & $\begin{array}{l}49,71 \\
49,7\end{array}$ & 500,56 & 64,43 & 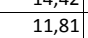 & $\begin{array}{l}3,4,40 \\
36,\end{array}$ & \begin{tabular}{|l|l|}
172,66 \\
\end{tabular} & 58,66 & $\begin{array}{l}59,34 \\
5\end{array}$ & 136,50 \\
\hline Epidalea calamita & 30SWH44 & 100,00 & 120,14 & 121,30 & 38,00 & 6578,54 & 305,68 & $-10,05$ & 315,73 & 98,81 & 209,57 & 209,66 & 42,99 & 529,28 & 67,71 & 13,53 & 35,21 & 182,61 & 64,91 & 65,25 & 142,30 \\
\hline Epidalea calamita & 30 SWH45 & 100,00 & 122,26 & 121,51 & 38,00 & 6578,14 & 307,64 & $-8,31$ & 315,95 & 101,38 & 211,55 & 211,58 & 44,91 & 515,95 & 65,98 & 13,00 & 35,23 & 178,04 & 63,34 & 64,24 & 137,55 \\
\hline Epidalea calamita & $30 S W H 46$ & 100,00 & 115,51 & 122,13 & 38,00 & 6610,28 & 302,89 & $-14,96$ & 317,85 & 94,21 & 205,38 & 205,49 & 38,10 & 545,61 & 69,02 & 14,80 & 33,92 & 188,01 & 69,40 & 70,86 & 143,76 \\
\hline Epidalea calamita & 30 SWH49 & 100,00 & 128,22 & 122,94 & 38,11 & 6595,74 & 313,58 & $-3,23$ & 316,81 & \begin{tabular}{|r|r|}
108,98 \\
\end{tabular} & 217,13 & 217,37 & 49,82 & 472,48 & 59,60 & 11,15 & 34,59 & 162,55 & 59,05 & 61,93 & 121,60 \\
\hline Epidalea calamita & 30SWH50 & 100,00 & 120,56 & $\begin{array}{l}12,34 \\
118,94\end{array}$ & 38,00 & 6456, 646 & 302,08 & $\begin{array}{l}-3,25 \\
-7,79 \\
\end{array}$ & \begin{tabular}{|l|}
309,87 \\
30,8
\end{tabular} & \begin{tabular}{|l|}
98,62 \\
98,6
\end{tabular} & 208,15 & 208,87 & $\begin{array}{l}45,98 \\
44,98\end{array}$ & \begin{tabular}{|l|}
530,73 \\
40,0
\end{tabular} & $\begin{array}{l}3,000 \\
68,54 \\
\end{array}$ & $\mid \frac{1,130}{13,60}$ & $\begin{array}{l}4,359 \\
35,69 \\
\end{array}$ & \begin{tabular}{|l|}
181,69 \\
18,6
\end{tabular} & $\begin{array}{l}3,0095 \\
62,95\end{array}$ & $\begin{array}{l}1,34,42 \\
64,\end{array}$ & $\begin{array}{l}14,100 \\
146,11\end{array}$ \\
\hline Epidalea calamita & 30SWH51 & 100,00 & 102,68 & 120,33 & 37,85 & 6578,31 & 289,47 & $-25,73$ & 315,19 & 79,39 & 192,83 & 193,01 & 26,90 & 627,86 & 79,82 & 19,57 & 32,97 & 214,10 & 82,39 & 82,44 & 169,05 \\
\hline Epidalea calamita & 30SWH52 & 100,00 & 116,10 & 120,35 & 38,00 & 6533,21 & 300,31 & $-12,83$ & 313,14 & 94,07 & 205,03 & 205,38 & 40,06 & 548,71 & 70,60 & 14,86 & 34,53 & 188,31 & 68,69 & 68,93 & 147,66 \\
\hline Epidalea calamita & 30SWH54 & 100,00 & 131,29 & 120,31 & 38,04 & 6476,47 & 312,01 & 1,13 & 310,89 & 110,88 & 218,81 & 218,99 & 54,62 & 468,32 & 60,97 & 10,81 & 36,17 & 161,00 & 56,14 & 56,56 & 124,16 \\
\hline Epidalea calamita & 30SWH59 & 100,00 & 129,59 & 122,39 & 38,30 & 6539,40 & 312,89 & $-1,79$ & 314,68 & 110,51 & 217,68 & 218,04 & 51,72 & 460,34 & 58,64 & 11,2 & 34,25 & 157,76 & 58,58 & 62,27 & 115,81 \\
\hline Epidalea calamita & 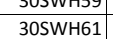 & 100,00 & $\begin{array}{l}12,58,09 \\
108,09\end{array}$ & $\begin{array}{l}12,39 \\
119,62\end{array}$ & $\begin{array}{l}30,50 \\
37,93\end{array}$ & $\begin{array}{l}0339,44 \\
6511,14\end{array}$ & $\begin{array}{l}31,89,89 \\
291,89\end{array}$ & \begin{tabular}{|c|}
$-1,1 / 90$ \\
$-19,90$
\end{tabular} & \begin{tabular}{|l|}
311,790 \\
311,79
\end{tabular} & \begin{tabular}{|}
10,51, \\
85,27
\end{tabular} & \begin{tabular}{|l|}
197,10 \\
197
\end{tabular} & \begin{tabular}{|l|}
197,384 \\
197
\end{tabular} & $\begin{array}{ll}1,1 / 2 \\
32,68\end{array}$ & \begin{tabular}{|l|}
592,348 \\
592,88
\end{tabular} & $\begin{array}{l}30,04 \\
75,97\end{array}$ & $\begin{array}{l}11,4 \\
18,1\end{array}$ & $\begin{array}{l}4,425 \\
33,04 \\
\end{array}$ & \begin{tabular}{|l|}
$17,161,65$ \\
201
\end{tabular} & \begin{tabular}{|l|l|}
20,30 \\
78,14
\end{tabular} & $\frac{02,21}{78,20}$ & $\begin{array}{l}115,81 \\
157,47\end{array}$ \\
\hline Epidalea calamita & 30SWH62 & 100,00 & 122,64 & 119,54 & 38,00 & 6448,83 & 303,26 & $-6,08$ & 309,34 & 101,19 & 210,08 & 210,48 & 47,03 & 510,83 & 66,39 & 13,34 & 34,84 & 174,56 & 63,86 & 64,27 & 135,26 \\
\hline Epidalea calamita & 30SWH64 & 100,00 & 143,58 & 119,04 & 38,44 & 6357,51 & 318,63 & 13,18 & 305,45 & 124,52 & 228,84 & 229,14 & 67,52 & 406,88 & 53,85 & 8,03 & 37,66 & 138,73 & 46,86 & 47,79 & 106,31 \\
\hline Epidalea calamita & 30SWH65 & 100,00 & 137,79 & 120,16 & 38,4 & 6408,61 & 315,40 & 7,05 & 308,36 & 118,61 & 224,08 & 224,23 & 61 & 430,13 & 56,60 & 9,38 & 36,48 & 146,97 & 52,01 & 52,64 & 110,77 \\
\hline Epidalea calamita & 30 SWH66 & 100,00 & 125,89 & 121,30 & 38 & $\begin{array}{l}6490,018 \\
6490\end{array}$ & 307,56 & $\begin{array}{l}-4,69 \\
-1,09\end{array}$ & 312,25 & \begin{tabular}{|l|}
105,67 \\
\end{tabular} & 213,69 & 213,75 & 49,07 & \begin{tabular}{|l|}
483,00 \\
483
\end{tabular} & 62,73 & \begin{tabular}{|c|}
$, 2,45$ \\
12,4
\end{tabular} & 34,30 & 165,42 & $\frac{62,13}{62,13}$ & 63,59 & 122,54 \\
\hline Epidalea calamita & 30SWH71 & 100,00 & 119,08 & 118,76 & 38,03 & 6412,77 & 298,25 & $-8,89$ & 307,14 & 97,06 & 205,94 & 206,61 & 44,11 & 528,87 & 68,66 & 14,74 & 34,00 & 179,50 & 67,99 & 68,50 & 138,95 \\
\hline Epidalea calamita & 30SWH72 & 100,00 & 116,62 & 119,38 & 38,00 & 6439,80 & 297,18 & \begin{tabular}{|c|}
$-11,63$ \\
$-1,03$
\end{tabular} & 308,81 & 94,75 & 204,30 & 204,62 & 41,43 & 539,06 & 69,85 & 15,50 & 33,44 & 183,02 & 71,05 & 71,07 & 140,00 \\
\hline Epidalea calamita & 30 SWH73 & 100,00 & 122,36 & 119,87 & 38,13 & 6426,94 & 301,87 & $-6,58$ & 308,45 & 101,08 & 209,64 & 209,83 & 47,00 & 505,47 & 65,92 & 13,66 & 34,00 & 171,94 & 65,78 & 65,79 & 129,99 \\
\hline Epidalea calamita & 30SWH77 & 100,00 & 123,18 & 121,17 & 38,41 & 6470,92 & 304,12 & $-7,16$ & 311,29 & 102,78 & 210,74 & 210,77 & 46,77 & 489,06 & 63,27 & 13,52 & 33,29 & 43 & 65,67 & 68,23 & 120,31 \\
\hline Epidalea calamita & 30SWH78 & 100,00 & 119 & 12 & $\frac{00}{38}$ & 640194,99| & 301 & \begin{tabular}{|l|l|}
$-1,10$ \\
$-10,78$
\end{tabular} & \begin{tabular}{|l|}
312,37 \\
31,3
\end{tabular} & \begin{tabular}{|c|}
92,10 \\
98,80
\end{tabular} & \begin{tabular}{|l|}
207,46 \\
\end{tabular} & 207,51 & $\begin{array}{ll}43,04 \\
43\end{array}$ & $\begin{array}{l}504,06 \\
504,06\end{array}$ & $\begin{array}{l}63,44 \\
64,44\end{array}$ & 14,5 & $\begin{array}{ll}32,25 \\
32,28\end{array}$ & $\begin{array}{l}171,28 \\
171\end{array}$ & $\begin{array}{l}69,07 \\
690\end{array}$ & $\begin{array}{l}0,255 \\
72,55\end{array}$ & $\begin{array}{l}122,91 \\
122,98\end{array}$ \\
\hline Epidalea calamita & 30SWH80 & 100,00 & 134,74 & 116,71 & 38,58 & 6236,81 & 306,19 & 6,65 & 299,54 & 114,16 & 218,45 & 219,43 & 60,74 & 447,71 & 58,71 & 10,38 & 36,28 & 150,32 & 52,66 & 55,54 & 118,30 \\
\hline Epidalea calamita & 30 SWH82 & 100,00 & 123,14 & 118,79 & \begin{tabular}{|c|}
38,38 \\
\end{tabular} & 6366,40 & 300,15 & $-5,17$ & 305,32 & 101,86 & 209,27 & 209,86 & 48,48 & 502,28 & 65,59 & $\mid 13,74$ & 33,91 & 169,65 & 65,89 & 66,19 & 128,66 \\
\hline Epidalea calamita & 30 SWH83 & 100,00 & 127,20 & 119,13 & 38,56 & 6355,33 & 303,63 & $-1,80$ & 305,43 & 106,50 & 213,11 & 213,46 & 52,27 & 479,97 & 63,04 & 12,64 & 34,44 & 162,31 & 62,58 & 62,96 & 121,56 \\
\hline Epidalea calamita & 30 SWH84 & 100,00 & 141,39 & 119,12 & 38,93 & 6275,90 & 313,94 & 11,17 & 302 & 122,32 & 225,54 & 225 & 66,34 & 411,11 & 54,83 & 8,93 & 36,70 & 138,72 & 50,65 & 51,52 & 103,15 \\
\hline Epidalea calamita & $\begin{array}{l}30 \text { SWH } 85 \\
3\end{array}$ & 100,00 & $\begin{array}{l}141,53 \\
148,53\end{array}$ & 1118,95 & 年, 39,00 & | 6241,77 & 319,29 & $\begin{array}{l}1,11 \\
17,79 \\
\end{array}$ & 301,50 & \begin{tabular}{|l|}
130,34 \\
134
\end{tabular} & \begin{tabular}{|l|}
231,99 \\
231
\end{tabular} & \begin{tabular}{|l|}
232,27 \\
232
\end{tabular} & $\begin{array}{l}00,34 \\
73,44 \\
\end{array}$ & \begin{tabular}{|l|}
377,51 \\
371
\end{tabular} & \begin{tabular}{|l|}
4,003 \\
50,75
\end{tabular} & 年, & $\begin{array}{l}30,10 \\
37,82\end{array}$ & $\begin{array}{l}150,1 / 2 \\
126,92 \\
\end{array}$ & $\begin{array}{l}0,030 \\
45,61\end{array}$ & $\begin{array}{l}1,52 \\
46,44 \\
\end{array}$ & 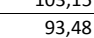 \\
\hline Epidalea calamita & 30SWH86 & 100,00 & 139,91 & 120,07 & 38,97 & 6323,97 & 314,17 & 9,01 & 305,16 & 120,78 & 225,01 & 225,06 & 64,40 & 410,44 & 54,92 & 9,30 & 36,04 & 138,60 & 52,97 & 53,56 & 99,77 \\
\hline Epidalea calamita & 30SWH87 & 100,00 & 130,85 & 120,71 & 38,95 & 6393,79 & 308,12 & 0,47 & 307,66 & 111,27 & 217,19 & 217,21 & 55,06 & 448,12 & 59,10 & 11,66 & 34,21 & 151,61 & 60,12 & 62,05 & 107,57 \\
\hline Epidalea calamita & 30SWH90 & 100,00 & 139,71 & 116,29 & 38,98 & 6148,27 & 307,94 & 11,79 & 296,15 & 119,46 & 221, & 222, & 66,79 & 422,94 & 55,66 & 9,25 & 36,99 & 140,90 & 48,95 & 52,66 & 110,38 \\
\hline Epidalea calamita & 30SWH92 & 100,00 & 137,53 & 117,82 & 38,78 & 6220,34 & 308,26 & 8,64 & 299,62 & 117,55 & 220,95 & 221,68 & 63,68 & 433,09 & 57,22 & 10,15 & 36,25 & 144,87 & 53,48 & 55,89 & 109,89 \\
\hline
\end{tabular}




\begin{tabular}{|c|c|c|c|c|c|c|c|c|c|c|c|c|c|c|c|c|c|c|c|c|c|}
\hline TAXON & UTM & $\mathrm{km} 2$ & B101 & B102 & $\mathrm{BIO3}$ & BIO4 & B105 & B106 & B107 & B108 & 8109 & B1010 & BIO11 & BIO12 & 81013 & BIO14 & BIO15 & B1016 & B1017 & B1018 & B1019 \\
\hline Epidalea calamita & 30SWH93 & 100,00 & 141,58 & 118,42 & 39,03 & 6211,47 & 311,88 & 11,96 & 299,92 & 122,12 & 224,78 & 225,34 & 67,37 & 411,29 & 54,77 & 9,06 & 36,84 & 137,69 & 50,45 & 52,65 & 103,01 \\
\hline Epidalea calamita & 30SWH94 & 100,00 & 152,20 & 118,30 & 39,15 & 6143,11 & 319,57 & 21,88 & 297,69 & 133,95 & 234,10 & 234,45 & 78,05 & 365,16 & 49,16 & 6,70 & 38,84 & 121,72 & 42,36 & 44,79 & 90,51 \\
\hline Epidalea calamita & 30SWH95 & 100,00 & 150,41 & 118,84 & 39,14 & 6175,10 & 318,85 & 19,76 & 299,09 & 132,24 & 232,81 & 233,03 & 75,88 & 370,24 & 49,90 & 7,21 & 38,17 & 123,54 & 45,03 & 46,55 & 90,10 \\
\hline Epidalea calamita & 30SWH96 & 100,00 & 146,16 & 119,44 & 39,02 & 6231,48 & 316,62 & 15,25 & 301,38 & 127,58 & 229,58 & 229,75 & 71,24 & \begin{tabular}{|l|l|}
384,08 \\
\end{tabular} & 51,70 & 8,15 & 37,09 & 128,34 & 49,41 & 50,04 & 91,68 \\
\hline Epidalea calamita & 30SWJo0 & 100,00 & 133,64 & 123,97 & 37,98 & \begin{tabular}{|l|l|}
6738,74 \\
\end{tabular} & 323,58 & 0,03 & 323,55 & \begin{tabular}{|l|l|}
115,06 \\
\end{tabular} & 224,59 & 224,63 & 53,19 & \begin{tabular}{|l|l|}
468,19 \\
\end{tabular} & 57,16 & 9,00 & 37,27 & 162,41 & 51,96 & 52,12 & 129,69 \\
\hline Epidalea calamita & 30SWJO1 & 100,00 & 135,83 & 123,65 & 38,00 & 6718,88 & 324,97 & 2,06 & 322,91 & 117,75 & 226,59 & 226,64 & 55,40 & 454,33 & 55,12 & 8,55 & 37,33 & 156,72 & 50,76 & 50,82 & 125,18 \\
\hline Epidalea calamita & 30SWJ04 & 100,00 & 143,40 & 122,08 & 37,94 & 6680,46 & 329,58 & 9,51 & 320,07 & \begin{tabular}{ll|}
127,12 \\
\end{tabular} & 233,38 & 233,38 & 62,58 & 414,97 & 48,45 & 7,54 & 37,03 & 139,45 & 46,61 & 46,61 & 112,97 \\
\hline Epidalea calamita & 30sWJ06 & 100,00 & 141,19 & 121,88 & 37,88 & 6682,22 & 326,79 & 7,55 & 319,24 & 125,00 & 231,17 & 231,17 & 60,55 & 419,66 & 47,80 & 8,17 & 35,69 & 139,11 & 49,30 & 49,30 & 113,53 \\
\hline Epidalea calamita & 30SWJ07 & 100,00 & 138,27 & 121,39 & 37,40 & 6693,20 & 324,12 & 4,90 & 319,22 & 122,05 & 228,10 & 228,25 & 57,68 & 429,80 & 48,92 & 9,08 & 34,97 & 141,21 & 51,73 & 51,88 & 116,28 \\
\hline Epidalea calamita & 30SWJO9 & 100,00 & 133,87 & 120,34 & 37,21 & 6694,42 & 319,23 & 1,57 & 317,66 & $\begin{array}{l}117,67 \\
\end{array}$ & 223,67 & 224,06 & 53,23 & 443,46 & 50,47 & 10,30 & 33,66 & 143,49 & 55,45 & 55,73 & 119,49 \\
\hline Epidalea calamita & 30SWJ10 & 100,00 & 133,74 & 123,38 & 38,00 & 6685,27 & 322,20 & 0,64 & 321,56 & 115,28 & 223,74 & 224,19 & 53,98 & 461,31 & 56,75 & 9,04 & 36,79 & 159,66 & 52,44 & 53,18 & 125,69 \\
\hline Epidalea calamita & 30SWJ11 & 100,00 & 132,95 & 123,77 & 38,00 & 6688,70 & 321,48 & $-0,02$ & 321,50 & 114,59 & 222,89 & 223,38 & 53,13 & 461,69 & 56,23 & 9,45 & 36,06 & 159,09 & 53,73 & 54,64 & 124,72 \\
\hline Epidalea calamita & 30SWJ15 & 100,00 & 141,64 & 122,00 & 38,00 & 6662,83 & 326,70 & 7,86 & 318,84 & 125,15 & 230,81 & 231,25 & 60,91 & 417,19 & 48,00 & 8,08 & 35,97 & 139,83 & 49,29 & 49,64 & 111,50 \\
\hline Epidalea calamita & 30SWJ16 & 100,00 & 140,12 & 122,00 & 38,00 & 6666,75 & 325,28 & 6,48 & 318,80 & 123,81 & 229,56 & 229,85 & 59,51 & 421,10 & 48,23 & 8,81 & 34,97 & 139,57 & 51,18 & 51,48 & 112,48 \\
\hline Epidalea calamita & 30SWJ19 & 100,00 & 130,61 & 121,07 & 37,97 & 6666,29 & 315,92 & $-1,29$ & 317,21 & 114,14 & 219,31 & 220,34 & 50,49 & 456,24 & 52,56 & 11,38 & 32,73 & 148,64 & 58,92 & 60,44 & $\begin{array}{ll}121,03 \\
\end{array}$ \\
\hline Epidalea calamita & 30 SWJ20 & 100,00 & 131,13 & 123,12 & 38,00 & 6662,72 & 318,97 & $-1,20$ & 320,17 & 112,30 & 220,61 & 221,16 & 51,47 & 467,97 & 57,76 & 10,03 & 35,65 & 161,54 & 55,42 & 57,01 & 124,75 \\
\hline Epidalea calamita & 30 SWJ22 & 100,00 & 133,82 & 123,21 & 38,00 & 6650,44 & 320,84 & 0,63 & 320,21 & 115,83 & 222,95 & 223,58 & 54,08 & 450,48 & 54,31 & 9,68 & 35,27 & 154,04 & 54,21 & 55,92 & 119,01 \\
\hline Epidalea calamita & 30 SWJ25 & 100,00 & 140,69 & 122,05 & 38,00 & 6627,31 & 325,09 & 7,04 & \begin{tabular}{|l|}
318,05 \\
\end{tabular} & $\begin{array}{ll}123,91 \\
\end{array}$ & 229,06 & 229,84 & 60,76 & 418,63 & 48,04 & 8,94 & 34,96 & 140,03 & 51,64 & 52,42 & 109,46 \\
\hline Epidalea calamita & 30 SWJ30 & 100,00 & 128,96 & 123,06 & 38,00 & 6630,43 & 315,81 & $-3,09$ & 318,89 & 110,17 & 218,38 & 218,71 & 49,96 & 471,51 & 58,39 & 10,96 & 34,82 & 162,29 & 57,77 & 60,31 & 123,33 \\
\hline Epidalea calamita & 30 SWJ31 & 100,00 & 128,17 & 123,36 & 38.01 & 6632,26 & 315,34 & $-3,90$ & 319,24 & 109,36 & 217,53 & 218,01 & 49,30 & 472,30 & 57,84 & $\mid 11,16$ & 34,40 & $\mid 162.02$ & 58,61 & 61,64 & 122,75 \\
\hline Epidalea calamita & 30SWJ35 & 100,00 & 139,61 & 122,23 & 38,00 & 6602,26 & 323,10 & 5,96 & 317,14 & 122,99 & 227,25 & 228,23 & 59,88 & 418,74 & 48,49 & 9,09 & 34,62 & 140,41 & 52,32 & 54,39 & 107,86 \\
\hline Epidalea calamita & \begin{tabular}{|l|}
30 SWJ36 \\
\end{tabular} & 100,00 & 137,85 & 122,21 & 38,00 & 6609,06 & 321,68 & 4,37 & 317,31 & 121,38 & 225,68 & 226,77 & 58,10 & 425,92 & 49,39 & 9,90 & 33,36 & 141,92 & 54,77 & 56,73 & 109,35 \\
\hline Epidalea calamita & 30SWJ41 & 100,00 & 126,03 & 123,10 & 38,06 & 6601,84 & 312,03 & $-5,62$ & 317,64 & 106,86 & 214,97 & 215,51 & 47,59 & 4777,60 & 58,75 & 11,99 & 33,60 & 163,49 & 61,18 & 65,34 & 121,45 \\
\hline Epidalea calamita & 30 SWJ42 & 100,00 & 131,83 & 123,01 & 38,05 & 6587,52 & 316,54 & $-0,47$ & 317,01 & 113,56 & 220,20 & 220,78 & 53,18 & 449,84 & 54,76 & 10,71 & 33,92 & 153,20 & 57,27 & 60,92 & 113,88 \\
\hline Epidalea calamita & 30 SWJ46 & 100,00 & 136,78 & 122,53 & 38,12 & 6566,74 & 319,42 & 3,19 & 316,23 & 120,23 & 224,10 & 224,92 & 57,32 & 427,77 & 49,95 & 10,41 & 32,70 & 142,63 & 56,45 & 59,32 & 107,68 \\
\hline Epidalea calamita & 30 SWJ48 & 100,00 & 128,28 & 123,04 & 38,01 & 6587,38 & 312,77 & $-4,47$ & 317,24 & 111,47 & 216,01 & 216,95 & 49,06 & 465,45 & 55,03 & 12,82 & 31,04 & 154,44 & 64,16 & 68,21 & 117,49 \\
\hline Epidalea calamita & 30SWJ52 & 100,00 & 133,79 & 122,73 & 38,44 & 6540,52 & 316,21 & 1,21 & 315,00 & 115,63 & 221,32 & 221,88 & 55,37 & $\begin{array}{l}40,45,92 \\
436,92\end{array}$ & 53,67 & \begin{tabular}{l|l}
10,58 \\
10.5
\end{tabular} & 33,69 & $\begin{array}{l}148,18 \\
\end{array}$ & 56,80 & $\begin{array}{l}0,21,01 \\
61\end{array}$ & $\begin{array}{l}107,49 \\
107,97\end{array}$ \\
\hline Epidalea calamita & 30 SWJ55 & 100,00 & 137,90 & 122,05 & 38,07 & 6523,64 & 319,00 & 4,82 & 314,18 & 120,70 & 224,86 & 225,56 & 59,19 & 420,32 & 49,08 & 10,09 & 32,81 & 140,42 & 55,85 & 59,46 & 103,44 \\
\hline Epidalea calamita & 30 SWJ58 & 100,00 & 128,65 & 123,07 & 38,53 & 6547,10 & 311,84 & $-3,84$ & 315,68 & 111,64 & 215,87 & 216,81 & 49,99 & 462,92 & 55,10 & 13,25 & 30,64 & 153,75 & 65,49 & 70,16 & 114,59 \\
\hline Epidalea calamita & 30 SWJ60 & 100,00 & 134,71 & 121,98 & 38,47 & 6486,79 & 314,99 & 2,36 & 312,63 & 116,08 & 221,78 & 221,99 & 57,04 & 429,84 & 55,11 & 10,40 & 34,42 & 146,15 & 55,77 & 60,15 & 104,57 \\
\hline Epidalea calamita & 30 SWJ65 & 100,00 & 136,36 & 122,01 & 38,46 & 6492,55 & 316,32 & 3,75 & 312,57 & 119,43 & 222,97 & 223,73 & 58,16 & 421,97 & 49,60 & 11,02 & 32,38 & 140,84 & 58,07 & 62,45 & 101,46 \\
\hline Epidalea calamita & 30SWJ66 & 100,00 & 131,50 & 122,62 & 38,46 & 6513,74 & 312,67 & $\begin{array}{c}-0,94 \\
-0,1 / 2\end{array}$ & 313,61 & 114,47 & 218,39 & \begin{tabular}{|l|}
219,19 \\
\end{tabular} & 53,04 & \begin{tabular}{|l|l|}
444,68 \\
42,17
\end{tabular} & 52,74 & $\begin{array}{l}1,2,27 \\
12,\end{array}$ & 31,21 & $\begin{array}{l}148,34 \\
\end{array}$ & $\begin{array}{ll}62,54 \\
62\end{array}$ & $\begin{array}{l}67,70 \\
67,70\end{array}$ & 107,13 \\
\hline Epidalea calamita & 30SWJ67 & 100,00 & 129,14 & 122,88 & 38,81 & 6515,61 & 310,72 & $-3,15$ & 313,87 & 111,88 & 216,03 & 216,81 & 50,73 & 456,79 & 54,53 & 13,23 & 30,51 & 151,96 & 65,64 & 70,90 & 110,35 \\
\hline Epidalea calamita & 30SWJ77 & 100,00 & 128,87 & 122,03 & 38,82 & 6483,01 & 308,72 & $-3,01$ & 311,73 & 111,45 & 215,26 & 215,97 & 50,74 & 454,88 & 54,52 & 13,78 & 29,97 & 150,85 & 67,42 & 73,20 & 107,28 \\
\hline Epidalea calamita & 30SWJ79 & 100,00 & 121,50 & 122,86 & 38,85 & 6498,68 & 303,26 & $-10,85$ & 314,11 & 104,04 & 208,18 & 209,10 & 43,54 & 491,58 & 59,79 & 16,25 & 28,70 & 163,10 & 75,51 & 82,05 & 117,06 \\
\hline Epidalea calamita & 30 SWJ82 & 100,00 & 141,60 & 120,25 & 38,99 & 6360,39 & 315,90 & $\begin{array}{l}9,92 \\
9,0\end{array}$ & 305,98 & 140,59 & 226,51 & 226,81 & 64,90 & 391,05 & 49,97 & 9,95 & 34,44 & 130,69 & 53,97 & 59,14 & 88,66 \\
\hline Epidalea calamita & 30 SWJ84 & 100,00 & 138,64 & 120,26 & 38,88 & 6389,12 & 313,60 & 6,79 & 306,81 & 121,05 & 223,71 & 224,19 & 61,56 & 405,77 & 48,75 & 10,81 & 32,57 & 134,10 & 57,99 & 63,25 & 92,36 \\
\hline Epidalea calamita & 30SWJ98 & 100,00 & 124,07 & 119,64 & 38,88 & 6412,39 & 299,97 & $-6,04$ & 306,01 & 106,33 & 209,64 & 210,42 & 47,23 & 468,76 & 57,28 & 16,19 & 28,50 & 154,03 & 75,62 & 82,00 & 105,15 \\
\hline Epidalea calamita & 30SWJ99 & 100,00 & 118,33 & 119,86 & 38,51 & 6436,01 & 295,44 & $-11,94$ & 307,38 & 100,21 & 204,26 & 205,12 & 41,34 & 494,68 & 61,08 & 18,13 & 27,68 & 162,79 & 81,62 & 88,84 & 111,42 \\
\hline Epidalea calamita & 30SWK00 & 100,00 & 132,31 & 119,43 & 37,07 & 6687,66 & 316,81 & 0,61 & 316,19 & 116,15 & 221,89 & 222,30 & 51,86 & 447,76 & 50,90 & 10,93 & 33,16 & 143,58 & 56,99 & 57,34 & 120,51 \\
\hline Epidalea calamita & 30SWK01 & 100,00 & 129,76 & 118,74 & 37,04 & 6681,85 & 313,66 & $-0,85$ & 314,51 & 113,12 & 219,06 & 219,66 & 49,36 & 455,79 & 51,75 & 11,65 & 32,54 & 144,84 & 59,03 & 59,56 & 122,38 \\
\hline Epidalea calamita & 305WK10 & 100,00 & $\begin{array}{l}127,10 \\
127,28\end{array}$ & 1120,63 & $\frac{37,44}{37,75}$ & | $6008,1,06$ & 31,00 & $\begin{array}{l}-2,85 \\
-3,96\end{array}$ & \begin{tabular}{|l|}
314,41 \\
316,41
\end{tabular} & $\begin{array}{l}113,12 \\
110,82 \\
\end{array}$ & 212,00 & \begin{tabular}{|l|}
217,120 \\
217
\end{tabular} & \begin{tabular}{|l|}
45,20 \\
47,25 \\
\end{tabular} & \begin{tabular}{|l|l|}
453,195 \\
467,55
\end{tabular} & 51,01 & $\begin{array}{l}1,253 \\
12,32 \\
\end{array}$ & 32,02 & $\begin{array}{l}154,04 \\
151,45 \\
\end{array}$ & $\begin{array}{l}3,, 50 \\
61,53 \\
\end{array}$ & $\begin{array}{l}3,30 \\
63,37 \\
\end{array}$ & $\begin{array}{l}124,30 \\
123,73\end{array}$ \\
\hline Epidalea calamita & 30SWK11 & 100,00 & 127,21 & 119,86 & 37,71 & 6654,59 & 311,46 & $-3,37$ & 314,83 & 110,91 & 215,81 & 216,84 & 47,49 & 464,80 & 53,60 & 12,60 & 31,68 & 149,25 & 62,02 & 63,58 & 122,94 \\
\hline Epidalea calamita & 30SWK12 & 100,00 & 124,11 & 119,03 & 37,44 & 6643,19 & 307,64 & $-5,88$ & 313,52 & 107,91 & 212,52 & 213,62 & 44,65 & 474,90 & 54,89 & 13,53 & 31,11 & 151,70 & 64,56 & 66,55 & 125,21 \\
\hline Epidalea calamita & 30SWK21 & 100,00 & 126,89 & 120,70 & 38,00 & 6626,87 & 310,87 & $-4,46$ & 315,33 & 110,69 & 214,99 & 215,99 & 47,21 & 467,38 & 54,53 & 13,16 & 31,07 & 151,26 & 63,78 & 66,23 & 121,84 \\
\hline Epidalea calamita & 30SWK80 & 100,00 & 113,99 & 121,85 & 38,6 & 6483,76 & 294,69 & $-17,24$ & 311,93 & $\begin{array}{ll}10,03 \\
95,93\end{array}$ & 200,63 & 201,60 & $\begin{array}{l}1,12 \\
36,80 \\
\end{array}$ & |520,77 & 64,36 & 19,1 & $\begin{array}{l}1,31 \\
27,34\end{array}$ & $\begin{array}{l}172,34 \\
172\end{array}$ & $\begin{array}{l}0,100 \\
84,60\end{array}$ & $\begin{array}{l}0,25 \\
92,57 \\
\end{array}$ & $\begin{array}{l}2121,04 \\
121,23\end{array}$ \\
\hline Epidalea calamita & 30SWK81 & 100,00 & 110,82 & 121,81 & 38, & 6483,51 & 291,80 & $-20,39$ & 312,19 & 92,95 & $\begin{array}{l}197,45 \\
\end{array}$ & 198,55 & 33,73 & 534,36 & 66,63 & 20,4 & 27,09 & 176,77 & 88,24 & 96,72 & 124,56 \\
\hline Epidalea calamita & 30SWK82 & 100,00 & 110,53 & 121,79 & 38,60 & 6481,56 & 291,16 & $-21,05$ & 312,21 & 92,89 & 196,90 & 198,10 & 33,16 & 535,29 & 67,24 & 20,84 & 27,04 & 176,77 & 89,48 & 98,00 & 124,87 \\
\hline Epidalea calamita & 30SWK92 & 100,00 & 111,82 & 119,45 & 38,27 & 6446,76 & 288,67 & $-18,55$ & 307,22 & 94,28 & 197,75 & 198,81 & 34,66 & 517,63 & 65,91 & 20,95 & 26,86 & 170,08 & 89,76 & 98,07 & 116,28 \\
\hline Epidalea calamita & $30 S \times G 00$ & 22,00 & 177,38 & 90,29 & 38,00 & 4995,43 & 302,86 & 68,57 & 234,29 & 153,43 & 241,62 & 245,48 & 117,48 & 259,38 & 37,62 & 2,14 & 48,76 & 100,86 & 16,05 & 24,00 & 83,14 \\
\hline Epidalea calamita & 30SXG01 & 50,00 & 180,97 & $\begin{array}{l}00,21 \\
91,21\end{array}$ & 38,06 & $\begin{array}{l}4539,45 \\
4995,75\end{array}$ & 30,00 & \begin{tabular}{|l|l|}
71,09 \\
71,5
\end{tabular} & 235,36 & $\begin{array}{l}156,82 \\
156,\end{array}$ & 245,13 & \begin{tabular}{|l|}
248,810 \\
\end{tabular} & \begin{tabular}{|l|}
120,57 \\
\end{tabular} & $\mid$ & 37,21 & 2,03 & $\begin{array}{ll}40,10 \\
49,72\end{array}$ & $\begin{array}{r}0,00 \\
98,54 \\
\end{array}$ & $\begin{array}{l}\mid 0,03 \\
15,19 \\
\end{array}$ & 24,28 & $\begin{array}{l}5,14 \\
79,87 \\
\end{array}$ \\
\hline Epidalea calamita & $305 \times G 02$ & 91,00 & 179,73 & 94,34 & 38,73 & 5102,44 & 308,78 & 67,37 & 241,41 & 154,57 & 245,46 & 248,79 & 117,92 & 256,57 & 38,31 & 2,04 & 48,58 & 100,13 & 15,94 & 24,59 & 79,92 \\
\hline Epidalea calamita & 30 XX03 & 100,00 & 171,10 & 99,29 & 38,84 & 5329,23 & 308,21 & 55,03 & 253,19 & 144,08 & 240,42 & 243,24 & 106,86 & 288,73 & 40,82 & 2.97 & 45,78 & 107,49 & 20,84 & 29,28 & 87,01 \\
\hline Epidalea calamita & 30 XX04 & 100,00 & 166,78 & 102,84 & 38,98 & 5472,15 & 308,97 & 48,11 & 260,86 & 138,57 & 238,39 & 240,78 & 100,93 & 306,03 & 42,30 & 3,57 & 44,33 & 111,04 & 23,83 & 32,17 & 89,97 \\
\hline Epidalea calamita & 30 XG05 & 100,00 & 159,90 & 106,58 & 38,99 & 5646,30 & 308,39 & 38,58 & 269,81 & 130,17 & 234,18 & 236,40 & 92,16 & 334,54 & 44,43 & 4,76 & 42,45 & 117,23 & 28,87 & 36,72 & 95,59 \\
\hline Epidalea calamita & 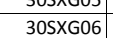 & 100,00 & 154,71 & $\begin{array}{l}109,30 \\
1093\end{array}$ & 30,05 & 50475,40 & 308,06 & $\begin{array}{l}0,30 \\
31,32 \\
\end{array}$ & $\begin{array}{l}276,74 \\
276,\end{array}$ & $\begin{array}{l}124,32 \\
124\end{array}$ & 230,10 & \begin{tabular}{|l|}
232,80 \\
232,8
\end{tabular} & $\begin{array}{ll}2,10 \\
85,58\end{array}$ & | $353,, 84$ & $\begin{array}{l}44,45 \\
46,59 \\
\end{array}$ & $\begin{array}{ll}4,1 / 82 \\
5,2\end{array}$ & $\begin{array}{l}42,45 \\
40,90\end{array}$ & $\begin{array}{l}122,11 \\
123\end{array}$ & $\begin{array}{l}2,01 \\
33,55 \\
\end{array}$ & $\begin{array}{l}30,1 / 25 \\
40,85 \\
\end{array}$ & \begin{tabular}{|l|l}
99,85 \\
99,
\end{tabular} \\
\hline Epidalea calamita & $30 \mathrm{SXG07}$ & 100,00 & 157,85 & 110,81 & 39,21 & 5790,11 & 311,88 & 33,35 & 278,53 & 126,88 & 234,36 & 235,93 & 88,32 & 345,32 & 45,54 & 5,28 & 41,50 & 118,36 & 31,96 & 39,56 & 95,20 \\
\hline Epidalea calamita & 30SXG08 & 100,00 & 151,93 & 113,00 & 39,05 & 5913,57 & 310,81 & 25,90 & 284,92 & $\begin{array}{ll}120,67 \\
\end{array}$ & 230,39 & 231,78 & 81,08 & 370,31 & 48,05 & 6,40 & 40,01 & 123,52 & 37,22 & 43,93 & 99,67 \\
\hline Epidalea calamita & 30SXG09 & 100,00 & 142,73 & 114,96 & 38,99 & 6051,80 & 307,07 & 15,66 & 291, & 122,28 & 223,36 & 224,67 & 70,64 & 410,66 & 53,64 & 8,66 & 37,56 & 135,18 & 46,12 & 51,16 & 107,71 \\
\hline Epidalea calamita & 30SXG12 & 12,00 & 176,47 & 96,60 & 38,93 & 5177,47 & 308,33 & 62,20 & 246,13 & 150,80 & 243,40 & 246,40 & 113,73 & 271,33 & 39,87 & 2,47 & 47,87 & 104,73 & 17,87 & 26,67 & 83,27 \\
\hline
\end{tabular}




\begin{tabular}{|c|c|c|c|c|c|c|c|c|c|c|c|c|c|c|c|c|c|c|c|c|c|}
\hline TAXON & UTM & $\mathrm{km} 2$ & B101 & B102 & $\mathrm{BIO3}$ & 8104 & B105 & B106 & B107 & B108 & 8109 & BIO10 & BIO11 & BIO12 & 81013 & BIO14 & BIO15 & B1016 & B1017 & 81018 & B1019 \\
\hline Epidalea calamita & 30SXG13 & 77,00 & 177,22 & 98,53 & 39,01 & 5218,30 & 310,74 & 61,50 & 249,24 & 150,96 & 244,65 & 247,50 & 113,88 & 271,97 & 40,23 & 2,32 & 47,83 & 104,89 & 18,07 & 27,37 & 82,33 \\
\hline Epidalea calamita & 30 XSG14 & 100,00 & 169,89 & 102,74 & 39,03 & 5405,75 & 310,13 & 51,13 & 259,00 & 142,17 & 240,30 & 242,78 & 104,59 & 298,53 & 42,45 & 3,26 & 45,36 & 110,75 & 22,45 & 31,53 & 87,54 \\
\hline Epidalea calamita & 30 XG15 & 100,00 & 164,24 & 106,18 & 39,19 & 5558,26 & 309,92 & 43,11 & 266,81 & 135,26 & 237,14 & 239,29 & 97,39 & 320,81 & 44,07 & 4,30 & 43,36 & 115,13 & 26,66 & 35,56 & 91,47 \\
\hline Epidalea calamita & 30 SXG16 & 100,00 & 167,10 & 107,93 & 39,82 & 5582,04 & 313,74 & 44,56 & 269,18 & 137,78 & 240,38 & 242,22 & 99,66 & 311,22 & 43,68 & 4,04 & 43,83 & 112,11 & 25,76 & 35,06 & 87,63 \\
\hline Epidalea calamita & 30SXG17 & 100,00 & $\begin{array}{ll}160,87 \\
\end{array}$ & 110,77 & 39,68 & 5727,21 & 312,77 & 36,10 & \begin{tabular}{|l|l|}
276,67 \\
\end{tabular} & \begin{tabular}{|l|l|}
130,43 \\
\end{tabular} & \begin{tabular}{|l|l|}
236,43 \\
\end{tabular} & 237,94 & \begin{tabular}{|c|}
91,78 \\
\end{tabular} & \begin{tabular}{|l|}
336,38 \\
\end{tabular} & \begin{tabular}{|l|l|}
45,67 \\
\end{tabular} & 4,90 & 42,20 & 117,44 & 30,48 & 39,09 & 92,01 \\
\hline Epidalea calamita & 30SXG19 & 100,00 & 137,75 & 115,23 & 39,00 & 6059,27 & 302,45 & 10,86 & 291,59 & 113,05 & 218,54 & 219,89 & 65,82 & 438,75 & 56,95 & 10,43 & 36,39 & 144,39 & 52,37 & 57,23 & 113,23 \\
\hline Epidalea calamita & 30 XSG24 & 92,00 & 174,82 & 102,19 & 39,44 & 5312,10 & 312,18 & 56,31 & 255,86 & \begin{tabular}{ll|l}
147,92 & \\
\end{tabular} & 243,68 & 246,19 & 110,24 & 286,39 & 42,23 & 2,73 & 47,11 & 109,56 & 20,19 & 30,23 & 84,23 \\
\hline Epidalea calamita & 30 SXG25 & 100,00 & 155,85 & 107,76 & 39,13 & 5647,52 & 305,13 & 33,72 & 271,41 & 126,53 & 230,18 & 232,29 & 88,24 & 358,72 & 47,48 & 5,86 & 41,38 & 125,83 & 33,14 & 41,58 & 100,24 \\
\hline Epidalea calamita & 30 SXG26 & 100,00 & 160,43 & 109,38 & 39,67 & 5650,78 & 309,95 & 36,90 & 273,06 & 130,81 & 234,73 & 236,59 & 92,43 & 341,46 & 46,58 & 5,14 & 42,40 & 120,97 & 30,62 & 39,83 & 94,29 \\
\hline Epidalea calamita & $30 \mathrm{SXG28}$ & 100,00 & 150,61 & 113,57 & 39,63 & 5862,45 & 308,13 & 24,37 & 283,76 & 120,82 & 228,34 & 229,78 & 80,49 & 383,29 & 50,60 & 7,32 & 39,63 & 129,49 & 40,27 & 48,06 & 100,86 \\
\hline Epidalea calamita & $30 \mathrm{SXG29}$ & 100,00 & 135,25 & 115,02 & 39,09 & 6045,20 & 299,51 & 8,79 & 290,73 & 110,42 & 215,94 & 217,42 & 63,70 & 455,83 & 58,89 & 11,65 & 35,79 & 149,59 & 56,40 & 61,37 & 116,24 \\
\hline Epidalea calamita & $30 \mathrm{SXG35}$ & & & & & & & & & & & & & & & & & & & & \\
\hline Epidalea calamita & 305XG36 & 100,00 & 163,48 & 109,57 & 39,90 & 5591,43 & 311,36 & 39,76 & 271,60 & 134,42 & 236,87 & 238,66 & 95,97 & 334,28 & 46,94 & 4,62 & 43,48 & 120,96 & 28,96 & 39,17 & 92,25 \\
\hline Epidalea calamita & 30SXG37 & 100,00 & 170,68 & 111,53 & 40,27 & 5575,54 & 318,12 & 45,05 & 273,07 & 141,30 & 243,66 & 245,13 & 102,73 & 308,52 & 45,40 & 3,31 & 45,62 & 114,05 & 24,54 & 35,88 & 84,61 \\
\hline Epidalea calamita & 30 XSG39 & 100,00 & 159,56 & 115,53 & 40,17 & 5803,77 & 315,15 & 31,25 & 283,89 & 128,48 & 236,18 & 237,14 & 89,25 & 351,11 & 48,74 & 5,53 & 42,01 & 122,20 & 34,09 & 44,18 & 91,23 \\
\hline Epidalea calamita & $30 S \times G 49$ & 100,00 & 172,06 & 116,70 & 40,96 & 5678,09 & 323,75 & 42,29 & 281,46 & 141,68 & 246,43 & 247,30 & 102,42 & 311,38 & 46,99 & 3,44 & 46,39 & 114,59 & 25,34 & 38,59 & 81,97 \\
\hline Epidalea calamita & 30SXG55 & 7,00 & 182,64 & 105,86 & 40,57 & 5257,71 & 319,00 & 60,86 & 258,14 & 155,86 & 250,07 & 252,07 & 117,64 & 277,93 & 44,79 & 2,00 & 49,93 & 112,64 & 18,00 & 30,93 & 79,64 \\
\hline Epidalea calamita & 30SXG58 & 100,00 & 166,45 & 114,37 & 40,78 & 5636,22 & 316,64 & 38,75 & 277,88 & $\begin{array}{ll}136,84 \\
\end{array}$ & 240,20 & 241,47 & 97,68 & 335,43 & 49,68 & 4,56 & 44,66 & 123,39 & 29,46 & 42,21 & 88,57 \\
\hline Epidalea calamita & 30SXG59 & 100,00 & 166,25 & 116,63 & 40,82 & 5702,91 & 318,91 & 36,84 & 282,08 & 136,12 & 241,15 & 242,01 & 96,73 & 338,28 & 50,04 & 4,80 & 44,89 & 122,95 & 30,47 & 43,63 & 87,60 \\
\hline Epidalea calamita & $305 \times 667$ & 100,00 & 176,16 & 111,23 & 40,98 & 5423,55 & 319,54 & 50,73 & 268,80 & 148,60 & 246,62 & 248,09 & $\mid 109,50$ & 306,58 & 48,77 & 3,15 & 47,94 & 120,43 & 23,23 & 37,23 & 83,56 \\
\hline Epidalea calamita & 30 30SG69 & 100,00 & 167,66 & 116,15 & 41,02 & 5638,52 & 318,49 & 38,72 & 279,77 & 138,34 & \begin{tabular}{|l|l|}
241,47 \\
\end{tabular} & 242,52 & 98,66 & 335,36 & 51,4 & 4,60 & 45,19 & 124,75 & 29,79 & 43,90 & 86,18 \\
\hline Epidalea calamita & 30 SXG76 & 86,00 & 179,86 & 106,64 & 40,80 & 5252,99 & 317,07 & 57,88 & 259,19 & 153,89 & 247,61 & 249,56 & $\begin{array}{r}115,17 \\
\end{array}$ & 300,50 & 49,40 & 3,09 & 50,35 & 123,67 & 21,62 & 35,51 & 84,13 \\
\hline Epidalea calamita & 30SXG77 & 100,00 & 180,15 & 109,34 & 40,99 & 5321,32 & 319,97 & 56,12 & 263,84 & 153,61 & 248,97 & 250,64 & $\begin{array}{ll}114,68 \\
\end{array}$ & 299,15 & 49,98 & 3,00 & 50,05 & 122,11 & 22,14 & 36,73 & 81,47 \\
\hline Epidalea calamita & 30 XSG79 & 100,00 & 172,11 & 114,82 & 41,00 & 5538,27 & 319,84 & 44,04 & 275,80 & 143,75 & 244,36 & 245,53 & 104,17 & 323,20 & 52,45 & 4,23 & 46,96 & 125,00 & 27,66 & 42,76 & 82,68 \\
\hline Epidalea calamita & $30 \mathrm{SXG86}$ & 94,00 & 178,55 & 105,16 & 40,65 & 5208,12 & 314,32 & 57,88 & 256,44 & 153,40 & 245,61 & 247,91 & 114,68 & 311,91 & 51,57 & 3,66 & 49,66 & 129,58 & 23,65 & 37,63 & 86,85 \\
\hline Epidalea calamita & 30 XSG96 & 69,00 & 179,66 & 103,47 & 40,45 & 5139,44 & 313,11 & 60,37 & 252,74 & 155,30 & 245,58 & 248,07 & 116,57 & 314,34 & 53,02 & 3,88 & 50,74 & 133,41 & 23,84 & 38,22 & 87,56 \\
\hline Epidalea calamita & 30SXG97 & 13,00 & 182,75 & 104,45 & 40,95 & 5133,95 & 316,20 & 62,65 & 253,55 & 158,25 & $\begin{array}{l}248,55 \\
24,5\end{array}$ & 250,90 & 119,50 & 305,05 & 53,45 & 3,55 & 52,10 & \begin{tabular}{|l|}
131,05 \\
13,41
\end{tabular} & 22,90 & $\begin{array}{l}30,42 \\
37,40\end{array}$ & 83,55 \\
\hline Epidalea calamita & $30 \mathrm{SXH}$ & 100,00 & 151,39 & 116,77 & 39,44 & 6040,76 & 315,11 & 22,50 & 292,61 & 128,53 & 231,71 & 232,53 & 78,78 & 372,17 & 49,41 & 6,80 & 39,20 & 123,07 & 40,48 & 46,20 & 95,36 \\
\hline Epidalea calamita & $30 \mathrm{~S} \times \mathrm{HO3}$ & 100,00 & 159,70 & 117,63 & 39,90 & 6014,01 & 322,24 & 29,60 & 292,64 & 132,09 & 239,51 & 239,92 & 86,75 & 339,37 & 45,99 & 5,39 & 40,88 & 113,35 & 36,12 & 42,16 & 84,78 \\
\hline Epidalea calamita & $30 \mathrm{~S} \times \mathrm{HO}$ & 100,00 & 157,30 & 118,10 & 39,75 & 6065,95 & 321,49 & 26,75 & 294,74 & 134,09 & 237,81 & 238,18 & 83,81 & 346,90 & 46,75 & 5,89 & 40,07 & 114,89 & 38,99 & 43,45 & 84,99 \\
\hline Epidalea calamita & $30 \mathrm{~S} \times \mathrm{HOG}$ & 100,00 & 148,47 & 119,07 & 39,28 & 6166,10 & 316,46 & 17,93 & 298,53 & 130,31 & 230,76 & 231,07 & 74,21 & 375,99 & 50,61 & 7,90 & 37,55 & 124,49 & 48,54 & 49,66 & 88,50 \\
\hline Epidalea calamita & 30SXH07 & 100,00 & $\begin{array}{l}141,71 \\
141,71\end{array}$ & 119,43 & 39,01 & 6233,71 & 312,12 & |11,10 & 301,02 & $\begin{array}{l}122,98 \\
120\end{array}$ & 225,34 & 225,46 & $\begin{array}{l}67,07 \\
67\end{array}$ & 399,46 & 53,55 & 9,48 & 36,12 & \begin{tabular}{|l|}
132,63 \\
\end{tabular} & $\begin{array}{l}54,67 \\
54,\end{array}$ & 55,28 & $\begin{array}{l}92,22 \\
\end{array}$ \\
\hline Epidalea calamita & $30 \mathrm{SXH10}$ & 100,00 & 143,76 & 116,03 & 39,24 & 6040,71 & 307,85 & 15,79 & 292,06 & 120,10 & 224,36 & 225,40 & 71,79 & 408,06 & 53,51 & 8,69 & 37,64 & 134,36 & 47,08 & 52,55 & 104,28 \\
\hline Epidalea calamita & $30 \mathrm{~S} \times \mathrm{H} 12$ & 100,00 & 160,97 & 117,42 & 40,00 & 5947,23 & 321,29 & 31,01 & 290,28 & 128,20 & 239,56 & 240,31 & 88,66 & 337,19 & 46,14 & 5,14 & 41,70 & 114,03 & 34,47 & $|42,27|$ & 84,77 \\
\hline Epidalea calamita & $30 \mathrm{~S} \times \mathrm{H} 13$ & 100,00 & 163,85 & 117,87 & 40,00 & 5951,82 & 323,92 & 33,54 & 290,38 & 131,48 & 242,43 & 243,01 & 91,25 & 326,75 & 45,59 & 4,71 & 42,19 & 111,07 & 33,41 & 40,68 & 80,99 \\
\hline Epidalea calamita & $30 \mathrm{~S} \times \mathrm{H} 14$ & 100,00 & 160,29 & 118,20 & 39,97 & 6002,46 & 322,25 & 29,85 & 292,40 & 128,42 & 239,85 & 240,23 & 87,23 & 338,39 & 46,36 & 5,46 & 41,05 & 113,10 & 37,17 & 42,51 & 82,03 \\
\hline Epidalea calamita & \begin{tabular}{|l}
$30 \mathrm{~S} X \mathrm{NH} 18$ \\
\end{tabular} & 100,00 & 137,11 & $\begin{array}{l}111,20 \\
118,97\end{array}$ & $\frac{39,00}{49}$ & 6231,74 & 306,20 & $\begin{array}{l}20,00 \\
7,16 \\
\end{array}$ & \begin{tabular}{|l|}
299,73 \\
\end{tabular} & $\begin{array}{l}12,42 \\
118,08\end{array}$ & 220,88 & \begin{tabular}{|l|}
220,88 \\
225
\end{tabular} & $\begin{array}{l}1,25 \\
62,67 \\
\end{array}$ & | & $\begin{array}{l}40,00 \\
55,03\end{array}$ & $\begin{array}{l}0,400 \\
11,02\end{array}$ & $\begin{array}{l}44,05 \\
34,61\end{array}$ & 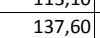 & $\begin{array}{l}3,1,27 \\
60,27\end{array}$ & 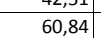 & $\begin{array}{l}4,200 \\
94,20\end{array}$ \\
\hline Epidalea calamita & $30 \mathrm{SXH} 2 \mathrm{O}$ & 100,00 & 160,52 & 116,36 & 40,07 & 5859,28 & 318,01 & 31,53 & 286,48 & 128,67 & 237,89 & 238,85 & 89,54 & 342,41 & 47,22 & 5,10 & 42,01 & 117,74 & 33,39 & 42,79 & 88,05 \\
\hline Epidalea calamita & $30 \mathrm{SXH} 21$ & 100,00 & 156,96 & 117,32 & 40,01 & 5925,39 & 316,88 & 27,34 & 289,54 & 124,47 & 235,36 & 236,27 & 85,19 & 355,44 & 48,15 & 5,88 & 40,88 & 120,02 & 37,18 & 45,51 & 89,45 \\
\hline Epidalea calamita & $30 \mathrm{~S} \times \mathrm{H} 22$ & 100,00 & 161,75 & 118,02 & 40,03 & 5912,38 & 321,08 & 31,27 & 289,82 & 129,47 & 239,76 & 240,55 & 89,86 & 337,68 & 47,16 & 5,08 & 42,06 & 115,29 & 34,35 & 43,14 & 83,95 \\
\hline Epidalea calamita & $30 \mathrm{~S} \times \mathrm{H} 23$ & 100,00 & 166,99 & 118,20 & 40,32 & 5891,20 & 325,24 & 36,20 & 289,04 & 134,37 & 244,73 & 245,19 & 95,04 & 320,00 & 46,28 & 4,3 & 43,28 & 110,82 & 31,59 & 40,88 & 78,78 \\
\hline Epidalea calamita & $\mid$ & 100,00 & $\begin{array}{l}10,989 \\
158,82\end{array}$ & $\begin{array}{l}111,20 \\
118,82\end{array}$ & $\begin{array}{ll}40,52 \\
40,12\end{array}$ & \begin{tabular}{|l|}
5991,20 \\
597828
\end{tabular} & 320,24 & $\begin{array}{ll}28,20 \\
28,14\end{array}$ & $\begin{array}{l}295,04 \\
292,0 \\
\end{array}$ & $\begin{array}{l}124,712 \\
126,72 \\
\end{array}$ & 238,04 & $\mid \frac{\mid 243,19}{238,46}$ & $\begin{array}{l}30,124 \\
86,12\end{array}$ & 年220,00 & $\begin{array}{l}40,26 \\
47,89 \\
\end{array}$ & $5, \frac{1}{4,5}$ & $\begin{array}{l}4,20 \\
40,63 \\
\end{array}$ & \begin{tabular}{|l|}
$116,18<$ \\
116,1
\end{tabular} & \begin{tabular}{|l|l|}
1,393 \\
38,84
\end{tabular} & $\begin{array}{l}40,00 \\
45,43\end{array}$ & $\begin{array}{l}10,10 \\
83,17\end{array}$ \\
\hline Epidalea calamita & $30 \mathrm{~S} \times \mathrm{H} 30$ & 100,00 & 163,99 & 117,15 & 40,55 & 5806,50 & 320,01 & 34,19 & 285,81 & 132,64 & 240,55 & 241,29 & 93,27 & 333,58 & 47,67 & 4,60 & 43,46 & 117,17 & 31,16 & 41,92 & 85,57 \\
\hline Epidalea calamita & $30 \mathrm{SXH} 31$ & 100,00 & 163,71 & 118,16 & 40,51 & 5851,48 & 320,97 & 33,14 & 287,83 & $\begin{array}{ll}131,87 \\
\end{array}$ & 240,82 & 241,51 & 92,36 & 335,63 & 48,00 & 4,85 & 43,15 & 116,94 & 32,51 & 42,78 & 84,45 \\
\hline Epidalea calamita & $30 \mathrm{SXH33}$ & 100,00 & 168,96 & 118,92 & 40,94 & 5848,79 & 325,87 & 37,70 & 288,17 & 137,05 & 246,03 & 246,49 & 97,40 & 317,30 & 47,37 & 4,1 & 44,38 & 111,85 & 30,50 & 41,24 & 77,54 \\
\hline Epidalea calamita & $30 \mathrm{~S} \times \mathrm{H} 34$ & 100,00 & 163,03 & 118,92 & 40,78 & 5905,04 & 321 & 32,18 & 289,73 & 130,41 & 240,97 & 241,51 & 91,01 & 336,90 & 48,69 & 5,2 & 42,42 & 115,52 & 36,00 & 45,22 & 80,27 \\
\hline Epidalea calamita & $30 \mathrm{SXH36}$ & 100,00 & 146,88 & 117,98 & 40,00 & 6050,49 & 310 & 17,26 & 292,90 & 125,80 & 227,36 & 228,03 & 74,01 & 395,32 & 51,84 & 9,04 & 36,91 & 127,41 & 52,43 & 56,84 & 90,37 \\
\hline Epidalea calamita & 30 SXH37 & 100,00 & 143,78 & 117,68 & 39,80 & 6078,03 & 307,79 & 14,75 & 293,04 & 125,21 & 224,82 & 225,29 & 70,81 & 406,04 & 52,48 & 9,99 & 35,65 & 130,06 & 56,65 & 59,47 & 91,44 \\
\hline Epidalea calamita & $30 \mathrm{~S} \times \mathrm{H} 38$ & 100,00 & 137,55 & 117,26 & 39,29 & 6126,10 & 302,96 & 9,10 & 293,86 & 118,36 & 219,49 & 219,99 & 64,43 & 429,92 & 54,45 & 11,76 & 33,95 & 137,54 & 63,85 & 64,80 & 95,74 \\
\hline Epidalea calamita & $30 \mathrm{~S} \times \mathrm{H} 4 \mathrm{O}$ & 100,00 & 170,94 & 118,49 & 41,05 & 5741,97 & 324,94 & 39,75 & 285,19 & 139,95 & 246,27 & 246,95 & 100,42 & \begin{tabular}{|c|}
315,08 \\
\end{tabular} & 47,42 & 3,53 & 46,19 & 114,44 & 26,56 & 38,82 & 81,21 \\
\hline Epidalea calamita & 30SXH41 & 100,00 & 171,99 & $\frac{11}{11 !}$ & 40 & 5769,64 & 32 & \begin{tabular}{|l|l|}
40,00 \\
40,
\end{tabular} & \begin{tabular}{|l|}
286,82 \\
286
\end{tabular} & \begin{tabular}{|l|}
140,71 \\
140
\end{tabular} & $\begin{array}{l}247,56 \\
\end{array}$ & \begin{tabular}{|l|}
248,23 \\
\end{tabular} & \begin{tabular}{|l|l|}
101,04 \\
\end{tabular} & | & $\begin{array}{l}41,42 \\
47,45\end{array}$ & $\begin{array}{l}3,435 \\
3,45\end{array}$ & $\begin{array}{l}40,15 \\
46,32\end{array}$ & \begin{tabular}{|l|}
112,96 \\
\end{tabular} & $\begin{array}{l}2,030 \\
26,67 \\
\end{array}$ & $\begin{array}{l}30,0<7 \\
39,47\end{array}$ & $\begin{array}{l}1,24 \\
78,94\end{array}$ \\
\hline Epidalea calamita & $30 \mathrm{~S} \times \mathrm{H} 42$ & 100,00 & 169,81 & 119,50 & 41,01 & 5798,55 & 325,57 & 37,98 & 287,59 & 138,33 & 245,83 & 246,50 & 98,54 & 319,48 & 48,45 & 3,99 & 45,53 & 114,22 & 29,29 & 42,20 & 78,85 \\
\hline Epidalea calamita & $30 \mathrm{SXH} 43$ & 100,00 & 164,89 & 118,93 & 40,86 & 5849,01 & 322,05 & 33,71 & 288,34 & 133,06 & 241.92 & 242,58 & 93,44 & 336,60 & 49,91 & 5,00 & 43,68 & 117,83 & 34,13 & 45,94 & 81,16 \\
\hline Epidalea calamita & $30 \mathrm{~S} \times \mathrm{H} 44$ & 100,00 & 158,34 & 118,55 & 40,55 & 5904,42 & 317,16 & 28,03 & 289,14 & 126,46 & 236,41 & 237,12 & 86,62 & 359,19 & 51,39 & 6,35 & 41,01 & 122,34 & 40,51 & 50,44 & 84,57 \\
\hline Epidalea calamita & $30 \mathrm{SXH} 45$ & 100,00 & 153,31 & 117,88 & 40,10 & 5951,01 & 313 & 23,56 & 289,58 & 127,44 & 232,03 & 233 & 81,24 & 378,31 & 52,56 & 7,68 & 38,99 & 126,14 & 46,28 & 54,47 & 87,53 \\
\hline Epidalea calamita & $30 \mathrm{~S} \times \mathrm{H} 46$ & 100,00 & 148,49 & 117,36 & 39,99 & 5991,87 & 309,28 & 19,41 & 289,87 & 148,49 & 227,92 & 228,73 & 76,22 & 396,39 & 53,53 & 9,01 & 37,29 & 129,54 & 51,91 & 58,53 & 90,28 \\
\hline Epidalea calamita & $30 \mathrm{~S} \times \mathrm{H} 47$ & 100,00 & 139,29 & 116,61 & 39,69 & 6063,79 & 302,22 & 11,19 & 291,03 & 128,43 & 220,07 & 220,89 & 66,78 & 433,17 & 55,26 & 11,52 & 34,49 & 137,38 & 62,04 & 65,94 & 97,50 \\
\hline Epidalea calamita & $30 \mathrm{SXH} 48$ & 100,00 & 137,41 & 116,19 & 39,42 & 6078,15 & 300,53 & 9,62 & 290,91 & 130,16 & 218,48 & 219,18 & 64,59 & 439,88 & 55,64 & 12,19 & 33,73 & 139,74 & 65,08 & 68,10 & 97,91 \\
\hline Epidalea calamita & 30SXH51 & 100,00 & 176,58 & 120,63 & 41,65 & 5711,35 & 330,13 & 43,54 & 286,59 & 145,69 & 251,24 & 251, & 105,99 & 302,26 & 47,95 & 2,98 & 48,54 & 112,50 & 23,96 & 36,14 & 76,50 \\
\hline Epidalea calamita & 30SXH52 & 100,00 & 171,71 & 119,89 & 41,05 & 5754,33 & 326,11 & 39,55 & 286,56 & 140,78 & 247,06 & 247,60 & 100,79 & 317,41 & 49,66 & 3,78 & 46,59 & 115,72 & 28,24 & 42,29 & 77, \\
\hline
\end{tabular}




\begin{tabular}{|c|c|c|c|c|c|c|c|c|c|c|c|c|c|c|c|c|c|c|c|c|c|}
\hline TAXON & UTM & $\mathrm{km2}$ & B101 & $\mathrm{B1O2}$ & $\mathrm{BIO3}$ & $\mathrm{B104}$ & B105 & B106 & B107 & B108 & BI09 & 81010 & B1011 & BIO12 & B1013 & 81014 & BIO15 & B1016 & B1017 & BIO18 & B1019 \\
\hline Epidalea calamita & 30SXH53 & 100,00 & 152,10 & 117,47 & 40,34 & 5896,20 & 310,52 & 22,78 & 287,74 & 120,85 & 230,07 & 230,98 & 80,87 & 391,85 & 54,71 & 8,12 & 39,48 & 132,68 & 46,29 & 56,29 & 93,03 \\
\hline Epidalea calamita & $30 \mathrm{SXH} 54$ & 100,00 & 156,87 & 117,74 & 40,52 & 5866,33 & 314,06 & 27,24 & 286,82 & 133,13 & 234,34 & 235,11 & 85,81 & 370,83 & 53,79 & 6,99 & 40,52 & 127,31 & 42,57 & 53,45 & 86,72 \\
\hline Epidalea calamita & $30 \mathrm{~S} \times \mathrm{H} 56$ & 100,00 & 146,71 & 116,34 & 40,01 & 5950,56 & 305,92 & 18,71 & 287,21 & 155,11 & 225,60 & 226,49 & 75,18 & 411,71 & 56,05 & 9,79 & 36,74 & 135,81 & 54,56 & 62,28 & 93,67 \\
\hline Epidalea calamita & 30 XXH58 & 100,00 & 142,56 & 115,13 & $\begin{array}{l}39,85 \\
\end{array}$ & 5982,00 & 301,74 & 15,49 & 286,25 & 152,41 & 222,02 & 222,81 & 70,77 & 428,47 & 56,95 & 11,25 & 34,88 & 140,04 & 61,05 & 67,12 & 95,49 \\
\hline Epidalea calamita & 30SXH59 & 100,00 & 135,55 & 114,40 & 39,23 & 6036,75 & 296,21 & 9,44 & \begin{tabular}{|l|l|}
286,77 \\
\end{tabular} & 145,05 & 215,97 & 216,92 & 63,60 & 456,20 & 57,92 & 13,42 & 32,73 & 145,29 & 69,34 & 73,31 & 100,69 \\
\hline Epidalea calamita & $30 \mathrm{~S} \times \mathrm{H} 60$ & 100,00 & 179,11 & 119,22 & 41,82 & 5622,63 & 329,72 & 47,06 & 282,67 & 149,38 & 252,55 & 252,93 & 109,56 & 298,01 & 48,85 & 2,73 & 49,87 & 114,67 & 22,28 & 37,67 & 76,57 \\
\hline Epidalea calamita & $30 \mathrm{SXH61}$ & 100,00 & 176,46 & 119,74 & 41,76 & 5663,48 & 328,16 & 44,19 & 283,96 & 146,50 & 250,49 & 250,92 & 106,40 & 305,60 & 50,02 & 3,25 & 48,83 & 115,76 & 24,74 & 40,22 & 76,27 \\
\hline Epidalea calamita & 30SXH62 & 100,00 & 174,28 & 119,26 & 41,53 & 5689,21 & 326,38 & 42,57 & 283,81 & 144,11 & 248,62 & 249,25 & 104,05 & 311,99 & 51,08 & 3,57 & 47,87 & 116,82 & 27,08 & 42,08 & 75,82 \\
\hline Epidalea calamita & 30 SXH65 & 100,00 & 144,24 & 115,33 & 39,92 & 5911,52 & 302,10 & 17,10 & 285,01 & 139,66 & 222,62 & 223,77 & 73,39 & 432,05 & 58,99 & 10,63 & 36,29 & 143,74 & 56,97 & 65,91 & 99,61 \\
\hline Epidalea calamita & $30 \mathrm{SXH66}$ & 100,00 & 149,38 & 115,34 & 40,01 & 5874,64 & 305,55 & 22,10 & 283,45 & 159,56 & 227,07 & 228,18 & 78,64 & 410,53 & 58,13 & 9,49 & 37,49 & $\mid 139,62$ | & 53,10 & 63,02 & 93,43 \\
\hline Epidalea calamita & $30 \mathrm{~S} \times \mathrm{H} 67$ & 100,00 & 149,41 & 114,73 & 40,00 & 5872,88 & 305,05 & 22,55 & 282,49 & 159,75 & 227,07 & 228,20 & 78,63 & 411,25 & 58,21 & 9,72 & 37,14 & 140,16 & 54,33 & 63,98 & 92,81 \\
\hline Epidalea calamita & $30 \mathrm{SXH68}$ & 100,00 & 142,02 & 113,82 & 39,87 & 5933,72 & 298,99 & 16,03 & 282,95 & 152,27 & 220,73 & 221,85 & 70,98 & 441,90 & 59,60 & 11,88 & 34,58 & 146,62 & 62,88 & 70,57 & 98,86 \\
\hline Epidalea calamita & $30 \mathrm{SXH69}$ & 100,00 & 134,60 & 112,94 & 39,23 & 5987,64 & 292,94 & $\begin{array}{l}9,47 \\
\end{array}$ & 283,47 & 144,47 & 214,34 & 215,40 & 63,29 & 472,17 & 60,75 & 14,14 & 32,32 & 152,42 & 71,63 & 77,29 & 104,75 \\
\hline Epidalea calamita & $30 \mathrm{SXH70}$ & 100,00 & 174,36 & 116,30 & \begin{tabular}{|l|l|}
41,38 \\
\end{tabular} & 5564,22 & 322,79 & 45,05 & 277,75 & 145,70 & 246,91 & 247,90 & 105,84 & 314,42 & 52,30 & 3,89 & 48,16 & 121,95 & 26,56 & 42,57 & 78,83 \\
\hline Epidalea calamita & $30 \mathrm{SXH71}$ & 100,00 & 178,63 & 116,88 & 41,76 & 5550,24 & 326,59 & 48,83 & 277,76 & 150,00 & 250,95 & 251,82 & 110,09 & 298,88 & 51,72 & 3,32 & 49,93 & 1117,47 & 24,25 & 41,11 & 73,47 \\
\hline Epidalea calamita & $30 \mathrm{~S} \times \mathrm{H} 72$ & 100,00 & 177,32 & 117,13 & 41,63 & 5578,35 & 325,76 & 47,36 & 278,40 & 163,10 & 250,02 & 250,90 & 108,56 & 303,84 & 52,70 & 3,46 & 49,61 & 117,92 & 26,08 & 43,02 & 72,70 \\
\hline Epidalea calamita & $30 \mathrm{~S} \times \mathrm{H73}$ & 100,00 & 163,55 & 116,26 & 40,89 & 5699,90 & 315,38 & 34,92 & 280,47 & 164,81 & 238,28 & 239,44 & 94,13 & 357,52 & 56,34 & 6,06 & 43,71 & 130,13 & 37,74 & 52,36 & 83,97 \\
\hline Epidalea calamita & $30 \mathrm{SXH75}$ & 100,00 & 149,40 & 114,43 & 40,08 & 5814,46 & 303,77 & 22,72 & 281,06 & 156,23 & 226,13 & 227,51 & 79,30 & 419,80 & 60,28 & 9,59 & 37,78 & 144,82 & 52,92 & 64,41 & 96,90 \\
\hline Epidalea calamita & $30 \mathrm{SXH76}$ & 100,00 & 142,36 & 113,50 & 39,83 & 5868,98 & 297,99 & 16,76 & 281,22 & 146,74 & 220,05 & 221,49 & 72,16 & 452,18 & 61,99 & 11,76 & 35,44 & 151,84 & 61,42 & 71,16 & 103,74 \\
\hline Epidalea calamita & 30 XXH78 & 100,00 & 149,39 & 112,52 & 40,00 & 5810,07 & 302,00 & 24,32 & 277,68 & 160,09 & 226,17 & 227,48 & 79,46 & 425,31 & 61,31 & 10,38 & 37,02 & 148,14 & 56,93 & 68,25 & 95,77 \\
\hline Epidalea calamita & 30 XXH79 & 100,00 & 141,31 & 111,56 & 39,74 & 5872,12 & 295,28 & 17,17 & 278,11 & 151,85 & 219,13 & 220,37 & 71,08 & 457,82 & 62,48 & 12,7 & 34,08 & 154,45 & 66,08 & 75,32 & 102,43 \\
\hline Epidalea calamita & $30 \mathrm{~S} \times \mathrm{H} 8 \mathrm{O}$ & 100,00 & 174,23 & 113,75 & 41,06 & 5479,27 & 319,85 & 47,18 & 272,66 & 146,66 & 245,51 & 246,92 & 106,90 & 315,42 & 54,56 & 4,29 & 48,86 & 125,56 & 27,70 & 43,78 & 77,58 \\
\hline Epidalea calamita & $30 \mathrm{SXH} 82$ & 100,00 & 180,74 & 114,12 & 41,63 & 5454,53 & 324,83 & 53,30 & 271,53 & 190,49 & 251,38 & 252,86 & 113,27 & 293,09 & 54,26 & 3,24 & 52,47 & 119,61 & 24,64 & 42,30 & 68,99 \\
\hline Epidalea calamita & $30 \mathrm{~S} \times \mathrm{H} 83$ & 100,00 & 168,56 & 114,31 & 41,02 & 5579,27 & 316,39 & 41,38 & 275,01 & 175,92 & 241,35 & 242,81 & 100,41 & 344,30 & 57,59 & 5,64 & 46,19 & 131,40 & 35,20 & 51,27 & 80,19 \\
\hline Epidalea calamita & $30 \mathrm{~S} \times \mathrm{H} 86$ & 100,00 & 153,65 & 112,64 & 40,14 & 5720,67 & 304,35 & 28,32 & 276,03 & 164,83 & 228,76 & 230,38 & 84,65 & 416,38 & 62,51 & 9,19 & 39,25 & 149,24 & 51,68 & 65,43 & 95,64 \\
\hline Epidalea calamita & $30 \mathrm{SXH87}$ & 100,00 & 153,86 & 111,85 & 40,23 & 5709,21 & 303,69 & 29,32 & 274,37 & 165,01 & 228,82 & 230,47 & 85,08 & 419,51 & 63,23 & 9,43 & 38,86 & 151,08 & 52,95 & 66,84 & 95,90 \\
\hline Epidalea calamita & 30SXH88 & 100,00 & 148,49 & 111,03 & 39,90 & 5756,81 & 299,16 & 24,64 & 274,52 & \begin{tabular}{|l|l|}
159,64 \\
\end{tabular} & $\begin{array}{l}224,32 \\
220\end{array}$ & 225,93 & 79,31 & $\mid \begin{array}{l}\mid 42,69 \\
442,\end{array}$ & $\begin{array}{l}64,23 \\
640\end{array}$ & \begin{tabular}{|c|}
10,99 \\
10
\end{tabular} & 36,91 & 155,94 & 59,21 & $\begin{array}{ll}0,1097 \\
\end{array}$ & 100,71 \\
\hline Epidalea calamita & 30 XXH89 & 100,00 & 148,21 & 110,09 & 39,95 & 5750,68 & 298,07 & 25,22 & 272,85 & 159,33 & 223,96 & 225,60 & 79,03 & 446,46 & 64,77 & 11,42 & 36,43 & 157,67 & 60,70 & 73,58 & 101,23 \\
\hline Epidalea calamita & 30 SXH90 & 100,00 & 179,64 & 110,48 & 41,03 & 5337,68 & 320,01 & 54,99 & 265,02 & 160,94 & 248,46 & 250,44 & 113,81 & 293,90 & 55,32 & 3,97 & 53,07 & 124,36 & 24,82 & 41,74 & 71,05 \\
\hline Epidalea calamita & $30 \mathrm{~S} \times \mathrm{H} 92$ & 100,00 & 182,93 & 111,19 & 41,27 & 5337,78 & 322,79 & 57,58 & 265,22 & 195,09 & 251,56 & 253,29 & 116,55 & 288,90 & 56,03 & 3,51 & 54,63 & 123,30 & 24,35 & 42,49 & 67,24 \\
\hline Epidalea calamita & 30SXH93 & 100,00 & 178,78 & 111,72 & 41,09 & 5400,40 & 320,62 & 53,39 & 267,23 & 191,18 & 248,55 & 250,44 & 112,20 & 309,93 & 57,72 & 4,22 & 51,72 & 128,54 & 28,58 & 46,75 & 71,09 \\
\hline Epidalea calamita & \begin{tabular}{|l|l|}
$305 \times \mathrm{SH} 94$ \\
\end{tabular} & 100,00 & 170,06 & 112,04 & 4 & 5492,12 & 314,73 & \begin{tabular}{|l|l|}
44,80 \\
4,50
\end{tabular} & 269,93 & 182,25 & \begin{tabular}{|l|l|}
241,54 \\
\end{tabular} & \begin{tabular}{|l|}
243,40 \\
\end{tabular} & $\begin{array}{l}103,08 \\
103\end{array}$ & \begin{tabular}{|l|l|}
350,82 \\
\end{tabular} & 60,63 & $\begin{array}{l}4,2<4 \\
5,69\end{array}$ & $\begin{array}{l}1,1 / 96 \\
46,96\end{array}$ & $\begin{array}{l}138,28 \\
\end{array}$ & 36,41 & 53,73 & 80,22 \\
\hline Epidalea calamita & 30 XXH96 & 100,00 & 148,28 & 110,82 & 40,10 & 5709,03 & 298,50 & 24,74 & 273,76 & 156,32 & 223,42 & 225,22 & 79,91 & 452,91 & 66,12 & 10,99 & 37,57 & 160,68 & 58,26 & 72,30 & 105,57 \\
\hline Epidalea calamita & 30 XXH97 & 100,00 & 140,39 & 109,89 & \begin{tabular}{|c|}
39,67 \\
\end{tabular} & 5779,53 & 292,01 & 17,73 & 274,28 & 148,18 & 216,67 & 218,58 & 71,50 & 489,68 & 67,88 & 13,31 & 34,66 & 168,39 & 67,32 & 79,84 & 113,96 \\
\hline Epidalea calamita & 30 XH98 & 100,00 & 144,32 & 109,36 & 39,72 & 5737,64 & 294,20 & 22,01 & 272,20 & 155,50 & 219,91 & 221,75 & 75,75 & 475,68 & 67,75 & 12,47 & 35,70 & 166,80 & 64,63 & 78,26 & 110,11 \\
\hline Epidalea calamita & $\begin{array}{l}30 \text { SXH99 } \\
\end{array}$ & 100,00 & 142,93 & 108,45 & 39,56 & 5746,21 & 292,33 & 21,17 & 271,16 & 154,30 & 218,71 & 220,58 & 74,29 & 482,94 & 68,26 & 13,15 & 34,97 & 168,86 & 67,18 & 80,69 & 111,19 \\
\hline Epidalea calamita & $30 \mathrm{~S} \times J 00$ & 100,00 & 138,71 & 119,25 & 39,00 & 6273,29 & 309,82 & 8,36 & 301,47 & 155,50 & 222,71 & 222,88 & 63,34 & 401,66 & 53,12 & 10,60 & 34,82 & 135,45 & 57,28 & 59,96 & 88,33 \\
\hline Epidalea calamita & $305 \times 108$ & 100,00 & 122,13 & 117,97 & 38,70 & 6381,62 & 295,58 & $-6,56$ & 302,14 & 104,82 & 207,47 & 208,10 & 45,69 & 473,02 & 57,98 & 17,31 & 28,02 & 154,30 & 79,13 & 85,51 & 103,34 \\
\hline Epidalea calamita & $305 \times 115$ & 100,00 & 136,45 & 116,47 & 38,99 & 6254,43 & 304,08 & 7,71 & 296,37 & 153,76 & 219,94 & 220,14 & 61,22 & 415,01 & 48,68 & 13,01 & 31,09 & 135,38 & 66,56 & 69,74 & 88,71 \\
\hline Epidalea calamita & $305 \times J 21$ & 100,00 & 129,34 & 117,26 & 39,00 & 6243,76 & 298,25 & 1,06 & 297,18 & 145,09 & 213,32 & 213,34 & 54,82 & 453,12 & 55,82 & 14,22 & 31,57 & 147,84 & 70,92 & 72,19 & 98,47 \\
\hline Epidalea calamita & $305 \times 129$ & 100,00 & 126,43 & 112,75 & 38,00 & 6289,60 & 291,53 & 0,37 & 291,16 & 144,61 & 210,27 & 210,82 & 51,06 & 446,32 & 55,21 & 17,49 & 28,18 & 145,12 & 80,79 & 84,38 & 91,66 \\
\hline Epidalea calamita & 305x>34 & 100,00 & $\begin{array}{l}12,45 \\
139,38 \\
\end{array}$ & $\begin{array}{ll}111,135 \\
113,51\end{array}$ & 30,00 & $\begin{array}{l}028,900 \\
6117,73 \\
\end{array}$ & 300,82 & \begin{tabular}{|c|}
0,313 \\
13,09 \\
\end{tabular} & $\begin{array}{l}281,10 \\
287,73 \\
\end{array}$ & $\begin{array}{l}144,01 \\
155,73\end{array}$ & $\frac{\mid 10,27}{221,11}$ & \begin{tabular}{|l|}
221,21 \\
221
\end{tabular} & $\begin{array}{l}1,00 \\
65,98 \\
\end{array}$ & $\begin{array}{l}440,32 \\
414,42 \\
\end{array}$ & $\begin{array}{l}30,21 \\
51,00\end{array}$ & \begin{tabular}{l|}
$1,, 45$ \\
12,93
\end{tabular} & \begin{tabular}{|l|l|}
20,10 \\
31,95
\end{tabular} & $\begin{array}{l}135,12 \\
131,54 \\
\end{array}$ & $\begin{array}{l}0,1 / 38 \\
68,38\end{array}$ & $\begin{array}{l}8,3050 \\
68,73\end{array}$ & $\begin{array}{l}97,00 \\
87,14\end{array}$ \\
\hline Epidalea calamita & $305 \times 135$ & 100,00 & 142,52 & 112,52 & 39,00 & 6093,07 & 302,14 & 16,90 & 285,25 & 155,35 & $\begin{array}{ll}223,78 \\
\end{array}$ & 223,99 & 69,16 & 403,19 & 50,40 & 12,57 & 31,85 & 129,24 & 66,36 & 67,54 & 84,77 \\
\hline Epidalea calamita & $305 \times 136$ & 100,00 & 141,98 & 111,71 & 38,92 & 6101,21 & 301,05 & $\begin{array}{ll}16,47 \\
\end{array}$ & 284,58 & 154,50 & 223,22 & 223,39 & 68,34 & 402,47 & 50,05 & 12,97 & 31,48 & 128,76 & 67,55 & 68,61 & 83,69 \\
\hline Epidalea calamita & $305 \times 137$ & 100,00 & 129,43 & 112,05 & 38,30 & 6210,37 & 291,93 & 4,19 & 287,74 & 146,47 & 212,47 & 212,64 & 55,10 & 445,05 & 52,90 & 16 & 28,95 & 22,84 & 79,29 & 80,87 & 91,56 \\
\hline Epidalea calamita & $305 \times 138$ & 100,00 & 124,98 & 111,35 & 38,03 & 6245,07 & 288,08 & 0,40 & 287,68 & 142,25 & 208,58 & 208,88 & 50,44 & 457,55 & 55,49 & $\begin{array}{ll}18,08 \\
\end{array}$ & 28,18 & $\begin{array}{l}147,84 \\
147\end{array}$ & 83,66 & 86,22 & 93,11 \\
\hline Epidalea calamita & $305 \times 146$ & 100,00 & 140,77 & 109,92 & 38,90 & 6050,06 & 297,10 & 16,81 & 280,29 & 150,23 & 221,32 & 221,66 & 67,97 & 413,15 & 52,03 & $13, \varepsilon$ & 31,29 & 132,51 & 70,02 & 72,27 & 85,21 \\
\hline Epidalea calamita & $305 \times 148$ & 100,00 & 126,77 & 109,15 & 38,01 & 6183,54 & 286,05 & 3,45 & 282,60 & 143,61 & 209,52 & 209,62 & 52,92 & 454,79 & 54,45 & 18,17 & 28,26 & 145,25 & 84,73 & 85,71 & 91,40 \\
\hline Epidalea calamita & $305 \times 151$ & 100,00 & 133,18 & 112,97 & 39,00 & 6048,94 & 293,03 & 8,12 & 284,91 & 139,41 & 213,86 & 214,76 & 61,01 & 463,61 & 57,82 & 14,67 & 31,29 & 146,88 & 74,18 & 77,11 & 100,44 \\
\hline Epidalea calamita & $305 \times 152$ & 100,00 & 129,60 & 112,21 & 38,96 & 6071,79 & 289,74 & 5,25 & 284,49 & 131,89 & 210,86 & 211,45 & 57,43 & 478,03 & 58,38 & 16,09 & 30,25 & 151,48 & 78,93 & 81,26 & 102,80 \\
\hline Epidalea calamita & 305XJ56 & 100,00 & $\frac{14}{14}$ & 107,21 & $\begin{array}{l}30, \\
38,\end{array}$ & 5975,50 & $\begin{array}{l}20,14 \\
294,88\end{array}$ & $\begin{array}{r}, 20 \\
20,05 \\
\end{array}$ & \begin{tabular}{|l|}
274,84 \\
274,
\end{tabular} & $\begin{array}{l}151,129 \\
151\end{array}$ & \begin{tabular}{|l|}
221,59 \\
220
\end{tabular} & \begin{tabular}{|l|}
222,31 \\
\end{tabular} & $\begin{array}{l}1,435 \\
70,39\end{array}$ & \begin{tabular}{|l|}
$417,13,13$ \\
4
\end{tabular} & $\begin{array}{l}30,00 \\
54,42\end{array}$ & $\begin{array}{l}\mid 0,09 \\
13,94 \\
\end{array}$ & $\begin{array}{l}30,25 \\
31,68\end{array}$ & $\begin{array}{l}137,42 \\
137\end{array}$ & $\begin{array}{l}0,59 \\
69,68 \\
\end{array}$ & $\begin{array}{l}1,200 \\
74,75\end{array}$ & $\begin{array}{l}0,0,00 \\
86,15\end{array}$ \\
\hline Epidalea calamita & 305XJ57 & 100,00 & 135,43 & 107,41 & 38,28 & 6046,96 & 289,62 & 13,45 & 276,17 & 144,99 & 215,97 & 216,39 & 62,89 & 435,39 & 53,66 & 15,97 & 29,95 & 139,20 & 77,11 & 80,02 & 88,35 \\
\hline Epidalea calamita & $305 \times 159$ & 100,00 & 120,95 & 106,30 & 37,90 & 6167,78 & 277,81 & \begin{tabular}{|l|}
0,17 \\
$-0,17$
\end{tabular} & $\begin{array}{l}277,97 \\
\end{array}$ & $\begin{array}{l}137,32 \\
\end{array}$ & $\begin{array}{l}163,31 \\
\end{array}$ & 203,76 & $\begin{array}{l}47,78 \\
47,7\end{array}$ & 477,04 & 57,77 & 20,75 & 27,53 & 152,52 & $\begin{array}{ll}92,88 \\
\end{array}$ & $\begin{array}{ll}93,98 \\
93\end{array}$ & $\begin{array}{ll}93,77 \\
9,5\end{array}$ \\
\hline Epidalea calamita & $305 \times 161$ & 100,00 & 137,99 & 111,40 & 39,21 & 5952,97 & 293,82 & 13,92 & 279,90 & 147,24 & 217,15 & 218,16 & 66,81 & 456,65 & 59,88 & 13,80 & 32,50 & 149,99 & 70,42 & 76,63 & 99,5 \\
\hline Epidalea calamita & $305 \times 162$ & 100,00 & 140,55 & 110,31 & 39,25 & 5927,19 & 294,52 & 17,05 & 277,47 & 150,31 & 215 & 220,26 & 69,46 & 446,74 & 59,58 & 13,52 & 32,87 & 148,61 & 69,04 & 75,92 & 96,7 \\
\hline Epidalea calamita & $305 \times 163$ & $\begin{array}{l}100,00 \\
\end{array}$ & $\begin{array}{l}14,54 \\
144,75\end{array}$ & 109,03 & | 39,23 & | 5877,77 & 296,22 & $\begin{array}{l}1,0016 \\
22,16\end{array}$ & 274,06 & \begin{tabular}{|l|}
154,58 \\
15,5
\end{tabular} & \begin{tabular}{|l|}
222,55 \\
221
\end{tabular} & \begin{tabular}{|l|}
223,61 \\
220
\end{tabular} & $\begin{array}{l}34,08 \\
74,08\end{array}$ & \begin{tabular}{|l|}
$440,74,61$ \\
430,
\end{tabular} & | & $\begin{array}{l}1,32,8 \\
12,83 \\
\end{array}$ & $\begin{array}{l}2,01 \\
33,59 \\
\end{array}$ & $\begin{array}{l}140,010 \\
146,08 \\
\end{array}$ & $\begin{array}{l}3,0401 \\
66,01\end{array}$ & 74,06 & $\begin{array}{l}0,1,64 \\
92,64\end{array}$ \\
\hline Epidalea calamita & $305 \times 164$ & 100,00 & 149,53 & 107,54 & 39,27 & 5826,07 & 298,32 & 27,84 & 270,48 & 159,32 & 226,47 & 227,62 & 79,22 & 412,81 & 58,55 & 12,10 & 34,66 & 143,23 & 62,50 & 71,75 & 88,25 \\
\hline Epidalea calamita & $305 \times 165$ & 100,00 & 140,37 & 107.06 & 38.91 & 5923.89 & 291,50 & 19,09 & 272,41 & 149.81 & 218.99 & 219,93 & 69,25 & 438.99 & 58,03 & 14.58 & 31,61 & 146,35 & 71.97 & 78.82 & 9203 \\
\hline Epidalea calamita & $305 \times 166$ & 100,00 & 137,73 & 106,27 & 38,63 & 5952,26 & 288,87 & 16,69 & 272,18 & $146, \varepsilon$ & 216,82 & 217 & 66, & 444,08 & 57,30 & 15,64 & 30 & 146 & 75,42 & 81,56 & 91,85 \\
\hline Epidalea calamita & $305 \times 167$ & 100,00 & 134,58 & 105,47 & 38,08 & 5986,80 & 286,09 & 14,12 & 271,97 & 143,41 & 214,29 & 214,93 & 63,03 & 449,14 & 56,28 & 16,73 & 29,75 & 145,65 & 79,29 & 84,23 & 91, \\
\hline
\end{tabular}




\begin{tabular}{|c|c|c|c|c|c|c|c|c|c|c|c|c|c|c|c|c|c|c|c|c|c|}
\hline TAXON & UTM & $\mathrm{km} 2$ & B101 & B102 & $\mathrm{BIO3}$ & B104 & B105 & B106 & B107 & B108 & B109 & BIO10 & B1011 & BIO12 & B1013 & BIO14 & BIO15 & BIO16 & BIO17 & B1018 & B1019 \\
\hline Epidalea calamita & 305XJ68 & 100,00 & 122,35 & 105,18 & 37,93 & 6098,75 & 276,92 & 2,28 & 274,63 & 136,46 & 203,99 & 204,38 & 50,08 & 487,44 & 57,57 & 20,50 & 27,48 & 153,17 & 92,86 & 94,41 & 97,42 \\
\hline Epidalea calamita & $305 \times 169$ & 100,00 & 130,08 & 103,49 & 37,92 & $\begin{array}{l}6039,47 \\
\end{array}$ & 281,31 & \begin{tabular}{ll|}
10,47 \\
\end{tabular} & 270,84 & 141,93 & 203,62 & 210,93 & 58,12 & 452,30 & 55,16 & 18,70 & 29,05 & 145,00 & 85,51 & 88,67 & 88,76 \\
\hline Epidalea calamita & $305 \times 170$ & 100,00 & 137,53 & 110,71 & 39,32 & 5904,00 & 291,80 & 14,12 & 277,68 & 147,94 & 215,93 & 217,18 & 67,21 & 472,94 & 62,96 & 14,05 & 32,67 & 157,32 & 71,03 & 79,28 & 105,05 \\
\hline Epidalea calamita & $305 \times 172$ & 100,00 & 135,05 & 108,85 & 39,00 & 5916,15 & 288,28 & 13,03 & 275,26 & 145,11 & 213,66 & 214,93 & 64,58 & 480,25 & 62,86 & 15,44 & 31,38 & 158,73 & 75,77 & 83,35 & 104,77 \\
\hline Epidalea calamita & $305 \times 173$ & 100,00 & 134,74 & 107,78 & 38,92 & 5912,92 & 287,08 & 13,31 & 273,78 & \begin{tabular}{ll|}
144,68 \\
\end{tabular} & 213,34 & 214,45 & 64,27 & 479,66 & 62,49 & 15,88 & 30,90 & 158,43 & 77,23 & 84,66 & 103,68 \\
\hline Epidalea calamita & $305 \times 174$ & 100,00 & 144,64 & 106,00 & 38,97 & 5808,97 & 292,51 & 24,30 & 268,21 & 154,66 & 221,46 & 222,71 & 74,91 & 443,42 & 61,79 & 13,75 & 33,54 & 153,08 & 68,48 & 78,70 & 95,51 \\
\hline Epidalea calamita & $305 \times 176$ & 100,00 & 136,34 & 104,40 & 38,32 & 5894,38 & 285,41 & 16,88 & 268,53 & 145,73 & 214,62 & 215,66 & 65,99 & 462,44 & 60,29 & 16,51 & 30,46 & 154,06 & 78,14 & 86,10 & 96,48 \\
\hline Epidalea calamita & $305 \times 177$ & 100,00 & 129,46 & 103,84 & 38,05 & 5965,21 & 280,00 & 10,43 & 269,57 & 138,84 & 208,95 & 209,79 & 58,54 & 479,80 & 59,22 & 18,64 & 28,75 & 155,00 & 85,94 & 91,66 & 98,22 \\
\hline Epidalea calamita & $305 \times 178$ & 100,00 & 134,17 & 102,25 & $\begin{array}{l}37,95 \\
\end{array}$ & 5919,14 & 282,15 & 16,04 & 266,11 & 144,01 & 212,92 & 213,66 & 63,56 & 458,25 & 58,45 & 17,81 & 29,83 & 151,35 & 81,92 & 88,97 & 92,58 \\
\hline Epidalea calamita & $305 \times 179$ & 100,00 & 145,16 & 100,16 & \begin{tabular}{|l|l|}
37,99 \\
\end{tabular} & 5811,26 & 288,28 & 27,86 & 260,41 & 154,01 & 221,87 & 222,82 & 75,13 & 417,16 & 56,96 & 15,33 & 32,41 & 144,09 & 71,62 & 81,59 & 83,63 \\
\hline Epidalea calamita & $305 \times 180$ & 100,00 & 144,00 & 109,08 & 39,48 & 5785,34 & 294,12 & 21,79 & 272,33 & 154,88 & 220,38 & 221,94 & 74,64 & 463,92 & 65,44 & 12,84 & 34,78 & 161,16 & 66,09 & 78,03 & 104,46 \\
\hline Epidalea calamita & $305 \times 182$ & 100,00 & 142,61 & 106,86 & 39,12 & 5781,11 & 291,03 & 22,04 & 268,99 & 153,31 & 219,00 & 220,57 & 73,45 & 468,84 & 65,57 & 13,90 & 33,69 & 162,69 & 69,65 & 81,45 & 104,05 \\
\hline Epidalea calamita & $305 \times 183$ & 100,00 & 143,86 & 105,54 & 39,10 & 5758,33 & 290,70 & 24,10 & 266,60 & 154,37 & 219,85 & 221,39 & 74,88 & 464,10 & 65,49 & 13,98 & 33,84 & 162,18 & 69,61 & 81,77 & 102,29 \\
\hline Epidalea calamita & $305 \times 184$ & 100,00 & 143,71 & 104,29 & 39,00 & 5747,43 & 289,46 & 24,87 & 264,59 & 154,15 & 219,55 & 221,15 & 75,00 & 462,29 & 65,19 & 14,37 & 33,59 & 161,71 & 70,50 & 82,78 & 100,98 \\
\hline Epidalea calamita & $305 \times 185$ & 100,00 & 151,95 & 102,27 & 38,99 & 5649,61 & 293,41 & 34,26 & 259,15 & 162,57 & 226,08 & 227,78 & 83,80 & 435,08 & 65,18 & 12,88 & 35,90 & 158,16 & 63,79 & 78,46 & 94,93 \\
\hline Epidalea calamita & $305 \times 187$ & 100,00 & 134,47 & 101,46 & 38,03 & 5847,57 & 280,78 & 17,18 & 263,60 & 143,95 & 212,11 & 213,25 & 64,92 & 477,32 & 62,23 & 17,79 & 30,15 & 160,24 & 82,06 & 91,49 & 99,19 \\
\hline Epidalea calamita & $305 \times 188$ & 100,00 & 150,47 & 98,58 & 38,21 & 5662,01 & 289,49 & 34,89 & 254,60 & 160,34 & 224,78 & 226,36 & 82,20 & 425,20 & 62,30 & 14,31 & 34,76 & 153,35 & 67,35 & 81,33 & 88,84 \\
\hline Epidalea calamita & 305XI89 & 100,00 & 151,22 & 97,45 & 38,00 & 5660,88 & 289,16 & 36,08 & 253,09 & 160,92 & 225,42 & 226,98 & 82,86 & 416,22 & 60,92 & 14,41 & 34,58 & 150,62 & 67,12 & 81,19 & 85,54 \\
\hline Epidalea calamita & $305 \times 190$ & 100,00 & 153,25 & 107,17 & 39,81 & 5630,23 & 298,25 & 32,30 & 265,95 & 164,95 & 227,01 & 228,96 & 85,40 & 449,15 & 68,17 & 11,03 & 38,19 & 164,83 & 58,95 & 75,35 & 103,51 \\
\hline Epidalea calamita & $305 \times 91$ & 100,00 & 154,65 & 105,88 & $39,80 \mid$ & 5600,81 & 298,09 & 34,84 & 263,25 & 166,33 & 227,97 & 230,00 & 87,14 & $\mid 446,79$ & 68,62 & $\mid 11,06$ & 38,44 & 165,52 & 58,81 & 75,95 & 102,75 \\
\hline Epidalea calamita & $305 \times 192$ & 100,00 & 157,11 & 104,43 & 39,78 & 5563,59 & 298,29 & 38,17 & 260,11 & 168,70 & 229,72 & 231,88 & 89,87 & 440,43 & 69,03 & 10,91 & 39,15 & 165,36 & 57,65 & 75,60 & 101,15 \\
\hline Epidalea calamita & $305 \times 195$ & 100,00 & 154,12 & 100,07 & 38,95 & 5546,10 & 291,99 & 38,17 & 253,82 & 165,20 & 226,60 & 228,75 & 87,31 & 447,85 & 69,32 & 12,82 & 37,47 & 166,93 & 63,14 & 81,01 & 100,04 \\
\hline Epidalea calamita & 305XJ97 & 100,00 & 157,92 & 96,72 & \begin{tabular}{|l|l|}
38,69 \\
\end{tabular} & 5480,10 & 291,59 & 44,24 & 247,35 & 168,84 & 229,31 & 231,46 & 91,61 & 430,08 & 68,64 & 12,78 & 38,43 & 163,54 & 61,12 & 80,02 & 94,32 \\
\hline Epidalea calamita & $305 \times 198$ & 100,00 & 161,99 & 95,04 & 38,54 & 5418,89 & 292,97 & 49,34 & 243,62 & 172,81 & 232,29 & 234,62 & 96,34 & 414,44 & 67,98 & 12,27 & 39,74 & 160,49 & 58,30 & 78,11 & 90,18 \\
\hline Epidalea calamita & $305 \times 199$ & 100,00 & 156,57 & 94,70 & 38,02 & 5501,31 & 289,38 & 43,62 & 245,76 & 166,92 & 228,32 & 230,32 & 90,09 & 420,21 & 65,46 & 13,67 & 37,23 & 158,42 & 63,57 & 81,59 & 88,81 \\
\hline Epidalea calamita & 30SXK10 & 100,00 & 119,41 & 114,96 & 38,03 & 6364,99 & 289,05 & $-7,86$ & 296,91 & 134,11 & 204,31 & 205,06 & 43,17 & 474,57 & 59,86 & 19,29 & 27,44 & 154,89 & 85,25 & 91,36 & 99,81 \\
\hline Epidalea calamita & 30SXK12 & 100,00 & 107,80 & 113,86 & 37,99 & 6396,03 & 277,60 & $-18,99$ & 296,59 & $\begin{array}{l}126,32 \\
12,\end{array}$ & \begin{tabular}{|l|}
193,10 \\
\end{tabular} & $\begin{array}{l}194,14 \\
\end{array}$ & 31,64 & 514,64 & $\begin{array}{l}3,06,77 \\
66\end{array}$ & 23,34 & 26,70 & 169,85 & $\begin{array}{l}96,25 \\
96,73\end{array}$ & 105,32 & 107,11 \\
\hline Epidalea calamita & $30 \mathrm{SXK22}$ & 100,00 & 105,08 & 111,26 & 37,82 & 6372,31 & 272,03 & $-19,79$ & 291,83 & 123,10 & 188,12 & 191,08 & 29,40 & 520,37 & 67,76 & 24,79 & 26,65 & 173,16 & 101,24 & 109,76 & 104,98 \\
\hline Epidalea calamita & 30 SXK30 & 100,00 & 117,71 & 110,05 & \begin{tabular}{|l|l|}
37,95 \\
\end{tabular} & 6293,58 & 280,91 & $-6,02$ & 286,93 & 135,21 & 201,84 & 202,31 & 42,81 & 476,10 & 60,00 & 20,90 & 27,42 & 156,32 & 91,20 & 95,71 & 94,79 \\
\hline Epidalea calamita & 30 XXK31 & 100,00 & 113,36 & 109,34 & 37,76 & 6319,51 & 276,69 & $-10,14$ & 286,82 & 131,17 & 140,04 & 198,55 & 38,41 & 486,33 & 62,48 & 22,50 & 27,36 & 161,19 & 94,60 & 101,05 & 95,69 \\
\hline Epidalea calamita & $30 \mathrm{SXK32}$ & 100,00 & 108,52 & 108,46 & 37,33 & 6339,29 & 271,47 & $-14,69$ & 286,15 & 126,45 & 58,98 & 194,06 & 33,24 & 499,43 & 65,36 & 24,27 & 27,34 & 167,26 & 97,03 & 107,17 & 97,07 \\
\hline Epidalea calamita & 305XK40 & 100,00 & 116,01 & 107,73 & 37,78 & $\begin{array}{ll}6252,44 \\
625\end{array}$ & 276,27 & \begin{tabular}{|c|}
$-6,16$ \\
-16
\end{tabular} & 282,43 & \begin{tabular}{|l|l|}
133,03 \\
\end{tabular} & \begin{tabular}{|l|}
123,01 \\
\end{tabular} & 200,16 & $\begin{array}{l}30,24 \\
41,92\end{array}$ & \begin{tabular}{|l|}
485,12 \\
45,45
\end{tabular} & $\begin{array}{l}60,79 \\
60\end{array}$ & 22,01 & 27,28 & 158,67 & 94,35 & 98,94 & 95,01 \\
\hline Epidalea calamita & 30SXK41 & 100,00 & 113,97 & 106,82 & \begin{tabular}{|l|l|}
37,28 \\
\end{tabular} & 6276,32 & 273,90 & $-7,82$ & 281,73 & 131,38 & 40,80 & 198,58 & 39,77 & 483,34 & 61,95 & 22,85 & 27,58 & 159,95 & 92,75 & 101,60 & 92,75 \\
\hline Epidalea calamita & $30 \mathrm{SXK42}$ & 100,00 & 116,05 & 105,51 & 37,03 & 6277,06 & 274,28 & $-5,51$ & 279,79 & 133,90 & 41,45 & 200,47 & 41,45 & 464,69 & 60,71 & 22,55 & 28,61 & 155,38 & 86,90 & 99,96 & 86,90 \\
\hline Epidalea calamita & 30SXK50 & 100,00 & 127,65 & 104,81 & 37,71 & 6135,18 & 281,71 & 6,70 & 275,01 & 142,82 & 92,14 & 209,82 & 54,41 & 442,77 & 54,53 & 19,12 & 28,90 & 142,62 & 84,56 & 87,90 & 84,95 \\
\hline Epidalea calamita & $305 \times K 52$ & 100,00 & 116,95 & 103,14 & 37,03 & 6232,40 & 272,18 & $-2,82$ & 275,00 & 134,51 & 42,97 & 200,73 & 42,97 & 464,15 & 60,12 & 22,83 & 28,82 & 154,08 & 85,43 & 100,12 & 85,43 \\
\hline Epidalea calamita & $\begin{array}{l}\text { 305XKK60 } \\
305 \times 1\end{array}$ & 100,00 & 133,08 & 102,24 & 37,55 & 6028,01 & 282,71 & \begin{tabular}{|c|}
13,90 \\
13,
\end{tabular} & 268,81 & \begin{tabular}{|l|}
$144,14,14$ \\
144
\end{tabular} & \begin{tabular}{|l|}
135,44 \\
\end{tabular} & 213,70 & 年 61,01 & \begin{tabular}{|l|}
432,27 \\
432,
\end{tabular} & $\begin{array}{l}00,12 \\
53,45 \\
\end{array}$ & $\begin{array}{l}2,30 \\
18,14 \\
\end{array}$ & $\begin{array}{l}29,02 \\
29,76\end{array}$ & 139,75 & $\begin{array}{l}0,45 \\
81,08\end{array}$ & $\begin{array}{r}85,84 \\
85\end{array}$ & $\begin{array}{l}0,4,45 \\
82,95\end{array}$ \\
\hline Epidalea calamita & 30SXK62 & 100,00 & 106,15 & 101,78 & 36,92 & 6218,09 & 261,26 & $-12,13$ & 273,40 & 122,72 & 32,84 & 190,04 & 32,84 & 520,18 & 66,47 & 26,72 & 27,06 & 171,32 & 97,31 & 113,83 & 97,31 \\
\hline Epidalea calamita & $305 \times K 72$ & 100,00 & 95,77 & 100,65 & 36,45 & 6182,98 & 250,53 & $-21,31$ & 271,84 & 111,17 & 23,68 & 179,33 & 23,68 & 584,80 & 73,13 & 30,58 & 25,11 & 189,64 & 113,11 & 126,81 & 113,11 \\
\hline Epidalea calamita & $305 \times K 80$ & 100,00 & 133,40 & 98,33 & 37,20 & 5881,55 & 277,88 & 17,42 & 260,45 & 142,60 & 180,96 & 212,31 & 63,21 & 457,53 & 58,17 & 18,99 & 29,97 & 152,34 & 84,32 & 93,37 & 89,68 \\
\hline Epidalea calamita & 30 XXK81 & 100,00 & 107,43 & 99,34 & 36,75 & 6087,26 & 258,74 & $-8,79$ & 267,52 & 121,45 & 36,15 & 189,55 & 36 & 548,46 & 66,48 & 26,89 & 25,90 & 173,45 & 106,31 & 115,03 & 106,31 \\
\hline Epidalea calamita & 30SXK82 & 100,00 & 95,14 & 99,06 & 36,2 & 6135,27 & 247,94 & $-20,86$ & 268,79 & 110,04 & 23,55 & 178,07 & 23,55 & 600,15 & 73,97 & 31,18 & 24,62 & 192,01 & 117,01 & 128,30 & 117,01 \\
\hline Epidalea calamita & $305 \times K 90$ & 100,00 & 137,15 & 96,17 & 37,23 & 5766,21 & 277,84 & 22,66 & 255,19 & 146,16 & 210,50 & 214,60 & 68,34 & 461,90 & 60,83 & 18,45 & 30,90 & 158,33 & 82,55 & 94,14 & 92,39 \\
\hline Epidalea calamita & 30SXK91 & 100,00 & 118,16 & 97,05 & 36,70 & 5962,03 & 264,77 & 3,03 & 261,74 & 128,88 & 86,00 & 198,45 & 47,94 & 516,47 & 61,85 & 23,82 & 27,32 & 164,19 & 99,90 & 108,37 & 100,35 \\
\hline Epidalea calamita & $305 \times K 92$ & 100,00 & 118,22 & 96,24 & 36,31 & 5976,35 & 264,32 & 3,29 & 261,02 & 129,84 & 58,95 & 198,64 & 47,90 & 505,18 & 61,45 & 23,95 & 27,82 & 160,42 & 95,62 & 107,63 & 95,73 \\
\hline Epidalea calamita & 30SYG06 & 10,00 & 181,91 & 102,00 & 40,91 & 5058,64 & 312,73 & 64,45 & 248,27 & 158,64 & 246,73 & 249,27 & 119,73 & 311,55 & 53,73 & 3,82 & 52,45 & 135,18 & 23,00 & 37,91 & 87,09 \\
\hline Epidalea calamita & $30 \mathrm{SYHC}$ & 33,00 & 182,53 & 108,27 & 41, & 5246,55 & 319,78 & 59,71 & 260,06 & 182,18 & 250,04 & 252,10 & 117,90 & 282,22 & 56,1 & 3,96 & 56,27 & 124,12 & 23,45 & 41,18 & 66,90 \\
\hline Epidalea calamita & 30SYHO1 & 62,00 & 182,16 & 108,79 & 41,00 & 5270,48 & 320,05 & 58,99 & 261,06 & 194,93 & 249,99 & 252,12 & 117,15 & 286,90 & 56,79 & 4,00 & 55,98 & 125,45 & 24,32 & 42,38 & 67,05 \\
\hline Epidalea calamita & 30SYHO2 & 80,00 & 182,46 & 108,92 & 41,00 & 5276,77 & 320,21 & 59,09 & 261,13 & 195,28 & 250,29 & 252,49 & 117,35 & 297,04 & 58,03 & 4,00 & 54,71 & 128,71 & 26,03 & 44,69 & 68,70 \\
\hline Epidalea calamita & 30SYHO4 & 100,00 & 173,90 & 109,71 & 41,00 & 5389,70 & 314,83 & 50,47 & 264,37 & 186,78 & 243,55 & 245,87 & 107,85 & 346,29 & 62,24 & 5,29 & 49,14 & 70 & 34,85 & 53,52 & 78,97 \\
\hline Epidalea calamita & $\begin{array}{l}30 \text { SYHO5 } \\
3 \text { Y }\end{array}$ & 100,00 & 16 & $\frac{10}{10}$ & 40 & 5465,29 & 309,83 & \begin{tabular}{|l|l|}
43,67 \\
43
\end{tabular} & \begin{tabular}{|l|}
266,15 \\
266
\end{tabular} & \begin{tabular}{|l|l|}
179,36 \\
179
\end{tabular} & \begin{tabular}{|l|}
237,69 \\
23,5
\end{tabular} & \begin{tabular}{|l|}
240,01 \\
\end{tabular} & \begin{tabular}{|l|}
100,20 \\
100,0
\end{tabular} & \begin{tabular}{|l|}
380,295 \\
384,95
\end{tabular} & $\begin{array}{l}62,44 \\
64,88\end{array}$ & $\begin{array}{l}3,25 \mid \\
6,78\end{array}$ & $\frac{4,44}{45,22}$ & 151,15 & $\begin{array}{l}4,30 \\
41,97\end{array}$ & $\begin{array}{ll}60,32 \\
60,32\end{array}$ & 89,22 \\
\hline Epidalea calamita & 30SYHO6 & 100,00 & 144,42 & 108,84 & 39,61 & 5689,09 & 293,55 & 22,42 & 271,13 & 144,48 & 219,20 & 221,28 & 76,49 & 486,58 & 69,47 & 12,40 & 36,53 & 172,01 & 63,57 & 78,33 & 115,60 \\
\hline Epidalea calamita & 30SYH08 & 100,00 & $\begin{array}{l}143,42 \\
133,87\end{array}$ & 107,45 & 39,09 & 5786,82 & 284,80 & \begin{tabular}{|l|l|l|}
13,19 \\
\end{tabular} & 271,61 & \begin{tabular}{l|l|}
144,48 \\
\end{tabular} & 210,39 & 212,43 & $\begin{array}{ll}05,38 \\
\end{array}$ & 534,69 & 71,73 & 15,72 & 32,70 & 181,60 & 76,45 & 89,32 & 125,78 \\
\hline Epidalea calamita & 30SYHO9 & 100,00 & 148,30 & 106,84 & 39,64 & 5640,08 & 294,15 & 27,77 & 266,38 & 160,23 & 222,30 & 224,45 & 80,64 & 481,97 & 70,89 & 12,15 & 37,05 & 174,40 & 63,64 & 80,44 & 113,50 \\
\hline Epidalea calamita & 30SYH13 & 75,00 & 181,61 & 107,03 & 41,00 & 5237,53 & 317,59 & 59,90 & 257,70 & 194,88 & 248,67 & 251,29 & 117,18 & 322,56 & 61,49 & 4,09 & 53,53 & 139,03 & 29,04 & 48,90 & 75 \\
\hline Epidalea calamita & 30SYH14 & 84,00 & $\begin{array}{l}101,01 \\
180,26\end{array}$ & 107,10 & $\begin{array}{l}41,00 \\
41,00\end{array}$ & $\begin{array}{l}5257,41 \\
5251,\end{array}$ & 316,59 & 58,60 & 257,99 & \begin{tabular}{|l|l|}
193,68 \\
193
\end{tabular} & \begin{tabular}{|l|}
247,77 \\
247
\end{tabular} & $\begin{array}{l}51,29 \\
250,42\end{array}$ & $\begin{array}{l}115,62 \\
115,62 \\
\end{array}$ & \begin{tabular}{|l|l|}
336,75 \\
336,5
\end{tabular} & $\begin{array}{l}61,44 \\
63,16 \\
\end{array}$ & $\begin{array}{l}4,4056 \\
4,36\end{array}$ & $\begin{array}{l}5,35 \\
52,08\end{array}$ & 143,41 & $\begin{array}{ll}20,04 \\
31,77\end{array}$ & $\begin{array}{l}40,90 \\
51,94 \\
\end{array}$ & $\begin{array}{l}77,25 \\
77,46\end{array}$ \\
\hline Epidalea calamita & 30SYH15 & 100,00 & 175,28 & 107,31 & 40,93 & 5313,91 & 313,30 & 53,72 & 259,57 & 188,76 & 243,76 & 246,37 & 110,37 & 366,35 & 65,66 & 5,46 & 49,10 & 151,58 & 37,05 & 57,48 & 84,94 \\
\hline Epidalea calamita & 30SYH16 & 100,00 & 159,20 & 107.47 & 40,10 & 5490.83 & 302,30 & 37.95 & 264,34 & 169.42 & 230.56 & 233,14 & 92.89 & 442.74 & 69.88 & 8.99 & 41.99 & 168,76 & 51.36 & 70,57 & 106.53 \\
\hline Epidalea calamita & 30SYH17 & 100,00 & 137,58 & 106,62 & 39,14 & 5704,24 & 286,43 & 17,54 & 268,89 & 126,61 & 212,69 & 215 & 69,98 & 534,91 & 73,47 & 14,70 & 34,32 & 186,51 & 72,75 & 87,84 & 129,03 \\
\hline Epidalea calamita & 30SYH18 & 100,00 & 135,72 & 105,93 & 39,01 & 5715,70 & 284,32 & 16,26 & 268,07 & 135,22 & 211,13 & 213,36 & 68,11 & 545,95 & 74,34 & 15,54 & 33,65 & 189,00 & 76,09 & 91,16 & 130,99 \\
\hline
\end{tabular}




\begin{tabular}{|c|c|c|c|c|c|c|c|c|c|c|c|c|c|c|c|c|c|c|c|c|c|}
\hline TAXON & UTM & $\mathrm{km} 2$ & B101 & B102 & $\mathrm{BIO3}$ & B104 & B105 & B106 & B107 & B108 & B109 & B1010 & BIO11 & BIO12 & B1013 & BIO14 & BIO15 & BIO16 & BIO17 & BIO18 & B1019 \\
\hline Epidalea calamita & 30SYH19 & 100,00 & 140,82 & 105,29 & 39,20 & 5663,73 & 287,27 & 21,68 & 265,59 & 149,01 & 215,32 & 217,56 & 73,55 & 529,39 & 74,34 & 14,42 & 35,07 & 187,23 & 72,32 & 89,16 & 126,96 \\
\hline Epidalea calamita & 30 SYH24 & 13,00 & 181,85 & 105,46 & 41,00 & 5196,85 & 316,00 & 61,77 & 254,23 & 196,08 & 248,23 & 251,23 & 118,00 & 352,31 & 65,31 & 4,23 & 52,23 & 151,00 & 32,31 & 54,23 & 84,31 \\
\hline Epidalea calamita & 30 SYH 25 & 77,00 & 180,16 & 105,37 & 41,00 & 5215,02 & 314,92 & 60,07 & 254,85 & 194,17 & 247,07 & 250,04 & 116,15 & 369,19 & 67,10 & 4,91 & 51,03 & 156,33 & 34,86 & 57,50 & 89,25 \\
\hline Epidalea calamita & 30SYH26 & 100,00 & 162,06 & 105,68 & 40,10 & 5418,68 & 302,65 & 42,09 & 260,56 & 164,62 & 232,30 & 235,03 & 96,54 & 452,93 & 72,10 & 8,67 & 43,43 & 176,14 & 50,53 & 71,93 & 112,25 \\
\hline Epidalea calamita & 30SYH27 & 100,00 & 138,36 & 105,00 & \begin{tabular}{|l|}
39,08 \\
\end{tabular} & 5652,75 & 285,28 & 19,41 & 265,87 & 113,91 & 212,66 & 215,09 & 71,39 & 550,86 & 75,99 & 14,68 & 34,98 & 195,63 & 73,13 & 90,20 & 135,87 \\
\hline Epidalea calamita & 30SYH28 & 100,00 & 143,83 & 104,61 & 39,25 & 5600,58 & 288,71 & 25,05 & 263,66 & 129,31 & 217,22 & 219,66 & 77,15 & 534,83 & 76,21 & 13,50 & 36,49 & 193,59 & 69,20 & 88,25 & 132,28 \\
\hline Epidalea calamita & $30 \mathrm{SYH} 29$ & 100,00 & 157,11 & 103,99 & 39,83 & 5462,54 & 297,39 & 38,60 & 258,79 & 160,71 & 228,11 & 230,76 & 91,36 & 495,67 & 76,34 & 10,57 & 41,07 & 189,27 & 58,63 & 81,85 & 124,46 \\
\hline Epidalea calamita & $\begin{array}{l}30 \text { SYH } 36 \\
\end{array}$ & 76,00 & 172,53 & 104,27 & 40,29 & 5282,72 & 308,81 & 53,31 & 255,50 & 157,76 & 240,39 & 243,27 & \begin{tabular}{|c|}
108,08 \\
\end{tabular} & 439,99 & 73,14 & 6,73 & 47,77 & 180,04 & 43,50 & 68,74 & 114,51 \\
\hline Epidalea calamita & 30SYH37 & 100,00 & 156,46 & 103,95 & 39,66 & 5443,78 & 297,10 & 37,91 & 259,19 & 131,88 & 227,12 & 229,92 & 90,96 & 507,02 & 76,68 & 10,34 & 41,72 & 195,70 & 57,87 & 81,19 & 130,93 \\
\hline Epidalea calamita & 30SYH38 & 100,00 & 130,60 & 102,73 & 38,43 & 5683,61 & 277,40 & 13,50 & 263,90 & \begin{tabular}{|l|}
103,87 \\
\end{tabular} & 205,45 & 208,02 & 63,76 & 603,69 & 79,85 & 17,44 & 33,08 & 211,11 & 83,60 & 100,75 & 150,39 \\
\hline Epidalea calamita & $30 \mathrm{SYH} 46$ & 30,00 & 180,65 & 102,84 & 40,40 & 5191,81 & 313,65 & 62,23 & 251,42 & 158,72 & 246,81 & 249,93 & 116,88 & 444,02 & 74,65 & 5,37 & 51,47 & 191,30 & 39,09 & 67,95 & 123,14 \\
\hline Epidalea calamita & 30SYH47 & 100,00 & 161,13 & 102,73 & 39,57 & 5376,77 & 299,46 & 43,28 & 256,17 & 137,70 & 230,58 & 233,57 & 96,22 & 517,59 & 78,54 & 9,54 & 44,19 & 206,86 & 55,42 & 81,62 & 139,68 \\
\hline Epidalea calamita & 30SYH56 & & & & & & & & & & & & & & & & & & & & \\
\hline Epidalea calamita & 30SYH57 & 71,00 & 178,86 & 101,94 & 40,00 & 5217,23 & 312,31 & 60,79 & 251,52 & 157,38 & 245,42 & 248,61 & 114,68 & 492,36 & 78,70 & 6,12 & 51,98 & 214,95 & 42,95 & 75,21 & 143,88 \\
\hline Epidalea calamita & 30SYJO0 & 100,00 & 155,61 & 105,66 & 39,80 & 5555,91 & 298,20 & 35,92 & 262,28 & 167,72 & 228,19 & 230,44 & 88,69 & 460,32 & 71,19 & 10,76 & 39,49 & 172,56 & 58,32 & 77,35 & 108,73 \\
\hline Epidalea calamita & $30 \mathrm{SYYO4}$ & 100,00 & 164,61 & 98,55 & 39,45 & 5354,88 & 297,08 & 50,29 & 246,79 & 176,84 & 233,95 & 236,69 & 99,77 & 442,46 & 74,50 & 10,55 & 42,74 & 174,80 & 54,69 & 77,86 & 104,31 \\
\hline Epidalea calamita & 30SYJO5 & 100,00 & 166,41 & 96,64 & 39,28 & 5302,08 & 296,17 & 53,60 & 242,58 & 178,57 & 234,92 & 237,66 & 102,14 & 436,16 & 75,19 & 10,58 & 43,50 & 174,36 & 53,81 & 77,63 & 102,01 \\
\hline Epidalea calamita & 30SYJ06 & 100,00 & 165,44 & 95,01 & 39,01 & 5293,51 & 293,86 & 53,87 & 239,99 & 177,42 & 233,86 & 236,68 & 101,27 & 438,06 & 75,39 & 11,25 & 42,87 & 174,73 & 55,44 & 79,30 & 101,17 \\
\hline Epidalea calamita & 30SYJO7 & 100,00 & 166,40 & 93,37 & 38,95 & 5267,47 & 293,03 & 55,71 & 237,33 & 178,25 & 234,31 & 237,26 & 102,52 & 431,58 & 74,97 & 11,56 & 43,03 & 173,01 & 55,33 & 79,25 & 98,46 \\
\hline Epidalea calamita & 30 SYYJ08 & 100,00 & 167,01 & 92,15 & 38,61 & 5261.87 & 292,83 & 56,86 & $235,97 \mid$ & 178,53 & 234,81 & 237,69 & $\mid 103,18$ & 421,74 & 73,28 & 11.57 & 42,99 & 169,44 & 55,16 & 78,88 & 94,67 \\
\hline Epidalea calamita & 30SYJO9 & 100,00 & 160,41 & 92,08 & 37,99 & 5362,79 & 288,70 & 49,75 & 238,95 & 171,34 & 230,00 & 232,42 & 95,51 & 428,82 & 69,92 & 13,27 & 39,42 & 166,71 & 61,35 & 82,93 & 93,31 \\
\hline Epidalea calamita & $30 \mathrm{SYJ11}$ & 100,00 & 169,64 & 102,15 & 40,01 & 5328,99 & 304,21 & 52,64 & 251,57 & 182,70 & 238,42 & 241,24 & $\mid \begin{array}{r}\mid 104,81 \\
\end{array}$ & 445,22 & 75,33 & 8,56 & 45,40 & 179,08 & 49,42 & 74,85 & 110,63 \\
\hline Epidalea calamita & $30 \mathrm{SYJ12}$ & 100,00 & 175,42 & 99,84 & 40,01 & 5239,15 & 305,98 & 59,97 & 246,01 & 188,69 & 242,74 & 245,67 & 111,35 & 431,18 & 76,26 & 8,03 & 47,87 & 178,21 & 46,04 & 73,26 & 107,94 \\
\hline Epidalea calamita & 30SYJ14 & 100,00 & 175,11 & 95,80 & 39,95 & 5162,86 & 301,05 & 63,02 & 238,03 & 188,26 & 241,27 & 244,49 & 112,14 & 434,26 & 78,86 & 8,61 & 48,27 & 181,00 & 47,58 & 75,66 & 107,15 \\
\hline Epidalea calamita & 30SYJ15 & 100,00 & 170,39 & 94,29 & 39,39 & 5182,47 & 295,91 & 59,55 & 236,36 & 183,27 & 236,85 & 240,14 & 107,42 & 446,90 & 79,84 & 10,05 & 46,41 & 183,66 & 51,78 & 79,39 & 108,19 \\
\hline Epidalea calamita & 30SYJ16 & 100,00 & 171,46 & 92,07 & 39,13 & 5121,67 & 294,22 & 62,56 & 231,66 & 184,23 & 237,18 & 240,61 & 109,48 & 442,56 & 80,9 & 10,23 & 47,32 & 183,66 & 51,43 & 79,50 & 106,04 \\
\hline Epidalea calamita & 30 SYJ17 & 100,00 & 170,87 & $\begin{array}{l}2,0,37 \\
90\end{array}$ & 39,00 & 5111,14 & 292,25 & |62,94 & 229,31 & 183,49 & 236,36 & \begin{tabular}{|l|}
239,79 \\
\end{tabular} & 108,94 & 441,61 & $\begin{array}{l}80,99 \\
80\end{array}$ & 10,95 & 46,75 & 183,14 & 52,74 & 80,69 & 104,02 \\
\hline Epidalea calamita & $30 \mathrm{SYJ18}$ & 100,00 & 167,99 & 89,79 & 38,51 & 5159,09 & 290,30 & 59,94 & 230,36 & 180,15 & 234,19 & 237,46 & 105,51 & 438,38 & 77,94 & 11,82 & 44,56 & 179,09 & 55,45 & 82,12 & 100,81 \\
\hline Epidalea calamita & $30 \mathrm{SYJ19}$ & 100,00 & 155,37 & 90,99 & 37,79 & 5357,42 & 283,63 & 45,56 & 238,07 & 166,40 & 224,88 & 227,57 & 90,93 & 458,99 & 72,35 & 14,63 & 38,07 & 175,92 & 67,17 & 89,65 & 100,94 \\
\hline Epidalea calamita & $30 \mathrm{SYJ} 21$ & 100,00 & 165,65 & 101,30 & 39,79 & 5339,22 & 300,55 & 49,14 & 251,41 & 176,73 & 234,67 & 237,43 & 100,84 & 481,21 & 78,40 & 9,51 & 44,28 & 190,88 & 54,07 & 80,95 & 122,79 \\
\hline Epidalea calamita & $30 \mathrm{SYJ} 22$ & 100,00 & 168,81 & 99,36 & 39,81 & 5279,18 & 300,68 & 53,71 & 246,97 & 182,04 & 236,77 & 239,79 & 104,65 & 475,11 & 79,52 & 9,31 & 45,55 & 191,42 & 52,57 & 80,87 & 121,54 \\
\hline Epidalea calamita & $30 \mathrm{SY} 225$ & 100,00 & 176,56 & 92,18 & 39,57 & 5054,61 & 297,92 & $\begin{array}{ll}67,46 \\
\end{array}$ & \begin{tabular}{|l|}
230,45 \\
\end{tabular} & \begin{tabular}{|l|}
$190,01,01$ \\
\end{tabular} & 240,95 & \begin{tabular}{|l|}
244,55 \\
\end{tabular} & 115,05 & | & $\begin{array}{l}82,85 \\
82,\end{array}$ & 8,90 & | & 189,43 & 48,38 & $\begin{array}{l}0,01,53 \\
\end{array}$ & 112,10 \\
\hline Epidalea calamita & 30SYJ26 & 99,00 & 175,54 & 89,83 & 39,25 & 5005,52 & 294,31 & 68,41 & 225,90 & 188,86 & 239,28 & 243,17 & 114,93 & 444,15 & 83,98 & 9,09 & 50,35 & 189,34 & 49,09 & 80,34 & 109,50 \\
\hline Epidalea calamita & 30 SYJ27 & 100,00 & 173,96 & 87,97 & 39,00 & 4986,04 & 290,95 & 68,09 & 222,85 & 187,11 & 237,27 & 241,28 & 113,45 & 441,73 & 84,26 & 9,91 & 50,22 & 188,59 & 50,72 & 82,28 & 106,80 \\
\hline Epidalea calamita & $30 \mathrm{SYJ} 28$ & 100,00 & 171,52 & 87,47 & 38,46 & 5040,85 & 289,88 & 65,15 & 224,73 & 184,22 & 235,74 & 239,41 & 110,39 & 440,88 & 81,19 & 10,77 & 47,69 & 185,17 & 53,23 & 83,39 & 104,10 \\
\hline Epidalea calamita & $30 \mathrm{SYJ} 29$ & 100,00 & 160,16 & 88,68 & 37,70 & 5226,04 & 284,34 & 52,04 & 232,30 & 171,93 & 227,54 & 230,65 & 97,17 & 462,29 & 75,74 & 13,71 & 40,62 & 182,64 & 63,83 & 90,03 & 104,77 \\
\hline Epidalea calamita & $305 Y 30$ & 100,00 & $\begin{array}{l}10,10 \\
157,99\end{array}$ & $\begin{array}{l}0,00 \\
101,69\end{array}$ & 39,41 & $\begin{array}{l}522,0,04 \\
5412,07\end{array}$ & 295,78 & $\begin{array}{l}2,040 \\
41,07 \\
\end{array}$ & $\begin{array}{l}32,30 \\
254,72 \\
\end{array}$ & \begin{tabular}{|l|l|}
133,98 \\
13
\end{tabular} & $\mid$\begin{tabular}{|l|}
228,08 \\
\end{tabular} & \begin{tabular}{|l|}
230,90 \\
230
\end{tabular} & $\begin{array}{l}1,114 \\
92,74\end{array}$ & \begin{tabular}{|l|l|}
524,14 \\
524
\end{tabular} & 80,05 & 10,99 & $\begin{array}{l}40,064 \\
41,91\end{array}$ & $\frac{102,04}{203,56}$ & $\begin{array}{l}3,05 \\
60,87\end{array}$ & $\begin{array}{ll}07,18 \\
87,18\end{array}$ & 136,38 \\
\hline Epidalea calamita & 30SYJ31 & 100,00 & 165,65 & 100,49 & 39,72 & 5323,01 & 300,06 & 49,58 & 250,49 & 150,78 & 234,32 & 237,24 & 101,08 & 508,10 & 80,91 & 9,80 & 44,84 & 203,56 & 55,90 & 85,08 & 134,45 \\
\hline Epidalea calamita & 30 SYJ32 & 100,00 & 168,37 & 98,61 & 39,62 & 5263,81 & 299,92 & 53,56 & 246,36 & 155,07 & 236,04 & 239,10 & 104,44 & 501,73 & 81,88 & 9,56 & 46,00 & 202,90 & 54,54 & 85,01 & 132,77 \\
\hline Epidalea calamita & 30 SYJ33 & 94,00 & 175,58 & 96,19 & 39,77 & 5151,25 & 302,46 & 62,88 & 239,58 & 175,71 & 241,48 & 244,84 & 112,74 & 478,48 & 82,56 & 8,56 & 49,07 & 199,01 & 49,47 & 81,90 & 127,13 \\
\hline Epidalea calamita & $30 \mathrm{SY} 3 \mathrm{J3}$ & 40,00 & 174,18 & 86,54 & 38,47 & 4984,38 & 291,01 & 68,26 & 222,75 & 187,19 & 237,71 & 241,18 & 113,76 & 440,35 & 81,18 & 10,03 & 48,81 & 187,10 & 51,87 & 83,85 & 105,65 \\
\hline Epidalea calamita & 30SYJ39 & 93,00 & 171,91 & 85,77 & 37,67 & 5036,25 & 289,90 & 65,66 & 224,24 & $\begin{array}{l}184,57 \\
\end{array}$ & 236,06 & 239,78 & 110,72 & 440,55 & $77, \varepsilon$ & 11,16 & $\begin{array}{l}40,01 \\
46,32\end{array}$ & 184,18 & 54,45 & 85,56 & 103,47 \\
\hline Epidalea calamita & 30SYJ41 & 92,00 & 178,72 & 99,65 & 39,99 & 5194,28 & 309,11 & 62,64 & 246,47 & 156,51 & 244,90 & 248,08 & 114,94 & 503,61 & 82,83 & 7,26 & 51,03 & 216,47 & 47,22 & 82,13 & 143,56 \\
\hline Epidalea calamita & $30 \mathrm{SYJ42}$ & 37,00 & 179,44 & 97,85 & 39,97 & 5155,15 & 307,64 & 64,85 & 242,79 & 156,95 & 245,13 & 248,38 & 116,18 & 491,85 & 82,98 & 7,20 & 51,16 & 210,54 & 46,64 & 81,48 & 137,85 \\
\hline Epidalea calamita & $30 \mathrm{SYJ43}$ & 2,00 & 179,67 & 96,50 & 40,00 & 5101,33 & 306,00 & 66,83 & 239,17 & 157,33 & 244,83 & 248,00 & 117,33 & 484,17 & 83,00 & 8,00 & 50,67 & 205,50 & 47,00 & 82,00 & 133,33 \\
\hline Epidalea calamita & $30 \mathrm{SYYSO}$ & $\begin{array}{l}2,00 \\
91,00 \\
\end{array}$ & 178,28 & 100,93 & 39,94 & 5233,66 & 310,87 & $\begin{array}{l}0,00,86 \\
60\end{array}$ & 250,01 & $\begin{array}{l}156,53 \\
\end{array}$ & 245,10 & $\begin{array}{l}248,07 \\
\end{array}$ & 113,90 & 537,55 & $\begin{array}{l}84,02 \\
84,02\end{array}$ & 7,42 & 51,87 & 234,68 & 48,71 & 85,38 & 160,51 \\
\hline Epidalea calamita & 30SYKOO & 100,00 & 139,41 & 94,26 & 37,13 & 5666,42 & 277,01 & 26,49 & 250,53 & 148,94 & 214,20 & 215,70 & 71,98 & 472,11 & 64, & 18,16 & 31,70 & 165,66 & 81,42 & 95,94 & 96,76 \\
\hline Epidalea calamita & 30SYK01 & 100,00 & 134,56 & 94,06 & 36,96 & 5741,43 & 273,68 & 21,12 & 252,56 & 143,61 & 209,48 & 211,81 & 66,34 & 477,33 & 61,79 & 19,63 & 30,41 & 163,17 & 86,90 & 99,28 & 95,21 \\
\hline Epidalea calamita & 30SYKO2 & 100,00 & 133,17 & 93,51 & 36,64 & 5766,06 & 272,32 & 19,80 & 252,52 & 141,83 & 170,55 & 210,65 & 64,64 & 472,90 & 60,31 & 20,15 & 30,38 & 160,07 & 87,72 & 100,21 & 92,38 \\
\hline Epidalea calamita & 30SYK10 & 100,00 & 143,46 & 92,15 & 37,02 & 5547,72 & 277,29 & 31,91 & 245,38 & 153,64 & 216,17 & 218,25 & 77,29 & 479,42 & 67,76 & 17,51 & 33,16 & 173,14 & 78,71 & 96,77 & 101,15 \\
\hline Epidalea calamita & 30SYK11 & 100,00 & $\frac{149}{149}$ & $\begin{array}{l}92,11 \\
90,61\end{array}$ & 36 & 5478,63 & 280,43 & \begin{tabular}{|l|l|}
38,69 \\
3
\end{tabular} & \begin{tabular}{|l|}
241,74 \\
241
\end{tabular} & \begin{tabular}{|l|}
$159,46,4$ \\
15
\end{tabular} & \begin{tabular}{|l|}
221,06 \\
221
\end{tabular} & \begin{tabular}{|l|}
$223,19,19$ \\
\end{tabular} & 83,84 & \begin{tabular}{|l|}
453,34 \\
453
\end{tabular} & $\begin{array}{l}6,1,30 \\
66,\end{array}$ & 16,24 & $\begin{array}{l}3,10 \\
34,97 \\
\end{array}$ & 167,62 & $\frac{73,16}{73,26}$ & 92,60 & $\begin{aligned} 94,66 \\
94,66\end{aligned}$ \\
\hline Epidalea calamita & 30SYK12 & 100,00 & 134,80 & 92,09 & 36,45 & 5682,40 & 271,49 & 22,29 & 249,21 & 143,69 & 208,88 & 211,21 & 67,34 & 486,30 & 63,02 & 19,95 & 30,71 & 167,47 & 88,44 & 102,36 & 97,31 \\
\hline Epidalea calamita & 30SYK20 & 100,00 & 160,35 & 87,92 & 37,24 & 5238,23 & 284,38 & 52,25 & 232,14 & 171,66 & 227,90 & 230,92 & 97,21 & 451,01 & 72,79 & 13,91 & 39,85 & 177,48 & 64,00 & 89,53 & 100,12 \\
\hline Epidalea calamita & 30 SYK21 & 100,00 & 145,32 & 89,86 & 36,76 & 5470,59 & 276,20 & 34,98 & 241,22 & 155,35 & 216,84 & 219,06 & 80,06 & 483,17 & 68,68 & 17,47 & 33,96 & 176,54 & 78,74 & 98,83 & 102,43 \\
\hline Epidalea calamita & 30 SYK22 & 100,00 & 141,91 & 89,99 & 36,38 & 5542,24 & 274,33 & 30,88 & 243,45 & 151,30 & 214,58 & 216,54 & 75,93 & 483,39 & 66,07 & 18,39 & 32,69 & 172,99 & 82,58 & 100,81 & 99,84 \\
\hline Epidalea calamita & 30SYK30 & 100,00 & 167,69 & 85,61 & 37,08 & 5105,08 & 287,56 & 60,99 & 226,56 & $\begin{array}{l}179,79 \\
\end{array}$ & 232,99 & 236,47 & 105,86 & 442,63 & 74,27 & 12,40 & 43,17 & 180,40 & 58,61 & 87,77 & 100,94 \\
\hline Epidalea calamita & 30SYK31 & 100,00 & 156,25 & 86,80 & 36,88 & 5275,68 & 281,12 & 48,02 & 233,10 & 167,22 & 224,50 & 227,43 & 93,01 & 466,86 & 71,02 & 15,19 & 37,94 & 179,61 & 69,63 & 94,88 & 102,45 \\
\hline Epidalea calamita & 30SYK32 & 100,00 & 160,29 & 85,89 & 36,64 & 5244,68 & 283,74 & 51,95 & 231,79 & 170,88 & 227,87 & 230,75 & 97,07 & 446,44 & 68,37 & 14,57 & 38,74 & 173,66 & 66,49 & 91,97 & 96,40 \\
\hline Epidalea calamita & 30SYK42 & 100,00 & 168,88 & 83,31 & 36,31 & 5093,37 & 287,97 & 61,97 & 226,00 & 180, & 233,98 & 237 & 107 & 432,64 & 68,52 & 13,02 & 41 & 174,65 & 59,97 & 89,27 & 95, \\
\hline Epidalea calamita & 30SYK51 & 6,00 & 172,20 & 83,00 & 36,90 & 5063,60 & 290,00 & 65,90 & 224,10 & 184,20 & 236,90 & 240,90 & 111,00 & 436,90 & 70,60 & 12,00 & 43,40 & 179,00 & 57,90 & 89,00 & 99,20 \\
\hline
\end{tabular}




\begin{tabular}{|c|c|c|c|c|c|c|c|c|c|c|c|c|c|c|c|c|c|c|c|c|c|}
\hline TAXON & UTM & $\mathrm{km2}$ & B101 & $\mathrm{B1O2}$ & $\mathrm{BIO3}$ & $\mathrm{B104}$ & B105 & B106 & B107 & B108 & B109 & 81010 & B1011 & BIO12 & BIO13 & 81014 & B1015 & B1O16 & B1017 & BIO18 & B1019 \\
\hline Epidalea calamita & 30SYK52 & 57,00 & 171,46 & 82,73 & 36,02 & 5099,43 & 289,46 & 63,70 & 225,76 & 182,67 & 236,61 & 239,70 & 109,33 & 435,60 & 69,07 & 12,52 & 42,66 & 177,43 & 58,92 & 89,85 & 97,71 \\
\hline Epidalea calamita & 30TTK43 & 60,00 & 149,16 & 110,74 & \begin{tabular}{|l|l}
36,88 \\
\end{tabular} & 6409,49 & 324,89 & 26,98 & 297,91 & 78,57 & 234,93 & 234,93 & 71,07 & 468,07 & 57,26 & 5,87 & 44,11 & 167,16 & 38,90 & 38,90 & 154,18 \\
\hline Epidalea calamita & 30TTK44 & 60,00 & 132,45 & 109,16 & 36,60 & 6377,70 & 307,43 & 12,65 & 294,78 & 62,97 & 217,85 & 218,38 & 55,81 & 543,52 & 66,52 & 8,45 & 42,58 & 193,49 & 48,58 & 49,33 & 179,36 \\
\hline Epidalea calamita & 30TTK48 & 40,00 & 134,10 & 111,33 & 37,38 & 6306,80 & 307,13 & 13,61 & 293,52 & 64,43 & 218,56 & 218,64 & 57,33 & 483,51 & 59,92 & 8,43 & 40,90 & 171,39 & 46,87 & 46,92 & 156,69 \\
\hline Epidalea calamita & 30TTK56 & 100,00 & 125,09 & 110,34 & 36,99 & \begin{tabular}{ll|l}
6336,47 \\
\end{tabular} & 299,69 & 5,54 & 294,16 & 55,85 & 209,65 & 210,40 & 48,89 & 532,56 & 65,03 & 9,79 & 40,50 & 186,53 & 52,18 & 52,97 & 171,06 \\
\hline Epidalea calamita & 30TTK57 & 100,00 & 125,48 & 111,03 & \begin{tabular}{|l|l|}
37,08 \\
\end{tabular} & 6317,04 & 299,69 & 5,65 & 294,04 & 56,32 & 209,99 & 210,54 & 49,34 & 515,12 & 63,05 & 9,67 & 39,93 & 180,10 & 51,77 & 52,14 & 164,56 \\
\hline Epidalea calamita & 30TTK58 & 100,00 & 125,15 & 111,64 & \begin{tabular}{|l|l|}
37,57 \\
\end{tabular} & 6296,49 & 298,85 & 5,27 & 293,58 & 56,00 & 209,26 & 209,81 & 49,13 & 503,89 & 61,86 & 9,69 & 39,55 & 175,86 & 51,83 & 52,15 & 159,95 \\
\hline Epidalea calamita & $\begin{array}{l}30 T \pi K 59 \\
\end{array}$ & 100,00 & 118,74 & 111,53 & 37,89 & 6264,91 & 292,03 & 0,06 & 291,97 & 50,05 & 202,19 & 203,01 & 43,41 & 522,27 & 64,35 & $\begin{array}{l}10,65 \\
10,\end{array}$ & 38,81 & 182,02 & 55,69 & 56,28 & 164,96 \\
\hline Epidalea calamita & 30TTK65 & 100,00 & 113,49 & 109,94 & 36,78 & 6341,39 & 289,57 & $-5,24$ & 294,81 & 45,07 & 198,60 & 199,43 & 38,40 & 586,38 & 70,42 & 12,04 & 39,20 & 201,93 & 59,78 & 61,71 & 185,52 \\
\hline Epidalea calamita & 30TTK66 & 100,00 & 79,21 & 106,14 & 36,41 & 6224,39 & 253,47 & $-34,09$ & 287,56 & 14,25 & 163,83 & 164,57 & 7,95 & 803,94 & 95,97 & 19,66 & 37,45 & 276,18 & 86,49 & 92,45 & 257,79 \\
\hline Epidalea calamita & 30TTK67 & 100,00 & 109,14 & 110,24 & \begin{tabular}{|c|}
37,07 \\
\end{tabular} & 6281,82 & 283,90 & $-8,71$ & 292,61 & 41,20 & 192,97 & 194,39 & 34,75 & 578,51 & 69,88 & 12,63 & 37,97 & 198,20 & 62,04 & 64,14 & 180,73 \\
\hline Epidalea calamita & 30TTK68 & 100,00 & 121,72 & 112,60 & \begin{tabular}{|c|}
37,88 \\
\end{tabular} & 6290,36 & 296,40 & 1,58 & 294,82 & 52,69 & 205,55 & 206,38 & 46,00 & 494,14 & 59,95 & 10,43 & 38,06 & 168,79 & 53,79 & 54,29 & 152,38 \\
\hline Epidalea calamita & 30TTK69 & 100,00 & 116,55 & 112,76 & 38,00 & 6255,50 & 290,74 & $-2,36$ & 293,10 & 54,45 & 199,44 & 200,97 & 41,45 & 504,86 & 61,34 & 11,15 & 37,32 & 171,90 & 56,85 & 57,70 & 154,59 \\
\hline Epidalea calamita & 30TTK74 & 100,00 & 134,76 & 112,76 & 36,99 & 6418,78 & 312,39 & 11,83 & 300,57 & 68,51 & 220,79 & 221,21 & 57,26 & 470,09 & 55,91 & 8,45 & 40,06 & 159,85 & 46,18 & 46,69 & 145,14 \\
\hline Epidalea calamita & 30TTK76 & 100,00 & 91,53 & 108,77 & 36,79 & 6260,14 & 267,27 & $-24,49$ & 291,75 & 25,18 & 175,92 & 177,06 & 18,91 & 680,86 & 80,72 & 16,69 & 36,68 & 229,91 & 75,34 & 79,58 & 211,18 \\
\hline Epidalea calamita & 30TTK77 & 100,00 & 97,20 & 109,86 & 37,13 & 6246,57 & 272,49 & $-19,59$ & 292,07 & 30,34 & 180,93 & 182,39 & 24,13 & 626,00 & 74,51 & 15,30 & 36,35 & 210,42 & 70,67 & 74,09 & 191,65 \\
\hline Epidalea calamita & 30TTK78 & 100,00 & 114,63 & 112,80 & 37,91 & 6271,61 & 289,86 & $-4,61$ & 294,47 & 55,68 & 197,59 & 199,56 & 39,69 & 504,84 & 60,39 & 11,68 & 36,46 & 168,65 & 57,96 & 59,24 & 151,39 \\
\hline Epidalea calamita & 30TTK79 & 100,00 & 116,93 & 113,89 & 38,05 & 6247,73 & 291,87 & $-2,66$ & 294,53 & 73,70 & 199,32 & 201,36 & 41,94 & 479,76 & 57,49 & 11,22 & 36,02 & 159,91 & 56,53 & 57,49 & 142,51 \\
\hline Epidalea calamita & 30TTK84 & 100,00 & 134,41 & 113,27 & 37,00 & 6425,82 & 312,65 & 10,59 & 302,07 & 81,47 & 220,52 & 220,95 & 56,82 & 456,62 & 53,71 & 8,67 & 39,33 & 153,00 & 46,50 & 47,06 & 137,83 \\
\hline Epidalea calamita & 30TTK86 & 100,00 & 104,01 & 111,33 & \begin{tabular}{|l|l|}
37,03 \\
\end{tabular} & 6298,99 & 281,10 & $-14,76$ & 295,86 & 38,62 & 188,25 & 189,81 & 30,01 & 569,76 & 66,99 & 14,01 & 36,09 & 188,25 & 65,19 & 67,68 & 169,77 \\
\hline Epidalea calamita & 30TTK87 & 100,00 & 112,29 & 112,73 & 37,60 & 6295,44 & 288,80 & $-7,63$ & 296,43 & 62,51 & 195,94 & 197,81 & 37,44 & 507,78 & 59,81 & 12,44 & 35,86 & 166,60 & 59,43 & 61,05 & 148,84 \\
\hline Epidalea calamita & 30TTK88 & 100,00 & 115,08 & 113,70 & 37,98 & 6268,39 & 290,92 & $-5,17$ & $\begin{array}{l}296,09 \\
\end{array}$ & 72,80 & $\begin{array}{l}197,78 \\
\end{array}$ & 200,01 & 40,13 & 480,61 & 56,77 & 11,78 & 35,36 & 157,37 & 57,66 & 58,97 & 139,60 \\
\hline Epidalea calamita & 30TтK89 & 100,00 & 114,12 & 114,19 & 38,01 & 6219,95 & 289,16 & $-5,91$ & 295,07 & 73,80 & 195,95 & 198,39 & 39,77 & 472,86 & 55,95 & 11,97 & 34,69 & 154,65 & 58,43 & 59,90 & 136,11 \\
\hline Epidalea calamita & 30TTK93 & 100,00 & 158,23 & 114,87 & 37,00 & 6478,21 & 336,17 & 31,10 & 305,07 & 116,45 & 244,77 & 244,77 & 78,48 & 365,64 & 43,12 & 5,03 & 41,74 & 124,73 & 32,99 & 32,99 & 110,07 \\
\hline Epidalea calamita & 30TTK94 & 100,00 & 150,38 & 114,48 & 37,00 & 6451,97 & 328,03 & 24,12 & 303,91 & 108,28 & 236,77 & 236,78 & 71,27 & 381,23 & 44,71 & 6,37 & 39,86 & 128,30 & 37,38 & 37,38 & 113,13 \\
\hline Epidalea calamita & 30TTK96 & 100,00 & 91,54 & 110,67 & 37,01 & 6268,13 & 268,93 & $-26,01$ & 294,93 & 33,22 & 176,05 & 177,31 & 18,89 & 629,13 & 73,17 & 17,20 & 34,74 & 204,69 & 75,06 & 79,02 & 184,84 \\
\hline Epidalea calamita & 30TाK97 & 100,00 & 99,04 & 111,70 & 37,34 & 6257,05 & 275,69 & $-19,61$ & 295,30 & 48,24 & 182,84 & $\begin{array}{l}184,34 \\
\end{array}$ & 25,79 & 565,46 & 66,21 & 15,39 & 34,41 & 182,77 & 69,10 & 72,18 & 162,84 \\
\hline Epidalea calamita & 30TTK98 & 100,00 & 111,33 & 113,54 & 37,94 & 6252,65 & 287,35 & $-8,85$ & 296,19 & 70,37 & $\begin{array}{ll}194,08 \\
\end{array}$ & 196,31 & 37,04 & 480,69 & 57,37 & 12,67 & 34,32 & 155,03 & 60,19 & 61,95 & 135,37 \\
\hline Epidalea calamita & 30TTK99 & 100,00 & 107,21 & 113,47 & 38,00 & 6202,06 & 282,46 & $-12,23$ & 294,69 & 67,18 & 189,34 & 191,49 & 33,69 & 488,99 & 58,71 & 13,45 & 33,69 & 157,33 & 63,01 & 65,25 & 136,74 \\
\hline Epidalea calamita & 30TTL40 & 39,00 & 117,22 & 110,80 & 37,98 & 6241,55 & 289,36 & $-0,44$ & 289,80 & 48,96 & 200,42 & 201,29 & 42,09 & 537,40 & 66,89 & 10,84 & 39,51 & 189,65 & 56,73 & 57,22 & 172,22 \\
\hline Epidalea calamita & 30TTL45 & 20,00 & 119,76 & 113,97 & 38,97 & 6206,59 & 291,48 & 0,07 & 291,41 & 79,59 & 202,28 & 202,28 & 43,86 & 458,03 & 59,00 & 10,34 & 38,24 & 163,90 & 53,28 & 53,28 & 141,10 \\
\hline Epidalea calamita & $\begin{array}{l}30 T T L 50 \\
\end{array}$ & 100,00 & 114,93 & 111,65 & 37,99 & 6240,78 & 287,90 & $-2,85$ & 290,75 & 47,54 & \begin{tabular}{|l|}
202,26 \\
197,78 \\
\end{tabular} & \begin{tabular}{|l|}
199,05 \\
19,05
\end{tabular} & $\begin{array}{l}40,00 \\
40,02\end{array}$ & 528,61 & $\begin{array}{l}5,29 \\
65,29\end{array}$ & $\begin{array}{ll}11,17 \\
117\end{array}$ & $\begin{array}{ll}38,41 \\
3\end{array}$ & \begin{tabular}{|l|l|}
183,98 \\
\end{tabular} & $\begin{array}{l}57,20 \\
57,94\end{array}$ & $\begin{array}{l}58,20 \\
58,66\end{array}$ & 166,05 \\
\hline Epidalea calamita & 30TTL51 & 100,00 & 114,77 & 112,50 & \begin{tabular}{|l|}
38,08 \\
\end{tabular} & 6230,42 & 287,68 & $-3,20$ & 290,88 & 64,41 & 197,93 & 198,57 & 39,84 & 514,20 & 63,74 & 11,21 & 38,14 & 179,09 & 57,85 & 58,21 & 160,08 \\
\hline Epidalea calamita & 30TTL52 & 100,00 & 118,54 & 113,86 & 38,51 & 6232,96 & 291,42 & $-0,62$ & 292,05 & 78,26 & 201,92 & 201,92 & 42,90 & 480,01 & 60,34 & 10,69 & 38,36 & 168,97 & 54,94 & 54,94 & 147,61 \\
\hline Epidalea calamita & 30TTL54 & 100,00 & 119,97 & 114,95 & 38,97 & 6214,41 & 292,67 & 0,09 & 292,57 & 79,86 & 202,86 & 202,86 & 44,03 & 445,01 & 57,31 & 10,31 & 38,63 & 159,45 & 52,65 & 52,65 & 133,95 \\
\hline Epidalea calamita & 30TTL55 & 100,00 & 119,49 & 114,99 & 39,00 & 6194,68 & 291,90 & $-0,15$ & 292,05 & 79,42 & 202,05 & 202,05 & 43,64 & 438,15 & 56,37 & 10,58 & 38,23 & 156,80 & 52,87 & 52,87 & 131,30 \\
\hline Epidalea calamita & 30TTL56 & 100,00 & 115,04 & 114,44 & 39,00 & 6165,01 & 287,15 & $\mid-3,84$ & 290,99 & 75,32 & 197,15 & 197,26 & 39,83 & 452,74 & 57,87 & 11,27 & 37,59 & 161,16 & 55,84 & 55,92 & 135,98 \\
\hline Epidalea calamita & 30TTL57 & 100,00 & 115,39 & 114,42 & 39,00 & 6158,74 & 287,28 & $-3,76$ & 291,04 & 75,66 & 197,18 & 197,42 & 40,06 & 444,03 & 56,61 & 11,27 & 37,08 & 157,38 & 55,33 & 55,47 & 133,44 \\
\hline Epidalea calamita & 30TTL58 & 100,00 & 118,25 & 114,45 & 39,00 & 6157,61 & 289,66 & $-1,44$ & 291,09 & 78,51 & 199,50 & 199,90 & 42,43 & 426,35 & 54,25 & 10,94 & 36,63 & 150,60 & 53,39 & 53,63 & 128,16 \\
\hline Epidalea calamita & 30TTL59 & 100,00 & 120,08 & 114,38 & 38,99 & 6142,13 & 290,93 & $-0,17$ & 291,10 & 80,44 & 200,75 & 201,21 & 44,09 & 416,59 & 52,89 & 10,56 & 36,11 & 146,84 & 52,66 & 52,95 & 125,25 \\
\hline Epidalea calamita & 30TTL60 & 100,00 & 114,36 & 113,21 & $38, \mathrm{C}$ & 6233,21 & 288,24 & $-4,33$ & 292,57 & 69,27 & 197,00 & 198,49 & 39,50 & 502,62 & 61,29 & 11,47 & 36,97 & 171,10 & 58,14 & 58,96 & 152,82 \\
\hline Epidalea calamita & 30TTL61 & 100,00 & $\begin{array}{l}11,30 \\
113,50\end{array}$ & $\begin{array}{l}111,21 \\
113,97\end{array}$ & $\begin{array}{l}38,01 \\
38,46\end{array}$ & $\begin{array}{l}\mid 023,2,11 \\
6218,07\end{array}$ & 280,24 & $\begin{array}{l}-2,53 \\
-5,21\end{array}$ & $\begin{array}{l}229,, 43 \\
292,4 \\
\end{array}$ & $\begin{array}{l}\mid c 5,27 \\
72,68\end{array}$ & $\begin{array}{l}196,09 \\
196,09\end{array}$ & \begin{tabular}{|l|}
$190,4,31$ \\
197
\end{tabular} & $\begin{array}{l}35,70 \\
38,71\end{array}$ & \begin{tabular}{|l|}
$402,02,07$ \\
492
\end{tabular} & $\begin{array}{l}1,24 \\
60,22\end{array}$ & $\begin{array}{l}\mid 1,47 \\
11,71 \\
\end{array}$ & $\begin{array}{l}30,91 \\
36,64\end{array}$ & $\begin{array}{l}11,10 \\
168,50\end{array}$ & \begin{tabular}{|l|l|}
58,69 \\
58,69
\end{tabular} & $\begin{array}{l}00,59 \\
59,31\end{array}$ & $\begin{array}{l}152,82 \\
148,05\end{array}$ \\
\hline Epidalea calamita & 30TTL62 & 100,00 & 116,47 & 115,31 & \begin{tabular}{l|l|}
38,95 \\
\end{tabular} & 6219,87 & 290,42 & $-2,82$ & 293,24 & 76,27 & 199,71 & 199,86 & 41,25 & 462,77 & 57,19 & 11,12 & 37,00 & 160,84 & 56,27 & 56,35 & 137,50 \\
\hline Epidalea calamita & 30TTL63 & 100,00 & 119,51 & 116,51 & 39,01 & 6228,66 & 293,60 & $-0,62$ & 294,22 & 79,06 & 202,72 & 202,72 & 43,67 & 431,98 & 54,71 & 10,97 & 37,70 & 153,08 & 53,65 & 53,65 & 125,65 \\
\hline Epidalea calamita & 30TTL64 & 100,00 & 120,29 & 116,82 & 39,05 & 6221,36 & 294,10 & $-0,18$ & 294,27 & 80,06 & 203,19 & 203,19 & 44 & 413,41 & 52,97 & 10,68 & 38,41 & 148,23 & 52,13 & 52,13 & 118,31 \\
\hline Epidalea calamita & 30TTL65 & 100,00 & 118,88 & 116,50 & 39,01 & 6191,56 & 292,08 & $\begin{array}{l}-1,21 \\
-1,21 \\
\end{array}$ & 293,29 & 78,72 & 201,26 & 201,26 & 433,07 & $\begin{array}{l}413,41 \\
410,75 \\
\end{array}$ & 52,21 & $\begin{array}{l}0,009 \\
10,97\end{array}$ & 37,74 & $\begin{array}{l}40,505 \\
146,54\end{array}$ & 53,00 & 53,00 & 116,99 \\
\hline Epidalea calamita & 30TTL66 & 100,00 & 114,36 & 115,74 & 39,00 & 6172,04 & 287,32 & $-5,11$ & 292,43 & 74,34 & 196,24 & 196,68 & 39,04 & 426,80 & 53,56 & 11,65 & 36,71 & 150,57 & 56,11 & 56,36 & 122,45 \\
\hline Epidalea calamita & 30TTL67 & 100,00 & 115,36 & 115,55 & 39,00 & 6155,89 & 287,85 & $-4,08$ & 291,93 & 75,61 & 196,41 & 197,42 & 40,03 & 417,49 & 52,16 & 11,57 & 36,18 & 146,45 & 55,03 & 55,53 & 119,99 \\
\hline Epidalea calamita & 30TTL68 & 100,00 & 119,86 & 115,30 & 39,00 & 6157,26 & 291,68 & $-0,43$ & 292,11 & 80,01 & 199,99 & 201,51 & 43,94 & 390,48 & 48,65 & 10,34 & 35,71 & 136,31 & 51,33 & 52,09 & 111,71 \\
\hline Epidalea calamita & 30TTL69 & 100,00 & 122,06 & 115,03 & 39,00 & 6155,46 & 293,29 & 0,89 & 292,40 & 82,50 & 201,72 & 203,25 & 45,71 & 378,28 & 47,02 & 9,83 & 35,32 & 131,58 & 49,88 & 50,85 & 107,96 \\
\hline Epidalea calamita & $30 T T L$ & 100,00 & $\frac{118}{118}$ & $\begin{array}{l}111,05 \\
114,98\end{array}$ & 38,57 & $\begin{array}{l}61519,40 \\
6219,90\end{array}$ & 293,06 & $\begin{array}{c}-1,05 \\
-1,30\end{array}$ & $\begin{array}{l}294,36 \\
294\end{array}$ & $\begin{array}{ll}78,33 \\
78,3\end{array}$ & $\begin{array}{l}201,28 \\
20\end{array}$ & \begin{tabular}{|l|}
202,53 \\
\end{tabular} & $\begin{array}{l}43,11 \\
43,78\end{array}$ & \begin{tabular}{|l|l|}
458,78 \\
48,0
\end{tabular} & $\begin{array}{l}34,1,16 \\
55,16\end{array}$ & \begin{tabular}{|c|}
3,00 \\
11,02
\end{tabular} & $\begin{array}{ll}35,52 \\
35,67\end{array}$ & \begin{tabular}{|l|}
153,44 \\
15,4
\end{tabular} & $\begin{array}{l}5,00 \\
55,54\end{array}$ & $\begin{array}{l}0,0,09 \\
56,09\end{array}$ & 135,18 \\
\hline Epidalea calamita & 30TTL71 & 100,00 & 115,19 & 115,41 & 38,99 & 6196,44 & 289,38 & $-4,39$ & 293,77 & 74,78 & 196,90 & 198,69 & 40,55 & 461,69 & 55,62 & 11,56 & 35,19 & 154,96 & 57,72 & 58,52 & 134,75 \\
\hline Epidalea calamita & 30TTL72 & 100,00 & 116,09 & 116,63 & 39,11 & 6185,27 & 290,35 & $-3,85$ & 294,19 & 75,68 & 198,19 & 199,27 & 41,39 & $\mid 443,39$ & 53,56 & 11,38 & 35,13 & 150,09 & 56,90 & 57.37 & 127,97 \\
\hline Epidalea calamita & 30TTL73 & 100,00 & 120,48 & 118,22 & 39,59 & 6217,77 & 295,16 & $-0,53$ & 295,68 & 79,94 & 203,51 & 203,67 & 44,79 & 414,32 & 50,82 & 10,99 & 35,68 & 142,51 & 53,90 & 53,97 & 118,64 \\
\hline Epidalea calamita & 30TTL74 & 100,00 & 119,74 & 118,07 & 39,74 & 6189,04 & 293,94 & $-1,06$ & 295,01 & 79,43 & 202 & 202,54 & 44 & 397,47 & 49,66 & 10,92 & 36,87 & 139,32 & 53,40 & 53,40 & 105 \\
\hline Epidalea calamita & $\begin{array}{l}30 T T L 75 \\
\end{array}$ & $\begin{array}{l}100,00 \\
\end{array}$ & 118,14 & $\begin{array}{ll}11,0,07 \\
117,62\end{array}$ & 39,62 & $\begin{array}{l}\mid l 10,040 \\
6170,04\end{array}$ & $\begin{array}{l}293,54,09 \\
292,0\end{array}$ & $\begin{array}{l}-1,00 \\
-1,89 \\
\end{array}$ & \begin{tabular}{|l|}
293,97 \\
\end{tabular} & $\begin{array}{l}\mid 7,435 \\
78,08\end{array}$ & \begin{tabular}{|l|}
200,762 \\
\end{tabular} & \begin{tabular}{|l|}
200,92 \\
\end{tabular} & $\begin{array}{l}44,50 \\
43,20\end{array}$ & \begin{tabular}{|l|}
394,41 \\
394,29
\end{tabular} & \begin{tabular}{|l|}
49,000 \\
49,
\end{tabular} & $\begin{array}{l}0,325 \\
11,00 \\
\end{array}$ & $\begin{array}{l}0,01 \\
36,49\end{array}$ & \begin{tabular}{|l|}
137,82 \\
137,
\end{tabular} & $\begin{array}{l}5,40 \\
53,90\end{array}$ & $\begin{array}{l}3,40 \\
53,96\end{array}$ & $\begin{array}{l}108,48 \\
108,\end{array}$ \\
\hline Epidalea calamita & 30TTL76 & 100,00 & 115,98 & 116,93 & 39,04 & 6154,60 & 289,42 & $-4,00$ & 293,42 & 75,96 & 197,03 & 198,15 & 40,83 & 399,35 & 49,00 & 11,38 & 35,69 & 138,35 & 54,94 & 55,48 & 110,35 \\
\hline Epidalea calamita & 30TTL77 & 100,00 & 115,30 & 116,42 & 39,02 & 6142,99 & 288,43 & $-4,77$ & 293,20 & 75,46 & 195,38 & 197,22 & 40,21 & 399,37 & 48,49 & 11,80 & 34,90 & 137,61 & 55,20 & 56,19 & 110,71 \\
\hline Epidalea calamita & 30TTL78 & 100,00 & 119,71 & 116,10 & 39,00 & 6150,08 & 292,16 & $-0,90$ & 293,06 & 79,96 & 199,2 & 201, & 43, & 375,74 & 45,45 & 10,79 & 34,65 & 12 & 51,47 & 52,77 & 103 \\
\hline Epidalea calamita & 30TTL82 & 100,00 & 117,57 & 117,17 & 39,34 & 6116,41 & 290,95 & $-2,46$ & 293,41 & 77,21 & 197,13 & 200,08 & 43,72 & 421,53 & 50,03 & 11,24 & 33,00 & 137,38 & 56,54 & 57,75 & 118,50 \\
\hline
\end{tabular}




\begin{tabular}{|c|c|c|c|c|c|c|c|c|c|c|c|c|c|c|c|c|c|c|c|c|c|}
\hline TAXON & UTM & $\mathrm{km} 2$ & B101 & B102 & $\mathrm{BIO3}$ & 8104 & B105 & B106 & B107 & B108 & B109 & B1010 & B1011 & BIO12 & B1013 & BIO14 & BIO15 & B1016 & B1017 & BIO18 & B1019 \\
\hline Epidalea calamita & 30TTL83 & 100,00 & 120,42 & 118,34 & 40,00 & 6087,64 & 293,26 & $-0,31$ & 293,57 & 79,91 & 199,28 & 202,43 & 46,64 & 400,26 & 47,40 & 11,00 & 32,46 & 130,21 & 54,99 & 56,17 & 111,81 \\
\hline Epidalea calamita & 30TTL84 & 100,00 & 118,22 & 118,05 & 40,00 & 6094,94 & 291,11 & $-2,11$ & 293,22 & 77,77 & 197,44 & 200,09 & 44,13 & 395,58 & 47,83 & 11,05 & 33,18 & 130,74 & 55,48 & 56,54 & 108,39 \\
\hline Epidalea calamita & 30TTL85 & 100,00 & 117,38 & 117,95 & 39,95 & 6110,75 & 290,40 & $-3,05$ & 293,45 & 76,89 & 196,71 & 199,36 & 43,06 & 390,23 & 47,82 & 11,22 & 33,78 & 130,64 & 55,23 & 56,36 & 105,81 \\
\hline Epidalea calamita & 30TTL86 & 100,00 & 114,99 & 117,17 & 39,21 & 6118,82 & 288,09 & $-5,01$ & 293,10 & 74,80 & 194,29 & 196,82 & 40,29 & 395,85 & 48,46 & 11,95 & 33,60 & 132,92 & 56,56 & 57,97 & 107,10 \\
\hline Epidalea calamita & 30TTL88 & 100,00 & 120,04 & $\begin{array}{lll}116,87 & \end{array}$ & 39,00 & $\begin{array}{ll}6129,04 \\
\end{array}$ & 292,54 & $-0,96$ & 293,50 & 80,56 & 199,23 & 201,35 & 44,43 & 369,22 & 44,14 & 11,29 & 33,43 & 124,61 & 52,34 & 54,01 & 99,94 \\
\hline Epidalea calamita & 30TTL91 & 100,00 & 117,60 & 116,18 & 39,00 & 6136,11 & 291,29 & $-2,71$ & 294,00 & 77,22 & 197,47 & 200,64 & 43,65 & 418,35 & 50,18 & 11,39 & 32,73 & 133,71 & 56,42 & 58,07 & 115,02 \\
\hline Epidalea calamita & 30TTL92 & 100,00 & 119,23 & 117,02 & 39,26 & 6087,00 & 291,85 & $-1,21$ & 293,05 & 78,44 & 197,85 & 201,35 & 45,51 & 402,74 & 48,03 & 11,02 & 31,95 & 127,79 & 55,75 & 57,51 & 110,08 \\
\hline Epidalea calamita & \begin{tabular}{|l|l|}
$30 T T L 93$ \\
\end{tabular} & 100,00 & 119,44 & 117,50 & 39,96 & 6030,78 & 291,30 & \begin{tabular}{|c|c|c|}
$-0,79$ \\
-12
\end{tabular} & 292,09 & 78,96 & $\begin{array}{l}197,04 \\
\end{array}$ & 200,89 & 46,37 & \begin{tabular}{|l|}
391,78 \\
\end{tabular} & 46,69 & 11,02 & 31,25 & 123,57 & 55,69 & 57,79 & 106,13 \\
\hline Epidalea calamita & 30TTL94 & 100,00 & 117,14 & 117,62 & 39,89 & 6042,23 & 289,38 & $-2,95$ & 292,33 & 76,99 & 195,08 & 198,61 & 43,79 & 392,83 & 47,39 & 11,57 & 31,49 & 125,51 & 56,71 & 58,87 & 105,48 \\
\hline Epidalea calamita & 30TTL95 & 100,00 & 117,80 & 117,64 & 39,72 & 6069,91 & 290,40 & $-2,62$ & 293,02 & 77,74 & 196,23 & 199,40 & 44,09 & 383,52 & 46,63 & 11,36 & 32,12 & 124,15 & 55,46 & 57,44 & 102,38 \\
\hline Epidalea calamita & 30TTL96 & 100,00 & 117,16 & 117,26 & 39,36 & 6097,63 & 290,05 & $-3,19$ & 293,24 & 77,09 & 196,05 & 198,89 & 42,75 & 382,61 & 46,59 & 11,75 & 32,22 & 124,92 & 55,61 & 57,70 & 102,01 \\
\hline Epidalea calamita & 30TTL99 & 100,00 & 123,40 & 116,79 & 39,00 & 6113,62 & 295,29 & 1,44 & 293,85 & 84,35 & 202,00 & 204,42 & 47,40 & 361,10 & 42,50 & 11,65 & 32,23 & 120,58 & 52,20 & 54,24 & 97,04 \\
\hline Epidalea calamita & 30TTM50 & 100,00 & 118,92 & 114,25 & 39,00 & 619,15 & 289,53 & $\begin{array}{c}-1,20 \\
-1,20 \\
\end{array}$ & 290,73 & $\mid 79,56$ & 199,50 & \begin{tabular}{|l|l|}
199,86 \\
\end{tabular} & 43,12 & 425,39 & 54,04 & 11,10 & 35,80 & $\begin{array}{l}150,07 \\
150\end{array}$ & 54,46 & 54,70 & 128,83 \\
\hline Epidalea calamita & 30TTM51 & 100,00 & 118,76 & 114,38 & 39,00 & 6098,89 & 289,06 & $-1,49$ & 290,55 & 79,56 & 199,21 & 199,38 & 42,84 & 432,61 & 54,87 & 11,70 & 35,37 & 152,99 & 56,31 & 56,41 & 131,65 \\
\hline Epidalea calamita & 30TTM52 & 95,00 & 116,33 & 114,59 & 39,00 & 6081,45 & 286,63 & $-3,58$ & 290,21 & 77,34 & 196,83 & 196,83 & 40,68 & 452,17 & 57,37 & 13,01 & 34,89 & 160,40 & 60,13 & 60,13 & 138,52 \\
\hline Epidalea calamita & 30TTM53 & 90,00 & 116,54 & 114,76 & 39,00 & 6052,98 & 286,48 & $-3,53$ & 290,01 & 77,97 & 196,54 & 196,54 & 41,24 & 461,58 & 58,57 & 13,78 & 34,71 & 164,57 & 62,22 & 62,22 & 141,87 \\
\hline Epidalea calamita & 30TTM56 & 80,00 & 115,43 & 114,79 & 39,02 & 5976,23 & 283,90 & $-4,84$ & 288,73 & 77,50 & 194,25 & 194,25 & 40,71 & 500,38 & 63,39 & 16,95 & 34,12 & 181,13 & 71,15 & 71,15 & 153,10 \\
\hline Epidalea calamita & 30TTM60 & 100,00 & 120,34 & 115,00 & 39,00 & 6131,49 & 291,38 & $-0,43$ & 291,81 & 80,93 & $\begin{array}{l}199,72 \\
\end{array}$ & 201,24 & 44,30 & 389,94 & 48,50 & 10,63 & 34,65 & 135,93 & 52,24 & 53,13 & 112,21 \\
\hline Epidalea calamita & 30TTM61 & 100,00 & 120,34 & 115,00 & 39,00 & 6111,14 & 291,01 & $-0,41$ & 291,42 & 80,98 & 200,24 & 200,94 & 44,43 & 400,67 & 49,91 & 11,19 & 34,43 & 140,49 & 54,41 & 54,76 & 116,63 \\
\hline Epidalea calamita & 30тTM62 & 100,00 & 120,20 & 115,04 & $39,00 \mid$ & 6087,90 & 290,52 & $-0,55$ & 291.06 & 81.15 & 200,17 & 200,39 & 44.52 & 413,72 & 51,54 & 12,11 & 34,03 & 145,85 & 57,31 & 57,43 & 121,43 \\
\hline Epidalea calamita & 30TTM63 & 100,00 & 119,25 & 115,18 & 39,00 & 6062,60 & 289,37 & $-1,77$ & 291,14 & 80,81 & 199,31 & 199,31 & 43,73 & 429,64 & 53,5 & 13,31 & 33,78 & 152,42 & 60,47 & 60,47 & 126,97 \\
\hline Epidalea calamita & 30TTM64 & 100,00 & 118,42 & 115,20 & 39,00 & 6033,58 & 288,30 & $-2,81$ & 291,11 & 80,39 & 198,16 & 198,16 & 43,04 & 445,77 & 55,58 & 14,38 & 33,53 & 159,09 & 63,73 & 63,73 & 132,16 \\
\hline Epidalea calamita & 30TTM68 & 100,00 & 115,66 & 115,14 & 39,30 & 5920,82 & 283,44 & $-4,84$ & 288,27 & 78,75 & 193,59 & 193,59 & 41,14 & 510,51 & 65,92 & 19,61 & 33,18 & 186,15 & 78,70 & 78,70 & 149,35 \\
\hline Epidalea calamita & 30TTM70 & 100,00 & 123,60 & 115,39 & 39,00 & 6134,25 & 294,63 & 1,73 & 292,90 & 84,40 & 202,34 & 204,45 & 47,04 & 363,72 & 44,02 & 10,25 & 33,86 & 125,23 & 50,36 & 51,65 & 100,75 \\
\hline Epidalea calamita & 30TTM72 & 100,00 & 121,22 & 115,76 & 39,00 & 6085,42 & 292,07 & $-0,26$ & 292,33 & 82,42 & 200,30 & 201,51 & 45,26 & 396,00 & 48,23 & 12,26 & 33,17 & 138,25 & 56,89 & 57,44 & 112,25 \\
\hline Epidalea calamita & 30TTM75 & 100,00 & 119,06 & 115,99 & 39,01 & 6000,19 & 289,02 & $-2,23$ & 291,25 & 81,85 & 198,19 & 198,19 & 43,90 & 441,94 & 55,03 & 15,57 & 32,62 & 157,67 & 66,79 & 66,79 & 126,77 \\
\hline Epidalea calamita & 30TTM80 & 100,00 & 121,60 & 116,17 & 39,01 & 6115,09 & 293,37 & 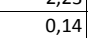 & 293,23 & $\begin{array}{ll}82,48 \\
82\end{array}$ & 200,24 & 202,43 & 45,55 & 368,92 & 43,55 & 11,36 & 32,91 & 125,50 & 52,76 & 54,50 & 100,62 \\
\hline Epidalea calamita & 30TTM81 & 100,00 & 121,71 & 116,06 & 39,00 & 6095,45 & 293,17 & 0,01 & 293,16 & 82,96 & 200,07 & 202,17 & 45,78 & 377,01 & 44,77 & 11,90 & 32,52 & 129,05 & 54,64 & 56,07 & 103,53 \\
\hline Epidalea calamita & 30TTM82 & 100,00 & 121,96 & 116,00 & 39,00 & 6064,74 & 292,99 & $-0,03$ & 293,02 & 83,87 & 199,86 & 201,93 & 46,20 & 386,85 & 46,24 & 12,59 & 32,27 & 133,54 & 56,88 & 58,06 & 107,09 \\
\hline Epidalea calamita & 30TTM83 & 100,00 & 121,46 & 116,04 & 39,00 & 6028,39 & 292,09 & $-0,39$ & 292,48 & 84,00 & 199,86 & 200,99 & 46,17 & 400,38 & 48,43 & 13,59 & 31,92 & 139,41 & 60,23 & 60,83 & 111,39 \\
\hline Epidalea calamita & 30TTM84 & 100,00 & 119,90 & 116,05 & 39,03 & 6009,51 & 290,27 & $-2,04$ & 292,31 & 82,80 & 198,69 & 199,16 & 44,65 & 418,84 & 51,22 & 14,87 & 31,77 & $\begin{array}{l}146,78 \\
\end{array}$ & 64,48 & 64,70 & 116,88 \\
\hline Epidalea calamita & 30TTM87 & 100,00 & 117,81 & 116,00 & 39,49 & 5920,41 & 286,75 & $\begin{array}{l}-3,045 \\
-3,75 \\
\end{array}$ & 290,50 & $\begin{array}{ll}81,81 \\
81\end{array}$ & 195,85 & $\begin{array}{l}195,85 \\
\end{array}$ & 43,28 & \begin{tabular}{|l|}
466,17 \\
46,04
\end{tabular} & $\begin{array}{l}1,26 \\
59,07 \\
\end{array}$ & \begin{tabular}{|l|}
18,60 \\
18,0
\end{tabular} & 31,97 & \begin{tabular}{|l|}
167,09 \\
167,09
\end{tabular} & $\begin{array}{l}74,465 \\
75,59\end{array}$ & 75,59 & 129,48 \\
\hline Epidalea calamita & 30TTM89 & 100,00 & 115,22 & 115,85 & \begin{tabular}{|l|l|}
39,87 \\
\end{tabular} & 5866,60 & 283,20 & $-6,04$ & 289,24 & 79,92 & 192,64 & 192,64 & 41,29 & 504,66 & 65,27 & 21,97 & 32,22 & 183,22 & 85,25 & 85,25 & 138,31 \\
\hline Epidalea calamita & 30TTM92 & 100,00 & 120,89 & 116,64 & 39,00 & 6061,87 & 292,44 & $-1,17$ & 293,61 & 83,17 & 198,99 & 201,06 & 45,29 & 389,62 & 46,38 & 13,51 & 31,44 & 132,64 & 58,42 & 60,35 & 106,25 \\
\hline Epidalea calamita & 30TTM93 & 100,00 & 121,63 & 116,31 & 39,02 & 6017,12 & 292,34 & $-0,49$ & 292,83 & 84,57 & 199,03 & 201,21 & 46,42 & 398,03 & 48,02 & 14,06 & 31,29 & 136,86 & 60,54 & 62,02 & 108,93 \\
\hline Epidalea calamita & 30TTM98 & 100,00 & 115,31 & 115,94 & 39,65 & 5873,47 & 283,65 & $-6,28$ & 289,93 & 80,58 & 192,79 & 192,79 & 41,40 & 486,16 & 61,73 & 21,00 & 31,12 & 173,32 & 82,64 & 82,64 & 131,60 \\
\hline Epidalea calamita & 30TTN61 & 100,00 & 109,29 & 114,10 & 39,99 & 5768,96 & 273,99 & $\begin{array}{l}-9,38 \\
-9,38 \\
\end{array}$ & 283,37 & 73,76 & 185,24 & 185,24 & 36,90 & 590,31 & 77,69 & 25,53 & 32,54 & 215,87 & 96,86 & 96,86 & 168,97 \\
\hline Epidalea calamita & 30TTN62 & 100,00 & 104,34 & 112,87 & 40,00 & 5683,40 & 266,90 & $-12,56$ & 279,46 & 69,82 & 179,35 & 179,35 & 33,50 & 640,29 & 84,06 & 28,65 & 31,66 & 232,06 & 106,62 & 106,62 & 182,98 \\
\hline Epidalea calamita & 30TTN63 & 100,00 & 97,88 & 110,95 & 40,00 & 5567,66 & 257,41 & $-16,42$ & 273,84 & 64,54 & 171,46 & 171,46 & 28,97 & 704,86 & 91,85 & 32,32 & 30,37 & 252,02 & $\mid 118,46$ & 118,46 & 202,02 \\
\hline Epidalea calamita & 30TTN64 & 100,00 & 88,79 & 108,26 & 40,01 & 5445,67 & 244,62 & $-22,48$ & 267,11 & 56,85 & 160,94 & 160,94 & 22,20 & 795,50 & 102,14 & 37,00 & 28,97 & 279,16 & 134,13 & 134,13 & 230,18 \\
\hline Epidalea calamita & 30TTN66 & 100,00 & 75,87 & 102,94 & 40,22 & 5193,28 & 223,88 & $-29,61$ & 253,49 & 46,30 & 144,83 & 144,96 & 13,51 & 955,68 & 120,26 & 45,30 & 27,28 & 325,99 & 161,73 & 162,86 & 279,55 \\
\hline Epidalea calamita & 30TTN70 & 100,00 & 111,83 & 115,86 & 39,87 & \begin{tabular}{|l|l|}
5876,95 \\
\end{tabular} & 279,96 & $\begin{array}{l}-8,85 \\
-8,0\end{array}$ & 288,81 & 76,08 & 189,31 & 189,31 & 37,82 & 541,07 & 70,76 & 23,03 & 32,95 & 198,52 & 90,65 & 90,65 & 151,22 \\
\hline Epidalea calamita & 30TTN71 & 100,00 & 108,29 & 115,51 & 39,98 & 5833,44 & 275,83 & $-11,51$ & 287,33 & 72,84 & 185,29 & 185,29 & 35,15 & 574,51 & 75,41 & 23,60 & 32,70 & 210,81 & 98,28 & 98,28 & 159,69 \\
\hline Epidalea calamita & 30TTN72 & 100,00 & 101,50 & 113,74 & 39,99 & 5728,56 & 266,30 & $-16,17$ & 282,47 & 67,27 & 177,26 & 177,26 & 30,08 & 637,13 & 83,05 & 28,18 & 31,32 & 230,49 & 109,92 & 109,92 & 178,09 \\
\hline Epidalea calamita & 30TTN73 & 100,00 & 96,86 & 111,50 & 40,00 & 5591,34 & 257,71 & $-18,05$ & 275,76 & 63,91 & 170,84 & 170,84 & 27,56 & 694,81 & 90,14 & 32,83 & 29,98 & 247,84 & 120,24 & 120,24 & 195,01 \\
\hline Epidalea calamita & 30TTN74 & 100,00 & 83,51 & 107,91 & 39,82 & $\begin{array}{l}5452,56 \\
\end{array}$ & 240,04 & $-27,45$ & 267,49 & 52,10 & 155,92 & $\begin{array}{l}150,94 \\
15,92\end{array}$ & 17,04 & \begin{tabular}{|l|}
818,40 \\
\end{tabular} & $\begin{array}{r}03,75 \\
103,75\end{array}$ & $\begin{array}{l}2,05 \\
39,17 \\
\end{array}$ & 28,25 & \begin{tabular}{|l|}
284,09 \\
\end{tabular} & 140,87 & 140,88 & 234,68 \\
\hline Epidalea calamita & 30TTN75 & 100,00 & 78,74 & 105,74 & 39,91 & 5340,06 & 231,84 & $-29,75$ & 261,59 & 48,48 & 149,70 & 149,71 & 14,15 & 879,32 & 110,85 & 42,46 & 27,29 & 302,26 & 151,78 & 151,81 & 252,92 \\
\hline Epidalea calamita & 30TTN80 & 100,00 & 113,69 & 115,72 & 39,90 & 5842,43 & 281,21 & $-7,17$ & 288,38 & 78,73 & 190,70 & 190,70 & 39,93 & 525,78 & 68,56 & 22,37 & 32,40 & 191,86 & 90,45 & 90,45 & 143,16 \\
\hline Epidalea calamita & 30TTN81 & 100,00 & 112,09 & 115,44 & 39,99 & 5801,20 & 278,79 & $-8,02$ & 286,81 & 77,48 & 188,47 & 188,47 & 38,95 & 549,74 & 72,17 & 22,12 & 32,53 & 201,18 & 96,41 & 96,41 & 148,43 \\
\hline Epidalea calamita & 30TTN82 & 100,00 & 108,29 & 114,24 & 40,00 & 5713,11 & 272,77 & $-10,27$ & 283,04 & 74,53 & 183,56 & 183,56 & 36,55 & 591,44 & 77,61 & 24,31 & 31,73 & 95 & 104,96 & 104,96 & 159,59 \\
\hline Epidalea calamita & $\begin{array}{l}\text { 30TTN90 } \\
\end{array}$ & 100,00 & $\frac{11}{11}$ & $\begin{array}{l}1144,24 \\
114,52\end{array}$ & 39,93 & 5754,04 & 280,47 & \begin{tabular}{|c|c|c|}
$-4,69$ \\
-12
\end{tabular} & \begin{tabular}{|l|}
285,1646 \\
285,
\end{tabular} & \begin{tabular}{|l|l|}
42,10 \\
8
\end{tabular} & \begin{tabular}{|l|}
191,30 \\
190
\end{tabular} & \begin{tabular}{|l|}
191,30 \\
190
\end{tabular} & $\begin{array}{l}30,03 \\
42,93\end{array}$ & $\mid \begin{array}{l}\mid 51,44,09 \\
521\end{array}$ & $\begin{array}{l}11,01 \\
67,51 \\
\end{array}$ & \begin{tabular}{|l|l|}
23,59 \\
23,5
\end{tabular} & 31,24 & \begin{tabular}{|l|}
187,63 \\
\end{tabular} & 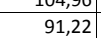 & $\begin{array}{r}01,50 \\
91,22\end{array}$ & $\begin{array}{l}139,00 \\
139,00\end{array}$ \\
\hline Epidalea calamita & 30TTN91 & 100,00 & 112,42 & 114,10 & 39,99 & 5708,68 & 276,63 & $-6,76$ & 283,39 & 79,24 & 187,61 & 187,61 & 40,64 & 551,70 & 71,77 & 24,11 & 31,20 & 198,91 & 98,15 & 98,15 & 146,58 \\
\hline Epidalea calamita & 30TTN92 & 100,00 & 107,67 & 113,09 & 40,00 & 5642,44 & 270,31 & $-10,03$ & 280,35 & 75,30 & \begin{tabular}{|l|}
182,14 \\
\end{tabular} & 182,14 & 36,94 & 595,94 & 77,47 & 26,22 & 30,55 & 213,70 & 107,31 & 107,31 & 158,62 \\
\hline Epidalea calamita & 30TTN94 & 100,00 & 93,59 & 108,77 & 40,01 & 5418,02 & 249,74 & $-18,79$ & 268,53 & 63,35 & 165,26 & 165,26 & 26,95 & 733,11 & 93,67 & 36,51 & 27,87 & 255,42 & 132,52 & 132,52 & 199,38 \\
\hline Epidalea calamita & 30TTN95 & 100,00 & 76,79 & 105,17 & 39,78 & 5315,46 & 229,65 & $-31,55$ & 261,19 & 47,66 & 147,52 & 147 & 12 & 876 & 108,91 & 44,02 & 26,10 & 296,94 & 156,47 & 156,71 & 245,86 \\
\hline Epidalea calamita & \begin{tabular}{|l|l|} 
30TUKO3 \\
\end{tabular} & $\begin{array}{l}100,00 \\
\end{array}$ & 156,90 & $\begin{array}{l}10,17 \\
114,99\end{array}$ & | & 6503,86 & $\begin{array}{l}24,05 \\
335,39\end{array}$ & 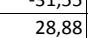 & \begin{tabular}{|l|}
206,51 \\
306
\end{tabular} & \begin{tabular}{|l|}
41,006 \\
114,68
\end{tabular} & $\begin{array}{l}41,325 \\
243,94 \\
\end{array}$ & \begin{tabular}{|l|}
243,94 \\
243
\end{tabular} & $\begin{array}{l}\mid 2,, 539 \\
76,89\end{array}$ & \begin{tabular}{|l|l|}
361,34 \\
364
\end{tabular} & \begin{tabular}{|c|c|}
40,13 \\
42,13
\end{tabular} & $\begin{array}{r}5,25 \\
5,25\end{array}$ & $\begin{array}{l}0,101 \\
40,71\end{array}$ & \begin{tabular}{|l|}
122,40 \\
12,4
\end{tabular} & $\begin{array}{r}\mid 0,0,4 ! \\
33,81 \\
\end{array}$ & $\begin{array}{r}33,11 \\
33,81 \\
\end{array}$ & $\begin{array}{l}24,00 \\
106,76\end{array}$ \\
\hline Epidalea calamita & 30TUK04 & 100,00 & 152,48 & 114,92 & 37,00 & 6473,37 & 330,21 & 25,06 & 305,15 & 110,58 & 239,14 & 239,14 & 72,90 & 365,59 & 42,55 & 6,31 & 39,21 & 122,56 & 36,52 & 36,52 & 106,51 \\
\hline Epidalea calamita & 30TUK05 & 100,00 & 91,60 & 111,19 & 36,98 & 6312,57 & 270,40 & $-26,92$ & 297,31 & 37,66 & 177,25 & 178,03 & 18,63 & 640,32 & 74,19 & 17,84 & 34,65 & 206,66 & 76,97 & 80,68 & 186,89 \\
\hline Epidalea calamita & 30TUK06 & 100,00 & 80,47 & 110,13 & 36,98 & 6240,22 & 258,27 & $-35,89$ & 294,16 & 23,13 & 165,30 & 166,20 & 9, & 683,23 & 79,23 & 20,24 & 33,51 & 219,28 & 84,51 & 89,35 & 198, \\
\hline Epidalea calamita & $\begin{array}{l}\text { 30TUK07 } \\
\end{array}$ & 100,00 & 76,67 & 109,66 & 37,02 & 6199,42 & 253,59 & $-38,70$ & 292,29 & 15,36 & 161,19 & 161,95 & 5,96 & $\begin{array}{l}693,74 \\
\end{array}$ & 80,34 & 21,14 & 32,93 & 222,01 & 87,41 & 93,44 & 200,16 \\
\hline
\end{tabular}




\begin{tabular}{|c|c|c|c|c|c|c|c|c|c|c|c|c|c|c|c|c|c|c|c|c|c|}
\hline TAXON & UTM & $\mathrm{km} 2$ & B101 & B102 & $\mathrm{BIO3}$ & BIO4 & B105 & B106 & B107 & B108 & B109 & BIO10 & BIO11 & BIO12 & 81013 & BIO14 & BIO15 & B1016 & B1017 & 81018 & B1019 \\
\hline Epidalea calamita & 30TUK08 & 100,00 & 105,93 & 113,03 & 37,83 & 6234,50 & 282,07 & $-14,19$ & 296,26 & 64,14 & 188,86 & 190,86 & 32,37 & 495,59 & 60,24 & 14,20 & 33,61 & 157,74 & 64,29 & 66,78 & 136,18 \\
\hline Epidalea calamita & 30TUK13 & 100,00 & 153,80 & 115,00 & 37,00 & 6529,68 & 332,82 & 25,31 & 307,51 & 111,49 & 241,18 & 241,18 & 73,63 & 362,19 & 41,65 & 5,97 & 39,65 & 121,37 & 35,44 & 35,44 & 104,84 \\
\hline Epidalea calamita & 30TUK14 & 100,00 & 151,35 & 114,68 & 37,00 & 6499,67 & 329,40 & 23,35 & 306,06 & 109,40 & 238,49 & 238,49 & 71,49 & 361,03 & 41,78 & 6,41 & 38,95 & 120,26 & 36,98 & 36,98 & 103,24 \\
\hline Epidalea calamita & 30TUK15 & 100,00 & 107,17 & 112,56 & 37,00 & 6357,38 & 286,19 & $-14,32$ & 300,52 & 71,97 & 192,81 & 193,76 & 32,42 & 526,62 & 62,91 & 14,19 & 34,84 & 168,06 & 64,68 & 66,84 & 147,18 \\
\hline Epidalea calamita & 30TUK16 & 100,00 & 82,40 & 110,78 & 37,00 & 6241,99 & 260,71 & $-34,80$ & 295,51 & 35,77 & \begin{tabular}{|l|l|}
167,32 \\
\end{tabular} & \begin{tabular}{|l|}
168,13 \\
\end{tabular} & 10,85 & \begin{tabular}{ll|}
646,15 \\
\end{tabular} & 76,49 & 19,65 & 32,89 & 203,86 & 82,49 & 87,53 & 181,66 \\
\hline Epidalea calamita & 30TUK17 & 100,00 & 79,97 & 110,37 & 37,01 & 6204,22 & 257,10 & $-36,50$ & 293,60 & 31,32 & 164,45 & 165,12 & 9,03 & 648,18 & 77,16 & 20,45 & 32,38 & 203,69 & 84,44 & 89,93 & 181,01 \\
\hline Epidalea calamita & 30TUK18 & 100,00 & 85,68 & 110,95 & 37,17 & 6184,79 & 261,81 & $-31,63$ & 293,44 & 40,94 & 169,28 & 170,44 & 14,40 & 600,66 & 72,73 & 19,18 & 32,23 & 188,44 & 80,13 & 85,09 & 164,78 \\
\hline Epidalea calamita & \begin{tabular}{|l|} 
30TUK19 \\
\end{tabular} & 100,00 & 92,96 & 111,70 & 37,53 & 6162,45 & 268,20 & $-25,55$ & 293,75 & 55,26 & 175,56 & 177,18 & 21,10 & 536,76 & 66,86 & 17,20 & 32,19 & 168,07 & 73,77 & 77,81 & 143,09 \\
\hline Epidalea calamita & 30TUK23 & 100,00 & 151,83 & 114,95 & 37,00 & 6558,41 & 331,25 & 23,05 & 308,19 & 109,52 & 239,88 & 239,88 & 71,45 & 361,57 & 41,58 & 6,19 & 39,18 & 120,32 & 36,54 & 36,54 & 102,94 \\
\hline Epidalea calamita & 30TUK24 & 100,00 & 148,45 & 114,23 & 37,00 & 6501,82 & 326,70 & 20,22 & 306,48 & 106,40 & 235,77 & 235,77 & 68,69 & 362,49 & 42,40 & 6,90 & 38,08 & 119,71 & 38,77 & 38,77 & 101,54 \\
\hline Epidalea calamita & 30TUK25 & 100,00 & 135,47 & 113,90 & 37,00 & 6441,15 & 313,42 & 9,08 & 304,35 & 104,99 & 222,13 & 222,33 & 57,18 & 389,31 & 47,34 & 8,90 & 36,26 & 126,13 & 46,22 & 46,31 & 105,63 \\
\hline Epidalea calamita & 30TUK28 & 100,00 & 80,02 & 110,48 & 37,01 & 6176,16 & 256,19 & $-36,62$ & 292,81 & 47,95 & 163,94 & 164,79 & 9,42 & 625,94 & 76,25 & 21,04 & 31,64 & 195,47 & 85,60 & 91,35 & 169,35 \\
\hline Epidalea calamita & 30TUK29 & 100,00 & 97,39 & 111,69 & 37,25 & 6172,59 & 272,32 & $-22,07$ & 294,39 & 77,13 & 179,98 & 181,63 & 24,99 & 497,97 & 64,06 & 16,68 & 32,32 & 155,57 & 71,03 & 74,46 & 127,42 \\
\hline Epidalea calamita & 30TUK33 & 100,00 & 148,26 & 114,36 & \begin{tabular}{|l|}
36,68 \\
\end{tabular} & 6573,51 & 328,10 & 19,23 & 308,86 & \begin{tabular}{|l|l|}
110,18 \\
\end{tabular} & 236,68 & 236,68 & 67,90 & 366,73 & 43,08 & 6,69 & 38,38 & 120,75 & 38,74 & 38,74 & 102,31 \\
\hline Epidalea calamita & 30TUK34 & 100,00 & 146,30 & 113,97 & 36,92 & 6520,96 & 324,74 & 17,80 & 306,94 & 108,63 & 233,89 & 233,89 & 66,48 & 363,94 & 43,27 & 7,34 & 37,36 & 119,40 & 40,36 & 40,36 & 99,86 \\
\hline Epidalea calamita & 30TUK35 & 100,00 & 129,37 & 113,05 & 36,90 & 6435,29 & 307,23 & 3,53 & 303,71 & 102,52 & 215,81 & 216,31 & 51,82 & 408,73 & 50,69 & 10,20 & 35,68 & 132,82 & 50,62 & 51,16 & 108,39 \\
\hline Epidalea calamita & 30TUK37 & 100,00 & 95,44 & 111,44 & 37,00 & 6240,27 & 272,10 & $-24,57$ & 296,67 & 77,51 & 179,49 & 180,74 & 22,86 & 520,51 & 67,05 & 16,80 & 32,78 & 165,76 & 72,71 & 76,01 & 133,20 \\
\hline Epidalea calamita & 30TUK38 & 100,00 & 85,05 & 110,75 & 37,00 & 6175,64 & 261,01 & $-32,71$ & 293,72 & 65,94 & 168,71 & 169,68 & 13,97 & 576,70 & 72,81 & 19,77 & 31,65 & 181,17 & 81,46 & 86,51 & 149,94 \\
\hline Epidalea calamita & 30TUK39 & 100,00 & 104,10 & 111,62 & 37,10 & 6184,29 & 278,08 & $-17,14$ & 295,22 & 97,69 & 186,34 & 188,11 & 30,71 & 449,96 & 60,10 & 15,34 & 32,89 & 142,87 & 66,47 & 69,05 & 109,53 \\
\hline Epidalea calamita & 30TUK45 & 100,00 & 146,31 & 112,88 & 36,51 & 6512,57 & 323,18 & 17,87 & 305,31 & 107,34 & 233,69 & 233,69 & 66,26 & 353,29 & 42,51 & 7,55 & 37,12 & 115,64 & 40,71 & 40,71 & 94,95 \\
\hline Epidalea calamita & 30TUK46 & 100,00 & 100,93 & 111,37 & 36,83 & 6305,77 & 278,33 & $-20,28$ & 298,61 & 82,70 & 186,21 & 186,97 & 27,26 & 508,86 & 65, & 15,92 & 33,13 & 163,43 & 70,14 & 72,82 & 130,45 \\
\hline Epidalea calamita & $\begin{array}{l}\text { 30TUK47 } \\
\end{array}$ & 100,00 & 114,25 & 111,30 & 36,96 & 6312,72 & 289,66 & $-9,22$ & 298,88 & 98,77 & 198,49 & 199,77 & 38,77 & 421,32 & 56,28 & 12,95 & 34,11 & 136,14 & 60,19 & 61,26 & 102,46 \\
\hline Epidalea calamita & 30TUK48 & 100,00 & 88,76 & 110,42 & 37,00 & $\begin{array}{ll}6176,06 \\
\end{array}$ & 264,24 & $-29,81$ & 294,05 & 71,09 & \begin{tabular}{|l|l|}
172,36 \\
\end{tabular} & 173,36 & 17,44 & 539,78 & 70,30 & 18,85 & 31,91 & \begin{tabular}{|l|l|}
171,63 \\
\end{tabular} & 78,73 & 83,12 & 134,92 \\
\hline Epidalea calamita & 30TUK53 & 100,00 & 150,74 & 113,37 & 36,00 & 6632,21 & 330,08 & 20,54 & 309,54 & 109,54 & 239,77 & 239,77 & 69,22 & 357,35 & 42,01 & 6,85 & 38,16 & 117,52 & 38,30 & 38,30 & 98,42 \\
\hline Epidalea calamita & 30TUK54 & 100,00 & 131,14 & 112,60 & 36,09 & 6545,57 & 310,48 & 3,62 & 306,87 & 113,72 & 219,40 & 219,58 & 52,15 & 401,54 & 50,23 & 9,73 & 35,69 & 130,93 & 49,81 & 49,99 & 104,96 \\
\hline Epidalea calamita & 30TUK55 & 100,00 & 140,85 & 112,00 & 36,01 & 6541,56 & 318,01 & 12,68 & 305,33 & 110,79 & 228,88 & 228,88 & 60,92 & 365,31 & 44,80 & 8,45 & 35,97 & 118,38 & 44,29 & 44,29 & 96,25 \\
\hline Epidalea calamita & $\begin{array}{l}30 T U K 56 \\
\end{array}$ & 100,00 & $\begin{array}{l}148,05 \\
118,29\end{array}$ & 111,17 & 36,41 & 6398,64 & 294,72 & $\begin{array}{l}-5,92 \\
\end{array}$ & $\begin{array}{l}300,64 \\
30,50\end{array}$ & 92,11 & 204,53 & $\begin{array}{l}204,95 \\
204\end{array}$ & 41,94 & 438,19 & 55,93 & $\begin{array}{l}0,475 \\
12,85\end{array}$ & 34,18 & $\begin{array}{l}141,45 \\
141,45\end{array}$ & 59,34 & 60,68 & 111,31 \\
\hline Epidalea calamita & 30TUK57 & 100,00 & 117,59 & 110,53 & 36,51 & 6344,52 & 292,32 & $-6,49$ & 298,81 & \begin{tabular}{ll|}
102,44 \\
\end{tabular} & 202,68 & 203,47 & 41,46 & 410,25 & 54,77 & 12,60 & 34,25 & 132,62 & 58,94 & 59,81 & 98,93 \\
\hline Epidalea calamita & 30TUK58 & 100,00 & 96,35 & 109,92 & 36,98 & 6196,46 & 270,65 & $-23,76$ & 294,41 & 85,99 & $\begin{array}{ll}179,84 \\
\end{array}$ & 180,83 & 24,11 & 484,28 & 65,80 & 16,94 & 32,88 & 156,43 & 73,19 & 76,41 & 114,71 \\
\hline Epidalea calamita & 30TUK59 & 100,00 & 103,59 & 109,52 & 36,96 & 6183,07 & 275,94 & $-17,90$ & 293,85 & 121,31 & 186,10 & 187,49 & 30,31 & 432,48 & 60,85 & 15,26 & 34,09 & 142,54 & 67,51 & 69,93 & 97,73 \\
\hline Epidalea calamita & 30TUK64 & 100,00 & 143,47 & 111,86 & 36,00 & 6613,83 & 321,64 & 14,24 & 307,40 & 113,18 & 232,51 & 232,51 & 62,66 & 368,43 & 44,41 & \begin{tabular}{|c|}
8,08 \\
\end{tabular} & 36,43 & 120,08 & 43,36 & 43,36 & 98,32 \\
\hline Epidalea calamita & 30TUK65 & 100,00 & 132,66 & 111,17 & 36,00 & 6534,47 & 309,78 & $\begin{array}{r}4,24 \\
5,08 \\
\end{array}$ & 304,70 & $\begin{array}{l}113,12 \\
113,\end{array}$ & 220,75 & 220,75 & 53,25 & $\begin{array}{l}30,45 \\
387,33 \\
\end{array}$ & 48,71 & $\begin{array}{l}0,006 \\
9,88\end{array}$ & 35,14 & 125,27 & 49,91 & $\begin{array}{l}43,901 \\
49,91\end{array}$ & $\begin{array}{l}99,34 \\
99,5\end{array}$ \\
\hline Epidalea calamita & 30TUK66 & 100,00 & 113,97 & 110,31 & 36,34 & 6387,97 & 290,11 & $-9,62$ & 299,73 & 93,62 & 200,12 & 200,66 & 38,09 & 443,80 & 57,94 & 13,48 & 33,95 & 143,79 & 62,19 & 63,67 & 109,62 \\
\hline Epidalea calamita & 30TUK68 & 100,00 & 112,38 & 108,73 & 36,22 & 6287,41 & 284,87 & $-10,69$ & 295,57 & 119,11 & 196,26 & 197,41 & 37,17 & 413,36 & 57,04 & 13,77 & 34,30 & 134,88 & 62.91 & 64,33 & 94,84 \\
\hline Epidalea calamita & 30TUK69 & 100,00 & 100,89 & 108,38 & 36,53 & 6170,98 & 272,44 & $-20,11$ & 292,55 & 118,39 & 183,75 & 184,77 & 28,19 & 441,47 & 62,70 & 16,10 & 34,16 & 146,82 & 70,40 & 73,12 & 97,69 \\
\hline Epidalea calamita & $\begin{array}{l}\text { 30TUK74 } \\
\end{array}$ & 100,00 & 148,29 & 111,08 & 35,77 & 6661,16 & 326,08 & 18,42 & 307,66 & 106,53 & 237,77 & 237,77 & 66,49 & 360,88 & 42,33 & 7,73 & 36,76 & 118,60 & 41,34 & 41,34 & 97,94 \\
\hline Epidalea calamita & 30TUK75 & 100,00 & $\begin{array}{l}14,25 \\
136,04\end{array}$ & $\begin{array}{l}11,00 \\
110,17\end{array}$ & 35,75 & 65001, & 312,70 & $\frac{10,44}{8,06}$ & $\begin{array}{l}304,64 \\
304\end{array}$ & $\begin{array}{l}107,44 \\
10,40\end{array}$ & 224,68 & 224,68 & $\begin{array}{l}5,4,91 \\
551\end{array}$ & $\begin{array}{l}30,00 \\
383,44\end{array}$ & $\begin{array}{l}42,53 \\
47,17\end{array}$ & 9,64 & $\begin{array}{l}35,107 \\
35,07\end{array}$ & \begin{tabular}{|l|l|l|l|l|l}
123,98 \\
\end{tabular} & $\begin{array}{l}\mid l 1,44 \\
48,72\end{array}$ & 年18,74 & $\begin{array}{l}99,62 \\
99,6\end{array}$ \\
\hline Epidalea calamita & 30TUK76 & 100,00 & 126,44 & 109,29 & 35,91 & 6486,12 & 301,51 & 0,41 & 301,10 & 104,01 & 213,75 & 214,03 & 48,02 & 399,10 & 51,13 & 11,25 & 34,41 & 128,63 & 54,68 & 54,91 & 99,41 \\
\hline Epidalea calamita & 30TUK77 & 100,00 & 128,57 & 108,45 & \begin{tabular}{|l|l|}
35,97 \\
\end{tabular} & 6458,48 & 301,79 & 2,79 & 299,00 & $\begin{array}{l}98,53 \\
9\end{array}$ & 215,16 & 215,53 & 50,03 & 387,77 & 49,53 & 11,21 & 34,19 & 124,92 & 53,75 & 54,05 & 96,10 \\
\hline Epidalea calamita & 30TUK79 & 100,00 & 95,53 & 107,68 & 36,53 & 6167,27 & 267,01 & $-23,95$ & 290,96 & 111,88 & 178,89 & 179,49 & 23,83 & 475,36 & 65,91 & 17,76 & 32,92 & 156,51 & 75,28 & 79,14 & 107,48 \\
\hline Epidalea calamita & 30TUK84 & 100,00 & 147,45 & 110,31 & 35,2 & 6700,32 & 325,16 & 17,49 & 307,68 & 104,51 & 237,42 & 237,42 & 65,15 & 368,48 & 42,69 & 8,10 & 36,39 & \begin{tabular}{|l|l|}
121,08 \\
\end{tabular} & 42,55 & 42,55 & 100,48 \\
\hline Epidalea calamita & 30TUK85 & 100,00 & 145,18 & 109,17 & 35,10 & 6648,13 & 321,11 & 16,44 & 304,68 & 102,51 & 234,40 & 234,40 & 63,61 & 368,66 & 42,96 & 8,57 & 35,71 & 121,13 & 43,99 & 43,99 & 99,45 \\
\hline Epidalea calamita & 30TUK86 & 100,00 & 133,66 & 108,22 & 35,36 & 6561,83 & 308,14 & 6,79 & 301,35 & 98,74 & 221,89 & 222,00 & 53,67 & 390,65 & 47,58 & 10,50 & 34,35 & 125,95 & 51,28 & 51,34 & 101,24 \\
\hline Epidalea calamita & 30TUK87 & 100,00 & 133,51 & 107,34 & 35,38 & 6530,87 & 306,06 & 7,06 & 299,00 & 93,52 & 220,89 & 221,09 & 53,58 & 385,86 & 47,13 & 10,80 & 34,08 & 124,41 & 51,68 & 51,78 & 99,15 \\
\hline Epidalea calamita & 30TUK88 & 100,00 & 120,92 & 106,42 & 35,70 & 6408,92 & 291,84 & $-2,97$ & 294,81 & 109,49 & 205,88 & 207,34 & 43,50 & 407,06 & 52,75 & 12,9 & 33,55 & 30,32 & 59,09 & 60,40 & 98,12 \\
\hline Epidalea calamita & 30 TUK89 & 100,00 & 98,05 & 106,76 & 36,38 & 6211,20 & 268,70 & $-21,19$ & 289,90 & 113,77 & $\begin{array}{ll}181,84 \\
\end{array}$ & 182,58 & 25,62 & 478,86 & 64,70 & $17, \varepsilon$ & 32,27 & 155,90 & 74,58 & 78,62 & 110,54 \\
\hline Epidalea calamita & 30TUK! & 100,00 & 144,71 & 110,81 & 35,00 & 6769,67 & 324,72 & 14,06 & 310,66 & 101,16 & 235,86 & 235,86 & 61,94 & 386,97 & 44,53 & 8,6 & 36,02 & 126,17 & 44,55 & 44,55 & 106,40 \\
\hline Epidalea calamita & $\begin{array}{l}\text { 30TUK94 } \\
\end{array}$ & 100,00 & 143,14 & 109,56 & 35,00 & 6725,91 & 321,14 & 13,71 & 307,44 & 100,04 & 233,56 & 233,56 & 60,79 & 386,98 & 44,44 & 8,99 & 35,52 & 126,62 & 45,84 & 45,84 & 105,94 \\
\hline Epidalea calamita & 30TUK95 & 100,00 & 145,68 & 108,31 & 35,00 & 6683,45 & 321,35 & 16,88 & 304,47 & 102,77 & 235,29 & 235,29 & 63,46 & 376,91 & 43,02 & 8,79 & 35,68 & 124,77 & 44,47 & 44,47 & 103,72 \\
\hline Epidalea calamita & 30TUK96 & 100,00 & 142,41 & 107,19 & 35,01 & 6629,52 & 316,24 & 14,88 & 301,36 & 100,00 & 231,30 & 231,30 & 60,84 & 380,83 & 44,26 & 9,53 & 35,10 & 125,81 & 46,72 & 46,72 & 103,71 \\
\hline Epidalea calamita & 30TUK5 & 100,00 & 13 & 106,23 & 35,08 & 6502, 65,23 & 302,11 & $\begin{array}{r}4,06 \\
4,72 \\
\end{array}$ & \begin{tabular}{|l|}
297,39 \\
297
\end{tabular} & $\begin{array}{l}1,01 \\
91,01\end{array}$ & \begin{tabular}{|l|}
217,24 \\
\end{tabular} & 217,90 & $\begin{array}{l}0,044 \\
50,46\end{array}$ & \begin{tabular}{|l|l|}
500,05 \\
406,46
\end{tabular} & $\begin{array}{l}44,20 \\
48,70\end{array}$ & $\mid$\begin{tabular}{|c|}
$, 3,65$ \\
11,65
\end{tabular} & 33,54 & $\begin{array}{l}132,01 \\
131,35 \\
\end{array}$ & $\begin{array}{l}40,1 / 2 \\
54,53\end{array}$ & 54,97 & 105,93 \\
\hline Epidalea calamita & 30TUK98 & 100,00 & 117,08 & 105,55 & 35,46 & 6424,03 & 287,68 & $-5,43$ & 293,11 & 92,36 & 202,24 & 203,76 & 39,80 & 433,53 & 54,70 & 14,08 & 32,57 & 137,60 & 62,24 & 64,39 & 106,93 \\
\hline Epidalea calamita & $\begin{array}{l}\text { 30TUK99 } \\
3\end{array}$ & 100,00 & 96,32 & 106,41 & 36,45 & $\mid 6227,65$ & 266,97 & \begin{tabular}{|l|l|l|l|}
$-21,79$ \\
-2
\end{tabular} & 288,76 & \begin{tabular}{|l|}
105,56 \\
\end{tabular} & $\begin{array}{l}28,24 \\
180,69 \\
\end{array}$ & $\begin{array}{l}2181,32 \\
\end{array}$ & 24,05 & |503,34 & 65,66 & 18,77 & 31,15 & 161,06 & 76,80 & 81,29 & 120,12 \\
\hline Epidalea calamita & 30TUL01 & 100,00 & 116,99 & 115,61 & 38,79 & 6125,72 & 290,26 & $-4,01$ & 294,27 & 76,75 & 196,66 & 199,79 & 43,19 & 409,76 & 50,29 & 11,94 & 32,06 & 129,01 & 57,22 & 59,14 & 109,13 \\
\hline Epidalea calamita & 30TUL03 & 100,00 & 118,01 & 116,63 & 39,36 & 6071,70 & 290,22 & $-2,33$ & 292,55 & 77,63 & 196,35 & 199,95 & 44,42 & 390,95 & 47,67 & 11,58 & 31,22 & 122,40 & 56,58 & 58,81 & 103,3 \\
\hline Epidalea calamita & \begin{tabular}{|l|} 
30TULO4 \\
30l
\end{tabular} & $\begin{array}{l}100,00 \\
\end{array}$ & $\begin{array}{ll}11,0,01 \\
118,51\end{array}$ & $\begin{array}{l}111,03 \\
116,89\end{array}$ & | 39,44 & $\mid 6066,89$ & 290,54 & $\begin{array}{l}-2,502 \\
-2,02\end{array}$ & $\begin{array}{l}292,56 \\
292,56\end{array}$ & $\begin{array}{l}1,, 03 \\
78,15\end{array}$ & $\begin{array}{l}19,50,72 \\
196,72\end{array}$ & \begin{tabular}{|l|l|}
200,28 \\
\end{tabular} & $\begin{array}{l}44,424 \\
44,73 \\
\end{array}$ & | & $\begin{array}{l}1,017 \\
46,77\end{array}$ & \begin{tabular}{l|l}
$1,1,48$ \\
11,4
\end{tabular} & $\begin{array}{l}1,22 \\
31,17\end{array}$ & \begin{tabular}{|l|l|l}
120,88 \\
120
\end{tabular} & $\begin{array}{l}50,00 \\
56,10\end{array}$ & $\begin{array}{l}50,01 \\
58,44\end{array}$ & $\begin{array}{l}101,31 \\
101,3\end{array}$ \\
\hline Epidalea calamita & 30TUL05 & 100,00 & 119,92 & 117,01 & 39,21 & 6073,97 & 292,05 & $-0,88$ & 292,92 & 79,81 & 198,15 & 201,49 & 45,87 & 374,10 & 45,45 & 11,11 & 31,60 & 119,13 & 54,34 & 56,68 & 98,92 \\
\hline Epidalea calamita & 30TUL11 & 100,00 & 112,50 & 114,35 & 38,20 & 6142,97 & 285,96 & $-8,51$ & 294,47 & 77,47 & 193,01 & 195,76 & 38,67 & 418,29 & 52,93 & 12,89 & 32,10 & 130,44 & 59,94 & 62,39 & 107,87 \\
\hline Epidalea calamita & 30TUL13 & 100,00 & 117,23 & 115,59 & 38,98 & 6106,01 & 289,51 & $-3,42$ & 292,93 & 83,52 & 196,31 & 199, & 43, & 389,36 & 48,44 & 12,00 & 31,30 & 121,10 & 57,11 & 59,78 & 100,52 \\
\hline Epidalea calamita & 30TUL14 & 100,00 & 119,47 & 116,01 & 39,00 & 6096,91 & 291,40 & $\begin{array}{l}-1,53 \\
-1,53 \\
\end{array}$ & 292,94 & 79,08 & 198,12 & 201,34 & 44,98 & 379,21 & 46,62 & 11,81 & 30,89 & 118,57 & 56,08 & 58,75 & 98,30 \\
\hline
\end{tabular}




\begin{tabular}{|c|c|c|c|c|c|c|c|c|c|c|c|c|c|c|c|c|c|c|c|c|c|}
\hline TAXON & UTM & $\mathrm{km} 2$ & B101 & B102 & $\mathrm{BIO3}$ & 8104 & B105 & B106 & B107 & B108 & B109 & BIO10 & BIO11 & BIO12 & 81013 & BIO14 & BIO15 & B1016 & B1017 & BIO18 & B1019 \\
\hline Epidalea calamita & 30TUL15 & 100,00 & 120,68 & 116,36 & 39,02 & 6096,79 & 292,68 & $-0,61$ & 293,29 & 80,60 & 199,20 & 202,54 & 46,05 & 373,62 & 45,62 & 11,35 & 31,03 & 117,61 & 54,56 & 57,46 & 97,78 \\
\hline Epidalea calamita & 30TUL16 & 100,00 & 121,14 & 116,50 & 39,06 & 6101,75 & 293,16 & $-0,21$ & 293,38 & 81,37 & 199,89 & 202,88 & 46,11 & 371,73 & 44,97 & 11,71 & 30,99 & 117,60 & 54,68 & 57,42 & 97,91 \\
\hline Epidalea calamita & 30TUL20 & 100,00 & 99,61 & 112,22 & 37,90 & 6148,64 & 273,89 & $-19,95$ & 293,84 & 96,97 & 181,58 & 183,42 & 27,20 & 475,32 & 61,68 & 15,97 & 32,11 & 148,31 & 69,01 & 72,51 & 120,04 \\
\hline Epidalea calamita & 30TUL22 & 100,00 & 113,64 & 113,85 & 38,04 & 6132,68 & 286,00 & $-7,79$ & 293,79 & 130,43 & 193,77 & 196,52 & 39,75 & 401,84 & 51,69 & 12,96 & 31,82 & 125,55 & 59,50 & 62,28 & 100,61 \\
\hline Epidalea calamita & 30TUL23 & 100,00 & 116,90 & 114,53 & 38,55 & 6121,92 & 288,76 & $-4,31$ & \begin{tabular}{|l|l|}
293,07 \\
\end{tabular} & \begin{tabular}{|l|}
129,16 \\
\end{tabular} & \begin{tabular}{|l|l|}
196,38 \\
\end{tabular} & 199,30 & 42,62 & 388,19 & 49,19 & 12,16 & 31,45 & 120,77 & 57,43 & 60,30 & 98,07 \\
\hline Epidalea calamita & 30TUL24 & 100,00 & 119,42 & 114,94 & 38,87 & 6127,27 & 291,15 & $-1,90$ & 293,05 & 93,05 & 198,64 & 201,77 & 44,47 & 379,32 & 47,25 & 12,00 & 31,03 & 118,09 & 56,54 & 59,31 & 97,02 \\
\hline Epidalea calamita & 30TUL25 & 100,00 & 120,94 & 115,34 & 39,00 & 6132,99 & 292,69 & $-0,53$ & 293,22 & 80,93 & 200,23 & 203,11 & 45,72 & 374,95 & 46,05 & 11,99 & 30,37 & 117,06 & 55,76 & 58,77 & 97,00 \\
\hline Epidalea calamita & \begin{tabular}{|l|}
30 TUL26 \\
\end{tabular} & 100,00 & 122,08 & 115,74 & 39,00 & 6117,69 & 293,66 & 0,09 & 293,57 & 82,10 & 200,90 & 203,64 & 46,73 & 372,66 & 45,12 & 11,98 & 30,64 & 117,00 & 55,19 & 58,17 & 97,17 \\
\hline Epidalea calamita & 30TUL27 & 100,00 & 121,95 & 116,01 & 39,00 & 6121,77 & 293,83 & 0,06 & 293,77 & 82,36 & 200,81 & 203,47 & 46,22 & 375,81 & 45,01 & 12,00 & 30,34 & 118,29 & 55,65 & 58,75 & 99,25 \\
\hline Epidalea calamita & 30TUL30 & 100,00 & 95,80 & 111,23 & 37,54 & 6133,05 & 269,38 & $-23,46$ & 292,84 & 103,81 & 177,94 & 179,37 & 23,76 & 485,58 & 64,25 & 17,28 & 32,02 & 153,65 & 72,46 & 76,43 & 119,35 \\
\hline Epidalea calamita & 30TUL33 & 100,00 & 117,32 & 113,31 & 38,09 & 6159,14 & 288,86 & $-4,16$ & 293,02 & 138,29 & 197,56 & 200,19 & 42,31 & 385,28 & 49,53 & 12,49 & 31,67 & 121,03 & 57,71 & 60,76 & 95,71 \\
\hline Epidalea calamita & 30TUL34 & 100,00 & 120,33 & 113,72 & 38,06 & 6157,84 & 291,43 & $-1,59$ & 293,02 & 122,55 & 200,13 & 202,90 & 44,89 & 377,64 & 47,43 & 12,01 & 31,18 & 117,38 & 56,37 & 59,41 & 95,32 \\
\hline Epidalea calamita & 30TUL36 & 100,00 & 122,90 & 114,72 & 38,71 & 6153,03 & 294,14 & 0,59 & 293,55 & 83,43 & 202,46 & 205,13 & 46,99 & 375,59 & 45,42 & 12,00 & 30,11 & 117,00 & 55,89 & 58,94 & 97,66 \\
\hline Epidalea calamita & 30TUL37 & 100,00 & 123,01 & 115,12 & 38,94 & 6148,21 & 294,36 & 0,76 & 293,60 & 83,53 & 202,46 & 204,89 & 46,99 & 378,58 & 45,09 & 12,03 & 30,32 & 118,36 & 55,86 & 59,21 & 100,03 \\
\hline Epidalea calamita & 30TUL40 & 100,00 & 98,29 & 110,34 & 37,06 & 6137,15 & 271,00 & $-21,99$ & 292,99 & 115,20 & 180,48 & 181,82 & 26,00 & 459,96 & 62,84 & 16,79 & 32,74 & 148,90 & 70,95 & 74,44 & 108,01 \\
\hline Epidalea calamita & 30TUL42 & 100,00 & 117,11 & 111,48 & 37,70 & 6190,93 & 287,91 & $-5,11$ & 293,03 & 137,87 & 198,17 & 200,36 & 42,06 & 385,70 & 50,87 & 13,01 & 32,17 & 123,17 & 59,00 & 61,30 & 92,32 \\
\hline Epidalea calamita & \begin{tabular}{|l|l|}
$30 T U L 45$ \\
\end{tabular} & 100,00 & 121,37 & 112,94 & 38,00 & 6173,82 & 291,62 & $-0,67$ & 292,29 & 121,33 & 201,36 & 203,87 & 45,39 & 380,49 & 47,15 & 12,10 & 30,85 & 118,29 & 56,43 & 60,15 & 96,74 \\
\hline Epidalea calamita & 30TUL47 & 100,00 & 123,20 & 114,10 & 38,24 & 6176,62 & 294,00 & 0,69 & 293,31 & 83,98 & 203,08 & 205,38 & 46,46 & 385,30 & 45,72 & 12,04 & 30,30 & 120,18 & 56,13 & 60,02 & 101,96 \\
\hline Epidalea calamita & 30TUL48 & 100,00 & 121,62 & 114,72 & 38,82 & 6148,09 & 292,76 & $-0,10$ & 292,86 & 82,72 & 201,16 & 203,36 & 45,36 & 396,06 & 46,36 & 12,66 & 29,93 & 123,46 & 57,60 & 62,23 & 106,48 \\
\hline Epidalea calamita & 30TUL49 & 100,00 & 123,73 & 115,15 & 39,00 & 6132,16 & 294,86 & 1,85 & 293,01 & 85,12 & 202,97 & 204,89 & 47,32 & 397,40 & 46,06 & 12,77 & 29,75 & 124,49 & 57,33 & 61,80 & 108,98 \\
\hline Epidalea calamita & 30TUL50 & 100,00 & 106,06 & 109,31 & 36,96 & 6168,92 & 277,19 & $-15,90$ & 293,08 & 124,70 & 188,09 & 189,54 & 32,53 & 414,73 & 58,77 & 15,01 & 34,32 & 137,72 & 65,86 & 68,31 & 92,25 \\
\hline Epidalea calamita & 30TUL52 & 100,00 & 117,23 & 109,92 & 37,11 & 6205,52 & 286,90 & $-5,14$ & 292,04 & 137,77 & 198,64 & 200,75 & 41,84 & 385,60 & 51,36 & 13,13 & 32,48 & 124,47 & 59,16 & 62,07 & 90,53 \\
\hline Epidalea calamita & 30TUL53 & 100,00 & 118,52 & 110,30 & \begin{tabular}{|l|l|}
37,23 \\
\end{tabular} & 6213,88 & 287,99 & $-3,96$ & 291,95 & 139,38 & 199,74 & 201,81 & 42,62 & 386,00 & 50,15 & 13,00 & 31,80 & 123,15 & 58,54 & 62,00 & 93,21 \\
\hline Epidalea calamita & 30TUL56 & 100,00 & 122,10 & 112,07 & 38,00 & 6182,96 & 291,54 & $-0,10$ & 291,64 & 108,31 & 202,33 & 204,53 & 45,69 & 388,29 & 47,19 & 12,05 & 30,90 & 120,47 & 56,23 & 61,05 & 100,49 \\
\hline Epidalea calamita & 30TUL57 & 100,00 & 123,07 & 112,78 & 38,02 & 6181,97 & 293,06 & 0,34 & 292,72 & 84,41 & 203,18 & 205,50 & 46,37 & 391,90 & 46,43 & 12,03 & 30,66 & 121,94 & 56,41 & 61,21 & 103,59 \\
\hline Epidalea calamita & 30TUL58 & 100,00 & 123,85 & 113,52 & 38,29 & 6158,24 & 294,08 & 1,67 & 292,41 & 85,56 & 203,82 & 205,75 & 47,39 & 397,03 & 46,06 & 12,08 & 30,10 & 123,65 & 56,97 & 61,73 & 106,99 \\
\hline Epidalea calamita & \begin{tabular}{|l|l|l|l|l|}
$30 T U L 59$ \\
\end{tabular} & 100,00 & 124,59 & 114,18 & 38,41 & 6141,55 & 294,91 & 2,19 & \begin{tabular}{|l|}
292,73 \\
\end{tabular} & 86,62 & \begin{tabular}{|l|}
203,97 \\
\end{tabular} & 205,89 & 47,84 & 403,19 & 46,57 & 12,84 & 29,82 & 125,94 & 57,73 & 62,66 & 110,59 \\
\hline Epidalea calamita & 30TUL60 & 100,00 & 104,58 & 107,76 & 36,22 & 6148,58 & 274,42 & $-17,22$ & 291,64 & 122,81 & 186,65 & 187,74 & 31,39 & 412,56 & 60,01 & 15,35 & 35,14 & 139,47 & 67,69 & 70,06 & 87,97 \\
\hline Epidalea calamita & 30TUL61 & 100,00 & 109,68 & 107,73 & 36,43 & 6183,77 & 278,66 & $-12,53$ & 291,19 & 128,92 & 191,70 & 193,16 & 35,45 & 401,21 & 56,55 & 14,90 & 34,20 & 133,92 & 64,43 & 67,35 & 88,12 \\
\hline Epidalea calamita & 30TUL66 & 100,00 & 121,00 & 110,45 & $\begin{array}{l}37,55 \\
\end{array}$ & 6210,75 & 289,58 & $-0,94$ & 290,52 & 122,36 & 201,98 & 204,01 & 44,47 & 398,79 & 48,28 & 12,53 & 30,18 & 123,56 & 58,21 & 63,56 & 102,40 \\
\hline Epidalea calamita & 30TUL67 & 100,00 & 122,54 & 111,32 & 37,93 & 6189,27 & 291,36 & $-0,03$ & 291,39 & 90,32 & 203,01 & 204,96 & 45,99 & 399,58 & 47,35 & 12,35 & 30,15 & 123,99 & 57,42 & 63,21 & 104,70 \\
\hline Epidalea calamita & \begin{tabular}{|c|} 
30TUL69 \\
\end{tabular} & 100,00 & 122,60 & 111,92 & 38,06 & 6127,94 & 292,03 & $\begin{array}{l}-0,01 \\
-0,01 \\
-1\end{array}$ & 292,04 & $\begin{array}{l}85,78 \\
85\end{array}$ & \begin{tabular}{|l|}
202,30 \\
\end{tabular} & 203,99 & 46,31 & \begin{tabular}{|l|l|}
412,80 \\
\end{tabular} & 47,56 & $\begin{array}{ll}13,17 \\
13\end{array}$ & 29,66 & \begin{tabular}{|l|l|}
128,49 \\
\end{tabular} & 58,56 & $\begin{array}{l}0,24 \\
65,24\end{array}$ & 111,82 \\
\hline Epidalea calamita & 30TUL70 & 100,00 & 95,84 & 107,16 & 36,46 & 6136,64 & 265,89 & $-23,49$ & 289,38 & 112,59 & 178,64 & 179,37 & 24,13 & 465,38 & 65,18 & 17,91 & 33,21 & 154,68 & 75,01 & 79,26 & 103,41 \\
\hline Epidalea calamita & 30TUL78 & 100,00 & 120,36 & 110,48 & 37,54 & 6159,98 & 288,13 & $-2,19$ & 290,31 & 96,41 & 200,69 & 202,44 & 44,06 & 417,91 & 48,99 & 13,38 & 29,81 & 129,16 & 59,82 & 67,49 & 109,73 \\
\hline Epidalea calamita & 30TUL79 & 100,00 & 116,90 & 111,40 & 37,96 & 6113,09 & 285,53 & $-5,35$ & 290,88 & 86,07 & 196,91 & 198,48 & 41,60 & 432,60 & 50,56 & 14,06 & 29,12 & 133,23 & 61,81 & 70,69 & 114,12 \\
\hline Epidalea calamita & 30TUL80 & 100,00 & 92,66 & 106,66 & 36,56 & 6150,71 & 262,51 & $-25,10$ & 287,61 & 107,84 & 176,05 & 176,55 & 21,48 & 499,76 & 67,25 & 19,42 & 31,58 & 162,96 & 78,63 & 83,80 & 115,60 \\
\hline Epidalea calamita & 30TUL81 & 100,00 & $\begin{aligned} 5,2,00 \\
105,88\end{aligned}$ & $\begin{array}{l}104,00 \\
104,96\end{array}$ & 35,99| & $\mid 6242,37$ & 272,87 & - $-14,65$ & \begin{tabular}{|l|}
287,52 \\
287
\end{tabular} & \begin{tabular}{|l|}
124,39 \\
12,4
\end{tabular} & $\begin{array}{l}189,19 \\
189,19\end{array}$ & \begin{tabular}{|l|}
190,15 \\
190,15
\end{tabular} & $\begin{array}{l}31,404 \\
31,43\end{array}$ & \begin{tabular}{|l|}
440,81 \\
\end{tabular} & 59,41 & $\begin{array}{l}0,424 \\
16,20\end{array}$ & $\begin{array}{l}1,30 \\
32,55 \\
\end{array}$ & \begin{tabular}{|l|}
144,80 \\
14,0
\end{tabular} & $\begin{array}{l}0,090 \\
69,11 \\
\end{array}$ & $\begin{array}{l}3,00 \\
73,87\end{array}$ & 100,32 \\
\hline Epidalea calamita & \begin{tabular}{|l|}
30 TUL82 \\
\end{tabular} & 100,00 & 113,51 & 104,40 & 35,99 & 6303,42 & 279,17 & \begin{tabular}{|c|}
$-7,94$ \\
\end{tabular} & 287,11 & 133,44 & 196,90 & 198,34 & 37,24 & 424,25 & 54,80 & 14,23 & 31,99 & 136,62 & 64,28 & 69,23 & 100,23 \\
\hline Epidalea calamita & 30TUL88 & 100,00 & 118,28 & 108,75 & 37,06 & 6172,89 & 284,97 & $-3,97$ & 288,95 & 106,98 & 199,23 & 200,66 & 42,14 & 430,05 & 50,49 & 13,62 & 29,58 & 132,71 & 61,48 & 70,13 & 111,92 \\
\hline Epidalea calamita & 30TUL89 & 100,00 & 115,78 & 109,77 & 37,20 & 6117,25 & 282,95 & $-6,84$ & 289,78 & 126,76 & 196,10 & 197,42 & 40,47 & 440,64 & 51,64 & 14,72 & 28,99 & 135,42 & 63,55 & 73,62 & 114,46 \\
\hline Epidalea calamita & 30TUL90 & 100,00 & 88,55 & 106,60 & 36,78 & 6147,86 & 258,66 & $-27,33$ & 285,99 & 96,43 & 172,41 & 172,71 & 18,22 & 541,27 & 69,7 & 20,88 & 30,08 & 172,62 & 83,43 & 88,12 & 130,46 \\
\hline Epidalea calamita & $\begin{array}{l}\text { SOTUL91 } \\
\text { 30TU }\end{array}$ & 100,00 & $\begin{array}{l}0,53,04 \\
103,04\end{array}$ & $\begin{array}{l}10,00 \\
104,20\end{array}$ & 30,11 & $\begin{array}{l}014,700 \\
6268,38 \\
\end{array}$ & 26,00 & $\begin{array}{l}-2,15,95 \\
-15,97 \\
\end{array}$ & $\begin{array}{l}285,72 \\
285\end{array}$ & \begin{tabular}{|l|}
\multicolumn{9}{|c|}{$\mid 0,45$} \\
120,93
\end{tabular} & \begin{tabular}{|l|l|l|l|}
187,10 \\
\end{tabular} & \begin{tabular}{|l|l|l|l|}
187,99 \\
\end{tabular} & $\begin{array}{l}\frac{10,22}{28,96} \\
\end{array}$ & \begin{tabular}{|l|}
$471,27,41$ \\
474
\end{tabular} & $\frac{0,9,2}{61,0}$ & $\frac{20,0}{16,8}$ & $\begin{array}{l}0,00 \\
31,16\end{array}$ & $\begin{array}{l}152,40< \\
152\end{array}$ & $\begin{array}{l}3,34 \\
72,34\end{array}$ & $\begin{array}{l}0,11 \\
78,09\end{array}$ & $\begin{array}{l}150,40 \\
112,79\end{array}$ \\
\hline Epidalea calamita & 30TUMO0 & 100,00 & 121,52 & 117,00 & 39,00 & 6099,22 & 293,63 & $-0,48$ & 294,12 & 82,95 & 199,86 & 202,31 & 45,59 & 376,10 & 44,12 & 12,70 & 31,45 & 124,40 & 55,38 & 58,17 & 101,02 \\
\hline Epidalea calamita & 30TUM01 & 100,00 & 119,56 & 117,00 & 39,00 & 6081,99 & 291,62 & $-2,32$ & 293,94 & 81,27 & 197,82 & 200,03 & 43,72 & 390,11 & 46,00 & 13,86 & 30,87 & 129,80 & 58,25 & 61,39 & 105,43 \\
\hline Epidalea calamita & 30TUM03 & 100,00 & 120,97 & 116,78 & 39,21 & 6005,81 & 291,66 & $-1,18$ & 292,85 & 84,42 & 198,15 & 200,36 & 45,91 & 402,68 & 48,42 & 4,99 & 30,90 & 136,69 & 61,80 & 64,28 & 109,08 \\
\hline Epidalea calamita & 30TUM06 & 100,00 & $11 \varepsilon$ & 115 & 39,44 & 5893,34 & 287,0 & $-3,74$ & 290,76 & 83,73 & 194,35 & 196,05 & 44,21 & 448,20 & 55,47 & 18 & 30,23 & 155,69 & 73,56 & 74,99 & 120,66 \\
\hline Epidalea calamita & 30TUM09 & 100,00 & 113,76 & 114,72 & 39,50 & 5767,30 & 279,73 & $-7,10$ & 286,83 & 80,94 & 189,89 & 189,89 & 41,24 & 510,43 & 64, & 23,2 & 30,11 & 180,32 & 89,68 & 89,68 & 135,52 \\
\hline Epidalea calamita & 30TUM11 & 100,00 & 118,37 & 117,00 & 39,00 & 6073,24 & 290,72 & $-3,53$ & 294,26 & 80,71 & 196,67 & 199,01 & 42,72 & 399,96 & 47,04 & 14,32 & 30,24 & 131,10 & 59,76 & 63,84 & 108,02 \\
\hline Epidalea calamita & 30TUM12 & 100,00 & 120,33 & 117,00 & 39,04 & 6027,55 & 291,77 & $-1,68$ & 293,45 & 83,54 & 197,97 & 200,15 & 45,17 & 401,44 & 47,66 & 14,76 & 30,04 & 132,89 & 60,66 & 64,34 & 108,45 \\
\hline Epidalea calamita & 30TUM13 & 100,00 & 120,75 & 116,94 & 39,21 & 5977,65 & 291,32 & $-1,57$ & 292,89 & 85,24 & 197,89 & 199,78 & 46,04 & 408,67 & 48,88 & 15,53 & 29,84 & 136,65 & 62,41 & 66,12 & 110,30 \\
\hline Epidalea calamita & 30 & 100,00 & 11 & $\frac{115}{115}$ & 39,24 & 5806,82 & 284,13 & $\begin{array}{l}-4,37 \\
-4,69 \\
-3\end{array}$ & $\begin{array}{l}28,, 30 \\
288,82\end{array}$ & $\begin{array}{l}\mid l, 24 \\
84,79 \\
\end{array}$ & \begin{tabular}{|l|}
192,30 \\
192,0
\end{tabular} & \begin{tabular}{|l|l|}
194,02 \\
\end{tabular} & $\begin{array}{l}40,54 \\
44,52\end{array}$ & \begin{tabular}{|l|}
469,07 \\
469
\end{tabular} & $\begin{array}{l}40,00 \\
58,02\end{array}$ & $\begin{array}{l}\mid 20,24 \\
20,24\end{array}$ & $\begin{array}{l}29,04 \\
29,21\end{array}$ & \begin{tabular}{|l|}
161,680 \\
161
\end{tabular} & $\begin{array}{l}2,4,54 \\
78,54\end{array}$ & 80,92 & 124,26 \\
\hline Epidalea calamita & 30TUM18 & 100,00 & 114,87 & 114,51 & 39,26 & 5750,62 & 280,61 & $-6,58$ & 287,19 & 83,02 & 189,36 & 190,87 & 42,83 & 493,50 & 61,48 & 22,02 & 29,04 & 170,85 & 84,79 & 86,58 & 130,20 \\
\hline Epidalea calamita & 30TUM22 & 100,00 & 116,34 & 117,00 & 39,00 & 6033,32 & 288,63 & $-5,76$ & 294,39 & 80,11 & 194,44 & 196,61 & 41,35 & 421,60 & 49,58 & 15,54 & 29,37 & 136,9 & 63,37 & 68.72 & 114,20 \\
\hline Epidalea calamita & 30TUM23 & 100,00 & 120,17 & 116,92 & 39,15 & 5964,66 & 290,75 & $-2,26$ & 293,01 & 85,50 & 197,48 & 199,12 & 45,63 & 417,02 & 49,59 & 15,83 & 29,43 & 137,30 & 63,17 & 68,10 & 112,54 \\
\hline Epidalea calamita & 30TUM24 & 100,00 & 118,63 & 116,41 & 39,05 & 5919,12 & 288,54 & $-4,22$ & 292,76 & 84,93 & 195,36 & 197,06 & 44,65 & 431,28 & 51,55 & 17,28 & 29,09 & 143,01 & 66,56 & 71,83 & 115 \\
\hline Epidalea calamita & 30TUM25 & 100,00 & $\begin{array}{l}11,0,05 \\
118,05\end{array}$ & $\begin{array}{l}1110,41 \\
116,00\end{array}$ & 39,00 & 5875,11 & $280,56,80$ & $-\frac{-2,24}{-5,09}$ & 291,90 & $\begin{array}{l}4,35 \\
85,13 \\
\end{array}$ & \begin{tabular}{|l|l}
194,26 \\
194
\end{tabular} & $\begin{array}{l}195,84 \\
190\end{array}$ & $\begin{array}{l}44,65 \\
44,66\end{array}$ & $\mid$\begin{tabular}{|l|}
443,61 \\
443,61
\end{tabular} & 53,41 & $\begin{array}{l}1,260 \\
18,29 \\
\end{array}$ & 28,99 & \begin{tabular}{|l|}
1438,39 \\
148
\end{tabular} & $\begin{array}{ll}69,82 \\
69,\end{array}$ & $\begin{array}{l}1,, 03 \\
75,11\end{array}$ & $\begin{array}{l}111,10 \\
118,03\end{array}$ \\
\hline Epidalea calamita & 30TUM26 & 100,00 & 117,05 & 115,38 & 39,03 & 5819,70 & 284,64 & $-5,93$ & 290,57 & 85,09 & 192,47 & 194,16 & 44,41 & 459,45 & 55,68 & 19,51 & 28,57 & 154,73 & 74,14 & 79,14 & 121,54 \\
\hline Epidalea calamita & 30TUM27 & 100,00 & 117.38 & 114,55 & 39,09 & 5749.96 & 28296 & $-4,90$ & 287.87 & 86.52 & 191.98 & 193,45 & 45.56 & 473.03 & 57.88 & 20.51 & 28.42 & 160,59 & 78.11 & 8248 & 124,39 \\
\hline Epidalea calamita & 30TUM29 & 100,00 & 112,78 & 112,65 & 39,19 & 5631,06 & 275,25 & $-7,28$ & 282,52 & 83,09 & 185,99 & 187, & 42, & 525,30 & 65,14 & 24,28 & 27,92 & 179,86 & 91,29 & 94,23 & 137,08 \\
\hline Epidalea calamita & 30TUM31 & 100,00 & 117,58 & 116,93 & 39,00 & 6063,27 & 289,83 & $-4,33$ & 294,16 & 80,52 & 196,14 & $\begin{array}{l}198,07 \\
\end{array}$ & 42,13 & 419,81 & $\mid$ & $\mid$ & 29,27 & 133,56 & 61,70 & $\begin{array}{l}4,25 \\
67,52\end{array}$ & 114, \\
\hline
\end{tabular}




\begin{tabular}{|c|c|c|c|c|c|c|c|c|c|c|c|c|c|c|c|c|c|c|c|c|c|}
\hline TAXON & UTM & $\mathrm{km} 2$ & B101 & B102 & $\mathrm{BIO3}$ & B104 & B105 & B106 & B107 & B108 & B109 & B1010 & BIO11 & BIO12 & B1013 & BIO14 & BIO15 & BIO16 & BIO17 & B1018 & B1019 \\
\hline Epidalea calamita & 30TUM32 & 100,00 & 116,04 & 117,00 & 39,00 & 6025,13 & 288,00 & $-6,39$ & 294,39 & 79,98 & 194,07 & 196,12 & 41,03 & 430,89 & 50,41 & 15,72 & 29,08 & 138,06 & 63,74 & 70,54 & 117,22 \\
\hline Epidalea calamita & 30TUM33 & 100,00 & 116,86 & 116,91 & 39,00 & 5964,17 & 287,89 & $-6,16$ & 294,05 & 82,65 & 194,20 & 196,15 & 42,60 & 435,02 & 51,10 & 16,41 & 28,95 & 140,78 & 65,07 & 72,13 & 117,56 \\
\hline Epidalea calamita & 30TUM34 & 100,00 & 120,10 & 116,06 & 39,00 & 5897,92 & 289,35 & $-3,58$ & 292,93 & 87,40 & 196,63 & 198,19 & 46,40 & 432,74 & 51,34 & 17,12 & 28,79 & 141,74 & 65,51 & 72,43 & 115,91 \\
\hline Epidalea calamita & 30TUM40 & 100,00 & 122,15 & 115,78 & 39,00 & 6114,58 & 293,78 & 0,52 & 293,26 & 78,23 & 201,19 & 203,18 & 45,84 & 410,07 & 47,65 & 13,35 & 29,65 & 129,07 & 58,92 & 63,97 & 113,83 \\
\hline Epidalea calamita & 30TUM41 & 100,00 & 116,48 & 116,22 & 39,00 & \begin{tabular}{|l|l|}
6077,18 \\
\end{tabular} & 289,07 & $-5,09$ & 294,16 & 77,72 & \begin{tabular}{|l|}
195,67 \\
\end{tabular} & \begin{tabular}{|l|}
197,33 \\
\end{tabular} & 41,18 & 432,19 & 50,04 & 14,91 & 29,02 & 135,79 & $\begin{array}{ll}62,79 \\
\end{array}$ & 69,55 & 119,23 \\
\hline Epidalea calamita & 30TUM42 & 100,00 & 115,97 & 116,61 & 39,00 & 6013,80 & 287,57 & $-6,76$ & 294,33 & 80,91 & 193,96 & 195,80 & 41,09 & 439,40 & 50,97 & 15,76 & 28,79 & 138,93 & 64,30 & 72,12 & 119,89 \\
\hline Epidalea calamita & 30TUM43 & 100,00 & 115,33 & 116,54 & 39,00 & 5937,94 & 286,39 & $-7,99$ & 294,38 & 82,39 & 192,84 & 194,41 & 41,83 & 445,14 & 51,89 & 16,70 & 28,48 & 142,24 & 65,52 & 74,47 & 119,81 \\
\hline Epidalea calamita & 30TUM44 & 100,00 & 119,96 & 115,96 & 39,00 & 5873,55 & 288,56 & $-4,79$ & 293,35 & 88,68 & $\begin{array}{l}196,36 \\
\end{array}$ & \begin{tabular}{|l|}
197,90 \\
\end{tabular} & 46,86 & 437,99 & 51,36 & 17,04 & 28,47 & 141,45 & \begin{tabular}{|l|l}
64,96 \\
\end{tabular} & 74,22 & 116,53 \\
\hline Epidalea calamita & 30TUM45 & 100,00 & 119,78 & 115,23 & 39,00 & 5786,69 & 286,76 & $-4,92$ & 291,69 & 90,38 & 195,00 & 196,53 & 47,87 & 447,41 & 52,79 & 18,40 & 28,20 & 145,73 & $\begin{array}{l}67,55 \\
\end{array}$ & 77,10 & 117,74 \\
\hline Epidalea calamita & 30TUM50 & 100,00 & 124,34 & 114,90 & 38,89 & 6106,90 & 295,01 & 2,06 & 292,94 & 62,07 & 203,37 & 205,14 & 47,94 & 412,16 & 47,90 & 13,03 & 29,88 & 130,10 & 58,24 & 63,54 & 115,23 \\
\hline Epidalea calamita & 30TUM51 & 100,00 & 122,95 & 115,51 & 38,98 & 6066,38 & 293,71 & 0,46 & 293,25 & 63,90 & 201,60 & 203,15 & 46,92 & 423,85 & 49,38 & 13,88 & 29,50 & 134,49 & 59,79 & 66,21 & 119,16 \\
\hline Epidalea calamita & 30TUM52 & 100,00 & 119,45 & 115,87 & 39,00 & 5989,92 & 290,00 & $-4,09$ & 294,09 & 85,37 & 197,37 & 198,91 & 44,80 & 435,69 & 50,38 & 15,16 & 28,94 & 137,52 & 61,99 & 70,81 & 119,59 \\
\hline Epidalea calamita & 30TUM53 & 100,00 & 115,88 & 116,02 & 39,00 & 5919,29 & 285,99 & $\begin{array}{ll}-9,34 \\
-9,4\end{array}$ & 295,32 & 84,67 & 193,06 & 194,61 & 42,60 & 448,14 & 51,67 & 16,64 & 28,66 & 141,64 & $\begin{array}{l}64,66 \\
\end{array}$ & 75,90 & 119,57 \\
\hline Epidalea calamita & 30TUM54 & 100,00 & 118,23 & 115,84 & 38,94 & 5842,82 & 286,59 & $-7,87$ & 294,45 & 89,16 & 194,26 & 195,91 & 45,86 & 446,61 & 51,50 & 17,21 & 28,76 & 142,14 & 64,70 & 76,95 & 117,39 \\
\hline Epidalea calamita & 30TUM55 & 100,00 & 120,99 & 114,95 & 38,98 & 5756,24 & 287,11 & $-5,64$ & 292,75 & 93,99 & 195,90 & 197,43 & 49,67 & 446,02 & 51,90 & 18,06 & 28,31 & 143,43 & 65,46 & 77,75 & 115,77 \\
\hline Epidalea calamita & 30TUM58 & 100,00 & 112,95 & 111,22 & 38,98 & 5561,76 & 273,43 & $-9,44$ & 282,87 & 87,28 & 185,75 & 186,54 & 44,39 & 520,03 & 61,52 & 23,71 & 26,27 & 169,80 & 84,27 & 94,75 & 133,20 \\
\hline Epidalea calamita & 30TUM59 & 100,00 & 110,88 & 109,56 & 39,00 & 5495,01 & 268,95 & $-9,26$ & 278,22 & 85,30 & 182,86 & 183,40 & 43,01 & 548,82 & 65,37 & 25,64 & 25,81 & 180,01 & 91,50 & 100,58 & 140,82 \\
\hline Epidalea calamita & 30TUM60 & 100,00 & 122,48 & 113,60 & 38,15 & 6089,17 & 292,07 & $-0,49$ & 292,56 & 86,07 & 201,70 & 203,24 & 46,55 & 419,17 & 48,36 & 13,43 & 29,68 & 131,25 & 58,86 & 66,41 & 114,57 \\
\hline Epidalea calamita & 30TUM61 & 100,00 & 120,32 & 114,40 & \begin{tabular}{|l|l|}
38,47 \\
\end{tabular} & 6036,22 & 290,06 & $-3,31$ & 293,37 & 85,23 & 198,96 & 200,41 & 45,18 & 431,13 & 49,61 & 14,44 & 29,26 & 134,87 & 60,73 & 69,65 & 117,55 \\
\hline Epidalea calamita & 30TUM62 & 100,00 & 122,40 & 114,68 & 38.59 & 5961,61 & 291,22 & $-2,43$ & 293,65 & 90,55 & 200,06 & 201,50 & 48,14 & 428,31 & 49,35 & 14,77 & 29,23 & 135,19 & 59,98 & 70,13 & 115,71 \\
\hline Epidalea calamita & 30TUM63 & 100,00 & 119,17 & 115,22 & 38,41 & 5885,32 & 287,68 & $-7,44$ & 295,12 & 89,93 & 195,93 & 197,41 & 46,32 & 439,86 & 50,4 & 16,09 & 29,01 & 138,04 & 62,10 & 75,25 & 115,75 \\
\hline Epidalea calamita & 30TUM64 & 100,00 & 116,19 & 115,26 & 38,27 & 5815,91 & 283,91 & $-11,75$ & 295,66 & 89,12 & 192,21 & 193,42 & 44,57 & 454,02 & 52,14 & 17,58 & 28,65 & 142,29 & $\begin{array}{l}64,78 \\
\end{array}$ & 80,12 & 117,01 \\
\hline Epidalea calamita & 30TUM65 & 100,00 & 120,56 & 114,66 & 38,52 & 5723,75 & 285,82 & $-8,01$ & 293,82 & 95,88 & 194,97 & 196,42 & 50,15 & 447,48 & 51,29 & 18,07 & 28,54 & 141,68 & 64,24 & 79,89 & 113,66 \\
\hline Epidalea calamita & 30TUM66 & 100,00 & 118,44 & 113,53 & 38,58 & 5661,01 & 282,08 & $-8,95$ & 291,03 & 94,38 & 192,27 & 193,35 & 48,90 & 467,21 & 53,63 & 19,92 & 27,83 & 148,82 & 69,35 & 84,41 & 118,20 \\
\hline Epidalea calamita & 30TUM68 & 100,00 & 114,51 & 110,01 & 38,80 & 5524,72 & 273,23 & $-8,14$ & 281,38 & 90,16 & 186,78 & 187,56 & 46,52 & 518,49 & 60,62 & 23,53 & 26,12 & 167,51 & 82,83 & 94,81 & 131,75 \\
\hline Epidalea calamita & 30TUM70 & 100,00 & 120,65 & 112,09 & 38,00 & 6069,25 & 288,93 & $-2,75$ & 291,68 & 88,68 & 199,90 & 201,46 & 45,47 & 426,42 & 49,1 & 14,18 & 29,31 & 132,47 & 60,36 & 69,57 & 113,54 \\
\hline Epidalea calamita & 30TUM71 & 100,00 & 119,13 & 112,84 & 38,00 & 6011,37 & \begin{tabular}{|l|l|}
287,38 \\
\end{tabular} & $-2,13$ & 292,71 & 86,99 & $\begin{array}{l}197,57 \\
\end{array}$ & \begin{tabular}{l|l|}
199,08 \\
\end{tabular} & 44,55 & \begin{tabular}{|l|l|}
434,87 \\
\end{tabular} & \begin{tabular}{|l|l|}
49,93 \\
4
\end{tabular} & 14,78 & 28,91 & 134,93 & \begin{tabular}{|l|l|}
61,43 \\
\end{tabular} & 72,25 & 115,50 \\
\hline Epidalea calamita & 30TUM72 & 100,00 & 118,17 & 113,46 & 38,02 & 5946,90 & 286,29 & $-7,18$ & 293,47 & 94,90 & 195,99 & 197,31 & 44,71 & 440,20 & 50,73 & 15,58 & 28,85 & 136,36 & 62,00 & 74,74 & 115,50 \\
\hline Epidalea calamita & 30TUM73 & 100,00 & 120,60 & 113,79 & 38,01 & 5866,47 & 287,42 & $-6,64$ & 294,06 & 99,05 & 197,23 & 198,49 & 48,18 & 436,93 & 50,23 & 15,99 & 28,97 & 136,12 & 61,21 & 75,53 & 113,04 \\
\hline Epidalea calamita & 30TUM74 & 100,00 & 121,31 & 113,99 & 38,00 & 5780,65 & 286,95 & $-7,65$ & 294,60 & 103,09 & 196,71 & 197,91 & 50,21 & 438,37 & 50,55 & 16,69 & 29,02 & 136,96 & 61,24 & 77,77 & 111,05 \\
\hline Epidalea calamita & 30TUM75 & 100,00 & 118,92 & 113,79 & 38,02 & 5711,37 & 283,52 & $-10,29$ & 293,81 & 104,70 & 193,40 & 194,54 & 49,02 & 454,39 & 52,15 & 18,33 & 28,52 & 141,93 & 64,84 & 82,43 & 113,56 \\
\hline Epidalea calamita & 30TUM79 & 100,00 & 111,89 & 106,71 & 38,25 & 5428,82 & \begin{tabular}{|l|l|}
266,68 \\
266,
\end{tabular} & \begin{tabular}{|c|}
$-7,42$ \\
-12
\end{tabular} & \begin{tabular}{|l|}
274,10 \\
\end{tabular} & 87,91 & 183,20 & $\begin{array}{l}183,58 \\
\end{array}$ & $\begin{array}{ll}45,18 \\
45,\end{array}$ & 555,44 & $\begin{array}{l}2,112 \\
64,72\end{array}$ & 25,89 & 25,01 & 178,71 & $\begin{array}{l}91,41 \\
91,41\end{array}$ & \begin{tabular}{|l|}
02,45 \\
102,15
\end{tabular} & 141,46 \\
\hline Epidalea calamita & 30TUM80 & 100,00 & 118,00 & 110,56 & 37,59 & 6067,71 & 284,98 & $-5,22$ & 290,20 & 105,01 & 197,54 & 198,71 & 43,04 & 437,78 & 50,68 & 14,66 & 28,99 & 135,09 & 62,41 & 72,84 & 114,67 \\
\hline Epidalea calamita & 30TUM81 & 100,00 & 116,95 & 111,21 & 37,90 & 6006,65 & 284,05 & $-7,19$ & 291,23 & 108,06 & 195,69 & 196,92 & 42,89 & 443,65 & 51,36 & 15,47 & 28,75 & 136,57 & 63,39 & 75,42 & 115,59 \\
\hline Epidalea calamita & 30TUM82 & 100,00 & 117,95 & 111,66 & 38,00 & 5940,03 & 284,48 & $-7,22$ & 291,70 & 106,45 & 195,72 & 196,94 & 44,73 & 443,83 & 51,25 & 15,91 & 28,60 & 136,89 & 63,27 & 76,37 & 114,72 \\
\hline Epidalea calamita & $\begin{array}{l}\text { 30TUM87 } \\
\end{array}$ & 100,00 & 116,17 & 108,59 & 38,00 & 5572,34 & 274,58 & $-7,01$ & 281,59 & 92,07 & 189,17 & 189,63 & 47,62 & 501,96 & 56,91 & 22,37 & 26,03 & 158,15 & 77,71 & 91,85 & 126,35 \\
\hline Epidalea calamita & 30TUM91 & 100,00 & 115,85 & 109,53 & 37,30 & 6011,67 & 281,66 & $-7,52$ & 289,18 & 121,26 & $\begin{array}{l}194,78 \\
\end{array}$ & 195,85 & 41,82 & 450,98 & 52,22 & 15,98 & 28,32 & 138,54 & 65,35 & 77,33 & 116,20 \\
\hline Epidalea calamita & 30TUM: & 100,00 & 114,63 & 110,05 & \begin{tabular}{|c|}
37,68 \\
\end{tabular} & 5881,85 & 279,41 & $-9,63$ & 289,04 & 116,75 & 191,84 & 192,75 & 42,29 & 463,51 & 53,42 & 17,71 & 27,62 & 142,29 & 68,02 & 82,04 & 117,94 \\
\hline Epidalea calamita & 30TUNOO & 100,00 & 113,28 & 113,74 & 39,77 & 5700,10 & 277,23 & $-6,27$ & 283,50 & 81,03 & 188,47 & 188,47 & 41,84 & 531,77 & 67,99 & 24,85 & 30,01 & 188,38 & 94,56 & 94,56 & 140,40 \\
\hline Epidalea calamita & 30TUN01 & 100,00 & 111,04 & 112,70 & 39,98 & 5628,60 & 272,93 & $-7,22$ & 280,16 & 79,47 & 185,17 & 185,17 & 40,30 & 563,92 & 72,45 & 26,71 & 29,77 & 199,85 & 101,55 & 101,55 & 148,49 \\
\hline Epidalea calamita & 30TUN03 & 100,00 & 103,34 & 109,88 & 40,00 & 5459,93 & 260,54 & $-11,11$ & 271,66 & 73,21 & 175,34 & 175,34 & 35,38 & 650,41 & 83,54 & 32,09 & 28,48 & 228,09 & 118,83 & 118,83 & 172,09 \\
\hline Epidalea calamita & 30TUN05 & 100,00 & 80,94 & 105,08 & 39,84 & 5291,33 & 233,09 & $-27,70$ & 260,79 & 52,43 & 151,28 & 151,33 & 16,81 & 841,23 & 104,65 & 42,91 & 25,69 & 284,91 & 152,84 & 153,09 & 231,68 \\
\hline Epidalea calamita & 30TUN10 & 100,00 & 110,00 & 112,82 & 39,55 & 5650,92 & 272,87 & $-9,21$ & 282,08 & 78,96 & 184,15 & 184,58 & 39,22 & 549,77 & 69,22 & 26,07 & 28,63 & 191,38 & 98,66 & 99,03 & 144,40 \\
\hline Epidalea calamita & 30TUN11 & 100,00 & 109,07 & 111,48 & 39,88 & 5567,29 & 269,32 & $-8,31$ & 277,63 & 78,70 & 182,48 & 182,55 & 39,53 & 576,87 & 73,10 & 27,93 & 28,45 & 201,05 & 104,75 & 104,80 & 151,04 \\
\hline Epidalea calamita & 30TUN17 & 100,00 & 79,01 & 100,01 & 39,96 & 5033,41 & 222,44 & $-24,72$ & 247,16 & 53,18 & 145,73 & 146,35 & 18,47 & 921,48 & 114,09 & 47,83 & 24,58 & 307,72 & 168,94 & 171,41 & 252,54 \\
\hline Epidalea calamita & 30TUN24 & 100,0 & & 105,16 & 39,77 & 5281,60 & 241,81 & $-20,16$ & 261,97 & 62,69 & 160,11 & 160,14 & 25,69 & 760,14 & 94,1 & 38,96 & 25,36 & 256,25 & 140,39 & 140,77 & 203,05 \\
\hline Epidalea calamita & $30 T$ UN & 100,00 & 73,81 & 101,07 & 39,60 & 5150,06 & 221,03 & $-31,47$ & 252,51 & 47,44 & 142,43 & 142,67 & 12,10 & 917,93 & 111,60 & 47,71 & 23,88 & 303,48 & 168,51 & 169,33 & 252,25 \\
\hline Epidalea calamita & 30 TUN33 & 100,00 & 99,10 & 105,73 & 39,69 & 5295,84 & 250,86 & $-13,18$ & 264,04 & 72,29 & 168,86 & 169,11 & 33,99 & 687,41 & 85,03 & 34,75 & 25,42 & 231,73 & \begin{tabular}{|l|l|}
126,50 \\
\end{tabular} & 127,49 & 180,19 \\
\hline Epidalea calamita & 30TUN36 & 100,00 & 81,83 & 100,10 & 39,74 & 5077,09 & 226,35 & $-23,31$ & 249,66 & 56,39 & 149,19 & 149,59 & 20,72 & 872,92 & 106,65 & 45,55 & 23,93 & 289,19 & 161,93 & 162,79 & 235,85 \\
\hline Epidalea calamita & 30TUN50 & 100,00 & 108,18 & 107,94 & 39,00 & 5427,27 & 264,00 & $-9,95$ & 273,95 & 82,67 & 179,40 & 179,86 & 41,34 & 581,56 & 69,70 & 27,79 & 25,18 & 191,44 & 99,60 & 107,21 & 149,70 \\
\hline Epidalea calamita & 30TUN & 100,00 & 92,94 & 103,02 & 39, & 5238,93 & 242,56 & $-17,49$ & 260,05 & 67,53 & 162,39 & 162,39 & 29,32 & 730,08 & 87,81 & 37,11 & 23,85 & 239,81 & 132,59 & 134,37 & 192,08 \\
\hline Epidalea calamita & 30TUN65 & 100,00 & 69,90 & 98,53 & 38,94 & 5144,39 & 215,94 & $-34,28$ & 250,22 & 43,91 & 139,24 & 139,24 & 8,80 & 926,83 & 108,09 & 48,77 & 21,90 & 296,21 & 169,89 & 169,89 & 252,41 \\
\hline Epidalea calamita & 30TUN70 & 100,00 & 108,62 & 104,73 & 38,47 & 5357,18 & 260,88 & $\begin{array}{r}-3,200 \\
-7,79 \\
\end{array}$ & 268,68 & $\begin{array}{l}84,45 \\
84,4\end{array}$ & $\begin{array}{l}179,17 \\
\end{array}$ & $\begin{array}{l}179,25 \\
\end{array}$ & $0,42,87$ & 593,01 & \begin{tabular}{|c|c|}
69,56 \\
69
\end{tabular} & 28,22 & 24,35 & 191,54 & |100,47 & $\begin{array}{l}108,47 \\
\end{array}$ & 152,06 \\
\hline Epidalea calamita & 30TUN71 & 100,00 & 103,74 & 103,20 & 38,69 & 5300,40 & 254,09 & $-10,03$ & 264,13 & 79,26 & 173,72 & 173,73 & 38,92 & 638,52 & 75,21 & 31,10 & 23,84 & 206,53 & 110,94 & 114,36 & 165,02 \\
\hline Epidalea calamita & 30TUN73 & 100,00 & 95,15 & 99,90 & 38,9 & 5169,28 & 240,88 & $-13,69$ & 254,58 & 70,69 & 163,85 & 163 & 32,27 & 733,92 & 86,87 & 37,00 & 22,96 & 237,79 & 132,46 & 132,82 & 192 \\
\hline Epidalea calamita & \begin{tabular}{|l|}
$30 T U N 75$ \\
3
\end{tabular} & $\begin{array}{l}100,00 \\
\end{array}$ & $\begin{array}{l}3,10 \\
83,51\end{array}$ & $\begin{array}{l}96,70 \\
96,70\end{array}$ & | 30,95 & 5049,08 & \begin{tabular}{|l|}
225,18 \\
225
\end{tabular} & $\begin{array}{l}\mid-1,03 \\
-20,38 \\
\end{array}$ & $\begin{array}{l}245,56 \\
245\end{array}$ & $\begin{array}{l}\mid 0,095 \\
59,29\end{array}$ & $\begin{array}{l}151,16 \\
151,1\end{array}$ & \begin{tabular}{|l|}
151,18 \\
151,
\end{tabular} & $\begin{array}{ll}22,95 \\
22,95\end{array}$ & \begin{tabular}{|l|}
856,41 \\
856
\end{tabular} & \begin{tabular}{|l|}
$60,01,02$ \\
101
\end{tabular} & 40 & $\begin{array}{ll}22,20 \\
22\end{array}$ & 276,21 & $\begin{array}{l}5,2,40 \\
158,04\end{array}$ & $\begin{array}{l}152,0<2 \\
158,04 \\
\end{array}$ & $\begin{array}{l}25,000 \\
229,83\end{array}$ \\
\hline Epidalea calamita & 30TUN76 & 100,00 & 80,56 & 94,80 & 38,99 & 4971,70 & 219,32 & $-21,07$ & 240,39 & 56,74 & 147,03 & 147,40 & 21,09 & 907,74 & 107,14 & 47,28 & 22,14 & 292,77 & 168,25 & 168,85 & 245,53 \\
\hline Epidalea calamita & 30TUN83 & 100,00 & 97,92 & 97,97 & 38,61 & 5124,45 & 241.13 & -9.80 & 250.94 & 73,74 & 166.08 & 166,08 & 35,36 & 729.99 & 85,87 & 36.48 & 22.68 & 235,61 & $\mid 131.57$ & 131.59 & 192.01 \\
\hline Epidalea calamita & 30TUN84 & 100,00 & 95,87 & 95,97 & 38,78 & 5037,41 & 235,94 & $-9,26$ & 245,21 & 72,10 & 163,01 & 163,01 & 34 & 773,53 & 91,48 & 38,99 & 22,55 & 250,52 & 141,46 & 141,46 & 205 \\
\hline Epidalea calamita & 30TUN85 & 100,00 & 75,40 & 95,93 & 38,82 & 5077,38 & 217,77 & $-27,32$ & 245,09 & 50,12 & 143,84 & 143,85 & 14,98 & 908,83 & 105,03 & 47,62 & 21,45 & 88,47 & 167,41 & 167,41 & 246 \\
\hline
\end{tabular}




\begin{tabular}{|c|c|c|c|c|c|c|c|c|c|c|c|c|c|c|c|c|c|c|c|c|c|}
\hline TAXON & UTM & $\mathrm{km} 2$ & B101 & B102 & $\mathrm{BIO3}$ & B104 & B105 & B106 & B107 & B108 & B109 & BIO10 & BIO11 & BIO12 & 81013 & BIO14 & BIO15 & BIO16 & BIO17 & BIO18 & B1019 \\
\hline Epidalea calamita & 30TUN86 & 100,00 & 66,77 & 94,64 & 38,78 & 5038,34 & 207,94 & $-33,90$ & 241,84 & 40,28 & 134,84 & 135,01 & 7,35 & 990,20 & 113,64 & 52,54 & 21,05 & 312,65 & 183,28 & 183,33 & 271,50 \\
\hline Epidalea calamita & 30TUN90 & 100,00 & 109,22 & 101,28 & 38,00 & 5337,25 & 258,43 & $-4,49$ & 262,92 & 84,31 & 179,54 & 179,57 & 43,42 & 602,44 & 69,40 & 28,63 & 23,47 & 191,90 & 102,63 & 104,81 & 155,11 \\
\hline Epidalea calamita & 30TUN93 & 100,00 & 101,05 & 95,72 & 38,19 & 5085,48 & 241,52 & $-4,99$ & 246,51 & 76,96 & 168,68 & 168,68 & 38,88 & 728,04 & 85,35 & 35,99 & 22,53 & 234,67 & 131,51 & 131,51 & 192,18 \\
\hline Epidalea calamita & 30TUN94 & 100,00 & 97,51 & 94,17 & 38,50 & 5005,21 & 235,48 & $-6,21$ & 241,69 & 73,75 & 164,15 & 164,25 & 36,64 & 776,04 & 91,17 & 38,84 & 22,19 & 250,43 & 142,05 & 142,05 & 206,47 \\
\hline Epidalea calamita & 30TUN95 & 100,00 & 78,28 & 94,44 & \begin{tabular}{|l|l|}
38,47 \\
\end{tabular} & 5046,53 & 218,68 & $-23,58$ & 242,26 & 53,54 & 146,15 & 146,33 & 18,04 & 901,17 & \begin{tabular}{ll|}
103,65 \\
\end{tabular} & $\begin{array}{ll}46,95 \\
\end{array}$ & 21,24 & 285,22 & 166,28 & 166,34 & 244,29 \\
\hline Epidalea calamita & 30TVK04 & 100,00 & 141,82 & 108,82 & 35,00 & 6739,72 & 319,73 & 12,91 & 306,82 & 98,61 & 232,45 & 232,45 & 59,53 & 400,06 & 45,23 & 9,46 & 35,27 & 131,47 & 47,25 & 47,25 & 111,22 \\
\hline Epidalea calamita & 30TVK05 & 100,00 & 140,83 & 107,49 & 35,00 & 6692,88 & 316,60 & 13,12 & 303,48 & 98,00 & 230,73 & 230,73 & 58,72 & 400,28 & 45,81 & 9,84 & 35,06 & 132,45 & 48,01 & 48,01 & 111,60 \\
\hline Epidalea calamita & $\begin{array}{l}\text { 30TVKO6 } \\
\end{array}$ & 100,00 & 142,47 & 106,21 & 35,00 & 6653,52 & 315,94 & 15,49 & 300,45 & 99,92 & 231,60 & 231,60 & 60,65 & 393,55 & 45,92 & 9,78 & 35,14 & 131,53 & 47,31 & 47,31 & 110,19 \\
\hline Epidalea calamita & 30TVK07 & 100,00 & 138,22 & 105,19 & 35,00 & 6599,22 & 309,76 & 12,52 & 297,24 & 95,99 & 226,14 & 226,46 & 57,02 & 400,96 & 47,07 & \begin{tabular}{|c|}
10,68 \\
\end{tabular} & 34,48 & 133,24 & 50,14 & 50,30 & 110,73 \\
\hline Epidalea calamita & 30TVK08 & 100,00 & 124,39 & 104,41 & 35,06 & 6501,56 & 294,21 & 1,24 & 292,97 & 83,41 & 209,89 & 211,86 & 45,44 & 432,64 & 51,12 & 13,14 & 32,69 & 139,51 & 58,66 & 60,32 & 113,69 \\
\hline Epidalea calamita & 30TVKO9 & 100,00 & 113,60 & 104,19 & 35,39 & 6407,64 & 282,44 & $-7,01$ & 289,45 & 85,27 & 198,75 & 200,05 & 36,88 & 464,05 & 56,18 & 15,15 & 31,66 & 147,87 & 65,86 & 69,08 & 118,12 \\
\hline Epidalea calamita & 30TVK14 & 100,00 & 143,95 & 108,34 & 35,00 & 6764,50 & 321,63 & 15,06 & 306,57 & 100,59 & 234,79 & 234,79 & 61,20 & 403,45 & 46,28 & 9,30 & 35,95 & 134,67 & 46,24 & 46,24 & 115,13 \\
\hline Epidalea calamita & 30TVK15 & 100,00 & 142,04 & 106,75 & \begin{tabular}{|l|l|}
34,97 \\
\end{tabular} & 6705,94 & 317,49 & 14,75 & 302,73 & 99,14 & 231,96 & 231,96 & 59,81 & 408,66 & 47,75 & 9,86 & 35,56 & 137,26 & 47,68 & 47,68 & 117,06 \\
\hline Epidalea calamita & 30TVK16 & 100,00 & 139,82 & 105,44 & 34,99 & 6661,84 & 313,12 & 13,97 & 299,15 & 97,24 & 229,09 & 229,09 & 58,00 & 414,38 & 49,04 & \begin{tabular}{|l|l|}
10,47 \\
\end{tabular} & 35,36 & 139,58 & 49,25 & 49,25 & 118,99 \\
\hline Epidalea calamita & 30TVK17 & 100,00 & 138,91 & 104,25 & 34,96 & 6616,96 & 310,09 & 13,86 & 296,23 & 96,55 & 227,31 & 227,31 & 57,37 & 414,99 & 49,71 & 10,90 & 35,08 & 140,19 & 50,32 & 50,32 & 118,99 \\
\hline Epidalea calamita & 30TVK18 & 100,00 & 131,85 & 103,41 & 34,97 & 6562,13 & 301,39 & 8,21 & 293,18 & 90,01 & 218,54 & 219,79 & 51,45 & 430,06 & 51,12 & 11,99 & 33,87 & 143,24 & 54,72 & 55,46 & 120,27 \\
\hline Epidalea calamita & 30TVK19 & 100,00 & 122,10 & 103,03 & 35,01 & 6504,33 & 290,27 & 0,24 & 290,03 & 80,60 & 207,63 & 209,40 & 43,13 & 452,22 & 52,58 & 13,31 & 32,24 & 146,66 & 60,58 & 63,19 & 121,45 \\
\hline Epidalea calamita & 30TVK24 & 100,00 & 141,48 & 108,04 & 35,00 & 6754,49 & 319,12 & 13,49 & 305,64 & 98,16 & 232,17 & 232,17 & 58,82 & 420,04 & 49,14 & 9,77 & 36,11 & 141,53 & 47,61 & 47,61 & 122,13 \\
\hline Epidalea calamita & 30TVK25 & 100,00 & 139,38 & 106,45 & 34,98 & $\begin{array}{lll}6697,34 \\
\end{array}$ & 314,71 & 13,08 & 301,62 & 96,42 & 229,10 & 229,10 & 57,26 & 428,35 & 50,99 & 10,36 & 36,03 & 145,21 & 49,27 & 49,27 & 125,76 \\
\hline Epidalea calamita & 30 TVK26 & 100,00 & 138,25 & 104,76 & 34,99 & 6657,59 & 311,19 & 13,42 & 297,77 & 95,62 & 227,21 & 227,21 & 56,31 & 433,86 & 52,36 & \begin{tabular}{|l|l|}
10,97 \\
\end{tabular} & 35,88 & 147,81 & 50,58 & 50,58 & 128,45 \\
\hline Epidalea calamita & 30TVK28 & 100,00 & 134,52 & 102,71 & 34,77 & 6590,42 & 303,93 & 11,24 & 292,69 & 92,35 & 222,28 & 222,54 & 53,49 & 438,63 & 53,81 & 11,70 & 34,89 & 149,35 & 53,68 & 53,80 & 127,92 \\
\hline Epidalea calamita & 30TVK29 & 100,00 & 123,83 & 102,72 & 35,00 & 6522,81 & 292,25 & 2,43 & 289,82 & 82,35 & 209,81 & 211,40 & 44,65 & 461,17 & 55,11 & 13,13 & 33,00 & 152,18 & 60,21 & 62,15 & 128,16 \\
\hline Epidalea calamita & 30TVK35 & 100,00 & 140,79 & 106,29 & \begin{tabular}{|l|l|}
34,87 \\
\end{tabular} & 6709,03 & 316,27 & 14,32 & 301,95 & 97,58 & 230,45 & 230,45 & 58,30 & 432,71 & 53,08 & 10,14 & 37,05 & 149,43 & 48,10 & 48,10 & 129,22 \\
\hline Epidalea calamita & 30TVK36 & 100,00 & 139,30 & 104,45 & 34,74 & 6663,92 & 312,32 & 14,42 & 297,90 & 96,29 & 228,15 & 228,15 & 57,02 & 441,51 & 54,98 & 10,73 & 37,02 & 153,39 & 49,58 & 49,58 & 133,44 \\
\hline Epidalea calamita & 30TVK37 & 100,00 & 138,10 & 102,94 & 34,50 & 6626,82 & 309,23 & 14,46 & 294,77 & 95,56 & 226,59 & 226,59 & 56,19 & 444,80 & 56,12 & 11,12 & 36,95 & 155,32 & 50,47 & 50,47 & 134,92 \\
\hline Epidalea calamita & 30TVK38 & 100,00 & 136,31 & 102,21 & 34,23 & 6602,03 & 306,29 & 13,06 & 293,23 & 93,77 & 224,52 & 224,52 & 54,94 & 443,90 & 56,36 & 11,18 & 36,47 & 154,53 & 51,94 & 51,94 & 132,50 \\
\hline Epidalea calamita & $\begin{array}{l}\text { 30TVK39 } \\
\end{array}$ & 100,00 & 132,33 & 102,09 & 34,58 & 6564,50 & 301,02 & $\begin{array}{l}0,65 \\
9,65\end{array}$ & 291,37 & 90,28 & $\begin{array}{l}219,68 \\
210\end{array}$ & 220,00 & 51,72 & 447,13 & 56,23 & 11,54 & 35,06 & 153,56 & 55,03 & 55,22 & 130,17 \\
\hline Epidalea calamita & 30TVK43 & 100,00 & 146,90 & 110,28 & 35,02 & 6784,14 & 326,59 & 17,10 & 309,49 & 103,19 & 237,63 & 237,63 & 63,67 & 408,17 & 49,26 & 8,35 & 37,78 & 140,62 & 42,91 & 42,91 & 120,14 \\
\hline Epidalea calamita & 30TVK44 & 100,00 & 143,44 & 108,56 & 34,99 & 6760,64 & 321,77 & 15,10 & 306,66 & 99,78 & 233,83 & 233,83 & 60,45 & 423,37 & 52,28 & 9,23 & 37,69 & 146,93 & 45,40 & 45,40 & 125,90 \\
\hline Epidalea calamita & 30TVK45 & 100,00 & 141,73 & 106,88 & 34,73 & 6731,84 & 318,44 & 14,64 & 303,80 & 98,28 & 231,64 & 231,64 & 58,98 & 432,94 & 54,79 & 9,89 & 37,89 & 151,93 & 46,67 & 46,67 & 130,14 \\
\hline Epidalea calamita & 30TVK46 & 100,00 & 142,44 & 105,04 & 34,08 & 6722,08 & 317,54 & 15,72 & 301,82 & 99,19 & 232,04 & 232,04 & 59,47 & 433,65 & 56,45 & 9,89 & 38,66 & 154,29 & 46,01 & 46,01 & 131,79 \\
\hline Epidalea calamita & $\begin{array}{l}\text { 30TVK47 } \\
\end{array}$ & 100,00 & 137,47 & 103,58 & 34,19 & 6659,03 & 310,34 & $\mid 12,61$ & \begin{tabular}{|l|}
297,73 \\
\end{tabular} & $\begin{array}{ll}94,24 \\
94\end{array}$ & $\begin{array}{l}226,32 \\
22,3\end{array}$ & \begin{tabular}{|l|}
226,32 \\
\end{tabular} & 55,21 & $\begin{array}{l}449,72 \\
49,5\end{array}$ & 58,83 & $\mid$ & 38,01 & 159,53 & 49,71 & 49,71 & 136,32 \\
\hline Epidalea calamita & 30TVK48 & 100,00 & 135,62 & 103,27 & 34,38 & 6631,22 & 307,45 & 11,59 & 295,86 & 92,62 & 224,08 & 224,08 & 53,97 & 449,55 & 59,09 & 10,81 & 37,42 & 159,03 & 51,06 & 51,06 & 134,80 \\
\hline Epidalea calamita & 30TVK49 & 100,00 & 134,81 & 102,96 & 34,73 & 6603,20 & 305,15 & 11,37 & 293,78 & 92,12 & 222,82 & 222,82 & 53,66 & 442,82 & 58,10 & 10,74 & 36,60 & 155,84 & 52,14 & 52,14 & 130,55 \\
\hline Epidalea calamita & 30TVK53 & 100,00 & 144,53 & 111,16 & 35,28 & 6768,78 & 324,73 & 14,94 & 309,79 & 100,76 & 235,02 & 235,02 & 61,71 & 415,71 & 50,65 & 8,66 & 37,63 & 143,47 & 44,26 & 44,26 & 121,99 \\
\hline Epidalea calamita & 30TVK54 & 100,00 & 143,67 & 109,71 & 35,11 & 6755,05 & 322,69 & 15,08 & 307,61 & 99,94 & 233,95 & 233,95 & 60,92 & 420,95 & 52,77 & 9,08 & 37,83 & 147,14 & 44,87 & 44,87 & 124,71 \\
\hline Epidalea calamita & 30TVK55 & 100,00 & 141,85 & 108,40 & 34,99 & 6738,40 & 319,77 & 14,16 & 305,61 & 98,29 & 231,79 & 231,79 & 59,30 & 429,84 & 55,43 & 9,63 & 38,22 & 152,05 & 45,89 & 45,89 & 128,52 \\
\hline Epidalea calamita & 30TVK56 & 100,00 & 142,59 & 107,10 & 34,73 & 6737,97 & 319,71 & 15,12 & 304,59 & 99,05 & 232,33 & 232,33 & 59,72 & 429,50 & 57,3 & 9,44 & 39,30 & 154,57 & 44,76 & 44,76 & 129,99 \\
\hline Epidalea calamita & 30TVK57 & 100,00 & 140,80 & 106,21 & 34,44 & 6736,18 & 317,72 & 13,90 & 303,82 & 97,37 & 230,36 & 230,36 & 58,05 & 437,08 & 60,00 & 9,60 & 39,76 & 158,71 & 45,75 & 45,75 & 132,97 \\
\hline Epidalea calamita & 30TVK58 & 100,00 & 137,29 & 105,89 & 34,75 & 6671,55 & 312,08 & 12,03 & 300,05 & 93,89 & 225,91 & 225,91 & 55,51 & 441,80 & 60,58 & 10,14 & 38,73 & 159,91 & 48,39 & 48,39 & 132,82 \\
\hline Epidalea calamita & 30TVK59 & 100,00 & 135,08 & 104,62 & 34,94 & 6619,79 & 306,93 & 11,33 & 295,60 & 92,02 & 223,11 & 223,11 & 54,05 & 437,96 & 58,92 & 10,32 & 37,44 & 156,24 & 50,69 & 50,69 & 128,61 \\
\hline Epidalea calamita & 30TVK63 & 100,00 & 141,18 & 112,37 & 36,00 & 6743,88 & 321,63 & 11, & 309,73 & 97,42 & 231,27 & 231,27 & 58,88 & 423,68 & 51,31 & 9,18 & 36,88 & 144,92 & 46,64 & 46,64 & 122,68 \\
\hline Epidalea calamita & 30TVK64 & 100,00 & 135,64 & 111,39 & 35,88 & 6717,81 & 315,40 & 7,72 & 307,68 & 91,90 & 225,52 & 225,52 & 54,00 & 443,15 & 54,57 & 10,44 & 36,41 & 151,81 & 50,33 & 50,33 & 128,69 \\
\hline Epidalea calamita & 30TVK65 & 100,00 & 136,33 & 110,13 & 35,57 & 6706,47 & 314,83 & 9,29 & 305,54 & 92,67 & 225,97 & 225,97 & 54,79 & 441,00 & 56,15 & 10,42 & 37,09 & 154,02 & 49,42 & 49,42 & 129,26 \\
\hline Epidalea calamita & 30TVK66 & 100,00 & 135,15 & 109,35 & 35,54 & 6682,24 & 312,59 & 9,16 & 303,44 & 91,49 & 224,27 & 224,27 & 53,89 & 444,85 & 58,23 & 10,72 & 37,30 & 157,33 & 49,85 & 49,85 & 130,99 \\
\hline Epidalea calamita & $\begin{array}{l}\text { 30TVK67 } \\
\end{array}$ & 100,00 & 137,19 & 109,24 & 35,68 & $\begin{array}{ll}60061,03 \\
6661,03\end{array}$ & 313,95 & $\mid \frac{1,10}{11,86}$ & \begin{tabular}{|l|}
302,08 \\
\end{tabular} & $\begin{array}{l}93,44 \\
93,4\end{array}$ & 225,66 & 225,66 & 56,13 & $\begin{array}{l}436,79 \\
436,79\end{array}$ & 59,65 & 9,84 & 39,03 & 158,62 & 47,44 & $\begin{array}{l}47,03 \\
47,44\end{array}$ & 130,13 \\
\hline Epidalea calamita & 30TVKE & 100,00 & 136,47 & 108,46 & 35,96 & 6623,71 & 311,34 & 12,18 & 299,16 & 92,69 & 224,35 & 224,35 & 55,92 & 432,86 & 59,86 & 9,67 & 39,16 & 158,13 & 47,77 & 47,77 & 128,14 \\
\hline Epidalea calamita & $\begin{array}{l}\text { 30TVK69 } \\
\end{array}$ & 100,00 & 130,82 & 105,62 & 35,28 & 6593,60 & 302,23 & 8,04 & 294,19 & 87,81 & 218,64 & 218,64 & 50,92 & 440,21 & 58,48 & 10,84 & 36,21 & 155,32 & 53,21 & 53,21 & 125,62 \\
\hline Epidalea calamita & 30TVK73 & 100,00 & 141,02 & 113,14 & 36,00 & 6727,66 & 321,23 & 11,60 & 309,64 & 97,50 & 230,97 & 230,97 & 59,09 & 419,19 & 50,42 & 9,30 & 36,39 & 142,58 & 47,14 & 47,14 & 119,64 \\
\hline Epidalea calamita & 30TVK74 & 100,00 & 132,79 & 112,49 & 36,00 & 6702,53 & 312,62 & 5,07 & 307,55 & 89,18 & 222,58 & 222,58 & 51,62 & 446,31 & 53,93 & 10,94 & 35,29 & 150,76 & 52,65 & 52,65 & 126,82 \\
\hline Epidalea calamita & $30 \mathrm{TVK}$ & 100,00 & 133,78 & $\begin{array}{l}11,4,45 \\
111,15\end{array}$ & 36,00 & 6683,05 & 311 & $\frac{3,01}{6,99}$ & \begin{tabular}{|l|l|}
304,95 \\
305
\end{tabular} & $\begin{array}{l}\mid l 5,10 \\
90,26\end{array}$ & \begin{tabular}{|l|}
223,04 \\
223
\end{tabular} & \begin{tabular}{|l|}
223,04 \\
223
\end{tabular} & $\begin{array}{l}1,202 \\
52,85\end{array}$ & \begin{tabular}{|l|}
$440,31,63$ \\
440,
\end{tabular} & 54,90 & $\begin{array}{l}11,04 \\
11,08\end{array}$ & $\begin{array}{l}35,25 \\
35,72\end{array}$ & 151,22 & 51,74 & $\begin{array}{l}20,03 \\
51,74\end{array}$ & $\begin{array}{l}120,02 \\
125,60\end{array}$ \\
\hline Epidalea calamita & 30TVK76 & 100,00 & 127,98 & 110,16 & 36,00 & 6648,33 & 304,79 & 2,62 & 302,17 & 84,65 & 216,96 & 216,96 & 47,77 & 456,99 & 56,81 & 12,23 & 34,59 & 155,52 & 55,91 & 55,91 & 129,05 \\
\hline Epidalea calamita & 30TVK77 & 100,00 & 127,52 & 108,89 & 36,00 & 6620,45 & 302,52 & 3,27 & 299,25 & 84,27 & 215,99 & 215,94 & 47,71 & 453,90 & 57,35 & 12,08 & 34,72 & 155,45 & 56,17 & 56,17 & 127,52 \\
\hline Epidalea calamita & 30TVK78 & 100,00 & 132,00 & 107,07 & 35,82 & 6613,92 & 304,40 & 8,54 & 295,86 & 88,89 & 220,03 & 220,03 & 52,04 & 431,48 & 56,53 & 10,85 & 35,91 & 151,10 & 52,36 & 52,36 & 120,87 \\
\hline Epidalea calamita & 30TVK79 & 100,00 & 130,23 & 104,81 & 35,19 & 6592,21 & 299,79 & 7,80 & 291,99 & 87,36 & 218,03 & 218,03 & 50,57 & 428,29 & 55,77 & 10,97 & 34,90 & 148,50 & 54,04 & 54,04 & 117 \\
\hline Epidalea calamita & \begin{tabular}{|l|}
30 TVK 83 \\
\end{tabular} & $\begin{array}{l}100,00 \\
\end{array}$ & $\begin{array}{l}130,25 \\
138,79\end{array}$ & $\begin{array}{l}104,01 \\
113,98\end{array}$ & | 30,19 & $\begin{array}{l}0393,21 \\
6701,32\end{array}$ & 318,91 & $\begin{array}{l}, 00 \\
9,42 \\
\end{array}$ & \begin{tabular}{|l|}
309,49 \\
30,49
\end{tabular} & $\begin{array}{l}1,00 \\
95,62 \\
\end{array}$ & \begin{tabular}{|l|}
228,52 \\
22,
\end{tabular} & \begin{tabular}{|l|}
228,52 \\
22,
\end{tabular} & $\begin{array}{l}50,53 \\
57,55\end{array}$ & \begin{tabular}{|l|l|}
421,78 \\
421,78
\end{tabular} & |39,56 & | & $\begin{array}{ll}35,27 \\
35,27\end{array}$ & $\begin{array}{l}140,00 \\
141,03\end{array}$ & 44,49 & $\begin{array}{l}42,44 \\
49,49\end{array}$ & $\begin{array}{l}111,00 \\
118,06\end{array}$ \\
\hline Epidalea calamita & 30TVK84 & 100,00 & 136,38 & 112,93 & 36,00 & 6688,14 & 315,22 & 8,16 & 307,06 & 93,16 & 225,78 & 225,78 & 55,40 & 427,51 & 51,14 & 10,45 & 35,06 & 143,71 & 50,99 & 50,99 & 119,44 \\
\hline Epidalea calamita & 30TVK85 & 100,00 & 130,92 & 111,85 & 36,04 & 6663,29 & 308,86 & 3,97 & 304,89 & 87,80 & 220,08 & 220,08 & 50,55 & 442,93 & 53,19 & 11,81 & 34,14 & 148,08 & 54,91 & 54,91 & 122,79 \\
\hline Epidalea calamita & 30TVK86 & 100,00 & 129,06 & 110,40 & 36,00 & 6643,83 & 305,12 & 3,24 & 301,89 & 85,92 & 217,78 & 217,78 & 48, & 445,04 & 54,00 & 12,35 & 33,79 & 149,01 & 56,37 & 56,37 & 122,41 \\
\hline Epidalea calamita & 30TVK87 & 100,00 & 125,00 & 109,19 & 36,00 & 6611,96 & 299,33 & 1,01 & 298,32 & 82,09 & 213,40 & 213,40 & 45,56 & 453,26 & 54,74 & 12,95 & 32,86 & 150,36 & 59,67 & 59,67 & 123,08 \\
\hline
\end{tabular}




\begin{tabular}{|c|c|c|c|c|c|c|c|c|c|c|c|c|c|c|c|c|c|c|c|c|c|}
\hline TAXON & UTM & $\mathrm{km} 2$ & B101 & B102 & $\mathrm{BIO3}$ & 8104 & B105 & B106 & B107 & B108 & B109 & B1010 & BIO11 & BIO12 & B1013 & BIO14 & BIO15 & B1016 & B1017 & BIO18 & B1019 \\
\hline Epidalea calamita & 30TVK88 & 100,00 & 121,64 & 107,84 & 35,95 & 6583,24 & 294,27 & $-0,88$ & 295,15 & 79,05 & 209,83 & 209,84 & 42,75 & 458,95 & 54,87 & 13,65 & 32,03 & 150,42 & 62,90 & 62,91 & 122,69 \\
\hline Epidalea calamita & 30TVK89 & 100,00 & 126,58 & 104,72 & 35,36 & 6585,39 & 295,38 & 4,42 & 290,96 & 84,21 & 214,39 & 214,50 & 47,38 & 431,15 & 53,18 & 12,27 & 32,92 & 143,65 & 58,45 & 58,59 & 113,28 \\
\hline Epidalea calamita & 30TVK93 & 100,00 & 133,88 & 115,16 & 36,72 & 6682,34 & 314,40 & 4,33 & 310,06 & 91,02 & 223,35 & 223,35 & 53,06 & 435,85 & 49,31 & 11,01 & 33,60 & 141,44 & 54,57 & 54,57 & 119,15 \\
\hline Epidalea calamita & 30TVK94 & 100,00 & 138,49 & 113,19 & 36,39 & 6662,75 & 316,37 & 9,55 & 306,82 & 95,65 & 227,41 & 227,41 & 57,56 & 415,14 & 48,55 & 10,29 & 34,43 & 137,83 & 50,81 & 50,81 & 113,59 \\
\hline Epidalea calamita & 30TVK95 & 100,00 & 132,32 & 112,24 & 36,18 & 6644,92 & 309,54 & 4,81 & 304,73 & 89,54 & 221,22 & 221,22 & 52,02 & 432,00 & 50,47 & 11,76 & 33,33 & 142,08 & 55,31 & 55,31 & 117,16 \\
\hline Epidalea calamita & 30TVL00 & 100,00 & 103,47 & 104,36 & 35,96 & 6315,89 & 271,61 & $-14,89$ & 286,50 & 97,34 & 188,25 & 189,18 & 29,18 & 495,14 & 61,23 & 17,16 & 30,66 & 156,36 & 73,01 & 77,93 & 122,97 \\
\hline Epidalea calamita & 30TVL01 & 100,00 & 80,62 & 106,71 & 37,19 & 6073,35 & 250,45 & $-32,06$ & 282,52 & 83,05 & 164,19 & 164,30 & 12,32 & 595,66 & 74,22 & 23,49 & 28,36 & 187,09 & 91,97 & 95,44 & 147,75 \\
\hline Epidalea calamita & $\begin{array}{l}\text { 30TVL02 } \\
\end{array}$ & 100,00 & 104,18 & 102,76 & 35,80 & 6328,72 & 269,13 & $-14,21$ & 283,34 & 120,89 & 188,74 & 189,91 & 29,02 & 496,09 & 60,40 & 16,33 & 30,06 & 155,61 & 73,06 & 80,28 & 123,40 \\
\hline Epidalea calamita & 30TVL03 & 100,00 & 111,68 & 101,23 & 35,18 & 6409,99 & 274,44 & $-7,84$ & 282,27 & 123,56 & 196,60 & 198,14 & 34,33 & 477,20 & 56,09 & 14,21 & 30,30 & 148,11 & 68,19 & 76,25 & 121,31 \\
\hline Epidalea calamita & 30TVL09 & 100,00 & 114,39 & 106,79 & 36,99 & 6145,49 & 279,37 & $-7,09$ & 286,46 & 126,24 & 195,30 & 196,40 & 39,16 & 455,36 & 52,89 & 15,34 & 28,42 & 139,83 & 66,71 & 77,08 & 116,99 \\
\hline Epidalea calamita & 30TVL10 & 100,00 & 112,46 & 102,96 & 35,38 & 6427,44 & 279,75 & $-7,11$ & 286,86 & 80,22 & 197,93 & 199,25 & 35,60 & 478,21 & 56,21 & 15,01 & 30,94 & 150,99 & 67,21 & 71,88 & 123,97 \\
\hline Epidalea calamita & 30TVL11 & 100,00 & 77,29 & 106,95 & 37,36 & 6068,16 & 247,71 & $-34,23$ & 281,95 & 70,78 & 161,14 & 161,28 & 9,66 & 626,03 & 76,40 & 24,97 & 27,68 & 194,81 & 96,49 & 99,25 & 157,99 \\
\hline Epidalea calamita & 30TVL12 & 100,00 & 82,73 & 105,64 & 37,01 & 6128,99 & 251,27 & $-30,42$ & 281,69 & 86,58 & 166,66 & 167,03 & 13,17 & 603,08 & 72,94 & 23,32 & 27,85 & 187,35 & 92,53 & 97,16 & 152,35 \\
\hline Epidalea calamita & 30TVL14 & 100,00 & 107,35 & 102,19 & 35,99 & 6359,05 & 271,21 & $-11,09$ & 282,30 & 116,53 & 192,19 & 193,14 & 31,24 & 496,32 & 57,82 & 15,51 & 29,34 & 152,82 & 71,83 & 80,63 & 127,33 \\
\hline Epidalea calamita & 30TVL15 & 100,00 & 111,79 & 102,60 & 36,00 & 6345,76 & 275,35 & $-7,64$ & 282,99 & 91,05 & 195,92 & 197,13 & 35,17 & 478,00 & 55,14 & 14,66 & 29,35 & 147,29 & 68,66 & 77,28 & 123,44 \\
\hline Epidalea calamita & 30TVL16 & 100,00 & 115,36 & 103,26 & 36,00 & 6308,40 & 279,01 & $-4,90$ & 283,92 & 77,00 & 198,68 & 199,90 & 38,50 & 461,39 & 53,03 & 14,15 & 29,30 & 142,52 & 66,18 & 74,41 & 119,66 \\
\hline Epidalea calamita & 30TVL17 & 100,00 & 115,73 & 104,16 & 36,00 & 6265,15 & 279,67 & $-4,48$ & 284,15 & 77,97 & 198,56 & 199,49 & 39,31 & 457,07 & 52,53 & 14,51 & 28,91 & 140,66 & 66,03 & 74,70 & 118,49 \\
\hline Epidalea calamita & 30TVL18 & 100,00 & 115,06 & 104,96 & 36,06 & 6210,51 & 279,29 & $-5,45$ & 284,74 & 98,72 & 196,99 & 198,01 & 39,25 & 458,03 & 52,86 & 15,12 & 28,51 & 140,43 & 66,99 & 76,23 & 118,24 \\
\hline Epidalea calamita & 30TVL20 & 100,00 & 116,65 & 102,55 & 35,13 & 6465,02 & 284,01 & $-3,38$ & 287,39 & 75,82 & 202,20 & 203,73 & 38,82 & 477,18 & 55,71 & 14,20 & 31,40 & 153,59 & 64,93 & 68,63 & 128,32 \\
\hline Epidalea calamita & 30TVL21 & 100,00 & 84,19 & 106,10 & 36,89 & $\mid 6169,99$ & 254,29 & $-29,16$ & 283,45 & 61,23 & $\mid 168,71$ & $\mid 169,10$ & 14,22 & 607,58 & 72.58 & 23,35 & 27,95 & $\mid 188,62$ & 92,03 & 95,29 & 156,05 \\
\hline Epidalea calamita & 30TVL22 & 100,00 & 89,15 & 105,22 & 36,69 & 6195,81 & 257,50 & $-25,31$ & 282,81 & 82,82 & 173,58 & 173,95 & 18,03 & 575,22 & 68,69 & 21,29 & 27,97 & $\begin{array}{l}177,58 \\
\end{array}$ & 86,99 & 92,20 & 146,47 \\
\hline Epidalea calamita & 30TVL23 & 100,00 & 72,79 & 106,73 & 37,51 & 6045,02 & 242,56 & $-38,25$ & 280,81 & 68,29 & 156,35 & 156,48 & 5,44 & 658,42 & 78,70 & 27,16 & 26,32 & 202,81 & $\begin{array}{r}103,42 \\
\end{array}$ & 105,63 & 167,97 \\
\hline Epidalea calamita & 30TVL24 & 100,00 & 93,79 & 104,32 & 36,48 & 6221,50 & 260,20 & $-21,89$ & 282,09 & 103,11 & 177,89 & 178,38 & 21,18 & 554,28 & 65,42 & 19,96 & 27,84 & 170,44 & 83,91 & 90,92 & 141,50 \\
\hline Epidalea calamita & 30TVL25 & 100,00 & 108,37 & 102,99 & 35,99 & 6326,98 & 272,63 & $-10,23$ & 282,85 & 93,76 & 192,45 & 193,55 & 32,51 & 493,86 & 56,84 & 15,78 & 28,86 & 151,52 & 71,94 & 80,44 & 127,86 \\
\hline Epidalea calamita & 30TVL27 & 100,00 & 112,87 & 103,91 & 36,01 & 6262,71 & 276,90 & $-6,79$ & 283,69 & 86,03 & 195,63 & 196,50 & 36,60 & 471,66 & 54,16 & 15,43 & 28,28 & 144,47 & 69,39 & 77,94 & 122,11 \\
\hline Epidalea calamita & 30TVL30 & 100,00 & 119,57 & 102,73 & 35,07 & 6498,95 & 287,51 & $-0,85$ & 288,36 & 77,69 & 205,32 & 206,90 & 41,19 & 476,05 & 56,83 & 13,65 & 32,14 & 156,14 & 63,41 & 66,05 & 131,37 \\
\hline Epidalea calamita & 30TVL31 & 100,00 & 112,12 & 103,04 & 35,52 & $\mid 6428,78$ & 279,39 & $\begin{array}{l}-, 0,72 \\
-6,72 \\
-12\end{array}$ & 286,11 & 73,78 & \begin{tabular}{|l|}
197,50 \\
\end{tabular} & $\begin{array}{l}198,75 \\
\end{array}$ & 35,20 & 496,87 & $\begin{array}{l}58,30 \\
58,38\end{array}$ & 15,25 & 30,58 & $\begin{array}{l}158,92,9 \\
\end{array}$ & $\begin{array}{l}69,08 \\
69,0\end{array}$ & 73,27 & 133,32 \\
\hline Epidalea calamita & 30TVL32 & 100,00 & 89,33 & 105,67 & 36,72 & $\begin{array}{ll}6214,66 \\
\end{array}$ & 258,42 & $-25,45$ & 283,86 & 76,32 & 173,92 & 174,25 & 17,79 & 578,12 & 68,50 & 21,47 & 27,60 & 177,52 & 87,52 & 92,90 & 148,19 \\
\hline Epidalea calamita & 30TVL33 & 100,00 & 93,59 & 104,76 & 36,51 & 6246,76 & 261,29 & $-22,01$ & 283,30 & 79,89 & 178,09 & 178,63 & 20,99 & 562,40 & 65,76 & 20,43 & 27,73 & 172,92 & 84,79 & 90,65 & 145,03 \\
\hline Epidalea calamita & 30TVL34 & 100,00 & 86,44 & 105,55 & 36,82 & 6168,71 & 254,56 & $-27,94$ & 282,50 & 96,85 & 170,42 & 170,66 & 15,35 & 591,88 & 69,86 & 22,81 & 26,76 & 181,19 & 91,63 & 97,38 & 151,49 \\
\hline Epidalea calamita & 30TVL35 & 100,00 & 104,34 & 103,59 & 36,00 & 6301,34 & 269,84 & $-13,51$ & 283,36 & 89,26 & 188,49 & 189,34 & 29,28 & 510,81 & 58,92 & 17,23 & 28,11 & 155,47 & 75,87 & 84,21 & 132,27 \\
\hline Epidalea calamita & \begin{tabular}{|l|l|} 
30TVL37 \\
\end{tabular} & 100,00 & 107,35 & 104,11 & 36,11 & 6255,96 & 272,44 & \begin{tabular}{|l|l|}
$-11,06$ \\
$-11,0$
\end{tabular} & \begin{tabular}{|l|l|}
283,50 \\
\end{tabular} & $\begin{array}{l}105,80 \\
105\end{array}$ & \begin{tabular}{|l|}
$190,72,7$ \\
\end{tabular} & $\begin{array}{l}191,32 \\
191,4\end{array}$ & 32,04 & \begin{tabular}{|l|}
494,47 \\
\end{tabular} & 56,99 & \begin{tabular}{l|l}
17,06 \\
17
\end{tabular} & 27,40 & \begin{tabular}{|l|}
150,43 \\
15,4
\end{tabular} & 74,52 & $\begin{array}{l}8,217 \\
83,17\end{array}$ & 127,57 \\
\hline Epidalea calamita & 30TVL39 & 100,00 & 107,55 & 104,97 & 36,42 & 6161,29 & 272,40 & $-11,12$ & 283,52 & 123,65 & 189,48 & 190,04 & 33,00 & 492,28 & 56,88 & 18,05 & 26,70 & 149,55 & 75,81 & 85,15 & $\begin{array}{ll}126,47 \\
\end{array}$ \\
\hline Epidalea calamita & 30TVL40 & 100,00 & 127,79 & 102,91 & 35,01 & 6550,89 & 296,39 & 5,74 & 290,64 & 85,55 & 214,56 & 215,24 & 47,88 & 454,56 & 57,17 & 12,01 & 34,19 & 154,78 & 57,89 & 58,64 & 129,23 \\
\hline Epidalea calamita & 30TVL41 & 100,00 & 120,84 & 102,69 & 35,08 & 6501,78 & 288,23 & 0,27 & 287,97 & 79,02 & 206,51 & 207,87 & 42,13 & 468,87 & 56,71 & 13,27 & 31,97 & 154,61 & 63,08 & 65,25 & 129,18 \\
\hline Epidalea calamita & 30TVL42 & 100,00 & 106,04 & 103,99 & 36,08 & 6376,62 & 273,74 & $-11,87$ & 285,61 & 69,50 & 191,23 & 192,10 & 30,35 & 516,25 & 60,00 & 16,95 & 29,25 & 161,85 & 74,57 & 79,67 & 136,35 \\
\hline Epidalea calamita & $\begin{array}{l}\text { SOTVL43 } \\
30 \text {. }\end{array}$ & 100,00 & 109,23 & 103,29 & 30,00 & $\begin{array}{l}638,0204 \\
6385,04\end{array}$ & 275,66 & $\begin{array}{l}-1,01 \\
-9,20\end{array}$ & \begin{tabular}{|l|}
284,861 \\
284
\end{tabular} & $\begin{array}{l}58,98 \\
68,\end{array}$ & $\begin{array}{l}194,21 \\
194\end{array}$ & $\begin{array}{l}195,12 \\
195\end{array}$ & $\begin{array}{ll}0,03 \\
32,98\end{array}$ & \begin{tabular}{|l|}
499,32 \\
109
\end{tabular} & 50,90 & $\begin{array}{l}\mid 0,035 \\
15,97 \\
\end{array}$ & 29,15 & $\begin{array}{l}155,920 \\
155,\end{array}$ & $\begin{array}{l}74,09 \\
72,09\end{array}$ & 77,84 & $\begin{array}{l}131,74 \\
131,74\end{array}$ \\
\hline Epidalea calamita & 30TVL44 & 100,00 & 95,01 & 105,03 & 36,40 & 6252,22 & 262,72 & $-21,24$ & 283,96 & 86,56 & 179,36 & 179,79 & 21,82 & 555,86 & 64,66 & 20,44 & 27,23 & 170,18 & 84,87 & 90,53 & 143,55 \\
\hline Epidalea calamita & 30TVL45 & 100,00 & 94,63 & 105,17 & 36,48 & 6228,27 & 262,01 & $-21,67$ & 283,68 & 89,50 & 178,54 & 178,99 & 21,54 & 555,45 & 64,78 & 20,73 & 26,73 & 169,10 & 85,71 & 92,87 & 143,01 \\
\hline Epidalea calamita & 30TVL46 & 100,00 & 108,25 & 103,93 & 36,01 & 6293,78 & 273,65 & $-10,18$ & 283,83 & 72,81 & 192,06 & 192,79 & 32,78 & 494,32 & 56,55 & 16,91 & 27,56 & 150,54 & 74,33 & 81,69 & 128,35 \\
\hline Epidalea calamita & 30TVL47 & 100,00 & 110,21 & 104,01 & 36,01 & 6266,56 & 275,21 & $-8,54$ & 283,75 & 80,04 & 193,46 & 194,19 & 34,55 & 485,09 & 55,48 & 16,84 & 27,36 & 147,43 & 73,57 & 80,99 & 125,80 \\
\hline Epidalea calamita & $\begin{array}{l}\text { 30TVL48 } \\
30 \text { L }\end{array}$ & 100,00 & $\begin{array}{l}1104,21 \\
104,54\end{array}$ & $\begin{array}{l}104,01 \\
104,90\end{array}$ & $\begin{array}{l}30, \\
36,\end{array}$ & $\begin{array}{l}020,040 \\
6204,16\end{array}$ & 2770,09 & \begin{tabular}{|c|c|c|}
$--13,47$ \\
$-13,4$
\end{tabular} & \begin{tabular}{|l|}
283,56 \\
283
\end{tabular} & \begin{tabular}{|l|}
00,04 \\
117,58
\end{tabular} & \begin{tabular}{|l|}
187,40 \\
187,43
\end{tabular} & \begin{tabular}{|l|l|}
187,73 \\
187
\end{tabular} & | & \begin{tabular}{|l}
503,0953 \\
506,53
\end{tabular} & $\begin{array}{l}30,46 \\
58,59 \\
\end{array}$ & $\begin{array}{l}10,04 \\
18,77 \\
\end{array}$ & $\begin{array}{l}26,40 \\
26,41\end{array}$ & \begin{tabular}{|l|}
153,48 \\
153,38
\end{tabular} & $\begin{array}{l}\mid 73,71 \\
78,77\end{array}$ & $\begin{array}{l}0,97,40 \\
8,4\end{array}$ & $\begin{array}{l}12,80 \\
130,42\end{array}$ \\
\hline Epidalea calamita & 30TVL49 & 100,00 & 103,11 & 105,19 & 36,68 & 6153,76 & 268,55 & $-14,83$ & 283,38 & 119,62 & 185,19 & 185,55 & 29,06 & 512,73 & 59,46 & 19,73 & 25,87 & 155,59 & 80,97 & 90,08 & 131,61 \\
\hline Epidalea calamita & 30TVL50 & 100,00 & 133,14 & 103,39 & 35,00 & 6579,67 & 302,35 & 10,41 & 291,94 & 90,44 & 220,66 & 220,69 & 52,75 & 434,01 & 57,10 & 10,67 & 35,80 & 152,12 & 53,20 & 53,21 & 124,29 \\
\hline Epidalea calamita & 30TVL51 & 100,00 & 128,43 & 102,74 & 35,00 & 6538,75 & 296,04 & 6,70 & 289,35 & 86,38 & 215,28 & 215,54 & 48,77 & 440,69 & 55,86 & 11,65 & 33,64 & 99 & 57,75 & 58,04 & 122,79 \\
\hline Epidalea calamita & 30TVL52 & 100,00 & 119 & 103,05 & 35,4 & 6471,71 & 286,06 & $-0,94$ & 286,99 & | & 204,90 & \begin{tabular}{|l|}
205,77 \\
\end{tabular} & 40,94 & $\begin{array}{ll}4406,92 \\
466\end{array}$ & $\begin{array}{l}50,700 \\
55,77\end{array}$ & $\begin{array}{l}1,000 \\
13,73\end{array}$ & $\begin{array}{l}3,04 \\
31,05\end{array}$ & $\begin{array}{l}\mid \\
151,94 \\
\end{array}$ & 65,03 & $\begin{array}{l}0,074 \\
67,44\end{array}$ & 126,10 \\
\hline Epidalea calamita & 30TVL53 & 100,00 & 109,88 & 103 & 36,06 & 6394,79 & 277,01 & $-8,73$ & 285,74 & 72,46 & \begin{tabular}{|l|}
195,03 \\
\end{tabular} & 195,80 & 33,52 & 497,35 & 57,41 & 16,26 & 28,98 & 155,85 & 72,63 & 77,34 & 131,28 \\
\hline Epidalea calamita & 30TVL54 & 100,00 & 97,28 & 105,44 & 36,44 & 6285,75 & 265,47 & $-19,77$ & 285,24 & 84,53 & 181,84 & 182,24 & 23,39 & 546,22 & 63,27 & 20,09 & 26,97 & 166,33 & 83,72 & 89,91 & 141,45 \\
\hline Epidalea calamita & 30TVL55 & 100,00 & 76,54 & 107,27 & 37,39 & 6122,88 & 246,61 & $-37,30$ & 283,90 & 87,02 & 160,33 & 160,37 & 6,47 & 648,73 & 76,29 & 27,79 & 24,67 & 197,61 & 105,10 & 107,78 & 166,35 \\
\hline Epidalea calamita & 30TVL58 & 100,00 & 109,69 & 104,92 & 36,27 & 6237,29 & 274,93 & $-8,82$ & 283,75 & 114,42 & 192,60 & 193,04 & 34,23 & 486,60 & 55,97 & 17,97 & 26,23 & 29 & 76,12 & 83,23 & 125,49 \\
\hline Epidalea calamita & \begin{tabular}{|l|} 
30TVL59 \\
\end{tabular} & 100,00 & 108 & 105,03 & 36 & | 6185,94 & 273,14 & \begin{tabular}{|c|c|}
$-0,02$ \\
$-10,25$
\end{tabular} & \begin{tabular}{|l|}
283,39 \\
283
\end{tabular} & \begin{tabular}{|l|}
$124,27,27$ \\
\end{tabular} & $\begin{array}{l}190,180 \\
190,\end{array}$ & \begin{tabular}{|l|}
190,51 \\
190,
\end{tabular} & \begin{tabular}{|c|}
43,01 \\
33,01
\end{tabular} & $\begin{array}{l}400,00 \\
493,92 \\
\end{array}$ & $\mid 57,00$ & $\mid 18,96$ & $\begin{array}{l}25,250 \\
25,70\end{array}$ & $\begin{array}{l}448,625 \\
148,\end{array}$ & $\begin{array}{l}70,12 \\
78,66\end{array}$ & $\begin{array}{l}3,25 \\
86,02\end{array}$ & $\begin{array}{l}127,49 \\
127,11\end{array}$ \\
\hline Epidalea calamita & 30TVL60 & 100,00 & 126,06 & 104,05 & 35,02 & 6558,47 & 295,12 & 4,32 & 290,81 & 83,61 & 213,47 & 213,51 & 46,63 & 447,94 & 57,04 & 11,99 & 33,66 & 152,69 & 58,60 & 58,63 & 124,06 \\
\hline Epidalea calamita & 30TVL61 & 100,00 & 121,44 & 103,71 & 35,33 & 6520,14 & 289,47 & 0,86 & 288,61 & 79,56 & 208,07 & 208,63 & 42,72 & 457,78 & 56,02 & $\mid 13,16$ & 31.80 & $\mid 151,47$ & 263,16 & 63,89 & 124,21 \\
\hline Epidalea calamita & 30TVL62 & 100,00 & 122,19 & 103,14 & 35,32 & 6491,62 & 288,90 & 1,52 & 287,38 & 80,64 & 208,18 & 208,88 & 43,69 & 450,45 & 54,49 & 13,15 & 31,25 & 147,72 & 63,30 & 64,48 & 120,74 \\
\hline Epidalea calamita & 30TVL66 & 100,00 & 76,30 & 107,84 & 37,44 & 6119,81 & 246,56 & $-38,21$ & 284,77 & 90,68 & 159,88 & 159,89 & 5,98 & 651,92 & 76,56 & 28,84 & 23,88 & 198,39 & 107,84 & 110,04 & 16 \\
\hline Epidalea calamita & 30TVL68 & 100,00 & 108,25 & 105,39 & 36,51 & 6236,98 & 274,38 & \begin{tabular}{|c|c|c|}
$-10,43$ \\
-12
\end{tabular} & 284,81 & | 125,95 & 191,41 & 191,62 & 33,21 & $\begin{array}{l}493,10 \\
\end{array}$ & 56,96 & 18,96 & 25,61 & \begin{tabular}{|l|l|}
147,88 \\
\end{tabular} & 78,89 & 85,53 & 126,82 \\
\hline Epidalea calamita & 30TVL69 & 100,00 & 106,43 & 105,84 & 36,87 & 6183,36 & 272,43 & $-11,99$ & 284,42 & 125,00 & 188,59 & 188,91 & 31,81 & 501,68 & 58,22 & 19,90 & 25,01 & 150,88 & 81,42 & 88,42 & 129,08 \\
\hline Epidalea calamita & 30TVL72 & 100,00 & 117,74 & 104,08 & 35,80 & 6482,68 & 285,14 & $-2,35$ & 287,49 & 76,32 & 203,73 & 204,45 & 39,86 & 460,90 & 53,92 & 14,48 & 29,91 & 147,44 & 67,16 & 68,99 & 120,82 \\
\hline Epidalea calamita & 30TVL73 & 100,00 & 112,34 & 104,94 & 36,00 & 6424,94 & 280,08 & $-7,36$ & 287,45 & 72,50 & 197,80 & 198, & 35, & 480,68 & 55,10 & 16,20 & 28,44 & 149 & 72,21 & 75,72 & 125 \\
\hline Epidalea calamita & 30TVL76 & 100,00 & 84,50 & 108,12 & 37,05 & 6186,52 & 254,92 & $-32,07$ & 286,99 & 100,32 & 168,44 & 168,50 & 12,55 & 608,11 & 71,52 & 26,34 & $\begin{array}{l}23,44 \\
23,99\end{array}$ & 184,73 & 100,57 & 106,50 & 155,64 \\
\hline
\end{tabular}




\begin{tabular}{|c|c|c|c|c|c|c|c|c|c|c|c|c|c|c|c|c|c|c|c|c|c|}
\hline TAXON & UTM & $\mathrm{km} 2$ & B101 & B102 & $\mathrm{BIO3}$ & 8104 & B105 & B106 & B107 & B108 & B109 & B1010 & BIO11 & BIO12 & 81013 & BIO14 & BIO15 & B1016 & B1017 & B1018 & B1019 \\
\hline Epidalea calamita & 30TVL77 & 100,00 & 97,54 & 107,18 & 36,97 & 6228,79 & 266,13 & $-20,66$ & 286,78 & 115,05 & 181,13 & 181,36 & 23,63 & 543,17 & 63,46 & 22,25 & 24,68 & 163,89 & 88,89 & 95,62 & 139,32 \\
\hline Epidalea calamita & 30TVL80 & 100,00 & 128,46 & 102,32 & 35,07 & 6577,84 & 294,21 & 6,89 & 287,32 & 86,39 & 216,18 & 216,18 & 49,14 & 414,96 & 51,50 & 11,70 & 32,79 & 138,37 & 57,21 & 57,21 & 106,89 \\
\hline Epidalea calamita & 30TVL81 & 100,00 & 125,82 & 102,84 & 35,13 & 6542,43 & 291,63 & 4,37 & 287,25 & 84,01 & 213,03 & 213,07 & 46,97 & 423,35 & 51,04 & 12,59 & 31,28 & 138,47 & 60,82 & 60,87 & 108,85 \\
\hline Epidalea calamita & 30TVL82 & 100,00 & 121,66 & 103,83 & 35,64 & 6497,10 & 288,13 & 0,42 & 287,70 & 80,32 & 207,91 & 208,36 & 43,33 & 438,88 & 51,11 & 13,93 & 29,88 & 140,13 & 65,12 & 66,08 & 112,81 \\
\hline Epidalea calamita & 30TVL85 & 100,00 & 90,67 & 108,48 & \begin{tabular}{|l|l|}
37,08 \\
\end{tabular} & 6257,71 & 261,48 & $-27,51$ & 288,99 & \begin{tabular}{|l|l|}
105,87 \\
\end{tabular} & \begin{tabular}{|l|l|}
175,21 \\
\end{tabular} & 175,32 & 17,33 & 578,55 & 68,11 & 24,57 & 24,43 & 174,93 & 95,26 & 101,30 & 147,76 \\
\hline Epidalea calamita & 30TVL86 & 100,00 & 88,62 & 108,83 & 37,01 & 6219,83 & 259,37 & $-29,34$ & 288,71 & 105,40 & 172,68 & 172,75 & 15,67 & 588,72 & 69,34 & 25,68 & 23,87 & 178,59 & 98,32 & 104,12 & 150,35 \\
\hline Epidalea calamita & 30TVL87 & 100,00 & 94,49 & 108,47 & 37,00 & 6223,54 & 264,29 & $-24,13$ & 288,42 & \begin{tabular}{|l|l|}
111,81 \\
\end{tabular} & 178,15 & 178,29 & 20,81 & 559,91 & 65,81 & 24,12 & 23,88 & 169,43 & 93,76 & 100,73 & 143,13 \\
\hline Epidalea calamita & 30TVL88 & 100,00 & 102,05 & 107,89 & 37,00 & 6222,84 & 270,60 & $-17,08$ & 287,69 & 120,28 & 185,22 & 185,51 & 27,69 & 523,70 & 61,33 & 22,14 & 24,10 & 157,90 & 87,73 & 94,40 & 133,97 \\
\hline Epidalea calamita & 30TVL89 & 100,00 & 110,14 & 107,13 & 37,00 & 6215,73 & 276,77 & $-9,44$ & 286,21 & 129,18 & 192,51 & 192,81 & 34,86 & 489,47 & 57,12 & 20,56 & 24,16 & 146,90 & 82,44 & 87,78 & 125,10 \\
\hline Epidalea calamita & 30TVL91 & 100,00 & 121,90 & 104,96 & 35,73 & 6522,61 & 289,31 & $-0,26$ & 289,56 & 80,44 & 208,64 & 208,92 & 43,39 & 436,13 & 50,64 & 14,20 & 29,76 & 137,75 & 65,45 & 66,21 & 110,47 \\
\hline Epidalea calamita & 30TVL92 & 100,00 & 120,83 & 105,11 & 35,93 & 6492,10 & 287,99 & $-1,00$ & 288,99 & 79,70 & 206,94 & 207,49 & 42,66 & 438,51 & 50,65 & 14,73 & 28,94 & 136,86 & 67,03 & 68,37 & 110,90 \\
\hline Epidalea calamita & 30TVL93 & 100,00 & 115,93 & 106,16 & 36,04 & 6443,86 & 283,94 & $-5,49$ & 289,42 & 76,12 & 201,56 & 202,12 & 38,45 & 458,06 & 53,33 & 16,36 & 27,60 & 139,58 & 71,74 & 74,50 & 115,90 \\
\hline Epidalea calamita & 30TVL94 & 100,00 & 109,13 & 107,41 & 36,51 & 6384,33 & 278,25 & $-11,94$ & 290,19 & 94,15 & 194,22 & 194,69 & 32,82 & 488,23 & 57,34 & 18,77 & 26,21 & 146,03 & 78,52 & 83,07 & 123,73 \\
\hline Epidalea calamita & 30TVL96 & 100,00 & 91,51 & 109,60 & \begin{tabular}{|l|l|}
37,08 \\
\end{tabular} & 6245,60 & 262,68 & $-27,70$ & 290,38 & 108,68 & 175,71 & 175,85 & 17,98 & 575,53 & 68,11 & 25,49 & 23,55 & 174,62 & 97,43 & 103,34 & 146,49 \\
\hline Epidalea calamita & 30TVL97 & 100,00 & 95,54 & 109,50 & 37,04 & 6239,01 & 266,14 & $-24,09$ & 290,22 & 113,26 & 179,30 & 179,44 & 21,46 & 556,16 & 65,73 & 24,58 & 23,43 & 168,52 & 94,61 & 101,49 & 141,73 \\
\hline Epidalea calamita & 30TVL98 & 100,00 & 102,90 & 109,06 & 37,00 & 6234,93 & 272,28 & $-17,32$ & 289,59 & 121,48 & 186,19 & 186,44 & 28,34 & 521,41 & 61,49 & 22,74 & 23,61 & 157,47 & 88,92 & 95,45 & 132,97 \\
\hline Epidalea calamita & 30TVL99 & 100,00 & 112,22 & 108,10 & 37,00 & 6224,92 & 279,54 & $-8,33$ & 287,87 & 131,68 & 194,76 & 194,99 & 36,66 & 480,92 & 56,55 & 20,60 & 23,92 & 144,70 & 82,34 & 87,35 & 122,43 \\
\hline Epidalea calamita & 30TVM01 & 100,00 & 115,13 & 107,86 & 37,00 & 6026,62 & 279,86 & $-6,93$ & 286,79 & 120,48 & 194,45 & 195,32 & 41,08 & 457,26 & 52,80 & 16,45 & 27,97 & 139,88 & 67,56 & 78,95 & 117,33 \\
\hline Epidalea calamita & 30TVM04 & 100,00 & 111,20 & 107,91 & 37,24 & 5838,10 & 274,25 & $-10,61$ & 284,86 & 106,29 & 188,14 & 188,75 & 39,63 & 486,59 & 55,43 & 19,80 & 26,33 & 147,98 & 74,44 & 87,65 & 123,25 \\
\hline Epidalea calamita & 30TVM05 & 100,00 & 112,95 & 107.09 & $37,28 \mid$ & 5760,54 & 274,08 & $-8,37$ & 282.45 & 90,29 & 188,68 & $\mid 189,24$ & 42,01 & 491,35 & 55,07 & 20,69 & 25,91 & 150,16 & 76,06 & 88.95 & 124,25 \\
\hline Epidalea calamita & 30TVM06 & 100,00 & 113,92 & 105,86 & 37,31 & 5681,69 & 272,60 & $-6,31$ & 278,90 & 86,09 & 188,46 & 188,94 & 43,75 & 502,32 & 55,56 & 21,98 & 25,36 & 154,82 & 79,12 & 91,04 & 127,23 \\
\hline Epidalea calamita & 30TVM07 & 100,00 & 109,41 & 104,96 & 37,58 & 5617,43 & 266,83 & $\begin{array}{l}-9,09 \\
-9,5 \\
\end{array}$ & 275,92 & 81,92 & 183,45 & 183,60 & 40,16 & 534,38 & 59,16 & 24,54 & 24,48 & $\begin{array}{l}164,72 \\
\end{array}$ & 86,46 & 96,09 & 135,46 \\
\hline Epidalea calamita & 30TVM09 & 100,00 & 111,43 & 101,12 & $\begin{array}{l}37,86 \\
\end{array}$ & 5430,86 & 262,16 & $-2,76$ & 264,92 & 85,14 & 182,99 & 183,01 & 44,32 & 572,90 & 64,84 & 26,95 & 23,45 & 180,18 & 96,46 & 100,11 & 147,05 \\
\hline Epidalea calamita & 30TVM11 & 100,00 & 114,51 & 106,49 & 37,00 & 6042,88 & 278,37 & $-6,55$ & 284,92 & 115,84 & 194,09 & 194,96 & 40,25 & 462,86 & 53,24 & 16,96 & 27,29 & 141,17 & 69,51 & 80,18 & 118,63 \\
\hline Epidalea calamita & 30TVM14 & 100,00 & 109,34 & 106,34 & 37,00 & 5863,51 & 271,63 & $-10,27$ & 281,90 & 118,32 & 186,67 & 187,15 & 37,31 & 497,57 & 56,39 & 20,64 & 25,53 & 150,18 & 78,12 & 90,05 & 126,21 \\
\hline Epidalea calamita & 30TVM15 & 100,00 & 111,19 & 105,43 & 37,01 & 5789,24 & 271,59 & $-7,88$ & 279,47 & 82,72 & 187,42 & 187,72 & 39,77 & 500,25 & 55,85 & 21,35 & 25,09 & 151,78 & 79,31 & 90,31 & 126,99 \\
\hline Epidalea calamita & 30TVM16 & 100,00 & 111,97 & 104,21 & 37,01 & 5715,59 & 270,18 & $\begin{array}{l}-1,00 \\
-6,01 \\
\end{array}$ & 276,18 & 82,35 & \begin{tabular}{|l|l|l|l|l|}
186,99 \\
\end{tabular} & $\begin{array}{l}187,33 \\
\end{array}$ & 41,24 & 511,24 & 56,15 & 22,66 & 24,54 & 155,95 & 82,46 & $\begin{array}{ll}92,47 \\
92\end{array}$ & 129,83 \\
\hline Epidalea calamita & 30TVM17 & 100,00 & 110,73 & 103,01 & 37,13 & 5638,93 & 266,86 & $-5,55$ & 272,42 & 81,73 & \begin{tabular}{ll|}
184,87 \\
\end{tabular} & 185,04 & 40,97 & 532,14 & 58,37 & 24,53 & 23,95 & 163,16 & 87,60 & 94,81 & 135,47 \\
\hline Epidalea calamita & 30TVM19 & 100,00 & 106,62 & 100,06 & 37,50 & 5472,88 & 257,88 & $-5,60$ & 263,48 & 78,68 & 178,90 & 178,90 & 39,00 & 591,22 & 65,97 & 28,41 & 22,67 & 183,39 & 101,23 & 103,29 & 152,37 \\
\hline Epidalea calamita & 30TVM22 & 100,00 & 113,55 & 105,43 & 37,00 & 6006,30 & 276,36 & $-6,03$ & 282,39 & 118,28 & 192,68 & 193,21 & 39,70 & 472,53 & 53,98 & 18,31 & 26,17 & 142,92 & 73,27 & 83,16 & 120,81 \\
\hline Epidalea calamita & 30TVM23 & 100,00 & 109,67 & 105,44 & 37,00 & 5941,56 & 272,32 & $-9,19$ & 281,50 & 125,40 & 188,09 & 188,45 & 36,70 & 491,21 & 56,07 & 20,01 & 25,35 & 148,21 & 77,60 & 87,96 & 125,23 \\
\hline Epidalea calamita & 30TVM24 & 100,00 & 109,50 & 104,90 & 37,00 & 5880,93 & 271,14 & $-8,71$ & \begin{tabular}{|l|l|}
279,85 \\
\end{tabular} & $\begin{array}{l}106,82 \\
\end{array}$ & $\begin{array}{l}187,10 \\
187,10\end{array}$ & \begin{tabular}{|l|l|}
187,48 \\
\end{tabular} & $\begin{array}{ll}37,17 \\
37\end{array}$ & | & 56,35 & 20,91 & 25,01 & \begin{tabular}{|l|}
140,212 \\
149,86
\end{tabular} & 79,75 & $\begin{array}{ll}89,26 \\
8,\end{array}$ & 126,97 \\
\hline Epidalea calamita & 30 TVM25 & 100,00 & 111,49 & 103,89 & 37,00 & 5813,87 & 271,12 & $-5,72$ & 276,84 & 79,86 & \begin{tabular}{ll|l|}
187,97 \\
\end{tabular} & 188,22 & 39,69 & 501,24 & 55,78 & 21,67 & 24,59 & 151,04 & 81,29 & 90,25 & 127,60 \\
\hline Epidalea calamita & 30 TVM 26 & 100,00 & 111,23 & 102,81 & 37,00 & 5753,47 & 269,03 & $-4,78$ & 273,81 & 79,89 & 186,86 & 186,97 & 39,92 & 514,61 & 56,32 & 23,10 & 23,89 & 155,56 & 84,85 & 92.01 & 131,14 \\
\hline Epidalea calamita & 30TVM27 & 100,00 & 109,36 & 101,58 & 37,00 & 5678,57 & 265,35 & $-5,01$ & 270,37 & 78,58 & 183,95 & 184,03 & 38,87 & 536,70 & 58,13 & 25,04 & 23,22 & 162,80 & 90,19 & 95,39 & 137,09 \\
\hline Epidalea calamita & 30TVM28 & 100,00 & 106,77 & 100,34 & 37,02 & 5602,76 & 260,64 & $-5,78$ & 266,42 & 76,42 & 180,51 & 180,51 & 37,33 & 565,93 & 61,75 & 27,25 & 22,64 & 172,47 & 96,81 & 98,44 & 145,12 \\
\hline Epidalea calamita & 30TVM29 & 100,00 & 103,68 & $\begin{array}{r}00,54 \\
98,99\end{array}$ & 37,13 & \begin{tabular}{|l}
5518,38 \\
550
\end{tabular} & 255,18 & $\begin{array}{l}-2,10 \\
-6,58 \\
\end{array}$ & $\begin{array}{l}260,44 \\
261,75 \\
\end{array}$ & \begin{tabular}{|l|l|}
74,01 \\
\end{tabular} & $\begin{array}{l}10,51 \\
176,60\end{array}$ & \begin{tabular}{|l|}
176,601 \\
1760
\end{tabular} & $\begin{array}{l}35,58 \\
35,5\end{array}$ & \begin{tabular}{|l|l|}
601,44 \\
601
\end{tabular} & $\mid \frac{1,15}{66,36}$ & 29,42 & $\begin{array}{l}2,, 04 \\
22,04\end{array}$ & \begin{tabular}{|l|}
184,45 \\
184
\end{tabular} & 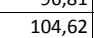 & $\begin{array}{r}90,44 \\
105,03 \\
\end{array}$ & 155,32 \\
\hline Epidalea calamita & 30TVM30 & 100,00 & 113,54 & 104,84 & 36,68 & 6124,35 & 277,16 & $-5,93$ & 283,09 & 117,41 & 194,40 & 195,11 & 38,66 & 470,29 & 53,89 & 17,29 & 26,70 & 142,25 & 72,34 & 80,95 & 121,05 \\
\hline Epidalea calamita & 30TVM31 & 100,00 & 116,31 & 104,60 & 36,68 & 6072,02 & 278,74 & $-3,36$ & 282,10 & 103,63 & 196,28 & 196,77 & 41,52 & 463,01 & 52,81 & 17,39 & 26,34 & 140,08 & 71,91 & 80,16 & 118,98 \\
\hline Epidalea calamita & 30TVM32 & 100,00 & 112,25 & 104,83 & 36,97 & 6015,64 & 274,71 & $-6,50$ & 281,21 & 123,59 & 191,55 & 191,91 & 38,29 & 479,94 & 54,83 & 19,08 & 25,51 & 144,56 & 76,05 & 84,79 & 123,00 \\
\hline Epidalea calamita & 30TVM33 & 100,00 & 108,27 & 104,77 & 37,00 & 5964,49 & 270,72 & $-9,20$ & 279,92 & 126,45 & 187,12 & 187,39 & 35,21 & 498,45 & 56,83 & 20,76 & 24,88 & 149,79 & 80,56 & 89,25 & 127,45 \\
\hline Epidalea calamita & 30TVM34 & 100,00 & $\begin{array}{l}10,27 \\
106,97\end{array}$ & $\begin{array}{l}104,11 \\
104,04\end{array}$ & 37,00 & \begin{tabular}{|l}
39004,49 \\
5908,60
\end{tabular} & 268,39 & $\begin{array}{l}-2,20 \\
-9,57 \\
\end{array}$ & $\begin{array}{l}277,97 \\
277\end{array}$ & $\begin{array}{l}12,45 \\
121,96\end{array}$ & $\begin{array}{l}18,12 \\
185,07 \\
\end{array}$ & \begin{tabular}{|l|}
185,15 \\
185,15
\end{tabular} & | & \begin{tabular}{|l|}
511,04 \\
511,04
\end{tabular} & $\begin{array}{l}30,03 \\
57,86\end{array}$ & $\begin{array}{l}20,10 \\
22,09\end{array}$ & \begin{tabular}{|l|}
24,00 \\
24,0
\end{tabular} & \begin{tabular}{|l|}
152,90 \\
1529
\end{tabular} & $\begin{array}{l}0,300 \\
83,91 \\
\end{array}$ & $\begin{array}{l}5,25 \\
91,86 \\
\end{array}$ & $\begin{array}{l}121,45 \\
130,41\end{array}$ \\
\hline Epidalea calamita & 30TVM36 & 100,00 & 107,53 & 102,06 & 37,00 & 5790,03 & 265,81 & $-6,63$ & 272,44 & 79,54 & 183,78 & 183,81 & 35,90 & 526,94 & 58,12 & 24,18 & 23,20 & 157,04 & 88,99 & 92,82 & 134,78 \\
\hline Epidalea calamita & 30TVM37 & 100,00 & 106,62 & 100,78 & 37,00 & 5733,36 & 263,24 & $-6,06$ & 269,30 & 74,05 & 182,03 & 182,05 & 35,59 & 543,52 & 58,96 & 25,78 & 22,52 & 162,43 & 93,38 & 95,74 & 139,28 \\
\hline Epidalea calamita & 30TVM38 & 100,00 & 106,07 & 99,22 & 37,00 & 5654,97 & 260,06 & $-4,72$ & 264,78 & 73,92 & 180,35 & 180,35 & 35,83 & 565,09 & 60 & 27,5 & 22 & 170,20 & 98,48 & 99,15 & 145,37 \\
\hline Epidalea calamita & 30TVM39 & 100,00 & 102,91 & 97,88 & 37,01 & 5555,62 & 254,1 & $-5,56$ & 259,75 & 71,68 & 176,22 & 176,22 & 34,31 & $\begin{array}{l}602,44 \\
\end{array}$ & 65, & 29, & 21,75 & 21 & 106,31 & 106,31 & 156,24 \\
\hline Epidalea calamita & 30TVM40 & 100,00 & 113,46 & 104,42 & 36,52 & 6135,33 & 276,98 & $-5,46$ & 282,45 & 122,49 & 194,55 & 195,09 & 38,56 & 472,12 & 54,16 & 17,76 & 26,23 & 142,26 & 74,12 & 81,77 & 121,43 \\
\hline Epidalea calamita & 30TVM41 & 100,00 & 115,39 & 104,04 & 36,71 & 6081,07 & 277,89 & $-3,05$ & 280,94 & 108,31 & 195,63 & 195,91 & 40,63 & 467,45 & 53,33 & 18,07 & 25,81 & 140,75 & 74,19 & 81,43 & 120,23 \\
\hline Epidalea calamita & 30TVM42 & 100,00 & 111,55 & 104,21 & 36,99 & 6041,66 & 274,06 & $-6,11$ & 280,17 & 129,77 & 191,33 & 191,65 & 37,41 & 484,68 & 55,41 & 19,70 & 24,98 & 145,36 & 78,42 & 84,94 & 124,35 \\
\hline Epidalea calamita & 30TVM43 & 100,00 & 107,22 & 104,07 & 37,00 & 5987,94 & 269,58 & $-9,39$ & 278,97 & 125,28 & 186,45 & 186,49 & 33,98 & 506,27 & 57,85 & 21,60 & 24,22 & 151,88 & 83,48 & 90,24 & 129,68 \\
\hline Epidalea calamita & 30TVM44 & 100,00 & 10 & 103 & 37,00 & 5929,56 & 266,49 & $-10,45$ & 276,94 & 122,79 & 183,57 & 183,60 & 32,48 & 520,90 & 59,21 & 23,12 & 23,55 & 155,71 & 87,36 & 93,38 & 133,58 \\
\hline Epidalea calamita & 30TVM45 & 100,00 & 106,31 & 102,81 & 37,00 & 5873,44 & 266,03 & $-8,04$ & 274,06 & 121,05 & 183,90 & 183,92 & 34,19 & 523,97 & 58,84 & 23,95 & 23,05 & 155,33 & 89,15 & 92,81 & 134,59 \\
\hline Epidalea calamita & 30TVM 46 & 100,00 & 102,56 & 102,01 & 37,00 & 5811,44 & 261,32 & $-10,13$ & 271,45 & $\mid 111,71$ & 179,48 & $\mid 179,48$ & 31,14 & 548,59 & 61,10 & 26,01 & 22,41 & $\mid 161,84$ & 94,85 & 95,70 & 141,36 \\
\hline Epidalea calamita & 30TVM47 & 100,00 & 103,58 & 100,47 & 37,00 & 5754,95 & 260,05 & $-7,40$ & 267,45 & 78,16 & 179,56 & 179,56 & 32,73 & 555,10 & 60,95 & 27,10 & 22,00 & 163,67 & 97,40 & 97,87 & 143,66 \\
\hline Epidalea calamita & 30TVM48 & 100,00 & 101,72 & 99,07 & 37,07 & 5679,72 & 255,82 & $-7,16$ & 262,98 & 68,78 & 176,82 & 176,82 & 31,73 & 578,09 & 62,43 & 28,77 & 21,59 & 171,22 & 102,78 & 102,78 & 150,41 \\
\hline Epidalea calamita & 30TVM49 & 100,00 & 102,13 & 97,24 & 37,12 & 5571,20 & 252,62 & $-4,45$ & 257,07 & 69,98 & $\begin{array}{l}175,98 \\
\end{array}$ & 175,98 & 33,61 & 602,61 & 65,54 & 29,99 & 21,43 & 181,30 & 108,10 & 108,10 & 158,06 \\
\hline Epidalea calamita & 30TVM50 & 100,00 & 110,55 & 104,77 & 36,84 & 6143,94 & 274,70 & $-7,78$ & 282,48 & 122,81 & 191,94 & 192,25 & 35,78 & 485,23 & 55,82 & 19,06 & 25,37 & 145,75 & 78,05 & 85,01 & 124,84 \\
\hline Epidalea cc & 30TVM51 & 100,00 & 113,26 & 104,34 & 36,74 & 6101.44 & 276,36 & $-4,91$ & 281,27 & 126.94 & 193.83 & $\mid 194,16$ & 38,61 & 476.93 & 54,66 & 19,11 & 25,11 & 142.94 & 77,42 & 84.06 & 122.55 \\
\hline Epidalea calamita & 30TVM52 & 100,00 & 110,15 & 104,31 & 37,00 & 6051,09 & 272,95 & $-7,05$ & 280,00 & 128,69 & 190,2 & 190, & 36 & 492,55 & 56,49 & 20,68 & 24 & 147,56 & 81,44 & 87,01 & 126,53 \\
\hline Epidalea calamita & 30TVM54 & 100,00 & 99,64 & 104,28 & 37,01 & 5928,96 & 261,78 & $-14,93$ & 276,71 & 116,67 & 178,42 & 178,42 & 27,65 & 550,25 & 62,66 & 25,36 & 22,82 & 164,55 & 94,37 & 96,50 & 141, \\
\hline
\end{tabular}




\begin{tabular}{|c|c|c|c|c|c|c|c|c|c|c|c|c|c|c|c|c|c|c|c|c|c|}
\hline TAXON & UTM & $\mathrm{km2}$ & B101 & $\mathrm{B1O2}$ & $\mathrm{BIO3}$ & $\mathrm{B104}$ & B105 & B106 & B107 & B108 & B109 & 81010 & B1011 & BIO12 & BIO13 & 81014 & B1015 & B1016 & B1017 & B1018 & B1019 \\
\hline Epidalea calamita & 30TVM55 & 100,00 & 101,93 & 103,01 & 37,03 & 5877,10 & 262,16 & $-11,48$ & 273,65 & 118,18 & 179,87 & 179,87 & 30,22 & 547,68 & 61,75 & 25,84 & 22,42 & 162,52 & 95,08 & 96,40 & 141,54 \\
\hline Epidalea calamita & 30TVM56 & 100,00 & 97,36 & 102,37 & 37,11 & 5809,75 & 256,47 & $-14,40$ & 270,87 & 113,70 & 174,64 & 174,64 & 26,77 & 579,32 & 64,67 & 28,43 & 21,82 & 170,90 & 102,09 & 102,18 & 150,45 \\
\hline Epidalea calamita & 30TVM57 & 100,00 & 98,61 & 100,84 & 37,11 & 5748,41 & 255,27 & $-11,40$ & 266,66 & 106,82 & 175,03 & 175,03 & 28,49 & 584,84 & 64,45 & 29,29 & 21,51 & 171,20 & 104,24 & 104,24 & 152,75 \\
\hline Epidalea calamita & 30TVM59 & 100,00 & 99,00 & 97,41 & 37,52 & 5574,17 & 249,40 & $-6,82$ & 256,22 & 66,52 & 173,22 & 173,22 & 31,22 & 624,74 & 66,83 & 31,49 & 21,03 & 185,39 & 113,75 & 113,75 & 166,05 \\
\hline Epidalea calamita & 30TVM60 & 100,00 & 111,15 & 105,20 & 36,93 & 6157,40 & 275,67 & $-7,15$ & 282,81 & 129,52 & 192,69 & 192,96 & 36,12 & 484,53 & 55,92 & $\begin{array}{ll}19,53 \\
\end{array}$ & 24,88 & 145,21 & 79,38 & 85,17 & 124,46 \\
\hline Epidalea calamita & 30TVM61 & 100,00 & 110,19 & 105,12 & 37,00 & 6111,20 & 274,16 & $-7,55$ & 281,71 & 128,98 & 191,00 & 191,29 & 35,64 & 491,30 & 56,61 & 20,54 & 24,34 & 147,28 & 81,72 & 86,87 & 126,25 \\
\hline Epidalea calamita & 30TVM63 & 100,00 & 101,94 & 105,06 & 37,04 & 5997,43 & 265,26 & $-13,73$ & 278,99 & 119,57 & 181,64 & 181,66 & 29,21 & 537,35 & 61,60 & 24,48 & 22,84 & 161,06 & 92,35 & 96,47 & 138,56 \\
\hline Epidalea calamita & 30TVM64 & 100,00 & 95,36 & 104,86 & 37,20 & 5925,16 & 258,21 & $-18,69$ & 276,90 & 111,96 & 174,48 & 174,49 & 24,00 & 577,95 & 65,75 & 27,61 & 22,01 & 172,62 & 101,03 & $\begin{array}{r}102,07 \\
\end{array}$ & 149,71 \\
\hline Epidalea calamita & 30 TVM 65 & 100,00 & 99,66 & 103,47 & 37,19 & 5877,67 & 260,07 & $-13,36$ & 273,44 & 116,60 & 177,81 & 177,81 & 28,24 & 565,63 & 63,77 & 27,44 & 21,85 & 167,67 & 99,91 & 100,37 & 146,89 \\
\hline Epidalea calamita & 30TVM66 & 100,00 & 96,82 & 102,54 & 37,51 & 5810,34 & 255,69 & $\begin{array}{l}-14,68 \\
\end{array}$ & 270,37 & 112,97 & 174,30 & 174,30 & 26,32 & 592,52 & 65,98 & 29,71 & 21,25 & 174,32 & 105,92 & 105,92 & 154,79 \\
\hline Epidalea calamita & 30TVM67 & 100,00 & 85,73 & 102,20 & 37,72 & 5724,80 & 243,80 & $-23,75$ & 267,55 & 100,12 & 162,63 & 162,63 & 17,15 & 672,44 & 73,45 & 35,13 & 20,31 & 195,63 & 121,75 & 121,75 & 177,26 \\
\hline Epidalea calamita & 30TVM68 & 100,00 & 93,86 & 100,04 & 37,83 & 5660,56 & 248,30 & $-14,12$ & 262,42 & 72,58 & 169,56 & 169,56 & 25,44 & 641,77 & 69,19 & 33,05 & 20,53 & 186,60 & 117,08 & 117,08 & 170,02 \\
\hline Epidalea calamita & 30TVM69 & 100,00 & 98,16 & 97,64 & 37,81 & 5565,22 & 248,23 & $-7,76$ & 255,99 & 65,35 & 172,37 & 172,37 & 30,50 & 646,26 & 68,22 & 32,82 & 20,34 & 190,43 & 118,83 & 118,83 & 172,83 \\
\hline Epidalea calamita & 30TVM70 & 100,00 & 112,55 & 105,87 & \begin{tabular}{|l|}
36,98 \\
\end{tabular} & 6160,84 & 277,34 & $-6,28$ & 283,62 & 131,70 & 194,07 & 194,32 & 37,54 & 480,44 & 55,58 & 19,82 & 24,49 & 143,77 & 80,06 & 85,36 & 123,15 \\
\hline Epidalea calamita & 30TVM72 & 100,00 & 106,10 & 105,89 & 37,01 & 6061,74 & 270,43 & $-10,91$ & 281,34 & 124,35 & 186,61 & 186,65 & 32,47 & 516,80 & 59,62 & 23,21 & 23,02 & 154,97 & 89,04 & 93,36 & 133,00 \\
\hline Epidalea calamita & 30TVM73 & 100,00 & 98,56 & 105,98 & 37,12 & 5997,22 & 262,84 & $-17,20$ & 280,04 & 115,77 & 178,54 & 178,56 & 26,25 & 559,55 & 64,18 & 26,39 & 22,13 & 167,59 & 98,07 & 99,80 & 144,61 \\
\hline Epidalea calamita & 30TVM74 & 100,00 & 100,22 & 105,01 & 37,27 & 5943,49 & 262,73 & $-14,36$ & 277,09 & 117,38 & 179,39 & 179,40 & 28,16 & 559,96 & 63,73 & 26,99 & 21,78 & 166,78 & 99,11 & 100,65 & 145,18 \\
\hline Epidalea calamita & 30TVM75 & 100,00 & 100,45 & 103,88 & 37,25 & 5882,88 & 261,01 & $-12,85$ & 273,87 & 117,54 & 178,77 & 178,77 & 28,93 & 569,77 & 64,18 & 28,18 & 21,36 & 168,50 & \begin{tabular}{|l|}
102,01 \\
\end{tabular} & 102,59 & 148,42 \\
\hline Epidalea calamita & 30TVM76 & 100,00 & 87,60 & 103,64 & 37,90 & 5792,22 & 247,70 & $-23,53$ & 271,22 & 102,96 & 165,40 & 165,40 & 18,18 & 656,62 & 72,67 & 34,20 & 20,29 & 192,43 & 119,18 & 119,18 & 172,73 \\
\hline Epidalea calamita & 30TVM77 & 100,00 & 77,65 & 102,83 & 37,99 & 5712,01 & 236,49 & $-31,63$ & 268,12 & 91,60 & 154,71 & 154,71 & 9,76 & 735,33 & 79,78 & 39,36 & 19,46 & 213,12 & 134,59 & 134,59 & 195,12 \\
\hline Epidalea calamita & 30TVM78 & 100,00 & 88,24 & 101,01 & 38,00 & 5655,53 & 243,54 & $-19,99$ & 263,53 & 69,76 & 164,02 & 164,02 & 20,13 & 687,79 & 73,85 & 36,12 & 19,78 & 198,62 & 126,73 & 126,73 & 183,08 \\
\hline Epidalea calamita & 30TVM79 & 100,00 & 98,67 & 98,00 & 37,93 & 5559,87 & 248,47 & $-7,68$ & 256,15 & 64,45 & 172,70 & 172,72 & 31,04 & 659,48 & 69,32 & 33,73 & 19,95 & 193,11 & 122,43 & 122,43 & 177,13 \\
\hline Epidalea calamita & 30TVM80 & 100,00 & 110,79 & 107,04 & 37,00 & \begin{tabular}{|l|l|}
6174,34 \\
\end{tabular} & 276,78 & $-8,55$ & 285,32 & 129,90 & \begin{tabular}{|l|}
192,57 \\
\end{tabular} & \begin{tabular}{|l|}
192,73 \\
\end{tabular} & 35,75 & 489,78 & 57,03 & 21,07 & 23,77 & 146,94 & 83,42 & 88,50 & 125,37 \\
\hline Epidalea calamita & 30TVM81 & 100,00 & 107,37 & 107,21 & 37,07 & 6121,69 & 273,23 & $-11,05$ & 284,28 & 125,88 & 188,52 & 188,66 & 33,26 & 509,37 & 59,19 & 22,79 & 23,06 & 152,96 & 88,11 & 93,40 & 130,80 \\
\hline Epidalea calamita & 30TVM82 & 100,00 & 101,36 & 107,39 & 37,35 & 6056,29 & 267,30 & $-15,85$ & 283,15 & 119,08 & 182,21 & 182,22 & 28,29 & 543,64 & 62,84 & 25,53 & 22,24 & 163,19 & 95,59 & 99,04 & 140,21 \\
\hline Epidalea calamita & 30TVM83 & 100,00 & 98,03 & 106,97 & 37,55 & 6000,19 & 263,21 & $-18,06$ & 281,27 & 115,23 & 178,17 & 178,18 & 25,65 & 568,01 & 65,21 & 27,55 & 21,58 & 169,93 & 101,13 & 104,28 & 147,14 \\
\hline Epidalea calamita & 30TVM84 & 100,00 & 97,05 & 106,23 & 37,68 & 5944,40 & 260,66 & $-17,95$ & 278,60 & $\begin{array}{l}114,03 \\
14,0\end{array}$ & 176,37 & 176,37 & 25,10 & 583,63 & $\begin{array}{l}0,113 \\
66,38 \\
\end{array}$ & 29,07 & 21,05 & \begin{tabular}{|l|l}
173,67 \\
\end{tabular} & 105,01 & \begin{tabular}{|l|}
107,08 \\
\end{tabular} & 151,81 \\
\hline Epidalea calamita & 30 TVM 85 & 100,00 & 87,08 & 105,51 & 37,98 & 5859,40 & 249,67 & $-25,81$ & 275,48 & 102,62 & 165,79 & 165,79 & 16,95 & 654,34 & 73,23 & 34,11 & 20,19 & 193,01 & 119,14 & 119,61 & 171,68 \\
\hline Epidalea calamita & 30TVM86 & 100,00 & 88,57 & 104,39 & 38,00 & 5798,97 & 249,07 & $-23,21$ & 272,28 & 103,98 & 166,36 & 166,36 & 18,99 & 659,17 & 72,95 & 34,65 & 19,81 & 193,02 & 120,91 & 120,91 & 173,76 \\
\hline Epidalea calamita & 30TVM87 & 100,00 & 69,26 & 103,39 & 38,00 & 5696,11 & 228,73 & $-39,70$ & 268,43 & 82,56 & 146,46 & 146,46 & 2,19 & 800,97 & 86,39 & 43,73 & 18,76 & 231,33 & 148,06 & 148,06 & 213,46 \\
\hline Epidalea calamita & 30TVM88 & 100,00 & 90,20 & 101,26 & 37,99 & 5654,98 & 245,08 & $-18,43$ & 263,51 & 76,82 & 165,95 & 165,95 & 22,02 & 690,99 & 74,06 & 36,42 & 19,29 & 199,16 & 128,53 & 128,53 & 184,51 \\
\hline Epidalea calamita & 30TVM89 & 100,00 & 103,03 & 97,94 & 37,92 & 5556,56 & 251,82 & $\begin{array}{l}-10,45 \\
-4,12 \\
\end{array}$ & \begin{tabular}{|l|}
255,95 \\
\end{tabular} & $\begin{array}{l}0,0656 \\
65,56\end{array}$ & $\begin{array}{l}176,62 \\
\end{array}$ & $\begin{array}{l}176,79 \\
\end{array}$ & $\frac{24,0<}{35,10}$ & |653,00 & 68,64 & $30,4,29$ & 19,55 & \begin{tabular}{|l|}
191,01 \\
\end{tabular} & \begin{tabular}{|l|l|}
122,43 \\
\end{tabular} & $\begin{array}{l}122,43 \\
120\end{array}$ & 175,85 \\
\hline Epidalea calamita & 30TVM90 & 100,00 & 109,67 & 108,41 & 37,01 & 6175,28 & 276,93 & $-10,38$ & 287,30 & 128,80 & 191,53 & \begin{tabular}{|l|}
191,73 \\
\end{tabular} & 34,72 & 497,12 & 58,27 & 22,23 & 23,19 & 149,60 & 86,38 & 91,22 & $\begin{array}{ll}127,03 \\
\end{array}$ \\
\hline Epidalea calamita & 30TVM91 & 100,00 & 105,88 & 108,52 & 37,18 & 6119,48 & 273,03 & $-13,45$ & 286,48 & 124,41 & 187,18 & 187,24 & 31,70 & 520,76 & 60,75 & 24,19 & 22,38 & 156,58 & 91,88 & 96,24 & 133,75 \\
\hline Epidalea calamita & 30TVM92 & 100,00 & 100,07 & 108,72 & 37,73 & 6058,65 & 267,23 & $-17,95$ & 285,18 & 117,93 & 180,93 & 180,94 & 27,00 & 556,12 & 64,39 & 26,95 & 21,52 & 166,86 & 99,45 & 103,55 & 143,63 \\
\hline Epidalea calamita & 30TVM93 & 100,00 & 95,84 & 108,37 & 37,98 & 6002,07 & 262,09 & $-20,98$ & 283,07 & 112,94 & 176,07 & 176,09 & 23,52 & 587,12 & 67,38 & 29,36 & 20,87 & $\begin{array}{ll}175,48 \\
\end{array}$ & 106,11 & 108,37 & 152,44 \\
\hline Epidalea calamita & 30TVM94 & 100,00 & 93,69 & 107,52 & 37,99 & 5940,38 & 258,53 & $-21,79$ & 280,32 & 110,41 & 173,17 & 173,17 & 22,16 & 609,52 & 69,25 & 31,33 & 20,35 & 181,15 & 111,26 & 112,79 & 159,04 \\
\hline Epidalea calamita & 30TVM95 & 100,00 & 73,65 & 106,18 & 38,00 & 5824,96 & 237,28 & $-38,38$ & 275,67 & 87,98 & 152,53 & 152,53 & 4,92 & 747,79 & 82,90 & 40,55 & 19,10 & 219,58 & 137,90 & 137,99 & 197,28 \\
\hline Epidalea calamita & 30TVM96 & 100,00 & 83,40 & 105,32 & 38,00 & 5793,34 & 244,72 & $-28,48$ & 273,21 & 98,52 & 161,39 & 161,39 & 14,36 & 701,13 & 77,27 & 37,58 & 19,15 & 204,79 & 129,98 & 129,98 & 185,41 \\
\hline Epidalea calamita & 30TVM97 & 100,00 & 71,52 & 103,63 & 38,00 & 5701,55 & 230,87 & $-37,93$ & 268,80 & 85,05 & 148,69 & 148,69 & 4,16 & 797,59 & 86,10 & 43,69 & 18,42 & 230,23 & 148,77 & 148,77 & 212,75 \\
\hline Epidalea calamita & 30TVM98 & 100,00 & 91,12 & 101,98 & 38,00 & 5661,91 & 246,27 & $-18,21$ & 264,47 & 84,41 & 166,85 & 166,85 & 22,79 & 696,98 & 74,72 & 36,97 & 18,87 & 200,20 & 130,80 & 130,80 & 186,20 \\
\hline Epidalea calamita & $\begin{array}{l}30 \text { TOTVM99 } \\
30\end{array}$ & 100,00 & $\begin{array}{r}91,12 \\
102,76\end{array}$ & $\begin{array}{l}90,90 \\
98,85\end{array}$ & 30,00 & 5500, & $\begin{array}{l}240,27 \\
252,12\end{array}$ & $\begin{array}{r}-1.0,21 \\
-5,18\end{array}$ & \begin{tabular}{|l|}
257,30 \\
257
\end{tabular} & \begin{tabular}{|l|l|}
64,41 \\
60,80
\end{tabular} & $\begin{array}{l}100,030 \\
176,65 \\
\end{array}$ & \begin{tabular}{|l|}
1760,73 \\
176,71
\end{tabular} & \begin{tabular}{|l|l|}
34,77 \\
34,
\end{tabular} & \begin{tabular}{|l|l|}
$690,90,93$ \\
662
\end{tabular} & $\begin{array}{l}7,2 \\
69,7\end{array}$ & |30,27! & $\begin{array}{l}19,01 \\
19,01\end{array}$ & $\begin{array}{l}200,202 \\
192,52\end{array}$ & $\begin{array}{l}130,00 \\
125,39 \\
\end{array}$ & $\begin{array}{l}120,00 \\
125,39 \\
\end{array}$ & $\begin{array}{l}180,20 \\
178,41\end{array}$ \\
\hline Epidalea calamita & 30TVNOO & 100,00 & 108,50 & 99,59 & 37,93 & 5349,25 & 256,73 & $-3,32$ & 260,05 & 82,66 & 179,20 & 179,20 & 42,52 & 609,08 & 69,48 & 29,05 & 23,06 & 192,55 & 104,69 & 105,56 & 157,47 \\
\hline Epidalea calamita & 30TVN01 & 100,00 & 105,02 & 97,94 & 38,00 & 5266,53 & 250,59 & $-4,35$ & 254,94 & 79,44 & 174,73 & 174,73 & 40,23 & 652,32 & 74,87 & 31,68 & 22,53 & 206,91 & 114,49 & 114,60 & 170,16 \\
\hline Epidalea calamita & 30TVN02 & 100,00 & 94,93 & 97,31 & 38,01 & 5225,65 & 240,01 & $-12,12$ & 252,13 & 69,28 & 164,63 & 164,63 & 31,41 & 724,43 & 82,86 & 36,32 & 21,84 & 28,54 & 29,62 & 129,62 & 191,08 \\
\hline Epidalea calamita & 30TVNO3 & 100,0 & 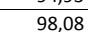 & 94,63 & 38,07 & 5091,35 & 238,07 & $-6,49$ & 244,56 & 73,30 & 165,73 & 165,91 & 36,01 & 748,90 & 86,70 & 37, & 21,95 & 239,08 & 135,73 & 135,79 & 199,06 \\
\hline Epidalea calamita & $30 \mathrm{TVNO}$ & 100,00 & 93,48 & 88,85 & 38,40 & 4816,21 & 223,41 & $-4,68$ & 228,10 & 70,61 & 156,37 & 158,01 & 35,10 & 882,73 & 103,43 & 44, & 22,11 & 285,17 & 162,07 & 165,37 & 240,34 \\
\hline Epidalea calamita & $\begin{array}{l}30 \text { TVN10 } \\
\end{array}$ & 100,00 & 106,85 & 98,15 & 37,69 & 5371,47 & 254,56 & $-3,10$ & 257,66 & 79,73 & 177,87 & \begin{tabular}{|l|l|}
177,87 \\
\end{tabular} & 40,46 & 618,46 & 69, 64 & 29,82 & 22,42 & $\begin{array}{l}193,83 \\
\end{array}$ & 107,60 & 107,86 & 160,68 \\
\hline Epidalea calamita & 30TVN15 & 100,00 & 96,76 & 89,05 & 38,07 & 4883,89 & 227,97 & $-2,11$ & 230,09 & 73,03 & 160,45 & 162,12 & 37,23 & 841,59 & 97,63 & 41,88 & 21,90 & 270,43 & 153,84 & 156,64 & 228,98 \\
\hline Epidalea calamita & 30TVN16 & 100,00 & 99,13 & 86,20 & 38,09 & 4748,31 & 225,22 & 2,60 & 222,62 & 76,54 & 160,81 & 162,70 & 41,35 & 876,76 & 102,58 & 43,28 & 22,32 & 48 & 159,04 & 164,78 & 240,62 \\
\hline Epidalea calamita & $30 \mathrm{TVN}$ & 100,00 & $\begin{array}{r}313,15 \\
113,51\end{array}$ & $\frac{60,20}{79,24}$ & 38 & | 44450,67 & 227 & 21,95 & \begin{tabular}{|l|}
$205,80<$ \\
\end{tabular} & $\begin{array}{l}0,04,08 \\
93,\end{array}$ & \begin{tabular}{|l|}
170,64 \\
170,64
\end{tabular} & $\begin{array}{l}172,86 \\
172\end{array}$ & $\begin{array}{l}41,35 \\
58,77\end{array}$ & $\begin{array}{l}894,42 \\
\end{array}$ & \begin{tabular}{|l|}
107,47 \\
107
\end{tabular} & $\begin{array}{l}41,87 \\
41,87 \\
\end{array}$ & $\begin{array}{ll}24,48 \\
24,4\end{array}$ & \begin{tabular}{|l|}
299,30 \\
299
\end{tabular} & \begin{tabular}{|l|}
157,15 \\
157,5
\end{tabular} & \begin{tabular}{|l|}
170,29 \\
170,29
\end{tabular} & $\begin{array}{l}24,02 \\
248,74\end{array}$ \\
\hline Epidalea calamita & 30TVN21 & 100,00 & 97,95 & 96,18 & 37,84 & 5330,46 & 243,94 & $-8,09$ & 252,03 & 69,77 & 168,82 & 168,82 & 32,69 & 684,67 & 76,71 & 34,11 & 21,41 & 212,27 & 122,51 & 122,51 & 180,58 \\
\hline Epidalea calamita & 30TVN22 & 100,00 & 98.18 & 94,05 & \begin{tabular}{|l|l|}
37,97 \\
\end{tabular} & 5211,92 & 239,98 & $-5,71$ & 245,69 & 71,22 & 167,44 & 167.58 & 34,47 & $722.47 \mid$ & 81,64 & 35.99 & 21,27 & 226,16 & 130,84 & 130,90 & 192,53 \\
\hline Epidalea calamita & 30 TVN23 & 100,00 & 97,04 & 91,99 & 37,98 & 5098,92 & 234,97 & $-4,75$ & 239,73 & 70,94 & 164,45 & 165,11 & 34,86 & 768,87 & 87,30 & 38,34 & 21,30 & 242,35 & 140,32 & 140,99 & 207,25 \\
\hline Epidalea calamita & 30 TVN24 & 100,00 & 101,35 & 88,78 & 37,6 & 4946,85 & 233,22 & 1,82 & 231,41 & 76,64 & 165 & 167 & 40,81 & 798 & 91,63 & 39,16 & 21,85 & 255,50 & 144,76 & 147,93 & 217,8 \\
\hline Epidalea calamita & $\begin{array}{l}30 \text { TVN25 } \\
3\end{array}$ & 100,00 & $\begin{array}{l}09,07 \\
99,07\end{array}$ & $\begin{array}{l}0,10 \\
87,23 \\
\end{array}$ & 38,01 & $\begin{array}{l}454,0,28 \\
4861,28\end{array}$ & 227,97 & $\begin{array}{l}\frac{1,02}{1,48} \\
\end{array}$ & \begin{tabular}{|l|}
226,50 \\
22,1
\end{tabular} & $\begin{array}{l}0,040 \\
75,07\end{array}$ & $\begin{array}{l}103,1 / 1 \\
162,11 \\
\end{array}$ & \begin{tabular}{|l|l|}
163,98 \\
168
\end{tabular} & 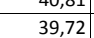 & \begin{tabular}{|l|}
847,18 \\
847,18
\end{tabular} & $\begin{array}{l}1,05 \\
97,49 \\
\end{array}$ & $\begin{array}{l}51,77 \\
41,7\end{array}$ & $\begin{array}{l}21,05 \\
21,85\end{array}$ & \begin{tabular}{|l|}
271,790 \\
271
\end{tabular} & \begin{tabular}{|l|}
154,740 \\
153,7
\end{tabular} & \begin{tabular}{|l|l|}
158,29 \\
151
\end{tabular} & 232,81 \\
\hline Epidalea calamita & 30 TVN26 & 100,00 & 99,52 & 84,82 & 38,02 & 4741,43 & 224,38 & 4,32 & 220,06 & 76,76 & 160,99 & 163,08 & 41,78 & 890,45 & 103,09 & 43,70 & 22,14 & 287,85 & 160,75 & 167,71 & 246,91 \\
\hline Epidalea calamita & 30 TVN30 & 100,00 & 99,40 & 96,63 & 37,33 & 5448,19 & 247,74 & -7.01 & 254,75 & 69,27 & 171,72 & 171,72 & 32.52 & 648,39 & 71,83 & 32,34 & 21.29 & 198.45 & 115.93 & 115.93 & 170,14 \\
\hline Epidalea calamita & 30TVN31 & 100,00 & 96,78 & 95,23 & 37,79 & 5345,47 & 242,09 & $-7,86$ & 249,9 & $67, \varepsilon$ & 167,90 & 167 & 31, & 694,26 & 77,24 & 34,87 & 21 & 213,68 & 125,51 & 125,51 & 184,37 \\
\hline Epidalea calamita & 30TVN32 & 100,00 & 8,01 & 93,01 & 37,90 & 5220,81 & 238,88 & $-4,56$ & 243,45 & 70,10 & 167,05 & 167,62 & 34,19 & 729,61 & 81,65 & 36,42 & 21,10 & 226,93 & 132,83 & $\begin{array}{l}133,19 \\
\end{array}$ & 196,12 \\
\hline
\end{tabular}




\begin{tabular}{|c|c|c|c|c|c|c|c|c|c|c|c|c|c|c|c|c|c|c|c|c|c|}
\hline TAXON & UTM & $\mathrm{km2}$ & BIO1 & $\begin{array}{l}\mathrm{BIO2} \\
\end{array}$ & $\mathrm{BIO3}$ & B104 & B105 & B106 & B107 & B108 & B109 & BIO10 & BIO11 & B1012 & BIO13 & BIO14 & BIO15 & BIO16 & BIO17 & BIO18 & BlO19 \\
\hline Epidalea calamita & 30TVN33 & 100,00 & 99,88 & 90,41 & 37,83 & 5087,54 & 235,72 & $-0,61$ & 236,32 & 73,30 & 166,10 & 167,68 & 37,62 & 768,08 & 86,51 & 37,99 & 21,23 & 241,69 & 139,82 & 141,61 & 209,01 \\
\hline Epidalea calamita & 30TVN35 & 100,00 & 100,09 & 85,70 & 37,99 & 4839,53 & 227,32 & 3,92 & 223,40 & 75,82 & 162,73 & 164,78 & 41,04 & 860,57 & 98,02 & 42,14 & 21,75 & 275,25 & 155,33 & 161,40 & 239,24 \\
\hline Epidalea calamita & 30TVN36 & 100,00 & 98,50 & 83,98 & 37,94 & 4741,51 & 222,92 & 4,39 & 218,54 & 75,08 & \begin{tabular}{ll|l}
159,90 \\
\end{tabular} & \begin{tabular}{ll|l}
161,99 \\
\end{tabular} & 40,86 & \begin{tabular}{ll|l}
910,65 \\
\end{tabular} & 104,03 & 44,72 & 21,92 & \begin{tabular}{|l|l|}
292,47 \\
\end{tabular} & $\begin{array}{l}164,27 \\
\end{array}$ & \begin{tabular}{l|l|}
171,98 \\
\end{tabular} & 255,13 \\
\hline Epidalea calamita & 30TVN40 & 100,00 & 100,81 & 95,65 & 37,49 & 5453,55 & 247,77 & $-3,97$ & 251,74 & \begin{tabular}{l|l|}
69,92 \\
\end{tabular} & \begin{tabular}{ll|l}
173,08 \\
1
\end{tabular} & 173,21 & 33,90 & 645,41 & \begin{tabular}{ll|}
70,98 \\
\end{tabular} & 32,20 & 21,06 & 196,42 & \begin{tabular}{ll|}
116,78 \\
\end{tabular} & \begin{tabular}{ll|}
116,78 \\
\end{tabular} & 171,18 \\
\hline Epidalea calamita & 30TVN41 & 100,00 & 97,97 & 94,24 & 37,84 & 5348,75 & 242,03 & $-5,08$ & 247,11 & \begin{tabular}{|l|l|}
68,22 \\
\end{tabular} & 168,75 & 169,27 & 32,69 & \begin{tabular}{|c|c|}
695,17 \\
\end{tabular} & 76,59 & 34,88 & 20,91 & 212,73 & \begin{tabular}{l|l|}
126,85 \\
\end{tabular} & \begin{tabular}{l|l|}
126,95 \\
\end{tabular} & 186,38 \\
\hline Epidalea calamita & 30TVN42 & 100,00 & 94,73 & 92,92 & 37,97 & 5248,90 & 235,92 & $-6,76$ & 242,68 & 66,10 & 163,77 & 164,82 & 30,91 & 748,93 & 82,50 & 37,81 & 20,56 & 230,02 & \begin{tabular}{|l|l|}
137,79 \\
\end{tabular} & \begin{tabular}{l|l|}
137,95 \\
\end{tabular} & 202,92 \\
\hline Epidalea calamita & 30TVN43 & 100,00 & 94,96 & 90,73 & 37,93 & 5126,11 & 232,01 & $-4,57$ & 236,57 & 67,53 & 161,78 & 163,49 & 32,63 & 793,42 & 87,77 & 39,94 & 20,51 & 245,95 & 145,83 & 147,30 & 217,37 \\
\hline Epidalea calamita & 30TVN46 & 100,00 & 101,68 & 82,19 & 37,70 & 4705,55 & 224,07 & $\begin{array}{l}8,78 \\
8\end{array}$ & 215,30 & 78,10 & \begin{tabular}{ll|l}
162,36 \\
\end{tabular} & $\begin{array}{l}164,63 \\
\end{array}$ & 44,20 & $\begin{array}{l}919,65 \\
\end{array}$ & 105,53 & \begin{tabular}{|l|l}
44,48 \\
\end{tabular} & 22,03 & \begin{tabular}{|l|l|}
295,47 \\
\end{tabular} & $\begin{array}{ll}164,43 \\
\end{array}$ & $\begin{array}{l}174,03 \\
\end{array}$ & 261,18 \\
\hline Epidalea calamita & 30TVN52 & 100,00 & 98,95 & 91,42 & 37,73 & 5221,31 & 237,64 & $-1,86$ & 239,51 & \begin{tabular}{ll|}
70,07 \\
\end{tabular} & $\begin{array}{ll}167,23 \\
\end{array}$ & \begin{tabular}{ll|}
168,60 \\
\end{tabular} & 35,30 & 749,14 & 81,75 & 37,43 & $\begin{array}{ll}20,46 \\
\end{array}$ & \begin{tabular}{|l|l|}
229,92 \\
\end{tabular} & \begin{tabular}{|l|l|}
137,40 \\
\end{tabular} & \begin{tabular}{|l|l|}
139,13 \\
\end{tabular} & 205,45 \\
\hline Epidalea calamita & 30TVN55 & 100,00 & 113,55 & 80,20 & 37,16 & 4694,17 & 233,01 & 20,75 & 212,25 & 89,81 . & 173,80 & 175,99 & 55,64 & 865,90 & 100,81 & \begin{tabular}{|l|l|}
40,08 \\
\end{tabular} & 22,87 & 280,37 & 151,47 & 163,42 & 249,80 \\
\hline Epidalea calamita & 30TVN56 & 100,00 & 106,14 & 80,16 & 37,35 & 4654,46 & 225,83 & 14,56 & 211,27 & \begin{tabular}{l|l|}
82,72 \\
\end{tabular} & 165,90 & 168,30 & 49,16 & $\begin{array}{l}930,85 \\
\end{array}$ & 108,16 & 44,22 & 22,41 & 299,67 & 164,75 & \begin{tabular}{|l|l|}
176,64 \\
\end{tabular} & 268,72 \\
\hline Epidalea calamita & 30TVN57 & 100,00 & 90,49 & 82,57 & 37,85 & 4709,62 & 214,55 & \begin{tabular}{l|l}
$-0,90$ \\
\end{tabular} & 215,45 & 52,83 & \begin{tabular}{ll|l}
151,43 \\
\end{tabular} & 153,93 & 33,92 & 1014,97 & 115,98 & 50,75 & 21,14 & 321,54 & $\begin{array}{l}184,65 \\
\end{array}$ & \begin{tabular}{|l|l|}
193,13 \\
\end{tabular} & 291,03 \\
\hline Epidalea calamita & 30TVN61 & 100,00 & 109,10 & 91,23 & 37,38 & 5275,72 & 247,20 & 6,92 & 240,28 & 79,42 & 177,51 & \begin{tabular}{ll|}
178,99 \\
\end{tabular} & 44,13 & 687,76 & 74,70 & 33,49 & \begin{tabular}{|l|l|}
20,67 \\
\end{tabular} & 210,78 & \begin{tabular}{ll|}
125,36 \\
\end{tabular} & \begin{tabular}{l|l|l|}
128,02 \\
\end{tabular} & 189,41 \\
\hline Epidalea calamita & 30TVN62 & 100,00 & 111,51 & 88,30 & 37,32 & 5124,11 & 244,29 & 11,61 & 232,68 & 81,37 & \begin{tabular}{ll|l}
177,68 \\
\end{tabular} & \begin{tabular}{ll|}
179,32 \\
\end{tabular} & 48,27 & \begin{tabular}{|l|l|}
728,47 \\
\end{tabular} & $\begin{array}{l}80,75 \\
\end{array}$ & 34,84 & 21,01 & 226,71 & \begin{tabular}{|l|}
131,29 \\
\end{tabular} & \begin{tabular}{ll|}
136,11 \\
\end{tabular} & 203,84 \\
\hline Epidalea calamita & 30TVN63 & 100,00 & 107,20 & 87,07 & 37,60 & 5038,53 & 238,05 & 9,28 & 228,77 & \begin{tabular}{ll|}
79,07 \\
\end{tabular} & $\begin{array}{ll}172,23 \\
\end{array}$ & 174,21 & 45,30 & 785,92 & 87,87 & 38,01 & 20,5 & 245,04 & \begin{tabular}{|l|l|}
141,95 \\
\end{tabular} & \begin{tabular}{|l|}
147,61 \\
\end{tabular} & 221,72 \\
\hline Epidalea calamita & 30TVN65 & 100,00 & 108,42 & 81,64 & 37,37 & \begin{tabular}{ll|}
4761,87 \\
\end{tabular} & 230,73 & \begin{tabular}{|l|}
15,28 \\
\end{tabular} & 215,45 & 82,29 & $\begin{array}{ll}169,62 \\
\end{array}$ & 171,90 & 50,06 & \begin{tabular}{l|l}
889,65 \\
\end{tabular} & 102,73 & 42,10 & 21,96 & 283,26 & 157,77 & 168,31 & 257,69 \\
\hline Epidalea calamita & 30TVN66 & 100,00 & 105,04 & 80,32 & 37,39 & 4675,92 & 225,36 & \begin{tabular}{|l|l|}
13,67 \\
\end{tabular} & 211,68 & 74,50 & \begin{tabular}{|l|l|}
164,97 \\
\end{tabular} & \begin{tabular}{l|l|}
167,42 \\
\end{tabular} & \begin{tabular}{ll|}
47,88 \\
\end{tabular} & 950,00 & \begin{tabular}{ll|}
110,36 \\
\end{tabular} & \begin{tabular}{ll|}
45,36 \\
\end{tabular} & 22,03 & 303,34 & \begin{tabular}{l|l|}
168,65 \\
\end{tabular} & \begin{tabular}{|l|l|}
180,39 \\
\end{tabular} & 276,88 \\
\hline Epidalea calamita & 30TVN67 & 100,00 & 101,25 & 79,16 & 37,55 & 4599,45 & 219,84 & 11,59 & 208,25 & 65,66 & 160,21 & 162,83 & 45,37 & 1010,80 & 117,99 & 48,59 & 22,10 & 323,75 & $\begin{array}{ll}179,86 \\
\end{array}$ & 192,51 & 296,21 \\
\hline Epidalea calamita & 30TVN70 & 100,00 & 104,58 & 94,92 & 37,86 & 5438,01 & 248,84 & \begin{tabular}{ll|}
0,10 \\
\end{tabular} & 248,73 & 73,09 & \begin{tabular}{|l|l|}
175,77 \\
\end{tabular} & \begin{tabular}{|l|l|}
176,68 \\
\end{tabular} & \begin{tabular}{l|l|}
37,92 \\
\end{tabular} & 669,04 & 70,87 & 33,55 & \begin{tabular}{l|l}
19,95 \\
\end{tabular} & \begin{tabular}{|l|l|l|}
199,48 \\
\end{tabular} & \begin{tabular}{l|l}
124,75 \\
\end{tabular} & \begin{tabular}{|l|l|}
125,08 \\
\end{tabular} & 182,08 \\
\hline Epidalea calamita & 30TVN71 & 100,00 & 109,94 & 91,44 & 37,53 & 5283,77 & 247,82 & 7,43 & \begin{tabular}{|l|l|}
240,39 \\
\end{tabular} & \begin{tabular}{|l|l|}
79,87 \\
\end{tabular} & \begin{tabular}{l|l|l|l|l|}
178,32 \\
\end{tabular} & $179, \varepsilon$ & 44,8 & 695,56 & 75, & 33,9 & 20, & 211,65 & $\begin{array}{ll}127,88 \\
\end{array}$ & \begin{tabular}{l|l}
130,55 \\
\end{tabular} & 192,67 \\
\hline Epidalea calamita & 30TVN74 & 100,00 & 107,62 & 84,58 & 37,51 & 4912,95 & 234,44 & \begin{tabular}{|l|l|}
12,03 \\
\end{tabular} & 222,40 & $\begin{array}{l}74,75 \\
\end{array}$ & \begin{tabular}{|l|l|}
170,82 \\
\end{tabular} & 172,86 & \begin{tabular}{|l|l}
47,35 \\
\end{tabular} & \begin{tabular}{|l|}
851,06 \\
\end{tabular} & 96,70 & 40,89 & 21,06 & 266,57 & 153,21 & 160,98 & 245,17 \\
\hline Epidalea calamita & 30TVN75 & 100,00 & 105,31 & 82,77 & 37,50 & 4807,18 & 229,48 & \begin{tabular}{l|l|l|}
11,75 \\
\end{tabular} & 217,73 & \begin{tabular}{ll|l}
67,09 \\
\end{tabular} & $\begin{array}{l}167,05 \\
1\end{array}$ & \begin{tabular}{ll|l}
169,38 \\
\end{tabular} & 46,57 & $\begin{array}{l}910,55 \\
\end{array}$ & 104,51 & 43,79 & 21,23 & 286,82 & \begin{tabular}{ll|}
163,32 \\
\end{tabular} & $\begin{array}{l}172,66 \\
1\end{array}$ & 264,81 \\
\hline Epidalea calamita & 30TVN77 & 100,00 & 122,34 & 71,61 & 36,73 & 4342,73 & 229,04 & 36,54 & 192,50 & 98,41 & \begin{tabular}{|l|l|}
177,24 \\
\end{tabular} & \begin{tabular}{|l|l|}
179,90 \\
\end{tabular} & \begin{tabular}{|l|l|}
68,68 \\
\end{tabular} & \begin{tabular}{|l|}
1009,67 \\
\end{tabular} & 123,94 & 44,06 & 25,19 & \begin{tabular}{|l|}
332,97 \\
\end{tabular} & $\begin{array}{ll}169,58 \\
\end{array}$ & $\begin{array}{l}190,88 \\
\end{array}$ & 310,96 \\
\hline Epidalea calamita & 30TVN82 & 100,00 & 103,17 & 91,27 & 37,89 & 5220,71 & 240,35 & 2,42 & 237,93 & $\begin{array}{ll}60,00 \\
\end{array}$ & \begin{tabular}{|l|l|}
170,94 \\
\end{tabular} & \begin{tabular}{|l|l|}
172,61 \\
\end{tabular} & 39,31 & 771,66 & 84,04 & $\begin{array}{l}38,65 \\
\end{array}$ & 19,54 & 233,49 & \begin{tabular}{|l|l|}
143,87 \\
\end{tabular} & \begin{tabular}{ll|}
146,24 \\
\end{tabular} & 215,95 \\
\hline Epidalea calamita & 30TVN83 & 100,00 & 104,94 & 88,13 & 37,73 & 5072,27 & 237,26 & 6,80 & 230,46 & 63,63 & \begin{tabular}{|l|l|}
170,70 \\
\end{tabular} & 172,44 & 42,99 & 820,28 & 91,21 & 40,44 & 20, & 252,12 & \begin{tabular}{|l|l|}
150,79 \\
\end{tabular} & \begin{tabular}{|l|l|}
155,49 \\
\end{tabular} & 233,70 \\
\hline Epidalea calamita & 30TVN85 & 100,00 & 104,85 & 83,38 & 37,74 & 4828,90 & 229,94 & 11,22 & 218,72 & 54,11 & 166,92 & 169,21 & 45,99 & 924,90 & \begin{tabular}{|l|l|}
105,84 \\
\end{tabular} & 44,83 & 20,84 & 290,18 & 167,04 & 175,80 & 270,28 \\
\hline Epidalea calamita & 30TVN86 & 100,00 & 105,44 & 80,40 & $\begin{array}{ll}37,56 \\
\end{array}$ & 4686,24 & 225,87 & \begin{tabular}{ll|}
14,56 \\
\end{tabular} & 211,31 & 57,21 & $\begin{array}{ll}165,48 \\
\end{array}$ & \begin{tabular}{ll|l}
167,92 \\
\end{tabular} & 48,38 & 987,13 & \begin{tabular}{ll|}
114,97 \\
\end{tabular} & 47,12 & 21,75 & \begin{tabular}{|l|l|}
313,49 \\
\end{tabular} & \begin{tabular}{|l|l|}
175,99 \\
\end{tabular} & \begin{tabular}{ll|}
187,50 \\
\end{tabular} & 293,23 \\
\hline Epidalea calamita & 30TVN91 & 100,00 & 113,53 & 92,15 & 37,94 & 5299,28 & 251,10 & \begin{tabular}{l|l|}
10,04 \\
\end{tabular} & 241,07 & 80,85 & $\begin{array}{ll}181,98 \\
\end{array}$ & \begin{tabular}{ll|}
183,36 \\
\end{tabular} & 48,11 & \begin{tabular}{ll|}
698,82 \\
\end{tabular} & 75,34 & $\begin{array}{l}4,55 \\
\end{array}$ & 19,53 & 209,99 & 131,21 & 133,30 & 193,97 \\
\hline Epidalea calamita & \begin{tabular}{|l|}
$30 T V N 92$ \\
\end{tabular} & 100,00 & 117,27 & 88,59 & 37,62 & 5141,02 & 249,09 & 16,71 & 232,37 & 86,20 & \begin{tabular}{|l|l|}
183,32 \\
\end{tabular} & 184,93 & 53,60 & $\begin{array}{l}738,05 \\
\end{array}$ & 81,65 & 35,49 & 20,21 & 225,82 & $\begin{array}{l}135,85 \\
\end{array}$ & \begin{tabular}{l|l|}
140,65 \\
\end{tabular} & 209,57 \\
\hline Epidalea calamita & \begin{tabular}{|l|}
$30 T V N 93$ \\
\end{tabular} & 100,00 & 115,36 & 86,42 & \begin{tabular}{l|l|}
37,65 \\
\end{tabular} & 5019,65 & 244,13 & 17,40 & 226,73 & \begin{tabular}{|l|}
80,67 \\
\end{tabular} & \begin{tabular}{ll|}
179,86 \\
\end{tabular} & 181,60 & 53,52 & \begin{tabular}{|l|}
797,27 \\
\end{tabular} & 89,48 & 38,23 & \begin{tabular}{|l|l|}
20,47 \\
\end{tabular} & 246,02 & \begin{tabular}{|l|l|}
145,48 \\
\end{tabular} & \begin{tabular}{|l|l|}
151,88 \\
\end{tabular} & 229,88 \\
\hline Epidalea calamita & \begin{tabular}{|l|l|}
$30 T V N 95$ \\
\end{tabular} & 100,00 & 106,38 & 83,55 & 37,77 & 4828,87 & 231,28 & 12,65 & 218,63 & 56,30 & \begin{tabular}{ll|}
168,32 \\
\end{tabular} & 170,60 & \begin{tabular}{l|l|}
47,55 \\
\end{tabular} & 938,21 & 107,38 & 45,50 & 20,76 & 293,76 & 170,03 & \begin{tabular}{l|l}
178,55 \\
\end{tabular} & 276,05 \\
\hline Epidalea calamita & 30TWK03 & 100,00 & 128,71 & 116,49 & 37,00 & 6654,67 & 309,92 & $-0,58$ & 310,50 & 97,56 & 217,61 & 218,09 & 48,58 & 453,25 & 51,19 & 12,36 & 32,14 & 142,93 & 60,10 & 60,51 & 121,34 \\
\hline Epidalea calamita & $\begin{array}{l}\text { 30TWK04 } \\
\end{array}$ & 100,00 & 130,37 & 114,95 & 36,94 & 6642,86 & 309,52 & 1,63 & \begin{tabular}{|l|}
307,89 \\
\end{tabular} & 92,86 & 219,20 & 219,43 & 50,21 & \begin{tabular}{|l|l|}
441,77 \\
\end{tabular} & 49,99 & \begin{tabular}{|l|l|}
12,28 \\
\end{tabular} & 32,11 & \begin{tabular}{|l|l|}
140,49 \\
\end{tabular} & 58,70 & 58,93 & 117,95 \\
\hline Epidalea calamita & $\begin{array}{l}\text { 30TWK05 } \\
\end{array}$ & 100,00 & 131,79 & 113,23 & 36,63 & 6630,84 & 308,71 & \begin{tabular}{ll|}
3,68 \\
\end{tabular} & 305,03 & 91,11 & 220,29 & 220,43 & 51,59 & 431,30 & 49,19 & 12,25 & 32,2 & 138,31 & 57,62 & 57,79 & 114,45 \\
\hline Epidalea calamita & $\begin{array}{l}\text { 30TWK09 } \\
\end{array}$ & 100,00 & 117,86 & 109,08 & 36,42 & 6537,21 & 289,89 & $-5,92$ & 295,81 & 85,81 & 204,90 & 205,53 & 39,51 & 461,75 & 53,70 & 16,00 & 29,13 & 142,66 & \begin{tabular}{|l|l|}
69,23 \\
\end{tabular} & 70,94 & 117,59 \\
\hline Epidalea calamita & 30TWK13 & 100,00 & 123,29 & 117,98 & 37,19 & 6629,14 & 305,54 & $-6,08$ & 311,62 & 107,24 & 211,53 & 212,54 & \begin{tabular}{|l|l|}
43,97 \\
\end{tabular} & 474,44 & 54,90 & \begin{tabular}{|l|l|l|}
13,98 \\
\end{tabular} & 30,69 & 150,29 & \begin{tabular}{|l|}
65,49 \\
\end{tabular} & 67,36 & 124,68 \\
\hline Epidalea calamita & 30TWK14 & 100,00 & 120,81 & 116,91 & 37,10 & 6612,59 & 301,81 & \begin{tabular}{|l|}
$-7,68$ \\
\end{tabular} & 309,48 & 104,56 & \begin{tabular}{|l|l|}
208,88 \\
\end{tabular} & 209,86 & 41,75 & 479,51 & 55,68 & \begin{tabular}{l|l}
14,85 \\
\end{tabular} & 30,15 & 151,01 & \begin{tabular}{ll|l}
67,53 \\
\end{tabular} & \begin{tabular}{|c|}
69,73 \\
\end{tabular} & 125,27 \\
\hline Epidalea calamita & 30TWK16 & 100,00 & 127,79 & 113,26 & 36,87 & 6594,18 & 303,69 & \begin{tabular}{l|l|}
0,04 \\
\end{tabular} & 303,65 & 99,34 & 215,59 & 216,07 & 48,31 & 438,84 & 50,71 & 13,74 & \begin{tabular}{|l|}
30,57 \\
\end{tabular} & 137,36 & 62,54 & 63,34 & 113,30 \\
\hline Epidalea calamita & $\begin{array}{l}\text { 30TWK18 } \\
\end{array}$ & 100,00 & 120,12 & 111,49 & 36,94 & 6549,52 & 29 & $-5,69$ & 299,71 & \begin{tabular}{|l|l|}
99,00 \\
\end{tabular} & 207,06 & 207,89 & 41, & 457,38 & $53, \mathrm{~s}$ & 16,1 & 28,9 & \begin{tabular}{|l|l|}
141,10 \\
\end{tabular} & 68,84 & 70,79 & 115,82 \\
\hline Epidalea calamita & \begin{tabular}{|l|l|}
$30 T W K 23$ \\
\end{tabular} & 100,00 & 120,92 & 119,29 & 37,89 & 6612,43 & 30 & $-9,18$ & 312,96 & 104,58 & 209,08 & 210,13 & 41,89 & 485,16 & 57,10 & 15,0 & 29,88 & 155,44 & 68,97 & 71,95 & 125,63 \\
\hline Epidalea calamita & 30TWK24 & 100,00 & 124,19 & 117,79 & 37,38 & 6596,71 & 304,64 & $-5,54$ & 310,18 & \begin{tabular}{|l|l|}
108,39 \\
\end{tabular} & \begin{tabular}{|l|l|}
211,75 \\
\end{tabular} & 212,77 & 44,76 & $\begin{array}{l}466,35 \\
\end{array}$ & 54,82 & 14,50 & 29,86 & \begin{tabular}{|l|l|}
147,90 \\
\end{tabular} & 66,71 & \begin{tabular}{l|l|}
69,05 \\
\end{tabular} & 120,30 \\
\hline Epidalea calamita & 30TWK26 & 100,00 & 128,90 & 114,41 & 37,02 & 6576,52 & 304,81 & 0,05 & 304,76 & 114,28 & 215,90 & 216,89 & 49,34 & 433,33 & 51,13 & 13,79 & 29,99 & 134,91 & 63,40 & 64,64 & 110,08 \\
\hline Epidalea calamita & 30TWK27 & 100,00 & 127,68 & 113,24 & 36,99 & 6562,92 & 302,00 & $-0,41$ & 302,41 & 112,77 & 214,41 & 215,34 & 48,19 & 431,81 & 51,31 & \begin{tabular}{ll|}
14,39 \\
\end{tabular} & 29,62 & \begin{tabular}{|l|l|}
133,89 \\
\end{tabular} & \begin{tabular}{l|l|l|}
64,42 & \\
\end{tabular} & 65,81 & 108,68 \\
\hline Epidalea calamita & 30TWK28 & 100,00 & 122,64 & 112,57 & 37,00 & 77 & 296,27 & $-4,50$ & 300,77 & \begin{tabular}{|l|l|}
107,37 \\
\end{tabular} & 209,05 & 210,05 & 43, & 446,70 & 53,55 & 15,97 & 28,5 & 138,34 & $f$ & 70,90 & 111,56 \\
\hline Epidalea calamita & \begin{tabular}{|l|}
$30 T W K 29$ \\
\end{tabular} & 100,00 & 120,61 & 111,60 & 36,97 & 6519,43 & 293 & $-5,77$ & 298,87 & 105,81 & 206,94 & 207,78 & 42, & 449,01 & 54,25 & 16,81 & 28,10 & 138,53 & 70,50 & 73,21 & 111,14 \\
\hline Epidalea calamita & 30TWK33 & 100,00 & 116,66 & 120,74 & 38,00 & 6585,14 & 300,33 & $-14,06$ & 314,40 & 100,01 & $\begin{array}{ll}204,55 \\
\end{array}$ & 205,58 & 38,06 & 505,99 & 60,53 & 16,58 & 29,01 & \begin{tabular}{|l|}
163,99 \\
\end{tabular} & 74,23 & 78,88 & 129,05 \\
\hline Epidalea calamita & 30TWK35 & 100,00 & 121,19 & 117,90 & 37,73 & 6561,97 & 300,68 & $-8,71$ & \begin{tabular}{|l|l|}
309,39 \\
\end{tabular} & \begin{tabular}{|l|l|}
105,44 \\
\end{tabular} & \begin{tabular}{|l|l|}
208,23 \\
\end{tabular} & 209,28 & 42,12 & $\begin{array}{l}474,27 \\
\end{array}$ & $\begin{array}{l}57,05 \\
\end{array}$ & \begin{tabular}{l|l|l|}
15,95 \\
\end{tabular} & 28,80 & \begin{tabular}{|l|l|}
151,19 \\
\end{tabular} & 71,10 & 74,64 & 119,71 \\
\hline Epidalea calamita & 30TWK38 & 100,00 & 118,60 & 114,31 & 37,01 & 6511,69 & 293,20 & $-9,39$ & 302,60 & 103,35 & 204,84 & 205,76 & 40,13 & 463,81 & 56,89 & \begin{tabular}{|l|l|}
17,48 \\
\end{tabular} & 27,65 & 145,43 & 73,58 & 77,58 & 114,14 \\
\hline Epidalea calamita & 30TWK43 & 100,00 & 115,33 & 121,93 & 38,00 & 51 & \begin{tabular}{|l|l|}
299,45 \\
\end{tabular} & $-16,16$ & 315,60 & \begin{tabular}{|c|}
98,45 \\
\end{tabular} & 202,97 & 204,06 & 36,84 & 515,11 & 62,31 & 17,43 & 28,55 & 168,05 & 77,36 & 82,94 & 129,92 \\
\hline Epidalea calamita & \begin{tabular}{|l|l|}
$30 T W K 46$ \\
\end{tabular} & 100,00 & 120,01 & 117,84 & 37,90 & 6528,19 & 297 & $-10,22$ & 308,21 & 104,49 & 206,46 & 207,61 & 41,21 & 473,49 & 58,31 & 17,00 & 27,97 & 151,43 & 74,06 & 78,60 & 116,90 \\
\hline Epidalea calamita & \begin{tabular}{|l|}
$30 T W K 48$ \\
\end{tabular} & 100,00 & 118,36 & 115,32 & 37,49 & 6495,22 & 292,94 & $-10,56$ & 303,49 & 103,10 & \begin{tabular}{|l|l|}
204,25 \\
\end{tabular} & 205,29 & 39,91 & \begin{tabular}{|l|l|}
464,03 \\
\end{tabular} & 58,03 & 17,97 & 27,41 & \begin{tabular}{ll|}
146,60 \\
\end{tabular} & 75,60 & 80,51 & 112,32 \\
\hline Epidalea calamita & $\begin{array}{l}30 T W K 57 \\
\end{array}$ & 100,00 & 119,51 & 117,14 & 37,99 & 6488,75 & 295,10 & $-10,90$ & 306,00 & 104,30 & \begin{tabular}{|l|}
205,19 \\
\end{tabular} & 206,31 & 40,91 & 466,33 & 58,95 & 17,86 & 27,57 & $\begin{array}{l}149,15 \\
\end{array}$ & 76,57 & \begin{tabular}{|l|l|}
81,97 \\
\end{tabular} & 111,85 \\
\hline Epidalea calamita & 30TWK58 & 100,00 & 118,81 & 115,73 & 37,71 & 6474,79 & 292,47 & $-11,08$ & 303,55 & \begin{tabular}{|l|l|}
103,83 \\
\end{tabular} & 204,13 & 205,10 & 40,08 & 460,90 & 58,77 & 18,3 & 27,2 & 146,40 & 77,21 & 82,94 & 109,38 \\
\hline Epidalea calam & $30 \mathrm{TV}$ & 100, & 105 & & 37,6 & 643 & 279 & $-23,0$ & 302, & 91, & 190, & 191 & 28, & 513,53 & 65,75 & 22, & 25,86 & 162,88 & 89,14 & 97,38 & 121 \\
\hline Epidalea calamita & 30TWK64 & 100,00 & 112,60 & 122,68 & 38,29 & 6511,99 & 295,09 & $-20,03$ & 315,11 & 95,84 & \begin{tabular}{|l|l|}
199,12 \\
\end{tabular} & 200,32 & 34,38 & 528,38 & 65,84 & 19,68 & 27,66 & $\begin{array}{ll}173,52 \\
\end{array}$ & 84,80 & 92,23 & 129,07 \\
\hline Epidalea calamita & 30TWK66 & 100,00 & 114,23 & 119,39 & 38,00 & 6481,22 & 292,02 & $-17,12$ & 309,14 & 98,42 & \begin{tabular}{|l|}
200,04 \\
\end{tabular} & 201,21 & 36,14 & \begin{tabular}{|l|l|}
498,53 \\
\end{tabular} & $\begin{array}{l}63,48 \\
\end{array}$ & 19,64 & 27,18 & \begin{tabular}{|l|l|}
161,69 \\
\end{tabular} & 83,12 & 90,30 & 118,71 \\
\hline Epidalea calamita & 30TWK68 & 100,00 & 106,73 & 116,36 & 37,98 & \begin{tabular}{ll|}
6444,07 \\
\end{tabular} & 281,06 & $-22,78$ & \begin{tabular}{|l|l|}
303,84 \\
\end{tabular} & \begin{tabular}{|c|}
92,12 \\
\end{tabular} & $\begin{array}{l}192,05 \\
\end{array}$ & \begin{tabular}{|l|l|}
193,18 \\
\end{tabular} & \begin{tabular}{l|l|}
29,05 \\
\end{tabular} & 511,24 & 66,21 & 22,38 & 26,24 & \begin{tabular}{|l|l|}
163,79 \\
\end{tabular} & 89,62 & \begin{tabular}{|l|l|}
98,37 \\
\end{tabular} & 119,01 \\
\hline Epidale & 30 & 100,00 & 113, & 123,69 & 38,7 & 797 & 205 & $-19, \mathrm{~s}$ & & $\begin{array}{l}96,05 \\
\end{array}$ & \begin{tabular}{|l|l|}
199,46 \\
\end{tabular} & 200,74 & 34,86 & 533 & 66, & & & 176 & 86,49 & 94,15 & 12 \\
\hline Epidalea calamita & $\begin{array}{l}30 T W K 79 \\
\end{array}$ & 100,00 & 93,35 & 114,29 & 37,94 & 6378,5 & 265 & $-34,21$ & 299,57 & 112,60 & 178,20 & 179,19 & 16,96 & 562,2 & 73,74 & 27,55 & 25,18 & 182,72 & \begin{tabular}{|l|l|}
104,53 \\
\end{tabular} & \begin{tabular}{|l|l|}
116,45 \\
\end{tabular} & 127 , \\
\hline Epidalea calamita & 30TWK83 & 100,00 & 102,58 & 120,26 & 38,17 & 6476,73 & 282,14 & $-27,89$ & \begin{tabular}{|l|l|}
310,03 \\
\end{tabular} & $\begin{array}{l}84,56 \\
\end{array}$ & \begin{tabular}{|l|l|}
189,01 \\
\end{tabular} & 190,08 & 25,43 & 562,12 & 71,36 & 23,60 & 26,19 & 184,82 & \begin{tabular}{|l|l|}
96,95 \\
\end{tabular} & \begin{tabular}{|l|l|}
106,93 \\
\end{tabular} & 129,77 \\
\hline
\end{tabular}




\begin{tabular}{|c|c|c|c|c|c|c|c|c|c|c|c|c|c|c|c|c|c|c|c|c|c|}
\hline TAXON & UTM & $\mathrm{km2}$ & BIO1 & $\mathrm{B1O2}$ & $\mathrm{BIO3}$ & B104 & B105 & B106 & B107 & B108 & B109 & 81010 & B1011 & B1O12 & BIO13 & 81014 & BIO15 & B1016 & B1017 & B1018 & B1019 \\
\hline Epidalea calamita & 30TWK84 & 100,00 & 96,47 & 118,36 & 38,01 & 6457,47 & 274,20 & $-32,79$ & 306,99 & 78,13 & 182,81 & 183,78 & 19,61 & 580,26 & 74,21 & 25,90 & 25,51 & 189,63 & 102,94 & 114,16 & 132,22 \\
\hline Epidalea calamita & 30TWK85 & 100,00 & 95,13 & 117,38 & 38,00 & 6441,05 & 271,36 & $-33,71$ & 305,07 & 78,52 & 181,13 & 182,19 & 18,36 & 578,71 & 74,69 & 26,55 & 25,51 & 188,32 & 104,36 & 115,87 & 131,04 \\
\hline Epidalea calamita & 30TWK86 & 100,00 & 88,77 & 115,56 & 37,99 & 6414,97 & 263,32 & $-38,73$ & 302,05 & 92,32 & 174,60 & 175,45 & 12,55 & 600,71 & 77,74 & 29,01 & 24,95 & 194,99 & 110,73 & 123,49 & 135,10 \\
\hline Epidalea calamita & 30TWK87 & 100,00 & 91,65 & 114,86 & 37,95 & 6400,00 & 264,45 & $-36,16$ & 300,61 & 106,94 & 176,90 & 177,95 & 15,38 & 579,10 & 75,79 & 28,23 & 25,25 & 188,82 & 107,97 & 120,48 & 129,32 \\
\hline Epidalea calamita & 30TWK88 & 100,00 & 86,30 & 113,60 & 37,80 & $\begin{array}{ll}6367,38 \\
\end{array}$ & 257,78 & $-40,42$ & 298,21 & 104,73 & 171,25 & 172,19 & 10,56 & 599,53 & 78,42 & 30,40 & 24,72 & 196,11 & 113,56 & 127,13 & 133,66 \\
\hline Epidalea calamita & 30TWK89 & 100,00 & 87,80 & 112,80 & 37,62 & 6350,86 & 257,53 & $-39,03$ & 296,56 & 106,71 & 172,23 & 173,13 & 11,91 & 584,62 & 77,23 & 30,11 & 25,07 & 192,41 & 112,14 & 125,67 & 129,43 \\
\hline Epidalea calamita & 30TWK93 & 100,00 & 102,88 & 118,10 & 38,03 & 6449,12 & 279,10 & $-26,42$ & 305,52 & 85,18 & 188,95 & 190,01 & 25,99 & 549,82 & 70,66 & 24,09 & 26,09 & 180,04 & 98,38 & 108,40 & 122,41 \\
\hline Epidalea calamita & 30TWK94 & 100,00 & 92,23 & 116,03 & 38,00 & 6430,56 & 267,20 & $-35,36$ & 302,56 & 88,19 & 178,35 & 179,33 & 16,06 & 590,88 & 76,23 & 27,84 & 25,12 & 192,64 & \begin{tabular}{|c|}
108,68 \\
\end{tabular} & 120,74 & 130,77 \\
\hline Epidalea calamita & 30TWK95 & 100,00 & 92,36 & 115,23 & 38,00 & 6416,55 & 265,77 & $-35,26$ & 301,03 & 104,81 & 178,05 & 179,08 & 16,05 & 583,27 & 75,98 & 28,08 & 25,35 & 190,72 & 108,82 & 121,12 & 128,16 \\
\hline Epidalea calamita & 30TWK97 & 100,00 & 80,60 & 112,32 & 37,32 & 6361,69 & 251,36 & $-44,86$ & 296,22 & 98,38 & 165,82 & 166,64 & 5,25 & 630,88 & 82,18 & 32,84 & 24,31 & 207,19 & 121,55 & \begin{tabular}{l|l|}
136,08 \\
\end{tabular} & 138,47 \\
\hline Epidalea calamita & 30TWK98 & 100,00 & 80,94 & 111,58 & 37,14 & 6340,80 & 250,10 & $-44,57$ & 294,66 & 98,89 & 165,63 & 166,52 & 5,51 & 622,34 & 81,77 & 32,99 & 24,56 & 205,50 & 121,34 & 136,15 & 135,74 \\
\hline Epidalea calamita & 30TWK99 & 100,00 & 85,59 & 111,09 & 37,27 & 6324,33 & 252,81 & $-40,40$ & 293,21 & 104,34 & 169,66 & 170,64 & 9,83 & 589,39 & 78,67 & 31,47 & 25,33 & 196,45 & 116,27 & 130,66 & 127,00 \\
\hline Epidalea calamita & 30TWL01 & 100,00 & 112,37 & 108,54 & 36,55 & 6474,92 & 283,21 & $-10,34$ & 293,56 & 93,09 & 198,60 & 199,14 & 34,89 & 477,49 & 56,35 & 17,70 & 27,35 & 145,03 & 74,67 & 77,99 & 120,09 \\
\hline Epidalea calamita & 30TWL03 & 100,00 & 118,13 & 107,04 & 36,16 & 6446,04 & 286,24 & $-4,34$ & 290,58 & 86,60 & 203,59 & 204,21 & 40,31 & 446,77 & 52,88 & 16,51 & 27,15 & 134,88 & 71,42 & 74,17 & 111,64 \\
\hline Epidalea calamita & 30TWL04 & 100,00 & 111,49 & 108,35 & 36,71 & 6393,51 & 280,81 & $-10,72$ & 291,53 & 108,95 & 196,57 & 196,98 & 34,78 & 476,03 & 56,68 & 18,80 & 25,92 & 142,80 & 77,88 & 82,26 & 119,36 \\
\hline Epidalea calamita & 30TWL07 & 100,00 & 97,13 & 110,66 & 37,37 & 6252,88 & 268,36 & $-23,79$ & 292,15 & 115,05 & 180,97 & 181,10 & 22,64 & 549,99 & 65,41 & 24,94 & 23,07 & 167,04 & 95,15 & 102,44 & 139,62 \\
\hline Epidalea calamita & 30TWL11 & 100,00 & 111,94 & 110,05 & 36,88 & 6467,81 & 283,48 & $-12,04$ & 295,51 & 95,51 & 197,93 & 198,69 & 34,63 & 478,39 & 57,52 & 18,76 & 26,85 & 146,10 & 76,74 & 80,79 & 118,94 \\
\hline Epidalea calamita & 30TWL13 & 100,00 & 114,15 & 109,12 & 36,77 & 6428,10 & 283,77 & $-9,39$ & 293,16 & 102,65 & 199,37 & 200,05 & 36,77 & 463,86 & 55,97 & 18,51 & 26,19 & 140,01 & 76,30 & 80,35 & 114,78 \\
\hline Epidalea calamita & 30TWL14 & 100,00 & 111,38 & 109,54 & 37,00 & \begin{tabular}{|l|l|}
6393,14 \\
\end{tabular} & 281,39 & $-11,82$ & 293,21 & 127,34 & 196,38 & 196,90 & 34,62 & 475,03 & 57,42 & 19,64 & 25,46 & 143,82 & 79,57 & 84,34 & 117,86 \\
\hline Epidalea calamita & 30TWL17 & 100,00 & 103,53 & 111,29 & 37,17 & 6279,43 & 274,65 & $-19,02$ & $293,67 \mid$ & 122,61 & $\mid 187,15$ & $\mid 187,58$ & 28,16 & 519,04 & 62,40 & 23,79 & 23,10 & 158,25 & 91,01 & 97,74 & 130,71 \\
\hline Epidalea calamita & 30TWL19 & 100,00 & $\begin{array}{ll}110,87 \\
\end{array}$ & 111,19 & 37,55 & 6229,64 & 280,75 & $-11,81$ & 292,56 & 130,53 & 193,55 & 193,84 & 35,34 & 490,44 & 58,62 & 22,78 & 22,84 & 148,93 & 87,42 & 93,05 & 124,01 \\
\hline Epidalea calamita & 30TWL23 & 100,00 & 107,73 & 111,14 & 37,00 & 6395,07 & 279,09 & \begin{tabular}{|l|l|l|}
$-16,64$ \\
-1,
\end{tabular} & 295,73 & 117,25 & 192,73 & 193,40 & 30,99 & 492,52 & $\begin{array}{l}0,48 \\
60,48\end{array}$ & 21,39 & 25,13 & 150,85 & 83,67 & 89,55 & 120,92 \\
\hline Epidalea calamita & 30TWL24 & 100,00 & $\begin{array}{ll}107,67 \\
\end{array}$ & 111,21 & 37,00 & 6371,25 & 278,73 & $-16,60$ & 295,33 & 127,47 & 192,42 & 192,95 & 31,09 & \begin{tabular}{|l|l|}
491,85 \\
\end{tabular} & 60,39 & 21,70 & 24,67 & 150,90 & 84,58 & 90,68 & 121,06 \\
\hline Epidalea calamita & 30TWL26 & 100,00 & 105,36 & 111,83 & 37,18 & 6306,08 & 276,62 & $-18,44$ & 295,06 & 124,83 & 189,21 & 189,83 & 29,54 & 506,69 & 61,87 & 23,41 & 23,57 & 155,68 & 89,50 & 96,17 & 125,79 \\
\hline Epidalea calamita & 30TWL27 & 100,00 & 103,26 & 112,48 & 37,56 & 6274,36 & 274,86 & $-20,32$ & 295,18 & 122,43 & 186,79 & 187,23 & 27,83 & 520,87 & 63,32 & 24,73 & 22,91 & 159,92 & 93,13 & 100,17 & 130,19 \\
\hline Epidalea calamita & 30TWL28 & 100,00 & 104,37 & 112,80 & 37,86 & 6240,78 & 276,01 & $-19,05$ & 295,06 & 123,50 & 187,44 & 187,69 & 29,20 & 519,80 & 62,82 & 25,08 & 22,39 & 159,21 & 93,81 & 100,57 & 130,73 \\
\hline Epidalea calamita & 30TWL31 & 100,00 & 109,99 & 112,48 & 37,02 & 6438,92 & 282,18 & $-16,21$ & 298,39 & \begin{tabular}{|c|c|}
55,99 \\
9
\end{tabular} & $\begin{array}{l}195,36 \\
\end{array}$ & \begin{tabular}{|l|l|}
196,18 \\
\end{tabular} & 32,47 & 486,30 & $\begin{array}{l}60,61 \\
60,61\end{array}$ & 20,92 & 25,80 & \begin{tabular}{|l|}
150,60 \\
\end{tabular} & \begin{tabular}{|l|}
82,16 \\
82,16
\end{tabular} & \begin{tabular}{|l|l|}
88,14 \\
\end{tabular} & 117,84 \\
\hline Epidalea calamita & 30TWL34 & 100,00 & 103,25 & 112,50 & 37,45 & 6352,49 & 274,90 & $-21,79$ & 296,68 & 122,84 & 187,75 & 188,19 & 26,94 & 512,13 & 63,82 & 24,03 & 24,14 & 159,32 & 90,44 & 98,01 & 124,74 \\
\hline Epidalea calamita & 30TWL35 & 100,00 & 101,26 & 112,75 & 37,71 & 6319,27 & 272,95 & $-23,49$ & 296,44 & 120,55 & 185,24 & 185,87 & 25,27 & 523,95 & 65,03 & 25,26 & 23,49 & 162,96 & 93,88 & \begin{tabular}{|l|l|}
101,78 \\
\end{tabular} & 128,29 \\
\hline Epidalea calamita & 30TWL36 & 100,00 & 100,93 & 113,00 & 37,98 & 6291,45 & 272,63 & $-23,75$ & 296,38 & 120,11 & 184,61 & 185,22 & 25,24 & 528,39 & 65,26 & 25,80 & 23,01 & 164,10 & 95,48 & 103,54 & 130,21 \\
\hline Epidalea calamita & 30TWL37 & 100,00 & 103,16 & 113,23 & 37,99 & 6272,93 & 274,97 & $-21,53$ & 296,50 & 122,53 & 186,64 & 186,98 & 27,49 & 520,99 & 64,03 & 25,62 & 22,73 & 161,25 & 94,88 & 102,47 & 129,11 \\
\hline Epidalea calamita & 30TWL38 & 100,00 & 107,05 & 113,55 & 38,00 & 6243,97 & 278,66 & $\begin{array}{l}-17,82 \\
-17,82\end{array}$ & 296,47 & \begin{tabular}{|l|l|}
126,84 \\
\end{tabular} & \begin{tabular}{|l|}
$189,90,9$ \\
\end{tabular} & $\begin{array}{l}190,27 \\
\end{array}$ & $\begin{array}{ll}1,4,47 \\
31\end{array}$ & 506,42 & $\begin{array}{l}62,06 \\
62,0\end{array}$ & 24,94 & 22,58 & $\begin{array}{l}156,39 \\
\end{array}$ & $\begin{array}{l}4,00 \\
92,73 \\
\end{array}$ & $\begin{array}{l}0,2,67 \\
99,67\end{array}$ & 126,17 \\
\hline Epidalea calamita & 30TWL39 & 100,00 & 109,03 & 113,99 & 38,00 & 6221,73 & 280,64 & $-15,73$ & 296,38 & 128,99 & 191,51 & 191,92 & 33,55 & 503,57 & 61,23 & 25,10 & 22,12 & 154,73 & 92,94 & 99,47 & $\begin{array}{ll}126,49 \\
\end{array}$ \\
\hline Epidalea calamita & 30TWL41 & 100,00 & 106,50 & 113,52 & 37,50 & 6418,01 & 278,90 & $-20,49$ & 299,39 & 114,28 & 191,60 & 192,40 & 29,29 & 499,84 & 63,39 & 22,43 & 25,43 & 156,57 & 86,91 & 94,42 & 119,41 \\
\hline Epidalea calamita & 30TWL44 & 100,00 & 100,16 & 113,00 & 37,92 & 6332,47 & 271,53 & $-25,25$ & 296,78 & 119,71 & 184,47 & 184,87 & 23,89 & 525,41 & 66,40 & 25,63 & 23,86 & 165,53 & 95,10 & 104,01 & 126,38 \\
\hline Epidalea calamita & 30TWL45 & 100,00 & 101,42 & 113,01 & 37,96 & 6313,14 & 272,55 & $-24,05$ & 296,60 & 120,94 & 185,25 & 185,75 & 25,16 & 521,14 & 65,67 & 25,74 & 23,55 & 163,99 & 95,18 & 103,92 & 125,89 \\
\hline Epidalea calamita & $\begin{array}{l}30 \text { TWL48 } \\
\end{array}$ & 100,00 & $\begin{array}{ll}107,87 \\
107\end{array}$ & $\begin{array}{l}1114,01 \\
114,02\end{array}$ & 38,00 & $\mid 6247,87$ & 279,03 & $\begin{array}{l}-24,03 \\
-17,74 \\
\end{array}$ & \begin{tabular}{|l|}
296,77 \\
\end{tabular} & \begin{tabular}{|l|}
128,00 \\
\end{tabular} & \begin{tabular}{|l|}
190,51 \\
190,51
\end{tabular} & \begin{tabular}{|l|l|}
191,08 \\
101
\end{tabular} & $\begin{array}{l}30,85 \\
31,85\end{array}$ & 501,45 & $\begin{array}{l}62,41 \\
62,4\end{array}$ & 25,29 & 22,61 & $\begin{array}{l}156,52 \\
15,5\end{array}$ & $\begin{array}{l}|c| c \mid \\
93,48\end{array}$ & $\begin{array}{l}101,12 \\
10,1\end{array}$ & $\begin{array}{l}x_{12,03} \\
123,39\end{array}$ \\
\hline Epidalea calamita & 30TWL49 & 100,00 & 106,99 & 114,69 & 38,00 & 6217,22 & 278,67 & $-18,62$ & 297,29 & 126,85 & 189,35 & 189,79 & 31,42 & 514,24 & 63,20 & 26,27 & 22,00 & 159,39 & 96,54 & 104,10 & 128,16 \\
\hline Epidalea calamita & 30TWL51 & 100,00 & 106,28 & 113,61 & 37,56 & 6404,01 & 277,77 & $-21,32$ & 299,08 & 126,63 & 190,97 & 191,94 & 28,86 & 497,92 & 64,29 & 22,93 & 25,53 & 158,24 & 88,77 & 97,15 & 116,70 \\
\hline Epidalea calamita & 30TWL52 & 100,00 & 104,23 & 113,21 & 37,31 & 6375,36 & 275,06 & $-23,18$ & 298,23 & 124,50 & 188,55 & 189,52 & 27,03 & 504,13 & 65,19 & 23,91 & 25,12 & 160,82 & 91,22 & 100,04 & 118,13 \\
\hline Epidalea calamita & 30TWL54 & 100,00 & 98 & 113,00 & $37, \varepsilon$ & 6319,16 & 268,42 & $-28,34$ & 296,76 & 117,66 & 181,79 & 182,50 & 21,83 & 533,39 & 68,4 & 26,86 & 23,96 & 170,27 & 99,07 & 109,13 & 126,11 \\
\hline Epidalea calamita & 30TWL55 & 100,00 & 100,28 & 113,00 & 38,00 & 6305,38 & 270,42 & $-25,85$ & 296,27 & 120,17 & 183,82 & 184,44 & 24,16 & 523,34 & $67, \mathrm{C}$ & 26,47 & 23,74 & 166,91 & 97,78 & $\begin{array}{l}107,47 \\
\end{array}$ & 124,24 \\
\hline Epidalea calamita & 30TWL57 & 100,00 & 109,50 & 113,14 & 37,89 & 6275,19 & 278,71 & $-17,05$ & 295,76 & 130,26 & 192,22 & 192,81 & 32,96 & 484,23 & 62,01 & 24,46 & 23,93 & $\begin{array}{ll}154,03 \\
\end{array}$ & 91,11 & 99,48 & 115,77 \\
\hline Epidalea calamita & 30TWL59 & 100,00 & 101,72 & 114,83 & 38,00 & 6195,27 & 272,78 & $-24,05$ & 296,83 & 121,25 & 183,77 & 184,08 & 26,56 & 541,03 & 67,11 & 28,44 & 21,87 & 169,30 & 103,28 & 112,47 & 133,71 \\
\hline Epidalea calamita & 30TWL60 & 100,00 & 94,10 & 114,24 & 37,96 & 6381,00 & 266,57 & $-33,26$ & 299,83 & 113,47 & 178,96 & 179,83 & 17,73 & 558,08 & 72,39 & 27,06 & 24,92 & 179,49 & 102,08 & 113,34 & 129,12 \\
\hline Epidalea calamita & 30TWL61 & 100,00 & 101,79 & 113,57 & 37, & 6377,40 & 272,29 & $\begin{array}{l}-25,99 \\
-25\end{array}$ & 298,28 & $\begin{array}{l}122,08 \\
120\end{array}$ & 186,20 & \begin{tabular}{|l|l|}
187,18 \\
\end{tabular} & 24,97 & 514,26 & $\begin{array}{l}67,48 \\
67\end{array}$ & 24,75 & 25,52 & 166,23 & $\begin{array}{l}4,57 \\
94,5 \\
\end{array}$ & $\begin{array}{l}104,59 \\
10,5\end{array}$ & 118,06 \\
\hline Epidalea calamita & 30TW & 100,00 & 101,37 & 113,01 & 37,79 & 6352,98 & 271,03 & $-25,93$ & 296,96 & 121,79 & 185,60 & 186,39 & 24,84 & 512,22 & 67 & 25,23 & 25,26 & 166,09 & 95,40 & 105,62 & 117,44 \\
\hline Epidalea calamita & 30TWL65 & 100,00 & 99,31 & 112,50 & 37,70 & 6279,44 & 267,61 & $\begin{array}{l}-27,34 \\
-21\end{array}$ & 294,95 & 119,48 & 182,29 & 182,98 & 23,38 & 523,26 & 68,26 & 27,16 & 24,29 & 169,50 & 99,93 & 110,74 & 121,65 \\
\hline Epidalea calamita & 30TWL66 & 100,00 & 114,62 & 111,92 & 37,67 & 6300,59 & 281,14 & $-12,89$ & 294,03 & 136,46 & 197,15 & 197,90 & 37,27 & 450,62 & 59,66 & 22,53 & 25,83 & 146,55 & 85,56 & 94,23 & 103,89 \\
\hline Epidalea calamita & 30TWL68 & 100,00 & 112,19 & 112,81 & 38,00 & 6249,84 & 279,79 & $-14,71$ & 294,50 & 133,40 & 194,21 & 194,71 & 35,50 & \begin{tabular}{|l|l|}
472,48 \\
\end{tabular} & 61,37 & 24,37 & 24 & 06 & 90,60 & 99,71 & 111,62 \\
\hline Epidalea calamita & $30 \mathrm{TWL}$ & 100,00 & 100,38 & $\frac{11}{11}$ & 37,64 & $\begin{array}{l}0243,54,85 \\
63345\end{array}$ & 268,58 & $-27,65$ & 296,23 & \begin{tabular}{|l|}
120,78 \\
120,7
\end{tabular} & \begin{tabular}{|l|}
184,12 \\
184,12
\end{tabular} & $\begin{array}{l}184,1,14 \\
185,14\end{array}$ & |30,60 & $\begin{array}{l}|r|, 40 \\
515,33\end{array}$ & $\begin{array}{l}68,84 \\
68,8\end{array}$ & $\begin{array}{ll}24,7,71 \\
251\end{array}$ & $\begin{array}{l}24,11 \\
25,99\end{array}$ & $\begin{array}{l}169,48 \\
1690\end{array}$ & $\begin{array}{l}90,001 \\
97,71\end{array}$ & \begin{tabular}{|l|}
108,87 \\
10,8
\end{tabular} & 1115,26 \\
\hline Epidalea calamita & 30TWL72 & 100,00 & 97,97 & 112,17 & 37,49 & 6323,04 & 265,56 & $-29,31$ & 294,87 & 118,24 & 181,43 & 182,42 & 21,56 & 523,62 & 69,92 & 26,82 & 25,62 & 172,54 & 100,47 & 112,13 & 117,24 \\
\hline Epidalea calamita & 30TWL73 & 100,00 & 93,65 & 111,76 & 37,56 & 6290,51 & 260,84 & $-33,12$ & 293,96 & \begin{tabular}{|l|}
113,37 \\
\end{tabular} & $\begin{array}{l}176,73 \\
\end{array}$ & $\begin{array}{l}177,65 \\
\end{array}$ & 17,67 & 545,30 & 72,27 & 28,73 & 24,99 & 179,37 & 105,62 & 1118,20 & 123,04 \\
\hline Epidalea calamita & 30TWL75 & 100,00 & 98,98 & 111,59 & 37,72 & 6259,97 & 265,10 & $-28,05$ & 293,15 & 119,32 & 181,33 & 182,17 & 22,70 & 519,39 & 69,04 & 27,63 & 25,09 & 170,99 & 101,44 & 113,35 & 117,90 \\
\hline Epidalea calamita & 30TWL76 & 100,00 & 112,91 & 111,12 & 37,57 & 6278,00 & 277,68 & $-14,69$ & 292,37 & 134,77 & 195,01 & 195,79 & 35,59 & 452,82 & 61,19 & 23,25 & 26,56 & 149,84 & 87,80 & 97,69 & 102 \\
\hline Epidalea calamita & \begin{tabular}{|l|}
30 TWL77 \\
\end{tabular} & $\begin{array}{l}100,00 \\
\end{array}$ & $\begin{array}{l}1117,54 \\
112\end{array}$ & $\begin{array}{l}111,1< \\
111,09\end{array}$ & $\begin{array}{ll}3,51 \\
37,73\end{array}$ & $\begin{array}{l}0270,00 \\
6268,72\end{array}$ & 281,85 & \begin{tabular}{|l|l|}
$-10,17$ \\
$-10,03$
\end{tabular} & \begin{tabular}{|l|}
$292,02,0$ \\
\end{tabular} & \begin{tabular}{|l|}
139,66 \\
139,6
\end{tabular} & \begin{tabular}{|l|}
199,26 \\
\end{tabular} & \begin{tabular}{|l|l|}
199,98 \\
199,
\end{tabular} & \begin{tabular}{|l|l|}
40,00 \\
40,0
\end{tabular} & $\begin{array}{l}532,0< \\
436,76\end{array}$ & $\begin{array}{l}\mid c 1,11 \\
58,95 \\
\end{array}$ & $\mid \frac{25,23}{22,26}$ & \begin{tabular}{|l|l|}
26,70 \\
260
\end{tabular} & $\begin{array}{l}144,124 \\
144,12\end{array}$ & $\begin{array}{l}1,00 \\
84,49 \\
\end{array}$ & \begin{tabular}{|l|l|}
$1,1,89$ \\
3,39
\end{tabular} & $\begin{array}{r}90,12 \\
99,04 \\
\end{array}$ \\
\hline Epidalea calamita & 30TWL78 & 100,00 & 109,95 & 111,92 & 37,99 & 6229,92 & 275,54 & $-17,08$ & 292,62 & 131,30 & 191,48 & 192,07 & 33,09 & 478,85 & 63,33 & 25,29 & 25,01 & 156,50 & 93,44 & 103,94 & 110,95 \\
\hline Epidalea calamita & 30TWL80 & 100,00 & 93,70 & 112,16 & 37,43 & 6338,13 & 261,37 & $-33,88$ & 295,25 & 113,39 & 177,54 & 178,62 & 17,14 & 547,11 & 73,40 & 28,23 & 25,82 & 181,65 & 106,07 & 118,79 & 119,77 \\
\hline Epidalea calamita & 30TWL88 & 100,00 & 109,63 & 110,71 & 37,85 & 6213,37 & 272,84 & $-17,42$ & 290,27 & 131,20 & 190,6 & 191, & 32 & 474,43 & 64,01 & 25,48 & 26 & 157,47 & 94,00 & 105,57 & 107,51 \\
\hline Epidalea calamita & 30TWL90 & 100,00 & 89,55 & 110,45 & 37,31 & 6306,30 & 254,72 & $-37,08$ & 291,80 & 109,03 & 172,94 & 173,98 & 13,40 & 560,82 & 76,00 & 30,19 & 26,20 & 188,81 & 112,05 & 126,10 & 119 \\
\hline
\end{tabular}




\begin{tabular}{|c|c|c|c|c|c|c|c|c|c|c|c|c|c|c|c|c|c|c|c|c|c|}
\hline TAXON & UTM & $\mathrm{km} 2$ & B101 & B102 & $\mathrm{BIO3}$ & BIO4 & B105 & B106 & B107 & B108 & B109 & B1010 & BIO11 & BIO12 & B1013 & BIO14 & BIO15 & B1016 & B1017 & BIO18 & B1019 \\
\hline Epidalea calamita & 30TWL98 & 100,00 & 113,05 & 109,24 & 37,46 & 6207,38 & 273,55 & $-14,03$ & 287,58 & 135,14 & 193,65 & 194,38 & 36,22 & 453,66 & 62,75 & 24,44 & 27,61 & 153,12 & 90,73 & 102,77 & 100,08 \\
\hline Epidalea calamita & 30TWM01 & 100,00 & 104,08 & 110,34 & $\begin{array}{l}37,95 \\
\end{array}$ & 6120,19 & 272,82 & $-16,05$ & 288,87 & 122,54 & 185,46 & 185,58 & 30,11 & 533,79 & 62,47 & 25,71 & 21,72 & 160,79 & 95,90 & 100,66 & 137,17 \\
\hline Epidalea calamita & 30TWMO2 & 100,00 & 97,86 & 110,42 & 37,99 & 6061,51 & 266,39 & $-21,04$ & 287,44 & 115,60 & 178,84 & 178,89 & 24,96 & 574,46 & 66,58 & 28,80 & 20,96 & 172,38 & 104,40 & 107,16 & 148,76 \\
\hline Epidalea calamita & 30TWM03 & 100,00 & 93,98 & 109,78 & 38,00 & 6001,04 & 261,56 & $-23,63$ & 285,19 & 110,94 & 174,33 & 174,36 & 21,81 & 605,37 & 69,45 & 31,18 & 20,27 & 180,79 & 110,97 & 113,23 & 157,66 \\
\hline Epidalea calamita & 30TWM04 & 100,00 & 85,75 & 108,61 & 38,00 & 5923,26 & 251,68 & $-29,78$ & 281,46 & \begin{tabular}{|l|l|}
101,73 \\
\end{tabular} & 165,23 & 165,23 & 14,97 & $\mid 666,40$ & 75,31 & 35,51 & 19,49 & 197,55 & 123,31 & $\begin{array}{ll}124,57 \\
\end{array}$ & 174,60 \\
\hline Epidalea calamita & 30TWM05 & 100,00 & 70,14 & 106,53 & 38,00 & 5815,45 & 233,82 & $-42,16$ & 275,98 & 84,29 & 148,92 & 148,92 & 1,64 & 779,62 & 86,31 & 42,85 & 18,61 & 228,66 & 145,29 & 145,29 & 205,86 \\
\hline Epidalea calamita & 30TWM06 & 100,00 & 91,56 & 106,05 & 38,00 & 5817,45 & 252,79 & $-21,79$ & 274,57 & 107,69 & 169,41 & 169,41 & 21,56 & 661,18 & 73,31 & 35,29 & 19,10 & 193,37 & 124,01 & 124,21 & 174,34 \\
\hline Epidalea calamita & 30TWM07 & 100,00 & 70,76 & 104,27 & 38,01 & 5708,69 & 230,51 & $-39,31$ & 269,82 & 84,63 & 148,01 & 148,01 & 3,28 & 811,61 & 87,62 & 44,84 & 18,14 & 234,22 & 152,54 & 152,54 & 216,71 \\
\hline Epidalea calamita & 30TWM08 & 100,00 & 89,97 & 103,04 & 38,06 & 5672,90 & 245,93 & $-20,14$ & 266,06 & 100,88 & 165,91 & 165,91 & 21,54 & 712,04 & 76,42 & 38,20 & 18,40 & 204,14 & 134,80 & 134,80 & 190,31 \\
\hline Epidalea calamita & 30TWM09 & 100,00 & 110,86 & 98,72 & \begin{tabular}{|l|l|}
37,98 \\
\end{tabular} & 5573,69 & 258,66 & 1,71 & 256,95 & 78,18 & 184,26 & 184,34 & 42,14 & 629,40 & 66,34 & 32,35 & 18,93 & 182,56 & 120,69 & 120,69 & 168,21 \\
\hline Epidalea calamita & 30TWM11 & 100,00 & 103,61 & 112,07 & 38,00 & 6125,34 & 273,87 & $-17,73$ & 291,61 & 122,12 & 185,23 & 185,33 & 29,68 & 541,47 & 63,54 & 26,93 & 21,18 & 163,32 & 98,87 & 104,65 & 139,26 \\
\hline Epidalea calamita & 30TWM12 & 100,00 & 97,65 & 111,98 & 38,00 & 6063,67 & 267,47 & $-22,53$ & 290,01 & 115,41 & 178,63 & 178,69 & 24,68 & 582,73 & 67,62 & 30,02 & 20,29 & 174,84 & 107,47 & 111,59 & 151,12 \\
\hline Epidalea calamita & 30TWM13 & 100,00 & $\begin{array}{l}36,87 \\
96,0\end{array}$ & $\mid 111,31$ & 38,04 & 6017,11 & 265,36 & $-22,23$ & 287,59 & \begin{tabular}{|l|l|}
114,39 \\
\end{tabular} & 177,16 & $\begin{array}{l}177,21 \\
\end{array}$ & 24,34 & 596,68 & $\begin{array}{l}68,64 \\
68<\end{array}$ & 31,22 & 19,93 & 178,25 & $\begin{array}{l}110,88 \\
\end{array}$ & 114,29 & 155,30 \\
\hline Epidalea calamita & 30TWM14 & 100,00 & 79,04 & 109,12 & 38,02 & 5905,41 & 245,44 & $-36,45$ & 281,89 & 94,44 & 158,69 & 158,69 & 9,01 & 716,27 & 80,58 & 38,98 & 18,83 & 211,92 & 133,97 & 134,53 & 188,09 \\
\hline Epidalea calamita & 30TWM15 & 100,00 & 68,97 & 107,08 & 38,02 & 5817,98 & 232,96 & $-43,81$ & 276,77 & 83,09 & 147,78 & 147,78 & 0,49 & 794,58 & 87,97 & 44,08 & 18,21 & 233,03 & 149,38 & 149,38 & 209,87 \\
\hline Epidalea calamita & 30TWM16 & 100,00 & 80,61 & 106,79 & 38,04 & 5796,00 & 242,94 & $-32,60$ & 275,54 & 95,78 & 158,64 & 158,64 & 11,50 & 737,33 & 81,18 & 40,38 & 18,32 & 215,15 & 139,25 & 139,33 & 195,45 \\
\hline Epidalea calamita & 30TWM17 & 100,00 & 93,83 & 105,35 & 38,08 & 5763,45 & 252,61 & $-19,24$ & 271,85 & 110,11 & 170,63 & 170,63 & 24,09 & 674,93 & 74,07 & 36,31 & 18,55 & 196,01 & 128,47 & 128,65 & 178,33 \\
\hline Epidalea calamita & 30TWM18 & 100,00 & 110,04 & 102,28 & 38,03 & 5706,21 & 262,98 & $-2,26$ & 265,24 & 124,43 & 185,29 & 185,29 & 39,92 & 602,75 & 65,87 & 31,60 & 18,93 & 173,77 & 116,27 & 116,44 & 157,84 \\
\hline Epidalea calamita & 30TWM19 & 100,00 & 120,28 & 98,44 & \begin{tabular}{|l|l|}
37,98 \\
\end{tabular} & 5591,73 & 266,30 & 9,67 & 256,62 & 88,06 & 193,38 & 193,38 & 50,78 & 581,66 & 62,07 & 29,70 & 19,11 & 168,78 & 113,38 & 113,42 & 152,68 \\
\hline Epidalea calamita & 30TWM21 & 100,00 & 100,66 & 113,99 & 38,01 & 6121,36 & 272,66 & $-21,70$ & 294,36 & 119,20 & 182,35 & 182,44 & 26,96 & 563,46 & 66,20 & 28,99 & 20,58 & 170,03 & 104,49 & 110,10 & 145,54 \\
\hline Epidalea calamita & 30TWM22 & 100,00 & 96,86 & 113,61 & 38,16 & 6066,54 & 268,07 & $-24,41$ & 292,48 & 114,77 & 177,89 & 177,97 & 24,04 & 594,34 & 68, & 31,16 & 19,96 & 178,36 & 111,02 & 115,83 & 154,58 \\
\hline Epidalea calamita & 30TWM23 & 100,00 & 100,11 & 113,02 & 38,18 & 6033,19 & 269,86 & \begin{tabular}{|c|c|}
$-20,79$ \\
-20
\end{tabular} & 290,66 & 118,09 & 180,38 & 180,43 & 27,22 & 585,53 & 67,66 & 30,79 & 19,88 & 175,20 & 110,05 & 114,06 & 152,42 \\
\hline Epidalea calamita & 30TWM24 & 100,00 & 76,56 & 109,64 & \begin{tabular}{|l|}
38,18 \\
\end{tabular} & 5900,86 & 243,23 & \begin{tabular}{|l|l|}
$-39,27$ \\
\end{tabular} & 282,50 & 91,92 & 156,19 & 156,19 & 6,65 & 738,56 & 83,14 & 40,72 & 18,55 & 218,56 & 139,47 & 140,34 & 193,94 \\
\hline Epidalea calamita & 30TWM25 & 100,00 & 68,24 & 107,45 & 38,15 & 5819,86 & 232,22 & $-45,10$ & 277,32 & 82,59 & 147,03 & $\begin{array}{ll}147,03 \\
\end{array}$ & $-0,29$ & 807,14 & 89,42 & 45,16 & 17,94 & 236,86 & 153,03 & 153,23 & 212,90 \\
\hline Epidalea calamita & 30TWM26 & 100,00 & 88,12 & 108,23 & 38,21 & 5828,86 & 251,09 & $-27,02$ & 278,11 & 104,26 & 166,05 & 166,05 & 18,05 & 698,10 & 77,51 & 38,12 & 18,28 & 204,48 & 132,99 & 133,36 & 184,37 \\
\hline Epidalea calamita & 30TWM27 & 100,00 & 91,55 & 106,67 & 38,27 & 5774,84 & 251,68 & $-22,38$ & 274,06 & 107,79 & 168,63 & 168,63 & 21,84 & 694,45 & 76,45 & 37,87 & 18,18 & 202,16 & 133,02 & 133,16 & 183,65 \\
\hline Epidalea calamita & 30TWM28 & 100,00 & 99,88 & 104,49 & 38,32 & 5719,76 & 255,82 & $\begin{array}{l}-2,930 \\
-12,94 \\
\end{array}$ & 268,76 & 116,42 & 175,71 & 175,71 & 30,24 & 666,60 & 72,70 & 36,00 & 18,18 & 192,58 & \begin{tabular}{|l|}
128,78 \\
128
\end{tabular} & 128,95 & 175,86 \\
\hline Epidalea calamita & 30TWM29 & 100,00 & 120,41 & 100,10 & 38,02 & 5642,81 & 268,08 & 8,30 & 259,78 & 117,56 & 194,07 & 194,07 & 50,30 & 572,70 & 62,49 & 29,95 & 18,94 & 165,38 & 113,07 & 113,23 & 147,71 \\
\hline Epidalea calamita & 30TWM30 & 100,00 & 104,56 & 115,04 & 38,02 & 6178,03 & 277,30 & $-19,92$ & 297,21 & 123,75 & 186,70 & 186,90 & 29,64 & 537,74 & 64,31 & 27,47 & 21,05 & 163,83 & 100,23 & 106,71 & 137,27 \\
\hline Epidalea calamita & 30TWM31 & 100,00 & 103,45 & 115,62 & 38,23 & 6134,85 & 276,37 & $-20,69$ & 297,06 & 122,47 & 184,84 & 185,21 & 29,02 & 554,93 & 65,48 & 28,72 & 20,44 & 167,84 & 104,20 & 110,61 & 143,26 \\
\hline Epidalea calamita & 30TWM32 & 100,00 & 100,33 & 115,52 & 38,74 & 6085,66 & 272,95 & $-22,71$ & 295,66 & 118,86 & 181,43 & 181,54 & 26,86 & 582,24 & 67,90 & 30,58 & 19,91 & 175,02 & 110,07 & 115,38 & 151,54 \\
\hline Epidalea calamita & 30TWM 33 & 100,00 & 99,18 & \begin{tabular}{|l|}
114,38 \\
114,2
\end{tabular} & 38,68 & 6035,13 & 269,98 & $-22,77$ & 292,75 & $\begin{array}{l}117,33 \\
110,0\end{array}$ & $\begin{array}{l}179,49 \\
179,4\end{array}$ & $\begin{array}{l}179,60 \\
\end{array}$ & $\begin{array}{l}20,17 \\
26,17 \\
\end{array}$ & \begin{tabular}{|l|l|}
597,93 \\
\end{tabular} & 69,21 & 31,78 & $\begin{array}{l}19,53 \\
19\end{array}$ & 179,08 & 113,60 & 119,15 & 155,93 \\
\hline Epidalea calamita & 30TWM34 & 100,00 & 85,60 & 111,58 & 38,56 & 5936,16 & 253,40 & $-32,75$ & 286,15 & 102,03 & 165,18 & 165,19 & 14,49 & 689,98 & 78,33 & 37,81 & 18,55 & 204,94 & 131,59 & $\begin{array}{ll}133,87 \\
\end{array}$ & 180,82 \\
\hline Epidalea calamita & 30TWM 35 & 100,00 & 73,56 & 108,60 & 38,32 & 5840,88 & 238,10 & $-41,36$ & 279,45 & 88,67 & 152,30 & 152,30 & 4,19 & 778,78 & 86,81 & 43,56 & 17,84 & 229,28 & 148,81 & 149,08 & 205,05 \\
\hline Epidalea calamita & 30TWM36 & 100,00 & 86,13 & 108,96 & 38,61 & 5831,72 & 249,59 & $-29,72$ & 279,31 & 102,28 & 164,16 & 164,16 & 16,16 & 717,70 & 79,76 & 39,59 & 18,01 & 210,42 & 137,64 & 138,29 & 189,70 \\
\hline Epidalea calamita & 30TWM37 & 100,00 & 96,07 & 107,64 & 38,54 & 5802,31 & 256,53 & $-19,25$ & 275,78 & 113,14 & 173,14 & 173,14 & 25,69 & 672,42 & 74,59 & 36,74 & 18,16 & 196,71 & 129,78 & 130,72 & 176,85 \\
\hline Epidalea calamita & 30TWM38 & 100,00 & 101,31 & 105,51 & 38,45 & 5753,02 & 257,99 & $-12,79$ & 270,79 & 118,73 & 177,34 & 177,35 & 31,06 & 658,51 & 72,71 & 35,99 & 18,21 & 191,93 & 128,10 & 128,79 & 172,10 \\
\hline Epidalea calamita & 30TWM39 & 100,00 & 119,79 & 101,93 & 38,06 & 5702,21 & 269,49 & 6,12 & 263,36 & 138,85 & 194,02 & 194,02 & 48,82 & 563,84 & 63,13 & 30,29 & 19,03 & 164,95 & 112,64 & 113,63 & 142,30 \\
\hline Epidalea calamita & 30TWM40 & 100,00 & 106,05 & 115,52 & 38,05 & 6179,69 & 278,45 & $-19,45$ & 297,90 & 125,65 & 187,90 & 188,35 & 30,78 & 530,34 & 64,28 & 27,42 & 21,32 & 162,98 & 100,19 & 107,63 & 134,11 \\
\hline Epidalea calamita & 30TWM41 & 100,00 & 105,43 & 116,28 & 38,4 & 6140,06 & 278,34 & $-19,78$ & 298,12 & 124,92 & 186,82 & 187,18 & 30,50 & 546,13 & 65,24 & 28,45 & 20,74 & 166,35 & 103,75 & 110,58 & 140,07 \\
\hline Epidalea calamita & 30TWM42 & 100,00 & 103,64 & 116,72 & 38,5 & 6096,81 & 276,75 & $-20,97$ & 297,71 & 122,70 & 184,62 & 184,78 & 29,42 & 568,59 & 66,7 & 29,94 & 19,90 & 171,65 & 108,52 & 115,21 & 147,62 \\
\hline Epidalea calamita & $\begin{array}{l}30 \mathrm{TWM} 43 \\
\end{array}$ & 100,00 & $\begin{array}{l}10,04,79 \\
101,79\end{array}$ & $\begin{array}{l}10,1 / 2 \\
115,45\end{array}$ & 38,4 & $\begin{array}{l}\mid 6005,010 \\
6050,05\end{array}$ & 273,08 & $\begin{array}{l}-21,51 \\
-21,62\end{array}$ & \begin{tabular}{|l|}
294,71 \\
291
\end{tabular} & $\begin{array}{l}122,0,42 \\
120,\end{array}$ & \begin{tabular}{|l|}
$184,02,06$ \\
182
\end{tabular} & \begin{tabular}{|l|}
182,210 \\
182,
\end{tabular} & $\begin{array}{l}25,44 \\
28,19\end{array}$ & \begin{tabular}{|l|}
$580,39,40$ \\
586,
\end{tabular} & $\begin{array}{l}60,1 / 4 \\
68,46 \\
\end{array}$ & 31,3 & $\begin{array}{l}19,54 \\
19,\end{array}$ & 171,03 & $\begin{array}{l}112,42 \\
112,42\end{array}$ & 1119,54 & $\begin{array}{l}14,02 \\
152,32 \\
\end{array}$ \\
\hline Epidalea calamita & 30TWM44 & 100,00 & 91,01 & 112,88 & 38,79 & 5964,44 & 259,40 & $-29,18$ & 288,57 & 108,27 & 170,54 & 170,55 & 19,05 & 662,31 & 75,82 & 36,30 & 18,65 & 197,60 & 127,36 & 131,80 & 173,05 \\
\hline Epidalea calamita & 30TWM45 & 100,00 & 82,08 & 110,24 & 38,58 & 5878,70 & 247,42 & $-35,12$ & 282,54 & 98,21 & 160,86 & 160,86 & 11,45 & 731,03 & 82,29 & 40,77 & 17,89 & 216,24 & 140,76 & 141,49 & 191,97 \\
\hline Epidalea calamita & 30TWM46 & 100,00 & 80,56 & 108,70 & 38,5 & 5819,04 & 243,60 & $-34,96$ & 278,56 & 96,40 & 158,60 & 158,60 & 10,80 & 757,90 & 84,18 & 42,44 & 17,65 & 222,38 & 146,11 & 46,57 & 200,06 \\
\hline Epidalea calamita & 30TWM47 & 100,00 & 97,51 & 108,40 & 38 & 5830,24 & 258,3 & \begin{tabular}{|l|}
$-19,01$ \\
\end{tabular} & 277,40 & $\begin{array}{r}115,15 \\
115\end{array}$ & $\begin{array}{l}174,78 \\
\end{array}$ & $\begin{array}{l}174,78 \\
\end{array}$ & 26,59 & 667,01 & 74, & $\begin{array}{l}42,446 \\
36,66\end{array}$ & $\begin{array}{l}18,24 \\
18\end{array}$ & 196,31 & 129,31 & 130,20 & 174,48 \\
\hline Epidalea calamita & 30TWM & 100,00 & 105,81 & 106,21 & 38,58 & 5790,45 & 262 & $-9,79$ & 272,38 & 124,10 & 181,99 & 181,99 & 34,73 & 631,48 & 70,8 & 34,70 & 18,56 & 185,93 & 123,74 & 124,95 & 162,81 \\
\hline Epidalea calamita & 30TWM49 & 100,00 & 126,24 & 102,65 & 38,02 & 5775,38 & 276,19 & 10,47 & 265,72 & 146,67 & 195,92 & 200,91 & 54,01 & 508,37 & 59,42 & 27,88 & 20,34 & 153,06 & 104,01 & 107,40 & 122,04 \\
\hline Epidalea calamita & 30TWM50 & 100,00 & 107,07 & 115,01 & 38,01 & 6181,32 & 278,07 & $-18,90$ & 296,97 & 127,18 & 188,72 & 189,23 & 31,86 & 520,60 & 64,27 & 27,27 & 21,79 & 162,18 & 99,62 & 107,97 & 129,36 \\
\hline Epidalea calamita & 30TWM51 & 100,00 & 106,51 & 115,54 & 38,41 & 6147,29 & 277,73 & $-19,11$ & 296,84 & 126,08 & 187,71 & 187,97 & 31,51 & 535,59 & 65,18 & 28,19 & 21,02 & 165,40 & 102,76 & 10,74 & 134,96 \\
\hline Epidalea calamita & 30TWM & 100,00 & 10 & 115 & 38 & 609 & 273,15 & $\frac{1,114}{-22,72}$ & 295,87 & 120,85 & 182,51 & 182,69 & 27,64 & 574,92 & 68,56 & 30,83 & 20,09 & 175,47 & 110,84 & 118,72 & 147,09 \\
\hline Epidalea calamita & 30TWM53 & 100,00 & 99,08 & 114,75 & 38,75 & 6046,90 & 269,09 & $-24,29$ & 293,38 & 117,79 & 179,33 & 179,43 & 25,55 & 601,88 & 70,87 & 32,60 & 19,51 & 182,47 & 116,30 & 123,77 & 154,95 \\
\hline Epidalea calamita & 30TWM54 & 100,00 & 84,73 & 111,67 & 38,62 & 5938,56 & 251,56 & $-34,74$ & 286,30 & 101,62 & 164,07 & 164,10 & 13,18 & 701,31 & 80,52 & 39,10 & 18,36 & 210,06 & 135,73 & 139,05 & 182,08 \\
\hline Epidalea calamita & 30TWM55 & 100,00 & 88,05 & 110,97 & 38,73 & 5908,63 & 253,33 & $-30,57$ & 283,90 & 105,21 & 166,83 & 166,84 & 16,68 & 696,33 & 79,36 & 38,76 & 18,22 & 207,43 & 134,85 & 136,98 & 181,61 \\
\hline Epidalea calamita & 30TWM56 & 100,00 & 92,81 & 109,93 & 38,7 & 5880,87 & 255,93 & $-25,41$ & 281,34 & 110,30 & 170,93 & 170 & 21,33 & 683,68 & 77,52 & 37,95 & 18,29 & 202,97 & 132,50 & 134,67 & 178 \\
\hline Epidalea calamita & 30TWM57 & 100,00 & 98,21 & 108,81 & 38,69 & 5848,62 & 259,01 & $-19,15$ & 278,16 & 116,20 & 175,60 & 175,60 & 26,84 & $\begin{array}{ll}668,28 \\
\end{array}$ & 75,31 & 36,92 & 18,31 & 197,56 & 129,69 & 131,56 & 174,25 \\
\hline Epidalea calamita & 30TWM58 & 100,00 & 109,72 & 106,79 & 38,52 & 5832,45 & 266,50 & $\begin{array}{r}-7,27 \\
\end{array}$ & 273,77 & 128,72 & 186,08 & 186,09 & 37,64 & 609,73 & 69,41 & 33,60 & 18,94 & 181,50 & 119,68 & 121,36 & 155,08 \\
\hline Epidalea calamita & 30TWM59 & 100,00 & 127,97 & 103,66 & 38,01 & 5820,68 & 278,78 & 10,88 & 267,90 & 148,81 & 191,49 & 203,04 & 54,83 & 495,98 & 59,03 & 27,62 & 20,81 & 152,26 & 101,55 & 105,95 & 115,83 \\
\hline Epidalea calamita & 30TWM63 & 100,00 & 91,97 & 112,84 & 38,32 & 6018,94 & 259,63 & $-30,03$ & 289,66 & 110 & 171, & 172 & 19, & 640,81 & 75,90 & 35,53 & 19,41 & 195,60 & 124,72 & 131,51 & 163 \\
\hline Epidalea calamita & 30TWM64 & 100,00 & 91,17 & 111,90 & 38,49 & 5971,71 & 257,24 & $-29,86$ & 287,10 & 109,08 & 170,47 & 170,52 & 18,71 & 661,68 & 77,32 & 82 & 18,96 & 0,35 & 128,66 & 132,58 & 169, \\
\hline
\end{tabular}




\begin{tabular}{|c|c|c|c|c|c|c|c|c|c|c|c|c|c|c|c|c|c|c|c|c|c|}
\hline TAXON & UTM & $\mathrm{km2}$ & BIO1 & B102 & $\mathrm{BIO3}$ & B104 & B105 & B106 & B107 & B108 & B109 & BIO10 & BIO11 & B1012 & BIO13 & BIO14 & BIO15 & BIO16 & BIO17 & B1018 & BI019 \\
\hline Epidalea calamita & 30TWM65 & 100,00 & 91,99 & 111,00 & 38,69 & 5931,07 & 256,52 & $-27,79$ & 284,32 & 109,95 & 170,67 & 170,70 & 19,94 & 673,25 & 77,72 & 37,49 & 18,67 & 202,23 & 130,87 & 134,42 & 173,94 \\
\hline Epidalea calamita & 30TWM66 & 100,00 & 97,99 & 110,15 & 38,76 & 5916,93 & 260,65 & $-21,48$ & \begin{tabular}{l|l|}
282,12 \\
\end{tabular} & \begin{tabular}{l|l}
116,42 \\
\end{tabular} & $\begin{array}{l}176,20 \\
17\end{array}$ & 176,23 & 25,69 & 653,75 & 75,19 & 36,20 & \begin{tabular}{ll|}
18,76 \\
\end{tabular} & \begin{tabular}{ll|}
195,80 \\
\end{tabular} & $\begin{array}{ll}126,85 \\
\end{array}$ & 130,21 & 168,89 \\
\hline Epidalea calamita & 30TWM67 & 100,00 & 105,56 & 108,59 & 38,47 & 5898,47 & 265,38 & $-13,16$ & 278,54 & 124,65 & $\begin{array}{l}183,04 \\
184\end{array}$ & \begin{tabular}{|l|l|}
183,08 \\
\end{tabular} & 32,92 & 625,73 & 71,84 & 34,36 & 19,22 & \begin{tabular}{l|l|}
187,22 \\
\end{tabular} & \begin{tabular}{|l|l|}
121,40 \\
\end{tabular} & \begin{tabular}{|l|l|}
124,74 \\
\end{tabular} & 160,55 \\
\hline Epidalea calamita & 30TWM68 & 100,00 & 114,52 & 106,87 & 38,35 & 5868,51 & 270,81 & $-3,59$ & 274,41 & \begin{tabular}{|l|l|l|l}
134,39 \\
\end{tabular} & \begin{tabular}{|l|l|}
191,10 \\
1
\end{tabular} & 191,13 & \begin{tabular}{l|l|}
41,65 \\
\end{tabular} & 589,48 & 67,82 & 32,29 & \begin{tabular}{ll|}
19,56 \\
\end{tabular} & \begin{tabular}{ll|}
176,80 \\
\end{tabular} & \begin{tabular}{|l|l|}
115,20 \\
\end{tabular} & 118,20 & 148,52 \\
\hline Epidalea calamita & 30TWM69 & 100,00 & 130,87 & 103,68 & 38,11 & 5811,44 & 280,87 & 13,60 & 267,27 & 151,81 & \begin{tabular}{|l|}
205,82 \\
\end{tabular} & 205,84 & 57,84 & 516,60 & 59,99 & 28,08 & 20,37 & 156,31 & \begin{tabular}{|l|l|}
103,10 \\
\end{tabular} & 106,02 & 123,92 \\
\hline Epidalea calamita & 30TWM73 & 100,00 & 98,35 & 112,10 & 38,12 & 6048,86 & 264,16 & $-24,80$ & 288,95 & 117,78 & 178,12 & 178,32 & 24,46 & $\begin{array}{l}600,17 \\
\end{array}$ & 72,80 & 33,19 & 20,39 & 185,91 & \begin{tabular}{|l|l|}
117,19 \\
\end{tabular} & 126,24 & 150,12 \\
\hline Epidalea calamita & 30TWM74 & 100,00 & 104,64 & 111,38 & 38,15 & 6037,67 & 268,88 & $-18,07$ & 286,95 & 124,35 & \begin{tabular}{l|l|}
183,90 \\
\end{tabular} & \begin{tabular}{|l|l|}
184,07 \\
\end{tabular} & 30,39 & 579,31 & 70,04 & 31,70 & 20,70 & $\begin{array}{ll}178,88 \\
\end{array}$ & 112,50 & 119,76 & 145,13 \\
\hline Epidalea calamita & 30TWM75 & 100,00 & 105,81 & 110,60 & 38,19 & 6005,52 & 268,75 & $-15,87$ & \begin{tabular}{|l|l|}
284,62 \\
\end{tabular} & \begin{tabular}{l|l|}
125,63 \\
\end{tabular} & \begin{tabular}{|l|l|}
184,67 \\
\end{tabular} & 184,71 & 31,91 & $\begin{array}{l}589,35 \\
\end{array}$ & 70,32 & 32,27 & 20,32 & $\begin{array}{l}180,49 \\
\end{array}$ & $\begin{array}{l}114,13 \\
\end{array}$ & 120,21 & 148,72 \\
\hline Epidalea calamita & 30TWM76 & 100,00 & 108,27 & 109,80 & 38,40 & 5979,02 & 269,63 & $-12,52$ & 282,15 & 128,21 & $\begin{array}{l}186,54 \\
18\end{array}$ & 186,61 & \begin{tabular}{ll|}
34,49 \\
\end{tabular} & 593,73 & 69,97 & 32,39 & 20,06 & 180,44 & $\begin{array}{l}114,66 \\
14\end{array}$ & 121,32 & \begin{tabular}{ll|l}
150,67 \\
\end{tabular} \\
\hline Epidalea calamita & 30TWM77 & 100,00 & 122,10 & 107,81 & $38,04[$ & 5973,97| & 279,65 & 1,33 & 278,32 & 143,23 & 199,55 & 199,65 & 47,51 & 536,37 & 63,52 & 28,69 & 20,92 & 163,45 & 103,33 & 108,63 & 133,39 \\
\hline Epidalea calamita & 30TWM78 & 100,00 & 128,49 & 105,82 & 38,03 & 5904,04 & 282,21 & 9,08 & 273,14 & 149,75 & \begin{tabular}{|l|l|}
204,79 \\
\end{tabular} & 204,81 & \begin{tabular}{|l|l|}
54,47 \\
\end{tabular} & 533,57 & 61,81 & 28,16 & 20,74 & 160,44 & 102,74 & 106,73 & 132,77 \\
\hline Epidalea calamita & 30TWM79 & 100,00 & 131,83 & 103,92 & 38,15 & 5807,65 & 281,63 & \begin{tabular}{ll|}
14,43 \\
\end{tabular} & 267,20 & \begin{tabular}{l|l|}
148,30 \\
\end{tabular} & \begin{tabular}{|l|l|}
206,70 \\
\end{tabular} & 206,71 & 58,81 & 559,05 & 62,46 & 29,22 & 20,09 & \begin{tabular}{ll|}
164,46 \\
\end{tabular} & \begin{tabular}{|l|l|l|}
107,43 \\
\end{tabular} & 108,30 & 141,47 \\
\hline Epidalea calamita & 30TWM81 & 100,00 & 95,19 & 111,13 & 38,00 & 6093,47 & 259,76 & $-28,84$ & 288,61 & \begin{tabular}{ll|}
114,84 \\
\end{tabular} & $\begin{array}{l}175,50 \\
\end{array}$ & \begin{tabular}{|l|l|}
175,73 \\
\end{tabular} & \begin{tabular}{|l|l|}
20,67 \\
\end{tabular} & 584,71 & $\begin{array}{l}73,75 \\
\end{array}$ & 32,71 & 21,90 & $\begin{array}{l}186,25 \\
\end{array}$ & \begin{tabular}{|l|l|}
115,83 \\
\end{tabular} & 127,53 & 140,88 \\
\hline Epidalea calamita & 30TWM82 & 100,00 & 93,96 & 110,92 & 38,00 & 6058,28 & 258,25 & $-29,35$ & 287,60 & \begin{tabular}{l|l|}
113,12 \\
\end{tabular} & \begin{tabular}{l|l|}
173,90 \\
\end{tabular} & $\begin{array}{l}173,96 \\
\end{array}$ & \begin{tabular}{l|l}
19,82 \\
\end{tabular} & \begin{tabular}{ll|}
607,35 \\
\end{tabular} & 75,29 & 34,08 & 21,12 & \begin{tabular}{|l|l|}
191,30 \\
\end{tabular} & $\begin{array}{l}119,85 \\
\end{array}$ & 131,13 & 148,50 \\
\hline Epidalea calamita & 30TWM83 & 100,00 & 102,29 & 111,08 & 38,01 & 6063,83 & 266,08 & $-21,32$ & \begin{tabular}{|l|}
287,40 \\
\end{tabular} & \begin{tabular}{|l|}
122,23 \\
\end{tabular} & \begin{tabular}{|l|l|}
181,75 \\
\end{tabular} & 182,01 & 27,54 & 575,06 & 71,24 & 31,73 & 21, & \begin{tabular}{|l|l|l|}
180,48 \\
\end{tabular} & \begin{tabular}{|l|l|}
112,34 \\
\end{tabular} & \begin{tabular}{|l|}
123,17 \\
\end{tabular} & 141,63 \\
\hline Epidalea calamita & 30TWM84 & 100,00 & 112,56 & 110,32 & 38,00 & 6074,30 & 274,85 & $-10,78$ & 285,63 & 133,44 & \begin{tabular}{|l|l|l|}
191,83 \\
\end{tabular} & $\begin{array}{l}191,95 \\
\end{array}$ & 37,15 & 536,46 & 66,46 & 28,88 & 22,09 & 167,91 & \begin{tabular}{ll|}
103,46 \\
\end{tabular} & 111,82 & 132,19 \\
\hline Epidalea calamita & 30TWM85 & 100,00 & 120,81 & 109,32 & 38,00 & \begin{tabular}{ll|}
6070,69 \\
\end{tabular} & 281,26 & $-2,30$ & 283,56 & \begin{tabular}{l|l|l|l}
142,39 \\
\end{tabular} & $\begin{array}{l}199,63 \\
\end{array}$ & \begin{tabular}{|l|l|}
199,70 \\
\end{tabular} & $\begin{array}{l}45,06 \\
\end{array}$ & 512,43 & 63,00 & 27,03 & 22,39 & \begin{tabular}{|l|l|}
159,30 \\
\end{tabular} & \begin{tabular}{|l|l|}
97,77 \\
\end{tabular} & 106,13 & 126,51 \\
\hline Epidalea calamita & 30TWM86 & 100,00 & 114,20 & 109,04 & 38,09 & 6006,60 & 274,05 & $-7,30$ & 281,35 & 134,91 & \begin{tabular}{|l|l|}
192,58 \\
\end{tabular} & \begin{tabular}{|l|l|}
192,63 \\
\end{tabular} & 39,61 & 570,80 & 67,81 & $\begin{array}{l}30,55 \\
\end{array}$ & \begin{tabular}{|l|l|}
20,97 \\
\end{tabular} & \begin{tabular}{|l|l|}
174,04 \\
\end{tabular} & \begin{tabular}{|l|l|}
108,84 \\
\end{tabular} & 113,47 & \begin{tabular}{ll|l}
144,47 \\
\end{tabular} \\
\hline Epidalea calamita & 30TWM87 & 100,00 & 128,35 & 107,02 & 38,02 & 5975,87 & 284,11 & 7,13 & 276,98 & 149,45 & \begin{tabular}{|l|l|}
205,52 \\
\end{tabular} & 205,54 & $\begin{array}{l}53,25 \\
\end{array}$ & 532,35 & 62,14 & \begin{tabular}{|l|l|}
27,45 \\
\end{tabular} & 21,42 & \begin{tabular}{l|l}
160,02 \\
\end{tabular} & \begin{tabular}{|l|}
100,23 \\
\end{tabular} & 104,59 & 134,85 \\
\hline Epidalea calamita & 30TWM88 & 100,00 & 134,35 & 105,10 & 38,04 & 5889,37 & 286,21 & 14,87 & 271,33 & \begin{tabular}{l|l|}
132,12 \\
\end{tabular} & 210,31 & 210,31 & 60,3 & $\begin{array}{l}546,65 \\
\end{array}$ & 61, & 27,6 & 21, & \begin{tabular}{|l|l|}
160,87 \\
\end{tabular} & \begin{tabular}{|l|l|}
102,44 \\
\end{tabular} & 104,23 & 141,00 \\
\hline Epidalea calamita & 30TWM89 & 100,00 & 131,38 & 104,44 & 38,28 & 5824,87 & 281,87 & 13,37 & 268,50 & 108,01 & 206,61 & 206,61 & 58,00 & 599,62 & 65,11 & 30,34 & \begin{tabular}{|l|l|}
20,55 \\
\end{tabular} & \begin{tabular}{|l|l|}
175,85 \\
\end{tabular} & 111,50 & \begin{tabular}{|l|l|}
111,85 \\
\end{tabular} & 158,52 \\
\hline Epidalea calamita & 30TWM91 & 100,00 & 87,84 & 108,99 & \begin{tabular}{l|l|}
37,95 \\
\end{tabular} & 6050,08 & 249,71 & $-35,05$ & \begin{tabular}{|l|l|}
284,76 \\
\end{tabular} & $\begin{array}{ll}106,85 \\
\end{array}$ & $\begin{array}{l}167,60 \\
1\end{array}$ & \begin{tabular}{|l|l|}
167,79 \\
\end{tabular} & 13,94 & 624,44 & 78,82 & 35,82 & 21,71 & $\begin{array}{l}199,61 \\
\end{array}$ & \begin{tabular}{|l|l|}
125,27 \\
\end{tabular} & 139,48 & 148,70 \\
\hline Epidalea calamita & 30TWM92 & 100,00 & 72,64 & 106,71 & 37,77 & 5954,64 & 233,16 & $-46,25$ & 279,41 & 89,69 & \begin{tabular}{|l|l|}
152,01 \\
\end{tabular} & \begin{tabular}{ll|}
152,06 \\
\end{tabular} & 0,86 & 739,71 & 89,38 & 43,41 & \begin{tabular}{l|l|}
19,55 \\
\end{tabular} & 230,16 & 148,20 & 155,56 & 180,58 \\
\hline Epidalea calamita & 30TWM93 & 100,00 & 108,87 & 109,70 & 38,00 & 6087,02 & 270,50 & $-15,03$ & 285,53 & 129,85 & \begin{tabular}{|l|l|}
188,27 \\
\end{tabular} & \begin{tabular}{|l|l|}
188,40 \\
\end{tabular} & 33,36 & 539,83 & 68,31 & 29,30 & 22,86 & 171,31 & \begin{tabular}{|l|l|}
104,81 \\
\end{tabular} & 115,50 & 130,99 \\
\hline Epidalea calamita & 30TWM94 & 100,00 & 116,65 & 109,32 & 38,00 & 6088,93 & 277,28 & $-6,85$ & 284,12 & 138,12 & \begin{tabular}{ll|}
195,80 \\
\end{tabular} & \begin{tabular}{|l|l|}
195,84 \\
\end{tabular} & 40,77 & 518,92 & 65,08 & 27,44 & $23, \mathrm{C}$ & \begin{tabular}{|l|}
163,27 \\
\end{tabular} & \begin{tabular}{l|l}
99,03 \\
\end{tabular} & 108,04 & 127,24 \\
\hline Epidalea calamita & 30TWM95 & 100,00 & 125,99 & 108,46 & 38,00 & 6076,73 & 284,75 & 2,67 & 282,08 & 148,08 & 204,72 & 204,73 & 49,95 & 501,18 & 61,53 & 25,72 & 22,97 & \begin{tabular}{|l|l|}
154,93 \\
\end{tabular} & 94,08 & 100,50 & 124,61 \\
\hline Epidalea calamita & 30TWM96 & 100,00 & 131,71 & 107,23 & 38,00 & 6028,23 & 288,08 & \begin{tabular}{l|l}
9,28 \\
\end{tabular} & 278,79 & 153,84 & 209,61 & 209,62 & 55,88 & 508,03 & 60,32 & 25,39 & 22,64 & \begin{tabular}{|l|l|}
153,29 \\
\end{tabular} & 94,21 & 97,98 & 128,91 \\
\hline Epidalea calamita & 30TWM97 & 100,00 & 135,62 & 105,89 & 38,00 & 5954,58 & 289,29 & 14,64 & 274,65 & 134,12 & 212,38 & \begin{tabular}{|l|l|}
212,38 \\
\end{tabular} & 60,68 & 530,99 & 60,56 & 26,04 & 22,04 & \begin{tabular}{|l|l|}
156,61 \\
\end{tabular} & $\begin{array}{l}97,62 \\
\end{array}$ & 99,75 & 138,13 \\
\hline Epidalea calamita & 30TWM98 & 100,00 & 132,69 & 105,57 & 38,03 & 5901,17 & 285,19 & \begin{tabular}{|l|l|}
12,88 \\
\end{tabular} & 272,31 & 98,97 & \begin{tabular}{|l|l|}
208,86 \\
\end{tabular} & 208,86 & 58,47 & \begin{tabular}{|l|l|}
581,45 \\
\end{tabular} & 64,16 & 28,73 & 21,48 & \begin{tabular}{|l|l|}
171,39 \\
\end{tabular} & \begin{tabular}{|l|l|}
106,18 \\
\end{tabular} & 106,63 & 155,19 \\
\hline Epidalea calamita & \begin{tabular}{|l|l|} 
30TWM99 \\
\end{tabular} & 100,00 & 131,07 & 104,91 & 38,25 & 5841,19 & 282,14 & 12,33 & 269,81 & \begin{tabular}{|c|}
95,75 \\
\end{tabular} & 206,50 & 206,50 & 57,70 & 635,06 & 70,00 & 31,24 & 21,29 & 189,54 & \begin{tabular}{|l|l|}
114,88 \\
\end{tabular} & 115,15 & 174,14 \\
\hline Epidalea calamita & 30TWN00 & 100,00 & 120,38 & 94,44 & 37,97 & 5419,18 & 260,53 & 13,68 & 246,85 & 88,49 & 190,40 & 191,40 & 53,06 & 629,12 & 66,32 & 31,18 & \begin{tabular}{l|l}
19,25 \\
\end{tabular} & 187,06 & 120,44 & \begin{tabular}{|l|l|}
121,28 \\
\end{tabular} & 170,86 \\
\hline Epidalea calamita & 30TWN01 & 100,00 & 120,28 & 91,73 & 37,94 & 5288,90 & 256,13 & 16,42 & 239,71 & \begin{tabular}{|l|l}
88,03 \\
\end{tabular} & \begin{tabular}{|l|l}
188,49 \\
\end{tabular} & 189,70 & 54,88 & 677,58 & 72,94 & 33,23 & 19,58 & 203,86 & 128,09 & 130,50 & 187,86 \\
\hline Epidalea calamita & 30TWN02 & 100,00 & 122,30 & 88,59 & 37,80 & 5134,56 & 253,13 & 21,27 & 231,85 & 92,57 & \begin{tabular}{|l|l|l|}
188,13 \\
\end{tabular} & \begin{tabular}{|l|l|}
189,59 \\
\end{tabular} & \begin{tabular}{l|l|}
58,65 \\
\end{tabular} & 725,80 & 80,04 & 34,78 & 20,01 & 221,58 & \begin{tabular}{|l|l|}
134,57 \\
\end{tabular} & 139,36 & 206,13 \\
\hline Epidalea calamita & 30TWN03 & 100,00 & 116,25 & 87,55 & 37,88 & 5049,03 & 246,02 & 17,38 & 228,64 & 76,28 & \begin{tabular}{|l|l|}
181,08 \\
\end{tabular} & 182,81 & 54,08 & 797,32 & 88,72 & 38,69 & 19,84 & 243,94 & \begin{tabular}{|l|l|}
147,58 \\
\end{tabular} & 152,84 & 229,04 \\
\hline Epidalea calamita & 30TWN04 & 100,00 & 108,15 & 86,93 & 37,99 & 4972,08 & 237,41 & \begin{tabular}{ll|}
11,42 \\
\end{tabular} & 225,99 & 55,08 & 172,15 & 174,14 & $\begin{array}{l}47,45 \\
\end{array}$ & 881,71 & 98,74 & 43,52 & \begin{tabular}{|l|}
19,67 \\
\end{tabular} & 271,41 & 163,24 & 168,67 & 255,44 \\
\hline Epidalea calamita & \begin{tabular}{|l|l|}
$30 T W N 05$ \\
\end{tabular} & 100,00 & 111,15 & 83,25 & 37,86 & 4804,25 & 234,88 & 17,47 & 217,42 & 60,22 & 172,58 & 174,81 & 52,45 & 940,18 & 107,73 & 45,27 & 20,77 & 294,35 & 170,42 & 179,21 & 278,61 \\
\hline Epidalea calamita & 30TWN09 & 99,00 & 138,12 & 61,59 & 35,64 & 3978,81 & 229,93 & 59,82 & 170,11 & 90,52 & 187,26 & 190,50 & \begin{tabular}{l|l|}
88,95 \\
\end{tabular} & 1202,85 & 157,78 & 47,29 & 30,38 & 411,24 & 187,22 & 220,79 & 410,73 \\
\hline Epidalea calamita & \begin{tabular}{|l|l|} 
30TWN10 \\
\end{tabular} & 100,00 & 121,39 & 95,73 & 38,00 & 5462,53 & 262,62 & \begin{tabular}{l|l|l|}
13,45 \\
\end{tabular} & 249,18 & 88,99 & \begin{tabular}{|l|l|}
192,30 \\
\end{tabular} & \begin{tabular}{|l|l|}
192,78 \\
\end{tabular} & 53,50 & 617,79 & 64,5 & \begin{tabular}{|l|l|}
31,17 \\
\end{tabular} & 18,99 & \begin{tabular}{|l|l|}
181,58 \\
\end{tabular} & \begin{tabular}{|l|l|}
120,47 \\
\end{tabular} & 120,61 & 165,39 \\
\hline Epidalea calamita & 30TWN11 & 100,00 & \begin{tabular}{|l|l|}
121,17 \\
\end{tabular} & 92,97 & 38,03 & 5325,25 & 258,05 & 16,19 & 241,87 & 87,30 & \begin{tabular}{l|l|}
189,92 \\
\end{tabular} & 190 & 55,10 & 671,24 & 71,3 & 33,48 & $19, \mathrm{C}$ & 200,12 & 129,18 & 130,57 & 183,99 \\
\hline Epidalea calamita & 30TWN12 & 100,00 & 116,42 & 91,61 & 38,06 & 5218,73 & 251,37 & 13,86 & 237,50 & $\begin{array}{ll}78,65 \\
\end{array}$ & \begin{tabular}{|l|l|}
183,78 \\
\end{tabular} & 185,01 & 51,99 & 741,39 & 80,05 & 37,07 & 18,90 & 222,10 & \begin{tabular}{|l|l|}
141,43 \\
\end{tabular} & 143,53 & 207,29 \\
\hline Epidalea calamita & \begin{tabular}{|l|l|} 
30TWN13 \\
\end{tabular} & 100,00 & 117,52 & 88,77 & 38,00 & 5076,73 & 248,27 & \begin{tabular}{|l|l|l|}
17,84 \\
\end{tabular} & 230,43 & 75,49 & \begin{tabular}{|l|l|}
182,56 \\
\end{tabular} & 184,25 & 54,99 & 795,94 & 87,64 & 39,16 & \begin{tabular}{|l|l|}
19,33 \\
\end{tabular} & 241,68 & \begin{tabular}{|l|}
149,44 \\
\end{tabular} & 153,49 & 227,16 \\
\hline Epidalea calamita & 30TWN14 & 100,00 & 114,06 & 86,70 & 38,04 & 4951,83 & 242,09 & 17,31 & 224,79 & 60,66 & \begin{tabular}{|l|l|}
177,48 \\
\end{tabular} & 179,45 & 53,44 & 873,38 & 97,76 & 42,79 & 19,69 & 268,69 & 161,95 & \begin{tabular}{|l|l|}
167,58 \\
\end{tabular} & 253,84 \\
\hline Epidalea calamita & 30TWN20 & 100,00 & 126,10 & 96,62 & 38,00 & 5507,50 & 267,48 & 16,71 & 250,77 & $\begin{array}{l}94,30 \\
\end{array}$ & \begin{tabular}{|l|l|}
197,64 \\
\end{tabular} & $\begin{array}{l}197,75 \\
\end{array}$ & 57,42 & 585,64 & 61,84 & 29,96 & 18,98 & $\begin{array}{l}170,90 \\
\end{array}$ & 116,21 & 116,25 & \begin{tabular}{|l|l|}
153,13 \\
\end{tabular} \\
\hline Epidalea calamita & 30TWN21 & 100,00 & 110,79 & 96,77 & 38,36 & 5416,85 & 252 & 4,19 & 248,79 & 66,36 & 182,05 & 182,15 & 44 & \begin{tabular}{ll|}
711,86 \\
\end{tabular} & 74,3 & \begin{tabular}{l|l}
37,25 \\
\end{tabular} & 17, & 207,94 & $\begin{array}{l}138,90 \\
\end{array}$ & 138,90 & 192,77 \\
\hline Epidalea calamita & \begin{tabular}{|l|}
$30 T W N 22$ \\
\end{tabular} & 100,00 & 111,72 & 94,34 & 38,29 & 5288,91 & 250 & 7,67 & 242,52 & 61,67 & 180,75 & 181,31 & 46,66 & 758,46 & 80,55 & 39,13 & 18,04 & 223,91 & \begin{tabular}{|l|l|}
147,33 \\
\end{tabular} & 147,51 & 209,39 \\
\hline Epidalea calamita & 30TWN23 & 100,00 & 112,54 & 91,62 & 38,28 & 5147,34 & 246,88 & 11,33 & 235,56 & 60,18 & $\begin{array}{l}178,85 \\
\end{array}$ & \begin{tabular}{l|l|}
180,25 \\
\end{tabular} & 49,36 & 813,72 & 88,10 & 41,36 & 18,3 & 244,33 & 156,34 & 157,56 & 229,17 \\
\hline Epidalea calamita & 30TWN24 & 100,00 & 119,93 & 86,90 & 38,16 & 4940,64 & 247,10 & 22,81 & \begin{tabular}{|l|l|}
224,29 \\
\end{tabular} & 66,12 & \begin{tabular}{l|l|}
182,88 \\
\end{tabular} & $\begin{array}{l}184,78 \\
\end{array}$ & \begin{tabular}{l|l|l|}
59,15 \\
\end{tabular} & 862,41 & 95,99 & \begin{tabular}{ll|l}
42,06 \\
\end{tabular} & \begin{tabular}{l|l|}
19,59 \\
\end{tabular} & 264,73 & $\begin{array}{l}160,61 \\
\end{array}$ & 165,94 & 250,16 \\
\hline Epidalea calamita & 30TWN30 & 100,00 & 127,14 & 98,39 & 38,01 & 5580,14 & 270,47 & 15,84 & 254,63 & 115,86 & $\begin{array}{l}199,45 \\
\end{array}$ & $\begin{array}{l}199,45 \\
\end{array}$ & 57,31 & 562,21 & 61,32 & 29,66 & 19,05 & 162,42 & \begin{tabular}{|l|l|}
113,49 \\
\end{tabular} & 113,76 & 142,64 \\
\hline Epidalea calamita & 30TWN31 & 100,00 & 112,62 & 98,18 & 38,56 & 5463,45 & 255,92 & 4,41 & 251,51 & 69,11 & \begin{tabular}{|l|l|}
184,18 \\
\end{tabular} & \begin{tabular}{|l|l|}
184,18 \\
\end{tabular} & 45,1 & \begin{tabular}{|l|l|}
698,07 \\
\end{tabular} & 73,03 & 37,09 & 17, & 201,94 & \begin{tabular}{|l|l|}
137,27 \\
\end{tabular} & 137,27 & 186,42 \\
\hline Epidalea calamita & $30 T_{W N}$ & 100,00 & 108,82 & 96,39 & 38,76 & 5341,01 & 249,64 & 3,40 & 246,24 & 51,29 & $\begin{array}{l}179,08 \\
\end{array}$ & $\begin{array}{l}179,08 \\
\end{array}$ & 43,24 & 775,71 & 81,65 & 40,84 & 17,59 & 227,76 & 150,97 & 150,97 & 212,72 \\
\hline Epidalea calamita & 30TWN33 & 100,00 & 103,56 & 94,58 & 38,90 & 5221,61 & 242,10 & 1,07 & \begin{tabular}{|l|l|}
241,03 \\
\end{tabular} & 47,20 & \begin{tabular}{ll|}
172,36 \\
\end{tabular} & \begin{tabular}{|l|l|}
172,57 \\
\end{tabular} & 39,87 & 862,93 & 92,57 & 45,23 & \begin{tabular}{ll|}
17,73 \\
\end{tabular} & 257,56 & \begin{tabular}{ll|l}
166,55 \\
\end{tabular} & 166,66 & 241,63 \\
\hline Epidalea calamita & 30TWN34 & 100,00 & 118,90 & 89,15 & 38,76 & 4985,27 & 248,45 & 20,54 & 227,91 & 64,53 & \begin{tabular}{ll|}
182,50 \\
\end{tabular} & \begin{tabular}{|l|l|}
184,28 \\
\end{tabular} & 57,72 & 871,82 & $\begin{array}{l}95,63 \\
\end{array}$ & 43,42 & 18,82 & 265,85 & $\begin{array}{l}165,05 \\
\end{array}$ & 168,09 & 249,88 \\
\hline Epidalea calamita & 30TWN35 & 100,00 & 112,87 & 87,58 & 38,92 & 4872,46 & 240,42 & 17,16 & 223,26 & \begin{tabular}{|c|}
60,24 \\
\end{tabular} & $\begin{array}{ll}175,05 \\
\end{array}$ & 177, & 53,48 & 969,30 & 108,05 & 48,3 & 19,1 & 299,53 & \begin{tabular}{|l|l|}
181,38 \\
\end{tabular} & 185,61 & 282,65 \\
\hline Epidalea calamit & 30TWI & 100,00 & 128 & 100,21 & 38,06 & 5669,25 & 273 & 15,2 & $25 \varepsilon$ & 148, & 191 & 201 & $5 /$ & 533,26 & 60,36 & 29, & 19, & 156 & \begin{tabular}{|l|}
109,49 \\
\end{tabular} & 112,01 & 130 \\
\hline Epidalea calamita & 30TWN41 & 100,00 & 113,05 & 99,65 & 38,75 & 5511,61 & 257,95 & 3,55 & 254,40 & 78,84 & 185,14 & 185,14 & 44,99 & 697,21 & 73,21 & 37,48 & \begin{tabular}{|l|l|}
17,57 \\
\end{tabular} & 200,54 & \begin{tabular}{|l|l|}
137,18 \\
\end{tabular} & 137,18 & 184,62 \\
\hline Epidalea calamita & 30TWN42 & 100,00 & 111,66 & 97,48 & 38,97 & 5372,17 & 253,22 & \begin{tabular}{l|l|}
4,92 \\
\end{tabular} & 248,30 & 55,80 & \begin{tabular}{|l|l|}
182,10 \\
\end{tabular} & 182,10 & 45,54 & 765,08 & 79,88 & 40,51 & 17,51 & 223,68 & \begin{tabular}{|l|l|}
149,08 \\
\end{tabular} & \begin{tabular}{|l|l|}
149,08 \\
\end{tabular} & 207,95 \\
\hline Epidalea calamita & 30TWN44 & 100,00 & 116,32 & 91,52 & 39,00 & 5041,25 & 248,65 & \begin{tabular}{l|l|l|}
16,52 \\
\end{tabular} & 232,13 & 61,40 & \begin{tabular}{|l|l|}
180,99 \\
\end{tabular} & \begin{tabular}{|l|l|}
182,51 \\
\end{tabular} & 54,49 & \begin{tabular}{l|l|}
893,15 \\
\end{tabular} & 97,14 & 45,32 & \begin{tabular}{ll|}
18,33 \\
\end{tabular} & \begin{tabular}{|l|l|}
271,42 \\
\end{tabular} & \begin{tabular}{|l|l|}
170,94 \\
\end{tabular} & 171,69 & 254,05 \\
\hline Epidale & 30 & 100,00 & 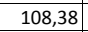 & & $39, \mathrm{C}$ & 4932 & & 11 & 227 & 55, & & & 48 & $\begin{array}{ll}998,88 \\
\end{array}$ & 110, & 50, & 18, & 307 & 185 & & 285 \\
\hline Epidalea calamita & 30TWN50 & 100,00 & 128,81 & 101,63 & 38,17 & 5707,3 & 275 & 14,16 & 261,43 & 149,29 & 178,54 & 202,48 & 57,20 & \begin{tabular}{|l|l|}
531,73 \\
\end{tabular} & 60,97 & 29,42 & 19,74 & 159,20 & 108,66 & 111,32 & 127,16 \\
\hline Epidalea calamita & 30TWN51 & 100,00 & 117,27 & 100,71 & 38,83 & 5560,53 & 262,85 & 6,08 & 256,77 & 96,97 & \begin{tabular}{|l|l|}
189,70 \\
\end{tabular} & 189,70 & 48,22 & 677,80 & 71,69 & 36,57 & 17,82 & $\begin{array}{ll}194,92 \\
\end{array}$ & 133,18 & 133,23 & 177,28 \\
\hline
\end{tabular}




\begin{tabular}{|c|c|c|c|c|c|c|c|c|c|c|c|c|c|c|c|c|c|c|c|c|c|}
\hline TAXON & UTM & $\mathrm{km2}$ & BIO1 & $\begin{array}{l}\mathrm{BIO2} \\
\end{array}$ & $\mathrm{BIO3}$ & B104 & B105 & B106 & B107 & B108 & B109 & BIO10 & BIO11 & B1012 & BIO13 & BIO14 & BIO15 & BIO16 & BIO17 & BIO18 & BlO19 \\
\hline Epidalea calamita & 30TWN52 & 100,00 & 111,01 & 98,69 & 38,99 & 5410,56 & 253,88 & 3,30 & 250,58 & 54,19 & 181,92 & 181,92 & 44,35 & 784,16 & 81,97 & 41,74 & 17,60 & 229,51 & 151,86 & 151,86 & 213,21 \\
\hline Epidalea calamita & 30TWN53 & 100,00 & 99,05 & 97,23 & 39,00 & 5289,83 & 240,71 & $-5,51$ & $\begin{array}{ll}246,22 \\
\end{array}$ & 42,19 & $\begin{array}{ll}169,02 \\
\end{array}$ & 169,02 & 34,61 & 912,83 & 98,09 & \begin{tabular}{ll|}
48,79 \\
\end{tabular} & $\begin{array}{l}17,47 \\
\end{array}$ & 272,35 & \begin{tabular}{ll|}
174,91 \\
\end{tabular} & \begin{tabular}{ll|}
174,91 \\
\end{tabular} & 255,66 \\
\hline Epidalea calamita & 30TWN54 & 100,00 & 108,16 & 93,91 & 39,01 & 5109,92 & 243,98 & 6,90 & 237,08 & 52,94 & $\begin{array}{ll}175,02 \\
1\end{array}$ & \begin{tabular}{ll|}
175,43 \\
\end{tabular} & 45,78 & 945,86 & $\begin{array}{ll}103,08 \\
\end{array}$ & 49,09 & 18,18 & 287,36 & \begin{tabular}{ll|}
180,52 \\
\end{tabular} & $\begin{array}{l}180,55 \\
\end{array}$ & 269,18 \\
\hline Epidalea calamita & 30TWN55 & 100,00 & 101,96 & 91,96 & 39,17 & 4992,10 & 235,34 & 3,58 & 231,76 & 48,52 & \begin{tabular}{ll|}
167,24 \\
1
\end{tabular} & 168,02 & 41,50 & 1042,61 & 115,05 & 54,16 & 18,39 & 320,16 & \begin{tabular}{ll|l}
197,85 \\
\end{tabular} & \begin{tabular}{l|l|l|}
198,55 \\
\end{tabular} & 300,92 \\
\hline Epidalea calamita & 30TWN60 & 100,00 & 128,49 & 102,42 & 38,65 & 5712,74 & 275,91 & 13,51 & 262,40 & $\begin{array}{ll}148,66 \\
\end{array}$ & \begin{tabular}{|l|l|}
202,28 \\
\end{tabular} & 202,28 & 56,78 & 570,93 & 63,70 & 30,87 & \begin{tabular}{|l|}
19,23 \\
\end{tabular} & \begin{tabular}{ll|}
168,39 \\
\end{tabular} & \begin{tabular}{|l|l|}
113,13 \\
\end{tabular} & \begin{tabular}{ll|}
114,32 \\
\end{tabular} & 141,37 \\
\hline Epidalea calamita & 30TWN61 & 100,00 & 123,57 & 101,06 & 38,90 & 5586,07 & 268,85 & 11,30 & 257,55 & 97,75 & \begin{tabular}{|l|l|}
195,97 \\
\end{tabular} & \begin{tabular}{|l|}
195,97 \\
\end{tabular} & 53,90 & 664,02 & 70,13 & 35,35 & 18,29 & 191,84 & \begin{tabular}{ll|}
129,09 \\
\end{tabular} & \begin{tabular}{ll|}
129,09 \\
\end{tabular} & 173,33 \\
\hline Epidalea calamita & 30TWN62 & 100,00 & 116,46 & 99,48 & 39,00 & 5443,10 & 259,68 & 7,43 & 252,25 & 61,06 & \begin{tabular}{|l|l|}
187,44 \\
\end{tabular} & 187,44 & 49,16 & 775,19 & 81,60 & 40,88 & 18,03 & 228,47 & 148,49 & 148,49 & 211,26 \\
\hline Epidalea calamita & 30TWN63 & 100,00 & 103,32 & 97,94 & 39,01 & 5316,96 & 245,23 & $-2,27$ & 247,50 & 45,76 & \begin{tabular}{|l|l|}
173,31 \\
\end{tabular} & \begin{tabular}{|l|}
173,31 \\
\end{tabular} & 38,25 & 914,81 & 99,12 & 48,44 & \begin{tabular}{|l|l|}
17,94 \\
\end{tabular} & 274,80 & \begin{tabular}{|l|}
173,71 \\
\end{tabular} & \begin{tabular}{|l|}
173,71 \\
\end{tabular} & 257,41 \\
\hline Epidalea calamita & 30TWN64 & 100,00 & 104,07 & 95,58 & 39,10 & 5166,61 & 242,19 & \begin{tabular}{l|l}
1,56 \\
\end{tabular} & 240,63 & 48,36 & \begin{tabular}{|l|}
172,21 \\
\end{tabular} & \begin{tabular}{ll|}
172,21 \\
\end{tabular} & \begin{tabular}{|l|l}
41,03 \\
\end{tabular} & $\begin{array}{l}984,99 \\
\end{array}$ & 108,32 & \begin{tabular}{l|l|}
51,52 \\
\end{tabular} & 18,30 & \begin{tabular}{l|l}
300,55 \\
\end{tabular} & $\begin{array}{l}186,36 \\
\end{array}$ & \begin{tabular}{ll|}
186,36 \\
\end{tabular} & 281,81 \\
\hline Epidalea calamita & 30TWN65 & 100,00 & 114,75 & 92,10 & 39,59 & 4941,28 & 246,34 & 16,24 & 230,10 & 61,12 . & 178,84 & $179,67 \mid$ & 54,48 & 1037,83 & 115,65 & 52,42 & 19,30 & 323,01 & 194,30 & 195,10 & 302,10 \\
\hline Epidalea calamita & \begin{tabular}{|l|l|} 
30TWN70 \\
\end{tabular} & 100,00 & 128,26 & 103,05 & 38,81 & 5722,17 & 276,35 & 12,53 & \begin{tabular}{|l|l|}
263,82 \\
\end{tabular} & \begin{tabular}{|l|l|}
117,08 \\
\end{tabular} & 202,17 & 202,17 & 56,39 & 621,40 & 66,86 & 32,47 & \begin{tabular}{l|l|}
19,35 \\
\end{tabular} & 180,75 & \begin{tabular}{|l|l|}
118,47 \\
\end{tabular} & \begin{tabular}{ll|}
118,66 \\
\end{tabular} & 161,95 \\
\hline Epidalea calamita & 30TWN71 & 100,00 & 122,45 & 101,95 & 38,96 & 5618,81 & 269,19 & $\begin{array}{l}9,36 \\
\end{array}$ & 259,82 & 75,45 & \begin{tabular}{|l|l|}
195,46 \\
\end{tabular} & 195,46 & 52,41 & 709,88 & 75,19 & 37,01 & \begin{tabular}{|l|}
18,93 \\
\end{tabular} & 208,65 & 134,01 & $\begin{array}{l}134,01 \\
\end{array}$ & 191,71 \\
\hline Epidalea calamita & $\begin{array}{l}\text { 30TWN72 } \\
\end{array}$ & 100,00 & 120,18 & 100,16 & 39,00 & 5473,56 & 264,10 & 10,08 & \begin{tabular}{|l|}
254,02 \\
\end{tabular} & \begin{tabular}{|l|l|}
59,92 \\
\end{tabular} & $\begin{array}{ll}191,43 \\
\end{array}$ & 191,43 & 52,22 & $\begin{array}{l}795,65 \\
\end{array}$ & 86,12 & \begin{tabular}{|l|}
40,98 \\
\end{tabular} & \begin{tabular}{l|l|l|}
18,93 \\
\end{tabular} & 239,09 & $\begin{array}{ll}148,78 \\
\end{array}$ & $\begin{array}{ll}148,78 \\
\end{array}$ & 221,42 \\
\hline Epidalea calamita & 30TWN73 & 100,00 & 103,41 & 98,80 & 39,01 & 5350,09 & 246,23 & $-3,39$ & 249,61 & 45,57 & \begin{tabular}{|l|l}
173,73 \\
\end{tabular} & \begin{tabular}{|l|l|}
173,73 \\
\end{tabular} & \begin{tabular}{|l|l|}
37,87 \\
\end{tabular} & $\begin{array}{l}936,65 \\
\end{array}$ & 102,89 & \begin{tabular}{l|l}
49,35 \\
\end{tabular} & 18,41 & 283,47 & $\begin{array}{l}175,99 \\
\end{array}$ & $\begin{array}{l}175,99 \\
\end{array}$ & 265,79 \\
\hline Epidalea calamita & 30TWN74 & 100,00 & 100,62 & 96,62 & 39,21 & 5208,45 & 240,12 & $-2,82$ & 242,94 & \begin{tabular}{ll|}
44,68 \\
\end{tabular} & \begin{tabular}{|l|l|}
169,38 \\
\end{tabular} & 169,38 & \begin{tabular}{|l|l|}
37,17 \\
\end{tabular} & 1021,25 & \begin{tabular}{|l|l|}
113,47 \\
\end{tabular} & 53,57 & 18,5 & 312,86 & \begin{tabular}{|l|l|}
191,86 \\
\end{tabular} & \begin{tabular}{|l|l|}
191,86 \\
\end{tabular} & 293,94 \\
\hline Epidalea calamita & 30TWN80 & 100,00 & 129,95 & 103,38 & 38,72 & 5737,03 & 278,56 & \begin{tabular}{l|l|l}
13,85 \\
\end{tabular} & 264,71 & \begin{tabular}{|l|l|}
94,26 \\
\end{tabular} & \begin{tabular}{|l|l|}
204,09 \\
\end{tabular} & 204,09 & 57,87 & 659,71 & 71,18 & 33,21 & 20,28 & \begin{tabular}{|l|}
196,01 \\
\end{tabular} & \begin{tabular}{|l|l|}
121,57 \\
\end{tabular} & \begin{tabular}{|l|l|}
121,57 \\
\end{tabular} & 179,50 \\
\hline Epidalea calamita & 30TWN81 & 100,00 & 127,08 & 102,29 & 38,90 & 5634,65 & 274,04 & \begin{tabular}{ll|}
12,96 \\
\end{tabular} & \begin{tabular}{|l|l|}
261,09 \\
\end{tabular} & \begin{tabular}{|l|l|}
69,60 \\
\end{tabular} & \begin{tabular}{|l|l|}
200,10 \\
\end{tabular} & 200,10 & 56,46 & 736,82 & 81,42 & 36,91 & 20,25 & 222,85 & \begin{tabular}{|l|l|}
134,50 \\
\end{tabular} & \begin{tabular}{|l|}
134,50 \\
\end{tabular} & 206,27 \\
\hline Epidalea calamita & 30TWN82 & 100,00 & 122,08 & 101,03 & 38,99 & 5523,64 & 267,28 & 10,41 & 256,87 & \begin{tabular}{|l|l|}
61,07 \\
\end{tabular} & $\begin{array}{l}193,86 \\
\end{array}$ & $\begin{array}{l}193,86 \\
\end{array}$ & 53,14 & 830,67 & 93,74 & 41,59 & 20,33 & 255,99 & $\begin{array}{ll}150,78 \\
\end{array}$ & $\begin{array}{ll}150,78 \\
\end{array}$ & 238,30 \\
\hline Epidalea calamita & 30TWN83 & 100,00 & 110,64 & 99,59 & 39,01 & 5397,98 & 254,13 & 2,25 & 251,88 & 51,75 & \begin{tabular}{ll|}
181,21 \\
\end{tabular} & 181,21 & 43,90 & 943,14 & 106,92 & 48,21 & \begin{tabular}{|l|l|l|}
19,84 \\
\end{tabular} & 291,81 & \begin{tabular}{|l|l|}
172,73 \\
\end{tabular} & $\begin{array}{ll}172,73 \\
\end{array}$ & 273,47 \\
\hline Epidalea calamita & 30TWN84 & 100,00 & 91,57 & 97,49 & 39,01 & 5276,41 & 233,10 & $-13,28$ & 246,38 & 35,46 & \begin{tabular}{ll|}
161,44 \\
\end{tabular} & 161,44 & 27,5 & 1060,01 & 118,21 & 56,62 & 18, & 323,42 & \begin{tabular}{|l|l|}
199,51 \\
\end{tabular} & \begin{tabular}{ll|}
199,51 \\
\end{tabular} & 305,06 \\
\hline Epidalea calamita & 30TWN86 & 100,00 & 113,46 & 92,50 & 39,91 & 4893,48 & 244,21 & 14,93 & 229,28 & 60,58 & 176,77 & 177,71 & 53,68 & 1171,81 & 135,21 & 58,72 & 20,63 & \begin{tabular}{|l|l|}
373,55 \\
\end{tabular} & 215,77 & 216,84 & 349,65 \\
\hline Epidalea calamita & \begin{tabular}{|l|l|} 
30TWN90 \\
\end{tabular} & 100,00 & 130,41 & 103,87 & 38,51 & 5766,03 & 279,85 & 13,29 & 266,56 & 90,01 & \begin{tabular}{|l|l|}
204,94 \\
\end{tabular} & 204,94 & 57,74 & 694,81 & 78,47 & 33,90 & 21,38 & 210,72 & \begin{tabular}{|l|l|}
124,39 \\
\end{tabular} & $\begin{array}{l}124,39 \\
\end{array}$ & 195,88 \\
\hline Epidalea calamita & 30TWN91 & 100,00 & 129,65 & $\begin{array}{l}102,72 \\
\end{array}$ & 38,78 & 5672,55 & 277,29 & 14,55 & 262,73 & 67,71 & 202,99 & 202,99 & 58,42 & 767,09 & 88,85 & 37,06 & 21,72 & 238,28 & \begin{tabular}{ll|}
135,92 \\
\end{tabular} & \begin{tabular}{l|l|}
135,92 \\
\end{tabular} & 222,37 \\
\hline Epidalea calamita & 30TWN92 & 100,00 & 124,90 & 101,77 & 38,94 & 5574,60 & 271,25 & 11,91 & 259,34 & 63,38 & \begin{tabular}{|l|l|}
197,29 \\
\end{tabular} & \begin{tabular}{|l|l|}
197,29 \\
\end{tabular} & \begin{tabular}{|l|l|}
55,07 \\
\end{tabular} & 861,72 & 101,88 & 41,69 & 22,23 & 272,79 & \begin{tabular}{|l|l|}
151,59 \\
\end{tabular} & \begin{tabular}{|l|l|}
151,59 \\
\end{tabular} & 255,62 \\
\hline Epidalea calamita & \begin{tabular}{|l|l|} 
30TWN93 \\
\end{tabular} & 100,00 & 114,54 & 100,49 & 39,01 & 5454,66 & 259,17 & 4,41 & 254,76 & 54,88 & \begin{tabular}{|l|l|}
185,74 \\
\end{tabular} & 185,74 & 46,83 & \begin{tabular}{|c|}
966,57 \\
\end{tabular} & 113,87 & 48,01 & 21,4 & 306,26 & \begin{tabular}{|l|l|}
172,27 \\
\end{tabular} & \begin{tabular}{|l|}
172,27 \\
\end{tabular} & 287,92 \\
\hline Epidalea calamita & 30TWN99 & 100,00 & 133,51 & 83,01 & 40,83 & 4317,29 & 244,87 & 43,87 & 201,01 & $\begin{array}{l}90,02 \\
\end{array}$ & 186,91 & 189,84 & 80,53 & 1355,71 & \begin{tabular}{l|l}
159,45 \\
\end{tabular} & 66,82 & 22,10 & 441,31 & \begin{tabular}{|l|l|}
248,15 \\
\end{tabular} & 264,33 & 409,19 \\
\hline Epidalea calamita & \begin{tabular}{|l|l|}
$30 T W P 40$ \\
\end{tabular} & & & & & & & & & & & & & & & & & & & & \\
\hline Epidalea calamita & \begin{tabular}{|l|l|}
$30 T W P 90$ \\
\end{tabular} & 28,00 & 138,83 & 80,55 & $\begin{array}{l}40,75 \\
\end{array}$ & 4220,05 & 245,72 & 50,41 & 195,31 & 105,70 & \begin{tabular}{|l|l|}
190,86 \\
\end{tabular} & 193,91 & 86,75 & 1355,98 & 160,34 & 66,73 & 22,59 & 442,94 & 248,83 & 269,58 & 409,41 \\
\hline Epidalea calamita & 30TХK04 & 100,00 & 91,29 & 113,85 & 37,81 & 6408,16 & 263,32 & $-35,17$ & 298,49 & 109,31 & \begin{tabular}{|l|l|}
177,06 \\
\end{tabular} & \begin{tabular}{ll|l}
177,95 \\
\end{tabular} & 15,51 & 588,74 & 76,51 & 28,84 & 25,23 & 193,61 & \begin{tabular}{|l|l|}
111,69 \\
\end{tabular} & 123,91 & 126,51 \\
\hline Epidalea calamita & 30TXK05 & 100,00 & 85,42 & 112,53 & \begin{tabular}{|l|l|}
37,48 \\
\end{tabular} & 6386,84 & 256,24 & $-40,19$ & 296,44 & 103,25 & \begin{tabular}{|l|l|}
170,92 \\
\end{tabular} & 171,92 & \begin{tabular}{l|l|}
9,99 \\
\end{tabular} & 611,81 & 79,73 & 31,25 & 24,81 & 201,77 & \begin{tabular}{|l|l|}
117,99 \\
\end{tabular} & \begin{tabular}{|l|l|}
131,47 \\
\end{tabular} & 131,33 \\
\hline Epidalea calamita & 30TXKO6 & 100,00 & 79,90 & 111,37 & 37,18 & 6361,73 & 249,61 & $-44,79$ & 294,40 & 97,32 & 165,13 & 165,92 & 4,81 & 636,51 & 82,84 & 33,56 & 24,36 & 209,90 & 124,25 & 138,84 & 136,99 \\
\hline Epidalea calamita & 30TXK07 & 100,00 & 76,83 & 110,40 & 37,03 & 6336,85 & 245,38 & $-47,18$ & 292,56 & 94,26 & 161,80 & 162,60 & 1,99 & \begin{tabular}{|c|}
646,58 \\
\end{tabular} & 84,44 & \begin{tabular}{l|l|l}
34,85 \\
\end{tabular} & 24,10 & 213,76 & \begin{tabular}{l|l}
127,65 \\
\end{tabular} & $\begin{array}{ll}142,93 \\
\end{array}$ & 139,03 \\
\hline Epidalea calamita & 30TXK08 & 100,00 & 77,03 & 109,66 & 37,08 & 6312,45 & 243,99 & $-46,97$ & 290,96 & \begin{tabular}{|l|l}
94,68 \\
\end{tabular} & \begin{tabular}{ll|}
161,59 \\
\end{tabular} & 162,30 & 2,12 & 639,09 & 84,13 & 35,02 & 24,46 & 212,45 & $\begin{array}{ll}127,62 \\
\end{array}$ & 143,21 & 136,57 \\
\hline Epidalea calamita & 30TXK13 & 100,00 & 103,18 & 112,92 & $\begin{array}{l}37,95 \\
\end{array}$ & 6398,18 & 272,30 & $-23,34$ & 295,64 & \begin{tabular}{|l|l|}
121,64 \\
\end{tabular} & \begin{tabular}{|l|l|}
188,49 \\
\end{tabular} & 189,50 & 27,14 & 528,20 & 69,37 & 25,15 & 26,55 & 175,43 & \begin{tabular}{|l|l|}
101,53 \\
\end{tabular} & 111,21 & 109,10 \\
\hline Epidalea calamita & 30TXK16 & 100,00 & 80,38 & 109,45 & 37,00 & 6342,31 & 247,30 & $-43,47$ & 290,77 & 97,85 & \begin{tabular}{|l|l|}
161,94 \\
\end{tabular} & \begin{tabular}{|l|l|}
166,18 \\
\end{tabular} & 5,42 & 626,66 & 82,40 & 33,88 & 24,82 & 208,97 & \begin{tabular}{|l|}
125,47 \\
\end{tabular} & \begin{tabular}{|l|}
140,04 \\
\end{tabular} & 131,01 \\
\hline Epidalea calamita & 30TXK18 & 100,00 & 75,69 & 107,67 & 37,00 & 6288,67 & 239,92 & $-47,22$ & 287,14 & 93,29 & 120,62 & 160,59 & 1,25 & 642,11 & 84,96 & 36,08 & 24,72 & 215,03 & \begin{tabular}{|l|}
130,37 \\
\end{tabular} & \begin{tabular}{|l|l|}
147,04 \\
\end{tabular} & 134,20 \\
\hline Epidalea calamita & 30TXK19 & 100,00 & 83,36 & 107,15 & 37,00 & 6276,76 & 244,69 & $-41,06$ & 285,75 & 102,17 & 44,08 & 167,57 & 8,08 & 586,94 & $\begin{array}{l}80,05 \\
\end{array}$ & 33,30 & 26,64 & \begin{tabular}{|l|l|}
200,45 \\
\end{tabular} & 118,56 & 137,53 & 119,29 \\
\hline Epidalea calamita & 30 TXK23 & 100,00 & 100,11 & 110,21 & 37,39 & 6373,31 & 266,38 & $-24,35$ & 290,73 & 118,26 & \begin{tabular}{|l|l|}
146,67 \\
\end{tabular} & 186,21 & 24,56 & 535,75 & 70,58 & 26,75 & 26,5 & \begin{tabular}{|l|l|}
179,48 \\
\end{tabular} & \begin{tabular}{|l|l|}
105,99 \\
\end{tabular} & \begin{tabular}{ll|}
116,16 \\
\end{tabular} & 107,35 \\
\hline Epidalea calamita & 30 TXK26 & 100,00 & 87,08 & 107,41 & 37,00 &, 36 & 250,13 & $-36,45$ & 286,58 & 105,25 & 49,88 & $\begin{array}{l}172,45 \\
\end{array}$ & 11,8 & 580,73 & 78,10 & 31,95 & 26,4 & \begin{tabular}{|l|l|}
197,09 \\
\end{tabular} & \begin{tabular}{|l|l|}
115,44 \\
\end{tabular} & \begin{tabular}{|l|}
133,34 \\
\end{tabular} & 115,90 \\
\hline Epidalea calamita & 30TXK27 & 100,00 & 90,92 & 106,46 & 36,99 & 6310,71 & 251,44 & $-33,16$ & 284,60 & 109,82 & 15,49 & 175,78 & 15,49 & 549,27 & 75,58 & 30,67 & 27,89 & 189,27 & 106,92 & 128,99 & 106,92 \\
\hline Epidalea calamita & 30TXK28 & 100,00 & 84,80 & 105,77 & 36,99 & 6281,25 & 244,63 & \begin{tabular}{|c|}
$-38,76$ \\
\end{tabular} & 283,39 & \begin{tabular}{|l|l|}
103,45 \\
\end{tabular} & \begin{tabular}{ll|}
18,02 \\
\end{tabular} & 169,19 & 9,7 & 578,01 & 79,11 & 32,97 & 27,26 & \begin{tabular}{ll|}
198,66 \\
\end{tabular} & $\begin{array}{ll}113,88 \\
\end{array}$ & $\begin{array}{l}137,05 \\
\end{array}$ & 113,97 \\
\hline Epidalea calamita & 30TXK29 & 100,00 & 85,15 & 105,01 & 36,99 & 6255,66 & 243,10 & $-38,75$ & 281,85 & 104,12 & 9,82 & \begin{tabular}{|l|l|}
168,88 \\
\end{tabular} & 9,82 & 569,58 & 78,84 & 32,90 & 27,86 & 197,32 & \begin{tabular}{|l|l|}
111,47 \\
\end{tabular} & 137,19 & 111,47 \\
\hline Epidalea calamita & 30TXK34 & 100,00 & 96,54 & 106,77 & 37,00 & 6341,71 & 258,65 & $-26,12$ & 284,78 & 114,40 & 23,29 & \begin{tabular}{ll|}
182,16 \\
\end{tabular} & 21,10 & 541,29 & 72,33 & 28,84 & 27,11 & \begin{tabular}{|l|l|}
183,53 \\
\end{tabular} & \begin{tabular}{|l|l|}
104,59 \\
\end{tabular} & 122,41 & 104,60 \\
\hline Epidalea calamita & 30 TXK35 & 100,00 & 91,11 & 10 & 37,00 & 329,52 & 252. & $-31,06$ & 283,59 & 109,05 & 34,57 & 176,71 & 16,1 & 562,28 & 75,46 & 30,82 & 6,9 & 191,22 & \begin{tabular}{|l|l|}
109,01 \\
\end{tabular} & \begin{tabular}{l|l|}
129,35 \\
\end{tabular} & 109,10 \\
\hline Epidalea calamita & 30тХK36 & 100,00 & 89,36 & 10 & 36,96 & 6310,23 & 249 & $-33,01$ & 282,33 & 107,46 & 14,43 & 174,49 & 14 & 562,61 & 76,48 & 31,49 & 27,46 & 192,96 & \begin{tabular}{|l|l|}
108,06 \\
\end{tabular} & 132,04 & 108,06 \\
\hline Epidalea calamita & 30тХК37 & 100,00 & 96,51 & 103 & 36,84 & 6301,96 & 252,85 & $-26,35$ & 279,20 & \begin{tabular}{|l|l|}
115,90 \\
\end{tabular} & 21,12 & 181,14 & 21, & \begin{tabular}{|l|}
510,25 \\
\end{tabular} & 71,81 & 27,73 & 30, & \begin{tabular}{|l|}
179,23 \\
\end{tabular} & 93,54 & 123,62 & 93,54 \\
\hline Epidalea calamita & 30TXK38 & 100,00 & 95,22 & 102,94 & 36,59 & 6273,83 & 249,72 & $-28,17$ & \begin{tabular}{|l|l|}
277,89 \\
\end{tabular} & 115,05 & \begin{tabular}{ll|}
19,50 \\
\end{tabular} & \begin{tabular}{|l|l|}
179,20 \\
\end{tabular} & \begin{tabular}{ll|}
19,50 \\
\end{tabular} & 508,38 & 72,46 & 27,36 & \begin{tabular}{l|l|}
30,95 \\
\end{tabular} & $\begin{array}{l}180,26 \\
\end{array}$ & \begin{tabular}{|l|l|}
92,49 \\
\end{tabular} & $\begin{array}{l}125,50 \\
\end{array}$ & 92,49 \\
\hline Epidalea calamita & 30TXK39 & 100,00 & 96,64 & 102,03 & 36,50 & 6237,25 & 248,21 & $-27,50$ & 275,72 & \begin{tabular}{|l|l|}
117,08 \\
\end{tabular} & 20,75 & 179,66 & 20,75 & \begin{tabular}{|l|l|}
493,07 \\
\end{tabular} & 71,48 & 25,97 & 32,38 & 177,07 & 88,36 & \begin{tabular}{|l|l|}
124,17 \\
\end{tabular} & 88,36 \\
\hline Epidalea calamita & 30TXK44 & 100,00 & 115,99 & 103,29 & 36,95 & 6304,84 & 27 & $-5,23$ & 276,98 & 134, & 40,46 & 200,65 & 40,4 & 442,88 & 60,61 & 22,91 & 30, & 152,32 & 78,36 & \begin{tabular}{ll|}
100,94 \\
\end{tabular} & 78,36 \\
\hline Epidalea calamita & 30TXK45 & 100,00 & 100,83 & 103 & 36,74 & \begin{tabular}{|l|l|l|l|}
63185 \\
\end{tabular} & 257 & $-20,10$ & 278,04 & 119,41 & 25,62 & 186,08 & 25,6 & 503,32 & 69,24 & 27,13 & 29,50 & 174,30 & 91,03 & 118,84 & 91,03 \\
\hline Epidalea calamita & 30TXK46 & 100,00 & 100,39 & 102,03 & 36,38 & 6310,30 & 255,61 & $-20,58$ & 276,19 & 119,41 & 25,17 & 185,30 & 25,17 & 494,29 & 69,28 & 26,03 & 30,70 & 173,50 & \begin{tabular}{|l|}
87,49 \\
\end{tabular} & 119,83 & 87,49 \\
\hline Epidalea calamita & 30TXK47 & 100,00 & 105,58 & 100,56 & 36,06 & 6302,53 & 257,69 & $-15,92$ & 273,61 & 125,56 & 29,86 & \begin{tabular}{|l|l|}
189,98 \\
\end{tabular} & 29,86 & \begin{tabular}{l|l}
456,05 \\
\end{tabular} & 66,08 & 22,62 & 33,51 & $\begin{array}{ll}163,82 \\
\end{array}$ & 76,81 & \begin{tabular}{|l|l|}
114,08 \\
\end{tabular} & 76,81 \\
\hline Epidalea calamita & 30TXK48 & 100,00 & 106,64 & 99,68 & 36,05 & 6268,44 & 255,85 & $-15,66$ & 271,51 & 127,33 & \begin{tabular}{|l|l|}
30,49 \\
\end{tabular} & 190,24 & 30,49 & 442,42 & \begin{tabular}{ll|}
65,35 \\
\end{tabular} & 21,40 & $35, \mathrm{C}$ & 161,32 & \begin{tabular}{|l|}
73,19 \\
\end{tabular} & \begin{tabular}{|l|l|l|}
113,16 \\
\end{tabular} & 7310 \\
\hline Epidalea calamita & 30TXK49 & 100, & 105,09 & 99,04 & 36,0 & 6222 & 251 & -18, & 269 & 126 & 29, & 187,64 & 29, & 443,49 & 66,29 & 21, & 35, & 163 & 73,09 & 115,32 & \\
\hline Epidalea calamita & 30TXK53 & 100,00 & 104,61 & 102,85 & 36,96 & 6278,89 & 261,26 & $-14,89$ & \begin{tabular}{|l|l|}
276,15 \\
\end{tabular} & 122,03 & 30,58 & 189,31 & 30,58 & 509,56 & 67,23 & 26,95 & 28,05 & $\begin{array}{ll}171,62 \\
\end{array}$ & \begin{tabular}{|l|}
93,89 \\
\end{tabular} & \begin{tabular}{|l|}
114,91 \\
\end{tabular} & 93,89 \\
\hline Epidalea calamita & 30TXK55 & 100,00 & 113,78 & 99,76 & 36,03 & 6306,82 & 267,17 & $-5,13$ & 272,30 & 132,75 & 38,54 & 198,56 & 38,54 & 438,72 & 61,46 & 21,63 & 32,73 & 153,64 & 73,11 & \begin{tabular}{|l|l|}
104,93 \\
\end{tabular} & 73,11 \\
\hline Epidalea calamita & 30TXK56 & 100,00 & 112,06 & 98,56 & 35,93 & 6318,25 & 264,44 & $-6,62$ & \begin{tabular}{|l|l|}
271,06 \\
\end{tabular} & \begin{tabular}{|l|l|l|l|}
131,48 \\
\end{tabular} & \begin{tabular}{|l|l|}
36,42 \\
\end{tabular} & $\begin{array}{l}196,96 \\
\end{array}$ & \begin{tabular}{|l|l}
36,42 \\
\end{tabular} & \begin{tabular}{l|l|}
432,95 \\
\end{tabular} & 62,20 & 20,58 & \begin{tabular}{|l|}
34,39 \\
\end{tabular} & $\begin{array}{ll}154,45 \\
\end{array}$ & \begin{tabular}{|l|l|}
69,78 \\
\end{tabular} & \begin{tabular}{|l|}
107,29 \\
\end{tabular} & 69,78 \\
\hline Epidale & $30 \mathrm{TKK}$ & & & & 36,0 & & & $-21,20$ & 269,6 & 118 & & 182,72 & & 484,26 & 69,93 & 24, & 33 & 173 & \begin{tabular}{l|l}
81,65 \\
\end{tabular} & 123,21 & \\
\hline Epidalea calamita & 30TXK59 & 100,00 & 94,94 & 98,25 & 36,00 & 6198,1 & 243, & $-25,97$ & $268,97 \mid$ & 114,45 & 20,13 & 177,62 & 20,13 & 503,23 & 72,60 & 25,45 [ & 32,69 & $180,55[$ & 86,46 & 128,89 & 86,46 \\
\hline Epidalea calamita & 30TXK63 & 100,00 & 82,82 & 102,00 & 36,40 & 6236,43 & 241,01 & $-35,06$ & 276,07 & \begin{tabular}{|c|}
98,15 \\
\end{tabular} & 38,77 & 167,37 & 10,31 & 644,46 & 81,18 & 35,28 & 24,06 & 210,51 & 127,79 & \begin{tabular}{|l|l|}
140,53 \\
\end{tabular} & 127,99 \\
\hline
\end{tabular}




\begin{tabular}{|c|c|c|c|c|c|c|c|c|c|c|c|c|c|c|c|c|c|c|c|c|c|}
\hline TAXON & UTM & $\mathrm{km} 2$ & BIO1 & B102 & $\mathrm{BIO3}$ & B104 & B105 & B106 & B107 & B108 & B109 & B1010 & BIO11 & BIO12 & B1013 & BIO14 & BIO15 & B1016 & B1017 & B1018 & B1019 \\
\hline Epidalea calamita & 30TXK64 & 100,00 & 87,24 & 100,95 & 36,13 & 6239,38 & 243,50 & $-30,71$ & 274,21 & 103,31 & 23,44 & 171,63 & 14,31 & 605,14 & 78,26 & 33,42 & 25,65 & 201,08 & 116,08 & 137,66 & 116,18 \\
\hline Epidalea calamita & 30TXK65 & 100,00 & 101,19 & 98,94 & 36,00 & \begin{tabular}{ll|}
6251,87 \\
\end{tabular} & 254,13 & $-16,56$ & 270,68 & 118,92 & 27,25 & 185,38 & 27,25 & 510,44 & 69,27 & 26,68 & 29,66 & 174,93 & 89,85 & 121,25 & 89,85 \\
\hline Epidalea calamita & 30 TXK66 & 100,00 & 108,23 & 97,32 & 35,94 & 6269,53 & 259,48 & $-9,12$ & 268,61 & 126,95 & 33,81 & 192,60 & 33,81 & 458,11 & 64,67 & 22,13 & 33,10 & 161,26 & 74,98 & 112,78 & 74,98 \\
\hline Epidalea calamita & 30TXK67 & 100,00 & 104,56 & 96,94 & 35,79 & 6246,24 & 254,15 & $-13,47$ & 267,62 & 123,62 & 30,08 & 188,43 & 30,08 & 469,72 & 66,91 & 22,78 & 33,33 & 166,56 & 77,30 & $\begin{array}{ll}117,66 \\
\end{array}$ & 77,30 \\
\hline Epidalea calamita & 30TXK68 & 100,00 & 102,25 & 96,64 & 35,91 & 6212,39 & 249,82 & \begin{tabular}{|l|l|}
$-16,64$ \\
\end{tabular} & 266,47 & 121,72 & 27,74 & 185,44 & 27,74 & 474,20 & 68,32 & 22,89 & 33,66 & 169,64 & 78,10 & 120,54 & 78,10 \\
\hline Epidalea calamita & 30TXK69 & 100,00 & 100,38 & 96,35 & 35,97 & 6177,58 & 245,97 & $-19,36$ & 265,34 & 120,29 & 25,86 & 182,75 & 25,86 & 478,58 & 69,53 & 23,12 & 34,12 & 172,34 & 79,11 & 123,21 & 79,11 \\
\hline Epidalea calamita & 30TXK73 & 100,00 & 90,47 & 99,95 & 36,11 & 6192,30 & 245,25 & $-26,30$ & 271,55 & 106,12 & 20,42 & 174,21 & 18,38 & 604,95 & 76,52 & 32,69 & 25,01 & $\begin{array}{l}197,56 \\
\end{array}$ & 116,88 & 134,35 & 116,88 \\
\hline Epidalea calamita & $\begin{array}{l}30 T \times K 74 \\
\end{array}$ & 100,00 & 91,00 & 99,13 & 36,01 & 6192,24 & 244,61 & $-25,81$ & 270,42 & \begin{tabular}{|l|l|}
107,01 \\
\end{tabular} & 18,69 & 174,65 & 18,69 & 590,92 & 76,16 & 32,35 & 25,95 & 195,32 & 111,82 & 134,20 & 111,82 \\
\hline Epidalea calamita & 30TXK75 & 100,00 & 103,40 & 97,31 & 35,99 & 6193,90 & 254,00 & $-13,27$ & 267,27 & 120,72 & 30,15 & 186,71 & 30,15 & 508,76 & 68,34 & 26,39 & 29,45 & 172,57 & 89,17 & 119,69 & 89,17 \\
\hline Epidalea calamita & 30TXK76 & 100,00 & 96,20 & 97,25 & 35,99 & 6186,08 & 246,59 & $-20,73$ & 267,32 & 113,50 & 23,07 & 179,41 & 23,07 & 539,14 & 72,73 & 28,49 & 28,82 & 183,65 & 95,95 & 128,89 & 95,95 \\
\hline Epidalea calamita & 30TXK77 & 100,00 & 88,03 & 97,19 & 36,00 & 6165,48 & 238,27 & $-29,22$ & 267,50 & 105,11 & 15,14 & 170,92 & 15,14 & 579,55 & 77,91 & 31,66 & 27,76 & 197,02 & 105,96 & 139,66 & 105,96 \\
\hline Epidalea calamita & 30TXK78 & 100,00 & 86,79 & 96,62 & 35,98 & 6147,74 & 235,81 & $-30,66$ & 266,47 & 104,22 & 13,87 & 169,33 & 13,87 & 581,24 & 78,81 & 31,64 & 28,28 & 198,74 & 105,94 & 141,88 & 105,94 \\
\hline Epidalea calamita & 30TXK79 & 100,00 & 90,39 & 96,06 & 35,95 & 6131,76 & 237,29 & $-27,62$ & 264,91 & 108,73 & 17,29 & 172,42 & 17,29 & 551,11 & 76,38 & 28,97 & 30,00 & 191,40 & 97,79 & 137,19 & 97,79 \\
\hline Epidalea calamita & 30TXK83 & 100,00 & 106,31 & 97,56 & \begin{tabular}{|l|l|}
36,03 \\
\end{tabular} & 6113,81 & 256,51 & $-9,25$ & 265,75 & 122,37 & 34,74 & 188,70 & 34,74 & 529,97 & 67,17 & 27,57 & 27,21 & 171,99 & 98,04 & 116,27 & 98,04 \\
\hline Epidalea calamita & 30TXK85 & 100,00 & 113,47 & 95,37 & 35,96 & 6117,38 & 260,95 & $-1,89$ & 262,84 & 130,88 & 41,07 & 195,58 & 41,07 & 474,12 & 63,06 & 23,84 & 30,62 & 158,27 & 81,69 & 108,52 & 81,69 \\
\hline Epidalea calamita & 30TXK86 & 100,00 & 102,09 & 95,56 & 35,84 & 6136,09 & 250,16 & $-13,75$ & 263,91 & 119,14 & 29,49 & 184,51 & 29,49 & 519,94 & 69,72 & 26,87 & 29,38 & 175,49 & 91,25 & 122,76 & 91,25 \\
\hline Epidalea calamita & 30TXK87 & 100,00 & 86,28 & 96,04 & 35,94 & 6125,23 & 235,37 & $-29,68$ & 265,04 & 102,63 & 14,27 & 168,73 & 14,27 & 603,92 & 79,63 & 33,52 & 26,50 & 202,00 & 112,33 & 142,80 & 112,33 \\
\hline Epidalea calamita & 30TXK88 & 100,00 & 86,99 & 95,60 & 35,78 & 6107,93 & 234,77 & $-29,32$ & 264,09 & 103,80 & 14,83 & 168,97 & 14,83 & 591,79 & 79,21 & 32,33 & 27,40 & 199,92 & 108,56 & 142,45 & 108,56 \\
\hline Epidalea calamita & 30TXK89 & 100,00 & 89,89 & 95,19 & 35,86 & 6094,73 & 236,24 & $-26,91$ & 263,15 & 107,44 & 17,72 & 171,58 & 17,72 & 566,46 & 77,28 & 30,17 & 28,85 & 193,84 & 101,71 & 138,72 & 101,71 \\
\hline Epidalea calamita & 30TXK93 & 100,00 & 115,89 & 95,69 & 36,00 & 6010,63 & 262,18 & 1,05 & 261,12 & 130,54 & 45,08 & 196,67 & 45,08 & 502,89 & 62,32 & 24,72 & 28,11 & 159,14 & 93,18 & 108,58 & 93,18 \\
\hline Epidalea calamita & 30TXK94 & 100,00 & 119,28 & 94,74 & 36,00 & 6011,05 & 264,14 & 4,03 & 260,11 & 134,87 & 48,01 & 199,74 & 48,01 & 479,71 & 60,69 & 23,89 & 29,46 & 153,64 & 86,55 & 104,66 & 86,55 \\
\hline Epidalea calamita & 30TXK95 & 100,00 & 108,05 & 94,79 & 35,99 & 6058,85 & 254,35 & $-6,84$ & 261,19 & 124,64 & $\begin{array}{l}36,56 \\
365\end{array}$ & 189,29 & 36,56 & 518,90 & 67,10 & 27,16 & 28,55 & 169,40 & 93,58 & 116,73 & 93,58 \\
\hline Epidalea calamita & 30TXK96 & 100,00 & 87,55 & 95,38 & \begin{tabular}{|l|l|}
35,88 \\
\end{tabular} & $\begin{array}{ll}6087,28 \\
\end{array}$ & 236,15 & $-27,25$ & 263,40 & 103,18 & 16,42 & 169,58 & 16,42 & 620,63 & 79,56 & 34,40 & 25,38 & 202,81 & 117,91 & 141,56 & 117,91 \\
\hline Epidalea calamita & 30TXK97 & 100,00 & 76,32 & 95,25 & 35,61 & 6078,79 & 225,79 & $-38,10$ & 263,89 & 91,31 & 5,56 & 158,37 & 5,56 & 684,15 & 86,82 & 39,06 & 23,75 & 222,42 & 133,91 & 155,19 & 133,91 \\
\hline Epidalea calamita & 30TXK98 & 100,00 & 82,76 & 94,76 & 35,80 & 6063,78 & 230,25 & $-32,22$ & 262,47 & 98,75 & 11,65 & 164,31 & 11,65 & 634,63 & 82,64 & 35,73 & 25,51 & 209,67 & 120,22 & 148,25 & 120,22 \\
\hline Epidalea calamita & 30TXK99 & 100,00 & 87,85 & 94,31 & 35,77 & 6050,55 & 233,66 & $-27,96$ & 261,61 & 104,72 & 16,28 & 168,97 & 16,28 & 596,15 & 79,43 & 32,70 & 27,18 & 199,91 & 109,85 & 142,78 & 109,85 \\
\hline Epidalea calamita & 30TXL11 & 100,00 & $\begin{array}{l}1,0,93 \\
91,93\end{array}$ & 105,71 & 37,00 & 6228,03 & 248,16 & $-34,27$ & 282,43 & \begin{tabular}{|l|l|}
112,37 \\
\end{tabular} & 15,75 & $\begin{array}{l}174,65 \\
\end{array}$ & 15,75 & 523,98 & $\begin{array}{l}74,34 \\
74,38\end{array}$ & 30,10 & 29,51 & 184,00 & $\begin{array}{l}102,93 \\
\end{array}$ & $\begin{array}{l}127,41 \\
127\end{array}$ & 102,93 \\
\hline Epidalea calamita & 30TXL12 & 100,00 & 95,85 & 105,01 & 37,00 & 6202,83 & 249,54 & $-31,10$ & 280,64 & 117,09 & 26,91 & 177,72 & 19,57 & 497,81 & 71,90 & 28,04 & 30,91 & 176,99 & 96,26 & 122,93 & 96,50 \\
\hline Epidalea calamita & 30TXL13 & 100,00 & 98,47 & 104,71 & 37,00 & 6186,85 & 251,01 & $-28,75$ & 279,77 & 120,31 & 31,71 & 179,94 & 22,29 & 482,34 & 70,19 & 26,68 & 31,63 & 172,32 & 92,00 & 119,73 & 93,40 \\
\hline Epidalea calamita & 30TXL14 & 100,00 & 99,84 & 104,72 & 37,00 & 6169,05 & 252,13 & $-27,52$ & 279,65 & 121,90 & 33,18 & 180,88 & 23,67 & 477,12 & 69,48 & 26,47 & 31,68 & 170,33 & 90,88 & 118,34 & 93,38 \\
\hline Epidalea calamita & 30TXL15 & 100,00 & 101,91 & 104,92 & 37,00 & 6164,67 & 254,79 & $-25,08$ & 279,87 & 123,88 & 35,51 & 182,76 & 25,54 & 472,58 & 68,59 & 26,54 & 31,25 & 167,73 & 90,85 & 116,22 & 94,02 \\
\hline Epidalea calamita & 30TXL20 & 100,00 & 90,82 & 103,97 & 36,94 & 6227,62 & 245,18 & $\begin{array}{l}-24,25 \\
-34,25 \\
\end{array}$ & 279,44 & \begin{tabular}{|l|}
110,870 \\
\end{tabular} & \begin{tabular}{|l|l|}
15,03 \\
15
\end{tabular} & 173,66 & 15,03 & 527,99 & $\begin{array}{l}0,0308 \\
75,0\end{array}$ & 29,67 & 30,20 & 186,55 & 100,45 & \begin{tabular}{|l|l|}
130,35 \\
\end{tabular} & 100,45 \\
\hline Epidalea calamita & 30TXL21 & 100,00 & 97,52 & 102,87 & \begin{tabular}{|l|l|}
36,87 \\
\end{tabular} & 6191,58 & 247,66 & $-28,73$ & 276,39 & 119,02 & 26,43 & 179,32 & 21,33 & 482,29 & 70,89 & 25,56 & 33,13 & 174,63 & 88,47 & 122,35 & 88,61 \\
\hline Epidalea calamita & 30TXL22 & 100,00 & 99,03 & 102,34 & 36,82 & 6166,32 & 247,45 & $-27,74$ & 275,19 & 121,14 & 32,12 & 180,13 & 22,89 & 470,05 & 69,89 & 24,30 & 33,92 & 171,59 & 84,86 & 120,63 & 85,96 \\
\hline Epidalea calamita & 30TXL23 & 100,00 & 101,91 & 102,08 & 36,85 & 6139,68 & 248,97 & $-25,49$ & 274,47 & 124,33 & 35,14 & 182,20 & 25,52 & 455,18 & 68,36 & 23,12 & 34,76 & 167,11 & 80,94 & 117,21 & 83,37 \\
\hline Epidalea calamita & $\begin{array}{l}30 T X L 24 \\
\end{array}$ & 100,00 & 96,83 & 102,61 & 36,90 & 6129,49 & 245,92 & $-29,65$ & 275,58 & 118,51 & 30,43 & 177,20 & 20,92 & 487,09 & 71,41 & 26,08 & 32,53 & $\begin{array}{l}175,48 \\
\end{array}$ & 90,18 & 123,84 & 92,75 \\
\hline Epidalea calamita & $\begin{array}{l}30 T X L 25 \\
3042\end{array}$ & 100,00 & \begin{tabular}{r|r}
508,26 \\
108,26
\end{tabular} & 102,91 & 36,90 & $\begin{array}{l}012,49,97 \\
6139,97\end{array}$ & \begin{tabular}{|l|}
24,3724 \\
257,01
\end{tabular} & $\begin{array}{l}-29,05 \\
-19,15 \\
\end{array}$ & $\mid$ & \begin{tabular}{|l|}
131,01 \\
131,1
\end{tabular} & $\begin{array}{l}0,45 \\
41,78 \\
\end{array}$ & 188,19 & $\begin{array}{ll}30,625 \\
31,62\end{array}$ & \begin{tabular}{|l|l|}
436,55 \\
46,5
\end{tabular} & $\begin{array}{l}1,1,41 \\
65,32\end{array}$ & $\begin{array}{l}20,00 \\
22,83\end{array}$ & $\begin{array}{l}2,35 \\
34,09 \\
\end{array}$ & $\begin{array}{l}158,52 \\
152\end{array}$ & $\begin{array}{l}\mid 0,100 \\
79,22\end{array}$ & $\begin{array}{l}109,89,8 \\
109\end{array}$ & 82,84 \\
\hline Epidalea calamita & 30TXL29 & 100,00 & 129,03 & 105,79 & 37,00 & 6199,42 & 284,79 & 2,71 & 282,08 & 152,03 & 186,86 & 209,20 & 51,42 & 390,97 & 56,82 & 19,76 & 31,35 & 134,55 & 76,47 & 87,68 & 83,30 \\
\hline Epidalea calamita & 30TXL30 & 100,00 & 102,60 & 100,66 & 36,42 & 6193,90 & 249,52 & $-22,81$ & 272,34 & 124,19 & 28,63 & 184,34 & 26,32 & 452,95 & 67,82 & 22,46 & 35,47 & 166,78 & 77,95 & 117,45 & 77,98 \\
\hline Epidalea calamita & 30TXL31 & 100,00 & 104,71 & 99,65 & 36,29 & 6145,01 & 248,19 & $-21,79$ & 269,98 & 127,27 & 37,75 & 185,23 & 28,40 & 435,22 & 66,48 & 20,53 & 37,38 & 162,89 & 72,70 & 115,31 & 73,72 \\
\hline Epidalea calamita & $\begin{array}{l}30 T X L 32 \\
\end{array}$ & 100,00 & 102,32 & 99,48 & 36,2 & 6111,27 & 244,66 & $-24,75$ & 269,41 & 124,86 & 35,49 & 182,03 & 26,05 & \begin{tabular}{|l|l|}
444,99 \\
\end{tabular} & 67,97 & 20,99 & 37,29 & 166,56 & 74,21 & 118,63 & 76,57 \\
\hline Epidalea calamita & 30TXL33 & 100,00 & 100,56 & 99,81 & 36,35 & 6097,72 & 243,69 & $-26,50$ & 270,19 & $\begin{array}{ll}122,92 \\
\end{array}$ & 33,88 & $\begin{array}{ll}180,03 \\
\end{array}$ & 24,34 & 455,56 & 69,13 & 21,99 & 36,32 & $\begin{array}{l}169,37 \\
\end{array}$ & 77,45 & 120,71 & 80,36 \\
\hline Epidalea calamita & $\begin{array}{l}30 T X L 34 \\
\end{array}$ & 100,00 & 106,06 & 100,24 & 36,46 & 6100,01 & 249,72 & $-21,32$ & 271,04 & $\begin{array}{l}128,83 \\
128\end{array}$ & 39,46 & 185,23 & 29,41 & 435,01 & 66,35 & 21,07 & 36,42 & $\begin{array}{l}161,47 \\
\end{array}$ & 74,15 & 113,91 & 77,61 \\
\hline Epidalea calamita & 30TXL35 & 100,00 & 106,74 & 100,94 & 36,57 & 6099,30 & 252,09 & $-20,23$ & 272,32 & 129,56 & 40,47 & 185,94 & 30,32 & 436,62 & 66,18 & 21,77 & 35,22 & 160,59 & 76,35 & 112,66 & 79,99 \\
\hline Epidalea calamita & 30TXL36 & 100,00 & 104,84 & 101,67 & 36,72 & 6102,20 & 252,37 & $-21,44$ & 273,81 & 127,21 & 38,86 & 184,29 & 28,90 & 452,16 & 67,47 & 23,57 & 33,69 & 163,90 & 81,97 & 114,75 & 85,73 \\
\hline Epidalea calamita & $\begin{array}{l}0 T X L 39 \\
30 T L\end{array}$ & 100,00 & 136,03 & 105,08 & 37,00 & 6222,39 & 291,81 & $\begin{array}{r}2,4,97 \\
9,97 \\
\end{array}$ & 281,83 & \begin{tabular}{|l|l|l|l|}
159,19 \\
\end{tabular} & 209,55 & 216,24 & 57,93 & 367,27 & 54,08 & 17,66 & $\begin{array}{l}3,27 \\
32,27 \\
\end{array}$ & 126,19 & $\begin{array}{l}1,170 \\
70,79\end{array}$ & | & 77,73 \\
\hline Epidalea calamita & 30TXL40 & 100,00 & 98,19 & 99,03 & 36,00 & 6177,33 & 244,29 & $-25,42$ & 269,70 & 119,08 & 23,32 & 179,94 & 22,66 & 477,14 & 70,56 & 23,76 & 34,72 & 174,42 & 81,71 & 124,25 & 81,71 \\
\hline Epidalea calamita & 30TXL41 & 100,00 & 97,45 & 98,44 & 36,00 & 6130,43 & 241,32 & $\begin{array}{l}-27,00 \\
-2,4\end{array}$ & 268,32 & 118,89 & 27,51 & 178,22 & 21,91 & 474,47 & 70,94 & 23,18 & 35,55 & 175,01 & 80,73 & 125,40 & 81,19 \\
\hline Epidalea calamita & 30TXL42 & 100,00 & 103,06 & 97,26 & 36,00 & 6075,59 & 241,99 & $-23,24$ & 265,22 & 125,75 & 36,52 & 182,22 & 27,15 & 437,31 & 67,55 & 19,54 & 38,94 & 165,59 & 69,53 & 118,96 & 72,10 \\
\hline Epidalea calamita & 30TXL43 & 100,00 & 103,52 & 97,70 & 36,03 & 6064,31 & 242,87 & $-22,97$ & 265,83 & 126,45 & 37,18 & 182,36 & 27,64 & 437,57 & 67,50 & 19,82 & 38,29 & 165,04 & 70,36 & 118,27 & 73,68 \\
\hline Epidalea calamita & $30 T x$ & 100,00 & 99 & 98,60 & 36, & 6063,16 & 241,76 & $-26,03$ & 267,80 & 121,83 & 33,31 & 178,59 & 23,97 & 462,21 & 69,90 & 22,22 & 35,83 & 171,22 & 78,36 & 122,62 & 81,31 \\
\hline Epidalea calamita & 30TXL45 & 100,00 & 103,29 & 99,36 & 36,30 & 6071,57 & 246,90 & $-22,48$ & 269,38 & 125,80 & 37,30 & 182,32 & 27,53 & 450,06 & 68,11 & 22,12 & 35,47 & 165,82 & 77,56 & 117,56 & 80,82 \\
\hline Epidalea calamita & 30TXL50 & 100,00 & 91,90 & 98,01 & 36,01 & 6162.41 & 238,94 & $-29,51$ & 268,45 & 111,65 & 17,40 & 173,98 & 17,40 & 515,99 & 74,51 & 26,49 & 32.53 & $|185,27|$ & 89,94 & $\mid 132.90$ & 89,94 \\
\hline Epidalea calamita & 30TXL51 & 100,00 & 87,73 & 98,07 & 36,00 & 6124,77 & 234,65 & $-33,71$ & 268,35 & 107,34 & 13,52 & 169,11 & 13,46 & 539,12 & 77,24 & 28,50 & 31,44 & 192,34 & 96,55 & 138,61 & 96,55 \\
\hline Epidalea calamita & $30 \mathrm{TX}$ & 100,00 & 95,48 & 97,20 & 36,00 & 6089,01 & 238,10 & $-27,74$ & 265,83 & 116,36 & 26,76 & 175,60 & 20,49 & 487,24 & 72,39 & 23,87 & 34,90 & 178,61 & 83,15 & 128,89 & 83 \\
\hline Epidalea calamita & 30TXL53 & 100,00 & 93,34 & 97,36 & 36,00 & 6066,05 & 236,19 & $-29,89$ & 266 & 114,21 & 26,24 & 173,12 & 18,58 & 500,72 & 73,83 & 25,11 & 34,01 & $\begin{array}{l}182,28 \\
\end{array}$ & 87,26 & $\begin{array}{l}131,60 \\
\end{array}$ & 88,09 \\
\hline Epidalea calamita & 30TXL54 & 100,00 & 90,49 & 97,91 & 36,00 & 6048,23 & 234,72 & $-32,40$ & 267,12 & 111,02 & 24,29 & 169,99 & 16,06 & 520,93 & 75,81 & 27,03 & 32,34 & 187,29 & 93,71 & 135,29 & 94,70 \\
\hline Epidalea calamita & 30TXL55 & 100,00 & 99,63 & 98,26 & 36,01 & 60498 & 242.98 & $-24,70$ & 267.68 & $\mid 121.47$ & 33,74 & 178,65 & 24.53 & 472.58 & 70,42 & 23,61 & 34.13 & 172,20 & 82.48 & 122.96 & 84,61 \\
\hline Epidalea calamita & 30TXL56 & 100,00 & 108,24 & 99,50 & 36,17 & 6072,37 & 253,65 & $-16,47$ & 270,12 & 130,6 & 42,57 & 187,2 & 32, & 438,60 & 65,96 & 22,22 & 34,36 & 159,44 & 77,44 & 111,43 & 79,67 \\
\hline Epidalea calamita & 30 TXL60 & 100,00 & 94,83 & 96,48 & 36,00 & 6139,80 & 239,94 & $-25,42$ & 265,35 & 114,68 & 20,78 & 176,50 & 20,78 & 505,03 & 73,01 & 25,25 & 33,01 & 181,19 & 86,05 & 130,33 & 86,05 \\
\hline
\end{tabular}




\begin{tabular}{|c|c|c|c|c|c|c|c|c|c|c|c|c|c|c|c|c|c|c|c|c|c|}
\hline TAXON & UTM & $\mathrm{km2}$ & B101 & $\mathrm{B1O2}$ & $\mathrm{BIO3}$ & B104 & B105 & B106 & B107 & B108 & B109 & 81010 & B1011 & BIO12 & B1013 & 81014 & B1015 & B1O16 & BIO17 & BIO18 & B1019 \\
\hline Epidalea calamita & 30TXL61 & 100,00 & 90,23 & 96,60 & 35,99 & 6104,58 & 235,41 & $-30,41$ & 265,82 & 109,78 & 16,47 & 171,37 & 16,47 & 529,44 & 75,96 & 27,37 & 31,93 & 188,81 & 92,93 & 136,23 & 92,93 \\
\hline Epidalea calamita & 30TXL62 & 100,00 & 93,88 & 96,39 & 36,00 & 6076,15 & 237,07 & $-27,70$ & 264,77 & 114,11 & 21,47 & 174,17 & 19,72 & 505,76 & 73,78 & 25,51 & 33,43 & 182,48 & 87,48 & 131,67 & 87,48 \\
\hline Epidalea calamita & 30TXL63 & 100,00 & 90,23 & 96,66 & 36,00 & 6052,86 & 234,09 & $-31,12$ & 265,21 & 110,10 & 19,00 & 170,15 & 16,26 & 527,51 & 76,18 & 27,39 & 31,97 & 188,53 & 94,05 & 136,34 & 94,05 \\
\hline Epidalea calamita & 30TXL64 & 100,00 & 97,19 & 96,94 & 36,00 & 6042,81 & 240,17 & $-25,19$ & 265,35 & 118,09 & 31,02 & 176,54 & 22,75 & 489,91 & 72,06 & 24,70 & 33,49 & 176,98 & 85,80 & 126,94 & 86,37 \\
\hline Epidalea calamita & 30TXL65 & 100,00 & 107,50 & 97,78 & 36,00 & \begin{tabular}{|l|l|}
6055,16 \\
\end{tabular} & 250,82 & $-16,10$ & 266,92 & 129,47 & 41,66 & \begin{tabular}{|l|}
186,47 \\
\end{tabular} & 32,33 & 441,42 & 66,32 & 21,81 & 34,95 & 160,91 & 75,92 & 113,19 & 77,19 \\
\hline Epidalea calamita & 30TXL66 & 100,00 & 112,34 & 99,02 & 36,03 & 6072,31 & 258,01 & $-11,55$ & 269,56 & 134,55 & 46,83 & 191,31 & 36,57 & 426,14 & 63,97 & 21,66 & 34,21 & 154,11 & 75,15 & 106,67 & 76,26 \\
\hline Epidalea calamita & \begin{tabular}{|l|} 
30TXL67 \\
\end{tabular} & 100,00 & 117,43 & 100,42 & 36,10 & 6102,58 & 265,95 & $-6,52$ & 272,46 & 139,90 & 51,90 & 196,82 & 41,34 & 411,37 & 61,44 & 21,69 & 33,30 & 147,14 & 74,86 & 99,97 & 75,70 \\
\hline Epidalea calamita & $\begin{array}{l}30 T X L 68 \\
\end{array}$ & 100,00 & 123,29 & 101,80 & 36,25 & 6140,66 & 274,94 & $-0,96$ & 275,90 & 145,87 & 57,65 & 203,00 & 46,66 & 396,42 & 58,78 & 21,01 & 32,39 & 139,89 & 74,69 & 93,15 & 75,25 \\
\hline Epidalea calamita & 30TXL69 & 100,00 & 131,13 & 103,27 & 36,36 & 6188,04 & 286,48 & 6,68 & 279,80 & 154,08 & 105,36 & 211,40 & 53,98 & 377,27 & 55,39 & 18,90 & 31,50 & 130,90 & 73,64 & 84,45 & 74,45 \\
\hline Epidalea calamita & 30TXL70 & 100,00 & 91,62 & 95,82 & 35,95 & 6104,33 & 237,03 & $-26,92$ & 263,95 & 110,41 & 18,39 & 173,10 & 18,39 & 535,96 & 75,51 & 27,64 & 30,93 & 188,29 & 93,76 & 135,37 & 93,76 \\
\hline Epidalea calamita & 30TXL71 & 100,00 & 88,97 & 95,70 & 35,92 & 6076,17 & 234,03 & $-29,79$ & 263,82 & 107,70 & 15,86 & 169,95 & 15,86 & 549,70 & 77,34 & 28,97 & 30,47 & 192,75 & 97,80 & 139,05 & 97,80 \\
\hline Epidalea calamita & 30TXL72 & 100,00 & 101,13 & 95,36 & 35,98 & 6059,70 & 243,06 & $-19,58$ & 262,65 & 121,64 & 27,75 & 181,10 & 27,18 & 478,34 & 70,08 & 23,47 & 34,08 & 172,16 & 80,84 & 123,14 & 80,84 \\
\hline Epidalea calamita & 30TXL73 & 100,00 & 99,16 & 95,91 & 35,99| & 6045,63 & 241,52 & $-22,07$ & 263,58 & $\begin{array}{l}119,70 \\
\end{array}$ & 27,72 & 178,85 & 25,26 & 487,42 & 71,25 & 24,47 & 33,50 & 174,96 & $\begin{array}{ll}8,04 \\
83,98\end{array}$ & 125,23 & 83,98 \\
\hline Epidalea calamita & 30TXL74 & 100,00 & 109,47 & 96,76 & 36,00 & 6044,27 & 252,24 & $-13,11$ & 265,36 & 131,08 & 42,85 & 188,66 & 34,88 & 439,68 & 65,54 & 21,57 & 34,89 & 158,99 & 74,79 & 111,64 & 74,89 \\
\hline Epidalea calamita & 30TXL75 & 100,00 & 114,92 & 97,98 & 36,00 & 6066,83 & 259,62 & $-8,03$ & 267,65 & 136,97 & 48,13 & 194,08 & 39,80 & 419,59 & 62,66 & 20,99 & 34,60 & 151,11 & 72,50 & 104,34 & 72,64 \\
\hline Epidalea calamita & 30TXL76 & 100,00 & 120,30 & 99,40 & 36,04 & 6087,55 & 267,63 & $-3,09$ & 270,72 & 142,67 & 52,88 & 199,61 & 44,59 & 403,03 & 60,00 & 20,77 & 33,93 & 143,90 & 71,35 & 97,52 & 71,46 \\
\hline Epidalea calamita & $\begin{array}{l}30 T X L 77 \\
\end{array}$ & 100,00 & 120,89 & 100,23 & 36,03 & 6099,63 & 270,27 & $-2,44$ & 272,71 & 143,32 & 52,76 & 200,37 & 45,11 & 404,11 & 59,66 & 21,35 & 32,80 & 143,03 & 73,46 & 96,21 & 73,56 \\
\hline Epidalea calamita & $\begin{array}{l}30 T \times L 78 \\
\end{array}$ & 100,00 & 123,44 & 101,37 & $\begin{array}{l}30,05 \\
36,06\end{array}$ & 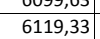 & 275,03 & $\begin{array}{l}-2,44 \\
-0,11 \\
\end{array}$ & 275,14 & $\begin{array}{l}445,326 \\
145,86\end{array}$ & 52,43 & \begin{tabular}{|l|}
203,01 \\
\end{tabular} & 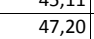 & \begin{tabular}{|l|}
304,11 \\
399,68
\end{tabular} & $\begin{array}{l}53,00 \\
58,42\end{array}$ & $\begin{array}{l}\mid 1,1,03 \\
21,03\end{array}$ & $\begin{array}{l}3,200 \\
31,61\end{array}$ & \begin{tabular}{|l|}
$139,80,80$ \\
\end{tabular} & 74,66 & $\begin{array}{l}0,2,2 \\
93,08 \\
\end{array}$ & $\begin{array}{l}74,50 \\
74,68\end{array}$ \\
\hline Epidalea calamita & 30TXL79 & 100,00 & 127,20 & 102,48 & 36,18 & 6146,71 & 281,60 & 3,56 & 278,04 & 149,99 & 54,67 & 207,17 & 50,63 & 391,98 & 56,46 & 20,06 & 30,52 & 135,25 & 75,40 & 88,81 & 75,40 \\
\hline Epidalea calamita & $30 T \times 180$ & 100,00 & 92,12 & 94,93 & 35,88 & 6074,91 & 237,01 & $-25,42$ & 262.43 & $\mid 110,20$ & $\mid 19,59$ & $\mid 173,29$ & 19,59 & 548,33 & 75,97 & 28,70 & 29,87 & $\mid 189,62$ & 97,12 & 135,95 & 97,12 \\
\hline Epidalea calamita & 30TXL81 & 100,00 & 90,67 & 94,95 & 35,90 & 6049,47 & 235,18 & $-27,06$ & 262,24 & 109,03 & 18,25 & 171,36 & 18,25 & 555,37 & 77,05 & 29,46 & 29,80 & 191,96 & 99,52 & 138,05 & 99,52 \\
\hline Epidalea calamita & $\begin{array}{l}30 T X L 82 \\
\end{array}$ & 100,00 & 105,61 & 95,06 & 36,00 & 6036,24 & 247,85 & $\begin{array}{l}-14,08 \\
-14\end{array}$ & 261,93 & 125,84 & 32,08 & 185,38 & 32,08 & 471,49 & 68,23 & 23,19 & 33,44 & 167,17 & 79,96 & 118,27 & 79,96 \\
\hline Epidalea calamita & 30TXL83 & 100,00 & 109,49 & 95,77 & \begin{tabular}{|l|l|}
35,97 \\
\end{tabular} & \begin{tabular}{|l|l|}
6035,23 \\
\end{tabular} & 252,01 & $-11,32$ & 263,33 & 130,29 & 36,04 & 188,90 & 35,78 & 452,96 & 66,15 & 22,27 & 33,96 & 161,12 & 76,89 & 112,97 & 76,89 \\
\hline Epidalea calamita & 30TXL84 & 100,00 & 115,72 & 96,93 & 36,00 & 6040,90 & 259,44 & $-6,17$ & 265,62 & 137,23 & 43,16 & 194,89 & 41,48 & 427,11 & 62,83 & 21,12 & 34,23 & 151,85 & 72,94 & 104,76 & 72,94 \\
\hline Epidalea calamita & 30TXL85 & 100,00 & 116,66 & 97,82 & 36,00 & 6051,52 & 261,97 & $-5,50$ & 267,48 & 138,31 & 43,75 & 195,76 & 42,05 & 424,05 & 62,31 & 21,52 & 33,57 & 150,21 & 73,66 & 102,92 & 73,66 \\
\hline Epidalea calamita & 30TXL86 & 100,00 & 126,49 & 99,79 & 36,01 & 6088,22 & 275,16 & 2,99 & 272,17 & 148,82 & 52,40 & 205,93 & 51,04 & 391,26 & 57,25 & 20,01 & 33,19 & 137,14 & 69,25 & 91,28 & 69,25 \\
\hline Epidalea calamita & $\begin{array}{l}\text { 30TXL87 } \\
\end{array}$ & 100,00 & 132,95 & 101,34 & 36,00 & 6120,77 & 284,55 & 8,68 & 275,87 & \begin{tabular}{|l|}
155,74 \\
155,4
\end{tabular} & 56,94 & 212,68 & 56,86 & 373,65 & 53,97 & 18,64 & 32,14 & 129,19 & 67,90 & $\begin{array}{ll}1,27 \\
84,27\end{array}$ & 67,90 \\
\hline Epidalea calamita & 30TXL88 & 100,00 & 134,58 & 102,23 & 36,03 & 6145,04 & 288,41 & 10,24 & 278,17 & 157,57 & 58,01 & 214,51 & 58,01 & 370,96 & 52,88 & 18,25 & 31,04 & 127,03 & 68,71 & 82,26 & 68,71 \\
\hline Epidalea calamita & 30TXL89 & 100,00 & 136,03 & 103,14 & 36,15 & 6159,41 & 291,93 & 11,69 & 280,24 & 159,19 & 59,18 & 216,21 & 59,18 & 370,19 & 51,84 & 18,06 & 29,77 & 125,34 & 70,01 & 80,77 & 70,01 \\
\hline Epidalea calamita & 30TXL90 & 100,00 & 93,26 & 94,10 & 35,88 & 6037,54 & 237,51 & $-23,38$ & 260,88 & 110,95 & 21,41 & 173,85 & 21,41 & 560,38 & 76,22 & 29,78 & 28,83 & 190,28 & 100,83 & 135,84 & 100,83 \\
\hline Epidalea calamita & 30TXL91 & 100,00 & 92,79 & 94,06 & 35,91 & 6024,18 & 236,62 & $-24,29$ & 260,91 & 110,82 & 20,82 & 173,14 & 20,82 & 558,18 & 76,49 & 29,75 & 29,18 & 190,50 & 100,44 & 136,29 & 100,44 \\
\hline Epidalea calamita & 30TXL92 & 100,00 & 108,34 & 94,90 & 35,97 & $\begin{array}{ll}60213,94 \\
6010\end{array}$ & 250,88 & $\begin{array}{l}-2,10,67 \\
-12\end{array}$ & 261,55 & \begin{tabular}{|l|l|}
128,18 \\
\end{tabular} & $\begin{array}{l}20,0<6 \\
35,46\end{array}$ & \begin{tabular}{|l|}
187,89 \\
\end{tabular} & $\begin{array}{l}30,064 \\
35,46\end{array}$ & \begin{tabular}{|l|l|}
475,73 \\
\end{tabular} & $\mid 67,67$ & 23,81 & 32,43 & $\begin{array}{l}165,47 \\
\end{array}$ & 81,84 & 115,82 & 81,84 \\
\hline Epidalea calamita & 30TXL93 & 100,00 & 119,24 & 96,28 & 35,99 & 6024,23 & 262,65 & $-1,61$ & 264,25 & 140,10 & 45,57 & 198,47 & 45,57 & 430,39 & 61,95 & 21,19 & 33,56 & 149,75 & 73,45 & 102,24 & 73,45 \\
\hline Epidalea calamita & 30TXL94 & 100,00 & 121,76 & 97,31 & 36,00 & 6022,52 & 266,54 & 0,07 & 266,46 & 143,10 & 48,05 & 200,89 & 48,05 & 420,08 & 60,59 & 21,03 & 33,48 & 146,01 & 72,48 & 98,88 & 72,48 \\
\hline Epidalea calamita & 30TXL95 & 100,00 & 119,29 & 97,91 & 36,00 & 6025,98 & 265,34 & $-2,58$ & 267,92 & 140,63 & 45,32 & 198,40 & 45,32 & 428,44 & 61,70 & 21,84 & 32,63 & 148,84 & 75,02 & 101,15 & 75,02 \\
\hline Epidalea calamita & 30TXL96 & 100,00 & 134,56 & 100,49 & 36,02 & 6076,06 & 284,31 & 10,75 & 273,56 & 157,00 & 59,40 & 213,91 & 59,40 & 377,88 & 53,95 & 18,37 & 32,59 & 129,18 & 67,32 & 84,10 & 67,32 \\
\hline Epidalea calamita & $\begin{array}{l}\text { 30TXL97 } \\
\end{array}$ & 100,00 & 139,50 & 101,88 & 36,10 & 6104,79 & 291,85 & 15,07 & 276,78 & 162,47 & 63,90 & 219,12 & 63,90 & 364,50 & 51,29 & 17,19 & 31,80 & 123,17 & 66,23 & 79,08 & 66,23 \\
\hline Epidalea calamita & 30TXL98 & 100,00 & 142,43 & 102,88 & 36,18 & 6118,22 & 296,53 & 17,65 & 278,88 & 165,50 & 66,35 & 222,14 & 66,35 & 358,47 & 49,68 & 16,66 & 30,96 & 119,94 & 66,09 & 76,27 & 66,09 \\
\hline Epidalea calamita & 30TXM00 & 100,00 & 108,51 & 108,36 & 37,66 & 6146,17 & 267,97 & $-16,90$ & 284,86 & 130,14 & 188,45 & 188,81 & 32,33 & 491,57 & 66,69 & 27,04 & 26,42 & 163,83 & 98,31 & 111,92 & 111,05 \\
\hline Epidalea calamita & 30TXM01 & 100,00 & 95,38 & 108,00 & 37,85 & 6071,08 & 255,01 & $-28,10$ & 283,11 & 115,35 & 174,92 & 175,13 & 20,77 & 577,34 & 74,88 & 32,82 & 23,46 & 187,54 & 116,08 & 129,63 & 134,59 \\
\hline Epidalea calamita & 30TXM02 & 100,00 & 100,94 & 108,08 & 37,93 & 6066,93 & 260,75 & $-22,31$ & 283,06 & 121,12 & 180,29 & 180,39 & 26,02 & 566,20 & 72,63 & 31,53 & 23,29 & 181,91 & 112,00 & 124,01 & 134,25 \\
\hline Epidalea calamita & 30TXM03 & 100,00 & 10,94 & $\begin{array}{l}10,08 \\
108,53\end{array}$ & | 37,93 & $\begin{array}{l}000,239 \\
6123,89 \\
\end{array}$ & 278,13 & $\begin{array}{r}-2,51 \\
-5,19\end{array}$ & \begin{tabular}{|l|}
284,140 \\
284
\end{tabular} & \begin{tabular}{|l|}
140,97 \\
142
\end{tabular} & \begin{tabular}{|l|}
198,29 \\
198,70
\end{tabular} & \begin{tabular}{|l|l|}
198,78 \\
198,
\end{tabular} & $\begin{array}{l}\mid 20,0<2 \\
42,79 \\
\end{array}$ & \begin{tabular}{|l|}
$300,20,67$ \\
490,
\end{tabular} & $\begin{array}{l}\mid 2,05 \\
63,53\end{array}$ & $\begin{array}{l}1,53 \\
25,64 \\
\end{array}$ & $\begin{array}{l}24,29 \\
24,61\end{array}$ & $\begin{array}{l}157,001 \\
157\end{array}$ & $\begin{array}{r}11,200 \\
93,63\end{array}$ & 102,45 & $\begin{array}{l}354,25 \\
117,71\end{array}$ \\
\hline Epidalea calamita & 30TXM05 & 100,00 & 133,34 & 107,29 & 37,99 & 6057,35 & 290,14 & 10,14 & 279,99 & 155,39 & 211,64 & 211,64 & 57,25 & 485,86 & 59,23 & 23,80 & 23,70 & 148,22 & 89,40 & 92,39 & 122,30 \\
\hline Epidalea calamita & 30TXM06 & 100,00 & 134,37 & 106,67 & 37,99 & 6021,66 & 289,83 & 12,23 & 277,60 & 155,06 & 212,27 & 212,27 & 58,71 & 513,80 & 60,26 & 25,03 & 22,90 & 152,93 & 93,81 & 95,71 & 132,79 \\
\hline Epidalea calamita & 30TXM07 & 100,00 & 136,85 & 105,91 & 38,00 & 5960,25 & 290,10 & 15,45 & 274,65 & 102,64 & 213,73 & 213,73 & 61,61 & 545,48 & 61,27 & 26,12 & 22,41 & t & 98,66 & 98,93 & 144,92 \\
\hline Epidalea calamita & 30TXM08 & 100,00 & 134,51 & 105,33 & 38,00 & 5906,84 & 286,66 & 14,23 & 272,43 & $\begin{array}{l}\mid 96,204 \\
98,32 \\
\end{array}$ & 210,73 & 210,73 & $\begin{array}{l}1,0,05 \\
60\end{array}$ & $\begin{array}{l}595,02 \\
\end{array}$ & 66,05 & 28, & 22,00 & 07 & 106,76 & 106,98 & 162,32 \\
\hline Epidalea calamita & 30TXM09 & 100,00 & 13 & 105,03 & \begin{tabular}{|c|}
38,08 \\
\end{tabular} & 5861,17 & 282,84 & 12,12 & 270,72 & 94,86 & 207,03 & 207,03 & 57,59 & 657,07 & 74,7 & 31,6 & 21,99 & 198,86 & 116,63 & 116,63 & 184,39 \\
\hline Epidalea calamita & 30TXM11 & 100,00 & 108,93 & 107,27 & 37,33 & 6114,24 & 266,96 & $-15,77$ & 282,72 & 130,41 & 188,38 & 188,64 & 33,11 & 500,37 & 67,56 & 27,44 & 26,07 & 165,91 & 99,46 & 112,92 & 113,78 \\
\hline Epidalea calamita & 30TXM12 & 100,00 & 117,64 & 107,61 & 37,63 & 6132,64 & 276,22 & $-6,61$ & 282,83 & 139,49 & 197,34 & 197,41 & 41,34 & 477,46 & 63,91 & 25,09 & 26,04 & 156,16 & 92,14 & 101,36 & 111,16 \\
\hline Epidalea calamita & 30TXM13 & 100,00 & 121,44 & 107,69 & 37,73 & 6119,63 & 279,95 & $-2,63$ & 282,58 & 143,28 & 200,77 & 200,86 & 44,90 & 481,73 & \begin{tabular}{l|l}
63,05 \\
\end{tabular} & 24,77 & 25,32 & 56 & 91,31 & 100,01 & 115,08 \\
\hline Epidalea calamita & $\frac{30 T x}{30 T x}$ & 100,00 & $\begin{array}{l}121,44 \\
132,42\end{array}$ & 107,17 & 37,69 & $\frac{6}{6}$ & 289,75 & $\begin{array}{c}-2,0,56 \\
8,56\end{array}$ & \begin{tabular}{|l|}
281,19 \\
2819
\end{tabular} & \begin{tabular}{|l|}
1534,720 \\
154
\end{tabular} & \begin{tabular}{|l|}
211,33 \\
\end{tabular} & \begin{tabular}{|l|}
211,37 \\
\end{tabular} & 45,81 & $\mid \begin{array}{l}\mid 401,15 \\
466,15\end{array}$ & $\begin{array}{l}\mid 50,05 \\
59,06\end{array}$ & 22,67 & 24,96 & $\begin{array}{l}145,23 \\
145\end{array}$ & 85,77 & $\begin{array}{r}0,01,68 \\
8,6\end{array}$ & $\begin{array}{l}1114,00 \\
114,99\end{array}$ \\
\hline Epidalea calamita & 30TXM15 & 100,00 & 137,34 & 106,54 & 37,96 & 6040,20 & 292,78 & 14,55 & 278,22 & 159,61 & 215,33 & 215,33 & 61,35 & 480,36 & 58,18 & 22,85 & 24,02 & 145,01 & 87,32 & 89,54 & 122,01 \\
\hline Epidalea calamita & 30TXM16 & 100,00 & 136,42 & 106,17 & 38,00 & 6012,49 & 291,15 & 14,39 & 276,76 & \begin{tabular}{|l|}
134,60 \\
\end{tabular} & $\mid 213,97$ & 213,97 & 60,58 & 516,44 & 60,18 & 24,55 & 23,20 & 152,87 & 93,38 & 95,00 & 134,77 \\
\hline Epidalea calamita & 30TXM17 & 100,00 & 132,53 & 106,19 & 38,00 & 5976,67 & 286,65 & 11,06 & 275,59 & 102,39 & 209,63 & 209,63 & 57,17 & 567,05 & 63,84 & 27,16 & 22,45 & 167,42 & 101,85 & 102,41 & 152,02 \\
\hline Epidalea calamita & 30TXM18 & 100,00 & 130,54 & 105,84 & 38,00 & 5931,66 & 283,74 & 9,80 & 273,94 & 94,21 & 207,13 & 207 & 55,90 & 618,58 & 69,70 & 29,63 & 22,02 & 185,17 & 110,02 & 110,09 & 170 \\
\hline Epidalea calamita & \begin{tabular}{|}
$30 \mathrm{TXM19}$ \\
3
\end{tabular} & 100,00 & $\begin{array}{l}130,54 \\
130,52\end{array}$ & $\begin{array}{l}105,04 \\
105,12\end{array}$ & 38,01 & 5871,83 & $\begin{array}{l}20,14 \\
282,08\end{array}$ & \begin{tabular}{|c|}
10,50 \\
10,
\end{tabular} & \begin{tabular}{|l|}
271,58 \\
270
\end{tabular} & \begin{tabular}{l|l}
44,21 \\
94,28
\end{tabular} & \begin{tabular}{|l|}
206,24 \\
201
\end{tabular} & \begin{tabular}{|l|}
206,24 \\
201
\end{tabular} & $\begin{array}{l}50,29 \\
56,29\end{array}$ & \begin{tabular}{|c|}
673,35 \\
673,5
\end{tabular} & $\begin{array}{l}05,10 \\
77,95\end{array}$ & \begin{tabular}{|l|l|}
31,95 \\
31
\end{tabular} & $\frac{22,21}{22,21}$ & \begin{tabular}{|l|}
205,12 \\
20,11
\end{tabular} & 118,55 & 118,55 & $\begin{array}{l}11,00 \\
191,28\end{array}$ \\
\hline Epidalea calamita & $30 \mathrm{TXM} 20$ & 100,00 & 120,56 & 106,08 & 37,00 & 6164,38 & 276,99 & $-4,47$ & 281,46 & 143,08 & 196,55 & 200,55 & 43,73 & 431,75 & 61,31 & 22,69 & 29,33 & 146,86 & 85,24 & 97,42 & 94,21 \\
\hline Epidalea calamita & 30TXM21 & 100,00 & 120,15 & 106,34 & 37,10 & 6151,16 & 277,36 & $-4,48$ & 281,84 & 142,54 & 199,81 & 199,93 & 43,44 & 447,68 & 62,19 & 23,31 & 28,18 & 149,69 & 87,07 & 97,29 & 100,56 \\
\hline Epidalea calamita & 30TXM23 & 100,00 & 133,82 & 106,67 & 37,25 & 6133,99 & 291,05 & 9,61 & 281,44 & 156,30 & 213,06 & 213, & 56, & 437,57 & 57,78 & 20,95 & 26,66 & 139,33 & 80,58 & 82,35 & 104,92 \\
\hline Epidalea calamita & 30TXM24 & 100,00 & 138,28 & 106,28 & 37,48 & 6087,83 & 294,44 & 15,01 & 279,43 & 160,78 & 216,96 & 216,96 & 61,71 & 449,59 & 56,90 & 21,03 & 25,46 & 138,72 & 81,65 & 82,90 & 111,29 \\
\hline
\end{tabular}




\begin{tabular}{|c|c|c|c|c|c|c|c|c|c|c|c|c|c|c|c|c|c|c|c|c|c|}
\hline TAXON & UTM & $\mathrm{km2}$ & B101 & $\mathrm{B1O2}$ & $\mathrm{BIO3}$ & B104 & B105 & B106 & B107 & B108 & B109 & 81010 & B1011 & BIO12 & BIO13 & 81014 & B1015 & B1O16 & B1017 & B1018 & B1019 \\
\hline Epidalea calamita & 30TXM25 & 100,00 & 135,71 & 106,21 & 37,74 & 6045,86 & 291,28 & 12,96 & 278,32 & 157,97 & 213,74 & 213,74 & 59,53 & 487,17 & 59,36 & 23,02 & 24,15 & 147,02 & 88,34 & 90,45 & 123,83 \\
\hline Epidalea calamita & 30TXM26 & 100,00 & 132,34 & 106,18 & $\begin{array}{l}37,95 \\
\end{array}$ & 6011,91 & 287,35 & 10,14 & 277,21 & 140,20 & 209,87 & 209,87 & 56,56 & 530,36 & 62,22 & 25,35 & 23,09 & 157,15 & 95,82 & 99,69 & 138,38 \\
\hline Epidalea calamita & 30TXM27 & 100,00 & 133,69 & 105,99 & 38,00 & 5966,34 & 287,39 & 12,47 & 274,92 & 96,91 & 210,66 & 210,66 & 58,58 & 564,81 & 63,52 & 26,71 & 22,52 & 167,48 & 101,29 & 102,42 & 151,60 \\
\hline Epidalea calamita & 30TXM28 & 100,00 & 127,85 & 105,90 & 38,00 & 5923,58 & 280,96 & 7,13 & 273,82 & 91,65 & 204,24 & 204,24 & 53,19 & 630,60 & 71,13 & 30,23 & 21,98 & 188,22 & 112,42 & 112,42 & 173,84 \\
\hline Epidalea calamita & 30 TXM29 & 100,00 & 126,49 & 105,21 & 38,02 & 5856,42 & 278,16 & 6,71 & 271,46 & 87,33 & 202,15 & 202,15 & 52,67 & 689,63 & 79,75 & 32,97 & 21,94 & 209,18 & 122,07 & 122,07 & 195,51 \\
\hline Epidalea calamita & 30TXM30 & 100,00 & 133,31 & 105,50 & 37,00 & 6201,89 & 289,74 & 7,93 & 281,81 & 156,36 & 213,27 & 213,35 & 55,65 & 385,79 & 55,91 & 18,82 & 31,03 & 130,92 & 73,59 & 82,72 & 84,01 \\
\hline Epidalea calamita & 30TXM32 & 100,00 & 134,91 & 106,01 & 37,00 & 6158,24 & 292,16 & 10,49 & 281,66 & 157,51 & 214,41 & 214,42 & 57,63 & 410,03 & 56,70 & 19,42 & 28,87 & 133,87 & 75,70 & 79,25 & 94,99 \\
\hline Epidalea calamita & $30 \mathrm{TXM} 34$ & 100,00 & 139,01 & 106,00 & 37,13 & 6091,52 & 295,14 & 16,02 & 279,12 & 161,30 & 217,59 & 217,59 & 62,35 & 445,40 & 56,66 & 20,54 & 25,57 & 137,27 & 80,77 & 82,81 & 109,71 \\
\hline Epidalea calamita & 30TXM35 & 100,00 & 127,31 & 106,02 & 37,54 & 6041,35 & 283,19 & 4,91 & 278,28 & 149,26 & 205,41 & 205,41 & 51,55 & 509,78 & 62,90 & 24,80 & 23,64 & 155,61 & 93,61 & 96,50 & 127,89 \\
\hline Epidalea calamita & 30TXM37 & 100,00 & 129,39 & 105,94 & 38,00 & 5959,24 & 283,29 & 8,04 & 275,24 & 95,12 & 206,40 & 206,40 & 54,34 & 575,10 & 65,06 & 27,44 & 22,10 & 168,96 & 103,88 & 104,77 & 153,17 \\
\hline Epidalea calamita & 30TXM38 & 100,00 & 127,53 & 105,31 & 38,00 & 5906,47 & 279,88 & 6,84 & 273,04 & 91,61 & 203,72 & 203,72 & 52,95 & 626,84 & 70,12 & 29,96 & 21,65 & 186,67 & 112,73 & 113,19 & 171,50 \\
\hline Epidalea calamita & 30TXM39 & 100,00 & 124,96 & 104,99 & 38,09 & 5850,36 & 275,92 & 5,17 & 270,75 & 89,49 & 200,52 & 200,52 & 51,20 & 687,19 & 78,48 & 32,94 & 21,50 & 207,19 & 123,07 & 123,44 & 192,83 \\
\hline Epidalea calamita & 30TXM42 & 100,00 & 139,63 & 105,96 & 37,00 & 6174,59 & 297,19 & 15,96 & 281,24 & 162,39 & 219,56 & 219,56 & 62,39 & 391,62 & 54,69 & 17,77 & 29,69 & 127,56 & 71,12 & 71,12 & 90,34 \\
\hline Epidalea calamita & 30TXM44 & 100,00 & 138,46 & 105,95 & \begin{tabular}{|l|l|}
37,08 \\
\end{tabular} & 6090,79 & 294,70 & 15,47 & 279,23 & 160,71 & 217,24 & 217,24 & 61,92 & 439,31 & 56,51 & 20,22 & 25,72 & 136,14 & 79,98 & 80,42 & 106,61 \\
\hline Epidalea calamita & 30TXM45 & 100,00 & 134,59 & 105,80 & 37,72 & 6029,52 & 290,12 & 12,27 & 277,86 & 156,46 & 212,67 & 212,67 & 58,95 & 477,71 & 59,03 & 22,36 & 24,01 & 144,83 & 87,31 & 89,01 & 118,78 \\
\hline Epidalea calamita & 30TXM47 & 100,00 & 127,01 & 105,15 & 38,00 & 5924,83 & 280,12 & 5,91 & 274,20 & 114,17 & 203,30 & 203,30 & 52,28 & 574,10 & 65,48 & 27,61 & 21,59 & 167,26 & 105,23 & 107,09 & 150,34 \\
\hline Epidalea calamita & 30TXM48 & 100,00 & 120,32 & 104,88 & 38,03 & 5861,92 & 272,18 & 0,66 & 271,51 & 84,90 & 196,10 & 196,10 & 46,53 & 641,09 & 70,74 & 31,44 & 20,65 & 187,44 & 117,89 & 119,70 & 171,65 \\
\hline Epidalea calamita & 30TXM49 & 100,00 & 111,52 & 104,06 & 38,12 & 5778,43 & 261,90 & $-6,27$ & 268,17 & 76,92 & 186,52 & 186,52 & 39,16 & 720,40 & 78,95 & 36,34 & 19,71 & 210,17 & 133,69 & 136,21 & 195,68 \\
\hline Epidalea calamita & 30TXM50 & 100,00 & 127,07 & 103,95 & 36,92 & 6172,05 & 282,81 & 2,99 & 279,82 & 149,81 & 172,08 & 207,02 & 50,14 & 398,22 & 58,16 & 20,01 & 30,77 & 136,78 & 78,05 & 88,28 & 82,88 \\
\hline Epidalea calamita & 30TXM51 & 100,00 & 139,49 & 105,15 & 37,00 & 6207,42 & 297,79 & 16,05 & 281,74 & 162,24 & 220,04 & 220,05 & 62,15 & 370,43 & 54,14 & 16,79 & 31,68 & 124,02 & 67,68 & 68,56 & 81,76 \\
\hline Epidalea calamita & 30TXM53 & 100,00 & 132,01 & 105,19 & 37,00 & 6110,04 & 289,16 & 9,31 & 279,85 & 154,31 & 211,09 & 211,12 & 55,67 & 426,69 & 57, & 20,29 & 26,89 & 137,25 & 79,52 & 81,85 & 98,06 \\
\hline Epidalea calamita & 30TXM54 & 100,00 & 131,54 & 105,22 & 37,02 & 6068,09 & 288,00 & 9,05 & 278,95 & 153,54 & 210,17 & 210,17 & 55,69 & 450,30 & 58,54 & 21,42 & 25,18 & 141,39 & 83,80 & 86,24 & 106,26 \\
\hline Epidalea calamita & 30TXM55 & 100,00 & 130,65 & 105,09 & 37,32 & 6008,16 & 285,82 & 8,62 & 277,20 & 152,32 & 208,28 & 208,36 & 55,40 & 481,03 & 59,89 & 22,92 & 23,46 & 146,85 & 89,62 & 92,53 & 116,77 \\
\hline Epidalea calamita & 30TXM56 & 100,00 & 131,77 & 105,01 & 37,91 & 5949,14 & 285,46 & 10,50 & 274,96 & 153,61 & 208,60 & 208,63 & 57,17 & 509,43 & 60,64 & 24,06 & 22,18 & 151,01 & 94,66 & 98,75 & 127,41 \\
\hline Epidalea calamita & 30TXM57 & 100,00 & 124,80 & 104,84 & 38,00 & 5881,56 & 277,18 & 4,57 & 272,62 & 137,31 & 200,75 & 200,76 & 50,84 & 569,34 & 65,41 & 27,60 & 20,89 & 165,63 & 106,48 & 109,27 & 145,84 \\
\hline Epidalea calamita & 30TXM58 & 100,00 & 113,90 & 103,95 & 38,00 & 5797,35 & 264,50 & $-4,35$ & 268,85 & 116,61 & 188,90 & 188,90 & 41,18 & 649,11 & 72,57 & 32,71 & 19,63 & 186,95 & 122,80 & 126,16 & 168,81 \\
\hline Epidalea calamita & 30TXM59 & 100,00 & 103,55 & 102,68 & 38,04 & 5708,48 & 252,07 & \begin{tabular}{|l|l|}
$-12,97$ \\
-12,
\end{tabular} & 265,04 & \begin{tabular}{|c|}
93,71 \\
93
\end{tabular} & $\begin{array}{l}177,73 \\
\end{array}$ & 177,74 & $\begin{array}{l}41,16 \\
32,32\end{array}$ & $\mid \begin{array}{l}\mid 734,06 \\
\end{array}$ & 79,99 & 38,29 & 18,39 & 209,68 & 140,80 & $\begin{array}{l}144,08 \\
\end{array}$ & 193,00 \\
\hline Epidalea calamita & 30TXM60 & 100,00 & 135,65 & 104,38 & 36,44 & 6225,17 & 293,69 & 11,31 & 282,38 & 158,78 & 207,07 & 216,32 & 58,02 & 371,20 & 53,65 & 17,91 & 30,35 & 126,58 & 71,97 & 79,83 & 76,02 \\
\hline Epidalea calamita & 30TXM62 & 100,00 & 140,27 & 105,20 & 36,92 & 6196,80 & 299,27 & 16,77 & 282,50 & 163,26 & 220,23 & 220,33 & 62,77 & 378,15 & 52,03 & 17,40 & 27,95 & 123,81 & 70,57 & 75,92 & 82,54 \\
\hline Epidalea calamita & 30TXM64 & 100,00 & 119,33 & 104,01 & 37,06 & 5984,79 & 273,83 & $-1,61$ & 275,44 & 140,75 & 196,83 & 196,96 & 44,60 & 484,83 & 62,92 & 24,45 & 23,75 & 153,50 & 94,64 & 102,13 & 110,14 \\
\hline Epidalea calamita & 30TXM65 & 100,00 & 121,25 & 104,19 & 37,42 & 5940,58 & 275,03 & 0,62 & 274,40 & 142,57 & 198,01 & 198,11 & 46,95 & 503,56 & 63,01 & 25,09 & 22,43 & 155,19 & 97,32 & 103,62 & 118,05 \\
\hline Epidalea calamita & 30TXM66 & 100,00 & 128,08 & 104,69 & 37,91 & 5906,69 & 281,10 & $\begin{array}{l}0,02 \\
7,36 \\
\end{array}$ & 273,74 & \begin{tabular}{|l|l|}
149,54 \\
\end{tabular} & 204,25 & 204,33 & $\begin{array}{ll}53,87 \\
50,5\end{array}$ & 508,92 & $\begin{array}{l}60,97 \\
60\end{array}$ & 24,51 & $\begin{array}{l}21,45 \\
21,57\end{array}$ & \begin{tabular}{|l|}
151,79 \\
15,7
\end{tabular} & $\begin{array}{l}1,02 \\
97,01 \\
\end{array}$ & $\begin{array}{l}100,58 \\
10,5\end{array}$ & 123,64 \\
\hline Epidalea calamita & 30TXM67 & 100,00 & 118,97 & 103,90 & 38,00 & 5817,41 & 270,15 & 0,01 & 270,13 & 139,65 & 194,19 & 194,25 & 46,15 & 572,81 & 66,77 & 28,48 & 20,11 & 168,26 & 110,30 & 114,96 & 141,91 \\
\hline Epidalea calamita & 30TXM68 & 100,00 & 109,32 & 102,91 & 38,01 & 5729,41 & 258,29 & $-7,86$ & 266,14 & 129,00 & 183,44 & 183,52 & 37,62 & 649,78 & 73,60 & 33,38 & 18,82 & 188,19 & 126,30 & 131,44 & 164,01 \\
\hline Epidalea calamita & 30TXM69 & 100,00 & 96,15 & 101,10 & \begin{tabular}{l|l}
38,05 \\
\end{tabular} & 5631,87 & 242,63 & $-18,79$ & 261,42 & 113,00 & 169,56 & 169,58 & 26,19 & 753,18 & 83,07 & 40,55 & 17,42 & 215,76 & 148,84 & 152,24 & 192,26 \\
\hline Epidalea calamita & 30TXM70 & 100,00 & 139,91 & 104,45 & 36,05 & 6233,91 & 299,11 & 15,36 & 283,75 & 163,46 & 148,13 & 220,96 & 62,00 & 362,75 & 50,22 & 17,38 & 28,79 & 122,03 & 71,01 & 77,63 & 71,93 \\
\hline Epidalea calamita & 30TXM71 & 100,00 & 146,76 & 105,24 & $\begin{array}{l}30,03 \\
36,17\end{array}$ & \begin{tabular}{|c|}
6257,39 \\
6251,5
\end{tabular} & 307,56 & 21,90 & $\mid$\begin{tabular}{|l|}
285,66 \\
251
\end{tabular} & $\begin{array}{l}103,40,51 \\
170\end{array}$ & \begin{tabular}{|l|}
227,09 \\
22709
\end{tabular} & \begin{tabular}{|l|}
227,87 \\
\end{tabular} & $\begin{array}{l}68,17 \\
68,0\end{array}$ & \begin{tabular}{|l|l|}
356,92 \\
352
\end{tabular} & $\begin{array}{l}30,2<4 \\
46,94\end{array}$ & $\begin{array}{l}1,30 \\
16,56\end{array}$ & $\begin{array}{l}26,19 \\
26,97\end{array}$ & \begin{tabular}{|l|}
116,55 \\
11,5
\end{tabular} & $\begin{array}{l}1,101 \\
69,08\end{array}$ & $\begin{array}{l}73,65 \\
73,65\end{array}$ & 72,93 \\
\hline Epidalea calamita & 30TXM72 & 100,00 & 139,49 & 105,01 & 36,78 & 6172,47 & 298,75 & $\begin{array}{ll}15,87 \\
\end{array}$ & 282,87 & 162,73 & 218,90 & 219,44 & 62,19 & 380,41 & 50,38 & 17,99 & 26,22 & 123,59 & 73,79 & 79,24 & 79,60 \\
\hline Epidalea calamita & 30TXM73 & 100,00 & 131,66 & 104,51 & 37,00 & 6070,27 & 288,66 & 9,10 & 279,56 & 154,20 & 209,85 & 210,23 & 55,69 & 415,18 & 54,69 & 20,04 & 25,16 & 133,22 & 81,21 & 86,91 & 89,29 \\
\hline Epidalea calamita & 30TXM74 & 100,00 & 123,39 & 103,77 & 37,03 & 5963,16 & 277,90 & 2,33 & 275,57 & 145,01 & 200,31 & 200,54 & 48,69 & 461,11 & 59,48 & 22,87 & 23,54 & 145,45 & 91,31 & 97,31 & 101,83 \\
\hline Epidalea calamita & $30 \mathrm{TXM75}$ & 100,00 & 122,42 & 103,73 & 37,22 & 5894,58 & 275,50 & 2,08 & 273,42 & 143,58 & 198,42 & 198,74 & 48,47 & \begin{tabular}{|l|l|}
487,62 \\
\end{tabular} & 61,03 & 24,21 & 22,26 & 150,28 & 96,39 & \begin{tabular}{|c|}
101,83 \\
\end{tabular} & 110,87 \\
\hline Epidalea calamita & 30TXM77 & 100,00 & 114,39 & 102,89 & 38,00 & 5741,08 & 263,99 & $-3,34$ & 267,33 & 134,57 & 188,62 & 188,75 & 42,53 & 574,25 & 67,66 & 29,0 & 19,62 & 169,91 & $\begin{array}{r}113,86 \\
\end{array}$ & 118,68 & 137,66 \\
\hline Epidalea calamita & $30 T X N$ & 100,00 & 94,27 & 100,14 & 38,01 & 5578,12 & 239,18 & $-20,06$ & 259,24 & 112,36 & 166,83 & 166,86 & 24,87 & 748,31 & 83,20 & 40,77 & 16,95 & 215,23 & 151,02 & 156,15 & 186,56 \\
\hline Epidalea calamita & 30TXM80 & 100,00 & 145,28 & 104,63 & 36,21 & 6190,31 & 303,61 & 20,15 & 283,46 & 168,93 & 79,03 & 225,67 & 67,72 & 355,22 & 47,42 & 16,52 & 28,16 & 116,99 & 69,07 & 74,27 & 69,08 \\
\hline Epidalea calamita & 30TXM81 & 100,00 & 144,28 & 104,85 & 36,36 & 6169,93 & 303,16 & 19,72 & 283,44 & 167,74 & 140,13 & 224,41 & 66,73 & 363,76 & 47,59 & 16 & 26,93 & 18,23 & 71,85 & 75,41 & 72,28 \\
\hline Epidalea calamita & 30TXM82 & 100,00 & $\begin{array}{l}139,35 \\
139,35 \\
\end{array}$ & 104,73 & 36,89 & 6112,10 & 297,35 & 15,57 & \begin{tabular}{|l|}
281,78 \\
\end{tabular} & 162,46 & \begin{tabular}{|l|}
174,81 \\
174,
\end{tabular} & 218,70 & 62,77 & 381,90 & 49,74 & $\frac{18}{18}$ & 25,86 & 92 & 76,19 & 79,36 & 77,58 \\
\hline Epidalea calamita & 30TXM & 100,00 & 13 & 104,30 & \begin{tabular}{|l|l|}
37,08 \\
\end{tabular} & 5953,49 & 288,14 & 11,68 & 276,45 & 155,49 & 209,82 & 210,30 & 58,63 & 422,34 & 53, & 20,11 & 23,76 & 131,74 & 84,71 & 86,98 & 90,53 \\
\hline Epidalea calamita & $30 \mathrm{TXM} 86$ & 100,00 & 124,99 & 103,48 & 37,99 & 5784,12 & 275,87 & 5,21 & 270,66 & 146,09 & \begin{tabular}{|l|l|}
199,47 \\
\end{tabular} & 199,92 & 52,24 & 488,99 & 59,35 & 23,81 & 21,27 & 147,01 & 98,59 & \begin{tabular}{|l|}
100,42 \\
\end{tabular} & 110,74 \\
\hline Epidalea calamita & 30TXM89 & 100,00 & 102,23 & 100,74 & 38,23 & 5560,33 & 246,57 & $-12,78$ & 259,35 & 120,78 & 174,27 & 174,50 & 32,76 & 687,58 & 76,95 & 36,54 & 17,18 & 197,48 & 140,41 & 144,25 & 167,70 \\
\hline Epidalea calamita & 30TXM92 & 100,00 & 129,35 & 103,44 & 36,99 & 5994,92 & 284,30 & 6,92 & 277,38 & 151,60 & 54,36 & 207,39 & 54,36 & 404,14 & 53,86 & 19,69 & 26,35 & 131,16 & 79,34 & 86,07 & 79,34 \\
\hline Epidalea calamita & $30 T \times N$ & 100,00 & 12 & 103,53 & 37,00 & 5941,32 & 283,25 & 7,50 & 275,75 & 151,18 & 76,57 & 206,39 & 54,61 & 412,78 & 53,9 & 19,98 & 25,28 & 131,66 & 82,86 & 86,85 & 82,89 \\
\hline Epidalea calamita & 30TXM96 & 100,00 & 121,81 & 102,79 & \begin{tabular}{|c|}
37,98 \\
\end{tabular} & 5713,07 & 271,06 & 2,91 & 268,15 & 142,77 & 195,99 & 196,03 & 50,15 & 483,54 & 59,36 & 23,76 & 21,50 & 146,06 & 100,17 & 100,21 & 105,26 \\
\hline Epidalea calamita & 30TXM99 & 100,00 & 94,60 & 99,09 & 38,08 & 5505,17 & 237,16 & $-18,87$ & 256,03 & 112,80 & 166,07 & 166,36 & 26,08 & $718,17 \mid$ & 81,02 & 39,44 & 16,76 & 208,06 & 150,51 & 154.57 & 170,46 \\
\hline Epidalea calamita & 30 TXNOO & 100,00 & 127,58 & 104,76 & 38,30 & 5801,83 & 278,61 & 9,32 & 269,29 & 70,78 & 202,65 & 202,65 & 54,66 & 733,37 & 85,78 & 35,25 & 22,26 & 226,05 & 128,43 & 128,43 & 212,22 \\
\hline Epidalea calamita & 30 TXN01 & 100,00 & 122,08 & 104,38 & 38,45 & 5749,16 & 272,88 & 5,07 & 267 & 58,33 & 196,59 & 196,59 & 49,94 & 823,10 & 98,48 & 39,67 & 22,73 & 259,36 & 142,68 & 142,68 & 244,35 \\
\hline Epidalea calamita & \begin{tabular}{|l|}
30 TXNO2 \\
\end{tabular} & 100,00 & $\begin{array}{l}12,00 \\
118,55\end{array}$ & $\begin{array}{l}103,50 \\
103,34\end{array}$ & $\begin{array}{l}30,45 \\
38,71\end{array}$ & 5664,61 & $\begin{array}{l}27,2,00 \\
267,93\end{array}$ & 3,58 & \begin{tabular}{|l|}
264,35 \\
264
\end{tabular} & $\begin{array}{l}0,33 \\
56,29 \\
\end{array}$ & \begin{tabular}{|l|}
192,16 \\
1929
\end{tabular} & \begin{tabular}{|l|l|}
192,16 \\
1925
\end{tabular} & $\begin{array}{l}47,55 \\
47,5\end{array}$ & \begin{tabular}{|l|l|}
908,59 \\
90,
\end{tabular} & \begin{tabular}{|l|}
50,40 \\
110,43
\end{tabular} & $\begin{array}{l}3,78 \\
43,78\end{array}$ & 23,08 & \begin{tabular}{|l|}
291,15 \\
2910
\end{tabular} & \begin{tabular}{|l|}
152,000 \\
156,75 \\
\end{tabular} & $\begin{array}{l}142,00 \\
156,75 \\
\end{array}$ & $\begin{array}{l}244,53 \\
274,93\end{array}$ \\
\hline Epidalea calamita & 30TXNO3 & 100,00 & 117,28 & 101,84 & 38,87 & 5563,04 & 264,31 & 4,46 & 259,85 & 56,19 & 189,71 & 189,71 & 47,87 & 987,76 & 121,64 & 47,40 & 23,51 & 321,10 & 170,42 & 170,42 & 303,38 \\
\hline Epidalea calamita & 30TXN04 & 100,00 & 120,11 & 99,69 & 38,96 & 5424,70 & 263,16 & 9,95 & 253,21 & 60,57 & 190,76 & 190,76 & 52,43 & 1054,55 & 130,95 & 50,27 & 23,93 & 346,91 & 182,97 & 182,97 & 327,25 \\
\hline Epidalea calamita & 30TXN05 & 100,00 & 110,26 & 97,76 & 39,07 & 5256,90 & 249,72 & 3,59 & 246,12 & 53,32 & 179,04 & 179,04 & 45, & 1130,85 & 136,25 & 56,18 & 21,96 & 365 & 203,32 & 203,32 & 344,20 \\
\hline Epidalea calamita & 30 XN10 & 100,00 & 123,99 & 105,02 & 38,19 & 5829,79 & 275,63 & 5,13 & 270,50 & 65,01 & 199,39 & 199,39 & 50,54 & 757,65 & 89,75 & 36,32 & 22,51 & 234,27 & 132,08 & 132,08 & $221, \mathrm{C}$ \\
\hline
\end{tabular}




\begin{tabular}{|c|c|c|c|c|c|c|c|c|c|c|c|c|c|c|c|c|c|c|c|c|c|}
\hline TAXON & UTM & $\mathrm{km} 2$ & B101 & B102 & $\mathrm{BIO3}$ & B104 & B105 & B106 & B107 & B108 & B109 & BIO10 & BIO11 & BIO12 & 81013 & BIO14 & BIO15 & BIO16 & BIO17 & B1018 & B1019 \\
\hline Epidalea calamita & 30TXN11 & 100,00 & 112,57 & 104,39 & 38,63 & 5739,69 & 263,64 & $-3,90$ & 267,55 & 49,56 & 187,27 & 187,27 & 40,99 & 859,66 & 101,79 & 42,53 & 21,75 & 267,27 & 151,36 & 151,36 & 252,99 \\
\hline Epidalea calamita & 30TXN12 & 100,00 & 104,16 & 102,64 & \begin{tabular}{|l|l|}
38,87 \\
\end{tabular} & 5612,40 & 252,62 & $-9,53$ & 262,15 & 43,29 & 177,51 & 177,51 & 34,44 & 941,64 & 110,28 & $\begin{array}{l}47,85 \\
\end{array}$ & 20,74 & 291,98 & 169,21 & 169,21 & 276,37 \\
\hline Epidalea calamita & 30TXN13 & 100,00 & 118,26 & 102,80 & 38,63 & 5631,79 & 266,64 & 3,42 & 263,22 & 56,39 & 191,36 & 191,36 & 47,70 & 996,28 & 125,80 & 47,05 & 24,63 & 327,85 & 169,48 & 169,48 & 310,93 \\
\hline Epidalea calamita & $30 T X N 20$ & 100,00 & 116,12 & 104,93 & 38,45 & 5801,88 & 267,64 & $-1,72$ & 269,35 & 55,99 & 191,37 & 191,37 & 43,40 & 782,81 & 91,30 & $\begin{array}{l}38,45 \\
\end{array}$ & 21,42 & 238,41 & 138,98 & 138,98 & 225,49 \\
\hline Epidalea calamita & 30TXN21 & 100,00 & 110,77 & 103,97 & 38,69 & 5720,06 & 260,75 & $-5,38$ & 266,14 & 48,12 & 185,19 & 185,19 & 39,23 & 858,42 & 100,73 & $\begin{array}{ll}42,72 \\
\end{array}$ & 21,16 & 264,27 & 153,29 & 153,29 & 250,21 \\
\hline Epidalea calamita & $30 \mathrm{TXN} 22$ & 100,00 & 103,37 & 102,39 & 38,82 & 5608,17 & 251,24 & $-10,44$ & 261,68 & 42,50 & 176,68 & 176,68 & 33,57 & 936,79 & 109,38 & 47,68 & 20,38 & 288,82 & 169,79 & 169,79 & 273,40 \\
\hline Epidalea calamita & 30 TXN23 & 100,00 & 111,31 & 102,05 & 38,93 & 5571,81 & 257,65 & $-2,50$ & 260,15 & 50,36 & 183,84 & 183,84 & 41,60 & 988,25 & 120,37 & 48,46 & 22,30 & 315,84 & 175,14 & 175,14 & 299,01 \\
\hline Epidalea calamita & 30TXN24 & 100,00 & 105,82 & 100,25 & 38,97 & 5446,53 & 249,11 & $-5,28$ & 254,39 & 46,76 & 176,99 & 176,99 & 37,91 & 1056,73 & 127,07 & 53,08 & 21,29 & 336,13 & 191,33 & 191,33 & 317,75 \\
\hline Epidalea calamita & 30 TXN25 & 100,00 & 100,82 & 98,30 & 39,01 & 5322,00 & 240,78 & $-7,48$ & 248,25 & 43,32 & 170,44 & 170,44 & 34,87 & 1122,83 & 133,32 & 57,64 & 20,37 & 355,39 & 207,64 & 207,64 & 335,49 \\
\hline Epidalea calamita & 30 TXN30 & 100,00 & 115,90 & 104,45 & 38,38 & 5773,08 & 266,18 & $-2,04$ & 268,22 & 67,10 & 190,80 & 190,80 & 43,46 & 772,37 & 88,94 & 38,00 & 20,84 & 232,83 & 139,04 & 139,04 & 219,86 \\
\hline Epidalea calamita & $30 \mathrm{TXN} 31$ & 100,00 & 120,59 & 103,87 & 38,52 & 5721,66 & 268,99 & 2,92 & 266,06 & 65,57 & 194,55 & 194,55 & 48,45 & 814,16 & 96,60 & 39,15 & 21,72 & 252,33 & 145,09 & 145,09 & 238,28 \\
\hline Epidalea calamita & 30TXN32 & 100,00 & 113,49 & 102,85 & 38,92 & 5636,46 & 260,48 & $-2,03$ & 262,51 & 51,78 & 186,71 & 186,71 & 42,65 & 896,38 & 106,61 & 44,13 & 21,28 & 279,60 & 161,46 & 161,46 & 264,25 \\
\hline Epidalea calamita & 30 TXN33 & 100,00 & 113,11 & 101,81 & 38,94 & 5557,36 & 257,84 & $-1,08$ & 258,92 & 52,09 & 185,17 & 185,17 & 43,17 & 960,76 & 115,81 & 47,24 & 21,58 & 303,97 & 173,33 & 173,33 & 287,33 \\
\hline Epidalea calamita & 30 TXN40 & 100,00 & 108,21 & 103,44 & \begin{tabular}{|l|l|}
38,47 \\
\end{tabular} & 5707,76 & 256,78 & $-8,56$ & 265,34 & 71,64 & 182,34 & 182,34 & 36,77 & 781,12 & 86,62 & 39,74 & 19,31 & 229,63 & 145,28 & 146,48 & 215,80 \\
\hline Epidalea calamita & 30 TXN41 & 100,00 & 119,31 & 103,47 & 38,94 & 5672,28 & 266,17 & 1,97 & 264,20 & 81,03 & 192,59 & 192,59 & 47,78 & 796,64 & 92,31 & 38,74 & 20,62 & 243,00 & 145,39 & 145,78 & 228,46 \\
\hline Epidalea calamita & $30 \mathrm{TXN} 42$ & 100,00 & 107,87 & 101,97 & 38,86 & 5576,71 & 252,92 & $-6,84$ & 259,76 & 48,18 & 180,30 & 180,30 & 37,93 & 892,28 & 102,53 & 45,19 & 19,58 & 271,23 & 165,82 & 165,88 & 255,72 \\
\hline Epidalea calamita & $30 \mathrm{TXN51}$ & 100,00 & 108,88 & 102,45 & 38,88 & 5601,82 & 254,21 & $-6,87$ & 261,08 & 73,79 & 181,44 & 181,44 & 38,63 & 810,39 & 89,62 & 41,22 & 18,58 & 239,75 & 153,41 & 154,05 & 224,22 \\
\hline Epidalea calamita & 30TXN52 & 100,00 & 94,12 & 100,09 & 38,71 & 5497,32 & 237,15 & $-18,39$ & 255,54 & 40,05 & 165,93 & 165,93 & 25,84 & 916,59 & 99,80 & \begin{tabular}{|l|l|}
49,03 \\
\end{tabular} & 17,30 & 267,96 & 177,47 & 177,65 & 251,91 \\
\hline Epidalea calamita & 30 TXN60 & 100,00 & 96,16 & 100,88 & 38,29 & 5581,02 & 241,26 & $-18,22$ & 259,48 & 85,60 & 168,81 & 168,82 & 26,77 & 795,91 & 85,27 & 42,70 & 17,05 & 226,86 & 156,68 & 159,86 & 207,69 \\
\hline Epidalea calamita & 30 TXN62 & 100,00 & 102,55 & 100,90 & 38,94 & 5489,47 & 244,74 & $-11,35$ & 256,10 & 66,79 & 173,81 & 173,82 & 33,73 & 857,75 & 92,71 & 44,94 & 17,23 & 250,88 & 167,34 & 168,63 & 233,86 \\
\hline Epidalea calamita & 30TXN73 & 100,00 & 85,05 & 97,78 & 38,79 & 5374,32 & 223,78 & $-25,52$ & 249,30 & 41,20 & 155,22 & 155,22 & 18,37 & 957,36 & 99,77 & 53,41 & 15,22 & 272,27 & 193,53 & 194,56 & 254,34 \\
\hline Epidalea calamita & $30 T \times N 80$ & 100,00 & 95,74 & 99,77 & 38,26 & 5501,36 & 238,35 & $-18,12$ & 256,46 & 111,46 & 167,05 & 167,16 & 27,15 & 759,75 & 82,89 & 41,34 & 16,27 & 215,49 & 155,52 & 160,27 & 188,89 \\
\hline Epidalea calamita & 30 TXN81 & 100,00 & 100,32 & 100,29 & 38,84 & 5463,93 & 241,77 & $-13,60$ & 255,36 & 77,98 & 171,12 & 171,20 & 31,85 & 777,44 & 82,15 & \begin{tabular}{|l|l|}
41,64 \\
\end{tabular} & 16,02 & 220,54 & 158,28 & 161,55 & 198,11 \\
\hline Epidalea calamita & 30TXN83 & 100,00 & 75,68 & 95,40 & 38,34 & 5342,54 & 212,55 & $-33,13$ & 245,68 & 55,34 & 145,72 & 145,72 & 9,74 & 993,85 & 102,26 & 57,44 & 14,39 & 278,46 & 205,26 & 206,54 & 257,59 \\
\hline Epidalea calamita & 30 TXN84 & 100,00 & 50,41 & 89,26 & 37,13 & 5272,72 & 183,66 & $-53,41$ & 237,07 & 35,53 & 120,55 & 120,55 & $-13,35$ & 1171,25 & 119,66 & 71,51 & 13,39 & 325,22 & 244,61 & 244,93 & 302,94 \\
\hline Epidalea calamita & 30TXN90 & 100,00 & 93,84 & 99,07 & 38,37 & 5463,30 & 235,24 & $-19,39$ & 254,62 & 111,83 & 164,67 & 164,93 & 25,66 & 755,96 & \begin{tabular}{|l|}
83,18 \\
\end{tabular} & 41,68 & 15,97 & 215,56 & 158,02 & 162,15 & 183,27 \\
\hline Epidalea calamita & 30TXN91 & 100,00 & $\begin{array}{l}90,04 \\
94,57\end{array}$ & 99,19 & 38,74 & 5424,62 & 234,78 & \begin{tabular}{|l|l|}
$-18,37$ \\
\end{tabular} & 253,15 & $\begin{array}{l}100,32 \\
100\end{array}$ & 164,88 & 165,09 & 26,64 & 790,45 & $\mid \begin{array}{l}\mid 8,10 \\
84,67\end{array}$ & $43,4,56$ & 15,38 & 222,04 & 164,76 & 169,02 & 195,90 \\
\hline Epidalea calamita & 30TYKO3 & 100,00 & 121,97 & 93,96 & 36,01 & 5896,13 & 264,49 & 7,97 & 256,52 & 131,42 & 70,05 & 201,18 & 52,27 & 500,34 & 61,01 & 23,30 & 28,63 & 161,39 & 94,81 & 108,03 & 95,10 \\
\hline Epidalea calamita & 30TYKO4 & 100,00 & 123,28 & 93,37 & 36,00 & 5899,78 & 264,98 & 9,00 & 255,98 & 132,69 & 57,10 & 202,31 & 53,42 & 485,57 & 60,07 & 22,98 & 29,46 & 156,54 & 90,19 & 105,87 & 90,23 \\
\hline Epidalea calamita & 30TYK05 & 100,00 & 100,61 & 94,21 & 35,98 & 6014,84 & 246,59 & $-13,39$ & 259,98 & 116,11 & 30,21 & 181,51 & 30,21 & 575,43 & 72,34 & 30,21 & 26,24 & 183,80 & 108,59 & 126,76 & 108,59 \\
\hline Epidalea calamita & $\begin{array}{l}\text { 30TYKO6 } \\
\end{array}$ & 100,00 & 82,51 & 94,53 & 35,76 & 6042,75 & 230,55 & $-31,23$ & 261,78 & 97,21 & 12,21 & 164,17 & 12,21 & 668,16 & 83,47 & 36,83 & 23,72 & 213,93 & 130,97 & 147,32 & 130,97 \\
\hline Epidalea calamita & 30TYK07 & 100,00 & $\frac{2,11}{68,33}$ & 94,32 & 35,40 & 6042,30 & 217,98 & $\begin{array}{l}-44,36 \\
-44\end{array}$ & 262,34 & $\begin{array}{ll}82,14 \\
8\end{array}$ & $\mid-1,25$ & 150,22 & $\frac{12,12}{-1,25}$ & 753,29 & $\begin{array}{l}0,479 \\
92,79 \\
\end{array}$ & $\begin{array}{l}40,75 \\
42,78\end{array}$ & 21,72 & 239,41 & 152,74 & 163,50 & 152,74 \\
\hline Epidalea calamita & 30TYK08 & 100,00 & 75,69 & 93,84 & 35,46 & 6025,71 & 223,34 & $-37,81$ & 261,16 & 90,59 & 5,51 & 156,97 & 5,51 & 697,84 & 87,99 & 39,66 & 23,44 & 224,99 & 137,49 & 155,86 & $\begin{array}{ll}137,49 \\
\end{array}$ \\
\hline Epidalea calamita & 30TYK13 & 100,00 & 133,52 & 91,90 & 36,12 & 5720,51 & 270,72 & 20,66 & 250,06 & 141,93 & 190,10 & 210,40 & 65,70 & 480,60 & 60,84 & 20,39 & 30,59 & 163,49 & 89,91 & 102,94 & 94,05 \\
\hline Epidalea calamita & 30TYK14 & 100,00 & 123,12 & 92,46 & 36,00 & 5828,78 & 263,21 & 9,57 & 253,64 & 131,23 & 74,62 & 201,51 & 54,37 & 506,39 & 61,50 & 23,19 & 28,91 & 164,30 & 96,57 & 110,36 & 96,83 \\
\hline Epidalea calamita & 30TYK15 & 100,00 & 107,86 & 92,99 & 35,94 & 5930,00 & 251,03 & $-5,59$ & 256,62 & 121,00 & 39,34 & 187,61 & 38,37 & 561,84 & 69,31 & 27,93 & 26,82 & 177,01 & 107,34 & 122,82 & 107,34 \\
\hline Epidalea calamita & 30TYK16 & 100,00 & 89,12 & 93,38 & 35,75 & 5989,60 & 234,93 & $-23,77$ & 258,70 & 103,82 & 19,38 & 169,94 & 19,38 & 647,59 & 80,16 & 34,49 & 24,11 & 204,66 & 126,70 & 141,65 & 126,70 \\
\hline Epidalea calamita & 30TYK17 & 100,00 & 79,80 & 93,19 & 35,45 & 5998,27 & 226,32 & $-32,95$ & 259,27 & 94,19 & 10,12 & 160,93 & 10,12 & 696,13 & 86,12 & 38,19 & 23,01 & 220,55 & 138,31 & 152,19 & 138,31 \\
\hline Epidalea calamita & 30TYK18 & 100,00 & 82,81 & 92,92 & 35,28 & 5984,08 & 228,21 & $-30,54$ & 258,75 & 97,72 & 12,92 & 163,42 & 12,92 & 670,47 & 84,31 & 37,02 & 23,94 & 214,57 & 131,01 & 148,71 & 131,01 \\
\hline Epidalea calamita & 30TYK23 & 100,00 & 144,56 & 89,52 & 36,22 & 5531,22 & 276,12 & 33,26 & 242,86 & 153,56 & 217,08 & 218,90 & 78,57 & 466,90 & \begin{tabular}{c|c|}
64,05 \\
\end{tabular} & \begin{tabular}{l|l}
17,85 \\
\end{tabular} & 33,37 & 167,93 & 80,47 & 98,66 & 94,84 \\
\hline Epidalea calamita & 30TYK24 & 100,00 & 128,92 & 91,07 & 36,01 & 5715,12 & 265,81 & $\begin{array}{ll}16,21 \\
\end{array}$ & 249,60 & 137,03 & 174,89 & 205,76 & 61,53 & 508,72 & 62,90 & 21,82 & 29,73 & 170,49 & 96,40 & 109,53 & 100,30 \\
\hline Epidalea calamita & 30TYK25 & 100,00 & 107,68 & 92,12 & 35,88 & 5869,38 & 249,48 & \begin{tabular}{|l|l|}
$-5,07$ \\
\end{tabular} & 254,55 & |118,68 & $\begin{array}{l}48,43 \\
4\end{array}$ & 186,86 & 39,12 & 584,87 & 70,64 & 28,20 & 26,23 & 183,42 & 114,63 & 126,74 & 114,80 \\
\hline Epidalea calamita & 30TYK26 & 100,00 & 100,24 & 92,26 & 35,75 & 5912,12 & 243,11 & $-12,43$ & 255,55 & 114,83 & 31,38 & 179,99 & 31,38 & 609,25 & 74,69 & 30,53 & 25,43 & 189,27 & 118,88 & 132,87 & 118,88 \\
\hline Epidalea calamita & 30TYK27 & 100,00 & 94,48 & 92,16 & 35,46 & 5924,91 & 237,75 & $-18,30$ & 256,05 & 108,97 & 25,47 & 174,32 & 25,47 & 632,28 & 78,20 & 32,69 & 24,78 & 198,42 & 123,46 & 138,70 & 123,46 \\
\hline Epidalea calamita & 30TYK33 & 100,00 & 157,83 & 86,51 & 36,2 & 5315,71 & 282,90 & 48,26 & 234,65 & 167,63 & 226,74 & 229,22 & 93,87 & 445,7 & 66,24 & 15, & 37,56 & 170,38 & 69,38 & 93,29 & 93,96 \\
\hline Epidalea calamita & 30TYK34 & 100,00 & 142,37 & 88,91 & 36,6 & 5524,07 & 273,7 & $\begin{array}{l}0,20 \\
30,99 \\
\end{array}$ & 242,71 & 150,77 & 214,97 & 216,80 & 76,91 & $\begin{array}{l}486,08 \\
486,0\end{array}$ & 65,09 & 18 & 32,92 & 173,11 & 84,74 & 103,44 & $\begin{array}{l}99,05 \\
99\end{array}$ \\
\hline Epidalea calamita & 30 TYK & 100,00 & 13 & 90,27 & 35,99 & 5665,03 & 265,95 & 18,15 & 247,80 & 138,52 & 179,23 & 206,97 & 64,04 & 516,23 & 64,66 & 21, & 30,31 & 174,27 & 96,55 & 111,27 & 102,75 \\
\hline Epidalea calamita & $\begin{array}{l}30 \text { TYK36 } \\
\end{array}$ & 100,00 & 120,48 & 90,97 & 35,82 & 5759,56 & 258,38 & $\begin{array}{ll}7,41 \\
7,41\end{array}$ & 250,97 & 128,45 & 105,86 & 197,99 & 52,83 & 546,76 & 66,65 & 24,28 & 28,53 & 176,65 & 105,75 & 118,76 & 107,49 \\
\hline Epidalea calamita & 30TYK37 & 100,00 & 114,97 & 91,26 & 35,73 & 5801,89 & 254,09 & 1,70 & 252,38 & 124,68 & 54,33 & 193,03 & 46,97 & 560,99 & 68,52 & 25,89 & 27,74 & 177,86 & 109,10 & 122,68 & 109,30 \\
\hline Epidalea calamita & 30TYK38 & 100,00 & 105,05 & 91,56 & 35,64 & 5850,46 & 245,73 & $-7,82$ & 253,55 & 119,73 & 36,66 & 183,72 & 36,64 & 594,96 & 73,63 & 28,94 & 26,24 & 184,55 & 115,64 & 129,85 & 115,64 \\
\hline Epidalea calamita & $30 \mathrm{TYK}$ & 100,00 & 11 & 92 & 35 & 5842,47 & 253,56 & $-0,98$ & 254,55 & 125,77 & 46,14 & 191,87 & 44,99 & 552,52 & 69,58 & 26,05 & 28,10 & 173,67 & 105,55 & 120,14 & 105,55 \\
\hline Epidalea calamita & 30TYK43 & 100,00 & 160,71 & 85,01 & 36,01 & 5244,10 & 283,73 & 51,85 & 231,88 & 170,75 & 228,53 & 231,13 & 97,66 & 453,06 & 67,77 & 14,71 & 38,72 & 175,56 & 68,20 & 94,68 & 97,40 \\
\hline Epidalea calamita & 30TYK44 & 100,00 & 154,11 & 86,016 & 36,03 & 5356,39 & 280,45 & $\begin{array}{l}1,03 \\
43,74 \\
\end{array}$ & 236,70 & 162,89 & \begin{tabular}{|l|}
224,01 \\
\end{tabular} & 226,19 & 90,39 & 469,68 & 67,13 & 16,07 & 36,26 & 175,98 & 75,34 & 99,29 & $\begin{array}{l}9,40 \\
98,57\end{array}$ \\
\hline Epidalea calamita & 30TYK45 & 100,00 & 150,55 & 87,93 & 36,01 & 5431,52 & 279,02 & 38,95 & 240,07 & 158,45 & 221,68 & 223,55 & 86,16 & 475,36 & 66,03 & 16,77 & 35,12 & 174,40 & 79,41 & 101,47 & 97,80 \\
\hline Epidalea calamita & 30TYK46 & 100,00 & 135,10 & 89,75 & 35,99 & 5606,18 & 268,66 & 22,27 & 246,39 & 142,36 & 206,40 & 210,55 & 69,29 & 518,79 & 65,81 & 20,37 & 31,31 & 177,99 & 94,90 & 111,56 & 104 \\
\hline Epidalea calamita & $\begin{array}{l}\text { 30TYK47 } \\
\end{array}$ & $\begin{array}{l}100,00 \\
\end{array}$ & $\begin{array}{l}13,10 \\
121,71\end{array}$ & $\begin{array}{l}50,79 \\
90,79\end{array}$ & 35,97 & $\begin{array}{l}500,100 \\
5728,22\end{array}$ & $\begin{array}{l}258,00 \\
258,75\end{array}$ & $\begin{array}{r}2<, 21 \\
8,35 \\
\end{array}$ & \begin{tabular}{|l|}
250,40 \\
250
\end{tabular} & \begin{tabular}{|l|}
128,71 \\
128,7
\end{tabular} & $\begin{array}{l}00,40 \\
137,52 \\
\end{array}$ & \begin{tabular}{|l|l|}
198,86 \\
190
\end{tabular} & $\begin{array}{l}5,26 \\
54,79 \\
\end{array}$ & \begin{tabular}{|l|l|}
557,17 \\
\end{tabular} & $\begin{array}{l}03,01 \\
67,35\end{array}$ & 23,85 & $\begin{array}{l}1,1,51 \\
28,58\end{array}$ & 180,73 & 108,31 & 120,55 & $\begin{array}{l}104,05 \\
110,92\end{array}$ \\
\hline Epidalea calamita & 30TYK49 & 100,00 & 112,81 & 91,67 & 35,87 & 5799,99 & 252,14 & $-1,10$ & 253,24 & 120,85 & 46,74 & 190,63 & 44,90 & 578,67 & 71,28 & 26,39 & 27,33 & 179,76 & 113,38 & 125,70 & 113,40 \\
\hline Epidalea calamita & 30TYK53 & 60,00 & 165,35 & 83,90 & 36,00 & 5208,10 & 286,17 & 56,26 & 229,91 & 175,53 & 232,55 & 235,01 & 102,42 & 451,74 & 68,84 & 13,92 & 40,39 & 178,36 & 65,44 & 94,38 & 98,85 \\
\hline Epidalea calamita & 30TYK54 & 60,00 & 153,71 & 86,33 & 36,02 & 5332,60 & 279,54 & 43,44 & 236,10 & 162, & 223,34 & 225,66 & 90 & 486,86 & 69,44 & 16,11 & 36,36 & 182,61 & 77,08 & 102,47 & 103,82 \\
\hline Epidalea calamita & 30TYK55 & 50,00 & 149,13 & 87,66 & 36,01 & 5415,34 & 277,37 & 37,77 & 239,60 & 156,94 & 220,15 & 222,02 & 85,26 & 496,01 & 68,51 & $\mid \begin{array}{l}17,13 \\
17,13\end{array}$ & 34,70 & 181,50 & 82,24 & 105,34 & 103,52 \\
\hline
\end{tabular}




\begin{tabular}{|c|c|c|c|c|c|c|c|c|c|c|c|c|c|c|c|c|c|c|c|c|c|}
\hline TAXON & UTM & $\mathrm{km} 2$ & B101 & B102 & $\mathrm{BIO3}$ & B104 & B105 & B106 & B107 & B108 & B109 & BIO10 & BIO11 & BIO12 & B1013 & BIO14 & BIO15 & B1016 & B1017 & BIO18 & B1019 \\
\hline Epidalea calamita & 30TYK57 & 50,00 & 132,20 & 90,22 & 35,99 & 5624,92 & 266,61 & 18,71 & 247,89 & 138,72 & 204,88 & 208,01 & 66,71 & 539,14 & 66,88 & 21,00 & 30,62 & 182,24 & 99,75 & 115,82 & 109,14 \\
\hline Epidalea calamita & 30TYK59 & 40,00 & 112,86 & 91,12 & 35,82 & 5774,23 & 251,69 & $-0,48$ & 252,17 & 119,95 & 59,28 & 190,71 & 45,66 & 595,51 & 72,06 & 26,45 & 26,98 & 185,86 & 118,42 & 128,97 & 118,77 \\
\hline Epidalea calamita & 30TYLOO & 100,00 & 100,68 & 93,65 & 35,72 & 5991,09 & 243,55 & $-15,63$ & 259,18 & 118,49 & 29,31 & 180,54 & 29,31 & 540,35 & 72,88 & 28,51 & 29,16 & 180,99 & 97,22 & 127,50 & 97,22 \\
\hline Epidalea calamita & 30TYL02 & 100,00 & 108,92 & 94,52 & 36,00 & 5980,92 & 251,53 & $-9,03$ & 260,56 & 128,27 & 36,94 & 188,23 & 36,94 & 492,30 & 68,41 & 25,25 & 31,07 & 167,44 & 86,54 & 116,54 & 86,54 \\
\hline Epidalea calamita & 30TYL03 & 100,00 & 120,38 & 96,21 & 36,00 & 5988,00 & 264,03 & 0,13 & 263,90 & \begin{tabular}{|l|l|}
140,84 \\
\end{tabular} & 47,60 & 199,38 & 47,60 & 442,49 & 62,33 & 22,27 & 32,47 & 150,72 & 77,01 & \begin{tabular}{|l|l|}
102,17 \\
\end{tabular} & 77,01 \\
\hline Epidalea calamita & 30TYL04 & 100,00 & 128,06 & 97,86 & 36,00 & 6000,80 & 273,61 & 6,32 & 267,29 & 149,40 & 54,93 & 206,99 & 54,88 & 414,35 & 58,48 & 20,44 & 32,87 & 140,48 & 72,46 & 93,32 & 72,46 \\
\hline Epidalea calamita & 30TYL05 & 100,00 & 135,72 & 99,61 & 36,04 & 6025,13 & 283,62 & 12,59 & 271,03 & 157,66 & 61,97 & 214,66 & 61,74 & 388,46 & 54,65 & 18,39 & 32,93 & 130,68 & 68,50 & 85,03 & 68,50 \\
\hline Epidalea calamita & 30TYL06 & 100,00 & 142,20 & 101,20 & 36,22 & 6042,49 & 292,40 & 18,20 & 274,20 & 164,69 & 68,48 & 221,25 & 67,81 & 368,36 & 51,33 & 16,74 & 32,70 & 122,58 & 65,86 & 78,34 & 65,86 \\
\hline Epidalea calamita & 30TYL07 & 100,00 & 144,08 & 102,25 & \begin{tabular}{|l|l|}
36,37 \\
\end{tabular} & 6057,12 & 296,00 & 19,68 & 276,32 & 167,03 & 69,18 & 223,23 & 69,18 & 362,62 & 50,07 & 16,34 & 31,95 & 120,05 & 65,58 & 76,32 & 65,58 \\
\hline Epidalea calamita & 30TYL08 & 100,00 & 147,00 & 103,29 & 36,75 & 6075,08 & 300,51 & 22,25 & \begin{tabular}{|l|l|}
278,27 \\
\end{tabular} & 170,25 & 71,66 & 226,18 & 71,66 & 355,77 & 48,37 & 15,92 & 31,24 & 116,53 & 65,40 & 73,91 & 65,40 \\
\hline Epidalea calamita & 30TYL10 & 100,00 & 102,54 & 93,13 & 35,82 & 5950,25 & 244,84 & $-13,08$ & 257,92 & 120,08 & 32,05 & 181,99 & 32,05 & 552,67 & 72,99 & 29,41 & 28,32 & 181,29 & 101,44 & \begin{tabular}{|c|}
126,59 \\
\end{tabular} & 101,44 \\
\hline Epidalea calamita & 30TYL11 & 100,00 & 106,53 & 93,56 & 35,70 & 5941,94 & 248,77 & $-10,01$ & 258,77 & 124,49 & 35,74 & 185,55 & 35,74 & 528,69 & 70,90 & 27,69 & 29,27 & 174,84 & 95,94 & 121,62 & 95,94 \\
\hline Epidalea calamita & 30TYL12 & 100,00 & 114,35 & $\begin{array}{l}34,74 \\
94\end{array}$ & 35,98 & 5948,82 & 256,97 & $\mid-3,66$ & 260,62 & 133,53 & 42,95 & \begin{tabular}{|l|}
193,27 \\
\end{tabular} & 42,95 & 488,99 & 66,71 & 25,01 & 30,69 & \begin{tabular}{|l|}
162,80 \\
\end{tabular} & 87,40 & 111,36 & 87,40 \\
\hline Epidalea calamita & 30TYL13 & 100,00 & 120,96 & 96,19 & 36,00 & 5955,15 & 264,72 & 1,18 & 263,54 & 140,97 & 49,06 & 199,65 & 49,06 & 458,44 & 63,28 & 22,79 & 31,53 & 153,08 & 81,40 & \begin{tabular}{|l|l|}
103,08 \\
\end{tabular} & 81,40 \\
\hline Epidalea calamita & 30TYL14 & 100,00 & 127,50 & 97,79 & 36,00 & 5971,89 & 273,09 & 6,11 & 266,98 & 148,28 & 55,17 & 206,20 & 55,06 & 431,76 & 59,89 & 20,81 & 32,13 & 143,95 & 76,56 & 95,36 & 76,56 \\
\hline Epidalea calamita & 30TYL15 & 100,00 & 137,35 & 99,78 & 36,18 & 5990,26 & 285,10 & 14,33 & 270,77 & 159,05 & 65,33 & 215,87 & 64,22 & 398,05 & 55,03 & 18,12 & 32,69 & 131,48 & 70,89 & 84,97 & 70,89 \\
\hline Epidalea calamita & 30TYL17 & 100,00 & 148,10 & 102,69 & 36,80 & 6032,76 & 299,68 & 23,34 & 276,34 & 168,94 & 75,64 & 226,92 & 73,75 & 363,62 & 49,38 & 15,61 & 32,39 & 118,29 & 65,78 & 74,51 & 65,78 \\
\hline Epidalea calamita & 30TYL18 & 100,00 & 147,57 & 103,69 & 37,00 & 6050,88 & 300,35 & 22,33 & 278,02 & 170,80 & 73,70 & 226,38 & 72,64 & 362,82 & 48,91 & 15,84 & 31,35 & 117,70 & 66,06 & $\begin{array}{l}74,69 \\
\end{array}$ & 66,06 \\
\hline Epidalea calamita & 30TYL19 & 100,00 & 143,86 & 104,00 & 37,00 & 6048,36 & 297,79 & 19,04 & 278,75 & 167,22 & 68,66 & 222,69 & 68,66 & 369,18 & 49,70 & 16,53 & 30,38 & 120,01 & 67,52 & 76,78 & 67,52 \\
\hline Epidalea calamita & 30TYL20 & 100,00 & 110,80 & 92,95 & 35,91 & 5895,90 & 251,75 & $-4,60$ & 256,35 & 128,26 & 40,93 & $\mid 189,42$ & 40,93 & 535,13 & 69,78 & 26,77 & 28,71 & $\mid 172,13$ & 99,11 & 118,94 & 99,11 \\
\hline Epidalea calamita & 30TYL21 & 100,00 & 123,69 & 94,50 & 36,00 & 5880,54 & 264,86 & 5,84 & 259,02 & 140,88 & 55,55 & 201,77 & 53,63 & 480,97 & 63,6 & 22,64 & 30,88 & 154,82 & 87,78 & 104,53 & 87,79 \\
\hline Epidalea calamita & 30TYL22 & 100,00 & 121,20 & 95,16 & 36,00 & 5905,73 & 263,52 & 2,64 & 260,88 & $\begin{array}{l}139,69 \\
\end{array}$ & 51,91 & 199,39 & 50,53 & 484,13 & 64,79 & 23,21 & 30,65 & $\begin{array}{l}157,38 \\
157,0\end{array}$ & 88,16 & 105,77 & 88,17 \\
\hline Epidalea calamita & 30TYL23 & 100,00 & 129,53 & 96,95 & 36,01 & 5917,39 & 273,45 & 9,05 & 264,40 & 149,44 & 60,86 & 207,72 & 58,37 & 449,66 & 60,72 & 20,57 & 31,81 & 146,05 & 81,33 & $\begin{array}{l}96,20 \\
\end{array}$ & 81,34 \\
\hline Epidalea calamita & 30TYL24 & 100,00 & 134,76 & 98,59 & 36,18 & 5938,88 & 280,62 & 12,99 & 267,63 & 155,68 & 67,53 & 213,03 & 63,11 & 427,03 & 57,93 & 19,04 & 32,34 & 138,71 & 77,01 & 90,07 & 77,03 \\
\hline Epidalea calamita & 30TYL25 & 100,00 & 142,00 & 100,52 & 36,74 & 5961,88 & 289,83 & 18,81 & 271,02 & 161,28 & 75,85 & 220,33 & 69,60 & 400,61 & 54,32 & 17,21 & 32,90 & 129,56 & 72,24 & 82,60 & 72,25 \\
\hline Epidalea calamita & 30TYL26 & 100,00 & 147,16 & 102,06 & 36,92 & 5984,36 & 296,88 & 22,70 & 274,18 & 160,48 & 82,08 & 225,53 & 73,97 & 381,64 & 51,51 & 16,00 & 33,10 & 123,42 & 68,83 & 77,54 & 68,86 \\
\hline Epidalea calamita & 30TYL27 & 100,00 & 150,22 & 103,28 & 37,00 & 6004,46 & 301,46 & 25,15 & 276,31 & $\begin{array}{l}159,53 \\
\end{array}$ & 83,54 & 228,75 & 76,40 & 369,90 & $\begin{array}{l}\mid 1,11 \\
49,51\end{array}$ & 15,42 & 32,65 & $\begin{array}{l}119,92 \\
119,\end{array}$ & $\begin{array}{l}6,07,10 \\
\end{array}$ & $\begin{array}{l}74,68 \\
\end{array}$ & 67,15 \\
\hline Epidalea calamita & 30TYL28 & 100,00 & 141,27 & 103,36 & 37,00 & 6026,76 & 293,91 & 16,48 & 277,43 & 163,92 & 67,06 & 220,09 & 66,99 & 387,27 & 52,42 & 17,14 & 31,11 & 125,88 & 70,01 & 80,77 & 70,01 \\
\hline Epidalea calamita & 30TYL29 & 100,00 & 138,55 & 103,86 & 36,99 & 6033,03 & 292,02 & 13,74 & 278,28 & 161,56 & 63,97 & 217,26 & 63,97 & 391,10 & 52,82 & 17,75 & 30,19 & 127,30 & 70,85 & 82,48 & 70,85 \\
\hline Epidalea calamita & 30TYL30 & 100,00 & 118,61 & 93,06 & 35,99 & 5838,37 & 258,66 & 2,61 & 256,04 & 131,25 & 51,76 & 196,54 & 49,72 & 527,06 & 67,34 & 24,41 & 29,16 & 166,63 & 99,49 & 115,73 & 99,57 \\
\hline Epidalea calamita & 30TYL31 & 100,00 & 122,49 & 94,09 & 36,00 & 5848,88 & 263,37 & 5,04 & 258,33 & 136,73 & 55,75 & 200,25 & 53,10 & 507,43 & 65,71 & 23,12 & 29,93 & 161,32 & 94,97 & 109,91 & 95,10 \\
\hline Epidalea calamita & 30TYL32 & 100,00 & 133,59 & \begin{tabular}{|l|l|}
96,09 \\
96,
\end{tabular} & 36,10 & 5848,65 & 275,59 & $\begin{array}{l}, 04 \\
13,999 \\
\end{array}$ & 261,60 & $\begin{array}{l}140,98 \\
\end{array}$ & $\frac{\mid 5,11}{696}$ & \begin{tabular}{|l|}
210,97 \\
\end{tabular} & $\frac{63,95}{63,95}$ & \begin{tabular}{|l|l|}
464,46 \\
\end{tabular} & $\begin{array}{l}60,79 \\
60\end{array}$ & $\begin{array}{l}25,12 \\
19,82\end{array}$ & 31,84 & \begin{tabular}{|l|l|}
149,59 \\
\end{tabular} & $\begin{array}{ll}4,75 \\
85,77\end{array}$ & \begin{tabular}{|c|}
97,49 \\
\end{tabular} & 86,31 \\
\hline Epidalea calamita & 30TYL33 & 100,00 & 136,96 & 97,60 & 36,23 & 5872,92 & 280,81 & 16,10 & 264,72 & 144,41 & 73,30 & 214,55 & 66,74 & 447,91 & 59,08 & 18,85 & 32,32 & 144,72 & 82,19 & 92,25 & 82,85 \\
\hline Epidalea calamita & 30TYL34 & 100,00 & 142,34 & 99,50 & 36,76 & 5901,58 & 288,19 & 19,92 & 268,27 & 146,99 & 78,78 & 220,24 & 71,52 & 423,89 & 56,32 & 17,36 & 32,97 & 137,90 & 76,94 & 85,89 & 77,94 \\
\hline Epidalea calamita & 30TYL36 & 100,00 & 149,20 & 102,61 & 36,94 & 5967,16 & 298,83 & 24,44 & 274,39 & 153,92 & 85,32 & 227,44 & 76,60 & 390,97 & 52,10 & 15,74 & 33,37 & 128,10 & 70,41 & 78,03 & 71,10 \\
\hline Epidalea calamita & 30TYL38 & 100,00 & 140,16 & 103,91 & 37,00 & 6023,04 & 292,97 & 15,12 & 277,85 & 162,99 & 66,52 & 219,07 & 66,27 & 402,41 & 54,10 & 17,74 & 31,13 & 129,98 & 72,69 & 83,93 & 72,69 \\
\hline Epidalea calamita & \begin{tabular}{|l}
30 TYL40 \\
\end{tabular} & 100,00 & $\begin{array}{l}14,10 \\
109,39\end{array}$ & \begin{tabular}{|l|l|}
91,87 \\
90
\end{tabular} & 35,70 & $\begin{array}{l}5023,04,57 \\
582,\end{array}$ & 249,52 & $\begin{array}{l}\mid 2,124 \\
-4,65\end{array}$ & 254,17 & $\begin{array}{l}102,53 \\
122,61\end{array}$ & $\begin{array}{ll}42,23 \\
42,\end{array}$ & \begin{tabular}{|l|}
187,43 \\
\end{tabular} & $\begin{array}{ll}41,16 \\
4\end{array}$ & \begin{tabular}{|l|l|}
589,35 \\
58,35
\end{tabular} & $\begin{array}{l}4,10 \\
73,23\end{array}$ & 27,54 & $\begin{array}{l}\frac{1,11}{26,94} \\
\end{array}$ & \begin{tabular}{|l|}
182,63 \\
183
\end{tabular} & \begin{tabular}{|l|}
115,19 \\
115
\end{tabular} & \begin{tabular}{|l}
0,93 \\
128,43
\end{tabular} & $\begin{array}{l}115,21 \\
115,\end{array}$ \\
\hline Epidalea calamita & 30TYL42 & 100,00 & 123,81 & 94,93 & 36,01 & 5838,01 & 265,70 & 5,77 & 259,93 & 134,76 & 59,92 & 201,50 & 54,81 & 520,60 & 66,62 & 22,74 & 29,64 & 163,75 & 99,13 & 111,31 & 99,43 \\
\hline Epidalea calamita & 30TYL43 & 100,00 & 133,19 & 97,27 & \begin{tabular}{|l|l|}
36,27 \\
\end{tabular} & 5854,53 & 276,90 & 12,92 & 263,97 & 138,21 & 69,69 & 210,85 & 63,74 & 481,13 & 62,31 & 19,97 & 31,23 & 154,15 & 89,95 & 99,95 & 90,99 \\
\hline Epidalea calamita & 30TYL44 & 100,00 & 140,32 & 99,42 & 36,68 & 5888,21 & 286,16 & 18,08 & 268,09 & 143,57 & 76,69 & 218,13 & 70,13 & 450,49 & 58,86 & 18,01 & 32,39 & 146,43 & 82,97 & 90,82 & 84,47 \\
\hline Epidalea calamita & 30TYL45 & 100,00 & 145,58 & 101,43 & 36,95 & 5916,80 & 293,39 & 21,75 & 271,64 & 149,00 & 81,82 & 223,47 & 74,58 & 426,60 & 56,07 & 16,75 & 33,06 & 139,95 & 77,66 & 84,61 & 79,26 \\
\hline Epidalea calamita & 30TYL46 & 100,00 & $\begin{array}{l}14,50,73 \\
150,73\end{array}$ & $\begin{array}{l}101,45 \\
103,24\end{array}$ & 37,00 & $\begin{array}{l}591,07,93 \\
5957,93\end{array}$ & $\begin{array}{l}29,59 \\
300,52\end{array}$ & \begin{tabular}{|l|}
$2,1 / 43$ \\
25,43
\end{tabular} & $\begin{array}{l}271,04 \\
275,08 \\
\end{array}$ & $\begin{array}{l}153,39 \\
150\end{array}$ & $\begin{array}{l}1,162 \\
86,88 \\
\end{array}$ & $\mid$\begin{tabular}{|l|}
228,96 \\
\end{tabular} & \begin{tabular}{r|}
4,30 \\
78,75 \\
\end{tabular} & \begin{tabular}{|l|}
402,34 \\
402,34
\end{tabular} & $\begin{array}{l}30,019 \\
52,94\end{array}$ & $\begin{array}{l}0,15 \\
15,59 \\
\end{array}$ & 33,50 & \begin{tabular}{|l|}
$133,93,19$ \\
133
\end{tabular} & $\begin{array}{l}1,200 \\
72,40\end{array}$ & \begin{tabular}{|l|}
$0,0,01$ \\
78,88
\end{tabular} & $\begin{array}{l}79,20 \\
74,04\end{array}$ \\
\hline Epidalea calamita & 30TYL47 & 100,00 & 152,55 & 104,68 & 37,01 & 6001,37 & 304,22 & 26,26 & 277,96 & 155,34 & 88,44 & 231,15 & 79,55 & 388,64 & 51,21 & 15,34 & 33,43 & 128,15 & 69,58 & 76,82 & 70,90 \\
\hline Epidalea calamita & 30TYL48 & 100,00 & 140,81 & 104,68 & 37,00 & 6037,27 & 294,13 & 14,99 & 279,14 & 162,67 & 69,21 & 219,93 & 66,72 & 414,60 & 55,17 & 17,81 & 30,88 & 133,07 & 75,60 & 85,93 & 75,63 \\
\hline Epidalea calamita & 30TYL50 & 39,00 & 110,93 & 91,70 & 35,70 & 5798,36 & 250,68 & $-2,77$ & 253,45 & 120,29 & 45,79 & 188,80 & 43,29 & 598,38 & 73,23 & 27,07 & 26,75 & 184,88 & 118,50 & 130,05 & 118,63 \\
\hline Epidalea calamita & 30TYL53 & 28,00 & 128,54 & 96,54 & 36,07 & 5848,34 & 271,93 & 9,02 & 262,90 & 132,63 & 65,00 & $\begin{array}{ll}206,22 \\
\end{array}$ & $\begin{array}{ll}45,39 \\
59,39\end{array}$ & 511,17 & $\begin{array}{l}65,32 \\
652\end{array}$ & 21,34 & 30,10 & \begin{tabular}{|l|}
$161,73,3$ \\
\end{tabular} & $\begin{array}{lll}97,24 \\
9\end{array}$ & $\begin{array}{l}106,76 \\
\end{array}$ & 98,34 \\
\hline Epidalea calamita & 30 TYL5 & 20,00 & 147,33 & 101,73 & 37,00 & 5906,85 & 295,18 & 23,21 & 271,97 & $\begin{array}{ll}149,97 \\
\end{array}$ & 83,45 & 225,12 & 76,67 & 432,97 & 56,36 & 16, & 33,30 & 143,39 & 78,88 & 85,85 & 81,06 \\
\hline Epidalea calamita & 30TYM01 & 100,00 & 133,27 & 103,61 & 37,00 & 6003,54 & 287,89 & 10,21 & 277,68 & 155,81 & 58,41 & 211,50 & 58,41 & 390,14 & 52,38 & 18,70 & 27,95 & 127,22 & 73,48 & 83,02 & 73,48 \\
\hline Epidalea calamita & 30TYM02 & 100,00 & 119,04 & 101,79 & 37,00 & 5880,27 & 270,87 & $-1,21$ & 272,07 & 140,31 & 45,86 & 195,83 & 45,86 & 436,98 & 58,78 & 22,03 & 26,51 & 142,13 & 83,77 & 95,42 & 83,77 \\
\hline Epidalea calamita & 30TYM03 & 100,00 & 121,30 & 102,29 & 37,03 & 5829,62 & 272,96 & 1,40 & 271,56 & 142,63 & 48,45 & 197 & 48,45 & 432,10 & 57,20 & 21,41 & 25,71 & 24 & 84,15 & 92,54 & 84,15 \\
\hline Epidalea calamita & 30TYM06 & 100,00 & $\frac{1219}{119}$ & $\begin{array}{l}102,02 \\
102,02\end{array}$ & 38,00 & 50240,66 & 267,08 & $\begin{array}{l}\frac{1,40}{1,31} \\
\end{array}$ & $\begin{array}{l}265,77 \\
\end{array}$ & $\begin{array}{l}139,90 \\
139,\end{array}$ & \begin{tabular}{|l|}
400,33 \\
140,3
\end{tabular} & 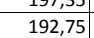 & $\begin{array}{l}40,45 \\
48,47 \\
\end{array}$ & \begin{tabular}{|l|}
472,105 \\
474,58
\end{tabular} & 59,00 & $\begin{array}{l}\mid 1,41+3 \\
23,38\end{array}$ & 22,34 & \begin{tabular}{|l|}
143,94, \\
143
\end{tabular} & $\begin{array}{l}4,113 \\
98,43 \\
\end{array}$ & \begin{tabular}{|l|}
99,03 \\
99,03
\end{tabular} & $\begin{array}{l}0,13 \\
9,21\end{array}$ \\
\hline Epidalea calamita & 30TYM08 & 100,00 & 88,36 & 97,26 & 37,60 & 5508,18 & 230,50 & $-24,23$ & 254,73 & 105,88 & 160,23 & 160,39 & 20,16 & 720,99 & 83,39 & 40,79 & 17,43 & 213,13 & 154,64 & 158,41 & 164,13 \\
\hline Epidalea calamita & 30TYM10 & 100,00 & 138,18 & \begin{tabular}{|l|}
103,97 \\
\end{tabular} & 37,00 & 6015,59 & 292,35 & $\begin{array}{l}-14,01 \\
14,\end{array}$ & 278,34 & $\begin{array}{l}161,16 \\
\end{array}$ & \begin{tabular}{|l|l|}
63,17 \\
6
\end{tabular} & 216,51 & 63,17 & 382,09 & $\begin{array}{l}\mid 51,42 \\
51,4\end{array}$ & $\begin{array}{l}\mid 17,67 \\
17,6\end{array}$ & 29,34 & 124,46 & 70,11 & \begin{tabular}{|c|}
80,60 \\
\end{tabular} & 70,11 \\
\hline Epidalea calamita & 30TYM11 & 100,00 & 125,77 & 102,62 & 37,00 & 5933,21 & 278,42 & 3,96 & 274,46 & 147,69 & 51,95 & 203,28 & 51,95 & 418,11 & 56,35 & 20,45 & 27,92 & 136,35 & 77,60 & 90,70 & 77,60 \\
\hline Epidalea calamita & 30TYM12 & 100,00 & 123,51 & 102,56 & 37,00 & 5870,74 & 275,46 & 2,51 & 272,95 & 145,18 & 50,33 & 200 & 50,33 & 424 & 56,76 & 20,91 & 27,06 & 137,15 & 79,59 & 91,71 & 79, \\
\hline Epidalea calamita & 30TYM15 & $\begin{array}{l}100,00 \\
\end{array}$ & 125,70 & \begin{tabular}{|l|}
102,99 \\
10,9
\end{tabular} & 37,97 & 5700,40 & 274,90 & $\begin{array}{l}2,31 \\
5,97 \\
\end{array}$ & $\begin{array}{l}26,939 \\
2682\end{array}$ & \begin{tabular}{|l|}
147,01 \\
147
\end{tabular} & \begin{tabular}{|c|}
53,81 \\
53,8
\end{tabular} & $\begin{array}{l}200,11 \\
199,82 \\
\end{array}$ & \begin{tabular}{|l|l|}
53,81 \\
53
\end{tabular} & \begin{tabular}{|l|l|}
424,21 \\
433,63
\end{tabular} & $\begin{array}{l}50,17 \\
55,17\end{array}$ & $\mid \begin{array}{l}\mid 20,911 \\
20,96\end{array}$ & 24,46 & \begin{tabular}{|l|l|}
133,81 \\
130
\end{tabular} & $\begin{array}{l}5,59 \\
85,59\end{array}$ & \begin{tabular}{|l|}
1,11 \\
90,75
\end{tabular} & 85,59 \\
\hline Epidalea calamita & 30TYM16 & 100,00 & 120,28 & 102,10 & 38,00 & 5599,41 & 267,16 & 2,13 & 265,03 & 140,79 & 50,66 & 193,06 & 49,74 & 460,89 & 57,81 & 22,69 & 23,24 & 140,17 & 92,80 & 96,65 & 92,80 \\
\hline Epidalea calamita & 30TYM17 & 100,00 & 109,20 & 100,33 & 37,99 & 5503,85 & 253,56 & $-6,10$ & 259,65 & 128,66 & 49,70 & 180,85 & 40,14 & 533,35 & 65,20 & 27,54 & 20,99 & 160,23 & 111,46 & 114,45 & 111,49 \\
\hline Epidalea calamita & 30TYM19 & 100,00 & 88,36 & 97,19 & 37,89 & 5459,20 & 228,76 & $-23,99$ & 252,76 & 105,96 & 159,32 & 159 & 20,57 & 748,71 & 84,95 & 42,66 & 16,45 & 218,88 & 162,66 & 166,63 & 170,54 \\
\hline Epidalea calamita & 30TYM21 & 100,00 & 123,33 & 102,64 & 37,00 & 5920,71 & 275,51 & 1,51 & 274,00 & 145,27 & 49,79 & 200,74 & 49,79 & 433,55 & 58,24 & 21,28 & 27,84 & 141,01 & 79,66 & \begin{tabular}{|c|}
94,68 \\
\end{tabular} & 79,66 \\
\hline
\end{tabular}




\begin{tabular}{|c|c|c|c|c|c|c|c|c|c|c|c|c|c|c|c|c|c|c|c|c|c|}
\hline TAXON & UTM & $\mathrm{km} 2$ & B101 & B102 & $\mathrm{BIO3}$ & B104 & B105 & B106 & B107 & B108 & B109 & B1010 & BIO11 & BIO12 & B1013 & BIO14 & BIO15 & B1016 & B1017 & 81018 & B1019 \\
\hline Epidalea calamita & 30TYM22 & 100,00 & 132,19 & 104,33 & 37,03 & 5924,70 & 285,49 & 8,90 & 276,59 & 154,73 & 57,99 & 209,31 & 57,99 & 405,34 & 53,59 & 19,24 & 27,73 & 129,82 & 75,04 & 86,23 & 75,04 \\
\hline Epidalea calamita & 30TYM23 & 100,00 & 133,82 & 104,75 & 37,54 & 5886,82 & 286,82 & 10,93 & 275,89 & 156,65 & 59,92 & 210,54 & 59,92 & 404,49 & 52,69 & 19,04 & 27,00 & 127,86 & 75,98 & 85,29 & 75,98 \\
\hline Epidalea calamita & 30TYM24 & 100,00 & 128,66 & 103,96 & 37,82 & 5790,78 & 279,75 & 7,34 & 272,41 & 150,75 & 55,90 & 204,04 & 55,90 & 422,33 & 54,45 & 20,46 & 25,78 & 132,25 & 80,26 & 89,67 & 80,26 \\
\hline Epidalea calamita & 30TYM26 & 100,00 & 114,57 & 101,09 & 38,00 & 5542,32 & 260,48 & $-1,73$ & 262,21 & 134,72 & 45,07 & 186,83 & 45,07 & 477,26 & 60,33 & 24,09 & 23,59 & 146,04 & 93,28 & 102,42 & 93,28 \\
\hline Epidalea calamita & 30TYM27 & 100,00 & 104,51 & 99,64 & 37,96 & 5510,83 & 248,36 & $-10,49$ & 258,85 & 123,77 & 35,49 & 176,45 & 35,49 & 568,04 & 69,02 & 30,34 & 20,63 & 171,32 & 117,18 & 125,31 & 117,18 \\
\hline Epidalea calamita & 30TYM28 & 100,00 & 80,47 & 94,96 & 37,23 & 5496,64 & 220,75 & $-30,73$ & 251,48 & 97,38 & 95,71 & 152,59 & 12,68 & 787,18 & 90,38 & 46,20 & 16,86 & 233,47 & 172,16 & 178,97 & 174,81 \\
\hline Epidalea calamita & 30TYM30 & 100,00 & 133,48 & 104,51 & 37,00 & 6012,76 & 287,51 & 8,84 & 278,67 & 156,45 & 58,93 & 211,93 & 58,93 & 413,99 & 55,36 & 19,37 & 29,03 & 134,10 & 75,30 & 88,75 & 75,30 \\
\hline Epidalea calamita & 30TYM33 & 100,00 & 134,14 & 105,67 & 37,61 & 5933,01 & 287,56 & 10,00 & 277,56 & 157,45 & 59,48 & 211,13 & 59,48 & 414,51 & 53,65 & 19,94 & 26,74 & 131,27 & 76,99 & 89,01 & 76,99 \\
\hline Epidalea calamita & 30TYM34 & 100,00 & 128,81 & 104,79 & 37,88 & 5843,16 & 280,60 & 6,17 & 274,43 & 151,32 & 55,13 & 204,69 & 55,13 & 434,10 & 55,61 & 21,29 & 25,61 & 136,36 & 81,52 & \begin{tabular}{|l|l|}
93,95 \\
\end{tabular} & 81,52 \\
\hline Epidalea calamita & 30TYM35 & 100,00 & 122,90 & 103,67 & 38,00 & 5744,74 & 272,47 & 2,21 & 270,26 & 144,74 & 50,46 & 197,59 & 50,46 & 459,48 & 58,16 & 23,14 & 24,39 & 142,73 & 87,64 & 100,19 & 87,64 \\
\hline Epidalea calamita & 30TYM37 & 100,00 & 108,87 & 100,92 & 37,97 & 5575,51 & 253,72 & $-7,55$ & 261,27 & 129,00 & 38,75 & 181,38 & 38,75 & 561,21 & 67,92 & 30,15 & 20,78 & 169,79 & 113,60 & 125,45 & 113,60 \\
\hline Epidalea calamita & 30TYM38 & 100,00 & 78,61 & 94,14 & 36,99 & 5512,26 & 218,56 & $-32,14$ & 250,70 & 95,54 & 56,50 & 151,07 & 10,81 & 816,36 & 93,06 & 48,68 & 16,69 & 242,03 & 177,78 & 186,64 & 179,85 \\
\hline Epidalea calamita & 30TYM43 & 90,00 & 130,45 & 105,99 & 37,41 & 5970,19 & 284,57 & $\begin{array}{r}20,44 \\
5,68\end{array}$ & 278,89 & $\mid$\begin{tabular}{|c|}
153,76 \\
\end{tabular} & 55,27 & 207,92 & 55,27 & 439,32 & 56,62 & $\begin{array}{l}21,78 \\
21,7\end{array}$ & 26,46 & \begin{tabular}{|l|}
139,74 \\
\end{tabular} & \begin{tabular}{|c|}
81,06 \\
\end{tabular} & \begin{tabular}{|c|}
96,76 \\
96,7
\end{tabular} & 81,06 \\
\hline Epidalea calamita & 30TYM44 & 90,00 & 125,50 & 104,97 & 37,73 & 5892,04 & 278,01 & 2,38 & 275,64 & 148,18 & 51,16 & 202,16 & 51,16 & 461,30 & 58,73 & 23,45 & 25,10 & 145,44 & 86,27 & 102,47 & 86,27 \\
\hline Epidalea calamita & 30 TYM 46 & 80,00 & 116,98 & 103,20 & 38,00 & 5734,44 & 265,45 & $-2,60$ & 268,05 & 138,54 & 44,49 & 191,44 & 44,49 & 520,43 & 63,95 & 27,64 & 22,29 & 160,19 & 101,33 & 117,36 & 101,33 \\
\hline Epidalea calamita & 30TYM 48 & 72,00 & 85,12 & 95,56 & 37,28 & 5544,62 & 225,99 & $-27,19$ & 253,18 & 102,81 & 19,26 & 157,72 & 16,49 & 784,91 & 89,55 & 46,55 & 17,06 & 233,23 & 169,40 & 183,31 & 169,44 \\
\hline Epidalea calamita & 30TYM49 & 70,00 & 81,19 & 94,76 & 37,22 & 5508,15 & 220,63 & $-30,19$ & 250,82 & 98,42 & 23,08 & 153,32 & 13,07 & 838,58 & 93,89 & 50,40 & 15,92 & 246,55 & 184,52 & 197,08 & 184,86 \\
\hline Epidalea calamita & 30TYNOO & 100,00 & 89,01 & 97,77 & 38,10 & 5436,31 & 229,17 & $-23,37$ & 252,54 & \begin{tabular}{|c|}
106,64 \\
\end{tabular} & 159,62 & 159,92 & 21,38 & 777,07 & 85,95 & 43,85 & 15,60 & 223,04 & 165,59 & 170,13 & 184,36 \\
\hline Epidalea calamita & 30TYN01 & 100,00 & 87,26 & 97,46 & 38,44 & 5402,29 & 226,07 & $-24,44$ & 250,51 & 104,60 & 157,51 & 157,71 & 20,01 & 824,62 & 89,14 & 46,93 & 14,90 & 233,53 & 175,42 & 179,88 & 199,54 \\
\hline Epidalea calamita & 30TYNO2 & 100,00 & 68,75 & 93,02 & $\mid 37,67$ & 5353,69 & 204,51 & $-39,25$ & 243,76 & 84,01 & $\mid$\begin{tabular}{|l|l|}
139,07 \\
\end{tabular} & $\mid \begin{array}{l}139,08 \\
\end{array}$ & 2,90 & 982.46 & $|104,07|$ & 58,76 & 13,90 & 276,88 & 209,18 & 212.16 & 242,29 \\
\hline Epidalea calamita & 30TYN03 & 99,00 & 36,88 & 84,36 & 35,64 & 5266,47 & 167,53 & $-65,62$ & 233,15 & 48,42 & 107,42 & 107,42 & $-25,95$ & 1224,93 & 127,53 & 77,30 & 13,04 & 343,70 & 260,60 & 260,76 & 307,40 \\
\hline Epidalea calamita & $\begin{array}{l}\text { 30TYN20 } \\
\end{array}$ & 100,00 & 79,04 & 94,91 & 37,70 & 5429,96 & 217,15 & \begin{tabular}{|l|l|}
$-31,43$ \\
-3
\end{tabular} & 248,58 & 95,84 & 149,84 & 150,06 & 11,87 & 852,74 & $\begin{array}{l}94,30 \\
\end{array}$ & 50,61 & 15,16 & 247,23 & 187,08 & 193,73 & 196,25 \\
\hline Epidalea calamita & 31SBC48 & & & & & & & & & & & & & & & & & & & & \\
\hline Epidalea calamita & 31SBC49 & 100,00 & 174,19 & 100,95 & 39,64 & 5282,85 & 308,67 & 56,60 & 252,07 & 152,84 & 241,82 & 244,76 & 109,48 & 573,36 & 87,54 & 7,64 & 51,85 & 250,76 & 51,53 & 88,73 & 176,00 \\
\hline Epidalea calamita & 31SBC59 & 73,00 & 178,30 & 99,98 & 39,52 & 5248,02 & 311,31 & 60,82 & 250,49 & 157,60 & 245,06 & 248,11 & 113,73 & 578,22 & 91,41 & 6,83 & 54,31 & 258,70 & 48,95 & 88,32 & 182,77 \\
\hline Epidalea calamita & 31SBE42 & 6,00 & 171,25 & 83,00 & 36,00 & 5146,13 & 289,75 & 62,75 & 227,00 & 181,88 & 237,38 & 240,13 & 108,75 & 440,88 & 69,88 & 12,38 & 42,88 & 179,25 & 60,13 & 91,38 & 98,25 \\
\hline Epidalea calamita & 31TBE43 & 42,00 & 168,69 & 83,80 & 36,00 & 5191,27 & 288,73 & 59,20 & 229,53 & \begin{tabular}{|l|l|}
178,49 \\
\end{tabular} & $\begin{array}{l}235,78 \\
230\end{array}$ & 238,10 & 105,92 & $\begin{array}{l}450,08 \\
450,\end{array}$ & $\begin{array}{l}69,67 \\
690\end{array}$ & 13,00 & $\begin{array}{l}42,00 \\
41,61\end{array}$ & 180,04 & $\begin{array}{l}0,15 \\
63,59 \\
\end{array}$ & $\begin{array}{l}94,02 \\
94,0\end{array}$ & $\begin{array}{l}98,96 \\
98,2\end{array}$ \\
\hline Epidalea calamita & 31TBE44 & 53,00 & 153,70 & 86,17 & 36,00 & 5322,66 & 279,40 & 43,45 & 235,94 & 162,33 & 223,42 & 225,59 & 90,90 & 497,59 & 71,08 & 16,06 & 36,24 & 186,84 & 77,97 & 104,35 & 107,06 \\
\hline Epidalea calamita & 31TBE45 & 57,00 & 153,66 & 87,05 & 36,01 & 5360,26 & 280,27 & 42,42 & 237,85 & 161,39 & 223,80 & 225,93 & 90,54 & 493,76 & 69,85 & 16,15 & 36,06 & 184,06 & 79,28 & 104,61 & 104,30 \\
\hline Epidalea calamita & 31TBE47 & 42,00 & 139,21 & 89,90 & 36,00 & 5553,37 & 271,91 & 25,73 & 246,19 & 145,64 & 212,67 & 214,06 & 74,59 & 527,90 & 68,06 & 19,19 & 32,11 & 183,50 & 93,84 & 112,96 & 108,14 \\
\hline Epidalea calamita & 31TBE49 & 40,00 & 119,56 & 91,25 & 35,92 & 5731,29 & 257,22 & 5,59 & 251,63 & 125,81 & 145,69 & 196,73 & 52,88 & 581,34 & 69,86 & 24,46 & 28,17 & 185,85 & 113,97 & 125,36 & 116,83 \\
\hline Epidalea calamita & \begin{tabular}{|l|} 
31TBE53 \\
\end{tabular} & & & & | & & & & & 年 & & & & & & 24,40 & 20,19 & - & 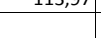 & 年 & 110,00 \\
\hline Epidalea calamita & 31TBE54 & 80,00 & 164,95 & 85,25 & 36,02 & 5226,37 & 287,26 & 54,61 & 232,65 & 173,45 & 233,00 & 235,31 & 103,00 & 473,82 & 71,71 & 13,63 & 39,91 & 185,67 & 69,66 & 99,72 & 103,14 \\
\hline Epidalea calamita & 31TBE55 & 100,00 & 159,40 & 86,61 & 36,07 & 5294,17 & 284,20 & 48,04 & 236,16 & 166,89 & 228,64 & 230,73 & 97,16 & \begin{tabular}{|l|l|}
490,98 \\
\end{tabular} & 71,74 & 14,86 & 37,91 & 187,11 & 75,92 & 104,02 & 105,02 \\
\hline Epidalea calamita & 31TBE59 & 100,00 & 126,75 & 91,35 & 36,00 & 5672,10 & 263,16 & 12,45 & 250,71 & 132,39 & 198,51 & 203,30 & 61,11 & 573,99 & 69,69 & 22,45 & 29,45 & 188,32 & 108,58 & 122,88 & 117,01 \\
\hline Epidalea calamita & 31TBE65 & 61,00 & 169,18 & 86,34 & 36,36 & 5208,07 & 291,59 & 57,66 & 233,93 & 176,24 & 237,21 & 239,49 & $\begin{array}{r}108,25 \\
\end{array}$ & 475,79 & 73,49 & 12,71 & 41,21 & 188,24 & 69,84 & 101,51 & 102,36 \\
\hline Epidalea calamita & 31TBE66 & 101,00 & 159,37 & 87,61 & 36,12 & 5304,93 & 285,12 & 47,15 & 237,97 & 165,57 & 229,12 & 231,24 & 98,10 & 510,59 & 74,43 & 14,72 & 37,96 & 193,39 & 79,62 & 108,70 & 108,96 \\
\hline Epidalea calamita & \begin{tabular}{|l|} 
31TBE67 \\
\end{tabular} & 99,00 & 151,74 & 89,09 & 36,22 & 5395,38 & 280,51 & 38,61 & 241,91 & 157,12 & 223,05 & 224,85 & 89,94 & 532,20 & 74,02 & 16,31 & 35,63 & 194,55 & 87,19 & 113,19 & 112,28 \\
\hline Epidalea calamita & 31TBE76 & 47,00 & 160,62 & 87,60 & 36,32 & 5279,43 & 285,97 & 48,37 & 237,60 & 166,48 & 230,10 & 232,30 & 100,23 & 522,03 & 76,90 & 14,48 & 38,40 & 198,53 & 80,72 & $\mid 111,20$ & 112,05 \\
\hline Epidalea calamita & 31TBE78 & 100,00 & 163,46 & 90,35 & 37,00 & 5309,51 & 290,76 & 49,03 & 241,74 & 166,95 & 233,61 & 235,45 & 103,63 & 521,50 & 76,95 & 14,03 & 38,96 & 197,60 & 82,61 & 112,80 & 104,24 \\
\hline Epidalea calamita & 31TBE88 & 74,00 & 168,71 & 89,88 & 37,00 & 5244,22 & 294,39 & 54,71 & 239,69 & 172,01 & 237,96 & 240,06 & 109,76 & 520,70 & 79,70 & 13,07 & 41,03 & 201,58 & 80,84 & 114,04 & 97,06 \\
\hline Epidalea calamita & $\begin{array}{l}\text { 31DEO0 } \\
\text { 31TBE89 }\end{array}$ & $\frac{17,000}{100,00}$ & $\begin{array}{l}10,1 \\
162,13\end{array}$ & $\begin{array}{l}5,20 \\
91,20\end{array}$ & 36,03 & $\begin{array}{l}324,42,26 \\
532,69\end{array}$ & $\begin{array}{l}294,59 \\
290,57\end{array}$ & $\frac{\mid 4,1 / 15}{47,15}$ & \begin{tabular}{|l|}
243,42 \\
243,42
\end{tabular} & \begin{tabular}{|l|}
$12,01,59$ \\
164
\end{tabular} & $\mid \frac{\mid 31,90}{232,68}$ & \begin{tabular}{|l|}
234,53 \\
234
\end{tabular} & $\begin{array}{l}102,40 \\
102,0\end{array}$ & 547,65 & $\begin{array}{l}1,10,27 \\
80\end{array}$ & $\begin{array}{l}3,01 \\
14,27 \\
\end{array}$ & $\begin{array}{l}4,103 \\
38,82\end{array}$ & \begin{tabular}{|l|}
205,27 \\
\end{tabular} & $\begin{array}{l}0,04 \\
87,58 \\
\end{array}$ & $\begin{array}{l}114,04 \\
118,50\end{array}$ & $\begin{array}{l}91,03,46 \\
103\end{array}$ \\
\hline Epidalea calamita & 31TBE99 & 42,00 & 163,34 & 90,17 & 36,85 & 5294,15 & 290,62 & 49,19 & 241,43 & 166,13 & 233,26 & 235,49 & 103,72 & 555,15 & 82,38 & 14,23 & 39,66 & 209,34 & 88,68 & 121,32 & 104,89 \\
\hline Epidalea calamita & 31TBF40 & 33,00 & 108,69 & 91,31 & 35,60 & 5789,89 & 248,31 & $-4,47$ & 252,78 & 118,67 & 43,71 & 186,73 & 41,31 & 616,76 & 74,91 & 27,93 & 26,22 & 189,78 & 123,22 & 133,71 & 123,42 \\
\hline Epidalea calamita & 31TBF43 & 23,00 & 130,70 & 96,81 & 36,14 & 5835,59 & 274,08 & 10,97 & 263,11 & 134,95 & 67,38 & 208,35 & 61,97 & 511,16 & 64,92 & 20,78 & 30,35 & 163,16 & 97,27 & 106,70 & 98,78 \\
\hline Epidalea calamita & \begin{tabular}{|l|}
$31 \mathrm{TBF} 49$ \\
\end{tabular} & 4,00 & 142,56 & 106,56 & 37,00 & 6097,78 & 298,00 & 15,44 & $\frac{28}{28}$ & $\begin{array}{l}166,56 \\
\end{array}$ & 71,33 & 222,44 & 67,67 & 411,67 & 54,44 & 17,89 & 30,56 & 131,67 & 74,89 & 86,00 & 74,89 \\
\hline Epidalea calamita & 31TBF51 & 100,00 & 112 & 92,11 & 35,72 & 5780,48 & 252,82 & $-1,59$ & 254,41 & 120,27 & 57,08 & 190,44 & 45,43 & 610,58 & 74,07 & 26,6 & 26,86 & 188,91 & 122,06 & 131,81 & 122,89 \\
\hline Epidalea calamita & 31TBF52 & 100,00 & 128,46 & 95,00 & 36,10 & 5780,01 & 269,75 & 10,60 & 259,16 & 132,84 & 94,40 & 205,69 & 60,90 & 543,51 & 67,21 & 21,61 & 29,82 & 174,41 & 105,04 & 117,11 & 107,66 \\
\hline Epidalea calamita & 31TBF53 & 100,00 & 136,58 & 97,57 & 36,49 & 5812,02 & 280,01 & 16,22 & 263,80 & 139,80 & 80,42 & 213,90 & 68,49 & 507,23 & 63,65 & 19,22 & 31,35 & 165,47 & 96,33 & 106,67 & 99,39 \\
\hline Epidalea calamita & 31TBF54 & 99,00 & 140,39 & 99,64 & 36,83 & 5861,34 & 286,07 & 18,20 & 267,87 & 143,16 & 76,75 & 218,07 & 71,29 & 482,97 & 61,42 & 18,17 & 31,96 & 157,98 & 90,49 & 97,66 & 93,44 \\
\hline Epidalea calamita & $31 \mathrm{TBF}$ & 99,00 & 14 & 101,81 & 36, & 5914 & 293,11 & 20,89 & 272,22 & 147,36 & 81,11 & 22 & 74,75 & 454,87 & 58,50 & 17,02 & 32,76 & 149,69 & 83,71 & 90,81 & 86,57 \\
\hline Epidalea calamita & $\begin{array}{l}\text { 31TBF58 } \\
\end{array}$ & 100,00 & 147,11 & 106,32 & 37,06 & 6087,26 & 301,49 & 19,42 & 282,06 & 160,37 & 81,35 & 226,64 & 72,42 & 411,32 & 53,87 & 16,99 & 31,73 & 132,36 & 74,40 & 83,85 & 75,21 \\
\hline Epidalea calamita & 31TBF59 & 100,00 & 143,56 & 107,13 & 37,00 & 6127,80 & 299,68 & 15,58 & 284,10 & 167,14 & $\mid 74,32$ & 223,41 & 67,83 & \begin{tabular}{|l|l|}
414,24 \\
41,24
\end{tabular} & 54,45 & 17,95 & 30,49 & 132,41 & 75,43 & 86,64 & 75,47 \\
\hline Epidalea calamita & 31TBF60 & 100,00 & 131,81 & 92,23 & 36,17 & 5648,64 & 268,52 & 16,45 & 252,08 & 136,55 & 206,01 & 207,95 & 66,86 & 576,26 & 70,87 & 21,04 & 30,52 & 191,29 & 106,43 & 122,69 & 118,72 \\
\hline Epidalea calamita & 31TBF61 & 99,00 & 109,30 & 90,92 & 35,52 & 5755,61 & 248,77 & $-3,78$ & 252,55 & 116 & 146,49 & 186 & 42,61 & 648,49 & 76,95 & 28,02 & 25,89 & 199,39 & 130,34 & 138,81 & 133,36 \\
\hline Epidalea calamita & \begin{tabular}{|l|} 
31TBF62 \\
\end{tabular} & \begin{tabular}{|l|}
101,00 \\
100
\end{tabular} & 126,41 & $\begin{array}{ll}0,25 \\
94,24\end{array}$ & | 36,04 & $\begin{array}{l}3757,01 \\
5757,05\end{array}$ & 267,19 & $\begin{aligned}-9,10 \\
9,53\end{aligned}$ & \begin{tabular}{|l|}
257,66 \\
25,6
\end{tabular} & \begin{tabular}{|l|}
130,90 \\
130
\end{tabular} & $\begin{array}{l}180,495 \\
188,52 \\
\end{array}$ & \begin{tabular}{|l|}
203,58 \\
20,5
\end{tabular} & $\begin{array}{l}42,10 \\
59,55 \\
\end{array}$ & \begin{tabular}{|l|}
576,400 \\
576,00
\end{tabular} & $\begin{array}{l}0,535 \\
69,50 \\
\end{array}$ & $\begin{array}{l}\mid 20,0<4 \\
22,39 \\
\end{array}$ & 29,10 & \begin{tabular}{|l|}
184,31 \\
183
\end{tabular} & \begin{tabular}{|l|}
111,21 \\
11,21
\end{tabular} & $\begin{array}{l}300,01 \\
123,23 \\
\end{array}$ & $\begin{array}{l}150,00 \\
116,88\end{array}$ \\
\hline Epidalea calamita & 31TBF63 & 100,00 & 136,87 & 97,23 & 36,51 & 5786,36 & 279,66 & 16,86 & 262,80 & 139,95 & 196,36 & 214,02 & 69,52 & 531,63 & 65,19 & 19,19 & 31,10 & 174,12 & 100,18 & 113,19 & 106,70 \\
\hline Epidalea calamita & 31TBF64 & 100,00 & 142.25 & 99,74 & 36.88 & 5840,12 & 287,64 & 19.92 & 267.72 & 144,62 & 139.80 & 219,75 & 73.86 & 500,73 & 62.41 & 17.86 & 32.10 & 165,21 & 93.88 & 102.80 & 99.04 \\
\hline Epidalea calamita & 31TBF65 & 100,00 & 148,14 & 102,33 & 36,99 & 5906,11 & 296,24 & 23,44 & 272,80 & 150,01 & 86,07 & 226, & 78, & 464,28 & 58,74 & 16,47 & 33,28 & 154,86 & 85,46 & 93,14 & 89,80 \\
\hline Epidalea calamita & 31TBF70 & 100,00 & 150,82 & 93,17 & 36,79 & 5497,04 & 284,54 & 34,28 & 250,26 & 153,43 & 223,81 & 225,19 & 89,03 & 552,58 & 74,84 & 16,49 & 35,08 & 196,49 & 93,63 & $\mid \begin{array}{l}\mid 117,83 \\
\end{array}$ & 111,35 \\
\hline
\end{tabular}




\begin{tabular}{|c|c|c|c|c|c|c|c|c|c|c|c|c|c|c|c|c|c|c|c|c|c|}
\hline TAXON & UTM & $\mathrm{km2}$ & BIO1 & B102 & $\mathrm{BIO3}$ & B104 & BIO5 & B106 & B107 & B108 & B109 & BIO10 & BIO11 & B1012 & BIO13 & BIO14 & BIO15 & BIO16 & BIO17 & BIO18 & BIO19 \\
\hline Epidalea calamita & 31TBF71 & 101,00 & 132,77 & 92,82 & 36,20 & 5636,99 & 270,10 & 17,10 & 252,99 & 136,79 & 207,72 & 208,94 & 68,45 & 596,72 & 74,31 & 21,14 & 30,76 & 197,60 & 109,47 & 126,59 & 123,37 \\
\hline Epidalea calamita & 31TBF73 & 100,00 & 136,20 & 96,45 & 36,51 & 5760,37 & 278,20 & 16,94 & 261,26 & 139,32 & 212,64 & 213,25 & 69,49 & 559,53 & 67,84 & 19,63 & 30,87 & $\begin{array}{l}183,26 \\
\end{array}$ & 103,73 & \begin{tabular}{l|l|l|l|}
118,88 \\
\end{tabular} & 114,94 \\
\hline Epidalea calamita & 31TBF74 & 101,00 & 142,97 & 99,32 & 36,83 & 5817,97 & 287,63 & 21,03 & 266,60 & 145,31 & 218,19 & 220,40 & 75,26 & 523,57 & 64,41 & $\begin{array}{ll}17,75 \\
\end{array}$ & 32,12 & \begin{tabular}{ll|}
173,46 \\
\end{tabular} & 96,28 & \begin{tabular}{l|l|}
109,95 \\
\end{tabular} & 106,11 \\
\hline Epidalea calamita & 31TBF75 & 100,00 & 144,56 & 101,47 & 36,99 & 5904,87 & 292,23 & 20,69 & 271,54 & \begin{tabular}{ll|}
146,80 \\
\end{tabular} & \begin{tabular}{l|l|}
152,31 \\
\end{tabular} & 222,69 & 75,06 & 498,08 & 61,53 & 17,34 & \begin{tabular}{|l|l|}
32,07 \\
\end{tabular} & \begin{tabular}{|l|l|}
163,84 \\
\end{tabular} & 92,94 & $\begin{array}{l}101,99 \\
1\end{array}$ & 99,09 \\
\hline Epidalea calamita & 31TBF76 & 100,00 & 151,21 & 104,35 & 37,05 & 5991,01 & 301,78 & 24,64 & 277,14 & 153,10 & 86,74 & 229,97 & 79,66 & \begin{tabular}{ll|}
451,58 \\
\end{tabular} & 57,12 & \begin{tabular}{|l|l|}
15,97 \\
\end{tabular} & 33,44 & 150,71 & 81,91 & 88,18 & 86,67 \\
\hline Epidalea calamita & 31TBF77 & 101,00 & 148,88 & 106,04 & 37,03 & 6095,90 & 302,54 & 20,89 & 281,65 & 153,15 & 83,70 & 228,66 & 74,99 & 442,50 & 56,48 & \begin{tabular}{ll|}
16,89 \\
\end{tabular} & \begin{tabular}{|l|l|}
32,27 \\
\end{tabular} & 143,66 & 80,04 & 87,99 & 83,36 \\
\hline Epidalea calamita & 31TBF79 & 100,00 & 147,25 & 109,20 & 37,12 & 6269,06 & 305,94 & 16,52 & 289,42 & \begin{tabular}{ll|}
167,96 \\
\end{tabular} & 80,10 & 228,66 & 69,30 & 425,51 & 54,70 & 18,52 & \begin{tabular}{l|l}
30,45 \\
\end{tabular} & 135,98 & 76,58 & 90,17 & 77,48 \\
\hline Epidalea calamita & 31TBF80 & 99,00 & 161,91 & 93,13 & 37,04 & 5377,75 & 292,75 & 45,29 & 247,46 & 163,14 & 233,20 & 234,91 & \begin{tabular}{|l|l|}
101,67 \\
\end{tabular} & 550,62 & 80,09 & \begin{tabular}{ll|}
14,42 \\
\end{tabular} & 38,54 & 204,72 & \begin{tabular}{l|l}
89,35 \\
\end{tabular} & \begin{tabular}{l|l}
119,45 \\
\end{tabular} & 103,11 \\
\hline Epidalea calamita & 31TBF81 & 100,00 & 164,48 & 95,48 & 37,50 & 5414,10 & 297,55 & \begin{tabular}{l|l}
46,15 \\
\end{tabular} & 251,40 & \begin{tabular}{|l|l|}
164,37 \\
\end{tabular} & 236,30 & 237,81 & \begin{tabular}{|l|l|}
103,97 \\
\end{tabular} & 542,19 & $\begin{array}{l}79,46 \\
\end{array}$ & $\begin{array}{l}14,17 \\
\end{array}$ & 39,14 & \begin{tabular}{ll|}
202,26 \\
\end{tabular} & 88,71 & $\begin{array}{l}118,75 \\
\end{array}$ & 100,01 \\
\hline Epidalea calamita & 31 TBF82 & 100,00 & 162,39 & 97,16 & 37,52 & 5505,06 & 298,44 & $42,41 \mid$ & 256,03 & $161,91 \mid$ & 235,44 & 236,63 & $100,91 \mid$ & 534,86 & 76,70 & 14,34 & 38,35 & 196,78 & $88,67 \mid$ & 116,74 & 100,34 \\
\hline Epidalea calamita & 31TBF83 & 101,00 & 154,13 & 97,79 & 37,09 & 5636,11 & 293,67 & 33,58 & \begin{tabular}{|l|}
260,09 \\
\end{tabular} & \begin{tabular}{ll|}
155,13 \\
\end{tabular} & 228,81 & 229,75 & $\begin{array}{l}90,46 \\
9\end{array}$ & 533,66 & 71,59 & \begin{tabular}{ll|}
15,66 \\
\end{tabular} & 35,76 & 188,14 & $\begin{array}{l}1,76 \\
\end{array}$ & \begin{tabular}{|l|l|}
115,07 \\
\end{tabular} & 106,59 \\
\hline Epidalea calamita & 31TBF84 & 99,00 & 147,68 & 98,95 & \begin{tabular}{|c|}
36,85 \\
\end{tabular} & 5772,38 & 290,93 & 25,93 & 265,00 & \begin{tabular}{|l|l|}
149,58 \\
\end{tabular} & \begin{tabular}{|l|l|}
223,98 \\
\end{tabular} & 224,66 & 80,99 & 533,00 & 66,84 & \begin{tabular}{l|l|}
16,69 \\
\end{tabular} & 33,26 & \begin{tabular}{|l|l|}
180,07 \\
\end{tabular} & 94,50 & \begin{tabular}{|l|l|}
113,37 \\
\end{tabular} & 110,08 \\
\hline Epidalea calamita & 31TBF85 & 101,00 & 142,05 & 100,12 & 36,88 & 5881,26 & 288,46 & 19,33 & 269,13 & \begin{tabular}{l|l}
144,82 \\
\end{tabular} & 217,74 & 220,00 & 72,75 & 531,10 & 64,24 & 18,12 & 31,31 & \begin{tabular}{|l|l|}
172,97 \\
\end{tabular} & 98,56 & \begin{tabular}{ll|}
109,81 \\
\end{tabular} & 108,51 \\
\hline Epidalea calamita & 31TBF86 & 100,00 & 148,39 & 103,03 & 36,97 & 5982,27 & 297,99 & 22,86 & 275,14 & \begin{tabular}{l|l|l|}
150,98 \\
\end{tabular} & \begin{tabular}{l|l|l|l|}
118,25 \\
\end{tabular} & 227,11 & 76,95 & \begin{tabular}{l|l}
480,05 \\
\end{tabular} & 59,84 & \begin{tabular}{l|l|l|}
16,85 \\
\end{tabular} & 32,73 & \begin{tabular}{l|l}
158,42 \\
\end{tabular} & 88,56 & \begin{tabular}{|c|}
96,58 \\
\end{tabular} & 94,17 \\
\hline Epidalea calamita & 31TBF87 & 99,00 & 146,56 & 105,28 & 37,01 & 6113,84 & 299,91 & $\begin{array}{ll}19,08 \\
\end{array}$ & \begin{tabular}{|l|l|}
280,83 \\
\end{tabular} & \begin{tabular}{l|l|l|l|}
150,82 \\
\end{tabular} & 81,16 & 226,53 & $\begin{array}{ll}72,37 \\
\end{array}$ & 467,65 & 58,68 & 17,79 & 31, & \begin{tabular}{l|l}
149,93 \\
\end{tabular} & 86,02 & 94,01 & 89,59 \\
\hline Epidalea calamita & 31TBF88 & 100,00 & 147,34 & 108,04 & 37,01 & 6253,64 & 304,80 & 17,25 & 287,55 & 165,05 & 81,18 & 228,70 & \begin{tabular}{|l|}
70,27 \\
\end{tabular} & 447,09 & 56,39 & 18,29 & 30,66 & \begin{tabular}{|l|l|}
140,92 \\
\end{tabular} & \begin{tabular}{l|l}
81,15 \\
\end{tabular} & 92,29 & 83,36 \\
\hline Epidalea calamita & 31TBF89 & 100,00 & 153,62 & 110,83 & 37,14 & 6365,95 & 313,92 & 20,69 & 293,23 & \begin{tabular}{ll|}
175,86 \\
\end{tabular} & 86,64 & 235,78 & 73,82 & 410,63 & 52,12 & 17,70 & 31,02 & \begin{tabular}{ll|}
130,95 \\
\end{tabular} & 72,10 & 87,34 & 73,76 \\
\hline Epidalea calamita & 31TBF90 & 101,00 & 166,11 & 91,45 & 36,95 & 5296,97 & 294,19 & 50,89 & 243,29 & 167,91 & 236,18 & 238,11 & \begin{tabular}{ll|l}
106,50 \\
\end{tabular} & 549,27 & 82,41 & \begin{tabular}{|l|l|}
13,79 \\
\end{tabular} & 40,63 & 208,34 & 88,54 & $\begin{array}{l}121,87 \\
1\end{array}$ & 101,14 \\
\hline Epidalea calamita & 31TBF91 & 99,00 & 167,58 & 93,52 & 37,26 & 5338,64 & 297,71 & 50,72 & 246,99 & \begin{tabular}{|l|l|}
168,19 \\
\end{tabular} & 238,26 & \begin{tabular}{|l|}
240,07 \\
\end{tabular} & \begin{tabular}{|l|l|}
107,74 \\
\end{tabular} & 544,71 & 82,29 & 13,61 & \begin{tabular}{|l|l|}
40,87 \\
\end{tabular} & 207,22 & 88,10 & \begin{tabular}{|l|l|}
121,40 \\
\end{tabular} & 98,81 \\
\hline Epidalea calamita & 31TBF92 & 100,00 & 154,42 & 94,27 & 36,87 & 5503,33 & 289,07 & 36,95 & 252,12 & 156,01 & 227,38 & 228,80 & 92,6 & $\begin{array}{ll}574,65 \\
\end{array}$ & 78,97 & 15,6 & 36,2 & 204,95 & 95,11 & \begin{tabular}{ll|}
121,81 \\
\end{tabular} & 114,87 \\
\hline Epidalea calamita & 31TBF93 & 100,00 & 149,18 & 95,28 & 36,69 & 5614,96 & 286,96 & 30,72 & 256,24 & 151,58 & 223,56 & 224,74 & 85,42 & 572,98 & 74,83 & 16,53 & 34,38 & \begin{tabular}{|l|l|}
197,79 \\
\end{tabular} & 97,31 & 120,03 & 120,59 \\
\hline Epidalea calamita & 31TBF94 & 101,00 & 158,05 & 98,10 & 36,99 & 5668,52 & 297,90 & 36,88 & \begin{tabular}{|l|l|}
261,03 \\
\end{tabular} & \begin{tabular}{ll|l}
159,60 \\
\end{tabular} & \begin{tabular}{|l|l|}
232,83 \\
\end{tabular} & 233,79 & 93,17 & 517,33 & 70,50 & \begin{tabular}{l|l|l|}
14,62 \\
\end{tabular} & 36,83 & $\begin{array}{l}184,75 \\
\end{array}$ & 87,80 & \begin{tabular}{ll|}
112,56 \\
\end{tabular} & 105,25 \\
\hline Epidalea calamita & 31TBF95 & 99,00 & 154,05 & 99,80 & 36,98 & 5812,87 & 297,87 & 31,06 & 266,81 & 156,35 & 221,29 & 231,13 & 85,82 & 504,44 & 64,91 & 15,38 & 34,84 & \begin{tabular}{|l|l|}
173,88 \\
\end{tabular} & 88,90 & \begin{tabular}{|l|}
109,29 \\
\end{tabular} & 102,07 \\
\hline Epidalea calamita & 31 TBF96 & 100,00 & 157,82 & 102,20 & 36,99 & 5922,54 & 304,71 & 32,44 & 272,26 & 160,45 & \begin{tabular}{|l|l|}
108,67 \\
\end{tabular} & 235,67 & 87,02 & 455,63 & 59,54 & 14,90 & 35,59 & 158,33 & 80,41 & 99,20 & 87,44 \\
\hline Epidalea calamita & 31TBF97 & 100,00 & 150,85 & 104,56 & 36,98 & 6106,51 & 302,97 & 23,46 & 279,50 & 154,13 & 85,60 & 230,65 & 76,53 & 465,73 & 58,01 & 17, & 32, & 151,95 & 84,56 & 94,34 & 89,10 \\
\hline Epidalea calamita & 31TBF98 & 100,00 & 143,68 & 106,40 & 36,92 & 6260,13 & 300,11 & 14,77 & 285,34 & 167,25 & 77,50 & 225,03 & 66,34 & 481,50 & 59,19 & 19,92 & 29,32 & \begin{tabular}{|l|l|}
150,18 \\
\end{tabular} & 89,43 & \begin{tabular}{|l|}
100,59 \\
\end{tabular} & 91,37 \\
\hline Epidalea calamita & 31TBF99 & 101,00 & 150,74 & 110,81 & 37,00 & 6448,52 & 312,39 & 17,50 & 294,89 & 177,01 & 83,19 & \begin{tabular}{|l|l|}
233,87 \\
\end{tabular} & 69,58 & 432,38 & 54,02 & \begin{tabular}{ll|}
19,18 \\
\end{tabular} & 30,09 & \begin{tabular}{|l|l|}
138,39 \\
\end{tabular} & 76,89 & 94,13 & 78,06 \\
\hline Epidalea calamita & 31TBG51 & 98,00 & 140,50 & 108,08 & 37,28 & 6144,25 & 297,68 & 12,34 & 285,34 & 165,08 & 63,47 & 220,31 & 63,47 & 417,50 & 54,31 & \begin{tabular}{ll|}
19,66 \\
\end{tabular} & 28,53 & \begin{tabular}{|l|l|}
134,04 \\
\end{tabular} & 75,74 & 90,68 & 75,74 \\
\hline Epidalea calamita & 31TBG53 & 91,00 & 136,99 & 108,07 & 37,84 & 6081,00 & 293,13 & 9,83 & 283,30 & \begin{tabular}{|l|l|}
161,46 \\
\end{tabular} & 59,98 & 215,63 & 59,98 & 433,43 & 55,19 & 21,52 & 26,36 & \begin{tabular}{|l|l|}
137,94 \\
\end{tabular} & \begin{tabular}{|c|}
79,68 \\
\end{tabular} & 96,34 & 79,68 \\
\hline Epidalea calamita & 31TBG54 & 87,00 & 133,04 & 107,32 & \begin{tabular}{l|l|l|}
37,95 \\
\end{tabular} & 6022,70 & 287,83 & 7,08 & 280,74 & \begin{tabular}{|l|l|}
157,12 \\
\end{tabular} & 56,73 & 211,02 & 56,73 & 454,14 & 57,03 & 23,13 & 24,92 & 143,35 & 84,73 & \begin{tabular}{|l|l|}
102,08 \\
\end{tabular} & 84,73 \\
\hline Epidalea calamita & \begin{tabular}{|l|l} 
31TBG60 \\
\end{tabular} & 99,00 & 142,24 & 109,03 & 37,06 & 6230,79 & 300,97 & \begin{tabular}{l|l|}
12,59 \\
\end{tabular} & 288,37 & \begin{tabular}{ll|}
167,32 \\
\end{tabular} & \begin{tabular}{ll|l}
65,65 \\
\end{tabular} & 223,13 & \begin{tabular}{|l|l|l|}
64,47 \\
\end{tabular} & 425,82 & 55,24 & \begin{tabular}{l|l|}
19,53 \\
\end{tabular} & 29,18 & 136,97 & 77,25 & 92,28 & 77,25 \\
\hline Epidalea calamita & 31TBG62 & 101,00 & 141,25 & 109,92 & 37,57 & 6229,27 & 300,44 & 11,38 & 289,06 & 166,70 & \begin{tabular}{|l|l|}
62,44 \\
\end{tabular} & 221,72 & \begin{tabular}{|l|l|}
62,44 \\
\end{tabular} & 428,83 & 54,71 & 21,03 & 27,52 & 137,81 & 77,77 & $\begin{array}{l}95,93 \\
\end{array}$ & 77,77 \\
\hline Epidalea calamita & 31TBG70 & 100,00 & 148,52 & 110,90 & 37,29 & 6343,37 & 309,34 & 16,40 & 292,94 & \begin{tabular}{ll|}
174,56 \\
\end{tabular} & 79,91 & 230,50 & \begin{tabular}{ll|l}
68,86 \\
\end{tabular} & 414,38 & 53,14 & \begin{tabular}{l|l|l|}
18,95 \\
\end{tabular} & 29,71 & 133,12 & \begin{tabular}{l|l}
74,25 \\
\end{tabular} & 90,12 & 74,59 \\
\hline Epidalea calamita & 31TBG74 & 99,00 & 130,29 & 108,41 & 37,46 & 6184,54 & 287,63 & 2,37 & 285,26 & 155,17 & \begin{tabular}{|l|l|}
51,54 \\
\end{tabular} & 210,03 & 51,54 & 504,80 & 62,03 & 27,39 & 24,00 & 160,76 & 93,78 & 119,62 & 93,78 \\
\hline Epidalea calamita & 31TBG78 & 99,00 & 102,97 & 99,91 & 37,51 & 5746,41 & 248,14 & $-14,53$ & 262,66 & 123,41 & $\begin{array}{l}30,65 \\
\end{array}$ & 177,66 & 30,65 & 739,11 & 83,06 & $\begin{array}{l}44,05 \\
\end{array}$ & \begin{tabular}{|l|l|l|}
17,83 \\
\end{tabular} & 221,14 & 152,64 & $\begin{array}{ll}179,85 \\
\end{array}$ & 152,64 \\
\hline Epidalea calamita & 31TBG80 & 101,00 & 149,01 & 112,34 & 37,09 & 6464,87 & \begin{tabular}{|l|l|}
312,28 \\
\end{tabular} & \begin{tabular}{|l|l|l|}
14,98 \\
\end{tabular} & 297,29 & 175,95 & \begin{tabular}{|l|l|}
77,63 \\
\end{tabular} & 232,22 & 67,21 & 420,91 & 53,57 & 19,66 & 29,46 & \begin{tabular}{|l|l|}
136,49 \\
\end{tabular} & \begin{tabular}{|l|l|}
74,87 \\
\end{tabular} & $\begin{array}{l}93,65 \\
\end{array}$ & 75,19 \\
\hline Epidalea calamita & 31TBG81 & 99,00 & 144,13 & 112,80 & 37,06 & 6500,57 & 308,62 & 10,08 & 298,54 & 171,27 & \begin{tabular}{|l|l|}
61,88 \\
\end{tabular} & 227,81 & 61,49 & 438,79 & 55,56 & 21,46 & 27,92 & 143,53 & 78,34 & $\begin{array}{ll}101,32 \\
\end{array}$ & 78,34 \\
\hline Epidalea calamita & 31TBG82 & 100,00 & 143,98 & 112,66 & 37,23 & 6478,19 & 307,79 & \begin{tabular}{|l|}
10,23 \\
\end{tabular} & 297,56 & \begin{tabular}{|l|l|}
171,12 \\
\end{tabular} & 61,10 & 227,17 & 61,10 & \begin{tabular}{ll|}
443,75 \\
\end{tabular} & 55,64 & 22,25 & 27, & $\begin{array}{ll}144,72 \\
\end{array}$ & 79,36 & 104,20 & 79,36 \\
\hline Epidalea calamita & 31TBG83 & 101,00 & 137,87 & 111,04 & 37,18 & 6392,31 & 299,49 & 6,20 & 293,29 & 164,28 & 56,06 & 219,93 & 56,06 & 478,1 & 59,13 & 24,9 & 25,4 & 154,74 & 86,73 & \begin{tabular}{ll|}
114,39 \\
\end{tabular} & 86,73 \\
\hline Epidalea calamita & 31TBG84 & 100,00 & 122,59 & 105,93 & 37,01 & 6166,65 & 278,31 & $-2,91$ & 281,22 & 146,39 & 44,41 & 202,31 & 44,41 & 573,46 & 68,98 & 31,92 & 22,78 & 181,56 & 107,77 & 139,78 & 107,77 \\
\hline Epidalea calamita & 31TBG85 & 100,00 & 111,18 & 102,07 & \begin{tabular}{|l|l|}
36,97 \\
\end{tabular} & 5990,59 & 262,31 & $-9,83$ & 272,14 & \begin{tabular}{|l|l|}
133,19 \\
\end{tabular} & 35,87 & \begin{tabular}{|l|l|}
189,03 \\
\end{tabular} & 35,8 & 659,40 & $\begin{array}{l}77,26 \\
\end{array}$ & 38,34 & 20,88 & 204,44 & \begin{tabular}{l|l|}
127,95 \\
\end{tabular} & \begin{tabular}{ll|}
162,20 \\
\end{tabular} & 127,95 \\
\hline Epidalea calamita & 31TBG88 & 100,00 & 102,18 & 99,13 & 37,23 & 5787,06 & 247,31 & $-15,22$ & 262,53 & 122,68 & 29,38 & 177,36 & 29,38 & 781,35 & 86,61 & 47,50 & 17,60 & 233,39 & \begin{tabular}{|l|l|}
161,03 \\
\end{tabular} & 193,46 & 161,03 \\
\hline Epidalea calamita & 31TBG89 & 100,00 & 93,12 & 96,45 & 37,06 & 5683,73 & 235,14 & $-21,42$ & 256,56 & \begin{tabular}{ll|}
112,22 \\
\end{tabular} & 22,11 & $\begin{array}{l}167,15 \\
\end{array}$ & 22,11 & $\begin{array}{l}865,35 \\
\end{array}$ & 94,12 & 53,61 & 16,39 & 254,89 & 183,38 & 214,32 & 183,38 \\
\hline Epidalea calamita & 31TBG90 & 99,00 & 152,19 & 113,57 & 37,03 & 585 & 317,6 & 16,56 & \begin{tabular}{|l|}
301,09 \\
\end{tabular} & \begin{tabular}{|l|l|}
180,08 \\
\end{tabular} & 81,88 & 236,65 & 68,3 & 417,11 & 52,39 & \begin{tabular}{l|l}
19,15 \\
\end{tabular} & 29,7 & 136,25 & 73,12 & $\begin{array}{l}94,92 \\
\end{array}$ & 73,43 \\
\hline Epidalea calamita & 31TBG94 & 99,00 & 121 & 104,69 & 36,97 & 6185 & 276, & $-3,73$ & 280,01 & 144,80 & 42,76 & 201,11 & 42,7 & 607,27 & 72,09 & 33,76 & 22,46 & \begin{tabular}{|l|l|}
191,85 \\
\end{tabular} & \begin{tabular}{|l|l|}
114,17 \\
\end{tabular} & \begin{tabular}{|l|l|}
150,78 \\
\end{tabular} & 114,17 \\
\hline Epidalea calamita & 31TBG96 & 101,00 & 109,28 & 100,57 & 36,94 & 5963,55 & 258,51 & $-10,71$ & 269,22 & 130,88 & 34,30 & \begin{tabular}{ll|}
186,76 \\
\end{tabular} & 34,3 & 722,32 & 82,19 & 42,91 & 19,70 & 221,37 & 141,81 & 182,01 & 141,81 \\
\hline Epidalea calamita & 31TBH91 & 100,00 & 57,69 & 84,80 & 35,00 & 5466,00 & 190,84 & $\begin{array}{l}-47,45 \\
\end{array}$ & 238,29 & 71,85 & 34,21 & \begin{tabular}{ll|}
130,24 \\
\end{tabular} & $-8,32$ & 1130,54 & 119,98 & 73,84 & \begin{tabular}{l|l|l|}
13,92 \\
\end{tabular} & \begin{tabular}{|l|l|}
325,03 \\
\end{tabular} & 251,39 & 264,91 & 256,33 \\
\hline Epidalea calamita & 31TCF00 & 91,00 & 170,15 & 88,95 & 36,96 & 5216,73 & 294,89 & 56,82 & 238,07 & 173,18 & 239,02 & 241,14 & 111,33 & 542,26 & 85,01 & 13,00 & 42,55 & 211,58 & \begin{tabular}{l|l|}
85,65 \\
\end{tabular} & 122,43 & 97,56 \\
\hline Epidalea calamita & 31TCF01 & 91,00 & 169,24 & 90,59 & 37,01 & 5270,78 & $295, \varepsilon$ & 54,37 & 241,51 & \begin{tabular}{|l|l|}
171,44 \\
\end{tabular} & 238,53 & 240,62 & $\begin{array}{ll}109,85 \\
\end{array}$ & 544,22 & 84,76 & 13,71 & 42,07 & 211,19 & \begin{tabular}{|l|l|}
87,53 \\
\end{tabular} & \begin{tabular}{|l|l|}
123,63 \\
\end{tabular} & 97,33 \\
\hline Epidalea calamita & 31TCF02 & 96,00 & 159,45 & 91,76 & 36,80 & 5411 & 290, & 43,73 & 246,40 & 161,96 & 230,93 & 232,68 & 98,68 & 572,99 & 83,03 & 14,95 & 38,52 & 211,12 & 92,86 & 123,94 & 113,35 \\
\hline Epidalea calamita & 31TCF03 & 100,00 & 155,72 & 93,07 & 36,66 & 5515,29 & 289,47 & \begin{tabular}{|l|}
38,63 \\
\end{tabular} & 250,84 & 158,56 & 228,46 & 230,07 & \begin{tabular}{|c|}
93,19 \\
\end{tabular} & \begin{tabular}{|l|}
575,78 \\
\end{tabular} & 79,59 & 15,14 & \begin{tabular}{|l|l|}
36,69 \\
\end{tabular} & 205,50 & 93,77 & 121,01 & 123,05 \\
\hline Epidalea calamita & 31 TCF04 & 100,00 & 154,40 & 94,64 & 36,57 & 5617,50 & 291,10 & 35,83 & 255,28 & 157,61 & 228,30 & 229,60 & 89,45 & 554,93 & 74,48 & 15,61 & 35,81 & $\begin{array}{l}194,72 \\
\end{array}$ & 93,81 & \begin{tabular}{ll|}
118,16 \\
\end{tabular} & 116,40 \\
\hline Epidalea calamita & \begin{tabular}{|l|}
31 TCF05 \\
\end{tabular} & 100,00 & 159,51 & 96,97 & 36,84 & 5707,16 & 298,92 & 38,62 & 260,29 & \begin{tabular}{ll|}
162,82 \\
\end{tabular} & 205,02 & 235,38 & 92,4 & 502,93 & 68,89 & \begin{tabular}{|l|}
14,89 \\
\end{tabular} & 36,6 & \begin{tabular}{|l|}
179,87 \\
\end{tabular} & 87,99 & 112,60 & (2007 \\
\hline Epidalea calamita & $31 \mathrm{TC}$ & 100,00 & 146,94 & 98,80 & 36,36 & 5915,29 & 292 & 24, & 267 & 151 & 177, & 224,94 & 75, & 530,69 & 64,09 & 11, & 31,50 & 173,85 & 99,04 & 112,21 & 107 \\
\hline Epidalea calamita & 31TCF07 & 101,00 & 142,31 & 100,70 & 36,31 & 6051,46 & 291,38 & 18,27 & 273,10 & 147,80 & \begin{tabular}{|c|}
78,59 \\
\end{tabular} & 221,51 & 68,61 & 528,52 & 62,41 & 19,92 & 29,48 & 166,29 & \begin{tabular}{|l|l|}
101,07 \\
\end{tabular} & $\begin{array}{ll}111,62 \\
\end{array}$ & 104,64 \\
\hline Epidalea calamita & 31TCF09 & 100,00 & 146,17 & 107,88 & 36,88 & 6403,92 & 305,28 & 15,33 & 289,95 & 171,55 & 78,90 & 228,72 & 65,59 & 471,30 & 57,43 & 21,07 & 28,69 & 149,71 & 85,98 & \begin{tabular}{|l|l|}
103,90 \\
\end{tabular} & 86,57 \\
\hline Epidalea calamita & 31TCF10 & 64,00 & 169,45 & 86,30 & 36,35 & 5173,92 & 292,05 & 58,19 & 233,86 & \begin{tabular}{|l|l|l|l}
174,08 \\
\end{tabular} & \begin{tabular}{|l|l|}
237,55 \\
\end{tabular} & 239,82 & 111,01 & 549,32 & 87,30 & 13,34 & 42,91 & 216,00 & 86,18 & \begin{tabular}{|l|l|}
124,69 \\
\end{tabular} & 98,97 \\
\hline Epidalea & $31 \mathrm{TCl}+\mathrm{S}$ & 34,00 & 16 & & 36,5 & & 292 & 57, & 235, & 173 & 23 & 239, & 110 & 549 & 87, & & 42, & 215 & 87,46 & 125,54 & \\
\hline Epidalea calamita & 31TCF12 & 25,00 & 165,97 & 89,63 & 36,91 & 5319,4 & 292,9 & 51,66 & 241, & 169,56 & $235,78 \mid$ & 237,7 & $105,91[$ & 552,69 & 86,22 & 14,84 & 41,78 & 213,66 & 90,25 & 126,19 & 107, \\
\hline Epidalea calamita & 31TCF13 & 95,00 & 155,01 & 89,43 & 36,08 & 5443,29 & 285,01 & 40,86 & 244,15 & \begin{tabular}{|l|l|}
159,62 \\
\end{tabular} & 226,56 & 228,42 & 92,51 & 584,05 & 82,37 & 16,18 & \begin{tabular}{|l|l|}
37,03 \\
\end{tabular} & 210,66 & 97,51 & \begin{tabular}{|l|l|}
126,43 \\
\end{tabular} & 121,91 \\
\hline
\end{tabular}




\begin{tabular}{|c|c|c|c|c|c|c|c|c|c|c|c|c|c|c|c|c|c|c|c|c|c|}
\hline TAXON & UTM & $\mathrm{km} 2$ & B101 & B102 & $\mathrm{BIO3}$ & B104 & B105 & B106 & B107 & B108 & B109 & B1010 & B1011 & BIO12 & B1013 & BIO14 & BIO15 & B1016 & B1017 & B1018 & B1019 \\
\hline Epidalea calamita & 31TCF14 & 99,00 & 141,43 & 90,34 & 35,86 & 5617,71 & 276,12 & 26,61 & 249,51 & 147,04 & 215,30 & 216,78 & 75,68 & 614,80 & 76,57 & 18,80 & 31,62 & 204,52 & 107,99 & 128,10 & 133,09 \\
\hline Epidalea calamita & 31TCF16 & 100,00 & 144,25 & 94,60 & 35,96 & 5815,44 & 284,88 & 25,33 & 259,55 & 149,85 & 199,48 & 221,21 & 74,36 & 562,22 & 68,15 & 19,17 & 30,79 & 183,79 & 106,39 & 122,69 & 114,40 \\
\hline Epidalea calamita & 31TCF17 & 99,00 & 125,28 & 93,84 & 35,53 & 5901,09 & 268,66 & 7,94 & 260,72 & 133,01 & 61,14 & 203,30 & 54,08 & 630,37 & 72,59 & 26,30 & 25,89 & 190,87 & \begin{tabular}{ll|}
126,36 \\
\end{tabular} & $\begin{array}{l}138,57 \\
\end{array}$ & 127,53 \\
\hline Epidalea calamita & 31TCF19 & 100,00 & 141,51 & 102,39 & 36,10 & 6233,94 & 294,30 & 15,42 & 278,88 & 164,79 & 74,35 & 222,12 & 63,49 & 517,98 & 61,49 & 22,94 & 27,60 & 161,22 & 96,77 & \begin{tabular}{ll|}
114,76 \\
\end{tabular} & 96,87 \\
\hline Epidalea calamita & 31TCF23 & & & & & & & & & & & & & & & & & & & & \\
\hline Epidalea calamita & 31TCF25 & 99,00 & 145,13 & 87,91 & 35,27 & 5575,42 & 277,06 & 31,92 & 245,14 & 152,12 & 204,07 & 219,64 & 78,86 & 593,26 & 75,52 & 19,18 & 31,89 & 200,03 & 108,90 & 130,00 & 122,54 \\
\hline Epidalea calamita & $\begin{array}{l}31 \text { TCF } 26 \\
\end{array}$ & 101,00 & 134,25 & 89,96 & 35,21 & 5736,76 & 271,14 & 19,53 & 251,61 & 141,36 & 186,22 & 210,50 & 65,48 & 618,71 & 72,03 & 22,63 & 28,15 & 196,75 & 120,61 & 135,04 & 127,73 \\
\hline Epidalea calamita & 31TCF27 & 100,00 & 120,60 & 89,93 & 35,00 & 5805,41 & 260,19 & 6,82 & 253,36 & 128,42 & 年, & 197,84 & 50,98 & 670,91 & 76,09 & 28,75 & 24,87 & 202,60 & 135,85 & 149,16 & 136,49 \\
\hline Epidalea calamita & 31 TCF28 & 100,00 & 129,82 & 93,38 & 35,30 & 5923,63 & 272,63 & 12,25 & 260,38 & 138,93 & 64,02 & 207,74 & 57,47 & 610,76 & 70,25 & 26,00 & 25,96 & 184,97 & 120,04 & 137,98 & 120,13 \\
\hline Epidalea calamita & 31 TCF29 & 100,00 & 139,84 & 97,39 & 35,82 & 6073,80 & 286,59 & 17,96 & 268,64 & 158,81 & 71,07 & 218,75 & 64,14 & 546,20 & 63,61 & 23,82 & 27,30 & 167,30 & $\begin{array}{ll}102,78 \\
\end{array}$ & 125,16 & 102,78 \\
\hline Epidalea calamita & 31TCF34 & 34,00 & 163,41 & 81,22 & 34,85 & 5237,07 & 284,63 & 55,20 & 229,44 & 172,05 & 105,51 & 233,73 & 101,17 & 547,44 & 82,49 & 16,22 & 38,78 & 205,51 & 95,22 & 130,27 & 104,29 \\
\hline Epidalea calamita & 31TCF35 & 101,00 & 157,66 & 81,96 & 34,79 & 5332,40 & 281,05 & 48,75 & 232,30 & 166,51 & 109,39 & 228,96 & 93,82 & 557,55 & 78,55 & 17,36 & 35,67 & 201,06 & 100,08 & 130,69 & 109,36 \\
\hline Epidalea calamita & 31TCF36 & 100,00 & 136,20 & 85,52 & 34,78 & 5605,32 & 267,82 & 25,11 & 242,71 & \begin{tabular}{|l|l|}
144,68 \\
\end{tabular} & \begin{tabular}{|l|}
167,76 \\
\end{tabular} & 210,99 & 68,909 & 624,55 & $\begin{array}{l}74,92 \\
74,\end{array}$ & 22,99 & 28,69 & 202,11 & 121,90 & 139,31 & 128,05 \\
\hline Epidalea calamita & 31TCF38 & 101,00 & 130,78 & 89,58 & $\begin{array}{l}34,95 \\
\end{array}$ & 5816,48 & 269,14 & 16,21 & 252,92 & 138,87 & 64,10 & 207,49 & 59,81 & 621,44 & 70,68 & 26,14 & 26,05 & 190,56 & 122,19 & 141,97 & 122,21 \\
\hline Epidalea calamita & 31TCF39 & 100,00 & 133,43 & 91,90 & 35,08 & 5911,36 & 274,57 & 16,60 & 257,97 & 145,94 & 60,67 & 210,86 & 60,54 & 597,88 & 68,80 & 26,49 & 26,11 & 181,22 & 114,03 & 139,69 & 114,03 \\
\hline Epidalea calamita & 31TCF44 & 18,00 & 163,59 & 75,71 & 34,00 & 5096,00 & 279,18 & 59,82 & 219,35 & 174,12 & 114,35 & 232,00 & 102,65 & 550,18 & 80,12 & 16,59 & 37,71 & 204,47 & 96,35 & 132,65 & 111,82 \\
\hline Epidalea calamita & 31TCF45 & 98,00 & 160,62 & 75,79 & 33,81 & 5147,51 & 277,23 & 56,59 & 220,64 & 171,42 & 103,96 & 229,48 & 98,64 & 553,08 & 77,58 & 17,17 & 36,42 & 201,01 & 97,92 & 132,79 & 113,60 \\
\hline Epidalea calamita & 31TCF46 & 100,00 & 150,92 & 79,54 & 34,11 & 5368,23 & 273,71 & 43,88 & 229,83 & 161,10 & 122,53 & 222,42 & 85,92 & 572,10 & 73,85 & 19,23 & 32,18 & \begin{tabular}{|l|l|}
196,31 \\
\end{tabular} & 106,64 & 133,27 & 117,32 \\
\hline Epidalea calamita & 31TCF49 & 101,00 & 128,02 & 87,40 & 34,56 & 5785,10 & 264,77 & 15,34 & 249,44 & 140,59 & 57,40 & 204,29 & 57,40 & 644,86 & 73,53 & 29,42 & 25,06 & 194,61 & 124,06 & 151,48 & 124,06 \\
\hline Epidalea calamita & 31TCF55 & 69,00 & 160,04 & 71,70 & 33,01 & 5056,42 & 272,84 & 59,35 & 213,49 & $|172,27|$ & $\mid 199,78$ & 227,65 & 99,01 & 559,29 & 75,85 & 17,51 & 35,78 & 200,36 & 98,77 & $\mid 133,98$ & 122,29 \\
\hline Epidalea calamita & 31TCF56 & 101,00 & 155,31 & 74,55 & 33,22 & 5207,45 & 272,43 & 52,23 & 220,20 & 166,81 & 167,68 & 224,65 & 92,09 & 566,00 & 74,36 & 19,01 & 32,80 & 197,41 & 104,13 & 134,60 & 119,22 \\
\hline Epidalea calamita & 31TCF57 & 99,00 & 147,41 & 78,90 & 33,88 & 5423,19 & 270,97 & 40,84 & 230,14 & 157,99 & 100,81 & 219,44 & 81,40 & 581,84 & 72,51 & 21,21 & 29,63 & 194,63 & 112,55 & 136,12 & 117,33 \\
\hline Epidalea calamita & 31TCF58 & 101,00 & 134,09 & 82,51 & 34,01 & 5616,82 & 264,21 & 25,09 & 239,12 & 143,74 & 67,24 & 208,60 & 65,96 & 633,71 & 72,56 & 26,48 & 26,18 & 199,10 & 124,34 & 147,58 & 124,36 \\
\hline Epidalea calamita & 31TCF59 & 100,00 & 125,75 & 84,04 & 34,01 & 5699,40 & 259,38 & 16,02 & 243,36 & 136,53 & 56,71 & 201,32 & 56,71 & 673,17 & 76,18 & 31,49 & 24,39 & 203,12 & 129,86 & 159,53 & 129,86 \\
\hline Epidalea calamita & 31TCF65 & 46,00 & 162,50 & 71,04 & 33,00 & 5050,68 & 274,52 & 62,36 & 212,16 & 175,04 & 227,02 & 230,05 & $\begin{array}{ll}101,48 \\
\end{array}$ & 558,36 & 77,79 & 18,38 & 34,71 & 201,48 & 99,46 & 134,50 & 120,18 \\
\hline Epidalea calamita & 31TCF66 & 100,00 & 154,23 & 73,09 & 33,01 & 5191,91 & 270,40 & 52,41 & 217,99 & 165,97 & 220,92 & 223,55 & 91,57 & 583,63 & 76,96 & 20,63 & 31,16 & 202,41 & 108,47 & 138,47 & 122,70 \\
\hline Epidalea calamita & 31TCF67 & 101,00 & 145,25 & 76,66 & 33,25 & 5386,18 & 267,13 & $\begin{array}{l}2,4+66 \\
40,66\end{array}$ & 226,47 & $\begin{array}{l}156,07 \\
\end{array}$ & \begin{tabular}{|l|}
176,01 \\
\end{tabular} & 217,00 & 80,06 & 608,72 & 75,16 & 23,26 & 28,20 & \begin{tabular}{|l|}
201,90 \\
\end{tabular} & 119,23 & $\begin{array}{l}142,62 \\
\end{array}$ & 123,55 \\
\hline Epidalea calamita & 31TCF68 & 99,00 & 131,15 & 79,81 & 33,66 & 5559,16 & 259,21 & 24,77 & 234,45 & 141,26 & 64,97 & 205,27 & 64,24 & 666,55 & 75,62 & 29,08 & 25,12 & 208,11 & 131,83 & 156,38 & 131,86 \\
\hline Epidalea calamita & 31TCF69 & 101,00 & 126,00 & 81,38 & 33,80 & 5630,80 & 256,95 & 18,44 & 238,52 & 135,73 & 58,01 & 200,83 & 58,01 & 688,63 & 77,25 & 32,79 & 23,99 & 208,25 & 132,74 & 164,76 & 132,74 \\
\hline Epidalea calamita & 31TCF75 & & & & & & & & & & & & & & & & & & & & \\
\hline Epidalea calamita & 31TCF76 & 100,00 & 158,41 & 71,91 & 32,99 & 5151,24 & 272,81 & 57,54 & 215,27 & 170,21 & 224,63 & 227,14 & 96,04 & 582,02 & 79,99 & 21,60 & 31,08 & 204,76 & 108,70 & 139,79 & 120,42 \\
\hline Epidalea calamita & 31TCF77 & 101,00 & 145,54 & 74,80 & 33,01 & 5344,03 & 265,69 & 42,47 & 223,23 & \begin{tabular}{|l|l|l}
156,52 \\
\end{tabular} & \begin{tabular}{|l|l|}
193,43 \\
\end{tabular} & $\begin{array}{l}216,74 \\
210\end{array}$ & 81,12 & $\begin{array}{l}627,43 \\
627\end{array}$ & $\begin{array}{l}78,06 \\
\end{array}$ & 25,09 & $\begin{array}{l}1,100 \\
27,47\end{array}$ & 208,00 & $\begin{array}{l}123,24 \\
\end{array}$ & \begin{tabular}{|l|l|}
148,06 \\
\end{tabular} & 127,46 \\
\hline Epidalea calamita & 31TCF78 & 101,00 & 130,54 & 77,56 & 33,05 & 5504,74 & 256,71 & 26,05 & 230,66 & 140,87 & 72,92 & 204,04 & 64,67 & 687,65 & 77,72 & 30,72 & 24,46 & 214,64 & 136,78 & 162,16 & 136,81 \\
\hline Epidalea calamita & 31TCF79 & 100,00 & 128,91 & 78,91 & 33,06 & 5569,67 & 257,32 & 23,18 & 234,14 & 138,99 & 61,92 & 203,09 & 61,92 & 687,95 & 76,92 & 32,81 & 24,03 & 210,20 & 132,79 & 165,84 & 132,79 \\
\hline Epidalea calamita & 31TCF86 & 91,00 & 159,65 & 71,41 & 32,97 & 5147,19 & 273,63 & 59,16 & 214,47 & 171,28 & 226,06 & 228,23 & 97,46 & 592,90 & 83,01 & 22,78 & 30,74 & 209,33 & 111,23 & 142,36 & 121,67 \\
\hline Epidalea calamita & $\begin{array}{l}\text { 31TCF87 } \\
\end{array}$ & 99,00 & 154,53 & 72,64 & 32,94 & 5250,76 & 271,23 & 52,83 & 218,40 & 165,66 & 222,41 & 224,40 & 90,97 & 606,20 & 80,03 & 24,43 & 28,57 & 207,34 & 117,39 & 145,62 & 122,55 \\
\hline Epidalea calamita & 31TCF88 & 101,00 & 146,61 & 74,55 & \begin{tabular}{l|l}
32,95 \\
\end{tabular} & 5379,89 & 267,30 & 43,24 & 224,06 & 157,43 & 124,63 & 218,17 & 81,53 & 630,24 & 76,94 & 26,90 & 26,52 & 206,60 & 124,75 & 151,34 & 125,14 \\
\hline Epidalea calamita & 31TCF89 & 101,00 & 139,33 & 76,38 & 32,97 & 5485,22 & 263,93 & 34,78 & 229,15 & 149,73 & 72,92 & 212,16 & 72,92 & 652,83 & 74,95 & 30,19 & 25,02 & 205,62 & 126,21 & 158,68 & 126,21 \\
\hline Epidalea calamita & 31TCF96 & 63,00 & 162,17 & 71,02 & 32,93 & 5135,33 & 275,55 & 61,89 & 213,65 & 173,63 & 228,45 & 230,55 & 100,06 & 597,04 & 85,61 & 22,81 & 31,43 & 213,67 & 111,73 & 143,07 & 122,33 \\
\hline Epidalea calamita & 31TCF97 & 101,00 & 155,44 & 71,73 & 32,62 & 5239,23 & 271,63 & 54,42 & 217,21 & 166,41 & 223,38 & 225,25 & 92,23 & 620,28 & 82,75 & 25,01 & 28,58 & 213,10 & 119,15 & 148,12 & 126,26 \\
\hline Epidalea calamita & 31TCF99 & 100,00 & 150,56 & 74,29 & 32,61 & 5400,68 & 271,62 & 46,79 & 224,84 & 161,05 & 84,77 & 222,03 & 84 & 616,26 & 74,95 & 28,32 & 26,30 & 201,81 & 118,82 & 152,44 & 118,82 \\
\hline Epidalea calamita & 31TCG00 & 101,00 & 150,62 & 112,15 & 37,00 & 6602,27 & 315,20 & 15,70 & 299,50 & 178,15 & 76,80 & 235,19 & 66,23 & 437,61 & 53,96 & 20,16 & 29,04 & $\begin{array}{l}142,76 \\
\end{array}$ & 77,21 & 101,21 & 77,22 \\
\hline Epidalea calamita & 31TCG01 & 100,00 & 149,52 & 113,44 & 37,00 & 6668,43 & 315,83 & 13,52 & 302,31 & 177,81 & 64,06 & 234,61 & 63,75 & 440,78 & 54,38 & 20,69 & 28,24 & 145,22 & 77,05 & 105,55 & 77,05 \\
\hline Epidalea calamita & 31TCG03 & 100,00 & 131,63 & 107,10 & 36,88 & 6366,07 & 290,37 & 2,88 & 287,50 & 156,82 & 50,46 & 213,46 & 50,46 & 551,20 & 66,24 & 28,90 & 24,44 & 177,22 & 100,41 & 137,19 & 100,41 \\
\hline Epidalea calamita & 31TCG05 & 101,00 & 113,19 & 100,43 & 36,5 & 6053,24 & 263,76 & $-7,62$ & 271,38 & 135,18 & 37,09 & 191,81 & 37,09 & 700,20 & 80,56 & 40,33 & 20,96 & 217,23 & 34,33 & 77,91 & 134,33 \\
\hline Epidalea calamita & 31TCG06 & 100,00 & 107,47 & $\begin{array}{l}98,54 \\
90,\end{array}$ & 36,5 & 5951,47 & 255,26 & \begin{tabular}{|l|l|}
$-11,17$ \\
-117
\end{tabular} & 266,43 & \begin{tabular}{|l|l|}
128,46 \\
\end{tabular} & 32,85 & $\begin{array}{l}184,80 \\
\end{array}$ & 32,85 & 762,64 & 85,91 & $\begin{array}{l}45,06 \\
45,0\end{array}$ & 19,62 & 233,25 & $\begin{array}{l}149,42 \\
\end{array}$ & \begin{tabular}{|l|l|}
195,38 \\
\end{tabular} & 149,42 \\
\hline Epidalea calamita & 31TCG08 & 100,00 & 89 & 93,30 & 36,13 & 5736,36 & 231,35 & $-23,12$ & 254,47 & 107,97 & 18,78 & 164,74 & 18 & 926,25 & 100,54 & 57,79 & 17,01 & 274,68 & 192,09 & 233,37 & 192,09 \\
\hline Epidalea calamita & 31TCG10 & 100,00 & 148,09 & 106,57 & 36,55 & 6410,78 & 305,75 & 17,94 & 287,81 & 173,48 & 74,81 & 230,39 & 66,60 & 474,01 & 56,88 & 22,27 & 28,30 & 150,99 & 84,91 & 108,93 & 84,92 \\
\hline Epidalea calamita & 31TCG11 & 100,00 & 148,88 & 108,25 & 36,80 & 6481,73 & 308,54 & 17,17 & 291,36 & 175,20 & 66,22 & 231,77 & 65,83 & 466,93 & 56,24 & 22,36 & 27,81 & 150,37 & 82,35 & 110,83 & 82,35 \\
\hline Epidalea calamita & 31 TCG12 & 101,00 & 145,60 & 108,07 & 36,81 & 6466,74 & 305,13 & 14,48 & 290,65 & 171,97 & 62,63 & $22 \varepsilon$ & 62,63 & 485,26 & 58,42 & 23,85 & 26,74 & 156,84 & 85,61 & 118,50 & 85,61 \\
\hline Epidalea calamita & 31TCG13 & $\begin{array}{l}100,00 \\
100\end{array}$ & 13 & $\frac{10}{10}$ & 36 & $\begin{array}{l}\frac{640,1 / 4}{6324,92} \\
\end{array}$ & 290,34 & $\begin{array}{r}\frac{r 4,46}{6,70} \\
\end{array}$ & $\mid 283,64$ & \begin{tabular}{|l|}
158,86 \\
151
\end{tabular} & $\begin{array}{l}\mid c,, 35 \\
53,53\end{array}$ & $\begin{array}{l}215,41 \\
215,44 \\
\end{array}$ & 53 & $\begin{array}{l}403,20 \\
557,00\end{array}$ & $\begin{array}{l}30,442 \\
66,26\end{array}$ & $\begin{array}{l}29,00 \\
29,01\end{array}$ & 24,74 & $\begin{array}{l}178,38 \\
178,3\end{array}$ & \begin{tabular}{|l|}
100,51 \\
10,5
\end{tabular} & \begin{tabular}{|l|l|}
139,94 \\
130
\end{tabular} & $\begin{array}{l}0,01 \\
100,51 \\
\end{array}$ \\
\hline Epidalea calamita & 31TCG14 & 100,00 & 119,22 & 100,30 & 36,13 & 6123,16 & 270,38 & $-2,44$ & 272,82 & 141,63 & 42,18 & 198,48 & 42,18 & 663,98 & 77,33 & 36,82 & 22,38 & 208,67 & 123,72 & 170,29 & 123,72 \\
\hline Epidalea calamita & 31TCG15 & 99,00 & 101,89 & 95,01 & 35,75 & 5921,92 & 247,70 & \begin{tabular}{|c|c|c|}
$-2,44,87$ \\
$-13,8$
\end{tabular} & \begin{tabular}{|l|l|}
261,58 \\
\end{tabular} & \begin{tabular}{|l|l|}
121,46 \\
\end{tabular} & 28,49 & $\begin{array}{l}179,32 \\
\end{array}$ & 28,49 & 793,30 & $\begin{array}{l}90,01 \\
90\end{array}$ & $\begin{array}{l}40,061 \\
46,81\end{array}$ & $\begin{array}{ll}19,97 \\
19\end{array}$ & 242,68 & 155,53 & 200,06 & 155,53 \\
\hline Epidalea calamita & 31TCG21 & 99,00 & 146,83 & 102,35 & 36,07 & 6271,19 & 299,19 & 20,17 & 279,02 & 170,87 & 66,94 & 227,23 & 66,94 & 499,75 & 59,08 & 24,52 & 27,28 & 157,64 & 89,08 & 117,97 & 89,08 \\
\hline Epidalea calamita & 31 TCG22 & 100,00 & 144,19 & 102,99 & 36,1 & 6293,54 & 297,54 & 17,28 & 280,26 & 168,62 & 63,81 & 224,93 & 63,81 & 513,65 & 60,86 & 25,78 & 26,49 & 163,31 & 90,99 & 125,23 & 90 \\
\hline Epidalea calamita & 31TCG23 & 100,00 & 137,21 & 102,12 & 36,16 & 6250,79 & 289,87 & 11,62 & 278,25 & $\begin{array}{ll}161,13 \\
\end{array}$ & 57,51 & 217,54 & 57,51 & 557,68 & 65,90 & 28,83 & 25,16 & \begin{tabular}{|l|l|}
177,63 \\
\end{tabular} & \begin{tabular}{|l|l|}
99,39 \\
\end{tabular} & 140,63 & 99,39 \\
\hline Epidalea calamita & 31TCG24 & 100,00 & 119,50 & 97,78 & 35,88 & 6070,98 & 268,10 & $-0,65$ & 268,75 & 140,95 & 43,20 & 198,17 & 43,20 & 679,44 & 78,79 & 37,49 & 22,68 & 212,84 & 125,75 & 175,27 & 125,75 \\
\hline Epidalea calamita & 31 T1TG26 & 100,00 & 121,80 & 99,03 & 36,10 & 6058,95 & 270,30 & 0,71 & 269,59 & 144,06 & 44,99 & 200,04 & 44,99 & 689,62 & 78,65 & 38,37 & 21,92 & 215,45 & 127,89 & 183,79 & 127,89 \\
\hline Epidalea calamita & 31TCG27 & 100,00 & 110,40 & 96,15 & 36,03 & 5934,42 & 255,86 & $-6,91$ & 262,77 & 131,10 & 35,86 & 187 & 35,86 & 790,05 & 88,08 & 45,32 & 20,25 & 242 & 151,64 & 211,22 & 151,64 \\
\hline Epidalea calamita & 31TCG28 & 99,00 & 85,87 & 89,44 & 35,39 & 5711,95 & 225,33 & $-23,97$ & 249,30 & 102,84 & 15,88 & 160,93 & 15,79 & 965,62 & 105,61 & 59,56 & 17,35 & 287,94 & 197,62 & 245,02 & 197,62 \\
\hline
\end{tabular}




\begin{tabular}{|c|c|c|c|c|c|c|c|c|c|c|c|c|c|c|c|c|c|c|c|c|c|}
\hline TAXON & UTM & $\mathrm{km} 2$ & B101 & B102 & $\mathrm{BIO3}$ & BIO4 & B105 & B106 & B107 & B108 & B109 & B1010 & BIO11 & BIO12 & 81013 & BIO14 & BIO15 & B1016 & B1017 & BIO18 & B1019 \\
\hline Epidalea calamita & 31TCG30 & 100,00 & 141,64 & 94,83 & 35,43 & 6015,75 & 285,34 & 21,63 & 263,71 & 163,24 & 66,24 & 219,57 & 66,24 & 547,84 & 63,60 & 25,13 & 26,98 & 167,79 & 100,53 & 130,45 & 100,53 \\
\hline Epidalea calamita & 31TCG31 & 101,00 & 144,05 & 96,82 & 35,74 & 6086,38 & 289,93 & 21,95 & 267,99 & 166,11 & 67,02 & 222,39 & 67,02 & 533,50 & 62,27 & 26,14 & 26,87 & 165,44 & 95,64 & 127,96 & 95,64 \\
\hline Epidalea calamita & 31TCG34 & 100,00 & 126,66 & 96,48 & 35,73 & 6057,52 & 273,47 & 6,68 & 266,79 & 148,22 & 50,25 & 204,90 & 50,25 & 646,01 & 75,22 & 34,60 & 23,94 & 203,36 & 116,24 & 168,70 & 116,24 \\
\hline Epidalea calamita & 31TCG35 & 100,00 & 102,56 & 91,07 & 35,19 & 5855,30 & 244,94 & $-10,29$ & 255,23 & 120,90 & 30,50 & 179,28 & 30,50 & 813,86 & 92,62 & 46,27 & 20,91 & 250,31 & 154,85 & 211,10 & 154,85 \\
\hline Epidalea calamita & 31TCG36 & 100,00 & 117,81 & 95,62 & 35,85 & 5979,94 & 263,39 & $-0,18$ & 263,56 & 138,88 & 42,61 & 195,41 & 42,61 & 723,82 & 82,78 & 39,32 & 22,59 & 226,92 & 131,99 & 198,32 & 131,99 \\
\hline Epidalea calamita & 31TCG37 & 101,00 & 105,48 & 92,90 & 35,55 & 5864,52 & 248,53 & $-8,86$ & 257,39 & 124,87 & 32,59 & 181,90 & 32,59 & 822,30 & 92,24 & 46,80 & 20,57 & 252,73 & 156,84 & 221,14 & 156,84 \\
\hline Epidalea calamita & 31TCG38 & 101,00 & 100,74 & 92,05 & 35,65 & 5808,73 & 242,40 & $-12,33$ & 254,73 & 119,60 & 28,60 & 176,52 & 28,60 & 875,04 & 97,42 & 50,57 & 19,64 & 266,84 & 169,90 & 237,59 & 169,90 \\
\hline Epidalea calamita & 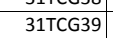 & 100,00 & 72,43 & 84,84 & 34,63 & 5608,18 & 208,53 & $-33,39$ & 241,93 & 87,47 & 13,71 & 146,77 & 4,76 & 1056,72 & \begin{tabular}{|l|}
114,67 \\
\end{tabular} & 66,88 & 16,13 & 310,90 & 222,37 & 261,89 & 223,34 \\
\hline Epidalea calamita & 31TCG40 & 100,00 & 134,28 & 89,61 & 34,87 & 5866,07 & 273,02 & 19,04 & 253,98 & 153,05 & 61,62 & 210,99 & 61,62 & 604,61 & 69,64 & 28,48 & 25,80 & 182,92 & 112,33 & 145,81 & 112,33 \\
\hline Epidalea calamita & 31TCG41 & 100,00 & 139,26 & 91,73 & 35,06 & 5936,46 & 279,99 & 21,87 & 258,12 & 159,79 & 64,88 & 216,22 & 64,88 & 575,31 & 66,70 & 28,43 & 26,16 & \begin{tabular}{ll|}
176,43 \\
\end{tabular} & $\mid 103,80$ & 140,88 & 103,80 \\
\hline Epidalea calamita & 31TCG43 & 101,00 & 134,01 & 93,72 & 35,06 & 6002,69 & 277,59 & 15,22 & 262,37 & 155,12 & 58,41 & 211,45 & 58,41 & 607,39 & 71,19 & 31,74 & 25,31 & 190,79 & 106,90 & 155,82 & 106,90 \\
\hline Epidalea calamita & 31TCG44 & 100,00 & 131,50 & 94,24 & 35,22 & 6007,63 & 275,71 & 12,66 & 263,05 & 152,78 & 55,70 & 209,05 & 55,70 & 626,31 & 73,35 & 32,62 & 25,01 & $\begin{array}{l}197,87 \\
\end{array}$ & 109,67 & 165,11 & 109,67 \\
\hline Epidalea calamita & 31TCG45 & 101,00 & 114,29 & 91,50 & 35,01 & 5901,49 & 256,68 & \begin{tabular}{|c|c|}
$-0,45$ \\
\end{tabular} & 257,13 & $\begin{array}{l}133,68 \\
\end{array}$ & 40,92 & \begin{tabular}{|l|}
191,16 \\
\end{tabular} & 40,92 & 741,55 & 85,76 & $\begin{array}{l}32,78 \\
39,78\end{array}$ & 23,26 & 232,24 & 134,15 & 198,86 & 134,15 \\
\hline Epidalea calamita & 31TCG49 & 101,00 & 83,04 & 86,28 & 34,86 & 5660,96 & 220,30 & $-24,22$ & 244,53 & 99,18 & 16,94 & 157,79 & 14,22 & 986,01 & 108,81 & 60,63 & 17,82 & 294,88 & 200,65 & 253,99 & 200,96 \\
\hline Epidalea calamita & 31TCG50 & 100,00 & 125,20 & 85,47 & 34,08 & 5757,16 & 260,77 & 14,22 & 246,55 & 141,68 & 54,95 & 201,17 & 54,95 & 672,70 & 77,02 & 33,49 & 24,15 & 201,27 & 126,60 & 163,08 & 126,60 \\
\hline Epidalea calamita & 31TCG51 & 100,00 & 132,65 & 87,34 & 34,39 & 5814,95 & 269,45 & 19,29 & 250,15 & 151,20 & 60,71 & 208,69 & 60,71 & 628,48 & 72,75 & 32,14 & 25,29 & 191,25 & 113,97 & 156,53 & 113,97 \\
\hline Epidalea calamita & 31TCG52 & 101,00 & 133,87 & 88,88 & 34,67 & 5867,08 & 272,45 & 19,13 & 253,33 & 153,15 & 60,71 & 210,23 & 60,71 & 621,01 & 72,45 & 32,35 & 25,55 & 191,85 & 109,86 & 157,58 & 109,86 \\
\hline Epidalea calamita & 31TCG54 & 100,00 & 128,47 & 90,52 & 34,94 & 5904,12 & 269,06 & 12,75 & 256,31 & 148,32 & 54,50 & 204,86 & 54,50 & 656,86 & 77,26 & 33,38 & 25,45 & 207,43 & 113,50 & 175,72 & 113,50 \\
\hline Epidalea calamita & 31TCG55 & 100,00 & 122,96 & 90,48 & 34,96 & 5889,88 & 263,85 & 7,80 & 256,05 & 142,53 & 49,29 & 199,42 & 49,29 & 693,17 & 81,14 & 35,47 & 25,08 & 219,27 & 120,52 & 189,14 & 120,52 \\
\hline Epidalea calamita & 31TCG56 & 100,00 & 101,21 & 87,01 & 34,60 & 5759,90 & 239,94 & $-8,37$ & 248,31 & $\mid 118,44$ & 30,82 & $\mid 177,04$ & 30,82 & 836,70 & 95,76 & 46,51 & 21,94 & 258,07 & $\mid 156,10$ & 221,74 & 156,10 \\
\hline Epidalea calamita & 31TCG60 & 101,00 & 123,97 & 82,54 & 33,89 & 5682,52 & 256,82 & 15,55 & 241,28 & 151,45 & 55,06 & 199,25 & 55,06 & 695,57 & 79,27 & 35,38 & 23,78 & 206,99 & 130,82 & 170,18 & 130,82 \\
\hline Epidalea calamita & 31TCG61 & 99,00 & 125,74 & 83,80 & 33,97 & 5727,71 & 259,95 & 15,87 & 244,08 & 143,41 & 55,75 & 201,19 & 55,75 & 683,17 & 78,92 & 35,98 & 24,29 & 206,36 & $\begin{array}{l}124,60 \\
\end{array}$ & 171,33 & 124,60 \\
\hline Epidalea calamita & 31TCG62 & 100,00 & 128,55 & 85,27 & 34,02 & 5765,80 & 263,99 & 17,17 & 246,82 & 146,21 & 57,46 & 204,06 & 57,46 & 667,49 & 77,95 & 34,40 & 25,03 & 205,20 & 118,07 & 171,74 & 118,07 \\
\hline Epidalea calamita & \begin{tabular}{|l|}
$31 \mathrm{TCG} 3$ \\
\end{tabular} & 100,00 & 128,65 & 86,51 & 34,10 & 5808,17 & 265,45 & 16,13 & 249,32 & 147,04 & 56,57 & 204,41 & 56,57 & 667,53 & 78,55 & 33,57 & 25,63 & 208,33 & 115,35 & 175,76 & 115,35 \\
\hline Epidalea calamita & 31TCG64 & 101,00 & 120,85 & 86,78 & 34,10 & 5815,49 & 258,77 & 8,88 & 249,89 & 139,11 & 48,99 & 196,76 & 48,99 & 712,98 & 84,27 & 35,55 & 25,45 & 224,98 & 122,59 & 192,38 & 122,59 \\
\hline Epidalea calamita & 31TCG65 & 101,00 & 121,13 & 87,71 & 34,33 & 5831,24 & 259,73 & 8,37 & 251,36 & 139,89 & 48,66 & 197,02 & 48,66 & 711,34 & 84,13 & 35,08 & 25,96 & 226,18 & 120,89 & 196,85 & 120,89 \\
\hline Epidalea calamita & 31TCG70 & 100,00 & 134,73 & 80,03 & 33,31 & 5606,56 & 263,71 & 27,21 & 236,49 & \begin{tabular}{|l|l|}
179,06 \\
\end{tabular} & $\begin{array}{ll}66,32 \\
66,32\end{array}$ & 208,80 & $\begin{array}{l}40,30 \\
66,32\end{array}$ & $\mid 653,16$ & 74,56 & 32,30 & 24,83 & \begin{tabular}{|l|l|}
199,86 \\
\end{tabular} & $\begin{array}{l}\mid 121,51 \\
121\end{array}$ & 162,07 & 121,51 \\
\hline Epidalea calamita & 31TCG71 & 101,00 & 127,45 & 81,27 & 33,46 & 5665,09 & 259,12 & 19,54 & 239,58 & 161,52 & 58,44 & 202,31 & 58,44 & 687,89 & 79,31 & 35,96 & 24,35 & 207,74 & 124,61 & 174,50 & 124,61 \\
\hline Epidalea calamita & 31TCG73 & 100,00 & 121,63 & 83,25 & 33,79 & 5723,55 & 256,15 & 12,41 & 243,74 & 138,51 & 51,61 & 196,92 & 51,61 & 720,62 & 85,22 & 35,85 & 25,23 & 224,42 & 124,60 & 191,02 & 124,60 \\
\hline Epidalea calamita & 31TCG74 & 100,00 & 116,23 & 83,76 & 33,94 & 5734,19 & 251,71 & 7,01 & 244,69 & 133,10 & 46,16 & 191,64 & 46,16 & 752,23 & 89,30 & 37,21 & 25,30 & 236,62 & 129,29 & 203,23 & 129,29 \\
\hline Epidalea calamita & 31TCG75 & 100,00 & 113,46 & 84,33 & 33,99 & 5744,27 & 249,75 & 4,17 & 245,58 & 130,70 & 43,18 & 188,87 & 43,18 & 767,56 & 90,93 & 38,16 & 25,40 & 242,60 & 131,87 & 211,41 & 131,87 \\
\hline Epidalea calamita & 31TCG80 & 100,00 & 142,39 & $\begin{array}{l}77,58 \\
77,58\end{array}$ & 33,01 & 5522,76 & 268,04 & 36,43 & 231,61 & $\begin{array}{l}182,38 \\
180\end{array}$ & $\begin{array}{l}45,93 \\
74,93\end{array}$ & \begin{tabular}{|l|}
215,34 \\
213
\end{tabular} & $\begin{array}{l}45,93 \\
74,93\end{array}$ & 629,71 & 73,18 & $\begin{array}{ll}30,010 \\
30,88\end{array}$ & 25,36 & \begin{tabular}{|l|}
197,39 \\
\end{tabular} & \begin{tabular}{|l|}
117,18 \\
11,18
\end{tabular} & 157,80 & 117,18 \\
\hline Epidalea calamita & 31TCG81 & 100,00 & 127,46 & 79,08 & 33,01 & 5607,84 & 257,22 & 21,31 & 235,91 & 169,23 & 59,53 & 201,81 & 59,53 & 699,47 & 80,66 & 36,45 & 24,19 & 211,40 & 126,42 & 179,08 & 126,42 \\
\hline Epidalea calamita & 31TCG82 & 100,00 & 125,96 & 80,09 & 33,02 & 5639,63 & 257,04 & 18,88 & 238,16 & 152,77 & 57,31 & 200,52 & 57,31 & 705,59 & 82,69 & 35,65 & 24,78 & 215,71 & 123,66 & 185,27 & 123,66 \\
\hline Epidalea calamita & 31TCG83 & 101,00 & 126,54 & 81,20 & 33,17 & 5680,40 & 258,87 & 18,34 & 240,54 & 143,76 & 57,05 & 201,30 & 57,05 & 704,03 & 83,77 & 34,09 & 25,99 & 219,07 & 119,07 & 189,24 & 119,07 \\
\hline Epidalea calamita & 31TCG90 & 101,00 & 136,36 & 75,89 & 32,62 & 5509,64 & 261,97 & 32,01 & 229,96 & 171,63 & 69,87 & 209,50 & 69,87 & 671,94 & 76,56 & 34,14 & 24,21 & 207,62 & 126,49 & 167,94 & 126,49 \\
\hline Epidalea calamita & 31TCG95 & 101,00 & 111,81 & 80,22 & 33,02 & 5654,02 & 244,94 & \begin{tabular}{r|}
6,04 \\
\end{tabular} & 238,90 & 127,50 & 43,42 & 186,65 & 43,42 & 788,95 & 94,18 & 39,23 & 25,53 & 246,95 & 135,20 & 217,09 & 135,20 \\
\hline Epidalea calamita & 31TCG96 & 101,00 & 83,33 & 77,80 & 32,93 & 5542,42 & 215,76 & $-16,57$ & 232,33 & 95,44 & 20,50 & 157,85 & 18,52 & 965,67 & 108,47 & 57,35 & 18,90 & 283,52 & 192,36 & 241,41 & 193,01 \\
\hline Epidalea calamita & 31TCG99 & 99,00 & 73,05 & 78,05 & 33,11 & 5513,07 & 205,46 & $-26,95$ & 232,41 & 85,52 & 20,57 & 146,93 & 8,37 & \begin{tabular}{|c|}
1043,01 \\
\end{tabular} & 114,88 & 64,81 & 16,92 & 303,95 & 215,59 & 257,31 & 218,58 \\
\hline Epidalea calamita & $31 \mathrm{TCH} 23$ & 101,00 & 39,35 & 77,48 & 33,21 & 5379,69 & 168,15 & $-61,19$ & 229,34 & 50,94 & 43,30 & 111,59 & $-24,16$ & 1278,98 & 134,37 & 86,22 & 12,74 & 363,34 & 286,52 & 294,29 & 297,12 \\
\hline Epidalea calamita & 31TDF06 & 37,00 & 157,68 & 70,70 & 32,57 & 5176,48 & 272,55 & 58,09 & 214,45 & \begin{tabular}{|c|}
168,68 \\
\end{tabular} & 224,93 & 226,84 & 95,61 & 632,00 & 88,07 & 24,34 & 30,05 & 222,25 & 117,84 & 148,61 & 131,50 \\
\hline Epidalea calamita & 31TDF07 & 100,00 & 148,43 & 71,25 & 32,08 & 5291,64 & 266,58 & 48,21 & 218,37 & 159,33 & 217,47 & 219,19 & 85,31 & 668,64 & 85,49 & 27,15 & 27,00 & 223,53 & 127,41 & 155,86 & 139,43 \\
\hline Epidalea calamita & 31TDF09 & 100,00 & 157,57 & 73,07 & 32,23 & 5337,48 & 276,76 & 54,45 & 222,32 & 168,05 & 93,54 & 228,09 & 92,38 & 597,40 & 76,89 & 27,83 & 27,82 & 201,93 & 114,38 & 150,33 & 114,39 \\
\hline Epidalea calamita & 31TDF16 & & & & & & & & & & & & & & & & & & & & \\
\hline Epidalea calamita & 31TDF17 & 101,00 & 160,92 & 70,50 & 32,28 & 5174,62 & 276,34 & 61,01 & 215,33 & 171,39 & 221,88 & 229,63 & 98,42 & 629,25 & 90,08 & 24,99 & 31,01 & 224,52 & 120,14 & 150,01 & 129,05 \\
\hline Epidalea calamita & 31TDF18 & 99,00 & 160,91 & 71,10 & 3 & 5239,75 & 277,92 & 59,79 & 218,13 & 171,23 & 130,82 & 230,38 & 97,46 & 609,35 & 84,18 & 26,58 & 29,69 & 213,79 & 118,71 & 150,19 & 120,98 \\
\hline Epidalea calamita & $\begin{array}{l}\text { 31TDF19 } \\
\end{array}$ & 101,00 & 158,29 & 71,93 & 31,99 & 5322,04 & 277,37 & 55,97 & 221,40 & 169,71 & 96,54 & 228,56 & 93,61 & 602,55 & 78,29 & 29,03 & 27,86 & 204,69 & 115,31 & 153,16 & 115,54 \\
\hline Epidalea calamita & 31TDF27 & 85,00 & 166,22 & 70,16 & 32,17 & 5089,19 & 280,30 & 66,64 & 213,66 & 176,56 & 218,22 & 233,41 & \begin{tabular}{r|r|}
104,49 \\
\end{tabular} & 618,62 & 94,89 & 23,92 & 33,86 & 229,10 & 117,70 & 148,27 & 125,51 \\
\hline Epidalea calamita & 31TDF28 & 101,00 & 158,99 & 70,16 & 31,69 & 5227,88 & 276,22 & 58,85 & 217,37 & 169,24 & 158,51 & 228,43 & 95,97 & 626,99 & 86,51 & 27,97 & 28,92 & 218,95 & 124,19 & 154,23 & 126,40 \\
\hline Epidalea calamita & 31TDF29 & 101,00 & 159,89 & 70,96 & 31,86 & 5280,03 & 278,34 & 58,46 & 219,88 & 175,16 & 99,82 & 229,64 & 95,80 & 601,07 & 80,09 & 29,35 & 28,43 & 206,58 & 115,70 & 153,82 & 116,03 \\
\hline Epidalea calamita & $\begin{array}{l}\text { 31TDF38 } \\
31 \text { D }\end{array}$ & 52,00 & 16 & 70 & 32 & \begin{tabular}{|l|}
5079,68 \\
50,03
\end{tabular} & 278,7 & $\begin{array}{l}0,405 \\
64,25 \\
\end{array}$ & \begin{tabular}{|l|}
214,53 \\
2140
\end{tabular} & \begin{tabular}{|l|}
174,00 \\
170
\end{tabular} & \begin{tabular}{|l|}
199,54 \\
1994
\end{tabular} & \begin{tabular}{|l|}
230,92 \\
\end{tabular} & \begin{tabular}{|c|}
102,04 \\
102,04
\end{tabular} & \begin{tabular}{|l|l|l|l|l|}
607,25 \\
\end{tabular} & $\begin{array}{l}90,054 \\
90,54\end{array}$ & $\begin{array}{l}25,82 \\
25,8\end{array}$ & $\begin{array}{l}20,45 \\
32,14\end{array}$ & \begin{tabular}{|l|}
220,47 \\
22
\end{tabular} & $\mid$ & 149,02 & $\begin{array}{l}1120,03 \\
122,51\end{array}$ \\
\hline Epidalea calamita & 31TDF39 & 99,00 & 159,05 & 70,45 & 31,72 & 5221,53 & 276,62 & 58,24 & 218,38 & 169,22 & 122,48 & 227,97 & 95,63 & 625,82 & 85,89 & 29,41 & 28,45 & 215,99 & 124,66 & 157,10 & 125,50 \\
\hline Epidalea calamita & 31TDF49 & 74,00 & 155,34 & 69,84 & 31,34 & 5248,01 & 273,44 & $\begin{array}{ll}5,, 54 \\
\end{array}$ & 218,91 & $\begin{array}{l}166,02 \\
16,20\end{array}$ & $\begin{array}{l}191,46 \\
\end{array}$ & 224,66 & 91,70 & \begin{tabular}{|l|l|}
669,03 \\
\end{tabular} & $\begin{array}{l}90,030 \\
91,23\end{array}$ & $\begin{array}{l}31,05 \\
31,0\end{array}$ & 27,32 & 226,69 & $\begin{array}{l}133,39 \\
\end{array}$ & 164,11 & 139,00 \\
\hline Epidalea calamita & 31TDF59 & 14,00 & 161,65 & 69,94 & 31,41 & 5210,88 & 278,76 & 60,24 & 218,53 & 171,76 & 216,00 & 230,12 & 98,29 & 649,65 & 96,41 & 27,29 & 30,94 & 228,76 & 121,53 & 155,41 & 138,59 \\
\hline Epidalea calamita & 31TDG00 & 100,00 & 147,12 & 74,17 & 32 & 5444,61 & 269,96 & 43,25 & 226 & 187,89 & 81,00 & 215 & 81,00 & 632,84 & 75,08 & 32,57 & 25,41 & 202,78 & 118,11 & 161,49 & 11 \\
\hline Epidalea calamita & 31TDG01 & $\begin{array}{l}101,00 \\
100\end{array}$ & $\begin{array}{l}14,14 \\
148,37 \\
\end{array}$ & 75,39 & $\begin{array}{ll}32,10 \\
32,31\end{array}$ & S488, 54.51 & 272,64 & $\begin{array}{l}3,25 \\
43,17 \\
\end{array}$ & \begin{tabular}{|l|}
229,47 \\
22,1
\end{tabular} & \begin{tabular}{|l|}
196,91 \\
196,9
\end{tabular} & $\begin{array}{l}81,180 \\
81,18\end{array}$ & \begin{tabular}{|l|}
220,65 \\
22,6
\end{tabular} & \begin{tabular}{l|l|}
81,180 \\
818
\end{tabular} & \begin{tabular}{|l|}
$632,04,92$ \\
613,
\end{tabular} & $\begin{array}{l}\mid 7,, 00 \\
72,77\end{array}$ & \begin{tabular}{|c|c|}
32,55 \\
32,5
\end{tabular} & $\begin{array}{l}25,41 \\
25,69\end{array}$ & \begin{tabular}{|l|}
197,42 \\
197
\end{tabular} & \begin{tabular}{|l|}
109,00 \\
10,11
\end{tabular} & 162,21 & $\begin{array}{l}1+0,11 \\
109,00\end{array}$ \\
\hline Epidalea calamita & 31TDG02 & 101,00 & 146,68 & 76,64 & 32,45 & 5543,49 & 272,71 & 40,25 & 232,46 & 195,43 & 78,39 & 219,41 & 78,39 & 612,12 & 72,23 & 31,38 & 26,17 & 196,17 & 103,62 & 166,15 & 103,62 \\
\hline Epidalea calamita & 31TDG03 & 100,00 & 138,99 & 77,70 & 32,62 & 5595,96 & 267,33 & 32,06 & 235,27 & 185,64 & 70,21 & 212,47 & 70,21 & 646,98 & 76,68 & 31,46 & 26,92 & 203,51 & 105,68 & 179,85 & 105,68 \\
\hline Epidalea calamita & 31TDG04 & 100,00 & 133,54 & 78,74 & 32,86 & 5641,89 & 263,69 & 26,12 & 237, & 158,12 & 64,3 & 207,5 & 64 & 674,76 & 81,50 & 31,44 & 27,99 & 212,37 & 107,54 & 190,92 & 107,54 \\
\hline Epidalea calamita & 31TDG05 & 100,00 & 127,55 & 79,61 & 32,97 & 5659,60 & 259,13 & 19,95 & 239,18 & 144,45 & 58,10 & 201,78 & 58,10 & 706,09 & 86,06 & 32,36 & 28,71 & 225,31 & 111,86 & 203,49 & 111,86 \\
\hline
\end{tabular}




\begin{tabular}{|c|c|c|c|c|c|c|c|c|c|c|c|c|c|c|c|c|c|c|c|c|c|}
\hline TAXON & UTM & $\mathrm{km} 2$ & B101 & B102 & $\mathrm{BIO3}$ & B104 & B105 & B106 & B107 & B108 & B109 & BIO10 & BIO11 & BIO12 & B1013 & BIO14 & BIO15 & B1016 & B1017 & B1018 & B1019 \\
\hline Epidalea calamita & 31TDG06 & 100,00 & 106,21 & 79,00 & 32,99 & 5609,13 & 238,65 & 2,26 & 236,39 & 121,23 & 39,69 & 180,73 & 38,92 & 829,94 & 97,73 & 43,36 & 24,43 & 255,93 & 147,61 & 225,40 & 147,75 \\
\hline Epidalea calamita & 31TDG07 & 101,00 & 97,75 & 79,20 & 33,01 & 5585,81 & 230,65 & $-4,96$ & 235,61 & 112,18 & 32,50 & 172,05 & 31,12 & 884,39 & 102,25 & 48,81 & 21,83 & 268,99 & 165,19 & 234,06 & 165,33 \\
\hline Epidalea calamita & 31TDG08 & 101,00 & 67,80 & 75,83 & 32,65 & 5466,88 & 199,08 & $-29,52$ & 228,60 & 74,25 & 25,33 & 141,74 & 4,84 & 1075,86 & 116,99 & 67,49 & 15,94 & 307,24 & 226,72 & 258,04 & 230,88 \\
\hline Epidalea calamita & 31TDG09 & 101,00 & 88,07 & 79,57 & 33,42 & 5552,21 & 221,40 & $-13,35$ & 234,75 & 102,11 & 28,74 & 162,03 & 22,14 & 952,05 & 107,28 & 56,50 & 18,73 & 284,35 & 188,33 & 243,10 & 189,54 \\
\hline Epidalea calamita & 31TDG10 & 100,00 & 143,65 & 72,82 & 31,99 & 5436,23 & 266,45 & 41,19 & \begin{tabular}{|l|l|}
225,27 \\
\end{tabular} & \begin{tabular}{|l|l|}
191,40 \\
\end{tabular} & 78,13 & 215,81 & 78,13 & 661,58 & 76,92 & 35,13 & 24,44 & 210,32 & 124,08 & 170,04 & 124,08 \\
\hline Epidalea calamita & 31TDG11 & 100,00 & 130,92 & 73,96 & 32,00 & 5506,36 & 256,72 & 28,36 & 228,36 & 179,89 & 64,96 & 204,11 & 64,96 & 711,82 & 81,20 & 37,69 & 23,64 & 220,30 & 129,34 & 187,13 & 129,34 \\
\hline Epidalea calamita & 31TDG12 & 101,00 & 138,82 & 74,97 & 31,99 & 5534,36 & 264,97 & 34,06 & 230,90 & 187,60 & 71,46 & 211,89 & 71,46 & 664,54 & 77,32 & 33,73 & 25,52 & 209,84 & 113,45 & 180,96 & 113,45 \\
\hline Epidalea calamita & 31TDG13 & 100,00 & 137,51 & 76,02 & 32,01 & 5576,41 & 265,12 & 31,67 & 233,45 & 186,14 & 69,31 & 210,99 & 69,31 & 668,60 & 79,16 & 32,45 & 26,82 & 210,84 & 109,50 & 187,69 & 109,50 \\
\hline Epidalea calamita & 31TDG14 & 101,00 & 129,63 & 76,99 & 32,13 & 5603,61 & 258,87 & 23,76 & 235,10 & 155,03 & 61,35 & 203,38 & 61,35 & 702,44 & 85,59 & 32,35 & 28,71 & 221,47 & 111,01 & 202,88 & 111,01 \\
\hline Epidalea calamita & 31TDG15 & 101,00 & 123,04 & 77,90 & 32,41 & 5614,28 & 253,69 & 17,34 & 236,35 & 138,98 & 54,84 & \begin{tabular}{|l|}
197,03 \\
\end{tabular} & 54,84 & 734,72 & 89,87 & 33,72 & 28,82 & 233,69 & 1116,68 & 213,33 & 116,68 \\
\hline Epidalea calamita & 31TDG16 & 100,00 & 109,61 & 78,14 & 32,94 & 5594,27 & 241,39 & 5,90 & 235,49 & 124,73 & 42,68 & 183,93 & 42,52 & 816,30 & 97,07 & 41,02 & 25,05 & 253,79 & 141,82 & 225,21 & 141,82 \\
\hline Epidalea calamita & 31TDG17 & 100,00 & 92,30 & 77,43 & 32,98 & 5530,63 & 224,15 & $-7,93$ & 232,07 & 105,48 & 30,03 & 166,30 & 27,32 & 927,47 & 105,12 & 53,59 & 19,78 & 274,98 & 180,58 & 237,38 & 181,09 \\
\hline Epidalea calamita & 31TDG18 & 98,00 & 62,33 & 74,21 & 32,38 & 5421,81 & 192,68 & $-33,11$ & 225,79 & 60,52 & 21,32 & 135,92 & 0,71 & 1113,96 & 119,15 & 70,54 & 14,95 & 312,34 & 240,85 & 260,57 & 245,94 \\
\hline Epidalea calamita & 31TDG19 & 44,00 & 74,09 & 76,62 & 32,84 & 5468,72 & 205,63 & $-23,84$ & 229,47 & 82,36 & 21,98 & 147,66 & 10,64 & 1044,01 & 113,79 & 65,48 & 16,03 & 299,40 & 218,83 & 252,53 & 222,53 \\
\hline Epidalea calamita & 31TDG20 & 100,00 & 152,94 & 71,68 & 31,71 & 5379,99 & 273,79 & 50,50 & 223,29 & 200,40 & 87,61 & 223,95 & 87,61 & 634,60 & 77,02 & 33,88 & 25,47 & 208,06 & 119,64 & 165,13 & 119,64 \\
\hline Epidalea calamita & 31TDG21 & 101,00 & 134,01 & 72,64 & 31,69 & 5474,85 & 258,67 & 31,96 & 226,71 & 182,80 & 68,49 & 206,92 & 68,49 & 718,32 & 81,31 & 38,66 & 23,28 & 224,13 & 132,51 & 188,93 & 132,51 \\
\hline Epidalea calamita & 31TDG22 & 99,00 & 125,49 & 73,69 & 31,92 & 5511,67 & 252,13 & 23,39 & 228,73 & 174,44 & 59,73 & 198,87 & 59,73 & 746,68 & 87,10 & 38,10 & 23,96 & 229,79 & 133,40 & 201,19 & 133,40 \\
\hline Epidalea calamita & 31TDG23 & 101,00 & 120,63 & 74,58 & 32,00 & 5523,95 & 248,55 & 18,30 & 230,24 & 167,35 & 54,73 & 194,10 & 54,73 & 769,68 & 90,82 & 38,58 & 24,64 & 234,97 & 134,90 & 209,82 & 134,90 \\
\hline Epidalea calamita & 31TDG24 & 100,00 & 126,73 & 75,58 & 32,00 & 5574,07 & 255,26 & 22,19 & 233,07 & 149,77 & 59,32 & 200,34 & 59,32 & 739,43 & 89,01 & 34,71 & 27,42 & 230,37 & 121,26 & 210,88 & 121,26 \\
\hline Epidalea calamita & 31TDG25 & 100,00 & 120,53 & 76,48 & 32,00 & 5584,37 & 250,26 & 15,99 & 234,26 & 135,76 & 53,10 & 194,30 & 53,10 & 770,56 & 92,84 & 36,19 & 27,23 & 241,75 & 127,33 & 219,72 & 127,33 \\
\hline Epidalea calamita & 31TDG26 & 101,00 & 110,29 & 77,01 & 32,33 & 5569,27 & 241,08 & 7,03 & 234,05 & 124,80 & 43,82 & 184,24 & 43,67 & 832,47 & 97,84 & 42,1 & 24,08 & 256,10 & 147,86 & 225,80 & 147,86 \\
\hline Epidalea calamita & 31TDG27 & 101,00 & 99,41 & 77,17 & 32,82 & 5532,74 & 230,85 & $-1,67$ & 232,51 & 113,10 & 36,06 & 173,24 & 34,05 & 897,92 & 102,41 & 49,96 & 20,58 & 268,64 & 171,64 & 232,58 & 171,86 \\
\hline Epidalea calamita & 31TDG29 & 24,00 & 35,25 & 70,26 & 31,27 & 5344,72 & 163,50 & $-57,55$ & 221,05 & 15,77 & 73,62 & 108,52 & $-23,64$ & \begin{tabular}{ll|}
1292,58 \\
\end{tabular} & 133,03 & 81,08 & 13,01 & 360,84 & 282,65 & 286,08 & 305,85 \\
\hline Epidalea calamita & 31TDG30 & 100,00 & 157,83 & 71,01 & 31,53 & 5300,33 & 277,10 & 55,68 & 221,42 & 197,57 & 96,21 & 227,47 & 93,06 & 632,38 & 82,25 & 31,86 & 26,59 & 212,42 & 124,07 & 160,28 & 124,09 \\
\hline Epidalea calamita & 31TDG31 & 101,00 & 144,71 & 71,51 & 31,09 & 5430,91 & 267,32 & 42,09 & 225,23 & 192,77 & 78,92 & 216,44 & 78,92 & 701,68 & 81,71 & 38,45 & 23,28 & 223,49 & 133,61 & 182,06 & 133,61 \\
\hline Epidalea calamita & 31TDG32 & 101,00 & 126,55 & 72,56 & 31,49 & 5485,82 & 252,29 & 24,87 & 227,42 & 175,21 & 61,18 & 199,62 & 61,18 & 777,76 & 87,68 & 41,15 & 22,50 & 238,41 & 144,73 & 204,14 & 144,73 \\
\hline Epidalea calamita & 31 TDG33 & 100,00 & 127,01 & 73,42 & 31,53 & $\begin{array}{l}5519,44 \\
551,04\end{array}$ & 253,66 & 24,32 & 229,34 & $\begin{array}{l}175,75 \\
\end{array}$ & $\begin{array}{l}1,10 \\
60,87 \\
\end{array}$ & 200,29 & $\begin{array}{l}\mid 60,87 \\
60,0\end{array}$ & 774,75 & 89,25 & $\begin{array}{l}39,24 \\
39,2\end{array}$ & 23,82 & \begin{tabular}{|l|}
237,88 \\
\end{tabular} & $\begin{array}{l}138,84 \\
\end{array}$ & 209,39 & 138,84 \\
\hline Epidalea calamita & 31TDG34 & 101,00 & 129,94 & 74,44 & 31,72 & 5552,03 & 257,43 & 25,65 & 231,78 & 165,59 & 62,72 & 203,31 & 62,72 & 768,28 & 89,48 & 36,97 & 25,35 & 236,62 & 132,24 & 212,86 & 132,24 \\
\hline Epidalea calamita & 31TDG35 & 100,00 & 124,92 & 75,47 & 31,97 & 5577,89 & 253,79 & 20,32 & 233,47 & 140,55 & 57,43 & 198,57 & 57,43 & 794,52 & 92,92 & 37,77 & 25,36 & 245,58 & 137,07 & 218,86 & 137,07 \\
\hline Epidalea calamita & 31TDG36 & 100,00 & 114,79 & 76,19 & 32,08 & 5563,09 & 244,76 & 11,45 & 233,31 & 130,09 & 48,35 & 188,44 & 48,04 & 837,99 & 96,99 & 42,20 & 23,51 & 256,19 & 151,28 & 225,56 & 151,35 \\
\hline Epidalea calamita & 31TDG37 & 101,00 & 107,25 & 76,76 & 32,33 & 5546,01 & 238,00 & 4,78 & 233,22 & 121,53 & 42,10 & 180,97 & 41,12 & 876,42 & 99,70 & 46,81 & 21,35 & 263,89 & 165,67 & 227,95 & 165,95 \\
\hline Epidalea calamita & 31TDG40 & 101,00 & 153,92 & 70,08 & 31,02 & 5322,70 & 273,35 & 51,94 & 221,41 & 184,27 & 153,09 & \begin{tabular}{|l|l|}
224,08 \\
\end{tabular} & $\begin{array}{l}41,12 \\
89,16\end{array}$ & \begin{tabular}{|l|l|l|l|l|}
686,11 \\
\end{tabular} & 89,72 & 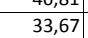 & 25,24 & \begin{tabular}{|l|}
226,52 \\
220
\end{tabular} & $\begin{array}{l}139,44 \\
\end{array}$ & \begin{tabular}{|l|l|}
169,65 \\
\end{tabular} & 141,06 \\
\hline Epidalea calamita & 31TDG41 & 100,00 & 143,57 & 70,61 & 31,01 & 5418,05 & 265,73 & 41,25 & 224,47 & 191,17 & 83,61 & 215,19 & 78,09 & 744,65 & 88,99 & 40,05 & 22,43 & 234,86 & 148,77 & 186,25 & 148,81 \\
\hline Epidalea calamita & 31TDG42 & 100,00 & 113,04 & 71,73 & 31,59 & 5434,21 & 238,94 & 14,74 & 224,20 & 152,19 & 57,00 & 186,19 & 49,79 & 869,95 & 97,70 & 48,67 & 20,16 & 260,21 & 174,95 & 213,02 & 175,78 \\
\hline Epidalea calamita & 31TDG43 & 101,00 & 120,79 & 72,53 & 31,36 & 5480,88 & 247,16 & 19,81 & 227,36 & 168,24 & 56,24 & 193,96 & 55,80 & 841,38 & 93,61 & 44,30 & 21,43 & 251,91 & 161,19 & 215,44 & 161,25 \\
\hline Epidalea calamita & 31TDG44 & 101,00 & 130,89 & 73,43 & 31,21 & 5539,31 & 257,59 & 26,91 & 230,68 & 168,05 & 63,87 & 204,03 & 63,87 & 819,11 & 91,15 & 40,15 & 22,82 & 246,08 & 151,03 & 214,89 & 151,03 \\
\hline Epidalea calamita & 31TDG45 & 100,00 & 123,43 & 74,48 & 31,81 & 5541,19 & 251,55 & 19,82 & 231,73 & 138,59 & 56,68 & 196,77 & 56,65 & 844,31 & 94,95 & 41,38 & 22,77 & 254,73 & 155,64 & 222,07 & 155,64 \\
\hline Epidalea calamita & 31TDG46 & 101,00 & 98,81 & 74,53 & 32,16 & 5461,29 & 227,98 & 0,29 & 227,69 & 123,23 & 38,16 & 172,11 & 35,25 & 935,05 & 102,41 & 54,20 & 18,70 & 269,63 & 188,71 & 229,59 & 189,68 \\
\hline Epidalea calamita & 31TDG48 & 99,00 & 90,22 & 75,53 & 32,75 & 5453,60 & 220,57 & $-7,82$ & 228,39 & 99,62 & 32,26 & 163,59 & 26,84 & 975,65 & 105,37 & 59,03 & 17,02 & 278,09 & 203,11 & 234,79 & 205,54 \\
\hline Epidalea calamita & 31TDG50 & 100,00 & 149,07 & 69,41 & 30,93 & 5340,44 & 268,83 & 47,51 & 221,32 & 172,34 & 184,93 & 219,62 & 84,45 & 739,98 & 97,36 & 35,59 & 24,90 & 240,67 & 149,22 & 177,14 & 156,74 \\
\hline Epidalea calamita & 31TDG51 & 100,00 & 150,52 & 69,89 & 30,82 & 5412,19 & 271,39 & 47,10 & 224,29 & 175,65 & 190,74 & 221,70 & 84,58 & 751,99 & 97,13 & 37,05 & 23,69 & 241,22 & $\begin{array}{l}152,85 \\
\end{array}$ & 178,44 & 159,64 \\
\hline Epidalea calamita & 31TDG52 & 100,00 & 121,05 & 70,84 & 31 & 5416,66 & 245,56 & 21,77 & 223,79 & 158,67 & 73,56 & 193,60 & 57,38 & 871,94 & 101,31 & 48,10 & 20,27 & 261,90 & $\begin{array}{ll}179,63 \\
\end{array}$ & 207,94 & 181,17 \\
\hline Epidalea calamita & 31TDG56 & 101,00 & 126,48 & 74,94 & 31,73 & 5552,87 & 254,68 & 21,49 & 233,19 & 143,13 & 59,32 & 199,65 & 59,17 & 878,35 & 94,59 & 43,36 & 21,32 & 261,01 & 171,38 & 218,56 & 171,39 \\
\hline Epidalea calamita & 31TDG57 & 100,00 & 129,29 & 76,38 & 31,96 & 5582,05 & 258,48 & 22,78 & 235,70 & 147,30 & 61,07 & 202,62 & 61,07 & 845,98 & 92,13 & 42,93 & 20,88 & 250,54 & 166,34 & 210,12 & 166,34 \\
\hline Epidalea calamita & 31TDG60 & 61,00 & 154,39 & 69,16 & 30,85 & 5341,51 & 273,27 & 51,57 & 221,70 & 165,06 & 219,98 & 224,61 & 89,12 & 727,44 & 103,91 & 31,62 & 28,39 & 44,78 & 37,27 & 168,24 & 159,08 \\
\hline Epidalea calamita & 31TDG61 & 101,00 & 146,85 & 69,27 & 30 & 5401,26 & 267,46 & 44,08 & 223,38 & 169,79 & 194,63 & 218,05 & 81,26 & 781,72 & 103,63 & 37,41 & 24,57 & 249,46 & 157,06 & 180,94 & 168,79 \\
\hline Epidalea calamita & 31TDG62 & 101,00 & 149,18 & 69,89 & 30,11 & 5469,89 & 270,71 & 44,27 & 226,44 & 175,51 & 190,11 & 220,84 & 82,05 & 782,31 & 103,47 & 38,13 & 24,38 & 247,74 & 157,19 & 178,56 & 168,20 \\
\hline Epidalea calamita & 31TDG63 & 100,00 & 134,37 & 70,82 & 30,71 & 5472,86 & 258,25 & 31,14 & 227,11 & 182,29 & 82,49 & 206,82 & 68,42 & 864,54 & 102,08 & 45,97 & 21,14 & 257,04 & 178,28 & 202,84 & 178,94 \\
\hline Epidalea calamita & 31TDG64 & 100,00 & 133,71 & 71,88 & 30,84 & 5515,80 & 258,82 & 29,58 & 229,23 & 177,28 & 81,89 & 206,53 & 66,99 & 870,25 & 101,28 & 45,16 & 21,27 & 255,94 & 178,43 & 203,14 & 178,73 \\
\hline Epidalea calamita & 31TDG66 & 101,00 & 128,84 & 74,49 & 31,64 & 5531,15 & 256,26 & 23,76 & 232,50 & 153,06 & 61,83 & 201,77 & 61,83 & 877,56 & 97,45 & 45,15 & 20,81 & 255,27 & 177,86 & 209,00 & 177,86 \\
\hline Epidalea calamita & 31TDG70 & & & & & & & & & & & & & & & & & & & & \\
\hline Epidalea calamita & 31TDG71 & 99,00 & 156,87 & 69,51 & 30,60 & 5364,56 & 275,70 & 52,56 & 223,14 & 167,35 & 224,72 & 227,13 & 90,86 & 711,45 & 107,54 & 29,23 & 30,94 & 243,24 & 129,62 & 160,29 & 156,59 \\
\hline Epidalea calamita & 31TDG72 & 101,00 & 154,90 & 69,47 & 30,09 & 5459,06 & 275,20 & 48,78 & 226,42 & 165,21 & 225,52 & 226,12 & 87,35 & 736,21 & 108,20 & 31,73 & 28,88 & 244,81 & 137,61 & 161,82 & 162,07 \\
\hline Epidalea calamita & 31TDG73 & 100,00 & 151,59 & 69,54 & 29,97 & 5553,31 & 273,66 & 44,30 & 229,36 & 165,46 & 222,68 & 223,75 & 82,63 & 769,42 & 108,47 & 35,29 & 26,44 & 246,62 & 149,64 & 161,79 & 168,62 \\
\hline Epidalea calamita & 31TDG74 & 101,00 & 148 & 70,75 & 30,06 & 5587,62 & 272,30 & 40,82 & 231,48 & 177,15 & 209,99 & 221,44 & 79,36 & 785,67 & 106,68 & 38,35 & 24,72 & 244,16 & 159,67 & 167,53 & 165 \\
\hline Epidalea calamita & $\begin{array}{l}31 \text { TDG75 } \\
3\end{array}$ & $\begin{array}{l}101,00 \\
100\end{array}$ & $\begin{array}{l}14,0,01 \\
138,71\end{array}$ & 72,55 & $\begin{array}{l}30,90 \\
30,92\end{array}$ & 55023,73 & 263,75 & $\begin{array}{l}40,024 \\
32,51 \\
\end{array}$ & $\begin{array}{l}231,240 \\
231,24 \\
\end{array}$ & $\begin{array}{l}117,250 \\
182,50 \\
\end{array}$ & \begin{tabular}{|l|}
104,51 \\
10,5
\end{tabular} & \begin{tabular}{|l|}
211,21 \\
\end{tabular} & $\begin{array}{l}71,13 \\
71,13\end{array}$ & \begin{tabular}{|l|}
832,95 \\
832
\end{tabular} & \begin{tabular}{|l|}
103,27 \\
103
\end{tabular} & \begin{tabular}{|l|l|}
40,33 \\
43,47
\end{tabular} & 22,28 & \begin{tabular}{|l|}
247,40 \\
2470
\end{tabular} & \begin{tabular}{|l|}
173,37 \\
173
\end{tabular} & \begin{tabular}{|l|l|}
186,58 \\
180
\end{tabular} & $\begin{array}{l}103,21 \\
174,80\end{array}$ \\
\hline Epidalea calamita & 31TDG76 & 100,00 & 143,13 & 74,41 & 31,20 & 5552,16 & 269,17 & 35,16 & 234,01 & 185,68 & 111,35 & 215,67 & 74,65 & 784,79 & 99,79 & 41,08 & 22,69 & 235,03 & 163,83 & 173,85 & 164,27 \\
\hline Epidalea calamita & 31TDG77 & 100,00 & 138.85 & 75,89 & 31,95 & 5538,66 & 266.13 & 30.97 & 235.15 & 177,79 & 103.96 & 211.36 & 70,83 & $782.67 \mid$ & 97,23 & 41.56 & 21.97 & 231.89 & 164.30 & 174,28 & 164,77 \\
\hline Epidalea calamita & 31TDG79 & 46,00 & 113,70 & 77,44 & 32,85 & 5476,17 & 243,58 & 10,14 & 233,44 & 142,50 & 62,03 & 186 & 48 & 879,16 & 98,03 & 50,52 & 18,20 & 248 & 189,73 & 200,52 & 191,48 \\
\hline Epidalea calamita & 31TDG81 & 58,00 & 156,33 & 69,67 & 30,77 & 5324,65 & 274,68 & 52,23 & 222,45 & 166,76 & 221,85 & 226,11 & 91,01 & 700,06 & 108,38 & 27,85 & 32,13 & 241,39 & 125,74 & 155,80 & 153,82 \\
\hline
\end{tabular}




\begin{tabular}{|c|c|c|c|c|c|c|c|c|c|c|c|c|c|c|c|c|c|c|c|c|c|}
\hline TAXON & UTM & $\mathrm{km2}$ & B101 & B1O2 & $\mathrm{BIO3}$ & $\mathrm{B104}$ & B105 & B106 & B107 & B108 & B109 & 81010 & B1011 & BIO12 & $\mathrm{B1O13}$ & BIO14 & B1015 & BIO16 & B1017 & BIO18 & B1019 \\
\hline Epidalea calamita & 31TDG82 & 99,00 & 151,01 & 69,29 & 30,32 & 5396,79 & 270,51 & 46,31 & 224,20 & 161,54 & 221,06 & 221,71 & 84,91 & 744,17 & 109,39 & 31,64 & 28,92 & 246,43 & 139,20 & 164,30 & 163,79 \\
\hline Epidalea calamita & 31TDG83 & 101,00 & 152,89 & 69,74 & 30,10 & 5483,13 & 273,79 & 46,21 & 227,58 & 163,03 & 223,94 & 224,33 & 85,14 & 738,58 & 109,55 & 31,46 & 29,01 & 243,75 & 137,25 & 159,43 & 163,03 \\
\hline Epidalea calamita & 31TDG84 & 101,00 & 151,60 & 71,06 & 30,56 & 5502,87 & 273,56 & 44,03 & 229,53 & 161,75 & 222,87 & 223,26 & 83,40 & 745,99 & 107,99 & 33,42 & 27,63 & 240,70 & 143,15 & 156,73 & 162,27 \\
\hline Epidalea calamita & 31TDG85 & 101,00 & 151,47 & 73,02 & 31,16 & 5489,76 & 274,51 & 43,28 & 231,23 & 163,92 & 222,63 & 222,94 & 83,53 & 727,58 & 104,06 & 33,71 & 26,96 & 232,38 & 143,45 & 154,74 & 155,45 \\
\hline Epidalea calamita & 31TDG86 & 100,00 & 150,17 & 74,92 & 31,76 & 5484,51 & 274,44 & 41,47 & 232,96 & 160,93 & 221,32 & 221,62 & 82,25 & 708,14 & 99,79 & 33,60 & 26,14 & 224,22 & 142,91 & 150,56 & 149,80 \\
\hline Epidalea calamita & 31TDG87 & 101,00 & 149,24 & 76,75 & 32,16 & 5487,27 & 274,86 & 39,84 & 235,02 & 160,05 & 216,56 & 220,80 & 81,28 & 689,46 & 96,19 & 32,82 & 25,71 & 217,65 & 140,02 & 146,09 & 146,16 \\
\hline Epidalea calamita & 31TDG88 & 100,00 & 145,31 & 78,30 & 32,55 & 5499,28 & 272,62 & 35,72 & 236,90 & 157,99 & 205,09 & 217,05 & 77,44 & 700,65 & 94,38 & 33,65 & 24,44 & 217,15 & 142,92 & 147,29 & 151,21 \\
\hline Epidalea calamita & 31TDG89 & 82,00 & 138,88 & 79,63 & 32,99 & 5506,15 & 267,94 & 29,75 & 238,19 & 152,98 & 186,80 & 211,01 & 71,29 & 724,75 & 93,55 & 35,45 & 22,99 & 219,97 & 148,58 & 152,88 & 159,90 \\
\hline Epidalea calamita & 31TDG91 & & & & & & & & & & & & & & & & & & & & \\
\hline Epidalea calamita & 31TDG92 & 90,00 & 150,89 & 70,44 & 31,30 & 5265,40 & 268,98 & 47,70 & 221,29 & 161,82 & 218,54 & 220,26 & 86,91 & 712,95 & 106,85 & 28,68 & 30,50 & 240,38 & 130,56 & 156,86 & 156,52 \\
\hline Epidalea calamita & 31TDG93 & 101,00 & 149,48 & 71,06 & 31,22 & 5302,24 & 268,45 & 45,39 & 223,06 & 160,19 & 218,27 & 219,19 & 84,88 & 722,41 & 106,15 & 30,10 & 29,09 & 238,99 & 135,13 & 158,25 & 157,90 \\
\hline Epidalea calamita & 31TDG94 & 101,00 & 148,97 & 72,30 & 31,68 & 5318,50 & 269,01 & 43,99 & 225,02 & 159,60 & 218,08 & 218,93 & 84,16 & 721,56 & 104,28 & 31,32 & 28,05 & 234,82 & 138,13 & 157,69 & 156,27 \\
\hline Epidalea calamita & 31TDG95 & 100,00 & 155,34 & 74,30 & 32,15 & 5331,84 & 276,12 & 48,17 & 227,95 & 165,50 & 224,38 & 224,95 & 89,64 & 666,18 & 100,65 & 28,02 & 29,82 & \begin{tabular}{|l|l|}
222,45 \\
\end{tabular} & 124,31 & 143,50 & 143,07 \\
\hline Epidalea calamita & 31TDG96 & 101,00 & 154,32 & 76,03 & 32,57 & 5354,37 & 276,69 & 46,32 & 230,38 & 164,47 & 223,78 & 224,28 & 88,29 & 645,72 & 96,88 & 27,87 & 29,30 & 214,89 & 123,38 & 138,33 & 136,76 \\
\hline Epidalea calamita & 31TDG97 & 101,00 & 154,91 & 77,94 & 32,98 & 5376,61 & 278,77 & 45,78 & 232,99 & 164,75 & 224,66 & 225,07 & 88,52 & 620,55 & 93,45 & 26,50 & 29,39 & 207,71 & 118,15 & 129,83 & 131,77 \\
\hline Epidalea calamita & 31TDG98 & 101,00 & 154,16 & 79,68 & 33,31 & 5404,67 & 279,85 & 43,98 & 235,87 & 163,77 & 224,38 & 224,69 & 87,42 & 614,88 & 91,59 & 25,70 & 28,95 & 205,24 & 114,78 & 123,02 & 133,82 \\
\hline Epidalea calamita & 31TDG99 & 101,00 & 144,56 & 80,52 & 33,46 & 5443,28 & 272,35 & 34,86 & 237,48 & 151,97 & 215,52 & 215,81 & 77,70 & 669,90 & 92,67 & 29,61 & 25,82 & 213,72 & 128,84 & 135,24 & 149,82 \\
\hline Epidalea calamita & 31TDHOO & 28,00 & 50,10 & 74,04 & 32,22 & 5406,83 & 179,99 & $-45,96$ & 225,95 & 54,34 & 38,71 & 123,44 & $-11,53$ & 1195,66 & 126,85 & 77,40 & 13,68 & 334,47 & 260,85 & 277,01 & 270,95 \\
\hline Epidalea calamita & 31TDH10 & 1,00 & 66,35 & 76,06 & 32,71 & 5443,68 & $\begin{array}{ll}197,47 \\
\end{array}$ & $-31,08$ & 228,54 & 73,65 & 28,11 & 139,74 & 3,46 & \begin{tabular}{|l|l|}
1094,46 \\
\end{tabular} & 117,96 & 69,86 & 14,97 & 310,84 & 233,85 & 260,63 & 239,64 \\
\hline Epidalea calamita & 31TDH90 & 17,00 & 130,04 & 80,65 & 33,43 & 5452.04 & 259,87 & 22.49 & 237,38 & $\mid 119,93$ & 201.55 & 201,87 & 63,90 & 750,58 & 95,23 & 35,71 & 22.82 & 229,15 & 150,32 & 154,35 & 172,62 \\
\hline Epidalea calamita & 31TEG02 & 28,00 & 159,86 & 72,57 & 32,57 & 5126,33 & 275,57 & 56,43 & 219,14 & 170,95 & 218,33 & 227,33 & 97,29 & 631,48 & 102,14 & 21,71 & 35,33 & 225,67 & 106,76 & 137,62 & 139,43 \\
\hline Epidalea calamita & \begin{tabular}{|l|} 
31TEG03 \\
\end{tabular} & 93,00 & 153,07 & 72,72 & 32,65 & 5129,58 & 269,70 & 50,30 & 219,40 & 164,14 & 219,05 & 220,85 & 91,19 & 659,64 & 100,74 & 24,89 & 31,94 & 226,71 & 118,30 & 144,85 & 143,42 \\
\hline Epidalea calamita & 31TEG04 & 100,00 & 156,39 & 74,26 & 33,10 & 5126,21 & 273,53 & 52,28 & 221,25 & 167,27 & 222,84 & 223,95 & 94,16 & 632,72 & 98,18 & \begin{tabular}{|l|l|}
23,59 \\
\end{tabular} & 32,44 & 219,16 & 112,16 & 137,79 & 137,12 \\
\hline Epidalea calamita & 31TEG05 & 101,00 & 159,00 & 76,01 & 33,36 & 5156,94 & 277,61 & 53,28 & 224,33 & 169,69 & 225,81 & 226,69 & 95,95 & 606,38 & 95,44 & 22,60 & 32,90 & 211,53 & 107,01 & 130,96 & 130,71 \\
\hline Epidalea calamita & 31TEG06 & 97,00 & 158,23 & 77,35 & 33,63 & 5215,84 & 278,52 & 51,12 & 227,39 & 168,48 & 225,83 & 226,54 & 94,18 & 597,79 & 93,37 & 22,87 & 32,11 & 207,20 & 107,21 & 128,67 & 128,37 \\
\hline Epidalea calamita & 31TEG07 & 99,00 & 158,76 & 79,15 & 33,82 & 5266,93 & 280,93 & 50,05 & 230,89 & 168,66 & 227,07 & 227,46 & 93,87 & 582,46 & 91,29 & 22,05 & 32,32 & 202,72 & 103,44 & 119,33 & 126,14 \\
\hline Epidalea calamita & 31TEG08 & 101,00 & 156,38 & 80,48 & 33,02 & 5305,64 & 280,52 & 46,90 & 233,62 & $\begin{array}{l}166,31 \\
\end{array}$ & 225,23 & 225,66 & 90,90 & 587,55 & $\begin{array}{l}1,26 \\
90,46 \\
\end{array}$ & 22,33 & 31,40 & 202,46 & $\begin{array}{l}103,81 \\
\end{array}$ & 119,66 & 129,73 \\
\hline Epidalea calamita & 31TEG09 & 90,00 & 144,42 & 80,68 & 33,90 & 5361,71 & 271,10 & 35,65 & 235,45 & 153,62 & 214,34 & 214,71 & 78,84 & 656,66 & 92,80 & 27,31 & 27,12 & 213,79 & 121,92 & 133,07 & 148,59 \\
\hline Epidalea calamita & 31TEG13 & 37,00 & 159,26 & 74,63 & 33,92 & 4974,95 & 273,68 & 56,92 & 216,76 & 170,61 & 210,58 & 225,08 & 99,42 & 587,89 & 94,26 & 19,53 & 35,63 & 211,92 & 100,21 & 130,21 & 126,39 \\
\hline Epidalea calamita & 31TEG14 & 82,00 & 158,10 & 75,46 & 34,12 & 4968,86 & 273,17 & 55,60 & 217,57 & 169,46 & 218,00 & 223,94 & 98,45 & 581,97 & 92,08 & 19,95 & 34,63 & 207,98 & 101,27 & 129,57 & 123,84 \\
\hline Epidalea calamita & 31TEG15 & 64,00 & 158,06 & 76,80 & 34,23 & 5037,93 & 274,93 & 53,78 & 221,16 & 169,04 & 223,27 & 224,47 & 97,10 & 582,48 & 91,69 & 20,63 & 33,81 & 206,16 & 102,02 & 127,89 & 124,51 \\
\hline Epidalea calamita & 31TEG16 & 17,00 & 158,85 & 77,65 & 34,00 & 5097,04 & 277,38 & 53,23 & 224,15 & \begin{tabular}{|l|}
169,54 \\
\end{tabular} & \begin{tabular}{|l|}
224,85 \\
\end{tabular} & 225,92 & 96,69 & \begin{tabular}{|l|}
576,65 \\
\end{tabular} & $\begin{array}{l}1,23 \\
91,23 \\
\end{array}$ & 20,46 & 33,62 & 204,23 & \begin{tabular}{|l|}
$100,58<$ \\
102
\end{tabular} & 125,35 & 123,88 \\
\hline Epidalea calamita & 31TEG17 & 27,00 & 152,47 & 79,42 & 34,11 & 5163,58 & 274,11 & 45,63 & 228,47 & 162,74 & 219,58 & 220,32 & 89,89 & 597,79 & 91,05 & 21,89 & 31,53 & 206,53 & 105,05 & 127,42 & 132,21 \\
\hline Epidalea calamita & 31TEG18 & 92,00 & 150,02 & 80,18 & 34,19 & 5227,00 & 273,39 & 42,56 & 230,83 & 160,23 & 218,03 & 218,70 & 86,39 & 614,06 & 91,62 & 23,13 & 30,37 & 208,97 & 108,82 & 128,38 & 137,49 \\
\hline Epidalea calamita & 31TEG19 & 30,00 & 151,89 & 82,00 & 34,39 & 5309,02 & 277,59 & 42,27 & 235,32 & 161,70 & 220,98 & 221,36 & 86,77 & 602,16 & 90,39 & 22,30 & 30,66 & 205,52 & $\begin{array}{l}104,05 \\
\end{array}$ & 120,39 & 137,52 \\
\hline Epidalea calamita & 31TEG28 & 31,00 & 152,98 & 80,93 & 34,83 & 5170,83 & 275,50 & 45,63 & 229,88 & 163,23 & 220,27 & 220,98 & 90,05 & 588,20 & 90,30 & 20,48 & 32,55 & 205,35 & $\begin{array}{l}99,82 \\
\end{array}$ & 120,45 & 132,93 \\
\hline Epidalea calamita & 31TEHOO & $\frac{51,00}{8,00}$ & $\begin{array}{l}13,50 \\
143,60\end{array}$ & $\begin{array}{l}00,35 \\
82,49 \\
\end{array}$ & $\frac{34,05}{34,11}$ & 5406,03 & 272,29 & $\begin{array}{l}3,00 \\
33,72 \\
\end{array}$ & \begin{tabular}{|l|}
238,57 \\
28,0
\end{tabular} & \begin{tabular}{|l|}
147,51 \\
147,51
\end{tabular} & \begin{tabular}{|l|}
214,13 \\
213
\end{tabular} & $\mid$ & 77,38 & \begin{tabular}{|l|l|}
656,68 \\
65,68
\end{tabular} & $\begin{array}{l}\mid 00,30 \\
91,94\end{array}$ & $\begin{array}{l}20,40 \\
26,81\end{array}$ & $\begin{array}{l}27,45 \\
27,44\end{array}$ & $\begin{array}{l}213,72 \\
213,72\end{array}$ & \begin{tabular}{|l|}
119,09 \\
119,09
\end{tabular} & 127,74 & 152,85 \\
\hline Hyla meridionalis & 29SMC69 & 100,00 & 147,96 & 70,09 & 41,09 & 3488,38 & 238,79 & 70,50 & 168,29 & 111,22 & 189,22 & 193,04 & 102,87 & 825,55 & 127,97 & 5,09 & 64,31 & 370,27 & 36,55 & 38,54 & 344,46 \\
\hline Hyla meridionalis & 29SMC79 & 100,00 & 150,21 & 73,67 & 40,95 & 3685,18 & 248,04 & 70,05 & 177,99 & 111,34 & 194,26 & 198,41 & 103,30 & 825,94 & 128,66 & 4,51 & 64,91 & 371,05 & 34,95 & 36,68 & 348,66 \\
\hline Hyla meridionalis & 29SMC87 & 85,00 & 166,33 & 80,39 & 41,04 & 3928,81 & 275,72 & 82,47 & 193,25 & 125,15 & 213,91 & 218,71 & 117,74 & 709,73 & 108,26 & 3,85 & 63,78 & 318,88 & 29,62 & 32,39 & 304,79 \\
\hline Hyla meridionalis & $295 M C 88$ & 76,00 & 164,78 & 79,29 & 40,77 & 3947,81 & 273,54 & 81,14 & 192,41 & 123,28 & 212,72 & 217,34 & 115,89 & 731,80 & 111,36 & 3,84 & 63,98 & 328,19 & 30,27 & 32,97 & 314,90 \\
\hline Hyla meridionalis & $295 M C 89$ & 101,00 & 162,23 & 77,29 & 40, & 3890,32 & 267,64 & 79,42 & 188,21 & 121,02 & 209,27 & 213,48 & 113,54 & 744,37 & 113,05 & 3,82 & 64,03 & 333,09 & 30,62 & 33,27 & 318,85 \\
\hline Hyla meridionalis & 29SMD60 & 71,00 & 150,13 & 67,85 & 41,05 & 3399,25 & 237,06 & 73,70 & 163,36 & 114,29 & 190,23 & 193,60 & 105,75 & 791,66 & 123,77 & 4,56 & 64,30 & 356,92 & 33,85 & 36,46 & 330,30 \\
\hline Hyla meridionalis & 29SMD84 & 101,00 & 154,34 & 64,55 & 40,99 & 3237,16 & 236,09 & 80,47 & 155,62 & 120,55 & 192,73 & 195,36 & 112,40 & 698,05 & 113,05 & 4,00 & 62,10 & 309,29 & 30,02 & 35,43 & 289,73 \\
\hline Hyla meridionalis & 29SMD85 & 99,00 & 153,92 & 63,22 & 41,25 & 3141,44 & 232,59 & 81,14 & 151,45 & 121,16 & 190,92 & 193,39 & 113,04 & 693,97 & 113,00 & 4,06 & 61,81 & 305,79 & 30,54 & 36,53 & 286,46 \\
\hline Hyla meridionalis & $295 M D 94$ & 100,00 & 154,66 & $\begin{array}{l}0,2,63 \\
69,63\end{array}$ & $\frac{40,84}{404}$ & 3484,84 & 245,8 & 77,01 & $\begin{array}{l}168,82 \\
\end{array}$ & 118,17 & |196,54 & 199,51 & 110,10 & 725,66 & $\begin{array}{l}113,71 \\
113\end{array}$ & 4,11 & $\begin{array}{ll}1,01,57 \\
61,5\end{array}$ & 318,32 & 32,08 & 36,79 & 302,73 \\
\hline Hyla meridionalis & $295 \mathrm{SDS}$ & 101,00 & 153,52 & 67,99 & 41,25 & 3337,48 & 240,05 & 77,19 & 162,86 & 118,46 & 193,38 & 195,98 & 110,44 & 732,84 & 115,06 & 4,58 & 60,60 & 317,84 & 34,29 & 40,05 & 302,60 \\
\hline Hyla meridionalis & 29SMD97 & 92,00 & 153,65 & 67,96 & 41,64 & 3283,66 & 238,79 & 77,36 & 161,43 & 119,03 & 192,74 & 195,21 & 111,05 & 740,74 & 115,77 & 4,83 & 60,01 & 319,21 & 35,65 & 41,78 & 304,47 \\
\hline Hyla meridionalis & 29SMD98 & 58,00 & 154,47 & 68,99 & 42,01 & 3275,73 & 239,79 & 77,49 & 162,30 & 119,74 & 193,37 & 195,76 & 111,73 & 752,49 & 116,18 & 5,30 & 59,35 & 321,62 & 37,58 & 44,10 & 307,90 \\
\hline Hyla meridiona & 29SNA99 & 53,00 & 172,39 & 90,87 & 42,93 & 4136,21 & 287,45 & 77,59 & 209,86 & 131,51 & 224,27 & 228,45 & 123,00 & 502,21 & 86,95 & 1,00 & 70,80 & 73 & 14,27 & 17,51 & 228,90 \\
\hline Hyla meridionalis & $29 \mathrm{NNB1}$ & 83,00 & 163 & $\begin{array}{ll}0,30 \\
86,34\end{array}$ & 44 & $\begin{array}{l}4150,41 \\
3628,14\end{array}$ & $\begin{array}{l}271,4 \\
271,7 \\
\end{array}$ & 80,42 & \begin{tabular}{|l|}
191,27 \\
\end{tabular} & \begin{tabular}{|l|}
128,07 \\
12,0
\end{tabular} & 207,95 & 212,23 & \begin{tabular}{|l|}
119,51 \\
\end{tabular} & $\mid \begin{array}{l}\mid 502,21 \\
516,43\end{array}$ & \begin{tabular}{|l|l|}
80,13 \\
83,19
\end{tabular} & $\begin{array}{l}1,00 \\
1,00\end{array}$ & 68,47 & $\begin{array}{l}243,15 \\
241,95\end{array}$ & $\begin{array}{l}4,27 \\
18,35 \\
\end{array}$ & $\begin{array}{l}19,41 \\
19,41\end{array}$ & 231,30 \\
\hline Hyla meridionalis & 29SNB13 & 51,00 & 165,90 & 86,91 & 44,25 & 3706,64 & 276,06 & 81,89 & 194,17 & 129,33 & 211,51 & 215,80 & 121,01 & 513,94 & 82,24 & 1,00 & 68,10 & 240,26 & 18,46 & 19,60 & 229,58 \\
\hline Hyla meridionalis & 29 SNB14 & 19,00 & 166,42 & 87,92 & 44,00 & 3803,89 & 279,44 & 81,19 & 198,25 & 128,75 & 213,33 & 217,72 & 120,36 & 522,64 & 82,56 & 1,00 & 67,69 & 243,06 & $\mid 18,89$ & 19,89 & 232,81 \\
\hline Hyla meridionalis & 29 SNB16 & 24,00 & 167,33 & 88,92 & 43,73 & 3885,90 & 282,76 & 81,06 & 201,69 & 128,55 & 215,29 & 219,73 & 120,39 & 539,57 & 83,76 & 1,00 & 66,53 & 248,24 & 20,00 & 21,00 & 238,41 \\
\hline Hyla meridionalis & 29SNB17 & 20,00 & 167,92 & 89, & 43,3 & 3939,44 & 285,08 & 81,17 & 203,92 & 128,25 & 216,47 & 221 & 120,08 & 549,53 & 84,28 & 1,56 & 65,78 & 250,86 & 21,03 & 22,08 & 24 \\
\hline Hyla meridionalis & 29SNB19 & 31,00 & 168,49 & $\begin{array}{l}90,00 \\
90,07 \\
\end{array}$ & $\begin{array}{ll}43,00 \\
43,0\end{array}$ & $\begin{array}{l}35304,34,32 \\
404,\end{array}$ & $\begin{array}{l}20,00 \\
288,02\end{array}$ & $\begin{array}{l}1,11 \\
80,83 \\
\end{array}$ & \begin{tabular}{|l|}
207,20 \\
207
\end{tabular} & \begin{tabular}{|l|}
127,34 \\
127
\end{tabular} & $\begin{array}{l}218,217 \\
218,22\end{array}$ & \begin{tabular}{|l|}
222,93 \\
223
\end{tabular} & 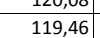 & \begin{tabular}{|l|l|}
569,29 \\
569,29
\end{tabular} & $\begin{array}{l}4,26 \\
86,15 \\
\end{array}$ & $\begin{array}{l}, 50 \\
2,00\end{array}$ & $\begin{array}{l}03,100 \\
64,95\end{array}$ & \begin{tabular}{|l|}
257,37 \\
257
\end{tabular} & $\begin{array}{l}1,250 \\
22,49 \\
\end{array}$ & $\begin{array}{l}23,78 \\
23,7\end{array}$ & $\begin{array}{l}241,44 \\
248,22\end{array}$ \\
\hline Hyla meridionalis & 29 SNB21 & 101,00 & 166,71 & 86,81 & 43,34 & 3809,92 & 278,55 & 80,58 & 197,97 & 129,16 & 214,36 & 218,16 & 120,69 & 498,75 & 80,82 & 0,90 & 69,59 & 237,30 & 16,71 & 17,97 & 225,62 \\
\hline Hyla meridionalis & 29SNB22 & 101,00 & 159,48 & 88,59 & 43,57 & 3863,33 & 274,21 & 73,06 & 201,15 & 121,65 & 207,70 & 211,89 & 113,22 & 545,39 & 86,20 & 1,08 & 67,90 & 254,36 & 19,78 & 20,69 & 243,9 \\
\hline Hyla meridionalis & 29SNB23 & 101,00 & 160,57 & 89,23 & 43,49 & 3904,89 & 276,69 & 73,70 & 202,99 & 122,19 & 209 & 213 & 113 & 548,35 & 86,14 & 1,15 & 67,36 & 254,48 & 20,17 & 21,04 & 244 \\
\hline Hyla meridionalis & 29 SNB24 & 100,00 & 162,44 & 89,79 & 43,41 & 3953,88 & 280,03 & 75,26 & 204,76 & 123,45 & 211,84 & 216,11 & 115,18 & 546,36 & 85,42 & 1,08 & 67,06 & 252,79 & 20,07 & 20,88 & 242,88 \\
\hline
\end{tabular}




\begin{tabular}{|c|c|c|c|c|c|c|c|c|c|c|c|c|c|c|c|c|c|c|c|c|c|}
\hline TAXON & UTM & $\mathrm{km} 2$ & B101 & B102 & $\mathrm{BIO3}$ & B104 & B105 & B106 & B107 & B108 & B109 & B1010 & BIO11 & BIO12 & B1013 & BIO14 & BIO15 & B1016 & B1017 & B1018 & B1019 \\
\hline Hyla meridionalis & 29SNB25 & 100,00 & 164,72 & 90,25 & 43,24 & 3981,16 & 283,08 & 77,15 & 205,94 & 125,25 & 214,24 & 218,62 & 116,82 & 543,22 & 84,29 & 1,00 & 66,73 & 250,47 & 20,04 & 20,94 & 240,79 \\
\hline Hyla meridionalis & 29SNB26 & 101,00 & 167,37 & 90,54 & \begin{tabular}{|l|l|}
43,07 \\
\end{tabular} & 4006,83 & 286,40 & 79,38 & 207,03 & 127,37 & 217,05 & 221,60 & 119,02 & 539,28 & 83,16 & 1,06 & 66,34 & 247,82 & 20,04 & 21,07 & 238,29 \\
\hline Hyla meridionalis & 29SNB27 & 101,00 & 164,85 & 91,51 & 43,02 & 4077,94 & 286,17 & 76,15 & 210,02 & 124,01 & 215,44 & 219,99 & 115,74 & 565,10 & 86,24 & 1,72 & 65,40 & 256,79 & 22,20 & 22,99 & 248,03 \\
\hline Hyla meridionalis & 29SNB28 & 101,00 & 163,45 & 91,99 & 42,92 & 4134,08 & 286,67 & 74,44 & 212,23 & 121,86 & 214,92 & 219,54 & 113,86 & 584,01 & 88,30 & 2,00 & 64,69 & 263,26 & 23,58 & 24,30 & 255,08 \\
\hline Hyla meridionalis & 29SNB29 & 101,00 & 164,16 & 92,20 & 42,84 & $\begin{array}{ll}4175,37 \\
\end{array}$ & 288,44 & 74,92 & 213,52 & 122,01 & 216,06 & 220,71 & 113,97 & 590,88 & 88,76 & 2,00 & 64,15 & 265,09 & 24,11 & 24,86 & 257,27 \\
\hline Hyla meridionalis & 29SNB31 & 100,00 & 169,93 & 88,04 & 42,32 & 3993,05 & 285,92 & 80,82 & 205,09 & 130,58 & 220,37 & 224,08 & 121,95 & 491,29 & 79,47 & 0,87 & 69,85 & 235,53 & 15,71 & 17,27 & 223,19 \\
\hline Hyla meridionalis & 29SNB32 & 100,00 & 157,21 & 90,43 & 42,89 & 4051,06 & 276,71 & 68,08 & 208,63 & 117,62 & 208,32 & 212,39 & 109,04 & 568,47 & 89,90 & 1,46 & 67,30 & 263,84 & 21,14 & 22,08 & 253,54 \\
\hline Hyla meridionalis & 29SNB33 & 101,00 & 153,17 & 91,73 & 42,96 & 4104,42 & 275,13 & 63,85 & 211,28 & 113,12 & 205,01 & 209,21 & 104,51 & 597,67 & 93,49 & 1,78 & 66,16 & 273,78 & 23,43 & 24,04 & 264,44 \\
\hline Hyla meridionalis & 29SNB34 & 100,00 & 160,98 & 91,92 & 42,89 & 4116,92 & 283,24 & 71,08 & 212,15 & 120,35 & 212,75 & 217,05 & 111,80 & 557,87 & 87,50 & 1,29 & 66,59 & 257,51 & 20,82 & 21,67 & 247,82 \\
\hline Hyla meridionalis & 29SNB35 & 101,00 & 167,48 & 91,98 & 42,96 & 4111,58 & 289,42 & 77,29 & 212,13 & 126,46 & 219,01 & 223,26 & 118,07 & 528,77 & 82,62 & 1,01 & 67,01 & 244,88 & 19,08 & 20,13 & 235,08 \\
\hline Hyla meridionalis & 29 SNB36 & 101,00 & 165,93 & 92,97 & $\begin{array}{l}42,95 \\
\end{array}$ & 4165,94 & 289,95 & 75,37 & 214,58 & 124,09 & 217,99 & 222,40 & 115,90 & 546,52 & 84,50 & 1,23 & 66,02 & 250,43 & 20,62 & 21,50 & 241,41 \\
\hline Hyla meridionalis & 29SNB37 & 100,00 & 164,94 & 93,73 & 42,83 & 4219,59 & 290,82 & 74,07 & 216,75 & 122,57 & 217,72 & 222,23 & 114,44 & 561,68 & 85,97 & 1,82 & 65,17 & 254,92 & 22,07 & 22,89 & 246,65 \\
\hline Hyla meridionalis & 29SNB38 & 101,00 & 165,56 & 94,17 & 42,70 & 4258,45 & 292,73 & 74,44 & 218,29 & 122,77 & 218,79 & 223,35 & 114,49 & 567,57 & 86,11 & 2,00 & 64,57 & 256,00 & 22,76 & 23,43 & 248,21 \\
\hline Hyla meridionalis & 29SNB39 & 100,00 & 165,48 & 94,48 & 42,38 & 4301,43 & 293,85 & 74,15 & 219,70 & 122,07 & 219,27 & 223,98 & 114,02 & 576,49 & 86,88 & 2,00 & 64,22 & 258,47 & 23,19 & 24,02 & 251,19 \\
\hline Hyla meridionalis & 29SNB41 & 101,00 & 170,42 & 89,54 & 42,32 & 4071,24 & 288,31 & 79,58 & 208,73 & 130,01 & 221,89 & 225,72 & 121,66 & 494,19 & 80,91 & 1,00 & 69,76 & 237,45 & 15,99 & 17,53 & 224,66 \\
\hline Hyla meridionalis & 29 SNB42 & 101,00 & 163,34 & 91,49 & 42,31 & 4153,20 & 284,97 & 71,88 & 213,09 & 122,27 & 215,89 & 219,81 & 113,77 & 536,63 & 86,44 & 1,15 & 68,24 & 252,48 & 18,58 & 19,76 & 241,22 \\
\hline Hyla meridionalis & 29SNB43 & 100,00 & 158,19 & 93,15 & 42,49 & 4219,30 & 282,90 & 66,29 & 216,61 & 116,56 & 211,49 & 215,67 & 108,04 & 570,05 & 90,55 & 1,33 & 66,86 & 263,84 & 21,04 & 21,89 & 253,89 \\
\hline Hyla meridionalis & 29SNB44 & 101,00 & 165,33 & 93,32 & 42,45 & 4231,12 & 290,31 & 73,10 & 217,20 & 123,17 & 218,62 & 222,87 & 114,75 & 534,47 & 84,80 & 1,00 & 67,20 & 248,69 & 18,80 & 19,94 & 238,53 \\
\hline Hyla meridionalis & 29SNB45 & 101,00 & 165,68 & 94,29 & $\begin{array}{l}42,55 \\
\end{array}$ & 4266,08 & 292,32 & 73,34 & 218,98 & 122,99 & 219,44 & 223,80 & 114,73 & 538,78 & 84,63 & 1,02 & 66,67 & 248,75 & 19,45 & 20,42 & 239,24 \\
\hline Hyla meridionalis & 29SNB46 & 100,00 & 161,56 & 95,68 & 42,42 & 4340,36 & 291,18 & 68,73 & 222,45 & 118,32 & 216,23 & 220,75 & 109,95 & 570,36 & 88,19 & 1,79 & 65,12 & 258,97 & 22,44 & 23,13 & 250,85 \\
\hline Hyla meridionalis & 29SNB47 & 100,00 & 163,18 & 96,28 & \begin{tabular}{|l|l|}
42,48 \\
\end{tabular} & 4369,40 & 293,99 & 70,04 & 223,95 & 119,40 & 218,06 & 222,73 & 111,14 & 569,30 & 87,2 & 2,00 & 64,67 & 257,01 & 22,82 & 23,42 & 249,30 \\
\hline Hyla meridionalis & 29SNB48 & 101,00 & 167,66 & 96,33 & 42,62 & 4369,44 & 298,26 & 74,38 & 223,87 & 123,46 & 222,40 & 226,92 & 115,25 & 551,81 & 83,96 & 2,00 & 64,54 & 248,81 & 21,95 & 22,84 & 241,24 \\
\hline Hyla meridionalis & 29SNB49 & 101,00 & 168,13 & 96,77 & \begin{tabular}{|l|l|}
42,39 \\
\end{tabular} & 4402,72 & 299,73 & 74,62 & 225,11 & 123,45 & 223,21 & 227,86 & 115,34 & 557,31 & 84,01 & 2,00 & 64,01 & 249,32 & 22,72 & 23,49 & 242,42 \\
\hline Hyla meridionalis & 29 SNB51 & 100,00 & 169,62 & 90,95 & 42,34 & 4135,12 & 289,13 & 77,28 & 211,85 & 128,81 & 221,94 & 225,75 & 120,05 & 502,62 & 83,26 & 1,00 & 69,36 & 241,57 & 16,27 & 18,05 & 228,53 \\
\hline Hyla meridionalis & 29 SNB52 & 101,00 & 164,37 & 92,97 & 42,21 & 4241,13 & 288,17 & 71,28 & 216,89 & 122,52 & 218,10 & 222,13 & 113,81 & 533,03 & 86,93 & 1,00 & 68,19 & 251,74 & 17,99 & 19,46 & 240,04 \\
\hline Hyla meridionalis & 29SNB53 & 100,00 & 164,55 & 94,13 & 42,08 & 4297,53 & 290,68 & 70,92 & 219,76 & 121,89 & 218,86 & 223,08 & 113,30 & 535,86 & 86,47 & 1,00 & 67,62 & 251,14 & 18,31 & 19,68 & 240,12 \\
\hline Hyla meridionalis & 29SNB55 & 100,00 & 162,91 & $\begin{array}{l}\mid 4,11 \\
96,57 \\
\end{array}$ & 42,24 & 4398,71 & 293,67 & 68,26 & 225,41 & \begin{tabular}{|l|l|}
118,99 \\
\end{tabular} & 218,50 & 222,80 & $\begin{array}{l}110,58 \\
10\end{array}$ & 555,57 & $\begin{array}{l}0,47,30 \\
87,0\end{array}$ & $\begin{array}{l}1,00 \\
1,36\end{array}$ & 65,95 & 254,66 & 20,70 & 21,57 & 245,62 \\
\hline Hyla meridionalis & 29 SNB56 & 101,00 & 159,93 & 97,96 & 42,07 & 4473,81 & 293,72 & 64,86 & 228,86 & 115,26 & 216,56 & 221,03 & 106,94 & 579,15 & 89,53 & 2,00 & 64,59 & 261,53 & 23,14 & 23,72 & 253,80 \\
\hline Hyla meridionalis & 29 SNB57 & 101,00 & 165,13 & 98,47 & 42,25 & 4481,33 & 299,41 & 69,77 & 229,64 & 119,95 & 221,66 & 226,18 & 111,69 & 554,76 & 85,12 & 1,99 & 64,53 & 250,30 & 21,91 & 22,56 & 242,74 \\
\hline Hyla meridionalis & 29 SNB58 & 100,00 & 167,38 & 98,91 & 42,36 & 4491,59 & 302,26 & 72,00 & 230,26 & 121,99 & 223,90 & 228,48 & 113,80 & 548,53 & 83,37 & 2,00 & 64,49 & 246,13 & 21,50 & 22,24 & 239,15 \\
\hline Hyla meridionalis & 29SNB59 & 100,00 & 168,86 & 99,21 & 42,32 & 4520,42 & 304,48 & 73,29 & 231,19 & 122,86 & 225,62 & 230,19 & 114,75 & 547,27 & 82,53 & 2,00 & 63,86 & 244,05 & 22,02 & 22,64 & 237,48 \\
\hline Hyla meridionalis & 29SNB61 & 101,00 & 168,60 & $\begin{array}{ll}32,44 \\
92\end{array}$ & 42,55 & 42000,03 & 289,83 & $\begin{array}{l}3,25 \\
74,99 \\
\end{array}$ & 214,85 & $\begin{array}{l}127,13 \\
127,1\end{array}$ & \begin{tabular}{|l|}
221,86 \\
226
\end{tabular} & \begin{tabular}{|l|}
225,84 \\
\end{tabular} & 118,45 & 511,83 & \begin{tabular}{|l|}
85,67 \\
8
\end{tabular} & 2,00 & 69,11 & \begin{tabular}{|l|}
245,74 \\
\end{tabular} & $\begin{array}{l}2<, 0<6 \\
16,66\end{array}$ & $\mid 18,50$ & 232,36 \\
\hline Hyla meridionalis & 29SNB62 & 100,00 & $\begin{array}{ll}164,87 \\
\end{array}$ & 94,21 & 42,18 & 4299,61 & 290,15 & 70,25 & 219,91 & 122,35 & 219,43 & 223,56 & 113,72 & 533,42 & 87,70 & 1,01 & 68,11 & 252,20 & 17,90 & 19,49 & 240,04 \\
\hline Hyla meridionalis & 29SNB63 & 101,00 & 160,97 & 95,93 & \begin{tabular}{|l|l|}
42,07 \\
\end{tabular} & 4400,78 & 290,09 & 65,53 & 224,56 & 117,48 & 216,88 & 221,05 & 108,72 & 558,03 & 89,99 & 1,27 & 66,82 & 259,41 & 19,8 & 21,14 & 248,62 \\
\hline Hyla meridionalis & 29 SNB64 & 100,00 & 158,55 & 97,46 & 42,01 & 4485,71 & 291,07 & 62,47 & 228,60 & 114,12 & 215,45 & 219,80 & 105,29 & 576,21 & 91,25 & 1,79 & 65,55 & 263,75 & 21,95 & 23,02 & 254,29 \\
\hline Hyla meridionalis & $295 \mathrm{NB} 65$ & 100,00 & 162,17 & 98,47 & 42,03 & 4511,04 & 296,07 & 65,55 & 230,53 & 117,11 & 219,31 & 223,70 & 108,42 & 559,05 & 87,77 & 1,70 & 65,36 & 255,09 & 20,98 & 22,00 & 246,12 \\
\hline Hyla meridionalis & 29 SNB66 & 101,00 & 162,98 & 99,69 & 42,06 & 4555,55 & 299,11 & 66,03 & 233,08 & 117,41 & 220,63 & 225,06 & 108,82 & 559,86 & 86,75 & 1,99 & 64,56 & 253,15 & 21,71 & 22,47 & 245,11 \\
\hline Hyla meridionalis & 29SNB67 & 100,00 & 165,05 & 100,68 & 42,10 & 4589,97 & 302,86 & 67,74 & 235,12 & 118,94 & 223,03 & 227,53 & 110,40 & 553,32 & 84,75 & 2,00 & 64,32 & 248,44 & 21,63 & 22,47 & 241,14 \\
\hline Hyla meridionalis & 29SNB69 & 101,00 & 167,56 & 102,06 & \begin{tabular}{|l|l|}
42,17 \\
\end{tabular} & 4654,46 & 307,85 & 69,73 & 238,13 & 120,29 & 226,15 & 230,81 & 111,92 & 549,62 & 82,76 & 2,00 & 63,20 & 243,19 & 22,15 & 23,03 & 237,45 \\
\hline Hyla meridionalis & 29SNB71 & 100,00 & 165,37 & 93,75 & 42,25 & 4281,43 & 288,74 & 70,12 & 218,62 & 123,08 & 219,68 & 223,82 & 114,36 & 532,25 & 89,16 & 1,00 & 68,54 & 253,83 & 17,50 & 19,48 & 240,31 \\
\hline Hyla meridionalis & 29 SNB72 & 101,00 & 158,56 & 95,96 & 42 & 4413,77 & 287,27 & 62,45 & 224,82 & 114,93 & 214,69 & 218,96 & 106,39 & 571,05 & 92, & 1,49 & 66,85 & 265,98 & 20,14 & 21,88 & 254,31 \\
\hline Hyla meridionalis & 29SNB73 & 101,00 & 155,11 & 97,55 & 42, & 4511,24 & 287,61 & 58,42 & \begin{tabular}{|l|l|}
229,19 \\
\end{tabular} & $\begin{array}{l}110,50 \\
\end{array}$ & 212,56 & 216,92 & \begin{tabular}{|l|l|}
102,06 \\
\end{tabular} & 594,00 & $\begin{array}{l}2,005 \\
94,58\end{array}$ & 1,8 & 65,52 & 272,01 & 22,33 & 23,79 & 261,73 \\
\hline Hyla meridionalis & 29 SNB74 & 100,00 & 155,46 & 98,99 & 42,00 & 4582,57 & 290,88 & 57,98 & 232,90 & 109,87 & 213,81 & 218,20 & 101,36 & 595,08 & 93,54 & 2,00 & 64,75 & 269,91 & 23,20 & 24,36 & 260,62 \\
\hline Hyla meridionalis & 29SNB75 & 101,00 & 159,78 & 100,28 & 42,00 & 4621,93 & 297,04 & 61,54 & 235,50 & 113,35 & 218,43 & 222,83 & 105,05 & 572,95 & 89,41 & 2,00 & 64,65 & 259,20 & 22,04 & 23,10 & 250,47 \\
\hline Hyla meridionalis & 29SNB77 & 101,00 & 162,11 & 103,12 & 42,01 & 4726,24 & 304,26 & 62,65 & 241,60 & 114,45 & 221,96 & 226,48 & 106,06 & 566,85 & 86,19 & 2,00 & 63,50 & 252,11 & 22,82 & 23,23 & 245,35 \\
\hline Hyla meridionalis & 295NB78 & 100,00 & 163,24 & 104,39 & $\frac{42,0}{42,0}$ & 47765,14 & 307,4 & $\begin{array}{ll}63,36 \\
\end{array}$ & 244,05 & 115,13 & 223,53 & $22 \varepsilon$ & 106,63 & 564,42 & 85,12 & 2,00 & 63,00 & 248,94 & 23,12 & 23,48 & $\begin{array}{l}243,17 \\
243\end{array}$ \\
\hline Hyla meridionalis & 29SNB79 & 100,00 & 166,09 & 105,06 & 42,25 & 4779,42 & 311,19 & 66,12 & 245,07 & 117,61 & 226,48 & 231,18 & 109,12 & 553,21 & 83, & 2,00 & 62,53 & 242,47 & 22,90 & 23,34 & 237,38 \\
\hline Hyla meridionalis & $295 \mathrm{NB} 80$ & 97,00 & 169,36 & 92,45 & 42,75 & 4192,89 & 288,39 & 74,36 & 214,03 & 128,18 & 222,39 & 226,50 & 119,50 & \begin{tabular}{|l|l|}
515,13 \\
\end{tabular} & 88,79 & 1,00 & 69,74 & 249,99 & 15,82 & 18,36 & 234,58 \\
\hline Hyla meridionalis & 29 SNB81 & 101,00 & 162,83 & 94,57 & 42,07 & 4366,06 & 287,94 & 66,33 & 221,61 & 119,65 & 218,25 & 222,48 & 111,04 & 548,10 & 91,22 & 1,09 & 67,97 & 259,42 & 18,07 & 20,46 & 245,71 \\
\hline Hyla meridionalis & 29 SNB82 & 101,00 & 157,12 & 96,63 & 41,9 & 4496,11 & 287,34 & 59,58 & 227,76 & 112,64 & 214,29 & 218,59 & 103,89 & 581,80 & 93,5 & 1,63 & 66,26 & 269,03 & 20,85 & 22,90 & 257,09 \\
\hline Hyla meridionalis & 295NB83 & 99,00 & 153,72 & $\begin{array}{l}0,030 \\
98,40\end{array}$ & 41, & 25 & 288,04 & $\begin{array}{l}55,56 \\
55,\end{array}$ & 232,47 & \begin{tabular}{|l|}
108,30 \\
10,3
\end{tabular} & \begin{tabular}{|l|}
212,29 \\
212,
\end{tabular} & \begin{tabular}{|l|}
216,575 \\
216
\end{tabular} & $\begin{array}{l}0,03 \\
99,42 \\
\end{array}$ & $\begin{array}{l}\mid 201,00 \\
603,65\end{array}$ & $\begin{array}{l}30,311 \\
95,34 \\
\end{array}$ & $\begin{array}{l}1,005 \\
2,03\end{array}$ & $\begin{array}{ll}64,86 \\
64,\end{array}$ & \begin{tabular}{|l|}
274,47 \\
\end{tabular} & $\mid 22,90$ & 24,69 & $\begin{array}{ll}264,03 \\
264,03\end{array}$ \\
\hline Hyla meridionalis & 29SNB84 & 101,00 & 156,82 & 99,72 & 41,99 & 4649,05 & 293,62 & 58,02 & 235,60 & 110,58 & 215,99 & 220,47 & 101,90 & 587,33 & 91,97 & 2,00 & 64,52 & 265,77 & 22,60 & 24,20 & 255,97 \\
\hline Hyla meridionalis & 29 SNB85 & 101,00 & 160,15 & 101,33 & 42,00 & 4701,10 & 299,33 & 60,68 & 238,64 & 113,07 & 219,98 & 224,36 & 104,50 & 569,56 & 88,36 & 2,00 & 64,34 & 256.54 & 21,87 & 23,07 & 247,50 \\
\hline Hyla meridionalis & 29 SNB86 & 100,00 & 162,07 & 103,04 & 42,00 & 4757,32 & 303,96 & 61,80 & 242,16 & 114,11 & 222,48 & 226,92 & 105,67 & 561,37 & 85,89 & 2,00 & 63,65 & 250,74 & 22,00 & 23,10 & 242,69 \\
\hline Hyla meridionalis & 29SNB88 & 101,00 & 164,83 & 106,41 & 42,0 & 4854,87 & 311,95 & 63,26 & 248,70 & 115,54 & 226,35 & 230 & 107,07 & 551,99 & 83 & 2,00 & 62,32 & 242,05 & 22,81 & 23,29 & 236 \\
\hline Hyla meridionalis & $\begin{array}{l}\text { 29SNB80 } \\
\end{array}$ & $\begin{array}{l}100,00 \\
100\end{array}$ & $\begin{array}{l}104,03 \\
165,90\end{array}$ & \begin{tabular}{|l|}
107,83 \\
107
\end{tabular} & $\begin{array}{l}42,05 \\
42,29\end{array}$ & $\begin{array}{l}4034,01 \\
4898,78\end{array}$ & 315,21 & 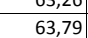 & $\begin{array}{l}40,1,4 \\
251,42\end{array}$ & \begin{tabular}{|l|}
115,99 \\
115,9
\end{tabular} & \begin{tabular}{|l|}
227,84 \\
227
\end{tabular} & \begin{tabular}{|l|}
232,60 \\
232
\end{tabular} & $\begin{array}{l}107,52 \\
107\end{array}$ & \begin{tabular}{|l|l|}
549,89 \\
549
\end{tabular} & \begin{tabular}{|l|}
82,33 \\
82,33
\end{tabular} & 2,00 & $\begin{array}{ll}6,52 \\
61,86\end{array}$ & \begin{tabular}{|l|}
238,70 \\
238,7
\end{tabular} & $\begin{array}{l}22,01 \\
23,05\end{array}$ & $\begin{array}{l}23,35 \\
23,82\end{array}$ & $\begin{array}{l}230,15 \\
233,98\end{array}$ \\
\hline Hyla meridionalis & 29 SNB91 & 101,00 & 158,51 & 95,20 & 41,90 & 4472,75 & 285,95 & 60,85 & 225,10 & 114,12 & 215,32 & 219,49 & 105,46 & 573,59 & 93,32 & 1,59 & 66,76 & 267,24 & 19,59 & 22,46 & 253,81 \\
\hline Hyla meridionalis & 29SNB92 & 100,00 & 150,90 & 97,38 & 41,39 & 4624,20 & 284,06 & 52,19 & 231,87 & 105,03 & 209,76 & 213,97 & 96,25 & 620,53 & 97,73 & 1,99 & 64,87 & 281,73 & 23,16 & 25,60 & 270,38 \\
\hline Hyla meridionalis & 29SNB94 & 100,00 & 159,33 & 99,98 & 41,80 & 4709,88 & 296,68 & 59,39 & 237,29 & 112,16 & 219 & 223, & 103 & 571,80 & 89,02 & 2,00 & 64,30 & 258,27 & 21,49 & 23,73 & 247,61 \\
\hline Hyla meridionalis & 29 SNB95 & 100,00 & 162,10 & 101,68 & 41,85 & 4764,64 & 301,97 & 61,28 & 240,69 & 114,21 & 222,62 & 226,94 & 105,44 & 557,84 & 85,81 & 2,00 & 63,79 & 250,25 & 21,36 & 23,25 & 240,45 \\
\hline
\end{tabular}




\begin{tabular}{|c|c|c|c|c|c|c|c|c|c|c|c|c|c|c|c|c|c|c|c|c|c|}
\hline TAXON & UTM & $\mathrm{km} 2$ & B101 & B102 & $\mathrm{BIO3}$ & B104 & B105 & B106 & B107 & B108 & B109 & B1010 & BIO11 & BIO12 & B1013 & BIO14 & BIO15 & B1016 & B1017 & BIO18 & B1019 \\
\hline Hyla meridionalis & 29SNB96 & 101,00 & 163,94 & 103,58 & 42,00 & 4820,32 & 306,60 & 62,39 & 244,21 & 115,39 & 225,06 & 229,47 & 106,53 & 548,79 & 83,65 & 2,00 & 63,29 & 244,15 & 21,60 & 23,07 & 235,36 \\
\hline Hyla meridionalis & 29SNB98 & 100,00 & 166,44 & 107,51 & \begin{tabular}{l|l|l}
42,05 \\
\end{tabular} & 4933,26 & 315,14 & 63,07 & 252,06 & 116,25 & 228,91 & 233,37 & 107,37 & 539,69 & 81,21 & 2,00 & 61,85 & 235,36 & 22,26 & 23,41 & 228,93 \\
\hline Hyla meridionalis & 29SNB99 & 101,00 & 165,62 & 110,00 & 42,07 & 5015,02 & 318,32 & 61,18 & 257,14 & 114,36 & 229,15 & 233,73 & 105,83 & 547,67 & 81,68 & 2,00 & 61,23 & 235,78 & 23,44 & 23,94 & 231,03 \\
\hline Hyla meridionalis & 29SNC10 & 71,00 & 168,25 & 89,65 & 42,91 & 4045,68 & 287,78 & 80,78 & 207,00 & 127,19 & 218,07 & 222,81 & 119,20 & 583,03 & 87,85 & 2,00 & 64,57 & 262,35 & 23,98 & 24,99 & 253,35 \\
\hline Hyla meridionalis & 29SNC20 & 100,00 & 163,43 & 92,33 & 42,46 & 4224,95 & 288,91 & 73,92 & 214,99 & 120,64 & 215,90 & 220,69 & 112,66 & 606,74 & 90,73 & 2,30 & 63,70 & 270,56 & 25,52 & 26,30 & 263,18 \\
\hline Hyla meridionalis & $295 N C 21$ & 101,00 & 164,38 & 92,12 & 42,16 & 4247,06 & 290,22 & 74,66 & 215,56 & 121,27 & 217,10 & 221,97 & 113,42 & 612,68 & 91,38 & 2,49 & 63,49 & 272,22 & 25,95 & 26,81 & 265,08 \\
\hline Hyla meridionalis & $295 N C 22$ & 99,00 & 166,10 & 91,82 & 42,02 & 4275,52 & 292,11 & 76,33 & 215,78 & 122,47 & 219,16 & 224,04 & 114,58 & \begin{tabular}{|l|l|}
614,17 \\
\end{tabular} & 91,45 & 2,67 & 63,12 & 272,23 & 26,19 & 27,32 & 265,21 \\
\hline Hyla meridionalis & $295 \mathrm{NC23}$ & 101,00 & 168,86 & 91,32 & 42,00 & 4281,82 & 294,32 & 78,88 & 215,44 & 124,77 & 221,79 & 226,66 & 116,93 & 608,71 & 90,47 & 2,99 & 63,12 & 269,53 & 25,78 & 27,64 & 262,48 \\
\hline Hyla meridionalis & 29SNC30 & 100,00 & 164,80 & 94,76 & 42,16 & 4339,40 & 294,27 & 73,09 & 221,18 & 120,82 & 218,96 & 223,73 & 112,79 & 591,55 & 88,55 & 2,06 & 63,69 & 263,40 & 24,27 & 24,90 & 256,82 \\
\hline Hyla meridionalis & 29SNC31 & 101,00 & 161,27 & 94,95 & 42,00 & 4402,58 & 292,56 & 69,61 & 222,95 & 116,77 & 216,36 & 221,20 & 108,72 & 624,36 & 92,71 & 2,89 & 62,71 & 274,96 & 27,25 & 27,68 & 269,36 \\
\hline Hyla meridionalis & 29 SNC32 & 101,00 & 164,58 & 94,37 & 41,92 & 4412,68 & 295,47 & 72,80 & 222,67 & 119,62 & 219,70 & 224,62 & 111,69 & 614,58 & 90,98 & 2,73 & 62,64 & 270,49 & 26,43 & 27,17 & 264,92 \\
\hline Hyla meridionalis & $295 N C 33$ & 100,00 & 167,77 & 93,79 & 41,93 & 4408,51 & 297,79 & 76,01 & 221,78 & 122,43 & 222,68 & 227,53 & 114,64 & 605,45 & 89,46 & 2,95 & 62,79 & 266,27 & 25,92 & 26,94 & 260,68 \\
\hline Hyla meridionalis & $295 N C 40$ & 101,00 & 167,25 & 97,05 & \begin{tabular}{ll|l}
42,15 \\
\end{tabular} & 4438,80 & 300,13 & 73,75 & 226,38 & 122,15 & 222,81 & 227,46 & 114,11 & 570,75 & 85,50 & 2,00 & 63,50 & 253,58 & 23,46 & 24,21 & 247,48 \\
\hline Hyla meridionalis & 29SNC41 & 101,00 & 166,46 & 97,10 & 42,00 & 4485,43 & 300,43 & 72,71 & 227,71 & 120,71 & 222,62 & 227,24 & 112,62 & 584,59 & 86,96 & 2,10 & 63,03 & 257,83 & 24,48 & 25,09 & 252,44 \\
\hline Hyla meridionalis & 29SNC42 & 99,00 & 168,70 & 96,55 & 42,00 & 4483,66 & 302,16 & 75,09 & 227,07 & 122,67 & 224,64 & 229,38 & 114,78 & 580,33 & 85,94 & 2,06 & 62,96 & 255,20 & 24,26 & 25,13 & 250,04 \\
\hline Hyla meridionalis & 29 SNC43 & 101,00 & 169,53 & 95,90 & 42,00 & 4501,04 & 302,69 & 76,17 & 226,52 & 123,27 & 225,75 & 230,51 & 115,38 & 585,04 & 86,01 & 2,62 & 62,24 & 255,76 & 25,29 & 26,29 & 251,02 \\
\hline Hyla meridionalis & 29 SNC47 & 100,00 & 167,73 & 92,62 & 40,97 & 4524,31 & 299,07 & 75,36 & 223,71 & 120,67 & 224,19 & 228,77 & 112,91 & 635,36 & 92,66 & 3,44 & 60,82 & 272,81 & 29,39 & 30,81 & 269,64 \\
\hline Hyla meridionalis & 29SNC49 & 101,00 & 167,49 & 90,72 & 40,48 & 4504,72 & 296,56 & 75,55 & 221,01 & 120,28 & 223,71 & 227,97 & 112,67 & 655,11 & 95,53 & 3,96 & 60,30 & 279,75 & 31,13 & 32,90 & 276,80 \\
\hline Hyla meridionalis & 29SNC50 & 101,00 & 169,36 & 99,40 & 42,16 & 4546,86 & 305,86 & 73,78 & 232,08 & 122,96 & 226,42 & 231,14 & 114,82 & 551,54 & 82,71 & 2,00 & 63,51 & 244,19 & 22,46 & 23,32 & 238,44 \\
\hline Hyla meridionalis & 29SNC51 & 101,00 & 169,44 & 99,28 & 42,04 & 4569,18 & 306,46 & 73,87 & 232,59 & 122,67 & 226,81 & 231,38 & 114,65 & 560,00 & 83,21 & 2,00 & 62,58 & 245,94 & 23,75 & 24,40 & 240,90 \\
\hline Hyla meridionalis & 29 SNC52 & 101,00 & 169,67 & 98,88 & 42,01 & 4587,13 & 306,68 & 74,25 & 232,43 & 122,60 & 227,16 & 231,83 & 114,48 & 566,97 & 83,5 & 2,08 & 62,27 & 247,49 & 24,29 & 24,99 & 243,05 \\
\hline Hyla meridionalis & 29 SNC53 & 100,00 & 170,04 & 98,17 & 41,97 & 4596,44 & 306,70 & 74,80 & 231,89 & 122,87 & 227,55 & 232,26 & 114,58 & 573,44 & 83,86 & 2,58 & 61,79 & 248,75 & 25,34 & 26,21 & 244,83 \\
\hline Hyla meridionalis & 29 SNC54 & 101,00 & 168,58 & 97,49 & 41,65 & 4619,20 & 305,30 & 73,76 & 231,54 & \begin{tabular}{|l|}
121,07 \\
\end{tabular} & 226,41 & 231,19 & 113,01 & 590,22 & 85,94 & 2,99 & 61,12 & 254,27 & 26,74 & 27,45 & 251,14 \\
\hline Hyla meridionalis & 29 SNC55 & 100,00 & 168,90 & 96,51 & 41,20 & 4621,95 & 304,91 & 74,40 & 230,51 & 121,21 & 226,82 & 231,37 & 113,07 & 597,31 & 86,69 & 3,00 & 60,85 & 256,22 & 27,24 & 28,15 & 253,45 \\
\hline Hyla meridionalis & 29 SNC56 & 101,00 & 164,47 & 95,36 & 40,94 & 4653,64 & 300,76 & 70,51 & 230,25 & 116,51 & 222,78 & 227,54 & 108,55 & 636,12 & 92,18 & 3,69 & 60,01 & 270,33 & 30,59 & 31,18 & 268,80 \\
\hline Hyla meridionalis & 29SNC57 & 100,00 & 163,63 & 94,28 & 40,87 & 4652,67 & 298,97 & 70,09 & 228,88 & 115,47 & 221,89 & 226,65 & 107,55 & 653,05 & 94,55 & 4,00 & 59,70 & 276,30 & 32,10 & 32,64 & 275,18 \\
\hline Hyla meridionalis & 29 SNC59 & 101,00 & 166,11 & 92,51 & 40,31 & 4606,06 & 298,89 & 73,02 & 225,86 & 118,06 & 223,91 & 228,27 & 110,24 & 657,11 & \begin{tabular}{|l|l|}
45,19 \\
\end{tabular} & 4,00 & 59,58 & 277,46 & 32,31 & 33,59 & 275,99 \\
\hline Hyla meridionalis & 29 SNC64 & 100,00 & 167,67 & 99,66 & 41,58 & 4728,05 & 308,14 & 71,10 & 237,04 & 118,99 & 227,06 & 231,73 & 110,79 & \begin{tabular}{|c|}
586,38 \\
\end{tabular} & 84,68 & 2,98 & 60,50 & 249,87 & 27,36 & 27,77 & 247,77 \\
\hline Hyla meridionalis & 29 SNC65 & 101,00 & 165,21 & 98,42 & 41,09 & 4744,75 & 305,35 & 69,42 & 235,94 & 116,34 & 224,94 & 229,67 & 108,29 & 609,86 & 87,75 & 3,01 & 60,04 & 257,88 & 29,32 & 29,53 & 256,77 \\
\hline Hyla meridionalis & 29 SNC66 & 100,00 & 163,32 & 96,95 & 40,96 & 4748,38 & 302,52 & 68,20 & 234,32 & 113,71 & 223,07 & 227,75 & 106,26 & 633,58 & 90,95 & 3,66 & 59,27 & 266,10 & 31,68 & 31,91 & 265,71 \\
\hline Hyla meridionalis & 29SNC67 & 101,00 & 160,92 & 95,55 & 40,51 & 4762,73 & 299,50 & 66,41 & 233,08 & 108,31 & 221,06 & 225,57 & 103,85 & 660,70 & 94,83 & 4,00 & 58,89 & 276,39 & 33,88 & 33,97 & 276,32 \\
\hline Hyla meridionalis & $295 \mathrm{NC} 68$ & 101,00 & 163,25 & 94,70 & 40,31 & 4730,67 & 300,30 & $\begin{array}{l}68,96 \\
68,9\end{array}$ & \begin{tabular}{|l|}
231,34 \\
\end{tabular} & \begin{tabular}{|l|}
111,72 \\
110,1
\end{tabular} & 222,91 & \begin{tabular}{|l|}
227,37 \\
\end{tabular} & $\begin{array}{l}106,33 \\
106\end{array}$ & 657,62 & $\begin{array}{l}4,00 \\
94,41 \\
\end{array}$ & 4,00 & 58,85 & 274,96 & $\begin{array}{l}3,70 \\
33,71 \\
\end{array}$ & 34,14 & 274,80 \\
\hline Hyla meridionalis & $295 N C 72$ & 101,00 & 168,99 & 104,16 & 42,00 & 4819,09 & 314,36 & 69,59 & 244,77 & 119,59 & 229,74 & 234,33 & 111,15 & 554,55 & 80,84 & 2,28 & 61,04 & 237,65 & 24,72 & 25,06 & 234,67 \\
\hline Hyla meridionalis & 29 SNC73 & 101,00 & 167,30 & 103,29 & 41,94 & 4840,16 & 312,68 & 68,40 & 244,28 & 117,58 & 228,25 & 233,07 & 109,32 & 571,18 & 81,99 & 3,00 & 59,96 & 242,07 & 27,26 & 27,38 & 240,14 \\
\hline Hyla meridionalis & 29 SNC74 & 101,00 & 164,58 & 101,83 & 41,31 & 4855,15 & 309,36 & 66,51 & 242,84 & 114,73 & 226,27 & 230,53 & 106,55 & 594,93 & 84,9 & 3,00 & 59,55 & 250,03 & 28,86 & 28,86 & 249,31 \\
\hline Hyla meridionalis & 29 SNC75 & 100,00 & 164,53 & 100,09 & 41,03 & 4838,18 & 307,66 & 67,28 & 240,38 & 114,29 & 226,21 & 230,19 & 106,54 & 604,28 & 86,00 & 3,00 & 59,13 & 252,46 & 30,18 & 30,18 & 252,28 \\
\hline Hyla meridionalis & 29 SNC76 & 101,00 & 160,29 & 98,06 & 40,77 & 4851,99 & 302,55 & 64,27 & 238,27 & 104,42 & 223,43 & 226,39 & 102,36 & 641,73 & 91,18 & 3,81 & 58,25 & 266,81 & 33,29 & 33,29 & 266,81 \\
\hline Hyla meridionalis & 29SNC77 & 101,00 & 158,54 & 96,49 & 40,18 & 4855,58 & 299,73 & 63,38 & 236,35 & 100,76 & 222,23 & 224,66 & 100,60 & 666,05 & 94,64 & 4,08 & 57,82 & 276,19 & 35,39 & 35,39 & 276,19 \\
\hline Hyla meridionalis & 29SNC78 & 99,00 & 160,21 & 95,62 & 40,11 & 4836,39 & 300,15 & 65,21 & 234,94 & 102,41 & 222,25 & 225,85 & 102,35 & 669,04 & 95,14 & 4,02 & 57,86 & 277,31 & 35,75 & 35,75 & 277,31 \\
\hline Hyla meridionalis & 29SNC79 & 101,00 & 163,50 & 95,29 & 40,00 & 4822,36 & 302,59 & 68,15 & 234,43 & 106,34 & 224,34 & 228,70 & 105,38 & 659,75 & 93,8 & 4,00 & 57,83 & 273,29 & 35,38 & 35,75 & 273,29 \\
\hline Hyla meridionalis & $295 N C 81$ & 101,00 & 165,59 & 108,62 & 42,09 & 4964,21 & 317,28 & 63,29 & 253,99 & 114,89 & 228,42 & 233 & 106,27 & 561,88 & 82, & 2,18 & 60,46 & 239,21 & 25,24 & 25,36 & 236,65 \\
\hline Hyla meridionalis & 29 SNC82 & 99,00 & 167,03 & 107,19 & 42,0 & 4950,75 & 317,14 & 65,50 & 251,64 & 116,11 & 229,61 & 234,29 & $\begin{array}{l}107,79 \\
\end{array}$ & 559,42 & 80,96 & 2,64 & 60,02 & 236,69 & 26,40 & 26,50 & 234,41 \\
\hline Hyla meridionalis & 29 SNC83 & 101,00 & 165,01 & 105,72 & 41,89 & 4963,12 & 314,42 & 64,19 & 250,23 & 113,99 & 228,62 & 232,37 & 105,65 & 577,32 & 82,20 & 3,00 & 59,25 & 241,88 & 28,08 & 28,08 & 240,77 \\
\hline Hyla meridionalis & $295 N C 84$ & 101,00 & 163,50 & 103,66 & 41,22 & 4958,27 & 311,40 & $\begin{array}{ll}63,87 \\
\end{array}$ & 247,52 & 112,01 & 227,62 & 230,76 & 104,36 & 593,24 & 83,70 & 3,01 & 58,59 & 246,40 & 29,81 & 29,81 & 246,24 \\
\hline Hyla meridionalis & $295 N C 86$ & 100,00 & 161,19 & 99,26 & 40,70 & 4930,57 & 305,38 & 63,90 & 241,49 & 102,56 & 226,06 & 228, & 102,29 & 624,39 & 87,5 & 3,77 & 57,59 & 257,09 & 33,38 & 33,38 & 257,09 \\
\hline Hyla meridionalis & $295 N C 87$ & 100,00 & 157,48 & 97,19 & 40,03 & 4938,52 & 300,5 & $\begin{array}{l}61,44 \\
61\end{array}$ & 239,15 & $\begin{array}{l}98,67 \\
98,\end{array}$ & 223,75 & 224 & \begin{tabular}{|c|}
98,67 \\
98,6
\end{tabular} & 661,51 & $\begin{array}{l}92,89 \\
92,\end{array}$ & 4,07 & 57,07 & 271,88 & $\begin{array}{l}3,13 \\
36,14 \\
\end{array}$ & 36,14 & 271,88 \\
\hline Hyla meridionalis & $29 \mathrm{SNC8}$ & 101,00 & 158,80 & 96,51 & 39,99 & 4931,32 & 301, & 62,78 & 238,47 & 100,02 & 224,18 & 225,94 & 100,02 & 667,61 & 93,90 & 4,19 & 56,95 & 274,30 & 36,84 & 36,84 & 274,30 \\
\hline Hyla meridionalis & 29SNC89 & 100,00 & 163,08 & 96,52 & 40,01 & 4922,84 & 304,76 & 66,54 & 238,22 & 104,04 & 225,79 & 229,75 & 103,99 & 654,01 & 92,12 & 4,03 & 57,18 & 268,90 & 36,06 & 36,14 & 268,90 \\
\hline Hyla meridionalis & 29 SNC90 & 100,00 & 163,67 & 112,38 & 42,31 & 5089,53 & 320,41 & 58,57 & 261,84 & 111,71 & 228,54 & 232,88 & 103,12 & 562,60 & 82,93 & 2,10 & 60,35 & 238,93 & 25,01 & 25,10 & 235,98 \\
\hline Hyla meridiona & 29SNC91 & 100,00 & 164,76 & 111,73 & 42,12 & 5095,89 & 321,09 & 60,14 & 260,95 & 112,42 & 229,47 & 233,99 & 103,97 & 560,86 & 81,73 & 2,19 & 59,75 & 236,43 & 26,09 & 26,09 & 234,05 \\
\hline Hyla meridionalis & 295NC94 & 100,00 & 161,65 & $\frac{11}{10}$ & $\frac{42}{41}$ & $\begin{array}{l}5052,039 \\
5062,79\end{array}$ & 312, & $\begin{array}{l}60,52 \\
60,4\end{array}$ & \begin{tabular}{|l|}
251,92 \\
\end{tabular} & $\begin{array}{l}1<2,4< \\
107,12 \\
\end{array}$ & \begin{tabular}{|l|}
228,18 \\
\end{tabular} & \begin{tabular}{|l|}
230,52 \\
\end{tabular} & \begin{tabular}{|l|}
101,29 \\
101
\end{tabular} & $\begin{array}{l}500,00 \\
597,04\end{array}$ & $\mid \begin{array}{l}\mid 1,1 / 3 \\
83,31\end{array}$ & 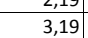 & 57,84 & 245,71 & $\begin{array}{l}0,0,75 \\
30,5\end{array}$ & 30,75 & 245,55 \\
\hline Hyla meridionalis & 29 SNC95 & 101,00 & 162,26 & 102,82 & 40,99 & 5036,47 & 310,58 & 62,31 & 248,27 & 103,86 & 228,90 & 230,65 & 102,00 & 598,80 & 83,23 & 3,07 & 57,54 & 245,44 & 31,23 & 31,23 & 245,44 \\
\hline Hyla meridionalis & $295 \mathrm{NC} 96$ & 100,00 & 161,72 & 100,41 & 40,40 & 5014,36 & 307,90 & $\begin{array}{l}63,07 \\
63,\end{array}$ & 244,83 & $\begin{array}{l}101,64 \\
\end{array}$ & $\begin{array}{l}227,53 \\
225\end{array}$ & 229,77 & 101,64 & 6100,86 & $\begin{array}{l}0,25 \\
84,42 \\
\end{array}$ & 3,90 & 56,55 & 248,98 & 33,86 & $\begin{array}{l}1,125 \\
3,86\end{array}$ & 248,98 \\
\hline Hyla meridionalis & 29 SNC97 & 101,00 & 160,32 & 98,67 & 40,00 & 5013,92 & 305,33 & 62,47 & 242,87 & 100,35 & 227,13 & 228,47 & 100,35 & 630,48 & 87,14 & 4,00 & 56,21 & 256,55 & 35,39 & 35,39 & 256,55 \\
\hline Hyla meridiona & 29SNC98 & 101,00 & 160,41 & 97,95 & 40,00 & 5019,94 & 305,06 & 62,60 & 242,46 & 100,33 & 226,64 & $22 \varepsilon$ & 100,33 & 646,31 & 89,76 & 4,01 & 56,42 & 263,36 & 36,37 & 36,37 & 26 \\
\hline Hyla meridionalis & $295 \mathrm{SC}$ & $\begin{array}{l}100,00 \\
100\end{array}$ & $\begin{array}{l}10,41 \\
162,60\end{array}$ & $\begin{array}{l}1,50 \\
97,82\end{array}$ & 39,99 & 5028,22 & 307,13 & $\begin{array}{l}6,, 40 \\
64,41 \\
\end{array}$ & \begin{tabular}{|l|}
242,40 \\
242,72 \\
\end{tabular} & \begin{tabular}{|l|}
102,16 \\
10,16
\end{tabular} & \begin{tabular}{|l|}
226,964 \\
\end{tabular} & \begin{tabular}{|l|}
230,84 \\
230
\end{tabular} & \begin{tabular}{|l|l|}
102,16 \\
102
\end{tabular} & $\begin{array}{l}\quad 640,51 \\
649,82\end{array}$ & $\begin{array}{l}30,10 \\
90,50 \\
\end{array}$ & $\begin{array}{l}4,010 \\
4,00\end{array}$ & $\begin{array}{l}0,42 \\
56,37\end{array}$ & $\begin{array}{l}200,50 \\
264,99\end{array}$ & $\begin{array}{l}|c| \\
36,64\end{array}$ & $\begin{array}{l}30,31 \\
36,65\end{array}$ & $\begin{array}{l}200,00 \\
264,99\end{array}$ \\
\hline Hyla meridionalis & 29SND03 & 101,00 & 160,54 & 75,24 & 40,72 & 3756,82 & 261,73 & 78,79 & 182,94 & 120,86 & 206,23 & 209,56 & 113,18 & 707,24 & 108,25 & 3,99 & 61,58 & 309,55 & 31,18 & 35,44 & 297,42 \\
\hline Hyla meridionalis & 29SND06 & 101,00 & 149,04 & 73,22 & 40,77 & 3633,73 & 246,47 & 68,94 & 177,54 & 111,00 & 193,27 & 196,21 & 103,07 & 806,23 & 121,74 & 5,64 & 59,51 & 345,03 & 40,37 & 44,62 & 333,78 \\
\hline Hyla meridionalis & 29SND07 & 100,00 & 150,55 & 72,97 & 41,12 & 3560,35 & 245,8 & 70,64 & 175,2 & 112,96 & 193 & 196, & 105 & 801,02 & 121,01 & 5,78 & 59,06 & 341,15 & 40,96 & 45,75 & 329,98 \\
\hline Hyla meridionalis & 29SND08 & 101,00 & 154,16 & 73,18 & 41,81 & 3476,62 & 247,18 & 74,14 & 173,04 & 117,32 & 195,93 & 198,56 & 109,29 & 778,49 & 117,54 & 5,62 & 58,76 & 330,55 & 39,95 & 45,65 & 319,44 \\
\hline
\end{tabular}




\begin{tabular}{|c|c|c|c|c|c|c|c|c|c|c|c|c|c|c|c|c|c|c|c|c|c|}
\hline TAXON & UTM & $\mathrm{km} 2$ & B101 & B102 & $\mathrm{BIO3}$ & B104 & B105 & B106 & B107 & B108 & B109 & B1010 & B1011 & BIO12 & B1013 & BIO14 & BIO15 & BIO16 & B1017 & B1018 & B1019 \\
\hline Hyla meridionalis & 29SND11 & 101,00 & 168,36 & 81,61 & 40,94 & 4048,53 & 280,49 & 82,40 & 198,09 & 125,47 & 217,97 & 221,82 & 118,03 & 666,83 & 99,99 & 3,01 & 62,14 & 292,33 & 28,04 & 31,66 & 283,46 \\
\hline Hyla meridionalis & 29SND17 & 101,00 & 140,89 & 77,42 & 40,20 & \begin{tabular}{ll|l}
3896,44 \\
\end{tabular} & 247,82 & 57,69 & 190,13 & 100,32 & 189,19 & 192,27 & 92,55 & 923,35 & 136,53 & 7,84 & 57,81 & 387,36 & 51,57 & 54,11 & 380,57 \\
\hline Hyla meridionalis & 29SND18 & 100,00 & 150,32 & 77,86 & 41,17 & 3751,52 & 253,42 & 66,79 & 186,64 & 110,63 & 196,26 & 199,05 & 102,79 & 842,71 & 124,44 & 6,59 & 57,92 & 354,03 & 45,62 & 49,85 & 346,48 \\
\hline Hyla meridionalis & 29SND21 & 101,00 & 168,28 & 84,36 & 40,69 & 4184,02 & 285,37 & 80,20 & 205,17 & 124,08 & 219,84 & 223,76 & 116,43 & 668,57 & 98,90 & 3,69 & 61,35 & 290,17 & 29,67 & 32,85 & 283,33 \\
\hline Hyla meridionalis & 29SND22 & 100,00 & 167,60 & 83,33 & 40,74 & $\begin{array}{lll}4124,58 \\
\end{array}$ & 282,55 & 80,19 & 202,35 & 123,82 & 218,37 & 222,03 & 116,25 & 674,42 & 99,93 & 3,95 & 61,12 & 291,85 & 30,32 & 33,83 & 284,68 \\
\hline Hyla meridionalis & 29SND30 & 101,00 & 168,25 & 87,76 & 40,79 & 4347,72 & 291,76 & 78,26 & 213,50 & 122,54 & 222,27 & 226,40 & 114,98 & 663,01 & 97,42 & 3,95 & 60,75 & 285,61 & 30,54 & 32,95 & 280,85 \\
\hline Hyla meridionalis & 29SND38 & 101,00 & 154,11 & 86,06 & 40,92 & 4160,23 & 272,22 & 64,23 & 207,99 & 109,68 & 205,85 & 208,84 & 101,98 & 852,33 & 124,75 & 6,88 & 57,12 & 353,53 & 48,20 & 50,95 & 350,97 \\
\hline Hyla meridionalis & 29SND45 & 101,00 & 165,76 & 88,03 & 40,78 & 4321,19 & 288,15 & 74,32 & 213,82 & 119,42 & 219,42 & 222,85 & 111,97 & 723,74 & 105,79 & 4,87 & 58,48 & 304,00 & 37,37 & 40,32 & 300,70 \\
\hline Hyla meridionalis & 29SND50 & 101,00 & 167,79 & 91,83 & 40,21 & 4577,92 & 299,08 & 74,61 & 224,47 & 119,69 & 225,07 & 229,25 & 111,94 & 656,23 & 95,12 & 4,00 & 59,42 & 277,02 & 32,25 & 33,94 & 275,19 \\
\hline Hyla meridionalis & 29SND56 & 100,00 & 164,14 & 90,99 & 40,28 & 4499,20 & 292,42 & 70,03 & 222,39 & 115,91 & 220,46 & 223,79 & 108,37 & 758,66 & 110,26 & 5,55 & 57,46 & 314,56 & 41,55 & 43,99 & 313,51 \\
\hline Hyla meridionalis & 29SND57 & 101,00 & 163,58 & 91,65 & 40,52 & 4487,99 & 292,20 & 68,96 & 223,24 & 114,77 & 219,93 & 223,01 & 107,82 & 778,36 & 112,98 & 5,93 & 57,09 & 321,51 & 43,46 & 45,93 & 320,79 \\
\hline Hyla meridionalis & 29SND58 & 99,00 & 160,41 & 92,24 & 40,51 & 4511,64 & 290,14 & 65,14 & 224,99 & 108,50 & 217,14 & 220,11 & 104,43 & 823,70 & 119,57 & 6,61 & 56,51 & 338,98 & 47,61 & 49,76 & 338,68 \\
\hline Hyla meridionalis & 29SND60 & 100,00 & 167,56 & 93,60 & 40,16 & 4693,55 & 302,33 & 73,11 & 229,22 & 118,44 & 226,51 & 230,75 & 110,51 & 652,08 & 93,74 & 4,00 & 58,75 & 272,51 & 33,19 & 34,41 & 271,85 \\
\hline Hyla meridionalis & 29SND70 & 101,00 & 166,85 & 95,14 & \begin{tabular}{|l|l|}
40,07 \\
\end{tabular} & 4804,47 & 305,03 & 70,95 & 234,08 & 113,76 & 227,38 & 231,65 & 108,60 & 651,19 & 92,75 & 4,00 & 57,94 & 269,61 & 34,63 & 35,48 & 269,59 \\
\hline Hyla meridionalis & 29SND80 & 101,00 & 166,63 & 96,48 & 40,00 & 4914,35 & 307,64 & 69,17 & 238,47 & 107,97 & 228,70 & 232,91 & 107,09 & 646,56 & 91,14 & 4,00 & 57,21 & 265,65 & 35,67 & 36,13 & 265,65 \\
\hline Hyla meridionalis & 29 SND82 & 100,00 & 166,25 & 95,78 & 39,86 & 4933,50 & 307,14 & 68,68 & 238,46 & 107,86 & 228,73 & 232,66 & 106,37 & 683,16 & 97,01 & 4,95 & 56,91 & 280,67 & 38,24 & 39,23 & 280,67 \\
\hline Hyla meridionalis & 29SND83 & 101,00 & 165,65 & 95,47 & 39,54 & 4946,11 & 306,57 & 67,94 & 238,62 & 106,90 & 228,45 & 232,34 & 105,62 & 704,76 & 100,50 & 5,00 & 56,88 & 289,71 & 39,38 & 40,52 & 289,71 \\
\hline Hyla meridionalis & 29SND85 & 99,00 & 163,36 & 95,07 & 39,14 & 4975,53 & 304,82 & 65,19 & 239,63 & 103,05 & 226,75 & 230,31 & 103,01 & 759,23 & 109,09 & 5,89 & 56,40 & 311,86 & 43,72 & 44,89 & 311,86 \\
\hline Hyla meridionalis & 29SND91 & 100,00 & 165,52 & 97,41 & 39,74 & 5042,61 & 309,69 & 66,78 & 242,92 & 105,51 & 229,67 & 233,77 & 104,78 & 666,33 & 93,51 & 4,71 & 56,51 & 272,06 & 38,02 & 38,47 & 272,06 \\
\hline Hyla meridionalis & 29SND92 & 100,00 & 167,01 & 97,38 & 39,53 & 5049,72 & 311,14 & 67,58 & 243,55 & $\mid 108,42$ & 231,32 & 235,16 & $|105,97|$ & 672,80 & 94,69 & 4,91 & 56,41 & 274,65 & 38,37 & 39,36 & 274,65 \\
\hline Hyla meridionalis & 29SND94 & 100,00 & 164,63 & 96,36 & 39,00 & 5094,30 & 309,10 & 65,31 & 243,79 & 103,10 & 229,80 & 233,27 & 103,05 & 729,34 & 103,74 & 5,38 & 56,13 & 298,24 & 42,26 & 43,34 & 298,24 \\
\hline Hyla meridionalis & 29SND95 & 101,00 & 164,40 & 96,29 & 38,97 & 5107,33 & 308,97 & 64,56 & 244,41 & 102,61 & 229,69 & 233,08 & 102,46 & 749,64 & 107,05 & 5,86 & 56,03 & 306,62 & 43,75 & 44,92 & 306,62 \\
\hline Hyla meridionalis & 29SND96 & 101,00 & 161,90 & 95,79 & \begin{tabular}{|l|l|}
38,71 \\
\end{tabular} & 5140,64 & 307,12 & 61,99 & 245,13 & 99,61 & 227,89 & 231,10 & 99,61 & 788,45 & 113,31 & 6,03 & 55,97 & \begin{tabular}{|l|l|}
322,89 \\
\end{tabular} & 46,10 & 47,06 & 322,89 \\
\hline Hyla meridionalis & 29SNE01 & 71,00 & 155,54 & 75,36 & 43,04 & 3391,56 & 246,96 & 73,98 & 172,98 & 118,78 & 195,81 & 198,16 & 110,94 & 820,20 & 120,06 & 6,99 & 56,68 & 341,42 & 46,29 & 53,10 & 331,97 \\
\hline Hyla meridionalis & 29SNE42 & 100,00 & 150,50 & 94,55 & 41,80 & 4357,86 & 278,69 & 54,41 & 224,29 & 95,73 & 205,08 & 207,75 & 95,73 & 981,85 & 141,10 & 9,75 & 54,39 & 398,97 & 63,27 & 65,08 & 398,97 \\
\hline Hyla meridionalis & 29SNE52 & 100,00 & 145,71 & 94,36 & 40,55 & 4572,50 & 278,62 & 48,77 & 229,86 & 89,08 & 204,36 & 206,28 & 89,08 & 1042,81 & 151,36 & 10,45 & 54,69 & 424,94 & 67,24 & 68,03 & 424,94 \\
\hline Hyla meridionalis & 29SPBO0 & 100,00 & 168,65 & 91,91 & 411,97 & 4323,17 & 288,65 & 71,93 & 216,72 & \begin{tabular}{|l|}
125,49 \\
\end{tabular} & 223,02 & 227,16 & \begin{tabular}{|l|}
116,65 \\
16
\end{tabular} & $\begin{array}{r}520,02 \\
520\end{array}$ & \begin{tabular}{|l|}
86,18 \\
\end{tabular} & $\begin{array}{c}\frac{1,4}{1,01} \\
\end{array}$ & 68,52 & 247,88 & $\begin{array}{ll}15,63 \\
\end{array}$ & 19,26 & 231,80 \\
\hline Hyla meridionalis & 29SPB01 & 101,00 & 162,03 & 94,36 & 41,61 & 4497,07 & 288,29 & 63,89 & 224,40 & 117,19 & 218,91 & 223,10 & 108,31 & 555,68 & 89,50 & 1,30 & 66,64 & 258,63 & 18,44 & 21,93 & 244,09 \\
\hline Hyla meridionalis & 29SPB02 & 100,00 & 156,21 & 96,72 & 41,06 & 4645,49 & 288,15 & 56,77 & 231,38 & 109,81 & 215,06 & 219,32 & 100,94 & 589,35 & 92,50 & 1,92 & 64,92 & 268,40 & 21,17 & 24,40 & 255,58 \\
\hline Hyla meridionalis & 29SPB03 & 101,00 & 158,06 & 98,16 & 41,13 & 4706,17 & 292,82 & 57,77 & 235,05 & 110,68 & 217,75 & 221,95 & 101,91 & 579,27 & 90,05 & 1,99 & 64,43 & 262,06 & 21,21 & 24,19 & 249,89 \\
\hline Hyla meridionalis & 29SPB05 & 100,00 & 163,97 & 101,37 & 41,34 & 4816,27 & 303,75 & 62,08 & 241,66 & 115,01 & 224,98 & 229,16 & 106,18 & 546,64 & 83,50 & 2,00 & 63,37 & 244,04 & 20,84 & 23,48 & 233,34 \\
\hline Hyla meridionalis & 29SPBO6 & 101,00 & 166,78 & 103,09 & | 41,77 & 4864,45 & 308,96 & $\begin{array}{l}64,24 \\
64,\end{array}$ & $\begin{array}{l}444,73 \\
\end{array}$ & \begin{tabular}{|l|l|}
117,18 \\
\end{tabular} & \begin{tabular}{|l|}
228,35 \\
\end{tabular} & 232,62 & \begin{tabular}{|l|l|}
108,45 \\
\end{tabular} & \begin{tabular}{|l|}
531,27 \\
\end{tabular} & $\begin{array}{l}0,80 \\
80,81\end{array}$ & $\frac{1,00}{1,99}$ & $\begin{array}{l}52,92 \\
62\end{array}$ & 235,55 & $\mid \begin{array}{l}\mid 20,77 \\
20,7\end{array}$ & 23,04 & 225,63 \\
\hline Hyla meridionalis & 29SPB11 & 99,00 & 168,63 & 92,33 & 41,09 & 4481,92 & 291,86 & 70,19 & 221,67 & 123,23 & 224,88 & 228,95 & 114,35 & 520,10 & 83,18 & 1,01 & 66,93 & 242,62 & 16,15 & 20,50 & 226,66 \\
\hline Hyla meridionalis & 29SPB13 & 100,00 & 163,67 & 96,69 & 40,97 & 4727,12 & 296,40 & 62,81 & 233,59 & 115,68 & 223,35 & 227,42 & 106,75 & 545,74 & 84,32 & 1,70 & 64,48 & 246,99 & 19,23 & 23,10 & 233,35 \\
\hline Hyla meridionalis & 29SPB14 & 100,00 & 164,15 & 98,47 & 40,99 & 4808,23 & 300,24 & 62,28 & 237,96 & 114,95 & 224,83 & 228,98 & 106,16 & 543,03 & 83,13 & 1,86 & 63,62 & 243,27 & 19,80 & 23,49 & 230,58 \\
\hline Hyla meridionalis & 29SPB15 & 101,00 & 166,02 & 100,20 & 41,00 & 4869,35 & 304,94 & 63,33 & 241,61 & 115,96 & 227,46 & 231,61 & 107,26 & 532,74 & 81,03 & 1,93 & 63,12 & 236,72 & 20,00 & 23,43 & 224,84 \\
\hline Hyla meridionalis & 29SPB16 & 100,00 & 169,62 & $\begin{array}{l}101,78 \\
\end{array}$ & 41,12 & 4908,01 & 310,38 & 66,19 & 244,19 & 118,84 & 231,52 & 235,58 & 110,12 & 514,27 & 77,93 & 1,73 & 62,67 & 227,15 & 19,65 & 22,79 & 215,99 \\
\hline Hyla meridionalis & 29SPB17 & 100,00 & 168,05 & 104,46 & 41,20 & 5005,48 & 313,51 & 63,50 & 250,01 & 116,38 & 231,39 & 235,43 & 107,52 & 524,31 & 78,49 & 1,98 & 61,72 & 228,42 & 21,01 & 23,75 & 218,70 \\
\hline Hyla meridionalis & 29SPB18 & 101,00 & 168,43 & \begin{tabular}{ll|}
106,74 \\
\end{tabular} & 41,49 & 5064,67 & 317,17 & 62,97 & 254,19 & 116,14 & 232,58 & 236,60 & 107,19 & 524,31 & 77,78 & 2,00 & 60,91 & 225,94 & 21,78 & 23,97 & 217,52 \\
\hline Hyla meridionalis & 29SPB21 & 97,00 & 172,04 & 90,53 & 40,61 & 4512,68 & 293,65 & 73,35 & 220,30 & 125,89 & 228,34 & 232,29 & 116,95 & 501,29 & 79,80 & 1,00 & 66,59 & 232,37 & 14,78 & 20,05 & 215,44 \\
\hline Hyla meridionalis & 29SPB23 & 101,00 & 168,25 & 94,56 & 40, & 4735,29 & 298,46 & 67,19 & 231,27 & 119,61 & 227,77 & 23 & 110,66 & 519,73 & 80,23 & 1,19 & 64,47 & 234,68 & 17,37 & 22,16 & 219,59 \\
\hline Hyla meridionalis & 29SPB24 & 100,00 & 165,69 & $\begin{array}{ll}47,05 \\
97\end{array}$ & 40,46 & 4849,47 & 300,64 & 63,40 & 237,24 & \begin{tabular}{|l|}
115,70 \\
\end{tabular} & 226,89 & 230,83 & 107,08 & 533,69 & 81,11 & 1,86 & 63,31 & 237,35 & 19,21 & 23,72 & 223,55 \\
\hline Hyla meridionalis & 29SPB25 & 100,00 & 169,33 & 98,40 & 40,57 & 4894,24 & 306,29 & 66,31 & 239,97 & 118,59 & 231,09 & 234,90 & 110,06 & 513,84 & 77,78 & 1,62 & 62,78 & 227,38 & 18,76 & 23,11 & 214,10 \\
\hline Hyla meridionalis & 29SPB26 & 101,00 & 169,08 & 100,77 & 40,72 & 4972,45 & 309,87 & 64,94 & 244,93 & 117,62 & 231,85 & 235,79 & 108,74 & 516,25 & 77,31 & 1,88 & 61,94 & 225,79 & 19,77 & 23,69 & 213,66 \\
\hline Hyla meridionalis & 29SPB27 & 100,00 & 167,14 & 103,45 & 40,86 & 5076,86 & 312,47 & 61,61 & 250,86 & 4,53 & 231,33 & 235,27 & 105,58 & 528,04 & 78,16 & 2,00 & 61,08 & 28,12 & 21,14 & 24,51 & 217,42 \\
\hline Hyla meridionalis & 29SPB28 & 100,00 & 167,52 & 105,62 & $\frac{40,9}{40,9}$ & 5143,11 & 316,07 & $\begin{array}{l}1,00,92 \\
60\end{array}$ & 255,16 & \begin{tabular}{|l|l|l|l|l}
113,99 \\
\end{tabular} & 232,69 & 236,56 & \begin{tabular}{|l|}
105,07 \\
\end{tabular} & 527,53 & 77,44 & 2,00 & $\begin{array}{l}1,00 \\
60,50 \\
\end{array}$ & $\begin{array}{l}225,69 \\
225,69 \\
\end{array}$ & 21,84 & 24,69 & 216,24 \\
\hline Hyla meridionalis & 29SPB29 & 101,00 & 167,13 & 107,53 & 41, & 5203,95 & 318,63 & 59,81 & 258,82 & 112,92 & 233,18 & 237,07 & 103,92 & 531,36 & 77,24 & 2,00 & 59,86 & 225,10 & 22,59 & 25,19 & 216,82 \\
\hline Hyla meridionalis & 29SPB31 & 58,00 & 174,81 & 88,67 & 40,00 & 4559,20 & 295,23 & 75,87 & 219,36 & 127,54 & 231,51 & 235,26 & 118,59 & 486,49 & 76,64 & 1,00 & 65,94 & 222,86 & 14,03 & 19,99 & 205,03 \\
\hline Hyla meridionalis & 29SPB32 & 101,00 & 173,23 & 90,13 & 39,87 & 4653,86 & 296,81 & 73,27 & 223,54 & 124,94 & 231,23 & 234,90 & 115,92 & 493,39 & 76,86 & 1,00 & 65,25 & 224,21 & 14,76 & 20,66 & 206,99 \\
\hline Hyla meridiona & 29SPB33 & 100,00 & 172,24 & 92,08 & $39, \varepsilon$ & 4756,22 & 299,82 & 71,13 & 228,69 & 122,83 & 231,68 & 235 & 113 & 497,26 & 76,39 & 1,00 & 64,32 & 223,32 & 15,71 & 21,49 & 206,86 \\
\hline Hyla meridionalis & 29SPB34 & 101,00 & 170,86 & $\begin{array}{l}2,060 \\
94,32 \\
\end{array}$ & 39 & 485 & 302,54 & $\begin{array}{l}1,15 \\
68,46\end{array}$ & \begin{tabular}{|l|}
$234,07,03$ \\
\end{tabular} & \begin{tabular}{|l|}
120,14 \\
12,1
\end{tabular} & \begin{tabular}{|l|}
231,780 \\
\end{tabular} & \begin{tabular}{|l|}
235,505 \\
235
\end{tabular} & \begin{tabular}{|l|}
$111,38<$ \\
111,38
\end{tabular} & $\begin{array}{l}\mid 504,14 \\
504,0\end{array}$ & $\begin{array}{l}\mid 0,35 \\
76,40\end{array}$ & $\frac{1,00}{1,15}$ & $\begin{array}{l}64,32 \\
63,32\end{array}$ & $\begin{array}{l}223,70 \\
223,70\end{array}$ & $\begin{array}{l}\mid 3,1 / 1 \\
16,99\end{array}$ & $\begin{array}{ll}21,45 \\
22,58\end{array}$ & 208,22 \\
\hline Hyla meridionalis & $295 \mathrm{SB} 35$ & 101,00 & 169,60 & 96,90 & 39,96 & 4957,53 & 305,73 & 65,96 & 239,77 & 117,77 & 231,96 & 235,63 & 109,06 & 511,72 & 76,62 & 1,60 & 62,32 & 224,38 & 18,45 & 23,57 & 210,04 \\
\hline Hyla meridionalis & 29SPB36 & 99,00 & 171,07 & 98,97 & 40,02 & 5027,06 & 310,27 & 66,23 & 244,03 & 118,48 & 234,36 & 238,01 & 109,54 & 504,43 & 74,85 & 1,80 & \begin{tabular}{|l|l|}
61,47 \\
6
\end{tabular} & 219,22 & $\begin{array}{l}19,0303 \\
19,0\end{array}$ & 23,80 & 205,73 \\
\hline Hyla meridionalis & 29SPB37 & 101,00 & 168,89 & 101,83 & 40,13 & 5123,45 & 312,79 & 62,74 & 250,05 & 115,32 & 233,65 & 237,34 & 106,44 & 517,24 & 75,86 & 2,00 & 60,68 & 222,11 & 20,43 & 24,79 & 209,98 \\
\hline Hyla meridiona & 29SPB39 & 100,00 & 165,47 & 106,32 & 40,48 & 5275,48 & 316,66 & 57,26 & 259,40 & 110,34 & 232,63 & 236 & 101 & 539,62 & 77,46 & 2,16 & 59,39 & 226,96 & 23,19 & 26,27 & 217 \\
\hline Hyla meridionalis & \begin{tabular}{|l|}
$295 \mathrm{SPB} 42$ \\
\end{tabular} & $\begin{array}{l}100,00 \\
\end{array}$ & $\begin{array}{l}10,41 \\
174,39\end{array}$ & $\begin{array}{r}0,51 \\
87,81 \\
\end{array}$ & $\begin{array}{l}40,40 \\
39,07\end{array}$ & 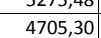 & 291,00 & $\begin{array}{l}1,20 \\
74,27 \\
\end{array}$ & \begin{tabular}{|l|}
222,13 \\
22,1
\end{tabular} & \begin{tabular}{|l|}
125,04 \\
12,4
\end{tabular} & \begin{tabular}{|l|}
232,760 \\
232
\end{tabular} & \begin{tabular}{|l|}
236,31 \\
231
\end{tabular} & $\begin{array}{l}116,11 \\
11,00\end{array}$ & \begin{tabular}{|l|l|} 
\\
486,66
\end{tabular} & $\begin{array}{l}71,406 \\
74,96\end{array}$ & $\frac{1,10}{1,00}$ & $\begin{array}{l}55,00 \\
65\end{array}$ & $\begin{array}{l}228,90 \\
218,79\end{array}$ & \begin{tabular}{|l|}
14,07 \\
140
\end{tabular} & $\begin{array}{l}20,21 \\
21,01\end{array}$ & 200,46 \\
\hline Hyla meridionalis & 29SPB43 & 100,00 & 171,07 & 90,36 & 39,05 & 4835,05 & 298,26 & 69,46 & 228,80 & 120,41 & 231,39 & 234,94 & 111,54 & 503,00 & 76,14 & 1,00 & 63,58 & $\begin{array}{ll}223,05 \\
\end{array}$ & 15,97 & 22,78 & 205,61 \\
\hline Hyla meridionalis & 29SPB44 & 100,00 & 168,94 & 93,08 & 39,08 & 4953,04 & 301,00 & 65,92 & 235,08 & 116,97 & 230,92 & 234,64 & 108,21 & 514,36 & 76,65 & 1,65 & 62,62 & 225,14 & 17,70 & 24,14 & 208,76 \\
\hline Hyla meridionalis & 29SPB45 & 101,00 & 167,17 & 95,93 & 39,15 & 5057,97 & 303,87 & 62,46 & 241, & 114,03 & 230, & 234 & 105 & 524,81 & 77,31 & 1,95 & 61 & 227,20 & 19,13 & 25,01 & 212,03 \\
\hline Hyla meridionalis & 29SPB46 & 101,00 & 170,38 & 97,69 & 39,49 & 5097,67 & 309,21 & 64,66 & 244,55 & 116,60 & 234,40 & 237,99 & 107,66 & 508,40 & 74,47 & 2,00 & 61,12 & 218,77 & 19,17 & 24,74 & 204,27 \\
\hline
\end{tabular}




\begin{tabular}{|c|c|c|c|c|c|c|c|c|c|c|c|c|c|c|c|c|c|c|c|c|c|}
\hline TAXON & UTM & $\mathrm{km} 2$ & B101 & B102 & $\mathrm{BIO3}$ & B104 & B105 & B106 & B107 & B108 & B109 & BIO10 & BIO11 & BIO12 & B1013 & BIO14 & BIO15 & BIO16 & B1017 & B1018 & B1019 \\
\hline Hyla meridionalis & 29SPB47 & 100,00 & 168,88 & 100,49 & 39,82 & 5191,89 & 311,99 & 61,96 & 250,03 & 114,28 & 234,42 & 237,89 & 105,12 & 517,01 & 75,01 & 2,00 & 60,66 & 220,39 & 20,28 & 25,11 & 207,22 \\
\hline Hyla meridionalis & 29SPB48 & 100,00 & 167,76 & 102,78 & 39,96 & 5275,35 & 314,51 & 59,57 & 254,94 & 112,04 & 234,53 & 238,02 & 103,20 & 523,92 & 75,31 & 2,00 & 59,87 & 221,33 & 21,22 & 25,76 & 209,24 \\
\hline Hyla meridionalis & 29SPB49 & 100,00 & 166,50 & 105,08 & 40,00 & 5340,31 & 316,69 & 57,41 & 259,28 & 110,07 & 234,41 & 237,71 & 101,40 & 532,89 & 75,91 & 2,06 & 59,35 & 223,19 & 22,59 & 26,21 & 212,30 \\
\hline Hyla meridionalis & 29SPB52 & 100,00 & 175,19 & 85,50 & 38,19 & 4763,32 & 295,72 & 74,92 & 220,80 & 124,69 & 233,97 & 237,43 & 115,81 & 482,36 & 73,92 & 1,00 & 64,48 & \begin{tabular}{|l|l|}
214,43 \\
\end{tabular} & 13,55 & 21,57 & 194,99 \\
\hline Hyla meridionalis & 29SPB53 & 101,00 & 172,90 & 87,90 & 38,16 & 4887,35 & 298,20 & 71,02 & 227,18 & 121,10 & 233,55 & 236,92 & 112,13 & 493,46 & 74,73 & 1,01 & 63,42 & 216,54 & 15,33 & 23,12 & 197,79 \\
\hline Hyla meridionalis & 29SPB54 & 101,00 & 170,45 & 90,94 & 38,30 & 5007,82 & 300,94 & 66,97 & 233,97 & 117,41 & 232,94 & 236,36 & 108,48 & 506,42 & 75,65 & 1,51 & 62,28 & 219,73 & 17,00 & 24,36 & 202,13 \\
\hline Hyla meridionalis & 29SPB55 & 99,00 & 166,69 & 94,61 & 38,71 & 5134,48 & 303,20 & 61,36 & 241,84 & 112,48 & 231,25 & 234,60 & 103,59 & 528,04 & 77,56 & 2,00 & 61,28 & 226,42 & 19,01 & 25,85 & 210,22 \\
\hline Hyla meridionalis & 29SPB56 & 100,00 & 168,05 & 96,89 & 38,95 & 5204,47 & 307,65 & 61,30 & 246,35 & 112,94 & 233,58 & 236,92 & 103,94 & 520,95 & 76,11 & 2,00 & 60,74 & 221,98 & 19,40 & 25,68 & 206,68 \\
\hline Hyla meridionalis & 29SPB57 & 100,00 & 168,52 & 99,30 & \begin{tabular}{l|l|l|}
39,05 \\
\end{tabular} & 5265,48 & 311,35 & 60,62 & 250,73 & 112,74 & 235,06 & 238,25 & 103,76 & 519,26 & 75,34 & 2,00 & 60,09 & 219,62 & 20,12 & 25,82 & 205,28 \\
\hline Hyla meridionalis & 29SPB58 & 101,00 & 165,17 & 102,30 & 39,26 & 5365,91 & 312,87 & 56,02 & 256,85 & 108,46 & 233,42 & 236,58 & 99,60 & 539,10 & 77,02 & 2,18 & 59,31 & 225,79 & 22,22 & 27,10 & 212,91 \\
\hline Hyla meridionalis & 29SPB59 & 100,00 & 166,71 & 104,28 & 39,71 & 5416,16 & 316,71 & 56,52 & 260,20 & 109,16 & 235,61 & 238,69 & 100,55 & 531,41 & 75,54 & 2,18 & 58,79 & 221,23 & 22,63 & 27,04 & 209,20 \\
\hline Hyla meridionalis & 29SPB62 & 100,00 & 176,32 & 82,94 & 37,30 & 4827,46 & 295,47 & 75,96 & 219,51 & 124,72 & 235,65 & 238,97 & 115,88 & 476,06 & 73,79 & 1,00 & 64,06 & 209,23 & 13,14 & 22,10 & 188,61 \\
\hline Hyla meridionalis & 29SPB63 & 100,00 & 173,50 & 85,69 & 37,29 & 4955,21 & 297,65 & 71,32 & 226,33 & 120,63 & 234,78 & 237,93 & 111,59 & 490,51 & 75,08 & 1,01 & 62,88 & 213,02 & 14,88 & 23,59 & 193,09 \\
\hline Hyla meridionalis & 29SPB64 & 100,00 & 171,35 & 89,14 & 37,69 & 5074,96 & 300,92 & 67,29 & 233,63 & 117,19 & 234,48 & 237,69 & 108,34 & 502,45 & 75,84 & 1,52 & 62,03 & \begin{tabular}{|l|l|}
215,97 \\
\end{tabular} & 16,64 & 24,62 & 197,18 \\
\hline Hyla meridionalis & 29SPB65 & 101,00 & 170,61 & 92,24 & 37,94 & 5171,80 & 304,69 & 64,81 & 239,88 & 115,30 & 235,21 & 238,42 & 106,43 & 507,57 & 75,85 & 1,94 & 61,13 & 216,36 & 17,85 & 25,54 & 198,55 \\
\hline Hyla meridionalis & 29SPB66 & 100,00 & 167,46 & 96,09 & 38,26 & 5281,79 & 307,19 & 59,68 & 247,51 & 111,22 & 233,90 & 237,04 & 102,17 & 526,75 & 77,38 & 2,00 & 60,41 & 222,67 & 19,45 & 26,22 & 206,49 \\
\hline Hyla meridionalis & 29SPB71 & 11,00 & 178,00 & 79,38 & 36,38 & 4854,08 & 293,31 & 77,85 & 215,46 & 125,85 & 236,69 & 240,08 & 116,31 & 471,38 & 74,15 & 1,00 & 64,08 & 205,62 & 12,00 & 22,00 & 183,46 \\
\hline Hyla meridionalis & 29SPB72 & 100,00 & 177,28 & 80,30 & 36,32 & 4889,62 & 294,83 & 76,74 & 218,10 & 124,96 & 237,14 & 240,23 & 115,76 & 471,86 & 74,05 & 1,00 & 63,85 & 205,10 & 12,65 & 22,54 & 183,14 \\
\hline Hyla meridionalis & 29SPB73 & 101,00 & 176,50 & 82,76 & $\begin{array}{l}36,45 \\
\end{array}$ & 5001,32 & 298,23 & 74,25 & 223,98 & 123,65 & 237,87 & 240,98 & 113,67 & 476,04 & 74,01 & 1,00 & 63,01 & 204,82 & 13,89 & 23,71 & $\begin{array}{ll}183,47 \\
\end{array}$ \\
\hline Hyla meridionalis & 29SPB74 & 100,00 & 174,51 & 86,77 & 36,99 & 5116,97 & 301,96 & 70,11 & 231,86 & 119,42 & 237,91 & 240,89 & 110,45 & 487,26 & 74,79 & 1,03 & 62,14 & \begin{tabular}{|l|l|}
208,15 \\
\end{tabular} & 15,20 & 24,17 & 187,95 \\
\hline Hyla meridionalis & 29SPB75 & 100,00 & 173,17 & 90,78 & $\begin{array}{l}37,35 \\
\end{array}$ & 5223,84 & 306,17 & 66,62 & 239,55 & 116,95 & 238,22 & 241,18 & 108,03 & 497,01 & 75,2 & 1,7 & 61,08 & 210,63 & 16,92 & 25,31 & 191,71 \\
\hline Hyla meridionalis & 29SPB76 & 101,00 & 172,13 & 94,68 & 37,97 & 5322,15 & 310,30 & 63,59 & 246,72 & 115,01 & 238,91 & 241,79 & 105,99 & 504,11 & 75,30 & 1,99 & 60,38 & 212,14 & 18,20 & 25,85 & 194,57 \\
\hline Hyla meridionalis & 29SPB79 & 100,00 & 158,60 & 105,26 & \begin{tabular}{|l|l|}
38,94 \\
\end{tabular} & 5641,23 & 313,68 & 45,54 & 268,14 & $\begin{array}{l}98,76 \\
\end{array}$ & 231,00 & 233,69 & 89,80 & 585,79 & 82,62 & 3,10 & 57,73 & 239,91 & 26,44 & 31,26 & 227,16 \\
\hline Hyla meridionalis & 29SPB81 & 49,00 & 177,89 & 79,56 & 36,00 & 4901,23 & 294,59 & 76,90 & 217,69 & 136,93 & 238,02 & 241,00 & 116,18 & 476,69 & 75,25 & 1,00 & 63,82 & 206,57 & 12,51 & 22,87 & 183,93 \\
\hline Hyla meridionalis & 29SPB82 & 101,00 & 177,98 & 79,33 & 35,82 & 4964,47 & 295,56 & 76,60 & 218,96 & 144,32 & 238,62 & 241,52 & 115,22 & 472,48 & 74,62 & 1,00 & 63,57 & 203,23 & 12,62 & 23,47 & 180,27 \\
\hline Hyla meridionalis & 29SPB83 & 99,00 & 177,82 & 81,79 & 35,97 & 5067,99 & 299,41 & 74,67 & 224,73 & 146,24 & 239,98 & 242,83 & 113,78 & 473,24 & 74,27 & 1,00 & 62,87 & 202,07 & 13,64 & 23,87 & 179,64 \\
\hline Hyla meridionalis & 29SPB84 & 101,00 & 174,38 & 87,23 & 36,64 & 5210,35 & 303,54 & 68,52 & 235,02 & \begin{tabular}{|l|}
120,05 \\
12,4
\end{tabular} & 239,13 & \begin{tabular}{|l|}
241,89 \\
\end{tabular} & $\begin{array}{l}109,09 \\
\end{array}$ & $\mid 493,86$ & 76,00 & $\begin{array}{l}1,20 \\
1,26\end{array}$ & $\begin{array}{l}2,1,76 \\
61,\end{array}$ & 209,21 & $\mid 15,46$ & 24,91 & 188,50 \\
\hline Hyla meridionalis & 29SPB85 & 100,00 & 172,92 & 91,72 & 37,08 & 5321,27 & 307,98 & 64,69 & 243,29 & 115,49 & 239,49 & 242,16 & 106,45 & 504,88 & 76,49 & 1,83 & 61,00 & 212,53 & 17,19 & 25,68 & 193,27 \\
\hline Hyla meridionalis & 29SPB86 & 100,00 & 169,77 & 96,12 & 37,83 & 5442,40 & 311,10 & 59,32 & 251,78 & 111,16 & 238,45 & 241,03 & 102,23 & 523,43 & 77,89 & 2,00 & 60,25 & 218,73 & 18,97 & 26,66 & 201,01 \\
\hline Hyla meridionalis & 29SPB87 & 100,00 & 168,34 & 99,61 & 38,00 & 5531,28 & 314,37 & 56,26 & 258,11 & 108,81 & 238,52 & 241,06 & 99,98 & 531,65 & 78,12 & 2,02 & 59,57 & 220,72 & 20,46 & 27,36 & 204,23 \\
\hline Hyla meridionalis & $295 P B 89$ & 100,00 & 153,82 & 106,46 & 38,23 & 5757,84 & 312,54 & 38,85 & 273,69 & 92,73 & 228,07 & 230,59 & 83,71 & 620,39 & 86,93 & 3,43 & 57,47 & 252,59 & 28,53 & 33,33 & 239,85 \\
\hline Hyla meridionalis & 29SPB90 & 10,00 & & & & & & & 270,00 & & $2<0,01$ & & & & | & & W & 202,05 & 20,5 & & 20,00 \\
\hline Hyla meridionalis & 29SPB91 & 91,00 & 176,63 & 82,44 & 36,29 & 4991,09 & 297,27 & 73,43 & 223,85 & 129,05 & 238,21 & 241,18 & 113,96 & 495,43 & 77,43 & 1,00 & 63,73 & \begin{tabular}{|l|l|}
213,67 \\
\end{tabular} & 13,84 & 23,77 & $\begin{array}{ll}191,63 \\
\end{array}$ \\
\hline Hyla meridionalis & 29SPB92 & 101,00 & 176,34 & 83,35 & 36,08 & 5092,33 & 299,59 & 72,02 & 227,57 & 134,69 & 239,17 & 242,06 & 112,29 & 493,55 & 77,15 & 1,00 & 63,20 & 211,19 & 14,05 & 24,00 & 189,05 \\
\hline Hyla meridionalis & 29SPB93 & 100,00 & 178,35 & 85,09 & 36,17 & 5167,99 & 304,21 & 72,76 & 231,45 & 147,42 & 242,25 & 244,99 & 113,29 & 482,24 & 75,46 & 1,00 & 62,70 & 205,42 & 14,09 & 24,00 & 183,32 \\
\hline Hyla meridionalis & 29SPB94 & 101,00 & 174,68 & 89,65 & 36,78 & 5315,18 & 307,38 & 66,53 & 240,84 & 122,55 & 241,05 & 243,73 & 108,15 & 502,46 & 77,16 & 1,28 & 61,65 & 212,05 & 15,74 & 24,94 & 191,58 \\
\hline Hyla meridionalis & 29SPB95 & 99,00 & 169,82 & 94,92 & 37,18 & 5462,90 & 310,08 & 58,89 & 251,19 & 110,79 & 238,72 & 241,25 & 101,85 & 531,43 & 79,77 & 2,00 & 60,74 & 222,38 & 18,52 & 26,68 & 203,61 \\
\hline Hyla meridionalis & 29SPB96 & 100,00 & 169,28 & 98,16 & 37,82 & 5549,99 & 313,89 & 56,72 & 257,17 & 109,34 & 239,57 & 242,12 & 100,46 & 534,59 & 79,41 & 2,00 & 60,10 & 222,36 & 19,56 & 27,16 & 204,72 \\
\hline Hyla meridionalis & 29SPB97 & 100,00 & 170,11 & 100,77 & 38,00 & 5609,81 & 317,98 & 56,11 & 261,87 & 109,56 & 241,47 & 243,77 & 100,57 & 529,92 & 78,18 & 2,00 & 59,68 & 219,39 & 20,10 & 27,11 & 202,56 \\
\hline Hyla meridionalis & 29SPB98 & 100,00 & 164,84 & 104,28 & 38,01 & 5721,95 & 318,91 & 49,21 & 269,70 & 103,34 & 238,19 & 240,41 & 94,44 & 558,94 & 80,74 & 2,51 & 58,66 & 229,30 & 23,06 & 29,22 & 214,00 \\
\hline Hyla meridionalis & 29SPB99 & 100,00 & 152,23 & 107,69 & 38,0 & 5848,46 & 313,92 & 35,78 & 278,14 & 90,23 & 227,96 & 230,29 & 81,17 & 635,97 & 88, & 3,6 & 57,37 & 257,79 & 29,35 & 34,22 & 245,06 \\
\hline Hyla meridionalis & 29SPCO0 & 101,00 & 165,29 & 112,18 & 42,05 & 5145,05 & 322,05 & 59,05 & 263,01 & 112,51 & 230,68 & 235,07 & 103,90 & 548,84 & 80,47 & 2,00 & 59,99 & 232,29 & 24,28 & 25,03 & 228,07 \\
\hline Hyla meridionalis & $29 \mathrm{SPCO2}$ & 101,00 & 166,33 & 110,50 & 41,87 & 5160,53 & 322,00 & 60,85 & 261,15 & 112,99 & 231,84 & 236,18 & 104,34 & 552,50 & 78,82 & 2,58 & 58,68 & 229,86 & 26,91 & 27,28 & 227,05 \\
\hline Hyla meridionalis & 29SPC03 & 101,00 & 160,69 & 108,62 & 41,23 & 5185,48 & 316,10 & 56,55 & 259,55 & 107,39 & 227,90 & 231,14 & 98,85 & 592,32 & 82,64 & 3,04 & 57,66 & 243,29 & 30,44 & 30,45 & 242,18 \\
\hline Hyla meridionalis & 29SPC04 & 100,00 & 161,82 & 106,48 & 41,04 & 5164,14 & 314,94 & 58,80 & 256,14 & 108,27 & 229,01 & 231,91 & 100,14 & 589,98 & 81,4 & 3,02 & 57,23 & 241,04 & 30,93 & 30,93 & 240,44 \\
\hline Hyla meridionalis & 29SPC05 & 101,00 & 163,99 & 104,51 & | $41,0,97$ & 5131,42 & 314,60 & $\begin{array}{ll}61,82 \\
61,\end{array}$ & 252,78 & \begin{tabular}{|l|}
109,97 \\
\end{tabular} & 230,79 & 233,51 & 102,35 & 583,41 & 80,05 & 3,00 & 57,05 & 237,34 & 31,10 & \begin{tabular}{|l|l|}
31,10 \\
\end{tabular} & 236,97 \\
\hline Hyla meridionalis & 29SPC06 & 100,00 & 163,16 & 102,61 & 40,53 & 5122,15 & 312,29 & 62,04 & 250,25 & 105,59 & 229,36 & 232,55 & 101,71 & 596,58 & 81,61 & 3,75 & 56,34 & 241,45 & 33,24 & 33,24 & 241,42 \\
\hline Hyla meridionalis & 29SPC07 & 101,00 & 162,37 & 101,10 & 40,03 & 5119,50 & 310,44 & 61,96 & 248,48 & 101,92 & 229,31 & 231,74 & 100,87 & $\begin{array}{ll}613,08 \\
\end{array}$ & 83,86 & 4,00 & 55,95 & 247,58 & 35,10 & 35,10 & 247,58 \\
\hline Hyla meridionalis & 29SPC08 & 100,00 & 160,69 & 99,94 & 39,98 & 5139,34 & 308,49 & 60,77 & 247,72 & 99,37 & 228,08 & 230,42 & 99,08 & 640,14 & 87,99 & 4,12 & 55,88 & 258,78 & 36,81 & 36,81 & 258,78 \\
\hline Hyla meridiona & $29 \mathrm{SPC} 12$ & 99,00 & 167,73 & 109,94 & 41,19 & 5225,10 & 323,02 & 60,97 & 262,05 & 113,38 & 234,04 & 238,20 & 104,57 & 540,49 & 76,70 & 2,27 & 58,39 & 17 & 26,18 & 27,20 & 219,97 \\
\hline Hyla meridionalis & $295 P C 13$ & \begin{tabular}{|c|}
50,00 \\
101,00
\end{tabular} & 160,51 & 109,02 & 41, & 5282,23 & 317,10 & $\begin{array}{l}54,79 \\
54\end{array}$ & \begin{tabular}{|l|}
262,31 \\
262
\end{tabular} & \begin{tabular}{|l|}
105,93 \\
103
\end{tabular} & $\begin{array}{l}228,42 \\
22,4\end{array}$ & \begin{tabular}{|l|}
232,21 \\
232
\end{tabular} & \begin{tabular}{|c|}
07,33 \\
97,33
\end{tabular} & $\mid$\begin{tabular}{|l|l|}
589,14 \\
\end{tabular} & 81,72 & $\frac{2,21}{3,00}$ & \begin{tabular}{|l|l|}
57,24 \\
57
\end{tabular} & $\begin{array}{l}224,11 \\
240,98\end{array}$ & \begin{tabular}{|l|}
30,63 \\
306
\end{tabular} & $\begin{array}{l}\mid 1,20,77 \\
30,\end{array}$ & 238,69 \\
\hline Hyla meridionalis & $295 \mathrm{SP} 14$ & 101,00 & 162,18 & 107,55 & 40,99 & 5257,45 & 316,92 & 57,16 & 259,76 & 107,77 & 229,61 & 233,36 & 99,09 & 584,99 & 80,21 & 3,18 & 56,79 & 237,86 & 31,36 & 31,48 & 236,03 \\
\hline Hyla meridionalis & $295 P C 15$ & 99,00 & 165,51 & 106,22 & 40,89 & 5234,90 & 318,45 & 60,80 & 257,65 & 110,85 & $\begin{array}{l}232,12 \\
23\end{array}$ & 236,15 & \begin{tabular}{|c|}
102,37 \\
\end{tabular} & 570,58 & \begin{tabular}{l|l}
77,63 \\
\end{tabular} & $\begin{array}{l}3,101 \\
3,01 \\
\end{array}$ & 56,58 & 231,28 & $\begin{array}{l}30,94 \\
30\end{array}$ & 31,19 & 229,58 \\
\hline Hyla meridionalis & 29SPC17 & 99,00 & 163,81 & 103,55 & 40,05 & 5233,55 & 314,91 & 60,52 & 254,39 & 108,59 & 230,76 & 234,53 & 100,84 & 601,24 & 81,32 & 4,00 & 55,57 & 241,35 & 34,91 & 34,91 & 240,92 \\
\hline Hyla meridiona & $29 \mathrm{SPC18}$ & 101,00 & 160,60 & 102,15 & 39,90 & 5255,88 & 311,74 & 58,30 & 253,45 & 102,59 & 228,97 & 231,89 & 97,68 & 638,67 & 86,96 & 4,34 & 55,44 & 256,29 & 37,43 & 37,43 & 256 \\
\hline Hyla meridionalis & \begin{tabular}{|l}
$295 P C 19$ \\
\end{tabular} & $\begin{array}{l}101,00 \\
100\end{array}$ & $\begin{array}{l}10,00 \\
161,79\end{array}$ & $\begin{array}{l}10,101 \\
101,60\end{array}$ & 39,82 & $\begin{array}{l}525,100 \\
5264,89\end{array}$ & 312,60 & $\begin{array}{ll}59,40 \\
590\end{array}$ & \begin{tabular}{|l|}
253,21 \\
253
\end{tabular} & \begin{tabular}{|l|}
104,32 \\
10,35
\end{tabular} & \begin{tabular}{|l|}
229,51 \\
\end{tabular} & \begin{tabular}{|l|}
233,04 \\
23304
\end{tabular} & $\begin{array}{ll}98,68 \\
98\end{array}$ & \begin{tabular}{|l|l|}
646,77 \\
646
\end{tabular} & \begin{tabular}{|l|}
80,30 \\
88,31
\end{tabular} & $\begin{array}{l}4,434 \\
4,52 \\
\end{array}$ & $\begin{array}{l}5,4,33 \\
55,3\end{array}$ & $\mid$ & $\begin{array}{l}1,45 \\
38,18 \\
\end{array}$ & $\begin{array}{l}1,45 \\
38,21 \\
\end{array}$ & $\begin{array}{l}250,20 \\
259,71\end{array}$ \\
\hline Hyla meridionalis & $29 \mathrm{SPC} 20$ & 100,00 & 167,25 & 108,79 & 41,00 & 5254,52 & 320,84 & 59,51 & 261,33 & 112,50 & 233,96 & 237,92 & 103,49 & 532,54 & 76,72 & 2,00 & 59,38 & 223,71 & 23,36 & 25,51 & 216,45 \\
\hline Hyla meridionalis & 29SPC22 & 101,00 & 168.42 & 109,29 & 40.99 & 529734 & 323,47 & 60,32 & 263.15 & 113,02 & 235,75 & 239,61 & 104,16 & 533,19 & 75,13 & 2.37 & 58.07 & 220.33 & 25.82 & 27,36 & 214,65 \\
\hline Hyla meridionalis & $29 S P C 23$ & 100,00 & 165,26 & 109,13 & 40,97 & 31,75 & 321,37 & 57,58 & 263,80 & 109, & 233,19 & 237 & 100 & 556,98 & 77,25 & 3,00 & 57,18 & 227,79 & 28,54 & 29,44 & 223,46 \\
\hline Hyla meridionalis & 29SPC25 & 101,00 & 165,01 & 107,59 & 40,39 & 5344,68 & 320,41 & 58,02 & 262,39 & 109,00 & 233,26 & 236,94 & 100,45 & 569,88 & 77,21 & 3,12 & 55,98 & 230,09 & 31,34 & 31,72 & 227,01 \\
\hline
\end{tabular}




\begin{tabular}{|c|c|c|c|c|c|c|c|c|c|c|c|c|c|c|c|c|c|c|c|c|c|}
\hline TAXON & UTM & $\mathrm{km2}$ & B101 & $\mathrm{B1O2}$ & $\mathrm{BIO3}$ & B104 & B105 & B106 & B107 & B108 & B109 & 81010 & B1011 & B1012 & B1013 & 81014 & B1015 & B1016 & B1017 & BIO18 & B1019 \\
\hline Hyla meridionalis & 29SPC26 & 100,00 & 163,38 & 106,58 & 40,03 & 5357,52 & 318,45 & 57,03 & 261,42 & 107,29 & 231,94 & 235,68 & 98,68 & 588,79 & 78,97 & 3,99 & 55,43 & 236,50 & 33,58 & 33,74 & 234,22 \\
\hline Hyla meridionalis & 29SPC28 & 100,00 & 159,59 & 104,11 & 39,72 & 5380,03 & 313,91 & 54,76 & 259,15 & 102,98 & 229,49 & 232,40 & 95,14 & 642,65 & 86,77 & 4,51 & 54,97 & 256,99 & 38,20 & 38,24 & 255,93 \\
\hline Hyla meridionalis & $29 \mathrm{SPC} 30$ & 101,00 & 166,07 & 107,70 & 40,62 & 5327,15 & 319,31 & 57,17 & 262,14 & 110,25 & 233,87 & 237,53 & 101,40 & 538,07 & 76,59 & 2,32 & 58,83 & 224,42 & 24,33 & 27,07 & 215,93 \\
\hline Hyla meridionalis & 29SPC32 & 100,00 & 168,44 & 108,99 & 40,68 & 5377,66 & 323,78 & 58,78 & 265,00 & 111,72 & 236,88 & 240,46 & 103,10 & 530,80 & 74,13 & 2,80 & 57,45 & 218,09 & 26,20 & 28,24 & 211,01 \\
\hline Hyla meridionalis & 29SPC33 & 100,00 & 168,65 & 109,01 & 40,48 & 5392,90 & 324,63 & 58,97 & 265,66 & 111,64 & 237,36 & 240,86 & 103,12 & 533,38 & 73,80 & 2,99 & 56,89 & 217,75 & 27,26 & 28,95 & 211,42 \\
\hline Hyla meridionalis & 29SPC34 & 101,00 & 167,87 & 109,05 & 40,35 & 5414,99 & 324,48 & 58,33 & 266,15 & 110,67 & 236,92 & 240,31 & 102,11 & 542,35 & 74,31 & 3,00 & 56,41 & 220,05 & 28,47 & 29,80 & 214,46 \\
\hline Hyla meridionalis & 29SPC35 & 100,00 & 167,02 & 108,80 & 40,12 & 5433,43 & 323,99 & 57,58 & 266,41 & 109,55 & 236,34 & 239,79 & 101,03 & 553,34 & 75,23 & 3,16 & 55,95 & 223,18 & 30,26 & 31,26 & 218,25 \\
\hline Hyla meridionalis & 29SPC36 & 101,00 & 164,36 & 108,31 & 40,00 & 5467,16 & 321,97 & 55,28 & 266,69 & 106,72 & 234,42 & 237,79 & $\begin{array}{l}08,15 \\
98,\end{array}$ & 577,66 & 77,96 & 3,98 & 55,18 & 231,45 & 33,13 & 33,78 & 227,34 \\
\hline Hyla meridionalis & 29SPC37 & 100,00 & 165,27 & 107,92 & 40,00 & 5472,45 & 322,58 & 56,23 & 266,34 & 107,39 & 235,64 & 238,79 & 98,97 & 581,16 & 78,36 & 4,00 & 54,85 & 232,22 & 34,01 & 34,58 & 228,44 \\
\hline Hyla meridionalis & 29SPC38 & 100,00 & 162,29 & 106,91 & 39,89 & 5492,93 & 319,66 & 54,09 & 265,57 & 104,35 & 233,02 & 236,21 & 95,88 & 614,36 & 82,31 & 4,41 & 54,57 & 244,89 & 36,96 & 37,18 & 241,92 \\
\hline Hyla meridionalis & $29 \mathrm{SPC} 40$ & 101,00 & 164,01 & 106,92 & 40,01 & 5409,63 & 317,65 & 54,14 & 263,51 & 107,14 & 233,05 & 236,42 & 98,43 & 550,22 & 77,29 & 2,92 & 57,95 & 227,62 & 25,75 & 28,88 & 218,07 \\
\hline Hyla meridionalis & 29SPC41 & 100,00 & 166,05 & 108,00 & 40,01 & 5437,09 & 321,08 & 55,40 & 265,69 & 108,56 & 235,40 & 238,69 & 99,84 & 540,63 & 75,50 & 3,00 & 57,42 & 222,30 & 26,20 & 29,02 & 213,41 \\
\hline Hyla meridionalis & 29SPC42 & 100,00 & 168,63 & 108,80 & 40,06 & 5456,22 & 324,43 & 57,49 & 266,93 & 110,51 & 238,29 & 241,35 & 102,19 & 527,43 & 73,36 & 2,99 & 56,99 & 215,81 & 26,20 & 28,86 & 207,36 \\
\hline Hyla meridionalis & 29SPC43 & 101,00 & 167,88 & 109,24 & 40,02 & 5501,38 & 325,44 & 56,36 & 269,08 & 109,36 & 238,23 & 241,34 & 100,77 & 533,92 & 73,76 & 3,00 & 56,68 & 217,10 & 27,27 & 29,37 & 209,34 \\
\hline Hyla meridionalis & 29SPC44 & 100,00 & 168,91 & 109,81 & 40,04 & 5516,29 & 327,01 & 57,07 & 269,94 & 110,10 & 239,67 & 242,44 & 101,43 & 531,63 & 73,28 & 3,00 & 56,19 & 215,10 & 27,82 & 29,73 & 207,85 \\
\hline Hyla meridionalis & 29SPC45 & 100,00 & 168,72 & 109,90 & 40,02 & 5520,70 & 327,46 & 56,84 & 270,62 & 109,73 & 239,59 & 242,28 & 101,23 & 536,43 & 73,75 & 3,02 & 55,77 & 215,92 & 28,96 & 30,40 & 209,14 \\
\hline Hyla meridionalis & $29 \mathrm{SPC} 46$ & 100,00 & 168,21 & 110,05 & 40,00 & 5541,22 & 327,67 & 56,19 & 271,48 & 108,93 & 239,34 & 242,04 & 100,49 & 546,01 & 74,72 & 3,51 & 55,06 & 218,49 & 31,15 & 32,31 & 212,21 \\
\hline Hyla meridionalis & 29SPC47 & 101,00 & 167,52 & 110,02 & 40,00 & 5572,71 & 327,53 & 55,35 & 272,18 & 107,90 & 239,20 & 241,86 & 99,60 & 557,72 & 76,07 & 3,98 & 54,43 & 222,23 & 32,93 & 33,83 & 216,36 \\
\hline Hyla meridionalis & 29SPC48 & 100,00 & 166,22 & 109,81 & 39,98 & 5599,39 & 326,71 & 54,12 & 272,59 & 106,36 & 238,41 & 241,00 & 98,04 & 575,10 & 78,17 & 4,08 & 54,29 & 228,73 & 34,55 & 35,15 & 223,27 \\
\hline Hyla meridionalis & 29SPC49 & 101,00 & 165,01 & 109,48 & 39,91 & 5613,73 & 325,70 & 53,33 & 272,37 & 105,11 & 237,55 & 240,08 & 96,82 & \begin{tabular}{|l|l|}
595,18 \\
\end{tabular} & 80,41 & 4,58 & 53,77 & 236,19 & 36,72 & 37,23 & 231,34 \\
\hline Hyla meridionalis & 29SPC50 & 100,00 & 165,21 & 106,32 & 39,84 & 5479,81 & 318,78 & 54,19 & 264,59 & 107,29 & 235,18 & 238,30 & 98,45 & 542,76 & 76,27 & 2,7 & 57,73 & 223,62 & 25,01 & 28,78 & 212,74 \\
\hline Hyla meridionalis & 29SPC51 & 101,00 & 167,10 & 107,59 & 39,88 & 5507,90 & 322,31 & 55,03 & 267,28 & 108,55 & 237,41 & 240,46 & 99,80 & 533,46 & 74,70 & 3,00 & 57,20 & 218,51 & 25,75 & 29,11 & 208,22 \\
\hline Hyla meridionalis & 29SPC53 & 100,00 & 166,86 & 109,71 & 39,99 & \begin{tabular}{|l|l|}
5586,67 \\
\end{tabular} & 325,93 & 53,65 & 272,28 & 107,14 & 238,44 & 241,20 & 98,53 & \begin{tabular}{|l|l|}
537,68 \\
\end{tabular} & 74,58 & 3,00 & 56,35 & 217,67 & 27,47 & 29,91 & 208,80 \\
\hline Hyla meridionalis & 29SPC54 & 100,00 & 167,86 & 110,35 & 40,00 & 5602,91 & 327,94 & 54,27 & 273,67 & 107,78 & 239,81 & 242,30 & 99,23 & 534,37 & 73,98 & 3,03 & 55,77 & 215,26 & 28,15 & 30,24 & 206,77 \\
\hline Hyla meridionalis & 29SPC57 & 100,00 & 168,13 & 111,79 & 39,96 & 5684,87 & 331,09 & 53,09 & 278,00 & 106,93 & 241,54 & 243,71 & 98,65 & 543,91 & 74,76 & 3,99 & 53,94 & 215,79 & 32,57 & 33,71 & 208,22 \\
\hline Hyla meridionalis & 29SPC58 & 100,00 & 168,60 & 112,24 & 39,97 & 5700,35 & 332,14 & 53,08 & 279,07 & 107,03 & 242,20 & 244,23 & 98,73 & 546,20 & 75,06 & 4,00 & 53,57 & 216,33 & 33,25 & 34,09 & 208,90 \\
\hline Hyla meridionalis & 29SPC59 & 100,00 & 167,52 & 112,36 & 39,84 & 5728,25 & 331,77 & 51,96 & 279,81 & $\begin{array}{l}105,68 \\
\end{array}$ & $\begin{array}{l}42,1,69 \\
241,69\end{array}$ & 243,64 & 97,36 & 562,54 & 76,98 & $\begin{array}{l}4,17 \\
4,17\end{array}$ & 53,42 & 222,29 & 35,05 & 35,62 & 215,23 \\
\hline Hyla meridionalis & 29SPC60 & 100,00 & 163,18 & 106,26 & 39,15 & 5569,55 & 317,99 & 50,66 & 267,33 & 104,12 & 234,43 & 237,22 & 95,19 & 556,04 & 78,26 & 2,98 & 57,41 & 227,75 & 25,89 & 29,93 & 216,04 \\
\hline Hyla meridionalis & 29SPC62 & 100,00 & 167,16 & 108,97 & 39,37 & 5633,15 & 325,76 & 52,92 & 272,84 & 107,02 & 239,42 & 241,86 & 98,14 & 532,84 & 74,71 & 3,00 & 56,49 & 216,13 & 26,27 & 29,60 & 205,40 \\
\hline Hyla meridionalis & 29SPC63 & 101,00 & 165,10 & 110,21 & 39,51 & 5678,03 & 326,27 & 50,42 & 275,85 & 104,51 & 238,20 & 240,63 & 95,64 & 545,39 & 75,90 & 3,00 & 56,10 & 219,89 & 27,74 & 30,49 & 209,94 \\
\hline Hyla meridionalis & 29SPC67 & 100,00 & 163,22 & 112,86 & 39,25 & 5799,65 & 329,68 & 46,44 & 283,24 & 101,10 & 238,40 & 240,30 & 92,42 & 565,42 & 77,51 & 4,10 & 53,61 & 223,34 & 34,08 & 35,10 & 214,86 \\
\hline Hyla meridionalis & 29SPC68 & 101,00 & 165,88 & 113,77 & 39,39 & 5827,84 & 333,01 & $\begin{array}{l}48,04 \\
48,04\end{array}$ & \begin{tabular}{|l|}
$284,97,9$ \\
\end{tabular} & \begin{tabular}{|l|l|}
102,98 \\
\end{tabular} & $\begin{array}{l}241,62 \\
241\end{array}$ & \begin{tabular}{|l|}
243,26 \\
\end{tabular} & $\begin{array}{l}92,44 \\
94,45 \\
\end{array}$ & $\begin{array}{l}50,40,29 \\
550\end{array}$ & 75,81 & 4,00 & 53,27 & \begin{tabular}{|l|}
216,66 \\
\end{tabular} & $\begin{array}{l}34,90 \\
33,90\end{array}$ & $\begin{array}{l}34,73 \\
34,15\end{array}$ & 207,97 \\
\hline Hyla meridionalis & 29SPC70 & 100,00 & 161,09 & 106,73 & 38,95 & 5675,07 & 318,19 & 46,80 & 271,38 & 100,66 & 233,89 & 236,54 & 91,70 & 571,07 & 80,41 & 3,15 & 57,24 & 232,70 & 26,59 & 31,03 & 220,35 \\
\hline Hyla meridionalis & 29SPC71 & 101,00 & 158,40 & 108,44 & 38,92 & 5732,58 & 318,87 & 43,40 & 275,47 & 97,48 & 232,29 & 234,86 & 88,52 & 587,30 & 81,78 & 3,3 & 56,56 & 237,71 & 28,70 & 32,39 & 226,39 \\
\hline Hyla meridionalis & $29 S P C 72$ & 100,00 & 165,22 & 109,58 & 39,03 & 5735,12 & 326,20 & 49,42 & 276,78 & 103,68 & 239,04 & 241,32 & 95,01 & 543,63 & 76,32 & 3,01 & 56,35 & 219,52 & 26,65 & 30,28 & 208,00 \\
\hline Hyla meridionalis & \begin{tabular}{|l|}
$29 S P C 73$ \\
\end{tabular} & 100,00 & 164,62 & 110,88 & 39,01 & 5774,34 & 327,87 & 47,88 & 279,99 & 102,55 & 239,21 & 241,35 & 94,00 & 546,35 & 76,21 & 3,05 & 55,68 & 219,18 & 27,99 & 31,12 & 208,24 \\
\hline Hyla meridionalis & $29 S P C 74$ & 100,00 & 162,33 & 111,87 & 39,01 & 5819,58 & 327,60 & 45,12 & 282,49 & \begin{tabular}{|c|}
99,79 \\
9
\end{tabular} & 237,63 & 239,69 & 91,24 & 560,86 & 77,53 & 3,71 & 54,81 & 223,50 & 30,66 & 33,10 & 213,25 \\
\hline Hyla meridionalis & 29SPC75 & 100,00 & 160,62 & 112,54 & 38,99 & 5859,96 & 327,79 & 43,08 & 284,70 & 97,82 & 236,75 & 238,66 & 89,31 & 570,99 & 78,47 & 4,01 & 54,31 & 226,36 & 32,31 & 34,26 & 216,50 \\
\hline Hyla meridionalis & 29SPC77 & 99,00 & 161,64 & 113,86 & 39,01 & 5906,86 & 330,81 & 43,08 & 287,73 & 97,98 & 238,62 & 240,14 & 89,56 & 564,18 & 77,44 & 4,05 & 53,31 & 221,7 & 34,09 & 35,34 & 212,05 \\
\hline Hyla meridionalis & 29SPC80 & 101,00 & 154,66 & 107,93 & 38,41 & 5795,37 & 315,84 & 39,03 & 276,81 & 93,23 & 229,63 & 232,06 & 84,21 & 614,21 & 85,61 & 3,64 & 56,86 & 248,62 & 29,24 & 33,59 & 236,45 \\
\hline Hyla meridionalis & $295 P C 81$ & 99,00 & 159,18 & 109,25 & 38,81 & 5818,30 & 321,64 & 42,67 & 278,97 & 97,08 & 234,43 & 236,60 & 88,26 & 583,86 & $\begin{array}{l}81,56 \\
\end{array}$ & 3,29 & 56,41 & 235,44 & 28,32 & 32,34 & 223,32 \\
\hline Hyla meridionalis & $29 S P C 82$ & 101,00 & 160,19 & 110,52 & 38, & 5854,69 & 324,58 & 42,86 & 281,71 & 97,50 & \begin{tabular}{|l|}
235,97 \\
\end{tabular} & 238,01 & 88,63 & 575,40 & $\begin{array}{l}1,09 \\
80,0\end{array}$ & 3,43 & 55,90 & 230,86 & 28,88 & 32,50 & 219,15 \\
\hline Hyla meridionalis & 29SPC83 & 100,00 & 162,91 & 111,65 & 38,96 & 5873,63 & 328,54 & 44,51 & 284,04 & 99,78 & 238,88 & 240,86 & 91,00 & 557,23 & 77,57 & 3,32 & 55,43 & 222,59 & 28,81 & 32,01 & 210,99 \\
\hline Hyla meridionalis & 29SPC84 & 101,00 & 157,50 & 112,40 & 38,91 & 5936,03 & 326,01 & 39,01 & 286,99 & 93,97 & 234,75 & 236,48 & 85,22 & 589,00 & 80,89 & 4,03 & 54,68 & 233,65 & 32,11 & 34,68 & 222,91 \\
\hline Hyla meridionalis & 29SPC85 & 100,00 & 154,08 & 112,77 & 38,61 & 5968,82 & 324,12 & 35,77 & 288,36 & 90,35 & 231,94 & 233,88 & 81,75 & 611,60 & 83,11 & 4,36 & 53,93 & 241,21 & 34,97 & 36,92 & 231,16 \\
\hline Hyla meridionalis & $295 P C 87$ & 101,00 & 159,43 & 114,49 & 38,6 & 6000,35 & 331,08 & 39,33 & 291,75 & 94,80 & 237,95 & $\begin{array}{l}239,14 \\
2390\end{array}$ & 86,38 & 570,55 & $\begin{array}{l}\mid 78,01 \\
78,01\end{array}$ & 4,14 & 52,95 & 223,31 & 34,51 & 36,02 & 212,68 \\
\hline Hyla meridionalis & 29SPC90 & 100,00 & 155,39 & 109,04 & 38,17 & 5882,69 & 318,88 & 38,08 & 280,80 & 92,63 & 231,65 & 233,82 & 83,79 & 613,37 & 85,57 & 3,45 & 56,86 & 247,51 & 28,96 & 33,52 & 234,93 \\
\hline Hyla meridionalis & 29SPC91 & 101,00 & 158,57 & 110,27 & 38,30 & 5915,33 & 323,67 & 40,32 & 283,35 & 95,27 & 235,23 & 237,27 & 86,32 & 589,82 & 82,32 & 3,35 & 56,42 & 237,01 & 28,48 & 32,65 & 224,46 \\
\hline Hyla meridionalis & 29SPC92 & 99,00 & 153,35 & 111,44 & 38,22 & 5977,65 & 321,58 & 34,63 & 286,95 & 89,59 & 231,15 & 233,13 & 80,78 & 621,02 & 85,31 & 3,99 & 55,51 & 247,66 & 31,83 & 35,31 & 236,26 \\
\hline Hyla meridiona & 29SPC93 & 101,00 & 159,94 & 112,53 & 38,63 & 5969,28 & 328,46 & 40,33 & 288,14 & 95,84 & 237,50 & 239,16 & 87,01 & 576,55 & 79,75 & 3,52 & 55,27 & 229,36 & 29,91 & 33,20 & 217,51 \\
\hline Hyla meridionalis & $295 P C 94$ & 99,00 & 158,64 & 111,33 & $\begin{array}{l}30, \\
38,\end{array}$ & \begin{tabular}{|l|}
6010,83 \\
603
\end{tabular} & 329,04 & $\begin{array}{l}40,35 \\
38,53 \\
\end{array}$ & \begin{tabular}{|l|}
290,14 \\
290,51
\end{tabular} & $\begin{array}{l}30,04 \\
93,99\end{array}$ & \begin{tabular}{|l|}
236,90 \\
230
\end{tabular} & \begin{tabular}{|l|}
238,53 \\
230
\end{tabular} & $\begin{array}{l}81,01 \\
85,32\end{array}$ & 581,60 & $\mid 79,89$ & 3,74 & $\begin{array}{l}30,21 \\
54,58\end{array}$ & \begin{tabular}{|l|}
230,01 \\
\end{tabular} & \begin{tabular}{|l|l|}
31,40 \\
3
\end{tabular} & $\begin{array}{l}30,26 \\
34,26\end{array}$ & 218,55 \\
\hline Hyla meridionalis & $295 P C 95$ & 101,00 & 153,03 & 113,44 & 38,21 & 6051,86 & 325,26 & 33,25 & 292,01 & 88,29 & 232,23 & 233,77 & 79,68 & 615,80 & 83,41 & 4,51 & 53,75 & 241,99 & 35,09 & 37,22 & 231,30 \\
\hline Hyla meridionalis & 29SPC96 & 100,00 & 150,56 & 113,48 & 38,09 & $\begin{array}{l}6081,97 \\
\end{array}$ & 323,90 & 31,03 & 292,87 & \begin{tabular}{|l|l|}
85,66 \\
85
\end{tabular} & 230,35 & 231,96 & 77,15 & 631,10 & \begin{tabular}{l|l|}
84,78 \\
847
\end{tabular} & 年, & 53,20 & \begin{tabular}{l|l}
246,78 \\
\end{tabular} & $\begin{array}{l}37,25 \\
37,2\end{array}$ & 38,97 & 236,59 \\
\hline Hyla meridionalis & 29SPC99 & 100,00 & 165,35 & 116,18 & 38,94 & 6062,52 & 338,82 & 42,56 & 296,26 & 99,26 & 244,25 & 245,25 & 90,75 & 516,90 & 71,06 & 4,00 & 51,87 & 200,16 & 32,14 & 34,00 & 187,97 \\
\hline Hyla meridiona & 29SPD00 & 101,00 & 164,58 & 99,37 & 39,79 & 5146,66 & 311,81 & 64,14 & 247,67 & 103,56 & 230,05 & 234,15 & 102,51 & 650,04 & 89,94 & 4,54 & 55,90 & 263,25 & 37,71 & 38,10 & 26 \\
\hline Hyla meridionalis & 29SPD01 & $\begin{array}{l}101,00 \\
100\end{array}$ & $\begin{array}{l}104,50 \\
164,77\end{array}$ & $\begin{array}{ll}98,75 \\
98\end{array}$ & $\begin{array}{l}35,130 \\
39,30\end{array}$ & 515,80 & $\begin{array}{l}31,01 \\
311,99\end{array}$ & $\begin{array}{l}64,27 \\
64,27\end{array}$ & \begin{tabular}{|l|}
247,72 \\
247
\end{tabular} & \begin{tabular}{|l|l|}
104,12 \\
10,0
\end{tabular} & \begin{tabular}{|l|}
230,51 \\
\end{tabular} & \begin{tabular}{|l|}
234,52 \\
234
\end{tabular} & \begin{tabular}{|l|}
102,75 \\
102,75
\end{tabular} & $\mid \begin{array}{l}\mid 530,04 \\
667,05\end{array}$ & $\begin{array}{l}\mid c 5,34 \\
92,81 \\
\end{array}$ & $\begin{array}{l}4,434 \\
5,00\end{array}$ & 55,91 & \begin{tabular}{|l|}
270,59 \\
270
\end{tabular} & $\begin{array}{l}1,1 / 1 \\
38,92 \\
\end{array}$ & $\begin{array}{l}30,10 \\
39,36 \\
\end{array}$ & $\begin{array}{l}203,25 \\
270,59\end{array}$ \\
\hline Hyla meridionalis & 29SPD02 & 100,00 & 167,21 & 98,91 & 39,28 & 5169,43 & 314,35 & 66,14 & 248,21 & 109,00 & 233,19 & 236,94 & 104,65 & 665,74 & 92,82 & 4,97 & 55,84 & 270,11 & 38,65 & 39,55 & 270,11 \\
\hline Hyla meridionalis & 29SPD03 & 101,00 & 167.25 & 98,55 & 39,03 & 5191.98 & 314,55 & 65.88 & 248,68 & 109,20 & 233,68 & 237.16 & 104.42 & 682.99 & 95,73 & 5,00 & 55,90 & 277.45 & 39.46 & 40,56 & 277.45 \\
\hline Hyla meridionalis & 29SPD04 & 101,00 & 167,18 & 98,12 & 39,00 & 5207,99 & 314,58 & 65,51 & $249, \mathrm{C}$ & 108,01 & 233,88 & 237,27 & 104 & 701,80 & 98,94 & 5,02 & 55,98 & 285,48 & 40,41 & 41,68 & 285,48 \\
\hline Hyla meridionalis & 29SPD05 & 100,00 & 164,19 & 97,09 & 38,45 & 5241,36 & 311,97 & 63,09 & 248,88 & 101,06 & 231,63 & 234,92 & 100,91 & 747,79 & 106,27 & 5,92 & 55,64 & 304,62 & 44,26 & 45,40 & 304, \\
\hline
\end{tabular}




\begin{tabular}{|c|c|c|c|c|c|c|c|c|c|c|c|c|c|c|c|c|c|c|c|c|c|}
\hline TAXON & UTM & $\mathrm{km} 2$ & B101 & B102 & $\mathrm{BIO3}$ & B104 & B105 & B106 & B107 & B108 & B109 & BIO10 & BIO11 & BIO12 & B1013 & B1014 & 81015 & B1016 & BIO17 & B1018 & \begin{tabular}{|l|} 
B1019 \\
\end{tabular} \\
\hline Hyla meridionalis & 29SPD06 & 101,00 & 162,42 & 96,54 & 38,07 & 5278,41 & 310,58 & 61,03 & 249,54 & 98,67 & 230,34 & 233,67 & $98,67 \mid$ & 781,05 & 111,75 & 6,01 & 55,70 & 318,61 & 46,15 & 47,22 & 318,61 \\
\hline Hyla meridionalis & 29SPD07 & 100,00 & \begin{tabular}{|l|l|}
163,07 \\
\end{tabular} & 96,93 & 38,15 & 5303,94 & 311,69 & 60,67 & 251,02 & 99,04 & 231,54 & 234,37 & 98,93 & 789,75 & 113,19 & 6,18 & 55,53 & 321,77 & 47,18 & 48,37 & 321,77 \\
\hline Hyla meridionalis & 29SPD08 & 101,00 & 164,65 & 97,86 & 38,19 & 5326,48 & 313,87 & 60,86 & 253,01 & 100,50 & 233,51 & 235,92 & 99,80 & 788,15 & 112,94 & 6,20 & 55,25 & 320,35 & 47,34 & 48,77 & 320,35 \\
\hline Hyla meridionalis & 29SPD09 & 101,00 & 161,29 & 97,32 & 37,86 & 5371,68 & 311,23 & 57,29 & 253,94 & $\begin{array}{ll}96,06 \\
\end{array}$ & 230,99 & 233,26 & 96,06 & 833,96 & 120,30 & 6,85 & 55,16 & 339,27 & 50,81 & 51,89 & 339,27 \\
\hline Hyla meridionalis & 29SPD11 & 101,00 & 164,59 & 100,59 & 39,14 & 5276,51 & 314,93 & 62,16 & 252,77 & \begin{tabular}{|l|}
107,17 \\
\end{tabular} & 232,23 & 235,88 & \begin{tabular}{|l|l|}
101,03 \\
\end{tabular} & 662,80 & 91,24 & 5,00 & 55,36 & 266,99 & 39,18 & 39,92 & 266,87 \\
\hline Hyla meridionalis & 29SPD12 & 100,00 & 166,36 & 100,31 & 39,03 & 5282,65 & 316,66 & 63,77 & 252,89 & 110,21 & 234,10 & 237,65 & 102,66 & 666,77 & 92,14 & 5,00 & 55,42 & 268,94 & 39,34 & 40,14 & 268,71 \\
\hline Hyla meridionalis & $29 \mathrm{SPD} 13$ & 100,00 & 165,32 & 99,37 & 38,84 & 5312,71 & 315,68 & 63,01 & 252,67 & 107,43 & 233,46 & 237,16 & 101,29 & 694,89 & 96,87 & 5,21 & 55,44 & 280,93 & 41,01 & 42,06 & 280,87 \\
\hline Hyla meridionalis & 29SPD14 & 101,00 & 165,21 & 98,75 & 38,55 & 5330,92 & 315,60 & 62,83 & 252,77 & 106,32 & 233,90 & 237,29 & 101,11 & 714,56 & 100,17 & 5,54 & 55,28 & 289,08 & 42,56 & 43,73 & 289,07 \\
\hline Hyla meridionalis & 29SPD15 & 99,00 & 162,46 & 97,29 & 38,02 & 5371,46 & 312,91 & 60,64 & 252,27 & \begin{tabular}{|l|l|}
98,53 \\
\end{tabular} & 231,79 & 235,15 & $\begin{array}{ll}97,96 \\
\end{array}$ & 757,44 & 107,32 & 5,99 & 55,27 & 307,57 & 45,20 & 46,33 & 307,57 \\
\hline Hyla meridionalis & 29SPD16 & 100,00 & 161,78 & 96,94 & 37,96 & 5407,71 & 312,48 & 59,44 & 253,04 & 96,84 & 231,64 & 234,87 & 96,84 & 780,17 & 111,29 & 6,00 & 55,41 & 317,28 & 46,43 & 47,58 & 317,28 \\
\hline Hyla meridionalis & 29SPD17 & 100,00 & 162,40 & 97,18 & 37,83 & 5441,73 & 313,80 & 59,03 & 254,77 & 97,30 & 232,95 & 235,84 & 96,87 & 787,81 & 112,55 & 6,00 & 55,10 & 319,82 & 47,48 & 48,64 & 319,82 \\
\hline Hyla meridionalis & 29SPD19 & 100,00 & 163,73 & 98,30 & 37,49 & 5511,66 & 316,45 & 57,86 & 258,59 & 99,38 & 235,47 & 237,44 & 96,75 & 798,04 & 114,38 & 6,44 & 54,99 & 322,98 & 48,53 & 49,92 & 322,95 \\
\hline Hyla meridionalis & 29SPD22 & 100,00 & 166,06 & 102,14 & 39,02 & 5404,88 & 319,60 & 61,34 & \begin{tabular}{|l|l}
258,25 \\
\end{tabular} & \begin{tabular}{|l|l}
109,06 \\
\end{tabular} & 235,63 & 238,95 & \begin{tabular}{|l|l|}
100,95 \\
\end{tabular} & 661,05 & 90,44 & 5,06 & 54,90 & 265,60 & 39,65 & 40,57 & 264,47 \\
\hline Hyla meridionalis & 29SPD23 & 101,00 & 162,56 & 99,87 & 38,44 & 5420,56 & 315,60 & 59,50 & 256,09 & 105,28 & 232,51 & 236,07 & 97,74 & 712,61 & 98,85 & 5,84 & 54,81 & 286,88 & 43,34 & 44,26 & 286,62 \\
\hline Hyla meridionalis & 29SPD24 & 100,00 & 163,64 & 99,38 & 38,08 & 5448,06 & 316,78 & 60,27 & 256,51 & $\begin{array}{ll}106,05 \\
\end{array}$ & 234,11 & 237,44 & 98,42 & 720,95 & 100,47 & 5,90 & 54,74 & 290,40 & 43,93 & 45,10 & 290,08 \\
\hline Hyla meridionalis & 29SPD25 & 101,00 & 160,69 & 97,33 & 37,76 & 5474,17 & 313,32 & 58,49 & 254,84 & \begin{tabular}{|c|}
98,78 \\
\end{tabular} & 231,64 & 235,06 & 95,46 & 766,08 & 108,18 & 6,11 & 55,04 & 309,96 & 46,21 & 47,49 & 309,96 \\
\hline Hyla meridionalis & 29SPD26 & 101,00 & 160,01 & 96,71 & 37,40 & 5512,44 & 312,78 & 57,41 & 255,37 & $\begin{array}{l}95,55 \\
\end{array}$ & 231,52 & 234,88 & 94,22 & 787,61 & 111,94 & $6,6,14$ & 55,06 & 319,04 & 47,62 & 48,89 & 319,04 \\
\hline Hyla meridionalis & 29SPD27 & 100,00 & 161,47 & 97,40 & 37,06 & 5567,78 & 315,33 & 57,12 & 258,21 & 98,03 & 233,97 & 236,64 & $\begin{array}{l}94,68 \\
\end{array}$ & 784,94 & 111,68 & 6,06 & 54,87 & 317,36 & 47,71 & 48,92 & 317,33 \\
\hline Hyla meridionalis & $29 S P D 28$ & 101,00 & 163,53 & 98,34 & 37,12 & 5619,06 & 318,43 & 57,26 & 261,16 & 101,12 & 236,92 & 238,95 & 95,64 & 774,94 & 110,22 & 5,99 & 54,79 & 312,52 & 47,14 & 48,58 & 312,37 \\
\hline Hyla meridionalis & 29SPD29 & 101,00 & 165,74 & 99,41 & 37,31 & 5638,23 & 320,90 & 57,92 & 262,98 & 103,96 & 239,38 & 240,89 & 97,06 & 762,84 & 108,38 & 5,99 & 54,66 & 306,90 & 46,46 & 48,16 & 306,55 \\
\hline Hyla meridionalis & 29SPD30 & 100,00 & 161,50 & 105,37 & 39,15 & 5515,50 & 318,91 & 54,19 & 264,71 & 103,47 & 232,66 & 236,00 & 95,16 & 649,40 & 87,17 & 5,00 & 54,22 & 259,03 & 39,70 & 40,00 & 256,64 \\
\hline Hyla meridionalis & 29SPD31 & 101,00 & \begin{tabular}{|l|l|}
164,08 \\
\end{tabular} & 105,16 & 39,06 & 5516,52 & 321,40 & 56,66 & 264,73 & $\begin{array}{l}105,84 \\
\end{array}$ & 235,25 & 238,34 & 97,68 & $\begin{array}{l}647,409 \\
647,09\end{array}$ & 86,94 & 5,00 & 54,20 & 258,42 & 39,55 & 40,13 & 255,93 \\
\hline Hyla meridionalis & $29 S P D 32$ & 101,00 & 164,90 & 104,14 & 38,99 & 5524,03 & 321,94 & 57,97 & 263,97 & 106,51 & 236,26 & 239,30 & 98,44 & 659,01 & 89,18 & 5,07 & 54,34 & 263,67 & 40,15 & 41,02 & 261,42 \\
\hline Hyla meridionalis & $29 S P D 33$ & 100,00 & 162,66 & 101,92 & 38,40 & 5533,15 & 318,94 & 57,36 & 261,57 & 104,52 & 234,36 & 237,56 & 96,38 & 699,47 & 95,88 & 5,75 & 54,18 & 280,39 & 43,21 & 44,24 & 278,84 \\
\hline Hyla meridionalis & $29 S P D 34$ & 101,00 & 160,24 & 99,30 & 37,85 & 5550,93 & 315,39 & 56,72 & 258,67 & 102,24 & 232,29 & 235,74 & 94,27 & 740,95 & 103,04 & 6,14 & 54,40 & 298,01 & 45,47 & 46,65 & 297,21 \\
\hline Hyla meridionalis & 29SPD35 & 100,00 & 150,96 & 93,90 & 36,71 & 5549,48 & 303,30 & 51,48 & 251,82 & 87,76 & 223,30 & 227,27 & 86,22 & 847,69 & 120,82 & 7,24 & 54,84 & 343,56 & 52,06 & 53,06 & 343,56 \\
\hline Hyla meridionalis & 29SPD36 & 101,00 & \begin{tabular}{|l|l|}
153,98 \\
153
\end{tabular} & $\begin{array}{ll}93,90 \\
94,90\end{array}$ & 36,77 & 5604,19 & $\begin{array}{l}\mid \\
307,60\end{array}$ & \begin{tabular}{|l}
51,40 \\
52,43
\end{tabular} & $\begin{array}{l}25,02 \\
255,18\end{array}$ & $\begin{array}{l}0,1,06 \\
91,66\end{array}$ & 227,18 & 230,49 & $\begin{array}{l}00,2 \mathrm{e} \\
87,92\end{array}$ & $\begin{array}{l}\mid 84,03 \\
831,12\end{array}$ & $\begin{array}{l}\mid 2,0<, 0<9 \\
118,49\end{array}$ & 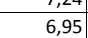 & $\begin{array}{l}4,6464 \\
54,64\end{array}$ & 336,25 & 51,13 & $\begin{array}{l}52,00 \\
52,08\end{array}$ & $\begin{array}{l}43,10 \\
336,14 \\
\end{array}$ \\
\hline Hyla meridionalis & 29SPD37 & 100,00 & 162,36 & 98,66 & 37,05 & 5674,95 & 318,45 & 56,13 & 262,32 & 101,76 & 236,42 & 238,79 & 94,20 & 758,86 & 106,97 & 5,99 & 54,36 & 305,26 & 46,45 & 47,80 & 304,45 \\
\hline Hyla meridionalis & 29SPD38 & 101,00 & 162,82 & $\begin{array}{ll}98,87 \\
88\end{array}$ & 36,98 & 5732,46 & 319,80 & 55,39 & 264,41 & 101,39 & 237,89 & 239,77 & 93,75 & 761,73 & 107,66 & 5,93 & 54,35 & 305,98 & | 40,83 & 48,18 & 305,15 \\
\hline Hyla meridionalis & $29 S P D 39$ & 101,00 & 163,06 & 99,01 & 36,69 & 5777,13 & 320,64 & 54,43 & 266,21 & 100,55 & 238,81 & 240,35 & 93,17 & 767,51 & 108,81 & 5,99 & 54,15 & 307,94 & 47,38 & 48,78 & 307,06 \\
\hline Hyla meridionalis & 29SPD41 & 100,00 & 162,43 & $\begin{array}{r}\mid 107,64 \\
\end{array}$ & 39,01 & 5644,46 & 323,51 & 52,29 & 271,22 & 102,49 & 235,74 & 238,27 & $\begin{array}{l}94,25 \\
94\end{array}$ & 645,10 & 年, & 5,02 & 53,74 & 256,50 & 40,14 & 40,61 & 252,58 \\
\hline Hyla meridionalis & 29SPD42 & 100,00 & \begin{tabular}{|l|l|l|l|l|}
164,73 \\
\end{tabular} & \begin{tabular}{|l|}
107,12 \\
107
\end{tabular} & 39,01 & 50446,44 & $\begin{array}{l}25,31, \\
325,62\end{array}$ & 54 & 270,98 & $\begin{array}{l}104,53 \\
104\end{array}$ & 238,01 & 240,52 & 94,25 & $\begin{array}{l}643,10 \\
643,72\end{array}$ & $\begin{array}{l}00,11 \\
86,33 \\
\end{array}$ & $\begin{array}{l}3,0<1 \\
5,01 \\
\end{array}$ & $\mid \begin{array}{l}\mid 5,7,71 \\
53,\end{array}$ & \begin{tabular}{|l|l|}
256,23 \\
256,
\end{tabular} & $\begin{array}{l}40,14 \\
39,98\end{array}$ & 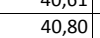 & 252,39 \\
\hline Hyla meridionalis & $29 S P D 43$ & 99,00 & 163,16 & 104,89 & 38,67 & 5647,58 & 323,13 & 54,71 & 268,42 & 103,38 & 236,58 & 239,30 & 95,26 & 675,98 & 91,26 & 5,35 & 53,69 & 269,65 & 42,25 & 43,30 & 266,46 \\
\hline Hyla meridionalis & 29SPD44 & 101,00 & 155,18 & 99,28 & 37,57 & 5640,11 & 312,16 & 51,31 & 260,85 & 96,60 & 228,72 & 232,15 & 88,58 & 767,07 & 106,42 & 6,42 & 54,01 & 307,69 & 47,74 & 48,74 & 306,19 \\
\hline Hyla meridionalis & $29 \mathrm{SPD} 45$ & 99,00 & 145,56 & 94,44 & 36,50 & 5659,10 & 300,09 & 44,74 & 255,35 & 86,12 & 220,27 & 223,39 & 79,69 & 866,89 & 122,89 & 7,64 & 54,20 & 348,96 & 54,20 & 54,73 & 348,51 \\
\hline Hyla meridionalis & 29SPD46 & $\begin{array}{r}100,00 \\
\end{array}$ & 156,64 & 97,92 & 36,98 & 5715,55 & 313,60 & 51,85 & 261,75 & 96,79 & 231,46 & 234,36 & 88,84 & 779,71 & 109,38 & 6,38 & 54,05 & 313,09 & 48,41 & 49,55 & 311,72 \\
\hline Hyla meridionalis & \begin{tabular}{|l|}
$29 S P D 47$ \\
\end{tabular} & 100,00 & \begin{tabular}{ll|}
161,78 \\
\end{tabular} & 99,90 & 37,00 & 5777,09 & 320,23 & 53,95 & 266,28 & \begin{tabular}{|l|l|}
100,13 \\
\end{tabular} & 237,49 & 239,55 & 92,44 & 738,82 & 103,05 & 5,96 & 53,79 & 295,82 & 45,84 & 47,24 & 293,69 \\
\hline Hyla meridionalis & 29SPD48 & 100,00 & 163,51 & 100,30 & 37,01 & 5812,85 & 322,29 & 54,38 & 267,91 & 100,95 & 239,86 & 241,48 & 93,31 & 729,76 & 101,92 & 5,83 & 53,78 & 291,85 & 45,22 & 46,76 & 289,49 \\
\hline Hyla meridionalis & 29SPD49 & 99,00 & 164,02 & 100,39 & 36,89 & 5853,23 & 323,01 & 53,88 & 269,13 & 100,56 & 240,91 & 242,15 & \begin{tabular}{|c|}
93,07 \\
\end{tabular} & 730,46 & 102,34 & 5,78 & 53,71 & 291,92 & 45,35 & 46,81 & 289,43 \\
\hline Hyla meridionalis & 29SPD51 & 100,00 & 164,01 & 111,44 & 39,36 & 5761,51 & 328,97 & 49,73 & 279,23 & 102,11 & 239,04 & 240,87 & 93,99 & 614,70 & 82,82 & 4,99 & 52,89 & 242,76 & 39,40 & 39,88 & 236,78 \\
\hline Hyla meridionalis & 29SPD52 & 101,00 & $\mid \begin{array}{l}\mid 164,26 \\
166,26\end{array}$ & $\begin{array}{l}111,13 \\
111,4\end{array}$ & 39,15 & 5767,16 & 33 & 51,92 & 279,45 & \begin{tabular}{|l|l|l|l|}
104,00 \\
\end{tabular} & 241,34 & 243,14 & 96,06 & 610,44 & $\begin{array}{ll}82,21 \\
821\end{array}$ & 4,99 & 52,86 & 241,30 & 38,96 & $\begin{array}{l}3,00 \\
39,79\end{array}$ & 235,35 \\
\hline Hyla meridionalis & 29SPD53 & 101,00 & 162,51 & 10 & 38,71 & 5768,06 & 326,25 & 50,88 & 275,37 & 100,99 & 237,82 & 239,95 & 92,98 & 656,75 & 87,85 & 5,19 & 52,99 & 260,40 & 41,79 & 42,66 & 255,47 \\
\hline Hyla meridionalis & 29SPD54 & 100,00 & $\mid \begin{array}{l}\mid 159,58 \\
159,\end{array}$ & 104,37 & 37,96 & 5772,25 & 321,21 & 50,21 & 271,00 & \begin{tabular}{|l|l|}
98,48 \\
\end{tabular} & 235,00 & 237,44 & 90,46 & 698,68 & $\begin{array}{l}94,38 \\
94,\end{array}$ & 5,69 & 53,15 & 277,95 & 44,20 & 45,22 & 273,87 \\
\hline Hyla meridionalis & $29 S P D 58$ & 101,00 & 160,07 & 100,45 & 36,76 & 5897,48 & 320,11 & 50, & 269,86 & $\begin{array}{l}96,85 \\
\end{array}$ & 237,75 & 239,16 & 89,13 & 729,97 & 101,25 & 5,89 & 53,19 & 290,69 & 45,96 & 47,07 & 287,24 \\
\hline Hyla meridionalis & 29SPD59 & 101,00 & 163,90 & 101,51 & 36,84 & 5918,49 & 324,06 & 52,29 & 271,77 & 99,59 & 241,73 & 242,68 & 92,03 & 700,88 & 96,96 & 5,47 & 53,10 & 278,58 & 43,96 & 45,45 & 274,74 \\
\hline Hyla meridionalis & 29SPD65 & 99,00 & $\begin{array}{l}159,07 \\
159,07\end{array}$ & \begin{tabular}{|l|}
105,07 \\
105
\end{tabular} & | 30,04 & 5905,09 & 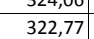 & 47,30 & 275,47 & 96, 96,15 & $\begin{array}{l}24,13 \\
236,66\end{array}$ & $\begin{array}{l}24,00 \\
238,35\end{array}$ & $\begin{array}{ll}32,03 \\
88,16\end{array}$ & $\mid 682,61$ & $\begin{array}{l}90,30 \\
91,35 \\
\end{array}$ & 5,51 & $\frac{53,40}{52,42}$ & \begin{tabular}{|l|l|}
269,79 \\
269
\end{tabular} & $\begin{array}{l}43,50 \\
43,77\end{array}$ & $\begin{array}{l}43,45 \\
44,68\end{array}$ & 264,17 \\
\hline Hyla meridionalis & 29SPD67 & 100,00 & 160,17 & 102,90 & 37,00 & 5953,39 & 322,70 & 48,59 & 274,10 & \begin{tabular}{|c|}
96,39 \\
\end{tabular} & 238,64 & 239,99 & 88,50 & 689,63 & 93,57 & 5,52 & 52,62 & 272,83 & 43,92 & 45,00 & 267,58 \\
\hline Hyla meridionalis & 29SPD68 & 100,00 & 162,31 & 102,78 & 37,01 & 5974,32 & 324,56 & 49,86 & 274,70 & \begin{tabular}{|l|l|}
97,69 \\
\end{tabular} & 240,99 & 242,01 & 89,96 & 677,68 & 92,17 & 5,34 & 52,48 & 267,94 & 43,03 & 44,25 & 262,65 \\
\hline Hyla meridionalis & 29SPD69 & 99,00 & 163,36 & 102,63 & 36,88 & 5985,69 & 325,23 & 50,4 & 274,77 & 98,32 & 242,23 & 242,91 & 90,58 & 672,44 & 91, & 5,20 & 52,53 & 265,70 & 42,64 & 44,03 & 260,42 \\
\hline Hyla meridionalis & 29SPD70 & 101,00 & 168 & 11 & 39,00 & 5985,76 & & 46 & 293,60 & \begin{tabular}{|l|l|}
102,76 \\
\end{tabular} & 246 & 247,24 & 94 & 521,55 & 72,42 & 4,00 & 51,71 & 202,79 & 34,94 & 35,31 & 192,28 \\
\hline Hyla meridionalis & 29SPD74 & 101,00 & 160,95 & 109,50 & 38,06 & 5989,27 & 328,78 & 45,17 & 283,62 & 96,34 & 239,74 & 240,83 & 88,44 & 626,49 & 83,05 & 5,03 & 51,66 & 245,22 & 40,97 & 41,77 & 237,36 \\
\hline Hyla meridionalis & $295 P D 77$ & 100,00 & 163,55 & 105,60 & 37,01 & 6029,43 & 328,94 & 49,05 & 279,88 & 98,36 & 243,08 & 243,80 & 90,37 & 630,06 & 83,43 & 4,99 & 51,70 & 246,92 & 40,79 & 42,02 & 239,72 \\
\hline Hyla meridionalis & 29SPD78 & 101,00 & 163,18 & 104,46 & 36,98 & 6042,43 & 327,73 & 48,82 & 278,91 & \begin{tabular}{|c|}
97,58 \\
\end{tabular} & 242,86 & 243,48 & 89,67 & 638,86 & 85,31 & 4,99 & 51,72 & 250,58 & 41,22 & 42,48 & 243,70 \\
\hline Hyla meridionalis & 29SPD79 & 100,00 & 164,08 & 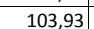 & 36,99 & 6046,74 & 328,12 & 49,5 & 278,56 & 98,2 & 243,88 & 244, & 90,47 & 634,59 & 85, & 4,96 & 51,6 & 248,84 & 40,90 & 42,10 & 242,06 \\
\hline Hyla meridionalis & 29SPD81 & 100,00 & 167 & & 39,00 & 600 & 33 & 45,34 & 294,27 & 101, & 245 & 246,56 & 93,46 & 517,34 & 71,18 & 4,00 & 51,31 & 200,32 & $33,97 \mid$ & 35,08 & 188,84 \\
\hline Hyla meridionalis & \begin{tabular}{|l|} 
29SPD82 \\
\end{tabular} & 100,00 & 167,14 & 115,38 & 38,95 & 6039,30 & |339,05 & 45,73 & 293,31 & $\begin{array}{l}101,06 \\
\end{array}$ & 246,31 & 246,66 & 93,00 & 532,86 & 72,48 & 4,00 & 51,25 & 206,41 & 35,04 & 35,95 & 195,55 \\
\hline Hyla meridionalis & \begin{tabular}{|l|}
$29 S P D 83$ \\
\end{tabular} & 100,00 & 164,86 & 113,41 & 38,41 & 6057,41 & 336,19 & 44,88 & 291,31 & 98,84 & 244,34 & 244,99 & 90,78 & 559,73 & 75,01 & 4,28 & 51,20 & 216,95 & 36,56 & 37,66 & 206,87 \\
\hline Hyla meridionalis & $29 S P D 84$ & 100,00 & 164,51 & 111,56 & 38,02 & 6072,79 & 334,88 & 45,70 & 289,18 & 98,41 & 244,35 & 244,90 & 90,37 & 571,99 & 76,07 & 4,41 & 51,20 & 222,03 & 37,21 & 38,09 & 212,3 \\
\hline Hyla meridionalis & $29 S P D 86$ & 100,00 & 160 & & 37,0 & 6100,6 & 329 & 44, & 284 & 94, & 241,38 & 242 & 86,92 & 614 & 80 & 4,97 & 51,01 & 238,84 & 40,42 & 41,25 & 230 \\
\hline Hyla meridionalis & 29SPD87 & 100,00 & \begin{tabular}{|l|}
162,66 \\
162
\end{tabular} & 106,46 & 37,01 & 6105,22 & 330,23 & 4 & 283,56 & $\begin{array}{l}94,41 \\
96,46\end{array}$ & 243,22 & 243,79 & 88,46 & $\mid$ & $\begin{array}{l}\mid 79,40 \\
79,40\end{array}$ & 4,95 & \begin{tabular}{|l|l|l|l|l|}
50,99 \\
\end{tabular} & 235,81 & $\begin{array}{l}40,42 \\
40,01\end{array}$ & 41,02 & 227,34 \\
\hline
\end{tabular}




\begin{tabular}{|c|c|c|c|c|c|c|c|c|c|c|c|c|c|c|c|c|c|c|c|c|c|}
\hline TAXON & UTM & $\mathrm{km} 2$ & B101 & B102 & $\mathrm{BIO3}$ & B104 & B105 & B106 & B107 & B108 & B109 & BIO10 & B1011 & BIO12 & B1013 & BIO14 & BIO15 & BIO16 & B1017 & 81018 & B1019 \\
\hline Hyla meridionalis & 29SPD89 & 100,00 & 160,42 & 104,07 & 36,61 & 6124,59 & 326,65 & 45,32 & 281,34 & 93,82 & 241,47 & 241,73 & 86,14 & 627,26 & 83,17 & 5,00 & 51,11 & 244,16 & 41,07 & 41,74 & 236,20 \\
\hline Hyla meridionalis & 29SPD94 & 101,00 & 162,61 & 111,41 & 37,79 & 6154,11 & 335,04 & 43,05 & 291,99 & 95,77 & 243,83 & 244,16 & 87,60 & 563,05 & 74,21 & 4,31 & 50,71 & 216,84 & 36,79 & 37,66 & 206,23 \\
\hline Hyla meridionalis & 29SPD95 & 100,00 & 161,11 & 109,48 & 37,20 & 6168,92 & 332,58 & 42,74 & 289,84 & 94,19 & 242,64 & 242,97 & 86,19 & 580,94 & 75,82 & 4,72 & 50,47 & 223,68 & 38,61 & 39,40 & 213,55 \\
\hline Hyla meridionalis & 29SPD96 & 101,00 & 160,82 & 107,91 & \begin{tabular}{|l|l|}
36,97 \\
\end{tabular} & 6178,85 & 331,39 & 43,34 & 288,05 & 93,88 & 242,63 & 242,93 & 85,88 & 586,53 & 76,25 & 4,64 & 50,48 & 226,01 & 38,76 & 39,28 & 216,13 \\
\hline Hyla meridionalis & 29SPD98 & 101,00 & 158,49 & 105,22 & 36,24 & \begin{tabular}{|l|l|}
6194,16 \\
\end{tabular} & 327,42 & 42,24 & 285,18 & 91,57 & 240,63 & 240,91 & 83,50 & 608,33 & 79,12 & 4,98 & 50,55 & \begin{tabular}{|l|l|}
234,68 \\
\end{tabular} & 40,44 & 40,87 & 225,43 \\
\hline Hyla meridionalis & 29SPE11 & 101,00 & 157,91 & 97,35 & 36,95 & 5583,85 & 311,32 & 51,39 & 259,93 & 90,01 & 231,04 & 232,51 & 90,01 & 875,06 & 127,01 & 7,26 & 54,90 & 354,47 & 54,36 & 55,11 & 354,47 \\
\hline Hyla meridionalis & 29SPE20 & 100,00 & 159,02 & 97,11 & \begin{tabular}{|l|l|}
36,27 \\
\end{tabular} & 5736,83 & 315,15 & 51,62 & 263,53 & 91,49 & 234,44 & 235,76 & 89,70 & 838,95 & 120,98 & 6,83 & 54,74 & 338,78 & 51,89 & 52,70 & 338,73 \\
\hline Hyla meridionalis & 29SPE21 & 100,00 & 157,59 & 97,04 & 36,15 & 5765,61 & 313,94 & 49,60 & 264,34 & 88,08 & 233,56 & 234,55 & 87,85 & 858,44 & 124,23 & $\begin{array}{l}, 0,02 \\
\end{array}$ & 54,74 & 346,39 & 53,52 & 54,15 & 346,39 \\
\hline Hyla meridionalis & 29SPE30 & 100,00 & 165,01 & 99,91 & \begin{tabular}{l|l|l}
36,85 \\
\end{tabular} & 5785,91 & 322,58 & 55,11 & 267,47 & 101,66 & 240,95 & 241,99 & 94,62 & 754,97 & 106,97 & 6,00 & 54,14 & \begin{tabular}{|l|l|}
302,59 \\
\end{tabular} & 46,47 & 48,13 & 301,33 \\
\hline Hyla meridionalis & 29SPE31 & 101,00 & 157,49 & 97,29 & 36,01 & 5870,90 & 315,45 & 48,45 & 267,00 & 91,57 & 234,94 & 235,83 & 86,60 & 833,36 & 120,00 & 6,90 & 54,25 & 334,68 & 52,14 & 52,80 & 334,45 \\
\hline Hyla meridionalis & 29SPE32 & 100,00 & 155,12 & 96,91 & 36,01 & 5844,35 & 312,09 & 46,21 & 265,88 & 88,22 & 232,29 & 232,95 & 84,38 & 856,54 & 123,96 & 7,15 & 54,26 & 343,94 & 53,86 & 54,35 & 343,80 \\
\hline Hyla meridionalis & 29SPE40 & 101,00 & 164,31 & 100,45 & 36,85 & 5868,35 & 323,23 & 53,36 & 269,86 & 100,41 & 241,48 & 242,36 & 92,96 & 733,33 & 103,07 & 5,98 & 53,64 & 292,77 & 45,60 & 47,25 & 290,38 \\
\hline Hyla meridionalis & 29SPE41 & 100,00 & 163,53 & 100,25 & 36,75 & 5876,42 & 322,10 & 52,19 & 269,90 & 99,20 & 240,77 & 241,49 & 91,83 & 744,16 & 105,12 & 6,05 & 53,53 & 296,93 & 46,41 & 48,04 & 294,75 \\
\hline Hyla meridionalis & 29SPE42 & 99,00 & 156,54 & 97,94 & 36,04 & 5903,14 & 314,45 & 46,30 & 268,15 & 92,15 & 234,38 & 234,94 & 84,72 & 808,24 & 115,72 & 6,78 & 53,88 & 322,90 & 50,98 & 51,71 & 321,60 \\
\hline Hyla meridionalis & 29SPE50 & 100,00 & 163,77 & 101,27 & 36,87 & 5932,29 & 323,69 & 51,76 & 271,94 & 99,08 & 241,85 & 242,54 & $|91,55|$ & 705,68 & 98,12 & 5,53 & 53,11 & 280,54 & 44,12 & 45,66 & 276,80 \\
\hline Hyla meridionalis & 29SPE51 & 101,00 & 162,83 & 100,88 & 36,68 & 5941,95 & 322,45 & 50,59 & 271,86 & 97,88 & 241,23 & 241,63 & 90,42 & 716,97 & 100,21 & 5,86 & 53,12 & 284,78 & 45,20 & 46,64 & 281,24 \\
\hline Hyla meridionalis & 29SPE52 & 101,00 & 157,55 & 99,13 & 36,10 & 5958,68 & 316,43 & 46,10 & 270,33 & 92,54 & 236,26 & 236,52 & 84,95 & 761,84 & \begin{tabular}{|l|}
107,67 \\
\end{tabular} & 6,19 & 53,17 & 302,85 & 48,50 & 49,19 & 300,00 \\
\hline Hyla meridionalis & 29SPE60 & 101,00 & 160,83 & 101,30 & 36,43 & 6005,53 & 322,03 & 48,31 & 273,71 & 95,56 & 240,07 & 240,54 & 87,79 & 697,13 & 96,08 & 5,66 & 52,50 & 275,62 & 44,60 & 45,66 & 270,71 \\
\hline Hyla meridionalis & 29SPE61 & 99,00 & 159,52 & 100,65 & 36,13 & 6011,88 & 320,19 & 46,94 & 273,24 & 94,04 & 238,99 & 239,26 & 86,33 & 709,88 & 98,39 & 5,94 & 52,45 & 280,56 & 45,79 & 46,52 & 275,97 \\
\hline Hyla meridionalis & 29SPE62 & 100,00 & 155,44 & 99,42 & 36,04 & 6016,15 & 315,34 & 43,59 & 271.75 & 90,01 & 235,19 & 235,31 & 82,29 & 739,68 & $\mid 103,40$ & 6,29 & 52.52 & 292,50 & 48,01 & 48,30 & 288,25 \\
\hline Hyla meridionalis & 29SPE70 & 101,00 & 160,68 & 102,50 & 36,39 & 6061,68 & 323,93 & 46,84 & 277,09 & 94,72 & 240,89 & 241,08 & 86,94 & 661,91 & 89,78 & 5,25 & 51,91 & 259,85 & 42,67 & 43,48 & 253,48 \\
\hline Hyla meridionalis & 29SPE71 & 100,00 & 159,82 & 101,92 & 36,35 & 6065,58 & 322,31 & 45,97 & 276,34 & 93,66 & 240,05 & 240,17 & 85,82 & 670,65 & 91,49 & 5,45 & 51,84 & 263,29 & 43,56 & 44,06 & 257,20 \\
\hline Hyla meridionalis & 29SPE72 & 101,00 & 157,64 & 101,21 & \begin{tabular}{|l|}
36,08 \\
\end{tabular} & 6065,15 & 319,49 & 44,06 & 275,43 & 91,42 & 237,94 & 238,00 & 83,62 & 684,95 & 93,96 & 5,83 & 51,77 & 268,81 & 45,03 & 45,28 & 262,93 \\
\hline Hyla meridionalis & 29SPE81 & 100,00 & 160,04 & 103,15 & 36,37 & 6120,16 & 324,52 & 44,95 & 279,57 & 93,18 & 240,99 & 241,01 & 85,30 & 632,97 & 84,87 & 5,11 & 51,11 & 246,61 & 41,57 & 41,67 & 239,18 \\
\hline Hyla meridionalis & 29SPE82 & 100,00 & 156,19 & 101,95 & 36,03 & 6125,07 & 319,99 & 41,74 & 278,25 & 89,41 & 237,48 & 237,48 & 81,48 & 657,45 & 88,73 & 5,76 & 50,90 & 256,01 & 44,06 & 44,06 & 248,87 \\
\hline Hyla meridionalis & 29SQA19 & 10,00 & 178,00 & 87,00 & 37,00 & 4992,64 & 302,64 & 72,00 & 230,64 & \begin{tabular}{|l|l|}
136,73 \\
\end{tabular} & 240,55 & 243,45 & 115,64 & 523,27 & 80,91 & 1,00 & 64,91 & 227,91 & 14,00 & 22,00 & 207,55 \\
\hline Hyla meridionalis & $295 \mathrm{SA26}$ & & & & & & & & & 每 & & & & & & & & & & & \\
\hline Hyla meridionalis & 29SQA28 & 14,00 & 178,46 & 86,77 & $\begin{array}{l}37,23 \\
\end{array}$ & 4954,31 & 301,69 & 73,00 & 228,69 & 152,23 & 240,62 & 243,69 & 116,85 & 536,15 & 83,08 & 1,00 & 65,62 & \begin{tabular}{|l|l|}
234,08 \\
\end{tabular} & 14,00 & 22,00 & 214,69 \\
\hline Hyla meridionalis & 29SQA29 & 85,00 & 178,83 & 87,79 & 37,13 & 5027,68 & 304,23 & 72,22 & 232,02 & 143,22 & 241,99 & 245,02 & 116,11 & 528,25 & 81,26 & 1,00 & 64,74 & 230,03 & 14,15 & 22,00 & 210,30 \\
\hline Hyla meridionalis & 29SQA35 & 24,00 & 177,69 & 83,83 & 38,69 & 4534,21 & 291,17 & 77,52 & 213,66 & 155,45 & 234,41 & 238,17 & 122,10 & 557,24 & 92,62 & 0,00 & 67,28 & 248,90 & 12,69 & 20,00 & 230,62 \\
\hline Hyla meridionalis & 29SQA36 & 95,00 & 177,07 & 84,66 & 38,31 & 4649,30 & 293,27 & 75,19 & 218,08 & 153,02 & 235,24 & 238,90 & 119,87 & 554,28 & 90,71 & 0,00 & 66,75 & 246,68 & 13,00 & 20,40 & 228,02 \\
\hline Hyla meridionalis & 29SQA37 & 70,00 & 177,22 & 84,36 & 37,45 & 4807,11 & 296,27 & 74,12 & 222,15 & \begin{tabular}{|l|l|}
$152,46<$ \\
\end{tabular} & \begin{tabular}{|l|}
237,56 \\
\end{tabular} & \begin{tabular}{|l|l|}
241,03 \\
\end{tabular} & \begin{tabular}{|l|}
117,86 \\
117
\end{tabular} & 551,16 & \begin{tabular}{|l|l|}
87,79 \\
\end{tabular} & $0,0,53$ & 60,13 & $\begin{array}{r}240,00 \\
242,48\end{array}$ & 13,59 & 21,43 & 223,57 \\
\hline Hyla meridionalis & 29SQA38 & 99,00 & 178,11 & 85,82 & 37,06 & 4961,88 & 301,15 & 73,00 & 228,15 & 152,06 & 240,71 & 243,84 & 116,70 & 544,02 & 84,41 & 1,00 & 65,20 & 236,98 & 14,46 & 22,00 & 217,83 \\
\hline Hyla meridionalis & 29SQA39 & 100,00 & 178,93 & 88,43 & 37,01 & 5120,94 & 306,79 & 71,23 & 235,55 & 143,96 & 243,43 & 246,48 & 115,26 & 540,45 & 82,58 & 1,00 & 64,61 & 233,88 & 14,96 & 22,00 & 214,68 \\
\hline Hyla meridionalis & 29SQA43 & 19,00 & 179,33 & 70,04 & 35,96 & 4462,26 & 279,67 & 86,48 & 193,19 & 158,41 & 234,30 & 238,67 & 123,78 & 609,26 & 105,11 & 0,93 & 68,96 & 264,70 & 11,96 & 22,00 & 248,44 \\
\hline Hyla meridionalis & 29SQA44 & 26,00 & 179,26 & 71,10 & 35,90 & 4487,74 & 281,03 & 85,62 & 195,41 & 157,85 & 234,28 & 238,97 & 123,28 & 601,95 & 100,23 & 0,38 & 68,10 & 258,90 & 11,90 & 21,03 & 243,23 \\
\hline Hyla meridionalis & $29 \mathrm{SQA45}$ & 69,00 & 176,93 & 76,35 & 36,36 & 4649,63 & 286,27 & 79,15 & 207,12 & 153,94 & 234,81 & 238,93 & 119,44 & 587,01 & 95,92 & 0,38 & 66,81 & 255,15 & 13,02 & 21,31 & 237,94 \\
\hline Hyla meridionalis & 29SQA46 & 101,00 & 175,51 & 79,22 & 36,27 & 4778,15 & 290,15 & 74,90 & 215,25 & 151,44 & 235,35 & 239,28 & 116,57 & 579,61 & 92,91 & 0,65 & 66,18 & 252,08 & 13,88 & 21,77 & 234,53 \\
\hline Hyla meridionalis & 29SQA47 & 99,00 & 176,25 & 80,88 & \begin{tabular}{|l|l|}
35,97 \\
\end{tabular} & 4931,20 & 295,24 & 73,49 & 221,75 & 150,49 & 238,23 & 241,92 & 115,29 & 568,75 & 88,95 & 0,97 & 65,60 & 246,05 & 14,79 & 21,97 & 227,88 \\
\hline Hyla meridionalis & 29SOA48 & 99,00 & 177,43 & 83,96 & 36,08 & 5077,41 & 301,60 & 72,08 & 229,52 & 148,23 & 241,44 & 244,77 & 114,47 & 561,33 & 86,13 & 1,00 & 65,01 & 241,91 & 15,03 & 22,02 & 223,48 \\
\hline Hyla meridionalis & 29SQA52 & & & & & & & & & & & & & & & & & & & & \\
\hline Hyla meridionalis & 29SQA53 & 100,00 & 177,64 & 70,43 & 35,65 & $\begin{array}{l}4493,07 \\
\end{array}$ & 279,11 & 84,29 & 194,82 & 143,26 & 232,93 & 237,52 & 121,50 & 635,77 & 110,43 & 1,00 & 69,06 & 277,45 & 13,16 & 23,23 & 262,34 \\
\hline Hyla meridionalis & 29SQA54 & 93,00 & 177,06 & 70,42 & 34,92 & 4627,92 & 281,23 & 82,24 & $\begin{array}{l}198,99 \\
\end{array}$ & 149,73 & 234,27 & 238,95 & 119,38 & 623,61 & 105,06 & 1,00 & 68,15 & 269,05 & 13,48 & 23,19 & 253,37 \\
\hline Hyla meridionalis & 29SQA56 & 100,00 & 173,87 & 72,93 & 33,94 & 4924,18 & 286,72 & 74,69 & 212,03 & 144,30 & 235,60 & 239,56 & 112,85 & 606,72 & 95,02 & 1,00 & 65,93 & 257,52 & 15,55 & 23,43 & 241,52 \\
\hline Hyla meridionalis & 29SQA57 & 100,00 & 174,19 & 75,94 & 34,00 & 5074,94 & 292,53 & 72,25 & 220,28 & 137,56 & 238,01 & 241,78 & 111,32 & 594,55 & 90,93 & 1,00 & 65,47 & 52,01 & 16,14 & 23,23 & 235,14 \\
\hline Hyla meridionalis & 29SQA58 & 101,00 & 175,78 & 81,62 & 34,94 & 5197,06 & 300,87 & 70,73 & 230,14 & 126,74 & \begin{tabular}{|l|}
241,48 \\
\end{tabular} & 244,90 & $\begin{array}{l}\mid 11,1,45 \\
111,45\end{array}$ & 585,37 & 88,62 & 1,00 & 65,05 & 248,94 & 16,59 & 22,96 & 231,55 \\
\hline Hyla meridionalis & 29SQA61 & 69,00 & 173,72 & 74,04 & 37,77 & 4251,75 & 275,40 & 81,89 & 193,51 & 129,78 & 226,25 & 230,55 & 120,81 & 723,45 & \begin{tabular}{|l|l|}
126,98 \\
\end{tabular} & 0,92 & 71,45 & 326,94 & 14,62 & 23,06 & 313,23 \\
\hline Hyla meridionalis & 29SQA62 & 96,00 & 173,91 & 72,69 & 36,69 & 4381,85 & 276,29 & 80,88 & $\begin{array}{l}195,42 \\
\end{array}$ & 128,33 & 228,08 & 232,35 & 119,18 & 703,15 & 122,12 & 1,00 & 70,45 & 313,64 & 14,39 & 23,54 & 299,47 \\
\hline Hyla meridionalis & 29SQA63 & 91,00 & 174,26 & 71,55 & 35,73 & 4530,08 & 278,14 & 80,13 & 198,02 & 127,05 & 230,42 & 234,79 & 117,85 & 680,79 & 116,33 & 1,00 & 69,49 & 299,66 & 14,39 & 23,80 & 284,77 \\
\hline Hyla meridiona & 29SQA64 & 82,00 & 173,11 & 71,60 & 34,7 & 4697,90 & 280,25 & 77,27 & 202,98 & 123,76 & 231,64 & 235,93 & 114,68 & 667,31 & 111,07 & 1,00 & 68,47 & 289,70 & 14,79 & 24,00 & 274,71 \\
\hline Hyla meridionalis & 29SQA65 & 82,0 & 173,45 & $\begin{array}{ll}1,1,17 \\
71,\end{array}$ & $\begin{array}{l}34, \\
33,\end{array}$ & $\frac{4 c}{4 \varepsilon}$ & 282 & 76,20 & \begin{tabular}{|l|}
206,74 \\
20,0
\end{tabular} & $\begin{array}{l}123,52 \\
\end{array}$ & \begin{tabular}{|l|}
233,764 \\
\end{tabular} & \begin{tabular}{|l|}
237,93 \\
237
\end{tabular} & \begin{tabular}{|l|}
113,34 \\
113,
\end{tabular} & \begin{tabular}{|l|l|l}
646,16 \\
\end{tabular} & \begin{tabular}{|l|}
104,12 \\
104
\end{tabular} & $\begin{array}{l}1,00 \\
1,00\end{array}$ & $\begin{array}{l}0,4,41 \\
67,41\end{array}$ & $\begin{array}{l}203,10 \\
276,87\end{array}$ & $\begin{array}{ll}4,, 43 \\
15,43\end{array}$ & 24,90 & 261,60 \\
\hline Hyla meridionalis & 29SQA66 & 81,00 & 172,10 & 71,69 & 33,18 & 5004,39 & 285,84 & 72,94 & 212,90 & 120,75 & 234,93 & 238,95 & 110,16 & 634,60 & 98,66 & 1,00 & 66,61 & 268,96 & 16,27 & 24,00 & 253,05 \\
\hline Hyla meridionalis & 29SQBOO & 46,00 & 176,74 & 85,34 & 37,00 & 5008,82 & 299,92 & 71,94 & 227,98 & 123,20 & $\begin{array}{l}239,08 \\
\end{array}$ & \begin{tabular}{|l|l|}
242,08 \\
\end{tabular} & 114,04 & 511,26 & $\begin{array}{l}79,38 \\
79,38\end{array}$ & $\begin{array}{l}, 00 \\
1,00\end{array}$ & 64,36 & 221,58 & 14,00 & 23,00 & 200,42 \\
\hline Hyla meridionalis & 29SQB01 & 100,00 & 177,03 & 85,80 & 36,91 & 5086,65 & 301,93 & 71,36 & 230,57 & 128,89 & 240,26 & 243,19 & 113,39 & 505,93 & 78,73 & 1,00 & 63,83 & 218,10 & 14,01 & 23,13 & 196,75 \\
\hline Hyla meridiona & 29SQB02 & 100,00 & 175,71 & 87,83 & 36,7 & 5211,77 & 304,69 & 68,22 & 236,47 & 12 & 240,67 & 243 & 11 & 511,72 & 79,20 & 1,00 & 63,09 & 218,53 & 14,72 & 23,99 & 197 \\
\hline Hyla meridionalis & $\begin{array}{l}\text { 29SQBOB } \\
\end{array}$ & $\begin{array}{l}100,00 \\
\end{array}$ & 171,11 & $\begin{array}{l}0,03 \\
90,04\end{array}$ & $\begin{array}{l}30,10 \\
36,92\end{array}$ & 5313,06 & 309,19 & $\begin{array}{l}0,2<2 \\
67,62\end{array}$ & \begin{tabular}{|l|}
$241,57 \mid$ \\
241
\end{tabular} & \begin{tabular}{|l|}
130,20 \\
130
\end{tabular} & \begin{tabular}{|l|}
243,06 \\
240
\end{tabular} & \begin{tabular}{|l|}
245,67 \\
245
\end{tabular} & \begin{tabular}{|l|l|l|l|l|}
110,08 \\
\end{tabular} & \begin{tabular}{|l|l|l|l|l|}
505,56 \\
\end{tabular} & 78,12 & $\begin{array}{l}, 00 \\
1,00\end{array}$ & $\begin{array}{l}3,02,66 \\
62,6\end{array}$ & $\begin{array}{l}\mid 10,33 \\
214,59\end{array}$ & $\begin{array}{l}4,1 / 2 \\
15,01 \\
\end{array}$ & $\begin{array}{ll}23,97 \\
23,\end{array}$ & $\begin{array}{l}193,00 \\
193,80\end{array}$ \\
\hline Hyla meridionalis & 29SQB04 & 100,00 & 175,53 & 93,32 & 37,02 & 5425,44 & 312,93 & 64,53 & 248,41 & 120,14 & 243,71 & 246,19 & 107,63 & 511,63 & 78,33 & 1,29 & 61,96 & 215,68 & 16,04 & 24,62 & 195,76 \\
\hline Hyla meridionalis & 29SQB05 & 101,00 & 169,79 & 97,85 & 37,29 & 5573,42 & 314,27 & 56,43 & 257,84 & 109,60 & 240,50 & 242,85 & 100,61 & 543,49 & 81,20 & 2,00 & 60,59 & 226,67 & 19,23 & 27,11 & 208,41 \\
\hline Hyla meridionalis & 29SQB06 & 101,00 & 165,53 & 101,65 & 37,97 & 5683,37 & 315,98 & 50,49 & 265,49 & 104,53 & 238,24 & 240,44 & 95, & 566,49 & 83,17 & 2,01 & 59,96 & 234,53 & 21,17 & 28,32 & 217,67 \\
\hline Hyla meridionalis & 29SQB07 & 100,00 & 164,82 & 104,21 & 38,00 & 5762,46 & 319,25 & 48,34 & 270,91 & 102,79 & 238,75 & 240,87 & 93,82 & 569,38 & 82,77 & 2,29 & 59,36 & 234,26 & 22,28 & 28,82 & 218,29 \\
\hline
\end{tabular}




\begin{tabular}{|c|c|c|c|c|c|c|c|c|c|c|c|c|c|c|c|c|c|c|c|c|c|}
\hline TAXON & UTM & $\mathrm{km} 2$ & B101 & B102 & $\mathrm{BIO3}$ & B104 & B105 & B106 & B107 & B108 & B109 & BIO10 & BIO11 & BIO12 & B1013 & BIO14 & BIO15 & B1016 & B1017 & B1018 & B1019 \\
\hline Hyla meridionalis & 29SQB08 & 100,00 & 163,17 & 106,56 & 38,00 & 5835,67 & 321,68 & 45,53 & 276,15 & 100,43 & 238,34 & 240,40 & 91,52 & 576,80 & 82,82 & 2,68 & 58,52 & 235,69 & 23,96 & 29,93 & 220,70 \\
\hline Hyla meridionalis & 29SQB09 & 101,00 & 149,98 & 109,34 & 38,00 & 5955,40 & 315,23 & 31,79 & 283,43 & 86,71 & 227,37 & 229,53 & 77,75 & 655,52 & 90,98 & 3,83 & 57,21 & 264,65 & 30,41 & 35,23 & 252,11 \\
\hline Hyla meridionalis & 29SQB10 & 96,00 & 177,80 & 87,58 & 37,01 & 5066,93 & 303,78 & 71,44 & 232,34 & 130,63 & 241,16 & 244,08 & 114,66 & 518,74 & 80,20 & 1,00 & 64,27 & 224,79 & 14,00 & 22,93 & 204,25 \\
\hline Hyla meridionalis & 29SQB12 & 99,00 & 177,09 & 91,82 & 37,01 & 5318,58 & 311,16 & 67,03 & 244,13 & 119,89 & 244,00 & 246,56 & 110,55 & 519,52 & 80,10 & 1,00 & 63,16 & 221,75 & 15,04 & 23,39 & 201,42 \\
\hline Hyla meridionalis & 29SQB14 & 100,00 & 177,04 & 97,18 & $\begin{array}{l}37,40 \\
\end{array}$ & 5528,40 & 319,21 & \begin{tabular}{|l|l|}
63,27 \\
\end{tabular} & 255,94 & 117,12 & 247,02 & 249,25 & 108,02 & 518,64 & 79,16 & 1,11 & 62,08 & 218,60 & 16,14 & 24,15 & 199,43 \\
\hline Hyla meridionalis & 29SQB15 & 100,00 & 171,39 & 101,11 & 37,85 & 5671,57 & 320,33 & 55,58 & 264,75 & 110,05 & 243,75 & 245,90 & 101,01 & 548,55 & 81,87 & 1,99 & 60,71 & 228,67 & 19,41 & 26,72 & 210,85 \\
\hline Hyla meridionalis & 29SQB16 & 99,00 & 168,83 & 104,02 & 38,00 & 5771,93 & 322,70 & 51,44 & 271,26 & 106,39 & 242,73 & 244,82 & 97,38 & 560,74 & 82,61 & 2,01 & 60,17 & 232,12 & 20,69 & 27,51 & 215,31 \\
\hline Hyla meridionalis & 29SQB17 & 101,00 & 163,36 & 107,06 & 38,00 & 5877,79 & 322,84 & 44,57 & 278,27 & $\begin{array}{l}99,97 \\
99\end{array}$ & 239,10 & 241,08 & 90,98 & 589,06 & 85,03 & 2,50 & 59,22 & 241,64 & 23,35 & 29,53 & 226,20 \\
\hline Hyla meridionalis & 29SQB18 & 100,00 & 159,01 & 109,34 & 38,00 & 5957,20 & 322,97 & 39,38 & 283,59 & 95,16 & 236,25 & 238,07 & 86,15 & 610,38 & 86,62 & 2,97 & 58,25 & 248,23 & 25,93 & 31,53 & 233,97 \\
\hline Hyla meridionalis & 29SQB19 & 99,00 & 151,81 & 111,03 & 38,00 & 6028,69 & 319,92 & 31,80 & 288,13 & 87,58 & 230,39 & 232,23 & 78,65 & 649,94 & 90,32 & 3,61 & 57,35 & 262,00 & 29,59 & 34,50 & 249,20 \\
\hline Hyla meridionalis & $29 \mathrm{SQB} 20$ & 100,00 & 179,04 & 89,73 & \begin{tabular}{|c|}
37,08 \\
\end{tabular} & 5151,40 & 308,35 & 70,87 & 237,48 & 134,68 & 243,99 & 246,81 & 114,96 & 524,89 & 80,86 & 1,00 & 64,52 & 227,17 & 14,90 & 22,01 & 207,32 \\
\hline Hyla meridionalis & 29SQB21 & 101,00 & 179,80 & 92,42 & 37,20 & 5285,69 & 313,51 & 69,27 & 244,24 & 131,97 & 246,44 & 249,12 & 113,76 & 522,48 & 80,46 & 1,00 & 63,68 & 224,48 & 15,00 & 22,31 & 204,82 \\
\hline Hyla meridionalis & 29SQB25 & 99,00 & 170,63 & 105,14 & 37,99 & 5800,16 & 325,97 & 51,97 & 274,00 & 107,85 & 245,09 & 247,13 & 98,82 & 567,97 & 84,15 & 1,98 & 60,84 & 236,44 & 20,20 & 26,87 & 219,51 \\
\hline Hyla meridionalis & 29SQB26 & 101,00 & 165,03 & 108,10 & 38,00 & 5908,15 & 325,85 & 45,03 & 280,81 & 101,40 & 241,28 & 243,17 & 92,26 & 594,59 & 86,44 & 2,06 & 60,03 & 245,36 & 22,21 & 28,46 & 229,72 \\
\hline Hyla meridionalis & 29SQB28 & 100,00 & 158,95 & 111,69 & 38,00 & 6054,53 & 326,96 & 37,32 & 289,64 & 94,01 & 237,72 & 239,36 & 85,00 & 619,95 & 87,61 & 2,99 & 58,42 & 251,77 & 26,12 & 31,53 & 237,91 \\
\hline Hyla meridionalis & 29SQB31 & 100,00 & 180,39 & 95,44 & 37,43 & 5399,35 & 319,24 & 67,63 & 251,61 & 121,85 & 248,92 & 251,55 & 113,18 & 535,35 & 82,11 & 1,00 & 63,83 & 229,68 & 15,20 & 22,00 & 210,79 \\
\hline Hyla meridionalis & 29SQB35 & 101,00 & 175,74 & 109,07 & \begin{tabular}{|l|l|}
38,05 \\
\end{tabular} & 5890,17 & 336,24 & 54,13 & 282,11 & 111,61 & 251,58 & 253,33 & 102,63 & 558,45 & 83,11 & 1,74 & 61,18 & 233,21 & 19,53 & 25,44 & 216,83 \\
\hline Hyla meridionalis & 29SQB37 & 100,00 & 165,23 & 112,90 & 38,01 & 6067,55 & 333,76 & 42,02 & 291,74 & 99,63 & 243,99 & 245,63 & 90,71 & 602,17 & 86,41 & 2,31 & 59,48 & 246,70 & 23,48 & 28,98 & 232,27 \\
\hline Hyla meridionalis & 29SQB38 & 101,00 & 165,25 & 114,19 & \begin{tabular}{|l|l|}
38,03 \\
\end{tabular} & 6120,83 & 336,06 & 41,25 & 294,81 & 99,12 & 244,91 & 246,42 & 90,10 & 596,49 & 84,86 & 2,55 & 58,82 & 242,79 & 24,17 & 29,42 & 228,80 \\
\hline Hyla meridionalis & $2950 B 40$ & 99,00 & 179,69 & 93,24 & $37,00 \mid$ & 5365,82 & 316,83 & 68,17 & 248,66 & $\mid 121,89$ & 247,90 & 250,69 & $\mid 112.98$ & 553,37 & 84,17 & 1,00 & 64.45 & 237,47 & 15,55 & 22,00 & 219,19 \\
\hline Hyla meridionalis & 29SQB41 & 100,00 & 180,84 & 98,40 & 37,65 & 5512,73 & 324,91 & 66,20 & 258,72 & 121,24 & 251,24 & 253,74 & 112,42 & 550,42 & 83,90 & 1,00 & 64,00 & 235,61 & 16,05 & 22,08 & 217,62 \\
\hline Hyla meridionalis & 29SQB43 & 100,00 & 180,23 & 108,01 & 38,05 & 5804,21 & 338,22 & 59,06 & 279,16 & 117,10 & 254,92 & 256,92 & 108,11 & 558,84 & 84,54 & 1,00 & 62,92 & 237,05 & 17,80 & 23,23 & 220,29 \\
\hline Hyla meridionalis & 29SQB44 & 101,00 & 180,49 & 111,05 & $\begin{array}{l}38,36 \\
\end{array}$ & 5900,58 & 342,96 & 57,41 & 285,55 & 116,18 & 256,64 & 258,40 & 107,23 & 556,03 & 83,69 & 1,12 & 62,60 & 234,70 & 18,32 & 23,41 & 218,49 \\
\hline Hyla meridionalis & 29SQB45 & 99,00 & 179,99 & 113,45 & 38,61 & 5980,75 & 346,22 & 55,51 & 290,71 & 114,92 & 257,41 & 259,01 & 105,74 & 555,42 & 82,92 & 1,41 & 61,79 & 232,99 & 18,81 & 24,00 & 217,38 \\
\hline Hyla meridionalis & 29SQB46 & 99,00 & 173,66 & 115,02 & 38,40 & 6082,63 & 343,56 & 48,44 & 295,12 & 107,63 & 252,68 & 254,05 & 98,53 & 579,42 & 84,77 & 2,00 & 60,85 & 240,38 & 20,83 & 25,98 & 225,57 \\
\hline Hyla meridionalis & 29SQB47 & 101,00 & 169,77 & 116,00 & 38,36 & 6146,51 & 342,23 & 44,27 & 297,96 & 103,11 & 249,79 & 251,23 & 94,08 & 591,41 & 85,13 & 2,04 & 59,97 & 242,96 & 22,34 & 27,42 & 228,87 \\
\hline Hyla meridionalis & $29 S Q B 48$ & 99,00 & 165,34 & $\mid 116,84$ & 38,20 & 6207,25 & 340,24 & 39,51 & 300,73 & | & \begin{tabular}{|l|}
246,41 \\
\end{tabular} & 247,64 & 89,31 & $\mid 606,48$ & $\begin{array}{l}5,710 \\
85,72\end{array}$ & $2,2,53$ & 58,92 & 246,50 & 24,30 & 29,31 & 233,16 \\
\hline Hyla meridionalis & 29SQB49 & 99,00 & 160,27 & 117,41 & 38,07 & 6265,76 & 337,49 & 34,39 & 303,10 & 92,76 & 242,46 & 243,63 & 83,80 & 624,67 & 86,79 & 3,01 & 58,13 & 251,52 & 26,41 & 31,25 & 238,92 \\
\hline Hyla meridionalis & $29 \mathrm{SQB} 50$ & 101,00 & 179,57 & 95,10 & 37,05 & 5466,56 & 320,40 & 67,05 & 253,35 & 120,67 & 249,35 & 252,07 & 111,92 & 570,72 & 86,26 & 1,00 & 64,35 & 243,91 & 16,70 & 22,70 & 226,31 \\
\hline Hyla meridionalis & 29SQB53 & 100,00 & 181,30 & 113,02 & 38,63 & 5927,42 & 346,34 & 57,17 & 289,17 & 116,76 & 258,02 & 259,85 & 107,85 & 573,75 & 86,57 & 1,00 & 63,24 & 243,96 & 18,11 & 22,87 & 228,30 \\
\hline Hyla meridionalis & $29 \mathrm{SQB5} 4$ & 100,00 & 179,52 & 116,15 & 38,86 & 6034,62 & 349,50 & 53,49 & 296,01 & 113,93 & 257,94 & 259,54 & 104,97 & 580,19 & 86,72 & 1,33 & 62,52 & 245,06 & 19,19 & 23,63 & 230,07 \\
\hline Hyla meridionalis & $29 \mathrm{SQBB55}$ & 100,00 & 182,80 & \begin{tabular}{|l|l|}
117,92 \\
17
\end{tabular} & 38,98 & 6077,18 & 354,84 & $\begin{array}{l}55,47 \\
5,4\end{array}$ & \begin{tabular}{|l|l|}
299,36 \\
\end{tabular} & \begin{tabular}{|l|l|}
116,50 \\
\end{tabular} & $\begin{array}{l}261,79 \\
\end{array}$ & \begin{tabular}{|l|}
263,16 \\
\end{tabular} & $\begin{array}{l}107,47 \\
\end{array}$ & 559,71 & 83,53 & 年, & 62,24 & 235,80 & 18,43 & 23,01 & 221,17 \\
\hline Hyla meridionalis & 29SQB56 & 100,00 & 176,11 & 118,63 & 38,93 & 6163,05 & 350,68 & 48,61 & 302,07 & 109,00 & 256,31 & 257,66 & 100,02 & 582,65 & 85,06 & 1,97 & 61,03 & 242,14 & 20,77 & 25,32 & 228,14 \\
\hline Hyla meridionalis & 29SQB58 & 100,00 & 164,45 & 119,16 & 38,45 & 6288,16 & 342,96 & 37,21 & 305,74 & 96,54 & 246,97 & 248,00 & 87,55 & 621,15 & 87,10 & 2,57 & 59,09 & 252,23 & 24,62 & 29,52 & 239,62 \\
\hline Hyla meridionalis & 29SQB59 & 100,00 & 161,72 & 119,53 & 38,08 & 6337,03 & 341,97 & 34,20 & 307,77 & 93,37 & 244,95 & 245,92 & 84,36 & 626,22 & 86,57 & 2,97 & 58,34 & 251,97 & 25,99 & 30,74 & 239,89 \\
\hline Hyla meridionalis & 29SQB60 & 65,00 & 179,53 & $\begin{array}{l}96,98 \\
\end{array}$ & 37,24 & 5525,91 & 323,05 & 66,35 & 256,70 & 119,86 & 250,19 & 252,96 & 111,27 & 583,09 & 88,29 & 1,00 & 64,75 & 249,96 & 17,00 & 22,73 & 232,56 \\
\hline Hyla meridionalis & $29 \mathrm{SQB61}$ & 66,00 & 181,26 & 103,97 & 38,03 & 5680,70 & 333,38 & 63,80 & 269,58 & 119,67 & 254,26 & 256,66 & 111,03 & 576,63 & 87,65 & 1,00 & 64,41 & 247,51 & 17,00 & 22,01 & 230,55 \\
\hline Hyla meridionalis & 29SQB63 & 57,00 & 184,32 & 116,90 & 39,00 & 5995,94 & 353,94 & 58,03 & 295,91 & 119,06 & 262,14 & 263,82 & 110,10 & 574,31 & 86,98 & 1,00 & 63,84 & 245,33 & 18,05 & 22,11 & 230,18 \\
\hline Hyla meridionalis & 29SQB64 & 54,00 & 184,91 & 120,33 & 39,01 & 6101,45 & 359,34 & 55,90 & 303,44 & 118,35 & 264,13 & 265,64 & 109,23 & 571,64 & 86,08 & 1,00 & 63,33 & 243,27 & 18,19 & 22,17 & 228,95 \\
\hline Hyla meridionalis & 29SQB67 & 43,00 & 170,53 & 120,97 & 38,97 & 6280,84 & 349,67 & 42,23 & 307,44 & 102,34 & 252,81 & 253,81 & 93,31 & 608,03 & 86,59 & 2,00 & 60,22 & 249,81 & 22,67 & 27,20 & 236,97 \\
\hline Hyla meridionalis & 29SQB69 & 40,00 & 164,02 & 121,00 & 38, & 6377,10 & 346,10 & 35,40 & 310,70 & 95,05 & 247,85 & 248,63 & 86,07 & 620,57 & 85, & 2,72 & 58,52 & 249,95 & 25,08 & 29,77 & 238,12 \\
\hline Hyla meridionalis & $29 S Q C 00$ & 100,00 & 152,57 & 110,61 & 38,01 & 5987,54 & 319,70 & 33,50 & 286,20 & 88,75 & 230,46 & 232,42 & 79,85 & \begin{tabular}{|l|}
634,96 \\
\end{tabular} & $88, \mathrm{c}$ & 3,70 & 56,71 & 255,20 & 30,10 & 34,59 & 242,76 \\
\hline Hyla meridionalis & $2950 C 0$ & 100,00 & 150,73 & 111,68 & 38,02 & 6030,24 & 320,13 & 31,31 & 288,82 & 86,57 & 229,46 & 231,34 & 77,71 & 643,26 & 88,33 & 4,06 & 56,03 & 256,93 & 31,92 & 35,85 & 245,11 \\
\hline Hyla meridionalis & $29 \mathrm{SQC02}$ & 101,00 & 150,90 & 112,55 & 38,00 & 6064,71 & 322,05 & 30,95 & 291,10 & 86,38 & 230,08 & 231,97 & 77,51 & 638,97 & 87,25 & 4,11 & 55,41 & 253,83 & 32,80 & 36,32 & 242,32 \\
\hline Hyla meridionalis & $29 S Q C 05$ & 100,00 & 151,69 & 114,27 & 38,05 & 6140,97 & 326,38 & 30,66 & 295,72 & 85,99 & 232,26 & 233,59 & 77,36 & 622,94 & 83,87 & 4,57 & 53,71 & 243,87 & 35,20 & 37,55 & 232,90 \\
\hline Hyla meridionalis & $295 Q C 06$ & 100,00 & 151,43 & 114,50 & 38,00 & 6152,60 & 326 & 30,33 & 296,57 & $\begin{array}{l}85,56 \\
85,5 \\
\end{array}$ & 232,32 & |233,59 & 77,10 & $\begin{array}{l}20,3,49 \\
619,90\end{array}$ & $\begin{array}{l}\mid \\
83,06 \\
83,06\end{array}$ & $\begin{array}{ll}4,68 \\
4\end{array}$ & 53,24 & \begin{tabular}{|l|}
241,60 \\
241
\end{tabular} & 36,05 & 38,10 & 230,70 \\
\hline Hyla meridionalis & $2950 C 09$ & 101,00 & 165,31 & 116,39 & 38,40 & 6139,80 & 340, & 41,61 & 298,98 & 98,23 & 245,51 & 246,18 & 89,80 & 516,38 & 70,23 & 3,88 & 51,95 & 199,27 & 31,38 & 33,42 & 186,85 \\
\hline Hyla meridionalis & $295 Q C 10$ & 101,00 & 157,87 & 112,11 & 38,00 & 6052,92 & 326,94 & 36,77 & 290,16 & 92,90 & 236,66 & 238,34 & 84,15 & 608,89 & 85,03 & 3,21 & 57,12 & 244,71 & 27,85 & 32,59 & 231,55 \\
\hline Hyla meridionalis & $29 S Q C 11$ & 100,00 & 148,36 & 113,07 & 38,00 & 6121,03 & 320,93 & 27,46 & 293,47 & 83,27 & 228,53 & 230,22 & 74,29 & 662,73 & 90,34 & 4,26 & 56,03 & 263,69 & 32,92 & 36,88 & 252,11 \\
\hline Hyla meridiona & $29 \mathrm{SQC12}$ & 100,00 & 150,30 & 113,83 & 38,00 & 6146,70 & 324,17 & 28,77 & 295,39 & 84,84 & 230,91 & 232,48 & 75,97 & 644,97 & 87,74 & 4,05 & 55,47 & 255,49 & 32,72 & 36,30 & 243,86 \\
\hline Hyla meridionalis & $29 \mathrm{SQC13}$ & $\begin{array}{l}100,00 \\
100\end{array}$ & 157,54 & $\frac{11}{11}$ & 38,01 & $\frac{0140,1 / 86}{6161,86}$ & 331 & 34,74 & $\mid$\begin{tabular}{|l|}
297,06 \\
\end{tabular} & $\begin{array}{l}4,044 \\
91,12\end{array}$ & \begin{tabular}{|l|}
238,20 \\
230
\end{tabular} & \begin{tabular}{|l|}
239,410 \\
\end{tabular} & 82,41 & \begin{tabular}{|l|l|}
594,93 \\
\end{tabular} & $\mid \begin{array}{l}\mid 0,1,4 \\
81,35\end{array}$ & $\begin{array}{l}4,3001 \\
3,71\end{array}$ & $\begin{array}{l}35,41 \\
55,09\end{array}$ & \begin{tabular}{|l|}
234,82 \\
\end{tabular} & 30,46 & $\begin{array}{l}30,00 \\
33,99\end{array}$ & $\begin{array}{l}243,00 \\
222,73\end{array}$ \\
\hline Hyla meridionalis & $29 \mathrm{SQC14}$ & 101,00 & 159,23 & 115,59 & 38,01 & 6171,35 & 334,37 & 35,95 & 298,41 & 92,41 & 239,95 & 241,13 & 83,86 & 579,12 & 79,00 & 3,69 & 54,64 & 227,61 & 30,38 & 33,67 & 215,52 \\
\hline Hyla meridionalis & $29 \mathrm{SQC15}$ & 100,00 & 153,88 & $\mid 115,50$ & 38,00 & 6216,08 & 330,77 & $\begin{array}{l}31,06 \\
31,5\end{array}$ & \begin{tabular}{|l|}
299,71 \\
\end{tabular} & \begin{tabular}{|l|}
87,03 \\
\end{tabular} & $\begin{array}{l}235,64 \\
\end{array}$ & $\begin{array}{l}236,60 \\
236\end{array}$ & 78,50 & $\mid 607,10$ & 81,63 & $\begin{array}{l}3,19 \\
4,19\end{array}$ & 53,79 & $\mid \begin{array}{l}\mid 236,94 \\
\end{array}$ & 33,57 & 36,28 & 225,45 \\
\hline Hyla meridionalis & $295 Q C 16$ & 100,00 & 158,39 & 116,15 & 38,01 & 6218,94 & 335,43 & 34,82 & 300,61 & 91,30 & 240,07 & 241,02 & 82,66 & 573,53 & 77,26 & 4,05 & 53,32 & 222,97 & 32,25 & 34,93 & 211,15 \\
\hline Hyla meridiona & $295 Q C 20$ & 100,00 & 158,69 & 114,03 & 38,00 & 6141,20 & 330,86 & 35,80 & 295,06 & 92,59 & 238,82 & 240,27 & 83,67 & 610,75 & 84,96 & 3,20 & 57,20 & 244,88 & 27,67 & 32,37 & 23 \\
\hline Hyla meridionalis & $295 \mathrm{SQC21}$ & $\begin{array}{l}100,00 \\
\end{array}$ & $\begin{array}{l}15,05 \\
145,29\end{array}$ & \begin{tabular}{|l|l|}
114,35 \\
1145
\end{tabular} & 38,00 & $\begin{array}{l}0141,202 \\
6208,92\end{array}$ & $\begin{array}{l}33,00 \\
321,02\end{array}$ & $\begin{array}{l}3,00 \\
23,04 \\
\end{array}$ & \begin{tabular}{|l|}
297,98 \\
298
\end{tabular} & $\begin{array}{l}32,39 \\
79,29\end{array}$ & \begin{tabular}{|l|}
227,0101 \\
\end{tabular} & \begin{tabular}{|l|}
228,47 \\
227
\end{tabular} & $\begin{array}{l}70,48 \\
70,\end{array}$ & \begin{tabular}{|l|l|}
684,79 \\
\end{tabular} & $\begin{array}{l}4,50 \\
92,50 \\
\end{array}$ & $\begin{array}{l}3,201 \\
4,51 \\
\end{array}$ & $\begin{array}{ll}31,20 \\
55,84\end{array}$ & \begin{tabular}{|l|}
274,200 \\
271,28 \\
\end{tabular} & 34,24 & $\begin{array}{ll}2,317 \\
38,10\end{array}$ & 260,10 \\
\hline Hyla meridionalis & $295 Q C 22$ & 100,00 & 152,88 & 115,44 & 38,00 & 6225,07 & 329,21 & 29,54 & 299,66 & 86,07 & 234,56 & 235,86 & 77,28 & 632,78 & 85,95 & 3,97 & 55,60 & 250,05 & 31,60 & 35,43 & 238,19 \\
\hline Hyla meridionalis & $29 S Q C 25$ & 100,00 & 154,87 & 116,72 & 38,00 & 6296.31 & 333.94 & 30.57 & 303,37 & 86.94 & 237,62 & 238.51 & 78.50 & 601.18 & 80,36 & 4,00 & 53,84 & 233,81 & 32.68 & 35,64 & 222.19 \\
\hline Hyla meridionalis & $295 \mathrm{SQC26}$ & 100,00 & 157,30 & 117,01 & 38,00 & 6306,67 & 336,74 & 32,57 & 304, & 89,24 & 240,2 & 241, & 80 & 579,70 & 77,33 & 4,01 & 53,38 & 224 & 32,31 & 35,03 & 212,53 \\
\hline Hyla meridionalis & $2950 C 28$ & 101,00 & 162,42 & 117,04 & 38,00 & 6296,73 & 341,58 & 37,15 & 304,44 & 93,96 & 245,39 & 245,72 & 85,55 & 537,24 & 71,40 & 3,97 & 52,31 & 206,15 & \begin{tabular}{|c|}
31,56 \\
\end{tabular} & 33,13 & 193,92 \\
\hline
\end{tabular}




\begin{tabular}{|c|c|c|c|c|c|c|c|c|c|c|c|c|c|c|c|c|c|c|c|c|c|}
\hline TAXON & UTM & $\mathrm{km2}$ & BIO1 & B102 & $\mathrm{BIO3}$ & B104 & B105 & B106 & B107 & B108 & B109 & BIO10 & BIO11 & BIO12 & BIO13 & BIO14 & BIO15 & BIO16 & BIO17 & BIO18 & Bl019 \\
\hline Hyla meridionalis & 29SQC29 & 99,00 & 163,70 & 116,98 & 37,99 & 6310,48 & 342,96 & 38,34 & 304,62 & 94,99 & 247,14 & 247,18 & 86,50 & 523,24 & 69,29 & 3,71 & 51,97 & 200,01 & 30,94 & 31,56 & 187,75 \\
\hline Hyla meridionalis & $295 Q C 30$ & 100,00 & 153,54 & 115,83 & 38,00 & 6238,75 & 329,83 & 29,25 & 300,58 & 86,61 & 235,49 & 236,64 & 77,72 & 646,89 & 88,68 & 3,60 & \begin{tabular}{ll|}
56,96 \\
\end{tabular} & 258,16 & 29,81 & 34,28 & 246,06 \\
\hline Hyla meridionalis & 29SQC31 & 101,00 & 143,35 & 115,71 & 37,99 & 6285,63 & 321,80 & 20,01 & \begin{tabular}{|l|l|}
301,79 \\
\end{tabular} & 76,51 & 226,30 & 227,65 & 67,74 & \begin{tabular}{ll|}
700,80 \\
\end{tabular} & 93,93 & 4,65 & 55,87 & 276,69 & 34,98 & 38,88 & 265,89 \\
\hline Hyla meridionalis & 29SQC32 & 100,00 & 150,07 & 116,82 & 38,00 & 6311,19 & 329,47 & 25,56 & \begin{tabular}{|l|}
303,92 \\
\end{tabular} & 82,63 & 233,28 & 234,30 & 73,90 & 652,92 & 87,76 & 4,06 & 55,58 & 257,04 & 32,41 & 36,21 & 245,72 \\
\hline Hyla meridionalis & $29 \mathrm{SQC33}$ & 100,00 & 153,02 & 117,28 & 38,00 & 6330,62 & 333,25 & 27,94 & 305,31 & 85,31 & \begin{tabular}{|l|l|}
236,62 \\
\end{tabular} & 237,48 & 76,49 & 627,71 & 84,15 & 4,00 & 55,13 & 245,93 & 31,71 & 35,48 & 234,45 \\
\hline Hyla meridionalis & 295QC34 & 101,00 & 153,91 & 117,59 & 38,00 & 6343,62 & 334,60 & 28,48 & \begin{tabular}{|l|}
306,12 \\
\end{tabular} & 85,62 & 237,58 & 238,24 & 76,99 & \begin{tabular}{|l|l|}
616,08 \\
\end{tabular} & 82,05 & 4,00 & 54,58 & 239,90 & \begin{tabular}{l|l}
32,05 \\
\end{tabular} & 35,34 & 228,58 \\
\hline Hyla meridionalis & $295 Q C 35$ & 100,00 & 153,54 & 117,59 & 38,00 & 6363,24 & 335,03 & 28,24 & 306,79 & 85,10 & 237,65 & 238,31 & 76,50 & $\begin{array}{ll}609,65 \\
\end{array}$ & 80,58 & 4,00 & 54,00 & 236,09 & 32,50 & 35,71 & 224,86 \\
\hline Hyla meridionalis & $295 Q C 36$ & 100,00 & 157,07 & 117,85 & 38,00 & 6360,65 & 338,56 & 31,38 & \begin{tabular}{|l|l|}
307,18 \\
\end{tabular} & 88,35 & \begin{tabular}{|l|l|}
241,04 \\
\end{tabular} & 241,64 & 79,81 & \begin{tabular}{|l|l|}
581,93 \\
\end{tabular} & 76,87 & 4,00 & 53,48 & 224,35 & 31,94 & 34,76 & 212,76 \\
\hline Hyla meridionalis & 29SQC37 & 100,00 & 160,43 & 117,97 & 38,00 & 6361,74 & 341,86 & 34,42 & 307,44 & 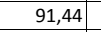 & \begin{tabular}{|l|l}
244,49 \\
\end{tabular} & 244,74 & 82,93 & $\begin{array}{l}555,56 \\
\end{array}$ & 73,23 & 3,90 & 52,90 & 213,13 & 31,30 & 33,37 & 201,28 \\
\hline Hyla meridionalis & $2950 C 38$ & 100,00 & 163,23 & 117,86 & 38,00 & 6367,95 & 344,36 & 36,86 & 307,50 & 93,88 & 247,29 & 247,38 & 85,35 & 532,76 & 70,17 & 3,44 & $52,54[$ & 203,66 & 30,08 _ & 31,66 & 191,64 \\
\hline Hyla meridionalis & \begin{tabular}{|l|}
$295 Q C 39$ \\
\end{tabular} & 101,00 & 165,75 & 117,51 & \begin{tabular}{|l|l|}
37,97 \\
\end{tabular} & 6367,88 & 346,27 & 39,30 & 306,97 & 96,22 & \begin{tabular}{|l|l|}
249,75 \\
\end{tabular} & \begin{tabular}{ll|}
249,85 \\
\end{tabular} & 87,54 & 511,19 & 67,20 & 3,08 & 52,34 & \begin{tabular}{|l|l|}
194,91 \\
\end{tabular} & 28,83 & 30,27 & 182,78 \\
\hline Hyla meridionalis & $295 Q C 40$ & 101,00 & 158,58 & 118,01 & 38,01 & 6304,75 & 337,41 & 32,34 & 305,07 & 90,67 & 241,28 & 242,38 & 81,72 & \begin{tabular}{|l|l|}
626,43 \\
\end{tabular} & 86,06 & 3,03 & 57,45 & 250,37 & 27,34 & 32,01 & 238,25 \\
\hline Hyla meridionalis & $295 Q C 41$ & 99,00 & 150,44 & 117,83 & 38,00 & 6353,23 & 331,26 & 24,82 & 306,44 & 82,53 & 234,27 & 235,31 & 73,66 & 662,91 & 89,17 & 3,90 & 56,33 & 261,88 & 31,52 & 35,70 & 250,75 \\
\hline Hyla meridionalis & $295 Q C 45$ & 101,00 & 155,37 & 118,87 & 38,00 & 6435,91 & 338,99 & 28,40 & \begin{tabular}{|l|l|}
310,59 \\
\end{tabular} & 85,98 & \begin{tabular}{|l|l|}
240,62 \\
\end{tabular} & 240,92 & 77,21 & \begin{tabular}{|l|l|}
600,77 \\
\end{tabular} & 79,28 & 3,96 & 54,09 & 231,94 & 31,57 & 34,04 & 220,74 \\
\hline Hyla meridionalis & $295 Q C 46$ & 100,00 & 159,70 & 119,06 & \begin{tabular}{ll|}
37,99 \\
\end{tabular} & 6443,91 & 343,06 & 32,26 & 310,81 & 89,84 & \begin{tabular}{l|l|}
244,80 \\
\end{tabular} & 244,96 & 81,12 & 569,21 & 75,04 & 3,69 & 53,6 & 218,71 & \begin{tabular}{|l|l|}
30,47 \\
\end{tabular} & 32,42 & 207,26 \\
\hline Hyla meridionalis & \begin{tabular}{|l|}
$295 Q C 47$ \\
\end{tabular} & 99,00 & 162,97 & 118,88 & 37,99 & 6437,15 & 345,94 & 35,39 & 310,55 & 92,87 & 248,00 & 248,04 & 84,26 & 542,14 & 71,52 & 3,23 & 53,43 & \begin{tabular}{|l|l|}
207,59 \\
\end{tabular} & 29,09 & 30,04 & 195,96 \\
\hline Hyla meridionalis & $295 Q C 49$ & 99,00 & 163,25 & 117,95 & 37,60 & 6448,65 & 346,10 & 36,12 & \begin{tabular}{|l|l|}
309,98 \\
\end{tabular} & \begin{tabular}{ll|}
92,98 \\
\end{tabular} & 248,56 & 248,66 & 84,46 & \begin{tabular}{|l|l|}
523,97 \\
\end{tabular} & 68,46 & 3,31 & 52,23 & \begin{tabular}{l|l|l|l|}
198,42 \\
\end{tabular} & 29,73 & 30,41 & 186,63 \\
\hline Hyla meridionalis & 29SQC51 & 100,00 & 157,25 & 120,01 & 38,00 & 6413,78 & 340,24 & 29,40 & 310,84 & 88,09 & 241,84 & 242,56 & 79,16 & \begin{tabular}{|l|l|}
631,14 \\
\end{tabular} & 85,14 & 3,27 & 56,81 & 249,59 & 28,48 & 32,89 & 238,35 \\
\hline Hyla meridionalis & $295 Q C 52$ & 100,00 & 158,74 & 120,32 & 38,00 & 6435,63 & 342,47 & 30,48 & 311,99 & 89,27 & \begin{tabular}{|l|l|}
243,72 \\
\end{tabular} & 244,24 & 80,33 & \begin{tabular}{ll|}
613,54 \\
\end{tabular} & 82,38 & 3,19 & 56,22 & 241,10 & 28,37 & 32,57 & 229,94 \\
\hline Hyla meridionalis & 29SQC53 & 100,00 & 152,34 & 119,87 & 38,00 & 6469,16 & 337,34 & 24,95 & \begin{tabular}{|l|l|}
312,39 \\
\end{tabular} & 82,86 & 237,97 & 238,62 & 74,10 & \begin{tabular}{|l|l|}
638,24 \\
\end{tabular} & \begin{tabular}{l|l|}
84,75 \\
\end{tabular} & 3,94 & 55,3 & 248,30 & 31,58 & \begin{tabular}{l|l}
35,35 \\
\end{tabular} & 237,69 \\
\hline Hyla meridionalis & $295 Q C 55$ & 100,00 & 158,21 & 120,08 & 38,00 & 6492,21 & 343,57 & 29,89 & 313,68 & 87,86 & 244,27 & 244,42 & 79,23 & 588,23 & 77,81 & 3,70 & 54,34 & 226,40 & 30,18 & 32,39 & 215,47 \\
\hline Hyla meridionalis & $295 Q C 56$ & 99,00 & 160,23 & 120,02 & 37,93 & 6499,58 & 345,58 & 31,79 & 313,79 & 89,49 & \begin{tabular}{l|l}
246,42 \\
\end{tabular} & 246,50 & 81,13 & \begin{tabular}{ll|l}
566,80 \\
\end{tabular} & \begin{tabular}{ll|}
74,75 \\
\end{tabular} & 3,33 & 53,84 & 216,93 & 29,53 & 31,24 & 205,91 \\
\hline Hyla meridionalis & 29 SQC57 & 101,00 & 157,18 & 119,37 & 37,73 & 6509,74 & 342,79 & 29,19 & 313,61 & 86,55 & 243,60 & \begin{tabular}{|l|l|}
243,67 \\
\end{tabular} & \begin{tabular}{ll|l}
77,96 \\
\end{tabular} & \begin{tabular}{l|l}
573,23 \\
\end{tabular} & \begin{tabular}{|l|l|}
74,97 \\
\end{tabular} & 3,87 & 53,01 & 217,74 & 31,36 & 32,25 & 206,81 \\
\hline Hyla meridionalis & 29 SQC58 & 100,00 & 160,35 & 119,09 & 37,65 & 6510,78 & 345,55 & 32,21 & 313,33 & 89,57 & \begin{tabular}{|l|l|}
246,70 \\
\end{tabular} & 246,74 & 81,06 & $\begin{array}{l}547,69 \\
\end{array}$ & 71,51 & 3,60 & 52,61 & 207,06 & 30,33 & 30,64 & \begin{tabular}{|l|l|}
195,84 \\
\end{tabular} \\
\hline Hyla meridionalis & $\begin{array}{l}29 S Q C 60 \\
\end{array}$ & 32,00 & 155,24 & 120,45 & 38,00 & 6427,15 & 339,05 & 27,25 & 311,80 & 86,07 & 240,15 & \begin{tabular}{l|l|}
240,95 \\
\end{tabular} & 77,16 & \begin{tabular}{ll|}
654,55 \\
\end{tabular} & 88,64 & 3,35 & \begin{tabular}{|l|l|}
57,42 \\
\end{tabular} & 259,98 & 28,73 & \begin{tabular}{l|l}
33,25 \\
\end{tabular} & 249,11 \\
\hline Hyla meridionalis & 295aC61 & 36,00 & 161,81 & 121,29 & 38,02 & 6448,65 & 345,96 & 32,98 & 312,98 & 92,10 & 246,90 & 247,63 & 83,29 & 611,21 & 82,88 & 3,02 & 57,23 & 242,10 & 26,58 & 31,02 & 230,92 \\
\hline Hyla meridionalis & $29 \mathrm{SQC62}$ & 30,00 & 158,40 & 121,10 & 38,00 & 6484,80 & 343,60 & 29,48 & 314,13 & 88,45 & 244,20 & 244,60 & 79,50 & \begin{tabular}{|l|l|l|}
619,28 \\
\end{tabular} & 83,18 & 3,25 & 56,40 & 242,82 & 28,33 & 32,40 & 232,15 \\
\hline Hyla meridionalis & $29 \mathrm{SQC63}$ & 22,00 & 148,95 & 120,27 & \begin{tabular}{l|l|}
37,98 \\
\end{tabular} & 6508,00 & 335,43 & 21,27 & 314,16 & \begin{tabular}{ll|}
79,09 \\
\end{tabular} & 235,43 & 235,86 & \begin{tabular}{ll|}
70,36 \\
\end{tabular} & 658,91 & 87,20 & 4,20 & 55,09 & 255,39 & 32,91 & 35,98 & 245,32 \\
\hline Hyla meridionalis & 29SQD03 & 99,00 & 162,05 & 112,89 & 37,65 & 6217,30 & 336,97 & 40,74 & 296,23 & 94,54 & \begin{tabular}{|l|l|}
244,16 \\
\end{tabular} & 244,37 & 86,30 & \begin{tabular}{|l|l|}
543,79 \\
\end{tabular} & 71,43 & 4,07 & 50,64 & 207,91 & 35,20 & 35,89 & 196,42 \\
\hline Hyla meridionalis & \begin{tabular}{|l|l|}
$29 S Q D 05$ \\
\end{tabular} & 99,00 & 159,20 & 109,38 & 36,93 & 6248,82 & 332,70 & \begin{tabular}{l|l}
40,15 \\
\end{tabular} & 292,56 & 91,71 & 242,11 & 242,33 & 83,56 & 570,26 & 73,62 & 4,45 & 50,23 & 217,73 & 37,80 & 38,31 & 206,77 \\
\hline Hyla meridionalis & \begin{tabular}{|l|l|}
$29 S Q D 06$ \\
\end{tabular} & 100,00 & 162,13 & 108,65 & 36,89 & 6249,81 & 334,75 & \begin{tabular}{l|l}
43,05 \\
\end{tabular} & 291,70 & 94,37 & \begin{tabular}{|l|l|}
244,94 \\
\end{tabular} & 245,01 & 86,27 & 553,42 & 71,32 & 4,17 & 50,11 & 211,10 & 36,57 & \begin{tabular}{|l|}
36,87 \\
\end{tabular} & 200,20 \\
\hline Hyla meridionalis & 29SQD13 & 101,00 & 161,91 & 112,93 & 37,27 & 6289,60 & 338,44 & 39,80 & 298,64 & 93,62 & 245,15 & 245,26 & 85,32 & \begin{tabular}{|l|l|}
532,07 \\
\end{tabular} & 69,11 & 4,03 & 50,50 & 201,98 & 34,28 & 34,72 & 190,05 \\
\hline Hyla meridionalis & 29SQD18 & 100,00 & 158,95 & 106,70 & 36,00 & 6328,08 & 331,75 & 40,47 & 291,28 & 90,38 & \begin{tabular}{|l|l|}
243,22 \\
\end{tabular} & 243,22 & 82,34 & 550,14 & \begin{tabular}{ll|}
69,56 \\
\end{tabular} & 4,51 & 49,38 & 207,69 & 37,51 & 37,51 & \begin{tabular}{ll|l}
196,47 \\
\end{tabular} \\
\hline Hyla meridionalis & \begin{tabular}{|l|} 
29SQD19 \\
\end{tabular} & 101,00 & 162,86 & 107,15 & 36,24 & 6303,35 & 334,62 & 43,71 & \begin{tabular}{|l|}
290,90 \\
\end{tabular} & \begin{tabular}{|l|l|}
94,08 \\
\end{tabular} & \begin{tabular}{|l|l|}
246,61 \\
\end{tabular} & 246,61 & 86,02 & \begin{tabular}{|l|l|}
526,36 \\
\end{tabular} & 66,90 & 4,10 & 49,34 & 198,82 & 35,70 & 35,70 & 187,74 \\
\hline Hyla meridionalis & 29SQD21 & 101,00 & 167,54 & 115,88 & 37,93 & 6306,67 & 345,66 & 42,66 & 302,99 & \begin{tabular}{|c|}
98,62 \\
\end{tabular} & 250,56 & 250,69 & $\begin{array}{l}90,15 \\
\end{array}$ & \begin{tabular}{l|l|}
493,85 \\
\end{tabular} & 65,03 & 3,03 & 51,52 & 187,80 & 29,46 & 30,62 & 175,35 \\
\hline Hyla meridionalis & 29SQD23 & 100,00 & 162,78 & 113,37 & 37,00 & 6357,80 & 341,02 & 39,52 & \begin{tabular}{|l|l|}
301,50 \\
\end{tabular} & \begin{tabular}{|c|}
93,64 \\
\end{tabular} & \begin{tabular}{|l|l|}
247,12 \\
\end{tabular} & 247,14 & 85,36 & \begin{tabular}{|l|l|}
515,75 \\
\end{tabular} & $\begin{array}{l}66,36 \\
\end{array}$ & 4,00 & 50,40 & \begin{tabular}{|l|l|}
194,20 \\
\end{tabular} & \begin{tabular}{|l|l|}
32,93 \\
\end{tabular} & 33,12 & 182,06 \\
\hline Hyla meridionalis & 29SQD31 & 100,00 & 165,92 & 116,10 & 37,53 & 6383,78 & 346,06 & 40,36 & 305,70 & 96,25 & 250,19 & 250,23 & 87,68 & 499,24 & 64,97 & 3,08 & 51,30 & 188,50 & 29,97 & 30,39 & 176,32 \\
\hline Hyla meridionalis & 29SQD34 & 100,00 & 158,26 & 112,18 & 36,66 & 6447,42 & 337,87 & 35,26 & 302,62 & 88,47 & \begin{tabular}{|l|l}
244,05 \\
\end{tabular} & 244,05 & 80,09 & 526,71 & 67,01 & 4,03 & 49,66 & $\begin{array}{l}195,96 \\
\end{array}$ & 34,72 & 34,72 & 183,75 \\
\hline Hyla meridionalis & 29SQD36 & 100,00 & 158,56 & 109,69 & 36,00 & 6453,55 & 336,64 & 37,03 & 299,60 & 88,73 & \begin{tabular}{|l|l|}
244,68 \\
\end{tabular} & 244,68 & 80, & 515,19 & 66,62 & 4,06 & 49,2 & \begin{tabular}{ll|}
190,48 \\
\end{tabular} & 34,98 & $\begin{array}{l}4,98 \\
4, \quad 1\end{array}$ & 178,10 \\
\hline Hyla meridionalis & \begin{tabular}{|l|}
$29 S Q D 38$ \\
\end{tabular} & 100,00 & 162,23 & 109,03 & 36,06 & 6418,17 & 338,20 & 40,89 & 297,31 & 92,29 & 247,74 & 247,74 & 84,08 & \begin{tabular}{|l|l|}
488,93 \\
\end{tabular} & \begin{tabular}{|l|l|}
61,73 \\
\end{tabular} & 4,00 & 48,59 & 180,47 & 33,92 & 33,92 & 168,29 \\
\hline Hyla meridionalis & 29SQD39 & 99,00 & 158,01 & 108,29 & 36,00 & 6420,54 & 333,44 & 37,18 & \begin{tabular}{|l|l|}
296,26 \\
\end{tabular} & 88,09 & 243,70 & 243,70 & \begin{tabular}{ll|}
79,96 \\
\end{tabular} & 505,57 & 62,88 & 4,44 & 48,10 & $\begin{array}{ll}186,62 \\
\end{array}$ & 35,82 & 35,82 & 174,49 \\
\hline Hyla meridionalis & 29SQD41 & 100,00 & 167,40 & 116,77 & 37,13 & 6444,88 & 349,11 & 40,70 & 308,41 & $\begin{array}{ll}96,92 \\
\end{array}$ & 252,81 & 252,81 & 88,49 & \begin{tabular}{l|l}
488,53 \\
\end{tabular} & 63,47 & 3,01 & 51,48 & $\begin{array}{l}183,45 \\
\end{array}$ & 28,49 & 28,51 & 171,45 \\
\hline Hyla meridionalis & \begin{tabular}{|l|}
$29 S Q D 42$ \\
\end{tabular} & 101,00 & 163,45 & 115,65 & 37,00 & 6467,77 & 345,24 & 37,56 & \begin{tabular}{|l|l|}
307,68 \\
\end{tabular} & \begin{tabular}{|l|l|}
92,97 \\
\end{tabular} & \begin{tabular}{|l|l|}
249,25 \\
\end{tabular} & 249,25 & 84,56 & \begin{tabular}{|l|l|}
501,69 \\
\end{tabular} & 64,52 & 3,59 & $\begin{array}{l}50,63 \\
\end{array}$ & $\begin{array}{l}187,05 \\
\end{array}$ & 30,86 & 30,86 & 175,00 \\
\hline Hyla meridionalis & \begin{tabular}{|l|l|}
$29 S Q D 48$ \\
\end{tabular} & 101,00 & 161,55 & 110,35 & 36,08 & 6466,01 & 339,07 & 38,76 & 300,31 & $\begin{array}{l}90,95 \\
\end{array}$ & 247,84 & 247,84 & \begin{tabular}{l|l|}
82,85 \\
\end{tabular} & 475,51 & 60,13 & 4,00 & 48,1 & 173,82 & 33,42 & 33,42 & 161,51 \\
\hline Hyla meridionalis & \begin{tabular}{|l|}
$29 S Q D 57$ \\
\end{tabular} & 80,00 & 160,28 & 111,88 & 36,03 & 6511,11 & 340,08 & 36,26 & 303,83 & 89,31 & 247,30 & 247,30 & 81,00 & 474,24 & 60,62 & 4,00 & \begin{tabular}{|l|l|}
48,02 \\
\end{tabular} & 172,21 & 33,12 & 33,12 & 159,87 \\
\hline Hyla meridionalis & $\begin{array}{l}\text { 29SQE10 } \\
\end{array}$ & 100,00 & 161,27 & 106,66 & 36,20 & 6291,10 & 332,27 & 42,40 & 289,87 & 92,50 & \begin{tabular}{|l|l|}
244,82 \\
\end{tabular} & 244,8 & 84,49 & 533,24 & 67,80 & 4,52 & \begin{tabular}{l|l|l}
48,95 \\
\end{tabular} & \begin{tabular}{|l|}
201,42 \\
\end{tabular} & 36,81 & 36,81 & 190,60 \\
\hline Hyla meridionalis & $\begin{array}{l}\text { 29SQE30 } \\
\end{array}$ & 100,00 & 160,68 & 108,58 & \begin{tabular}{ll|}
36,06 \\
\end{tabular} & 6384,78 & 334,81 & 39,60 & 295,20 & $\begin{array}{l}0,75 \\
9\end{array}$ & \begin{tabular}{|l|l|}
245,78 \\
\end{tabular} & 245,78 & 82,71 & \begin{tabular}{l|l}
488,52 \\
\end{tabular} & 60,88 & 4,24 & \begin{tabular}{ll|}
47,79 \\
\end{tabular} & \begin{tabular}{l|l|}
180,53 \\
\end{tabular} & 34,82 & 34,82 & 168,60 \\
\hline Hyla meridionalis & 29SQE31 & 100,00 & 151,70 & 107,43 & 35,99 & 6391,73 & 325,58 & 31,99 & 293,58 & 82,12 & 237,20 & 237,20 & 74,27 & 528,86 & 65,88 & 5,36 & 47,12 & 195,34 & 39,53 & 39,53 & 183,23 \\
\hline Hyla meridionalis & 29SQE32 & 100,00 & 157,19 & 108,24 & 36,26 & 6358,92 & 330,00 & 36,44 & 293,56 & 87,21 & \begin{tabular}{|l|l|}
241,85 \\
\end{tabular} & 241,85 & 79,41 & 495,20 & 61,98 & 4,97 & 46,81 & 182,80 & 36,92 & 36,92 & 170,93 \\
\hline Hyla meridionalis & 29SQE41 & 101,00 & 154,90 & 109,12 & 36,13 & 6419,67 & 330,21 & 33,53 & 296,68 & 84,60 & 240,72 & 240,72 & 76,87 & 489,60 & 60,49 & 4,99 & \begin{tabular}{|l|}
46,49 \\
\end{tabular} & \begin{tabular}{|l|}
178,67 \\
\end{tabular} & 36,92 & 36,92 & 166,26 \\
\hline Hyla meridionalis & 29SQE42 & 100,00 & 153,12 & 109,16 & 36,26 & 6395,85 & 327,66 & 32,03 & 295,63 & 82,96 & 238,64 & 238,64 & 75,36 & \begin{tabular}{|l|l|}
489,82 \\
\end{tabular} & 60,62 & 5,12 & 46,01 & \begin{tabular}{|l|l|}
178,57 \\
\end{tabular} & 37,77 & 37,77 & 166,24 \\
\hline Hyla meridionalis & 29SQE50 & 70,00 & 159,94 & 110,91 & 36,59 & 6450,74 & 336,84 & 36,84 & 300,00 & 89,39 & \begin{tabular}{|l|l|}
246,15 \\
\end{tabular} & 246,15 & 81,11 & \begin{tabular}{|l|l|}
456,27 \\
\end{tabular} & 56,13 & 4,02 & 46,66 & $\begin{array}{l}165,05 \\
\end{array}$ & 33,50 & 33,50 & 152,85 \\
\hline Hyla meridionalis & 29SQE51 & 63,00 & 158,98 & 110,69 & 36,68 & $6427,51$. & 334,89 & 36,06 & 298,83 & 88,21 & 244,68 & 244,68 & 80,34 & 454,36 & 55,83 & 4,50 & 46,1 & 164,21 & 34,23 & 34,23 & 151,88 \\
\hline Hyla meridionalis & \begin{tabular}{|l|} 
29SQEE52 \\
\end{tabular} & 66,00 & 155,05 & 110,34 & 36,5 & 6425,27 & 330 & 32,56 & 297, & 84, & 240, & 240, & 76,57 & 463,73 & 57,01 & 5,01] & 45,64 & 167,40 & 36,06 & 36,06 & 154 \\
\hline Hyla meridionalis & \begin{tabular}{|l|} 
29TNE14 \\
\end{tabular} & 94,00 & 153,37 & 80,69 & 43,99 & 3489,40 & 249,04 & 67,60 & \begin{tabular}{|l|l|}
181,44 \\
\end{tabular} & \begin{tabular}{ll|}
114,96 \\
\end{tabular} & \begin{tabular}{|l|l|}
194,89 \\
\end{tabular} & 196,96 & 106,94 & \begin{tabular}{|l|l|}
915,43 \\
\end{tabular} & 130,14 & 8,93 & 54,31 & 372,73 & 57,22 & $\begin{array}{ll}64,43 \\
\end{array}$ & 366,66 \\
\hline Hyla meridionalis & 29TNE45 & 101,00 & 159,50 & 98,46 & 43,90 & 4164,52 & 283,32 & $\begin{array}{ll}60,82 \\
\end{array}$ & 222,49 & 108,75 & 210,58 & 212,78 & 105,32 & 936,35 & 130,70 & 9,70 & 52,90 & \begin{tabular}{l|l|}
374,25 \\
\end{tabular} & 62,54 & 67,44 & 374,14 \\
\hline Hyla meridionalis & 29TPE23 & 100,00 & 136,93 & 89,41 & 34,98 & 5655,55 & 286,47 & 34,08 & 252,39 & 69,31 & 212,77 & 212,88 & 69,31 & 1072,25 & $\begin{array}{ll}160,25 \\
\end{array}$ & 9,60 & 55,52 & 436,33 & \begin{tabular}{ll|}
65,86 \\
\end{tabular} & 65,86 & 436,33 \\
\hline Hyla & 29TPE24 & 100,00 & & & 35,6 & 654 & & \begin{tabular}{l|l|}
37,45 \\
\end{tabular} & 256, & 74, & 217 & 218 & 74, & 1014 & 150,67 & 8,95 & 55 & \begin{tabular}{|l|l|}
411,38 \\
\end{tabular} & 63,29 & 63,31 & 41 \\
\hline Hyla meridionalis & 29TPE43 & 101,00 & 153,35 & 97,14 & 35,97 & 5887,5 & 310,1 & 43,60 & 266,59 & 89,12 & 231,20 & 231,48 & 81,69 & 837,38 & 120,72 & 7,00 & $53,85[$ & 334,35 - & 53,38 & 53,65 & 333,63 \\
\hline Hyla meridionalis & 29TPE45 & 101,00 & 142,38 & 93,54 & 35,41 & 5824,43 & 295,68 & 34,92 & 260,76 & 74,84 & 219,54 & 219,65 & 71,49 & $\begin{array}{l}934,96 \\
\end{array}$ & 137,33 & 8,42 & 54,35 & 374,92 & 59,48 & 59,90 & 374,91 \\
\hline
\end{tabular}




\begin{tabular}{|c|c|c|c|c|c|c|c|c|c|c|c|c|c|c|c|c|c|c|c|c|c|}
\hline TAXON & UTM & $\mathrm{km} 2$ & BIO1 & BIO2 & $B 103$ & BIO4 & B105 & B106 & B107 & B108 & B109 & B1010 & BIO11 & BIO12 & BIO13 & B1014 & BIO15 & B1016 & B1017 & B1018 & 81019 \\
\hline Hyla meridionalis & 29TPE53 & 100,00 & 151,91 & 97,36 & 35,85 & 5953,50 & 309,70 & 41,55 & 268,15 & 87,23 & 230,81 & 231,01 & 79,58 & 808,77 & 115,52 & 6,97 & 53,33 & 321,81 & 52,04 & 52,23 & 319,62 \\
\hline Hyla meridionalis & 29TPE54 & 100,00 & 147,75 & 95,98 & 35,62 & 5933,51 & 304,19 & 38,06 & 266,13 & 83,16 & 226,32 & 226,50 & 75,69 & 844,05 & 121,51 & 7,38 & 53,61 & 335,96 & 54,66 & 54,79 & 334,47 \\
\hline Hyla meridionalis & 29TPE55 & 100,00 & 139,99 & 93,16 & 35,09 & 5892,53 & \begin{tabular}{|l|l|}
294,01 \\
\end{tabular} & 32,20 & 261,81 & 76,16 & 218,11 & 218,19 & 68,40 & 909,11 & 132,39 & 8,41 & 53,90 & 362,66 & 58,54 & 59,38 & 361,92 \\
\hline Hyla meridionalis & 29TPE56 & 101,00 & 128,25 & 88,22 & 34,20 & 5835,14 & \begin{tabular}{|l|}
278,60 \\
\end{tabular} & 23,79 & 254,82 & 62,95 & 205,80 & 206,08 & 57,84 & 1007,41 & 148,40 & 9,62 & 54,15 & $\begin{array}{l}403,27 \\
\end{array}$ & 64,49 & 67,35 & 403,21 \\
\hline Hyla meridionalis & 29TPE63 & 100,00 & 147,31 & 96,56 & 35,56 & 6005,60 & 305,46 & 37,25 & 268,21 & 82,40 & 227,14 & 227,18 & 74,60 & 805,58 & 114,23 & 7,23 & 52,82 & 319,18 & 52,55 & 52,87 & 315,84 \\
\hline Hyla meridionalis & 29TPE73 & 100,00 & 150,30 & $\begin{array}{ll}98,84 \\
\end{array}$ & 35,77 & 6062,09 & 310,71 & 38,27 & 272,44 & 84,43 & 230,77 & 230,80 & 76,58 & 739,65 & \begin{tabular}{|l|l|}
102,88 \\
\end{tabular} & 6,62 & 51,89 & 290,90 & 49,06 & 49,23 & 285,78 \\
\hline Hyla meridionalis & 29TPE74 & 100,00 & 151,09 & 99,45 & 35,99 & 6044,12 & 311,10 & 38,55 & 272,55 & 85,01 & 231,27 & 231,27 & 77,25 & 730,10 & 101,60 & 6,54 & 51,86 & 286,93 & 48,63 & 48,65 & 281,99 \\
\hline Hyla meridionalis & 29TPE93 & 100,00 & 159,60 & 104,03 & \begin{tabular}{l|l}
36,55 \\
\end{tabular} & 6147,39 & 324,55 & 43,22 & 281,32 & 91,70 & 240,92 & 240,92 & 84,00 & 597,31 & 79,00 & 5,03 & 50,11 & 230,72 & 40,36 & 40,36 & 222,36 \\
\hline Hyla meridionalis & 29TQE03 & 101,00 & 157,84 & 104,90 & \begin{tabular}{l|l|}
36,25 \\
\end{tabular} & 6197,98 & 324,68 & 40,68 & 284,00 & 89,63 & 240,05 & 240,05 & 81,88 & $\begin{array}{l}573,08 \\
\end{array}$ & 74,32 & 5,06 & 49,47 & 219,34 & 39,70 & 39,70 & 209,86 \\
\hline Hyla meridionalis & 29TQE04 & 100,00 & 154,81 & 104,37 & 36,24 & $\begin{array}{ll}6192,69 \\
\end{array}$ & 321,03 & $\begin{array}{ll}38,01 \\
\end{array}$ & 283,02 & 86,55 & 237,01 & 237,01 & 78,85 & 586,07 & 76,24 & 5,54 & 48,99 & 224,24 & 41,44 & 41,44 & 214,93 \\
\hline Hyla meridionalis & 29TQE14 & 100,00 & 151,00 & 105,03 & \begin{tabular}{l|l|}
36,02 \\
\end{tabular} & 6245,07 & 319,05 & 33,85 & 285,20 & 82,28 & 234,02 & 234,02 & 74,70 & 573,23 & 73,34 & 6,00 & 47,74 & 216,81 & 42,50 & 42,50 & 206,36 \\
\hline Hyla meridionalis & 29TQE15 & 100,00 & 146,55 & 104,35 & 36,06 & 6231,45 & 313,85 & 29,86 & 283,99 & 78,17 & 229,47 & 229,52 & 70,50 & \begin{tabular}{|l|l|}
592,07 \\
\end{tabular} & 76,03 & 6,48 & 47,61 & 224,16 & 44,50 & 44,61 & 213,74 \\
\hline Hyla meridionalis & 29TQE24 & 99,00 & 149,99 & 106,28 & 36,22 & 6291,31 & 319,92 & 31,59 & 288,33 & 80,97 & 233,87 & 233,87 & 73,29 & 545,39 & 69,12 & 5,95 & 46,76 & 203,85 & \begin{tabular}{ll|}
41,63 \\
\end{tabular} & 41,63 & 192,54 \\
\hline Hyla meridionalis & 29TQE33 & 100,00 & 159,17 & 108,60 & 36,74 & 6323,18 & 330,81 & $\begin{array}{ll}38,28 \\
\end{array}$ & 292,54 & 89,22 & 243,18 & 243,18 & 81,60 & \begin{tabular}{ll|}
480,89 \\
\end{tabular} & 60,47 & 5,00 & 46,54 & \begin{tabular}{|l|l|}
177,64 \\
\end{tabular} & 36,23 & 36,23 & 165,88 \\
\hline Hyla meridionalis & 29TQE36 & 101,00 & 141,63 & 107,36 & 36,79 & $\begin{array}{l}6292,12 \\
\end{array}$ & 312,02 & 22,93 & 289,09 & 72,36 & 225,59 & 225,64 & 65,01 & 539,11 & $\begin{array}{l}67,97 \\
\end{array}$ & 7,11 & 44,88 & $\begin{array}{l}198,78 \\
\end{array}$ & 44,67 & 44,72 & 186,33 \\
\hline Hyla meridionalis & 29TQE37 & 99,00 & 132,68 & 106,64 & \begin{tabular}{|l|l|}
36,72 \\
\end{tabular} & \begin{tabular}{|l|l|}
6260,68 \\
\end{tabular} & 302,26 & 15,30 & 286,96 & 64,04 & 216,10 & 216,41 & 56,71 & \begin{tabular}{|l|l|}
576,18 \\
\end{tabular} & 72,79 & 8,43 & 44,17 & 212,34 & 49,52 & 49,99 & 199,15 \\
\hline Hyla meridionalis & 29TQE43 & 100,00 & 153,78 & 109,25 & 36,69 & 6364,03 & 327,23 & 32,72 & 294,51 & 83,69 & 238,77 & 238,77 & 76,06 & $\begin{array}{l}479,93 \\
\end{array}$ & 59,67 & 5,32 & 45,56 & \begin{tabular}{|l|l|}
174,91 \\
\end{tabular} & 37,56 & 37,56 & 162,53 \\
\hline Hyla meridionalis & 29TQE44 & 100,00 & 152,58 & 109,43 & 36,98 & $\begin{array}{ll}6344,64 \\
\end{array}$ & 325,43 & 31,54 & 293,89 & 82,55 & 237,27 & 237,27 & 74,89 & 477,37 & 59,45 & 5,67 & 45,00 & 173,76 & 38,39 & 38,39 & 161,35 \\
\hline Hyla meridionalis & 29TQE45 & 100,00 & 151,61 & 109,59 & 37,00 & 6324,97 & 323,68 & 30,62 & 293,06 & 81,56 & 235,82 & 235,82 & 74,03 & $\begin{array}{l}473,99 \\
\end{array}$ & 59,14 & 5,99 & 44,33 & 172,29 & 39,09 & 39,09 & 159,80 \\
\hline Hyla meridionalis & 29TQE46 & 100,00 & 146,14 & 109,54 & 36,99 & \begin{tabular}{|l|l|}
6308,07 \\
\end{tabular} & 317,85 & 25,67 & 292,17 & 76,37 & 230,16 & 230,17 & 69,01 & \begin{tabular}{|l|l|}
487,99 \\
\end{tabular} & 61,0 & 6,55 & 43,85 & \begin{tabular}{ll|l|}
177,18 \\
\end{tabular} & 41,57 & 41,57 & 164,23 \\
\hline Hyla meridionalis & 29TQE53 & 60,00 & 149,80 & 109,92 & 36,70 & \begin{tabular}{ll|l|l|}
6408,64 \\
\end{tabular} & 324,57 & \begin{tabular}{|l|l}
27,94 \\
\end{tabular} & 296,63 & 79,16 & 235,42 & 235,42 & 71,58 & 480,32 & 59,08 & 5,85 & 44,56 & 173,02 & 39,20 & 39,20 & 160,24 \\
\hline Hyla meridionalis & 29TQE54 & 53,00 & 143,79 & 109,60 & 36,76 & 6381,46 & 318,09 & 22,92 & 295,17 & 73,69 & 229,20 & 229,32 & 66,36 & $\begin{array}{l}499,15 \\
\end{array}$ & 61,49 & 6,79 & 43,84 & 179,41 & 42,44 & 42,54 & 166,18 \\
\hline Hyla meridionalis & 29TQE55 & 57,00 & 150,76 & 110,57 & 37,00 & 6358,67 & 323,98 & 28,98 & 295,00 & 80,15 & 235,62 & 235,62 & 72,85 & 458,15 & 56,78 & 6,03 & 43,63 & \begin{tabular}{ll|}
164,68 \\
\end{tabular} & 39,14 & 39,14 & 151,80 \\
\hline Hyla meridionalis & 30STE49 & & & & & & & & & & & & & & & & & & & & \\
\hline Hyla meridionalis & 30STE59 & & & & & & & & & & & & & & & & & & & & \\
\hline Hyla meridionalis & 30STE68 & & & & & & & & & & & & & & & & & & & & \\
\hline Hyla meridionalis & 30STE69 & 90,00 & 166,92 & 83,47 & \begin{tabular}{|l|}
39,98 \\
\end{tabular} & 4208,93 & 277,68 & 71,14 & 206,55 & 123,23 & 220,05 & 223,59 & 115,12 & 848,89 & \begin{tabular}{ll|}
146,18 \\
\end{tabular} & 0,58 & 76,41 & $\begin{array}{l}404,67 \\
\end{array}$ & 13,56 & 22,34 & 401,74 \\
\hline Hyla meridionalis & 30STE79 & 80,00 & 165,85 & 86,17 & 40,60 & 4236,28 & 280,03 & 69,61 & 210,41 & 121,75 & 219,52 & 223,38 & 114,45 & 815,53 & 141,61 & 0,99 & 76,60 & 396,23 & 13,03 & 22,71 & 390,32 \\
\hline Hyla meridionalis & 30STF30 & 17,00 & 172,45 & 75,41 & 38,41 & 4164,14 & 274,41 & 81,00 & 193,41 & 129,27 & 224,23 & 228,09 & 120,68 & 769,41 & 134,77 & 0,41 & 72,95 & 352,82 & 14,77 & 22,41 & 340,09 \\
\hline Hyla meridionalis & 30STF31 & 98,00 & 172,86 & 74,49 & $\begin{array}{ll}37,92 \\
\end{array}$ & 4225,17 & 274,71 & 80,89 & 193,82 & 129,00 & 225,26 & 229,20 & 120,17 & 756,80 & 131,74 & 0,44 & 72,26 & 344,73 & 14,59 & 22,62 & 331,52 \\
\hline Hyla meridionalis & 30STF32 & 90,00 & 172,06 & 73,73 & 36,93 & 4378,73 & 275,79 & 78,71 & 197,08 & 126,41 & 226,50 & 230,49 & 1117,51 & \begin{tabular}{|l|l|}
741,70 \\
\end{tabular} & 127,34 & 1,00 & 71,14 & 333,93 & \begin{tabular}{|l|l|}
15,08 \\
\end{tabular} & 23,50 & 320,08 \\
\hline Hyla meridionalis & 30STF33 & 90,00 & 171,30 & 73,63 & 35,99 & $\begin{array}{l}4544,89 \\
\end{array}$ & 278,05 & 76,28 & 201,77 & 123,77 & 228,06 & 232,17 & 114,86 & 724,33 & 122,30 & 1,00 & 70,20 & 322,57 & 15,14 & 23,99 & 307,85 \\
\hline Hyla meridionalis & 30STF34 & 90,00 & 171,41 & 73,47 & \begin{tabular}{|l|l|}
35,17 \\
\end{tabular} & \begin{tabular}{ll|l|}
4698,44 \\
\end{tabular} & $\begin{array}{l}280,66 \\
\end{array}$ & 74,99 & 205,66 & 122,05 & 230,19 & 234,29 & 113,12 & 700,70 & \begin{tabular}{|l|l|}
115,90 \\
\end{tabular} & 1,00 & 69,12 & 308,26 & 15,67 & 24,01 & 292,74 \\
\hline Hyla meridionalis & 30STF35 & 81,00 & 172,92 & 73,12 & 34,53 & 4830,34 & 284,27 & 75,48 & 208,79 & 121,93 & 233,49 & 237,52 & 113,13 & 668,82 & \begin{tabular}{ll|}
108,03 \\
\end{tabular} & 1,00 & 68,07 & 290,48 & 15,98 & 23,88 & 274,22 \\
\hline Hyla meridionalis & $\begin{array}{l}\text { 30STF36 } \\
\end{array}$ & 80,00 & $\begin{array}{l}171,69 \\
\end{array}$ & 75,24 & 34,32 & 5009,00 & 288,16 & 71,81 & 216,35 & \begin{tabular}{|l|l|}
118,67 \\
\end{tabular} & 234,80 & 238,68 & 109,86 & 657,79 & \begin{tabular}{|l|l|}
103,48 \\
\end{tabular} & 1,00 & 67,23 & 283,17 & 16,55 & 23,91 & 266,49 \\
\hline Hyla meridionalis & 30STF38 & 72,00 & $\begin{array}{l}171,74 \\
\end{array}$ & 86,27 & 35,82 & 5325,61 & 303,23 & 65,21 & 238,02 & 114,89 & 239,46 & 242,79 & $\begin{array}{l}106,25 \\
\end{array}$ & \begin{tabular}{|c|}
637,94 \\
\end{tabular} & $\begin{array}{l}97,45 \\
\end{array}$ & 1,00 & 65,84 & 273,76 & 17,25 & 23,73 & 256,61 \\
\hline Hyla meridionalis & 30STF40 & 79,00 & 170,05 & 77,24 & $\begin{array}{l}38,86 \\
\end{array}$ & \begin{tabular}{|l|l|}
4149,76 \\
\end{tabular} & 273,55 & 77,47 & 196,08 & 127,19 & 221,86 & 225,45 & 118,45 & 822,55 & 142,23 & 0,24 & 73,99 & 380,45 & 15,04 & 22,30 & 370,92 \\
\hline Hyla meridionalis & 30STF41 & 100,00 & 172,72 & 74,78 & 38,32 & 4162,68 & 273,71 & 80,79 & 192,92 & 129,06 & 224,63 & 228,16 & 120,80 & \begin{tabular}{|l|l|}
787,68 \\
\end{tabular} & 135,86 & 0,05 & 73,02 & 361,95 & 15,05 & 22,06 & 349,54 \\
\hline Hyla meridionalis & 30STF42 & 100,00 & 172,28 & 74,59 & \begin{tabular}{l|l|}
37,45 \\
\end{tabular} & 4314,16 & 275,88 & 79,09 & 196,79 & 127,13 & 226,17 & 229,93 & 118,57 & 768,15 & 131,09 & 0,67 & 71,80 & 349,92 & 15,67 & 22,89 & 335,87 \\
\hline Hyla meridionalis & \begin{tabular}{|l|}
$30 S T F 43$ \\
\end{tabular} & 100,00 & 171,37 & 75,07 & 36,61 & 4494,42 & 278,71 & 76,42 & 202,28 & 124,26 & 227,63 & 231,55 & 115,70 & 748,11 & 125,94 & 1,00 & 70,66 & 337,59 & 15,96 & 23,63 & 322,29 \\
\hline Hyla meridionalis & 30STF44 & 100,00 & 170,27 & 76,41 & 36,06 & 4680,85 & 282,25 & 73,23 & 209,02 & 121,12 & 229,12 & 233,04 & $\begin{array}{l}112,49 \\
\end{array}$ & $\begin{array}{l}729,53 \\
\end{array}$ & \begin{tabular}{|l|l|}
120,67 \\
\end{tabular} & 1,00 & 69,77 & $\begin{array}{l}326,03 \\
\end{array}$ & 16,01 & 24,01 & 309,93 \\
\hline Hyla meridionalis & 30STF45 & 100,00 & 169,68 & 78,14 & 35,66 & 4861,25 & 286,50 & 70,68 & 215,82 & 118,62 & 231,10 & 234,95 & $\begin{array}{l}109,92 \\
\end{array}$ & 708,52 & $\begin{array}{l}114,95 \\
\end{array}$ & 1,00 & 68,80 & \begin{tabular}{|l|l|}
313,47 \\
\end{tabular} & 16,20 & 24,13 & 296,85 \\
\hline Hyla meridionalis & 30STF46 & 100,00 & 172,40 & 79,32 & 35,49 & \begin{tabular}{|l|l|}
4987,73 \\
\end{tabular} & 292,23 & 71,79 & 220,45 & 119,53 & 235,35 & 239,11 & 110,95 & \begin{tabular}{|c|}
673,38 \\
\end{tabular} & $\begin{array}{l}107,45 \\
\end{array}$ & 1,00 & 67,82 & 295,25 & 16,53 & 23,51 & 277,60 \\
\hline Hyla meridionalis & 30STF47 & 100,00 & 171,66 & 83,90 & 35,81 & 5167,62 & 298,66 & 68,02 & 230,64 & 116,63 & 237,20 & 240,68 & 108,14 & 662,66 & 103,91 & 1,00 & 66,96 & 288,72 & 17,01 & 23,58 & 271,04 \\
\hline Hyla meridionalis & $\begin{array}{l}\text { 30STF48 } \\
\end{array}$ & 100,00 & 171,85 & 89,53 & 36,60 & 5327,55 & 306,51 & 64,98 & 241,53 & 114,99 & 239,74 & 242,99 & 106,50 & 650,58 & \begin{tabular}{|l|l|}
100,83 \\
\end{tabular} & 1,00 & 66,49 & 282,57 & $\begin{array}{ll}17,13 \\
\end{array}$ & 23,46 & 264,93 \\
\hline Hyla meridionalis & 30STF50 & 100,00 & 168,95 & 78,27 & 39,21 & 4103,92 & 272,40 & 75,62 & $\begin{array}{l}196,79 \\
\end{array}$ & 126,26 & 220,38 & 223,74 & 1117,77 & 855,68 & \begin{tabular}{ll|l}
146,48 \\
\end{tabular} & 0,21 & 74,96 & 398,75 & 15,01 & 22,30 & 392,21 \\
\hline Hyla meridionalis & 30STF51 & 100,00 & 167,76 & 78,74 & 38,64 & \begin{tabular}{|l|l|}
4257,40 \\
\end{tabular} & \begin{tabular}{|l|l|}
274,60 \\
\end{tabular} & 73,17 & 201,43 & 123,72 & 221,33 & 224,81 & $\begin{array}{l}114,96 \\
\end{array}$ & 835,94 & 142,24 & 0,58 & 73,81 & $\begin{array}{l}388,02 \\
\end{array}$ & 15,32 & 23,08 & 378,19 \\
\hline Hyla meridionalis & 30STF52 & 100,00 & 169,60 & 77,73 & 38,01 & 4336,43 & 276,87 & 74,98 & 201,89 & 124,45 & 224,16 & 227,73 & 116,00 & 802,55 & 136,23 & 0,89 & 72,62 & 371,01 & 15,89 & 23,25 & 357,32 \\
\hline Hyla meridionalis & 30STF53 & 100,00 & 171,09 & 77,64 & 37,41 & 4455,91 & 280,34 & 75,76 & 204,58 & 124,36 & 227,16 & 230,82 & 116,13 & 768,19 & 129,70 & 1,00 & 71,54 & 353,12 & 16,00 & 23,21 & 336,74 \\
\hline Hyla meridionalis & 30STFS & 100,00 & 167,50 & 81,14 & 37,10 & 4709,99 & 284,60 & 68,95 & 215,66 & 118,41 & 227,11 & 230,79 & 109,68 & 760,61 & 125,99 & 1,00 & 70,60 & 346,04 & 16,13 & 24,07 & 329,51 \\
\hline Hyla meridionalis & 30STF55 & 100,00 & 165,22 & 84,72 & $\begin{array}{l}37,05 \\
\end{array}$ & 4918,91 & 289,35 & 63,82 & 225,53 & 113,95 & 227,76 & 231,43 & 105,18 & 749,39 & 121,80 & 1,00 & 69,44 & 337,26 & $\begin{array}{ll}17,08 \\
\end{array}$ & 24,59 & 320,86 \\
\hline Hyla meridionalis & 30STF56 & 100,00 & 169,24 & 85,20 & 36,86 & 5007,16 & 295,14 & 67,15 & 227,99 & 116,47 & 232,86 & 236,40 & 108,03 & 708,52 & \begin{tabular}{|l|l|}
114,43 \\
\end{tabular} & 1,00 & 68,59 & 316,82 & 16,82 & 23,70 & 298,76 \\
\hline Hyla meridionalis & 30STF57 & 100,00 & 169,81 & 89,57 & 37,21 & 5177,85 & 302,29 & 64,88 & 237,41 & 114,88 & 235,72 & 239,06 & 106,60 & 688,84 & 109,76 & $1, \mathrm{C}$ & 67,71 & 305,73 & 17,10 & 23,52 & 287,59 \\
\hline Hyla meridionalis & 305 & 100, & 173,72 & 99,87 & 38 & 5464 & 319,76 & 63, & 256,55 & 115 & 243 & 246 & 10 & 643 & 100 & 1,00 & 66,33 & 282,79 & 17,21 & 22,81 & 26 \\
\hline Hyla meridionalis & 30STF60 & 100,00 & 163,12 & 85,08 & 39,39 & 4376,18 & 278,43 & 65,18 & 213,25 & 118,40 & 218,60 & 222,23 & 109,53 & 853,79 & \begin{tabular}{ll|}
144,88 \\
\end{tabular} & 0,93 & 75,37 & 403,55 & 14,45 & 23,76 & 398,62 \\
\hline Hyla meridionalis & 30STF61 & 100,00 & 164,61 & 83,27 & 39,14 & 4365,90 & 278,12 & 67,86 & 210,26 & 120,64 & 219,93 & 223,56 & 111,16 & 840,99 & \begin{tabular}{|l|l|}
143,07 \\
\end{tabular} & 1,00 & 74,27 & 396,99 & 15,20 & 23,82 & 386,95 \\
\hline Hyla meridionalis & 30STF62 & 100,00 & 165,14 & 82,93 & \begin{tabular}{|l|}
38,78 \\
\end{tabular} & \begin{tabular}{|l|l|}
4449,51 \\
\end{tabular} & 279,79 & 68,02 & 211,77 & 119,86 & 221,57 & 225,24 & 110,77 & 820,39 & 138,76 & 1,00 & 73,24 & 384,86 & 15,59 & 23,91 & 371,59 \\
\hline Hyla meridiona & 30ST & 100,00 & 16 & 84,68 & 38, & 621 & 283,21 & 65,09 & 2 & 2 & 222 & 22 & 107,74 & 800,63 & 133 & 1,01 & 71,88 & 371,84 & 16,41 & 50 & 35 \\
\hline Hyla meridionalis & 30STF64 & 100,00 & 153,75 & 92,74 & 38,40 & 5011,22 & 287,09 & 48,51 & 238,58 & 102,94 & 218,40 & 221,77 & 93,13 & 819,93 & \begin{tabular}{|l|l|}
131,07 \\
\end{tabular} & 1,40 & 70,22 & \begin{tabular}{|l|l|}
371,48 \\
\end{tabular} & 18,62 & 27,59 & 360,28 \\
\hline Hyla meridionalis & 30STF65 & 100,00 & 165,30 & 87,84 & 37,91 & 4897,96 & 291,96 & 63,35 & 228,62 & 114,42 & 227,81 & 231,30 & 105,79 & 754,59 & 123,63 & 1,03 & 69,99 & 344,99 & 16,89 & 24,36 & 327,48 \\
\hline
\end{tabular}




\begin{tabular}{|c|c|c|c|c|c|c|c|c|c|c|c|c|c|c|c|c|c|c|c|c|c|}
\hline TAXON & UTM & $\mathrm{km} 2$ & B101 & B102 & $\mathrm{BIO3}$ & B104 & B105 & B106 & B107 & B108 & B109 & B1010 & BIO11 & BIO12 & B1013 & BIO14 & BIO15 & B1016 & B1017 & BIO18 & B1019 \\
\hline Hyla meridionalis & 30STF66 & 100,00 & 165,34 & 90,67 & 37,88 & 5056,80 & 297,25 & 61,18 & 236,06 & 112,45 & 230,04 & 233,33 & 103,99 & 737,02 & 119,37 & 1,00 & 69,04 & 333,87 & 17,22 & 24,32 & 315,92 \\
\hline Hyla meridionalis & 30STF68 & 100,00 & 171,47 & 97,29 & 38,64 & 5297,85 & 312,87 & 63,87 & 249,01 & 115,13 & 239,32 & 242,31 & 107,15 & 674,89 & 108,22 & 1,00 & 67,69 & 302,13 & 17,01 & 23,00 & 283,13 \\
\hline Hyla meridionalis & $\begin{array}{l}\text { 30STF69 } \\
\end{array}$ & 100,00 & 172,93 & 102,83 & 39,14 & 5452,05 & 321,68 & 62,42 & 259,26 & 114,55 & 242,83 & 245,58 & 106,81 & 654,38 & 104,17 & 1,00 & 67,05 & 291,10 & 16,96 & 22,61 & 272,50 \\
\hline Hyla meridionalis & 30STF70 & 100,00 & 170,76 & 82,27 & 40,56 & 4070,03 & 278,45 & 77,89 & 200,57 & 129,87 & 222,10 & 225,97 & 121,34 & 806,82 & 143,07 & 1,00 & 76,03 & 396,34 & 13,86 & 22,01 & 381,87 \\
\hline Hyla meridionalis & 30STF71 & 100,00 & 168,40 & 83,23 & 40,00 & 4224,27 & 279,62 & 73,68 & 205,94 & 126,16 & 221,77 & 225,72 & 117,17 & 808,52 & 141,14 & 1,00 & 75,01 & 393,01 & 14,41 & 22,69 & 376,83 \\
\hline Hyla meridionalis & 30STF72 & 100,00 & 166,30 & 84,93 & 39,37 & 4410,77 & 282,35 & 69,29 & 213,06 & 121,98 & 222,38 & 226,13 & 112,89 & 800,83 & 137,35 & 1,00 & 73,74 & 383,87 & 15,21 & 23,45 & 367,23 \\
\hline Hyla meridionalis & 30STF73 & 100,00 & 163,52 & 87,45 & 39,04 & $\begin{array}{lll}4622,44 \\
\end{array}$ & 285,46 & 63,84 & 221,63 & 116,84 & 222,47 & 226,19 & 107,54 & 793,29 & 133,20 & 1,00 & 72,50 & 374,14 & 15,97 & 24,37 & 357,96 \\
\hline Hyla meridionalis & 30STF74 & 100,00 & 158,09 & 92,03 & 38,87 & 4898,94 & 288,79 & 54,41 & 234,38 & 108,48 & 221,05 & 224,46 & \begin{tabular}{|l|}
98,97 \\
\end{tabular} & 797,05 & 129,72 & 1,23 & 70,83 & 367,79 & 17,65 & 26,06 & 353,45 \\
\hline Hyla meridionalis & 30STF75 & 100,00 & 157,73 & 94,24 & 38,77 & 5045,92 & 292,93 & 52,28 & 240,65 & 106,20 & 222,78 & 226,04 & 96,92 & 784,05 & 126,18 & 1,29 & 69,82 & 358,35 & 18,22 & 26,35 & 343,30 \\
\hline Hyla meridionalis & 30STF76 & 100,00 & 162,57 & 94,47 & 38,71 & 5093,79 & 298,56 & 57,03 & 241,52 & $\begin{array}{l}109,78 \\
\end{array}$ & 228,15 & 231,24 & 101,07 & 750,01 & 121,26 & 1,13 & 69,25 & 342,29 & 17,83 & 25,01 & 324,72 \\
\hline Hyla meridionalis & 30STF78 & 100,00 & 164,69 & 100,93 & 38,99 & 5369,97 & 310,85 & 55,05 & 255,80 & 108,20 & 233,97 & 236,78 & 99,91 & 714,16 & 113,74 & 1,04 & 67,65 & 320,81 & 18,01 & 24,51 & 302,89 \\
\hline Hyla meridionalis & 30STF80 & 43,00 & 175,91 & 82,28 & 41,56 & 3927,69 & 281,94 & 86,09 & 195,84 & 137,66 & 225,39 & 229,80 & 129,36 & 749,14 & 138,61 & 1,00 & 76,92 & 382,69 & 13,02 & 20,77 & 358,81 \\
\hline Hyla meridionalis & 30STF81 & 100,00 & 173,15 & 83,09 & \begin{tabular}{|l|l|}
40,87 \\
\end{tabular} & 4074,54 & 282,17 & 81,16 & 201,01 & 133,03 & 224,64 & 228,83 & 124,45 & 760,43 & 137,52 & 1,00 & 75,86 & 382,20 & 13,55 & 21,39 & 358,96 \\
\hline Hyla meridionalis & 30STF82 & 100,00 & 173,59 & 83,40 & 40,32 & 4196,64 & 284,72 & 80,30 & 204,42 & 131,67 & 226,76 & 230,81 & 123,30 & 749,50 & 133,75 & 1,00 & 74,76 & 371,99 & 14,12 & 21,54 & 348,06 \\
\hline Hyla meridionalis & 30STF83 & 100,00 & 173,10 & 84,66 & 39,84 & 4358,86 & 287,95 & 77,71 & 210,25 & 129,07 & 228,36 & 232,25 & 120,63 & 739,53 & 129,64 & 1,00 & 73,58 & 361,28 & 14,88 & 21,88 & 337,73 \\
\hline Hyla meridionalis & 30STF84 & 100,00 & 159,27 & 93,11 & 39,21 & 4853,83 & 290,15 & 55,91 & 234,24 & 110,40 & 221,77 & 225,12 & 100,94 & 779,16 & 127,61 & 1,32 & 71,04 & 363,68 & 17,39 & 25,77 & 347,73 \\
\hline Hyla meridionalis & 30STF85 & 100,00 & 147,33 & 100,24 & 39,00 & 5242,53 & 291,33 & 37,85 & 253,47 & 94,49 & 215,79 & 218,57 & 84,58 & 816,53 & 126,63 & 2,14 & 68,67 & 367,17 & 21,33 & 30,02 & 356,10 \\
\hline Hyla meridionalis & 30STF86 & 100,00 & 139,97 & 104,57 & 39,00 & 5481,88 & 291,96 & 26,83 & 265,13 & 84,45 & 212,01 & 214,44 & 74,54 & 840,73 & 126,14 & 2,85 & 66,86 & 369,18 & 24,63 & 33,24 & 359,97 \\
\hline Hyla meridionalis & 30STF87 & 100,00 & 144,08 & 105,08 & 39,00 & 5527,88 & 297,17 & 30,56 & 266,61 & 87,53 & 216,61 & 219,03 & 77,99 & 815,38 & 123,04 & 2,60 & 66,53 & 358,10 & 23,87 & 31,97 & 346,90 \\
\hline Hyla meridionalis & 30STF88 & 100,00 & 159,18 & 103,34 & 39,01 & 5441,13 & 308,69 & 47,81 & 260,88 & 102,47 & 229,94 & 232,45 & 93,75 & 739,03 & 116,06 & 1,46 & 67,26 & 330,99 & 19,64 & 26,47 & 314,51 \\
\hline Hyla meridionalis & 30STF89 & 100,00 & 164,97 & 105,62 & 39,37 & 5509,10 & 317,27 & 52,51 & 264,76 & 106,85 & 236,40 & 238,74 & 98,66 & 703,42 & 111,41 & 1,05 & 67,10 & 314,99 & 18,34 & 24,40 & 297,42 \\
\hline Hyla meridionalis & 30STF90 & & & & & & & & & & & & & & & & & & & & \\
\hline Hyla meridionalis & 30STF91 & 39,00 & 176,17 & 83,33 & \begin{tabular}{|l|l|l|}
41,17 & \\
\end{tabular} & 4017,94 & 284,50 & 85,06 & 199,44 & 137,06 & 226,75 & 231,21 & 128,54 & 719,27 & 131,94 & 1,00 & 76,06 & 365,92 & 13,00 & 20,62 & 341,06 \\
\hline Hyla meridionalis & 30STF92 & 93,00 & 174,60 & 84,83 & 40,84 & 4174,83 & 286,67 & 81,19 & 205,48 & 133,55 & 227,43 & 231,57 & 124,91 & 713,66 & 128,04 & 1,00 & 74,88 & 357,33 & 13,87 & 21,17 & 333,13 \\
\hline Hyla meridionalis & 30STF93 & 100,00 & 166,98 & 89,40 & 40,09 & 4514,49 & 288,77 & 68,36 & 220,41 & 122,21 & 224,76 & 228,44 & 113,05 & 735,55 & 125,81 & 1,13 & 72,92 & 356,18 & 15,45 & 23,38 & 336,01 \\
\hline Hyla meridionalis & 30STF94 & 100,00 & 159,15 & 94,59 & 39,62 & 4860,97 & 291,42 & 55,28 & 236,14 & 110,56 & 221,89 & 225,26 & 100,99 & 759,01 & 124,04 & 1,38 & 70,95 & 355,90 & 17,41 & 25,68 & 339,61 \\
\hline Hyla meridionalis & 30STF95 & 100,00 & 151,72 & 99,36 & 39,19 & 5148,58 & 293,22 & $\begin{array}{l}3,20 \\
43,49\end{array}$ & 249,72 & $\begin{array}{ll}99,93 \\
90\end{array}$ & $\begin{array}{l}218,81 \\
2181\end{array}$ & 221,64 & \begin{tabular}{|c|}
90,19 \\
\end{tabular} & 783,50 & $\begin{array}{l}123,22 \\
123,4\end{array}$ & $\begin{array}{l}1,1,91 \\
1,1\end{array}$ & 69,12 & 357,32 & $\begin{array}{l}1,19,93 \\
193\end{array}$ & 28,33 & 343,75 \\
\hline Hyla meridionalis & 30STF96 & 100,00 & 140,76 & 105,24 & 39,02 & 5472,22 & 292,95 & 27,36 & 265,59 & 85,59 & 212,85 & 215,11 & 75,54 & 823,41 & 123,36 & 2,90 & 66,79 & 362,83 & 24,15 & 32,79 & 353,24 \\
\hline Hyla meridionalis & 30STF97 & 100,00 & 150,34 & 103,86 & 39,00 & 5436,48 & 300,43 & 38,15 & 262,28 & 94,78 & 221,63 & 223,92 & 85,39 & 776,73 & 119,36 & 2,20 & 67,05 & 346,44 & 21,62 & 29,46 & 332,90 \\
\hline Hyla meridionalis & 30STF98 & 100,00 & 156,77 & 104,40 & 39,06 & 5475,32 & 307,66 & 44,50 & 263,16 & 100,01 & 228,30 & 230,60 & 91,14 & 743,66 & 115,82 & 1,85 & 67,04 & 332,79 & 20,44 & 27,36 & 317,06 \\
\hline Hyla meridionalis & 30STF99 & 100,00 & 162,62 & 106,09 & 39,23 & 5534,61 & 315,61 & 49,36 & 266,25 & 104,63 & 234,77 & 236,86 & 96,04 & 712,37 & 111,81 & 1,42 & 66,75 & 318,54 & 19,35 & 25,61 & 301,63 \\
\hline Hyla meridionalis & 30STG34 & 56,00 & 185,45 & 121,81 & 39,35 & $\frac{653,12,18}{6122}$ & 361,35 & 年, & 305,29 & $\begin{array}{l}118,62 \\
104\end{array}$ & 264,96 & $\begin{array}{l}260,50 \\
2665\end{array}$ & $\begin{array}{r}09,75 \\
109,75\end{array}$ & 574,53 & \begin{tabular}{|l|}
86,42 \\
86,
\end{tabular} & 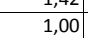 & 60,36 & \begin{tabular}{|l|}
244,78 \\
\end{tabular} & 18,00 & 22,00 & 230,79 \\
\hline Hyla meridionalis & 30STG39 & 40,00 & 170,22 & 122,02 & 38,84 & 6377,82 & 352,44 & 40,78 & 311,65 & 100,87 & 253,89 & 254,67 & 91,93 & 593,58 & 82,44 & 2,22 & 59,20 & 239,95 & 22,91 & 27,60 & 228,11 \\
\hline Hyla meridionalis & 30STG41 & 100,00 & 180,59 & 108,40 & 39,07 & 5727,80 & 336,93 & 62,84 & 274,09 & 118,44 & 254,23 & 256,61 & 110,24 & 594,63 & 90,80 & 1,00 & 64,95 & 257,31 & 17,29 & 22,00 & 240,40 \\
\hline Hyla meridionalis & 30STG43 & 100,00 & 181,69 & 119,12 & 39,88 & 6025,71 & 352,62 & 56,32 & 296,30 & 116,07 & 260,01 & 261,71 & 107,65 & 592,01 & 89,27 & 1,00 & 64,06 & 253,86 & 18,01 & 22,01 & 238,95 \\
\hline Hyla meridionalis & 30STG44 & 100,00 & 183,53 & 121,81 & 39,90 & 6117,17 & 358,86 & 55,53 & 303,33 & 116,78 & 263,25 & 264,59 & 108,12 & 581,99 & 87,18 & 1,00 & 63,46 & 248,29 & 18,00 & 22,00 & 234,10 \\
\hline Hyla meridionalis & 30STG45 & 100,00 & 183,83 & 122,90 & 39,83 & 6180,29 & 361,25 & 54,79 & 306,46 & 116,39 & 264,59 & 265,65 & 107,65 & 573,19 & 84,99 & 1,00 & 63,01 & 242,74 & 18,00 & 22,00 & 229,10 \\
\hline Hyla meridionalis & 30STG46 & 100,00 & 182,42 & 122,99 & 39,41 & 6229,88 & 361,25 & 53,28 & 307,97 & 114,58 & 264,03 & 264,75 & 105,65 & 570,93 & 83,33 & 1,17 & 62,17 & 239,24 & 18,65 & 22,78 & 226,07 \\
\hline Hyla meridionalis & 30STG47 & 100,00 & 175,54 & 122,95 & 39,06 & 6315,07 & 356,46 & 45,87 & 310,59 & 106,78 & 258,24 & 259,07 & 97,82 & 593,90 & 84,53 & 1,76 & 60,90 & 245,11 & 20,94 & 25,34 & 232,64 \\
\hline Hyla meridionalis & 30STG48 & 100,00 & 174,66 & 123,03 & 39,00 & 6355,98 & 356,75 & $\begin{array}{ll}44,67 \\
\end{array}$ & 312,08 & 105,38 & 258,06 & 258,77 & 96,49 & 588,01 & 82,80 & 2,04 & 60,20 & 240,29 & 21,39 & 25,70 & 228,30 \\
\hline Hyla meridionalis & \begin{tabular}{|l|l|}
30 STG49 \\
\end{tabular} & 100,00 & 165,69 & 122,71 & 38,70 & 6434,94 & 349,90 & 35,92 & 313,99 & 95,88 & 250,41 & 251 & 87,03 & 620,24 & 85,77 & 2,65 & 58,86 & 249,59 & 24,31 & 29,03 & 238,44 \\
\hline Hyla meridionalis & 30STG50 & 100,00 & 177,03 & 105,44 & 39,14 & 5583,52 & 329,56 & 63,59 & 265,97 & \begin{tabular}{|l|}
116,68 \\
1100
\end{tabular} & 248,59 & 251,21 & \begin{tabular}{|c|}
108,93 \\
\end{tabular} & |618,46 & 96,50 & 1,00 & $\begin{array}{ll}6,200 \\
66,22\end{array}$ & 271,26 & 16,58 & 21,61 & 253,39 \\
\hline Hyla meridionalis & 30STG55 & 100,00 & 181,37 & 123,03 & 39,98 & 6195,43 & 358,79 & 53,10 & 305,69 & 113,67 & 262,20 & 263,24 & 105,06 & 586,47 & 86,35 & 1,00 & 63,07 & 248,40 & 18,00 & 22,19 & 234,90 \\
\hline Hyla meridionalis & 30STG56 & 100,00 & 183,18 & 123,41 & 39,64 & 6237,61 & 361,81 & 53,85 & 307,96 & 115,05 & 264,77 & 265,45 & 106,17 & 571,86 & 83,34 & 1,00 & 62,52 & 240,11 & 18,05 & 22,14 & 227,19 \\
\hline Hyla meridionalis & 30STG57 & 100,00 & 178,89 & 124,02 & 39,27 & 6320,81 & 360,30 & 48,86 & 311,45 & 110,09 & 261,71 & 262,37 & 100,99 & 584,72 & 83,77 & 1,46 & 61,38 & 241,95 & 19,40 & 23,80 & 229,87 \\
\hline Hyla meridionalis & 30STG58 & 100,00 & 168,71 & 123,92 & 39,00 & 6427,23 & 353,35 & 38,44 & $\begin{array}{l}114,92 \\
314,\end{array}$ & $\begin{array}{ll}99,08 \\
9\end{array}$ & 253,38 & 254,00 & \begin{tabular}{|c|}
90,12 \\
\end{tabular} & 621,32 & 87,25 & 2,6 & $\begin{array}{ll}1,03 \\
59,98\end{array}$ & 252,34 & 22,64 & 27,19 & 241,33 \\
\hline Hyla meridionalis & 30STG59 & 100,00 & 162,75 & 123,58 & 38,49 & 6489,78 & 349,12 & 32,60 & 316,52 & 92,60 & 248,53 & 249,06 & 83,68 & 639,22 & 88,46 & 2,5 & 58,97 & 255,99 & 24,94 & 29,09 & 245,75 \\
\hline Hyla meridionalis & $\begin{array}{l}\text { 30STG60 } \\
\end{array}$ & 100,00 & 174,76 & 108,79 & 39,92 & 5594,85 & 330,94 & 61,34 & 269,60 & 114,40 & 246,56 & 249,06 & \begin{tabular}{|l|}
106,93 \\
\end{tabular} & 634,01 & 100,54 & 1,00 & 66,62 & 280,69 & 16,59 & 21,63 & 262,52 \\
\hline Hyla meridionalis & 30STG67 & 100,00 & 175,46 & 124,19 & 39,23 & 6358,80 & 357,91 & 45,78 & 312,14 & 106,27 & 259,13 & 259,64 & 97,48 & 605,06 & 87,20 & 1,63 & 61,45 & 249,46 & 19,86 & 24,03 & 238,20 \\
\hline Hyla meridiona & 30STG68 & 100,00 & 168,27 & 124,46 & 38,92 & 6463,01 & 353,97 & 37,80 & 316,17 & 98,27 & 253,63 & 253,86 & 89,14 & 629,00 & 88,82 & 2,00 & 60,12 & 54,86 & 22,39 & 25,94 & 244,62 \\
\hline Hyla meridionalis & \begin{tabular}{|l}
30 STG69 \\
3
\end{tabular} & 100,00 & $\frac{100}{158}$ & $\begin{array}{l}123,40 \\
123,72\end{array}$ & 38,13 & $\begin{array}{l}\frac{640,0,01}{6543,04} \\
\end{array}$ & 346,16 & $\begin{array}{l}\frac{11,00}{27,98} \\
\end{array}$ & \begin{tabular}{|l|}
318,18 \\
318
\end{tabular} & 80,73 & $\mid \begin{array}{l}245,06 \\
245\end{array}$ & \begin{tabular}{|l|}
245,34 \\
240
\end{tabular} & $\begin{array}{l}03,14 \\
78,92\end{array}$ & 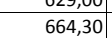 & $\begin{array}{ll}0,026 \\
91,73\end{array}$ & 2,86 & $\begin{array}{ll}58,72 \\
\end{array}$ & \begin{tabular}{|l|}
264,30 \\
\end{tabular} & \begin{tabular}{|l|l|}
26,15 \\
2,3
\end{tabular} & 28,46 & 254,02 \\
\hline Hyla meridionalis & 30STG78 & 100,00 & 168,50 & 124,56 & 38,92 & 6485,80 & 354,55 & 37,93 & 316,62 & 98,37 & 254,24 & 254,40 & 89,27 & 633,13 & 89,94 & 2,00 & 60,40 & 255,87 & 21,89 & 24,68 & 246,41 \\
\hline Hyla meridionalis & 30STG79 & 100,00 & 158,45 & 124,13 & $38,25 \mid$ & 6569,95 & 347,11 & 27,77 & 319,34 & 87,62 & 245,74 & 245,83 & 78,66 & 668,05 & 92.56 & 2,95 & 58,80 & 264.99 & 25,84 & 27.06 & 256,60 \\
\hline Hyla meridionalis & 30STG88 & 100,00 & 171,70 & 124,24 & 38,91 & 6496,07 & 357,21 & 40,91 & 316,29 & 101,11 & 257,59 & 257,70 & 92,28 & 624,53 & 89,52 & 2,00 & 60,71 & 252,07 & 20,61 & 22,20 & 243,36 \\
\hline Hyla meridiona & 30STG89 & 100,00 & 165,30 & 124,77 & 38,4 & 6580,47 & 353,79 & 33,74 & 320,05 & 93,88 & 252,60 & 252,63 & 85,04 & 643,30 & 90,31 & 2,47 & 59,56 & 255,34 & 23,07 & 23,72 & 24 \\
\hline Hyla meridionalis & |30STG91 & $\begin{array}{l}100,00 \\
\end{array}$ & $\begin{array}{l}10,50 \\
168,78\end{array}$ & $\begin{array}{l}124,11 \\
11,41\end{array}$ & 年0,45 & $\begin{array}{l}030,4)^{2} \\
575,98\end{array}$ & 329,38 & $\begin{array}{ll}51,78 \\
51,78\end{array}$ & \begin{tabular}{|l|}
270,605 \\
277
\end{tabular} & \begin{tabular}{|r|}
30,00 \\
107,57 \\
\end{tabular} & \begin{tabular}{|l|}
243,88 \\
240
\end{tabular} & \begin{tabular}{|l|}
245,63 \\
245
\end{tabular} & $\begin{array}{l}95,34 \\
99,31 \\
\end{array}$ & \begin{tabular}{|l|}
672,11 \\
672,11
\end{tabular} & \begin{tabular}{|r|r|}
105,18 \\
\end{tabular} & $\begin{array}{l}2,447 \\
1,06\end{array}$ & $\begin{array}{l}3,30 \\
65,85 \\
\end{array}$ & \begin{tabular}{|l|}
296,474 \\
296
\end{tabular} & $\begin{array}{l}5,01 \\
18,01 \\
\end{array}$ & 23,129 & $\begin{array}{l}24,04 \\
280,25\end{array}$ \\
\hline Hyla meridionalis & 30STG97 & 100,00 & 180,20 & 122,08 & 39,01 & 6349,77 & 359,43 & 50,93 & 308,51 & 111,03 & 263,92 & 264,04 & 101,95 & 600,20 & 88,64 & 1,05 & 62,49 & 246,44 & 17,11 & 19,23 & 237,14 \\
\hline Hyla meridionalis & 30STG98 & 100,00 & 173,99 & 123,66 & 38,80 & 6501,44 & 358,65 & 43,13 & 315,52 & 103,21 & 260,03 & 260,10 & 94,35 & 621,06 & 89,58 & 1,93 & 61,14 & 250,08 & 19,47 & 20,25 & 242,25 \\
\hline Hyla meridionalis & 30STG99 & 100,00 & 168,38 & 124,53 & 38,18 & 6596,17 & 356,69 & 36,42 & 320,2 & 96,58 & 256,00 & $256, \mathrm{C}$ & 87,88 & 634,99 & 89,69 & 2,26 & 59,99 & 251,33 & 21,56 & 21,75 & 244,56 \\
\hline Hyla meridionalis & 30STH30 & 38,00 & 162,02 & 121,69 & 38,05 & 6437,09 & 346,07 & 32,84 & 313,24 & 92,33 & 246,85 & 247,60 & 83,40 & 623,24 & 85,07 & 2,93 & 57,98 & 248,53 & 26,09 & 30,42 & 237,40 \\
\hline
\end{tabular}




\begin{tabular}{|c|c|c|c|c|c|c|c|c|c|c|c|c|c|c|c|c|c|c|c|c|c|}
\hline TAXON & UTM & $\mathrm{km} 2$ & B101 & B102 & $\mathrm{BIO3}$ & 8104 & B105 & B106 & B107 & B108 & B109 & BIO10 & BIO11 & BIO12 & B1013 & BIO14 & BIO15 & B1016 & B1017 & B1018 & B1019 \\
\hline Hyla meridionalis & 30STH40 & 100,00 & 160,71 & 122,37 & 38,23 & 6479,99 & 346,34 & 31,07 & 315,27 & 90,63 & 246,38 & 246,83 & 81,72 & 633,15 & 86,42 & 2,97 & 58,00 & 251,74 & 26,43 & 30,23 & 241,17 \\
\hline Hyla meridionalis & 30STH41 & 100,00 & 160,59 & 122,44 & 38,03 & \begin{tabular}{|l|}
6501,08 \\
\end{tabular} & 346,94 & 30,69 & 316,24 & 90,13 & 246,60 & 246,97 & 81,27 & 623,32 & 84,59 & 3,05 & 57,23 & 245,85 & 26,93 & 30,72 & 235,46 \\
\hline Hyla meridionalis & 30STH42 & 100,00 & 151,34 & 121,54 & 37,99 & \begin{tabular}{|l|}
6546,37 \\
\end{tabular} & 339,06 & 22,35 & 316,71 & 81,06 & 238,43 & 238,74 & 72,14 & 658,05 & 87,87 & 3,93 & 55,88 & 256,05 & 31,06 & 34,19 & 246,37 \\
\hline Hyla meridionalis & 30STH43 & 100,00 & 152,44 & 121,60 & 38,00 & 6564,90 & 340,64 & 23,11 & 317,53 & 81,97 & 239,73 & 240,03 & 72,92 & 641,43 & 85,26 & 4,01 & 55,44 & 247,99 & 30,97 & 34,01 & 238,21 \\
\hline Hyla meridionalis & 30STH50 & 100,00 & 154,55 & 122,76 & 38,00 & \begin{tabular}{|l|l|}
6541,03 \\
\end{tabular} & 342,21 & 24,70 & 317,51 & 84,12 & 241,26 & 241,71 & 75,17 & 667,25 & 90,76 & 3,32 & 57,67 & 263,34 & 28,34 & 32,51 & 253,95 \\
\hline Hyla meridionalis & 30STH51 & 100,00 & 153,72 & 122,75 & 38,00 & 6576,28 & 342,43 & 23,63 & 318,80 & 82,89 & 241,05 & 241,33 & 74,09 & 661,33 & 89,25 & 3,54 & 56,83 & 258,68 & 29,39 & 32,99 & 249,47 \\
\hline Hyla meridionalis & 30STH55 & 100,00 & 155,17 & 122,07 & 37,85 & 6633,65 & 344,99 & 24,61 & 320,37 & 83,29 & 243,63 & 243,64 & 74,65 & 606,76 & 79,93 & 3,98 & 54,26 & 230,53 & 30,33 & 30,50 & 221,18 \\
\hline Hyla meridionalis & \begin{tabular}{|l|l|}
30 STH58 \\
\end{tabular} & 100,00 & 160,03 & 120,83 & 37,06 & 6641,15 & 348,80 & 29,68 & 319,12 & 87,60 & 248,34 & 248,34 & 79,01 & 546,29 & 71,27 & 3,55 & 52,77 & 203,87 & 29,41 & 29,41 & 193,80 \\
\hline Hyla meridionalis & 30STH59 & 100,00 & 158,08 & 120,01 & 37,01 & 6644,11 & 346,61 & 28,50 & 318,10 & 85,85 & 246,69 & 246,69 & 77,37 & 543,94 & 70,90 & 3,76 & 51,89 & 201,49 & 30,76 & 30,76 & 191,24 \\
\hline Hyla meridionalis & 30STH60 & 100,00 & 154,76 & 123,63 & 38,00 & 6584,50 & 343,96 & 24,34 & 319,62 & 83,79 & 242,28 & 242,47 & 74,96 & 669,32 & 91,24 & 3,44 & 57,66 & 263,09 & 28,16 & 29,76 & 254,51 \\
\hline Hyla meridionalis & 30STH61 & 100,00 & 152,05 & 123,47 & 38,00 & 6622,53 & 342,36 & 21,54 & 320,82 & 80,86 & 240,30 & 240,46 & 72,04 & 670,25 & 90,40 & 3,68 & 56,78 & 260,80 & 29,55 & 31,25 & 252,50 \\
\hline Hyla meridionalis & 30STH62 & 100,00 & 157,57 & 123,87 & 38,00 & 6630,11 & 347,98 & 26,14 & 321,84 & 85,75 & 245,83 & 245,90 & 76,93 & 634,27 & 85,54 & 3,25 & 56,54 & 245,70 & 27,79 & 28,80 & 237,15 \\
\hline Hyla meridionalis & 30STH63 & 100,00 & 157,68 & 123,72 & 38,00 & 6652,56 & 348,56 & 26,31 & 322,26 & 85,60 & 246,30 & 246,33 & 76,89 & 621,23 & 83,23 & 3,33 & 56,03 & 238,75 & 28,07 & 28,60 & 230,16 \\
\hline Hyla meridionalis & 30STH64 & 100,00 & 154,32 & 123,17 & \begin{tabular}{|l|l|}
37,97 \\
\end{tabular} & 6682,70 & 345,85 & 23,28 & 322,57 & 82,10 & 243,38 & 243,40 & 73,25 & 623,00 & 82,64 & 4,00 & 54,93 & 236,89 & 30,16 & 30,75 & 228,46 \\
\hline Hyla meridionalis & 30STH65 & 100,00 & 154,76 & 122,96 & 37,73 & 6691,52 & 346,54 & 23,53 & 323,01 & 82,50 & 243,94 & 243,94 & 73,56 & 607,96 & 80,52 & 4,00 & 54,32 & 229,53 & 30,39 & 30,42 & 221,02 \\
\hline Hyla meridionalis & 30STH66 & 100,00 & 152,23 & 122,15 & 37,22 & 6697,95 & 343,97 & 21,39 & 322,58 & 79,81 & 241,83 & 241,83 & 71,41 & 607,75 & 80,32 & 4,09 & 53,43 & 227,41 & 31,95 & 31,95 & 218,64 \\
\hline Hyla meridionalis & 30STH67 & 100,00 & 153,41 & 121,93 & 37,29 & 6697,93 & 344,63 & 22,75 & 321,87 & 80,85 & 242,91 & 242,91 & 72,37 & 589,51 & 77,81 & 4,05 & 52,76 & 219,29 & 31,78 & 31,78 & 210,29 \\
\hline Hyla meridionalis & 30STH68 & 100,00 & 158,55 & 121,57 & 37,19 & 6686,85 & 349,00 & 27,63 & 321,37 & 85,77 & 247,87 & 247,87 & 77,34 & 551,79 & 72,81 & 3,78 & 52,64 & 204,48 & 29,63 & 29,63 & 195,11 \\
\hline Hyla meridionalis & 30STH70 & 100,00 & 151,81 & 123,86 & 38,00 & 6621,13 & 342,24 & 21,17 & 321,08 & 80,58 & 240,03 & 240,17 & 71,88 & 685,67 & 93,23 & 3,73 & 57,39 & 267,92 & 29,08 & 30,53 & 260,25 \\
\hline Hyla meridionalis & 30STH72 & 100,00 & 161.12 & 124,65 & 38,00 & 6671,75 & 352.56 & 28,79 & 323,77 & 88,78 & 249,95 & 249,95 & 79,81 & $\mid 621,28$ & 84,23 & 3,12 & 57,01 & 239,88 & 26,17 & 26,17 & 232,06 \\
\hline Hyla meridionalis & 30STH73 & 100,00 & 157,96 & 124,19 & 38,00 & 6695,41 & 350,16 & 25,70 & 324,46 & 85,29 & 247,26 & 247,26 & 76,62 & 621,96 & 83,71 & 3,38 & 55,96 & 237,66 & 27,83 & 27,83 & 229,96 \\
\hline Hyla meridionalis & 30STH75 & 100,00 & 155,29 & 123,65 & 37,63 & 6738,76 & 348,04 & 23,29 & 324,75 & 82,23 & 245,27 & 245,27 & 73,59 & 606,42 & 81,36 & 4,00 & 54,31 & 227,60 & 29,78 & 29,78 & 219,78 \\
\hline Hyla meridionalis & 30STH76 & 100,00 & 152,99 & 122,95 & \begin{tabular}{|l|l|}
37,08 \\
\end{tabular} & $\begin{array}{ll}6744,62 \\
\end{array}$ & 346,10 & 21,23 & 324,86 & 80,04 & 243,23 & 243,23 & 71,27 & 602,77 & 80,62 & 4,09 & 53,45 & 224,19 & 31,37 & 31,37 & 216,19 \\
\hline Hyla meridionalis & \begin{tabular}{|l|}
30 STH78 \\
\end{tabular} & 100,00 & 158,94 & 122,04 & 37,07 & 6726,54 & 350,29 & 27,17 & 323,12 & 85,86 & 248,81 & 248,81 & 77,15 & 548,75 & 73,09 & 3,63 & 52,59 & 201,97 & 29,17 & 29,17 & 193,23 \\
\hline Hyla meridionalis & 30STH79 & 100,00 & 161,64 & 121,60 & 37,05 & 6709,72 & 352,14 & 29,99 & 322,15 & 88,46 & 251,24 & 251,24 & 79,87 & 522,23 & 69,38 & 3,30 & 52,32 & 191,36 & 28,09 & 28,09 & 182,27 \\
\hline Hyla meridionalis & 30STH80 & 100,00 & 159,47 & 124,72 & 38,00 & 6639,36 & 350,07 & 27,82 & 322,25 & 87,76 & 247,96 & 247,97 & 78,89 & 656,20 & 90,41 & 3,03 & 58,29 & 256,68 & 25,59 & 25,70 & 249,59 \\
\hline Hyla meridionalis & 30STH81 & 100,00 & 164,93 & 124,97 & 38,00 & 6622,85 & 355,81 & 32,29 & 323,52 & 92,55 & 253,64 & 253,64 & 83,63 & 622,20 & $\begin{array}{l}0,41+72 \\
85\end{array}$ & 2,64 & 58,18 & 241,91 & 23,87 & 23,87 & $\begin{array}{l}234,87 \\
234,87\end{array}$ \\
\hline Hyla meridionalis & 30STH82 & 100,00 & 160,47 & 124,88 & 37,99 & 6717,64 & 353,05 & 27,63 & 325,43 & 87,61 & 250,08 & 250,08 & 78,63 & 626,84 & 85,41 & 3,14 & 57,05 & 240,49 & 26,13 & 26,13 & 233,82 \\
\hline Hyla meridionalis & 30STH83 & 100,00 & 152,89 & 124,35 & 37,89 & 6749,92 & 346,89 & 20,61 & 326,28 & 79,97 & 243,25 & 243,25 & 71,38 & 644,83 & 87,63 & 3,99 & 55,49 & 243,88 & 29,88 & 29,88 & 237,43 \\
\hline Hyla meridionalis & 30STH85 & 100,00 & 153,88 & 124,01 & 37,63 & 6775,67 & 347,84 & 21,45 & 326,39 & 80,45 & 244,69 & 244,69 & 72,05 & 611,90 & 83,02 & 4,00 & 54,14 & 227,90 & 30,21 & 30,21 & 221,07 \\
\hline Hyla meridionalis & 30STH86 & 100,00 & 156,58 & 123,79 & 37,37 & 6782,16 & 350,26 & 23,82 & 326,44 & 82,86 & 247,33 & 247,33 & 74,38 & 585,63 & 79,31 & 3,89 & 53,74 & 216,73 & 29,32 & 29,32 & 209,48 \\
\hline Hyla meridionalis & 30STH87 & 100,00 & 153,78 & 123,07 & 37,00 & 6781,37 & 347,53 & 21,35 & \begin{tabular}{|l|}
326,18 \\
\end{tabular} & $\begin{array}{ll}8,100 \\
80,12\end{array}$ & \begin{tabular}{|l|}
244,73 \\
\end{tabular} & \begin{tabular}{|l|}
244,73 \\
\end{tabular} & 71,63 & $\begin{array}{l}582,79 \\
\end{array}$ & $\begin{array}{l}78,53 \\
\end{array}$ & $\begin{array}{l}3,111 \\
4,11\end{array}$ & 52,72 & 213,69 & 31,03 & 31,03 & 206,22 \\
\hline Hyla meridionalis & 30STH88 & 100,00 & 155,86 & 122,67 & 37,00 & 6769,27 & 348,66 & 23,55 & 325,12 & 82,16 & 246,48 & 246,48 & 73,69 & 559,13 & 75,05 & 3,98 & 52,15 & 203,81 & 30,58 & 30,58 & 195,84 \\
\hline Hyla meridionalis & 30STH89 & 100,00 & 160,79 & 122,07 & 37,01 & 6751,70 & 352,34 & 28,51 & 323,83 & 87,16 & 251,17 & 251,17 & 78,56 & 523,03 & 69,94 & 3,46 & 52,02 & 189,93 & 28,30 & 28,30 & 181,55 \\
\hline Hyla meridionalis & 30STH9O & 100,00 & 165,87 & 124,90 & 38,01 & 6649,20 & 356,02 & 33,41 & 322,61 & 93,65 & 254,33 & 254,33 & 84,77 & 634,47 & 88,36 & 2,52 & 59,05 & 247,76 & 22,97 & 22,97 & 241,61 \\
\hline Hyla meridionalis & 30STH91 & 100,00 & 163,51 & 124,97 & 37,99 & 6701,95 & 355,13 & 30,47 & 324,66 & 90,71 & 252,71 & 252,71 & 81,61 & 631,52 & 87,42 & 2,86 & 58,05 & 243,73 & 24,30 & 24,30 & 237,81 \\
\hline Hyla meridionalis & 30STH94 & 100,00 & 155,75 & 124,84 & 37,59 & 6791,60 & 350,71 & 22,55 & 328,16 & 82,34 & 246,94 & 246,94 & 73,25 & 617,97 & 85,14 & 3,79 & 55,09 & 230,59 & 28,66 & 28,66 & 224,83 \\
\hline Hyla meridionalis & 30STH95 & 100,00 & 154,11 & 124,24 & 37,09 & 6804,66 & 349,13 & 21,09 & 328,03 & 80,45 & 245,41 & 245,41 & 71,63 & 609,40 & 83,61 & 4,01 & 54,18 & 225,23 & 29,96 & 29,96 & 219,28 \\
\hline Hyla meridionalis & 30STH97 & 100,00 & 159,33 & 123,80 & 37,09 & 6807,79 & 353,41 & 25,99 & 327,42 & 85,22 & 250,69 & 250,69 & 76,50 & 555,60 & 75,74 & 3,37 & 53,54 & 203,08 & 27,64 & 27,64 & 196,31 \\
\hline Hyla meridionalis & 30STH98 & 100,00 & 154,08 & 123,05 & 37,01 & 6809,59 & 348,09 & 21,13 & 326,96 & 79,90 & 245,35 & 245,35 & 71,55 & 563,20 & 76,05 & 4,14 & 51,94 & 203,41 & 31,01 & 31,01 & 196,29 \\
\hline Hyla meridionalis & 30STJ44 & 90,00 & 162,42 & 115,44 & 36,93 & 6560,68 & 345,72 & 35,69 & 310,02 & 90,72 & 249,89 & 249,89 & 82,45 & 479,24 & 61,85 & 3, & 49,47 & 174,85 & 30,70 & 30,70 & 163,08 \\
\hline Hyla meridionalis & 30STJ45 & 90,00 & 155,14 & 114,11 & 36,52 & 6576,14 & 338,30 & 29,58 & 308,71 & 83,58 & $\begin{array}{l}243,04 \\
\end{array}$ & 243,04 & 75,36 & 505,07 & $\begin{array}{l}1,050 \\
65,06\end{array}$ & 4,2 & 48,59 & $\begin{array}{l}183,02 \\
\end{array}$ & 34,39 & 34,39 & 171,02 \\
\hline Hyla meridionalis & $\begin{array}{l}30 \text { TIJ55 } \\
\end{array}$ & 100,00 & 158,09 & 115,29 & 36,66 & 6600,31 & 342,14 & 31,33 & 310,82 & 86,12 & 246,40 & 246,40 & 77,93 & 481,99 & 61,95 & 4,14 & 48,14 & $\begin{array}{l}173,26 \\
\end{array}$ & 32,86 & 32,86 & 161,53 \\
\hline Hyla meridionalis & 30STJ57 & 100,00 & 153,24 & 113,56 & 36,34 & 6576,88 & 335,72 & 27,88 & 307,84 & 81,56 & 241,36 & 241,36 & 73,40 & 485,68 & 61,27 & 4,99 & 46,87 & 173,18 & 35,75 & 35,75 & 160,91 \\
\hline Hyla meridionalis & 30STJ60 & 100,00 & 162,60 & 120,19 & 37,01 & 6670,16 & 351,09 & 32,07 & 319,02 & 89,56 & 251,53 & 251,53 & 81,13 & 507,73 & 66,73 & 3,06 & 51,73 & 186,28 & 28,21 & 28,21 & 176,27 \\
\hline Hyla meridionalis & 30 STJ62 & 100,00 & 166,71 & 118,79 & 37,00 & 6630,30 & 352,93 & 36,76 & $\mid 316,17$ & \begin{tabular}{|l|l|}
93,99 \\
3
\end{tabular} & 255,07 & 255,07 & 85,52 & 466,96 & $\begin{array}{l}0,83 \\
60,83\end{array}$ & 3,00 & 50,72 & $\begin{array}{l}169,80 \\
\end{array}$ & 27,38 & $\begin{array}{l}20,11 \\
27,38\end{array}$ & 159,24 \\
\hline Hyla meridionalis & 30STJ64 & 100,00 & 162,51 & 117,17 & 37,00 & 6632,60 & 347,78 & 33,68 & 314,10 & 89,64 & 251,03 & 251,03 & 81,49 & 464,40 & 59,96 & 3,73 & 48,80 & 166,62 & 29,91 & 29,91 & 155,51 \\
\hline Hyla meridionalis & 30STJ70 & 100,00 & 162,94 & 120,93 & 37,00 & 6711,61 & 352,53 & 31,34 & 321,19 & 89,45 & 252,49 & 252,49 & 80,99 & 503,63 & 66,61 & 3,16 & 51,62 & 183,48 & 27,84 & 27,84 & 174,04 \\
\hline Hyla meridionalis & 30STJ73 & 100,00 & 165,03 & 118,73 & 37,00 & 6656,66 & 351,75 & 34,71 & 317,04 & 91,92 & 253,87 & 253,87 & 83,65 & 457,19 & 59,44 & 3,02 & 49,79 & 163,93 & 27,85 & 27,85 & 153,66 \\
\hline Hyla meridionalis & 30STJ78 & 100,00 & 149,32 & 115,03 & 36,47 & 6607,44 & 332,96 & 22,44 & 310,52 & 77,11 & 238,01 & 238,01 & 69,21 & 468,16 & 57,26 & 5,28 & 44,98 & 162,83 & 36,89 & 36,89 & 150,40 \\
\hline Hyla meridionalis & $30 \mathrm{TTS}$ & 100,00 & 142,30 & 1121,46 & $30,47,00$ & \begin{tabular}{|l|l|}
6739,35 \\
\end{tabular} & $\begin{array}{l}352, \\
352, \\
\end{array}$ & $\begin{array}{l}2,44 \\
30,08\end{array}$ & \begin{tabular}{|l|}
322,90 \\
320
\end{tabular} & $\begin{array}{ll}11,11 \\
88,63\end{array}$ & \begin{tabular}{|l|}
252,38 \\
\end{tabular} & \begin{tabular}{|l|}
252,38 \\
\end{tabular} & $\begin{array}{l}\mid c 5,14 \\
79,85\end{array}$ & $\begin{array}{l}\mid l 00,10 \\
502,74\end{array}$ & $\begin{array}{l}31,26 \\
66,85 \\
\end{array}$ & $\frac{3,20}{3,20}$ & $\begin{array}{l}44,40 \\
51,45\end{array}$ & \begin{tabular}{|l|}
181,60 \\
181,68
\end{tabular} & $\begin{array}{l}30,09 \\
27,79\end{array}$ & 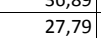 & $\begin{array}{l}350,40 \\
172,88\end{array}$ \\
\hline Hyla meridionalis & 30STIS1 & 100,00 & 163,48 & 120,86 & 37,00 & 6732,77 & 353,18 & 31,55 & 321,62 & 89,64 & 253,32 & 253,32 & 81,22 & 484,17 & 63,95 & 3,17 & 50,84 & 173,96 & 27,62 & 27,62 & 164,79 \\
\hline Hyla meridionalis & 30STJ83 & 100,00 & 164,26 & 119,30 & 37,00 & 6693,97 & 351,82 & 33,32 & 318,50 & $\begin{array}{l}91,13 \\
91,13\end{array}$ & \begin{tabular}{|l|}
253,90 \\
\end{tabular} & 253,90 & 82,54 & 454,95 & \begin{tabular}{|l|l|}
59,16 \\
\end{tabular} & 3,09 & $\begin{array}{l}0,496 \\
49,66\end{array}$ & 161,80 & 27,59 & 27,59 & 151,82 \\
\hline Hyla meridionalis & 30STJ85 & 100,00 & 156,96 & 117,95 & 36,97 & 6694,57 & 344,17 & 27,14 & 317,03 & 83,64 & 246,83 & 246,83 & 75,42 & 460,36 & 58,52 & 4,14 & 47,29 & 161,05 & 31,85 & 31,85 & 150,23 \\
\hline Hyla meridionalis & 30STIS8 & 100,00 & 139,32 & 115,41 & 36,44 & 6633,73 & 324,53 & 12,55 & 311,98 & 67,20 & 228,75 & 228,76 & 59,59 & 498,80 & 59,71 & 6,71 & 43,49 & 170,82 & 42,19 & 42,20 & 158 \\
\hline Hyla meridionalis & 30STJ91 & $\begin{array}{l}100,00 \\
\end{array}$ & $\begin{array}{l}13,22 \\
160,67\end{array}$ & 121,41 & 37,00 & $\begin{array}{l}\mid 6057,1 / 12 \\
6770,12\end{array}$ & 351,61 & \begin{tabular}{l|l}
28,18 \\
28,
\end{tabular} & \begin{tabular}{|l|}
323,43 \\
32,4
\end{tabular} & $\begin{array}{l}1,20 \\
86,43\end{array}$ & \begin{tabular}{|l|}
251,34 \\
251
\end{tabular} & $\begin{array}{l}251,34 \\
251,3\end{array}$ & \begin{tabular}{|l|}
78,01 \\
78,01
\end{tabular} & \begin{tabular}{|l|}
491,00 \\
491,08
\end{tabular} & $\begin{array}{ll}30,1 / 9 \\
64,97\end{array}$ & $\begin{array}{l}0,1 / 4 \\
3,69\end{array}$ & $\begin{array}{l}5,44 \\
50,11 \\
\end{array}$ & \begin{tabular}{|l|l|l|l|l}
174,53 \\
\end{tabular} & 29,03 & $\begin{array}{ll}29,03 \\
2903\end{array}$ & $\begin{array}{l}150,02 \\
165,92\end{array}$ \\
\hline Hyla meridionalis & 30STJ92 & 100,00 & 162,71 & 120,71 & 37,00 & 6751,35 & 352,47 & 30,39 & 322,09 & 91,52 & 253,05 & 253,05 & 80,01 & 468,96 & 61,53 & 3,40 & 49,86 & 165,95 & 28,06 & 28,06 & 156,97 \\
\hline Hyla meridionalis & 30STJ94 & 100,00 & 158,84 & 119,27 & 37,00 & 6728.99 & 347.22 & 27,64 & 319.58 & 86,10 & 248.96 & 248.96 & 76,88 & 458,23 & 58,68 & 4,08 & 47,70 & $\mid 159,69$ & 30,84 & 30,84 & 149,71 \\
\hline Hyla meridionalis & 30STK41 & 70,00 & 160,83 & 111,62 & 36,88 & 6438,31 & 337,22 & 37,00 & 300,22 & 89,67 & 246,68 & 246, & 81, & 435,49 & 53,34 & 4,25 & 45 & 156,26 & 32,98 & 32,98 & 143,93 \\
\hline Hyla meridionalis & 30STK42 & 61,00 & 159,72 & 111,47 & 37,00 & 6405,93 & 335,10 & 36,22 & 298,88 & 88,79 & 244,95 & 244,95 & 80,91 & 433,38 & 53,14 & 4,72 & 45,05 & 155,24 & 33,98 & 33,98 & 142,80 \\
\hline
\end{tabular}




\begin{tabular}{|c|c|c|c|c|c|c|c|c|c|c|c|c|c|c|c|c|c|c|c|c|c|}
\hline TAXON & UTM & $\mathrm{km} 2$ & BIO1 & B102 & $\mathrm{BIO3}$ & B104 & B105 & B106 & B107 & B108 & B109 & BIO10 & BIO11 & BIO12 & B1013 & B1014 & 81015 & BIO16 & 81017 & B1018 & \begin{tabular}{|l|} 
B1019 \\
\end{tabular} \\
\hline Hyla meridionalis & 30STK51 & 100,00 & 161,28 & 112,52 & 36,93 & 6469,97 & 338,53 & 36,40 & 302,13 & 89,56 & 247,40 & 247,40 & 81,93 & 420,85 & 51,29 & 4,13 & 45,34 & 149,64 & 32,44 & 32,44 & 137,23 \\
\hline Hyla meridionalis & 30STK52 & 100,00 & 161,90 & 112,44 & 37,00 & 6442,02 & 338,05 & 37,23 & 300,82 & 90,26 & 247,52 & 247,52 & 82,78 & 411,27 & 50,17 & 4,20 & 44,75 & 146,01 & 32,27 & 32,27 & 133,61 \\
\hline Hyla meridionalis & 30STK61 & 100,00 & 161,41 & 113,45 & 37,00 & 6464,10 & 339,30 & 35,73 & 303,57 & 89,90 & 247,71 & 247,71 & 82,00 & 405,86 & 49,08 & 4,07 & 44,62 & 142,62 & 31,97 & 31,97 & 130,32 \\
\hline Hyla meridionalis & 30STK71 & 100,00 & 159,49 & 114,03 & 37,00 & 6506,11 & 338,62 & 32,78 & 305,84 & $\begin{array}{l}94,35 \\
\end{array}$ & 246,32 & 246,32 & 79,77 & 400,66 & 47,97 & 4,71 & 43,70 & 138,88 & 32,83 & 32,83 & 126,42 \\
\hline Hyla meridionalis & 30STK72 & 100,00 & 160,40 & 114,00 & 37,00 & 6459,10 & 338,21 & 34,19 & 304,02 & \begin{tabular}{|l|l|}
108,40 \\
\end{tabular} & 246,64 & 246,64 & \begin{tabular}{l|l|l|}
81,15 \\
\end{tabular} & 388,79 & 46,46 & 5,00 & 43,09 & 134,24 & 32,95 & 32,95 & 121,76 \\
\hline Hyla meridionalis & 30STK81 & 100,00 & 157,36 & 114,90 & 37,00 & 6538,47 & 337,27 & 30,14 & 307,14 & 109,29 & 244,77 & 244,77 & 77,19 & 397,06 & 46,97 & 5,00 & 43,09 & \begin{tabular}{|l|l|}
135,98 \\
\end{tabular} & 33,42 & 33,42 & 123,21 \\
\hline Hyla meridionalis & 30STK82 & 100,00 & 159,99 & 114,49 & 37,00 & 6497,45 & 338,29 & 33,01 & 305,28 & 118,40 & 246,75 & 246,75 & 80,04 & 379,04 & 44,91 & 5,00 & 42,66 & 130,14 & 32,23 & 32,23 & 117,00 \\
\hline Hyla meridionalis & 30STK90 & 100,00 & 154,91 & 115,74 & 36,95 & 6592,40 & 337,13 & 26,57 & 310,57 & 112,30 & 243,39 & 243,39 & 74,49 & 403,36 & 47,36 & 5,11 & 42,98 & 137,03 & 34,03 & 34,03 & 123,97 \\
\hline Hyla meridionalis & 30STK91 & 100,00 & 158,53 & 115,07 & 37,00 & 6558,74 & 338,88 & 30,31 & \begin{tabular}{|l|}
308,57 \\
\end{tabular} & \begin{tabular}{|l|l|}
116,44 \\
\end{tabular} & 246,30 & 246,30 & 78,05 & 382,92 & 44,90 & 5,00 & 42,83 & 130,80 & 32,58 & 32,58 & 117,11 \\
\hline Hyla meridionalis & 30STK92 & 100,00 & 158,97 & 115,00 & 37,00 & 6517,41 & 337,92 & 31,26 & 306,66 & $\begin{array}{ll}116,95 \\
\end{array}$ & 246,07 & 246,07 & 78,94 & 372,09 & 43,72 & 5,00 & 42,38 & 127,20 & 32,20 & 32,20 & 113,03 \\
\hline Hyla meridionalis & 30SUF03 & 82,00 & 169,39 & 89,49 & 40,47 & 4467,10 & 290,21 & 71,31 & 218,90 & 125,21 & 226,56 & 230,21 & 116,17 & 700,22 & 120,39 & 1,22 & 73,03 & 341,09 & 15,43 & 22,72 & 320,33 \\
\hline Hyla meridionalis & 30SUF06 & 100,00 & 141,85 & 105,55 & 39,09 & 5464,68 & 294,05 & 28,43 & 265,62 & \begin{tabular}{|c|}
86,67 \\
\end{tabular} & 213,94 & 216,01 & 76,81 & 802,06 & 120,23 & 3,02 & 66,62 & 354,21 & 24,06 & 32,49 & 343,76 \\
\hline Hyla meridionalis & 30SUF09 & 100,00 & 153,81 & 107,61 & 39,00 & 5651,03 & 310,21 & 38,57 & 271,64 & 95,21 & 228,32 & 229,94 & 86,20 & 742,10 & 112,92 & 2,29 & 65,64 & 326,77 & 22,01 & 28,98 & 312,48 \\
\hline Hyla meridionalis & 30SUF13 & 41,00 & 177,76 & 86,60 & 40,55 & 4321,56 & 293,13 & 81,98 & \begin{tabular}{|l|l|}
211,15 \\
\end{tabular} & 135,25 & 232,73 & 236,49 & 126,22 & 639,44 & 112,78 & 1,00 & 73,62 & 317,35 & 14,11 & 20,27 & 294,35 \\
\hline Hyla meridionalis & 30SUF15 & 100,00 & 137,05 & 106,49 & 39,38 & 5453,24 & 289,99 & 23,00 & 266,99 & 82,54 & 209,28 & 211,17 & 72,27 & $\begin{array}{l}805,45 \\
\end{array}$ & 119,46 & 3,47 & 66,20 & 353,64 & 25,29 & 34,08 & 345,22 \\
\hline Hyla meridionalis & $30 S U F 24$ & 94,00 & 168,45 & 92,06 & 40,05 & 4652,58 & 293,99 & 66,92 & 227,07 & 122,51 & 228,58 & 231,67 & 113,12 & 654,52 & 109,13 & 1,48 & 71,20 & 313,71 & 16,63 & 23,23 & 294,45 \\
\hline Hyla meridionalis & 30 SUF 25 & 100,00 & 151,94 & 100,82 & 39,72 & 5156,42 & 294,15 & 42,55 & 251,60 & 100,47 & 219,74 & 221,94 & 90 & 720,34 & 111,42 & 2,52 & 67,90 & 328,08 & 20,82 & 28,60 & 314,10 \\
\hline Hyla meridionalis & 30SUF34 & 86,00 & 168,50 & 91,96 & 39,99 & 4679,37 & 294,07 & 66,24 & 227,83 & 122,48 & 229,17 & 232,01 & 113,01 & 630,40 & 103,78 & 1,59 & 70,51 & 301,26 & 16,97 & 23,19 & 282,53 \\
\hline Hyla meridionalis & 30SUF35 & 100,00 & 158,75 & 97,82 & 39,57 & 5031,04 & 295,61 & 51,20 & 244,41 & 108,57 & 224,73 & 226,96 & 98,93 & 671,78 & 105,65 & 2,26 & 68,27 & 310,74 & 19,50 & 26,30 & 294,46 \\
\hline Hyla meridionalis & 30SUF43 & & & & & & & & & & & & & & & & & & & & \\
\hline Hyla meridionalis & 30SUF44 & 99,00 & 175,94 & 87,81 & 39,80 & 528,52 & 294,53 & 75,85 & 218,68 & 131,70 & 234,36 & 237,40 & 122,17 & 584,84 & 98,22 & 1,33 & 71,14 & 283,83 & 16,13 & 21,07 & 263,71 \\
\hline Hyla meridionalis & 30 SUF 46 & 100,00 & 178,09 & \begin{tabular}{|l|l|}
89,38 \\
\end{tabular} & 39,01 & 4774, & 301,57 & 74,88 & 226,69 & 130,14 & 240,01 & 242,55 & 121,06 & 595,38 & \begin{tabular}{|r|}
100,12 \\
12
\end{tabular} & 1,28 & 70,45 & 285,75 & 16,65 & 21,29 & 263,75 \\
\hline Hyla meridionalis & 30 SUF54 & 49,00 & 180,49 & 85,28 & 39,21 & 4478,44 & 295,30 & 80,95 & 214,34 & 136,74 & 238,13 & 241,05 & 127,16 & 556,48 & 94,54 & 1,16 & 71,26 & 271,38 & 15,97 & 20,07 & 250,74 \\
\hline Hyla meridionalis & 30SUF55 & 100,00 & 166,07 & 93,57 & 39,03 & 4922,22 & 296,25 & 59,76 & 236,49 & 117,03 & 230,54 & 232,58 & 107,47 & 602,98 & 97,23 & 2,34 & 68,10 & 281,26 & 19,05 & 24,29 & 263,55 \\
\hline Hyla meridionalis & 30SUF56 & 100,00 & 179,54 & 87,59 & 38,50 & 4770,36 & 300,70 & 76,10 & 224,60 & 131,76 & 241,54 & 243,85 & 122,45 & 574,20 & 97,38 & 1,66 & 70,02 & 275,22 & 17,46 & 21,11 & 253,32 \\
\hline Hyla meridionalis & 30SUF65 & 71,00 & 178,18 & 86,28 & 38,39 & 4686,09 & 296,79 & 75,63 & 221,16 & 131,94 & 239,13 & 241,45 & 122,25 & 553,97 & 93,95 & 1,93 & 69,95 & 265,73 & 17,57 & 21,24 & 245,09 \\
\hline Hyla meridionalis & 30SUF66 & 100,00 & \begin{tabular}{|l|l|}
181,38 \\
181
\end{tabular} & $\begin{array}{l}80,20 \\
85,40\end{array}$ & 38,01 & 4744,54 & $\mid$ & 78,08 & 221,63 & $\mid 134,01$ & 243,11 & 242,45 & $\begin{array}{l}124,25 \\
124,52\end{array}$ & $\mid$ & $\begin{array}{ll}04,13 \\
94,1\end{array}$ & 1,94 & $\mid 69,57$ & $\begin{array}{l}\mid 263,15 \\
263,32\end{array}$ & 17,94 & $\begin{array}{l}21,24 \\
21,02\end{array}$ & 241,76 \\
\hline Hyla meridionalis & 30 SUF67 & 100,00 & 170,32 & 93,93 & 38,20 & 5138,18 & 303,49 & 61,14 & 242,35 & \begin{tabular}{|l|l|}
117,80 \\
\end{tabular} & 238,01 & 239,35 & 108,82 & 573,92 & 93,08 & 2,34 & 66,71 & \begin{tabular}{l|l}
264,25 \\
\end{tabular} & 18,82 & 23,33 & 245,63 \\
\hline Hyla meridionalis & 30 SUF68 & 100,00 & 160,01 & 101,65 & 38,30 & 5489,69 & 306,78 & 45,54 & 261,24 & \begin{tabular}{|l|}
103,07 \\
\end{tabular} & 233,11 & 233,63 & 94,37 & 604,52 & 93,12 & 3,17 & 64,03 & 268,35 & 21,43 & 25,48 & 252,56 \\
\hline Hyla meridionalis & 30SUF69 & 100,00 & 148,18 & 108,52 & 38,10 & 5824,46 & 308,79 & 29,03 & 279,76 & 87,60 & 226,42 & 226,51 & 78,91 & 649,50 & 94,31 & 4,30 & 61,40 & 276,40 & 25,32 & 26,83 & 264,26 \\
\hline Hyla meridionalis & 30SUF76 & 60,00 & 178,71 & \begin{tabular}{|c|}
86,90 \\
8,
\end{tabular} & 37,95 & 4863,15 & 300,02 & 73,37 & 226,66 & 129,82 & 242,24 & 244,01 & 120,51 & 525,85 & 87,91 & 2,07 & 67,84 & 246,26 & 17,54 & 21,09 & 227,32 \\
\hline Hyla meridionalis & 30SUF77 & 100,00 & 159,55 & 100,20 & 38,38 & 5393,29 & 303,62 & 46,13 & 257,50 & \begin{tabular}{|l|l|}
104,07 \\
\end{tabular} & 231,38 & 231,93 & 95,20 & 575,35 & 88,88 & 3,26 & 63,66 & 255,70 & 21,20 & 24,50 & 240,32 \\
\hline Hyla meridionalis & 30SUF79 & 100,00 & 146,45 & 109,68 & 38,06 & 5890,52 & 309,60 & 26,14 & 283,45 & $\begin{array}{l}84,89 \\
\end{array}$ & 225,82 & 225,82 & 76,33 & 629,21 & 90,48 & 4,67 & 60,19 & 264,72 & 26,09 & 26,35 & 253,12 \\
\hline Hyla meridionalis & 30SUF89 & 100,00 & 138,18 & 113,21 & 38,01 & 6037,40 & 308,46 & 15,46 & 293,00 & 75,24 & 219,99 & 219,99 & 66,65 & 639,85 & 88,60 & 5,89 & 57,88 & 261,41 & 29,57 & 29,63 & 252,07 \\
\hline Hyla meridionalis & 30SUF96 & 57,00 & 178,52 & 89,16 & 38,00 & 4952,90 & 303,42 & 71,3 & 232,08 & 127,89 & 243,63 & 244,81 & $\mid 119,07$ & 456,51 & 73,92 & 2,04 & 65,26 & 209,08 & 15,84 & 19,48 & 193,53 \\
\hline Hyla meridionalis & 30SUF97 & 100,00 & 175,94 & 91,94 & 37,94 & 5114,45 & 306,17 & 66,45 & 239,72 & \begin{tabular}{|l|l|}
123,09 \\
\end{tabular} & 243,52 & 244,29 & 114,42 & 464,87 & 74,74 & 2,26 & 64,55 & 210,69 & 16,53 & 20,02 & 194,90 \\
\hline Hyla meridionalis & 30SUF98 & 100,00 & 164,71 & 100,24 & 38,00 & 5490,06 & 309,73 & 49,53 & 260,20 & 107,06 & 238,20 & 238,29 & 98,92 & 499,38 & 77,35 & 3,34 & 61,90 & 218,94 & 19,81 & 20,69 & 203,59 \\
\hline Hyla meridionalis & $\begin{array}{l}\text { 30SUF99 } \\
\end{array}$ & 100,00 & 131,28 & 115,92 & 38,00 & 6159,14 & 307,14 & 6,72 & 300,42 & 67,43 & 214,93 & 214,93 & 58,55 & 651,95 & 87,41 & 7,08 & 55,91 & 259,09 & 33,13 & 33,13 & 251,82 \\
\hline Hyla meridionalis & 30SUG07 & 100,00 & 178,95 & 121,29 & 38,99 & 6379,80 & 358,43 & 49,71 & 308,72 & 109,61 & 263,26 & 263,31 & 100,66 & 612,95 & 90,28 & 1,50 & 62,29 & 249,83 & 17,50 & 18,83 & 241,77 \\
\hline Hyla meridionalis & 30SUG09 & 100,00 & 171,41 & 90 & 38,02 & 601,14 & 359,11 & 39,39 & 319,72 & 99,62 & 259,17 & 259,17 & 90,60 & 629,89 & 89,50 & 2,11 & 60,41 & 248,30 & 20,38 & 20,38 & 242,66 \\
\hline Hyla meridionalis & 30SUG17 & 100,00 & \begin{tabular}{|l|l|l|l|l|}
176,59 \\
\end{tabular} & 120,83 & 38,41 & $\begin{array}{l}6426,45 \\
6426\end{array}$ & $\mid 357,16$ & 46,85 & 310,31 & \begin{tabular}{|c|}
106,78 \\
\end{tabular} & 261,70 & 261,72 & 97,71 & 630,39 & $\begin{array}{ll}92,22 \\
2,2\end{array}$ & 2,00 & $\begin{array}{l}62,41 \\
62,09\end{array}$ & 254,40 & 18,00 & 18,23 & 248,02 \\
\hline Hyla meridionalis & 30SUG19 & 100,00 & \begin{tabular}{|l|l|}
170,83 \\
\end{tabular} & 12 & 38,00 & 6637,60 & 358,88 & 38,45 & 320,44 & 98,80 & 259,16 & 259,16 & 89,47 & 637,10 & 91,01 & 2,26 & 60,45 & 249,29 & 20,32 & 20,32 & 245,07 \\
\hline Hyla meridionalis & 30SUG28 & 100,00 & 178,36 & \begin{tabular}{|l|}
121,08 \\
121,08
\end{tabular} & 38,00 & 6541,79 & 361,68 & 46,696 & 314,99 & \begin{tabular}{|l|l|}
106,93 \\
\end{tabular} & 265,16 & 265,16 & $\begin{array}{l}\mid c 0,47,76 \\
97,7\end{array}$ & 623,62 & $\begin{array}{l}90,72 \\
0,1\end{array}$ & 2,00 & $\begin{array}{ll}62,02 \\
62,02\end{array}$ & 246,41 & $\begin{array}{l}21,23 \\
17,23\end{array}$ & 17,23 & 242,49 \\
\hline Hyla meridionalis & 30 SUG29 & 100,00 & 171,23 & 122,66 & 37,88 & 6667,74 & 359,38 & 38 & 321,03 & 100,62 & 260,12 & 260,12 & 89,40 & 638,74 & 92,99 & 2,38 & 60,78 & 248,38 & 19,95 & 19,95 & 244,96 \\
\hline Hyla meridionalis & 30SUG33 & 100,00 & 170,43 & 111,18 & 38,29 & 6014,66 & 334,47 & 48,73 & 285,74 & 106,37 & 250,28 & 250,43 & 97,68 & 644,45 & 96,44 & 2,01 & 63,51 & 273,78 & 19,10 & 22,07 & 262,59 \\
\hline Hyla meridionalis & 30SUG34 & 100,00 & \begin{tabular}{|l|l|}
175,81 \\
\end{tabular} & \begin{tabular}{|l|}
112,36 \\
112,
\end{tabular} & 38,18 & $\begin{array}{l}6089,49 \\
6089\end{array}$ & | & $\begin{array}{l}40,13 \\
52,48\end{array}$ & 280,14 & 110,43 & $\begin{array}{l}\mid 250,20 \\
256,49\end{array}$ & $\begin{array}{l}250,45 \\
256,55\end{array}$ & \begin{tabular}{|l|r|}
101,55 \\
101
\end{tabular} & $\begin{array}{l}64,435 \\
626,32\end{array}$ & $\begin{array}{l}\mid 0,4,4 \\
93,86 \\
\end{array}$ & 2,00 & $\begin{array}{l}03,3,4 \\
63,44\end{array}$ & \begin{tabular}{|l|}
263,17 \\
\end{tabular} & $\begin{array}{l}17,10 \\
17,58\end{array}$ & 219,36 & 253,45 \\
\hline Hyla meridionalis & 30 SUG 36 & 100,00 & 174,02 & 116,99 & 37,99 & 6375,32 & 350,62 & 46,18 & 304,44 & \begin{tabular}{|l|l|l|}
105,03 \\
\end{tabular} & 258,75 & 258,75 & 96,00 & \begin{tabular}{|l|l|}
637,83 \\
\end{tabular} & 93,10 & 2,00 & 62,23 & 258,14 & 18,25 & 18,25 & 252,49 \\
\hline Hyla meridionalis & 30SUG38 & 100,00 & 176,44 & 120,40 & 37,75 & 6576,82 & 360,40 & 44,73 & 315,68 & 106,72 & 264,12 & 264,12 & 95,58 & 632,80 & 93,53 & 2,01 & 62,00 & 248,47 & 17,71 & 17,71 & 245,31 \\
\hline Hyla meridionalis & 30SUG39 & 100,00 & 172,72 & 121,66 & 37,46 & 6673,92 & 360,28 & 39,7 & 320,55 & 103,10 & 261,75 & 261,75 & 90,77 & 634,97 & 94,36 & 2,40 & 60,84 & 247,91 & 19,40 & 19,40 & 242,96 \\
\hline Hyla meridionalis & 30 SUG40 & 100,00 & 16 & 10 & 38,48 & 566 & 31 & & 268 & 105 & 239 & 240 & 96,60 & 643,79 & 97,35 & 2,44 & 64 & 283,87 & 20,00 & 25,60 & 268,63 \\
\hline Hyla meridionalis & $\begin{array}{l}305004041 \\
30 S U G\end{array}$ & $\begin{array}{l}100,00 \\
100\end{array}$ & $\begin{array}{l}104,02 \\
163,92 \\
\end{array}$ & \begin{tabular}{|l|}
104,02 \\
107,10
\end{tabular} & $\begin{array}{l}30,40 \\
38,08\end{array}$ & $\begin{array}{l}3000,13 \\
5819,24\end{array}$ & \begin{tabular}{|l|l|}
321,13 \\
321
\end{tabular} & 40,21 & $\begin{array}{l}20,53 \\
275,83\end{array}$ & $\begin{array}{l}\mid 0,23,48 \\
102,48\end{array}$ & $\begin{array}{l}24,1,36 \\
241,36\end{array}$ & $\begin{array}{l}24,42 \\
241,74\end{array}$ & $\begin{array}{l}90,00 \\
94,05\end{array}$ & $\begin{array}{l}64,19 \\
648,59\end{array}$ & $\begin{array}{l}1,35 \\
96,53 \\
\end{array}$ & $2,2,91$ & 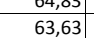 & \begin{tabular}{|l|}
$280,01,68$ \\
280
\end{tabular} & 21,20 & $\begin{array}{l}25,00 \\
25,07\end{array}$ & $\begin{array}{l}20,03,16 \\
267,16\end{array}$ \\
\hline Hyla meridionalis & 30SUG48 & 100,00 & 176,47 & 118,81 & 37,23 & 6575,07 & 359,06 & 45,15 & 313,91 & 107,69 & 264,08 & 264,08 & 95,61 & 620,24 & 91,78 & 2,03 & 61,67 & 243,40 & 17,58 & 17,58 & 239,99 \\
\hline Hyla meridionalis & 30SUG49 & 100,00 & 177,84 & 119,92 & 37,05 & 6641,07 & 362,81 & 45,38 & 317,43 & 108,48 & 266,49 & 266,49 & $\begin{array}{l}96,15 \\
\end{array}$ & 608,36 & 91,39 & 2,03 & 61,38 & 238,32 & 17,34 & 17,34 & 233,03 \\
\hline Hyla meridionalis & 30SUG51 & 100,00 & 162,12 & 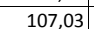 & 38,00 & 5867,14 & 320,7 & 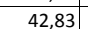 & 277,90 & 100,31 & 240,56 & 240,65 & 91,79 & 632,73 & 92,63 & 3,03 & 62,6 & 271,50 & 21,88 & 24,04 & 258,61 \\
\hline Hyla meridionalis & 30SUG54 & & & & 37,68 & 6182 & & 45, & 291,68 & 103,08 & 251,95 & 251,95 & 94,54 & 619,5 & 89,40 & $2, \varepsilon$ & 61, & 255,64 & 20,03 & 20,03 & 247,58 \\
\hline Hyla meridionalis & 30SUG55 & 100,00 & 170,56 & 112,87 & 37,33 & 6300,87 & 342,64 & 45,02 & 297,62 & 102,83 & 254,71 & 254,71 & 94,03 & 619,35 & 88,62 & 2,86 & 61,12 & 251,06 & 20,03 & 20,03 & 245,03 \\
\hline Hyla meridionalis & 30 SUG58 & 100,00 & 174,33 & 117,37 & 37,00 & 6577,87 & 356,15 & 44,03 & 312,11 & 105,81 & 262,29 & 262,29 & 93,83 & 609,07 & 89,21 & 2,52 & 60,53 & 238,13 & 19,02 & 19,02 & 234,34 \\
\hline Hyla meridionalis & 30SUG62 & 100,00 & 166,75 & 106,91 & 37,78 & 5953,24 & 326,69 & 46,31 & 280,38 & 103,38 & 246,45 & 246,45 & 95,07 & 598,20 & 86,39 & 3,00 & 61,96 & 253,34 & 20,42 & 20,42 & 241,88 \\
\hline Hyla meridionalis & 30 SUG & 100, & 16 & 110 & 37,07 & 6241 & & 41, & 293,78 & 99,02 & 249,73 & 249,73 & 90,74 & 609, & 85 & 3, & 60, & & 21,10 & 21,10 & 24 \\
\hline Hyla meridionalis & 30SUG69 & 100,00 & 176,63 & 116,65 & 37,00 & 6616,37 & $\mid$ & $\begin{array}{l}41,02 \\
46,02\end{array}$ & 312,54 & | & 265,08 & 265,08 & 95,63 & \begin{tabular}{|l|l|}
574,91 \\
\end{tabular} & $\begin{array}{l}84,76 \\
8\end{array}$ & 2,27 & 59,89 & $\begin{array}{l}240,1< \\
223,89 \\
\end{array}$ & 18,28 & 18,28 & 218,58 \\
\hline
\end{tabular}




\begin{tabular}{|c|c|c|c|c|c|c|c|c|c|c|c|c|c|c|c|c|c|c|c|c|c|}
\hline TAXON & UTM & $\mathrm{km} 2$ & B101 & B102 & $\mathrm{BIO3}$ & BIO4 & B105 & B106 & B107 & B108 & B109 & BIO10 & B1011 & BIO12 & B1013 & BIO14 & BIO15 & B1016 & B1017 & BIO18 & B1019 \\
\hline Hyla meridionalis & 30SUG73 & 100,00 & 160,62 & 110,39 & 37,03 & 6209,98 & 329,74 & 37,22 & 292,52 & 94,11 & 244,16 & 244,16 & 86,08 & 598,01 & 82,75 & 3,88 & 59,53 & 244,13 & 22,91 & 22,91 & 235,89 \\
\hline Hyla meridionalis & 30SUG74 & 100,00 & 155,15 & 113,29 & 37,00 & 6391,20 & 331,46 & 29,64 & 301,81 & 86,90 & 241,43 & 241,43 & 78,57 & 624,57 & 84,86 & 4,55 & 58,31 & 247,93 & 25,42 & 25,42 & 242,53 \\
\hline Hyla meridionalis & 30SUG75 & 100,00 & 155,82 & 114,23 & 37,00 & 6483,09 & 334,95 & 29,28 & 305,67 & 86,84 & 243,34 & 243,34 & 78,06 & 628,75 & 85,66 & 4,59 & 57,93 & 245,89 & 25,79 & 25,79 & 242,22 \\
\hline Hyla meridionalis & 30SUG79 & 100,00 & 174,32 & 115,61 & 36,68 & 6642,51 & 356,23 & 44,43 & 311,80 & 105,50 & 263,37 & 263,37 & 93,36 & 566,28 & 83,23 & 2,84 & 58,80 & 220,16 & 19,61 & 19,61 & 213,69 \\
\hline Hyla meridionalis & 30SUG80 & 100,00 & 145,86 & 111,84 & 38,00 & \begin{tabular}{ll|l|}
6057,58 \\
\end{tabular} & 314,52 & 23,17 & 291,35 & 81,99 & 227,83 & 227,83 & 73,82 & 607,50 & 85,53 & 5,29 & 58,42 & 250,28 & 26,89 & 26,89 & 239,62 \\
\hline Hyla meridionalis & 30SUG81 & 100,00 & 153,52 & 110,27 & 37,74 & 6081,48 & 320,52 & 31,07 & 289,45 & 88,59 & 235,66 & 235,66 & 80,89 & 579,69 & 82,66 & 4,74 & 58,76 & 239,96 & 24,57 & 24,57 & 228,61 \\
\hline Hyla meridionalis & 30SUG83 & 100,00 & 146,88 & 114,40 & 37,01 & 6387,08 & 324,88 & 21,16 & 303,71 & 78,95 & 233,39 & 233,39 & 70,75 & 626,14 & 83,73 & 5,68 & 56,84 & 246,76 & 28,60 & 28,60 & 240,65 \\
\hline Hyla meridionalis & 30 SUG84 & 100,00 & 153,59 & 113,48 & 36,98 & 6436,52 & 331,44 & 27,62 & 303,83 & 84,82 & 240,74 & 240,74 & 76,60 & 607,21 & 80, & 4,97 & 57,11 & 237,89 & 26,17 & 26,17 & 233,38 \\
\hline Hyla meridionalis & 30SUG85 & 100,00 & 148,31 & 115,62 & 36,83 & 6568,63 & 331,42 & 20,96 & 310,46 & 80,28 & 237,43 & 237,43 & 69,99 & 636,94 & 86,21 & 5,68 & 56,18 & 244,56 & 29,24 & 29,24 & 241,33 \\
\hline Hyla meridionalis & 30SUG86 & 100,00 & 166,49 & 112,03 & 36,32 & 6502,36 & 343,51 & 40,11 & 303,40 & 98,99 & 254,17 & 254,17 & 87,96 & 578,36 & 80,01 & 3,79 & 58,17 & 224,45 & 22,03 & 22,03 & 221,88 \\
\hline Hyla meridionalis & 30SUG91 & 100,00 & 154,26 & 110,16 & 37,51 & 6085,34 & 321,24 & 31,49 & 289,75 & 89,03 & 236,53 & 236,53 & 81,49 & 549,58 & 78,58 & 4,79 & 58,01 & 226,02 & 24,42 & 24,42 & 214,44 \\
\hline Hyla meridionalis & 30SUG94 & 100,00 & 154,81 & 113,20 & 36,90 & 6460,44 & 332,98 & 28,65 & 304,33 & 85,55 & 242,41 & 242,41 & 77,56 & 581,53 & 76,64 & 5,13 & 56,41 & 225,90 & 25,89 & 25,89 & 221,69 \\
\hline Hyla meridionalis & 30SUHO1 & 100,00 & 161,68 & 124,97 & \begin{tabular}{|l|l|}
37,98 \\
\end{tabular} & 6747,20 & 354,36 & 28,29 & 326,07 & 88,75 & 251,77 & 251,77 & 79,41 & 640,75 & 89,85 & 3,03 & 58,01 & 245,15 & 24,70 & 24,70 & 240,57 \\
\hline Hyla meridionalis & 30SUHO4 & 100,00 & 152,84 & 124,93 & $\begin{array}{l}37,05 \\
\end{array}$ & 6831,90 & 348,81 & 19,41 & 329,40 & 81,84 & 244,76 & 244,76 & 70,04 & 628,36 & 87,41 & 3,97 & 54,82 & 232,80 & 29,55 & 29,55 & 227,64 \\
\hline Hyla meridionalis & 30SUHO5 & 100,00 & 154,29 & 124,77 & 37,14 & 6832,25 & 350,07 & 20,79 & 329,28 & 83,11 & 246,08 & 246,08 & 71,36 & 606,60 & 84,11 & 4,00 & 54,17 & 222,77 & 29,59 & 29,59 & 217,47 \\
\hline Hyla meridionalis & 30SUHOG & 100,00 & 156,69 & 124,19 & 37,01 & 6840,76 & 351,82 & 22,84 & 328,98 & 84,58 & 248,40 & 248,40 & 73,47 & 581,11 & 80,24 & 3,99 & 53,46 & 211,54 & 29,10 & 29,10 & 206,06 \\
\hline Hyla meridionalis & 30SUH08 & 100,00 & 156,61 & 123,59 & 37,00 & 6837,61 & 350,97 & 22,84 & 328,13 & 81,95 & 248,43 & 248,43 & 73,45 & 549,13 & 74,76 & 3,80 & 52,03 & 197,04 & 29,49 & 29,49 & 190,72 \\
\hline Hyla meridionalis & 30SUH11 & 100,00 & 153,44 & 124,32 & 37,41 & 6790,20 & 347,48 & 20,28 & 327,20 & 82,93 & 244,46 & 244,46 & 71,11 & 668,52 & 94,50 & 3,88 & 56,90 & 253,99 & 27,99 & 27,99 & 249,24 \\
\hline Hyla meridionalis & 30SUH12 & 100,00 & 152,39 & 124,68 & 37,23 & 6821,05 & 347,75 & 19,14 & 328,61 & 81,93 & 243,99 & 243,99 & 69,83 & 657,64 & 92,90 & 3,98 & 56,20 & 247,94 & 28,79 & 28,79 & 242,44 \\
\hline Hyla meridionalis & 30SUH13 & 100,00 & 154,20 & 124,93 & 37,09 & 6841,54 & 350,06 & 20,50 & 329,56 & 83,68 & 246,18 & 246,18 & 71,38 & 636,21 & 89,85 & 3,75 & 55,83 & 238,13 & 28,24 & 28,24 & 232,44 \\
\hline Hyla meridionalis & 30SUH16 & 100,00 & 156,14 & 124,60 & 37,00 & 6864,75 & 351,95 & 21,92 & 330,03 & 85,47 & 248,42 & 248,42 & 72,77 & 580,00 & 80,6 & 4,00 & 53,32 & 210,65 & 29,02 & 29,02 & 204,95 \\
\hline Hyla meridionalis & 30SUH17 & 100,00 & 159,76 & 124,03 & 37,00 & 6852,95 & 354,63 & 25,22 & 329,41 & 88,66 & 251,68 & 251,68 & 76,34 & 548,21 & 75,84 & 3,42 & 53,12 & 197,20 & 27,31 & 27,31 & 191,87 \\
\hline Hyla meridionalis & 30SUH18 & 100,00 & 160,50 & 123,94 & 37,00 & 6853,55 & 354,88 & 26,04 & 328,84 & 87,45 & 252,51 & 252,51 & 76,96 & 528,38 & 72,45 & 3,32 & 52,48 & 188,55 & 27,29 & 27,29 & 183,01 \\
\hline Hyla meridionalis & 30SUH19 & 100,00 & 156,72 & 123,25 & 37,00 & 6850,13 & 351,13 & 22,66 & 328,47 & 82,51 & 248,74 & 248,74 & 73,43 & 527,22 & 71,32 & 3,82 & 51,09 & 186,22 & 29,49 & 29,49 & 180,06 \\
\hline Hyla meridionalis & $30 \mathrm{SUH} 20$ & 100,00 & 164,69 & 123,62 & 37,62 & 6753,70 & 356,12 & 31,21 & 324,91 & 94,63 & 255,00 & 255,00 & 82,13 & 645,91 & 93,62 & 2,86 & 59,03 & 248,81 & 22,74 & 22,74 & 244,30 \\
\hline Hyla meridionalis & $30 \mathrm{SUH} 21$ & 100,00 & 155,18 & 124,01 & 37,13 & 6815,08 & 349,27 & 21,83 & 327,44 & 84,73 & 246,69 & 246,69 & 72,49 & 660,60 & 94,63 & 3,78 & 57,17 & 251,76 & 27,13 & 27,13 & 245,69 \\
\hline Hyla meridionalis & 30SUH22 & 100,00 & $\begin{array}{l}157,27 \\
157\end{array}$ & 124,38 & 37,08 & 6836,77 & 352,36 & 23,58 & 328,78 & 86,77 & $\begin{array}{l}249,13 \\
\end{array}$ & 249,13 & 74,42 & 638,21 & $\begin{array}{l}4,1,70 \\
91\end{array}$ & 3,51 & 56,67 & 241,62 & 26,43 & 26,43 & 235,18 \\
\hline Hyla meridionalis & $30 \mathrm{SUH} 23$ & 100,00 & 149,64 & 124,64 & 37,01 & 6867,08 & 346,31 & 16,29 & 330,03 & 79,18 & 242,11 & 242,11 & 66,75 & 647,95 & 91,83 & 4,34 & 54,98 & 242,28 & 30,37 & 30,37 & 235,08 \\
\hline Hyla meridionalis & 30SUH24 & 100,00 & 152,59 & 124,99 & 37,00 & 6879,76 & 349,49 & 18,78 & 330,70 & 82,04 & 245,28 & 245,28 & 69,63 & 621,17 & 88,01 & 4,03 & 54,46 & 230,47 & 29,16 & 29,16 & 223,26 \\
\hline Hyla meridionalis & $30 \mathrm{SUH} 25$ & 100,00 & 155,16 & 124,99 & 37,00 & 6879,92 & 351,62 & 20,82 & 330,80 & 84,49 & 247,76 & 247,76 & 71,97 & 596,25 & 84,09 & 3,99 & 54,09 & 219,10 & 28,85 & 28,85 & 212,30 \\
\hline Hyla meridionalis & $30 \mathrm{SUH} 26$ & 100,00 & 157,27 & 124,76 & 37,00 & 6887,23 & 353,44 & 22,57 & 330,86 & 86,49 & 249,83 & 249,83 & 73,66 & 571,73 & 80,10 & 3,89 & 53,37 & 207,64 & 28,53 & 28,53 & 201,17 \\
\hline Hyla meridionalis & 30SUH28 & 100,00 & 159,77 & 124,01 & 37,00 & 6870,03 & 354,71 & 25,01 & \begin{tabular}{|l|}
$329,70,0$ \\
\end{tabular} & $\begin{array}{l}0,4,82 \\
88,8\end{array}$ & \begin{tabular}{|l|}
252,06 \\
\end{tabular} & \begin{tabular}{|l|}
252,06 \\
250
\end{tabular} & 76,10 & 525,57 & $\frac{70,21}{72,21}$ & 3,41 & 52,07 & $\begin{array}{l}286,35 \\
186\end{array}$ & $\begin{array}{l}\mid 27,45 \\
27,5\end{array}$ & $\begin{array}{l}27,45 \\
27,5\end{array}$ & 180,92 \\
\hline Hyla meridionalis & $30 \mathrm{SUH} 30$ & 100,00 & 162,30 & 122,87 & 37,04 & 6771,33 & 354,04 & 29,24 & 324,80 & 92,31 & 253,16 & 253,16 & 80,00 & 647,49 & 94,59 & 3,26 & 58,61 & 249,89 & 23,69 & 23,69 & 243,64 \\
\hline Hyla meridionalis & 30SUH31 & 100,00 & 159,11 & 123,50 & 37,05 & 6820,64 & 352,68 & 25,53 & 327,15 & 88,65 & 250,72 & 250,72 & 76,22 & 643,77 & 93,65 & 3,54 & 57,47 & 246,45 & 25,46 & 25,46 & 239,30 \\
\hline Hyla meridionalis & 30SUH32 & 100,00 & 156,88 & 123,97 & 37,00 & 6859,15 & 351,87 & 22,99 & 328,88 & 86,10 & 249,13 & 249,13 & 73,61 & 635,38 & 92,01 & 3,77 & 56,51 & 240,96 & 26,70 & 26,70 & 233,23 \\
\hline Hyla meridionalis & 30SUH33 & 100,00 & 155,03 & 124,15 & 37,00 & 6882,36 & 351,03 & 20,96 & 330,08 & 84,19 & 247,63 & 247,63 & 71,67 & 625,04 & 89,89 & 3,97 & 55,43 & 234,58 & 27,97 & 27,97 & 226,59 \\
\hline Hyla meridionalis & 30SUH34 & 100,00 & 152,05 & 124,73 & 37,00 & 6907,64 & 348,98 & 17,85 & 331,13 & 81,11 & 245,16 & 245,16 & 68,66 & 617,62 & 87,99 & 4,11 & 54,31 & 229,10 & 29,42 & 29,42 & 220,93 \\
\hline Hyla meridionalis & 30SUH35 & 100,00 & 153,47 & 124,96 & 37,00 & 6914,82 & 350,41 & 18,82 & 331,59 & 82,61 & 246,64 & 246,64 & 69,85 & 595,47 & 84,36 & 4,00 & 53,71 & 218,63 & 29,03 & 29,03 & 210,82 \\
\hline Hyla meridionalis & 30SUH36 & 100,00 & 156,80 & 124,81 & 37,00 & 6903,97 & 353,21 & 21,85 & 331,37 & 86,01 & 249,63 & 249,63 & 72,98 & $566,97 \mid$ & 79,78 & 3,86 & 53,20 & 205,78 & 28.44 & 28.44 & 198,61 \\
\hline Hyla meridionalis & 30SUH37 & 100,00 & 158,19 & 124,25 & 37,00 & 6893,18 & 353,98 & 23,16 & 330,82 & 87,52 & 250,85 & 250,85 & 74,40 & 543,75 & 75,72 & 3,51 & 52,56 & 194,90 & 27,77 & 27,77 & 188,42 \\
\hline Hyla meridionalis & 30SUH38 & 100,00 & 160,64 & 124,02 & 37,00 & 6885,64 & 355,60 & 25,47 & 330,13 & 89,97 & 253,13 & 253,13 & 76,72 & 517,02 & 71,21 & 3,28 & 52,03 & 182,91 & 26,94 & 26,94 & 177,24 \\
\hline Hyla meridionalis & $30 \mathrm{SUH} 40$ & 100,00 & 166,59 & 121,69 & 37,01 & 6766,19 & 356,73 & 33,38 & 323,35 & 96,41 & 257,32 & 257,32 & 83,97 & 627,45 & 92,90 & 3,00 & 58,99 & 243,12 & 22,05 & 22,05 & 235,93 \\
\hline Hyla meridionalis & $30 \mathrm{SUH} 41$ & 100,00 & 163,68 & 122,52 & 37,00 & 6815,77 & 355,97 & 29,91 & 326,06 & 93,17 & 255,18 & 255,18 & 80,68 & 621,48 & 91,61 & 3,31 & 57,85 & 238,69 & 23,62 & 23,62 & 230,69 \\
\hline Hyla meridionalis & 30SUH44 & 100,00 & 151,10 & 124,14 & 37,00 & 6935,14 & 348,41 & 16,70 & 331,71 & 79,95 & 244,71 & 244,71 & 67,39 & 613,34 & 87,64 & 4,10 & 53,95 & 227,34 & 29,66 & 29,66 & 218,34 \\
\hline Hyla meridionalis & $30 \mathrm{SUH} 45$ & 100,00 & 153,57 & 124,49 & 37,00 & 6930,52 & 350,69 & 18,71 & 331,98 & 82,64 & 247,05 & 247,05 & 69,74 & 587,65 & 83,48 & 4,00 & 53,46 & 215,42 & 28,93 & 28,93 & 206,93 \\
\hline Hyla meridionalis & \begin{tabular}{|l|l|}
30 SUH47 \\
\end{tabular} & 100,00 & 156,62 & 124,50 & 37,00 & 6912,72 & 352,90 & 21,42 & \begin{tabular}{|l|l|}
331,48 \\
\end{tabular} & $\begin{array}{l}\mid 85,87 \\
85,87\end{array}$ & 249,65 & 249,65 & 72,71 & 541,91 & $\begin{array}{l}75,45 \\
75,4\end{array}$ & 3,73 & 52,08 & \begin{tabular}{|l|}
193,57 \\
\end{tabular} & 28,44 & 28,44 & 186,43 \\
\hline Hyla meridionalis & $30 \mathrm{SUH} 48$ & 100,00 & 158,87 & 124,11 & 37,00 & 6901,36 & 354,40 & 23,56 & 330,84 & 88,28 & 251,73 & 251,73 & 75,01 & 516,26 & 70,91 & 3,53 & 51,42 & 181,79 & 27,87 & 27,87 & 175,64 \\
\hline Hyla meridionalis & 30SUH49 & 100,00 & 156,20 & 124,03 & 37,00 & 6904,72 & 351,85 & 21,02 & 330,83 & 85,84 & 249,25 & 249,25 & 72,32 & 508,38 & 68,64 & 3,86 & 50,16 & 176,05 & 29,40 & 29,40 & 170,30 \\
\hline Hyla meridionalis & 30 SUH50 & 100,00 & 175,19 & 119,49 & 37,00 & 6695,72 & 361,25 & 42,80 & 318,44 & 105,48 & 264,70 & 264,70 & 93,00 & 587,42 & 87,73 & 2,28 & 59,74 & 228,21 & 18,78 & 18,78 & 221,46 \\
\hline Hyla meridionalis & 30SUH56 & 100,00 & 156,92 & 124,19 & 37,00 & 6927,64 & 353,20 & 21,55 & 331,65 & 85,88 & 250,18 & 250,18 & 72,80 & 550,41 & 77,53 & 3,89 & 52,44 & 198,71 & 28,34 & 28,34 & 190,68 \\
\hline Hyla meridionalis & 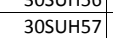 & 100,00 & 151 & $\begin{array}{l}124,19 \\
124,89\end{array}$ & 37,00 & 69333,85 & 348,32 & \begin{tabular}{|l|}
$1,35,91$ \\
\end{tabular} & \begin{tabular}{|l|}
332,42 \\
332
\end{tabular} & $\begin{array}{l}80,00 \\
80,23 \\
\end{array}$ & \begin{tabular}{|l|}
244,52 \\
240
\end{tabular} & \begin{tabular}{|l|}
244,52 \\
\end{tabular} & 67,21 & $\mid \begin{array}{l}\mid 500,41 \\
552,66\end{array}$ & $\begin{array}{l}71,235 \\
76,26\end{array}$ & (3,34 & 50,95 & \begin{tabular}{|l|}
$195,91 / 1$ \\
\end{tabular} & $\begin{array}{l}\mid 2,34 \\
31,15 \\
\end{array}$ & $\begin{array}{l}20,34 \\
31,15\end{array}$ & $\begin{array}{l}190,00 \\
188,14\end{array}$ \\
\hline Hyla meridionalis & 30SUH58 & 100,00 & 155,92 & 124,62 & 37,00 & 6916,51 & 352,13 & 20,50 & 331,63 & 87,59 & 249,11 & 249,11 & 72,13 & 518,13 & 70,77 & 3,93 & 50,58 & 181,39 & 29,22 & 29,22 & 174,72 \\
\hline Hyla meridionalis & 30SUH61 & 100,00 & 168,19 & 119,91 & 36,98 & 6799,46 & 357,62 & 35,53 & 322,10 & 98,02 & 259,55 & 259,55 & 85,31 & $|583,79|$ & 86,68 & 3,14 & 57,68 & 224,48 & 22.09 & 22.09 & 215,60 \\
\hline Hyla meridionalis & 30SUH63 & 100,00 & 151,72 & 122,97 & 37,00 & 6927,43 & 347,90 & 18,08 & 329,83 & 80,69 & 245,28 & 245,28 & 68,30 & 609,03 & 88,09 & 4,53 & 53,90 & 227,54 & 29,81 & 29,81 & 216,79 \\
\hline Hyla meridionalis & 30SUH65 & 100,00 & 153,88 & 123,98 & 37,00 & 6938,73 & 350,60 & 19,02 & 331,58 & 82,97 & 247,51 & 247,51 & 69 & 568,39 & 80,88 & 4,03 & 52,71 & 207,44 & 29,00 & 29,00 & 198 \\
\hline Hyla meridionalis & \begin{tabular}{|l|}
30 SUH66 \\
306
\end{tabular} & $\begin{array}{l}100,00 \\
\end{array}$ & $\begin{array}{l}13,00 \\
147,75\end{array}$ & $\begin{array}{l}124,50 \\
124,62\end{array}$ & 37,00 & $\begin{array}{l}\mid 650,1 / 0 \\
6951,08 \\
\end{array}$ & 345,61 & $\begin{array}{l}1,, 0<4 \\
13,05 \\
\end{array}$ & \begin{tabular}{|l|l|}
332,56 \\
336
\end{tabular} & 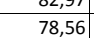 & \begin{tabular}{|l|}
241,74 \\
241
\end{tabular} & \begin{tabular}{|l|}
241,74 \\
241
\end{tabular} & $\mid 64,00$ & \begin{tabular}{|l|l|}
573,10 \\
5730
\end{tabular} & $\begin{array}{l}0,000 \\
79,68\end{array}$ & $\begin{array}{l}4,400 \\
4,80\end{array}$ & $\begin{array}{ll}2,11 \\
50,88\end{array}$ & \begin{tabular}{|l|}
204,96 \\
\end{tabular} & 32,71 & 32,71 & $\begin{array}{l}150,00 \\
195,86\end{array}$ \\
\hline Hyla meridionalis & 30SUH67 & 100,00 & 149,16 & 124,99 & 37,00 & 6940,01 & 346,73 & 13,99 & 332,74 & 88,94 & 242,86 & 242,86 & 65,36 & 549,43 & 75,42 & 4,36 & 50,23 & 194,17 & 32,05 & 32,05 & 185,56 \\
\hline Hyla meridionalis & 30SUH68 & 100,00 & 153,25 & 124,97 & 37,00 & 6928,40 & 350,03 & 17,89 & 332,15 & 104,50 & 246,76 & 246,76 & 69,48 & 517,11 & 70,02 & 4,09 & 49,73 & 180,85 & 30,47 & 30,47 & 172,72 \\
\hline Hyla meridionalis & 30SUH71 & 100,00 & 173,71 & 117,85 & 36,75 & 6743,01 & 359,66 & 42,01 & 317, & 103,97 & 264,08 & $264, \mathrm{C}$ & 91, & 550,19 & 81,64 & 2,86 & 57,58 & 211,40 & 20,33 & 20,33 & 203,06 \\
\hline Hyla meridionalis & 30SUH73 & 100,00 & 150,43 & 122,52 & 36,84 & 6938,53 & 346,58 & 16,95 & 329,64 & 79,37 & 244,26 & 244,26 & 66,90 & 603,05 & 87,12 & 4,85 & 53,18 & 224,50 & 30,80 & 30,80 & 213,05 \\
\hline
\end{tabular}




\begin{tabular}{|c|c|c|c|c|c|c|c|c|c|c|c|c|c|c|c|c|c|c|c|c|c|}
\hline TAXON & UTM & $\mathrm{km} 2$ & BIO1 & B102 & $\mathrm{BIO3}$ & B104 & 8105 & B106 & B107 & B108 & 8109 & B1010 & B1011 & B1012 & B1013 & B1014 & B1015 & B1016 & B1017 & B1018 & B1019 \\
\hline Hyla meridionalis & 30SUH74 & 100,00 & 151,78 & 123,02 & 37,00 & 6941,81 & 348,19 & 17,94 & 330,25 & 80,72 & 245,66 & 245,66 & 68,25 & 582,21 & 83,49 & 4,44 & 52,59 & 214,36 & 30,20 & 30,20 & 203,55 \\
\hline Hyla meridionalis & $30 \mathrm{SUH75}$ & 100,00 & 148,38 & 123,98 & 37,00 & 6945,49 & 345,76 & 14,17 & 331,59 & 81,12 & 242,28 & 242,28 & 64,94 & 577,95 & 81,45 & 4,75 & 51,44 & 209,36 & 32,20 & 32,20 & 198,97 \\
\hline Hyla meridionalis & 30SUH76 & 100,00 & 141,94 & 124,88 & 37,00 & 6962,21 & 340,69 & 7,44 & 333,25 & 90,01 & 236,19 & 236,19 & 58,53 & 583,66 & 80,33 & 5,47 & 49,59 & 208,01 & 35,86 & 35,86 & 197,16 \\
\hline Hyla meridionalis & 30 SUH80 & 100,00 & 177,70 & 114,64 & 36,24 & 6641,40 & 358,53 & 48,07 & 310,46 & 108,80 & 266,67 & 266,67 & 96,51 & 528,09 & 77,71 & 2,45 & 58,08 & 203,85 & 18,58 & 18,58 & 196,87 \\
\hline Hyla meridionalis & 30SUH81 & 100,00 & 173,46 & 116,62 & 36,23 & 6739,70 & 358,49 & 42,42 & 316,07 & 103,77 & 263,92 & 263,92 & 91,24 & 537,50 & 79,71 & 2,97 & 57,01 & 206,38 & 20,59 & 20,59 & 197,35 \\
\hline Hyla meridionalis & 30SUH82 & 100,00 & 158,93 & 119,88 & 36,38 & 6896,57 & 351,39 & 26,70 & 324,69 & 88,28 & 252,11 & 252,11 & 75,77 & 578,24 & 85,17 & 4,16 & 54,55 & 218,97 & 26,85 & 26,85 & 207,22 \\
\hline Hyla meridionalis & 30SUH83 & 100,00 & 150,42 & 121,94 & 36,52 & 6952,54 & 346,31 & 17,11 & 329,19 & 79,19 & 244,50 & 244,50 & 66,77 & 593,26 & 85,86 & 4,98 & 52,75 & 220,49 & 31,11 & 31,11 & 208,25 \\
\hline Hyla meridionalis & 30SUH84 & 100,00 & 154,04 & 122,48 & 36,91 & 6943,70 & 349,56 & 20,06 & 329,49 & 83,92 & 247,77 & 247,77 & 70,27 & 563,59 & 80,97 & 4,26 & 52,42 & 207,25 & 29,19 & 29,19 & 196,12 \\
\hline Hyla meridionalis & 30SUH85 & 100,00 & 141,49 & 124,08 & 37,00 & 6965,81 & 339,93 & 7,69 & 332,24 & 91,04 & 235,90 & 235,90 & 58,33 & 591,33 & 82,19 & 5,76 & 49,85 & 213,17 & 36,21 & 36,21 & 200,69 \\
\hline Hyla meridionalis & 30SUH90 & 100,00 & 176,26 & 113,60 & 36,00 & 6676,15 & 357,25 & 47,11 & 310,14 & 107,19 & 265,76 & 265,76 & 94,81 & 521,21 & 76,92 & 2,81 & 57,10 & 201,13 & 19,64 & 19,64 & 192,75 \\
\hline Hyla meridionalis & 30SUH91 & 100,00 & 173,91 & 115,37 & 36,04 & 6737,19 & 357,76 & 43,66 & 314,10 & 104,35 & 264,36 & 264,36 & 91,91 & 522,34 & 77,31 & 3,08 & 56,38 & 200,06 & 20,91 & 20,91 & 190,64 \\
\hline Hyla meridionalis & 30SUH92 & 100,00 & 163,76 & 118,20 & 36,05 & 6865,54 & 353,73 & 32,17 & 321,56 & $\begin{array}{ll}93,18 \\
\end{array}$ & 256,31 & 256,31 & 80,76 & 550,32 & 81,49 & 3,78 & 54,71 & 208,74 & 24,99 & 24,99 & 196,92 \\
\hline Hyla meridionalis & 30SUH93 & 100,00 & 157,60 & 120,31 & 36,39 & 6920,18 & 350,89 & 25,01 & 325,88 & 91,03 & 251,12 & 251,12 & 74,21 & 557,10 & 81,35 & 4,24 & 53,21 & 207,95 & 27,88 & 27,88 & 195,62 \\
\hline Hyla meridionalis & 30SUH94 & 100,00 & 155,04 & 121,73 & 36,89 & 6927,27 & 349,65 & 21,51 & 328,14 & 100,29 & 248,67 & 248,67 & 71,53 & 549,85 & 78,94 & 4,31 & 52,02 & 202,57 & 29,14 & 29,14 & 190,15 \\
\hline Hyla meridionalis & 30SUJO1 & 100,00 & 160,82 & 121,92 & 37,00 & 6783,25 & 352,34 & 27,82 & 324,52 & 89,92 & 251,71 & 251,71 & 78,15 & 485,01 & 64,20 & 3,49 & 50,32 & 170,88 & 28,56 & 28,56 & 162,91 \\
\hline Hyla meridionalis & 30SUJ02 & 100,00 & 159,36 & 121,10 & 37,00 & 6790,35 & 350,59 & 26,64 & 323,95 & 89,07 & 250,54 & 250,54 & 76,72 & \begin{tabular}{|c|}
476,07 \\
\end{tabular} & 62,28 & 3,92 & 49,00 & 166,33 & 29,72 & 29,72 & 157,84 \\
\hline Hyla meridionalis & \begin{tabular}{|l|l|}
$305 \mathrm{Nu} 03$ \\
\end{tabular} & 100,00 & 158,62 & 120,52 & 37,00 & 6769,54 & 348,91 & 26,27 & 322,64 & 99,67 & 249,47 & 249,47 & 76,11 & 465,44 & 60,16 & 3,94 & 48,21 & $\begin{array}{l}161,70 \\
\end{array}$ & 30,25 & 30,25 & 152,66 \\
\hline Hyla meridionalis & $\begin{array}{l}30 \text { SUJ08 } \\
\end{array}$ & 100,00 & 137,04 & 116,82 & 36,70 & 6673,35 & 323,89 & 8,81 & 315,09 & 77,53 & 227,21 & 227,23 & 56,81 & 486,26 & 57,10 & 7,11 & 42,11 & 162,30 & 43,28 & 43,30 & 149,61 \\
\hline Hyla meridionalis & 30SUJ12 & 100,00 & 158,19 & 121,74 & 37,00 & 6812,73 & 350,10 & 25,05 & 325,05 & 103,86 & 249,71 & 249,71 & 75,26 & 474,85 & 61,96 & 3,89 & 48,81 & 164,18 & 29,88 & 29,88 & 156,28 \\
\hline Hyla meridionalis & 30SUJ13 & 100,00 & 156,64 & 121,00 & 37,00 & 6801,50 & 347,80 & 23,78 & 324,02 & 105,67 & 248,01 & 248,01 & 73,92 & 465,89 & 59,87 & 4,12 & 47,67 & 160,01 & 31,00 & 31,00 & 151,35 \\
\hline Hyla meridionalis & 30SUJ14 & 100,00 & 158,51 & 120,24 & 37,00 & 6776,48 & 348,22 & 25,77 & 322,45 & 113,71 & 249,50 & 249,50 & 75,81 & 446,28 & 56,61 & 4,03 & 47,15 & 153,15 & 30,48 & 30,48 & 143,51 \\
\hline Hyla meridionalis & 30suj15 & 100,00 & 156,77 & 119,64 & 36,98 & 6758,22 & $\begin{array}{l}445,78 \\
345\end{array}$ & 24,61 & $\begin{array}{l}321,17 \\
\end{array}$ & $\begin{array}{l}114,42 \\
114,4\end{array}$ & 247,55 & 247,55 & $\begin{array}{l}74,36 \\
74.36\end{array}$ & $\begin{array}{l}440,20 \\
439,26 \\
\end{array}$ & 54,84 & $\begin{array}{l}4,23 \\
4,23 \\
\end{array}$ & 46,27 & 149,96 & 31,43 & $\begin{array}{l}31,43 \\
31,43\end{array}$ & 139,35 \\
\hline Hyla meridionalis & 30SUJ21 & 100,00 & 150,90 & 122,81 & 37,00 & 6860,03 & 345,34 & 17,14 & 328,20 & 83,00 & 243,38 & 243,38 & 67,96 & 511,42 & 67,13 & 4,54 & 48,50 & 175,59 & 32,87 & 32,87 & 168,88 \\
\hline Hyla meridionalis & 30 SUJ 22 & 100,00 & 154,62 & 122,09 & 37,00 & 6835,34 & 347,53 & 20,91 & 326,62 & 106,33 & 246,51 & 246,51 & 71,58 & \begin{tabular}{|l|l|}
481,43 \\
\end{tabular} & 62,50 & 4,12 & 48,03 & 164,49 & 31,29 & 31,29 & 157,19 \\
\hline Hyla meridionalis & 30 SUJ 23 & 100,00 & 154,21 & 121,51 & 37,00 & 6828,54 & 346,38 & 21,01 & 325,37 & 117,96 & 246,11 & 246,11 & 71,29 & 468,02 & 59,81 & 4,23 & 47,12 & 159,10 & 31,90 & 31,90 & 150,66 \\
\hline Hyla meridionalis & 30 SUJ 30 & 100,00 & 155,59 & 123,52 & 37,00 & 6887,42 & 350,41 & 20,78 & 329,63 & 88,74 & 248,21 & 248,21 & 71,77 & \begin{tabular}{|l|l|}
501,47 \\
\end{tabular} & 66,86 & 4,02 & 49,37 & 172,05 & 30,23 & 30,23 & 166,73 \\
\hline Hyla meridionalis & \begin{tabular}{|l|}
$30 \mathrm{SUJU} 31$ \\
\end{tabular} & 100,00 & 150,96 & 123,14 & 37,00 & 6882,02 & 345,94 & 16,56 & 329,38 & 115,15 & 243,83 & 243,83 & 67,74 & 502,99 & 65,85 & 4,31 & 48,20 & 171,38 & 32,64 & 32,64 & 164,81 \\
\hline Hyla meridionalis & 30SUJ32 & 100,00 & 151,82 & 122,74 & 37,00 & 6864,87 & 345,74 & 17,56 & 328,18 & 132,25 & 244,36 & 244,36 & 68,72 & 484,56 & 62,45 & 4,38 & 47,40 & 164,73 & 32,69 & 32,69 & 156,66 \\
\hline Hyla meridionalis & 30SUJ33 & 100,00 & 149,19 & 122,03 & 37,00 & 6854,45 & 342,55 & 15,48 & 327,07 & 131,88 & 241,58 & 241,58 & 66,27 & 479,43 & 60,62 & 4,86 & 46,07 & 162,71 & 34,47 & 34,47 & 152,56 \\
\hline Hyla meridionalis & 30 SUJ35 & 100,00 & 152,93 & 120,36 & 37,00 & 6810,05 & 343,39 & 19,86 & 323,53 & 133,26 & 244,65 & 244,65 & 70,08 & 439,24 & 53,72 & 4,65 & 44,76 & 148,41 & 33,46 & 33,46 & 136,42 \\
\hline Hyla meridionalis & \begin{tabular}{|l|l|}
$305 U J 39$ \\
\end{tabular} & 100,00 & 138,86 & 117,22 & 36,46 & 6705,00 & 325,71 & 8,81 & 317,10 & 122,84 & 229,62 & 229,62 & 58,14 & 437,96 & 50,32 & 7,14 & 40,21 & $\begin{array}{l}146,02 \\
\end{array}$ & 42,50 & 42,50 & 127,45 \\
\hline Hyla meridionalis & 30 SUJ 40 & 100,00 & 152,11 & 124,00 & 37,00 & 6903,59 & 347,91 & 17,13 & 330,78 & 115,87 & 245,17 & 245,17 & 68,48 & 506,47 & 67,03 & 4,21 & 48,74 & 173,36 & 31,73 & 31,73 & 166,86 \\
\hline Hyla meridionalis & 30SUJ41 & 100,00 & 150,18 & 123,80 & 37,00 & 6888,35 & 345,62 & 15,44 & 330,18 & 133,39 & 243,10 & 243,10 & 66,82 & 497,24 & 64,62 & 4,46 & 47,59 & 170,07 & 32,98 & 32,98 & 161,42 \\
\hline Hyla meridionalis & 30SUJ42 & 100,00 & 146,07 & 123,11 & 37,00 & 6891,55 & 341,34 & 11,74 & 329,60 & 129,14 & 239,19 & 239,19 & 62,95 & 497,35 & 63,27 & 5,08 & 46,15 & 169,92 & 35,59 & 35,59 & 158,83 \\
\hline Hyla meridionalis & 30SUJ43 & 100,00 & 145,44 & 122,64 & 37,00 & 6874,67 & 339,72 & 11,30 & 328,42 & 128,48 & 238,21 & 238,21 & 62,43 & 485,61 & 60,68 & 5,23 & 45,29 & 165,68 & 36,31 & 36,31 & 152,99 \\
\hline Hyla meridionalis & $\begin{array}{l}30 \text { SUJ } 45 \\
\end{array}$ & 100,00 & 150,62 & 120,88 & 36,99 & 6831,53 & 341,75 & 17,01 & 324,75 & 134,62 & 242,70 & 242,70 & 67,85 & 4 & 53,18 & 4,99 & 44,07 & 149,37 & 34,59 & 34,59 & 135,15 \\
\hline Hyla meridionalis & 30SUJ50 & 100,00 & 148,90 & 124,47 & 37,00 & 6917,34 & 345,44 & 13,79 & 331,64 & 128,63 & 242,25 & 242,25 & 65,34 & 509,58 & 66,83 & 4,47 & 47,94 & 175,40 & 33,10 & 33,10 & 166,39 \\
\hline Hyla meridionalis & 30SUJ51 & 100,00 & 150,69 & 124,01 & 37,00 & 6903,21 & 346,19 & 15,61 & 330,58 & 133,95 & 243,75 & 243,75 & 67,07 & 486,99 & 62,77 & 4,30 & 47,21 & 167,55 & 32,59 & 32,59 & 156,91 \\
\hline Hyla meridionalis & 30SUJ52 & 100,00 & 147,69 & 123,67 & 37,00 & 6888,11 & 342,84 & 12,90 & 329,94 & 130,79 & 240,73 & 240,73 & 64,54 & 482,92 & 60,95 & 4,93 & 45,89 & 165,87 & 34,88 & 34,88 & 153,01 \\
\hline Hyla meridionalis & 30SUJ62 & 100,00 & 149,63 & 123,97 & 37,00 & 6899,46 & 344,74 & 14,23 & 330,51 & 133,09 & 242,72 & 242,72 & 66,02 & 467,27 & 58,39 & 4,57 & 45,74 & 161,13 & 33,77 & 33,77 & 147,07 \\
\hline Hyla meridionalis & 305UJ65 & 100,00 & 141,45 & 121,91 & 36,99 & 6863,46 & 334,63 & $\begin{array}{l}74,25 \\
7,48 \\
\end{array}$ & \begin{tabular}{|l|l|}
327,16 \\
\end{tabular} & $\begin{array}{l}124,84 \\
\end{array}$ & $\begin{array}{l}234,37 \\
\end{array}$ & \begin{tabular}{|l|}
234,37 \\
\end{tabular} & 58,69 & 459,14 & 53,75 & 5,96 & 42,35 & $\begin{array}{l}157,07 \\
\end{array}$ & 39,61 & 39,61 & 137,65 \\
\hline Hyla meridionalis & 30SUJ66 & 100,00 & 138,87 & 120,82 & 36,84 & 6853,41 & 330,98 & 5,46 & 325,52 & 122,02 & 231,64 & 231,64 & 56,39 & 456,53 & 52,59 & 6,61 & 41,24 & 155,54 & 41,78 & 41,78 & 134,68 \\
\hline Hyla meridionalis & 30sUJ74 & 100,00 & 143,51 & 123,26 & 37,00 & $\begin{array}{l}68084,85 \\
6884\end{array}$ & 337,84 & $\begin{array}{l}8,40 \\
8,47 \\
\end{array}$ & 329,36 & $\begin{array}{l}126,77 \\
12,0\end{array}$ & 236,64 & 236,64 & 60,49 & 455,14 & 53,60 & 5,38 & $\begin{array}{l}42,94 \\
42,92\end{array}$ & $\begin{array}{l}156,66 \\
15,4\end{array}$ & 37,91 & 37,91 & 137,36 \\
\hline Hyla meridionalis & 30SUJ75 & 100,00 & 140,25 & 122,33 & 37,00 & 6876,04 & 333,81 & 5,96 & 327,85 & 123,67 & 233,36 & 233,36 & 57,40 & 456,66 & 52,75 & 6,19 & 41,78 & 156,56 & 40,66 & 40,66 & 135,52 \\
\hline Hyla meridionalis & 30SUKOO & 100,00 & 154,22 & 116,00 & 36,98 & 6606,87 & 336,84 & 25,18 & 311,66 & 111,86 & 242,90 & 242,90 & 73,32 & 397,89 & 46,22 & 5,18 & 42,40 & \begin{tabular}{|l|l|}
134,44 \\
\end{tabular} & 34,42 & 34,42 & 120,55 \\
\hline Hyla meridionalis & $\begin{array}{l}\text { SOSUK01 } \\
\end{array}$ & 100,00 & $\begin{array}{l}154,26 \\
154,70\end{array}$ & 115,56 & $\frac{10,00}{37,00}$ & $\begin{array}{l}600,010 \\
6570,73 \\
\end{array}$ & \begin{tabular}{|l|}
335,045 \\
335,95
\end{tabular} & \begin{tabular}{|l|}
26,02 \\
26
\end{tabular} & $\begin{array}{l}31,0909 \\
309,9\end{array}$ & $\begin{array}{l}111,200 \\
112,48 \\
\end{array}$ & \begin{tabular}{|l|}
242,89 \\
240
\end{tabular} & \begin{tabular}{|l|}
242,80 \\
\end{tabular} & $\begin{array}{l}73,18 \\
74,18\end{array}$ & | & $\begin{array}{l}40,2< \\
44,60 \\
\end{array}$ & $\begin{array}{l}3,100 \\
5,27\end{array}$ & $\begin{array}{l}44,40 \\
41,76\end{array}$ & $\begin{array}{l}130,38 \\
130,3\end{array}$ & $\begin{array}{l}34,44 \\
34,47\end{array}$ & $\begin{array}{l}34,44 \\
34,47 \\
\end{array}$ & 115,88 \\
\hline Hyla meridionalis & 30SUK12 & 100,00 & 155,81 & 115,07 & 37,00 & 6556,55 & 335,75 & 26,94 & 308,82 & 113,23 & 243,57 & 243,57 & 75,22 & 366,27 & 42,02 & 5,35 & 40,46 & 123,19 & 34,38 & 34,38 & 107,31 \\
\hline Hyla meridionalis & 30 SUK22 & 100,00 & 153,51 & 115,03 & 36,75 & 6590,10 & 334,04 & 24,14 & 309,90 & 110,88 & 241.71 & 241,71 & 72,60 & 366.62 & 41.84 & 6.00 & 40,20 & 122,49 & 35,40 & 35,40 & 105,70 \\
\hline Hyla meridionalis & 30SUK30 & 100,00 & 150,69 & 116,42 & 36,44 & 6677,44 & 334,52 & 19,78 & 314,74 & 120,12 & 240,44 & 240,44 & 69,27 & 389,56 & 44,3 & 5,99 & 40,58 & 129,62 & 36,67 & 36,67 & 113,05 \\
\hline Hyla meridionalis & 30SUK31 & 100,00 & 154,50 & 115,69 & 36,49 & 6643,90 & 336,36 & 23,79 & 312,57 & 113,64 & 243,60 & \begin{tabular}{|l|}
243,60 \\
\end{tabular} & 73,10 & 368,84 & 41 & 5,61 & 40,27 & 123,02 & 35,06 & 35,06 & 106,35 \\
\hline Hyla meridionalis & 30 SUK42 & 100,00 & 153,17 & 114,75 & 36,09 & 6644,08 & 333,95 & 22,73 & 311,21 & 112,53 & 242,41 & 242,41 & 71,86 & 359,77 & 41,62 & 6,11 & 39,30 & 119,29 & 36,19 & 36,19 & 101,33 \\
\hline Hyla meridionalis & 30SVF06 & 32,00 & 182,14 & 88,44 & 38,00 & 4926,03 & 305,81 & 75,25 & 230,56 & 131,58 & 246,78 & 248,14 & 122,78 & 418,61 & 67,00 & 2,00 & 64,61 & 190,67 & 14,67 & 18,11 & 176,56 \\
\hline Hyla meridionalis & 30SVF07 & 100,00 & 167,91 & 97,84 & 38,12 & 5325,12 & 307,58 & 54,66 & 252,93 & 112,35 & 238,92 & 239,17 & 103,99 & 454,88 & 70,73 & 2,98 & 61,86 & 201,03 & 17,95 & 19,37 & 186,34 \\
\hline Hyla meridiona & 30SVF08 & 100,00 & 133,56 & 113,95 & 38,03 & 6023,94 & 304,68 & 10,38 & 294,30 & 71,01 & 215,36 & 215 & 62,47 & 616,68 & 84,16 & 7,03 & 55,93 & 246,27 & 32,40 & 32,95 & 237,63 \\
\hline Hyla meridionalis & $\begin{array}{l}\text { 30SVF09 } \\
\end{array}$ & 100,00 & 136,99 & 115,65 & 38,00 & 6143,62 & 311,83 & 11,90 & 299,92 & 72,73 & 220,46 & 220,46 & $\mid 64,20$ & 596,54 & $\begin{array}{l}4,0,01 \\
80,\end{array}$ & 6,42 & 55,62 & 238,08 & 29,95 & 29,95 & 229,69 \\
\hline Hyla meridionalis & 30SVF16 & & & & & & & & & & & & & & & & & & & & \\
\hline Hyla meridionalis & 30SVF17 & 100,00 & 159,46 & 103,53 & 38,19 & 5540,32 & 309,17 & 42,39 & 266,78 & \begin{tabular}{|l|l|}
101,41 \\
\end{tabular} & 233,86 & 233,92 & 93,12 & 458,48 & 67,69 & 3,80 & 59,34 & 196,04 & 19,99 & 20,58 & 183,33 \\
\hline Hyla meridionalis & 30SVF18 & 100,00 & 126,82 & 117,46 & 38,02 & 6171,08 & 304,79 & 1,30 & 303,49 & 63,14 & 210,80 & 210,83 & 54,17 & 631,64 & 82,95 & 7,90 & 53,93 & 245,10 & 35,22 & 35,73 & 239,22 \\
\hline Hyla meridionalis & 30SVF19 & 100,00 & 139,25 & 116,15 & 38,00 & 6168,30 & 314,74 & 13,34 & 301,40 & 74,45 & 223,03 & 223,03 & 65,97 & 561,14 & 75,10 & 6,36 & 54,89 & 222,64 & 28,74 & 28,74 & 214,1 \\
\hline Hyla meridionalis & 30 SVF26 & & & & & & & & & & & & & & & & & & & & \\
\hline
\end{tabular}




\begin{tabular}{|c|c|c|c|c|c|c|c|c|c|c|c|c|c|c|c|c|c|c|c|c|c|}
\hline TAXON & UTM & $\mathrm{km} 2$ & B101 & B102 & $\mathrm{BIO3}$ & B104 & B105 & B106 & B107 & B108 & B109 & BIO10 & B1011 & BIO12 & B1013 & BIO14 & BIO15 & B1016 & B1017 & B1018 & B1019 \\
\hline Hyla meridionalis & 30SVF27 & 100,00 & 141,26 & 111,30 & 38,16 & 5870,76 & 306,13 & 19,53 & 286,61 & 80,52 & 220,65 & 220,71 & 71,64 & 534,35 & 72,65 & 6,17 & 55,57 & 213,17 & 28,24 & 29,07 & 205,17 \\
\hline Hyla meridionalis & 30SVF28 & 100,00 & 132,77 & 117,33 & 38,04 & 6163,82 & 309,87 & 6,88 & 302,99 & 69,12 & 216,59 & 216,59 & 59,94 & 577,46 & 76,14 & 7,13 & 53,57 & 224,27 & 31,52 & 31,52 & 218,23 \\
\hline Hyla meridionalis & 30 SVF29 & 100,00 & 135,92 & 117,76 & 38,00 & 6238,52 & 314,48 & 9,06 & 305,41 & 70,73 & 220,70 & 220,70 & 62,00 & 564,20 & 74,42 & 6,97 & 53,54 & 218,67 & 30,59 & 30,59 & 211,99 \\
\hline Hyla meridionalis & 30SVF46 & 39,00 & 176,27 & 94,16 & 38,00 & 5177,69 & 309,59 & 64,71 & 244,88 & 122,35 & 244,45 & 245,33 & 113,53 & 341,96 & 49,25 & 2,31 & 59,10 & 146,37 & 13,47 & 17,37 & 137,31 \\
\hline Hyla meridionalis & 30SVF49 & 100,00 & 144,52 & 117,92 & 38,00 & $\begin{array}{ll}6222,36 \\
\end{array}$ & 322,06 & 16,38 & 305,67 & 79,48 & 228,90 & 228,90 & 70,24 & 488,69 & 66,22 & 5,89 & 52,86 & 187,38 & 25,87 & 25,87 & 181,41 \\
\hline Hyla meridionalis & 30SVF56 & 72,00 & 177,14 & 92,92 & 37,97 & 5138,75 & 308,87 & 66,64 & 242,23 & 124,12 & 244,73 & 245,98 & 115,02 & 323,99 & 46,75 & 2,07 & 58,29 & 137,38 & 12,52 & 17,56 & 129,49 \\
\hline Hyla meridionalis & 30SVF57 & 100,00 & 159,37 & 105,05 & 38,01 & 5647,74 & 312,63 & 40,51 & 272,12 & 100,78 & 234,96 & 235,27 & 91,68 & \begin{tabular}{|l|}
398,57 \\
\end{tabular} & 54,91 & 3,90 & 55,24 & 159,44 & 19,14 & 22,90 & 152,46 \\
\hline Hyla meridionalis & 30SVF66 & & & & & & & & & & & & & & & & & & & & \\
\hline Hyla meridionalis & 30SVF68 & 100,00 & 145,95 & 111,88 & 38,00 & 5986,90 & 313,21 & 22,53 & 290,68 & 85,22 & 226,68 & 226,92 & 74,84 & $\begin{array}{l}459,45 \\
\end{array}$ & 61,02 & 5,88 & 51,92 & 172,95 & 26,35 & 31,35 & 168,28 \\
\hline Hyla meridionalis & 30SVF96 & 31,00 & 172,63 & 91,29 & 37,20 & 5181,34 & 304,29 & 62,76 & 241,54 & 120,05 & 240,20 & 242,66 & 110,12 & 296,85 & 41,29 & 2,17 & 54,78 & 117,63 & 13,05 & 18,63 & 112,80 \\
\hline Hyla meridionalis & 30SVG10 & 100,00 & 146,56 & 114,97 & 37,99 & 6181,29 & 320,53 & 20,79 & 299,74 & 80,53 & 230,58 & 230,58 & 72,92 & 519,77 & 71,88 & 5,83 & 55,21 & 208,73 & 26,13 & 26,13 & 197,66 \\
\hline Hyla meridionalis & 30SVG14 & 100,00 & 143,62 & 117,40 & 36,89 & 6630,32 & 330,15 & 14,90 & 315,25 & 75,28 & 233,90 & 233,90 & 64,83 & 589,65 & 77,39 & 6,85 & 53,37 & 220,12 & 31,00 & 31,00 & 217,41 \\
\hline Hyla meridionalis & 30 SVG24 & 100,00 & 144,54 & 117,80 & 36,96 & 6647,62 & 331,67 & 15,37 & 316,30 & 75,56 & 235,03 & 235,03 & 65,56 & 568,15 & 74,36 & 6,89 & 52,60 & 210,27 & 30,69 & 30,69 & 207,29 \\
\hline Hyla meridionalis & 30 SVG34 & 100,00 & 139,93 & 119,43 & 36,99 & 6683,69 & 329,45 & 9,99 & 319,46 & 71,39 & 231,01 & 231,01 & 60,73 & 574,29 & 75,90 & 7,53 & 51,31 & 209,78 & 33,08 & 33,08 & 206,13 \\
\hline Hyla meridionalis & 30 SVG40 & 100,00 & 145,38 & 119,73 & 38,00 & 6347,76 & 327,09 & 15,72 & 311,37 & 78,74 & 231,55 & 231,55 & 69,68 & 491,34 & 66,55 & 5,95 & 52,60 & 186,27 & 25,97 & 25,97 & 180,81 \\
\hline Hyla meridionalis & 30 SVG 41 & 100,00 & 153,30 & 119,43 & 37,94 & 6373,83 & 334,49 & 23,04 & 311,45 & 85,31 & 239,83 & 239,83 & 76,87 & 453,80 & 62,06 & 5,21 & 53,01 & 173,27 & 22,75 & 22,75 & 166,64 \\
\hline Hyla meridionalis & 30SVG59 & 100,00 & 171,17 & 110,18 & 35,92 & 6609,16 & 348,34 & 44,54 & 303,81 & \begin{tabular}{|l|l|}
124,97 \\
\end{tabular} & 259,99 & 259,99 & 91,48 & 451,57 & 64,77 & 3,78 & 52,74 & 169,93 & 22,11 & 22,11 & 158,86 \\
\hline Hyla meridionalis & 30SVG61 & 100,00 & 112,41 & 121,28 & 37,86 & 6532,90 & 301,90 & $-16,22$ & 318,13 & 62,72 & 201,56 & 201,79 & 36,41 & 659,49 & 82,80 & 12,84 & 46,09 & 233,59 & 52,19 & 55,75 & 224,71 \\
\hline Hyla meridionalis & 30SVH01 & 100,00 & 173,25 & 114,34 & 36,00 & 6739,98 & 356,56 & 43,78 & 312,78 & 103,74 & 263,86 & 263,86 & 91,44 & 511,77 & 75,83 & 3,23 & 55,60 & 195,58 & 21,62 & 21,62 & 185,27 \\
\hline Hyla meridionalis & 30SVHO2 & 100,00 & 166,13 & 116,79 & 36,00 & 6846,37 & 354,41 & 35,08 & 319,33 & 96,84 & 258,37 & 258,37 & 83,31 & 530,30 & 78,73 & 3,62 & 54,44 & 201,04 & 24,27 & 24,27 & 188,86 \\
\hline Hyla meridionalis & 30SVH08 & 100,00 & 146,68 & 126,35 & 37,34 & 6917,47 & 344,27 & 10,82 & 333,44 & 123,90 & 240,12 & 240,12 & 63,49 & 495,58 & 64,12 & 4,31 & 46,88 & 175,07 & 33,86 & 33,86 & 159,05 \\
\hline Hyla meridionalis & 30SVH11 & 100,00 & 173,27 & 113,34 & 36,00 & 6740,93 & 355,86 & 44,18 & $\begin{array}{l}311,68 \\
31,4\end{array}$ & $\begin{array}{l}103,58 \\
\end{array}$ & 263,83 & 263,83 & 91,41 & 500,60 & 74,46 & 3,27 & 55,22 & 191,21 & 21,66 & 21,66 & 180,09 \\
\hline Hyla meridionalis & 30SVH12 & 100,00 & 165,95 & 116,11 & 36,00 & 6846,00 & 353,68 & 35,44 & 318,24 & 105,58 & 258,18 & 258,18 & 83,22 & 519,72 & 77,25 & 3,74 & 53,92 & 197,10 & 24,62 & 24,62 & 183,63 \\
\hline Hyla meridionalis & 30SVH13 & 100,00 & 163,29 & 117,95 & 36,05 & 6870,86 & 352,93 & 31,71 & 321,22 & 115,03 & 255,89 & 255,89 & 80,25 & \begin{tabular}{|l|l}
515,05 \\
\end{tabular} & 75,36 & 3,79 & 52,75 & 193,19 & 25,86 & 25,86 & 179,25 \\
\hline Hyla meridionalis & 30SVH14 & 100,00 & 157,62 & 120,27 & 36,56 & 6901,44 & 350,06 & 24,96 & 325,10 & 110,93 & 250,79 & 250,79 & 74,49 & 518,31 & 74,11 & 4,22 & 51,24 & 192,18 & 28,63 & 28,63 & 176,88 \\
\hline Hyla meridionalis & 30SVH15 & 100,00 & 155,79 & 121,83 & 36,99 & 6898,91 & 349,23 & 22,23 & 327,01 & 109,29 & 248,88 & 248,88 & 72,53 & 506,77 & 70,68 & 4,16 & 50,15 & 185,38 & 29,49 & 29,49 & 170,10 \\
\hline Hyla meridionalis & 30SVH21 & 100,00 & 175,23 & $\begin{array}{l}112,19 \\
119\end{array}$ & 36,00 & 6708,16 & 355,88 & 46,71 & 309,18 & 107,21 & $\begin{array}{l}40,060 \\
265,28 \\
\end{array}$ & $\begin{array}{l}40,260 \\
265,28 \\
\end{array}$ & 93,80 & 478,04 & 70,70 & 3,01 & 54,79 & \begin{tabular}{|l|}
181,60 \\
\end{tabular} & 20,69 & 20,69 & 170,99 \\
\hline Hyla meridionalis & 30SVH22 & 100,00 & 167,66 & 115,08 & 36,00 & 6811,41 & 353,58 & 37,68 & 315,90 & 117,58 & 259,44 & 259,44 & 85,38 & 498,74 & 73,72 & 3,62 & 53,34 & 188,84 & 24,08 & 24,08 & 174,98 \\
\hline Hyla meridionalis & $30 \mathrm{SVH} 23$ & 100,00 & 159,30 & 118,18 & 36,02 & 6893,52 & 349,99 & 27,74 & 322,25 & 112,12 & 252,44 & 252,44 & 76,32 & 517,86 & 75,42 & 4,36 & 51,70 & 194,73 & 28,09 & 28,09 & 177,84 \\
\hline Hyla meridionalis & 30SVH31 & 100,00 & 174,42 & 111,81 & 35,97 & 6694,98 & 354,43 & 46,19 & 308,23 & 120,97 & 264,31 & 264,31 & 93,27 & 464,98 & 68,30 & 3,05 & 54,04 & 176,06 & 21,03 & 21,03 & 164,68 \\
\hline Hyla meridionalis & $30 \mathrm{SVH} 32$ & 100,00 & 171,49 & 113,88 & 36,00 & 6739,60 & 354,18 & 42,16 & 312,03 & 125,20 & 262,05 & 262,05 & 89,90 & 467,04 & 68,03 & 3,12 & 52,92 & 175,95 & 22,52 & 22,52 & 162,79 \\
\hline Hyla meridionalis & \begin{tabular}{|c|c|}
$30 \mathrm{SVH} 33$ \\
\end{tabular} & 100,00 & 163,99 & \begin{tabular}{|l|l|}
116,79 \\
169
\end{tabular} & 36,00 & 6826,59 & 351,34 & $\begin{array}{ll}33,03 \\
33,4\end{array}$ & 318,31 & 117,36 & $\begin{array}{l}255,90 \\
250\end{array}$ & \begin{tabular}{|l|}
255,90 \\
\end{tabular} & 81,46 & | & $\begin{array}{l}69,84 \\
690\end{array}$ & 3,159 & 51,35 & \begin{tabular}{|l|l}
181,73 \\
\end{tabular} & 26,11 & 26,11 & 165,59 \\
\hline Hyla meridionalis & $30 \mathrm{SVH} 41$ & 100,00 & 172,06 & 112,09 & 36,00 & 6687,70 & 352,28 & 43,94 & 308,34 & 125,90 & 261,96 & 261,96 & 91,14 & 458,41 & 66,63 & 3,46 & 52,76 & 173,03 & 22,34 & 22,34 & 160,08 \\
\hline Hyla meridionalis & $30 \mathrm{SVH} 42$ & 100,00 & 168,91 & 114,17 & 36,00 & 6738,83 & 351,87 & 39,52 & 312,34 & 122,59 & 259,43 & 259,43 & 87,43 & 461,65 & 66,40 & 3,64 & 51,84 & 173,28 & 24,00 & 24,00 & 158,57 \\
\hline Hyla meridionalis & $30 \mathrm{SVH} 43$ & 100,00 & 163,33 & 116,73 & 36,05 & 6798,84 & 349,91 & 32,62 & 317,29 & 116,79 & 254,96 & 254,96 & 81,34 & 471,24 & 66,79 & 4,03 & 50,53 & 175,58 & 26,70 & 26,70 & 158,96 \\
\hline Hyla meridionalis & $30 \mathrm{SVH} 44$ & 100,00 & 148,33 & 120,66 & 36,76 & 6890,83 & 341,28 & 15,92 & 325,37 & 100,84 & 241,58 & 241,58 & 65,94 & 515,72 & 70,99 & 5,67 & 47,88 & 189,17 & 34,67 & 34,67 & 168,88 \\
\hline Hyla meridionalis & $30 \mathrm{SVH} 47$ & 100,00 & 145,99 & 124,14 & 37,00 & 6870,11 & 340,45 & 11,56 & 328,90 & 119,88 & 238,96 & 238,96 & 63,64 & 480,10 & 61,46 & 5,12 & 45,32 & 170,58 & 36,08 & 36,08 & 150,46 \\
\hline Hyla meridionalis & 30SVH53 & 100,00 & 163,20 & 116,49 & 36,24 & 6752,17 & 348,31 & 32,62 & 315,69 & 116,77 & 254,13 & 254,13 & 81,79 & 455,50 & 63,27 & 4,01 & 49,48 & 168,26 & 26,90 & 26,90 & 151,61 \\
\hline Hyla meridionalis & 30SVH54 & 100,00 & 152,54 & 119,68 & 36,80 & 6830,84 & 342,73 & 20,42 & 322,31 & 105,50 & 244,79 & 244,79 & 70,64 & 485,61 & 65,96 & 5,25 & 47,56 & $\mid 177,22$ & 32,77 & 32,77 & 157,69 \\
\hline Hyla meridionalis & 30 SVH62 & 100,00 & 164,73 & 114,86 & 36,16 & 6674,53 & 346,68 & 35,18 & 311,50 & 118,38 & 254,51 & 254,51 & 84,26 & 441,02 & 60,50 & 4,08 & 49,19 & 162,05 & 26,24 & 26,24 & 146,58 \\
\hline Hyla meridionalis & 30SVH63 & 100,00 & 164,47 & 116,01 & 36,64 & 6684,56 & 347,21 & 34,17 & 313,04 & 118,42 & 254,30 & 254,30 & 83,66 & 433,40 & 58,56 & 3,93 & 48,54 & 157,97 & 26,50 & 26,50 & 142,27 \\
\hline Hyla meridionalis & 30SVH64 & 100,00 & 154,19 & 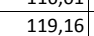 & 36,95 & 6780,69 & 342,24 & 22,47 & \begin{tabular}{|l|}
319,76 \\
\end{tabular} & $\begin{array}{l}107,34 \\
\end{array}$ & 245,70 & 245,70 & 72,69 & 464,67 & $\begin{array}{ll}61,84 \\
\end{array}$ & 5,0 & 46,69 & 168,01 & 32,31 & 32,31 & 148,91 \\
\hline Hyla meridionalis & $30 \mathrm{SVH} 65$ & 100,00 & 145,01 & 121,56 & 37,00 & 6830,51 & 336,83 & 12,36 & 324,47 & 98,63 & 237,55 & 237,55 & 63,40 & 490,13 & 63,78 & 6,22 & 44,91 & 175,06 & 37,89 & 37,89 & 153,67 \\
\hline Hyla meridionalis & 30SVH74 & 100,00 & 156,35 & 118,46 & 37,00 & 6713,76 & 341,89 & 24,83 & 317,06 & 109,79 & 246,80 & 246,80 & 75,59 & 442,10 & 57,42 & 4,87 & 45,98 & 158,07 & 31,52 & 31,52 & 139,85 \\
\hline Hyla meridionalis & 30SVH75 & 100,00 & 148,09 & 120,87 & 37,00 & 6772,70 & 337,37 & 15,63 & 321,74 & 110,62 & 239,64 & 239,64 & 66,96 & 466,38 & 59,56 & 5,5 & 44,41 & 165,41 & 36,67 & 36,67 & 144,59 \\
\hline Hyla meridionalis & 30SVH76 & 100,00 & $\begin{array}{l}142,16 \\
142,16\end{array}$ & 122,42 & 37,00 & 6812,50 & 333,83 & $\begin{array}{l}0,07 \\
9,0\end{array}$ & 324,76 & $\begin{array}{l}123,00 \\
\end{array}$ & 234,41 & 234,41 & 60,91 & 4 & 60,20 & 6,8 & 42,80 & $\begin{array}{l}170,17 \\
\end{array}$ & 40,83 & 40,83 & $\begin{array}{l}446,37 \\
146\end{array}$ \\
\hline Hyla meridionalis & 30 SVH81 & 100,00 & 159,91 & 114,97 & 36,91 & 6589,05 & 339,97 & 30,88 & 309,10 & 113,51 & 248,51 & 248,56 & 80,65 & 429,66 & 56,23 & 4,7 & 47,06 & 154,55 & 28,56 & 29,46 & 139,10 \\
\hline Hyla meridionalis & 30SVH83 & 100,00 & 152,89 & 118,31 & 37,00 & 6684,40 & 337,84 & 21,87 & 315,97 & 105,94 & 242,93 & 242,93 & 72,76 & 448,93 & 57,69 & 5,49 & 45,15 & 159,88 & 33,55 & 33,55 & 140,90 \\
\hline Hyla meridionalis & 30SVH85 & 100,00 & 146,29 & 120,92 & 37,01 & 6742,36 & 334,64 & 13,91 & 320,72 & 123,55 & 237,31 & 237,31 & 65,56 & 461,99 & 57,69 & 6,39 & 43,18 & 163,03 & 38,59 & 38,59 & 140,59 \\
\hline Hyla meridiona & 30SVH93 & 100,00 & 154,94 & 117,56 & 37,00 & 6602,10 & 336,82 & 24,36 & 312,46 & 111,42 & 243,77 & 243,82 & 75,61 & 425,90 & 53,23 & 5,27 & 44,41 & 149,47 & 32,83 & 33,28 & 131,48 \\
\hline Hyla meridionalis & \begin{tabular}{|l|}
$30 \mathrm{SVH} 94$ \\
\end{tabular} & 100,00 & 149,32 & \begin{tabular}{|l|}
119,44 \\
19,0
\end{tabular} & 37,01 & 66065,62 & 330,02 & $\begin{array}{l}4,30 \\
17,92 \\
\end{array}$ & \begin{tabular}{|l|}
316,51 \\
31
\end{tabular} & \begin{tabular}{|l|l|l|l|l|}
125,98 \\
\end{tabular} & \begin{tabular}{|l|}
239,23 \\
\end{tabular} & \begin{tabular}{|l|}
239,23 \\
230
\end{tabular} & $\begin{array}{l}69,01 \\
69,49\end{array}$ & 年 & $\begin{array}{ll}5,2528 \\
55,28\end{array}$ & $\frac{3,24}{6,04}$ & $\begin{array}{lll}43,18 \\
3,4\end{array}$ & $\begin{array}{l}155,66 \\
155,6\end{array}$ & 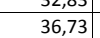 & 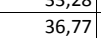 & $\begin{array}{l}131,40 \\
134,33\end{array}$ \\
\hline Hyla meridionalis & 30SVH95 & 100,00 & 143,64 & 121,02 & 37,12 & 6708,19 & 331,32 & 11,41 & 319,91 & 124,45 & 234,24 & 234,24 & 63,41 & 460,92 & 57,49 & 6,88 & 41,94 & 162,34 & 40,95 & 40,95 & 137,51 \\
\hline Hyla meridionalis & 30 SVJoo & 100,00 & 148,87 & 127,44 & 38,00 & 6881,30 & 345,65 & 11,99 & 333,65 & 132,29 & 241,78 & 241,78 & 65,87 & 452,13 & 55,12 & 4,00 & 45,43 & 158,93 & 32.90 & 32,90 & 140,79 \\
\hline Hyla meridionalis & 30SVJ11 & 100,00 & 147,16 & 128,77 & 38,00 & 6852,44 & 343,75 & 9,46 & 334,29 & 131,07 & 239,31 & 239,31 & 64,03 & 431,67 & 52,12 & 4,00 & 44,03 & 151,79 & 33,87 & 33,87 & 130,75 \\
\hline Hyla meridionalis & 30SVJ13 & 100,00 & 143,91 & 126,68 & 37,89 & 6858,15 & 339,39 & 7,36 & 332,03 & 127,80 & 236,59 & 236 & 61,18 & 430,37 & 51,26 & 4,76 & 42,04 & 149,31 & 37,37 & 37,37 & 127,06 \\
\hline Hyla meridionalis & | & $\begin{array}{l}100,00 \\
\end{array}$ & $\begin{array}{l}14,51,32 \\
133,\end{array}$ & \begin{tabular}{|l|}
123,81 \\
123,01
\end{tabular} & 年, 37,09 & $\begin{array}{l}6030,11 \\
6870,43\end{array}$ & $\begin{array}{l}327,87 \\
327,87\end{array}$ & 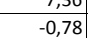 & \begin{tabular}{|l|}
328,665 \\
328,6
\end{tabular} & \begin{tabular}{|l|}
116,26 \\
116,2
\end{tabular} & \begin{tabular}{|l|}
226,57 \\
22,5
\end{tabular} & \begin{tabular}{|l|}
226,57 \\
22,5
\end{tabular} & $\begin{array}{l}\mid l, 10 \\
51,09\end{array}$ & | & $\begin{array}{l}1,26 \\
54,07 \\
\end{array}$ & $\begin{array}{l}4,10 \\
7,10\end{array}$ & $\begin{array}{l}42,04 \\
39,51\end{array}$ & $\begin{array}{l}155,011 \\
158,08 \\
\end{array}$ & $\begin{array}{l}3 r, 3,73 \\
45,73\end{array}$ & $\begin{array}{l}31,371 \\
45,73\end{array}$ & $\begin{array}{l}131,00 \\
133,26\end{array}$ \\
\hline Hyla meridionalis & 30SWF06 & 31,00 & 178,38 & $\begin{array}{l}85,78 \\
\end{array}$ & 36,97 & 4976,35 & 301,83 & 72,30 & 229,52 & 128,25 & 242,68 & 245,75 & 118,15 & 266,20 & 37,42 & 1,63 & 55,30 & 106,15 & 11,02 & 16,27 & 100,95 \\
\hline Hyla meridionalis & 30SWH23 & 100,00 & 135,81 & 119,95 & \begin{tabular}{|c|}
37,88 \\
\end{tabular} & 6573,86 & 319,58 & 5,31 & 314,27 & 115,67 & 224,68 & 224,79 & 57,81 & 473,78 & 60,36 & 9,25 & 39,12 & 164,77 & 48,83 & 49,47 & 135,25 \\
\hline Hyla meridionalis & 30 SWH25 & 100,00 & 140,51 & 120,64 & 38,00 & 6580,19 & 324,05 & 8,96 & 315,09 & 121,21 & 229,2 & 229, & 61, & 444,95 & 56,81 & 7,98 & 39,07 & 154,85 & 46,07 & 46,40 & 125, \\
\hline Hyla meridionalis & 30 SWH 35 & 100,00 & 135,10 & 120,94 & 38,00 & 6562,45 & 318,66 & 3,99 & 314,68 & 115,32 & 223,75 & 223,83 & 57,18 & 461,17 & 59,19 & 9,41 & 37,62 & 159,92 & 51,44 & 51,82 & 126,39 \\
\hline
\end{tabular}




\begin{tabular}{|c|c|c|c|c|c|c|c|c|c|c|c|c|c|c|c|c|c|c|c|c|c|}
\hline TAXON & UTM & $\mathrm{km} 2$ & B101 & B102 & $\mathrm{BIO3}$ & B104 & B105 & B106 & B107 & B108 & B109 & BIO10 & BIO11 & BIO12 & B1013 & BIO14 & BIO15 & B1016 & B1017 & BIO18 & B1019 \\
\hline Hyla meridionalis & 30SWH59 & 100,00 & 129,59 & 122,39 & 38,30 & 6539,40 & 312,89 & $-1,79$ & 314,68 & 110,51 & 217,68 & 218,04 & 51,72 & 460,34 & 58,64 & 11,23 & 34,25 & 157,76 & 58,58 & 62,27 & 115,81 \\
\hline Hyla meridionalis & 30SWH95 & 100,00 & 150,41 & 118,84 & 39,14 & 6175,10 & 318,85 & 19,76 & 299,09 & 132,24 & 232,81 & 233,03 & 75,88 & 370,24 & 49,90 & 7,21 & 38,17 & 123,54 & 45,03 & 46,55 & 90,10 \\
\hline Hyla meridionalis & $30 \mathrm{~S} \times \mathrm{H} 46$ & 100,00 & 148,49 & 117,36 & 39,99 & 5991,87 & 309,28 & 19,41 & 289,87 & 148,49 & 227,92 & 228,73 & 76,22 & 396,39 & 53,53 & 9,01 & 37,29 & 129,54 & 51,91 & 58,53 & 90,28 \\
\hline Hyla meridionalis & 30 XXH68 & 100,00 & 142,02 & 113,82 & 39,87 & 5933,72 & 298,99 & 16,03 & 282,95 & 152,27 & 220,73 & 221,85 & 70,98 & 441,90 & 59,60 & 11,88 & 34,58 & 146,62 & 62,88 & 70,57 & 98,86 \\
\hline Hyla meridionalis & 30TTK43 & 60,00 & 149,16 & 110,74 & 36,88 & 6409,49 & 324,89 & 26,98 & 297,91 & 78,57 & 234,93 & 234,93 & 71,07 & 468,07 & 57,26 & 5,87 & 44,11 & 167,16 & 38,90 & 38,90 & 154,18 \\
\hline Hyla meridionalis & 30TTK44 & 60,00 & 132,45 & 109,16 & 36,60 & 6377,70 & 307,43 & 12,65 & 294,78 & 62,97 & 217,85 & 218,38 & 55,81 & 543,52 & 66,52 & 8,45 & 42,58 & 193,49 & 48,58 & 49,33 & 179,36 \\
\hline Hyla meridionalis & 30TTK53 & 100,00 & 147,35 & 111,49 & 36,97 & 6429,11 & 323,85 & 24,52 & 299,33 & 76,59 & 233,48 & 233,54 & 69,23 & 461,32 & 56,02 & 6,25 & 43,28 & 162,79 & 39,68 & 39,72 & 149,46 \\
\hline Hyla meridionalis & 30TTK54 & 100,00 & 126,02 & 109,80 & 36,64 & 6379,98 & 302,00 & \begin{tabular}{|c|}
6,26 \\
6
\end{tabular} & 295,74 & 56,83 & 211,49 & 212,14 & 49,72 & 553,85 & $\begin{array}{ll}67,17 \\
\end{array}$ & 9,55 & 41,46 & 194,51 & 51,85 & 52,86 & 179,58 \\
\hline Hyla meridionalis & 30TTK55 & 100,00 & 108,84 & 107,86 & \begin{tabular}{|l|l|}
36,47 \\
\end{tabular} & 6312,55 & 283,49 & $-7,86$ & 291,36 & 41,26 & 193,66 & $\begin{array}{l}194,57 \\
\end{array}$ & 34,53 & 643,86 & 78,32 & 12,68 & 40,28 & 226,02 & 62,99 & 65,62 & 209,65 \\
\hline Hyla meridionalis & 30TTK57 & 100,00 & 125,48 & 111,03 & \begin{tabular}{|l|l|}
37,08 \\
\end{tabular} & \begin{tabular}{|l|l|}
6317,04 \\
\end{tabular} & 299,69 & 5,65 & 294,04 & 56,32 & 209,99 & 210,54 & 49,34 & 515,12 & 63,05 & 9,67 & 39,93 & 180,10 & 51,77 & 52,14 & 164,56 \\
\hline Hyla meridionalis & 30TTK58 & 100,00 & 125,15 & 111,64 & 37,57 & 6296,49 & 298,85 & 5,27 & 293,58 & 56,00 & 209,26 & 209,81 & 49,13 & 503,89 & 61,86 & 9,69 & 39,55 & 175,86 & 51,83 & 52,15 & 159,95 \\
\hline Hyla meridionalis & 30TTK63 & 100,00 & 151,82 & 112,81 & 37,00 & 6440,76 & 328,96 & 27,44 & 301,52 & 80,68 & 238,04 & 238,04 & 73,12 & 425,74 & 51,26 & 5,77 & 42,79 & 148,26 & 36,99 & 36,99 & 135,22 \\
\hline Hyla meridionalis & 30TTK65 & 100,00 & 113,49 & 109,94 & 36,78 & 6341,39 & 289,57 & $-5,24$ & 294,81 & 45,07 & 198,60 & $\begin{array}{l}199,43 \\
\end{array}$ & 38,40 & 586,38 & $\begin{array}{l}11,6 \\
70,42\end{array}$ & 12,04 & 39,20 & 201,93 & $\begin{array}{l}59,78 \\
5,7\end{array}$ & 61,71 & 185,52 \\
\hline Hyla meridionalis & 30TTK67 & 100,00 & 109,14 & 110,24 & \begin{tabular}{|l|l|}
37,07 \\
\end{tabular} & 6281,82 & 283,90 & $-8,71$ & 292,61 & 41,20 & 192,97 & 194,39 & 34,75 & 578,51 & 69,88 & 12,63 & 37,97 & 198,20 & 62,04 & 64,14 & 180,73 \\
\hline Hyla meridionalis & 30TTK68 & 100,00 & 121,72 & 112,60 & \begin{tabular}{|c|}
37,88 \\
\end{tabular} & 6290,36 & 296,40 & 1,58 & 294,82 & 52,69 & 205,55 & 206,38 & 46,00 & 494,14 & 59,95 & 10,43 & 38,06 & 168,79 & 53,79 & 54,29 & 152,38 \\
\hline Hyla meridionalis & 30TTK69 & 100,00 & 116,55 & 112,76 & 38,00 & 6255,50 & 290,74 & $-2,36$ & 293,10 & 54,45 & 199,44 & 200,97 & 41,45 & 504,86 & 61,34 & 11,15 & 37,32 & 171,90 & 56,85 & 57,70 & 154,59 \\
\hline Hyla meridionalis & 30TTK78 & 100,00 & 114,63 & 112,80 & 37,91 & 6271,61 & 289,86 & $-4,61$ & 294,47 & 55,68 & 197,59 & 199,56 & 39,69 & 504,84 & 60,39 & 11,68 & 36,46 & 168,65 & 57,96 & 59,24 & 151,39 \\
\hline Hyla meridionalis & 30TTK79 & 100,00 & 116,93 & 113,89 & 38,05 & 6247,73 & 291,87 & $-2,66$ & 294,53 & 73,70 & 199,32 & 201,36 & 41,94 & 479,76 & 57,49 & 11,22 & 36,02 & 159,91 & 56,53 & 57,49 & 142,51 \\
\hline Hyla meridionalis & 30TTK84 & 100,00 & 134,41 & 113,27 & 37,00 & 6425,82 & 312,65 & 10,59 & 302,07 & 81,47 & 220,52 & 220,95 & 56,82 & 456,62 & 53,71 & 8,67 & 39,33 & 153,00 & 46,50 & 47,06 & 137,83 \\
\hline Hyla meridionalis & 30TTK93 & 100,00 & 158,23 & 114,87 & 37,00 & 6478,21 & 336,17 & 31,10 & 305,07 & 116,45 & 244,77 & 244,77 & 78,48 & 365,64 & 43,12 & 5,03 & 41,74 & 124,73 & 32,99 & 32,99 & 110,07 \\
\hline Hyla meridionalis & 30TTK94 & 100,00 & 150,38 & 114,48 & 37,00 & 6451,97 & 328,03 & 24,12 & 303,91 & 108,28 & 236,77 & 236,78 & 71,27 & 381,23 & 44,7 & 6,37 & 39,86 & 128,30 & 37,38 & 37,38 & 113,13 \\
\hline Hyla meridionalis & 30TTK95 & 100,00 & 94,42 & 110,80 & 36,89 & 6314,75 & 272,60 & $-23,77$ & 296,37 & $\begin{array}{l}36,90 \\
36\end{array}$ & 179,93 & 180,69 & 21,05 & 643,16 & 74,43 & 17,05 & 35,56 & 210,75 & 74,63 & 78,42 & 191,89 \\
\hline Hyla meridionalis & 30TUK03 & 100,00 & 156,90 & 114,99 & 37,00 & 6503,86 & 335,39 & 28,88 & 306,51 & 114,68 & 243,94 & 243,94 & 76,89 & 361,34 & 42,13 & 5,25 & 40,71 & 122,40 & 33,81 & 33,81 & 106,76 \\
\hline Hyla meridionalis & 30TUK04 & 100,00 & 152,48 & 114,92 & 37,00 & 6473,37 & 330,21 & 25,06 & 305,15 & 110,58 & 239,14 & 239,14 & 72,90 & 365,59 & 42,55 & 6,31 & 39,21 & 122,56 & 36,52 & 36,52 & 106,51 \\
\hline Hyla meridionalis & 30TUK13 & 100,00 & 153,80 & 115,00 & 37,00 & 6529,68 & 332,82 & 25,31 & 307,51 & 111,49 & 241,18 & 241,18 & 73,63 & 362,19 & 41,65 & 5,97 & 39,65 & 121,37 & 35,44 & 35,44 & 104,84 \\
\hline Hyla meridionalis & 30TUK14 & 100,00 & 151,35 & 114,68 & 37,00 & 6499,67 & 329,40 & 23,35 & 306,06 & 109,40 & 238,49 & 238,49 & 71,49 & 361,03 & 41,7 & 6,41 & 38,95 & 120,26 & 36,98 & 36,98 & 103,24 \\
\hline Hyla meridionalis & 30TUK23 & 100,00 & 151,83 & 114,95 & 37,00 & 6558,41 & 331,25 & 23,05 & 308,19 & $\begin{array}{l}109,52 \\
\end{array}$ & \begin{tabular}{|l|}
239,88 \\
\end{tabular} & \begin{tabular}{|l|}
239,88 \\
\end{tabular} & 71,45 & 361,57 & $\begin{array}{l}41,1,58 \\
41\end{array}$ & $\begin{array}{l}0,4+19 \\
6,19\end{array}$ & 39,18 & 120,32 & 36,54 & 36,54 & 102,94 \\
\hline Hyla meridionalis & 30TUK24 & 100,00 & 148,45 & 114,23 & 37,00 & 6501,82 & 326,70 & 20,22 & 306,48 & 106,40 & 235,77 & 235,77 & 68,69 & 362,49 & 42,40 & 6,90 & 38,08 & 119,71 & 38,77 & 38,77 & 101,54 \\
\hline Hyla meridionalis & 30 TUK 25 & 100,00 & 135,47 & 113,90 & 37,00 & 6441,15 & 313,42 & 9,08 & 304,35 & 104,99 & 222,13 & 222,33 & 57,18 & 389,31 & 47,34 & 8,90 & 36,26 & 126,13 & 46,22 & 46,31 & 105,63 \\
\hline Hyla meridionalis & 30TUK34 & 100,00 & 146,30 & 113,97 & 36,92 & 6520,96 & 324,74 & 17,80 & 306,94 & 108,63 & 233,89 & 233,89 & 66,48 & 363,94 & 43,27 & 7,34 & 37,36 & 119,40 & 40,36 & 40,36 & 99,86 \\
\hline Hyla meridionalis & 30TUK35 & 100,00 & 129,37 & 113,05 & 36,90 & 6435,29 & 307,23 & 3,53 & 303,71 & 102,52 & 215,81 & 216,31 & 51,82 & 408,73 & 50,69 & 10,20 & 35,68 & 132,82 & 50,62 & 51,16 & 108,39 \\
\hline Hyla meridionalis & \begin{tabular}{|l|l|}
30 TUK43 \\
\end{tabular} & 100,00 & 145,94 & 114,02 & 36,11 & $\begin{array}{l}04501,61 \\
6601\end{array}$ & 326,07 & \begin{tabular}{|l|}
16,37 \\
16,
\end{tabular} & \begin{tabular}{|l|}
309,70 \\
\end{tabular} & \begin{tabular}{|l|l|}
117,03 \\
\end{tabular} & $\begin{array}{l}234,62 \\
24,5\end{array}$ & 234,62 & $\begin{array}{ll}1,30<2 \\
65,32\end{array}$ & 370,04 & $\begin{array}{l}0,030 \\
44,08 \\
\end{array}$ & 7,20 & $\begin{array}{l}3,90 \\
37,97 \\
\end{array}$ & \begin{tabular}{|l|}
121,24 \\
$12,0<$
\end{tabular} & $\begin{array}{l}0,37 \\
40,37 \\
\end{array}$ & $\begin{array}{l}1,10 \\
40,37\end{array}$ & 101,62 \\
\hline Hyla meridionalis & 30TUK45 & 100,00 & 146,31 & 112,88 & 36,51 & 6512,57 & 323,18 & \begin{tabular}{ll|}
17,87 \\
\end{tabular} & 305,31 & 107,34 & 233,69 & 233,69 & 66,26 & 353,29 & 42,51 & 7,55 & 37,12 & 115,64 & 40,71 & 40,71 & 94,95 \\
\hline Hyla meridionalis & 30 TUK46 & 100,00 & 100,93 & 111,37 & 36,83 & 6305,77 & 278,33 & $-20,28$ & 298,61 & 82,70 & 186,21 & 186,97 & 27,26 & 508,86 & 65,08 & 15,92 & 33,13 & 163,43 & 70,14 & 72,82 & 130,45 \\
\hline Hyla meridionalis & 30TUK53 & 100,00 & 150,74 & 113,37 & 36,00 & 6632,21 & 330,08 & 20,54 & 309,54 & 109,54 & 239,77 & 239,77 & 69,22 & 357,35 & 42,01 & 6,85 & 38,16 & 117,52 & 38,30 & 38,30 & 98,42 \\
\hline Hyla meridionalis & 30TUK54 & 100,00 & 131,14 & 112,60 & 36,09 & 6545,57 & 310,48 & 3,62 & 306,87 & 113,72 & 219,40 & 219,58 & 52,15 & 401,54 & 50,23 & 9,73 & 35,69 & 130,93 & 49,81 & 49,99 & 104,96 \\
\hline Hyla meridionalis & 30 TUK55 & 100,00 & 140,85 & 112,00 & 36,01 & 6541,56 & 318,01 & 12,68 & 305,33 & 110,79 & 228,88 & 228,88 & 60,92 & 365,31 & 44,80 & 8,45 & 35,97 & 118,38 & 44,29 & 44,29 & 96,25 \\
\hline Hyla meridionalis & \begin{tabular}{|l|}
$30 T U K 56$ \\
\end{tabular} & 100,00 & 118,29 & 111,17 & 36,41 & 6398,64 & 294,72 & $-5,92$ & 300,64 & 92,11 & 204,53 & 204,95 & 41,94 & 438,19 & 55,93 & 12,85 & 34,18 & 141,45 & 59,34 & 60,68 & 111,31 \\
\hline Hyla meridionalis & 30TUK64 & 100,00 & 143,47 & 111,86 & 36,00 & 6613,83 & 321,64 & 14,24 & 307,40 & 113,18 & 232,51 & 232,51 & 62,66 & 368,43 & 44,41 & 8,08 & 36,43 & 120,08 & 43,36 & 43,36 & 98,32 \\
\hline Hyla meridionalis & 30TUK65 & 100,00 & 132,66 & 111,17 & 36,00 & 6534,47 & 309,78 & 5,08 & 304,70 & 113,12 & 220,75 & 220,75 & 53,25 & 387,33 & 48,71 & 9,88 & 35,14 & 125,27 & 49,91 & 49,91 & 99,34 \\
\hline Hyla meridionalis & 30TUK66 & 100,00 & 113,97 & 110,31 & 36,34 & 6387,97 & 290,11 & $-9,62$ & 299,73 & 93,62 & 200,12 & 200,66 & 38,09 & 443,80 & 57,94 & 13,48 & 33,95 & 143,79 & 62,19 & 63,67 & 109,62 \\
\hline Hyla meridionalis & 30TUK74 & 100,00 & 148,29 & 111,08 & 35,77 & 6661,16 & 326,08 & 18,42 & 307,66 & \begin{tabular}{|c|}
106,53 \\
\end{tabular} & 237,77 & 237,77 & 60,49 & 360,88 & 42,33 & 7,73 & 36,76 & 118,60 & 41,34 & 41,34 & 97,94 \\
\hline Hyla meridionalis & 30TUK75 & 100,00 & 136,04 & 110,17 & 35,75 & 6585,37 & 312,70 & 8,06 & 304,64 & 107,44 & 224,68 & 224,68 & 55,91 & 383,44 & 47,17 & 9,64 & 35,07 & 123,98 & 48,72 & 48,72 & 99,62 \\
\hline Hyla meridionalis & 30TUK85 & 100,00 & 145,18 & 109,17 & 35,10 & 6648,13 & 321,11 & 16,44 & 304,68 & 102,51 & 234,40 & 234,40 & 63,61 & 368,66 & 42,96 & 8,57 & 35,71 & 121,13 & 43,99 & 43,99 & 99,45 \\
\hline Hyla meridionalis & 30TVK09 & 100,00 & 113,60 & 104,19 & 35,39 & 6407,64 & 282,44 & \begin{tabular}{|c|}
$-7,01$ \\
\end{tabular} & 289,45 & 85,27 & 198,75 & 200,05 & 36,88 & 464,05 & 56,18 & 15,15 & 31,66 & 47,87 & 65,86 & 69,08 & 118,12 \\
\hline Hyla meridionalis & $\begin{array}{l}\text { 30TWN79 } \\
\end{array}$ & 55,00 & 142,54 & $\begin{array}{l}79,19 \\
\end{array}$ & 41,4 & 4050,54 & 248,4 & 59,70 & $\begin{array}{l}188,74 \\
\end{array}$ & $\begin{array}{l}3,12 \\
98,79\end{array}$ & 191,96 & $\begin{array}{ll}195,32 \\
\end{array}$ & $\begin{array}{l}93,86 \\
93,85\end{array}$ & 1318,53 & $\mid \begin{array}{l}\mid 152,11 \\
\end{array}$ & $\begin{array}{l}51,78 \\
61,7\end{array}$ & 22,71 & $\begin{array}{l}428,98 \\
\end{array}$ & \begin{tabular}{|l|}
231,91 \\
\end{tabular} & 252,33 & 399,74 \\
\hline Hyla meridionalis & 30TWN89 & 84,00 & 141 & 80,34 & 41,12 & 4147,07 & 249,07 & 56,16 & 192,91 & 97,07 & 192,83 & 196,01 & 91,49 & 1324,87 & 154,41 & 63,41 & 22,63 & 431,54 & 237,27 & 257,20 & 400,51 \\
\hline Hyla meridionalis & \begin{tabular}{|c|}
$31 \mathrm{TBF} 63$ \\
\end{tabular} & 100,00 & 136,87 & 97,23 & 36,51 & 5786,36 & 279,66 & 16,86 & 262,80 & 139,95 & 196,36 & 214,02 & 69,52 & 531,63 & \begin{tabular}{|c|c|}
65,19 \\
\end{tabular} & 19,19 & 31,10 & 174,12 & 100,18 & 113,19 & 106,70 \\
\hline Hyla meridionalis & 31TBF71 & 101,00 & 132,77 & 92,82 & 36,20 & 5636,99 & 270,10 & 17,10 & 252,99 & 136,79 & 207,72 & 208,94 & 68,45 & 596,72 & 74,31 & 21,14 & 30,76 & 197,60 & 109,47 & 126,59 & 123,37 \\
\hline Hyla meridiona & 31TBF88 & 100,00 & 147,34 & 108,04 & 37,01 & 6253,64 & 304,80 & 17,25 & 287,55 & 165,05 & 81,18 & 228,70 & 70,27 & 447,09 & 56,39 & 18,29 & 30,66 & 92 & 81,15 & 92,29 & 83,36 \\
\hline Hyla meridionalis & $\begin{array}{l}\text { 31TBF89 } \\
31 \text { B }\end{array}$ & 100,00 & 153 & 110,04 & 37,14 & $\begin{array}{l}\frac{6253,04}{6365,95} \\
\end{array}$ & 313,92 & $\begin{array}{l}20,69 \\
20,5\end{array}$ & \begin{tabular}{|l|}
293,23 \\
293
\end{tabular} & \begin{tabular}{|l|}
$175,86,8$ \\
\end{tabular} & $\begin{array}{l}\mid l, 10 \\
86,64\end{array}$ & \begin{tabular}{|l|}
235,78 \\
230
\end{tabular} & 73,82 & \begin{tabular}{|l|l|}
410,63 \\
4103
\end{tabular} & $\begin{array}{l}\mid 50,13 \\
52,12\end{array}$ & \begin{tabular}{l|}
17,70 \\
17,7
\end{tabular} & 31,02 & \begin{tabular}{|l|}
130,95 \\
130,
\end{tabular} & $\begin{array}{l}\mid \frac{1,11}{72,10} \\
\end{array}$ & $\begin{array}{l}2,25 \\
87,34\end{array}$ & $\begin{array}{l}5,30 \\
73,76\end{array}$ \\
\hline Hyla meridionalis & 31TBF90 & 101,00 & 166,11 & 91,45 & 36,95 & 5296,97 & 294,19 & 50,89 & 243,29 & 167,91 & 236,18 & 238,11 & 106,50 & 549,27 & 82,41 & 13,79 & 40,63 & 208,34 & 88,54 & 121,87 & 101,14 \\
\hline Hyla meridionalis & 31TBF91 & 99,00 & 167,58 & 93,52 & 37,26 & 5338,64 & 297,71 & $\begin{array}{ll}50,72 \\
5\end{array}$ & \begin{tabular}{|l|}
246,99 \\
\end{tabular} & 168,19 & 238,26 & \begin{tabular}{|l|}
240,07 \\
\end{tabular} & 107,74 & 544,71 & \begin{tabular}{l|l|}
82,29 \\
\end{tabular} & 13,61 & 40,87 & 207,22 & $\mid 88,10$ & 121,40 & 98,81 \\
\hline Hyla meridionalis & 31TBF93 & 100,00 & 149,18 & 95,28 & 36,69 & 5614,96 & 286,96 & 30,72 & 256,24 & 151,58 & 223,56 & 224,74 & 85,42 & 572,98 & 74,83 & 16,53 & 34,38 & 197,79 & 97,31 & 120,03 & 120,59 \\
\hline Hyla meridionalis & 31TBF99 & 101,00 & 150,74 & 110,81 & 37,00 & 6448,52 & 312,39 & 17,50 & 294,89 & 177,01 & 83,19 & 233,87 & 69,58 & 432,38 & 54,02 & 19,18 & 30,09 & 138,39 & 76,89 & 94,13 & 78 \\
\hline Hyla meridionalis & 31TBG81 & 99,00 & 144,13 & 1112,80 & 37,06 & $\begin{array}{l}0440,25 \\
650,57\end{array}$ & 308,62 & $\begin{array}{l}1,008 \\
10,08 \\
\end{array}$ & $\begin{array}{l}298,50 \\
298,54\end{array}$ & \begin{tabular}{|l|l|}
171,27 \\
\end{tabular} & $\begin{array}{l}\mid l, 110 \\
61,88 \\
\end{array}$ & \begin{tabular}{|l|}
227,81 \\
228
\end{tabular} & $\begin{array}{l}51,49 \\
61,49 \\
\end{array}$ & \begin{tabular}{|l|}
$432,30,79$ \\
438
\end{tabular} & $\begin{array}{l}4,0<2 \\
55,56\end{array}$ & $\begin{array}{l}\mid 5,106 \\
21,46\end{array}$ & $\begin{array}{l}0,03 \\
27,92\end{array}$ & \begin{tabular}{|l|l|}
143,53 \\
1430
\end{tabular} & $\begin{array}{l}\mid 0,090 \\
78,34\end{array}$ & $\begin{array}{r}4,13 \\
101,32 \\
\end{array}$ & $\begin{array}{l}10,00 \\
78,34\end{array}$ \\
\hline Hyla meridionalis & 31TCF00 & 91,00 & 170,15 & 88,95 & 36,96 & 5216,73 & 294,89 & 56,82 & 238,07 & 173,18 & 239,02 & 241,14 & 111,33 & 542,26 & 85,01 & 13,00 & 42,55 & 211,58 & 85,65 & 122,43 & 97,56 \\
\hline Hyla meridionalis & 31TCF01 & 91,00 & 169,24 & 90,59 & 37,01 & 5270,78 & 295,88 & 54,37 & 241,51 & 171,44 & 238,53 & 240,62 & 109,85 & 544,22 & 84,76 & 13,71 & 42,07 & 211,19 & 87,53 & 123,63 & 97,33 \\
\hline Hyla meridionalis & 31TCF10 & 64,00 & 169,45 & 86,30 & 36,35 & 5173,92 & 292,05 & 58,19 & 233,86 & 174,08 & 237 & 239,82 & 111, & 549,32 & 87,30 & 13,34 & 42 & 216,00 & 86,18 & 124,69 & 98,97 \\
\hline Hyla meridionalis & 31TCF11 & 34,00 & 169,20 & 87,21 & 36,55 & 5197,79 & 292,89 & 57,21 & 235,68 & 173,32 & 237,71 & 239,98 & 110,73 & 549,23 & 87,16 & 14,00 & 42,80 & 215,45 & 87,46 & 125,54 & 98,16 \\
\hline
\end{tabular}




\begin{tabular}{|c|c|c|c|c|c|c|c|c|c|c|c|c|c|c|c|c|c|c|c|c|c|}
\hline TAXON & UTM & $\mathrm{km} 2$ & BIO1 & B102 & $\mathrm{BIO3}$ & B104 & B105 & B106 & B107 & 8108 & 8109 & BIO10 & B1011 & B1012 & 81013 & B1014 & B1015 & B1016 & B1017 & 81018 & B1019 \\
\hline Hyla meridionalis & 31TCF16 & 100,00 & 144,25 & 94,60 & 35,96 & 5815,44 & 284,88 & 25,33 & 259,55 & 149,85 & 199,48 & 221,21 & 74,36 & 562,22 & 68,15 & 19,17 & 30,79 & 183,79 & 106,39 & 122,69 & 114,40 \\
\hline Hyla meridionalis & 31TCF25 & 99,00 & 145,13 & 87,91 & 35,27 & 5575,42 & 277,06 & 31,92 & 245,14 & 152,12 & 204,07 & 219,64 & 78,86 & \begin{tabular}{|l|l|}
593,26 \\
\end{tabular} & 75,52 & 19,18 & 31,89 & 200,03 & 108,90 & 130,00 & 122,54 \\
\hline Hyla meridionalis & 31TCF28 & 100,00 & 129,82 & 93,38 & 35,30 & 5923,63 & 272,63 & $\frac{1,2,25}{12,}$ & $\begin{array}{l}260,38 \\
260,38\end{array}$ & 138,93 & 64,02 & 207,74 & 57,47 & 610,76 & 70,25 & 26,00 & 25,96 & 184,97 & 120,04 & $\begin{array}{l}137,98 \\
13\end{array}$ & 120,13 \\
\hline Hyla meridionalis & 31TCF34 & 34,00 & 163,41 & 81,22 & 34,85 & 5237,07 & 284,63 & 55,20 & 229,44 & 172,05 & 105,51 & 233,73 & 101,17 & 547,44 & 82,49 & 16,22 & 38,78 & 205,51 & 95,22 & 130,27 & 104,29 \\
\hline Hyla meridionalis & 31TCF35 & 101,00 & 157,66 & 81,96 & 34,79 & 5332,40 & 281,05 & 48,75 & 232,30 & 166,51 & 109,39 & 228,96 & $\begin{array}{l}93,82 \\
93\end{array}$ & 557,55 & 78,55 & 17,36 & 35,67 & 201,06 & \begin{tabular}{|c|}
100,08 \\
\end{tabular} & 130,69 & 109,36 \\
\hline Hyla meridionalis & 31TCF36 & 100,00 & 136,20 & 85,52 & 34,78 & 5605,32 & 267,82 & 25,11 & 242,71 & 144,68 & 167,76 & 210,99 & 68,99 & 624,55 & 74,92 & 22,99 & 28,69 & 202,11 & 121,90 & 139,31 & 128,05 \\
\hline Hyla meridionalis & 31TCF44 & 18,00 & 163,59 & 75,71 & 34,00 & 5096,00 & 279,18 & 59,82 & 219,35 & 174,12 & 114,35 & 232,00 & 102,65 & 550,18 & 80,12 & 16,59 & 37,71 & 204,47 & 96,35 & 132,65 & 111,82 \\
\hline Hyla meridionalis & 31TCF45 & 98,00 & 160,62 & 75,79 & 33,81 & 5147,51 & 277,23 & 56,59 & 220,64 & 171,42 & 103,96 & 229,48 & 98,64 & 553,08 & 77,58 & 17,17 & 36,42 & 201,01 & 97,92 & 132,79 & 113,60 \\
\hline Hyla meridionalis & 31TCF46 & 100,00 & 150,92 & 79,54 & 34,11 & 5368,23 & 273,71 & 43,88 & 229,83 & 161,10 & 122,53 & 222,42 & 85,92 & 572,10 & 73,85 & 19,23 & 32,18 & 196,31 & 106,64 & 133,27 & 117,32 \\
\hline Hyla meridionalis & 31TCF55 & 69,00 & 160,04 & 71,70 & 33,01 & 5056,42 & 272,84 & 59,35 & 213,49 & 172,27 & 199,78 & 227,65 & 99,01 & 559,29 & 75,85 & 17,51 & 35,78 & 200,36 & 98,77 & 133,98 & 122,29 \\
\hline Hyla meridionalis & 31TCF56 & 101,00 & 155,31 & 74,55 & 33,22 & 5207,45 & 272,43 & 52,23 & 220,20 & 166,81 & 167,68 & 224,65 & 92,09 & 566,00 & 74,36 & 19,01 & 32,80 & 197,41 & 104,13 & 134,60 & 119,22 \\
\hline Hyla meridionalis & 31TCF57 & 99,00 & 147,41 & 78,90 & 33,88 & 5423,19 & 270,97 & 40,84 & 230,14 & 157,99 & 100,81 & 219,44 & 81,40 & 581,84 & 72,51 & 21,21 & 29,63 & 194,63 & 112,55 & 136,12 & 117,33 \\
\hline Hyla meridionalis & 31TCF65 & 46,00 & 162,50 & 71,04 & 33,00 & 5050,68 & 274,52 & 62,36 & 212,16 & 175,04 & 227,02 & 230,05 & \begin{tabular}{ll|}
101,48 \\
\end{tabular} & 558,36 & 77,79 & 18,38 & 34,71 & 201,48 & 99,46 & 134,50 & 120,18 \\
\hline Hyla meridionalis & 31TCF77 & 101,00 & 145,54 & 74,80 & 33,01 & 5344,03 & 265,69 & 42,47 & 223,23 & 156,52 & 193,43 & 216,74 & 81,12 & 627,43 & 78,06 & 25,09 & 27,47 & 208,00 & 123,24 & 148,06 & 127,46 \\
\hline Hyla meridionalis & 31TCF79 & 100,00 & 128,91 & 78,91 & 33,06 & 5569,67 & 257,32 & 23,18 & 234,14 & 138,99 & 61,92 & 203,09 & 61,92 & 687,95 & 76,92 & 32,81 & 24,03 & 210,20 & 132,79 & 165,84 & 132,79 \\
\hline Hyla meridionalis & 31TCF86 & 91,00 & 159,65 & 71,41 & 32,97 & 5147,19 & 273,63 & 59,16 & 214,47 & 171,28 & 226,06 & 228,23 & 97,46 & 592,90 & 83,01 & 22,78 & 30,74 & 209,33 & 111,23 & 142,36 & 121,67 \\
\hline Hyla meridionalis & 31TCF87 & 99,00 & 154,53 & 72,64 & 32,94 & 5250,76 & 271,23 & 52,83 & 218,40 & 165,66 & 222,41 & 224,40 & 90,97 & 606,20 & 80,03 & 24,43 & 28,57 & 207,34 & 117,39 & 145,62 & 122,55 \\
\hline Hyla meridionalis & 31TCF 89 & 101,00 & 139,33 & 76,38 & 32,97 & 5485,22 & 263,93 & 34,78 & 229,15 & 149,73 & 72,92 & 212,16 & 72,92 & 652,83 & 74,95 & 30,19 & 25,02 & 205,62 & 126,21 & 158,68 & 126,21 \\
\hline Hyla meridionalis & 31TCF97 & 101,00 & 155,44 & 71,73 & 32,62 & 5239,23 & 271,63 & 54,42 & 217,21 & 166,41 & 223,38 & 225,25 & 92,23 & 620,28 & 82,75 & 25,01 & 28,58 & 213,10 & 119,15 & 148,12 & 126,26 \\
\hline Hyla meridionalis & 31TCF98 & 100,00 & 154,06 & 72,97 & 32,69 & 5317,90 & 272,40 & 51,77 & 220,63 & 164,93 & 143,72 & 224,68 & 89,57 & 613,12 & 78,77 & 26,30 & 27,63 & 206,61 & 120,71 & 149,15 & 121,59 \\
\hline Hyla meridionalis & 31TCF99 & 100,00 & 150,56 & 74,29 & 32,61 & 5400,68 & 271,62 & 46,79 & 224,84 & 161,05 & 84,77 & 222,03 & 84,77 & 616,26 & 74,95 & 28,32 & 26,30 & 201,81 & 118,82 & 152,44 & 118,82 \\
\hline Hyla meridionalis & 31TCG10 & 100,00 & 148,09 & 106,57 & 36,55 & $\begin{array}{l}640,0,78 \\
6410\end{array}$ & 305,75 & $\begin{array}{ll}17,94 \\
17\end{array}$ & 287,81 & $\begin{array}{l}173,48 \\
\end{array}$ & 74,81 & 230,39 & 66,60 & 474,01 & 56,88 & $\begin{array}{l}20,2,27 \\
22\end{array}$ & 28,30 & $\begin{array}{l}250,99 \\
159\end{array}$ & \begin{tabular}{|c|}
84,91 \\
84,91
\end{tabular} & 108,93 & 84,92 \\
\hline Hyla meridionalis & 31TCG11 & 100,00 & 148,88 & 108,25 & 36,80 & 6481,73 & 308,54 & 17,17 & 291,36 & 175,20 & 66,22 & 231,77 & 65,83 & 466,93 & 56,24 & 22,36 & 27,81 & 150,37 & 82,35 & 110,83 & 82,35 \\
\hline Hyla meridionalis & 31TCG21 & 99,00 & 146,83 & 102,35 & 36,07 & 6271,19 & 299,19 & 20,17 & 279,02 & 170,87 & 66,94 & 227,23 & 66,94 & 499,75 & 59,08 & 24,52 & 27,28 & 157,64 & 89,08 & 117,97 & 89,08 \\
\hline Hyla meridionalis & 31TCG31 & 101,00 & 144,05 & 96,82 & 35,74 & 6086,38 & 289,93 & 21,95 & 267,99 & 166,11 & 67,02 & 222,39 & 67,02 & 533,50 & 62,27 & 26,14 & 26,87 & 165,44 & 95,64 & 127,96 & 95,64 \\
\hline Hyla meridionalis & 31TCG42 & 99,00 & 138,89 & 93,20 & 35,08 & 5983,99 & 281,33 & 20,20 & 261,13 & 159,89 & 63,45 & 216,18 & 63,45 & 577,85 & 67,41 & 30,03 & 25,98 & 179,55 & 102,43 & 144,34 & 102,43 \\
\hline Hyla meridionalis & 31TCG44 & 100,00 & 131,50 & 94,24 & 35,22 & 6007,63 & 275,71 & 12,66 & 263,05 & 152,78 & 55,70 & 209,05 & 55,70 & 626,31 & 73,35 & 32,62 & 25,01 & 197,87 & 109,67 & 165,11 & 109,67 \\
\hline Hyla meridionalis & 31TCG52 & 101,00 & 133,87 & 88,88 & 34,67 & 5867,08 & 272,45 & 19,13 & 253,33 & 153,15 & 60,71 & 210,23 & 60,71 & 621,01 & 72,45 & 32,35 & 25,55 & 191,85 & 109,86 & 157,58 & 109,86 \\
\hline Hyla meridionalis & 31TCG53 & 100,00 & 133,98 & 90,15 & 34,92 & 5900,41 & 273,85 & 18,03 & 255,82 & 153,91 & 60,08 & 210,46 & 60,08 & 622,11 & 72,87 & 31,93 & 25,73 & 194,46 & 108,20 & 161,22 & 108,20 \\
\hline Hyla meridionalis & 31TCG54 & 100,00 & 128,47 & 90,52 & 34,94 & 5904,12 & 269,06 & 12,75 & 256,31 & 148,32 & 54,50 & 204,86 & 54,50 & 656,86 & 77,26 & 33,38 & 25,45 & 207,43 & 113,50 & 175,72 & 113,50 \\
\hline Hyla meridionalis & 31TCG55 & 100,00 & 122,96 & 90,48 & 34,96 & 5889,88 & 263,85 & 7,80 & 256,05 & 142,53 & 49,29 & 199,42 & 49,29 & 693,17 & 81,14 & 35,47 & 25,08 & 219,27 & 120,52 & 189,14 & 120,52 \\
\hline Hyla meridionalis & $\begin{array}{l}31 \text { TCG57 } \\
\end{array}$ & 101,00 & 93,94 & 86,16 & 34,51 & 5718,43 & 231,94 & $-14,21$ & 246,15 & 110,49 & 24,77 & 169,36 & 24,33 & 890,55 & 100,86 & 51,10 & 20,70 & 272,21 & \begin{tabular}{l|}
170,57 \\
\end{tabular} & 235,88 & 170,58 \\
\hline Hyla meridionalis & 31TCG61 & 99,00 & 125,74 & 83,80 & 33,97 & 5727,71 & 259,95 & 15,87 & 244,08 & 143,41 & 55,75 & 201,19 & 55,75 & 683,17 & 78,92 & 35,98 & 24,29 & 206,36 & 124,60 & 171,33 & 124,60 \\
\hline Hyla meridionalis & 31TCG62 & 100,00 & 128,55 & 85,27 & 34,02 & 5765,80 & 263,99 & 17,17 & 246,82 & 146,21 & 57,46 & 204,06 & 57,46 & 667,49 & 77,95 & 34,40 & 25,03 & 205,20 & 118,07 & 171,74 & 118,07 \\
\hline Hyla meridionalis & 31TCG64 & 101,00 & 120,85 & 86,78 & 34,10 & 5815,49 & 258,77 & 8,88 & 249,89 & 139,11 & 48,99 & 196,76 & 48,99 & 712,98 & 84,27 & 35,55 & 25,45 & 224,98 & 122,59 & 192,38 & 122,59 \\
\hline Hyla meridionalis & 31TCG65 & 101,00 & 121,13 & 87,71 & 34,33 & 5831,24 & 259,73 & 8,37 & 251,36 & 139,89 & 48,66 & 197,02 & 48,66 & 711,34 & 84,13 & 35,08 & 25,96 & 226,18 & 120,89 & 196,85 & 120,89 \\
\hline Hyla meridionalis & 31 TCG70 & 100,00 & 134,73 & 80,03 & 33,31 & 5606,56 & 263,71 & 27,21 & 236,49 & 179,06 & 66,32 & 208,80 & 66,32 & 653,16 & 74,56 & 32,30 & 24,83 & 199,86 & 121,51 & 162,07 & 121,51 \\
\hline Hyla meridionalis & 31TCG71 & 101,00 & 127,45 & 81,27 & 33,46 & 5665,09 & 259,12 & 19,54 & 239,58 & 161,52 & 58,44 & 202,31 & 58,44 & 687,89 & 79,31 & 35,96 & 24,35 & 207,74 & 124,61 & 174,50 & 124,61 \\
\hline Hyla meridionalis & 31TCG72 & 101,00 & 126,24 & 82,42 & 33,64 & 5699,56 & 259,27 & 17,33 & 241,95 & 142,78 & 56,45 & 201,25 & 56,45 & 694,37 & 81,27 & 35,29 & 24,88 & 212,50 & 122,24 & 180,40 & 122,24 \\
\hline Hyla meridionalis & 31TCG73 & 100,00 & 121,63 & 83,25 & 33,79 & 5723,55 & 256,15 & 12,41 & 243,74 & 138,51 & 51,61 & 196,92 & 51,61 & 720,62 & 85,22 & 35,85 & 25,23 & 224,42 & 124,60 & 191,02 & 124,60 \\
\hline Hyla meridionalis & 31TCG74 & 100,00 & 116,23 & 83,76 & 33,94 & 5734,19 & 251,71 & 72,01 & \begin{tabular}{|l|}
244,69 \\
\end{tabular} & \begin{tabular}{|l|l|}
133,10 \\
\end{tabular} & $\begin{array}{ll}46,16 \\
\end{array}$ & $\begin{array}{l}191,64 \\
\end{array}$ & \begin{tabular}{l|l}
46,16 \\
4
\end{tabular} & 752,23 & $\begin{array}{l}\mid 8,26 \\
89,30\end{array}$ & 37,21 & 25,30 & $\begin{array}{l}236,62 \\
236,2\end{array}$ & 129,29 & 203,23 & 129,29 \\
\hline Hyla meridionalis & 31TCG75 & 100,00 & 113,46 & 84,33 & 33,99 & 5744,27 & 249,75 & 4,17 & 245,58 & 130,70 & 43,18 & 188,87 & 43,18 & 767,56 & 90,93 & 38,16 & 25,40 & 242,60 & 131,87 & 211,41 & 131,87 \\
\hline Hyla meridionalis & 31TCG80 & 100,00 & 142,39 & $\begin{array}{l}77,58 \\
77,58\end{array}$ & 33,01 & 5522,76 & 268,04 & 36,43 & \begin{tabular}{|l|}
$231,61,61$ \\
\end{tabular} & 182,38 & $\begin{array}{l}4,109 \\
74,93\end{array}$ & $\begin{array}{l}150,013 \\
215,34\end{array}$ & $\begin{array}{l}74,93 \\
74,9\end{array}$ & 629,71 & 73,18 & 30,88 & 25,36 & 197,39 & $\begin{array}{l}117,18 \\
118\end{array}$ & $\begin{array}{l}157,80 \\
15,1\end{array}$ & 117,18 \\
\hline Hyla meridionalis & 31TCG81 & 100,00 & 127,46 & 79,08 & 33,01 & 5607,84 & 257,22 & 21,31 & 235,91 & 169,23 & 59,53 & 201,81 & 59,53 & 699,47 & 80,66 & 36,45 & 24,19 & 211,40 & 126,42 & 179,08 & 126,42 \\
\hline Hyla meridionalis & 31TCG82 & 100,00 & 125,96 & 80,09 & 33,02 & 5639,63 & 257,04 & 18,88 & 238,16 & 152,77 & 57,31 & 200,52 & 57,31 & 705,59 & 82,69 & 35,65 & 24,78 & 215,71 & 123,66 & 185,27 & 123,66 \\
\hline Hyla meridionalis & 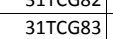 & 101,00 & 126,54 & $\begin{array}{l}80,2030 \\
81,20\end{array}$ & $\begin{array}{l}35,02 \\
33,17\end{array}$ & 5680,40 & 258,87 & \begin{tabular}{|l|l|}
18,340 \\
18,34
\end{tabular} & $\begin{array}{l}240,54 \\
240,5\end{array}$ & 143,76 & \begin{tabular}{|l|l|}
57,05 \\
\end{tabular} & \begin{tabular}{|l|}
201,30 \\
\end{tabular} & $\begin{array}{l}\mid 7,01 \\
57,05 \\
\end{array}$ & 704,03 & $\begin{array}{l}\mid l<, 095 \\
83,77\end{array}$ & $\begin{array}{l}30,09 \\
34,09 \\
\end{array}$ & $\begin{array}{l}25,10 \\
25,99\end{array}$ & \begin{tabular}{|l|}
$219,07,1$ \\
\end{tabular} & \begin{tabular}{|l|l|}
119,07 \\
\end{tabular} & \begin{tabular}{|l|}
189,24 \\
189
\end{tabular} & $\begin{array}{l}112,00 \\
119,07\end{array}$ \\
\hline Hyla meridionalis & 31TCG84 & 101,00 & 127,57 & 82,38 & 33,35 & 5708,55 & 260,98 & 18,27 & 242,71 & 144,95 & 57,26 & 202,28 & 57,26 & 702,92 & 84,28 & 32,92 & 27,02 & 222,55 & 115,79 & 193,19 & 115,79 \\
\hline Hyla meridionalis & 31TCG85 & 99,00 & 114,33 & 82,40 & 33,63 & 5699,1 & 248,77 & 6,58 & 242.19 & $\begin{array}{ll}130,87 \\
\end{array}$ & 44,84 & 189,38 & 44,84 & 773.50 & 92.16 & 37.98 & 25,73 & 243.95 & 131.94 & 21251 & 131,94 \\
\hline Hyla meridionalis & 31TCG86 & 101,00 & 95,66 & 80,92 & 33,60 & 5627,15 & 229,94 & $-8,22$ & 238,16 & 110,43 & 29,12 & 170,56 & 28,44 & 882,62 & 101,85 & 48,92 & 21,74 & 269,03 & 164,82 & 31,88 & 164,88 \\
\hline Hyla meridionalis & 31TCG90 & 101,00 & 136,36 & 75,89 & 32,62 & 5509,64 & 261,97 & 32,01 & 229,96 & 171,63 & $\begin{array}{ll}69,87 \\
\end{array}$ & 20 & 69,87 & 671,94 & $\begin{array}{l}7,0,56 \\
7\end{array}$ & 34 & 24,21 & 207,62 & $\begin{array}{l}126,49 \\
\end{array}$ & $\begin{array}{ll}167,94 \\
167\end{array}$ & 126,49 \\
\hline Hyla meridionalis & $\begin{array}{l}\text { 31TCG93 } \\
31 \text { Cas }\end{array}$ & $\begin{array}{l}101,00 \\
101\end{array}$ & $\begin{array}{l}130,50 \\
136,70\end{array}$ & $\begin{array}{l}3,595 \\
79,54\end{array}$ & $\begin{array}{l}20,202 \\
32,99\end{array}$ & $\begin{array}{l}3500,2044 \\
5642,96\end{array}$ & 260,97 & $\begin{array}{l}2,010 \\
28,65\end{array}$ & $\begin{array}{l}237,95 \\
237,95\end{array}$ & $\begin{array}{l}11,03 \\
174,71 \\
\end{array}$ & $\begin{array}{l}69,28 \\
67,27 \\
\end{array}$ & \begin{tabular}{|l|}
210,65 \\
2106
\end{tabular} & $\begin{array}{l}65,01 \\
67,27 \\
\end{array}$ & $\begin{array}{l}\mid l / 1,94 \\
652,16\end{array}$ & $\begin{array}{l}\mid 0,00 \\
77,27\end{array}$ & \begin{tabular}{|l|l|}
31,63 \\
314
\end{tabular} & $\begin{array}{l}2,21 \\
26,70\end{array}$ & $\begin{array}{l}201,320 \\
2039 \\
\end{array}$ & $\begin{array}{l}100,494 \\
107,92 \\
\end{array}$ & $\begin{array}{l}178,76 \\
178,7\end{array}$ & $\begin{array}{l}x_{120,49} \\
107,92\end{array}$ \\
\hline Hyla meridionalis & 31TCG94 & 100,00 & 127,57 & 80,26 & 33,00 & 5672,18 & 259,42 & 19,64 & 239,77 & 145,23 & 57,99 & 202,01 & 57,99 & 702,18 & 84,92 & 32,64 & 27,54 & 221,86 & 113,81 & 196,36 & 113,81 \\
\hline Hyla meridionalis & 31TCG95 & 101,00 & 111,81 & 80,22 & 33,02 & 5654,02 & 244,94 & 6,04 & 238,90 & 127,50 & 43,42 & 186,65 & 43,42 & 788,95 & 94,18 & 39,23 & 25,53 & 246,95 & 135,20 & 217,09 & 135,20 \\
\hline Hyla meridiona & 31TCG96 & 101,00 & 83,33 & 77,80 & 32,93 & 5542,42 & 215,76 & $-16,57$ & 232,33 & 95,44 & 20,50 & 157,85 & 18,52 & 965,67 & 108,47 & 57,35 & 18,90 & 283,52 & 192,36 & 241,41 & 193,01 \\
\hline Hyla meridionalis & 31TCH23 & 101,00 & 39,35 & 77,48 & 33,21 & 5379,69 & 168,15 & $-61,19$ & 229,34 & 50,94 & 43,30 & 111, & $\frac{-24,16}{-24,16}$ & 1278,98 & 134,37 & 86,22 & 12,74 & $\begin{array}{ll}2653,34 \\
363\end{array}$ & 286,52 & \begin{tabular}{|l|}
294,29 \\
\end{tabular} & 297 \\
\hline Hyla meridionalis & 31TDF06 & 37,00 & 157,68 & 70,70 & 32,57 & 5176,48 & 272,55 & 58,09 & 214,45 & 168,68 & 224,93 & 226,84 & 95,61 & 632,00 & 88,07 & 24,34 & 30,05 & 222,25 & 117,84 & 148,61 & 131,50 \\
\hline Hyla meridionalis & 31TDF07 & 100,00 & 148,43 & 71,25 & 32,08 & 5291,64 & 266,58 & 48,21 & 218,37 & 159,33 & 217,47 & 219,19 & 85,31 & 668,64 & 85,49 & 27,15 & 27,00 & 223,53 & 127,41 & 155,86 & 139,43 \\
\hline Hyla meridionalis & 31TDF08 & 101,00 & 149,24 & 72,06 & 32,09 & 5339,18 & 268,69 & 47,90 & 220,79 & 159,90 & 173,09 & 220,30 & 85,04 & 650,99 & 81,38 & 28,46 & 26,38 & 215,60 & 128,65 & 156,33 & 131,18 \\
\hline Hyla meridionalis & 31TDF09 & 100,00 & 157,57 & 73,07 & 32,23 & 5337,48 & 276,76 & 54,45 & 222,32 & 168,05 & \begin{tabular}{|l|l|}
93,54 \\
\end{tabular} & 228,09 & 92,38 & 597,40 & 76,89 & 27,83 & 27,82 & 201,93 & 114,38 & 150,33 & 114,39 \\
\hline Hyla meridionalis & 31TDF16 & & & & & & & & & & & & & & & & & & & & \\
\hline
\end{tabular}




\begin{tabular}{|c|c|c|c|c|c|c|c|c|c|c|c|c|c|c|c|c|c|c|c|c|c|}
\hline TAXON & UTM & $\mathrm{km} 2$ & B101 & B102 & $\mathrm{BIO3}$ & BIO4 & B105 & B106 & B107 & B108 & B109 & BIO10 & BIO11 & BIO12 & 81013 & BIO14 & BIO15 & B1016 & B1017 & B1018 & B1019 \\
\hline Hyla meridionalis & 31TDF17 & 101,00 & 160,92 & 70,50 & 32,28 & 5174,62 & 276,34 & 61,01 & 215,33 & 171,39 & 221,88 & 229,63 & 98,42 & 629,25 & 90,08 & 24,99 & 31,01 & 224,52 & 120,14 & 150,01 & 129,05 \\
\hline Hyla meridionalis & 31TDF18 & 99,00 & 160,91 & 71,10 & 32,03 & 5239,75 & 277,92 & 59,79 & 218,13 & 171,23 & 130,82 & 230,38 & 97,46 & 609,35 & 84,18 & 26,58 & 29,69 & 213,79 & 118,71 & 150,19 & 120,98 \\
\hline Hyla meridionalis & 31TDF19 & 101,00 & 158,29 & 71,93 & 31,99 & 5322,04 & 277,37 & 55,97 & 221,40 & 169,71 & 96,54 & 228,56 & 93,61 & 602,55 & 78,29 & 29,03 & 27,86 & 204,69 & 115,31 & 153,16 & 115,54 \\
\hline Hyla meridionalis & 31TDF27 & 85,00 & 166,22 & 70,16 & 32,17 & 5089,19 & 280,30 & 66,64 & 213,66 & 176,56 & 218,22 & 233,41 & 104,49 & 618,62 & 94,89 & 23,92 & 33,86 & 229,10 & 117,70 & 148,27 & 125,51 \\
\hline Hyla meridionalis & 31TDF28 & 101,00 & 158,99 & 70,16 & 31,69 & 5227,88 & 276,22 & 58,85 & 217,37 & 169,24 & 158,51 & 228,43 & 95,97 & 626,99 & 86,51 & 27,97 & 28,92 & 218,95 & 124,19 & 154,23 & 126,40 \\
\hline Hyla meridionalis & 31TDF29 & 101,00 & 159,89 & 70,96 & 31,86 & 5280,03 & 278,34 & 58,46 & 219,88 & 175,16 & 99,82 & 229,64 & 95,80 & 601,07 & 80,09 & 29,35 & 28,43 & 206,58 & 115,70 & 153,82 & 116,03 \\
\hline Hyla meridionalis & 31TDF37 & & & & & & & & & & & & & & & & & & & & \\
\hline Hyla meridionalis & 31TDF38 & 52,00 & 163,90 & 70,18 & 32,17 & 5079,68 & 278,78 & 64,25 & 214,53 & 174,00 & 199,54 & 230,92 & 102,04 & 607,25 & 90,54 & 25,82 & 32,14 & 220,47 & 117,99 & 149,53 & 122,51 \\
\hline Hyla meridionalis & 31TDF39 & 99,00 & 159,05 & 70,45 & 31,72 & 5221,53 & 276,62 & 58,24 & 218,38 & 169,22 & 122,48 & 227,97 & 95,63 & 625,82 & 85,89 & 29,41 & 28,45 & 215,99 & 124,66 & 157,10 & 125,50 \\
\hline Hyla meridionalis & 31TDF49 & 74,00 & 155,34 & 69,84 & 31,34 & 5248,01 & 273,44 & 54,54 & 218,91 & 166,02 & 191,46 & 224,66 & 91,70 & 669,03 & 91,23 & 31,05 & 27,32 & 226,69 & 133,39 & 164,11 & 139,00 \\
\hline Hyla meridionalis & 31TDF59 & 14,00 & 161,65 & 69,94 & 31,41 & 5210,88 & 278,76 & 60,24 & 218,53 & 171,76 & 216,00 & 230,12 & 98,29 & 649,65 & 96,41 & 27,29 & 30,94 & 228,76 & 121,53 & 155,41 & 138,59 \\
\hline Hyla meridionalis & 31TDG00 & 100,00 & 147,12 & 74,17 & 32,10 & 5444,61 & 269,96 & 43,25 & 226,71 & 187,89 & 81,00 & 219,13 & 81,00 & 632,84 & 75,08 & 32,57 & 25,41 & 202,78 & 118,11 & 161,49 & 118,11 \\
\hline Hyla meridionalis & 31TDG02 & 101,00 & 146,68 & 76,64 & 32,45 & 5543,49 & 272,71 & 40,25 & 232,46 & 195,43 & 78,39 & 219,41 & 78,39 & 612,12 & 72,23 & 31,38 & 26,17 & 196,17 & 103,62 & 166,15 & 103,62 \\
\hline Hyla meridionalis & 31TDG03 & 100,00 & 138,99 & 77,70 & 32,62 & 5595,96 & 267,33 & 32,06 & 235,27 & 185,64 & 70,21 & 212,47 & 70,21 & 646,98 & 76,68 & 31,46 & 26,92 & 203,51 & 105,68 & 179,85 & 105,68 \\
\hline Hyla meridionalis & 31TDG04 & 100,00 & 133,54 & 78,74 & 32,86 & 5641,89 & 263,69 & 26,12 & 237,57 & 158,12 & 64,30 & 207,59 & 64,30 & 674,76 & 81,50 & 31,44 & 27,99 & 212,37 & 107,54 & 190,92 & 107,54 \\
\hline Hyla meridionalis & 31TDG05 & 100,00 & 127,55 & 79,61 & 32,97 & 5659,60 & 259,13 & 19,95 & 239,18 & 144,45 & 58,10 & 201,78 & 58,10 & 706,09 & 86,06 & 32,36 & 28,71 & 225,31 & 111,86 & 203,49 & 111,86 \\
\hline Hyla meridionalis & 31TDG06 & 100,00 & 106,21 & 79,00 & 32,99 & 5609,13 & 238,65 & 2,26 & 236,39 & 121,23 & 39,69 & 180,73 & 38,92 & 829,94 & 97,73 & 43,36 & 24,43 & 255,93 & 147,61 & 225,40 & 147,75 \\
\hline Hyla meridionalis & 31TDG07 & 101,00 & 97,75 & 79,20 & 33,01 & 5585,81 & 230,65 & $-4,96$ & 235,61 & 112,18 & 32,50 & 172,05 & 31,12 & 884,39 & 102,25 & 48,81 & 21,83 & 268,99 & 165,19 & 234,06 & 165,33 \\
\hline Hyla meridionalis & 31TDG10 & 100,00 & 143,65 & 72,82 & 31,99 & 5436,23 & 266,45 & 41,19 & 225,27 & 191,40 & 78,13 & 215,81 & 78,13 & 661,58 & 76,92 & 35,13 & 24,44 & 210,32 & 124,08 & 170,04 & 124,08 \\
\hline Hyla meridionalis & 31TDG11 & 100,00 & 130,92 & 73,96 & 32,00 & 5506,36 & 256,72 & 28,36 & 228,36 & $\mid 179,89$ & 64,96 & 204,11 & 64.96 & 711,82 & 81,20 & 37,69 & 23,64 & 220,30 & 129,34 & $\mid 187,13$ & 129,34 \\
\hline Hyla meridionalis & 31TDG12 & 101,00 & 138,82 & 74,97 & 31,99 & 5534,36 & 264,97 & 34,06 & 230,90 & 187,60 & 71,46 & 211,89 & 71,46 & 664,54 & 77,32 & 33,73 & 25,52 & 209,84 & 113,45 & 180,96 & 113,45 \\
\hline Hyla meridionalis & 31TDG13 & 100,00 & 137,51 & 76,02 & 32,01 & 5576,41 & 265,12 & 31,67 & 233,45 & 186,14 & 69,31 & 210,99 & 69,31 & 668,60 & 79,16 & 32,45 & 26,82 & 210,84 & 109,50 & 187,69 & 109,50 \\
\hline Hyla meridionalis & 31TDG14 & 101,00 & 129,63 & 76,99 & 32,13 & 5603,61 & 258,87 & 23,76 & 235,10 & 155,03 & 61,35 & 203,38 & 61,35 & 702,44 & 85,59 & 32,35 & 28,71 & 221,47 & 111,01 & 202,88 & 111,01 \\
\hline Hyla meridionalis & 31TDG15 & 101,00 & 123,04 & 77,90 & 32,41 & 5614,28 & 253,69 & 17,34 & 236,35 & 138,98 & 54,84 & $\begin{array}{ll}197,03 \\
\end{array}$ & 54,84 & 734,72 & 89,87 & 33,72 & 28,82 & 233,69 & 116,68 & 213,33 & 116,68 \\
\hline Hyla meridionalis & 31TDG16 & 100,00 & 109,61 & 78,14 & 32,94 & 5594,27 & 241,39 & 5,90 & 235,49 & 124,73 & 42,68 & 183,93 & 42,52 & 816,30 & 97,07 & 41,02 & 25,05 & 253,79 & 141,82 & 225,21 & 141,82 \\
\hline Hyla meridionalis & 31TDG17 & 100,00 & 92,30 & 77,43 & 32,98 & 5530,63 & 224,15 & $-7,93$ & 232,07 & 105,48 & 30,03 & 166,30 & 27,32 & 927,47 & 105,12 & 53,59 & 19,78 & 274,98 & 180,58 & 237,38 & 181,09 \\
\hline Hyla meridionalis & 31 TDG20 & 100,00 & 152,94 & 71,68 & 31,71 & 5379,99 & 273,79 & 50,50 & 223,29 & 200,40 & 87,61 & 223,95 & 87,61 & 634,60 & $\begin{array}{l}77,02 \\
\end{array}$ & 33,88 & 25,47 & 208,06 & \begin{tabular}{|l|l|}
119,64 \\
\end{tabular} & $\begin{array}{l}165,13 \\
\end{array}$ & 119,64 \\
\hline Hyla meridionalis & 31TDG21 & 101,00 & 134,01 & 72,64 & 31,69 & 5474,85 & 258,67 & 31,96 & 226,71 & 182,80 & 68,49 & 206,92 & 68,49 & 718,32 & 81,31 & 38,66 & 23,28 & 224,13 & 132,51 & 188,93 & 132,51 \\
\hline Hyla meridionalis & 31TDG22 & 99,00 & 125,49 & 73,69 & 31,92 & 5511,67 & 252,13 & 23,39 & 228,73 & 174,44 & 59,73 & 198,87 & 59,73 & 746,68 & 87,10 & 38,10 & 23,96 & 229,79 & 133,40 & 201,19 & 133,40 \\
\hline Hyla meridionalis & 31TDG23 & 101,00 & 120,63 & 74,58 & 32,00 & 5523,95 & 248,55 & 18,30 & 230,24 & 167,35 & 54,73 & 194,10 & 54,73 & 769,68 & 90,82 & 38,58 & 24,64 & 234,97 & 134,90 & 209,82 & 134,90 \\
\hline Hyla meridionalis & 31TDG24 & 100,00 & 126,73 & 75,58 & 32,00 & 5574,07 & 255,26 & 22,19 & 233,07 & 149,77 & 59,32 & 200,34 & 59,32 & 739,43 & 89,01 & 34,71 & 27,42 & 230,37 & 121,26 & 210,88 & 121,26 \\
\hline Hyla meridionalis & 31 TDG25 & 100,00 & 120,53 & 76,48 & 32,00 & 5584,37 & 250,26 & $\begin{array}{l}24,139 \\
15,99 \\
\end{array}$ & 234,26 & $\begin{array}{l}135,76 \\
\end{array}$ & 53,10 & \begin{tabular}{|l|}
194,30 \\
\end{tabular} & 53,10 & 770,56 & 92,84 & $\begin{array}{ll}36,19 \\
36\end{array}$ & 27,23 & 241,75 & $\begin{array}{l}127,33 \\
\end{array}$ & $\begin{array}{l}219,720 \\
\end{array}$ & 127,33 \\
\hline Hyla meridionalis & 31TDG26 & 101,00 & 110,29 & 77,01 & 32,33 & 5569,27 & 241,08 & 7,03 & 234,05 & 124,80 & 43,82 & 184,24 & 43,67 & 832,47 & 97,84 & 42,19 & 24,08 & 256,10 & 147,86 & 225,80 & 147,86 \\
\hline Hyla meridionalis & 31TDG27 & 101,00 & 99,41 & 77,17 & 32,82 & 5532,74 & 230,85 & $-1,67$ & 232,51 & 113,10 & 36,06 & 173,24 & 34,05 & 897,92 & 102,41 & 49,96 & 20,58 & 268,64 & 171,64 & 232,58 & 171,86 \\
\hline Hyla meridionalis & 31TDG30 & 100,00 & 157,83 & 71,01 & 31,53 & 5300,33 & 277,10 & 55,68 & 221,42 & 197,57 & 96,21 & 227,47 & 93,06 & 632,38 & 82,25 & 31,86 & 26,59 & 212,42 & 124,07 & 160,28 & 124,09 \\
\hline Hyla meridionalis & 31TDG31 & 101,00 & 144,71 & 71,51 & 31,09 & 5430,91 & 267,32 & 42,09 & 225,23 & 192,77 & 78,92 & 216,44 & 78,92 & 701,68 & 81,71 & 38,45 & 23,28 & 223,49 & 133,61 & 182,06 & 133,61 \\
\hline Hyla meridionalis & 31TDG32 & 101,00 & 126,55 & 72,56 & 31,49 & 5485,82 & 252,29 & 24,87 & 227,42 & 175,21 & 61,18 & 199,62 & 61,18 & 777,76 & 87,68 & 41,15 & 22,50 & 238,41 & 144,73 & 204,14 & 144,73 \\
\hline Hyla meridionalis & 31TDG33 & 100,00 & 127,01 & 73,42 & 31,53 & 5519,44 & 253,66 & 24,32 & 229,34 & 175,75 & 60,87 & 200,29 & 60,87 & 774,75 & 89,25 & 39,24 & 23,82 & 237,88 & 138,84 & 209,39 & 138,84 \\
\hline Hyla meridionalis & 31TDG34 & 101,00 & 129,94 & 74,44 & 31,72 & 5552,03 & 257,43 & 25,65 & 231,78 & 165,59 & 62,72 & 203,31 & 62,72 & 768,28 & 89,48 & 36,97 & 25,35 & 236,62 & $\mid 132,24$ & 212,86 & 132,24 \\
\hline Hyla meridionalis & 31TDG35 & 100,00 & 124,92 & 75,47 & 31,97 & 5577,89 & 253,79 & 20,32 & 233,47 & 140,55 & 57,43 & 198,57 & 57,43 & 794,52 & 92,92 & 37,77 & 25,36 & 245,58 & 137,07 & 218,86 & 137,07 \\
\hline Hyla meridionalis & 31TDG36 & 100,00 & 114,79 & 76,19 & 32,08 & 5563,09 & 244,76 & 11,45 & 233,31 & 130,09 & 48,35 & 188,44 & 48,04 & 837,99 & 96,99 & 42,20 & 23,51 & 256,19 & 151,28 & 225,56 & 151,35 \\
\hline Hyla meridionalis & 31TDG37 & 101,00 & 107,25 & 76,76 & 32,33 & 5546,01 & 238,00 & $\begin{array}{l}41,7+78 \\
4\end{array}$ & 233,22 & 121,53 & 42,10 & 180,97 & 41,12 & 876,42 & 99,70 & 46,81 & 21,35 & 263,89 & $\begin{array}{l}165,67 \\
\end{array}$ & 227,95 & 165,95 \\
\hline Hyla meridionalis & 31TDG40 & 101,00 & 153,92 & 70,08 & 31,02 & 5322,70 & 273,35 & 51,94 & 221,41 & 184,27 & 153,09 & 224,08 & 89,16 & 686,11 & 89,72 & 33,67 & 25,24 & 226,52 & 139,44 & 169,65 & 141,06 \\
\hline Hyla meridionalis & 31TDG41 & 100,00 & 143,57 & 70,61 & 31,01 & 5418,05 & 265,73 & 41,25 & 224,47 & 191,17 & 83,61 & 215,19 & 78,09 & 744,65 & 88,99 & 40,05 & 22,43 & 234,86 & 148,77 & 186,25 & 148,81 \\
\hline Hyla meridionalis & 31TDG42 & 100,00 & 113,04 & 71,73 & 31,59 & 5434,21 & 238,94 & 14,74 & 224,20 & 152,19 & 57,00 & 186,19 & 49,79 & 869,95 & 97,70 & 48,67 & 20,16 & 260,21 & 174,95 & 213,02 & 175,78 \\
\hline Hyla meridionalis & 31TDG43 & 101,00 & 120,79 & 72,53 & 31, & 5480,88 & 247,16 & 19,81 & 227,36 & 168,24 & 56,24 & 193,96 & 55,80 & \begin{tabular}{|l|l|}
841,38 \\
\end{tabular} & 93,61 & $\begin{array}{ll}44,30 \\
440\end{array}$ & 21,43 & 251,91 & $\begin{array}{l}161,19 \\
\end{array}$ & 215,44 & 161,25 \\
\hline Hyla meridionalis & 31TDG44 & 101,00 & 130,89 & 73,43 & 31,21 & 5539,31 & 257,59 & 26,91 & 230,68 & 168,05 & 63,87 & 204,03 & 63,87 & 819,11 & 91,15 & 40,15 & 22,82 & 246,08 & 151,03 & 214,89 & 151,03 \\
\hline Hyla meridionalis & 31TDG45 & 100,00 & 123,43 & 74,48 & 31,81 & 5541,19 & 251,55 & 19,82 & 231,73 & 138,59 & 56,68 & 196,77 & 56,65 & 844,31 & 94,95 & 41,38 & 22,77 & 254,73 & 155,64 & 222,07 & 155,64 \\
\hline Hyla meridionalis & 31TDG46 & 101,00 & 98,81 & 74,53 & 32,16 & 5461,29 & 227,98 & 0,29 & 227,69 & 123,23 & 38,16 & 172,11 & 35,25 & 935,05 & 102,41 & 54,20 & 18,70 & 269,63 & 188,71 & 229,59 & 189,68 \\
\hline Hyla meridiona & 31TDG47 & 100,00 & 107,07 & 76,01 & 32,18 & 5516,90 & 237,20 & 5,42 & 231,79 & 122,12 & 43,70 & 180,49 & 41,55 & 899,99 & 99,75 & 49,27 & 19,80 & 265,71 & 79 & 226,44 & 177,02 \\
\hline Hyla meridionalis & 31TDG49 & 61,00 & 55,44 & 71 & 31 & | 5347,45 & 184,37 & \begin{tabular}{|c|c|}
$-37,63$ \\
-37
\end{tabular} & 222,00 & 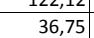 & $\begin{array}{ll}62,02 \\
62,0\end{array}$ & $\begin{array}{l}128,455 \\
128,52\end{array}$ & \begin{tabular}{|c|}
$-4,12$ \\
$-4,12$
\end{tabular} & $\mid \begin{array}{l}03,753 \\
1168,61\end{array}$ & $\mid$ & $\begin{array}{l}45,21 \\
72,21\end{array}$ & 14,13 & \begin{tabular}{|l|}
228,65 \\
326
\end{tabular} & 255,93 & \begin{tabular}{|l|}
262,42 \\
\end{tabular} & 270,85 \\
\hline Hyla meridionalis & 31TDG50 & 100,00 & 149,07 & 69,41 & 30,93 & 5340,44 & 268,83 & 47,51 & 221,32 & 172,34 & 184,93 & 219,62 & 84,45 & 739,98 & 97,36 & 35,59 & 24,90 & 240,67 & 149,22 & 177,14 & 156,74 \\
\hline Hyla meridionalis & 31TDG51 & 100,00 & 150,52 & 69,89 & 30,82 & 5412,19 & 271,39 & 47,10 & 224,29 & 175,65 & 190,74 & 221,70 & 84,58 & 751.99 & 97,13 & 37,05 & 23,69 & 241,22 & $\begin{array}{l}152,85 \\
\end{array}$ & $\mid 178,44$ & 159,64 \\
\hline Hyla meridionalis & 31TDG52 & 100,00 & 121,05 & 70,84 & 31,14 & 5416,66 & 245,56 & 21,77 & 223,79 & 158,67 & 73,56 & 193,60 & 57,38 & 871,94 & 101,31 & 48,10 & 20,27 & 261,90 & 179,63 & 207,94 & 181,17 \\
\hline Hyla meridionalis & 31TDG53 & 101,00 & 120,29 & 71,75 & 31 & 5454,72 & 245,94 & 19,90 & 226,03 & 168,79 & 56,34 & 193 & 55,81 & 879,46 & 97,58 & 47,86 & 20,11 & 259,23 & 176,63 & 214,88 & 17 \\
\hline Hyla meridionalis & 31TDG54 & 100,00 & 125,16 & 72,61 & 31,28 & 5493,16 & 251,46 & 22,80 & 228,67 & 159,72 & 59,79 & 198,10 & 59,49 & 882,49 & 96,36 & 45,17 & 20,85 & 259,02 & 173,86 & 217,20 & 173,90 \\
\hline Hyla meridionalis & 31TDG55 & 101,00 & 112,93 & 73,61 & 31,78 & 5470,40 & 240,58 & 12,28 & 228,29 & 146,27 & 49,85 & 185,97 & 48,41 & 911,09 & 98,75 & 49,15 & 19,85 & 264,80 & 182,35 & 222,98 & 182,41 \\
\hline Hyla meridionalis & 31TDG56 & 101,00 & 126,48 & 74,94 & 31,73 & 5552,87 & 254,68 & 21,49 & 233,19 & 143,13 & 59,32 & 199,65 & 59,17 & 878,35 & 94,59 & 43,36 & 21,32 & 261,01 & 171,38 & 218,56 & 171,39 \\
\hline Hyla meridionalis & 31TDG57 & 100,00 & 129,29 & 76,38 & 31,96 & 5582,05 & 258,48 & 22,78 & 235,70 & 147,30 & $61, \mathrm{C}$ & 202,62 & 61 , & 845,98 & 92,13 & 42,93 & 20,88 & 250,54 & 166,34 & 210,12 & 166,34 \\
\hline Hyla meridionalis & 31TDG60 & 61,00 & 154,39 & 69,16 & 30,85 & 5341,51 & 273,27 & 51,57 & 221,70 & 165,06 & 219,98 & 224,61 & 89,12 & 727,44 & 103,91 & 31,62 & 28,39 & 244,78 & 137,27 & 168,24 & 159, \\
\hline
\end{tabular}




\begin{tabular}{|c|c|c|c|c|c|c|c|c|c|c|c|c|c|c|c|c|c|c|c|c|c|}
\hline TAXON & UTM & $\mathrm{km} 2$ & BIO1 & B102 & $\mathrm{BIO3}$ & B104 & B105 & B106 & B107 & B108 & B109 & BIO10 & BIO11 & BIO12 & B1013 & B1014 & B1015 & B1016 & BIO17 & B1018 & B1019 \\
\hline Hyla meridionalis & 31TDG61 & 101,00 & 146,85 & 69,27 & 30,42 & 5401,26 & 267,46 & 44,08 & 223,38 & 169,79 & 194,63 & 218,05 & 81,26 & 781,72 & 103,63 & 37,41 & 24,57 & 249,46 & 157,06 & 180,94 & 168,79 \\
\hline Hyla meridionalis & 31TDG62 & 101,00 & 149,18 & 69,89 & 30,11 & 5469,89 & 270,71 & 44,27 & 226,44 & 175,51 & 190,11 & 220,84 & 82,05 & 782,31 & 103,47 & 38,13 & 24,38 & 247,74 & 157,19 & 178,56 & 168,20 \\
\hline Hyla meridionalis & 31TDG63 & 100,00 & 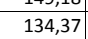 & 70,82 & 30,71 & 5472,86 & 258,25 & 31,14 & 227,11 & 182,29 & \begin{tabular}{|r|r|r|}
82,49 \\
\end{tabular} & 206,82 & 68,42 & 864,54 & 102,08 & 45,97 & 21,14 & 257,04 & 178,28 & 202,84 & 178,94 \\
\hline Hyla meridionalis & 31TDG64 & 100,00 & 133,71 & 71,88 & 30,84 & 5515,80 & 258,82 & 29,58 & \begin{tabular}{|l|l|}
229,23 \\
\end{tabular} & \begin{tabular}{|l|l|}
177,28 \\
\end{tabular} & 81,89 & 206,53 & 66,99 & 870,25 & 101,28 & 45,16 & 21,27 & 255,94 & 178,43 & 203,14 & 178,73 \\
\hline Hyla meridionalis & 31TDG65 & 100,00 & 134,61 & 73,08 & 31,10 & 5543,73 & 260,82 & 29,16 & 231,66 & 171,21 & $\begin{array}{l}67,05 \\
\end{array}$ & 207,58 & $\begin{array}{l}67,05 \\
\end{array}$ & 869,24 & 99,53 & 44,63 & 21,17 & 253,62 & 177,00 & 205,04 & 177,00 \\
\hline Hyla meridionalis & 31TDG66 & 101,00 & 128,84 & 74,49 & 31,64 & 5531,15 & 256,26 & 23,76 & 232,50 & 153,06 & 61,83 & 201,77 & 61,83 & 877,56 & 97,45 & 45,15 & 20,81 & 255,27 & 177,86 & 209,00 & 177,86 \\
\hline Hyla meridionalis & 31TDG67 & 100,00 & 137,40 & 76,11 & 31,80 & 5580,44 & 265,66 & 29,24 & 236,41 & 175,68 & 68,76 & 210,45 & 68,73 & 808,42 & 94,24 & 42,97 & 21,05 & 236,38 & 165,84 & 188,53 & 165,85 \\
\hline Hyla meridionalis & 31TDG68 & 86,00 & 114,42 & 76,43 & 32,34 & 5500,76 & 243,88 & 11,05 & 232,83 & 134,60 & 51,47 & 187,37 & 48,63 & 893,25 & 96,76 & 50,69 & 18,58 & 255,03 & 186,61 & 211,05 & 187,34 \\
\hline Hyla meridionalis & 31TDG71 & 99,00 & $\begin{array}{lll}156,87 & \\
\end{array}$ & 69,51 & 30,60 & 5364,56 & 275,70 & 52,56 & 223,14 & 167,35 & 224,72 & 227,13 & 90,86 & \begin{tabular}{|l|l|}
711,45 \\
\end{tabular} & 107,54 & 29,23 & 30,94 & 243,24 & 129,62 & 160,29 & 156,59 \\
\hline Hyla meridionalis & 31TDG72 & 101,00 & 154,90 & 69,47 & 30,09 & 5459,06 & 275,20 & 48,78 & 226,42 & 165,21 & 225,52 & 226,12 & 87,35 & 736,21 & 108,20 & 31,73 & 28,88 & 244,81 & 137,61 & 161,82 & $\begin{array}{ll}162,07 \\
\end{array}$ \\
\hline Hyla meridionalis & 31TDG73 & 100,00 & 151,59 & 69,54 & 29,97 & 5553,31 & 273,66 & 44,30 & 229,36 & 165,46 & 222,68 & 223,75 & 82,63 & 769,42 & 108,47 & 35,29 & 26,44 & 246,62 & 149,64 & 161,79 & 168,62 \\
\hline Hyla meridionalis & 31TDG74 & 101,00 & 148,67 & 70,75 & 30,06 & 5587,62 & 272,30 & 40,82 & 231,48 & 177,15 & 209,99 & 221,44 & 79,36 & 785,67 & 106,68 & 38,35 & 24,72 & 244,16 & 159,67 & 167,53 & 169,21 \\
\hline Hyla meridionalis & 31TDG75 & 101,00 & 138,71 & 72,55 & 30,92 & 5523,73 & 263,75 & 32,51 & 231,24 & 182,50 & 104,51 & 211,21 & 71,13 & 832,95 & 103,27 & 43,47 & 22,28 & 247,40 & 173,37 & 186,58 & 174,80 \\
\hline Hyla meridionalis & 31TDG76 & 100,00 & 143,13 & 74,41 & 31,20 & 5552,16 & 269,17 & 35,16 & 234,01 & \begin{tabular}{|l|}
185,68 \\
\end{tabular} & 111,35 & 215,67 & 74,65 & 784,79 & 99,79 & 41,08 & 22,69 & 235,03 & 163,83 & 173,85 & 164,27 \\
\hline Hyla meridionalis & 31TDG77 & 100,00 & 138,85 & 75,89 & 31,95 & 5538,66 & 266,13 & 30,97 & 235,15 & \begin{tabular}{|l|l|}
177,79 \\
\end{tabular} & 103,96 & 211,36 & 70,83 & \begin{tabular}{|l|l|}
782,67 \\
\end{tabular} & 97,23 & 41,56 & 21,97 & 231,89 & 164,30 & 174,28 & 164,77 \\
\hline Hyla meridionalis & 31TDG78 & 93,00 & 127,93 & 77,01 & 32,06 & 5514,09 & 256,73 & 21,64 & 235,10 & 166,72 & 73,70 & 200,46 & 60,95 & 827,53 & 96,41 & 45,54 & 20,13 & 238,31 & 175,62 & 187,78 & 175,90 \\
\hline Hyla meridionalis & 31TDG81 & 58,00 & 156,33 & 69,67 & 30,77 & 5324,65 & 274,68 & 52,23 & 222,45 & 166,76 & 221,85 & 226,11 & 91,01 & 700,06 & \begin{tabular}{|r|r|}
108,38 \\
\end{tabular} & 27,85 & 32,13 & 241,39 & 125,74 & 155,80 & 153,82 \\
\hline Hyla meridionalis & 31TDG83 & 101,00 & 152,89 & 69,74 & 30,10 & 5483,13 & 273,79 & 46,21 & 227,58 & 163,03 & 223,94 & 224,33 & 85,14 & 738,58 & 109,55 & 31,46 & 29,01 & 243,75 & \begin{tabular}{l|l|}
137,25 \\
\end{tabular} & 159,43 & 163,03 \\
\hline Hyla meridionalis & 31TDG84 & 101,00 & 151,60 & 71,06 & 30,56 & 5502,87 & 273,56 & \begin{tabular}{|l|l|}
44,03 \\
\end{tabular} & 229,53 & 161,75 & 222,87 & 223,26 & 83,40 & 745,99 & 107,99 & 33,42 & 27,63 & 240,70 & 143,15 & 156,73 & 162,27 \\
\hline Hyla meridionalis & 31TDG85 & 101,00 & 151,47 & 73,02 & 31,16 & 5489,76 & 274,51 & 43,28 & 231,23 & 163,92 & 222,63 & 222,94 & 83,53 & 727,58 & 104,06 & 33,71 & 26,96 & 232,38 & $\begin{array}{l}143,45 \\
\end{array}$ & 154,74 & 155,45 \\
\hline Hyla meridionalis & 31TDG86 & 100,00 & 150,17 & 74,92 & 31,76 & 5484,51 & 274,44 & 41,47 & 232,96 & 160,93 & 221,32 & 221,62 & 82,25 & 708,14 & 99,79 & 33,60 & 26,14 & 224,22 & 142,91 & 150,56 & 149,80 \\
\hline Hyla meridionalis & 31TDG87 & 101,00 & 149,24 & 76,75 & 32,16 & 5487,27 & 274,86 & 39 & 235,02 & $\begin{array}{l}160,05 \\
\end{array}$ & 216,56 & 220,80 & 81,28 & 689,46 & 96,19 & 32,82 & 25,71 & 217,65 & $\begin{array}{l}140,02 \\
\end{array}$ & $\begin{array}{l}146,09 \\
\end{array}$ & $\begin{array}{l}14,00 \\
146,16\end{array}$ \\
\hline Hyla meridionalis & 31TDG88 & 100,00 & 145,31 & 78,30 & 32,55 & 5499,28 & 272,62 & 35,72 & 236,90 & 157,99 & 205,09 & 217,05 & 77,44 & 700,65 & 94,38 & 33,65 & 24,44 & 217,15 & 142,92 & 147,29 & 151,21 \\
\hline Hyla meridionalis & 31TDG89 & 82,00 & 138,88 & 79,63 & 32,99 & 5506,15 & 267,94 & 29,75 & 238,19 & 152,98 & 186,80 & 211,01 & 71,29 & 724,75 & 93,55 & 35,45 & 22,99 & 219,97 & 148,58 & 152,88 & 159,90 \\
\hline Hyla meridionalis & 31TDG91 & & & & & & & & & & & & & & & & & & & & \\
\hline Hyla meridionalis & 31TDG92 & 90,00 & 150,89 & 70,44 & 31,30 & 55,40 & 268,98 & 47,70 & 221,29 & 161,82 & 218,54 & 220,26 & 86,91 & 712,95 & 106,85 & 28,68 & 30,50 & 240,38 & 130,56 & 156,86 & 156,52 \\
\hline Hyla meridionalis & 31TDG93 & 101,00 & $\begin{array}{ll}130,05 \\
149,48\end{array}$ & $\mid 71,06$ & $\begin{array}{l}31,22 \\
31,22\end{array}$ & 5302,24 & $\mid$ & 45,39 & 223,06 & $\begin{array}{l}\mid 010,02 \\
160,19\end{array}$ & 218,27 & $\begin{array}{l}219,20 \\
219,19\end{array}$ & $\begin{array}{l}80,71 \\
84,88\end{array}$ & 722,41 & $\begin{array}{l}\mid 0,05,15 \\
106,15\end{array}$ & $\begin{array}{l}20,00 \\
30,10\end{array}$ & $\begin{array}{l}30,00 \\
29,09 \\
\end{array}$ & \begin{tabular}{|l}
24,30 \\
238,99
\end{tabular} & \begin{tabular}{|l|l|}
135,13 \\
\end{tabular} & $\begin{array}{l}50,00 \\
158,25\end{array}$ & $\begin{array}{l}150,52 \\
157,90\end{array}$ \\
\hline Hyla meridionalis & 31TDG95 & 100,00 & 155,34 & 74,30 & 32,15 & 5331,84 & 276,12 & 48,17 & 227,95 & 165,50 & 224,38 & 224,95 & 89,64 & 666,18 & 100,65 & 28,02 & 29,82 & 222,45 & 124,31 & 143,50 & 143,07 \\
\hline Hyla meridionalis & 31TDG96 & 101,00 & 154,32 & 76,03 & 32,57 & 5354,37 & 276,69 & 46,32 & 230,38 & 164,47 & 223,78 & 224,28 & 88,29 & 645,72 & $\begin{array}{l}0,06 \\
96,88 \\
\end{array}$ & 27,87 & 29,30 & 214,89 & \begin{tabular}{|l|}
123,38 \\
123,1
\end{tabular} & 138,33 & 136,76 \\
\hline Hyla meridionalis & 31TDG97 & 101,00 & 154,91 & 77,94 & 32,98 & 5376,61 & 278,77 & 45,78 & 232,99 & 164,75 & 224,66 & 225,07 & 88,52 & 620,55 & 93,45 & 26,50 & 29,39 & 207,71 & 118,15 & 129,83 & 131,77 \\
\hline Hyla meridionalis & 31TDG98 & 101,00 & 154,16 & 79,68 & 33,31 & 5404,67 & 279,85 & 43,98 & 235,87 & 163,77 & 224,38 & 224,69 & 87,42 & 614,88 & 91,59 & 25,70 & 28,95 & 205,24 & 114,78 & 123,02 & 133,82 \\
\hline Hyla meridionalis & 31TDG99 & 101,00 & 144,56 & 80,52 & 33,46 & 5443,28 & 272,35 & 34,86 & 237,48 & 151,97 & 215,52 & 215,81 & 77,70 & 669,90 & 92,67 & 29,61 & 25,82 & 213,72 & 128,84 & 135,24 & 149,82 \\
\hline Hyla meridionalis & 31TDH80 & 1,00 & 143,90 & 82,12 & 33,46 & 5540,21 & 274,54 & 32,40 & 242,14 & 151,89 & 212,72 & 216,18 & 75,45 & 677,58 & 90,55 & 30,60 & 24,48 & 211,47 & 130,48 & \begin{tabular}{|l|l|}
131,98 \\
\end{tabular} & 154,59 \\
\hline Hyla meridionalis & 31TDH90 & 17,00 & 130,04 & 80,65 & 33,43 & 5452,04 & 259,87 & 22,49 & 237,38 & 119,93 & 201,55 & 201,87 & 63,90 & 750,58 & 95,23 & 35,71 & 22,82 & 229,15 & 150,32 & 154,35 & 172,62 \\
\hline Hyla meridionalis & 31TEG02 & 28,00 & 159,86 & 72,57 & 32,57 & 5126,33 & 275,57 & 56, & 219,1 & 170,95 & 218,33 & 227,33 & 97,29 & 631,48 & 102,14 & 21,7 & 35,33 & 225,67 & \begin{tabular}{|l|}
106,76 \\
\end{tabular} & 137,62 & 139,43 \\
\hline Hyla meridionalis & 31TEG03 & 93,00 & 153,07 & 72,72 & 32,65 & 5129,58 & 269,70 & 50,30 & 219,40 & 164,14 & 219,05 & 220,85 & 91,19 & 659,64 & 100,74 & 24,89 & 31,94 & 226,71 & 118,30 & 144,85 & 143,42 \\
\hline Hyla meridionalis & 31TEG04 & 100,00 & 156,39 & 74,26 & 33,10 & 5126,21 & 273,53 & 52,28 & 221,25 & 167,27 & 222,84 & 223,95 & 94,16 & 632,72 & 98,18 & 23,59 & 32,44 & 219,16 & 112,16 & 137,79 & 137,12 \\
\hline Hyla meridionalis & 31TEG05 & 101,00 & 159,00 & 76,01 & 33,36 & 5156,94 & 277,61 & 53,28 & 224,33 & $\begin{array}{l}169,69 \\
\end{array}$ & 225,81 & 226,69 & 95,95 & 606,38 & 95,44 & 22,60 & 32,90 & 211,53 & 107,01 & 130,96 & 130,71 \\
\hline Hyla meridionalis & 31TEG06 & 97,00 & 158,23 & 77,35 & 33,63 & 5215,84 & 278,52 & 51,12 & 227,39 & 168,48 & 225,83 & 226,54 & 94,18 & 597,79 & 93,37 & 22,87 & 32,11 & 207,20 & 107,21 & 128,67 & 128,37 \\
\hline Hyla meridionalis & 31TEG07 & 99,00 & 158,76 & 79,15 & 33,82 & 266,93 & 0,93 & 50,05 & 230,89 & 168,66 & 227,07 & 227,46 & 93,87 & 582,46 & 91,29 & 22,05 & 32,32 & 202,72 & 103,44 & 119,33 & 126,14 \\
\hline Hyla meridionalis & 31TEG08 & \begin{tabular}{|c|}
101,00 \\
\end{tabular} & 156,38 & 80,48 & 33,99 & 5305,64 & 280,52 & 46,90 & 233,62 & 166,31 & 225,23 & 225,66 & 90,90 & 587,55 & 90,46 & 22,33 & 31,40 & 202,46 & 103,81 & 119,66 & 129,73 \\
\hline Hyla meridionalis & 31TEG09 & 90,00 & 144,42 & 80,68 & 33,90 & 5361,71 & 271,10 & 35,65 & 235,45 & 153,62 & 214,34 & 214,71 & 78,84 & 656,66 & 92,80 & 27,31 & 27,12 & 213,79 & 121,92 & 133,07 & 148,59 \\
\hline Hyla meridionalis & 31TEG13 & 37,00 & 159,26 & 74,63 & 33,92 & 4974,95 & 273,68 & 56,92 & $\begin{array}{l}216,76 \\
216,76\end{array}$ & 170,61 & 210,58 & 225,08 & 99,42 & 587,89 & 94,26 & 19,53 & 35,63 & 211,92 & 100,21 & 130,21 & 126,39 \\
\hline Hyla meridionalis & 31TEG14 & 82,00 & 158,10 & 75,46 & 34,12 & 4968,86 & 273,17 & 55,60 & 217,57 & 169,46 & 218,00 & 223,94 & 98,45 & 581,97 & 92,08 & 19,95 & 34,63 & \begin{tabular}{|l|l|}
207,98 \\
\end{tabular} & 101,27 & 129,57 & 123,84 \\
\hline Hyla meridionalis & 31TEG15 & 64,00 & 158,06 & 76,80 & 34,23 & 5037,93 & 274,93 & 53,78 & 221,16 & 169,04 & 223,27 & 224,47 & 97,10 & 582,48 & 91,69 & 20,63 & 33,81 & 206,16 & 102,02 & 127,89 & 124,51 \\
\hline Hyla meridionalis & \begin{tabular}{|l|} 
31TEG17 \\
\end{tabular} & 27,00 & \begin{tabular}{|l|}
152,470 \\
\end{tabular} & $\begin{array}{l}70,0,42 \\
99\end{array}$ & 34,11 & 5163,58 & 274,11 & $\begin{array}{l}45,103 \\
45,63\end{array}$ & 228,47 & $\begin{array}{l}\mid 0,04,74 \\
162,7\end{array}$ & \begin{tabular}{|l|l|}
219,58 \\
221
\end{tabular} & $\begin{array}{l}224,4 ! \\
220,32\end{array}$ & 89,89 & \begin{tabular}{|l}
50,40 \\
597,79
\end{tabular} & $\begin{array}{l}\mid 1,09 \\
91,05 \\
\end{array}$ & $\begin{array}{l}0,05 \\
21,89 \\
\end{array}$ & $\begin{array}{l}30,01 \\
31,53 \\
\end{array}$ & 206,53 & $\begin{array}{l}105,05 \\
105\end{array}$ & $\begin{array}{l}\mid 27,03 \\
127,42\end{array}$ & 132,21 \\
\hline Hyla meridionalis & 31TEG18 & 92,00 & 150,02 & 80,18 & 34,19 & 5227,00 & 273,39 & 42,56 & 230,83 & 160,23 & 218,03 & 218,70 & 86,39 & 614,06 & 91,62 & 23,13 & 30,37 & 208,97 & 108,82 & 128,38 & 137,49 \\
\hline Hyla meridionalis & 31TEG19 & 30,00 & 151,89 & 82,00 & 34,39 & 5309,02 & 277,59 & 42,27 & 235,32 & 161,70 & 220,98 & 221,36 & 86,77 & 602,16 & 90,39 & 22,30 & 30,66 & 205,52 & 104,05 & 120,39 & 137,52 \\
\hline Hyla meridionalis & 31TEG28 & 31,00 & 152,98 & 80,93 & 34,83 & 5170,83 & 275 & 45, & 229 & 163 & 220,27 & 220,98 & $\begin{array}{l}90,05 \\
\end{array}$ & 588,20 & 90,30 & 20,48 & 32,55 & 205,35 & 99,82 & 120,45 & 132,93 \\
\hline Hyla meridionalis & 31TEHOO & 8,00 & 14 & 82 & 34, & 3 & 272 & & 238, & 147 & 214 & 214,46 & 77,38 & 656,68 & 91,94 & 26,81 & 27,44 & 213,72 & 119,09 & 127,74 & 152,85 \\
\hline Hyla molleri & $295 M C 86$ & 60,00 & 166,21 & 81,36 & 41,33 & 3924,44 & 276,58 & 82,44 & 194,15 & 125,29 & 213,76 & 218,67 & 117,97 & 698,01 & 106,28 & $\begin{array}{r}\mid c, 01 \\
3,82\end{array}$ & 63,62 & 313,06 & $\begin{array}{l}\mid c 5,58 \\
29,58\end{array}$ & 32,19 & 299,45 \\
\hline Hyla molleri & $295 \mathrm{MC} 87$ & 85,00 & 166,33 & 80,39 & 41,04 & 3928,81 & 275,72 & 82,47 & 193,25 & 125,15 & 213,91 & 218,71 & 117,74 & 709,73 & 108,26 & 3,85 & 63,78 & 318,88 & 29,62 & 32,39 & 304,79 \\
\hline Hyla molleri & 29SMC89 & 101,00 & 162,23 & 77,29 & 40,59 & 3890,32 & 267,64 & 79,42 & 188,21 & 121,02 & 209,27 & 213,48 & 113,54 & 744,37 & 113,05 & 3,82 & 64,03 & 333,09 & 30,62 & 33,27 & 318,85 \\
\hline Hyla moll & 29SMC95 & 57,00 & 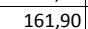 & & 41,27 & 4053,90 & 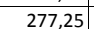 & 76,7 & 200,52 & 120,01 & 211,56 & 4 & 112,46 & 712, & 107,07 & 3, & 62,97 & 316,56 & 31,18 & 33,15 & 305,23 \\
\hline Hyla molleri & $295 \mathrm{SD} 73$ & \begin{tabular}{|r|}
101,00 \\
\end{tabular} & & & $\frac{41}{41}$ & 313 & 231 & 81, & 149,66 & 120,85 & 190,32 & 193,01 & 112,66 & 696,19 & 114,21 & 4,00 & 62,63 & 311,64 & 29,42 & 34,60 & 288,44 \\
\hline Hyla molleri & 29SMD84 & 101,00 & 154,34 & 64,55 & 40,99 & 3237,16 & 236,09 & 80,47 & 155,62 & 120,55 & 192,73 & 195,36 & 112,40 & 698,05 & 113,05 & 4,00 & 62,10 & 309,29 & 30,02 & 35,43 & 289,73 \\
\hline Hyla molleri & $29 \mathrm{SMD} 85$ & 99,00 & 153,92 & 63,22 & 41,25 & 3141,44 & 232,59 & 81,14 & \begin{tabular}{|l|l|}
151,45 \\
\end{tabular} & 121,16 & 190,92 & 193,39 & 113,04 & 693,97 & 113,00 & 4,06 & 61,81 & 305,79 & 30,54 & 36,53 & 286,46 \\
\hline Hyla molleri & 29SMD86 & 79,00 & 154,64 & 62,85 & 41,60 & 3081,51 & 231,56 & 82,21 & 149,35 & 122,49 & 190,84 & 193,19 & 114,37 & 691,11 & 112,46 & 4,04 & 61,43 & 302,84 & 30,71 & 37,30 & 284,19 \\
\hline Hyla mo & 29SMD95 & 101,00 & & & 41,0 & 3290 & 202 & 77 & 165,08 & 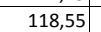 & 194 & 197 & 110,5 & 724 & 114 & 4,2 & 61,16 & 316,49 & 32,79 & 38,09 & 300,91 \\
\hline Hyla molleri & 29SMD97 & $\begin{array}{l}32,00 \\
92,00\end{array}$ & 153,65 & $\begin{array}{l}\mid c 0,40 \\
67,96 \\
\end{array}$ & $\begin{array}{l}41,1,64 \\
41\end{array}$ & 3283,66 & 238,79 & 77,36 & $\begin{array}{l}161,43 \\
161,40\end{array}$ & \begin{tabular}{|l|l|}
119,03 \\
119,03
\end{tabular} & $\begin{array}{l}1932,74 \\
\end{array}$ & 195,21 & 111,05 & 740,74 & $\mid$ & 4, 4,83 & \begin{tabular}{|l|l|}
60,01 \\
\end{tabular} & \begin{tabular}{|l|}
319,21 \\
319
\end{tabular} & 35,65 & $\begin{array}{l}40,79 \\
41,78\end{array}$ & 304,47 \\
\hline
\end{tabular}




\begin{tabular}{|c|c|c|c|c|c|c|c|c|c|c|c|c|c|c|c|c|c|c|c|c|c|}
\hline$\overline{\text { TAXON }}$ & UTM & $\mathrm{km} 2$ & BIO1 & BIO2 & B103 & 8104 & B105 & B106 & B107 & B108 & B109 & BIO10 & BIO11 & BIO12 & B1013 & B1014 & B1015 & B1016 & B1017 & BIO18 & 81019 \\
\hline Hyla molleri & 29SMD98 & 58,00 & 154,47 & 68,99 & 42,01 & 3275,73 & 239,79 & 77,49 & 162,30 & 119,74 & 193,37 & 195,76 & 111,73 & 752,49 & 116,18 & 5,30 & 59,35 & 321,62 & 37,58 & 44,10 & 307,90 \\
\hline Hyla molleri & 29SMD99 & 35,00 & 152,45 & 70,03 & 42,11 & 3291,15 & 238,72 & 74,76 & 163,96 & 117,54 & \begin{tabular}{ll|}
191,64 \\
\end{tabular} & 194,07 & 109,53 & 788,54 & 119,77 & 6,00 & 58,43 & \begin{tabular}{|l|l|}
334,07 \\
\end{tabular} & 41,22 & 47,77 & 321,45 \\
\hline Hyla molleri & 29SNB12 & 83,00 & \begin{tabular}{ll|}
163,34 \\
\end{tabular} & 86,34 & 44,66 & 3628,14 & 271,70 & 80,42 & 191,27 & $\begin{array}{l}128,07 \\
\end{array}$ & 207,95 & 212,23 & 119,51 & 516,43 & 83,19 & 1,00 & $\begin{array}{l}68,47 \\
\end{array}$ & 241,95 & 18,35 & 19,41 & 231,30 \\
\hline Hyla molleri & 29SNB13 & 51,00 & 165,90 & 86,91 & 44,25 & $\begin{array}{ll}3706,64 \\
\end{array}$ & 276,06 & 81,89 & $\begin{array}{l}194,17 \\
\end{array}$ & 129,33 & 211,51 & 215,80 & 121,01 & 513,94 & 82,24 & 1,00 & 68,10 & 240,26 & \begin{tabular}{ll|}
18,46 \\
\end{tabular} & \begin{tabular}{ll|}
19,60 \\
\end{tabular} & 229,58 \\
\hline Hyla molleri & 295NB14 & 19,00 & 166,42 & 87,92 & 44,00 & 3803,89 & 279,44 & 81,19 & 198,25 & 128,75 & 213,33 & 217,72 & 120,36 & 522,64 & 82,56 & 1,00 & 67,69 & 243,06 & 18,89 & 19,89 & 232,81 \\
\hline Hyla molleri & 29SNB16 & 24,00 & 167,33 & 88,92 & 43,73 & 3885,90 & 282,76 & 81,06 & 201,69 & 128,55 & 215,29 & 219,73 & 120,39 & 539,57 & 83,76 & 1,00 & 66,53 & 248,24 & 20,00 & 21,00 & 238,41 \\
\hline Hyla molleri & 29SNB17 & 20,00 & 167,92 & 89,56 & 43,36 & 3939,44 & 285,08 & 81,17 & 203,92 & 128,25 & 216,47 & 221,03 & 120,08 & 549,53 & 84,28 & 1,56 & 65,78 & 250,86 & 21,03 & 22,08 & 241,44 \\
\hline Hyla molleri & 29SNB19 & 31,00 & 168,49 & $\begin{array}{ll}90,07 \\
\end{array}$ & 43,00 & 4041,32 & 288,02 & 80,83 & 207,20 & 127,34 & 218,22 & 222,93 & $\begin{array}{l}119,46 \\
\end{array}$ & 569,29 & 86,15 & 2,00 & \begin{tabular}{ll|l}
64,95 \\
\end{tabular} & 257,37 & 22,49 & 23,78 & 248,22 \\
\hline Hyla molleri & 29SNB22 & 101,00 & 159,48 & 88,59 & 43,57 & 3863,33 & 274,21 & $\begin{array}{l}73,06 \\
\end{array}$ & 201,15 & 121,65 & 207,70 & \begin{tabular}{|l|l|}
211,89 \\
\end{tabular} & \begin{tabular}{l|l|}
113,22 \\
\end{tabular} & 545,39 & 86,20 & 1,08 & 67,90 & 254,36 & 19,78 & 20,69 & 243,97 \\
\hline Hyla molleri & 29SNB23 & 101,00 & 160,57 & 89,23 & 43,49 & 3904,89 & 276,69 & 73,70 & 202,99 & 122,19 & 209,27 & 213,56 & \begin{tabular}{|l|l|}
113,87 \\
\end{tabular} & 548,35 & 86,14 & 1,15 & 67,36 & 254,48 & 20,17 & 21,04 & 244,38 \\
\hline Hyla molleri & 29SNB24 & 100,00 & \begin{tabular}{ll|}
162,44 \\
\end{tabular} & 89,79 & 43,41 & 3953,88 & 280,03 & $\begin{array}{l}75,26 \\
\end{array}$ & 204,76 & 123,45 & 211,84 & 216,11 & \begin{tabular}{|l|l|}
115,18 \\
\end{tabular} & 546,36 & 85,42 & 1,08 & $\begin{array}{l}67,06 \\
\end{array}$ & 252,79 & 20,07 & 20,88 & 242,88 \\
\hline Hyla molleri & 29SNB25 & 100,00 & 164,72 & 90,25 & 43,24 & 3981,16 & 283,08 & \begin{tabular}{ll|l}
77,15 \\
\end{tabular} & 205,94 & 125,25 & 214,24 & 218,62 & \begin{tabular}{l|l|}
116,82 \\
\end{tabular} & 543,22 & 84,29 & 1,00 & \begin{tabular}{ll|}
66,73 \\
\end{tabular} & 250,47 & 20,04 & 20,94 & 240,79 \\
\hline Hyla molleri & 29SNB26 & 101,00 & 167,37 & 90,54 & 43,07 & 4006,83 & 286,40 & 79,38 & 207,03 & 127,37 & 217,05 & 221,60 & 119,02 & 539,28 & 83,16 & 1,06 & 66,34 & 247,82 & 20,04 & 21,07 & 238,29 \\
\hline Hyla molleri & 29SNB27 & 101,00 & 164,85 & 91,51 & 43,02 & 4077,94 & 286,17 & $\begin{array}{l}76,15 \\
\end{array}$ & 210,02 & 124,01 & 215,44 & 219,99 & \begin{tabular}{|l|l|}
115,74 \\
\end{tabular} & 565,10 & 86,24 & 1,72 & 65,40 & 256,79 & 22,20 & 22,99 & 248,03 \\
\hline Hyla molleri & 29SNB28 & 101,00 & 163,45 & 91,99 & 42,92 & 4134,08 & 286,67 & 74,44 & 212,23 & \begin{tabular}{ll|}
121,86 \\
\end{tabular} & 214,92 & 219,54 & 113,86 & 584,01 & 88,30 & 2,00 & 64,69 & 263,26 & 23,58 & 24,30 & 255,08 \\
\hline Hyla molleri & 29SNB29 & 101,00 & 164,16 & 92,20 & 42,84 & \begin{tabular}{ll|l}
4175,37 \\
\end{tabular} & 288,44 & 74,92 & 213,52 & 122,01 & 216,06 & 220,71 & \begin{tabular}{|l|l|}
113,97 \\
\end{tabular} & 590,88 & 88,76 & 2,00 & 64,15 & 265,09 & 24,11 & 24,86 & 257,27 \\
\hline Hyla molleri & 29SNB33 & 101,00 & 153,17 & 91,73 & 42,96 & 4104,42 & 275,13 & 63,85 & 211,28 & 113,12 & 205,01 & 209,21 & 104,51 & 597,67 & 93,49 & 1,78 & 66,16 & 273,78 & 23,43 & 24,04 & 264,44 \\
\hline Hyla molleri & 29SNB34 & 100,00 & 160,98 & 91,92 & 42,89 & 4116,92 & 283,24 & 71,08 & 212,15 & 120,35 & 212,75 & \begin{tabular}{|l|l|}
217,05 \\
\end{tabular} & 111,80 & 557,87 & 87,50 & 1,29 & 66,59 & 257,51 & 20,82 & \begin{tabular}{ll|}
21,67 \\
\end{tabular} & 247,82 \\
\hline Hyla molleri & 29SNB35 & 101,00 & 167,48 & 91,98 & 42,96 & 4111,58 & 289,42 & 77,29 & 212,13 & 126,46 & 219,01 & 223,26 & \begin{tabular}{|l|l|}
118,07 \\
\end{tabular} & 528,77 & 82,62 & 1,01 & 67,01 & 244,88 & \begin{tabular}{|l|l}
19,08 \\
\end{tabular} & 20,13 & 235,08 \\
\hline Hyla molleri & 295NB36 & 101,00 & 165,93 & 92,97 & 42,95 & 4165,94 & 289,95 & 75,37 & 214,58 & 124,09 & 217,99 & 222,40 & 115,90 & 546,52 & 84,50 & 1,23 & 66,02 & 250,43 & 20,62 & 21,50 & 241,41 \\
\hline Hyla molleri & 29SNB37 & 100,00 & 164,94 & 93,73 & 42,83 & 4219,59 & 290,82 & \begin{tabular}{|l|l|}
74,07 \\
\end{tabular} & 216,75 & 122,57 & 217,72 & 222,23 & \begin{tabular}{|l|l|}
114,44 \\
\end{tabular} & 561,68 & 85,97 & 1,82 & 65,17 & 254,92 & 22,07 & 22,89 & 246,65 \\
\hline \begin{tabular}{|l|} 
Hyla molleri \\
\end{tabular} & 29SNB38 & 101,00 & 165,56 & 94,17 & 42,70 & 4258,45 & 292,73 & 74,44 & 218,29 & 122,77 & 218,79 & 223,35 & $\begin{array}{l}114,49 \\
14\end{array}$ & 567,57 & 86,11 & 2,00 & 64,57 & 256,00 & 22,76 & 23,43 & 248,21 \\
\hline Hyla molleri & 29SNB39 & 100,00 & 165,48 & 94,48 & 42,38 & 4301,43 & 293,85 & 74,15 & 219,70 & $\begin{array}{l}122,07 \\
\end{array}$ & 219,27 & 223,98 & \begin{tabular}{ll|}
114,02 \\
\end{tabular} & 576,49 & 86,88 & 2,00 & $\begin{array}{ll}64,22 \\
\end{array}$ & 258,47 & 23,19 & 24,02 & 251,19 \\
\hline Hyla molleri & 29SNB43 & 100,00 & 158,19 & 93,15 & 42,49 & 4219,30 & 282,90 & 66,29 & 216,61 & \begin{tabular}{ll|}
116,56 \\
\end{tabular} & 211,49 & \begin{tabular}{|l|l|}
215,67 \\
\end{tabular} & $\begin{array}{l}108,04 \\
\end{array}$ & 570,05 & 90,55 & 1,33 & \begin{tabular}{ll|}
66,86 \\
\end{tabular} & 263,84 & 21,04 & 21,89 & 253,89 \\
\hline Hyla molleri & 29SNB44 & 101,00 & 165,33 & 93,32 & 42,45 & 4231,12 & 290,31 & 73,10 & 217,20 & 123,17 & 218,62 & \begin{tabular}{|l|}
222,87 \\
\end{tabular} & $\begin{array}{l}114,75 \\
\end{array}$ & 534,47 & 84,80 & 1,00 & 67,20 & 248,69 & 18,80 & 19,94 & 238,53 \\
\hline Hyla molleri & 29SNB45 & 101,00 & 165,68 & 94,29 & 42,55 & 4266,08 & 292,32 & 73,34 & 218,98 & 122,99 & 219,44 & 223,80 & 114,73 & 538,78 & 84,63 & 1,02 & 66,67 & 248,75 & 19,45 & 20,42 & 239,24 \\
\hline Hyla molleri & 29SNB47 & 100,00 & 163,18 & 96,28 & 42,48 & 4369,40 & 293,99 & 70,04 & 223,95 & 119,40 & 218,06 & 222,73 & \begin{tabular}{|l|l|}
111,14 \\
\end{tabular} & 569,30 & 87,22 & 2,00 & \begin{tabular}{ll|l}
64,67 \\
\end{tabular} & 257,01 & 22,82 & 23,42 & 249,30 \\
\hline Hyla molleri & 29SNB48 & 101,00 & 167,66 & 96,33 & 42,62 & 4369,44 & 298,26 & 74,38 & 223,87 & 123,46 & 222,40 & 226,92 & $\begin{array}{l}115,25 \\
15\end{array}$ & 551,81 & 83,96 & 2,00 & 64,54 & 248,81 & 21,95 & 22,84 & 241,24 \\
\hline Hyla molleri & 29SNB49 & 101,00 & 168,13 & 96,77 & 42,39 & 4402,72 & 299,73 & 74,62 & 225,11 & 123,45 & 223,21 & 227,86 & \begin{tabular}{|l|l|}
115,34 \\
\end{tabular} & 557,31 & 84,01 & 2,00 & 64,01 & 249,32 & 22,72 & 23,49 & 242,42 \\
\hline Hyla molleri & 29SNB53 & 100,00 & 164,55 & \begin{tabular}{|c|c|}
94,13 \\
\end{tabular} & 42,08 & \begin{tabular}{|l|l|l|}
4297,53 \\
\end{tabular} & 290,68 & \begin{tabular}{|c|c|c|}
70,92 &
\end{tabular} & 219,76 & \begin{tabular}{|l|l|}
121,89 \\
\end{tabular} & 218,86 & 223,08 & $\mid 113,30$ & 535,86 & $\mid 86,47$ & 1,00 & $\begin{array}{lll}67,62 & \end{array}$ & 251,14 & $\mid 18,31$ & \begin{tabular}{|c|c|}
19,68 & \\
\end{tabular} & 240,12 \\
\hline Hyla molleri & 29SNB55 & 100,00 & 162,91 & 96,57 & 42,24 & 4398,71 & 293,67 & $\begin{array}{ll}68,26 \\
\end{array}$ & 225,41 & 118,99 & 218,50 & 222,80 & \begin{tabular}{ll|l}
110,58 \\
\end{tabular} & 555,57 & 87,30 & 1,36 & 65,95 & 254,66 & 20,70 & 21,57 & 245,62 \\
\hline Hyla molleri & 29SNB58 & 100,00 & 167,38 & 98,91 & 42,36 & 4491,59 & 302,26 & 72,00 & 230,26 & 121,99 & 223,90 & 228,48 & 113,80 & 548,53 & 83,37 & 2,00 & 64,49 & 246,13 & 21,50 & 22,24 & 239,15 \\
\hline Hyla molleri & 29SNB59 & 100,00 & 168,86 & 99,21 & 42,32 & 4520,42 & 304,48 & 73,29 & 231,19 & 122,86 & 225,62 & 230,19 & $\begin{array}{l}114,75 \\
\end{array}$ & 547,27 & 82,53 & 2,00 & $\begin{array}{l}63,86 \\
\end{array}$ & 244,05 & 22,02 & 22,64 & 237,48 \\
\hline Hyla molleri & 29SNB69 & 101,00 & 167,56 & 102,06 & 42,17 & 4654,46 & 307,85 & 69,73 & 238,13 & 120,29 & 226,15 & 230,81 & \begin{tabular}{l|l|}
111,92 \\
\end{tabular} & 549,62 & 82,76 & 2,00 & 63,20 & 243,19 & 22,15 & 23,03 & 237,45 \\
\hline Hyla molleri & 29SNB79 & 100,00 & 166,09 & 105,06 & 42,25 & 4779,42 & 311,19 & 66,12 & 245,07 & \begin{tabular}{ll|}
117,61 \\
\end{tabular} & 226,48 & 231,18 & \begin{tabular}{l|l|}
109,12 \\
\end{tabular} & 553,21 & 83,07 & 2,00 & 62,53 & 242,47 & 22,90 & 23,34 & 237,38 \\
\hline \begin{tabular}{|l|} 
Hyla molleri \\
\end{tabular} & 29SNC06 & 92,00 & 166,43 & 85,60 & 41,05 & 4169,39 & 285,32 & $\begin{array}{l}79,35 \\
\end{array}$ & 205,97 & 122,99 & 217,60 & \begin{tabular}{|l|l|}
222,47 \\
\end{tabular} & \begin{tabular}{|l|l|}
115,64 \\
\end{tabular} & 681,47 & 101,62 & 3,41 & 63,05 & 302,61 & 28,84 & 31,25 & 293,11 \\
\hline Hyla molleri & 29SNC10 & 71,00 & 168,25 & 89,65 & 42,91 & 4045,68 & 287,78 & 80,78 & 207,00 & 127,19 & 218,07 & 222,81 & 119,20 & \begin{tabular}{|l|l|}
583,03 \\
\end{tabular} & 87,85 & 2,00 & 64,57 & 262,35 & 23,98 & 24,99 & 253,35 \\
\hline Hyla molleri & 295NC14 & 18,00 & 171,34 & 89,19 & 41,84 & 4214,47 & 293,56 & 82,31 & 211,25 & 127,59 & 223,0 & 228,06 & 119,66 & 612,06 & 91,03 & 3,00 & 63,09 & 271,59 & 26,00 & 28,00 & 263,56 \\
\hline Hyla molleri & 29SNC17 & 101,00 & 170,53 & 86,68 & 41,03 & 4232,24 & 291,12 & 82,37 & 208,75 & 126,37 & 222,68 & \begin{tabular}{|l|}
227,27 \\
\end{tabular} & \begin{tabular}{|l|l|}
118,88 \\
\end{tabular} & 648,25 & 95,83 & 3,00 & \begin{tabular}{ll|}
62,78 \\
\end{tabular} & 286,50 & 27,00 & 29,86 & 278,50 \\
\hline Hyla molleri & 29SNC18 & 101,00 & 170,36 & 85,57 & 40,95 & 4216,61 & 289,75 & 82,38 & 207,36 & 126,20 & 222,34 & 226,68 & $\begin{array}{l}118,63 \\
\end{array}$ & 654,34 & 96,99 & 3,00 & 62,89 & 288,89 & 27,13 & 30,05 & 280,95 \\
\hline Hyla molleri & $295 N C 20$ & 100,00 & 163,43 & 92,33 & 42,46 & 4224,95 & 288,91 & 73,92 & 214,99 & 120,64 & 215,90 & 220,69 & \begin{tabular}{ll|}
112,66 \\
\end{tabular} & 606,74 & 90,73 & 2,30 & 63,70 & 270,56 & 25,52 & 26,30 & 263,18 \\
\hline \begin{tabular}{|l|} 
Hyla molleri \\
\end{tabular} & 29SNC21 & 101,00 & $\begin{array}{ll}164,38 \\
\end{array}$ & 92,12 & 42,16 & 4247,06 & 290,22 & \begin{tabular}{ll|}
74,66 \\
\end{tabular} & 215,56 & 121,27 & 217,10 & \begin{tabular}{|l|l|}
221,97 \\
\end{tabular} & \begin{tabular}{l|l|}
113,42 \\
\end{tabular} & 612,68 & 91,38 & 2,49 & 63,49 & 272,22 & 25,95 & 26,81 & 265,08 \\
\hline Hyla molleri & 29SNC22 & 99,00 & 166,10 & 91,82 & 42,02 & 4275,52 & 292,11 & 76,33 & 215,78 & $\begin{array}{l}122,47 \\
\end{array}$ & 219,1 & 224,04 & \begin{tabular}{ll|l}
114,58 \\
\end{tabular} & 614,17 & 91,45 & 2,67 & 63,12 & 272,23 & 26,19 & 27,32 & 265,21 \\
\hline Hyla molleri & $295 N C 23$ & 101,00 & 168,86 & 91,32 & 42,00 & 4281,82 & 294,32 & 78,88 & 215,44 & 124,77 & 221,7 & 226,66 & \begin{tabular}{|l|l|}
116,93 \\
\end{tabular} & 608,71 & 90,47 & 2,99 & 63,12 & 269,53 & 25,78 & 27,64 & 262,48 \\
\hline Hyla molleri & 29SNC24 & 100,00 & 170,19 & 90,79 & 41,82 & 4295,90 & 295,24 & 80,06 & 215,18 & 125,66 & 223,30 & 228,07 & \begin{tabular}{|l|l|}
117,87 \\
\end{tabular} & 612,17 & 90,74 & 2,98 & 62,43 & 270,48 & 26,14 & 27,79 & 263,54 \\
\hline \begin{tabular}{|l} 
Hyla molleri \\
\end{tabular} & $295 N C 25$ & 72,00 & 171,37 & 90,26 & 41,50 & 4305,01 & 296,38 & 81,59 & 214,79 & 126,64 & 224,69 & 229,51 & \begin{tabular}{ll|}
119,16 \\
\end{tabular} & 611,59 & 90,23 & 3,00 & 62,83 & 269,90 & 25,77 & 27,76 & 263,10 \\
\hline Hyla molleri & 29SNC26 & 88,00 & 170,97 & 89,48 & 41,11 & 4314,14 & 295,55 & 81,21 & 214,34 & 126,11 & 224,43 & \begin{tabular}{|l|l|}
229,03 \\
\end{tabular} & \begin{tabular}{|l|l|}
118,54 \\
\end{tabular} & 625,67 & 92,01 & 3,00 & $\begin{array}{l}62,56 \\
\end{array}$ & 275,11 & 26,84 & 29,01 & 268,52 \\
\hline Hyla molleri & $295 N C 28$ & 101,00 & $\begin{array}{ll}169,01 \\
\end{array}$ & 87,66 & 40,97 & 4313,12 & 291,96 & 79,80 & 212,16 & 123,92 & 222,42 & \begin{tabular}{l|l|}
226,85 \\
\end{tabular} & \begin{tabular}{|l|l|}
116,38 \\
\end{tabular} & 654,50 & 96,47 & 3,00 & 62,12 & 286,12 & 28,15 & 30,59 & 279,97 \\
\hline Hyla molleri & 29SNC30 & 100,00 & 164,80 & 94,76 & 42,16 & 339,40 & 294,27 & 73,09 & 221,18 & 120,82 & 218,96 & 223,73 & \begin{tabular}{ll|}
112,79 \\
\end{tabular} & 591,55 & 88,55 & 2,06 & 63,69 & 263,40 & 24,27 & 24,90 & 256,82 \\
\hline Hyla molleri & 29SNC32 & & 164,58 & 94,37 & 41, & 4412,68 & 295,47 & 72,80 & 222,67 & 119,62 & 219,70 & 224,62 & \begin{tabular}{ll|}
111,69 \\
\end{tabular} & 614,58 & 90,98 & 2,73 & 62,64 & 270,49 & 26,43 & 27,17 & 264,92 \\
\hline \begin{tabular}{|l} 
Hyla molleri \\
\end{tabular} & $295 N C 33$ & 100,00 & 167,77 & 93,79 & 41,93 & 4408,51 & 297,79 & 76,01 & 221,78 & 122,43 & 222,68 & 227,53 & 114,64 & $\begin{array}{ll}605,45 \\
\end{array}$ & 89,46 & 2,95 & 62,79 & 266,27 & 25,92 & 26,94 & 260,68 \\
\hline Hyla molleri & $295 N C 34$ & 101,00 & 169,72 & 93,09 & 41,86 & 4404,57 & 299,00 & 78,24 & 220,76 & 124,28 & 224,49 & 229,21 & 116,51 & 603,04 & 88,72 & 2,98 & \begin{tabular}{ll|}
62,63 \\
\end{tabular} & 264,73 & 25,86 & 26,98 & 259,18 \\
\hline Hyla molleri & 29SNC35 & 101,00 & 171,03 & 92,25 & 41,48 & 4404,83 & 299,52 & 79,46 & 220,05 & 125,40 & 225,77 & 230,49 & 117,50 & 604,24 & 88,76 & 3,00 & 62,41 & 264,68 & 25,77 & 27,49 & 259, \\
\hline Hyla molleri & 29SNC37 & 101 & 169 & 90,66 & 40,99 & 4427 & 296,69 & 77,94 & $21 \varepsilon$ & 122 & 224,05 & 228,61 & \begin{tabular}{|l|l|}
115,18 \\
\end{tabular} & 636,97 & 93,47 & 3,05 & 61,64 & 276,64 & 28,14 & 30,01 & 271,91 \\
\hline Hyla molleri & 29SNC38 & 100,00 & 167,84 & 89,72 & 40,97 & 4423,35 & 294,69 & \begin{tabular}{|l|l|}
76,97 \\
\end{tabular} & 217,72 & 121,60 & 222,86 & $\begin{array}{l}227,25 \\
\end{array}$ & \begin{tabular}{|l|l|}
113,91 \\
\end{tabular} & 653,12 & 95,80 & 3,45 & 61,27 & 282,41 & 29,44 & 31,45 & 277,99 \\
\hline \begin{tabular}{|l|} 
Hyla molleri \\
\end{tabular} & 29SNC39 & 100,00 & 168,15 & 88,67 & 40,81 & 4385,91 & 293,38 & 77,73 & 215,65 & 122,21 & 222,70 & 227,00 & $\begin{array}{l}114,55 \\
145\end{array}$ & 657,82 & 96,56 & 3,71 & \begin{tabular}{ll|l}
61,08 \\
\end{tabular} & 283,95 & 29,97 & 32,20 & 279,29 \\
\hline Hyla molleri & $295 N C 40$ & 101,00 & 167,25 & 97,05 & 42,15 & 4438,80 & 300,13 & 73,75 & 226,38 & 122,15 & 222,81 & 227,46 & \begin{tabular}{|l|l|}
114,11 \\
\end{tabular} & 570,75 & 85,50 & 2,00 & 63,50 & 253,58 & 23,46 & 24,21 & 247,48 \\
\hline Hyla molleri & $295 N C 42$ & 99,00 & 16 & 96,55 & 42,00 & 183 & 302. & 75,09 & 227,07 & 122 & 224,64 & 229,38 & 114 & 580,33 & 85,94 & 2,06 & 62,96 & 255,20 & 24,26 & 25,13 & \\
\hline Hyla molleri & 29SNC43 & 101,00 & 169,53 & 95,90 & 42,00 & 4501,04 & 302,69 & 76,17 & 226,52 & 123,27 & 225,75 & 230,51 & $\begin{array}{l}115,38 \\
\end{array}$ & 585,04 & 86,01 & 2,62 & 62,24 & 255,76 & 25,29 & 26,29 & 251, \\
\hline Hyla molleri & 29 SNC44 & 101,00 & 169,99 & 95,22 & 41,79 & 4509,82 & 302,72 & 76,65 & 226,07 & 123,49 & 226,24 & 231,00 & \begin{tabular}{|l|l|}
115,48 \\
\end{tabular} & 591,50 & 86,65 & 2,87 & 61,89 & 257,60 & 25,84 & 27,04 & 253,18 \\
\hline
\end{tabular}




\begin{tabular}{|c|c|c|c|c|c|c|c|c|c|c|c|c|c|c|c|c|c|c|c|c|c|}
\hline$\overline{\text { TAXON }}$ & UTM & $\mathrm{km} 2$ & BIO1 & BIO2 & B103 & BIO4 & B105 & B106 & B107 & B108 & B109 & BIO10 & BIO11 & BIO12 & B1013 & B1014 & B1015 & B1016 & B1017 & BIO18 & BIO19 \\
\hline Hyla molleri & $295 N C 45$ & 101,00 & 169,94 & 94,46 & 41,41 & 4514,58 & 302,27 & 76,89 & 225,38 & 123,17 & 226,18 & 230,97 & 115,35 & 601,31 & 87,88 & 3,00 & 61,71 & 260,69 & 26,58 & 27,74 & 256,66 \\
\hline Hyla molleri & 295NC46 & 100,00 & $\begin{array}{r}168,48 \\
1677\end{array}$ & $\begin{array}{l}93,61 \\
2,2\end{array}$ & 41,02 & $\begin{array}{l}4534,77 \\
52,31\end{array}$ & $\begin{array}{r}300,59 \\
\end{array}$ & $\begin{array}{l}75,62 \\
75,36\end{array}$ & 224,97 & $\begin{array}{l}121,42 \\
12,6\end{array}$ & 225,07 & $\begin{array}{l}229,66 \\
20,77\end{array}$ & $\begin{array}{l}113,51 \\
11,91\end{array}$ & \begin{tabular}{|l|l|}
619,70 \\
6235
\end{tabular} & $\begin{array}{l}90,45 \\
0,2\end{array}$ & 3,03 & 61,34 & 267,23 & 27,81 & 29,05 & 263,86 \\
\hline Hyla molleri & 29SNC47 & 100,00 & 167,73 & 92,62 & 40,97 & 4524,31 & 299,07 & 75,36 & 223,71 & 120,67 & 224,19 & 228,77 & $\begin{array}{l}112,91 \\
\end{array}$ & 635,36 & $\begin{array}{l}92,66 \\
9\end{array}$ & 3,44 & 60,82 & $\begin{array}{r}272,81 \\
2719\end{array}$ & 29,39 & $\begin{array}{l}30,81 \\
2,21\end{array}$ & 269,64 \\
\hline Hyla molleri & 29SNC48 & 101,00 & 167,37 & \begin{tabular}{|l|}
91,63 \\
\end{tabular} & $\begin{array}{l}40,88 \\
\end{array}$ & $\begin{array}{l}4518,73 \\
\end{array}$ & 297,60 & $\begin{array}{l}75,26 \\
\end{array}$ & 222,34 & 120,13 & 223,69 & \begin{tabular}{|l|}
228,17 \\
\end{tabular} & \begin{tabular}{|l|l|}
112,45 \\
\end{tabular} & \begin{tabular}{|l|l|}
647,64 \\
\end{tabular} & \begin{tabular}{|l|l|}
94,44 \\
\end{tabular} & 3,90 & \begin{tabular}{ll|}
60,49 \\
\end{tabular} & 277,18 & \begin{tabular}{|l|}
30,66 \\
\end{tabular} & 32,10 & 274,15 \\
\hline Hyla molleri & 29SNC49 & 101,00 & 167,49 & 90,72 & 40,48 & 4504,72 & 296,56 & 75,55 & 221,01 & 120,28 & 223,71 & $227,97 \mid$ & $112,67 \mid$ & 655,11 & 95,53 & 3,96] & 60,30 & 279,75 & 31,13 & 32,90 & 276,80 \\
\hline Hyla molleri & 29SNC50 & 101,00 & 169,36 & 99,40 & 42,16 & 4546,86 & 305,86 & 73,78 & 232,08 & 122,96 & 226,42 & 231,14 & \begin{tabular}{|l|}
114,82 \\
\end{tabular} & 551,54 & 82,71 & 2,00 & 63,51 & 244,19 & 22,46 & 23,32 & 238,44 \\
\hline Hyla molleri & 29SNC51 & 101,00 & 169,44 & 99,28 & 42,04 & 4569,18 & 306,46 & 73,87 & 232,59 & 122,67 & 226,81 & 231,38 & \begin{tabular}{|l|}
114,65 \\
\end{tabular} & 560,00 & 83,21 & 2,00 & 62,58 & 245,94 & 23,75 & 24,40 & 240,90 \\
\hline Hyla molleri & 29SNC52 & 101,00 & 169,67 & 98,88 & 42,01 & 4587,13 & 306,68 & \begin{tabular}{l|l|}
74,25 \\
\end{tabular} & 232,43 & 122,60 & 227,16 & \begin{tabular}{|l|}
231,83 \\
\end{tabular} & \begin{tabular}{|l|l|}
114,48 \\
\end{tabular} & 566,97 & 83,56 & 2,08 & \begin{tabular}{|l|l|}
62,27 \\
\end{tabular} & 247,49 & 24,29 & 24,99 & 243,05 \\
\hline Hyla molleri & 29SNC53 & 100,00 & \begin{tabular}{|l|l|}
170,04 \\
\end{tabular} & 98,17 & 41,97 & 4596,44 & 306,70 & \begin{tabular}{|l|}
74,80 \\
\end{tabular} & 231,89 & \begin{tabular}{|l|}
122,87 \\
\end{tabular} & 227,55 & \begin{tabular}{|l|}
232,26 \\
\end{tabular} & \begin{tabular}{|l|l|}
114,58 \\
\end{tabular} & 573,44 & 83,86 & 2,58 & \begin{tabular}{|l|l|}
61,79 \\
\end{tabular} & 248,75 & 25,34 & 26,21 & 244,83 \\
\hline Hyla molleri & 295NC54 & 101,00 & \begin{tabular}{|l|}
168,58 \\
\end{tabular} & \begin{tabular}{|l|l|}
97,49 \\
\end{tabular} & 41,65 & 4619,20 & 305,30 & 73,76 & 231,54 & \begin{tabular}{|l|}
121,07 \\
\end{tabular} & 226,41 & 231,19 & \begin{tabular}{|l|}
113,01 \\
\end{tabular} & 590,22 & 85,94 & 2,99 & 61,12 & 254,27 & 26,74 & 27,45 & 251,14 \\
\hline Hyla molleri & 29SNC55 & 100,00 & 168,90 & 96,51 & 41,20 & 4621,95 & \begin{tabular}{|l|}
304,91 \\
\end{tabular} & \begin{tabular}{|l|l|}
74,40 \\
\end{tabular} & 230,51 & 121,21 & 226,82 & \begin{tabular}{|l|l|}
231,37 \\
\end{tabular} & \begin{tabular}{|l|l|}
113,07 \\
\end{tabular} & 597,31 & 86,69 & 3,00 & $\begin{array}{l}60,85 \\
\end{array}$ & 256,22 & 27,24 & 28,15 & 253,45 \\
\hline Hyla molleri & 29SNC58 & 101,00 & $\begin{array}{l}166,18 \\
\end{array}$ & \begin{tabular}{|l|}
93,38 \\
\end{tabular} & 40,73 & 4621,51 & 299,98 & 72,89 & 227,09 & 118,19 & 224,19 & 228,68 & \begin{tabular}{|l|}
110,35 \\
\end{tabular} & \begin{tabular}{|l|l|}
646,13 \\
\end{tabular} & 93,50 & 4,00 & \begin{tabular}{|l|l|}
59,70 \\
\end{tabular} & 273,34 & 31,76 & 32,74 & 271,86 \\
\hline Hyla molleri & 29SNC59 & 101,00 & 166,11 & 92,51 & 40,31 & 4606,06 & 298,89 & \begin{tabular}{ll|}
73,02 \\
\end{tabular} & 225,86 & 118,06 & 223,91 & \begin{tabular}{|l|}
228,27 \\
\end{tabular} & \begin{tabular}{|l|}
110,24 \\
\end{tabular} & 657,11 & 95,19 & 4,00 & \begin{tabular}{|l|}
59,58 \\
\end{tabular} & 277,46 & 32,31 & 33,59 & 275,99 \\
\hline Hyla molleri & 29SNC60 & 100,00 & 168,91 & 102,19 & 42,14 & 4666,86 & 309,80 & 71,14 & 238,66 & 121,42 & \begin{tabular}{|l|}
227,67 \\
\end{tabular} & 232,32 & \begin{tabular}{|l|l|}
113,08 \\
\end{tabular} & 548,16 & 81,95 & 2,00 & \begin{tabular}{|l|}
62,98 \\
\end{tabular} & 240,78 & 22,67 & 23,01 & 235,76 \\
\hline Hyla molleri & 29SNC61 & 100,00 & 169,39 & \begin{tabular}{|l|}
102,09 \\
\end{tabular} & 42,06 & 4689,62 & 310,75 & \begin{tabular}{|l|l|}
71,73 \\
\end{tabular} & 239,02 & \begin{tabular}{|l|}
121,44 \\
\end{tabular} & 228,44 & \begin{tabular}{|l|l|}
233,05 \\
\end{tabular} & 113,19 & 552,32 & 81,83 & 2,00 & 62,34 & 240,81 & 23,25 & 23,92 & 236,45 \\
\hline Hyla molleri & 29SNC62 & 101,00 & 169,70 & \begin{tabular}{|l|}
101,47 \\
\end{tabular} & 42,00 & 4702,51 & \begin{tabular}{|l|}
310,90 \\
\end{tabular} & \begin{tabular}{l|l|}
72,32 \\
\end{tabular} & 238,58 & \begin{tabular}{|l|}
121,60 \\
\end{tabular} & 228,84 & 233,60 & \begin{tabular}{|l|l|}
113,19 \\
\end{tabular} & 557,38 & 81,73 & 2,03 & \begin{tabular}{|l|l|}
61,72 \\
\end{tabular} & 241,28 & 24,33 & 24,76 & 237,62 \\
\hline Hyla molleri & 29SNC63 & 100,00 & 169,43 & 100,65 & $\begin{array}{l}41,97 \\
\end{array}$ & 4709,57 & \begin{tabular}{|l|}
310,18 \\
\end{tabular} & \begin{tabular}{l|l|}
72,45 \\
\end{tabular} & \begin{tabular}{|l|}
237,73 \\
\end{tabular} & 120,91 & 228,61 & \begin{tabular}{|l|}
233,21 \\
\end{tabular} & \begin{tabular}{|l|l|}
112,84 \\
\end{tabular} & 567,75 & 82,31 & 2,86 & \begin{tabular}{ll|}
60,67 \\
\end{tabular} & 243,66 & \begin{tabular}{|l|l|}
26,02 \\
\end{tabular} & 26,75 & 240,76 \\
\hline Hyla molleri & 295NC64 & 100,00 & 167,67 & \begin{tabular}{|c|}
99,66 \\
\end{tabular} & 41,58 & \begin{tabular}{|c|c|}
4728,05 \\
\end{tabular} & 308,14 & 71,10 & 237,04 & 118,99 & 227,06 & 231,73 & \begin{tabular}{|l|l|}
110,79 \\
\end{tabular} & 586,38 & \begin{tabular}{|l|l|}
84,68 \\
\end{tabular} & 2,98 & 60,50 & $249,87 \mid$ & 27,36 & 27,77 & 247,77 \\
\hline Hyla molleri & 29SNC65 & 101,00 & 165,21 & 98,42 & 41,09 & 4744,75 & 305,35 & \begin{tabular}{l|l}
69,42 \\
\end{tabular} & 235,94 & 116,34 & 224,94 & \begin{tabular}{|l|}
229,67 \\
\end{tabular} & \begin{tabular}{|l|}
108,29 \\
\end{tabular} & 609,86 & 87,75 & 3,01 & \begin{tabular}{ll|}
60,04 \\
\end{tabular} & 257,88 & 29,32 & 29,53 & 256,77 \\
\hline Hyla molleri & 29SNC66 & 100,00 & 163,32 & 96,95 & 40,96 & 4748,38 & 302,52 & 68,20 & 234,32 & 113,71 & 223,07 & \begin{tabular}{|l|}
227,75 \\
\end{tabular} & \begin{tabular}{|l|}
106,26 \\
\end{tabular} & 633,58 & 90,95 & 3,66 & 59,27 & 266,10 & \begin{tabular}{|l|}
31,68 \\
\end{tabular} & 31,91 & 265,71 \\
\hline Hyla molleri & 29SNC68 & 101,00 & 163,25 & 94,70 & 40,31 & 4730,67 & 300,30 & $\begin{array}{l}68,96 \\
\end{array}$ & 231,34 & 111,72 & 222,91 & \begin{tabular}{|l|l|}
227,37 \\
\end{tabular} & \begin{tabular}{|l|l|}
106,33 \\
\end{tabular} & 657,62 & 94,41 & 4,00 & 58,85 & 274,96 & 33,71 & 34,14 & 274,80 \\
\hline Hyla molleri & 29SNC70 & 101,00 & 166,79 & 105,49 & 42,09 & 4809,92 & 312,99 & \begin{tabular}{|l|l|}
66,70 \\
\end{tabular} & 246,29 & \begin{tabular}{|l|}
117,83 \\
\end{tabular} & \begin{tabular}{|l|}
227,47 \\
\end{tabular} & \begin{tabular}{|l|l|}
232,23 \\
\end{tabular} & \begin{tabular}{|l|}
109,28 \\
\end{tabular} & \begin{tabular}{|l|l|}
554,83 \\
\end{tabular} & 82,57 & 2,00 & \begin{tabular}{|l|l|}
61,93 \\
\end{tabular} & 241,11 & 23,42 & 23,73 & 236,96 \\
\hline Hyla molleri & 29SNC71 & 100,00 & 167,97 & \begin{tabular}{|l|l|}
105,13 \\
\end{tabular} & 42,01 & 4818,71 & 314,16 & 68,10 & 246,06 & \begin{tabular}{|l|}
118,71 \\
\end{tabular} & 228,77 & 233,40 & \begin{tabular}{|l|}
110,28 \\
\end{tabular} & 553,44 & \begin{tabular}{l|l|}
81,62 \\
\end{tabular} & 2,00 & \begin{tabular}{|l|l|}
61,39 \\
\end{tabular} & 238,80 & 23,73 & \begin{tabular}{|l|l|}
24,02 \\
\end{tabular} & 235,39 \\
\hline Hyla molleri & 29SNC72 & 101,00 & 168,99 & 104,16 & 42,00 & 4819,09 & 314,36 & 69,59 & 244,77 & 119,59 & 229,74 & \begin{tabular}{|l|l|}
234,33 \\
\end{tabular} & \begin{tabular}{|l|l|}
111,15 \\
\end{tabular} & 554,55 & 80,84 & 2,28 & \begin{tabular}{|l|l|}
61,04 \\
6
\end{tabular} & 237,65 & \begin{tabular}{|l|l|}
24,72 \\
\end{tabular} & \begin{tabular}{l|l|}
25,06 \\
\end{tabular} & 234,67 \\
\hline Hyla molleri & $295 N C 73$ & 101,00 & 167,30 & 103,29 & 41,94 & 4840,16 & 312,68 & 68,40 & 244,28 & 117,58 & 228,25 & \begin{tabular}{|l|}
233,07 \\
\end{tabular} & \begin{tabular}{|l|}
109,32 \\
\end{tabular} & 571,18 & 81,99 & 3,00 & \begin{tabular}{|l|}
59,96 \\
\end{tabular} & 242,07 & 27,26 & 27,38 & 240,14 \\
\hline Hyla molleri & $295 N C 74$ & 101,00 & 164,58 & 101,83 & 41,31 & 4855,15 & 309,36 & 66,51 & 242,84 & 114,73 & 226,27 & 230,53 & \begin{tabular}{|l|l|}
106,55 \\
\end{tabular} & 594,93 & 84,98 & 3,00 & 59,55 & 250,03 & 28,86 & 28,86 & 249,31 \\
\hline Hyla molleri & 29SNC75 & 100,00 & 164,53 & 100,09 & 41,03 & 4838,18 & 307,66 & \begin{tabular}{|l|}
67,28 \\
\end{tabular} & 240,38 & 114,29 & 226,21 & \begin{tabular}{|l|}
230,19 \\
\end{tabular} & \begin{tabular}{|l|}
106,54 \\
\end{tabular} & $\begin{array}{l}604,28 \\
\end{array}$ & 86,00 & 3,00 & \begin{tabular}{|l|l|}
59,13 \\
\end{tabular} & 252,46 & 30,18 & \begin{tabular}{|l|}
30,18 \\
\end{tabular} & 252,28 \\
\hline Hyla molleri & 29SNC76 & 101,00 & 160,29 & 98,06 & 40,77 & 4851,99 & 302,55 & \begin{tabular}{|l|l|}
64,27 \\
\end{tabular} & 238,27 & 104,42 & 223,43 & \begin{tabular}{|l|}
226,39 \\
\end{tabular} & \begin{tabular}{|l|}
102,36 \\
1
\end{tabular} & 641,73 & 91,18 & 3,81 & \begin{tabular}{l|l|}
58,25 \\
\end{tabular} & 266,81 & 33,29 & 33,29 & 266,81 \\
\hline Hyla molleri & $295 N C 77$ & 101,00 & 158,54 & \begin{tabular}{|c|}
96,49 \\
\end{tabular} & 40,18 & 4855,58 & 299,73 & \begin{tabular}{|l|}
63,38 \\
\end{tabular} & 236,35 & \begin{tabular}{|c|}
100,76 \\
\end{tabular} & 222,23 & 224,66 & \begin{tabular}{|l|l|}
100,60 \\
\end{tabular} & 666,05 & \begin{tabular}{|c|}
94,64 \\
\end{tabular} & \begin{tabular}{|l|l|}
4,08 \\
\end{tabular} & $\begin{array}{ll}57,82 \\
\end{array}$ & 276,19 & 35,39 & 35,39 & 276,19 \\
\hline Hyla molleri & 295NC78 & \begin{tabular}{|l|l}
99,00 \\
\end{tabular} & 160,21 & \begin{tabular}{|l|l|}
95,62 \\
\end{tabular} & 40,11 & \begin{tabular}{|l|l|l|}
4836,39 \\
\end{tabular} & 300,15 & 65,21 & 234,94 & $\mid 102,41$ & 222,25 & 225,85 & $\mid 102,35$ & \begin{tabular}{|l|l|l|}
669,04 \\
\end{tabular} & \begin{tabular}{|l|l|}
95,14 \\
\end{tabular} & \begin{tabular}{|l|l|}
4,02 \\
\end{tabular} & 57,86 & 277,31 & $\mid 35,75$ & $\mid 35,75$ & 277,31 \\
\hline Hyla molleri & 29SNC79 & 101,00 & 163,50 & 95,29 & 40,00 & 4822,36 & 302,59 & \begin{tabular}{ll|}
68,15 \\
\end{tabular} & 234,43 & $\begin{array}{l}106,34 \\
\end{array}$ & 224,34 & \begin{tabular}{|l|}
228,70 \\
\end{tabular} & \begin{tabular}{|l|}
105,38 \\
\end{tabular} & 659,75 & \begin{tabular}{|l|l|}
93,87 \\
\end{tabular} & 4,00 & \begin{tabular}{|l|l|}
57,83 \\
\end{tabular} & 273,29 & 35,38 & 35,75 & 273,29 \\
\hline Hyla molleri & 29SNC81 & \begin{tabular}{|l|}
101,00 \\
\end{tabular} & 165,59 & $\begin{array}{l}108,62 \\
\end{array}$ & 42,09 & 4964,21 & 317,28 & 63,29 & 253,99 & \begin{tabular}{|l|}
114,89 \\
\end{tabular} & 228,42 & \begin{tabular}{|l|}
233,08 \\
\end{tabular} & \begin{tabular}{|l|}
106,27 \\
\end{tabular} & 561,88 & 82,25 & 2,18 & $\begin{array}{l}60,46 \\
6\end{array}$ & 239,21 & 25,24 & 25,36 & 236,65 \\
\hline Hyla molleri & $295 N C 82$ & 99,00 & 167,03 & 107,19 & 42,01 & 4950,75 & \begin{tabular}{|l|l|}
317,14 \\
\end{tabular} & 65,50 & 251,64 & 116,11 & 229,61 & 234,29 & \begin{tabular}{|l|l|}
107,79 \\
\end{tabular} & 559,42 & 80,96 & 2,64 & \begin{tabular}{ll|}
60,02 \\
\end{tabular} & 236,69 & 26,40 & 26,50 & 234,41 \\
\hline Hyla molleri & $295 N C 84$ & 101,00 & 163,50 & 103,66 & 41,22 & 4958,27 & 311,40 & 63,87 & 247,52 & 112,01 & \begin{tabular}{|l|}
227,62 \\
\end{tabular} & 230,76 & \begin{tabular}{|l|}
104,36 \\
\end{tabular} & 593,24 & 83,70 & 3,01 & 58,59 & 246,40 & 29,81 & 29,81 & 246,24 \\
\hline Hyla molleri & 29SNC86 & 100,00 & 161,19 & $\begin{array}{l}99,26 \\
\end{array}$ & 40,70 & 4930,57 & 305,38 & \begin{tabular}{|l|l|}
63,90 \\
\end{tabular} & 241,49 & 102,56 & 226,06 & \begin{tabular}{|l|}
228,18 \\
\end{tabular} & \begin{tabular}{|l|l|}
102,29 \\
\end{tabular} & 624,39 & 87,51 & 3,77 & 57,59 & 257,09 & 33,38 & 33,38 & 257,09 \\
\hline Hyla molleri & 29SNC87 & 100,00 & $\begin{array}{l}157,48 \\
\end{array}$ & 97,19 & 40,03 & 4938,52 & 300,59 & \begin{tabular}{ll|}
61,44 \\
\end{tabular} & 239,15 & \begin{tabular}{|l|l|}
98,67 \\
\end{tabular} & 223,75 & \begin{tabular}{|l|l|}
224,75 \\
2
\end{tabular} & \begin{tabular}{|l|}
98,67 \\
\end{tabular} & 661,51 & \begin{tabular}{|c|}
92,89 \\
\end{tabular} & $\begin{array}{l}4,07 \\
\end{array}$ & \begin{tabular}{|l|l|}
57,07 \\
\end{tabular} & \begin{tabular}{|l|}
271,88 \\
\end{tabular} & 36,14 & 36,14 & 271,88 \\
\hline Hyla molleri & 29SNC88 & \begin{tabular}{|l|}
101,00 \\
\end{tabular} & $\begin{array}{l}158,80 \\
\end{array}$ & 96,51 & 39,99 & 4931,32 & 301,25 & \begin{tabular}{|l|l|}
62,78 \\
\end{tabular} & 238,47 & 100,02 & 224,18 & \begin{tabular}{|l|}
225,94 \\
\end{tabular} & \begin{tabular}{l|l|}
100,02 \\
\end{tabular} & \begin{tabular}{|l|l|}
667,61 \\
\end{tabular} & \begin{tabular}{|l|l|}
93,90 \\
\end{tabular} & 4,19 & 56,95 & 274,30 & 36,84 & 36,84 & 274,30 \\
\hline Hyla molleri & 295NC91 & 100,00 & 164,76 & 111,73 & 42,12 & 5095,89 & 321,09 & 60,14 & 260,95 & 112,42 & 229,47 & 233,99 & 103,97 & 560,86 & 81,73 & 2, & 59,7 & 236,43 & 26,09 & 26,09 & 234,05 \\
\hline Hyla molleri & $295 N C 96$ & 100,00 & 161,72 & 100,41 & 40,40 & 5014,36 & 307,90 & 63,07 & 244,83 & 101,64 & 227,53 & \begin{tabular}{|l|}
229,77 \\
\end{tabular} & \begin{tabular}{|l|}
101,64 \\
\end{tabular} & 610,86 & 84,42 & 3,90 & 56,55 & 248,98 & 33,86 & 33,86 & 248,98 \\
\hline Hyla molleri & 29SNC97 & 101,00 & 160,32 & \begin{tabular}{|l|l|}
98,67 \\
\end{tabular} & 40,00 & 5013,92 & $\begin{array}{l}305,33 \\
\end{array}$ & \begin{tabular}{|l|l|}
62,47 \\
\end{tabular} & 242,87 & 100,35 & 227,13 & \begin{tabular}{|l|}
228,47 \\
\end{tabular} & \begin{tabular}{|l|}
100,35 \\
\end{tabular} & 630,48 & 87,14 & 4,00 & 56,21 & 256,55 & 35,39 & 35,39 & 256,55 \\
\hline Hyla molleri & 29SNC98 & 101,00 & 160,41 & 97,95 & 40,00 & 5019,94 & 305,06 & \begin{tabular}{ll|}
62,60 \\
\end{tabular} & 242,46 & 100,33 & 226,64 & \begin{tabular}{|l|}
228,62 \\
\end{tabular} & \begin{tabular}{|l|}
100,33 \\
\end{tabular} & 646,31 & 89,76 & 4,01 & $\begin{array}{ll}56,42 \\
\end{array}$ & 263,36 & 36,37 & 36,37 & 263,36 \\
\hline Hyla molleri & 29SNC99 & 100,00 & \begin{tabular}{|l|}
162,60 \\
\end{tabular} & $\begin{array}{l}97,82 \\
\end{array}$ & 39,99 & 5028,22 & 307,13 & \begin{tabular}{ll|}
64,41 \\
\end{tabular} & 242,72 & 102,16 & 226,96 & \begin{tabular}{|l|}
230,84 \\
\end{tabular} & \begin{tabular}{l|l|}
102,16 \\
1
\end{tabular} & \begin{tabular}{ll|}
649,82 \\
\end{tabular} & 90,50 & 4,00 & \begin{tabular}{|l|l|}
56,37 \\
\end{tabular} & 264,99 & 36,64 & 36,65 & 264,99 \\
\hline Hyla molleri & 29SND00 & 86,00 & 168,99 & 80,29 & 40,89 & 3998,73 & 279,15 & 84,05 & 195,10 & 126,88 & $217,88 \mid$ & 221,80 & 119,13 & 669,94 & 101,14 & 3,00 & 62,94 & 296,62 & 27,01 & 30,94 & 286,32 \\
\hline Hyla molleri & 29SND01 & 100,00 & 167,07 & 78,62 & 40,80 & 3916,19 & 274,05 & 83,15 & \begin{tabular}{|l|l|}
190,90 \\
\end{tabular} & 125,68 & 214,87 & 218,61 & 118,06 & \begin{tabular}{|l|}
673,62 \\
\end{tabular} & 102,52 & 3,04 & 62,79 & 298,01 & \begin{tabular}{|l|l|}
27,32 \\
\end{tabular} & \begin{tabular}{|l|l|}
31,21 \\
\end{tabular} & 286,83 \\
\hline Hyla molleri & 29SND08 & 101,00 & 154,16 & 73,18 & 41,81 & 3476,62 & 247,18 & 74,14 & 173,04 & 117,32 & 195,93 & \begin{tabular}{|l|}
198,56 \\
\end{tabular} & \begin{tabular}{|l|}
109,29 \\
\end{tabular} & 778,49 & 117,54 & 5,62 & 58,76 & 330,55 & 39,95 & 45,65 & 319,44 \\
\hline Hyla molleri & 29SND09 & 101,00 & 152,42 & 73,80 & 42,05 & 3457,76 & 245,39 & \begin{tabular}{l|l|}
72,05 \\
\end{tabular} & 173,34 & 1115,68 & \begin{tabular}{|l|l|}
193,97 \\
\end{tabular} & \begin{tabular}{|l|l|}
196,45 \\
\end{tabular} & \begin{tabular}{|l|}
107,71 \\
\end{tabular} & 810,14 & 120,76 & 6,13 & 57,97 & \begin{tabular}{|l|}
341,25 \\
\end{tabular} & 43,40 & 49,26 & 330,91 \\
\hline Hyla molleri & 29SND10 & 101,00 & 169,07 & 82,95 & 40,83 & 4115,42 & 283,87 & \begin{tabular}{l|l|}
82,42 \\
\end{tabular} & 201,45 & 125,60 & 219,60 & \begin{tabular}{|l|}
223,64 \\
\end{tabular} & \begin{tabular}{|l|}
118,22 \\
\end{tabular} & 664,85 & $\begin{array}{l}99,11 \\
\end{array}$ & 3,00 & 62,31 & 292,12 & 27,81 & \begin{tabular}{|l|l|}
31,06 \\
\end{tabular} & 283,75 \\
\hline Hyla molleri & 29SND11 & 101,00 & 168,36 & 81,61 & 40,94 & 4048,53 & 280,49 & 82,40 & 198,09 & \begin{tabular}{|l|}
125,47 \\
\end{tabular} & \begin{tabular}{|l|}
217,97 \\
\end{tabular} & \begin{tabular}{|l|l|}
221,82 \\
\end{tabular} & \begin{tabular}{|l|l|}
118,03 \\
\end{tabular} & $\begin{array}{l}666,83 \\
\end{array}$ & 99,99 & 3,01 & \begin{tabular}{|l|l|}
62,14 \\
\end{tabular} & 292,33 & 28,04 & $\begin{array}{l}31,66 \\
\end{array}$ & 283,46 \\
\hline Hyla molleri & 29SND12 & \begin{tabular}{|l|l}
101,00 \\
\end{tabular} & 166,69 & \begin{tabular}{|l|l|}
80,13 \\
\end{tabular} & 40,82 & 3974,29 & 276,01 & 81,52 & \begin{tabular}{|l|l|}
194,50 \\
\end{tabular} & \begin{tabular}{|l|l|}
124,59 \\
\end{tabular} & 215,32 & 218,92 & $\mid 117,01$ & $\mid 675,43$ & \begin{tabular}{|l|l|}
101,78 \\
\end{tabular} & 3,45 & 61,80 & 295,13 & 29,08 & 32,92 & 285,80 \\
\hline Hyla molleri & 29SND18 & & & 77,86 & 41, & 375 & \begin{tabular}{|l|}
253,42 \\
\end{tabular} & $\begin{array}{l}66,79 \\
\end{array}$ & \begin{tabular}{|l|}
186,64 \\
\end{tabular} & 110,63 & 196,26 & \begin{tabular}{|l|l|}
199,05 \\
\end{tabular} & \begin{tabular}{|l|l|}
102,79 \\
\end{tabular} & 842,71 & 124,44 & 6,59 & \begin{tabular}{|l|l|}
57,92 \\
\end{tabular} & \begin{tabular}{|l|}
354,03 \\
\end{tabular} & 45,62 & $\begin{array}{l}49,85 \\
\end{array}$ & 346,48 \\
\hline Hyla molleri & $295 N D 20$ & 100,00 & 168,46 & 85,41 & 40,66 & 4240,96 & 287,78 & \begin{tabular}{|l|}
79,95 \\
\end{tabular} & 207,83 & 123,80 & 220,89 & \begin{tabular}{|l|}
224,97 \\
\end{tabular} & \begin{tabular}{|l|}
116,20 \\
\end{tabular} & 665,77 & 98,32 & 3,52 & 61,55 & 289,62 & 29,26 & 32,28 & 283,13 \\
\hline Hyla molleri & 29SND21 & 101,00 & 168,28 & 84,36 & 40,69 & 4184,02 & 285,37 & 80,20 & 205,17 & 124,08 & 219,84 & 223,76 & \begin{tabular}{|l|l|}
116,43 \\
\end{tabular} & 668,57 & 98,90 & 3,69 & $\begin{array}{l}61,35 \\
\end{array}$ & 290,17 & 29,67 & 32,85 & 283,33 \\
\hline Hyla molleri & 29SND22 & 100,00 & 167,60 & 83,33 & 40,74 & 4124,58 & 282,55 & 80,19 & 202,35 & 123,82 & 218,37 & 222,03 & \begin{tabular}{|l|}
116,25 \\
\end{tabular} & 674,42 & 99,93 & 3,5 & 61, & 291,85 & 30,32 & 33,83 & 284 \\
\hline Hyla molleri & 29SND25 & 101 & 161 & 81,61 & 40, & 3997,80 & 272,25 & \begin{tabular}{|l|}
74,87 \\
\end{tabular} & \begin{tabular}{|l|}
197,38 \\
\end{tabular} & 118,84 & 210,46 & \begin{tabular}{|l|l|}
213,58 \\
\end{tabular} & \begin{tabular}{|l|l|}
111,06 \\
\end{tabular} & 735,20 & \begin{tabular}{|c|}
108,67 \\
\end{tabular} & 4,19 & \begin{tabular}{|l|l|}
59,47 \\
\end{tabular} & 313,26 & 36,15 & 39,89 & 306,39 \\
\hline Hyla molleri & 29SND30 & 101,00 & 168,25 & 87,76 & 40,79 & 4347,72 & 291,76 & $\begin{array}{l}78,26 \\
\end{array}$ & 213,50 & 122,54 & 222,27 & \begin{tabular}{|l|l|}
226,40 \\
\end{tabular} & \begin{tabular}{|l|l|}
114,98 \\
\end{tabular} & 663,01 & $\begin{array}{l}97,42 \\
\end{array}$ & 3,95 & $\begin{array}{l}60,75 \\
\end{array}$ & 285,61 & 30,54 & 32,95 & 280,85 \\
\hline Hyla molleri & 29SND31 & 100,00 & \begin{tabular}{|l|}
167,67 \\
\end{tabular} & 86,84 & 40,60 & 4312,47 & 289,58 & 78,11 & 211,47 & 122,13 & 221,16 & \begin{tabular}{|l|}
225,22 \\
\end{tabular} & \begin{tabular}{|l|}
114,66 \\
\end{tabular} & 672,53 & $\begin{array}{l}98,92 \\
\end{array}$ & 3,92 & $\begin{array}{ll}60,59 \\
\end{array}$ & \begin{tabular}{|l|}
289,03 \\
\end{tabular} & 31,02 & 33,73 & 284,16 \\
\hline Hyla molleri & 29SND32 & 101,00 & 166,77 & 86,02 & 40,55 & 4269,76 & 287,08 & 77,51 & 209,56 & 121,58 & 219,75 & \begin{tabular}{|l|}
223,47 \\
\end{tabular} & \begin{tabular}{|l|l|}
114,09 \\
\end{tabular} & 684,15 & 100,70 & 4,00 & $\begin{array}{ll}60,36 \\
\end{array}$ & 293,18 & 31,87 & 34,80 & 288,13 \\
\hline Hyla molleri & $29 \mathrm{SND}$ & 101,00 & 16 & & 40,6 & 228,3 & 284,64 & 76, & 207,89 & 120,97 & 218,22 & 221,79 & 113, & 697,75 & $\mid 102,69$ & 4,10 & 59, & 297,75 & 33,50 & 36,59 & 29 \\
\hline Hyla molleri & 29SND34 & 100,00 & 166,83 & 85,17 & 40,92 & 4174,14 & 283,97 & 77,71 & 206,26 & 122,48 & 218,47 & \begin{tabular}{|l|}
221,85 \\
\end{tabular} & \begin{tabular}{|l|}
114,71 \\
\end{tabular} & 695,73 & 102,21 & \begin{tabular}{l|l|}
4,03 \\
\end{tabular} & \begin{tabular}{l|l|}
59,65 \\
\end{tabular} & 296,03 & 33,76 & 37,29 & 290,63 \\
\hline Hyla molleri & 29SND35 & 101,00 & 166,06 & 85,14 & 40,97 & 4148,63 & 282,49 & 76,77 & 205,72 & 121,66 & 217,32 & 220,53 & \begin{tabular}{|l|l|}
113,93 \\
\end{tabular} & 709,63 & 104,27 & 4,45 & \begin{tabular}{|l|}
59,05 \\
\end{tabular} & 300,66 & 35,14 & 38,83 & 295,42 \\
\hline
\end{tabular}




\begin{tabular}{|c|c|c|c|c|c|c|c|c|c|c|c|c|c|c|c|c|c|c|c|c|c|}
\hline$\overline{\text { TAXON }}$ & UTM & $\mathrm{km} 2$ & BIO1 & BIO2 & B103 & 8104 & B105 & B106 & B107 & B108 & B109 & BIO10 & BIO11 & BIO12 & B1013 & B1014 & B1015 & B1016 & B1017 & BIO18 & 81019 \\
\hline Hyla molleri & 29SND36 & 101,00 & 163,01 & 85,30 & 40,99 & 4139,85 & 279,47 & 73,62 & 205,86 & 118,69 & 214,20 & 217,29 & 110,95 & 745,59 & 109,38 & 5,01 & 58,52 & 313,82 & 38,47 & 41,99 & 309,20 \\
\hline Hyla molleri & 29SND40 & 100,00 & 168,20 & 89,94 & 40,42 & 4473,58 & 295,80 & 76,41 & 219,39 & 121,14 & 223,95 & 228,03 & 113,50 & 657,81 & 96,03 & 4,00 & 60,04 & 280,67 & 31,31 & 33,32 & 277,32 \\
\hline Hyla molleri & 29SND41 & 101,00 & 168,65 & 89,19 & 40,51 & 4432,78 & 294,78 & 77,14 & 217,64 & 121,91 & 223,91 & 227,95 & 114,21 & \begin{tabular}{ll|}
662,52 \\
\end{tabular} & 96,85 & 4,00 & \begin{tabular}{ll|}
60,02 \\
\end{tabular} & 282,14 & 31,64 & 34,01 & 278,72 \\
\hline Hyla molleri & 29SND42 & 101,00 & 165,60 & 88,53 & 40,27 & 4423,03 & 291,14 & 74,42 & 216,71 & 118,99 & 220,79 & 224,66 & \begin{tabular}{|l|l|}
111,24 \\
\end{tabular} & 694,78 & 101,68 & 4,13 & $\begin{array}{l}59,47 \\
\end{array}$ & 294,52 & 33,99 & 36,29 & 291,45 \\
\hline Hyla molleri & 29SND43 & 101,00 & 165,55 & 88,08 & 40,38 & 4386,48 & 289,87 & 74,40 & 215,47 & 119,04 & 220,25 & 223,94 & 111,32 & 704,16 & 103,05 & 4,47 . & 59,20 & 297,69 & 35,20 & 37,73 & 294,37 \\
\hline Hyla molleri & 29SND44 & 100,00 & 163,98 & 87,84 & 40,42 & 4365,45 & 287,47 & 72,59 & 214,88 & 117,42 & 218,27 & 221,88 & $\begin{array}{l}109,75 \\
\end{array}$ & 727,36 & 106,51 & 4,88 & 58,87 & 306,26 & 37,05 & 39,69 & 303,29 \\
\hline Hyla molleri & 29SND45 & 101,00 & 165,76 & 88,03 & 40,78 & 4321,19 & 288,15 & 74,32 & 213,82 & 119,42 & 219,42 & 222,85 & \begin{tabular}{|l|l|}
111,97 \\
\end{tabular} & 723,74 & 105,79 & 4,87 & 58,48 & 304,00 & 37,37 & 40,32 & 300,70 \\
\hline Hyla molleri & 29SND46 & 101,00 & 166,58 & 88,53 & 40,98 & 4293,35 & 288,52 & $\begin{array}{l}74,46 \\
\end{array}$ & 214,05 & 120,34 & 219,92 & 223,14 & \begin{tabular}{|l|}
112,81 \\
\end{tabular} & 727,41 & 106,05 & 5,03 & 58,10 & 304,27 & 38,17 & 41,38 & 301,09 \\
\hline Hyla molleri & 29SND47 & 101,00 & 163,11 & 89,05 & 40,96 & 4309,41 & 285,90 & 70,68 & 215,21 & 116,77 & 216,77 & 219,84 & $\begin{array}{l}109,16 \\
\end{array}$ & 770,68 & 112,25 & 5,77 & 57,55 & 320,32 & 42,06 & 45,06 & 318,06 \\
\hline Hyla molleri & 29SND50 & 101,00 & 167,79 & 91,83 & 40,21 & $\begin{array}{lll}4577,92 \\
\end{array}$ & 299,08 & 74,61 & 224,47 & 119,69 & 225,07 & \begin{tabular}{l|l|}
229,25 \\
\end{tabular} & \begin{tabular}{|l|l|}
111,94 \\
\end{tabular} & 656,23 & 95,12 & 4,00 & 59,42 & 277,02 & 32,25 & 33,94 & 275,19 \\
\hline Hyla molleri & 29SND51 & 100,00 & 168,79 & 91,31 & 40,28 & 4550,32 & 298,81 & 75,55 & 223,27 & 120,76 & 225,68 & 229,68 & 112,94 & 660,12 & 95,85 & 4,00 & 59,32 & 278,45 & 32,50 & 34,38 & 276,43 \\
\hline Hyla molleri & 29SND52 & 101,00 & 165,51 & 90,66 & 40,03 & 4560,99 & 295,47 & 72,48 & 222,99 & 117,32 & 222,66 & 226,66 & \begin{tabular}{|l|l|}
109,70 \\
\end{tabular} & 695,99 & 101,16 & 4,66 & 58,88 & 292,10 & 35,66 & 37,49 & 290,59 \\
\hline Hyla molleri & 29SND53 & 100,00 & 164,97 & 90,36 & 40,04 & 4544,14 & 294,20 & 71,92 & 222,29 & 116,87 & 221,92 & 225,62 & 109,24 & 712,40 & 103,62 & 4,94 & 58,43 & 298,19 & 37,14 & 39,10 & 296,69 \\
\hline Hyla molleri & 29SND54 & 100,00 & 163,62 & 90,20 & 40,02 & 4533,12 & 292,51 & $\begin{array}{l}70,56 \\
\end{array}$ & 221,95 & 115,70 & 220,47 & 224,08 & \begin{tabular}{l|l|l|}
107,92 \\
\end{tabular} & 735,01 & 107,10 & 5,02 & 58,32 & 306,96 & 38,58 & 40,59 & 305,63 \\
\hline Hyla molleri & 29SND55 & 100,00 & 162,59 & 90,29 & 40,09 & 4516,73 & 291,27 & 69,36 & 221,91 & \begin{tabular}{ll|}
114,68 \\
\end{tabular} & 219,35 & 222,82 & $\begin{array}{l}107,06 \\
\end{array}$ & 757,73 & 110,34 & 5,54 & 57,69 & 315,09 & 41,03 & 43,10 & 314,16 \\
\hline Hyla molleri & 29SND56 & 100,00 & 164,14 & $\begin{array}{l}0,99 \\
\end{array}$ & 40,28 & 4499,20 & 292,42 & \begin{tabular}{ll|}
70,03 \\
\end{tabular} & 222,39 & 115,91 & 220,46 & 223,79 & \begin{tabular}{|l|}
108,37 \\
\end{tabular} & 758,66 & 110,26 & 5,55 & 57,46 & 314,56 & 41,55 & 43,99 & 313,51 \\
\hline Hyla molleri & 29SND60 & 100,00 & 167,56 & 93,60 & 40,16 & 4693,55 & 302,33 & 73,11 & 229,22 & 118,44 & 226,51 & 230,75 & 110,51 & 652,08 & 93,74 & 4,00 & 58,75 & 272,51 & 33,19 & 34,41 & 271,85 \\
\hline Hyla molleri & 29SND61 & 100,00 & 168,42 & 93,18 & 40,17 & 4677,65 & 302,26 & 73,77 & 228,49 & 119,18 & 227,10 & 231,18 & $\begin{array}{ll}111,43 \\
\end{array}$ & 659,02 & 94,87 & 4,00 & 58,62 & 275,31 & 33,64 & 35,16 & 274,36 \\
\hline Hyla molleri & 29SND62 & 100,00 & 166,34 & 92,62 & 40,02 & 4682,53 & 300,06 & 71,66 & 228,40 & 116,55 & 225,23 & 229,08 & 109,13 & 689,45 & $\begin{array}{l}99,47 \\
\end{array}$ & 4,62 & 58,18 & 287,12 & 36,23 & 37,75 & 286,52 \\
\hline Hyla molleri & 29SND63 & 101,00 & 164,31 & 92,28 & 39,99 & 4680,84 & 298,07 & 69,76 & 228,31 & 114,41 & 223,45 & 227,20 & \begin{tabular}{ll|}
107,21 \\
\end{tabular} & 718,88 & 103,97 & 5,00 & \begin{tabular}{l|l|}
57,95 \\
\end{tabular} & 298,56 & 38,39 & 39,92 & 298,32 \\
\hline Hyla molleri & 29SND64 & 100,00 & 163,53 & 92,14 & 39,99 & 4671,31 & 296,93 & $\begin{array}{l}68,86 \\
\end{array}$ & 228,06 & 112,76 & 222,46 & 226,16 & 106,44 & 739,71 & 107,19 & 5,24 & 57,64 & 306,74 & 40,06 & 41,67 & 306,59 \\
\hline \begin{tabular}{|l|} 
Hyla molleri \\
\end{tabular} & 29SND65 & 101,00 & 162,54 & 92,21 & 39,99 & 4676,03 & 296,03 & 67,49 & 228,53 & 110,27 & 221,56 & 225,14 & $\begin{array}{l}105,29 \\
\end{array}$ & \begin{tabular}{ll|}
763,63 \\
\end{tabular} & 110,71 & 5,94 & 57,23 & 315,68 & 42,68 & 44,36 & 315,62 \\
\hline Hyla molleri & 29SND67 & 100,00 & 162,12 & 93,45 & 40,02 & 4683,37 & 296,33 & 65,63 & 230,70 & 106,61 & 221,41 & 224,52 & 104,51 & 799,38 & 115,80 & 6,27 & 56,69 & 329,00 & 45,86 & \begin{tabular}{ll|}
47,63 \\
\end{tabular} & 328,94 \\
\hline Hyla molleri & 29SND69 & 100,00 & 156,26 & 94,39 & 39,99 & 4724,42 & 292,26 & 58,78 & 233,49 & 98,11 & 216,29 & 219,20 & 98,11 & $888,65[$ & 129,02 & 7,71 . & 55,92 & 364,47 & 53,76 & 54,91. & 364,47 \\
\hline Hyla molleri & 29SND70 & 101,00 & 166,85 & 95,14 & 40,07 & 4804,47 & 305,03 & $\begin{array}{l}70,95 \\
\end{array}$ & 234,08 & 113,76 & 227,38 & 231,65 & \begin{tabular}{|l|l|}
108,60 \\
\end{tabular} & 651,19 & 92,75 & 4,00 & 57,94 & 269,61 & 34,63 & 35,48 & 269,59 \\
\hline Hyla molleri & 29SND71 & 100,00 & 168,11 & 94,80 & 40,01 & 4798,65 & 305,51 & 71,85 & 233,66 & 116,48 & 228,52 & 232,59 & \begin{tabular}{ll|}
109,66 \\
\end{tabular} & 657,29 & 93,77 & 4,01 & 57,93 & 271,99 & 34,92 & 36,13 & 271,84 \\
\hline Hyla molleri & 29SND72 & 101,00 & 167,56 & 94,45 & 40,00 & 4800,62 & 304,86 & 71,40 & 233,45 & 115,69 & 228,11 & \begin{tabular}{|l|}
232,07 \\
\end{tabular} & $\begin{array}{l}109,13 \\
\end{array}$ & 676,64 & 96,79 & 4,45 & 57,64 & 279,63 & 36,56 & 37,84 & 279,55 \\
\hline Hyla molleri & 29SND73 & 101,00 & 166,31 & 94,13 & 39,99 & 4803,72 & 303,41 & 70,01 & 233,40 & 113,13 & 226,98 & 230,79 & $\begin{array}{l}107,78 \\
\end{array}$ & $\begin{array}{ll}701,93 \\
\end{array}$ & 100,70 & 4,97 & 57,44 & 289,84 & 38,35 & 39,74 & 289,81 \\
\hline Hyla molleri & 29SND74 & 101,00 & 163,90 & 93,73 & 39,83 & 4823,81 & 301,46 & 67,69 & 233,77 & 106,79 & 225,15 & $\begin{array}{l}228,75 \\
\end{array}$ & $\begin{array}{l}105,49 \\
\end{array}$ & 737,46 & 106,23 & 5,32 & 57,22 & 304,37 & 41,04 & 42,31 & 304,37 \\
\hline Hyla molleri & 29SND75 & 100,00 & 164,11 & 93,99 & 39,71 & $\begin{array}{lll}4828,13 \\
\end{array}$ & 301,70 & \begin{tabular}{|l|l|}
67,27 \\
\end{tabular} & 234,44 & 106,90 & 225,40 & 228,76 & 105,26 & 751,74 & 108,35 & 5,77 & 56,91 & 309,75 & 42,51 & 43,99 & 309,75 \\
\hline Hyla molleri & 29SND76 & 101,00 & 166,34 & 94,80 & 39,87 & 4805,36 & 303,58 & 68,38 & 235,21 & \begin{tabular}{ll|}
111,06 \\
\end{tabular} & 227,19 & 230,44 & \begin{tabular}{|l|l|}
107,33 \\
\end{tabular} & 748,79 & 107,79 & 5,66 & 56,58 & \begin{tabular}{|l|l|}
307,78 \\
\end{tabular} & 42,49 & \begin{tabular}{ll|}
44,37 \\
\end{tabular} & 307,73 \\
\hline Hyla molleri & 29SND77 & 101,00 & 163,16 & 94,90 & 39,62 & 4845,10 & 301,51 & 64,80 & 236,71 & 105,01 & 224,73 & 227,83 & \begin{tabular}{|l|l|}
103,70 \\
\end{tabular} & 794,91 & 114,82 & 6,29 & 56,23 & 326,38 & 46,21 & \begin{tabular}{ll|}
47,79 \\
\end{tabular} & 326,38 \\
\hline Hyla molleri & 29SND80 & 101,00 & 166,63 & 96,48 & 40,00 & 4914,35 & 307,64 & 69,17 & 238,47 & 107,97 & 228,70 & 232,91 & \begin{tabular}{|l|l|}
107,09 \\
\end{tabular} & 646,56 & 91,14 & 4,00 & 57,21 & 265,65 & 35,67 & 36,13 & 265,65 \\
\hline Hyla molleri & 29SND81 & 101,00 & 168,40 & 96,43 & 40,00 & 4914,53 & 308,99 & 70,55 & 238,44 & 113,75 & 230,43 & 234,46 & $\begin{array}{l}108,68 \\
\end{array}$ & 649,91 & 91,89 & 4,05 & 57,22 & 267,05 & 35,42 & 36,48 & 267,05 \\
\hline Hyla molleri & 29SND82 & 100,00 & 166,25 & 95,78 & 39,86 & 4933,50 & 307,14 & \begin{tabular}{ll|}
68,68 \\
\end{tabular} & 238,46 & 107,86 & 228,73 & 232,66 & \begin{tabular}{|l|l|}
106,37 \\
\end{tabular} & 683,16 & 97,01 & 4,95 & 56,91 & 280,67 & 38,24 & 39,23 & 280,67 \\
\hline \begin{tabular}{|l|} 
Hyla molleri \\
\end{tabular} & 29SND83 & 101,00 & 165,65 & 95,47 & 39,54 & 4946,11 & 306,57 & 67,94 & 238,62 & 106,90 & 228,45 & 232,34 & \begin{tabular}{ll|}
105,62 \\
\end{tabular} & $\begin{array}{l}704,76 \\
\end{array}$ & 100,50 & 5,00 & 56,88 & 289,71 & 39,38 & 40,52 & 289,71 \\
\hline Hyla molleri & 29SND84 & 101,00 & 166,20 & 95,57 & 39,56 & 4949,48 & 307,08 & 67,86 & 239,22 & 107,46 & 229,05 & 232,68 & \begin{tabular}{|l|l|}
105,90 \\
\end{tabular} & 717,25 & 102,55 & 5,08 & 56,79 & 294,66 & 40,21 & 41,54 & 294,66 \\
\hline Hyla molleri & 29SND85 & 99,00 & 163,36 & 95,07 & 39,14 & 4975,53 & 304,82 & 65,19 & 239,63 & 103,05 & 226,75 & 230,31 & 103,01 & 759,23 & 109,09 & 5,89 & 56,40 & 311,86 & 43,72 & 44,89 & 311,86 \\
\hline Hyla molleri & 29SND86 & 100,00 & 164,90 & 95,70 & 39,27 & 775,12 & 306,28 & 65,64 & 240,64 & 105,07 & 228,30 & 231,51 & \begin{tabular}{|l|l|}
104,17 \\
\end{tabular} & 762,81 & 109,64 & 5,84 & 56,31 & 312,88 & 43,97 & 45,47 & 312,88 \\
\hline Hyla molleri & 29SND89 & 101,00 & 153,44 & 94,66 & 38,42 & 5085,55 & 297,12 & 53,67 & 243,45 & 91,82 & 219,37 & 221,80 & $\begin{array}{l}91,82 \\
\end{array}$ & 921,40 & 134,45 & 8,01 & 55,71 & 377,72 & 56,39 & 56,68 & 377,72 \\
\hline Hyla molleri & 29SND90 & 100,00 & 165,34 & 97,75 & 39,97 & 5033,34 & 309,49 & 66,49 & 243,01 & 104,96 & 229,23 & 233,44 & $\begin{array}{l}104,66 \\
1\end{array}$ & 649,04 & 90,68 & 4,01 & 56,50 & 264,87 & 36,60 & 36,92 & 264,87 \\
\hline \begin{tabular}{|l|} 
Hyla molleri \\
\end{tabular} & 29SND91 & 100,00 & 165,52 & 97,41 & 39,74 & 5042,61 & 309,69 & 66,78 & 242,92 & 105,51 & 229,67 & 233,77 & $\begin{array}{l}104,78 \\
\end{array}$ & 666,33 & 93,51 & 4,71 & 56,51 & 272,06 & 38,02 & 38,47 & 272,06 \\
\hline Hyla molleri & 29SND92 & 100,00 & 167,01 & 97,38 & 39,53 & 5049,72 & 311,14 & 67, & 243,55 & 108,42 & 231,32 & 235,16 & $\begin{array}{l}105,97 \\
\end{array}$ & 672,80 & \begin{tabular}{ll|}
94,69 \\
\end{tabular} & 4,91 & 56,41 & 274,65 & 38,37 & 39,36 & 274,65 \\
\hline Hyla molleri & 29SND94 & 100,00 & 164,63 & 96,36 & 39,00 & 5094,30 & 309,10 & 65,3 & 243,79 & 103,10 & 229,80 & 233,27 & 103,05 & 729,34 & $\mid 103,74$ & 5,38 & 56,1 & 298,24 & \begin{tabular}{|l|l|}
426 \\
\end{tabular} & 43,34 & 298,24 \\
\hline Hyla molleri & 29SND95 & 101,00 & 164,40 & 96,29 & 38,97 & 5107,33 & 308,97 & 64,56 & 244,41 & 102,61 & 229,69 & 233,08 & $\begin{array}{l}102,46 \\
\end{array}$ & 749,64 & 107,05 & 5,86 & 56,03 & 306,62 & 43,75 & 44,92 & 306,62 \\
\hline \begin{tabular}{|l} 
Hyla molleri \\
\end{tabular} & 29SND96 & 101,00 & 161,90 & 95,79 & 38,71 & 5140,64 & 307,12 & 61,99 & 245,13 & 99,61 & 227,89 & 231,10 & 99,61 & 788,45 & 113,31 & 6,03 & 55,97 & 322,89 & 46,10 & 47,06 & 322,89 \\
\hline Hyla molleri & 29SNE01 & 71,00 & 155,54 & 75,36 & 43,04 & 3391,56 & 246,96 & 73,98 & 172,98 & 118,78 & 195,81 & $\begin{array}{l}198,16 \\
\end{array}$ & \begin{tabular}{ll|}
110,94 \\
\end{tabular} & 820,20 & 120,06 & 6,99 & 56,68 & 341,42 & 46,29 & 53,10 & 331,97 \\
\hline Hyla molleri & 29SNE02 & 37,00 & 154,45 & 76,67 & 43,41 & 3404,48 & 246,83 & 72,06 & $\begin{array}{l}174,77 \\
\end{array}$ & \begin{tabular}{ll|}
117,64 \\
\end{tabular} & 195,06 & $\begin{array}{l}197,29 \\
\end{array}$ & \begin{tabular}{|l|l|}
109,50 \\
\end{tabular} & 851,18 & 123,02 & 7,56 & 55,97 & 351,79 & 49,67 & 56,62 & 343,38 \\
\hline Hyla molleri & 29SNE11 & 101,00 & 155,21 & 80,06 & 42,88 & 3601,97 & 254,96 & 70,29 & $\mid 184,66$ & $\mid 116,16$ & $\mid \begin{array}{l}198,65 \\
\end{array}$ & 201,09 & $\mid$\begin{tabular}{|l|l|}
108,34 \\
\end{tabular} & 845,97 & $\mid 122,64$ & 7,29 & 56,16 & 349,90 & $\begin{array}{lll}48,92 & \end{array}$ & 54,74 & 343,15 \\
\hline Hyla molleri & 29SNE21 & 100 & 154,41 & 85,30 & 42,49 & 3858 & 264,11 & 65, & 198,45 & 112 & 201,62 & 204,18 & 104,94 & 879,25 & 127,02 & 7,92 & 55,83 & 361,05 & 52,38 & 56,89 & 357,44 \\
\hline \begin{tabular}{|l} 
Hyla molleri \\
\end{tabular} & 29SNE22 & 101,00 & 156,45 & 86,16 & 43,06 & 3801,99 & 264,73 & 66,96 & 197,77 & 114,81 & 202,60 & 205,01 & \begin{tabular}{ll|}
107,05 \\
\end{tabular} & 877,24 & 125,73 & 8,03 & 55,11 & 358,35 & 53,36 & 58,58 & 354,81 \\
\hline Hyla molleri & 29SNE32 & 100,00 & 153,67 & 90,88 & 42,44 & 4083,90 & 272,45 & 60,72 & 211,73 & 106,56 & 204,07 & 206,71 & \begin{tabular}{ll|}
101,62 \\
\end{tabular} & 929,17 & 133,19 & 8,90 & 54,84 & 377,49 & 58,40 & 61,82 & 376,70 \\
\hline Hyla molleri & 29SPC04 & 100,00 & 161,82 & 106,48 & 41,04 & 5164,14 & 314,94 & 58,80 & 256,14 & 108,27 & 229,01 & 231,91 & 100,14 & 589,98 & 81,44 & 3,02 & 57,23 & 241,04 & 30,93 & 30,93 & 240,44 \\
\hline Hyla molleri & 29SPC07 & 101 & 162 & 101,10 & 40, & 5119 & 310 & \begin{tabular}{ll|}
61,96 \\
\end{tabular} & 248,48 & 101,92 & 229,31 & 231,74 & \begin{tabular}{|l|}
100,87 \\
\end{tabular} & 613,08 & 83,86 & 4,00 & 55, & 247,58 & 35,10 & 35,10 & 247,58 \\
\hline Hyla molleri & $295 \mathrm{SP} 08$ & 100,00 & 160,69 & $\begin{array}{ll}99,94 \\
\end{array}$ & 39,98 & 5139,34 & $\begin{array}{l}308,49 \\
\end{array}$ & 60,77 & 247,72 & $\begin{array}{l}99,37 \\
\end{array}$ & 228,08 & 230,42 & $\begin{array}{l}99,08 \\
\end{array}$ & 640,14 & 87,99 & 4,12 & 55,88 & 258,78 & 36,81 & 36,81 & 258,78 \\
\hline \begin{tabular}{|l|} 
Hyla molleri \\
\end{tabular} & 29SPC09 & 100,00 & 162,42 & 99,67 & 39,97 & 5141,97 & $\begin{array}{l}309,99 \\
\end{array}$ & 62,39 & 247,60 & 101,25 & 228,39 & 232,14 & \begin{tabular}{|l|l|}
100,70 \\
\end{tabular} & 646,09 & 89,10 & 4,17 & 55,93 & 261,45 & 37,30 & 37,32 & 261,45 \\
\hline Hyla molleri & 29SPC13 & 101,00 & 160,51 & 109,02 & 41,00 & 5282,23 & 317,10 & 54,79 & 262,31 & 105,93 & 228,42 & 232,21 & 97,33 & 589,14 & 81,72 & 3,00 & 57,24 & 240,98 & 30,63 & 30,77 & 238,69 \\
\hline Hyla molleri & 29SPC18 & 101,00 & 16 & 10215 & 39,90 & 255,8 & 311 & 58,30 & 253,45 & 102,59 & 228,97 & 231,89 & \begin{tabular}{|l|l|}
97,68 \\
\end{tabular} & 638, & 86,96 & 4,34 & 55,44 & 256,29 & 37,43 & 37,43 & \\
\hline Hyla molleri & $295 \mathrm{SP} 23$ & 100,00 & 165,26 & 109,13 & 40,97 & 5331,75 & 321,37 & 57,58 & 263,80 & 109,62 & 233,19 & 237,03 & \begin{tabular}{|c|}
100,88 \\
\end{tabular} & 556,98 & 77,25 & 3,00 & 57,18 & 227,79 & 28,54 & 29,44 & 223, \\
\hline Hyla molleri & 29SPC29 & 100,00 & 158,40 & 102,98 & 39,39 & 5393,15 & 312,64 & 54,31 & 258,34 & 102,07 & 228,38 & 231,60 & 94,01 & 668,10 & 90,58 & 5,07 & 54,64 & 267,01 & 40,43 & 40,47 & 266,42 \\
\hline
\end{tabular}




\begin{tabular}{|c|c|c|c|c|c|c|c|c|c|c|c|c|c|c|c|c|c|c|c|c|c|}
\hline TAXON & UTM & $\mathrm{km} 2$ & B101 & B102 & BIO3 & B104 & 8105 & B106 & B107 & B108 & B109 & BIO10 & B1011 & BIO12 & B1O13 & B1014 & 81015 & B1016 & B1017 & B1018 & \begin{tabular}{|l|} 
BIO19 \\
\end{tabular} \\
\hline Hyla molleri & 29SPC33 & 100,00 & 168,65 & 109,01 & 40,48 & 5392,90 & 324,63 & 58,97 & 265,66 & 111,64 & 237,36 & 240,86 & 103,12 & 533,38 & 73,80 & 2,99 & 56,89 & 217,75 & 27,26 & 28,95 & 211,42 \\
\hline Hyla molleri & 29SPC98 & 100,00 & \begin{tabular}{|l|}
163,77 \\
\end{tabular} & 115,99 & 38,94 & 6055,62 & 337,09 & 41,36 & 295,74 & 97,97 & 242,82 & 243,82 & \begin{tabular}{|l|}
89,72 \\
\end{tabular} & 531,38 & 72,98 & 4,00 & 52,47 & 206,67 & 32,15 & 34,00 & 194,75 \\
\hline Hyla molleri & 29SPD04 & 101,00 & 167,18 & 98,12 & 39,00 & 5207,99 & 314,58 & 65,51 & 249,07 & \begin{tabular}{|l|}
108,01 \\
\end{tabular} & 233,88 & 237,27 & 104,14 & 701,80 & 98,94 & 5,02 & 55,98 & 285,48 & 40,41 & 41,68 & 285,48 \\
\hline Hyla molleri & 29SPD05 & 100,00 & 164,19 & 97,09 & 38,45 & 5241,36 & 311,97 & 63,09 & 248,88 & \begin{tabular}{|l|l|l}
101,06 \\
\end{tabular} & 231,63 & 234,92 & 100,91 & \begin{tabular}{|l|l|}
747,79 \\
\end{tabular} & 106,27 & 5,92 & 55,64 & 304,62 & 44,26 & 45,40 & 304,62 \\
\hline Hyla molleri & 29SPD06 & 101,00 & 162,42 & 96,54 & 38,07 & 5278,41 & 310,58 & 61,03 & 249,54 & \begin{tabular}{|l|l|}
98,67 \\
\end{tabular} & 230,34 & \begin{tabular}{|l|l|}
233,67 \\
\end{tabular} & 98,67 & \begin{tabular}{|l|l|}
781,05 \\
\end{tabular} & 111,75 & 6,01 & 55,70 & 318,61 & 46,15 & 47,22 & 318,61 \\
\hline Hyla molleri & $29 S P D 07$ & 100,00 & 163,07 & 96,93 & 38,15 & 5303,94 & 311,69 & 60,67 & 251,02 & 99,04 & 231,54 & 234,37 & 98,93 & 789,75 & 113,19 & 6,18 & 55,53 & 321,77 & 47,18 & 48,37 & 321,77 \\
\hline Hyla molleri & 29SPD14 & 101,00 & 165,21 & 98,75 & 38,55 & 5330,92 & 315,60 & 62,83 & 252,77 & 106,32 & 233,90 & 237,29 & 101,11 & 714,56 & 100,17 & 5,54 & 55,28 & 289,08 & 42,56 & 43,73 & 289,07 \\
\hline Hyla molleri & 29SPD15 & 99,00 & 162,46 & 97,29 & 38,02 & 5371,46 & 312,91 & 60,64 & 252,27 & \begin{tabular}{|c|}
98,53 \\
\end{tabular} & 231,79 & 235,15 & 97,96 & 757,44 & 107,32 & 5,99 & 55,27 & 307,57 & 45,20 & 46,33 & 307,57 \\
\hline Hyla molleri & 29SPD16 & 100,00 & 161,78 & 96,94 & 37,96 & 5407,71 & 312,48 & 59,44 & 253,04 & \begin{tabular}{|l|l|}
96,84 \\
\end{tabular} & 231,64 & 234,87 & 96,84 & \begin{tabular}{|l|l|}
780,17 \\
\end{tabular} & 111,29 & 6,00 & 55,41 & 317,28 & 46,43 & $\begin{array}{l}47,58 \\
\end{array}$ & 317,28 \\
\hline Hyla molleri & 29SPD17 & 100,00 & 162,40 & 97,18 & 37,83 & 5441,73 & 313,80 & 59,03 & 254,77 & \begin{tabular}{|l|l|}
97,30 \\
\end{tabular} & 232,95 & 235,84 & 96,87 & 787,81 & 112,55 & 6,00 & 55,10 & 319,82 & 47,48 & 48,64 & 319,82 \\
\hline Hyla molleri & 29SPD20 & 100,00 & 159,85 & 102,48 & 39,07 & 5401,49 & 313,94 & 55,83 & 258,10 & 103,21 & 229,40 & 233,08 & 95,22 & 674,09 & 91,73 & 5,03 & 54,81 & 269,90 & 40,77 & 40,90 & 269,22 \\
\hline Hyla molleri & $29 S P D 25$ & 101,00 & \begin{tabular}{|l|}
160,69 \\
\end{tabular} & 97,33 & 37,76 & 5474,17 & 313,32 & 58,49 & 254,84 & \begin{tabular}{|c|}
98,78 \\
\end{tabular} & 231,64 & 235,06 & 95,46 & \begin{tabular}{|l|l|}
766,08 \\
\end{tabular} & 108,18 & 6,11 & 55,04 & 309,96 & 46,21 & 47,49 & 309,96 \\
\hline Hyla molleri & $29 S P D 26$ & 101,00 & 160,01 & 96,71 & 37,40 & 5512,44 & 312,78 & 57,41 & 255,37 & \begin{tabular}{|l|l}
95,55 \\
\end{tabular} & 231,52 & 234,88 & 94,22 & 787,61 & 111,94 & 6,14 & 55,06 & 319,04 & 47,62 & 48,89 & 319,04 \\
\hline Hyla molleri & $29 S P D 27$ & 100,00 & 161,47 & 97,40 & 37,06 & 5567,78 & 315,33 & 57,12 & 258,21 & \begin{tabular}{|l|l|}
98,03 \\
\end{tabular} & 233,97 & 236,64 & 94,68 & 784,94 & 111,68 & 6,06 & 54,87 & 317,36 & 47,71 & 48,92 & 317,33 \\
\hline Hyla molleri & 29SPD28 & 101,00 & 163,53 & 98,34 & 37,12 & 5619,06 & 318,43 & 57,26 & 261,16 & \begin{tabular}{|l|l|}
101,12 \\
\end{tabular} & 236,92 & 238,95 & 95,64 & 774,94 & 110,22 & 5,99 & 54,79 & 312,52 & 47,14 & 48,58 & 312,37 \\
\hline Hyla molleri & 29SPD29 & 101,00 & 165,74 & 99,41 & 37,31 & 5638,23 & 320,90 & 57,92 & 262,98 & 103,96 & 239,38 & 240,89 & 97,06 & 762,84 & 108,38 & 5,99 & 54,66 & 306,90 & 46,46 & 48,16 & 306,55 \\
\hline Hyla molleri & $29 S P D 33$ & 100,00 & 162,66 & 101,92 & 38,40 & 5533,15 & 318,94 & 57,36 & 261,57 & 104,52 & 234,36 & 237,56 & 96,38 & 699,47 & \begin{tabular}{|l|}
95,88 \\
\end{tabular} & 5,75 & 54,18 & 280,39 & 43,21 & 44,24 & 278,84 \\
\hline Hyla molleri & $29 S P D 34$ & 101,00 & 160,24 & 99,30 & 37,85 & 5550,93 & 315,39 & 56,72 & 258,67 & 102,24 & 232,29 & 235,74 & 94,27 & 740,95 & 103,04 & 6,14 & 54,40 & 298,01 & 45,47 & 46,65 & 297,21 \\
\hline Hyla molleri & $29 S P D 35$ & 100,00 & 150,96 & 93,90 & 36,71 & 5549,48 & 303,30 & \begin{tabular}{|l|l|}
51,48 \\
\end{tabular} & 251,82 & 87,76 & 223,30 & 227,27 & 86,22 & 847,69 & 120,82 & 7,24 & 54,84 & 343,56 & 52,06 & 53,06 & 343,56 \\
\hline Hyla molleri & 29SPD36 & 101,00 & 153,98 & 94,90 & 36,77 & 5604,19 & 307,60 & 52,43 & 255,18 & 91,66 & 227,18 & 230,49 & 87,92 & 831,12 & 118,49 & 6,95 & 54,64 & 336,25 & 51,13 & 52,08 & 336,14 \\
\hline Hyla molleri & 29SPD37 & 100,00 & 162,36 & 98,66 & 37,05 & 5674,95 & 318,45 & 56,13 & 262,32 & 101,76 & 236,42 & 238,79 & 94,20 & 758,86 & 106,97 & 5,99 & 54,36 & 305,26 & 46,45 & 47,80 & 304,45 \\
\hline Hyla molleri & 29SPD43 & 99,00 & 163,16 & \begin{tabular}{|r|r|}
104,89 \\
\end{tabular} & 38,67 & 5647,58 & 323,13 & 54,71 & 268,42 & $\begin{array}{l}103,38 \\
\end{array}$ & $\mid$\begin{tabular}{|l|l|l|l|}
236,58 \\
\end{tabular} & 239,30 & 95,26 & 675,98 & \begin{tabular}{|c|}
91,26 \\
\end{tabular} & 5,35 & 53,69 & 269,65 & $\begin{array}{l}42,25 \\
42,4\end{array}$ & 43,30 & 266,46 \\
\hline Hyla molleri & 29SPD44 & 101,00 & 155,18 & 99,28 & 37,57 & 5640,11 & 312,16 & 51,31 & 260,85 & $\begin{array}{r}96,60 \\
\end{array}$ & 228,72 & 232,15 & 88,58 & 767,07 & 106,42 & 6,42 & 54,01 & 307,69 & 47,74 & 48,74 & 306,19 \\
\hline Hyla molleri & 29SPD45 & 99,00 & 145,56 & 94,44 & 36,50 & 5659,10 & 300,09 & 44,74 & 255,35 & 86,12 & 220,27 & 223,39 & $\begin{array}{l}79,69 \\
\end{array}$ & 866,89 & 122,89 & 7,64 & 54,20 & 348,96 & 54,20 & 54,73 & 348,51 \\
\hline Hyla molleri & $29 S P D 46$ & 100,00 & 156,64 & 97,92 & 36,98 & 5715,55 & 313,60 & 51,85 & 261,75 & \begin{tabular}{|c|}
96,79 \\
\end{tabular} & 231,46 & 234,36 & 88,84 & 779,71 & 109,38 & 6,38 & 54,05 & 313,09 & 48,41 & 49,55 & 311,72 \\
\hline Hyla molleri & $295 P D 47$ & $\begin{array}{l}100,00 \\
\end{array}$ & $\begin{array}{l}161,78 \\
\end{array}$ & 99,90 & 37,00 & 5777,09 & 320,23 & 53,95 & 266,28 & \begin{tabular}{|c|}
100,13 \\
\end{tabular} & 237,49 & 239,55 & 92,44 & 738,82 & 103,05 & 5,96 & 53,79 & 295,82 & 45,84 & 47,24 & 293,69 \\
\hline Hyla molleri & 29SPD48 & 100,00 & 163,51 & $\mid$ & 37,01 & 5812,85 & $\begin{array}{l}322,29 \\
322,29\end{array}$ & | 54,38 & $\begin{array}{l}260,20 \\
267,91\end{array}$ & $\begin{array}{l}100,95 \\
10,13\end{array}$ & $\mid$ & $\mid$ & $\begin{array}{l}32,44 \\
93,31\end{array}$ & \begin{tabular}{|l|l}
729,02 \\
\end{tabular} & \begin{tabular}{|l|}
101,92 \\
101
\end{tabular} & 5,83 & $\mid$\begin{tabular}{|l|l|}
53,78 \\
\end{tabular} & $\begin{array}{l}2930,0<2 \\
291,85\end{array}$ & $\begin{array}{l}435,04 \\
45,22\end{array}$ & $\begin{array}{l}4 r i, 24 \\
46,76\end{array}$ & $\begin{array}{l}2959,03 \\
289,49\end{array}$ \\
\hline Hyla molleri & 29SPD52 & 101,00 & 166,26 & 111,13 & 39,15 & 5767,16 & 331,38 & 51,92 & 279,45 & 104,00 & 241,34 & 243,14 & 96,06 & 610,44 & 82,21 & 4,99 & 52,86 & 241,30 & 38,96 & 39,79 & 235,35 \\
\hline Hyla molleri & $29 \mathrm{SPD} 53$ & 101,00 & 162,51 & 107,88 & 38,71 & 5768,06 & 326,25 & 50,88 & 275,37 & 100,99 & 237,82 & 239,95 & 92,98 & 656,75 & 87,85 & 5,19 & 52,99 & 260,40 & $|41,79|$ & 42,66 & 255,47 \\
\hline Hyla molleri & $29 \mathrm{SPD} 55$ & 101,00 & 155,24 & 100,88 & 37,30 & 5793,53 & 315,14 & 48,08 & 267,07 & 94,52 & 231,21 & 233,80 & 86,40 & 749,56 & 103,06 & 6,22 & 53,30 & 298,95 & 47,35 & 48,26 & 295,74 \\
\hline Hyla molleri & 29SPD64 & 101,00 & 163,57 & 108,86 & 38,40 & 5889,68 & 329,05 & 49,39 & 279,66 & 100,14 & 240,79 & 242,18 & 92,22 & 634,25 & \begin{tabular}{|l|}
84,37 \\
\end{tabular} & 5,02 & 52,28 & 249,93 & 40,92 & 41,94 & 243,47 \\
\hline Hyla molleri & 29SPD69 & \begin{tabular}{|l|}
99,00 \\
\end{tabular} & 163,36 & 102,63 & 36,88 & 5985,69 & 325,23 & 50,46 & 274,77 & 98,32 & 242,23 & 242,91 & 90,58 & 672,44 & 91,76 & 5,20 & 52,53 & 265,70 & 42,64 & 44,03 & 260,42 \\
\hline Hyla molleri & $295 P D 70$ & \begin{tabular}{|l|}
101,00 \\
\end{tabular} & $\begin{array}{l}168,47 \\
\end{array}$ & 116,41 & 39,00 & 5985,76 & 339,92 & 46,32 & 293,60 & \begin{tabular}{|l|l|}
102,76 \\
\end{tabular} & 246,63 & 247,24 & 94,58 & 521,55 & 72,42 & 4,00 & 51,71 & 202,79 & 34,94 & 35,31 & 192,28 \\
\hline Hyla molleri & 29SPE12 & 100,00 & \begin{tabular}{|l|}
151,78 \\
\end{tabular} & 95,52 & 36,56 & 5580,80 & 303,98 & 46,12 & 257,86 & 84,14 & 225,44 & 226,36 & 84,14 & 943,37 & 138,41 & 8,12 & 55,08 & 383,08 & 58,69 & 59,05 & 383,08 \\
\hline Hyla molleri & 29SPE21 & 100,00 & 157,59 & 97,04 & 36,15 & 5765,61 & 313,94 & 49,60 & 264,34 & $88, \mathrm{C}$ & 233,56 & 234,55 & 87,85 & 858,44 & 124,23 & 7,02 & 54,74 & 346,39 & 53,52 & 54,15 & 346,39 \\
\hline Hyla molleri & $29 S P E 22$ & 100,00 & 153,76 & 96,17 & 36,13 & 5741,76 & 308,91 & 46,21 & 262,70 & 84,23 & 229,40 & 230,39 & 84,23 & 900,23 & 131,32 & 7,73 & 54,81 & 363,70 & 56,48 & 56,78 & 363,70 \\
\hline Hyla molleri & 29SPE30 & 100,00 & 165,01 & 99,91 & 36,85 & 5785,91 & 322,58 & 55,11 & 267,47 & $\begin{array}{ll}101,66 \\
\end{array}$ & 240,95 & 241,99 & 94,62 & 754,97 & 106,97 & 6,00 & 54,14 & 302,59 & 46,47 & 48,13 & 301,33 \\
\hline Hyla molleri & 29SPE31 & 101,00 & 157,49 & 97,29 & 36,01 & 5870,90 & 315,45 & \begin{tabular}{|l|}
48,45 \\
\end{tabular} & 267,00 & 91,57 & 234,94 & 235,83 & 86,60 & 833,36 & 120,00 & 6,90 & 54,25 & \begin{tabular}{|l|}
334,68 \\
\end{tabular} & 52,14 & 52,80 & 334,45 \\
\hline Hyla molleri & 29SPE32 & 100,00 & 155,12 & 96,91 & 36,01 & 5844,35 & 312,09 & 46,21 & 265,88 & 88,22 & 232,29 & 232,95 & 84,38 & 856,54 & 123,96 & 7,15 & 54,26 & 343,94 & 53,86 & 54,35 & 343,80 \\
\hline Hyla molleri & 29SPE40 & 101,00 & 164,31 & 100,45 & 36,85 & 5868,35 & 323,23 & 53,36 & 269,86 & 100,41 & 241,48 & 242,36 & 92,96 & 733,33 & 103,07 & 5,98 & 53,64 & 292,77 & 45,60 & 47,25 & 290,38 \\
\hline Hyla molleri & $29 S P E 42$ & 99,00 & \begin{tabular}{|l|}
156,54 \\
\end{tabular} & \begin{tabular}{|}
97,94 \\
97,94
\end{tabular} & 30,04 & 5903,14 & 314,45 & 46,30 & 268,15 & $\begin{array}{r} \\
92,15\end{array}$ & $\begin{array}{l}234,38 \\
234\end{array}$ & 234,94 & 84,72 & 808,24 & $\mid 115,72$ & 6,78 & 53,88 & 322,90 & 50 & 51,71 & 321,60 \\
\hline Hyla molleri & 29SPE51 & 101,00 & 162,83 & 100,88 & 36,68 & 5941,95 & 322,45 & 50,59 & 271,86 & \begin{tabular}{|l|}
97,88 \\
\end{tabular} & 241,23 & 241,63 & 90,42 & \begin{tabular}{|l|}
716,97 \\
\end{tabular} & 100,21 & 5,86 & 53,12 & \begin{tabular}{|l|}
284,78 \\
\end{tabular} & 45,20 & 46,64 & 281,24 \\
\hline Hyla molleri & 29SPE52 & 101,00 & $\begin{array}{l}157,55 \\
\end{array}$ & \begin{tabular}{|c|}
99,13 \\
99,0
\end{tabular} & 36,10 & 5958,68 & 316,43 & 46,10 & 270,33 & 92,54 & 236,26 & $\begin{array}{l}24,0,52 \\
236,52\end{array}$ & 84,95 & 761,84 & $\mid 107,67$ & 6 & 53,17 & 302,85 & 48,50 & 49,19 & 300,00 \\
\hline Hyla molleri & 29SPE82 & 100,00 & 156,19 & 101,95 & 36,03 & 6125,07 & 319,99 & 41, & 278,25 & 89,41 & 237,48 & 237,48 & 81,48 & 657,45 & 88,73 & 5,76 & 50,90 & 256,01 & 44,06 & 44,06 & 248,87 \\
\hline Hyla molleri & $29 \mathrm{SQB04}$ & 100,00 & 175,53 & 93,32 & 37,02 & 5425,44 & 312,93 & 64,53 & 248,41 & \begin{tabular}{|c|} 
\\
120,14
\end{tabular} & 243,71 & 246,19 & \begin{tabular}{|c|}
107,63 \\
\end{tabular} & 511,63 & 78,33 & 1,29 & 61,96 & 215,68 & 16,04 & 24,62 & 195,76 \\
\hline Hyla molleri & $295 \mathrm{SBO} 05$ & \begin{tabular}{|l|}
101,00 \\
\end{tabular} & \begin{tabular}{|l|}
169,79 \\
\end{tabular} & | & $\begin{array}{l}37,262 \\
37,29\end{array}$ & $\begin{array}{l}5425,144 \\
5573,42\end{array}$ & 314,27 & $\begin{array}{l}54,53 \\
56,43\end{array}$ & \begin{tabular}{|l|l|}
$24,47,81$ \\
25784
\end{tabular} & $\mid$ & \begin{tabular}{|l|}
$240,50,50$ \\
\end{tabular} & \begin{tabular}{|l|l}
240,13 \\
242,85
\end{tabular} & \begin{tabular}{|l|}
100,61 \\
100
\end{tabular} & \begin{tabular}{|l|l|l|l|l|}
543,49 \\
\end{tabular} & \begin{tabular}{|l}
81,20 \\
8
\end{tabular} & $\frac{1,25}{2,00}$ & \begin{tabular}{|l|l|}
60,59 \\
\end{tabular} & \begin{tabular}{|l}
$\mid 21,00$ \\
226,67
\end{tabular} & $\begin{array}{l}19,23 \\
19,23\end{array}$ & 2727,11 & 208,41 \\
\hline Hyla molleri & 29SQBOB & 101,00 & 165,53 & \begin{tabular}{|l|}
101,65 \\
\end{tabular} & 37,97 & 5683,37 & 315,98 & 50,49 & 265,49 & $\begin{array}{l}104,53 \\
\end{array}$ & 238,24 & 240,44 & $\begin{array}{l}95,45 \\
\end{array}$ & \begin{tabular}{|l|}
566,49 \\
\end{tabular} & 83,17 & 2,01 & 59,96 & 234,53 & 21,17 & 28,32 & 217,67 \\
\hline Hyla molleri & 29SQB15 & 100,00 & 171,39 & 101,11 & 37,85 & 5671,57 & 320,33 & 55,58 & 264,75 & 110,05 & 243,75 & 245,90 & 101,01 & 548,55 & 81,87 & 1,99 & 60,71 & 228,67 & 19,41 & 26,72 & 210,85 \\
\hline Hyla molleri & 29SQB16 & 99,00 & 168,83 & 104,02 & 38,00 & 5771,93 & 322,70 & 51,44 & 271,26 & 106,39 & 242,73 & 244,82 & $\mid 97,38$ & 560,74 & 82,61 & 2,01 & 60,17 & 232,12 & 20,69 & 27,51 & 215,31 \\
\hline Hyla molleri & 29SQB17 & 101,00 & 163,36 & 10 & 38, & 5877,79 & 322 & & 278,27 & \begin{tabular}{|l|}
99,97 \\
\end{tabular} & 239,10 & 241 & 90,98 & 589,06 & $\begin{array}{l}85,03 \\
\end{array}$ & 2,50 & 59,22 & 241,64 & 23,35 & 29,53 & 226,20 \\
\hline Hyla molleri & 29SQB18 & 100,00 & 159,01 & 109,34 & 38,00 & 5957,20 & 322,97 & 39,38 & 283,59 & 95,16 & 236,25 & 238,07 & 86,15 & 610,38 & 86,62 & 2,97 & 58,25 & 248,23 & 25,93 & 31,53 & 233,97 \\
\hline Hyla molleri & $295 \mathrm{SQB} 26$ & 101,00 & \begin{tabular}{|l|}
165,03 \\
\end{tabular} & 108,10 & 38,00 & 5908,15 & 325,85 & 45,03 & 280,81 & \begin{tabular}{|l|l|}
101,40 \\
\end{tabular} & 241,28 & 243,17 & 92,26 & \begin{tabular}{|l|}
594,59 \\
\end{tabular} & 86,44 & 2,06 & $\begin{array}{l}60,03 \\
\end{array}$ & 245,36 & 22,21 & 28,46 & 229,72 \\
\hline Hyla molleri & $29 S Q B 27$ & 100,00 & 162,82 & 109,90 & 38,00 & 5980,37 & 327,18 & 41,83 & 285,35 & 98,45 & 240,34 & 242,12 & 89,41 & 602,57 & 86,51 & 2,57 & 59,20 & 246,70 & 24,01 & 29,90 & 231,84 \\
\hline Hyla molle & $29 \mathrm{SQB} 34$ & 100,00 & $\begin{array}{ll}179,52 \\
\end{array}$ & 106,17 & 38,01 & 5772,33 & 334,80 & 59,5 & 275,24 & 116,6 & 253,47 & 255,4 & 107,67 & 542,4 & 81,89 & 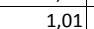 & 62,08 & 228,52 & 18,01 & 23,92 & 211,26 \\
\hline Hyla molleri & $29 \mathrm{SQB} 35$ & 101,00 & 175,74 & & 38,05 & 5890,17 & 336,24 & 54,13 & 282,11 & 111,61 & 251,58 & 253,33 & 102,63 & 558,45 & 83,11 & 1,7 & 61,18 & 233,21 & 19,53 & 25,44 & 216,83 \\
\hline Hyla molleri & 29SQB 45 & 99,00 & 179,99 & \begin{tabular}{|l|}
113,45 \\
\end{tabular} & $\begin{array}{l}38,61 \\
38,\end{array}$ & 5980,75 & 346,22 & 55,51 & 290,71 & 114,92 & 257,41 & 259,01 & \begin{tabular}{|l|}
105,74 \\
\end{tabular} & 555,42 & 82,92 & 1,41 & 61,79 & 232,99 & 18,81 & 24,00 & 217,38 \\
\hline Hyla molleri & $29 S Q C 16$ & 100,00 & 158,39 & 116,15 & 38,01 & 6218,94 & 335,43 & 34,82 & 300,61 & 91,30 & 240,07 & 241,02 & 82,66 & 573,53 & 77,26 & 4,05 & 53,32 & 222,97 & 32,25 & 34,93 & 211,15 \\
\hline Hyla molleri & $29 \mathrm{SQC} 29$ & 99,00 & 163,70 & 116,98 & 37,99 & 6310,48 & 342,96 & 38,34 & 304,62 & 94,99 & 247,14 & 247,18 & 86,50 & 523,24 & 69,29 & 3,71 & 51,97 & 200,01 & 30,94 & 31,56 & 187,7 \\
\hline Hyla molleri & $2950 C 39$ & 101,00 & 165 , & 117 & 37,97 & 6367,88 & 346,27 & 39,30 & 306,97 & 96,22 & 249,75 & 249,85 & 87,54 & 511 & 67, & 3,08 & 52,34 & 194,91 & 28,83 & 30,27 & 18 \\
\hline Hyla molleri & $29 \mathrm{SOC} 53$ & 100,00 & 152,34 & $\mid$ & 38,00 & 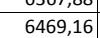 & 337,34 & 24,95 & 312,39 & 82,86 & \begin{tabular}{|l|}
237,97 \\
\end{tabular} & $\begin{array}{l}24,05 \\
238,62\end{array}$ & 74,10 & 638,24 & 84,75 & 3,94 & 55,30 & \begin{tabular}{|l}
248,30 \\
\end{tabular} & \begin{tabular}{|l|l|l|l|l|}
31,58 \\
\end{tabular} & 35,35 & 237,69 \\
\hline
\end{tabular}




\begin{tabular}{|c|c|c|c|c|c|c|c|c|c|c|c|c|c|c|c|c|c|c|c|c|c|}
\hline$\overline{\text { TAXON }}$ & UTM & km2 & BIO1 & BIO2 & $\begin{array}{l}\mathrm{BIO3} \\
\end{array}$ & BIO4 & 8105 & B106 & B107 & B108 & B109 & BIO10 & BIO11 & BIO12 & B1013 & B1014 & B1015 & B1016 & B1017 & BIO18 & 81019 \\
\hline Hyla molleri & $29 S Q C 57$ & 101,00 & $\begin{array}{r}157,18 \\
\end{array}$ & 119,37 & 37,73 & 6509,74 & 342,79 & 29,19 & 313,61 & 86,55 & 243,60 & 243,67 & 77,96 & 573,23 & 74,97 & 3,87 & 53,01 & 217,74 & 31,36 & 32,25 & 206,81 \\
\hline Hyla molleri & 29SQD03 & $\begin{array}{r}99,00 \\
\end{array}$ & 162,05 & 112,89 & 37,65 & 6217,30 & 336,97 & 40,74 & 296,23 & $\begin{array}{l}94,54 \\
23,5\end{array}$ & 244,16 & \begin{tabular}{|l|l|l|}
244,37 \\
25
\end{tabular} & $\begin{array}{l}86,30 \\
8527\end{array}$ & \begin{tabular}{|l|l|}
543,79 \\
5227
\end{tabular} & 71,43 & $\begin{array}{ll}4,07 \\
\end{array}$ & $\begin{array}{l}50,64 \\
5050\end{array}$ & 207,91 & \begin{tabular}{|l|l|}
35,20 \\
2,20
\end{tabular} & \begin{tabular}{|l|l|}
35,89 \\
2,72
\end{tabular} & $\begin{array}{l}196,42 \\
\end{array}$ \\
\hline Hyla molleri & 29SQD13 & 101,00 & 161,91 & \begin{tabular}{ll|}
112,93 \\
\end{tabular} & 37,27 & 6289,60 & 338,44 & 39,80 & 298,64 & 93,62 & 245,15 & 245,26 & 85,32 & \begin{tabular}{|l|l|}
532,07 \\
\end{tabular} & $\begin{array}{l}69,11 \\
6,6\end{array}$ & 4,03 & 50,50 & 201,98 & 34,28 & $\begin{array}{r}34,72 \\
2,2,2\end{array}$ & 190,05 \\
\hline Hyla molleri & $295 Q D 23$ & 100,00 & 162,78 & 113,37 & 37,00 & 6357,80 & 341,02 & 39,52 & 301,50 & \begin{tabular}{|l|l|}
93,64 \\
\end{tabular} & 247,12 & 247,14 & 85,36 & 515,75 & $\begin{array}{l}66,36 \\
\end{array}$ & 4,00 & 50,40 & \begin{tabular}{|l|l|}
194,20 \\
\end{tabular} & 32,93 & 33,12 & 182,06 \\
\hline Hyla molleri & 29SQD27 & 100,00 & 160,06 & 107,97 & 36,00 & 6397,26 & 335,49 & 39,85 & 295,64 & 90,75 & 245,32 & 245,32 & 82,60 & 521,58 & 66,06 & 4,07 & 49,38 & 194,52 & 35,48 & 35,48 & 182,45 \\
\hline Hyla molleri & $295 Q D 36$ & 100,00 & \begin{tabular}{|l|}
158,56 \\
\end{tabular} & \begin{tabular}{|l|}
109,69 \\
\end{tabular} & 36,00 & 6453,55 & 336,64 & 37,03 & 299,60 & 88,73 & 244,68 & 244,68 & 80,45 & 515,19 & \begin{tabular}{|l|l|}
66,62 \\
\end{tabular} & \begin{tabular}{|l|l}
4,06 \\
\end{tabular} & \begin{tabular}{|l|l|}
49,25 \\
\end{tabular} & \begin{tabular}{|l|l|}
190,48 \\
\end{tabular} & \begin{tabular}{|l|l|}
34,98 \\
\end{tabular} & \begin{tabular}{|l|l|}
34,98 \\
\end{tabular} & \begin{tabular}{l|l|}
178,10 \\
\end{tabular} \\
\hline Hyla molleri & 29SQD41 & 100,00 & 167,40 & 116,77 & 37,13 & 6444,88 & 349,11 & 40,70 & 308,41 & 96,92 & 252,81 & 252,81 & 88,49 & 488,53 & \begin{tabular}{|l|l|}
63,47 \\
\end{tabular} & 3,01 & 51,48 & \begin{tabular}{|l|l|}
183,45 \\
\end{tabular} & 28,49 & 28,51 & 171,45 \\
\hline Hyla molleri & 29SQD43 & 101,00 & 161,52 & 114,56 & 37,00 & 6485,11 & 343,00 & 36,40 & 306,60 & 90,96 & 247,73 & 247,73 & 82,47 & 504,86 & \begin{tabular}{l|l|}
64,52 \\
\end{tabular} & 3,99 & 50,27 & 187,34 & 32,06 & \begin{tabular}{l|l|}
32,06 \\
\end{tabular} & $\begin{array}{l}175,22 \\
\end{array}$ \\
\hline Hyla molleri & 29SQD46 & 101,00 & 158,61 & 111,09 & 36,02 & 6493,81 & 338,07 & \begin{tabular}{l|l|}
35,56 \\
\end{tabular} & 302,51 & 88,12 & 245,17 & \begin{tabular}{|l|}
245,17 \\
\end{tabular} & \begin{tabular}{|l|l|}
79,77 \\
\end{tabular} & 501,75 & \begin{tabular}{ll|}
64,84 \\
\end{tabular} & 4,00 & 48,76 & \begin{tabular}{ll|}
184,06 \\
\end{tabular} & 34,20 & 34,20 & 171,66 \\
\hline Hyla molleri & 295QD47 & 100,00 & 160,86 & 110,70 & 36,07 & \begin{tabular}{|l|l|}
6477,91 \\
\end{tabular} & 339,36 & 37,98 & \begin{tabular}{|l|}
301,38 \\
\end{tabular} & 90,34 & 247,32 & \begin{tabular}{|l|}
247,32 \\
\end{tabular} & \begin{tabular}{|l|l|}
82,02 \\
\end{tabular} & 484,05 & 62,15 & 4,00 & 48,47 & 177,12 & 33,49 & 33,49 & 164,73 \\
\hline Hyla molleri & 29SQD48 & \begin{tabular}{|l|}
101,00 \\
\end{tabular} & 161,55 & 110,35 & 36,08 & 6466,01 & 339,07 & 38,76 & 300,31 & 90,95 & 247,84 & 247,84 & \begin{tabular}{l|l|}
82,85 \\
\end{tabular} & 475,51 & 60,13 & 4,00 & 48,11 & 173,82 & 33,42 & 33,42 & $\begin{array}{l}161,51 \\
\end{array}$ \\
\hline Hyla molleri & 29SQD53 & 97,00 & 165,47 & 115,63 & 37,00 & 6512,83 & 347,79 & 38,87 & 308,92 & \begin{tabular}{|l|l|}
94,19 \\
\end{tabular} & 252,03 & \begin{tabular}{|l|}
252,03 \\
\end{tabular} & 85,84 & $\begin{array}{l}479,56 \\
\end{array}$ & \begin{tabular}{|l|l|}
61,44 \\
\end{tabular} & 3,16 & \begin{tabular}{|l|l|}
50,23 \\
\end{tabular} & \begin{tabular}{|l|}
176,96 \\
\end{tabular} & 29,56 & 29,56 & 165,02 \\
\hline Hyla molleri & 29SQD57 & 80,00 & 160,28 & 111,88 & 36,03 & 6511,11 & 340,08 & 36,26 & 303,83 & 89,31 & 247,30 & 247,30 & 81,00 & 474,24 & 60,62 & 4,00 & 48,02 & \begin{tabular}{|l|}
172,21 \\
\end{tabular} & 33,12 & 33,12 & $\begin{array}{l}159,87 \\
\end{array}$ \\
\hline Hyla molleri & 29SQE22 & 99,00 & 161,24 & 107,65 & 36,48 & 6301,11 & 332,08 & 41,32 & 290,76 & 91,85 & 245,08 & \begin{tabular}{|l|}
245,08 \\
\end{tabular} & \begin{tabular}{|l|}
83,98 \\
\end{tabular} & 500,32 & 63,38 & 4,59 & $\begin{array}{l}47,75 \\
\end{array}$ & \begin{tabular}{|l|l|}
187,07 \\
\end{tabular} & 35,98 & 35,98 & 175,85 \\
\hline Hyla molleri & 29тMH91 & 46,00 & 146,53 & \begin{tabular}{|l|l|}
59,04 \\
\end{tabular} & 38,62 & 3311,15 & 229,18 & 78,01 & 151,16 & 113,22 & 187,59 & \begin{tabular}{|l|l|}
189,99 \\
\end{tabular} & 104,65 & 1143,04 & 161,42 & 26,24 & 45,56 & 458,00 & 110,67 & 134,49 & 409,85 \\
\hline Hyla molleri & 29TMH92 & 25,00 & 141,23 & $\begin{array}{ll}60,49 \\
\end{array}$ & 38,14 & 3378,23 & 227,51 & \begin{tabular}{|l|}
71,47 \\
\end{tabular} & 156,05 & \begin{tabular}{|l|}
107,72 \\
\end{tabular} & \begin{tabular}{|l|}
183,44 \\
\end{tabular} & \begin{tabular}{|l|}
185,91 \\
\end{tabular} & \begin{tabular}{|l|l|}
99,12 \\
\end{tabular} & \begin{tabular}{|c|}
1175,86 \\
\end{tabular} & \begin{tabular}{|l|l|}
168,47 \\
\end{tabular} & 28,44 & \begin{tabular}{|l|}
44,98 \\
\end{tabular} & 469,60 & \begin{tabular}{|l|}
117,91 \\
\end{tabular} & \begin{tabular}{|l|l|}
141,35 \\
\end{tabular} & 420,91 \\
\hline Hyla molleri & 29TMH98 & 28,00 & $\begin{array}{l}142,80 \\
\end{array}$ & 61,16 & 39,53 & 3177,18 & 226,53 & $\begin{array}{ll}73,42 \\
\end{array}$ & 153,11 & $\begin{array}{ll}112,60 \\
\end{array}$ & \begin{tabular}{|l|l|}
181,80 \\
\end{tabular} & \begin{tabular}{l|l|}
185,62 \\
\end{tabular} & \begin{tabular}{|l|}
103,67 \\
\end{tabular} & \begin{tabular}{|l|l|}
1013,53 \\
\end{tabular} & 141,49 & 28,18 & 41,00 & 395,73 & \begin{tabular}{|l|l|}
117,49 \\
\end{tabular} & 142,60 & 341,07 \\
\hline Hyla molleri & 29TNE13 & 97,00 & 154,79 & 80,80 & 43,68 & 3528,08 & 252,14 & 69,20 & 182,95 & 116,15 & \begin{tabular}{|l|}
196,97 \\
\end{tabular} & \begin{tabular}{|l|}
199,18 \\
\end{tabular} & \begin{tabular}{|l|}
108,20 \\
\end{tabular} & 885,08 & 126,62 & 8,21 & 54,91 & 362,20 & 53,86 & 60,55 & 356,00 \\
\hline Hyla molleri & 29TNE14 & 94,00 & 153,37 & 80,69 & 43,99 & 3489,40 & 249,04 & 67,60 & 181,44 & 114,96 & 194,89 & 196,96 & 106,94 & 915,43 & 130,14 & $8,93 \mathrm{Z}$ & 54,31 & 372,73 & 57,22 & 64,43 & 366,66 \\
\hline Hyla molleri & 29TNE15 & 95,00 & 152,10 & 79,87 & 44,23 & 3433,91 & 244,94 & 66,57 & $\mid 178,37$ & 114,04 & $\mid 192,57$ & \begin{tabular}{|l|l|}
194,69 \\
\end{tabular} & $\mid 106,07$ & 940,82 & 132,95 & 9,80 & 53,87 & 381,66 & 60,01 & 67,97 & 375,23 \\
\hline Hyla molleri & 29TNE17 & 40,00 & 151,00 & 77,70 & 44,97 & 3321,38 & 237,20 & 65,97 & 171,23 & 113,99 & 189,58 & \begin{tabular}{|l|l|}
191,34 \\
\end{tabular} & \begin{tabular}{|l|}
105,62 \\
\end{tabular} & 973,01 & 136,21 & 10,34 & 53,00 & \begin{tabular}{|l|}
393,07 \\
\end{tabular} & 63,24 & 72,89 & 385,45 \\
\hline Hyla molleri & 29TNE23 & 100,00 & \begin{tabular}{ll|}
156,94 \\
\end{tabular} & 86,62 & 43,62 & 3755,01 & 263,74 & $\begin{array}{l}67,06 \\
\end{array}$ & \begin{tabular}{|l|}
196,68 \\
\end{tabular} & 115,60 & 202,23 & \begin{tabular}{|l|l}
204,55 \\
2
\end{tabular} & \begin{tabular}{|l|l|}
107,75 \\
1
\end{tabular} & 889,55 & 126,60 & 8,44 & 54,58 & 361,68 & 55,13 & \begin{tabular}{ll|}
60,88 \\
\end{tabular} & 358,13 \\
\hline Hyla molleri & 29TNE24 & \begin{tabular}{|l|}
101,00 \\
\end{tabular} & 157,05 & 86,34 & 43,98 & 3694,57 & 261,43 & \begin{tabular}{ll|}
67,16 \\
\end{tabular} & $\begin{array}{l}194,27 \\
\end{array}$ & $\begin{array}{l}116,16 \\
\end{array}$ & 201,40 & \begin{tabular}{|l|}
203,60 \\
\end{tabular} & \begin{tabular}{|l|l|}
108,25 \\
\end{tabular} & \begin{tabular}{|l|}
901,97 \\
\end{tabular} & 127,53 & 8,99 & 53,98 & 365,32 & \begin{tabular}{|l|l|}
57,08 \\
\end{tabular} & \begin{tabular}{|l|l|}
63,58 \\
\end{tabular} & 361,36 \\
\hline Hyla molleri & 29TNE25 & 101,00 & 153,77 & 85,81 & 44,09 & 3656,36 & 256,26 & \begin{tabular}{l|l|}
64,15 \\
\end{tabular} & 192,11 & 113,23 & 197,53 & \begin{tabular}{|l|}
199,63 \\
\end{tabular} & \begin{tabular}{|l|}
105,25 \\
\end{tabular} & \begin{tabular}{|l|l|}
947,18 \\
\end{tabular} & 133,35 & 9,75 & \begin{tabular}{|l|l|}
53,42 \\
\end{tabular} & \begin{tabular}{|l|}
382,17 \\
\end{tabular} & \begin{tabular}{ll|}
61,32 \\
\end{tabular} & \begin{tabular}{|l|l|}
68,27 \\
\end{tabular} & 378,15 \\
\hline Hyla molleri & 29TNE26 & 100,00 & 152,32 & 84,16 & 44,45 & 3581,52 & 250,69 & 63,32 & 187,37 & 112,44 & 194,77 & \begin{tabular}{|l|}
196,81 \\
\end{tabular} & \begin{tabular}{|l|}
104,39 \\
\end{tabular} & 969,56 & 136,02 & \begin{tabular}{ll|}
10,03 \\
\end{tabular} & 53,09 & 390,74 & 63,01 & 70,94 & 385,71 \\
\hline Hyla molleri & 29TNE27 & 100,00 & 150,94 & 81,77 & 44,72 & 3491,93 & 244,10 & \begin{tabular}{|l|}
63,03 \\
\end{tabular} & 181,07 & 111,95 & 191,99 & \begin{tabular}{|l|}
193,90 \\
\end{tabular} & \begin{tabular}{|l|}
103,76 \\
\end{tabular} & \begin{tabular}{|c|}
988,28 \\
\end{tabular} & 138,04 & 10,85 & 52,79 & \begin{tabular}{|l|}
397,95 \\
\end{tabular} & \begin{tabular}{|l|l|}
65,18 \\
\end{tabular} & 74,10 & 391,49 \\
\hline Hyla molleri & 29TNE28 & 101,00 & 149,73 & 78,91 & 45,04 & 3384,36 & 236,65 & 63,11 & 173,54 & 111,73 & 189,05 & 190,76 & 103,37 & 1002,72 & 139,53 & 11,00 & 52,55 & 403,88 & 66,14 & 76,54 & 395,56 \\
\hline Hyla molleri & 29TNE29 & 91,00 & $\begin{array}{l}148,62 \\
\end{array}$ & 76,34 & 45,23 & 3286,96 & 230,02 & \begin{tabular}{l|l}
63,25 \\
\end{tabular} & 166,77 & $\begin{array}{l}111,66 \\
\end{array}$ & 186,35 & \begin{tabular}{|l|l|}
187,93 \\
\end{tabular} & \begin{tabular}{|l|}
103,07 \\
1
\end{tabular} & $\begin{array}{l}1017,60 \\
\end{array}$ & 140,94 & 11,13 & \begin{tabular}{l|l|}
52,35 \\
\end{tabular} & \begin{tabular}{|l|}
410,05 \\
\end{tabular} & 67,19 & \begin{tabular}{|l|}
78,96 \\
\end{tabular} & 399,81 \\
\hline Hyla molleri & 29TNE33 & 101,00 & 158,16 & \begin{tabular}{|l|}
92,64 \\
\end{tabular} & 43,21 & 4010,56 & 275,56 & \begin{tabular}{|l|l|}
64,01 \\
\end{tabular} & 211,56 & 112,29 & 207,16 & \begin{tabular}{|l|}
209,62 \\
\end{tabular} & \begin{tabular}{|l|}
106,24 \\
\end{tabular} & \begin{tabular}{|c|}
902,78 \\
\end{tabular} & 127,94 & 8,7 & 54,15 & \begin{tabular}{|l|}
364,73 \\
\end{tabular} & 57,45 & 61,96 & 363,85 \\
\hline Hyla molleri & 29TNE34 & 100,00 & \begin{tabular}{|l|}
158,71 \\
\end{tabular} & $\begin{array}{l}92,86 \\
\end{array}$ & 43,79 & 3959,58 & 274,19 & $\begin{array}{ll}64,23 \\
\end{array}$ & 209,97 & 114,31 & 206,84 & 209,11 & \begin{tabular}{|c|}
106,97 \\
\end{tabular} & \begin{tabular}{|c|}
911,58 \\
\end{tabular} & 128,28 & $\begin{array}{l}9,09 \\
\end{array}$ & \begin{tabular}{|l|l|}
53,73 \\
\end{tabular} & 366,69 & \begin{tabular}{|l|l|}
58,88 \\
\end{tabular} & \begin{tabular}{|l|l|}
64,19 \\
\end{tabular} & 365,55 \\
\hline Hyla molleri & 29TNE35 & \begin{tabular}{|l|}
101,00 \\
\end{tabular} & 155,88 & 92,45 & 44,00 & 3919,27 & 269,56 & \begin{tabular}{ll|}
61,58 \\
\end{tabular} & 207,99 & 112,19 & 203,42 & \begin{tabular}{l|l|}
205,66 \\
\end{tabular} & \begin{tabular}{|l|}
104,51 \\
\end{tabular} & 950,94 & $\begin{array}{l}133,34 \\
\end{array}$ & 9,92 & 53,16 & 381,31 & 62,81 & \begin{tabular}{|l|l|}
68,60 \\
\end{tabular} & 379,90 \\
\hline Hyla molleri & 29TNE36 & \begin{tabular}{|l|}
101,00 \\
\end{tabular} & $\begin{array}{l}153,32 \\
\end{array}$ & 90,79 & 44,05 & 3857,75 & 263,38 & 59,66 & 203,71 & 110,21 & 199,93 & \begin{tabular}{|l|l|}
201,99 \\
\end{tabular} & \begin{tabular}{|l|}
102,41 \\
\end{tabular} & \begin{tabular}{|l|l|}
984,04 \\
\end{tabular} & 137,65 & 10,85 & 52,91 & \begin{tabular}{|l|}
394,26 \\
\end{tabular} & 65,75 & \begin{tabular}{|l|}
72,21 \\
\end{tabular} & 391,82 \\
\hline Hyla molleri & 29TNE43 & 100,00 & 152,01 & 96,88 & 42,29 & 4334,80 & 280,95 & 54,54 & 226,42 & 97,23 & 206,12 & 208,63 & \begin{tabular}{|l|}
97,14 \\
\end{tabular} & 988,34 & 140,82 & 10,21 & 53,90 & 399,77 & \begin{tabular}{|l|l|}
65,27 \\
\end{tabular} & \begin{tabular}{|l|l|}
67,43 \\
\end{tabular} & 399,77 \\
\hline Hyla molleri & 29TNE45 & 101,00 & 159,50 & 98,46 & 43,90 & 4164,52 & 283,32 & \begin{tabular}{ll|}
60,82 \\
\end{tabular} & 222,49 & 108,75 & 210,58 & \begin{tabular}{|l|l|}
212,78 \\
\end{tabular} & \begin{tabular}{|l|}
105,32 \\
\end{tabular} & 936,35 & 130,70 & 9,7 & 52,90 & \begin{tabular}{|l|l|}
374,25 \\
\end{tabular} & 62,54 & \begin{tabular}{|l|l|}
67,44 \\
\end{tabular} & \begin{tabular}{|l|l|}
374,14 \\
\end{tabular} \\
\hline Hyla molleri & 29TNE48 & 101,00 & \begin{tabular}{|l|}
153,62 \\
\end{tabular} & \begin{tabular}{|l|}
91,44 \\
\end{tabular} & 44,01 & 3947,35 & 263,56 & 57,81 & 205,75 & 109,17 & 201,37 & \begin{tabular}{|l|}
203,17 \\
\end{tabular} & \begin{tabular}{|l|l|}
101,12 \\
\end{tabular} & \begin{tabular}{l|l|}
1001,46 \\
\end{tabular} & 139,26 & \begin{tabular}{|l|}
10,96 \\
1
\end{tabular} & 52,41 & \begin{tabular}{l|l|}
401,25 \\
\end{tabular} & \begin{tabular}{|l|l|}
66,83 \\
\end{tabular} & \begin{tabular}{|l|}
75,53 \\
\end{tabular} & 395,36 \\
\hline Hyla molleri & 29TNE49 & 100,00 & \begin{tabular}{|l|}
151,63 \\
\end{tabular} & 89,81 & 43,97 & 3905,53 & 258,44 & \begin{tabular}{l|l|}
56,55 \\
\end{tabular} & 201,90 & $\begin{array}{l}107,68 \\
\end{array}$ & 198,79 & \begin{tabular}{|l|}
200,54 \\
\end{tabular} & \begin{tabular}{l|l|}
99,55 \\
\end{tabular} & \begin{tabular}{|l|l|}
1025,40 \\
\end{tabular} & 142,39 & \begin{tabular}{|l|}
11,30 \\
\end{tabular} & 52,40 & 412,01 & 68,11 & \begin{tabular}{ll|}
78,33 \\
\end{tabular} & 403,22 \\
\hline Hyla molleri & 29TNE53 & \begin{tabular}{|l|}
101,00 \\
\end{tabular} & \begin{tabular}{|l|}
151,81 \\
\end{tabular} & \begin{tabular}{|l|l|}
98,81 \\
\end{tabular} & 41,57 & 4545,58 & 286,84 & 52,19 & 234,65 & $\begin{array}{l}94,84 \\
\end{array}$ & 209,36 & \begin{tabular}{|l|}
211,64 \\
\end{tabular} & 94,84 & \begin{tabular}{|l|l|}
1002,83 \\
\end{tabular} & $\begin{array}{l}143,49 \\
\end{array}$ & \begin{tabular}{|l|}
10,28 \\
\end{tabular} & 53,94 & \begin{tabular}{ll|}
406,24 \\
\end{tabular} & \begin{tabular}{ll|}
66,25 \\
\end{tabular} & \begin{tabular}{ll|}
67,75 \\
\end{tabular} & 406,24 \\
\hline Hyla molleri & 29TNE54 & 101,00 & 156,27 & 102,18 & 42,50 & 4514,23 & 292,22 & 54,6 & 237,61 & 99,0 & 212,75 & 215,25 & 99,02 & 975,79 & 137,69 & 10, & 53, & $392,97 \mid$ & 65,87 & 68,08 & 392,97 \\
\hline Hyla molleri & 29TNE55 & 99,00 & 150,55 & 100,13 & 42,22 & 4497,70 & 284,29 & 49 & 234,45 & 93,64 & 207,01 & 209,27 & 93,64 & 1043,22 & 148,06 & 11,2 & 53,1 & $|419,77|$ & 70,97 & 73,17 & 419,77 \\
\hline Hyla molleri & 29TNE78 & 100,00 & 148,15 & \begin{tabular}{|l|}
99,57 \\
\end{tabular} & 41,25 & 4758,31 & 283,45 & $\begin{array}{l}44,56 \\
\end{array}$ & 238,88 & 92,48 & 208,55 & \begin{tabular}{|l|}
209,97 \\
\end{tabular} & 87,76 & \begin{tabular}{|l|l|}
1076,81 \\
\end{tabular} & 155,12 & \begin{tabular}{|l|l|}
11,07 \\
\end{tabular} & 53,44 & \begin{tabular}{|l|l|}
431,68 \\
\end{tabular} & 70,90 & 75,54 & 431,42 \\
\hline Hyla molleri & 29TNE85 & 100,00 & 147,50 & 97,92 & 39,26 & 5042,36 & 289,99 & 44,08 & 245,90 & 85,04 & 212,90 & 214,17 & 85,04 & \begin{tabular}{|c|}
1059,06 \\
\end{tabular} & 155,04 & \begin{tabular}{|l|}
10,29 \\
\end{tabular} & 54,51 & \begin{tabular}{|l|l|}
429,45 \\
\end{tabular} & 68,30 & \begin{tabular}{|l|l|}
69,66 \\
\end{tabular} & 429,45 \\
\hline Hyla molleri & 29TNE96 & 100,00 & 144,25 & 96,90 & 38,48 & 5194,21 & 288,55 & \begin{tabular}{|l|}
39,98 \\
\end{tabular} & 248,56 & 80,12 & 211,84 & 212,90 & \begin{tabular}{l|l|}
80,12 \\
\end{tabular} & \begin{tabular}{|l|l|}
1084,89 \\
\end{tabular} & 160,45 & \begin{tabular}{l|l|}
10,32 \\
\end{tabular} & 54,88 & 440,40 & \begin{tabular}{ll|}
69,82 \\
\end{tabular} & \begin{tabular}{ll|}
70,58 \\
\end{tabular} & 440,40 \\
\hline Hyla molleri & 29TNE98 & 100,00 & 146,38 & \begin{tabular}{|l|}
99,49 \\
\end{tabular} & 39,50 & 5130,69 & 289,32 & 40,5 & 248,78 & 82,20 & 212,43 & \begin{tabular}{|l|}
213,62 \\
\end{tabular} & 82,20 & \begin{tabular}{|l|l|}
1069,29 \\
\end{tabular} & 157,42 & 10,31 & \begin{tabular}{|l|l|}
54,43 \\
\end{tabular} & 431,66 & \begin{tabular}{ll|}
68,89 \\
\end{tabular} & \begin{tabular}{|l|}
71,63 \\
\end{tabular} & 431,66 \\
\hline Hyla molleri & 29TNF25 & 28,00 & 51 & ,81. & 44,94 & 3674,23 & 243,21 & 54,34 & $|188,87|$ & $\mid 104,47$ & 189,3 & \begin{tabular}{|l|l|l|}
1918 \\
\end{tabular} & \begin{tabular}{|l|l|}
97,09 \\
\end{tabular} & 1183,21 & 162,3 & 14,8 & 51,15 & 472,75 & \begin{tabular}{|l|l|}
81,40 \\
\end{tabular} & \begin{tabular}{|l|}
99,72 \\
\end{tabular} & 460,91 \\
\hline Hyla molleri & 29TNF27 & 83,00 & 14 & 83,67 & 44,84 & 3665,84 & 241,48 & 56,50 & 184,98 & 98,16 & \begin{tabular}{|l|}
188,60 \\
\end{tabular} & \begin{tabular}{|l|}
190,35 \\
\end{tabular} & 96,94 & \begin{tabular}{|l|l|}
1229,74 \\
\end{tabular} & 168,04 & 15,06 & 51,32 & \begin{tabular}{|l|l|}
488,82 \\
\end{tabular} & 83,48 & 101,82 & 488,58 \\
\hline Hyla molleri & 29TNF29 & 100,00 & 143,40 & 81,55 & 43,81 & 3705,16 & 242,68 & 58,44 & 184,24 & 96,74 & 189,45 & \begin{tabular}{|l|}
190,99 \\
\end{tabular} & 96,74 & 1253,60 & 172,57 & 14,95 & 51,94 & 500,80 & 83,10 & \begin{tabular}{|l|}
104,21 \\
\end{tabular} & 500,80 \\
\hline Hyla molleri & 29TNF30 & 97,00 & 149,38 & 82,52 & 44,75 & 3564,68 & 241,69 & \begin{tabular}{|l|l|}
59,15 \\
\end{tabular} & \begin{tabular}{|l|}
182,54 \\
\end{tabular} & 109,24 & \begin{tabular}{|l|}
191,41 \\
\end{tabular} & \begin{tabular}{|l|l|}
193,03 \\
\end{tabular} & 100,90 & \begin{tabular}{|l|l|}
1039,18 \\
\end{tabular} & 143,20 & $\begin{array}{l}11,86 \\
\end{array}$ & \begin{tabular}{|l|l|}
52,06 \\
\end{tabular} & \begin{tabular}{|l|}
418,81 \\
\end{tabular} & \begin{tabular}{ll|l}
69,12 \\
\end{tabular} & 81,84 & 406,13 \\
\hline Hyla molleri & 29TNF31 & 101,00 & 148,07 & 83,26 & 44,69 & 3597,97 & 241,68 & 57,46 & 184,22 & 107,87 & 190,73 & $\begin{array}{r}192,50 \\
\end{array}$ & 99,47 & 1065,36 & 146,05 & 12,24 & 52,00 & 429,98 & 71,06 & 85,21 & 414,46 \\
\hline Hyla molleri & 29TNF32 & \begin{tabular}{|l|}
101,00 \\
\end{tabular} & $\begin{array}{l}145,57 \\
\end{array}$ & 84,92 & $\begin{array}{l}4,51 \\
\end{array}$ & $\begin{array}{l}6882,73 \\
\end{array}$ & 242,81 & 53,91 & \begin{tabular}{|l|l|}
188,90 \\
\end{tabular} & \begin{tabular}{|l|}
104,71 \\
\end{tabular} & \begin{tabular}{|l|l|}
189,77 \\
\end{tabular} & \begin{tabular}{|l|l|}
191,53 \\
\end{tabular} & \begin{tabular}{l|l|}
96,39 \\
\end{tabular} & $\begin{array}{l}1108,58 \\
\end{array}$ & 151,23 & 13, & \begin{tabular}{|l|l|}
51,97 \\
\end{tabular} & 448,35 & \begin{tabular}{|l|}
74,67 \\
\end{tabular} & \begin{tabular}{|l|}
90,24 \\
\end{tabular} & 429,45 \\
\hline Hyla molleri & 29TNF33 & & 143 & \begin{tabular}{ll|}
86,64 \\
\end{tabular} & 44,26 & 3769,42 & 244,08 & 50,32 & 193,75 & 101,57 & 188,84 & \begin{tabular}{|l|}
190,75 \\
\end{tabular} & 93,44 & $\begin{array}{l}1153,38 \\
\end{array}$ & 156,89 & 14, & \begin{tabular}{|l|}
51,96 \\
\end{tabular} & \begin{tabular}{|l|}
467,44 \\
\end{tabular} & $\begin{array}{ll}78,42 \\
\end{array}$ & \begin{tabular}{|l|}
95,49 \\
\end{tabular} & 444,94 \\
\hline Hyla molleri & 29TNF35 & 101,00 & \begin{tabular}{|l|}
143,79 \\
\end{tabular} & \begin{tabular}{|l|}
89,17 \\
\end{tabular} & 44,34 & 3853,99 & 248,86 & 50,08 & $\begin{array}{l}198,78 \\
\end{array}$ & 101,82 & 191,19 & \begin{tabular}{|l|}
193,23 \\
\end{tabular} & \begin{tabular}{|l|}
93,92 \\
\end{tabular} & $\begin{array}{l}1176,16 \\
\end{array}$ & 162,85 & 15,00 & 51,60 & $\begin{array}{l}476,56 \\
\end{array}$ & 80,52 & \begin{tabular}{|l|l|}
100,90 \\
\end{tabular} & 450,62 \\
\hline Hyla molleri & 29TNF36 & 100,00 & 142,72 & 88,75 & 44,37 & 3874,54 & 248,10 & 50,30 & 197,80 & 100,59 & 190,60 & \begin{tabular}{|l|}
192,54 \\
\end{tabular} & \begin{tabular}{|l|l|}
93,19 \\
\end{tabular} & \begin{tabular}{|l|l|}
1208,89 \\
\end{tabular} & 165,64 & 15,18 & 51,16 & 484,74 & 82,84 & \begin{tabular}{|l|l|}
101,99 \\
\end{tabular} & 470,16 \\
\hline Hyla molleri & 29TNF59 & 101,00 & \begin{tabular}{ll|}
139,94 \\
\end{tabular} & 93,48 & 42,13 & 4393,00 & 261,73 & 42,64 & 219,10 & 91,63 & 195,73 & \begin{tabular}{l|l|}
196,85 \\
\end{tabular} & 84,56 & \begin{tabular}{|l|l|}
1243,58 \\
\end{tabular} & 167,10 & 16,1 & 50,99 & 493,44 & 87,40 & \begin{tabular}{|l|}
103,38 \\
\end{tabular} & 48 \\
\hline Hyla molleri & 29TNF61 & & & & 41,30 & 4545,64 & 261,58 & 36, & 225,31 & 84,47 & 193,36 & 1 & \begin{tabular}{|l|}
78,12 \\
\end{tabular} & \begin{tabular}{|l|l|}
1233,48 \\
\end{tabular} & \begin{tabular}{|c|}
177,66 \\
\end{tabular} & \begin{tabular}{|l|l|}
13,94 \\
\end{tabular} & 53,23 & 497,11 & 82,71 & \begin{tabular}{|l|l|}
89,56 \\
\end{tabular} & 492,25 \\
\hline Hyla molleri & 29TNF70 & 100,00 & 131,12 & 93,82 & 39,84 & 4794,23 & 263,60 & 31,18 & 232,42 & 74,29 & \begin{tabular}{|l|}
193,10 \\
\end{tabular} & \begin{tabular}{|l|}
194,21 \\
\end{tabular} & \begin{tabular}{|l|}
71,49 \\
\end{tabular} & \begin{tabular}{|l|l|}
1276,03 \\
\end{tabular} & \begin{tabular}{|l|l|}
187,97 \\
\end{tabular} & \begin{tabular}{|l|}
13,92 \\
\end{tabular} & 54,17 & 515,51 & 84,71 & 88,05 & 514,91 \\
\hline Hyla molleri & 29TNF84 & 101,00 & 118,90 & 93,61 & 39,19 & 4982,55 & \begin{tabular}{|l|}
254,88 \\
\end{tabular} & \begin{tabular}{l|l|}
19,09 \\
\end{tabular} & 235,79 & 58,28 & 184,21 & \begin{tabular}{|l|l|}
184,84 \\
\end{tabular} & \begin{tabular}{l|l|}
57,85 \\
\end{tabular} & $\begin{array}{l}1397,56 \\
\end{array}$ & 206,45 & $\begin{array}{l}16,64 \\
\end{array}$ & $\begin{array}{l}54,06 \\
\end{array}$ & 565,62 & \begin{tabular}{|l|}
95,33 \\
\end{tabular} & $\begin{array}{l}98,47 \\
\end{array}$ & 565,51 \\
\hline Hyla molleri & 29TNF97 & 100,00 & 115,88 & 95,90 & 39,03 & 5136,17 & \begin{tabular}{|l|l|}
257,03 \\
\end{tabular} & \begin{tabular}{ll|}
14,56 \\
\end{tabular} & 242,47 & 53,35 & 183,44 & \begin{tabular}{|l|}
183,91 \\
\end{tabular} & \begin{tabular}{l|l|}
53,35 \\
\end{tabular} & \begin{tabular}{|l|}
1372,61 \\
\end{tabular} & 199,44 & 17,95 & 53,49 & 553,49 & $\begin{array}{l}98,06 \\
\end{array}$ & 101,01 & 553,49 \\
\hline Hyla molleri & 29TNG16 & 63,00 & 14 & & 39,81 & $\sqrt{3}$ & 233,48 & $71, \mathrm{C}$ & 162, & $\mid 107,66$ & 189,68 & \begin{tabular}{|l|l|}
190,80 \\
\end{tabular} & \begin{tabular}{|l|l|}
99,84 \\
\end{tabular} & 13612 & 195,80 & 24 & \begin{tabular}{|l|l|}
49,54 \\
\end{tabular} & 549 & $|108,17|$ & \begin{tabular}{|l|l|}
128,84 \\
\end{tabular} & 52 \\
\hline Hyla molleri & 29TNG17 & 33,00 & 149,14 & 62,22 & 38,97 & 3510,00 & 234,61 & \begin{tabular}{|l|}
76,97 \\
\end{tabular} & 157,64 & 112,28 & 193,11 & \begin{tabular}{|l|l|}
194,33 \\
\end{tabular} & \begin{tabular}{|l|}
104,31 \\
\end{tabular} & \begin{tabular}{|l|l|}
1294,33 \\
\end{tabular} & 179,89 & \begin{tabular}{|l|}
25,03 \\
\end{tabular} & 48,31 & 519,61 & \begin{tabular}{|l|}
107,44 \\
\end{tabular} & 128,50 & 486, \\
\hline Hyla molleri & 29TNG18 & 45,00 & 144,43 & 61,74 & 38,37 & 3541,20 & 231,42 & 73,05 & 158,37 & 107,44 & 189,24 & \begin{tabular}{|l|l|}
190,36 \\
\end{tabular} & 99,57 & \begin{tabular}{|l|l|}
1364,63 \\
\end{tabular} & 199,30 & 28,12 & \begin{tabular}{|l|}
48,48 \\
\end{tabular} & 549,64 & 116,34 & \begin{tabular}{|l|l|}
136,83 \\
\end{tabular} & 520,34 \\
\hline
\end{tabular}




\begin{tabular}{|c|c|c|c|c|c|c|c|c|c|c|c|c|c|c|c|c|c|c|c|c|c|}
\hline$\overline{\text { TAXON }}$ & UTM & $\mathrm{km} 2$ & BIO1 & BIO2 & $\begin{array}{l}\mathrm{BIO3} \\
\end{array}$ & BIO4 & 8105 & B106 & B107 & B108 & B109 & BIO10 & BIO11 & BIO12 & BIO13 & BIO14 & BIO15 & B1016 & B1017 & BIO18 & 81019 \\
\hline Hyla molleri & 29TNG19 & 57,00 & 145,12 & 59,99 & 37,97 & 3519,84 & 230,93 & 75,11 & 155,82 & 108,43 & 189,61 & 191,00 & 100,84 & 1316,97 & 192,33 & 28,91 & 47,32 & 528,09 & 117,50 & 139,10 & 493,80 \\
\hline Hyla molleri & 29TNG24 & 99,00 & 142,72 & 73,68 & 40,92 & 3762,67 & 240,82 & 62,56 & 178,27 & 101,27 & 190,16 & 191,21 & 95,21 & $\begin{array}{l}1360,54 \\
\end{array}$ & 195,29 & 21,41 & $\begin{array}{l}50,56 \\
\end{array}$ & \begin{tabular}{|l|l|}
545,50 \\
\end{tabular} & \begin{tabular}{|l|l|}
101,24 \\
\end{tabular} & \begin{tabular}{|l|l|}
121,49 \\
\end{tabular} & 538,65 \\
\hline Hyla molleri & 29TNG25 & 101,00 & \begin{tabular}{|l|}
142,44 \\
\end{tabular} & \begin{tabular}{|l|}
71,61 \\
\end{tabular} & $\begin{array}{l}40,21 \\
\end{array}$ & 3755,29 & 239,25 & \begin{tabular}{|l|l|}
63,49 \\
\end{tabular} & $\begin{array}{l}175,77 \\
\end{array}$ & $\begin{array}{l}101,68 \\
\end{array}$ & \begin{tabular}{|l|l|}
189,94 \\
\end{tabular} & \begin{tabular}{|l|}
190,94 \\
\end{tabular} & 95,01 & \begin{tabular}{|l|l|}
1394,60 \\
\end{tabular} & 206,60 & 23,94 & 50,39 & 561,40 & \begin{tabular}{l|l|}
107,55 \\
\end{tabular} & \begin{tabular}{|l|l|}
126,99 \\
\end{tabular} & 552,19 \\
\hline Hyla molleri & 29TNG26 & 100,00 & $\begin{array}{l}137,42 \\
\end{array}$ & $\begin{array}{l}70,38 \\
\end{array}$ & 39,69 & \begin{tabular}{|l|l|}
3792,18 \\
\end{tabular} & 234,78 & 59,26 & 175,52 & 95,03 & $\begin{array}{l}185,76 \\
\end{array}$ & \begin{tabular}{|l|l|}
186,73 \\
\end{tabular} & 89,89 & \begin{tabular}{|l|l|}
1494,19 \\
\end{tabular} & 233,27 & 28,30 & \begin{tabular}{|l|l|}
50,67 \\
\end{tabular} & \begin{tabular}{ll|}
605,16 \\
\end{tabular} & \begin{tabular}{|l|l|}
120,03 \\
\end{tabular} & \begin{tabular}{|l|l|}
137,69 \\
\end{tabular} & 598,49 \\
\hline Hyla molleri & 29TNG27 & 80,00 & 142,23 & 66,90 & 39,02 & $3729,91 \mid$ & 235,55 & $66,17 \mid$ & 169,38 & 100,94 & 189,67 & 190,59 & 95,20 & 1456,53 & 226,75 & 28,89 & 50,29 & 590,88 & 119,23 & 137,56 & 576,63 \\
\hline Hyla molleri & 29TNG28 & 86,00 & $\mid$\begin{tabular}{|l|}
139,17 \\
\end{tabular} & 65,44 & 38,37 & 3735,36 & 232,63 & 64,36 & $\mid 168,28$ & \begin{tabular}{|l|l|}
99,83 \\
\end{tabular} & $|186,87|$ & \begin{tabular}{|l|l|}
187,97 \\
\end{tabular} & \begin{tabular}{|l|l|}
92,44 \\
\end{tabular} & \begin{tabular}{|l|l|}
1463,59 \\
\end{tabular} & 227,46 & 31,15 & \begin{tabular}{|l|l|}
49,23 \\
\end{tabular} & \begin{tabular}{|l|}
589,78 \\
\end{tabular} & \begin{tabular}{|l|l|}
125,44 \\
\end{tabular} & \begin{tabular}{|l|l|}
144,09 \\
\end{tabular} & 572,35 \\
\hline Hyla molleri & 29TNG29 & 72,00 & 142,90 & 62,57 & 37,89 & 3707,49 & 233,27 & \begin{tabular}{l|l|}
70,12 \\
\end{tabular} & 163,15 & 103,57 & 190,24 & \begin{tabular}{|l|}
191,12 \\
\end{tabular} & \begin{tabular}{|c|}
96,35 \\
\end{tabular} & \begin{tabular}{|l|}
1394,43 \\
\end{tabular} & 212,13 & 30,94 & 48,26 & 558,48 & \begin{tabular}{|l|}
122,62 \\
\end{tabular} & 142,96 & 533,75 \\
\hline Hyla molleri & 29TNG32 & 101,00 & 142,57 & 82,02 & 41,84 & 3972,07 & 249,88 & 55,81 & 194,06 & 98,75 & 192,74 & \begin{tabular}{|l|}
193,71 \\
\end{tabular} & 92,50 & \begin{tabular}{|c|}
1300,19 \\
\end{tabular} & 180,92 & \begin{tabular}{|l|}
17,88 \\
\end{tabular} & 51,01 & 516,76 & 92,01 & 111,91 & 515,34 \\
\hline Hyla molleri & 29TNG36 & 101,00 & 144,76 & 73,61 & 39,76 & 3928,62 & 246,38 & \begin{tabular}{l|l|}
62,98 \\
\end{tabular} & 183,40 & 101,35 & \begin{tabular}{|l|}
194,70 \\
\end{tabular} & \begin{tabular}{|l|l|}
195,47 \\
\end{tabular} & 95,00 & \begin{tabular}{l|l|}
1380,58 \\
\end{tabular} & 213,07 & 25,50 & 50,08 & \begin{tabular}{|l|l|}
554,99 \\
\end{tabular} & \begin{tabular}{|l|l|}
110,69 \\
\end{tabular} & \begin{tabular}{|l|}
128,51 \\
\end{tabular} & 543,54 \\
\hline Hyla molleri & 29TNG40 & 101,00 & 145,85 & 88,48 & 42,53 & 4128,39 & \begin{tabular}{|l|l|}
258,94 \\
\end{tabular} & \begin{tabular}{|l|}
53,25 \\
\end{tabular} & 205,69 & 100,52 & \begin{tabular}{|l|l|}
197,76 \\
\end{tabular} & \begin{tabular}{|l|l|}
198,85 \\
\end{tabular} & $\begin{array}{l}93,45 \\
\end{array}$ & \begin{tabular}{|l|l|}
1208,74 \\
\end{tabular} & 163,53 & 15,25 & 50,98 & \begin{tabular}{|l|l|}
478,58 \\
\end{tabular} & 83,25 & 102,33 & 474,61 \\
\hline Hyla molleri & 29TNG48 & 100,00 & 128,16 & 78,41 & 39,08 & 4198,61 & 239,79 & 41,84 & 197,95 & 83,04 & 182,58 & \begin{tabular}{|l|}
183,64 \\
\end{tabular} & \begin{tabular}{ll|}
76,66 \\
\end{tabular} & \begin{tabular}{|l|l|}
1502,07 \\
\end{tabular} & 239,28 & 32,79 & 48,85 & $\begin{array}{l}595,05 \\
\end{array}$ & \begin{tabular}{|l|}
133,86 \\
\end{tabular} & \begin{tabular}{|l|l|}
147,87 \\
\end{tabular} & 587,57 \\
\hline Hyla molleri & 29TNG59 & 100,00 & 113,55 & 80,92 & 38,72 & 4310,81 & 231,79 & 25,08 & 206,71 & 67,71 & $\begin{array}{l}170,02 \\
\end{array}$ & \begin{tabular}{|l|l|}
171,45 \\
1
\end{tabular} & \begin{tabular}{ll|}
62,24 \\
\end{tabular} & \begin{tabular}{|l|}
1509,61 \\
\end{tabular} & 226,36 & 35,67 & 46,38 & \begin{tabular}{|l|}
586,61 \\
\end{tabular} & $\begin{array}{ll}144,05 \\
\end{array}$ & \begin{tabular}{|l|}
155,97 \\
\end{tabular} & 575,97 \\
\hline Hyla molleri & 29TNG72 & 100,00 & 97,65 & 83,12 & 37,48 & 4745,83 & 225,53 & 6,75 & 218,78 & 42,20 & 160,59 & \begin{tabular}{|l|l|}
161,38 \\
\end{tabular} & \begin{tabular}{|l|}
41,58 \\
\end{tabular} & $\begin{array}{l}1545,54 \\
\end{array}$ & 206,22 & 28,51 & 49,13 & \begin{tabular}{|c|}
607,76 \\
\end{tabular} & \begin{tabular}{|l|}
130,75 \\
\end{tabular} & 134,74 & 607,72 \\
\hline Hyla molleri & \begin{tabular}{|l|} 
29TNG73 \\
\end{tabular} & 100,00 & 115,12 & 89,06 & 38,83 & 4792,36 & 245,33 & 18,81 & 226,53 & $\begin{array}{l}61,56 \\
\end{array}$ & \begin{tabular}{|c|}
177,89 \\
\end{tabular} & \begin{tabular}{|l|}
178,53 \\
\end{tabular} & \begin{tabular}{|l|l|}
57,06 \\
\end{tabular} & 1389,96 & 190,55 & 24,75 & $\begin{array}{ll}48,83 \\
\end{array}$ & 543,13 & \begin{tabular}{|l|l|}
116,06 \\
\end{tabular} & \begin{tabular}{|l|}
122,88 \\
\end{tabular} & 540,40 \\
\hline Hyla molleri & 29TNG77 & 101,00 & 133,18 & 91,21 & 39,10 & 4819,46 & 261,81 & \begin{tabular}{|l|}
31,66 \\
\end{tabular} & 230,15 & 79,49 & 195,82 & \begin{tabular}{|l|l|}
196,10 \\
\end{tabular} & 73,70 & \begin{tabular}{|l|l|}
1193,18 \\
\end{tabular} & \begin{tabular}{|l|}
176,81 \\
\end{tabular} & 24,51 & 46,56 & 456,50 & \begin{tabular}{|l|}
108,58 \\
\end{tabular} & \begin{tabular}{l|l|}
116,42 \\
\end{tabular} & 442,62 \\
\hline Hyla molleri & 29TNG78 & 100,00 & 139,06 & 89,04 & 38,86 & 4789,06 & 264,12 & \begin{tabular}{|l|}
37,72 \\
\end{tabular} & 226,40 & 85,44 & 201,18 & \begin{tabular}{|l|l|}
201,45 \\
\end{tabular} & \begin{tabular}{|l|l|}
79,82 \\
\end{tabular} & \begin{tabular}{|l|l|}
1126,93 \\
\end{tabular} & 167,65 & \begin{tabular}{|l|}
24,12 \\
\end{tabular} & \begin{tabular}{l|l|}
45,96 \\
\end{tabular} & \begin{tabular}{|l|l|}
428,39 \\
\end{tabular} & \begin{tabular}{|l|l|}
104,06 \\
\end{tabular} & \begin{tabular}{|l|l|}
112,19 \\
\end{tabular} & 412,40 \\
\hline Hyla molleri & \begin{tabular}{|l|} 
29TNG79 \\
\end{tabular} & \begin{tabular}{|l|}
101,00 \\
\end{tabular} & \begin{tabular}{|l|l|}
133,19 \\
\end{tabular} & 87,50 & 39,00 & 4661,57 & 256,21 & 34,45 & 221,75 & 81,21 & $\begin{array}{l}193,93 \\
\end{array}$ & \begin{tabular}{|l|l|}
194,44 \\
\end{tabular} & 76,28 & \begin{tabular}{|l|l|}
1197,87 \\
\end{tabular} & $\begin{array}{l}178,93 \\
\end{array}$ & \begin{tabular}{|l|}
27,37 \\
\end{tabular} & \begin{tabular}{|l|}
45,64 \\
\end{tabular} & 455,84 & \begin{tabular}{|l|}
113,58 \\
\end{tabular} & \begin{tabular}{|l|}
125,92 \\
\end{tabular} & 441,24 \\
\hline Hyla molleri & 29TNG83 & 100,00 & 95,35 & 82,54 & 36,89 & 4825,88 & 224,96 & 4,18 & 220,77 & 39,97 & 159,66 & 160,33 & 38,78 & 1502,75 & $|199,67|$ & \begin{tabular}{|l|l|}
29,19 \\
\end{tabular} & \begin{tabular}{|l|l|}
48,38 \\
\end{tabular} & 587,88 & 130,81 & \begin{tabular}{|l|l|}
134,52 \\
\end{tabular} & 587,87 \\
\hline Hyla molleri & 29TNG87 & 100,00 & 131,52 & 92,63 & 38,90 & 4978,81 & 263,13 & 27,19 & 235,94 & 75,96 & 196,55 & \begin{tabular}{|l|l|}
196,79 \\
\end{tabular} & \begin{tabular}{|l|}
70,46 \\
\end{tabular} & \begin{tabular}{|l|l|}
1135,81 \\
\end{tabular} & 164,80 & 23,53 & 46,00 & 431,70 & 103,51 & \begin{tabular}{|l|}
109,38 \\
\end{tabular} & 420,30 \\
\hline Hyla molleri & 29TNG92 & 101,00 & \begin{tabular}{|l|}
104,70 \\
\end{tabular} & 86,50 & 37,29 & 4987,78 & 238,55 & \begin{tabular}{|l|}
9,44 \\
\end{tabular} & 229,12 & 45,29 & 170,90 & \begin{tabular}{|l|}
171,31 \\
\end{tabular} & 45,2 & \begin{tabular}{|l|l|}
1385,85 \\
\end{tabular} & 185,38 & 24, & 49,44 & 545,62 & 114,51 & \begin{tabular}{|c|}
117,69 \\
\end{tabular} & 545,62 \\
\hline Hyla molleri & 29TNG93 & 100,00 & 96,32 & 83,47 & 36,63 & 4929,91 & 228,39 & 3,62 & 224,77 & 39,17 & \begin{tabular}{|l|}
162,07 \\
\end{tabular} & 162,53 & 38,30 & 1441,20 & 190,75 & 27,84 & 48,34 & 563,31 & 125,34 & 128,21 & 563,31 \\
\hline Hyla molleri & 29TNG94 & 100,00 & 104,76 & 86,30 & 37,24 & 4947,62 & 237,78 & 9,36 & 228,42 & 50,88 & \begin{tabular}{|l|l|}
170,56 \\
\end{tabular} & \begin{tabular}{|l|l|}
170,87 \\
\end{tabular} & 45,91 & \begin{tabular}{|l|l|}
1358,63 \\
\end{tabular} & 181,85 & 26,28 & 47,98 & 528,21 & \begin{tabular}{|l|}
118,26 \\
\end{tabular} & \begin{tabular}{|l|}
122,51 \\
\end{tabular} & 528,04 \\
\hline Hyla molleri & 29TNHOO & 16,00 & 147,29 & 59,00 & 38,48 & 3400,52 & 230,67 & \begin{tabular}{l|l|}
78,95 \\
\end{tabular} & \begin{tabular}{|l|}
151,71 \\
\end{tabular} & \begin{tabular}{|l|}
112,29 \\
\end{tabular} & $\begin{array}{l}190,24 \\
\end{array}$ & \begin{tabular}{|l|l|}
191,67 \\
\end{tabular} & \begin{tabular}{|l|l|}
104,38 \\
\end{tabular} & 1225,90 & $\begin{array}{l}174,48 \\
\end{array}$ & 26,95 & 46,81 & \begin{tabular}{|l|l|}
491,57 \\
\end{tabular} & \begin{tabular}{|l|}
111,81 \\
\end{tabular} & \begin{tabular}{|l|}
134,71 \\
\end{tabular} & 450,57 \\
\hline Hyla molleri & 29TNHO1 & 40,00 & 144,58 & 59,91 & 38,18 & 3389,01 & 229,52 & 75,00 & 154,52 & 110,27 & 186,96 & 189,12 & 101,96 & 1190,85 & 170,30 & 27,81 & 45,66 & $475,97 \mid$ & 115,04 & 138,49 & 430,70 \\
\hline Hyla molleri & 29TNHO2 & 97,00 & 132,26 & 63,14 & 37,98 & 3521,94 & 224,76 & \begin{tabular}{l|l}
60,48 \\
\end{tabular} & 164,28 & 97,19 & \begin{tabular}{|l|}
177,01 \\
\end{tabular} & \begin{tabular}{|l|}
179,36 \\
\end{tabular} & 89,11 & \begin{tabular}{|l|l|}
1311,65 \\
\end{tabular} & 191,91 & 32,7 & $\begin{array}{l}44,97 \\
\end{array}$ & 520,73 & \begin{tabular}{|l|}
131,71 \\
\end{tabular} & 153,40 & 479,06 \\
\hline Hyla molleri & 29TNH06 & 101,00 & 130,82 & 64,73 & 38,44 & 3443,75 & 224,58 & 58,12 & 166,45 & $\begin{array}{l}97,50 \\
\end{array}$ & 174,06 & \begin{tabular}{|l|}
177,48 \\
\end{tabular} & \begin{tabular}{|l|}
89,05 \\
\end{tabular} & \begin{tabular}{|l|}
1201,01 \\
\end{tabular} & 168,81 & 33,56 & 41,93 & 468,53 & \begin{tabular}{|l|l|}
134,43 \\
\end{tabular} & 157,51 & 418,84 \\
\hline Hyla molleri & \begin{tabular}{|l|} 
29TNH08 \\
\end{tabular} & 81,00 & 139,86 & 62,83 & 39,45 & 3245,91 & 226,50 & \begin{tabular}{|l|l|}
68,94 \\
\end{tabular} & 157,55 & 108,65 & \begin{tabular}{|l|}
179,71 \\
\end{tabular} & \begin{tabular}{|l|}
183,68 \\
\end{tabular} & \begin{tabular}{|l|}
99,93 \\
\end{tabular} & \begin{tabular}{|l|l|}
1066,54 \\
\end{tabular} & 146,17 & 30,11 & 40,82 & 414,13 & 122,84 & \begin{tabular}{|l|}
147,26 \\
\end{tabular} & 363,35 \\
\hline Hyla molleri & 29TNH10 & 61,00 & \begin{tabular}{|l|l|}
146,39 \\
\end{tabular} & $\begin{array}{ll}60,06 \\
\end{array}$ & 37,91 & 3519,36 & 232,27 & 76,11 & 156,16 & 109,72 & 190,75 & \begin{tabular}{|l|}
192,23 \\
\end{tabular} & \begin{tabular}{|l|}
101,94 \\
\end{tabular} & 1275,06 & 185,37 & 28,73 & 46,99 & \begin{tabular}{|l|}
509,45 \\
\end{tabular} & \begin{tabular}{|l|l|}
116,28 \\
\end{tabular} & \begin{tabular}{|l|}
138,47 \\
\end{tabular} & 472,93 \\
\hline Hyla molleri & 29TNH11 & 40,00 & 146,34 & 60,45 & 37,82 & 3518,47 & 233,20 & \begin{tabular}{|l|}
75,68 \\
\end{tabular} & 157,53 & \begin{tabular}{|l|}
109,97 \\
\end{tabular} & 190,80 & \begin{tabular}{|l|}
192,50 \\
\end{tabular} & \begin{tabular}{|l|l|}
102,30 \\
\end{tabular} & \begin{tabular}{|l|l|}
1241,93 \\
\end{tabular} & 180,28 & 28,89 & 46,24 & \begin{tabular}{|l|l|}
494,43 \\
\end{tabular} & \begin{tabular}{|l|l|}
116,57 \\
\end{tabular} & \begin{tabular}{|l|}
139,20 \\
\end{tabular} & 455,66 \\
\hline Hyla molleri & 29TNH12 & 80,00 & 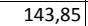 & 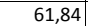 & 37,90 & \begin{tabular}{|l|l|}
3527,18 \\
\end{tabular} & 233,33 & \begin{tabular}{|l|l|}
72,06 \\
\end{tabular} & $|161,27|$ & \begin{tabular}{|l|l|}
107,84 \\
\end{tabular} & \begin{tabular}{|l|l|}
188,46 \\
\end{tabular} & \begin{tabular}{|l|l|}
190,54 \\
\end{tabular} & $\begin{array}{ll}99,85 \\
\end{array}$ & $\begin{array}{l}1225,40 \\
\end{array}$ & 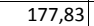 & 29,87 & \begin{tabular}{|l|l|}
45,22 \\
\end{tabular} & \begin{tabular}{|l|l|l|}
485,94 \\
\end{tabular} & \begin{tabular}{|l|l|}
119,86 \\
\end{tabular} & \begin{tabular}{|l|l|}
142,71 \\
\end{tabular} & \begin{tabular}{|l|l|l}
444,59 \\
\end{tabular} \\
\hline Hyla molleri & 29TNH22 & 98,00 & 142,56 & \begin{tabular}{ll|}
64,37 \\
\end{tabular} & $\begin{array}{l}37,83 \\
\end{array}$ & 3673,06 & 236,45 & \begin{tabular}{|l|}
68,27 \\
\end{tabular} & 168,18 & 104,48 & \begin{tabular}{|l|l|}
189,39 \\
\end{tabular} & \begin{tabular}{|l|l|}
191,20 \\
\end{tabular} & 97,00 & \begin{tabular}{l|l|}
1282,23 \\
\end{tabular} & 189,18 & 31,60 & 45,59 & $\begin{array}{l}505,62 \\
\end{array}$ & \begin{tabular}{|l|l|}
124,06 \\
\end{tabular} & \begin{tabular}{l|l|}
145,95 \\
\end{tabular} & 470,89 \\
\hline Hyla molleri & 29TNH23 & 100,00 & $\begin{array}{l}140,69 \\
\end{array}$ & 65,81 & 37,91 & 3675,02 & 236,85 & 65,44 & 171,42 & 102,96 & 187,49 & \begin{tabular}{|l|l|}
189,76 \\
\end{tabular} & \begin{tabular}{|l|}
95,38 \\
\end{tabular} & \begin{tabular}{l|l|}
1268,02 \\
\end{tabular} & 185,23 & 32,23 & 44,81 & \begin{tabular}{|l|}
497,28 \\
\end{tabular} & \begin{tabular}{|l|l|}
126,63 \\
\end{tabular} & \begin{tabular}{|l|l|}
148,60 \\
\end{tabular} & 460,75 \\
\hline Hyla molleri & 29TNH27 & 100,00 & 129,17 & $\begin{array}{l}68,83 \\
\end{array}$ & 38,77 & 3574,89 & 228,79 & 53,35 & 175,45 & \begin{tabular}{|l|l|}
94,07 \\
\end{tabular} & 174,25 & \begin{tabular}{|l|}
178,02 \\
\end{tabular} & 86,21 & \begin{tabular}{|l|l|}
1259,95 \\
\end{tabular} & 175,62 & 36,27 & 41,11 & \begin{tabular}{|l|l|}
484,03 \\
\end{tabular} & \begin{tabular}{|l|}
140,94 \\
\end{tabular} & \begin{tabular}{l|l|}
162,85 \\
\end{tabular} & 443,55 \\
\hline Hyla molleri & 29TNH28 & 101,00 & 138,15 & 66,22 & 39,76 & 3371,93 & 229,55 & 64,80 & 164,75 & 105,12 & \begin{tabular}{|l|}
179,97 \\
\end{tabular} & \begin{tabular}{|l|l|}
183,87 \\
\end{tabular} & \begin{tabular}{|l|}
96,86 \\
\end{tabular} & \begin{tabular}{l|l|}
1124,24 \\
\end{tabular} & 152,92 & 32,00 & 40,55 & \begin{tabular}{|l|l|}
432,17 \\
\end{tabular} & \begin{tabular}{|l|}
126,98 \\
\end{tabular} & \begin{tabular}{|l|}
150,29 \\
\end{tabular} & 389,89 \\
\hline Hyla molleri & 29TNH29 & 39,00 & \begin{tabular}{|l|l|}
138,94 \\
\end{tabular} & 65,60 & 40,11 & 3300,89 & 227,96 & \begin{tabular}{ll|}
66,33 \\
\end{tabular} & \begin{tabular}{|l|}
161,63 \\
\end{tabular} & \begin{tabular}{|l|}
106,78 \\
\end{tabular} & \begin{tabular}{|l|l|}
179,56 \\
\end{tabular} & \begin{tabular}{|l|}
183,64 \\
\end{tabular} & \begin{tabular}{l|l|}
98,28 \\
\end{tabular} & \begin{tabular}{|l|l|}
1096,42 \\
\end{tabular} & 147,44 & $\begin{array}{l}31,46 \\
\end{array}$ & 39,97 & 420,50 & \begin{tabular}{|l|}
125,51 \\
\end{tabular} & 149,00 & 378,18 \\
\hline Hyla molleri & 29TNH30 & 101,00 & \begin{tabular}{|l|}
136,38 \\
\end{tabular} & 68,31 & 37,86 & 3916,51 & 236,40 & \begin{tabular}{|l|}
58,16 \\
\end{tabular} & 178,24 & 94,75 & 186,93 & \begin{tabular}{|l|}
188,06 \\
\end{tabular} & 88,14 & $\begin{array}{l}1444,96 \\
\end{array}$ & 225,06 & 34,07 & 47,76 & \begin{tabular}{|l|l|}
572,47 \\
\end{tabular} & 132,50 & \begin{tabular}{l|l|}
151,25 \\
\end{tabular} & 553,08 \\
\hline Hyla molleri & 29TNH33 & \begin{tabular}{|l|}
101,00 \\
\end{tabular} & $\begin{array}{l}140,89 \\
\end{array}$ & $\begin{array}{ll}68,88 \\
\end{array}$ & 37,78 & 3814,67 & 241,68 & \begin{tabular}{l|l|}
61,72 \\
\end{tabular} & $\begin{array}{l}179,97 \\
\end{array}$ & 101,09 & $\begin{array}{l}189,69 \\
\end{array}$ & \begin{tabular}{l|l|}
191,86 \\
\end{tabular} & \begin{tabular}{|l|}
94,03 \\
9
\end{tabular} & \begin{tabular}{|l|l|}
1286,69 \\
\end{tabular} & $\begin{array}{l}188,93 \\
\end{array}$ & 32,96 & \begin{tabular}{|l|l|}
44,87 \\
\end{tabular} & 500,80 & \begin{tabular}{|l|l|}
127,77 \\
\end{tabular} & \begin{tabular}{|l|l|}
149,09 \\
\end{tabular} & 469,14 \\
\hline Hyla molleri & 29TNH34 & 100,00 & 137,98 & 70,61 & 37,67 & 3829,36 & 242,21 & 57,25 & 184,96 & 98,68 & 186,96 & \begin{tabular}{|l|l|}
189,58 \\
\end{tabular} & $\begin{array}{l}91,35 \\
\end{array}$ & \begin{tabular}{|l|}
1297,37 \\
\end{tabular} & 188,15 & 34,52 & 43,99 & 501,72 & 132,89 & 154,22 & 468,82 \\
\hline Hyla molleri & 29TNH35 & 101,00 & \begin{tabular}{l|l|}
132,84 \\
\end{tabular} & 72,28 & 37,68 & 3838,58 & 240,40 & 50,95 & 189,4 & 94,1 & 182,0 & \begin{tabular}{|l|l|}
185,10 \\
\end{tabular} & 86,7 & \begin{tabular}{|l|}
1326,75 \\
\end{tabular} & 190,10 & 36,6 & 43,10 & 509,81 & \begin{tabular}{|l|}
140,19 \\
\end{tabular} & 161,30 & 476,37 \\
\hline Hyla molleri & 29TNH37 & 101,00 & $\begin{array}{l}127,82 \\
\end{array}$ & 71,68 & 38,69 & 3685,61 & 231,99 & \begin{tabular}{l|l|}
48,85 \\
\end{tabular} & 183,14 & 91,12 & 174,58 & \begin{tabular}{|l|}
178,31 \\
\end{tabular} & 83,80 & \begin{tabular}{|l|l|}
1296,43 \\
\end{tabular} & 180,66 & \begin{tabular}{|l|}
37,63 \\
\end{tabular} & 41,15 & \begin{tabular}{|l|l|}
494,57 \\
\end{tabular} & \begin{tabular}{|l|l|}
144,29 \\
\end{tabular} & \begin{tabular}{|l|l|}
165,38 \\
\end{tabular} & 458,65 \\
\hline Hyla molleri & 29TNH39 & 66,00 & \begin{tabular}{|l|}
137,72 \\
\end{tabular} & 67,21 & 40,50 & 3335,65 & 228,27 & \begin{tabular}{|l|l|}
64,37 \\
\end{tabular} & 163,90 & 104,80 & 178,85 & \begin{tabular}{|l|l|}
182,93 \\
\end{tabular} & 96,84 & $\begin{array}{l}1111,28 \\
\end{array}$ & 148,76 & \begin{tabular}{|l|}
32,07 \\
\end{tabular} & 39,82 & 423,65 & \begin{tabular}{l|l|}
126,76 \\
\end{tabular} & \begin{tabular}{l|l|}
149,62 \\
\end{tabular} & 385,50 \\
\hline Hyla molleri & 29TNH42 & 100,00 & \begin{tabular}{|l|}
132,13 \\
\end{tabular} & $\begin{array}{l}74,96 \\
\end{array}$ & 37,98 & 4042,12 & 242,29 & $\begin{array}{l}47,15 \\
4\end{array}$ & 195,13 & 89,34 & 184,54 & \begin{tabular}{|l|}
186,42 \\
\end{tabular} & 83,32 & \begin{tabular}{|l|l|}
1407,67 \\
\end{tabular} & 212,28 & 35,99 & 45,57 & 545,52 & \begin{tabular}{|l|}
138,23 \\
\end{tabular} & \begin{tabular}{|l|l|}
156,49 \\
\end{tabular} & 523,46 \\
\hline Hyla molleri & 29TNH44 & 99,00 & 134,34 & 75,62 & 37,50 & 4016,51 & 247,01 & 47,82 & 199,18 & 92,76 & 186,25 & 188,81 & 86,23 & 1354,82 & 196,79 & 36,70 & 43,95 & 518,70 & 139,25 & 159,31 & 490,94 \\
\hline Hyla molleri & 29TNH45 & 100,00 & 133,85 & , 41 & 37,71 & 3948,35 & 245,54 & \begin{tabular}{|l|l|}
48,08 \\
\end{tabular} & 197,45 & 93,39 & 184,49 & 187,60 & \begin{tabular}{l|l|}
86,62 \\
\end{tabular} & $\mid 1327,24$ & \begin{tabular}{|l|l|}
189,42 \\
\end{tabular} & 36,86 & \begin{tabular}{|l|l|}
42,92 \\
\end{tabular} & 505,97 & \begin{tabular}{|l|l|}
139,84 \\
\end{tabular} & \begin{tabular}{|l|l|}
160,39 \\
\end{tabular} & \begin{tabular}{|l|l|}
476,27 \\
\end{tabular} \\
\hline Hyla molleri & 29TNH46 & 100,00 & 133,61 & 74,17 & 38,49 & 3807,22 & 241,03 & 50,75 & 190,27 & 94,78 & 182,11 & \begin{tabular}{|l|}
185,54 \\
\end{tabular} & 87,87 & $\begin{array}{l}1277,88 \\
\end{array}$ & 179,38 & 36,11 & \begin{tabular}{|l|}
41,96 \\
\end{tabular} & 486,11 & \begin{tabular}{|l|}
137,91 \\
\end{tabular} & \begin{tabular}{|l|}
158,76 \\
\end{tabular} & 454,57 \\
\hline Hyla molleri & 29TNH47 & 101,00 & 129,79 & 73,67 & 39,01 & 3726,10 & 235,43 & 48,83 & 186,61 & 92,02 & 177,26 & 180,80 & 85,29 & 1276,81 & 177,09 & 37,02 & 41,03 & \begin{tabular}{|l|l|}
484,24 \\
\end{tabular} & \begin{tabular}{|l|}
141,41 \\
\end{tabular} & 162,11 & 451,80 \\
\hline Hyla molleri & \begin{tabular}{|l|} 
29TNH48 \\
\end{tabular} & $\begin{array}{l}99,00 \\
\end{array}$ & 130,64 & 71,90 & 39,94 & 3580,81 & 231,16 & 52,91 & 178,25 & $\begin{array}{l}94,65 \\
\end{array}$ & \begin{tabular}{|l|l|}
175,87 \\
\end{tabular} & \begin{tabular}{|l|l|}
179,58 \\
\end{tabular} & \begin{tabular}{l|l|}
87,62 \\
\end{tabular} & \begin{tabular}{|l|l|}
1222,47 \\
\end{tabular} & \begin{tabular}{ll|}
166,76 \\
\end{tabular} & 35,87 & 40,09 & \begin{tabular}{|l|l|}
463,07 \\
\end{tabular} & \begin{tabular}{|l|}
138,08 \\
\end{tabular} & \begin{tabular}{|l|}
159,15 \\
\end{tabular} & 429,36 \\
\hline Hyla molleri & 29TNH49 & 99,00 & 138,44 & \begin{tabular}{|l|l|}
68,49 \\
\end{tabular} & 41,26 & 3334,69 & 228,73 & \begin{tabular}{|l|l|}
64,79 \\
\end{tabular} & \begin{tabular}{|l|}
163,94 \\
\end{tabular} & 105,25 & \begin{tabular}{|l|}
179,57 \\
\end{tabular} & \begin{tabular}{|l|}
183,74 \\
\end{tabular} & \begin{tabular}{l|l|}
97,48 \\
\end{tabular} & \begin{tabular}{|l|l|}
1091,49 \\
\end{tabular} & $\begin{array}{l}144,73 \\
\end{array}$ & 31,59 & 39,26 & 413,86 & \begin{tabular}{l|l|}
124,45 \\
1
\end{tabular} & \begin{tabular}{|l|}
146,72 \\
\end{tabular} & 379,25 \\
\hline Hyla molleri & 29TNH50 & \begin{tabular}{|l|l}
101,00 \\
\end{tabular} & 81 & 80,39 & 38,78 & 4246,05 & 232,99 & 27,72 & 205,27 & \begin{tabular}{|c|}
70,53 \\
\end{tabular} & $\mid$\begin{tabular}{|l|l|}
171,45 \\
\end{tabular} & $\mid 172,95$ & 65,34 & \begin{tabular}{|c|}
1493,95 \\
\end{tabular} & 224,52 & 36,57 & $\mid 45,84$ & \begin{tabular}{|l|l|}
578,78 \\
\end{tabular} & $\mid 145,19$ & \begin{tabular}{|l|}
158,22 \\
\end{tabular} & 565,92 \\
\hline Hyla molleri & 29TNH52 & & & 79,71 & 38, & 4121,18 & 23 & 34,24 & 202,96 & 77 & \begin{tabular}{|l|}
175,64 \\
\end{tabular} & \begin{tabular}{|l|}
177,56 \\
\end{tabular} & 73,6 & \begin{tabular}{|l|l|}
1442,01 \\
\end{tabular} & 214,66 & 37,59 & \begin{tabular}{|l|}
44,81 \\
\end{tabular} & 553,96 & 145,11 & 160,61 & 535,85 \\
\hline Hyla molleri & \begin{tabular}{|l|l|} 
29TNH55 \\
\end{tabular} & 101,00 & & 77,84 & 38,55 & 3952,98 & 244,93 & 45,58 & 199,35 & 91,08 & 183,42 & \begin{tabular}{|l|l|}
186,37 \\
\end{tabular} & \begin{tabular}{|l|}
85,47 \\
\end{tabular} & 1311,62 & 186,78 & 36,64 & 42,66 & \begin{tabular}{|l|l|}
496,98 \\
\end{tabular} & \begin{tabular}{|l|}
138,85 \\
\end{tabular} & 158,30 & 470,35 \\
\hline Hyla molleri & 29TNH57 & 100,00 & 129,49 & 75,79 & 39,47 & 3760,92 & 236,42 & 46,84 & 189,58 & 90,69 & 177,58 & \begin{tabular}{|l|}
181,00 \\
\end{tabular} & 84,70 & \begin{tabular}{|l|}
1264,25 \\
\end{tabular} & 174,91 & 36,84 & 40,79 & 476,82 & \begin{tabular}{|l|}
140,23 \\
\end{tabular} & 160,14 & 447,24 \\
\hline Hyla molleri & 29TNH58 & 101,00 & 136,43 & 72,36 & 40,72 & 3553,90 & 234,25 & 58,55 & 175,70 & 100,03 & 181,02 & \begin{tabular}{|l|l|}
184,78 \\
\end{tabular} & \begin{tabular}{|l|}
93,25 \\
\end{tabular} & \begin{tabular}{|l|l|}
1141,24 \\
\end{tabular} & 154,04 & 33,6 & 39,87 & 430,70 & 128,01 & 149,16 & 39 \\
\hline Hyla molleri & $29 \mathrm{TNh}$ & 98,00 & 140 & & 41,80 & 3381 & 231,80 & 66 & 165,56 & 106,31 & 182,51 & \begin{tabular}{|l|}
186,54 \\
\end{tabular} & \begin{tabular}{|l|}
99,09 \\
\end{tabular} & 105 & 139,63 & \begin{tabular}{|l|}
30,57 \\
\end{tabular} & 39,04 & 399,41 & \begin{tabular}{|l|}
120,42 \\
\end{tabular} & \begin{tabular}{|l|l|}
142,28 \\
\end{tabular} & 367,09 \\
\hline Hyla molleri & 29TNH61 & 101,00 & 119,95 & 82,67 & 39,13 & 4262,34 & 238,07 & 29,73 & 208,34 & $\begin{array}{l}73,64 \\
\end{array}$ & \begin{tabular}{|l|}
175,70 \\
\end{tabular} & \begin{tabular}{|l|l|}
177,29 \\
\end{tabular} & $\begin{array}{l}69,46 \\
\end{array}$ & $\begin{array}{l}1400,04 \\
\end{array}$ & 207,77 & \begin{tabular}{l|l|}
35,43 \\
\end{tabular} & 44,95 & 536,38 & \begin{tabular}{|l|l|}
139,36 \\
\end{tabular} & \begin{tabular}{|l|}
153,01 \\
\end{tabular} & 521,48 \\
\hline Hyla molleri & 29TNH64 & 101,00 & 133,27 & 80,09 & 39,73 & 3986,03 & 244,84 & 45,28 & 199,56 & 89,76 & 184,79 & \begin{tabular}{|l|}
187,14 \\
\end{tabular} & 85,81 & 1267,58 & 182,28 & 34,57 & 42,88 & \begin{tabular}{|l|}
479,13 \\
\end{tabular} & \begin{tabular}{|l|l|}
132,16 \\
13
\end{tabular} & $\begin{array}{l}150,26 \\
\end{array}$ & 456,27 \\
\hline Hyla molleri & 29TNH66 & 101,00 & 129,58 & 78,71 & 39,87 & 3857,86 & 239,18 & 44,01 & 195,17 & 88,47 & 179,21 & \begin{tabular}{|l|}
182,21 \\
\end{tabular} & 83,81 & \begin{tabular}{|l|}
1260,61 \\
\end{tabular} & 176,24 & 36,25 & 41,21 & \begin{tabular}{|l|l|}
474,02 \\
\end{tabular} & $\mid 137,71$ & $\begin{array}{l}156,45 \\
\end{array}$ & 447,92 \\
\hline Hyla m & $\mathrm{TNh}$ & 95, & & 77 & 41,5 & 500, & 233 & 61,39 & 172, & 102,55 & 182, & 186 & \begin{tabular}{|l|l|}
95,99 \\
\end{tabular} & 1070 & & 31 & 38 & 401 & 122,61 & & \\
\hline Hyla molleri & 29TNH70 & 101,00 & 121,99 & 85,74 & 39,01 & 4488,05 & 244,15 & 27,49 & 216,65 & 72,54 & 180,79 & \begin{tabular}{|l|}
181,86 \\
\end{tabular} & 68,41 & $\mid$\begin{tabular}{|l|l|}
1311,15 \\
\end{tabular} & 193,43 & \begin{tabular}{|l|l|}
31,86 \\
\end{tabular} & 44,90 & 500,27 & \begin{tabular}{|l|l|}
128,43 \\
\end{tabular} & \begin{tabular}{|l|l|}
141,17 \\
\end{tabular} & 487 \\
\hline Hyla molleri & 29TNH76 & 100,00 & 123,45 & 80,75 & 40,48 & 3913,96 & 234,63 & 37,28 & 197,35 & 81,06 & 174,02 & \begin{tabular}{|l|l|}
176,74 \\
\end{tabular} & \begin{tabular}{|l|}
77,42 \\
\end{tabular} & \begin{tabular}{|l|l|}
1263,07 \\
\end{tabular} & 175,84 & 36,85 & 40,71 & 472,81 & \begin{tabular}{l|l|}
140,15 \\
\end{tabular} & 157,23 & 448,44 \\
\hline
\end{tabular}




\begin{tabular}{|c|c|c|c|c|c|c|c|c|c|c|c|c|c|c|c|c|c|c|c|c|c|}
\hline TAXON & UTM & km2 & BIO1 & B102 & BIO3 & 8104 & B105 & B106 & B107 & B108 & B109 & 81010 & B1011 & BIO12 & B1O13 & B1014 & 81015 & B1016 & B1017 & B1018 & \begin{tabular}{|l|} 
BIO19 \\
\end{tabular} \\
\hline Hyla molleri & 29TNH78 & 100,00 & 125,41 & 78,00 & 40,75 & 3774,11 & 231,87 & 42,35 & 189,52 & 85,45 & 173,73 & 176,95 & 80,70 & 1203,79 & 163,01 & 36,49 & 39,10 & 448,58 & 138,77 & $\begin{array}{r}157,20 \\
\end{array}$ & 420,48 \\
\hline Hyla molleri & 29TNH85 & 101,00 & 121,53 & 83,23 & 40,44 & 4063,13 & 235,80 & 32,57 & 203,23 & 76,88 & 174,31 & 176,45 & 73,91 & 1235,25 & 172,50 & 35,55 & 40,89 & 461,64 & 135,93 & \begin{tabular}{|l|}
151,63 \\
\end{tabular} & 439,92 \\
\hline Hyla molleri & 29TNH86 & 101,00 & 115,94 & 82,36 & 40,29 & 4041,46 & 230,32 & 28,34 & 201,98 & 72,10 & 168,44 & 170,87 & 68,70 & 1270,44 & 175,37 & 37,83 & 39,99 & 473,87 & \begin{tabular}{|l|}
143,78 \\
\end{tabular} & 159,12 & 450,46 \\
\hline Hyla molleri & 29TNH87 & 100,00 & 120,24 & 81,21 & 40,53 & 3948,06 & 231,67 & 33,64 & \begin{tabular}{|l|l|}
198,03 \\
\end{tabular} & \begin{tabular}{|l|l|}
77,44 \\
\end{tabular} & 171,24 & 173,84 & 73,78 & 1223,72 & 167,01 & 37,04 & 39,34 & \begin{tabular}{|l|}
454,95 \\
\end{tabular} & 140,50 & 157,10 & $\begin{array}{l}429,47 \\
\end{array}$ \\
\hline Hyla molleri & 29TNH88 & 101,00 & 120,39 & 79,96 & 40,75 & 3879,56 & 229,84 & 35,39 & \begin{tabular}{|l|l}
194,45 \\
\end{tabular} & 78,82 & \begin{tabular}{|l|l|}
170,37 \\
\end{tabular} & 173,09 & 74,51 & 1209,88 & 163,08 & 37,42 & 38,62 & 448,59 & 141,75 & 158,84 & 421,24 \\
\hline Hyla molleri & 29TNH91 & 101,00 & 118,31 & 88,03 & 39,00 & 4616,37 & 244,04 & 21,27 & 222,77 & 67,07 & 178,96 & 179,91 & 63,44 & 1205,83 & 171,39 & 30,83 & 43,10 & 454,83 & 123,06 & 135,26 & 441,25 \\
\hline Hyla molleri & 29TNH98 & 101,00 & 121,27 & 81,36 & 40,79 & 3959,32 & 232,09 & 34,47 & 197,61 & 78,34 & 172,28 & 174,98 & 74,29 & 1159,91 & 155,18 & 36,09 & 38,11 & 428,21 & 137,12 & 153,85 & 401,04 \\
\hline Hyla molleri & 29TNJ51 & 48,00 & 137,32 & 69,06 & 42,18 & 3289,25 & 226,38 & 64,58 & 161,79 & 104,32 & 177,74 & 182,08 & 96,99 & 1053,97 & 136,43 & 32,00 & 37,81 & 395,00 & 125,51 & 147,40 & 360,88 \\
\hline Hyla molleri & 29TNJ61 & 82,00 & 138,78 & 70,46 & 42,23 & 3350,75 & 229,34 & 64,74 & 164,60 & \begin{tabular}{|l|l|}
104,63 \\
\end{tabular} & \begin{tabular}{|l|l|}
180,27 \\
\end{tabular} & 184,22 & 97,70 & \begin{tabular}{|l|}
1035,07 \\
\end{tabular} & 133,93 & 31,48 & 37,61 & 386,40 & 123,21 & \begin{tabular}{|l|l|}
144,96 \\
\end{tabular} & 352,94 \\
\hline Hyla molleri & 29TNJ72 & 101,00 & 133,10 & 72,15 & 42,08 & 3432,01 & 226,92 & 57,35 & \begin{tabular}{|l|l|}
169,57 \\
\end{tabular} & \begin{tabular}{|l|l|}
97,92 \\
\end{tabular} & 175,90 & 179,71 & 91,45 & 1067,50 & 137,07 & 34,02 & 36,65 & 394,97 & 131,15 & 152,16 & 360,88 \\
\hline Hyla molleri & 29TNI83 & 101,00 & 130,18 & 72,98 & 41,98 & 3479,40 & 225,55 & 53,48 & \begin{tabular}{|l|l|}
172,07 \\
\end{tabular} & \begin{tabular}{|l|}
94,38 \\
\end{tabular} & \begin{tabular}{|l|l|}
173,69 &
\end{tabular} & 177,47 & 88,12 & 1072,64 & 137,44 & 35,55 & 35,79 & 393,85 & \begin{tabular}{|l|l|}
135,68 \\
\end{tabular} & 156,29 & 358,51 \\
\hline Hyla molleri & 29TNI84 & 31,00 & 128,75 & 72,62 & 42,07 & 3463,58 & 223,64 & 52,51 & 171,13 & 93,16 & 172,00 & 175,75 & 86,98 & 1079,11 & 138,18 & 36,49 & 35,25 & 395,05 & 138,64 & 159,35 & 358,69 \\
\hline Hyla molleri & 29TNJ93 & 92,00 & 133,74 & 73,98 & 41,97 & 3525,79 & 229,64 & 55,54 & \begin{tabular}{|l|l|}
174,11 \\
\end{tabular} & \begin{tabular}{|l|}
96,84 \\
\end{tabular} & \begin{tabular}{|c|}
177,87 \\
\end{tabular} & \begin{tabular}{|l|}
181,48 \\
\end{tabular} & 91,05 & 1025,37 & 131,62 & 34,11 & 35,33 & 374,76 & \begin{tabular}{|l|}
130,39 \\
\end{tabular} & 150,86 & 339,41 \\
\hline Hyla molleri & 29TNJ94 & 26,00 & 139,35 & 72,33 & 42,44 & 3429,44 & 231,53 & 63,05 & \begin{tabular}{|l|l|}
168,49 &
\end{tabular} & 103,72 & \begin{tabular}{|l|l|}
181,98 \\
\end{tabular} & 185,72 & 97,65 & 980,72 & 127,09 & 32,65 & 35,09 & 358,56 & 125,33 & 146,77 & 322,12 \\
\hline Hyla molleri & 29TPE06 & 100,00 & 135,12 & 91,66 & 36,74 & 5328,00 & 278,88 & 32,86 & \begin{tabular}{|l|l|}
246,03 \\
\end{tabular} & 70,31 & 205,51 & 205,99 & 70,31 & 1164,94 & 175,36 & 11,03 & 55,58 & \begin{tabular}{|l|l|}
475,27 \\
\end{tabular} & 73,03 & 73,29 & $\begin{array}{ll}475,27 \\
\end{array}$ \\
\hline Hyla molleri & 29TPE07 & 101,00 & 141,90 & 96,20 & 37,94 & 5321,55 & 287,46 & 36,82 & 250,64 & 76,22 & 211,36 & 212,15 & 76,22 & 1091,34 & 162,71 & 10,26 & 55,15 & 443,22 & 69,66 & 70,37 & 443,22 \\
\hline Hyla molleri & 29TPE08 & 100,00 & 144,63 & 98,44 & 38,54 & 5297,72 & 290,27 & 38,25 & 252,02 & \begin{tabular}{|l|l|}
78,79 \\
\end{tabular} & 213,46 & 214,23 & 78,79 & 1062,03 & 157,71 & 9,92 & 54,88 & 429,93 & 67,87 & 69,61 & 429,93 \\
\hline Hyla molleri & 29TPE09 & 100,00 & 139,40 & 97,45 & 38,44 & 5293,84 & 284,18 & 33,86 & 250,32 & 73,69 & 208,42 & 209,06 & 73,69 & 1121,11 & 167,79 & 10,81 & 55,10 & \begin{tabular}{|l|l|}
454,88 \\
\end{tabular} & 72,02 & 73,49 & 454,88 \\
\hline Hyla molleri & 29TPE16 & 100,00 & 89,37 & 73,79 & 32,38 & 5308,01 & 222,81 & $-1,45$ & 224,25 & 29,35 & 162,23 & 162,23 & 29,35 & \begin{tabular}{|l|}
1627,76 \\
\end{tabular} & 249,32 & 17,25 & 56,10 & 663,37 & 100,90 & 100,90 & 663,37 \\
\hline Hyla molleri & 29TPE17 & 100,00 & 105,52 & 77,94 & 33,30 & 5333,84 & 240,87 & 11,12 & 229,75 & 43,46 & 177,77 & 177,83 & 43,46 & \begin{tabular}{|l|l|}
1488,39 \\
\end{tabular} & 230,10 & 14,23 & 56,81 & 610,46 & 89,59 & 89,68 & 610,46 \\
\hline Hyla molleri & 29TPE18 & 101,00 & 138,06 & 94,81 & 37,17 & 5436,40 & 284,38 & 32,78 & 251,60 & 71,02 & 209,38 & 209,73 & 71,02 & 1101,46 & 165,42 & 10,36 & 55,31 & 447,47 & 70,05 & 70,65 & 447,47 \\
\hline Hyla molleri & 29TPE23 & 100,00 & $\begin{array}{l}136,93 \\
\end{array}$ & \begin{tabular}{|l|l|}
89,41 \\
\end{tabular} & 34,98 & 5655,55 & \begin{tabular}{|l|l|}
286,47 \\
\end{tabular} & 34,08 & 252,39 & 69,31 & 212,77 & 212,88 & 69,31 & $\begin{array}{l}1072,25 \\
\end{array}$ & $\begin{array}{l}160,25 \\
\end{array}$ & \begin{tabular}{|l}
9,60 \\
\end{tabular} & 55 & $\begin{array}{l}44,1,4 \\
436,33 \\
\end{array}$ & 65,86 & 65,86 & 436,33 \\
\hline Hyla molleri & 29TPE24 & 100,00 & 142,68 & 92,77 & 35,65 & 5654,12 & 293,58 & 37,45 & 256,12 & \begin{tabular}{|l|l|}
74,19 \\
\end{tabular} & \begin{tabular}{|l|l|}
217,73 \\
\end{tabular} & 218,05 & 74,19 & 1014,30 & 150,67 & 8,95 & 55,21 & 411,38 & 63,29 & 63,31 & 411,38 \\
\hline Hyla molleri & 29TPE26 & 101,00 & 103,49 & 76,74 & 32,49 & 5450,47 & 240,55 & 9,06 & \begin{tabular}{|l|}
231,49 \\
\end{tabular} & 40,44 & 177,45 & 177,47 & 40,44 & 1460,65 & 224,47 & 13,97 & 56,51 & 598,38 & 87,92 & 88,13 & 598,38 \\
\hline Hyla molleri & 29TPE27 & 100,00 & 106,99 & 77,23 & 32,68 & 5450,44 & 243,96 & 11,69 & 232,27 & 43,10 & 180,52 & 180,54 & 43,10 & 1421,80 & 219,17 & 13,32 & 56,76 & 583,80 & 85,34 & 86,46 & 583,80 \\
\hline Hyla molleri & 29TPE33 & $\begin{array}{l}101,00 \\
\end{array}$ & 151,94 & 96,18 & 35,97 & 5812,66 & 307,44 & 43,36 & \begin{tabular}{|l|l|}
264,08 \\
\end{tabular} & 84,32 & 228,71 & 229,21 & 81,34 & \begin{tabular}{|l}
887,47 \\
\end{tabular} & 129,32 & $\begin{array}{l}7,58 \\
\end{array}$ & 54,42 & 356,64 & 56,06 & 56,28 & 356,61 \\
\hline Hyla molleri & 29TPE34 & \begin{tabular}{|l|l}
100,00 \\
\end{tabular} & $\begin{array}{l}144,07 \\
144,\end{array}$ & $\mid$ & 35,58 & $\begin{array}{l}501,200 \\
5763,97\end{array}$ & $\mid$ & | 37,53 & $\begin{array}{l}259,00 \\
259,47\end{array}$ & $\begin{array}{l}-04,32 \\
74,25\end{array}$ & 220,63 & $\mid$ & $\mid \frac{1,34}{74,25}$ & $\begin{array}{l}\mid c 0,1,41 \\
963,29\end{array}$ & \begin{tabular}{|l|}
142,08 \\
142,08
\end{tabular} & $\begin{array}{l}7,20 \\
8,48\end{array}$ & $\begin{array}{l}34,4 \mathrm{c} \\
54,82\end{array}$ & | & 60 & $\begin{array}{l}30,20 \\
60,78\end{array}$ & 388,56 \\
\hline Hyla molleri & 29TPE35 & 100,00 & 142,56 & 93,42 & 35,63 & 5737,22 & 294,59 & 35,97 & 258,62 & 72,78 & 218,54 & 218,67 & 72,78 & 976,71 & 144,52 & 8,80 & 54,84 & 394,12 & 61,76 & 61,99 & 394,12 \\
\hline Hyla molleri & 29TPE36 & 101,00 & 139,74 & 92,73 & 35,61 & 5699,14 & 290,19 & 33,56 & 256,64 & 70,23 & 215,06 & 215,18 & 70,23 & 1004,28 & 149,39 & 9,13 & 54,98 & \begin{tabular}{|l|l|}
405,67 \\
\end{tabular} & 63,55 & 64,08 & 405,67 \\
\hline Hyla molleri & 29TPE37 & 100,00 & 126,44 & 86,62 & 34,39 & 5632,12 & 272,12 & 24,14 & 247,98 & 58,40 & 201,32 & 201,39 & 58,40 & 1136,45 & 171,51 & 10,64 & 55,48 & 461,98 & 70,81 & 73,01 & 461,98 \\
\hline Hyla molleri & 29TPE38 & 101,00 & 108,42 & 77,78 & 32,55 & 5536,88 & 247,27 & $\begin{array}{l}11,75 \\
11,75\end{array}$ & 235,51 & 42,64 & \begin{tabular}{|l|l|}
182,53 \\
\end{tabular} & $\mid 182,68$ & 42,64 & $\begin{array}{l}1323,69 \\
\end{array}$ & 202,22 & 12,65 & 56,09 & 541,51 & 81,32 & 87,37 & 541,51 \\
\hline Hyla molleri & 29TPE 43 & \begin{tabular}{|l|l}
101,00 \\
\end{tabular} & $\begin{array}{l}10,434 \\
153,35\end{array}$ & $\mid$\begin{tabular}{|l|l|}
97,14 \\
\end{tabular} & $\begin{array}{l}2,35 \\
35,97\end{array}$ & $\begin{array}{l}530,000 \\
5887,56\end{array}$ & \begin{tabular}{|l|l|l|}
310,18 \\
3
\end{tabular} & 4 & $\mid$ & 89, 89,12 & $\mid$ & \begin{tabular}{|l|l|l|l|l|l|l|}
231,48 \\
\end{tabular} & $\begin{array}{l}42,04 \\
81,69 \\
\end{array}$ & $\begin{array}{r}530,03 \\
837,38\end{array}$ & $\begin{array}{l}\mid 02<, 2< \\
120,72\end{array}$ & $\mid$ & S3, & $\mid$ & 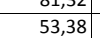 & | & 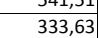 \\
\hline Hyla molleri & 29TPE44 & 100,00 & 149,48 & 96,03 & 35,86 & 5860,33 & 304,97 & 40,37 & 264,60 & \begin{tabular}{|l|l|}
84,59 \\
\end{tabular} & 226,95 & 227,18 & 78,09 & 871,44 & 126,58 & 7,52 & 54,06 & 348,36 & 55,63 & 55,78 & 347,93 \\
\hline Hyla molleri & 29TPE45 & 101,00 & 142,38 & 93,54 & 35,41 & 5824,43 & 295,68 & 34,92 & 260,76 & 74,84 & 219,54 & 219,65 & 71,49 & 934,96 & 137,33 & 8,42 & 54,35 & 374,92 & 59,48 & 59,90 & 374,91 \\
\hline Hyla molleri & 29TPE46 & 99,00 & 140,79 & 93,71 & 35,62 & 5799,87 & 293,41 & 33,34 & 260,08 & 71,02 & 217,52 & 217,64 & 70,0 & 944,75 & 139,10 & 8,62 & 54,33 & 378,87 & 60,64 & 61,32 & 378,87 \\
\hline Hyla molleri & 29TPE48 & 99,00 & 117,54 & 82,71 & 33,32 & 5674,60 & 261,50 & 16,91 & 244,60 & 48,96 & \begin{tabular}{|l|l|}
192,78 \\
\end{tabular} & 193,24 & 48,96 & 1155,77 & 173,94 & $\begin{array}{l}11,18 \\
1\end{array}$ & 55,15 & 468,54 & 73,04 & 77,68 & 468,54 \\
\hline Hyla molleri & 29TPE49 & 101,00 & 125,55 & 88,94 & 34,86 & 5693,66 & 273,09 & 21,39 & 251,70 & 56,06 & 200,71 & 201,07 & 56,06 & \begin{tabular}{|l|}
1071,79 \\
\end{tabular} & 160,32 & 10,53 & 54,81 & 432,91 & 69,15 & 71,71 & 432,91 \\
\hline Hyla molleri & 29TPE53 & 100,00 & 151,91 & 97,36 & 35,85 & 5953,50 & 309,70 & 41,55 & 268,15 & 87,23 & 230,81 & 231,01 & 79,58 & 808,77 & 115,52 & 6,97 & 53,33 & 321,81 & 52,04 & 52,23 & 319,62 \\
\hline Hyla molleri & 29TPE54 & 100,00 & 147,75 & 95,98 & 35,62 & 5933,51 & 304,19 & 38,06 & 266,13 & 83,16 & 226,32 & 226,50 & 75,69 & 844,05 & 121,51 & 7,38 & 53,61 & 335,96 & 54,66 & 54,79 & 334,47 \\
\hline Hyla molleri & 29TPE55 & 100,00 & 139,99 & 93,16 & 35,09 & 5892,53 & 294,01 & 32,20 & 261,81 & 76,16 & 218,11 & 218,19 & 68,40 & 909,11 & 132,39 & 8,41 & 53,90 & 362,66 & 58,54 & 59,38 & 361,92 \\
\hline Hyla molleri & 29TPE56 & $\begin{array}{l}101,00 \\
\end{array}$ & 128,25 & 88,22 & 34,20 & 5835,14 & 278,60 & 23,79 & 254,82 & 62,95 & 205,80 & 206,08 & 57,84 & $\begin{array}{r}1007,41 \\
\end{array}$ & 148,40 & \begin{tabular}{|l|}
$9,4,62$ \\
\end{tabular} & 54,15 & 403,27 & $64,4,49$ & 67,35 & 403,21 \\
\hline Hyla molleri & 29TPE58 & 101,00 & 120,47 & 85,76 & 33,81 & 5774,86 & 268,03 & 17,55 & 250,48 & 51, & \begin{tabular}{|l|l|}
196,97 \\
\end{tabular} & 197,58 & 50,51 & 1064,41 & 157,89 & 10,49 & 54,30 & 427,55 & 68,80 & 72,51 & 427,55 \\
\hline Hyla molleri & 29TPE59 & 100,00 & $\begin{array}{l}119,76 \\
\end{array}$ & 86,90 & $\begin{array}{l}34,11 \\
34,11\end{array}$ & 5766,20 & 267,68 & 16,35 & 251,34 & 49,78 & 196,01 & \begin{tabular}{|l|l|}
196,68 \\
\end{tabular} & 49,78 & \begin{tabular}{|l|l}
1061,22 \\
\end{tabular} & 157,39 & 10,70 & $\begin{array}{l}54,14 \\
54,\end{array}$ & 426,26 & 69,47 & 72,85 & 426,26 \\
\hline Hyla molleri & 29TPE63 & 100,00 & 147,31 & 96,56 & 35,56 & 6005,60 & 305,46 & 37, & 268,21 & 82,40 & 227,14 & 227,18 & 74,60 & 805,58 & 114,23 & 7,23 & 52,82 & 319,18 & 52,55 & 52,87 & 315,84 \\
\hline Hyla molleri & 29TPE64 & 101,00 & 148,18 & 97,18 & 35,78 & 5989,67 & 305,84 & 37,38 & \begin{tabular}{|l|}
268,45 \\
\end{tabular} & \begin{tabular}{|l|l|}
82,93 \\
\end{tabular} & 227,58 & 227,62 & 75,21 & 797,19 & 113,21 & 7,17 & 52,86 & 315,68 & 52,29 & 52,49 & 312,48 \\
\hline Hyla molleri & 29TPE65 & $\begin{array}{l}100,00 \\
\end{array}$ & \begin{tabular}{|l|}
129,91091 \\
129
\end{tabular} & \begin{tabular}{|l|}
90,14 \\
90
\end{tabular} & $\begin{array}{l}30,10 \\
34,26\end{array}$ & $\begin{array}{l}5929,70 \\
5929\end{array}$ & $\mid$ & 23, & \begin{tabular}{|l|l|}
259,45 \\
259
\end{tabular} & 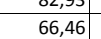 & \begin{tabular}{|l|l}
208,92 \\
\end{tabular} & 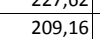 & $\begin{array}{l}58,67 \\
5\end{array}$ & \begin{tabular}{|l}
944,84 \\
94,
\end{tabular} & \begin{tabular}{|l|l|l|l|l}
136,77 \\
\end{tabular} & $\frac{1,21}{9,21}$ & $\begin{array}{l}52,00 \\
53,25\end{array}$ & \begin{tabular}{|l} 
\\
375,780
\end{tabular} & $\begin{array}{l}31,54 \\
61,54\end{array}$ & $\begin{array}{l}32,49 \\
63,95\end{array}$ & $\begin{array}{l}31,43,87 \\
373,87\end{array}$ \\
\hline Hyla molleri & 29TPE66 & 100,00 & 121,79 & 86,97 & 33,72 & 5881,62 & 272,26 & 17,83 & 254,43 & 59,20 & 200,18 & 200,57 & 51,21 & 1009,52 & 147,16 & 10,10 & 53,46 & 402,21 & 65,82 & 69,68 & 400,97 \\
\hline Hyla molleri & 29TPE67 & 101,00 & 125,29 & 89,10 & 34,18 & 5888,96 & 276,66 & 19,84 & 256,83 & \begin{tabular}{|l|l|}
61,99 \\
\end{tabular} & 203,34 & 203,90 & 54,13 & \begin{tabular}{|c|}
971,07 \\
\end{tabular} & 141,31 & 9,83 & 53,26 & 386,21 & 64,13 & 66,99 & 385,15 \\
\hline Hyla molleri & 29TPE68 & 99,00 & 124,21 & 89,65 & 34,41 & 5871,67 & 275,38 & 18,5 & $256, \varepsilon$ & 60,36 & 201,86 & 202,53 & 53,08 & 971,17 & 141,44 & 9,8 & 53,2 & 386,12 & 64,70 & 67,43 & 385,41 \\
\hline Hyla molleri & 29TPE69 & \begin{tabular}{|r|}
101,00 \\
\end{tabular} & 12 & 90, & 34,72 & 585 & 274 & 17 & 257,56 & 58 & 200,55 & 201,39 & 52 & \begin{tabular}{|l|l|l|}
969,08 \\
\end{tabular} & \begin{tabular}{|l|l|}
141,09 \\
\end{tabular} & 10,03 & 53,06 & 385,06 & 65,36 & 67,80 & 384,65 \\
\hline Hyla molleri & 29TPE73 & $\begin{array}{l}100,00 \\
100\end{array}$ & \begin{tabular}{|l|}
$150,30,3$ \\
150
\end{tabular} & \begin{tabular}{|l|l|}
90,84 \\
98,8
\end{tabular} & $\begin{array}{l}34,1 / 2 \\
35,77\end{array}$ & $\begin{array}{l}3050,27 \\
6062,09\end{array}$ & $\mid$\begin{tabular}{|l|l|l|l|}
310,71 \\
\end{tabular} & \begin{tabular}{|l|}
38,27 \\
38
\end{tabular} & 272,44 & 80,81 & $\mid$ & \begin{tabular}{|l|}
201,39 \\
230,80
\end{tabular} & $\begin{array}{c}32,01 \\
76,58\end{array}$ & \begin{tabular}{|l|l|l} 
\\
739,65
\end{tabular} & \begin{tabular}{|l|}
$141,02,88$ \\
102
\end{tabular} & $\begin{array}{r}\mid 0,035 \\
6,62\end{array}$ & S1, 51,89 & $\mid$ & | & $\begin{array}{l}01,80 \\
49,23\end{array}$ & $\begin{array}{l}384,03 \\
285,78\end{array}$ \\
\hline Hyla molleri & 29TPE76 & 101,00 & $\begin{array}{l}116,20 \\
\end{array}$ & 87,38 & 33,60 & 5936,45 & 267,97 & 12,02 & 255,95 & 53,37 & 195,55 & 196,01 & 45,46 & 998,94 & 143,22 & 10,53 & 52,42 & 395,43 & 67,06 & 71,63 & 392,21 \\
\hline Hyla molleri & 29TPE77 & 100,00 & 122,37 & 90,04 & 34,30 & 5945,46 & 275,26 & 16,19 & 259,07 & 58,62 & 201,30 & 201,94 & 50,77 & 938,22 & 134,22 & 9,98 & 52,23 & 370,92 & 63,72 & 66,87 & 367,88 \\
\hline Hyla molle & 29TPE78 & 101,00 & 123,45 & -1 & 34,80 & 5941,90 & 7276 & 16,45 & 260,49 & 59,43 & 202,15 & 202,87 & 51,50 & 917, & 131, & 9,8 & 52,04 & 362,22 & 63,19 & 65,75 & 359,37 \\
\hline Hyla molleri & 29TPE79 & 99,00 & 12 & & $35, \mathrm{C}$ & 593 & 279 & 16,71 & 262,37 & 60,47 & 203,1 & 204,08 & 52,60 & 896,75 & 127,89 & 9,73 & 51, & 353,66 & 62,66 & 64,50 & 351 , \\
\hline Hyla molleri & 29TPE86 & $\begin{array}{r}100,00 \\
\end{array}$ & 117,60 & $\begin{array}{l}90,52 \\
\end{array}$ & 34,02 & 6008,49 & 272,64 & 11,27 & 261,36 & 53,76 & 197,92 & 198,45 & 45,95 & 928,26 & 130,25 & 10,32 & 51,22 & 364,31 & 64,53 & 68,45 & 358,97 \\
\hline Hyla molleri & 29TPE87 & 100,00 & 124,01 & 93,18 & 34,67 & 6018,82 & 280,22 & 15,67 & 264,55 & 59,25 & 203,85 & 204,61 & 51,39 & 866,80 & 121,19 & 9,70 & 50,97 & 339,73 & 60,96 & 63,50 & 334,53 \\
\hline Hyla molleri & 29TPE88 & 100,00 & 124,78 & 94,46 & 35,08 & 6008,36 & 281,25 & 15,80 & 265,45 & 59,89 & 204,33 & 205,17 & 52,01 & 849,17 & 118,51 & 9,48 & 50,67 & 332,56 & 60,52 & 62,53 & 327,54 \\
\hline Hyla molle & 29TPE89 & 101,00 & 124 & 95 & 35,25 & 5995, & 280 & 14,8 & 265,97 & 59,14 & 203,39 & 204,31 & 51,4 & 843, & 117 & 9,60 & 50,67 & 330,28 & 60,83 & 62,57 & 325 \\
\hline Hyla molleri & 29TPE95 & 100,00 & 133,71 & 97,47 & $\begin{array}{l}35,24 \\
35,\end{array}$ & 6122,54 & $\mid$ & $\begin{array}{l}22,26 \\
22,26\end{array}$ & 272,71 & 67,52 & $\mid$ & $\mid$ & $\begin{array}{l}1,4,77 \\
59\end{array}$ & $\begin{array}{l}762,402 \\
762,82\end{array}$ & \begin{tabular}{|l|l|}
103,58 \\
\end{tabular} & 8,34 & | 49,95 & \begin{tabular}{|l|}
295,84 \\
\end{tabular} & $\begin{array}{l}54,30 \\
54,36\end{array}$ & 55,87 & 288,21 \\
\hline
\end{tabular}




\begin{tabular}{|c|c|c|c|c|c|c|c|c|c|c|c|c|c|c|c|c|c|c|c|c|c|}
\hline$\overline{\text { TAXON }}$ & UTM & $\mathrm{km} 2$ & BIO1 & BIO2 & B103 & BIO4 & B105 & B106 & B107 & B108 & B109 & BIO10 & BIO11 & BIO12 & B1013 & BIO14 & BIO15 & B1016 & B1017 & BIO18 & BIO19 \\
\hline Hyla molleri & 29TPE96 & 100,00 & 121,66 & 94,40 & 34,79 & 6085,22 & 280,54 & 12,66 & 267,88 & 56,49 & 202,72 & 203,40 & 48,71 & 839,86 & 114,81 & 9,92 & 49,81 & 326,27 & 60,70 & 63,49 & 318,88 \\
\hline Hyla molleri & 29TPE97 & 101,00 & 123,33 & 95,54 & 35,03 & 6081,09 & 282,39 & 13,56 & 268,83 & 57,85 & 204,07 & 204,93 & 50,15 & 815,68 & 111,21 & 9,77 & 49,60 & 316,66 & 59,75 & 62,02 & 309,32 \\
\hline Hyla molleri & 29TPE98 & 100,00 & 128,77 & 98,03 & 35,72 & 6080,10 & 288,79 & 17,22 & 271,56 & 62,50 & 209,12 & 209,95 & 54,96 & 765,26 & $\begin{array}{l}103,76 \\
\end{array}$ & 9,16 & 49,35 & 296,62 & 56,86 & 57,99 & 289,48 \\
\hline Hyla molleri & 29TPF00 & 101,00 & 139,06 & 98,71 & 38,88 & 5279,84 & 283,75 & 32,90 & 250,85 & 73,23 & 207,69 & 208,26 & 73,23 & 1127,70 & 168,86 & 10,94 & 55,06 & 457,17 & 72,42 & 74,61 & 457,17 \\
\hline Hyla molleri & 29TPF01 & 100,00 & 128,78 & 95,58 & 38,14 & 5282,38 & 272,01 & 24,88 & 247,14 & 63,64 & 197,92 & 198,34 & 63,64 & 1241,40 & 187,92 & 12,69 & 55,62 & 505,95 & 80,76 & 81,46 & 505,95 \\
\hline Hyla molleri & 29TPF13 & $\mid 101,00$ & 121,03 & 95,23 & 37,65 & 5397,58 & 266,55 & $\mid 17,10$ & 249,45 & 54,91 & 192,27 & \begin{tabular}{|l|l|}
192,40 \\
\end{tabular} & 54,91 & 1270,64 & 192,82 & \begin{tabular}{|c|c|}
13,83 \\
\end{tabular} & 55,64 & 518,67 & 83,82 & 84,37 & 518,67 \\
\hline Hyla molleri & 29TPF19 & 101,00 & 113,80 & 96,73 & 38,31 & 5336,32 & 259,53 & 10,18 & 249,36 & 48,93 & 184,38 & 184,52 & 48,93 & 1255,75 & 179,85 & 18,12 & 52,30 & 503,68 & 94,08 & 94,80 & 503,68 \\
\hline Hyla molleri & 29TPF20 & 100,00 & 131,99 & 94,76 & 36,96 & 5520,84 & 279,47 & 26,29 & 253,18 & 63,93 & 204,61 & 204,73 & 63,93 & \begin{tabular}{ll|l|}
1119,52 \\
\end{tabular} & 169,25 & 10,95 & 55,43 & 455,27 & 72,09 & 72,60 & 455,27 \\
\hline Hyla molleri & 29TPF30 & 101,00 & 138,54 & 97,73 & 37,13 & 5630,05 & 289,25 & 30,10 & 259,15 & 68,92 & 212,42 & 212,50 & \begin{tabular}{ll|l}
68,92 & \\
\end{tabular} & $\begin{array}{l}1001,01 \\
\end{array}$ & 149,52 & 9,60 & 54,78 & 403,99 & 64,84 & 65,10 & 403,99 \\
\hline Hyla molleri & 29TPF32 & 101,00 & 118,52 & 91,48 & 35,98 & 5579,90 & 265,56 & \begin{tabular}{ll|}
14,68 \\
\end{tabular} & 250,89 & 50,49 & 192,24 & \begin{tabular}{ll|}
192,61 \\
\end{tabular} & 50,49 & \begin{tabular}{|l|l|}
1181,51 \\
\end{tabular} & 178,55 & \begin{tabular}{ll|}
12,66 \\
\end{tabular} & 55,06 & 480,60 & 78,06 & 80,25 & 480,60 \\
\hline Hyla molleri & 29TPF33 & 101,00 & 117,67 & 93,44 & 36,47 & 5576,81 & 265,92 & 13,04 & 252,89 & 49,59 & 191,29 & \begin{tabular}{|l|l|}
191,61 \\
\end{tabular} & 49,59 & \begin{tabular}{ll|}
1180,34 \\
\end{tabular} & 177,86 & 13,10 & 54,92 & 479,81 & 79,46 & 81,04 & 479,81 \\
\hline Hyla molleri & 29TPF34 & 100,00 & 123,76 & 98,46 & 37,58 & 5598,62 & 274,87 & 16,29 & 258,58 & 54,90 & 197,58 & $\begin{array}{l}197,69 \\
\end{array}$ & 54,90 & 1117,24 & 167,71 & 12,54 & 54,69 & 453,09 & 75,71 & 76,31 & 453,09 \\
\hline Hyla molleri & 29TPF36 & 100,00 & 136,08 & 105,63 & 39,20 & 5593,92 & 290,39 & 23,96 & 266,43 & 66,31 & 209,21 & 209,21 & 66,31 & 987,88 & 145,90 & \begin{tabular}{ll|l}
11,16 \\
\end{tabular} & 53,79 & 397,09 & 67,05 & $\begin{array}{l}67,16 \\
\end{array}$ & 397,09 \\
\hline Hyla molleri & 29TPF42 & 101,00 & 129,46 & 97,21 & 36,92 & 5693,92 & 281,22 & 21,12 & 260,10 & 59,25 & 204,42 & 204,60 & \begin{tabular}{l|l|}
59,25 \\
\end{tabular} & 1019,33 & 152,01 & 10,78 & 54,30 & 410,91 & 68,29 & $\begin{array}{ll}68,78 \\
\end{array}$ & 410,91 \\
\hline Hyla molleri & 29TPF43 & 100,00 & 128,47 & 98,78 & 37,29 & 5690,11 & 281,10 & 19,51 & 261,59 & 58,25 & 203,40 & 203,53 & \begin{tabular}{l|l}
58,25 \\
\end{tabular} & $\begin{array}{l}1018,61 \\
\end{array}$ & 151,77 & 11,11 & 54,11 & 410,75 & 69,20 & $\begin{array}{ll}69,37 \\
\end{array}$ & 410,75 \\
\hline Hyla molleri & 29TPF44 & 100,00 & 132,75 & $\begin{array}{ll}102,47 \\
\end{array}$ & 38,08 & 5697,92 & 287,24 & 21,71 & 265,53 & 62,03 & 207,71 & 207,71 & \begin{tabular}{|l|l|}
62,03 \\
\end{tabular} & 972,21 & 144,25 & \begin{tabular}{|l|l|}
10,68 \\
\end{tabular} & 53,94 & 391,00 & 66,10 & 66,10 & 391,00 \\
\hline Hyla molleri & 29TPF46 & 101,00 & 123,35 & $\begin{array}{l}101,60 \\
\end{array}$ & 38,00 & 5663,76 & 277,73 & 13,58 & 264,15 & 53,73 & $\begin{array}{l}198,39 \\
\end{array}$ & $\begin{array}{l}198,39 \\
\end{array}$ & 53,73 & 1028,48 & 151,52 & 12,73 & 53,08 & 413,96 & 73,53 & 73,53 & 413,96 \\
\hline Hyla molleri & 29TPF48 & 101,00 & 140,12 & 107,65 & 39,32 & 5646,39 & 295,76 & 25,48 & 270,27 & 69,34 & 214,06 & 214,06 & 69,34 & 865,86 & 123,90 & 10,87 & 51,73 & 343,18 & 61,50 & 61,50 & 343,18 \\
\hline Hyla molleri & 29TPF50 & 100,00 & 126,65 & 92,55 & 35,46 & 5783,08 & 277,61 & 19,91 & 257,70 & 55,85 & 202,85 & 203,38 & 55,85 & 993,74 & 146,73 & 10,17 & 53,88 & 398,03 & 66,35 & 67,84 & 398,03 \\
\hline Hyla molleri & 29TPF52 & 100,00 & 137,54 & 101,08 & 37,46 & 5779,03 & 292,46 & 25,97 & 266,49 & 65,8 & 213,69 & 213,69 & 65,70 & 888,20 & 129,97 & 9,39 & 53,19 & 353,77 & 60,27 & 60,27 & 353,77 \\
\hline Hyla molleri & 29TPF53 & 100,00 & 141,10 & 103,66 & 38,12 & 5763,83 & 296,81 & 28,05 & 268,76 & 69,62 & 216,60 & 216,60 & \begin{tabular}{ll|l}
69,12 \\
\end{tabular} & 850,97 & 123,81 & 9,14 & 52,78 & 337,87 & 57,88 & 57,88 & 337,83 \\
\hline \begin{tabular}{|l|} 
Hyla molleri \\
\end{tabular} & 29TPF54 & 101,00 & 142,68 & 105,21 & 38,51 & 5744,58 & 298,77 & 28,79 & 269,97 & 72,03 & 217,84 & 217,84 & 70,80 & 832,23 & 120,63 & 9,06 & 52,52 & 329,99 & 56,84 & 56,84 & 329,90 \\
\hline Hyla molleri & 29TPF56 & 100,00 & $\begin{array}{l}139,49 \\
\end{array}$ & $\begin{array}{l}105,69 \\
\end{array}$ & 38,59 & 5705,64 & 295,63 & 25,55 & 270,08 & 70,99 & 214,41 & 214,41 & 68,22 & 837,54 & 120,32 & 9,97 & 51,84 & 331,83 & 59,22 & 59,22 & 331,53 \\
\hline Hyla molleri & 29TPF57 & 101,00 & 134,38 & 105,98 & 38,67 & 5715,32 & 291,15 & 20,48 & 270,66 & 63,93 & 209,56 & 209,56 & 63,28 & 863,64 & 124,24 & 11,01 & 51,61 & 343,18 & 62,44 & 62,44 & 343,14 \\
\hline Hyla molleri & 29TPF59 & 101,00 & 140,06 & 107,68 & 39,02 & 5679,65 & 296,10 & 24,35 & 271,75 & 70,61 & 214,39 & 214,39 & 68,77 & 794,76 & 111,26 & 10,91 & 50,2 & 312,01 & 58,91 & 58,91 & 312,01 \\
\hline Hyla molleri & 29TPF63 & 101,00 & 134,25 & 101,94 & 37,38 & 5835,98 & 290,96 & 21,88 & 269,08 & 63,60 & 211,38 & 211,38 & 61,97 & 844,73 & 121,62 & \begin{tabular}{ll|}
9,68 \\
\end{tabular} & 52,03 & 333,64 & 59,71 & 59,71 & 333,62 \\
\hline Hyla molleri & 29TPF67 & 100,00 & 138,89 & 107,36 & 38,83 & 5764,51 & 296,72 & 23,36 & 273,36 & 69,09 & 214,57 & \begin{tabular}{|l|l|}
214,57 \\
\end{tabular} & 66,78 & 768,30 & 108,26 & 9,93 & 50,41 & 301,58 & 56,62 & 56,62 & 301,41 \\
\hline Hyla molleri & 29TPF69 & 100,00 & 124,72 & 105,60 & 38,38 & 5737,43 & 282,95 & 11,12 & 271,83 & 53,84 & 200,67 & 200,69 & 53,80 & 842,56 & 118,37 & 12,49 & 49,51 & 332,58 & 66,68 & 66,71 & 332,58 \\
\hline Hyla molleri & 29TPF71 & 100,00 & \begin{tabular}{|l|l|}
127,17 \\
\end{tabular} & 97,36 & 36,08 & 5919,39 & 283,19 & $\begin{array}{l}17,05 \\
\end{array}$ & 266,14 & 62,28 & 205,32 & \begin{tabular}{|l|}
205,96 \\
\end{tabular} & 54,80 & 856,38 & 121,62 & 9,80 & 51,38 & 336,79 & 61,71 & 62,35 & 334,93 \\
\hline Hyla molleri & 29TPF72 & 100,00 & 127,59 & 99,08 & 36,53 & 5904,58 & 284,36 & 16,52 & 267,84 & 62,55 & 205,84 & \begin{tabular}{|l|}
205,97 \\
\end{tabular} & 55,05 & 843,94 & 119,73 & 9,89 & 51,16 & 331,56 & 61,64 & 61,79 & 330,15 \\
\hline Hyla molleri & 29TPF73 & 100,00 & 133,46 & 102,44 & 37,27 & 5891,66 & 291,47 & 20,37 & 271,10 & 67,96 & 211,44 & 211,44 & 60,61 & 792,11 & 111,81 & 9,37 & 50,82 & 310,49 & 57,83 & 57,83 & 309,20 \\
\hline Hyla molleri & 29TPF80 & 100,00 & \begin{tabular}{ll|}
124,54 \\
\end{tabular} & $\begin{array}{ll}96,64 \\
\end{array}$ & 35,69 & 5984,11 & 281,57 & 14,38 & 267,19 & 59,31 & 203,48 & 204,49 & 51,68 & 829,57 & 115,42 & 9,69 & 50,31 & 324,36 & \begin{tabular}{ll|}
60,92 \\
\end{tabular} & 62,19 & 319,90 \\
\hline Hyla molleri & 29TPF81 & 100,00 & 126,60 & 98,86 & 36,16 & 5977,64 & 284,65 & 15,28 & 269,37 & 60,96 & 205,60 & 206,19 & 53,50 & 801,99 & 111,22 & 9,53 & 50,05 & 313,21 & 59,84 & 60,40 & 308,99 \\
\hline Hyla molleri & 29TPF86 & 100,00 & 126,57 & 105,56 & 37,85 & 5900,58 & 287,13 & 11,93 & 275,19 & 60,90 & 204,84 & 204,84 & 53,61 & 744,61 & 101,80 & 10,30 & 48,49 & 289,46 & \begin{tabular}{l|l|}
59,65 \\
\end{tabular} & $\begin{array}{l}59,65 \\
\end{array}$ & 287,21 \\
\hline Hyla molleri & 29TPF88 & 101,00 & 131,27 & 108,01 & 38,51 & 5851,74 & 291,97 & $\begin{array}{l}14,96 \\
\end{array}$ & 277,01 & 65,44 & 208,61 & 208,61 & 58,38 & 695,99 & 94,18 & 10,34 & 47,79 & 270,13 & 56,85 & 56,85 & 268,09 \\
\hline \begin{tabular}{|l|} 
Hyla molleri \\
\end{tabular} & 29TPF93 & 100,00 & 125,30 & \begin{tabular}{|l|}
103,03 \\
\end{tabular} & 37,01 & 6001,13 & 286,26 & 11,60 & 274,66 & $\begin{array}{ll}59,07 \\
\end{array}$ & 205,17 & \begin{tabular}{|l|}
205,17 \\
\end{tabular} & \begin{tabular}{l|l|}
51,65 \\
\end{tabular} & 728,21 & 97,39 & 9,94 & 47,86 & 281,22 & 58,88 & 58,88 & 275,19 \\
\hline Hyla molleri & 29TPF95 & 100,00 & $\begin{array}{ll}123,98 \\
\end{array}$ & 105,18 & 37,72 & 5972,06 & 285,81 & 9,47 & 276,34 & 57,90 & 203,57 & \begin{tabular}{|l|l|}
203,57 \\
\end{tabular} & 50,66 & 712,27 & 94,80 & 9,98 & \begin{tabular}{ll|}
47,46 \\
\end{tabular} & 274,87 & 58,80 & 58,80 & 269,70 \\
\hline Hyla molleri & 29TPF96 & 100,00 & 125,79 & 106,55 & 38,02 & 5947,17 & 287,79 & 10,27 & 277,52 & 59,50 & 204,76 & 204,76 & 52,34 & 691,95 & 91,70 & 10,15 & 47,00 & 266,69 & 57,95 & 57,95 & 261,99 \\
\hline Hyla molleri & 29TPF97 & 101,00 & 1119,67 & 106,41 & 37,99 & 5930,73 & 282,07 & 4,67 & 277,39 & 53,80 & 198,61 & \begin{tabular}{ll|}
198,61 \\
\end{tabular} & \begin{tabular}{l|l|}
46,65 \\
\end{tabular} & 718,31 & 95,14 & $11, \mathrm{C}$ & 46,70 & 276,97 & \begin{tabular}{ll|l}
61,95 \\
\end{tabular} & 61,95 & 272,98 \\
\hline Hyla molleri & 29TPF98 & 100,00 & 120,57 & 107,46 & 38,12 & 5908,98 & 283,11 & 5,07 & 278,03 & 54,57 & 199,09 & $\begin{array}{l}199,09 \\
\end{array}$ & \begin{tabular}{ll|}
47,67 \\
\end{tabular} & 701,41 & 92,47 & 11,18 & 46,30 & 270,26 & 61,39 & 61,39 & 266,71 \\
\hline Hyla molleri & 29TPG05 & 101,00 & \begin{tabular}{ll|}
119,89 \\
\end{tabular} & 93,96 & 38,26 & 5155,67 & 258,22 & 15,84 & 242,38 & 63,14 & 187,92 & \begin{tabular}{ll|}
188,01 \\
\end{tabular} & 57,21 & 1153,20 & 156,06 & 22,16 & 47,08 & 443,66 & 100,34 & 101,71 & 440,77 \\
\hline \begin{tabular}{|l|} 
Hyla molleri \\
\end{tabular} & 29TPG06 & 101,00 & 120,72 & 93,71 & 38,19 & 5132,34 & 258,02 & 16,47 & 241,55 & 63,99 & 188,26 & $\begin{array}{l}188,35 \\
\end{array}$ & 58,39 & $\begin{array}{lll}1133,64 \\
\end{array}$ & 155,70 & 22,98 & 46,17 & 434,04 & 101,53 & \begin{tabular}{l|l|}
103,93 \\
\end{tabular} & 429,13 \\
\hline Hyla molleri & 29TPG13 & 101,00 & $\begin{array}{l}114,59 \\
\end{array}$ & 94,29 & 37,88 & 5258,16 & 256,75 & 11,16 & 245,59 & 51,08 & 184,25 & \begin{tabular}{ll|}
184,28 \\
\end{tabular} & 50,83 & 1171,31 & 155,10 & 20,77 & 48,71 & 457,27 & 97,45 & \begin{tabular}{ll|l|}
97,95 \\
\end{tabular} & 457,27 \\
\hline Hyla molleri & 29TPG14 & 101,00 & 113,99 & 93,88 & 37,92 & 5231,74 & 255,38 & 10,69 & 244,69 & 55,23 & 183,38 & \begin{tabular}{|l|l|}
183,44 \\
\end{tabular} & 50,77 & 1159,41 & 152,44 & 21,83 & 47,73 & 449,20 & 99,54 & 100,49 & 449,09 \\
\hline Hyla molleri & 29TPG22 & 101,00 & 133,16 & 103,27 & 39,01 & 5460,32 & 282,04 & 21,44 & 260,59 & 66,48 & 204,71 & 204,71 & 65,46 & 970,41 & 130,05 & 15,04 & 49,31 & 377,52 & 75,53 & 75,53 & 377,52 \\
\hline \begin{tabular}{|l} 
Hyla molleri \\
\end{tabular} & 29TPG23 & 100,00 & 128,44 & 100,89 & 38,75 & 5426,73 & 275,36 & 18,16 & 257,20 & 64,68 & 199,68 & \begin{tabular}{|l|l|}
199,68 \\
\end{tabular} & 61,42 & 993,49 & 130,73 & 16,78 & 48,38 & 385,02 & 80,62 & 80,62 & 384,57 \\
\hline Hyla molleri & 29TPG24 & 100,00 & 128,78 & 100,20 & 38,64 & 5413,35 & 274,57 & $\begin{array}{l}18,36 \\
\end{array}$ & 256,21 & 68,08 & 199,94 & $\begin{array}{l}199,94 \\
\end{array}$ & 62,10 & $\begin{array}{l}972,87 \\
\end{array}$ & 127,05 & 17,39 & 47,39 & 374,59 & 81,45 & 81,45 & 372,83 \\
\hline Hyla molleri & 29TPG33 & 100,00 & 121,95 & 100,70 & 38,33 & 5475,42 & 271,29 & 12,10 & 259,19 & 57,53 & 194,34 & \begin{tabular}{|l|l|}
194,34 \\
\end{tabular} & 54,80 & 986,87 & 131,60 & \begin{tabular}{ll|}
17,61 \\
\end{tabular} & 48,16 & 384,05 & 82,26 & 82,26 & 383,95 \\
\hline Hyla molleri & 29TPG34 & 101,00 & 119,10 & 99,36 & 38,15 & 5438,35 & 267,03 & 10,11 & 256,92 & 58,52 & 191,03 & \begin{tabular}{|l|l|}
191,03 \\
\end{tabular} & 52,56 & $\begin{array}{l}96,47 \\
\end{array}$ & 130,92 & 19,09 & 47,19 & 385,91 & 86,18 & 86,18 & 385,02 \\
\hline Hyla molleri & 29TPG47 & & & & 37,28 & 5272 & 23 & $-13,80$ & 246,38 & 30,69 & 158,08 & 158,1 & 25,0 & \begin{tabular}{ll|}
1178,80 \\
\end{tabular} & 154,82 & 30, & 43,01 & 449,01 & 123,01 & 123,16 & 441,24 \\
\hline \begin{tabular}{|l} 
Hyla molleri \\
\end{tabular} & 29TPG48 & 100,00 & 108,67 & 96,86 & 37,97 & 5314,99 & 253,42 & 2,25 & 251,18 & 49,64 & 179,27 & \begin{tabular}{|l|}
179,29 \\
\end{tabular} & 44,47 & 997,65 & 133,38 & 24,48 & 42,97 & \begin{tabular}{|l|}
380,02 \\
\end{tabular} & 101,32 & \begin{tabular}{|l|l|}
101,38 \\
\end{tabular} & 371,02 \\
\hline Hyla molleri & 29TPG50 & 100,00 & 137,60 & 107,47 & 39,01 & 5663,99 & 293,42 & 22,08 & 271,34 & 69,40 & 211,95 & $\begin{array}{l}211,95 \\
\end{array}$ & 66,82 & 797,61 & 110,60 & 11,75 & 49,53 & 312,43 & 60,95 & 60,95 & 312,37 \\
\hline Hyla molleri & 29TPG54 & 100,00 & 112,14 & 101,49 & 37,99 & 5549,06 & 265,44 & 2,10 & 263,34 & 50,57 & 186,01 & 186,01 & 44,43 & 933,69 & 123,73 & 19,01 & 46,45 & 363,30 & 84,68 & 84,68 & 361. \\
\hline Hyla molleri & $29 \mathrm{TPC}$ & 101 & 101,87 & 98,62 & 37,70 & 5478 & 253 & $-4,90$ & 258,12 & 41,72 & 175,11 & 175 & 35,82 & 1007,10 & 132,54 & 22,70 & 45,05 & 389,16 & 96,94 & 96,94 & 385,59 \\
\hline Hyla molleri & 29TPG59 & 101,00 & 120,87 & 99,39 & 38,56 & 5362,54 & 265,42 & \begin{tabular}{l|l|}
10,95 \\
\end{tabular} & 254,47 & 59,95 & \begin{tabular}{ll|}
191,56 \\
\end{tabular} & $\begin{array}{l}191,56 \\
\end{array}$ & \begin{tabular}{l|l}
55,12 \\
\end{tabular} & 854,10 & 114,17 & 21,06 & 41,95 & 323,58 & 88,29 & 88,29 & 311,47 \\
\hline \begin{tabular}{|l|} 
Hyla molleri \\
\end{tabular} & 29TPG60 & 100,00 & $\begin{array}{l}123,07 \\
\end{array}$ & 105,87 & 38,38 & 5712,51 & 281,58 & 9,35 & 272,23 & 52,57 & 198,73 & $\begin{array}{l}198,73 \\
\end{array}$ & 52,53 & 838,83 & 117,23 & 13,04 & 49,09 & 331,15 & 67,94 & 67,94 & 331,15 \\
\hline Hyla molleri & \begin{tabular}{|l|} 
29TPG64 \\
\end{tabular} & 100,00 & 104,22 & 101,47 & 37,91 & 5587,04 & 259,60 & $-4,87$ & 264,47 & 42,66 & 178,99 & \begin{tabular}{|l|l|}
178,99 \\
\end{tabular} & 36,56 & 935,40 & 123,39 & 19,90 & 45,50 & 363,13 & 88,84 & 88,84 & 360,58 \\
\hline Hyla molleri & 29TPG & 100,00 & 91, & 98 & 37,45 & 5510,9 & 244 & $-14,60$ & 258,7 & 31,40 & 165,31 & 165,32 & 25,4 & 1036,29 & 135, & 25, & 43 & 396,79 & \begin{tabular}{|l|l|}
105,96 \\
\end{tabular} & $\mid \begin{array}{l}106,01 \\
\end{array}$ & 39 \\
\hline Hyla molleri & 29TPG67 & 101,00 & 90,62 & 98,13 & 37,76 & 5449,74 & 241,65 & $-15,01$ & 256,66 & 31,18 & 163,81 & 163,81 & 25,53 & 1033,16 & 135,57 & 27,56 & 41,95 & 391,99 & \begin{tabular}{|l|l|}
111,28 \\
\end{tabular} & \begin{tabular}{|l|l|}
111,28 \\
\end{tabular} & 382. \\
\hline Hyla molleri & 29TPG68 & 101,00 & 95,38 & 98,77 & 37,99 & 5429,41 & 245,36 & $-11,17$ & 256,53 & 35,56 & 168,01 & 168,01 & 30,21 & 994,16 & 131,08 & 26,93 & 41,40 & 376,34 & 108,56 & 108,56 & 365,59 \\
\hline
\end{tabular}




\begin{tabular}{|c|c|c|c|c|c|c|c|c|c|c|c|c|c|c|c|c|c|c|c|c|c|}
\hline$\overline{\text { TAXON }}$ & UTM & km2 & BIO1 & BIO2 & B103 & BIO4 & B105 & B106 & B107 & B108 & B109 & BIO10 & BIO11 & BIO12 & BIO13 & BIO14 & BIO15 & B1016 & B1017 & BIO18 & 81019 \\
\hline Hyla molleri & 29TPG69 & 100,00 & 109,58 & 99,72 & 38,42 & 5401,83 & 256,87 & 0,74 & 256,13 & 48,89 & 181,12 & 181,12 & 43,70 & 891,67 & 118,02 & 23,64 & 41,01 & 336,82 & 96,95 & 96,95 & 323,83 \\
\hline Hyla molleri & 29TPG73 & 100,00 & 111,26 & 105,36 & 38,08 & 5681,64 & 270,72 & $-1,27$ & 271,99 & 48,18 & 187,11 & 187,11 & 41,70 & 830,16 & 111,22 & \begin{tabular}{|l|l|}
16,29 \\
\end{tabular} & 46,11 & \begin{tabular}{|l|}
324,27 \\
\end{tabular} & 76,84 & 76,84 & 322,77 \\
\hline Hyla molleri & 29TPG76 & 100,00 & 69,20 & 95,75 & \begin{tabular}{|l|}
37,03 \\
\end{tabular} & 5474,24 & 221,21 & $-33,69$ & 254,90 & 11,21 & \begin{tabular}{|l|l|}
143,07 \\
\end{tabular} & \begin{tabular}{|l|}
143,32 \\
\end{tabular} & 5,10 & $\begin{array}{l}1166,78 \\
\end{array}$ & \begin{tabular}{|l|}
148,91 \\
\end{tabular} & 33,61 & \begin{tabular}{|l|l|}
40,03 \\
\end{tabular} & 435,09 & \begin{tabular}{|l|}
133,11 \\
\end{tabular} & \begin{tabular}{|l|l|}
134,16 \\
\end{tabular} & 423,21 \\
\hline Hyla molleri & 29TPG77 & 100,00 & 72,02 & 96,50 & 37,33 & 5454,39 & 223,74 & $-31,34$ & 255,08 & 13,92 & \begin{tabular}{|l|}
145,64 \\
\end{tabular} & \begin{tabular}{|l|}
145,74 \\
\end{tabular} & \begin{tabular}{l|}
7,94 \\
\end{tabular} & $\begin{array}{l}1141,30 \\
\end{array}$ & $\begin{array}{l}146,33 \\
\end{array}$ & 33,84 & 39,61 & 424,73 & \begin{tabular}{|l|}
132,61 \\
\end{tabular} & \begin{tabular}{|l|}
133,18 \\
\end{tabular} & 411,98 \\
\hline Hyla molleri & 29TPG79 & 101,00 & 115,29 & 102,23 & 38,71 & 5504,49 & 264,82 & 3,55 & 261,28 & 52,63 & 187,88 & 187,88 & 47,61 & 798,91 & 105,84 & 21,01 & 40,71 & 302,25 & 87,53 & 87,53 & 288,56 \\
\hline Hyla molleri & 29TPG82 & \begin{tabular}{|l|}
101,00 \\
\end{tabular} & \begin{tabular}{|l|}
115,92 \\
\end{tabular} & 108,05 & 38,48 & 5741,87 & 278,21 & 1,19 & 277,01 & \begin{tabular}{|l|l|}
49,20 \\
\end{tabular} & \begin{tabular}{|l|l|}
192,39 \\
\end{tabular} & \begin{tabular}{|l|l|}
192,39 \\
\end{tabular} & \begin{tabular}{|l|l|}
45,23 \\
\end{tabular} & 751,50 & \begin{tabular}{|c|}
101,08 \\
\end{tabular} & \begin{tabular}{|l|l|}
13,75 \\
\end{tabular} & \begin{tabular}{|l|l|}
46,42 \\
\end{tabular} & 293,71 & 68,50 & 68,50 & 293,50 \\
\hline Hyla molleri & 29TPG83 & 100,00 & 114,34 & 107,76 & 38,57 & 5717,94 & 275,96 & $-0,14$ & 276,10 & $\begin{array}{l}49,76 \\
\end{array}$ & 190,63 & \begin{tabular}{|l|}
190,63 \\
\end{tabular} & 43,99 & 756,43 & 100,89 & \begin{tabular}{|l|}
14,92 \\
\end{tabular} & 45,71 & 294,30 & \begin{tabular}{|l|}
71,12 \\
\end{tabular} & 71,12 & 293,56 \\
\hline Hyla molleri & 29TPG84 & 100,00 & 101,08 & 104,58 & 38,04 & 5694,84 & 260,62 & $-10,39$ & 271,01 & 38,15 & $\begin{array}{l}177,42 \\
\end{array}$ & \begin{tabular}{|l|}
177,42 \\
\end{tabular} & 31,99 & 848,62 & 111,77 & 19,55 & \begin{tabular}{|l|}
43,67 \\
\end{tabular} & 325,23 & 86,52 & 86,52 & 320,86 \\
\hline Hyla molleri & 29TPG85 & 99,00 & 90,22 & $\begin{array}{l}102,10 \\
\end{array}$ & 37,74 & 5649,05 & 247,58 & $-18,81$ & 266,39 & 28,47 & 166,10 & \begin{tabular}{l|l|}
166,16 \\
\end{tabular} & 22,38 & 931,97 & \begin{tabular}{ll|}
121,43 \\
\end{tabular} & \begin{tabular}{|l|}
24,22 \\
\end{tabular} & 41,70 & 352,40 & $\begin{array}{l}101,25 \\
\end{array}$ & \begin{tabular}{|l|}
101,38 \\
\end{tabular} & 344,17 \\
\hline Hyla molleri & 29TPG86 & 101,00 & 80,34 & 100,06 & 37,57 & 5586,05 & \begin{tabular}{|l|l|}
235,83 \\
\end{tabular} & $-26,54$ & 262,37 & \begin{tabular}{|l|l|}
19,98 \\
\end{tabular} & 155,48 & \begin{tabular}{|l|}
155,64 \\
\end{tabular} & \begin{tabular}{|l|l|}
13,90 \\
\end{tabular} & 1015,72 & 130,94 & 29,10 & 40,06 & 379,28 & \begin{tabular}{|l|l|}
116,18 \\
\end{tabular} & 116,72 & 367,84 \\
\hline Hyla molleri & 29TPG87 & 100,00 & 60,76 & $\begin{array}{l}96,29 \\
\end{array}$ & 37,14 & 5479,39 & 213,40 & $-41,90$ & 255,30 & 3,18 & 134,78 & \begin{tabular}{|l|l|}
135,09 \\
\end{tabular} & \begin{tabular}{|c|}
$-3,08$ \\
\end{tabular} & \begin{tabular}{|l|l|}
1192,08 \\
\end{tabular} & 150,36 & 37,89 & 37,67 & \begin{tabular}{|l|}
436,76 \\
\end{tabular} & \begin{tabular}{l|l|}
145,06 \\
\end{tabular} & 146,84 & 421,17 \\
\hline Hyla molleri & 29TPG88 & 101,00 & 75,96 & \begin{tabular}{|l|}
99,19 \\
\end{tabular} & \begin{tabular}{|l|}
37,83 \\
\end{tabular} & 5498,03 & 229,16 & $-29,65$ & 258,81 & $\begin{array}{ll}16,66 \\
\end{array}$ & 149,91 & \begin{tabular}{|l|l|}
149,95 \\
\end{tabular} & \begin{tabular}{l|l|}
10,69 \\
\end{tabular} & \begin{tabular}{ll|}
1056,83 \\
\end{tabular} & 135,57 & 32,94 & 38,18 & 389,90 & \begin{tabular}{|l|l|}
128,19 \\
\end{tabular} & 128,45 & 374,70 \\
\hline Hyla molleri & 29TPG90 & 101,00 & 125,92 & 109,62 & 38,77 & 5856,70 & 288,50 & 8,71 & 279,79 & $\begin{array}{l}60,02 \\
\end{array}$ & 203,44 & 203,44 & 53,20 & 655,17 & 85,95 & 11,25 & 45,79 & 252,45 & 58,32 & 58,32 & 249,87 \\
\hline Hyla molleri & 29TPG93 & 100,00 & 1114,11 & 109,10 & 38,82 & 5783,44 & 276,86 & $-1,48$ & 278,34 & 48,78 & \begin{tabular}{|l|}
191,09 \\
\end{tabular} & \begin{tabular}{|l|l|}
191,09 \\
\end{tabular} & \begin{tabular}{ll|}
42,76 \\
\end{tabular} & 707,57 & 93,88 & 14,70 & 44,40 & 271,75 & 69,24 & 69,24 & \begin{tabular}{|l|l|}
270,03 \\
\end{tabular} \\
\hline Hyla molleri & 29TPG94 & 101,00 & 110,64 & 108,34 & 38,65 & 5772,11 & 272,62 & $-4,27$ & 276,90 & 45,99 & 187,51 & \begin{tabular}{|l|}
187,51 \\
\end{tabular} & \begin{tabular}{|l|}
39,68 \\
\end{tabular} & \begin{tabular}{|l|l|}
726,49 \\
\end{tabular} & $\begin{array}{l}96,60 \\
\end{array}$ & 16,51 & 43,40 & 277,94 & 73,92 & 73,92 & 274,29 \\
\hline Hyla molleri & 29TPG95 & 101,00 & 102,24 & 106,49 & 38,29 & 5749,81 & 262,78 & -11,04 & 273,82 & 38,15 & \begin{tabular}{|l|}
179,12 \\
\end{tabular} & \begin{tabular}{|l|}
179,12 \\
\end{tabular} & \begin{tabular}{|l|l|}
32,12 \\
\end{tabular} & \begin{tabular}{|l|l|}
781,86 \\
\end{tabular} & \begin{tabular}{|l|}
103,44 \\
\end{tabular} & 20,04 & \begin{tabular}{|l|}
41,76 \\
\end{tabular} & 296,35 & 84,39 & 84,39 & 288,95 \\
\hline Hyla molleri & 29TPG96 & 100,00 & 97,20 & 105,45 & 38,22 & 5715,20 & 256,35 & $-15,01$ & 271,35 & 33,71 & \begin{tabular}{|l|l|}
173,68 \\
\end{tabular} & \begin{tabular}{|l|l|}
173,68 \\
\end{tabular} & 27,75 & 820,67 & $\begin{array}{l}107,87 \\
\end{array}$ & 22,87 & 40,53 & \begin{tabular}{|l|}
308,33 \\
\end{tabular} & \begin{tabular}{|l|l|}
92,64 \\
\end{tabular} & \begin{tabular}{|l|l|}
92,64 \\
\end{tabular} & 298,22 \\
\hline Hyla molleri & 29TPG97 & 100,00 & 73,90 & 100,69 & 37,78 & 5591,12 & 229,81 & $-32,99$ & 262,80 & 13,84 & 149,23 & \begin{tabular}{|l|}
149,36 \\
\end{tabular} & $\begin{array}{ll}7,62 \\
\end{array}$ & \begin{tabular}{l|l|}
1021,92 \\
\end{tabular} & 130,38 & 32,26 & 37,71 & \begin{tabular}{|l|}
374,88 \\
\end{tabular} & \begin{tabular}{|l|}
125,27 \\
\end{tabular} & 125,90 & 359,55 \\
\hline Hyla molleri & 29TPH01 & 100,00 & 124,98 & 90,02 & 38,96 & 4776,79 & 252,75 & 24,07 & 228,67 & 71,31 & 187,58 & \begin{tabular}{|l|}
188,19 \\
\end{tabular} & 67,60 & \begin{tabular}{|l|l|}
1077,54 \\
\end{tabular} & 151,59 & 27,30 & 42,65 & 403,69 & \begin{tabular}{|l|}
109,82 \\
\end{tabular} & \begin{tabular}{|l|l|}
122,46 \\
\end{tabular} & 389,66 \\
\hline Hyla molleri & 29TPH07 & 100,00 & 123,13 & 83,78 & 40,52 & 4121,32 & 237,34 & 33,13 & 204,21 & 77,79 & 176,53 & 178,70 & 74,12 & 1106,65 & 148,29 & 33, & 38,2 & 408,04 & 129,36 & 145,35 & 382,48 \\
\hline Hyla molleri & 29TPH09 & 100,00 & 122,75 & 81,56 & 40,98 & 3966,66 & 232,91 & 35,86 & 197,05 & 79,73 & \begin{tabular}{|l|}
173,76 \\
\end{tabular} & \begin{tabular}{|l|l|}
176,37 \\
\end{tabular} & 75,50 & 1103,86 & 144,75 & 35,37 & 36,96 & $\begin{array}{l}404,69 \\
\end{array}$ & 134,34 & \begin{tabular}{|l|l|}
151,17 \\
\end{tabular} & 375,61 \\
\hline Hyla molleri & 29TPH18 & 101,00 & 125,68 & 83,80 & 40,68 & 4123,85 & 238,95 & 35,24 & 203,71 & 80,25 & \begin{tabular}{|l|}
178,80 \\
\end{tabular} & \begin{tabular}{|l|}
180,96 \\
\end{tabular} & \begin{tabular}{|l|}
76,07 \\
\end{tabular} & \begin{tabular}{|l|l|}
1044,09 \\
\end{tabular} & 136,94 & 32,81 & 37,04 & 382,20 & \begin{tabular}{ll|}
125,76 \\
\end{tabular} & \begin{tabular}{|l|}
142,04 \\
\end{tabular} & 354,40 \\
\hline Hyla molleri & 29TPH21 & 100,00 & \begin{tabular}{|l|}
131,78 \\
\end{tabular} & 93,25 & 38,97 & $\begin{array}{l}4996,08 \\
\end{array}$ & 263,61 & 26,14 & \begin{tabular}{|l|}
237,47 \\
\end{tabular} & \begin{tabular}{ll|}
75,01 \\
\end{tabular} & \begin{tabular}{|l|l|}
196,99 \\
\end{tabular} & \begin{tabular}{|l|}
197,21 \\
\end{tabular} & 70,90 & 914,56 & 125,36 & 22,94 & 41,58 & 340,74 & 94,05 & 100,10 & 325,66 \\
\hline Hyla molleri & 29TPH36 & 100,00 & \begin{tabular}{|l|}
116,71 \\
\end{tabular} & 89,59 & 39,98 & 4558,89 & 241,60 & 19,71 & 221,89 & 65,93 & 176,12 & \begin{tabular}{|l|l|}
177,35 \\
\end{tabular} & \begin{tabular}{|l|l|}
61,98 \\
\end{tabular} & \begin{tabular}{|l|l|}
1019,44 \\
\end{tabular} & 133,61 & 31,76 & 37,13 & 373,52 & 122,99 & $\begin{array}{l}136,32 \\
\end{array}$ & 348,31 \\
\hline Hyla molleri & 29TPH41 & 101,00 & 110,45 & 95,49 & 38,66 & 5128,06 & 250,03 & \begin{tabular}{l|l}
5,65 \\
\end{tabular} & 244,38 & 52,96 & 178,23 & \begin{tabular}{|l|}
178,27 \\
\end{tabular} & 48,54 & \begin{tabular}{|c|}
986,46 \\
\end{tabular} & 132,08 & 26,80 & 40,55 & 370,31 & \begin{tabular}{|l|}
108,08 \\
\end{tabular} & 108,69 & 355,08 \\
\hline Hyla molleri & 29TPH51 & 100,00 & 92,45 & 95,33 & 38,24 & 5173,82 & 235,67 & $-10,10$ & 245,76 & 35,76 & 161,46 & 161,51 & 30,84 & \begin{tabular}{|l|l|}
1078,35 \\
\end{tabular} & 141,86 & 31,88 & 39,27 & 402,52 & 125,19 & 125,91 & 386,28 \\
\hline Hyla molleri & 29TPH52 & 100,00 & 95,85 & 95,19 & 38,70 & 5107,97 & 237,01 & $-6,60$ & 243,60 & 39,57 & 163,73 & \begin{tabular}{|l|}
163,78 \\
\end{tabular} & 34,81 & 1057,17 & 138,92 & 31,84 & 38,58 & \begin{tabular}{|l|}
392,95 \\
\end{tabular} & \begin{tabular}{|l|}
124,87 \\
\end{tabular} & \begin{tabular}{|l|}
126,52 \\
\end{tabular} & 374,61 \\
\hline Hyla molleri & 29TPH55 & 101,00 & \begin{tabular}{|l|}
115,59 \\
\end{tabular} & 93,60 & 39,80 & 4824,02 & 247,23 & \begin{tabular}{l|l|}
14,03 \\
\end{tabular} & 233,20 & 61,30 & 178,62 & \begin{tabular}{|l|l|}
179,20 \\
\end{tabular} & \begin{tabular}{|l|l|}
57,08 \\
\end{tabular} & 937,10 & 121,15 & \begin{tabular}{|l|}
29,23 \\
\end{tabular} & 36,63 & 342,96 & \begin{tabular}{|l|l|}
114,97 \\
\end{tabular} & \begin{tabular}{|l|l|}
125,70 \\
\end{tabular} & 317,72 \\
\hline Hyla molleri & 29TPH56 & 100,00 & \begin{tabular}{|l|}
112,59 \\
\end{tabular} & \begin{tabular}{|l|}
92,57 \\
\end{tabular} & 39,92 & 4721,95 & 242,36 & 12,91 & 229,45 & 59,88 & \begin{tabular}{|l|}
174,30 \\
\end{tabular} & \begin{tabular}{|l|l|}
175,10 \\
\end{tabular} & $\begin{array}{l}55,56 \\
\end{array}$ & 969,45 & 124,37 & \begin{tabular}{|l|}
31,62 \\
\end{tabular} & 35,72 & \begin{tabular}{|l|}
352,59 \\
\end{tabular} & \begin{tabular}{|l|l|}
122,46 \\
\end{tabular} & \begin{tabular}{|l|}
134,51 \\
\end{tabular} & 325,18 \\
\hline Hyla molleri & 29TPH58 & \begin{tabular}{|l|l}
99,00 \\
\end{tabular} & \begin{tabular}{|c|}
111,89 \\
\end{tabular} & 90,21 & $\mid$\begin{tabular}{|l|l|}
40,17 \\
\end{tabular} & \begin{tabular}{|l|l|}
4511,60 \\
\end{tabular} & 236,79 & \begin{tabular}{|l|l|}
15,61 \\
\end{tabular} & \begin{tabular}{|l|l|}
221,18 \\
\end{tabular} & \begin{tabular}{|l|l|}
62,19 \\
\end{tabular} & \begin{tabular}{|l|l|l|}
170,64 \\
\end{tabular} & 171,93 & 57,57 & \begin{tabular}{|c|}
1001,05 \\
\end{tabular} & 128,05 & \begin{tabular}{|l|l|}
34,69 \\
\end{tabular} & \begin{tabular}{|l|l|}
34,26 \\
\end{tabular} & 360,09 & \begin{tabular}{|l|l|}
131,93 \\
\end{tabular} & \begin{tabular}{|l|l|}
144,69 \\
\end{tabular} & 328,66 \\
\hline Hyla molleri & 29TPH60 & \begin{tabular}{|l|}
101,00 \\
\end{tabular} & 104,75 & 99,05 & 38,49 & 5352,43 & 251,30 & $-2,77$ & 254,06 & \begin{tabular}{|l|}
44,83 \\
\end{tabular} & \begin{tabular}{|l|l|}
175,79 \\
\end{tabular} & \begin{tabular}{|l|l|}
175,79 \\
\end{tabular} & 39,85 & 926,98 & 122,54 & 25,86 & \begin{tabular}{|l|l|}
40,07 \\
\end{tabular} & \begin{tabular}{|l|}
348,48 \\
\end{tabular} & \begin{tabular}{|l|l|}
104,41 \\
\end{tabular} & \begin{tabular}{|l|l|}
104,43 \\
\end{tabular} & 333,57 \\
\hline Hyla molleri & 29TPH70 & 99,00 & 120,04 & 101,98 & 38,92 & 5464,69 & 267,27 & 7,93 & 259,34 & 57,30 & \begin{tabular}{|l|}
191,79 \\
\end{tabular} & \begin{tabular}{|l|l|}
191,79 \\
\end{tabular} & \begin{tabular}{|l|l|}
52,47 \\
\end{tabular} & \begin{tabular}{|l|}
768,84 \\
\end{tabular} & $\begin{array}{l}101,73 \\
\end{array}$ & \begin{tabular}{|l|}
20,23 \\
\end{tabular} & 40,17 & 290,06 & 85,34 & 85,34 & 274,12 \\
\hline Hyla molleri & 29TPH78 & 100,00 & 1114,42 & 92,48 & \begin{tabular}{l|l|}
40,65 \\
\end{tabular} & 4583,52 & 241,15 & $\begin{array}{ll}16,33 \\
\end{array}$ & 224,81 & \begin{tabular}{|c|}
67,71 \\
\end{tabular} & \begin{tabular}{|l|}
173,87 \\
\end{tabular} & \begin{tabular}{l|l|}
175,05 \\
\end{tabular} & 58,89 & 927,82 & 120,75 & 33,81 & 32,65 & 328,82 & \begin{tabular}{|l|l|}
128,45 \\
\end{tabular} & 140,50 & 294,39 \\
\hline Hyla molleri & 29TPH80 & 101,00 & 115,40 & 103,38 & 38,97 & 5547,08 & 265,72 & 2,60 & 263,12 & 51,78 & 188,51 & \begin{tabular}{|l|}
188,51 \\
\end{tabular} & 46,90 & 754,35 & 99,32 & 20,75 & 39,45 & 283,55 & 87,01 & 87,01 & 266,77 \\
\hline Hyla molleri & 29TPH81 & 99,00 & 126,87 & 102,37 & 39,00 & 5448,44 & 272,65 & \begin{tabular}{l|l|}
13,83 \\
\end{tabular} & 258,82 & \begin{tabular}{|l|l|}
63,77 \\
\end{tabular} & \begin{tabular}{|l|l|}
197,98 \\
\end{tabular} & \begin{tabular}{|l|l|}
197,98 \\
\end{tabular} & \begin{tabular}{|l|l|}
59,01 \\
\end{tabular} & \begin{tabular}{|l|l|}
694,68 \\
\end{tabular} & 91,52 & $\begin{array}{l}18,59 \\
\end{array}$ & 38,74 & 259,96 & 80,41 & 80,41 & 239,84 \\
\hline Hyla molleri & 29TPH84 & 99,00 & 84,45 & 98,01 & 39,11 & 5161,57 & 228,83 & $-18,65$ & 247,48 & 28,14 & 153,10 & \begin{tabular}{|l|l|}
153,23 \\
\end{tabular} & 22,80 & $\begin{array}{l}1035,10 \\
\end{array}$ & 131,26 & $\begin{array}{l}37,17 \\
\end{array}$ & 34,15 & 372,30 & \begin{tabular}{|l|l|}
140,47 \\
\end{tabular} & 142,00 & 346,19 \\
\hline Hyla molleri & 29TPH91 & 100,00 & $\begin{array}{l}123,96 \\
\end{array}$ & 104,01 & 39,00 & 5549,99 & 273,22 & 9,52 & 263,70 & 59,34 & 196,45 & \begin{tabular}{l|l|}
196,45 \\
\end{tabular} & 54,78 & $\begin{array}{l}671,06 \\
\end{array}$ & 89,20 & 18,55 & 38,11 & 250,52 & 80,57 & $\begin{array}{l}80,57 \\
\end{array}$ & 229,55 \\
\hline Hyla molleri & 29TPJo0 & 100,00 & 117,21 & 80,76 & 40,9 & 3933,58 & 227,10 & 31,59 & 195,51 & 75,0 & 167,82 & 170,58 & 70,49 & 1145,39 & 148,93 & 37, & 36,2 & 418,76 & 142,92 & 159,58 & 388,07 \\
\hline Hyla molleri & 29TPJ23 & 94,00 & 133,06 & 77,66 & 41,91 & 3722,46 & 234,09 & 50,41 & 183,68 & 93,41 & 180,09 & \begin{tabular}{|l|}
183,18 \\
\end{tabular} & \begin{tabular}{|l|}
88,03 \\
\end{tabular} & \begin{tabular}{|l|l|}
977,56 \\
\end{tabular} & 126,37 & 34,1 & 33,99 & 351,59 & \begin{tabular}{|l|l|}
129,36 \\
\end{tabular} & \begin{tabular}{|l|}
148,23 \\
\end{tabular} & 314,92 \\
\hline Hyla molleri & 29TQE04 & 100,00 & \begin{tabular}{|l|}
154,81 \\
\end{tabular} & 104,37 & 36,24 & 6192,69 & 321,03 & 38,01 & 283,02 & 86,55 & 237,01 & 237,01 & \begin{tabular}{|l|}
78,85 \\
\end{tabular} & 586,07 & 76,24 & 5,54 & 48,99 & 224,24 & 41,44 & \begin{tabular}{|l|}
41,44 \\
\end{tabular} & 214,93 \\
\hline Hyla molleri & 29TQE06 & 100,00 & 119,30 & $\begin{array}{l}96,47 \\
\end{array}$ & 34,97 & 6132,22 & 280,84 & 9,10 & \begin{tabular}{|l|}
271,74 \\
\end{tabular} & 53,72 & 201,13 & \begin{tabular}{|l|l|}
201,82 \\
\end{tabular} & \begin{tabular}{l|l|}
46,16 \\
\end{tabular} & 805,73 & 107,34 & \begin{tabular}{|l|}
10,19 \\
\end{tabular} & 48,41 & 309,67 & \begin{tabular}{ll|}
60,69 \\
\end{tabular} & \begin{tabular}{|l|l|}
63,48 \\
\end{tabular} & 300,38 \\
\hline Hyla molleri & 29TQE07 & 100,00 & \begin{tabular}{|l|}
123,62 \\
\end{tabular} & 98,16 & 35,33 & 6135,20 & 285,67 & \begin{tabular}{l|l|}
12,02 \\
\end{tabular} & \begin{tabular}{|l|}
273,65 \\
\end{tabular} & 57,43 & 204,98 & \begin{tabular}{|l|}
205,92 \\
\end{tabular} & \begin{tabular}{|l|}
49,78 \\
\end{tabular} & 759,97 & 100,67 & 9,58 & 48,27 & 291,79 & 57,97 & \begin{tabular}{|l|}
59,88 \\
\end{tabular} & 282,52 \\
\hline Hyla molleri & 29TQЕ09 & 100,00 & 131,30 & 101,86 & 36,17 & 6116,52 & 294,27 & 17,42 & 276,85 & 64,19 & 212,74 & 212,94 & 56,78 & $685,57 \mid$ & 89,87 & 8,81 & 47,62 & 262,67 & 54,02 & 54,22 & 253,71 \\
\hline Hyla molleri & 29TQE13 & 100,00 & 156,33 & 105,69 & 36,17 & 6251,36 & 324,88 & 38,28 & 286,60 & \begin{tabular}{|l|l|}
87,52 \\
\end{tabular} & 239,41 & 239,41 & 79,80 & 550,07 & $\mid 70,36$ & 5,31 & \begin{tabular}{|l|l|l|}
48,23 \\
\end{tabular} & 208,15 & \begin{tabular}{|l|l|}
39,49 \\
\end{tabular} & \begin{tabular}{|l|l|}
39,49 \\
\end{tabular} & \begin{tabular}{|l|l|}
197,77 \\
\end{tabular} \\
\hline Hyla molleri & 29TQE18 & 101,00 & 125,54 & 101,80 & 36,00 & 6169,60 & 290,29 & 11,75 & 278,54 & 58,30 & 207,24 & 208,30 & \begin{tabular}{|l|l|}
51,04 \\
\end{tabular} & 686,06 & 88,32 & 9,12 & 46,56 & 260,12 & 55,46 & 56,49 & 249,12 \\
\hline Hyla molleri & 29TQE19 & 100,00 & 127,25 & 103,00 & 36,19 & 6162,70 & 292,13 & 12,80 & 279,33 & 59,83 & 209,15 & 209,75 & 52,47 & 661,92 & 85,14 & 9,13 & 46,17 & 250,62 & 54,62 & 55,15 & 239,65 \\
\hline Hyla molleri & 29TQE28 & 100,00 & 119,46 & 102,97 & 36,06 & 6199,91 & 286,09 & 5,50 & 280,59 & \begin{tabular}{|l|l|}
52,27 \\
\end{tabular} & 201,76 & \begin{tabular}{|l|}
202,81 \\
\end{tabular} & \begin{tabular}{|l|l|}
44,99 \\
\end{tabular} & \begin{tabular}{ll|}
678,62 \\
\end{tabular} & 86,57 & $\begin{array}{l}10,04 \\
\end{array}$ & 44,90 & 253,79 & \begin{tabular}{|l|l|}
57,87 \\
\end{tabular} & 59,40 & 240,81 \\
\hline Hyla molleri & 29TQE39 & 101,00 & 109,91 & 104,34 & 36,66 & 6188,14 & 277,81 & \begin{tabular}{|c|} 
\\
\end{tabular} & 281,59 & 43,16 & 192,28 & \begin{tabular}{|l|l|}
193,47 \\
\end{tabular} & 36,11 & \begin{tabular}{|l|l|}
681,21 \\
\end{tabular} & 86,15 & \begin{tabular}{|l|}
11,77 \\
\end{tabular} & \begin{tabular}{|l|}
42,58 \\
\end{tabular} & 250,19 & 63,12 & 65,34 & 234,95 \\
\hline Hyla molleri & 29TQE48 & 99,00 & \begin{tabular}{|l|}
117,99 \\
\end{tabular} & \begin{tabular}{|l|}
107,09 \\
\end{tabular} & 36,82 & 6247,59 & 288,57 & 1,73 & 286,85 & 50,00 & 201,22 & \begin{tabular}{|l|}
202,15 \\
\end{tabular} & 43,11 & 606,94 & $\begin{array}{l}75,98 \\
\end{array}$ & 10,64 & \begin{tabular}{|l|}
41,83 \\
\end{tabular} & 219,55 & 57,39 & \begin{tabular}{|l|l|}
58,73 \\
\end{tabular} & 204,08 \\
\hline Hyla molleri & 29TQE49 & 100,00 & & & & 621 & & $-3,86$ & 285,09 & 43,78 & 193,70 & \begin{tabular}{|l|}
195,11 \\
\end{tabular} & 36,90 & 629,64 & 78,99 & \begin{tabular}{|l|l|}
11,61 \\
\end{tabular} & 41,15 & 227,45 & $\begin{array}{l}61,36 \\
\end{array}$ & 63,11 & 210,94 \\
\hline Hyla molleri & 29TQE56 & 50,00 & $\begin{array}{l}137,16 \\
\end{array}$ & 109,69 & 36,99 & 6325,01 & 310,13 & 17,17 & 292,96 & 67,55 & 221,57 & \begin{tabular}{|l|}
221,77 \\
\end{tabular} & 60,39 & 507,69 & 62,88 & 7,87 & 42,52 & \begin{tabular}{|l|}
181,96 \\
\end{tabular} & 45,81 & 46,01 & 168,04 \\
\hline Hyla molleri & 29TQE57 & 42,00 & 139,19 & 110,38 & 37,06 & 6308,52 & 311,71 & 18,79 & 292,92 & 69,40 & 223,40 & \begin{tabular}{|l|}
223,47 \\
\end{tabular} & 62,26 & 486,51 & 60,44 & 7,65 & 42,35 & \begin{tabular}{|l|l|}
174,30 \\
\end{tabular} & $\begin{array}{l}44,42 \\
\end{array}$ & 44,45 & $\begin{array}{ll}160,43 \\
\end{array}$ \\
\hline Hyla molleri & 29TQF00 & 101,00 & 125,68 & 101,47 & 36,07 & 6098,83 & 288,05 & 12,26 & 275,78 & 58,74 & 206,51 & \begin{tabular}{|l|}
207,12 \\
\end{tabular} & 51,41 & 708,92 & 92,76 & 9,3 & 47, & 271,62 & 56,76 & 57,37 & 26 \\
\hline Hyla molleri & 29TQF & & 122,89 & 103,03 & \begin{tabular}{|l|}
36,92 \\
\end{tabular} & & 285 & 9,05 & 276,44 & 56,28 & 203,29 & \begin{tabular}{|l|}
203,87 \\
\end{tabular} & & \begin{tabular}{|l|}
700,28 \\
\end{tabular} & 90, & 9,98 & 46 & 26 & 58,49 & \begin{tabular}{|l|l|}
58,88 \\
\end{tabular} & 258,90 \\
\hline Hyla molleri & 29TQF04 & 101,00 & $\begin{array}{l}123,46 \\
\end{array}$ & $\begin{array}{l}105,54 \\
\end{array}$ & $\begin{array}{l}37,25 \\
\end{array}$ & $\begin{array}{l}6028,68 \\
\end{array}$ & 286,61 & 8,46 & 278,16 & 56,72 & 203,73 & \begin{tabular}{|l|l|}
203,73 \\
\end{tabular} & \begin{tabular}{l|l|}
49,45 \\
\end{tabular} & \begin{tabular}{|l|l|}
672,08 \\
\end{tabular} & 86,70 & 9,91 & 45,98 & \begin{tabular}{|l|l|}
256,68 \\
\end{tabular} & 57,71 & 57,71 & 248,53 \\
\hline Hyla molleri & 29TQF05 & 99,00 & \begin{tabular}{|l|}
122,03 \\
\end{tabular} & $\begin{array}{l}106,32 \\
\end{array}$ & 37,58 & 6018,77 & 285,45 & 6,53 & 278,92 & 55,32 & 202,18 & \begin{tabular}{|l|l|}
202,18 \\
\end{tabular} & 48,14 & 667,94 & 85,85 & 10,00 & 45,79 & \begin{tabular}{|l|l|}
255,06 \\
\end{tabular} & \begin{tabular}{|l|l|}
58,03 \\
\end{tabular} & \begin{tabular}{|l|l|}
58,03 \\
\end{tabular} & 247,19 \\
\hline Hyla molleri & 29TQF07 & 100,00 & 124,47 & 108,48 & 38,15 & 5975,92 & 288,21 & 7,85 & 280,36 & 57,62 & 203,80 & 203,80 & 50,69 & 634,57 & 81,31 & \begin{tabular}{|l|}
10,33 \\
\end{tabular} & 45,02 & 241,67 & 56,70 & 56,70 & 235,01 \\
\hline Hyla molleri & 29TQF08 & 100,00 & 11 & 108, & 38,1 & 959, & 283, & 3,05 & 280,26 & 52,92 & 198,65 & \begin{tabular}{|l|l|}
198,65 \\
\end{tabular} & 45, & 654, & 84,20 & 11,16 & 44,66 & 24 & 60,21 & 60,21 & 24 \\
\hline Hyla molleri & 29TQF11 & 100,00 & 123, & \begin{tabular}{|l|l|}
104,14 \\
\end{tabular} & 36,98 & 6128,57 & 287,91 & 8,57 & 279,33 & 55,96 & 204,75 & 205,19 & \begin{tabular}{|l|l|}
48,69 \\
\end{tabular} & 659,94 & 84,82 & 9,63 & 45,38 & 249,59 & 56,55 & 56,89 & 238,38 \\
\hline Hyla molleri & 29TQF12 & 100,00 & 122,99 & 105,13 & 37,00 & 6111,62 & 287,74 & 7,87 & 279,87 & 55,62 & 204,36 & 204,60 & 48,39 & 647,71 & 83,04 & 9,79 & 44,91 & 244,60 & 56,76 & 56,92 & 233,47 \\
\hline
\end{tabular}




\begin{tabular}{|c|c|c|c|c|c|c|c|c|c|c|c|c|c|c|c|c|c|c|c|c|c|}
\hline$\overline{\text { TAXON }}$ & UTM & km2 & BIO1 & BIO2 & B103 & BIO4 & 8105 & B106 & B107 & B108 & B109 & BIO10 & BIO11 & BIO12 & B1013 & BIO14 & BIO15 & B1016 & B1017 & BIO18 & 81019 \\
\hline Hyla molleri & 29TQF13 & 101,00 & 123,01 & 106,11 & 37,06 & 6095,12 & 287,97 & 7,33 & 280,65 & 55,72 & 204,13 & 204,15 & 48,44 & 634,82 & 81,18 & 9,91 & 44,66 & 239,46 & 56,57 & 56,58 & 228,54 \\
\hline Hyla molleri & 29TQF14 & 99,00 & 120,89 & 106,77 & 37,49 & 6081,66 & 286,01 & 5,07 & 280,95 & 53,65 & 201,93 & 201,93 & \begin{tabular}{ll|}
46,56 \\
\end{tabular} & 633,33 & 80,74 & 10,00 & 44,27 & 238,69 & 57,48 & \begin{tabular}{|l|l|}
57,48 \\
\end{tabular} & 227,90 \\
\hline Hyla molleri & 29TQF16 & 100,00 & 119,86 & $\begin{array}{l}108,46 \\
\end{array}$ & 38,00 & 6049,59 & 285,22 & 3,36 & 281,85 & 52,53 & 200,33 & \begin{tabular}{|l|}
200,33 \\
\end{tabular} & 45,51 & 616,45 & $\begin{array}{l}78,70 \\
\end{array}$ & 10,64 & 43,43 & \begin{tabular}{|l|l|}
231,63 \\
\end{tabular} & \begin{tabular}{|l|l|}
58,12 \\
\end{tabular} & \begin{tabular}{|l|l|}
58,12 \\
\end{tabular} & 221,61 \\
\hline Hyla molleri & 29TQF17 & 99,00 & \begin{tabular}{|l|}
126,84 \\
\end{tabular} & 110,00 & 38,23 & 6022,16 & 292,13 & 8,85 & 283,28 & 59,28 & 206,62 & \begin{tabular}{l|l|}
206,62 \\
\end{tabular} & 52,31 & 571,63 & 73,31 & 9,92 & \begin{tabular}{|l|}
43,27 \\
\end{tabular} & 214,56 & 53,54 & 53,54 & 205,38 \\
\hline Hyla molleri & 29TQF18 & 100,00 & 122,60 & 110,21 & 38,40 & 6005,49 & 287,87 & 4,76 & 283,11 & 55,36 & 202,28 & 202,28 & 48,48 & 585,02 & 75,58 & 10,69 & 43,04 & 219,49 & 56,23 & 56,23 & 210,90 \\
\hline Hyla molleri & 29TQF19 & 100,00 & 118,95 & 1110,37 & 38,70 & $\begin{array}{l}5982,06 \\
\end{array}$ & 284,32 & 1,44 & 282,88 & 52,01 & 198,36 & \begin{tabular}{|l|}
198,36 \\
\end{tabular} & 45,22 & 596,50 & 77,51 & \begin{tabular}{|l|l|}
11,53 \\
\end{tabular} & 42,49 & 223,55 & \begin{tabular}{|l|l|}
59,05 \\
\end{tabular} & 59,05 & 215,39 \\
\hline Hyla molleri & 29TQF21 & 101,00 & 123,91 & 106,41 & 37,00 & 6166,18 & 290,78 & 7,72 & 283,06 & 55,99 & 206,19 & \begin{tabular}{|l|}
206,34 \\
\end{tabular} & 48,80 & 606,68 & 77,50 & 9,49 & 43,88 & 226,22 & 54,70 & 54,79 & 213,01 \\
\hline Hyla molleri & 29TQF23 & 100,00 & 121,07 & 107,80 & 37,57 & 6138,42 & 288,02 & 4,50 & 283,52 & 53,12 & 202,86 & \begin{tabular}{|l|}
202,95 \\
\end{tabular} & 46,11 & 594,91 & 75,73 & 9,97 & \begin{tabular}{|l|l|}
42,97 \\
\end{tabular} & 221,11 & 56,01 & 56,09 & 207,68 \\
\hline Hyla molleri & 29TQF25 & 100,00 & 118,78 & 109,07 & 38,00 & 6103,65 & 285,76 & 1,81 & 283,94 & 51,01 & 200,04 & \begin{tabular}{|l|}
200,04 \\
\end{tabular} & \begin{tabular}{|l|}
44,07 \\
\end{tabular} & 582,67 & $\begin{array}{l}74,56 \\
\end{array}$ & 10,54 & 42,24 & 215,88 & $\begin{array}{l}56,95 \\
\end{array}$ & $\begin{array}{l}56,95 \\
\end{array}$ & 202,80 \\
\hline Hyla molleri & 29TQF26 & 100,00 & 119,46 & 109,95 & 38,00 & \begin{tabular}{|c|}
6093,24 \\
\end{tabular} & 286,79 & 1,91 & 284,88 & 51,71 & 200,57 & \begin{tabular}{|l|}
200,57 \\
\end{tabular} & \begin{tabular}{|l|l|}
44,79 \\
\end{tabular} & 566,95 & \begin{tabular}{|l|}
72,83 \\
\end{tabular} & 10,62 & 41,69 & 209,51 & 56,51 & 56,51 & $\begin{array}{l}196,92 \\
\end{array}$ \\
\hline Hyla molleri & 29TQF28 & 100,00 & $\begin{array}{l}120,82 \\
\end{array}$ & 111,21 & 38,30 & 6056,09 & 287,94 & 2,60 & 285,34 & 53,22 & 201,28 & \begin{tabular}{|l|l|}
201,28 \\
\end{tabular} & 46,19 & 543,86 & 70,42 & \begin{tabular}{|l|}
10,86 \\
\end{tabular} & 41,16 & 200,26 & 55,77 & 55,77 & \begin{tabular}{|l|l|}
188,94 \\
\end{tabular} \\
\hline Hyla molleri & 29TQF29 & 100,00 & $\begin{array}{l}120,33 \\
\end{array}$ & \begin{tabular}{|l|}
111,61 \\
\end{tabular} & 38,78 & 6032,92 & 287,25 & 1,88 & 285,36 & 52,66 & 200,29 & 200,29 & 45,80 & 541,55 & 70,40 & \begin{tabular}{|l|}
11,25 \\
\end{tabular} & 40,85 & \begin{tabular}{|l|l|}
199,19 \\
\end{tabular} & 56,50 & 56,50 & 188,40 \\
\hline Hyla molleri & 29TQF30 & 100,00 & 119,31 & 106,94 & 37,00 & 6208,17 & 287,95 & 3,01 & 284,94 & 51,33 & 201,75 & 202,61 & \begin{tabular}{l|l|}
44,15 \\
\end{tabular} & 603,73 & 76,57 & \begin{tabular}{|l|}
10,06 \\
\end{tabular} & 42,51 & 221,76 & 56,64 & \begin{tabular}{|l|}
57,28 \\
\end{tabular} & 206,68 \\
\hline Hyla molleri & 29TQF33 & 100,00 & \begin{tabular}{|l|}
120,81 \\
\end{tabular} & 109,77 & 37,97 & 6173,76 & 289,77 & 3,13 & 286,63 & 52,61 & 203,35 & \begin{tabular}{|l|}
203,35 \\
\end{tabular} & \begin{tabular}{|l|}
45,52 \\
\end{tabular} & 549,90 & 69,94 & \begin{tabular}{|l|}
10,01 \\
\end{tabular} & 41,33 & 200,86 & \begin{tabular}{|l|}
54,96 \\
\end{tabular} & \begin{tabular}{|l|l|}
54,96 \\
\end{tabular} & 185,26 \\
\hline Hyla molleri & 29TQF36 & 100,00 & \begin{tabular}{|l|}
120,24 \\
\end{tabular} & \begin{tabular}{|l|}
111,54 \\
\end{tabular} & 38,22 & 6129,71 & 289,00 & 1,76 & 287,24 & 52,16 & 201,72 & \begin{tabular}{|l|}
201,72 \\
\end{tabular} & \begin{tabular}{|l|l|}
45,03 \\
\end{tabular} & 517,40 & 66,80 & \begin{tabular}{|l|}
10,28 \\
\end{tabular} & 40,33 & \begin{tabular}{|l|}
187,67 \\
\end{tabular} & \begin{tabular}{|l|l|}
54,43 \\
\end{tabular} & \begin{tabular}{|l|l|}
54,43 \\
\end{tabular} & $\begin{array}{l}172,97 \\
\end{array}$ \\
\hline Hyla molleri & 29TQF38 & 100,00 & 1117,16 & \begin{tabular}{|l|}
112,03 \\
\end{tabular} & 38,93 & 6097,53 & 285,87 & \begin{tabular}{|c|}
$-0,68$ \\
\end{tabular} & 286,55 & 50,01 & \begin{tabular}{|c|}
198,18 \\
\end{tabular} & \begin{tabular}{|l|l|}
198,18 \\
\end{tabular} & \begin{tabular}{l|l|}
42,05 \\
\end{tabular} & 517,13 & 66,94 & \begin{tabular}{|l|}
11,24 \\
\end{tabular} & 39,33 & \begin{tabular}{|l|l|}
186,47 \\
\end{tabular} & \begin{tabular}{l|l|}
57,05 \\
\end{tabular} & 57,05 & $\begin{array}{l}172,52 \\
\end{array}$ \\
\hline Hyla molleri & 29TQF39 & \begin{tabular}{|l|}
101,00 \\
\end{tabular} & $\begin{array}{l}117,53 \\
\end{array}$ & \begin{tabular}{|l|}
112,34 \\
\end{tabular} & 38,95 & 6073,13 & 286,20 & $-0,80$ & 287,00 & $\begin{array}{l}54,47 \\
\end{array}$ & \begin{tabular}{|l|l|}
198,29 \\
\end{tabular} & \begin{tabular}{|l|l|}
198,29 \\
\end{tabular} & \begin{tabular}{ll|}
42,66 \\
\end{tabular} & 509,77 & \begin{tabular}{ll|}
66,10 \\
\end{tabular} & \begin{tabular}{|l|l|}
11,77 \\
\end{tabular} & 38,87 & \begin{tabular}{|l|l|}
183,34 \\
\end{tabular} & $\begin{array}{ll}57,22 \\
\end{array}$ & \begin{tabular}{|l|l|}
57,22 \\
\end{tabular} & 169,97 \\
\hline Hyla molleri & 29TQF40 & 100,00 & 116,70 & 108,66 & 37,23 & 6227,32 & 287,15 & \begin{tabular}{|c|}
$-0,06$ \\
\end{tabular} & 287,21 & 48,54 & 199,46 & \begin{tabular}{|l|}
200,47 \\
\end{tabular} & \begin{tabular}{|l|}
41,83 \\
\end{tabular} & 578,11 & 72,63 & 10,60 & 40,89 & 208,46 & 57,44 & 58,19 & \begin{tabular}{|l|l|}
191,94 \\
\end{tabular} \\
\hline Hyla molleri & 29TQF44 & 99,00 & 118,41 & 112,01 & 38,09 & 6184,50 & 288,97 & \begin{tabular}{l|l|}
0,23 \\
\end{tabular} & 288,74 & 65,45 & 200,91 & 200,91 & \begin{tabular}{|l|}
42,97 \\
\end{tabular} & 506,69 & 65,08 & 10,55 & 39,66 & \begin{tabular}{|l|}
181,50 \\
\end{tabular} & \begin{tabular}{l|l}
54,95 \\
\end{tabular} & $\begin{array}{l}54,95 \\
\end{array}$ & \begin{tabular}{|l|l|}
163,34 \\
\end{tabular} \\
\hline Hyla molleri & 29TQF45 & 99,00 & 120,27 & 112,72 & 38,18 & 6173,60 & 290,70 & 1,01 & 289,68 & \begin{tabular}{|l|}
74,07 \\
\end{tabular} & 202,34 & \begin{tabular}{|l|}
202,34 \\
\end{tabular} & 44,59 & 485,16 & 62,58 & 10, & 39,43 & \begin{tabular}{ll|}
173,62 \\
\end{tabular} & 53,39 & 53,39 & 155,40 \\
\hline Hyla molleri & 29TQF46 & 101,00 & $\begin{array}{l}118,96 \\
\end{array}$ & \begin{tabular}{|l|}
112,92 \\
\end{tabular} & 38,60 & 6153,76 & 289,35 & 0,24 & 289,11 & 76,52 & 200,76 & 200,76 & \begin{tabular}{|l|}
43,42 \\
\end{tabular} & 481,04 & 62,11 & 10,63 & 38,93 & \begin{tabular}{|l|l|}
171,84 \\
\end{tabular} & 54,16 & 54,16 & $\begin{array}{l}153,67 \\
\end{array}$ \\
\hline Hyla molleri & 29TQF47 & 100,00 & 116,77 & 112,93 & 38,80 & 6141,71 & 287,25 & $-1,44$ & 288,68 & 76,17 & 198,53 & \begin{tabular}{|l|l|}
198,53 \\
\end{tabular} & \begin{tabular}{l|l|}
41,46 \\
\end{tabular} & 481,72 & \begin{tabular}{ll|}
62,16 \\
\end{tabular} & 11,00 & 38,46 & \begin{tabular}{|l|}
171,64 \\
\end{tabular} & 55,31 & 55,31 & 153,66 \\
\hline Hyla molleri & 29TQF48 & 100,00 & 116,89 & 113,23 & 38,97 & 6130,25 & 286,98 & $-1,75$ & 288,73 & $\mid 76,96$ & 198,25 & $\mid 198,25$ & \begin{tabular}{|l|l|}
41,58 \\
\end{tabular} & \begin{tabular}{|l|l|}
475,93 \\
\end{tabular} & $\mid 61,37$ & \begin{tabular}{|l|l|}
11,24 \\
\end{tabular} & |37,99| & 169,20 & 55,66 & 55,66 & \begin{tabular}{|l|l|}
151,72 \\
\end{tabular} \\
\hline Hyla molleri & 29TQF49 & 100,00 & 119,58 & 113,50 & 38,97 & 6115,42 & 289,29 & 0,01 & 289,29 & 80,05 & 200,47 & 200,48 & 43,96 & 459,76 & 59,24 & 11,05 & 37,64 & 163,38 & 54,36 & 54,37 & 146,34 \\
\hline Hyla molleri & 29TQF50 & 33,00 & 117,20 & 110,11 & 37,63 & 6238,59 & 288,82 & \begin{tabular}{|c|}
$-0,27$ \\
\end{tabular} & 289,09 & 48,91 & 200,27 & \begin{tabular}{|l|}
201,05 \\
\end{tabular} & 42,04 & 550,61 & 68,77 & 10,71 & 39,96 & \begin{tabular}{|c|}
195,89 \\
\end{tabular} & \begin{tabular}{|l|l|}
56,96 \\
\end{tabular} & 57,45 & \begin{tabular}{|l|l|}
178,63 \\
\end{tabular} \\
\hline Hyla molleri & 29TQF54 & 26,00 & 118,31 & 113,03 & 38,26 & 6183,91 & 289,74 & $-0,34$ & 290,09 & 78,54 & 200,80 & 200,80 & 42,91 & 483,09 & 62,06 & \begin{tabular}{ll|}
10,69 \\
\end{tabular} & 39,00 & 172,43 & 54,46 & 54,46 & 151,34 \\
\hline Hyla molleri & 29TQG00 & 99,00 & 123,09 & 110,27 & 38,96 & 5918,68 & 286,88 & 5,41 & 281,47 & 56,58 & 201,70 & \begin{tabular}{|l|}
201,70 \\
\end{tabular} & \begin{tabular}{|l|}
49,72 \\
\end{tabular} & 619,22 & 80,70 & \begin{tabular}{|l|l|}
11,43 \\
\end{tabular} & 44,19 & 235,64 & 58,29 & 58,29 & 230,85 \\
\hline Hyla molleri & 29TQG02 & 100,00 & 1118,31 & 110,55 & 39,00 & 5867,35 & 282,03 & 1,14 & 280,89 & 52,36 & 196,31 & \begin{tabular}{|l|}
196,31 \\
\end{tabular} & 45,68 & 636,56 & 84,01 & 13,14 & 43,33 & 241,71 & \begin{tabular}{|l|l|}
63,07 \\
\end{tabular} & \begin{tabular}{|l|l|}
63,07 \\
\end{tabular} & 237,84 \\
\hline Hyla molleri & 29TQG03 & 100,00 & 114,88 & 110,19 & \begin{tabular}{|l|}
38,98 \\
\end{tabular} & 5844,04 & 278,26 & $-1,66$ & 279,92 & 49,20 & \begin{tabular}{|l|}
192,60 \\
\end{tabular} & \begin{tabular}{|l|}
192,60 \\
\end{tabular} & 42,71 & 654,32 & \begin{tabular}{|l|}
86,67 \\
\end{tabular} & \begin{tabular}{l|l|}
14,58 \\
\end{tabular} & 42,81 & 247,97 & \begin{tabular}{|l|}
66,98 \\
\end{tabular} & \begin{tabular}{|l|}
66,98 \\
\end{tabular} & 243,35 \\
\hline Hyla molleri & 29TQG04 & 99,00 & 107,72 & 109,04 & 38,75 & 5831,01 & 270,54 & \begin{tabular}{|c|}
$-7,80$ \\
\end{tabular} & 278,34 & 42,36 & 185,45 & \begin{tabular}{|l|}
185,45 \\
\end{tabular} & $\begin{array}{l}36,15 \\
\end{array}$ & 697,38 & 92,22 & 17,25 & 41,55 & 262,69 & 75,26 & 75,26 & 255,74 \\
\hline Hyla molleri & 29TQG05 & 99,00 & 104,21 & 108,35 & 38,61 & 5812,30 & 266,16 & $-10,78$ & 276,93 & 39,18 & $\begin{array}{l}181,82 \\
\end{array}$ & \begin{tabular}{l|l|}
181,82 \\
\end{tabular} & 33,12 & \begin{tabular}{|l|l|}
720,31 \\
\end{tabular} & \begin{tabular}{|l|l|}
95,06 \\
\end{tabular} & \begin{tabular}{|l|}
19,42 \\
\end{tabular} & $\begin{array}{l}40,52 \\
\end{array}$ & \begin{tabular}{|l|}
270,01 \\
\end{tabular} & 80,76 & \begin{tabular}{|l|l|}
80,76 \\
\end{tabular} & 260,84 \\
\hline Hyla molleri & 29TQG06 & 101,00 & 97,59 & 107,19 & 38,63 & 5777,70 & 258,37 & $-16,03$ & 274,40 & 33,35 & \begin{tabular}{|l|}
174,90 \\
\end{tabular} & \begin{tabular}{|l|l|}
174,90 \\
\end{tabular} & 27,26 & 770,14 & 100,90 & 22,35 & 39,27 & 286,20 & \begin{tabular}{|l|l|}
90,40 \\
\end{tabular} & \begin{tabular}{|l|}
90,40 \\
\end{tabular} & 274,29 \\
\hline Hyla molleri & 29TQG10 & 101,00 & 116,77 & 1110,67 & 39,00 & 5974,82 & 282,16 & $-0,12$ & 282,28 & 50,13 & 196,21 & \begin{tabular}{|l|}
196,21 \\
\end{tabular} & 43,23 & 602,56 & 78,66 & \begin{tabular}{|l|}
12,23 \\
\end{tabular} & 42,09 & 225,51 & 61,11 & 61,11 & 217,74 \\
\hline Hyla molleri & 29TQG13 & 101,00 & 1111,71 & 110,86 & 39,00 & 5909,07 & 276,33 & $-5,18$ & 281,51 & 45,45 & 190,29 & \begin{tabular}{|l|}
190,29 \\
\end{tabular} & 38,81 & 625,53 & $\begin{array}{l}82,37 \\
\end{array}$ & 15, & \begin{tabular}{|l|}
40,67 \\
\end{tabular} & 232,93 & \begin{tabular}{|l|l|}
68,39 \\
\end{tabular} & 68,39 & 224,64 \\
\hline Hyla molleri & 29TQG14 & 100,00 & 106,12 & 110,05 & 38,93 & 5890,84 & 270,36 & $-10,14$ & 280,50 & 40,21 & \begin{tabular}{|l|}
184,73 \\
\end{tabular} & \begin{tabular}{|l|l|}
184,73 \\
\end{tabular} & \begin{tabular}{|l|l|}
33,77 \\
\end{tabular} & 662,20 & 87,05 & \begin{tabular}{|l|l|}
17,70 \\
\end{tabular} & 39,73 & 245,46 & 75,48 & 75,48 & 235,49 \\
\hline Hyla molleri & 29TQG16 & 100,00 & 100,74 & 109,21 & 38,89 & 5841,69 & 263,66 & $-14,63$ & 278,29 & 35,43 & \begin{tabular}{|l|}
178,66 \\
\end{tabular} & \begin{tabular}{l|l|}
178,66 \\
\end{tabular} & \begin{tabular}{|l|}
29,22 \\
\end{tabular} & \begin{tabular}{|l|l|}
704,69 \\
\end{tabular} & $\begin{array}{l}92,02 \\
\end{array}$ & \begin{tabular}{|l|l|}
21,13 \\
\end{tabular} & 38,13 & \begin{tabular}{|l|}
258,67 \\
\end{tabular} & 85,76 & 85,76 & 245,22 \\
\hline Hyla molleri & 29TQG20 & 100,00 & 116,37 & 111,62 & 38,94 & 6018,44 & 283,37 & \begin{tabular}{|c|}
$-1,28$ \\
\end{tabular} & 284,65 & \begin{tabular}{|l|l|}
49,07 \\
\end{tabular} & 196,27 & \begin{tabular}{|l|}
196,27 \\
\end{tabular} & 42,19 & 557,49 & 72,66 & 12,32 & 40,29 & 204,73 & \begin{tabular}{|l|}
59,88 \\
\end{tabular} & \begin{tabular}{|l|}
59,88 \\
\end{tabular} & \begin{tabular}{|l|l|}
194,08 \\
\end{tabular} \\
\hline Hyla molleri & 29TQG21 & 101,00 & 113,17 & 111,51 & 38,93 & 6004,49 & 280,10 & $-4,34$ & 284,44 & 46,17 & 193,10 & \begin{tabular}{|l|l|}
193,10 \\
\end{tabular} & 39,30 & 572,97 & 74,83 & 13,54 & 39,72 & 210,03 & 63,41 & 63,41 & \begin{tabular}{|l|l|}
199,39 \\
\end{tabular} \\
\hline Hyla molleri & 29TQG25 & 101,00 & 110,34 & 111,69 & 39,00 & 5924,36 & 275,84 & \begin{tabular}{|c|}
$-7,58$ \\
\end{tabular} & 283,42 & 47,51 & 189,06 & \begin{tabular}{|l|}
189,06 \\
\end{tabular} & 36,88 & 598,86 & 78,31 & 17,36 & 37,81 & 217,92 & 72,90 & 72,90 & 204,71 \\
\hline Hyla molleri & 29TQG28 & 99,00 & \begin{tabular}{|l|l}
90,53 \\
\end{tabular} & $\begin{array}{l}108,82 \\
\end{array}$ & \begin{tabular}{|l|}
38,88 \\
\end{tabular} & 5790,17 & 253,27 & $-23,63$ & 276,91 & 40,68 & 167,92 & \begin{tabular}{|l|l|}
167,93 \\
\end{tabular} & 20,00 & 757,65 & \begin{tabular}{|c|}
96,61 \\
\end{tabular} & 26,40 & 34,76 & 270,71 & \begin{tabular}{|l|}
103,29 \\
\end{tabular} & \begin{tabular}{|l|l|}
103,30 \\
\end{tabular} & 250,27 \\
\hline Hyla molleri & 29TQG30 & 99,00 & \begin{tabular}{|l|}
118,24 \\
\end{tabular} & \begin{tabular}{|l|}
112,71 \\
\end{tabular} & 38,98 & 6054,24 & 286,54 & $-0,55$ & 287,09 & 58,13 & \begin{tabular}{|l|l|}
198,47 \\
\end{tabular} & \begin{tabular}{|l|l|}
198,47 \\
\end{tabular} & \begin{tabular}{l|l|}
43,35 \\
4
\end{tabular} & \begin{tabular}{|l|l|}
504,83 \\
\end{tabular} & $\begin{array}{ll}65,56 \\
\end{array}$ & 12,00 & 38,70 & \begin{tabular}{|l|l|}
181,38 \\
\end{tabular} & 57,28 & \begin{tabular}{|l|l|}
57,28 \\
\end{tabular} & $\begin{array}{l}168,57 \\
\end{array}$ \\
\hline Hyla molleri & 29TQG32 & 101,00 & 115,15 & 112,95 & 39,00 & 6022,04 & 283,26 & $-3,62$ & 286,87 & 62,35 & 194,93 & \begin{tabular}{|l|l|}
194,93 \\
\end{tabular} & \begin{tabular}{l|l|}
40,52 \\
\end{tabular} & 521,67 & \begin{tabular}{ll|}
67,79 \\
\end{tabular} & \begin{tabular}{|l|l|}
13,77 \\
\end{tabular} & 37,72 & \begin{tabular}{|l|}
187,15 \\
\end{tabular} & \begin{tabular}{|l|l|}
62,19 \\
\end{tabular} & \begin{tabular}{|l|l|}
62,19 \\
\end{tabular} & \begin{tabular}{|l|l|}
173,83 \\
\end{tabular} \\
\hline Hyla molleri & 29TQG34 & 100,00 & 109,08 & 112,74 & 38,97 & 5982,61 & 276,92 & \begin{tabular}{|c|}
$-9,39$ \\
\end{tabular} & 286,31 & 65,83 & 188,59 & \begin{tabular}{|l|l|}
188,59 \\
\end{tabular} & \begin{tabular}{|l|l|}
35,17 \\
\end{tabular} & 564,89 & 73,18 & 16,72 & 36,65 & 202,73 & 71,26 & 71,26 & 187,20 \\
\hline Hyla molleri & 29TQG35 & 100,00 & 113,57 & 113,09 & 39,00 & 5964,48 & 280,43 & $-5,71$ & 286,14 & 74,8 & 192,4 & \begin{tabular}{|l|l|}
192,48 \\
\end{tabular} & 39,41 & 547,40 & 70,94 & 16,45 & 36, & \begin{tabular}{|l|l|}
197,66 \\
\end{tabular} & \begin{tabular}{|l|}
69,83 \\
\end{tabular} & \begin{tabular}{|l|l|}
69,83 \\
\end{tabular} & 180,30 \\
\hline Hyla molleri & 29TQG36 & 100,00 & 111,99 & 112,95 & 39,00 & 5944,72 & 278,49 & $-7,13$ & 285,62 & 73,74 & 190,64 & 190,64 & 38,05 & 562,72 & 72,66 & \begin{tabular}{|l|l|}
17,69 \\
\end{tabular} & 36,04 & \begin{tabular}{|l|}
203,73 \\
\end{tabular} & 73,84 & 73,84 & 183,80 \\
\hline Hyla molleri & 29TQG37 & 100,00 & 107,03 & 112,53 & 39,00 & 5911,25 & 273,25 & \begin{tabular}{|c|}
$-11,47$ \\
\end{tabular} & 284,72 & 69,31 & 185,40 & \begin{tabular}{|l|}
185,40 \\
\end{tabular} & 33,77 & 599,10 & 77,00 & 20,05 & 35,24 & 216,74 & 81,45 & 81,45 & 193,97 \\
\hline Hyla molleri & 29TQG40 & 100,00 & 116,85 & \begin{tabular}{|l|}
113,49 \\
\end{tabular} & \begin{tabular}{|l|}
38,97 \\
\end{tabular} & 6098,32 & 286,63 & $-2,42$ & 289,05 & 77,78 & 197,83 & \begin{tabular}{|l|l|}
197,83 \\
\end{tabular} & \begin{tabular}{|l|l|}
41,59 \\
\end{tabular} & 470,69 & $\begin{array}{l}60,57 \\
\end{array}$ & \begin{tabular}{|l|}
11,96 \\
1
\end{tabular} & 37,01 & \begin{tabular}{l|l|}
167,12 \\
\end{tabular} & \begin{tabular}{|l|l}
57,16 \\
\end{tabular} & \begin{tabular}{|l|l|}
57,16 \\
\end{tabular} & 149,90 \\
\hline Hyla molleri & 29TQG41 & 98,00 & \begin{tabular}{|l|l|}
116,63 \\
\end{tabular} & 113,70 & 39,00 & \begin{tabular}{|c|c|}
6077,83 \\
\end{tabular} & 286,10 & $-2,87$ & 288,97 & 77,60 & 197,19 & \begin{tabular}{|l|l|}
197,19 \\
\end{tabular} & \begin{tabular}{l|l|}
41,35 \\
4
\end{tabular} & 474,35 & $\begin{array}{ll}61,05 \\
\end{array}$ & \begin{tabular}{|l|}
12,53 \\
\end{tabular} & 36,5 & \begin{tabular}{l|l|}
168,65 \\
\end{tabular} & 58,62 & \begin{tabular}{ll|}
58,62 \\
\end{tabular} & $\begin{array}{l}151,31 \\
\end{array}$ \\
\hline Hyla molleri & 29TQG43 & 91,00 & 109,68 & 113,67 & 39,00 & 6041,99 & 279,31 & $-9,32$ & 288,63 & 71,14 & 189,93 & \begin{tabular}{|l|}
189,93 \\
\end{tabular} & 34,99 & 522,63 & 67,10 & 15,6 & 35, & \begin{tabular}{|l|l|}
186,39 \\
\end{tabular} & 68,06 & 68,06 & 167,33 \\
\hline Hyla molleri & 29TQ & 86,00 & 116 & \begin{tabular}{|l|}
114,02 \\
\end{tabular} & 39, & 5989,02 & 284 & \begin{tabular}{|l|}
$-4,08$ \\
\end{tabular} & 288,09 & 78,0 & 195,22 & \begin{tabular}{|l|}
195,22 \\
\end{tabular} & 41 & 506,24 & 64,85 & 15, & 35,28 & \begin{tabular}{|l|l|}
182,75 \\
\end{tabular} & \begin{tabular}{|l|l|}
67,67 \\
\end{tabular} & \begin{tabular}{|l|l|}
67,67 \\
\end{tabular} & 160,55 \\
\hline Hyla molleri & 29TQG46 & 80,00 & $\begin{array}{l}114,57 \\
\end{array}$ & 113,95 & 39,00 & 5963,28 & 282,04 & $\begin{array}{l}-5,28 \\
\end{array}$ & 287,32 & 76,54 & 193,27 & \begin{tabular}{|l|}
193,27 \\
\end{tabular} & 40,03 & 523,95 & 66,95 & 17,08 & 34,98 & \begin{tabular}{|l|}
189,85 \\
\end{tabular} & 71,64 & 71,64 & 165,34 \\
\hline Hyla molleri & 29TQH05 & 100,00 & 74,91 & $\begin{array}{l}99,24 \\
\end{array}$ & 39,39 & 5169,66 & 220,93 & $-28,05$ & 248,98 & 21,71 & 143,89 & \begin{tabular}{|l|}
143,99 \\
\end{tabular} & \begin{tabular}{|l|}
13,48 \\
\end{tabular} & 1055,92 & 132,96 & 42,27 & 31,32 & 370,01 & \begin{tabular}{|l|l|}
155,47 \\
\end{tabular} & 156,53 & 339,66 \\
\hline Hyla molleri & 29TQH12 & 101,00 & 109,52 & 106,53 & 39,84 & 511,58 & 262,08 & \begin{tabular}{|c|}
$-3,35$ \\
\end{tabular} & 265,42 & 74,24 & 182,02 & \begin{tabular}{|l|l|}
182,02 \\
\end{tabular} & \begin{tabular}{|l|}
41,22 \\
\end{tabular} & 714,61 & 94,32 & 24,98 & 34,1 & 257,79 & \begin{tabular}{|l|}
99,18 \\
\end{tabular} & \begin{tabular}{|l|l|}
99,18 \\
\end{tabular} & 225 \\
\hline Hyla molleri & 29тQH15 & 101,00 & 81,08 & 101,33 & 39, & 5205 & 228,01 & \begin{tabular}{|l|}
$-23,78$ \\
\end{tabular} & 251,80 & $\begin{array}{l}40,02 \\
\end{array}$ & 150,30 & 150 & \begin{tabular}{|l|}
18,68 \\
\end{tabular} & \begin{tabular}{|c|}
976,59 \\
\end{tabular} & 124,20 & \begin{tabular}{|l|l|}
40,07 \\
\end{tabular} & 30,67 & 340,54 & \begin{tabular}{|l|l|}
147,50 \\
\end{tabular} & \begin{tabular}{|l|l|}
148,47 \\
\end{tabular} & 307,29 \\
\hline Hyla molleri & 29TQH16 & 100,00 & $\begin{array}{ll}66,93 \\
\end{array}$ & \begin{tabular}{|l|l|}
98,64 \\
\end{tabular} & 39,36 & 5134,50 & 212,62 & $-34,94$ & 247,56 & 17,86 & 135,50 & 135,73 & 6,21 & 1106,53 & 138,03 & 47,02 & 29,70 & 382,01 & \begin{tabular}{|l|}
170,17 \\
\end{tabular} & 172,03 & 349,10 \\
\hline Hyla molleri & 29TQH21 & 99,00 & \begin{tabular}{|l|}
90,49 \\
\end{tabular} & \begin{tabular}{|l|}
107,60 \\
\end{tabular} & 39,20 & 5617,95 & 248,60 & \begin{tabular}{|l|}
$-21,87$ \\
\end{tabular} & 270,47 & 53,99 & 165,27 & \begin{tabular}{|l|}
165,27 \\
\end{tabular} & 21,89 & 794,80 & 101,78 & \begin{tabular}{|l|}
30,23 \\
\end{tabular} & 32,91 & \begin{tabular}{|l|}
282,67 \\
\end{tabular} & \begin{tabular}{|l|l|}
115,17 \\
\end{tabular} & \begin{tabular}{|l|l|}
115,17 \\
\end{tabular} & 254,36 \\
\hline Hyla molleri & 29TQH26 & 100,00 & 67,82 & 99,91 & 39,58 & 5166,21 & 214,59 & $-35,04$ & 249,64 & 28,79 & 136,77 & \begin{tabular}{|l|}
136,99 \\
\end{tabular} & 6,55 & \begin{tabular}{|l|}
1070,76 \\
\end{tabular} & 133,82 & 46,89 & 28,95 & 367,11 & 168,84 & 170,41 & 332,03 \\
\hline Hyla molleri & 29тQH27 & 100,00 & & 100,2 & \begin{tabular}{|l|l|}
40,40 \\
\end{tabular} & 5017, & 225 , & $-20,01$ & $245,3 \varepsilon$ & 50,25 & 149,06 & \begin{tabular}{|l|l|}
149,50 \\
\end{tabular} & 22,69 & 987, & $\mid 126,24$ & 43 & 28 & 340,24 & $\mid$\begin{tabular}{|l|l|}
157,60 \\
\end{tabular} & \begin{tabular}{|l|l|}
162,62 \\
\end{tabular} & \\
\hline Hyla molleri & 29TQH32 & 100,00 & 97,68 & 109,41 & \begin{tabular}{|l|l|}
39,95 \\
\end{tabular} & 5598,78 & 256,04 & $-15,92$ & 271,96 & \begin{tabular}{|c|}
63,06 \\
\end{tabular} & \begin{tabular}{|c|}
171,74 \\
\end{tabular} & \begin{tabular}{|l|l|}
171,74 \\
\end{tabular} & 28,74 & 731,32 & 95,02 & 29,60 & 31,83 & 261,96 & \begin{tabular}{|l|l|}
111,86 \\
\end{tabular} & \begin{tabular}{|l|l|}
111,86 \\
\end{tabular} & 224, \\
\hline Hyla molleri & 29TQH37 & 99,00 & 76,09 & 100,54 & \begin{tabular}{|l|}
40,23 \\
\end{tabular} & 5063,42 & 220,15 & $-26,83$ & 246,98 & 43,00 & 143,21 & \begin{tabular}{|l|}
143,59 \\
\end{tabular} & 15,63 & 1014,50 & \begin{tabular}{|l|}
128,25 \\
\end{tabular} & 46,39 & 27,91 & \begin{tabular}{|l|l|}
346,75 \\
\end{tabular} & \begin{tabular}{l|l|}
165,85 \\
\end{tabular} & 169,67 & 304,04 \\
\hline
\end{tabular}




\begin{tabular}{|c|c|c|c|c|c|c|c|c|c|c|c|c|c|c|c|c|c|c|c|c|c|}
\hline$\overline{\text { TAXON }}$ & UTM & $\mathrm{km} 2$ & BIO1 & BIO2 & B103 & BIO4 & B105 & B106 & B107 & B108 & B109 & BIO10 & BIO11 & BIO12 & B1013 & B1014 & B1015 & B1016 & B1017 & BIO18 & 81019 \\
\hline Hyla molleri & 29TQH44 & 55,00 & 85,53 & 106,75 & 39,96 & 5416,52 & 239,67 & $-24,34$ & 264,01 & 53,52 & 157,49 & 157,49 & 19,69 & 842,54 & $\begin{array}{r}107,92 \\
\end{array}$ & 37,39 & 29,48 & 295,18 & 136,52 & 136,52 & 251,94 \\
\hline Hyla molleri & 29TQJ32 & 74,00 & 134,23 & 83,35 & 43,00 & 3796,84 & 238,70 & 46,89 & 191,82 & 116,10 & \begin{tabular}{|l|}
181,84 \\
\end{tabular} & \begin{tabular}{|l|}
185,14 \\
\end{tabular} & 88,38 & 858,30 & 117,33 & \begin{tabular}{|l|}
40,27 \\
\end{tabular} & 28,58 & \begin{tabular}{|l|l|}
290,85 \\
\end{tabular} & \begin{tabular}{|l|l|}
144,00 \\
\end{tabular} & 156,31 & 226,00 \\
\hline Hyla molleri & 30STH59 & 100,00 & \begin{tabular}{|l|}
158,08 \\
\end{tabular} & 120,01 & 37,01 & 6644,11 & 346,61 & 28,50 & 318,10 & 85,85 & 246,69 & \begin{tabular}{|l|l|}
246,69 \\
\end{tabular} & $\begin{array}{l}77,37 \\
\end{array}$ & 543,94 & 70,90 & 3,76 & 51,89 & \begin{tabular}{|l|l|}
201,49 \\
\end{tabular} & 30,76 & \begin{tabular}{|l|}
30,76 \\
\end{tabular} & \begin{tabular}{|l|l|}
191,24 \\
\end{tabular} \\
\hline Hyla molleri & 30STH60 & 100,00 & 154,76 & \begin{tabular}{l|l|}
123,63 \\
\end{tabular} & 38,00 & 6584,50 & 343,96 & 24,34 & 319,62 & 83,79 & 242,28 & \begin{tabular}{|l|l|}
242,47 \\
\end{tabular} & $\begin{array}{l}74,96 \\
\end{array}$ & $\begin{array}{ll}669,32 \\
\end{array}$ & 91,24 & 3,44 & 57,66 & 263,09 & 28,16 & 29,76 & 254,51 \\
\hline Hyla molleri & 30STH72 & 100,00 & 161,12 & 124,65 & 38,00 & 6671,75 & 352,56 & 28,79 & 323,77 & 88,78 & 249,95 & 249,95 & 79,81 & 621,28 & 84,23 & 3,12 & 57,01 & 239,88 & 26,17 & 26,17 & 232,06 \\
\hline Hyla molleri & 30STH82 & 100,00 & 160,47 & 124,88 & 37,99 & \begin{tabular}{|l|l|l}
6717,64 \\
\end{tabular} & 353,05 & \begin{tabular}{|l|}
27,63 \\
\end{tabular} & 325,43 & 87,61 & 250,08 & 250,08 & \begin{tabular}{|l|}
78,63 \\
\end{tabular} & 626,84 & 85,41 & 3,14 & 57,05 & 240,49 & 26,13 & 26,13 & 233,82 \\
\hline Hyla molleri & 30STJ41 & 100,00 & 168,00 & 118,16 & 37,00 & 6540,08 & 352,32 & 39,14 & 313,18 & 96,26 & 254,77 & \begin{tabular}{|l|}
254,77 \\
\end{tabular} & 87,71 & 479,60 & \begin{tabular}{|l|l|}
61,97 \\
\end{tabular} & 3,00 & 51,34 & \begin{tabular}{|l|l|}
177,79 \\
\end{tabular} & 27,78 & 27,78 & 166,52 \\
\hline Hyla molleri & 30STJ52 & 100,00 & 167,62 & 117,97 & 37,00 & 6582,42 & 352,50 & 38,25 & 314,25 & 95,18 & 254,94 & 254,94 & \begin{tabular}{l|l|}
86,75 \\
\end{tabular} & 469,10 & 60,64 & 3,00 & 50,56 & \begin{tabular}{|l|l|}
171,66 \\
\end{tabular} & 27,95 & 27,95 & $\begin{array}{ll}160,63 \\
\end{array}$ \\
\hline Hyla molleri & 30STJ53 & 100,00 & 166,45 & \begin{tabular}{|l|l|}
117,24 \\
\end{tabular} & 37,00 & 6592,93 & 350,83 & \begin{tabular}{|l|}
37,91 \\
\end{tabular} & 312,92 & \begin{tabular}{|l|}
94,09 \\
\end{tabular} & 254,25 & \begin{tabular}{|l|l|}
254,25 \\
\end{tabular} & $\begin{array}{l}85,66 \\
\end{array}$ & 462,89 & \begin{tabular}{|l|l|}
59,97 \\
\end{tabular} & 3,01 & 50,18 & \begin{tabular}{ll|}
168,80 \\
\end{tabular} & 28,12 & \begin{tabular}{|l|}
28,12 \\
\end{tabular} & $\begin{array}{l}157,63 \\
\end{array}$ \\
\hline Hyla molleri & 30STI59 & 100,00 & 153,68 & \begin{tabular}{|l|l|}
112,63 \\
\end{tabular} & 36,43 & 6536,26 & 333,96 & 28,91 & 305,05 & 82,08 & 241,23 & \begin{tabular}{|l|l|}
241,23 \\
\end{tabular} & \begin{tabular}{|l|}
74,07 \\
\end{tabular} & 466,74 & 57,20 & \begin{tabular}{|l|l|}
4,98 \\
\end{tabular} & \begin{tabular}{|l|l|}
45,69 \\
\end{tabular} & \begin{tabular}{|l|}
165,74 \\
\end{tabular} & 35,83 & 35,83 & 153,15 \\
\hline Hyla molleri & 30STJ62 & 100,00 & \begin{tabular}{|l|}
166,71 \\
\end{tabular} & 118,79 & 37,00 & 6630,30 & \begin{tabular}{|l|l|}
352,93 \\
\end{tabular} & 36,76 & 316,17 & 93,99 & 255,07 & \begin{tabular}{|l|}
255,07 \\
\end{tabular} & \begin{tabular}{l|l|}
85,52 \\
\end{tabular} & 466,96 & 60,83 & 3,00 & 50,72 & 169,80 & 27,38 & 27,38 & \begin{tabular}{|l|l|}
159,24 \\
\end{tabular} \\
\hline Hyla molleri & 30STJ73 & 100,00 & \begin{tabular}{|l|}
165,03 \\
\end{tabular} & 118,73 & 37,00 & 6656,66 & 351,75 & 34,71 & 317,04 & 91,92 & \begin{tabular}{|l|}
253,87 \\
\end{tabular} & \begin{tabular}{|l|}
253,87 \\
\end{tabular} & 83,65 & 457,19 & 59,44 & 3,02 & \begin{tabular}{|l|}
49,79 \\
\end{tabular} & \begin{tabular}{|l|}
163,93 \\
\end{tabular} & 27,85 & 27,85 & 153,66 \\
\hline Hyla molleri & 30STJ74 & 100,00 & 162,17 & $\begin{array}{l}117,93 \\
\end{array}$ & 37,00 & 6665,46 & 348,56 & 32,45 & 316,11 & 89,02 & 251,31 & 251,31 & 80,81 & 458,88 & 59,24 & 3,78 & 48,81 & \begin{tabular}{|l|l|}
163,27 \\
\end{tabular} & 29,70 & 29,70 & 152,46 \\
\hline Hyla molleri & 30STJ83 & 100,00 & 164,26 & 119,30 & 37,00 & 6693,97 & 351,82 & 33,32 & 318,50 & 91,13 & 253,90 & 253,90 & 82,54 & 454,95 & 59,16 & 3,09 & 49,66 & \begin{tabular}{|l|l|}
161,80 \\
\end{tabular} & 27,59 & 27,59 & \begin{tabular}{ll|}
151,82 \\
\end{tabular} \\
\hline Hyla molleri & 30STJ86 & 100,00 & 140,42 & 116,69 & 36,62 & 6683,16 & 327,95 & 12,71 & 315,23 & \begin{tabular}{|l|l|}
67,77 \\
\end{tabular} & 230,58 & \begin{tabular}{|l|}
230,58 \\
\end{tabular} & \begin{tabular}{ll|}
60,09 \\
\end{tabular} & 519,05 & $\begin{array}{ll}64,15 \\
\end{array}$ & 6,31 & 44,92 & \begin{tabular}{|l|}
179,38 \\
\end{tabular} & 41,07 & 41,07 & 167,52 \\
\hline Hyla molleri & 30STJ96 & 100,00 & 141,01 & 1117,50 & 36,58 & 6708,53 & 329,46 & \begin{tabular}{l|l|}
12,15 \\
\end{tabular} & 317,31 & 68,05 & 231,51 & 231,51 & \begin{tabular}{|l|l|}
60,23 \\
\end{tabular} & 505,65 & \begin{tabular}{ll|}
62,12 \\
\end{tabular} & \begin{tabular}{l|l|}
6,26 \\
\end{tabular} & \begin{tabular}{ll|}
44,46 \\
\end{tabular} & \begin{tabular}{|l|l|}
172,77 \\
\end{tabular} & 40,59 & 40,59 & 161,21 \\
\hline Hyla molleri & 30STK41 & 70,00 & $\begin{array}{l}160,83 \\
\end{array}$ & $\begin{array}{l}111,62 \\
\end{array}$ & 36,88 & 6438,31 & 337,22 & 37,00 & 300,22 & \begin{tabular}{|l|l|}
89,67 \\
\end{tabular} & 246,68 & \begin{tabular}{|l|}
246,68 \\
\end{tabular} & \begin{tabular}{|l|l|}
81,92 \\
\end{tabular} & 435,49 & 53,34 & 4,25 & 45,75 & \begin{tabular}{ll|}
156,26 \\
\end{tabular} & 32,98 & 32,98 & 143,93 \\
\hline Hyla molleri & 30STK81 & 100,00 & 157,36 & 114,90 & 37,00 & 6538,47 & 337,27 & 30,14 & 307,14 & 109,29 & 244,77 & \begin{tabular}{|l|}
244,77 \\
\end{tabular} & \begin{tabular}{ll|}
77,19 \\
\end{tabular} & 397,06 & \begin{tabular}{|l|l|}
46,97 \\
\end{tabular} & 5,00 & 43,09 & \begin{tabular}{|l|}
135,98 \\
\end{tabular} & 33,42 & 33,42 & 123,21 \\
\hline Hyla molleri & 30STK82 & 100,00 & 159,99 & 114,49 & 37,00 & 6497,45 & 338,29 & 33,01 & 305,28 & 118,40 & 246,75 & \begin{tabular}{|l|}
246,75 \\
\end{tabular} & 80,04 & 379,04 & 44,91 & 5,00 & 42,66 & 130,14 & 32,23 & 32,23 & 117,00 \\
\hline Hyla molleri & 30STK91 & 100,00 & 158,53 & \begin{tabular}{|l|}
115,07 \\
\end{tabular} & 37,00 & 6558,74 & 338,88 & 30,31 & 308,57 & 116,44 & 246,30 & 246,30 & \begin{tabular}{l|}
78,05 \\
\end{tabular} & 382,92 & 44,90 & 5,00 & $\begin{array}{l}42,83 \\
\end{array}$ & 130,80 & 32,58 & \begin{tabular}{l|l|}
32,58 \\
\end{tabular} & \begin{tabular}{|l|l|}
117,11 \\
\end{tabular} \\
\hline Hyla molleri & 30SUH08 & 100,00 & \begin{tabular}{|l|}
156,61 \\
\end{tabular} & \begin{tabular}{|l|}
123,59 \\
\end{tabular} & 37,00 & 6837,61 & 350,97 & 22,84 & 328,13 & 81,95 & 248,43 & \begin{tabular}{|l|}
248,43 \\
\end{tabular} & \begin{tabular}{|l|}
73,45 \\
\end{tabular} & 549,13 & 74,76 & 3,80 & 52,03 & 197,04 & 29,49 & 29,49 & $\begin{array}{l}190,72 \\
\end{array}$ \\
\hline Hyla molleri & 30SUH37 & 100,00 & 158,19 & 124,25 & 37,00 & 6893,18 & 353,98 & 23,16 & 330,82 & 87,52 & 250,85 & \begin{tabular}{|l|l|}
250,85 \\
\end{tabular} & 74,40 & \begin{tabular}{|l|l|}
543,75 \\
\end{tabular} & 75,72 & 3,51 & 52,56 & \begin{tabular}{|l|l|}
194,90 \\
\end{tabular} & 27,77 & 27,77 & $\begin{array}{l}188,42 \\
\end{array}$ \\
\hline Hyla molleri & 30SUH47 & 100,00 & 156,62 & 124,50 & 37,00 & 6912,72 & 352,90 & 21,42 & 331,48 & 85,87 & 249,65 & \begin{tabular}{|l|}
249,65 \\
\end{tabular} & 72,71 & 541,91 & 75,45 & 3,73 & 52,08 & \begin{tabular}{|l|l|}
193,57 \\
\end{tabular} & 28,44 & 28,44 & 186,43 \\
\hline Hyla molleri & 30SUH48 & 100,00 & 158,87 & 124,11 & 37,00 & 6901,36 & 354,40 & 23,56 & 330,84 & 88,28 & 251,73 & 251,73 & 75,01 & 516,26 & 70,91 & 3,53 & 51,42 & 181,79 & 27,87 & 27,87 & 175,64 \\
\hline Hyla molleri & 30SUH56 & 100,00 & 156,92 & \begin{tabular}{|l|}
124,19 \\
\end{tabular} & 37,00 & 6927,64 & 353,20 & 21,55 & 331,65 & 85,88 & 250,18 & 250,18 & 72,80 & 550,41 & 77,53 & 3,89 & 52,44 & \begin{tabular}{|c|}
198,71 \\
\end{tabular} & 28,34 & 28,34 & 190,68 \\
\hline Hyla molleri & 30SUH57 & 100,00 & 151,04 & 124,89 & 37,00 & 6933,85 & 348,32 & 15,91 & 332,42 & 80,23 & 244,52 & 244,52 & 67,21 & 552,66 & 76,26 & 4,34 & 50,95 & 195,91 & 31,15 & 31,15 & 188,14 \\
\hline Hyla molleri & 30SUH58 & 100,00 & 155,92 & 124,62 & 37,00 & 6916,51 & 352,13 & 20,50 & 331,63 & 87,59 & 249,11 & 249,11 & 72,13 & 518,13 & 70,77 & 3,93 & 50,58 & \begin{tabular}{|l|l|}
181,39 \\
\end{tabular} & 29,22 & 29,22 & $\begin{array}{l}174,72 \\
\end{array}$ \\
\hline Hyla molleri & 30SUH64 & 100,00 & 150,72 & 123,71 & 37,00 & 6944,50 & 347,86 & 16,61 & 331,26 & 79,53 & 244,57 & \begin{tabular}{|l|}
244,57 \\
\end{tabular} & \begin{tabular}{l|l|}
67,15 \\
\end{tabular} & 596,67 & 85,45 & 4,58 & 52,90 & 220,07 & 30,67 & 30,67 & 209,74 \\
\hline Hyla molleri & 30SUH65 & 100,00 & \begin{tabular}{|l|}
153,88 \\
\end{tabular} & 123,98 & 37,00 & 6938,73 & 350,60 & \begin{tabular}{|l|l|}
19,02 \\
\end{tabular} & 331,58 & \begin{tabular}{|l|l|}
82,97 \\
\end{tabular} & 247,51 & 247,51 & \begin{tabular}{|l|l|}
69,97 \\
\end{tabular} & 568,39 & 80,88 & \begin{tabular}{l|l|}
4,03 \\
\end{tabular} & 52,71 & \begin{tabular}{|l|}
207,44 \\
\end{tabular} & 29,00 & 29,00 & 198,00 \\
\hline Hyla molleri & 30SUH66 & 100,00 & 147,75 & 124,62 & 37,00 & 6951,08 & 345,61 & 13,05 & 332,56 & 78,56 & 241,74 & 241,74 & 64,00 & 573,10 & 79,68 & 4,80 & 50,88 & 204,96 & 32,71 & 32,71 & 195,86 \\
\hline Hyla molleri & 30SUH67 & 100,00 & 149,16 & 124,99 & 37,00 & 6940,01 & 346,73 & \begin{tabular}{|l|}
13,99 \\
\end{tabular} & 332,74 & 88,94 & 242,86 & 242,86 & $\begin{array}{l}65,36 \\
\end{array}$ & 549,43 & 75,42 & 4,36 & $\begin{array}{l}50,23 \\
\end{array}$ & \begin{tabular}{|l|l|}
194,17 \\
\end{tabular} & 32,05 & 32,05 & 185,56 \\
\hline Hyla molleri & 30SUH69 & 100,00 & 148,55 & $\begin{array}{l}125,02 \\
\end{array}$ & 37,00 & 6936,00 & 345,94 & 13,06 & 332,88 & 116,64 & 242,25 & 242,25 & 64,80 & 517,39 & 68,56 & 4,43 & 48,32 & \begin{tabular}{|l|}
179,27 \\
\end{tabular} & 32,96 & 32,96 & 169,88 \\
\hline Hyla molleri & 30SUH73 & 100,00 & 150,43 & 122,52 & 36,84 & 6938,53 & 346,58 & \begin{tabular}{l|l|}
16,95 \\
\end{tabular} & 329,64 & 79,37 & 244,26 & 244,26 & 66,90 & 603,05 & 87,12 & 4,85 & 53,18 & 224,50 & 30,80 & 30,80 & 213,05 \\
\hline Hyla molleri & 30SUH74 & 100,00 & $\begin{array}{l}151,78 \\
\end{array}$ & 123,02 & 37,00 & 6941,81 & 348,19 & \begin{tabular}{|l|l|}
17,94 \\
\end{tabular} & 330,25 & 80,72 & 245,66 & 245,66 & \begin{tabular}{l|l|}
68,25 \\
\end{tabular} & 582,21 & 83,49 & 4,44 & 52,59 & 214,36 & 30,20 & 30,20 & 203,55 \\
\hline Hyla molleri & 30SUH75 & 100,00 & 148,38 & 123,98 & 37,00 & 6945,49 & 345,76 & \begin{tabular}{|l|l|}
14,17 \\
\end{tabular} & 331,59 & 81,12 & 242,28 & \begin{tabular}{|l|l|}
242,28 \\
\end{tabular} & \begin{tabular}{|l|l|}
64,94 \\
\end{tabular} & 577,95 & 81,45 & 4,75 & \begin{tabular}{|l|l|}
51,44 \\
\end{tabular} & 209,36 & 32,20 & 32,20 & \begin{tabular}{|l|l|}
198,97 \\
\end{tabular} \\
\hline Hyla molleri & 30SUH76 & 100,00 & 141,94 & 124,88 & 37,00 & 6962,21 & 340,69 & 7,44 & 333,25 & 90,01 & 236,19 & 236,19 & $\begin{array}{ll}58,53 \\
\end{array}$ & 583,66 & 80,33 & 5,47 & $\begin{array}{l}49,59 \\
\end{array}$ & \begin{tabular}{|l|}
208,01 \\
\end{tabular} & 35,86 & 35,86 & 197,16 \\
\hline Hyla molleri & 30SUH77 & 100,00 & $\begin{array}{l}147,90 \\
\end{array}$ & 125,00 & 37,00 & $\begin{array}{l}6946,68 \\
\end{array}$ & 345,71 & \begin{tabular}{|l|}
12,77 \\
\end{tabular} & 332,94 & 101,20 & 241,78 & \begin{tabular}{|l|l|}
241,78 \\
\end{tabular} & \begin{tabular}{ll|}
64,02 \\
\end{tabular} & 543,49 & \begin{tabular}{ll|}
74,16 \\
\end{tabular} & 4,66 & $\begin{array}{l}49,51 \\
\end{array}$ & \begin{tabular}{|l|l|}
192,43 \\
\end{tabular} & 32,81 & 32,81 & $\begin{array}{l}181,97 \\
\end{array}$ \\
\hline Hyla molleri & 30SUH78 & 100,00 & 147,51 & 125,44 & 37,00 & 6943,53 & 345,35 & $\begin{array}{ll}11,86 \\
\end{array}$ & 333,49 & 101,89 & 241,28 & \begin{tabular}{|l|l|}
241,28 \\
\end{tabular} & \begin{tabular}{|l|}
63,78 \\
\end{tabular} & 527,11 & 70,51 & 4,5 & 48,64 & \begin{tabular}{|l|}
184,42 \\
\end{tabular} & 33,20 & 33,20 & 174,00 \\
\hline Hyla molleri & 30SUH79 & 100,00 & 146,89 & 125,74 & 37,00 & 6936,43 & 344,63 & \begin{tabular}{l|l|}
10,99 \\
\end{tabular} & 333,6 & 126,48 & 240,77 & \begin{tabular}{|l|}
240,77 \\
\end{tabular} & \begin{tabular}{l|l|}
63,22 \\
\end{tabular} & 511,78 & 67,01 & 4,5 & 47,64 & \begin{tabular}{|l|}
178,23 \\
\end{tabular} & 33,67 & 33,67 & $\begin{array}{l}166,41 \\
\end{array}$ \\
\hline Hyla molleri & 30SUH82 & 100,00 & 158,93 & 119,88 & 36,38 & 6896,57 & 351,39 & 26,70 & \begin{tabular}{|l|}
324,69 \\
\end{tabular} & 88,28 & 252,11 & 252,11 & 75,77 & 578,24 & 85,17 & $\begin{array}{l}4,16 \\
\end{array}$ & 54,55 & \begin{tabular}{|l|l|}
218,97 \\
\end{tabular} & \begin{tabular}{|l|}
26,85 \\
\end{tabular} & 26,85 & 207,22 \\
\hline Hyla molleri & 30SUH83 & 100,00 & 150,42 & \begin{tabular}{|l|}
121,94 \\
\end{tabular} & 36,52 & 6952,54 & 346,31 & 17,11 & 329,19 & 79,19 & 244,50 & 244,50 & \begin{tabular}{|l|l|}
66,77 \\
\end{tabular} & 593,26 & 85,86 & 4,98 & 52,75 & 220,49 & 31,11 & 31,11 & 208,25 \\
\hline Hyla molleri & 30SUH84 & 100,00 & \begin{tabular}{|l|}
154,04 \\
\end{tabular} & $\begin{array}{l}122,48 \\
\end{array}$ & 36,91 & 6943,70 & 349,56 & \begin{tabular}{|l|}
20,06 \\
\end{tabular} & 329,49 & 83,92 & 247,77 & \begin{tabular}{|l|}
247,77 \\
\end{tabular} & \begin{tabular}{ll|}
70,27 \\
\end{tabular} & 563,59 & 80,97 & 4,26 & $\begin{array}{l}52,42 \\
\end{array}$ & \begin{tabular}{|l|}
207,25 \\
\end{tabular} & 29,19 & 29,19 & $\begin{array}{l}196,12 \\
\end{array}$ \\
\hline Hyla molleri & 30SUH85 & 100,00 & 141,49 & 124,08 & 37,00 & 6965,81 & 339,93 & 7,69 & 332,24 & 91,04 & 235,90 & 235,90 & 58,33 & 591,33 & 82,19 & 5,76 & 49,85 & $213,17 \mid$ & 36,21 & 36,21 & 200,69 \\
\hline Hyla molleri & 30SUH86 & 100,00 & 145,59 & 4,74 & 37,00 & 964,43 & 343,72 & 10,73 & 332,9 & 98,6 & 239,8 & 239,85 & \begin{tabular}{|l|l|}
61,92 \\
\end{tabular} & 559,53 & 77,06 & 5,04 & 49,66 & 200,49 & 33,95 & 33,95 & 188,22 \\
\hline Hyla molleri & 30SUH87 & 100,00 & 146,01 & 125,26 & 37,00 & 6949,86 & 344,13 & \begin{tabular}{|l|}
10,88 \\
\end{tabular} & 333,25 & 99,38 & 240,03 & 240,03 & 62,22 & 539,66 & 72,92 & 4,84 & 48,75 & 191,20 & \begin{tabular}{|l|}
33,88 \\
\end{tabular} & \begin{tabular}{|l|}
33,88 \\
\end{tabular} & $\begin{array}{l}179,09 \\
\end{array}$ \\
\hline Hyla molleri & 30SUH93 & 100,00 & 157,60 & 120,31 & 36,39 & 6920,18 & 350,89 & 25,01 & 325,88 & 91,03 & 251,12 & 251,12 & 74,21 & 557,10 & 81,35 & 4,24 & 53,21 & \begin{tabular}{|l|}
207,95 \\
\end{tabular} & 27,88 & 27,88 & 195,62 \\
\hline Hyla molleri & 30SUH94 & 100,00 & 155,04 & \begin{tabular}{|l|}
121,73 \\
\end{tabular} & 36,89 & 6927,27 & 349,65 & 21,51 & 328,14 & 100,29 & \begin{tabular}{|l|}
248,67 \\
\end{tabular} & \begin{tabular}{|l|}
248,67 \\
\end{tabular} & $\begin{array}{ll}71,53 \\
\end{array}$ & 549,85 & \begin{tabular}{|l|}
78,94 \\
\end{tabular} & 4,31 & 52,02 & \begin{tabular}{|l|}
202,57 \\
\end{tabular} & 29,14 & 29,14 & 190,15 \\
\hline Hyla molleri & 30SUH95 & 100,00 & 140,41 & \begin{tabular}{|l|l|}
124,03 \\
\end{tabular} & 37,00 & 6966,58 & \begin{tabular}{|l|l|}
338,94 \\
\end{tabular} & $\begin{array}{ll}6,78 \\
\end{array}$ & 332,16 & \begin{tabular}{|l|}
92,96 \\
\end{tabular} & 235,03 & \begin{tabular}{|l|l|}
235,03 \\
\end{tabular} & 57,38 & 584,27 & 80,83 & $\begin{array}{l}5,92 \\
\end{array}$ & 49,15 & \begin{tabular}{|l|l|}
211,03 \\
\end{tabular} & 37,01 & 37,01 & $\begin{array}{l}196,48 \\
\end{array}$ \\
\hline Hyla molleri & 30SUH97 & 100,00 & 146,86 & 25,39 & 37,00 & 6938,87 & 344,56 & 11,62 & 332,94 & 100,52 & 240,75 & 240,75 & \begin{tabular}{|l|}
63,27 \\
\end{tabular} & 525,40 & 70,56 & 4,64 & 48,40 & 186,60 & \begin{tabular}{|l|}
33,58 \\
\end{tabular} & 33,58 & 173,00 \\
\hline Hyla molleri & $30 \mathrm{SUH}$ & 100,00 & 14 & & 37, & 6930,67 & 344,96 & 11,24 & 333,72 & 118,62 & 240,77 & 240,77 & \begin{tabular}{|l|l|}
63,63 \\
\end{tabular} & 505,15 & 66,19 & 4,324 & 47,51 & \begin{tabular}{|l|l|}
177,79 \\
\end{tabular} & 33,52 & 33,52 & 163,80 \\
\hline Hyla molleri & 30SUH99 & 100,00 & 146,58 & $\begin{array}{l}126,61 \\
\end{array}$ & 37,44 & 6909,73 & 344,29 & 10,52 & 333,77 & 129,35 & 239,97 & 239,97 & \begin{tabular}{|l|}
63,37 \\
\end{tabular} & 489,23 & 62,42 & 4,24 & 46,61 & $\begin{array}{l}171,92 \\
\end{array}$ & 33,88 & 33,88 & 156,11 \\
\hline Hyla molleri & 30SUJ03 & 100,00 & 158,62 & 120,52 & 37,00 & 6769,54 & 348,91 & 26,27 & 322,64 & 99,67 & 249,47 & \begin{tabular}{|l|}
249,47 \\
\end{tabular} & 76,11 & 465,44 & 60,16 & 3,94 & 48,21 & \begin{tabular}{|l|}
161,70 \\
\end{tabular} & 30,25 & 30,25 & 152,66 \\
\hline Hyla molleri & 30SUJ14 & 100,00 & 158,51 & 120,24 & \begin{tabular}{|l|}
37,00 \\
\end{tabular} & \begin{tabular}{|c|c|}
6776,48 \\
\end{tabular} & 48,22 & 25,77 & 322,45 & $\mid 113,71$ & 249,50 & 249,50 & 75,81 & \begin{tabular}{|l|l|}
446,28 \\
\end{tabular} & 56,61 & \begin{tabular}{l|l|}
4,03 \\
\end{tabular} & 47,15 & \begin{tabular}{|l|l|}
153,15 \\
\end{tabular} & 30,48 & 30,48 & 143,51 \\
\hline Hyla molleri & 30SUJ15 & 100 & 156,77 & 119,64 & \begin{tabular}{|l|}
36,98 \\
\end{tabular} & 6758 & 345,78 & 24, & 321,17 & 114,42 & 247,55 & \begin{tabular}{|l|}
247,55 \\
\end{tabular} & 74,36 & 439,26 & 54,84 & $\begin{array}{l}, 23 \\
\end{array}$ & 46,27 & \begin{tabular}{|l|l|}
149,96 \\
\end{tabular} & \begin{tabular}{|l|}
31,43 \\
\end{tabular} & \begin{tabular}{|l|}
31,43 \\
\end{tabular} & 139,35 \\
\hline Hyla molleri & 30SUJ17 & 100,00 & 144,12 & 118,10 & 36,65 & 6722,19 & 332,29 & \begin{tabular}{l|l|}
13,95 \\
\end{tabular} & 318,35 & 112,25 & 234,75 & 234,75 & \begin{tabular}{|l|l|}
62,97 \\
\end{tabular} & 459,73 & 54,85 & 6,05 & 42,98 & \begin{tabular}{|l|l|}
153,58 \\
\end{tabular} & 38,86 & 38,86 & 141,30 \\
\hline Hyla molleri & 30SUJ18 & 100,00 & 139,00 & \begin{tabular}{|l|}
117,31 \\
\end{tabular} & 36,77 & 6694,77 & \begin{tabular}{|l|l|}
326,16 \\
\end{tabular} & \begin{tabular}{l|l}
9,66 \\
\end{tabular} & 316,50 & 112,17 & 229,44 & \begin{tabular}{|l|l|}
229,45 \\
2
\end{tabular} & $\begin{array}{l}58,38 \\
\end{array}$ & 467,38 & 54,50 & 6,79 & 41,90 & \begin{tabular}{|l|l|}
155,04 \\
\end{tabular} & 41,88 & 41,89 & $\begin{array}{l}141,82 \\
\end{array}$ \\
\hline Hyla molleri & 30SUJ20 & 100,00 & 156,96 & 123,03 & 37,00 & 6860,53 & 351,14 & 22,51 & 328,63 & 86,62 & 249,08 & \begin{tabular}{|l|}
249,08 \\
\end{tabular} & \begin{tabular}{|l|}
73,57 \\
\end{tabular} & 503,85 & 67,41 & 3,88 & 50,11 & 174,82 & 29,59 & 29,59 & 168,86 \\
\hline Hyla molleri & 30SUJ23 & 100,00 & 15 & 1 & 37,00 & 6828, & 346 & 21, & 325,37 & 117,96 & 246 & 246,11 & 71,29 & 468,02 & 59,81 & 4,23 & 47,12 & 159,10 & 31,90 & 31,90 & 150 \\
\hline Hyla molleri & 30SUJ35 & 100,00 & 152,93 & 120,36 & 37,00 & 6810,05 & 343,39 & \begin{tabular}{l|l|}
19,86 \\
\end{tabular} & 323,53 & 133,26 & 244,65 & \begin{tabular}{|l|}
244,65 \\
\end{tabular} & \begin{tabular}{|l|}
70,08 \\
\end{tabular} & 439,24 & 53,72 & 4,65 & 44,76 & 148,41 & 33,46 & 33,46 & $\begin{array}{l}136,42 \\
\end{array}$ \\
\hline Hyla molleri & 30SUJ37 & 100,00 & 144,70 & 119,00 & 36,75 & 6775,17 & 333,91 & 12,81 & 321,10 & 128,67 & 236,24 & 236,24 & 62,83 & 441,99 & 51,74 & 5,98 & 42,35 & \begin{tabular}{|l|l|}
148,48 \\
\end{tabular} & 38,34 & 38,34 & \begin{tabular}{|l|l|}
132,89 \\
\end{tabular} \\
\hline
\end{tabular}




\begin{tabular}{|c|c|c|c|c|c|c|c|c|c|c|c|c|c|c|c|c|c|c|c|c|c|}
\hline$\overline{\text { TAXON }}$ & UTM & $\mathrm{km} 2$ & BIO1 & BIO2 & BIO3 & BIO4 & BIO5 & B106 & B107 & B108 & B109 & BIO10 & BIO11 & BIO12 & B1013 & B1014 & B1015 & B1016 & B1017 & BIO18 & 81019 \\
\hline Hyla molleri & 30 SUJ 40 & 100,00 & 152,11 & 124,00 & 37,00 & 6903,59 & 347,91 & 17,13 & 330,78 & 115,87 & 245,17 & 245,17 & 68,48 & 506,47 & 67,03 & 4,21 & 48,74 & 173,36 & 31,73 & 31,73 & 166,86 \\
\hline Hyla molleri & 30SUJ42 & 100,00 & 146,07 & 123,11 & 37,00 & 6891,55 & 341,34 & 11,74 & 329,60 & 129,14 & 239,19 & 239,19 & 62,95 & 497,35 & 63,27 & 5,08 & 46,15 & 169,92 & 35,59 & 35,59 & 158,83 \\
\hline Hyla molleri & $30 \mathrm{SUJ43}$ & 100,00 & 145,44 & \begin{tabular}{ll|}
122,64 \\
\end{tabular} & 37,00 & $\begin{array}{ll}6874,67 \\
\end{array}$ & 339,72 & 11,30 & 328,42 & $\begin{array}{l}128,48 \\
\end{array}$ & 238,21 & 238,21 & \begin{tabular}{ll|}
62,43 \\
\end{tabular} & 485,61 & 60,68 & 5,23 & 45,29 & \begin{tabular}{ll|}
165,68 \\
\end{tabular} & 36,31 & 36,31 & 152,99 \\
\hline Hyla molleri & $30 \mathrm{SUJ46}$ & 100,00 & 149,38 & 120,01 & 36,91 & 6803,76 & 339,39 & 16,32 & 323,06 & 133,49 & 241,15 & 241,15 & 66,78 & 431,73 & 51,15 & 5,34 & 43,24 & 146,16 & 35,74 & 35,74 & 130,47 \\
\hline Hyla molleri & 30SUJ47] & 100,00 & 139,20 & 119,04 & 36,58 & 6777,43 & 328,92 & 7,78 & 321,14 & 122,71 & 231,06 & 231,06 & 57,63 & 456,81 & $52,81$. & 6,85 & 41,34 & 153,92 & 41,97| & 41,97| & 135,41 \\
\hline Hyla molleri & 30 SUJ50 & 100,00 & 148,90 & 124,47 & 37,00 & $\begin{array}{lll}6917,34 \\
\end{array}$ & 345,44 & 13,79 & 331,64 & 128,63 & 242,25 & 242,25 & 65,34 & 509,58 & 66,83 & 4,47 & 47,94 & 175,40 & 33,10 & 33,10 & 166,39 \\
\hline Hyla molleri & 30SUJ51 & 100,00 & 150,69 & 124,01 & 37,00 & 6903,21 & 346,19 & 15,61 & 330,58 & 133,95 & 243,75 & 243,75 & 67,07 & 486,99 & 62,77 & 4,30 & 47,21 & 167,55 & 32,59 & 32,59 & 156,91 \\
\hline Hyla molleri & 30 SUJ52 & 100,00 & 147,69 & 123,67 & 37,00 & 6888,11 & 342,84 & 12,90 & 329,94 & 130,79 & 240,73 & 240,73 & 64,54 & 482,92 & 60,95 & 4,93 & 45,89 & 165,87 & 34,88 & 34,88 & 153,01 \\
\hline Hyla molleri & $30 \mathrm{SUJ53}$ & 100,00 & 149,64 & 122,92 & 37,00 & 6866,68 & 343,38 & 14,90 & 328,48 & 133,16 & 242,41 & 242,41 & 66,54 & 462,56 & 57,40 & 4,74 & 45,35 & \begin{tabular}{ll|l}
158,46 \\
\end{tabular} & 34,27 & 34,27 & \begin{tabular}{|l|l|}
144,74 \\
\end{tabular} \\
\hline Hyla molleri & 30 SUJ55 & 100,00 & \begin{tabular}{|l|l|}
146,73 \\
\end{tabular} & 121,31 & 37,00 & 6863,51 & 338,99 & 12,70 & 326,29 & 130,64 & 239,38 & 239,38 & \begin{tabular}{|c|}
63,78 \\
\end{tabular} & 446,39 & 53,20 & 5,31 . & 43,38 & 152,17 & 36,42 & 36,42 & 135,53 \\
\hline Hyla molleri & 30 SUJ56 & 100,00 & 144,03 & 120,42 & 36,71 & 6835,28 & 335,41 & 10,61 & 324,80 & 127,69 & 236,51 & 236,51 & 61,60 & 443,45 & 51,75 & 5,95 & 42,22 & 150,82 & 38,71 & 38,71 & 132,20 \\
\hline Hyla molleri & 30SUJ61 & 100,00 & 147,49 & 124,72 & 37,00 & $\begin{array}{ll}6918,40 \\
\end{array}$ & 343,85 & \begin{tabular}{|l|l|}
11,91 \\
\end{tabular} & 331,94 & 130,79 & 240,96 & 240,96 & 63,70 & 489,01 & 62,27 & 4,62 & 46,51 & 169,13 & 34,19 & 34,19 & 155,95 \\
\hline Hyla molleri & 30 SUJ62 & 100,00 & 149,63 & 123,97 & 37,00 & 6899,46 & 344,74 & 14,23 & 330,51 & 133,09 & 242,72 & 242,72 & 66,02 & 467,27 & 58,39 & 4,57 & 45,74 & 161,13 & 33,77 & 33,77 & \begin{tabular}{|l|l|}
147,07 \\
\end{tabular} \\
\hline Hyla molleri & 30 SUJ63 & 100,00 & 145,25 & 123,52 & 37,00 & 6890,92 & 340,28 & 10,49 & 329,79 & 128,27 & 238,45 & $\begin{array}{l}238,45 \\
\end{array}$ & 62,09 & 469,25 & 57,34 & 5,25 & 44,38 & $\begin{array}{l}161,49 \\
\end{array}$ & 36,57 & 36,57 & 145,12 \\
\hline Hyla molleri & 30SUJ64 & 100,00 & 145,08 & \begin{tabular}{ll|}
122,74 \\
\end{tabular} & 37,00 & 6870,34 & 338,94 & 10,49 & 328,45 & 128,49 & 238,01 & 238,01 & 62,12 & 457,61 & 54,77 & 5,32 & 43,57 & 157,08 & 37,04 & 37,04 & 139,56 \\
\hline Hyla molleri & 30SUJ65 & 100,00 & 141,45 & 121,91 & 36,99 & 6863,46 & 334,63 & 7,48 & 327,16 & 124,84 & 234,37 & \begin{tabular}{|l|l|}
234,37 \\
\end{tabular} & 58,69 & 459,14 & 53,75 & $\begin{array}{l}5,96 \\
\end{array}$ & 42,35 & \begin{tabular}{|l|l|}
157,07 \\
\end{tabular} & 39,61 & 39,61 & 137,65 \\
\hline Hyla molleri & 30 SUJ66 & 100,00 & \begin{tabular}{ll|}
138,87 \\
\end{tabular} & $\begin{array}{l}120,82 \\
\end{array}$ & 36,84 & 6853,41 & 330,98 & 5,46 & 325,52 & 122,02 & 231,64 & 231,64 & 56,39 & 456,53 & 52,59 & 6,61 & 41,24 & 155,54 & 41,78 & 41,78 & 134,68 \\
\hline Hyla molleri & 30SUJ67 & 100,00 & 133,27 & 119,57 & 36,55 & $\begin{array}{ll}6810,94 \\
\end{array}$ & 324,28 & 1,23 & 323,05 & 116,30 & 225,70 & 225,72 & 51,75 & 467,28 & 54,22 & 7,76 & 39,82 & 158,18 & 45,99 & 46,01 & 135,44 \\
\hline Hyla molleri & $30 \mathrm{SUJ70}$ & 100,00 & 149,86 & 125,35 & 37,00 & 6926,91 & 346,50 & 13,57 & 332,92 & 133,03 & 243,32 & 243,32 & 66,07 & 485,27 & 62,41 & 4,04 & $\begin{array}{l}47,35 \\
\end{array}$ & 168,93 & 32,20 & 32,20 & 156,07 \\
\hline Hyla molleri & 30SUJ71 & 100,00 & 150,08 & 125,08 & 37,00 & 6909,14 & 346,05 & 13,92 & 332,12 & 133,77 & 243,34 & 243,34 & 66,37 & 469,68 & 59,18 & 4,21 . & 46,36 & 163,15 & 32,79 & 32,79 & 148,78 \\
\hline Hyla molleri & $30 \mathrm{SUJ72}$ & 100,00 & $\begin{array}{ll}144,93 \\
\end{array}$ & 124,86 & 37,00 & 6910,35 & 341,01 & 9,19 & 331,82 & 128,45 & 238,29 & 238,29 & 61,42 & 474,52 & 58,32 & 4,97 & 44,83 & 164,41 & 36,07 & 36,07 & 147,54 \\
\hline \begin{tabular}{|l|} 
Hyla molleri \\
\end{tabular} & $30 \mathrm{SUJ73}$ & 100,00 & 140,36 & 124,17 & 37,00 & 6901,19 & 336,28 & 5,26 & 331,02 & 123,41 & 233,78 & 233,78 & 57,29 & 478,84 & 57,47 & $\begin{array}{l}5,66 \\
\end{array}$ & 43,40 & 165,37 & 39,18 & 39,18 & 146,33 \\
\hline Hyla molleri & 30SUJ74 & 100,00 & 143,51 & 123,26 & 37,00 & 6884,85 & 337,84 & 8,47 & 329,36 & 126,77 & 236,64 & 236,64 & 60,49 & 455,14 & 53,60 & 5,38 & 42,92 & \begin{tabular}{ll|l}
156,66 \\
\end{tabular} & 37,91 & 37,91 & 137,36 \\
\hline Hyla molleri & 30SUJ75| & 100,00 & 140,25 & 122,33 & 37,00 & 6876,04 & 333,81 & 5,96 & 327,85 & 123,67 & 233,36 & 233,36 & 57,40 & 456,66 & 52,75 & 6,19 & 41,78 & 156,56 & 40,66 & 40,66 & 135,52 \\
\hline Hyla molleri & 30 SUJ76 & 100,00 & 131,62 & 121,11 & 36,99 & 6845,36 & 324,71 & $-0,64$ & 325,36 & 114,22 & 224,64 & 224,64 & \begin{tabular}{l|l|}
49,95 \\
\end{tabular} & 478,72 & 55,45 & 7,72 & $\begin{array}{l}40,05 \\
\end{array}$ & 163,20 & 46,50 & 46,50 & 139,57 \\
\hline Hyla molleri & 30SUJ77 & 100,00 & 129,08 & 119,84 & 36,69 & 6811,62 & 320,59 & $-2,58$ & 323,17 & 111,64 & 221,71 & 221,73 & 47,82 & 479,38 & 56,10 & 8,50 & 38,99 & 162,42 & 49,09 & 49,11 & 137,63 \\
\hline Hyla molleri & 30 SUJ78 & 100,00 & 129,47 & 118,53 & 36,27 & 6797,85 & 319,50 & $-1,77$ & 321,27 & 112,44 & 221,84 & 221,86 & 48,38 & 467,19 & 55,19 & 8,76 & 38,21 & $\begin{array}{l}157,42 \\
\end{array}$ & 49,51 & 49,52 & 132,25 \\
\hline Hyla molleri & 30 SUJ81 & 100,00 & 146,86 & 125,88 & 37,04 & 6901,70 & 343,59 & 10,77 & 332,83 & 130,04 & 240,18 & 240,18 & 63,61 & 470,88 & 58,30 & 4,47 & 45,48 & $\begin{array}{l}164,25 \\
\end{array}$ & 34,40 & 34,40 & 147,42 \\
\hline Hyla molleri & 30 SUJ82 & 100,00 & 142,16 & \begin{tabular}{|l|l|}
125,58 \\
\end{tabular} & 37,00 & \begin{tabular}{|l|l|}
6902,37 \\
\end{tabular} & 338,97 & $\begin{array}{l}6,55 \\
\end{array}$ & 332,42 & 125,21 & 235,64 & 235,64 & $\begin{array}{l}59,16 \\
\end{array}$ & 475,08 & 57,40 & 5,16 & 44,01 & \begin{tabular}{l|l|}
165,12 \\
\end{tabular} & 37,56 & 37,56 & 146,14 \\
\hline Hyla molleri & 30 SUJ84 & 100,00 & 147,10 & 123,58 & 37,00 & 6891,58 & 341,06 & 11,29 & 329,77 & 130,97 & 240,20 & 240,20 & 63,63 & 435,05 & 50,60 & 5,04 & 43,12 & 150,06 & 36,03 & 36,03 & 130,50 \\
\hline Hyla molleri & $30 \mathrm{SUJ85}$ & 100,00 & 139,86 & 122,68 & 37,00 & 6883,90 & 333,48 & 5,15 & 328,33 & 123,22 & 233,10 & 233,10 & 57,01 & 452,03 & 52,22 & 6,18 & 41,36 & 154,99 & 41,14 & 41,14 & 133,15 \\
\hline Hyla molleri & $30 \mathrm{SUJ88}$ & 100,00 & 137,01 & 118,73 & 36,06 & 6843,51 & 326,82 & 3,88 & 322,94 & 120,65 & 229,86 & 229,86 & 54,64 & 436,48 & 51,38 & 7,67 & 38,58 & \begin{tabular}{ll|}
147,06 \\
\end{tabular} & 45,13 & 45,13 & 123,42 \\
\hline Hyla molleri & 30 SUJ89 & 100,00 & 141,21 & 117,18 & 36,00 & 6841,64 & 328,87 & 8,27 & 320,60 & 125,26 & 233,80 & 233,80 & 58,44 & 415,03 & 48,84 & 7,40 & 38,23 & 138,75 & 43,40 & 43,40 & 116,36 \\
\hline Hyla molleri & 30 SUJ90 & 100,00 & 147,43 & 126,93 & 37,81 & 6900,37 & 344,48 & 11,01 & 333,48 & 130,56 & 240,56 & 240,56 & 64,01 & 470,35 & 58,48 & 4,19 & 45,79 & 164,89 & 33,69 & 33,69 & 147,89 \\
\hline Hyla molleri & 30 SUJ92 & 100,00 & 146,89 & 126,23 & 37,28 & 6888,05 & 342,90 & \begin{tabular}{l|l}
10,26 \\
\end{tabular} & 332,64 & 130,50 & 239,83 & 239,83 & 63,38 & 447,19 & 53,12 & 4,36 & 44,15 & $\begin{array}{l}155,79 \\
\end{array}$ & 34,83 & 34,83 & 136,70 \\
\hline \begin{tabular}{|l|} 
Hyla molleri \\
\end{tabular} & 30SUJ95 & 100,00 & 136,17 & 123,12 & 37,00 & $\begin{array}{ll}6876,93 \\
\end{array}$ & 330,38 & 1,78 & 328,60 & 119,18 & 229,47 & \begin{tabular}{|l|l|}
229,47 \\
\end{tabular} & 53,59 & 460,05 & 53,51 & 6,70 & 40,60 & 157,81 & 43,56 & 43,56 & 134,31 \\
\hline Hyla molleri & 30 SUJ96 & 100,00 & $\begin{array}{ll}140,58 \\
\end{array}$ & 121,71 & 36,98 & $\begin{array}{ll}6881,84 \\
\end{array}$ & 332,97 & 5,60 & 327,37 & 124,21 & 233,66 & 233,66 & 57,52 & 435,73 & 50,77 & 6,36 & 40,32 & 148,64 & \begin{tabular}{ll|}
41,68 \\
\end{tabular} & 41,68 & 125,90 \\
\hline Hyla molleri & 30SUK12 & 100,00 & 155,81 & 115,07 & 37,00 & 6556,55 & 335,75 & 26,94 & 308,82 & 113,23 & 243,57 & 243,57 & 75,22 & 366,27 & 42,02 & 5, & 40,46 & 123,19 & 34,38 & 34,38 & 107,31 \\
\hline Hyla molleri & 30SVH17 & 100,00 & 147,46 & 125,23 & 37,01 & 6913,02 & 344,08 & 12,32 & 331,76 & 104,38 & 240,95 & \begin{tabular}{l|l|}
240,95 \\
\end{tabular} & $\begin{array}{l}64,36 \\
\end{array}$ & 499,75 & 65,82 & 4,5 & 47,34 & 177,79 & 33,55 & 33,55 & 161,52 \\
\hline Hyla molleri & $30 \mathrm{SVH} 29$ & 100,00 & 145,92 & 127,20 & 37,97 & 6871,08 & 342,44 & 9,62 & 332,82 & 128,69 & 238,79 & 238,79 & 63,22 & 461,63 & 56,56 & 4,32 & \begin{tabular}{ll|}
44,88 \\
\end{tabular} & \begin{tabular}{ll|l}
163,25 \\
\end{tabular} & 34,75 & 34,75 & 143,18 \\
\hline Hyla molleri & $30 \mathrm{SVH} 44$ & 100,00 & $\begin{array}{l}148,33 \\
\end{array}$ & 120,66 & 36,76 & $\begin{array}{ll}6890,83 \\
\end{array}$ & 341,28 & \begin{tabular}{l|l|}
15,92 \\
\end{tabular} & 325,37 & 100,84 & 241,58 & 241,58 & 65,94 & 515,72 & 70,99 & 5,67 & 47,88 & $\begin{array}{l}189,17 \\
\end{array}$ & 34,67 & 34,67 & 168,88 \\
\hline \begin{tabular}{|l|} 
Hyla molleri \\
\end{tabular} & $30 \mathrm{SVH} 46$ & 100,00 & $\begin{array}{l}146,07 \\
\end{array}$ & 123,18 & 37,00 & $\begin{array}{ll}6878,33 \\
\end{array}$ & 340,31 & 12,33 & 327,98 & 99,86 & 239,18 & 239,18 & 63,76 & 494,85 & 65,02 & 5,43 & 45,99 & \begin{tabular}{|l|l|}
177,10 \\
\end{tabular} & 36,01 & 36,01 & 157,28 \\
\hline Hyla molleri & $30 \mathrm{SVH} 48$ & 100,00 & 146,49 & 124,96 & 37,16 & 6857,76 & 340,81 & 11,58 & 329,23 & $\begin{array}{l}128,84 \\
\end{array}$ & 239,18 & 239,18 & 63,97 & 464,11 & 57,69 & 5,01 & 44,44 & \begin{tabular}{ll|}
164,26 \\
\end{tabular} & 35,99 & 35,99 & 143,41 \\
\hline Hyla molleri & 30SVH54 & 100,00 & 152,54 & 119,68 & 36,80 & 6830,84 & 342,73 & 20,42 & 322,31 & 105,50 & $244,7 !$ & 244,79 & 70,64 & 485,61 & 65,96 & 5,25 & \begin{tabular}{|c|c|}
47,56 \\
\end{tabular} & $\mid 177,26$ & 32,77 & 32,77 & \begin{tabular}{|l|l|l|}
157,69 \\
\end{tabular} \\
\hline Hyla molleri & 30SVH59 & 100,00 & 144,79 & 124,84 & 37,39 & 6825,02 & 338,13 & 9,79 & 328,35 & 127,27 & 236,96 & 236,96 & 62,84 & 454,60 & 55,18 & 5,40 & 42,85 & 160,04 & 38,25 & 38,25 & 136,98 \\
\hline \begin{tabular}{|l} 
Hyla molleri \\
\end{tabular} & $30 \mathrm{SVH76}$ & 100,00 & 142,16 & 122,42 & 37,00 & 6812,50 & 333,83 & 9,07 & 324,76 & 123,00 & 234,41 & 234,41 & 60,91 & 480,67 & 60,20 & 6,83 & 42,80 & \begin{tabular}{|l|}
170,17 \\
\end{tabular} & 40,83 & 40,83 & 146,37 \\
\hline Hyla molleri & 30 SVJo0 & 100,00 & \begin{tabular}{ll|}
148,87 \\
\end{tabular} & \begin{tabular}{ll|}
127,44 \\
\end{tabular} & 38,00 & 6881,30 & 345,65 & \begin{tabular}{ll|}
11,99 \\
\end{tabular} & 333,65 & 132,29 & 241,78 & 241,78 & 65,87 & 452,13 & 55,12 & 4,00 & 45,43 & \begin{tabular}{ll|l}
158,93 \\
\end{tabular} & 32,90 & 32,90 & 140,79 \\
\hline Hyla molleri & 30SVJO3 & 100,00 & 142,10 & 126,30 & $\begin{array}{l}37,46 \\
\end{array}$ & $\begin{array}{ll}6881,69 \\
\end{array}$ & 338,09 & 5,64 & 332,45 & 125,62 & 235,12 & 235,12 & 59,01 & 445,49 & 52,57 & 5,19 & 42,22 & 154,66 & 38,37 & 38,37 & 132,61 \\
\hline Hyla molleri & 30SVJ05 & 100,00 & 130,97 & 123,47 & 37,00 & 6870,26 & 325,77 & $-2,56$ & 328,33 & $\mid 113,57$ & 224,31 & 224,31 & \begin{tabular}{ll|l}
48,85 & \\
\end{tabular} & 475,61 & $\mid 55,56$ & 7,50 & 39,55 & 162,95 & $\mid 47,10$ & 47,10 & 137,71 \\
\hline Hyla molleri & 30SVJ07 & 100,00 & 13 & & 36, & 6862,95 & 323,58 & $-1,03$ & 324,61 & 114,59 & 224,92 & 224,92 & 49,54 & 460,03 & 54,08 & 8,21 & 38,10 & 155,29 & 48,46 & 48,46 & 130,47 \\
\hline \begin{tabular}{|l} 
Hyla molleri \\
\end{tabular} & 30SVJ11 & 100,00 & 147,16 & 128,77 & 38,00 & 6852,44 & 343,75 & 9,46 & 334,29 & 131,07 & 239,31 & 239,31 & 64,03 & 431,67 & 52,12 & 4,00 & 44,03 & \begin{tabular}{|l|l|}
151,79 \\
\end{tabular} & 33,87 & 33,87 & 130,75 \\
\hline Hyla molleri & 30SVJ13 & 100,00 & 143,91 & 126,68 & 37,89 & 6858,15 & 339,39 & 7,36 & 332,03 & 127,80 & 236,59 & 236,59 & 61,18 & 430,37 & 51,26 & 4,76 & 42,04 & 149,31 & 37,37 & 37,37 & 127,06 \\
\hline Hyla molleri & 30SVJ15 & 100,00 & 133,32 & 123,81 & 37,00 & 6870,43 & 327,87 & $-0,78$ & 328,66 & 116,26 & 226,57 & 226,57 & 51,09 & 461,95 & 54,07 & 7,10 & 39,51 & 158,08 & 45,73 & 45,73 & 133,26 \\
\hline Hyla molleri & $30 \mathrm{SVJ} 22$ & 100 & 146,95 & 127,78 & 38,00 & 683 & 342,15 & $\begin{array}{l}9,75 \\
9\end{array}$ & 332,40 & 130,93 & 239,15 & \begin{tabular}{|l|l|}
239,15 \\
\end{tabular} & \begin{tabular}{|l|l|}
64,08 \\
\end{tabular} & 418,04 & 50,58 & 4,00 & 43,23 & \begin{tabular}{|l|l|}
146,07 \\
\end{tabular} & 34,69 & 34,69 & 124,21 \\
\hline Hyla molleri & $305 \mathrm{SV} 23$ & 100,00 & 145,52 & 126,56 & 37,99 & $\begin{array}{ll}6840,83 \\
\end{array}$ & 340,04 & 8,74 & 331,30 & 129,61 & 237,74 & 237,74 & 62,74 & 420,08 & 50,24 & 4,60 & 42,20 & 145,53 & 36,85 & 36,85 & 123,39 \\
\hline \begin{tabular}{|l|} 
Hyla molleri \\
\end{tabular} & $30 \mathrm{SV} J 33$ & 100,00 & $\begin{array}{l}146,07 \\
\end{array}$ & $\begin{array}{ll}125,88 \\
\end{array}$ & \begin{tabular}{l|l|l}
37,83 \\
\end{tabular} & 6835,78 & \begin{tabular}{ll|}
339,76 \\
\end{tabular} & 9,77 & 329,99 & 130,11 & 238,23 & 238,23 & $\begin{array}{l}63,47 \\
\end{array}$ & 417,42 & \begin{tabular}{ll|}
49,97 \\
\end{tabular} & 4,87 & 41,82 & 144,18 & 37,16 & 37,16 & 122,00 \\
\hline Hyla molleri & 30 SVJ35 & 100,00 & 133,50 & 123,81 & 37,00 & 6852,51 & 327,30 & $-0,71$ & 328,01 & 116,49 & 226,45 & $\begin{array}{l}226,45 \\
\end{array}$ & 51,56 & 458,12 & 53,57 & 7,31 & 39,04 & 155,94 & 46,49 & 46,49 & 131,32 \\
\hline Hyla molleri & $30 \mathrm{SVJ}$ & 100,00 & 13 & 122, & 37,00 & 6858,0 & 328,01 & 1,46 & 326,55 & 1 & 228,45 & 228, & 53,19 & 446,68 & 51,84 & 7,35 & 38, & \begin{tabular}{|l|l|}
150,40 \\
\end{tabular} & $\mid 46,07$ & $\mid 46,07$ & 12 \\
\hline Hyla molleri & $30 \mathrm{SVJ} 42$ & 100,00 & 147,07 & 125,73 & 37,80 & 6824,05 & 340,22 & \begin{tabular}{l|l|l}
11,03 \\
\end{tabular} & 329,18 & 130,93 & 239,08 & 239,08 & 64,71 & 419,65 & 50,44 & 4,93 & 41,76 & \begin{tabular}{|l|l|}
145,29 \\
\end{tabular} & 36,93 & 36,93 & 123, \\
\hline Hyla molleri & $30 \mathrm{SVJ} 43$ & 100,00 & 146,62 & 125,01 & 37,45 & 6823,15 & 339,09 & 10,59 & 328,50 & 130,47 & 238,72 & 238,72 & 64,20 & 415,36 & 49,60 & 5,00 & 41,53 & 142,82 & 37,42 & 37,42 & $\begin{array}{lll}121,07 \\
\end{array}$ \\
\hline
\end{tabular}




\begin{tabular}{|c|c|c|c|c|c|c|c|c|c|c|c|c|c|c|c|c|c|c|c|c|c|}
\hline$\overline{\text { TAXON }}$ & UTM & km2 & BIO1 & BIO2 & $\begin{array}{l}\mathrm{BIO3} \\
\end{array}$ & BIO4 & 8105 & B106 & B107 & B108 & B109 & BIO10 & BIO11 & BIO12 & BIO13 & BIO14 & B1015 & B1016 & B1017 & BIO18 & 81019 \\
\hline Hyla molleri & 30SVJ44 & 100,00 & 134,94 & 124,47 & 37,18 & 6837,59 & 328,72 & 0,39 & 328,33 & 117,92 & 227,52 & 227,52 & 52,91 & 457,44 & 53,83 & 7,13 & 39,26 & 156,41 & 46,03 & 46,03 & 131,50 \\
\hline Hyla molleri & 30SVJ77 & 100,00 & 142,13 & 120,53 & 37,00 & 6778,90 & 329,51 & 8,49 & 321,02 & 126,27 & 233,47 & \begin{tabular}{|l|l|}
233,47 \\
2
\end{tabular} & 60,07 & 419,88 & 47,05 & 7,60 & 36,94 & 137,13 & 45,58 & $\begin{array}{l}45,58 \\
\end{array}$ & 117,90 \\
\hline Hyla molleri & 30SWH57 & 100,00 & $\begin{array}{l}114,82 \\
\end{array}$ & \begin{tabular}{|l|}
122,09 \\
\end{tabular} & 38,00 & 6587,10 & 300,95 & $-15,36$ & 316,31 & 93,56 & 204,25 & \begin{tabular}{|l|}
204,32 \\
\end{tabular} & 37,72 & 539,45 & 68,25 & \begin{tabular}{|l|}
15,29 \\
\end{tabular} & \begin{tabular}{|l|}
32,92 \\
\end{tabular} & \begin{tabular}{|l|l|}
185,07 \\
\end{tabular} & \begin{tabular}{|l|l|}
70,97 \\
\end{tabular} & 73,38 & 138,21 \\
\hline Hyla molleri & 30SWH59 & 100,00 & 129,59 & 122,39 & 38,30 & 6539,40 & 312,89 & $-1,79$ & 314,68 & 110,51 & 217,68 & \begin{tabular}{|l|}
218,04 \\
\end{tabular} & \begin{tabular}{|l|l|}
51,72 \\
\end{tabular} & 460,34 & 58,64 & 11,23 & \begin{tabular}{l|l|}
34,25 \\
\end{tabular} & \begin{tabular}{ll|}
157,76 \\
\end{tabular} & \begin{tabular}{|l|l|}
58,58 \\
\end{tabular} & \begin{tabular}{|l|l|}
62,27 \\
\end{tabular} & 115,81 \\
\hline Hyla molleri & 30SWH67 & 100,00 & 121,15 & 121,71 & 38,09 & 6519,50 & 304,16 & $-9,30$ & 313,46 & 100,49 & 209,50 & 209,64 & 44,39 & 503,36 & 64,59 & 13,88 & 33,23 & 172,13 & 66,52 & 69,38 & 126,38 \\
\hline Hyla molleri & 30SWJ11 & 100,00 & 132,95 & $\mid 123,77$ & 38,00 & 6688,70 & 321,48 & \begin{tabular}{|l|l|}
$-0,02$ \\
\end{tabular} & 321,50 & 114,59 & 222,89 & 223,38 & 53,13 & $\mid$\begin{tabular}{|l|l|}
461,69 \\
\end{tabular} & 56,23 & 9,45 & \begin{tabular}{|c|}
36,06 \\
\end{tabular} & \begin{tabular}{|l|l|}
159,09 \\
\end{tabular} & 53,73 & 54,64 & $\begin{array}{l}124,72 \\
\end{array}$ \\
\hline Hyla molleri & 30TTK57 & 100,00 & 125,48 & 111,03 & 37,08 & 6317,04 & 299,69 & 5,65 & 294,04 & 56,32 & 209,99 & \begin{tabular}{|l|}
210,54 \\
\end{tabular} & 49,34 & 515,12 & \begin{tabular}{|l|}
63,05 \\
\end{tabular} & 9,67 & 39,93 & \begin{tabular}{|l|}
180,10 \\
\end{tabular} & 51,77 & 52,14 & 164,56 \\
\hline Hyla molleri & 30TाK59 & 100,00 & 118,74 & 111,53 & 37,89 & 6264,91 & 292,03 & \begin{tabular}{l|l}
0,06 \\
\end{tabular} & 291,97 & 50,05 & 202,19 & \begin{tabular}{|l|}
203,01 \\
\end{tabular} & 43,41 & 522,27 & $\begin{array}{l}64,35 \\
\end{array}$ & \begin{tabular}{l|l|}
10,65 \\
\end{tabular} & 38,81 & \begin{tabular}{l|l|}
182,02 \\
\end{tabular} & 55,69 & \begin{tabular}{|l|l|}
56,28 \\
\end{tabular} & 164,96 \\
\hline Hyla molleri & 30TTK66 & 100,00 & 79,21 & \begin{tabular}{|l|l|}
106,14 \\
\end{tabular} & 36,41 & 6224,39 & 253,47 & $-34,09$ & 287,56 & 14,25 & 163,83 & \begin{tabular}{|l|}
164,57 \\
\end{tabular} & \begin{tabular}{l|l}
7,95 \\
\end{tabular} & 803,94 & \begin{tabular}{|l|l|}
95,97 \\
\end{tabular} & \begin{tabular}{ll|}
19,66 \\
\end{tabular} & \begin{tabular}{l|l|}
37,45 \\
\end{tabular} & 276,18 & 86,49 & \begin{tabular}{l|l|}
92,45 \\
\end{tabular} & 257,79 \\
\hline Hyla molleri & 30ТтК67 & 100,00 & \begin{tabular}{|l|l|}
109,14 \\
\end{tabular} & \begin{tabular}{|l|l|}
110,24 \\
\end{tabular} & 37,07 & 6281,82 & 283,90 & $-8,71$ & 292,61 & 41,20 & \begin{tabular}{|l|}
192,97 \\
\end{tabular} & \begin{tabular}{|l|l|}
194,39 \\
\end{tabular} & $\begin{array}{l}34,75 \\
\end{array}$ & 578,51 & \begin{tabular}{ll|}
69,88 \\
\end{tabular} & 12,63 & 37,97 & 198,20 & 62,04 & 64,14 & $\begin{array}{l}180,73 \\
\end{array}$ \\
\hline Hyla molleri & 30TTK69 & 100,00 & 116,55 & $\begin{array}{l}112,76 \\
\end{array}$ & 38,00 & 6255,50 & 290,74 & $-2,36$ & 293,10 & 54,45 & 199,44 & \begin{tabular}{|l|}
200,97 \\
\end{tabular} & \begin{tabular}{l|l|}
41,45 \\
\end{tabular} & 504,86 & 61,34 & \begin{tabular}{|l|}
11,15 \\
\end{tabular} & 37,32 & \begin{tabular}{|l|l|}
171,90 \\
\end{tabular} & 56,85 & 57,70 & $\begin{array}{l}154,59 \\
\end{array}$ \\
\hline Hyla molleri & 30TTK73 & 100,00 & 156,65 & \begin{tabular}{|l|}
113,84 \\
\end{tabular} & 37,00 & 6445,10 & 333,92 & \begin{tabular}{|l|}
30,98 \\
\end{tabular} & 302,94 & 103,79 & 242,73 & 242,73 & 77,59 & 393,18 & \begin{tabular}{|l|}
47,05 \\
\end{tabular} & 5,31 & 42,28 & 135,41 & 34,34 & 34,34 & 122,65 \\
\hline Hyla molleri & 30TTK74 & 100,00 & 134,76 & 112,76 & 36,99 & 6418,78 & 312,39 & \begin{tabular}{|l|}
11,83 \\
\end{tabular} & 300,57 & 68,51 & 220,79 & 221,21 & 57,26 & 470,09 & 55,91 & 8,45 & 40,06 & 159,85 & 46,18 & 46,69 & 145,14 \\
\hline Hyla molleri & 30TTK75 & 100,00 & 81,44 & 107,65 & 36,44 & 6263,92 & 257,81 & $-33,16$ & 290,97 & \begin{tabular}{ll|}
16,03 \\
\end{tabular} & $\begin{array}{l}166,67 \\
\end{array}$ & \begin{tabular}{|l|}
167,38 \\
\end{tabular} & $\begin{array}{l}9,72 \\
\end{array}$ & 767,13 & 90,58 & 19,21 & 36,84 & 259,87 & $\begin{array}{l}83,75 \\
\end{array}$ & $\begin{array}{l}88,86 \\
\end{array}$ & 241,18 \\
\hline Hyla molleri & 30TTK76 & 100,00 & 91,53 & 108,77 & 36,79 & 6260,14 & 267,27 & $-24,49$ & 291,75 & 25,18 & $\begin{array}{l}175,92 \\
\end{array}$ & \begin{tabular}{|l|}
177,06 \\
\end{tabular} & \begin{tabular}{|l|l|}
18,91 \\
\end{tabular} & 680,86 & 80,72 & 16,69 & 36,68 & 229,91 & 75,34 & 79,58 & 211,18 \\
\hline Hyla molleri & 30TTK77 & 100,00 & 97,20 & 109,86 & \begin{tabular}{|l|}
37,13 \\
\end{tabular} & 6246,57 & 272,49 & $-19,59$ & \begin{tabular}{|l|}
292,07 \\
\end{tabular} & 30,34 & \begin{tabular}{|l|}
180,93 \\
\end{tabular} & \begin{tabular}{|l|}
182,39 \\
\end{tabular} & \begin{tabular}{|l|}
24,13 \\
\end{tabular} & 626,00 & 74,51 & $\begin{array}{l}15,30 \\
\end{array}$ & 36,35 & \begin{tabular}{|l|}
210,42 \\
\end{tabular} & \begin{tabular}{|l|}
70,67 \\
\end{tabular} & 74,09 & 191,65 \\
\hline Hyla molleri & 30TTK78 & 100,00 & 114,63 & 112,80 & 37,91 & 6271,61 & 289,86 & $-4,61$ & 294,47 & 55,68 & 197,59 & \begin{tabular}{l|l|}
199,56 \\
\end{tabular} & 39,69 & 504,84 & \begin{tabular}{ll|}
60,39 \\
\end{tabular} & \begin{tabular}{|l|}
11,68 \\
\end{tabular} & 36,46 & \begin{tabular}{l|l|}
168,65 \\
\end{tabular} & \begin{tabular}{|l|l|}
57,96 \\
\end{tabular} & \begin{tabular}{|l|l|}
59,24 \\
\end{tabular} & 151,39 \\
\hline Hyla molleri & 30TTK83 & 100,00 & 158,97 & \begin{tabular}{|l|l|}
114,14 \\
\end{tabular} & 37,00 & 6461,66 & 336,39 & 32,36 & 304,03 & 117,50 & 245,23 & 245,23 & \begin{tabular}{|l|}
79,43 \\
\end{tabular} & \begin{tabular}{|l|l|}
373,42 \\
\end{tabular} & 44,45 & 5,01 & 42,10 & \begin{tabular}{|l|}
128,14 \\
\end{tabular} & 32,99 & 32,99 & 114,34 \\
\hline Hyla molleri & 30TTK84 & 100,00 & 134,41 & 113,27 & 37,00 & 6425,82 & 312,65 & 10,59 & 302,07 & 81,47 & 220,52 & \begin{tabular}{|l|}
220,95 \\
\end{tabular} & \begin{tabular}{|l|l|}
56,82 \\
\end{tabular} & 456,62 & 53,71 & 8,67 & 39,33 & 153,00 & 46,50 & $\begin{array}{l}47,06 \\
\end{array}$ & $\begin{array}{l}137,83 \\
\end{array}$ \\
\hline Hyla molleri & 30TTK85 & 100,00 & 78,37 & $\mid 108,42$ & 36,60 & 6264,29 & 255,69 & $-36,63$ & 292,32 & $\mid 13,03$ & 163,74 & 164,41 & 6,90 & 760,19 & 88,73 & 20,16 & 35,67 & 253,42 & 86,09 & 91,79 & 233,99 \\
\hline Hyla molleri & 30TTK86 & 100,00 & 104,01 & \begin{tabular}{|l|}
111,33 \\
\end{tabular} & 37,03 & \begin{tabular}{|c|}
6298,99 \\
\end{tabular} & 281,10 & $-14,76$ & 295,86 & 38,62 & 188,25 & \begin{tabular}{|l|}
189,81 \\
\end{tabular} & 30,01 & 569,76 & 66,99 & 14,01 & 36,09 & \begin{tabular}{|l|l|}
188,25 \\
\end{tabular} & \begin{tabular}{|l|}
65,19 \\
\end{tabular} & \begin{tabular}{|l|l|}
67,68 \\
\end{tabular} & 169,77 \\
\hline Hyla molleri & 30TTK87 & 100,00 & \begin{tabular}{|l|}
112,29 \\
\end{tabular} & 112,73 & 37,60 & 6295,44 & 288,80 & \begin{tabular}{|l|l|}
$-7,63$ \\
\end{tabular} & 296,43 & 62,51 & 195,94 & \begin{tabular}{|l|}
197,81 \\
\end{tabular} & 37,44 & \begin{tabular}{|l|l|}
507,78 \\
\end{tabular} & 59,81 & \begin{tabular}{|l|l|}
12,44 \\
\end{tabular} & \begin{tabular}{|l|}
35,86 \\
\end{tabular} & \begin{tabular}{ll|}
166,60 \\
\end{tabular} & \begin{tabular}{|l|l|}
59,43 \\
\end{tabular} & $\begin{array}{l}61,05 \\
\end{array}$ & \begin{tabular}{|l|l|}
148,84 \\
\end{tabular} \\
\hline Hyla molleri & 30TTK88 & 100,00 & \begin{tabular}{|l|}
115,08 \\
\end{tabular} & 113,70 & \begin{tabular}{|l|}
37,98 \\
\end{tabular} & 6268,39 & 290,92 & \begin{tabular}{|l|} 
\\
\end{tabular} & 296,09 & 72,80 & \begin{tabular}{|l|l|}
197,78 \\
\end{tabular} & 200,01 & \begin{tabular}{|l|l|}
40,13 \\
\end{tabular} & \begin{tabular}{|l|}
480,61 \\
\end{tabular} & $\begin{array}{l}56,77 \\
\end{array}$ & \begin{tabular}{|l|l|}
11,78 \\
\end{tabular} & 35,36 & \begin{tabular}{|l|l|}
157,37 \\
\end{tabular} & \begin{tabular}{|l|l|}
57,66 \\
\end{tabular} & \begin{tabular}{|l|l|}
58,97 \\
\end{tabular} & 139,60 \\
\hline Hyla molleri & 30TाK93 & 100,00 & 158,23 & $\begin{array}{ll}114,87 \\
\end{array}$ & 37,00 & $\begin{array}{l}6478,21 \\
\end{array}$ & 336,17 & 31,10 & 305,07 & 116,45 & 244,77 & \begin{tabular}{|l|l|}
244,77 \\
\end{tabular} & \begin{tabular}{|l|}
78,48 \\
\end{tabular} & 365,64 & 43,12 & 5,03 & 41,74 & \begin{tabular}{|l|l|}
124,73 \\
\end{tabular} & 32,99 & 32,99 & $\begin{array}{ll}110,07 \\
\end{array}$ \\
\hline Hyla molleri & 30TTK94 & 100,00 & 150,38 & 114,48 & 37,00 & 6451,97 & 328,03 & \begin{tabular}{|l|}
24,12 \\
\end{tabular} & 303,91 & 108,28 & 236,77 & \begin{tabular}{|l|}
236,78 \\
\end{tabular} & \begin{tabular}{|l|}
71,27 \\
\end{tabular} & 381,23 & 44,71 & 6,37 & 39,86 & \begin{tabular}{|l|l|}
128,30 \\
\end{tabular} & \begin{tabular}{|l|}
37,38 \\
\end{tabular} & \begin{tabular}{|l|}
37,38 \\
\end{tabular} & 113,13 \\
\hline Hyla molleri & 30TाK95 & 100,00 & 94,42 & 110,80 & 36,89 & 6314,75 & 272,60 & $-23,77$ & 296,37 & 36,90 & 179,93 & \begin{tabular}{|l|}
180,69 \\
\end{tabular} & 21,05 & 643,16 & \begin{tabular}{|l|}
74,43 \\
\end{tabular} & 17,05 & 35,56 & 210,75 & 74,63 & 78,42 & 191,89 \\
\hline Hyla molleri & 30TTK96 & 100,00 & 91,54 & 110,67 & 37,01 & 6268,13 & 268,93 & $-26,01$ & 294,93 & 33,22 & 176,05 & \begin{tabular}{|l|}
177,31 \\
\end{tabular} & 18,89 & 629,13 & 73,17 & \begin{tabular}{|l|}
17,20 \\
\end{tabular} & 34,74 & \begin{tabular}{|l|}
204,69 \\
\end{tabular} & 75,06 & \begin{tabular}{l|l|}
79,02 \\
\end{tabular} & \begin{tabular}{|l|l|}
184,84 \\
\end{tabular} \\
\hline Hyla molleri & 30TTK98 & 100,00 & 111,33 & 113,54 & 37,94 & 6252,65 & 287,35 & $-8,85$ & 296,19 & $\begin{array}{l}70,37 \\
\end{array}$ & 194,08 & \begin{tabular}{|l|}
196,31 \\
\end{tabular} & 37,04 & 480,69 & \begin{tabular}{|l|l|}
57,37 \\
\end{tabular} & \begin{tabular}{|l|l|}
12,67 \\
1
\end{tabular} & 34,32 & \begin{tabular}{|l|}
155,03 \\
\end{tabular} & 60,19 & $\begin{array}{l}61,95 \\
\end{array}$ & $\begin{array}{l}135,37 \\
\end{array}$ \\
\hline Hyla molleri & 30TTL40 & 39,00 & 1117,22 & 1110,80 & \begin{tabular}{|l|}
37,98 \\
\end{tabular} & 6241,55 & 289,36 & $-0,44$ & 289,80 & \begin{tabular}{|l|}
48,96 \\
\end{tabular} & 200,42 & \begin{tabular}{|l|}
201,29 \\
\end{tabular} & \begin{tabular}{|l|}
42,09 \\
\end{tabular} & 537,40 & 66,89 & \begin{tabular}{|l|l|}
10,84 \\
\end{tabular} & 39,51 & \begin{tabular}{|l|}
189,65 \\
\end{tabular} & \begin{tabular}{|l|l|}
56,73 \\
\end{tabular} & \begin{tabular}{l|l}
57,22 \\
\end{tabular} & $\begin{array}{l}172,22 \\
\end{array}$ \\
\hline Hyla molleri & 30TTL45 & 20,00 & 1119,76 & \begin{tabular}{|l|}
113,97 \\
\end{tabular} & 38,97 & \begin{tabular}{|c|}
6206,59 \\
\end{tabular} & 291,48 & \begin{tabular}{|l|}
0,07 \\
\end{tabular} & 291,41 & 79,59 & 202,28 & \begin{tabular}{|l|l|}
202,28 \\
\end{tabular} & \begin{tabular}{l|l|}
43,86 \\
\end{tabular} & \begin{tabular}{|l|l|}
458,03 \\
\end{tabular} & 59,00 & $\begin{array}{l}10,34 \\
\end{array}$ & 38,24 & 163,90 & 53,28 & 53,28 & 141,10 \\
\hline Hyla molleri & 30TTL50 & 100,00 & \begin{tabular}{|l|l|}
114,93 \\
\end{tabular} & 111,65 & 37,99 & 6240,78 & 287,90 & $-2,85$ & 290,75 & 47,54 & $\begin{array}{l}197,78 \\
\end{array}$ & \begin{tabular}{|l|l|}
199,05 \\
\end{tabular} & \begin{tabular}{|l|l|}
40,02 \\
\end{tabular} & 528,61 & 65,29 & \begin{tabular}{|l|l|}
11,17 \\
\end{tabular} & 38,41 & \begin{tabular}{|l|l|}
183,98 \\
\end{tabular} & 57,94 & \begin{tabular}{|l|l|}
58,66 \\
\end{tabular} & 166,05 \\
\hline Hyla molleri & 30TTL54 & 100,00 & 119,97 & 114,95 & 38,97 & 6214,41 & 292,67 & 0,09 & 292,57 & \begin{tabular}{|l|}
79,86 \\
\end{tabular} & 202,86 & \begin{tabular}{l|l|}
202,86 \\
\end{tabular} & \begin{tabular}{|l|}
44,03 \\
4
\end{tabular} & 445,01 & 57,31 & 10,31 & \begin{tabular}{|l|}
38,63 \\
\end{tabular} & \begin{tabular}{|l|}
159,45 \\
\end{tabular} & 52,65 & 52,65 & 133,95 \\
\hline Hyla molleri & 30TTL55 & 100,00 & 1119,49 & 114,99 & 39,00 & 6194,68 & 291,90 & \begin{tabular}{l|l}
$-0,15$ \\
\end{tabular} & 292,05 & 79,42 & 202,05 & \begin{tabular}{|l|}
202,05 \\
\end{tabular} & 43,64 & 438,15 & 56,37 & \begin{tabular}{|l|}
10,58 \\
\end{tabular} & 38,23 & 156,80 & 52,87 & 52,87 & 131,30 \\
\hline Hyla molleri & 30TTL56 & 100,00 & 115,04 & 114,44 & 39,00 & 6165,01 & 287,15 & $-3,84$ & 290,99 & 75,32 & 197,15 & \begin{tabular}{|l|}
197,26 \\
\end{tabular} & \begin{tabular}{|l|}
39,83 \\
\end{tabular} & 452,74 & \begin{tabular}{|l|l|}
57,87 \\
\end{tabular} & \begin{tabular}{|l|l|}
11,27 \\
\end{tabular} & 37,59 & \begin{tabular}{|l|l|}
161,16 \\
\end{tabular} & 55,84 & \begin{tabular}{|l|l|}
55,92 \\
\end{tabular} & 135,98 \\
\hline Hyla molleri & 30TTL57 & 100,00 & 115,39 & \begin{tabular}{ll|}
114,42 \\
\end{tabular} & 39,00 & \begin{tabular}{|c|}
6158,74 \\
\end{tabular} & 287,28 & $-3,76$ & \begin{tabular}{|l|}
291,04 \\
\end{tabular} & 75,66 & 197,18 & \begin{tabular}{|l|l|}
197,42 \\
\end{tabular} & \begin{tabular}{ll|}
40,06 \\
\end{tabular} & \begin{tabular}{|l|l|}
444,03 \\
\end{tabular} & 56,61 & \begin{tabular}{|l|l|}
11,27 \\
\end{tabular} & \begin{tabular}{|l|}
37,08 \\
\end{tabular} & \begin{tabular}{|l|}
157,38 \\
\end{tabular} & 55,33 & 55,47 & \begin{tabular}{|l|l|}
133,44 \\
\end{tabular} \\
\hline Hyla molleri & 30TTL58 & 100,00 & \begin{tabular}{|l|}
118,25 \\
\end{tabular} & \begin{tabular}{|l|}
114,45 \\
\end{tabular} & 39,00 & 6157,61 & 289,66 & $-1,44$ & 291,09 & 78,51 & 199,50 & \begin{tabular}{|l|l|}
199,90 \\
\end{tabular} & \begin{tabular}{|l|l}
42,43 \\
\end{tabular} & 426,35 & 54,25 & \begin{tabular}{|c|}
10,94 \\
\end{tabular} & \begin{tabular}{|l|}
36,63 \\
\end{tabular} & \begin{tabular}{|l|l|}
150,60 \\
\end{tabular} & 53,39 & \begin{tabular}{|l|l|}
53,63 \\
\end{tabular} & 128,16 \\
\hline Hyla molleri & 30TTL59 & 100,00 & \begin{tabular}{|l|}
120,08 \\
\end{tabular} & 114,38 & 38,99 & 6142,13 & 290,93 & \begin{tabular}{|c|}
$-0,17$ \\
\end{tabular} & 291,10 & $\begin{array}{l}80,44 \\
\end{array}$ & 200,75 & \begin{tabular}{|l|}
201,21 \\
\end{tabular} & \begin{tabular}{|l|}
44,09 \\
\end{tabular} & 416,59 & 52,89 & $\begin{array}{l}10,56 \\
\end{array}$ & 36,11 & \begin{tabular}{|l|}
146,84 \\
\end{tabular} & 52,66 & 52,95 & 125,25 \\
\hline Hyla molleri & 30TTL61 & 100,00 & 113,50 & 113,97 & 38,46 & 6218,07 & 287,22 & $-5,21$ & 292,44 & 72,68 & 196,09 & 197,31 & 38,71 & $492,07 \mid$ & 60,22 & 11,71 & 36,64 & 168,50 & 58,69 & 59,31 & 148,05 \\
\hline Hyla molleri & 30TTL62 & 100,00 & 116,47 & 115,31 & 38,95 & 6219,87 & 290,42 & $-2,82$ & 293,24 & 76,27 & 199,71 & \begin{tabular}{|l|}
199,86 \\
\end{tabular} & \begin{tabular}{l|l|}
41,25 \\
\end{tabular} & 462,77 & 57,19 & 11,12 & 37,00 & 160,84 & 56,27 & 56,35 & 137,50 \\
\hline Hyla molleri & 30TTL63 & 100,00 & 119,51 & 116,51 & 39,01 & 6228,66 & 293,60 & $-0,62$ & 294,22 & 79,06 & 202,72 & \begin{tabular}{|l|}
202,72 \\
\end{tabular} & \begin{tabular}{|l|}
43,67 \\
\end{tabular} & 431,98 & 54,71 & \begin{tabular}{|l|l|}
10,97 \\
\end{tabular} & 37,70 & \begin{tabular}{|l|}
153,08 \\
\end{tabular} & 53,65 & 53,65 & 125,65 \\
\hline Hyla molleri & 30TTL64 & 100,00 & 120,29 & 116,82 & 39,05 & 6221,36 & 294,10 & $-0,18$ & 294,27 & 80,06 & 203,19 & \begin{tabular}{|l|}
203,19 \\
\end{tabular} & \begin{tabular}{|l|l|}
44,14 \\
\end{tabular} & 413,41 & \begin{tabular}{|l|l|}
52,97 \\
\end{tabular} & \begin{tabular}{|l|}
10,68 \\
\end{tabular} & 38,41 & \begin{tabular}{|l|l|}
148,23 \\
\end{tabular} & \begin{tabular}{|l|l|}
52,13 \\
\end{tabular} & 52,13 & $\begin{array}{l}118,31 \\
\end{array}$ \\
\hline Hyla molleri & 30TTL65 & 100,00 & $\begin{array}{l}118,88 \\
\end{array}$ & 116,50 & 39,01 & 6191,56 & 292,08 & $-1,21$ & 293,29 & 78,72 & 201,26 & \begin{tabular}{|l|}
201,26 \\
\end{tabular} & \begin{tabular}{|l|l|}
43,07 \\
\end{tabular} & 410,75 & 52,21 & \begin{tabular}{|l|l|}
10,97 \\
\end{tabular} & 37,74 & 146,54 & 53,00 & 53,00 & 116,99 \\
\hline Hyla molleri & 30TTL67 & 100,00 & 115,36 & 115,55 & 39,00 & 6155,89 & 287,85 & \begin{tabular}{|c|} 
\\
\end{tabular} & 291,93 & $\begin{array}{l}75,61 \\
\end{array}$ & \begin{tabular}{|l|l|}
196,41 \\
\end{tabular} & \begin{tabular}{l|l|}
197,42 \\
\end{tabular} & \begin{tabular}{|l|}
40,03 \\
\end{tabular} & 417,49 & 52,16 & $\begin{array}{l}11,57 \\
\end{array}$ & 36,18 & \begin{tabular}{ll|}
146,45 \\
\end{tabular} & \begin{tabular}{|l|l|}
55,03 \\
\end{tabular} & 55,53 & 119,99 \\
\hline Hyla molleri & 30TTL68 & 100,00 & 119,86 & 5,30 & 39,00 & \begin{tabular}{|l|l|}
6157,26 \\
\end{tabular} & 291,68 & $-0,43$ & 292,11 & 80,01 & 199,99 & 201,51 & \begin{tabular}{|l|}
43,94 \\
\end{tabular} & 390,48 & \begin{tabular}{|l|l|}
48,65 \\
\end{tabular} & 10,34 & 35,71 & \begin{tabular}{|l|}
136,31 \\
\end{tabular} & \begin{tabular}{|l|}
51,33 \\
\end{tabular} & 52,09 & 1111,71 \\
\hline Hyla molleri & 30TTL69 & 100,00 & 122,06 & 115,03 & 39,00 & 6155,46 & 293,29 & 0,89 & 292,40 & 82,50 & 201,72 & 203,25 & 45,71 & 378,28 & \begin{tabular}{l|l|}
47,02 \\
\end{tabular} & 9,83 & 35,32 & 131,58 & 49,88 & 50,85 & 107,96 \\
\hline Hyla molleri & 30TTL71 & 100,00 & 115,19 & 115,41 & 38,99 & 6196,44 & 289,38 & \begin{tabular}{|l|} 
\\
\end{tabular} & 293,77 & 74,78 & 196,90 & \begin{tabular}{|l|}
198,69 \\
\end{tabular} & \begin{tabular}{l|l|}
40,55 \\
\end{tabular} & 461,69 & \begin{tabular}{l|l|}
55,62 \\
\end{tabular} & 11,56 & 35,19 & 154,96 & 57,72 & 58,52 & 134,75 \\
\hline Hyla molleri & 30TTL73 & 100,00 & 120,48 & 118,22 & 39,59 & 6217,77 & 295,16 & $-0,53$ & 295,68 & 79,94 & 203,51 & \begin{tabular}{|l|}
203,67 \\
\end{tabular} & \begin{tabular}{|l|}
44,79 \\
\end{tabular} & 414,32 & $\begin{array}{l}50,82 \\
\end{array}$ & \begin{tabular}{|l|}
10,99 \\
\end{tabular} & 35,68 & \begin{tabular}{|l|}
142,51 \\
\end{tabular} & 53,90 & 53,97 & 118,64 \\
\hline Hyla molleri & 30TTL75 & 100,00 & 118,36 & \begin{tabular}{ll|}
117,62 \\
\end{tabular} & 39,62 & 170,04 & 292,09 & $-1,89$ & \begin{tabular}{|l|}
293,97 \\
\end{tabular} & 78,08 & 200,76 & \begin{tabular}{|l|}
200,92 \\
\end{tabular} & 43,20 & 394,29 & 49,00 & \begin{tabular}{|l|}
11,00 \\
\end{tabular} & 36,49 & \begin{tabular}{|l|l|}
137,82 \\
\end{tabular} & 53,90 & 53,96 & 108,48 \\
\hline Hyla molleri & 30TTL76 & 100,00 & \begin{tabular}{|l|l|}
115,98 \\
\end{tabular} & 116,93 & $\mid 39,04$ & 6154,60 & 289,42 & $-4,00$ & \begin{tabular}{|l|}
293,42 \\
\end{tabular} & $\mid 75,96$ & \begin{tabular}{|l|l|}
197,03 \\
\end{tabular} & $\mid 198,15$ & \begin{tabular}{|l|l|}
40,83 \\
\end{tabular} & 399,35 & \begin{tabular}{|l|l|}
49,00 \\
\end{tabular} & \begin{tabular}{|l|l|}
11,38 \\
\end{tabular} & 35,69 & \begin{tabular}{|l|l|}
138,35 \\
\end{tabular} & 54,94 & 55,48 & 110,35 \\
\hline Hyla molleri & 30TTL77 & 100 & & & 39 & 614 & 288,43 & $-4,77$ & 293, & $\begin{array}{l}75,46 \\
\end{array}$ & 195,38 & \begin{tabular}{|l|}
197,22 \\
\end{tabular} & 40,21 & 399,37 & 48,49 & 11,80 & 34,90 & \begin{tabular}{|l|}
137,61 \\
\end{tabular} & 55,20 & 56,19 & 110,71 \\
\hline Hyla molleri & 30TTL79 & 100,00 & $\begin{array}{l}123,62 \\
\end{array}$ & $\begin{array}{l}115,62 \\
\end{array}$ & 39,00 & 6148,60 & 295,08 & 1,99 & 293,09 & 84,09 & 202,65 & \begin{tabular}{|l|l|}
204,89 \\
\end{tabular} & $\begin{array}{l}47,22 \\
\end{array}$ & 358,17 & 43,27 & 9,79 & 34,54 & $\begin{array}{l}122,99 \\
\end{array}$ & 49,01 & 50,37 & 98,48 \\
\hline Hyla molleri & 30TTL82 & 100,00 & 117,57 & 117,17 & 39,34 & 6116,41 & 290,95 & $-2,46$ & 293,41 & 77,21 & 197,13 & \begin{tabular}{|l|}
200,08 \\
\end{tabular} & \begin{tabular}{|l|}
43,72 \\
\end{tabular} & 421,53 & 50,03 & 11,24 & 33,00 & \begin{tabular}{|l|}
137,38 \\
\end{tabular} & 56,54 & 57,75 & 118,50 \\
\hline Hyla molleri & 30TTL83 & 100,00 & 120,42 & 118,34 & 40,00 & 6087,64 & 293,26 & $-0,31$ & 293,57 & 79,91 & 199,28 & 202,43 & 46,64 & 400,26 & 47,40 & 11,00 & 32,46 & 130,21 & 54,99 & 56,17 & 111,81 \\
\hline Hyla molleri & $30 \pi T$ & 10 & & 118,05 & 40,00 & \begin{tabular}{|c|}
6094,94 \\
\end{tabular} & 291,11 & $-2,11$ & 293,22 & 77,77 & 197,44 & 200,09 & \begin{tabular}{|l|l|}
44,13 \\
\end{tabular} & \begin{tabular}{|l|}
395,58 \\
\end{tabular} & \begin{tabular}{|l|l|}
47,83 \\
\end{tabular} & \begin{tabular}{|l|l|}
11,05 \\
\end{tabular} & \begin{tabular}{|l|}
33,18 \\
\end{tabular} & 130,74 & 55,48 & 56,54 & 108,39 \\
\hline Hyla molleri & 30TTL85 & 100,00 & \begin{tabular}{|l|}
117,38 \\
\end{tabular} & 1117,95 & 39,95 & 6110,75 & 290,40 & \begin{tabular}{|c|}
$-3,05$ \\
\end{tabular} & 293,45 & 76,89 & \begin{tabular}{|l|}
196,71 \\
\end{tabular} & \begin{tabular}{|l|}
199,36 \\
\end{tabular} & \begin{tabular}{ll|}
43,06 \\
\end{tabular} & 390,23 & $\begin{array}{l}47,82 \\
\end{array}$ & \begin{tabular}{|l|}
11,22 \\
\end{tabular} & 33,78 & \begin{tabular}{|l|l|}
130,64 \\
\end{tabular} & 55,23 & $\begin{array}{l}56,36 \\
\end{array}$ & 105,81 \\
\hline Hyla molleri & 30TTL87 & 100,00 & \begin{tabular}{|l|}
117,45 \\
\end{tabular} & \begin{tabular}{|l|}
117,01 \\
\end{tabular} & 39,01 & 6128,10 & 290,28 & $-3,02$ & 293,30 & 77,47 & 196,72 & \begin{tabular}{|l|l|}
199,04 \\
\end{tabular} & 42,31 & 381,31 & 46,22 & \begin{tabular}{|l|l|}
11,59 \\
\end{tabular} & 33,62 & \begin{tabular}{|l|}
128,43 \\
\end{tabular} & 54,19 & 55,82 & 103,11 \\
\hline Hyla molleri & 30TTL91 & 100,00 & 117,60 & 116,18 & 39,00 & 6136,11 & 291,29 & $-2,71$ & 294,00 & 77,22 & 197,47 & 200,64 & \begin{tabular}{l|l|}
43,65 \\
\end{tabular} & 418,35 & 50,18 & \begin{tabular}{|l|l|}
11,39 \\
\end{tabular} & 32,73 & 133,71 & 56,42 & 58,07 & $\begin{array}{ll}115,02 \\
\end{array}$ \\
\hline Hyla molleri & $30 T T$ & 100,00 & 11 & & $\mid 39,26$ & 087 & 291 & $-1,2$ & 293,05 & 78,44 & \begin{tabular}{|c|}
197,85 \\
\end{tabular} & 201, & \begin{tabular}{|l|l|}
45,51 \\
\end{tabular} & \begin{tabular}{|l|l|}
402,74 \\
\end{tabular} & \begin{tabular}{|l|l|}
48,03 \\
\end{tabular} & 11, & & \begin{tabular}{|l|l|}
127,79 \\
\end{tabular} & 55,75 & 57,51 & \\
\hline Hyla molleri & 30TTL93 & 100,00 & \begin{tabular}{|l|l|}
119,44 \\
\end{tabular} & 117,50 & 39,96 & 6030,78 & 291,30 & $-0,79$ & 292,09 & 78,96 & 197,04 & 200,89 & \begin{tabular}{|l|l|}
46,37 \\
\end{tabular} & 391,78 & 46,69 & \begin{tabular}{l|l|}
11,02 \\
\end{tabular} & \begin{tabular}{l|l|}
31,25 \\
\end{tabular} & \begin{tabular}{|l|l|}
123,57 \\
\end{tabular} & 55,69 & 57,79 & $\begin{array}{l}106,13 \\
\end{array}$ \\
\hline Hyla molleri & 30TTL94 & 100,00 & 117,14 & 117,62 & 39,89 & 6042,23 & 289,38 & $-2,95$ & 292,33 & 76,99 & 195,08 & \begin{tabular}{|l|l|}
198,61 \\
\end{tabular} & 43,79 & 392,83 & 47,39 & 11,57 & 31,49 & 125,51 & 56,71 & 58,87 & 105,48 \\
\hline
\end{tabular}




\begin{tabular}{|c|c|c|c|c|c|c|c|c|c|c|c|c|c|c|c|c|c|c|c|c|c|}
\hline$\overline{\text { TAXON }}$ & UTM & km2 & BIO1 & BIO2 & $\begin{array}{l}\mathrm{BIO3} \\
\end{array}$ & BIO4 & B105 & B106 & B107 & B108 & B109 & BIO10 & BIO11 & BIO12 & B1013 & B1014 & B1015 & B1016 & B1017 & BIO18 & 81019 \\
\hline Hyla molleri & 30TTL95 & 100,00 & 117,80 & 117,64 & 39,72 & 6069,91 & $\begin{array}{r}290,40 \\
\end{array}$ & $-2,62$ & 293,02 & 77,74 & 196,23 & 199,40 & 44,09 & 383,52 & 46,63 & 11,36 & 32,12 & 124,15 & 55,46 & 57,44 & 102,38 \\
\hline Hyla molleri & 30TTL98 & 100,00 & 120,71 & 117,00 & 39,00 & 6116,87 & 293,11 & $-0,66$ & 293,78 & 81,40 & 199,52 & 202,03 & 45,15 & 367,73 & 43,89 & 11,57 & 32,38 & 121,95 & 53,17 & 55,27 & 98,40 \\
\hline Hyla molleri & 30TTM50 & 100,00 & 118,92 & 114,25 & 39,00 & 6119,15 & 289,53 & $-1,20$ & 290,73 & $\begin{array}{l}79,56 \\
\end{array}$ & \begin{tabular}{|l|}
199,50 \\
\end{tabular} & \begin{tabular}{l|l|}
199,86 \\
\end{tabular} & \begin{tabular}{|l|l|}
43,12 \\
\end{tabular} & 425,39 & 54,04 & \begin{tabular}{|l|}
11,10 \\
1
\end{tabular} & 35,80 & \begin{tabular}{|l|}
150,07 \\
\end{tabular} & \begin{tabular}{|l|l|}
54,46 \\
\end{tabular} & 54,70 & 128,83 \\
\hline Hyla molleri & 30TTM53 & 90,00 & 116,54 & 114,76 & 39,00 & 6052,98 & 286,48 & $-3,53$ & 290,01 & \begin{tabular}{|l|l|}
77,97 \\
\end{tabular} & $\begin{array}{l}196,54 \\
\end{array}$ & \begin{tabular}{|l|l|}
196,54 \\
\end{tabular} & \begin{tabular}{|l|}
41,24 \\
\end{tabular} & 461,58 & 58,57 & 13,78 & 34,71 & \begin{tabular}{|l|l|}
164,57 \\
\end{tabular} & \begin{tabular}{ll|}
62,22 \\
\end{tabular} & \begin{tabular}{ll|}
62,22 \\
\end{tabular} & $\begin{array}{ll}141,87 \\
\end{array}$ \\
\hline Hyla molleri & ЗотTM55 & 84,00 & 117,11 & 114,77 & 39,00 & 6000,72 & 285,95 & $-3,43$ & 289,39 & 78,98 & 196,27 & 196,27 & 42,17 & 481,39 & 60,98 & 15,51 & 34,29 & 173,54 & 66,96 & 66,96 & 147,86 \\
\hline Hyla molleri & 30тTM56 & 80,00 & 115,43 & \begin{tabular}{|l|l|}
114,79 \\
\end{tabular} & 39,02 & 5976,23 & 283,90 & $-4,84$ & 288,73 & 77,50 & 194,25 & \begin{tabular}{|l|l|}
194,25 \\
\end{tabular} & \begin{tabular}{|l|l|}
40,71 \\
\end{tabular} & 500,38 & $\mid 63,39$ & \begin{tabular}{|l|l|}
16,95 \\
\end{tabular} & 34,12 & \begin{tabular}{|l|l|}
181,13 \\
\end{tabular} & 71,15 & 71,15 & $\begin{array}{l}153,10 \\
\end{array}$ \\
\hline Hyla molleri & 30TTM60 & 100,00 & 120,34 & 115,00 & 39,00 & 6131,49 & 291,38 & $-0,43$ & 291,81 & 80,93 & 199,72 & \begin{tabular}{|l|}
201,24 \\
\end{tabular} & 44,30 & 389,94 & 48,50 & 10,63 & 34,65 & 135,93 & 52,24 & 53,13 & 112,21 \\
\hline Hyla molleri & 30тTM61 & 100,00 & 120,34 & 115,00 & 39,00 & 6111,14 & 291,01 & $-0,41$ & 291,42 & 80,98 & 200,24 & 200,94 & \begin{tabular}{|l|}
44,43 \\
\end{tabular} & 400,67 & 49,91 & \begin{tabular}{|l|l|}
11,19 \\
\end{tabular} & $\begin{array}{l}34,43 \\
\end{array}$ & \begin{tabular}{|l|l|}
140,49 \\
\end{tabular} & 54,41 & \begin{tabular}{|l|l}
54,76 \\
\end{tabular} & \begin{tabular}{|l|l|}
116,63 \\
\end{tabular} \\
\hline Hyla molleri & 30TTM64 & 100,00 & 118,42 & 115,20 & 39,00 & 6033,58 & 288,30 & $-2,81$ & 291,11 & 80,39 & 198,16 & \begin{tabular}{|l|l|}
198,16 \\
\end{tabular} & \begin{tabular}{|l|l|}
43,04 \\
\end{tabular} & 445,77 & 55,58 & 14,38 & 33,53 & \begin{tabular}{|l|}
159,09 \\
\end{tabular} & \begin{tabular}{|l|l|}
63,73 \\
\end{tabular} & \begin{tabular}{|l|l|}
63,73 \\
\end{tabular} & 132,16 \\
\hline Hyla molleri & 30тTM68 & 100,00 & 115,66 & \begin{tabular}{|l|l|}
115,14 \\
\end{tabular} & 39,30 & 5920,82 & \begin{tabular}{|l|l|}
283,44 \\
\end{tabular} & $-4,84$ & 288,27 & 78,75 & 193,59 & \begin{tabular}{|l|l|}
193,59 \\
\end{tabular} & \begin{tabular}{|l|l|}
41,14 \\
\end{tabular} & 510,51 & \begin{tabular}{ll|}
65,92 \\
\end{tabular} & \begin{tabular}{|l|}
19,61 \\
\end{tabular} & 33,18 & \begin{tabular}{|l|l|}
186,15 \\
\end{tabular} & 78,70 & 78,70 & 149,35 \\
\hline Hyla molleri & 30тTM69 & 100,00 & \begin{tabular}{|l|}
114,35 \\
\end{tabular} & $\begin{array}{l}114,99 \\
\end{array}$ & 39,66 & 5869,97 & 281,20 & \begin{tabular}{|l|}
$-6,07$ \\
\end{tabular} & 287,28 & 77,94 & 191,56 & \begin{tabular}{|l|}
191,56 \\
\end{tabular} & \begin{tabular}{|l|}
40,43 \\
\end{tabular} & 531,65 & 69,26 & 21,31 & 33,10 & \begin{tabular}{|l|}
194,55 \\
\end{tabular} & 83,77 & 83,77 & 154,35 \\
\hline Hyla molleri & 30тTM70 & 100,00 & \begin{tabular}{|l|}
123,60 \\
\end{tabular} & 115,39 & 39,00 & 6134,25 & 294,63 & 1,73 & 292,90 & 84,40 & 202,34 & \begin{tabular}{|l|l|}
204,45 \\
\end{tabular} & 47,04 & 363,72 & \begin{tabular}{l|l}
44,02 \\
\end{tabular} & \begin{tabular}{|l|}
10,25 \\
\end{tabular} & 33,86 & \begin{tabular}{|l|}
125,23 \\
\end{tabular} & 50,36 & \begin{tabular}{|l|l|}
51,65 \\
\end{tabular} & 100,75 \\
\hline Hyla molleri & 30TTM72 & 100,00 & 121,22 & 115,76 & 39,00 & 6085,42 & 292,07 & $-0,26$ & 292,33 & 82,42 & 200,30 & 201,51 & \begin{tabular}{l|l}
45,26 \\
\end{tabular} & 396,00 & 48,23 & \begin{tabular}{l|l|}
12,26 \\
\end{tabular} & 33,17 & \begin{tabular}{|l|}
138,25 \\
\end{tabular} & 56,89 & 57,44 & 112,25 \\
\hline Hyla molleri & 30TTM73 & 100,00 & 119,93 & 115,98 & 39,00 & 6054,20 & 290,56 & $-1,70$ & 292,26 & 81,61 & 199,49 & \begin{tabular}{|l|l|}
199,75 \\
\end{tabular} & \begin{tabular}{|l|}
44,16 \\
\end{tabular} & 413,48 & 50,49 & 13,51 & 32,68 & \begin{tabular}{|l|l|}
145,36 \\
\end{tabular} & $\begin{array}{l}60,75 \\
\end{array}$ & $\begin{array}{ll}60,88 \\
\end{array}$ & $\begin{array}{l}118,08 \\
\end{array}$ \\
\hline Hyla molleri & 30тTM76 & 100,00 & 117,59 & 115,99 & 39,30 & 5980,07 & 287,18 & $-3,66$ & 290,84 & 80,61 & 196,48 & \begin{tabular}{|l|l|}
196,48 \\
\end{tabular} & \begin{tabular}{|l|}
42,61 \\
\end{tabular} & 461,07 & 58,07 & $\begin{array}{l}17,05 \\
\end{array}$ & 32,64 & 165,55 & 71,11 & 71,11 & 132,08 \\
\hline Hyla molleri & 30тTM78 & 100,00 & \begin{tabular}{|l|}
115,38 \\
\end{tabular} & 116,00 & 39,77 & 5922,14 & 284,42 & $-5,63$ & 290,05 & 78,96 & \begin{tabular}{|l|}
193,60 \\
\end{tabular} & \begin{tabular}{|l|l|}
193,60 \\
\end{tabular} & $\begin{array}{l}41,05 \\
\end{array}$ & \begin{tabular}{|l|l|}
496,08 \\
\end{tabular} & \begin{tabular}{|l|l|}
63,83 \\
\end{tabular} & \begin{tabular}{|l|}
19,98 \\
\end{tabular} & 32,71 & \begin{tabular}{|l|}
180,31 \\
\end{tabular} & 79,54 & 79,54 & $\begin{array}{l}140,71 \\
\end{array}$ \\
\hline Hyla molleri & 30TTM83 & 100,00 & $\begin{array}{l}121,46 \\
\end{array}$ & 116,04 & 39,00 & 6028,39 & 292,09 & $-0,39$ & 292,48 & 84,00 & \begin{tabular}{|l|l|}
199,86 \\
\end{tabular} & \begin{tabular}{|l|}
200,99 \\
\end{tabular} & \begin{tabular}{|l|l|}
46,17 \\
\end{tabular} & 400,38 & 48,43 & 13,59 & 31,92 & \begin{tabular}{|l|l|}
139,41 \\
\end{tabular} & \begin{tabular}{|l|l|}
60,23 \\
\end{tabular} & \begin{tabular}{ll|}
60,83 \\
\end{tabular} & 111,39 \\
\hline Hyla molleri & 30TTM84 & 100,00 & 119,90 & 116,05 & 39,03 & 6009,51 & 290,27 & $-2,04$ & 292,31 & 82,80 & \begin{tabular}{|l|l|}
198,69 \\
\end{tabular} & \begin{tabular}{|l|l|}
199,16 \\
\end{tabular} & \begin{tabular}{|l|l|}
44,65 \\
\end{tabular} & 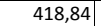 & 51,22 & \begin{tabular}{|l|l|}
14,87 \\
\end{tabular} & 31,77 & \begin{tabular}{|l|l|}
146,78 \\
\end{tabular} & $\mid 64,48$ & \begin{tabular}{|l|l|}
64,70 \\
\end{tabular} & 116,88 \\
\hline Hyla molleri & 30TTM86 & 100,00 & 118,72 & 116,01 & 39,16 & 5951,78 & 288,12 & $-2,99$ & 291,11 & 82,34 & \begin{tabular}{|l|}
197,08 \\
\end{tabular} & \begin{tabular}{|l|}
197,08 \\
\end{tabular} & 43,80 & 448,88 & 56,30 & $\begin{array}{l}17,25 \\
\end{array}$ & 31,89 & \begin{tabular}{|c|}
159,88 \\
\end{tabular} & 71,49 & 71,49 & 125,12 \\
\hline Hyla molleri & 30TTM88 & 100,00 & 116,48 & 116,00 & 39,73 & 5897,23 & 285,04 & $-4,91$ & 289,96 & 80,79 & 194,24 & \begin{tabular}{|l|}
194,24 \\
\end{tabular} & \begin{tabular}{|l|}
42,16 \\
\end{tabular} & 485,22 & \begin{tabular}{ll|}
62,16 \\
\end{tabular} & 20,3 & 31,97 & \begin{tabular}{|l|l|}
175,15 \\
\end{tabular} & 80,31 & 80,31 & 133,90 \\
\hline Hyla molleri & 30тTM89 & 100,00 & 115,22 & 115,85 & 39,87 & 5866,60 & 283,20 & \begin{tabular}{|c|}
$-6,04$ \\
\end{tabular} & 289,24 & $\begin{array}{l}79,92 \\
\end{array}$ & \begin{tabular}{|l|}
192,64 \\
\end{tabular} & \begin{tabular}{|l|l|}
192,64 \\
\end{tabular} & 41,29 & 504,66 & 65,27 & 21,97 & 32,22 & 183,22 & 85,25 & 85,25 & 138,31 \\
\hline Hyla molleri & 30тTM93 & 100,00 & 121,63 & 116,31 & 39,02 & 6017,12 & 292,34 & $-0,49$ & 292,83 & $\begin{array}{l}84,57 \\
\end{array}$ & \begin{tabular}{|l|}
199,03 \\
\end{tabular} & \begin{tabular}{|l|}
201,21 \\
\end{tabular} & \begin{tabular}{|l|l|}
46,42 \\
\end{tabular} & \begin{tabular}{|l|}
398,03 \\
\end{tabular} & 48,02 & $\begin{array}{l}14,06 \\
\end{array}$ & 31,29 & \begin{tabular}{|l|l|}
136,86 \\
13
\end{tabular} & \begin{tabular}{ll|}
60,54 \\
\end{tabular} & \begin{tabular}{ll|}
62,02 \\
\end{tabular} & $\begin{array}{l}108,93 \\
\end{array}$ \\
\hline Hyla molleri & 30TTM96 & 100,00 & 117,91 & 116,07 & 39,13 & 5937,17 & 287,51 & $\mid-4,03$ & 291,53 & 82,30 & \begin{tabular}{|l|l|}
196,05 \\
\end{tabular} & \begin{tabular}{|l|l|}
196,30 \\
\end{tabular} & 43,35 & \begin{tabular}{|l|l|}
448,11 \\
\end{tabular} & 55,80 & \begin{tabular}{|l|l|}
17,87 \\
\end{tabular} & 31,11 & \begin{tabular}{|l|}
157,64 \\
\end{tabular} & 73,34 & 73,50 & \begin{tabular}{l|l|l|}
122,49 \\
\end{tabular} \\
\hline Hyla molleri & 30TTN53 & 58,00 & 93,44 & 109,66 & 39,99 & 5543,63 & 251,73 & $-19,50$ & 271,23 & 60,25 & $166,97 \mid$ & $166,97 \mid$ & 25,44 & 749,48 & 97,07 & 33,26 & 30,23 & 266,40 & 122,49 & 122,49 & 220,42 \\
\hline Hyla molleri & 30TTN54 & 50,00 & 85,92 & $\begin{array}{l}107,32 \\
\end{array}$ & 39,96 & 5432,77 & 240,95 & $-24,42$ & 265,37 & 54,00 & 157,99 & \begin{tabular}{|l|}
157,99 \\
\end{tabular} & \begin{tabular}{l|l|}
19,85 \\
\end{tabular} & 827,83 & 105,94 & 37, & 29,26 & 289,86 & \begin{tabular}{|l|}
136,27 \\
\end{tabular} & 136,33 & 244,65 \\
\hline Hyla molleri & 30TTN60 & 100,00 & 112,30 & 114,63 & 39,92 & 5825,36 & 278,29 & \begin{tabular}{|c|} 
\\
\end{tabular} & 285,67 & 76,30 & 189,01 & \begin{tabular}{|l|}
189,01 \\
\end{tabular} & \begin{tabular}{|l|}
39,02 \\
\end{tabular} & 557,37 & 73,12 & 23,30 & 32,92 & 204,20 & 89,71 & 89,71 & 160,39 \\
\hline Hyla molleri & 30TTN61 & 100,00 & 109,29 & 114,10 & 39,99 & 5768,96 & 273,99 & \begin{tabular}{|c|} 
\\
\end{tabular} & 283,37 & 73,76 & 185,24 & \begin{tabular}{|l|}
185,24 \\
\end{tabular} & 36,90 & 590,31 & 77,69 & \begin{tabular}{|l|}
25,53 \\
\end{tabular} & 32,54 & 215,87 & $\begin{array}{l}96,86 \\
\end{array}$ & $\begin{array}{l}96,86 \\
\end{array}$ & 168,97 \\
\hline Hyla molleri & 30TTN62 & 100,00 & 104,34 & 112,87 & 40,00 & 5683,40 & 266,90 & $-12,56$ & 279,46 & $\begin{array}{l}69,82 \\
\end{array}$ & 179,35 & \begin{tabular}{|l|l|}
179,35 \\
1
\end{tabular} & 33,50 & 640,29 & 84,06 & 28,65 & 31,66 & 232,06 & \begin{tabular}{l|l|}
106,62 \\
\end{tabular} & \begin{tabular}{l|l|}
106,62 \\
\end{tabular} & 182,98 \\
\hline Hyla molleri & 30TTN63 & 100,00 & 97,88 & 110,95 & 40,00 & 5567,66 & 257,41 & $-16,42$ & 273,84 & 64,54 & 171,46 & 171,46 & 28,97 & 704,86 & 91,85 & 32,32 & 30,37 & 252,02 & 118,46 & 118,46 & 202,02 \\
\hline Hyla molleri & 30TTN64 & 100,00 & 88,79 & 108,26 & 40,01 & 5445,67 & 244,62 & $-22,48$ & 267,11 & 56,85 & 160,94 & \begin{tabular}{|l|}
160,94 \\
\end{tabular} & 22,20 & 795,50 & 102,14 & 37,00 & 28,97 & 279,16 & \begin{tabular}{|l|l|}
134,13 \\
\end{tabular} & 134,13 & 230,18 \\
\hline Hyla molleri & 30TTN66 & 100,00 & \begin{tabular}{|l|}
75,87 \\
\end{tabular} & \begin{tabular}{|l|l|}
102,94 \\
\end{tabular} & 40,22 & 5193,28 & 223,88 & $-29,61$ & 253,49 & 46,30 & 144,83 & \begin{tabular}{|l|l}
144,96 \\
\end{tabular} & 13,51 & \begin{tabular}{|l|l|}
955,68 \\
\end{tabular} & 120,26 & 45,30 & 27,28 & \begin{tabular}{|l|l|}
325,99 \\
\end{tabular} & \begin{tabular}{|l|l|}
161,73 \\
\end{tabular} & \begin{tabular}{|l|l|}
162,86 \\
\end{tabular} & 279,55 \\
\hline Hyla molleri & 30TTN70 & 100,00 & 111,83 & 115,86 & 39,87 & 5876,95 & 279,96 & $-8,85$ & 288,81 & 76,08 & 189,31 & \begin{tabular}{|l|}
189,31 \\
\end{tabular} & \begin{tabular}{|l|l|}
37,82 \\
\end{tabular} & 541,07 & $\begin{array}{l}70,76 \\
\end{array}$ & \begin{tabular}{|l|}
23,03 \\
\end{tabular} & 32,95 & \begin{tabular}{l|l|}
198,52 \\
\end{tabular} & \begin{tabular}{|l|l|}
90,65 \\
\end{tabular} & \begin{tabular}{l|l|}
90,65 \\
\end{tabular} & 151,22 \\
\hline Hyla molleri & 30TTN71 & 100,00 & \begin{tabular}{|l|}
108,29 \\
\end{tabular} & 115,51 & 39,98 & 5833,44 & 275,83 & $-11,51$ & 287,33 & 72,84 & 185,29 & \begin{tabular}{|l|}
185,29 \\
\end{tabular} & \begin{tabular}{l|l|}
35,15 \\
\end{tabular} & 574,51 & 75,41 & 23,60 & 32,70 & 210,81 & \begin{tabular}{|l|}
98,28 \\
\end{tabular} & \begin{tabular}{|l|}
98,28 \\
\end{tabular} & 159,69 \\
\hline Hyla molleri & 30TTN72 & 100,00 & 101,50 & 113,74 & 39,99 & 5728,56 & 266,30 & $-16,17$ & 282,47 & \begin{tabular}{|l|l|}
67,27 \\
\end{tabular} & 177,26 & \begin{tabular}{|l|}
177,26 \\
\end{tabular} & \begin{tabular}{|l|}
30,08 \\
\end{tabular} & 637,13 & 83,05 & 28,7 & 31,32 & 230,49 & \begin{tabular}{|l|}
109,92 \\
\end{tabular} & \begin{tabular}{|l|}
109,92 \\
\end{tabular} & $\begin{array}{l}178,09 \\
\end{array}$ \\
\hline Hyla molleri & 30TTN73 & 100,00 & $\begin{array}{l}96,86 \\
\end{array}$ & 111,50 & 40,00 & 5591,34 & 257,71 & $-18,05$ & 275,76 & 63,91 & 170,84 & 170,84 & 27,56 & 694,81 & 90,14 & 32,83 & 29,98 & 247,84 & 120,24 & 120,24 & $\begin{array}{l}195,01 \\
\end{array}$ \\
\hline Hyla molleri & 30TTN74 & 100,00 & 83,51 & 107,91 & 39,82 & 5452,56 & 240,04 & $-27,45$ & 267,49 & 52,10 & 155,92 & \begin{tabular}{|l|l|}
155,92 \\
15
\end{tabular} & \begin{tabular}{|l|l|}
17,04 \\
\end{tabular} & 818,40 & 103,75 & 39,17 & 28,25 & \begin{tabular}{|l|l|}
284,09 \\
\end{tabular} & \begin{tabular}{|l|l|}
140,87 \\
\end{tabular} & \begin{tabular}{|l|}
140,88 \\
\end{tabular} & 234,68 \\
\hline Hyla molleri & 30TTN75 & 100,00 & $\begin{array}{l}78,74 \\
\end{array}$ & 105,74 & 39,91 & 5340,06 & 231,84 & $-29,75$ & 261,59 & 48,48 & \begin{tabular}{|l|}
149,70 \\
\end{tabular} & \begin{tabular}{|l|}
149,71 \\
\end{tabular} & \begin{tabular}{l|l|}
14,15 \\
\end{tabular} & \begin{tabular}{|l|}
879,32 \\
\end{tabular} & 110,85 & \begin{tabular}{|l|}
42,46 \\
\end{tabular} & \begin{tabular}{|l|}
27,29 \\
\end{tabular} & 302,26 & \begin{tabular}{ll|}
151,78 \\
\end{tabular} & \begin{tabular}{|l|}
151,81 \\
\end{tabular} & 252,92 \\
\hline Hyla molleri & 30TTN80 & 100,00 & 113,69 & 115,72 & 39,90 & 5842,43 & 281,21 & \begin{tabular}{|l|}
$-7,17$ \\
\end{tabular} & 288,38 & 78,73 & 190,70 & \begin{tabular}{|l|}
190,70 \\
\end{tabular} & \begin{tabular}{|l|}
39,93 \\
\end{tabular} & 525,78 & 68,56 & 22, & 32,40 & \begin{tabular}{|l|}
191,86 \\
\end{tabular} & $\begin{array}{l}90,45 \\
\end{array}$ & 90,45 & 143,16 \\
\hline Hyla molleri & 30TTN81 & 100,00 & 112,09 & \begin{tabular}{l|l|}
115,44 \\
\end{tabular} & 39,99 & 5801,20 & 278,79 & $-8,02$ & 286,81 & 77,48 & \begin{tabular}{|l|}
188,47 \\
\end{tabular} & \begin{tabular}{|l|}
188,47 \\
\end{tabular} & \begin{tabular}{l|l|}
38,95 \\
\end{tabular} & 549,74 & 72,17 & 22,7 & 32,5 & 201,18 & 96,41 & 96,41 & \begin{tabular}{ll|}
148,43 \\
\end{tabular} \\
\hline Hyla molleri & 30TTN82 & 100,00 & \begin{tabular}{|l|}
108,29 \\
\end{tabular} & 114,24 & 40,00 & 5713,11 & 272,77 & $-10,27$ & 283,04 & $\begin{array}{l}74,53 \\
\end{array}$ & 183,56 & \begin{tabular}{|l|}
183,56 \\
\end{tabular} & \begin{tabular}{l|l|}
36,55 \\
\end{tabular} & 591,44 & 77,61 & 24,31 & 31,73 & 214,95 & \begin{tabular}{|l|}
104,96 \\
\end{tabular} & \begin{tabular}{|l|}
104,96 \\
\end{tabular} & 159,59 \\
\hline Hyla molleri & 30TTN85 & 100,00 & 81,85 & 106,21 & 39,96 & 5333,53 & 235,12 & $-27,29$ & 262,41 & 52,04 & \begin{tabular}{|l|}
152,64 \\
\end{tabular} & \begin{tabular}{l|l|}
152,66 \\
\end{tabular} & \begin{tabular}{|l|l|}
17,04 \\
\end{tabular} & 846,14 & 106,77 & $\begin{array}{l}41,86 \\
\end{array}$ & 27,03 & 290,70 & \begin{tabular}{|l|}
149,41 \\
\end{tabular} & \begin{tabular}{|l|l|}
149,46 \\
\end{tabular} & 238,33 \\
\hline Hyla molleri & 30TTN90 & 100,00 & \begin{tabular}{|l|}
115,60 \\
\end{tabular} & 114,52 & 39,93 & 5754,04 & 280,47 & $-4,69$ & 285,16 & 82,10 & 191,30 & \begin{tabular}{|l|l|}
191,30 \\
\end{tabular} & \begin{tabular}{|l|}
42,93 \\
\end{tabular} & 521,09 & 67,51 & 23,59 & 31,24 & \begin{tabular}{|l|l|}
187,63 \\
\end{tabular} & \begin{tabular}{l|l}
91,22 \\
\end{tabular} & \begin{tabular}{l|l|}
91,22 \\
\end{tabular} & 139,00 \\
\hline Hyla molleri & З0TTN92 & 100,00 & $107,67 \mid$ & 113,09 & 40,00 & 5642,44 & 270,31 & $-10,03$ & 280,35 & 75,30 & 182,14 & 182,14 & 36,94 & 595,94 & 77,47 & 26,22 & 30,55 & 213,70 & 107,31 & 107,31 & 158,62 \\
\hline Hyla molleri & 30TTN93 & 100,00 & \begin{tabular}{|l|l|}
101,07 \\
\end{tabular} & 11,23 & 40,01 & 538,27 & 260,69 & $-14,21$ & 274,90 & 69,69 & 174,09 & \begin{tabular}{|l|l|}
174,09 \\
\end{tabular} & 32,1 & \begin{tabular}{|l|}
658,48 \\
\end{tabular} & 84,97 & 31, & 29, & 233,02 & 119,10 & 119,10 & 176,86 \\
\hline Hyla molleri & 30TTN94 & 100,00 & 93,59 & 108,77 & 40,01 & 5418,02 & 249,74 & $-18,79$ & 268,53 & 63,35 & 165,26 & \begin{tabular}{|l|}
165,26 \\
\end{tabular} & 26,9 & 733,11 & \begin{tabular}{|l|}
93,67 \\
\end{tabular} & 36, & 27,87 & 255,42 & 132,52 & 132,52 & $\begin{array}{l}199,38 \\
\end{array}$ \\
\hline Hyla molleri & 30TTP82 & 60,00 & 138,75 & 71,62 & 40,72 & 3679,04 & 230,37 & 56,65 & 173,71 & 122,63 & 185,16 & \begin{tabular}{|l|}
188,74 \\
\end{tabular} & \begin{tabular}{l|l}
94,25 \\
\end{tabular} & 829,42 & 113,76 & 40,20 & 28,83 & 282,16 & \begin{tabular}{|l|l|}
143,90 \\
\end{tabular} & 157,39 & 211,51 \\
\hline Hyla molleri & 30TUK03 & 100,00 & 156,90 & 114,99 & 37,00 & 6503,86 & 335,39 & \begin{tabular}{|l|}
28,88 \\
\end{tabular} & 306,51 & \begin{tabular}{|l|}
114,68 \\
\end{tabular} & 243,94 & \begin{tabular}{|l|}
243,94 \\
\end{tabular} & 76,89 & 361,34 & 42,13 & 5,25 & 40,71 & \begin{tabular}{|l|l|}
122,40 \\
\end{tabular} & 33,81 & 33,81 & 106,76 \\
\hline Hyla molleri & 30TUK04 & 100,00 & 152,48 & 114,92 & 37,00 & 6473,37 & 330,21 & 25,06 & 305,15 & 110,58 & 239,14 & \begin{tabular}{|l|}
239,14 \\
\end{tabular} & 72,90 & 365,59 & 42,55 & 6,31 & 39,21 & \begin{tabular}{|l|l|}
122,56 \\
1
\end{tabular} & 36,52 & 36,52 & 106,51 \\
\hline Hyla molleri & 30TUK06 & 100,00 & 80,47 & 0,13 & 36,98 & 6240,22 & 258,27 & $-35,89$ & 294,16 & 23,13 & 165,30 & 166,20 & 9,04 & 683,23 & 79,23 & 20,24 & 33,51 & 219,28 & 84,51 & 89,35 & 198,20 \\
\hline Hyla molleri & 30TU & & & & 37, & 6199 & & $-38,70$ & 292,29 & 15, & 161,19 & \begin{tabular}{l|l|}
161,95 \\
\end{tabular} & 5,9 & 693,74 & 80,34 & 21,14 & 32,93 & 222,01 & 87,41 & 93,44 & 200,16 \\
\hline Hyla molleri & 30TUK08 & 100,00 & \begin{tabular}{|l|}
105,93 \\
\end{tabular} & \begin{tabular}{|l|}
113,03 \\
\end{tabular} & 37,83 & 6234,50 & 282,07 & $-14,19$ & 296,26 & 64,14 & 188,86 & \begin{tabular}{|l|}
190,86 \\
\end{tabular} & 32,37 & 495,59 & 60,24 & 14,20 & 33,61 & 157,74 & 64,29 & 66,78 & 136,18 \\
\hline Hyla molleri & 30TUK14 & 100,00 & 151,35 & 114,68 & 37,00 & 6499,67 & 329,40 & 23,35 & 306,06 & 109,40 & 238,49 & 238,49 & \begin{tabular}{|l|l|}
71,49 \\
\end{tabular} & 361,03 & 41,78 & 6,41 & 38,95 & 120,26 & 36,98 & 36,98 & \begin{tabular}{|l|l|}
103,24 \\
\end{tabular} \\
\hline Hyla molleri & 30TUK15 & 100,00 & \begin{tabular}{|l|l|}
107,17 \\
\end{tabular} & 112,56 & 37,00 & 357,38 & 286,19 & $-14,32$ & 300,52 & \begin{tabular}{|l|}
71,97 \\
\end{tabular} & \begin{tabular}{|c|}
192,81 \\
\end{tabular} & \begin{tabular}{|l|}
193,76 \\
\end{tabular} & \begin{tabular}{|l|}
32,42 \\
\end{tabular} & 526,62 & 62,91 & \begin{tabular}{|l|l|}
14,19 \\
\end{tabular} & 34,84 & \begin{tabular}{|l|l|}
168,06 \\
\end{tabular} & \begin{tabular}{|l|l|}
64,68 \\
\end{tabular} & 66,84 & $\begin{array}{l}147,18 \\
\end{array}$ \\
\hline Hyla molleri & 30TUK & 100 & 82, & 1110,78 & 37,00 & 62 & 260,71 & $-34,80$ & 295,51 & 35,77 & 167,32 & \begin{tabular}{|l|l|}
168,13 \\
\end{tabular} & \begin{tabular}{l|l|}
10,85 \\
\end{tabular} & 646,15 & 76,49 & 19,65 & 32,89 & 203,86 & 82,49 & \begin{tabular}{|l|}
87,53 \\
\end{tabular} & 181,66 \\
\hline Hyla molleri & 30TUK17 & 100,00 & \begin{tabular}{|l|l|}
79,97 \\
\end{tabular} & 1110,37 & 37,01 & 6204,22 & 257,10 & $-36,50$ & 293,60 & 31,32 & 164,45 & 165,12 & \begin{tabular}{|l|}
9,03 \\
\end{tabular} & 648,18 & 77,16 & 20,45 & 32,38 & 203,69 & 84,44 & 89,93 & 181,01 \\
\hline Hyla molleri & 30TUK24 & 100,00 & $\begin{array}{l}148,45 \\
\end{array}$ & \begin{tabular}{|l|}
114,23 \\
\end{tabular} & 37,00 & 6501,82 & \begin{tabular}{|l|}
326,70 \\
\end{tabular} & \begin{tabular}{l|l|}
20,22 \\
\end{tabular} & 306,48 & 106,40 & 235,77 & \begin{tabular}{|l|}
235,77 \\
\end{tabular} & \begin{tabular}{ll|}
68,69 \\
\end{tabular} & 362,49 & 42,40 & 6,90 & 38,08 & \begin{tabular}{|l|}
119,71 \\
\end{tabular} & 38,77 & 38,77 & $\begin{array}{l}101,54 \\
\end{array}$ \\
\hline Hyla molleri & 30TUK25 & 100,00 & \begin{tabular}{ll|}
135,47 \\
\end{tabular} & 113,90 & 37,00 & 6441,15 & 313,42 & \begin{tabular}{|l|}
9,08 \\
\end{tabular} & 304,35 & 104,99 & 222,13 & 222,33 & \begin{tabular}{|l|l|}
57,18 \\
\end{tabular} & 389,31 & 47,34 & 8,90 & 36,26 & \begin{tabular}{|l|l|}
126,13 \\
\end{tabular} & 46,22 & 46,31 & $\begin{array}{ll}105,63 \\
\end{array}$ \\
\hline Hyla moll & 30TUK & 100,00 & 80 & 1 & 37,6 & 1761 & $256 \mathrm{C}$ & $-36,62$ & 292,81 & 47,95 & 163,94 & \begin{tabular}{|l|l|}
164,79 \\
\end{tabular} & \begin{tabular}{l|l}
9,42 \\
\end{tabular} & 625,94 & 76, & 21,04 & 31,64 & \begin{tabular}{|l|}
195,47 \\
\end{tabular} & 85,60 & 91,35 & 165 \\
\hline Hyla molleri & 30TUK29 & 100,00 & 97,39 & 111,69 & 37,25 & 6172,59 & 272,32 & $-22,07$ & 294,39 & 77,13 & 179,98 & \begin{tabular}{|l|l|}
181,63 \\
\end{tabular} & 24,99 & 497,97 & 64,06 & \begin{tabular}{|l|l|}
16,68 \\
\end{tabular} & 32,32 & \begin{tabular}{|c|}
155,57 \\
\end{tabular} & \begin{tabular}{|l|}
71,03 \\
\end{tabular} & 74,46 & $\begin{array}{l}127,42 \\
\end{array}$ \\
\hline Hyla molleri & 30TUK33 & 100,00 & 148,26 & 114,36 & 36,68 & 6573,51 & 328,10 & 19,23 & 308,86 & 110,18 & 236,68 & 236,68 & 67,90 & 366,73 & 43,08 & 6,69 & 38,38 & \begin{tabular}{|l|l|}
120,75 \\
\end{tabular} & 38,74 & 38,74 & 102,31 \\
\hline
\end{tabular}




\begin{tabular}{|c|c|c|c|c|c|c|c|c|c|c|c|c|c|c|c|c|c|c|c|c|c|}
\hline$\overline{\text { TAXON }}$ & UTM & km2 & BIO1 & BIO2 & $\begin{array}{l}\mathrm{BIO3} \\
\end{array}$ & 8104 & B105 & B106 & B107 & B108 & B109 & BIO10 & BIO11 & BIO12 & BIO13 & BIO14 & BIO15 & B1016 & B1017 & BIO18 & BIO19 \\
\hline Hyla molleri & 30TUK34 & 100,00 & 146,30 & 113,97 & 36,92 & 6520,96 & 324,74 & 17,80 & 306,94 & 108,63 & 233,89 & 233,89 & 66,48 & 363,94 & 43,27 & 7,34 & 37,36 & 119,40 & 40,36 & 40,36 & 99,86 \\
\hline Hyla molleri & 30TUK35 & 100,00 & 129,37 & 113,05 & 36,90 & 6435,29 & 307,23 & 3,53 & 303,71 & 102,52 & 215,81 & 216,31 & 51,82 & 408,73 & 50,69 & 10,20 & 35,68 & \begin{tabular}{l|l|}
132,82 \\
\end{tabular} & 50,62 & 51,16 & 108,39 \\
\hline Hyla molleri & 30TUK39 & 100,00 & \begin{tabular}{|l|}
104,10 \\
\end{tabular} & $\begin{array}{l}111,62 \\
\end{array}$ & 37,10 & \begin{tabular}{|l|l|l}
6184,29 \\
\end{tabular} & \begin{tabular}{|l|}
278,08 \\
\end{tabular} & $-17,14$ & 295,22 & \begin{tabular}{|l|l|}
97,69 \\
\end{tabular} & \begin{tabular}{|l|l|}
186,34 \\
\end{tabular} & \begin{tabular}{|l|}
188,11 \\
\end{tabular} & 30,71 & \begin{tabular}{|l|}
449,96 \\
\end{tabular} & \begin{tabular}{ll|}
60,10 \\
\end{tabular} & 15,34 & 32,89 & \begin{tabular}{|l|}
142,87 \\
\end{tabular} & \begin{tabular}{|l|l|}
66,47 \\
\end{tabular} & \begin{tabular}{ll|}
69,05 \\
\end{tabular} & 109,53 \\
\hline Hyla molleri & 30TUK45 & 100,00 & 146,31 & 112,88 & 36,51 & 6512,57 & 323,18 & \begin{tabular}{|l|}
17,87 \\
\end{tabular} & 305,31 & \begin{tabular}{|l|}
107,34 \\
\end{tabular} & 233,69 & \begin{tabular}{|l|}
233,69 \\
\end{tabular} & \begin{tabular}{l|l|}
66,26 \\
\end{tabular} & 353,29 & 42,51 & 7,55 & 37,12 & \begin{tabular}{|l|}
115,64 \\
\end{tabular} & 40,71 & 40,71 & 94,95 \\
\hline Hyla molleri & 30TUK49 & 100,00 & 106,49 & 110,67 & 37,00 & 6192,96 & 279,53 & $-15,58$ & 295,10 & 120,31 & 188,72 & 190,49 & 32,85 & 428,51 & 58,98 & 14,66 & 33,71 & 138,90 & 64,95 & 67,18 & 100,21 \\
\hline Hyla molleri & 30TUK55 & 100,00 & 140,85 & 112,00 & 36,01 & 6541,56 & 318,01 & \begin{tabular}{l|l|}
12,68 \\
\end{tabular} & 305,33 & 110,79 & 228,88 & \begin{tabular}{|l|}
228,88 \\
\end{tabular} & \begin{tabular}{l|l|}
60,92 \\
\end{tabular} & 365,31 & 44,80 & $\begin{array}{l}8,45 \\
\end{array}$ & 35,97 & \begin{tabular}{|l|l|}
118,38 \\
\end{tabular} & 44,29 & 44,29 & 96,25 \\
\hline Hyla molleri & 30TUK56 & 100,00 & 118,29 & 111,17 & 36,41 & 6398,64 & 294,72 & $-5,92$ & 300,64 & 92,11 & 204,53 & \begin{tabular}{|l|}
204,95 \\
\end{tabular} & 41,94 & 438,19 & \begin{tabular}{|l|}
55,93 \\
\end{tabular} & 12,85 & 34,18 & \begin{tabular}{|l|l|}
141,45 \\
\end{tabular} & 59,34 & \begin{tabular}{ll|}
60,68 \\
\end{tabular} & 111,31 \\
\hline Hyla molleri & 30TUK57 & 100,00 & 117,59 & 110,53 & 36,51 & 6344,52 & 292,32 & \begin{tabular}{|c|}
$-6,49$ \\
\end{tabular} & 298,81 & 102,44 & 202,68 & \begin{tabular}{|l|}
203,47 \\
\end{tabular} & \begin{tabular}{|l|}
41,46 \\
\end{tabular} & \begin{tabular}{l|l|}
410,25 \\
\end{tabular} & 54,77 & 12,60 & 34,25 & \begin{tabular}{l|l|}
132,62 \\
\end{tabular} & 58,94 & 59,81 & 98,93 \\
\hline Hyla molleri & 30TUK59 & 100,00 & 103,59 & 109,52 & \begin{tabular}{ll|}
36,96 \\
\end{tabular} & \begin{tabular}{|l|l|}
6183,07 \\
\end{tabular} & 275,94 & $-17,90$ & 293,85 & 121,31 & 186,10 & \begin{tabular}{|l|l|}
187,49 \\
\end{tabular} & 30,31 & 432,48 & 60,85 & \begin{tabular}{l|l|}
15,26 \\
\end{tabular} & 34,09 & 142,54 & 67,51 & \begin{tabular}{|l|l|}
69,93 \\
\end{tabular} & 97,73 \\
\hline Hyla molleri & 30TUK64 & 100,00 & \begin{tabular}{|l|}
143,47 \\
\end{tabular} & \begin{tabular}{ll|}
111,86 \\
\end{tabular} & 36,00 & 6613,83 & \begin{tabular}{|l|l|}
321,64 \\
\end{tabular} & 14,24 & 307,40 & \begin{tabular}{|l|}
113,18 \\
\end{tabular} & 232,51 & 232,51 & \begin{tabular}{ll|}
62,66 \\
\end{tabular} & \begin{tabular}{|l|}
368,43 \\
\end{tabular} & \begin{tabular}{|l|l|}
44,41 \\
\end{tabular} & \begin{tabular}{|l|}
8,08 \\
\end{tabular} & 36,43 & \begin{tabular}{|l|l|}
120,08 \\
\end{tabular} & \begin{tabular}{|l|l|}
43,36 \\
\end{tabular} & \begin{tabular}{ll|}
43,36 \\
\end{tabular} & $\begin{array}{l}8,32 \\
\end{array}$ \\
\hline Hyla molleri & 30TUK65 & 100,00 & 132,66 & 111,17 & 36,00 & 6534,47 & 309,78 & \begin{tabular}{|l|}
5,08 \\
\end{tabular} & 304,70 & 113,12 & 220,75 & \begin{tabular}{|l|}
220,75 \\
\end{tabular} & \begin{tabular}{l|l|}
53,25 \\
\end{tabular} & 387,33 & 48,71 & 9,88 & 35,14 & \begin{tabular}{|l|}
125,27 \\
\end{tabular} & 49,91 & 49,91 & 99,34 \\
\hline Hyla molleri & 30TUK66 & 100,00 & \begin{tabular}{|l|}
113,97 \\
\end{tabular} & 110,31 & 36,34 & 6387,97 & 290,11 & $-9,62$ & 299,73 & 93,62 & 200,12 & \begin{tabular}{l|l|}
200,66 \\
\end{tabular} & 38,09 & 443,80 & 57,94 & 13,48 & 33,95 & \begin{tabular}{|l|l|}
143,79 \\
\end{tabular} & \begin{tabular}{|l|l|}
62,19 \\
\end{tabular} & \begin{tabular}{|l|l|}
63,67 \\
\end{tabular} & 109,62 \\
\hline Hyla molleri & 30TUK69 & 100,00 & 100,89 & 108,38 & 36,53 & 6170,98 & 272,44 & $-20,11$ & 292,55 & 118,39 & 183,75 & \begin{tabular}{|l|}
184,77 \\
\end{tabular} & 28,19 & \begin{tabular}{|l|l|}
441,47 \\
\end{tabular} & \begin{tabular}{|l|}
62,70 \\
\end{tabular} & 16,10 & 34,16 & \begin{tabular}{l|l|}
146,82 \\
\end{tabular} & 70,40 & 73,12 & 97,69 \\
\hline Hyla molleri & 30TUK74 & 100,00 & 148,29 & 111,08 & 35,77 & 6661,16 & 326,08 & \begin{tabular}{l|l|}
18,42 \\
\end{tabular} & 307,66 & 106,53 & 237,77 & \begin{tabular}{|l|}
237,77 \\
\end{tabular} & 66,49 & \begin{tabular}{|c|}
360,88 \\
\end{tabular} & 42,33 & 7,73 & 36,76 & 118,60 & 41,34 & 41,34 & 97,94 \\
\hline Hyla molleri & 30TUK75 & 100,00 & 136,04 & 110,17 & $\begin{array}{l}35,75 \\
\end{array}$ & 6585,37 & 312,70 & 8,06 & 304,64 & 107,44 & \begin{tabular}{|l|}
224,68 \\
\end{tabular} & \begin{tabular}{|l|l|}
224,68 \\
\end{tabular} & 55,91 & \begin{tabular}{|l|}
383,44 \\
\end{tabular} & $\begin{array}{l}47,17 \\
\end{array}$ & 9,64 & 35,07 & \begin{tabular}{|l|}
123,98 \\
\end{tabular} & \begin{tabular}{|l|l|}
48,72 \\
\end{tabular} & \begin{tabular}{|l|l|}
48,72 \\
\end{tabular} & 99,62 \\
\hline Hyla molleri & 30TUK76 & 100,00 & 126,44 & 109,29 & 35,91 & 6486,12 & 301,51 & 0,41 & 301,10 & \begin{tabular}{|l|}
104,01 \\
\end{tabular} & 213,75 & \begin{tabular}{|l|l|}
214,03 \\
\end{tabular} & \begin{tabular}{|l|l|}
48,02 \\
\end{tabular} & \begin{tabular}{|c|}
399,10 \\
\end{tabular} & 51,13 & \begin{tabular}{l|l|}
11,25 \\
\end{tabular} & 34,41 & \begin{tabular}{|l|}
128,63 \\
\end{tabular} & \begin{tabular}{|l|l|}
54,68 \\
\end{tabular} & 54,91 & 99,41 \\
\hline Hyla molleri & 30TUK77 & 100,00 & $\begin{array}{l}128,57 \\
\end{array}$ & 108,45 & 35,97 & 6458,48 & 301,79 & 2,79 & 299,00 & 98,53 & 215,16 & \begin{tabular}{|l|}
215,53 \\
\end{tabular} & \begin{tabular}{|l|l|}
50,03 \\
\end{tabular} & \begin{tabular}{|l|}
387,77 \\
\end{tabular} & \begin{tabular}{|l|}
49,53 \\
\end{tabular} & 11,21 & 34,19 & \begin{tabular}{|l|l|}
124,92 \\
\end{tabular} & 53,75 & 54,05 & 96,10 \\
\hline Hyla molleri & 30TUK86 & 100,00 & 133,66 & 108,22 & 35,36 & $\begin{array}{l}6561,83 \\
\end{array}$ & 308,14 & 6,79 & 301,35 & 98,74 & 221,89 & 222,00 & \begin{tabular}{|l|}
53,67 \\
\end{tabular} & 390,65 & 47,58 & 10,50 & 34,35 & \begin{tabular}{|l|}
125,95 \\
\end{tabular} & 51,28 & 51,34 & 101,24 \\
\hline Hyla molleri & 30TUK88 & 100,00 & 120,92 & 106,42 & 35,70 & 6408,92 & 291,84 & $-2,97$ & 294,81 & 109,49 & 205,88 & \begin{tabular}{|l|}
207,34 \\
\end{tabular} & 43,50 & \begin{tabular}{l|l|}
407,06 \\
\end{tabular} & 52,75 & \begin{tabular}{|l|}
12,92 \\
\end{tabular} & 33,55 & \begin{tabular}{|l|}
130,32 \\
\end{tabular} & 59,09 & $\begin{array}{ll}60,40 \\
\end{array}$ & 98,12 \\
\hline Hyla molleri & 30TUK89 & 100,00 & 98,05 & 106,76 & 36,38 & 6211,20 & 268,70 & $-21,19$ & 289,90 & 113,77 & 181,84 & \begin{tabular}{|l|l|}
182,58 \\
\end{tabular} & \begin{tabular}{|l|}
25,62 \\
\end{tabular} & \begin{tabular}{|l|}
478,86 \\
\end{tabular} & 64,70 & 17,80 & 32,27 & 155,90 & 74,58 & \begin{tabular}{l|l|}
78,62 \\
\end{tabular} & 110,54 \\
\hline Hyla molleri & 30TUK98 & 100,00 & 117,08 & 105,55 & 35,46 & 6424,03 & 287,68 & $-5,43$ & 293,11 & \begin{tabular}{|l|}
92,36 \\
\end{tabular} & 202,24 & 203,76 & 39,80 & \begin{tabular}{|l|l|}
433,53 \\
\end{tabular} & 54,70 & 14,08 & 32,57 & 137,60 & 62,24 & 64,39 & $\begin{array}{l}106,93 \\
\end{array}$ \\
\hline Hyla molleri & 30TUK99 & 100,00 & 96,32 & 106,41 & 36,45 & 6227,65 & 266,97 & $-21,79$ & 288,76 & 105,56 & 180,69 & \begin{tabular}{|l|}
181,32 \\
\end{tabular} & \begin{tabular}{l|l|}
24,05 \\
\end{tabular} & 503,34 & \begin{tabular}{ll|}
65,66 \\
\end{tabular} & \begin{tabular}{|l|l|}
18,77 \\
\end{tabular} & 31,15 & $\begin{array}{l}161,06 \\
1\end{array}$ & 76,80 & 81,29 & 120,12 \\
\hline Hyla molleri & 30TUL01 & 100,00 & 116,99 & 115,61 & 38,79 & 6125,72 & 290,26 & $-4,01$ & 294,27 & $\mid 76,75$ & \begin{tabular}{|l|l|}
196,66 \\
\end{tabular} & \begin{tabular}{|l|l|}
199,79 \\
\end{tabular} & \begin{tabular}{|l|l|}
43,19 \\
\end{tabular} & \begin{tabular}{|l|l|}
409,76 \\
\end{tabular} & 50,29 & $\mid$\begin{tabular}{|l|l|}
11,94 \\
\end{tabular} & \begin{tabular}{|l|l|}
32,06 \\
\end{tabular} & \begin{tabular}{|l|}
129,01 \\
\end{tabular} & 57,22 & 59,14 & \begin{tabular}{|l|l|l|}
109,13 \\
\end{tabular} \\
\hline Hyla molleri & 30TUL03 & 100,00 & 118,01 & $\mid 116,63$ & 39,36 & 6071,70 & 290,22 & $-2,33$ & 292,55 & 77,63 & 196,35 & 199,95 & 44,42 & 390,95 & 47,67 & 11,58 & 31,22 & 122,40 & 56,58 & 58,81 & 103,35 \\
\hline Hyla molleri & 30TUL04 & 100,00 & 118,51 & 116,89 & 39,44 & 6066,89 & 290,54 & $-2,02$ & 292,56 & 78,15 & 196,72 & 200,28 & 44,73 & 384,11 & 46,77 & 11, & 31,1 & \begin{tabular}{|l|}
120,88 \\
\end{tabular} & 56,10 & 58,44 & 101,31 \\
\hline Hyla molleri & 30TUL05 & 100,00 & 119,92 & 117,01 & 39,21 & 6073,97 & 292,05 & $-0,88$ & 292,92 & 79,81 & 198,15 & \begin{tabular}{|l|}
201,49 \\
\end{tabular} & 45,87 & 374,10 & 45,45 & 11,11 & 31,60 & 119,13 & 54,34 & 56,68 & 98,92 \\
\hline Hyla molleri & 30TUL09 & 100,00 & 124,48 & 117,00 & 39,01 & 6110,66 & 296,34 & $\begin{array}{ll}1,98 \\
\end{array}$ & 294,37 & 85,50 & 202,91 & 205,33 & 48,39 & \begin{tabular}{l|l|}
362,45 \\
\end{tabular} & 42,43 & \begin{tabular}{|l|l|}
11,87 \\
\end{tabular} & 31,51 & 119,34 & 53,11 & 55,39 & $\begin{array}{l}96,87 \\
\end{array}$ \\
\hline Hyla molleri & 30TUL11 & 100,00 & 112,50 & 114,35 & 38,20 & 6142,97 & 285,96 & $-8,51$ & 294,47 & 77,47 & 193,01 & \begin{tabular}{|l|}
195,76 \\
\end{tabular} & 38,67 & \begin{tabular}{|l|l|}
418,29 \\
\end{tabular} & \begin{tabular}{|l|}
52,93 \\
\end{tabular} & \begin{tabular}{|l|}
12,89 \\
\end{tabular} & 32,10 & 130,44 & \begin{tabular}{|l|l|}
59,94 \\
\end{tabular} & 62,39 & $\begin{array}{ll}107,87 \\
\end{array}$ \\
\hline Hyla molleri & 30TUL13 & 100,00 & \begin{tabular}{|l|}
117,23 \\
\end{tabular} & 115,59 & \begin{tabular}{|l|}
38,98 \\
\end{tabular} & 6106,01 & 289,51 & $-3,42$ & 292,93 & 83,52 & 196,31 & \begin{tabular}{|l|l|}
199,53 \\
\end{tabular} & \begin{tabular}{|l|l|}
43,05 \\
\end{tabular} & 389,36 & \begin{tabular}{|l|}
48,44 \\
\end{tabular} & 12,00 & 31,30 & \begin{tabular}{|l|l|}
121,10 \\
\end{tabular} & 57,11 & \begin{tabular}{|l|l|}
59,78 \\
\end{tabular} & 100,52 \\
\hline Hyla molleri & 30TUL14 & 100,00 & 119,47 & 116,01 & 39,00 & 6096,91 & 291,40 & $-1,53$ & 292,94 & 79,08 & 198,12 & 201,34 & \begin{tabular}{|l|}
44,98 \\
\end{tabular} & 379,21 & 46,62 & 11,81 & 30,89 & \begin{tabular}{|l|}
118,57 \\
\end{tabular} & \begin{tabular}{|l|l|}
56,08 \\
\end{tabular} & 58,75 & 98,30 \\
\hline Hyla molleri & 30TUL18 & 100,00 & 123,31 & 116,90 & 39,00 & 6114,50 & 295,28 & \begin{tabular}{l|l}
1,28 \\
\end{tabular} & 293,99 & 83,96 & \begin{tabular}{|l|}
201,97 \\
\end{tabular} & \begin{tabular}{|l|l|}
204,40 \\
\end{tabular} & \begin{tabular}{|l|}
47,29 \\
\end{tabular} & 368,44 & 43,48 & \begin{tabular}{|l|l|}
11,85 \\
\end{tabular} & 31,01 & \begin{tabular}{|l|l|}
118,60 \\
\end{tabular} & 53,89 & \begin{tabular}{ll|}
56,66 \\
\end{tabular} & 98,44 \\
\hline Hyla molleri & 30TUL24 & 100,00 & 119,42 & \begin{tabular}{l|l|}
114,94 \\
\end{tabular} & 38,87 & 6127,27 & 291,15 & $-1,90$ & 293,05 & 93,05 & \begin{tabular}{|l|}
198,64 \\
\end{tabular} & \begin{tabular}{|l|}
201,77 \\
\end{tabular} & \begin{tabular}{|l|}
44,47 \\
\end{tabular} & \begin{tabular}{|l|}
379,32 \\
\end{tabular} & 47,25 & 12,00 & \begin{tabular}{|l|}
31,03 \\
\end{tabular} & \begin{tabular}{|l|l|}
118,09 \\
\end{tabular} & 56,54 & 59,31 & 97,02 \\
\hline Hyla molleri & 30TUL29 & 100,00 & 124,35 & 116,46 & 39,00 & 6110,26 & 295,87 & \begin{tabular}{l|l|}
1,75 \\
\end{tabular} & 294,12 & 85,78 & 202,97 & 205,22 & 47,91 & \begin{tabular}{|l|l|}
377,03 \\
\end{tabular} & 44,03 & \begin{tabular}{|l|}
12,18 \\
\end{tabular} & 30,50 & \begin{tabular}{|l|}
120,93 \\
\end{tabular} & 54,84 & $\begin{array}{l}58,46 \\
\end{array}$ & \begin{tabular}{|l|l|}
101,84 \\
\end{tabular} \\
\hline Hyla molleri & 30TUL30 & 100,00 & 95,80 & 111,23 & 37,54 & 6133,05 & 269,38 & $-23,46$ & 292,84 & 103,81 & 177,94 & \begin{tabular}{|l|l|}
179,37 \\
\end{tabular} & 23,76 & \begin{tabular}{|l|l|}
485,58 \\
\end{tabular} & 64,25 & \begin{tabular}{|l|}
17,28 \\
\end{tabular} & 32,02 & \begin{tabular}{|l|}
153,65 \\
\end{tabular} & \begin{tabular}{|l|}
72,46 \\
\end{tabular} & \begin{tabular}{|l|}
76,43 \\
\end{tabular} & 119,35 \\
\hline Hyla molleri & 30TUL31 & 100,00 & 1110,07 & 112,10 & \begin{tabular}{|l|}
37,95 \\
\end{tabular} & 6161,63 & 282,53 & $-11,16$ & 293,69 & 129,88 & 191,28 & \begin{tabular}{|l|l|}
193,63 \\
\end{tabular} & \begin{tabular}{|l|l|}
36,37 \\
\end{tabular} & \begin{tabular}{|l|l|}
412,57 \\
\end{tabular} & 54,86 & \begin{tabular}{|l|}
13,98 \\
\end{tabular} & 32,59 & \begin{tabular}{|l|l|}
131,55 \\
\end{tabular} & 62,12 & 64,94 & 99,73 \\
\hline Hyla molleri & 30TUL38 & 100,00 & \begin{tabular}{|l|}
122,01 \\
\end{tabular} & 115,66 & 39,00 & 6139,48 & 293,63 & 0,19 & 293,44 & 82,82 & 201,31 & \begin{tabular}{|l|}
203,60 \\
\end{tabular} & \begin{tabular}{l|l|}
45,82 \\
\end{tabular} & \begin{tabular}{|l|}
386,17 \\
\end{tabular} & 45,38 & 12,31 & 30,30 & \begin{tabular}{|l|l|}
121,43 \\
1
\end{tabular} & 56,31 & \begin{tabular}{ll|}
60,28 \\
\end{tabular} & 103,48 \\
\hline Hyla molleri & 30TUL39 & 100,00 & \begin{tabular}{|l|}
124,29 \\
\end{tabular} & \begin{tabular}{|l|}
115,97 \\
\end{tabular} & 39,00 & 6127,98 & 295,91 & 2,29 & 293,62 & 85,70 & 203,32 & 205,50 & \begin{tabular}{l|l|}
47,89 \\
\end{tabular} & 385,62 & 44,94 & 12,25 & 30,20 & \begin{tabular}{|l|l|}
122,30 \\
\end{tabular} & 55,58 & \begin{tabular}{|l|l|}
59,60 \\
\end{tabular} & 105,06 \\
\hline Hyla molleri & 30TUL50 & 100,00 & 106,06 & 109,31 & 36,96 & 6168,92 & 277,19 & $-15,90$ & 293,08 & 124,70 & 188,09 & \begin{tabular}{|l|}
189,54 \\
\end{tabular} & 32,53 & 414,73 & 58,77 & 15,01 & 34,32 & \begin{tabular}{|l|}
137,72 \\
\end{tabular} & 65,86 & 68,31 & 92,25 \\
\hline Hyla molleri & 30TUL55 & 100,00 & 120,87 & 111,34 & 37,96 & 6203,96 & 290,23 & $-1,04$ & 291,27 & 139,61 & 201,57 & 203,75 & 44,4 & \begin{tabular}{|l|l|}
386,99 \\
\end{tabular} & 48,02 & 12,09 & 31,04 & \begin{tabular}{|l|}
120,80 \\
\end{tabular} & 56,94 & \begin{tabular}{|l|l|}
61,18 \\
\end{tabular} & 97,56 \\
\hline Hyla molleri & 30TUL56 & 100,00 & 122,10 & \begin{tabular}{|l|l|}
112,07 \\
\end{tabular} & 38,00 & 6182,96 & 291,54 & $-0,10$ & 291,64 & 108,31 & 202,33 & \begin{tabular}{|l|l|}
204,53 \\
\end{tabular} & 45,69 & 388,29 & 47,19 & \begin{tabular}{|l|}
12,05 \\
\end{tabular} & 30,90 & \begin{tabular}{|l|l|}
120,47 \\
\end{tabular} & 56,23 & $\begin{array}{ll}61,05 \\
\end{array}$ & 100,49 \\
\hline Hyla molleri & 30TUL57 & 100,00 & \begin{tabular}{|l|}
123,07 \\
\end{tabular} & \begin{tabular}{|l|}
112,78 \\
\end{tabular} & 38,02 & 6181,97 & 293,06 & 0,34 & 292,72 & 84,41 & 203,18 & 205,50 & $\begin{array}{l}46,37 \\
\end{array}$ & 391,90 & 46,43 & \begin{tabular}{|l|}
12,03 \\
\end{tabular} & $\begin{array}{l}30,66 \\
\end{array}$ & \begin{tabular}{|l|l|}
121,94 \\
\end{tabular} & 56,41 & 61,21 & 103,59 \\
\hline Hyla molleri & 30TUL58 & 100,00 & \begin{tabular}{|l|}
123,85 \\
\end{tabular} & \begin{tabular}{|l|}
113,52 \\
\end{tabular} & 38,29 & 6158,24 & 294,08 & $\begin{array}{l}1,67 \\
\end{array}$ & 292,41 & 85,56 & 203,82 & \begin{tabular}{|l|}
205,75 \\
\end{tabular} & 47,39 & \begin{tabular}{|l|l|}
397,03 \\
\end{tabular} & 46,06 & \begin{tabular}{|l|}
12,08 \\
\end{tabular} & 30,10 & \begin{tabular}{l|l|}
123,65 \\
1
\end{tabular} & 56,97 & \begin{tabular}{|l|l|}
61,73 \\
\end{tabular} & 106,99 \\
\hline Hyla molleri & 30TUL59 & 100,00 & 124,59 & 114,18 & 38,41 & 6141,55 & 294,91 & 2,19 & 292,73 & 86,62 & 203,97 & \begin{tabular}{|l|}
205,89 \\
\end{tabular} & 47,84 & \begin{tabular}{|l|}
403,19 \\
\end{tabular} & 46,57 & 12,84 & 29,82 & \begin{tabular}{|l|l|}
125,94 \\
\end{tabular} & 57,73 & $\begin{array}{ll}62,66 \\
\end{array}$ & 110,59 \\
\hline Hyla molleri & 30TUL61 & 100,00 & 109,68 & $\begin{array}{l}7,73 \\
\end{array}$ & 36,43 & 183,77 & 278,66 & $-12,53$ & 291,19 & 128,92 & 191,70 & \begin{tabular}{|l|}
193,16 \\
\end{tabular} & \begin{tabular}{l|l|}
35,45 \\
\end{tabular} & 401,21 & 56,55 & 14,6 & 34, & 133,92 & \begin{tabular}{|l|l|}
64,43 \\
\end{tabular} & 67,35 & 88,12 \\
\hline Hyla molleri & 30TUL66 & 100,00 & 121,00 & 110,45 & 37,55 & 6210,75 & 289,58 & $-0,94$ & 290,52 & 122,36 & 201,98 & \begin{tabular}{|l|}
204,01 \\
\end{tabular} & \begin{tabular}{|l|l|}
44,47 \\
\end{tabular} & 398,79 & 48,28 & 12,53 & 30,18 & 123,56 & 58,21 & 63,56 & 102,40 \\
\hline Hyla molleri & 30TUL67 & 100,00 & 122,54 & 111,32 & 37,93 & 6189,27 & 291,36 & $-0,03$ & 291,39 & 90,32 & 203,01 & \begin{tabular}{|l|}
204,96 \\
\end{tabular} & 45,99 & 399,58 & 47,35 & 12,35 & 30,15 & 123,99 & 57,42 & 63,21 & 104,70 \\
\hline Hyla molleri & 30TUL69 & 100,00 & \begin{tabular}{|l|}
122,60 \\
\end{tabular} & \begin{tabular}{|l|}
112,92 \\
\end{tabular} & 38,06 & 6127,94 & 292,03 & $-0,01$ & \begin{tabular}{|l|}
292,04 \\
\end{tabular} & 85,78 & 202,30 & \begin{tabular}{|l|}
203,99 \\
\end{tabular} & 46,31 & 412,80 & 47,56 & \begin{tabular}{|l|l|}
13,17 \\
\end{tabular} & 29,66 & \begin{tabular}{|l|l|}
128,49 \\
\end{tabular} & $\begin{array}{l}58,56 \\
\end{array}$ & \begin{tabular}{ll|}
65,24 \\
\end{tabular} & 111,82 \\
\hline Hyla molleri & 30TUL70 & 100,00 & $\begin{array}{l}95,84 \\
\end{array}$ & 107,16 & 36,46 & 6136,64 & 265,89 & $-23,49$ & 289,38 & 112,59 & \begin{tabular}{|l|}
178,64 \\
\end{tabular} & \begin{tabular}{|l|l|}
179,37 \\
\end{tabular} & \begin{tabular}{|l|l|}
24,13 \\
\end{tabular} & 465,38 & 65,18 & \begin{tabular}{|l|l|}
17,91 \\
\end{tabular} & 33,21 & \begin{tabular}{|l|}
154,68 \\
\end{tabular} & 75,01 & $\begin{array}{l}79,26 \\
\end{array}$ & $\begin{array}{l}103,41 \\
\end{array}$ \\
\hline Hyla molleri & 30TUL71 & 100,00 & 106,17 & 106,36 & 36,08 & 6191,89 & 274,05 & $-15,29$ & 289,34 & 124,98 & 188,57 & 189,81 & 32,22 & 418,26 & 58,89 & 15,86 & $34, \mathrm{C}$ & 140,14 & 67,73 & 71,37 & 91,20 \\
\hline Hyla molleri & 30TUL78 & 100,00 & & 11 & 37,54 & 6155 & 288 & $-2,19$ & 290, & 96,41 & 200,69 & 202,44 & 44,06 & 417,91 & 48,99 & 13,38 & 29,81 & 129,16 & 59,82 & 67,49 & 109,73 \\
\hline Hyla molleri & 30TUL79 & 100,00 & 116,90 & 111,40 & 37,96 & 6113,09 & 285,53 & $\begin{array}{l}-5,35 \\
\end{array}$ & 290,88 & 86,07 & 196,91 & \begin{tabular}{|l|l|}
198,48 \\
\end{tabular} & 41,60 & 432,60 & 50,56 & 14,06 & 29,12 & 133,23 & 61,81 & 70,69 & 114,12 \\
\hline Hyla molleri & 30TUL80 & 100,00 & 92,66 & 106,66 & 36,56 & 6150,71 & 262,51 & $-25,10$ & 287,61 & 107,84 & 176,05 & \begin{tabular}{|l|l|}
176,55 \\
\end{tabular} & \begin{tabular}{|l|}
21,48 \\
\end{tabular} & 499,76 & 67,25 & 19,42 & 31,58 & \begin{tabular}{|l|l|}
162,96 \\
\end{tabular} & \begin{tabular}{|l|}
78,63 \\
\end{tabular} & 83,80 & 115,60 \\
\hline Hyla molleri & 30TUL81 & 100,00 & 105,88 & 104,96 & 35,99 & \begin{tabular}{|l|l|}
6242,37 \\
\end{tabular} & 272,87 & $-14,65$ & 287,52 & \begin{tabular}{|l|}
124,39 \\
\end{tabular} & 189,19 & \begin{tabular}{|l|l|}
190,15 \\
\end{tabular} & \begin{tabular}{|l|}
31,43 \\
\end{tabular} & \begin{tabular}{|l|}
440,81 \\
\end{tabular} & 59,41 & 16,20 & 32,55 & 144,80 & 69,11 & 73,87 & 100,32 \\
\hline Hyla molleri & 30TUL & 100 & & \begin{tabular}{|l|}
104,40 \\
\end{tabular} & 35,99 & 6303,42 & 279,17 & \begin{tabular}{|c|}
$-7,94$ \\
\end{tabular} & 287,11 & 133,44 & 196,90 & \begin{tabular}{|l|}
198,34 \\
\end{tabular} & 37,24 & \begin{tabular}{|l|l|}
424,25 \\
\end{tabular} & 54,80 & \begin{tabular}{|l|}
14,23 \\
\end{tabular} & 31,99 & \begin{tabular}{ll|}
136,62 \\
\end{tabular} & \begin{tabular}{|l|l}
64,28 \\
\end{tabular} & \begin{tabular}{|l|}
69,23 \\
\end{tabular} & \begin{tabular}{|l|l|}
100,23 \\
\end{tabular} \\
\hline Hyla molleri & 30TUL89 & 100,00 & \begin{tabular}{|l|l|}
115,78 \\
\end{tabular} & 109,77 & 37,20 & 6117,25 & 282,95 & $-6,84$ & 289,78 & 126,76 & 196,10 & \begin{tabular}{|l|}
197,42 \\
\end{tabular} & \begin{tabular}{|l|l|}
40,47 \\
\end{tabular} & 440,64 & 51,64 & 14,72 & 28,99 & 135,42 & 63,55 & 73,62 & 114,46 \\
\hline Hyla molleri & 30TUL90 & 100,00 & 88,55 & $\begin{array}{l}106,60 \\
\end{array}$ & 36,78 & $\begin{array}{l}6147,86 \\
\end{array}$ & 258,66 & \begin{tabular}{|l|}
$-27,33$ \\
\end{tabular} & 285,99 & 96,43 & \begin{tabular}{|l|}
172,41 \\
\end{tabular} & \begin{tabular}{|l|l|}
172,71 \\
\end{tabular} & \begin{tabular}{l|l|}
18,22 \\
\end{tabular} & \begin{tabular}{|l|l|}
541,27 \\
\end{tabular} & 69,75 & 20,88 & 30,08 & \begin{tabular}{ll|}
172,62 \\
\end{tabular} & 83,43 & 88,12 & 130,46 \\
\hline Hyla molleri & 30TUL91 & 100,00 & \begin{tabular}{|l|l|}
103,04 \\
\end{tabular} & 104,20 & 36,11 & 6268,38 & 269,75 & $-15,97$ & 285,72 & 120,93 & 187,10 & \begin{tabular}{|l|}
187,99 \\
\end{tabular} & 28,96 & 474,41 & \begin{tabular}{|l|}
61,07 \\
\end{tabular} & 16,82 & 31,16 & \begin{tabular}{|l|l|}
152,40 \\
\end{tabular} & 72,34 & 78,09 & 112,79 \\
\hline Hyla molleri & 30TUM00 & 100,00 & 121,52 & 117,00 & 39,00 & (299 & 293,6 & \begin{tabular}{|c|}
$-0,48$ \\
\end{tabular} & 294 & 82,95 & 199,86 & 202, & 45, & 376,10 & 44, & 12,70 & 31 & \begin{tabular}{|l|l|}
124,40 \\
\end{tabular} & 55,38 & 58,17 & 10 \\
\hline Hyla molleri & 30TUM01 & 100,00 & 119,56 & 117,00 & 39,00 & 6081,99 & 291,62 & $-2,32$ & 293,94 & 81,27 & 197,82 & 200,03 & \begin{tabular}{|l|}
43,72 \\
\end{tabular} & 390,11 & 46,00 & \begin{tabular}{ll|}
13,86 \\
\end{tabular} & 30,87 & 129,80 & \begin{tabular}{l|l|}
58,25 \\
\end{tabular} & 61,39 & $\begin{array}{ll}105,43 \\
\end{array}$ \\
\hline Hyla molleri & 30TUM06 & 100,00 & 118,18 & 115,99 & 39,44 & 5893,34 & 287,03 & $-3,74$ & 290,76 & 83,73 & 194,35 & \begin{tabular}{l|l|}
196,05 \\
\end{tabular} & 44,21 & 448,20 & 55,47 & \begin{tabular}{|l|l|}
18,38 \\
\end{tabular} & 30,23 & 155,69 & 73,56 & 74,99 & 120,66 \\
\hline
\end{tabular}




\begin{tabular}{|c|c|c|c|c|c|c|c|c|c|c|c|c|c|c|c|c|c|c|c|c|c|}
\hline TAXON & UTM & $\mathrm{km} 2$ & BIO1 & B102 & $\mathrm{BIO3}$ & B104 & B105 & B106 & B107 & B108 & B109 & BIO10 & B1011 & BIO12 & B1013 & B1014 & 81015 & B1016 & BIO17 & B1018 & B1019 \\
\hline Hyla molleri & 30TUM07 & 100,00 & 115,87 & 115,88 & 39,41 & 5863,27 & 284,32 & $-6,15$ & 290,46 & 81,90 & 192,13 & 193,39 & 42,38 & 469,99 & 58,59 & 20,04 & 30,04 & 164,18 & 79,36 & 80,14 & 125,95 \\
\hline Hyla molleri & 30TUM08 & 100,00 & 112,89 & 115,63 & 39,50 & 5831,26 & 280,83 & $-8,69$ & 289,52 & 79,33 & \begin{tabular}{|l|}
189,69 \\
\end{tabular} & 190,05 & 39,80 & 495,76 & 62,20 & 21,96 & 30,09 & 174,06 & 85,81 & 86,02 & 132,63 \\
\hline Hyla molleri & 30TUM11 & 100,00 & 118,37 & 117,00 & 39,00 & 6073,24 & 290,72 & $-3,53$ & 294,26 & 80,71 & 196,67 & 199,01 & 42,72 & 399,96 & 47,04 & 14,32 & 30,24 & 131,10 & 59,76 & 63,84 & 108,02 \\
\hline Hyla molleri & 30TUM15 & 100,00 & 119,22 & 116,09 & 39,10 & 5907,52 & 288,30 & $-3,32$ & 291,62 & \begin{tabular}{|l|}
85,19 \\
\end{tabular} & \begin{tabular}{ll|}
195,62 \\
\end{tabular} & 197,24 & 45,13 & \begin{tabular}{|l|l|}
434,67 \\
\end{tabular} & 52,85 & 17,52 & 29,52 & 147,70 & 69,14 & 72,57 & 116,46 \\
\hline Hyla molleri & 30TUM16 & 100,00 & 118,70 & 115,79 & 39,37 & 5856,60 & 286,73 & $-3,77$ & 290,50 & \begin{tabular}{l|l|}
85,25 \\
\end{tabular} & 194,20 & 196,06 & 45,19 & \begin{tabular}{|l|l|}
449,58 \\
\end{tabular} & 55,12 & 18,70 & 29,39 & 153,91 & 73,29 & 76,26 & 119,81 \\
\hline Hyla molleri & 30TUM17 & 100,00 & 117,29 & 115,08 & 39,24 & 5806,82 & 284,13 & $-4,69$ & 288,82 & 84,79 & 192,30 & 194,02 & 44,52 & 469,07 & 58,02 & 20,24 & 29,21 & \begin{tabular}{|l|l|}
161,68 \\
\end{tabular} & 78,54 & 80,92 & 124,26 \\
\hline Hyla molleri & 30TUM18 & 100,00 & 114,87 & 114,51 & 39,26 & 5750,62 & 280,61 & $-6,58$ & 287,19 & \begin{tabular}{|l|l}
83,02 \\
\end{tabular} & 189,36 & 190,87 & 42,83 & 493,50 & 61,48 & 22,02 & 29,04 & 170,85 & 84,79 & 86,58 & 130,20 \\
\hline Hyla molleri & 30TUM19 & 100,00 & 112,08 & 113,84 & 39,45 & 5711,47 & 276,81 & $-8,39$ & 285,20 & 80,59 & 186,43 & 187,57 & 40,66 & 521,27 & 65,33 & 24,05 & 28,83 & 181,12 & 91,78 & 92,82 & 137,14 \\
\hline Hyla molleri & 30TUM20 & 100,00 & 120,71 & 116,99 & 39,00 & 6089,06 & 292,77 & $-1,37$ & 294,14 & 82,76 & \begin{tabular}{|l|}
199,27 \\
\end{tabular} & 201,29 & 44,73 & 394,51 & 46,10 & 13,34 & 30,16 & 126,82 & 58,12 & 62,25 & 106,86 \\
\hline Hyla molleri & 30TUM22 & 100,00 & 116,34 & 117,00 & 39,00 & 6033,32 & 288,63 & $-5,76$ & 294,39 & 80,11 & \begin{tabular}{ll|}
194,44 \\
\end{tabular} & 196,61 & 41,35 & 421,60 & 49,58 & 15,54 & 29,37 & 136,94 & 63,37 & 68,72 & 114,20 \\
\hline Hyla molleri & 30TUM23 & 100,00 & 120,17 & 116,92 & 39,15 & 5964,66 & 290,75 & $-2,26$ & 293,01 & 85,50 & 197,48 & 199,12 & 45,63 & 417,02 & 49,59 & 15,83 & 29,43 & 137,30 & 63,17 & 68,10 & 112,54 \\
\hline Hyla molleri & 30TUM27 & 100,00 & 117,38 & 114,55 & 39,09 & 5749,96 & 282,96 & $-4,90$ & 287,87 & 86,52 & 191,98 & 193,45 & 45,56 & 473,03 & 57,88 & 20,51 & 28,42 & 160,59 & 78,11 & 82,48 & 124,39 \\
\hline Hyla molleri & 30TUM28 & 100,00 & 116,00 & 113,62 & 39,21 & 5688,18 & 279,92 & $-5,54$ & 285,46 & \begin{tabular}{|l|l|}
85,75 \\
\end{tabular} & 189,75 & 191,17 & 44,94 & 494,83 & 61,05 & 22,19 & 28,15 & 169,00 & 83,81 & 87,49 & 129,43 \\
\hline Hyla molleri & 30TUM29 & 100,00 & 112,78 & 112,65 & 39,19 & 5631,06 & 275,25 & $-7,28$ & 282,52 & 83,09 & 185,99 & 187,28 & 42,63 & 525,30 & 65,14 & 24,28 & 27,92 & 179,86 & 91,29 & 94,23 & 137,08 \\
\hline Hyla molleri & 30TUM33 & 100,00 & 116,86 & 116,91 & 39,00 & 5964,17 & 287,89 & $-6,16$ & 294,05 & \begin{tabular}{l|l|}
82,65 \\
\end{tabular} & 194,20 & \begin{tabular}{|l|l|}
196,15 \\
\end{tabular} & 42,60 & 435,02 & 51,10 & 16,41 & 28,95 & 140,78 & 65,07 & 72,13 & 117,56 \\
\hline Hyla molleri & 30TUM34 & 100,00 & 120,10 & 116,06 & 39,00 & 5897,92 & 289,35 & $-3,58$ & 292,93 & 87,40 & \begin{tabular}{|l|l|}
196,63 \\
\end{tabular} & 198,19 & 46,40 & 432,74 & 51,34 & 17,12 & 28,79 & 141,74 & 65,51 & 72,43 & 115,91 \\
\hline Hyla molleri & 30TUM 35 & 100,00 & 119,29 & 115,69 & 39,01 & 5833,60 & 287,07 & $-4,72$ & 291,80 & 87,83 & 194,83 & 196,56 & 46,54 & 445,27 & 53,14 & 18,44 & 28,56 & 146,99 & 68,80 & 76,01 & 117,87 \\
\hline Hyla molleri & 30TUM40 & 100,00 & 122,15 & 115,78 & 39,00 & 6114,58 & 293,78 & 0,52 & 293,26 & 78,23 & 201,19 & 203,18 & 45,84 & \begin{tabular}{|l|l|}
410,07 \\
\end{tabular} & 47,65 & 13,35 & 29,65 & 129,07 & 58,92 & 63,97 & 113,83 \\
\hline Hyla molleri & 30TUM41 & 100,00 & 116,48 & 116,22 & 39,00 & 6077,18 & 289,07 & $-5,09$ & 294,16 & 77,72 & 195,67 & 197,33 & 41,18 & 432,19 & 50,04 & 14,91 & 29,02 & 135,79 & 62,79 & 69,55 & 119,23 \\
\hline Hyla molleri & 30TUM45 & 100,00 & 119,78 & 115,23 & 39,00 & 5786,69 & 286,76 & $-4,92$ & 291,69 & 90,38 & 195,00 & 196,53 & 47,87 & 447,41 & 52,79 & 18,40 & 28,20 & 145,73 & 67,55 & 77,10 & 117,74 \\
\hline Hyla molleri & 30TUM50 & 100,00 & 124,34 & 114,90 & 38,89 & 6106,90 & 295,01 & 2,06 & 292,94 & 62,07 & 203,37 & 205,14 & 47,94 & 412,16 & 47,90 & 13,03 & 29,88 & 130,10 & 58,24 & 63,54 & 115,23 \\
\hline Hyla molleri & 30TUM51 & 100,00 & 122,95 & 115,51 & 38,98 & 6066,38 & 293,71 & 0,46 & 293,25 & 63,90 & 201,60 & 203,15 & 46,92 & 423,85 & 49,38 & 13,88 & 29,50 & $\begin{array}{l}134,49 \\
\end{array}$ & $\begin{array}{l}59,79 \\
59,79\end{array}$ & 66,21 & 119,16 \\
\hline Hyla molleri & 30TUM55 & 100,00 & 120,99 & 114,95 & 38,98 & 5756,24 & 287,11 & $-5,64$ & 292,75 & 93,99 & 195,90 & 197,43 & 49,67 & 446,02 & 51,90 & 18,06 & 28,31 & 143,43 & 65,46 & 77,75 & \begin{tabular}{|l|l|}
115,77 \\
\end{tabular} \\
\hline Hyla molleri & 30TUM56 & 100,00 & 119,70 & 113,90 & 38,97 & 5683,32 & 283,72 & $-5,96$ & 289,69 & 93,62 & 193,73 & 194,98 & 49,34 & 462,42 & 54,10 & 19,69 & 27,77 & 149,64 & 69,88 & 82,09 & 118,81 \\
\hline Hyla molleri & 30TUM59 & 100,00 & 110,88 & 109,56 & 39,00 & 5495,01 & 268,95 & $-9,26$ & 278,22 & 85,30 & 182,86 & 183,40 & 43,01 & 548,82 & 65,37 & 25,64 & 25,81 & 180,01 & 91,50 & 100,58 & 140,82 \\
\hline Hyla molleri & 30TUM60 & 100,00 & 122,48 & 113,60 & 38,15 & 6089,17 & 292,07 & $-0,49$ & 292,56 & 86,07 & 201,70 & 203,24 & 46,55 & 419,17 & 48,36 & 13,43 & 29,68 & 131,25 & 58,86 & 66,41 & 114,57 \\
\hline Hyla molleri & 30TUM61 & 100,00 & $\begin{array}{l}120,32 \\
120,32\end{array}$ & 114,40 & 年0,151 & $\begin{array}{l}0003,1,22 \\
603,22\end{array}$ & $\mid$ & $\begin{array}{l}-3,49 \\
-3,31\end{array}$ & 293,37 & $\begin{array}{l}80,01 \\
85,23\end{array}$ & 198,96 & 200,41 & $\begin{array}{l}40,33 \\
45,18\end{array}$ & | 431,13 & $\begin{array}{l}49,301 \\
49,61\end{array}$ & $\begin{array}{l}30,454 \\
14,44\end{array}$ & \begin{tabular}{|l|l|}
29,26 \\
20
\end{tabular} & \begin{tabular}{|l|l|l|l|}
134,87 \\
\end{tabular} & $\begin{array}{l}30,00 \\
60,73\end{array}$ & $\begin{array}{l}60,41 \pm \\
69,65\end{array}$ & 117,55 \\
\hline Hyla molleri & 30TUM63 & 100,00 & 119,17 & 115,22 & 38,41 & 5885,32 & 287,68 & $-7,44$ & 295,12 & 89,93 & \begin{tabular}{|l|}
195,93 \\
\end{tabular} & 197,41 & 46,32 & 439,86 & 50,41 & 16,09 & 29,01 & 138,04 & 62,10 & 75,25 & 115,75 \\
\hline Hyla molleri & 30TUM67 & 100,00 & 116,04 & 111,89 & 38,72 & 5599,05 & 277,43 & $-8,96$ & 286,39 & \begin{tabular}{|c|}
91,78 \\
\end{tabular} & 189,24 & 190,09 & 47,21 & 492,99 & 57,07 & 21,84 & 26,85 & 158,02 & 76,02 & 89,84 & 124,90 \\
\hline Hyla molleri & 30TUM68 & 100,00 & 114,51 & 110,01 & 38,80 & 5524,72 & 273,23 & $-8,14$ & 281,38 & 90,16 & 186,78 & 187,56 & 46,52 & 518,49 & 60,62 & 23,53 & 26,12 & 167,51 & 82,83 & 94,81 & 131,75 \\
\hline Hyla molleri & 30TUM70 & 100,00 & 120,65 & 112,09 & 38,00 & 6069,25 & 288,93 & $-2,75$ & 291,68 & 88,68 & 199,90 & 201,46 & 45,47 & 426,42 & 49,18 & 14,18 & 29,31 & 132,47 & 60,36 & 69,57 & 113,54 \\
\hline Hyla molleri & 30TUM76 & 100,00 & 118,33 & 112,23 & 38,03 & 5644,23 & 280,66 & $-9,05$ & 289,70 & 95,17 & 192,05 & 193,00 & 49,30 & 471,03 & 53,46 & 20,07 & 27,54 & 148,38 & 69,53 & 85,92 & 117,91 \\
\hline Hyla molleri & 30TUM80 & 100,00 & 118,00 & 110,56 & 37,59 & 6067,71 & 284,98 & $-5,22$ & 290,20 & 105,01 & 197,54 & 198,71 & 43,04 & 437,78 & 50,68 & 14,66 & 28,99 & 135,09 & 62,41 & 72,84 & 114,67 \\
\hline Hyla molleri & 30TUM88 & 100,00 & 114,21 & 106,84 & 38,00 & 5498.59 & 270,20 & $\mid-6.47$ & 276,67 & \begin{tabular}{|c|c|}
90,12 \\
\end{tabular} & 186,30 & 186,76 & 46.57 & 528.80 & 60,47 & 24,17 & 25,22 & 167,67 & 84.56 & 96.95 & 133.87 \\
\hline Hyla molleri & 30TUNO0 & 100,00 & 113,28 & 113,74 & 39,77 & 5700,10 & 277,23 & $-6,27$ & 283,50 & 81,03 & 188,47 & 188,47 & 41,84 & 531,77 & 67,99 & 24,8 & 30,01 & 188,38 & 94,56 & 94,56 & 140,40 \\
\hline Hyla molleri & 30TUN01 & 100,00 & 111,04 & 112,70 & 39,98 & 5628,60 & 272,93 & $-7,22$ & 280,16 & 79,47 & 185,17 & 185,17 & 40,30 & 563,92 & 72,45 & 26,71 & 29,77 & 199,85 & 101,55 & 101,55 & 148,49 \\
\hline Hyla molleri & 30TUNO2 & 100,00 & 106,83 & 111,48 & 40,00 & 5549,11 & 266,75 & $-9,47$ & 276,22 & 76,01 & 180,08 & 180,08 & 37,55 & 606,52 & 77,94 & 29,18 & 29,16 & 213,89 & 110,31 & 110,31 & 159,96 \\
\hline Hyla molleri & $\begin{array}{l}\text { 30TUN03 } \\
\end{array}$ & 100,00 & 103,34 & 109,88 & 40,00 & 5459,93 & 260,54 & $-11,11$ & 271,66 & 73,21 & 175,34 & 175,34 & 35,38 & 650,41 & 83,54 & 32,09 & 28,48 & 228,09 & 118,83 & 118,83 & 172,09 \\
\hline Hyla molleri & 30TUNO4 & 100,00 & 96,16 & 107,92 & 39,99 & 5364,44 & 250,54 & $-16,02$ & 266,56 & \begin{tabular}{|c|}
66,93 \\
\end{tabular} & 167,02 & 167,02 & 30,00 & 718,23 & 91,48 & 36,42 & 27,36 & 248,75 & 131,44 & 131,44 & 192,26 \\
\hline Hyla molleri & 30TUN05 & 100,00 & 80,94 & 105,08 & 39,84 & 5291,33 & 233,09 & $-27,70$ & 260,79 & 52,43 & 151,28 & 151,33 & 16,81 & 841,23 & 104,65 & 42,91 & 25,69 & 284,91 & 152,84 & 153,09 & 231,68 \\
\hline Hyla molleri & 30TUNO6 & 100,00 & 67,79 & 102,16 & 39,56 & 5215,84 & 217,31 & $-37,60$ & 254,91 & 40,02 & 137,45 & 137,62 & $\mid$\begin{tabular}{|l|l|}
5,61 \\
\end{tabular} & \begin{tabular}{|l|l|}
963,07 \\
963
\end{tabular} & 117,60 & 49,21 & 24,66 & 320,48 & $\mid 173,26$ & $\mid 173,77$ & 271,29 \\
\hline Hyla molleri & 30TUN11 & 100,00 & 109,07 & 111,48 & 39,88 & 5567,29 & 269,32 & $-8,31$ & \begin{tabular}{|l|l|}
277,63 \\
\end{tabular} & 78,70 & 182,48 & \begin{tabular}{|l|l|}
182,55 \\
\end{tabular} & 39,53 & 576,87 & 73,10 & 27,93 & 28,45 & 201,05 & \begin{tabular}{|l|l|}
104,75 \\
\end{tabular} & 104,80 & 151,04 \\
\hline Hyla molleri & 30TUN12 & 100,00 & 105,21 & 110,09 & 39,98 & 5484,01 & 263,13 & $-10,52$ & 273,65 & $\begin{array}{l}75,65 \\
\end{array}$ & $\begin{array}{l}177,55 \\
\end{array}$ & $\begin{array}{l}177,55 \\
\end{array}$ & 36,96 & 619,48 & 78,58 & 30,70 & 27,93 & 215,26 & 113,46 & 113,46 & 162,66 \\
\hline Hyla molleri & 30TUN14 & 100,00 & 91,91 & 106,65 & 39,90 & 5329,67 & 245,37 & $-19,25$ & 264,62 & 63,65 & 162,49 & 162,50 & 26,67 & 743,89 & 93,24 & 37,99 & 26,26 & 253,88 & 136,95 & 137,00 & 199,17 \\
\hline Hyla molleri & 30TUN16 & 100,00 & 78,12 & 102,39 & 39,84 & 5167,15 & 226,15 & $-28,03$ & 254,18 & 51,17 & 146,75 & 147,05 & 15,97 & 888,69 & 109,61 & 45,98 & 24,75 & 297,35 & 162,91 & 163,98 & 243,87 \\
\hline Hyla molleri & \begin{tabular}{|l|}
$30 T U N 17$ \\
\end{tabular} & 100,00 & $\begin{array}{l}70,121 \\
79,01\end{array}$ & 100,01 & $\begin{array}{ll}35,04 \\
39,96\end{array}$ & 5033,41 & $\mid$ & $\begin{array}{l}-24,03 \\
-24,72\end{array}$ & $\begin{array}{l}24,10 \\
247,16\end{array}$ & 53,18 & \begin{tabular}{|l|l|}
145,73 \\
\end{tabular} & $\begin{array}{l}4,05 \\
146,35 \\
\end{array}$ & 18,47 & 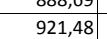 & \begin{tabular}{|l|l|}
114,09 \\
\end{tabular} & $\begin{array}{l}45,30 \\
47,83 \\
\end{array}$ & 24,58 & $\begin{array}{l}307,72 \\
307,72\end{array}$ & \begin{tabular}{|l|l|}
168,94 \\
\end{tabular} & \begin{tabular}{|l|}
171,41 \\
171,41
\end{tabular} & 242,01 \\
\hline Hyla molleri & 30 TUN22 & 100,00 & 103,05 & 108,81 & 39,66 & 5432,62 & 259,46 & $-12,24$ & 271,70 & 74,61 & 174,47 & 174,79 & 35,75 & 634,62 & 79,38 & 31,56 & 26,73 & 217,08 & 116,31 & 116,92 & 166,18 \\
\hline Hyla molleri & 30TUN27 & 100,00 & 75,72 & 99,31 & 39,73 & 5038,60 & 219,20 & $-27,67$ & 246,87 & 50,11 & 142,64 & 143,19 & 15,47 & 937,74 & 114,70 & 48,99 & 23,88 & 310,48 & 172,98 & 174,52 & 257,13 \\
\hline Hyla molleri & 30TUN32 & 100,00 & 103,38 & 107,30 & 39,40 & 5369,91 & 257,61 & $-11,1$ & 268,72 & 76 & 173,92 & 174,31 & 37,19 & 640,16 & 79,22 & $31, \varepsilon$ & 25,89 & 216,41 & 116,32 & 118,36 & 166,88 \\
\hline Hyla molleri & \begin{tabular}{|l|l|}
$30 T U N 33$ \\
\end{tabular} & 100,00 & $\begin{array}{r}99,10 \\
90\end{array}$ & 105,73 & 39,69 & 5295,84 & 250 & \begin{tabular}{|c|c|}
$-13,18$ \\
\end{tabular} & 264,04 & 72 & 168,86 & 169,11 & 33,99 & 687,41 & 85,03 & 34 & 25,42 & 231,73 & 126,50 & 127,49 & 180,19 \\
\hline Hyla molleri & 30 TUN38 & 100,00 & 77,77 & 95,54 & 39,75 & 4880,97 & 215,01 & $-22,60$ & 237,61 & 52,92 & 142,35 & 143,25 & 19,38 & 971,99 & 118,52 & 50,96 & 23,61 & 319,81 & 179,35 & 182,11 & 265,67 \\
\hline Hyla molleri & $\begin{array}{l}\text { 30TUN41 } \\
\end{array}$ & 100,00 & 101,74 & $\begin{array}{r}107,86 \\
\end{array}$ & 39,02 & 5420,32 & 257,66 & $-14,34$ & 271,99 & 75,09 & 173,02 & 173,41 & 35,02 & 627,36 & 76,11 & 30,86 & 25,24 & 208,63 & 111,03 & 116,13 & 163,18 \\
\hline Hyla molleri & 30TUN43 & 100,00 & 93,60 & 104,56 & 39,16 & 5282,69 & 244,86 & $-17,88$ & 262,73 & 67,40 & 163,50 & 163,55 & 29,04 & 719,69 & 87,54 & 36,59 & 24,45 & 238,82 & 131,28 & 133,60 & 189,55 \\
\hline Hyla molle & 30TUN50 & 100,00 & 108,18 & 107,94 & 39,00 & 5427,27 & 264,00 & $-9,95$ & 273,95 & 82,67 & 179,40 & 179,86 & 41,34 & 581, & 69,70 & 27,7 & 25,18 & 191,44 & 99,60 & 107,21 & 149,70 \\
\hline Hyla molleri & 30TUN53 & 100 & 92, & 103,02 & 39,01 & 5238,93 & 242 & $-17,49$ & 260,05 & 67,53 & 162,39 & 162,39 & 29,3 & 730,08 & 87,81 & 37, & 23,85 & 239,81 & 132,59 & 134,37 & 192,08 \\
\hline Hyla molleri & 30TUN55 & 100,00 & 67,09 & \begin{tabular}{|c|c|}
99,61 \\
99
\end{tabular} & 38,96 & 5184,02 & 214,98 & $-37,53$ & 252,51 & 40,85 & 137,07 & 137,07 & 5,56 & 938,72 & 109,96 & 49,34 & 22,30 & 301,20 & 171,41 & 171,43 & 256,99 \\
\hline Hyla molleri & 30TUN61 & 100,00 & 103,72 & 104,85 & 38,99 & 5328,17 & 255,71 & $-11,23$ & 266,94 & 79,01 & 174,02 & 174,09 & 38,44 & 631,21 & 75,10 & 30,81 & 24,13 & 205,94 & 109,97 & 1115,17 & 163,11 \\
\hline Hyla molleri & 30TUN70 & 100,00 & 108,62 & 104,73 & 38,47 & 5357,18 & 260,88 & $-7,79$ & 268,68 & $\begin{array}{l}84,45 \\
\end{array}$ & 179,17 & 179,25 & 42,87 & 593,01 & 69,56 & 28,22 & 24,35 & 191,54 & 100,47 & 108,47 & 152,06 \\
\hline Hyla molle & 30TUN & 100,00 & 103,7 & 103, & 38 & 5300, & 254, & $-10,03$ & 264,13 & 79,26 & 173,72 & 173,73 & 38,92 & 638 & 75 & 31,10 & 23,84 & 206,53 & 110,94 & 114,36 & 165 \\
\hline Hyla molleri & 30TUN74 & 100,00 & $\begin{array}{ll}89,82 \\
89,82\end{array}$ & $\begin{array}{l} \\
98,09 \\
\end{array}$ & 30,98 & 5102,09 & 233,30 & $-16,41$ & 249,71 & 65,46 & 157,94 & 157,94 & $\begin{array}{l}0,32,13 \\
28,13\end{array}$ & $\mid 792,77$ & 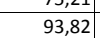 & $\mid 40,51$ & $\begin{array}{l}25,646 \\
22,65\end{array}$ & \begin{tabular}{|l|l}
256,46 \\
\end{tabular} & $\mid \begin{array}{l}\mid \\
144,87\end{array}$ & \begin{tabular}{|l|l|l}
144,87 \\
\end{tabular} & 210,52 \\
\hline
\end{tabular}




\begin{tabular}{|c|c|c|c|c|c|c|c|c|c|c|c|c|c|c|c|c|c|c|c|c|c|}
\hline$\overline{\text { TAXON }}$ & UTM & $\mathrm{km} 2$ & BIO1 & BIO2 & $\begin{array}{l}\mathrm{BIO3} \\
\end{array}$ & BIO4 & B105 & B106 & B107 & B108 & B109 & BIO10 & BIO11 & BIO12 & B1013 & B1014 & BIO15 & B1016 & B1017 & BIO18 & 81019 \\
\hline Hyla molleri & 30TUN83 & 100,00 & 97,92 & 97,97 & 38,61 & 5124,45 & 241,13 & $-9,80$ & 250,94 & 73,74 & 166,08 & 166,08 & 35,36 & 729,99 & 85,87 & 36,48 & 22,68 & 235,61 & 131,57 & 131,59 & 192,01 \\
\hline Hyla molleri & 30TUN84 & 100,00 & 95,87 & 95,97 & 38,78 & 5037,41 & 235,94 & $-9,26$ & 245,21 & 72,10 & 163,01 & 163,01 & 34,63 & $\begin{array}{l}773,53 \\
\end{array}$ & 91,48 & 38,99 & 22,55 & 250,52 & $\begin{array}{l}141,46 \\
1\end{array}$ & \begin{tabular}{|l|l|}
141,46 \\
\end{tabular} & 205,00 \\
\hline Hyla molleri & 30TUN90 & 100,00 & 109,22 & 101,28 & 38,00 & 5337,25 & \begin{tabular}{|l|}
258,43 \\
\end{tabular} & $-4,49$ & 262,92 & 84,31 & \begin{tabular}{|l|}
179,54 \\
\end{tabular} & \begin{tabular}{|l|}
179,57 \\
\end{tabular} & \begin{tabular}{|l|}
43,42 \\
\end{tabular} & \begin{tabular}{|l|l|}
602,44 \\
\end{tabular} & \begin{tabular}{ll|}
69,40 \\
\end{tabular} & \begin{tabular}{|l|}
28,63 \\
\end{tabular} & \begin{tabular}{|l|}
23,47 \\
\end{tabular} & \begin{tabular}{|l|l|}
191,90 \\
\end{tabular} & \begin{tabular}{|l|l|}
102,63 \\
\end{tabular} & \begin{tabular}{|l|}
104,81 \\
\end{tabular} & 155,11 \\
\hline Hyla molleri & 30TUN93 & 100,00 & 101,05 & 95,72 & 38,19 & 5085,48 & 241,52 & $-4,99$ & 246,51 & $\begin{array}{l}76,96 \\
\end{array}$ & $\begin{array}{l}168,68 \\
\end{array}$ & \begin{tabular}{l|l|}
168,68 \\
\end{tabular} & 38,88 & \begin{tabular}{|l|}
728,04 \\
\end{tabular} & 85,35 & 35,99 & 22,53 & \begin{tabular}{|l|l|}
234,67 \\
\end{tabular} & 131,51 & 131,51 & 192,18 \\
\hline Hyla molleri & 30TUN94 & 100,00 & 97,51 & 94,17 & 38,50 & 5005,21 & 235,48 & $-6,21 \mid$ & 241,69 & 73,75 & 164,15 & 164,25 & 36,64 & 776,04 & 91,17 . & 38,84 & 22,19 & 250,43 & 142,05 & 142,05 & 206,47 \\
\hline Hyla molleri & 30TUP01 & 98,00 & 132,84 & 77,05 & 40,95 & \begin{tabular}{|l|l|}
3870,73 \\
\end{tabular} & 232,49 & \begin{tabular}{|l|l|}
46,63 \\
\end{tabular} & 185,86 & \begin{tabular}{|l|l|}
115,81 \\
\end{tabular} & 181,85 & \begin{tabular}{|l|l|}
184,96 \\
\end{tabular} & $\begin{array}{l}85,62 \\
\end{array}$ & 834,29 & $\mid 112,99$ & \begin{tabular}{|l|l|}
41,12 \\
\end{tabular} & 27,93 & 284,33 & \begin{tabular}{|l|l|}
147,81 \\
\end{tabular} & $|160,77|$ & 212,72 \\
\hline Hyla molleri & 30TUP11 & 96,00 & 128,99 & 78,27 & 40,69 & 3961,70 & 231,50 & 41,54 & 189,96 & 111,36 & 179,31 & \begin{tabular}{|l|}
182,19 \\
\end{tabular} & 80,64 & 846,18 & 113,34 & 41,76 & 27,45 & 289,11 & 150,50 & 163,76 & 218,27 \\
\hline Hyla molleri & 30TVK08 & 100,00 & 124,39 & 104,41 & 35,06 & 6501,56 & 294,21 & 1,24 & 292,97 & 83,41 & 209,89 & \begin{tabular}{|l|l|}
211,86 \\
\end{tabular} & 45,44 & 432,64 & 51,12 & 13,14 & 32,69 & 139,51 & 58,66 & $\begin{array}{l}60,32 \\
\end{array}$ & 113,69 \\
\hline Hyla molleri & 30TVK09 & 100,00 & 113,60 & \begin{tabular}{|l|l|l}
104,19 \\
\end{tabular} & 35,39 & \begin{tabular}{l|l|l|}
6407,64 \\
\end{tabular} & 282,44 & $-7,01$ & 289,45 & 85,27 & 198,75 & \begin{tabular}{|l|l|}
200,05 \\
\end{tabular} & 36,88 & 464,05 & 56,18 & \begin{tabular}{l|l|}
15,15 \\
\end{tabular} & 31,66 & \begin{tabular}{|l|l|}
147,87 \\
\end{tabular} & $\begin{array}{l}65,86 \\
\end{array}$ & \begin{tabular}{|l|l|}
69,08 \\
\end{tabular} & 118,12 \\
\hline Hyla molleri & 30TVK18 & 100,00 & 131,85 & 103,41 & 34,97 & 6562,13 & 301,39 & 8,21 & 293,18 & \begin{tabular}{|c|}
90,01 \\
\end{tabular} & 218,54 & \begin{tabular}{|l|}
219,79 \\
\end{tabular} & $\begin{array}{l}51,45 \\
\end{array}$ & 430,06 & 51,12 & \begin{tabular}{|l|l|}
11,99 \\
\end{tabular} & 33,87 & 143,24 & 54,72 & 55,46 & $\begin{array}{l}120,27 \\
\end{array}$ \\
\hline Hyla molleri & 30TVK19 & 100,00 & \begin{tabular}{|l|}
122,10 \\
\end{tabular} & \begin{tabular}{|l|}
103,03 \\
\end{tabular} & 35,01 & 6504,33 & 290,27 & \begin{tabular}{l|l|}
0,24 \\
\end{tabular} & 290,03 & 80,60 & 207,63 & 209,40 & \begin{tabular}{|l|l|}
43,13 \\
\end{tabular} & 452,22 & 52,58 & 13,31 & 32,24 & \begin{tabular}{l|l|}
146,66 \\
\end{tabular} & \begin{tabular}{ll|}
60,58 \\
\end{tabular} & 63,19 & 121,45 \\
\hline Hyla molleri & 30TVK29 & 100,00 & \begin{tabular}{|l|}
123,83 \\
\end{tabular} & 102,72 & 35,00 & 6522,81 & 292,25 & 2,43 & 289,82 & 82,35 & 209,81 & 211,40 & \begin{tabular}{|l|}
44,65 \\
\end{tabular} & 461,17 & 55,11 & \begin{tabular}{|l|}
13,13 \\
\end{tabular} & 33,00 & \begin{tabular}{|l|l|}
152,18 \\
\end{tabular} & 60,21 & \begin{tabular}{|l|l|}
62,15 \\
\end{tabular} & 128,16 \\
\hline Hyla molleri & 30TVL00 & 100,00 & 103,47 & 104,36 & 35,96 & 6315,89 & 271,61 & $-14,89$ & 286,50 & 97,34 & 188,25 & \begin{tabular}{|l|}
189,18 \\
\end{tabular} & 29,18 & 495,14 & 61,23 & 17,16 & \begin{tabular}{ll|}
30,66 \\
\end{tabular} & 156,36 & 73,01 & 77,93 & 122,97 \\
\hline Hyla molleri & 30TVL01 & 100,00 & 80,62 & 106,71 & 37,19 & 6073,35 & 250,45 & $-32,06$ & 282,52 & 83,05 & 164,19 & \begin{tabular}{|l|l|}
164,30 \\
\end{tabular} & \begin{tabular}{l|l|}
12,32 \\
\end{tabular} & 595,66 & 74,22 & 23,49 & 28,36 & \begin{tabular}{|l|l|}
187,09 \\
\end{tabular} & \begin{tabular}{|l|l|}
91,97 \\
\end{tabular} & 95,44 & 147,75 \\
\hline Hyla molleri & 30TVL02 & 100,00 & \begin{tabular}{|l|l|}
104,18 \\
\end{tabular} & 102,76 & 35,80 & 6328,72 & 269,13 & $-14,21$ & 283,34 & \begin{tabular}{|l|}
120,89 \\
\end{tabular} & 188,74 & \begin{tabular}{|l|}
189,91 \\
\end{tabular} & \begin{tabular}{|l|l|}
29,02 \\
\end{tabular} & 496,09 & 60,40 & 16,33 & 30,06 & \begin{tabular}{|l|}
155,61 \\
\end{tabular} & $\begin{array}{l}73,06 \\
\end{array}$ & 80,28 & 123,40 \\
\hline Hyla molleri & 30TVL10 & 100,00 & $\begin{array}{l}112,46 \\
\end{array}$ & 102,96 & 35,38 & $\begin{array}{l}6427,44 \\
\end{array}$ & 279,75 & $-7,11$ & 286,86 & 80,22 & 197,93 & \begin{tabular}{|l|l|}
199,25 \\
\end{tabular} & 35,60 & 478,21 & 56,21 & \begin{tabular}{|l|}
15,01 \\
\end{tabular} & 30,94 & \begin{tabular}{ll|}
150,99 \\
\end{tabular} & 67,21 & \begin{tabular}{|l|}
71,88 \\
\end{tabular} & $\begin{array}{l}123,97 \\
\end{array}$ \\
\hline Hyla molleri & 30TVL12 & 100,00 & 82,73 & $\begin{array}{l}105,64 \\
\end{array}$ & 37,01 & 6128,99 & 251,27 & $-30,42$ & 281,69 & 86,58 & $\begin{array}{l}166,66 \\
\end{array}$ & \begin{tabular}{|l|l|}
167,03 \\
\end{tabular} & \begin{tabular}{|l|}
13,17 \\
\end{tabular} & \begin{tabular}{|l|l|}
603,08 \\
\end{tabular} & 72,94 & 23,32 & 27,85 & \begin{tabular}{|l|}
187,35 \\
\end{tabular} & \begin{tabular}{|l|}
92,53 \\
\end{tabular} & \begin{tabular}{l|l|}
97,16 \\
\end{tabular} & 152,35 \\
\hline Hyla molleri & 30TVL13 & 100,00 & 96,53 & 103,59 & 36,31 & 6254,86 & 262,27 & $-19,81$ & 282,08 & \begin{tabular}{|l|l|}
112,64 \\
\end{tabular} & \begin{tabular}{|l|}
180,82 \\
\end{tabular} & \begin{tabular}{|l|l|}
181,56 \\
\end{tabular} & 23,29 & 537,20 & $|64,27|$ & \begin{tabular}{|l|l|}
18,65 \\
\end{tabular} & 28,74 & \begin{tabular}{|l|l|}
166,76 \\
\end{tabular} & \begin{tabular}{|l|l|}
80,23 \\
\end{tabular} & 87,89 & $\begin{array}{ll}135,82 \\
\end{array}$ \\
\hline Hyla molleri & 30TVL14 & 100,00 & 107,35 & 102,19 & 35,99 & 6359,05 & 271,21 & $-11,09$ & 282,30 & 116,53 & 192,19 & \begin{tabular}{|l|}
193,14 \\
\end{tabular} & 31,24 & 496,32 & $\begin{array}{l}57,82 \\
\end{array}$ & 15,51 & 29,34 & 152,82 & \begin{tabular}{|l|}
71,83 \\
\end{tabular} & \begin{tabular}{l|l|}
80,63 \\
\end{tabular} & $\begin{array}{l}127,33 \\
\end{array}$ \\
\hline Hyla molleri & 30TVL15 & 100,00 & 111,79 & 102,60 & 36,00 & 6345,76 & 275,35 & \begin{tabular}{|l|} 
\\
\end{tabular} & 282,99 & 91,05 & 195,92 & \begin{tabular}{|l|l|}
197,13 \\
\end{tabular} & 35,17 & 478,00 & 55,14 & \begin{tabular}{l|l|}
14,66 \\
\end{tabular} & 29,35 & \begin{tabular}{|l|}
147,29 \\
\end{tabular} & \begin{tabular}{ll|}
68,66 \\
\end{tabular} & \begin{tabular}{|l|}
77,28 \\
\end{tabular} & \begin{tabular}{|l|l|}
123,44 \\
\end{tabular} \\
\hline Hyla molleri & 30TVL17 & 100,00 & 115,73 & $\begin{array}{l}104,16 \\
\end{array}$ & 36,00 & 6265,15 & \begin{tabular}{|l|}
279,67 \\
\end{tabular} & $-4,48$ & 284,15 & \begin{tabular}{|l|l|}
77,97 \\
\end{tabular} & 198,56 & \begin{tabular}{|l|l|}
199,49 \\
\end{tabular} & 39,31 & 457,07 & 52,53 & 14,51 & 28,91 & 140,66 & 66,03 & 74,70 & 118,49 \\
\hline Hyla molleri & 30TVL19 & 100,00 & 115,14 & $\begin{array}{l}105,68 \\
\end{array}$ & 36,66 & 6155,45 & 279,34 & \begin{tabular}{|c|}
$-5,68$ \\
\end{tabular} & 285,02 & 107,13 & 196,25 & \begin{tabular}{|l|l|}
197,19 \\
\end{tabular} & \begin{tabular}{l|l|}
39,82 \\
\end{tabular} & 457,84 & 52,77 & \begin{tabular}{l|l|}
15,62 \\
\end{tabular} & 27,99 & \begin{tabular}{ll|}
140,09 \\
\end{tabular} & \begin{tabular}{|l|l|}
67,60 \\
\end{tabular} & \begin{tabular}{ll|}
77,27 \\
\end{tabular} & 117,99 \\
\hline Hyla molleri & 30TVL20 & 100,00 & 116,65 & 102,55 & 35,13 & 6465,02 & 284,01 & \begin{tabular}{|c|}
$-3,38$ \\
\end{tabular} & 287,39 & \begin{tabular}{|l|l|}
75,82 \\
\end{tabular} & 202,20 & 203,73 & 38,82 & \begin{tabular}{|l|l|}
477,18 \\
\end{tabular} & 55,71 & \begin{tabular}{|l|l|}
14,20 \\
\end{tabular} & 31,40 & \begin{tabular}{|l|}
153,59 \\
\end{tabular} & \begin{tabular}{|c|}
64,93 \\
\end{tabular} & \begin{tabular}{|c|c|}
68,63 \\
\end{tabular} & 128,32 \\
\hline Hyla molleri & 30TVL21 & 100,00 & 84,19 & 106,10 & 36,89 & 6169,99 & 254,29 & $-29,16$ & 283,45 & 61,23 & 168,71 & 169,10 & 14,22 & $607,58 \mid$ & 72,58 & 23,35 & 27,95 & 188,62 & 92,03 & 95,29 & 156,05 \\
\hline Hyla molleri & 30TVL22 & 100,00 & 89,15 & 105,22 & 36,69 & 6195,81 & 257,50 & $-25,31$ & 282,81 & 82,82 & 173,58 & \begin{tabular}{|l|}
173,95 \\
\end{tabular} & \begin{tabular}{|l|l|}
18,03 \\
\end{tabular} & 575,22 & 68,69 & 21, & 27,97 & \begin{tabular}{|l|l|}
177,58 \\
\end{tabular} & 86,99 & 92,20 & $\begin{array}{l}146,47 \\
\end{array}$ \\
\hline Hyla molleri & 30TVL23 & 100,00 & 72,79 & 106,73 & 37,51 & 6045,02 & 242,56 & $-38,25$ & 280,81 & 68,29 & 156,35 & \begin{tabular}{|l|l|}
156,48 \\
\end{tabular} & 5,44 & 658,42 & 78,70 & 27,16 & 26,32 & 202,81 & \begin{tabular}{|l|}
103,42 \\
\end{tabular} & 105,63 & 167,97 \\
\hline Hyla molleri & 30TVL24 & 100,00 & 93,79 & 104,32 & 36,48 & 6221,50 & 260,20 & $-21,89$ & 282,09 & 103,11 & \begin{tabular}{|l|}
177,89 \\
\end{tabular} & \begin{tabular}{|l|}
178,38 \\
\end{tabular} & 21,18 & 554,28 & 65,42 & $\begin{array}{l}19,96 \\
\end{array}$ & 27,84 & \begin{tabular}{|l|}
170,44 \\
\end{tabular} & 83,91 & \begin{tabular}{l|l|}
90,92 \\
\end{tabular} & 141,50 \\
\hline Hyla molleri & 30TVL26 & 100,00 & 112,70 & 103,07 & 36,00 & 6315,11 & 276,66 & $\begin{array}{l}-6,85 \\
\end{array}$ & 283,51 & 74,65 & 196,25 & \begin{tabular}{|l|l|}
197,43 \\
\end{tabular} & \begin{tabular}{l|l|}
36,25 \\
\end{tabular} & 475,34 & 54,32 & \begin{tabular}{l|l|}
15,05 \\
\end{tabular} & 28,77 & \begin{tabular}{|l|}
146,19 \\
\end{tabular} & 69,14 & 77,29 & 123,50 \\
\hline Hyla molleri & 30TVL27 & 100,00 & \begin{tabular}{|l|}
112,87 \\
\end{tabular} & \begin{tabular}{|l|}
103,91 \\
\end{tabular} & 36,01 & 6262,71 & 276,90 & $-6,79$ & 283,69 & 86,03 & \begin{tabular}{|l|}
195,63 \\
\end{tabular} & \begin{tabular}{|l|}
196,50 \\
\end{tabular} & 36,60 & $\begin{array}{l}471,66 \\
\end{array}$ & 54,16 & \begin{tabular}{|l|}
15,43 \\
\end{tabular} & 28,28 & \begin{tabular}{|l|l|}
144,47 \\
\end{tabular} & \begin{tabular}{|l|l|}
69,39 \\
\end{tabular} & 77,94 & 122,11 \\
\hline Hyla molleri & 30TVL30 & 100,00 & 119,57 & 102,73 & 35,07 & 6498,95 & 287,51 & $-0,85$ & 288,36 & 77,69 & 205,32 & 206,90 & 41,19 & 476,05 & 56,83 & 13,65 & 32,14 & 156,14 & 63,41 & 66,05 & \begin{tabular}{|l|l|}
131,37 \\
\end{tabular} \\
\hline Hyla molleri & 30TVL31 & 100,00 & 112,12 & \begin{tabular}{|l|l|}
103,04 \\
\end{tabular} & 35,52 & 6428,78 & 279,39 & $-6,72$ & 286,11 & 73,78 & $\begin{array}{l}197,50 \\
\end{array}$ & \begin{tabular}{|l|l|}
198,75 \\
\end{tabular} & 35,20 & $\begin{array}{l}496,87 \\
\end{array}$ & 58,38 & 15,25 & 30,58 & \begin{tabular}{|l|}
158,92 \\
\end{tabular} & \begin{tabular}{|l|l|}
69,08 \\
\end{tabular} & \begin{tabular}{|l|}
73,27 \\
\end{tabular} & 133,32 \\
\hline Hyla molleri & 30TVL32 & 100,00 & 89,33 & \begin{tabular}{|l|}
105,67 \\
\end{tabular} & 36,72 & 6214,66 & 258,42 & \begin{tabular}{|l|} 
\\
\end{tabular} & 283,86 & 76,32 & $\begin{array}{l}173,92 \\
\end{array}$ & \begin{tabular}{|l|l|}
174,25 \\
\end{tabular} & \begin{tabular}{|l|}
17,79 \\
\end{tabular} & \begin{tabular}{ll|}
578,12 \\
\end{tabular} & 68,50 & \begin{tabular}{|l|l|}
21,47 \\
\end{tabular} & \begin{tabular}{ll|}
27,60 \\
\end{tabular} & \begin{tabular}{ll|}
177,52 \\
\end{tabular} & \begin{tabular}{l|l|}
87,52 \\
\end{tabular} & \begin{tabular}{|l|}
92,90 \\
\end{tabular} & 148,19 \\
\hline Hyla molleri & 30TVL33 & 100,00 & 93,59 & 104,76 & 36,51 & 6246,76 & 261,29 & $-22,01$ & 283,30 & 79,89 & 178,09 & \begin{tabular}{|l|l|}
178,63 \\
\end{tabular} & 20,99 & 562,40 & 65,76 & \begin{tabular}{|l|l|}
20,43 \\
\end{tabular} & 27,73 & \begin{tabular}{|l|}
172,92 \\
\end{tabular} & 84,79 & $\begin{array}{l}90,65 \\
\end{array}$ & \begin{tabular}{|l|l|}
145,03 \\
\end{tabular} \\
\hline Hyla molleri & 30TVL34 & 100,00 & 86,44 & 105,55 & 36,82 & 6168,71 & 254,56 & $-27,94$ & 282,50 & 96,85 & 170,42 & \begin{tabular}{|l|}
170,66 \\
\end{tabular} & \begin{tabular}{l|l|}
15,35 \\
\end{tabular} & 591,88 & \begin{tabular}{ll|}
69,86 \\
\end{tabular} & 22,81 & 26,76 & \begin{tabular}{|l|l|}
181,19 \\
\end{tabular} & \begin{tabular}{|l|}
91,63 \\
\end{tabular} & \begin{tabular}{|l|}
97,38 \\
\end{tabular} & 151,49 \\
\hline Hyla molleri & 30TVL35 & 100,00 & \begin{tabular}{|l|l|l}
104,34 \\
\end{tabular} & \begin{tabular}{|l|}
103,59 \\
\end{tabular} & 36,00 & 6301,34 & 269,84 & $-13,51$ & 283,36 & 89,26 & \begin{tabular}{|l|}
188,49 \\
\end{tabular} & \begin{tabular}{|l|}
189,34 \\
\end{tabular} & \begin{tabular}{|l|}
29,28 \\
\end{tabular} & 510,81 & \begin{tabular}{ll|}
58,92 \\
\end{tabular} & \begin{tabular}{l|l|}
17,23 \\
\end{tabular} & 28,11 & \begin{tabular}{|l|l|}
155,47 \\
\end{tabular} & \begin{tabular}{|l|l|}
75,87 \\
\end{tabular} & 84,21 & $\begin{array}{l}132,27 \\
\end{array}$ \\
\hline Hyla molleri & 30TVL42 & 100,00 & \begin{tabular}{|l|l|}
106,04 \\
\end{tabular} & \begin{tabular}{|l|}
103,99 \\
\end{tabular} & \begin{tabular}{|l|}
36,08 \\
\end{tabular} & 6376,62 & 273,74 & $-11,87$ & 285,61 & 69,50 & 191,23 & \begin{tabular}{|l|}
192,10 \\
\end{tabular} & \begin{tabular}{l|l|}
30,35 \\
\end{tabular} & 516,25 & 60,00 & $\begin{array}{l}16,95 \\
\end{array}$ & 29,25 & \begin{tabular}{l|l|}
161,85 \\
\end{tabular} & 74,57 & \begin{tabular}{|l|l|}
79,67 \\
\end{tabular} & 136,35 \\
\hline Hyla molleri & 30TVL43 & 100,00 & 109,23 & \begin{tabular}{|l|}
103,29 \\
\end{tabular} & 36,00 & 6385,04 & 275,66 & $-9,20$ & 284,86 & 68,98 & 194,21 & \begin{tabular}{|l|}
195,12 \\
\end{tabular} & 32,98 & $\begin{array}{l}499,32 \\
\end{array}$ & 56,90 & \begin{tabular}{|l|}
15,97 \\
\end{tabular} & 29,15 & \begin{tabular}{ll|}
155,92 \\
\end{tabular} & \begin{tabular}{|l|}
72,09 \\
\end{tabular} & \begin{tabular}{|l|}
77,84 \\
\end{tabular} & 131,74 \\
\hline Hyla molleri & 30TVL44 & 100,00 & 95,01 & 105,03 & 36,40 & 6252,22 & 262,72 & $-21,24$ & 283,96 & 86,56 & 179,36 & \begin{tabular}{|l|l|}
179,79 \\
\end{tabular} & \begin{tabular}{|l|}
21,82 \\
\end{tabular} & 555,86 & 64,66 & 20,44 & 27,23 & \begin{tabular}{|l|l|}
170,18 \\
\end{tabular} & 84,87 & \begin{tabular}{|l|}
90,53 \\
\end{tabular} & 143,55 \\
\hline Hyla molleri & 30TVL47 & 100,00 & 110,21 & $\begin{array}{l}104,01 \\
\end{array}$ & 36,01 & 266,56 & 275,21 & $-8,5$ & 283,7 & 80,04 & 193,46 & \begin{tabular}{|l|}
194,19 \\
\end{tabular} & \begin{tabular}{l|l|}
34,55 \\
\end{tabular} & 485,09 & 55,48 & 16,84 & 27,36 & \begin{tabular}{|l|}
147,43 \\
\end{tabular} & 73,57 & 80,99 & 125,80 \\
\hline Hyla molleri & 30TVL52 & 100,00 & 119,14 & \begin{tabular}{|l|}
103,05 \\
\end{tabular} & 35,49 & 6471,71 & 286,06 & $-0,94$ & 286,99 & 77,81 & 204,90 & \begin{tabular}{|l|}
205,77 \\
\end{tabular} & \begin{tabular}{|l|}
40,94 \\
\end{tabular} & 466,92 & 55,77 & \begin{tabular}{|l|l|}
13,73 \\
\end{tabular} & 31,05 & \begin{tabular}{|l|}
151,94 \\
\end{tabular} & \begin{tabular}{|l|}
65,03 \\
\end{tabular} & \begin{tabular}{|l|l|}
67,44 \\
\end{tabular} & 126,10 \\
\hline Hyla molleri & 30TVL53 & 100,00 & 109,88 & \begin{tabular}{|l|}
103,92 \\
\end{tabular} & \begin{tabular}{ll|}
36,06 \\
\end{tabular} & 6394,79 & 277,01 & $-8,73$ & 285,74 & $\begin{array}{l}72,46 \\
\end{array}$ & 195,03 & \begin{tabular}{|l|}
195,80 \\
\end{tabular} & 33,52 & 497,35 & 57,41 & \begin{tabular}{l|l|}
16,26 \\
1
\end{tabular} & 28,98 & \begin{tabular}{l|l|}
155,85 \\
\end{tabular} & \begin{tabular}{|l|}
72,63 \\
\end{tabular} & 77,34 & 131,28 \\
\hline Hyla molleri & 30TVL54 & 100,00 & $\begin{array}{ll}97,28 \\
\end{array}$ & \begin{tabular}{|l|}
105,44 \\
\end{tabular} & 36,44 & 6285,75 & 265,47 & $-19,77$ & 285,24 & 84,53 & \begin{tabular}{|l|l|}
181,84 \\
\end{tabular} & \begin{tabular}{|l|}
182,24 \\
\end{tabular} & 23,39 & 546,22 & \begin{tabular}{|l|l|}
63,27 \\
\end{tabular} & 20,09 & 26,97 & $\begin{array}{ll}166,33 \\
\end{array}$ & 83,72 & 89,91 & 141,45 \\
\hline Hyla molleri & 30TVL55 & 100,00 & 76,54 & 107,27 & 37,39 & 6122,88 & 246,61 & $-37,30$ & 283,90 & 87,02 & 160,33 & \begin{tabular}{|l|}
160,37 \\
\end{tabular} & $\begin{array}{l}6,47 \\
\end{array}$ & 648,73 & 76,29 & 27,79 & 24,67 & \begin{tabular}{|l|}
197,61 \\
\end{tabular} & \begin{tabular}{|l|}
105,10 \\
\end{tabular} & \begin{tabular}{|l|}
107,78 \\
\end{tabular} & 166,35 \\
\hline Hyla molleri & 30TVL57 & 100,00 & 104,72 & 105,03 & 36,17 & 252,04 & 271,03 & $-13,48$ & 284,51 & 114,02 & 188,2 & \begin{tabular}{|l|l|}
188,65 \\
\end{tabular} & 29,89 & 507,95 & 58,64 & 18, & 26, & 152,99 & 79,18 & 86,79 & 131,05 \\
\hline Hyla molleri & 30TVL65 & 100,00 & 82,45 & 107,44 & 37,18 & 6178,77 & 252,63 & \begin{tabular}{|c|} 
\\
\end{tabular} & 285,58 & 94,10 & 166,53 & \begin{tabular}{|l|l|}
166,60 \\
\end{tabular} & 10,9 & 619,44 & 72,69 & 26,20 & 24,73 & \begin{tabular}{|l|}
188,03 \\
\end{tabular} & \begin{tabular}{|l|}
100,53 \\
\end{tabular} & 105,39 & $\begin{array}{l}158,82 \\
\end{array}$ \\
\hline Hyla molleri & 30TVL66 & 100,00 & 76,30 & 107,84 & 37,44 & 6119,81 & 246,56 & $-38,21$ & 284,77 & 90,68 & 159,88 & \begin{tabular}{|l|}
159,89 \\
\end{tabular} & 5,98 & 651,92 & 76,56 & 28,84 & 23,88 & 198,39 & \begin{tabular}{|l|}
107,84 \\
\end{tabular} & 110,04 & 166,99 \\
\hline Hyla molleri & 30TVL67 & 100,00 & 100,57 & $\begin{array}{l}106,06 \\
\end{array}$ & 36,81 & 6237,13 & 268,01 & $-17,44$ & 285,45 & 118,41 & 184,05 & \begin{tabular}{|l|}
184,31 \\
\end{tabular} & \begin{tabular}{|l|}
26,33 \\
\end{tabular} & \begin{tabular}{|l|l|}
527,83 \\
\end{tabular} & \begin{tabular}{|l|}
61,34 \\
\end{tabular} & \begin{tabular}{l|l|}
20,66 \\
\end{tabular} & 25,47 & \begin{tabular}{|l|}
159,01 \\
\end{tabular} & \begin{tabular}{|l|l|}
84,49 \\
\end{tabular} & \begin{tabular}{|l|l|}
91,42 \\
9
\end{tabular} & $\begin{array}{l}135,66 \\
\end{array}$ \\
\hline Hyla molleri & 30TVL72 & 100,00 & \begin{tabular}{|l|l|}
117,74 \\
\end{tabular} & \begin{tabular}{|l|l|l|l|}
104,8 \\
\end{tabular} & 35,80 & 482,68 & 285,14 & $-2,35$ & 287,49 & 76,32 & 203,73 & \begin{tabular}{|l|l|}
204,45 \\
2
\end{tabular} & 39,86 & 460,90 & $\begin{array}{l}53,92 \\
\end{array}$ & \begin{tabular}{|l|l|}
14,48 \\
\end{tabular} & 29,91 & \begin{tabular}{|l|}
147,44 \\
\end{tabular} & $\begin{array}{l}67,16 \\
\end{array}$ & \begin{tabular}{|l|l|}
68,99 \\
\end{tabular} & $\begin{array}{l}120,82 \\
\end{array}$ \\
\hline Hyla molleri & 30TVL77 & 100,00 & 97,54 & 107,18 & \begin{tabular}{|l|l|}
36,97 \\
\end{tabular} & 6228,79 & 266,13 & $-20,66$ & 286,78 & \begin{tabular}{|l|}
115,05 \\
\end{tabular} & \begin{tabular}{|l|l|}
181,13 \\
\end{tabular} & $\mid 181,36$ & 23,63 & 543,17 & 63,46 & 22,25 & 24,68 & \begin{tabular}{|l|l|}
163,89 \\
\end{tabular} & 88,89 & 95,62 & 139,32 \\
\hline Hyla molleri & 30TV & 100 & & & 37, & 6223 & 26 & \begin{tabular}{|l|}
$-24,13$ \\
\end{tabular} & 288,42 & 111 & 178,15 & \begin{tabular}{|l|}
178,29 \\
\end{tabular} & 20,8 & 559,91 & 65,81 & 24,12 & 23,88 & 169,43 & 93,76 & 100,73 & 143,13 \\
\hline Hyla molleri & 30TVL88 & 100,00 & $\begin{array}{l}102,05 \\
\end{array}$ & 107,89 & 37,00 & 6222,84 & 270,60 & \begin{tabular}{|c|}
$-17,08$ \\
\end{tabular} & 287,69 & 120,28 & 185,22 & \begin{tabular}{|l|}
185,51 \\
\end{tabular} & 27,69 & 523,70 & 61,33 & 22,14 & 24,10 & \begin{tabular}{|l|}
157,90 \\
\end{tabular} & 87,73 & 94,40 & 133,97 \\
\hline Hyla molleri & 30TVL96 & 100,00 & 91,51 & 109,60 & 37,08 & 6245,60 & 262,68 & \begin{tabular}{|l|}
$-27,70$ \\
\end{tabular} & 290,38 & 108,68 & 175,71 & \begin{tabular}{|l|l|}
175,85 \\
\end{tabular} & \begin{tabular}{|l|}
17,98 \\
\end{tabular} & 575,53 & 68,11 & 25,49 & 23,55 & 174,62 & \begin{tabular}{|l|}
97,43 \\
\end{tabular} & 103,34 & $\begin{array}{ll}146,49 \\
\end{array}$ \\
\hline Hyla molleri & 30TVL97 & 100,00 & 95,54 & 109,50 & 37,04 & 239,01 & 266,14 & $-24,09$ & 290,22 & 113,26 & 179,30 & \begin{tabular}{|l|l|}
179,44 \\
\end{tabular} & \begin{tabular}{|l|l|}
21,46 \\
\end{tabular} & 556,16 & 65,73 & \begin{tabular}{|l|}
24,58 \\
\end{tabular} & 23, & \begin{tabular}{|l|}
168,52 \\
\end{tabular} & 94,61 & \begin{tabular}{|l|l|}
101,49 \\
\end{tabular} & 14 \\
\hline Hyla molleri & 30TV & 100 & 102,90 & 109,06 & 37,00 & 6234 & 272 & $-17,32$ & 289,59 & 121,48 & 186,19 & \begin{tabular}{|l|l|}
186,44 \\
\end{tabular} & 28 & 52 & 61,49 & 22,74 & 23 & \begin{tabular}{|c|}
157,47 \\
\end{tabular} & \begin{tabular}{|l|}
88,92 \\
\end{tabular} & \begin{tabular}{|l|l|}
95,45 \\
\end{tabular} & 132,97 \\
\hline Hyla molleri & 30TVL99 & 100,00 & 1112,22 & 108,10 & 37,00 & 6224,92 & 279,54 & \begin{tabular}{|l|}
$-8,33$ \\
\end{tabular} & \begin{tabular}{|l|}
287,87 \\
\end{tabular} & \begin{tabular}{|l|}
131,68 \\
\end{tabular} & \begin{tabular}{|l|}
194,76 \\
\end{tabular} & \begin{tabular}{|l|l|}
194,99 \\
\end{tabular} & \begin{tabular}{|l|}
36,66 \\
\end{tabular} & \begin{tabular}{|l|}
480,92 \\
\end{tabular} & 56,55 & 20,60 & 23,92 & \begin{tabular}{|l|l|}
144,70 \\
\end{tabular} & 82,34 & 87,35 & $\begin{array}{l}122,43 \\
\end{array}$ \\
\hline Hyla molleri & 30TVM01 & 100,00 & \begin{tabular}{|l|}
115,13 \\
\end{tabular} & $\begin{array}{l}107,86 \\
\end{array}$ & 37,00 & 6026,62 & 279,86 & $-6,93$ & 286,79 & 120,48 & 194,45 & \begin{tabular}{|l|}
195,32 \\
\end{tabular} & \begin{tabular}{|l|}
41,08 \\
\end{tabular} & 457,26 & 52,80 & $\begin{array}{l}16,45 \\
\end{array}$ & \begin{tabular}{|l|}
27,97 \\
\end{tabular} & \begin{tabular}{|l|}
139,88 \\
\end{tabular} & $\begin{array}{l}67,56 \\
\end{array}$ & $\begin{array}{l}78,95 \\
\end{array}$ & \begin{tabular}{|l|l|}
117,33 \\
\end{tabular} \\
\hline Hyla molleri & 30TVM09 & 100,00 & $\begin{array}{ll}111,43 \\
\end{array}$ & $\begin{array}{l}101,12 \\
\end{array}$ & $\begin{array}{l}37,86 \\
\end{array}$ & 5430,86 & 262,16 & $-2,76$ & 264,92 & 85,14 & 182,99 & \begin{tabular}{|l|}
183,01 \\
\end{tabular} & \begin{tabular}{|l|l|}
44,32 \\
\end{tabular} & 572,90 & 64,84 & 26,95 & 23,45 & \begin{tabular}{|c|}
180,18 \\
\end{tabular} & \begin{tabular}{|l|l}
96,46 \\
\end{tabular} & 100,11 & 147,05 \\
\hline Hyla molleri & 30TVM & 100,00 & 10 & 106, & \begin{tabular}{|l|}
37,00 \\
\end{tabular} & 863,5 & 271, & $-10,27$ & 281,90 & 118, & $|186,67|$ & $\mid 187,15$ & 37,31 & 497, & 56,39 & 20,64 & 25,5 & \begin{tabular}{|l|}
150,18 \\
\end{tabular} & \begin{tabular}{|l|l|}
78,12 \\
\end{tabular} & \begin{tabular}{|l|l|}
90,05 \\
\end{tabular} & \\
\hline Hyla molleri & 30TVM15 & 100,00 & 111,19 & $\begin{array}{l}105,43 \\
\end{array}$ & 37,01 & 5789,24 & 271,59 & \begin{tabular}{|c|}
$-7,88$ \\
\end{tabular} & 279,47 & 82,72 & 187,42 & \begin{tabular}{|l|}
187,72 \\
\end{tabular} & \begin{tabular}{|l|}
39,77 \\
\end{tabular} & 500,25 & 55,85 & 21,35 & 25,09 & \begin{tabular}{|l|l|}
151,78 \\
\end{tabular} & 79,31 & 90,31 & 126,99 \\
\hline Hyla molleri & 30TVM16 & 100,00 & 111,97 & 104,21 & 37,01 & 5715,59 & 270,18 & $-6,01$ & 276,18 & 82,35 & 186,99 & \begin{tabular}{|l|l|}
187,33 \\
\end{tabular} & 41,24 & 511,24 & 56,15 & 22,66 & 24,54 & \begin{tabular}{|l|l|}
155,95 \\
\end{tabular} & 82,46 & 92,47 & \begin{tabular}{|l|l|}
129,83 \\
\end{tabular} \\
\hline
\end{tabular}




\begin{tabular}{|c|c|c|c|c|c|c|c|c|c|c|c|c|c|c|c|c|c|c|c|c|c|}
\hline TAXON & UTM & $\mathrm{km} 2$ & BIO1 & B102 & $\mathrm{BIO3}$ & B104 & B105 & B106 & B107 & B108 & B109 & BIO10 & B1011 & BIO12 & B1013 & B1014 & 81015 & B1016 & BIO17 & B1018 & B1019 \\
\hline Hyla molleri & 30TVM17 & 100,00 & 110,73 & 103,01 & 37,13 & 5638,93 & 266,86 & $-5,55$ & 272,42 & 81,73 & 184,87 & 185,04 & 40,97 & 532,14 & 58,37 & 24,53 & 23,95 & 163,16 & 87,60 & 94,81 & 135,47 \\
\hline Hyla molleri & 30TVM19 & 100,00 & 106,62 & 100,06 & 37,50 & 5472,88 & 257,88 & $-5,60$ & 263,48 & 78,68 & 178,90 & 178,90 & 39,00 & 591,22 & 65,97 & 28,41 & 22,67 & 183,39 & 101,23 & \begin{tabular}{|l|}
103,29 \\
\end{tabular} & 152,37 \\
\hline Hyla molleri & 30TVM23 & 100,00 & 109,67 & 105,44 & 37,00 & 5941,56 & 272,32 & $-9,19$ & 281,50 & 125,40 & \begin{tabular}{|l|l|}
188,09 \\
\end{tabular} & $\begin{array}{l}188,45 \\
\end{array}$ & 36,70 & 491,21 & 56,07 & 20,01 & 25,35 & 148,21 & 77,60 & 87,96 & 125,23 \\
\hline Hyla molleri & 30TVM24 & 100,00 & 109,50 & 104,90 & 37,00 & 5880,93 & 271,14 & $-8,71$ & 279,85 & 106,82 & 187,10 & \begin{tabular}{|l|l|}
187,48 \\
\end{tabular} & 37,17 & 498,61 & 56,35 & 20,91 & 25,01 & 149,86 & 79,75 & 89,26 & 126,97 \\
\hline Hyla molleri & 30 TVM25 & 100,00 & 111,49 & 103,89 & 37,00 & 5813,87 & 271,12 & $-5,72$ & 276,84 & 79,86 & \begin{tabular}{|l|l|}
187,97 \\
\end{tabular} & 188,22 & 39,69 & 501,24 & 55,78 & 21,67 & 24,59 & 151,04 & 81,29 & 90,25 & 127,60 \\
\hline Hyla molleri & 30TVM26 & 100,00 & 111,23 & 102,81 & 37,00 & 5753,47 & 269,03 & $-4,78$ & 273,81 & 79,89 & 186,86 & 186,97 & 39,92 & 514,61 & 56,32 & 23,10 & 23,89 & 155,56 & \begin{tabular}{l|l}
84,85 \\
\end{tabular} & 92,01 & 131,14 \\
\hline Hyla molleri & 30TVM27 & 100,00 & 109,36 & 101,58 & 37,00 & 5678,57 & 265,35 & $-5,01$ & 270,37 & 78,58 & 183,95 & 184,03 & 38,87 & 536,70 & 58,13 & 25,04 & 23,22 & 162,80 & 90,19 & 95,39 & 137,09 \\
\hline Hyla molleri & 30TVM28 & 100,00 & 106,77 & 100,34 & 37,02 & 5602,76 & 260,64 & $-5,78$ & 266,42 & 76,42 & 180,51 & 180,51 & 37,33 & 565,93 & 61,75 & 27,25 & 22,64 & 172,47 & 96,81 & 98,44 & 145,12 \\
\hline Hyla molleri & 30TVM32 & 100,00 & 112,25 & 104,83 & 36,97 & $\begin{array}{ll}6015,64 \\
\end{array}$ & 274,71 & $-6,50$ & 281,21 & 123,59 & \begin{tabular}{|l|l|}
191,55 \\
\end{tabular} & 191,91 & 38,29 & 479,94 & 54,83 & 19,08 & 25,51 & 144,56 & 76,05 & 84,79 & 123,00 \\
\hline Hyla molleri & 30TVM34 & 100,00 & 106,97 & 104,04 & 37,00 & 5908,60 & 268,39 & $-9,57$ & 277,97 & 121,96 & \begin{tabular}{|l|}
185,07 \\
\end{tabular} & \begin{tabular}{ll|}
185,15 \\
\end{tabular} & 34,46 & 511,04 & 57,86 & 22,09 & 24,09 & 152,90 & 83,91 & 91,86 & 130,41 \\
\hline Hyla molleri & 30TVM35 & 100,00 & 109,45 & 103,08 & 37,00 & 5851,53 & 269,04 & $-6,22$ & 275,25 & 91,42 & 186,56 & 186,61 & 37,19 & 509,54 & 56,90 & 22,61 & 23,77 & 151,84 & 84,68 & 91,23 & 130,31 \\
\hline Hyla molleri & 30TVM36 & 100,00 & 107,53 & 102,06 & 37,00 & 5790,03 & 265,81 & $-6,63$ & 272,44 & 79,54 & \begin{tabular}{|l|l|}
183,78 \\
\end{tabular} & 183,81 & 35,90 & 526,94 & 58,12 & 24,18 & 23,20 & 157,04 & 88,99 & 92,82 & 134,78 \\
\hline \begin{tabular}{|l} 
Hyla molleri \\
\end{tabular} & 30TVM38 & 100,00 & 106,07 & 99,22 & 37,00 & 5654,97 & 260,06 & $-4,72$ & 264,78 & 73,92 & $\begin{array}{l}180,35 \\
\end{array}$ & \begin{tabular}{|l|l|}
180,35 \\
\end{tabular} & 35,83 & 565,09 & 60,68 & 27,50 & 22,06 & 170,20 & 98,48 & 99,15 & 145,37 \\
\hline Hyla molleri & 30TVM39 & 100,00 & 102,91 & 97,88 & 37,01 & 5555,62 & 254,18 & $-5,56$ & 259,75 & 71,68 & 176,22 & 176,22 & 34,31 & 602,44 & 65,96 & 29,75 & 21,75 & 183,21 & 106,31 & 106,31 & 156,24 \\
\hline Hyla molleri & 30TVM40 & 100,00 & 113,46 & 104,42 & 36,52 & 6135,33 & 276,98 & $-5,46$ & 282,45 & 122,49 & $\begin{array}{l}194,55 \\
\end{array}$ & 195,09 & 38,56 & 472,12 & 54,16 & 17,76 & 26,23 & 142,26 & 74,12 & 81,77 & 121,43 \\
\hline Hyla molleri & 30TVM41 & 100,00 & 115,39 & 104,04 & 36,71 & 6081,07 & 277,89 & $-3,05$ & 280,94 & 108,31 & \begin{tabular}{|l|l|}
195,63 \\
\end{tabular} & 195,91 & 40,63 & $\begin{array}{l}467,45 \\
\end{array}$ & 53,33 & 18,07 & 25,81 & 140,75 & 74,19 & 81,43 & 120,23 \\
\hline Hyla molleri & $\begin{array}{l}\text { 30TVM42 } \\
\end{array}$ & 100,00 & 111,55 & 104,21 & 36,99 & 6041,66 & 274,06 & $-6,11$ & 280,17 & 129,77 & 191,33 & 191,65 & 37,41 & 484,68 & 55,41 & 19,70 & 24,98 & 145,36 & 78,42 & 84,94 & 124,35 \\
\hline Hyla molleri & 30TVM43 & 100,00 & 107,22 & 104,07 & 37,00 & 5987,94 & 269,58 & $-9,39$ & 278,97 & 125,28 & 186,45 & 186,49 & 33,98 & 506,27 & 57,85 & 21,60 & 24,22 & 151,88 & 83,48 & 90,24 & 129,68 \\
\hline Hyla molleri & 30TVM44 & 100,00 & 105,16 & 103,69 & 37,00 & 5929,56 & 266,49 & $-10,45$ & 276,94 & 122,79 & 183,57 & 183,60 & 32,48 & 520,90 & 59,21 & 23,12 & 23,55 & 155,71 & 87,36 & 93,38 & 133,58 \\
\hline Hyla molleri & 30TVM45 & 100,00 & 106,31 & 102,81 & 37,00 & 5873,44 & 266,03 & $-8,04$ & 274,06 & 121,05 & 183,90 & 183,92 & 34,19 & 523,97 & 58,84 & 23,95 & 23,05 & 155,33 & 89,15 & 92,81 & 134,59 \\
\hline Hyla molleri & 30TVM46 & 100,00 & 102,56 & 102,01 & 37,00 & 5811,44 & 261,32 & $-10,13$ & 271,45 & 111,71 & 179,48 & 179,48 & 31,14 & 548,59 & 61,10 & 26,01 & 22,41 & 161,84 & 94,85 & 95,70 & 141,36 \\
\hline Hyla molleri & 30TVM49 & 100,00 & 102,13 & $\begin{aligned} & \\
& 97,24 \\
& 97,24\end{aligned}$ & 37,12 & 5571,20 & 252,62 & $-4,45$ & 257,07 & | & $\begin{array}{l}175,98 \\
\end{array}$ & 175,98 & 33,61 & 602,61 & 65,54 & 29,99 & 21,43 & $\begin{array}{l}181,30 \\
181,3\end{array}$ & \begin{tabular}{|l|l|}
108,10 \\
\end{tabular} & \begin{tabular}{|c|}
108,10 \\
\end{tabular} & 158,06 \\
\hline Hyla molleri & 30TVM55 & 100,00 & 101,93 & 103,01 & 37,03 & 5877,10 & 262,16 & $-11,48$ & 273,65 & 118,18 & 179,87 & 179,87 & 30,22 & 547,68 & 61,75 & 25,84 & 22,42 & 162,52 & $\begin{array}{l}95,08 \\
\end{array}$ & 96,40 & 141,54 \\
\hline Hyla molleri & 30TVM56 & 100,00 & 97,36 & 102,37 & 37,11 & 5809,75 & 256,47 & $-14,40$ & 270,87 & 113,70 & 174,64 & 174,64 & 26,77 & 579,32 & 64,67 & 28,43 & 21,82 & 170,90 & 102,09 & 102,18 & 150,45 \\
\hline Hyla molleri & 30TVM58 & 100,00 & 98,86 & 99,24 & 37,44 & 5667,41 & 252,48 & $-9,10$ & 261,58 & 69,68 & 174,25 & 174,25 & 29,75 & 600,95 & 65,14 & 30,32 & 21,19 & 176,48 & 108,41 & 108,41 & 158,28 \\
\hline Hyla molleri & \begin{tabular}{|l|}
$30 T V M 59$ \\
\end{tabular} & 100,00 & 99,00 & 97,41 & 37,52 & 5574,17 & 249,40 & $-6,82$ & 256,22 & 66,52 & 173,22 & 173,22 & 31,22 & 624,74 & 66,83 & 31,49 & 21,03 & 185,39 & 113,75 & 113,75 & 166,05 \\
\hline Hyla molleri & \begin{tabular}{|l|l|} 
30TVM63 \\
\end{tabular} & 100,00 & $\begin{array}{ll}501,94 \\
101\end{array}$ & $\begin{array}{l}5,41 \\
105,06\end{array}$ & 37,04 & 5997,43 & $\begin{array}{l}\mid 24,40 \\
265,26\end{array}$ & $\begin{array}{l}-0,02 \\
-13,73\end{array}$ & 278,249 & \begin{tabular}{|l|}
119,57 \\
19,5
\end{tabular} & 181,64 & $\begin{array}{l}181,26 \\
181,66\end{array}$ & $\begin{array}{l}31,26 \\
29,21\end{array}$ & $\mid 537,35$ & $\begin{array}{l}60,030 \\
61,60\end{array}$ & $\begin{array}{l}24,498 \\
24,48\end{array}$ & $\begin{array}{l}21,303 \\
22,84\end{array}$ & \begin{tabular}{|l|l|}
161,06 \\
161,06
\end{tabular} & \begin{tabular}{|l|}
92,35 \\
92,35
\end{tabular} & \begin{tabular}{|l|}
96,47 \\
96,
\end{tabular} & $\begin{array}{l}10,05,56 \\
138,56\end{array}$ \\
\hline Hyla molleri & 30TVM64 & 100,00 & 95,36 & 104,86 & 37,20 & 5925,16 & 258,21 & $-18,69$ & 276,90 & 111,96 & 174,48 & $\begin{array}{ll}174,49 \\
\end{array}$ & 24,00 & 577,95 & 65,75 & 27,61 & 22,01 & 172,62 & 101,03 & 102,07 & 149,71 \\
\hline Hyla molleri & 30TVM65 & 100,00 & 99,66 & 103,47 & 37,19 & 5877,67 & 260,07 & $-13,36$ & 273,44 & 116,60 & 177,81 & 177,81 & 28,24 & 565,63 & 63,77 & 27,44 & 21,85 & 167,67 & 99,91 & $|100,37|$ & 146,89 \\
\hline Hyla molleri & 30TVM66 & 100,00 & 96,82 & 102,54 & 37,51 & 5810,34 & 255,69 & $-14,68$ & 270,37 & 112,97 & 174,30 & 174,30 & 26,32 & 592,52 & 65,98 & 29,71 & 21,25 & 174,32 & 105,92 & 105,92 & 154,79 \\
\hline Hyla molleri & 30TVM68 & 100,00 & 93,86 & 100,04 & 37,83 & 5660,56 & 248,30 & $-14,12$ & 262,42 & 72,58 & 169,56 & 169,56 & 25,44 & 641,77 & 69,19 & 33,05 & 20,53 & 186,60 & \begin{tabular}{|l|l|}
117,08 \\
\end{tabular} & \begin{tabular}{|l|l|}
117,08 \\
\end{tabular} & 170,02 \\
\hline Hyla molleri & 30TVM69 & 100,00 & 98,16 & 97,64 & 37,81 & 5565,22 & 248,23 & $-7,76$ & 255,99 & 65,35 & 172,37 & 172,37 & 30,50 & 646,26 & 68,22 & 32,82 & 20,34 & 190,43 & 118,83 & 118,83 & 172,83 \\
\hline Hyla molleri & 30TVM70 & 100,00 & 112,55 & 105,87 & 36,98 & 6160,84 & 277,34 & $-6,28$ & 283,62 & 131,70 & 194,07 & 194,32 & 37,54 & 480,44 & 55,58 & 19,82 & 24,49 & 143,77 & 80,06 & 85,36 & 123,15 \\
\hline Hyla molleri & 30TVM72 & 100,00 & 106,10 & 105,89 & 37,01 & 6061,74 & 270,43 & $-10,91$ & 281,34 & 124,35 & 186,61 & 186,65 & 32,47 & 516,80 & 59,62 & 23,21 & 23,02 & 154,97 & 89,04 & 93,36 & 133,00 \\
\hline Hyla molleri & 30TVM73 & 100,00 & 98,56 & 105,98 & 37,12 & 5997,22 & 262,84 & $-17,20$ & 280,04 & 115,77 & 178,54 & 178,56 & 26,25 & 559,55 & 64,18 & 26, & 22,13 & 167,59 & 98,07 & 99,80 & 144,61 \\
\hline Hyla molleri & 30TVM74 & 100,00 & 100,22 & 105,01 & 37,27 & 5943,49 & 262,73 & $-14,36$ & 277,09 & 117,38 & 179,39 & 179,40 & 28,16 & 559,96 & 63,73 & 26,99 & 21,78 & 166,78 & 99,11 & 100,65 & 145,18 \\
\hline Hyla molleri & 30TVM75 & 100,00 & 100,45 & 103,88 & 37,25 & 5882,88 & 261,01 & $-12,85$ & 273,87 & 117,54 & 178,77 & 178,77 & 28,93 & 569,77 & 64,18 & 28,18 & 21,36 & 168,50 & 102,01 & 102,59 & 148,42 \\
\hline Hyla molleri & 30TVM76 & 100,00 & 87,60 & 103,64 & 37,90 & 5792,22 & 247,70 & $-23,53$ & 271,22 & 102,96 & 165,40 & 165,40 & 18,18 & 656,62 & 72,67 & 34,20 & 20,29 & 192,43 & 119,18 & 119,18 & 172,73 \\
\hline Hyla molleri & 30TVM78 & 100,00 & 88,24 & 101,01 & 38,00 & 5655,53 & 243,54 & $-19,99$ & 263,53 & 69,76 & 164,02 & 164,02 & 20,13 & 687,79 & 73,85 & 36,12 & 19,78 & 198,62 & 126,73 & 126,73 & 183,08 \\
\hline Hyla molleri & 30TVM79 & 100,00 & 98,67 & 98,00 & 37,93 & 5559,87 & 248,47 & $-7,68$ & 256,15 & 64,45 & 172,70 & 172,72 & 31,04 & 659,48 & 69,32 & 33,73 & 19,95 & 193,11 & 122,43 & 122,43 & 177,13 \\
\hline Hyla molleri & 30TVM81 & 100,00 & 107,37 & 107,21 & 37,07 & 6121,69 & 273,23 & $-11,05$ & 284,28 & \begin{tabular}{|l|l|}
125,88 \\
\end{tabular} & 188,52 & 188,66 & 33,26 & 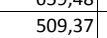 & 59,19 & 22,79 & 23,06 & $\mid 152,96$ & \begin{tabular}{|l|}
88,11 \\
\end{tabular} & \begin{tabular}{|c|}
93,40 \\
93,40
\end{tabular} & 130,80 \\
\hline Hyla molleri & 30TVM83 & 100,00 & 98,03 & 106,97 & 37,55 & 6000,19 & 263,21 & $-18,06$ & 281,27 & 115,23 & \begin{tabular}{|l|}
178,17 \\
\end{tabular} & 178,18 & 25,65 & 568,01 & 65,21 & 27,55 & 21,58 & 169,93 & 101,13 & 104,28 & 147,14 \\
\hline Hyla molleri & 30TVM84 & 100,00 & 97,05 & 106,23 & 37,68 & 5944,40 & 260,66 & $-17,95$ & 278,60 & 114,03 & 176,37 & 176,37 & 25,10 & 583,63 & $\begin{array}{l}\mid 66,38 \\
66,3\end{array}$ & 29,07 & 21,05 & 173,67 & 105,01 & \begin{tabular}{|l|l|l}
107,08 \\
\end{tabular} & 151,81 \\
\hline Hyla molleri & 30TVM86 & 100,00 & 88,57 & 104,39 & 38,00 & 5798,97 & 249,07 & $-23,21$ & 272,28 & 103,98 & 166,36 & 166,36 & 18,99 & 659,17 & 72,95 & 34,65 & 19,81 & 193,02 & 120,91 & 120,91 & 173,76 \\
\hline Hyla molleri & 30TVM90 & 100,00 & 109,67 & 108,41 & 37,01 & 6175,28 & 276,93 & $-10,38$ & 287,30 & 128,80 & 191,53 & 191,73 & 34,72 & 497,12 & 58,27 & 22,23 & 23,19 & 149,60 & 86,38 & 91,22 & 127,03 \\
\hline Hyla molleri & 30TVM91 & 100,00 & $\begin{array}{l}105,88 \\
108\end{array}$ & $\begin{array}{l}108,52 \\
108,\end{array}$ & $\begin{array}{ll}37,1818 \\
37,18\end{array}$ & $\begin{array}{l}01 / 19,40 \\
6119,48\end{array}$ & $\begin{array}{l}273,03 \\
273,03\end{array}$ & - & $\begin{array}{l}286,48 \\
286,48\end{array}$ & \begin{tabular}{|l|}
124,41 \\
124,41
\end{tabular} & \begin{tabular}{|l|l|}
187,18 \\
187
\end{tabular} & $\begin{array}{l}187,24 \\
187\end{array}$ & $\begin{array}{l}34,1 / 2 \\
31,70\end{array}$ & $\begin{array}{l}|c| c \mid, 12 \\
520,76\end{array}$ & $\begin{array}{l}\mid 0,27 \\
60,75 \\
\end{array}$ & $\begin{array}{l}24,25 \\
24,19\end{array}$ & 22,38 & $\begin{array}{l}4,06 \\
156,58 \\
\end{array}$ & $\begin{array}{l}\mid c 0,30 \\
91,88 \\
\end{array}$ & $\begin{array}{l}91,2< \\
96,24\end{array}$ & 133,75 \\
\hline Hyla molleri & 30TVM92 & 100,00 & 100,07 & 108,72 & 37,73 & 6058,65 & 267,23 & $-17,95$ & 285,18 & 117,93 & 180,93 & 180,94 & 27,00 & 556,12 & 64,39 & 26,95 & 21,52 & 166,86 & 99,45 & \begin{tabular}{l|l|}
103,55 \\
\end{tabular} & 143,63 \\
\hline Hyla molleri & 30TVM93 & 100,00 & 95,84 & 108,37 & 37,98 & 6002,07 & 262,09 & $-20,98$ & 283,07 & 112,94 & \begin{tabular}{|l|l|}
176,07 \\
\end{tabular} & 176,09 & 23,52 & 587,12 & 67,38 & 29,36 & 20,87 & \begin{tabular}{ll|}
175,48 \\
\end{tabular} & 106,11 & 108,37 & 152,44 \\
\hline Hyla molleri & 30TVM94 & 100,00 & 93,69 & 107,52 & 37,99 & 5940,38 & 258,53 & $-21,79$ & 280,32 & 110, & 173,17 & 173,17 & 22,16 & 609,52 & 69,2 & 31, & 20,35 & 181,15 & 111,26 & 112,79 & 159,04 \\
\hline Hyla molleri & 30TVM95 & 100,00 & 73,6 & 106,18 & 38,00 & 582 & 237 & -38, & 275, & 87 & 152,53 & 152,53 & 4,92 & 747,79 & 82,90 & 40, & 19,10 & 219,58 & 137,90 & 137,99 & 197,28 \\
\hline Hyla molleri & 30TVM96 & 100,00 & 83,40 & 105,32 & 38,00 & 5793,34 & 244,72 & $-28,48$ & 273,21 & 98,52 & 161,39 & 161,39 & 14,36 & 701,13 & 77,27 & 37,58 & 19,15 & 204,79 & 129,98 & 129,98 & 185,41 \\
\hline Hyla molleri & $\begin{array}{l}\text { 30TVM97 } \\
\end{array}$ & 100,00 & 71,52 & 103,63 & 38,00 & 5701,55 & 230,87 & $-37,93$ & 268,80 & 85,05 & \begin{tabular}{|l|l|}
148,69 \\
\end{tabular} & \begin{tabular}{|l|l|}
148,69 \\
\end{tabular} & 4,16 & 797,59 & 86,10 & 43,69 & 18,42 & 230,23 & 148,77 & 148,77 & 212,75 \\
\hline Hyla molleri & 30TVM98 & 100,00 & 91,12 & 101,98 & 38,00 & 5661,91 & 246,27 & $-18,21$ & 264,47 & 84,41 & 166,85 & 166,85 & 22,79 & 696,98 & 74,72 & 36,97 & 18,87 & 200,20 & 130,80 & 130,80 & 186,20 \\
\hline Hyla molle & 30TVM99 & 100,00 & 102,76 & 98 & 37,97 & 5568,33 & 252,1 & $-5,18$ & 257,30 & 60,80 & 176,65 & 176 & 34,77 & 662, & & 34 & 19,01 & 192,52 & 125,39 & 125,39 & 178,41 \\
\hline Hyla molleri & 30TVNOO & 100,00 & 108, & & 37,93 & 5349 & 256 & $-3,32$ & 260,05 & 82,6 & 179,20 & 179,20 & 42,52 & 609,08 & 69,48 & 29, & 23,06 & 192,55 & 104,69 & 105,56 & 157,47 \\
\hline Hyla molleri & 30 TVNO2 & 100,00 & 94,93 & 97,31 & 38,01 & 5225,65 & 240,01 & $-12,12$ & 252,13 & 69,28 & 164,63 & 164,63 & 31,41 & 724,43 & 82,86 & 36,32 & 21,84 & 228,54 & 129,62 & 129,62 & 191,08 \\
\hline Hyla molleri & 30TVNO3 & 100,00 & 98,08 & 94,63 & 38,07 & 5091,35 & 238,07 & $\begin{array}{r}2,1,49 \\
\end{array}$ & 244,56 & 73,30 & 165,73 & 165,91 & 36,01 & 748,90 & 86,70 & 37,29 & 21,95 & 239,08 & 135,73 & 135,79 & 199,06 \\
\hline Hyla molleri & 30 TVN10 & 100,00 & 106,85 & 98,15 & 37,69 & 5371,47 & 254,56 & $-3,10$ & 257,66 & 79,73 & 177,87 & 177,87 & 40,46 & 618,46 & 69,84 & 29,82 & 22,42 & 193,83 & 107,60 & 107,86 & 160,68 \\
\hline Hyla molle & 30TVN12 & 100,00 & 97 & 95 & 38,0 & 5209 & 240 & $-8,07$ & 248, & 71,01 & 166,72 & 166,72 & 33,68 & 720, & 81 & 35,5 & 21,62 & 226 & 129,66 & 129,66 & 196 \\
\hline Hyla molleri & $\begin{array}{l}30 \text { TVN13 } \\
\end{array}$ & 100,00 & 100,03 & 92,71 & 30,09 & 5074,66 & \begin{tabular}{|l|}
237,86 \\
237
\end{tabular} & $\mid-3,24$ & \begin{tabular}{|l|l|}
241,09 \\
241,09
\end{tabular} & 74,87 & \begin{tabular}{|l|l|}
167,07 \\
\end{tabular} & 167,61 & $\begin{array}{l}30,00 \\
37,92\end{array}$ & 750,81 & $\begin{array}{l}86,35 \\
86,3\end{array}$ & 37,08 & $\mid$\begin{tabular}{|l|}
21,81 \\
21
\end{tabular} & 239,05 & \begin{tabular}{|l|l|}
136,11 \\
\end{tabular} & 136,80 & 200,91 \\
\hline
\end{tabular}




\begin{tabular}{|c|c|c|c|c|c|c|c|c|c|c|c|c|c|c|c|c|c|c|c|c|c|}
\hline$\overline{\text { TAXON }}$ & UTM & km2 & BIO1 & BIO2 & $\begin{array}{l}\mathrm{BIO3} \\
\end{array}$ & 8104 & B105 & B106 & B107 & B108 & B109 & BIO10 & BIO11 & BIO12 & B1013 & B1014 & B1015 & B1016 & B1017 & BIO18 & 81019 \\
\hline Hyla molleri & 30TVN15 & 100,00 & 96,76 & 89,05 & 38,07 & 4883,89 & $\begin{array}{r}227,97 \\
\end{array}$ & $-2,11$ & 230,09 & 73,03 & 160,45 & 162,12 & 37,23 & 841,59 & 97,63 & 41,88 & 21,90 & 270,43 & 153,84 & 156,64 & 228,98 \\
\hline Hyla molleri & 30TVN16 & 100,00 & 99,13 & 86,20 & 38,09 & 4748,31 & 225,22 & 2,60 & 222,62 & 76,54 & 160,81 & 162,70 & 41,35 & 876,76 & 102,58 & 43,28 & 22,32 & 284,48 & 159,04 & $\begin{array}{l}164,78 \\
\end{array}$ & 240,62 \\
\hline Hyla molleri & 30TVN19 & 100,00 & 133,52 & \begin{tabular}{l|l|}
67,70 \\
\end{tabular} & 37,55 & 3946,92 & 229,38 & 51,28 & \begin{tabular}{|l|}
178,10 \\
\end{tabular} & $\begin{array}{l}116,49 \\
\end{array}$ & 183,18 & \begin{tabular}{|l|}
186,10 \\
\end{tabular} & \begin{tabular}{|l|}
84,48 \\
\end{tabular} & \begin{tabular}{|l|l|}
947,99 \\
\end{tabular} & \begin{tabular}{|l|l|}
118,90 \\
\end{tabular} & 40,98 & 28,14 & 331,66 & \begin{tabular}{|l|l|}
158,69 \\
\end{tabular} & \begin{tabular}{|l|l|}
184,71 \\
\end{tabular} & 268,72 \\
\hline Hyla molleri & 30TVN22 & 100,00 & 98,18 & 94,05 & 37,97 & 5211,92 & 239,98 & $-5,71$ & 245,69 & $\begin{array}{l}71,22 \\
\end{array}$ & \begin{tabular}{|l|}
167,44 \\
\end{tabular} & \begin{tabular}{l|l|}
167,58 \\
\end{tabular} & \begin{tabular}{|l|}
34,47 \\
\end{tabular} & \begin{tabular}{|l|}
722,47 \\
\end{tabular} & \begin{tabular}{|l|l|}
81,64 \\
\end{tabular} & 35,99 & \begin{tabular}{|l|}
21,27 \\
\end{tabular} & 226,16 & \begin{tabular}{|l|}
130,84 \\
\end{tabular} & 130,90 & $\begin{array}{l}192,53 \\
\end{array}$ \\
\hline Hyla molleri & 30TVN23 & 100,00 & 97,04 & 91,99 & 37,98 & 5098,92 & 234,97 & $-4,75$ & 239,73 & 70,94 & 164,45 & 165,11 & 34,86 & $768,87 \mid$ & 87,30 & 38,34 & 21,30 & 242,35 & 140,32 & 140,99 & 207,25 \\
\hline Hyla molleri & 30TVN24 & 100,00 & 101,35 & 88,78 & 37,93 & 4946,85 & 233,22 & 1,82 & 231,41 & $\mid 76,64$ & \begin{tabular}{|l|}
165,72 \\
\end{tabular} & 167,33 & \begin{tabular}{|l|l|}
40,81 \\
\end{tabular} & \begin{tabular}{|l|}
798,72 \\
\end{tabular} & \begin{tabular}{|l|l|}
91,63 \\
\end{tabular} & $\mid$\begin{tabular}{|l|l|}
39,16 \\
\end{tabular} & 21,85 & 255,50 & \begin{tabular}{|l|l|}
144,76 \\
\end{tabular} & \begin{tabular}{|l|l|l|}
147,93 \\
\end{tabular} & 217,80 \\
\hline Hyla molleri & 30TVN25 & 100,00 & 99,07 & 87,23 & 38,01 & 4861,28 & 227,97 & 1,48 & 226,50 & 75,07 & 162,11 & \begin{tabular}{|l|}
163,98 \\
\end{tabular} & 39,72 & 847,18 & 97,49 & 41,77 & 21,85 & 271,79 & 153,74 & 158,29 & 232,81 \\
\hline Hyla molleri & 30 TVN26 & 100,00 & $\begin{array}{l}99,52 \\
\end{array}$ & 84,82 & 38,02 & 4741,43 & 224,38 & 4,32 & 220,06 & 76,76 & 160,99 & \begin{tabular}{|l|}
163,08 \\
\end{tabular} & \begin{tabular}{|l|}
41,78 \\
\end{tabular} & 890,45 & 103,09 & 43,70 & 22,14 & \begin{tabular}{|l|}
287,85 \\
\end{tabular} & \begin{tabular}{|l|}
160,75 \\
\end{tabular} & 167,71 & 246,91 \\
\hline Hyla molleri & 30TVN30 & 100,00 & 99,40 & 96,63 & \begin{tabular}{ll|}
37,33 \\
\end{tabular} & 5448,19 & 247,74 & $-7,01$ & 254,75 & \begin{tabular}{|l|l|}
69,27 \\
\end{tabular} & \begin{tabular}{|l|}
171,72 \\
\end{tabular} & \begin{tabular}{|l|}
171,72 \\
\end{tabular} & \begin{tabular}{l|l|}
32,52 \\
\end{tabular} & 648,39 & \begin{tabular}{ll|}
71,83 \\
\end{tabular} & 32,34 & 21,29 & \begin{tabular}{l|l|}
198,45 \\
\end{tabular} & \begin{tabular}{|l|}
115,93 \\
\end{tabular} & \begin{tabular}{|l|l|}
115,93 \\
\end{tabular} & \begin{tabular}{|l|l|}
170,14 \\
\end{tabular} \\
\hline Hyla molleri & 30TVN31 & 100,00 & \begin{tabular}{|c|}
96,78 \\
\end{tabular} & \begin{tabular}{|l|}
95,23 \\
\end{tabular} & 37,79 & 5345,47 & 242,09 & $-7,86$ & 249,95 & \begin{tabular}{|l|}
67,83 \\
\end{tabular} & 167,90 & \begin{tabular}{|l|l|}
167,90 \\
\end{tabular} & \begin{tabular}{|l|l|}
31,47 \\
\end{tabular} & \begin{tabular}{|c|}
694,26 \\
\end{tabular} & 77,24 & 34,87 & 21,03 & 213,68 & 125,51 & 125,51 & $\begin{array}{l}184,37 \\
\end{array}$ \\
\hline Hyla molleri & 30TVN32 & 100,00 & \begin{tabular}{|l|}
98,01 \\
\end{tabular} & 93,01 & 37,90 & 5220,81 & \begin{tabular}{|l|l|}
238,88 \\
\end{tabular} & $-4,56$ & 243,45 & 70,10 & 167,05 & \begin{tabular}{|l|}
167,62 \\
\end{tabular} & 34,19 & 729,61 & 81,65 & 36,42 & 21,10 & 226,93 & \begin{tabular}{|l|}
132,83 \\
\end{tabular} & 133,19 & 196,12 \\
\hline Hyla molleri & 30TVN33 & 100,00 & $\begin{array}{l}99,88 \\
\end{array}$ & \begin{tabular}{|l|}
90,41 \\
\end{tabular} & \begin{tabular}{|l|}
37,83 \\
\end{tabular} & 5087,54 & 235,72 & $-0,61$ & 236,32 & 73,30 & \begin{tabular}{|l|}
166,10 \\
\end{tabular} & \begin{tabular}{l|l|}
167,68 \\
\end{tabular} & \begin{tabular}{l|l|}
37,62 \\
\end{tabular} & \begin{tabular}{|l|l|}
768,08 \\
\end{tabular} & 86,51 & 37,99 & \begin{tabular}{|l|}
21,23 \\
\end{tabular} & 241,69 & $\begin{array}{ll}139,82 \\
\end{array}$ & \begin{tabular}{|l|}
141,61 \\
\end{tabular} & 209,01 \\
\hline Hyla molleri & 30TVN35 & 100,00 & 100,09 & 85,70 & 37,99 & 4839,53 & 227,32 & 3,92 & 223,40 & 75,82 & 162,73 & 164,78 & \begin{tabular}{|l|l|}
41,04 \\
4
\end{tabular} & 860,57 & 98,02 & 42,14 & 21,75 & 275,25 & 155,33 & 161,40 & 239,24 \\
\hline Hyla molleri & 30TVN36 & 100,00 & 98,50 & 83,98 & 37,94 & 4741,51 & 222,92 & 4,39 & 218,54 & 75,08 & 159,90 & \begin{tabular}{|l|l|}
161,99 \\
\end{tabular} & \begin{tabular}{l|l}
40,86 \\
\end{tabular} & 910,65 & 104,03 & 44,72 & \begin{tabular}{|l|}
21,92 \\
\end{tabular} & 292,47 & \begin{tabular}{|l|l|}
164,27 \\
\end{tabular} & \begin{tabular}{|l|l|}
171,98 \\
\end{tabular} & 255,13 \\
\hline Hyla molleri & 30TVN37 & 100,00 & 106,25 & 78,95 & 37,64 & 4519,87 & 222,60 & 15,81 & 206,80 & 83,86 & 164,41 & \begin{tabular}{|l|l|}
166,69 \\
\end{tabular} & 51,04 & \begin{tabular}{|l|l|}
948,49 \\
\end{tabular} & 110,55 & 45,01 & 23,36 & 311,21 & \begin{tabular}{l|l|}
167,55 \\
\end{tabular} & \begin{tabular}{l|l|}
180,65 \\
\end{tabular} & 269,49 \\
\hline Hyla molleri & 30TVN40 & 100,00 & \begin{tabular}{|l|}
100,81 \\
\end{tabular} & 95,65 & 37,49 & 5453,55 & 247,77 & $-3,97$ & 251,74 & $\begin{array}{ll}69,92 \\
\end{array}$ & \begin{tabular}{|l|}
173,08 \\
\end{tabular} & \begin{tabular}{|l|}
173,21 \\
\end{tabular} & 33,90 & 645,41 & 70,98 & 32,20 & 21,06 & \begin{tabular}{l|l|}
196,42 \\
\end{tabular} & \begin{tabular}{|l|}
116,78 \\
\end{tabular} & \begin{tabular}{|l|}
116,78 \\
\end{tabular} & 171,18 \\
\hline Hyla molleri & 30TVN41 & 100,00 & \begin{tabular}{|l|}
97,97 \\
\end{tabular} & $\begin{array}{l}94,24 \\
\end{array}$ & 37,84 & 5348,75 & 242,03 & $-5,08$ & 247,11 & 68,22 & 168,75 & \begin{tabular}{|l|}
169,27 \\
\end{tabular} & 32,69 & 695,17 & 76,59 & 34,88 & 20,91 & 212,73 & $\begin{array}{ll}126,85 \\
\end{array}$ & 126,95 & 186,38 \\
\hline Hyla molleri & 30TVN42 & 100,00 & 94,73 & 92,92 & \begin{tabular}{|l|l|}
37,97 \\
\end{tabular} & 5248,90 & 235,92 & $-6,76$ & 242,68 & 66,10 & $\begin{array}{l}163,77 \\
\end{array}$ & \begin{tabular}{l|l|}
164,82 \\
\end{tabular} & 30,91 & 748,93 & 82,50 & 37,81 & \begin{tabular}{l|l|}
20,56 \\
\end{tabular} & 230,02 & \begin{tabular}{|l|l|}
137,79 \\
\end{tabular} & \begin{tabular}{|l|l|}
137,95 \\
\end{tabular} & 202,92 \\
\hline Hyla molleri & 30TVN43 & 100,00 & 94,96 & 90,73 & 37,93 & 5126,11 & 232,01 & $-4,57$ & 236,57 & 67,53 & 161,78 & 163,49 & 32,63 & 793,42 & 87,77 & 39,94 & 20,51 & 245,95 & 145,83 & 147,30 & 217,37 \\
\hline Hyla molleri & 30TVN44 & 100,00 & 99,73 & 87,26 & \begin{tabular}{|l|}
37,82 \\
\end{tabular} & 4960,01 & 230,43 & 2,49 & 227,94 & 73,85 & 164,09 & 165,94 & $\begin{array}{l}39,32 \\
\end{array}$ & 829,36 & 92,90 & 40,8 & 21,28 & 261,53 & 150,31 & 155,01 & 230,64 \\
\hline Hyla molleri & 30TVN46 & 100,00 & 101,68 & 82,19 & 37,70 & 4705,55 & 224,07 & 8,78 & 215,30 & 78,10 & $\begin{array}{l}162,36 \\
\end{array}$ & \begin{tabular}{|l|l|}
164,63 \\
\end{tabular} & 44,20 & \begin{tabular}{|l|}
919,65 \\
\end{tabular} & 105,53 & 44,48 & 22,03 & \begin{tabular}{|l|}
295,47 \\
\end{tabular} & \begin{tabular}{|l|l|}
164,43 \\
\end{tabular} & \begin{tabular}{|l|l|}
174,03 \\
\end{tabular} & 261,18 \\
\hline Hyla molleri & 30TVN53 & 100,00 & 99,65 & 89,08 & 37,80 & 5092,41 & 234,07 & 0,99 & 233,08 & 71,91 & 165,73 & \begin{tabular}{|l|l|}
167,58 \\
\end{tabular} & \begin{tabular}{|l|l|}
37,53 \\
\end{tabular} & $\begin{array}{l}792,05 \\
\end{array}$ & 87,44 & 39,24 & 20,59 & 245,68 & \begin{tabular}{l|l|}
144,52 \\
\end{tabular} & \begin{tabular}{|l|l|}
147,93 \\
\end{tabular} & 219,92 \\
\hline Hyla molleri & 30TVN56 & 100,00 & 106,14 & 80,16 & 37,35 & \begin{tabular}{l|l|l|}
4654,46 \\
\end{tabular} & 225,83 & \begin{tabular}{|l|l}
14,56 \\
\end{tabular} & 211,27 & \begin{tabular}{|l|l|}
82,72 \\
\end{tabular} & \begin{tabular}{|l|l|}
165,90 \\
\end{tabular} & $\mid 168,30$ & \begin{tabular}{|l|l|}
49,16 \\
\end{tabular} & 930,85 & $\mid 108,16$ & \begin{tabular}{|l|l|}
44,22 \\
\end{tabular} & 22,41 & $299,67 \mid$ & $\mid 164,75$ & \begin{tabular}{|l|l|}
176,64 \\
\end{tabular} & 268,72 \\
\hline Hyla molleri & 30TVN57 & 100,00 & 90,49 & 82,57 & 37,85 & 4709,62 & 214,55 & $-0,90$ & 215,45 & 52,83 & $\mid 151,43$ & 153,93 & 33,92 & 1014,97 & 115,98 & 50,75 & 21,14 & 321,54 & 184,65 & 193,13 & 291,03 \\
\hline Hyla molleri & 30TVN64 & 100,00 & 1110,67 & 83,52 & 37,36 & 4865,24 & 235,67 & \begin{tabular}{l|l}
15,42 \\
\end{tabular} & 220,24 & 84,28 & 173,25 & \begin{tabular}{|l|}
175,36 \\
\end{tabular} & 50,84 & \begin{tabular}{|l|}
832,07 \\
\end{tabular} & 95,12 & 39,3 & 21,70 & 263,67 & \begin{tabular}{|l|}
147,92 \\
\end{tabular} & \begin{tabular}{|l|}
156,78 \\
\end{tabular} & 238,93 \\
\hline Hyla molleri & 30TVN67 & 100,00 & 101,25 & 79,16 & 37,55 & 4599,45 & 219,84 & 11,59 & 208,25 & 65,66 & 160,21 & \begin{tabular}{|l|l|}
162,83 \\
\end{tabular} & 45,37 & 1010,80 & 117,99 & 48,59 & 22,10 & 323,75 & \begin{tabular}{|l|}
179,86 \\
\end{tabular} & 192,51 & 296,21 \\
\hline Hyla molleri & 30TVN74 & 100,00 & 107,62 & 84,58 & 37,51 & 4912,95 & 234,44 & \begin{tabular}{|l|}
12,03 \\
\end{tabular} & 222,40 & 74,75 & 170,82 & \begin{tabular}{|l|}
172,86 \\
\end{tabular} & \begin{tabular}{l|l|}
47,35 \\
\end{tabular} & 851,06 & \begin{tabular}{|c|}
96,70 \\
\end{tabular} & \begin{tabular}{|l|}
40,89 \\
\end{tabular} & 21,06 & 266,57 & 153,21 & \begin{tabular}{|l|}
160,98 \\
\end{tabular} & 245,17 \\
\hline Hyla molleri & 30TVN75 & 100,00 & 105,31 & 82,77 & 37,50 & 4807,18 & 229,48 & $\begin{array}{l}11,75 \\
\end{array}$ & 217,73 & $\begin{array}{l}67,09 \\
\end{array}$ & 167,05 & \begin{tabular}{|l|}
169,38 \\
\end{tabular} & 46,57 & 910,55 & 104,51 & \begin{tabular}{|l|l|}
43,79 \\
\end{tabular} & 21,23 & 286,82 & \begin{tabular}{l|l|}
163,32 \\
\end{tabular} & \begin{tabular}{|l|l|}
172,66 \\
\end{tabular} & 264,81 \\
\hline Hyla molleri & 30TVN76 & 100,00 & \begin{tabular}{|l|}
107,88 \\
\end{tabular} & 79,40 & 37,36 & 4649,58 & 226,83 & \begin{tabular}{|l|}
17,28 \\
\end{tabular} & 209,55 & 67,34 & \begin{tabular}{|l|}
167,40 \\
\end{tabular} & \begin{tabular}{|l|}
169,86 \\
\end{tabular} & \begin{tabular}{|l|l|}
51,09 \\
\end{tabular} & $\begin{array}{l}964,32 \\
\end{array}$ & \begin{tabular}{|l|}
112,88 \\
\end{tabular} & \begin{tabular}{|l|l|}
45,46 \\
\end{tabular} & 22,21 & 308,11 & \begin{tabular}{|l|}
170,29 \\
\end{tabular} & \begin{tabular}{|l|l|}
183,10 \\
\end{tabular} & 285,22 \\
\hline Hyla molleri & 30TVN82 & 100,00 & \begin{tabular}{|l|l|}
103,17 \\
\end{tabular} & \begin{tabular}{|l|l|}
91,27 \\
\end{tabular} & \begin{tabular}{|l|l|}
37,89 \\
\end{tabular} & 5220,71 & 240,35 & 2,42 & 237,93 & \begin{tabular}{|l|l|}
60,00 \\
\end{tabular} & \begin{tabular}{|l|l|}
170,94 \\
\end{tabular} & \begin{tabular}{|l|l|}
172,61 \\
\end{tabular} & 39,31 & \begin{tabular}{|l|l|}
771,66 \\
\end{tabular} & \begin{tabular}{|l|l|}
84,04 \\
\end{tabular} & $\mid$\begin{tabular}{|l|l|}
38,65 \\
\end{tabular} & \begin{tabular}{|l|l|}
19,54 \\
\end{tabular} & \begin{tabular}{|l|l|}
233,49 \\
\end{tabular} & 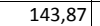 & \begin{tabular}{|l|l|l|l|}
144 \\
\end{tabular} & 215,95 \\
\hline Hyla molleri & 30TVN83 & 100,00 & $\begin{array}{l}104,94 \\
\end{array}$ & 88,13 & 37,73 & 5072,27 & 237,26 & 6,80 & 230,46 & $\begin{array}{l}63,63 \\
\end{array}$ & \begin{tabular}{|l|}
170,70 \\
\end{tabular} & \begin{tabular}{|l|}
172,44 \\
\end{tabular} & \begin{tabular}{|l|}
42,99 \\
\end{tabular} & 820,28 & 91,21 & \begin{tabular}{|l|}
40,44 \\
\end{tabular} & \begin{tabular}{|l|}
20,14 \\
\end{tabular} & \begin{tabular}{|l|l|}
252,12 \\
\end{tabular} & \begin{tabular}{|l|l|}
150,79 \\
\end{tabular} & \begin{tabular}{|l|l|}
155,49 \\
\end{tabular} & 233,70 \\
\hline Hyla molleri & 30TVN84 & 100,00 & $\begin{array}{l}103,96 \\
\end{array}$ & 86,15 & \begin{tabular}{l|l|}
37,85 \\
\end{tabular} & 4963,33 & 233,21 & 7,87 & 225,33 & 55,78 & 167,96 & \begin{tabular}{|l|}
170,04 \\
\end{tabular} & \begin{tabular}{|l|}
43,42 \\
\end{tabular} & 871,21 & \begin{tabular}{ll|}
98,06 \\
\end{tabular} & 42,76 & 20,30 & 269,96 & $\begin{array}{ll}159,22 \\
\end{array}$ & 165,50 & 250,88 \\
\hline Hyla molleri & 30TVN85 & 100,00 & 104,85 & 83,38 & 37,74 & 4828,90 & 229,94 & \begin{tabular}{l|l|}
11,22 \\
\end{tabular} & 218,72 & 54,11 & 166,92 & \begin{tabular}{|l|}
169,21 \\
\end{tabular} & \begin{tabular}{|l|l|}
45,99 \\
\end{tabular} & 924,90 & 105,84 & \begin{tabular}{|l|}
44,83 \\
\end{tabular} & 20,84 & 290,18 & \begin{tabular}{|l|}
167,04 \\
\end{tabular} & \begin{tabular}{|l|}
175,80 \\
\end{tabular} & 270,28 \\
\hline Hyla molleri & 30TVN86 & 100,00 & 105,44 & 80,40 & 37,56 & 4686,24 & 225,87 & 14,56 & 211,31 & 57,21 & 165,48 & \begin{tabular}{|l|l|}
167,92 \\
\end{tabular} & \begin{tabular}{|l|}
48,38 \\
\end{tabular} & 987,13 & 114,97 & 47,12 & 21,75 & 313,49 & \begin{tabular}{|l|l|}
175,99 \\
\end{tabular} & 187,50 & 293,23 \\
\hline Hyla molleri & 30TVN91 & 100,00 & \begin{tabular}{|l|}
113,53 \\
\end{tabular} & 92,15 & 37,94 & 5299,28 & 251,10 & 10,04 & \begin{tabular}{|l|}
241,07 \\
\end{tabular} & 80,85 & \begin{tabular}{|l|l|}
181,98 \\
\end{tabular} & \begin{tabular}{|l|}
183,36 \\
\end{tabular} & 48,11 & \begin{tabular}{ll|}
698,82 \\
\end{tabular} & 75,34 & 34,55 & \begin{tabular}{|l|}
19,53 \\
\end{tabular} & 209,99 & \begin{tabular}{|l|}
131,21 \\
\end{tabular} & 133,30 & $\begin{array}{l}193,97 \\
\end{array}$ \\
\hline Hyla molleri & 30TVN92 & 100,00 & \begin{tabular}{|l|}
117,27 \\
\end{tabular} & 88,59 & \begin{tabular}{l|l|}
37,62 \\
\end{tabular} & 5141,02 & 249,09 & 16,71 & 232,37 & 86,20 & 183,32 & \begin{tabular}{|l|l|}
184,93 \\
\end{tabular} & 53,60 & 738,05 & 81,65 & 35,49 & 20,21 & \begin{tabular}{|l|}
225,82 \\
\end{tabular} & \begin{tabular}{l|l|}
135,85 \\
\end{tabular} & \begin{tabular}{l|l|}
140,65 \\
\end{tabular} & 209,57 \\
\hline Hyla molleri & 30TVN94 & 100,00 & \begin{tabular}{|l|}
108,73 \\
\end{tabular} & 85,55 & 37,76 & 4938,92 & 236,51 & \begin{tabular}{|l|}
12,67 \\
\end{tabular} & 223,84 & \begin{tabular}{|l|l|}
62,07 \\
\end{tabular} & \begin{tabular}{|l|}
172,20 \\
\end{tabular} & \begin{tabular}{|l|}
174,24 \\
\end{tabular} & 48,30 & 872,13 & 98,54 & 42,44 & 20,30 & \begin{tabular}{|l|l|}
270,24 \\
\end{tabular} & \begin{tabular}{|l|}
159,39 \\
\end{tabular} & 166,11 & 253,37 \\
\hline Hyla molleri & 30TVN95 & 100,00 & 106,38 & 83,55 & 37,77 & 4828,87 & 231,28 & 12, & 218,63 & 56,30 & 168,32 & 170,60 & 47,55 & 938,21 & 107,38 & 45, & 20,76 & 293,76 & 170,03 & 178,55 & 276,05 \\
\hline Hyla molleri & 30TVP10 & 91,00 & 140,29 & 63,68 & 37,35 & 3761,53 & 229,76 & 61,62 & 168,14 & 124,53 & 180,70 & \begin{tabular}{|l|}
190,41 \\
\end{tabular} & 93,41 & 969,80 & 123,50 & 40,8 & 29,56 & \begin{tabular}{|l|}
344,03 \\
\end{tabular} & \begin{tabular}{|l|}
159,72 \\
\end{tabular} & 190,60 & 276,50 \\
\hline Hyla molleri & 30TVP11 & 3,00 & $\begin{array}{l}142,42 \\
\end{array}$ & 61,75 & 37,17 & 3685,50 & 228,75 & \begin{tabular}{|l|l|}
65,08 \\
\end{tabular} & $\begin{array}{l}163,67 \\
\end{array}$ & 126,75 & \begin{tabular}{|l|}
171,08 \\
\end{tabular} & \begin{tabular}{|l|l|}
191,25 \\
\end{tabular} & \begin{tabular}{|l|}
96,33 \\
\end{tabular} & \begin{tabular}{|l|}
988,92 \\
\end{tabular} & 126,33 & 41,25 & 30,00 & \begin{tabular}{|l|}
352,42 \\
\end{tabular} & \begin{tabular}{|l|l|}
161,17 \\
\end{tabular} & \begin{tabular}{|l|l|}
195,08 \\
\end{tabular} & 283,42 \\
\hline Hyla molleri & 30TVP20 & 99,00 & 139,47 & 61,90 & \begin{tabular}{|l|}
37,03 \\
\end{tabular} & 3723,07 & 227,32 & \begin{tabular}{|l|l|}
62,40 \\
\end{tabular} & 164,92 & 123,90 & \begin{tabular}{|l|}
174,73 \\
\end{tabular} & \begin{tabular}{|l|}
189,11 \\
\end{tabular} & \begin{tabular}{l|l|}
93,06 \\
\end{tabular} & \begin{tabular}{|l|l|}
1010,81 \\
\end{tabular} & 127,51 & 42,12 & 29,70 & 358,71 & \begin{tabular}{|l|l|}
165,13 \\
\end{tabular} & \begin{tabular}{|l|l|}
198,97 \\
\end{tabular} & 291,94 \\
\hline Hyla molleri & 30TVP30 & 86,00 & 138,58 & $\begin{array}{ll}60,93 \\
\end{array}$ & 36,75 & 3722,42 & 226,02 & \begin{tabular}{l|l}
62,32 \\
\end{tabular} & 163,70 & 122,92 & \begin{tabular}{|l|}
174,77 \\
\end{tabular} & \begin{tabular}{|l|}
188,31 \\
\end{tabular} & $\begin{array}{l}92,36 \\
\end{array}$ & 1043,38 & 131,23 & \begin{tabular}{|l|l|}
43,16 \\
\end{tabular} & 29,64 & 369,18 & \begin{tabular}{|l|}
169,38 \\
\end{tabular} & 204,99 & 306,25 \\
\hline Hyla molleri & 30TVP31 & 33,00 & $\begin{array}{l}141,27 \\
\end{array}$ & 58,56 & 36,50 & 3605,85 & 224,90 & 67,10 & 157,79 & $\begin{array}{l}126,46 \\
\end{array}$ & $\begin{array}{l}168,79 \\
\end{array}$ & \begin{tabular}{|l|}
189,33 \\
\end{tabular} & \begin{tabular}{l|l}
96,25 \\
\end{tabular} & \begin{tabular}{|l|l|}
1070,27 \\
\end{tabular} & 135,50 & 43,90 & 30,44 & \begin{tabular}{|l|l|}
381,94 \\
\end{tabular} & \begin{tabular}{|l|}
170,77 \\
\end{tabular} & \begin{tabular}{|l|l|}
211,92 \\
\end{tabular} & 313,67 \\
\hline Hyla molleri & 30TVP41 & 44,00 & 138,96 & 58,91 & $|36,27|$ & 3675,51 & 223,92 & 64,09 & 159,83 & 123,56 & $\mid$\begin{tabular}{|l|l|}
171,44 \\
\end{tabular} & \begin{tabular}{|l|l|}
187,82 \\
\end{tabular} & \begin{tabular}{|c|}
33,19 \\
\end{tabular} & 1103,65 & $\mid 140,79$ & 45,1 & 29,7 & $389,87 \mid$ & 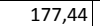 & 216,39 & 332,03 \\
\hline Hyla molleri & 30TVP50 & 100,00 & 135,87 & 60,90 & 36,17 & 3806,96 & 224,75 & 58,97 & 165,78 & 119,22 & 183,13 & \begin{tabular}{|l|}
186,40 \\
\end{tabular} & 88,57 & \begin{tabular}{|l|l|}
1097,40 \\
\end{tabular} & 139,97 & 45, & 29,04 & 382,13 & \begin{tabular}{|l|l|}
177,06 \\
\end{tabular} & 212,35 & 336,43 \\
\hline Hyla molleri & 30TVP51 & 62,00 & 139,49 & 58,70 & 36,04 & 3704,47 & 224,75 & 64,47 & 160,28 & 123,59 & 181,65 & 188,60 & 93,16 & 1118,94 & 143,78 & 45,42 & 29,88 & \begin{tabular}{|l|}
393,06 \\
\end{tabular} & \begin{tabular}{|l|}
179,04 \\
\end{tabular} & 217,62 & 343,98 \\
\hline Hyla molleri & 30TVP60 & 70,00 & 135,37 & 61,27 & 36,10 & 3860,41 & 225,37 & \begin{tabular}{|l|l|}
57,86 \\
\end{tabular} & 167,51 & 118,11 & 183,29 & \begin{tabular}{l|l|}
186,66 \\
\end{tabular} & 87,44 & \begin{tabular}{|l|l|}
1113,97 \\
\end{tabular} & $\begin{array}{l}142,87 \\
\end{array}$ & 45,54 & 28,87 & 384,38 & $\begin{array}{l}178,76 \\
\end{array}$ & \begin{tabular}{|l|}
213,35 \\
\end{tabular} & 349,47 \\
\hline Hyla molleri & 30TVP61 & 17,00 & 137,40 & 59,60 & 36,00 & 3760,60 & 224,27 & 61,20 & \begin{tabular}{|l|}
163,07 \\
\end{tabular} & 120,93 & \begin{tabular}{|l|}
183,73 \\
\end{tabular} & \begin{tabular}{|l|l|}
187,13 \\
\end{tabular} & \begin{tabular}{|l|}
90,33 \\
\end{tabular} & \begin{tabular}{|c|}
1137,47 \\
\end{tabular} & 146,53 & 46,2 & 29,33 & \begin{tabular}{|l|}
395,47 \\
\end{tabular} & 181,73 & 219,20 & 356,13 \\
\hline Hyla molleri & 30TWK53 & 100,00 & 111,27 & 122,96 & 38,14 & 6545,77 & 295,52 & $-20,88$ & 316,40 & $\begin{array}{l}4,02 \\
\end{array}$ & $\begin{array}{l}198,63 \\
\end{array}$ & \begin{tabular}{|l|l|}
199,73 \\
\end{tabular} & 33,01 & \begin{tabular}{|l|l|}
537,06 \\
\end{tabular} & 65,77 & 19,21 & \begin{tabular}{|l|l|}
27,92 \\
\end{tabular} & \begin{tabular}{|l|l|}
176,51 \\
\end{tabular} & 83,23 & 90,26 & 133,53 \\
\hline Hyla molleri & $30 \mathrm{TW}$ & & & & 37,71 & \begin{tabular}{|l|l|}
6474,79 \\
\end{tabular} & & \begin{tabular}{|l|}
$-11,08$ \\
\end{tabular} & 303,55 & \begin{tabular}{|l|}
103,83 \\
\end{tabular} & 204 & \begin{tabular}{|l|l|}
205,10 \\
\end{tabular} & \begin{tabular}{|l|}
40,08 \\
\end{tabular} & 460,90 & 58,77 & \begin{tabular}{|l|}
18,36 \\
\end{tabular} & $27,27 \mid$ & \begin{tabular}{|l|}
146,40 \\
\end{tabular} & 77,21 & 82,94 & 109,38 \\
\hline Hyla molleri & 30TWK73 & 100,00 & 113,13 & 123,69 & 38,75 & 6497,97 & 295,96 & $-19,97$ & 315,93 & 96,05 & 199,46 & 200,74 & 34,86 & 533,75 & 66,63 & 19,82 & 27,77 & \begin{tabular}{l|l|}
176,55 \\
\end{tabular} & 86,49 & 94,15 & 128,91 \\
\hline Hyla molleri & 30TWK78 & 100,00 & 97,08 & 115,41 & 37,98 & 6407,53 & 270,31 & $-31,59$ & 301,90 & 109,17 & 182,16 & \begin{tabular}{|l|}
183,24 \\
\end{tabular} & 20,19 & 550,90 & 72,06 & 26,03 & 25,54 & 178,22 & 100,62 & 111,84 & 125,32 \\
\hline Hyla molleri & 30TWK79 & 100,00 & 93,35 & 114,29 & 37,94 & 6378,58 & 265,36 & $-34,21$ & 299,57 & 112,60 & 178,20 & \begin{tabular}{|l|}
179,19 \\
\end{tabular} & 16,96 & 562,22 & 73,74 & 27,55 & 25,18 & 182,72 & 104,53 & 116,45 & 127, \\
\hline Hyla molleri & $30 \mathrm{TWI}$ & 10 & 102,58 & 1 & \begin{tabular}{|l|l|}
38,17 \\
\end{tabular} & 6476 & 282 & $-27,89$ & 310,03 & 84,56 & 189 & \begin{tabular}{|l|l|}
190,08 \\
\end{tabular} & 25 & 56 & 71,36 & 23,60 & 26,19 & \begin{tabular}{|l|}
184,82 \\
\end{tabular} & $\begin{array}{l}96,95 \\
\end{array}$ & \begin{tabular}{|l|l|}
106,93 \\
\end{tabular} & 129, \\
\hline Hyla molleri & 30TWK84 & 100,00 & 96,47 & 118,36 & 38,01 & 6457,47 & 274,20 & $-32,79$ & 306,99 & 78,13 & 182,81 & \begin{tabular}{|l|l|}
183,78 \\
\end{tabular} & \begin{tabular}{|l|l|}
19,61 \\
\end{tabular} & 580,26 & 74,21 & 25,90 & 25,51 & \begin{tabular}{|l|}
189,63 \\
\end{tabular} & \begin{tabular}{|l|}
102,94 \\
\end{tabular} & \begin{tabular}{|l|l|}
114,16 \\
\end{tabular} & 132,22 \\
\hline Hyla molleri & 30TWK86 & 100,00 & 88,77 & 115,56 & 37,99 & 6414,97 & \begin{tabular}{|l|}
263,32 \\
\end{tabular} & $-38,73$ & 302,05 & 92,32 & \begin{tabular}{|l|}
174,60 \\
\end{tabular} & \begin{tabular}{|l|l|}
175,45 \\
1
\end{tabular} & \begin{tabular}{l|l|}
12,55 \\
\end{tabular} & 600,71 & $\begin{array}{l}77,74 \\
\end{array}$ & 29,01 & 24,95 & \begin{tabular}{l|l|}
194,99 \\
\end{tabular} & \begin{tabular}{|l|l|}
110,73 \\
\end{tabular} & \begin{tabular}{|l|l|}
123,49 \\
\end{tabular} & 135,10 \\
\hline Hyla molleri & 30TWK88 & 100,00 & 86,30 & 113,60 & 37,80 & 6367,38 & 257,78 & $-40,42$ & 298,21 & 104,73 & 171,25 & \begin{tabular}{|l|}
172,19 \\
\end{tabular} & \begin{tabular}{l|l|}
10,56 \\
\end{tabular} & 599,53 & 78,42 & 30,40 & 24,72 & \begin{tabular}{|c|}
196,11 \\
\end{tabular} & $\begin{array}{l}113,56 \\
\end{array}$ & 127,13 & 133,66 \\
\hline Hyla molleri & 30TWK & 100,00 & 102,8 & & 38,0 & 6449 & 279 & $-26,4$ & 305,52 & 85,18 & 188,95 & \begin{tabular}{|l|}
190,01 \\
\end{tabular} & 25,99 & 549,8 & 70,66 & 24,09 & $26, \mathrm{C}$ & 180 & \begin{tabular}{|l|l|}
98,38 \\
\end{tabular} & \begin{tabular}{|l|}
108,40 \\
\end{tabular} & \begin{tabular}{l|l|}
122,41 \\
\end{tabular} \\
\hline Hyla molleri & 30TWK95 & 100,00 & 92,36 & 115,23 & 38,00 & 6416,55 & 265,77 & $-35,26$ & 301,03 & 104,81 & 178,05 & \begin{tabular}{|l|}
179,08 \\
\end{tabular} & \begin{tabular}{l|l|}
16,05 \\
\end{tabular} & 583,27 & 75,98 & 28,08 & 25,35 & \begin{tabular}{|l|}
190,72 \\
\end{tabular} & \begin{tabular}{|l|}
108,82 \\
\end{tabular} & \begin{tabular}{|l|}
121,12 \\
\end{tabular} & 128,16 \\
\hline Hyla molleri & \begin{tabular}{|c|} 
30TWK \\
\end{tabular} & 100,00 & 80,94 & 111,58 & 37,14 & 6340,80 & 250,10 & $-44,57$ & 294,66 & 98,89 & 165,63 & \begin{tabular}{l|l|}
166,52 \\
\end{tabular} & 5,51 & 622,34 & 81,77 & 32,99 & 24,56 & 205,50 & 121,34 & \begin{tabular}{|c|}
136,15 \\
\end{tabular} & \begin{tabular}{|l|l|}
135,74 \\
\end{tabular} \\
\hline
\end{tabular}




\begin{tabular}{|c|c|c|c|c|c|c|c|c|c|c|c|c|c|c|c|c|c|c|c|c|c|}
\hline TAXON & UTM & km2 & BIO1 & B102 & BIO3 & 8104 & 8105 & B106 & B107 & B108 & B109 & BIO10 & B1011 & BIO12 & B1O13 & B1014 & 81015 & B1016 & B1017 & B1018 & \begin{tabular}{|l|} 
BIO19 \\
\end{tabular} \\
\hline Hyla molleri & 30TWL07 & 100,00 & 97,13 & 110,66 & 37,37 & 6252,88 & 268,36 & $-23,79$ & 292,15 & 115,05 & 180,97 & 181,10 & 22,64 & 549,99 & 65,41 & 24,94 & 23,07 & 167,04 & 95,15 & 102,44 & $\begin{array}{r}139,62 \\
\end{array}$ \\
\hline Hyla molleri & 30TWL17 & 100,00 & \begin{tabular}{|l|}
103,53 \\
\end{tabular} & 111,29 & 37,17 & 6279,43 & 274,65 & $-19,02$ & 293,67 & \begin{tabular}{|l|}
122,61 \\
\end{tabular} & 187,15 & \begin{tabular}{|l|}
187,58 \\
\end{tabular} & 28,16 & 519,04 & 62,40 & 23,79 & 23,10 & 158,25 & 91,01 & 97,74 & 130,71 \\
\hline Hyla molleri & 30TWL19 & 100,00 & 110,87 & 111,19 & 37,55 & 6229,64 & 280,75 & $-11,81$ & 292,56 & 130,53 & 193,55 & 193,84 & 35,34 & 490,44 & 58,62 & 22,78 & 22,84 & 148,93 & 87,42 & 93,05 & 124,01 \\
\hline Hyla molleri & 30TWL26 & 100,00 & 105,36 & 111,83 & 37,18 & 6306,08 & 276,62 & $-18,44$ & 295,06 & 124,83 & 189,21 & 189,83 & 29,54 & 506,69 & 61,87 & 23,41 & 23,57 & \begin{tabular}{|l|}
155,68 \\
\end{tabular} & 89,50 & 96,17 & \begin{tabular}{ll|}
125,79 \\
\end{tabular} \\
\hline Hyla molleri & 30TWL27 & 100,00 & 103,26 & 112,48 & 37,56 & 6274,36 & 274,86 & $-20,32$ & 295,18 & 122,43 & 186,79 & \begin{tabular}{|l|l|}
187,23 \\
\end{tabular} & 27,83 & 520,87 & 63,32 & 24,73 & 22,91 & 159,92 & 93,13 & 100,17 & $\begin{array}{l}130,19 \\
\end{array}$ \\
\hline Hyla molleri & 30TWL34 & 100,00 & 103,25 & 112,50 & 37,45 & 6352,49 & 274,90 & $-21,79$ & 296,68 & 122,84 & 187,75 & 188,19 & 26,94 & 512,13 & 63,82 & 24,03 & 24,14 & 159,32 & 90,44 & 98,01 & 124,74 \\
\hline Hyla molleri & 30TWL35 & 100,00 & 101,26 & 112,75 & 37,71 & 6319,27 & 272,95 & $-23,49$ & 296,44 & 120,55 & 185,24 & 185,87 & 25,27 & 523,95 & 65,03 & 25,26 & 23,49 & 162,96 & 93,88 & \begin{tabular}{|l|l|}
101,78 \\
\end{tabular} & 128,29 \\
\hline Hyla molleri & 30TWL36 & 100,00 & 100,93 & 113,00 & 37,98 & 6291,45 & 272,63 & $-23,75$ & 296,38 & 120,11 & 184,61 & 185,22 & 25,24 & 528,39 & 65,26 & 25,80 & 23,01 & 164,10 & 95,48 & 103,54 & 130,21 \\
\hline Hyla molleri & 30TWL38 & 100,00 & 107,05 & 113,55 & 38,00 & 6243,97 & 278,66 & $-17,82$ & 296,47 & 126,84 & 189,90 & 190,27 & 31,47 & 506,42 & 62,06 & 24,94 & 22,58 & 156,39 & 92,73 & 99,67 & $\begin{array}{ll}126,17 \\
\end{array}$ \\
\hline Hyla molleri & 30TWL39 & 100,00 & 109,03 & 113,99 & 38,00 & 6221,73 & 280,64 & $-15,73$ & 296,38 & 128,99 & 191,51 & 191,92 & 33,55 & 503,57 & 61,23 & 25,10 & 22,12 & 154,73 & 92,94 & 99,47 & 126,49 \\
\hline Hyla molleri & 30TWL45 & 100,00 & 101,42 & 113,01 & 37,96 & 6313,14 & 272,55 & $-24,05$ & 296,60 & 120,94 & 185,25 & 185,75 & 25,16 & 521,14 & 65,67 & 25,74 & 23,55 & 163,99 & 95,18 & 103,92 & 125,89 \\
\hline Hyla molleri & 30TWL48 & 100,00 & $\begin{array}{l}107,87 \\
\end{array}$ & 114,02 & 38,00 & 6247,87 & 279,03 & $-17,74$ & 296,77 & 128,00 & 190,51 & \begin{tabular}{|c|}
191,08 \\
\end{tabular} & 31,85 & 501,45 & 62,41 & 25,29 & 22,61 & 156,52 & 93,48 & 101,12 & 123,39 \\
\hline Hyla molleri & 30TWL49 & 100,00 & 106,99 & 114,69 & 38,00 & 6217,22 & 278,67 & $-18,62$ & 297,29 & 126,85 & 189,35 & \begin{tabular}{|l|l|}
189,79 \\
\end{tabular} & 31,42 & 514,24 & 63,20 & 26,27 & 22,00 & \begin{tabular}{|l|l|}
159,39 \\
\end{tabular} & 96,54 & \begin{tabular}{|l|l|}
104,10 \\
\end{tabular} & 128,16 \\
\hline Hyla molleri & 30TWL55 & 100,00 & 100,28 & 113,00 & 38,00 & 6305,38 & 270,42 & $-25,85$ & 296,27 & 120,17 & 183,82 & 184,44 & 24,16 & 523,34 & 67,03 & 26,47 & 23,74 & 166,91 & 97,78 & 107,47 & 124,24 \\
\hline Hyla molleri & 30TWL63 & 100,00 & 96,81 & 112,75 & 37,77 & 6317,62 & 266,10 & $-29,95$ & 296,05 & 116,80 & 180,55 & \begin{tabular}{|l|l|}
181,35 \\
\end{tabular} & 20,76 & 534,33 & 69,84 & 27,17 & 24,62 & \begin{tabular}{|l|l|}
173,16 \\
\end{tabular} & 100,73 & 111,84 & $\begin{array}{ll}123,35 \\
\end{array}$ \\
\hline Hyla molleri & 30TWL65 & 100,00 & 99,31 & 112,50 & 37,70 & 6279,44 & 267,61 & $-27,34$ & 294,95 & 119,48 & 182,29 & 182,98 & 23,38 & 523,26 & 68,26 & 27,16 & 24,29 & 169,50 & 99,93 & 110,74 & 121,65 \\
\hline Hyla molleri & 30TWL66 & 100,00 & 114,62 & 111,92 & 37,67 & 6300,59 & 281,14 & $-12,89$ & 294,03 & 136,46 & 197,15 & 197,90 & 37,27 & 450,62 & 59,66 & 22,53 & 25,83 & 146,55 & 85,56 & 94,23 & 103,89 \\
\hline Hyla molleri & 30TWL68 & 100,00 & 112,19 & 112,81 & 38,00 & 6249,84 & 279,79 & $-14,71$ & 294,50 & 133,40 & 194,21 & \begin{tabular}{|l|}
194,71 \\
\end{tabular} & 35,50 & \begin{tabular}{|l|l|}
472,48 \\
\end{tabular} & 61,37 & 24,37 & 24,31 & 152,06 & 90,60 & 99,71 & 111,62 \\
\hline Hyla molleri & 30TWL71 & 100,00 & 100,38 & 112,73 & 37,64 & 6345,85 & 268,58 & $-27,65$ & 296,23 & 120,78 & 184,12 & 185,14 & 23,60 & 515,33 & 68,84 & 25,71 & 25,99 & 169,48 & 97,71 & 108,87 & 115,26 \\
\hline Hyla molleri & 30TWL72 & 100,00 & 97,97 & 112,17 & 37,49 & 6323,04 & 265,56 & $-29,31$ & 294,87 & 118,24 & 181,43 & 182,42 & 21,56 & 523,62 & 69,92 & 26,82 & 25,62 & 172,54 & 100,47 & 112,13 & 117,24 \\
\hline Hyla molleri & 30TWL80 & 100,00 & 93,70 & 112,16 & 37,43 & 6338,13 & 261,37 & \begin{tabular}{|c|}
$-33,88$ \\
\end{tabular} & 295,25 & 113,39 & 177,54 & 178,62 & 17,14 & 547,11 & 73,40 & 28,23 & 25,82 & 181,65 & 106,07 & 118,79 & 119,77 \\
\hline Hyla molleri & 30TWM02 & 100,00 & 97,86 & 110,42 & 37,99 & 60 & 266,39 & $\mid-21,04$ & 287,44 & |115,60 & 178,84 & $\begin{array}{l}178,89 \\
\end{array}$ & 24,96 & \begin{tabular}{|l|l|l|l|}
574,46 \\
\end{tabular} & 66,58 & 28,80 & 20,96 & \begin{tabular}{|l|l|}
172,38 \\
\end{tabular} & 104,40 & \begin{tabular}{|l|l|l|l|l}
107,16 \\
\end{tabular} & 148,76 \\
\hline Hyla molleri & 30TWM03 & 100,00 & 93,98 & 109,78 & 38,00 & 6001,04 & 261,56 & $-23,63$ & 285,19 & 110,94 & 174,33 & 174,36 & 21,81 & 605,37 & 69,45 & 31,18 & 20,27 & 180,79 & \begin{tabular}{|l|l|}
110,97 \\
\end{tabular} & 113,23 & 157,66 \\
\hline Hyla molleri & 30TWM04 & 100,00 & 85,75 & 108,61 & 38,00 & 5923,26 & 251,68 & $-29,78$ & 281,46 & 101,73 & 165,23 & 165,23 & 14,97 & 666,40 & 75,31 & 35,51 & 19,49 & 197,55 & 123,31 & 124,57 & 174,60 \\
\hline Hyla molleri & 30TWMO5 & 100,00 & 70,14 & 106,53 & 38,00 & 5815,45 & 233,82 & $-42,16$ & 275,98 & 84,29 & 148,92 & 148,92 & 1,64 & 779,62 & 86,31 & 42,85 & 18,61 & 228,66 & 145,29 & 145,29 & 205,86 \\
\hline Hyla molleri & 30TWM06 & $\begin{array}{l}100,00 \\
\end{array}$ & 91,56 & 106,05 & 38,00 & 5817,45 & 252,79 & $-21,79$ & 274,57 & \begin{tabular}{|r|}
107,69 \\
\end{tabular} & \begin{tabular}{|l|}
169,41 \\
\end{tabular} & 169,41 & 21,56 & \begin{tabular}{|l|l|}
661,18 \\
\end{tabular} & 73,31 & 35,29 & 19,10 & 193,37 & 124,01 & 124,21 & 174,34 \\
\hline Hyla molleri & 30TWM07 & 100,00 & $\mid$ & 104,27 & 38,01 & $\begin{array}{l}301,45 \\
5708,69\end{array}$ & 230,51 & $\mid-39,31$ & \begin{tabular}{|l|}
269,82 \\
\end{tabular} & \begin{tabular}{|c|}
84,63 \\
\end{tabular} & \begin{tabular}{|l|}
$148,01,01$ \\
\end{tabular} & 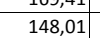 & $\begin{array}{r}\mid 1,20 \\
3,28\end{array}$ & \begin{tabular}{|c|}
811,61 \\
81,61
\end{tabular} & \begin{tabular}{|l|}
87,62 \\
87,2
\end{tabular} & $\mid$ & \begin{tabular}{|l|}
18,14 \\
18,
\end{tabular} & 234,22 & \begin{tabular}{|l}
152,51 \\
152,54
\end{tabular} & \begin{tabular}{|l|}
152,54 \\
152,54
\end{tabular} & 216,71 \\
\hline Hyla molleri & 30TWM08 & 100,00 & 89,97 & 103,04 & 38,06 & 5672,90 & 245,93 & $-20,14$ & 266,06 & 100,88 & 165,91 & 165,91 & 21,54 & 712,04 & 76,42 & 38,20 & 18,40 & 204,14 & 134,80 & 134,80 & 190,31 \\
\hline Hyla molleri & 30TWMO9 & $\begin{array}{l}100,00 \\
\end{array}$ & \begin{tabular}{ll|}
110,86 \\
1
\end{tabular} & \begin{tabular}{|c|}
98,72 \\
98,72
\end{tabular} & 37,98 & 5573,69 & 258,66 & 1,71 & 256,95 & \begin{tabular}{|}
78,18 \\
78
\end{tabular} & \begin{tabular}{|l|l|l}
184,26 \\
\end{tabular} & |184,34 & 42,14 & 629,40 & $60,6,34$ & 32,35 & 18,93 & $\mid 182,56$ & $\begin{array}{l}120,69 \\
\end{array}$ & $\begin{array}{l}120,69 \\
120\end{array}$ & 168,21 \\
\hline Hyla molleri & 30TWM11 & 100,00 & 103,61 & 112,07 & 38,00 & 6125,34 & 273,87 & $-17,73$ & 291,61 & 122,12 & 185,23 & 185,33 & 29,68 & 541,47 & 63,54 & 26,93 & 21,18 & 163,32 & 98,87 & 104,65 & 139,26 \\
\hline Hyla molleri & 30TWM12 & 100,00 & $\begin{array}{r}97,65 \\
9\end{array}$ & 111,98 & 38,00 & 6063,67 & 267,47 & $-22,53$ & 290,01 & 115,41 & 178,63 & \begin{tabular}{|l|l|}
178,69 \\
\end{tabular} & 24,68 & 582,73 & 67,62 & 30,02 & 20,29 & 174,84 & \begin{tabular}{|r|}
107,47 \\
\end{tabular} & 111,59 & 151,12 \\
\hline Hyla molleri & 30TWM13 & 100,00 & 96,87 & 111,31 & 38,04 & 6017,11 & 265,36 & $-22,23$ & 287,59 & 114,39 & 177,16 & 177,21 & 24,34 & 596,68 & 68,64 & 31,22 & 19,93 & 178,25 & $\mid$ & 114,29 & 155,30 \\
\hline Hyla molleri & 30TWM14 & 100,00 & 79,04 & 109,12 & 38,02 & 5905,41 & 245,44 & $-36,45$ & 281,89 & 94,44 & 158,69 & 158,69 & 9,01 & 716,27 & 80,58 & 38,98 & 18,83 & 211,92 & 133,97 & 134,53 & 188,09 \\
\hline Hyla molleri & 30TWM15 & 100,00 & 68,97 & 107,08 & 38,02 & 5817,98 & 232,96 & $-43,81$ & 276,77 & 83,09 & 147,78 & 147,78 & 0,49 & 794,58 & 87,97 & 44,08 & 18,21 & 233,03 & 149,38 & 149,38 & 209,87 \\
\hline Hyla molleri & 30TWM16 & 100,00 & 80,61 & \begin{tabular}{|l|}
106,79 \\
\end{tabular} & 38,04 & 5796,00 & 242,94 & $-32,60$ & 275,54 & 95,78 & 158,64 & 158,64 & 11,50 & 737,33 & 81,18 & $40,3 \varepsilon$ & 18,32 & 215,15 & 139,25 & 139,33 & 195,45 \\
\hline Hyla molleri & 30TWM17 & 100,00 & 93,83 & 105,35 & 38,08 & 5763,45 & 252,61 & $-19,24$ & 271,85 & 110,11 & 170,63 & 170,63 & 24,09 & 674,93 & $\begin{array}{l}74,07 \\
7\end{array}$ & 36,31 & 18,55 & 196,01 & 128,47 & 128,65 & 178,33 \\
\hline Hyla molleri & 30TWM18 & 100,00 & \begin{tabular}{|l|l|}
110,04 \\
\end{tabular} & 102,28 & 38,03 & 5706,21 & 262,98 & $-2,26$ & 265,24 & 124,43 & 185,29 & 185,29 & 39,92 & 602,75 & 65,87 & 31,60 & 18,93 & 173,77 & 116,27 & 116,44 & 157,84 \\
\hline Hyla molleri & 30TWM20 & 100,00 & 108,08 & 113,43 & 38,00 & 6181,40 & 279,25 & $-15,51$ & 294,77 & 127,45 & $\begin{array}{l}190,08 \\
\end{array}$ & \begin{tabular}{|l|}
190,28 \\
\end{tabular} & 33,06 & 515,06 & 61,47 & 25,51 & 21,60 & 156,53 & \begin{tabular}{|l|}
94,49 \\
\end{tabular} & 100,55 & 131,18 \\
\hline Hyla molleri & 30TWM22 & 100,00 & 96,86 & 113,61 & 38,16 & 6066,54 & 268,07 & $-24,41$ & 292,48 & 114,77 & 177,89 & 177,97 & 24,04 & 594,34 & 68,98 & 31,16 & 19,96 & 178,36 & 111,02 & 115,83 & 154,58 \\
\hline Hyla molleri & 30TWM23 & 100,00 & 100,11 & 113,02 & 38,1 & 6033,19 & 269,86 & $-20,79$ & 290,66 & 118,09 & 180,38 & 180,43 & 27,22 & 585,53 & 67,66 & 30,79 & 19,88 & 175,20 & 110,05 & 114,06 & 152,42 \\
\hline Hyla molleri & 30TWM24 & 100,00 & $\begin{array}{c}\mid c 11 \\
76,56\end{array}$ & 109,64 & 38,1 & 5900,86 & 243,23 & $-39,27$ & 282,50 & \begin{tabular}{|}
91,92 \\
91,0
\end{tabular} & $\begin{array}{l}156,19 \\
\end{array}$ & \begin{tabular}{|l|l|}
156,19 \\
\end{tabular} & $\begin{array}{r}\mid r, 25 \\
6,65 \\
\end{array}$ & 738,56 & 83,14 & 40,72 & $\begin{array}{l}18,50 \\
18,55\end{array}$ & 218,56 & $\begin{array}{l}139,47 \\
\end{array}$ & 140,34 & 193,94 \\
\hline Hyla molleri & 30TWM25 & 100,00 & 68,24 & 45 & 38,15 & 5819,86 & 232,22 & $-45,10$ & 277,32 & 82,59 & \begin{tabular}{|l|}
147,03 \\
\end{tabular} & \begin{tabular}{|l|}
147,03 \\
\end{tabular} & $-0,29$ & 807,14 & 89,42 & 45,16 & 17,94 & 236,86 & 153,03 & 153,23 & 212,90 \\
\hline Hyla molleri & 30TWM26 & 100,00 & 88,12 & 108,23 & 38,21 & 5828,86 & 251,09 & $-27,02$ & 278,11 & \begin{tabular}{|l|}
104,26 \\
\end{tabular} & \begin{tabular}{|l|}
166,05 \\
\end{tabular} & 166,05 & 18,05 & 698,10 & $\mid \frac{\mid 30,42}{77,51}$ & 38,12 & 18,28 & 204,48 & \begin{tabular}{|l}
132,99 \\
\end{tabular} & $\begin{array}{l}133,36 \\
\end{array}$ & 184,37 \\
\hline Hyla molleri & 30TWM27 & 100,00 & 91,55 & 106,67 & 38,27 & 5774,84 & 251,68 & $-22,38$ & 274,06 & 107,79 & 168,63 & 168,63 & 21,84 & 694,45 & 76,45 & 37,87 & 18,18 & 202,16 & 133,02 & 133,16 & 183,65 \\
\hline Hyla molleri & 30TWM28 & 100,00 & 99,88 & 104,49 & 38,32 & 5719,76 & 255,82 & $-12,94$ & 268,76 & 116,42 & 175,71 & 175,71 & 30,24 & 666,60 & 72,70 & 36,00 & 18,18 & 192,58 & 128,78 & 128,95 & 175,86 \\
\hline Hyla molleri & 30TWM29 & \begin{tabular}{|l}
100,00 \\
\end{tabular} & \begin{tabular}{|}
50,00 \\
120,41 \\
\end{tabular} & \begin{tabular}{|}
100,40 \\
100,10
\end{tabular} & $\begin{array}{l}30,022 \\
38,02\end{array}$ & 5642,81 & 20 & $\begin{array}{r}\mid \\
8,30\end{array}$ & \begin{tabular}{|l|}
259,78 \\
\end{tabular} & \begin{tabular}{|l|}
117,56 \\
117
\end{tabular} & \begin{tabular}{|l|}
194,07 \\
\end{tabular} & \begin{tabular}{|l|l|l|l|l|}
194,07 \\
\end{tabular} & $\begin{array}{l}50,24 \\
50,30\end{array}$ & $\mid$ & 62,10 & 290,95 & \begin{tabular}{|l|}
18,94 \\
18,94
\end{tabular} & \begin{tabular}{|l|l|l|l|l|}
165,38 \\
\end{tabular} & \begin{tabular}{|l|}
113,07 \\
1207
\end{tabular} & 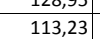 & $\begin{array}{l}147,00 \\
14,71\end{array}$ \\
\hline Hyla molleri & 30TWM30 & 100,00 & 104,56 & $\begin{array}{l}115,04 \\
\end{array}$ & 38,02 & 6178,03 & 277,30 & $-19,92$ & 297,21 & 123,75 & \begin{tabular}{|l|}
186,70 \\
\end{tabular} & 186,90 & 29,64 & 537,74 & 64,31 & 27,47 & 21,05 & \begin{tabular}{|l|}
163,83 \\
\end{tabular} & 100,23 & 106,71 & 137,27 \\
\hline Hyla molleri & 30TWM31 & 100,00 & 103,45 & 115,62 & 38,23 & 6134,85 & 276,37 & $-20,69$ & 297,06 & 122,47 & 184,84 & 185,21 & 29,02 & 554,93 & 65,48 & 28,72 & 20,44 & 167,84 & 104,20 & 110,61 & 143,26 \\
\hline Hyla molleri & 30TWM32 & 100,00 & 100,33 & 52 & 38,74 & 6085,66 & 272,95 & $-22,7$ & 295,66 & 118,86 & 181,43 & 181,54 & 26,86 & 582,24 & 67,90 & 30,5 & $19, \mathrm{~s}$ & 175,02 & 110,07 & 115,38 & 151,54 \\
\hline Hyla molleri & 30TWM33 & 100,00 & 99, & 114 & 38, & 6039 & 269 & $-22,77$ & 292,75 & 111 & 179,49 & 179,60 & 26 & 597 & 69,21 & 31 , & 19,53 & 179,08 & 113,60 & 119,15 & 155,93 \\
\hline Hyla molleri & 30TWM34 & 100,00 & 85,60 & 111,58 & 38,56 & 5936,16 & 253,40 & $-32,75$ & 286,15 & 102,03 & 165,18 & 165,19 & 14,49 & 689,98 & 78,33 & 37,81 & 18,55 & 204,94 & 131,59 & 133,87 & 180,82 \\
\hline Hyla molleri & 30TWM 35 & 100,00 & 73,56 & 108,60 & 38,32 & 5840,88 & 238,10 & $-41,36$ & 279,45 & \begin{tabular}{|l|}
88,67 \\
\end{tabular} & 152,30 & 152,30 & 4,19 & \begin{tabular}{|l|l|}
778,78 \\
\end{tabular} & 86,81 & 43,56 & 17,84 & 229,28 & 148,81 & \begin{tabular}{|l|l|}
149,08 \\
\end{tabular} & 205,05 \\
\hline Hyla molleri & 30TWM36 & 100,00 & 86,13 & 108,96 & 38,61 & 5831,72 & 249,59 & $-29,72$ & 279,31 & 102,28 & 164,16 & 164,16 & 16,16 & 717,70 & 79,76 & 39,59 & 18,01 & 210,42 & 137,64 & 138,29 & 189,70 \\
\hline Hyla molle & 30TWM37 & 100,00 & 96,07 & \begin{tabular}{|l|l|}
107,64 \\
\end{tabular} & 38,5 & 5802,31 & 256,53 & $-19,25$ & 275,78 & 113,14 & 173,14 & 173,14 & 8 & 672 & 74 & 36 & 18,16 & 196,71 & 129,78 & 130,72 & 176,85 \\
\hline Hyla molle & 30TW & 100 & & & 38,45 & 5753 & 257 & $\mid-12,79$ & 270,79 & 118,73 & 177,34 & 171 & 31,06 & 658 , & 72,71 & 35, & 18,21 & 191,93 & 128,10 & 128,79 & 172,10 \\
\hline Hyla molleri & 30TWM39 & 100,00 & \begin{tabular}{|l|}
119,79 \\
\end{tabular} & 101,93 & $\begin{array}{l}30,40 \\
38,06\end{array}$ & 5702,21 & 269 & 6,12 & 263,36 & 138,85 & $\begin{array}{l}194,02 \\
\end{array}$ & 194,02 & 48,82 & 563,84 & 63,13 & 30,29 & 19,03 & 164,95 & 112,64 & 113,63 & 142,30 \\
\hline Hyla molleri & 30TWM 40 & 100,00 & 106,05 & 115,52 & 38,05 & 6179,69 & 278,45 & $-19,45$ & 297,90 & 125,65 & 187,90 & 188,35 & 30,78 & 530,34 & 64,28 & 27,42 & 21,32 & 162,98 & 100,19 & 107,63 & 134,11 \\
\hline Hyla molleri & 30TWM41 & 100,00 & 105,43 & 116,28 & 38,43 & 6140,06 & 278,34 & $-19,78$ & 298,12 & 124,92 & 186,82 & 187,18 & 30,50 & 546,13 & 65,24 & 28,45 & 20,74 & 166,35 & 103,75 & 110,58 & 140,07 \\
\hline Hyla moll & 30TW & 10 & & & 38 & 6096,81 & 276 & $-20,97$ & 297,71 & 22,70 & 184,62 & 184,78 & 29,4 & 568 & 66 , & 29,94 & 19,90 & 171,65 & 108,52 & 115,21 & 147 \\
\hline Hyla molleri & 30TWM43 & 100,00 & $\begin{array}{l}101,74 \\
101,79\end{array}$ & 115,125 & \begin{tabular}{|l|l|}
38,91 \\
38,
\end{tabular} & $\begin{array}{l}60050,05 \\
6050\end{array}$ & 273,08 & $-21,62$ & \begin{tabular}{|l|}
294,71 \\
\end{tabular} & 120,42 & 182,06 & 182,21 & 28,19 & 586,40 & 68,46 & 31,32 & 19,54 & 176,49 & 112,42 & 119,54 & 152,32 \\
\hline
\end{tabular}




\begin{tabular}{|c|c|c|c|c|c|c|c|c|c|c|c|c|c|c|c|c|c|c|c|c|c|}
\hline TAXON & UTM & km2 & BIO1 & B102 & BIO3 & 8104 & B105 & B106 & B107 & B108 & B109 & BIO10 & B1011 & BIO12 & B1O13 & B1014 & 81015 & B1016 & BIO17 & B1018 & B1019 \\
\hline Hyla molleri & 30TWM44 & 100,00 & 91,01 & 112,88 & 38,79 & 5964,44 & 259,40 & $-29,18$ & 288,57 & 108,27 & 170,54 & 170,55 & 19,05 & 662,31 & 75,82 & 36,30 & 18,65 & 197,60 & 127,36 & 131,80 & 173,05 \\
\hline Hyla molleri & 30TWM45 & 100,00 & 82,08 & 110,24 & 38,58 & 5878,70 & 247,42 & $-35,12$ & 282,54 & 98,21 & \begin{tabular}{|l|}
160,86 \\
\end{tabular} & \begin{tabular}{|l|}
160,86 \\
\end{tabular} & 11,45 & 731,03 & 82,29 & 40,77 & 17,89 & 216,24 & \begin{tabular}{|l|l|}
140,76 \\
\end{tabular} & \begin{tabular}{|l|l|}
141,49 \\
\end{tabular} & 191,97 \\
\hline Hyla molleri & 30TWM46 & 100,00 & 80,56 & 108,70 & 38,54 & 5819,04 & 243,60 & $-34,96$ & 278,56 & \begin{tabular}{|l|l|}
96,40 \\
\end{tabular} & 158,60 & 158,60 & 10,80 & 757,90 & 84,18 & 42,44 & 17,65 & 222,38 & 146,11 & 146,57 & 200,06 \\
\hline Hyla molleri & 30TWM47 & 100,00 & 97,51 & 108,40 & 38,58 & 5830,24 & 258,38 & $-19,01$ & 277,40 & \begin{tabular}{|l|l|}
115,15 \\
\end{tabular} & \begin{tabular}{|l|l|}
174,78 \\
\end{tabular} & \begin{tabular}{|l|l|}
174,78 \\
\end{tabular} & 26,59 & 667,01 & 74,69 & 36,66 & 18,24 & 196,31 & 129,31 & 130,20 & 174,48 \\
\hline Hyla molleri & 30TWM48 & 100,00 & 105,81 & 106,21 & 38,58 & 5790,45 & 262,59 & $-9,79$ & 272,38 & \begin{tabular}{|l|l|}
124,10 \\
\end{tabular} & \begin{tabular}{|l|l|}
181,99 \\
\end{tabular} & \begin{tabular}{|l|l|}
181,99 \\
\end{tabular} & 34,73 & \begin{tabular}{|l|l|}
631,48 \\
\end{tabular} & 70,85 & 34,70 & 18,56 & \begin{tabular}{|l|l|}
185,93 \\
\end{tabular} & 123,74 & 124,95 & $\begin{array}{ll}162,81 \\
\end{array}$ \\
\hline Hyla molleri & 30TWM49 & 100,00 & 126,24 & 102,65 & 38,02 & 5775,38 & 276,19 & 10,47 & 265,72 & 146,67 & 195,92 & 200,91 & 54,01 & 508,37 & 59,42 & 27,88 & 20,34 & 153,06 & 104,01 & 107,40 & 122,04 \\
\hline Hyla molleri & 30TWM50 & 100,00 & 107,07 & 115,01 & 38,01 & 6181,32 & 278,07 & $-18,90$ & 296,97 & 127,18 & 188,72 & 189,23 & 31,86 & 520,60 & 64,27 & 27,27 & 21,79 & 162,18 & 99,62 & 107,97 & 129,36 \\
\hline Hyla molleri & 30TWM51 & 100,00 & 106,51 & 115,54 & 38,41 & 6147,29 & 277,73 & $-19,11$ & 296,84 & 126,08 & 187,71 & 187,97 & 31,51 & 535,59 & 65,18 & 28,19 & 21,02 & 165,40 & \begin{tabular}{|c|}
102,76 \\
\end{tabular} & 110,74 & 134,96 \\
\hline Hyla molleri & 30TWM52 & 100,00 & 101,71 & 115,63 & 38,63 & 6093,30 & 273,15 & $-22,72$ & 295,87 & \begin{tabular}{|l|l|}
120,85 \\
\end{tabular} & 182,51 & 182,69 & 27,64 & 574,92 & 68,56 & 30,83 & 20,09 & \begin{tabular}{|l|}
175,47 \\
\end{tabular} & 110,84 & 118,72 & $\begin{array}{l}147,09 \\
\end{array}$ \\
\hline Hyla molleri & 30TWM53 & 100,00 & 99,08 & 114,75 & 38,75 & 6046,90 & 269,09 & $-24,29$ & 293,38 & \begin{tabular}{|l|l|}
117,79 \\
\end{tabular} & \begin{tabular}{|l|l|}
179,33 \\
\end{tabular} & \begin{tabular}{|l|l|}
179,43 \\
\end{tabular} & 25,55 & \begin{tabular}{|l|l|}
601,88 \\
\end{tabular} & 70,87 & 32,60 & 19,51 & 182,47 & 116,30 & 123,77 & 154,95 \\
\hline Hyla molleri & 30TWM54 & 100,00 & 84,73 & 111,67 & 38,62 & 5938,56 & 251,56 & $-34,74$ & 286,30 & 101,62 & 164,07 & 164,10 & 13,18 & 701,31 & 80,52 & 39,10 & 18,36 & 210,06 & 135,73 & 139,05 & 182,08 \\
\hline Hyla molleri & 30TWM55 & 100,00 & 88,05 & 110,97 & 38,73 & 5908,63 & 253,33 & $-30,57$ & 283,90 & 105,21 & \begin{tabular}{|l|l|}
166,83 \\
\end{tabular} & 166,84 & 16,68 & \begin{tabular}{|l|l|}
696,33 \\
\end{tabular} & 79,36 & 38,76 & 18,22 & 207,43 & 134,85 & \begin{tabular}{|l|l|}
136,98 \\
\end{tabular} & 181,61 \\
\hline Hyla molleri & 30TWM56 & 100,00 & 92,81 & 109,93 & 38,73 & 5880,87 & 255,93 & $-25,41$ & 281,34 & 110,30 & 170,93 & 170,93 & 21,33 & 683,68 & 77,52 & 37,95 & 18,29 & 202,97 & 132,50 & 134,67 & 178,30 \\
\hline Hyla molleri & 30TWM57 & 100,00 & 98,21 & 108,81 & 38,69 & 5848,62 & 259,01 & $-19,15$ & 278,16 & 116,20 & 175,60 & 175,60 & 26,84 & 668,28 & 75,31 & 36,92 & 18,31 & 197,56 & 129,69 & 131,56 & 174,25 \\
\hline Hyla molleri & 30TWM58 & 100,00 & 109,72 & 106,79 & 38,52 & 5832,45 & 266,50 & $-7,27$ & 273,77 & 128,72 & \begin{tabular}{|l|l|}
186,08 \\
\end{tabular} & 186,09 & 37,64 & \begin{tabular}{|c|}
609,73 \\
\end{tabular} & 69,41 & 33,60 & 18,94 & 181,50 & \begin{tabular}{|l|l|}
119,68 \\
\end{tabular} & 121,36 & 155,08 \\
\hline Hyla molleri & 30TWM61 & 100,00 & 104,70 & 114,36 & 38,02 & 6142,12 & 273,87 & $-21,08$ & 294,95 & \begin{tabular}{|l|l|}
124,69 \\
\end{tabular} & \begin{tabular}{|l|l|}
185,66 \\
\end{tabular} & 186,01 & 29,73 & 540,70 & 66,96 & 28,98 & 21,50 & 169,23 & 104,81 & 114,32 & 133,84 \\
\hline Hyla molleri & 30TWM62 & 100,00 & 99,40 & 114,24 & 38,26 & 6087,27 & 268,43 & $-25,07$ & 293,51 & 118,60 & 179,88 & 180,16 & 25,34 & 583,53 & 70,72 & 31,80 & 20,43 & 180,39 & 113,42 & 123,01 & 146,80 \\
\hline Hyla molleri & 30TWM63 & 100,00 & 91,97 & 112,84 & 38,32 & 6018,94 & 259,63 & $-30,03$ & 289,66 & 110,27 & 171,93 & 172,04 & 19,11 & 640,81 & 75,90 & 35,53 & 19,41 & 195,60 & 124,72 & 131,51 & 163,30 \\
\hline Hyla molleri & 30TWM65 & 100,00 & 91,99 & 111,00 & 38,69 & 5931,07 & 256,52 & $-27,79$ & 284,32 & 109,95 & 170,67 & 170,70 & 19,94 & \begin{tabular}{|l|}
673,25 \\
\end{tabular} & 77,72 & 37,49 & 18,67 & 202,23 & 130,87 & 134,42 & 173,94 \\
\hline Hyla molleri & 30TWM66 & 100,00 & 97,99 & 110,15 & 38,76 & 5916,93 & 260,65 & $-21,48$ & 282,12 & 116,42 & 176,20 & 176,23 & 25,69 & 653,75 & 75,19 & 36,20 & 18,76 & 195,80 & 126,85 & 130,21 & 168,89 \\
\hline Hyla molleri & 30TWM67 & 100,00 & 105,56 & 108,59 & 38,47 & 5898,47 & 265,38 & $-13,16$ & 278,54 & 124,65 & 183,04 & \begin{tabular}{|l|}
183,08 \\
\end{tabular} & 32,92 & 625,73 & 71,84 & 34, & 19,22 & 187,22 & 121,40 & 124,74 & 160,55 \\
\hline Hyla molleri & 30TWM68 & 100,00 & $\begin{array}{l}114,52 \\
\end{array}$ & \begin{tabular}{|l|}
106,87 \\
\end{tabular} & 38,35 & 5868,51 & 270,81 & $\begin{array}{l}-3,59 \\
\end{array}$ & 274,41 & $\begin{array}{l}134,39 \\
\end{array}$ & 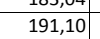 & \begin{tabular}{|l}
191,13 \\
\end{tabular} & 41,65 & 589,48 & 67,87 & 32,29 & 19,56 & \begin{tabular}{|l|l|l|l|l|}
176,80 \\
\end{tabular} & 1115,20 & 1118,20 & 148,52 \\
\hline Hyla molleri & 30TWM69 & 100,00 & 130,87 & 103,68 & 38,11 & 5811,44 & 280,87 & 13,60 & 267,27 & 151,81 & 205,82 & 205,84 & 57,84 & 516,60 & 59,99 & 28,08 & 20,37 & 156,31 & 103,10 & 106,02 & 123,92 \\
\hline Hyla molleri & 30TWM71 & 100,00 & 101,91 & 112,94 & 38,00 & 6127,89 & 268,84 & $-23,36$ & 292,20 & 121,79 & 182,53 & 182,80 & 26,99 & 551,28 & 69,26 & 30,10 & 22,04 & 174,53 & 107,93 & 118,84 & 134,36 \\
\hline Hyla molleri & 30TWM72 & 100,00 & 99,36 & 112,68 & 38,05 & 6087,58 & 266,03 & $-24,67$ & 290,70 & 119,00 & 179,66 & 179,81 & 25,04 & 578,93 & 71,36 & 31,90 & 21,09 & 181,13 & 113,30 & 123,71 & 143,23 \\
\hline Hyla molleri & 30TWM73 & $\begin{array}{l}100,00 \\
\end{array}$ & 98,35 & 112,10 & 38,12 & 6048,86 & 264,16 & $-24,80$ & 288,95 & \begin{tabular}{|l|}
117,78 \\
\end{tabular} & 178,12 & 178,32 & 24,46 & 600,17 & 72,80 & 33,19 & 20,39 & 185,91 & 117,19 & 126,24 & 150,12 \\
\hline Hyla molleri & 30TWM74 & 100,00 & | & 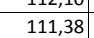 & $\frac{30,12}{38,15}$ & $\begin{array}{l}6003,000 \\
603,67\end{array}$ & \begin{tabular}{|l|l|l|l|l|l|}
268,88 \\
\end{tabular} & $\begin{array}{l}-24,00 \\
-18,07\end{array}$ & $\mid$ & $\begin{array}{l}1124,35 \\
\end{array}$ & \begin{tabular}{|l|l|l|l}
183,90 \\
\end{tabular} & 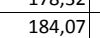 & $\begin{array}{l}24,40 \\
30,39\end{array}$ & $\mid$ & $\begin{array}{l}70,04 \\
70,0\end{array}$ & | & 20,70 & \begin{tabular}{|l|}
178,88 \\
178,8
\end{tabular} & \begin{tabular}{|l|l|l|}
112,50 \\
\end{tabular} & \begin{tabular}{|l|l|l|l|}
119,76 \\
\end{tabular} & 145,13 \\
\hline Hyla molleri & 30TWM75 & 100,00 & 105,81 & 110,60 & 38,19 & 6005,52 & 268,75 & $-15,87$ & 284,62 & 125,63 & \begin{tabular}{|c|}
184,67 \\
\end{tabular} & 184,71 & 31,91 & 589,35 & 70,32 & 32,27 & 20,32 & 180,49 & 114,13 & 120,21 & 148,72 \\
\hline Hyla molleri & 30TWM77 & 100,00 & 122,10 & 107,81 & 38,04 & 5973,97 & 279,65 & 1,33 & 278,32 & 143,23 & 199,55 & 199,65 & 47,51 & 536,37 & 63,52 & 28,69 & 20,92 & 163,45 & 103,33 & 108,63 & 133,39 \\
\hline Hyla molleri & 30TWM78 & 100,00 & 128,49 & 105,82 & 38,03 & 5904,04 & 282,21 & 9,08 & 273,14 & 149,75 & 204,79 & 204,81 & 54,47 & 533,57 & 61,81 & 28,16 & 20,74 & 160,44 & 102,74 & 106,73 & 132,77 \\
\hline Hyla molleri & 30TWM79 & 100,00 & 131,83 & $\begin{array}{l}103,92 \\
\end{array}$ & 38,15 & 5807,65 & 281,63 & 14,43 & 267,20 & $\begin{array}{l}148,30 \\
\end{array}$ & 206,70 & 206,71 & 58,81 & 559,05 & 62,46 & 29,22 & 20,09 & 164,46 & $\mid 107,43$ & 108,30 & 141,47 \\
\hline Hyla molleri & 30TWM81 & 100,00 & 95,19 & 111,13 & 38,00 & 6093,47 & 259,76 & $-28,84$ & 288,61 & 114,84 & 175,50 & 175,73 & 20,67 & 584,71 & 73,75 & 32,71 & 21,90 & 186,25 & 115,83 & 127,53 & 140,88 \\
\hline Hyla molleri & 30TWM82 & 100,00 & 93,96 & 110,92 & 38,00 & 6058,28 & 258,25 & $-29,35$ & 287,60 & 113,12 & $\begin{array}{l}173,90 \\
\end{array}$ & 173,96 & 19,82 & 607,35 & 75,29 & 34,08 & 21,12 & 191,30 & 119,85 & 131,13 & 148,50 \\
\hline Hyla molleri & 30TWM83 & 100,00 & 102,29 & 111,08 & 38,01 & 6063,83 & 266,08 & $-21,32$ & 287,40 & 122,23 & 181,75 & 182,01 & 27,54 & 575,06 & 71,24 & 31,73 & 21,45 & 180,48 & 112,34 & 123,17 & \begin{tabular}{|l|l|}
141,63 \\
\end{tabular} \\
\hline Hyla molleri & 30TWM84 & 100,00 & 112,56 & 110,32 & 38,00 & 6074,30 & 274,85 & $-10,78$ & 285,63 & 133,44 & 191,83 & |191,95 & 37,15 & 536,46 & 66,46 & 28,8 & 22,0 & 167,91 & 103,46 & 111,82 & 132,19 \\
\hline Hyla molleri & 30TWM85 & 100,00 & \begin{tabular}{|l|}
120,81 \\
\end{tabular} & 109,32 & 38,00 & 6070,69 & 281,26 & $-2,30$ & 283,56 & 142,39 & \begin{tabular}{|l|l|}
199,63 \\
\end{tabular} & \begin{tabular}{|l|l|}
199,70 \\
\end{tabular} & 45,06 & 512,43 & 63,00 & 27,03 & 22,39 & 159,30 & \begin{tabular}{|}
97,77 \\
\end{tabular} & \begin{tabular}{|l|l|l|l|l|l|}
106,13 \\
\end{tabular} & 126,51 \\
\hline Hyla molleri & 30TWM87 & 100,00 & 128,35 & 107,02 & 38,02 & 5975,87 & 284,11 & 7,13 & 276,98 & 149,45 & 205,52 & 205,54 & 53,25 & 532,35 & 62,14 & 27,45 & 21,42 & 160,02 & 100,23 & 104,59 & 134,85 \\
\hline Hyla molleri & 30TWM88 & 100,00 & 134,35 & 105,10 & 38,04 & 5889,37 & 286,21 & 14,87 & 271,33 & 132,12 & 210,31 & 210,31 & 60,31 & 546,65 & 61,38 & 27,62 & 21,02 & $\mid$ & 102,44 & \begin{tabular}{|l|l|}
104,23 \\
\end{tabular} & 141,00 \\
\hline Hyla molleri & 30TWM91 & 100,00 & 87,84 & 108,99 & 37,95 & 6050,08 & 249,71 & $-35,05$ & 284,76 & 106,85 & 167,60 & 167,79 & 13,94 & 624,44 & 78,82 & 35,82 & 21,71 & 199,61 & 125,27 & 139,48 & 148,70 \\
\hline Hyla molleri & 30TWM92 & 100,00 & 72,64 & 106,71 & 37,77 & 5954,64 & 233,16 & $-46,25$ & 279,41 & 89,69 & 152,01 & 152,06 & 0,86 & 739,71 & 89,38 & 43,41 & 19,55 & 230,16 & 148,20 & 155,56 & 180,58 \\
\hline Hyla molleri & 30TWM93 & 100,00 & \begin{tabular}{|l|l|l|l|l|}
108,87 \\
\end{tabular} & 109,70 & 38,00 & 6087,02 & 270,50 & - & 285,53 & \begin{tabular}{|l|l|}
129,85 \\
\end{tabular} & |188,27 & 188,40 & 33,36 & 539,83 & $\mid 68,31$ & $\begin{array}{l}295,41 \\
29,3\end{array}$ & 22,86 & 171,31 & $\begin{array}{l}104,81 \\
\end{array}$ & 115,50 & 130,99 \\
\hline Hyla molleri & 30TWM94 & 100,00 & 11 & 109,32 & 38,00 & 6088,93 & 277,28 & $-6,85$ & \begin{tabular}{|l|l|}
284,12 \\
\end{tabular} & \begin{tabular}{|l|l|}
138,12 \\
\end{tabular} & 195,80 & 195,84 & 40,77 & 518,92 & 65,08 & 27,44 & 23,06 & 163,27 & 99,03 & 108,04 & 127,24 \\
\hline Hyla molleri & 30TWM97 & 100,00 & $\begin{array}{l}135,62 \\
\end{array}$ & 105,89 & 38,00 & 5954,58 & 289,29 & 14,64 & 20 & 134,12 & 212,38 & 212,38 & 60,68 & 530,99 & 60 & 26,04 & 22,04 & 156,61 & 97,62 & 99,75 & 138,13 \\
\hline Hyla molleri & 30TWM99 & 100,00 & \begin{tabular}{|l|}
131,07 \\
\end{tabular} & 104,91 & 38,25 & 5841,19 & 282,14 & 12,33 & 269,81 & 95,75 & 206,50 & 206,50 & 57,70 & 635,06 & 70,00 & 31,24 & 21,29 & 189,54 & \begin{tabular}{|l|}
114,88 \\
\end{tabular} & 115,15 & 174,14 \\
\hline Hyla molleri & 30TWN02 & 100,00 & 122,30 & 88,59 & 37,80 & 5134,56 & 253,13 & 21,27 & \begin{tabular}{|l|l|}
231,85 \\
\end{tabular} & 92,57 & 188,13 & 189,59 & 58,65 & 725,80 & 80,04 & 34,78 & 20,01 & 221,58 & 134,57 & 139,36 & 206,13 \\
\hline Hyla molleri & 30TWN04 & \begin{tabular}{|l}
100,00 \\
\end{tabular} & \begin{tabular}{|l|l|l|l|l}
108,15 \\
\end{tabular} & \begin{tabular}{|l|l|}
86,939 \\
86,9
\end{tabular} & $\begin{array}{l}37,00 \\
37,99\end{array}$ & $\begin{array}{l}1972,08 \\
4972,08\end{array}$ & $\mid \frac{237,43}{237,41}$ & $\begin{array}{l}21,27 \\
11,42\end{array}$ & $\begin{array}{l}225,05 \\
225,99\end{array}$ & 52,08 & $\begin{array}{l}100,13 \\
172,15\end{array}$ & \begin{tabular}{|l|}
174,14 \\
174,14
\end{tabular} & $\begin{array}{l}30,003 \\
47,45\end{array}$ & $\begin{array}{l}88,01,71 \\
88\end{array}$ & $\mid \begin{array}{l}\mid \\
98,74\end{array}$ & 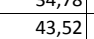 & \begin{tabular}{|l|l|}
19,67 \\
\end{tabular} & 271,40 & \begin{tabular}{|l|}
163,24 \\
163
\end{tabular} & \begin{tabular}{|l|}
168,67 \\
1687
\end{tabular} & 255,44 \\
\hline Hyla molleri & 30TWN05 & 100,00 & & 83,25 & 37,86 & 4804,25 & 234,88 & 17,47 & 217,42 & 60,22 & 172,58 & 174,81 & 52,45 & \begin{tabular}{|l|l|}
940,18 \\
\end{tabular} & 107,73 & 45,27 & 20,77 & 294,35 & 170,42 & 179,21 & 278,61 \\
\hline Hyla molleri & 30TWN06 & 100,00 & 120,93 & 76,99 & 37,38 & 4558,16 & 235,22 & 31,95 & 203,28 & \begin{tabular}{|l|l|}
72,35 \\
\end{tabular} & \begin{tabular}{|l|l}
178,65 \\
\end{tabular} & \begin{tabular}{|l|l|}
181,13 \\
\end{tabular} & 65,04 & \begin{tabular}{|c|}
998,87 \\
\end{tabular} & 119,07 & 45,23 & 23,21 & 320,68 & \begin{tabular}{|l|l|}
173,37 \\
\end{tabular} & 188,61 & 308,02 \\
\hline Hyla molleri & 30TWN08 & 100,00 & 79 & 67,22 & 36,46 & 4178,09 & 230,99 & 49 & 181,86 & 84 & 182,80 & 185,90 & 79,4 & 1139,08 & 144,30 & 47, & 27,5 & 380,12 & 184,84 & 211,30 & 374,92 \\
\hline Hyla molleri & 30 TWN10 & 100,00 & 12 & 95 & 38,00 & 5462 & 26 & 13, & 249,18 & 88,99 & 192,30 & \begin{tabular}{|l|l|}
192,78 \\
\end{tabular} & 53 & \begin{tabular}{|l}
617,79 \\
\end{tabular} & \begin{tabular}{|l|}
64,51 \\
\end{tabular} & 31, & 18, & \begin{tabular}{|l|l|l|}
181,58 \\
\end{tabular} & \begin{tabular}{|l|}
120,47 \\
\end{tabular} & 120,61 & 165,39 \\
\hline Hyla molleri & 30TWN11 & 100,00 & 121,17 & 92,97 & 38,03 & 5325,25 & 258,05 & 16,19 & 241,87 & 87,30 & 189,92 & 190,83 & 55,10 & 671,24 & 71,31 & 33,48 & 19,01 & 200,12 & 129,18 & 130,57 & 183,99 \\
\hline Hyla molleri & 30TWN14 & 100,00 & 114,06 & 86,70 & 38,04 & 4951,83 & 242,09 & 17,31 & 224,79 & 60,66 & \begin{tabular}{|l|l|l|}
177,48 \\
\end{tabular} & 179,45 & 53,44 & 873,38 & $\begin{array}{l}97,76 \\
\end{array}$ & 42,79 & 19,69 & 268,69 & 161,95 & \begin{tabular}{|l|l|}
167,58 \\
\end{tabular} & 253,84 \\
\hline Hyla molleri & 30TWN15 & 100,00 & 110,09 & 85,02 & 38,03 & 4845,20 & 235,85 & 15,60 & 220,25 & \begin{tabular}{|l|l|}
58,25 \\
\end{tabular} & 172,10 & 174,23 & 51,07 & 950,45 & 107,55 & 46,56 & 19,95 & 295,50 & 174,82 & 181,79 & 279,59 \\
\hline Hyla molle & 30TWN & 100,00 & 126,10 & 96,62 & 38,00 & 5507,50 & 267 & 16,71 & 250,77 & 94,30 & 197,64 & 197,75 & 57,42 & 585,64 & 61,8 & 29, & 18 & 170,90 & 116,21 & 116,25 & 153,13 \\
\hline Hyla molle & 30 TWN21 & 100,00 & & & 38, & 5416,8 & & 4,19 & 248,79 & 66,36 & 182,05 & 182,15 & 44,2 & 711,86 & 74 & 37 & & 207,94 & 138,90 & 138,90 & 192 \\
\hline Hyla molleri & 30 TWN23 & 100,00 & 112,54 & 91,62 & 38,28 & 5147,34 & 246,88 & 11,33 & 235,56 & 60,18 & 178,85 & 180,25 & 49,36 & 813,72 & 88,10 & 41,36 & 18,36 & 244,33 & 156,34 & 157,56 & 229,17 \\
\hline Hyla molleri & 30TWN24 & 100,00 & 119,93 & 86,90 & 38,16 & 4940,64 & 247,10 & 22,81 & 224,29 & 66,12 & \begin{tabular}{|l|l|}
182,88 \\
\end{tabular} & \begin{tabular}{|l|l|}
184,78 \\
\end{tabular} & $|59,15|$ & 862,41 & $|95,99|$ & $42,06 \mid$ & \begin{tabular}{|l|l|}
19,59 \\
\end{tabular} & 264,73 & $\mid 160,61$ & 165,94 & 250,16 \\
\hline Hyla molleri & 30TWN25 & 100,00 & 117,45 & 84,69 & 38,13 & 4802,05 & 241,38 & 23,20 & 218,18 & 65,44 & 178,44 & 180,66 & 58,75 & \begin{tabular}{|l|l|}
945,48 \\
\end{tabular} & 107,01 & 45,75 & 20,05 & 294,32 & 173,45 & 180,86 & 279,21 \\
\hline Hyla moll & 30TW & 100,00 & 113 & 82, & 38, & 4690,10 & 23 & 21, & 213,27 & 62,92 & 172,61 & 175,10 & 56,1 & 1031 , & 118 & 49, & 20,60 & 324 & 18 & 196,33 & 308 \\
\hline Hyla molleri & 30 TWN28 & 100,00 & 132,12 & $\mid \frac{\mid l, 50}{71,51}$ & 37,82 & 4217,71 & $\mid$ & 50,52 & $\mid$ & 86,93 & \begin{tabular}{|l|l|l|}
184,41 \\
\end{tabular} & 187,61 & $\begin{array}{l}0,1,1 \\
81,19\end{array}$ & 1160,03 & \begin{tabular}{|l|}
142,02 \\
\end{tabular} & $\begin{array}{l}45,32 \\
50,33\end{array}$ & 25,43 & 382,14 & $\begin{array}{l}10,44,445 \\
194\end{array}$ & 216,73 & $\begin{array}{l}30,42,79 \\
377,79\end{array}$ \\
\hline
\end{tabular}




\begin{tabular}{|c|c|c|c|c|c|c|c|c|c|c|c|c|c|c|c|c|c|c|c|c|c|}
\hline$\overline{\text { TAXON }}$ & UTM & $\mathrm{km} 2$ & BIO1 & BIO2 & $\begin{array}{l}\mathrm{BIO3} \\
\end{array}$ & BIO4 & B105 & B106 & B107 & B108 & B109 & BIO10 & BIO11 & BIO12 & B1013 & B1014 & B1015 & B1016 & B1017 & BIO18 & B1019 \\
\hline Hyla molleri & 30TWN31 & 100,00 & 112,62 & 98,18 & 38,56 & 5463,45 & $\begin{array}{r}255,92 \\
\end{array}$ & 4,41 & 251,51 & 69,11 & 184,18 & 184,18 & 45,19 & 698,07 & 73,03 & 37,09 & 17,75 & 201,94 & 137,27 & 137,27 & 186,42 \\
\hline Hyla molleri & 30TWN32 & 100,00 & 108,82 & 96,39 & 38,76 & 5341,01 & 249,64 & 3,40 & 246,24 & 51,29 & 179,08 & 179,08 & 43,24 & 775,71 & 81,65 & 40,84 & 17,59 & 227,76 & 150,97 & 150,97 & 212,72 \\
\hline Hyla molleri & 30TWN33 & 100,00 & 103,56 & 94,58 & 38,90 & 5221,61 & 242,10 & 1,07 & 241,03 & 47,20 & $\begin{array}{l}172,36 \\
\end{array}$ & \begin{tabular}{|l|}
172,57 \\
\end{tabular} & 39,87 & \begin{tabular}{|l|l|}
862,93 \\
\end{tabular} & $\begin{array}{l}92,57 \\
\end{array}$ & \begin{tabular}{|l|}
45,23 \\
\end{tabular} & $\begin{array}{l}17,73 \\
\end{array}$ & 257,56 & 166,55 & \begin{tabular}{ll|}
166,66 \\
\end{tabular} & 241,63 \\
\hline Hyla molleri & 30TWN34 & 100,00 & 118,90 & 89,15 & 38,76 & 4985,27 & 248,45 & 20,54 & 227,91 & $\begin{array}{l}64,53 \\
\end{array}$ & 182,50 & \begin{tabular}{|l|}
184,28 \\
\end{tabular} & $\begin{array}{ll}57,72 \\
\end{array}$ & \begin{tabular}{|l|}
871,82 \\
\end{tabular} & \begin{tabular}{l|l}
95,63 \\
\end{tabular} & 43,42 & $\begin{array}{l}18,82 \\
\end{array}$ & 265,85 & 165,05 & \begin{tabular}{|l|l|}
168,09 \\
\end{tabular} & 249,88 \\
\hline Hyla molleri & 30TWN35 & 100,00 & 112,87 & 87,58 & 38,92 & 4872,46 & 240,42 & 17,16 & 223,26 & 60,24 & 175,05 & 177,12 & 53,48 & 969,30 & 108,05 & 48,34 & 19,18 & 299,53 & 181,38 & 185,61 & 282,65 \\
\hline Hyla molleri & 30TWN36 & 100,00 & \begin{tabular}{|l|}
118,93 \\
\end{tabular} & 83,30 & 38,89 & 4648,14 & 239,72 & 27,74 & 211,98 & $\begin{array}{ll}68,82 \\
\end{array}$ & \begin{tabular}{|l|}
177,68 \\
\end{tabular} & \begin{tabular}{|l|l|}
180,22 \\
\end{tabular} & \begin{tabular}{ll|}
62,58 \\
\end{tabular} & $\begin{array}{l}1040,38 \\
\end{array}$ & 118,56 & 50,06 & 20,62 & 327,62 & \begin{tabular}{|l|}
188,78 \\
\end{tabular} & \begin{tabular}{|l|l|}
197,71 \\
\end{tabular} & 311,32 \\
\hline Hyla molleri & 30TWN40 & 100,00 & 128,64 & 100,21 & 38,06 & 5669,25 & 273,99 & 15,27 & 258,73 & 148,38 & 191,98 & 201,80 & 57,55 & 533,26 & 60,36 & 29,04 & 19,70 & 156,83 & \begin{tabular}{|l|l|}
109,49 \\
\end{tabular} & 112,01 & 130,23 \\
\hline Hyla molleri & 30TWN41 & 100,00 & 113,05 & 99,65 & 38,75 & 5511,61 & 257,95 & \begin{tabular}{l|l}
3,55 \\
\end{tabular} & 254,40 & 78,84 & 185,14 & \begin{tabular}{|l|}
185,14 \\
\end{tabular} & \begin{tabular}{|l|}
44,99 \\
\end{tabular} & 697,21 & 73,21 & \begin{tabular}{|l|}
37,48 \\
\end{tabular} & \begin{tabular}{|l|}
17,57 \\
\end{tabular} & 200,54 & \begin{tabular}{|l|l|}
137,18 \\
\end{tabular} & \begin{tabular}{|l|l|}
137,18 \\
\end{tabular} & 184,62 \\
\hline Hyla molleri & 30TWN42 & 100,00 & 111,66 & 97,48 & 38,97 & 5372,17 & 253,22 & 4,92 & 248,30 & 55,80 & 182,10 & \begin{tabular}{|l|l|}
182,10 \\
\end{tabular} & 45,54 & \begin{tabular}{|l|l|}
765,08 \\
\end{tabular} & 79,88 & 40,51 & 17,51 & \begin{tabular}{|l|}
223,68 \\
\end{tabular} & \begin{tabular}{|l|}
149,08 \\
\end{tabular} & \begin{tabular}{|l|}
149,08 \\
\end{tabular} & 207,95 \\
\hline Hyla molleri & 30TWN43 & 100,00 & \begin{tabular}{|l|}
104,69 \\
\end{tabular} & 95,80 & 39,00 & 5253,68 & 244,22 & 1,10 & 243,12 & \begin{tabular}{|l|}
47,78 \\
\end{tabular} & \begin{tabular}{|l|}
173,98 \\
\end{tabular} & \begin{tabular}{|l|l|}
173,98 \\
\end{tabular} & $\begin{array}{l}40,45 \\
\end{array}$ & \begin{tabular}{|l|l|}
867,38 \\
\end{tabular} & \begin{tabular}{|c|}
92,76 \\
\end{tabular} & 45,79 & 17,66 & 258,43 & 167,34 & 167,34 & 241,97 \\
\hline Hyla molleri & 30TWN44 & 100,00 & $\begin{array}{l}116,32 \\
\end{array}$ & 91,52 & 39,00 & 5041,25 & 248,65 & \begin{tabular}{l|l}
16,52 \\
\end{tabular} & 232,13 & 61,40 & 180,99 & \begin{tabular}{|l|}
182,51 \\
\end{tabular} & 54,49 & 893,15 & 97,14 & 45,32 & 18,33 & 271,42 & 170,94 & 171,69 & 254,05 \\
\hline Hyla molleri & 30TWN45 & 100,00 & \begin{tabular}{|l|}
108,38 \\
\end{tabular} & 90,08 & 39,01 & 4932,58 & 239,01 & \begin{tabular}{|l|}
11,27 \\
\end{tabular} & 227,75 & 55,25 & \begin{tabular}{|l|}
171,85 \\
\end{tabular} & \begin{tabular}{|l|l|}
173,45 \\
\end{tabular} & \begin{tabular}{|l|}
48,43 \\
\end{tabular} & \begin{tabular}{|c|}
998,88 \\
\end{tabular} & 110,42 & \begin{tabular}{|l|l|}
50,92 \\
\end{tabular} & 18,72 & 307,34 & \begin{tabular}{|l|l|}
189,19 \\
\end{tabular} & \begin{tabular}{|l|}
190,92 \\
\end{tabular} & 289,05 \\
\hline Hyla molleri & 30TWN46 & 100,00 & 123,61 & 83,98 & 39,18 & 4612,31 & 243,96 & 32,62 & 211,34 & 73,60 & 181,61 & 184,19 & \begin{tabular}{l|l|}
67,65 \\
\end{tabular} & \begin{tabular}{ll|}
1057,52 \\
\end{tabular} & 120,02 & 50,76 & 20,66 & 333,64 & 191,58 & 200,33 & 315,99 \\
\hline Hyla molleri & 30TWN50 & 100,00 & 128,81 & 101,63 & 38,17 & 5707,35 & 275,59 & \begin{tabular}{l|l|}
14,16 \\
\end{tabular} & 261,43 & 149,29 & 178,54 & \begin{tabular}{|l|l|}
202,48 \\
\end{tabular} & 57,20 & \begin{tabular}{|l|l|}
531,73 \\
\end{tabular} & \begin{tabular}{|c|}
60,97 \\
\end{tabular} & 29,42 & \begin{tabular}{|l|l|}
19,74 \\
\end{tabular} & 159,20 & \begin{tabular}{|l|}
108,66 \\
\end{tabular} & 111,32 & 127,16 \\
\hline Hyla molleri & 30TWN52 & 100,00 & 111,01 & $\begin{array}{l}98,69 \\
\end{array}$ & 38,99 & 5410,56 & 253,88 & 3,30 & 250,58 & 54,19 & \begin{tabular}{|l|}
181,92 \\
\end{tabular} & \begin{tabular}{|l|l|}
181,92 \\
\end{tabular} & \begin{tabular}{l|l|}
44,35 \\
4
\end{tabular} & 784,16 & \begin{tabular}{|l|l|}
81,97 \\
\end{tabular} & 41,74 & 17,60 & 229,51 & 151,86 & 151,86 & 213,21 \\
\hline Hyla molleri & 30TWN53 & 100,00 & 99,05 & \begin{tabular}{|l|}
97,23 \\
\end{tabular} & 39,00 & 5289,83 & 240,71 & $-5,51$ & 246,22 & 42,19 & 169,02 & \begin{tabular}{|l|l|}
169,02 \\
\end{tabular} & \begin{tabular}{|l|}
34,61 \\
\end{tabular} & \begin{tabular}{|l|l|}
912,83 \\
\end{tabular} & 98,09 & \begin{tabular}{|l|}
48,79 \\
\end{tabular} & \begin{tabular}{|l|}
17,47 \\
\end{tabular} & 272,35 & \begin{tabular}{|l|l|}
174,91 \\
\end{tabular} & \begin{tabular}{|l|l|}
174,91 \\
\end{tabular} & 255,66 \\
\hline Hyla molleri & 30TWN54 & 100,00 & 108,16 & 93,91 & 39,01 & 5109,92 & 243,98 & 6,90 & 237,08 & 52,94 & $\begin{array}{l}175,02 \\
\end{array}$ & \begin{tabular}{|l|l|}
175,43 \\
\end{tabular} & \begin{tabular}{|l|}
45,78 \\
\end{tabular} & 945,86 & $\begin{array}{l}103,08 \\
\end{array}$ & \begin{tabular}{|l|l|}
49,09 \\
\end{tabular} & 18,18 & 287,36 & \begin{tabular}{ll|}
180,52 \\
\end{tabular} & 180,55 & 269,18 \\
\hline Hyla molleri & 30TWN63 & 100,00 & $\begin{array}{l}03,32 \\
\end{array}$ & 97,94 & 39,01 & 5316,96 & 245,23 & $-2,27$ & 247,50 & 45,76 & 173,31 & \begin{tabular}{|l|}
173,31 \\
\end{tabular} & \begin{tabular}{|l|}
38,25 \\
\end{tabular} & \begin{tabular}{|l|l|}
914,81 \\
\end{tabular} & $\begin{array}{l}99,12 \\
\end{array}$ & 48,44 & 17,94 & 274,80 & 173,71 & 173,71 & 257,41 \\
\hline Hyla molleri & 30TWN64 & 100,00 & 104,07 & 95,58 & 39,10 & 5166,61 & 242,19 & 1,56 & 240,63 & 48,36 & 172,21 & \begin{tabular}{|l|}
172,21 \\
\end{tabular} & \begin{tabular}{|l|}
41,03 \\
\end{tabular} & \begin{tabular}{|c|}
984,99 \\
\end{tabular} & 108,32 & 51,52 & 18,30 & 300,55 & \begin{tabular}{|l|l|}
186,36 \\
\end{tabular} & \begin{tabular}{|l|l|}
186,36 \\
\end{tabular} & 281,81 \\
\hline Hyla molleri & 30TWN65 & 100,00 & 114,75 & 92,10 & 39,59 & 4941,28 & 246,34 & 16,24 & 230,10 & 61,12 & 1778,84 & $|179,67|$ & 54,48 & 1037,83 & 115,65 & 52, & 19,30 & 323,01 & 194,30 & 195,10 & 302,10 \\
\hline Hyla molleri & 30TWN66 & 100,00 & 130,98 & 86,46 & 40,11 & 4575,07 & 251,84 & 39,33 & 212,51 & 81,00 & \begin{tabular}{|l|l|}
188,09 \\
\end{tabular} & \begin{tabular}{|l|}
190,77 \\
\end{tabular} & 75,39 & \begin{tabular}{ll|}
1103,43 \\
\end{tabular} & 124,59 & 52,88 & 20,87 & 350,55 & \begin{tabular}{|l|l|}
199,35 \\
\end{tabular} & \begin{tabular}{|l|}
206,77 \\
\end{tabular} & 327,82 \\
\hline Hyla molleri & 30TWN74 & 100,00 & 100,62 & 96,62 & 39,21 & 5208,45 & 240,12 & $\begin{array}{l} \\
\end{array}$ & 242,94 & 44,68 & 169,38 & \begin{tabular}{|l|l|}
169,38 \\
\end{tabular} & \begin{tabular}{|l|}
37,17 \\
\end{tabular} & \begin{tabular}{|l|l|}
1021,25 \\
\end{tabular} & $\begin{array}{l}113,47 \\
\end{array}$ & 53,57 & 18,56 & 312,86 & \begin{tabular}{l|l|}
191,86 \\
\end{tabular} & \begin{tabular}{|l|l|}
191,86 \\
\end{tabular} & 293,94 \\
\hline Hyla molleri & 30TWN75 & 100,00 & 108,49 & 94,04 & 39,53 & 5036,57 & 243,08 & 7,88 & 235,20 & 54,16 & \begin{tabular}{|l|}
174,61 \\
\end{tabular} & \begin{tabular}{l|l|}
174,66 \\
\end{tabular} & \begin{tabular}{|l|}
46,97 \\
\end{tabular} & $\begin{array}{l}1073,28 \\
\end{array}$ & 120,82 & 54,95 & 19,36 & \begin{tabular}{|l|}
334,82 \\
\end{tabular} & 200,40 & 200,40 & 313,61 \\
\hline Hyla molleri & 30TWN79 & 55,00 & 142,54 & 79,19 & 41,49 & 4050,54 & 248,44 & 59,70 & 188,74 & 98,79 & $\begin{array}{l}191,96 \\
\end{array}$ & \begin{tabular}{l|l|}
195,32 \\
\end{tabular} & \begin{tabular}{l|l|}
93,85 \\
\end{tabular} & \begin{tabular}{|l|l|}
1318,53 \\
\end{tabular} & 152,11 & \begin{tabular}{|l|l|}
61,78 \\
\end{tabular} & 22,71 & \begin{tabular}{|l|l|}
428,98 \\
\end{tabular} & 231,91 & 252,33 & 399,74 \\
\hline Hyla molleri & 30TWN80 & 100,00 & 129,95 & 103,38 & 38,72 & 5737,03 & 278,56 & 13,85 & 264,71 & 94,26 & 204,09 & 204,09 & \begin{tabular}{|l|}
57,87 \\
\end{tabular} & \begin{tabular}{|l|}
659,71 \\
\end{tabular} & 71,18 & 33,21 & 20,28 & \begin{tabular}{|l|}
196,01 \\
\end{tabular} & \begin{tabular}{|l|l|}
121,57 \\
\end{tabular} & \begin{tabular}{|l|}
121,57 \\
\end{tabular} & 179,50 \\
\hline Hyla molleri & 30TWN84 & 100,00 & 91,57 & 97,49 & 39,01 & 5276,41 & 233,10 & $-13,28$ & 246,38 & 35,46 & 161,44 & \begin{tabular}{|l|}
161,44 \\
\end{tabular} & 27,57 & \begin{tabular}{|l|}
1060,01 \\
\end{tabular} & 118,21 & $\begin{array}{l}56,62 \\
\end{array}$ & 18,24 & 323,42 & 199,51 & 199,51 & 305,06 \\
\hline Hyla molleri & 30TWN85 & 100,00 & 106,58 & 95,36 & \begin{tabular}{|l|}
39,43 \\
\end{tabular} & 5114,41 & 243,07 & 4,09 & 238,99 & 51,34 & \begin{tabular}{|l|}
173,73 \\
\end{tabular} & \begin{tabular}{|l|l|}
173,73 \\
\end{tabular} & 43,91 & \begin{tabular}{|l|l|}
1099,31 \\
\end{tabular} & 125,91 & 56,20 & 19,88 & 345,57 & 203,27 & 203,27 & 324,35 \\
\hline Hyla molleri & 30TWN86 & 100,00 & 1113,46 & 92,50 & 39,91 & 4893,48 & 244,21 & \begin{tabular}{l|l|}
14,93 \\
\end{tabular} & 229,28 & 60,58 & 176,77 & \begin{tabular}{|l|l|}
177,71 \\
\end{tabular} & 53,68 & \begin{tabular}{|l|l|}
1171,81 \\
\end{tabular} & 135,21 & $\begin{array}{l}58,72 \\
\end{array}$ & 20,63 & \begin{tabular}{|l|}
373,55 \\
\end{tabular} & 215,77 & 216,84 & 349,65 \\
\hline Hyla molleri & 30TWN89 & 84,00 & 141,98 & 80,34 & 41,12 & 4147,07 & \begin{tabular}{|l|l|}
249,07 \\
\end{tabular} & 56,16 & \begin{tabular}{|l|}
192,91 \\
\end{tabular} & \begin{tabular}{|c|}
97,07 \\
\end{tabular} & \begin{tabular}{|l|}
192,83 \\
\end{tabular} & \begin{tabular}{|l|}
196,01 \\
\end{tabular} & \begin{tabular}{|l|}
91,49 \\
\end{tabular} & \begin{tabular}{|c|}
1324,87 \\
\end{tabular} & 154,41 & \begin{tabular}{|c|}
63,41 \\
\end{tabular} & 22,63 & 431,54 & $237,27 \mid$ & 257,20 & 400,51 \\
\hline Hyla molleri & 30TWN92 & 100,00 & \begin{tabular}{|l|}
124,90 \\
\end{tabular} & 101,77 & \begin{tabular}{|l|l|}
38,94 \\
\end{tabular} & 5574,60 & 271,25 & \begin{tabular}{|l|l|}
11,91 \\
\end{tabular} & 259,34 & \begin{tabular}{|l|l|}
63,38 \\
\end{tabular} & \begin{tabular}{|l|l|l|l}
197,29 \\
\end{tabular} & 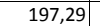 & \begin{tabular}{|l|l|}
55,07 \\
\end{tabular} & \begin{tabular}{|l|l|}
861,72 \\
\end{tabular} & \begin{tabular}{|c|}
101,88 \\
\end{tabular} & \begin{tabular}{|l|l|l|}
41,69 \\
\end{tabular} & 22,23 & \begin{tabular}{|l|l|}
272,79 \\
\end{tabular} & \begin{tabular}{|l|l|}
151,59 \\
\end{tabular} & \begin{tabular}{|l|l|l|}
151,59 \\
\end{tabular} & 255,62 \\
\hline Hyla molleri & 30TWN93 & 100,00 & 114,54 & 100,49 & 39,01 & 5454,66 & 259,17 & 4,41 & 254,76 & 54,88 & $\begin{array}{l}185,74 \\
\end{array}$ & \begin{tabular}{|l|}
185,74 \\
\end{tabular} & \begin{tabular}{|l|}
46,83 \\
\end{tabular} & 966,57 & $\begin{array}{l}113,87 \\
\end{array}$ & 48,01 & 21,46 & 306,26 & \begin{tabular}{|l|l|}
172,27 \\
\end{tabular} & \begin{tabular}{|l|}
172,27 \\
\end{tabular} & 287,92 \\
\hline Hyla molleri & 30TWN94 & 100,00 & 112,33 & \begin{tabular}{ll|}
98,54 \\
\end{tabular} & \begin{tabular}{|l|}
39,03 \\
\end{tabular} & 5324,67 & 253,68 & 5,05 & 248,64 & 54,25 & 181,91 & \begin{tabular}{|l|}
181,91 \\
\end{tabular} & 46,41 & \begin{tabular}{|l|l|}
1044,64 \\
\end{tabular} & \begin{tabular}{|l|}
123,47 \\
\end{tabular} & 52,04 & 21,45 & 333,16 & \begin{tabular}{|l|}
187,74 \\
\end{tabular} & \begin{tabular}{|l|}
187,74 \\
\end{tabular} & 313,34 \\
\hline Hyla molleri & 30TWN95 & 100,00 & 112,46 & 96,45 & 39,30 & 5169,92 & 249,99 & 7,99 & 242,00 & 56,38 & 180,13 & \begin{tabular}{|l|}
180,13 \\
\end{tabular} & \begin{tabular}{l|l|}
48,65 \\
\end{tabular} & \begin{tabular}{|l|l|}
1115,28 \\
\end{tabular} & 131,91 & 55,58 & 21,42 & \begin{tabular}{|c|}
357,89 \\
\end{tabular} & \begin{tabular}{|l|l|}
201,88 \\
\end{tabular} & 201,88 & 336,12 \\
\hline Hyla molleri & 30TWN96 & 100,00 & 104,13 & 94,60 & 39,59 & 5054,56 & 238,99 & 2,51 & 236,48 & 49,88 & $\begin{array}{l}170,57 \\
\end{array}$ & \begin{tabular}{|l|l|}
170,57 \\
\end{tabular} & 42,31 & 1187,49 & 138,57 & \begin{tabular}{ll|}
60,62 \\
\end{tabular} & 20,39 & 378,00 & 219,52 & 219,52 & 355,21 \\
\hline Hyla molleri & 30TWP20 & 75,00 & 136,08 & 66,31 & 37,61 & \begin{tabular}{|l|l|}
3978,94 \\
\end{tabular} & 233,33 & 59,44 & \begin{tabular}{|l|}
173,89 \\
\end{tabular} & 93,78 & 184,80 & \begin{tabular}{|l|}
188,46 \\
\end{tabular} & 88,51 & \begin{tabular}{ll|}
1263,98 \\
\end{tabular} & 158,65 & 53,35 & 27,25 & \begin{tabular}{|l|l|}
422,90 \\
\end{tabular} & \begin{tabular}{|l|}
205,95 \\
\end{tabular} & 236,04 & 415,55 \\
\hline Hyla molleri & 30TXK05 & 100,00 & 85,42 & \begin{tabular}{|l|}
112,53 \\
\end{tabular} & \begin{tabular}{|l|}
37,48 \\
\end{tabular} & $\begin{array}{ll}6386,84 \\
\end{array}$ & 256,24 & $-40,19$ & 296,44 & 103,25 & 170,92 & \begin{tabular}{|l|l|}
171,92 \\
\end{tabular} & 9,99 & 611,81 & 79,73 & 31,25 & 24,81 & 201,77 & \begin{tabular}{|l|}
117,99 \\
\end{tabular} & \begin{tabular}{|l|l|}
131,47 \\
\end{tabular} & 131,33 \\
\hline Hyla molleri & 30TXK06 & 100,00 & 79,90 & 111,37 & \begin{tabular}{|l|}
37,18 \\
\end{tabular} & 6361,73 & 249,61 & $-44,79$ & 294,40 & $\begin{array}{l}97,32 \\
\end{array}$ & 165,13 & \begin{tabular}{l|l|}
165,92 \\
\end{tabular} & 4,81 & 636,51 & 82,84 & 33,56 & 24,36 & 209,90 & \begin{tabular}{|l|}
124,25 \\
\end{tabular} & \begin{tabular}{|l|}
138,84 \\
\end{tabular} & 136,99 \\
\hline Hyla molleri & ЗоТХК07 & 100,00 & 76,83 & 110,40 & 37,03 & 6336,85 & 245,38 & $-47,18$ & 292,56 & 94,26 & 161,80 & 162,60 & 1,9 & 646,58 & 84,44 & $34, \varepsilon$ & 24,10 & 213,76 & 127,65 & 142,93 & 139,03 \\
\hline Hyla molleri & ЗоТХК08 & 100,00 & 77,03 & 109,66 & 37,08 & 6312,45 & 243,99 & $-46,97$ & 290,96 & 94,68 & 161,59 & 162,30 & 2,12 & 639,09 & 84,13 & 35,0 & 24,46 & 212,45 & 127,62 & 143,21 & 136,57 \\
\hline Hyla molleri & 30TXK09 & 100,00 & 79,59 & 109,00 & 37,00 & 6294,38 & 244,64 & $-44,95$ & 289,60 & 97,81 & 162,42 & \begin{tabular}{|l|l|}
164,38 \\
\end{tabular} & \begin{tabular}{l|l}
4,53 \\
\end{tabular} & 617,75 & 82,36 & 34,29 & 25,07 & 206,99 & \begin{tabular}{|l|}
124,88 \\
\end{tabular} & 140,40 & 130,87 \\
\hline Hyla molleri & 30TXK16 & 100,00 & 80,38 & 109,45 & 37,00 & 6342,31 & 247,30 & $-43,47$ & 290,77 & 97,85 & \begin{tabular}{|l|}
161,94 \\
\end{tabular} & \begin{tabular}{|l|l|}
166,18 \\
\end{tabular} & 5,42 & 626,66 & 82,40 & 33,88 & 24,82 & \begin{tabular}{|l|}
208,97 \\
\end{tabular} & \begin{tabular}{|l|l|}
125,47 \\
\end{tabular} & \begin{tabular}{|l|}
140,04 \\
\end{tabular} & $\begin{array}{l}31,01 \\
\end{array}$ \\
\hline Hyla molleri & 30TXK17 & 100,00 & 81,07 & $\begin{array}{l}108,66 \\
\end{array}$ & 37,00 & 6320,35 & 246,23 & $-42,92$ & 289,15 & 98,94 & 129,53 & \begin{tabular}{|l|l|}
166,37 \\
\end{tabular} & 6,01 & \begin{tabular}{|l|l|}
614,81 \\
\end{tabular} & 81,79 & 33,82 & 25,33 & 206,54 & \begin{tabular}{|l|l|}
124,02 \\
\end{tabular} & \begin{tabular}{l|l|}
139,62 \\
\end{tabular} & \begin{tabular}{|l|l|}
127,34 \\
\end{tabular} \\
\hline Hyla molleri & 30ТХК18 & 100,00 & 75,69 & 107,67 & 37,00 & 288,67 & 239,92 & $-47,22$ & 287,14 & 93,29 & 120,62 & 160,59 & 1,25 & 642,11 & 84,96 & 36,08 & 24,72 & 215,03 & 130,37 & 147,04 & 134,20 \\
\hline Hyla molleri & 30ТХК27 & 100,00 & \begin{tabular}{|l|}
90,92 \\
\end{tabular} & 106,46 & 36,99 & 6310,71 & 251,44 & $-33,16$ & 284,6 & \begin{tabular}{|l|}
109,82 \\
\end{tabular} & $\mid 15,49$ & \begin{tabular}{|l|l|}
175,78 \\
\end{tabular} & 15,49 & 549,27 & 75,58 & $|30,67|$ & 27,89 & $|189,27|$ & \begin{tabular}{|l|l|}
106,92 \\
\end{tabular} & \begin{tabular}{|l|l|}
128,99 \\
\end{tabular} & \begin{tabular}{l|l|}
106,92 \\
\end{tabular} \\
\hline Hyla molleri & 30TXK28 & 100,00 & 84,80 & 105,77 & 36,99 & 6281,25 & 244,63 & \begin{tabular}{|c|}
$-38,76$ \\
\end{tabular} & 283,39 & 103,45 & \begin{tabular}{ll|}
18,02 \\
\end{tabular} & \begin{tabular}{|l|}
169,19 \\
\end{tabular} & 9,79 & 578,01 & 79,11 & 32,97 & 27,26 & $\begin{array}{l}198,66 \\
\end{array}$ & \begin{tabular}{|l|}
113,88 \\
\end{tabular} & $\begin{array}{l}137,05 \\
\end{array}$ & 113,97 \\
\hline Hyla molleri & 30 TKK29 & 100,00 & 85,15 & 105,01 & 36,99 & 6255,66 & 243,10 & \begin{tabular}{|c|} 
\\
\end{tabular} & 281,85 & 104,12 & 9,82 & \begin{tabular}{|l|}
168,88 \\
\end{tabular} & 9,82 & 569,58 & 78,84 & 32,90 & 27,86 & \begin{tabular}{|l|}
197,32 \\
\end{tabular} & \begin{tabular}{|l|l|}
111,47 \\
\end{tabular} & 137,19 & $\begin{array}{l}111,47 \\
\end{array}$ \\
\hline Hyla molleri & 30TXK39 & 100,00 & $\begin{array}{l}96,64 \\
\end{array}$ & \begin{tabular}{l|l|}
102,03 \\
\end{tabular} & 36,50 & 6237,25 & 248,21 & $-27,50$ & 275,72 & \begin{tabular}{|l|}
117,08 \\
\end{tabular} & 20,75 & \begin{tabular}{l|l|}
179,66 \\
\end{tabular} & \begin{tabular}{|l|}
20,75 \\
\end{tabular} & 493,07 & 71,48 & \begin{tabular}{|l|}
25,97 \\
\end{tabular} & 32,38 & \begin{tabular}{|l|}
177,07 \\
\end{tabular} & $\begin{array}{l}88,36 \\
\end{array}$ & \begin{tabular}{|l|l|}
124,17 \\
\end{tabular} & 88,36 \\
\hline Hyla molleri & 30TXK48 & 100,00 & 106,64 & 99,68 & 36,05 & 268,44 & 255,85 & $-15,66$ & 271,51 & 127,33 & 30,49 & 190,24 & 30,49 & 442,42 & 65,35 & 21,40 & 35,04 & 161,32 & 73,19 & 113,16 & 73,19 \\
\hline Hyla molleri & 30TXL00 & 100,00 & 87,40 & \begin{tabular}{|l|}
108,49 \\
\end{tabular} & 37,00 & 279,95 & 249,65 & \begin{tabular}{|l|} 
\\
\end{tabular} & 288,19 & $\begin{array}{l}106,84 \\
\end{array}$ & 120,01 & \begin{tabular}{|l|l|}
171,49 \\
\end{tabular} & \begin{tabular}{ll|}
11,81 \\
\end{tabular} & 564,10 & $\begin{array}{l}77,31 \\
\end{array}$ & 31,40 & 26,81 & \begin{tabular}{|l|l|}
192,40 \\
\end{tabular} & \begin{tabular}{|l|l|}
115,47 \\
\end{tabular} & 130,72 & 116,72 \\
\hline Hyla molleri & 30TXL11 & & & & 37, & 6228,03 & 24 & $-34,27$ & 282,43 & 112 & 15,75 & $\begin{array}{l}174,65 \\
1\end{array}$ & \begin{tabular}{l|l|}
15,75 \\
\end{tabular} & \begin{tabular}{|l|l|}
523,98 \\
\end{tabular} & 74,38 & 30,10 & 29,51 & 184,00 & \begin{tabular}{|l|l|}
102,93 \\
\end{tabular} & \begin{tabular}{|l|}
127,41 \\
\end{tabular} & 102,93 \\
\hline Hyla molleri & 30TXL12 & 100,00 & 95,85 & $\begin{array}{l}105,01 \\
\end{array}$ & 37,00 & 6202,83 & 249,54 & $-31,10$ & 280,64 & 117,09 & 26,91 & \begin{tabular}{|l|l|}
177,72 \\
\end{tabular} & 19,57 & 497,81 & 71,90 & 28,04 & 30,91 & \begin{tabular}{|l|l|}
176,99 \\
\end{tabular} & 96,26 & 122,93 & 96,50 \\
\hline Hyla molleri & 30TXL13 & 100,00 & 98,47 & 104,71 & 37,00 & 6186,85 & 251,01 & $-28,75$ & 279,77 & 120,31 & 31,71 & \begin{tabular}{|l|}
179,94 \\
\end{tabular} & 22,29 & 482,34 & 70,19 & 26,68 & 31,63 & 172,32 & 92,00 & 119,73 & 93,40 \\
\hline Hyla molleri & 30TXL20 & 100,00 & 90,82 & 103,97 & 36,94 & 6227,62 & 245,18 & $-34,25$ & 279,44 & 110,87 & $\mid 15,03$ & 173,66 & $\begin{array}{l}15,03 \\
\end{array}$ & 527,99 & 75,08 & 29,6 & 30,20 & 186,55 & 100,45 & 130,35 & 100,45 \\
\hline Hyla molleri & $30 T X$ & & \begin{tabular}{|l|l|}
99,03 \\
\end{tabular} & 102 & \begin{tabular}{|l|}
36,82 \\
\end{tabular} & 6166,32 & 247,45 & \begin{tabular}{|l|} 
\\
\end{tabular} & 275,19 & 121,14 & 32,12 & 180 & 22,89 & 470,05 & 69,89 & 24,30 & 33 & \begin{tabular}{|l|l|}
171,59 \\
\end{tabular} & \begin{tabular}{|l|}
84,86 \\
\end{tabular} & \begin{tabular}{|l|}
120,63 \\
\end{tabular} & 85,96 \\
\hline Hyla molleri & 30TXL23 & 100,00 & 101,91 & $\begin{array}{ll}102,08 \\
\end{array}$ & 36,85 & \begin{tabular}{|l|l|}
6139,68 \\
\end{tabular} & 248,97 & \begin{tabular}{|l|}
$-25,49$ \\
\end{tabular} & \begin{tabular}{|l|}
274,47 \\
\end{tabular} & 124,33 & 35,14 & \begin{tabular}{|l|}
182,20 \\
\end{tabular} & \begin{tabular}{|l|l|}
25,52 \\
\end{tabular} & 455,18 & $\begin{array}{ll}68,36 \\
\end{array}$ & \begin{tabular}{|l|}
23,12 \\
\end{tabular} & 34,76 & 167,11 & 80,94 & \begin{tabular}{|l|}
117,21 \\
\end{tabular} & $\begin{array}{l}83,37 \\
\end{array}$ \\
\hline Hyla molleri & 30TXL32 & 100,00 & \begin{tabular}{|l|}
102,32 \\
\end{tabular} & $\begin{array}{l}99,48 \\
\end{array}$ & 36,27 & 6111,27 & 244,66 & $\begin{array}{l} \\
\end{array}$ & 269,41 & \begin{tabular}{|l|l|}
124,86 \\
\end{tabular} & 35,49 & \begin{tabular}{|l|l|}
182,03 \\
\end{tabular} & \begin{tabular}{l|l|}
26,05 \\
\end{tabular} & 444,99 & \begin{tabular}{|l|l|}
67,97 \\
\end{tabular} & 20,99 & $\begin{array}{l}37,29 \\
\end{array}$ & \begin{tabular}{ll|}
166,56 \\
\end{tabular} & 74,21 & \begin{tabular}{|l|}
118,63 \\
\end{tabular} & 76,57 \\
\hline Hyla molleri & 30TXL33 & 100,00 & 100,56 & 99,81 & 36,35 & 6097,72 & 243,69 & $-26,50$ & 270,19 & 122,92 & 33,88 & \begin{tabular}{|l|l|}
180,03 \\
\end{tabular} & 24,34 & 455,56 & 69,13 & 21,99 & 36,32 & \begin{tabular}{|c|}
169,37 \\
\end{tabular} & 77,45 & 120,71 & 80,36 \\
\hline Hyla molleri & 30TXL53 & 100,00 & 93 & 97,36 & 36,00 & 066,0 & 236 & $-29,89$ & 266,08 & & 26,24 & $17 !$ & \begin{tabular}{l|l|}
18,58 \\
\end{tabular} & 500,72 & $|73,83|$ & 25, & 34,01 & \begin{tabular}{|l|l|}
182,28 \\
\end{tabular} & 87,26 & \begin{tabular}{|l|l|}
131,60 \\
\end{tabular} & \\
\hline Hyla molleri & 30TXL61 & 100,00 & 90,23 & 96,60 & 35,99 & 6104,58 & 235,41 & $-30,41$ & 265,82 & 109,78 & 16,47 & \begin{tabular}{|l|l|}
171,37 \\
\end{tabular} & \begin{tabular}{l|l|}
16,47 \\
\end{tabular} & 529,44 & 75,96 & 27,37 & \begin{tabular}{|l|}
31,93 \\
\end{tabular} & \begin{tabular}{|l|}
188,81 \\
\end{tabular} & \begin{tabular}{|l|}
92,93 \\
\end{tabular} & \begin{tabular}{|l|l|}
136,23 \\
\end{tabular} & 92, \\
\hline Hyla molleri & 30TXL62 & 100,00 & 93,88 & 96,39 & 36,00 & 6076,15 & 237,07 & $-27,70$ & 264,77 & 114,11 & 21,47 & \begin{tabular}{|l|l|}
174,17 \\
\end{tabular} & \begin{tabular}{|l|}
19,72 \\
\end{tabular} & 505,76 & 73,78 & 25,51 & 33,43 & \begin{tabular}{|l|l|}
182,48 \\
\end{tabular} & 87,48 & 131,67 & 87,48 \\
\hline
\end{tabular}




\begin{tabular}{|c|c|c|c|c|c|c|c|c|c|c|c|c|c|c|c|c|c|c|c|c|c|}
\hline TAXON & UTM & $\mathrm{km2}$ & B101 & B102 & $\mathrm{BIO3}$ & B104 & B105 & B106 & B107 & B108 & B109 & 81010 & B1011 & BIO12 & BIO13 & BIO14 & B1015 & B1016 & BIO17 & B1018 & B1019 \\
\hline Hyla molleri & 30TXL63 & 100,00 & 90,23 & 96,66 & 36,00 & 6052,86 & 234,09 & $-31,12$ & 265,21 & 110,10 & 19,00 & 170,15 & 16,26 & 527,51 & 76,18 & 27,39 & 31,97 & 188,53 & 94,05 & 136,34 & 94,05 \\
\hline Hyla molleri & 30TXM01 & 100,00 & 95,38 & 108,00 & \begin{tabular}{|l|l|}
37,85 \\
\end{tabular} & 6071,08 & 255,01 & $-28,10$ & 283,11 & 115,35 & 174,92 & \begin{tabular}{|l|}
175,13 \\
\end{tabular} & 20,77 & 577,34 & 74,88 & 32,82 & 23,46 & 187,54 & 116,08 & 129,63 & 134,59 \\
\hline Hyla molleri & $30 \mathrm{TXM02}$ & 100,00 & 100,94 & 108,08 & 37,93 & 6066,93 & 260,75 & $-22,31$ & 283,06 & 121,12 & \begin{tabular}{|l|}
180,29 \\
\end{tabular} & 180,39 & 26,02 & 566,20 & 72,63 & \begin{tabular}{|l|l|}
31,53 \\
\end{tabular} & 23,29 & 181,91 & 112,00 & 124,01 & 134,25 \\
\hline Hyla molleri & 30TXM07 & 100,00 & 136,85 & 105,91 & 38,00 & 5960,25 & 290,10 & 15,45 & 274,65 & 102,64 & 213,73 & 213,73 & 61,61 & 545,48 & 61,27 & 26,12 & 22,41 & 161,47 & 98,66 & 98,93 & 144,92 \\
\hline Hyla molleri & 30TXM12 & 100,00 & 117,64 & 107,61 & \begin{tabular}{|l|l|}
37,63 \\
\end{tabular} & \begin{tabular}{|c|}
6132,64 \\
\end{tabular} & 276,22 & $-6,61$ & 282,83 & 139,49 & 197,34 & 197,41 & 41,34 & 477,46 & 63,91 & 25,09 & 26,04 & 156,16 & 92,14 & 101,36 & 111,16 \\
\hline Hyla molleri & 30TXM22 & 100,00 & 127,92 & 106,83 & 37,01 & 6162,55 & 285,68 & 3,08 & 282,60 & 150,46 & 207,61 & 207,66 & 50,89 & 435,64 & 59,43 & 21,63 & 27,76 & 142,55 & 81,97 & 87,91 & 101,12 \\
\hline Hyla molleri & $30 \mathrm{TXM} 23$ & 100,00 & 133,82 & 106,67 & 37,25 & 6133,99 & 291,05 & 9,61 & 281,44 & 156,30 & 213,06 & 213,06 & 56,85 & 437,57 & 57,78 & 20,95 & 26,66 & 139,33 & 80,58 & 82,35 & 104,92 \\
\hline Hyla molleri & $30 \mathrm{TXM} 27$ & 100,00 & 133,69 & 105,99 & 38,00 & 5966,34 & 287,39 & \begin{tabular}{|l|}
12,47 \\
\end{tabular} & 274,92 & \begin{tabular}{|c|}
96,91 \\
\end{tabular} & 210,66 & \begin{tabular}{|l|}
210,66 \\
\end{tabular} & 58,58 & 564,81 & $\begin{array}{l}63,52 \\
\end{array}$ & 26,71 & 22,52 & 167,48 & 101,29 & \begin{tabular}{|l|}
102,42 \\
\end{tabular} & 151,60 \\
\hline Hyla molleri & 30TXM28 & 100,00 & 127,85 & 105,90 & 38,00 & 5923,58 & 280,96 & 7,13 & 273,82 & 91,65 & 204,24 & 204,24 & 53,19 & 630,60 & 71,13 & 30,23 & 21,98 & 188,22 & 112,42 & 112,42 & 173,84 \\
\hline Hyla molleri & 30TXM71 & 100,00 & 146,76 & 105,24 & \begin{tabular}{|l|l|}
36,17 \\
\end{tabular} & 6257,39 & 307,56 & 21,90 & 285,66 & 170,51 & 227,09 & 227,87 & 68,17 & 356,92 & 46,94 & 16,56 & 26,97 & 116,55 & 69,08 & 73,65 & 72,93 \\
\hline Hyla molleri & 30TXM80 & 100,00 & 145,28 & 104,63 & 36,21 & 6190,31 & 303,61 & 20,15 & 283,46 & 168,93 & 79,03 & 225,67 & 67,72 & 355,22 & 47,42 & 16,52 & 28,16 & 116,99 & 69,07 & 74,27 & 69,08 \\
\hline Hyla molleri & 30TXM81 & 100,00 & 144,28 & 104,85 & 36,36 & 6169,93 & 303,16 & 19,72 & 283,44 & 167,74 & 140,13 & 224,41 & 66,73 & 363,76 & 47,59 & 16,95 & 26,93 & 118,23 & 71,85 & 75,41 & 72,28 \\
\hline Hyla molleri & 30TXN01 & 100,00 & 122,08 & 104,38 & \begin{tabular}{|l|l|}
38,45 \\
\end{tabular} & 5749,16 & 272,88 & 5,07 & 267,82 & 58,33 & $\begin{array}{l}196,59 \\
\end{array}$ & $\begin{array}{l}196,59 \\
\end{array}$ & 49,94 & 823,10 & 98,48 & 39,67 & 22,73 & 259,36 & 142,68 & 142,68 & 244,35 \\
\hline Hyla molleri & 30 TXN02 & 100,00 & 118,55 & 103,34 & 38,71 & 5664,61 & 267,93 & 3,58 & 264,35 & 56,29 & \begin{tabular}{|l|}
192,16 \\
\end{tabular} & $\begin{array}{l}192,16 \\
\end{array}$ & 47,55 & 908,59 & 110,43 & \begin{tabular}{|l|l|}
43,78 \\
\end{tabular} & 23,08 & 291,15 & 156,75 & 156,75 & 274,93 \\
\hline Hyla molleri & 30TXN04 & 100,00 & 120,11 & 99,69 & 38,96 & 5424,70 & 263,16 & 9,95 & 253,21 & 60,57 & 190,76 & 190,76 & 52,43 & $\begin{array}{l}1054,55 \\
\end{array}$ & 130,95 & 50,27 & 23,93 & 346,91 & 182,97 & 182,97 & 327,25 \\
\hline Hyla molleri & 30 TXN05 & 100,00 & 110,26 & 97,76 & 39,07 & 5256,90 & 249,72 & 3,59 & 246,12 & 53,32 & 179,04 & 179,04 & 45,21 & 1130,85 & 136,25 & 56,18 & 21,96 & 365,42 & 203,32 & 203,32 & 344,20 \\
\hline Hyla molleri & 30 TXN06 & 100,00 & 106,18 & 95,55 & 39,43 & 5116,10 & 241,79 & 2,54 & 239,25 & 50,97 & 173,27 & 173,27 & 43,10 & 1195,82 & 142,30 & 60,52 & 21,15 & 384,30 & 219,61 & 219,61 & 361,55 \\
\hline Hyla molleri & 30TXN12 & 100,00 & 104,16 & 102,64 & 38,87 & 5612,40 & 252,62 & $-9,53$ & 262,15 & 43,29 & 177,51 & 177,51 & 34,44 & $\begin{array}{l}941,64 \\
\end{array}$ & 110,28 & \begin{tabular}{l|l}
47,85 \\
\end{tabular} & 20,74 & 291,98 & 169,21 & 169,21 & 276,37 \\
\hline Hyla molleri & 30 TXN13 & 100,00 & 118,26 & 102,80 & 38,63 & 5631,79 & 266,64 & 3,42 & 263,22 & 56,39 & 191,36 & 191,36 & 47,70 & 996,28 & 125,80 & \begin{tabular}{|l|l|}
47,05 \\
\end{tabular} & 24,63 & 327,85 & 169,48 & 169,48 & \begin{tabular}{|l|l|}
310,93 \\
\end{tabular} \\
\hline Hyla molleri & 30TXN14 & 100,00 & 114,75 & 100,62 & 38,90 & 5484,35 & 259,12 & 3,13 & 255,99 & 54,69 & $\mid 186,16$ & $\mid 186,16$ & 46,05 & $\mid 1064,60$ & $\mid 132.53$ & 51,37| & 23,62 & 348,62 & 185,86 & $\mid 185,86$ & 329,79 \\
\hline Hyla molleri & 30TXN15 & 100,00 & 107,71 & 98,34 & 39,02 & 5316,13 & 247,88 & $-0,46$ & 248,34 & 50,04 & 177,17 & 177,17 & 41,58 & 1130,84 & 136,92 & 56,58 & 21,81 & 364,65 & 204,42 & 204,42 & 344,08 \\
\hline Hyla molleri & 30 XN16 & 100,00 & 94,84 & 95,87 & 39,18 & 5175,51 & 231,62 & $-9,67$ & 241,29 & 39,67 & 162,94 & 162,95 & 31,27 & 1194,21 & \begin{tabular}{|l}
139,45 \\
\end{tabular} & 62,56 & 19,60 & 376,12 & 224,05 & 224,05 & 354,54 \\
\hline Hyla molleri & 30TXN17 & 100,00 & 121,06 & 92,23 & \begin{tabular}{|l|l|}
39,79 \\
\end{tabular} & 4938,64 & 248,44 & 18,70 & 229,73 & 67,68 & \begin{tabular}{|c|}
183,71 \\
\end{tabular} & 185,35 & 59,33 & 1233,22 & 149,93 & \begin{tabular}{|l|l|}
61,36 \\
\end{tabular} & 22,18 & 402,18 & 228,79 & 233,11 & 376,19 \\
\hline Hyla molleri & $30 \mathrm{TXN} 21$ & 100,00 & 110,77 & 103,97 & 38,69 & 5720,06 & 260,75 & $-5,38$ & 266,14 & 48,12 & 185,19 & $\begin{array}{l}185,19 \\
\end{array}$ & 39,23 & 858,42 & 100,73 & 42,72 & 21,16 & 264,27 & 153,29 & 153,29 & 250,21 \\
\hline Hyla molleri & $30 \mathrm{~T} \times N 22$ & 100,00 & 103,37 & 102,39 & 38,82 & 5608,17 & 251,24 & $-10,44$ & 261,68 & 42,50 & $\begin{array}{l}176,68 \\
\end{array}$ & $\begin{array}{ll}176,68 \\
\end{array}$ & 33,57 & 936,79 & 109,38 & \begin{tabular}{|l|l|}
47,68 \\
\end{tabular} & 20,38 & 288,82 & 169,79 & 169,79 & 273,40 \\
\hline Hyla molleri & $30 \mathrm{TXN} 23$ & 100,00 & 111,31 & 102,05 & 38,93 & 5571,81 & 257,65 & $-2,50$ & 260,15 & 50,36 & 183,84 & 183,84 & 41,60 & 988,25 & 120,37 & 48,46 & 22,30 & 315,84 & 175,14 & 175,14 & 299,01 \\
\hline Hyla molleri & 30TXN27 & 72,00 & 109,27 & $\begin{array}{l}94,73 \\
\end{array}$ & 39,63 & 5078,57 & 241,06 & 4,33 & \begin{tabular}{|l|}
236,72 \\
\end{tabular} & 54,34 & $\begin{array}{l}174,584 \\
\end{array}$ & \begin{tabular}{|l|}
175,53 \\
\end{tabular} & 45,96 & $\mid$ & $\mid$ & 62,18 & 21,02 & 393,30 & 230,13 & 231,38 & 369,47 \\
\hline Hyla molleri & 30TXN31 & 100,00 & 120,59 & 103,87 & 38,52 & 5721,66 & 268,99 & 2,92 & 266,06 & 65,57 & $\begin{array}{l}194,55 \\
\end{array}$ & $\begin{array}{l}194,55 \\
\end{array}$ & 48,45 & 814,16 & 96,60 & 39,15 & 21,72 & 252,33 & 145,09 & 145,09 & 238,28 \\
\hline Hyla molleri & $30 \mathrm{TXN} 34$ & 100,00 & 102,45 & 99,88 & 39,00 & 5425,73 & 244,40 & $-8,52$ & 252,92 & 43,64 & 173,20 & 173,20 & 34,78 & 1043,23 & 122,97 & 53,41 & 20,09 & 326,28 & 193,20 & 193,20 & 308,08 \\
\hline Hyla molleri & $30 \mathrm{TXN} 43$ & 100,00 & 105,35 & 101,11 & 39,00 & 5500,27 & 248,66 & $-7,84$ & 256,50 & 45,35 & 176,90 & 176,90 & 36,38 & 954,67 & 110,75 & 48,62 & 19,55 & 293,38 & 178,09 & 178,09 & 276,66 \\
\hline Hyla molleri & $30 \mathrm{TXN} 50$ & 100,00 & 104,72 & 102,40 & 38,53 & 5650,83 & 251,56 & $-11,08$ & 262,63 & 76,05 & 178,11 & 178,11 & 34,09 & 777,70 & 84,18 & 40,27 & 18,30 & 225,41 & 148,41 & 150,99 & 209,58 \\
\hline Hyla molleri & 30TXN51 & 100,00 & 108,88 & 102,45 & 38,88 & 5601,82 & 254,21 & \begin{tabular}{|c|}
1,008 \\
$-6,87$
\end{tabular} & \begin{tabular}{|l|}
261,08 \\
\end{tabular} & 73,79 & \begin{tabular}{|l|l|l|l}
181,44 \\
\end{tabular} & \begin{tabular}{|l|l|l|l}
181,44 \\
\end{tabular} & 38,63 & 810,39 & $\begin{array}{l}4,10 \\
89,62\end{array}$ & 41,22 & $\begin{array}{l}18,58 \\
\end{array}$ & 239,75 & 153,41 & \begin{tabular}{|l|}
154,05 \\
\end{tabular} & 224,22 \\
\hline Hyla molleri & 30 TXN52 & 100,00 & 94,12 & 100,09 & 38,71 & 5497,32 & 237,15 & $-18,39$ & 255,54 & 40,05 & 165,93 & 165,93 & 25,84 & 916,59 & 99,80 & \begin{tabular}{|l|l|}
49,03 \\
\end{tabular} & 17,30 & 267,96 & 177,47 & 177,65 & 251,91 \\
\hline Hyla molleri & $30 \mathrm{TXN63}$ & 100,00 & 94,94 & 99,57 & 38,95 & 5416,45 & 235,38 & $-17,14$ & 252,52 & 42,68 & $\begin{array}{l}165,40 \\
\end{array}$ & 165,40 & 27,29 & 934,84 & 101,29 & 50,20 & 16,66 & 273,25 & 183,96 & $\mid 184,22$ & 256,22 \\
\hline Hyla molleri & $30 T$ XN80 & 100,00 & 95,74 & 99,77 & 38,26 & 5501,36 & 238,35 & $-18,12$ & 256,46 & 111,46 & 167,05 & 167,16 & 27,15 & 759,75 & 82,89 & 41,34 & 16,27 & 215,49 & 155,52 & 160,27 & 188,89 \\
\hline Hyla molleri & 30 TXN90 & 100,00 & 93,84 & 99,07 & 38,37 & 5463,30 & 235,24 & \begin{tabular}{|l|l|}
$-19,39$ \\
\end{tabular} & 254,62 & 111,83 & $\begin{array}{l}164,67 \\
\end{array}$ & 164,93 & 25,66 & 755,96 & 83,18 & 41,68 & 15,97 & 215,56 & 158,02 & 162,15 & 183,27 \\
\hline Hyla molleri & ב-TXN91 & 100,00 & $\begin{array}{l}54,54 \\
94,57\end{array}$ & $\begin{array}{l}99,19 \\
99\end{array}$ & 30,74 & $\begin{array}{l}5400,34,62 \\
5424\end{array}$ & 234,78 & \begin{tabular}{|l|l|}
$-18,37$ \\
$-18,3$
\end{tabular} & \begin{tabular}{|l|}
$253,15<$ \\
253
\end{tabular} & \begin{tabular}{|l|}
100,32 \\
100
\end{tabular} & \begin{tabular}{|l|}
164,88 \\
\end{tabular} & \begin{tabular}{|l|}
$164,05,09$ \\
\end{tabular} & 26,64 & \begin{tabular}{|l|}
790,45 \\
700
\end{tabular} & \begin{tabular}{|l|}
84,67 \\
84,67
\end{tabular} & 年1 & $\begin{array}{l}15,38 \\
\end{array}$ & 222,04 & $\begin{array}{l}13,04,76 \\
164,7\end{array}$ & \begin{tabular}{|l|}
169,02 \\
\end{tabular} & $\begin{array}{l}10,27 \\
195,90\end{array}$ \\
\hline Hyla molleri & 30TYM13 & 100,00 & 128,50 & 103,47 & 37,09 & 5851,02 & 280,64 & 7,01 & 273,63 & 150,32 & 55,15 & 204,77 & 55,15 & 410,73 & 53,94 & 19,79 & 26,40 & 130,45 & 78,10 & 86,84 & 78,10 \\
\hline Hyla molleri & 30TYM14 & 100,00 & 130,28 & 103,85 & \begin{tabular}{|l|l|}
37,67 \\
\end{tabular} & 5801,79 & 281,78 & 9,05 & 272,73 & 152,18 & 57,36 & 205,72 & 57,36 & 414,41 & 53,27 & 19,90 & 25,41 & 129,40 & 80,60 & 86,65 & 80,60 \\
\hline Hyla molleri & 30TYM15 & 100,00 & 125,70 & 102,99 & 37,9 & 5700,40 & 274 & 5,97 & 268,92 & \begin{tabular}{|l|}
147,01 \\
\end{tabular} & 53,81 & 199,82 & 53,81 & 433,63 & 55,17 & 20,96 & 24,46 & 133,81 & 85,59 & 90,75 & 85,59 \\
\hline Hyla molleri & 30TYM & 100 & 120,28 & 102,10 & $38, \mathrm{C}$ & 5599,41 & 267,16 & 2,13 & 265,03 & 140,79 & 50,66 & 193,06 & 49,74 & 460,89 & 57,81 & 22,69 & 23,24 & 140,17 & 92,80 & 96,65 & 92,80 \\
\hline Hyla molleri & 30 TYM18 & 100,00 & 84,91 & 96,38 & 37,59 & 5494,60 & 226,17 & $\frac{2,116}{-27,16}$ & \begin{tabular}{|l|}
253,33 \\
\end{tabular} & $\begin{array}{l}102,28 \\
\end{array}$ & \begin{tabular}{|l|}
141,59 \\
\end{tabular} & \begin{tabular}{|l|}
156,87 \\
\end{tabular} & 17,03 & $\begin{array}{l}744,17 \\
\end{array}$ & \begin{tabular}{|l|l|}
86,03 \\
\end{tabular} & 42,78 & 17,13 & 220,64 & 161,93 & $\begin{array}{l}167,48 \\
167\end{array}$ & 166,72 \\
\hline Hyla molleri & 30 TYM24 & 100,00 & 128,66 & 103,96 & 37,82 & 5790,78 & 279,75 & 7,34 & 272,41 & $\begin{array}{l}150,75 \\
\end{array}$ & 55,90 & 204,04 & 55,90 & 422,33 & 54,45 & 20,46 & 25,78 & 132,25 & 80,26 & 89,67 & 80,26 \\
\hline Hyla molleri & 30ТУM 33 & 10000 & 134,14 & 105,67 & 37.61 & 593301 & 28756 & 1000 & 277.56 & 157.45 & 59,48 & 211.13 & 59.48 & 414.51 & 53,65 & 19.94 & 2674 & 131,27 & 7699 & 89.01 & 7699 \\
\hline Hyla molleri & 30TYN01 & 100,00 & 87,26 & 97,46 & 38,44 & 5402,29 & 226,07 & $\begin{array}{l}-24,44 \\
\end{array}$ & 250,51 & 104,60 & 157,51 & 157,71 & 20,01 & 824,62 & 89,14 & 46,93 & 14,90 & 233,53 & 175,42 & 179,88 & 199,54 \\
\hline Hyla molleri & 30TYNO2 & 100,00 & 6 & 93,02 & $37,67,67$ & 5353,69 & 204,51 & $\begin{array}{l}-29,25 \\
-39,25 \\
\end{array}$ & 243,76 & $\begin{array}{r}44,01 \\
84 \\
\end{array}$ & $\mid \begin{array}{l}\mid 39,07 \\
139,0\end{array}$ & 139,08 & 2,90 & \begin{tabular}{|l|l|l|l|l|}
982,46 \\
\end{tabular} & \begin{tabular}{|c|}
104,07 \\
\end{tabular} & 58,76 & 13,90 & 276,88 & 209,18 & 212,16 & 242,29 \\
\hline Hyla molleri & 30 TYNO & 24,00 & 37,92 & 84,46 & 35,90 & 5244,13 & 168,00 & $-64,05$ & 232,05 & 49,61 & 108,08 & 108,08 & $-24,88$ & 1240,59 & 127,92 & 78,29 & 12,91 & 345,81 & 264,09 & 264,09 & 313,63 \\
\hline Hyla molleri & 30TYN12 & 100,00 & 59,95 & 90,18 & 37,03 & 5337,92 & 193,96 & $-46,36$ & 240,32 & 74,31 & 130,37 & 130,42 & $-5,22$ & 1041,24 & 110,51 & 63,90 & 13,66 & 294,87 & 224,28 & 227,15 & 253,79 \\
\hline Hyla molleri & 31TBH51 & 66,00 & 72,18 & 91,90 & 37,08 & 5440,33 & 208,14 & $-36,69$ & 244,83 & 88,29 & 81,93 & 143,57 & 5,17 & 963,17 & 103,96 & 59,76 & 14,44 & 277,84 & 214,91 & 223,19 & 220,08 \\
\hline Ichthyosaura alpestris & 29TPH86 & 100,00 & 92,14 & 96,67 & 39,75 & 4962,72 & 231,10 & $-9,28$ & 40,38 & 37,85 & 157,69 & 158,06 & 32,74 & 1009,01 & 128,96 & 37,55 & 32,85 & 359,18 & 141,06 & 47,50 & 328,58 \\
\hline Ichthyosaura alpestris & $29 \mathrm{TPHS}$ & 100,00 & & $\begin{array}{ll}90,32 \\
98,32\end{array}$ & $\begin{array}{l}35, \\
40,\end{array}$ & $\begin{array}{ll}450,2,16 \\
4996,45\end{array}$ & 234,96 & $\begin{array}{l}-3,20 \\
-7,69 \\
\end{array}$ & $\mid$\begin{tabular}{|l|}
$\mid 4242,65$ \\
242
\end{tabular} & $\begin{array}{l}1,303 \\
43,34 \\
\end{array}$ & \begin{tabular}{|l|}
160,89 \\
169
\end{tabular} & $\begin{array}{l}30,1,15 \\
161\end{array}$ & \begin{tabular}{|c|c|}
34,80 \\
34,4
\end{tabular} & \begin{tabular}{|c|}
956,82 \\
950
\end{tabular} & \begin{tabular}{|l|}
123,38 \\
123,
\end{tabular} & 36,55 & $\begin{array}{l}2,2,05 \\
32,03\end{array}$ & 337,68 & 137,32 & $\begin{array}{l}142,85 \\
140\end{array}$ & $\begin{array}{l}320,30 \\
305,49\end{array}$ \\
\hline Ichthyosaura alpestris & 29TQH06 & 100,00 & 75,75 & 98,36 & 39,55 & 5077,99 & 219,51 & $-26,07$ & 245,58 & 25,65 & 143,30 & 143,55 & 15,40 & 1068,91 & 134,83 & 43,64 & 30,77 & 372,93 & 159,67 & 162,90 & 340,47 \\
\hline Ichthyosaura alpestris & 29TQH16 & 100,00 & 66,93 & 98,64 & 39,36 & 5134,50 & 212,62 & $-34,94$ & 247,56 & 17,86 & 135,50 & 135,73 & 6,21 & 1106,53 & 138,03 & 47,02 & 29,70 & 382,01 & 170,17 & 172,03 & 349,10 \\
\hline Ichthyosaura alpestris & 29TQH17 & 101,00 & 79,56 & 98,86 & 40,06 & 5002,85 & 221,57 & $-22,19$ & 243,76 & 40,09 & 145,80 & 146,25 & 19,84 & 1034,18 & 131,39 & 44,28 & 29,41 & 357,21 & 160,63 & 165,63 & 319,74 \\
\hline Ichthyosaura al & $29 \mathrm{TQH} 26$ & 100,00 & 67,82 & 99,91 & 39,58 & 5166,21 & 214,59 & $-35,04$ & 249,64 & 28,79 & 136,77 & 136,99 & 6,55 & 1070,76 & 133,82 & 46,89 & 28,95 & 367,11 & 168,84 & 170,41 & 332 \\
\hline Ichthyosaura alpestris & 29TQH27 & 100,00 & $\begin{array}{l}1,02 \\
82,73\end{array}$ & $\begin{array}{r}300,29 \\
100\end{array}$ & 年, 40,40 & $\mid \begin{array}{ll}5017,24 \\
5017\end{array}$ & 225,37 & $\begin{array}{l}-30,04 \\
-20,01 \\
\end{array}$ & \begin{tabular}{|l|}
$245,38,3$ \\
\end{tabular} & $\mid \begin{array}{ll}50,25 \\
5\end{array}$ & \begin{tabular}{|l|}
149,06 \\
\end{tabular} & \begin{tabular}{|l|l|}
149,50 \\
140
\end{tabular} & \begin{tabular}{|c|c|}
22,69 \\
22
\end{tabular} & \begin{tabular}{|l|}
087,79 \\
987
\end{tabular} & \begin{tabular}{|c|}
$153,0<24$ \\
126,24 \\
\end{tabular} & 年0,05| & $\begin{array}{l}28,73 \\
28,73\end{array}$ & 340,11 & $\begin{array}{l}150,04 \\
157,60\end{array}$ & $\begin{array}{l}16,41,62 \\
162\end{array}$ & $\begin{array}{l}352,05 \\
298,65\end{array}$ \\
\hline Ichthyosaura alpestris & 29TQH36 & 100,00 & 63,68 & 100,41 & 39,56 & 5201,10 & 211,47 & $-39,53$ & 251,01 & 22,61 & 133,22 & 133,42 & 2,10 & 1080,66 & 134,02 & 48,65 & 28,20 & 368,40 & 174,22 & 175,09 & 331,37 \\
\hline Ichthyosaura alpestris & 29TQH37 & 99,00 & 76,09 & 100,54 & 40,23 & 5063,42 & 220,15 & $-26,83$ & 246,98 & 43,00 & 143,21 & 143,59 & 15,63 & 1014,50 & 128,25 & 46,39 & 27,91 & 346,75 & 165,85 & 169,67 & 304,04 \\
\hline Ichthyosa & 29TQH49 & 36,00 & 119,17 & 96,75 & 43,23 & 4295,38 & 243,54 & 22,00 & 221,54 & 96,79 & 173,94 & 176 & 67 & 850,54 & 115,13 & 41,21 & 27,98 & 287,88 & 146,23 & 154,65 & 224,27 \\
\hline Ichthyosaura alpestris & 30TTN58 & 40,00 & 101,37 & 100,83 & 41,87 & 4746,45 & 237,37 & $-0,77$ & 238,13 & 75,35 & 163,05 & 164,07 & 43,82 & 878,58 & 115,75 & 42,27 & 27,45 & 00,85 & 150,50 & 157,87 & 243,32 \\
\hline
\end{tabular}




\begin{tabular}{|c|c|c|c|c|c|c|c|c|c|c|c|c|c|c|c|c|c|c|c|c|c|}
\hline TAXON & UTM & $\mathrm{km} 2$ & BIO1 & B102 & $\mathrm{BIO3}$ & BIO4 & BIO5 & B106 & B107 & B108 & 8109 & B1010 & B1011 & BIO12 & $\begin{array}{lll}B 1013 \\
\end{array}$ & B1014 & B1015 & $\begin{array}{lll}\text { B1016 } & \end{array}$ & $\begin{array}{lll}\text { B1017 } & \\
\end{array}$ & $\begin{array}{lll}B 1018 & \end{array}$ & B1019 \\
\hline Ichthyosaura alpestris & 30TTN59 & 34,00 & 107,65 & 97,71 & 42,53 & 4464,14 & 236,69 & 9,24 & 227,45 & 84,37 & 165,18 & 167,02 & 53,90 & 894,86 & 118,92 & 43,80 & 27,39 & 303,14 & 154,69 & 162,37 & 241,67 \\
\hline Ichthyosaura alpestris & 30TTN66 & 100,00 & 75,87 & 102,94 & 40,22 & 5193,28 & 223,88 & $-29,61$ & 253,49 & 46,30 & 144,83 & 144,96 & 13,51 & \begin{tabular}{|c|}
955,68 \\
\end{tabular} & 120,26 & 45,30 & 27,28 & 325,99 & 161,73 & 162,86 & 279,55 \\
\hline Ichthyosaura alpestris & 30TTN68 & 100,00 & 101,04 & 100,21 & 41,91 & 4702,54 & 235,95 & $\begin{array}{c}2,0,29 \\
\end{array}$ & 236,24 & 75,69 & 162,18 & 163,41 & 44,19 & 883,46 & 116,07 & 43,34 & 27,26 & 300,97 & 153,54 & 160,40 & 241,76 \\
\hline Ichthyosaura alpestris & 30TTN69 & 100,00 & 119,03 & 95,86 & 43,27 & 4250,99 & 241,90 & 22,63 & 219,26 & 97,51 & 173,16 & 175,43 & 67,69 & 853,09 & 115,27 & 42,55 & 27,79 & 287,22 & 149,88 & 157,86 & 220,65 \\
\hline Ichthyosaura alpestris & 30TTN96 & 100,00 & 67,08 & 102,48 & 39,64 & 5231,01 & 217,01 & $-38,30$ & 255,30 & 38,78 & 136,90 & 137,01 & 4,63 & 974,58 & 119,49 & 49,01 & 25,20 & 325,77 & 172,95 & 173,32 & 277,70 \\
\hline Ichthyosaura alpestris & 30TTN97 & 100,00 & 91,15 & 101,79 & 40,74 & 4985,50 & 233,21 & $-13,42$ & 246,64 & 64,77 & 156,72 & 157,24 & 30,60 & 860,57 & 110,01 & 44,04 & 26,18 & 292,84 & 155,83 & 160,33 & 233,59 \\
\hline Ichthyosaura alpestris & 30TTN99 & 100,00 & 111,96 & 94,06 & \begin{tabular}{|l|l|l|}
41,93 & \\
\end{tabular} & 4421,27 & 235,97 & 14,48 & 221,49 & 90,40 & 168,91 & 170,79 & 58,23 & 847,86 & 112,47 & 43,76 & 26,80 & 287,18 & 154,42 & 162,50 & 218,54 \\
\hline Ichthyosaura alpestris & 30TTP60 & 100,00 & 129,66 & 89,93 & 43,73 & 3918,14 & 241,79 & 38,42 & 203,37 & 111,05 & \begin{tabular}{|l|l|}
178,84 \\
\end{tabular} & 181,95 & 82,53 & 850,03 & 116,32 & 42,40 & 28,38 & 284,03 & 149,06 & 158,09 & 214,18 \\
\hline Ichthyosaura alpestris & 30TTP80 & 100,00 & 126,93 & 86,91 & 42,80 & 3981,43 & 237,32 & 36,17 & 201,14 & 108,64 & \begin{tabular}{|l|l}
177,37 \\
\end{tabular} & 180,30 & 78,91 & 843,78 & \begin{tabular}{|c|}
114,67 \\
\end{tabular} & 42,99 & 27,94 & 283,30 & 151,37 & 160,74 & 211,27 \\
\hline Ichthyosaura alpestris & 30TTP81 & 100,00 & 128,72 & 81,98 & 42,32 & 3853,70 & 232,81 & 41,31 & 191,50 & 111,41 & \begin{tabular}{|l|l|}
177,37 \\
\end{tabular} & 180,64 & 82,31 & 862,20 & 117,24 & 43,63 & 27,98 & 289,66 & 153,70 & 164,37 & 217,26 \\
\hline Ichthyosaura alpestris & 30TTP82 & 60,00 & 138,75 & 71,62 & 40,72 & 3679,04 & 230,37 & 56,65 & 173,71 & 122,63 & 185,16 & 188,74 & 94,25 & 829,42 & 113,76 & 40,20 & 28,83 & 282,16 & 143,90 & 157,39 & 211,51 \\
\hline Ichthyosaura alpestris & 30TтP90 & 100,00 & 125,74 & 85,39 & 42,02 & 4035,10 & 235,66 & 34,97 & 200,69 & 107,35 & 177,08 & 179,92 & 76,99 & 839,03 & 113,34 & 42,65 & 27,70 & 283,30 & 151,08 & 161,13 & 211,51 \\
\hline Ichthyosaura alpestris & 30TUN06 & 100,00 & 67,79 & 102,16 & 39,56 & 5215,84 & 217,31 & $-37,60$ & 254,91 & 40,02 & 137,45 & 137,62 & 5,61 & \begin{tabular}{|c|}
963,07 \\
\end{tabular} & 117,60 & 49,21 & 24,66 & 320,48 & 173,26 & 173,77 & 271,29 \\
\hline Ichthyosaura alpestris & 30TUN07 & 100,00 & 74,75 & 100,90 & 39,99 & 5084,37 & 219,96 & $-29,25$ & 249,21 & 48,05 & 142,29 & 142,70 & 13,83 & 947,55 & 117,25 & 48,74 & 24,89 & 316,92 & 171,84 & 174,25 & 263,42 \\
\hline Ichthyosaura alpestris & 30TUN16 & 100,00 & 78,12 & 102,39 & 39,84 & 5167,15 & 226,15 & $-28,03$ & 254,18 & 51,17 & 146,75 & 147,05 & 15,97 & 888,69 & 109,61 & 45,98 & 24,75 & 297,35 & 162,91 & 163,98 & 243,87 \\
\hline Ichthyosaura alpestris & 30TUN17 & 100,00 & 79,01 & 100,01 & 39,96 & 5033,41 & 222,44 & $-24,72$ & 247,16 & 53,18 & 145,73 & 146,35 & 18,47 & \begin{tabular}{|l|}
921,48 \\
\end{tabular} & 114,09 & 47,83 & 24,58 & 307,72 & 168,94 & 171,41 & 252,54 \\
\hline Ichthyosaura alpestris & 30TUN18 & 100,00 & 89,65 & 97,48 & 40,52 & 4836,49 & 226,22 & $-11,92$ & 238,14 & 65,36 & 153,17 & 154,21 & 31,25 & 898,12 & 113,38 & 46,80 & 24,96 & 301,86 & 165,37 & 170,20 & 241,54 \\
\hline Ichthyosaura alpestris & 30TUN37 & 100,00 & 79,28 & 97,90 & 39,70 & 4982,78 & 220,31 & $-23,47$ & 243,78 & 54,46 & 145,36 & 145,99 & 19,53 & 923,41 & 112,72 & 48,30 & 23,67 & 304,85 & 171,00 & 172,65 & 251,05 \\
\hline Ichthyosaura alpestris & 30TUN39 & 100,00 & 107,75 & 88,69 & 40,18 & 4470,70 & 229,18 & 11,69 & 217,48 & 87,06 & 165,69 & 167,45 & 53,23 & 867,20 & 111,23 & 44,20 & 25,51 & 293,17 & 158,73 & 167,19 & 228,33 \\
\hline Ichthyosaura alpestris & 30TUN47 & 100,00 & 66,54 & 97,04 & 39,20 & 5034,80 & 209,15 & $-35,25$ & 244,41 & 40,70 & 134,10 & 134,40 & 6,82 & 1002,78 & 119,17 & 52,86 & 22,54 & 324,81 & 184,95 & 185,50 & 276,72 \\
\hline Ichthyosaura alpestris & 30TUN48 & 100,00 & 67,51 & 94,53 & 39,34 & 4919,88 & 205,76 & $-31,83$ & 237,59 & 39,98 & 133,37 & 134,05 & 9,35 & 1040,16 & 123,97 & 54,86 & 22,76 & 337,29 & 191,38 & 193,21 & 288,05 \\
\hline Ichthyosaura alpestris & 30TUN49 & 100,00 & 100,95 & 88,36 & 39,92 & 4525,81 & 223,92 & 5,10 & 218,82 & 80,02 & 159,82 & 161,59 & 46,13 & 905,04 & 113,95 & 46,21 & 24,80 & 303,52 & 165,79 & $\begin{array}{l}173,43 \\
1721\end{array}$ & 241,78 \\
\hline Ichthyosaura alpestris & 30TUN55 & 100,00 & 67,09 & 99,61 & 38,96 & 5184,02 & 214,98 & $-37,53$ & 252,51 & 40,85 & 137,07 & 137,07 & 5,56 & 938,72 & 109,96 & 49,34 & 22,30 & 301,20 & 171,41 & 171,43 & 256,99 \\
\hline Ichthyosaura alpestris & 30TUN56 & 100,00 & 54,14 & 97,61 & 38,77 & 5154,62 & 200,68 & $-47,84$ & 248,52 & 24,53 & 124,04 & 124,04 & $-6,25$ & $\begin{array}{r}1057,32 \\
\end{array}$ & 122,17 & 56,16 & 21,65 & 335,88 & 192,65 & 192,66 & 294,61 \\
\hline Ichthyosaura alpestris & 30TUN57 & 100,00 & 76,96 & 95,17 & 39,27 & 4934,79 & 215,46 & $-24,06$ & 239,52 & 52,90 & 142,68 & 143,37 & 18,05 & 952,74 & 114,06 & 49,92 & 22,76 & 310,09 & 176,30 & 177,79 & 259,61 \\
\hline Ichthyosaura alpestris & 30TUN58 & 100,00 & 64,12 & 93,81 & 39,15 & 4927,86 & 202,28 & $-34,64$ & 236,92 & 36,02 & 130,13 & 130,90 & 6,13 & 1062,61 & 125,24 & 56,25 & 22,12 & 342,21 & 195,97 & 197,36 & 294,85 \\
\hline Ichthyosaura alpestris & 30TUN65 & 100,00 & $\frac{\mid 4,119}{69,90}$ & 98,53 & 38,94 & 5144,39 & 215,94 & $\begin{array}{l}-34,28 \\
-34,4\end{array}$ & 250,22 & 43,91 & 139,24 & 139,24 & 8,80 & 926,83 & $\mid 108,09$ & 48,77 & 21,90 & \begin{tabular}{|l|l|}
296,21 \\
\end{tabular} & 169,89 & 169,89 & 252,41 \\
\hline Ichthyosaura alpestris & 30TUN66 & 100,00 & 64,93 & 96,69 & 38,92 & 5085,61 & 208,57 & $-37,11$ & 245,68 & 39,03 & 133,55 & 133,73 & 4,92 & 990,62 & 115,28 & 52,41 & 21,68 & 315,93 & 182,13 & 182,35 & 272,32 \\
\hline Ichthyosaura alpestris & 30TUN67 & 100,00 & 106,29 & 89,65 & 39,20 & 4654,97 & 232,62 & 7,29 & 225,33 & 85,08 & 166,82 & 168,31 & 49,38 & 828,46 & 103,01 & 41,33 & 24,41 & 277,75 & 151,40 & 157,16 & 220,10 \\
\hline Ichthyosaura alpestris & 30TUN68 & 100,00 & 96,86 & 88,38 & 39,26 & 4626,31 & 222,21 & 0,02 & 222,19 & 75,25 & 157,31 & 158,81 & 40,88 & \begin{tabular}{|c|}
912,28 \\
\end{tabular} & 112,01 & 46,25 & 23,97 & 302,74 & 166,82 & 173,13 & 246,33 \\
\hline Ichthyosaura alpestris & 30TUN69 & 100,00 & 117,26 & 81,33 & 39,36 & 4297,31 & 229,34 & 25,31 & 204,04 & 98,33 & 172,43 & 174,63 & 64,57 & 870,67 & 110,78 & 42,19 & 25,82 & 296,73 & 155,49 & 167,92 & 233,20 \\
\hline Ichthyosaura alpestris & 30TUN75 & 100,00 & 83,51 & 96,70 & 38,99 & 5049,08 & 225,18 & $-20,38$ & 245,56 & 59,29 & 151,16 & 151,18 & 22,95 & 856,41 & 101,02 & 44,38 & 22,20 & 276,21 & 158,04 & 158,04 & 229,83 \\
\hline Ichthyosaura alpestris & 30TUN85 & 100,00 & 75,40 & 95,93 & 38,82 & 5077,38 & 217,77 & $-27,32$ & 245,09 & 50,12 & \begin{tabular}{|l|l|}
143,84 \\
\end{tabular} & 143,85 & 14,98 & 908,83 & 105,03 & 47,62 & 21,45 & 288,47 & 167,41 & 167,41 & 246,18 \\
\hline Ichthyosaura alpestris & 30TUN86 & 100,00 & 66,77 & 94,64 & 38,78 & 5038,34 & 207,94 & $-33,90$ & 241,84 & 40,28 & 134,84 & 135,01 & 7,35 & 990,20 & 113,64 & 52,54 & 21,05 & 312,65 & 183,28 & 183,33 & 271,50 \\
\hline Ichthyosaura alpestris & 30TUN87 & 100,00 & 88,78 & 89,96 & 38,97 & 4779,18 & 219,30 & $-9,24$ & 228,53 & 66,52 & 151,61 & 153,06 & 31,26 & 919,68 & 109,43 & 47,08 & 22,49 & 299,16 & 169,77 & 173,11 & 249,70 \\
\hline Ichthyosaura alpestris & 30 UN 89 & 100,00 & 127,09 & 75,33 & 38,78 & 4128,39 & 231,24 & 38,99 & 192,25 & 109,28 & 179,62 & 182,10 & 76,02 & 878,53 & 111,87 & 40,39 & 26,85 & 303,48 & 152,44 & 170,10 & 239,38 \\
\hline Ichthyosaura alpestris & 30TUN95 & 100,00 & 78,28 & 94,44 & 38,47 & 5046,53 & 218,68 & $-23,58$ & 242,26 & 53,54 & 146,15 & 146,33 & 18,04 & 901,17 & 103,65 & 46,95 & 21,24 & 285,22 & 166,28 & 166,34 & 244,29 \\
\hline Ichthyosaura alpestris & 30TUN96 & 100,00 & 78,44 & 92,35 & 38,73 & 4948,25 & 215,06 & $-21,10$ & 236,15 & 54,41 & 144,41 & 145,20 & 19,49 & 937,75 & 108,48 & 48,88 & 21,28 & 298,43 & 173,79 & 174,56 & 255,77 \\
\hline Ichthyosaura alpestris & 30TUN98 & 100,00 & 117,02 & 79,04 & 38,54 & 4334,54 & 228,44 & 25,87 & 202,56 & 97,81 & \begin{tabular}{|l|l|}
172,57 \\
\end{tabular} & 174,82 & 63,65 & 887,01 & 109,93 & 41,75 & 25,30 & 300,98 & 156,30 & 170,18 & 242,66 \\
\hline Ichthyosaura alpestris & 30TUN99 & 100,00 & 129,86 & 72,59 & 38,2 & 4062,29 & 231,07 & 43,82 & 187,25 & 112,45 & 181,34 & 183,99 & 79,52 & 896,31 & 113,76 & 40,26 & 27,29 & 311,29 & 153,49 & 173,86 & 247,30 \\
\hline Ichthyosaura alpestris & 30TUPO0 & 100,00 & 126,74 & 83,46 & 41,4 & 4057,12 & 235,08 & 36,23 & 198,85 & 108,39 & 178,43 & 181,14 & 77,34 & 829,34 & 111,57 & 41,76 & 27,54 & 281,62 & 149,04 & 159,96 & 210,49 \\
\hline Ichthyosaura alpestris & 30TUPC & 98,00 & 13 & 77,05 & 40, & 3870,73 & 232,49 & 46,63 & 185,86 & 115,81 & 181,85 & 184,96 & 85,62 & 834,29 & 112,99 & 41,12 & 27,93 & 284,33 & 147,81 & 160,77 & 212,72 \\
\hline Ichthyosaura alpestris & 30TUP11 & 96,00 & 128,99 & 78,27 & 40,69 & 3961,70 & 231,50 & 41,54 & 189,96 & 111,36 & 179,31 & 182,19 & 80,64 & 846,18 & 113,34 & 41,76 & 27,45 & 289,11 & 150,50 & 163,76 & 218,27 \\
\hline Ichthyosaura alpestris & 30TUP20 & 100,00 & 134,88 & 77,88 & 40,2 & 3995,93 & 237, & 46,48 & 190,63 & 117,35 & 185,62 & 188,38 & 85,65 & 802,19 & 107,72 & 38,63 & 27,90 & 76,54 & 34 & 155,20 & 206,81 \\
\hline Ichthyosaura alpestris & 30TUP21 & 65,00 & 132,62 & 76,72 & 40, & 3942,74 & 233,28 & 45,64 & 187 & 115,31 & 18 & 185,54 & 84,31 & 833,38 & 111,64 & 40, & 27,68 & 286,53 & 147,33 & 161,81 & 215,78 \\
\hline Ichthyosaura alpestris & 30TUP31 & 47,00 & 138,43 & 74,00 & 40 & 389 & 235,65 & \begin{tabular}{|c|c|}
52,49 \\
\end{tabular} & 183,16 & 121,57 & 187,60 & \begin{tabular}{|l|l|}
190,48 \\
\end{tabular} & $\begin{array}{l}90,33 \\
90,1\end{array}$ & 8 & \begin{tabular}{|l|l|l|l|l|}
109,47 \\
\end{tabular} & 38,40 & 28,28 & 283,51 & 141,96 & $\begin{array}{ll}158,43 \\
\end{array}$ & 213,59 \\
\hline Ichthyosaura alpestris & 30TUP60 & 75,00 & 129,85 & 75,75 & 39,19 & 4064,14 & 232,53 & 42,05 & 190,47 & 112,40 & 181,46 & 184,08 & 79,68 & 859,68 & 111,71 & 40,19 & 27,31 & 297,76 & 149,96 & 167,00 & 230,73 \\
\hline Ichthyosaura alpestris & 30TUP80 & 52,00 & 140,72 & 69,54 & 38,38 & 3892,03 & 235,48 & 57,06 & 178,42 & 124,28 & 189,84 & 192,54 & 92,19 & 868,10 & $\mid 112,90$ & 37,91 & 28,77 & 306,16 & 146,00 & 169,13 & 238,68 \\
\hline Ichthyosaura alpestris & 30TVL10 & 100,00 & 112,46 & 102,96 & 35, & 6427,44 & 279,75 & $-7,11$ & 286,86 & 80,22 & 197,93 & 199,25 & 35,60 & 478,21 & 56,21 & 15,01 & 30,94 & 99 & 67,21 & 71,88 & 123,97 \\
\hline Ichthyosaura alpestris & 30TVLI & 100,00 & 82,73 & 105,64 & 37, & & 251,27 & $-30,42$ & & 86,58 & 16 & & 13 & 603,08 & $124+2+2$ & & 27,85 & & 92,53 & 97,16 & 152,35 \\
\hline Ichthyosaura alpestris & $30 \mathrm{TV}$ & 100,00 & 89,15 & 105,22 & 36,69 & 6195,81 & 257,50 & $-25,31$ & 282,81 & 82,82 & 173,58 & 173,95 & 18,03 & 575,22 & 68,69 & 21,29 & 27,97 & 177,58 & 86,99 & 92,20 & 146,47 \\
\hline Ichthyosaura alpestris & $\begin{array}{l}30 \text { TVNO6 } \\
\end{array}$ & 100,00 & 93,48 & 88,85 & 38,40 & 4816,21 & 223,41 & $-4,68$ & 228,10 & 70,61 & 156,37 & 158,01 & 35,10 & 882,73 & \begin{tabular}{|c|}
103,43 \\
\end{tabular} & 44,41 & 22,11 & 285,17 & 162,07 & 165,37 & 240,34 \\
\hline Ichthyosaura alpestris & 30TVN07 & 100,00 & 100,52 & 84,68 & 38,35 & 4629,05 & 223,08 & 5,55 & 217,53 & 79,01 & 160,53 & 162,49 & 44,18 & 903,90 & 107,70 & 44,50 & 22,99 & 296,89 & 163,57 & 171,12 & 247,80 \\
\hline Ichthyosaura alpest & 30TVN15 & 100,00 & 96, & 89,05 & 38,07 & 4883,89 & 227,97 & $-2,11$ & 5 & 73,03 & 160 & & 37,23 & 841,59 & 97,63 & 41,88 & 21,90 & 43 & 84 & 64 & 22 \\
\hline Ichthyosaura alpestris & $30 \mathrm{TVI}$ & 100,00 & 99,13 & 86,20 & 38,09 & 4748,31 & 225,22 & 2,60 & 222,62 & 76,54 & 160,81 & 162,70 & 41,35 & 876,76 & 102,58 & 43,28 & 22,32 & 284,48 & 159,04 & 164,78 & 240,62 \\
\hline Ichthyosaura alpestris & 30TVN18 & 100,00 & 123,42 & 73,44 & 37,91 & 4194,33 & 228,38 & 36,56 & 191,82 & 104,73 & 176,70 & 179,34 & 71,52 & 922,62 & 113,21 & 41,53 & 26,22 & 315,78 & 158,21 & 177,78 & 259,29 \\
\hline Ichthyosaura alpestris & 30TVN25 & 100,00 & 99,07 & 87,23 & 38,01 & 4861,28 & 227,97 & 1,48 & 226,50 & 75,07 & 162,11 & 163,98 & 39,72 & 847,18 & 97,49 & 41,77 & 21,85 & 271,79 & 153,74 & 158,29 & 232,81 \\
\hline Ichthyosaura alpestris & 30 TVN26 & 100,00 & 99,52 & 84,82 & 38,02 & 4741,43 & 224,38 & 4,32 & 220,06 & 76,76 & 160,99 & 163,08 & 41,78 & 890,45 & 103,09 & 43,70 & 22,14 & 287,85 & 16075 & 167,71 & 246,91 \\
\hline Ichthyosau & 30TVN35 & 100,00 & 100,09 & 85,70 & 37, & 4839,53 & 227,32 & , & 223,40 & 75 & & & & 860,57 & 98,02 & 42,14 & 21,75 & 275,25 & 155,33 & 161,40 & 239 \\
\hline Ichthyosaura alpestris & 30TVN36 & 100,00 & 98,50 & 83,98 & 37,94 & 4741,51 & 222,92 & 4,39 & 218,54 & 75,08 & 159,90 & 161,99 & 40,86 & 910,65 & $\begin{array}{r}104,03 \\
\end{array}$ & 44,72 & 21,92 & 292,47 & $\begin{array}{l}164,27 \\
\end{array}$ & $\begin{array}{l}171,989 \\
\end{array}$ & 255,13 \\
\hline
\end{tabular}




\begin{tabular}{|c|c|c|c|c|c|c|c|c|c|c|c|c|c|c|c|c|c|c|c|c|c|}
\hline TAXON & UTM & $\mathrm{km} 2$ & B101 & $\mathrm{B1O2}$ & $\mathrm{BIO3}$ & BIO4 & B105 & 8106 & B107 & $\mathrm{B108}$ & B109 & B1010 & BIO11 & BIO12 & B1013 & BIO14 & B1015 & BIO16 & B1017 & BIO18 & B1019 \\
\hline Ichthyosaura alpestris & 30TVN37 & 100,00 & 106,25 & 78,95 & 37,64 & 4519,87 & 222,60 & 15,81 & 206,80 & 83,86 & 164,41 & 166,69 & 51,04 & 948,49 & 110,55 & 45,01 & 23,36 & 311,21 & 167,55 & 180,65 & 269,49 \\
\hline Ichthyosaura alpestris & 30TVN47 & 100,00 & 84,44 & 84,65 & \begin{tabular}{|l|l|}
37,98 \\
\end{tabular} & 4773,45 & 211,57 & $-8,16$ & 219,73 & 50,17 & 146,53 & 148,96 & 27,38 & 1012,71 & 114,26 & 51,64 & 20,71 & 319,08 & 186,35 & 192,27 & 286,46 \\
\hline Ichthyosaura alpestris & 30TVN48 & 100,00 & 94,57 & 79,63 & 37,77 & 4553,22 & 213,35 & 5,26 & 208,09 & 65,35 & 153,28 & 155,92 & 39,71 & 1037,07 & 120,07 & 50,90 & 22,20 & 334,28 & 186,41 & 198,12 & 297,73 \\
\hline Ichthyosaura alpestris & 30TVN49 & 100,00 & 121,90 & 67,96 & 36,93 & 4068,85 & 221,70 & 40,18 & 181,52 & 103,62 & 173,25 & 176,26 & 71,89 & 1048,45 & 128,75 & 46,12 & 26,42 & \begin{tabular}{|c|}
356,67 \\
\end{tabular} & 176,45 & 202,64 & 309,96 \\
\hline Ichthyosaura alpestris & 30TVN57 & 100,00 & 90,49 & 82,57 & $\begin{array}{l}37,85 \\
\end{array}$ & 4709,62 & 214,55 & $-0,90$ & 215,45 & 52,83 & 151,43 & 153,93 & 33,92 & 1014,97 & 115,98 & 50,75 & 21,14 & 321,54 & 184,65 & 193,13 & 291,03 \\
\hline Ichthyosaura alpestris & 30TVN58 & 100,00 & 108,37 & 74,56 & 37,25 & 4385,44 & 219,45 & 21,93 & 197,52 & 82,71 & 164,34 & 167,09 & 54,88 & 1034,62 & 123,48 & 48,07 & 23,87 & 339,52 & 179,88 & 197,78 & 305,10 \\
\hline Ichthyosaura alpestris & 30TVN59 & 100,00 & 126,02 & 66,15 & 36,59 & 4031,09 & 223,35 & 45,27 & 178,07 & 107,64 & 176,66 & 179,72 & 76,24 & 1066,38 & 132,93 & 45,83 & 27,00 & 363,23 & 176,75 & 205,10 & 322,81 \\
\hline Ichthyosaura alpestris & 30TVN67 & 100,00 & 101,25 & 79,16 & 37,55 & 4599,45 & 219,84 & 11,59 & 208,25 & 65,66 & 160,21 & 162,83 & 45,37 & 1010,80 & 117,99 & 48,59 & 22,10 & 323,75 & 179,86 & 192,51 & 296,21 \\
\hline Ichthyosaura alpestris & 30TVN74 & 100,00 & 107,62 & 84,58 & 37,51 & 4912,95 & 234,44 & 12,03 & 222,40 & 74,75 & 170,82 & 172,86 & 47,35 & 851,06 & 96,70 & 40,89 & 21,06 & 266,57 & 153,21 & 160,98 & 245,17 \\
\hline Ichthyosaura alpestris & 30TVN77 & 100,00 & 122,34 & 71,61 & 36,73 & 4342,73 & 229,04 & 36,54 & 192,50 & 98,41 & 177,24 & 179,90 & 68,68 & 1009,67 & 123,94 & 44,06 & 25,19 & 332,97 & 169,58 & 190,88 & 310,96 \\
\hline Ichthyosaura alpestris & 30TVN85 & 100,00 & 104,85 & 83,38 & 37,74 & 4828,90 & 229,94 & 11,22 & 218,72 & 54,11 & 166,92 & 169,21 & 45,99 & 924,90 & 105,84 & 44,83 & 20,84 & 290,18 & 167,04 & 175,80 & 270,28 \\
\hline Ichthyosaura alpestris & 30 TVN86 & 100,00 & 105,44 & 80,40 & 37,56 & 4686,24 & 225,87 & 14,56 & 211,31 & 57,21 & 165,48 & 167,92 & 48,38 & 987,13 & 114,97 & 47,12 & 21,75 & 313,49 & 175,99 & 187,50 & 293,23 \\
\hline Ichthyosaura alpestris & 30TVN88 & 100,00 & 126,70 & 67,62 & 36,38 & 4189,88 & 227,43 & 44,06 & 183,37 & 89,67 & 179,27 & 182,15 & 74,93 & 1088,14 & 136,91 & 45,96 & 26,80 & 362,44 & 178,49 & 204,42 & 347,08 \\
\hline Ichthyosaura alpestris & 30TVN89 & 100,00 & 128,19 & 64,79 & 36,19 & 4057,18 & 224,63 & 47,99 & 176,64 & 90,41 & 178,88 & 181,96 & 78,10 & 1143,30 & 145,65 & 47,71 & 27,72 & 384,24 & 185,29 & 214,87 & 368,93 \\
\hline Ichthyosaura alpestris & 30TVN94 & 100,00 & 108,73 & 85,55 & 37,76 & 4938,92 & 236,51 & 12,67 & 223,84 & 62,07 & 172,20 & 174,24 & 48,30 & 872,13 & 98,54 & 42,44 & 20,30 & 270,24 & 159,39 & 166,11 & 253,37 \\
\hline Ichthyosaura alpestris & 30 TVN95 & 100,00 & 106,38 & 83,55 & 37,77 & 4828,87 & 231,28 & 12,65 & 218,63 & 56,30 & 168,32 & 170,60 & 47,55 & 938,21 & 107,38 & 45,50 & 20,76 & 293,76 & 170,03 & 178,55 & 276,05 \\
\hline Ichthyosaura alpestris & 30TVPOO & 64,00 & 137,12 & 66,61 & 37,79 & 3851,80 & 230,15 & 55,92 & 174,23 & 120,96 & 185,16 & 188,49 & 89,16 & 941,17 & 120,19 & 40,62 & 28,75 & 331,77 & 157,24 & 184,34 & 264,64 \\
\hline Ichthyosaura alpestris & 30TVP10 & 91,00 & 140,29 & 63,68 & 37,35 & 3761,53 & 229,76 & 61,62 & 168,14 & 124,53 & 180,70 & 190,41 & 93,41 & 969,80 & 123,50 & 40,83 & 29,56 & 344,03 & 159,72 & 190,60 & 276,50 \\
\hline Ichthyosaura alpestris & 30TVP20 & 99,00 & 139,47 & 61,90 & \begin{tabular}{|l|l|l|l|}
37,03 & \\
\end{tabular} & 3723,07 & 227,32 & 62,40 & 164,92 & 123,90 & 174,73 & 189,11 & 93,06 & 1010,81 & 127,51 & 42,12 & 29,70 & 358,71 & 165,13 & 198,97 & 291,94 \\
\hline Ichthyosaura alpestris & 30TVP30 & 86,00 & 138,58 & 60,93 & 36,75 & 3722,42 & 226,02 & 62,32 & 163,70 & 122,92 & 174,77 & 188,31 & 92,36 & 1043,38 & 131,23 & 43,16 & 29,64 & \begin{tabular}{|c|}
369,18 \\
\end{tabular} & 169,38 & 204,99 & 306,25 \\
\hline Ichthyosaura alpestris & 30TVP40 & 99,00 & 137,02 & 60,62 & 36,34 & 3756,43 & 224,89 & 60,58 & 164,32 & 120,99 & 179,46 & 187,05 & 90,33 & 1075,99 & 136,42 & 44,40 & 29,36 & 378,07 & 174,43 & 210,23 & 322,33 \\
\hline Ichthyosaura alpestris & 30TVP50 & 100,00 & 135,87 & 60,90 & 36,17 & 3806,96 & 224,75 & 58,97 & \begin{tabular}{|l|l|}
165,78 \\
\end{tabular} & 119,22 & 183,13 & 186,40 & 88,57 & 1097,40 & 139,97 & 45,10 & 29,04 & 382,13 & 177,06 & 212,35 & 336,43 \\
\hline Ichthyosaura alpestris & 30TWN05 & 100,00 & 111,15 & 83,25 & 37,86 & 4804,25 & 234,88 & 17,47 & 217,42 & 60,22 & 172,58 & 174,81 & 52,45 & 940,18 & $\mid 107,73$ & \begin{tabular}{|c|}
45,27 \\
\end{tabular} & 20,77 & 294,35 & 170,42 & 179,21 & 278,61 \\
\hline Ichthyosaura alpestris & 30TWN15 & 100,00 & 110,09 & 85,02 & 38,03 & 4845,20 & 235,85 & 15,60 & 220,25 & 58,25 & 172,10 & 174,23 & 51,07 & 950,45 & 107,55 & 46,56 & 19,95 & 295,50 & 174,82 & 181,79 & 279,59 \\
\hline Ichthyosaura alpestris & 30TWN16 & 100,00 & 98,64 & 85,16 & 38,28 & 4807,67 & 225,03 & 5,69 & 219,33 & 47,92 & 160,34 & 162,73 & 40,71 & 1045,75 & 118,43 & 52,56 & 19,70 & 326,01 & 193,81 & 199,88 & 307,97 \\
\hline Ichthyosaura alpestris & 30TWN26 & 100,00 & 113,08 & 82,98 & 38,30 & 4690,10 & 234,81 & 21,53 & 213,27 & 62,92 & 172,61 & 175,10 & 56,11 & 1031,02 & 118,07 & 49, & 20,60 & 324,36 & 187,44 & 196,33 & 308,42 \\
\hline Ichthyosaura alpestris & 30TWN27 & 100,00 & 120,50 & $\frac{72,30}{77,90}$ & 38,17 & 4471,05 & 234,66 & 33,45 & 201,21 & 72,74 & 176,71 & 179,56 & $\mid 66,37$ & 1097,43 & $\mid 129,37$ & 50,81 & 22,51 & 352,25 & 192,55 & 207,20 & 338,87 \\
\hline Ichthyosaura alpestris & 30TWN33 & 100,00 & 103,56 & 94,58 & 38,90 & 5221,61 & 242,10 & 1,07 & 241,03 & 47,20 & 172,36 & 172,57 & 39,87 & 862,93 & 92,57 & 45,23 & 17,73 & 257,56 & 166,55 & 166,66 & 241,63 \\
\hline Ichthyosaura alpestris & 30TWN36 & 100,00 & 118,93 & 83,30 & 38,89 & 4648,14 & 239,72 & 27,74 & 211,98 & 68,82 & 177,68 & 180,22 & 62,58 & 1040,38 & 118,56 & 50,06 & 20,62 & 327,62 & 188,78 & 197,71 & 311,32 \\
\hline Ichthyosaura alpestris & 30TWN53 & 100,00 & 99,05 & 97,23 & 39,00 & 5289,83 & 240,71 & $-5,51$ & 246,22 & 42,19 & 169,02 & 169,02 & 34,61 & 912,83 & 98,09 & 48,79 & 17,47 & 272,35 & 174,91 & 174,91 & 255,66 \\
\hline Ichthyosaura alpestris & 30TWN54 & 100,00 & 108,16 & 93,91 & 39,01 & 5109,92 & 243,98 & 6,90 & 237,08 & 52,94 & 175,02 & 175,43 & 45,78 & 945,86 & \begin{tabular}{|c|}
103,08 \\
\end{tabular} & 49,09 & 18,18 & 287,36 & 180,52 & 180,55 & 269,18 \\
\hline Ichthyosaura alpestris & 30TWN63 & 100,00 & 103,32 & 97,94 & 39,01 & 5316,96 & 245,23 & $\begin{array}{l}-2,27 \\
-2,2 \\
\end{array}$ & 247,50 & $\begin{array}{ll}45,76 \\
4\end{array}$ & $\begin{array}{l}173,31 \\
173,\end{array}$ & 173,31 & 38,25 & \begin{tabular}{|l|}
914,81 \\
\end{tabular} & \begin{tabular}{|l|}
99,12 \\
\end{tabular} & | 48,44 & $\begin{array}{ll}17,94 \\
17,94\end{array}$ & 274,80 & \begin{tabular}{|l|l|}
173,71 \\
\end{tabular} & 173,71 & 257,41 \\
\hline Ichthyosaura alpestris & 30TWN64 & 100,00 & 104,07 & 95,58 & 39,10 & 5166,61 & 242,19 & 1,56 & 240,63 & 48,36 & 172,21 & 172,21 & 41,03 & 984,99 & 108,32 & 51,52 & 18,30 & 300,55 & 186,36 & 186,36 & 281,81 \\
\hline Ichthyosaura alpestris & 30TWN73 & 100,00 & 103,41 & 98,80 & 39,01 & 5350,09 & 246,23 & $-3,39$ & 249,61 & 45,57 & 173,73 & 173,73 & 37,87 & 936,65 & 102,89 & 49,35 & 18,41 & 283,47 & 175,99 & 175,99 & 265,79 \\
\hline Ichthyosaura alpestris & 30TWN74 & 100,00 & 100,62 & 96,62 & 39,21 & 5208,45 & 240,12 & $-2,82$ & 242,94 & 44,68 & 169,38 & 169,38 & 37,17 & 1021,25 & 113,47 & 53,57 & 18,56 & 312,86 & 191,86 & 191,86 & 293,94 \\
\hline Ichthyosaura alpestris & 30TWN75 & 100,00 & 108,49 & 94,04 & 39,53 & 5036,57 & 243,08 & 7,88 & 235,20 & 54,16 & 174,61 & 174,66 & 46,97 & 1073,28 & 120,82 & 54,95 & 19,36 & 334,82 & 200,40 & 200,40 & 313,61 \\
\hline Ichthyosaura alpestris & $\begin{array}{l}30 \text { TWN76 } \\
\end{array}$ & 100,00 & 111,01 & $\begin{array}{l}94,044 \\
90,73\end{array}$ & 39,88 & 4809,98 & 239,75 & \begin{tabular}{r|r}
14,90 \\
14
\end{tabular} & \begin{tabular}{|l|l|l}
224,85 \\
\end{tabular} & $\begin{array}{ll}4,10,29 \\
59\end{array}$ & $\begin{array}{l}174,01 \\
172,92\end{array}$ & $\begin{array}{l}174,38 \\
174,\end{array}$ & $\begin{array}{l}40,2,67 \\
52\end{array}$ & 1155,76 & \begin{tabular}{|l|}
130,57 \\
$130<$
\end{tabular} & 58,43 & $\begin{array}{ll}19,83 \\
19,0\end{array}$ & 年354,02 & \begin{tabular}{|l|}
213,91 \\
213
\end{tabular} & 216,84 & 340,01 \\
\hline Ichthyosaura alpestris & $30 T W N \S$ & 100,00 & 110,64 & 99,59 & 39,01 & 5397,98 & 254,13 & 2,25 & 251,88 & 51,75 & 181,21 & 181,21 & 43,90 & 943,14 & 106,92 & 48,21 & 19,84 & 291,81 & 172,73 & 172,73 & 273,47 \\
\hline Ichthyosaura alpestris & 30TWN84 & 100,00 & 91,57 & 97,49 & 39,01 & 5276,41 & 233,10 & $-13,28$ & 246,38 & 35,46 & 161,44 & 161,44 & 27,57 & 1060,01 & 118,21 & 56,62 & 18,24 & 323,42 & 199,51 & 199,51 & 305,06 \\
\hline Ichthyosaura alpestris & 30TWN85 & 100,00 & 106,58 & 95,36 & 39,43 & 5114,41 & 243,07 & 4,09 & 238,99 & 51,34 & 173,73 & 173,73 & 43,91 & 1099,31 & 125,91 & 56,20 & 19,88 & 345,57 & 203,27 & 203,27 & 324,35 \\
\hline Ichthyosaura alpestris & 30TWN86 & 100,00 & 113,46 & 92,50 & 39,91 & 4893,48 & 244,21 & 14,93 & 229,28 & 60,58 & 176,77 & 17 & 53,68 & 1171,81 & 135,21 & 58,72 & 20,63 & 373,55 & 215,77 & 216,84 & 349,65 \\
\hline Ichthyosaura alpestris & 30TWN & 100,00 & 11 & 98,54 & 39,03 & 5324,67 & 253,68 & 5,05 & 248,64 & 54,25 & 181,91 & 181,91 & 46,41 & 1044,64 & 123,47 & 52,04 & 21,45 & 333,16 & 187,74 & 187,74 & 313,34 \\
\hline Ichthyosaura alpestris & 30TWN & 100,00 & 112,46 & 96,45 & 39,30 & 5169,92 & 249,99 & 7,99 & 242,00 & 56,38 & 180,13 & 180,13 & 48,65 & 1115,28 & 131,91 & 55,58 & 21,42 & 357,89 & 201,88 & 201,88 & 336,12 \\
\hline Ichthyosaura alpestris & 30TWP30 & 40,00 & 137,65 & 69,00 & 38,61 & 3995,39 & 236,84 & 60,23 & 176,61 & 94,85 & 186,32 & 190,00 & 89,87 & 1267,71 & 155,84 & 54,73 & 26,05 & 421,16 & 210,02 & 237,97 & 409,79 \\
\hline Ichthyosaura alpestris & 30 TXN12 & 100,00 & 104,16 & 102,64 & 38 & 5612,40 & 252,62 & $-9,53$ & ct & 43,29 & 51 & 177,51 & 34,44 & 64 & 10,28 & 47,8 & 20,74 & 98 & 169,21 & 169,21 & 276,37 \\
\hline Lissotriton boscai & $295 M C 69$ & 100,00 & 147 & 70,09 & 4 & 3488,38 & 238,79 & 70,50 & $\frac{20}{16}$ & $\frac{43,20}{111,22}$ & 18 & & \begin{tabular}{|r|r|}
102,87 \\
\end{tabular} & 825,55 & \begin{tabular}{|l|l|}
127,97 \\
\end{tabular} & $\frac{4, c, 6}{5,6}$ & 64,31 & 370,27 & \begin{tabular}{r|}
36,55 \\
36
\end{tabular} & 38,54 & 344,46 \\
\hline Lissotriton boscai & $29 \mathrm{SMC}$ & 84,00 & 158 & 75,36 & 41,23 & 3702,77 & 257,79 & 77,44 & 180,35 & 119,08 & 202,40 & 206,80 & 111,26 & 771,92 & 120,92 & 4,6 & 64,95 & 348,70 & 31,93 & 34,07 & 328,03 \\
\hline Lissotriton boscai & $295 M C 79$ & 100,00 & 150,21 & 73,67 & 40,95 & 3685,18 & 248,04 & 70,05 & 177,99 & 111,34 & 194,26 & 198,41 & 103,30 & 825,94 & 128,66 & 4,51 & 64,91 & 371,05 & 34,95 & 36,68 & 348,66 \\
\hline Lissotriton boscai & $295 M C 85$ & 48,00 & 162,61 & 81,58 & 41,70 & 3901,56 & 272,91 & 79,16 & 193,75 & 122,18 & 209,94 & 214,84 & 114,66 & 712,75 & 108,22 & 3,94 & 63,17 & 318,22 & 31,22 & 33,31 & 304,73 \\
\hline Lissotriton boscai & $295 M C 86$ & 60,00 & 166 & 81,36 & 41,3 & 3924,44 & 276,58 & 82,44 & 5 & 125,29 & 213 & $21 \varepsilon$ & 117,97 & 98,01 & 06,28 & 3,82 & 63,62 & 06 & 29,58 & 32,19 & 299,45 \\
\hline Lissotriton boscai & $295 M C$ & 85,00 & $\frac{16}{16}$ & 80 & $\begin{array}{ll}41, \\
41,\end{array}$ & 81 & 275,72 & $\begin{array}{l}2,44 \\
82,47 \\
\end{array}$ & \begin{tabular}{|l|l|}
193,25 \\
\end{tabular} & \begin{tabular}{|l|l|l|l|l|l|}
125,15 \\
\end{tabular} & 213,91 & $\frac{218}{218}$ & \begin{tabular}{|l|l|l|l|l|l|}
117,74 \\
\end{tabular} & \begin{tabular}{|l|}
$709,73,1$ \\
\end{tabular} & \begin{tabular}{|l|}
108,26 \\
108,26
\end{tabular} & $\begin{array}{l}, 02 \\
3,85\end{array}$ & $\begin{array}{ll}63,02 \\
63,78\end{array}$ & $\begin{array}{l}11,00 \\
318,88\end{array}$ & | 29,62 & $\begin{array}{l}25,11 \\
32,39\end{array}$ & $\begin{array}{l}353,45 \\
304,79\end{array}$ \\
\hline Lissotriton boscai & 29SMC88 & 76,00 & 164,78 & 79,29 & 40,77 & 3947,81 & 273,54 & 81,14 & 192,41 & 123,28 & 212,72 & 217,34 & 115,89 & 731,80 & 111,36 & 3,84 & 63,98 & 328,19 & 30,27 & 32,97 & 314,90 \\
\hline Lissotriton boscai & 29SMC96 & 101,00 & 166,61 & 83,55 & 41,10 & 4057,78 & 281,52 & 81,08 & 200,44 & 124,31 & 216,16 & 221,07 & 116,95 & $|689,66|$ & 104,09 & 3,57 & 63,35 & 308,21 & 28,87 & 31,62 & 296,61 \\
\hline Lissotriton boscai & $295 M D 60$ & 71,00 & 150,13 & 67,85 & 41,05 & 3399,25 & 237,06 & 73,70 & 163,36 & 114,29 & 190,23 & 193,60 & 105,75 & 791,66 & 123,77 & 4,56 & 64,30 & 356,92 & 33,85 & 36,46 & 330,30 \\
\hline Lissotriton boscai & $29 \mathrm{SMD}$ & 56,00 & 151,29 & 65,25 & $41, \mathrm{C}$ & 3287,54 & 233,99 & 76,85 & 157 & 116,75 & 189 & 193 & $10 \varepsilon$ & 756,94 & 120,51 & 4,18 & 63,64 & 340,78 & 32,10 & 35,60 & 314,88 \\
\hline \begin{tabular}{|l|l} 
Lissotriton boscai \\
\end{tabular} & 29SMD63 & $\begin{array}{c}30,00 \\
9,00\end{array}$ & $\begin{array}{l}13,25 \\
153,06\end{array}$ & $\begin{array}{l}59,78 \\
59,\end{array}$ & 年11,09 & | 32022,06 & 226,25 & $\begin{array}{l}0,03 \\
82,44 \\
\end{array}$ & \begin{tabular}{|l|}
143,81 \\
14,
\end{tabular} & \begin{tabular}{|l|}
121,75 \\
127
\end{tabular} & \begin{tabular}{|l|}
188,0606 \\
188,0
\end{tabular} & \begin{tabular}{|l|l|}
190,53 \\
\end{tabular} & \begin{tabular}{|l|l|}
113,19 \\
1130
\end{tabular} & \begin{tabular}{|l|}
692,31 \\
692,3
\end{tabular} & \begin{tabular}{|c|}
114,81 \\
114,1
\end{tabular} & \begin{tabular}{|l}
4,10 \\
4,00
\end{tabular} & $\begin{array}{l}3,044 \\
62,66\end{array}$ & $\begin{array}{l}340,10 \\
310,81\end{array}$ & $\begin{array}{l}32,106 \\
29,66 \\
\end{array}$ & $\begin{array}{l}3,, 00 \\
34,88 \\
\end{array}$ & $\begin{array}{l}281,00 \\
285,31\end{array}$ \\
\hline Lissotriton boscai & 29SMD70 & 101,00 & 148,41 & 71,26 & 40,70 & 3610,41 & 242,95 & 69,60 & 173,35 & 110,39 & 191,61 & 195,28 & 102,18 & 819,75 & 125,51 & 4,69 & 64,12 & 366,94 & 35,28 & 37,52 & 344,42 \\
\hline Lissotriton boscai & 29SMD71 & 100,00 & 150,71 & 68,40 & 40,60 & 3472,66 & 240,14 & 73,81 & 166,34 & 114,08 & 192,05 & 195,36 & 105.94 & 776.9 & 121.19 & 4.36 & 63.53 & 348.12 & 33,01 & 36.16 & 325,55 \\
\hline Lissotriton boscai & 29SMD7 & 101,00 & 153,51 & 62,06 & 41,03 & 3133,32 & 231,06 & 81,4 & 49, & 120,85 & 190, & 193 & 112,66 & 696,19 & 114,21 & 4,00 & 62 & 311,64 & 25 & 34,60 & 288,44 \\
\hline Lissotriton boscai & $295 M D 74$ & 88,00 & 151,73 & 59,61 & 41,06 & 3010,96 & 224,95 & 81,51 & 143,43 & 120,61 & 186,91 & 189,33 & 112,29 & 688,41 & 114,38 & 3,95 & 62,44 & 306,73 & 29,59 & 35,33 & 283,5 \\
\hline
\end{tabular}




\begin{tabular}{|c|c|c|c|c|c|c|c|c|c|c|c|c|c|c|c|c|c|c|c|c|c|}
\hline TAXON & UTM & $\mathrm{km} 2$ & BIO1 & B102 & $B 103$ & BIO4 & B105 & B106 & 8107 & B108 & B109 & B1010 & BIO11 & BIO12 & BIO13 & BIO14 & BIO15 & B1016 & B1017 & B1018 & 81019 \\
\hline Lissotriton boscai & 29SMD75 & 89,00 & 151,32 & 57,80 & 41,23 & 2903,17 & 220,92 & 82,61 & 138,31 & 121,57 & 185,03 & 187,33 & 113,25 & 677,61 & 113,71 & 3,95 & 62,35 & 300,55 & 29,35 & 35,85 & 277,62 \\
\hline Lissotriton boscai & 29SMD80 & 101,00 & 155,19 & 74,75 & 40,26 & 3803,25 & 256,91 & 73,98 & 182,93 & 115,18 & 201,22 & 205,14 & 107,34 & 778,76 & 1117,50 & 4,20 & 63,64 & 346,89 & 32,86 & 35,49 & 330,61 \\
\hline Lissotriton boscai & 29SMD81 & 101,00 & 150,37 & 72,32 & 40,14 & 3700,78 & 248,21 & 70,74 & $\begin{array}{l}177,47 \\
\end{array}$ & $\begin{array}{l}111,64 \\
\end{array}$ & 195,10 & \begin{tabular}{ll|}
198,73 \\
\end{tabular} & $\begin{array}{l}103,66 \\
\end{array}$ & 795,14 & 120,81 & 4,60 & 62,82 & 352,42 & 34,73 & 37,59 & 335,04 \\
\hline Lissotriton boscai & 29SMD82 & 101,00 & 153,03 & 69,44 & 40,40 & 3534,30 & 244,96 & 75,42 & 169,54 & 116,00 & 195,51 & $\begin{array}{l}198,77 \\
\end{array}$ & 108,01 & 749,30 & $\begin{array}{l}116,86 \\
\end{array}$ & 4,18 & 62,60 & 333,04 & 32,12 & 35,86 & 314,60 \\
\hline Lissotriton boscai & 295MD84 & 101,00 & 154,34 & 64,55 & 40,99 & 3237,16 & 236,09 & 80,47 & 155,62 & 120,55 & 192,73 & 195,36 & 112,40 & 698,05 & 113,05 & 4,00 & 62,10 & 309,29 & 30,02 & 35,43 & 289,73 \\
\hline Lissotriton boscai & 29SMD85 & 99,00 & 153,92 & 63,22 & 41,25 & 3141,44 & 232,59 & 81,14 & $\mid 151,45$ & 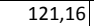 & \begin{tabular}{|l|l|}
190,92 \\
\end{tabular} & $\mid 193,39$ & $\mid$\begin{tabular}{|l}
113,04 \\
\end{tabular} & 693,97 & $\mid \begin{array}{l}113,00 \\
\end{array}$ & 4,06 & 61,81 & 305,79 & 30,54 & 36,53 & 286,46 \\
\hline Lissotriton boscai & 29SMD86 & 79,00 & 154,64 & 62,85 & 41,60 & 3081,51 & 231,56 & 82,21 & 149,35 & 122,49 & 190,84 & 193,19 & 114,37 & 691,11 & 112,46 & 4,04 & 61,43 & 302,84 & 30,71 & 37,30 & 284,19 \\
\hline Lissotriton boscai & 29SMD90 & 83,00 & 162,53 & 77,54 & \begin{tabular}{l|l}
40,45 \\
\end{tabular} & 3918,62 & 268,93 & 79,41 & 189,52 & 121,24 & 210,21 & 214,18 & 113,53 & 723,44 & \begin{tabular}{|l|}
109,03 \\
\end{tabular} & 3,60 & 63,15 & 321,26 & 30,05 & 33,21 & 308,79 \\
\hline Lissotriton boscai & 29SMD92 & 101,00 & 156,43 & 73,36 & \begin{tabular}{ll|l}
40,42 \\
\end{tabular} & 3718,49 & 255,45 & 76,15 & 179,30 & 117,38 & 201,57 & 204,95 & 109,56 & 738,14 & \begin{tabular}{|l|l|}
113,18 \\
\end{tabular} & 4,07 & 62,29 & 325,77 & 31,79 & 35,54 & 311,36 \\
\hline Lissotriton boscai & 29SMD94 & 100,00 & 154,66 & 69,63 & \begin{tabular}{|l|l|}
40,84 \\
\end{tabular} & 3484,84 & 245,83 & 77,01 & 168,82 & \begin{tabular}{|l|l|}
118,17 \\
\end{tabular} & 196,54 & 199,51 & 110,10 & 725,66 & 113,71 & 4,11 & 61,57 & 318,32 & 32,08 & 36,79 & 302,73 \\
\hline Lissotriton boscai & 29SMD95 & 101,00 & 154,16 & 68,46 & 41,02 & 3399,61 & 242,54 & 77,46 & 165,08 & 118,55 & 194,88 & $\begin{array}{l}197,66 \\
\end{array}$ & 110,52 & \begin{tabular}{ll|}
724,99 \\
\end{tabular} & \begin{tabular}{|l|l|}
114,07 \\
\end{tabular} & 4,23 & 61,16 & 316,49 & 32,79 & 38,09 & 300,91 \\
\hline Lissotriton boscai & 29SMD96 & 101,00 & 153,52 & 67,99 & \begin{tabular}{l|l|}
41,25 \\
\end{tabular} & 3337,48 & 240,05 & 77,19 & 162,86 & 118,46 & $\begin{array}{l}193,38 \\
\end{array}$ & $\begin{array}{l}195,98 \\
\end{array}$ & $\begin{array}{l}110,44 \\
\end{array}$ & 732,84 & $\begin{array}{l}115,06 \\
\end{array}$ & 4,58 & 60,60 & 317,84 & 34,29 & 40,05 & 302,60 \\
\hline Lissotriton boscai & 29SMD97 & 92,00 & 153,65 & 67,96 & 41,64 & 3283,66 & 238,79 & 77,36 & 161,43 & 1119,03 & 192,74 & 195,21 & 111,05 & 740,74 & 115,77 & 4,83 & 60,01 & 319,21 & 35,65 & 41,78 & 304,47 \\
\hline Lissotriton boscai & 295NB12 & 83,00 & 163,34 & 86,34 & 44,66 & 3628,14 & 271,70 & 80,42 & 191,27 & 128,07 & 207,95 & 212,23 & 119,51 & 516,43 & 83,19 & 1,00 & 68,47 & 241,95 & 18,35 & 19,41 & 231,30 \\
\hline Lissotriton boscai & 29SNB13 & 51,00 & 165,90 & 86,91 & \begin{tabular}{l|l|}
44,25 \\
\end{tabular} & $\begin{array}{ll}3706,64 \\
\end{array}$ & 276,06 & 81,89 & 194,17 & 129,33 & 211,51 & 215,80 & \begin{tabular}{|l|}
121,01 \\
\end{tabular} & 513,94 & 82,24 & 1,00 & 68,10 & 240,26 & 18,46 & \begin{tabular}{ll|}
19,60 \\
\end{tabular} & 229,58 \\
\hline Lissotriton boscai & 29SNB14 & 19,00 & 166,42 & 87,92 & 44,00 & 3803,89 & 279,44 & 81,19 & 198,25 & 128,75 & 213,33 & 217,72 & 120,36 & 522,64 & 82,56 & 1,00 & 67,69 & 243,06 & 18,89 & 19,89 & 232,81 \\
\hline Lissotriton boscai & 29SNB21 & 101,00 & 166,71 & 86,81 & 43,34 & 3809,92 & 278,55 & 80,58 & $\begin{array}{l}197,97 \\
\end{array}$ & 129,16 & 214,36 & 218,16 & $\begin{array}{l}120,69 \\
\end{array}$ & $\begin{array}{l}498,75 \\
\end{array}$ & 80,82 & 0,90 & 69,59 & 237,30 & 16,71 & \begin{tabular}{ll|}
17,97 \\
\end{tabular} & 225,62 \\
\hline Lissotriton boscai & 295NB22 & 101,00 & 159,48 & 88,59 & $\mid 43,57$ & 3863,33 & 274,21 & 73,06 & 201,15 & 121,65 & 207,70 & 211,89 & 113,22 & 545,39 & 86,20 & 1,08 & 67,90 & 254,36 & \begin{tabular}{|c|c|}
19,78 \\
\end{tabular} & 20,69 & 243,97 \\
\hline |Lissotriton boscai & 295NB23 & 101,00 & 160,57 & 89,23 & 43,49 & 3904,89 & 276,69 & 73,70 & 202,99 & 122,19 & 209,27 & 213,56 & 113,87 & 548,35 & 86,14 & 1,15 & 67,36 & 254,48 & 20,17 & 21,04 & 244,38 \\
\hline Lissotriton boscai & 29SNB24 & 100,00 & 162,44 & 89,79 & 43,41 & 3953,88 & 280,03 & 75,26 & 204,76 & 123,45 & 211,84 & 216,11 & 115,18 & 546,36 & 85,42 & 1,08 & 67,06 & 252,79 & 20,07 & 20,88 & 242,88 \\
\hline Lissotriton boscai & 29SNB25 & 100,00 & 164,72 & 90,25 & 43,24 & 3981,16 & 283,08 & 77,15 & 205,94 & 125,25 & 214,24 & 218,62 & 116,82 & $\begin{array}{l}543,22 \\
\end{array}$ & 84,29 & 1,00 & 66,73 & 250,47 & 20,04 & 20,94 & 240,79 \\
\hline Lissotriton boscai & 29SNB28 & 101,00 & 163,45 & 91,99 & \begin{tabular}{l|l|l}
42,92 \\
\end{tabular} & 4134,08 & 286,67 & 74,44 & 212,23 & $\begin{array}{l}121,86 \\
\end{array}$ & 214,92 & 219,54 & 113,86 & 584,01 & 88,30 & 2,00 & 64,69 & 263,26 & 23,58 & 24,30 & 255,08 \\
\hline Lissotriton boscai & 295NB29 & 101,00 & 164,16 & 92,20 & 42,84 & \begin{tabular}{|l|l|l}
4175,37 \\
\end{tabular} & 288,44 & 74,92 & 213,52 & 122,01 & 216,06 & 220,71 & $\mid 113,97$ & 590,88 & 88,76 & 2,00 & 64,15 & 265,09 & 24,11 & 24,86 & 257,27 \\
\hline Lissotriton boscai & 29SNB31 & 100,00 & 169,93 & 88,04 & 42,32 & 3993,05 & 285,92 & 80,82 & 205,09 & 130,58 & 220,37 & 224,08 & 121,95 & 491,29 & 79,47 & 0,87 & 69,85 & 235,53 & 15,71 & \begin{tabular}{ll|}
17,27 \\
\end{tabular} & 223,19 \\
\hline |Lissotriton boscai & 29SNB32 & 100,00 & 157,21 & 90,43 & 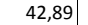 & 4051,06 & 276,71 & 68,08 & 208,63 & \begin{tabular}{|l|l|}
117,62 \\
\end{tabular} & 208,32 & 212,39 & $\mid 109,04$ & 568,47 & 89,90 & 1,46 & 67,30 & 263,84 & 21,14 & 22,08 & 253,54 \\
\hline Lissotriton boscai & 29SNB33 & 101,00 & 153,17 & 91,73 & 42,96 & 4104,42 & 275,13 & 63,85 & 211,28 & 113,12 & 205,01 & 209,21 & 104,51 & 597,67 & 93,49 & 1,78 & 66,16 & 273,78 & 23,43 & 24,04 & 264,44 \\
\hline Lissotriton boscai & 29SNB34 & 100,00 & 160,98 & 91,92 & \begin{tabular}{|l|l|}
42,89 \\
\end{tabular} & 4116,92 & 283,24 & 71,08 & 212,15 & 120,35 & 212,75 & 217,05 & 111,80 & 557,87 & 87,50 & 1,29 & 66,59 & 257,51 & 20,82 & 21,67 & 247,82 \\
\hline Lissotriton boscai & 29SNB36 & 101,00 & 165,93 & 92,97 & \begin{tabular}{l|l}
42,95 \\
\end{tabular} & $\begin{array}{lll}4165,94 \\
\end{array}$ & 289,95 & 75,37 & 214,58 & 124,09 & 217,99 & 222,40 & 115,90 & 546,52 & 84,50 & 1,23 & 66,02 & 250,43 & 20,62 & 21,50 & 241,41 \\
\hline Lissotriton boscai & 29SNB37 & 100,00 & 164,94 & 93,73 & $\begin{array}{ll}42,83 \\
\end{array}$ & 4219,59 & 290,82 & 74,07 & 216,75 & 122,57 & 217,72 & 222,23 & \begin{tabular}{|l|l|}
114,44 \\
\end{tabular} & 561,68 & 85,97 & 1,82 & 65,17 & 254,92 & 22,07 & 22,89 & 246,65 \\
\hline Lissotriton boscai & 29SNB39 & 100,00 & 165,48 & 94,48 & \begin{tabular}{ll|}
42,38 \\
\end{tabular} & $\begin{array}{l}4301,43 \\
\end{array}$ & 293,85 & 74,15 & 219,70 & \begin{tabular}{ll|}
122,07 \\
\end{tabular} & 219,27 & 223,98 & \begin{tabular}{ll|}
114,02 \\
\end{tabular} & $\begin{array}{l}576,49 \\
\end{array}$ & 86,88 & 2,00 & 64,22 & 258,47 & 23,19 & 24,02 & 251,19 \\
\hline Lissotriton boscai & 29SNB42 & 101,00 & 163,34 & 91,49 & 42,31 & 4153,20 & 284,97 & 71,88 & 213,09 & 122,27 & 215,89 & 219,81 & $\begin{array}{l}113,77 \\
\end{array}$ & 536,63 & 86,44 & 1,15 & 68,24 & 252,48 & 18,58 & 19,76 & 241,22 \\
\hline Lissotriton boscai & 29SNB43 & 100,00 & 158,19 & 93,15 & \begin{tabular}{|l|l|}
42,49 \\
\end{tabular} & 4219,30 & 282,90 & 66,29 & 216,61 & 116,56 & 211,49 & \begin{tabular}{|l|}
215,67 \\
\end{tabular} & 108,04 & 570,05 & 90,55 & 1,33 & 66,86 & 263,84 & 21,04 & 21,89 & 253,89 \\
\hline Lissotriton boscai & 29SNB44 & 101,00 & 165,33 & 93,32 & \begin{tabular}{l|l}
42,45 \\
\end{tabular} & 4231,12 & 290,31 & 73,10 & 217,20 & 123,17 & 218,62 & 222,87 & 114,75 & 534,47 & 84,80 & 1,00 & 67,20 & 248,69 & 18,80 & 19,94 & 238,53 \\
\hline Lissotriton boscai & 29SNB49 & 101,00 & 168,13 & 96,77 & 42,39 & 4402,72 & 299,73 & 74,62 & 225,11 & 123,45 & 223,21 & 227,86 & 115,34 & 557,31 & 84,01 & 2,00 & 64,01 & 249,32 & 22,72 & 23,49 & 242,42 \\
\hline Lissotriton boscai & 29SNB52 & 101,00 & 164,37 & 92,97 & 42,21 & 4241,13 & 288,17 & 71,28 & 216,89 & 122,52 & 218,10 & 222,13 & 113,81 & 533,03 & 86,93 & 1,00 & 68,19 & 251,74 & 17,99 & $\begin{array}{l}19,46 \\
\end{array}$ & 240,04 \\
\hline Lissotriton boscai & 29SNB54 & 101,00 & 161,55 & 95,59 & 42,24 & $\begin{array}{lll}4358,38 & \\
\end{array}$ & 290,54 & $\begin{array}{ll}67,43 \\
\end{array}$ & 223,11 & 118,29 & 216,73 & 220,94 & 109,71 & $\begin{array}{l}557,76 \\
\end{array}$ & 88,57 & 1,26 & 66,41 & 257,43 & 20,39 & 21,41 & 247,70 \\
\hline Lissotriton boscai & 29SNB55 & 100,00 & 162,91 & 96,57 & 42,24 & 4398,71 & $\begin{array}{l}293,67 \\
\end{array}$ & 68,26 & 225,41 & 118,99 & 218,50 & 222,80 & 110,58 & 555,57 & 87,30 & 1,36 & 65,95 & 254,66 & 20,70 & 21,57 & 245,62 \\
\hline |Lissotriton boscai & 295NB56 & 101,00 & 159,93 & 97,96 & 42,07 & 4473,81 & 293,72 & 64,86 & 228,86 & 115,26 & 216,56 & 221,03 & 106,94 & 579,15 & 89, & 2,00 & 64,59 & 261,53 & 23,14 & 23,72 & 253,80 \\
\hline Lissotriton boscai & 295NB57 & 101,00 & 165,13 & 98,47 & 42,25 & 4481,33 & 299,4 & 69,77 & 229,64 & 119,95 & 221,66 & 226,18 & $\mid 111,69$ & 554,76 & 85,12 & 1,99 & 64,53 & 250,30 & 21,91 & 22,56 & 242,74 \\
\hline Lissotriton boscai & 29SNB59 & 100,00 & 168,86 & 99,21 & 42,32 & 4520,42 & 304,48 & 73,29 & 231,19 & $\begin{array}{l}122,86 \\
\end{array}$ & 225,62 & 230,19 & 114,75 & 547,27 & 82,53 & 2,00 & 63,86 & 244,05 & 22,02 & 22,64 & 237,48 \\
\hline Lissotriton boscai & 29SNB62 & 100,00 & 164,87 & 94,21 & 42,18 & 4299,61 & 290,15 & 70,25 & 219,91 & 122,35 & 219,43 & 223,56 & \begin{tabular}{ll|}
113,72 \\
\end{tabular} & \begin{tabular}{l|l|}
533,42 \\
\end{tabular} & 87,70 & 1,01 & 68,11 & 252,20 & 17,90 & $\begin{array}{l}19,49 \\
\end{array}$ & 240,04 \\
\hline Lissotriton boscai & 29SNB63 & 101,00 & 160,97 & $\begin{array}{ll}95,93 \\
\end{array}$ & $\begin{array}{l}42,07 \\
\end{array}$ & 4400,78 & 290,09 & $\begin{array}{ll}65,53 \\
\end{array}$ & 224,56 & \begin{tabular}{ll|}
117,48 \\
\end{tabular} & 216,88 & 221,05 & 108,72 & 558,03 & 89,99 & 1,27 & 66,82 & 259,41 & 19,80 & 21,14 & 248,62 \\
\hline Lissotriton boscai & 29SNB66 & 101,00 & 162,98 & $\begin{array}{ll}99,69 \\
\end{array}$ & \begin{tabular}{ll|l}
42,06 \\
\end{tabular} & 4555,55 & 299,11 & 66,03 & 233,08 & \begin{tabular}{|l|}
117,41 \\
\end{tabular} & 220,63 & 225,06 & 108,82 & \begin{tabular}{|l|l|}
559,86 \\
\end{tabular} & 86,75 & 1,99 & 64,56 & 253,15 & 21,71 & 22,47 & 245,11 \\
\hline Lissotriton boscai & 295NB67 & 100,00 & 165,05 & 100,68 & 42,10 & \begin{tabular}{|l|l|}
4589,97 \\
\end{tabular} & 302,86 & 67,74 & 235,12 & 118,94 & 223,03 & 227,53 & 110,40 & 553,32 & 84,75 & 2,00 & 64,32 & 248,44 & 21,63 & 22,47 & 241,14 \\
\hline 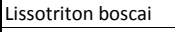 & 29SNB68 & 101,00 & 164,04 & 101,89 & $42,-1$ & 4647,18 & 304,28 & 66,41 & 237,87 & 117,29 & 222,77 & 227,32 & 108,81 & 564,32 & 85,29 & 2,00 & 63,15 & 250,55 & 23,05 & 23,58 & 244,48 \\
\hline Lissotriton boscai & 29SNB72 & 101,00 & 158,56 & 95,96 & 42,03 & 4413,77 & 287,27 & 62,45 & 224,82 & 114,93 & 214,69 & 218,96 & 106,39 & 571,05 & 92,86 & 1,49 & 66,85 & 265,98 & 20,14 & 21,88 & 254,31 \\
\hline Lissotriton boscai & 29SNB75 & 101,00 & 159,78 & 100,28 & 42,00 & 4621,93 & 297,04 & \begin{tabular}{|l|l|}
61,54 \\
\end{tabular} & 235,50 & 113,35 & 218,43 & 222,83 & 105,05 & $\begin{array}{l}572,95 \\
\end{array}$ & 89,41 & 2,00 & 64,65 & 259,20 & 22,04 & 23,10 & 250,47 \\
\hline Lissotriton boscai & 295NB76 & 100,00 & 161,25 & 101,73 & 42,01 & 4676,71 & 301,01 & 62,32 & 238,69 & 114,21 & 220,53 & 224,98 & 105,82 & 567,53 & 87,48 & 2,00 & 63,97 & 254,77 & 22,03 & 23,01 & 247,0 \\
\hline Lissotriton boscai & 29SNB81 & 101,00 & 162,83 & 94,57 & \begin{tabular}{|l|l|}
42,07 \\
\end{tabular} & 4366,06 & 287,94 & 66,33 & 221,61 & 119,65 & 218,25 & 222,48 & \begin{tabular}{|l|}
111,04 \\
\end{tabular} & 548,10 & 91,22 & 1,09 & 67,97 & 259,42 & \begin{tabular}{|l|l|}
18,07 \\
\end{tabular} & 20,46 & 245,71 \\
\hline Lissotriton boscai & $29 \mathrm{SNBE}$ & 101,00 & 157,12 & $\begin{array}{ll}96,63 \\
\end{array}$ & $41, \mathrm{~s}$ & 4496,11 & 287,34 & $\begin{array}{ll}59,58 \\
\end{array}$ & 227,76 & \begin{tabular}{ll|}
112,64 \\
\end{tabular} & 214,29 & 218,59 & 103,89 & 581,80 & 93,91 & 1,63 & 66,26 & 269,03 & 20,85 & 22,90 & 257,09 \\
\hline Lissotriton boscai & 29SNB83 & 99,00 & 153,72 & 98,40 & \begin{tabular}{ll|}
41,99 \\
\end{tabular} & 4596,25 & 288,04 & 55,56 & 232,47 & 108,30 & 212,29 & 216,57 & 99,42 & 603,65 & 95,34 & 2,03 & 64,86 & 274,47 & 22,96 & 24,69 & 264,03 \\
\hline Lissotriton boscai & 29SNB91 & 101,00 & 158,51 & 95,20 & 41,90 & 4472,75 & 285,95 & 60,85 & 225,10 & 114,12 & 215,32 & 219,49 & 105,46 & 573,59 & 93,32 & 1,59 & 66,76 & 267,24 & 19,59 & 22,46 & 253,81 \\
\hline Lissotriton boscai & 295NB92 & 100,00 & 150,90 & 97,38 & 41,3 & 4624,20 & 284,06 & 52,19 & 231,87 & 105 & 209,76 & $21:$ & 96 & 620,53 & 97 & 1,99 & 64,87 & 281,73 & 23,16 & 25,60 & 270,38 \\
\hline Lissotriton boscai & $295 N C$ & 92,00 & 166,43 & 85,60 & 4 & 9 & 285,32 & 79,35 & 205,97 & 122,99 & 217,60 & 222,47 & 115,64 & \begin{tabular}{|l|l|}
681,47 \\
\end{tabular} & \begin{tabular}{ll|}
101,62 \\
\end{tabular} & 3,41 & 63,05 & 302,61 & 28,84 & 31,25 & 293,11 \\
\hline Lissotriton boscai & 29SNC08 & 88,00 & 170,53 & 83,66 & \begin{tabular}{|l|l|l|}
40,89 \\
\end{tabular} & 4135,33 & 286,57 & 83,89 & 202,68 & 127,01 & 221,21 & 225,76 & \begin{tabular}{|l|l|}
119,78 \\
\end{tabular} & 664,00 & $\begin{array}{l}99,33 \\
\end{array}$ & 3,00 & 63,24 & 295,24 & 26,97 & 30,01 & 285,61 \\
\hline Lissotriton boscai & 29SNC17 & 101,00 & $\begin{array}{l}170,53 \\
\end{array}$ & 86,68 & $\begin{array}{ll}41,03 \\
\end{array}$ & 4232,24 & 291,12 & \begin{tabular}{|l|l}
82,37 \\
\end{tabular} & 208,75 & 126,37 & 222,68 & 227,27 & \begin{tabular}{ll|}
118,88 \\
\end{tabular} & \begin{tabular}{ll|}
648,25 \\
\end{tabular} & 95,83 & 3,00 & 62,78 & 286,50 & 27,00 & 29,86 & 278,50 \\
\hline Lissotriton boscai & 29SNC18 & 101,00 & 170,36 & 85,57 & \begin{tabular}{l|l|l|}
40,95 & \\
\end{tabular} & 216,61 & 289,75 & 82,38 & 07,36 & 26,20 & 222,34 & 226,68 & 18,63 & 654,34 & 96,99 & 3,00 & 62,89 & 288,89 & 27,13 & \begin{tabular}{l|l}
0,05 \\
\end{tabular} & 80,95 \\
\hline |Lissot! & 2 & 100,00 & & 92,33 & 4 & & 288 & 73, & & 4 & & & & 606,74 & 9 & 2,30 & 63 & 270,56 & 25 & 26,30 & 263,18 \\
\hline 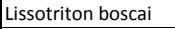 & 29SNC21 & 101,00 & 164,38 & 92,12 & 42,16 & 4247,06 & 290,22 & 74,66 & 215,56 & 121,27 & 217,10 & 221, & 113,42 & 612,68 & 91,38 & 2,49 & 63,49 & 272,22 & 25,95 & 26,81 & 265,08 \\
\hline Lissotriton boscai & 29SNC22 & 99,00 & 166,10 & 91,82 & 42,02 & 4275,52 & 292,11 & 76,33 & 215,78 & 122,47 & 219,16 & 224,04 & 114,58 & 614,17 & 91,45 & 2,67 & 63,12 & 272,23 & 26,19 & 27,32 & 265,21 \\
\hline
\end{tabular}




\begin{tabular}{|c|c|c|c|c|c|c|c|c|c|c|c|c|c|c|c|c|c|c|c|c|c|}
\hline TAXON & UTM & $\mathrm{km} 2$ & BIO1 & B102 & BIO3 & BIO4 & B105 & B106 & BI07 & B108 & B109 & 81010 & B1011 & B1012 & B1013 & BIO14 & BIO15 & BIO16 & B1017 & B1018 & B1019 \\
\hline Lissotriton boscai & 29SNC23 & 101,00 & 168,86 & 91,32 & 42,00 & 4281,82 & 294,32 & 78,88 & 215,44 & 124,77 & 221,79 & 226,66 & 116,93 & 608,71 & 90,47 & 2,99 & 63,12 & 269,53 & 25,78 & 27,64 & 262,48 \\
\hline Lissotriton boscai & 29SNC30 & 100,00 & 164,80 & 94,76 & \begin{tabular}{ll|}
42,16 \\
\end{tabular} & 4339,40 & 294,27 & 73,09 & 221,18 & 120,82 & 218,96 & 223,73 & 112,79 & 591,55 & 88,55 & 2,06 & 63,69 & 263,40 & 24,27 & 24,90 & 256,82 \\
\hline |Lissotriton boscai & 29SNC31 & 101,00 & 161,27 & 94,95 & 42,00 & 4402,58 & 292,56 & 69,61 & 222,95 & 116,77 & 216,36 & 221,20 & 108,72 & 624,36 & 92,71 & 2,89 & 62,71 & 274,96 & 27,25 & 27,68 & 269,36 \\
\hline Lissotriton boscai & 29SNC32 & 101,00 & 164,58 & 94,37 & 41,92 & 4412,68 & 295,47 & 72,80 & 222,67 & 119,62 & 219,70 & 224,62 & 111,69 & \begin{tabular}{|c|}
614,58 \\
\end{tabular} & 90,98 & 2,73 & 62,64 & 270,49 & 26,43 & 27,17 & 264,92 \\
\hline Lissotriton boscai & 29SNC33 & 100,00 & 167,77 & 93,79 & 41,93 & $\begin{array}{l}4408,51 \\
\end{array}$ & 297,79 & 76,01 & 221,78 & 122,43 & 222,68 & 227,53 & 1114,64 & $\begin{array}{l}605,45 \\
\end{array}$ & 89,46 & 2,95 & 62,79 & 266,27 & 25,92 & 26,94 & 260,68 \\
\hline Lissotriton boscai & 29SNC34 & 101,00 & 169,72 & 93,09 & 41,86 & 4404,57 & 299,00 & 78,24 & 220,76 & 124,28 & 224,49 & 229,21 & 116,51 & 603,04 & 88,72 & 2,98 & 62,63 & 264,73 & 25,86 & 26,98 & 259,18 \\
\hline Lissotriton boscai & 29SNC40 & 101,00 & 167,25 & 97,05 & \begin{tabular}{l|l|}
42,15 \\
\end{tabular} & 4438,80 & 300,13 & 73,75 & 226,38 & 122,15 & 222,81 & 227,46 & \begin{tabular}{|l|l|}
114,11 \\
\end{tabular} & \begin{tabular}{|l|l|}
570,75 \\
\end{tabular} & 85,50 & 2,00 & 63,50 & 253,58 & 23,46 & 24,21 & 247,48 \\
\hline Lissotriton boscai & 29SNC41 & 101,00 & $\begin{array}{lll}166,46 \\
\end{array}$ & 97,10 & 42,00 & \begin{tabular}{|l|l|l|l}
445,43 \\
\end{tabular} & 300,43 & 72,71 & 227,71 & \begin{tabular}{|l|l|}
120,71 \\
\end{tabular} & 222,62 & $\mid 227,24$ & \begin{tabular}{|l|l|}
112,62 \\
\end{tabular} & \begin{tabular}{|l|l|}
584,59 \\
\end{tabular} & $\mid 86,96$ & 2,10 & 63,03 & 257,83 & 24,48 & 25,09 & 252,44 \\
\hline Lissotriton boscai & 29SNC42 & 99,00 & 168,70 & 96,55 & 42,00 & 4483,66 & 302,16 & 75,09 & 227,07 & $\begin{array}{l}122,67 \\
\end{array}$ & 224,64 & 229,38 & 114,78 & 580,33 & 85,94 & 2,06 & 62,96 & 255,20 & 24,26 & 25,13 & 250,04 \\
\hline Lissotriton boscai & 29SNC44 & 101,00 & 169,99 & 95,22 & 41,79 & $\begin{array}{lll}4509,82 \\
\end{array}$ & 302,72 & 76,65 & 226,07 & 123,49 & 226,24 & 231,00 & 115,48 & 591,50 & 86,65 & 2,87 & 61,89 & 257,60 & 25,84 & 27,04 & 253,18 \\
\hline Lissotriton boscai & 29SNC46 & 100,00 & 168,48 & 93,61 & 41,02 & 4534,77 & 300,59 & 75,62 & 224,97 & 121,42 & 225,07 & 229,66 & 113,51 & 619,70 & 90,45 & 3,03 & 61,34 & 267,23 & 27,81 & 29,05 & 263,86 \\
\hline Lissotriton boscai & 29SNC48 & 101,00 & 167,37 & 91,63 & \begin{tabular}{ll|}
40,88 \\
\end{tabular} & 4518,73 & 297,60 & 75,26 & 222,34 & 120,13 & 223,69 & 228,17 & 112,45 & 647,64 & 94,44 & 3,90 & 60,49 & 277,18 & 30,66 & 32,10 & 274,15 \\
\hline Lissotriton boscai & 29SNC51 & 101,00 & 169,44 & 99,28 & \begin{tabular}{ll|}
42,04 \\
\end{tabular} & 4569,18 & 306,46 & 73,87 & 232,59 & \begin{tabular}{ll|}
122,67 \\
\end{tabular} & 226,81 & 231,38 & $\begin{array}{l}114,65 \\
\end{array}$ & 560,00 & 83,21 & 2,00 & 62,58 & 245,94 & 23,75 & 24,40 & 240,90 \\
\hline Lissotriton boscai & 29SNC52 & 101,00 & 169,67 & 98,88 & 42,01 & 4587,13 & 306,68 & 74,25 & 232,43 & 122,60 & 227,16 & 231,83 & \begin{tabular}{ll|}
114,48 \\
\end{tabular} & \begin{tabular}{|l|l|}
566,97 \\
\end{tabular} & 83,56 & 2,08 & 62,27 & 247,49 & 24,29 & 24,99 & 243,05 \\
\hline Lissotriton boscai & 295NC56 & 101,00 & 164,47 & 95,36 & 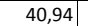 & \begin{tabular}{|l|l|}
4653,64 \\
\end{tabular} & 300,76 & 70,51 & 230,25 & 116,51 & 222,78 & 227,54 & 108,55 & 636,12 & \begin{tabular}{|c|c|}
92,18 \\
\end{tabular} & 3,69 & 60,01 & 270,33 & 30,59 & 31,18 & 268,80 \\
\hline Lissotriton boscai & 29SNC58 & 101,00 & 166,18 & 93,38 & 40,73 & 4621,51 & 299,98 & 72,89 & 227,09 & 118,19 & 224,19 & 228,68 & 110,35 & 646,13 & 93,50 & 4,00 & 59,70 & 273,34 & 31,76 & 32,74 & 271,86 \\
\hline Lissotriton boscai & 29SNC66 & 100,00 & 163,32 & 96,95 & $\begin{array}{l}40,96 \\
\end{array}$ & 4748,38 & 302,52 & 68,20 & 234,32 & 113,71 & 223,07 & 227,75 & 106,26 & \begin{tabular}{ll|}
633,58 \\
\end{tabular} & 90,95 & 3,66 & 59,27 & 266,10 & 31,68 & 31,91 & 265,71 \\
\hline Lissotriton boscai & 29SNC67 & 101,00 & 160,92 & 95,55 & 40,51 & 4762,73 & 299,50 & 66,41 & 233,08 & 108,31 & 221,06 & 225,57 & 103,85 & 660,70 & 94,83 & 4,00 & 58,89 & 276,39 & 33,88 & 33,97 & 276,32 \\
\hline Lissotriton boscai & 29SNC69 & 100,00 & 165,62 & 94,16 & 40,24 & 4717,41 & 301,63 & 71,25 & 230,38 & 115,59 & \begin{tabular}{|l|l|}
224,87 \\
\end{tabular} & 229,36 & $\begin{array}{l}108,58 \\
\end{array}$ & 652,73 & $\begin{array}{l}93,69 \\
\end{array}$ & 4,00 & 58,75 & 272,66 & 33,34 & 34,18 & 272,37 \\
\hline Lissotriton boscai & 295NC76 & 101,00 & $\begin{array}{lll}160,29 \\
\end{array}$ & 98,06 & $\mid 40,77$ & $\mid$\begin{tabular}{|l|l|l|}
4851,99 \\
\end{tabular} & 302,55 & 64,27 & 238,27 & $\begin{array}{ll}104,42 \\
\end{array}$ & 223,43 & 226,39 & $\mid \begin{array}{l}102,36 \\
\end{array}$ & $\mid 641,73$ & \begin{tabular}{|c|c|}
91,18 \\
\end{tabular} & $\begin{array}{lll}3,81 & & \\
\end{array}$ & 58,25 & 266,81 & 33,29 & 33,29 & 266,81 \\
\hline |Lissotriton boscai & 295NC77 & 101,00 & 158,54 & 96,49 & 40,18 & 4855,58 & 299,73 & 63,38 & 236,35 & 100,76 & 222,23 & 224,66 & 100,60 & 666,05 & 94,64 & 4,08 & 57,82 & 276,19 & 35,39 & 35,39 & 276,19 \\
\hline Lissotriton boscai & 29SNC79 & 101,00 & 163,50 & 95,29 & 40,00 & 4822,36 & 302,59 & 68,15 & 234,43 & 106,34 & 224,34 & 228,70 & 105,38 & 659,75 & 93,87 & 4,00 & 57,83 & 273,29 & 35,38 & 35,75 & 273,29 \\
\hline 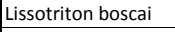 & 29SNC81 & 101,00 & 165,59 & 108,62 & 42,09 & 4964,21 & 317,28 & 63,29 & 253,99 & 114,89 & 228,42 & 233,08 & 106,27 & 561,88 & 82,25 & 2,18 & 60,46 & 239,21 & 25,24 & 25,36 & 236,65 \\
\hline Lissotriton boscai & 29SNC86 & 100,00 & 161,19 & 99,26 & 40,70 & 4930,57 & 305,38 & 63,90 & 241,49 & 102,56 & 226,06 & 228,18 & 102,29 & 624,39 & 87,51 & 3,77 & 57,59 & 257,09 & 33,38 & 33,38 & 257,09 \\
\hline Lissotriton boscai & 29SNC87 & 100,00 & 157,48 & 97,19 & 40,03 & 4938,52 & 300,59 & 61,44 & 239,15 & $\begin{array}{l}98,67 \\
\end{array}$ & 223,75 & 224,75 & 98,67 & 661,51 & 92,89 & 4,07 & 57,07 & 271,88 & 36,14 & 36,14 & 271,88 \\
\hline Lissotriton boscai & 29SNC96 & 100,00 & 161,72 & 100,41 & 40,40 & 5014,36 & 307,90 & 63,07 & 244,83 & 101,64 & 227,53 & 229,77 & 101,64 & 610,86 & 84,42 & 3,90 & 56,55 & 248,98 & 33,86 & 33,86 & 248,98 \\
\hline Lissotriton boscai & 29SNC97 & 101,00 & 160,32 & 98,67 & 40,00 & 5013,92 & 305,33 & 62,47 & 242,87 & 100,35 & 227,13 & 228,47 & 100,35 & \begin{tabular}{|c|}
630,48 \\
\end{tabular} & 87,14 & 4,00 & 56,21 & 256,55 & 35,39 & 35,39 & 256,55 \\
\hline Lissotriton boscai & 29SNC98 & 101,00 & 160,41 & 97,95 & 40,00 & \begin{tabular}{|l|l|l|}
5019,94 \\
\end{tabular} & 305,06 & 62,60 & 242,46 & 100,33 & 226,64 & 228,62 & 100,33 & $\begin{array}{l}646,31 \\
\end{array}$ & 89,76 & 4,01 & 56,42 & 263,36 & 36,37 & 36,37 & 263,36 \\
\hline Lissotriton boscai & 29SND03 & 101,00 & 160,54 & 75,24 & \begin{tabular}{l|l}
40,72 \\
\end{tabular} & 3756,82 & 261,73 & 78,79 & 182,94 & 120,86 & 206,23 & 209,56 & 113,18 & 707,24 & 108,25 & 3,99 & 61,58 & 309,55 & 31,18 & 35,44 & 297,42 \\
\hline Lissotriton boscai & 29SND05 & 101,00 & 155,97 & 73,29 & $40,97 \mid$ & 3622,09 & 252,84 & 75,74 & 177,10 & 117,80 & 199,97 & 202,88 & 109,98 & 738,07 & 113,12 & 4,51 & 60,61 & 319,44 & 34,41 & 39,11 & 307,22 \\
\hline Lissotriton boscai & 29SND06 & 101,00 & 149,04 & 73,22 & 40,77 & 3633,73 & 246,47 & \begin{tabular}{|c|c|}
68,94 \\
\end{tabular} & 177,54 & 111,00 & 193,27 & 196,21 & 103,07 & 806,23 & 121,74 & 5,64 & 59,51 & 345,03 & 40,37 & 44,62 & 333,78 \\
\hline Lissotriton boscai & 29SND07 & 100,00 & 150,55 & 72,97 & 41,12 & 3560,35 & 245,85 & 70,64 & 175,21 & 112,96 & 193,75 & 196,39 & 105,14 & 801,02 & $\begin{array}{l}121,01 \\
\end{array}$ & 5,78 & 59,06 & 341,15 & 40,96 & 45,75 & 329,98 \\
\hline Lissotriton boscai & 29SND08 & 101,00 & 154,16 & 73,18 & 41,81 & 3476,62 & 247,18 & 74,14 & 173,04 & 117,32 & $\begin{array}{l}195,93 \\
\end{array}$ & $\begin{array}{l}198,56 \\
\end{array}$ & 109,29 & $\begin{array}{l}778,49 \\
\end{array}$ & 117,54 & 5,62 & 58,76 & 330,55 & 39,95 & 45,65 & 319,44 \\
\hline Lissotriton boscai & 29SND13 & 100,00 & 162,92 & 79,09 & 40,77 & 3927,40 & 270,65 & 78,49 & $\begin{array}{l}192,16 \\
\end{array}$ & 121,42 & 211,05 & 214,49 & 113,77 & \begin{tabular}{ll|}
702,38 \\
\end{tabular} & 105,55 & 4,00 & 61,02 & 304,83 & 31,85 & 35,66 & 295,47 \\
\hline |Lissotriton boscai & 29SND15 & 100,00 & 159,96 & 77,63 & 40,96 & 3799,61 & 263,78 & 76,55 & 187,23 & 119,64 & 206,39 & 209,51 & 112,04 & 727,13 & 109,49 & 4,44 & 60,20 & 312,69 & 34,41 & 38,76 & 303,14 \\
\hline Lissotriton boscai & 29SND16 & 100,00 & 153,84 & 77,45 & 40,77 & 3808,84 & 257,99 & 70,53 & 187,46 & 113,59 & 200,48 & 203,54 & 105,87 & 788,12 & 117,47 & 5,51 & 59,16 & 335,49 & 39,89 & 43,88 & 326,82 \\
\hline Lissotriton boscai & 29SND17 & 101,00 & 140,89 & 77,42 & 40,20 & 3896,44 & 247,82 & 57,69 & 190,13 & 100,32 & 189,19 & 192,27 & 92,55 & $\begin{array}{l}923,35 \\
\end{array}$ & 136,53 & 7,84 & 57,81 & 387,36 & 51,57 & 54,11 & 380,57 \\
\hline Lissotriton boscai & 29SND18 & 100,00 & 150,32 & 77,86 & \begin{tabular}{|l|l|l|}
41,17 & \\
\end{tabular} & 3751,52 & 253,42 & 66,79 & 186,64 & 110,63 & 196,26 & $\begin{array}{l}199,05 \\
\end{array}$ & 102,79 & 842,71 & $\begin{array}{l}124,44 \\
\end{array}$ & 6,59 & 57,92 & $\begin{array}{l}354,03 \\
\end{array}$ & 45,62 & 49,85 & 346,48 \\
\hline Lissotriton boscai & 29SND23 & 101,00 & 166,88 & 82,44 & \begin{tabular}{ll|l|}
40,89 \\
\end{tabular} & 4062,76 & 279,72 & 79,88 & 199,84 & \begin{tabular}{ll|}
123,67 \\
\end{tabular} & 216,86 & 220,34 & $\begin{array}{l}116,05 \\
\end{array}$ & $\begin{array}{l}680,99 \\
\end{array}$ & 101,13 & 4,00 & 60,87 & 293,59 & 31,14 & 34,84 & 286,27 \\
\hline Lissotriton boscai & 29SND24 & 100,00 & 164,81 & 81,94 & \begin{tabular}{|l|l|}
40,97 \\
\end{tabular} & $\begin{array}{lll}4020,68 \\
\end{array}$ & 276,34 & 78,16 & 198,18 & 122,04 & 214,24 & 217,55 & 114,29 & 700,91 & 103,93 & 4,00 & 60,20 & 300,66 & 33,15 & 36,90 & 293,36 \\
\hline Lissotriton boscai & 29SND25 & 101,00 & 161,26 & 81,61 & 40,91 & 3997,80 & 272,25 & 74,87 & 197,38 & 118,84 & 210,46 & 213,58 & 111,06 & 735,20 & 108,67 & 4,79 & 59,47 & 313,26 & 36,15 & 39,89 & 306,39 \\
\hline Lissotriton boscai & 29SND26 & 101,00 & 159,71 & 81,56 & 41,01 & 3964,80 & 269,88 & 73,31 & 196,58 & 117,48 & 208,47 & 211,54 & 109,77 & 756,41 & 111,66 & 5,06 & 58,96 & 320,51 & 38,33 & 42,25 & 313,91 \\
\hline 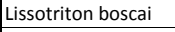 & 29SND27 & 101,00 & 147,54 & 81,31 & 40,44 & 4037,86 & 260,08 & 61,37 & 198,71 & 105,03 & $\begin{array}{l}197,73 \\
\end{array}$ & 200,82 & 97,41 & 880,62 & 129,94 & 7,08 & 57,73 & 368,51 & 48,65 & 51,27 & 363,81 \\
\hline Lissotriton boscai & 29SND28 & 101,00 & 144,18 & 81,60 & 40,51 & 4038,77 & 257,03 & 57,77 & 199,26 & 101,73 & 194,40 & 197,49 & 93,99 & 927,78 & 136,62 & 7,98 & 57,12 & 385,76 & 53,21 & 55,56 & 381,90 \\
\hline Lissotriton boscai & 29SND34 & 100,00 & 166,83 & 85,17 & 40,92 & 4174,14 & 283,97 & 77,71 & 206,26 & 122,48 & 218,47 & 221,85 & 114,71 & \begin{tabular}{|l|l|}
695,73 \\
\end{tabular} & 102,21 & 4, & 59,65 & 296,03 & 33,76 & 37,29 & 290,63 \\
\hline Lissotriton boscai & 29SND35 & 101,00 & 166,06 & 85,14 & \begin{tabular}{|l|l|}
40,97 \\
\end{tabular} & 4148,63 & 282,49 & 76,77 & 205,72 & $\begin{array}{l}121,66 \\
\end{array}$ & 217,32 & 220,53 & \begin{tabular}{ll|}
113,93 \\
\end{tabular} & $\begin{array}{ll}709,63 \\
\end{array}$ & $\begin{array}{l}104,27 \\
\end{array}$ & 4,4 & 59,05 & 300,66 & 35,14 & 38,83 & 295,42 \\
\hline Lissotriton boscai & 29SND36 & 101,00 & 163,01 & 85,30 & \begin{tabular}{ll|l}
40,99 \\
\end{tabular} & 4139,85 & 279,47 & 73,62 & 205,86 & $\begin{array}{l}118,69 \\
\end{array}$ & 214,20 & 217,29 & $\begin{array}{l}110,95 \\
\end{array}$ & 745,59 & 109,38 & 5,01 & 58,52 & 313,82 & 38,47 & 41,99 & 309,20 \\
\hline Lissotriton boscai & 29SND37 & 100,00 & 157,30 & 85,38 & \begin{tabular}{ll|}
40,79 \\
\end{tabular} & 4154,40 & 274,52 & $\begin{array}{ll}67,86 \\
\end{array}$ & 206,66 & $\begin{array}{l}112,97 \\
\end{array}$ & 208,89 & 211,94 & 105,38 & 810,35 & 118,84 & 6,19 & 57,83 & 338,33 & 44,14 & 47,12 & 334,79 \\
\hline |Lissotriton boscai & 29SND44 & 100,00 & 163,98 & 87,84 & 40,42 & 4365,45 & 287,47 & 72,59 & 214,88 & 117,42 & 218,27 & 221,88 & 109,75 & 727,36 & 106,51 & 4,88 & 58,87 & 306,26 & 37,05 & 39,69 & 303,29 \\
\hline Lissotriton boscai & 29SND45 & 101,00 & 165,76 & 88,03 & 40,7 & 4321,19 & 288,15 & 74,32 & 213,82 & 119,42 & 219,42 & 222 & 111 & 723,74 & 105,79 & 4,87 & 58,48 & 304,00 & 37,37 & 40,32 & 300,70 \\
\hline Lissotriton boscai & 29SND48 & 100,00 & 160,19 & 89 & 41,0 & 4 & 283,68 & 67,29 & 216,38 & 113,66 & 213,89 & 216,89 & 106,16 & 813,88 & $\begin{array}{l}118,38 \\
\end{array}$ & 6,42 & 56,90 & 336,12 & 46,13 & 48,98 & 334,85 \\
\hline Lissotriton boscai & 29SND49 & 101,00 & 159,09 & 90,97 & 41,13 & 4312,25 & 283,37 & 65,34 & 218,03 & \begin{tabular}{ll|}
111,86 \\
\end{tabular} & 212,82 & 215,70 & 104,90 & 840,45 & 121,77 & 7,01 & 56,19 & 345,12 & 49,12 & 51,90 & 344,49 \\
\hline Lissotriton boscai & 29SND60 & 100,00 & 167,56 & 93,60 & 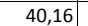 & 4693,55 & 302,33 & 73,11 & 229,22 & \begin{tabular}{|l|l|}
118,44 \\
\end{tabular} & 226,51 & 230,75 & 1110,51 & $\mid$\begin{tabular}{|l|l|}
652,08 \\
\end{tabular} & $\mid 93,74$ & 4,00 & 58,75 & 272,51 & $\mid 33,19$ & 34,41 & 271,85 \\
\hline Lissotriton boscai & 29SND64 & 100,00 & 163,53 & 92,14 & 39,99 & 4671,31 & 296,93 & 68,86 & 228,06 & 112,76 & 222,46 & 226,16 & 106,44 & 739,7 & 107,19 & 5,24 & 57,64 & 306,74 & 40,06 & 41,67 & 306,5 \\
\hline Lissotriton boscai & 29SND69 & 100,00 & 156,26 & 94,39 & 39,99 & 4724,42 & 292,26 & 58,78 & 233,49 & 98,11 & 216,29 & 21 & 98 & 888,65 & 129,02 & 7,71 & 55,92 & 364,47 & 53,76 & 54,91 & 364,47 \\
\hline Lissotriton boscai & 29SND71 & 100,00 & 168,11 & 94,80 & 40,01 & 4798,65 & 305,51 & 71,85 & 233,66 & 116,48 & 228,52 & 232,59 & 109,66 & 657,29 & 93,77 & 4,01 & 57,93 & 271,99 & 34,92 & 36,13 & 271,84 \\
\hline Lissotriton boscai & 29SND75 & 100,00 & 164,11 & 93,99 & 39,71 & 4828,13 & 301,70 & 67,27 & 234,44 & 106,90 & 225,40 & 228,76 & 105,26 & 751,74 & 108,35 & 5,77 & 56,91 & 309,75 & 42,51 & 43,99 & 309,75 \\
\hline Lissotriton boscai & 29SND77 & 101,00 & 163,16 & 94,90 & 39,62 & 4845,10 & 301,51 & 64,80 & 236,71 & 105,01 & 224,73 & 227,83 & 103,70 & 794,91 & $\begin{array}{l}114,82 \\
\end{array}$ & 6,29 & 56,23 & 326,38 & 46,21 & 47,79 & 326,33 \\
\hline Lissotriton boscai & 29SND79 & 101,00 & 153,58 & 94,51 & $\begin{array}{l}39,06 \\
\end{array}$ & 4917,92 & 293,90 & 55,02 & 238,88 & 93,68 & 216,89 & 219 & 93, & \begin{tabular}{|l|l|}
919,63 \\
\end{tabular} & 133,97 & 8,12 & 55,83 & 377,20 & 56,25 & 56,71 & 377,20 \\
\hline Lissotriton boscai & 29SND81 & 101,00 & 168,40 & 96,43 & 40,00 & 4914,53 & 308,99 & 70,55 & 238,44 & 113,75 & 230,43 & 234,46 & 108,68 & 649,91 & 91,89 & 4,05 & 57,22 & 267,05 & 35,42 & 36,48 & 267, \\
\hline
\end{tabular}




\begin{tabular}{|c|c|c|c|c|c|c|c|c|c|c|c|c|c|c|c|c|c|c|c|c|c|}
\hline TAXON & UTM & $\mathrm{km} 2$ & BIO1 & B102 & $B 103$ & BIO4 & B105 & B106 & B107 & B108 & B109 & B1010 & BIO11 & B1012 & BIO13 & B1014 & BIO15 & B1016 & B1017 & B1018 & 81019 \\
\hline Lissotriton boscai & 29SND82 & 100,00 & 166,25 & 95,78 & 39,86 & 4933,50 & 307,14 & 68,68 & 238,46 & 107,86 & 228,73 & 232,66 & 106,37 & 683,16 & 97,01 & 4,95 & 56,91 & 280,67 & 38,24 & 39,23 & 280,67 \\
\hline Lissotriton boscai & 29SND85 & 99,00 & 163,36 & 95,07 & 39,14 & 4975,53 & 304,82 & 65,19 & 239,63 & 103,05 & 226,75 & 230,31 & 103,01 & 759,23 & 109,09 & 5,89 & 56,40 & 311,86 & 43,72 & 44,89 & 311,86 \\
\hline Lissotriton boscai & 29SND87 & 101,00 & 163,28 & 95,93 & 39,23 & 5002,83 & 305,49 & 63,42 & 242,07 & 102,54 & 227,23 & 230,24 & 102,16 & $\begin{array}{l}794,42 \\
\end{array}$ & $\begin{array}{l}114,52 \\
\end{array}$ & 6,29 & 56,04 & 325,44 & 46,72 & 48,10 & 325,44 \\
\hline Lissotriton boscai & 29SND88 & 99,00 & 154,56 & 94,24 & 38,52 & 5066,11 & 297,74 & 55,48 & 242,26 & 93,30 & 220,01 & 222,74 & 93,30 & 894,16 & 130,22 & 7,64 & 55,91 & 366,97 & 54,09 & 54,49 & 366,97 \\
\hline Lissotriton boscai & 29SND89 & 101,00 & 153,44 & 94,66 & 38,42 & 5085,55 & 297,12 & 53,67 & 243,45 & 91,82 & 219,37 & 221,80 & 91,82 & 921,40 & 134,45 & 8,011 & 55,71 & 377,72 & 56,39 & 56,68 & 377,72 \\
\hline Lissotriton boscai & 29SND90 & 100,00 & 165,34 & 97,75 & 39,97 & 5033,34 & 309,49 & 66,49 & 243,01 & 104,96 & 229,23 & 233,44 & $\mid 104,66$ & 649,04 & $\begin{array}{lll}90,68 & \end{array}$ & 4,01 & 56,50 & 264,87 & 36,60 & $\begin{array}{lll}36,92 & \\
\end{array}$ & 264,87 \\
\hline Lissotriton boscai & 29SND91 & 100,00 & 165,52 & 97,41 & 39,74 & 5042,61 & 309,69 & 66,78 & 242,92 & 105,51 & 229,67 & 233,77 & 104,78 & 666,33 & 93,51 & 4,71 & 56,51 & 272,06 & 38,02 & 38,47 & 272,06 \\
\hline Lissotriton boscai & 29SND93 & 100,00 & 166,58 & $\begin{array}{ll}97,03 \\
\end{array}$ & 39,23 & 5067,16 & 310,69 & 67,06 & 243,63 & 107,18 & 231,19 & 234,92 & 105,31 & 693,44 & 98,05 & 5,00 & 56,36 & 283,46 & 39,40 & $\begin{array}{ll}40,47 \\
\end{array}$ & 283,46 \\
\hline Lissotriton boscai & 29SND94 & 100,00 & 164,63 & 96,36 & 39,00 & 5094,30 & 309,10 & 65,31 & 243,79 & 103,10 & 229,80 & 233,27 & 103,05 & 729,34 & \begin{tabular}{|l|l|}
103,74 \\
\end{tabular} & 5,38 & 56,13 & 298,24 & 42,26 & 43,34 & 298,24 \\
\hline Lissotriton boscai & 29SND95 & 101,00 & 164,40 & 96,29 & \begin{tabular}{|l|}
38,97 \\
\end{tabular} & 5107,33 & 308,97 & 64,56 & 244,41 & 102,61 & 229,69 & 233,08 & 102,46 & 749,64 & 107,05 & 5,86 & 56,03 & 306,62 & 43,75 & 44,92 & 306,62 \\
\hline Lissotriton boscai & 29SND96 & 101,00 & 161,90 & 95,79 & 38,71 & 5140,64 & 307,12 & 61,99 & 245,13 & 99,61 & 227,89 & 231,10 & 99,61 & $\begin{array}{l}788,45 \\
\end{array}$ & 113,31 & 6,03 & 55,97 & 322,89 & 46,10 & \begin{tabular}{ll|l}
47,06 \\
\end{tabular} & 322,89 \\
\hline Lissotriton boscai & 29SND97 & 100,00 & 163,64 & 96,61 & 38,69 & 5152,31 & 309,19 & 62,41 & 246,78 & 101,27 & 229,80 & 232,76 & 100,99 & 789,01 & 113,33 & 6,22 & 55,85 & 322,31 & 46,76 & \begin{tabular}{ll|}
48,03 \\
\end{tabular} & 322,31 \\
\hline Lissotriton boscai & 29SND98 & 101,00 & 159,65 & 96,07 & 38,20 & 5204,60 & 306,12 & 58,25 & 247,87 & 96,60 & 226,80 & 229,56 & 96,60 & 842,70 & 121,84 & 6,97 & 55,70 & 344,44 & 50,83 & 51,66 & 344,44 \\
\hline Lissotriton boscai & 29SND99 & 100,00 & 157,27 & 95,94 & 38,03 & 5233,99 & 304,20 & 55,38 & 248,82 & 93,83 & 224,97 & 227,49 & 93,83 & 880,99 & \begin{tabular}{|l|l|}
127,97 \\
\end{tabular} & 7,45 & 55,45 & 360,06 & 53,78 & 54,41 & 360,06 \\
\hline Lissotriton boscai & 29SNE21 & 100,00 & 154,41 & 85,30 & 42,49 & 3858,25 & 264,11 & 65,67 & 198,45 & 112,57 & 201,62 & 204,18 & $\begin{array}{l}104,94 \\
\end{array}$ & $\begin{array}{l}879,25 \\
\end{array}$ & \begin{tabular}{ll|l|}
127,02 \\
\end{tabular} & 7,92 & 55,83 & $\begin{array}{l}361,05 \\
\end{array}$ & 52,38 & 56,89 & 357,44 \\
\hline Lissotriton boscai & 29SNE22 & 101,00 & 156,45 & 86,16 & \begin{tabular}{ll|l}
43,06 \\
\end{tabular} & 3801,99 & 264,73 & $\begin{array}{ll}66,96 \\
\end{array}$ & $\begin{array}{l}197,77 \\
\end{array}$ & 114,81 & 202,60 & 205,01 & 107,05 & 877,24 & \begin{tabular}{ll|}
125,73 \\
\end{tabular} & 8,03 & 55,11 & $\begin{array}{l}358,35 \\
\end{array}$ & 53,36 & 58,58 & 354,81 \\
\hline Lissotriton boscai & 29SNE30 & 100,00 & 151,17 & 88,04 & 41,29 & $\begin{array}{l}4146,76 \\
\end{array}$ & 270,31 & $\begin{array}{ll}60,08 \\
\end{array}$ & 210,23 & 106,59 & 202,74 & 205,56 & 99,05 & $\begin{array}{l}915,09 \\
\end{array}$ & \begin{tabular}{ll|}
132,98 \\
\end{tabular} & 8,19 & 55,99 & 375,21 & 54,94 & 57,61 & 374,22 \\
\hline Lissotriton boscai & 29SNE31 & 101,00 & 153,26 & 89,56 & 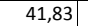 & 4109,05 & 272,14 & 61,12 & 211,03 & 107,35 & 204,18 & 206,82 & $\mid$\begin{tabular}{|l}
101,14 \\
\end{tabular} & 913,92 & \begin{tabular}{|l|l|}
131,86 \\
\end{tabular} & 8,50 & 55,35 & 373,01 & 56,08 & 59,22 & 372,06 \\
\hline |Lissotriton boscai & 29SNE41 & 101,00 & 152,76 & 93,14 & 41,49 & $4345,88 \mid$ & 279,68 & 57,65 & 222,03 & 98,66 & 207,16 & 209,86 & 98,28 & 939,08 & 135,46 & 8,86 & 55,12 & 382,81 & 58,79 & 60,79 & 382,81 \\
\hline Lissotriton boscai & 29SNE42 & 100,00 & 150,50 & 94,55 & 41,80 & 4357,86 & 278,69 & 54,41 & 224,29 & 95,73 & 205,08 & 207,75 & 95,73 & $\begin{array}{l}981,85 \\
\end{array}$ & \begin{tabular}{|l|l|}
141,10 \\
\end{tabular} & 9,75 & 54,39 & 398,97 & 63,27 & \begin{tabular}{ll|l}
65,08 \\
\end{tabular} & 398,97 \\
\hline Lissotriton boscai & 29SNE51 & 101,00 & 150,79 & 94,81 & 40,71 & 4567,43 & 283,90 & 53,75 & 230,15 & 94,13 & 208,58 & 211,30 & 94,13 & $\begin{array}{l}971,58 \\
\end{array}$ & \begin{tabular}{|l|l|}
140,67 \\
\end{tabular} & 9,29 & 54,97 & 396,61 & 61,51 & 62,51 & 396,61 \\
\hline Lissotriton boscai & 29SNE52 & 100,00 & 145,71 & 94,36 & \begin{tabular}{l|l|l}
40,55 \\
\end{tabular} & 4572,50 & $\begin{array}{l}278,62 \\
\end{array}$ & 48,77 & 229,86 & 89,08 & 204,36 & 206,28 & 89,08 & 1042,81 & $\begin{array}{l}151,36 \\
\end{array}$ & 10,45 & 54,69 & 424,94 & 67,24 & \begin{tabular}{ll|l}
68,03 \\
\end{tabular} & 424,94 \\
\hline Lissotriton boscai & 29SNE60 & 100,00 & 156,03 & 95,70 & 40,18 & 4727,17 & $\begin{array}{l}292,76 \\
\end{array}$ & 57,48 & 235,28 & 97,60 & 216,06 & 218,82 & 97,60 & 909,29 & $\begin{array}{l}131,69 \\
\end{array}$ & 8,14 & 55,40 & \begin{tabular}{|l|l|}
371,90 \\
\end{tabular} & 56,08 & 57,23 & 371,90 \\
\hline Lissotriton boscai & 29SNE61 & 100,00 & 151,40 & 95,90 & \begin{tabular}{l|l|}
40,15 \\
\end{tabular} & 4750,56 & 289,01 & 52,56 & 236,45 & 92,84 & 211,99 & 214,58 & 92,84 & 973,54 & 141,32 & 9,16 & 55,04 & 397,64 & 61,64 & 62,21 & 397,64 \\
\hline |Lissotriton boscai & 29SNE62 & 100,00 & 141,47 & 93,16 & 39,39 & 4773,60 & 277,94 & 44,03 & 233,92 & 83,16 & 204,14 & 205,27 & 83,16 & 1091,31 & $\mid 160,04$ & $\mid$\begin{tabular}{|l|l|}
10,87 \\
\end{tabular} & 54,99 & 445,90 & 69,95 & 70,01 & 445,90 \\
\hline Lissotriton boscai & 29SNE70 & 101,00 & 154,33 & 95,89 & 39,32 & 4917,30 & 295,29 & 54,54 & 240,75 & 94,07 & 217,36 & 219,94 & 94,07 & 929,76 & 135,19 & 8,27 & 55,35 & 380,43 & 57,70 & 58,26 & 380,43 \\
\hline Lissotriton boscai & 29SNE71 & 100,00 & 147,42 & 94,63 & 38,97 & 4938,86 & 288,14 & 48,14 & 240,01 & 87,19 & 211,97 & 213,50 & 87,19 & 1016,43 & 148,84 & 9,58 & 55,22 & 415,88 & 63,99 & 64,14 & 415,88 \\
\hline Lissotriton boscai & 29SNE72 & 101,00 & 147,01 & 95,68 & 39,19 & 4934,79 & 287,99 & 46,80 & 241,19 & 86,58 & 211,29 & 212,84 & 86,58 & 1037,05 & \begin{tabular}{|l|l|}
151,67 \\
\end{tabular} & 10,03 & 55,00 & 423,37 & 66,27 & 66,45 & 423,37 \\
\hline Lissotriton boscai & 29SNE80 & 101,00 & 147,36 & 93,38 & 38,00 & 5105,65 & 290,68 & 48,02 & 242,66 & 85,73 & 214,97 & 216,08 & 85,73 & \begin{tabular}{|c|}
999,48 \\
\end{tabular} & 146,99 & 9,09 & 55,62 & 409,81 & 61,75 & 61,78 & 409,81 \\
\hline Lissotriton boscai & 29SNE81 & 100,00 & 139,59 & 91,18 & 37,40 & 5112,34 & 281,58 & 41,21 & 240,36 & 78,28 & 208,20 & 208,53 & 78,28 & 1095,12 & 162,51 & 10,33 & 55,64 & $\begin{array}{l}449,06 \\
\end{array}$ & 67,73 & 67,73 & 449,06 \\
\hline Lissotriton boscai & 29SNE9O & 100,00 & 144,25 & 91,88 & 37,01 & 5263,55 & $\begin{array}{l}289,66 \\
\end{array}$ & 44,62 & 245,03 & 81,28 & 214,68 & 215,34 & 81,28 & 1026,81 & 151,79 & 9,32 & 55,69 & \begin{tabular}{|l|l|}
420,93 \\
\end{tabular} & 63,00 & \begin{tabular}{ll|}
63,03 \\
\end{tabular} & 420,93 \\
\hline Lissotriton boscai & 29SNE91 & 100,00 & 133,40 & 88,25 & 36,15 & 5252,89 & 276,32 & 35,82 & 240,49 & 71,19 & \begin{tabular}{|l|l|}
204,67 \\
\end{tabular} & \begin{tabular}{|l|l|}
204,67 \\
\end{tabular} & 71,19 & $\begin{array}{l}1151,78 \\
\end{array}$ & \begin{tabular}{ll|}
172,48 \\
\end{tabular} & 10,85 & 55,87 & 472,69 & $\begin{array}{l}70,36 \\
\end{array}$ & $\begin{array}{l}70,36 \\
\end{array}$ & 472,69 \\
\hline Lissotriton boscai & 29SNE92 & 100,00 & 141,13 & 92,11 & 37,01 & 5261,34 & 286,09 & 40,61 & 245,48 & 77,82 & 211,52 & 211,83 & 77,82 & 1085,70 & 161,39 & 10,10 & 55,59 & 444,37 & 67,32 & 67,38 & 444,37 \\
\hline Lissotriton boscai & 29SPB00 & 100,00 & 168,65 & 91,91 & \begin{tabular}{|l|l|}
41,97 \\
\end{tabular} & 4323,17 & 288,65 & 71,93 & 216,72 & 125,49 & 223,02 & 227,16 & 116,65 & 520,02 & 86,18 & 1,01 & 68,52 & 247,88 & 15,63 & $\begin{array}{l}19,26 \\
\end{array}$ & 231,80 \\
\hline Lissotriton boscai & 29SPB11 & 99,00 & 168,63 & $\begin{array}{l}92,33 \\
\end{array}$ & \begin{tabular}{ll|l}
41,09 \\
\end{tabular} & \begin{tabular}{ll|l|}
4481,92 \\
\end{tabular} & $\begin{array}{l}291,86 \\
\end{array}$ & 70,19 & 2221,67 & 123,23 & 224,88 & 228,95 & 114,35 & 520,10 & 83,18 & 1,01 & 66,93 & 242,62 & $\begin{array}{l}16,15 \\
\end{array}$ & 20,50 & 226,66 \\
\hline Lissotriton boscai & 29SPB12 & 101,00 & 159,55 & 95,59 & $\begin{array}{ll}40,93 \\
\end{array}$ & $\begin{array}{l}4684,63 \\
\end{array}$ & 290,54 & 59,33 & 231,21 & 112,27 & 218,81 & 222,92 & 103,22 & 570,01 & 88,50 & 1,90 & 64,84 & 258,87 & 19,90 & 23,92 & 244,94 \\
\hline Lissotriton boscai & 29SPB16 & 100,00 & 169,62 & 101,78 & 41,12 & 4908,01 & 310,38 & 66,19 & 244,19 & 118,84 & 231,52 & 235,58 & 110,12 & \begin{tabular}{|l|l|}
514,27 \\
\end{tabular} & 77,93 & 1,73 & 62,67 & 227,15 & 19,65 & 22,79 & 215,99 \\
\hline |Lissotriton boscai & 29SPB17 & 100,00 & 168,05 & 104,46 & 41,2 & 5005,48 & 313,51 & 63,50 & 250,01 & 116,38 & 231,39 & 235,43 & 107,52 & 524,31 & 78,4 & 1,9 & 61,72 & 228,42 & 21,01 & 23,75 & 218,70 \\
\hline Lissotriton boscai & 29SPB18 & 101,00 & 168,43 & 106,74 & 41,49 & 5064,67 & 317,17 & 62,97 & 254,19 & 116,14 & 232,58 & 236,60 & 107,19 & 524,31 & 77,78 & 2,00 & 60,91 & 225,94 & 21,78 & 23,97 & 217,52 \\
\hline Lissotriton boscai & 29SPB28 & 100,00 & 167,52 & 105,62 & 40,98 & 5143,11 & 316,07 & 60,92 & 255,16 & 113,99 & 232,69 & 236,56 & \begin{tabular}{|l|}
105,07 \\
\end{tabular} & 527,53 & 77,44 & 2,00 & 60,50 & 225,69 & 21,84 & 24,69 & 216,24 \\
\hline Lissotriton boscai & 29SPB29 & 101,00 & 167,13 & 107,53 & \begin{tabular}{ll|l}
41,02 \\
\end{tabular} & 5203,95 & 318,63 & 59,81 & 258,82 & 112,92 & 233,18 & \begin{tabular}{|l|}
237,07 \\
\end{tabular} & $\begin{array}{l}103,92 \\
\end{array}$ & $\begin{array}{l}531,36 \\
\end{array}$ & 77,24 & 2,00 & 59,86 & 225,10 & 22,59 & 25,19 & 216,82 \\
\hline Lissotriton boscai & 29SPB33 & 100,00 & 172,24 & 92,08 & \begin{tabular}{l|l|}
39,85 \\
\end{tabular} & 4756,22 & 299,82 & 71,13 & 228,69 & 122,83 & 231,68 & 235,45 & $\begin{array}{l}113,82 \\
\end{array}$ & $\begin{array}{l}497,26 \\
4\end{array}$ & 76,39 & 1,00 & 64,32 & 223,32 & 15,71 & 21,49 & 206,86 \\
\hline Lissotriton boscai & 29SPB35 & 101,00 & 169,60 & 96,90 & \begin{tabular}{ll|}
39,96 \\
\end{tabular} & 4957,53 & 305,73 & 65,96 & 239,77 & \begin{tabular}{|l|l|}
117,77 \\
\end{tabular} & 231,96 & 235,63 & 109,06 & 511,72 & 76,62 & 1,60 & 62,32 & 224,38 & 18,45 & 23,57 & 210,04 \\
\hline Lissotriton boscai & 29SPB38 & 100,00 & 165,74 & 104,48 & 40,26 & 5217,51 & 314,11 & 58,52 & 255,59 & 111,43 & 231,94 & 235,57 & 102,43 & 536,33 & 77,76 & 2,00 & 60,14 & 227,63 & 22,05 & 25,60 & 217,14 \\
\hline 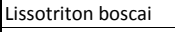 & 29SPB39 & 100,00 & 165,47 & 106,32 & \begin{tabular}{|l|l|}
40,48 \\
\end{tabular} & 5275,48 & 316 & 57,26 & 259,40 & 110,34 & 232,63 & 236,23 & 101,60 & 539,62 & 77,46 & 2,16 & 59,39 & 226,96 & 23,19 & 26,27 & 217,56 \\
\hline Lissotriton boscai & 29SPB42 & 100,00 & 174,39 & 87,81 & \begin{tabular}{|l|}
39,07 \\
\end{tabular} & 4705,30 & 296,40 & 74,27 & 222,13 & 125,04 & 232,76 & 236,31 & 116,11 & 486,66 & 74,96 & 1,00 & 65,00 & 218,79 & 14,07 & 21,01 & 200,46 \\
\hline Lissotriton boscai & 29SPB44 & 100,00 & 168,94 & $\begin{array}{ll}93,08 \\
\end{array}$ & $\begin{array}{ll}39,08 \\
\end{array}$ & $\begin{array}{l}4953,04 \\
\end{array}$ & 301,00 & \begin{tabular}{ll|}
65,92 \\
\end{tabular} & 235,08 & $\begin{array}{l}116,97 \\
\end{array}$ & 230,92 & 234,64 & 108,21 & $\begin{array}{l}514,36 \\
\end{array}$ & 76,65 & 1,65 & 62,62 & 225,14 & 17,70 & 24,14 & 208,76 \\
\hline Lissotriton boscai & 29SPBA5 & 101,00 & 167,17 & 95,93 & 39,15 & 5057,97 & 303,87 & 62,46 & 441,41 & 114,03 & 230,75 & 234,29 & 105,23 & 524,81 & 77,31 & 1,95 & 61,65 & 227,20 & 19,13 & 25,01 & 212,6 \\
\hline Lissotriton boscai & 29SPB46 & 101,00 & 170,38 & $\begin{array}{ll}97,69 \\
\end{array}$ & 39,49 & \begin{tabular}{|l|}
5097,67 \\
\end{tabular} & 309,21 & 64,66 & 244,55 & $\begin{array}{l}116,60 \\
\end{array}$ & 234,40 & 237,99 & $\begin{array}{l}107,66 \\
\end{array}$ & 508,40 & 74,47 & 2,00 & 61,12 & 218,77 & 19,17 & 24,74 & 204,27 \\
\hline Lissotriton boscai & 29SPB47 & 100,00 & 168,88 & 100,49 & \begin{tabular}{ll|l}
39,82 & \\
\end{tabular} & \begin{tabular}{|l|}
5191,89 \\
\end{tabular} & 311,99 & 61,96 & 250,03 & 114,28 & 234,42 & 237,89 & 105,12 & 517,01 & 75,01 & 2,00 & 60,66 & 220,39 & 20,28 & 25,11 & 207,22 \\
\hline Lissotriton boscai & 29SPB48 & 100,00 & 167,76 & 102,78 & \begin{tabular}{l|l|}
39,96 \\
\end{tabular} & 5275,35 & 314,51 & $\begin{array}{ll}59,57 \\
\end{array}$ & 254,94 & \begin{tabular}{ll|}
112,04 \\
\end{tabular} & 234,53 & 238,02 & \begin{tabular}{|l|}
103,20 \\
\end{tabular} & 523,92 & 75,31 & 2,00 & 59,87 & 221,33 & 21,22 & 25,76 & 209,24 \\
\hline Lissotriton boscai & 29SPB54 & 101,00 & 170,45 & 90,94 & 38,30 & 5007,82 & 300,94 & 66,97 & 233,97 & 117,41 & 232,94 & 236,36 & 108,48 & 506,42 & 75,65 & 1,51 & 62,28 & 219,73 & 17,00 & 24,36 & 202,13 \\
\hline Lissotriton boscai & 29SPB56 & 100,00 & 168,05 & 96,89 & 38,95 . & 5204,47 & 307,65 & 61,30 & 246,35 & 112,94 & 233,58 & 236 & 103,94 & 520,95 & 76 & 2,00 & 60,74 & 221,98 & 19,40 & 25,68 & 206 \\
\hline Lissotriton boscai & 29SPB57 & 100,00 & 168 & 99,30 & 39,05 & $5.5-2+$ & 311,35 & 60,62 & 25 & 11 & 235,06 & & 103,76 & 519,26 & 75,34 & 2,00 & 60,09 & 219,62 & 20,12 & 25,82 & 205,28 \\
\hline Lissotriton boscai & 29SPB58 & 101,00 & 165,17 & 102,30 & 39,26 & 5365,91 _ & 312,87 & 56,02 & 256,85 & 108,46 & 233,42 & 236,58 & 99,60 & 539,10 & 77,02 & 2,18 & 59,31 & 225,79 & 22,22 & 27,10 & 212,91 \\
\hline Lissotriton boscai & 29SPB59 & 100,00 & 166,71 & 104,28 & 39,71 & 5416,16 & 316,71 & 56,52 & 260,20 & 109,16 & 235,61 & 238,69 & 100,55 & 531,41 & 75,54 & 2,18 & 58,79 & 21,23 & 22,63 & 27,04 & 209,20 \\
\hline Lissotriton boscai & 29SPB65 & 101,00 & 170,61 & 92,24 & 7,94 & 5171,80 & 304,69 & 64,81 & 39,88 & 15,30 & 35,21 & 238,42 & 106,43 & 507,57 & 75,85 & 1,94 & 61,13 & 16,36 & 17,85 & 25,54 & 198,55 \\
\hline \begin{tabular}{|l|l|l|l} 
Lissotr & \\
\end{tabular} & 29SPB68 & 99 & & 102,50 & 38 & 6 & 310,95 & 50,86 & & F & & & & 565,09 & 80,49 & 2,59 & & 234,47 & 24,03 & 29,36 & 221,11 \\
\hline 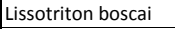 & 29SPB72 & 100,00 & 177,28 & 80,30 & 36,32 & 4889,62 & 294,83 & 76,74 & 218,10 & 124,96 & 237,14 & 240,23 & 115,76 & $\begin{array}{l}471,86 \\
\end{array}$ & 74,05 & 1,00 & 63,85 & 205,10 & $\begin{array}{l}12,65 \\
\end{array}$ & 22,54 & 183,14 \\
\hline Lissotriton boscai & 29SPB75 & 100,00 & 173,17 & 90,78 & 37,35 & 5223,84 & 306,17 & 66,62 & 239,55 & 116,95 & 238,22 & 241,18 & 108,03 & 497,01 & 75,20 & 1,71 & 61,08 & 210,63 & 16,92 & 25,31 & 191,71 \\
\hline
\end{tabular}




\begin{tabular}{|c|c|c|c|c|c|c|c|c|c|c|c|c|c|c|c|c|c|c|c|c|c|}
\hline TAXON & UTM & $\mathrm{km} 2$ & BI01 & BIO2 & $B 103$ & BIO4 & B105 & B106 & B107 & B108 & B109 & B1010 & BIO11 & B1012 & BIO13 & BIO14 & BIO15 & B1016 & B1017 & B1018 & 81019 \\
\hline Lissotriton boscai & 29SPB76 & 101,00 & 172,13 & 94,68 & 37,97 & 5322,15 & 310,30 & 63,59 & 246,72 & 115,01 & 238,91 & 241,79 & 105,99 & 504,11 & 75,30 & 1,99 & 60,38 & 212,14 & 18,20 & 25,85 & 194,57 \\
\hline Lissotriton boscai & 29SPB77 & 100,00 & 169,75 & 98,39 & 38,18 & 5425,29 & 313,11 & 59,47 & 253,64 & 111,36 & 238,29 & 241,06 & 102,64 & 517,79 & 76,19 & 2,01 & 59,74 & 216,32 & 19,64 & 26,46 & 200,12 \\
\hline Lissotriton boscai & 29SPB78 & 101,00 & 163,20 & 102,44 & 38,68 & 5548,81 & 313,16 & 51,22 & 261,94 & $\begin{array}{l}104,07 \\
\end{array}$ & 233,97 & 236,76 & 95,18 & 557,05 & 79,98 & 2,45 & 58,67 & 230,14 & 23,44 & 29,16 & 215,80 \\
\hline Lissotriton boscai & 29SPB79 & 100,00 & 158,60 & 105,26 & 38,94 & 5641,23 & 313,68 & 45,54 & 268,14 & 98,76 & 231,00 & 233,69 & 89,80 & 585,79 & 82,62 & 3,10 & 57,73 & 239,91 & 26,44 & 31,26 & 227,16 \\
\hline Lissotriton boscai & 29SPB81 & 49,00 & 177,89 & 79,56 & 36,00 & 4901,23 & 294,59 & 76,90 & 217,69 & 136,93 & 238,02 & 241,00 & 116,18 & 476,69 & 75,25 & 1,00 & 63,82 & 206,57 & 12,51 & 22,87 | & 183,93 \\
\hline Lissotriton boscai & 29SPB82 & 101,00 & 177,98 & 79,33 & 35,82 & \begin{tabular}{|l|l|l|}
4964,47 \\
\end{tabular} & 295,56 & 76,60 & 218,96 & 144,32 & 238,62 & 241,52 & 115,22 & \begin{tabular}{|l|l|}
472,48 \\
\end{tabular} & 74,62 & 1,00 & 63,57 & 203,23 & $\begin{array}{ll}12,62 \\
\end{array}$ & 23,47 & \begin{tabular}{ll|l}
180,27 \\
\end{tabular} \\
\hline Lissotriton boscai & 29SPB86 & 100,00 & 169,77 & 96,12 & 37,83 & 5442,40 & 311,10 & 59,32 & 251,78 & 111,16 & 238,45 & 241,03 & 102,23 & 523,43 & 77,89 & 2,00 & 60,25 & 218,73 & 18,97 & 26,66 & 201,01 \\
\hline Lissotriton boscai & 29SPB87 & 100,00 & 168,34 & 99,61 & 38,00 & 5531,28 & 314,37 & 56,26 & 258,11 & 108,81 & 238,52 & 241,06 & $\begin{array}{ll}99,98 \\
\end{array}$ & $\begin{array}{l}531,65 \\
\end{array}$ & 78,12 & 2,02 & 59,57 & 220,72 & 20,46 & 27,36 & 204,23 \\
\hline Lissotriton boscai & 29SPB88 & 100,00 & 162,84 & 103,31 & 38,20 & 5644,99 & 314,91 & \begin{tabular}{ll|l}
48,97 \\
\end{tabular} & 265,94 & 102,43 & 235,01 & 237,46 & 93,42 & 564,64 & 81,17 & 2,69 & 58,47 & 232,19 & 23,76 & 29,72 & 217,38 \\
\hline Lissotriton boscai & 29SPB89 & 100,00 & 153,82 & 106,46 & 38,23 & \begin{tabular}{|l|l|l}
5757,84 \\
\end{tabular} & 312,54 & 38,85 & 273,69 & 92,73 & 228,07 & 230,59 & 83,71 & 620,39 & 86,93 & 3,43 & 57,47 & 252,59 & 28,53 & 33,33 & 239,85 \\
\hline Lissotriton boscai & 29SPB91 & 91,00 & 176,63 & 82,44 & 36,29 & 4991,09 & 297,27 & 73,43 & 223,85 & 129,05 & 238,21 & 241,18 & \begin{tabular}{|l|}
113,96 \\
\end{tabular} & \begin{tabular}{l|l|}
495,43 \\
\end{tabular} & 77,43 & 1,00 & 63,73 & 213,67 & 13,84 & 23,77 & 191,63 \\
\hline Lissotriton boscai & 29SPB92 & 101,00 & 176,34 & 83,35 & 36,08 & 5092,33 & 299,59 & 72,02 & 227,57 & 134,69 & 239,17 & 242,06 & \begin{tabular}{|l|}
112,29 \\
\end{tabular} & $\begin{array}{l}493,55 \\
\end{array}$ & 77,15 & 1,00 & 63,20 & 211,19 & 14,05 & 24,00 & 189,05 \\
\hline 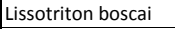 & 29SPB93 & 100,00 & 178,35 & 85,09 & 36,17 & 5167,99 & 304,21 & 72,76 & 231,45 & 147,42 & 242,25 & 244,99 & 113,29 & 482,24 & 75,46 & 1,00 & 62,70 & 205,42 & 14,09 & 24,00 & 183,32 \\
\hline Lissotriton boscai & 29SPB94 & 101,00 & 174,68 & 89,65 & 36,78 & 5315,18 & 307,38 & 66,53 & 240,84 & 122,55 & 241,05 & 243,73 & 108,15 & $\begin{array}{l}502,46 \\
\end{array}$ & 77,16 & 1,28 & 61,65 & 212,05 & 15,74 & 24,94 & 191,58 \\
\hline Lissotriton boscai & 29SPB95 & 99,00 & 169,82 & 94,92 & 37,18 & 5462,90 & 310,08 & 58,89 & 251,19 & 110,79 & 238,72 & 241,25 & 101,85 & 531,43 & 79,77 & 2,00 & 60,74 & 222,38 & 18,52 & 26,68 & 203,61 \\
\hline Lissotriton boscai & 29SPB97 & 100,00 & 170,11 & 100,77 & 38,00 & 5609,81 & 317,98 & 56,11 & 261,87 & 109,56 & 241,47 & 243,77 & 100,57 & \begin{tabular}{ll|}
529,92 \\
\end{tabular} & 78,18 & 2,00 & 59,68 & 219,39 & 20,10 & 27,11 & 202,56 \\
\hline Lissotriton boscai & 29SPB99 & 100,00 & 152,23 & $\begin{array}{l}107,69 \\
\end{array}$ & 38,00 & 5848,46 & 313,92 & 35,78 & 278,14 & 90,23 & 227,96 & 230,29 & 81,17 & \begin{tabular}{|l|l|}
635,97 \\
\end{tabular} & 88,77 & 3,60 & 57,37 & 257,79 & 29,35 & 34,22 & 245,06 \\
\hline Lissotriton boscai & $295 \mathrm{SC02}$ & 101,00 & 166,33 & 110,50 & 41,87 & 5160,53 & 322,00 & 60,85 & 261,15 & 112,99 & 231,84 & 236,18 & $\mid 104,34$ & 552,50 & 78,82 & 2,58 & 58,68 & 229,86 & 26,91 & \begin{tabular}{|l|l|l|}
27,28 \\
\end{tabular} & 227,05 \\
\hline |Lissotriton boscai & 295PC07 & 101,00 & 162,37 & 101,10 & 40,03 & 5119,50 & 310,44 & 61,96 & 248,48 & 101,92 & 229,31 & 231,74 & 100,87 & 613,08 [ & 83,86 & 4,00 & 55,95 & 247,58 & 35,10 & 35,10 & 247,58 \\
\hline Lissotriton boscai & 29SPC08 & 100,00 & 160,69 & $\begin{array}{ll}99,94 \\
\end{array}$ & 39,98 & 5139,34 & 308,49 & 60,77 & 247,72 & 99,37 & 228,08 & 230,42 & 99,08 & 640,14 & 87,9 & 4,12 & 55,88 & 258,78 & 36,81 & 36,81 & 258,78 \\
\hline Lissotriton boscai & 29SPC09 & 100,00 & 162,42 & 99,67 & 39,97 & 5141,97 & 309,99 & 62,39 & 247,60 & 101,25 & 228,39 & 232,14 & 100,70 & $\begin{array}{l}646,09 \\
\end{array}$ & 89,10 & 4,17 & 55,93 & $\begin{array}{l}261,45 \\
\end{array}$ & 37,30 & 37,32 & 261,45 \\
\hline Lissotriton boscai & 29SPC13 & 101,00 & 160,51 & $\begin{array}{ll}109,02 \\
\end{array}$ & 41,00 & 5282,23 & 317,10 & 54,79 & 262,31 & 105,93 & 228,42 & 232,21 & 97,33 & 589,14 & 81,72 & 3,00 & 57,24 & 240,98 & 30,63 & 30,77 & 238,69 \\
\hline Lissotriton boscai & 29SPC17 & $\begin{array}{ll}99,00 \\
\end{array}$ & 163,81 & 103,55 & 40,05 & 5233,55 & 314,91 & 60,52 & 254,39 & $\mid \begin{array}{l}108,59 \\
\end{array}$ & 230,76 & 234,53 & $\mid$\begin{tabular}{|l|l|}
100,84 \\
\end{tabular} & $\mid 601,24$ & 81,32 & 4,00 & 55,57 & 241,35 & 34,91 & 34,91 & 240,92 \\
\hline |Lissotriton boscai & 29SPC18 & 101,00 & 160,60 & 102,15 & 39,90 & 5255,88 & 311,74 & 58,30 & 253,45 & 102,59 & 228,97 & 231,89 & 97,68 & $638,67 \mid$ & 86,96 & 4,34 & 55,44 & 256,29 & 37,43 & 37,43 & 256,26 \\
\hline Lissotriton boscai & 29SPC23 & 100,00 & 165,26 & 109,13 & 40,97 & 5331,75 & 321,37 & 57,58 & 263,80 & 109,62 & 233,19 & 237,03 & 100,88 & 556,98 & 77,25 & 3,00 & 57,18 & 227,79 & 28,54 & 29,44 & 223,46 \\
\hline Lissotriton boscai & 29SPC28 & 100,00 & 159,59 & 104,11 & 39,72 & 5380,03 & 313,91 & 54,76 & 259,15 & 102,98 & 229,49 & 232,40 & 95,14 & 642,65 & 86,77 & 4,51 & 54,97 & 256,99 & 38,20 & 38,24 & 255,93 \\
\hline Lissotriton boscai & 29SPC30 & 101,00 & 166,07 & 107,70 & 40,62 & 5327,15 & 319,31 & 57,17 & 262,14 & 110,25 & 233,87 & 237,53 & 101,40 & \begin{tabular}{|l|l|}
538,07 \\
\end{tabular} & 76,59 & 2,32 & 58,83 & 224,42 & 24,33 & 27,07 & 215,93 \\
\hline Lissotriton boscai & 29SPC32 & 100,00 & 168,44 & 108,99 & 40,68 & 5377,66 & 323,78 & 58,78 & 265,00 & 111,72 & 236,88 & 240,46 & 103,10 & 530,80 & 74,13 & 2,80 & 57,45 & 218,09 & 26,20 & 28,24 & 211,01 \\
\hline Lissotriton boscai & 29SPC33 & 100,00 & 168,65 & 109,01 & 40,48 & 5392,90 & $324,63 \mid$ & 58,97 & 265,66 & \begin{tabular}{ll|}
111,64 \\
\end{tabular} & 237,36 & 240,86 & 103,12 & 533,38 & 73,80 & 2,99 & 56,89 & 217,75 & 27,26 & 28,95 & 211,42 \\
\hline Lissotriton boscai & 29SPC36 & 101,00 & 164,36 & 108,31 & 40,00 & 5467,16 & 321,97 & 55,28 & 266,69 & 106,72 & 234,42 & 237,79 & 98,15 & 577,66 & 77,96 & 3,98 & 55,18 & 231,45 & 33,13 & 33,78 & 227,34 \\
\hline Lissotriton boscai & 29SPC37 & 100,00 & 165,27 & 107,92 & 40,00 & 5472,45 & 322,58 & 56,23 & 266,34 & 107,39 & 235,64 & 238,79 & 98,97 & 581,16 & 78,36 & 4,00 & 54,85 & 232,22 & 34,01 & 34,58 & 228,44 \\
\hline Lissotriton boscai & 29SPC39 & 101,00 & 158,32 & 105,42 & 39,32 & 5511,46 & 315,80 & 51,43 & 264,37 & 100,70 & 229,73 & 232,91 & 92,33 & 658,86 & 88,45 & 5,04 & 54,28 & 262,54 & 40,31 & 40,40 & 260,37 \\
\hline Lissotriton boscai & 29SPC42 & 100,00 & 168,63 & 108,80 & 40,06 & 5456,22 & 324,43 & 57,49 & 266,93 & 110,51 & 238,29 & 241,35 & 102,19 & 527,43 & 73,36 & 2,99 & 56,99 & 215,81 & 26,20 & 28,86 & 207,36 \\
\hline Lissotriton boscai & 29SPC43 & 101,00 & 167,88 & 109,24 & 40,02 & 5501,38 & 325,44 & 56,36 & 269,08 & 109,36 & 238,23 & 241,34 & 100,77 & 533,92 & 73,76 & 3,00 & 56,68 & 217,10 & 27,27 & 29,37 & 209,34 \\
\hline Lissotriton boscai & 29SPC44 & 100,00 & 168,91 & 109,81 & 40,04 & 5516,29 & 327,01 & 57,07 & 269,94 & 110,10 & 239,67 & 242,44 & 101,43 & 531,63 & 73,28 & 3,00 & 56,19 & 215,10 & 27,82 & 29,73 & 207,85 \\
\hline Lissotriton boscai & 29SPC45 & 100,00 & 168,72 & 109,90 & 40,02 & 5520,70 & 327,46 & 56,84 & 270,62 & 109,73 & 239,59 & 242,28 & 101,23 & 536,43 & 73,75 & 3,02 & 55,77 & 215,92 & 28,96 & 30,40 & 209,14 \\
\hline Lissotriton boscai & 29SPC47 & 101,00 & 167,52 & 110,02 & 40,00 & 5572,71 & 327,53 & 55,35 & 272,18 & 107,90 & 239,20 & 241,86 & \begin{tabular}{ll|}
99,60 \\
\end{tabular} & 557,72 & 76,07 & 3,98 & 54,43 & 222,23 & 32,93 & 33,83 & 216,36 \\
\hline |Lissotriton boscai & 29SPC49 & 101,00 & 165,01 & 109,48 & 39,91 & 5613,73 & 325,70 & 53,33 & 272,37 & 105,11 & 237,55 & 240,08 & 96,82 & 595,18 & 80,41 & 4,58 & 53,77 & 236,19 & 36,72 & 37,23 & 231,34 \\
\hline Lissotriton boscai & 29SPC50 & 100,00 & 165,21 & 106,32 & 39,84 & 5479,81 & 318,78 & 54,19 & 264,59 & 107,29 & 235,18 & 238,30 & 98,45 & 542,76 & 76,27 & 2,73 & 57,73 & 223,62 & 25,01 & 28,78 & 212,74 \\
\hline Lissotriton boscai & 29SPC51 & 101,00 & 167,10 & $\begin{array}{l}107,59 \\
\end{array}$ & 39,88 & 5507,90 & 322,31 & 55,03 & 267,28 & 108,55 & 237,41 & 240,46 & 99,80 & $\begin{array}{l}533,46 \\
\end{array}$ & 74,70 & 3,00 & 57,20 & 218,51 & 25,75 & 29,11 & 208,22 \\
\hline Lissotriton boscai & 29SPC52 & 100,00 & 168,43 & 108,65 & 39,99 & 5543,99 & 325,30 & 55,72 & 269,58 & 109,37 & 239,34 & 242,17 & 100,59 & $\begin{array}{l}526,22 \\
\end{array}$ & 73,52 & 3,00 & 56,66 & 214,39 & 26,14 & 29,12 & 204,65 \\
\hline Lissotriton boscai & 29SPC53 & 100,00 & 166,86 & 109,71 & 39,99 & 5586,67 & 325,93 & 53,65 & 272,28 & 107,14 & 238,44 & 241,20 & 98,53 & $\begin{array}{l}537,68 \\
\end{array}$ & 74,58 & 3,00 & 56,35 & 217,67 & 27,47 & 29,91 & 208,80 \\
\hline Lissotriton boscai & 29SPC54 & 100,00 & 167,86 & 110,35 & 40,00 & $5602,91]$ & 327,94 & 54,27 & 273,67 & 107,78 & 239,81 & 242,30 & 99,23 & 534,37 & 73,98 & 3,03 & 55,77 & 15,26 & 28,15 & 30,24 & 206,77 \\
\hline Lissotriton boscai & 29SPC56 & 100,00 & $\begin{array}{lll}166,97 \\
\end{array}$ & 111,41 & 39,97 & 5663,56 & 329,39 & 52,77 & 276,63 & 106,25 & 240,07 & 242,45 & 97,86 & 546,35 & $75, \mathrm{C}$ & 3,92 & 54,31 & 217,49 & 31,92 & 33,19 & 209,91 \\
\hline Lissotriton boscai & 29SPC57 & 100,00 & 168,13 & 111,79 & 39,96 & 5684,87 & 331 & 53,09 & 278,00 & 106,93 & 241,54 & 243,71 & 98,65 & 543,91 & 74,7 & 3,99 & 53,94 & 215,79 & 32,57 & 33,71 & 208,22 \\
\hline Lissotriton boscai & 29SPC60 & 100,00 & 163,18 & 106,26 & 39,15 & 5569,55 & 317,99 & 50,66 & 267,33 & 104,12 & 234,43 & 237,22 & 95,19 & 556,04 & 78,26 & 2,98 & 57,41 & 227,75 & 25,89 & 29,93 & 216,04 \\
\hline Lissotriton boscai & 29SPC61 & 100,00 & 162,79 & $\begin{array}{l}107,89 \\
\end{array}$ & 39,17 & 5622,32 & 320,55 & 49,19 & 271,36 & 103,19 & 234,95 & 237,86 & 94,22 & 558,30 & 78,06 & 3,08 & 56,97 & 227,34 & 26,79 & 30,50 & 216,45 \\
\hline Lissotriton boscai & 29SPC62 & 100,00 & 167,16 & 108,97 & 39,37 & 5633,15 & 325,76 & 52,92 & 272,84 & 107,02 & 239,42 & 241,86 & \begin{tabular}{ll|}
98,14 \\
\end{tabular} & 532,84 & 74,71 & 3,00 & 56,49 & 216,13 & 26,27 & 29,60 & 205,40 \\
\hline Lissotriton boscai & 29SPC67 & 100,00 & 163,22 & 112,86 & 39,25 & 5799,65 & 329,68 & 46,44 & 283,24 & 101,10 & 238,40 & 240,30 & 92,42 & 565,42 & 77,51 & 4,10 & 53,61 & 223,34 & 34,08 & 35,10 & 214,86 \\
\hline Lissotriton boscai & 29SPC68 & 101,00 & 165,88 & 113,77 & 39,39 & 5827,84 & 333 & 48,04 & 284,97 & 102,98 & 241,62 & 243,26 & 94,45 & 550,29 & 75,81 & 4,00 & 53,27 & 216,66 & 33,90 & 34,73 & 207,97 \\
\hline Lissotriton boscai & $29 S P C 70$ & 100,00 & 161,09 & 106,73 & 38,95 & 5675,07 & 318,19 & 46,80 & 271,38 & 100,66 & 233,89 & 236,54 & 91,70 & $\begin{array}{l}571,07 \\
\end{array}$ & 80,41 & 3,15 & 57,24 & 232,70 & 26,59 & 31,03 & 220,35 \\
\hline Lissotriton boscai & 29SPC71 & 101,00 & 158,40 & 108,44 & 38,92 & 5732,58 & 318,87 & 43,40 & 275,47 & 97,48 & 232,29 & 234,86 & 88,52 & 587,30 & 81,78 & 3,33 & 56,56 & 237,71 & 28,70 & 32,39 & 226,39 \\
\hline Lissotriton boscai & 29SPC72 & 100,00 & 165,22 & 109,58 & 39,03 & 5735,12 & 326,20 & 49,42 & 276,78 & 103,68 & 239,04 & 24 & 95,01 & 543,63 & 76,32 & 3,01 & 56,35 & 219 & 26,65 & 30,28 & 208,0 \\
\hline Lissotriton boscai & 29SPC73 & 100,00 & 164,62 & 110,88 & 39,01 & 577 & 327,87 & $\begin{array}{ll}47,88 \\
\end{array}$ & 279,99 & 102,55 & & & 94,00 & 546 & 76 & 3,05 & 55,68 & 219,18 & 27,99 & 31,12 & 208,24 \\
\hline Lissotriton boscai & 29SPC74 & 100,00 & 162,33 & 111,87 & 39,01 & \begin{tabular}{|l|l|l|}
5819,58 \\
\end{tabular} & 327,60 & 45,12 & 282,49 & $\begin{array}{ll}99,79 \\
\end{array}$ & 237,63 & 239,69 & 91,24 & $\begin{array}{l}560,86 \\
\end{array}$ & 77,53 & 3,71 & 54,81 & 223,50 & 30,66 & 33,10 & 213,25 \\
\hline Lissotriton boscai & 29SPC75 & 100,00 & 160,62 & \begin{tabular}{ll|}
112,54 \\
\end{tabular} & 38,99 & $\begin{array}{ll}5859,96 \\
\end{array}$ & 327,79 & 43,08 & 284,70 & $\begin{array}{l}97,82 \\
\end{array}$ & 236,75 & 238,66 & 89,31 & $\begin{array}{l}570,99 \\
\end{array}$ & 78,47 & 4,01 & 54,31 & 226,36 & 32,31 & 34,26 & 216,50 \\
\hline Lissotriton boscai & 29SPC76 & 101,00 & 159,65 & 113,05 & 39,00 & 5884,03 & 328,04 & 41,70 & 286,34 & 96,49 & 236,10 & 238,09 & 88,08 & 578,22 & 79,15 & 4,05 & 53,77 & 228,21 & 33,88 & 35,32 & 218,64 \\
\hline LLS & 295PC77 & 99 & 161 & 113 & $39, \mathrm{C}$ & 5906 & 330,81 & 43, & & \begin{tabular}{|c|c|}
97,98 \\
\end{tabular} & & & 89 & 564 & 77,44 & 4,05 & 5 & 22 & 34,09 & 35,34 & 212 \\
\hline Lissotriton boscai & 29SPC80 & 101,00 & 154,66 & 107,93 & 38,41 & 5795,37 & 315,84 & 39,03 & 276,81 & 93,23 & 229,63 & 232,06 & 84,21 & 614,21 & 85,61 & 3,64 & 56,86 & 248,62 & 29,24 & 33,59 & 236,45 \\
\hline Lissotriton boscai & 29SPC81 & 99,00 & 159,18 & 109,25 & 38,81 & 5818,30 & 321,64 & 42,67 & 278,97 & 97,08 & 234,43 & 236,60 & 88,26 & 583,86 & 81,56 & 3,29 & 56,41 & 235,44 & 28,32 & 32,34 & 223,32 \\
\hline
\end{tabular}




\begin{tabular}{|c|c|c|c|c|c|c|c|c|c|c|c|c|c|c|c|c|c|c|c|c|c|}
\hline TAXON & UTM & $\mathrm{km2}$ & BIO1 & B102 & $\mathrm{BIO3}$ & BIO4 & B105 & B106 & B107 & B108 & B109 & BIO10 & BIO11 & B1012 & BIO13 & BI014 & BIO15 & BIO16 & BIO17 & BIO18 & BIO19 \\
\hline Lissotriton boscai & 29SPC82 & 101,00 & 160,19 & 110,52 & 38,84 & 5854,69 & 324,58 & 42,86 & 281,71 & 97,50 & 235,97 & 238,01 & 88,63 & 575,40 & 80,09 & 3,43 & 55,90 & 230,86 & 28,88 & 32,50 & 219,15 \\
\hline Lissotriton boscai & $295 P C 87$ & 101,00 & 159,43 & 114,49 & 38,96 & 6000,35 & 331,08 & 39,33 & 291,75 & 94,80 & 237,95 & 239,14 & 86,38 & $\begin{array}{l}570,55 \\
\end{array}$ & 78,01 & 4,14 & \begin{tabular}{l|l|}
52,95 \\
\end{tabular} & 223,31 & 34,51 & 36,02 & 212,68 \\
\hline Lissotriton boscai & 29SPC90 & 100,00 & 155,39 & 109,04 & 38,17 & 5882,69 & 318,88 & 38,08 & 280,80 & 92,63 & 231,65 & 233,82 & 83,79 & \begin{tabular}{|l|l|}
613,37 \\
\end{tabular} & 85,57 & 3,45 & 56,86 & 247,51 & 28,96 & 33,52 & 234,93 \\
\hline Lissotriton boscai & 29SPC91 & 101,00 & 158,57 & 110,27 & 38,30 & 5915,33 & 323,67 & 40,32 & 283,35 & 95,27 & 235,23 & \begin{tabular}{|l|l|}
237,27 \\
\end{tabular} & 86,32 & 589,82 & 82,32 & 3,35 & 56,42 & 237,01 & 28,48 & 32,65 & 224,46 \\
\hline Lissotriton boscai & 29SPC92 & 99,00 & 153,35 & 111,44 & 38,22 & 5977,65 & 321,58 & 34,63 & 286,95 | & 89,59 [ & 231,15 , & 233,13 & 80,78 _ ب & 621,02 & 85,31 & 3,99 & 55,51 . & $247,66 \mid$ & 31,83 , & $35,31 \mid$ & 236,26 \\
\hline Lissotriton boscai & 29SPC94 & 99,00 & 158,64 & 113,32 & 38,53 & 6010,83 & 329,04 & 38,53 & 290,51 & \begin{tabular}{|l|l|}
93,99 \\
\end{tabular} & 236,90 & 238,53 & 85,32 & 581,60 & 79,89 & 3,74 & 54,58 & 230,01 & 31,40 & 34,26 & 218,55 \\
\hline Lissotriton boscai & 29SPC95 & 101,00 & 153,03 & 113,44 & 38,21 & 6051,86 & 325,26 & 33,25 & 292,01 & 88,29 & 232,23 & 233,77 & 79,68 & 615,80 & 83,41 & 4,51 & 53,75 & 241,99 & \begin{tabular}{|l|}
35,09 \\
\end{tabular} & 37,22 & 231,30 \\
\hline Lissotriton boscai & 29SPD05 & 100,00 & 164,19 & 97,09 & \begin{tabular}{l|l}
38,45 \\
\end{tabular} & 5241,36 & 311,97 & 63,09 & 248,88 & \begin{tabular}{|l|l|}
101,06 \\
\end{tabular} & \begin{tabular}{|l|l}
231,63 \\
\end{tabular} & 234,92 & 100,91 & \begin{tabular}{|l|l|}
747,79 \\
\end{tabular} & 106,27 & 5,92 & 55,64 & $\begin{array}{ll}304,62 \\
\end{array}$ & 44,26 & 45,40 & 304,62 \\
\hline Lissotriton boscai & 29SPD06 & 101,00 & 162,42 & 96,54 & \begin{tabular}{|l|l|}
38,07 \\
\end{tabular} & 5278,41 & 310,58 & 61,03 & 249,54 & \begin{tabular}{|c|}
98,67 \\
\end{tabular} & 230,34 & \begin{tabular}{|l|l|}
233,67 \\
\end{tabular} & $\begin{array}{l}98,67 \\
\end{array}$ & 781,05 & 111,75 & 6,01 & 55,70 & 318,61 & 46,15 & 47,22 & 318,61 \\
\hline Lissotriton boscai & 29SPD07 & 100,00 & 163,07 & 96,93 & 38,15 & 5303,94 & 311,69 & $60,67[$ & 251,02 & $99,04[$ & 231,54 & 234,37 & 98,93 & 789,75 & 113,19 & 6,18 & 55,53 & 321,77 & 47,18 , & 48,37 & 321,77 \\
\hline Lissotriton boscai & 29SPD08 & 101,00 & 164,65 & 97,86 & 38,19 & 5326,48 & 313,87 & 60,86 & 253,01 & 100,50 & 233,51 & 235,92 & 99,80 & $\begin{array}{l}788,15 \\
\end{array}$ & 112,94 & 6,20 & 55,25 & 320,35 & 47,34 & 48,77 & 320,35 \\
\hline Lissotriton boscai & 29SPD09 & 101,00 & 161,29 & 97,32 & 37,86 & 5371,68 & 311,23 & 57,29 & 253,94 & 96,06 & \begin{tabular}{|l|l|}
230,99 \\
\end{tabular} & 233,26 & \begin{tabular}{ll|}
96,06 \\
\end{tabular} & 833,96 & 120,30 & 6,85 & 55,16 & 339,27 & 50,81 & 51,89 & 339,27 \\
\hline Lissotriton boscai & 29SPD12 & 100,00 & 166,36 & 100,31 & 39,03 & 5282,65 & 316,66 & 63,77 & 252,89 & 110,21 & 234,10 & 237,65 & \begin{tabular}{ll|l}
102,66 \\
\end{tabular} & \begin{tabular}{|c|c|}
666,77 \\
\end{tabular} & 92,14 & 5,00 & 55,42 & \begin{tabular}{|l|l|}
268,94 \\
\end{tabular} & 39,34 & 40,14 & 268,71 \\
\hline Lissotriton boscai & 29SPD13 & 100,00 & 165,32 & 99,37 & 38,84 & 5312,71 & 315,68 & 63,01 & 252,67 & \begin{tabular}{l|l}
107,43 \\
\end{tabular} & 233,46 & 237,16 & \begin{tabular}{|l|l|}
101,29 \\
\end{tabular} & 694,89 & 96,87 & 5,21 & 55,44 & \begin{tabular}{|l|}
280,93 \\
\end{tabular} & 41,01 & 42,06 & 280,87 \\
\hline Lissotriton boscai & 29SPD14 & 101,00 & 165,21 & 98,75 & \begin{tabular}{l|l|}
38,55 \\
\end{tabular} & 5330,92 & 315,60 & 62,83 & 252,77 & \begin{tabular}{l|l|l|l|l|}
106,32 \\
\end{tabular} & 233,90 & 237,29 & \begin{tabular}{l|l|}
101,11 \\
\end{tabular} & \begin{tabular}{ll|}
714,56 \\
\end{tabular} & 100,17 & 5,54 & 55,2 & 289,08 & 42,56 & 43,73 & 289,07 \\
\hline Lissotriton boscai & 29SPD15 & 99,00 & 162,46 & 97,29 & 38,02 & 5371,46 & 312,91 & \begin{tabular}{|c|}
60,64 \\
\end{tabular} & 252,27 & 98,53 & 231,79 & 235,15 & $\begin{array}{ll}97,96 \\
\end{array}$ & 757,44 & 107,32 & 5,99 & \begin{tabular}{|l|l|}
55,27 \\
\end{tabular} & 307,57 & 45,20 & 46,33 & 307,57 \\
\hline Lissotriton boscai & 29SPD17 & 100,00 & 162,40 & 97,18 & 37,83 & 5441,73 & 313,80 & 59,03 & 254,77 & 97,30 & 232,95 & 235,84 & 96,87 & 787,81 & 112,55 & 6,00 & 55,10 & \begin{tabular}{l|l|}
319,82 \\
\end{tabular} & 47,48 & 48,64 & 319,82 \\
\hline Lissotriton boscai & 29SPD18 & 100,00 & 165,73 & 98,61 & 37,78 & 5466,37 & 317,80 & 60,42 & 257,38 & 102,76 & 236,73 & 238,93 & 99,37 & 766,83 & \begin{tabular}{|l|l|}
109,26 \\
\end{tabular} & 6,00 & 55,04 & 310,27 & \begin{tabular}{|l|l|}
46,09 \\
\end{tabular} & 47,75 & 310,24 \\
\hline Lissotriton boscai & 29SPD19 & 100,00 & 163,73 & 98,30 & 37,49 & 5511,66 & \begin{tabular}{|l|l}
316,45 \\
\end{tabular} & 57,86 & 258,59 & 99,38 & 235,47 & 237,44 & 96,75 & 798,04 & 114,38 & 6,44 & 54,99 & 322,98 & 48,53 & \begin{tabular}{l|l}
49,92 \\
\end{tabular} & 322,95 \\
\hline Lissotriton boscai & 29SPD24 & 100,00 & 163,64 & 99,38 & 38,08 & 5448,06 & 316,78 & 60,27 & 256,51 & 106,05 & 234,11 & 237,44 & 98,4 & $\begin{array}{ll}720,95 \\
\end{array}$ & \begin{tabular}{|l|}
100,47 \\
\end{tabular} & 5,90 & 54,74 & 290,40 & 43,93 & 45,10 & 290,08 \\
\hline Lissotriton boscai & 29 SPD25 & 101,00 & 160,69 & 97,33 & \begin{tabular}{ll|}
37,76 \\
\end{tabular} & 5474,17 & 313,32 & 58,49 & 254,84 & $\begin{array}{l}98,78 \\
\end{array}$ & 231,64 & 235,06 & 95,46 & 766,08 & 108,18 & 6,11 & 55,04 & 309,96 & 46,21 & 47,49 & 309,96 \\
\hline Lissotriton boscai & 29SPD26 & 101,00 & 160,01 & 96,71 & 37,40 & 5512,44 & 312,78 & 57,41 & 255,37 & 95,55 & \begin{tabular}{l|l|}
231,52 \\
\end{tabular} & 234,88 & 94,22 & 787,61 & 111,94 & 6,14 & \begin{tabular}{l|l|}
55,06 \\
\end{tabular} & \begin{tabular}{|l|l|}
319,04 \\
\end{tabular} & 47,62 & \begin{tabular}{ll|}
48,89 \\
\end{tabular} & 319,04 \\
\hline Lissotriton boscai & 29SPD27 & 100,00 & $\begin{array}{l}161,47 \\
\end{array}$ & 97,40 & 37,06 & 5567,78 & 315,33 & 57,12 & 258,21 & \begin{tabular}{l|l}
98,03 \\
\end{tabular} & 233,97 & 236,64 & 94,68 & 784,94 & 111,68 & 6,06 & \begin{tabular}{|l|l|}
54,87 \\
\end{tabular} & 317,36 & 47,71 & 48,92 & 317,33 \\
\hline Lissotriton boscai & 29SPD28 & 101,00 & 163,53 & 98,34 & 37,12 & 5619,06 & 318,43 & 57,26 & 261,16 & 101,12 & 236,92 & 238,95 & $95,64[$ & $774,94[$ & 110,22 & 5,99 & 54,79 & 312,52 & 47,14 & 48,58 & 312,37 \\
\hline Lissotriton boscai & 29SPD29 & 101,00 & 165,74 & 99,41 & 37,31 & 5638,23 & 320,90 & 57,92 & 262,98 & \begin{tabular}{ll|}
103,96 \\
\end{tabular} & 239,38 & 240,89 & \begin{tabular}{ll|}
97,06 \\
\end{tabular} & 762,84 & 108,38 & 5,99 & 54,66 & 306,90 & \begin{tabular}{ll|}
46,46 \\
\end{tabular} & 48,16 & 306,55 \\
\hline Lissotriton boscai & 29SPD30 & 100,00 & 161,50 & 105,37 & 39,15 & 5515,50 & 318,91 & 54,19 & 264,71 & 103,47 & 232,66 & 236,00 & 95,16 & 649,40 & 87,17 & 5,00 & 54,22 & 259,03 & 39,70 & 40,00 & 256,64 \\
\hline Lissotriton boscai & 29SPD31 & 101,00 & 164,08 & 105,16 & 39,06 & 5516,52 & 321,40 & 56,66 & 264,73 & \begin{tabular}{|l|l|}
105,84 \\
\end{tabular} & 235,25 & 238,34 & 97,68 & \begin{tabular}{ll|}
647,09 \\
\end{tabular} & 86,94 & 5,00 & 54,20 & 258,42 & \begin{tabular}{l|l|}
39,55 \\
\end{tabular} & 40,13 & 255,93 \\
\hline Lissotriton boscai & 29SPD33 & 100,00 & 162,66 & 101,92 & 38,40 & 5533,15 & 318,94 & 57,36 & 261,57 & 104,52 & 234,36 & 237,56 & 96,38 & $\begin{array}{l}699,47 \\
\end{array}$ & 95,88 & 5,75 & 54,18 & 280,39 & 43,21 & 44,24 & 278,84 \\
\hline Lissotriton boscai & 29SPD34 & 101,00 & 160,24 & 99,30 & 37,85| & 5550,93] & 315,39 & 56,72 & $258,67 \mid$ & 102,24 & 232,29 & 235,74 & $94,27 \mid$ & 740,95 & 103,04 & 6,14 & 54,40| & 298,01 & $45,47 \mid$ & 46,65 & 297,21 \\
\hline Lissotriton boscai & 29SPD35 & 100,00 & 150,96 & 93,90 & 36,71 & 5549,48 & 303,30 & 51,48 & 251,82 & 87,76 & 223,30 & 227,27 & 86,22 & 847,69 & 120,82 & 7,24 & 54,84 & 343,56 & 52,06 & 53,06 & 343,56 \\
\hline Lissotriton boscai & 29SPD36 & 101,00 & 153,98 & 94,90 & 36,77 & 5604,19 & 307,60 & 52,43 & 255,18 & $\begin{array}{l}91,66 \\
\end{array}$ & 227,18 & 230,49 & \begin{tabular}{l|l}
87,92 \\
\end{tabular} & 831,12 & 118,49 & 6,95 & 54,64 & $\begin{array}{l}36,25 \\
\end{array}$ & 51,13 & 52,08 & 336,14 \\
\hline Lissotriton boscai & 29SPD37 & 100,00 & 162,36 & 98,66 & 37,05 & 5674,95 & \begin{tabular}{|l|l|}
318,45 \\
\end{tabular} & 56,13 & 262,32 & 101,76 & \begin{tabular}{|l|l|}
236,42 \\
\end{tabular} & 238,79 & 94,20 & \begin{tabular}{ll|}
758,86 \\
\end{tabular} & 106,97 & 5,99 & 54,36 & 305,26 & \begin{tabular}{l|l}
46,45 \\
\end{tabular} & 47,80 & 304,45 \\
\hline Lissotriton boscai & 29SPD38 & 101,00 & 162,82 & 98,87 & 36,98 & 5732,46 & 319,80 & 55,39 & 264,41 & \begin{tabular}{|l|l|l|l|}
1019 \\
\end{tabular} & 237,89 & 239,77 & $\begin{array}{l}93,75 \\
\end{array}$ & 761,73 & 107,66 & 5,93 & 54,35 & \begin{tabular}{|l|}
305,98 \\
\end{tabular} & 46,83 & 48,18 & 305,15 \\
\hline Lissotriton boscai & 29SPD39 & 101,00 & 163,06 & 99,01 & 36,69 & 5777,13 & 320,64 & 54,43 & 266,21 & 100,55 & 238,81 & 240,35 & 93,17 & 767,51 & 108,81 & 5,99 & \begin{tabular}{l|l}
54,15 \\
\end{tabular} & 307,94 & 47,38 & 48,78 & 307,06 \\
\hline Lissotriton boscai & 29SPD40 & 100,00 & 160,85 & 107,88 & 39,32 & 5634,39 & 321,61 & 50,65 & 270,96 & \begin{tabular}{|l|l|}
101,18 \\
\end{tabular} & 233,86 & 236,68 & \begin{tabular}{|l|l|}
93,03 \\
\end{tabular} & \begin{tabular}{|l|l|}
641,53 \\
\end{tabular} & 85,81 & 5,19 & 53,71 & 254,70 & 40,13 & 40,43 & 250,73 \\
\hline Lissotriton boscai & 29SPD43 & 99,00 & 163,16 & 104,89 & \begin{tabular}{|l|}
38,67 \\
\end{tabular} & 5647,58 & 323,13 & 54,71 & \begin{tabular}{|l|l|}
268,42 \\
\end{tabular} & \begin{tabular}{|l|l|}
103,38 \\
\end{tabular} & \begin{tabular}{|l|l|}
236,58 \\
\end{tabular} & 239,30 & \begin{tabular}{ll|}
95,26 \\
\end{tabular} & \begin{tabular}{|l|l|}
675,98 \\
\end{tabular} & 91,26 & 5,35 & \begin{tabular}{|l|l|}
53,69 \\
\end{tabular} & \begin{tabular}{|l|l|}
269,65 \\
\end{tabular} & \begin{tabular}{l|l}
42,25 \\
\end{tabular} & 43,30 & 266,46 \\
\hline Lissotriton boscai & 29SPD44 & 101,00 & 155,18 & 99,28 & 37,57 & 5640,11 & 312,16 & 51,31 & 260,85 & 96,60 & \begin{tabular}{|l|l|}
228,72 \\
\end{tabular} & 232,15 & 88,58 & \begin{tabular}{|l|}
767,07 \\
\end{tabular} & $\begin{array}{ll}106,42 \\
\end{array}$ & 6,42 & 54,01 & 307,69 & 47,74 & 48,74 & 306,19 \\
\hline Lissotriton boscai & 29SPD45 & 99,00 & 145,56 & 94,44 & 36,50 & 5659,10 & 300,09 & 44,74 & 255,35 & 86,12 & 220,27 & 223,39 & 79,6 & 866,89 & 122,89 & 7,64 & 54,20 & 348,96 & 54,20 & 54,73 & 348,51 \\
\hline Lissotriton boscai & 29SPD46 & 100,00 & 156,64 & 97,92 & 36,98 & 5715,55 & 313,60 & 51,85 & 261,75 & 96,79 & 231,46 & 234 & 88,8 & 779,71 & 109,38 & 6,38 & \begin{tabular}{l|l}
54,05 \\
\end{tabular} & 313,09 & 8,41 & 9,55 & 311,72 \\
\hline Lissotriton boscai & \begin{tabular}{|l|}
$29 S P D 47$ \\
\end{tabular} & 100,00 & 161,78 & 99,90 & 37,00 & 5777,09 & 320,23 & 53,95 & 266,28 & 100,13 & 237,49 & 239,55 & 92,44 & 738,82 & 103,05 & 5,96 & 53,79 & 295,82 & 45,84 & 47,24 & 293,69 \\
\hline Lissotriton boscai & 29SPD48 & 100,00 & 163,51 & 100,30 & 37,01 & 5812,85 & 322,29 & 54,38 & 267,91 & $\begin{array}{ll}100,95 \\
\end{array}$ & 239,86 & 241,48 & 93,3 & 729,76 & 101,92 & 5,83 & 53,78 & \begin{tabular}{l|l|}
291,85 \\
\end{tabular} & 45,22 & 46,76 & 289,49 \\
\hline Lissotriton boscai & 29SPD49 & 99,00 & 164,02 & 100,39 & \begin{tabular}{ll|}
36,89 \\
\end{tabular} & 5853,23 & 323,01 & 53,88 & 269,13 & \begin{tabular}{ll|}
100,56 \\
\end{tabular} & 240,91 & 242,15 & \begin{tabular}{|c|}
93,07 \\
\end{tabular} & 730,46 & 102,34 & 5,78 & 53,71 & \begin{tabular}{|l|l|}
291,92 \\
\end{tabular} & \begin{tabular}{l|l|l}
45,35 \\
\end{tabular} & 46,81 & 289,43 \\
\hline Lissotriton boscai & 29SPD52 & 101,00 & 166,26 & 111,13 & \begin{tabular}{l|l}
39,15 \\
\end{tabular} & 5767,16 & 331,38 & 51,92 & 279,45 & 104,00 & 241,34 & 243,14 & $\begin{array}{ll}96,06 \\
\end{array}$ & 610,44 & 82,21 & 4,99 & 52,86 & 241,30 & 38,96 & 39,79 & 235,35 \\
\hline Lissotriton boscai & 29SPD53 & 101,00 & 162,51 & 107,88 & 38,71 & 768,06 & 326,25 & 50,8 & 275,37 & \begin{tabular}{|l|l|}
100,99 \\
\end{tabular} & 237,82 & 239, & 92, & \begin{tabular}{ll|}
656,75 \\
\end{tabular} & 87,85 & 5,19 & 52,5 & 260,40 & 1,79 & 2,66 & 255,47 \\
\hline Lissotriton boscai & 29SPD54 & 100,00 & 15 & 10 & 37,96 & 5772,25 & 3 & 50,21 & 271,00 & \begin{tabular}{l|l|}
98,48 \\
\end{tabular} & 235,00 & 237,44 & 90, & 698,68 & 94,38 & 5,69 & 53, & \begin{tabular}{|l|l|}
277,95 \\
\end{tabular} & 44,20 & 45,22 & 273,87 \\
\hline Lissotriton boscai & 29SPD55 & 101,00 & 155,24 & 100,88 & 37,30 & 5793,53 & 315,14 & 48,08 & 267,07 & 94,52 & 231,21 & 233,80 & 86,4 & 749,56 & \begin{tabular}{l|l|}
103,06 \\
\end{tabular} & 6,22 & 53,30 & 298,95 & \begin{tabular}{l|l}
47,35 \\
\end{tabular} & 48,26 & 295,74 \\
\hline Lissotriton boscai & 29SPD56 & 101,00 & 157,86 & 100,85 & 37,00 & 5829,21 & 317,95 & \begin{tabular}{ll|}
49,67 \\
\end{tabular} & 268,29 & \begin{tabular}{|c|}
96,27 \\
\end{tabular} & 234,37 & 236,51 & 88,25 & 735,80 & \begin{tabular}{ll|}
101,26 \\
\end{tabular} & 6,06 & 53,23 & \begin{tabular}{|l|l|}
293,24 \\
\end{tabular} & 46,52 & 47,58 & 289,84 \\
\hline Lissotriton boscai & 29SPD58 & 101,00 & 160,07 & 100,45 & 36,76 & 5897,48 & 320,11 & 50,25 & 269,86 & 96,85 [ & 237,75 & 239,16 & 89,13 & $729,97 \mid$ & 101,25 & 5,89 & 53,19 & 290,69 & 45,96 & 47,07 & 287,24 \\
\hline Lissotriton boscai & 29SPD59 & 101,00 & 163,90 & 101,51 & 36,84 & 5918,49 & 324 & 52,29 & 271,77 & \begin{tabular}{|l|}
99,59 \\
\end{tabular} & 241,73 & 242,68 & 92,0 & 700,88 & 96,96 & 5,47 & 53,10 & 278,58 & 3,96 & \begin{tabular}{l|l|}
45,45 \\
\end{tabular} & 274,74 \\
\hline Lissotriton boscai & 29SPD60 & 100,00 & 168,81 & 115,08 & 39,66 & 5867,40 & 337 & 49,50 & 287,52 & 104,80 & 245,21 & 246,19 & 96,5 & 544,56 & 75,00 & 4,03 & 52,36 & 213,40 & \begin{tabular}{l|l}
35,45 \\
\end{tabular} & 35,99 & 204,68 \\
\hline Lissotriton boscai & 29SPD63 & 99,00 & 165,28 & 111,71 & 39,01 & 5881,51 & 332,24 & 49,14 & 283,10 & 101,48 & 242,15 & $\begin{array}{l}243,45 \\
\end{array}$ & 93,61 & 608,40 & 81,64 & 4,91 & 52,16 & 239,24 & 39,44 & \begin{tabular}{l|l}
40,35 \\
\end{tabular} & 232,05 \\
\hline Lissotriton boscai & 29SPD65 & 99,00 & 159,07 & 105,07 & 37,66 & 5905,09 & 322,77 & 47,30 & 275,47 & 96,15 & 236,66 & 238,35 & 88,16 & 682,61 & 91,35 & 5,51 & 52,42 & 269,79 & 3,77 & 44,68 & 264,17 \\
\hline Lissotriton boscai & 29SPD66 & 100,00 & 155,77 & 102,29 & 36,99 & 5927,89 & 318 & 45, & 272,7 & 92, & 233,73 & 235,56 & 84 & 719,31 & 97,68 & 5,9 & 52 & 284,73 & 46, & 47,04 & \\
\hline Lissotriton boscai & 29SPD67 & 100,00 & 160,17 & 102,90 & 37,00 & 5953, & 322 & 48, & 274, & 96 , & 238,64 & 239,99 & 88,, & 689,63 & 93,57 & 5,52 & 52 , & 272,83 & $43,92[$ & 45,00 & 267 \\
\hline Lissotriton boscai & 29SPD68 & 100,00 & 162,31 & 102,78 & 37,01 & 5974,32 & 324,56 & 49,86 & \begin{tabular}{|l|l|}
274,70 \\
\end{tabular} & \begin{tabular}{|c|}
97,69 \\
\end{tabular} & \begin{tabular}{|l|l|}
240,99 \\
\end{tabular} & 242,01 & 89,96 & \begin{tabular}{|c|c|}
677,68 \\
\end{tabular} & 92,17 & 5,34 & 52,48 & 267,94 & 43,03 & 44,25 & 262,65 \\
\hline Lissotriton boscai & 29SPD69 & 99,00 & 163,36 & 102,63 & 36,88 & 5985,69 & 325,23 & 50,46 & 274,77 & 98,32 & 242,23 & 242,91 & 90,58 & 672,44 & 91,76 & 5,20 & 52,53 & 265,70 & 42,64 & 44,03 & 260,42 \\
\hline Lissotriton boscai & 29SPD72 & 101,00 & 167,95 & 115,53 & 39,09 & 5969,52 & 338,12 & \begin{tabular}{|l|l|}
47,37 \\
\end{tabular} & 290,75 & 102,45 & \begin{tabular}{|l|l|}
245,99 \\
\end{tabular} & 246,49 & 94,50 & 549,09 & 74,84 & 4,03 & 51,63 & 214,01 & 6,08 & 36,81 & 204,42 \\
\hline Lissotrito & $29 \mathrm{SPD}$ & & 16 & & 38,83 & & & 46, & 287, & 99, & 9 & & & 586 & 78 & 4,75 & 51,5 & 4 & & 36 & \\
\hline Lissotriton boscai & 29SPD74 & 101,00 & 160,95 & 109,50 & 38,06 & 5989,2 & 328,78 & \begin{tabular}{|l|l|}
45,17 \\
\end{tabular} & \begin{tabular}{|l|l|}
283,62 \\
\end{tabular} & 96,34 & 239,74 & 240,8 & 88,44 & 626,49 & 83,05 & 5,03 & 51,66 & 245,22 & 40,97 & 41,77 & 237,36 \\
\hline Lissotriton boscai & 29SPD75 & 100,00 & 160,41 & 107,47 & 37,79 & $\begin{array}{ll}6004,66 \\
\end{array}$ & 327,26 & \begin{tabular}{|l|l|}
45,64 \\
\end{tabular} & 281,61 & 95,76 & 239,45 & 240,56 & 87,78 & 640,06 & 84,48 & 5,02 & 51,79 & 250,86 & 41,51 & 42,46 & 243,36 \\
\hline
\end{tabular}




\begin{tabular}{|c|c|c|c|c|c|c|c|c|c|c|c|c|c|c|c|c|c|c|c|c|c|}
\hline TAXON & UTM & $\mathrm{km} 2$ & BIO1 & BIO2 & $B 103$ & BIO4 & B105 & B106 & B107 & B108 & B109 & B1010 & BIO11 & B1012 & BIO13 & B1014 & BIO15 & B1016 & B1017 & B1018 & 81019 \\
\hline Lissotriton boscai & 29SPD78 & 101,00 & 163,18 & 104,46 & 36,98 & 6042,43 & 327,73 & 48,82 & 278,91 & 97,58 & 242,86 & 243,48 & 89,67 & 638,86 & 85,31 & 4,99 & 51,72 & 250,58 & 41,22 & 42,48 & 243,70 \\
\hline Lissotriton boscai & 29SPD83 & 100,00 & 164,86 & 113,41 & 38,41 & 6057,41 & 336,19 & 44,88 & 291,31 & 98,84 & 244,34 & 244,99 & 90,78 & 559,73 & 75,01 & 4,28 & 51,20 & 216,95 & 36,56 & 37,66 & 206,87 \\
\hline Lissotriton boscai & 29SPD86 & 100,00 & 160,82 & 107,20 & 37,01 & 6100,64 & 329,33 & $\begin{array}{ll}44,68 \\
\end{array}$ & 284,66 & 94,91 & 241,38 & 242,02 & 86,92 & $\begin{array}{l}614,69 \\
\end{array}$ & 80,48 & 4,97 & 51,01 & 238,84 & 40,42 & 41,25 & 230,18 \\
\hline Lissotriton boscai & 29SPD89 & 100,00 & 160,42 & $\begin{array}{l}104,07 \\
\end{array}$ & 36,61 & 6124,59 & 326,65 & 45,32 & 281,34 & 93,82 & 241,47 & 241,73 & 86,14 & $\begin{array}{l}627,26 \\
\end{array}$ & 83,17 & 5,00 & 51,11 & 244,16 & \begin{tabular}{|l|l|}
41,07 \\
\end{tabular} & 41,74 & 236,20 \\
\hline Lissotriton boscai & 29SPD96 & 101,00 & 160,82 & 107,91 & 36,97 | & 6178,85 & 331,39 & 43,34 & 288,05 & 93,88 & 242,63 & 242,93 & 85,88 & 586,53 & 76,25 & 4,64 & 50,48 & 226,01 & 38,76 & 39,28 & 216,13 \\
\hline Lissotriton boscai & 29SPD99 & 100,00 & 158,30 & 104,49 & 36,06 & 6195,90 & 326,29 & 42,27 & 284,01 & 90,98 & 240,64 & 240,69 & 83,27 & 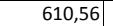 & 79,83 & 5,00 & 50,47 & 235,55 & \begin{tabular}{|l|l|}
40,64 \\
\end{tabular} & \begin{tabular}{|l|l|}
40,75 \\
\end{tabular} & 226,44 \\
\hline Lissotriton boscai & 29SPE00 & 100,00 & 156,61 & 96,31 & 37,36 & 5412,16 & 306,87 & 52,65 & 254,22 & 91,06 & 227,34 & 229,15 & 91,06 & 892,60 & 129,81 & 7,50 & 55,12 & 363,46 & 55,07 & 55,67 & 363,46 \\
\hline Lissotriton boscai & 29SPE01 & 101,00 & 148,83 & 94,02 & 36,76 & 5429,34 & 298,03 & 45,95 & 252,07 & 83,36 & 220,92 & 221,77 & 83,36 & $\begin{array}{l}983,23 \\
\end{array}$ & 144,85 & 8,69 & 55,36 & 401,42 & 60,77 & 60,98 & 401,42 \\
\hline Lissotriton boscai & 29SPE02 & 101,00 & 138,63 & 90,45 & 36,04 & 5409,04 & 285,24 & \begin{tabular}{|l|l|}
37,94 \\
\end{tabular} & 247,30 & 73,95 & 211,46 & 211,53 & 73,95 & $\begin{array}{l}1097,44 \\
\end{array}$ & \begin{tabular}{|l|l|}
163,97 \\
\end{tabular} & 10,08 & 55,76 & \begin{tabular}{ll|}
449,22 \\
\end{tabular} & 67,41 & 67,41 & 449,22 \\
\hline Lissotriton boscai & 29SPE10 & 100,00 & 159,18 & 97,18 & \begin{tabular}{l|l|}
36,95 \\
\end{tabular} & 5576,36 & 312,60 & 53,12 & 259,48 & 91,49 & 232,06 & 233,77 & 91,49 & 854,46 & 123,62 & 6,97 & 54,95 & 346,49 & 52,60 & 53,47 & 346,49 \\
\hline Lissotriton boscai & 29SPE11 & 101,00 & 157,91 & 97,35 & 36,95 & 5583,85 & 311,32 & 51,39 & 259,93 & 90,01 & 231,04 & 232,51 & 90,01 & 875,06 & 127,01 & 7,26 & 54,90 & \begin{tabular}{|l|l|}
354,47 \\
\end{tabular} & 54,36 & 55,11 & 354,47 \\
\hline Lissotriton boscai & 29SPE12 & 100,00 & 151,78 & 95,52 & 36,56 & 5580,80 & 303,98 & 46,12 & 257,86 & 84,14 & 225,44 & 226,36 & 84,14 & \begin{tabular}{|l|l|}
943,37 \\
\end{tabular} & 138,41 & 8,12 & 55,08 & \begin{tabular}{|l|l|}
383,08 \\
\end{tabular} & 58,69 & $\begin{array}{ll}59,05 \\
\end{array}$ & 383,08 \\
\hline Lissotriton boscai & 29SPE20 & 100,00 & 159,02 & 97,11 & 36,27 & 5736,83 & 315,15 & 51,62 & 263,53 & 91,49 & 234,44 & 235,76 & 89,70 & 838,95 & 120,98 & 6,83 & 54,74 & 338,78 & 51,89 & 52,70 & 338,73 \\
\hline Lissotriton boscai & 29SPE21 & 100,00 & 157,59 & 97,04 & 36,15 | & $5765,61 \mid$ & 313,94 & 49,60 & 264,34 & 88,08 & 233,56 & 234,55 & 87,85 & 858,44 & 124,23 & 7,02 & 54,74 & 346,39 & 53,52 & 54,15 & 346,39 \\
\hline Lissotriton boscai & 29SPE22 & 100,00 & 153,76 & 96,17 & 36,13 & 5741,76 & 308,91 & 46,21 & 262,70 & 84,23 & 229,40 & 230,39 & 84,23 & $\begin{array}{l}900,23 \\
\end{array}$ & \begin{tabular}{ll|}
131,32 \\
\end{tabular} & 7,73 & 54,81 & 363,70 & 56,48 & 56,78 & 363,70 \\
\hline Lissotriton boscai & 29SPE30 & 100,00 & 165,01 & 99,91 & $\begin{array}{l}36,85 \\
\end{array}$ & \begin{tabular}{|l|}
5785,91 \\
\end{tabular} & 322,58 & 55,11 & 267,47 & $\begin{array}{ll}101,66 \\
\end{array}$ & 240,95 & 241,99 & 94,62 & \begin{tabular}{|l|l|}
754,97 \\
\end{tabular} & \begin{tabular}{|l|l|}
106,97 \\
\end{tabular} & 6,00 & 54,14 & 302,59 & 46,47 & 48,13 & 301,33 \\
\hline Lissotriton boscai & 29SPE31 & 101,00 & 157,49 & 97,29 & 36,01 & 5870,90 & 315,45 & 48,45 & 267,00 & $\begin{array}{l}91,57 \\
\end{array}$ & 234,94 & 235,83 & 86,60 & 833,36 & 120,00 & 6,90 & 54,25 & \begin{tabular}{|l|l|}
334,68 \\
\end{tabular} & 52,14 & 52,80 & 334,45 \\
\hline Lissotriton boscai & 29SPE32 & 100,00 & 155,12 & \begin{tabular}{|c|c|}
96,91 \\
\end{tabular} & 36,01 & 5844,35 & 312,09 & 46,21 & 265,88 & 88,22 & 232,29 & 232,95 & 84,38 & 856,54 & \begin{tabular}{|l|l|}
123,96 \\
\end{tabular} & 7,15 & 54,26 & 343,94 & 53,86 & 54,35 & 343,80 \\
\hline |Lissotriton boscai & 29SPE40 & 101,00 & 164,31 & 100,45 & 36,85 [ & $5868,35[$ & 323,23 & 53,36 & 269,86 & 100,41 & 241,48 & 242,36 & 92,96 & 733,33 & 103,07 & 5,98 & 53,64 & 292,77 & 45,60 & 47,25 & 290,38 \\
\hline Lissotriton boscai & 29SPE41 & 100,00 & 163,53 & 100,25 & 36,75 & 5876,42 & 322,10 & 52,19 & 269,90 & 99,20 & 240,77 & 241,49 & 91,83 & 744,16 & 105,12 & 6,05 & 53,53 & 296,93 & 46,41 & 48,04 & 294,75 \\
\hline Lissotriton boscai & 29SPE42 & 99,00 & 156,54 & 97,94 & 36,04 & 5903,14 & 314,45 & 46,30 & 268,15 & 92,15 & 234,38 & 234,94 & 84,72 & 808,24 & $\begin{array}{l}115,72 \\
\end{array}$ & 6,78 & 53,88 & 322,90 & 50,98 & 51,71 & 321,60 \\
\hline Lissotriton boscai & 29SPE51 & 101,00 & 162,83 & 100,88 & 36,68 & 5941,95 & 322,45 & 50,59 & 271,86 & 97,88 & 241,23 & 241,63 & 90,42 & \begin{tabular}{|l|l|}
716,97 \\
\end{tabular} & 100,21 & 5,86 & 53,12 & 284,78 & 45,20 & 46,64 & 281,24 \\
\hline Lissotriton boscai & 29SPE52 & 101,00 & 157,55 & 99,13 & 36,10 & 5958,68 & 316,43 & 46,10 & 270,33 & 92,54 & 236,26 & 236,52 & 84,95 & 761,84 & $|107,67|$ & 6,19 & 53,17 & 302,85 & \begin{tabular}{|l|l|}
48,50 \\
\end{tabular} & \begin{tabular}{|l|l|}
49,19 \\
\end{tabular} & 300,00 \\
\hline |Lissotriton boscai & 29SPE61 & 99,00 & 159,52 & 100,65 & 36,13 & 6011,88 & 320,19 & 46,94 & 273,24 & 94,04 & 238,99 & 239,26 & 86,33 & 709,88 & 98,39 & 5,94 & 52,45 & 280,56 & 45,79 & 46,52 & 275,97 \\
\hline 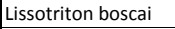 & 29SPE62 & 100,00 & 155,44 & 99,42 & 36,04 & 6016,15 & 315,34 & 43,59 & 271,75 & 90,01 & 235,19 & 235,31 & 82,29 & 739,68 & 103,40 & 6,29 & 52,52 & 292,50 & 48,01 & 48,30 & 288,25 \\
\hline Lissotriton boscai & 29SPE70 & 101,00 & 160,68 & 102,50 & 36,39 & 6061,68 & 323,93 & 46,84 & 277,09 & 94,72 & 240,89 & 241,08 & 86,94 & 661,91 & 89,78 & 5,25 & 51,91 & 259,85 & 42,67 & 43,48 & 253,48 \\
\hline Lissotriton boscai & 29SPE71 & 100,00 & 159,82 & 101,92 & $\begin{array}{l}36,35 \\
\end{array}$ & 6065,58 & 322,31 & 45,97 & 276,34 & 93,66 & 240,05 & 240,17 & 85,82 & $\begin{array}{l}670,65 \\
\end{array}$ & 91,49 & 5,45 & 51,84 & 263,29 & 43,56 & $\begin{array}{l}44,06 \\
\end{array}$ & 257,20 \\
\hline Lissotriton boscai & 29SPE80 & 100,00 & 161,60 & 103,86 & 36,56 & 6119,63 & 326,96 & 46,28 & 280,68 & $\begin{array}{l}94,92 \\
\end{array}$ & 242,58 & 242,65 & 87,03 & $\begin{array}{l}621,49 \\
\end{array}$ & 82,74 & 5,02 & 51,02 & 241,96 & 40,81 & $\begin{array}{l}41,16 \\
\end{array}$ & 234,20 \\
\hline Lissotriton boscai & 29SPE81 & 100,00 & 160,04 & 103,15 & \begin{tabular}{ll|}
36,37 \\
\end{tabular} & 6120,16 & 324,52 & 44,95 & 279,57 & 93,18 & 240,99 & 241,01 & 85,30 & \begin{tabular}{|c|}
632,97 \\
\end{tabular} & 84,87 & 5,11 & 51,11 & 246,61 & 41,57 & 41,67 & 239,18 \\
\hline Lissotriton boscai & 29SPE82 & 100,00 & 156,19 & 101,95 & 36,03 & \begin{tabular}{|l|}
6125,07 \\
\end{tabular} & 319,99 & \begin{tabular}{|l|l|}
41,74 \\
\end{tabular} & 278,25 & 89,41 & 237,48 & 237,48 & 81,48 & $\begin{array}{l}657,45 \\
\end{array}$ & 88,73 & 5,76 & 50,90 & 256,01 & $\begin{array}{l}44,06 \\
\end{array}$ & 44,06 & 248,87 \\
\hline Lissotriton boscai & 29SQA29 & 85,00 & 178,83 & 87,79 & 37,13 & 5027,68 & 304,23 & 72,22 & 232,02 & 143,22 & 241,99 & 245,02 & 116,11 & $\begin{array}{l}528,25 \\
\end{array}$ & 81,26 & 1,00 & 64,74 & 230,03 & 14,15 & 22,00 & 210,30 \\
\hline Lissotriton boscai & 2950A39 & 100,00 & 178,93 & 88,43 & 37,01 & 5120,94 & 306,79 & 71,23 & 235,55 & 143,96 & 243,43 & 246,48 & 115,26 & 540,45 & 82,58 & 1,00 & 64,61 & 233,88 & \begin{tabular}{|l|l|l|}
14,96 \\
\end{tabular} & 22,00 & 214,68 \\
\hline Lissotriton boscai & 29SQB00 & 46,00 & 176,74 & 85,34 & 37,00 & 5008,82 & 299,92 & 71,94 & 227,98 & 123,20 & 239,08 & 242,08 & 114,04 & 511,26 & 79,3 & 1,00 & 64,36 & 221,58 & 14,00 & 23,00 & 200,42 \\
\hline Lissotriton boscai & 29SQB01 & 100,00 & 177,03 & 85,80 & 36,91 & 5086,65 & 301,93 & 71,36 & 230,57 & 128,89 & 240,26 & 243,19 & 113,39 & 505,93 & 78,73 & 1,00 & 63,83 & 218,10 & 14,01 & 23,13 & 196,75 \\
\hline Lissotriton boscai & 29SQB02 & 100,00 & 175,71 & 87,83 & \begin{tabular}{|l|}
36,78 \\
\end{tabular} & 5211,77 & \begin{tabular}{|l|l|}
304,69 \\
\end{tabular} & 68,22 & 236,47 & \begin{tabular}{ll|}
121,68 \\
\end{tabular} & 240,67 & 243,42 & 110,32 & 511,72 & 79,20 & 1,00 & 63,09 & 218,53 & 14,72 & 23,99 & $\begin{array}{l}197,38 \\
1\end{array}$ \\
\hline Lissotriton boscai & 29SQB03 & 100,00 & 176,62 & 90,04 & 36,92 & \begin{tabular}{|l|}
5313,06 \\
\end{tabular} & 309,19 & $\begin{array}{ll}67,62 \\
\end{array}$ & 241,57 & 130,20 & 243,06 & 245,67 & 110,08 & $\begin{array}{l}505,56 \\
\end{array}$ & 78,12 & 1,00 & 62,66 & 214,59 & 15,01 & 23,97 & 193,80 \\
\hline Lissotriton boscai & 29SQB04 & 100,00 & 175,53 & 93,32 & 37,02 & 5425,44 & 312,93 & 64,53 & 248,41 & 120,14 & 243,71 & 246,19 & $\begin{array}{l}107,63 \\
\end{array}$ & $\begin{array}{l}511,63 \\
\end{array}$ & 78,33 & 1,29 & 61,96 & 215,68 & 16,04 & 24,62 & 195,76 \\
\hline |Lissotriton boscai & 295QB06 & 101,00 & 165,53 & 101,65 & $37,97 \mid$ & 5683,37 & 315,98 & 50,49 & 265,49 & 104,53 & 238,24 & 240,44 & 95,45 & 566,49 & 83, & $2, \mathrm{C}-\mathrm{l}$ & 59,96 & 234,53 & 21,17 & 28,32 & 217,67 \\
\hline Lissotriton boscai & 29SQB07 & 100,00 & 164,82 & 104,21 & 38,00 & 5762,46 & 319,25 & 48,34 & 270,91 & 102,79 & 238,75 & 240,87 & 93,82 & 569,38 & $2, I I$ & 2,29 & 59,36 & 234,26 & 22,28 & 28,82 & 218,29 \\
\hline Lissotriton boscai & 29SQB08 & 100,00 & 163,17 & 106,56 & 38,00 & 5835,67 & 321,68 & 45,53 & 276,15 & 100,43 & 238,34 & 240,40 & 91,52 & 576,80 & 82,82 & 2,68 & 58,52 & 235,69 & 23,96 & 29,93 & 220,70 \\
\hline Lissotriton boscai & 29SQB09 & 101,00 & 149,98 & 109,34 & 38,00 & \begin{tabular}{|l|}
5955,40 \\
\end{tabular} & 315,23 & 31,79 & 283,43 & 86,71 & 227,37 & 229,53 & 77,75 & \begin{tabular}{ll|}
655,52 \\
\end{tabular} & $\begin{array}{l}90,98 \\
\end{array}$ & 3,83 & 57,21 & 264,65 & 30,41 & 35,23 & 252,11 \\
\hline Lissotriton boscai & 29SQB10 & 96,00 & 177,80 & 87,58 & 37,01 & 5066,93 & 303,78 & 71,44 & 232,34 & 130,63 & 241,16 & 244,08 & \begin{tabular}{ll|}
114,66 \\
\end{tabular} & 518,74 & 80,20 & 1,00 & 64,27 & 224,79 & 14,00 & 22,93 & 204,25 \\
\hline |Lissotriton boscai & 29SQB11 & 100,00 & 178,60 & 89,13 & 37,01 & 5175,99 & 307,72 & 70,57 & 237,15 & 130,95 & 243,40 & 246,23 & 113,90 & 513,12 & 79,52 & 1,00 & 63,83 & 220,93 & 14,38 & 23,00 & 200,28 \\
\hline Lissotriton boscai & 29SQB12 & 99,00 & 177,09 & \begin{tabular}{|c|c|}
91,82 \\
\end{tabular} & 37,01 & 5318,58 & 311,16 & 67,03 & 244,13 & 119,89 & 244,00 & 246,56 & 110,55 & 519,52 & 80,10 & 1,00 & 63,16 & 221,75 & $\mid \begin{array}{ll}15,04 \\
\end{array}$ & 23,39 & 201,42 \\
\hline 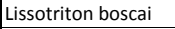 & 29SQB14 & 100,00 & 177,04 & 97,18 & 37,40 & \begin{tabular}{|l|}
5528,40 \\
\end{tabular} & 319,21 & 63,27 & 255,94 & 117,12 & 247,02 & 249,25 & 108,02 & 518,64 & 79,16 & 1,11 & 62,08 & 218,60 & 16,14 & 24,15 & 199,43 \\
\hline Lissotriton boscai & 29SQB15 & 100,00 & 171,39 & 101,11 & \begin{tabular}{l|l|l}
37,85 \\
\end{tabular} & \begin{tabular}{|l|}
5671,57 \\
\end{tabular} & 320,33 & 55,58 & 264,75 & 110,05 & 243,75 & 245,90 & 101,01 & \begin{tabular}{l|l|}
548,55 \\
\end{tabular} & 81,87 & 1,99 & 60,71 & 228,67 & 19,41 & 26,72 & 210,85 \\
\hline Lissotriton boscai & 29SQB16 & 99,00 & 168,83 & 104,02 & 38,00 & 5771,93 & 322,70 & 51,44 & 271,26 & 106,39 & 242,73 & 244,82 & 97,38 & 560,74 & 82,61 & 2,01 & 60,17 & 232,12 & 20,69 & 27,51 & 215,31 \\
\hline Lissotriton boscai & 295QB17 & 101,00 & 163,36 & 107,06 & 38,00 & 5877,79 & 322,84 & 44,57 & 278,27 & 99,97 & 239,10 & 241,08 & 90,98 & 589,06 & 85,03 & 2,50 & 59,22 & 241,64 & 23,35 & 29,53 & 226,20 \\
\hline Lissotriton boscai & 29SQB18 & 100,00 & 159,01 & 109,34 & 38,00 & \begin{tabular}{|l|}
5957,20 \\
\end{tabular} & 322,97 & 39,38 & 283,59 & 95,16 & 236,25 & 238,07 & 86,15 & \begin{tabular}{|c|}
610,38 \\
\end{tabular} & 86,62 & 2,97 & 58,25 & 248,23 & 25,93 & 31,53 & 233,97 \\
\hline Lissotriton boscai & 29SQB19 & 99,00 & $\begin{array}{lll}151,81 & \\
\end{array}$ & \begin{tabular}{|l|}
111,03 \\
\end{tabular} & 38,00 & $\begin{array}{l}6028,69 \\
\end{array}$ & 319,92 & 31,80 & 288,13 & 87,58 & 230,39 & 232,23 & 78,65 & 649,94 & 90,32 & 3,61 & 57,35 & 262,00 & 29,59 & 34,50 & 249,20 \\
\hline Lissotriton boscai & 29SQB20 & 100,00 & $\begin{array}{l}179,04 \\
\end{array}$ & 89,73 & 37,08 & 5151,40 & 308,35 & 70,87 & 237,48 & 134,68 & 243,99 & 246,81 & \begin{tabular}{ll|}
114,96 \\
\end{tabular} & 524,89 & 80,86 & 1,00 & 64,52 & 227,17 & 14,90 & 22,01 & 207,32 \\
\hline Lissotriton boscai & 29SQB21 & 101,00 & 179,80 & 92,42 & 37,20 & $5285,69 \mid$ & 313,51 & 69,27 & 244,24 & 131,97 & 246,44 & 249,12 & 113,76 & 522,48 & 80,46 & 1,00 & 63,68 & 224,48 & 15,00 & 22,31 & 204,82 \\
\hline Lissotriton boscai & 295QB22 & 100,00 & 178,30 & 95,58 & 37,40 & 5428,78 & 317,3 & 65,47 & 251,87 & 119,33 & 247,04 & 249, & 110,55 & 529,87 & 81,28 & 1,00 & 63,28 & 226,09 & 15,47 & 22,99 & 206 \\
\hline Lissotriton boscai & 29SQB24 & 100,00 & 175,60 & 101,94 & 37, & 567 & 325,06 & 58,67 & 266,40 & 114,06 & 248,11 & 25 & 104,99 & 543,60 & 81,97 & 1,36 & 61,76 & 228,44 & 18,02 & 24,99 & 210,41 \\
\hline Lissotriton boscai & 29SQB29 & 100,00 & \begin{tabular}{|l|l|}
158,47 \\
\end{tabular} & 112,97 & 38,00 & \begin{tabular}{|l|l|}
6098,34 \\
\end{tabular} & 328,68 & 36,09 & 292,59 & 92,97 & 237,91 & 239,45 & 83,95 & $\begin{array}{l}619,05 \\
\end{array}$ & 86,71 & 3,20 & 57,68 & 249,70 & 27,20 & \begin{tabular}{|l|l|}
32,28 \\
\end{tabular} & 236,40 \\
\hline Lissotriton boscai & 29SQB35 & 101,00 & $\begin{array}{l}175,74 \\
\end{array}$ & \begin{tabular}{|l|}
109,07 \\
\end{tabular} & $\begin{array}{l}38,05 \\
\end{array}$ & \begin{tabular}{|l|l|}
5890,17 \\
\end{tabular} & 336,24 & 54,13 & 282,11 & 111,61 & 251,58 & 253,33 & $\begin{array}{ll}102,63 \\
\end{array}$ & $\begin{array}{l}558,45 \\
\end{array}$ & 83,11 & 1,74 & 61,18 & 233,21 & 19,53 & 25,44 & 216,83 \\
\hline Lissotriton boscai & 29SQB38 & 101,00 & 165,25 & 114,19 & 38,03 & 6120,83 & 336,06 & 41,25 & 294,81 & 99,12 & 44,91 & 246,42 & 90,10 & 596,49 & 84,86 & 2,55 & 58,82 & 42,79 & 24,17 & 9,42 & 228,80 \\
\hline | Lissotri & 295QB39 & 100,00 & 163,07 & 115,24 & 38,00 & 172,04 & 336,21 & 38, & 197, & 96 & 24 & & 87 & 601,53 & 8 & 2,78 & & 242,94 & 25,49 & 30,41 & 22 \\
\hline 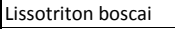 & 29SQB45 & 99,00 & 179,99 & 113,45 & 38,61 & 5980,75 & 346,2 & 55,51 & 290,71 & 114,92 & 257,41 & 259,01 & 105,74 & 555,42 & 82,92 & 1,41 & 61,79 & 232,99 & 18,81 & 24,00 & 217,38 \\
\hline Lissotriton boscai & 29SQB48 & 99,00 & 165,34 & 116,84 & 38,20 & 6207,25 & 340,24 & 39,51 & 300,73 & 98,16 & 246,41 & 247,64 & 89,31 & \begin{tabular}{|c|}
606,48 \\
\end{tabular} & 85,72 & 2,53 & 58,92 & 246,50 & 24,30 & 29,31 & 233,16 \\
\hline
\end{tabular}




\begin{tabular}{|c|c|c|c|c|c|c|c|c|c|c|c|c|c|c|c|c|c|c|c|c|c|}
\hline TAXON & UTM & $\mathrm{km2}$ & BIO1 & B102 & $\mathrm{BIO3}$ & B104 & B105 & B106 & B107 & B108 & B109 & BIO10 & BIO11 & B1012 & BIO13 & BIO14 & BIO15 & BIO16 & BIO17 & B1018 & BIO19 \\
\hline Lissotriton boscai & 29SQB49| & 99,00 & 160,27 & 117,41 & 38,07 & 6265,76 & 337,49 & 34,39 & 303,10 & 92,76 & 242,46 & 243,63 & 83,80 & 624,67 & 86,79 & 3,01 & 58,13 & 251,52 & 26,41 & 31,25 & 238,92 \\
\hline Lissotriton boscai & 29SQB55 & 100,00 & 182,80 & 117,92 & 38,98 & 6077,18 & 354,84 & 55,47 & 299,36 & 116,50 & $\begin{array}{l}261,79 \\
\end{array}$ & 263,16 & \begin{tabular}{ll|}
107,47 \\
\end{tabular} & 559,71 & 83,53 & 1,13 & 62,24 & 235,80 & 18,43 & 23,01 & 221,17 \\
\hline Lissotriton boscai & $29 \mathrm{SQB56}$ & 100,00 & 176,11 & $\begin{array}{ll}118,63 \\
\end{array}$ & 38,93 & 6163,05 & 350,68 & 48,61 & \begin{tabular}{|l|}
302,07 \\
\end{tabular} & \begin{tabular}{l|l|}
109,00 \\
\end{tabular} & 256,31 & 257,66 & 100,02 & 582,65 & 85,06 & 1,97 & 61,03 & 242,14 & 20,77 & 25,32 & 228,14 \\
\hline Lissotriton boscai & 29SQB59 & 100,00 & 161,72 & 119,53 & 38,08 & 6337,03 & 341,97 & 34,20 & \begin{tabular}{|l|l|}
307,77 \\
\end{tabular} & 93,37 & 244,95 & 245,92 & 84,36 & 626,22 & 86,57 & 2,97 & 58,34 & \begin{tabular}{|l|l|}
251,97 \\
\end{tabular} & 25,99 & 30,74 & 239,89 \\
\hline Lissotriton boscai & 295QB66 & 49,00 & 179,39 & 121,08 & 39,00 _ & 6213,04 & 356,69 & $50,47 \mid$ & 306,22 & 111,55 | & 260,39 . & 261,53 . & 102,69 & 576,55 & 84,32 & 1,69 & 61,45 & 240,57 & 19,96 & 24,26 & 226,99 \\
\hline Lissotriton boscai & 29SQB69 & 40,00 & 164,02 & 121,00 & 38,38 & 6377,10 & 346,10 & 35,40 & 310,70 & $\begin{array}{l}95,05 \\
\end{array}$ & 247,85 & 248,63 & 86,07 & 620,57 & 85,65 & 2,72 & 58,52 & 249,95 & 25,08 & 29,77 & 238,12 \\
\hline Lissotriton boscai & $295 Q C 00$ & 100,00 & 152,57 & 110,61 & 38,01 & 5987,54 & 319,70 & 33,50 & 286,20 & 88,75 & 230,46 & 232,42 & \begin{tabular}{l|l|}
79,85 \\
\end{tabular} & \begin{tabular}{ll|}
634,96 \\
\end{tabular} & 88,02 & 3,70 & 56,71 & 255,20 & 30,10 & 34,59 & 242,76 \\
\hline Lissotriton boscai & $295 Q C 01$ & 100,00 & 150,73 & 111,68 & 38,02 & 6030,24 & 320,13 & 31,31 & 288,82 & 86,57 & \begin{tabular}{|l|l}
229,46 \\
\end{tabular} & 231,34 & 77,71 & \begin{tabular}{ll|}
643,26 \\
\end{tabular} & 88,33 & 4,06 & 56,03 & \begin{tabular}{|l|}
256,93 \\
\end{tabular} & 31,92 & \begin{tabular}{l|l}
35,85 \\
\end{tabular} & 245,11 \\
\hline Lissotriton boscai & 29SQC02 & 101,00 & 150,90 & 112,55 & 38,00 & 6064,71 & 322,05 & 30,95 & 291,10 & 86,38 & \begin{tabular}{|l|l|}
230,08 \\
\end{tabular} & 231,97 & 77,51 & \begin{tabular}{|l|l|}
638,97 \\
\end{tabular} & \begin{tabular}{l|l}
87,25 \\
\end{tabular} & 4,11 & 55,41 & 253,83 & 32,80 & 36,32 & 242,32 \\
\hline Lissotriton boscai & $2950 \mathrm{Co6}$ & 100,00 & 151,43 & 114,50 & 38,00 & 6152,60 & 326,90 & 30,33 & 296,57 & 85,56 [ & 232,32 & $233,59[$ & 77,10 . & 619,90 & 83,06 & 4,68 & 53,24 & 241,60 & 36,05 & 38,10 & 230,70 \\
\hline Lissotriton boscai & $295 Q C 10$ & 101,00 & 157,87 & 112,11 & 38,00 & 6052,92 & 326,94 & 36,77 & 290,16 & $\begin{array}{l}92,90 \\
\end{array}$ & 236,66 & 238,34 & \begin{tabular}{l|l|}
84,15 \\
\end{tabular} & \begin{tabular}{ll|}
608,89 \\
\end{tabular} & 85,03 & 3,21 & 57,12 & 244,71 & 27,85 & 32,59 & 231,55 \\
\hline Lissotriton boscai & 29SQC11 & 100,00 & 148,36 & 113,07 & 38,00 & 6121,03 & 320,93 & 27,46 & 293,47 & 83,27 & 228,53 & 230,22 & 74,29 & 662,73 & 90,34 & 4,26 & 56,03 & 263,69 & 32,92 & 36,88 & 252,11 \\
\hline Lissotriton boscai & 29SQC15 & 100,00 & 153,88 & 115,50 & 38,00 & 6216,08 & 330,77 & 31,06 & 299,71 & 87,03 & 235,64 & 236,60 & 78,50 & 607,10 & 81,63 & 4,19 & 53,79 & \begin{tabular}{|l|}
236,94 \\
\end{tabular} & 33,57 & 36,28 & 225,45 \\
\hline Lissotriton boscai & $295 Q C 21$ & 100,00 & 145,29 & 114,35 & 38,00 & 6208,92 & 321,02 & 23,04 & 297,98 & 79,29 & 227,01 & 228,47 & 70,48 & \begin{tabular}{ll|l}
684,79 \\
\end{tabular} & 92,50 & 4,51 & 55,84 & 271,28 & 34,24 & 38,10 & 260,10 \\
\hline Lissotriton boscai & $295 Q C 23$ & 101,00 & 156,44 & 116,22 & 38,00 & 6236,16 & 333,51 & 32,47 & 301,04 & 89,36 & 238,35 & 239,41 & 80,62 & 605,30 & 82,13 & 3,85 & 55,16 & 238,15 & 30,84 & 34,48 & 226,19 \\
\hline Lissotriton boscai & $295 Q C 25$ & 100,00 & 154,87 & 116,72 & 38,00 & 6296,31 & 333,94 & 30,57 & 303,37 & 86,94 & \begin{tabular}{|l|l|}
237,62 \\
\end{tabular} & 238,51 & 78,50 & \begin{tabular}{|c|}
601,18 \\
\end{tabular} & 80,36 & 4,00 & 53,84 & 233,81 & 32,68 & 35,64 & 222,19 \\
\hline Lissotriton boscai & $29 \mathrm{SQC30}$ & 100,00 & 153,54 & 115,83 & 38,00 & 6238,75 & 329,83 & 29,25 & 300,58 & 86,61 & 235,49 & 236,64 & 77,72 & 646,89 & 88,68 & 3,60 & 56,96 & 258,16 & 29,81 & 34,28 & 246,06 \\
\hline Lissotriton boscai & $295 \mathrm{Sa} 31$ & 101,00 & 143,35 & 115,71 & 37,99 & 6285,63 & 321,80 & 20,01 & 301,79 & 76,51 . & 226,30 & 227,65 & 67,74 & 700,80 & 93,93 . & $\mid 4,65$ & 55,87 & 276,69 & \begin{tabular}{|c|c|}
34,98 \\
\end{tabular} & \begin{tabular}{|c|c|}
38,88 &
\end{tabular} & 265,89 \\
\hline Lissotriton boscai & $295 Q C 37$ & 100,00 & 160,43 & 117,97 & 38,00 & 6361,74 & 341,86 & 34,42 & 307,44 & 91,44 & \begin{tabular}{|l|l|l|}
244,49 \\
\end{tabular} & 244,74 & 82,93 & 555,56 & 73,23 & 3,90 & 52,90 & 213,13 & 31,30 & 33,37 & 201,28 \\
\hline Lissotriton boscai & $295 Q C 40$ & 101,00 & 158,58 & 118,01 & 38,01 & 6304,75 & 337,41 & 32,34 & 305,07 & 90,67 & 241,28 & 242,38 & 81,7 & 626,43 & 86,06 & 3,03 & 57,4 & 250,37 & 27,34 & 32,01 & 238,25 \\
\hline Lissotriton boscai & 29SQC41 & 99,00 & 150,44 & 117,83 & 38,00 & 6353,23 & 331,26 & 24,82 & 306,44 & 82,53 & 234,27 & 235,31 & 73,66 & 662,91 & 89,17 & 3,90 & 56,33 & 261,88 & 31,52 & 35,70 & 250,75 \\
\hline Lissotriton boscai & $295 Q C 42$ & 101,00 & 152,95 & 118,39 & 38,00 & 6376,73 & 334,71 & 26,75 & 307,97 & 84,57 & 237,21 & \begin{tabular}{|l|l|}
237,92 \\
\end{tabular} & \begin{tabular}{|c|}
75,77 \\
\end{tabular} & 640,44 & 85,79 & 3,86 & \begin{tabular}{l|l|}
55,69 \\
\end{tabular} & \begin{tabular}{|l|l|}
251,67 \\
\end{tabular} & 31,08 & 35,10 & 240,44 \\
\hline Lissotriton boscai & $29 \mathrm{SQC50}$ & 100,00 & 154,05 & 119,27 & 38,01 & 6389,85 & 336,10 & 27,00 & 309,10 & 85,45 & 238,34 & 239,30 & 76,60 & 656,46 & 88,95 & 3,43 & 57,26 & 260,95 & 29,22 & 33,80 & 249,81 \\
\hline Lissotriton boscai & 29SQC51 & 100,00 & 157,25 & 120,01 & 38,00 & 6413,78 & 340,24 & 29,40 & 310,84 & 88,09 & 241,84 & 242,56 & 79,16 & 631,14 & 85,14 & 3,27 & $56,81 \mid$ & 249,59 & 28,48 _ & 32,89 & 238,35 \\
\hline Lissotriton boscai & 29SQC52 & 100,00 & 158,74 & 120,32 & 38,00 & 6435,63 & 342,47 & 30,48 & 311,99 & 89,27 & 243,72 & 244,24 & 80,33 & 613,54 & 82,38 & 3,19 & 56,22 & 241,10 & 28,37 & 32,57 & 229,94 \\
\hline Lissotriton boscai & \begin{tabular}{|l|}
$295 Q C 63$ \\
\end{tabular} & 22,00 & 148,95 & 120,27 & \begin{tabular}{|l|}
37,98 \\
\end{tabular} & 6508,00 & 335,43 & 21,27 & 314,16 & \begin{tabular}{|l|l}
79,09 \\
\end{tabular} & 235,43 & 235,86 & 70,36 & 658,91 & 87,20 & 4,20 & 55,09 & 255,39 & 32,91 & 35,98 & 245,32 \\
\hline Lissotriton boscai & 29SQD03 & 99,00 & 162,05 & 112,89 & \begin{tabular}{l|l}
37,65 \\
\end{tabular} & 6217,30 & 336,97 & 40,74 & 296,23 & 94,54 & 244,16 & 244,37 & 86,30 & 543,79 & 71,43 & 4,07 & 50,64 & 207,91 & 35,20 & 35,89 & 196,42 \\
\hline Lissotriton boscai & \begin{tabular}{|l|} 
29SQD07 \\
\end{tabular} & 100,00 & 160,93 & 107,44 & 36,60 & 6257,25 & 332,73 & 42,59 & \begin{tabular}{|l|l|}
290,13 \\
\end{tabular} & 93,20 & 243,99 & 244,13 & 85,12 & \begin{tabular}{|l|l}
562,46 \\
\end{tabular} & 72,17 & 4,35 & 49,91 & 214,50 & \begin{tabular}{l|l}
37,65 \\
\end{tabular} & 37,91 & 203,80 \\
\hline Lissotriton boscai & 29SQD09 & 99,00 & 158,24 & 105,39 & $36,01 \mid$ & 6260,37 & 328,33 & 40,89 & 287,44 & 90,36 [ & $241,45[$ & $241,47 \mid$ & 82,33 & 580,27 & 74,52 & 4,97 & 49,78 & 221,52 & 39,41 . & 39,46 _ & 211,38 \\
\hline Lissotriton boscai & \begin{tabular}{|l|}
$29 S Q D 15$ \\
\end{tabular} & 100,00 & 160,22 & 109,91 & 36,91 & 6318,99 & 335,55 & 39,81 & 295,74 & \begin{tabular}{|l|}
91,89 \\
\end{tabular} & \begin{tabular}{|l|l|}
244,16 \\
\end{tabular} & 244,19 & 83,61 & 543,83 & 69,39 & 4,14 & 49,90 & 205,40 & 36,18 & 36,36 & 193,78 \\
\hline Lissotriton boscai & 29SQD21 & 101,00 & 167,54 & 115,88 & 37,93 & 6306,67 & 345,66 & 42,66 & \begin{tabular}{|l|l|}
302,99 \\
\end{tabular} & \begin{tabular}{|l|l|}
98,62 \\
\end{tabular} & \begin{tabular}{|l|l|}
250,56 \\
\end{tabular} & 250,69 & \begin{tabular}{l|l}
90,15 \\
\end{tabular} & \begin{tabular}{l|l|}
493,85 \\
\end{tabular} & 65,03 & 3,03 & 51,52 & 187,80 & 29,46 & 30,62 & 175,35 \\
\hline Lissotriton boscai & 29SQD23 & 100,00 & 162,78 & 113,37 & 37,00 & 6357,80 & 341,02 & 39,52 & 301,50 & \begin{tabular}{|l|l|}
93,64 \\
\end{tabular} & \begin{tabular}{|l|l|}
247,12 \\
\end{tabular} & 247,14 & 85,36 & 515,75 & 66,36 & 4,00 & 50,40 & 194,20 & 32,93 & 33,12 & 182,06 \\
\hline Lissotriton boscai & 29SQD27 & 100,00 & 160,06 & 107,97 & 36,00 & 6397,26 & 335,49 & 39,85 & 295,64 & 90,75 & 245,32 & 245,32 & 82,60 & \begin{tabular}{|l|l|}
521,58 \\
\end{tabular} & \begin{tabular}{ll|l}
66,06 \\
\end{tabular} & 4,07 & 49,38 & $\begin{array}{ll}194,52 \\
\end{array}$ & 35,48 & 35,48 & 182,45 \\
\hline Lissotriton boscai & \begin{tabular}{|l|} 
29SQD32 \\
\end{tabular} & 99,00 & 163,79 & 115,06 & $\begin{array}{l}37,05 \\
\end{array}$ & 6406,58 & 344,01 & 38,80 & 305,22 & \begin{tabular}{ll|}
94,02 \\
\end{tabular} & 248,83 & 248,84 & 85,67 & 506,41 & 65,30 & 3,67 & 50,66 & \begin{tabular}{l|l|}
190,02 \\
\end{tabular} & 31,50 & 31,52 & 177,81 \\
\hline Lissotriton boscai & 29SQD33 & 100,00 & 159,75 & 113,57 & 36,93 & 6431,24 & 339,81 & 35,92 & \begin{tabular}{|l|}
303,89 \\
\end{tabular} & \begin{tabular}{|c|}
90,02 \\
\end{tabular} & \begin{tabular}{|l|}
245,19 \\
\end{tabular} & 245,19 & 81,60 & 523,70 & 66,91 & 4,03 & 50,19 & \begin{tabular}{|l|l|}
195,72 \\
\end{tabular} & 33,60 & 33,66 & 183,56 \\
\hline Lissotriton boscai & 29SQD34 & 100,00 & 158,26 & 112,18 & 36,66 & 6447,42 & 337,87 & 35,26 & \begin{tabular}{|l|}
302,62 \\
\end{tabular} & \begin{tabular}{|l|l|}
88,47 \\
\end{tabular} & \begin{tabular}{|l|l|}
244,05 \\
\end{tabular} & \begin{tabular}{|l|l|}
244,05 \\
\end{tabular} & 80,09 & 526,71 & 67,01 & 4,03 & \begin{tabular}{ll|}
49,66 \\
\end{tabular} & \begin{tabular}{|l|l|}
195,96 \\
\end{tabular} & 34,72 & 34,72 & 183,75 \\
\hline Lissotriton boscai & 29SQD41 & 100,00 & 167,40 & 116,77 & 37,13 & 6444,88 & 349,11 & 40,70 & 308,41 & \begin{tabular}{|l|l|}
96,92 \\
\end{tabular} & 252,81 & 252,81 & 88,49 & 488,53 & 63,47 & 3,01 & 51,48 & \begin{tabular}{|l|l|}
183,45 \\
\end{tabular} & 28,49 & 28,51 & 171,45 \\
\hline Lissotriton boscai & \begin{tabular}{|l|} 
29SQD44 \\
\end{tabular} & 100,00 & 153,60 & 112,60 & 36,38 & 6501,45 & 334,92 & 30,10 & 304,82 & 83,36 & \begin{tabular}{|l|l|}
240,45 \\
\end{tabular} & \begin{tabular}{|l|l|}
240,45 \\
\end{tabular} & 75,10 & 541,58 & 69,07 & 4,51 & 49,49 & $\begin{array}{l}199,98 \\
\end{array}$ & 36,22 & 36,23 & 187,85 \\
\hline Lissotriton boscai & 29SQD46 & 101,00 & 158,61 & 111,09 & 36,02 & 93,81 & 338,07 & 35,56 & 302,51 & 88,12 & 245,17 & 245,17 & \begin{tabular}{|c|}
79,77 \\
\end{tabular} & $\begin{array}{l}501,75 \\
\end{array}$ & 64,84 & 4,00 & 48,76 & \begin{tabular}{ll|}
184,06 \\
\end{tabular} & 4,20 & 4,20 & 171,66 \\
\hline Lissotriton boscai & \begin{tabular}{|l|} 
29SQD47 \\
\end{tabular} & 100,00 & 160,86 & 110,70 & 36,07 & 6477,91 & 339,36 & 37,98 & 301,38 & 90,34 & 247,32 & 247,32 & 82,02 & 484,05 & 62,15 & 4,00 & 48,47 & 177,12 & 33,49 & 33,49 & 164,73 \\
\hline Lissotriton boscai & $\begin{array}{l}29 S Q D 54 \\
\end{array}$ & 90,00 & 156,13 & 113,97 & 36,59 & 6540,17 & 338,76 & 31,17 & \begin{tabular}{|l|l|}
307,59 \\
\end{tabular} & 85,11 & 243,50 & 243,50 & 76,94 & \begin{tabular}{|l|l|}
517,89 \\
\end{tabular} & 66,59 & 4,21 & \begin{tabular}{ll|}
49,36 \\
\end{tabular} & \begin{tabular}{ll|}
189,84 \\
\end{tabular} & 34,20 & 34,20 & 177,86 \\
\hline Lissotriton boscai & 29SQD55 & 82,00 & 156,69 & 113,12 & 36,23 & 6542,17 & 338,71 & 32,22 & 306,49 & 85,59 & 244,25 & \begin{tabular}{|l|l|}
244,25 \\
\end{tabular} & 77,52 & 505,80 & \begin{tabular}{l|l}
65,25 \\
\end{tabular} & 4,08 & 48,90 & $\begin{array}{l}184,66 \\
\end{array}$ & 34,11 & 34,11 & 172,52 \\
\hline Lissotriton boscai & 29SQE31 & 100,00 & 151,70 & 107,43 & 35,99 & 6391,73 & 325,58 & 31,99 & 293,58 & 82,12 & 237,20 & 237,20 & 74,27 & 528,86 & 65,88 & 5,36 & 47,12 & \begin{tabular}{|l|l|}
195,34 \\
\end{tabular} & 39,53 & 39,53 & 183,23 \\
\hline Lissotriton boscai & 29SQE41 & 101,00 & 154,90 & 109,12 & 36,13 & 419,67 & 30,21 & 33,53 & 296,68 & 84,60 & 240,72 & 240,72 & 76,87 & 489,60 & 60, & 4,5 & 46,4 & 178,67 & 36,92 & 36,92 & 166,26 \\
\hline Lissotriton boscai & \begin{tabular}{|l|l|}
$295 Q E 50$ \\
\end{tabular} & 70,00 & 159,94 & 110,91 & 36,59 & 6450,74 & 336,84 & 36,84 & 300,00 & 89,39 & 246,15 & 246,15 & 81, & 456,27 & 56,1 & 4,02 & 46,66 & 165,05 & 33,50 & 33,50 & 152,85 \\
\hline Lissotriton boscai & 29SQE51 & 63,00 & 158,98 & 110,69 & 36,68 & 6427,51 & 334,89 & 36,06 & \begin{tabular}{|l|l|}
298,83 \\
\end{tabular} & 88,21 & 244,68 & 244,68 & 80,34 & 454,36 & 55,83 & 4,50 & 46,13 & \begin{tabular}{ll|}
164,21 \\
\end{tabular} & 34,23 & 34,23 & 151,88 \\
\hline Lissotriton boscai & 29TMH76 & 18,00 & 142,36 & 59,45 & 39,14 & 3130,50 & 224,05 & 74,18 & \begin{tabular}{ll|l}
149,86 \\
\end{tabular} & \begin{tabular}{|l|l|}
112,64 \\
\end{tabular} & $\begin{array}{l}180,45 \\
\end{array}$ & \begin{tabular}{|l|l|}
184,00 \\
\end{tabular} & \begin{tabular}{ll|}
103,45 \\
\end{tabular} & 970,82 & 140,59 & 26,09 & \begin{tabular}{l|l}
42,05 \\
\end{tabular} & \begin{tabular}{|l|l|}
384,09 \\
\end{tabular} & \begin{tabular}{ll|}
112,86 \\
\end{tabular} & \begin{tabular}{|l|}
138,27 \\
\end{tabular} & 322,23 \\
\hline Lissotriton boscai & 29тMH83 & & & & & & & & & & & & & & & & & & & & \\
\hline Lissotriton boscai & 29TMH84 & 11,00 & 139,81 & 60,94 & \begin{tabular}{l|l}
38,75 \\
\end{tabular} & 3273,38 & 225,63 & $\begin{array}{l}0,25 \\
\end{array}$ & \begin{tabular}{|l|l|}
155,38 \\
\end{tabular} & 108,50 & 180,31 & \begin{tabular}{|l|l|}
183,69 \\
\end{tabular} & 99,50 & 1055,56 & \begin{tabular}{|l|l|}
150,25 \\
\end{tabular} & 27,56 & 43,06 & \begin{tabular}{ll|}
419,00 \\
\end{tabular} & \begin{tabular}{ll|}
116,56 \\
\end{tabular} & 140,94 & 361,06 \\
\hline Lissotriton boscai & 29TMH85 & 76,00 & 139,86 & 60,66 & 38,86 & 3227,67 & 224,58 & 70,50 & 154,08 & \begin{tabular}{|l|l|}
109,07 \\
\end{tabular} & \begin{tabular}{|l|l|}
179,49 \\
\end{tabular} & 182,91 & 99,89 & 1022,70 & 146,27 & 27,14 & 42,50 & \begin{tabular}{|l|l|}
405,09 \\
\end{tabular} & \begin{tabular}{|l|}
116,07 \\
\end{tabular} & $\begin{array}{ll}140,82 \\
\end{array}$ & 344,98 \\
\hline Lissotriton boscai & 29TMH86 & 101,00 & 140,88 & 60,43 & 39,01 & 3189,41 & 224,79 & 71,89 & 152,90 & 110,68 & \begin{tabular}{ll|}
179,94 \\
\end{tabular} & \begin{tabular}{|l|l}
183,48 \\
\end{tabular} & \begin{tabular}{|l|l|}
101,52 \\
\end{tabular} & 1001,25 & 143,27 & 27,08 & \begin{tabular}{|l|}
41,99 \\
\end{tabular} & \begin{tabular}{|l|}
395,29 \\
\end{tabular} & $\begin{array}{ll}115,62 \\
\end{array}$ & \begin{tabular}{|l|l|}
140,68 \\
\end{tabular} & 334,91 \\
\hline Lissotriton boscai & 29TMH87 & 60,00 & 143,94 & 60,09 & 39,43 & 3139,24 & 225,93 & 75,29 & 150,63 & 114,11 & 182,18 & 185,88 & 104,93 & 980,60 & 139,88 & 26,78 & 41,41 & 385,48 & \begin{tabular}{l|l|}
113,95 \\
\end{tabular} & \begin{tabular}{|l|l|}
139,40 \\
\end{tabular} & 326,89 \\
\hline Lissotriton boscai & 29TMH90 & 6,00 & 148,43 & 58,79 & \begin{tabular}{|l|}
38,79 \\
\end{tabular} & 288,93 & 229,93 & 80,5 & 149,43 & 115,14 & \begin{tabular}{ll|}
189,36 \\
\end{tabular} & \begin{tabular}{|l|l|l|}
191,43 \\
\end{tabular} & \begin{tabular}{ll|}
106,64 \\
\end{tabular} & 1150,64 & 161,21 & 25, & 46 & 461,43 & 107,86 & $\begin{array}{l}131,50 \\
\end{array}$ & 415,43 \\
\hline Lissotriton boscai & 29TMH91 & 46,00 & 14 & 59,04 & 38 & 331 & 229 & 78, & 151 & 113 & 187 & 189 & 104, & 1143,04 & 161 & 26,24 & 45,56 & 458,00 & 110,67 & \begin{tabular}{|l|l|}
134,49 \\
\end{tabular} & $40 s$ \\
\hline Lissotriton boscai & 29TMH92 & 25,00 & 141,23 & 60,49 & 38,14 & 3378,23 & 227,51 & 71,47 & 156,05 & \begin{tabular}{|l|}
107,72 \\
\end{tabular} & \begin{tabular}{|l|l|}
183,44 \\
\end{tabular} & 185,91 & 99,12 & 1175,86 & \begin{tabular}{|l|l|}
168,47 \\
\end{tabular} & 28,44 & 44,98 & 469,60 & 117,91 & $\begin{array}{l}141,35 \\
\end{array}$ & 420,91 \\
\hline Lissotriton boscai & 29TMH93 & 45,00 & 142,97 & 60,38 & 38,58 & 3303,65 & 228,01 & 73,36 & 154,65 & \begin{tabular}{|l|l|}
110,67 \\
\end{tabular} & \begin{tabular}{|l|l|}
183,91 \\
\end{tabular} & \begin{tabular}{l|l|}
186,81 \\
\end{tabular} & 101,71 & 1081,97 & 153,14 & 26,94 & 44,01 & \begin{tabular}{ll|}
431,12 \\
\end{tabular} & \begin{tabular}{|l|l|}
113,87 \\
11
\end{tabular} & \begin{tabular}{|l|l|}
138,10 \\
\end{tabular} & 376,59 \\
\hline Lissotriton boscai & 29TMH94 & 96,00 & 134,43 & 62,32 & 38,30 & 3383,03 & 224,15 & 63,56 & \begin{tabular}{|l|l|}
160,59 \\
\end{tabular} & $\begin{array}{ll}101,66 \\
\end{array}$ & \begin{tabular}{|l|l|}
176,79 \\
\end{tabular} & $\begin{array}{ll}179,88 \\
\end{array}$ & $\begin{array}{l}2,99 \\
\end{array}$ & 1163,86 & 165,96 & 30,57 & 43,29 & 460,44 & \begin{tabular}{ll|}
125,92 \\
\end{tabular} & \begin{tabular}{ll|}
149,26 \\
\end{tabular} & 407,56 \\
\hline Lissotriton boscai & 29TMH & 10100 & & & 38, & & & 60, & 161 & 99 & & 177 & 90,84 & & 163 & 31,54 & 42, & 457,27 & $12 \mathrm{~s}$ & \begin{tabular}{|l|l|}
152,73 \\
\end{tabular} & \\
\hline Lissotriton boscai & 29TMH96 & 101,00 & \begin{tabular}{|l|l|}
132,67 \\
\end{tabular} & 62,76 & 38,41 & 3336,9 & 222,47 & \begin{tabular}{l|l|}
61,55 \\
\end{tabular} & \begin{tabular}{l|l|}
160,92 \\
\end{tabular} & \begin{tabular}{ll|}
100,76 \\
\end{tabular} & \begin{tabular}{|l|l|}
174,14 \\
\end{tabular} & 177,7 & \begin{tabular}{l|l}
91,95 \\
\end{tabular} & 1134,29 & 158,51 & 31,50 & 41,88 & \begin{tabular}{|l|l|}
444,68 \\
\end{tabular} & \begin{tabular}{|l|}
129,01 \\
\end{tabular} & \begin{tabular}{|l|l|}
152,87 \\
\end{tabular} & 389 \\
\hline Lissotriton boscai & 29TMH97 & 100,00 & 138,07 & 61,86 & 38,93 & 3246,93 & 224,66 & \begin{tabular}{|l|l|}
67,91 \\
\end{tabular} & 156,75 & \begin{tabular}{|l|l}
107,19 \\
\end{tabular} & \begin{tabular}{|l|l|}
178,13 \\
\end{tabular} & 181,82 & 98,28 & 1062,28 & 147,82 & 29,67 & 41,14 & 415,54 & 122,71 & \begin{tabular}{|l|}
147,29 \\
\end{tabular} & 360,00 \\
\hline
\end{tabular}




\begin{tabular}{|c|c|c|c|c|c|c|c|c|c|c|c|c|c|c|c|c|c|c|c|c|c|}
\hline TAXON & UTM & $\mathrm{km} 2$ & BIO1 & B102 & $B 103$ & BIO4 & B105 & B106 & B107 & B108 & B109 & B1010 & BIO11 & BIO12 & BIO13 & BIO14 & BIO15 & B1016 & B1017 & B1018 & 81019 \\
\hline Lissotriton boscai & 29TMH98 & 28,00 & 142,80 & 61,16 & 39,53 & 3177,18 & 226,53 & 73,42 & 153,11 & 112,60 & 181,80 & 185,62 & 103,67 & 1013,53 & 141,49 & 28,18 & 41,00 & 395,73 & 117,49 & 142,60 & 341,07 \\
\hline Lissotriton boscai & 29TNE13 & 97,00 & 154,79 & 80,80 & 43,68 & 3528,08 & 252,14 & 69,20 & 182,95 & 116,15 & 196,97 & 199,18 & 108,20 & 885,08 & 126,62 & 8,21 & 54,91 & 362,20 & 53,86 & 60,55 & 356,00 \\
\hline Lissotriton boscai & 29TNE14 & 94,00 & 153,37 & 80,69 & 43,99 & 3489,40 & 249,04 & 67,60 & $\begin{array}{l}181,44 \\
\end{array}$ & $\begin{array}{l}114,96 \\
\end{array}$ & $\begin{array}{l}194,89 \\
\end{array}$ & $\begin{array}{l}196,96 \\
\end{array}$ & $\begin{array}{l}106,94 \\
\end{array}$ & $\begin{array}{l}915,43 \\
\end{array}$ & \begin{tabular}{|l|l|}
130,14 \\
\end{tabular} & 8,93 & 54,31 & \begin{tabular}{|l|l|}
372,73 \\
\end{tabular} & 57,22 & 64,43 & 366,66 \\
\hline Lissotriton boscai & 29TNE15 & 95,00 & 152,10 & 79,87 & 44,23 & 3433,91 & 244,94 & 66,57 & $\begin{array}{l}178,37 \\
\end{array}$ & $\begin{array}{l}114,04 \\
\end{array}$ & 192,57 & $\begin{array}{l}194,69 \\
\end{array}$ & $\begin{array}{l}106,07 \\
\end{array}$ & 940,82 & 132,95 & 9,80 & 53,87 & 381,66 & 60,01 & 67,97 & 375,23 \\
\hline Lissotriton boscai & 29TNE17 & 40,00 & 151,00 & 77,70 & 44,97 & 3321,38 & 237,20 & 65,97 & 171,23 & 113,99 & 189,58 & 191,34 & 105,62 & 973,01 & 136,21 & 10,34 & 53,00 & 393,07 & 63,24 & 72,89 & 385,45 \\
\hline Lissotriton boscai & 29TNE26 & 100,00 & 152,32 & 84,16 & 44,45 & 3581,52 & 250,69 & 63,32 & 187,37 & 112,44 & 194,77 & 196,81 & 104,39 & 969,56 & 136,02 & $\begin{array}{ll}10,03 \\
\end{array}$ & 53,09 & 390,74 & 63,01 & 70,94 & 385,71 \\
\hline Lissotriton boscai & 29TNE27 & 100,00 & 150,94 & 81,77 & 44,72 & 3491,93 & 244,10 & 63,03 & \begin{tabular}{|l|l|}
181,07 \\
\end{tabular} & 111,95 & 191,99 & 193,90 & 103,76 & 988,28 & 138,04 & 10,85 & 52,79 & 397,95 & 65,18 & 74,10 & 391,49 \\
\hline Lissotriton boscai & 29TNE28 & 101,00 & 149,73 & 78,91 & 45,04 & 3384,36 & 236,65 & 63,11 & 173,54 & 111,73 & 189,05 & $\begin{array}{l}190,76 \\
\end{array}$ & $\begin{array}{l}103,37 \\
\end{array}$ & 1002,72 & \begin{tabular}{|l|l|}
139,53 \\
\end{tabular} & 11,00 & 52,55 & \begin{tabular}{ll|}
403,88 \\
\end{tabular} & 66,14 & 76,54 & 395,56 \\
\hline Lissotriton boscai & 29TNE34 & 100,00 & 158,71 & 92,86 & 43,79 & 3959,58 & \begin{tabular}{|l|l|}
274,19 \\
\end{tabular} & $\begin{array}{ll}64,23 \\
\end{array}$ & 209,97 & 114,31 & 206,84 & 209,11 & \begin{tabular}{|l|l|}
106,97 \\
\end{tabular} & $\begin{array}{l}911,58 \\
\end{array}$ & \begin{tabular}{ll|}
128,28 \\
\end{tabular} & 9,09 & 53,73 & $\begin{array}{l}366,69 \\
\end{array}$ & 58,88 & 64,19 & 365,55 \\
\hline Lissotriton boscai & 29TNE36 & 101,00 & 153,32 & 90,79 & 44,05 & 3857,75 & 263,38 & 59,66 & 203,71 & 110,21 & 199,93 & 201,99 & 102,41 & 984,04 & $\begin{array}{l}137,65 \\
\end{array}$ & 10,85 & 52,91 & 394,26 & 65,75 & 72,21 & 391,82 \\
\hline Lissotriton boscai & 29TNE37 & 100,00 & 151,92 & 88,12 & 44,21 & 3760,17 & $\begin{array}{l}256,36 \\
\end{array}$ & 59,47 & 196,88 & 109,94 & 196,99 & $\begin{array}{l}198,97 \\
\end{array}$ & 101,90 & $\begin{array}{l}999,56 \\
\end{array}$ & $\begin{array}{l}139,38 \\
\end{array}$ & 11,00 & 52,72 & 400,87 & 66,69 & 74,56 & 396,25 \\
\hline Lissotriton boscai & 29TNE39 & 101,00 & 149,99 & 83,28 & 44,75 & 3590,40 & 244,10 & 59,58 & 184,53 & 109,52 & 192,36 & $\begin{array}{ll}194,02 \\
\end{array}$ & 101,25 & 1023,95 & $\begin{array}{l}141,72 \\
\end{array}$ & 11,49 & 52,18 & 411,92 & 68,18 & \begin{tabular}{|l|}
79,27 \\
\end{tabular} & 402,06 \\
\hline 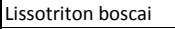 & 29TNE44 & 101,00 & 157,36 & 99,73 & 43,31 & 4271,78 & 286,11 & 58,28 & 227,83 & 102,93 & 210,29 & 212,65 & 102,55 & 952,53 & 133,76 & 10,00 & 53,12 & 382,72 & 63,82 & 67,21 & 382,71 \\
\hline Lissotriton boscai & 29TNE45 & 101,00 & 159,50 & 98,46 & 43,90 & 4164,52 & 283,32 & \begin{tabular}{ll|}
60,82 \\
\end{tabular} & 222,49 & 108,75 & 210,58 & 212,78 & 105,32 & $\begin{array}{l}936,35 \\
\end{array}$ & \begin{tabular}{|l|l|}
130,70 \\
\end{tabular} & 9,70 & 52,90 & $\begin{array}{l}374,25 \\
\end{array}$ & 62,54 & 67,44 & 374,14 \\
\hline Lissotriton boscai & 29TNE46 & 100,00 & 155,75 & 96,92 & 43,75 & 4129,05 & \begin{tabular}{|l|}
276,81 \\
\end{tabular} & 57,49 & 219,32 & 107,60 & 206,33 & 208,40 & $\begin{array}{l}101,84 \\
\end{array}$ & $\begin{array}{l}981,31 \\
\end{array}$ & $\begin{array}{l}136,99 \\
\end{array}$ & $\begin{array}{l}10,65 \\
\end{array}$ & 52,63 & 391,48 & 66,27 & 71,75 & 391,01 \\
\hline Lissotriton boscai & 29TNE48 & 101,00 & 153,62 & 91,44 & 44,01 & 3947,35 & 263,56 & $\begin{array}{ll}57,81 \\
\end{array}$ & 205,75 & 109,17 & 201,37 & 203,17 & 101,12 & $\begin{array}{l}1001,46 \\
\end{array}$ & $\begin{array}{l}139,26 \\
\end{array}$ & $\begin{array}{l}10,96 \\
\end{array}$ & 52,41 & $\begin{array}{l}401,25 \\
\end{array}$ & 66,83 & 75,53 & 395,36 \\
\hline Lissotriton boscai & 29TNE49 & 100,00 & 151,63 & 89,81 & 43,97 & 3905,53 & 258,44 & 56,55 & 201,90 & 107,68 & $\begin{array}{l}198,79 \\
\end{array}$ & 200,54 & 99,55 & $\begin{array}{l}1025,40 \\
\end{array}$ & 142,39 & 11,30 & 52,40 & 412,01 & 68,11 & 78,33 & 403,22 \\
\hline Lissotriton boscai & 29TNE55 & 99,00 & 150,55 & 100,13 & 42,22 & \begin{tabular}{|l|l|l|}
4497,70 \\
\end{tabular} & 284,29 & 49,83 & 234,45 & 93,64 & 207,01 & 209,27 & 93,64 & 1043,22 & \begin{tabular}{|l|l|}
148,06 \\
\end{tabular} & \begin{tabular}{|l|l|l|}
11,27 \\
\end{tabular} & 53,18 & $\mid 419,77$ & 70,97 & 73,17 & \begin{tabular}{ll|l}
419,77 \\
\end{tabular} \\
\hline |Lissotriton boscai & 29TNE56 & 101,00 & 150,10 & 99,40 & 42,36 & 4444,24 & 281,01 & 49,47 & 231,54 & 93,55 & 205,67 & 207,82 & 93,41 & 1053,40 & 149,12 & 11,49 & 52,88 & 422,23 & 71,75 & 75,15 & 422,23 \\
\hline Lissotriton boscai & 29TNE57 & 101,00 & 148,69 & 97,64 & 42,53 & 4378,99 & 275,62 & 48,79 & 226,84 & 97,88 & 203,34 & 205,27 & 92,45 & $\begin{array}{l}1070,57 \\
\end{array}$ & 151,49 & 11,72 & 52,86 & 428,03 & 72,49 & 77,32 & 427,56 \\
\hline Lissotriton boscai & 29TNE59 & 101,00 & 145,60 & 94,24 & 42,64 & 4275,39 & 265,54 & 47,09 & 218,45 & 98,05 & \begin{tabular}{ll|}
198,66 \\
\end{tabular} & 200,38 & 90,22 & 1107,62 & $\begin{array}{l}156,50 \\
\end{array}$ & 12,31 & 52,68 & 444,74 & 74,34 & 82,05 & 439,23 \\
\hline Lissotriton boscai & 29TNE63 & 101,00 & 130,56 & $\begin{array}{ll}89,14 \\
\end{array}$ & 38,42 & $\begin{array}{lll}4769,88 \\
\end{array}$ & $\begin{array}{l}264,01 \\
\end{array}$ & 35,22 & 228,79 & 72,92 & 194,23 & $\begin{array}{l}194,62 \\
\end{array}$ & 72,92 & \begin{tabular}{|l|}
1221,84 \\
\end{tabular} & $\begin{array}{l}181,18 \\
\end{array}$ & \begin{tabular}{l|l|}
12,82 \\
\end{tabular} & 55,21 & $\begin{array}{l}499,16 \\
\end{array}$ & 78,16 & 78,31 & 499,16 \\
\hline Lissotriton boscai & 29TNE64 & 100,00 & 155,81 & 101,81 & 41,50 & 4683,46 & 294,72 & 53,07 & 241,64 & 96,83 & 215,14 & 217,20 & 96,83 & $\begin{array}{l}978,93 \\
\end{array}$ & 139,33 & $\begin{array}{ll}9,92 \\
\end{array}$ & 53,46 & $\begin{array}{l}394,96 \\
\end{array}$ & 65,10 & 67,15 & 394,96 \\
\hline Lissotriton boscai & 29TNE65 & 101,00 & 154,92 & 102,10 & 41,75 & 4672,85 & 292,96 & 51,79 & 241,18 & 95,81 & 213,88 & 216,01 & 95,81 & $\begin{array}{l}997,15 \\
\end{array}$ & 141,65 & 10,31 & 53,17 & \begin{tabular}{|l|l|}
401,08 \\
\end{tabular} & 66,87 & \begin{tabular}{ll|}
69,43 \\
\end{tabular} & 401,08 \\
\hline |Lissotriton boscai & 29TNE66 & 100,00 & 156,09 & 101,84 & 42,18 & 4606,32 & 291,36 & 52,82 & 238,53 & 97,33 & 213,92 & 215,92 & 97,29 & 989,81 & 139,97 & 10,23 & 52,97 & 396,23 & 66,28 & 70,18 & 396,23 \\
\hline Lissotriton boscai & 29TNE68 & 101,00 & 134,72 & 93,55 & 40,41 & 4632,53 & 264,80 & 36,08 & 228,72 & 80,31 & 194,14 & 195,64 & 76,89 & 1229,75 & 179,29 & 13,54 & 53,76 & 495,74 & 82,40 & 85,19 & 495,61 \\
\hline Lissotriton boscai & 29TNE69 & 101,00 & 128,02 & 91,01 & 39,86 & 4638,69 & 256,21 & 30,75 & 225,47 & 73,66 & 187,77 & 189,16 & 70,46 & 1311,34 & $\begin{array}{l}192,53 \\
\end{array}$ & 14,74 & 54,03 & 529,92 & 88,13 & 90,71 & 529,25 \\
\hline Lissotriton boscai & 29TNE73 & 100,00 & 130,48 & 89,04 & 37,71 & 4935,42 & 267,29 & 34,12 & 233,17 & 71,19 & 196,84 & 196,95 & 71,19 & 1223,43 & \begin{tabular}{|l|l|}
182,48 \\
\end{tabular} & \begin{tabular}{ll|}
12,47 \\
\end{tabular} & 55,44 & 500,58 & 77,23 & 77,23 & 500,58 \\
\hline Lissotriton boscai & 29TNE74 & 100,00 & 144,66 & 96,62 & 39,51 & 4909,73 & \begin{tabular}{|l|l|}
284,97 \\
\end{tabular} & 43,52 & 241,46 & 84,22 & 208,62 & 209,88 & 84,22 & $1088,21]$ & \begin{tabular}{|l|l|}
159,07 \\
\end{tabular} & $\begin{array}{l}10,86 \\
\end{array}$ & 54,50 & 442,33 & 70,82 & \begin{tabular}{|l|l|}
71,38 \\
\end{tabular} & 442,33 \\
\hline Lissotriton boscai & 29TNE75 & 101,00 & 154,08 & 101,29 & 40,82 & $\begin{array}{lll}4855,81 \\
\end{array}$ & 295,17 & $\begin{array}{ll}49,96 \\
\end{array}$ & 245,21 & 93,12 & 215,94 & 217,84 & 93,12 & $\begin{array}{l}998,76 \\
\end{array}$ & $\begin{array}{l}143,36 \\
\end{array}$ & 9,90 & 53,72 & $\begin{array}{l}402,78 \\
\end{array}$ & 65,75 & 68,01 & 402,78 \\
\hline Lissotriton boscai & 29TNE76 & 101,00 & 154,06 & 101,53 & 41,08 & 4813,66 & 293,38 & $\begin{array}{ll}49,62 \\
\end{array}$ & 243,76 & 93,18 & 215,14 & 216,88 & 93,18 & $\begin{array}{l}1005,56 \\
\end{array}$ & \begin{tabular}{|l|l|}
143,97 \\
\end{tabular} & 9,99 & 53,47 & 404,01 & 66,34 & \begin{tabular}{ll|l}
69,56 \\
\end{tabular} & 404,01 \\
\hline Lissotriton boscai & 29TNE77 & 100,00 & 151,71 & 100,66 & 41,18 & 4778,52 & 288,89 & 47,59 & 241,30 & $\begin{array}{ll}91,92 \\
\end{array}$ & 212,30 & 213,84 & \begin{tabular}{|c|c|}
91,08 \\
\end{tabular} & 1035,22 & 148,55 & \begin{tabular}{|l|l|}
10,42 \\
\end{tabular} & 53,45 & $\mid 415,23$ & 68,17 & 72,12 & 415,23 \\
\hline Lissotriton boscai & 29TNE78 & 100,00 & 148,15 & $\begin{array}{ll}99,57 \\
\end{array}$ & 41,25 & 4758,31 & 283,45 & 44,56 & 238,88 & 92,48 & 208,55 & 209,97 & 87,76 & 1076,81 & 155,12 & $\begin{array}{l}11,07 \\
\end{array}$ & 53,44 & \begin{tabular}{|l|l|}
431,68 \\
\end{tabular} & 70,90 & 75,54 & 431,42 \\
\hline Lissotriton boscai & 29TNE79 & 101,00 & 134,17 & \begin{tabular}{|l|l}
94,47 \\
\end{tabular} & 39,91 & 4800,60 & 267,62 & 33,70 & 233,92 & 76,77 & 196,11 & 197,26 & 74,32 & 1237,77 & $\begin{array}{l}181,96 \\
\end{array}$ & 13,33 & 54,13 & $\begin{array}{l}499,57 \\
\end{array}$ & 81,97 & 84,94 & 499,52 \\
\hline Lissotriton boscai & 29TNE83 & 100,00 & 136,83 & 91,53 & 37,62 & 5092,52 & \begin{tabular}{|l|}
278,06 \\
\end{tabular} & 37,73 & 240,33 & 75,38 & 204,90 & 205,18 & 75,38 & $\begin{array}{l}1153,36 \\
\end{array}$ & \begin{tabular}{|l|l|}
171,78 \\
\end{tabular} & \begin{tabular}{|l|l|}
11,27 \\
\end{tabular} & 55,46 & 471,89 & 72,49 & 72,49 & 471,89 \\
\hline Lissotriton boscai & 29TNE84 & 101,00 & 133,66 & 90,79 & 37,47 & 5087,30 & $\begin{array}{l}273,82 \\
\end{array}$ & 34,71 & 239,11 & 72,27 & 201,61 & 201,88 & 72,27 & $\begin{array}{l}1197,70 \\
\end{array}$ & $\begin{array}{l}179,06 \\
\end{array}$ & \begin{tabular}{ll|l}
11,86 \\
\end{tabular} & 55,43 & 489,74 & 75,49 & 75,49 & 489,74 \\
\hline Lissotriton boscai & 29TNE85 & 100,00 & 147,50 & $\begin{array}{ll}97,92 \\
\end{array}$ & 39,26 & 5042,36 & 289,99 & 44,08 & 245,90 & 85,04 & 212,90 & 214,17 & 85,04 & \begin{tabular}{|l|l|}
1059,06 \\
\end{tabular} & $\mid$\begin{tabular}{|l|l|}
155,04 \\
\end{tabular} & $\mid$\begin{tabular}{|l|l|}
10,29 \\
\end{tabular} & 54,51 & 429,45 & 68,30 & 69,66 & 429,45 \\
\hline |Lissotriton boscai & 29TNE86 & 100,00 & 150,11 & 99,94 & 39,99 & 5010,48 & 292,48 & 45,38 & 247,10 & 87,50 & 214,40 & 215,94 & 87,50 & 1037,19 & 150,83 & 10,03 & 54,12 & 418,79 & 67,60 & 69,74 & 418,79 \\
\hline Lissotriton boscai & 29TNE87 & 101,00 & 151,38 & 100,69 & 40,36 & 969,05 & 292,3 & 46,06 & 246,27 & 88,92 & 214,94 & 216,3 & 88,82 & 1027,25 & 148,92 & \begin{tabular}{l|l|}
9,93 \\
\end{tabular} & 53,91 & 13,26 & 66,69 & \begin{tabular}{ll|}
70,08 \\
\end{tabular} & 413,26 \\
\hline Lissotriton boscai & 29TNE88 & 101,00 & 149,07 & 100,28 & 40,46 & 4943,27 & 288,54 & 43,95 & 244,59 & 88,11 & 212,25 & 213,54 & 86,67 & $\begin{array}{l}1056,45 \\
\end{array}$ & 153,52 & 10,50 & 53,85 & 424,47 & 68,67 & 72,72 & 424,47 \\
\hline Lissotriton boscai & 29TNE89 & 99,00 & 143,28 & $\begin{array}{ll}98,96 \\
\end{array}$ & 40,16 & 4954,20 & 281,94 & 38,90 & 243,03 & 81,35 & 206,81 & 207,99 & 80,99 & 1124,35 & $\begin{array}{l}164,80 \\
\end{array}$ & 11,31 & 54,06 & 452,74 & 73,25 & 77,10 & 452,74 \\
\hline Lissotriton boscai & 29TNE96 & 100,00 & 144,25 & 96,90 & 38,48 & 5194,21 & 288,55 & $\begin{array}{ll}39,98 \\
\end{array}$ & 248,56 & 80,12 & 211,84 & 212,90 & 80,12 & 1084,89 & $\begin{array}{l}160,45 \\
\end{array}$ & 10,32 & 54,88 & 4440,40 & $\begin{array}{l}69,82 \\
\end{array}$ & 70,58 & 440,40 \\
\hline Lissotriton boscai & 29TNE97 & 100,00 & 147,75 & 99,20 & 39,25 & 5155,38 & 291,58 & 42,09 & 249,49 & 83,40 & 214,19 & 215,39 & 83,40 & 1050,55 & $\begin{array}{l}154,38 \\
\end{array}$ & 9,97 & 54,49 & 424,55 & 67,60 & \begin{tabular}{|c|}
69,74 \\
\end{tabular} & 424,55 \\
\hline Lissotriton boscai & 29TNE98 & 100,00 & 146,38 & 99,49 & 39,50 & 5130,69 & 289,32 & 40,54 & 248,78 & 82,20 & 212,43 & 213,62 & 82,20 & 1069,29 & 157,42 & 10,31 & 54,43 & 431,66 & 68,89 & \begin{tabular}{ll|}
71,63 \\
\end{tabular} & 431,66 \\
\hline 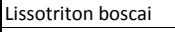 & 29TNF20 & 39,00 & 148,11 & 75,99 & 45 & 3278,87 & 228,40 & 62,72 & 165,68 & 111,24 & 185,74 & 187,30 & 102,70 & \begin{tabular}{|l}
1033,57 \\
\end{tabular} & 142,44 & 11,91 & 52,02 & 416,51 & 68,59 & 81,88 & 404,38 \\
\hline Lissotriton boscai & 29TNF27 & 83,00 & 143,39 & 83,67 & 44,84 & 3665,84 & 241,48 & 56,50 & 184,98 & 98,16 & 188,60 & 190,35 & 96,94 & 1229,74 & 168,04 & 15,06 & 51,32 & 488,82 & 83,48 & 101,82 & 488,58 \\
\hline Lissotriton boscai & 29TNF28 & 101,00 & 142,97 & 82,67 & 44,28 & 3688,89 & 241,72 & 57,07 & 184,65 & 96,45 & $\begin{array}{l}188,66 \\
\end{array}$ & $\begin{array}{l}190,33 \\
\end{array}$ & 96,40 & $\begin{array}{l}1246,49 \\
\end{array}$ & $\begin{array}{l}171,06 \\
\end{array}$ & \begin{tabular}{ll|}
15,08 \\
\end{tabular} & 51,64 & \begin{tabular}{ll|}
496,82 \\
\end{tabular} & 83,70 & 103,29 & 496,82 \\
\hline Lissotriton boscai & 29TNF29 & 100,00 & 143,40 & 81,55 & 43,81 & 3705,16 & 242,68 & 58,44 & 184,24 & 96,74 & 189,45 & 190,99 & 96,74 & 1253,60 & 172,57 & 14,95 & 51,94 & 500,80 & 83,10 & 104,21 & 500,80 \\
\hline Lissotriton boscai & 29TNF30 & 97,00 & 149,38 & 82,52 & 44,75 & 3564,68 & 241,69 & 59,15 & 182,54 & 109,24 & 191,41 & \begin{tabular}{|l|}
193,03 \\
\end{tabular} & 100,90 & 1039,18 & \begin{tabular}{|l|l|}
143,20 \\
\end{tabular} & \begin{tabular}{|c|}
11,86 \\
\end{tabular} & 52,06 & 418,81 & 69,12 & 81,84 & 406,13 \\
\hline Lissotriton boscai & 29TNF31 & 101,00 & 148,07 & 83,26 & 44,69 & 3597,97 & 241,68 & 57,46 & 184,22 & $\begin{array}{l}107,87 \\
\end{array}$ & 190,73 & $\begin{array}{l}192,50 \\
\end{array}$ & 99,47 & $\begin{array}{l}1065,36 \\
\end{array}$ & $\begin{array}{l}146,05 \\
\end{array}$ & 12,24 & 52,00 & 429,98 & 71,06 & 85,21 & 414,46 \\
\hline Lissotriton boscai & 29TNF32 & 101,00 & 145,57 & 84,92 & 44,51 & 3682,73 & 242,81 & $\begin{array}{ll}53,91 \\
\end{array}$ & 188,90 & 104,71 & $\begin{array}{l}189,77 \\
\end{array}$ & $\begin{array}{l}191,53 \\
\end{array}$ & 96,39 & $\begin{array}{l}1108,58 \\
\end{array}$ & 151,23 & \begin{tabular}{ll|}
13,26 \\
\end{tabular} & 51,97 & 448,35 & 74,67 & 90,24 & 429,45 \\
\hline Lissotriton boscai & 29TNF33 & 100,00 & 143,08 & 86,64 & 44,26 & 3769,42 & 244,08 & 50,32 & 193,75 & 101,57 & 188,84 & 190,75 & 93,44 & 1153,38 & 156,89 & 14,21 & 51,96 & 467,44 & 78,42 & 95,49 & 444,94 \\
\hline Lissotriton boscai & 29TNF34 & 101,00 & 142,93 & 88,24 & 44,24 & 3832,79 & 246,60 & 49,26 & 97,34 & 100,95 & 189,74 & 191 & 92 & 1169 & 160 & 14,84 & 51 & 475,06 & 79 & 99,15 & 447 \\
\hline Lissotriton boscai & $29 \mathrm{TN}$ & 101 & 143,79 & 89,17 & 44 & & $24 \varepsilon$ & 50,08 & \begin{tabular}{|l|l|}
198,78 \\
\end{tabular} & 101,82 & 191,19 & 193,23 & 93,92 & 117 & 16 & 15,00 & 51,60 & 4776,56 & 80,52 & 100,90 & 450,62 \\
\hline Lissotriton boscai & 29TNF36 & 100,00 & 142,72 & 88,75 & 44,37 & 3874,54 & \begin{tabular}{|l|}
248,10 \\
\end{tabular} & 50,30 & 197,80 & 100,59 & 190,60 & 192,54 & 93,19 & $\begin{array}{l}1208,89 \\
\end{array}$ & 165,64 & 15,18 & 51,16 & 484,74 & 82,84 & \begin{tabular}{|l|l|}
101,99 \\
\end{tabular} & 470,16 \\
\hline Lissotriton boscai & 29TNF37 & 101,00 & 143,27 & 87,78 & 44,23 & 3880,42 & 248,43 & 52,12 & 196,31 & 100,95 & 191,39 & 193,10 & 3,98 & 1219,17 & $\begin{array}{l}165,45 \\
\end{array}$ & $\begin{array}{l}15,05 \\
\end{array}$ & 51,07 & 485,64 & 82,94 & $\begin{array}{l}101,87 \\
\end{array}$ & 478,73 \\
\hline Lissotriton boscai & 29TNF38 & 101,00 & 142,52 & 86,87 & 43,81 & 3905,18 & 248,58 & 52,35 & 96,23 & 99,41 & 191,21 & 192,75 & 93,25 & 1241,90 & 168,32 & 15,31 & 51,18 & 493,36 & 84,21 & 103,44 & 490,86 \\
\hline \begin{tabular}{|l|l|l|} 
Lissotr \\
\end{tabular} & & 100 & & & & & $24 \subseteq$ & 53,49 & • & 97, & 191 & & & 1252,93 & 16 & & & \begin{tabular}{|c|}
497,59 \\
\end{tabular} & & 104,50 & 49 \\
\hline 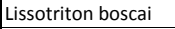 & 29TNF40 & 100,00 & 147,44 & 89,30 & 43,83 & 3923,90 & 254,03 & 52,39 & 201,63 & 103,46 & 195,05 & $\begin{array}{l}196,67 \\
\end{array}$ & 95 & 1079,1 & 149,73 & 12,26 & 52,06 & 434,59 & 72,22 & 83,50 & 423,05 \\
\hline Lissotriton boscai & 29TNF41 & 101,00 & 142,38 & 89,36 & 43,37 & 3991,40 & 250,94 & 47,24 & 203,70 & 98,11 & 191,25 & \begin{tabular}{|l|l|}
193,01 \\
\end{tabular} & 90,04 & $\begin{array}{l}1145,99 \\
\end{array}$ & 159,30 & 13,48 & 52,06 & 462,52 & 77,32 & 89,31 & 448,96 \\
\hline
\end{tabular}




\begin{tabular}{|c|c|c|c|c|c|c|c|c|c|c|c|c|c|c|c|c|c|c|c|c|c|}
\hline TAXON & UTM & $\mathrm{km} 2$ & BIO1 & B102 & $B 103$ & BIO4 & B105 & B106 & B107 & B108 & 8109 & B1010 & BIO11 & BIO12 & BIO13 & BIO14 & BIO15 & B1016 & B1017 & B1018 & 81019 \\
\hline Lissotriton boscai & 29TNF42 & 100,00 & 139,86 & 89,98 & 43,29 & 4039,26 & 249,99 & 44,34 & 205,65 & 95,41 & 189,66 & 191,42 & 87,24 & 1184,27 & 164,08 & 14,18 & 52,01 & 478,82 & 80,25 & 93,42 & 462,77 \\
\hline 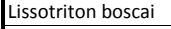 & 29TNF43 & 100,00 & 139,21 & 90,71 & 43,30 & 4069,14 & 250,59 & 43,39 & 207,20 & 94,59 & 189,62 & 191,44 & 86,51 & 1202,18 & 165,41 & 14,71 & 52,01 & 486,77 & 81,77 & 96,65 & 467,70 \\
\hline Lissotriton boscai & 29TNF44 & 101,00 & 145,19 & 91,73 & 43,95 & 4024,80 & 255,19 & 48,47 & 206,73 & 100,89 & $\begin{array}{l}194,71 \\
\end{array}$ & $\begin{array}{l}196,60 \\
\end{array}$ & 92,76 & 1143,15 & 155,45 & 13,92 & 51,95 & 463,79 & 77,06 & 95,12 & 439,23 \\
\hline Lissotriton boscai & 29TNF45 & 100,00 & 143,60 & 92,24 & 43,84 & $\begin{array}{l}4070,49 \\
\end{array}$ & 255,27 & 46,97 & 208,31 & $\begin{array}{ll}98,94 \\
\end{array}$ & 194,03 & 195,90 & 91,10 & 1174,73 & 159,85 & 14,55 & 51,68 & 475,51 & 79,77 & 98,42 & 452,40 \\
\hline Lissotriton boscai & 29TNF46 & 101,00 & 139,99 & 92,04 & 43,58 & 4124,76 & 253,26 & 44,26 & 208,99 & 94,91] & 191,59 & 193,29 & 87,44 & 1229,65 & 167,21 & 15,41 & 51,34 & 495,06 & 84,11 & 101,93 & 478,38 \\
\hline Lissotriton boscai & 29TNF47 & 100,00 & 139,14 & 91,24 & 43,32 & 4147,14 & 252,84 & 44,35 & 208,48 & 93,89 & 191,25 & $\mid \begin{array}{l}192,76 \\
\end{array}$ & 86,61 & 1253,11 & 169,91 & \begin{tabular}{|c|c|}
15,81 \\
\end{tabular} & 51,14 & 501,37 & 86,32 & $\mid \begin{array}{l}103,48 \\
\end{array}$ & 491,26 \\
\hline 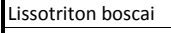 & 29TNF48 & 100,00 & 142,13 & 90,79 & 43,15 & 4135,87 & 255,81 & 47,93 & 207,87 & 96,82 & 194,12 & 195,50 & 89,72 & 1230,59 & 165,88 & 15,35 & 51,02 & 490,29 & 84,29 & 102,44 & 483,04 \\
\hline Lissotriton boscai & 29TNF49 & 101,00 & 139,80 & 89,86 & 42,66 & 4175,54 & 254,55 & 46,33 & 208,22 & \begin{tabular}{|l|l|}
94,19 \\
\end{tabular} & $\begin{array}{l}192,55 \\
\end{array}$ & $\begin{array}{l}193,76 \\
\end{array}$ & 87,19 & 1270,24 & $\begin{array}{l}171,95 \\
\end{array}$ & 16,30 & 51,01 & 504,73 & \begin{tabular}{l|l}
88,23 \\
\end{tabular} & 105,84 & 500,86 \\
\hline Lissotriton boscai & 29TNF50 & 101,00 & 139,58 & 92,61 & 42,17 & 4304,23 & 258,99 & 41,99 & 217,01 & \begin{tabular}{|l|l}
92,04 \\
\end{tabular} & $\begin{array}{l}193,36 \\
\end{array}$ & 195,11 & 84,30 & 1181,11 & $\begin{array}{l}167,89 \\
\end{array}$ & \begin{tabular}{l|l|l}
13,43 \\
\end{tabular} & 52,76 & \begin{tabular}{|l|l|}
475,58 \\
\end{tabular} & 79,54 & 87,48 & 468,92 \\
\hline Lissotriton boscai & 29TNF51 & 101,00 & $\begin{array}{ll}130,68 \\
\end{array}$ & 90,91 & 41,39 & 4383,84 & 251,56 & 34,36 & 217,20 & 83,11 & \begin{tabular}{ll|}
186,06 \\
\end{tabular} & \begin{tabular}{|l|l|}
187,79 \\
\end{tabular} & 75,27 & 1291,53 & 185,22 & 15,29 & 52,99 & 520,41 & 88,04 & 94,96 & 515,26 \\
\hline Lissotriton boscai & 29TNF53 & 101,00 & 139,12 & 93,95 & 42,65 & 4304,01 & 258,06 & 40,55 & 217,52 & 91,75 & 192,97 & $\begin{array}{l}194,65 \\
\end{array}$ & 83,83 & 1206,82 & $\begin{array}{l}168,46 \\
\end{array}$ & 14,26 & 52,14 & 487,19 & 81,32 & 94,06 & 473,32 \\
\hline Lissotriton boscai & 29TNF54 & 101,00 & 143,24 & 94,76 & 43,14 & $\begin{array}{l}4278,36 \\
\end{array}$ & 261,19 & 44,06 & 217,13 & 96,03 & $\begin{array}{ll}196,62 \\
\end{array}$ & \begin{tabular}{ll|}
198,24 \\
\end{tabular} & 88,15 & 1165,91 & 160,49 & 13,81 & 51,97 & 470,68 & 78,26 & 93,43 & 453,65 \\
\hline Lissotriton boscai & 29TNF55 & 100,00 & 140,87 & 95,08 & 42,94 & 4326,04 & 260,24 & 41,73 & 218,51 & 93,30 & 195,21 & 196,68 & 85,53 & 1202,49 & 165,11 & 14,53 & 51,85 & 484,56 & 81,28 & 96,84 & 468,84 \\
\hline Lissotriton boscai & 29TNF56 & 101,00 & 139,94 & 95,13 & 42,95 & 4354,26 & 260,13 & 41,13 & 219,00 & 92,16 & $\begin{array}{l}194,79 \\
\end{array}$ & $\begin{array}{l}196,27 \\
\end{array}$ & 84,56 & 1221,82 & $\begin{array}{l}166,99 \\
\end{array}$ & \begin{tabular}{ll|}
14,97 \\
\end{tabular} & 51,64 & $\begin{array}{l}490,56 \\
\end{array}$ & 83,17 & 98,86 & 477,69 \\
\hline Lissotriton boscai & 29TNF57 & 101,00 & 136,33 & 94,43 & 42,54 & 4395,62 & 257,89 & 38,43 & 219,46 & 88,25 & 192,09 & 193,38 & 80,76 & 1271,83 & 173,49 & 15,97 & 51,45 & 508,53 & 87,85 & 102,68 & 500,28 \\
\hline Lissotriton boscai & 29TNF58 & 100,00 & 142,10 & 94,36 & 42,68 & 4362,30 & 262,89 & 44,19 & 218,70 & 94,05 & $\begin{array}{ll}197,22 \\
\end{array}$ & 198,42 & 86,75 & 1212,75 & $\begin{array}{l}162,86 \\
\end{array}$ & \begin{tabular}{l|l|}
15,06 \\
\end{tabular} & 51,03 & $\begin{array}{l}482,85 \\
\end{array}$ & 83,48 & $\begin{array}{lll}99,97 \\
\end{array}$ & 474,72 \\
\hline Lissotriton boscai & 29TNF59 & 101,00 & 139,94 & 93,48 & 42,13 & 4393,00 & 261,73 & 42,64 & 219,10 & $\begin{array}{ll}91,63 \\
\end{array}$ & 195,73 & 196,85 & 84,56 & $\begin{array}{l}1243,58 \\
\end{array}$ & \begin{tabular}{|l|l|}
167,10 \\
\end{tabular} & 16,12 & 50,99 & 493,44 & 87,40 & $\begin{array}{l}103,38 \\
\end{array}$ & 487,78 \\
\hline Lissotriton boscai & 29TNF60 & 100,00 & 135,03 & 94,39 & 41,03 & 4585,71 & 262,88 & 35,58 & 227,30 & 84,44 & 193,27 & $\begin{array}{l}194,86 \\
\end{array}$ & 77,17 & 1237,64 & \begin{tabular}{|l|l|}
179,24 \\
\end{tabular} & 13,79 & 53,37 & 498,24 & 82,88 & 88,33 & 495,79 \\
\hline |Lissotriton boscai & 29TNF61 & 100,00 & 135,59 & 94,12 & 41,30 & 4545,64 & 261,58 & 36,27 & 225,31 & 84,47 & 193,36 & 194,77 & 78,12 & 1233,48 & 177,66 & 13,94 & 53,23 & 497,11 & 82,71 & 89,56 & 492,25 \\
\hline 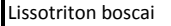 & 29TNF62 & 101,00 & 119,24 & 89,37 & 39,56 & 4648,32 & 246,04 & 23,36 & 222,68 & 65,19 & 179,50 & 180,74 & 62,13 & 1421,55 & 207,84 & 17,24 & 53,69 & 573,99 & 97,86 & 101,46 & 572,57 \\
\hline 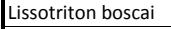 & 29TNF63 & 100,00 & 137,18 & 96,37 & 41,92 & 4552,30 & 263,63 & 36,45 & 227,18 & 87,09 & \begin{tabular}{|l|l}
194,87 \\
\end{tabular} & 196,22 & 79,29 & 1227,80 & 174,69 & 14,04 & 52,72 & \begin{tabular}{|l|l|}
494,00 \\
\end{tabular} & 82,05 & 92,22 & 486,62 \\
\hline Lissotriton boscai & 29TNF64 & 100,00 & 139,87 & 96,89 & 42,25 & 4533,38 & 265,28 & 38,81 & 226,47 & $\begin{array}{ll}89,13 \\
\end{array}$ & $\begin{array}{l}197,19 \\
\end{array}$ & 198,52 & 82,13 & 1200,42 & 169,04 & 13,86 & 52,38 & 482,70 & 80,33 & 92,20 & 473,27 \\
\hline Lissotriton boscai & 29TNF65 & 101,00 & 141,16 & 97,96 & 42,54 & 4548,34 & 267,19 & 39,49 & 227,70 & 90,78 & 198,67 & $\begin{array}{l}199,98 \\
\end{array}$ & 83,18 & 1191,76 & 166,29 & 13,82 & 52,13 & 478,12 & 79,78 & 93,05 & 468,42 \\
\hline Lissotriton boscai & 29TNF66 & 100,00 & 140,95 & 98,10 & 42,56 & 4557,92 & 267,53 & 39,38 & 228,15 & 90,49 & 198,65 & 199,92 & 82,92 & $\begin{array}{l}1198,66 \\
\end{array}$ & \begin{tabular}{ll|}
165,92 \\
\end{tabular} & 14,16 & 51,88 & 479,50 & 80,88 & 94,69 & 470,84 \\
\hline Lissotriton boscai & 29TNF67 & 100,00 & 139,03 & 97,85 & 42,15 & 4589,24 & 266,73 & 37,67 & 229,06 & 88,29 & 197,36 & 198,49 & 80,91 & 1225,60 & 168,33 & 14,86 & 51,72 & 488,61 & 83,77 & 97,47 & 482,14 \\
\hline 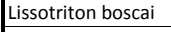 & 29TNF68 & 101,00 & 137,90 & 97,23 & 41,97 & 4606,79 & 266,17 & 37,05 & 229,12 & 87,12 & $\begin{array}{l}196,63 \\
\end{array}$ & $\begin{array}{l}197,66 \\
\end{array}$ & 79,77 & 1240,93 & 168,44 & 15,51 & 51,33 & 492,91 & 86,19 & 99,84 & 488,19 \\
\hline Lissotriton boscai & 29TNF69 & 100,00 & 135,31 & 96,15 & 41,53 & 4630,85 & 264,13 & 35,32 & 228,80 & 83,85 & 194,67 & 195,62 & 77,28 & 1267,98 & 170,11 & 16,66 & 50,99 & 502,08 & 90,32 & 103,32 & 498,82 \\
\hline Lissotriton boscai & 29TNF70 & 100,00 & 131,12 & 93,82 & 39,84 & 4794,23 & 263,60 & 31,18 & 232,42 & 74,29 & 193,10 & 194,21 & 71,49 & $\begin{array}{l}1276,03 \\
\end{array}$ & \begin{tabular}{|l|l|}
187,97 \\
\end{tabular} & 13,92 & 54,17 & 515,51 & 84,71 & 88,05 & 514,91 \\
\hline Lissotriton boscai & 29TNF71 & 101,00 & 138,55 & 97,23 & 41,02 & 4748,50 & 270,65 & 36,33 & 234,32 & 84,96 & 199,28 & 200,42 & 78,59 & 1195,33 & 173,64 & 12,91 & 53,50 & 480,83 & 78,99 & 85,21 & 478,45 \\
\hline Lissotriton boscai & 29TNF72 & 100,00 & 124,75 & 93,12 & 39,79 & \begin{tabular}{|l|l|}
4811,33 \\
\end{tabular} & 256,79 & 25,56 & 231,23 & 67,57 & \begin{tabular}{|l|l|}
187,14 \\
\end{tabular} & 188,20 & 65,25 & \begin{tabular}{ll|}
1354,86 \\
\end{tabular} & \begin{tabular}{|l|l|}
199,64 \\
\end{tabular} & \begin{tabular}{|l|l|}
15,47 \\
\end{tabular} & 54,07 & 547,42 & 91,22 & 94,88 & 546,90 \\
\hline Lissotriton boscai & 29TNF73 & 100,00 & 125,97 & 94,19 & 40,16 & 4798,34 & 257,82 & 26,19 & 231,62 & \begin{tabular}{|l|l|}
69,94 \\
\end{tabular} & 188,03 & \begin{tabular}{|l|l|}
189,07 \\
\end{tabular} & 66,37 & $\begin{array}{l}1340,38 \\
\end{array}$ & $\begin{array}{l}195,83 \\
\end{array}$ & \begin{tabular}{ll|}
15,66 \\
\end{tabular} & 53,65 & 540,51 & 90,73 & 95,98 & 538,99 \\
\hline Lissotriton boscai & 29TNF74 & 101,00 & 128,99 & 95,57 & 40,63 & 4783,60 & 260,61 & 28,37 & 232,24 & 72,85 & 190,58 & \begin{tabular}{|l|l|}
191,63 \\
\end{tabular} & 69,36 & 1309,76 & $\mid 189,73$ & 15,35 & 53,31 & 527,26 & 88,82 & 95,55 & 524,72 \\
\hline Lissotriton boscai & 29TNF75 & 100,00 & 137,44 & 99,71 & 41,73 & 4775,34 & 270,14 & 34,08 & 236,05 & 82,59 & 198,39 & 199,50 & 77,09 & 1223,22 & 174,59 & 13,90 & 52,80 & 489,74 & 81,78 & 91,80 & 486,31 \\
\hline Lissotriton boscai & 29TNF76 & 101,00 & 141,79 & 100,39 & 41,96 & 4748,21 & 274,06 & 37,90 & 236,17 & 87,98 & 202,21 & 203,32 & 81,53 & 1172,75 & 164,56 & 13,40 & 52,24 & 467,99 & 78,52 & 90,37 & 462,94 \\
\hline Lissotriton boscai & 29TNF77 & 100,00 & 139,96 & 100,63 & 41,82 & \begin{tabular}{ll|l|}
4786,69 \\
\end{tabular} & 273,79 & 35,96 & \begin{tabular}{|l|l}
237,83 \\
\end{tabular} & 85,58 & \begin{tabular}{|l|l|}
201,14 \\
\end{tabular} & 201,93 & 79,40 & $\begin{array}{l}1195,50 \\
\end{array}$ & \begin{tabular}{ll|l}
166,38 \\
\end{tabular} & 14,04 & 52,04 & $\begin{array}{l}475,06 \\
\end{array}$ & 81,10 & 92,96 & 472,06 \\
\hline Lissotriton boscai & 29TNF78 & 101,00 & 126,95 & 97,32 & 40,78 & \begin{tabular}{ll|l|}
4844,60 \\
\end{tabular} & 261,42 & 25,75 & $\begin{array}{ll}235,68 \\
\end{array}$ & \begin{tabular}{|l|l|}
68,04 \\
\end{tabular} & $\begin{array}{ll}189,60 \\
\end{array}$ & $\begin{array}{l}190,52 \\
\end{array}$ & 66,83 & 1333,31 & 185,94 & 17,30 & 52,04 & 531,44 & 94,53 & 103,38 & 531,32 \\
\hline Lissotriton boscai & 29TNF79 & 101,00 & 124,43 & 95,81 & 40,47 & 4841,80 & 258,19 & 24,30 & 233,89 & 65,58 & 187,19 & 188,09 & 64,62 & 1349,39 & 185,11 & 18,55 & 51,51 & 536,28 & 98,47 & 107,09 & 536,16 \\
\hline Lissotriton boscai & 29TNF80 & 101,00 & 137,26 & 97,59 & 39,95 & $4966,71 \mid$ & 275,12 & 33,90 & 241,22 & 75,65 & 201,18 & 202,29 & 75,13 & 1195,95 & 176,73 & 12, & 54,37 & 482,82 & 78,28 & 81,81 & 482,81 \\
\hline Lissotriton boscai & 29TNF81 & 101,00 & 138,58 & 98,97 & 40,41 & 4957,04 & 276,29 & 34,33 & 241,95 & 78,33 & 202,15 & 203,23 & 76,25 & 1184,88 & $\mid 174,47$ & 12,24 & 54,20 & 477,17 & 77,25 & 82,20 & 477,00 \\
\hline Lissotriton boscai & 29TNF82 & 100,00 & 133,58 & $\begin{array}{ll}98,23 \\
\end{array}$ & 40,21 & 4971,25 & 271,19 & \begin{tabular}{|l|l|}
30,14 \\
\end{tabular} & 241,06 & 73,00 & $\begin{array}{l}197,70 \\
\end{array}$ & $\begin{array}{l}198,66 \\
\end{array}$ & 71,47 & $\begin{array}{l}1244,51 \\
\end{array}$ & $\begin{array}{l}184,08 \\
\end{array}$ & 13,26 & 54,36 & 502,42 & 81,71 & 86,36 & 502,12 \\
\hline Lissotriton boscai & 29TNF83 & 101,00 & 109,14 & 87,77 & 37,62 & 4975,93 & 242,62 & 12,70 & 229,92 & 49,47 & \begin{tabular}{|l|l|}
175,17 \\
\end{tabular} & 175,58 & 49,22 & $\begin{array}{l}1493,52 \\
\end{array}$ & 222,19 & \begin{tabular}{|l|}
18,53 \\
\end{tabular} & 54,42 & 606,03 & 102,49 & 103,59 & 606,01 \\
\hline Lissotriton boscai & 29TNF84 & 101,00 & 118,90 & 93,61 & 39,19 & 4982,55 & 254,88 & 19,09 & 235,79 & 58,28 & 184,21 & 184,84 & 57,85 & $\begin{array}{l}1397,56 \\
\end{array}$ & $\begin{array}{l}206,45 \\
\end{array}$ & 16,64 & 54,06 & $\begin{array}{l}565,62 \\
\end{array}$ & $\begin{array}{ll}95,33 \\
\end{array}$ & $\begin{array}{l}98,47 \\
\end{array}$ & 565,51 \\
\hline Lissotriton boscai & 29TNF85 & 100,00 & 136,01 & 101,39 & 41,17 & 4965,90 & 274,28 & 30,99 & 243,29 & 75,89 & 199,76 & 200,67 & 73,51 & 1222,05 & 177,54 & 13,56 & 53,63 & 490,55 & 81,16 & $89,01$. & 489,57 \\
\hline 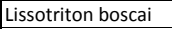 & 29TNF86 & 101,00 & 125,67 & 98,43 & 40,38 & \begin{tabular}{|l|l|}
4998,73 \\
\end{tabular} & 264,11 & 23,07 & 241,04 & $\begin{array}{ll}64,83 \\
\end{array}$ & 190,54 & \begin{tabular}{|l|l|}
191,36 \\
\end{tabular} & 63,74 & $\begin{array}{l}1325,58 \\
\end{array}$ & 192,39 & 15,93 & 53,57 & 533,46 & 91,11 & 96,93 & 533,22 \\
\hline 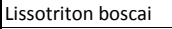 & 29TNF87 & 101,00 & 135,01 & 101,65 & 41,07 & $\begin{array}{l}4987,46 \\
\end{array}$ & 274,44 & 29,83 & 244,61 & 74,73 & 199,17 & 199,92 & 72,50 & 1223,35 & 174,13 & 14,38 & 52,84 & 488,05 & 83,36 & 92,32 & 487,44 \\
\hline 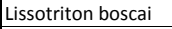 & 29TNF88 & 99,00 & 141,71 & 103,14 & 41,42 & 4974,24 & 281,45 & 35,06 & 246,39 & 83,10 & 205,58 & 206,22 & 78,92 & \begin{tabular}{|l|}
1144,18 \\
\end{tabular} & 158,88 & 13,41 & 52,08 & 452,19 & 78,01 & 89,11 & 451,23 \\
\hline Lissotriton boscai & 29TNF89 & 101,00 & $\begin{array}{ll}138,03 \\
\end{array}$ & 102,06 & 40,95 & 4999,15 & 277,95 & 31,91 & \begin{tabular}{|l|l|}
246,04 \\
\end{tabular} & 78,21 & 202,41 & 202,92 & 75,17 & $\begin{array}{l}1176,14 \\
\end{array}$ & $\begin{array}{l}161,05 \\
\end{array}$ & $\begin{array}{l}14,66 \\
\end{array}$ & 51,68 & \begin{tabular}{ll|}
463,52 \\
\end{tabular} & 82,57 & $\begin{array}{l}92,81 \\
\end{array}$ & 463,14 \\
\hline Lissotriton boscai & 29TNF90 & 100,00 & 135,74 & 97,24 & 39,11 & 5140,79 & 277,09 & 31,58 & 245,51 & 71,87 & 202,41 & 203,33 & 71,87 & 1192,29 & 178,24 & 11,99 & 54,96 & 483,60 & 77,32 & 79,46 & 483,60 \\
\hline 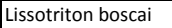 & 29TNF91 & 100,00 & 132,75 & 97,32 & 39,23 & 5137,78 & 273,84 & 28,79 & 245,06 & 68,99 & 199,50 & 200,32 & \begin{tabular}{|c|}
68,99 \\
\end{tabular} & \begin{tabular}{|l|}
1228,40 \\
\end{tabular} & \begin{tabular}{|l|}
184,01 \\
\end{tabular} & 12,60 & 55,01 & \begin{tabular}{|l|l|}
498,40 \\
\end{tabular} & 79,94 & 82,35 & 498,40 \\
\hline Lissotriton boscai & 29TNF92 & 101,00 & 126 & $\begin{array}{l}96,14 \\
\end{array}$ & 39,03 & 514 & 267,40 & 23,92 & 243,48 & 63,31 & \begin{tabular}{ll|l|}
193,92 \\
\end{tabular} & \begin{tabular}{ll|}
194,57 \\
\end{tabular} & 63,31 & \begin{tabular}{|l|}
1295,64 \\
\end{tabular} & \begin{tabular}{|l|l|}
194,83 \\
\end{tabular} & 13,75 & 55,18 & 526,94 & 85,17 & 87,05 & 526,94 \\
\hline Lissotriton boscai & 29TNF93 & 100,00 & 112,22 & 89,85 & 37,50 & 5123,48 & 249,76 & $\begin{array}{ll}13,62 \\
\end{array}$ & $\begin{array}{ll}236,13 \\
\end{array}$ & \begin{tabular}{|l|l|}
50,27 \\
\end{tabular} & 180,26 & $\begin{array}{l}180,45 \\
\end{array}$ & 50,27 & 1440,64 & 216,60 & 16,93 & 55,02 & 587,21 & 97,41 & $\begin{array}{l}97,51 \\
\end{array}$ & 587,21 \\
\hline Lissotriton boscai & 29TNF94 & 100,00 & 117,18 & 94,18 & 38,63 & 5143,77 & 257,13 & 16,22 & 240,91 & 54,41 & \begin{tabular}{|l|l|}
184,94 \\
\end{tabular} & 185,37 & 54,41 & $\begin{array}{l}1388,86 \\
\end{array}$ & 207,75 & 16,25 & 54,85 & 564,88 & 94,28 & 95,58 & 564,88 \\
\hline Lissotriton boscai & 29TNF95 & 101,00 & 138,40 & 103,35 & 40,82 & 5122,49 & 281,31 & 31,16 & 250,14 & 75,40 & 204,41 & 205,04 & 74,01 & 1168,52 & $\mid 171,57$ & $\mid 12,46$ & 54,07 & 469,70 & 76,62 & 82,85 & 469,33 \\
\hline Lissotriton boscai & 29TNF96 & 100,00 & 122 & 99,04 & 39,6 & 516 & 265 & 18,77 & 246 & 58,88 & 189 & 190,40 & 58,88 & \begin{tabular}{|l|}
1327,04 \\
\end{tabular} & 195,32 & $\begin{array}{ll}16,05 \\
\end{array}$ & 54,19 & 536,19 & 91,36 & 95,12 & 536,19 \\
\hline Lissotriton boscai & 29TNF97 & 100,00 & \begin{tabular}{ll|}
115,88 \\
\end{tabular} & 95,90 & 39,03 & 5136,17 & 257,03 & 14,56 & 242,47 & 53,35 & \begin{tabular}{|l|l|}
183,44 \\
\end{tabular} & 183,91 & 53,35 & \begin{tabular}{|l|}
1372,61 \\
\end{tabular} & \begin{tabular}{|l|l|}
199,44 \\
\end{tabular} & 17,95 & 53,49 & 553,49 & 98,06 & 101,01 & 553,49 \\
\hline Lissotriton boscai & 29TNF98 & 101,00 & $\begin{array}{ll}121,02 \\
\end{array}$ & 98,41 & 39,61 & 5139,73 & 263,22 & 17,96 & 245,26 & \begin{tabular}{|l|l|}
57,91 \\
\end{tabular} & 188,29 & \begin{tabular}{ll|}
188,76 \\
\end{tabular} & 57,91 & 1316,53 & 188,74 & $\begin{array}{l}17,26 \\
\end{array}$ & 53,01 & 528,34 & 94,25 & $\begin{array}{l}98,83 \\
\end{array}$ & 528,34 \\
\hline Lissotriton boscai & 29TNF99 & 100,00 & 135,05 & 103,43 & 40,67 & 5161,06 & 279,51 & 27,52 & 251,99 & 71,37| & 201,96 & 202,26 & 70,61 & 1168,49 & 163,49 & 14,49 & 52,32 & 463,38 & 81,88 & $88,21$. & 463,32 \\
\hline Lissotriton boscai & 29TNG06 & 3,00 & 146,50 & 63,83 & 40,00 & 3452,67 & 231,67 & 74,33 & 157,33 & 110,50 & 189,33 & $\begin{array}{l}191,17 \\
\end{array}$ & 102,50 & 307,17 & 181,00 & 23,00 & 49,00 & 525,83 & 103,17 & 125,33 & 502,17 \\
\hline Lissotriton boscai & 29TNG08 & & & & & & & & & & & & & & & & & & & & \\
\hline Lissotriton boscai & 29TNG09 & & & & & & & & & & & & & & & & & & & & \\
\hline
\end{tabular}




\begin{tabular}{|c|c|c|c|c|c|c|c|c|c|c|c|c|c|c|c|c|c|c|c|c|c|}
\hline TAXON & UTM & $\mathrm{km} 2$ & BIO1 & B102 & $B 103$ & BIO4 & B105 & B106 & B107 & B108 & B109 & B1010 & BIO11 & B1012 & BIO13 & BIO14 & BIO15 & B1016 & B1017 & B1018 & 81019 \\
\hline Lissotriton boscai & 29TNG11 & 68,00 & 142,97 & 75,17 & 42,97 & 3566,09 & 236,70 & 63,82 & 172,88 & 98,36 & 187,37 & 188,68 & 98,36 & 1288,24 & 180,59 & 15,17 & 52,45 & 518,55 & 83,56 & 108,22 & 518,55 \\
\hline Lissotriton boscai & 29TNG12 & 87,00 & 137,29 & 73,96 & 42,06 & 3627,14 & 232,43 & 58,62 & 173,81 & 92,83 & 182,87 & $\begin{array}{l}184,29 \\
\end{array}$ & 92,14 & $\begin{array}{r}1378,35 \\
\end{array}$ & 191,82 & 19,18 & 51,61 & 553,01 & 96,64 & 118,57 & 552,97 \\
\hline Lissotriton boscai & 29TNG13 & 86,00 & 140,49 & 72,13 & \begin{tabular}{ll|}
41,64 \\
\end{tabular} & 3603,62 & 234,13 & 62,90 & 171,23 & 100,04 & 185,70 & $\begin{array}{l}187,01 \\
\end{array}$ & 95,30 & 1358,91 & $\begin{array}{l}189,08 \\
\end{array}$ & 19,68 & 51,07 & \begin{tabular}{|l|l|}
544,43 \\
\end{tabular} & 96,92 & 119,11 & 541,84 \\
\hline Lissotriton boscai & 29TNG14 & 99,00 & 141,35 & 69,97 & 41,01 & 3592,14 & 233,55 & 65,01 & 168,54 & 103,58 & 186,44 & $\begin{array}{l}187,73 \\
\end{array}$ & 96,16 & 1368,59 & $\begin{array}{l}193,12 \\
\end{array}$ & 21,54 & 50,70 & 549,61 & 101,51 & 122,99 & 542,04 \\
\hline Lissotriton boscai & 29TNG15 & 101,00 & 132,16 & 69,72 & 40,14 & 3685,33 & 227,32 & 55,75 & 171,56 & 93,81 & 178,93 & 180,33 & 86,39 & 1509,91 & 227,25 & 27,33 & 50,50 & 609,48 & 119,62 & 138,03 & 604,19 \\
\hline Lissotriton boscai & 29TNG16 & 63,00 & 144,91 & 65,38 & 39,81 & 3554,55 & 233,48 & 71,05 & $\mid 162,43$ & $\mid 107,66$ & 189,68 & 190,80 & |99,84 & 1361,27 & \begin{tabular}{|l|l|}
195,80 \\
\end{tabular} & 24,69 & 49,54 & 549,03 & $\mid 108,17$ & $\mid 128,84$ & 528,42 \\
\hline Lissotriton boscai & 29TNG17 & 33,00 & 149,14 & 62,22 & 38,97 & 3510,00 & $234,61 \mid$ & 76,97 & 157,64 & 112,28 & 193,11 & 194,33 & 104,31 & 1294,33 & 179,89 & 25,03 & 48,31 & 519,61 & 107,44 & 128,50 & 486,56 \\
\hline Lissotriton boscai & 29TNG18 & 45,00 & 144,43 & 61,74 & 38,37 & 3541,20 & 231,42 & 73,05 & 158,37 & 107,44 & 189,24 & $\begin{array}{l}190,36 \\
\end{array}$ & 99,57 & 1364,63 & \begin{tabular}{|l|l|}
199,30 \\
\end{tabular} & 28,12 & 48,48 & 549,64 & 116,34 & $\begin{array}{l}136,83 \\
\end{array}$ & 520,34 \\
\hline Lissotriton boscai & 29TNG19 & 57,00 & 145,12 & 59,99 & $\begin{array}{l}37,97 \\
3\end{array}$ & 3519,84 & 230,93 & 75,11 & 155,82 & 108,43 & 189,61 & 191,00 & 100,84 & 1316,97 & $\begin{array}{l}192,33 \\
\end{array}$ & 28,91 & 47,32 & 528,09 & 117,50 & \begin{tabular}{|l|l|}
139,10 \\
\end{tabular} & 493,80 \\
\hline Lissotriton boscai & 29TNG20 & 101,00 & 138,63 & 80,62 & 42,90 & \begin{tabular}{ll|l|}
3774,84 \\
\end{tabular} & $239,93 \mid$ & 54,36 & \begin{tabular}{ll|}
185,56 \\
\end{tabular} & 91,40 & \begin{tabular}{|l|l|}
185,97 \\
\end{tabular} & $\begin{array}{l}187,32 \\
\end{array}$ & 91,40 & 1326,01 & 182,29 & 16,74 & 51,84 & 531,55 & 89,82 & 110,74 & 531,55 \\
\hline Lissotriton boscai & 29TNG21 & 100,00 & 140,46 & 79,05 & 42,58 & 3766,11 & 241,19 & 57,32 & $\begin{array}{l}183,88 \\
\end{array}$ & 93,37 & $\begin{array}{l}187,78 \\
\end{array}$ & 188,95 & 93,37 & 1319,70 & 182,44 & 16,80 & 51,79 & 528,80 & 89,38 & 111,32 & 528,80 \\
\hline Lissotriton boscai & 29TNG22 & 101,00 & 137,87 & 77,71 & \begin{tabular}{|l|l|}
41,84 \\
\end{tabular} & 3802,67 & 239,14 & 55,51 & 183,63 & 92,15 & 185,93 & \begin{tabular}{|l|l|}
187,09 \\
\end{tabular} & 90,40 & 1364,18 & 189,74 & 19,11 & 51,39 & 545,54 & 96,55 & $\begin{array}{l}117,25 \\
\end{array}$ & 545,41 \\
\hline 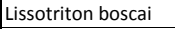 & 29 TNG23 & 100,00 & 133,12 & 76,64 & 41,04 & 3855,64 & 235,53 & 51,17 & 184,36 & 88,49 & 182,12 & 183,32 & 85,21 & 1450,79 & 209,92 & 22,81 & 50,88 & 581,76 & 108,37 & 126,68 & 581,25 \\
\hline Lissotriton boscai & 29TNG24 & 99,00 & 142,72 & 73,68 & $40,92[$ & $3762,67 \mid$ & 240,82 & 62,56 & 178,27 & 101,27 & 190,16 & 191,21 & 95,21 & 1360,54 & 195,29 & 21,41 & 50,56 & 545,50 & 101,24 & 121,49 & 538,65 \\
\hline Lissotriton boscai & 29TNG25 & 101,00 & 142,44 & 71,61 & 40,21 & 3755,29 & 239,25 & 63,49 & 175,77 & 101,68 & 189,94 & 190,94 & 95,01 & $\begin{array}{l}1394,60 \\
\end{array}$ & 206,60 & 23,94 & 50,39 & 561,40 & 107,55 & $\begin{array}{l}126,99 \\
\end{array}$ & 552,19 \\
\hline Lissotriton boscai & 29TNG26 & 100,00 & 137,42 & 70,38 & \begin{tabular}{ll|}
39,69 \\
\end{tabular} & 3792,18 & 234,78 & 59,26 & 175,52 & 95,03 & 185,76 & \begin{tabular}{ll|}
186,73 \\
\end{tabular} & 89,89 & $\begin{array}{l}1494,19 \\
\end{array}$ & 233,27 & 28,30 & 50,67 & $\begin{array}{l}605,16 \\
\end{array}$ & $\begin{array}{ll}120,03 \\
\end{array}$ & $\begin{array}{l}137,69 \\
\end{array}$ & 598,49 \\
\hline Lissotriton boscai & 29TNG27 & 80,00 & 142,23 & 66,90 & 39,02 & 3729,91 & 235,55 & 66,17 & 169,38 & 100,94 & $\begin{array}{l}189,67 \\
\end{array}$ & 190,59 & 95,20 & $\begin{array}{l}1456,53 \\
\end{array}$ & 226,75 & 28,89 & 50,29 & 590,88 & $\begin{array}{l}119,23 \\
\end{array}$ & $\begin{array}{l}137,56 \\
\end{array}$ & 576,63 \\
\hline Lissotriton boscai & 29TNG28 & 86,00 & 139,17 & 65,44 & 38,37 & 3735,36 & 232,63 & 64,36 & 168,28 & 99,83 & $\mid 186,87$ & $\mid 187,97$ & 92,44 & 1463,59 & 227,46 & 31,15 & 49,23 & 589,78 & $\mid 125,44$ & $\mid$ & 572,35 \\
\hline |Lissotriton boscai & 29TNG29 & 72,00 & 142,90 & 62,57 & 37,89 ] & 3707,49 & 233,27 & 70,12 & 163,15 & 103,57 & 190,24 & 191,12 & 96,35 & 1394,43 & 212,13 & 30,94 & 48,26 & 558,48 & 122,62 & 142,96 & 533,75 \\
\hline Lissotriton boscai & 29TNG30 & 100,00 & 142,44 & 84,53 & \begin{tabular}{|l|l|l|l|l|}
42,87 & \\
\end{tabular} & 3938,87 & 249,38 & 54,16 & 195,22 & 95,44 & $\begin{array}{l}191,86 \\
\end{array}$ & 193,10 & 92,81 & 1270,66 & 172,69 & 15,94 & 51,41 & $\begin{array}{l}505,15 \\
\end{array}$ & 86,42 & 106,61 & 504,88 \\
\hline Lissotriton boscai & 29TNG32 & 101,00 & 142,57 & 82,02 & 41,84 & 3972,07 & 249,88 & 55,81 & 194,06 & 98,75 & $\begin{array}{l}192,74 \\
\end{array}$ & \begin{tabular}{|l|}
193,71 \\
\end{tabular} & 92,50 & 1300,19 & \begin{tabular}{ll|}
180,92 \\
\end{tabular} & \begin{tabular}{ll|}
17,88 \\
\end{tabular} & 51,01 & $\begin{array}{l}516,76 \\
\end{array}$ & $\begin{array}{l}92,01 \\
\end{array}$ & $\begin{array}{l}111,91 \\
\end{array}$ & 515,34 \\
\hline Lissotriton boscai & 29TNG33 & 100,00 & 128,02 & 80,92 & \begin{tabular}{ll|}
40,79 \\
\end{tabular} & 4087,55 & 238,12 & $\begin{array}{ll}41,92 \\
\end{array}$ & 196,20 & 79,68 & 180,45 & 181,48 & 77,39 & 1483,19 & 217,87 & 24,47 & 50,58 & 592,61 & 114,75 & $\begin{array}{l}129,94 \\
\end{array}$ & 592,45 \\
\hline Lissotriton boscai & 29TNG34 & 100,00 & 130,47 & 79,59 & 40,55 & 4068,19 & 239,44 & 45,08 & $\mid \begin{array}{l}194,36 \\
\end{array}$ & 84,61 & 182,58 & $\mid 183,56$ & 79,95 & $\mid 1482,56$ & 223,25 & 25,55 & 50,53 & 593,07 & \begin{tabular}{|l|l|}
116,73 \\
\end{tabular} & $\mid \frac{132,15}{}$ & 591,82 \\
\hline |Lissotriton boscai & 29TNG35 & 100,00 & 145,15 & 76,03 & 40,07 & 3941,12 & 248,67 & 61,79 & 186,88 & 101,87 & 195,09 & 195,83 & 95,17 & 1342,05 & 200,47 & 22,86 & 50,10 & 537,04 & 104,42 & 122,88 & 526,61 \\
\hline Lissotriton boscai & 29TNG36 & 101,00 & 144,76 & 73,61 & 39,76 & 3928,62 & 246,38 & \begin{tabular}{|c|}
62,98 \\
\end{tabular} & 183,40 & 101,35 & 194,70 & 195,47 & 95,00 & 1380,58 & 213,07 & 25,50 & 50,08 & 554,99 & 110,69 & 128,51 & 543,54 \\
\hline Lissotriton boscai & 29TNG37 & 100,00 & 139,44 & 72,37 & 39,17 & 3952,22 & 241,01 & 58,61 & 182,39 & 95,37 & 190,05 & 190,83 & 89,86 & \begin{tabular}{|l|l|}
1472,17 \\
\end{tabular} & 236,44 & 29,55 & 50,39 & 593,97 & 122,06 & 138,70 & 586,24 \\
\hline Lissotriton boscai & 29TNG38 & 88,00 & 139,79 & 70,11 & 38,73 & 3935,64 & 239,20 & 60,43 & 178,77 & 97,45 & 190,29 & \begin{tabular}{ll|}
191,03 \\
\end{tabular} & $\begin{array}{l}0,49 \\
\end{array}$ & 1461,61 & 233,79 & 31,05 & 49,66 & $\begin{array}{l}586,56 \\
\end{array}$ & $\begin{array}{l}124,93 \\
\end{array}$ & 141,71 & 575,20 \\
\hline Lissotriton boscai & 29TNG39 & 101,00 & 136,77 & 68,86 & 38,12 & 3933,53 & 236,40 & 58,27 & 178,13 & $\begin{array}{l}94,66 \\
\end{array}$ & 187,42 & 188,34 & 87,94 & $\begin{array}{l}1478,41 \\
\end{array}$ & 235,28 & 33,27 & 48,80 & $\begin{array}{l}590,26 \\
\end{array}$ & 130,99 & 148,84 & 576,22 \\
\hline Lissotriton boscai & 29TNG40 & 101,00 & 145,85 & 88,48 & \begin{tabular}{|l|l|}
42,53 \\
\end{tabular} & \begin{tabular}{|l|l|}
4128,39 \\
\end{tabular} & \begin{tabular}{|l|l|}
258,94 \\
\end{tabular} & 53,25 & 205,69 & 100,52 & $\begin{array}{l}197,76 \\
\end{array}$ & 198,85 & 93,45 & 1208,74 & \begin{tabular}{|l|l|}
163,53 \\
\end{tabular} & 15,25 & 50,98 & \begin{tabular}{|l|l|}
478,58 \\
\end{tabular} & 83,25 & 102,33 & 474,61 \\
\hline Lissotriton boscai & 29TNG41 & 100,00 & \begin{tabular}{ll|l}
138,67 & \\
\end{tabular} & 87,77 & \begin{tabular}{|l|l|}
41,79 \\
\end{tabular} & \begin{tabular}{|l|l|}
4212,47 \\
\end{tabular} & 254,27 & 46,55 & 207,72 & 92,38 & 192,13 & 193,18 & $\begin{array}{l}85,67 \\
\end{array}$ & \begin{tabular}{|l|}
1304,64 \\
\end{tabular} & \begin{tabular}{|l|l|}
181,44 \\
\end{tabular} & 18,13 & 50,77 & 517,18 & 94,26 & 111,32 & 514,42 \\
\hline Lissotriton boscai & 29TNG42 & 100,00 & 137,73 & 86,50 & 41,29 & 4229,46 & 253,40 & 46,41 & 206,99 & 90,97 & $\begin{array}{l}191,60 \\
\end{array}$ & 192,52 & 84,68 & $\begin{array}{l}1324,39 \\
\end{array}$ & \begin{tabular}{|l|l|}
187,27 \\
\end{tabular} & 19,51 & 50,38 & 524,80 & 98,47 & \begin{tabular}{|l|l|}
114,94 \\
\end{tabular} & 521,03 \\
\hline Lissotriton boscai & 29TNG43 & 101,00 & 137,51 & 85,64 & \begin{tabular}{|l|l|}
40,89 \\
\end{tabular} & 4235,56 & 253,34 & 46,66 & 206,68 & 91,15 & 191,53 & 192,29 & 84,30 & 1342,99 & 195,19 & 21,10 & 50,03 & 532,19 & 103,16 & 118,92 & 527,01 \\
\hline Lissotriton boscai & 29TNG44 & 100,00 & 130,60 & 84,27 & \begin{tabular}{l|l}
40,42 \\
\end{tabular} & 4270,75 & 246,88 & 40,75 & 206,14 & 84,49 & 185,44 & 186,28 & 77,45 & 1431,34 & 214,47 & 24,88 & 49,83 & 567,90 & 115,32 & 129,11 & 563,75 \\
\hline Lissotriton boscai & 29TNG45 & 101,00 & 142,30 & 82,14 & 40,13 & 4197,28 & 255,32 & 53,36 & 201,96 & 96,35 & 195,81 & 196,38 & 89,24 & 1323,49 & 199,84 & 23,13 & 49,47 & $\begin{array}{l}524,75 \\
\end{array}$ & 106,82 & 122,21 & 513,46 \\
\hline Lissotriton boscai & 29TNG48 & 100,00 & 128,16 & 78,41 & $\begin{array}{ll}39,08 \\
\end{array}$ & \begin{tabular}{ll|l|}
4198,61 \\
\end{tabular} & 239,79 & \begin{tabular}{|l|l}
41,84 \\
\end{tabular} & 197,95 & 83,04 & 182,58 & \begin{tabular}{ll|}
183,64 \\
\end{tabular} & 76,66 & $\begin{array}{l}1502,07 \\
\end{array}$ & 239,28 & 32,79 & 48,85 & $\begin{array}{l}595,05 \\
\end{array}$ & $\begin{array}{ll}133,86 \\
\end{array}$ & $\begin{array}{l}147,87 \\
\end{array}$ & 587,57 \\
\hline Lissotriton boscai & 29TNG49 & 101,00 & 125,64 & 77,56 & $\begin{array}{l}38,85 \\
\end{array}$ & 4165,73 & 237,61 & $\begin{array}{ll}39,97 \\
\end{array}$ & $\begin{array}{l}197,64 \\
\end{array}$ & 81,13 & $\begin{array}{ll}179,86 \\
\end{array}$ & \begin{tabular}{ll|}
181,09 \\
\end{tabular} & 75,07 & 1508,88 & 237,59 & 34,66 & 47,92 & $\begin{array}{l}594,55 \\
\end{array}$ & 138,65 & 153,11 & 584,39 \\
\hline Lissotriton boscai & 29TNG50 & 101,00 & 140,38 & 92,44 & 41,82 & 4400,09 & 262,18 & 43,75 & 218,44 & 91,96 & $\begin{array}{l}196,36 \\
\end{array}$ & $\begin{array}{l}197,28 \\
\end{array}$ & 84,86 & 1243,80 & 168,81 & 16,54 & 50,69 & \begin{tabular}{|l|l|}
492,03 \\
\end{tabular} & 88,82 & 104,69 & 487,03 \\
\hline |Lissotriton boscai & 29TNG51 & 100,00 & 138,16 & 91,40 & 41,41 & 4425,39 & 260,50 & 42,19 & 218,31 & 89,59 & 194,64 & 195,49 & 82,54 & 1274,66 & 176,06 & 17,98 & 50,29 & 503,34 & 93,86 & 109,01 & 498,60 \\
\hline Lissotriton boscai & 29TNG52 & 100,00 & 130,71 & 89,65 & 40,70 & 4468,95 & 253,57 & 35,99 & 217,57 & 81,64 & 188,20 & 188,95 & 75,02 & 1357,70 & 191,48 & 21,14 & 49,95 & 35,88 & 104,88 & 86 & 532,10 \\
\hline Lissotriton boscai & 29TNG53 & 101,00 & 131,96 & 89,04 & 40,50 & 4465,45 & 254,88 & 37,47 & 217,42 & 83,37 & 189,44 & 190,19 & 76,41 & $\begin{array}{l}1345,19 \\
\end{array}$ & \begin{tabular}{|l|l|}
193,52 \\
\end{tabular} & 21,98 & 49,53 & 529,65 & 106,91 & 1119,50 & 523,62 \\
\hline Lissotriton boscai & 29TNG54 & 101,00 & 107,50 & 82,47 & 38,62 & 4465,10 & 228,68 & 18,35 & 210,33 & 60,80 & 166,06 & \begin{tabular}{ll|}
167,06 \\
\end{tabular} & 54,06 & $\begin{array}{l}1555,27 \\
\end{array}$ & 221,33 & 30,16 & 48,53 & $\begin{array}{l}611,15 \\
\end{array}$ & 134,21 & $\begin{array}{l}142,65 \\
\end{array}$ & 608,70 \\
\hline Lissotriton boscai & 29TNG56 & 101,00 & 134,95 & 86,64 & 39,84 & 4443,65 & 256,33 & \begin{tabular}{ll|l}
41,37 \\
\end{tabular} & 214,96 & 86,19 & 192,04 & $\begin{array}{l}192,69 \\
\end{array}$ & 79,37 & \begin{tabular}{|l|}
1329,41 \\
\end{tabular} & 202,14 & 25,73 & 48,28 & 520,27 & 115,85 & $\begin{array}{l}126,77 \\
\end{array}$ & 506,14 \\
\hline |Lissotriton boscai & 29TNG58 & 99,00 & 113,23 & 81,48 & 38, & 4356,27 & 232,03 & 24,34 & 207,69 & 66,96 & 170,34 & 171,53 & 61,18 & 1517,29 & 227,58 & 34,32 & 47,03 & 91,85 [ & 141,42 & 152,52 & 583,34 \\
\hline Lissotriton boscai & 29TNG59 & 100,00 & 113,55 & 80,92 & 38,72 & 4310,81 & 231,7 & 25,08 & 206,71 & 67,71 & 170,02 & 171,45 & 62,24 & 1509,61 & 226,36 & 35,67 & 46,38 & 86,61 & 144,05 & 55,97 & 575,97 \\
\hline 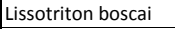 & 29TNG60 & 100,00 & 134,74 & 95,32 & 41, & 4644 & 263,68 & 35,02 & 228,66 & 83,36 & 194,34 & 195,08 & 76,56 & $\begin{array}{l}1273,15 \\
\end{array}$ & 170,29 & 17,49 & 50,72 & 502,46 & 92,99 & 105,74 & 499,23 \\
\hline Lissotriton boscai & 29TNG61 & 101,00 & 129,52 & 92,96 & 40,52 & 4652,63 & 257,84 & 31,49 & 226,34 & 76,71 & 189,55 & 190,32 & 71,80 & $\begin{array}{l}1320,79 \\
\end{array}$ & 179,13 & 19,68 & 50,09 & 520,45 & 100,31 & 1111,37 & 517,43 \\
\hline Lissotriton boscai & 29TNG62 & 101,00 & 115,32 & 87,95 & 39,30 & \begin{tabular}{ll|l|}
4647,57 \\
\end{tabular} & 241,85 & 21,15 & 220,70 & 62,37 & 176,03 & \begin{tabular}{ll|}
176,82 \\
\end{tabular} & 58,84 & 1450,71 & \begin{tabular}{|l|l|}
198,80 \\
\end{tabular} & 24,52 & 49,68 & \begin{tabular}{|l|l|}
571,37 \\
\end{tabular} & $\begin{array}{l}116,97 \\
\end{array}$ & \begin{tabular}{ll|}
125,53 \\
\end{tabular} & 570,44 \\
\hline Lissotriton boscai & 29TNG63 & 100,00 & 123,83 & 90,23 & 39,73 & 4660,90 & 251,54 & 27,50 & 224,04 & 72,50 & \begin{tabular}{ll|}
184,36 \\
\end{tabular} & 185,01 & $\begin{array}{l}66,47 \\
\end{array}$ & 1369,05 & \begin{tabular}{ll|}
192,82 \\
\end{tabular} & 23,31 & 49,05 & 57 & 11,71 & 21,10 & 531,94 \\
\hline Lissotriton boscai & 29TNG64 & 101,00 & 110,77 & 85,49 & 38,75 & \begin{tabular}{|c|c|}
4618,93 \\
\end{tabular} & 235,92 & 18,21 & 217,71 & \begin{tabular}{|c|c|}
61,90 \\
\end{tabular} & $\mid \begin{array}{l}171,38 \\
\end{array}$ & 172,25 & 55,21 & $\mid 1481,37$ & 208,95 & 28,14 & 48,52 & 579,94 & 126,96 & $\mid$ & 577,66 \\
\hline Lissotriton boscai & $29 \mathrm{TNC}$ & 100,00 & 104,96 & 83,10 & 38,2 & 4 & 228,97 & 14,35 & 214,62 & 57,06 & 165,27 & 166,23 & 50,52 & $\begin{array}{l}1523,45 \\
\end{array}$ & 215,64 & 31,05 & 47,71 & 594,87 & 135,51 & 143,03 & 591,62 \\
\hline Lissotriton boscai & 29TNG66 & 100,00 & $\begin{array}{l}132,97 \\
\end{array}$ & 90,07 & 39,70 & 4650,79 & 259,97 & 35,22 & 224,75 & 81,72 & $\begin{array}{l}193,13 \\
\end{array}$ & $\begin{array}{l}193,56 \\
\end{array}$ & 75,17 & 1269,36 & 188,81 & 24,75 & 47,50 & 491,39 & 112,81 & 122,05 & 476,26 \\
\hline Lissotriton boscai & 29TNG67 & 101,00 & 131,55 & 88,09 & \begin{tabular}{|l|l}
39,38 \\
\end{tabular} & 4616,44 & 255,96 & 34,71 & 221,25 & 80,76 & 191,40 & 191,92 & 74,53 & $\begin{array}{l}1285,02 \\
\end{array}$ & \begin{tabular}{|l|l|}
193,17 \\
\end{tabular} & 26,55 & 47,19 & 96,80 & 116,35 & \begin{tabular}{|l|l|}
126,10 \\
\end{tabular} & 482,80 \\
\hline Lissotriton boscai & 29TNG68 & 101,00 & 125,16 & 85,59 & 38, & 4545,41 & 247,24 & 30,58 & 0 & 75,50 & 184,41 & 18 & \begin{tabular}{ll|}
69,87 \\
\end{tabular} & 1345,60 & 201,85 & 29,79 & 46,67 & 19,66 & 125,28 & 137,12 & 507,16 \\
\hline Lissotriton boscai & $29 \mathrm{TN}$ & 100 & 125,96 & 95,39 & 40, & & 259 & 25,65 & 233,80 & 69,04 & $\begin{array}{l}188,61 \\
\end{array}$ & 18 & 66,06 & 1323,33 & 177, & 18,87 & 50,92 & 523,00 & $\begin{array}{ll}98,51 \\
\end{array}$ & 107,73 & 522,32 \\
\hline Lissotriton boscai & 29TNG71 & 101,00 & \begin{tabular}{ll|l}
123,47 \\
\end{tabular} & 93,49 & $\begin{array}{l}39,85 \\
\end{array}$ & \begin{tabular}{|l|l|}
4824,53 \\
\end{tabular} & 255,95 & 24,26 & 231,69 & 67,47 & 186,21 & \begin{tabular}{ll|}
186,93 \\
\end{tabular} & 64,12 & 1335,23 & \begin{tabular}{|l|l|}
178,47 \\
\end{tabular} & 20,38 & 50,23 & 525,75 & 102,88 & \begin{tabular}{|l|l|}
111,40 \\
\end{tabular} & 524,43 \\
\hline Lissotriton boscai & 29TNG72 & 100,00 & 97,65 & 83,12 & 37,48 & $\begin{array}{ll}4745,83 \\
\end{array}$ & 225,53 & 6,75 & 218,78 & 42,20 & 160,59 & 161,38 & 41,58 & $\begin{array}{l}1545,54 \\
\end{array}$ & 206,22 & 28,51 & 49,13 & $\begin{array}{l}607,76 \\
\end{array}$ & 130,75 & 134,74 & 607,7 \\
\hline Lissotriton boscai & 29TNG73 & 100,00 & 115,12 & 89,06 & 38,83 & 4792,36 & 245,33 & 18,81 & 226,53 & 61,56 & 177,89 & 178,53 & 57,06 & 1389,96 & 190,55 & 24,75 & 48,83 & 543,13 & 116,06 & 122,88 & 540,40 \\
\hline LLS & $2 \mathrm{c}$ & 100, & 118 & 89 & 39, & 3 & & 20,96 & 2 & 66, & 181 & & 60, & 1355,98 & 189,64 & 24,99 & 48 & 52 & & 12 & 52 \\
\hline Lissotriton boscai & 29TNG75 & 100,00 & 95,31 & 81,82 & 37,30 & \begin{tabular}{ll|}
4670,94 \\
\end{tabular} & 221,61 & 5,29 & 216,32 & 47,01 & 157,29 & 158,27 & 40,48 & 1539,21 & 211,15 & 32,58 & 47,17 & 598,54 & 140,23 & \begin{tabular}{|l|l|}
145,68 \\
\end{tabular} & 596, \\
\hline Lissotriton boscai & 29TNG76 & 101,00 & 119,59 & 88,52 & 38,71 & 4750,27 & 247,99 & 22,54 & 225,45 & 68,06 & 181,81 & 182,36 & 61,94 & 1331,79 & \begin{tabular}{|l|l|}
191,78 \\
\end{tabular} & 27,01 & 47,14 & 514,88 & 119,36 & \begin{tabular}{|l|l|}
127,88 \\
\end{tabular} & 506,72 \\
\hline
\end{tabular}




\begin{tabular}{|c|c|c|c|c|c|c|c|c|c|c|c|c|c|c|c|c|c|c|c|c|c|}
\hline TAXON & UTM & $\mathrm{km} 2$ & BIO1 & B102 & $B 103$ & BIO4 & B105 & B106 & 8107 & B108 & B109 & B1010 & BIO11 & BIO12 & BIO13 & BIO14 & BIO15 & B1016 & B1017 & B1018 & 81019 \\
\hline Lissotriton boscai & 29TNG77 & 101,00 & 133,18 & 91,21 & 39,10 & 4819,46 & 261,81 & 31,66 & 230,15 & 79,49 & 195,82 & 196,10 & 73,70 & 1193,18 & 176,81 & 24,51 & 46,56 & 456,50 & 108,58 & 116,42 & 442,62 \\
\hline Lissotriton boscai & 29TNG78 & 100,00 & 139,06 & 89,04 & 38,86 & 4789,06 & 264,12 & 37,72 & 226,40 & 85,44 & 201,18 & 201,45 & 79,82 & 1126,93 & $\begin{array}{l}167,65 \\
\end{array}$ & 24,12 & 45,96 & 428,39 & $\begin{array}{l}104,06 \\
\end{array}$ & 112,19 & 412,40 \\
\hline Lissotriton boscai & 29TNG80 & 101,00 & 112,87 & 91,32 & 38,75 & \begin{tabular}{|l|l|}
4947,97 \\
\end{tabular} & 247,61 & 15,16 & 232,45 & 53,01 & 177,90 & \begin{tabular}{ll|}
178,60 \\
\end{tabular} & 53,01 & 1400,14 & 192,11 & 21,42 & 51,11 & 556,51 & $\begin{array}{l}107,68 \\
\end{array}$ & 112,99 & 556,51 \\
\hline Lissotriton boscai & 29TNG81 & 99,00 & 115,24 & 91,50 & 38,82 & 4947,70 & 249,65 & 16,98 & 232,68 & 55,94 & 180,29 & $\begin{array}{l}180,76 \\
\end{array}$ & 55,18 & 1364,75 & $\begin{array}{l}183,45 \\
\end{array}$ & 21,60 & 50,37 & 539,13 & 106,90 & 111,89 & 538,88 \\
\hline Lissotriton boscai & 29TNG82 & 101,00 & 108,29 & 87,72 & $38,01\}$ & $4896,41]$ & 240,41 & 12,73 & 227,68 & 49,93 & 172,98 & 173,49 & 49,60 & 1410,36 & 187,29 & 24,39 & 49,53 & 554,55 & 115,56 & 120,32 & 554,48 \\
\hline Lissotriton boscai & 29TNG83 & 100,00 & 95,35 & 82,54 & 36,89 & 4825,88 & 224,96 & 4,18 & 220,77 & 39,97 & 159,66 & 160,33 & 38,78 & $\mid 1502,75$ & $|199,67|$ & 29,19 & 48,38 & 587,88 & 130,81 & 134,52 & 587,87 \\
\hline Lissotriton boscai & 29TNG84 & 101,00 & 115,06 & 89,61 & 38,44 & 4900,82 & 247,18 & 17,13 & 230,05 & 62,29 & 179,62 & 180,01 & 55,89 & 1330,30 & 182,38 & 24,65 & 48,11 & 516,80 & 113,30 & 119,51 & 514,85 \\
\hline Lissotriton boscai & 29TNG86 & 100,00 & 118,55 & 89,98 & 38,52 & 4887,39 & 249,84 & 19,15 & 230,69 & 65,38 & 182,86 & 183,30 & 59,50 & 1277,69 & 180,86 & 25,94 & 46,84 & 491,94 & 114,51 & 120,97 & 485,73 \\
\hline Lissotriton boscai & 29TNG87 & 100,00 & 131,52 & 92,63 & 38,90 & \begin{tabular}{ll|l|}
4978,81 \\
\end{tabular} & 263,13 & 27,19 & 235,94 & 75,96 & 196,55 & 196,79 & 70,46 & 1135,81 & $\begin{array}{l}164,80 \\
\end{array}$ & 23,53 & 46,00 & \begin{tabular}{|l|l|}
431,70 \\
\end{tabular} & 103,51 & \begin{tabular}{|l|l|}
109,38 \\
\end{tabular} & 420,30 \\
\hline Lissotriton boscai & 29TNG88 & 100,00 & 134,92 & 90,86 & 38,50 & 4962,84 & 263,78 & 30,42 & 233,36 & 79,33 & 199,65 & 199,84 & 74,12 & $\begin{array}{l}1091,09 \\
\end{array}$ & 159,33 & 23,65 & 45,35 & 411,98 & 101,28 & 106,87 & 399,33 \\
\hline Lissotriton boscai & 29TNG90 & 100,00 & 120,45 & 96,51 & 39,18 & 5118,80 & 260,85 & $\begin{array}{ll}17,93 \\
\end{array}$ & 242,93 & 57,81 & 187,52 & 187,92 & 57,81 & 1287,23 & \begin{tabular}{|l|l|}
177,84 \\
\end{tabular} & 18,68 & 51,39 & 510,95 & 96,68 & $\begin{array}{l}101,54 \\
\end{array}$ & 510,95 \\
\hline Lissotriton boscai & 29TNG91 & 101,00 & 106,49 & 88,55 & 37,63 & 5026,95 & 242,03 & 9,90 & 232,12 & 46,30 & $\begin{array}{l}173,06 \\
\end{array}$ & $\begin{array}{l}173,50 \\
\end{array}$ & 46,30 & 1386,53 & $\begin{array}{l}188,86 \\
\end{array}$ & 23,03 & 50,32 & 548,86 & 111,20 & 114,51 & 548,86 \\
\hline Lissotriton boscai & 29TNG92 & 101,00 & 104,70 & 86,50 & 37,29 & 4987,78 & 238,55 & 9,44 & 229,12 & 45,29 & 170,90 & $\mid 171,31$ & 45,29 & 1385,85 & 185,38 & 24,36 & 49,44 & 545,62 & 114,51 & 117,69 & 545,62 \\
\hline Lissotriton boscai & 29TNG93 & 100,00 & 96,32 & 83,47 & 36,63 & 4929,91] & 228,39 & 3,62 & 224,77 & 39,17 & 162,07 & 162,53 & 38,30 & 1441,20 & 190,75 & 27,84 & 48,34 & 563,31 & 125,34 & 128,21 & 563,31 \\
\hline Lissotriton boscai & 29TNG94 & 100,00 & 104,76 & 86,30 & 37,24 & 4947,62 & 237,78 & 9,36 & 228,42 & 50,88 & \begin{tabular}{ll|}
170,56 \\
\end{tabular} & \begin{tabular}{ll|}
170,87 \\
\end{tabular} & 45,91 & 1358,63 & $\begin{array}{l}181,85 \\
\end{array}$ & 26,28 & 47,98 & 528,21 & $\begin{array}{ll}118,26 \\
\end{array}$ & 122,51 & 528,04 \\
\hline Lissotriton boscai & 29TNG96 & 100,00 & 116,26 & 90,73 & 38,15 & $\begin{array}{l}4979,74 \\
\end{array}$ & 250,19 & 15,81 & 234,38 & 62,01 & 181,98 & 182,26 & 56,26 & \begin{tabular}{|l|}
1238,14 \\
\end{tabular} & \begin{tabular}{|l|l|}
172,01 \\
\end{tabular} & 25,34 & 46,58 & 475,99 & 111,39 & $\begin{array}{l}116,99 \\
\end{array}$ & 471,15 \\
\hline Lissotriton boscai & 29TNG97 & 101,00 & 128,47 & 93,28 & 38,48 & 5077,27 & 262,36 & 22,92 & 239,45 & 71,72 & $\begin{array}{l}194,96 \\
\end{array}$ & $\begin{array}{l}195,08 \\
\end{array}$ & 66,47 & 1102,83 & 156,57 & 22,98 & 45,68 & 418,49 & 100,50 & $\begin{array}{l}103,93 \\
\end{array}$ & 409,70 \\
\hline Lissotriton boscai & 29TNG98 & 101,00 & 137,22 & 92,45 & 37,87 & 5162,84 & 269,37 & 28,60 & 240,77 & 79,01 & 204,71 & 204,75 & 73,95 & 989,93 & $\mid 142,03$ & 21,46 & 44,79 & $\mid 370,10$ & 91,71 & 93,81 & 359,00 \\
\hline |Lissotriton boscai & 29TNG99 & 101,00 & 134,39 & 91,03 & 38,14 & 5016,64 & 264,07 & 28,52 & 235,55 & 77,88 & 199,94 & 200,11 & 73,24 & 1026,37 & 147,59 & 23,51 & 44,20 & 384,14 & 97,82 & 102,91 & 372,22 \\
\hline Lissotriton boscai & 29TNHOO & 16,00 & 147,29 & 59,00 & 38,48 & 3400,52 & 230,67 & 78,95 & 151,71 & 112,29 & 190,24 & $\mid 191,67$ & 104,38 & 1225,90 & 174,48 & 26,95 & 46,81 & 491,57 & 111,81 & 134,71 & 450,57 \\
\hline Lissotriton boscai & 29TNH01 & 40,00 & 144,58 & 59,91 & 38,18 & 3389,01 & 229,52 & 75,00 & 154,52 & 110,27 & 186,96 & 189,12 & $\begin{array}{l}101,96 \\
\end{array}$ & \begin{tabular}{|l|}
1190,85 \\
\end{tabular} & 170,30 & 27,81 & 45,66 & \begin{tabular}{|l|l|}
475,97 \\
\end{tabular} & 1115,04 & $\begin{array}{l}138,49 \\
\end{array}$ & 430,70 \\
\hline Lissotriton boscai & $29 \mathrm{TNHO2}$ & 97,00 & 132,26 & 63,14 & 37,98 & 3521,94 & 224,76 & 60,48 & 164,28 & 97,19 & 177,01 & 179,36 & 89,11 & 1311,65 & 191,91 & 32,75 & 44,97 & 520,73 & 131,71 & 153,40 & 479,06 \\
\hline Lissotriton boscai & 29TNH03 & 72,00 & 140,28 & 62,04 & 38,15 & 3441,65 & 229,47 & $\begin{array}{ll}68,97 \\
\end{array}$ & 160,50 & 106,00 & 183,51 & $\begin{array}{l}186,10 \\
\end{array}$ & 97,60 & \begin{tabular}{|l|l|}
1187,87 \\
\end{tabular} & $\begin{array}{l}170,53 \\
\end{array}$ & 29,84 & 44,38 & 470,94 & 121,46 & $\begin{array}{ll}144,58 \\
\end{array}$ & 424,12 \\
\hline Lissotriton boscai & 29TNHO4 & 98,00 & 137,01 & 63,14 & 38,09 & 3452,36 & 228,38 & $\begin{array}{ll}64,98 \\
\end{array}$ & 163,40 & 103,02 & 180,45 & 183,28 & 94,56 & 1187,81 & 169,67 & 31,04 & 43,51 & 468,51 & 125,83 & 148,93 & 420,04 \\
\hline |Lissotriton boscai & 29TNHO5 & \begin{tabular}{|l|l|}
99,00 \\
\end{tabular} & 130,21 & 64,82 & 38,15 & 3496,92 & 225,11 & 57,22 & 167,89 & 96,18 & 174,38 & 177,55 & 87,89 & $\mid 1236,42$ & $\mid 176,17$ & 33,76 & 42,70 & 484,35 & 135,19 & 157,82 & 436,14 \\
\hline Lissotriton boscai & 29TNH06 & 101,00 & 130,82 & 64,73 & 38,44 & 3443,75 & 224,58 & 58,12 & 166,45 & 97,50 & $\begin{array}{ll}174,06 \\
\end{array}$ & 177,48 & 89,05 & 1201,01 & 168,81 & 33,56 & 41,93 & 468,53 & 134,43 & 157,51 & 418,84 \\
\hline Lissotriton boscai & 29TNH07 & 101,00 & 135,56 & 63,77 & 38,93 & 3340,52 & 225,72 & 63,71 & 162,01 & 103,33 & 176,99 & 180,78 & 94,75 & 1124,75 & 155,33 & 31,65 & 41,14 & 437,83 & 128,10 & 152,02 & 386,81 \\
\hline Lissotriton boscai & 29TNH08 & 81,00 & 139,86 & 62,83 & \begin{tabular}{l|l}
39,45 \\
\end{tabular} & 3245,91 & 226,50 & \begin{tabular}{|l|l|}
68,94 \\
\end{tabular} & 157,55 & 108,65 & 179,71 & 183,68 & $\begin{array}{ll}99,93 \\
\end{array}$ & $\begin{array}{l}1066,54 \\
\end{array}$ & \begin{tabular}{|l|l|}
146,17 \\
\end{tabular} & 30,11 & 40,82 & 414,13 & $\begin{array}{ll}122,84 \\
\end{array}$ & 147,26 & 363,35 \\
\hline Lissotriton boscai & 29TNHO9 & 36,00 & 140,84 & 62,53 & 39,81 . & 3197,92 & 225,89 & 70,47 & 155,42 & 110,27 & 179,88 & 184,00 & 101,47 & 1046,33 & 142,86 & 29,83 & 40,06 & 404,94 & 121,86 & 146,55 & 354,73 \\
\hline Lissotriton boscai & 29TNH10 & 61,00 & 146,39 & 60,06 & 37,91 & 3519,36 & 232,27 & 76,11 & 156,16 & 109,72 & 190,75 & 192,23 & 101,94 & $\begin{array}{l}1275,06 \\
\end{array}$ & \begin{tabular}{|l|l|}
185,37 \\
\end{tabular} & 28,73 & 46,99 & $\begin{array}{l}509,45 \\
\end{array}$ & $\begin{array}{ll}116,28 \\
\end{array}$ & $\begin{array}{ll}138,47 \\
\end{array}$ & 472,93 \\
\hline Lissotriton boscai & 29TNH11 & 40,00 & 146,34 & 60,45 & 37,82 & 3518,47 & 233,20 & 75,68 & 157,53 & \begin{tabular}{|l|l|}
109,97 \\
\end{tabular} & 190,80 & $\begin{array}{l}192,50 \\
\end{array}$ & 102,30 & 1241,93 & 180,28 & 28,89 & 46,24 & \begin{tabular}{|l|l|}
494,43 \\
\end{tabular} & 116,57 & $\begin{array}{l}139,20 \\
\end{array}$ & 455,66 \\
\hline Lissotriton boscai & 29TNH12 & 80,00 & 143,85 & 61,84 & \begin{tabular}{|c|c|}
37,90 \\
\end{tabular} & 3527,18 & 233,33 & 72,06 & $\mid 161,27$ & 107,84 & 188,46 & 190,54 & 99,85 & 1225,40 & $\mid \begin{array}{l}177,83 \\
\end{array}$ & 29,87 & 45,22 & $\mid 485,94$ & $\mid 119,86$ & \begin{tabular}{|l|l|}
142,71 \\
\end{tabular} & 444,59 \\
\hline Lissotriton boscai & 29TNH13 & 101,00 & 134,28 & 65,16 & 37,83 & 3618,45 & 230,51 & 60,17 & 170,34 & $\begin{array}{l}97,99 \\
\end{array}$ & 180,32 & 182,90 & 90,05 & $\begin{array}{l}1306,88 \\
\end{array}$ & $\begin{array}{l}191,55 \\
\end{array}$ & 33,69 & 44,61 & 514,94 & 132,93 & 154,63 & 475,23 \\
\hline Lissotriton boscai & 29TNH14 & 100,00 & 133,17 & 66,01 & 37,97 & 3607,29 & 230,45 & 58,59 & 171,85 & 97,29 & 178,97 & 181,81 & 89,22 & 1284,45 & |186,08 & 34,10 & 43,76 & 503,35 & $\mid 34,48$ & 156,51 & 461,63 \\
\hline Lissotriton boscai & 29TNH15 & 101,00 & 131,49 & 66,60 & $\begin{array}{l}38,05 \\
\end{array}$ & 3585,35 & 229,44 & 56,70 & 172,74 & 96,06 & 176,92 & 180,04 & 88,01 & 1269,31 & \begin{tabular}{|l|l|}
181,60 \\
\end{tabular} & 34,69 & 42,87 & 4994,86 & 136,62 & 158,82 & 451,55 \\
\hline Lissotriton boscai & 29TNH16 & 100,00 & 129,53 & 66,99 & 38,23 & 3553,02 & 227,55 & 54,86 & $\begin{array}{l}172,69 \\
\end{array}$ & 94,82 & $\begin{array}{l}174,47 \\
\end{array}$ & \begin{tabular}{ll|}
177,92 \\
\end{tabular} & 86,69 & $\begin{array}{l}1258,25 \\
\end{array}$ & $\begin{array}{l}177,72 \\
\end{array}$ & 35,39 & 41,99 & 487,99 & $\begin{array}{ll}139,03 \\
\end{array}$ & $\begin{array}{ll}161,37 \\
\end{array}$ & 443,71 \\
\hline Lissotriton boscai & 29TNH17 & 101,00 & 129,68 & 66,59 & 38,59 & 3486,06 & 225,87 & 55,66 & 170,21 & 95,86 & $\mid 173,47$ & $\mid$\begin{tabular}{|l}
177,07 \\
\end{tabular} & 87,56 & $\mid 1227,19$ & \begin{tabular}{|l|l|}
170,96 \\
\end{tabular} & $\mid 35,16$ & 41,07 & $\mid 474,12$ & 138,50 & $\mid 161,14$ & 429,01 \\
\hline |Lissotriton boscai & 29TNH18 & 99,00 & 138, & 64,56 & 39,53 & $3317,71 \mid$ & 227,61 & 66,00 & 161,61 & 106,04 & 179,15 & 183,05 & 97,47 & 1106,27 & 150,80 & 31,4 & 40,66 & 427,34 & 126,22 & 150,06 & 380,75 \\
\hline Lissotriton boscai & 29TNH19 & 64,00 & 140,89 & 63,56 & 39,93 & 3223,95 & 227,11 & 69,77 & 157,34 & 109,84 & 180,43 & 184,43 & $\mid 101,17$ & 1059,58 & 143,29 & 30,28 & 40,01 & 408,67 & 122,48 & $\mid 46,75$ & 361,63 \\
\hline Lissotriton boscai & $29 \mathrm{TNH} 20$ & 100,00 & 140,04 & 63,04 & 37,60 & 3718,64 & 232,42 & 66,87 & 165,55 & 101,01 & 187,74 & 188,88 & 93,81 & \begin{tabular}{|l|}
1395,50 \\
\end{tabular} & 212,46 & 32,47 & 47,52 & 556,28 & 127,28 & 147,77 & 529,68 \\
\hline Lissotriton boscai & 29TNH21 & 101,00 & 143,07 & 62,99 & 37,73 & 3680,33 & 234,96 & 69,79 & 165,16 & 104,60 & 190,07 & 191,50 & 97,21 & $\begin{array}{l}1313,98 \\
\end{array}$ & \begin{tabular}{|l|l|}
195,41 \\
\end{tabular} & 31,39 & 46,36 & 520,52 & 123,46 & 145,06 & 488,04 \\
\hline Lissotriton boscai & 29TNH22 & 98,00 & 142,56 & 64,37 & $\begin{array}{l}37,83 \\
\end{array}$ & 3673,06 & 236,45 & $\begin{array}{ll}68,27 \\
\end{array}$ & 168,18 & 104,48 & 189,39 & 191,20 & 97,00 & 1282,23 & $\begin{array}{l}189,18 \\
\end{array}$ & 31,60 & 45,59 & 505,62 & $\begin{array}{l}124,06 \\
\end{array}$ & 145,95 & 470,89 \\
\hline |Lissotriton boscai & 29TNH23 & 100,00 & 140,69 & $65,81$. & 37,91 . & 3675,02 & 236,85 & 65,44 & 171,42 & 102,96 & 187,49 & 189,76 & 95,38 & 1268,02 & 185,23 & 32,23 & 44,81 & 497,28 & 126,63 & 48,60 & 460,75 \\
\hline Lissotriton boscai & 29TNH24 & 101,00 & 139,46 & 66,85 & 38,14 & 3657,53 & 237,04 & 63,64 & 173,40 & 102,32 & 185,96 & 188,60 & 94,54 & $\begin{array}{l}1247,55 \\
\end{array}$ & \begin{tabular}{|l|l|}
180,10 \\
\end{tabular} & 32,75 & 43,93 & 86,78 & 128,33 & 150,59 & 448,39 \\
\hline 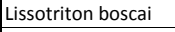 & $29 \mathrm{TNH} 25$ & 101,00 & 134,22 & 68,49 & 38,0 & 367 & 235 & 57,13 & 177 & 97,31 & 180,95 & 184,04 & 89,61 & 1277,87 & 182,81 & 34,92 & 42,98 & 495,32 & 135,80 & 157,76 & 456,50 \\
\hline Lissotriton boscai & $29 \mathrm{TNH} 26$ & 101,00 & 129,38 & 69,40 & 38,11 & 3658,94 & 231,39 & 52,28 & 179,10 & 93,09 & 175,81 & 179,24 & 85,42 & 1295,09 & 183,16 & 36,61 & 42,07 & 499,18 & 141,72 & 163,38 & 459,85 \\
\hline Lissotriton boscai & 29TNH27 & 100,00 & 129,17 & 68,83 & 38,77 & 3574,89 & 228,79 & 53,35 & 175,45 & \begin{tabular}{ll|}
94,07 \\
\end{tabular} & 174,25 & \begin{tabular}{ll|}
178,02 \\
\end{tabular} & 86,21 & $\begin{array}{l}1259,95 \\
\end{array}$ & \begin{tabular}{ll|}
175,62 \\
\end{tabular} & 36,27 & 41,11 & \begin{tabular}{ll|l}
484,03 \\
\end{tabular} & $\begin{array}{ll}140,94 \\
\end{array}$ & 162,85 & 443,55 \\
\hline Lissotriton boscai & 29TNH28 & 101,00 & 138,15 & 66,22 & 39,76 & 3371,93 & 229,55 & 64,80 & 164,75 & 105,12 & 179,97 & 183,87 & 96,86 & 1124,24 & 152,92 & 32,00 & 40,55 & , 17 & 126,98 & 50,29 & 389,89 \\
\hline Lissotriton boscai & 29TNH29 & 39,00 & 138,94 & 65,60 & 40,11 & 3300,89 & 227,96 & 66,33 & 161,63 & 106,78 & $\begin{array}{l}179,56 \\
\end{array}$ & \begin{tabular}{ll|}
183,64 \\
\end{tabular} & 98,28 & 1096,42 & 147,44 & 31,46 & 39,97 & 420,50 & 125,51 & $\begin{array}{l}149,00 \\
\end{array}$ & 378,18 \\
\hline Lissotriton boscai & 29TNH31 & 100,00 & 135,63 & 69,05 & $\begin{array}{l}37,66 \\
\end{array}$ & \begin{tabular}{|l|l|}
3905,13 \\
\end{tabular} & 237,49 & 56,52 & 180,97 & 94,42 & \begin{tabular}{|l|}
186,07 \\
\end{tabular} & \begin{tabular}{ll|}
187,56 \\
\end{tabular} & 87,79 & 1419,43 & 217,60 & 34,79 & 46,73 & 558,64 & 134,36 & 153,66 & 535,47 \\
\hline Lissotriton boscai & 29TNH32 & 101,00 & 133,93 & 70,52 & 37,54 & 3913,20 & 238,69 & 53,32 & 185,36 & 93,06 & 184,50 & 186,35 & 86,34 & 1407,16 & 212,47 & 35,74 & 45,82 & 550,13 & 137,36 & 57,02 & 524,18 \\
\hline Lissotriton boscai & 29TNH33 & 101,00 & 140,89 & 68,88 & 37,78 & 3814,67 & 241,68 & 61,72 & 179,97| & 101,09 & 189,69 & 191,86 & 94,03 & 1286,69 & 188,93 & 32,96 & 44,87 & 500,80 & 127,77 & |49,09| & 469,14 \\
\hline Lissotriton boscai & 29TNH34 & 100,00 & 137,98 & 70,61 & 37,6 & 3829,36 & 242,2 & 57,25 & 84,96 & 98,68 & 186,96 & 189,58 & 91, & 1297,37 & 188,15 & 34 & 4 & 501,72 & 89 & ,22. & 468 \\
\hline Lissotriton boscai & 29 & 101,00 & 132 & 72,28 & 37,68 & 3 & 240,40 & 50,95 & 189,45 & 94,15 & 182,04 & & 86,75 & $\begin{array}{l}1326,75 \\
\end{array}$ & \begin{tabular}{|l|l|}
190,10 \\
\end{tabular} & 36,64 & 43,10 & 509,81 & 140,19 & 161,30 & 476, \\
\hline Lissotriton boscai & $29 \mathrm{TNH} 36$ & 101,00 & 129,84 & 72,27 & 38,05 & 3774,65 & 236,38 & 49,07 & 187,31 & 92,04 & 178,03 & 181,37 & 84,62 & \begin{tabular}{|l|}
1317,82 \\
\end{tabular} & \begin{tabular}{|l|l|}
186,12 \\
\end{tabular} & 37,45 & 42,10 & 504,27 & 143,19 & 164,27 & 469,58 \\
\hline Lissotriton boscai & 29TNH37 & 101,00 & $\begin{array}{ll}127,82 \\
\end{array}$ & 71,68 & 38,69 & 3685,61 & 231,99 & $\begin{array}{ll}48,85 \\
\end{array}$ & 183,14 & 91,12 & 174,58 & 178,31 & 83,80 & $\begin{array}{l}1296,43 \\
\end{array}$ & $\begin{array}{l}180,66 \\
\end{array}$ & \begin{tabular}{l|l|}
37,63 \\
\end{tabular} & 41,15 & 94,57 & $\begin{array}{l}144,29 \\
\end{array}$ & 665,38 & 458,65 \\
\hline Lissotriton boscai & 29TNH38 & 100,00 & 130,25 & 69,90 & 39,58 & 3529,25 & 228,82 & 54,21 & 74,62 & 95,40 & 174,66 & 178,55 & 87,84 & 1225,75 & 167,86 & 35,84 & 40,29 & 467,01 & 138,82 & 60,53 & 429,7 \\
\hline Lissot & & 66,00 & & 67,21 & 40, & & 228,27 & & 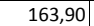 & 104,80 & & & 96 & & & & & 42 & & & 385 \\
\hline 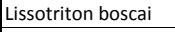 & $29 \mathrm{TNH}^{2}$ & 101,00 & 124,43 & 76,64 & 38,40 & 4126 & 236,23 & 39,22 & 197,01 & 80,58 & 178,19 & 179,63 & 74,68 & 1499,32 & 232,05 & 36,10 & 47,05 & 587,15 & 141,93 & 157,16 & 573,21 \\
\hline Lissotriton boscai & $29 \mathrm{TNH} 42$ & 100,00 & 132,13 & 74,96 & 37,98 & 4042,12 & 242,29 & 47,15 & 195,13 & 89,34 & 184,54 & 186,42 & 83,32 & $\begin{array}{l}1407,67 \\
\end{array}$ & 212,28 & 35,99 & 45,57 & 545,52 & 138,23 & 156,49 & 523,46 \\
\hline
\end{tabular}




\begin{tabular}{|c|c|c|c|c|c|c|c|c|c|c|c|c|c|c|c|c|c|c|c|c|c|}
\hline TAXON & UTM & $\mathrm{km2}$ & BIO1 & B102 & $\mathrm{BIO3}$ & B104 & B105 & B106 & B107 & B108 & B109 & BIO10 & BIO11 & BIO12 & BIO13 & BIO14 & BIO15 & BIO16 & BIO17 & BIO18 & BI019 \\
\hline Lissotriton boscai & 29TNH43 & 101,00 & 140,12 & 72,87 & 37,98 & 3953,22 & 246,17 & 56,53 & 189,64 & 98,34 & 190,91 & 193,06 & 91,84 & 1293,19 & 190,16 & 33,42 & 44,74 & 499,02 & 128,68 & 149,06 & 471,50 \\
\hline Lissotriton boscai & \begin{tabular}{|l|} 
29TNH44 \\
\end{tabular} & 99,00 & 134,34 & 75,62 & 37,50 & 4016,51 & 247,01 & 47,82 & $\begin{array}{ll}199,18 \\
\end{array}$ & 92,76 & $\begin{array}{l}186,25 \\
1\end{array}$ & \begin{tabular}{|l|}
188,81 \\
\end{tabular} & 86,23 & $\begin{array}{l}1354,82 \\
\end{array}$ & 196,79 & 36,70 & \begin{tabular}{l|l}
43,95 \\
\end{tabular} & \begin{tabular}{|l|l|}
518,70 \\
\end{tabular} & $\begin{array}{l}139,25 \\
\end{array}$ & 159,31 & 490,94 \\
\hline Lissotriton boscai & 29TNH45 & 100,00 & 133,85 & 75,41 & 37,71 & 3948,35 & 245,54 & 48,08 & 197,45 & 93,39 & $\begin{array}{l}184,49 \\
18\end{array}$ & \begin{tabular}{|l|l|}
187,60 \\
\end{tabular} & 86,62 & \begin{tabular}{|l|}
1327,24 \\
\end{tabular} & 189,42 & 36,86 & 42,92 & \begin{tabular}{|l|l|}
505,97 \\
\end{tabular} & \begin{tabular}{|l|l|}
139,84 \\
\end{tabular} & \begin{tabular}{ll|}
160,39 \\
\end{tabular} & 476,27 \\
\hline Lissotriton boscai & 29TNH46 & 100,00 & 133,61 & 74,17 & 38,49 & 3807,22 & 241,03 & 50,75 & \begin{tabular}{|l|l|}
190,27 \\
\end{tabular} & \begin{tabular}{|l|l}
94,78 \\
\end{tabular} & \begin{tabular}{|l|}
182,11 \\
\end{tabular} & 185,54 & 87,87 & \begin{tabular}{|l|}
1277,88 \\
\end{tabular} & 179,38 & 36,11 & \begin{tabular}{ll|l}
41,96 \\
\end{tabular} & \begin{tabular}{|l|l|}
486,11 \\
\end{tabular} & \begin{tabular}{|l|}
137,91 \\
\end{tabular} & $\begin{array}{l}158,76 \\
\end{array}$ & 454,57 \\
\hline Lissotriton boscai & 29TNH47 & 101,00 & 129,79 & 73,67 & 39,01 . & 3726,10 & 235,43 & 48,83 & $186,61 \mid$ & $92,02 \mid$ & 177,26 | & 180,80 & 85,29 & 1276,81 & 177,09 & 37,02 & 41,03 & $484,24 \mid$ & $141,41 \mid$ & 162,11 & 451,80 \\
\hline Lissotriton boscai & \begin{tabular}{|l|l|} 
29TNH48 \\
\end{tabular} & 99,00 & 130,64 & 71,90 & 39,94 & 3580,81 & 231,16 & 52,91 & 178,25 & 94,65 & \begin{tabular}{|l|l|}
175,87 \\
\end{tabular} & 179,58 & 87,62 & 1222,47 & 166,76 & 35,87 & 40,09 & 463,07 & 138,08 & $\begin{array}{l}159,15 \\
\end{array}$ & 429,36 \\
\hline Lissotriton boscai & \begin{tabular}{|l|l|} 
29TNH49 \\
\end{tabular} & 99,00 & 138,44 & 68,49 & 41,26 & 3334,69 & 228,73 & 64,79 & \begin{tabular}{|l|l|}
163,94 \\
\end{tabular} & 105,25 & \begin{tabular}{|l|l|}
179,57 \\
\end{tabular} & 183,74 & 97,48 & 1091,49 & 144,73 & 31,59 & 39,26 & 413,86 & \begin{tabular}{l|l}
124,45 \\
\end{tabular} & 146,72 & 379,25 \\
\hline Lissotriton boscai & $\begin{array}{l}\text { 29TNH50 } \\
\end{array}$ & 101,00 & 115,81 & 80,39 & 38,78 & 4246,05 & 232,99 & 27,72 & 205,27 & 70,53 & $\begin{array}{l}171,45 \\
\end{array}$ & \begin{tabular}{l|l}
172,95 \\
\end{tabular} & 65,34 & 1493,95 & 224,52 & 36,57 & \begin{tabular}{ll|}
45,84 \\
\end{tabular} & 578,78 & \begin{tabular}{|l|}
145,19 \\
\end{tabular} & \begin{tabular}{l|l|l|}
158,22 \\
\end{tabular} & 565,92 \\
\hline Lissotriton boscai & 29TNH52 & 101,00 & 121,80 & 79,71 & 38,86 & 4121,18 & 237,20 & 34,24 & \begin{tabular}{|l|l|}
202,96 \\
\end{tabular} & 77,75 & $\begin{array}{l}175,64 \\
174\end{array}$ & \begin{tabular}{ll|l}
177,56 \\
\end{tabular} & $\begin{array}{ll}73,05 \\
\end{array}$ & 1442,01 & 214,66 & 37,59 & 44,81 & 553,96 & \begin{tabular}{|l|l|}
145,11 \\
\end{tabular} & \begin{tabular}{ll|}
160,61 \\
\end{tabular} & 535,85 \\
\hline Lissotriton boscai & \begin{tabular}{|l|l|} 
29TNH53 \\
\end{tabular} & 101,00 & 136,65 & 77,41 & 38,54 & 4049,65 & 247,69 & 49,24 & \begin{tabular}{l|l|l|l|}
198,45 \\
\end{tabular} & 93,11 & \begin{tabular}{|l|l|}
188,96 \\
\end{tabular} & 191,10 & 87,81 & 1301,01 & 191,18 & 34,07 & 44,30 & \begin{tabular}{ll|l}
497,36 \\
\end{tabular} & \begin{tabular}{l|l|}
130,92 \\
\end{tabular} & \begin{tabular}{|l|l|}
149,73 \\
\end{tabular} & 473,88 \\
\hline Lissotriton boscai & \begin{tabular}{l|l|} 
29TNH55 \\
\end{tabular} & 101,00 & 132,55 & 77,84 & 38,55 & 3952,98 & 244,93 & 45,58 & 199,35 & \begin{tabular}{|l|l|}
91,08 \\
\end{tabular} & \begin{tabular}{ll|}
183,42 \\
\end{tabular} & \begin{tabular}{|l|l|}
186,37 \\
\end{tabular} & 85,47 & 1311,62 & \begin{tabular}{|l|l|}
186,78 \\
\end{tabular} & 36,64 & 42,66 & \begin{tabular}{|l|l|}
496,98 \\
\end{tabular} & \begin{tabular}{l|l}
138,85 \\
\end{tabular} & 158,30 & 470,35 \\
\hline Lissotriton boscai & $\begin{array}{l}\text { 29TNH56 } \\
\end{array}$ & 101,00 & 131,83 & 76,71 & 38,90 & 3858,57 & 241,48 & 46,94 & 194,54 & 91,76 & 181,28 & 184,54 & 85,86 & 1281,64 & \begin{tabular}{|l|l|}
179,77 \\
\end{tabular} & 36,54 & \begin{tabular}{ll|}
41,76 \\
\end{tabular} & $\begin{array}{l}484,46 \\
\end{array}$ & \begin{tabular}{|l|l|}
138,73 \\
\end{tabular} & \begin{tabular}{l|l|}
158,58 \\
\end{tabular} & 456,12 \\
\hline Lissotriton boscai & \begin{tabular}{|l|} 
29TNH57 \\
\end{tabular} & 100,00 & 129,49 & 75,79 & 39,47 & 3760,92 & 236,42 & 46,84 & 189,58 & \begin{tabular}{|c|}
0,69 \\
\end{tabular} & \begin{tabular}{|l|l}
177,58 \\
\end{tabular} & 181,00 & 84,70 & 1264,25 & 174,91 & 36,84 & 40,79 & \begin{tabular}{|l|l|}
476,82 \\
\end{tabular} & \begin{tabular}{l|l|}
140,23 \\
\end{tabular} & 160,14 & 447,24 \\
\hline Lissotriton boscai & $\begin{array}{l}\text { 29TNH58 } \\
\end{array}$ & 101,00 & 136,43 & 72,36 & 40,72 & 3553,90 & 234,25 & 58,55 & \begin{tabular}{|l|l|}
175,70 \\
\end{tabular} & \begin{tabular}{|l|l|}
100,03 \\
\end{tabular} & \begin{tabular}{l|l|l|l|}
181,02 \\
\end{tabular} & $\begin{array}{l}184,78 \\
\end{array}$ & \begin{tabular}{|c|}
93,25 \\
\end{tabular} & 1141,24 & 154,04 & 33,02 & \begin{tabular}{|l|l|}
39,87 \\
\end{tabular} & 430,70 & \begin{tabular}{|l|}
128,01 \\
\end{tabular} & \begin{tabular}{ll|}
149,16 \\
\end{tabular} & 399,31 \\
\hline Lissotriton boscai & $\begin{array}{l}\text { 29TNH59 } \\
\end{array}$ & 98,00 & 140,77 & 69,91 & \begin{tabular}{ll|}
41,80 \\
\end{tabular} & 3381,91 & 231,80 & 66,23 & \begin{tabular}{ll|}
165,56 \\
\end{tabular} & 106,31 & 182,51 & 186,54 & \begin{tabular}{l|l|}
99,09 \\
\end{tabular} & 1058,70 & 139,63 & 30,57 & 39,04 & 399,41 & 120,42 & \begin{tabular}{ll|}
142,28 \\
\end{tabular} & 367,09 \\
\hline Lissotriton boscai & \begin{tabular}{|l|l|} 
29TNH60 \\
\end{tabular} & 100,00 & 118,94 & 83,20 & 38,98 & 4353,18 & 238,48 & 27,84 & 210,64 & $\begin{array}{ll}71,76 \\
\end{array}$ & \begin{tabular}{|l|l|}
175,90 \\
\end{tabular} & \begin{tabular}{ll|}
177,36 \\
\end{tabular} & 67,11 & 1409,20 & 210,16 & 34,42 & \begin{tabular}{l|l}
45,45 \\
\end{tabular} & \begin{tabular}{|l|l|}
541,88 \\
\end{tabular} & $\begin{array}{l}137,56 \\
\end{array}$ & \begin{tabular}{|l|l|}
150,38 \\
\end{tabular} & 528,85 \\
\hline Lissotriton boscai & 29TNH61 & 101,00 & 119,95 & 82,67 & 39,13 & 4262,34 & 238,07 & 29,73 & 208,34 & 73,64 & \begin{tabular}{|l|l|}
175,70 \\
\end{tabular} & \begin{tabular}{ll|}
177,29 \\
\end{tabular} & 69,46 & 1400,04 & 207,77 & 35,43 & 44,95 & 536,38 & \begin{tabular}{ll|}
139,36 \\
\end{tabular} & \begin{tabular}{ll|}
153,01 \\
\end{tabular} & 521,48 \\
\hline Lissotriton boscai & 29TNH62 & 101,00 & 126,70 & 82,14 & 39,66 & 4142,87 & 242,07 & 37,06 & 205,01 & 81,27 & $\begin{array}{ll}180,62 \\
18\end{array}$ & 182,46 & 77,59 & \begin{tabular}{|l|}
1348,88 \\
\end{tabular} & 199,73 & 34,98 & 44,38 & $\begin{array}{l}514,25 \\
\end{array}$ & \begin{tabular}{ll|}
135,83 \\
\end{tabular} & \begin{tabular}{ll|}
151,36 \\
\end{tabular} & 496,63 \\
\hline Lissotriton boscai & \begin{tabular}{|l|l|} 
29TNH63 \\
\end{tabular} & 100,00 & 127,69 & 81,29 & 39,80 & 4046,96 & 241,44 & 39,35 & 202,09 & 83,45 & 180,25 & 182,44 & 79,89 & 1331,88 & 194,42 & 35,67 & \begin{tabular}{l|l}
43,65 \\
\end{tabular} & \begin{tabular}{l|l}
505,65 \\
\end{tabular} & \begin{tabular}{l|l|l|}
137,02 \\
\end{tabular} & \begin{tabular}{l|l|}
153,53 \\
\end{tabular} & 485,67 \\
\hline Lissotriton boscai & 29TNH64 & 101,00 & 133,27 & 80,09 & 39,73 & 3986,03 & 244,84 & 45,28 & \begin{tabular}{ll|}
199,56 \\
\end{tabular} & 89,76 & \begin{tabular}{|l|l|}
184,79 \\
\end{tabular} & 187,14 & 85,8 & $\begin{array}{ll}1267,58 \\
\end{array}$ & 182,28 & 34,57 & 42,8 & 479,13 & \begin{tabular}{ll|}
132,16 \\
\end{tabular} & \begin{tabular}{l|l|}
150,26 \\
\end{tabular} & 456,27 \\
\hline Lissotriton boscai & 29TNH65 & 101,00 & 130,40 & 79,78 & 39,77 & 3917,78 & 241,68 & 43,59 & \begin{tabular}{l|l|l|l|l|}
198,09 \\
\end{tabular} & 88,21 & \begin{tabular}{l|l|l|l|}
181,02 \\
\end{tabular} & 183,65 & \begin{tabular}{|l|l|l|}
84,03 \\
\end{tabular} & 1279,46 & \begin{tabular}{|l|l|}
181,47 \\
\end{tabular} & 35,99 & \begin{tabular}{l|l}
42,05 \\
\end{tabular} & \begin{tabular}{ll|}
482,16 \\
\end{tabular} & $\begin{array}{ll}136,82 \\
\end{array}$ & \begin{tabular}{|l|l|}
155,12 \\
\end{tabular} & 457,82 \\
\hline Lissotriton boscai & \begin{tabular}{|l|l|} 
29TNH67 \\
\end{tabular} & 100,00 & 126,03 & 77,79 & 40,01 & 3800,28 & 234,24 & 42,32 & \begin{tabular}{l|l|l|}
191,92 \\
\end{tabular} & 86,01 & $\begin{array}{l}174,86 \\
19\end{array}$ & \begin{tabular}{|l|l|}
178,03 \\
\end{tabular} & 81,18 & \begin{tabular}{|l|l|}
1264,47 \\
\end{tabular} & 174,59 & 37,33 & 40,38 & \begin{tabular}{|l|l|}
474,41 \\
\end{tabular} & $\begin{array}{l}141,64 \\
\end{array}$ & 160,31 & 446,85 \\
\hline Lissotriton boscai & $\begin{array}{l}\text { 29TNH68 } \\
\end{array}$ & 101,00 & 134,85 & 74,68 & 40,77 & 3631,25 & 235,43 & 54,60 & \begin{tabular}{l|l|l|l|}
180,83 \\
\end{tabular} & 96,81 & $\begin{array}{ll}180,73 \\
\end{array}$ & 184,20 & 90,95 & 1139,74 & \begin{tabular}{ll|}
153,76 \\
\end{tabular} & 33,40 & 39,51 & \begin{tabular}{ll|}
427,46 \\
\end{tabular} & \begin{tabular}{ll|}
128,78 \\
\end{tabular} & \begin{tabular}{|l|}
149,04 \\
\end{tabular} & 397,92 \\
\hline Lissotriton boscai & 29TNH69 & 95,00 & 138,76 & 72,50 & $41,54[$ & 3500,36 & 233,97] & 61,39 & 172,57 & 102,55 & 182,52 & 186,15 & 95,99 & 1070,00 & $141,51 \mid$ & 31,45 & 38,83 & 401,11 & $122,61 \mid$ & 143,65 & 370,04 \\
\hline Lissotriton boscai & \begin{tabular}{|l|l|} 
29TNH70 \\
\end{tabular} & 101,00 & 121,99 & 85,74 & 39,01 & 4488,05 & 244,15 & 27,49 & 216,65 & 72,54 & \begin{tabular}{|l|l|}
180,79 \\
\end{tabular} & 181,86 & 68,41 & 1311,15 & 193,43 & 31,86 & 44,90 & 500,27 & $\begin{array}{ll}128,43 \\
\end{array}$ & \begin{tabular}{|l|l|}
141,17 \\
\end{tabular} & 487,17 \\
\hline Lissotriton boscai & \begin{tabular}{|l|} 
29TNH71 \\
\end{tabular} & 99,00 & 118,16 & 84,62 & 39,24 & 4357,75 & 238,68 & 26,08 & 212,61 & \begin{tabular}{|l|}
70,47 \\
\end{tabular} & $\begin{array}{l}175,35 \\
\end{array}$ & 176,65 & 66,72 & \begin{tabular}{|l|}
1346,03 \\
\end{tabular} & 196,75 & 34,18 & 44,25 & 512,73 & 135,22 & 148,12 & 498,57 \\
\hline Lissotriton boscai & 29TNH72 & 100,00 & 120,88 & 84,11 & 39,92 & 4229,67 & 238,74 & 30,06 & 208,68 & 74,28 & \begin{tabular}{|l|l|}
176,17 \\
\end{tabular} & \begin{tabular}{ll|l}
177,82 \\
\end{tabular} & 71,15 & 1325,34 & 192,94 & 34,76 & \begin{tabular}{|l|l|}
43,67 \\
\end{tabular} & \begin{tabular}{l|l|}
502,72 \\
\end{tabular} & $\begin{array}{l}135,75 \\
\end{array}$ & \begin{tabular}{ll|}
149,76 \\
\end{tabular} & 486,41 \\
\hline Lissotriton boscai & 29TNH73 & 101,00 & 126,68 & 83,29 & \begin{tabular}{l|l}
40,45 \\
\end{tabular} & 4067,70 & 240,51 & 37,36 & 203,15 & 81,38 & $\begin{array}{l}179,54 \\
1\end{array}$ & $\begin{array}{l}181,47 \\
\end{array}$ & 78,91 & \begin{tabular}{|l|}
1275,06 \\
\end{tabular} & 184,29 & 34,28 & \begin{tabular}{|l|l}
43,04 \\
\end{tabular} & 481,31 & 132,43 & \begin{tabular}{|l|l|}
148,01 \\
\end{tabular} & 462,41 \\
\hline Lissotriton boscai & 29TNH74 & 99,00 & 132,39 & 81,96 & 40,60 & 3987,50 & 243,52 & 43,78 & 199,74 & $88,08 \mid$ & 184,03 & 186,11 & 85,16 . & 1213,25 & 173,05 & 33,25 & 42,24 & 455,95 & 127,77 & 145,03 & 434,40 \\
\hline Lissotriton boscai & \begin{tabular}{|l|l|} 
29TNH75 \\
\end{tabular} & 100,00 & 126,05 & 81,54 & 40,60 & 3942,56 & 237,71 & 38,92 & \begin{tabular}{|l|l|}
198,78 \\
\end{tabular} & \begin{tabular}{|l|l|}
82,92 \\
\end{tabular} & \begin{tabular}{|l|l|}
177,11 \\
\end{tabular} & \begin{tabular}{|l|l|}
179,57 \\
\end{tabular} & 79,78 & \begin{tabular}{|l|}
1257,87 \\
\end{tabular} & 177,32 & 35,75 & 41,48 & 472,00 & \begin{tabular}{|l|l|}
136,39 \\
\end{tabular} & \begin{tabular}{|l|l|}
153,28 \\
\end{tabular} & 449,29 \\
\hline Lissotriton boscai & \begin{tabular}{|l|l|} 
29TNH76 \\
\end{tabular} & 100,00 & 123,45 & 80,75 & 40,48 & 3913,96 & 234,63 & 37,28 & 197,35 & \begin{tabular}{l|l|}
81,06 \\
\end{tabular} & \begin{tabular}{|l|l|l|l|}
174,02 \\
\end{tabular} & \begin{tabular}{|l|l|}
176,74 \\
\end{tabular} & 77,42 & \begin{tabular}{|l|l|}
1263,07 \\
\end{tabular} & 175,84 & 36,85 & 40,71 & 472,81 & $\begin{array}{l}140,15 \\
1\end{array}$ & \begin{tabular}{ll|}
157,23 \\
\end{tabular} & 448,44 \\
\hline Lissotriton boscai & 29TNH77 & 100,00 & 122,67 & 79,66 & 40,36 & 3855,55 & 232,35 & 37,61 & 194,73 & 81,38 & 172,28 & 175,29 & 77,27 & 1252,18 & 172,13 & 37,44 & 39,90 & 467,53 & 142,08 & 159,52 & 441,33 \\
\hline Lissotriton boscai & \begin{tabular}{|l|l|} 
29TNH78 \\
\end{tabular} & 100,00 & 125,41 & 78,00 & \begin{tabular}{l|l|}
40,75 \\
\end{tabular} & 3774,11 & 231,87 & 42,35 & \begin{tabular}{l|l|}
189,52 \\
\end{tabular} & 85,45 & 173,73 & \begin{tabular}{ll|}
176,95 \\
\end{tabular} & 80,70 & 1203,79 & 163,01 & 36,49 & 39,10 & 448,58 & \begin{tabular}{|l|l|}
138,77 \\
\end{tabular} & \begin{tabular}{|l|}
157,20 \\
\end{tabular} & 420,48 \\
\hline Lissotriton boscai & \begin{tabular}{|l|l|} 
29TNH79 \\
\end{tabular} & 101,00 & 127,95 & 76,35 & \begin{tabular}{ll|}
40,99 \\
\end{tabular} & 3677,10 & 230,73 & 46,82 & \begin{tabular}{|l|l|}
183,90 \\
\end{tabular} & 89,37 & $\begin{array}{l}174,66 \\
\end{array}$ & \begin{tabular}{|l|l|}
178,06 \\
\end{tabular} & 84,01 & \begin{tabular}{|l|}
1160,08 \\
\end{tabular} & 154,75 & 35,67 & 38,39 & 431,51 & \begin{tabular}{|l|l|}
135,97 \\
\end{tabular} & \begin{tabular}{|l|l|}
155,20 \\
\end{tabular} & 401,73 \\
\hline Lissotriton boscai & 29TNH80 & 101,00 & 121,66 & 87,60 & 38,94 & 4624,64 & 246,68 & 24,51 & 222,16 & \begin{tabular}{|l|l|}
70,44 \\
\end{tabular} & \begin{tabular}{|l|l|}
182,41 \\
\end{tabular} & 183,22 & \begin{tabular}{|l|l|}
66,42 \\
\end{tabular} & 1237,66 & \begin{tabular}{|l|l|}
179,48 \\
\end{tabular} & 30,18 & 44,30 & 469,27 & 122,14 & \begin{tabular}{|l|l|l|}
134,09 \\
\end{tabular} & 456,60 \\
\hline Lissotriton boscai & 29TNH82 & 100,00 & 116,25 & 85,54 & 39,56 & 4367,94 & 237,33 & 23,49 & 213,84 & 68,15 & $\begin{array}{l}173,50 \\
170\end{array}$ & \begin{tabular}{|l|l|}
175,03 \\
\end{tabular} & 64,72 & \begin{tabular}{|l|l|}
1291,08 \\
\end{tabular} & 184,62 & 34,22 & 42,98 & $\begin{array}{ll}487,78 \\
\end{array}$ & \begin{tabular}{|l|l|}
134,11 \\
\end{tabular} & \begin{tabular}{|l|l|}
147,04 \\
\end{tabular} & 472,19 \\
\hline Lissotriton boscai & \begin{tabular}{|l|l|} 
29TNH84 \\
\end{tabular} & 100,00 & 127,03 & 83,97 & 40,56 & 4104,26 & 241,13 & 36,61 & 204,52 & 81,13 & $\begin{array}{l}180,29 \\
18\end{array}$ & 182,31 & 78,65 & \begin{tabular}{|l|}
1198,23 \\
\end{tabular} & 169,39 & 33,26 & \begin{tabular}{ll|}
41,66 \\
\end{tabular} & 448,57 & \begin{tabular}{|l|l|}
128,19 \\
\end{tabular} & \begin{tabular}{l|l|l|}
144,12 \\
\end{tabular} & 428,34 \\
\hline Lissotriton boscai & 29TNH85 & 101,00 & 121,53 & 83,23 & 40,44 & 4063,13 & 235,80 & 32,57 & 203,23 & 76,88 & \begin{tabular}{|l|l|}
174,31 \\
\end{tabular} & $\begin{array}{l}176,45 \\
\end{array}$ & 73,91 & 1235,25 & 172,50 & 35,55 & 40,89 & 461,64 & \begin{tabular}{|l|l|}
135,93 \\
\end{tabular} & \begin{tabular}{|l|l|}
151,63 \\
\end{tabular} & 439,92 \\
\hline Lissotriton boscai & 29TNH86 & 101,00 & 4 & $827+2$ & 40,29 & 4041,46 & 230,32 & 28,3 & 201,98 & 72,10 & 168,44 & \begin{tabular}{|l|}
170,87 \\
\end{tabular} & 68,70 & 1270,44 & 175,37 & 37,8 & , & 473,87 & \begin{tabular}{|l|l|}
143,78 \\
\end{tabular} & \begin{tabular}{l|l|}
159,12 \\
\end{tabular} & 450,46 \\
\hline Lissotriton boscai & 29TNH88 & 101,00 & 12 & 79,96 & \begin{tabular}{|l|l|}
40,75 \\
\end{tabular} & 3879,56 & 229,84 & 35,39 & 194,45 & 78,82 & 170,37 & 173,09 & 74,51 & 1209,88 & 163,08 & 37,42 & 38,62 & 448,59 & 141,75 & 158,84 & 421,24 \\
\hline Lissotriton boscai & $\begin{array}{l}\text { 29TNH89 } \\
\end{array}$ & 100,00 & 118,54 & 78,92 & \begin{tabular}{l|l}
40,75 \\
\end{tabular} & 3828,43 & 226,61 & \begin{tabular}{|l|l}
34,99 \\
\end{tabular} & \begin{tabular}{l|l|l|}
191,62 \\
\end{tabular} & 77,91 & \begin{tabular}{|l|l|}
167,77 \\
\end{tabular} & $\begin{array}{ll}170,85 \\
\end{array}$ & 73,56 & \begin{tabular}{|l|l|}
1211,67 \\
\end{tabular} & 161,56 & 38,36 & $\begin{array}{ll}37,93 \\
\end{array}$ & \begin{tabular}{ll|}
448,19 \\
\end{tabular} & \begin{tabular}{|l|l}
144,90 \\
\end{tabular} & $\begin{array}{l}162,40 \\
\end{array}$ & 419,19 \\
\hline Lissotriton boscai & $\begin{array}{l}\text { 29TNH9O } \\
\end{array}$ & 100,00 & 122,24 & 89,38 & \begin{tabular}{ll|}
38,96 \\
\end{tabular} & 4753,56 & 249,93 & 22,45 & 227,48 & 69,16 & \begin{tabular}{|l|}
184,61 \\
\end{tabular} & \begin{tabular}{ll|}
185,24 \\
\end{tabular} & 65,15 & $\begin{array}{ll}1166,68 \\
\end{array}$ & 166,79 & 28,45 & \begin{tabular}{ll|}
43,87 \\
\end{tabular} & $\begin{array}{l}440,45 \\
\end{array}$ & \begin{tabular}{|l|l|}
115,60 \\
\end{tabular} & \begin{tabular}{|l|l|}
126,20 \\
\end{tabular} & 428,22 \\
\hline Lissotriton boscai & 29TNH91 & 101,00 & 118,31 & 88,03 & 39,00 & 4616,37 & 244,04 & 21,27 & 222,77 & \begin{tabular}{|l|l|}
67,07 \\
\end{tabular} & $\begin{array}{l}178,96 \\
\end{array}$ & \begin{tabular}{|l|}
179,91 \\
\end{tabular} & \begin{tabular}{|c|}
63,44 \\
\end{tabular} & 1205,83 & 171,39 & 30,83 & 43,10 & \begin{tabular}{|l|l|}
454,83 \\
\end{tabular} & \begin{tabular}{ll|}
123,06 \\
\end{tabular} & \begin{tabular}{ll|}
135,26 \\
\end{tabular} & 441,25 \\
\hline Lissotriton boscai & 29TNH92 & 101,00 & 11 & 87,18 & 39,25 & 506,3 & 240,98 & 22,00 & 218,98 & 67,39 & \begin{tabular}{ll|}
176,50 \\
\end{tabular} & 177. & $64, \mathrm{C}$ & 121 & \begin{tabular}{ll|l}
171,45 \\
\end{tabular} & 32,25 & 42,4 & 456,32 & \begin{tabular}{l|l|}
126,99 \\
\end{tabular} & \begin{tabular}{|l|}
139,71 \\
\end{tabular} & 440,75 \\
\hline Lissotriton boscai & \begin{tabular}{|l|l|} 
29TNH93 \\
\end{tabular} & 100,00 & 12 & 86,50 & 39,86 & 4380,79 & 240,84 & 26,01 & 214,82 & 71,35 & 177,34 & 178,84 & 68,3 & 1192,53 & 167,75 & 32,62 & \begin{tabular}{l|l}
41,76 \\
\end{tabular} & \begin{tabular}{|l|l|}
446,68 \\
\end{tabular} & 127,21 & 141,04 & 429,09 \\
\hline Lissotriton boscai & \begin{tabular}{|l|} 
29TNH94 \\
\end{tabular} & 101,00 & 120,48 & 85,68 & 40,00 & 4286,38 & 239,28 & 27,86 & 211,42 & 72,89 & \begin{tabular}{|l|l|}
176,37 \\
\end{tabular} & \begin{tabular}{|l|l|}
178,07 \\
\end{tabular} & 69, & 1187,30 & 165,77 & 33,41 & 41,03 & 443,28 & 129,30 & \begin{tabular}{ll|}
143,69 \\
\end{tabular} & 423,85 \\
\hline Lissotriton boscai & $\begin{array}{l}\text { 29TNH95 } \\
\end{array}$ & 101,00 & 120,38 & 84,72 & 40,10 & 4199,03 & 237,33 & 29,28 & 208,05 & \begin{tabular}{ll|}
73,99 \\
\end{tabular} & $\begin{array}{l}175,04 \\
17\end{array}$ & $\begin{array}{l}176,95 \\
\end{array}$ & 70,86 & 1186,55 & 164,11 & 34,36 & \begin{tabular}{ll|}
40,28 \\
\end{tabular} & \begin{tabular}{|l|l|}
441,78 \\
\end{tabular} & $\begin{array}{l}132,04 \\
13\end{array}$ & \begin{tabular}{l|l|l|}
146,98 \\
\end{tabular} & 420,39 \\
\hline Lissotriton boscai & 29TNH97| & 100,00 & 122,66 & 82,42 & $\begin{array}{l}40,76 \\
\end{array}$ & 4034,11 & 235,08 & 34 & 200,57 & 78,55 & $174,71 \mid$ & 177,24 & 74,77 & 1155,42 & 156,30 & 35,05 & 38,88 . & 427,68 & 133,61 & 150,03 & 402,29 \\
\hline Lissotriton boscai & \begin{tabular}{|l|} 
29TNH99 \\
\end{tabular} & 100,00 & 121,31 & 80,24 & \begin{tabular}{|l|l|}
40,97 \\
\end{tabular} & 3889,75 & 230,11 & 36,08 & \begin{tabular}{|l|l|l|}
194,03 \\
\end{tabular} & 79,50 & 171,34 & 174,06 & 75,10 & 1152,55 & 152,47 & 36,63 & 37,4 & $\begin{array}{l}424,45 \\
\end{array}$ & 138,80 & 156,01 & 395,57 \\
\hline Lissotriton boscai & 29TNJ40 & 18,00 & 140,90 & 67,00 & 41,90 & 3225,38 & 226 & 68,62 & 158,34 & \begin{tabular}{|l|l|}
109,17 \\
\end{tabular} & \begin{tabular}{|l|l|}
180,34 \\
\end{tabular} & 184,66 & 101,00 & 1040,24 & 135,86 & 30,03 & 39,00 & 394,31 & $\begin{array}{ll}119,52 \\
\end{array}$ & \begin{tabular}{|l|l|}
142,10 \\
\end{tabular} & 359,59 \\
\hline Lissotriton boscai & 29TNJ50 & 35,00 & 140,32 & 69,33 & \begin{tabular}{l|l}
42,05 \\
\end{tabular} & 3314,98 & 229,41 & 66,90 & 162,51 & 106,79 & \begin{tabular}{|l|l|}
181,08 \\
\end{tabular} & $\begin{array}{l}185,25 \\
\end{array}$ & $\begin{array}{l}99,56 \\
\end{array}$ & 1041,52 & \begin{tabular}{l|l|}
135,65 \\
\end{tabular} & 30,56 & 38,54 & 392,02 & \begin{tabular}{|l|l|}
120,49 \\
\end{tabular} & 142,51 & 359,29 \\
\hline Lissotriton boscai & 29TNJ51 & 48,00 & 137,32 & 69,06 & 42,18 & 3289,25 & 226,38 & 64,58 & \begin{tabular}{|l|l|}
161,79 \\
\end{tabular} & 104,32 & \begin{tabular}{|l|l|}
177,74 \\
\end{tabular} & 182,08 & $\begin{array}{ll}96,99 \\
\end{array}$ & 1053,97 & 136,43 & 32,00 & 37,81 & 395,00 & 125,51 & \begin{tabular}{|l|l|}
147,40 \\
\end{tabular} & 360,88 \\
\hline Lissotriton boscai & 29TNJ52 & 12,00 & 13 & 68,29 & 42,50 & 3239,32 & 226 & 67,6 & 159,00 & \begin{tabular}{|l|l|}
107,07 \\
\end{tabular} & \begin{tabular}{|l|l|l|}
179,29 \\
\end{tabular} & \begin{tabular}{|l|l|}
183,57 \\
\end{tabular} & 99, & 1024,82 & 132,75 & 31,04 & 37,5 & 383,82 & 122,86 & $\begin{array}{ll}145,32 \\
\end{array}$ & 34 \\
\hline Lissotriton boscai & $29 \mathrm{TN}$ & 66,00 & 13 & 71,58 & 41, & 342 & $231+1+2$ & 62,7 & 168 & 103 & 181 & 184 & 96, & 105 & 137,08 & 31,55 & 38,09 & 393,14 & 123,14 & 144 & 360 \\
\hline Lissotriton boscai & 29TNJ61 & 82,00 & 138,78 & 70,46 & 42,23 & 3350,75 & 229,34 & \begin{tabular}{|l|l|}
64,74 \\
\end{tabular} & 164,60 & \begin{tabular}{|l|}
104,63 \\
\end{tabular} & \begin{tabular}{|l|}
180,27 \\
\end{tabular} & 184,22 & 97,70 & \begin{tabular}{|l|}
1035,07 \\
\end{tabular} & 133,93 & 31,48 & 37,61 & 386,40 & 123,21 & \begin{tabular}{ll|}
144,96 \\
\end{tabular} & 352,94 \\
\hline Lissotriton boscai & 29TNJ62 & 77,00 & 138,50 & 69,71 & 42,42 & 3311,98 & 227,83 & \begin{tabular}{l|l}
65,35 \\
\end{tabular} & \begin{tabular}{l|l|l|l|l|}
162,48 \\
\end{tabular} & $\begin{array}{ll}104,89 \\
\end{array}$ & \begin{tabular}{|l|}
179,31 \\
1
\end{tabular} & \begin{tabular}{|l|l|}
183,41 \\
\end{tabular} & 97,82 & 1028,44 & 132,74 & 31,91 & 37,02 & \begin{tabular}{|l|l|}
383,10 \\
\end{tabular} & $\begin{array}{l}124,55 \\
1\end{array}$ & \begin{tabular}{l|l}
146,55 \\
1
\end{tabular} & 348,41 \\
\hline Lissotriton boscai & 29TNJ70 & 100,00 & 127,38 & 75,21 & 41,21 & 3607,29 & 228,03 & 47,99 & 180,04 & 89,86 & $\begin{array}{ll}172,98 \\
\end{array}$ & \begin{tabular}{|l|l|}
176,58 \\
\end{tabular} & 84,18 & 1147,25 & 151,21 & 35,90 & 37,79 & $\begin{array}{ll}425,82 \\
\end{array}$ & \begin{tabular}{|l|l|}
137,08 \\
\end{tabular} & $\begin{array}{ll}156,62 \\
\end{array}$ & 394,60 \\
\hline Lissotriton boscai & $29 \mathrm{TN}$ & 10 & & & 41, & 3531, & & 51, & 175, & 92, & & 177 & 86 & & & 35,26 & 37. & 412 & 135,00 & $\begin{array}{ll}155,22 \\
\end{array}$ & \\
\hline Lissotriton boscai & 29TNJ72 & 101,00 & 133,10 & 72,1 & \begin{tabular}{|l|l|}
42,08 \\
\end{tabular} & 3432,0 & 226,9 & \begin{tabular}{|l|l|l|}
57,35 \\
\end{tabular} & 169,57 & 97,9 & \begin{tabular}{l|l|}
175,90 \\
\end{tabular} & 179,7 & \begin{tabular}{l|l}
91,45 \\
\end{tabular} & 1067,50 & 137,07 & 34,02 & 36,65 & 394,97 & $\begin{array}{l}131,15 \\
\end{array}$ & \begin{tabular}{ll|}
152,16 \\
\end{tabular} & 360, \\
\hline Lissotriton boscai & 29TNJ73 & 59,00 & 136,04 & 70,98 & 42,29 & 3368,61 & 227,33 & \begin{tabular}{|c|}
61,57 \\
\end{tabular} & \begin{tabular}{|l|l|}
165,76 \\
\end{tabular} & \begin{tabular}{|l|l|}
101,66 \\
\end{tabular} & 177,81 & 181,81 & 95,03 & 1033,72 & 133,07 & 33,30 & 36,18 & 381,82 & 128,65 & 150,28 & 346,35 \\
\hline
\end{tabular}




\begin{tabular}{|c|c|c|c|c|c|c|c|c|c|c|c|c|c|c|c|c|c|c|c|c|c|}
\hline TAXON & UTM & $\mathrm{km} 2$ & BIO1 & BIO2 & $B 103$ & BIO4 & B105 & B106 & B107 & B108 & B109 & B1010 & BIO11 & BIO12 & BIO13 & B1014 & BIO15 & B1016 & B1017 & B1018 & 81019 \\
\hline Lissotriton boscai & 29TNJ80 & 100,00 & 122,17 & 77,45 & 40,97 & 3732,97 & 226,80 & 40,28 & 186,52 & 82,75 & 169,73 & 173,01 & 77,78 & 1168,66 & 153,90 & 37,45 & 37,24 & 431,41 & 141,75 & 160,10 & 400,68 \\
\hline Lissotriton boscai & 29TNJ81 & 100,00 & 123,92 & 76,14 & 41,25 & 3653,63 & 225,79 & 43,65 & 182,14 & 85,62 & 170,26 & 173,78 & 80,28 & 1142,11 & 148,61 & 37,10 & 36,76 & 420,70 & $\begin{array}{l}140,61 \\
\end{array}$ & 159,65 & 388,46 \\
\hline Lissotriton boscai & 29TNJ82 & 100,00 & 130,16 & 74,18 & 41,87 & 3535,37 & 227,38 & 52,20 & 175,18 & 93,44 & 174,59 & $\begin{array}{l}178,24 \\
\end{array}$ & 87,60 & 1077,42 & \begin{tabular}{|l|l|}
138,13 \\
\end{tabular} & 35,11 & 36,12 & $\begin{array}{l}396,33 \\
\end{array}$ & $\begin{array}{l}134,04 \\
\end{array}$ & $\begin{array}{l}154,27 \\
\end{array}$ & 362,51 \\
\hline Lissotriton boscai & 29TNJ83 & 101,00 & 130,18 & 72,98 & 41,98 & 3479,40 & 225,55 & 53,48 & $\begin{array}{l}172,07 \\
\end{array}$ & 94,38 & $\begin{array}{l}173,69 \\
\end{array}$ & $\begin{array}{l}177,47 \\
\end{array}$ & 88,12 & 1072,64 & 137,44 & 35,55 & 35,79 & 393,85 & $\begin{array}{l}135,68 \\
\end{array}$ & $\begin{array}{ll}156,29 \\
\end{array}$ & 358,51 \\
\hline Lissotriton boscai & 29TNJ84 & 31,00 & 128,75 & 72,62 & 42,07 & 3463,58 & 223,64 & 52,51 & 171,13 & 93,16 & 172,00 & 175,75 & 86,98 & 1079,11 & 138,18 & 36,49 & 35,25 & 395,05 & 138,64 & 159,35 & 358,69 \\
\hline Lissotriton boscai & 29TNJ90 & 101,00 & 120,50 & 79,13 & 40,94 & 3826,89 & 227,57 & 36,78 & \begin{tabular}{|l|l|}
190,79 \\
\end{tabular} & 79,70 & $\mid 169,58$ & $\mid 172,59$ & 75,19 & 1151,81 & \begin{tabular}{|l|l|}
150,82 \\
\end{tabular} & $\mid 37,43$ & 36,92 & 423,15 & $\mid 141,40$ & 158,99 & 392,64 \\
\hline Lissotriton boscai & 29TNJ91 & 101,00 & 119,44 & 78,01 & 41,06 & 3765,45 & 224,70 & 37,15 & 187,55 & 79,81 & 167,50 & 170,67 & 74,70 & 1154,74 & 149,70 & 38,31 & 36,17 & 423,15 & 144,50 & 162,42 & 391,05 \\
\hline Lissotriton boscai & 29TNJ92 & 99,00 & 122,03 & 76,58 & 41,33 & 3678,40 & 224,31 & 41,38 & 182,93 & 83,46 & 168,71 & 172,09 & 78,17 & 1126,56 & 144,34 & 37,91 & 35,67 & 411,83 & 143,04 & 161,75 & 378,12 \\
\hline Lissotriton boscai & 29TNJ93 & 92,00 & 133,74 & 73,98 & 41,97 & 3525,79 & 229,64 & 55,54 & 174,11 & 96,84 & $\begin{array}{l}177,87 \\
\end{array}$ & \begin{tabular}{ll|}
181,48 \\
\end{tabular} & 91,05 & $\begin{array}{l}1025,37 \\
\end{array}$ & \begin{tabular}{l|l|}
131,62 \\
\end{tabular} & 34,11 & 35,33 & $\begin{array}{l}374,76 \\
\end{array}$ & $\begin{array}{l}130,39 \\
\end{array}$ & $\begin{array}{ll}150,86 \\
\end{array}$ & 339,41 \\
\hline Lissotriton boscai & 29TNJ94 & 26,00 & 139,35 & 72,33 & 42,44 & 3429,44 & 231,53 & 63,05 & 168,49 & 103,72 & 181,98 & 185,72 & 97,65 & $\begin{array}{l}980,72 \\
\end{array}$ & 127,09 & 32,65 & 35,09 & 358,56 & 125,33 & 146,77 & 322,12 \\
\hline Lissotriton boscai & 29TPE05 & 101,00 & 126,58 & 86,64 & 35,51 & 5336,17 & 268,16 & 27,58 & 240,57 & 62,81 & 198,19 & 198,24 & 62,81 & 1256,14 & 190,94 & 11,95 & 56,14 & 514,50 & 76,92 & 76,93 & 514,50 \\
\hline Lissotriton boscai & 29TPE06 & 100,00 & 135,12 & 91,66 & 36,74 & 5328,00 & 278,88 & 32,86 & 246,03 & 70,31 & 205,51 & 205,99 & 70,31 & $\begin{array}{l}1164,94 \\
\end{array}$ & 175,36 & $\begin{array}{ll}11,03 \\
\end{array}$ & 55,58 & 475,27 & 73,03 & 73,29 & 475,27 \\
\hline Lissotriton boscai & 29TPE07 & 101,00 & 141,90 & 96,20 & 37,94 & 5321,55 & 287,46 & 36,82 & 250,64 & 76,22 & 211,36 & 212,15 & 76,22 & 1091,34 & 162,71 & $\mid 10,26$ & 55,15 & 443,22 & 69,66 & 70,37 & 443,22 \\
\hline Lissotriton boscai & 29TPE08 & 100,00 & 144,63 & 98,44 & 38,54 & 5297,72 & 290,27 & 38,25 & 252,02 & 78,79 & 213,46 & 214,23 & 78,79 & 1062,03 & 157,71 & 9,92 & 54,88 & 429,93 & 67,87 & 69,61 & 429,93 \\
\hline Lissotriton boscai & 29TPE09 & 100,00 & 139,40 & 97,45 & 38,44 & 5293,84 & 284,18 & 33,86 & 250,32 & 73,69 & 208,42 & 209,06 & 73,69 & 1121,11 & $\begin{array}{l}167,79 \\
\end{array}$ & 10,81 & 55,10 & 454,88 & 72,02 & 73,49 & 454,88 \\
\hline Lissotriton boscai & 29TPE13 & 101,00 & 138,06 & 90,21 & 35,47 & 5541,54 & 286,28 & $\begin{array}{ll}35,83 \\
\end{array}$ & 250,45 & 71,63 & 212,30 & 212,50 & 71,63 & 1089,64 & 163,14 & 9,87 & 55,65 & 444,77 & 66,97 & 66,98 & 444,77 \\
\hline Lissotriton boscai & 29TPE14 & 101,00 & 143,73 & $\begin{array}{ll}93,64 \\
\end{array}$ & 36,32 & 5535,10 & 293,33 & 39,08 & 254,25 & 76,45 & 217,15 & 217,53 & 76,45 & 1033,99 & \begin{tabular}{|l|l|}
153,73 \\
\end{tabular} & 9,37 & 55,26 & 420,45 & 64,75 & 64,79 & 420,45 \\
\hline Lissotriton boscai & 29TPE15 & 99,00 & 129,26 & 87,30 & 35,12 & 5467,14 & 273,53 & 28,66 & 244,87 & 63,75 & 202,52 & 202,53 & 63,75 & $\begin{array}{l}1199,32 \\
\end{array}$ & \begin{tabular}{|l|l|}
181,90 \\
\end{tabular} & $\begin{array}{l}11,09 \\
\end{array}$ & 55,96 & 490,30 & 73,40 & 73,40 & 490,30 \\
\hline |Lissotriton boscai & 29TPE16 & 100,00 & 89,37 & 73,79 & 32,38 & 5308,01 & 222,81 & $-1,45$ & 224,25 & 29,35 & 162,23 & 162,23 & 29,35 & 1627,76 & 249,32 & 17,25 & 56,10 & 663,37 & 100,90 & 100,90 & 663,37 \\
\hline Lissotriton boscai & 29TPE17 & 100,00 & 105,52 & 77,94 & 33,30 & 5333,84 & 240,87 & 11,12 & 229,75 & 43,46 & 177,77 & 177,83 & 43,46 & 1488,39 & 230,10 & 14,23 & 56,81 & 610,46 & 89,59 & 89,68 & 610,46 \\
\hline Lissotriton boscai & 29TPE18 & 101,00 & 138,06 & 94,81 & 37,17 & 5436,40 & 284,38 & 32,78 & 251,60 & 71,02 & 209,38 & 209,73 & 71,02 & 1101,46 & 165,42 & 10,36 & 55,31 & 447,47 & 70,05 & 70,65 & 447,47 \\
\hline Lissotriton boscai & 29TPE19 & 101,00 & 138,73 & 96,68 & 37,72 & 5420,53 & 285,38 & 32,53 & 252,85 & 71,60 & 209,64 & 209,95 & 71,60 & 1094,17 & 164,30 & 10,36 & 55,31 & 444,18 & 69,92 & 70,79 & 444,18 \\
\hline Lissotriton boscai & 29TPE23 & 100,00 & 136,93 & 89,41 & 34,98 & 5655,55 & 286,47 & 34,08 & 252,39 & 69,31 & 212,77 & 212,88 & 69,31 & 1072,25 & $\begin{array}{l}160,25 \\
\end{array}$ & 9,60 & 55,52 & $\begin{array}{l}436,33 \\
\end{array}$ & 65,86 & 65,86 & 436,33 \\
\hline Lissotriton boscai & 29TPE24 & 100,00 & 142,68 & 92,77 & 35,65 & 5654,12 & 293,58 & 37,45 & 256,12 & 74,19 & 217,73 & 218,05 & 74,19 & 1014,30 & 150,67 & 8,95 & 55,21 & 411,38 & 63,29 & 63,31 & 411,38 \\
\hline 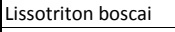 & 29TPE25 & 101,00 & 137,34 & 90,80 & 35,35 & 5606,22 & 285,74 & 33,34 & 252,40 & 69,51 & 211,78 & 212,03 & 69,51 & 1075,73 & 161,29 & 9,71 & 55,46 & 437,30 & 66,83 & 66,87 & 437,30 \\
\hline Lissotriton boscai & 29TPE26 & 101,00 & 103,49 & 76,74 & 32,49 & 5450,47 & 240,55 & 9,06 & 231,49 & 40,44 & 177,45 & 177,47 & 40,44 & 1460,65 & 224,47 & 13,97 & 56,51 & 598,38 & 87,92 & 88,13 & 598,38 \\
\hline L Lissotriton boscai & 29TPE27 & 100,00 & 106,99 & 77,23 & 32,68 & 5450,44 & 243,96 & 11,69 & 232,27 & 43,10 & 180,52 & 180,54 & 43,10 & 1421,80 & 219,17 & 13,32 & 56,76 & 583,80 & 85,34 & 86,46 & 583,80 \\
\hline Lissotriton boscai & 29TPE28 & 100,00 & 115,82 & 82,63 & 34,00 & 5469,42 & 255,98 & 17,15 & 238,83 & 50,50 & 188,84 & 188,97 & 50,50 & 1311,44 & 200,81 & 12,45 & 56,23 & 537,03 & 80,49 & 82,35 & 537,03 \\
\hline Lissotriton boscai & 29TPE29 & 101,00 & 140,71 & 97,32 & 37,40 & 5537,38 & 289,73 & 33,15 & 256,58 & 72,15 & 213,23 & 213,42 & 72,15 & 1031,62 & $\begin{array}{l}154,36 \\
\end{array}$ & 9,59 & 55,08 & 417,47 & 65,82 & $\begin{array}{ll}66,46 \\
\end{array}$ & 417,47 \\
\hline Lissotriton boscai & 29TPE33 & 101,00 & 151,94 & 96,18 & 35,97 & 5812,66 & $\begin{array}{l}307,44 \\
\end{array}$ & 43,36 & 264,08 & 84,32 & 228,71 & 229,21 & 81,34 & 887,47 & 129,32 & 7,58 & 54,42 & $\begin{array}{ll}356,64 \\
\end{array}$ & 56,06 & $\begin{array}{ll}56,28 \\
\end{array}$ & 356,61 \\
\hline Lissotriton boscai & 29TPE34 & 100,00 & 144,07 & 93,37 & 35,58 & 5763,97 & 297,00 & 37,53 & 259,47 & 74,25 & 220,63 & 220,80 & 74,25 & 963,29 & \begin{tabular}{ll|}
142,08 \\
\end{tabular} & 8,48 & 54,82 & \begin{tabular}{ll|}
388,56 \\
\end{tabular} & 60,65 & $\begin{array}{ll}60,78 \\
\end{array}$ & 388,56 \\
\hline Lissotriton boscai & 29TPE35 & 100,00 & 142,56 & 93,42 & 35,63 & 5737,22 & 294,59 & 35,97 & 258,62 & 72,78 & 218,54 & 218,67 & 72,78 & 976,71 & \begin{tabular}{|l|l|}
144,52 \\
\end{tabular} & 8,80 & 54,84 & 394,12 & 61,76 & 61,99 & 394,12 \\
\hline |Lissotriton boscai & 29TPE36 & 101,00 & 139,74 & 92,73 & 35,61 & 5699,14 & 290,19 & 33,56 & 256,64 & 70,23 & 215,06 & 215,18 & 70,23 & 1004,28 & 149,39 & 9,13 & 54,98 & 405,67 & 63,55 & 64,08 & 405,67 \\
\hline Lissotriton boscai & 29TPE37 & 100,00 & 126,44 & 86,62 & 34,39 & 5632,12 & 272,12 & 24,14 & 247,98 & 58,40 & 201,32 & 201,39 & 58,40 & 1136,45 & 171,51 & $\mid 10,64$ & 55,48 & 461,98 & 70,81 & 73,01 & 461,98 \\
\hline Lissotriton boscai & 29TPE38 & 101,00 & 108,42 & 77,78 & 32,55 & 5536,88 & 247,27 & 11,75 & 235,51 & 42,64 & 182,53 & 182,68 & 42,64 & 1323,69 & 202,22 & 12,65 & 56,09 & 541,51 & 81,32 & 87,37 & 541,51 \\
\hline Lissotriton boscai & 29TPE39 & 99,00 & 129,36 & 90,95 & 35,62 & 5612,20 & 276,53 & 24,79 & 251,73 & 60,76 & 203,41 & 203,57 & 60,76 & $\begin{array}{l}1096,85 \\
\end{array}$ & $\begin{array}{l}165,15 \\
\end{array}$ & 10,54 & 55,27 & $\begin{array}{l}444,89 \\
\end{array}$ & 69,91 & 71,83 & 444,89 \\
\hline Lissotriton boscai & 29TPE43 & 101,00 & 153,35 & \begin{tabular}{ll|}
97,14 \\
\end{tabular} & 35,97 & 5887,56 & 310,18 & 43,60 & 266,59 & 89,12 & 231,20 & 231,48 & 81,69 & 837,38 & \begin{tabular}{l|l|}
120,72 \\
\end{tabular} & 7,00 & 53,85 & 334,35 & 53,38 & 53,65 & 333,63 \\
\hline Lissotriton boscai & 29TPE44 & 100,00 & 149,48 & 96,03 & 35,86 & 5860,33 & 304,97 & 40,37 & 264,60 & 84,59 & 226,95 & 227,18 & 78,09 & 871,44 & 126,58 & 7,52 & 54,06 & 348,36 & 55,63 & 55,78 & 347,93 \\
\hline 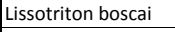 & 29TPE45 & 101,00 & 142,38 & 93,54 & 35,41 & 5824,43 & 295,68 & 34,92 & 260,76 & 74,84 & 219,54 & 219,65 & 71,49 & 934,96 & 137,33 & 8,42 & 54,35 & 374,92 & 59,48 & 59,90 & 374,91 \\
\hline Lissotriton boscai & 29TPE46 & 99,00 & 140,79 & 93,71 & 35,62 & 5799,87 & 293,41 & 33,34 & 260,08 & 71,02 & 217,52 & 217,64 & 70,04 & 944,75 & 139,10 & 8,62 & 54,33 & 378,87 & 60,64 & 61,32 & 378,87 \\
\hline Lissotriton boscai & 29TPE47 & 101,00 & 132,53 & 90,33 & 34,91 & 5754,58 & 282,24 & 27,16 & 255,08 & 62,33 & 208,59 & 208,83 & 62,33 & 1017,71 & 151,31 & 9,63 & 54,73 & 409,90 & 64,86 & 66,79 & 409,90 \\
\hline Lissotriton boscai & 29TPE48 & 99,00 & 117,54 & 82,71 & 33,32 & 5674,60 & 261,50 & 16,91 & 244,60 & 48,96 & 192,78 & \begin{tabular}{|l|}
193,24 \\
\end{tabular} & 48,96 & 1155,77 & 173,94 & 11,18 & 55,15 & \begin{tabular}{ll|}
468,54 \\
\end{tabular} & 73,04 & 77,68 & 468,54 \\
\hline Lissotriton boscai & 29TPE49 & 101,00 & 125,55 & 88,94 & 34,86 & 5693,66 & 273,09 & 21,39 & 251,70 & 56,06 & 200,71 & 201,07 & 56,06 & 1071,79 & 160,32 & 10,53 & 54,81 & 2,91 & 69,15 & 71,71 & 432,91 \\
\hline Lissotriton boscai & 29TPE53 & 100,00 & 151,91 & 97,36 & 35,85 & 5953,50 & 309,70 & 41,55 & 268,15 & 87,23 & 230,81 & 231,01 & 79,58 & 808,77 & 115,52 & 6,97 & 53,33 & 321,81 & 52,04 & 52,23 & 319,62 \\
\hline 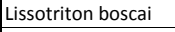 & 29TPE54 & 100,00 & 147,75 & 95,98 & 35,62 & 5933,51 & 304,19 & 38,06 & 266,13 & 83,16 & 226,32 & 226,50 & 75,69 & 844,05 & 121,51 & 7,38 & 53,61 & 335,96 & 54,66 & 54,79 & 334,47 \\
\hline Lissotriton boscai & 29TPE55 & 100,00 & 139,99 & 93,16 & 35,09 & 5892,53 & 294,01 & 32,20 & 261,81 & 76,16 & 218,11 & 218,19 & 68,40 & 909,11 & 132,39 & 8,41 & 53,90 & 362,66 & 58,54 & 59,38 & 361,92 \\
\hline Lissotriton boscai & 29TPE56 & 101,00 & 128,25 & 88,22 & 34,20 & 5835,14 & 278,60 & 23,79 & 254,82 & 62,95 & 205,80 & 206,08 & 57,84 & 1007,41 & 148,40 & 9,62 & 54,15 & 403,27 & 64,49 & 67,35 & 403,21 \\
\hline Lissotriton boscai & 29TPE63 & 100,00 & 147,31 & 96,56 & 35,56 & 6005,60 & 305,46 & 37,25 & 268,2 & 82,40 & 227,14 & 227,18 & 74,60 & 805,58 & 114,23 & 7,23 & 52,82 & 18 & 52,55 & 52,87 & 315,84 \\
\hline Lissotriton boscai & 29TPE64 & 101,00 & 148,18 & 97,18 & 35,78 & 5989,67 & 305, & 37,38 & 268,45 & 82,93 & 227,58 & 227,62 & 75,21 & 797,19 & \begin{tabular}{|l|}
113,21 \\
\end{tabular} & 7,17 & 52,86 & $\begin{array}{ll}315,68 \\
\end{array}$ & 52,29 & 52,49 & 312,48 \\
\hline Lissotriton boscai & 29TPE65 & 100,00 & 129,91 & 90,14 & 34,26 & 5929,70 & 283,01 & 23,91 & 259,10 & 66,46 & 208,92 & 209,16 & 58,67 & 944,84 & \begin{tabular}{|l|l|}
136,77 \\
\end{tabular} & 9,21 & 53,25 & 375,78 & 61,54 & 63,95 & 373,87 \\
\hline Lissotriton boscai & 29TPE66 & 100,00 & $\begin{array}{l}121,79 \\
\end{array}$ & 86,97 & 33,72 & $\begin{array}{l}5881,62 \\
\end{array}$ & 272,26 & 17,83 & 254,43 & 59,20 & 200,18 & 200,57 & 51,21 & 1009,52 & 147,16 & 10,10 & 53,46 & 402,21 & 65,82 & $\begin{array}{ll}69,68 \\
\end{array}$ & 400,97 \\
\hline Lissotriton boscai & 29TPE67 & 101,00 & 125,29 & 89,10 & 34,18 & $\begin{array}{ll}5888,96 \\
\end{array}$ & 276,66 & 19,84 & 256,83 & 61,99 & 203,34 & 203,90 & 54,13 & 971,07 & 141,31 & 9,83 & 53,26 & 386,21 & 64,13 & 66,99 & 385,15 \\
\hline Lissotriton boscai & 29TPE68 & 99,00 & 124,21 & 89,65 & 34,41 & 5871,67 & 275,38 & 18,51 & 256,87 & 60,36 & 201,86 & 202,53 & 53,08 & \begin{tabular}{|c|}
971,17 \\
\end{tabular} & 141,44 & 9,89 & 53,21 & 386,12 & 64,70 & 67,43 & 385,41 \\
\hline Lissotriton boscai & 29TPE & 101,00 & 123 & 90,59 & 34,72 & 5856,27 & 274,74 & 17,18 & 257,56 & 58,81 & 200,55 & 201,39 & 52,01 & \begin{tabular}{|c|}
969,08 \\
\end{tabular} & 141,09 & 10,03 & 53,06 & 385,06 & 65,36 & 67,80 & 384,65 \\
\hline Lissotriton boscai & 29TPE73 & 100,00 & 150,30 & 98,84 & 35,77 & 6062,09 & 310,71 & 38,27 & 272,44 & 84,43 & 230,77 & 230,80 & 76,58 & 739,65 & 102,88 & 6,62 & 51,89 & 290,90 & 49,06 & 49,23 & 285,78 \\
\hline Lissotriton boscai & 29TPE74 & 100,00 & 151,09 & 99,45 & 35,99 & 6044,12 & 311,10 & 38,55 & 272,55 & 85,01 & 231,27 & 231,27 & 77,25 & 730,10 & 101,60 & 6,54 & 51,86 & 286,93 & 48,63 & 48,65 & 281,9 \\
\hline Lissotriton boscai & 29TPE75 & 99,00 & 135,54 & 94,15 & 34,92 & 6008,58 & 292,03 & 26,54 & 265,49 & 70,70 & 215,39 & 215,63 & 62,83 & 847,52 & 119,95 & 8, & 52,10 & 334,35 & 56,87 & 58,58 & 330 \\
\hline Lissotriton boscai & $29 \mathrm{~T}$ & 10 & 116,20 & & 35,00 & & & 12,02 & & & & & 45,46 & 998,94 & & 10,53 & 52,42 & 395,43 & 67,06 & 71,63 & 392,21 \\
\hline Lissotriton boscai & 29TPE77 & 100,00 & 122,37 & 90,04 & 34,30 & 5945,46 & 275,26 & 16,19 & 259,07 & 58,62 & 201,30 & 201,94 & 50,77 & 938,22 & 134,22 & 9,98 & 52,23 & 370,92 & 63,72 & 66,87 & 367,88 \\
\hline Lissotriton boscai & 29TPE78 & 101,00 & 123,45 & 91,55 & 34,80 & 5941,90 & 276,94 & 16,45 & 260,49 & 59,43 & 202,15 & 202,87 & 51,50 & 917,39 & $\mid 131,03$ & 9,84 & 52,04 & 362,22 & 63,19 & 65,75 & 359,37 \\
\hline
\end{tabular}




\begin{tabular}{|c|c|c|c|c|c|c|c|c|c|c|c|c|c|c|c|c|c|c|c|c|c|}
\hline TAXON & UTM & $\mathrm{km2}$ & BIO1 & B102 & $\mathrm{BIO3}$ & B104 & B105 & B106 & B107 & B108 & B109 & BIO10 & BIO11 & B1012 & BIO13 & BIO14 & BIO15 & BIO16 & BIO17 & BIO18 & BlO19 \\
\hline Lissotriton boscai & 29TPE79 & 99,00 & 124,77 & 93,29 & 35,09 & 5934,79 & 279,08 & 16,71 & 262,37 & 60,47 & 203,18 & 204,08 & 52,60 & 896,75 & 127,89 & 9,73 & 51,82 & 353,66 & 62,66 & 64,50 & 351,17 \\
\hline Lissotriton boscai & 29TPE83 & 100,00 & 155,39 & 101,75 & \begin{tabular}{l|l|}
36,05 \\
\end{tabular} & 6107,25 & 318,29 & \begin{tabular}{l|l}
40,92 \\
\end{tabular} & \begin{tabular}{|l|l|}
277,37 \\
\end{tabular} & 88,51 & 236,29 & 236,29 & \begin{tabular}{l|l}
80,65 \\
\end{tabular} & $\begin{array}{ll}662,07 \\
\end{array}$ & 89,77 & 5,86 & 50,92 & \begin{tabular}{|l|l|}
258,07 \\
\end{tabular} & 44,53 & 44,53 & 251,09 \\
\hline Lissotriton boscai & 29TPE84 & 101,00 & $\begin{array}{ll}146,87 \\
\end{array}$ & 99,36 & 35,82 & 6104,88 & 308,40 & 33,98 & \begin{tabular}{l|l}
274,42 \\
\end{tabular} & 80,31 & 227,97 & 228,03 & 72,56 & 717,78 & $\begin{array}{l}98,46 \\
\end{array}$ & 6,86 & 51,03 & 280,18 & 49,20 & 49,35 & 273,80 \\
\hline Lissotriton boscai & 29TPE85 & 101,00 & 126,42 & 93,40 & 34,64 & 6044,36 & 283,86 & 18,13 & 265,73 & 61,90 & 207,17 & 207,49 & 54,01 & 867,71 & 120,90 & 9,38 & 51,16 & 339,84 & 60,08 & 62,81 & 334,06 \\
\hline Lissotriton boscai & 29TPE86 & 100,00 & 1117,60 & 90,52 . & 34,02 & 6008,49 & 272,64 & $11,27 \mid$ & 261,36 | & 53,76 [ & 197,92 & $198,45[$ & 45,95 & 928,26 & 130,25 & 10,32 & 51,22 & $364,31 \mid$ & 64,53 , & 68,45 [ & 358,97 \\
\hline Lissotriton boscai & 29TPE87 & 100,00 & 124,01 & 93,18 & 34,67 & 6018,82 & 280,22 & \begin{tabular}{|l|l|}
15,67 \\
\end{tabular} & 264,55 & 59,25 & 203,85 & 204,61 & 51,39 & 866,80 & 121,19 & 9,70 & 50,97 & 339,73 & $\begin{array}{ll}60,96 \\
\end{array}$ & 63,50 & 334,53 \\
\hline Lissotriton boscai & 29TPE89 & 101,00 & 124,13 & 95,26 & 35,25 & 5995,30 & 280,81 & 14,85 & 265,97 & 59,14 & 203,39 & 204,31 & 51,43 & 843,46 & 117,63 & 9,60 & 50,67 & 330,28 & $\begin{array}{ll}60,83 \\
\end{array}$ & 62,57 & 325,45 \\
\hline Lissotriton boscai & 29TPE95 & 100,00 & 133,71 & 97,47 & 35,24 & 6122,54 & 294,97 & 22,26 & 272,71 & 67,52 & 215,21 & 215,54 & 59,77 & 762,82 & \begin{tabular}{|l|l|}
103,58 \\
\end{tabular} & 8,34 & 49,95 & \begin{tabular}{|l|l|}
295,84 \\
\end{tabular} & 54,36 & \begin{tabular}{|l|l|}
55,87 \\
\end{tabular} & 288,21 \\
\hline Lissotriton boscai & 29TPE96 & 100,00 & 121,66 & 94,40 & 34,79 & 6085,22 & 280,54 & 12,66 & 267,88 & 56,49 & \begin{tabular}{|l|l|}
202,72 \\
\end{tabular} & 203,40 & 48,71 & 839,86 & 114,81 & 9,92 & 49,81 & \begin{tabular}{|l|l|}
326,27 \\
\end{tabular} & 60,70 & 63,49 & 318,88 \\
\hline Lissotriton boscai & 29TPE97 & 101,00 & 123,33 & 95,54 & \begin{tabular}{|l|}
35,03 \\
\end{tabular} & 6081,09 & 282,39 & 13,56 & \begin{tabular}{|l|l|}
268,83 \\
\end{tabular} & 57,85 & 204,07 & 204,93 & \begin{tabular}{l|l}
50,15 \\
\end{tabular} & 815,68 & 111,21 & 9,77 & 49,60 & 316,66 & 59,75 & \begin{tabular}{ll|}
62,02 \\
\end{tabular} & 309,32 \\
\hline Lissotriton boscai & 29TPE98 & 100,00 & 128,77 & 98,03 & 35,72 & 6080,10 & 288,79 & 17,22 & 271,56 & 62,50 & \begin{tabular}{|l|l|}
209,12 \\
\end{tabular} & \begin{tabular}{l|l|}
209,95 \\
\end{tabular} & 54,96 & 765,26 & \begin{tabular}{ll|}
103,76 \\
\end{tabular} & 9,16 & 49,35 & 296,62 & 56,86 & 57,99 & 289,48 \\
\hline Lissotriton boscai & 29TPF00 & 101,00 & 139,06 & 98,71 & 38,88 & 5279,84 & 283,75 & 32,90 & 250,85 & 73,23 & $\begin{array}{l}207,69 \\
2\end{array}$ & 208,26 & 73,23 & 1127,70 & 168,86 & 10,94 & 55,06 & \begin{tabular}{|l|l|}
457,17 \\
\end{tabular} & 72,42 & 74,61 & 457,17 \\
\hline Lissotriton boscai & 29TPF01 & 100,00 & 128,78 & 95,58 & 38,14 & 5282,38 & 272,01 & 24,88 & 247,14 & 63,64 & \begin{tabular}{l|l|l|}
197,92 \\
\end{tabular} & \begin{tabular}{|l|l|}
198,34 \\
\end{tabular} & 63,64 & 1241,40 & 187,92 & 12,69 & 55,62 & \begin{tabular}{l|l}
505,95 \\
\end{tabular} & 80,76 & 81,46 & 505,95 \\
\hline Lissotriton boscai & 29TPF04 & 100,00 & 128,77 & 101,16 & \begin{tabular}{l|l}
39,55 \\
\end{tabular} & 5306,69 & 275,19 & 22,47 & 252,72 & 62,85 & $\begin{array}{l}197,94 \\
\end{array}$ & \begin{tabular}{|l|l|}
198,38 \\
\end{tabular} & \begin{tabular}{l|l}
62,85 \\
\end{tabular} & 1242,10 & 187,23 & 13,26 & 55,32 & \begin{tabular}{l|l}
505,25 \\
\end{tabular} & 81,75 & \begin{tabular}{l|l}
84,25 \\
\end{tabular} & 505,25 \\
\hline Lissotriton boscai & 29TPF05 & 100,00 & 142,96 & 106,65 & 40,84 & 5279,31 & 290,93 & 32,77 & 258,16 & 78,24 & 210,95 & 211,44 & 76,3 & \begin{tabular}{ll|l|}
1091,92 \\
\end{tabular} & 161,79 & 10,97 & 54,62 & 439,34 & 70,24 & 76,22 & 439,25 \\
\hline Lissotriton boscai & 29TPF06 & 100,00 & 141,31 & 108,38 & $\begin{array}{ll}40,93 \\
\end{array}$ & 5312,79 & 291,76 & 30,46 & 261,30 & \begin{tabular}{|l|l|}
79,60 \\
\end{tabular} & \begin{tabular}{|l|l|}
209,92 \\
\end{tabular} & 210,29 & 74,38 & \begin{tabular}{|l|l|}
1113,87 \\
\end{tabular} & 165,33 & 11,38 & 54,92 & 449,72 & 71,98 & 77,73 & 448,75 \\
\hline Lissotriton boscai & 29TPF07 & 101,00 & 129,25 & 104,96 & \begin{tabular}{ll|}
40,17 \\
\end{tabular} & 5320,59 & 279,02 & 21,27 & 257,75 & 69,15 & \begin{tabular}{ll|l}
198,58 \\
\end{tabular} & \begin{tabular}{ll|l}
198,93 \\
\end{tabular} & 63,25 & 1223,92 & 181,16 & 14,12 & 54,73 & \begin{tabular}{|l|l|}
496,20 \\
\end{tabular} & 82,95 & 87,13 & 494,77 \\
\hline Lissotriton boscai & 29TPF08 & 100,00 & 108,66 & 93,52 & 38,00 & 5223,34 & 250,90 & 8,30 & 242,61 & 45,75 & $\begin{array}{l}178,02 \\
12\end{array}$ & $\begin{array}{l}178,18 \\
\end{array}$ & 45,68 & 1370,44 & 197,65 & 19,63 & 52,80 & 551,13 & $\begin{array}{ll}101,85 \\
\end{array}$ & $\begin{array}{l}103,26 \\
1\end{array}$ & 551,12 \\
\hline Lissotriton boscai & 29TPF09 & 100,00 & 1111,77| & 94,08 & 38,18 . & 5213,47 & 253,83 & 10,63 & 243,20 & $48,68 \mid$ & 180,74 & 180,98 - & 48,68 & 1325,43 & 188,43 & 19,36 & 52,06 & 530,87 & $99,87 \mid$ & 101,47 & 530,87 \\
\hline Lissotriton boscai & 29TPF11 & 100,00 & 128,63 & 95,37 & 37,60 & 5404,76 & 274,24 & 23,95 & \begin{tabular}{|l|}
250,29 \\
\end{tabular} & 62,05 & $\begin{array}{ll}199,63 \\
\end{array}$ & \begin{tabular}{|l|l|}
199,88 \\
\end{tabular} & \begin{tabular}{l|l}
62,05 \\
\end{tabular} & 1200,90 & 182,25 & 12,14 & 55,80 & 489,67 & 77,94 & 78,26 & 489,67 \\
\hline Lissotriton boscai & 29TPF12 & 100,00 & 118,88 & 91,96 & 36,84 & 5385,78 & 262,58 & \begin{tabular}{l|l}
16,65 \\
\end{tabular} & 245,93 & 53,27 & \begin{tabular}{|l|l|}
190,27 \\
\end{tabular} & \begin{tabular}{l|l|}
190,32 \\
\end{tabular} & 53,27 & 1295,22 & \begin{tabular}{|l|l|}
197,19 \\
\end{tabular} & 13,90 & 55,95 & 529,52 & 84,37 & 85,12 & 529,52 \\
\hline Lissotriton boscai & 29TPF13 & 101,00 & 121,03 & 95,23 & \begin{tabular}{l|l|}
37,65 \\
\end{tabular} & 5397,58 & 266,55 & 17,10 & 249,45 & 54,91 & \begin{tabular}{|l|l|}
192,27 \\
\end{tabular} & \begin{tabular}{|l|l|}
192,40 \\
\end{tabular} & 54,91 & 1270,64 & 192,82 & 13,83 & 55,64 & \begin{tabular}{|l|l|}
518,67 \\
\end{tabular} & 83,82 & 84,37 & 518,67 \\
\hline Lissotriton boscai & 29TPF14 & 100,00 & 124,50 & 99,18 & 38,54 & 5414,99 & 272,28 & 18,51 & 253,77 & 57,77 & \begin{tabular}{l|l|}
195,61 \\
\end{tabular} & \begin{tabular}{|l|l|}
195,77 \\
\end{tabular} & 57,77 & 1234,38 & $\begin{array}{l}186,67 \\
\end{array}$ & 13,56 & 55,38 & \begin{tabular}{ll|}
502,96 \\
\end{tabular} & 82,15 & 83,12 & 502,96 \\
\hline Lissotriton boscai & 29TPF15 & 100,00 & 140,38 & 106,18 & 40,16 & 5405,68 & 290,95 & 29,63 & 261,32 & 73,99 ] & 210,42 & 210,69 & 72,49 & 1074,86 & $160,31 \mid$ & 10,99 & 54,83 & 433,77 & 69,73 & 73,32 & 433,71 \\
\hline Lissotriton boscai & 29TPF16 & 101,00 & 133,02 & 106,93 & 40,08 & 5451,47 & 286,04 & 22,66 & 263,38 & 70,80 & 203,93 & 204,22 & 65,01 & 1150,71 & 172,83 & 12,42 & 55,22 & 467,60 & 76,12 & 78,60 & 466,91 \\
\hline Lissotriton boscai & 29TPF18 & 101,00 & 116,77 & 98,81 & 38,68 & 5375,05 & 264,19 & 11,86 & 252,33 & 51,10 & \begin{tabular}{|l|l|}
187,58 \\
\end{tabular} & 187,81 & 51,10 & 1252,20 & 182,52 & 16,84 & 53,27 & 505,01 & 90,84 & \begin{tabular}{|l|l|}
91,97 \\
\end{tabular} & 505,01 \\
\hline Lissotriton boscai & 29TPF19 & 101,00 & 113,80 & 96,73 & 38,31 & 5336,32 & 259,53 & 10,18 & 249,36 & \begin{tabular}{l|l}
48,93 \\
\end{tabular} & \begin{tabular}{|l|l|}
184,38 \\
\end{tabular} & 184,52 & 48,93 & 1255,75 & $\begin{array}{ll}179,85 \\
\end{array}$ & 18,12 & 52,30 & 503,68 & $\begin{array}{ll}94,08 \\
\end{array}$ & 94,80 & 503,68 \\
\hline Lissotriton boscai & 29TPF21 & 101,00 & 126,21 & 93,56 & 36,68 & 5513,60 & 272,97 & 21,53 & 251,44 & 58,52 & \begin{tabular}{l|l|l|}
198,83 \\
\end{tabular} & $\begin{array}{l}198,97 \\
1\end{array}$ & 58,52 & 1172,13 & 177,94 & 11,92 & 55,70 & $\begin{array}{l}477,64 \\
\end{array}$ & 75,95 & 76,74 & 477,64 \\
\hline Lissotriton boscai & 29TPF23 & 100,00 & 126,79 & 98,25 & \begin{tabular}{ll|}
37,87 \\
\end{tabular} & 5516,59 & 275,90 & \begin{tabular}{l|l}
19,95 \\
\end{tabular} & 255,94 & 58,64 & \begin{tabular}{|l|l|}
199,26 \\
\end{tabular} & $\begin{array}{l}199,34 \\
\end{array}$ & 58,6 & 1160, & 175, & 12,2 & 55,3 & \begin{tabular}{ll|l}
472,38 \\
\end{tabular} & 76,56 & \begin{tabular}{l|l}
77,15 \\
\end{tabular} & 472,38 \\
\hline Lissotriton boscai & 29TPF24 & 101,00 & 126,75 & \begin{tabular}{|l|}
100,17 \\
\end{tabular} & 38,32 & 5518,90 & 277,01 & 19,14 & 257,87 & \begin{tabular}{|l|l|}
58,60 \\
\end{tabular} & \begin{tabular}{|l|l|}
199,25 \\
\end{tabular} & \begin{tabular}{ll|}
199,32 \\
\end{tabular} & 58,60 & 1155,55 & $\begin{array}{l}174,45 \\
\end{array}$ & 12,59 & 55,08 & 469,91 & \begin{tabular}{|l|l|}
77,07 \\
\end{tabular} & 77,46 & 469,91 \\
\hline Lissotriton boscai & 29TPF25 & 100,00 & 140,51 & 106,44 & 39,69 & 5513,85 & 293,37 & 28,59 & 264,78 & 71,32 & 212,18 & 212,25 & 71,32 & 1019,19 & 151,94 & 10,54 & 54,60 & \begin{tabular}{|l|l|}
410,81 \\
\end{tabular} & 66,63 & 67,38 & 410,81 \\
\hline Lissotriton boscai & 29TPF26 & 100,00 & 140,98 & 107,60 & 39,89 & 5514,54 & 294,66 & 28,42 & 266,25 & 73,20 & 212,58 & 212,65 & 71,78 & 1005,65 & 149,08 & 10,67 & 54,36 & \begin{tabular}{ll|l}
404,49 \\
\end{tabular} & $\begin{array}{ll}66,37 \\
\end{array}$ & 67,06 & 404,46 \\
\hline Lissotriton boscai & 29TPF27 & 101,00 & 127,74 & 104,65 & 39,24 & 5523,54 & 281,02 & 17,96 & 263,06 & 61,29 & 200,19 & 200,25 & 59,37 & 1117,23 & 165,84 & 13,31 & 54,31 & \begin{tabular}{|l|l|}
451,90 \\
\end{tabular} & \begin{tabular}{l|l}
77,02 \\
\end{tabular} & $\begin{array}{ll}77,42 \\
\end{array}$ & 451,81 \\
\hline Lissotriton boscai & 29TPF28 & 101,00 & 124,70 & 103,28 & 39,13 & 5499,98 & 276,56 & 15,72 & 260,84 & 56,85 & $\begin{array}{l}197,01 \\
\end{array}$ & \begin{tabular}{|l|l|}
197,03 \\
\end{tabular} & \begin{tabular}{l|l}
56,85 \\
\end{tabular} & 1124,99 & 164,65 & 14,44 & 53,30 & 453,16 & 80,03 & 80,49 & 453,16 \\
\hline Lissotriton boscai & 29TPF29 & 100,00 & 119,33 & 100,64 & 38,58 & 5460,93 & 269,38 & 12,14 & 257,24 & 52,55 & \begin{tabular}{|l|l|}
191,46 \\
\end{tabular} & \begin{tabular}{|l|l|}
191,47 \\
\end{tabular} & 52,55 & \begin{tabular}{ll|}
1147,42 \\
\end{tabular} & 165,13 & 16,19 & 52,33 & 460,08 & 85,13 & 85,52 & 460,08 \\
\hline Lissotriton boscai & 29TPF30 & 101,00 & 138,54 & 97,73 & 37,13 & 5630,05 & 289,25 & 30,10 & 259,15 & \begin{tabular}{ll|}
68,92 \\
\end{tabular} & \begin{tabular}{l|l|}
212,42 \\
\end{tabular} & 212,50 & 68,92 & 1001,01 & 149,52 & 9,60 & 54,78 & \begin{tabular}{ll|l}
403,99 \\
\end{tabular} & 64,84 & 65,10 & 403,99 \\
\hline Lissotriton boscai & 29TPF31 & 100,00 & 122,01 & 91,03 & 35,81 & 5592,34 & 269,00 & \begin{tabular}{|l|l|}
17,97 \\
\end{tabular} & \begin{tabular}{|l|l|}
251,03 \\
\end{tabular} & 53,63 & \begin{tabular}{ll|l}
195,80 \\
\end{tabular} & \begin{tabular}{ll|l}
196,16 \\
\end{tabular} & 53,63 & 1153,91 & 174,51 & 11,85 & 55,18 & \begin{tabular}{|l|l|}
469,29 \\
\end{tabular} & 75,12 & 77,18 & 469,29 \\
\hline Lissotriton boscai & 29TPF32 & 101,00 & 118,52 & 91,48 & 35,98 & 5579,90 & 265,56 & 14,68 . & 250,89 & 50,49 & 192,24 & $192,61 \mid$ & 50,4 & 1181,51 & 178,55 & 12,66 & 55,06 & 480,60 & $78,06\left[\begin{array}{l}78 \\
\end{array}\right.$ & 80,25 & 480,60 \\
\hline Lissotriton boscai & 29TPF33 & 101,00 & 117,67 & 93,44 & \begin{tabular}{|l|}
36,47 \\
\end{tabular} & 5576,81 & 265,92 & 13,04 & 252,89 & $\begin{array}{l}49,59 \\
\end{array}$ & \begin{tabular}{|l|l|}
191,29 \\
\end{tabular} & \begin{tabular}{|l|l|}
191,61 \\
\end{tabular} & 49,59 & 1180,34 & 177,86 & 13,10 & 54,92 & 479,81 & 79,46 & 81,04 & 479,81 \\
\hline Lissotriton boscai & 29TPF34 & 100,00 & 123,76 & 98,46 & 37,58 & 5598,62 & 274,87 & 16,29 & 258,58 & 54,90 & $\begin{array}{l}197,58 \\
\end{array}$ & $\begin{array}{l}197,69 \\
\end{array}$ & 54,90 & 1117,24 & 167,71 & 12,54 & 54,69 & \begin{tabular}{|l|l|}
453,09 \\
\end{tabular} & 75,71 & 76,31 & 453,09 \\
\hline Lissotriton boscai & 29TPF35 & 101,00 & 137,94 & 105,49 & \begin{tabular}{l|l|}
39,15 \\
\end{tabular} & 5607,72 & 292,31 & 25,79 & 266,52 & 67,82 & 211,25 & 211,27 & 67,82 & 982,27 & 146,01 & 10,54 & 54,18 & \begin{tabular}{|l|l|}
395,49 \\
\end{tabular} & 65,43 & 65,51 & 395,49 \\
\hline Lissotriton boscai & 29TPF36 & 100,00 & 136,08 & 105,63 & 39,20 & 5593,92 & 290,39 & 23,96 & 266,43 & 66,31 & 209,21 & 209,21 & 66,31 & $\begin{array}{ll}987,88 \\
\end{array}$ & 145,90 & 11,16 & 53,79 & \begin{tabular}{|l|l|}
397,09 \\
\end{tabular} & \begin{tabular}{ll|l}
67,05 \\
\end{tabular} & 67,16 & 397,09 \\
\hline Lissotriton boscai & 29TPF37 & 101,00 & 136,96 & 106,85 & 39,4 & 5597,15 & 291 & 23,9 & 267,78 & 66,93 & 209,96 & 209,98 & 66 & 970,32 & 142,2 & 11,3 & 53,3 & \begin{tabular}{|l|l|}
388,98 \\
\end{tabular} & 66,55 & 66,61 & 388,98 \\
\hline Lissotriton boscai & 29TPF38 & 99,00 & 135,86 & 107,09 & 39,57 & 5593,05 & 290,65 & 22,66 & 267,99 & \begin{tabular}{ll|l}
66,02 \\
\end{tabular} & \begin{tabular}{|l|l|}
208,89 \\
\end{tabular} & 208,89 & 66,02 & 963,54 & 139,80 & 11,88 & 52,75 & 385,04 & 67,49 & 67,52 & 385,04 \\
\hline Lissotriton boscai & 29TPF39 & 101,00 & 128,98 & 104,90 & 39,08 & 5570,40 & 282,66 & 17,49 & 265,18 & \begin{tabular}{|l|l|}
60,08 \\
\end{tabular} & 202,29 & 202,29 & 60,08 & 1002,01 & 143,85 & 13,58 & 51,97 & \begin{tabular}{l|l}
400,05 \\
\end{tabular} & 73,12 & 73,12 & 400,05 \\
\hline Lissotriton boscai & 29TPF41 & 100,00 & 130,09 & 95,51 & 36,44 & 5704,54 & 281,07 & 22,43 & 258,64 & 59,81 & 205,16 & 205,40 & 59,81 & 1019,40 & 152,10 & 10,51 & 54,47 & 410,99 & 67,65 & 68,26 & 410,99 \\
\hline Lissotriton boscai & 29TPF43 & 100,00 & 128,47 & 98,78 & 37,29 & 5690,11 & 281,10 & 19,51 & \begin{tabular}{|l|l|}
261,59 \\
\end{tabular} & $\begin{array}{l}58,25 \\
\end{array}$ & 203,40 & 203,53 & \begin{tabular}{l|l|}
58,25 \\
\end{tabular} & 1018,61 & 151,77 & 11,11 & 54,11 & \begin{tabular}{l|l}
410,75 \\
\end{tabular} & 69,20 & 69,37 & 410,75 \\
\hline Lissotriton boscai & 29TPF44 & 100,00 & 132,75 & 102,47 & 38,08 & 5697,92 & 287,24 & 21,7 & 265,5 & 62,03 & 207,71 & 207, & 62 & 972,21 & 144,25 & 10,68 & 53,94 & 391,00 & 10 & \begin{tabular}{ll|l}
6,10 \\
\end{tabular} & 391,00 \\
\hline Lissotriton boscai & 29TPF45 & 100,00 & 140,70 & 105,77 & 38,89 & 5667,42 & 295,95 & 27,37 & 268,58 & \begin{tabular}{ll|}
70,06 \\
\end{tabular} & 214,86 & 214,86 & 69, & \begin{tabular}{ll|l}
898,03 \\
\end{tabular} & \begin{tabular}{|l|}
131,61 \\
\end{tabular} & 9,86 & 53,24 & 358,68 & 60,80 & 60,80 & 358,68 \\
\hline Lissotriton boscai & 29TPF46 & 101,00 & 123,35 & 101,60 & 38,00 & 5663,76 & 277,73 & 13,58 & 264,15 & 53,73 & $\begin{array}{l}198,39 \\
\end{array}$ & $\begin{array}{l}198,39 \\
\end{array}$ & 53,73 & 1028,48 & 151,52 & 12,73 & 53,08 & 413,96 & 73,53 & 73,53 & 413,96 \\
\hline Lissotriton boscai & 29TPF47 & 99,00 & 132,70 & 105,43 & 38,83 & 5659,92 & 288,25 & 20,00 & 268,25 & 62,32 & \begin{tabular}{l|l|}
207,06 \\
\end{tabular} & 207,06 & 62,32 & 938,61 & 136,65 & \begin{tabular}{ll|}
11,66 \\
\end{tabular} & 52,49 & 375,35 & 66,55 & 66,55 & 375,35 \\
\hline Lissotriton boscai & 29TPF48 & 101,00 & 140,12 & 107,65 & 39,32 & 5646,39 & 295,76 & 25,48 _ & $270,27 \mid$ & $69,34[$ & 214,06 & 214,06 & 69,34 & 865,86 & 123,90 & 10,87 & 51,73 & 343,18 | & 61,50 [ & 61,50 & 343,18 \\
\hline Lissotriton boscai & 29TPF49 & 100,00 & 137,42 & 106,91 & 39,23 & 5629,61 & 292,32 & 23,1 & 269, & 67,2 & 211,12 & 211,12 & 66,99 & 873,61 & 123,63 & 11,76 & 51,03 & 345,28 & \begin{tabular}{|c|}
63,87 \\
\end{tabular} & \begin{tabular}{ll|l}
63,87 \\
\end{tabular} & 345,28 \\
\hline Lissotriton boscai & 29TPF52 & 100,00 & 137,54 & 101,08 & \begin{tabular}{ll|}
37,46 \\
\end{tabular} & 5779,03 & 292,46 & 25, & \begin{tabular}{|l|l|}
266,49 \\
\end{tabular} & 65,88 & 213,69 & 213,69 & 65,70 & 888,20 & \begin{tabular}{|l|l|}
129,97 \\
\end{tabular} & 9,39 & 53,19 & \begin{tabular}{|l|l|}
353,77 \\
\end{tabular} & \begin{tabular}{ll|}
60,27 \\
\end{tabular} & \begin{tabular}{ll|}
60,27 \\
\end{tabular} & 353,77 \\
\hline Lissotriton boscai & 29TPF54 & 101,00 & 142,68 & 105,21 & 38,51 & 5744,58 & 298,77 & 28,79 & \begin{tabular}{|l|l|}
269,97 \\
\end{tabular} & $\begin{array}{ll}72,03 \\
\end{array}$ & \begin{tabular}{ll|}
217,84 \\
\end{tabular} & 217,84 & 70,80 & 832,23 & 120,63 & 9,06 & 52,52 & \begin{tabular}{|l|l|}
329,99 \\
\end{tabular} & 56,84 & 56,84 & 329,90 \\
\hline Lissotriton boscai & 29TPF55 & 100,00 & 143,81 & 106,25 & 38,74 & 5720,69 & 300,02 & 29,27 & \begin{tabular}{|l|l|}
270,76 \\
\end{tabular} & 74,26 & 218,64 & 218,64 & 72,02 & 814,43 & 117,22 & 9,14 & 52,12 & 322,14 & 56,22 & 56,22 & 321,98 \\
\hline Lissotriton boscai & 29TPF56 & 100,00 & 139,49 & 105,69 & 38,59 & 5705,64 & 295,63 & 25,5 & \begin{tabular}{|l|l|}
270,08 \\
\end{tabular} & \begin{tabular}{ll|}
70,99 \\
\end{tabular} & 214, & 214, & \begin{tabular}{ll|}
68,22 \\
\end{tabular} & 837,54 & 120,32 & 9,97 & 51,84 & 331 & 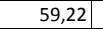 & 59,22 & 331,53 \\
\hline Lissotriton boscai & 29 & 101 & & $10 !$ & 38 & 5715, & 291 & 20, & 270, & 63 & $20=$ & 209 & 63 & 863 & 124,2 & 11,01 & 5 & $345-3>$ & 62,44 & 62,44 & 345 \\
\hline Lissotriton boscai & 29TPF58 & 99,00 & 136,87 & 107,07 & 38,82 & 5702,16 & 293,58 & 22,00 & 271,58 & 65,83 & 211,69 & 211,69 & 65,64 & \begin{tabular}{l|l|}
829,85 \\
\end{tabular} & 117,91 & 11,02 & 50,93 & \begin{tabular}{l|l}
327,95 \\
\end{tabular} & 60,81 & 60,81 & 327,95 \\
\hline Lissotriton boscai & 29TPF59 & 101,00 & 140,06 & 107,68 & 39,02 & 5679,65 & 296,10 & 24,35 & 271,75 & $70,61 \mid$ & 214,39 & 214,39 & 68,77 & 794,76 & 111,26 & 10,91 & 50,28 & 312,01 & 58,91 & 58,91 & 312,01 \\
\hline
\end{tabular}




\begin{tabular}{|c|c|c|c|c|c|c|c|c|c|c|c|c|c|c|c|c|c|c|c|c|c|}
\hline TAXON & UTM & $\mathrm{km} 2$ & BIO1 & B102 & $B 103$ & BIO4 & B105 & B106 & B107 & B108 & 8109 & B1010 & BIO11 & B1012 & BIO13 & BIO14 & BIO15 & B1016 & B1017 & B1018 & 81019 \\
\hline Lissotriton boscai & 29TPF61 & 100,00 & 132,16 & 97,93 & 36,39 & 5855,03 & 287,09 & 21,78 & 265,31 & 64,63 & 209,47 & 209,65 & 59,93 & 881,01 & 127,52 & 9,52 & 52,48 & 348,64 & 61,25 & 61,44 & 348,50 \\
\hline Lissotriton boscai & 29TPF62 & 100,00 & 131,94 & 99,50 & 36,82 & 5846,01 & 287,62 & 20,89 & 266,74 & 63,30 & 209,20 & 209,32 & 59,75 & 870,22 & 125,57 & 9,66 & 52,26 & $\begin{array}{l}344,02 \\
\end{array}$ & 61,16 & 61,35 & 343,96 \\
\hline Lissotriton boscai & 29TPF63 & 101,00 & 134,25 & 101,94 & 37,38 & 5835,98 & 290,96 & 21,88 & 269,08 & 63,60 & 211,38 & 211,38 & 61,97 & 844,73 & $\begin{array}{ll}121,62 \\
\end{array}$ & 9,68 & 52,03 & 333,64 & 59,71 & \begin{tabular}{|l|l|}
59,71 \\
\end{tabular} & 333,62 \\
\hline Lissotriton boscai & 29TPF64 & 99,00 & 141,58 & 105,17 & 38,20 & 5807,07 & 298,94 & 27,17 & 271,77 & 72,58 & 217,82 & 217,82 & \begin{tabular}{ll|}
69,07 \\
\end{tabular} & 782,20 & 111,55 & 8,88 & 51,52 & 307,77 & 55,02 & 55,02 & 307,29 \\
\hline Lissotriton boscai & 29TPF65 & 101,00 & 133,16 & 104,27 & 37,93 & 5804,01 & 290,69 & 19,73 & 270,97 & 62,06 & 209,68 & 209,68 & 61,14 & 831,42 & 118,91 & 10,13 & 51,36 & 328,13 & 60,39 & 60,39 & 328,13 \\
\hline Lissotriton boscai & 29TPF66 & 100,00 & 138,95 & 106,55 & 38,53 & 5783,69 & 296,75 & 23,90 & 272,85 & 68,93 & 214,97 & 214,97 & 66,74 & 780,99 & 110,72 & 9,66 & 50,94 & \begin{tabular}{|l|l|}
307,18 \\
\end{tabular} & 56,57 & 56,57 & 306,92 \\
\hline Lissotriton boscai & 29TPF67 & 100,00 & 138,89 & 107,36 & 38,83 & 5764,51 & 296,72 & 23,36 & 273,36 & 69,09 & 214,57 & 214,57 & 66,78 & 768,30 & 108,26 & 9,93 & 50,41 & 301,58 & 56,62 & 56,62 & 301,41 \\
\hline Lissotriton boscai & 29TPF68 & 101,00 & 125,92 & 105,07 & 38,24 & 5746,97 & 283,86 & 12,69 & 271,17 & 55,71 & 201,92 & 201,94 & 54,87 & 847,90 & 119,58 & 11,95 & 50,01 & 334,57 & 65,86 & 65,90 & 334,55 \\
\hline Lissotriton boscai & 29TPF69 & 100,00 & 124,72 & 105,60 & 38,38 & $\begin{array}{l}5737,43 \\
\end{array}$ & 282,95 & 11,12 & 271,83 & 53,84 & 200,67 & 200,69 & 53,80 & $\begin{array}{l}842,56 \\
\end{array}$ & \begin{tabular}{|l|l|}
118,37 \\
\end{tabular} & 12,49 & 49,51 & \begin{tabular}{|l|l|}
332,58 \\
\end{tabular} & 66,68 & 66,71 & 332,58 \\
\hline Lissotriton boscai & 29TPF70 & 101,00 & 126,52 & 95,46 & 35,48 & 5924,88 & 281,66 & 17,39 & 264,27 & 61,88 & 204,75 & 205,50 & 54,21 & 874,26 & 124,50 & 9,71 & 51,57 & 344,34 & 61,95 & 63,13 & 342,25 \\
\hline Lissotriton boscai & 29TPF71 & 100,00 & 127,17 & 97,36 & 36,08 & 5919,39 & 283,19 & 17,05 & 266,14 & 62,28 & 205,32 & 205,96 & 54,80 & $\begin{array}{l}856,38 \\
\end{array}$ & \begin{tabular}{l|l|}
121,62 \\
\end{tabular} & 9,80 & 51,38 & 336,79 & 61,71 & 62,35 & 334,93 \\
\hline Lissotriton boscai & 29TPF72 & 100,00 & 127,59 & $\begin{array}{ll}99,08 \\
\end{array}$ & 36,53 & 5904,58 & 284,36 & 16,52 & $\begin{array}{ll}267,84 \\
\end{array}$ & 62,55 & \begin{tabular}{|l|l|}
205,84 \\
\end{tabular} & 205,97 & 55,05 & 843,94 & \begin{tabular}{|l|l|}
119,73 \\
\end{tabular} & 9,89 & 51,16 & 331,56 & $\begin{array}{ll}61,64 \\
\end{array}$ & 61,79 & 330,15 \\
\hline Lissotriton boscai & 29TPF73 & 100,00 & 133,46 & 102,44 & 37,27 & 5891,66 & 291,47 & 20,37 & 271,10 & 67,96 & 211,44 & 211,44 & 60,61 & 792,11 & 111,81 & 9,37 & 50,82 & 310,49 & 57,83 & 57,83 & 309,20 \\
\hline Lissotriton boscai & 29TPF74 & 101,00 & 141,89 & 105,77 & 38,07 & 5862,92 & 300,65 & 26,54 & 274,11 & 75,85 & 218,98 & 218,98 & 68,70 & 723,89 & 101,04 & 8,58 & 50,33 & 282,67 & 52,56 & 52,56 & 280,76 \\
\hline Lissotriton boscai & 29TPF75 & 99,00 & 134,33 & 105,26 & 37,99 & 5864,59 & 293,29 & 19,66 & 273,63 & 67,46 & 211,71 & 211,71 & 61,42 & \begin{tabular}{|l|l|}
765,39 \\
\end{tabular} & \begin{tabular}{|l|l|}
107,37 \\
\end{tabular} & 9,63 & 50,20 & 299,43 & 57,12 & 57,12 & 298,61 \\
\hline Lissotriton boscai & 29TPF76 & 101,00 & 133,84 & 105,95 & 38,20 & 5841,09 & 292,79 & $\begin{array}{ll}18,91 \\
\end{array}$ & $\begin{array}{ll}273,88 \\
\end{array}$ & $\begin{array}{ll}66,99 \\
\end{array}$ & 210,85 & 210,86 & 61,26 & \begin{tabular}{|l|l|}
757,77 \\
\end{tabular} & 105,79 & 9,82 & 49,82 & 296,32 & 57,40 & 57,40 & 295,41 \\
\hline Lissotriton boscai & 29TPF77 & 100,00 & 137,67 & 107,68 & 38,62 & 5820,77 & 296,98 & 21,54 & \begin{tabular}{|l|l|}
275,44 \\
\end{tabular} & 71,36 & 214,26 & 214,26 & \begin{tabular}{ll|}
64,96 \\
\end{tabular} & \begin{tabular}{|l|l|}
721,04 \\
\end{tabular} & 99,86 & 9,74 & 49,31 & 281,24 & 54,96 & 54,96 & 280,28 \\
\hline Lissotriton boscai & 29TPF78 & 100,00 & 129,88 & 107,05 & 38,40 & 5809,03 & 289,73 & 14,60 & 275,14 & 62,27 & 206,69 & \begin{tabular}{|l|l|}
206,69 \\
\end{tabular} & 57,73 & 759,94 & 105,55 & 10,85 & 49,07 & 297,53 & 59,92 & 59,92 & 297,20 \\
\hline |Lissotriton boscai & 29TPF79 & 100,00 & 123,01 & 106,30 & 38,32 & 5778,23 & 282,90 & 8,87 & 274,03 & 54,38 & 199,62 & 199,64 & 51,64 & 793,80 & 109,92 & 12,11 & 48,60 & 311,30 & 65,06 & 65,08 & 311,22 \\
\hline Lissotriton boscai & 29TPF81 & 100,00 & 126,60 & 98,86 & 36,16 & 5977,64 & 284,65 & 15,28 & 269,37 & 60,96 & 205,60 & 206,19 & 53,50 & 801,99 & 111,22 & 9,53 & 50,05 & 313,21 & 59,84 & 60,40 & 308,99 \\
\hline Lissotriton boscai & 29TPF82 & 100,00 & 131,03 & 101,63 & 36,88 & 5965,24 & 290,16 & 18,01 & 272,15 & 64,99 & 210,07 & 210,10 & 57,57 & 761,25 & 105,14 & 9,16 & 49,85 & 296,71 & 57,24 & 57,26 & 292,83 \\
\hline Lissotriton boscai & 29TPF83 & 101,00 & 129,88 & 102,77 & 37,09 & 5951,56 & 289,35 & 16,37 & 272,99 & 63,97 & 208,81 & 208,81 & 56,52 & 756,55 & 104,25 & 9,48 & 49,50 & 294,66 & 57,70 & 57,70 & 291,10 \\
\hline Lissotriton boscai & 29TPF84 & 99,00 & 136,85 & 105,53 & 37,81 & 5927,83 & 296,95 & 21,49 & 275,46 & 70,53 & 215,16 & 215,16 & 63,22 & 702,12 & 96,03 & 8,77 & 49,13 & 272,78 & 53,29 & 53,29 & 269,14 \\
\hline Lissotriton boscai & 29TPF85 & 101,00 & 133,76 & 105,84 & 37,90 & \begin{tabular}{|l|l|l|}
5913,94 \\
\end{tabular} & 294,04 & 18,42 & 275,63 & 67,60 & 211,91 & 211,91 & 60,34 & 713,10 & 97,54 & 9,38 & 48,85 & 277,16 & 55,33 & 55,33 & 274,08 \\
\hline 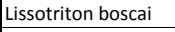 & 29TPF86 & 100,00 & 126,57 & 105,56 & 37,85 & 5900,58 & 287,13 & 11,93 & 275,19 & 60,90 & 204,84 & 204,84 & 53,61 & 744,61 & 101,80 & 10,30 & 48,49 & 289,46 & 59,65 & 59,65 & 287,21 \\
\hline Lissotriton boscai & 29TPF87 & 99,00 & 128,44 & 106,95 & 38,07 & 5880,29 & 289,34 & 12,93 & 276,42 & 62,64 & 206,21 & 206,21 & 55,45 & 721,95 & 98,36 & 10,32 & 48,11 & 280,52 & 58,36 & 58,36 & 278,59 \\
\hline L Lissotriton boscai & 29TPF88 & 101,00 & 131,27 & 108,01 & 38,51 & 5851,74 & 291,97 & 14,96 & 277,01 & 65,44 & 208,61 & 208,61 & 58,38 & 695,99 & 94,18 & 10,34 & 47,79 & 270,13 & 56,85 & 56,85 & 268,09 \\
\hline Lissotriton boscai & 29TPF89 & 100,00 & 127,67 & 108,27 & 38,52 & 5831,94 & 288,98 & 11,46 & 277,52 & 62,03 & 204,89 & 204,89 & 55,23 & 706,50 & 95,57 & 11,02 & 47,46 & 274,56 & 59,14 & 59,14 & 273,30 \\
\hline Lissotriton boscai & 29TPF94 & 100,00 & 127,14 & 104,70 & 37,31 & 5992,22 & 288,67 & 12,45 & 276,22 & 60,62 & 206,74 & 206,74 & 53,35 & $\begin{array}{l}706,35 \\
\end{array}$ & $\begin{array}{l}94,23 \\
\end{array}$ & 9,63 & 47,70 & 272,59 & 57,28 & 57,28 & 267,10 \\
\hline Lissotriton boscai & 29TPF95 & 100,00 & 123,98 & 105,18 & 37,72 & $\begin{array}{l}5972,06 \\
\end{array}$ & 285,81 & 9,47 & 276,34 & 57,90 & 203,57 & 203,57 & 50,66 & \begin{tabular}{|l|l|}
712,27 \\
\end{tabular} & 94,80 & $\begin{array}{ll}9,98 \\
\end{array}$ & 47,46 & 274,87 & 58,80 & 58,80 & 269,70 \\
\hline Lissotriton boscai & 29TPF96 & 100,00 & 125,79 & 106,55 & 38,02 & 5947,17 & 287,79 & 10,27 & 277,52 & 59,50 & 204,76 & 204,76 & 52,34 & \begin{tabular}{ll|l}
691,95 \\
\end{tabular} & 91,70 & 10,15 & 47,00 & 266,69 & 57,95 & 57,95 & 261,99 \\
\hline Lissotriton boscai & 29TPF97 & 101,00 & 119,67 & 106,41 & 37,99 & 5930,73 & 282,07 & 4,67 & 277,39 & 53,80 & 198,61 & 198,61 & 46,65 & 718,31 & 95,14 & 11,02 & 46,70 & 276,97 & 61,95 & 61,95 & 272,98 \\
\hline |Lissotriton boscai & 29TPF98 & 100,00 & 120,57 & 107,46 & 38,12 & 5908,98 & 283,11 & 5,07| & 278,03 & 54,57 & 199,09 & 199,09 & 47,67 & 701,41 & 92,47 & 11,18 & 46,30 & 270,26 & 61,39 & 61,39 & 266,71 \\
\hline Lissotriton boscai & 29TPF999 & 100,00 & 130,68 & 109,56 & 38,84 & 5876,27 & 292,54 & 13,18 & 279,36 & 64,36 & 208,23 & 208,23 & 57,49 & 638,01 & 83,60 & 10,49 & 46,07 & 245,56 & 55,23 & 55,23 & 241,94 \\
\hline Lissotriton boscai & 29TPG00 & 101,00 & 128,55 & 101,51 & 39,68 & 5268,55 & 274,20 & 21,32 & 252,88 & 63,34 & 197,31 & 197,49 & 63,30 & 1164,34 & 161,88 & 15,93 & 51,68 & 461,28 & 85,32 & 88,02 & 461,28 \\
\hline Lissotriton boscai & 29TPG01 & 100,00 & 111,76 & 92,42 & 37,99 & 5168,72 & 251,69 & 11,49 & 240,20 & 49,41 & 180,21 & 180,35 & 49,41 & 1289,31 & $\begin{array}{l}176,79 \\
\end{array}$ & 20,77 & 50,47 & 510,67 & $\begin{array}{l}101,87 \\
\end{array}$ & 103,85 & 510,67 \\
\hline Lissotriton boscai & 29TPG02 & 100,00 & 106,85 & 88,80 & 37,21 & 5111,32 & 244,26 & 9,02 & 235,24 & 45,71 & 174,80 & $\begin{array}{l}174,99 \\
\end{array}$ & 45,71 & $\begin{array}{l}1310,86 \\
\end{array}$ & $\begin{array}{l}176,48 \\
\end{array}$ & 22,83 & 49,52 & 516,13 & $\begin{array}{l}107,83 \\
\end{array}$ & 110,31 & 516,13 \\
\hline Lissotriton boscai & 29TPG03 & 101,00 & 100,34 & 86,02 & 36,70 & 5053,09 & 235,86 & 4,79 & 231,07 & 40,97 & 167,75 & 168,01 & 40,55 & 1349,43 & 178,69 & 25,66 & 48,45 & 527,55 & 116,37 & 118,48 & 527,53 \\
\hline 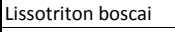 & 29TPG04 & 100,00 & 105,08 & 88,21 & 37,23 & 5064,05 & 241,28 & 7,38 & 233,90 & 49,16 & 172,41 & 172,65 & 44,73 & \begin{tabular}{|l|}
1295,86 \\
\end{tabular} & 171,56 & 25,20 & 47,82 & 502,97 & 113,33 & 115,43 & 502,81 \\
\hline Lissotriton boscai & 29TPG06 & 101,00 & 120,72 & 93,71 & 38,19 & 5132,34 & 258,02 & 16,47 & 241,55 & 63,99 & 188,26 & 188,35 & 58,39 & 1133,64 & 155,70 & 22,98 & 46,17 & 434,04 & 101,53 & 103,93 & 429,13 \\
\hline Lissotriton boscai & 29TPG07 & 100,00 & 123,10 & 93,56 & 38,15 & 5116,46 & 259,22 & 18,05 & 241,17 & 66,16 & 190,42 & 190,56 & 60,93 & $\begin{array}{l}1099,61 \\
\end{array}$ & 152,97 & 23,37 & 45,42 & 418,36 & 101,12 & 104,45 & 411,31 \\
\hline Lissotriton boscai & 29TPG08 & 101,00 & 122,86 & 92,65 & 38,09 & 5064,76 & 257,47 & 18,36 & 239,11 & 66,42 & 189,60 & 189,72 & 61,56 & 1094,30 & 153,24 & 24,48 & 44,66 & 414,44 & 103,56 & 107,31 & 405,74 \\
\hline Lissotriton boscai & 29TPG09 & 99,00 & 123,31 & 91,60 & 38,18 & 4991,49 & 255,79 & 19,62 & 236 & 67,51 & 188,94 & 189,15 & 63,01 & 1087,23 & 152,76 & 25,49 & 43,95 & 21. & 105,63 & 112,58 & 399,86 \\
\hline Lissotriton boscai & 29TPG10 & 100,00 & 126,91 & 102,29 & 39,40 & 5384,67 & 275,27 & 18,51 & 256,76 & 60,43 & 197,61 & $\begin{array}{l}197,66 \\
\end{array}$ & 60,43 & $\begin{array}{l}1124,66 \\
\end{array}$ & $\begin{array}{l}158,03 \\
\end{array}$ & 15,63 & 51,73 & 446,89 & 82,92 & 83,49 & 446,89 \\
\hline 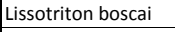 & 29TPG13 & 101,00 & 114,59 & 94,29 & 37,88 & 5258,16 & 256,75 & 11,16 & 245,59 & 51,08 & 184,25 & 184,28 & 50,83 & 1171,31 & 155,10 & 20,77 & 48,71 & 457,27 & 97,45 & 97,95 & 457,27 \\
\hline Lissotriton boscai & 29TPG15 & 99,00 & 117,40 & 94,81 & 38,05 & 5235,88 & 258,51 & 12,64 & 245,87 & 59,84 & 186,75 & 186,77 & 53,92 & 1115,37 & 149,09 & 21,82 & 46,89 & 429,50 & 97,90 & $\begin{array}{ll}99,06 \\
\end{array}$ & 427,21 \\
\hline Lissotriton boscai & 29TPG19 & 100,00 & 120,84 & 92,62 & 38,10 & 5065,62 & 255,79 & 16,38 & 239,41 & 64,25 & 187,53 & 187,64 & 59,66 & 1054,15 & 145,66 & 24,97 & 43,47 & 397,87 & 103,63 & 107,49 & 387,71 \\
\hline Lissotriton boscai & 29TPG20 & 100,00 & 116,5 & 98,57 & 38,25 & 5422,90 & 264,90 & 10,39 & 254,51 & 50,42 & 188,25 & 188,27 & 50,42 & 1146,33 & 161,59 & 17,49 & 51,15 & 30 & 88,32 & 88,41 & 456,30 \\
\hline Lissotriton boscai & 29TPG21 & 101,00 & 126,25 & 102,04 & 38 & 5451,82 & 275 & 16,75 & \begin{tabular}{|l|l|}
258,84 \\
\end{tabular} & 59,06 & 197,96 & 197,96 & 59,06 & \begin{tabular}{|l|}
1047,46 \\
\end{tabular} & $\begin{array}{l}144,56 \\
\end{array}$ & 15,91 & 50,38 & 412,99 & 80,47 & 80,47 & 412,99 \\
\hline Lissotriton boscai & 29TPG22 & 101,00 & 133,16 & 103,27 & 39,01 & 5460,32 & 282,04 & 21,44 & 260,59 & \begin{tabular}{|c|}
66,48 \\
\end{tabular} & 204,71 & 204,71 & 65,46 & 970,41 & $\begin{array}{l}130,05 \\
\end{array}$ & 15,04 & 49,31 & 377,52 & 75,53 & 75,53 & 377,52 \\
\hline Lissotriton boscai & 29TPG23 & 100,00 & \begin{tabular}{ll|}
128,44 \\
\end{tabular} & 100,89 & 38,75 & 5426,73 & 275,36 & 18,16 & 257,20 & $\begin{array}{ll}64,68 \\
\end{array}$ & 199,68 & \begin{tabular}{ll|}
199,68 \\
\end{tabular} & 61,42 & $\begin{array}{l}993,49 \\
\end{array}$ & 130,73 & 16,78 & 48,38 & 385,02 & 80,62 & 80,62 & 384,57 \\
\hline Lissotriton boscai & 29TPG24 & 100,00 & 128,78 & 100,20 & 38,64 & 5413,35 & 274,57 & 18,36 & 256,21 & 68,08 & 199,94 & 199,94 & 62,10 & $972,87 \mid$ & $\begin{array}{l}127,05 \\
\end{array}$ & 17,39 & 47,39 & 374,59 & 81,45 & 81,45 & 372,83 \\
\hline Lissotriton boscai & 29TPG25 & 100,00 & 120,04 & 97,11 & 38,12 & 5336,47 & 263,87 & 12,51 & 251,36 & 60,75 & 190,56 & 190,56 & 54,99 & 1034,95 & 137,25 & 20,39 & 46,61 & 398,36 & 91,23 & 91,43 & 395,74 \\
\hline Lissotriton boscai & $29 \mathrm{TPG}$ & 100,00 & 92 & 89,78 & 37, & 5108,96 & 231,86 & $-6,13$ & 237,99 & 37,64 & 160,60 & 160,72 & 31,96 & \begin{tabular}{|l|}
1256,74 \\
\end{tabular} & \begin{tabular}{|l|l|}
167,10 \\
\end{tabular} & 30,40 & 44,18 & 481,01 & 125,38 & 126,75 & 474,89 \\
\hline Lissotriton boscai & 29TPG28 & 101,00 & 102,96 & 91,96 & 37,86 & 5109,11 & 242,32 & 1,67 & 240,65 & 47,18 & 170,96 & 171,02 & 42,07 & \begin{tabular}{|l|}
1159,66 \\
\end{tabular} & 156,59 & 27,99 & 43,84 & 442,53 & 115,48 & 117,44 & 435,04 \\
\hline Lissotriton boscai & 29TPG29 & 101,00 & 122,35 & 94,68 & 38,28 & 5148,38 & 259,82 & 16,03 & 243,79 & 64,46 & 190,05 & 190,13 & 59,80 & 988,89 & 135,44 & 23,41 & 43,19 & 373,42 & 97,58 & 99,85 & 363,0 \\
\hline Lissotriton boscai & 29TPG30 & 101,00 & 129,20 & 104,36 & 38,86 & 5549,78 & 281,83 & 17,57 & 264,26 & 60,49 & 202,10 & 202, & 60,49 & 983,61 & 138,69 & 14,19 & 51,07 & 390,06 & 73,76 & 73,76 & $39 \mathrm{C}$ \\
\hline Lissotriton boscai & & 100 & & & 38,42 & 12 & & & 9 & 54,58 & & & 54,26 & 1006,25 & 137,16 & 16,95 & 15 & & 81,34 & 81,34 & 395,01 \\
\hline Lissotriton boscai & 29TPG33 & 100,00 & 121,95 & 100,70 & 38,33 & 5475,42 & 271,29 & 12,10 & 259,19 & 57,53 & 194,34 & 194,34 & 54,80 & \begin{tabular}{|c|}
986,87 \\
\end{tabular} & 131,60 & 17,61 & 48,16 & 384,05 & 82,26 & 82,26 & 383,95 \\
\hline Lissotriton boscai & 29TPG34 & 101,00 & 119,10 & 99,36 & 38,15 & 5438,35 & 267,03 & 10,11 & 256,92 & 58,52 & 191,03 & 191,03 & 52,56 & 996,47 & 130,92 & 19,09 & 47,19 & 385,91 & 86,18 & 86,18 & 385,02 \\
\hline
\end{tabular}




\begin{tabular}{|c|c|c|c|c|c|c|c|c|c|c|c|c|c|c|c|c|c|c|c|c|c|}
\hline TAXON & UTM & $\mathrm{km} 2$ & BIO1 & B102 & $B 103$ & BIO4 & B105 & B106 & B107 & B108 & 8109 & B1010 & BIO11 & BIO12 & BIO13 & BIO14 & BIO15 & B1016 & B1017 & B1018 & 81019 \\
\hline Lissotriton boscai & 29TPG37 & 100,00 & 81,18 & 89,85 & 36,97 & 5161,60 & 223,24 & $-16,66$ & 239,90 & 26,61 & 150,66 & 150,77 & 20,92 & 1289,79 & 168,92 & 33,27 & 43,10 & 490,73 & 134,79 & 135,32 & 482,99 \\
\hline Lissotriton boscai & 29TPG38 & 100,00 & 96,75 & 92,85 & 37,72 & 5178,34 & 238,76 & $-4,64$ & \begin{tabular}{|l|l|}
243,39 \\
\end{tabular} & $\begin{array}{ll}40,47 \\
\end{array}$ & 165,90 & 165,96 & 35,20 & 1152,50 & $\begin{array}{l}153,75 \\
\end{array}$ & 28,99 & 43,10 & \begin{tabular}{ll|}
438,96 \\
\end{tabular} & 118,41 & $\begin{array}{l}119,17 \\
\end{array}$ & 430,55 \\
\hline Lissotriton boscai & 29TPG40 & 100,00 & 139,68 & 107,25 & 39,28 & 5619,81 & $\begin{array}{l}294,02 \\
\end{array}$ & 24,54 & 269,48 & $\begin{array}{ll}69,90 \\
\end{array}$ & 213,18 & 213,18 & 69,41 & \begin{tabular}{|l|l|}
839,87 \\
\end{tabular} & $\begin{array}{l}116,78 \\
\end{array}$ & \begin{tabular}{ll|}
11,78 \\
\end{tabular} & 50,19 & $\begin{array}{l}329,39 \\
\end{array}$ & 62,42 & 62,42 & 329,39 \\
\hline Lissotriton boscai & 29TPG41 & 100,00 & 132,24 & 105,64 & 38,95 & 5603,97 & 286,01 & 18,46 & 267,55 & 63,01 & 205,82 & 205,82 & 62,58 & 880,38 & \begin{tabular}{|l|}
121,57 \\
\end{tabular} & 13,71 & 49,58 & 345,71 & 68,32 & 68,32 & 345,69 \\
\hline Lissotriton boscai & 29TPG42 & 101,00 & 119,50 & 102,14 & 38,32 & 5551,84 & 272,26 & 8,95 & 263,32 & 51,70 & 193,03 & 193,03 & 51,39 & 962,54 & 131,89 & 16,71 & 48,75 & 378,48 & 79,34 & 79,34 & 378,47 \\
\hline Lissotriton boscai & 29TPG44 & 100,00 & 113,68 & $\begin{array}{ll}99,82 \\
\end{array}$ & 38,01 & 5485,88 & 264,16 & \begin{tabular}{|c|c|}
4,66 \\
\end{tabular} & 259,50 & 52,80 & 186,67 & $\mid 186,67$ & 46,81 & 981,93 & 129,95 & \begin{tabular}{|c|c|}
19,66 \\
\end{tabular} & 46,90 & 381,73 & 87,10 & 87,10 & 380,84 \\
\hline Lissotriton boscai & 29TPG47 & 101,00 & 87,27 & 93,12 & 37,28 & 5272,05 & 232,57 & $-13,80$ & 246,38 & 30,69 & 158,08 & 158,12 & 25,08 & 1178,80 & 154,82 & 30,25 & 43,01 & 449,01 & 123,01 & 123,16 & 441,24 \\
\hline Lissotriton boscai & 29TPG48 & 100,00 & 108,67 & 96,86 & 37,97 & 5314,99 & 253,42 & 2,25 & 251,18 & \begin{tabular}{|l|l|}
49,64 \\
\end{tabular} & \begin{tabular}{|l|l|}
179,27 \\
\end{tabular} & 179,29 & 44,47 & $\begin{array}{l}997,65 \\
\end{array}$ & \begin{tabular}{|l|l|}
133,38 \\
\end{tabular} & 24,48 & 42,97 & 380,02 & $\begin{array}{l}101,32 \\
\end{array}$ & $\begin{array}{l}101,38 \\
\end{array}$ & 371,02 \\
\hline Lissotriton boscai & 29TPG49 & 101,00 & 118,67 & $\begin{array}{ll}97,49 \\
\end{array}$ & 38,41 & 5283,64 & 261,09 & 10,54 & 250,55 & 58,99 & 188,28 & 188,28 & 54,20 & 919,91 & \begin{tabular}{ll|}
123,69 \\
\end{tabular} & 22,59 & 42,35 & $\begin{array}{l}348,53 \\
\end{array}$ & $\begin{array}{l}93,97 \\
9\end{array}$ & $\begin{array}{l}93,97 \\
\end{array}$ & 337,24 \\
\hline Lissotriton boscai & 29TPG50 & 100,00 & 137,60 & \begin{tabular}{ll|l}
107,47 \\
\end{tabular} & 39,01 & 5663,99 & 293,42 & 22,08 & 271,34 & 69,40 & 211,95 & 211,95 & 66,82 & 797,61 & \begin{tabular}{|l|l|}
110,60 \\
\end{tabular} & 11,75 & 49,53 & 312,43 & 60,95 & 60,95 & 312,37 \\
\hline Lissotriton boscai & 29TPG51 & 100,00 & 135,10 & 106,82 & 38,97 & \begin{tabular}{|l|}
5652,70 \\
\end{tabular} & $\begin{array}{l}290,36 \\
\end{array}$ & $\begin{array}{ll}19,93 \\
\end{array}$ & 270,43 & 68,85 & 209,35 & 209,35 & 64,65 & 802,20 & 109,94 & 12,67 & 48,85 & 313,40 & 63,25 & 63,25 & 313,23 \\
\hline Lissotriton boscai & 29TPG52 & 99,00 & 126,28 & 105,19 & 38,73 & 5629,65 & 281,48 & 12,63 & 268,85 & 59,49 & 200,62 & 200,62 & 56,60 & 851,88 & 116,31 & 14,69 & 48,20 & $\begin{array}{l}333,63 \\
\end{array}$ & 70,27 & \begin{tabular}{ll|}
70,27 \\
\end{tabular} & 333,50 \\
\hline 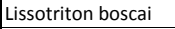 & 29TPG53 & 101,00 & 118,10 & 103,22 & 38,19 & 5593,68 & 272,73 & 6,29 & 266,44 & 54,78 & 192,35 & 192,35 & 49,42 & 897,29 & $\begin{array}{l}121,15 \\
\end{array}$ & 16,78 & 47,42 & 350,83 & 77,64 & 77,64 & 350,43 \\
\hline Lissotriton boscai & 29TPG54 & 100,00 & 112,14 & 101,49 & 37,99 & 5549,06 & 265,44 & 2,10 & 263,34 & 50,57 & 186,01 & 186,01 & 44,43 & 933,69 & 123,73 & 19,01 & 46,45 & 363,30 & 84,68 & 84,68 & 361,72 \\
\hline Lissotriton boscai & 29TPG59 & 101,00 & 120,87 & $\begin{array}{ll}99,39 \\
\end{array}$ & 38,56 & 5362,54 & 265,42 & 10,95 & 254,47 & 59,95 & 191,56 & \begin{tabular}{ll|}
191,56 \\
\end{tabular} & 55,12 & 854,10 & \begin{tabular}{|l|l|}
114,17 \\
\end{tabular} & 21,06 & 41,95 & 323,58 & 88,29 & 88,29 & 311,47 \\
\hline Lissotriton boscai & 29TPG61 & 101,00 & 124,66 & 106,28 & 38,58 & 5691,35 & 282,65 & 10,37 & 272,28 & 56,10 & \begin{tabular}{|l|l|}
199,97 \\
\end{tabular} & \begin{tabular}{|l|l|}
199,97 \\
\end{tabular} & 54,20 & $\begin{array}{l}816,66 \\
\end{array}$ & 112,80 & \begin{tabular}{l|l|l}
13,43 \\
\end{tabular} & 48,38 & 321,04 & 67,43 & 67,43 & 320,98 \\
\hline Lissotriton boscai & 29TPG62 & 101,00 & 117,17 & 104,76 & 38,23 & 5659,64 & 274,68 & 4,41 & 270,26 & 52,34 & \begin{tabular}{|l|l|}
192,27 \\
\end{tabular} & $\begin{array}{l}192,27 \\
\end{array}$ & 47,48 & 857,09 & $\begin{array}{l}117,25 \\
\end{array}$ & 15,25 & 47,61 & $\begin{array}{l}336,34 \\
\end{array}$ & 74,11 & 74,11 & 336,18 \\
\hline Lissotriton boscai & 29TPG63 & 100,00 & 112,97 & 103,74 & 38,15 & 5628,42 & 269,69 & 1,35 & 268,34 & 50,38 & 187,93 & 187,93 & 44,10 & 878,27 & 118,15 & $\mid 16,94$ & 46,75 & 343,20 & 79,00 & 79,00 & 342,17 \\
\hline |Lissotriton boscai & 29TPG64 & 100,00 & 104,22 & 101,47 & 37,91 & 5587,04 & 259,60 & $-4,87$ & $264,47 \mid$ & 42,66 & 178,99 & 178,99 & 36,56 & 935,40 & 123,39 & 19,90 & 45,50 & 363,13 & 88,84 & 88,84 & 360,58 \\
\hline Lissotriton boscai & 29TPG67 & 101,00 & 90,62 & 98,13 & 37,76 & 5449,74 & 241,65 & $-15,01$ & 256,66 & 31,18 & 163,81 & 163,81 & 25,53 & 1033,16 & 135,57 & 27,56 & 41,95 & 391,99 & 1111,28 & 111,28 & 382,79 \\
\hline Lissotriton boscai & 29TPG68 & 101,00 & 95,38 & 98,77 & 37,99 & 5429,41 & 245,36 & $-11,17$ & 256,53 & 35,56 & 168,01 & 168,01 & 30,21 & 994,16 & $\begin{array}{l}131,08 \\
\end{array}$ & 26,93 & 41,40 & $\begin{array}{l}376,34 \\
\end{array}$ & $\begin{array}{l}108,56 \\
\end{array}$ & 108,56 & 365,59 \\
\hline Lissotriton boscai & 29TPG69 & 100,00 & 109,58 & $\begin{array}{ll}99,72 \\
\end{array}$ & 38,42 & 5401,83 & \begin{tabular}{|l|}
256,87 \\
\end{tabular} & 0,74 & \begin{tabular}{|l|l|}
256,13 \\
\end{tabular} & $\begin{array}{ll}48,89 \\
\end{array}$ & $\begin{array}{ll}181,12 \\
\end{array}$ & 181,12 & 43,70 & \begin{tabular}{|l|l|}
891,67 \\
\end{tabular} & \begin{tabular}{ll|}
118,02 \\
\end{tabular} & 23,64 & 41,01 & $\begin{array}{ll}336,82 \\
\end{array}$ & $\begin{array}{l}96,95 \\
\end{array}$ & 96,95 & 323,83 \\
\hline Lissotriton boscai & 29TPG70 & 101,00 & 120,49 & 106,61 & 38,23 & 5758,56 & 281,01 & 6,19 & 274,81 & 50,93 & 197,05 & $\begin{array}{l}197,05 \\
\end{array}$ & 49,40 & 797,41 & \begin{tabular}{|l|l|}
110,24 \\
\end{tabular} & 12,70 & 48,25 & 313,45 & 66,84 & 66,84 & 313,45 \\
\hline Lissotriton boscai & 29TPG71 & 99,00 & 106,29 & 103,38 & 37,79 & 5709,64 & 265,63 & $-4,35$ & \begin{tabular}{|l|l|}
269,98 \\
\end{tabular} & 41,02 & 182,72 & 182,73 & 36,85 & 887,24 & 120,34 & 15,88 & 47,03 & 346,53 & 79,77 & 79,77 & 346,12 \\
\hline |Lissotriton boscai & 29TPG72 & 100,00 & 104,66 & 103,39 & 37,88 & 5685,59 & 263,66 & $-5,85$ & 269,52 & 42,04 & 180,79 & 180,80 & 35,52 & 889,11 & 119,21 & 17,01 & 46,29 & 346,30 & 82,30 & 82,30 & 345,29 \\
\hline Lissotriton boscai & 29TPG73 & 100,00 & 111,26 & 105,36 & 38,08 & 5681,64 & 270,72 & $-1,27$ & 271,99 & 48,18 & 187,11 & 187,11 & 41,70 & 830,16 & 111,22 & 16,29 & 46,11 & 324,27 & 76,84 & 76,84 & 322,77 \\
\hline Lissotriton boscai & 29TPG74 & 100,00 & 102,89 & 103,19 & 37,94 & 5639,26 & 260,53 & $-7,56$ & 268,10 & 40,61 & 178,40 & 178,40 & 34,42 & 888,01 & 117,14 & 19,58 & 44,67 & 343,11 & 87,15 & 87,15 & 339,61 \\
\hline Lissotriton boscai & 29TPG76 & 100,00 & 69,20 & 95,75 & 37,03 & 5474,24 & 221,21 & $-33,69$ & 254,90 & 11,21 & 143,07 & 143,32 & 5,10 & $\begin{array}{l}1166,78 \\
\end{array}$ & 148,91 & 33,61 & 40,03 & 435,09 & 133,11 & $\begin{array}{l}134,16 \\
\end{array}$ & 423,21 \\
\hline Lissotriton boscai & 29TPG77 & 100,00 & 72,02 & 96,50 & 37,33 & 5454,39 & 223,74 & $-31,34$ & $255,08 \mid$ & 13,92 & 145,64 & 145,74 & 7,94 & 1141,30 & 146,33 & 33,84] & 39,61 & 424,73 & 132,61 & 133,18 & 411,98 \\
\hline Lissotriton boscai & 29TPG78 & 99,00 & 84,24 & $\begin{array}{ll}98,73 \\
\end{array}$ & 37,94 & \begin{tabular}{|l|}
5461,01 \\
\end{tabular} & 235,92 & $-21,51$ & \begin{tabular}{|l|l|}
257,42 \\
\end{tabular} & 24,81 & \begin{tabular}{|l|l|}
157,54 \\
\end{tabular} & 157,55 & 19,16 & 1035,81 & 134,64 & 30,25 & 39,76 & 387,35 & 119,61 & \begin{tabular}{|l|l|}
119,70 \\
\end{tabular} & 374,39 \\
\hline Lissotriton boscai & 29TPG79 & 101,00 & 115,29 & 102,23 & 38,71 & 5504,49 & 264,82 & 3,55 & 261,28 & 52,63 & 187,88 & 187,88 & 47,61 & 798,91 & 105,84 & 21,01 & 40,71 & 302,25 & 87,53 & 87,53 & 288,56 \\
\hline Lissotriton boscai & 29TPG80 & 100,00 & 121,05 & 107,95 & 38,31 & 5805,80 & 283,05 & 5,75 & 277,30 & 55,69 & 198,22 & 198,22 & 49,43 & 736,72 & 99,75 & \begin{tabular}{|c|c|}
12,07 \\
\end{tabular} & 47,20 & 287,01 & \begin{tabular}{|c|c|}
63,76 \\
\end{tabular} & \begin{tabular}{|c|c|}
63,76 \\
\end{tabular} & 286,57 \\
\hline Lissotriton boscai & 29TPG81 & 100,00 & 112,63 & 106,89 & 38,07 & 5769,69 & 274,83 & $-0,95$ & 275,78 & 47,70 & \begin{tabular}{|l|l|}
189,63 \\
\end{tabular} & 189,63 & 41,79 & 781,52 & 105,21 & 13,80 & 46,54 & 304,45 & 70,73 & 70,73 & 304,31 \\
\hline Lissotriton boscai & 29TPG82 & 101,00 & 115,92 & 108,05 & 38,48 & 5741,87 & 278,21 & 1,19 & 277,01 & 49,20 & 192,39 & 192,39 & 45,23 & 751,50 & $\mid \begin{array}{l}101,08 \\
\end{array}$ & 13,75 & 46,42 & 293,71 & 68,50 & 68,50 & 293,50 \\
\hline Lissotriton boscai & 29TPG83 & 100,00 & 114,34 & 107,76 & 38,57 & 5717,94 & $\begin{array}{l}275,96 \\
\end{array}$ & $-0,14$ & \begin{tabular}{|l|l|}
276,10 \\
\end{tabular} & 49,76 & \begin{tabular}{|l|l|}
190,63 \\
\end{tabular} & \begin{tabular}{ll|}
190,63 \\
\end{tabular} & 43,99 & \begin{tabular}{|l|l|}
756,43 \\
\end{tabular} & 100,89 & \begin{tabular}{ll|}
14,92 \\
\end{tabular} & 45,71 & 294,30 & 71,12 & 71,12 & 293,56 \\
\hline Lissotriton boscai & 29TPG84 & 100,00 & 101,08 & 104,58 & 38,04 & \begin{tabular}{|l|}
5694,84 \\
\end{tabular} & 260,62 & $-10,39$ & 271,01 & 38,15 & \begin{tabular}{ll|l}
177,42 \\
\end{tabular} & \begin{tabular}{ll|}
177,42 \\
\end{tabular} & 31,99 & 848,62 & \begin{tabular}{|l|l|}
111,77 \\
\end{tabular} & 19,55 & 43,67 & $\begin{array}{l}325,23 \\
\end{array}$ & 86,52 & 86,52 & 320,86 \\
\hline Lissotriton boscai & 29TPG85 & 99,00 & 90,22 & 102,10 & 37,74 & 5649,05 & 247,58 & $-18,81$ & 266,39 & 28,47 & 166,10 & $\begin{array}{l}166,16 \\
\end{array}$ & 22,38 & $\begin{array}{l}931,97 \\
9\end{array}$ & 121,43 & 24,22 & 41,70 & $\begin{array}{l}352,40 \\
\end{array}$ & $\begin{array}{l}101,25 \\
\end{array}$ & 101,38 & 344,17 \\
\hline Lissotriton boscai & 29TPG86 & 101,00 & 80,34 & 100,06 & 37,57 & 5586,05 & 235,83 & $-26,54$ & 262,37 & $\begin{array}{ll}19,98 \\
\end{array}$ & 155,48 & 155,64 & 13,90 & 1015,72 & 130,94 & 29,10 & 40,06 & $\begin{array}{ll}379,28 \\
\end{array}$ & 16,18 & 16,72 & 367,84 \\
\hline Lissotriton boscai & 29TPG87 & 100,00 & 60,76 & 96,29 & 37,14 & 5479,39 & 213,40 & $-41,90$ & 255,30 & 3,18 & 134,78 & 135,09 & $-3,08$ & 1192,08 & 150,36 & 37,89 & 37,67 & 436,76 & 145,06 & 146,84 & 421,17 \\
\hline Lissotriton boscai & 29TPG88 & 101,00 & 75,96 & 99,19 & 37,83 & 5498,03 & 229,16 & $-29,65$ & 258,81 & 16,66 & 149,91 & 149,95 & 10,69 & 1056,83 & 135,57 & 32,94 & 38,18 & 389,90 & 128,19 & $\begin{array}{l}128,45 \\
\end{array}$ & 374,70 \\
\hline Lissotriton boscai & 29TPG89 & 100,00 & 93,45 & 101,35 & 38,41 & 5516,40 & 245,72 & $-15,37$ & 261,10 & 32,30 & 167,04 & 167,05 & 26,82 & $\begin{array}{l}919,95 \\
\end{array}$ & \begin{tabular}{|l|}
119,41 \\
\end{tabular} & 27,68 & 38,68 & 341,52 & \begin{tabular}{|l|l|}
110,07 \\
\end{tabular} & 1110,10 & 325,83 \\
\hline Lissotriton boscai & 29TPG90 & 101,00 & 125,92 & 109,62 & 38,77 & 5856,70 & 288,50 & 8,71 & \begin{tabular}{|l|l|}
279,79 \\
\end{tabular} & $\begin{array}{ll}60,02 \\
\end{array}$ & 203,44 & 203,44 & 53,20 & \begin{tabular}{|c|}
655,17 \\
\end{tabular} & 85,95 & $\begin{array}{l}11,25 \\
\end{array}$ & 45,79 & 252,45 & 58,32 & 58,32 & 249,87 \\
\hline |Lissotriton boscai & 29TPG91 & 100,00 & 118,94 & 109,38 & 38,64 & 5827,16 & 282,27 & 2,54 & $279,73 \mid$ & 53,38 & 196,21 & 196,21 & 46,87 & 687,62 & 90,57 & 12,47 & 45,58 & 265,21 & 63,42 & 63,42 & 264,07 \\
\hline Lissotriton boscai & 29TPG92 & 100,00 & 117,79 & 109,49 & 38,73 & 5801,07 & 281,12 & 1,55 & 279,58 & 51,24 & 194,91 & 194,91 & 45,98 & $\begin{array}{l}690,75 \\
\end{array}$ & 91,31 & 13,20 & 45,22 & 266,29 & 65,12 & 65,12 & 265,58 \\
\hline 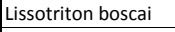 & 29TPG93 & 100,00 & 114,11 & 109,10 & 38,82 & 5783,44 & 276,86 & $-1,48$ & 278,34 & 48,78 & 191,09 & 191,09 & 42,76 & 707,57 & 93,88 & 14,70 & 44,40 & 271,75 & 69,24 & 69,24 & 270,03 \\
\hline Lissotriton boscai & 29TPG94 & 101,00 & 110,64 & 108,34 & 38,65 & 5772,11 & 272,62 & $-4,27$ & 276,90 & 45,99 & 187,51 & 187,51 & 39,68 & 726,49 & 96,60 & 16,51 & 43,40 & 277,94 & 73,92 & 73,92 & 274,29 \\
\hline Lissotriton boscai & 29TPG95 & 101,00 & 102,24 & 106,49 & 38,29 & \begin{tabular}{|l|}
5749,81 \\
\end{tabular} & 262,78 & $-11,04$ & \begin{tabular}{|l|l|}
273,82 \\
\end{tabular} & 38,15 & \begin{tabular}{|l|l|}
179,12 \\
\end{tabular} & $\begin{array}{l}179,12 \\
\end{array}$ & 32,12 & $\begin{array}{l}781,86 \\
\end{array}$ & \begin{tabular}{|l|l|}
103,44 \\
\end{tabular} & 20,04 & 41,76 & 296,35 & 84,39 & 84,39 & 288,95 \\
\hline Lissotriton boscai & 29TPG96 & 100,00 & 97,20 & 105,45 & 38,22 & 5715,20 & 256,35 & $-15,01$ & 35 | & 33,71 & 173,68 & 173,68 & 27,75 & 820,67 & 107,87 & 22,87 & 40,53 & 8,33 & 92,64 & 92,64 & 298 \\
\hline Lissotriton boscai & 29TPG97 & 100,00 & 73,90 & 100,69 & 37,78 & 5591,12 & 229,81 & $-32,99$ & 262,80 & 13,84 & \begin{tabular}{|l|l|}
149,23 \\
\end{tabular} & 149,36 & 7,62 & 1021,92 & $\begin{array}{l}130,38 \\
\end{array}$ & 32,26 & 37,71 & $\begin{array}{ll}374,88 \\
\end{array}$ & 125,27 & 125,90 & 359,55 \\
\hline Lissotriton boscai & 29TPH & 101,00 & \begin{tabular}{ll|l}
125,61 \\
\end{tabular} & 90,94 & 38,56 & 4901,53 & 255,80 & 22,76 & 233,04 & 70,59 & \begin{tabular}{|l|l|}
189,97 \\
\end{tabular} & 190,31 & 66,55 & 1067,43 & $\begin{array}{l}150,45 \\
\end{array}$ & 25,92 & 43,21 & 400,80 & \begin{tabular}{|l|l|}
106,02 \\
\end{tabular} & 114,20 & 388,56 \\
\hline Lissotriton boscai & 29TPH01 & 100,00 & 124,98 & \begin{tabular}{|l|l|}
90,02 \\
\end{tabular} & 38,96 & \begin{tabular}{|l|l|}
4776,79 \\
\end{tabular} & 252,75 & 24,07 & 228,67 & 71,31 & $\mid 187,58$ & $\mid \begin{array}{l}188,19 \\
\end{array}$ & \begin{tabular}{|c|c|}
67,60 \\
\end{tabular} & $\mid 1077,54$ & $\mid \begin{array}{l}151,59 \\
\end{array}$ & 27,30 & 42,65 & 403,69 & \begin{tabular}{|l|l|}
109,82 \\
\end{tabular} & $\mid$\begin{tabular}{|l|l|}
122,46 \\
\end{tabular} & 389,66 \\
\hline Lissotriton boscai & 29TPH02 & 99,00 & 126,84 & 89,12 & 39,16 & 4652,13 & 251,70 & 27,49 & $224,21 \mid$ & 74,29 & 187,64 & 188,44 & 70,94 & 1066,92 & 149,59 & 27,96 & 41,88 & 398,26 & 111,13 & 125,05 & 382,20 \\
\hline Lissotriton boscai & 29TPH03 & 101,00 & 122,39 & 88,14 & 39,68 & 4526,5 & 245,68 & 25,57 & 220,12 & 71,62 & 181,60 & 182, & 68 & 1110 & 154,52 & 30,34 & 41,20 & 414,15 & 9,09 & 83 & 396,58 \\
\hline Lissotriton boscai & 29TPH05 & 100 & 120,25 & 86,16 & 40, & 4 & 239,66 & 26,82 & 21 & 72,25 & 176,64 & & 68,88 & $\begin{array}{l}1130,62 \\
\end{array}$ & 154,64 & 32,99 & 39,74 & 419,44 & 127,24 & $\begin{array}{l}141,76 \\
\end{array}$ & 397,95 \\
\hline Lissotriton boscai & 29TPH06 & 100,00 & 122,37 & 85,04 & 40,24 & \begin{tabular}{|l|l|}
4221,63 \\
\end{tabular} & 238,92 & 30,56 & \begin{tabular}{|l|l|}
208,36 \\
\end{tabular} & 75,70 & 177,15 & 178,95 & 72,04 & 1114,61 & $\begin{array}{l}150,96 \\
\end{array}$ & 33,28 & 38,97 & 412,09 & 127,86 & \begin{tabular}{|l|l|}
143,18 \\
\end{tabular} & 388,61 \\
\hline Lissotriton boscai & 29TPH07 & 100,00 & 123,13 & 83,78 & 40,52 & $\begin{array}{l}4121,32 \\
\end{array}$ & 237,34 & 33,13 & 204,21 & 77,79 & 176,53 & $\begin{array}{l}178,70 \\
\end{array}$ & 74,12 & 1106,65 & $\begin{array}{l}148,29 \\
\end{array}$ & 33,80 & 38,24 & 08,04 & $\begin{array}{l}129,36 \\
\end{array}$ & 145,35 & 382,48 \\
\hline Lissotriton boscai & 29TPH08 & 100,00 & 124,56 & 82,49 & 40,96 & 4047,40 & 236,24 & 36,13 & $200,11 \mid$ & 80,26 & 176,78 & 179,07 & 76,20 & 1090,69 & 144,51 & 34,03 & 37,66 & 400,97 & 129,85 & 146,52 & 373,57 \\
\hline \begin{tabular}{|l|l|l|} 
Lissot \\
\end{tabular} & 29 & 100,00 & & 81,56 & 40, & 3 & & 35, & & 79 & & & 79 & 103,86 & & 35 & & 40 & 34 & & 375,61 \\
\hline 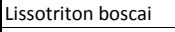 & $29 \mathrm{TPH} 1$ & 101,00 & 125,62 & 91,67 & 38,90 & 4884,10 & 255,94 & 22,64 & $233, \mathbf{3}$ & 70,55 & 189,69 & 190,05 & 66,56 & 1016,7 & $\begin{array}{l}141,15 \\
\end{array}$ & 25,85 & 42,03 & 380,19 & 104,54 & 113,04 & 366,03 \\
\hline Lissotriton boscai & 29TPH13 & 101,00 & 119,95 & 89,56 & 39,25 & 4654,25 & 246,39 & 21,29 & 225,10 & 67,82 & 180,91 & 181,77 & 64,29 & 1074,00 & $\begin{array}{l}147,45 \\
\end{array}$ & 29,69 & 40,64 & 400,06 & 1116,88 & \begin{tabular}{ll|}
129,88 \\
\end{tabular} & 382,25 \\
\hline
\end{tabular}




\begin{tabular}{|c|c|c|c|c|c|c|c|c|c|c|c|c|c|c|c|c|c|c|c|c|c|}
\hline TAXON & UTM & $\mathrm{km} 2$ & BIO1 & BIO2 & $B 103$ & BIO4 & B105 & B106 & B107 & B108 & B109 & B1010 & BIO11 & BIO12 & BIO13 & BIO14 & BIO15 & B1016 & B1017 & B1018 & 81019 \\
\hline Lissotriton boscai & 29TPH14 & 100,00 & 127,77 & 88,45 & 39,92 & 4530,25 & 250,04 & 30,10 & 219,94 & 76,72 & 186,71 & 187,88 & 73,19 & 1014,92 & 138,48 & 28,44 & 39,90 & 375,81 & 111,82 & 126,42 & 355,63 \\
\hline Lissotriton boscai & 29TPH16 & 101,00 & 125,04 & 86,30 & 40,07 & 4330,92 & 243,26 & 31,13 & 212,13 & 76,77 & 181,15 & 182,83 & 73,01 & $\begin{array}{l}1042,90 \\
\end{array}$ & $\begin{array}{l}139,56 \\
\end{array}$ & 31,21 & 38,41 & $\begin{array}{l}383,96 \\
\end{array}$ & $\begin{array}{l}120,74 \\
\end{array}$ & \begin{tabular}{|l|l|}
136,01 \\
\end{tabular} & 359,84 \\
\hline Lissotriton boscai & 29TPH18 & 101,00 & 125,68 & 83,80 & 40,68 & 4123,85 & 238,95 & 35,24 & 203,71 & 80,25 & $\begin{array}{l}178,80 \\
\end{array}$ & $\begin{array}{l}180,96 \\
\end{array}$ & 76,07 & 1044,09 & \begin{tabular}{|l|l|}
136,94 \\
\end{tabular} & 32,81 & 37,04 & 382,20 & 125,76 & $\begin{array}{ll}142,04 \\
\end{array}$ & 354,40 \\
\hline Lissotriton boscai & 29TPH20 & 100,00 & 128,59 & 94,28 & 38,67 & 5087,38 & 263,24 & 21,88 & 241,35 & 70,80 & 195,16 & $\begin{array}{l}195,28 \\
\end{array}$ & 66,58 & $\begin{array}{l}936,27 \\
9\end{array}$ & 128,52 & 22,83 & 42,26 & 350,85 & 94,21 & 97,52 & 337,98 \\
\hline Lissotriton boscai & 29TPH21 & 100,00 & 131,78 & 93,25 & 38,97 & 4996,08 & 263,61 & 26,14 & 237,47 & 75,01 & 196,99 & 197,21 & 70,90 & 914,56 & 125,36 & 22,94 & 41,58 & 340,74 & 94,05 & 100,10 & 325,66 \\
\hline Lissotriton boscai & 29TPH25 & 100,00 & 126,69 & 88,78 & 40,00 & 4525,55 & 249,07 & 29,25 & 219,82 & 75,85 & 185,51 & $\mid 186,73$ & 72,08 & 981,64 & $\mid 131,10$ & 28,68 & 38,56 & $\mid 361,47$ & $\mid 112,42$ & 126,98 & 338,67 \\
\hline Lissotriton boscai & 29TPH26 & 100,00 & 121,66 & 87,84 & 40,00 & $\begin{array}{l}4444,56 \\
\end{array}$ & 243,07 & 26,02 & 217,05 & 71,93 & 179,43 & 180,73 & 68,04 & 1026,71 & 136,01 & 31,28 & 37,83 & 377,12 & 121,13 & 135,50 & 352,61 \\
\hline Lissotriton boscai & 29TPH27 & 100,00 & 123,01 & 86,66 & 40,23 & 4337,90 & 241,68 & 29,27 & 212,41 & 74,82 & 179,25 & 180,94 & 70,80 & 1019,81 & 133,69 & 31,80 & 37,10 & \begin{tabular}{|l|l|}
373,07 \\
\end{tabular} & 122,70 & $\begin{array}{l}137,63 \\
\end{array}$ & 346,56 \\
\hline Lissotriton boscai & 29TPH30 & 100,00 & 125,13 & 95,64 & 38,73 & $\begin{array}{l}5150,07 \\
\end{array}$ & 262,55 & 17,90 & 244,65 & 66,68 & 192,63 & \begin{tabular}{|l|}
192,70 \\
\end{tabular} & 62,20 & $\begin{array}{l}918,66 \\
\end{array}$ & \begin{tabular}{|l|l|}
124,73 \\
\end{tabular} & 22,65 & 41,96 & $\begin{array}{l}345,25 \\
\end{array}$ & $\begin{array}{ll}93,92 \\
\end{array}$ & $\begin{array}{ll}95,44 \\
\end{array}$ & 332,19 \\
\hline Lissotriton boscai & 29TPH32 & 101,00 & 111,82 & 93,24 & 38,93 & 4954,82 & 246,85 & 9,55 & 237,30 & 56,42 & 177,15 & \begin{tabular}{ll|}
177,45 \\
\end{tabular} & 52,28 & 1029,96 & 138,71 & 28,51 & 40,24 & 384,92 & 113,70 & 120,04 & 368,31 \\
\hline Lissotriton boscai & 29TPH33 & 100,00 & 118,60 & 92,65 & 39,09 & 4857,10 & 250,24 & 16,57 & 233,68 & 63,89 & 182,29 & 182,76 & 59,89 & \begin{tabular}{|c|}
983,53 \\
\end{tabular} & 132,01 & 27,70 & 39,46 & 365,39 & 110,18 & 120,45 & 346,38 \\
\hline Lissotriton boscai & 29TPH39 & 100,00 & 120,33 & 85,68 & 40,81 & 4224,79 & 236,71 & 28,66 & 208,05 & 73,78 & $\begin{array}{l}174,85 \\
\end{array}$ & $\begin{array}{l}176,75 \\
\end{array}$ & 69,58 & $\begin{array}{l}1018,56 \\
\end{array}$ & 129,79 & 34,29 & 35,07 & 368,25 & 130,32 & $\begin{array}{l}145,46 \\
\end{array}$ & 337,16 \\
\hline 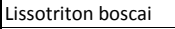 & 29TPH40 & 100,00 & 122,17 & 96,97 & 38,64 & 5220,98 & 262,21 & 14,28 & 247,94 & 62,99 & 190,75 & 190,76 & 58,29 & 893,50 & 120,14 & 22,50 & 41,55 & 336,45 & 93,20 & $\begin{array}{ll}93,37 \\
\end{array}$ & 322,83 \\
\hline Lissotriton boscai & 29TPH41 & 101,00 & 110,45 & 95,49 & 38,66 & 5128,06 & 250,03 & 5,65 & 244,38 & 52,96 & 178,23 & 178,27 & 48,54 & $\begin{array}{l}986,46 \\
\end{array}$ & \begin{tabular}{|l|l|}
132,08 \\
\end{tabular} & 26,80 & 40,55 & 370,31 & 108,08 & 108,69 & 355,08 \\
\hline Lissotriton boscai & 29TPH44 & 99,00 & 109,30 & 93,09 & 39,19 & \begin{tabular}{|l|l|}
4862,07 \\
\end{tabular} & $\begin{array}{l}242,56 \\
\end{array}$ & 8,30 & 234,26 & $\begin{array}{l}54,97 \\
\end{array}$ & 173,19 & \begin{tabular}{|l|l|}
173,70 \\
\end{tabular} & 50,86 & \begin{tabular}{|l|l|}
1015,57 \\
\end{tabular} & $\begin{array}{l}133,86 \\
\end{array}$ & 30,74 & 37,96 & 375,15 & $\begin{array}{l}120,36 \\
\end{array}$ & $\begin{array}{ll}129,85 \\
\end{array}$ & 353,36 \\
\hline Lissotriton boscai & 29TPH48 & 101,00 & 117,97 & 88,31 & 40,36 & \begin{tabular}{ll|l}
4404,92 \\
\end{tabular} & 239,19 & 23,24 & 215,96 & 69,26 & 175,12 & $\begin{array}{l}176,65 \\
\end{array}$ & 64,93 & $\begin{array}{l}993,69 \\
9\end{array}$ & \begin{tabular}{l|l|}
127,02 \\
\end{tabular} & 33,38 & 34,98 & $\begin{array}{l}359,06 \\
\end{array}$ & 127,50 & $\begin{array}{ll}141,46 \\
\end{array}$ & 328,68 \\
\hline Lissotriton boscai & 29TPH50 & 99,00 & 103,52 & 97,16 & 38,31 & 5267,63 & 247,89 & $-2,19$ & 250,08 & 44,77 & 173,39 & \begin{tabular}{|l|}
173,39 \\
\end{tabular} & 40,01 & 986,10 & \begin{tabular}{|l|}
131,01 \\
\end{tabular} & 27,03 & 40,63 & 371,34 & $\begin{array}{l}108,83 \\
\end{array}$ & $\begin{array}{l}108,87 \\
\end{array}$ & 357,52 \\
\hline Lissotriton boscai & 29TPH51 & 100,00 & 92,45 & 95,33 & 38,24 & 5173,82 & 235,67 & $-10,10$ & 245,76 & 35,76 & $\mid 161,46$ & \begin{tabular}{|l|l|}
161,51 \\
\end{tabular} & 30,84 & $\mid 1078,35$ & \begin{tabular}{|l|l|l|l|}
146 \\
\end{tabular} & \begin{tabular}{|l|l|l|}
31,88 \\
\end{tabular} & 39,27 & 402,52 & $\mid 125,19$ & 125,91 & 386,28 \\
\hline |Lissotriton boscai & 29TPH54 & 100,00 & 115,34 & 94,76 & 39,46 & $4935,88 \mid$ & 249,56 & 12,04 & 237,52 & 59,65 & 179,89 & 180,24 & 55,34 & 926,28 & 120,82 & 27,95 & 37,42 & 341,19 & 110,92 & 118,09 & 318,13 \\
\hline Lissotriton boscai & 29TPH55 & 101,00 & 115,59 & 93,60 & 39,80 & 4824,02 & 247,23 & $\begin{array}{ll}14,03 \\
\end{array}$ & 233,20 & 61,30 & $\begin{array}{l}178,62 \\
\end{array}$ & 179,20 & 57,08 & \begin{tabular}{|c|}
937,10 \\
\end{tabular} & $\begin{array}{l}121,15 \\
\end{array}$ & 29,23 & 36,63 & $\begin{array}{l}342,96 \\
\end{array}$ & 114,97 & 125,70 & 317,72 \\
\hline Lissotriton boscai & 29TPH56 & 100,00 & 112,59 & 92,57 & 39,92 & 4721,95 & 242,36 & 12,91 & 229,45 & 59,88 & $\begin{array}{l}174,30 \\
\end{array}$ & \begin{tabular}{|l|l|}
175,10 \\
\end{tabular} & 55,56 & $\begin{array}{l}969,45 \\
\end{array}$ & \begin{tabular}{|l|l|}
124,37 \\
\end{tabular} & 31,62 & 35,72 & 352,59 & $\begin{array}{ll}122,46 \\
\end{array}$ & \begin{tabular}{|l|l|}
134,51 \\
\end{tabular} & 325,18 \\
\hline Lissotriton boscai & 29TPH57 & 101,00 & 108,53 & 91,48 & 39,99 & $\begin{array}{lll}4634,93 \\
\end{array}$ & 236,83 & 10,77 & 226,06 & 57,27 & 169,01 & $\begin{array}{l}170,10 \\
\end{array}$ & 52,83 & $\begin{array}{l}1012,28 \\
\end{array}$ & 129,34 & 34,45 & 34,89 & 366,04 & $\begin{array}{l}131,43 \\
\end{array}$ & $\begin{array}{l}143,40 \\
\end{array}$ & 336,67 \\
\hline Lissotriton boscai & 29TPH58 & 99,00 & 111,89 & 90,21 & 40,17 & $\begin{array}{l}4511,60 \\
\end{array}$ & 236,79 & 15,61 & 221,18 & 62,19 & $\begin{array}{l}170,64 \\
\end{array}$ & $\begin{array}{l}171,93 \\
\end{array}$ & 57,57 & 1001,05 & 128,05 & 34,69 & 34,26 & 360,09 & $\begin{array}{l}131,93 \\
\end{array}$ & $\begin{array}{l}144,69 \\
\end{array}$ & 328,66 \\
\hline Lissotriton boscai & 29TPH60 & 101,00 & 104,75 & 99,05 & 38,49 & 5352,43 & 251,30 & $-2,77$ & 254,06 & 44,83 & $\begin{array}{l}175,79 \\
\end{array}$ & $\begin{array}{l}175,79 \\
\end{array}$ & 39,85 & $\begin{array}{l}926,98 \\
\end{array}$ & 122,54 & 25,86 & 40,07 & 348,48 & 104,41 & $\begin{array}{l}104,43 \\
\end{array}$ & 333,57 \\
\hline |Lissotriton boscai & 29TPH62 & 100,00 & 100,06 & 97,43 & 38,86 & 5205,83 & 243,35 & $-4,92$ & 248,28 & 41,99 & 169,03 & 169,06 & 37,23 & 973,89 & $\mid 127,40$ & 29,47 & 38,08 & 361,44 & 116,54 & 116,88 & 342,10 \\
\hline Lissotriton boscai & 29TPH63 & 100,00 & 96,65 & 96,45 & 38,91 & 5119,07 & 238,28 & $-6,57$ & 244,86 & 39,94 & 164,49 & 164,55 & 35,18 & 1010,04 & 131,23 & 31,90 & 37,11 & 372,28 & 124,46 & 125,75 & 350,78 \\
\hline Lissotriton boscai & 29TPH64 & 100,00 & 101,18 & $\begin{array}{ll}95,94 \\
\end{array}$ & 39,16 & 5028,11 & 240,07 & $-1,63$ & 241,70 & 45,30 & 167,53 & 167,73 & 40,68 & $\begin{array}{l}986,45 \\
\end{array}$ & $\begin{array}{l}127,35 \\
\end{array}$ & 31,77 & 36,41 & 361,41 & 123,68 & 127,55 & 337,53 \\
\hline Lissotriton boscai & 29TPH67 & 100,00 & 111,40 & $\begin{array}{ll}92,64 \\
\end{array}$ & 40,16 & 4672,44 & 240,37 & 12,48 & 227,89 & 59,48 & 172,27 & 173,21 & 54,89 & 959,28 & 123,40 & 33,20 & 34,14 & \begin{tabular}{|l|l|}
344,70 \\
\end{tabular} & 127,14 & $\begin{array}{ll}138,91 \\
\end{array}$ & 313,97 \\
\hline Lissotriton boscai & 29TPH68 & 100,00 & 112,91 & 91,50 & 40,35 & 4561,33 & 239,10 & 15,52 & 223,58 & 62,99 & 172,22 & $\begin{array}{l}173,42 \\
\end{array}$ & 57,89 & $\begin{array}{l}963,04 \\
\end{array}$ & $\begin{array}{l}124,25 \\
\end{array}$ & 34,13 & 33,53 & $\begin{array}{l}344,15 \\
\end{array}$ & 129,85 & 142,22 & 311,33 \\
\hline Lissotriton boscai & 29TPH70 & 99,00 & 120,04 & 101,98 & 38,92 & \begin{tabular}{|l|}
5464,69 \\
\end{tabular} & 267,27 & 7,93 & 259,34 & 57,30 & $\begin{array}{l}191,79 \\
\end{array}$ & $\begin{array}{l}191,79 \\
\end{array}$ & 52,47 & 768,84 & $\begin{array}{l}101,73 \\
\end{array}$ & \begin{tabular}{l|l|}
20,23 \\
\end{tabular} & 40,17 & 290,06 & 85,34 & \begin{tabular}{ll|l}
85,34 \\
\end{tabular} & 274,12 \\
\hline Lissotriton boscai & 29TPH71 & 100,00 & 113,94 & 100,82 & 38,97 & 5392,16 & 260,03 & 3,76 & 256,27 & 52,37 & 184,91 & 184,91 & 47,68 & 816,87 & 107,39 & 22,93 & 39,03 & 305,75 & 94,65 & 94,65 & 287,50 \\
\hline Lissotriton boscai & 29TPH72 & 100,00 & 106,85 & $\begin{array}{ll}99,74 \\
\end{array}$ & 38,99 & 5300,89 & 251,67 & $-0,98$ & 252,65 & 46,96 & 176,72 & 176,72 & 42,12 & 876,57 & 114,23 & 26,39 & 37,74 & 324,95 & 106,04 & 106,04 & 304,42 \\
\hline Lissotriton boscai & 29TPH73 & 101,00 & 86,82 & $\begin{array}{ll}97,28 \\
\end{array}$ & 38,88 & 5179,44 & 231,19 & $-16,28$ & 247,47 & 30,10 & 155,82 & 155,92 & 25,01 & $\begin{array}{l}1044,37 \\
\end{array}$ & $\begin{array}{l}133,86 \\
\end{array}$ & 35,11 & 35,84 & 381,04 & 134,58 & 135,46 & 358,23 \\
\hline Lissotriton boscai & 29TPH74 & 100,00 & 79,80 & $\begin{array}{ll}95,67 \\
\end{array}$ & 38,76 & 5085,43 & 222,37 & $-21,16$ & 243,53 & 24,80 & 147,66 & 147,86 & $\begin{array}{ll}19,67 \\
\end{array}$ & 1114,89 & 141,35 & 39,34 & 34,79 & 402,99 & 148,23 & 150,17 & 377,98 \\
\hline Lissotriton boscai & 29TPH75 & 101,00 & $\begin{array}{ll}94,02 \\
\end{array}$ & 96,11 & 39,45 & $\begin{array}{l}4995,44 \\
\end{array}$ & 233,21 & $-7,67$ & 240,88 & 39,08 & 160,11 & 160,38 & 34,17 & 1015,93 & \begin{tabular}{|l|l|}
129,58 \\
\end{tabular} & 35,50 & 34,52 & $\begin{array}{l}366,79 \\
\end{array}$ & $\begin{array}{l}135,23 \\
\end{array}$ & $\begin{array}{ll}139,76 \\
\end{array}$ & 339,58 \\
\hline Lissotriton boscai & 29TPH77 & 101,00 & 109,22 & 93,94 & 40,19 & 4735,34 & 240,26 & 9,41 & 230,85 & 57,06 & 171,00 & \begin{tabular}{|l|l|}
171,77 \\
\end{tabular} & 51,94 & 943,31 & $\begin{array}{l}121,95 \\
\end{array}$ & 33,73 & 33,37 & $\begin{array}{l}336,65 \\
\end{array}$ & $\begin{array}{l}128,55 \\
\end{array}$ & \begin{tabular}{ll|}
139,42 \\
\end{tabular} & 304,64 \\
\hline Lissotriton boscai & 29TPH78 & 100,00 & 114,42 & 92,48 & 40,65 & 4583,52 & 241,15 & 16,33 & 224,81 & 67,71 & $\mid 173,87$ & 175,05 & 58,89 & \begin{tabular}{|l|l|}
927,82 \\
\end{tabular} & $\mid 120,75$ & $\mid 33,81$ & 32,65 & 328,82 & 128,45 & 140,50 & 294,39 \\
\hline |Lissotriton boscai & 29TPH80 & 101,00 & 115,40 & 103,38 & 38,97 & 5547,08 & 265,72 & 2,60 & 263,12 & 51,78 & 188,51 & 188,51 & 46,90 & 754,35 & 99,32 & 20,75 & 39,45 & 283,55 & 87,01 & 87,01 & 266,77 \\
\hline Lissotriton boscai & 29TPH82 & 99,00 & 115,22 & 101,69 & 39,04 & 5381,48 & \begin{tabular}{|l|}
260,87 \\
\end{tabular} & 4,64 & 256,23 & 53,53 & 185,86 & 185,86 & 48,75 & 776,09 & 101,55 & 22,88 & 37,42 & 87,61 & 94,74 & \begin{tabular}{|l|l}
94,74 \\
\end{tabular} & 265,39 \\
\hline Lissotriton boscai & 29TPH83 & 101,00 & 103,10 & 100,38 & 39,18 & 5272,73 & 248,04 & $-4,25$ & 252,29 & 43,77 & 172,58 & 172,58 & 38,79 & 876,14 & \begin{tabular}{|l|l|}
113,19 \\
\end{tabular} & 28,54 & 35,80 & 320,06 & 112,79 & 112,79 & 295,79 \\
\hline Lissotriton boscai & 29TPH84 & 99,00 & 84,45 & $\begin{array}{l}98,01 \\
\end{array}$ & 39,11 & 5161,57 & 228,83 & $-18,65$ & 247,48 & 28,14 & 153,10 & 153,23 & 22,80 & 1035,10 & $\begin{array}{l}131,26 \\
\end{array}$ & 37,17 & 34,15 & 372,30 & $\begin{array}{l}140,47 \\
\end{array}$ & 142,00 & 346,19 \\
\hline Lissotriton boscai & 29TPH86 & 100,00 & $\begin{array}{ll}92,14 \\
\end{array}$ & $\begin{array}{ll}96,67 \\
\end{array}$ & 39,75 & $\begin{array}{l}4962,72 \\
\end{array}$ & 231,10 & $-9,28$ & 240,38 & 37,85 & 157,69 & \begin{tabular}{ll|}
158,06 \\
\end{tabular} & 32,74 & 1009,01 & $\begin{array}{l}128,96 \\
\end{array}$ & 37,55 & 32,85 & 359,18 & 141,06 & $\begin{array}{l}147,50 \\
\end{array}$ & 328,58 \\
\hline Lissotriton boscai & 29TPH93 & 101,00 & 107,31 & 102,32 & 39,65 & 5336,26 & 253,68 & $-1,99$ & 255,66 & 46,81 & 177,48 & \begin{tabular}{ll|}
177,48 \\
\end{tabular} & 41,85 & 807,54 & 105,61 & 26,68 & 35,10 & 293,24 & 106,52 & 106,52 & 267,56 \\
\hline Lissotriton boscai & 29TPH94 & 100,00 & 95,70 & 100,75 & 39,73 & 5221,88 & 241,01 & $-10,36$ & 251,37 & 37,77 & 164,72 & 164,75 & 32,52 & 909,10 & 117,19 & 32,61 & 33,67 & 25,71 & 125,11 & $\begin{array}{ll}125,58 \\
\end{array}$ & 298,14 \\
\hline 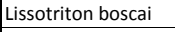 & 29TPH95 & 101,00 & 82,12 & 98,49 & 39, & 5119 & 226,07 & $-20,73$ & 246,80 & 26,62 & 150,14 & 150,32 & 21,01 & 1033,23 & 130,99 & 39,47 & 32,41 & 366,08 & 147,11 & 149,18 & 336,68 \\
\hline Lissotriton boscai & 29TPH96 & 100,00 & 95,13 & 98,32 & 40,01 & 4996,45 & 234,96 & $-7,69$ & 242,65 & 43,34 & 160,89 & 161,15 & 34,80 & 956,82 & 123,38 & 36,55 & 32,03 & 337,68 & 137,32 & 142,85 & 305,49 \\
\hline Lissotriton boscai & 29TPJ02 & 101,00 & 123,80 & 77,64 & 41,36 & 3730,50 & 226,94 & 41,71 & 185,24 & 84,33 & 171,23 & \begin{tabular}{ll|}
174,39 \\
\end{tabular} & 79,08 & 1089,72 & $\begin{array}{l}138,96 \\
\end{array}$ & 36,99 & 35,12 & $\begin{array}{l}396,56 \\
\end{array}$ & $\begin{array}{ll}139,64 \\
\end{array}$ & $\begin{array}{l}158,09 \\
\end{array}$ & 362,56 \\
\hline Lissotriton boscai & 29ТPJ03 & 101,00 & 127,49 & 76,06 & 41,66 & $3640,31$. & 227,42 & 47,19 & 180,23 & 89,29 & 173,45 & 176,91 & 83,71 & 1057,71 & 135,04 & 36,25 & 34,85 & 34,15 & 137,13 & 6,45 & 348,6 \\
\hline Lissotriton boscai & 29TPJ04 & 56,00 & 137,36 & 73,90 & 42,15 & \begin{tabular}{|l|}
3514,50 \\
\end{tabular} & 232,05 & 58,87 & 173,18 & 100,53 & 181,14 & 184,83 & 94,53 & \begin{tabular}{|l|l|}
981,99 \\
\end{tabular} & 127,14 & 33,35 & 34,81 & 356,73 & 127,39 & 148,12 & 319,92 \\
\hline Lissotriton boscai & 29TPJ1 & 101,00 & 112,25 & 82,44 & 40, & 4047,22 & 225,37 & 25,05 & 200,32 & \begin{tabular}{ll|l}
68,87 \\
\end{tabular} & 164,45 & 167,13 & $\begin{array}{l}64,32 \\
\end{array}$ & $\begin{array}{l}1150,58 \\
\end{array}$ & 148,39 & 39,02 & 35,57 & 418,62 & 146,55 & $\begin{array}{ll}162,06 \\
\end{array}$ & 387,48 \\
\hline Lissotriton boscai & 29TPJ11 & 99,00 & 107,59 & 81,49 & 40,67 & 4002,55 & 220,11 & 21,82 & 198,28 & 65,15 & 159,35 & \begin{tabular}{ll|}
162,08 \\
\end{tabular} & \begin{tabular}{ll|}
60,56 \\
\end{tabular} & $\begin{array}{l}1187,50 \\
\end{array}$ & 151,90 & 41,50 & 34,98 & 430,71 & $\begin{array}{ll}154,62 \\
\end{array}$ & 170,05 & 397,96 \\
\hline Lissotriton boscai & 29TPJ13 & 90,00 & 132,24 & 76,74 & 41,84 & 3674,46 & 232,24 & 50,79 & 181,45 & 93,37 & 178,62 & 181,91 & 87,82 & 1000,76 & 128,78 & 34,41 & 34,42 & 361,84 & 130,66 & 149,97 & 325,86 \\
\hline Lissotriton boscai & 29TPJ21 & 100,00 & 120,79 & 81,71 & 41,15 & 3971,63 & 230,49 & 34,14 & 196,35 & 77,94 & 171,70 & 174,29 & 73,26 & 1057 & 134,68 & 36,63 & 34,61 & 381,88 & 137,79 & 154,38 & $348,>>$ \\
\hline Lissotriton boscai & 29TP. & 101,00 & 128,39 & 79,59 & 41,46 & 3830,80 & 233,22 & 43,66 & $\begin{array}{l}189,56 \\
\end{array}$ & 87,41 & 177,09 & 180,01 & 82,31 & 1008,09 & 129,29 & 35,01 & 34,31 & 363,16 & 132,31 & 150,16 & 327,9 \\
\hline Lissotriton boscai & 29ТРנ33 & & & & & & & & & & & & & & & & & & & & \\
\hline Lissotriton boscai & 29TPJ40 & 101,00 & 128,17 & 84,57 & $\begin{array}{lll}41,07 \\
\end{array}$ & 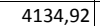 & 240,82 & 37,28 & 03,54 & 82,84 & \begin{tabular}{|l|l|}
181,01 \\
\end{tabular} & 183,25 & 77,93 & \begin{tabular}{|c|c|}
945,88 \\
\end{tabular} & \begin{tabular}{|l|l|}
122,14 \\
\end{tabular} & $\mid 32,70$ & 34,02 & 338,76 & $\mid$\begin{tabular}{|l|l|}
124,47 \\
\end{tabular} & \begin{tabular}{|l|l|}
140,34 \\
\end{tabular} & 304,66 \\
\hline Lissotriton boscai & 29TPJ41 & 100,00 & 129,11 & 83,08 & 41,29 & 4026,54 & 238,90 & 40,38 & 98,52 & 85,34 & 180,45 & 182,99 & 80,33 & $948,94[$ & 122,89 & 33,48 & 33,49 & 338,62 & 126,88 & 143,42 & 302,84 \\
\hline 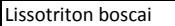 & 29 & 53 & & 80, & & & $2 x+2+$ & & & 96 & & & 85 & 902 & 11 & 31,63 & & & 77 & & 28 \\
\hline 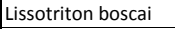 & 29TPJ50 & 100,00 & 121,44 & 86,51 & 40,99 & 4230,20 & 237,81 & 29,27 & 208,54 & 75,28 & 175,91 & \begin{tabular}{|l|l|}
177,87 \\
\end{tabular} & 70,33 & 965,29 & $\begin{array}{l}124,76 \\
\end{array}$ & 34,64 & 33,15 & 343,49 & 130,84 & 145,53 & 308,23 \\
\hline Lissotriton boscai & 29TPJ52 & 41,00 & 139,23 & 81,22 & 41,72 & 3912,25 & 244,14 & 51,68 & 192,46 & 111,51 & $\begin{array}{l}188,72 \\
\end{array}$ & \begin{tabular}{|l|l|}
191,29 \\
\end{tabular} & 91,29 & 874,91 & 115,40 & 31,32 & 32,94 & 309,83 & 119,20 & 136,62 & 271,68 \\
\hline
\end{tabular}




\begin{tabular}{|c|c|c|c|c|c|c|c|c|c|c|c|c|c|c|c|c|c|c|c|c|c|}
\hline TAXON & UTM & $\mathrm{km} 2$ & BIO1 & B102 & $B 103$ & BIO4 & B105 & B106 & B107 & B108 & 8109 & B1010 & BIO11 & BIO12 & BIO13 & BIO14 & BIO15 & B1016 & B1017 & B1018 & 81019 \\
\hline Lissotriton boscai & 29TPJ60 & 100,00 & 108,41 & 88,88 & 40,73 & 4367,70 & 230,35 & 15,04 & 215,32 & 61,15 & 165,12 & 166,80 & 56,09 & 1025,98 & 132,00 & 38,71 & 32,21 & 362,76 & 144,13 & 156,86 & 326,34 \\
\hline Lissotriton boscai & 29TPJ61 & 101,00 & 128,73 & 85,00 & 41,49 & 4095,14 & 240,69 & 38,16 & 202,54 & 93,10 & 180,98 & \begin{tabular}{|l|l|}
183,27 \\
\end{tabular} & 79,05 & 912,44 & 119,82 & 33,86 & 32,17 & 321,09 & 127,55 & 142,96 & 282,41 \\
\hline Lissotriton boscai & 29TPJ62 & 54,00 & 139,54 & 81,85 & 41,87 & 3920,14 & 244,99 & 51,45 & $\begin{array}{l}193,54 \\
\end{array}$ & 117,69 & $\begin{array}{ll}189,06 \\
\end{array}$ & \begin{tabular}{|l|l|}
191,73 \\
\end{tabular} & 91,50 & 858,44 & $\begin{array}{l}114,06 \\
\end{array}$ & 31,57 & 32,26 & $\begin{array}{l}302,67 \\
\end{array}$ & 119,81 & 136,55 & 261,82 \\
\hline Lissotriton boscai & 29TPJ71 & 100,00 & 120,92 & 87,16 & 41,43 & 4187,18 & 236,81 & 29,09 & 207,72 & 87,25 & 174,57 & $\begin{array}{l}176,78 \\
\end{array}$ & 70,42 & 941,81 & 123,60 & 36,55 & 31,16 & 328,99 & $\begin{array}{l}136,06 \\
\end{array}$ & $\begin{array}{l}150,07 \\
\end{array}$ & 288,43 \\
\hline Lissotriton boscai & 29TPJ81 & 101,00 & 126,36 & 87,08 & 41,82 & 4144,52 & 240,59 & 34,49 & 206,10 & 102,20 & 179,16 | & 181,45 & 75,99 & 896,35 & 118,96 & 35,47 & 30,70 & 311,92 & 132,18 & 146,10 & 267,74 \\
\hline Lissotriton boscai & 29TPJ82 & 58,00 & 138,31 & 83,19 & \begin{tabular}{|l|l|}
42,02 \\
\end{tabular} & 3938,42 & 244,93 & 49,47 & 195,46 & 117,08 & 188,16 & $\mid 190,77$ & 90,12 & 844,71 & $\mid 113,54$ & 33,05 & 30,98 & 295,40 & $\mid 123,81$ & $\mid 139,59$ & 248,57 \\
\hline Lissotriton boscai & 29TPJ91 & 99,00 & 119,93 & 88,97 & 41,88 & 4195,91 & 237,16 & 27,14 & 210,02 & 96,71 & 173,61 & 175,77 & 69,22 & 921,04 & 122,25 & 38,30 & 29,70 & 317,98 & 140,67 & 153,30 & 270,80 \\
\hline Lissotriton boscai & 29TPJ92 & 60,00 & 135,50 & 84,06 & 42,06 & 3954,26 & 243,15 & 46,30 & 196,86 & 114,32 & 185,50 & 188,13 & 87,30 & 853,51 & \begin{tabular}{|l|l|}
114,98 \\
\end{tabular} & 34,70 & 30,12 & 296,43 & 128,88 & 143,72 & 246,58 \\
\hline Lissotriton boscai & 29TQE04 & 100,00 & 154,81 & 104,37 & 36,24 & $\begin{array}{ll}6192,69 \\
\end{array}$ & \begin{tabular}{|l|l|}
321,03 \\
\end{tabular} & 38,01 & 283,02 & 86,55 & 237,01 & 237,01 & 78,85 & \begin{tabular}{|l|l|}
586,07 \\
\end{tabular} & 76,24 & 5,54 & 48,99 & 224,24 & 41,44 & 41,44 & 214,93 \\
\hline Lissotriton boscai & 29TQE05 & 101,00 & 138,92 & 100,86 & 35,66 & 6179,17 & 303,34 & 24,93 & 278,40 & 71,73 & 221,24 & 221,47 & 63,98 & \begin{tabular}{|c|}
681,18 \\
\end{tabular} & 89,82 & 7,55 & 48,70 & 261,17 & 50,10 & 50,85 & 251,98 \\
\hline Lissotriton boscai & 29TQE06 & 100,00 & 119,30 & 96,47 & 34,97 & 6132,22 & 280,84 & 9,10 & 271,74 & 53,72 & 201,13 & 201,82 & 46,16 & 805,73 & 107,34 & 10,19 & 48,41 & $\begin{array}{l}309,67 \\
\end{array}$ & 60,69 & \begin{tabular}{ll|}
63,48 \\
\end{tabular} & 300,38 \\
\hline Lissotriton boscai & 29TQE07 & 100,00 & 123,62 & 98,16 & 35,33 & 6135,20 & 285,67 & 12,02 & 273,65 & 57,43 & \begin{tabular}{|l|l|}
204,98 \\
\end{tabular} & 205,92 & 49,78 & \begin{tabular}{|l|l|}
759,97 \\
\end{tabular} & \begin{tabular}{|l|l|}
100,67 \\
\end{tabular} & 9,58 & 48,27 & 291,79 & 57,97 & 59,88 & 282,52 \\
\hline Lissotriton boscai & 29TQE08 & 99,00 & 125,47 & 99,36 & 35,85 . & 6122,78 & 287,60 & 13,15 & 274,45 & 58,98 & 206,49 & 207,47 & 51,45 & 736,57 & 97,22 & 9,29 & 48,01 & 282,68 & 56,92 & 58,27 & 273,55 \\
\hline Lissotriton boscai & 29TQE09 & 100,00 & 131,30 & 101,86 & $36,17 \mid$ & 6116,52 & 294,27 & 17,42 & 276,85 & 64,19 & 212,74 & 212,94 & 56,78 & $685,57 \mid$ & 89,87 & 8,81 & 47,62 & 262,67 & 54,02 & 54,22 & 253,71 \\
\hline Lissotriton boscai & 29TQE15 & 100,00 & 146,55 & 104,35 & 36,06 & 6231,45 & 313,85 & 29,86 & 283,99 & 78,17 & 229,47 & 229,52 & 70,50 & \begin{tabular}{|l|l|}
592,07 \\
\end{tabular} & 76,03 & 6,48 & 47,61 & 224,16 & 44,50 & 44,61 & 213,74 \\
\hline Lissotriton boscai & 29TQE16 & 100,00 & 126,83 & 100,71 & 35,60 & \begin{tabular}{ll|l|}
6194,17 \\
\end{tabular} & 292,02 & 13,50 & $\begin{array}{ll}278,52 \\
\end{array}$ & 59,89 & $\begin{array}{ll}209,38 \\
\end{array}$ & \begin{tabular}{|l|l|}
209,97 \\
\end{tabular} & 52,39 & 705,71 & 90,99 & 9,18 & 47,08 & 267,62 & 55,30 & 56,81 & 256,77 \\
\hline Lissotriton boscai & 29TQE17 & 100,00 & 116,90 & $\begin{array}{ll}99,27 \\
\end{array}$ & 35,58 & 6162,49 & 280,77 & 5,20 & 275,57 & 50,61 & $\begin{array}{l}198,90 \\
\end{array}$ & $\begin{array}{l}199,93 \\
\end{array}$ & 43,24 & 757,81 & 97,69 & 10,55 & 46,63 & 287,30 & 60,86 & 63,32 & 276,08 \\
\hline Lissotriton boscai & 29TQE18 & 101,00 & 125,54 & 101,80 & 36,00 & 6169,60 & 290,29 & 11,75 & 278,54 & 58,30 & 207,24 & 208,30 & 51,04 & 686,06 & 88,32 & 9,12 & 46,56 & 260,12 & 55,46 & 56,49 & 249,12 \\
\hline |Lissotriton boscai & 29TQE19 & 100,00 & 127,25 & 103,00 & 36,19 & 6162,70 & 292,13 & 12,80 & 279,33 & 59,83 & 209,15 & 209,75 & 52,47 & 661,92 & 85,14 & 9,13 & 46,17 & 250,62 & 54,62 & 55,15 & 239,65 \\
\hline Lissotriton boscai & 29TQE26 & 101,00 & 136,78 & 104,80 & \begin{tabular}{|c|}
36,17 \\
\end{tabular} & 6252,37 & 305,10 & 20,15 & 284,95 & 68,32 & 220,21 & 220,43 & \begin{tabular}{ll|l}
60,87 \\
\end{tabular} & 600,82 & 76,44 & 7,80 & 46,06 & 224,75 & 48,41 & 48,75 & 212,96 \\
\hline Lissotriton boscai & 29TQE27 & 100,00 & 115,21 & 101,46 & 35,89 & 6193,50 & 281,50 & 2,46 & 279,03 & 48,61 & \begin{tabular}{|l}
197,91 \\
\end{tabular} & 198,74 & 41,40 & 724,32 & 92,23 & 10,95 & 45,11 & 270,80 & 61,14 & 63,60 & 257,91 \\
\hline Lissotriton boscai & 29TQE28 & 100,00 & 119,46 & 102,97 & 36,06 & 6199,91 & 286,09 & 5,50 & 280,59 & \begin{tabular}{|l|l}
52,27 \\
\end{tabular} & 201,76 & 202,81 & 44,99 & \begin{tabular}{ll|}
678,62 \\
\end{tabular} & 86,57 & 10,04 & 44,90 & 253,79 & 57,87 & 59,40 & 240,81 \\
\hline Lissotriton boscai & 29TQE35 & 99,00 & 149,72 & 108,06 & 36,90 & 6304,32 & 320,61 & 30,16 & 290,45 & 80,12 & 233,76 & 233,76 & 72,64 & $\begin{array}{l}508,86 \\
\end{array}$ & 64,10 & 6,03 & 45,44 & 187,75 & 40,64 & 40,64 & 175,75 \\
\hline Lissotriton boscai & 29TQE37 & 99,00 & 132,68 & 106,64 & 36,72 & 6260,68 & 302,26 & 15,30 & 286,96 & 64,04 & 216,10 & 216,41 & 56,71 & \begin{tabular}{|l|l|}
576,18 \\
\end{tabular} & 72,79 & 8,43 & 44,17 & 212,34 & 49,52 & 49,99 & 199,15 \\
\hline 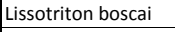 & 29TQE38 & 100,00 & 110,46 & 103,62 & 36,32 & \begin{tabular}{ll|l|}
6198,67 \\
\end{tabular} & 278,44 & $-3,04$ & 281,49 & 43,78 & 193,30 & 194,22 & 36,73 & 697,16 & 88,05 & 11,78 & 43,03 & 256,34 & 63,16 & 65,78 & 241,57 \\
\hline Lissotriton boscai & 29TQE39 & 101,00 & 109,91 & 104,34 & 36,66 & 6188,14 & 277,81 & $-3,78$ & 281,59 & 43,16 & 192,28 & 193,47 & 36,11 & 681,21 & 86,15 & 11,77 & 42,58 & 250,19 & 63,12 & 65,34 & 234,95 \\
\hline Lissotriton boscai & 29TQE43 & 100,00 & 153,78 & 109,25 & 36,69 & 6364,03 & 327,23 & 32,72 & 294,51 & 83,69 & 238,77 & 238,77 & 76,06 & 479,93 & 59,67 & 5,32 & 45,56 & 174,91 & 37,56 & 37,56 & 162,53 \\
\hline Lissotriton boscai & 29TQE44 & 100,00 & 152,58 & 109,43 & 36,98 & 6344,64 & 325,43 & 31,54 & 293,89 & 82,55 & 237,27 & 237,27 & 74,89 & \begin{tabular}{|l|l|}
477,37 \\
\end{tabular} & 59,45 & 5,67 & 45,00 & 173,76 & 38,39 & 38,39 & 161,35 \\
\hline Lissotriton boscai & 29TQЕ47 & 101,00 & 140,64 & 109,38 & 37,03 & 6294,98 & 312,04 & 20,83 & 291,21 & 71,06 & 224,69 & 224,75 & 63,78 & 502,05 & 62,86 & 7,40 & 43,31 & 182,16 & 44,17 & 44,21 & 168,79 \\
\hline Lissotriton boscai & 29TQE48 & 99,00 & 117,99 & 107,09 & 36,82 & $\begin{array}{l}6247,59 \\
\end{array}$ & 288,57 & 1,73 & 286,85 & 50,00 & $\begin{array}{ll}201,22 \\
\end{array}$ & 202,15 & 43,11 & $\begin{array}{l}606,94 \\
\end{array}$ & 75,98 & 10,64 & 41,83 & 219,55 & 57,39 & 58,73 & 204,08 \\
\hline Lissotriton boscai & 29TQE49 & 100,00 & 111,13 & 106,74 & 36,98 & $\begin{array}{ll}6218,89 \\
\end{array}$ & 281,23 & $-3,86$ & 285,09 & 43,78 & $\begin{array}{l}193,70 \\
\end{array}$ & 195,11 & 36,90 & 629,64 & 78,99 & 11,61 & 41,15 & 227,45 & 61,36 & 63,11 & 210,94 \\
\hline Lissotriton boscai & 29TQE53 & 60,00 & 149,80 & 109,92 & 36,70 & 6408,64 & 324,57 & 27,94 & 296,63 & 79,16 & 235,42 & 235,42 & 71,58 & 480,32 & 59,08 & 5,85 & 44,56 & \begin{tabular}{|l|l|}
173,02 \\
\end{tabular} & 39,20 & 39,20 & 160,24 \\
\hline Lissotriton boscai & 29TQE55 & 57,00 & 150,76 & 110,57 & 37,00 & \begin{tabular}{|l|l|}
6358,67 \\
\end{tabular} & 323,98 & 28,98 & 295,00 & 80,15 & 235,62 & 235,62 & 72,85 & $\begin{array}{l}458,15 \\
\end{array}$ & 56,78 & 6,03 & 43,63 & \begin{tabular}{ll|}
164,68 \\
\end{tabular} & 39,14 & 39,14 & 151,80 \\
\hline Lissotriton boscai & 29TQE56 & 50,00 & 137,16 & 109,69 & 36,99 & 6325,01 & 310,13 & 17,17 & 292,96 & 67,55 & 221,57 & 221,77 & $\begin{array}{l}60,39 \\
\end{array}$ & 507,69 & $62, \varepsilon$ & 7,87 & 42,52 & $\begin{array}{l}181,96 \\
\end{array}$ & 45,81 & 46,01 & 168,04 \\
\hline Lissotriton boscai & 29TQE57 & 42,00 & 139,19 & 110,38 & 37,06 & $\begin{array}{l}6308,52 \\
\end{array}$ & 311,71 & 18,79 & \begin{tabular}{|l|l|}
292,92 \\
\end{tabular} & 69,40 & 223,40 & 223,47 & 62,26 & 486,51 & 60,44 & 7,65 & 42,35 & \begin{tabular}{|l|l|}
174,30 \\
\end{tabular} & 44,42 & 44,45 & 160,43 \\
\hline Lissotriton boscai & 29TQE58 & 47,00 & 134,90 & $\begin{array}{ll}110,69 \\
\end{array}$ & 37,23 & 6298,43 & $\begin{array}{l}307,31 \\
\end{array}$ & $\begin{array}{ll}14,87 \\
\end{array}$ & \begin{tabular}{|l|l|}
292,44 \\
\end{tabular} & 65,49 & 219,16 & 219,25 & 58,23 & $\begin{array}{l}493,18 \\
\end{array}$ & 61,34 & 8,28 & 41,59 & $\begin{array}{l}176,15 \\
\end{array}$ & 46,67 & 46,74 & 161,74 \\
\hline Lissotriton boscai & 29TQF05 & 99,00 & 122,03 & 106,32 & 37,58 & 6018,77 & 285,45 & 6,53 & 278,92 & 55,32 & 202,18 & 202,18 & 48,14 & 667,94 & 85,85 & 10,00 & 45,79 & 255,06 & 58,03 & 58,03 & 247,19 \\
\hline Lissotriton boscai & 29TQF07 & 100,00 & 124,47 & 108,48 & 38,15 & 5975,92 & 288,21 & 7,85 & 280,36 & 57,62 & 203,80 & 203,80 & 50,69 & 634,57 & 81,31 & $\begin{array}{l}10,33 \\
\end{array}$ & 45,02 & 41,67 & 56,70 & 56,70 & 235,01 \\
\hline Lissotriton boscai & 29TQF08 & 100,00 & 119,33 & 108,56 & 38,17 & 5959,95 & 283,3 & 3,05 & 280,26 & 52,92 & 198,65 & 198,65 & 45,99 & 654,23 & 84,20 & $\mid 11,16$ & 44,66 & 249,16 & 60,21 & 60,21 & 243,12 \\
\hline Lissotriton boscai & 29TQF09 & 101,00 & 126,93 & 110,16 & 38,94 & 5930,54 & 290,50 & 9,14 & 281,36 & 60,20 & 205,50 & 205,50 & 53,32 & 605,30 & 78,18 & 10,60 & 44,49 & 230,27 & 55,42 & 55,42 & 224,78 \\
\hline Lissotriton boscai & 29TQF10 & 99,00 & 123,20 & 103,09 & 36,52 & 6140,43 & 287,72 & 8,99 & $\begin{array}{ll}278,73 \\
\end{array}$ & 56,01 & 204,47 & 205,41 & \begin{tabular}{|l|l|}
48,67 \\
\end{tabular} & $\begin{array}{l}673,72 \\
\end{array}$ & 86,64 & 9,59 & 45,73 & 255,00 & 56,69 & 57,43 & 243,76 \\
\hline Lissotriton boscai & 29TQF15 & 101,00 & 120,75 & 107,73 & $\begin{array}{l}37,95 \\
\end{array}$ & 6071,48 & 286,05 & 4,44 & 281,61 & 53,44 & 201,50 & 201,50 & 46,21 & 621,94 & 79,17 & 10,14 & 43,99 & 234,15 & 57,15 & 57,15 & 223,71 \\
\hline |Lissotriton boscai & 29TQF16 & 100,00 & 119,86 & 108,46 & 38,00 & 6049,59 & 285,22 & 3,36 & 281,85 & 52,53 & 200,33 & 200,33 & 45,51 & 616,45 & 78,70 & 10,64 & 43,43 & 231,63 & 58,12 & 58,12 & 221,61 \\
\hline Lissotriton boscai & 29TQF17 & 99,00 & 126,84 & 110,00 & 38,23 & 6022,16 & 292,13 & 8,85 & \begin{tabular}{|l|l|}
283,28 \\
\end{tabular} & 59,28 & 206,62 & 206,62 & 52,31 & 571,63 & 73,31 & 9,92 & 43,27 & 214,56 & 53,54 & 53,54 & 205,38 \\
\hline 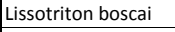 & 29TQF18 & 100,00 & 122,60 & 110,21 & 38,40 & 6005,49 & 287,87 & 4,76 & 283,11 & 55,36 & 202,28 & 202,28 & 48,48 & 585,02 & 75,58 & 10,69 & 43,04 & 219,49 & 56,23 & 56,23 & 210,90 \\
\hline Lissotriton boscai & 29TQF19 & 100,00 & 118,95 & 110,37 & 38,70 & 5982,06 & 284,32 & 1,44 & 282,88 & 52,01 & 198,36 & $\begin{array}{l}198,36 \\
\end{array}$ & 45,22 & 596,50 & 77,51 & 11,53 & 42,49 & 223,55 & 59,05 & 59,05 & 215,39 \\
\hline Lissotriton boscai & 29TQF20 & 100,00 & 122,60 & 105,19 & 36,93 & 6179,35 & 289,29 & 7,16 & 282,13 & 54,98 & 204,59 & 205,36 & \begin{tabular}{ll|}
47,62 \\
\end{tabular} & $\begin{array}{l}629,76 \\
\end{array}$ & 80,45 & 9,78 & 44,21 & 235,08 & 55,74 & 56,30 & 221,92 \\
\hline Lissotriton boscai & 29TQF21 & 101,00 & 123,91 & 106,41 & 37,00 & 6166,18 & 290,78 & 7,72 & 283,06 & 55,99 & 206,19 & 206,34 & 48,80 & 606,68 & 77,50 & 9,49 & 43,88 & 226,22 & 54,70 & 54,79 & 213,0 \\
\hline Lissotriton boscai & 29TQF25 & 100,00 & 118,78 & $\begin{array}{l}109,07 \\
\end{array}$ & 38,00 & 6103,65 & 285,76 & 1,81 & \begin{tabular}{|l|l|}
283,94 \\
\end{tabular} & 51,01 & 200,04 & 200,04 & \begin{tabular}{ll|}
44,07 \\
\end{tabular} & \begin{tabular}{|l|l|}
582,67 \\
\end{tabular} & 74,56 & 10,54 & 42,24 & 215,88 & 56,95 & 56,95 & 202,80 \\
\hline Lissotriton boscai & 29TQF28 & 100,00 & 120,82 & 111,21 & 38,30 & \begin{tabular}{|l|l|}
6056,09 \\
\end{tabular} & 287,94 & 2,60 & 285,34 & 53,22 & 201,28 & 201,28 & 46,19 & 543,86 & 70,42 & $\begin{array}{l}10,86 \\
\end{array}$ & 41,16 & 200,26 & 55,77 & 55,77 & 188,94 \\
\hline Lissotriton boscai & 29TQF29 & 100,00 & 120,33 & 111,61 & 38,78 & 6032,92 & 287,25 & 1,88 & 285,36 & 52,66 & 200,29 & 200,29 & 45,80 & 541,55 & 70,40 & $\begin{array}{l}11,25 \\
\end{array}$ & 40,85 & 199,19 & 56,50 & 56,50 & 188,40 \\
\hline Lissotriton boscai & 29TQF36 & 100,00 & 120,24 & 111,54 & 38,22 & 6129,71 & 289,00 & 1,76 & 287,24 & 52,16 & 201,72 & 201,72 & 45,03 & 517,40 & 66,80 & 10,28 & 40,33 & 187,67 & 54,43 & 54,43 & 172,97 \\
\hline Lissotriton boscai & 29TQF37 & 100,00 & 118,55 & $\mid 111,76$ & 38,46 & 6114,85 & 287,34 & 0,26 & 287,08 & 51,81 & 199,80 & 199,80 & 43,42 & 515,96 & 66,72 & $\mid 10,98$ & 39,88 & $\mid 186,47$ & 55,52 & 55,52 & 172,01 \\
\hline Lissotriton boscai & 29TQF & 100,00 & 117 & $\begin{array}{ll}112,03 \\
\end{array}$ & 38 & 66 & 285 & $-0,68$ & 286,55 & 50,01 & $\begin{array}{ll}198,18 \\
\end{array}$ & 198,18 & 42,05 & 517,13 & 66,94 & \begin{tabular}{|l|l|}
11,24 \\
\end{tabular} & 39,33 & \begin{tabular}{|l|l|}
186,47 \\
\end{tabular} & 57,05 & 57,05 & 172,52 \\
\hline Lissotriton boscai & 29TQF39 & 101,00 & 117,53 & 112,34 & 38,95 & 6073,13 & 286,20 & $-0,80 \mid$ & 287,00 & 54,47 & 198,29 & 198,29 & 42,66 & 509,77 & 66,10 & 11,77 & 38,87 & 183,34 & 57,22 & 57,22 & 169,97 \\
\hline Lissotriton boscai & 29TQF40 & 100,00 & 116,70 & 108,66 & 37,23 & 6227,32 & 287,15 & $-0,06$ & 287,21 & $\begin{array}{ll}48,54 \\
\end{array}$ & $\begin{array}{ll}199,46 \\
\end{array}$ & 200,47 & 41,83 & 578,11 & 72,63 & 10,60 & 40,89 & 208,46 & 57,44 & 58,19 & 191,94 \\
\hline Lissotriton boscai & 29TQF44 & 99,00 & 118,41 & 112,01 & $38,09]$ & 6184,50 & 288,97 & 0,23 & 88,74 & 65,45 & 200,91 & 200,91 & 42,97 & 506,69 & 65,08 & $\begin{array}{l}10,55 \\
\end{array}$ & 39,66 & 181,50 & 54,95 & 54,95 & 63,34 \\
\hline \begin{tabular}{|l|l|l|} 
Lissotr \\
\end{tabular} & & 99 & 12 & & 38 & 50 & & $\begin{array}{ll}1,01 \\
\end{array}$ & 2 & 74,07 & 202,34 & 20 & 44 & 485,16 & 62,58 & \begin{tabular}{|l|l|}
10,14 \\
\end{tabular} & 39,43 & 173,62 & 53,39 & 53,39 & 155,40 \\
\hline 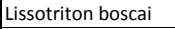 & 29TQF46 & 101,00 & 118,96 & 112,92 & 38,60 & 6153,76 & 289,35 & 0,24 & 289,11 & 76,52 & 200,76 & 200,76 & 43,42 & 481,04 & 62,11 & 10,63 & 38,93 & 171,84 & 54,16 & 54,16 & 153,67 \\
\hline Lissotriton boscai & 29TQF47 & 100,00 & 116,77 & 112,93 & 38,80 & 6141,71 & 287,25 & $-1,44$ & 288,68 & 76,17 & 198,53 & 198,53 & 41,46 & 481,72 & 62,16 & 11,00 & 38,46 & 171,64 & 55,31 & 55,31 & 153,66 \\
\hline
\end{tabular}




\begin{tabular}{|c|c|c|c|c|c|c|c|c|c|c|c|c|c|c|c|c|c|c|c|c|c|}
\hline TAXON & UTM & $\mathrm{km} 2$ & BIO1 & B102 & $B 103$ & BIO4 & B105 & B106 & B107 & B108 & B109 & B1010 & BIO11 & B1012 & BIO13 & BIO14 & BIO15 & B1016 & B1017 & B1018 & 81019 \\
\hline Lissotriton boscai & 29TQF48 & 100,00 & 116,89 & 113,23 & 38,97 & 6130,25 & 286,98 & $-1,75$ & 288,73 & 76,96 & 198,25 & 198,25 & 41,58 & 475,93 & 61,37 & 11,24 & 37,99 & 169,20 & 55,66 & 55,66 & 151,72 \\
\hline Lissotriton boscai & 29TQF49 & 100,00 & 119,58 & 113,50 & 38,97 & 6115,42 & 289,29 & 0,01 & 289,29 & 80,05 & 200,47 & 200,48 & 43,96 & 459,76 & 59,24 & 11,05 & 37,64 & 163,38 & 54,36 & 54,37 & 146,34 \\
\hline Lissotriton boscai & 29TQF50 & 33,00 & 117,20 & 110,11 & 37,63 & 6238,59 & 288,82 & $-0,27$ & 289,09 & 48,91 & 200,27 & 201,05 & 42,04 & 550,61 & 68,77 & 10,71 & 39,96 & 195,89 & 56,96 & 57,45 & 178,63 \\
\hline Lissotriton boscai & 29TQF51 & 36,00 & 117,76 & 111,09 & 38,00 & 6228,51 & 289,45 & $-0,02$ & 289,47 & 49,35 & 200,98 & 201,33 & 42,56 & 530,89 & 66,45 & 10,80 & 39,60 & 188,53 & 56,38 & 56,60 & 170,73 \\
\hline Lissotriton boscai & 29TQF54 & 26,00 & 118,31 & 113,03 & 38,26 & 6183,91 & 289,74 & $-0,34$ & 290,09 & 78,54 & 200,80 & 200,80 & 42,91 & 483,09 & 62,06 & 10,69 & 39,00 & 172,43 & 54,46 & 54,46 & 151,34 \\
\hline Lissotriton boscai & 29TQG00 & 99,00 & 123,09 & 110,27 & 38,96 & 5918,68 & 286,88 & 5,41 & 281,47 & 56,58 & 201,70 & 201,70 & \begin{tabular}{|l|l|}
49,72 \\
\end{tabular} & 619,22 & 80,70 & \begin{tabular}{|c|c|}
11,43 \\
\end{tabular} & 44,19 & 235,64 & 58,29 & 58,29 & 230,85 \\
\hline Lissotriton boscai & 29TQG01 & 101,00 & 120,16 & 110,37 & 39,00 & 5890,61 & 283,96 & 2,77 & 281,19 & 54,07 & $\begin{array}{l}198,46 \\
\end{array}$ & $\begin{array}{l}198,46 \\
\end{array}$ & 47,29 & 630,02 & 82,67 & 12,21 & 43,76 & 239,57 & 60,81 & 60,81 & 235,47 \\
\hline Lissotriton boscai & 29TQG02 & 100,00 & 118,31 & 110,55 & 39,00 & 5867,35 & 282,03 & 1,14 & 280,89 & 52,36 & 196,31 & 196,31 & 45,68 & 636,56 & 84,01 & 13,14 & 43,33 & 241,71 & 63,07 & 63,07 & 237,84 \\
\hline Lissotriton boscai & 29TQG03 & 100,00 & 114,88 & 110,19 & 38,98 & 5844,04 & 278,26 & $-1,66$ & 279,92 & 49,20 & 192,60 & $\begin{array}{l}192,60 \\
\end{array}$ & 42,71 & \begin{tabular}{ll|}
654,32 \\
\end{tabular} & 86,67 & $\begin{array}{l}14,58 \\
\end{array}$ & 42,81 & 247,97 & 66,98 & 66,98 & 243,35 \\
\hline Lissotriton boscai & 29TQG04 & 99,00 & 107,72 & 109,04 & 38,75 & $5831,01$. & 270,54 & $-7,80$ & 278,34 & 42,36 & 185,45 & 185,45 & 36,15 & \begin{tabular}{|c|}
697,38 \\
\end{tabular} & 92,22 & 17,25 & 41,55 & 262,69 & 75,26 & 75,26 & 255,74 \\
\hline Lissotriton boscai & 29TQG05 & 99,00 & 104,21 & 108,35 & 38,61 & 5812,30 & 266,16 & $-10,78$ & 276,93 & 39,18 & 181,82 & $\begin{array}{l}181,82 \\
\end{array}$ & 33,12 & 720,31 & 95,06 & 19,42 & 40,52 & 270,01 & 80,76 & 80,76 & 260,84 \\
\hline Lissotriton boscai & 29TQG06 & 101,00 & 97,59 & 107,19 & 38,63 & 5777,70 & 258,37 & $-16,03$ & 274,40 & 33,35 & 174,90 & 174,90 & 27,26 & 770,14 & 100,90 & 22,35 & 39,27 & 286,20 & 90,40 & 90,40 & 274,29 \\
\hline 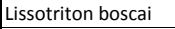 & 29TQG07 & 100,00 & 75,27 & 102,87 & 38,12 & 5659,24 & 233,23 & $-33,33$ & 266,56 & 14,21 & 151,42 & 151,61 & 7,86 & 961,33 & 122,26 & 31,36 & 36,71 & 349,51 & $\begin{array}{ll}121,47 \\
\end{array}$ & 122,08 & 332,88 \\
\hline Lissotriton boscai & 29TQG10 & 101,00 & 116,77 & 110,67 & 39,00 & 5974,82 & 282,16 & $-0,12$ & 282,28 & 50,13 & 196,21 & 196,21 & 43,23 & 602,56 & 78,66 & 12,23 & 42,09 & 225,51 & 61,11 & 61,11 & 217,74 \\
\hline Lissotriton boscai & 29TQG12 & 100,00 & 111,25 & 110,62 & 38,97 & 5928,59 & 276,26 & $-5,44$ & 281,70 & 44,90 & 190,13 & 190,13 & 38,21 & 629,53 & $\begin{array}{l}82,72 \\
\end{array}$ & $\begin{array}{l}14,56 \\
\end{array}$ & 41,12 & 234,74 & 67,54 & 67,54 & 226,96 \\
\hline Lissotriton boscai & 29TQG13 & 101,00 & 111,71 & 110,86 & 39,00 & \begin{tabular}{|l|}
5909,07 \\
\end{tabular} & 276,33 & $-5,18$ & 281,51 & 45,45 & 190,29 & $\begin{array}{l}190,29 \\
\end{array}$ & 38,81 & 625,53 & 82,37 & 15,30 & 40,67 & 232,93 & 68,39 & 68,39 & 224,64 \\
\hline Lissotriton boscai & 29TQG14 & 100,00 & 106,12 & 110,05 & 38,93 & 5890,84 & 270,36 & \begin{tabular}{|l|l|}
$-10,14$ \\
\end{tabular} & 280,50 & 40,21 & 184,73 & \begin{tabular}{|l|l|}
184,73 \\
\end{tabular} & 33,77 & 662,20 & 87,05 & 17,70 & 39,73 & 245,46 & 75,48 & 75,48 & 235,49 \\
\hline Lissotriton boscai & 29TQG15 & 100,00 & 106,85 & 110,18 & 38,99 & 5876,78 & 270,54 & $-9,53$ & 280,07 & 40,80 & 185,13 & 185,13 & 34,51 & 658,88 & 86,64 & 18,55 & 39,18 & 243,62 & 76,94 & 76,94 & 232,45 \\
\hline |Lissotriton boscai & 29TQG16 & 100,00 & 100,74 & 109,21 & 38,89 & $5841,69 \mid$ & 263,66 & $-14,63$ & 278,29 & 35,43 & 178,66 & 178,66 & 29,22 & 704,69 & 92,02 & 21,13 & 38,13 & 258,67 & 85,76 & 85,76 & 245,22 \\
\hline Lissotriton boscai & 29TQG17 & 99,00 & 86,69 & 106,75 & 38,59 & 5763,06 & 247,73 & $-25,75$ & 273,49 & 23,37 & 163,90 & 163,98 & 16,91 & 819,81 & 105,11 & 26,84 & 36,33 & 296,73 & 105,56 & 105,69 & 279,85 \\
\hline Lissotriton boscai & 29TQG18 & 100,00 & 80,36 & 105,43 & 38,57 & 5693,88 & 239,67 & $-30,51$ & 270,17 & 18,24 & 156,74 & 156,79 & 11,85 & $\begin{array}{l}880,15 \\
\end{array}$ & 111,79 & 30,29 & 35,26 & 316,01 & 117,00 & 117,16 & 297,01 \\
\hline Lissotriton boscai & 29TQG20 & 100,00 & 116,37 & 111,62 & 38,94 & 6018,44 & 283,37 & $-1,28$ & 284,65 & \begin{tabular}{ll|}
49,07 \\
\end{tabular} & 196,27 & \begin{tabular}{|l|l|}
196,27 \\
\end{tabular} & 42,19 & \begin{tabular}{|l|l|}
557,49 \\
\end{tabular} & 72,66 & 12,32 & 40,29 & 204,73 & 59,88 & 59,88 & $\begin{array}{l}194,08 \\
\end{array}$ \\
\hline Lissotriton boscai & 29TQG21 & 101,00 & 113,17 & 111,51 & 38,93 & 6004,49 & 280,10 & $-4,34$ & 284,44 & 46,17 & 193,10 & $\begin{array}{l}193,10 \\
\end{array}$ & 39,30 & \begin{tabular}{|l|l|}
572,97 \\
\end{tabular} & 74,83 & 13,54 & 39,72 & \begin{tabular}{|l|l|}
210,03 \\
\end{tabular} & 63,41 & 63,41 & 199,39 \\
\hline Lissotriton boscai & 29TQG24 & 99,00 & 106,53 & 111,31 & 38,98 & 5942,33 & 272,67 & $-10,62$ & 283,29 & 40,28 & 185,74 & 185,74 & 33,40 & 617,64 & 80,63 & 17,53 & 38,15 & 224,86 & 74,17 & 74,17 . & 212,30 \\
\hline |Lissotriton boscai & 29TQG26 & 100,00 & 107,80 & 111,40 & 39,00 & 5903,09 & 272,74 & $-9,90$ & 282,63 & 53,23 & $\mid 186,34$ & 186,34 & 34,78 & 619,73 & 80,76 & 18,88 & 37,12 & 224,81 & 77,87 & 77,87 & 209,72 \\
\hline Lissotriton boscai & 29TQG27 & 101,00 & 96,95 & 110,01 & 38,90 & 5850,44 & 261,05 & $-18,67$ & 279,72 & 45,32 & 175,08 & 175,08 & 25,39 & 700,54 & 90,26 & 23,14 & 35,87 & 251,96 & 92,35 & 92,35 & 234,13 \\
\hline Lissotriton boscai & 29TQG30 & 99,00 & 118,24 & 112,71 & 38,98 & 6054,24 & 286,54 & $-0,55$ & 287,09 & 58,13 & 198,47 & 198,47 & 43,35 & 504,83 & 65,56 & 12,00 & 38,70 & 181,38 & 57,28 & 57,28 & 168,57 \\
\hline Lissotriton boscai & 29TQG33 & 100,00 & 109,75 & 1112,69 & 38,99 & 6005,46 & 277,86 & $-8,55$ & 286,41 & 60,00 & 189,58 & 189,58 & 35,59 & 555,71 & 72,08 & 15,75 & 37,15 & \begin{tabular}{|l|l|}
199,17 \\
\end{tabular} & 68,57 & 68,57 & 184,91 \\
\hline Lissotriton boscai & 29TQG34 & 100,00 & 109,08 & 112,74 & 38,97 & 5982,61 & 276,92 & $-9,39$ & 286,31 & 65,83 & 188,59 & 188,59 & 35,17 & 564,89 & 73,18 & 16,72 & 36,65 & 202,73 & 71,26 & 71,26 & 187,20 \\
\hline Lissotriton boscai & 29TQG35 & 100,00 & 113,57 & $\begin{array}{l}113,09 \\
\end{array}$ & 39,00 & \begin{tabular}{|l|}
5964,48 \\
\end{tabular} & 280,43 & $-5,71$ & 286,14 & 74,89 & $\begin{array}{l}192,48 \\
\end{array}$ & $\begin{array}{l}192,48 \\
\end{array}$ & 39,41 & 547,40 & 70,94 & $\begin{array}{l}16,45 \\
\end{array}$ & 36,42 & $\begin{array}{l}197,66 \\
19\end{array}$ & 69,83 & 69,83 & 180,30 \\
\hline Lissotriton boscai & 29TQG36 & 100,00 & 111,99 & 112,95 & 39,00 & 5944,72 & 278,49 & $-7,13$ & 285,62 & 73,74 & $\begin{array}{l}190,64 \\
\end{array}$ & \begin{tabular}{ll|}
190,64 \\
\end{tabular} & 38,05 & 562,72 & 72,66 & \begin{tabular}{ll|}
17,69 \\
\end{tabular} & 36,04 & 203,73 & 73,84 & 73,84 & 183,80 \\
\hline Lissotriton boscai & 29TQG38 & 101,00 & 106,13 & 112,22 & 39,00 & 5872,46 & 271,28 & $-11,75$ & 283,03 & 68,77 & 184,03 & \begin{tabular}{ll|}
184,03 \\
\end{tabular} & 33,35 & 615,72 & 79,11 & 21,37 & 34,82 & 223,15 & 85,66 & 85,66 & 197,37 \\
\hline Lissotriton boscai & 29TQG40 & 100,00 & 116,85 & 113,49 & 38,97 & 6098,32 & 286,63 & $\begin{array}{l}-42,42 \\
\end{array}$ & 289,05 & 77,78 & 197,83 & 197,83 & 41,59 & 470,69 & 60,57 & 11,96 & 37,01 & 167,12 & 57,16 & 57,16 & 149,90 \\
\hline Lissotriton boscai & 29TQG43 & 91,00 & 109,68 & 113,67 & 39,00 & 6041,99 & 279,31 & $-9,32$ & 288,63 & 71,14 & 189,93 & 189,93 & 34,99 & 522,63 & 67,10 & | 15,60 & 35,67 & 186,39 & 68,06 & 68,06 & 167,33 \\
\hline Lissotriton boscai & 29TQG46 & 80,00 & 114,57 & 113,95 & 39,00 & 5963,28 & 282,04 & $-5,28$ & 287,32 & 76,54 & \begin{tabular}{|l|}
193,27 \\
\end{tabular} & \begin{tabular}{|l|}
193,27 \\
\end{tabular} & \begin{tabular}{ll|}
40,03 \\
\end{tabular} & $\begin{array}{l}523,95 \\
\end{array}$ & 66,95 & \begin{tabular}{|l|l|}
17,08 \\
\end{tabular} & 34,98 & 189,85 & 71,64 & 71,64 & 165,34 \\
\hline Lissotriton boscai & 29TQH17 & 101,00 & 79,56 & $\begin{array}{ll}98,86 \\
\end{array}$ & 40,06 & 5002,85 & 221,57 & $-22,19$ & 243,76 & 40,09 & 145,80 & 146,25 & 19,84 & $\begin{array}{l}1034,18 \\
\end{array}$ & 131,39 & 44,28 & 29,41 & 357,21 & \begin{tabular}{ll|}
160,63 \\
\end{tabular} & \begin{tabular}{ll|}
165,63 \\
\end{tabular} & 319,74 \\
\hline Lissotriton boscai & 29TQH21 & 99,00 & 90,49 & 107,60 & 39,20 & 5617,95 & 248,60 & $-21,87$ & 270,47 & 53,99 & 165,27 & 165,27 & 21,89 & 794,80 & \begin{tabular}{|l|l|}
101,78 \\
\end{tabular} & 30,23 & 32,91 & 282,67 & 115,17 & $\begin{array}{l}115,17 \\
\end{array}$ & 254,36 \\
\hline |Lissotriton boscai & 29TQH22 & 101,00 & 97,35 & 107,61 & 39,82 & 5548,37 & 253,24 & $-15,01$ & 268,25 & 62,72 & 170,84 & 170,84 & 29,21 & 763,37 & 99,10 & 29,43 & 32,63 & $72,84[$ & 112,24 & 112,24 & 240,44 \\
\hline Lissotriton boscai & 29TQJ00 & 100,00 & 113,08 & 92,84 & 41,78 & 4381,67 & 236,87 & 17,31 & 219,56 & 88,49 & 169,52 & 171,28 & 60,21 & 922,77 & 122,26 & 39,35 & 29,15 & 317,84 & 143,82 & 154,93 & 269,66 \\
\hline Lissotriton boscai & 29TQJ01 & 101,00 & 126,22 & 88,44 & 42,23 & 4110,48 & 240,86 & 34,05 & 206,81 & 104,11 & 178,50 & 180,95 & 76,45 & 878,86 & 118,09 & 37,42 & 29,36 & 302,72 & \begin{tabular}{|l|l|}
137,04 \\
\end{tabular} & 149,67 & 250,74 \\
\hline Lissotriton boscai & 29TQJ02 & 55,00 & 134,41 & 84,61 & 42,41 & 3939,63 & 242,38 & 45,21 & 197,17 & 113,77 & 184,19 & 186,89 & 86,64 & 853,56 & 115,54 & 36,12 & 29,65 & 294,62 & \begin{tabular}{|l|l|}
132,68 \\
\end{tabular} & 146,74 & 240,90 \\
\hline Lissotriton boscai & 29TQJ12 & 67,00 & \begin{tabular}{ll|}
128,44 \\
\end{tabular} & 86,26 & 42,76 & 3958,19 & 238,64 & 38,66 & 199,98 & 108,11 & 178,40 & 181,22 & 80,56 & 884,15 & 119,44 & 39,41 & 28,78 & 302,11 & 142,53 & $\begin{array}{l}155,16 \\
\end{array}$ & 244,59 \\
\hline |Lissotriton boscai & 29TQJ22 & 90,00 & 130,15 & 85,35 & 42,88 & 3889,16 & 238,31 & 41,39 & 196,92 & 110,84 & 179,08 & 182,20 & 83,20 & $877,27 \mid$ & 119,15 & 40,31 & 28,57 & 298,33 & 144,64 & 156,96 & 237,01 \\
\hline Lissotriton boscai & 29TQJ32 & 74,00 & 134,23 & 83,35 & 43,00 & 3796,84 & 238,70 & 46,89 & 191,82 & 116,10 & 181,84 & 185,14 & 88,38 & 858,30 & 117,33 & 40,27 & 28,58 & 90,85 & \begin{tabular}{|l|l|}
144,00 \\
\end{tabular} & \begin{tabular}{|l|}
156,31 \\
\end{tabular} & 226,00 \\
\hline 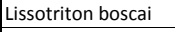 & 29TQJ41 & 25,00 & 123,32 & 90,61 & 43, & 3953,70 & 237,59 & 32,36 & 205,23 & 104,30 & 173,20 & 176,39 & 76,14 & 896,93 & 121,73 & 44,34 & 27,89 & 300,14 & 155,70 & 165,11 & 232,18 \\
\hline Lissotriton boscai & 30STG36 & 50,00 & 179,75 & 122,09 & 39,04 & 6222,42 & 358,25 & 50,54 & 307,72 & 111,81 & 261,12 & 262,19 & 103,03 & 579,31 & 84,54 & 1,48 & 61,61 & 241,93 & 19,79 & 23,93 & 228,63 \\
\hline Lissotriton boscai & 30STG39 & 40,00 & 170,22 & 122,02 & 38,84 & $\begin{array}{ll}6377,82 \\
\end{array}$ & \begin{tabular}{|l|l|}
352,44 \\
\end{tabular} & 40,78 & 311,65 & 100,87 & 253,89 & 254,67 & $\begin{array}{ll}91,93 \\
\end{array}$ & 593,58 & 82,44 & 2,22 & 59,20 & $\begin{array}{l}239,95 \\
\end{array}$ & 22,91 & 27,60 & 228,11 \\
\hline Lissotriton boscai & 30STG46 & 100,00 & 182,42 & 122,99 & 39,41 & 6229,88 & 361,25 & 53,28 & 307,97 & 114,58 & 264,03 & 264,75 & 105,65 & 570,93 & 83, & 1,17 & 62,17 & 239,24 & 18,65 & 22,78 & 226 \\
\hline Lissotriton boscai & 30STG48 & 100,00 & 174,66 & 123,03 & 39,00 & 6355,98 & 356,75 & 44,67 & 312,08 & 105,38 & 258,06 & 258,77 & \begin{tabular}{|c|}
96,49 \\
\end{tabular} & 588,01 & 82,80 & 2,04 & 60,20 & 240,29 & 21,39 & 25,70 & 228,30 \\
\hline Lissotriton boscai & 30STG49 & 100,00 & 165,69 & 122,71 & 38,70 & \begin{tabular}{ll|l|}
6434,94 \\
\end{tabular} & 349,90 & 35,92 & 313,99 & 95,88 & 250,41 & \begin{tabular}{|l|}
251,07 \\
\end{tabular} & 87,03 & 620,24 & 85,77 & 2,65 & 58,86 & 249,59 & 24,31 & 29,03 & 238,44 \\
\hline Lissotriton boscai & 305TG59 & 100,00 & 162,75 & 123,58 & 38,49 & 6489,78 & 349,12 & 32,60 & 316,52 & \begin{tabular}{|l|l|}
92,60 \\
\end{tabular} & 248,53 & 249,06 & 83,68 & 639,22 & 88,46 & 2,57 & 58,97 & 255,99 & 24,94 & 29,09 & 245,75 \\
\hline Lissotriton boscai & 30STG69 & 100,00 & 158,30 & 123,72 & 38,13 & 6543,04 & 346,16 & 27,98 & 318,18 & 87,73 & 245,06 & 245,34 & 78,92 & 664,30 & 91,73 & 2,86 & 58,72 & 264,30 & 26,15 & 28,46 & 255,15 \\
\hline Lissotriton boscai & 30STG79 & 100,00 & 158,45 & 124,13 & 38,25 & 6569,95 & 347,11 & 27,77 & 319, & 87,62 & 245,74 & 245,83 & 78,66 & $668, \mathrm{C}$ & 92,56 & 2, & 58 & 264,92 & 25,84 & 27,06 & 256 \\
\hline Lissotriton boscai & 30ST & 38,00 & 162,02 & $\begin{array}{l}121,69 \\
\end{array}$ & 38, & 6 & 34 & 32,84 & 313,24 & 92,33 & 246,85 & 24 & 83,40 & 623,24 & 85,07 & 2,93 & 57,98 & 248,53 & 26,09 & 30,42 & 237,40 \\
\hline Lissotriton boscai & 30STH40 & 100,00 & 160,71 & 122,37 & 38,23 & 6479,99 & 346,34 & 31,07 & 315,27 & 90,63 & 246,38 & 246,83 & 81,72 & $\begin{array}{l}633,15 \\
\end{array}$ & 86,42 & 2,97 & 58,00 & 251,74 & 26,43 & 30,23 & 241,17 \\
\hline Lissotriton boscai & 30STH43 & 100,00 & \begin{tabular}{ll|}
152,44 \\
\end{tabular} & 121,60 & 38,00 & $\begin{array}{ll}6564,90 \\
\end{array}$ & 340,64 & 23,11 & 317,53 & 81,97 & 239,73 & 240,03 & 72,92 & 641,43 & 85,26 & 4,01 & 55,44 & 247,99 & 30,97 & 34,01 & 238,21 \\
\hline Lissotriton boscai & 30STH50 & 100,00 & 154,55 & 122,76 & 38,00 & 6541,03 & 342,21 & 24,70 & 317,51 & 84,12 & 241,26 & 241,71 & 75,17 & 667,25 & 90,76 & 3,32 & 57,67 & 263,34 & 28,34 & 32,51 & 253,95 \\
\hline Lissot & 36 & 10 & & & 38,00 & 6 & & 24,05 & & 9 & 24 & 24 & 74,22 & 646,74 & $86-20$ & 61 & & $2=$ & 29,43 & \begin{tabular}{|c|c|}
31,63 \\
\end{tabular} & 241,95 \\
\hline 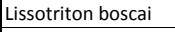 & 30STHE & 100,00 & 154,76 & 123,63 & 38,00 & 6584,50 & 343,96 & 24,34 & 319,62 & 83,79 & 242,28 & 242,47 & 74,96 & 669,32 & 91,24 & 3,44 & 57,66 & 263,09 & 28,16 & 29,76 & 254,51 \\
\hline Lissotriton boscai & 30STH61 & 100,00 & 152,05 & 123,47 & 38,00 & 6622,53 & 342,36 & 21,54 & 320,82 & 80,86 & 240,30 & 240,46 & 72,04 & $\begin{array}{l}670,25 \\
\end{array}$ & 90,40 & 3,68 & 56,78 & 260,80 & 29,55 & 31,25 & 252,50 \\
\hline
\end{tabular}




\begin{tabular}{|c|c|c|c|c|c|c|c|c|c|c|c|c|c|c|c|c|c|c|c|c|c|}
\hline TAXON & UTM & $\mathrm{km} 2$ & BIO1 & B102 & $B 103$ & BIO4 & B105 & B106 & B107 & B108 & B109 & B1010 & BIO11 & B1012 & BIO13 & BIO14 & BIO15 & B1016 & B1017 & B1018 & 81019 \\
\hline Lissotriton boscai & 30STH72 & 100,00 & 161,12 & 124,65 & 38,00 & 6671,75 & 352,56 & 28,79 & 323,77 & 88,78 & 249,95 & 249,95 & 79,81 & 621,28 & 84,23 & 3,12 & 57,01 & 239,88 & 26,17 & 26,17 & 232,06 \\
\hline Lissotriton boscai & 30STH82 & 100,00 & 160,47 & 124,88 & 37,99 & 6717,64 & 353,05 & 27,63 & 325,43 & 87,61 & 250,08 & 250,08 & 78,63 & 626,84 & 85,41 & 3,14 & 57,05 & 240,49 & 26,13 & 26,13 & 233,82 \\
\hline Lissotriton boscai & 30STH89 & 100,00 & 160,79 & $\begin{array}{l}122,07 \\
\end{array}$ & 37,01 & 6751,70 & 352,34 & 28,51 & 323,83 & 87,16 & 251,17 & 251,17 & 78,56 & 523,03 & 69,94 & 3,46 & 52,02 & $\begin{array}{ll}189,93 \\
\end{array}$ & 28,30 & 28,30 & 181,55 \\
\hline Lissotriton boscai & 30STH97 & 100,00 & 159,33 & 123,80 & 37,09 & 6807,79 & 353,41 & 25,99 & 327,42 & 85,22 & 250,69 & 250,69 & 76,50 & 555,60 & 75,74 & 3,37 & 53,54 & \begin{tabular}{|l|l|}
203,08 \\
\end{tabular} & 27,64 & 27,64 & 196,31 \\
\hline Lissotriton boscai & 30STJ47 | & 80,00 & 158,34 & 112,88 & 36,33 & 6544,45 & 339,35 & 33,48 & 305,87 & 86,83 & 245,83 & 245,83 & 78,67 & 472,85 & 60,15 & 4,06 & 47,72 & 170,54 & 33,28 & 33,28 & 158,29 \\
\hline Lissotriton boscai & 30STIS7 & 100,00 & 153,24 & 113,56 & 36,34 & 6576,88 & 335,72 & 27,88 & 307,84 & 81,56 & 241,36 & 241,36 & 73,40 & \begin{tabular}{|l|l|}
485,68 \\
\end{tabular} & 61,27 & 4,99 & 46,87 & $\mid$\begin{tabular}{|l|l|}
173,18 \\
\end{tabular} & 35,75 & 35,75 & 160,91 \\
\hline Lissotriton boscai & 30STJ76 & 100,00 & 140,27 & 115,77 & 36,36 & 6661,01 & 326,81 & 13,58 & 313,23 & 68,12 & 230,10 & 230,10 & 60,34 & 531,60 & 65,98 & 6,25 & 45,55 & 185,83 & 41,36 & 41,36 & 173,77 \\
\hline Lissotriton boscai & 30STJ77 & 100,00 & 147,64 & 115,50 & 36,43 & 6635,54 & 332,56 & 20,52 & 312,04 & 75,32 & 236,87 & 236,87 & 67,48 & \begin{tabular}{ll|l|}
485,83 \\
\end{tabular} & 60,11 & 5,42 & 45,44 & $\begin{array}{l}169,46 \\
\end{array}$ & 37,52 & 37,52 & 157,28 \\
\hline Lissotriton boscai & 30STI82 & 100,00 & 159,71 & 120,06 & 37,00 & 6722,78 & 349,14 & 28,61 & 320,54 & 86,01 & 249,70 & 249,70 & 77,87 & $\begin{array}{l}486,66 \\
4\end{array}$ & 63,75 & 3,78 & 49,62 & \begin{tabular}{|l|l|}
173,27 \\
\end{tabular} & 29,86 & 29,86 & 163,70 \\
\hline Lissotriton boscai & 30STJ86 & 100,00 & 140,42 & \begin{tabular}{ll|}
116,69 \\
\end{tabular} & \begin{tabular}{ll|}
36,62 \\
\end{tabular} & \begin{tabular}{|c|c|}
6683,16 \\
\end{tabular} & 327,95 & 12,71 & 315,23 & 67,77 & 230,58 & 230,58 & \begin{tabular}{ll|}
60,09 \\
\end{tabular} & $\begin{array}{l}519,05 \\
\end{array}$ & 64,15 & 6,31 & 44,92 & 179,38 & 41,07 & 41,07 & 167,52 \\
\hline Lissotriton boscai & 30STJ87 & 100,00 & 139,50 & 116,00 & 36,29 & 6660,10 & 326,07 & 12,18 & 313,89 & 67,07 & 229,44 & 229,44 & 59,43 & 510,14 & 62,04 & 6,55 & 44,22 & 175,34 & 41,84 & 41,84 & 162,97 \\
\hline Lissotriton boscai & 30STJ88 & 100,00 & 139,32 & 115,41 & 36,44 & 6633,73 & 324,53 & 12,55 & 311,98 & 67,20 & 228,75 & 228,76 & 59,59 & 498,80 & 59,71 & 6,71 & 43,49 & 170,82 & 42,19 & 42,20 & 158,02 \\
\hline Lissotriton boscai & 30STJ89 & 100,00 & 147,49 & 115,24 & 36,63 & 6605,04 & 331,02 & 20,20 & 310,82 & 75,09 & 236,35 & 236,35 & 67,44 & 452,42 & 53,79 & 5,80 & 43,54 & 154,66 & 37,88 & 37,88 & 141,99 \\
\hline Lissotriton boscai & 30STJ96 & 100,00 & 141,01 & 117,50 & 36,58 . & 6708,53 & 329,46 & 12,15 & 317,31 & 68,05 & 231,51 & 231,51 & 60,23 & 505,65 & 62,12 & 6,26 & 44,46 & 172,77 & 40,59 & 40,59 & 161,21 \\
\hline Lissotriton boscai & 30STJ97 & 100,00 & 127,72 & 116,23 & 36,51 & $\begin{array}{l}6662,72 \\
\end{array}$ & 315,44 & 1,45 & 313,99 & 55,93 & 218,06 & 218,12 & 48,59 & $\begin{array}{l}552,82 \\
\end{array}$ & 65,80 & 8,28 & 42,71 & 187,37 & $\begin{array}{l}48,65 \\
\end{array}$ & 48,73 & 174,55 \\
\hline Lissotriton boscai & 30STI98 & 100,00 & 132,35 & \begin{tabular}{ll|}
115,84 \\
\end{tabular} & 36,44 & $\begin{array}{l}6643,61 \\
\end{array}$ & 318,84 & 5,84 & 313,00 & 60,65 & 222,37 & 222,40 & 53,04 & \begin{tabular}{|l|l|}
517,27 \\
\end{tabular} & $\begin{array}{l}60,93 \\
\end{array}$ & 7,73 & 42,39 & 174,55 & 46,10 & 46,14 & 161,46 \\
\hline Lissotriton boscai & 30STK40 & 70,00 & 157,68 & 111,55 & 36,40 & 6477,31 & $\begin{array}{l}335,56 \\
\end{array}$ & 33,93 & 301,63 & 86,53 & 244,31 & 244,31 & 78,84 & $\begin{array}{l}455,27 \\
\end{array}$ & 55,76 & 4,71 & 46,00 & $\begin{array}{l}163,25 \\
\end{array}$ & 34,57 & 34,57 & 150,81 \\
\hline Lissotriton boscai & 305TK41 & 70,00 & 160,83 & 1111,62 & $\begin{array}{lll}36,88 & \end{array}$ & 6438,31 & 337,22 & 37,00 & 300,22 & 89,67 & 246,68 & 246,68 & 81,92 & $\mid 435,49$ & 53,34 & 4,25 & 45,75 & $\mid 156,26$ & \begin{tabular}{|c|c|}
32,98 \\
\end{tabular} & \begin{tabular}{|c|c|}
32,98 \\
\end{tabular} & $\begin{array}{lll}143,93 \\
\end{array}$ \\
\hline |Lissotriton boscai & 30STK42 & 61,00 & 159,72 & 111,47 & 37,00 & 6405,93 & 335,10 & 36,22 & 298,88 & 88,79 & 244,95 & 244,95 & 80,91 & 433,38 & 53,14 & 4,72 & 45,05 & 155,24 & 33,98 & 33,98 & 142,80 \\
\hline Lissotriton boscai & 30STK72 & 100,00 & 160,40 & 114,00 & 37,00 & 6459,10 & 338,21 & 34,19 & 304,02 & 108,40 & 246,64 & 246,64 & 81,15 & 388,79 & 46,46 & 5,00 & 43,09 & 134,24 & 32,95 & 32,95 & 121,76 \\
\hline Lissotriton boscai & 30SUH08 & 100,00 & 156,61 & 123,59 & 37,00 & 6837,61 & 350,97 & 22,84 & 328,13 & 81,95 & 248,43 & 248,43 & 73,45 & 549,13 & 74,76 & 3,80 & 52,03 & \begin{tabular}{|l|l|}
197,04 \\
\end{tabular} & 29,49 & 29,49 & 190,72 \\
\hline Lissotriton boscai & 30SUH19 & 100,00 & 156,72 & 123,25 & 37,00 & 6850,13 & 351,13 & 22,66 & 328,47 & 82,51 & 248,74 & 248,74 & 73,43 & 527,22 & 71,32 & 3,82 & 51,09 & 186,22 & 29,49 & 29,49 & 180,06 \\
\hline Lissotriton boscai & 30SUH20 & 100,00 & 164,69 & $\mid 123,62$ & 37,62 & 6753,70 & 356,12 & 31,21 & 324,91 & \begin{tabular}{|c|c|}
94,63 \\
\end{tabular} & 255,00 & 255,00 & 82,13 & 645,91 & 93,62 & 2,86 & 59,03 & 248,81 & 22,74 & 22,74 & 244,30 \\
\hline |Lissotriton boscai & 30SUH39 & 100,00 & 155,94 & 124,00 & 37,00 _ & 6899,70 & 351,46 & 21,01 & 330,45 & 85,36 & 248,87 & 248,87 & 72,04 & 516,53 & 69,93 & 3,90 & 50,60 & 179,69 & 29,56 & 29,56 & 174,11 \\
\hline Lissotriton boscai & 30SUH48 & 100,00 & 158,87 & 124,11 & 37,00 & 6901,36 & 354,40 & 23,56 & 330,84 & 88,28 & 251,73 & 251,73 & 75,01 & 516,26 & 70,91 & 3,53 & 51,42 & 181,79 & 27,87 & 27,87 & 175,64 \\
\hline Lissotriton boscai & 30SUH49 & 100,00 & 156,20 & 124,03 & 37,00 & 6904,72 & 351,85 & 21,02 & 330,83 & 85,84 & 249,25 & 249,25 & 72,32 & 508,38 & 68,64 & 3,86 & 50,16 & 176,05 & 29,40 & 29,40 & 170,30 \\
\hline Lissotriton boscai & 30SUH58 & 100,00 & 155,92 & 124,62 & 37,00 & 6916,51 & 352,13 & 20,50 & 331,63 & 87,59 & 249,11 & 249,11 & 72,13 & 518,13 & 70,77 & 3,93 & 50,58 & 181,39 & 29,22 & 29,22 & 174,72 \\
\hline Lissotriton boscai & 30SUH59 & 100,00 & 153,77 & 124,58 & 37,00 & 6913,86 & 349,99 & 18,56 & 331,43 & 100,63 & 247,06 & 247,06 & 70,13 & 508,30 & 68,12 & 4,05 & 49,48 & $\begin{array}{l}175,65 \\
\end{array}$ & 30,44 & 30,44 & 168,93 \\
\hline Lissotriton boscai & 30SUH61 & 100,00 & 168,19 & 1119,91 & 36,98 & \begin{tabular}{ll|l|}
6799,46 \\
\end{tabular} & 357,62 & $\begin{array}{l}35,53 \\
\end{array}$ & 322,10 & 98,02 & 259,55 & 259,55 & 85,31 & 583,79 & 86,68 & 3,14 & 57,68 & \begin{tabular}{|l|l|}
224,48 \\
\end{tabular} & 22,09 & 22,09 & 215,60 \\
\hline Lissotriton boscai & 30SUH66 & 100,00 & 147,75 & $\begin{array}{ll}124,62 \\
\end{array}$ & 37,00 & 6951,08 & 345,61 & 13,05 & 332,56 & 78,56 & 241,74 & 241,74 & 64,00 & 573,10 & 79,68 & 4,80 & 50,88 & 204,96 & 32,71 & 32,71 & 195,86 \\
\hline Lissotriton boscai & 30SUH68 & 100,00 & 153,25 & $\begin{array}{l}124,97 \\
\end{array}$ & 37,00 & 6928,40 & 350,03 & 17,89 & 332,15 & 104,50 & 246,76 & 246,76 & 69,48 & 517,11 & 70,02 & 4,09 & 49,73 & 180,85 & 30,47 & 30,47 & 172,72 \\
\hline Lissotriton boscai & 30SUH74 & 100,00 & 151,78 & 123,02 & 37,00 & 6941,81 & 348,19 & 17,94 & 330,25 & 80,72 & 245,66 & 245,66 & 68,25 & 582,21 & 83,49 & 4,44 & 52,59 & 214,36 & 30,20 & 30,20 & 203,55 \\
\hline Lissotriton boscai & 30SUH76 & 100,00 & 141,94 & 124,88 & 37,00 & 6962,21 & 340,69 & 7,44 & 333,25 & 90,01 & 236,19 & 236,19 & 58,53 & 583,66 & 80,33 & 5,47 & 49,59 & 208,01 & 35,86 & 35,86 & 197,16 \\
\hline Lissotriton boscai & 30SUH78 & 100,00 & 147,51 & 125,44 & 37,00 & 6943,53 & 345,35 & 11,86 & 333,49 & 101,89 & 241,28 & 241,28 & 63,78 & 527,11 & 70,51 & 4,52 & 48,64 & $\begin{array}{l}184,42 \\
\end{array}$ & 33,20 & 33,20 & 174,00 \\
\hline Lissotriton boscai & 30SUH79 & 100,00 & 146,89 & 125,74 & 37,00 & 6936,43 & 344,63 & 10,99 & 333,64 & 126,48 & 240,77 & 240,77 & 63,22 & \begin{tabular}{|l|l|}
511,78 \\
\end{tabular} & 67,01 & 4,52 & 47,64 & $\begin{array}{l}178,23 \\
\end{array}$ & 33,67 & 33,67 & 166,41 \\
\hline Lissotriton boscai & 30SUH83 & 100,00 & 150,42 & \begin{tabular}{ll|}
121,94 \\
\end{tabular} & 36,52 & 6952,54 & 346,31 & 17,11 & 329,19 & 79,19 & 244,50 & 244,50 & 66,77 & $\begin{array}{l}593,26 \\
\end{array}$ & 85,86 & 4,98 & 52,75 & 220,49 & 31,11 & 31,11 & 208,25 \\
\hline Lissotriton boscai & 30SUH84 & 100,00 & 154,04 & 122,48 & 36,91 & 6943,70 & 349,56 & 20,06 & 329,49 & 83,92 & 247,77 & 247,77 & 70,27 & 563,59 & 80,97 & 4,26 & 52,42 & 207,25 & 29,19 & 29,19 & 196,12 \\
\hline |Lissotriton boscai & 30SUH85 & 100,00 & 141,49 & 124,08 & 37,00 & $6965,81]$ & 339,93 & 7,69 & 332,24 & 91,04 & 235,90 & 235,90 & 58,33 & 591,33 & 82,19 & 5,76 & 49,85 & 213,17 & 36,21 & 36,21 . & 200,69 \\
\hline Lissotriton boscai & 30SUH86 & 100,00 & 145,59 & 124,74 & 37,00 & 6964,43 & 343,72 & 10,73 & 332,99 & 98,61 & 239,85 & 239,85 & 61,92 & 559,53 & 77,06 & 5,04 & 49,66 & 00,49 & 33,95 & 33,95 & 188,22 \\
\hline Lissotriton boscai & 30SUH91 & 100,00 & 173,91 & 1115,37 & 36,04 & \begin{tabular}{|l|l|}
6737,19 \\
\end{tabular} & 357,76 & 43,66 & 314,10 & 104,35 & 264,36 & 264,36 & 91,91 & 522,34 & 77,31 & 3,08 & 56,38 & 200,06 & 20,91 & 20,91 & 190,64 \\
\hline Lissotriton boscai & 30SUH92 & 100,00 & 163,76 & 118,20 & \begin{tabular}{l|l|l}
36,05 \\
\end{tabular} & 6865,54 & 353,73 & 32,17 & $\begin{array}{l}321,56 \\
\end{array}$ & 93,18 & 256,31 & 256,31 & 80,76 & 550,32 & 81,49 & 3,78 & 54,71 & 208,74 & 24,99 & 24,99 & 196,92 \\
\hline Lissotriton boscai & 30SUH93 & 100,00 & 157,60 & 120,31 & 36,39 & 6920,18 & 350,89 & 25,01 & 325,88 & 91,03 & 251,12 & 251,12 & 74,21 & 557,10 & 81,35 & 4,24 & 53,21 & $\begin{array}{l}207,95 \\
\end{array}$ & 27,88 & 27,88 & 195,62 \\
\hline Lissotriton boscai & 30SUH94 & 100,00 & 155,04 & 121,73 & 36,89 & 6927,27 & 349,65 & 21,51 & 328,14 & 100,29 & 248,67 & 248,67 & 71,53 & $\begin{array}{l}549,85 \\
\end{array}$ & 78,94 & 4,31 & 52,02 & 02,57 & 29,14 & 29,14 & 190,15 \\
\hline Lissotriton boscai & 30SUH95 & 100,00 & 140,41 & 124,03 & 37,00 & 6966,58 & 338,94 & 6,78 & 332,16 & 92,96 & 235,03 & 235,03 & 57,38 & \begin{tabular}{|l|l|}
584,27 \\
\end{tabular} & 80,83 & 5,92 & 49,15 & 211,03 & 37,01 & 37,01 & 196,48 \\
\hline 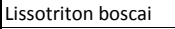 & 30SUJ02 & 100,00 & 159,36 & 121,10 & 37,00 & 6790,35 & 350,59 & 26,64 & 323,95 & 89,07 & 250,54 & 250,54 & 76,72 & \begin{tabular}{|l|l|}
476,07 \\
\end{tabular} & 62,28 & 3,92 & 49,00 & 166,33 & 29,72 & 29,72 & 157,84 \\
\hline Lissotriton boscai & 30SUJ03 & 100,00 & 158,62 & 120,52 & 37,00 & 6769,54 & 348,91 & 26,27 & 322,64 & 99,67 & 249,47 & 249,47 & 76,11 & 465,44 & 60,16 & 3,94 & 48,21 & 161,70 & 30,25 & 30,25 & 152,66 \\
\hline Lissotriton boscai & 30SUJ04 & 100,00 & 156,92 & 119,92 & 37,00 & \begin{tabular}{ll|l|}
6755,07 \\
\end{tabular} & 346,35 & 25,01 & 321,34 & 102,60 & 247,57 & 247,57 & 74,59 & $\begin{array}{l}458,75 \\
\end{array}$ & 58,51 & 4,14 & 47,32 & $\begin{array}{l}158,13 \\
\end{array}$ & 31,29 & 31,29 & 148,60 \\
\hline Lissotriton boscai & 30SUJ05 & 100,00 & 153,83 & 119,08 & 36,97 & \begin{tabular}{|l|l|}
6740,80 \\
\end{tabular} & 342,60 & 22,66 & 319,95 & 96,68 & 244,34 & 244,34 & 71,93 & 457,30 & 57,37 & 4,52 & 46,15 & $\begin{array}{l}156,56 \\
\end{array}$ & 33,04 & 33,04 & 146,30 \\
\hline Lissotriton boscai & 30SUJ08 & 100,00 & 137,04 & $\begin{array}{ll}116,82 \\
\end{array}$ & 36,70 & 6673,35 & 323,89 & 8,81 & 315,09 & $\mid 77,53$ & 227,21 & 227,23 & 56,81 & \begin{tabular}{|l|l|}
486,26 \\
\end{tabular} & 57,10 & 7,11 & 42,11 & $\mid$\begin{tabular}{|l|l|}
162,30 \\
\end{tabular} & 43,28 & 43,30 & \begin{tabular}{ll|l}
149,61 \\
\end{tabular} \\
\hline Lissotriton boscai & 30SUJ09 & 100,00 & 145,21 & 116,46 & 36,88 & $\begin{array}{l}6640,38 \\
\end{array}$ & 330,17 & 16,56 & 313,60 & 96,42 & $\begin{array}{l}234,72 \\
\end{array}$ & $\begin{array}{l}234,72 \\
\end{array}$ & \begin{tabular}{ll|l}
64,74 \\
\end{tabular} & 440,33 & 51,25 & 6,19 & 42,26 & 147,34 & 38,79 & 38,79 & 134,21 \\
\hline Lissotriton boscai & 30SUJ10 & 100,00 & 160,25 & 122,95 & 37,00 & 6834,18 & 353,38 & 26,25 & 327,13 & 88,09 & 251,96 & 251,96 & 76,84 & \begin{tabular}{|l|l|}
497,58 \\
\end{tabular} & 66,73 & 3,46 & 50,66 & $\mid$\begin{tabular}{|l|l|}
174,90 \\
\end{tabular} & 28,12 & 28,12 & 168,17 \\
\hline Lissotriton boscai & 30SUJ11 & 100,00 & 157,28 & 122,27 & 37,00 & 6821,56 & 350,13 & 23,83 & 326,31 & 87,09 & 248,91 & 248,91 & 74,36 & 493,68 & 65,26 & 4,00 & 49,40 & 171,72 & 30,24 & 30,24 & 164,36 \\
\hline Lissotriton boscai & 30SUJ12 & 100,00 & 158,19 & 121,74 & 37,00 & 6812,73 & 350,10 & 25,05 & 325,05 & 103,86 & 249,71 & 249,71 & 75,26 & 474,85 & 61,96 & 3,89 & 48,81 & $\mid 164,18$ & 29,88 & 29,88 & 156,28 \\
\hline Lissotriton boscai & 30SUJ13 & 100,00 & 156,64 & 121,00 & 37,00 & 6801,50 & 347,80 & 23,78 & 324,02 & \begin{tabular}{|l|}
105,67 \\
\end{tabular} & 248,01 & 248,01 & 73,92 & 465,89 & 59,87 & 4,12 & 47,67 & 160,01 & 31,00 & 31,00 & 151,35 \\
\hline Lissotriton boscai & 30SUJ14 & 100,00 & 158,51 & 120,24 & 37,00 & \begin{tabular}{|l|l|}
6776,48 \\
\end{tabular} & 348,22 & 25,77 & 322,45 & 1113,71 & 249,50 & 249,50 & 75,81 & \begin{tabular}{|l|l|}
446,28 \\
\end{tabular} & 56,61 & 4,03 & 47,15 & $\begin{array}{l}153,15 \\
\end{array}$ & \begin{tabular}{|l|l|}
30,48 \\
\end{tabular} & \begin{tabular}{|l|l|}
30,48 \\
\end{tabular} & 143,51 \\
\hline Lissotriton boscai & 30SUJ15 & 100,00 & 156,77 & \begin{tabular}{ll|}
119,64 \\
\end{tabular} & 36,98 & 6758,22 & 345,78 & 24,61 & 321,17 & 114,42 & 247,55 & 247,55 & 74,36 & 439,26 & 54,84 & 4,23 & 46,27 & $\begin{array}{l}149,96 \\
\end{array}$ & 31,43 & 31,43 & 139,35 \\
\hline Lissotriton boscai & 30SUJ19 & 100,00 & 148,04 & 116,97 & $36,97 \mid$ & $6669,21$. & 333,37 . & 18,23 & 15,14 & 109,39 & 237,87 & 237,87 & 67,00 & 421,03 & 48,61 & 5,94 & 41,92 & 140,41 & 37,41 & 37,41 & 126,60 \\
\hline Lissotriton bo & $305 \mathrm{UJ} 20$ & 100, & & 123 & 37,0 & 6860, & 251 & 22, & 3 & 86 & 249,08 & 24 & 73 & 503,85 & 67,41 & 38 & & 17 & 29,59 & 29,59 & 16 \\
\hline 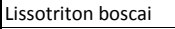 & 30SUJ21 & 100,00 & 150,90 & 122,81 & 37,00 & 6860,03 & 345,34 & 17,14 & 328,20 & 83,00 & 243,38 & 243,38 & 67,96 & 511,42 & 67,13 & 4,54 & 48,50 & 175,59 & 32,87 & 32,87 & 168,88 \\
\hline Lissotriton boscai & 30 SUJ22 & 100,00 & 154,62 & 122,09 & 37,00 & 6835,34 & 347,53 & 20,91 & 326,62 & 106,33 & 246,51 & 246,51 & 71,58 & 481,43 & 62,50 & 4,12 & 48,03 & 164,49 & 31,29 & 31,29 & 157,19 \\
\hline
\end{tabular}




\begin{tabular}{|c|c|c|c|c|c|c|c|c|c|c|c|c|c|c|c|c|c|c|c|c|c|}
\hline TAXON & UTM & $\mathrm{km2}$ & BIO1 & B102 & $\mathrm{BIO3}$ & B104 & B105 & B106 & B107 & B108 & B109 & BIO10 & BIO11 & B1012 & BIO13 & BIO14 & BIO15 & BIO16 & BIO17 & BIO18 & BI019 \\
\hline Lissotriton boscai & 30SUJ23 & 100,00 & 154,21 & 121,51 & 37,00 & 6828,54 & 346,38 & 21,01 & 325,37 & 117,96 & 246,11 & 246,11 & 71,29 & 468,02 & 59,81 & 4,23 & 47,12 & 159,10 & 31,90 & 31,90 & 150,66 \\
\hline Lissotriton boscai & 30SUJ24 & 100,00 & 155,18 & 120,80 & 37,00 & 6806,05 & 346,03 & 22,25 & 323,78 & 119,90 & \begin{tabular}{|l|l|}
246,76 \\
\end{tabular} & 246,76 & 72,42 & 450,64 & 56,65 & 4,29 & \begin{tabular}{l|l|}
46,35 \\
\end{tabular} & \begin{tabular}{|l|l|}
153,20 \\
\end{tabular} & 31,85 & \begin{tabular}{l|l|}
31,85 \\
\end{tabular} & 143,24 \\
\hline Lissotriton boscai & 30SUJ25 & 100,00 & 154,72 & 120,04 & 36,99 & 6787,16 & 344,53 & 21,95 & 322,58 & 120,57 & \begin{tabular}{|l|l|}
246,02 \\
\end{tabular} & 246,02 & 72,17 & 439,75 & 54,41 & 4,44 & 45,49 & \begin{tabular}{ll|}
148,96 \\
\end{tabular} & 32,50 & 32,50 & 138,06 \\
\hline Lissotriton boscai & 30 SUJ27 & 100,00 & 144,30 & 118,69 & 36,73 & 6749,11 & 333,08 & 13,26 & \begin{tabular}{|l|}
319,82 \\
\end{tabular} & \begin{tabular}{l|l|l|}
127,03 \\
\end{tabular} & 235,39 & 235,39 & 62,75 & 450,37 & 53,29 & 5,94 & 42,70 & \begin{tabular}{l|l|}
150,73 \\
\end{tabular} & 38,40 & 38,40 & 136,93 \\
\hline Lissotriton boscai & 30SUJ28 & 100,00 & 144,97 & 117,94 & 36,74 & 6718,73 & 332,18 & 14,32 & $317,86 \mid$ & $127,65 \mid$ & 235,58 & 235,58 . & 63,70 . & $436,21 \mid$ & 50,57 & 6,14 & 41,94 & $145,34 \mid$ & 38,68 & 38,68 & 130,82 \\
\hline Lissotriton boscai & 30 SUJ31 & 100,00 & 150,96 & 123,14 & 37,00 & 6882,02 & 345,94 & \begin{tabular}{|l|l|}
16,56 \\
\end{tabular} & 329,38 & 115,15 & 243,83 & 243,83 & 67,74 & 502,99 & 65,85 . & 4,31 & 48,20 & 171,38 & 32,64 & 32,64 & 164,81 \\
\hline Lissotriton boscai & 30SUJ32 & 100,00 & 151,82 & 122,74 & 37,00 & 6864,87 & 345,74 & 17,56 & 328,18 & 132,25 & 244,36 & 244,36 & 68,72 & \begin{tabular}{ll|}
484,56 \\
\end{tabular} & \begin{tabular}{l|l}
62,45 \\
\end{tabular} & 4,38 & 47,40 & $\begin{array}{ll}164,73 \\
\end{array}$ & 32,69 & 32,69 & 156,66 \\
\hline Lissotriton boscai & 30SUJ33 & 100,00 & 149,19 & 122,03 & 37,00 & 6854,45 & 342,55 & 15,48 & 327,07 & \begin{tabular}{|l|l|l|}
131,88 \\
\end{tabular} & 241,58 & 241,58 & 66,27 & 479,43 & 60,62 & 4,86 & \begin{tabular}{ll|l}
46,07 \\
\end{tabular} & \begin{tabular}{|l|l|}
162,71 \\
\end{tabular} & \begin{tabular}{|l|l|}
34,47 \\
\end{tabular} & \begin{tabular}{|l|l}
34,47 \\
\end{tabular} & 152,56 \\
\hline Lissotriton boscai & 30SUJ35 & 100,00 & 152,93 & 120,36 & 37,00 & 6810,05 & 343,39 & \begin{tabular}{ll|l}
19,86 \\
\end{tabular} & 323,53 & \begin{tabular}{ll|}
133,26 \\
\end{tabular} & 244,65 & 244,65 & 70,08 & 439,24 & 53,72 & 4,65 & 44,76 & \begin{tabular}{|l|l|}
148,41 \\
\end{tabular} & 33,46 & 33,46 & 136,42 \\
\hline Lissotriton boscai & 30SUJ36 & 100,00 & 152,20 & 119,78 & 36,92 & 6784,40 & 341,57 & 19,43 & 322,15 & 134,07 & 243,51 & 243,51 & 69,69 & 428,59 & 51,38 & 4,99 & 43,87 & 144,37 & 34,22 & 34,22 & 131,29 \\
\hline Lissotriton boscai & 30SUJ37 & 100,00 & 144,70 & 119,00 & 36,75 & 6775,17 & 333,91 & 12,81 & 321,10 & 128,67 & 236,24 & 236,24 & \begin{tabular}{|l|l|l|}
62,83 \\
\end{tabular} & 441,99 & 51,74 & 5,98 & \begin{tabular}{l|l}
42,35 \\
\end{tabular} & \begin{tabular}{|l|l|}
148,48 \\
\end{tabular} & 38,34 & 38,34 & 132,89 \\
\hline Lissotriton boscai & 30SUJ38 & 100,00 & 131,12 & 117,91 & 36,48 & 6727,14 & 319,99 & 1,57 & 318,42 & \begin{tabular}{|l|l|}
114,04 \\
\end{tabular} & 222,45 & 222,45 & 50,72 & $\begin{array}{l}480,95 \\
\end{array}$ & 55,18 & 8,10 & 40,09 & \begin{tabular}{l|l|}
160,68 \\
\end{tabular} & 46,89 & 46,89 & 141,54 \\
\hline Lissotriton boscai & 30SUJ40 & 100,00 & 152,11 & 124,00 & 37,00 & 6903,59 & 347,91 & 17,13 & 330,78 & 115,87 & 245,17 & 245,17 & 68,48 & 506,47 & 67,03 & 4,21 & 48,74 & 173,36 & 31,73 & 31,73 & 166,86 \\
\hline Lissotriton boscai & 30SUJ42 & 100,00 & 146,07 & 123,11 & 37,00 & 6891,55 & 341,34 & 11,74 & 329,60 & 129,14 & 239,19 & 239,19 & \begin{tabular}{l|l|l}
62,95 \\
\end{tabular} & $\begin{array}{l}497,35 \\
\end{array}$ & 63,27 & 5,08 & \begin{tabular}{l|l}
46,15 \\
\end{tabular} & \begin{tabular}{l|l|}
169,92 \\
\end{tabular} & \begin{tabular}{|l|}
35,59 \\
\end{tabular} & 35,59 & 158,83 \\
\hline Lissotriton boscai & 30SUJ43 & 100,00 & 145,44 & 122,64 & 37,00 & 6874,67 & 339,72 & 11,30 & \begin{tabular}{|l|l|}
328,42 \\
\end{tabular} & $\begin{array}{ll}128,48 \\
\end{array}$ & 238,21 & 238,21 & 62,43 & 485,61 & 60,68 & 5,23 & 45,2 & 165,68 & 36,31 & 36,31 & 152,99 \\
\hline Lissotriton boscai & 30SUJ46 & 100,00 & 149,38 & 120,01 & 36,91 & 6803,76 & 339,39 & 16,32 & \begin{tabular}{|l|l|}
323,06 \\
\end{tabular} & \begin{tabular}{|l|l|}
133,49 \\
\end{tabular} & \begin{tabular}{|l|l|}
241,15 \\
\end{tabular} & \begin{tabular}{|l|l|}
241,15 \\
\end{tabular} & \begin{tabular}{|l|l|l|}
66,78 \\
\end{tabular} & \begin{tabular}{|l|l|}
431,73 \\
\end{tabular} & $\begin{array}{l}51,15 \\
\end{array}$ & 5,34 & 43,24 & \begin{tabular}{|l|l|}
146,16 \\
\end{tabular} & 35,74 & 35,74 & 130,47 \\
\hline Lissotriton boscai & 30SUJ47 & 100,00 & 139,20 & 119,04 & 36,58 & 6777,43 & 328,92 & 7,78 & 321,14 & 122,71 & 231,06 & 231,06 & 57,63 & 456,81 & 52,81 & 6,85 & 41,34 & \begin{tabular}{l|l|}
153,92 \\
\end{tabular} & \begin{tabular}{|l|l|}
41,97 \\
\end{tabular} & \begin{tabular}{|l|l}
41,97 \\
\end{tabular} & 135,41 \\
\hline Lissotriton boscai & 30 SUJ 48 & 100,00 & 128,70 & 118,21 & 36,60 & 6735,84 & 318,01 & $-0,92$ & 318,93 & 111,44 & 220,25 & 220,25 & 48,31 & 482,80 & 55,92 & 8,52 & 39,42 & \begin{tabular}{|l|l|}
161,99 \\
\end{tabular} & 48,59 & 48,59 & 140,19 \\
\hline Lissotriton boscai & 30SUJ49 & 100,00 & 140,21 & 117,42 & 36,08 & 6738,94 & 327,38 & 9,10 & 318,27 & 124,44 & 231,39 & 231,39 & 58,99 & 427,31 & 49,60 & 6,98 & 39,94 & \begin{tabular}{ll|}
142,94 \\
\end{tabular} & \begin{tabular}{l|l|l}
41,89 \\
\end{tabular} & \begin{tabular}{ll|}
41,89 \\
\end{tabular} & 123,03 \\
\hline Lissotriton boscai & 30SUJ50 & 100,00 & 148,90 & 124,47 & 37,00 & 6917,34 & 345,44 & 13,79 & 331,64 & \begin{tabular}{l|l|}
128,63 \\
\end{tabular} & 242,25 & 242,25 & 65,3 & 509,58 & 66,83 & 4,47 & 47,94 & \begin{tabular}{|l|l|}
175,40 \\
\end{tabular} & 33,10 & 33,10 & 166,39 \\
\hline Lissotriton boscai & 30 SUJ52 & 100,00 & 147,69 & 123,67 & 37,00 & 6888,11 & 342,84 & 12,90 & 329,94 & \begin{tabular}{|l|l|}
130,79 \\
\end{tabular} & \begin{tabular}{|l|l}
240,73 \\
\end{tabular} & \begin{tabular}{|l|l|}
240,73 \\
\end{tabular} & 64,54 & 482,92 & $\begin{array}{ll}60,95 \\
\end{array}$ & 4,93 & \begin{tabular}{|l|}
45,89 \\
\end{tabular} & \begin{tabular}{|l|}
165,87 \\
\end{tabular} & 34,88 & 34,88 & 153,01 \\
\hline Lissotriton boscai & 30SUJ53 & 100,00 & 149,64 & 122,92 & 37,00 & 6866,68 & 343,38 & 14,90 & 328,48 & \begin{tabular}{|l|l|l|}
133,16 \\
\end{tabular} & 242,41 & 242,41 & 66,54 & 462,56 & 57,40 & 4,74 & \begin{tabular}{l|l|}
45,35 \\
\end{tabular} & $\begin{array}{l}158,46 \\
1\end{array}$ & \begin{tabular}{|l|l|}
34,27 \\
\end{tabular} & \begin{tabular}{|l|}
34,27 \\
\end{tabular} & 144,74 \\
\hline Lissotriton boscai & 30SUJ54 & 100,00 & $\begin{array}{ll}147,92 \\
\end{array}$ & 122,07 & 37,00 & 6864,75 & 340,99 & 13,44 & 327,55 & \begin{tabular}{|l|l|}
131,67 \\
\end{tabular} & 240,57 & 240,57 & 64,81 & 455,88 & 55,47 & 5,07 & 44,39 & $\begin{array}{l}155,87 \\
\end{array}$ & 35,52 & 35,52 & 140,57 \\
\hline Lissotriton boscai & 30SUJ55 & 100,00 & 146,73 & 121,31 & 37,00 & 6863,51. & 338,99 & 12,70 & 326,29 & 130,64 & 239,38 & 239,38 & 63,78 . & 446,39 | & 53,20 & 5,31. & 43,38 & $152,17 \mid$ & 36,42 & 36,42 & 135,53 \\
\hline Lissotriton boscai & 30SUJ56 & 100,00 & 144,03 & 120,42 & 36,71 & 6835,28 & 335,41 & 10,61 & 324,80 & \begin{tabular}{ll|}
127,69 \\
\end{tabular} & 236,51 & 236,51 & 61,60 & 443,45 & \begin{tabular}{ll|l}
51,75 \\
\end{tabular} & 5,95 & 42,22 & \begin{tabular}{l|l}
150,82 \\
\end{tabular} & 38,71 & 38,71 & 132,20 \\
\hline Lissotriton boscai & 30SUJ57 & 100,00 & 132,87 & 119,36 & 36,71 & 6787,24 & 323,47 & 1,64 & 321,84 & 115,81 & 224,95 & 224,97 & 51,61 & \begin{tabular}{|l|l|}
473,97 \\
\end{tabular} & 54,74 & 7,79 & 40,19 & 160,11 & 46,02 & 46,03 & 138,46 \\
\hline Lissotriton boscai & 30 SUJ58 & 100,00 & 131,10 & 118,38 & 36,48 & 6761,15 & 320,51 & \begin{tabular}{l|l|}
0,67 \\
\end{tabular} & 319,85 & \begin{tabular}{ll|}
114,06 \\
\end{tabular} & \begin{tabular}{|l|l|}
222,93 \\
\end{tabular} & 222,93 & 50,26 & \begin{tabular}{ll|}
467,69 \\
\end{tabular} & 54,66 & 8,25 & 39,29 & \begin{tabular}{ll|}
157,42 \\
\end{tabular} & 47,50 & 47,50 & 134,38 \\
\hline Lissotriton boscai & 30SUJ59 & 100,00 & 139,33 & 117,47 & 36,02 & 6758,71 & 326,81 & 7,85 & 318,96 & 123,33 & 230,97 & \begin{tabular}{|l|}
230,97 \\
\end{tabular} & 57,93 & 426,18 & $\begin{array}{l}49,96 \\
\end{array}$ & 7,13 & 39,41 & \begin{tabular}{|l|l|}
142,91 \\
\end{tabular} & \begin{tabular}{l|l}
42,85 \\
\end{tabular} & \begin{tabular}{l|l}
42,85 \\
\end{tabular} & 121,35 \\
\hline Lissotriton boscai & 30SUJ61 & 100,00 & 147,49 & 124,72 & 37,00 & 6918,40 & 343,85 & $11,91 \mid$ & $331,94 \mid$ & $130,79 \mid$ & $240,96[$ & 240,96 & 63,70 . & $489,01[$ & 62,27 & 4,62 & 46,51 . & 169,13 & 34,19 ] & 34,19 ] & 155,95 \\
\hline Lissotriton boscai & 30SUJ62 & 100,00 & 149,63 & 123,97 & 37,00 & 6899,46 & 344,74 & 14,23 & 330,51 & \begin{tabular}{|l|}
133,09 \\
\end{tabular} & 242,72 & 242,72 & \begin{tabular}{|l|l|l|}
66,02 \\
\end{tabular} & 467,27 & 58,39 & 4,57 & 45,74 & \begin{tabular}{|l|l|l|}
161,13 \\
\end{tabular} & 33,77 & 33,77 & $\begin{array}{lll}147,07 \\
\end{array}$ \\
\hline Lissotriton boscai & 30SUJ63 & 100,00 & 145,25 & 123,52 & 37,00 & 6890,92 & 340,28 & \begin{tabular}{l|l|l|}
10,49 \\
\end{tabular} & 329,79 & 128,27 & 238,45 & 238,45 & \begin{tabular}{ll|}
62,09 \\
\end{tabular} & 469,25 & 57,34 & 5,25 & 44,38 & \begin{tabular}{|l|l|l|}
161,49 \\
\end{tabular} & 36,57 & 36,57 & 145,12 \\
\hline Lissotriton boscai & 30 SUJ64 & 100,00 & 145,08 & 122,74 & 37,00 & 6870,34 & 338,94 & 10,49 & 328,45 & 128,49 & 238,01 & 238,01 & 62,12 & 457,61 & 54,77 & 5,32 & 43,57 & 157,08 & 37,04 & 37,04 & 139,56 \\
\hline Lissotriton boscai & 30SUJ65 & 100,00 & 141,45 & 121,91 & 36,99 & 6863,46 & 334,63 & 7,48 & 327,16 & 124,84 & 234,37 & 234,37 & 58,69 & 459,14 & $\begin{array}{l}53,75 \\
\end{array}$ & 5,96 & 42,35 & \begin{tabular}{|l|l|}
157,07 \\
\end{tabular} & 39,61 & 39,61 & 137,65 \\
\hline Lissotriton boscai & 30SUJ66 & 100,00 & 138,87 & 120,82 & 36,84 & 6853,41 & 330,98 & 5,46 & \begin{tabular}{|l|l|}
325,52 \\
\end{tabular} & \begin{tabular}{|l|l|}
122,02 \\
\end{tabular} & 231,64 & \begin{tabular}{|l|l|}
231,64 \\
\end{tabular} & 56,39 & \begin{tabular}{|l|l|}
456,53 \\
\end{tabular} & 52,59 & 6,61 & 41,24 & \begin{tabular}{|l|l|}
155,54 \\
\end{tabular} & \begin{tabular}{|l|l|}
41,78 \\
\end{tabular} & \begin{tabular}{|l|l|}
41,78 \\
\end{tabular} & 134,68 \\
\hline Lissotriton boscai & 30SUJ67 & 100,00 & 133,27 & 119,57 & 36,55 & 6810,94 & 324,28 & 1,23 & 323,05 & 116,30 & 225,70 & 225,72 & \begin{tabular}{l|l}
51,75 \\
\end{tabular} & 467,28 & 54,22 & 7,76 & 39,82 & 158,18 & 45,99 & 46,01 & 135,44 \\
\hline Lissotriton boscai & 30SUJ68 & 100,00 & 127,92 & 118,44 & $\begin{array}{ll}36,46 \\
\end{array}$ & 6771,95 & 317,75 & $-2,49$ & 320,25 & \begin{tabular}{l|l}
110,53 \\
\end{tabular} & \begin{tabular}{|l|l|}
220,03 \\
\end{tabular} & \begin{tabular}{|l|l|}
220,03 \\
\end{tabular} & 47,24 & 475,21 & 56,03 & 8,85 & 38,49 & $\begin{array}{ll}160,12 \\
\end{array}$ & \begin{tabular}{|l|l|}
49,94 \\
\end{tabular} & 49,94 & 135,27 \\
\hline Lissotriton boscai & 30SUJ69 & 100,00 & $\begin{array}{l}138,46 \\
\end{array}$ & 117,39 & 36,06 & 6776,79 & 326,03 & 6,79 & 319,24 & 122,33 & 230,29 & 230,29 & 56,83 & 426,07 & 50,24 & 7,51 & 38,77 & \begin{tabular}{ll|}
142,88 \\
\end{tabular} & 43,81 & 43,81 & 120,28 \\
\hline Lissotriton boscai & 30 SUJ70 & 100,00 & 149,86 & 125,35 & 37,00 & 6926,91 & 346,50 & 13,57 & \begin{tabular}{|l|}
332,92 \\
\end{tabular} & 133,03 & 243,32 & 243,32 & \begin{tabular}{|l|l|}
66,07 \\
\end{tabular} & 485,27 & 62,41 & 4,04 & $\begin{array}{ll}47,35 \\
\end{array}$ & \begin{tabular}{|l|l|}
168,93 \\
\end{tabular} & 32,20 & 32,20 & $\begin{array}{lll}156,07 \\
\end{array}$ \\
\hline Lissotriton boscai & 30SUJ71 & 100,00 & 150,08 & 125,08 & 37,00 & 6909,14 & 346,05 & 13,92 & 332,12 & 133,77 & 243,34 & 243,34 & 66, & 469,68 & 59,18 & 4,21 & 46,3 & $\begin{array}{l}163,15 \\
\end{array}$ & 2,79 & 2,79 & 148,78 \\
\hline Lissotriton boscai & 30SUJ72 & 100,00 & 144,93 & 124,86 & 37,00 & 6910,35 & 341,01 & \begin{tabular}{l|l|}
9,19 \\
\end{tabular} & \begin{tabular}{|l|l|}
331,82 \\
\end{tabular} & 128,45 & 238,29 & 238,29 & \begin{tabular}{|l|l|l|}
61,42 \\
\end{tabular} & 474,52 & 58,32 & 4,97 & \begin{tabular}{|l|l|l|}
44,83 & \\
\end{tabular} & \begin{tabular}{|l|l|}
164,41 \\
\end{tabular} & \begin{tabular}{|l|}
36,07 \\
\end{tabular} & \begin{tabular}{|l|l|}
36,07 \\
\end{tabular} & 147,54 \\
\hline Lissotriton boscai & 30SUJ73 & 100,00 & 140,36 & 124,17 & 37,00 & 6901,19 & 336,28 & 5,26 & \begin{tabular}{|l|l|}
331,02 \\
\end{tabular} & 123,41 & \begin{tabular}{|l|l|}
233,78 \\
\end{tabular} & 233,78 & 57,29 & 478,84 & 57,47 & 5,66 & 43,40 & \begin{tabular}{|l|l|}
165,37 \\
\end{tabular} & 39,18 & 39,18 & 146,33 \\
\hline Lissotriton boscai & 30 SUJ74 & 100,00 & 143,51 & 123,26 & 37,00 & 6884,85 & 337,84 & 8,47 & 329,36 & 126,77 & 236,64 & 236,64 & 60,49 & 455,14 & 53,60 & 5,38 & \begin{tabular}{ll|}
42,92 \\
\end{tabular} & $\begin{array}{l}156,66 \\
1\end{array}$ & 37,91 & 37,91 & 137,36 \\
\hline Lissotriton boscai & 30SUJ75 & 100,00 & 140,25 & 122,33 & 37,00 & 6876,04 & 333,81 . & 5,9 & 327,85 | & $123,67 \mid$ & 233,36 & 233,36 & $57,40 \mid$ & 456,66 & 52,75 & 6,19 & 41,78 & 156,56 & 40,66 & 40,66 & 135,52 \\
\hline Lissotriton boscai & 30 SUJ76 & 100,00 & 131,62 & 121,11 & 36,99 & 845,36 & 1 & $-0,64$ & 325,36 & 114,22 & 224,64 & 224,64 & \begin{tabular}{l|l}
49,95 \\
\end{tabular} & 478,72 & 55,45 & 7,72 & $40, \mathrm{C}$ & 163,20 & 6,50 & 6,50 & 139,57 \\
\hline Lissotriton boscai & 30SUI77 & 100,00 & 129,08 & 119,84 & 36,69 & 6811,62 & 32 & $-2,58$ & 323,17 & 111,64 & 221,71 & 221,73 & 47,82 & 479,38 & 56,10 & 8,50 & 38,99 & 162,42 & 49,09 & 49,11 & 137,63 \\
\hline Lissotriton boscai & 30SUJ78 & 100,00 & 129,47 & 118,53 & 36,27 & 6797,85 & 319,50 & $-1,77$ & 321,27 & 112,44 & 221,84 & 221,86 & 48,38 & 467,19 & 55,19 & 8,76 & 38,21 & \begin{tabular}{l|l|l|}
157,42 \\
\end{tabular} & 49,51 & 49,52 & 132,25 \\
\hline Lissotriton boscai & 30 SUJ82 & 100,00 & 142,16 & 125,58 & 37,00 & 6902,37 & 338,97 & 6,55 & \begin{tabular}{|l|l|}
332,42 \\
\end{tabular} & 125,21 & 235,64 & 235,64 & 59,16 & 475,08 & 57,40 & 5,16 & 44,01 & $\begin{array}{ll}165,12 \\
\end{array}$ & 37,56 & 37,56 & \begin{tabular}{|l|l|}
146,14 \\
\end{tabular} \\
\hline Lissotriton boscai & 30SUJ84 & 100,00 & 147,10 & 123,58 & 37,00 & 6891,58 & 341,06 & 11,29 & 329,77 & 130,97 & 240,20 & 240,20 & 63,63 & 435,05 & 50,60 & 5,04 & 43,12 & 150,06 & 36,03 & 36,03 & 130,50 \\
\hline Lissotriton boscai & 30SUJ85 & 100,00 & 139,86 & 122,68 & 37,00 & 6883,90 & 333,48 & 5,15 & 328,33 & 123,22 & 233,10 & 233,10 & 57,01 & 452,03 & 52,22 & 6,18 & 41,36 & \begin{tabular}{|l|l|}
154,99 \\
\end{tabular} & 41,14 & 41,14 & 133,15 \\
\hline Lissotriton boscai & 30 SUJ86 & 100,00 & 139,18 & 121,51 & 37,00 & 6872,99 & 331 & 5,03 & 326,69 & \begin{tabular}{|l|l|}
122,69 \\
\end{tabular} & 232,32 & 232,32 & 56,42 & 445,18 & 51,66 & 6,55 & 40,38 & 151,85 & 42,23 & 42,23 & 129,33 \\
\hline Lissotriton boscai & 30SUJ87 & 100,00 & 128,53 & 120,22 & 36,90 & 6825,34 & 320,44 & $-3,11$ & 323,55 & \begin{tabular}{ll|}
111,06 \\
\end{tabular} & 221,42 & 221,42 & \begin{tabular}{l|l|l}
47,25 \\
\end{tabular} & \begin{tabular}{ll|}
476,95 \\
\end{tabular} & 56,08 & 8,54 & 38,63 & \begin{tabular}{ll|}
161,68 \\
\end{tabular} & 49,58 & \begin{tabular}{|l|l|}
49,58 \\
\end{tabular} & 136,07 \\
\hline Lissotriton boscai & 30 SUJ88 & 100,00 & 137,01 & 118,73 & 36,06 & 6843,51 & 326,82 & 3,88 & 322,94 & 120,65 & 229,86 & 229,86 & 54,64 & 436,48 & 51,38 & 7,67 & 38,58 & \begin{tabular}{ll|}
147,06 \\
\end{tabular} & \begin{tabular}{|l|l|}
45,13 \\
\end{tabular} & 45,13 & 123,42 \\
\hline Lissotriton boscai & 30SUJ89 & 100,00 & 141,21 & 117,18 & 36,00 & 6841,64 & 32 & \begin{tabular}{|l|}
8,27 \\
\end{tabular} & 320,60 & 125,26 & 233,80 & 233,80 & 58, & 415,03 & 48,84 & 7,40 & 38,23 & 138,75 & 43,40 & 43,40 & 116,36 \\
\hline Lissotriton boscai & $305 \mathrm{~S}$ & 100,00 & 14 & 126,23 & 37 & 6888,05 & & 10,26 & 332 & 136 & 239 & 239 & 63, & 447 & 53,12 & \begin{tabular}{|l|l|}
4,36 \\
\end{tabular} & $44-2>3$ & 155,79 & 34,83 & $34,8>>3$ & $\mid 136,70$ \\
\hline Lissotriton boscai & 30SUJ97 & 100,00 & 132,15 & 120,44 & 36,84 & 6851,92 & 324,03 & $-0,53$ & \begin{tabular}{|l|l|}
324,56 \\
\end{tabular} & 115,20 & 225,31 & 225,31 & 50,23 & 460,33 & 54,11 & 8,08 & \begin{tabular}{|l|}
38,49 \\
\end{tabular} & 155,84 & 47,81 & 47,81 & 130,91 \\
\hline Lissotriton boscai & 30SUJ98 & 100,00 & 131,73 & 118,86 & 36,18 & 6842,66 & 322,13 & $-0,47$ & \begin{tabular}{|l|l|}
322,60 \\
\end{tabular} & \begin{tabular}{l|l|l|}
114,83 \\
\end{tabular} & \begin{tabular}{|l|l|}
224,72 \\
\end{tabular} & 224,73 & \begin{tabular}{|l|l|}
49,97 \\
\end{tabular} & $\begin{array}{l}454,45 \\
\end{array}$ & 53,69 & 8,53 & $\begin{array}{l}37,87 \\
\end{array}$ & \begin{tabular}{|l|l|}
152,77 \\
\end{tabular} & \begin{tabular}{l|l}
48,75 \\
\end{tabular} & \begin{tabular}{l|l}
48,75 \\
\end{tabular} & 127,88 \\
\hline Lissotriton boscai & 30SUK01 & 100,00 & 154,70 & 115,56 & 37,00 & 6570,73 & 335,95 & 26,02 & \begin{tabular}{|l|l|}
309,94 \\
\end{tabular} & \begin{tabular}{ll|}
112,48 \\
\end{tabular} & \begin{tabular}{|l|l|}
242,89 \\
\end{tabular} & \begin{tabular}{|l|l|}
242,89 \\
\end{tabular} & 74,18 & 386,27 & 44,60 & 5,27 & 41,76 & \begin{tabular}{|l|l|}
130,38 \\
\end{tabular} & \begin{tabular}{|l|}
34,47 \\
\end{tabular} & \begin{tabular}{|l|}
34,47 \\
\end{tabular} & \begin{tabular}{ll|l}
115,88 \\
\end{tabular} \\
\hline Lissotrit & $305 \mathrm{U} 20$ & 100,00 & 15 & & 36,72 & 565 & & 21, & 314, & 112 & 241,70 & 241,70 & 71,10 & 389,60 & 44,33 . & 5,61 & 41, & 130 & 35,49 & 35,49 & 11 \\
\hline Lissotriton boscai & 30SUK32 & 100,00 & 151,96 & 115,00 & 36,26 & 6621,2 & 332,9 & 22,09 & 310,85 & \begin{tabular}{ll|}
111,36 \\
\end{tabular} & 240,81 & 240,81 & \begin{tabular}{l|l}
70,95 \\
\end{tabular} & 366,31 & 42,20 & 6,19 & 39,38 & $\begin{array}{ll}121,68 \\
\end{array}$ & 36,48 & 36,48 & 104,07 \\
\hline Lissotriton boscai & 30SUK42 & 100,00 & 153,17 & 114,75 & 36,09 & 6644,08 & 333,95 & 22,73 & 311,21 & 112,53 & 242,41 & 242,41 & 71,86 & 359,77 & 41,62 & 6,11 & 39,30 & 119,29 & 36,19 & 36,19 & 101,33 \\
\hline
\end{tabular}




\begin{tabular}{|c|c|c|c|c|c|c|c|c|c|c|c|c|c|c|c|c|c|c|c|c|c|}
\hline TAXON & UTM & $\mathrm{km2}$ & BIO1 & B102 & B103 & B104 & B105 & B106 & B107 & B108 & B109 & BIO10 & BIO11 & BIO12 & BIO13 & BIO14 & BIO15 & BIO16 & BIO17 & BIO18 & BlO19 \\
\hline Lissotriton boscai & 30SUK70 & 100,00 & 146,87 & 115,74 & 36,00 & 6797,84 & 332,01 & 14,21 & 317,80 & 131,20 & 238,62 & 238,62 & 64,13 & 390,90 & 45,72 & 6,90 & 38,59 & 129,60 & 40,41 & 40,41 & 109,35 \\
\hline Lissotriton boscai & 30SUK80 & 100,00 & 149,30 & 115,40 & 35,95 & 6835,18 & 334,28 & 16,19 & 318,09 & 128,56 & 241,51 & 241,51 & 65,95 & \begin{tabular}{ll|}
384,66 \\
\end{tabular} & 44,56 & 6,71 & 38,52 & \begin{tabular}{|l|l|}
127,14 \\
\end{tabular} & 39,66 & 39,66 & 107,63 \\
\hline Lissotriton boscai & 30SVH01 & 100,00 & 173,25 & 114,34 & 36,00 & 6739,98 & 356,56 & 43,78 & 312,78 & 103,74 & 263,86 & 263,86 & 91,44 & 511,77 & 75,83 & 3,23 & 55,60 & \begin{tabular}{ll|}
195,58 \\
\end{tabular} & 21,62 & 21,62 & 185,27 \\
\hline Lissotriton boscai & $30 \mathrm{SVHO2}$ & 100,00 & 166,13 & 116,79 & 36,00 & 6846,37 & 354,41 & 35,08 & 319,33 & 96,84 & 258,37 & 258,37 & 83,31 & 530,30 & 78,73 & 3,62 & 54,44 & \begin{tabular}{|l|l|}
201,04 \\
\end{tabular} & 24,27 & 24,27 & 188,86 \\
\hline Lissotriton boscai & 30SVHO3 & 100,00 & 155,87 & 119,93 & 36,17 & 6936,06 & 349,27 & $23,47 \mid$ & $325,80 \mid$ & $103,94 \mid$ & 249,62 & 249,62 & $72,41 \mid$ & $553,67 \mid$ & 80,94 & 4,54 & 52,48 & 207,08 & 29,00 _ & 29,00 & 192,78 \\
\hline Lissotriton boscai & 30SVH04 & 100,00 & $\mid 152,67$ & 121,54 & 36,70 & 6943,12 & 347,59 & 19,47 & 328,12 & 105,63 & 246,53 & 246,53 & 69,13 & 547,43 & 78,34 & 4,60 & 51,14 & 202,35 & 30,55 & 30,55 & 187,44 \\
\hline Lissotriton boscai & 30SVH05 & 100,00 & 144,87 & 123,50 & 37,00 & 6956,21 & 342,06 & \begin{tabular}{|l|l|}
11,07 \\
\end{tabular} & 330,99 & $\begin{array}{l}97,66 \\
\end{array}$ & 239,15 & 239,15 & \begin{tabular}{l|l}
61,62 \\
\end{tabular} & 557,74 & 77,28 & 5,44 & 49,29 & 202,56 & 34,99 & 34,99 & 186,84 \\
\hline Lissotriton boscai & 30SVH08 & 100,00 & 146,68 & 126,35 & 37,34 & 6917,47 & 344,27 & \begin{tabular}{l|l}
10,82 \\
\end{tabular} & 333,44 & \begin{tabular}{l|l|}
123,90 \\
\end{tabular} & \begin{tabular}{|l|l|}
240,12 \\
\end{tabular} & \begin{tabular}{|l|l|}
240,12 \\
\end{tabular} & 63,49 & \begin{tabular}{l|l|l|}
495,58 \\
\end{tabular} & 64,12 & 4,31 & 46,88 & \begin{tabular}{|l|l|}
175,07 \\
\end{tabular} & 33,86 & 33,86 & 159,05 \\
\hline Lissotriton boscai & 30SVH11 & 100,00 & 173,27 & 113,34 & 36,00 & 6740,93 & 355,86 & 44,18 & 311,68 & $\begin{array}{ll}103,58 \\
\end{array}$ & \begin{tabular}{|l|l}
263,83 \\
\end{tabular} & 263,83 & 91,41 & 500,60 & 74,46 & 3,27 & 55,22 & 191,21 & 21,66 & 21,66 & 180,09 \\
\hline Lissotriton boscai & 30SVH12 & 100,00 & 165,95 & 116,11 & 36,00 & 6846,00 & 353,68 & 35,44 & 318,24 & 105,58 & 258,18 & 258,18 . & 83,22 & 519,72 & 77,25 & 3,74 & 53,92 & 197,10 & 24,62 & 24,62 & 183,63 \\
\hline Lissotriton boscai & 30SVH13 & 100,00 & 163,29 & 117,95 & 36,05 & 6870,86 & 352,93 & 31,71 & 321,22 & \begin{tabular}{|l|l|}
115,03 \\
\end{tabular} & 255,89 & 255,89 & \begin{tabular}{l|l|}
80,25 \\
\end{tabular} & \begin{tabular}{l|l}
515,05 \\
\end{tabular} & 75,36 & 3,79 & 52,75 & \begin{tabular}{|l|l|}
193,19 \\
\end{tabular} & 25,86 & 25,86 & 179,25 \\
\hline Lissotriton boscai & 30SVH14 & 100,00 & 157,62 & 120,27 & 36,56 & 6901,44 & 350,06 & 24,96 & 325,10 & \begin{tabular}{l|l|l|l|}
110,93 \\
\end{tabular} & \begin{tabular}{|l|l|}
250,79 \\
\end{tabular} & 250,79 & 74,49 & 518,31 & 74,11 & 4,22 & 51,24 & 192,18 & 28,63 & 28,63 & 176,88 \\
\hline Lissotriton boscai & $30 \mathrm{SVH} 22$ & 100,00 & 167,66 & 115,08 & 36,00 & 6811,41 & 353,58 & 37,68 & 315,90 & 117,58 & 259,44 & 259,44 & 85,38 & 498,74 & 73,72 & 3,62 & 53,34 & 188,84 & 24,08 & 24,08 & 174,98 \\
\hline Lissotriton boscai & $30 \mathrm{SVH} 25$ & 100,00 & 145,86 & 122,79 & 36,97 & 6929,03 & 341,56 & 12,40 & 329,17 & \begin{tabular}{ll|}
98,79 \\
\end{tabular} & 239,69 & 239,69 & \begin{tabular}{l|l|}
62,92 \\
\end{tabular} & 532,36 & 72,99 & 5,53 & 48,12 & \begin{tabular}{|l|l}
193,73 \\
\end{tabular} & 35,29 & 35,29 & 175,10 \\
\hline Lissotriton boscai & $30 \mathrm{SVH} 26$ & 100,00 & 149,29 & 123,54 & 37,00 & 6905,60 & 344,42 & 15,08 & 329,34 & \begin{tabular}{|l|l|}
102,72 \\
\end{tabular} & 242,76 & 242,76 & 66,32 & \begin{tabular}{|l|l|}
502,27 \\
\end{tabular} & 67,41 & 4,82 & 47,7 & 180,86 & 33,34 & 33,34 & 163,47 \\
\hline Lissotriton boscai & 30SVH28 & 100,00 & 144,50 & 126,24 & 37,59 & 6887,54 & 341,26 & 9,10 & 332,16 & 126,84 & \begin{tabular}{|l|l|}
237,76 \\
\end{tabular} & 237,76 & \begin{tabular}{|l|l|}
61,79 \\
\end{tabular} & \begin{tabular}{|l|l|l|}
484,93 \\
\end{tabular} & 61,33 & 4,74 & $\begin{array}{ll}45,53 \\
\end{array}$ & $\begin{array}{l}171,86 \\
\end{array}$ & 35,68 & \begin{tabular}{|l|}
35,68 \\
\end{tabular} & $\begin{array}{ll}152,64 \\
\end{array}$ \\
\hline Lissotriton boscai & 30SVH34 & 100,00 & 153,79 & 120,08 & 36,59 & 6892,22 & 345,85 & 21,45 & 324,40 & 106,64 & 246,91 & 246,91 & 71,05 & \begin{tabular}{ll|l}
508,68 \\
\end{tabular} & 71,43 & 4,85 & 49,44 & \begin{tabular}{|l|l|}
188,17 \\
\end{tabular} & 31,19 & 31,19 & 169,55 \\
\hline Lissotriton boscai & 30SVH35 & 100,00 & 140,37 & 123,03 & 37,00 & 6930,83 & 336,74 & 7,07 & 329,67 & 92,90 & 234,50 & 234,50 & 57,87 & 542,59 & 73,30 & 6,44 & 46,68 & \begin{tabular}{|l|l|}
196,41 \\
\end{tabular} & \begin{tabular}{|l|}
38,99 \\
\end{tabular} & 38,99 & 175,76 \\
\hline Lissotriton boscai & 30SVH41 & 100,00 & 172,06 & 112,09 & 36,00 & 6687,70 & 352,28 & 43,94 & 308,34 & \begin{tabular}{l|l|}
125,90 \\
\end{tabular} & 261,96 & 261,96 & 91,14 & 458,41 & 66,63 & 3,46 & 52,76 & 173,03 & 22,34 & 22,34 & 160,08 \\
\hline Lissotriton boscai & $30 \mathrm{SVH} 42$ & 100,00 & 168,91 & 114,17 & 36,00 & 6738,83 & 351,87 & 39,52 & 312,34 & \begin{tabular}{l|l|l|}
122,59 \\
\end{tabular} & \begin{tabular}{|l|l|}
259,43 \\
\end{tabular} & 259,43 & 87,4 & 461,65 & 66,40 & 3,64 & 51, & 173,28 & 24,00 & 24,00 & 158,57 \\
\hline Lissotriton boscai & $30 \mathrm{SVH} 43$ & 100,00 & 163,33 & 116,73 & 36,05 & 6798,84 & 349,91 & 32,62 & 317,29 & \begin{tabular}{|l|l|}
116,79 \\
\end{tabular} & \begin{tabular}{|l|l}
254,96 \\
\end{tabular} & \begin{tabular}{|l|l|}
254,96 \\
\end{tabular} & 81,34 & 471,24 & 66,79 & 4,03 & 50,53 & \begin{tabular}{|l|l|}
175,58 \\
\end{tabular} & 26,70 & 26,70 & 158,96 \\
\hline Lissotriton boscai & $30 \mathrm{SVH} 44$ & 100,00 & 148,33 & 120,66 & 36,76 & 6890,83 & 341,28 & \begin{tabular}{l|l}
15,92 \\
\end{tabular} & 325,37 & \begin{tabular}{|l|l|}
100,84 \\
\end{tabular} & \begin{tabular}{|l|l|}
241,58 \\
\end{tabular} & 241,58 & 65,94 & \begin{tabular}{|l|l|}
515,72 \\
\end{tabular} & 70,99 & 5,67 & \begin{tabular}{ll|}
47,88 \\
\end{tabular} & \begin{tabular}{|l|l|}
189,17 \\
\end{tabular} & \begin{tabular}{|l|l|}
34,67 \\
\end{tabular} & \begin{tabular}{|l|l|}
34,67 \\
\end{tabular} & 168,88 \\
\hline Lissotriton boscai & $30 \mathrm{SVH} 45$ & 100,00 & 135,75 & 123,29 & 37,00 & 6915,99 & 332,29 & 3,01 & 329,29 & 87,90 & 229,84 & 229,84 & 53,68 & 550,14 & \begin{tabular}{ll|}
72,97 \\
\end{tabular} & 7,40 & 45,32 & \begin{tabular}{ll|l}
197,48 \\
\end{tabular} & 42,56 & 42,56 & 175,34 \\
\hline Lissotriton boscai & 30SVH53 & 100,00 & 163,20 & 116,49 & 36,24 & 6752,17 . & 348,31 & 32,62 & 315,69 & 116,77 & 254,13 & 254,13 & 81,79 & 455,50 & 63,27 . & 4,01 & 49,48 & 168,26 & 26,90 & 26,90 _ & 151,61 \\
\hline Lissotriton boscai & 30 SVH54 & 100,00 & 152,54 & 119,68 & 36,80 & 6830,84 & 342,73 & 20,42 & 322,31 & \begin{tabular}{ll|}
105,50 \\
\end{tabular} & 244,79 & 244,79 & 70,6 & 485,61 & \begin{tabular}{ll|l}
65,96 \\
\end{tabular} & $\begin{array}{l}5,25 \\
\end{array}$ & 47,56 & \begin{tabular}{ll|}
177,26 \\
\end{tabular} & 32,77 & 32,77 & 157,69 \\
\hline Lissotriton boscai & 30 SVH55 & 100,00 & 144,77 & 121,94 & 37,00 & 6869,73 & 338,06 & 11,91 & 326,15 & \begin{tabular}{|l|}
97,47 \\
\end{tabular} & 237,79 & 237,79 & 62,63 & 502,61 & 66,60 & 6,10 & 45,87 & 180,92 & 37,33 & 37,33 & 159,71 \\
\hline Lissotriton boscai & 30SVH64 & 100,00 & 154,19 & 119,16 & 36,95 & 6780,69 & 342,24 & 22,47 & 319,76 & 107,34 & \begin{tabular}{|l|l|}
245,70 \\
\end{tabular} & 245,70 & 72,69 & \begin{tabular}{|l|l|}
464,67 \\
\end{tabular} & 61,84 & $\begin{array}{l}5,05 \\
\end{array}$ & \begin{tabular}{ll|}
46,69 \\
\end{tabular} & 168,01 & 32,31 & 32,31 & 148,91 \\
\hline Lissotriton boscai & 30 SVH65 & 100,00 & 145,01 & 121,56 & 37,00 & 6830,51 & 336,83 & 12,36 & 324,47 & \begin{tabular}{l|l}
98,63 \\
\end{tabular} & 237,55 & 237,55 & 63,40 & \begin{tabular}{|l|l}
490,13 \\
\end{tabular} & 63,78 & 6,22 & 44,91 & $\begin{array}{l}175,06 \\
\end{array}$ & 37,89 & 37,89 & 153,67 \\
\hline Lissotriton boscai & 30SVH74 & 100,00 & 156,35 & 118,46 & 37,00 & 6713,76 & 341,89 & 24,83 & 317,06 & $109,79 \mid$ & 246,80 _ & 246,80 & 75,59 ] & 442,10 & 57,42 & 4,87 & 45,98 & $158,07 \mid$ & 31,52 & 31,52 & 139,85 \\
\hline Lissotriton boscai & 30 SVH75 & 100,00 & 148,09 & 120,87 & 37,00 & 6772,70 & 337,37 & \begin{tabular}{|l|l}
15,63 \\
\end{tabular} & 321,74 & \begin{tabular}{ll|}
110,62 \\
\end{tabular} & \begin{tabular}{|l|l|}
239,64 \\
\end{tabular} & 239,64 & 66,96 & 466,38 & 59,56 & 5,92 & 44,41 & 165,41 & \begin{tabular}{|l|}
36,67 \\
\end{tabular} & \begin{tabular}{|l|}
36,67 \\
\end{tabular} & 144,59 \\
\hline Lissotriton boscai & 30 SVH76 & 100,00 & 142,16 & 122,42 & 37,00 & 6812,50 & 333,83 & \begin{tabular}{ll|}
9,07 \\
\end{tabular} & 324,76 & 123,00 & 234,41 & 234,41 & 60,91 & \begin{tabular}{|l|l|}
480,67 \\
\end{tabular} & 60,20 & 6,83 & 42,80 & $\begin{array}{l}170,17 \\
\end{array}$ & 40,83 & \begin{tabular}{ll|}
40,83 \\
\end{tabular} & 146,37 \\
\hline Lissotriton boscai & \begin{tabular}{|l|l|}
$30 S V J 05$ \\
\end{tabular} & 100,00 & 130,97 & 123,47 & 37,00 & 6870,26 & 325,77 & $-2,56$ & 328,33 & 113,57 & 224,31 & 224,31 & \begin{tabular}{l|l}
48,85 \\
\end{tabular} & 475,61 & 55,56 & 7,50 & \begin{tabular}{l|l}
39,55 \\
\end{tabular} & $\begin{array}{ll}162,95 \\
\end{array}$ & 47,10 & 47,10 & 137,71 \\
\hline Lissotriton boscai & 30 SVJ06 & 100,00 & 129,19 & 121,97 & 37,00 & 6851,31 & 322,54 & $-3,91$ & 326,45 & \begin{tabular}{ll|}
111,79 \\
\end{tabular} & 222,27 & 222,27 & \begin{tabular}{|l|l|l|}
47,47 \\
\end{tabular} & $\begin{array}{l}477,10 \\
\end{array}$ & 55,90 & 8,28 & 38,71 & \begin{tabular}{|l|}
162,20 \\
\end{tabular} & 49,38 & 49,38 & 136,52 \\
\hline Lissotriton boscai & 30SVJ08 & 100,00 & 128,99 & 118,95 & 36,32 & 6836,28 & 319,54 & $-2,78$ & 322,32 & \begin{tabular}{|l|l|}
111,71 \\
\end{tabular} & \begin{tabular}{|l|l|}
221,98 \\
\end{tabular} & 222,00 & 47,55 & \begin{tabular}{|l|l|}
465,26 \\
\end{tabular} & 54,82 & $\begin{array}{l}9,07 \\
\end{array}$ & 37,28 & \begin{tabular}{|l|l|}
155,83 \\
\end{tabular} & 51,08 & 51,10 & 130,69 \\
\hline Lissotriton boscai & 30SVJ11 & 100,00 & 147,16 & 128,77 & 38,00 & 6852,44 & 343,75 & \begin{tabular}{l|l|}
9,46 \\
\end{tabular} & 334,29 & 131,07 & 239,31 & 239,31 & \begin{tabular}{|l|l|l|}
64,03 \\
\end{tabular} & \begin{tabular}{|l|l|}
431,67 \\
\end{tabular} & 52,12 & 4,00 & 44,03 & \begin{tabular}{|l|l|}
151,79 \\
\end{tabular} & 33,87 & 33,87 & 130,75 \\
\hline Lissotriton boscai & 30SVJ13 & 100,00 & 143,91 & 126,68 & 37,89 & 6858,15 & 339,39 & 7,36 & 332,03 & \begin{tabular}{ll|}
127,80 \\
\end{tabular} & $\begin{array}{l}236,59 \\
\end{array}$ & 236,59 & 61,18 & \begin{tabular}{|l|l|}
430,37 \\
\end{tabular} & 51,26 & 4,76 & \begin{tabular}{|l|l|}
42,04 \\
\end{tabular} & 149,31 & 37,37 & 37,37 & 127,06 \\
\hline Lissotriton boscai & 30SVJ15 & 100,00 & 133,32 & 123,81 & 37,00 & 6870,43 & 327,87 & $-0,78$ & 328,66 & \begin{tabular}{ll|}
116,26 \\
\end{tabular} & 226,57 & 226,57 & 51,09 & 461,95 & 54,07 & 7,10 & 39,51 & \begin{tabular}{ll|}
158,08 \\
\end{tabular} & 45,73 & 45,73 & 133,26 \\
\hline Lissotriton boscai & $30 \mathrm{SVJ} 23$ & 100,00 & 145,52 & 126,56 & 37,99 & 6840,83 & 340,04 & 8,74 & 331,30 & 129,61 & 237,74 & 237,74 & 62,74 & 420,08 & 50,24 & 4,6 & 42,20 & $\begin{array}{ll}145,53 \\
\end{array}$ & 36,85 & 36,85 & 123,39 \\
\hline Lissotriton boscai & 30 SVJ33 & 100,00 & 146,07 & 125,88 & 37,83 & 835,78 & 339,76 & 9,77 & 329,99 & 130,11 & 238,23 & 238,23 & 63, & 417,42 & 49,97 & 4,87 & 41,8 & 144,18 & 7,16 & \begin{tabular}{l|l}
7,16 \\
\end{tabular} & 122,00 \\
\hline Lissotriton boscai & 30 SVJ34 & 100,00 & 136,18 & 125,01 & 37,16 & 6853,50 & 330,64 & 1,10 & 329,54 & 119,39 & 229,01 & 229,01 & 53,96 & 451,78 & 53,40 & 6,54 & 39,76 & 154,97 & \begin{tabular}{l|l}
44,15 \\
\end{tabular} & 44,15 & 130,48 \\
\hline Lissotriton boscai & 30SVJ43 & 100,00 & 146,62 & 125,01 & 37,45 & 6823,15 & 339,09 & 10,59 & 328,50 & \begin{tabular}{|l|l|}
130,47 \\
\end{tabular} & \begin{tabular}{|l|l|}
238,72 \\
\end{tabular} & 238,72 & 64,20 & \begin{tabular}{ll|l}
415,36 \\
\end{tabular} & 49,60 & 5,00 & \begin{tabular}{ll|l}
41,53 \\
\end{tabular} & \begin{tabular}{l|l}
142,82 \\
\end{tabular} & 37,42 & 37,42 & 121,07 \\
\hline Lissotriton boscai & 30 SVJ44 & 100,00 & 134,94 & 124,47 & 37,18 & 6837,59 & 328,72 & 0,39 & 328,33 & \begin{tabular}{l|l|l|l|l}
117,92 \\
\end{tabular} & $\begin{array}{ll}227,52 \\
\end{array}$ & $\begin{array}{ll}227,52 \\
\end{array}$ & 52,91 & $\begin{array}{l}457,44 \\
\end{array}$ & 53,83 & 7,13 & 39,26 & \begin{tabular}{ll|}
156,41 \\
\end{tabular} & 46,03 & 46,03 & 131,50 \\
\hline Lissotriton boscai & 30SVJ45 & 100,00 & 128,65 & 123,56 & 37,03 & 6835,67 & 322,47 & $-4,44$ & 326,91 & 111,14 & 221,50 & 221,50 & \begin{tabular}{ll|l}
47,35 \\
\end{tabular} & 478,31 & 55,59 & 8,50 & 37,84 & 162,32 & 50,98 & 50,98 & 136,15 \\
\hline Lissotriton boscai & 30 SVJ46 & 100,00 & 138,17 & 122,27 & 37,00 & 842,14 & 329,49 & 3,76 & 325,73 & 121,55 & 230,58 & 230,58 & 55,69 & 437,42 & 50,53 & 7,14 & 38,40 & 146,42 & 7 & 5,07 & 124,66 \\
\hline Lissotriton boscai & 30SVI77 & 100,00 & 142,13 & 120,53 & 37,00 & 6778,90 & 329,51 & 8,49 & 321,02 & 126,27 & 233,47 & 233,47 & 60,07 & \begin{tabular}{|l|l|}
419,88 \\
\end{tabular} & 47,05 & 7,60 & 36,94 & \begin{tabular}{|l|l|l|}
137,13 \\
\end{tabular} & 45,58 & 45,58 & 117,90 \\
\hline Lissotriton boscai & 30SVKo0 & 100,00 & 142,08 & 115,15 & 35,59 & 6885,85 & 328,40 & 8,99 & 319,41 & 126,45 & 235,29 & 235,29 & \begin{tabular}{l|l}
58,85 \\
\end{tabular} & \begin{tabular}{|l|}
410,00 \\
\end{tabular} & 47,49 & 8,07 & 36,99 & 134,34 & 45,10 & 45,10 & 114,06 \\
\hline Lissotriton boscai & 30SVK10 & 100,00 & 139,54 & 115,28 & 35,74 & 6879,58 & 326,16 & 7,09 & \begin{tabular}{|l|l|}
319,07 \\
\end{tabular} & \begin{tabular}{l|l|l|l|}
121,73 \\
\end{tabular} & 232,81 & 232,81 & 56,51 & \begin{tabular}{ll|}
420,94 \\
\end{tabular} & 48,24 & 8,56 & 36,62 & \begin{tabular}{|l|l|}
136,80 \\
\end{tabular} & 46,77 & 46,77 & 117,76 \\
\hline Lissotriton boscai & 30тTК44 & 60,00 & 132,45 & 109,16 & 36,60 & 6377,70 & 307,43 & 12,65 & 294,78 & 62,97 & 217,85 & 218,38 & 55,81 & 543,52 & 66,52 & 8,45 & 42,58 & 193,49 & 48,58 & 49,33 & 179,36 \\
\hline Lissotriton boscai & 30TTK45 & 50,00 & 131,76 & 109,35 & 36,72 & 6352,00 & 305,94 & \begin{tabular}{|l|l|}
12,08 \\
\end{tabular} & 293,86 & 62,33 & 216,75 & 217,14 & 55,19 & 538,41 & 66,14 & 8,77 & 42,37 & 191,61 & \begin{tabular}{l|l|}
49,05 \\
\end{tabular} & \begin{tabular}{|l|}
49,87 \\
\end{tabular} & 177,23 \\
\hline Lissotriton boscai & 30TTK46 & 50,00 & 135,01 & 110,26 & 36,96 & 6344,70 & 308,87 & \begin{tabular}{ll|}
14,62 \\
\end{tabular} & 294,25 & 65,34 & \begin{tabular}{|l|l|}
219,75 \\
\end{tabular} & 220,12 & 58,21 & 503,96 & 62,09 & 8,23 & 41,86 & \begin{tabular}{|l|l|}
178,99 \\
\end{tabular} & 46,81 & 47,03 & 164,68 \\
\hline Lissotriton boscai & 30TTK47 & 50,00 & 130,68 & 110,36 & 37,00 & 6328,70 & 304,17 & 10,70 & 293,48 & \begin{tabular}{l|l}
61,23 \\
\end{tabular} & 215,45 & 215,70 & 54,12 & 511,74 & 63,16 & 8,91 & 41,23 & $\begin{array}{ll}181,62 \\
\end{array}$ & 49,12 & 49,30 & 166,80 \\
\hline Lissotriton boscai & 30TTK48 & 40,00 & 134,10 & 111,33 & 37,38 & 6306,80 & 307,13 & 13,61 & 293,52 & \begin{tabular}{ll|l}
64,43 \\
\end{tabular} & 218,56 & \begin{tabular}{|l|}
218,64 \\
\end{tabular} & 57,33 & 483,51 & 59,92 & 8,43 & 40,90 & \begin{tabular}{|l|l|}
171,39 \\
\end{tabular} & \begin{tabular}{|l|l|}
46,87 \\
\end{tabular} & 46,92 & 156,69 \\
\hline Lissotriton boscai & 30TTK49 & 40,00 & \begin{tabular}{|l|l|}
115,98 \\
\end{tabular} & 109,66 & 37,29 & 252,05 & 288 & $-1,39$ & 289,64 & \begin{tabular}{|l|l|}
47,76 \\
\end{tabular} & \begin{tabular}{|l|l|}
199,29 \\
\end{tabular} & 200,2 & 41 & \begin{tabular}{|l|l|}
562,68 \\
\end{tabular} & 69,73 & \begin{tabular}{l|l|}
11,05 \\
\end{tabular} & \begin{tabular}{|l|l|}
39,69 \\
\end{tabular} & 198,97 & 57,68 & 58,81 & 182,14 \\
\hline Lissotriton boscai & 30TTK54 & 100,00 & 126 & 109,80 & 36,6 & 98 & 30 & \begin{tabular}{ll|}
6,26 \\
\end{tabular} & 295, & 56,8 & 211 & 212,14 & 49 & 553,85 & 67,17 & 9,55 & 41,46 & 194,51 & \begin{tabular}{|l|l|}
51,85 \\
\end{tabular} & 52,86 & 179 \\
\hline Lissotriton boscai & 30TTK56 & 100,00 & 125,09 & 110,34 & 36,99 & 6336,47 & 299,69 & \begin{tabular}{l|l|}
5,54 \\
\end{tabular} & \begin{tabular}{|l|l|}
294,16 \\
\end{tabular} & 55,85 & \begin{tabular}{|l|l|}
209,65 \\
\end{tabular} & 210,40 & 48,89 & 532,56 & 65,03 & 9,79 & 40,50 & \begin{tabular}{|l|l|}
186,53 \\
\end{tabular} & 52,18 & 52,97 & 171,06 \\
\hline Lissotriton boscai & 30TTK57 & 100,00 & 125,48 & 111,03 & 37,08 & 6317,04 & 299,69 & 5,65 & 294,04 & 56,32 & \begin{tabular}{|l|l|}
209,99 \\
\end{tabular} & \begin{tabular}{|l|l|}
210,54 \\
\end{tabular} & 49,34 & \begin{tabular}{|l|l|}
515,12 \\
\end{tabular} & $\begin{array}{ll}63,05 \\
\end{array}$ & 9,67 & $\begin{array}{ll}39,93 \\
\end{array}$ & \begin{tabular}{|l|l|}
180,10 \\
\end{tabular} & 51,77 & 52,14 & 164,56 \\
\hline Lissotriton boscai & 30TTK58 & 100,00 & 125,15 & 111,64 & 37,57 & 6296,49 & 298,85 & 5,27 & 293,58 & 56,00 & \begin{tabular}{|l|l|}
209,26 \\
\end{tabular} & 209,81 & \begin{tabular}{|l|l|}
49,13 \\
\end{tabular} & 503,89 & 61,86 & 9,69 & \begin{tabular}{l|l}
39,55 \\
\end{tabular} & \begin{tabular}{ll|}
175,86 \\
\end{tabular} & 51,83 & \begin{tabular}{l|l}
52,15 \\
\end{tabular} & $\begin{array}{ll}159,95 \\
\end{array}$ \\
\hline Lissotrito & 30TाK & $100,0 c$ & & & 37,89 & & & 0,0 & 291, & 50,05 & 202 & 203, & & 522, & 64, & 10,65 & & 182 & 9 & & \\
\hline Lissotriton boscai & 30TTK64 & 100,00 & 125,55 & 110,94 & 36,79 & 6392,01 & 302,5 & 4,83 & 297,67 & 56,05 & 211,25 & 211,87 & 49,1 & 535,59 & 64,29 & 9,79 & 40,50 & $\begin{array}{ll}185,12 \\
\end{array}$ & 51,99 & 53,12 & 169, \\
\hline Lissotriton boscai & 30TTK65 & 100,00 & 113,49 & 109,94 & 36,78 & 6341,39 & 289,57 & $-5,24$ & 294,81 & $45,07 \mid$ & \begin{tabular}{|c|}
198,60 \\
\end{tabular} & \begin{tabular}{|l|l|}
199,43 \\
\end{tabular} & 38,40 & \begin{tabular}{|l|l|}
586,38 \\
\end{tabular} & 70,42 & \begin{tabular}{|l|l|}
12,04 \\
\end{tabular} & 39,20 & 201,93 & 59,78 & 61,71 & 185,52 \\
\hline
\end{tabular}




\begin{tabular}{|c|c|c|c|c|c|c|c|c|c|c|c|c|c|c|c|c|c|c|c|c|c|}
\hline TAXON & UTM & $\mathrm{km2}$ & BIO1 & B102 & $\mathrm{BIO3}$ & B104 & B105 & B106 & B107 & B108 & B109 & BIO10 & BIO11 & BIO12 & BIO13 & BIO14 & BIO15 & BIO16 & BIO17 & B1018 & BIO19 \\
\hline Lissotriton boscai & 30TTK66 & 100,00 & 79,21 & 106,14 & 36,41 & 6224,39 & 253,47 & $-34,09$ & 287,56 & 14,25 & 163,83 & 164,57 & 7,95 & 803,94 & 95,97 & 19,66 & 37,45 & 276,18 & 86,49 & 92,45 & 257,79 \\
\hline Lissotriton boscai & 30TTK67 & 100,00 & 109,14 & 110,24 & 37,07 & 6281,82 & 283,90 & $-8,71$ & 292,61 & 41,20 & \begin{tabular}{|l|l|}
192,97 \\
\end{tabular} & \begin{tabular}{|l|l|l|l|l|}
194, \\
\end{tabular} & 34,75 & 578,51 & 69,88 & 12,63 & 37,97 & 198,20 & 62,04 & 64,14 & 180,73 \\
\hline Lissotriton boscai & 30TTK69 & 100,00 & 116,55 & $\begin{array}{ll}112,76 \\
\end{array}$ & 38,00 & 6255,50 & 290,74 & $-2,36$ & 293,10 & 54,45 & \begin{tabular}{|l|l|}
199,44 \\
\end{tabular} & 200,97 & 41,45 & \begin{tabular}{ll|}
504,86 \\
\end{tabular} & 61,34 & $\begin{array}{ll}11,15 \\
\end{array}$ & 37,32 & 171,90 & $\begin{array}{l}56,85 \\
\end{array}$ & 57,70 & 154,59 \\
\hline Lissotriton boscai & 30TTK74 & 100,00 & $\begin{array}{l}134,76 \\
\end{array}$ & 112,76 & 36,99 & 6418,78 & 312,39 & 11,83 & 300,57 & 68,51 & \begin{tabular}{|l|l|}
220,79 \\
\end{tabular} & 221,21 & 57,26 & $\begin{array}{l}470,09 \\
\end{array}$ & 55,91 & 8,45 & 40,06 & 159,85 & 46,18 & 46,69 & 145,14 \\
\hline Lissotriton boscai & 30TTK76 & 100,00 & 91,53 & 108,77 & 36,79 & 6260,14 & 267,27 & $-24,49$ & 291,75 | & $25,18 \mid$ & 175,92 & $177,06 \mid$ & $18,91]$ & 680,86 . & 80,72 & 16,69 & 36,68 & $229,91 \mid$ & $75,34 \mid$ & 79,58 & 211,18 \\
\hline Lissotriton boscai & 30TTK77 & 100,00 & 97,20 & 109,86 & 37,13 & 6246,57 & 272,49 & $-19,59$ & 292,07 & $30,34 \mid$ & $180,93 \mid$ & $\begin{array}{l}182,39 \\
\end{array}$ & 24,13 & 626,00 & 74,51 & 15,30 & 36,35 & 210,42 & $70,67 \mid$ & 74,09 & 191,65 \\
\hline Lissotriton boscai & 30TTK78 & 100,00 & 114,63 & 112,80 & 37,91 & 6271,61 & 289,86 & $-4,61$ & 294,47 & 55,68 & \begin{tabular}{|l|l|}
197,59 \\
\end{tabular} & $\begin{array}{l}199,56 \\
\end{array}$ & 39,69 & \begin{tabular}{|l|l|}
504,84 \\
\end{tabular} & 60,39 & \begin{tabular}{|l|l|}
11,68 \\
\end{tabular} & 36,46 & 168,65 & \begin{tabular}{ll|}
57,96 \\
\end{tabular} & 59,24 & 151,39 \\
\hline Lissotriton boscai & 30TTK79 & 100,00 & 116,93 & 113,89 & $\begin{array}{l}38,05 \\
\end{array}$ & 6247,73 & 291,87 & $-2,66$ & 294,53 & 73,70 & \begin{tabular}{l|l|l|}
199,32 \\
\end{tabular} & 201,36 & 41,94 & $\begin{array}{l}479,76 \\
\end{array}$ & 57,49 & 11,22 & 36,02 & \begin{tabular}{ll|l|}
159,91 \\
\end{tabular} & \begin{tabular}{ll|}
56,53 \\
\end{tabular} & 57,49 & 142,51 \\
\hline Lissotriton boscai & 30TTK84 & 100,00 & 134,41 & 113,27 & 37,00 & 6425,82 & 312,65 & \begin{tabular}{l|l|}
10,59 \\
\end{tabular} & \begin{tabular}{|l|}
302,07 \\
\end{tabular} & 81,47 & \begin{tabular}{l|l|}
220,52 \\
\end{tabular} & 220,95 & 56,82 & \begin{tabular}{ll|}
456,62 \\
\end{tabular} & 53,71 & 8,67 & 39,33 & \begin{tabular}{|l|l|}
153,00 \\
\end{tabular} & $\begin{array}{l}46,50 \\
4\end{array}$ & 47,06 & 137,83 \\
\hline Lissotriton boscai & 30тTк85 & 100,00 & 78,37 & 108,42 & 36,60 & 6264,29 & 255,69 & $-36,63$ & 292,32 & 13,03 & 163,74 & $164,41 \mid$ & 6,90 & 760,19 _ & 88,73 & 20,16 & 35,67 & 253,42 & 86,09 & 91,79 & 233,99 \\
\hline Lissotriton boscai & 30TTK86 & 100,00 & 104,01 & 111,33 & 37,03 & 6298,99 & 281,10 & $-14,76$ & 295,86 & \begin{tabular}{|l|l|}
38,62 \\
\end{tabular} & 188,25 & \begin{tabular}{ll|}
189,81 \\
\end{tabular} & 30,01 & 569,76 & 66,99 & 14,01 & 36,09 & $\begin{array}{ll}188,25 \\
\end{array}$ & \begin{tabular}{ll|}
65,19 \\
\end{tabular} & \begin{tabular}{|l|l|}
67,68 \\
\end{tabular} & 169,77 \\
\hline Lissotriton boscai & 30TTK87 & 100,00 & 112,29 & 112,73 & 37,60 & 6295,44 & 288,80 & $-7,63$ & 296,43 & 62,51 & \begin{tabular}{ll|}
195,94 \\
1
\end{tabular} & 197,81 & 37,44 & \begin{tabular}{|l|l|l|}
507,78 \\
\end{tabular} & 59,81 & 12,44 & 35,86 & 166,60 & \begin{tabular}{|l|l|}
59,43 \\
\end{tabular} & \begin{tabular}{ll|l}
61,05 \\
\end{tabular} & 148,84 \\
\hline Lissotriton boscai & 30TTK88 & 100,00 & 115,08 & 113,70 & 37,98 & 6268,39 & 290,92 & $-5,17$ & 296,09 & 72,80 & \begin{tabular}{|l|l|l|}
197,78 \\
\end{tabular} & 200,01 & 40,13 & 480,61 & 56,77 & 11,78 & \begin{tabular}{|l|}
35,36 \\
\end{tabular} & \begin{tabular}{|l|l|}
157,37 \\
\end{tabular} & \begin{tabular}{ll|}
57,66 \\
\end{tabular} & 58,97 & 139,60 \\
\hline Lissotriton boscai & 30TTK94 & 100,00 & 150,38 & 114,48 & 37,00 & 6451,97 & 328,03 & 24,12 & 303,91 & $\begin{array}{ll}108,28 \\
\end{array}$ & 236,77 & 236,78 & 71,27 & 381,23 & 44,71 & 6,37 & 39,86 & 128,30 & \begin{tabular}{ll|}
37,38 \\
\end{tabular} & 37,38 & 113,13 \\
\hline Lissotriton boscai & 30TTK95 & 100,00 & 94,42 & 110,80 & \begin{tabular}{ll|}
36,89 \\
\end{tabular} & 6314,75 & 272,60 & $-23,77$ & 296,37 & 36,90 & $\begin{array}{ll}179,93 \\
\end{array}$ & \begin{tabular}{ll|}
180,69 \\
\end{tabular} & 21,05 & 643,16 & 74,43 & \begin{tabular}{l|l}
17,05 \\
1
\end{tabular} & 35,5 & 210,75 & 74,63 & 78,42 & 191,89 \\
\hline Lissotriton boscai & 30TTK96 & 100,00 & 91,54 & 110,67 & 37,01 & 6268,13 & 268,93 & $-26,01$ & \begin{tabular}{|l|l|}
294,93 \\
\end{tabular} & 33,22 & 176,05 & \begin{tabular}{|l|l|}
177,31 \\
\end{tabular} & $\begin{array}{ll}18,89 \\
\end{array}$ & \begin{tabular}{|l|l|}
629,13 \\
\end{tabular} & 73,17 & 17,20 & 34,74 & \begin{tabular}{|l|l|}
204,69 \\
\end{tabular} & \begin{tabular}{ll|}
75,06 \\
\end{tabular} & 79,02 & 184,84 \\
\hline Lissotriton boscai & 30TTK98 & 100,00 & 111,33 & 113,54 & 37,94 & 6252,65 & 287,35 & $-8,85$ & 296,19 & 70,37 & \begin{tabular}{ll|l}
194,08 \\
\end{tabular} & 196,31 & 37,04 & \begin{tabular}{ll|l}
480,69 \\
\end{tabular} & 57,37 & \begin{tabular}{|l|l|}
12,67 \\
\end{tabular} & 34,32 & \begin{tabular}{l|l|}
155,03 \\
\end{tabular} & 60,19 & 61,95 & 135,37 \\
\hline Lissotriton boscai & 30ТТк99 & 100,00 & 107,21 & $\mid 113,47$ & 38,00 & 6202,06 & 282,46 & $-12,23$ & 294,69 & $67,18 \mid$ & 189,34 & $191,49 \mid$ & 33,69 & $488,99 \mid$ & 58,71 & 13,45 & 33,69 & 157,33 & $63,01 \mid$ & 65,25 & 136,74 \\
\hline Lissotriton boscai & $30 T T L 40$ & 39,00 & 117,22 & 110,80 & 37,98 & 6241,55 & 289,36 & $-0,44$ & 289,80 & \begin{tabular}{ll|}
48,96 \\
\end{tabular} & \begin{tabular}{|l|l|}
200,42 \\
\end{tabular} & 201,29 & 42,09 & 537,40 & 66,89 & 10,84 & 39,51 & $\begin{array}{l}189,65 \\
\end{array}$ & 56,73 & 57,22 & 172,22 \\
\hline Lissotriton boscai & $30 T T L 44$ & 20,00 & 118,67 & 113,70 & 38,73 & 6198,61 & 290,76 & $-0,12$ & \begin{tabular}{|l|l|}
290,88 \\
\end{tabular} & 78,94 & 201,64 & 201,64 & 43,21 & 472,52 & \begin{tabular}{ll|l}
60,76 \\
\end{tabular} & 10,61 & 39, & 168,88 & 53,97 & 53,97 & 146,48 \\
\hline Lissotriton boscai & 30TTL45 & 20,00 & 119,76 & 113,97 & \begin{tabular}{|l|l|}
38,97 \\
\end{tabular} & 6206,59 & 291,48 & $\begin{array}{l}0,07 \\
0,\end{array}$ & 291,41 & \begin{tabular}{|c|}
79,59 \\
\end{tabular} & 202,28 & 202,28 & 43,86 & \begin{tabular}{|l|l|l|}
458,03 \\
\end{tabular} & 59,00 & 10,34 & 38,24 & \begin{tabular}{|l|l|}
163,90 \\
\end{tabular} & 53,28 & 53,28 & 141,10 \\
\hline Lissotriton boscai & 30TTL50 & 100,00 & 114,93 & 111,65 & \begin{tabular}{ll|}
37,99 \\
\end{tabular} & 6240,78 & 287,90 & $-2,85$ & 290,75 & 47,54 & $\begin{array}{l}197,78 \\
1\end{array}$ & $\begin{array}{l}199,05 \\
19\end{array}$ & 40,02 & 528,61 & 65,29 & \begin{tabular}{|l|l|}
11,17 \\
\end{tabular} & 38,41 & \begin{tabular}{l|l|}
183,98 \\
\end{tabular} & 57,94 & 58,66 & 166,05 \\
\hline Lissotriton boscai & 30TTL51 & 100,00 & 114,77 & 112,50 & 38,08 & 6230,42 & 287,68 & $-3,20$ & 290,88 & 64,41 & \begin{tabular}{|l|l|l|}
197,93 \\
\end{tabular} & \begin{tabular}{|l|l|}
198,57 \\
\end{tabular} & 39,84 & 514,20 & 63,74 & 11,21 & 38,14 & \begin{tabular}{|l|l|}
179,09 \\
\end{tabular} & 57,85 & 58,21 & 160,08 \\
\hline Lissotriton boscai & 30TTL55 & 100,00 & 119,49 & 114,99 & 39,00 & 6194,68 & 291,90 & $-0,15$ & 292,05 & 79,42 & 202,05 & 202,05 & $43,64[$ & 438,15 & 56,37 & 10,58 & 38,23 & 156,80 & $52,87 \mid$ & $52,87 \mid$ & 131,30 \\
\hline Lissotriton boscai & 30TTL56 & 100,00 & 115,04 & 114,44 & 39,00 & 6165,01 & 287,15 & $-3,84$ & 290,99 & 75,32 & $\begin{array}{l}197,15 \\
\end{array}$ & \begin{tabular}{ll|}
197,26 \\
\end{tabular} & 39,83 & \begin{tabular}{|l|l|}
452,74 \\
\end{tabular} & 57,87 & \begin{tabular}{|l|l|}
11,27 \\
\end{tabular} & 37,59 & \begin{tabular}{|l|l|}
161,16 \\
\end{tabular} & 55,84 & 55,92 & 135,98 \\
\hline Lissotriton boscai & 30TTL59 & 100,00 & 120,08 & 114,38 & 38,99 & 6142,13 & 290,93 & $-0,17$ & 291,10 & 80,44 & 200,75 & 201,21 & 44,09 & 416,59 & 52,89 & 10,56 & 36,11 & 146,84 & 52,66 & 52,95 & 125,25 \\
\hline Lissotriton boscai & $30 T T L 60$ & 100,00 & 114,36 & 113,21 & 38,01 & 6233,21 & 288,24 & $-4,33$ & 292,57 & 69,27 & \begin{tabular}{|l|l|}
197,00 \\
\end{tabular} & \begin{tabular}{l|l|l|l|l|}
198,49 \\
\end{tabular} & 39,50 & \begin{tabular}{l|l|l|}
502,62 \\
\end{tabular} & 61,29 & \begin{tabular}{|l|l|}
11,47 \\
\end{tabular} & 36,97 & \begin{tabular}{ll|}
171,10 \\
\end{tabular} & 58,14 & 58,96 & 152,82 \\
\hline Lissotriton boscai & 30TTL69 & 100,00 & 122,06 & 115,03 & 39,00 & 6155,46 & 293,29 & \begin{tabular}{l|l}
0,89 \\
\end{tabular} & 292,40 & 82,50 & \begin{tabular}{|l|l|}
201,72 \\
\end{tabular} & \begin{tabular}{l|l|}
203,25 \\
\end{tabular} & 45,71 & \begin{tabular}{|l|}
378,28 \\
\end{tabular} & 47,02 & 9,83 & 35,32 & $\begin{array}{l}131,58 \\
\end{array}$ & 49,88 & \begin{tabular}{l|l}
50,85 \\
\end{tabular} & 107,96 \\
\hline Lissotriton boscai & 30TTL70 & 100,00 & 118,69 & 114,98 & $38,57 \mid$ & 6219,90 & 293,06 & $-1,30$ & 294,36 & 78,33 . & 201,28 & 202,53 & 43,78 & 458,78 & 55,16 & 11,02 & $35,67 \mid$ & $153,44 \mid$ & $55,54[$ & 56,09 & 135,18 \\
\hline Lissotriton boscai & 30TTL71 & 100,00 & 115,19 & 115,41 & 38,99 & 6196,44 & 289,38 & $-4,39$ & 293,77 & 74,78 & \begin{tabular}{|l|l|}
196,90 \\
\end{tabular} & \begin{tabular}{|l|l|}
198,69 \\
\end{tabular} & 40,55 & \begin{tabular}{ll|}
461,69 \\
\end{tabular} & 55,62 & 11,56 & \begin{tabular}{|l|}
35,19 \\
\end{tabular} & \begin{tabular}{ll|}
154,96 \\
\end{tabular} & 57,72 & 58,52 & 134,75 \\
\hline Lissotriton boscai & 30TTL72 & 100,00 & 116,09 & 116,63 & 39,11 & 6185,27 & 290,35 & $-3,85$ & 294,19 & 75,68 & \begin{tabular}{|l|l|}
198,19 \\
\end{tabular} & \begin{tabular}{|l|l|}
199,27 \\
\end{tabular} & 41,39 & 443,39 & 53,56 & 11,38 & 35,13 & \begin{tabular}{l|l|}
150,09 \\
\end{tabular} & 56,90 & 57,37 & 127,97 \\
\hline Lissotriton boscai & $30 T T L 73$ & 100,00 & 120,48 & 118,22 & 39,59 & 6217,77 & 295,16 & $-0,53$ & 295,68 & 79,94 & 203,51 & \begin{tabular}{|l|l|}
203,67 \\
\end{tabular} & 44,79 & 414,32 & 50,82 & \begin{tabular}{ll|}
10,99 \\
\end{tabular} & \begin{tabular}{|l|}
35,68 \\
\end{tabular} & \begin{tabular}{ll|}
142,51 \\
\end{tabular} & 53,90 & 53,97 & 118,64 \\
\hline Lissotriton boscai & $30 T T L 74$ & 100,00 & 119,74 & 118,07 & 39,74 & 6189,04 & 293,94 & $-1,06$ & 295,01 & 79,43 & \begin{tabular}{|l|l|}
202,52 \\
\end{tabular} & 202,54 & 44,36 & \begin{tabular}{|l|l|}
397,47 \\
\end{tabular} & \begin{tabular}{ll|}
49,66 \\
\end{tabular} & \begin{tabular}{l|l|}
10,92 \\
\end{tabular} & 36,87 & \begin{tabular}{|l|l|}
139,32 \\
\end{tabular} & 53,40 & 53,40 & 109,99 \\
\hline Lissotriton boscai & 30TTL80 & 100,00 & 116,94 & 115,38 & 38,70 & 6194,59 & 291,30 & $-3,28$ & 294,58 & 76,48 & $\begin{array}{l}198,09 \\
\end{array}$ & 200,76 & 42,40 & \begin{tabular}{ll|l}
447,38 \\
\end{tabular} & 53,07 & $\begin{array}{ll}11,43 \\
\end{array}$ & \begin{tabular}{|l|}
34,27 \\
\end{tabular} & \begin{tabular}{|l|l|}
146,34 \\
\end{tabular} & 56,69 & 57,84 & 127,78 \\
\hline Lissotriton boscai & 30TTL81 & 100,00 & 119,77 & 116,53 & 39,00 & 6165,85 & 293,85 & $-0,93$ & 294,78 & 79,18 & \begin{tabular}{|l|l|}
200,16 \\
\end{tabular} & 202,99 & 45,29 & \begin{tabular}{|l|l|}
424,89 \\
\end{tabular} & 50,31 & $\begin{array}{l}11,05 \\
\end{array}$ & 33,65 & \begin{tabular}{|l|l|}
138,73 \\
\end{tabular} & 55,23 & 56,31 & 120,59 \\
\hline Lissotriton boscai & 30TTM50 & 100,00 & 118,92 & 114,25 & 39,00 & 6119,15 & 289,53 & $-1,20$ & \begin{tabular}{|l|l}
290,73 \\
\end{tabular} & 79,56 & $\begin{array}{l}199,50 \\
190\end{array}$ & $\begin{array}{l}199,86 \\
196\end{array}$ & 43,12 & \begin{tabular}{ll|l}
425,39 \\
\end{tabular} & 54,04 & \begin{tabular}{|l|l|}
11,10 \\
\end{tabular} & 35,80 & \begin{tabular}{|l|l|}
150,07 \\
1
\end{tabular} & 54,46 & 54,70 & 128,83 \\
\hline Lissotriton boscai & 30TTM53 & 90,00 & 116,54 & 114,76 & 39,00 & 6052,98 & 286,48 & $-3,53$ & 290,01 & 77,97 & $\begin{array}{ll}196,54 \\
\end{array}$ & 196,54 & 41,24 & 461,58 & 58,57 & 13,78 & 34,71 & 164,57 & 62,22 & 62,22 & 141,87 \\
\hline Lissotriton boscai & 30TTM57 & 80,00 & 112,37 & 114,69 & 39,02 & 5954,96 & 280,73 & $-7,69$ & 288,41 & 74,69 & \begin{tabular}{|l|l|l|l|}
191,03 \\
\end{tabular} & \begin{tabular}{|l|l|l|l|}
191,03 \\
\end{tabular} & 37,8 & 527,27 & 67,28 & \begin{tabular}{ll|}
18,87 \\
\end{tabular} & 33,90 & $\begin{array}{l}191,45 \\
\end{array}$ & 76,99 & 76,99 & 160,66 \\
\hline Lissotriton boscai & 30тTM62 & 100,00 & 120,20 & 115,04 & 39,00 & 6087,90 & 290,52 & $-0,55$ & 291,06 & 81,15 & 200,17 & 200,39 & 44,5 & 413 & 51,54 & 12, & 34,03 & 145, & 57,31 & 57,43 & 121,43 \\
\hline Lissotriton boscai & 30TTN53 & 58,00 & 93,44 & 109,66 & 39,99 & 5543,63 & 251,73 & $-19,50$ & 271,23 & 60,25 & 166,97 & 166,97 & 25,44 & 749,48 & 97,07 & 33,2 & 30,23 & 266,40 & 122,49 & \begin{tabular}{|l|}
122,49 \\
\end{tabular} & 220,42 \\
\hline Lissotriton boscai & 30TTN54 & 50,00 & 85,92 & 107,32 & 39,96 & 5432,77 & 240,95 & $-24,42$ & 265,37 & 54,00 & $\begin{array}{l}157,99 \\
15\end{array}$ & \begin{tabular}{l|l|l|l|l|l}
157,99 \\
\end{tabular} & \begin{tabular}{l|l|l|}
19,85 \\
\end{tabular} & $\begin{array}{ll}827,83 \\
\end{array}$ & 105,94 & \begin{tabular}{l|l|}
37,45 \\
\end{tabular} & \begin{tabular}{l|l|}
29,26 \\
\end{tabular} & \begin{tabular}{ll|}
289,86 \\
\end{tabular} & \begin{tabular}{|l|l|}
136,27 \\
\end{tabular} & \begin{tabular}{ll|}
136,33 \\
\end{tabular} & 244,65 \\
\hline Lissotriton boscai & 30TTN63 & 100,00 & 97,88 & 110,95 & 40,00 & 5567,66 & 257,41 & $-16,42$ & 273,84 & 64,54 & $\begin{array}{l}171,46 \\
1\end{array}$ & $\begin{array}{l}171,46 \\
\end{array}$ & 28,97 & $\begin{array}{l}704,86 \\
\end{array}$ & $\begin{array}{l}91,85 \\
\end{array}$ & 32,32 & \begin{tabular}{|c|}
30,37 \\
\end{tabular} & \begin{tabular}{|l|l|}
252,02 \\
\end{tabular} & \begin{tabular}{ll|l}
118,46 \\
\end{tabular} & $\begin{array}{l}118,46 \\
\end{array}$ & 202,02 \\
\hline Lissotriton boscai & 30TTN64 & 100,00 & 88,79 & 108,26 & 40,01 & 5445,67 & 244,62 & $-22,48$ & 267,11 & 56,85 & \begin{tabular}{|l|l|}
160,94 \\
\end{tabular} & \begin{tabular}{|l|l|}
160,94 \\
\end{tabular} & 22,20 & $\begin{array}{l}795,50 \\
\end{array}$ & 102,14 & 37,00 & 28,97 & \begin{tabular}{|l|l|}
279,16 \\
\end{tabular} & \begin{tabular}{|l|l}
134,13 \\
\end{tabular} & \begin{tabular}{ll|}
134,13 \\
\end{tabular} & 230,18 \\
\hline Lissotriton boscai & 30TTN73 & 100,00 & 96,86 & 111,50 & 40,00 & 5591,34 & 257,71 & $-18,05$ & 275,76 & 63,91 & \begin{tabular}{|l|l|}
170,84 \\
\end{tabular} & \begin{tabular}{|l|l|}
170,84 \\
\end{tabular} & 27,5 & 694,8 & 90,14 & 32,83 & 29,98 & 247,84 & 120,24 & 120,24 & 195,01 \\
\hline Lissotriton boscai & 30TTN81 & 100,00 & 112,09 & 115,44 & 39,99 & 5801,20 & 278,79 & $-8,02$ & 286,81 & 77,48 & \begin{tabular}{|l|l|}
188,47 \\
\end{tabular} & \begin{tabular}{|l|}
188,47 \\
\end{tabular} & 38,9 & 549,74 & 72,17 & 22,12 & 32, & 201,18 & 96,41 & 96,41 & 148,43 \\
\hline Lissotriton boscai & 30TTP60 & 100,00 & 129,66 & 89,93 & 43,73 & 3918,14 & 241,79 & 38,42 & 203,37 & 111,05 & $\begin{array}{ll}178,84 \\
\end{array}$ & $\begin{array}{l}181,95 \\
\end{array}$ & 82,5 & \begin{tabular}{|l|l|}
850,03 \\
\end{tabular} & 116,32 & 42,40 & 28,38 & \begin{tabular}{|l|}
284,03 \\
\end{tabular} & \begin{tabular}{ll|}
149,06 \\
\end{tabular} & 158,09 & 214,18 \\
\hline Lissotriton boscai & 30TTP82 & 60,00 & 138,75 & 71,62 & 40,72 & 3679,04 & 230,37 & \begin{tabular}{l|l}
56,65 \\
\end{tabular} & 173,71 & \begin{tabular}{l|l}
122,63 \\
\end{tabular} & $\begin{array}{l}185,16 \\
16\end{array}$ & \begin{tabular}{l|l|}
188,74 \\
\end{tabular} & \begin{tabular}{l|l}
94,25 \\
\end{tabular} & \begin{tabular}{l|l}
829,42 \\
\end{tabular} & \begin{tabular}{ll|}
113,76 \\
\end{tabular} & 40,20 & 28,83 & 282,16 & \begin{tabular}{|l|l|}
143,90 \\
\end{tabular} & $\begin{array}{l}157,39 \\
\end{array}$ & 211,51 \\
\hline Lissotriton boscai & 30тTР90 & 100,00 & 125,74 & 85,39 & 42,02 & 4035,10 & 235,66 & $34,97 \mid$ & 200,69 & 107,35 & 177,08 & 179,92 & 76,99 & 839,03 & 113,34 & 42,65 & 27,70 & 283,30 & 151,08 & 161,13 & 211,51 \\
\hline Lissotriton boscai & 30TUK03 & 100,00 & 156,90 & 114,99 & 37,00 & 6503,86 & 335,39 & 28,88 & 306,51 & \begin{tabular}{|l|l|}
114,68 \\
\end{tabular} & 243,94 & 243,94 & 76,8 & 361,34 & 42,13 & 5,25 & 40, & 122,40 & 33,81 & 33,81 & 106,76 \\
\hline Lissotriton boscai & 30TUK04 & 100,00 & 152,48 & 114,92 & 37,00 & 6473,37 & 330,21 & 25,06 & 305,15 & 110,58 & 239,14 & 239,14 & 72,90 & \begin{tabular}{|l|}
365,59 \\
\end{tabular} & 42,55 & 6,31 & 39,21 & 122,56 & 36,52 & 36,52 & 106,51 \\
\hline Lissotriton boscai & 30TUK05 & 100,00 & 91,60 & 111,19 & 36,98 & 6312,57 & 270,40 & $-26,92$ & 297,31 & $\begin{array}{ll}37,66 \\
\end{array}$ & $\begin{array}{l}177,25 \\
\end{array}$ & \begin{tabular}{|l|l|l|l|l}
178,03 & \\
\end{tabular} & 18,63 & $\begin{array}{ll}640,32 \\
\end{array}$ & 74,19 & 17,84 & \begin{tabular}{l|l|}
34,65 \\
\end{tabular} & 206,66 & \begin{tabular}{|c|}
76,97 \\
\end{tabular} & 80,68 & 186,89 \\
\hline Lissotriton boscai & 30TUK08 & 100,00 & 105,93 & 113,03 & 37,83 & 6234,50 & 282,07 & $-14,19$ & 296,26 & 64,14 & \begin{tabular}{ll|l}
188,86 \\
\end{tabular} & $\begin{array}{l}190,86 \\
\end{array}$ & 32,37 & \begin{tabular}{|l|l}
495,59 \\
\end{tabular} & 60,24 & 14,20 & 33,61 & 157,74 & \begin{tabular}{|l|l|}
64,29 \\
\end{tabular} & 66,78 & 136,18 \\
\hline Lissotriton boscai & 30TUK13 & 100,00 & 153,80 & 115,00 & 37,00 & 6529,68 & 332 & 25,31 & 307,5 & 111, & 241,18 & 241,18 & 73 & 362,1 & \begin{tabular}{l|l|l}
41,65 \\
\end{tabular} & 5, & 39 & 121 & 35 & 35,44 & 104,84 \\
\hline Lissotriton boscai & $30 \mathrm{TUK}$ & 100,00 & 151,35 & 11 & 37,00 & 6499,67 & 32 & 23,3 & $306, \mathrm{C}$ & 109, & 238,49 & 238, & 71, & 361,03 & 41,78 & 0,4 & 38,5 & 120,26 & 36,98 & 36,98 & 103 \\
\hline Lissotriton boscai & 30TUK15 & 100,00 & 107,17 & 112,56 & 37,00 & 6357,38 & 286,19 & $-14,32$ & 300,52 & 71,97 & \begin{tabular}{|l|}
192,81 \\
\end{tabular} & \begin{tabular}{ll|}
193,76 \\
\end{tabular} & 32,42 & $\begin{array}{l}526,62 \\
\end{array}$ & 62,91 & \begin{tabular}{|l|l}
14,19 \\
\end{tabular} & 34,84 & 168,06 & \begin{tabular}{|c|}
64,68 \\
\end{tabular} & 66,84 & 147,18 \\
\hline Lissotriton boscai & 30TUK16 & 100,00 & 82,40 & 110,78 & 37,00 & 6241,99 & 260,71 & $-34,80$ & 295,51 & 35,77 & \begin{tabular}{ll|}
167,32 \\
\end{tabular} & \begin{tabular}{|l|l|l|}
168,13 \\
\end{tabular} & \begin{tabular}{l|l|l|l|}
10,85 \\
\end{tabular} & $\begin{array}{l}646,15 \\
6\end{array}$ & 76,49 & $\begin{array}{l}19,65 \\
1\end{array}$ & 32,89 & \begin{tabular}{ll|}
203,86 \\
\end{tabular} & 82,49 & 87,53 & 181,66 \\
\hline Lissotriton boscai & 30TUK24 & 100,00 & 148,45 & 114,23 & 37,00 & 6501,82 & 326,70 & 20,22 & \begin{tabular}{|l|l|}
306,48 \\
\end{tabular} & 106,40 & 235,77 & 235,77 & \begin{tabular}{ll|}
68,69 \\
\end{tabular} & 362,49 & 42,40 & 6,90 & 38,08 & 119,71 & 38,77 & 38,77 & 101,54 \\
\hline Lissotrite & 30 TUK2 & 100,00 & 135,4 & & 37,00 & 6441,15 & & $\overline{9,0}$ & 30 & \begin{tabular}{|l|l|l|l}
104,99 \\
\end{tabular} & 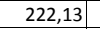 & 222 & 57, & 389 & 47,34 & 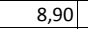 & 36 & & 46,22 & 46,31 & 10 \\
\hline Lissotriton boscai & 30TUK26 & 100,00 & 94,91 & 111,68 & 37,00 & 6277,7 & 272,94 & $-24,75$ & 297,69 & 72,72 & $\begin{array}{l}179,80 \\
\end{array}$ & \begin{tabular}{|l|l|}
180,69 \\
\end{tabular} & 21,95 & 555,93 & \begin{tabular}{ll|l}
68,55 \\
\end{tabular} & 16,80 & 33,22 & $\begin{array}{l}175,91 \\
\end{array}$ & \begin{tabular}{|c|}
73,17 \\
\end{tabular} & 76,48 & 149, \\
\hline Lissotriton boscai & 30TUK29 & 100,00 & 97,39 & 111,69 & 37,25 & 6172,59 & 272,32 & $-22,07$ & 294,39 & 77,13 & \begin{tabular}{|l|l|}
179,98 \\
\end{tabular} & \begin{tabular}{|l|l|l|}
181,63 \\
\end{tabular} & 24,99 & \begin{tabular}{|l|l|}
497,97 \\
\end{tabular} & 64,06 & \begin{tabular}{|l|l|}
16,68 \\
\end{tabular} & 32,32 & \begin{tabular}{|l|l|}
155,57 \\
\end{tabular} & 71,03 & 74,46 & 127,42 \\
\hline
\end{tabular}




\begin{tabular}{|c|c|c|c|c|c|c|c|c|c|c|c|c|c|c|c|c|c|c|c|c|c|}
\hline TAXON & UTM & $\mathrm{km} 2$ & BIO1 & B102 & $B 103$ & BIO4 & B105 & B106 & B107 & 8108 & B109 & B1010 & BIO11 & B1012 & BIO13 & B1014 & BIO15 & B1016 & B1017 & B1018 & 81019 \\
\hline Lissotriton boscai & 30TUK34 & 100,00 & 146,30 & 113,97 & 36,92 & 6520,96 & 324,74 & 17,80 & 306,94 & 108,63 & 233,89 & 233,89 & 66,48 & 363,94 & 43,27 & 7,34 & 37,36 & 119,40 & 40,36 & 40,36 & 99,86 \\
\hline Lissotriton boscai & 30TUK35 & 100,00 & 129,37 & 113,05 & 36,90 & 6435,29 & 307,23 & 3,53 & 303,71 & 102,52 & 215,81 & 216,31 & 51,82 & 408,73 & 50,69 & 10,20 & 35,68 & \begin{tabular}{ll|}
132,82 \\
\end{tabular} & 50,62 & 51,16 & 108,39 \\
\hline Lissotriton boscai & 30TUK43 & 100,00 & 145,94 & 114,02 & 36,11 & 6601,61 & $\begin{array}{l}326,07 \\
\end{array}$ & 16,37 & $\begin{array}{l}309,70 \\
\end{array}$ & $\begin{array}{l}117,03 \\
\end{array}$ & 234,62 & 234,62 & 65,32 & 370,04 & 44,08 & 7,20 & 37,97 & \begin{tabular}{|l|}
121,24 \\
\end{tabular} & 40,37 & 40,37 & 101,62 \\
\hline Lissotriton boscai & 30TUK46 & 100,00 & 100,93 & 111,37 & 36,83 & 6305,77 & 278,33 & $-20,28$ & 298,61 & 82,70 & 186,21 & $\begin{array}{l}186,97 \\
\end{array}$ & 27,26 & $\begin{array}{l}508,86 \\
\end{array}$ & 65,08 & 15,92 & 33,13 & 163,43 & \begin{tabular}{|l|l|}
70,14 \\
\end{tabular} & 72,82 & 130,45 \\
\hline Lissotriton boscai & 30TUK48 & 100,00 & 88,76 & 110,42 & 37,00 & 6176,06 & 264,24 & $-29,81$ & 294,05 & 71,09 & 172,36 & 173,36 & 17,44 & 539,78 & 70,30 & 18,85 & 31,91 & 171,63 & 78,73 & 83,12 & 134,92 \\
\hline Lissotriton boscai & 30TUK53 & 100,00 & 150,74 & 113,37 & 36,00 & 6632,21 & 330,08 & 20,54 & 309,54 & 109,54 & 239,77 & 239,77 & 69,22 & 357,35 & 42,01 & 6,85 & 38,16 & 117,52 & 38,30 & 38,30 & 98,42 \\
\hline Lissotriton boscai & 30TUK54 & 100,00 & 131,14 & 112,60 & 36,09 & 6545,57 & 310,48 & 3,62 & 306,87 & 113,72 & 219,40 & 219,58 & 52,15 & 401,54 & 50,23 & 9,73 & 35,69 & 130,93 & 49,81 & 49,99 & 104,96 \\
\hline Lissotriton boscai & 30TUK55 & 100,00 & 140,85 & 112,00 & 36,01 & 6541,56 & 318,01 & 12,68 & 305,33 & 110,79 & 228,88 & 228,88 & $\begin{array}{ll}60,92 \\
\end{array}$ & 365,31 & 44,80 & 8,45 & 35,97 & \begin{tabular}{ll|}
118,38 \\
\end{tabular} & 44,29 & 44,29 & 96,25 \\
\hline Lissotriton boscai & 30TUK56 & 100,00 & 118,29 & 111,17 & 36,41 & $\begin{array}{ll}6398,64 \\
\end{array}$ & 294,72 & $-5,92$ & \begin{tabular}{|l|l|}
300,64 \\
\end{tabular} & $\begin{array}{l}92,11 \\
\end{array}$ & 204,53 & 204,95 & 41,94 & $\begin{array}{l}438,19 \\
\end{array}$ & 55,93 & 12,85 & 34,18 & $\begin{array}{l}141,45 \\
\end{array}$ & 59,34 & \begin{tabular}{ll|l}
60,68 \\
\end{tabular} & 111,31 \\
\hline Lissotriton boscai & 30TUK57 & 100,00 & 117,59 & 110,53 & 36,51 & 6344,52 & 292,32 & $-6,49$ & 298,81 & \begin{tabular}{|l|l|}
102,44 \\
\end{tabular} & 202,68 & 203,47 & 41,46 & $\begin{array}{l}410,25 \\
\end{array}$ & 54,77 & 12,60 & 34,25 & 132,62 & 58,94 & 59,81 & 98,93 \\
\hline Lissotriton boscai & 30TUK59 & 100,00 & 103,59 & 109,52 & 36,96 & \begin{tabular}{|l|l|}
6183,07 \\
\end{tabular} & 275,94 & $-17,90$ & 293,85 & 121,31 & $\begin{array}{l}186,10 \\
\end{array}$ & $\begin{array}{l}187,49 \\
\end{array}$ & 30,31 & \begin{tabular}{|l|l|}
432,48 \\
\end{tabular} & 60,85 & 15,26 & 34,09 & 142,54 & 67,51 & \begin{tabular}{ll|l}
69,93 \\
\end{tabular} & 97,73 \\
\hline Lissotriton boscai & 30TUK64 & 100,00 & 143,47 & 111,86 & 36,00 & 6613,83 & \begin{tabular}{ll|}
321,64 \\
\end{tabular} & 14,24 & 307,40 & \begin{tabular}{|l|l|}
113,18 \\
\end{tabular} & 232,51 & 232,51 & 62,66 & 368,43 & 44,41 & 8,08 & 36,43 & \begin{tabular}{|l|l|}
120,08 \\
\end{tabular} & 43,36 & 43,36 & 98,32 \\
\hline 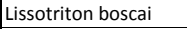 & 30TUK65 & 100,00 & 132,66 & 111,17 & 36,00 & 6534,47 & 309,78 & 5,08 & 304,70 & 113,12 & 220,75 & 220,75 & 53,25 & 387,33 & 48,71 & 9,88 & 35,14 & 125,27 & 49,91 & 49,91 & 99,34 \\
\hline Lissotriton boscai & 30TUK66 & 100,00 & 113,97 & 110,31 & 36,34 & 6387,97 & 290,11 & $-9,62$ & 299,73 & 93,62 & 200,12 & 200,66 & 38,09 & 443,80 & 57,94 & 13,48 & 33,95 & $\begin{array}{l}143,79 \\
\end{array}$ & 62,19 & 63,67 & 109,62 \\
\hline Lissotriton boscai & 30TUK67 & 100,00 & 115,18 & 109,57 & 36,26 & 6353,57 & 289,42 & $-8,52$ & 297,94 & 99,45 & 200,54 & 201,23 & 39,29 & 424,64 & 56,42 & 13,34 & 33,94 & 137,14 & 61,37 & 62,58 & 102,34 \\
\hline Lissotriton boscai & 30TUK68 & 100,00 & 112,38 & 108,73 & 36,22 & $\begin{array}{ll}6287,41 \\
\end{array}$ & 284,87 & $-10,69$ & $\begin{array}{ll}295,57 \\
\end{array}$ & 119,11 & 196,26 & $\begin{array}{l}197,41 \\
\end{array}$ & 37,17 & $\begin{array}{l}413,36 \\
4\end{array}$ & 57,04 & 13,77 & 34,30 & \begin{tabular}{ll|}
134,88 \\
\end{tabular} & 62,91 & 64,32 & 94,84 \\
\hline Lissotriton boscai & 30TUK69 & 100,00 & 100,89 & 108,38 & 36,53 & 6170,98 & 272,44 & $-20,11$ & 292,55 & $\begin{array}{l}118,39 \\
\end{array}$ & 183,75 & 184,77 & 28,19 & $\begin{array}{l}441,47 \\
4\end{array}$ & 62,70 & 16,10 & 34,16 & $\begin{array}{ll}146,82 \\
\end{array}$ & 70,40 & 73,12 & 97,69 \\
\hline Lissotriton boscai & 30TUK74 & 100,00 & 148,29 & 111,08 & 35,77 & 6661,16 & 326,08 & 18,42 & 307,66 & 106,53 & 237,77 & 237,77 & 66,49 & 360,88 & 42,33 & 7,73 & 36,76 & $\mid 118,60$ & 41,34 & $\mid 41,34$ & 97,94 \\
\hline Lissotriton boscai & 30TUK75 & 100,00 & 136,04 & 110,17 & 35,75 & 6585,37 & 312,70 & 8,06 & 304,64 & 107,44 & 224,68 & 224,68 & 55,91 & 383,44 & 47,17 & 9,64 & 35,07 & 123,98 & 48,72 & 48,72 & 99,62 \\
\hline Lissotriton boscai & 30TUK76 & 100,00 & 126,44 & 109,29 & 35,91 & 6486,12 & 301,51 & 0,41 & 301,10 & 104,01 & 213,75 & 214,03 & 48,02 & \begin{tabular}{|l|l|}
399,10 \\
\end{tabular} & 51,13 & 11,25 & 34,41 & \begin{tabular}{ll|}
128,63 \\
\end{tabular} & 54,68 & 54,91 & 99,41 \\
\hline Lissotriton boscai & 30TUK77 & 100,00 & 128,57 & 108,45 & 35,97 & 6458,48 & 301,79 & 2,79 & 299,00 & $\begin{array}{l}98,53 \\
\end{array}$ & 215,16 & 215,53 & 50,03 & 387,77 & 49,53 & 11,21 & 34,19 & \begin{tabular}{l|l|}
124,92 \\
\end{tabular} & 53,75 & 54,05 & 96,10 \\
\hline Lissotriton boscai & 30TUK78 & 100,00 & 110,91 & \begin{tabular}{ll|}
107,58 \\
\end{tabular} & 35,99 & 6295,12 & 282,65 & $-11,84$ & \begin{tabular}{|l|l|}
294,49 \\
\end{tabular} & $\begin{array}{ll}120,68 \\
\end{array}$ & \begin{tabular}{|l|l|}
194,87 \\
\end{tabular} & $\begin{array}{l}196,09 \\
\end{array}$ & 35,86 & 419,20 & 58,01 & 14,20 & 34,27 & \begin{tabular}{ll|}
137,62 \\
\end{tabular} & 64,45 & 66,14 & 95,07 \\
\hline Lissotriton boscai & 30TUK79 & 100,00 & $\begin{array}{ll}95,53 \\
\end{array}$ & $\begin{array}{l}107,68 \\
\end{array}$ & 36,53 & 6167,27 & 267,01 & $-23,95$ & 290,96 & 111,88 & $\begin{array}{l}178,89 \\
\end{array}$ & $\begin{array}{l}179,49 \\
\end{array}$ & 23,83 & 475,36 & 65,91 & 17,76 & 32,92 & 156,51 & 75,28 & \begin{tabular}{|l|l|}
79,14 \\
\end{tabular} & 107,48 \\
\hline Lissotriton boscai & 30TUK86 & 100,00 & 133,66 & 108,22 & 35,36 & $\begin{array}{ll}6561,83 \\
\end{array}$ & $\begin{array}{l}308,14 \\
\end{array}$ & 6,79 & 301,35 & 98,74 & 221,89 & 222,00 & 53,67 & 390,65 & 47,58 & 10,50 & 34,35 & 125,95 & 51,28 & 51,34 & 101,24 \\
\hline Lissotriton boscai & 30TUK87 & 100,00 & 133,51 & 107,34 & 35,38 & \begin{tabular}{ll|}
6530,87 \\
\end{tabular} & 306,06 & 7,06 & 299,00 & 93,52 & 220,89 & 221,09 & 53,58 & 385,86 & 47,13 & 10,80 & 34,08 & 124,41 & 51,68 & 51,78 & 99,15 \\
\hline Lissotriton boscai & 30TUK88 & 100,00 & 120,92 & 106,42 & 35,70 & 6408,92 & 291,84 & $-2,97$ & 294,81 & 109,49 & 205,88 & 207,34 & 43,50 & 407,06 & 52,75 & 12,92 & 33,55 & 130,32 & 59,09 & 60,40 & 98,12 \\
\hline Lissotriton boscai & 30TUK89 & 100,00 & 98,05 & 106,76 & 36,38 & 6211,20 & 268,70 & $-21,19$ & 289,90 & 113,77 & 181,84 & 182,58 & 25,62 & $\begin{array}{l}478,86 \\
\end{array}$ & 64,70 & 17,80 & 32,27 & 155,90 & 74,58 & 78,62 & 110,54 \\
\hline Lissotriton boscai & 30TUK97 & 100,00 & 130,01 & 106,23 & 35,08 & 6535,23 & 302,11 & 4,72 & 297,39 & $\begin{array}{ll}91,01 \\
\end{array}$ & 217,24 & 217,90 & 50,46 & $\begin{array}{l}406,46 \\
4\end{array}$ & 48,70 & 11,65 & 33,54 & $\begin{array}{l}131,35 \\
\end{array}$ & 54,53 & 54,97 & 105,93 \\
\hline Lissotriton boscai & 30TUK98 & 100,00 & 117,08 & 105,55 & 35,46 & $\begin{array}{l}6424,03 \\
\end{array}$ & 287,68 & $-5,43$ & 293,11 & 92,36 & 202,24 & 203,76 & 39,80 & \begin{tabular}{|l|l|}
433,53 \\
\end{tabular} & 54,70 & 14,08 & 32,57 & \begin{tabular}{|l|l|}
137,60 \\
\end{tabular} & 62,24 & 64,39 & $\begin{array}{l}106,93 \\
\end{array}$ \\
\hline Lissotriton boscai & 30TUK99 & 100,00 & 96,32 & 106,41 & 36,45 & 6227,65 & 266,97 & $-21,79$ & $\begin{array}{ll}288,76 \\
\end{array}$ & 105,56 & 180,69 & 181,32 & 24,05 & 503,34 & 65,66 & 18,77 & 31,15 & $\begin{array}{l}161,06 \\
\end{array}$ & 76,80 & 81,29 & 120,12 \\
\hline Lissotriton boscai & 30TUM02 & 100,00 & 121,08 & 117,00 & 39,00 & 6043,71 & 292,43 & $-0,94$ & \begin{tabular}{|l|l|}
293,37 \\
\end{tabular} & 83,58 & 198,70 & 200,97 & 45,49 & 392,60 & 46,74 & 14,08 & 30,80 & 132,01 & 59,13 & \begin{tabular}{ll|}
61,87 \\
\end{tabular} & 106,46 \\
\hline Lissotriton boscai & 30TUM22 & 100,00 & 116,34 & 117,00 & 39,00 & 6033,32 & 288,63 & $-5,76$ & 294,39 & 80,11 & 194,44 & 196,61 & 41,35 & 421,60 & \begin{tabular}{|l|l|l|}
498 \\
\end{tabular} & $\mid 15,54$ & 29,37 & $\mid 136,94$ & 63,37 & 68,72 & 114,20 \\
\hline Lissotriton boscai & 30TUN38 & 100,00 & 77,77 & 95,54 & 39,75 & 4880,97 & 215,01 & $-22,60$ & 237,61 & 52,92 & 142,35 & 143,25 & 19,38 & \begin{tabular}{|l|l|}
971,99 \\
\end{tabular} & \begin{tabular}{ll|}
118,52 \\
\end{tabular} & 50,96 & 23,61 & 319,81 & $\begin{array}{l}179,35 \\
\end{array}$ & 182,11 & 265,67 \\
\hline Lissotriton boscai & 30TUN39 & 100,00 & 107,75 & 88,69 & 40,18 & 4470,70 & 229,18 & 11,69 & 217,48 & 87,06 & 165,69 & 167,45 & 53,23 & 867,20 & 111,23 & 44,20 & 25,51 & 293,17 & 158,73 & 167,19 & 228,33 \\
\hline Lissotriton boscai & 30TUP10 & 100,00 & 128,41 & 81,58 & 40,93 & 4066,27 & 235,21 & $\begin{array}{ll}38,27 \\
\end{array}$ & \begin{tabular}{|l|l|}
196,94 \\
\end{tabular} & 110,11 & 180,23 & 182,88 & 78,61 & \begin{tabular}{|l|l|}
820,87 \\
\end{tabular} & \begin{tabular}{|l|l|}
109,97 \\
\end{tabular} & 40,75 & 27,43 & 280,47 & \begin{tabular}{ll|}
146,78 \\
\end{tabular} & $\begin{array}{l}158,76 \\
\end{array}$ & 210,20 \\
\hline Lissotriton boscai & 30TUP11 & 96,00 & 128,99 & 78,27 & 40,69 & 3961,70 & 231,50 & $\begin{array}{ll}41,54 \\
\end{array}$ & $\begin{array}{ll}189,96 \\
\end{array}$ & 111,36 & 179,31 & 182,19 & 80,64 & 846,18 & 113,34 & 41,76 & 27,45 & 289,11 & 150,50 & $\begin{array}{l}163,76 \\
\end{array}$ & 218,27 \\
\hline Lissotriton boscai & 30TUP20 & 100,00 & 134,88 & 77,88 & 40,29 & 3995,93 & 237,12 & 46,48 & 190,63 & 117,35 & 185,62 & $\begin{array}{l}188,38 \\
\end{array}$ & 85,65 & 802,19 & \begin{tabular}{|l|l|}
107,72 \\
\end{tabular} & 38,63 & 27,90 & 276,54 & 141,34 & 155,20 & 206,81 \\
\hline Lissotriton boscai & 30TVK07 & 100,00 & 138,22 & 105,19 & 35,00 & 6599,22 & 309,76 & 12,52 & 297,24 & 95,99 & 226,14 & 226,46 & 57,02 & 400,96 & 47,07 & 10,68 & 34,48 & 133,24 & 50,14 & 50,30 & 110,73 \\
\hline Lissotriton boscai & 30TVK08 & 100,00 & 124,39 & 104,41 & 35,06 & 6501,56 & 294,21 & 1,24 & 292,97 & 83,41 & 209,89 & 211,86 & 45,44 & 432,64 & 51,12 & 13,14 & 32,69 & 51 & 58,66 & 60,32 & 113,69 \\
\hline Lissotriton boscai & 30TVK09 & 100,00 & 113,60 & 104,19 & 35,39 & 6407,64 & 282,44 & $-7,01$ & 289,45 & 85,27 & 198,75 & 200,05 & 36,88 & $\begin{array}{l}464,05 \\
\end{array}$ & 56,18 & 15,15 & 31,66 & 147,87 & 65,86 & 69,08 & 118,12 \\
\hline Lissotriton boscai & 30TVK19 & 100,00 & 122,10 & 103,03 & 35,01 & 6504,33 & 290,27 & 0,24 & \begin{tabular}{|l|l|}
290,03 \\
\end{tabular} & 80,60 & 207,63 & 209,40 & 43,13 & 452,22 & 52,58 & 13,31 & 32,24 & $\begin{array}{l}146,66 \\
\end{array}$ & 60,58 & 63,19 & 121,45 \\
\hline Lissotriton boscai & 30TVK29 & 100,00 & 123,83 & 102,72 & 35,00 & 6522,81 & 292,25 & 2,43 & 289,82 & 82,35 & 209,81 & 211,40 & 44,65 & $\begin{array}{l}461,17 \\
4\end{array}$ & 55,11 & 13,13 & 33,00 & $\begin{array}{l}152,18 \\
\end{array}$ & 60,21 & $\begin{array}{l}62,15 \\
\end{array}$ & 128,16 \\
\hline Lissotriton boscai & 30TVL00 & 100,00 & 103,47 & 104,36 & 35,96 & $\begin{array}{ll}6315,89 \\
\end{array}$ & 271,61 & $-14,89$ & 286,50 & 97,34 & 188,25 & 189,18 & 29,18 & 495,14 & 61,23 & $\begin{array}{ll}17,16 \\
\end{array}$ & 30,66 & $\begin{array}{l}156,36 \\
\end{array}$ & 73,01 & \begin{tabular}{ll|}
77,93 \\
\end{tabular} & 122,97 \\
\hline Lissotriton boscai & 30TVL10 & 100,00 & 112,46 & 102,96 & 35,38 & $\begin{array}{ll}6427,44 \\
\end{array}$ & 279,75 & $-7,11$ & 286,86 & 80,22 & 197,93 & 199,25 & 35,60 & 478,21 & 56,21 & 15,01 & 30,94 & 150,99 & 67,21 & 71,88 & 123,97 \\
\hline \begin{tabular}{|l} 
Lissotriton boscai \\
\end{tabular} & 30TVL31 & 100,00 & 112 & 103,04 & 35,52 & 6428,78 & 279,39 & $-6,72$ & 286,11 & 73,78 & 197,50 & 198,75 & 35,20 & 496,87 & 58,38 & 15,25 & 30,58 & 158,92 & 69,08 & 73,27 & 133,32 \\
\hline Lissotriton boscai & 30TVL41 & 100,00 & 120,84 & 102,69 & 35,08 & 6501,78 & 288,23 & 0,27 & 287,97 & 79,02 & 206,51 & 207,87 & 42,13 & 468,87 & 56,71 & 13,27 & 31,97 & 154,61 & 63,08 & 65,25 & 129,18 \\
\hline Lissotriton boscai & 30TWN64 & 100,00 & 104,07 & 95,58 & 39,10 & 5166,61 & 242,19 & 1,56 & 240,63 & 48,36 & 172,21 & 172,21 & 41,03 & $\begin{array}{l}984,99 \\
\end{array}$ & 108,32 & 51,52 & 18,30 & 300,55 & 186,36 & 186,36 & 281,81 \\
\hline \begin{tabular}{|l} 
Lissotriton helveticus \\
\end{tabular} & 29тMH98 & 28,00 & 142,80 & 61,16 & 39,53 & 3177,18 & 226,53 & 73,42 & 153,11 & 112,60 & 181,80 & 185,62 & 103,67 & 1013,53 & 141,49 & 28,18 & 41,00 & 5,73 & 117,49 & 142,60 & 341,07 \\
\hline Lissotriton helveticus & 29TNE28 & 101,00 & 149,73 & 78,91 & 45,04 & 3384,36 & 236,65 & 63,11 & 173,54 & 111,73 & 189,05 & 190,76 & 103,37 & 1002,72 & \begin{tabular}{|c|}
139,53 \\
\end{tabular} & 11,00 & 52,55 & \begin{tabular}{|c|}
403,88 \\
\end{tabular} & 66,14 & 76,54 & 395,56 \\
\hline Lissotriton helveticus & 29TNE & 91,00 & 148,62 & 76,34 & 45,23 & 3286,96 & 230,02 & 63,25 & 166,77 & 111,66 & $\begin{array}{l}186,35 \\
\end{array}$ & 187,93 & \begin{tabular}{|l|}
103,07 \\
\end{tabular} & $\begin{array}{l}1017,60 \\
\end{array}$ & 140,94 & 11,13 & 52,35 & 410,05 & 67,19 & 78,96 & 399,81 \\
\hline Lissotriton helveticus & 29TNE37 & 100,00 & 151,92 & 88,12 & 44,21 & 3760,17 & 256,36 & 59,47 & $\begin{array}{ll}196,88 \\
\end{array}$ & \begin{tabular}{|l|l|}
109,94 \\
\end{tabular} & $\begin{array}{l}196,99 \\
\end{array}$ & \begin{tabular}{ll|}
198,97 \\
\end{tabular} & 101,90 & 999,56 & 139,38 & 11,00 & 52,72 & 400,87 & 66,69 & 74,56 & 396,25 \\
\hline Lissotriton helveticus & 29TNE38 & 100,00 & 151,17 & 85,28 & 44,48 & 3655,62 & 249,50 & 59,88 & 189,62 & 110,04 & 194,48 & 196,30 & 101,87 & 1009,27 & 140,22 & 11,01 & 52,38 & 405,38 & 67,20 & 76,61 & 398,25 \\
\hline \begin{tabular}{|l} 
Lissotriton helveticus \\
\end{tabular} & 29TNE39 & 101,00 & 149,99 & 83,28 & 44,75 & 3590,40 & 244,10 & 59,58 & 84,53 & 109,52 & 192,36 & 194 & 101 & 1023,95 & 41,72 & $\mid 11,49$ & 52,18 & 411 & 68,18 & 79,27 & 402,06 \\
\hline Lissotriton helveticus & $29 \mathrm{TN}$ & 101 & 159 & $\begin{array}{l}98,46 \\
\end{array}$ & 43 & & 283,32 & $\begin{array}{l}60,82 \\
\end{array}$ & 222,49 & 108,75 & 21 & 212,78 & 105,32 & 93 & 130,70 & 9,70 & 52,90 & 374,25 & 62,54 & 67,44 & 374,14 \\
\hline Lissotriton helveticus & 29TNE56 & 101,00 & 150,10 & 99,40 & 42,36 & 4444,24 & 281,01 & 49,47 & 231,54 & 93,55 & 205,67 & 207,82 & 93,41 & 1053,40 & \begin{tabular}{|l|l|}
149,12 \\
\end{tabular} & 11,49 & 52,88 & 422,23 & 71,75 & 75,15 & 422,23 \\
\hline Lissotriton helveticus & 29TNE63 & 101,00 & 130,56 & 89,14 & 38,42 & 4769,88 & 264,01 & 35,22 & 228,79 & 72,92 & 194,23 & 194,62 & 72,92 & \begin{tabular}{|l|}
1221,84 \\
\end{tabular} & 181,18 & 12,82 & 55,21 & 499,16 & 78,16 & 78,31 & 499,16 \\
\hline Lissotriton helveticus & 29TNE64 & 100,00 & 155,81 & 101,81 & 41,50 & 4683,46 & 294,72 & 53,07 & 241,64 & 96,83 & 215,14 & 217,20 & 96,83 & 978,93 & 139,33 & 9,92 & 53,46 & 394,96 & 65,10 & 67,15 & 394,96 \\
\hline |Lissot! & & 100,00 & & & & 09 & 284,97 & 43, & & 84 & 24 & & 84 & 108 & 07 & 10,86 & & 44 & 70 & 71,38 & 442,33 \\
\hline Lissotriton helveticus & 29TNE75 & 101,00 & 154,08 & 101,29 & 40,82 & 4855,81 & 295,17 & $\begin{array}{l}49,96 \\
\end{array}$ & 245,21 & 93,12 & 215,94 & 217,84 & 93,12 & $\begin{array}{l}998,76 \\
\end{array}$ & \begin{tabular}{|l|l|}
143,36 \\
\end{tabular} & 9,90 & 53,72 & 402,78 & 65,75 & 68,01 & 402,78 \\
\hline Lissotriton helveticus & 29TNE84 & 101,00 & 133,66 & 90,79 & 37,47 & 5087,30 & 273,82 & 34,71 & 239,11 & 72,27 & 201,61 & 201,88 & 72,27 & $\begin{array}{l}1197,70 \\
\end{array}$ & 179,06 & 11,86 & 55,43 & 489,74 & 75,49 & 75,49 & 489,74 \\
\hline
\end{tabular}




\begin{tabular}{|c|c|c|c|c|c|c|c|c|c|c|c|c|c|c|c|c|c|c|c|c|c|}
\hline TAXON & UTM & $\mathrm{km} 2$ & BIO1 & B102 & $B 103$ & BIO4 & B105 & B106 & B107 & B108 & $B 109$ & B1010 & BIO11 & B1012 & B1013 & BIO14 & B1015 & B1016 & B1017 & B1018 & 81019 \\
\hline Lissotriton helveticus & 29TNF25 & 28,00 & 144,51 & 85,81 & 44,94 & 3674,23 & 243,21 & 54,34 & 188,87 & 104,47 & 189,36 & 191,38 & 97,09 & 1183,21 & 162,30 & 14,83 & 51,15 & 472,75 & 81,40 & 99,72 & 460,91 \\
\hline Lissotriton helveticus & 29TNF26 & 68,00 & 143,71 & 84,72 & 45,01 & 3658,17 & 241,52 & 55,50 & 186,02 & 99,99 & 188,56 & 190,46 & 97,07 & 1215,52 & 165,55 & 15,08 & 51,03 & 482,21 & 83,56 & 100,72 & 480,78 \\
\hline Lissotriton helveticus & 29TNF27 & 83,00 & 143,39 & 83,67 & 44,84 & 3665,84 & 241,48 & 56,50 & 184,98 & 98,16 & \begin{tabular}{ll|}
188,60 \\
\end{tabular} & 190,35 & 96,94 & 1229,74 & 168,04 & 15,06 & 51,32 & \begin{tabular}{ll|}
488,82 \\
\end{tabular} & 83,48 & 101,82 & 488,58 \\
\hline Lissotriton helveticus & 29TNF30 & 97,00 & 149,38 & 82,52 & 44,75 & 3564,68 & 241,69 & 59,15 & 182,54 & 109,24 & 191,41 & $\begin{array}{l}193,03 \\
\end{array}$ & 100,90 & 1039,18 & 143,20 & 11,86 & 52,06 & 418,81 & 69,12 & 81,84 & 406,13 \\
\hline Lissotriton helveticus & 29TNF33 & 100,00 & 143,08 & 86,64 & 44,26 & 3769,42 & 244,08 & 50,32 & 193,75 & 101,57 & 188,84 & 190,75 & 93,44 & 1153,38 & 156,89 & 14,21 & 51,96 & 467,44 & 78,42 & 95,49 & 444,94 \\
\hline Lissotriton helveticus & 29TNF34 & 101,00 & 142,93 & 88,24 & 44,24 & 3832,79 & 246,60 & 49,26 & 197,34 & 100,95 & 189,74 & 191,72 & 92,80 & 1169,53 & 160,71 & 14,84 & 51,92 & 475,06 & 79,95 & 99,15 & 447,97 \\
\hline Lissotriton helveticus & 29TNF35 & 101,00 & 143,79 & 89,17 & 44,34 & 3853,99 & 248,86 & 50,08 & 198,78 & 101,82 & 191,19 & 193,23 & 93,92 & 1176,16 & 162,85 & 15,00 & 51,60 & 476,56 & 80,52 & 100,90 & 450,62 \\
\hline Lissotriton helveticus & 29TNF36 & 100,00 & 142,72 & 88,75 & \begin{tabular}{|l|l|}
44,37 \\
\end{tabular} & 3874,54 & 248,10 & 50,30 & 197,80 & 100,59 & 190,60 & $\begin{array}{l}192,54 \\
\end{array}$ & 93,19 & 1208,89 & 165,64 & 15,18 & 51,16 & 484,74 & 82,84 & 101,99 & 470,16 \\
\hline Lissotriton helveticus & 29TNF39 & 100,00 & 142,67 & 85,68 & 43,22 & 3921,25 & 249,19 & 53,49 & $\begin{array}{l}195,69 \\
\end{array}$ & 97,62 & 191,73 & 193,13 & 93,16 & 1252,93 & $\begin{array}{l}169,96 \\
\end{array}$ & 15,41 & 51,40 & 497,59 & 84,71 & \begin{tabular}{|l|l}
104,50 \\
\end{tabular} & 496,90 \\
\hline Lissotriton helveticus & 29TNF56 & 101,00 & \begin{tabular}{ll|l}
139,94 \\
\end{tabular} & 95,13 & \begin{tabular}{l|l}
42,95 \\
\end{tabular} & 4354,26 & 260,13 & 41,13 & 219,00 & 92,16 & 194,79 & \begin{tabular}{|c|}
196,27 \\
\end{tabular} & 84,56 & 1221,82 & 166,99 & \begin{tabular}{|l|l|}
14,97 \\
\end{tabular} & 51,64 & 490,56 & 83,17 & 98,86 & 477,69 \\
\hline Lissotriton helveticus & 29TNF67 & 100,00 & 139,03 & 97,85 & $\begin{array}{l}42,15 \\
\end{array}$ & 4589,24 & 266,73 & 37,67 & 229,06 & 88,29 & 197,36 & 198,49 & 80,91 & 1225,60 & 168,33 & \begin{tabular}{ll|}
14,86 \\
\end{tabular} & 51,72 & 488,61 & 83,77 & 97,47 & 482,14 \\
\hline Lissotriton helveticus & 29TNF69 & 100,00 & 135,31 & 96,15 & 41,53 & 4630,85 & 264,13 & 35,32 & 228,80 & 83,85 & $\begin{array}{l}194,67 \\
\end{array}$ & 195,62 & 77,28 & 1267,98 & 170,11 & 16,66 & 50,99 & 502,08 & 90,32 & 103,32 & 498,82 \\
\hline Lissotriton helveticus & 29TNF78 & 101,00 & 126,95 & 97,32 & 40,78 & 4844,60 & 261,42 & 25,75 & 235,68 & 68,04 & 189,60 & 190,52 & 66,83 & 1333,31 & 185,94 & 17,30 & 52,04 & 531,44 & $\begin{array}{l}94,53 \\
\end{array}$ & 103,38 & 531,32 \\
\hline Lissotriton helveticus & 29TNG11 & 68,00 & 142,97 & 75,17 & \begin{tabular}{|l|l|}
42,97 & \\
\end{tabular} & 3566,09 & 236,70 & 63,82 & 172,88 & 98,36 & 187,37 & 188,68 & 98,36 & 1288,24 & 180,59 & 15,17 & 52,45 & 518,55 & 83,56 & $\begin{array}{l}108,22 \\
\end{array}$ & 518,55 \\
\hline Lissotriton helveticus & 29TNG12 & 87,00 & 137,29 & 73,96 & 42,06 & 3627,14 & 232,43 & $\begin{array}{l}58,62 \\
\end{array}$ & 173,81 & 92,83 & 182,87 & 184,29 & \begin{tabular}{l|l}
92,14 \\
\end{tabular} & $\begin{array}{l}1378,35 \\
\end{array}$ & $\begin{array}{l}191,82 \\
\end{array}$ & 19,18 & 51,61 & 553,01 & 96,64 & \begin{tabular}{ll|}
118,57 \\
\end{tabular} & 552,97 \\
\hline Lissotriton helveticus & 29TNG14 & 99,00 & 141,35 & \begin{tabular}{|c|}
69,97 \\
\end{tabular} & 41,01 & 3592,14 & 233,55 & 65,01 & 168,54 & 103,58 & 186,44 & \begin{tabular}{|l|}
187,73 \\
\end{tabular} & 96,16 & 1368,59 & \begin{tabular}{|c|}
193,12 \\
\end{tabular} & 21,54 & 50,70 & 549,61 & 101,51 & 122,99 & 542,04 \\
\hline Lissotriton helveticus & 29TNG15 & 101,00 & 132,16 & 69,72 & 40,14 & 3685,33 & 227,32 & 55,75 & 171,56 & \begin{tabular}{l|l}
93,81 \\
\end{tabular} & 178,93 & 180,33 & 86,39 & 1509,91 & 227,25 & 27,33 & 50,50 & $\begin{array}{l}609,48 \\
\end{array}$ & 119,62 & $\begin{array}{ll}138,03 \\
\end{array}$ & 604,19 \\
\hline \begin{tabular}{|l} 
Lissotriton helveticus \\
\end{tabular} & 29TNG17 & 33,00 & 149,14 & 62,22 & 38,97 & 3510,00 & 234,61 & 76,97 & 157,64 & 112,28 & 193,11 & 194,33 & 104,31 & 1294,33 & 1799,89 & 25,03 & 48,31 & 519,61 & $\mid 107,44$ & 128,50 & 486,56 \\
\hline Lissotriton helveticus & 29TNG20 & 101,00 & 138,63 & 80,62 & 42,90 & 3774,84 & 239,93 & 54,36 & 185,56 & 91,40 & 185,97 & 187,32 & 91,40 & 1326,01 & 182,29 & 16,74 & 51,84 & 531,55 & 89,82 & 110,74 & 531,55 \\
\hline Lissotriton helveticus & 29TNG22 & 101,00 & 137,87 & 77,71 & 41,84 & 3802,67 & 239,14 & 55,51 & 183,63 & 92,15 & 185,93 & 187,09 & 90,40 & 1364,18 & 189,74 & 19,1 & 51,39 & 545,54 & 96,55 & 117,25 & 545,41 \\
\hline Lissotriton helveticus & 29 TNG23 & 100,00 & 133,12 & 76,64 & 41,04 & 3855,64 & 235,53 & 51,17 & 184,36 & 88,49 & 182,12 & 183,32 & 85,21 & 1450,79 & 209,92 & 22,81 & 50,88 & 581,76 & 108,37 & 126,68 & 581,25 \\
\hline Lissotriton helveticus & 29TNG26 & 100,00 & 137,42 & 70,38 & 39,69 & 3792,18 & 234,78 & $\begin{array}{l}59,26 \\
\end{array}$ & 175,52 & 95,03 & 185,76 & 186,73 & 89,89 & 1494,19 & 233,27 & 28,30 & 50,67 & 605,16 & $\begin{array}{ll}120,03 \\
\end{array}$ & \begin{tabular}{ll|}
137,69 \\
\end{tabular} & 598,49 \\
\hline Lissotriton helveticus & 29TNG27 & 80,00 & 142,23 & 66,90 & 39,02 & 3729,91 & 235,55 & 66,17 & 169,38 & 100,94 & $\mid 189,67$ & 190,59 & 95,20 & 1456,53 & 226,75 & 28,89 & 50,29 & 590,88 & 119,23 & 137,56 & 576,63 \\
\hline Lissotriton helveticus & 29TNG28 & 86,00 & 139,17 & 65,44 & 38,37 . & 3735,36 & 232,63 & 64,36 & 168,28 & 99,83 & 186,87 & 187,97 & 92,44 & 1463,59 & 227,46 & 31,15 & 49,23 & 589,78 & 125,44 & 144,09 & 572,35 \\
\hline Lissotriton helveticus & 29TNG29 & 72,00 & 142,90 & 62,57 & 37,89 & 3707,49 & 233,27 & 70,12 & 163,15 & 103,57 & 190,24 & 191,12 & 96,35 & 1394,43 & 212,13 & 30,94 & 48,26 & 558,48 & 122,62 & 142,96 & 533,75 \\
\hline Lissotriton helveticus & 29 TNG32 & 101,00 & 142,57 & 82,02 & 41,84 & 3972,07 & 249,88 & 55,81 & 194,06 & 98,75 & 192,74 & 193,71 & 92,50 & 1300,19 & 180,92 & 17,88 & 51,01 & 516,76 & 92,01 & 111,91 & 515,34 \\
\hline Lissotriton helveticus & 29TNG33 & 100,00 & 128,02 & 80,92 & \begin{tabular}{l|l|}
40,79 \\
\end{tabular} & 4087,55 & 238,12 & 41,92 & 196,20 & 79,68 & 180,45 & 181,48 & 77,39 & 1483,19 & 217,87 & 24,47 & 50,58 & 592,61 & 114,75 & \begin{tabular}{|l|l}
129,94 \\
\end{tabular} & 592,45 \\
\hline Lissotriton helveticus & 29TNG36 & 101,00 & 144,76 & 73,61 & 39,76 & 3928,62 & 246,38 & \begin{tabular}{l|l|}
62,98 \\
\end{tabular} & 183,40 & 101,35 & 194,70 & 195,47 & 95,00 & 1380,58 & 213,07 & 25,50 & 50,08 & 554,99 & 110,69 & \begin{tabular}{ll|}
128,51 \\
\end{tabular} & 543,54 \\
\hline Lissotriton helveticus & 29TNG37 & 100,00 & 139,44 & 72,37 & $39,17 \mid$ & 3952,22 & 241,01 & 58,61 & 182,39 & 95,37 & 190,05 & 190,83 & 89,86 & 1472,17 & 236,44 & 29,55 & 50,39 & 593,97 & 122,06 & 138,70 & 586,24 \\
\hline Lissotriton helveticus & 29TNG39 & 101,00 & 136,77 & 68,86 & 38,12 & 3933,53 & 236,40 & 58,27 & 178,13 & 94,66 & 187,42 & 188,34 & 87,94 & 1478,41 & 235,28 & 33,27 & 48,80 & 590,26 & 130,99 & 148,84 & 576,22 \\
\hline Lissotriton helveticus & 29TNG40 & 101,00 & 145,85 & 88,48 & 42,53 & 4128,39 & 258,94 & 53,25 & 205,69 & 100,52 & \begin{tabular}{|c|}
197,76 \\
\end{tabular} & 198,85 & 93,45 & \begin{tabular}{|l|}
1208,74 \\
\end{tabular} & 163,53 & \begin{tabular}{|c|}
15,25 \\
\end{tabular} & 50,98 & 478,58 & 83,25 & 102,33 & 474,61 \\
\hline Lissotriton helveticus & 29TNG51 & 100,00 & 138,16 & 91,40 & 41,41 & 4425,39 & 260,50 & 42,19 & 218,31 & 89,59 & 194,64 & 195,49 & 82,54 & 1274,66 & 176,06 & 17,98 & 50,29 & 503,34 & 93,86 & 109,01 & 498,60 \\
\hline Lissotriton helveticus & 29TNG53 & 101,00 & 131,96 & 89,04 & 40,50 & 4465,45 & 254,88 & 37,47 & 217,42 & 83,37 & 189,44 & 190,19 & 76,41 & $\begin{array}{l}1345,19 \\
\end{array}$ & \begin{tabular}{|c|}
193,52 \\
\end{tabular} & 21,98 & 49,53 & 529,65 & 106,91 & 119,50 & 523,62 \\
\hline Lissotriton helveticus & 29TNG58 & 99,00 & 113,23 & 81,48 & 38,81 & 4356,27 & 232,03 & 24,34 & 207,69 & $\begin{array}{c}66,96 \\
\end{array}$ & 170,34 & 171,53 & 61,18 & 1517,29 & 227,58 & 34,32 & 47,03 & 591,85 & 141,42 & 152,52 & 583,34 \\
\hline Lissotriton helveticus & 29TNG62 & 101,00 & 115,32 & 87,95 & 39,30 & 4647,57 & 241,85 & 21,15 & 220,70 & 62,37 & 176,03 & 176,82 & 58,84 & 1450,71 & 198,80 & 24,52 & 49,68 & 571,37 & 116,97 & 125,53 & 570,44 \\
\hline Lissotriton helveticus & 29TNG64 & 101,00 & 110,77 & 85,49 & $\begin{array}{l}38,75 \\
\end{array}$ & 4618,93 & 235,92 & 18,21 & 217,71 & 61,90 & 171,38 & 172,25 & 55,21 & 1481,37 & 208,95 & 28,14 & 48,52 & \begin{tabular}{ll|}
579,94 \\
\end{tabular} & \begin{tabular}{ll|}
126,96 \\
\end{tabular} & \begin{tabular}{|l|l}
135,08 \\
\end{tabular} & 577,66 \\
\hline Lissotriton helveticus & 29TNG65 & 100,00 & 104,96 & 83,10 & 38,21 & 4573,78 & 228,97 & 14,35 & 214,62 & 57,06 & 165,27 & 166,23 & 50,52 & 1523,45 & 215,64 & 31,05 & 47,71 & 594,87 & 135,51 & 143,03 & 591,62 \\
\hline Lissotriton helveticus & 29TNG75 & 100,00 & 95,31 & 81,82 & 37,30 & 4670,94 & 221,61 & 5,29 & 216,32 & 47,01 & 157,29 & 158,27 & 40,48 & 1539,21 & 211,15 & 32,58 & 47,17 & 98,54 & 140,23 & 145,68 & 596,07 \\
\hline Lissotriton helveticus & 29TNG80 & 101,00 & 112 & 91 & 38,7 & 7,97 & 247,6 & 15,16 & 45 & 53,01 & 177,90 & 178,60 & 53,01 & 1400,14 & 192, & 21,42 & 51 & 56,51 & 107,68 & 112,99 & 556,51 \\
\hline Lissotriton helveticus & 29TNG83 & 100,00 & 95,35 & 8 & 36,89 & 5,88 & 224,96 & 4,18 & 220,77 & 39,97 & 159,66 & 160,33 & 38,78 & 1502,75 & 199,67 & 29,19 & 48,38 & 587,88 & 130,81 & 134,52 & 587,87 \\
\hline Lissotriton helveticus & 29TNG86 & 100,00 & 118,55 & 89,98 & 38,52 & 4887,39 & 249,84 & 19,15 & 230,69 & 65,38 & 182,86 & 183,30 & 59,50 & 1277,69 & $\begin{array}{l}180,86 \\
\end{array}$ & 25,94 & 46,84 & 491,94 & 114,51 & \begin{tabular}{|l|l}
120,97 \\
\end{tabular} & 485,73 \\
\hline Lissotriton helveticus & 29TNG92 & 101,00 & 104,70 & 86,50 & 37,29 & 4987,78 & 238,55 & 9,44 & 229,12 & 45,29 & 170,90 & 171,31 & 45,29 & 1385,85 & 185,38 & 24,36 & 49,44 & 545,62 & 114,51 & \begin{tabular}{ll|}
117,69 \\
\end{tabular} & 545,62 \\
\hline Lissotriton helveticus & 29TNG93 & 100,00 & 96,32 & 83,47 & $\begin{array}{l}36,63 \\
\end{array}$ & 4929,91 & 228,39 & 3,62 & 224,77 & 39,17 & 162,07 & 162,53 & 38,30 & 1441,20 & 190,75 & 27,84 & 48,34 & 63,31 & 125,34 & 128,21 & 563,31 \\
\hline Lissotriton helveticus & 29TNG94 & 100,00 & 104, & 6,30 & 37, & 4947,62 & 237,7 & 9,36 & 228,42 & 50,88 & 170,56 & 170,87 & 45,91 & 1358,63 & 181,85 & 26,28 & 47,98 & 21 & 118,26 & 122,51 & 528,04 \\
\hline Lissotriton helveticus & 29TNG98 & 101,00 & 137,22 & 92,45 & 37, & 5162,84 & 269, & 28,60 & 240,77 & 79,01 & 204,71 & 204,75 & 73,95 & 989,93 & 142,03 & 21,4 & 44,79 & 370,10 & 91,71 & 93,81 & 359,00 \\
\hline Lissotriton helveticus & 29TNHOO & 16,00 & 14 & 59,00 & 38,48 & 3400,52 & 230,67 & 78,95 & 151,71 & 112,29 & 190,24 & \begin{tabular}{|l|l|}
191,67 \\
\end{tabular} & 104,38 & $\begin{array}{l}1225,90 \\
\end{array}$ & \begin{tabular}{|l|l|}
174,48 \\
\end{tabular} & 26,95 & 46,81 & 491,57 & 111,81 & 134,71 & 450,57 \\
\hline Lissotriton helveticus & 29TNH02 & 97,00 & 132,26 & 63,14 & \begin{tabular}{|c|}
37,98 \\
\end{tabular} & 3521,94 & 224,76 & 60,48 & 164,28 & 97,19 & 177,01 & 179,36 & 89,11 & $\begin{array}{l}1311,65 \\
\end{array}$ & $\mid 191,91$ & 32,75 & 44,97 & 520,73 & 131,71 & 153,40 & 479,06 \\
\hline Lissotriton helveticus & 29TNH08 & 81,00 & 139,86 & 62,83 & 39,4 & 3245,91 & 226,50 & 68,94 & 157,55 & 108,65 & 179,71 & 183,68 & 99,93 & 1066,54 & 146,17 & 30,11 & 40,82 & 414,13 & 122,84 & 447,26 & 363,35 \\
\hline Lissotriton helveticus & 29TNHO9 & 36,00 & 140,84 & 62,53 & 39, & 3197,92 & 225,89 & 70,47 & 155,42 & 110,27 & 179,88 & 184,00 & 101,47 & 1046,33 & 142,86 & 29,83 & 40,06 & 404,94 & 121,86 & 146,55 & 354,73 \\
\hline Lissotriton helveticus & $29 \mathrm{TNH}$ & 61,00 & 146,39 & 60,06 & 37, & 3519,36 & 232,27 & 76,11 & 156,16 & 109,72 & 190,75 & 192,23 & 101,94 & $\begin{array}{l}1275,06 \\
\end{array}$ & 185,3 & 28,73 & 46,99 & 509,45 & 116,28 & 138,47 & 472,93 \\
\hline \begin{tabular}{|l} 
Lissotriton helveticus \\
\end{tabular} & 29TNH11 & 40,00 & 146,34 & 60,45 & 37,82 & 3518,47 & 233,20 & 75,68 & 157,53 & 109,97 & 190,80 & 192,50 & 102,30 & 1241,93 & \begin{tabular}{|l|l|}
180,28 \\
\end{tabular} & 28,89 & 46,24 & 494,43 & 116,57 & 139,20 & 455,66 \\
\hline Lissotriton helveticus & 29TNH12 & 80,00 & 143,85 & 61,84 & 37,90 & 3527,18 & 233,33 & 72,06 & 161,27 & 107,84 & 188,46 & 190,54 & 99,85 & 1225,40 & 177,83 & 29,87 & 45,22 & 485,94 & 119,86 & 142,71 & 444,59 \\
\hline Lissotriton helveticus & 29TNH18 & 99,00 & 138 & 64,56 & 39,5 & 3317,71 & 227,61 & 66,00 & 161,61 & 106,04 & 17 & 18 & 97,47 & 1106 & $150, \varepsilon$ & 31 & 40 & 427,34 & 2 & 06 & 380,75 \\
\hline Lissotriton helveticus & $29 \mathrm{TNH}$ & $64, \mathrm{C}$ & 14 & 63 & 39 & & 227 & 69,77 & 157,34 & 109,84 & 180 & 18 & 101,17 & 1059,58 & 14 & 30,2 & 40,01 & 408,67 & 122,48 & 146,75 & 361 \\
\hline Lissotriton helveticus & 29TNH23 & 100,00 & 140,69 & 65,81 & 37,91 & 3675,02 & 236,85 & 65,44 & 171,42 & 102,96 & 187,49 & 189,76 & 95,38 & 1268,02 & 185,23 & 32,23 & 44,81 & 497,28 & 126,63 & 148,60 & 460,75 \\
\hline Lissotriton helveticus & 29TNH28 & 101,00 & 138,15 & 66,22 & 39,76 & 3371,93 & 229,55 & 64,80 & 164,75 & 105,12 & $\begin{array}{l}179,97 \\
\end{array}$ & $\begin{array}{l}183,87 \\
\end{array}$ & 96,86 & 1124,24 & $\begin{array}{l}152,92 \\
\end{array}$ & 32,00 & 40,55 & 432,17 & \begin{tabular}{ll|}
126,98 \\
\end{tabular} & \begin{tabular}{ll|}
150,29 \\
\end{tabular} & 389,89 \\
\hline Lissotriton helveticus & 29TNH29 & 39,00 & 138,94 & 65,60 & 40,11 & 3300,89 & 227,96 & 66,33 & 161,63 & 106,78 & 179,56 & 183,64 & 98,28 & 1096,42 & 147,44 & 31,46 & 39,97 & 420,50 & 125,51 & 149,00 & 378,18 \\
\hline Lissotri & 29 & 101, & & 70,52 & 37 & & 2 & 53, & & 93 & & 18 & 86 & & 212 & 35,74 & & 55 & & .02 & 52 \\
\hline Lissotriton helveticus & 29TNH34 & 100,00 & 137,98 & 70,61 & \begin{tabular}{|c|}
37,67 \\
\end{tabular} & 3829,36 & 242,2 & 57,25 & 184,96 & 98,68 & 186,96 & 189,58 & 91,35 & $\begin{array}{l}1297,37 \\
\end{array}$ & $\begin{array}{l}188,15 \\
\end{array}$ & 34,52 & 43,99 & 501,72 & 132,89 & 154,22 & 468, \\
\hline Lissotriton helveticus & 29TNH35 & 101,00 & 132,84 & 72,28 & \begin{tabular}{|c|}
37,68 \\
\end{tabular} & 3838,58 & 240,40 & 50,95 & 189,45 & 94,15 & 182,04 & 185,10 & 86,75 & 1326,75 & 190,10 & 36,64 & 43,10 & 509,81 & 140,19 & 161,30 & 476,37 \\
\hline
\end{tabular}




\begin{tabular}{|c|c|c|c|c|c|c|c|c|c|c|c|c|c|c|c|c|c|c|c|c|c|}
\hline TAXON & UTM & $\overline{\mathrm{km} 2}$ & BIO1 & $\mathrm{B1O2}$ & $\mathrm{BIO3}$ & $\begin{array}{ll}B 104 \\
\end{array}$ & B105 & B106 & B107 & B108 & B109 & BIO10 & BIO11 & $\overline{B 1012}$ & BIO13 & BIO14 & BIO15 & B1016 & BIO17 & BIO18 & BlO19 \\
\hline Lissotriton helveticus & 29TNH37 & 101,00 & 127,82 & 71,68 & 38,69 & 3685,61 & 231,99 & 48,85 & 183,14 & 91,12 & 174,58 & 178,31 & 83,80 & \begin{tabular}{|r|}
1296,43 \\
\end{tabular} & 180,66 & 37,63 & 41,15 & 494,57 & 144,29 & 165,38 & 458,65 \\
\hline Lissotriton helveticus & $\begin{array}{l}\text { 29TNH38 } \\
\end{array}$ & 100,00 & 130,25 & 69,90 & 39,58 & 3529,25 & 228,82 & 54,21 & $\begin{array}{ll}174,62 \\
17\end{array}$ & 95,40 & $\begin{array}{l}174,66 \\
\end{array}$ & $\begin{array}{l}178,55 \\
\end{array}$ & 87,84 & 1225,75 & 167,86 & 35,84 & $\begin{array}{l}40,29 \\
\end{array}$ & 467,01 & $\begin{array}{ll}138,82 \\
\end{array}$ & \begin{tabular}{ll|}
160,53 \\
\end{tabular} & 429,77 \\
\hline Lissotriton helveticus & 29TNH39 & 66,00 & 137,72 & 67,21 & 40,50 & 3335,65 & 228,27 & 64,37 & \begin{tabular}{|l|l|l|}
163,90 \\
\end{tabular} & 104,80 & $\begin{array}{l}178,85 \\
\end{array}$ & 182,93 & 96,84 & 1111,28 & 148,76 & 32,07 & 39,82 & 423,65 & \begin{tabular}{ll|}
126,76 \\
\end{tabular} & \begin{tabular}{ll|}
149,62 \\
\end{tabular} & 385,50 \\
\hline Lissotriton helveticus & 29TNH45 & 100,00 & 133,85 & 75,41 & 37,71 & 3948,35 & 245,54 & 48,08 & 197,45 & 93,39 & $\begin{array}{l}184,49 \\
1\end{array}$ & 187,60 & 86,62 & 1327,24 & 189,42 & 36,86 & 42,92 & \begin{tabular}{|l|l|}
505,97 \\
\end{tabular} & \begin{tabular}{|c|}
139,84 \\
\end{tabular} & \begin{tabular}{|c|}
160,39 \\
\end{tabular} & 476,27 \\
\hline Lissotriton helveticus & 29TNH46 & 100,00 & 133,61 & 74,17 & 38,49 & 3807,22 & 241,03 & 50,75 & $190,27 \mid$ & $94,78 \mid$ & $182,11 \mid$ & $185,54[$ & $87,87 \mid$ & 1277,88 & 179,38 & 36,11 . & 41,96 & $486,11 \mid$ & $137,91 \mid$ & 158,76 & 454,57] \\
\hline Lissotriton helveticus & \begin{tabular}{|l|} 
29TNH47 \\
\end{tabular} & 101,00 & 129,79 & 73,67 & 39,01 & 3726,10 & 235,43 & 48,83 & 186,61 & 92,02 & \begin{tabular}{|c|c|}
177,26 \\
\end{tabular} & 180,80 & 85,29 & 1276,81 & 177,09 & 37,02 & 41,03 & 484,24 & 141,41 & 162,11 & 451,80 \\
\hline Lissotriton helveticus & \begin{tabular}{|l|l|} 
29TNH48 \\
\end{tabular} & 99,00 & 130,64 & 71,90 & 39,94 & 3580,81 & 231,16 & 52,91 & 178,25 & 94,65 & \begin{tabular}{|l|l|}
175,87 \\
\end{tabular} & 179,58 & 87,62 & 1222,47 & 166,76 & 35,87 & 40,09 & 463,07 & 138,08 & 159,15 & 429,36 \\
\hline Lissotriton helveticus & 29TNH49 & 99,00 & 138,44 & 68,49 & 41,26 & 3334,69 & 228,73 & 64,79 & \begin{tabular}{|l|l|}
163,94 \\
\end{tabular} & 105,25 & \begin{tabular}{|c|}
179,57 \\
\end{tabular} & 183,74 & 97,48 & 1091,49 & 144,73 & 31,59 & 39,26 & \begin{tabular}{ll|}
413,86 \\
\end{tabular} & \begin{tabular}{l|l}
124,45 \\
\end{tabular} & \begin{tabular}{l|l}
146,72 \\
\end{tabular} & 379,25 \\
\hline Lissotriton helveticus & 29TNH50 & 101,00 & 115,81 & 80,39 & 38,78 & 4246,05 & 232,99 & 27,72 & 205,27 & 70,53 & $\begin{array}{l}171,45 \\
\end{array}$ & \begin{tabular}{ll|}
172,95 \\
\end{tabular} & 65,34 & 1493,95 & 224,52 & 36,57 & 45,84 & \begin{tabular}{|l|}
578,78 \\
\end{tabular} & \begin{tabular}{|c|}
145,19 \\
\end{tabular} & \begin{tabular}{ll|}
158,22 \\
\end{tabular} & 565,92 \\
\hline Lissotriton helveticus & 29TNH53 & 101,00 & 136,65 & 77,41 & 38,54 & 4049,65 & 247,69 & 49,24 & 198,45 & 93,11 [ & 188,96 & 191,10 & 87,81 . & 1301,01 & 191,18 & 34,07 & 44,30 & 497,36 & 130,92 & 149,73 & 473,88 \\
\hline Lissotriton helveticus & \begin{tabular}{l|l} 
29TNH55 \\
\end{tabular} & 101,00 & 132,55 & 77,84 & 38,55 & 3952,98 & 244,93 & 45,58 & 199,35 & \begin{tabular}{|c|}
91,08 \\
\end{tabular} & \begin{tabular}{|l|l|}
183,42 \\
\end{tabular} & \begin{tabular}{|c|}
186,37 \\
\end{tabular} & 85,47 & \begin{tabular}{ll|l}
1311,62 \\
\end{tabular} & 186,78 & 36,64 & 42,66 & 496,98 & \begin{tabular}{l|l|}
138,85 \\
\end{tabular} & 158,30 & 470,35 \\
\hline Lissotriton helveticus & $\begin{array}{l}\text { 29TNH56 } \\
\end{array}$ & 101,00 & 131,83 & 76,71 & 38,90 & 3858,57 & 241,48 & 46,94 & 194,54 & 91,76 & 181,28 & 184,54 & 85,86 & 1281,64 & 179,77 & 36,54 & \begin{tabular}{ll|}
41,76 \\
\end{tabular} & $\begin{array}{l}484,46 \\
\end{array}$ & 138,73 & \begin{tabular}{|c|}
158,58 \\
\end{tabular} & 456,12 \\
\hline Lissotriton helveticus & 29TNH57 & 100,00 & 129,49 & 75,79 & 39,47 & 3760,92 & 236,42 & 46,84 & \begin{tabular}{|c|}
189,58 \\
\end{tabular} & 90,69 & $\begin{array}{l}177,58 \\
\end{array}$ & 181,00 & 84,70 & 1264,25 & 174,91 & 36,84 & 40,79 & \begin{tabular}{ll|}
476,82 \\
\end{tabular} & \begin{tabular}{|l|}
140,23 \\
\end{tabular} & \begin{tabular}{|l|}
160,14 \\
\end{tabular} & 447,24 \\
\hline Lissotriton helveticus & 29TNH59 & 98,00 & 140,77 & 69,91 & 41,80 & 3381,91 & 231,80 & 66,23 & \begin{tabular}{ll|}
165,56 \\
\end{tabular} & 106,31 & \begin{tabular}{l|l|}
182,51 \\
\end{tabular} & 186,54 & \begin{tabular}{|c|}
99,09 \\
\end{tabular} & 1058,70 & 139,63 & 30,57 & 39,04 & 399,41 & \begin{tabular}{l|l}
120,42 \\
\end{tabular} & \begin{tabular}{|l|l|}
142,28 \\
\end{tabular} & 367,09 \\
\hline Lissotriton helveticus & $\begin{array}{l}\text { 29TNH64 } \\
\end{array}$ & 101,00 & 133,27 & 80,09 & 39,73 & 3986,03 & 244,84 & 45,28 & \begin{tabular}{ll|l}
199,56 \\
\end{tabular} & 89,76 & \begin{tabular}{|l|l|l|l|}
184,79 \\
\end{tabular} & 187,14 & 85,8 & 1267,58 & 182,28 & 34,57 & 42,8 & 479, & 132,16 & \begin{tabular}{ll|}
150,26 \\
\end{tabular} & 456,27 \\
\hline Lissotriton helveticus & $\begin{array}{l}\text { 29TNH66 } \\
\end{array}$ & 101,00 & 129,58 & 78,71 & 39,87 & 3857,86 & 239,18 & 44,01 & \begin{tabular}{|c|}
195,17 \\
\end{tabular} & 88,47 & \begin{tabular}{|l|}
179,21 \\
\end{tabular} & 182,21 & 83,81 & 1260,61 & 176,24 & 36,25 & 41,21 & \begin{tabular}{ll|}
474,02 \\
\end{tabular} & 137,71 & $\begin{array}{l}156,45 \\
\end{array}$ & 447,92 \\
\hline Lissotriton helveticus & $\begin{array}{l}\text { 29TNH68 } \\
\end{array}$ & 101,00 & 134,85 & 74,68 & 40,77 & 3631,25 & 235,43 & 54,60 & \begin{tabular}{l|l}
180,83 \\
\end{tabular} & 96,81 & \begin{tabular}{|l|l|}
180,73 \\
\end{tabular} & 184,20 & 90,95 & 1139,74 & 153,76 & 33,40 & 39,51 & \begin{tabular}{|l|l}
427,46 \\
\end{tabular} & 128,78 & \begin{tabular}{|l|}
149,04 \\
\end{tabular} & 397,92 \\
\hline Lissotriton helveticus & 29TNH69 & 95,00 & 138,76 & 72,50 & 41,54 & 3500,36 & $233,97 \mid$ & 61,39 & 172,57 & 102,55 & 182,52 & 186,15 & 95,99 | & 1070,00 & 141,51 & 31,45 & 38,83 & 401,11 & 122,61 & 143,65 & 370,04 \\
\hline Lissotriton helveticus & 29TNH72 & 100,00 & 120,88 & 84,11 & 39,92 & 4229,67 & 238,74 & 30,06 & 208,68 & 74,28 & \begin{tabular}{|l|l|}
176,17 \\
\end{tabular} & \begin{tabular}{ll|}
177,82 \\
\end{tabular} & 71,15 & 1325,34 & 192,94 & 34,76 & 43,67 & 502,72 & $\begin{array}{l}135,75 \\
\end{array}$ & \begin{tabular}{ll|}
149,76 \\
\end{tabular} & 486,41 \\
\hline Lissotriton helveticus & $\begin{array}{l}\text { 29TNH76 } \\
\end{array}$ & 100,00 & 123,45 & 80,75 & 40,48 & 3913,96 & 234,63 & 37,28 & 197,35 & 81,06 & \begin{tabular}{ll|l}
174,02 \\
\end{tabular} & 176,74 & 77,4 & 1263,0 & 175,84 & $36, \varepsilon$ & 40, & 472, & 140,15 & \begin{tabular}{ll|}
157,23 \\
\end{tabular} & 448,44 \\
\hline Lissotriton helveticus & 29TNH79 & 101,00 & 127,95 & 76,35 & \begin{tabular}{ll|}
40,99 \\
\end{tabular} & 3677,10 & 230,73 & 46,82 & \begin{tabular}{|l|l|}
183,90 \\
\end{tabular} & 89,37 & \begin{tabular}{|c|}
174,66 \\
\end{tabular} & 178,06 & 84,01 & \begin{tabular}{|l|l|}
1160,08 \\
\end{tabular} & \begin{tabular}{|l|l|}
154,75 \\
\end{tabular} & 35,67 & 38,39 & 431,51 & \begin{tabular}{|l|l|}
135,97 \\
\end{tabular} & 155,20 & 401,73 \\
\hline Lissotriton helveticus & \begin{tabular}{|l|} 
29TNH87 \\
\end{tabular} & 100,00 & 120,24 & 81,21 & 40,53 & 3948,06 & 231,67 & 33,64 & \begin{tabular}{l|l}
198,03 \\
\end{tabular} & 77,44 & \begin{tabular}{|l|l|}
171,24 \\
\end{tabular} & 173,84 & 73,78 & 1223,72 & 167,01 & 37,04 & 39,34 & \begin{tabular}{l|l}
454,95 \\
\end{tabular} & \begin{tabular}{|c|}
140,50 \\
\end{tabular} & \begin{tabular}{|c|}
157,10 \\
\end{tabular} & 429,47 \\
\hline Lissotriton helveticus & 29TNH91 & 101,00 & 118,31 & 88,03 & 39,00 & 4616,37 & 244,04 & 21,27 & 222,77 & \begin{tabular}{|c|c|}
67,07 \\
\end{tabular} & $\begin{array}{l}178,96 \\
\end{array}$ & \begin{tabular}{|l|}
179,91 \\
\end{tabular} & \begin{tabular}{|c|c|}
63,44 \\
\end{tabular} & 1205,83 & 171,39 & 30,83 & 43,10 & \begin{tabular}{|l|l|}
454,83 \\
\end{tabular} & \begin{tabular}{ll|}
123,06 \\
\end{tabular} & \begin{tabular}{ll|}
135,26 \\
\end{tabular} & 441,25 \\
\hline Lissotriton helveticus & 29TNH94 & 101,00 & 120,48 & 85,68 & 40,00 & 4286,38 & 239,28 & 27,86 & 211,42 & 72,89 & 176,37 & \begin{tabular}{|c|}
178,07 \\
\end{tabular} & \begin{tabular}{|c|}
69,93 \\
\end{tabular} & 1187,30 & 165,77 & 33,41 & 41,03 & 443,28 & 129,30 & \begin{tabular}{|c|}
143,69 \\
\end{tabular} & 423,85 \\
\hline Lissotriton helveticus & 29TNJ40 & 18,00 & 140,90 & 67,00 & 41,90 & 3225,38 & 226,97 & 68,62 & 158,34 & \begin{tabular}{|c|}
109,17 \\
\end{tabular} & 180,34 & 184,66 & 101,00 & 1040,24 & 135,86 & 30,03 & 39, & 394,31 & \begin{tabular}{l|l}
119,52 \\
\end{tabular} & \begin{tabular}{|l|l|}
142,10 \\
\end{tabular} & 359,59 \\
\hline Lissotriton helveticus & 29TNJ50 & 35,00 & 140,32 & 69,33 & 42,05 & 3314,98 & 229,41 & 66,90 & 162,51 & \begin{tabular}{|l|l|}
106,79 \\
\end{tabular} & \begin{tabular}{ll|}
181,08 \\
\end{tabular} & 185,25 & 99,56 & 1041,52 & 135,65 & 30,56 & 38,54 & 392,02 & 120,49 & 142,51 & 359,29 \\
\hline Lissotriton helveticus & 29TNJ51 & 48,00 & 137,32 & 69,06 & 42,18 & 3289,25 & 226,38 & 64,58 & 161,79 & 104,32 & \begin{tabular}{|c|}
177,74 \\
\end{tabular} & \begin{tabular}{ll|}
182,08 \\
\end{tabular} & 96,99 & 1053,97 & 136,43 & 32,00 & 37,81 & 395,00 & 125,51 & \begin{tabular}{|c|}
147,40 \\
\end{tabular} & 360,88 \\
\hline Lissotriton helveticus & 29TNJ60 & 66,00 & 138,42 & 71,58 & 41,92 & 3427,75 & 231,34 & 62,74 & 168,59 & 103,12 & $\begin{array}{l}181,05 \\
\end{array}$ & $\begin{array}{l}184,86 \\
\end{array}$ & 96,42 & 1051,61 & 137,08 & 31,55 & 38,09 & 393,14 & 123,14 & \begin{tabular}{|c|}
144,39 \\
\end{tabular} & 360,99 \\
\hline Lissotriton helveticus & 29TNJ61 & 82,00 & 138,78 & 70,46 & 42,23 & 3350,75 & 229,34 & $64,74[$ & $164,60 \mid$ & 104,63 & $180,27 \mid$ & 184,22 & $97,70 \mid$ & 1035,07 & 133,93 & 31,48 & $37,61 \mid$ & 386,40 & 123,21 & 144,96 & 352,94 \\
\hline Lissotriton helveticus & 29TNJ62 & 77,00 & 138,50 & 69,71 & 42,42 & 3311,98 & 227,83 & 65,35 & \begin{tabular}{|l|l|}
162,48 \\
\end{tabular} & \begin{tabular}{|l|l|l|l}
104,89 \\
\end{tabular} & \begin{tabular}{|l|l|}
179,31 \\
\end{tabular} & 183,41 & \begin{tabular}{ll|}
97,82 \\
\end{tabular} & 1028,44 & 132,74 & 31,91 & 37,02 & 383,10 & $\begin{array}{l}124,55 \\
\end{array}$ & \begin{tabular}{l|l|l}
146,55 \\
\end{tabular} & 348,41 \\
\hline Lissotriton helveticus & 29TNJ70 & 100,00 & 127,38 & 75,21 & 41,21 & 3607,29 & 228,03 & \begin{tabular}{l|l|l}
47,99 & \\
\end{tabular} & \begin{tabular}{|l|l|}
180,04 \\
\end{tabular} & 89,86 & \begin{tabular}{|l|l|l|l}
172,98 \\
\end{tabular} & \begin{tabular}{|c|}
176,58 \\
\end{tabular} & 84,18 & 1147,25 & 151,21 & 35,90 & 37,79 & \begin{tabular}{ll|}
425,82 \\
\end{tabular} & \begin{tabular}{|c|}
137,08 \\
\end{tabular} & \begin{tabular}{ll|}
156,62 \\
\end{tabular} & 394,60 \\
\hline Lissotriton helveticus & 29TNJ72 & 101,00 & 133,10 & 72,15 & 42,08 & 3432,01 & 226,92 & 57,35 & 169,57 & \begin{tabular}{ll|}
97,92 \\
\end{tabular} & 175,90 & 179,71 & $\begin{array}{l}91,45 \\
\end{array}$ & 1067,50 & 137,07 & 34,02 & 36,65 & 394,97 & \begin{tabular}{|l|l|}
131,15 \\
\end{tabular} & 152,16 & 360,88 \\
\hline Lissotriton helveticus & 29TNJ80 & 100,00 & 122,17 & 77,45 & \begin{tabular}{ll|}
40,97 \\
\end{tabular} & 3732,97 & 226,80 & 40,28 & \begin{tabular}{l|l|l|}
186,52 \\
\end{tabular} & 82,75 & \begin{tabular}{|l|l|l|}
169,73 \\
\end{tabular} & 173,01 & 77,78 & 1168,66 & 153,90 & 37,45 & 37,24 & 431,41 & $\begin{array}{l}141,75 \\
\end{array}$ & \begin{tabular}{|c|}
160,10 \\
\end{tabular} & 400,68 \\
\hline Lissotriton helveticus & 29TNJ83 & 101,00 & 130,18 & 72,98 & 41,98 & 3479,40 & 225,55 & 53,48 & \begin{tabular}{|l|l|}
172,07 \\
\end{tabular} & 94,38 & \begin{tabular}{ll|}
173,69 \\
\end{tabular} & \begin{tabular}{|c|}
177,47 \\
\end{tabular} & 88,12 & 1072,64 & 137,44 & 35,55 & 35,7 & 393,85 & \begin{tabular}{|c|}
135,68 \\
\end{tabular} & \begin{tabular}{|c|}
156,29 \\
\end{tabular} & 358,51 \\
\hline Lissotriton helveticus & 29TNJ84 & 31,00 & 128,75 & 72,62 & \begin{tabular}{|l|l|}
42,07 \\
\end{tabular} & 3463,58 & 223,64 & 52,51 & \begin{tabular}{|l|l|l|}
171,13 \\
\end{tabular} & 93,16 & 172,00 & \begin{tabular}{|c|c|}
175,75 \\
\end{tabular} & 86,98 & 1079,11 & 138,18 & 36,49 & \begin{tabular}{l|l}
35,25 \\
\end{tabular} & $\begin{array}{l}395,05 \\
\end{array}$ & \begin{tabular}{|c|}
138,64 \\
\end{tabular} & $\begin{array}{l}159,35 \\
\end{array}$ & 358,69 \\
\hline Lissotriton helveticus & 29TNJ93 & 92,00 & 133,74 & 73,98 & \begin{tabular}{|l|l}
41,97 \\
\end{tabular} & 3525,79 & 229,64 & 55,54 & 174,11 & 96,84 & \begin{tabular}{|c|c|}
177,87 \\
\end{tabular} & \begin{tabular}{ll|}
181,48 \\
\end{tabular} & \begin{tabular}{l|l}
91,05 \\
\end{tabular} & 1025,37 & 131,62 & 34,11 & 35,33 & $\begin{array}{l}374,76 \\
\end{array}$ & \begin{tabular}{|c|}
130,39 \\
\end{tabular} & $\begin{array}{l}150,86 \\
1\end{array}$ & 339,41 \\
\hline Lissotriton helveticus & 29TPHO5 & 100,00 & 120,25 & 86,16 & 40,00 & 4330,66 & 239,66 & 26,82 & 212,84 & 72,25 & \begin{tabular}{|l|l|}
176,64 \\
\end{tabular} & 178,33 & 68,88 & 1130,62 & 154,64 & 32,99 & 39,74 & 419,44 & 127,24 & 141,76 & 397,95 \\
\hline Lissotriton helveticus & 29TPH16 & 101,00 & 125,04 & 86,30 & 40,07 & 4330,92 & 243,26 & 31,13 & 212,13 & 76,77 & 181,15 & 182,83 & 73,01 & 1042,90 & 139,56 & 31,21 & 38, & 383,96 & 120,74 & 136,01 & 359,84 \\
\hline Lissotriton helveticus & 29TPH18 & 101,00 & 8 & 83,80 & 40,6 & 23,85 & 238, & 35,2 & 203,7 & 80,25 & 17 & 180 & 76,0 & 1044, & 136,94 & $32, \varepsilon$ & 37, & T & 125,76 & \begin{tabular}{|l|}
142,04 \\
\end{tabular} & 354,40 \\
\hline Lissotriton helveticus & 29TPH21 & 100,00 & 13 & 93,25 & 38,5 & 4996,08 & 1 & 26,14 & 237,47 & 75,01 & 99 & 21 & 70,90 & 914, & 125,36 & 22,94 & 41, & 340,74 & 94,05 & 100,10 & 325,66 \\
\hline Lissotriton helveticus & 29TPH41 & 101,00 & 110,45 & 95,49 & 38,66 & 5128,06 & 250,03 & 5,65 & 244,38 & 52,96 & \begin{tabular}{l|l}
178,23 \\
\end{tabular} & \begin{tabular}{|c|}
178,27 \\
\end{tabular} & 48, & 986,46 & 132,08 & 26,80 & 40, & 370,31 & $\begin{array}{l}108,08 \\
\end{array}$ & $\begin{array}{l}108,69 \\
\end{array}$ & 355,08 \\
\hline Lissotriton helveticus & 29TPH51 & 100,00 & 92,45 & 95,33 & 38,24 & 5173,82 & 235,67 & $-10,10$ & 245,76 & 35,76 & $\begin{array}{l}161,46 \\
1\end{array}$ & 161,51 & 30,84 & 1078,35 & 141,86 & 31,88 & 39,27 & 402,52 & 125,19 & \begin{tabular}{|l|}
125,91 \\
\end{tabular} & 386,28 \\
\hline Lissotriton helveticus & 29TPH55 & 101,00 & 115,59 & 93,60 & 39,80 & 4824,02 & 247,23 & \begin{tabular}{l|l|l|l|l|}
14,03 \\
\end{tabular} & 233,20 & 61,30 & \begin{tabular}{|l|l|}
178,62 \\
\end{tabular} & 179,20 & 57, & 937,10 & \begin{tabular}{|l|l|}
121,15 \\
\end{tabular} & 29,23 & \begin{tabular}{|c|}
36,63 \\
\end{tabular} & 342,96 & \begin{tabular}{|c|}
114,97 \\
\end{tabular} & 125,70 & 317,72 \\
\hline Lissotriton helveticus & 29TPH56 & 100,00 & 112,59 & 92,57 & 39,5 & 4721,95 & & 12,91 & 229,45 & 59 & 174,30 & 175,10 & 55 & 969,4 & 124,37 & 31,62 & 35,7 & 352,59 & 122,46 & 134,51 & 325,18 \\
\hline Lissotriton helveticus & 29TPH62 & 100,00 & 100,06 & 97,43 & 38,86 & 5205,83 & 24 & $-4,92$ & 248,28 & 41, & \begin{tabular}{|l|l|}
169,03 \\
\end{tabular} & 169,06 & 37 & 973,89 & 127,40 & 29,47 & 38, & 361,44 & 116,54 & \begin{tabular}{|c|}
116,88 \\
\end{tabular} & 342,10 \\
\hline Lissotriton helveticus & 29TPH63 & 100,00 & 96,65 & 96,45 & 38,91 & 5119,07 & 238,28 & $-6,57$ & 244,86 & 39,94 & \begin{tabular}{|l|l|l}
164,49 \\
\end{tabular} & \begin{tabular}{l|l|}
164,55 \\
\end{tabular} & 35,1 & 1010,04 & 131,23 & 31,90 & 37,1 & 372,28 & \begin{tabular}{|l|l}
124,46 \\
\end{tabular} & \begin{tabular}{l|l|}
125,75 \\
\end{tabular} & 350,78 \\
\hline Lissotriton helveticus & 29TPH64 & 100,00 & 101,18 & 95,94 & 39,16 & 5028,11 & 240,07 & $-1,63$ & 241,70 & 45,30 & \begin{tabular}{l|l|l|l|}
167,53 \\
\end{tabular} & \begin{tabular}{|c|}
167,73 \\
\end{tabular} & 40,68 & $\begin{array}{l}986,45 \\
\end{array}$ & 127,35 & 31,77 & 36,41 & 361,41 & \begin{tabular}{ll|}
123,68 \\
\end{tabular} & \begin{tabular}{l|l}
127,55 \\
\end{tabular} & 337,53 \\
\hline Lissotriton helveticus & 29TPH68 & 100,00 & 112,91 & 91,50 & 40,35 & 4561,33 & 239,10 & 15,52 & 223,58 & \begin{tabular}{|c|}
62,99 \\
\end{tabular} & 172,22 & 173,42 & 57,89 & 963,04 & 124,25 & 34,13 & 33,53 & 344,15 & $\begin{array}{ll}129,85 \\
\end{array}$ & 142,22 & 311,33 \\
\hline Lissotriton helveticus & 29TPH73 & 101,00 & 86,82 & 97,28 & 38,88 & 5179,44 & 23 & $-16,28$ & 247,47 & 30,10 & \begin{tabular}{|c|}
155,82 \\
\end{tabular} & 155, & 25, & 1044,37 & 133,86 & 35,11 & 35,84 & 381,04 & 134,58 & \begin{tabular}{|c|}
135,46 \\
\end{tabular} & 358,23 \\
\hline Lissotriton helveticus & 29TPH74 & 100,00 & 79,80 & 95,6 & 38,76 & 5085,43 & 222 & $-21,16$ & 243,53 & 24,80 & \begin{tabular}{|c|c|}
147,66 \\
\end{tabular} & 147,86 & 19,6 & 1114,89 & $\begin{array}{l}141,35 \\
\end{array}$ & 39,34 & 34,79 & 402,99 & \begin{tabular}{|l|l|}
148,23 \\
\end{tabular} & \begin{tabular}{|c|}
150,17 \\
\end{tabular} & 377,98 \\
\hline Lissotriton helveticus & 29TPH78 & 100,00 & 114,42 & 92,48 & $\begin{array}{l}40,65 \\
\end{array}$ & 4583,52 & 241,15 & 16,33 & 224,81 & 67,71 & 173,87 & \begin{tabular}{ll|}
175,05 \\
\end{tabular} & 58,89 & 927,82 & \begin{tabular}{l|l|}
120,75 \\
\end{tabular} & 33,81 & \begin{tabular}{l|l|}
32,65 \\
\end{tabular} & \begin{tabular}{l|l}
328,82 \\
\end{tabular} & 128,45 & 140,50 & 294,39 \\
\hline Lissotriton helveticus & 29TPH80 & 101,00 & 115,40 & 103,38 & 38,97 & 5547,08 & 265,72 & 2,60 & 263,12 & 51,78 & \begin{tabular}{|l|l|}
188,51 \\
\end{tabular} & 188,51 & 46,90 & $\begin{array}{l}754,35 \\
\end{array}$ & 99,32 & 20,75 & \begin{tabular}{l|l|}
39,45 \\
\end{tabular} & 283,55 & 87,01 & 87,01 & 266,77 \\
\hline Lissotriton helveticus & 29TPH86 & 100,00 & 92,14 & 96,67 & 39,75 & 4962,72 & 231,10 & $-9,28$ & 240,38 & 37,85 & $157,69 \mid$ & 158,06 & 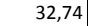 & 1009,01 & 128,96 & 37,55 & $32,8<-2$ & 359, & 141,06 & 147,50 & 328,58 \\
\hline Lissotriton helveticus & 29TPF & 100, & 95,70 & 100,75 & 39, & 5221,88 & & $-10,3$ & 251 & $3 /$, & & & 32 & 909, & 117,19 & 32,61 & 33 & 32 & 125,11 & \begin{tabular}{|c|}
125,58 \\
\end{tabular} & 298 \\
\hline Lissotriton helveticus & 29TPH96 & 100,00 & 95,13 & 98,32 & 40,01 & 4996,45 & 234,96 & \begin{tabular}{|c|}
$-7,69$ \\
\end{tabular} & 242,65 & 43,34 & \begin{tabular}{|c|}
160,89 \\
\end{tabular} & \begin{tabular}{ll|}
161,15 \\
\end{tabular} & 34,80 & 956,82 & 123,38 & 36,55 & 32,03 & 337,68 & 137,32 & \begin{tabular}{ll|}
142,85 \\
\end{tabular} & 305,49 \\
\hline Lissotriton helveticus & 29TPJ11 & 99,00 & 107,59 & 81,49 & \begin{tabular}{ll|}
40,67 \\
\end{tabular} & 4002,55 & 220,11 & 21,82 & \begin{tabular}{l|l|}
198,28 \\
\end{tabular} & 65,15 & $\begin{array}{l}159,35 \\
159\end{array}$ & \begin{tabular}{ll|}
162,08 \\
\end{tabular} & 60,56 & 1187,50 & 151,90 & 41,50 & 34,98 & 430,71 & \begin{tabular}{ll|}
154,62 \\
\end{tabular} & \begin{tabular}{l|l}
170,05 \\
1
\end{tabular} & 397,96 \\
\hline Lissotriton helveticus & 29TPJ21 & 100,00 & 120,79 & 81,71 & \begin{tabular}{l|l}
41,15 \\
\end{tabular} & 3971,63 & 230,49 & 34,14 & 196,35 & 77,94 & \begin{tabular}{|c|}
171,70 \\
\end{tabular} & \begin{tabular}{|c|}
174,29 \\
\end{tabular} & 73,26 & 1057,61 & 134,68 & 36,63 & 34,61 & 381,88 & \begin{tabular}{|c|}
137,79 \\
\end{tabular} & \begin{tabular}{|l|l|}
154,38 \\
\end{tabular} & 348,21 \\
\hline Lissotr & 29TPJ & 41, & & & 41, & & & 51, & & 11.5 & & & 91 & & & & 32, & & 119,20 & 136,62 & 271 \\
\hline Lissotriton helveticus & 29TPJ62 & 54,00 & 139,54 & 81,8 & \begin{tabular}{|l|l|}
41,87 & \\
\end{tabular} & 3920,1 & 244, & \begin{tabular}{|l|l}
51,45 \\
\end{tabular} & \begin{tabular}{|l|l|}
193,54 \\
\end{tabular} & $117,69 \mid$ & \begin{tabular}{ll|l}
189,06 \\
\end{tabular} & 191,1 & 91,5 & 858,44 & 114,06 & 31,5 & 32,26 & 302,67 & 119,81 & \begin{tabular}{l|l}
136,55 \\
\end{tabular} & 261 \\
\hline Lissotriton helveticus & 29TPJ92 & 60,00 & 135,50 & 84,06 & 42,06 & 3954,26 & 243,15 & 46,30 & 196,86 & 114,32 & 185,50 & 188,13 & 87,30 & 853,51 & 114,98 & 34,70 & 30,12 & 296,43 & 128,88 & 143,72 & 246,58 \\
\hline
\end{tabular}




\begin{tabular}{|c|c|c|c|c|c|c|c|c|c|c|c|c|c|c|c|c|c|c|c|c|c|}
\hline TAXON & UTM & $\mathrm{km} 2$ & BI01 & B102 & $B 103$ & BIO4 & B105 & B106 & 8107 & B108 & $B 109$ & B1010 & BIO11 & B1012 & BIO13 & BIO14 & B1015 & B1016 & B1017 & B1018 & B1019 \\
\hline Lissotriton helveticus & 29TQHO5 & 100,00 & 74,91 & 99,24 & 39,39 & 5169,66 & 220,93 & $-28,05$ & 248,98 & 21,71 & 143,89 & 143,99 & 13,48 & 1055,92 & 132,96 & 42,27 & 31,32 & 370,01 & 155,47 & 156,53 & 339,66 \\
\hline Lissotriton helveticus & 29TQH06 & 100,00 & 75,75 & 98,36 & 39,55 & 5077,99 & 219,51 & $-26,07$ & 245,58 & 25,65 & 143,30 & 143,55 & 15,40 & 1068,91 & \begin{tabular}{ll|}
134,83 \\
\end{tabular} & 43,64 & 30,77 & \begin{tabular}{ll|}
372,93 \\
\end{tabular} & \begin{tabular}{ll|}
159,67 \\
\end{tabular} & 162,90 & 340,47 \\
\hline Lissotriton helveticus & 29TQH15 & 101,00 & 81,08 & 101,33 & 39,73 & 5205,83 & 228,01 & $-23,78$ & 251,80 & 40,02 & 150,30 & 150,34 & 18,68 & 976,59 & 124,20 & 40,07 & 30,67 & 340,54 & 147,50 & 148,47 & 307,29 \\
\hline Lissotriton helveticus & 29TQH17 & 101,00 & 79,56 & 98,86 & 40,06 & 5002,85 & 221,57 & $-22,19$ & 243,76 & 40,09 & 145,80 & 146,25 & 19,84 & 1034,18 & 131,39 & 44,28 & 29,41 & 357,21 & 160,63 & 165,63 & 319,74 \\
\hline Lissotriton helveticus & 29TQH21 & 99,00 & 90,49 & 107,60 & 39,20 & 5617,95 & 248,60 & $-21,87$ & 270,47 & 53,99 & 165,27 & 165,27 & 21,89 & 794,80 & \begin{tabular}{|c|}
101,78 \\
\end{tabular} & 30,23 & 32,91 & 282,67 & 115,17 & 115,17 & 254,36 \\
\hline Lissotriton helveticus & 29TQH24 & 99,00 & 66,71 & 101,63 & 39,24 & 5330,72 & 217,60 & $-38,48$ & 256,08 & 21,64 & 138,11 & 138,12 & 3,36 & 1040,19 & 129,59 & 43,94 & 30,02 & 359,10 & 159,94 & 160,02 & 327,76 \\
\hline Lissotriton helveticus & 29TQH27 & 100,00 & 82,73 & 100,29 & 40,40 & 5017,34 & 225,37 & $-20,01$ & 245,38 & 50,25 & 149,06 & 149,50 & 22,69 & 987,79 & 126,24 & 43,63 & 28,73 & 340,24 & 157,60 & 162,62 & 298,65 \\
\hline Lissotriton helveticus & 29TQH36 & 100,00 & 63,68 & 100,41 & 39,56 & 5201,10 & 211,47 & $-39,53$ & 251,01 & 22,61 & 133,22 & 133,42 & 2,10 & 1080,66 & 134,02 & 48,65 & 28,20 & 368,40 & 174,22 & $\begin{array}{l}175,09 \\
\end{array}$ & 331,37 \\
\hline Lissotriton helveticus & 29TQH37 & 99,00 & 76,09 & 100,54 & 40,23 & 5063,42 & 220,15 & $-26,83$ & 246,98 & 43,00 & 143,21 & 143,59 & \begin{tabular}{l|l}
15,63 \\
\end{tabular} & 1014,50 & $\begin{array}{l}128,25 \\
\end{array}$ & 46,39 & 27,91 & $\begin{array}{l}346,75 \\
\end{array}$ & 165,85 & \begin{tabular}{|l|l|}
169,67 \\
\end{tabular} & 304,04 \\
\hline Lissotriton helveticus & 29TQH49 & 36,00 & 119,17 & 96,75 & 43,23 & 4295,38 & 243,54 & 22,00 & 221,54 & 96,79 & 173,94 & 176,08 & 67,15 & 850,54 & \begin{tabular}{|c|}
115,13 \\
\end{tabular} & 41,21 & 27,98 & 287,88 & \begin{tabular}{|l|l|}
146,23 \\
\end{tabular} & 154,65 & 224,27 \\
\hline Lissotriton helveticus & 29TQJ00 & 100,00 & 113,08 & 92,84 & \begin{tabular}{|c|}
41,78 \\
\end{tabular} & 4381,67 & 236,87 & 17,31 & 219,56 & 88,49 & 169,52 & 171,28 & 60,21 & 922,77 & 122,26 & 39,35 & 29,15 & 317,84 & 143,82 & 154,93 & 269,66 \\
\hline Lissotriton helveticus & 29TQJ11 & 99,00 & 116,27 & 91,42 & 42,38 & 4195,11 & 235,68 & 22,75 & 212,93 & \begin{tabular}{|c|}
93,97 \\
\end{tabular} & 169,88 & 172,19 & 65,80 & 923,49 & 123,35 & 41,56 & 28,29 & 315,14 & 149,59 & \begin{tabular}{ll|}
160,54 \\
\end{tabular} & 260,00 \\
\hline Lissotriton helveticus & 29TQJ12 & 67,00 & 128,44 & 86,26 & \begin{tabular}{ll|}
42,76 \\
\end{tabular} & 3958,19 & 238,64 & 38,66 & 199,98 & 108,11 & 178,40 & 181,22 & 80,56 & 884,15 & 119,44 & 39,41 & 28,78 & 302,11 & 142,53 & 155,16 & 244,59 \\
\hline Lissotriton helveticus & 29TQJ21 & 99,00 & 125,99 & 89,26 & \begin{tabular}{|l|l}
42,98 \\
\end{tabular} & \begin{tabular}{ll|}
4019,27 \\
\end{tabular} & 239,73 & $\begin{array}{ll}34,48 \\
\end{array}$ & 205,25 & 105,42 & 176,76 & 179,55 & 77,59 & 879,09 & 119,14 & 40,58 & 28,35 & 298,48 & 145,41 & 156,50 & 237,74 \\
\hline Lissotriton helveticus & 29TQJ32 & 74,00 & 134,23 & 83,35 & 43,00 & 3796,84 & 238,70 & 46,89 & 191,82 & 116,10 & 181,84 & 185,14 & 88,38 & 858,30 & 117,33 & 40,27 & 28,58 & 290,85 & 144,00 & 156,31 & 226,00 \\
\hline Lissotriton helveticus & 30TTM69 & 100,00 & 114,35 & 114,99 & 39,66 & 5869,97 & 281,20 & $-6,07$ & 287,28 & 77,94 & \begin{tabular}{|c|}
191,56 \\
\end{tabular} & 191,56 & 40,43 & $\begin{array}{l}531,65 \\
\end{array}$ & $\begin{array}{l}69,26 \\
\end{array}$ & 21,31 & 33,10 & 194,55 & 83,77 & 83,77 & 154,35 \\
\hline Lissotriton helveticus & 30TTM89 & 100,00 & 115,22 & 115,85 & 39,87 & 5866,60 & 283,20 & $-6,04$ & 289,24 & 79,92 & 192,64 & \begin{tabular}{ll|}
192,64 \\
\end{tabular} & 41,29 & 504,66 & 65,27 & 21,97 & 32,22 & 183,22 & 85,25 & 85,25 & 138,31 \\
\hline Lissotriton helveticus & 30TTN53 & 58,00 & \begin{tabular}{l|l}
93,44 \\
\end{tabular} & 109,66 & 39,99 & 5543,63 & 251,73 & $-19,50$ & 271,23 & 60,25 & 166,97 & 166,97 & 25,44 & 749,48 & 97,07 & 33,26 & 30,23 & 266,40 & 122,49 & 122,49 & 220,42 \\
\hline Lissotriton helveticus & 30TTN54 & 50,00 & 85,92 & 107,32 & 39,96 & 5432,77 & 240,95 & $-24,42$ & 265,37 & 54,00 & 157,99 & 157,99 & 19,85 & 827,83 & 105,94 & 37,45 & 29,26 & 289,86 & 136,27 & 136,33 & 244,65 \\
\hline Lissotriton helveticus & 30TTN56 & 47,00 & 65,31 & 101,61 & 39,72 & 5231,31 & 214,28 & $-38,83$ & 253,11 & 31,13 & 135,35 & 135,42 & 3,28 & 1038,97 & 128,89 & 48,32 & 27,40 & 352,92 & 172,06 & $\begin{array}{l}172,99 \\
\end{array}$ & 312,22 \\
\hline Lissotriton helveticus & 30TTN59 & 34,00 & 107,65 & 97,71 & \begin{tabular}{ll|}
42,53 \\
\end{tabular} & 4464,14 & 236,69 & 9,24 & 227,45 & 84,37 & 165,18 & 167,02 & 53,90 & 894,86 & 118,92 & 43,80 & 27,39 & 303,14 & 154,69 & 162,37 & 241,67 \\
\hline Lissotriton helveticus & 30TTN63 & 100,00 & 97,88 & 110,95 & 40,00 & $\begin{array}{l}5567,66 \\
\end{array}$ & 257,41 & $-16,42$ & 273,84 & 64,54 & $\begin{array}{l}171,46 \\
\end{array}$ & \begin{tabular}{|c|}
171,46 \\
\end{tabular} & 28,97 & $\begin{array}{l}704,86 \\
\end{array}$ & $\begin{array}{l}91,85 \\
\end{array}$ & 32,32 & 30,37 & 252,02 & 118,46 & $\begin{array}{ll}118,46 \\
\end{array}$ & 202,02 \\
\hline Lissotriton helveticus & 30TTN64 & 100,00 & 88,79 & 108,26 & 40,01 & 5445,67 & 244,62 & $-22,48$ & 267,11 & 56,85 & 160,94 & 160,94 & 22,20 & 795,50 & 102,14 & 37,00 & 28,97 & 279,16 & 134,13 & 134,13 & 230,18 \\
\hline Lissotriton helveticus & 30TTN66 & 100,00 & 75,87 & 102,94 & 40,22 & 5193,28 & 223,88 & $-29,61$ & 253,49 & 46,30 & 144,83 & 144,96 & 13,51 & 955,68 & 120,26 & 45,30 & 27,28 & 325,99 & 161,73 & 162,86 & 279,55 \\
\hline Lissotriton helveticus & 30TTN68 & 100,00 & 101,04 & 100,21 & 41,91 & 4702,54 & 235,95 & $-0,29$ & 236,24 & 75,69 & 162,18 & 163,41 & 44,19 & 883,46 & \begin{tabular}{|l|l|}
116,07 \\
\end{tabular} & 43,34 & 27,26 & 300,97 & 153,54 & 160,40 & 241,76 \\
\hline Lissotriton helveticus & 30TTN74 & 100,00 & 83,51 & 107,91 & 39,82 & 5452,56 & 240,04 & $-27,45$ & 267,49 & 52,10 & 155,92 & 155,92 & 17,04 & 818,40 & 103,75 & 39,17 & 28,25 & 284,09 & 140,87 & 140,88 & 234,68 \\
\hline Lissotriton helveticus & 30TTN77 & 100,00 & 98,10 & 102,69 & \begin{tabular}{l|l}
41,42 \\
\end{tabular} & 4924,04 & 238,68 & $-6,54$ & 245,21 & 71,23 & $\begin{array}{l}162,47 \\
\end{array}$ & 163,09 & 38,12 & $\begin{array}{l}840,56 \\
\end{array}$ & 109,74 & $\begin{array}{l}41,76 \\
\end{array}$ & 27,21 & 288,74 & 148,36 & \begin{tabular}{|l|l|}
153,87 \\
\end{tabular} & 229,47 \\
\hline Lissotriton helveticus & 30TTN79 & 100,00 & 121,60 & \begin{tabular}{l|l}
94,61 \\
\end{tabular} & \begin{tabular}{l|l}
43,25 \\
\end{tabular} & 4203,36 & 242,25 & 25,88 & 216,37 & 101,06 & 175,04 & 177,40 & 70,71 & 837,22 & 113,48 & 42,59 & 27,78 & 281,47 & 149,71 & 157,60 & 211,82 \\
\hline Lissotriton helveticus & 30TTN81 & 100,00 & 112,09 & 115,44 & 39,99 ] & 5801,20 & 278,79 & $-8,02$ & 286,81 & 77,48 & 188,47 & 188,47 & 38,95 & 549,74 & 72,17 & 22,12 & 32,53 & 201,18 & 96,41 & 96,41 & 148,43 \\
\hline Lissotriton helveticus & 30TTN82 & 100,00 & 108,29 & 114,24 & 40,00 & 5713,11 & 272,77 & $-10,27$ & 283,04 & 74,53 & 183,56 & 183,56 & 36,55 & 591,44 & 77,61 & 24,31 & 31,73 & 214,95 & 104,96 & 104,96 & 159,59 \\
\hline Lissotriton helveticus & 30TTN88 & 100,00 & 110,02 & \begin{tabular}{l|l}
98,86 \\
\end{tabular} & 42,09 & 4609,07 & 240,93 & 8,93 & 232,00 & 86,32 & 169,63 & 170,88 & 53,76 & 820,57 & 109,09 & \begin{tabular}{|l|l|}
41,97 \\
\end{tabular} & 27,09 & 279,84 & 148,35 & 155,84 & 213,51 \\
\hline Lissotriton helveticus & 30TTN92 & 100,00 & 107,67 & 113,09 & 40,00 & 5642,44 & 270,31 & $-10,03$ & 280,35 & 75,30 & 182,14 & 182,14 & 36,94 & 595,94 & \begin{tabular}{|l|l|}
77,47 \\
\end{tabular} & 26,22 & 30,55 & 213,70 & 107,31 & 107,31 & 158,62 \\
\hline Lissotriton helveticus & 30TTN94 & 100,00 & 93,59 & 108,77 & 40,01 & 5418,02 & 249,74 & $-18,79$ & 268,53 & 63,35 & 165,26 & 165,26 & 26,95 & 733,11 & 93,67 & 36,51 & 27,87 & 255,42 & 132,52 & 132,52 & 199,38 \\
\hline Lissotriton helveticus & 30TTN96 & 100,00 & 67,08 & 102,48 & 39,64 & 5231,01 & 217,01 & $-38,30$ & 255,30 & 38,78 & 136,90 & 137,01 & 4,63 & $\begin{array}{l}974,58 \\
\end{array}$ & 119,49 & 49,01 & 25,20 & 325,77 & 172,95 & 173,32 & 277,70 \\
\hline Lissotriton helveticus & 30TTN97 & 100,00 & 91,15 & 101,79 & 40,74 & 4985,50 & 233,21 & $-13,42$ & 246,64 & 64,77 & 156,72 & 157,24 & 30,60 & 860,57 & 110,01 & 44,04 & 26,18 & 292,84 & 155,83 & 160,33 & 233,59 \\
\hline Lissotriton helveticus & 30TTP60 & 100,00 & 129,66 & 89,93 & 43,73 & \begin{tabular}{|c|c|}
3918,14 \\
\end{tabular} & 241,79 & 38,42 & 203,37 & 111,05 & 178,84 & 181,95 & 82,53 & 850,03 & \begin{tabular}{|c|}
116,32 \\
\end{tabular} & 42,40 & 28,38 & 284,03 & 149,06 & 158,09 & 214,18 \\
\hline Lissotriton helveticus & 30TTP62 & 99,00 & 135,89 & 79,64 & 42,56 & 3713,09 & 235,61 & 50,83 & 184,78 & 118,95 & 182,44 & 185,98 & 91,25 & 853,17 & 117,04 & 41,15 & 28,65 & 288,29 & 146,45 & 158,71 & 219,36 \\
\hline Lissotriton helveticus & 30TTP70 & 100,00 & 129,49 & 87,84 & 43,33 & 3916,04 & 239,58 & 39,05 & 200,53 & 111,44 & 178,87 & 181,95 & 82,37 & 844,56 & 115,45 & 42,68 & 28,30 & 282,58 & 149,95 & 159,09 & 211,07 \\
\hline Lissotriton helveticus & 30TTP73 & & & & & & & & & & & & & & & & & & & & \\
\hline Lissotriton helveticus & 30TTP80 & 100,00 & 126,93 & 86,91 & 42,80 & 3981,43 & 237,32 & 36,17 & 201,14 & 108,64 & 177,37 & 180,30 & 78,91 & 843,78 & $\mid 114,67$ & 42,99 & 27,94 & 283,30 & 151,37 & 160,74 & 211,27 \\
\hline Lissotriton helveticus & 30TTP82 & 60,00 & 138,75 & 71,62 & \begin{tabular}{ll|}
40,72 \\
\end{tabular} & 3679,04 & 230,37 & 56,65 & 173,71 & \begin{tabular}{ll|}
122,63 \\
\end{tabular} & 185,16 & 188,74 & 94,25 & 829,42 & $\begin{array}{l}113,76 \\
\end{array}$ & 40,20 & 28,83 & 282,16 & 143,90 & \begin{tabular}{|l|l|}
157,39 \\
\end{tabular} & 211,51 \\
\hline Lissotriton helveticus & 30TTP90 & 100,00 & 125,74 & 85,39 & 42,02 & 4035,10 & 235,66 & 34,97 & 200,69 & 107,35 & 177,08 & 179,92 & 76,99 & 839,03 & 113,34 & 42,65 & 27,70 & 283,30 & 151,08 & 161,13 & 211,51 \\
\hline Lissotriton helveticus & 30TTP92 & 50,00 & 134,30 & 74,18 & 40,5 & \begin{tabular}{|l|l|}
3749,07 \\
\end{tabular} & 229,58 & 50,70 & 178,88 & 117,98 & 181,69 & 184,95 & 88,89 & 849,13 & 115,64 & 41,84 & 28,09 & 288,26 & 149,61 & 162,86 & 216,03 \\
\hline Lissotriton helveticus & 30TUN01 & 100,00 & 111, & 112,70 & 39,5 & 5628,60 & 272 & $-7,22$ & 28 & 79,47 & 185,17 & 17 & 40,30 & 563,92 & 72,4 & 26,71 & 29,77 & 99,85 & 101,55 & 101,55 & 148,49 \\
\hline Lissotriton helveticus & 30TUNO2 & 100,00 & 10 & 111,48 & 40 & 5549,11 & 266 & $-9,47$ & 27 & 76,01 & 18 & 180,08 & 37,55 & 606,52 & 77,94 & 29,18 & 29,16 & 213,89 & 110,31 & 110,31 & 159,96 \\
\hline Lissotriton helveticus & $30 \mathrm{TU}$ & 100,00 & 103,34 & 105 & 40,00 & 5459,93 & 260,54 & $-11,11$ & 271,66 & 73,21 & 175,34 & 175,34 & 35,38 & 650,41 & 83,54 & 32,09 & 28,48 & 228,09 & 118,83 & $\begin{array}{ll}118,83 \\
\end{array}$ & 172,09 \\
\hline Lissotriton helveticus & 30TUN06 & 100,00 & 67,79 & 102,16 & 39,56 & 5215,84 & 217,31 & $-37,60$ & 254,91 & 40,02 & 137,45 & 137,62 & 5,61 & \begin{tabular}{|c|c|}
963,07 \\
\end{tabular} & \begin{tabular}{|c|}
117,60 \\
\end{tabular} & 49,21 & 24,66 & $\mid 320,48$ & 173,26 & 173,77 & 271,29 \\
\hline Lissotriton helveticus & 30TUN07 & 100,00 & 74,75 & 100,90 & 39,99 & 5084,37 & 219,96 & $-29,25$ & 249,21 & 48,05 & 142,29 & 142,70 & 13,83 & $\begin{array}{l}947,55 \\
\end{array}$ & 117,25 & 48,74 & 24,89 & 316,92 & 171,84 & 74,25 & 263,42 \\
\hline Lissotriton helveticus & 30TUN08 & 100,00 & 104,95 & 97,14 & 41,16 & 4688,53 & 236,60 & 3,67 & 232,94 & 81,42 & 165,94 & 167,09 & 47,70 & 829,06 & 108,07 & 42,92 & 26,34 & 282,16 & 152,16 & 159,10 & 216,77 \\
\hline Lissotriton helveticus & $30 \mathrm{TUN}$ & 100,00 & 113,50 & 91,88 & 41, & 4408,31 & 235,32 & 16,71 & 218,61 & 92,32 & 170,29 & 172,15 & 59,72 & 837,19 & 110,64 & 43,07 & 26,64 & 284,16 & 152,86 & 161,35 & 215,59 \\
\hline Lissotriton helveticus & 30TUN12 & 100,00 & 105,21 & 110,09 & \begin{tabular}{ll|}
39,98 \\
\end{tabular} & \begin{tabular}{|l|}
5484,01 \\
\end{tabular} & 263,13 & $-10,52$ & 273,65 & 75,65 & 177,55 & 177,55 & 36,96 & $\begin{array}{l}619,48 \\
\end{array}$ & 78,58 & 30,70 & 27,93 & 215,26 & 113,46 & 113,46 & 162,66 \\
\hline Lissotriton helveticus & 30TUN16 & 100,00 & 78,12 & 102,39 & 39,84 & 5167,15 & 226,15 & $-28,03$ & 254,18 & 51,17 & 146,75 & 147,05 & 15,97 & 888,69 & 109,61 & 45,98 & 24,75 & 297,35 & 162,91 & 163,98 & 243,87 \\
\hline Lissotriton helveticus & 30TUN17 & 100,00 & 79,01 & 100,01 & 39, & 5033,41 & 222,44 & $-24,72$ & 号 & 53,18 & 14 & 146,35 & $\pi$ & \begin{tabular}{|c|}
921,48 \\
\end{tabular} & $114, \mathrm{C}$ & 47,8 & 24,58 & 30 & 94 & 41 & 252,54 \\
\hline Lissotriton helveticus & 30T & 100 & 89 & 97 & 40 & 4836,49 & 226 & -11, & $23 \varepsilon$ & 65,36 & 153 & & 31 & 898 & 113,38 & 46 & 24,96 & 301,86 & 165,37 & 170,20 & 24. \\
\hline Lissotriton helveticus & 30TUN22 & 100,00 & 103,05 & 108,81 & 39,66 & 5432,62 & 259,46 & $-12,24$ & 271,70 & 74,61 & 174,47 & 174,79 & 35,75 & 634,62 & 79,38 & 31,56 & 26,73 & 217,08 & 116,31 & 116,92 & 166,18 \\
\hline Lissotriton helveticus & 30TUN25 & 100,00 & 83,33 & 103,26 & 39,81 & 5209,53 & 232,64 & $-24,53$ & 257,17 & 56,47 & 152,47 & $\begin{array}{l}152,62 \\
\end{array}$ & 20,19 & 828,77 & \begin{tabular}{l|l|l|}
101,93 \\
\end{tabular} & 42,87 & 24,62 & 277,06 & \begin{tabular}{ll|}
152,97 \\
\end{tabular} & $\begin{array}{l}153,39 \\
\end{array}$ & 224,02 \\
\hline Lissotriton helveticus & 30TUN27 & 100,00 & 75,72 & 99,31 & 39,73 & 5038,60 & 219,20 & $-27,67$ & 246,87 & 50,11 & 142,64 & 143,19 & 15,47 & 937,74 & 114,70 & 48,99 & 23,88 & 310,48 & 172,98 & 174,52 & 257,13 \\
\hline Lisso & 36 & 100 & & 94 & 40,4 & 92,05 & 231,99 & 1, & 2 & & 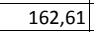 & & 44 & & 108, & & 25 & 28 & 156,44 & 58 & 22 \\
\hline Lissotriton helveticus & 30TUN29 & 100,0 & 120,79 & 86,30 & 40,7 & 4299,01 & 236,04 & 26,43 & 209,61 & \begin{tabular}{|c|}
101,17 \\
\end{tabular} & 176,11 & 178,13 & 68,15 & 816,80 & 107,64 & \begin{tabular}{l|l|}
40,96 \\
\end{tabular} & 26,72 & 278,91 & 147,87 & 158,09 & 210, \\
\hline Lissotriton helveticus & 30TUN32 & 100,00 & 103,38 & 107,30 & 39,40 & 5369,91 & 257,61 & $-11,11$ & 268,72 & 76,31 & \begin{tabular}{|l|l|}
173,92 \\
\end{tabular} & 174,31 & 37,19 & 640,16 & 79,22 & 31,81 & 25,89 & 216,41 & 116,32 & 118,36 & 166,88 \\
\hline
\end{tabular}




\begin{tabular}{|c|c|c|c|c|c|c|c|c|c|c|c|c|c|c|c|c|c|c|c|c|c|}
\hline TAXON & UTM & $\mathrm{km} 2$ & BI01 & BIO2 & $B 103$ & BIO4 & B105 & B106 & B107 & B108 & $B 109$ & B1010 & BI011 & B1012 & BIO13 & BIO14 & B1015 & B1016 & B1017 & B1018 & B1019 \\
\hline Lissotriton helveticus & 30TUN35 & 100,00 & 83,84 & 102,02 & 39,59 & 5166,43 & 231,60 & $-23,32$ & 254,91 & 57,79 & 152,46 & 152,70 & 21,45 & 828,77 & 101,18 & 42,98 & 24,12 & 275,09 & 153,42 & 153,77 & 222,86 \\
\hline Lissotriton helveticus & 30TUN37 & 100,00 & 79,28 & 97,90 & $\begin{array}{l}39,70 \\
\end{array}$ & 4982,78 & 220,31 & $-23,47$ & 243,78 & 54,46 & 145,36 & 145,99 & 19,53 & 923,41 & 112,72 & 48,30 & 23,67 & 304,85 & 171,00 & 172,65 & 251,05 \\
\hline Lissotriton helveticus & 30TUN38 & 100,00 & 77,77 & 95,54 & 39,75 & $\begin{array}{l}4880,97 \\
\end{array}$ & 215,01 & $-22,60$ & 237,61 & 52,92 & 142,35 & 143,25 & 19,38 & $\begin{array}{l}971,99 \\
\end{array}$ & 118,52 & 50,96 & 23,61 & 319,81 & 179,35 & 182,11 & 265,67 \\
\hline Lissotriton helveticus & 30TUN39 & 100,00 & 107,75 & 88,69 & 40,18 & 4470,70 & 229,18 & 11,69 & 217,48 & 87,06 & 165,69 & 167,45 & 53,23 & 867,20 & 111,23 & 44,20 & 25,51 & 293,17 & 158,73 & 167,19 & 228,33 \\
\hline Lissotriton helveticus & 30TUN47 & 100,00 & 66,54 & 97,04 & 39,20 & 5034,80 & 209,15 & $-35,25$ & 244,41 & 40,70 & 134,10 & 134,40 & 6,82 & 1002,78 & 119,17 & 52,86 & 22,54 & 324,81 & 184,95 & 185,50 & 276,72 \\
\hline Lissotriton helveticus & 30TUN49 & 100,00 & 100,95 & 88,36 & \begin{tabular}{l|l}
39,92 \\
\end{tabular} & 4525,81 & 223,92 & 5,10 & 218,82 & 80,02 & 159,82 & 161,59 & 46,13 & 905,04 & 113,95 & 46,21 & 24,80 & 303,52 & 165,79 & 173,43 & 241,78 \\
\hline Lissotriton helveticus & 30TUN51 & 100,00 & 102,94 & 106,35 & 39,00 & 5369,64 & 256,83 & $-12,45$ & 269,28 & 77,30 & 173,72 & 173,89 & 37,00 & 628,56 & 75,55 & 30,81 & 24,62 & 206,99 & 110,28 & 115,75 & 162,79 \\
\hline Lissotriton helveticus & 30TUN52 & 100,00 & 97,59 & 104,75 & 39,00 & 5309,83 & 249,49 & $-15,47$ & 264,96 & 71,96 & 167,75 & 167,78 & 32,71 & 679,19 & 81,65 & 34,02 & 24,14 & 223,35 & 121,52 & 125,41 & 177,32 \\
\hline Lissotriton helveticus & 30TUN57 & 100,00 & 76,96 & 95,17 & \begin{tabular}{|c|}
39,27 \\
\end{tabular} & $\begin{array}{l}4934,79 \\
\end{array}$ & 215,46 & $-24,06$ & 239,52 & 52,90 & 142,68 & 143,37 & 18,05 & 952,74 & $\begin{array}{l}114,06 \\
\end{array}$ & \begin{tabular}{ll|}
49,92 \\
\end{tabular} & 22,76 & 310,09 & 176,30 & \begin{tabular}{|c|}
177,79 \\
\end{tabular} & 259,61 \\
\hline Lissotriton helveticus & 30TUN58 & 100,00 & 64,12 & \begin{tabular}{|c|}
3,81 \\
\end{tabular} & \begin{tabular}{|c|c|}
39,15 \\
\end{tabular} & $\begin{array}{l}4927,86 \\
\end{array}$ & 202,28 & $-34,64$ & 236,92 & 36,02 & 130,13 & 130,90 & 6,13 & \begin{tabular}{ll|}
1062,61 \\
\end{tabular} & 125,24 & 56,25 & 22,12 & 342,21 & 195,97 & $\begin{array}{l}197,36 \\
\end{array}$ & 294,85 \\
\hline Lissotriton helveticus & 30TUN67 & 100,00 & 106,29 & 89,65 & 39,20 & \begin{tabular}{|l|l|}
4654,97 \\
\end{tabular} & 232,62 & 7,29 & 225,33 & 85,08 & 166,82 & 168,31 & 49,38 & 828,46 & 103,01 & 41,33 & 24,41 & 277,75 & 151,40 & 157,16 & 220,10 \\
\hline Lissotriton helveticus & 30TUN68 & 100,00 & 96,86 & 88,38 & 39,26 & 4626,31 & 222,21 & 0,02 & 222,19 & 75,25 & 157,31 & 158,81 & 40,88 & 912,28 & 112,01 & 46,25 & 23,97 & 302,74 & 166,82 & 173,13 & 246,33 \\
\hline Lissotriton helveticus & 30TUN69 & 100,00 & 117,26 & 81,33 & 39,36 & 4297,31 & 229,34 & 25,31 & 204,04 & 98,33 & 172,43 & 174,63 & 64,57 & 870,67 & \begin{tabular}{|c|}
110,78 \\
\end{tabular} & 42,19 & 25,82 & 296,73 & 155,49 & 167,92 & 233,20 \\
\hline Lissotriton helveticus & 30TUN74 & 100,00 & 89,82 & 98,09 & 38,98 & 5102,09 & 233,30 & $-16,41$ & 249,71 & 65,46 & 157,94 & 157,94 & 28,13 & \begin{tabular}{|c|}
792,77 \\
\end{tabular} & 93,82 & 40,51 & 22,65 & 256,46 & \begin{tabular}{|l|l|}
144,87 \\
\end{tabular} & 144,87 & 210,52 \\
\hline Lissotriton helveticus & 30TUN75 & 100,00 & 83,51 & 96,70 & 38,99 & 5049,08 & 225,18 & $-20,38$ & 245,56 & 59,29 & 151,16 & 151,18 & 22,95 & 856,41 & 101,02 & 44,38 & 22,20 & 276,21 & \begin{tabular}{|l|l}
158,04 \\
\end{tabular} & 158,04 & 229,83 \\
\hline Lissotriton helveticus & 30TUN83 & 100,00 & 97,92 & 97,97 & 38,61 & 5124,45 & 241,13 & $-9,80$ & 250,94 & 73,74 & 166,08 & 166,08 & 35,36 & 729,99 & 85,87 & 36,48 & 22,68 & 235,61 & 131,57 & 131,59 & 192,01 \\
\hline Lissotriton helveticus & 30TUN84 & 100,00 & 95,87 & 95,97 & 38,78 & 5037,41 & 235,94 & $-9,26$ & 245,21 & 72,10 & 163,01 & 163,01 & 34,63 & 773,53 & 91,48 & 38,99 & 22,55 & 250,52 & 141,46 & $\begin{array}{l}141,46 \\
\end{array}$ & 205,00 \\
\hline \begin{tabular}{|l} 
Lissotriton helveticus \\
\end{tabular} & 30TUN85 & 100,00 & 75,40 & 95,93 & 38,82 & 5077,38 & 217,77 & $-27,32$ & 245,09 & 50,12 & $\mid 143,84$ & 143,85 & 14,98 & 908,83 & 105,03 & |47,62 & 21,45 & 288,47 & 167,41 & 167,41 & 246,18 \\
\hline Lissotriton helveticus & 30TUN87 & 100,00 & 88,78 & 89,96 & \begin{tabular}{|c|}
38,97 \\
\end{tabular} & 4779,18 & 219,30 & $-9,24$ & 228,53 & 66,52 & 151,61 & 153,06 & 31,26 & $\begin{array}{l}919,68 \\
\end{array}$ & 109,43 & 47,08 & 22,49 & 299,16 & 169,77 & 173,11 & 249,70 \\
\hline Lissotriton helveticus & 30TUN88 & 100,00 & 112,28 & 82,25 & 38,92 & 4422,59 & 227,97 & 18,89 & 209,08 & 92,69 & 169,27 & 171,39 & \begin{tabular}{ll|}
58,07 \\
\end{tabular} & $\begin{array}{l}878,46 \\
\end{array}$ & $\begin{array}{l}108,95 \\
\end{array}$ & 42,39 & 24,85 & 296,31 & 157,07 & 168,16 & 237,92 \\
\hline Lissotriton helveticus & 30TUN92 & 100,00 & 101,90 & 97,83 & \begin{tabular}{l|l}
38,05 \\
\end{tabular} & 5179,18 & 245,87 & $-6,59$ & 252,46 & 77,36 & 170,68 & 170,68 & 38,63 & 691,31 & 80,48 & 33,97 & 22,56 & 221,58 & 122,90 & 122,90 & 181,06 \\
\hline Lissotriton helveticus & 30TUN93 & 100,00 & 101,05 & 95,72 & 38,19 & 5085,48 & 241,52 & $-4,99$ & 246,51 & 76,96 & 168,68 & 168,68 & 38,88 & 728,04 & 85,35 & 35,99 & 22,53 & 234,67 & 131,51 & 131,51 & $\begin{array}{l}192,18 \\
\end{array}$ \\
\hline Lissotriton helveticus & 30TUN95 & 100,00 & 78,28 & 94,44 & \begin{tabular}{|c|}
38,47 \\
\end{tabular} & 5046,53 & 218,68 & $-23,58$ & 242,26 & 53,54 & 146,15 & 146,33 & 18,04 & \begin{tabular}{|c|}
901,17 \\
\end{tabular} & 103,65 & 46,95 & 21,24 & 285,22 & 166,28 & 166,34 & 244,29 \\
\hline Lissotriton helveticus & 30TUN96 & 100,00 & 78,44 & 92,35 & 38,73 & 4948,25 & 215,06 & $-21,10$ & 236,15 & 54,41 & 144,41 & 145,20 & 19,49 & 937,75 & \begin{tabular}{|c|}
108,48 \\
\end{tabular} & 48,88 & 21,28 & 298,43 & 173,79 & 1774,56 & 255,77 \\
\hline Lissotriton helveticus & 30TUN97 & 100,00 & 96,77 & 86,74 & 38,76 & 4674,80 & 222,08 & 0,53 & 221,54 & 75,08 & 157,79 & 159,46 & \begin{tabular}{ll|}
40,07 \\
\end{tabular} & 905,34 & 108,1 & 45,29 & 22,97 & 296,79 & 165,17 & $\begin{array}{l}171,07 \\
\end{array}$ & 246,67 \\
\hline Lissotriton helveticus & 30TUN98 & 100,00 & 117,02 & 79,04 & 38,54 & 4334,54 & 228,44 & 25,87 & 202,56 & 97,81 & 172,57 & 174,82 & 63,65 & 887,01 & 109,93 & 41,75 & 25,30 & 300,98 & 156,30 & 170,18 & 242,66 \\
\hline Lissotriton helveticus & 30TUN99 & 100,00 & 129,86 & 72,59 & 38,23 & 4062,29 & 231,07 & 43,82 & 187,25 & 112,45 & 181,34 & 183,99 & 79,52 & 896,31 & \begin{tabular}{|c|}
113,76 \\
\end{tabular} & $\begin{array}{l}40,26 \\
\end{array}$ & 27,29 & 311,29 & 153,49 & $\begin{array}{l}173,86 \\
\end{array}$ & 247,30 \\
\hline Lissotriton helveticus & 30TUP00 & 100,00 & 126,74 & 83,46 & 41,44 & 4057,12 & 235,08 & 36,23 & 198,85 & 108,39 & 178,43 & 181,14 & 77,34 & 829,34 & 111,57 & 41,76 & 27,54 & 281,62 & 149,04 & $\begin{array}{l}159,96 \\
\end{array}$ & 210,49 \\
\hline Lissotriton helveticus & 30TUP01 & 98,00 & 132,84 & 77,05 & 40,95 & 3870,73 & 232,49 & 46,63 & 185,86 & 115,81 & 181,85 & 184,96 & 85,62 & 834,29 & 112,99 & 41,12 & 27,93 & 284,33 & 147,81 & 160,77 & 212,72 \\
\hline Lissotriton helveticus & 30TUP02 & 40,00 & 136,08 & 73,30 & \begin{tabular}{l|l|l}
40,65 & \\
\end{tabular} & 3764,03 & 230,71 & 52,45 & 178,26 & 119,80 & 183,68 & 186,80 & 90,21 & 839,39 & 114,00 & 40,95 & 28,24 & 286,77 & 147,48 & 161,79 & 215,03 \\
\hline Lissotriton helveticus & 30TUP10 & 100,00 & 128,41 & 81,58 & \begin{tabular}{|l|l}
40,93 \\
\end{tabular} & 4066,27 & 235,21 & \begin{tabular}{|c|}
38,27 \\
\end{tabular} & 196,94 & 110,11 & 180,23 & 182,88 & 78,61 & 820,87 & 109,97 & 40,75 & 27,43 & 280,47 & 146,78 & 158,76 & 210,20 \\
\hline Lissotriton helveticus & 30TUP11 & 96,00 & 128,99 & 78,27 & \begin{tabular}{ll|}
40,69 \\
\end{tabular} & 3961,70 & 231,50 & 41,54 & 189,96 & 111,36 & 179,31 & 182,19 & 80,64 & 846,18 & 113,34 & 41,76 & 27,45 & 289,11 & 150,50 & 163,76 & 218,27 \\
\hline Lissotriton helveticus & 30TUP12 & 20,00 & 136,32 & 73,40 & 40,36 & 3793,60 & 231,56 & 52,20 & 179,36 & 120,20 & 184,20 & 187,40 & 90,04 & 836,84 & \begin{tabular}{|c|}
113,28 \\
\end{tabular} & 40,60 & 28,04 & 287,08 & 147,12 & 161,92 & 215,56 \\
\hline Lissotriton helveticus & 30TUP20 & 100,00 & 134,88 & 77,88 & \begin{tabular}{l|l}
40,29 \\
\end{tabular} & 3995,93 & 237,12 & 46,48 & 190,63 & 117,35 & 185,62 & 188,38 & 85,65 & 802,19 & 107,72 & 38,63 & 27,90 & 276,54 & 141,34 & 155,20 & 206,81 \\
\hline Lissotriton helveticus & 30TUP21 & 65,00 & 132,62 & 76,72 & 40,33 & 3942,74 & 233,28 & 45,64 & 187,64 & 115,31 & 182,62 & 185,54 & 84,31 & 833,38 & 111,64 & 40,50 & 27,68 & 286,53 & 147,33 & 161,81 & 215,78 \\
\hline Lissotriton helveticus & 30TUP30 & 100,00 & 126,56 & 80,18 & 40,24 & 4107,21 & 233,28 & 36,55 & 196,73 & 108,50 & 178,94 & 181,48 & 76,06 & 836,94 & 110,50 & 40,98 & 27,01 & 287,16 & 149,31 & $\begin{array}{l}162,56 \\
\end{array}$ & 217,93 \\
\hline Lissotriton helveticus & 30TUP31 & 47,00 & 138,43 & 74,00 & 40,01 & 3894,79 & 235,65 & 52,49 & 183,16 & 121,57 & 187,60 & 190,48 & 90,33 & 816,59 & \begin{tabular}{|c|}
109,47 \\
\end{tabular} & 38,40 & 28,28 & 283,51 & 141,96 & 158,43 & 213,59 \\
\hline Lissotriton helveticus & 30TUP40 & 100,00 & 125,65 & 79,37 & \begin{tabular}{|c|}
39,98 \\
\end{tabular} & 4126,27 & 232,18 & 35,84 & 196,34 & 107,63 & 178,33 & 180,71 & 74,97 & 848,13 & 111,03 & 41,13 & 26,89 & 291,40 & 150,82 & 164,76 & 223,18 \\
\hline Lissotriton helveticus & 30TUP60 & 75,00 & 129,85 & 75,75 & 39, & 4064,14 & 232, & 42,05 & 190,47 & 112,40 & 181,46 & 08 & 79,68 & 859,68 & 111,71 & 40,19 & 27,31 & 297,76 & 149,96 & 67,00 & 230,73 \\
\hline Lissotriton helveticus & 30TUP80 & 52,00 & 140,72 & 69,54 & 38 & 3892,03 & 235,48 & 57,06 & 178,42 & 124,28 & 189,84 & 192,54 & 92,19 & 868,10 & 112,90 & 37,91 & 28,77 & 306,16 & 146,00 & 169,13 & 238,68 \\
\hline Lissotriton helveticus & 30TUP90 & 55,00 & 139,28 & $\begin{array}{c}68,17 \\
\end{array}$ & 38,04 & 3876,10 & 233,27 & 56,65 & $\begin{array}{l}176,62 \\
\end{array}$ & 123,02 & 187,99 & 190,92 & 91,08 & $\begin{array}{l}899,96 \\
\end{array}$ & 116,01 & 39,06 & 28,81 & $\begin{array}{l}317,35 \\
\end{array}$ & \begin{tabular}{ll|}
150,91 \\
\end{tabular} & $\begin{array}{l}175,76 \\
\end{array}$ & 250,17 \\
\hline Lissotriton helveticus & 30TVM06 & 100,00 & 113,92 & 105,86 & 37,31 & 5681,69 & 272,60 & $-6,31$ & 278,90 & 86,09 & 188,46 & 188,94 & 43,75 & 502,32 & 55,56 & 21,98 & 25,36 & 154,82 & 79,12 & 91,04 & 127,23 \\
\hline Lissotriton helveticus & 30 TVM25 & 100,00 & 111,49 & 103,89 & 37, & 5813,87 & 271,12 & $-5,72$ & 276,84 & 79,86 & 187,97 & 188,22 & 39,69 & 501,24 & 55,78 & 21,67 & 24,59 & 151,04 & 81,29 & 90,25 & 127,60 \\
\hline Lissotriton helveticus & 30TVM34 & 100,00 & 106,97 & 104,04 & $37, \mathrm{C}$ & 5908,60 & 268, & $-9,57$ & 277,97 & 121,96 & 185,07 & 185,15 & 34,46 & 511,04 & 57,86 & 22,09 & 24,09 & 152,90 & 83,91 & 91,86 & 130,41 \\
\hline Lissotriton helveticus & $30 \mathrm{TVM}$ & 100,00 & 107,53 & 102,06 & 37,00 & 5790,03 & 265 & $-6,63$ & 272,44 & 79,54 & 183,78 & 183,81 & 35,90 & 526,94 & 58, & 24,18 & 23,20 & 157,04 & 88,99 & 92,82 & 134,78 \\
\hline Lissotriton helveticus & $30 \mathrm{TVM}$ & 100,00 & 106,07 & 99,22 & 37,00 & \begin{tabular}{|l|}
5654,97 \\
\end{tabular} & 260,06 & $-4,72$ & 264,78 & 73,92 & 180,35 & 180,35 & 35,83 & 565,09 & 60, & 27,50 & 22,06 & 170,20 & \begin{tabular}{l|l}
98,48 \\
\end{tabular} & 99,15 & 145,37 \\
\hline Lissotriton helveticus & 30TVM39 & 100,00 & 102,91 & 97,88 & 37,01 & $\begin{array}{l}5555,62 \\
\end{array}$ & 254,18 & $-5,56$ & 259,75 & 71,68 & $\begin{array}{l}176,22 \\
\end{array}$ & $\begin{array}{l}176,22 \\
\end{array}$ & 34,31 & 602,44 & 65,96 & 29,75 & 21,75 & 183,21 & 106,31 & 106,31 & 156,24 \\
\hline Lissotriton helveticus & 30TVM41 & 100,00 & 115,39 & 104,04 & 36,7 & 6081,07 & 277,89 & $-3,05$ & 280,94 & 108,31 & 195,63 & 195,91 & 40,63 & 467,45 & 53,33 & 18,07 & 25,81 & 140,75 & 74,19 & 81,43 & 120,23 \\
\hline Lissotriton helveticus & 30 TVM 42 & 100,00 & 111,55 & 104,21 & 36,5 & $\begin{array}{l}6041,66 \\
\end{array}$ & 274,06 & $-6,11$ & 280,17 & 129,77 & 191,33 & 191,65 & 37,41 & 484,68 & 55,41 & 19,70 & 24,98 & 145,36 & 78,42 & 84,94 & 124,35 \\
\hline Lissotriton helveticus & $30 \mathrm{TVN}$ & 100,00 & 105,16 & 103,69 & $37, \mathrm{C}$ & 5 & 266,49 & $-10,45$ & 276,94 & 122,79 & 183,57 & 183,60 & 32,48 & 520,90 & 59,21 & 23,12 & 23,55 & 155,71 & 87,36 & 93,38 & 133,58 \\
\hline Lissotriton helveticus & 30TVM45 & 100,00 & 106,31 & 102,81 & 37,00 & 5873,44 & 266,03 & $-8,04$ & 274,06 & 121,05 & 183,90 & 183,92 & 34,19 & 523,97 & 58,84 & 23,95 & 23,05 & 155,33 & 89,15 & 92,81 & 134,59 \\
\hline Lissotriton helveticus & 30 TVM46 & 100,00 & 102,56 & 102,01 & 37,00 & 5811,44 & 261,32 & $-10,13$ & 271,45 & 111,71 & 179,48 & 179,48 & 31,14 & 548,59 & 61,10 & 26,01 & 22,41 & 161,84 & 94,85 & 95,70 & 141,36 \\
\hline Lissotriton helveticus & 30TVM48 & 100,00 & 101,72 & \begin{tabular}{|c|}
99,07 \\
\end{tabular} & \begin{tabular}{|c|}
37,07 \\
\end{tabular} & 5679,72 & 255,82 & $-7,16$ & 262,98 & 68,78 & 176,82 & 17 & 31, & 578,09 & 62 & $2 c$ & 21 & 7122 & 102,78 & 102,78 & 150,41 \\
\hline Lissotriton helveticus & $30 \mathrm{TV}$ & 100 & 102,13 & 97,24 & 37 & 557 & 252 & $-4,45$ & 257,07 & 69,98 & 175,98 & 179 & 33, & 602 & 65,54 & 29,99 & 21 & 10 & 108,10 & 108,10 & 15 \\
\hline Lissotriton helveticus & 30 TVM56 & 100,00 & 97,36 & 102,37 & 37,11 & 5809,75 & 256,47 & $-14,40$ & 270,87 & 113,70 & 174,64 & 174,64 & 26,77 & 579,32 & 64,67 & 28,43 & 21,82 & 170,90 & 102,09 & 102,18 & 150,45 \\
\hline Lissotriton helveticus & 30TVM58 & 100,00 & 98,86 & 99,24 & 37,44 & 5667,41 & 252,48 & $-9,10$ & 261,58 & 69,68 & 174,25 & 174,25 & 29,75 & $\begin{array}{l}600,95 \\
\end{array}$ & 65,14 & 30,32 & 21,19 & $\begin{array}{l}176,48 \\
\end{array}$ & $\begin{array}{ll}108,41 \\
\end{array}$ & 108,41 & 158,28 \\
\hline Lissotriton helveticus & 30TVM59 & 100,00 & 99,00 & 97,41 & $\begin{array}{l}37,52 \\
\end{array}$ & 5574,17 & 249,40 & $-6,82$ & 256,22 & 66,52 & 173,22 & 173,22 & 31,22 & 624,74 & 66,83 & 31,49 & 21,03 & 185,39 & 113,75 & 113,75 & 166,05 \\
\hline Lissotrit & $30 \mathrm{TVI}$ & 100 & 96 & 102,54 & 77 & + & 255,69 & $-14,6$ & & 112, & & & & 59 & 65,98 | & & & 11 & 105,92 & 105,92 & \\
\hline Lissotriton helveticus & 30TVM68 & 100,00 & \begin{tabular}{l|l}
93,86 \\
\end{tabular} & 100,04 & 37,83 & 5660,56 & 248,30 & $-14,12$ & 262,42 & 72,58 & 169,56 & 169,56 & 25,44 & \begin{tabular}{|c|c|}
641,77 \\
\end{tabular} & 69,19 & 33,05 & 20,53 & 186,60 & 117,08 & 117,08 & 170,02 \\
\hline Lissotriton helveticus & 30TVM73 & 100,00 & 98,56 & 105,98 & 37,12 & 5997,22 & 262,84 & $-17,20$ & 280,04 & 115,77 & 178,54 & 178,56 & 26,25 & 559,55 & 64,18 & 26,39 & 22,13 & 167,59 & 98,07 & 99,80 & 144,61 \\
\hline
\end{tabular}




\begin{tabular}{|c|c|c|c|c|c|c|c|c|c|c|c|c|c|c|c|c|c|c|c|c|c|}
\hline TAXON & UTM & $\mathrm{km} 2$ & $\mathrm{BIO1}$ & $\mathrm{B1O2}$ & $\mathrm{BIO3}$ & B104 & B105 & $\mathrm{B106}$ & 8107 & B108 & 8109 & 81010 & B1011 & BIO12 & 81013 & 81014 & B1015 & B1016 & B1017 & B1018 & B1019 \\
\hline Lissotriton helveticus & 30TVM74 & 100,00 & 100,22 & 105,01 & 37,27 & 5943,49 & 262,73 & $-14,36$ & 277,09 & 117,38 & 179,39 & 179,40 & 28,16 & 559,96 & 63,73 & 26,99 & 21,78 & 166,78 & 99,11 & 100,65 & 145,18 \\
\hline Lissotriton helveticus & 30TVM78 & 100,00 & 88,24 & 101,01 & 38,00 & 5655,53 & 243,54 & $-19,99$ & 263,53 & 69,76 & 164,02 & 164,02 & 20,13 & 687,79 & 73,85 & 36,12 & 19,78 & 198,62 & 126,73 & 126,73 & 183,08 \\
\hline Lissotriton helveticus & 30TVM79 & 100,00 & 98,67 & 98,00 & 37,93 & 5559,87 & 248,47 & $-7,68$ & 256,15 & 64,45 & 172,70 & 172,72 & 31,04 & 659,48 & 69,32 & 33,73 & 19,95 & 193,11 & 122,43 & 122,43 & 177,13 \\
\hline Lissotriton helveticus & 30TVM83 & 100,00 & 98,03 & 106,97 & 37,55 & 6000,19 & 263,21 & $-18,06$ & 281,27 & 115,23 & 178,17 & 178,18 & 25,65 & 568,01 & 65,21 & 27,55 & 21,58 & 169,93 & 101,13 & 104,28 & 147,14 \\
\hline Lissotriton helveticus & 30TVM84 & 100,00 & 97,05 & 106,23 & 37,68 & 5944,40 & 260,66 & $-17,95$ & 278,60 & 114,03 & \begin{tabular}{|l|l|}
176,37 \\
\end{tabular} & 176,37 & 25,10 & 583,63 & 66,38 & 29,07 & 21,05 & \begin{tabular}{|c|}
173,67 \\
\end{tabular} & 105,01 & 107,08 & 151,81 \\
\hline Lissotriton helveticus & 30TVM87 & 100,00 & 69,26 & 103,39 & 38,00 & 5696,11 & 228,73 & $-39,70$ & 268,43 & 82,56 & 146,46 & 146,46 & 2,19 & 800,97 & 86,39 & 43,73 & 18,76 & 231,33 & 148,06 & 148,06 & 213,46 \\
\hline Lissotriton helveticus & 30TVM88 & 100,00 & 90,20 & 101,26 & 37,99 & 5654,98 & 245,08 & $-18,43$ & 263,51 & 76,82 & 165,95 & 165,95 & 22,02 & 690,99 & 74,06 & 36,42 & 19,29 & 199,16 & 128,53 & 128,53 & 184,51 \\
\hline Lissotriton helveticus & 30TVM89 & 100,00 & 103,03 & 97,94 & 37,92 & 5556,56 & 251,82 & $\begin{array}{l}2,4,12 \\
-4,12\end{array}$ & 255,95 & 65,56 & 176,62 & 176,79 & 35,10 & 653,00 & 68,64 & 33,29 & 19,55 & 191,01 & 122,43 & 122,43 & 175,85 \\
\hline Lissotriton helveticus & 30TVM92 & 100,00 & 100,07 & 108,72 & 37,73 & 6058,65 & 267,23 & $-17,95$ & 285,18 & 117,93 & 180,93 & 180,94 & 27,00 & 556,12 & 64,39 & 26,95 & 21,52 & 166,86 & 99,45 & 103,55 & 143,63 \\
\hline Lissotriton helveticus & 30TVM93 & 100,00 & 95,84 & 108,37 & 37,98 & 6002,07 & 262,09 & $-20,98$ & 283,07 & 112,94 & 176,07 & 176,09 & 23,52 & 587,12 & 67,38 & 29,36 & 20,87 & 175,48 & 106,11 & 108,37 & 152,44 \\
\hline Lissotriton helveticus & 30TVM94 & 100,00 & 93,69 & 107,52 & 37,99 & 5940,38 & 258,53 & $-21,79$ & 280,32 & 110,41 & 173,17 & 173,17 & 22,16 & 609,52 & 69,25 & 31,33 & 20,35 & 181,15 & 111,26 & 112,79 & 159,04 \\
\hline Lissotriton helveticus & 30TVM95 & 100,00 & 73,65 & 106,18 & 38,00 & 5824,96 & 237,28 & $-38,38$ & 275,67 & 87,98 & 152,53 & 152,53 & 4,92 & 747,79 & 82,90 & 40,55 & 19,10 & 219,58 & 137,90 & 137,99 & 197,28 \\
\hline Lissotriton helveticus & 30 TVM96 & 100,00 & 83,40 & 105,32 & 38,00 & 5793,34 & 244,72 & $-28,48$ & 273,21 & 98,52 & 161,39 & 161,39 & 14,36 & 701,13 & 77,27 & 37,58 & 19,15 & 204,79 & 129,98 & 129,98 & 185,41 \\
\hline Lissotriton helveticus & 30TVM97 & 100,00 & 71,52 & 103,63 & 38,00 & 5701,55 & 230,87 & $-37,93$ & 268,80 & 85,05 & 148,69 & 148,69 & 4,16 & 797,59 & 86,10 & 43,69 & 18,42 & 230,23 & 148,77 & 148,77 & 212,75 \\
\hline Lissotriton helveticus & 30TVM98 & 100,00 & 91,12 & 101,98 & 38,00 & 5661,91 & 246,27 & $-18,21$ & 264,47 & 84,41 & 166,85 & 166,85 & 22,79 & 696,98 & 74,72 & 36,97 & 18,87 & 200,20 & 130,80 & 130,80 & 186,20 \\
\hline Lissotriton helveticus & 30TVM99 & 100,00 & 102,76 & 98,85 & 37,97 & 5568,33 & 252,12 & $-5,18$ & 257,30 & 60,80 & 176,65 & 176,71 & 34,77 & 662,93 & 69,71 & 34,25 & 19,01 & 192,52 & 125,39 & 125,39 & 178,41 \\
\hline Lissotriton helveticus & 30TVNOO & 100,00 & 108,50 & 99,59 & 37,93 & 5349,25 & 256,73 & $-3,32$ & 260,05 & 82,66 & 179,20 & 179,20 & 42,52 & 609,08 & 69,48 & 29,05 & 23,06 & 192,55 & 104,69 & 105,56 & 157,47 \\
\hline \begin{tabular}{|l} 
Lissotriton helveticus \\
\end{tabular} & 30TVNO1 & 100,00 & 105,02 & 97,94 & 38,00 & 5266,53 & 250,59 & $-4,35$ & 254,94 & 79,44 & 174,73 & 174,73 & 40,23 & 652,32 & 74,87 & 31,68 & 22,53 & 206,91 & 114,49 & 114,60 & 170,16 \\
\hline Lissotriton helveticus & 30TVN02 & 100,00 & 94,93 & 97,31 & 38,01 & 5225,65 & 240,01 & $-12,12$ & 252,13 & 69,28 & 164,63 & 164,63 & 31,41 & 724,43 & 82,86 & 36,32 & 21,84 & 228,54 & 129,62 & 129,62 & 191,08 \\
\hline $\mid$ Lissotriton helveticus & 30TVN03 & 100,00 & 98.08 & 94,63 & 38.07 & 5091,35 & 238,07 & -6.49 & 244.56 & 73,30 & 165,73 & 165,91 & 36,01 & 748,90 & 86,70 & 37,29 & 21,95 & 239,08 & 135,73 & $\mid 135,79$ & 199,06 \\
\hline Lissotriton helveticus & 30TVN04 & 100,00 & 97,56 & 92,57 & 38,09 & 4993,68 & 233,93 & $-4,75$ & 238,68 & 73,57 & \begin{tabular}{|l|l|}
163,47 \\
\end{tabular} & 164,29 & 36,67 & 786,93 & 91,65 & 39,27 & 21,97 & 252,69 & 144,27 & 144,50 & 210,75 \\
\hline Lissotriton helveticus & 30TVN05 & 100,00 & 95,42 & 90,73 & 38,30 & 4910,96 & 228,77 & $-4,67$ & 233,44 & 71,96 & 159,71 & 161,12 & 35,86 & 832,84 & 97,31 & 41,76 & 21,96 & 268,27 & 152,96 & 154,50 & 224,96 \\
\hline Lissotriton helveticus & 30TVN07 & 100,00 & 100,52 & 84,68 & 38,35 & 4629,05 & 223,08 & 5,55 & 217,53 & 79,01 & 160,53 & 162,49 & 44,18 & 903,90 & 107,70 & 44,50 & 22,99 & 296,89 & 163,57 & 171,12 & 247,80 \\
\hline Lissotriton helveticus & 30TVN12 & 100,00 & 97,30 & 95,50 & 38,00 & 5209,78 & 240,46 & $-8,07$ & 248,53 & 71,01 & 166,72 & 166,72 & 33,68 & 720,35 & 81,96 & 35,95 & 21,62 & 226,56 & 129,66 & 129,66 & 190,89 \\
\hline Lissotriton helveticus & 30TVN13 & 100,00 & 100,03 & 92,71 & 37,99 & 5074,66 & 237,86 & $-3,24$ & 241,09 & 74,87 & 167,07 & 167,61 & 37,92 & 750,81 & 86,35 & 37,08 & 21,81 & 239,05 & 136,11 & 136,80 & 200,91 \\
\hline Lissotriton helveticus & 30TVN15 & 100,00 & 96,76 & 89,05 & 38,07 & 4883,89 & 227,97 & $-2,11$ & 230,09 & 73,03 & 160,45 & 162,12 & 37,23 & 841,59 & 97,63 & 41,88 & 21,90 & 270,43 & 153,84 & 156,64 & 228,98 \\
\hline Lissotriton helveticus & 30TVN17 & 100,00 & 113,51 & 79,24 & 38,01 & 4450,67 & 227,75 & $\frac{2,11}{21,95}$ & 205,80 & $\begin{array}{l}93,08 \\
93,0\end{array}$ & 170,64 & \begin{tabular}{|l|l|}
172,86 \\
\end{tabular} & 58,77 & 894,42 & $\mid \begin{array}{r}\mid 107,47 \\
\end{array}$ & $\begin{array}{l}41,80 \\
41,87\end{array}$ & 24,48 & 299,30 & $\begin{array}{l}157,15 \\
150\end{array}$ & 170,29 & 248,74 \\
\hline Lissotriton helveticus & 30TVN18 & 100,00 & 123,42 & 73,44 & 37,91 & 4194,33 & 228,38 & 36,56 & 191,82 & 104,73 & 176,70 & 179,34 & 71,52 & 922,62 & 113,21 & 41,53 & 26,22 & 315,78 & 158,21 & 177,78 & 259,29 \\
\hline Lissotriton helveticus & 30TVN19 & 100,00 & 133,52 & 67,70 & 37,55 & 3946,92 & 229,38 & 51,28 & 178,10 & 116,49 & 183,18 & 186,10 & 84,48 & 947,99 & 118,90 & 40,98 & 28,14 & 331,66 & 158,69 & 184,71 & 268,72 \\
\hline Lissotriton helveticus & 30 TVN22 & 100,00 & 98,18 & 94,05 & 37,97 & 5211,92 & 239,98 & $-5,71$ & 245,69 & 71,22 & 167,44 & 167,58 & 34,47 & 722,47 & 81,64 & 35,99 & 21,27 & 226,16 & 130,84 & 130,90 & 192,53 \\
\hline Lissotriton helveticus & 30TVN23 & 100,00 & 97,04 & 91,99 & 37,98 & 5098,92 & 234,97 & $-4,75$ & 239,73 & 70,94 & 164,45 & 165,11 & 34,86 & 768,87 & 87,30 & 38,34 & 21,30 & 242,35 & 140,32 & 140,99 & 207,25 \\
\hline Lissotriton helveticus & 30TVN24 & 100,00 & 101,35 & 88,78 & 37,93 & 4946,85 & 233,22 & 1,82 & 231,41 & 76,64 & 165,72 & 167,33 & 40,81 & $\begin{array}{l}798,72 \\
\end{array}$ & 91,63 & \begin{tabular}{l|l|}
39,16 \\
\end{tabular} & 21,85 & 255,50 & $\begin{array}{l}144,76 \\
\end{array}$ & \begin{tabular}{|l|l|}
147,93 \\
\end{tabular} & 217,80 \\
\hline Lissotriton helveticus & 30 TVN25 & 100,00 & 99,07 & 87,23 & 38,01 & 4861,28 & 227,97 & 1,48 & 226,50 & 75,07 & 162,11 & 163,98 & 39,72 & 847,18 & 97,49 & 41,77 & 21,85 & 271,79 & 153,74 & 158,29 & 232,81 \\
\hline Lissotriton helveticus & 30 TVN26 & 100,00 & 99,52 & 84,82 & 38,02 & 4741,43 & 224,38 & 4,32 & 220,06 & 76,76 & 160,99 & 163,08 & 41,78 & 890,45 & 103,09 & 43,70 & 22,14 & 287,85 & 160,75 & 167,71 & 246,91 \\
\hline Lissotriton helveticus & 30 TVN30 & 100,00 & 99,40 & 96,63 & 37,33 & 5448,19 & 247,74 & $-7,01$ & 254,75 & 69,27 & 171,72 & 171,72 & 32,52 & 648,39 & 71,83 & 32,34 & 21,29 & 198,45 & 115,93 & 115,93 & 170,14 \\
\hline $\begin{array}{l}\text { Lissotriton helveticus } \\
\end{array}$ & 30TVN31 & 100,00 & 96,78 & 95,23 & 37,79 & 5345,47 & 242,09 & $-7,86$ & 249,95 & 67,83 & 167,90 & 167,90 & 31,47 & 694,26 & 77,24 & 34,87 & 21,03 & 213,68 & 125,51 & 125,51 & 184,37 \\
\hline \begin{tabular}{|l} 
Lissotriton helveticus \\
\end{tabular} & 30TVN34 & 100,00 & 102,11 & 87,56 & 37,89 & 4943,68 & 232,54 & 3,78 & 228,76 & 76,89 & 166,15 & 168,01 & 41,55 & 807,40 & 91,67 & 39,47 & 21,58 & 257,15 & 145,83 & 150,27 & 222,41 \\
\hline Lissotriton helveticus & 30TVN35 & 100,00 & 100,09 & 85,70 & 37,99 & 4839,53 & 227,32 & 3,92 & 223,40 & 75,82 & 162,73 & 164,78 & 41,04 & 860,57 & 98,02 & 42,14 & 21,75 & 275,25 & 155,33 & 161,40 & 239,24 \\
\hline Lissotriton helveticus & 30 TVN36 & 100,00 & 98,50 & 83,98 & 37,94 & 4741,51 & 222,92 & 4,39 & 218,54 & 75,08 & 159,90 & 161,99 & 40,86 & 910,65 & \begin{tabular}{|c|}
104,03 \\
\end{tabular} & 44,72 & 21,92 & 292,47 & 164,27 & 171,98 & 255,13 \\
\hline Lissotriton helveticus & 30TVN37 & 100,00 & 106,25 & 78,95 & 37,64 & 4519,87 & 222,60 & 15,81 & 206,80 & 83,86 & 164,41 & 166,69 & 51,04 & 948,49 & 110,55 & 45,01 & 23,36 & 311,21 & 167,55 & 180,65 & 269,49 \\
\hline Lissotriton helveticus & 30 TVN41 & 100,00 & 97,97 & 94,24 & 37,84 & 5348,75 & 242,03 & $-5,08$ & 247,11 & 68,22 & 168,75 & 169,27 & 32,69 & 695,17 & 76,59 & 34,88 & 20,91 & 212,73 & 126,85 & 126,95 & 186,38 \\
\hline Lissotriton helveticus & 30 TVN42 & 100,00 & 94,73 & 92,92 & 37,97 & 5248,90 & 235,92 & $-6,76$ & 242,68 & 66,10 & 163,77 & 164,82 & 30,91 & 748,93 & 82,50 & 37,8 & 20,56 & 230,02 & \begin{tabular}{|l|l|l|l|l}
137,79 \\
\end{tabular} & 137,95 & 202,92 \\
\hline Lissotriton helveticus & $\begin{array}{l} \\
30 \text { TVN43 } \\
\end{array}$ & 100,00 & 94,96 & 90,73 & 37,93 & 5126,11 & 232,01 & $-4,57$ & 236,57 & 67,53 & 161,78 & 163,49 & 32,63 & 793,42 & 87,77 & 39,94 & 20,51 & 245,95 & 145,83 & 147,30 & 217,37 \\
\hline Lissotriton helveticus & 30TVN45 & 100,00 & 103,27 & 83,95 & 37,82 & 4805,38 & 228,38 & 8,55 & 219,83 & 78,79 & 165,41 & 167,48 & 44,52 & 868,29 & 98,77 & 41,92 & 21,89 & 77,71 & 155,42 & 163,40 & 244,62 \\
\hline Lissotriton helveticus & 30 TVN46 & 100,00 & 101,68 & 82,19 & 37, & 4705,55 & 224,07 & 8,78 & 215,30 & 78,10 & 162,36 & 164,63 & 44,20 & 919,65 & 105,53 & 44,48 & 03 & 47 & 43 & 74,03 & 261,18 \\
\hline Lissotriton helveticus & 30TVN47 & 100, & 84,44 & 84,65 & 37,98 & 4773,45 & 211,57 & $\begin{array}{l}-8,16 \\
-8,16 \\
\end{array}$ & 219,73 & 50,17 & 146,53 & 148,96 & 27,38 & 1012,71 & $\begin{array}{l}114,26 \\
140\end{array}$ & 51,64 & 20,71 & $\begin{array}{ll}319,08 \\
319\end{array}$ & 186,35 & 192,27 & 286,46 \\
\hline Lissotriton helveticus & $30 \mathrm{TVN} 4$ & 100,00 & 94,57 & 79,63 & 37,77 & 4553,22 & 213,35 & 5,26 & 208,09 & 65,35 & 153,28 & 155,92 & 39,71 & 1037,07 & 120,07 & 50,90 & 22,20 & 334,28 & 186,41 & 198,12 & 297,73 \\
\hline Lissotriton helveticus & 30TVN49 & 100,00 & 121,90 & 67,96 & 36,93 & 4068,85 & 221,70 & 40,18 & 181,52 & \begin{tabular}{|c|}
103,62 \\
\end{tabular} & 173,25 & 176,26 & 71,89 & 1048,45 & 128,75 & 46,12 & 26,42 & 356,67 & 176,45 & 202,64 & 309,96 \\
\hline Lissotriton helveticus & 30 TVN52 & 100,00 & 98,95 & 91,42 & 37,73 & 5221,31 & 237,64 & $-1,86$ & 239,51 & 70,07 & 167,23 & 168,60 & 35,30 & 749,14 & 81,75 & 37,43 & 20,46 & 29,92 & 137,40 & 139,13 & 205,45 \\
\hline Lissotriton helveticus & 30 TVN54 & 100,00 & 106,21 & 84,98 & 37,53 & 4905,19 & 233,44 & 10,21 & 3 & 80,17 & 165 & 171,56 & 46,08 & 826,97 & 93,60 & & 21,58 & 92 & 148,03 & 155,24 & 233,76 \\
\hline $\begin{array}{l}\text { Lissotriton helveticus } \\
\end{array}$ & $\frac{50}{30}$ & 100,00 & $\frac{10}{11}$ & $\begin{array}{l}84,30 \\
80,20\end{array}$ & $\frac{3,35}{37,16}$ & \begin{tabular}{|}
4694,17 \\
4904
\end{tabular} & 233,01 & $\frac{10,21}{20,75}$ & $\frac{212,25}{212,25}$ & $\mid \frac{\mid 0,11}{89,81}$ & $\begin{array}{l}10,53,80 \\
173,8\end{array}$ & $\begin{array}{l}175,99 \\
175\end{array}$ & $\begin{array}{l}40,00 \\
55,64\end{array}$ & $\mid$\begin{tabular}{l|l|}
865,90 \\
\end{tabular} & \begin{tabular}{|c|c|}
500,81 \\
100
\end{tabular} & $\begin{array}{l}35,08 \\
40,08\end{array}$ & $\begin{array}{ll}22,87 \\
22,87\end{array}$ & \begin{tabular}{|l|l|}
280,37 \\
\end{tabular} & $\begin{array}{l}150,1,47 \\
151\end{array}$ & $\begin{array}{l}163,42 \\
163,4\end{array}$ & 249,80 \\
\hline Lissotriton helveticus & 30 TVN56 & 100,00 & 106,14 & 80,16 & 37,35 & 4654,46 & 225,83 & 14,56 & 211,27 & 82,72 & 165,90 & 168,30 & 49,16 & 930,85 & \begin{tabular}{|l|l|l|}
108,16 \\
\end{tabular} & 44,22 & 22,41 & 299,67 & 164,75 & 176,64 & 268,72 \\
\hline Lissotriton helveticus & 30TVN57 & 100,00 & 90,49 & 82,57 & 37,85 & 4709,62 & 214,55 & $-0,90$ & 215,45 & 52,83 & 151,43 & 153,93 & 33,92 & \begin{tabular}{|l|}
1014,97 \\
\end{tabular} & 115,98 & 50,75 & 21,14 & 321,54 & 184,65 & 193,13 & 291,03 \\
\hline Lissotriton helveticus & 30TVN58 & 100,00 & 108,37 & 74,56 & 37,25 & 4385,44 & 219,45 & 21,93 & 197,52 & 82,71 & 164,34 & 167,09 & 54,88 & 1034,62 & 123,48 & 48,07 & 23,87 & 339,52 & 179,88 & 197,78 & 305,10 \\
\hline Lissotriton helveticus & 30 TVN59 & 100,00 & 126,02 & 66,15 & 36, & 4031,09 & 223,35 & 45,27 & 178,07 & 107,64 & 176,66 & 179 & 76,24 & 1066,38 & 132,93 & 45,83 & 27,00 & 363,23 & 176,75 & 205,10 & 322 \\
\hline $\begin{array}{l}\text { Lissotriton helveticus } \\
\end{array}$ & 30TVN61 & $\begin{array}{l}100,00 \\
\end{array}$ & $\begin{array}{l}12,02 \\
109,10\end{array}$ & $\begin{array}{l}0,1123 \\
91,23\end{array}$ & $\begin{array}{ll}30,35 \\
37,38\end{array}$ & $\begin{array}{ll}4037,75,72 \\
5275\end{array}$ & 247,20 & $\begin{array}{c}4,27 \\
6,92 \\
\end{array}$ & $\begin{array}{ll}170,280 \\
240,28\end{array}$ & $\begin{array}{l}10,44 \\
79,42 \\
\end{array}$ & $\begin{array}{l}177,00 \\
177,51\end{array}$ & $\begin{array}{l}178,99 \\
178\end{array}$ & $\begin{array}{ll}0,24 \\
44,13\end{array}$ & \begin{tabular}{|l|}
687,76 \\
687
\end{tabular} & \begin{tabular}{|l|}
74,70 \\
74,50
\end{tabular} & \begin{tabular}{|l|}
33,49 \\
33,4
\end{tabular} & 20,67 & \begin{tabular}{|l|}
03,250 \\
210,78 \\
\end{tabular} & \begin{tabular}{|l|l|}
125,36 \\
\end{tabular} & $\begin{array}{ll}228,02 \\
120\end{array}$ & $\begin{array}{l}32,01 \\
189,41 \\
\end{array}$ \\
\hline Lissotriton helveticus & 30 TVN62 & 100,00 & 111,51 & 88,30 & 37,32 & 5124,11 & 244,29 & 11,61 & 232,68 & 81,37 & 177,68 & 179,32 & 48,27 & 728,47 & 80,75 & 34,84 & 21,01 & 226,71 & 131,29 & 136,11 & 203,84 \\
\hline Lissotriton helveticus & 30TVN64 & 100,00 & 110,67 & 83,52 & 37,36 & 4865,24 & 235,67 & 15,42 & 220,24 & 84,28 & 173,25 & 175,36 & 50,84 & 832,07 & 95,12 & 39,33 & 21,70 & 263,67 & 147,92 & 156,78 & 238,93 \\
\hline Lissotrito & 30 TVN65 & 100,00 & 108,42 & 81,64 & 37,37 & 4761,87 & 230,73 & 15,28 & 15 & 82,29 & 169 & 171 & 50, & 889,65 & 102,73 & 42 & 21,96 & 283,26 & 157,77 & 168,31 & 257, \\
\hline Lissotriton helveticus & 30 TVN67 & 100,00 & 101,25 & 79,16 & 37,55 & 4599,45 & 219,84 & 11,59 & 208,25 & 65,66 & 160,21 & 162,83 & 45,37 & 1010,80 & 117,99 & 48,59 & 22,10 & 323,75 & 179,86 & 192,51 & 296,21 \\
\hline
\end{tabular}




\begin{tabular}{|c|c|c|c|c|c|c|c|c|c|c|c|c|c|c|c|c|c|c|c|c|c|}
\hline TAXON & UTM & $\overline{\mathrm{km} 2}$ & B101 & $\mathrm{B1O2}$ & $\mathrm{BIO3}$ & $\begin{array}{ll}B 104 \\
\end{array}$ & B105 & B106 & B107 & B108 & B109 & B1010 & BIO11 & $\overline{B 1012}$ & 81013 & BIO14 & BIO15 & BIO16 & BIO17 & BIO18 & BlO19 \\
\hline Lissotriton helveticus & 30TVN68 & 100,00 & 120,69 & 69,95 & 36,74 & 4232,60 & 224,58 & 36,79 & 187,79 & 100,07 & 174,13 & 177,02 & 68,49 & 1042,82 & 128,30 & 45,78 & 25,59 & 347,40 & 175,27 & 198,70 & 317,65 \\
\hline Lissotriton helveticus & 30TVN70 & 100,00 & 104,58 & 94,92 & 37,86 & 5438,01 & 248,84 & 0,10 & 248,73 & 73,09 & 175,77 & 176,68 & 37,92 & 669,04 & 70,87 & 33,55 & 19,95 & \begin{tabular}{|c|}
199,48 \\
\end{tabular} & 124,75 & \begin{tabular}{l|l|}
125,08 \\
\end{tabular} & 182,08 \\
\hline Lissotriton helveticus & 30TVN72 & 100,00 & $\begin{array}{ll}106,97 \\
\end{array}$ & 89,83 & 37,74 & 5181,20 & 242,08 & 6,58 & 235,50 & 73,49 & \begin{tabular}{ll|l}
174,00 \\
\end{tabular} & \begin{tabular}{ll|}
175,75 \\
\end{tabular} & 43,37 & 749,71 & 82,34 & 36,79 & 20,27 & 229,53 & \begin{tabular}{|c|}
137,57 \\
\end{tabular} & \begin{tabular}{|l|l|}
141,17 \\
\end{tabular} & 209,90 \\
\hline Lissotriton helveticus & 30TVN73 & 100,00 & 112,44 & 85,79 & 37,43 & 5006,60 & 241,04 & 14,90 & 226,15 & 83,56 & $\begin{array}{l}176,85 \\
\end{array}$ & $\begin{array}{l}178,75 \\
\end{array}$ & 50,72 & 786,61 & 88,77 & 37,40 & 21,15 & 245,54 & \begin{tabular}{|l|l|}
141,27 \\
\end{tabular} & 148,32 & 225,13 \\
\hline Lissotriton helveticus & 30TVN74 & 100,00 & 107,62 & 84,58 & 37,51 . & 4912,95 & 234,44 & 12,03 & 222,40 | & 74,75| & 170,82 & 172,86 & 47,35 [ & 851,06 & 96,70 & 40,89 & 21,06 [ & $266,57 \mid$ & $153,21 \mid$ & 160,98 . & 245,17] \\
\hline Lissotriton helveticus & 30TVN75 & 100,00 & 105,31 & 82,77 & 37,50 & 4807,18 & 229,48 & \begin{tabular}{ll|l}
11,75 \\
\end{tabular} & 217,73 & \begin{tabular}{|c|}
67,09 \\
\end{tabular} & 167,05 & 169,38 & 46,57 & \begin{tabular}{l|l}
910,55 \\
\end{tabular} & 104,51 & 43,79 & 21,23 & 286,82 & 163,32 & \begin{tabular}{ll|}
172,66 \\
\end{tabular} & 264,81 \\
\hline Lissotriton helveticus & 30TVN76 & 100,00 & 107,88 & 79,40 & 37,36 & 4649,58 & 226,83 & 17,28 & 209,55 & 67,34 & \begin{tabular}{ll|}
167,40 \\
\end{tabular} & 169,86 & 51,09 & 964,32 & 112,88 & 45,46 & 22,21 & 308,11 & 170,29 & \begin{tabular}{|c|}
183,10 \\
\end{tabular} & 285,22 \\
\hline Lissotriton helveticus & 30TVN77 & 100,00 & 122,34 & 71,61 & 36,73 & 4342,73 & 229,04 & 36,54 & \begin{tabular}{|c|}
192,50 \\
\end{tabular} & 98,41 & \begin{tabular}{|c|}
177,24 \\
\end{tabular} & \begin{tabular}{|c|}
179,90 \\
\end{tabular} & 68,68 & 1009,67 & 123,94 & 44,06 & 25,19 & \begin{tabular}{|c|}
332,97 \\
\end{tabular} & 169,58 & $\begin{array}{l}190,88 \\
\end{array}$ & 310,96 \\
\hline Lissotriton helveticus & 30TVN78 & 100,00 & 120,92 & 69,74 & 36,68 & 4244,12 & 224,77 & 37,20 & 187,57 & 91,57 & \begin{tabular}{l|l|l}
174,43 \\
\end{tabular} & $\begin{array}{l}177,29 \\
\end{array}$ & 68,58 & 1066,48 & 131,83 & \begin{tabular}{l|l|}
46,55 \\
\end{tabular} & 25,63 & 353,54 & \begin{tabular}{ll|}
178,62 \\
\end{tabular} & 202,15 & 330,37 \\
\hline Lissotriton helveticus & 30TVN79 & 100,00 & 123,75 & 66,45 & 36,40 & 4096,70 & 222,63 & $42,77 \mid$ & 179,86 & 95,72 & 175,16 & 178,28 & 73,33 & 1118,18 & 140,30 & 47,95 & 26,70 & 374,65 _ & 184,63 & 212,21 & 350,73] \\
\hline Lissotriton helveticus & 30TVN82 & 100,00 & 103,17 & 91,27 & 37,89 & 5220,71 & 240,35 & 2,42 & 237,93 & \begin{tabular}{|c|}
60,00 \\
\end{tabular} & \begin{tabular}{|l|l|}
170,94 \\
\end{tabular} & 172,61 & 39,31 & 771,66 & 84,04 & \begin{tabular}{l|l|}
38,65 & \\
\end{tabular} & 19,54 & 233,49 & 143,87 & \begin{tabular}{|l|}
146,24 \\
\end{tabular} & 215,95 \\
\hline Lissotriton helveticus & 30TVN83 & 100,00 & 104,94 & 88,13 & 37,73 & 5072,27 & 237,26 & 6,80 & 230,46 & 63,63 & \begin{tabular}{|l|l}
170,70 \\
\end{tabular} & 172,44 & 42,99 & 820,28 & 91,21 & 40,44 & 20,14 & 252,12 & \begin{tabular}{|c|}
150,79 \\
\end{tabular} & \begin{tabular}{|l|l|}
155,49 \\
\end{tabular} & 233,70 \\
\hline Lissotriton helveticus & 30TVN84 & 100,00 & 103,96 & 86,15 & 37,85 & 4963,33 & 233,21 & 7,87 & 225,33 & 55,78 & \begin{tabular}{|c|}
167,96 \\
\end{tabular} & \begin{tabular}{|c|}
170,04 \\
\end{tabular} & 43,42 & 871,21 & 98,06 & 42,76 & 20,30 & 269,96 & \begin{tabular}{ll|}
159,22 \\
\end{tabular} & 165,50 & 250,88 \\
\hline Lissotriton helveticus & 30TVN85 & 100,00 & 104,85 & 83,38 & 37,74 & 4828,90 & 229,94 & 11,22 & 218,72 & 54,11 & \begin{tabular}{l|l|l|}
166,92 \\
\end{tabular} & 169,21 & 45,99 & 924,90 & 105,84 & 44,83 & 20,84 & 290,18 & $\begin{array}{l}167,04 \\
\end{array}$ & $\begin{array}{l}175,80 \\
\end{array}$ & 270,28 \\
\hline Lissotriton helveticus & 30TVN86 & 100,00 & 105,44 & 80,40 & 37,56 & 4686,24 & 225,87 & 14,56 & 211,31 & 57,21 & \begin{tabular}{ll|l}
165,48 \\
\end{tabular} & 167,92 & 48,3 & 987,13 & 114,97 & 47,1 & 21,7 & 313,49 & \begin{tabular}{ll|}
175,99 \\
\end{tabular} & \begin{tabular}{|c|}
187,50 \\
\end{tabular} & 293,23 \\
\hline Lissotriton helveticus & 30TVN87 & 100,00 & 124,55 & 70,93 & 36,59 & 4335,24 & 230,32 & 39,18 & 191,14 & 88,84 & \begin{tabular}{|c|}
179,24 \\
\end{tabular} & 181,90 & \begin{tabular}{|c|}
70,99 \\
\end{tabular} & $\begin{array}{ll}1029,46 \\
\end{array}$ & 127,20 & 44,41 & 25,55 & $\begin{array}{l}338,75 \\
\end{array}$ & \begin{tabular}{|c|}
171,69 \\
\end{tabular} & \begin{tabular}{|c|}
193,69 \\
\end{tabular} & 322,91 \\
\hline Lissotriton helveticus & 30TVN88 & 100,00 & 126,70 & 67,62 & 36,38 & 4189,88 & 227,43 & 44,06 & 183,37 & 89,67 & \begin{tabular}{|l|l|}
179,27 \\
\end{tabular} & $\begin{array}{l}182,15 \\
\end{array}$ & 74,93 & 1088,14 & 136,91 & \begin{tabular}{ll|}
45,96 \\
\end{tabular} & 26,80 & 362,44 & $\begin{array}{l}178,49 \\
\end{array}$ & 204,42 & 347,08 \\
\hline Lissotriton helveticus & 30TVN89 & 100,00 & 128,19 & 64,79 & 36,19 & 4057,18 & 224,63 & 47,99 & \begin{tabular}{|l|l|}
176,64 \\
\end{tabular} & 90,41 & $\begin{array}{ll}178,88 \\
\end{array}$ & 181,96 & 78,10 & 1143,30 & 145,65 & 47,71 & 27,72 & 384,24 & \begin{tabular}{|l|l|}
185,29 \\
\end{tabular} & 214,87 & 368,93 \\
\hline Lissotriton helveticus & 30TVN90 & 100,00 & 115,81 & 94,12 & 37,79 & 5412,15 & 256,61 & 9,92 & 246,69 & 84,13 & 185,79 & 186,93 & 48,72 & $\begin{array}{l}646,25 \\
\end{array}$ & 68,58 & 31,89 & \begin{tabular}{l|l}
19,62 \\
\end{tabular} & \begin{tabular}{|c|}
192,76 \\
\end{tabular} & \begin{tabular}{l|l}
122,05 \\
\end{tabular} & $\begin{array}{l}123,07 \\
\end{array}$ & 176,65 \\
\hline Lissotriton helveticus & 30TVN91 & 100,00 & 113,53 & 92,15 & 37,94 & 5299,28 & 251,10 & 10,04 & 241,07 & 80,85 & \begin{tabular}{|l|l|l|l|}
181,98 \\
\end{tabular} & 183,36 & 48, & 698,82 & 75,34 & 34, & 19,5 & 209,99 & 131,21 & \begin{tabular}{|c|}
133,30 \\
\end{tabular} & 193,97 \\
\hline Lissotriton helveticus & 30TVN92 & 100,00 & 117,27 & 88,59 & \begin{tabular}{l|l}
37,62 \\
\end{tabular} & 5141,02 & 249,09 & 16,71 & 232,37 & 86,20 & \begin{tabular}{l|l|l|}
183,32 \\
\end{tabular} & \begin{tabular}{|c|}
184,93 \\
\end{tabular} & 53,60 & $\begin{array}{l}738,05 \\
\end{array}$ & 81,65 & 35,49 & 20,21 & 225,82 & \begin{tabular}{l|l|}
135,85 \\
\end{tabular} & \begin{tabular}{l|l}
140,65 \\
\end{tabular} & 209,57 \\
\hline Lissotriton helveticus & 30TVN93 & 100,00 & 115,36 & 86,42 & \begin{tabular}{l|l|}
37,65 \\
\end{tabular} & 5019,65 & 244,13 & 17,40 & 226,73 & 80,67 & $\begin{array}{l}179,86 \\
1\end{array}$ & 181,60 & 53,52 & 797,27 & 89,48 & 38,23 & \begin{tabular}{|l|l|}
20,47 \\
\end{tabular} & 246,02 & 145,48 & \begin{tabular}{ll|}
151,88 \\
\end{tabular} & 229,88 \\
\hline Lissotriton helveticus & 30TVN94 & 100,00 & 108,73 & 85,55 & 37,76 & 4938,92 & 236,51 & 12,67 & 223,84 & 62,07 & \begin{tabular}{|l|l|}
172,20 \\
\end{tabular} & \begin{tabular}{|l|l|l|}
174,24 \\
\end{tabular} & 48,30 & 872,13 & 98,54 & 42,44 & 20,30 & 270,24 & $\begin{array}{l}159,39 \\
\end{array}$ & \begin{tabular}{|l|}
166,11 \\
\end{tabular} & 253,37 \\
\hline Lissotriton helveticus & 30TVN95 & 100,00 & 106,38 & 83,55 & 37,77 ] & 4828,87 & 231,28 & 12,65 | & 218,63 & 56,30 [ & 168,32 & 170,60 & 47,55 [ & $938,21 \mid$ & 107,38 & 45,50 & 20,76 & 293,76 & 170,03 & 178,55 & 276,05 \\
\hline Lissotriton helveticus & 30TVN96 & 100,00 & 119,40 & 76,09 & 37,08 & 4543,25 & 232,90 & 30,66 & 202,24 & 72,38 & \begin{tabular}{ll|l}
177,02 \\
\end{tabular} & 179,58 & 63,5 & 990,60 & 118,93 & 44,5 & 23, & 319,32 & \begin{tabular}{ll|}
170,56 \\
\end{tabular} & 186,73 & 305,49 \\
\hline Lissotriton helveticus & 30TVN99 & 92,00 & 132,29 & 63,55 & \begin{tabular}{l|l|}
35,85 \\
\end{tabular} & 4036,25 & 226,96 & 52,44 & 174,52 & \begin{tabular}{|l|}
89,47 \\
\end{tabular} & 182,50 & 185,60 & 82,34 & 1168,21 & 150,77 & 47,53 & 28,83 & 394,26 & 186,08 & 217,14 & 387,18 \\
\hline Lissotriton helveticus & 30TVP00 & 64,00 & 137,12 & 66,61 & 37,79 & 3851,80 & 230,15 & 55,92 & $\begin{array}{ll}174,23 \\
\end{array}$ & \begin{tabular}{ll|l}
120,96 \\
\end{tabular} & $\begin{array}{l}185,16 \\
\end{array}$ & $\begin{array}{l}188,49 \\
\end{array}$ & 89,16 & \begin{tabular}{|c|c|}
941,17 \\
\end{tabular} & 120,19 & \begin{tabular}{ll|}
40,62 \\
\end{tabular} & 28,75 & \begin{tabular}{|c|}
331,77 \\
\end{tabular} & \begin{tabular}{|c|}
157,24 \\
\end{tabular} & \begin{tabular}{|c|}
184,34 \\
\end{tabular} & 264,64 \\
\hline Lissotriton helveticus & 30TVP11 & 3,00 & 142,42 & 61,75 & 37,17 & 3685,50 & 228,75 & 65,08 & 163,67 & 126,75 & $\begin{array}{l}171,08 \\
\end{array}$ & \begin{tabular}{l|l}
191,25 \\
\end{tabular} & 96,33 & 988,92 & 126,33 & \begin{tabular}{l|l}
41,25 \\
\end{tabular} & 30,00 & 352,42 & 161,17 & \begin{tabular}{|l|l|}
195,08 \\
\end{tabular} & 283,42 \\
\hline Lissotriton helveticus & 30TVP20 & 99,00 & 139,47 & 61,90 & 37,03 & 3723,07 & 227,32 & 62,40 . & 164,92 & 123,90 & 174,73 & 189,11 & 93,06 & 1010,81 & 127,51 . & 42,12 & 29,70 | & 358,71 & 165,13 & $198,97 \mid$ & 291,94 \\
\hline Lissotriton helveticus & 30TVP30 & 86,00 & 138,58 & 60,93 & 36,75 & 3722,42 & 226,02 & 62,32 & 163,70 & \begin{tabular}{|l|l|}
122,92 \\
\end{tabular} & \begin{tabular}{|l|l|}
174,77 \\
\end{tabular} & 188,31 & 92,36 & \begin{tabular}{|l|l|l}
1043,38 \\
\end{tabular} & 131,23 & 43,16 & 29,64 & 369,18 & \begin{tabular}{|c|}
169,38 \\
\end{tabular} & 204,99 & 306,25 \\
\hline Lissotriton helveticus & 30TVP31 & 33,00 & 141,27 & 58,56 & 36,50 & 3605,85 & 224,90 & 67,10 & \begin{tabular}{|l|l|}
157,79 \\
\end{tabular} & 126,46 & 168,79 & 189,33 & 96,25 & 1070,27 & 135,50 & 43,90 & 30,44 & \begin{tabular}{|c|}
381,94 \\
\end{tabular} & \begin{tabular}{|c|}
170,77 \\
\end{tabular} & 211,92 & 313,67 \\
\hline Lissotriton helveticus & 30TVP40 & 99,00 & 137,02 & 60,62 & 36,34 & 3756,43 & 224,89 & 60,58 & 164,32 & 120,99 & \begin{tabular}{|l|l|}
179,46 \\
\end{tabular} & 187,05 & 90,33 & 1075,99 & 136,42 & 44,40 & 29,36 & 378,07 & 174,43 & 210,23 & 322,33 \\
\hline Lissotriton helveticus & 30TVP41 & 44,00 & 138,96 & 58,91 & 36,27 & 3675,51 & 223,92 & 64,09 & \begin{tabular}{l|l|l|l|}
159,83 \\
\end{tabular} & 123,56 & 171,44 & 187,82 & 93,1 & 1103,65 & 140,79 & 45,16 & 29,78 & \begin{tabular}{|c|}
389,87 \\
\end{tabular} & \begin{tabular}{|c|}
177,44 \\
\end{tabular} & 216,39 & 332,03 \\
\hline Lissotriton helveticus & 30TVP50 & 100,00 & 135,87 & 60,90 & \begin{tabular}{|c|}
36,17 \\
\end{tabular} & 3806,96 & 224,75 & 58,97 & 165,78 & \begin{tabular}{l|l|l|l|}
119,22 \\
\end{tabular} & 183,13 & 186,40 & 88,5 & 1097,40 & 139,97 & 45,1 & 29, & 382,13 & \begin{tabular}{ll|l}
177,06 \\
\end{tabular} & 212,35 & 336,43 \\
\hline Lissotriton helveticus & 30TVP61 & 17,00 & 137,40 & 59,60 & 36,00 & 3760,60 & 224,27 & 61,20 & 163,07 & 120,93 & 183,73 & 187,13 & 90,33 & \begin{tabular}{|l|l|}
1137,47 \\
\end{tabular} & 146,53 & 46,27 & 29,33 & 395,47 & 181,73 & 219,20 & 356,13 \\
\hline Lissotriton helveticus & 30TVP90 & 11,00 & 139,70 & 59,48 & 35,35 & 3886,30 & 228,13 & 62,13 & 166,00 & \begin{tabular}{|l|l|}
100,17 \\
\end{tabular} & \begin{tabular}{|c|}
187,70 \\
\end{tabular} & $\begin{array}{l}190,87 \\
1\end{array}$ & 91,13 & 1202,09 & 158,83 & 46,74 & \begin{tabular}{|c|}
30,87 \\
\end{tabular} & 411,13 & \begin{tabular}{|c|}
185,74 \\
\end{tabular} & 222,04 & 408,35 \\
\hline Lissotriton helveticus & 30TWM03 & 100,00 & 93,98 & 109,78 & 38,00 & 6001,04 & 261,56 & $-23,63$ & 285,19 & 110,94 & 174,33 & 174,36 & 21,81 & 605,37 & 69,45 & 31,18 & 20,27 & \begin{tabular}{|l|l|}
180,79 \\
\end{tabular} & 110,97 & 113,23 & 157,66 \\
\hline Lissotriton helveticus & 30TWM04 & 100,00 & 85,75 & 108,61 & 38,00 & 5923,26 & 251,68 & $-29,78$ & 281,46 & 101,73 & 165,23 & 165,23 & 14,9 & 666,40 & 75,31 & 35,5 & 19,49 & $\begin{array}{l}197,55 \\
\end{array}$ & 123,31 & \begin{tabular}{|c|}
124,57 \\
\end{tabular} & 174,60 \\
\hline Lissotriton helveticus & 30TWM05 & 100,00 & 70,14 & 106,53 & $38, \mathrm{C}$ & 45 & 233 & -42, & 275,98 & 84,2 & 8,92 & 92 & 1,6 & 779,62 & 86,31 & $42, \varepsilon$ & 18,6 & 228,66 & 145 & \begin{tabular}{|l|}
145,29 \\
\end{tabular} & 205,86 \\
\hline Lissotriton helveticus & 30TWM06 & 100,00 & 91,56 & 106,05 & 38,00 & 5817,45 & 252,79 & $-21,79$ & 274,57 & 107,69 & 169,41 & 169,41 & 21,5 & 661,18 & 73,31 & 35,29 & 19,10 & 193,37 & 124,01 & 124,21 & 174,34 \\
\hline Lissotriton helveticus & 30TWM07 & 100,00 & 70,76 & 104,27 & 38,01 & 5708,69 & 230,51 & $-39,31$ & 269,82 & 84,63 & 148,01 & 148,01 & 3,2 & 811,61 & 87,62 & 44,84 & \begin{tabular}{|l|l|}
18,14 \\
\end{tabular} & 234,22 & \begin{tabular}{|c|}
152,54 \\
\end{tabular} & \begin{tabular}{|c|}
152,54 \\
\end{tabular} & 216,71 \\
\hline Lissotriton helveticus & 30TWM08 & 100,00 & 89,97 & 103,04 & 38,06 & 5672,90 & 245,93 & $-20,14$ & 266,06 & $\begin{array}{ll}100,88 \\
\end{array}$ & \begin{tabular}{ll|}
165,91 \\
\end{tabular} & 165,91 & 21,54 & 712,04 & 76,42 & 38,20 & 18,40 & 204,14 & \begin{tabular}{|c|}
134,80 \\
\end{tabular} & $\begin{array}{l}134,80 \\
\end{array}$ & 190,31 \\
\hline Lissotriton helveticus & 30TWM09 & 100,00 & 110,86 & 98,72 & 37,98 & 5573,69 & 258,66 & 1,71 & 256,95 & 78,18 & 184,26 & 184,34 & 42,14 & 629,40 & 66,34 & 32,3 & 18,9 & 182,56 & \begin{tabular}{|c|}
120,69 \\
\end{tabular} & \begin{tabular}{|c|}
120,69 \\
\end{tabular} & 168,21 \\
\hline Lissotriton helveticus & 30TWM13 & 10 & 96,87 & 111,31 & $38, \mathrm{C}$ & 11 & 265 & $-22,23$ & 287,59 & 114,3 & 16 & 21 & 24,3 & 596, & 68,64 & 31, & 19, & 178,25 & 110,88 & \begin{tabular}{|c|}
114,29 \\
\end{tabular} & 155,30 \\
\hline Lissotriton helveticus & 30TWM14 & 10 & 79 & 16 & 38,02 & 590 & 245 & $-36,45$ & \begin{tabular}{|l|l|}
281,89 \\
\end{tabular} & 94,4 & \begin{tabular}{|c|}
158,69 \\
\end{tabular} & 158,69 & 9,0 & 716,27 & 80,58 & 38, & 18, & 211,92 & 133,97 & \begin{tabular}{l|l|l}
134,53 \\
\end{tabular} & 188,09 \\
\hline Lissotriton helveticus & 30TWM15 & 100,00 & 68,97 & & 38,02 & 5817,98 & 232,96 & $-43,81$ & 276,77 & \begin{tabular}{|l|}
83,09 \\
\end{tabular} & \begin{tabular}{|l|l|}
147,78 \\
\end{tabular} & \begin{tabular}{|l|l|}
147,78 \\
\end{tabular} & 0,4 & 794,58 & 87,97 & 44,08 & 18,2 & 233,03 & 149,38 & 149,38 & 209,87 \\
\hline Lissotriton helveticus & 30TWM16 & 100,00 & 80,61 & 106,79 & 38,04 & 5796,00 & 242,94 & $-32,60$ & 275,54 & 95,78 & $\begin{array}{l}158,64 \\
1\end{array}$ & \begin{tabular}{ll|}
158,64 \\
\end{tabular} & 11,50 & 737,33 & 81,18 & 40,38 & 18,32 & 215,15 & \begin{tabular}{l|l}
139,25 \\
\end{tabular} & \begin{tabular}{l|l}
139,33 \\
\end{tabular} & 195,45 \\
\hline Lissotriton helveticus & 30TWM17 & 100,00 & 93,83 & 105,35 & 38,08 & 5763,45 & 252,61 & $-19,24$ & 271,85 & 110,11 & 170,63 & 170,63 & 24, & 674,93 & 74,07 & 36,31 & 18,5 & 196,01 & 128,47 & 128,65 & 178,33 \\
\hline Lissotriton helveticus & 30TWM18 & 100,00 & 110,04 & 102,28 & 38,03 & 570 & 262,98 & $-2,26$ & 265,24 & 124,43 & 185,29 & 185,29 & 39, & $\begin{array}{l}602,75 \\
\end{array}$ & 65,87 & 31,6 & 18, & 173,77 & 116,27 & \begin{tabular}{|l|}
116,44 \\
\end{tabular} & 157,84 \\
\hline Lissotriton helveticus & 30TWM19 & 100,00 & 120,28 & 98, & 37,98 & 559 & 266,30 & 9,6 & 256,62 & $88, \mathrm{C}$ & 193,38 & 193,38 & 50,7 & 581,66 & 62,07 & 29,70 & 19, & \begin{tabular}{|c|}
168,78 \\
\end{tabular} & 113,38 & \begin{tabular}{|l|l|}
113,42 \\
\end{tabular} & 152,68 \\
\hline Lissotriton helveticus & 30TWM23 & 100,00 & 100,11 & 113,02 & 38,18 & 6033,19 & 269,86 & $-20,79$ & \begin{tabular}{ll|}
290,66 \\
\end{tabular} & 118,09 & \begin{tabular}{l|l|}
180,38 \\
\end{tabular} & 180,43 & 27,22 & 585,53 & \begin{tabular}{ll|}
67,66 \\
\end{tabular} & 30,79 & 19,88 & 175,20 & \begin{tabular}{l|l}
110,05 \\
\end{tabular} & \begin{tabular}{ll|}
114,06 \\
\end{tabular} & 152,42 \\
\hline Lissotriton helveticus & 30TWM24 & 100,00 & 76,56 & 109,64 & 38,18 & 5900,86 & 243,23 & $-39,27$ & 282,50 & \begin{tabular}{|c|}
91,92 \\
\end{tabular} & 156,19 & 156,19 & 6,65 & \begin{tabular}{ll|}
738,56 \\
\end{tabular} & 83,14 & 40,72 & 8,55 & 218,56 & \begin{tabular}{|l|l|}
139,47 \\
\end{tabular} & 140,34 & 193,94 \\
\hline Lissotriton helveticus & 30TWM25 & 100,00 & 68,24 & 107,45 & 38,1 & 581 & 232 & -45, & 277,3 & 82, & 14 & 147 & -0, & 807,14 & 89,4 & 45,1 & 17, & 236, & 15 & \begin{tabular}{|l|l|}
153,23 \\
\end{tabular} & 212,90 \\
\hline Lissotriton helveticus & 30TWM26 & & 88 & & 38 & 582 & 251 & $-27, \mathrm{C}$ & 278 & 104 & 166, & 166 & 18, & 698,10 & 77,5 & & 18, & 204 & \begin{tabular}{|l|l|}
132,99 \\
\end{tabular} & 133,36 & 18 \\
\hline Lissotriton helveticus & 30TWM27 & 100,00 & 91,55 & 106,67 & 38,27 & 5774,84 & 251,68 & $-22,38$ & 274,06 & \begin{tabular}{|l|l|}
107,79 \\
\end{tabular} & \begin{tabular}{|l|l|}
168,63 \\
\end{tabular} & 168,63 & 21,84 & $\begin{array}{l}694,45 \\
\end{array}$ & 76,45 & 37,87 & 18,18 & 202,16 & \begin{tabular}{|l|l|}
133,02 \\
\end{tabular} & 133,16 & 183,65 \\
\hline Lissotriton helveticus & 30TWM28 & 100,00 & 99,88 & 104,49 & 38,32 & 5719,76 & 255,82 & $-12,94$ & 268,76 & \begin{tabular}{l|l}
116,42 \\
\end{tabular} & \begin{tabular}{|l|l|}
175,71 \\
\end{tabular} & 175,71 & 30,24 & 666,60 & 72,70 & 36,00 & 18,18 & $\begin{array}{l}192,58 \\
\end{array}$ & \begin{tabular}{|l|l|}
128,78 \\
\end{tabular} & \begin{tabular}{l|l}
128,95 \\
1
\end{tabular} & 175,86 \\
\hline Lissotriton helveticus & 30TWM29 & 100,00 & 120,41 & 100,10 & 38,02 & 5642,81 & 268,08 & 8,30 & 259,78 & 117,56 & \begin{tabular}{|c|}
194,07 \\
\end{tabular} & \begin{tabular}{|c|}
194,07 \\
\end{tabular} & 50,30 & 572,70 & 62,49 & \begin{tabular}{l|l}
29,95 \\
\end{tabular} & 18,94 & 165,38 & 113,07 & 113,23 & 147,71 \\
\hline Lissot & $30 \mathrm{TWN}$ & & & & 38,5 & & 253 & $-32,7$ & 286, & 102, & & 9 & 14,49 & 689,9 & 78, & 37, & & & 131,59 & 133 & 18 \\
\hline Lissotriton helveticus & 30TWM35 & 100,00 & 73,56 & 108,60 & 38,32 & 5840,8 & 238,1 & $-41,36$ & 279,45 & 88,67 & \begin{tabular}{ll|}
152,30 \\
\end{tabular} & 152,30 & 4,19 & 778,78 & 86,81 & 43,56 & \begin{tabular}{|c|}
17,84 \\
\end{tabular} & 229,28 & 148,81 & \begin{tabular}{|l|l|}
149,08 \\
\end{tabular} & 205,05 \\
\hline Lissotriton helveticus & 30TWM36 & 100,00 & 86,13 & 108,96 & 38,61 & 5831,72 & 249,59 & $-29,72$ & 279,31 & 102,28 & \begin{tabular}{|c|c|}
164,16 \\
\end{tabular} & 164,16 & \begin{tabular}{|c|}
16,16 \\
\end{tabular} & 717,70 & 79,76 & 39,59 & 18,01 & 210,42 & 137,64 & 138,29 & 189,70 \\
\hline
\end{tabular}




\begin{tabular}{|c|c|c|c|c|c|c|c|c|c|c|c|c|c|c|c|c|c|c|c|c|c|}
\hline TAXON & UTM & $\mathrm{km} 2$ & BIO1 & $\mathrm{BIO2}$ & $\mathrm{BIO3}$ & B104 & BIO5 & B106 & B107 & B108 & B109 & B1010 & B1011 & B1012 & BIO13 & 81014 & B1015 & B1016 & $\begin{array}{ll}1017 \\
17\end{array}$ & B1018 & B1019 \\
\hline Lissotriton helveticus & 30TWM37 & 100,00 & 96,07 & 107,64 & 38,54 & 5802,31 & 256,53 & $-19,25$ & 275,78 & 113,14 & 173,14 & 173,14 & 25,69 & 672,42 & 74,59 & 36,74 & 18,16 & 196,71 & 129,78 & 130,72 & 176,85 \\
\hline Lissotriton helveticus & 30TWM39 & 100,00 & 119,79 & 101,93 & 38,06 & 5702,21 & 269,49 & 6,12 & 263,36 & 138,85 & 194,02 & 194,02 & 48,82 & 563,84 & 63,13 & 30,29 & 19,03 & 164,95 & 112,64 & 113,63 & 142,30 \\
\hline Lissotriton helveticus & 30TWM46 & 100,00 & 80,56 & 108,70 & 38,54 & 5819,04 & 243,60 & $-34,96$ & 278,56 & 96,40 & 158,60 & 158,60 & 10,80 & 757,90 & 84,18 & 42,44 & 17,65 & 222,38 & 146,11 & 146,57 & 200,06 \\
\hline Lissotriton helveticus & 30TWM47 & 100,00 & 97,51 & 108,40 & 38,58 & 5830,24 & 258,38 & $-19,01$ & 277,40 & 115,15 & 174,78 & 174,78 & 26,59 & 667,01 & 74,69 & 36,66 & 18,24 & 196,31 & 129,31 & 130,20 & 174,48 \\
\hline Lissotriton helveticus & 30TWM49 & 100,00 & 126,24 & 102,65 & 38,02 & 5775,38 & 276,19 & 10,47 & 265,72 & \begin{tabular}{|l|l|}
146,67 \\
\end{tabular} & \begin{tabular}{|c|}
195,92 \\
\end{tabular} & 200,91 & 54,01 & 508,37 & 59,42 & 27,88 & 20,34 & 153,06 & 104,01 & 107,40 & 122,04 \\
\hline Lissotriton helveticus & 30TWM82 & 100,00 & 93,96 & 110,92 & 38,00 & 6058,28 & 258,25 & $-29,35$ & 287,60 & 113,12 & 173,90 & 173,96 & 19,82 & 607,35 & 75,29 & 34,08 & 21,12 & 191,30 & 119,85 & 131,13 & 148,50 \\
\hline Lissotriton helveticus & 30TWM83 & 100,00 & 102,29 & 111,08 & 38,01 & 6063,83 & 266,08 & $-21,32$ & 287,40 & 122,23 & 181,75 & 182,01 & 27,54 & 575,06 & 71,24 & 31,73 & 21,45 & 180,48 & 112,34 & 123,17 & 141,63 \\
\hline \begin{tabular}{|l} 
Lissotriton helveticus \\
\end{tabular} & 30TWM87 & 100,00 & 128,35 & 107,02 & 38,02 & 5975,87 & 284,11 & 7,13 & 276,98 & 149,45 & 205,52 & 205,54 & 53,25 & $\begin{array}{l}532,35 \\
\end{array}$ & 62,14 & 27,45 & 21,42 & 160,02 & 100,23 & 104,59 & 134,85 \\
\hline Lissotriton helveticus & 30TWM92 & 100,00 & 72,64 & 106,71 & 37,77 & 5954,64 & 233,16 & $-46,25$ & 279,41 & 89,69 & 152,01 & 152,06 & 0,86 & 739,71 & 89,38 & 43,41 & 19,55 & 230,16 & 148,20 & 155,56 & 180,58 \\
\hline Lissotriton helveticus & 30TWM93 & 100,00 & 108,87 & 109,70 & 38,00 & 6087,02 & 270,50 & $-15,03$ & 285,53 & 129,85 & 188,27 & 188,40 & 33,36 & 539,83 & 68,31 & 29,30 & 22,86 & 171,31 & 104,81 & 115,50 & 130,99 \\
\hline Lissotriton helveticus & 30TWM94 & 100,00 & 116,65 & 109,32 & 38,00 & 6088,93 & 277,28 & $-6,85$ & 284,12 & 138,12 & 195,80 & 195,84 & 40,77 & 518,92 & 65,08 & 27,44 & 23,06 & \begin{tabular}{|l|l|}
163,27 \\
\end{tabular} & $\begin{array}{ll}99,03 \\
\end{array}$ & 108,04 & 127,24 \\
\hline $\begin{array}{l}\text { Lissotriton helveticus } \\
\end{array}$ & 30TWNOO & 100,00 & 120,38 & 94,44 & 37,97 & 5419,18 & 260,53 & 13,68 & 246,85 & 88,49 & 190,40 & 191,40 & 53,06 & 629,12 & 66,32 & 31,18 & 19,25 & 187,06 & 120,44 & 121,28 & 170,86 \\
\hline Lissotriton helveticus & 30TWN01 & 100,00 & 120,28 & 91,73 & 37,94 & 5288,90 & 256,13 & 16,42 & 239,71 & 88,03 & 188,49 & 189,70 & 54,88 & \begin{tabular}{|c|c|}
677,58 \\
\end{tabular} & 72,94 & 33,23 & 19,58 & 203,86 & 128,09 & 130,50 & 187,86 \\
\hline Lissotriton helveticus & 30TWN02 & 100,00 & 122,30 & 88,59 & 37,80 & 5134,56 & 253,13 & 21,27 & 231,85 & 92,57 & 188,13 & 189,59 & 58,65 & 725,80 & 80,04 & 34,78 & 20,01 & 221,58 & 134,57 & 139,36 & 206,13 \\
\hline Lissotriton helveticus & 30TWN03 & 100,00 & 116,25 & 87,55 & 37,88 & 5049,03 & 246,02 & 17,38 & 228,64 & 76,28 & 181,08 & 182,81 & 54,08 & 797,32 & 88,72 & 38,69 & 19,84 & 243,94 & 147,58 & 152,84 & 229,04 \\
\hline Lissotriton helveticus & 30TWN05 & 100,00 & 111,15 & 83,25 & 37,86 & 4804,25 & 234,88 & 17,47 & 217,42 & 60,22 & 172,58 & 174,81 & 52,45 & 940,18 & 107,73 & 45,27 & 20,77 & 294,35 & 170,42 & 179,21 & 278,61 \\
\hline $\begin{array}{l}\text { Lissotriton helveticus } \\
\end{array}$ & 30TWNO6 & 100,00 & 120,93 & 76,99 & 37,38 & 4558,16 & 235,22 & 31,95 & 203,28 & 72,35 & 178,65 & 181,13 & 65,04 & 998,87 & 119,07 & 45,23 & 23,21 & 320,68 & 173,37 & 188,61 & 308,02 \\
\hline Lissotriton helveticus & 30TWN07 & 100,00 & 127,93 & 71,26 & 36,86 & 4332,40 & 233,84 & 43,26 & 190,58 & 82,01 & \begin{tabular}{|l|l|}
182,27 \\
\end{tabular} & 185,03 & 74,73 & 1069,85 & 132,35 & 45,96 & 25,77 & 351,14 & 178,23 & 199,87 & 343,06 \\
\hline Lissotriton helveticus & 30TWN08 & 100,00 & 130,79 & 67,22 & 36,46 & 4178,09 & 230,99 & 49,14 & 181,86 & 84,61 & 182,80 & 185,90 & 79,44 & 1139,08 & 144,30 & 47,36 & 27,59 & 380,12 & 184,84 & 211,30 & 374,92 \\
\hline Lissotriton helveticus & 30TWN09 & 99,00 & 138,12 & 61,59 & 35,64 & 3978,81 & 229,93 & 59,82 & \begin{tabular}{|l|l|}
170,11 \\
\end{tabular} & 90,52 & 187,26 & 190,50 & 88,95 & 1202,85 & 157,78 & 47,29 & 30,38 & 411,24 & 187,22 & 220,79 & 410,73 \\
\hline Lissotriton helveticus & 30TWN10 & 100,00 & 121,39 & 95,73 & 38,00 & 5462,53 & 262,62 & 13,45 & 249,18 & 88,99 & 192,30 & 192,78 & 53,50 & 617,79 & 64,51 & 31,17 & 18,99 & 181,58 & 120,47 & 120,61 & 165,39 \\
\hline Lissotriton helveticus & 30TWN11 & 100,00 & 121,17 & 92,97 & 38,03 & 5325,25 & 258,05 & 16,19 & 241,87 & 87,30 & 189,92 & 190,83 & 55,10 & 671,24 & 71,31 & 33,48 & 19,01 & 200,12 & 129,18 & 130,57 & 183,99 \\
\hline Lissotriton helveticus & 30TWN13 & 100,00 & 117,52 & 88,77 & 38,00 & 5076,73 & 248,27 & 17,84 & 230,43 & 75,49 & 182,56 & 184,25 & 54,99 & 795,94 & 87,64 & 39,16 & 19,33 & 241,68 & 149,44 & 153,49 & 227,16 \\
\hline Lissotriton helveticus & 30TWN14 & 100,00 & 114,06 & 86,70 & 38,04 & 4951,83 & 242,09 & 17,31 & 224,79 & 60,66 & 177,48 & 179,45 & 53,44 & \begin{tabular}{|c|}
873,38 \\
\end{tabular} & 97,76 & 42,79 & 19,69 & 268,69 & 161,95 & 167,58 & 253,84 \\
\hline Lissotriton helveticus & 30TWN15 & 100,00 & 110,09 & 85,02 & 38,03 & 4845,20 & 235,85 & 15,60 & 220,25 & 58,25 & 172,10 & 174,23 & 51,07 & 950,45 & 107,55 & 46,56 & 19,95 & 295,50 & 174,82 & 181,79 & 279,59 \\
\hline Lissotriton helveticus & 30TWN16 & 100,00 & 98,64 & 85,16 & 38,28 & 4807,67 & 225,03 & 5,69 & 219,33 & 47,92 & 160,34 & 162,73 & 40,71 & 1045,75 & 118,43 & 52,56 & 19,70 & 326,01 & 193,81 & 199,88 & 307,97 \\
\hline Lissotriton helveticus & 30TWN17 & 100,00 & 128,64 & 72,98 & 37,36 & 4354,73 & 236,46 & 43,81 & 192,65 & 82,11 & 183,14 & 186,01 & 75,52 & 1079,46 & 131,80 & 47,04 & 24,96 & 352,18 & 181,94 & 201,95 & 344,04 \\
\hline Lissotriton helveticus & 30TWN18 & 100,00 & 134,32 & 68,06 & 36,94 & 4171,27 & 235,38 & 53,62 & 181,75 & 89,29 & 186,00 & 189,16 & 83,60 & 1148,38 & 144,51 & 47,86 & 27,29 & 381,57 & 186,91 & 212,95 & 377,88 \\
\hline Lissotriton helveticus & 30TWN19 & 100,00 & 136,81 & 64,62 & 36,64 & 4030,81 & 233,08 & 59,18 & 173,91 & 91,57 & 186,35 & 189,85 & 88,01 & 1213,41 & $\mid 155,48$ & 49,45 & 28,69 & 408,53 & 193,61 & 224,12 & 406,77 \\
\hline Lissotriton helveticus & 30TWN20 & 100,00 & 126,10 & 96,62 & 38,00 & 5507,50 & 267,48 & 16,71 & 250,77 & 94,30 & 197,64 & 197,75 & 57,42 & 585,64 & 61,84 & 29,96 & 18,98 & 170,90 & 116,21 & 116,25 & 153,13 \\
\hline Lissotriton helveticus & 30TWN21 & 100,00 & 110,79 & 96,77 & 38,36 & 5416,85 & 252,98 & 4,19 & 248,79 & 66,36 & 182,05 & 182,15 & 44,22 & 711,86 & 74,31 & 37,25 & 17,99 & 207,94 & 138,90 & 138,90 & 192,77 \\
\hline Lissotriton helveticus & 30TWN22 & 100,00 & 111,72 & 94,34 & 38,29 & 5288,91 & 250,19 & 7,67 & 242,52 & 61,67 & 180,75 & 181,31 & 46,66 & 758,46 & 80,55 & 39,13 & 18,04 & 223,91 & 147,33 & 147,51 & 209,39 \\
\hline Lissotriton helveticus & 30TWN23 & 100,00 & 112,54 & 91,62 & 38,28 & 5147,34 & 246,88 & 11,33 & 235,56 & 60,18 & 178,85 & 180,25 & 49,36 & 813,72 & 88,10 & 41,36 & 18,36 & 244,33 & 156,34 & 157,56 & 229,17 \\
\hline Lissotriton helveticus & 30 TWN24 & 100,00 & 119,93 & 86,90 & 38,16 & 4940,64 & 247,10 & 22,81 & 224,29 & 66,12 & 182,88 & 184,78 & 59,15 & 862,41 & 95,99 & 42,06 & 19,59 & 264,73 & 160,61 & 165,94 & 250,16 \\
\hline Lissotriton helveticus & 30 TWN25 & 100,00 & 117,45 & 84,69 & 38,13 & 4802,05 & 241,38 & 23,20 & 218,18 & 65,44 & 178,44 & 180,66 & 58,75 & \begin{tabular}{|c|}
945,48 \\
\end{tabular} & 107,01 & 45,75 & 20,05 & 294,32 & 173,45 & 180,86 & 279,21 \\
\hline $\begin{array}{l}\text { Lissotriton helveticus } \\
\end{array}$ & 30 TWN26 & 100,00 & 113,08 & 82,98 & 38,30 & 4690,10 & 234,81 & 21,53 & 213,27 & 62,92 & 172,61 & 175,10 & 56,11 & 1031,02 & $\mid 118,07$ & 49,92 & 20,60 & 324,36 & 187,44 & 196,33 & 308,42 \\
\hline Lissotriton helveticus & 30TWN27 & 100,00 & 120,50 & 77,90 & \begin{tabular}{|c|}
38,17 \\
\end{tabular} & 4471,05 & 234,66 & 33,45 & 201,21 & 72,74 & \begin{tabular}{|l|l|}
176,71 \\
\end{tabular} & \begin{tabular}{|c|}
179,56 \\
\end{tabular} & 66,37 & $\begin{array}{l}1097,43 \\
\end{array}$ & 129,37 & 50,81 & 22,51 & 352,25 & 192,55 & 207,20 & 338,87 \\
\hline Lissotriton helveticus & 30TWN28 & 100,00 & 132,12 & 71,51 & 37,82 & 4217,71 & 237,05 & 50,52 & 186,53 & 86,93 & 184,41 & 187,61 & 81,19 & 1160,03 & 142,02 & 50,33 & 25,43 & 381,14 & 194,15 & 216,73 & 372,79 \\
\hline Lissotriton helveticus & 30TWN29 & 100,00 & 136,55 & 67,88 & \begin{tabular}{|c|}
37,67 \\
\end{tabular} & 4062,26 & 236,21 & 58,40 & \begin{tabular}{|c|}
177,81 \\
\end{tabular} & 93,08 & 186,50 & 190,04 & 87,82 & 1216,98 & 151,89 & 51,40 & 26,91 & 405,01 & 199,13 & 226,79 & 398,51 \\
\hline Lissotriton helveticus & 30TWN31 & 100,00 & 112,62 & 98,18 & 38,56 & 5463,45 & 255,92 & 4,41 & 251,51 & 69,11 & 184,18 & 184,18 & 45,19 & 698,07 & 73,03 & 37,09 & 17,75 & 201,94 & 137,27 & 137,27 & 186,42 \\
\hline Lissotriton helveticus & 30 TWN32 & 100,00 & 108,82 & 96,39 & 38,76 & 5341,01 & 249,64 & 3,40 & 246,24 & 51,29 & 179,08 & 179,08 & 43,24 & 775,71 & 81,65 & 40,84 & 17,59 & 227,76 & 150,97 & 150,97 & 212,72 \\
\hline Lissotriton helveticus & $30 \mathrm{TWI}$ & 100,00 & 10 & 94,58 & 38,90 & 5221,61 & 242,10 & 1,07 & 241,03 & 47,20 & 172,36 & 172,57 & 39,87 & 862,93 & 92, & 45,23 & 17,73 & 257,56 & 166,55 & 166,66 & 241,63 \\
\hline Lissotriton helveticus & 30TWN34 & 100,00 & 118,90 & 89,15 & 38,76 & 4985,27 & 248,45 & 20,54 & 227,91 & 64,53 & 182,50 & 184,28 & 57,72 & 871,82 & 95,63 & 43,42 & 18,82 & 265,85 & 165,05 & $\mid 168,09$ & 249,88 \\
\hline Lissotriton helveticus & 30TWN35 & 100,00 & 112,87 & 87,58 & 38,5 & 4872,46 & 240,42 & 17,16 & 223,26 & 60,24 & 175,05 & 177,12 & 53,48 & 969,30 & 108,05 & 48,34 & 19,18 & 99,53 & 81,38 & 185,61 & 282,65 \\
\hline Lissotriton helveticus & 30TWN36 & 100,00 & 118,93 & 83,30 & 38,8 & 4648,14 & 239,72 & 27,74 & 211,98 & 68,82 & 177,68 & $18 \mathrm{C} \cdot \mathrm{l} \cdot \mathrm{l}$ & 62,58 & 1040,38 & 118,56 & 50,06 & 20,62 & 327,62 & 188,78 & 197,71 & 311,32 \\
\hline $\begin{array}{l}\text { Lissotriton helveticus } \\
\end{array}$ & $30 T_{W N 3}$ & 100,00 & 126 & 78,23 & 38, & 4416,47 & 240,09 & 40,70 & 199,39 & 79,37 & 182,17 & 185,09 & 73,65 & 1110,02 & 130,25 & 51,03 & 22,59 & 356,79 & 194,15 & 209,22 & 342,71 \\
\hline Lissotriton helveticus & 30TWN38 & 100,00 & 125,53 & 76,22 & 38,88 & 4295,56 & 235,67 & 41,87 & 193,80 & 79,55 & 178,97 & 182,14 & 73,98 & $\begin{array}{l}1184,68 \\
\end{array}$ & 140,08 & 54,29 & 23,10 & 383,79 & 205,43 & 223,01 & 368,89 \\
\hline Lissotriton helveticus & 30TWN39 & 100,00 & 130,98 & 72,34 & 38,82 & 4113,23 & 235,15 & 51,13 & 184,02 & 87,08 & 181,70 & 185,18 & 81,85 & 1246,81 & 150,37 & 55,51 & 24,49 & 409,47 & 211,22 & 234,16 & 396,09 \\
\hline Lissotriton helveticus & 30TWN40 & 100,00 & 128,64 & 100,21 & 38, & 5669,25 & 273,99 & 15,27 & 58,73 & 148,38 & 88 & 20 & 57,55 & 533,26 & 60,36 & 29,04 & 70 & 83 & 49 & 12,01 & 130,23 \\
\hline Lissotriton helveticus & $30 \mathrm{TWI}$ & 100 & 11 & 99, & $3 \varepsilon$ & 5 & 257 & 3,55 & 254,40 & 78,84 & 18 & 18 & 44 & 21 & & 8 & $17-2>3$ & 54 & & 18 & 184,62 \\
\hline Lissotriton helveticus & $30 \mathrm{TWI}$ & 100,00 & 111,66 & 97,48 & 38,5 & 5372,17 & 253,22 & 4,92 & 248,30 & 55,80 & 182,10 & 182,10 & 45,54 & 765,08 & 79,88 & 40,51 & 17,51 & 223,68 & 149,08 & 149,08 & 207,95 \\
\hline Lissotriton helveticus & 30TWN43 & 100,00 & 104,69 & 95,80 & 39,00 & 5253,68 & 244,22 & 1,10 & 243,12 & 47,78 & 173,98 & 173,98 & 40,45 & 867,38 & 92,76 & 45,79 & 17,66 & 258,43 & 167,34 & 167,34 & 241,97 \\
\hline Lissotriton helveticus & 30TWN44 & 100,00 & 116,32 & 91,52 & 39,00 & 5041,25 & 248,65 & 16,52 & 232,13 & 61,40 & 180,99 & 182,51 & 54,49 & 893,15 & 97,14 & 45,32 & 18,33 & 271,42 & 170,94 & 171,69 & 254,05 \\
\hline Lissotriton helveticus & $30 \mathrm{TWI}$ & 100,00 & 108 & 90,08 & 39,01 & 4932,58 & 239,01 & 11,27 & 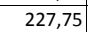 & 55,25 & 17. & & 48,43 & \begin{tabular}{|c|}
998,88 \\
\end{tabular} & 110,42 & 50,92 & & 307,34 & 19 & 92 & 28 \\
\hline Lissotriton helveticus & $30 \mathrm{TW}$ & 100,00 & & 83,98 & 39,18 & 4 & 243,96 & 32,62 & 211,34 & 73,60 & 181,61 & 184,19 & 67,65 & $\begin{array}{r}1057,52 \\
\end{array}$ & 120,02 & 50,76 & 20,66 & 333,64 & $\begin{array}{ll}191,58 \\
\end{array}$ & 200,33 & 315,99 \\
\hline Lissotriton helveticus & 30TWN47 & 100,00 & 127,37 & 80,59 & 39,48 & 4414,46 & 242,24 & 40,45 & 201,79 & 79,66 & 182,45 & 185,32 & 74,13 & \begin{tabular}{|l|}
1134,07 \\
\end{tabular} & 130,68 & 53,16 & 21,75 & 362,79 & 200,85 & 213,87 & 344,92 \\
\hline 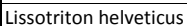 & 30TWN48 & 100,00 & 130,07 & 77,45 & 39,64 & 4246,62 & 240,05 & 46,70 & 193,35 & 84,39 & $\mid 182,71$ & $\mid 185,86$ & 79,20 & 1204,46 & 140,81 & 55,47 & 22,78 & 389,75 & 209,58 & 226,82 & 372,07 \\
\hline Lissotriton & 30TWN49 & 83,00 & 135,59 & 73,79 & 39,59 & 4081,88 & 239,93 & 55,56 & 184,37 & 91,69 & 185,64 & 189,10 & 86,91 & 1255,69 & 149,38 & 56,31 & 24,10 & 411,33 & 213,84 & 236,38 & 394,56 \\
\hline Lissotrit & & 100,00 & & 100,71 & 38,8 & 5560,53 & 262,85 & 6, & & 96,97| & 189 & & 48 & & $71,69 \mid$ & 36,57 & 17,82 & & 133,18 & 133,23 & 177 \\
\hline $\begin{array}{l}\text { Lissotriton helveticus } \\
\end{array}$ & 30TWN52 & 100,00 & 111,01 & 98,69 & 38,99 & 5410,56 & 253,88 & 3,30 & 250,58 & 54,19 & 181,92 & 181,92 & 44,35 & 784,16 & 81,97 & 41,74 & 17,60 & 229,51 & $\begin{array}{l}151,86 \\
\end{array}$ & 151,86 & 213,21 \\
\hline
\end{tabular}




\begin{tabular}{|c|c|c|c|c|c|c|c|c|c|c|c|c|c|c|c|c|c|c|c|c|c|}
\hline TAXON & UTM & $\mathrm{km} 2$ & BIO1 & $\mathrm{BIO2}$ & $\mathrm{BIO3}$ & B104 & B105 & B106 & BIO7 & B108 & B109 & 81010 & B1011 & BIO12 & B1013 & BI014 & B1015 & BIO16 & B1017 & B1018 & B1019 \\
\hline Lissotriton helveticus & 30TWN53 & 100,00 & 99,05 & 97,23 & 39,00 & 5289,83 & 240,71 & $-5,51$ & 246,22 & 42,19 & 169,02 & 169,02 & 34,61 & 912,83 & 98,09 & 48,79 & 17,47 & 272,35 & 174,91 & 174,91 & 255,66 \\
\hline Lissotriton helveticus & 30TWN54 & 100,00 & 108,16 & 93,91 & 39,01 & 5109,92 & 243,98 & 6,90 & 237,08 & 52,94 & 175,02 & 175,43 & 45,78 & 945,86 & \begin{tabular}{|c|}
103,08 \\
\end{tabular} & 49,09 & 18,18 & 287,36 & 180,52 & 180,55 & 269,18 \\
\hline Lissotriton helveticus & 30TWN55 & 100,00 & 101,96 & 91,96 & 39,17 & 4992,10 & 235,34 & 3,58 & 231,76 & 48,52 & 167,24 & 168,02 & 41,50 & 1042,61 & 115,05 & 54,16 & 18,39 & 320,16 & 197,85 & 198,55 & 300,92 \\
\hline Lissotriton helveticus & 30TWN56 & 100,00 & 121,30 & 86,70 & 39,73 & 4667,95 & 244,58 & 28,76 & 215,83 & 70,68 & 180,08 & 182,54 & 64,62 & 1082,56 & \begin{tabular}{|c|}
121,58 \\
\end{tabular} & 52,97 & 20,11 & 340,60 & 198,55 & 204,39 & 320,05 \\
\hline Lissotriton helveticus & 30TWN57 & 100,00 & 121,94 & 84,15 & 40,03 & 4490,28 & 240,93 & 32,96 & 207,97 & 73,57 & 178,16 & 180,97 & 67,85 & 1167,68 & $\begin{array}{l}132,45 \\
\end{array}$ & 56,49 & 20,77 & $\begin{array}{l}371,32 \\
\end{array}$ & 210,95 & 220,01 & 349,71 \\
\hline Lissotriton helveticus & 30 TWN58 & 100,00 & 128,13 & 80,12 & 40,23 & 4265,19 & 240,38 & 43,60 & 196,79 & 82,32 & 180,89 & 184,14 & 77,08 & 1240,29 & \begin{tabular}{ll|}
142,68 \\
\end{tabular} & 58,48 & 21,94 & 399,49 & 218,99 & 233,70 & 377,46 \\
\hline Lissotriton helveticus & 30 TWN59 & 44,00 & 139,91 & 75,83 & 40,32 & 4069,49 & 244,87 & 58,97 & \begin{tabular}{|c|}
185,90 \\
\end{tabular} & 95,91 & 189,63 & 193,12 & 91,12 & 1259,76 & $\begin{array}{l}147,65 \\
\end{array}$ & 57,21 & 23,51 & 411,15 & 216,65 & 238,33 & 390,14 \\
\hline Lissotriton helveticus & 30TWN61 & 100,00 & 123,57 & 101,06 & 38,90 & 5586,07 & 268,85 & 11,30 & 257,55 & 97,75 & 195,97 & 195,97 & 53,90 & 664,02 & 70,13 & 35,35 & 18,29 & 191,84 & 129,09 & 129,09 & 173,33 \\
\hline Lissotriton helveticus & 30TWN62 & 100,00 & 116,46 & 99,48 & 39,00 & 5443,10 & 259,68 & 7,43 & 252,25 & 61,06 & 187,44 & 187,44 & $\begin{array}{l}49,16 \\
\end{array}$ & 775,19 & 81,60 & 40,88 & 18,03 & 228,47 & 148,49 & 148,49 & 211,26 \\
\hline Lissotriton helveticus & 30TWN63 & 100,00 & 103,32 & 97,94 & 39,01 & 5316,96 & 245,23 & $-2,27$ & 247,50 & 45,76 & 173,31 & 173,31 & 38,25 & 914,81 & 99,12 & 48,44 & 17,94 & 274,80 & 173,71 & 173,71 & 257,41 \\
\hline Lissotriton helveticus & 30TWN64 & 100,00 & 104,07 & 95,58 & 39,10 & 5166,61 & 242,19 & 1,56 & 240,63 & 48,36 & 172,21 & 172,21 & 41,03 & 984,99 & 108,32 & 51,52 & 18,30 & 300,55 & \begin{tabular}{|c|}
186,36 \\
\end{tabular} & 186,36 & 281,81 \\
\hline Lissotriton helveticus & 30TWN65 & 100,00 & 114,75 & 92,10 & 39,59 & 4941,28 & 246,34 & 16,24 & 230,10 & 61,12 & 178,84 & 179,67 & 54,48 & 1037,83 & 115,65 & 52,42 & 19,30 & 323,01 & 194,30 & 195,10 & 302,10 \\
\hline Lissotriton helveticus & 30TWN66 & 100,00 & 130,98 & 86,46 & 40,11 & 4575,07 & 251,84 & \begin{tabular}{l|l}
39,33 \\
\end{tabular} & 212,51 & 81,00 & 188,09 & 190,77 & 75,39 & 1103,43 & 124,59 & 52,88 & 20,87 & 350,55 & 199,35 & 206,77 & 327,82 \\
\hline Lissotriton helveticus & 30TWN67 & 100,00 & 123,06 & 85,63 & 40,39 & 4495,82 & 243,12 & 33,38 & $\begin{array}{ll}209,73 \\
\end{array}$ & 74,62 & 179,28 & 182,14 & 68,95 & $\begin{array}{l}1199,36 \\
\end{array}$ & 135,85 & 58,32 & 20,85 & 382,33 & 217,09 & 225,01 & 358,30 \\
\hline Lissotriton helveticus & $\mid$ & 100,00 & 128,29 & 82,14 & 40,94 & $\mid 4248,49$ & 241,72 & 43,40 & 198,32 & 82,67 & 180,87 & 184,08 & 77,57| & 1282,11 & 145,99| & $\mid 61,18$ & 21,70 & 412,56 & 227,80 & 241,07 & 386,77 \\
\hline Lissotriton helveticus & 30TWN69 & 47,00 & 142,35 & 77,38 & 40,97 & 4040,34 & 247,61 & 61,04 & 186,56 & 98,65 & 191,69 & 195,08 & 93,94 & 1284,21 & 149,00 & 59,06 & 23,20 & 418,49 & 222,79 & 243,99 & 393,32 \\
\hline Lissotriton helveticus & 30TWN71 & 100,00 & 122,45 & 101,95 & 38,96 & 5618,81 & 269,19 & 9,36 & 259,82 & 75,45 & 195,46 & 195,46 & 52,41 & 709,88 & 75,19 & 37,01 & 18,93 & 208,65 & 134,01 & 34,01 & 191,71 \\
\hline Lissotriton helveticus & 30TWN72 & 100,00 & 120,18 & 100,16 & 39,00 & 5473,56 & 264,10 & 10,08 & 254,02 & 59,92 & 191,43 & 191,43 & 52,22 & $\begin{array}{l}795,65 \\
\end{array}$ & 86,12 & 40,98 & 18,93 & 239,09 & $\begin{array}{l}148,78 \\
\end{array}$ & 148,78 & 221,42 \\
\hline Lissotriton helveticus & 30TWN73 & 100,00 & 103,41 & 98,80 & 39,01 & 5350,09 & 246,23 & $-3,39$ & 249,61 & 45,57 & 173,73 & \begin{tabular}{ll|}
173,73 \\
\end{tabular} & 37,87 & $\begin{array}{l}936,65 \\
\end{array}$ & 102,89 & 49,35 & 18,41 & 283,47 & 175,99 & 175,99 & 265,79 \\
\hline Lissotriton helveticus & 30TWN74 & 100,00 & 100,62 & 96,62 & 39,21 & 5208,45 & 240,12 & $-2,82$ & 242,94 & 44,68 & 169,38 & 169,38 & 37,17 & 1021,25 & \begin{tabular}{|l|l|}
113,47 \\
\end{tabular} & 53,57 & 18,56 & 312,86 & $\begin{array}{l}191,86 \\
\end{array}$ & \begin{tabular}{ll|}
191,86 \\
\end{tabular} & 293,94 \\
\hline Lissotriton helveticus & 30TWN75 & 100,00 & 108,49 & 94,04 & 39,53 & 5036,57 & 243,08 & 7,88 & 235,20 & 54,16 & $\begin{array}{l}174,61 \\
\end{array}$ & $\begin{array}{l}174,66 \\
\end{array}$ & 46,97 & 1073,28 & 120,82 & 54,95 & 19,36 & 334,82 & 200,40 & 200,40 & 313,61 \\
\hline Lissotriton helveticus & 30TWN76 & 100,00 & 111,01 & 90,73 & 39,88 & 4809,98 & 239,75 & 14,90 & 224,85 & 59,29 & 172,92 & 174,38 & 52,67 & 1155,76 & $\mid 130,57$ & 58,44 & 19,83 & $\mid 363,66$ & 213,91 & 216,84 & 340,62 \\
\hline Lissotriton helveticus & 30TWN77 & 100,00 & 129,54 & 85,98 & 40,78 & 4449,01 & 248,19 & 39,74 & 208,45 & 81,29 & 184,82 & 187,75 & 75,75 & 1224,90 & 139,65 & 59,02 & 21,43 & 393,34 & 220,21 & 229,16 & 366,76 \\
\hline Lissotriton helveticus & 30TWN78 & 100,00 & 136,02 & 82,26 & 41,51 & 4169,84 & 247,28 & 51,34 & 195,95 & 90,94 & 187,18 & 190,48 & 86,04 & 1306,41 & 148,74 & 62,01 & 22,07 & 422,21 & 231,31 & 246,37 & 393,01 \\
\hline Lissotriton helveticus & 30TWN79 & 55,00 & 142,54 & 79,19 & 41,49 & 4050,54 & 248,44 & 59,70 & 188,74 & 98,79 & 191,96 & 195,32 & 93,85 & 1318,53 & 152,11 & 61,78 & 22,71 & 428,98 & 231,91 & 252,33 & 399,74 \\
\hline Lissotriton helveticus & 30TWN81 & 100,00 & 127,08 & 102,29 & 38,90 & 5634,65 & 274,04 & 12,96 & 261,09 & 69,60 & 200,10 & 200,10 & 56,46 & 736,82 & 81,42 & 36,91 & 20,25 & 222,85 & 134,50 & 134,50 & 206,27 \\
\hline Lissotriton helveticus & 30TWN82 & 100,00 & 122,08 & 101,03 & 38,99 & 5523,64 & 267,28 & 10,41 & 256,87 & \begin{tabular}{|c|}
61,07 \\
\end{tabular} & 193,86 & \begin{tabular}{|c|}
193,86 \\
\end{tabular} & 53,14 & \begin{tabular}{|c|}
830,67 \\
\end{tabular} & 93,74 & 41,59 & 20,33 & 255,99 & 150,78 & 150,78 & 238,30 \\
\hline Lissotriton helveticus & 30TWN83 & 100,00 & 110,64 & $\begin{array}{l}9,59 \\
\end{array}$ & 39,01 & 5397,98 & 254,13 & 2,25 & 251,88 & 51,75 & 181,21 & 181,21 & 43,90 & 943,14 & $\begin{array}{l}106,92 \\
\end{array}$ & 48,21 & 19,84 & 291,81 & 172,73 & 172,73 & 273,47 \\
\hline \begin{tabular}{|l} 
Lissotriton helveticus \\
\end{tabular} & $\mid$ & 100,00 & 91,57 & 97,49 & 39,01 & 5276,41 & 233,10 & $-13,28$ & 246,38 & 35,46 & $\mid 161,44$ & $\mid 161,44$ & 27,57 & 1060,01 & $\mid 118,21$ & 56,62 & 18,24 & 323,42 & 199,51 & 199,51 & 305,06 \\
\hline Lissotriton helveticus & 30TWN85 & 100,00 & 106,58 & 95,36 & 39,43 & 5114,41 & 243,07 & 4,09 & 238,99 & 51,34 & 173,73 & 173,73 & 43,91. & 1099,31 & 125,91 & 56,20 & 19,88 & 345,57 & 203,27 & 203,27 & 324,35 \\
\hline Lissotriton helveticus & 30 TWN86 & 100,00 & 113,46 & 92,50 & 39,91 & 4893,48 & 244,21 & \begin{tabular}{|l|l}
14,93 \\
\end{tabular} & 229,28 & 60,58 & 176,77 & 177,71 & 53,68 & 1171,81 & 135,21 & 58,72 & 20,63 & 373,55 & 215,77 & 216,84 & 349,65 \\
\hline Lissotriton helveticus & 30TWN87 & 100,00 & 114,38 & 90,20 & 40,28 & 4714,87 & 240,70 & 19,19 & 221,50 & 63,64 & 174,15 & 176,25 & 57,07 & $\begin{array}{l}1253,24 \\
\end{array}$ & \begin{tabular}{|l|l|}
144,73 \\
\end{tabular} & 62,59 & 20,78 & 401,85 & 230,62 & 233,34 & 375,75 \\
\hline Lissotriton helveticus & 30 TWN88 & 100,00 & 129,64 & 84,99 & 41,19 & 4340,68 & 245,11 & 41,00 & 204,11 & 82,85 & 183,45 & 186,52 & 77,15 & 1323,19 & 152,53 & 64,33 & 21,75 & 428,25 & 238,60 & 250,17 & 398,13 \\
\hline Lissotriton helveticus & 30TWN89 & 84,00 & 141,98 & 80,34 & 41,12 & 4147,07 & 249,07 & 56,16 & 192,91 & \begin{tabular}{l|l|}
97,07 \\
\end{tabular} & 192,83 & 196,01 & 91,49 & $\begin{array}{l}1324,87 \\
\end{array}$ & 154,41 & 63,41 & 22,63 & 431,54 & 237,27 & 257,20 & 400,51 \\
\hline Lissotriton helveticus & 30TWN90 & 100,00 & 130,41 & 103,87 & 38,51 & 5766,03 & 279,85 & 13,29 & 266,56 & 90,01. & 204,94 & 204,94 & 57,74 & 694,81 & 78,47 & 33,90 & 21,38 & 210,72 & 124,39 & 124,39 & 195,88 \\
\hline \begin{tabular}{|l} 
Lissotriton helveticus \\
\end{tabular} & 30TWN91 & 100,00 & 129,65 & 102,72 & 38,78 & 5672,55 & 277,29 & 14,55 & 262,73 & 67,71 & 202,99 & 202,99 & 58,42 & 767,09 & 88,85 & $\mid 37,06$ & 21,72 & 238,28 & 135,92 & 135,92 & 222,37 \\
\hline Lissotriton helveticus & 30TWN92 & 100,00 & 124,90 & 101,77 & 38,94 & 5574,60 & 271,25 & 11,91 & 259,34 & 63,38 & 197,29 & 197,29 & 55,07 & 861,72 & 101,88 & 41,69 & 22,23 & 272,79 & 151,59 & 151,59 & 255,62 \\
\hline Lissotriton helveticus & 30TWN93 & 100,00 & 114,54 & 100,49 & 39,01 & 5454,66 & 259,17 & 4,41 & 254,76 & 54,88 & 185,74 & 185,74 & 46,83 & \begin{tabular}{|c|}
966,57 \\
\end{tabular} & \begin{tabular}{|c|}
113,87 \\
\end{tabular} & 48,01 & 21,46 & 306,26 & \begin{tabular}{l|l|}
172,27 \\
\end{tabular} & \begin{tabular}{ll|}
172,27 \\
\end{tabular} & 287,92 \\
\hline Lissotriton helveticus & 30TWN94 & 100,00 & 112,33 & \begin{tabular}{l|l}
98,54 \\
\end{tabular} & 39,03 & 5324,67 & 253,68 & 5,05 & 248,64 & 54,25 & 181,91 & 181,91 & 46,41 & 1044,64 & \begin{tabular}{|c|}
123,47 \\
\end{tabular} & 52,04 & 21,45 & \begin{tabular}{|c|}
333,16 \\
\end{tabular} & 187,74 & 187,74 & 313,34 \\
\hline Lissotriton helveticus & 30TWN95 & 100,00 & 112,46 & 96,45 & 39,30 & 5169,92 & 249,99 & 7,99 & 242,00 & 56,38 & 180,13 & 180,13 & 48,65 & 1115,28 & 131,91 & 55,58 & 21,42 & 357,89 & 201,88 & 201,88 & 336,12 \\
\hline Lissotriton helveticus & 30TWN96 & 100,00 & 104,13 & 94,60 & 39,59 & 5054,56 & 238,99 & 2,51 & $\begin{array}{ll}236,48 \\
\end{array}$ & 49,88 & 170,57 & 170,57 & 42,31 & 1187,49 & 138,57 & 60,62 & 20,39 & 378,00 & 219,52 & 219,52 & 355,21 \\
\hline Lissotriton helveticus & 30TWN97 & 100,00 & 110,60 & 91,78 & 40,00 & 4839,21 & 239,44 & 12,53 & 226,92 & 58,56 & 172,80 & 174,20 & 51,36 & $\begin{array}{l}1259,47 \\
\end{array}$ & 147,50 & 63,49 & 20,90 & 404,84 & 233,16 & 234,64 & 379,23 \\
\hline Lissotriton helveticus & 30TWN98 & 100,00 & 120,70 & 87,94 & 40,59 & 4563,81 & 241,46 & 27,30 & 214,15 & 71,55 & 177,77 & 180,49 & 64,91 & 1332,12 & 156,15 & 66,26 & 21,49 & 431,84 & 244,48 & 251,74 & 402,44 \\
\hline Lissotriton helveticus & 30TWN99 & 100,00 & 133,51 & 83,01 & 40,83 & 4317,29 & 244,87 & 43,87 & 201,01 & 90,02 & 186,91 & 189,84 & 80 & 1355,71 & 159,45 & 66,82 & 22,10 & 41,31 & 248,15 & 264,33 & 409,19 \\
\hline Lissotriton helveticus & 30TWP00 & 79,00 & 137,7 & 60,59 & 35,91 & 3895,53 & 227, & 61,13 & 166,69 & 93, & 185,65 & 1 & 89, & 1245,64 & 63,35 & 49,3 & 30,33 & 02 & 31 & 29,77 & 424,19 \\
\hline Lissotriton helveticus & 30TWP10 & 94,00 & 132,38 & 64,68 & 36,92 & 3975,66 & 228,22 & 55,49 & 172,72 & 89,86 & 181,32 & 184,84 & 84,41 & 1266,20 & \begin{tabular}{|c|}
160,96 \\
\end{tabular} & 52,91 & 27,98 & 425,57 & 204,62 & 235,59 & 420,02 \\
\hline Lissotriton helveticus & 30TWP20 & 75,00 & 136,08 & 66,31 & 37,61 & \begin{tabular}{l|l|l}
3978,94 \\
\end{tabular} & 233,33 & 59,44 & $\begin{array}{ll}173,89 \\
\end{array}$ & 93,78 & 184,80 & $\begin{array}{l}188,46 \\
\end{array}$ & 88,51 & $\begin{array}{l}1263,98 \\
\end{array}$ & $\begin{array}{l}158,65 \\
\end{array}$ & 53,35 & 27,25 & 422,90 & 205,95 & 236,04 & 415,55 \\
\hline Lissotriton helveticus & 30TWP30 & 40,00 & 137,65 & 69,00 & 38,61 & 3995,39 & 236,84 & \begin{tabular}{l|l}
60,23 \\
\end{tabular} & 176,61 & 94,85 & 186,32 & 190,00 & 89,87 & 1267,71 & 155,84 & 54,73 & 26,05 & 21,16 & 210,02 & 237,97 & 409,79 \\
\hline Lissotriton helveticus & 30TWP90 & 28,00 & 138,83 & 80,55 & 40,75 & 4220,05 & 245,72 & 50,41 & 195,31 & 105,70 & $\begin{array}{l}190,86 \\
\end{array}$ & 193,91 & 86, & 1355,98 & 160,34 & 66,73 & 22,59 & 42,94 & 248,83 & 69,58 & 409,41 \\
\hline \begin{tabular}{|l} 
Lissotriton helveticus \\
\end{tabular} & $30 T \times L 30$ & 100,00 & 102 & 100,66 & 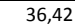 & 6193,90 & 249, & $-22,81$ & 4 & 24,19 & 28,63 & 184 & 26 & 452,95 & 67,82 & 46 & 35 & 78 & 77,95 . & 117,45 & 77, \\
\hline Lissotriton helveticus & 30 & 100,00 & 12 & 102,48 & 36, & 6 & 281 & 3,56 & 278,04 & 149,99 & $\begin{array}{l}54,67 \\
\end{array}$ & 20 & 50 & \begin{tabular}{|c|}
391,98 \\
\end{tabular} & 56,46 & 20,06 & 30,52 & 135,25 & 75,40 & 88,81 & 75,40 \\
\hline Lissotriton helveticus & 30TXM02 & 100,00 & 100,94 & 108,08 & 37,93 & 6066,93 & 260,75 & $-22,31$ & 283,06 & 121,12 & 180,29 & 180,39 & 26,02 & 566,20 & 72,63 & 31,53 & 23,29 & 181,91 & 112,00 & 124,01 & 134,25 \\
\hline Lissotriton helveticus & 30TXM03 & 100,00 & 119,16 & 108,53 & 37,97 & 6123,89 & 278,95 & $-5,19$ & 284,14 & 140,97 & 198,70 & \begin{tabular}{|c|}
198,78 \\
\end{tabular} & 42,79 & $\begin{array}{l}490,67 \\
\end{array}$ & 63,53 & 25,64 & 24,61 & 157,00 & 93,63 & 102,45 & 117,71 \\
\hline Lissotriton helveticus & 30TXM15 & 100,00 & 137,34 & 106,54 & 37,96 & 6040,20 & 292,78 & 14,55 & 278,22 & \begin{tabular}{|c|}
159,61 \\
\end{tabular} & 215,33 & 21 & 61, & 480,36 & 58,18 & 22,85 & 2 & 01 & 87,32 & 89,54 & 122,0 \\
\hline Lissotriton helveticus & $30 \mathrm{TXN}$ & 100,00 & 135,71 & 106 & 37,74 & 6045,86 & 291,28 & 12,96 & 278,32 & 157,97 & 213,74 & & 59 & $\mid 487,17$ & 59,36 & 23,02 & 24,15 & & 88,34 & 90,45 & 123,83 \\
\hline Lissotriton helveticus & 30TXM27 & 100,00 & 133,69 & 105,99 & 38,00 & $\begin{array}{l}5966,34 \\
\end{array}$ & 287,39 & 12,47 & 274,92 & 96,91 & 210,66 & 210,66 & 58,58 & 564,81 & 63,52 & 26,71 & 22,52 & 167,48 & 101,29 & 102,42 & 151,60 \\
\hline Lissotriton helveticus & 30TXM39 & 100,00 & 124,96 & 104,99 & 38,09 & 5850,36 & 275,92 & 5,17 & 270,75 & 89,49 & 200,52 & 200,52 & 51,20 & 687,19 & 78,48 & 32,94 & 21,50 & 207,19 & 123,07 & 123,44 & 192,83 \\
\hline Lissotriton & $30 \mathrm{TXM} 40$ & 100,00 & 136,26 & 105,00 & 36,99 & 6209,37 & 292,96 & 11,42 & 281,54 & 159,41 & 216,57 & 216,58 & 58,69 & 372,54 & 54,78 & 17,63 & 32,07 & $\begin{array}{l}126,86 \\
\end{array}$ & 70,29 & 75,02 & 80,25 \\
\hline Lissotriton helveticus & $30 \mathrm{TXn}$ & 100,00 & 138,05 & 105,43 & 37,00 & $6186,51]$ & 295,37 & 13,80 & 281,57 & 160,80 & 218, & 218, & 60 & 379,92 & 54,90 & 17,58 & 31,18 & 126 & 69,95 & 70,45 & 84 \\
\hline Lissotriton helveticus & 30TXM48 & 100,00 & 120,32 & 104,88 & 38,03 & 5861,92 & 272,18 & 0,66 & 271,51 & 84,90 & 196,10 & 196,10 & 46,53 & 641,09 & 70,74 & 31,44 & 20,65 & 187,44 & 117,89 & 119,70 & 171,6 \\
\hline
\end{tabular}




\begin{tabular}{|c|c|c|c|c|c|c|c|c|c|c|c|c|c|c|c|c|c|c|c|c|c|}
\hline TAXON & UTM & $\mathrm{km} 2$ & B101 & $\mathrm{B1O2}$ & $\mathrm{BIO3}$ & B104 & B105 & B106 & B107 & B108 & B109 & B1010 & BIO11 & BIO12 & 81013 & B1014 & B1015 & B1016 & $\begin{array}{ll}1017 \\
17\end{array}$ & B1018 & B1019 \\
\hline Lissotriton helveticus & 30TXM49 & 100,00 & 111,52 & 104,06 & 38,12 & 5778,43 & 261,90 & $-6,27$ & 268,17 & 76,92 & 186,52 & 186,52 & 39,16 & 720,40 & 78,95 & 36,34 & 19,71 & 210,17 & 133,69 & 136,21 & 195,68 \\
\hline Lissotriton helveticus & 30TXM50 & 100,00 & 127,07 & 103,95 & 36,92 & 6172,05 & 282,81 & 2,99 & 279,82 & 149,81 & 172,08 & 207,02 & 50,14 & 398,22 & 58,16 & 20,01 & 30,77 & 136,78 & 78,05 & 88,28 & 82,88 \\
\hline Lissotriton helveticus & 30TXM51 & 100,00 & 139,49 & 105,15 & 37,00 & 6207,42 & 297,79 & 16,05 & 281,74 & 162,24 & 220,04 & 220,05 & 62,15 & 370,43 & 54,14 & 16,79 & 31,68 & 124,02 & 67,68 & 68,56 & 81,76 \\
\hline Lissotriton helveticus & 30TXM52 & 100,00 & 143,09 & 105,50 & 37,00 & 6185,55 & 301,45 & 19,96 & 281,49 & 165,82 & 223,27 & 223,27 & 65,90 & 376,27 & 52,77 & 16,77 & 29,73 & 122,47 & 68,11 & 69,04 & 85,61 \\
\hline Lissotriton helveticus & 30TXM57 & 100,00 & 124,80 & 104,84 & 38,00 & 5881,56 & 277,18 & 4,57 & 272,62 & 137,31 & 200,75 & 200,76 & 50,84 & 569,34 & 65,41 & 27,60 & 20,89 & 165,63 & 106,48 & 109,27 & 145,84 \\
\hline Lissotriton helveticus & 30TXM58 & 100,00 & 113,90 & 103,95 & 38,00 & 5797,35 & 264,50 & $-4,35$ & 268,85 & 116,61 & 188,90 & 188,90 & 41,18 & 649,11 & 72,57 & 32,71 & 19,63 & 186,95 & 122,80 & 126,16 & 168,81 \\
\hline Lissotriton helveticus & 30TXM59 & 100,00 & 103,55 & 102,68 & 38,04 & 5708,48 & 252,07 & $-12,97$ & 265,04 & 93,71 & 177,73 & 177,74 & 32,32 & 734,06 & 79,99 & 38,29 & 18,39 & 209,68 & 140,80 & 144,08 & 193,00 \\
\hline Lissotriton helveticus & $30 \mathrm{TXM} 68$ & 100,00 & 109,32 & 102,91 & 38,01 & 5729,41 & 258,29 & $-7,86$ & 266,14 & 129,00 & 183,44 & 183,52 & 37,62 & 649,78 & 73,60 & 33,38 & 18,82 & 188,19 & 126,30 & 131,44 & 164,01 \\
\hline Lissotriton helveticus & 30TXM69 & 100,00 & 96,15 & 101,10 & 38,05 & 5631,87 & 242,63 & $-18,79$ & 261,42 & 113,00 & 169,56 & 169,58 & 26,19 & 753,18 & 83,07 & 40,55 & 17,42 & 215,76 & 148,84 & 152,24 & 192,26 \\
\hline Lissotriton helveticus & 30TXM71 & 100,00 & 146,76 & 105,24 & 36,17 & 6257,39 & 307,56 & 21,90 & 285,66 & 170,51 & 227,09 & 227,87 & 68,17 & 356,92 & 46,94 & 16,56 & 26,97 & 116,55 & 69,08 & 73,65 & 72,93 \\
\hline Lissotriton helveticus & 30TXM77 & 100,00 & 114,39 & 102,89 & 38,00 & 5741,08 & 263,99 & $-3,34$ & 267,33 & 134,57 & 188,62 & 188,75 & 42,53 & 574,25 & 67,66 & 29,05 & 19,62 & 169,91 & 113,86 & 118,68 & 137,66 \\
\hline Lissotriton helveticus & 30TXM78 & 100,00 & 105,11 & 101,80 & 38,00 & 5660,68 & 252,52 & $-11,02$ & 263,54 & 124,45 & 178,48 & 178,66 & 34,44 & 651,86 & 74,57 & 34,13 & 18,21 & 189,92 & 130,24 & 135,19 & 159,73 \\
\hline Lissotriton helveticus & 30TXM79 & 100,00 & 94,27 & 100,14 & 38,01 & 5578,12 & 239,18 & $-20,06$ & 259,24 & 112,36 & 166,83 & 166,86 & 24,87 & 748,31 & 83,20 & 40,77 & 16,95 & 215,23 & 151,02 & 156,15 & 186,56 \\
\hline Lissotriton helveticus & $30 \mathrm{TXM} 80$ & 100,00 & 145,28 & 104,63 & 36,21 & 6190,31 & 303,61 & 20,15 & 283,46 & 168,93 & 79,03 & 225,67 & 67,72 & 355,22 & 47,42 & 16,52 & 28,16 & 116,99 & 69,07 & 74,27 & 69,08 \\
\hline Lissotriton helveticus & 30TXM81 & 100,00 & 144,28 & 104,85 & 36,36 & 6169,93 & 303,16 & 19,72 & 283,44 & 167,74 & 140,13 & 224,41 & 66,73 & 363,76 & 47,59 & 16,95 & 26,93 & 118,23 & 71,85 & 75,41 & 72,28 \\
\hline Lissotriton helveticus & 30TXM82 & 100,00 & 139,35 & 104,73 & 36,89 & 6112,10 & 297,35 & 15,57 & 281,78 & 162,46 & 174,81 & 218,70 & 62,77 & 381,90 & 49,74 & 18,05 & 25,86 & 122,92 & 76,19 & 79,36 & 77,58 \\
\hline Lissotriton helveticus & 30TXM87 & 100,00 & 118,97 & 102,86 & 38,00 & 5709,54 & 267,58 & 0,43 & 267,16 & 139,37 & 192,36 & 192,87 & 47,08 & 538,87 & 63,79 & 26,86 & 19,88 & 159,26 & 109,08 & 111,22 & 125,26 \\
\hline \begin{tabular}{|l} 
Lissotriton helveticus \\
\end{tabular} & 30TXM88 & 100,00 & 112,24 & 102,10 & 38,10 & 5625,63 & 258,76 & $-4,53$ & 263,29 & 132,04 & 184,71 & 185,06 & 41,42 & 601,19 & 69,05 & 30,72 & 18,49 & 174,65 & 122,07 & 124,87 & 143,51 \\
\hline Lissotriton helveticus & 30TXM92 & 100,00 & 129,35 & 103,44 & 36,99 & 5994,92 & 284,30 & 6,92 & 277,38 & 151,60 & 54,36 & 207,39 & 54,36 & 404,14 & 53,86 & 19,69 & 26,35 & 131,16 & 79,34 & 86,07 & 79,34 \\
\hline Lissotriton helveticus & 30TXM93 & 100,00 & 129,09 & 103,53 & 37,00 & 5941,32 & 283,25 & 7,50 & 275,75 & 151,18 & 76,57 & 206,39 & 54,61 & 412,78 & 53,98 & 19,98 & 25,28 & 131,66 & 82,86 & 86,85 & 82,89 \\
\hline Lissotriton helveticus & $30 T X N 00$ & 100,00 & 127,58 & 104,76 & 38,30 & 5801,83 & 278,61 & 9,32 & 269,29 & 70,78 & 202,65 & 202,65 & 54,66 & 733,37 & 85, & 35,25 & 22,26 & 226,05 & 128,43 & 128,43 & 212,22 \\
\hline \begin{tabular}{|l} 
Lissotriton helveticus \\
\end{tabular} & 30 TXN01 & 100,00 & 122,08 & 104,38 & 38,45 & 5749,16 & 272,88 & 5,07 & 267,82 & 58,33 & 196,59 & 196,59 & 49,94 & 823,10 & 98,48 & 39,67 & 22,73 & 259,36 & 142,68 & 142,68 & 244,35 \\
\hline Lissotriton helveticus & $30 \mathrm{TXN02}$ & 100,00 & 118,55 & 103,34 & 38,71 & 5664,61 & 267,93 & 3,58 & 264,35 & 56,29 & \begin{tabular}{|c|}
192,16 \\
\end{tabular} & \begin{tabular}{|c|}
192,16 \\
\end{tabular} & 47,55 & 908,59 & 110,43 & 43,78 & 23,08 & 291,15 & 156,75 & 156,75 & 274,93 \\
\hline Lissotriton helveticus & 30TXN03 & 100,00 & 117,28 & 101,84 & 38,87 & 5563,04 & 264,31 & 4,46 & 259,85 & 56,19 & 189,71 & 189,71 & 47,87 & 987,76 & 121,64 & 47,40 & 23,51 & 321,10 & 170,42 & 170,42 & 303,38 \\
\hline Lissotriton helveticus & $30 \mathrm{TXNO4}$ & 100,00 & 120,11 & 99,69 & 38,96 & 5424,70 & 263,16 & 9,95 & 253,21 & 60,57 & 190,76 & 190,76 & 52,43 & 1054,55 & 130,95 & 50,27 & 23,93 & 346,91 & 182,97 & 182,97 & 327,25 \\
\hline Lissotriton helveticus & 30 TXN05 & 100,00 & 110,26 & 97,76 & 39,07 & 5256,90 & 249,72 & 3,59 & 246,12 & 53,32 & 179,04 & 179,04 & 45,21 & 1130,85 & 136,25 & 56,18 & 21,96 & 365,42 & 203,32 & 203,32 & 344,20 \\
\hline Lissotriton helveticus & 30TXN06 & 100,00 & 106,18 & 95,55 & 39,43 & 5116,10 & 241,79 & 2,54 & $\mid$\begin{tabular}{|l|l|l|l|}
239,25 \\
\end{tabular} & 50,97 & 173,27 & 173,27 & $\frac{43,12}{43,10}$ & $\begin{array}{l}1195,82 \\
1195\end{array}$ & $\mid 142,30$ & 60,52 & 21,15 & 384,30 & 219,61 & 219,61 & 361,55 \\
\hline Lissotriton helveticus & 30TXN07 & 100,00 & 120,29 & 91,28 & 39,95 & 4846,52 & 246,87 & 20,70 & 226,18 & 68,22 & 181,79 & 183,66 & 60,27 & 1249,93 & 149,77 & 62,11 & 21,78 & 406,52 & 230,56 & 234,53 & 379,90 \\
\hline Lissotriton helveticus & 30TXN08 & 100,00 & 127,35 & 87,62 & 40,13 & 4626,20 & 246,63 & 31,30 & 215,33 & 79,84 & 185,25 & 187,69 & 69,99 & 1304,00 & 156,08 & 64,90 & 21,99 & 425,17 & 241,37 & 251,01 & 395,35 \\
\hline Lissotriton helveticus & 30TXN09 & 67,00 & 131,10 & 84,45 & 40,21 & 4476,51 & 244,47 & 37,44 & 207,04 & 90,90 & 186,80 & 189,40 & 75,49 & 1344,08 & 160,62 & 67,51 & 22,10 & 438,57 & 250,79 & 265,82 & 405,86 \\
\hline Lissotriton helveticus & $30 \mathrm{TXN10}$ & 100,00 & 123,99 & 105,02 & 38,19 & 5829,79 & 275,63 & 5,13 & 270,50 & 65,01 & 199,39 & 199,39 & 50,54 & 757,65 & 89,75 & 36,32 & 22,51 & 234,27 & 132,08 & 132,08 & 221,01 \\
\hline Lissotriton helveticus & 30TXN11 & 100,00 & 112,57 & 104,39 & 38,63 & 5739,69 & 263,64 & $\begin{array}{c}-3,100 \\
-3,90\end{array}$ & 267,55 & $\begin{array}{l}5,56 \\
49,5 \\
\end{array}$ & \begin{tabular}{|l|l|}
187,27 \\
\end{tabular} & 187,27 & $\begin{array}{ll}0,049 \\
40,99\end{array}$ & 859,66 & \begin{tabular}{|c|c|}
101,79 \\
\end{tabular} & $\begin{array}{ll}40,53 \\
42,5\end{array}$ & 21,75 & 267,27 & 151,36 & $\begin{array}{ll}151,36 \\
156\end{array}$ & 252,99 \\
\hline Lissotriton helveticus & 30 TXN12 & 100,00 & 104,16 & 102,64 & 38,87 & 5612,40 & 252,62 & $-9,53$ & 262,15 & 43,29 & 177,51 & 177,51 & 34,44 & 941,64 & 110,28 & 47,85 & 20,74 & 291,98 & 169,21 & 169,21 & 276,37 \\
\hline Lissotriton helveticus & 30TXN13 & 100,00 & 118,26 & 102,80 & 38,63 & 5631,79 & 266,64 & 3,42 & 263,22 & 56,39 & 191,36 & 191,36 & 47,70 & 996,28 & 125,80 & 47,05 & 24,63 & 327,85 & 169,48 & 169,48 & 310,93 \\
\hline Lissotriton helveticus & 30 TXN14 & 100,00 & 114,75 & 100,62 & 38,90 & 5484,35 & 259,12 & 3,13 & 255,99 & 54,69 & 186,16 & 186,16 & 46,05 & 1064,60 & 132,53 & 51,37 & 23,62 & 348,62 & 185,86 & 185,86 & 329,79 \\
\hline Lissotriton helveticus & 30 TXN15 & 100,00 & 107,71 & 98,34 & 39,02 & 5316,13 & 247,88 & $-0,46$ & 248,34 & 50,04 & 177,17 & 177,17 & 41,58 & 1130,84 & 136,92 & 56,58 & 21,81 & 364,65 & 204,42 & 204,42 & 344,08 \\
\hline $\begin{array}{l}\text { Lissotriton helveticus } \\
\end{array}$ & 30TXN16 & 100,00 & 94,84 & $\begin{array}{ll}0,34 \\
95,87\end{array}$ & 39,18 & 5175,51 & $\begin{array}{l}24,00 \\
231,62\end{array}$ & $\begin{array}{l}-0,40 \\
-9,67\end{array}$ & $\mid \begin{array}{l}\mid 240,34,29 \\
\end{array}$ & \begin{tabular}{|l|}
39,67 \\
39,6
\end{tabular} & $\mid 162,94$ & 162,95 & $\begin{array}{l}1,20 \\
31,27 \\
\end{array}$ & $\begin{array}{l}115,04,21 \\
1194,2\end{array}$ & $\begin{array}{l}350,92 \\
139,45\end{array}$ & $\begin{array}{ll}62,56 \\
62,5\end{array}$ & $\begin{array}{l}21,01 \\
19,60\end{array}$ & \begin{tabular}{|l|l|}
376,12 \\
76
\end{tabular} & $\begin{array}{l}224,05 \\
224, \\
\end{array}$ & \begin{tabular}{|l|}
224,05 \\
224
\end{tabular} & 354,004 \\
\hline Lissotriton helveticus & 30TXN17 & 100,00 & 121,06 & 92,23 & 39,79 & 4938,64 & 248,44 & 18,70 & 229,73 & 67,68 & 183,71 & 185,35 & 59,33 & 1233,22 & 149,93 & 61,36 & 22,18 & 402,18 & 228,79 & 233,11 & 376,19 \\
\hline Lissotriton helveticus & 30TXN18 & 100,00 & 117,03 & 90,82 & 39,96 & 4835,37 & 241,98 & 16,72 & 225,26 & 65,70 & 178,11 & 180,21 & 56,93 & \begin{tabular}{|l|}
1297,17 \\
\end{tabular} & 156,49 & 65,53 & 21,61 & 421,85 & 243,14 & 248,53 & 394,30 \\
\hline Lissotriton helveticus & 30TXN19 & 26,00 & 129,97 & 85,70 & 39,9 & 4614,73 & 244,82 & 32,49 & 212,33 & 96,22 & 187,60 & 189,94 & 71,90 & 1314,87 & 159,18 & 66,88 & 22,29 & 17 & 49,34 & 264,29 & 396,94 \\
\hline Lissotriton helveticus & 30 TXN20 & 100,00 & 116,12 & 104,93 & 38,4 & 5801,88 & 267,64 & $-1,72$ & 269,35 & 55,99 & 191,37 & 191,37 & 43,40 & 782,81 & 91,3 & 38,45 & 21,42 & 238,41 & 138,98 & 138,98 & 225,49 \\
\hline Lissotriton helveticus & 30 TXN21 & 100,00 & 110,77 & 103,97 & 38,69 & 5720,06 & 260,75 & $-5,38$ & 266,14 & 48,12 & 185,19 & 185,19 & 39,23 & 858,42 & 100,7 & 42,7 & 21,16 & 264,27 & 153,29 & 153,29 & 250,21 \\
\hline Lissotriton helveticus & $30 \mathrm{TXN22}$ & 100,00 & 103,37 & 102,39 & 38,82 & 5608,17 & 251,24 & $-10,44$ & 261,68 & 42,50 & 176,68 & 176,68 & 33,57 & 936,79 & 109,38 & 47,68 & 20,38 & 288,82 & 169,79 & 169,79 & 273,40 \\
\hline Lissotriton helveticus & $30 \mathrm{TXN23}$ & 100,00 & 111,31 & 102,05 & 38,93 & 5571,81 & 257,65 & $-2,50$ & 260,15 & 50,36 & 183,84 & 183,84 & 41,60 & 988,25 & 120,37 & 48,46 & 22,30 & 15,84 & 175,14 & 175,14 & 299,01 \\
\hline Lissotriton helveticus & 30 TXN24 & 100,00 & 105,82 & 100,25 & 38,97 & 5446,53 & 249 & $-5,28$ & 254,39 & 46,76 & 176,99 & 176,99 & 37,91 & \begin{tabular}{|l|l|}
1056,73 \\
\end{tabular} & 127,07 & 53,08 & 21,29 & 13 & 191,33 & 91,33 & 317,75 \\
\hline Lissotriton helveticus & 30 TXN25 & 100,00 & 100,82 & 98,30 & 39,0 & 5322,00 & 240,78 & \begin{tabular}{|c|}
$-7,46$ \\
$-7,48$
\end{tabular} & 248,25 & 43,32 & 170,44 & 170,44 & 34,87 & 1122,83 & 1 & 57,64 & 20,37 & 355,39 & 207,64 & 207,64 & 335,49 \\
\hline Lissotriton helveticus & 30 TXN26 & 89,00 & 93,17 & 96,25 & 39,11 & 5206,27 & 230,03 & $-12,54$ & 242,57 & 37,57 & 161,61 & 161,63 & 28,95 & 1181,31 & $\mid 137,49$ & 62,37 & 19,12 & 369,64 & 223,78 & 223,78 & 348,52 \\
\hline Lissotriton helveticus & 30TXN27 & 72,00 & 109,27 & 94,73 & 39,63 & 5078,57 & 241,06 & 4,33 & 236,72 & 54,34 & $\begin{array}{l}174,58 \\
\end{array}$ & 175,53 & 45,96 & $\mid 1221,24$ & 147,16 & 62,18 & 21,02 & 393,30 & 230,13 & 231,38 & 369,47 \\
\hline Lissotriton helveticus & 30 TXN28 & 100,00 & 112,90 & 92,41 & 39,88 & 4942,30 & 239,95 & 9,99 & 229,95 & 59,69 & 175,67 & 177,35 & 51,08 & 1269,48 & 153,18 & 64,76 & 21,08 & 410,29 & 240,76 & 245,22 & 384,35 \\
\hline Lissotriton helveticus & $30 \mathrm{TXN} 30$ & 100,00 & 115,90 & 104,45 & 38,38 & 5773,08 & 266,18 & $-2,04$ & 68,22 & 67,10 & 190,80 & 190,80 & 43,46 & 772 & 88,94 & 38,00 & 20,84 & 83 & 04 & 139,04 & 219,86 \\
\hline $\begin{array}{l}\text { Lissotriton helveticus } \\
\end{array}$ & $30 T X N$ & 100,00 & $\frac{12}{12}$ & 103,87 & 38 & $\frac{5}{5}$ & 260,10 & $2,2,92$ & \begin{tabular}{|l|l|}
266,06 \\
\end{tabular} & $\begin{array}{l}1,10 \\
65,57 \\
\end{array}$ & $\begin{array}{l}190,00 \\
194,55 \\
\end{array}$ & $\begin{array}{l}190,00 \\
194,55 \\
\end{array}$ & $\begin{array}{ll}48,45 \\
48,4\end{array}$ & \begin{tabular}{|l|l|l|l|}
814,16 \\
\end{tabular} & $\begin{array}{l}00,34 \mid \\
96,60\end{array}$ & $\begin{array}{ll}30,00,15 \\
39\end{array}$ & $\frac{20,44}{21,72}$ & \begin{tabular}{|l|l|}
252,33 \\
\end{tabular} & $\begin{array}{l}145,09 \\
145,09\end{array}$ & $\begin{array}{l}35,04,09 \\
145\end{array}$ & $\begin{aligned} 23,00 \\
238,28\end{aligned}$ \\
\hline Lissotriton helveticus & 30 TXN32 & 100,00 & 113,49 & 102,85 & 38,92 & 5636,46 & 260,48 & $-2,03$ & 262,51 & 51,78 & 186,71 & 186,71 & 42,65 & 896,38 & 106,61 & 44,13 & 21,28 & 279,60 & 161,46 & 161,46 & 264,25 \\
\hline Lissotriton helveticus & 30 TXN33 & 100,00 & 113,11 & 101,81 & 38,94 & 5557,36 & 257,84 & $-1,08$ & 258,92 & 52,09 & 185,17 & 185,17 & 43,17 & 960,76 & 115,81 & 47,24 & 21,58 & 303,97 & 173,33 & 173,33 & 287,33 \\
\hline Lissotriton helveticus & 30 TXN34 & 100,00 & 102,45 & 99,88 & 39,00 & 5425,73 & 244,40 & $-8,52$ & 252,92 & 43,64 & 173,20 & 173,20 & 34,78 & 1043,23 & 122,97 & 53,41 & 20,09 & 326,28 & 193,20 & 193,20 & 308,08 \\
\hline Lissotriton helveticus & $30 \mathrm{TXN}$ & 100,00 & 91,78 & 97,76 & 38,99 & 5311,18 & 231,03 & $-16,31$ & 247,34 & $35, \mathrm{C}$ & 161,50 & 161 & 26,25 & 1113,44 & 128,04 & 59,14 & 18,53 & 343,19 & 211,70 & 211,70 & 323 \\
\hline $\begin{array}{l}\text { Lissotriton helveticus } \\
\end{array}$ & \begin{tabular}{|l|}
30 TXN36 \\
\end{tabular} & 81,00 & $\begin{array}{l}1,1,19 \\
90,19\end{array}$ & $\begin{array}{ll}1,10 \\
96,37\end{array}$ & 39, 39 & 5227,71 & 226,97 & $\begin{array}{l}-1.0,51 \\
-16,30 \\
\end{array}$ & \begin{tabular}{|l|}
243,27 \\
243
\end{tabular} & \begin{tabular}{|c|c|}
34,44 \\
34,
\end{tabular} & $\begin{array}{l}158,80 \\
158,80\end{array}$ & $\begin{array}{l}158,81 \\
158,\end{array}$ & \begin{tabular}{l|l}
25,69 \\
25,
\end{tabular} & $\mid \frac{111,344}{1166,10}$ & $\begin{array}{l}134,19 \\
134,19\end{array}$ & \begin{tabular}{|c|c|c|}
62,39 \\
\end{tabular} & $\begin{array}{l}0,353 \\
18,37\end{array}$ & \begin{tabular}{|l|}
360,71 \\
360
\end{tabular} & 223,80 & \begin{tabular}{|l|l|l|l|}
223,80 \\
\end{tabular} & $\begin{array}{l}52,02 \\
340,07\end{array}$ \\
\hline Lissotriton helveticus & 30 TXN37 & & & & & & & & & & & & & & & & & & & & \\
\hline Lissotriton helveticus & $30 \mathrm{TXN} 40$ & 100,00 & 108,21 & 103,44 & 38,47 & 5707,76 & 256,78 & $-8,56$ & 65,34 & 71,64 & 182,34 & 182,34 & 36,77 & 781,12 & 86,62 & 39,74 & 19,31 & 229,63 & 45,28 & 146,48 & 215,80 \\
\hline Lissotritc & $30 \mathrm{TXN} 41$ & 100,00 & 119,31 & 103,47 & 38,94 & 5672,28 & 266,17 & 1,9 & 64,20 & 5 & 192 & 192 & 47, & 796,64 & 92,31 & 38,74 & 20,62 & 243,00 & 145,39 & 145,78 & 228 \\
\hline Lissotriton helveticus & 30 TXN42 & 100,00 & 107,87 & 101,97 & 38,86 & 5576,71 & 252,92 & $-6,84$ & 259,76 & 48,18 & 180,30 & 180,30 & 37,93 & 892,28 & 102,53 & 45,19 & 19,58 & 271,23 & 165,82 & 165,88 & 255,72 \\
\hline
\end{tabular}




\begin{tabular}{|c|c|c|c|c|c|c|c|c|c|c|c|c|c|c|c|c|c|c|c|c|c|}
\hline TAXON & UTM & $\mathrm{km} 2$ & BIO1 & B102 & $\mathrm{BIO3}$ & B104 & BIO5 & B106 & B107 & B108 & B109 & B1010 & BIO11 & B1012 & BIO13 & 81014 & B1015 & B1016 & B1017 & B1018 & B1019 \\
\hline Lissotriton helveticus & 30TXN43 & 100,00 & 105,35 & 101,11 & 39,00 & 5500,27 & 248,66 & $-7,84$ & 256,50 & 45,35 & 176,90 & 176,90 & 36,38 & 954,67 & 110,75 & 48,62 & 19,55 & 293,38 & 178,09 & 178,09 & 276,66 \\
\hline Lissotriton helveticus & 30 TXN45 & 100,00 & 85,92 & 97,14 & 38,97 & 5304,76 & 224,21 & $-21,97$ & 246,18 & 29,51 & 155,51 & 155,51 & 20,47 & 1105,56 & 123,97 & 60,19 & 17,23 & 333,86 & 214,72 & 214,72 & 314,68 \\
\hline Lissotriton helveticus & 30TXN46 & 75,00 & 86,27 & 96,27 & 39,05 & 5234,26 & 222,50 & $-20,60$ & 243,10 & 30,64 & 154,88 & 154,91 & 21,63 & 1150,02 & 129,98 & 62,58 & 17,33 & 350,31 & 224,32 & 224,35 & 329,99 \\
\hline Lissotriton helveticus & 30 TXN50 & 100,00 & 104,72 & 102,40 & 38,53 & 5650,83 & 251,56 & $-11,08$ & 262,63 & 76,05 & 178,11 & 178,11 & 34,09 & 777,70 & 84,18 & 40,27 & 18,30 & 225,41 & 148,41 & 150,99 & 209,58 \\
\hline Lissotriton helveticus & 30TXN51 & 100,00 & 108,88 & 102,45 & 38,88 & 5601,82 & 254,21 & $-6,87$ & 261,08 & 73,79 & 181,44 & 181,44 & 38,63 & 810,39 & 89,62 & 41,22 & 18,58 & 239,75 & 153,41 & 154,05 & 224,22 \\
\hline Lissotriton helveticus & 30 TXN52 & 100,00 & 94,12 & 100,09 & 38,71 & 5497,32 & 237,15 & $-18,39$ & 255,54 & 40,05 & 165,93 & 165,93 & 25,84 & 916,59 & 99,80 & 49,03 & 17,30 & 267,96 & 177,47 & 177,65 & 251,91 \\
\hline Lissotriton helveticus & 30 TXN53 & 100,00 & 99,49 & 100,32 & 38,99 & 5455,79 & 241,25 & $-12,97$ & 254,22 & 40,27 & 170,50 & 170,50 & 31,29 & \begin{tabular}{|c|}
945,43 \\
\end{tabular} & \begin{tabular}{|c|}
105,78 \\
\end{tabular} & 49,59 & 17,88 & 282,90 & 181,64 & \begin{tabular}{ll|l}
181,64 \\
\end{tabular} & 266,11 \\
\hline Lissotriton helveticus & 30 TXN55 & 100,00 & 83,60 & 96,82 & 38,95 & 5296,25 & 221,06 & $-24,57$ & 245,62 & 27,39 & 153,08 & 153,08 & 18,14 & 1091,06 & 120,27 & 60,17 & 16,46 & 324,97 & 215,11 & 215,11 & 305,78 \\
\hline Lissotriton helveticus & 30 TXN56 & 37,00 & 79,52 & 95,46 & 38,96 & 5231,69 & 215,01 & $-27,01$ & 242,02 & 24,21 & 148,19 & 148,19 & 14,99 & 1149,13 & 126,64 & 64,19 & 16,15 & 343,11 & 228,41 & 228,41 & 322,84 \\
\hline Lissotriton helveticus & $30 T X N 60$ & 100,00 & 96,16 & 100,88 & 38,29 & 5581,02 & 241,26 & $-18,22$ & 259,48 & 85,60 & 168,81 & 168,82 & 26,77 & 795,91 & 85,27 & 42,70 & 17,05 & 226,86 & 156,68 & 159,86 & 207,69 \\
\hline Lissotriton helveticus & $30 T \times N 61$ & 100,00 & 103,46 & 101,43 & 38,79 & 5547,82 & 247,30 & $-11,17$ & 258,47 & 72,57 & 175,39 & 175,41 & 34,01 & 809,72 & 86,63 & 42,30 & 17,41 & 234,79 & 157,77 & 159,76 & 217,41 \\
\hline $\begin{array}{l}\text { Lissotriton helveticus } \\
\end{array}$ & 30 TXN62 & 100,00 & 102,55 & 100,90 & 38,94 & 5489,47 & 244,74 & $-11,35$ & 256,10 & 66,79 & 173,81 & 173,82 & 33,73 & 857,75 & 92,71 & 44,94 & 17,23 & 250,88 & 167,34 & 168,63 & 233,86 \\
\hline Lissotriton helveticus & 30TXN63 & 100,00 & 94,94 & 99,57 & 38,95 & 5416,45 & 235,38 & $-17,14$ & 252,52 & 42,68 & 165,40 & 165,40 & 27,29 & 934,84 & 101,29 & 50,20 & 16,66 & 273,25 & \begin{tabular}{|c|}
183,96 \\
\end{tabular} & 184,22 & 256,22 \\
\hline Lissotriton helveticus & 30 TXN64 & 100,00 & 83,53 & 97,27 & 38,80 & 5341,30 & 221,56 & $-25,87$ & 247,43 & 26,82 & 153,35 & 153,35 & 17,30 & 1027,09 & 110,20 & 57,12 & 15,75 & 298,96 & 204,99 & 205,07 & 280,60 \\
\hline Lissotriton helveticus & 30 TXN65 & 92,00 & 75,72 & 95,36 & 38,75 & 5277,87 & 211,78 & $-31,52$ & 243,30 & 20,16 & 145,08 & 145,08 & 10,64 & 1101,25 & 117,80 & 62,58 & 15,22 & 320,67 & 221,68 & 221,68 & 301,24 \\
\hline Lissotriton helveticus & 30 TXN66 & 6,00 & 87,25 & 96,60 & 39,35 & 5232,89 & 221,79 & $-20,99$ & 242,79 & 31,36 & 155,43 & 155,50 & 22,10 & $\begin{array}{l}1101,02 \\
\end{array}$ & 121,46 & 60,74 & 16,26 & 328,58 & 220,57 & 220,71 & 308,65 \\
\hline $\begin{array}{l}\text { Lissotriton helveticus } \\
\end{array}$ & 30 TXN70 & 100,00 & 93,34 & 99,94 & 38,19 & 5532,25 & 236,91 & $-20,37$ & 257,28 & 102,67 & 165,38 & 165,39 & 24,60 & \begin{tabular}{l|l}
791,18 \\
\end{tabular} & 85,56 & 43,09 & 16,42 & 224,03 & 159,32 & 163,03 & 201,26 \\
\hline Lissotriton helveticus & 30TXN72 & 100,00 & 99,76 & 100,32 & 38,92 & 5452,55 & 240,74 & $-13,67 \mid$ & 254,42 & 68,84 & 170,46 & 170,51 & 31,48 & 845,69 & 88,74 & 45,10 & 16,26 & 243,56 & 168,79 & 170,71 & 224,78 \\
\hline Lissotriton helveticus & 30TXN73 & 100,00 & 85,05 & 97,78 & 38,79 & 5374,32 & 223,78 & $-25,52$ & 249,30 & 41,20 & 155,22 & 155,22 & 18,37 & 957,36 & 99,77 & 53,41 & 15,22 & 272,27 & 193,53 & 194,56 & 254,34 \\
\hline Lissotriton helveticus & 30 TXN74 & 100,00 & 67,09 & 93,69 & 38,16 & 5304,14 & 202,82 & $-39,59$ & 242,41 & 15,92 & 136,99 & 136,99 & 2,03 & 1089,61 & 112,52 & 63,81 & 14,30 & 307,78 & 223,36 & 223,49 & 288,38 \\
\hline Lissotriton helveticus & 30 TXN75 & 83,00 & 65,57 & 93,03 & 38,28 & 5259,30 & 199,91 & $-40,09$ & 240,00 & 10,91 & \begin{tabular}{|l|l|}
134,93 \\
\end{tabular} & 134,93 & 1,10 & 1131,74 & \begin{tabular}{|c|}
117,47 \\
\end{tabular} & 66,48 & 14,20 & 322,24 & 232,28 & 232,28 & 302,19 \\
\hline Lissotriton helveticus & 30TXN80 & 100,00 & 95,74 & 99,77 & 38,26 & 5501,36 & 238,35 & $-18,12$ & 256,46 & 111,46 & 167,05 & 167,16 & 27,15 & 759,75 & 82,89 & 41,34 & 16,27 & 215,49 & 155,52 & $\begin{array}{l}262,27 \\
160,27\end{array}$ & 188,89 \\
\hline Lissotriton helveticus & 30TXN82 & 100,00 & 89,62 & 98,52 & 38,72 & 5404,83 & 229,01 & $-22,31$ & 251,32 & 68,85 & 159,91 & 159,98 & 22,28 & 875,33 & 91,00 & 48,59 & 15,18 & 246,25 & 179,37 & 182,28 & 225,52 \\
\hline Lissotriton helveticus & 30TXN83 & 100,00 & 75,68 & 95,40 & 38,34 & 5342,54 & 212,55 & $-33,13$ & 245,68 & 55,34 & 145,72 & 145,72 & 9,74 & $\begin{array}{l}993,85 \\
\end{array}$ & 102,26 & 57,44 & 14,39 & 278,46 & 205,26 & 206,54 & 257,59 \\
\hline Lissotriton helveticus & $30 \mathrm{TXN84}$ & 100,00 & 50,41 & 89,26 & 37,13 & 5272,72 & 183,66 & $-53,41$ & 237,07 & 35,53 & 120,55 & 120,55 & $-13,35$ & $\begin{array}{l}1171,25 \\
\end{array}$ & 119,66 & 71,51 & 13,39 & 325,22 & 244,61 & 244,93 & 302,94 \\
\hline Lissotriton helveticus & 30 TXN85 & 53,00 & 42,17 & 86,92 & 36,71 & 5231,16 & 173,46 & $-60,17$ & 233,62 & 9,99 & 112,02 & 112,02 & $-20,73$ & 1248,27 & 126,53 & 77,25 & 13,13 & 346,39 & 261,15 & 261,15 & 324,94 \\
\hline Lissotriton helveticus & 30TXN90 & 100,00 & $\begin{array}{ll}2,11 \\
93,84\end{array}$ & $\begin{array}{ll}99,07 \\
9,07\end{array}$ & 38,37 & 5463,30 & 235,24 & $-19,39$ & 254,62 & \begin{tabular}{|c|c|c|}
111,83 \\
1,93
\end{tabular} & 164,67 & $\begin{array}{ll}164,93 \\
\end{array}$ & 25,66 & 7555,96 & \begin{tabular}{|l|}
83,18 \\
\end{tabular} & 41,68 & 15,97 & 215,56 & 158,02 & $\begin{array}{l}2162,15 \\
162\end{array}$ & 183,27 \\
\hline Lissotriton helveticus & 30TXN91 & 100,00 & 94,57 & 99,19 & 38,74 & 5424,62 & 234,78 & $-18,37$ & 253,15 & 100,32 & 164,88 & 165,09 & 26,64 & 790,45 & 84,67 & 43,56 & 15,38 & 222,04 & 164,76 & 169,02 & 195,90 \\
\hline Lissotriton helveticus & 30 TXN94 & 50,00 & 49,03 & 88,31 & 36,92 & 5266,55 & 181,26 & $-54,64$ & 235,91 & 53,19 & $\mid 119,07$ & 119,07 & $-14,66$ & $\begin{array}{ll}1173,98 \\
\end{array}$ & 120,41 & 72,41 & 13,14 & 326,20 & 247,68 & 248,08 & 300,06 \\
\hline Lissotriton helveticus & 30TYL09 & 100,00 & 148,51 & 104,01 & 36,99 & 6077,60 & 303,15 & 23,56 & 279,59 & 171,91 & 72,67 & 227,53 & 72,67 & 353,00 & 47,32 & 15,67 & 30,28 & 114,69 & 65,39 & 72,80 & 65,39 \\
\hline $\begin{array}{l}\text { Lissotriton helveticus } \\
\end{array}$ & 30TYL19 & 100,00 & 143,86 & 104,00 & 37,00 & 6048,36 & 297,79 & 19,04 & 278,75 & 167,22 & 68,66 & 222,69 & 68,66 & 369,18 & 49,70 & 16,53 & 30,38 & 120,01 & 67,52 & 76,78 & 67,52 \\
\hline Lissotriton helveticus & 30TYM02 & 100,00 & 119,04 & 101,79 & 37,00 & 5880,27 & 270,87 & $-1,21$ & 272,07 & 140,31 & 45,86 & 195,83 & 45,86 & \begin{tabular}{|c|}
436,98 \\
\end{tabular} & 58,78 & 22,03 & 26,51 & 142,13 & 83,77 & 95,42 & 83,77 \\
\hline Lissotriton helveticus & 30TYN01 & 100,00 & 87,26 & 97,46 & 38,44 & 5402,29 & 226,07 & $-24,44$ & 250,51 & 104,60 & 157,51 & 157,71 & 20,01 & 824,62 & 89,14 & 46,93 & 14,90 & 233,53 & 175,42 & 179,88 & 199,54 \\
\hline Lissotriton helveticus & 30TYN03 & 99,00 & 36,88 & 84,36 & 35,64 & 5266,47 & 167,53 & $-65,62$ & 233,15 & 48,42 & 107,42 & 107,42 & $-25,95$ & 1224,93 & 127,53 & 77,30 & 13,04 & 343,70 & 260,60 & 260,76 & 307,40 \\
\hline Lissotriton helveticus & 30TYN04 & 24,00 & 37,92 & 84,46 & 35,90 & 5244,13 & 168,00 & $-64,05$ & 232,05 & 49,61 & 108,08 & 108,08 & $-24,88$ & 1240,59 & 127,92 & 78,29 & 12,91 & 345,81 & 264,09 & 264,09 & 313,63 \\
\hline $\begin{array}{l}\text { Lissotriton helveticus } \\
\end{array}$ & 30TYN12 & 100,00 & 59,95 & 90,18 & 37,03 & 5337,92 & 193,96 & $-46,36$ & 240,32 & 74,31 & 130,37 & 130,42 & $-5,22$ & 1041,24 & 110,51 & 63,90 & 13,66 & 294,87 & 224,28 & 227,15 & 253,79 \\
\hline Lissotriton helveticus & 30TYN13 & 100,00 & 47,94 & 86,82 & 36,42 & 5292,12 & 179,49 & $-55,73$ & 235,22 & 60,84 & 118,25 & 118,25 & $-16,06$ & 1150,14 & 120,31 & 72,13 & 13,03 & 323,51 & 247,41 & 248,28 & 284,42 \\
\hline Lissotriton helveticus & 30TYN14 & 42,00 & 31,99 & 81,89 & 35,16 & 5231,31 & 160,33 & $-69,29$ & 229,62 & 42,90 & 102,19 & 102,19 & $-30,23$ & 1279,76 & 132,24 & 81,80 & 12,62 & 357,57 & 274,11 & 274,11 & 321,20 \\
\hline Lissotriton helveticus & 30TYN23 & 100,00 & 31,49 & 80,98 & 34,68 & 5249,75 & 159,70 & $-70,20$ & 229,90 & 42,31 & 101,95 & 101,95 & $-30,77$ & 1263,16 & 131,94 & 81,12 & 12,65 & 355,52 & 272,37 & 273,15 & 312,09 \\
\hline Lissotriton helveticus & 30TYN24 & 45,00 & 12,23 & 75,01 & 33,06 & 5179,52 & 136,49 & $-86,88$ & 223,37 & 20,55 & 82,48 & 82,48 & $-47,96$ & 1414,76 & 146,01 & 92,52 & 12,06 & 395,43 & 303,44 & 303,44 & 355,09 \\
\hline Lissotriton helveticus & 31TBE89 & 100,00 & 162,13 & 91,20 & 36,93 & 5325,69 & 290,57 & 47,15 & 243,42 & 164,59 & 232,68 & 234,53 & 102,40 & 547,65 & \begin{tabular}{|l|}
80,27 \\
\end{tabular} & 14,27 & 38,82 & 205,27 & $\begin{array}{l}87,58 \\
\end{array}$ & 118,50 & 103,46 \\
\hline Lissotriton helveticus & 31TBES & 42,00 & 163,34 & 90,17 & 36,85 & 5294,15 & 290,62 & 49,19 & 241,43 & 166,13 & 233,26 & 235,49 & 103,72 & 555,15 & 82,38 & 14,23 & 39,66 & 209,34 & 88,68 & 121,32 & 104,89 \\
\hline Lissotriton helveticus & 31TBF90 & 101,00 & 166,11 & 91,45 & 36,95 & 5296,97 & 294,19 & 50,89 & 243,29 & 167,91 & 236,18 & 238,11 & 106,50 & 549,27 & 82,41 & 13,79 & 40,63 & 208,34 & 88,54 & \begin{tabular}{|l|l|}
121,87 \\
\end{tabular} & 101,14 \\
\hline Lissotriton helveticus & 31TBF91 & 99,00 & 167,58 & 93,52 & 37,26 & 5338,64 & 297,71 & 50,72 & 246,99 & 168,19 & 238,26 & 240,07 & 107,74 & 544,71 & 82,29 & 13,61 & 40,87 & 207,22 & 88,10 & 21,40 & 98,81 \\
\hline $\begin{array}{l}\text { Lissotriton helveticus } \\
\end{array}$ & 31твH62 & 100,00 & 46,28 & 83,24 & 35,06 & 5349,68 & 176,70 & $-57,15$ & 233,85 & 58,97 & 105,13 & 117,52 & $-18,02$ & 1169,48 & \begin{tabular}{|l|l|}
123,92 \\
\end{tabular} & 75,53 & 13,20 & 333,57 & 259,65 & 262,50 & 275,92 \\
\hline $\begin{array}{l}\text { Lissotriton helveticus } \\
\end{array}$ & 31твH91 & 100,00 & 57,69 & 84,80 & 35,00 & 5466,00 & 190,84 & $-47,45$ & 238,29 & 71,85 & 34,21 & 130,24 & $-8,32$ & 1130,54 & \begin{tabular}{|c|}
119,98 \\
\end{tabular} & 73,84 & 13,92 & 325,03 & 251,39 & 264,91 & 256,33 \\
\hline Lissotriton helveticus & 31ТВH92 & 100,00 & 27,92 & 75,45 & 32,68 & 5333,73 & 154,78 & $-72,13$ & 226,91 & 38,21 & 69,40 & 99,83 & $-34,58$ & 1322,21 & 138,87 & 87,78 & 12,61 & 374,57 & 293,48 & 295,91 & 313,36 \\
\hline Lissotriton helveticus & 31TCF00 & 91,00 & 170,15 & 88,95 & 36,96 & 5216,73 & 294,89 & 56,82 & 238,07 & 173,18 & 239,02 & 241,14 & 111,33 & 542,26 & 85,01 & 13,00 & 42,55 & 211,58 & 85,65 & 122,43 & 97,56 \\
\hline Lissotriton helveticus & 31TCF01 & 91,00 & 169,24 & 90,59 & 37,01 & 5270,78 & 295,88 & 54,37 & 241,51 & 171,44 & 238,53 & 240,62 & 109,85 & 544,22 & 84,76 & 13 & & 19 & 87,53 & 63 & 97,33 \\
\hline $\begin{array}{l}\text { Lissotriton helveticus } \\
\end{array}$ & 31TCG09 & 100,00 & 71 & 87,96 & 35 & 5589,51 & 208,91 & $-35,51$ & 244,42 & 87,62 & 5,34 & 145,74 & 3,81 & $\begin{array}{r}1035,52 \\
\end{array}$ & 111,78 & 67,04 & 15,48 & 303,12 & 223,27 & 250,01 & 223,32 \\
\hline Lissotriton helveticus & 31TCG99 & 99,00 & 73,05 & 78,05 & 33,11 & 5513,07 & 205,46 & $-26,95$ & 232,41 & 85,52 & 20,57 & 146,93 & 8,37 & 1043,01 & 114,88 & 64,81 & 16,92 & 303,95 & 215,59 & 257,31 & 218,58 \\
\hline Lissotriton helveticus & $31 \mathrm{TCHO2}$ & 95,00 & 16,76 & 72,03 & 31,69 & 5314,50 & 142,11 & $-81,48$ & 223,59 & 25,51 & 72,44 & 88,96 & $-44,56$ & 1402,13 & 146,60 & 93,52 & 12,24 & 394,75 & 310,47 & 310,92 & 335,91 \\
\hline Lissotriton helveticus & $31 \mathrm{TCH} 13$ & & & & & & & & & & & & & & & & & & & & \\
\hline Lissotriton helveticus & $31 \mathrm{TCH} 14$ & & & & & & & & & & & & & & & & & & & & \\
\hline Lissotriton helveticus & $31 \mathrm{TCH} 22$ & 100,00 & 36,77 & 76,64 & 32,94 & 5390,09 & 165,55 & $-63,34$ & 228,89 & 47,95 & 40,53 & 109,38 & -26 & 1286,02 & 135,51 & 86,24 & 12,79 & 365,47 & 286,99 & 294,17 & 298,24 \\
\hline Lissotriton helveticus & $31 \mathrm{TCH} 23$ & 101,00 & 39,35 & 77,48 & 33,21 & 5379,69 & 168,15 & $-61,19$ & 229,34 & 50,94 & 43,30 & 111,59 & $-24,16$ & 1278,98 & 134,37 & 86,22 & 12,74 & 363,34 & 286,52 & 294,29 & 297,12 \\
\hline Lissotriton helveticus & $31 \mathrm{TCH} 24$ & & & & & & & & & & & & & & & & & & & & \\
\hline Lissotriton helveticus & $31 \mathrm{TCH} 62$ & 86,00 & 25,43 & 72,18 & 31,67 & 6 & 2 & -7 & 9 & 6 & 42 & 98,35 & $-35,47$ & 91 & 2,62 & 10 & 01 & 74 & 3,49 & 27 & 321,17 \\
\hline Lissotrito & $31 \mathrm{TCH} 63$ & 7,00 & 50,29 & 78 & & & & -50 & & & & & & & & & & & 200 & 287,18 & \\
\hline $\begin{array}{l}\text { Lissotriton helveticus } \\
\end{array}$ & 31TCH72 & 2,00 & 31,13 & 72,90 & 31,93 & 5365,65 & 159,33 & $-65,51$ & 224,84 & 40,46 & 47,63 & 104,04 & $-30,04$ & 1324,96 & 139,04 & 88,49 & 12,24 & 370,43 & 295,28 & 301,96 & 309,85 \\
\hline
\end{tabular}




\begin{tabular}{|c|c|c|c|c|c|c|c|c|c|c|c|c|c|c|c|c|c|c|c|c|c|}
\hline TAXON & UTM & $\overline{\mathrm{km} 2}$ & BIO1 & $\mathrm{B1O2}$ & $\mathrm{BIO3}$ & $\begin{array}{ll}B 104 \\
\end{array}$ & B105 & B106 & B107 & B108 & B109 & BIO10 & BI011 & BIO12 & BIO13 & BIO14 & BIO15 & B1016 & BIO17 & BIO18 & \begin{tabular}{ll|} 
BIO19 \\
\end{tabular} \\
\hline Lissotriton helveticus & 31TDF28 & 101,00 & 158,99 & 70,16 & 31,69 & 5227,88 & 276,22 & 58,85 & 217,37 & 169,24 & 158,51 & 228,43 & 95,97 & 626,99 & 86,51 & 27,97 & 28,92 & 218,95 & 124,19 & 154,23 & 126,40 \\
\hline Lissotriton helveticus & \begin{tabular}{|l|l|}
31 TDG09 \\
\end{tabular} & 101,00 & 88,07 & 79,57 & 33,42 & 5552,21 & 221,40 & $-13,35$ & 234,75 & 102,11 & 28,74 & 162,03 & 22,14 & \begin{tabular}{l|l}
952,05 \\
\end{tabular} & 107,28 & 56,50 & 18,73 & 284,35 & 188,33 & 243,10 & 189,54 \\
\hline Lissotriton helveticus & 31TDG10 & 100,00 & 143,65 & 72,82 & 31,99 & 5436,23 & 266,45 & 41,19 & 225,27 & \begin{tabular}{|l|l|l|}
191,40 \\
\end{tabular} & 78,13 & 215,81 & 78,13 & 661,58 & 76,92 & 35,13 & 24,44 & 210,32 & \begin{tabular}{ll|}
124,08 \\
\end{tabular} & $\begin{array}{l}170,04 \\
\end{array}$ & 124,08 \\
\hline Lissotriton helveticus & 31TDG22 & 99,00 & 125,49 & 73,69 & 31,92 & 5511,67 & 252,13 & 23,39 & 228,73 & \begin{tabular}{ll|}
174,44 \\
\end{tabular} & 59,73 & \begin{tabular}{|c|}
198,87 \\
\end{tabular} & 59,73 & 746,68 & 87,10 & 38,10 & 23,96 & 229,79 & \begin{tabular}{|l|l|}
133,40 \\
\end{tabular} & 201,19 & 133,40 \\
\hline Lissotriton helveticus & 31TDG23 & 101,00 & 120,63 & 74,58 & 32,00 . & 5523,95 & 248,55 & 18,30 ] & $230,24 \mid$ & 167,35 | & 54,73 & 194,10 & 54,73 & 769,68 . & 90,82 & 38,58 & $24,64 \mid$ & $234,97 \mid$ & 134,90 | & 209,82 & 134,90| \\
\hline Lissotriton helveticus & 31TDG24 & 100,00 & 126,73 & 75,58 & 32,00 & 5574,07 & 255,26 & 22,19 & 233,07 & 149,77 & 59,32 & 200,34 & 59,32 & 739,43 & 89,01 & 34,71 & 27,42 & 230,37 & 121,26 & 210,88 & 121,26 \\
\hline Lissotriton helveticus & \begin{tabular}{|l|l|}
$31 T D G 26$ \\
\end{tabular} & 101,00 & 110,29 & 77,01 & 32,33 & 5569,27 & 241,08 & 7,03 & 234,05 & 124,80 & 43,82 & 184,24 & 43,67 & 832,47 & 97,84 & 42,19 & 24,08 & 256,10 & \begin{tabular}{ll|}
147,86 \\
\end{tabular} & 225,80 & 147,86 \\
\hline Lissotriton helveticus & $\begin{array}{l}31 \text { TDG35 } \\
\end{array}$ & 100,00 & 124,92 & 75,47 & 31,97 & 5577,89 & 253,79 & 20,32 & 233,47 & 140,55 & 57,43 & \begin{tabular}{|c|}
198,57 \\
\end{tabular} & 57,43 & \begin{tabular}{|c|}
794,52 \\
\end{tabular} & 92,92 & 37,77 & 25,36 & 245,58 & \begin{tabular}{|l|l|}
137,07 \\
\end{tabular} & 218,86 & 137,07 \\
\hline Lissotriton helveticus & $\begin{array}{l}\text { 31TDG43 } \\
\end{array}$ & 101,00 & 120,79 & 72,53 & 31,36 & 5480,88 & 247,16 & 19,81 & 227,36 & 168,24 & 56,24 & \begin{tabular}{ll|}
193,96 \\
\end{tabular} & 55,80 & 841,38 & 93,61 & 44,30 & 21,43 & 251,91 & \begin{tabular}{|c|}
161,19 \\
\end{tabular} & 215,44 & 161,25 \\
\hline Lissotriton helveticus & 31TDG44 & 101,00 & 130,89 & 73,43 & 31,21 & 5539,31 & 257,59 & 26,91 & 230,68 & 168,05 & \begin{tabular}{|c|}
63,87 \\
\end{tabular} & 204,03 & \begin{tabular}{|c|}
63,87 \\
\end{tabular} & 819,11 & $\begin{array}{l}91,15 \\
\end{array}$ & 40,15 & 22,82 & 246,08 & 151,03 & 214,89 & 151,03 \\
\hline Lissotriton helveticus & $\begin{array}{l}31 \text { TDG45 } \\
\end{array}$ & 100,00 & 123,43 & 74,48 & 31,81 & 5541,19 & 251,55 & \begin{tabular}{l|l}
19,82 \\
\end{tabular} & 231,73 & 138,59 & 56,68 & \begin{tabular}{|c|}
196,77 \\
\end{tabular} & $\begin{array}{l}56,65 \\
\end{array}$ & 844,31 & 94,95 & 41,38 & 22,77 & 254,73 & \begin{tabular}{|c|}
155,64 \\
\end{tabular} & \begin{tabular}{|l|l|}
222,07 \\
\end{tabular} & 155,64 \\
\hline Lissotriton helveticus & $\begin{array}{l}31 \text { TDG46 } \\
\end{array}$ & 101,00 & 98,81 & 74,53 & 32,16 & 5461,29 & 227,98 & 0,29 & 227,69 & \begin{tabular}{|l|l|l|l}
123,23 \\
\end{tabular} & 38,16 & 172,11 & 35,25 & \begin{tabular}{|c|}
935,05 \\
\end{tabular} & 102,41 & 54,20 & 18,70 & 269,63 & \begin{tabular}{|l|}
188,71 \\
\end{tabular} & 229,59 & 189,68 \\
\hline Lissotriton helveticus & \begin{tabular}{|l|l|}
$31 T D G 49$ \\
\end{tabular} & 61,00 & 55,44 & 71,98 & 31,95 & 5347,45 & 184,37 & $-37,63$ & 222,00 & 36,75 & 62,02 & 128,52 & $-4,12$ & 1168,61 & \begin{tabular}{l|l}
120,65 \\
\end{tabular} & 72,21 & 14,13 & \begin{tabular}{l|l}
328,65 \\
\end{tabular} & 255,93 & 262,42 & 270,85 \\
\hline Lissotriton helveticus & $\begin{array}{l}31 \text { TDG50 } \\
\end{array}$ & 100,00 & 149,07 & 69,41 & 30,93 & 5340,44 & 268,83 & 47,51 & 221,32 & 172,34 & \begin{tabular}{l|l|l|l|}
184,93 \\
\end{tabular} & 219,62 & \begin{tabular}{l|l}
84,45 \\
\end{tabular} & \begin{tabular}{|l|l|}
739,98 \\
\end{tabular} & 97,36 & 35,59 & 24,90 & 240,67 & \begin{tabular}{l|l}
149,22 \\
\end{tabular} & \begin{tabular}{|l|l|}
177,14 \\
\end{tabular} & 156,74 \\
\hline Lissotriton helveticus & 31TDG51 & 100,00 & 150,52 & 69,89 & 30,82 & 5412,19 & 271,39 & 47,10 & 224,29 & 175,65 & \begin{tabular}{|c|}
190,74 \\
\end{tabular} & 221,70 & 84,5 & $\begin{array}{l}751,99 \\
\end{array}$ & 97,13 & 37,05 & 23,69 & 241,22 & 152,85 & 178,44 & 159,64 \\
\hline Lissotriton helveticus & $\begin{array}{l}31 \text { TDG52 } \\
\end{array}$ & 100,00 & 121,05 & 70,84 & 31,14 & 5416,66 & 245,56 & 21,77 & 223,79 & 158,67 & 73,56 & \begin{tabular}{|c|}
193,60 \\
\end{tabular} & 57,38 & \begin{tabular}{|l|l}
871,94 \\
\end{tabular} & 101,31 & 48,10 & 20,27 & 261,90 & \begin{tabular}{|l|l|l|}
179,63 \\
\end{tabular} & \begin{tabular}{|l|}
207,94 \\
\end{tabular} & 181,17 \\
\hline Lissotriton helveticus & 31TDG53 & 101,00 & 120,29 & 71,75 & 31,31 & 5454,72 & 245,94 & \begin{tabular}{|c|}
19,90 \\
\end{tabular} & 226,03 & \begin{tabular}{ll|}
168,79 \\
\end{tabular} & 56,34 & 193,21 & 55,81 & $\begin{array}{l}879,46 \\
\end{array}$ & 97,58 & 47,86 & 20,11 & 259,23 & \begin{tabular}{ll|}
176,63 \\
\end{tabular} & 214,88 & 176,63 \\
\hline Lissotriton helveticus & 31TDG54 & 100,00 & 125,16 & 72,61 & 31,28 & 5493,16 & 251,46 & 22,80 & 228,67 & 159,72 & 59,79 & 198,10 & 59,49 & 882,49 & 96,36 & 45,17 & 20,85 & 259,02 & \begin{tabular}{ll|}
173,86 \\
\end{tabular} & 217,20 & 173,90 \\
\hline Lissotriton helveticus & 31TDG55 & 101,00 & 112,93 & 73,61 & 31,78 & 5470,40 & 240,58 & 12,28 | & 228,29 & 146,27 & $49,85[$ & $185,97 \mid$ & 48,41 & 911,09 [ & 98,75 & 49,15 & $19,85[$ & 264,80 & 182,35 & 222,98 & 182,41] \\
\hline Lissotriton helveticus & 31TDG56 & 101,00 & 126,48 & 74,94 & 31,73 & 5552,87 & 254,68 & 21,49 & 233,19 & 143,13 & 59,32 & 199,65 & 59,17 & 878, & 94,59 & 43, & 21,3 & 261,01 & 171,38 & 218,56 & 171,39 \\
\hline Lissotriton helveticus & 31TDG57 & 100,00 & 129,29 & 76,38 & 31,96 & 5582,05 & 258,48 & 22,78 & 235,70 & \begin{tabular}{|l|l}
147,30 \\
\end{tabular} & \begin{tabular}{|c|}
61,07 \\
\end{tabular} & 202,62 & \begin{tabular}{|c|}
61,07 \\
\end{tabular} & \begin{tabular}{l|l}
845,98 \\
\end{tabular} & 92,13 & 42,93 & 20,88 & 250,54 & \begin{tabular}{|c|}
166,34 \\
\end{tabular} & 210,12 & 166,34 \\
\hline Lissotriton helveticus & 31TDG61 & 101,00 & 146,85 & 69,27 & 30,42 & 5401,26 & 267,46 & 44,08 & 223,38 & \begin{tabular}{|l|l|l|}
169,79 \\
\end{tabular} & \begin{tabular}{ll|l}
194,63 \\
\end{tabular} & 218,05 & 81,26 & \begin{tabular}{ll|}
781,72 \\
\end{tabular} & 103,63 & 37,41 & 24,57 & 249,46 & $\begin{array}{l}157,06 \\
15\end{array}$ & \begin{tabular}{|c|}
180,94 \\
\end{tabular} & 168,79 \\
\hline Lissotriton helveticus & 31TDG62 & 101,00 & 149,18 & 69,89 & 30,11 & 5469,89 & 270,71 & 44,27 & 226,44 & 175,51 & 190,11 & 220,84 & 82,05 & 782,31 & \begin{tabular}{|l|l|}
103,47 \\
\end{tabular} & 38,13 & 24,38 & 247,74 & 157,19 & $\begin{array}{l}178,56 \\
\end{array}$ & 168,20 \\
\hline Lissotriton helveticus & 31TDG63 & 100,00 & 134,37 & 70,82 & 30,71 & 5472,86 & 258,25 & $31,14[$ & $227,11 \mid$ & 182,29 & 82,49 & 206,82 & 68,42 & 864,54 _ & 102,08 & 45,97 & 21,14 & 257,04 & 178,28 & 202,84 & 178,94 \\
\hline Lissotriton helveticus & $\begin{array}{l}31 \text { TDG65 } \\
\end{array}$ & 100,00 & 134,61 & 73,08 & 31,10 & 5543,73 & 260,82 & 29,16 & 231,66 & 171,21 & \begin{tabular}{l|l|l}
67,05 \\
\end{tabular} & 207,58 & $\begin{array}{l}67,05 \\
\end{array}$ & 869,24 & 99,53 & 44,63 & 21,17 & 253,62 & 177,00 & 205,04 & 177,00 \\
\hline Lissotriton helveticus & \begin{tabular}{|l|l|}
$31 T D G 66$ \\
\end{tabular} & 101,00 & 128,84 & 74,49 & 31,64 & 5531,15 & 256,26 & 23,76 & 232,50 & 153,06 & 61,83 & 201,77 & 61,83 & 877,56 & 97,45 & 45,15 & 20,81 & 255,27 & \begin{tabular}{ll|l}
177,86 \\
\end{tabular} & 209,00 & 177,86 \\
\hline Lissotriton helveticus & $\begin{array}{l}31 \text { TDG67 } \\
\end{array}$ & 100,00 & 137,40 & 76,11 & 31,80 & 5580,44 & 265,66 & 29,24 & 236,41 & 175,68 & \begin{tabular}{ll|l}
68,76 \\
\end{tabular} & \begin{tabular}{|l|l|}
210,45 \\
\end{tabular} & 68,73 & 808,42 & 94,24 & 42,97 & 21,05 & 236,38 & 165,84 & 188,53 & 165,85 \\
\hline Lissotriton helveticus & $\begin{array}{l}31 \text { TDG68 } \\
\end{array}$ & 86,00 & 114,42 & 76,43 & 32,34 & 5500,76 & 243,88 & \begin{tabular}{l|l}
11,05 \\
\end{tabular} & 232,83 & 134,60 & 51,47 & \begin{tabular}{|c|}
187,37 \\
\end{tabular} & 48,63 & 893,25 & 96,76 & 50,69 & 18,58 & 255,03 & 186,61 & \begin{tabular}{l|l}
211,05 \\
\end{tabular} & 187,34 \\
\hline Lissotriton helveticus & $\begin{array}{l}\text { 31TDG71 } \\
\end{array}$ & 99,00 & 156,87 & 69,51 & 30,60 & 5364,56 & 275,70 & 52,56 & 223,14 & \begin{tabular}{|c|}
167,35 \\
\end{tabular} & 224,72 & 227,13 & 90,86 & 711,45 & 107,54 & 29,23 & 30,94 & 243,24 & \begin{tabular}{|l|l|}
129,62 \\
\end{tabular} & \begin{tabular}{|c|}
160,29 \\
\end{tabular} & 156,59 \\
\hline Lissotriton helveticus & \begin{tabular}{|l|}
$31 T D G 72$ \\
\end{tabular} & 101,00 & 154,90 & 69,47 & 30,09 & 5459,06 & 275,20 & 48,78 & 226,42 & 165,21 & \begin{tabular}{|l|l|}
225,52 \\
\end{tabular} & 226,12 & 87,35 & 736,21 & 108,20 & 31,73 & 28,88 & 244,81 & 137,61 & \begin{tabular}{ll|}
161,82 \\
\end{tabular} & 162,07 \\
\hline Lissotriton helveticus & 31TDG73 & 100,00 & 151,59 & 69,54 & 29,97 & 5553,31 & 273,66 & 44,30 & 229,36 & \begin{tabular}{|l|l|l|l}
165,46 \\
\end{tabular} & 222,68 & 223,75 & 82,63 & 769,42 & \begin{tabular}{|l|l|}
108,47 \\
\end{tabular} & 35,29 & 26,44 & 246,62 & \begin{tabular}{|c|}
149,64 \\
\end{tabular} & \begin{tabular}{ll|}
161,79 \\
\end{tabular} & 168,62 \\
\hline Lissotriton helveticus & $\begin{array}{l}\text { 31TDG74 } \\
\end{array}$ & 101,00 & 148,67 & 70,75 & 30,06 & 5587,62 & 272,30 & 40,82 & 231,48 & 177,15 & 209,99 & 221,44 & 79,36 & $785,67 \mid$ & 106,68 & 38,35 & 24,72 & 244,16 & \begin{tabular}{|c|}
159,67 \\
\end{tabular} & \begin{tabular}{|c|}
167,53 \\
\end{tabular} & 169,21 \\
\hline Lissotriton helveticus & $\begin{array}{l}31 \text { TDG75 } \\
\end{array}$ & 101,00 & 138,71 & 72,55 & 30,92 & 5523,73 & 263,75 & 32,51 & 231,24 & \begin{tabular}{ll|}
182,50 \\
\end{tabular} & \begin{tabular}{l|l|}
104,51 \\
\end{tabular} & 211,21 & 71,13 & 832,95 & 103,27 & 43,47 & 22,28 & 247,40 & \begin{tabular}{|c|}
173,37 \\
\end{tabular} & \begin{tabular}{ll|}
186,58 \\
\end{tabular} & 174,80 \\
\hline Lissotriton helveticus & $\begin{array}{l}31 \text { TDG76 } \\
\end{array}$ & 100,00 & 143,13 & 74,41 & 31,20 & 5552,16 & 269,17 & 35,16 & 234,01 & \begin{tabular}{|l|l|}
185,68 \\
\end{tabular} & \begin{tabular}{ll|}
111,35 \\
\end{tabular} & 215, & 74 & 784, & 99,79 & 41,08 & 22,6 & 235,03 & \begin{tabular}{l|l|l|}
163,83 \\
\end{tabular} & \begin{tabular}{l|l}
173,85 \\
\end{tabular} & 164,27 \\
\hline Lissotriton helveticus & \begin{tabular}{|l|} 
31TDG77 \\
\end{tabular} & 100,00 & 138,85 & 75,89 & \begin{tabular}{|c|c|}
31,95 \\
\end{tabular} & 5538,66 & 266,13 & \begin{tabular}{|c|}
30,97 \\
\end{tabular} & 235,15 & \begin{tabular}{|l|l|}
177,79 \\
\end{tabular} & \begin{tabular}{ll|}
103,96 \\
\end{tabular} & 211,36 & 70,83 & 782,67 & 97,23 & 41,56 & 21,97 & 231,89 & 164,30 & 174,28 & 164,77 \\
\hline Lissotriton helveticus & 31TDG81 & 58,00 & 156,33 & 69,67 & 30,77 & 5324,65 & 274,68 & 52,23 & 222,45 & \begin{tabular}{ll|l}
166,76 \\
\end{tabular} & 221,85 & 226,11 & 91,01 & $\begin{array}{l}700,06 \\
\end{array}$ & 108,38 & 27,85 & 32,13 & 241,39 & \begin{tabular}{|c|}
125,74 \\
\end{tabular} & $\begin{array}{l}155,80 \\
\end{array}$ & 153,82 \\
\hline Lissotriton helveticus & 31TDG82 & 99,00 & 151,01 & 69,29 & 30,32 & 5396,79 & 270,51 & 46,31 & 224,20 & 161,54 & 221,06 & 221,71 & 84,91 & 744,17 & 109,39 & 31,64 & 28,92 & 246,43 & \begin{tabular}{|c|}
139,20 \\
\end{tabular} & \begin{tabular}{|l|l}
164,30 \\
\end{tabular} & 163,79 \\
\hline Lissotriton helveticus & 31TDG83 & 101,00 & 152,89 & 69,74 & 30,1 & 5483,13 & 273,79 & $46,21 \mid$ & 227,58 & 163,03 & 223,94 & 224,33 & 85, & 738,58 & 109,55 & 31,4 & 29, & 243,75 & 137,25 & 159,43 & 163,03 \\
\hline Lissotriton helveticus & $\begin{array}{l}31 \text { TDG84 } \\
\end{array}$ & 101,00 & 60 & 71,06 & 30,56 & 5502,87 & 27 & 44,03 & 229,53 & 161,75 & 222,8 & 223,2 & 83 & 745 & 107,99 & 33, & 27, & 240,70 & 143, & 156,73 & 162,27 \\
\hline Lissotriton helveticus & $\begin{array}{l}31 \text { TDG85 } \\
\end{array}$ & 101,00 & 47 & 73,02 & 31,16 & 5489,76 & 274,51 & 43,28 & 231,23 & \begin{tabular}{l|l|l|l|}
163,92 \\
\end{tabular} & 222,63 & 222,94 & 83 & \begin{tabular}{|c|}
727,58 \\
\end{tabular} & 104,06 & 33,71 & 26,96 & 232,38 & $\begin{array}{l}143,45 \\
\end{array}$ & \begin{tabular}{|l|l|}
154,74 \\
\end{tabular} & 155,45 \\
\hline Lissotriton helveticus & $\begin{array}{l}31 \text { TDG86 } \\
\end{array}$ & 100,00 & 150,17 & 74,92 & 31,76 & 5484,51 & 274,44 & 41,47 & 232,96 & \begin{tabular}{l|l}
160,93 \\
\end{tabular} & 221,32 & 221, & 82,2 & 708,14 & 99,79 & 33,60 & 26,14 & 224,22 & \begin{tabular}{|l|l|}
142,91 \\
\end{tabular} & $\begin{array}{l}150,56 \\
\end{array}$ & 149,80 \\
\hline Lissotriton helveticus & $\begin{array}{l}\text { 31TDG87 } \\
\end{array}$ & 101,00 & 149,24 & 76,75 & 32,16 & 5487,27 & 274,86 & 39,84 & \begin{tabular}{|l|l|}
235,02 \\
\end{tabular} & 160,05 & 216,56 & 220,80 & 81,28 & 689,46 & 96,19 & 32,82 & 25,71 & 217,65 & \begin{tabular}{l|l}
140,02 \\
\end{tabular} & \begin{tabular}{|l|l|}
146,09 \\
\end{tabular} & 146,16 \\
\hline Lissotriton helveticus & 31TDG93 & 101,00 & 149,48 & 71,06 & 31,22 & 5302,24 & $45 \mid$ & 45,3 & 223,06 & 160,19 ] & $218,27 \mid$ & 219,19 & 84 & $722,41 \mid$ & 106,15 & 30, & 29,0 & 238,99 | & 135,13 & 158,25 & 157,90 \\
\hline Lissotriton helveticus & $\begin{array}{l}\text { 31TDG94 } \\
\end{array}$ & 101,00 & 14 & 72,30 & 31,6 & 18,50 & 269,01 & 43, & 225,02 & 159,60 & Jo & 218 & 8 & 721,5 & 104,28 & 31, & 28,05 & 234,82 & 138,13 & \begin{tabular}{|c|}
157,69 \\
\end{tabular} & 156,27 \\
\hline Lissotriton helveticus & $\begin{array}{l}31 \text { TDG95 } \\
\end{array}$ & 100,00 & 15 & 74,30 & \begin{tabular}{|c|}
32,15 \\
\end{tabular} & 5331,84 & 27 & 48 & 227,95 & 165,50 & 224,38 & 224, & 89,64 & 666,18 & 100,65 & 28,02 & 29,82 & 222,45 & 124,31 & $\begin{array}{l}143,50 \\
\end{array}$ & 143,07 \\
\hline Lissotriton helveticus & $\begin{array}{l}31 \text { TDG96 } \\
\end{array}$ & & & 76,03 & 32,57 & 5354,37 & 276,69 & 46,32 & 230,38 & 164,47 & 223,78 & 224, & 88,29 & 645,72 & 96,88 & 27,87 & 29,30 & 214,89 & 123,38 & 138,33 & 136,76 \\
\hline Lissotriton helveticus & $\begin{array}{l}\text { 31TDG97 } \\
\end{array}$ & 101,00 & 154,91 & 77,94 & 32,98 & 5376,61 & 278,77 & 45,78 & 232,99 & 164,75 & 224,66 & \begin{tabular}{|l|l|}
225,07 \\
\end{tabular} & 88, & \begin{tabular}{l|l|}
620,55 \\
\end{tabular} & $\begin{array}{l}93,45 \\
\end{array}$ & 26,50 & 29, & 207,71 & \begin{tabular}{|c|}
118,15 \\
\end{tabular} & \begin{tabular}{l|l}
129,83 \\
\end{tabular} & 131,77 \\
\hline Lissotriton helveticus & $\begin{array}{l}\text { 31TDG98 } \\
\end{array}$ & 101,00 & 15 & 79,6 & 33,31 & 404,67 & 279,85 & 43, & 235,87 & \begin{tabular}{|l|l|}
163,77 \\
\end{tabular} & 224,38 & 224 & 87 & 614,8 & 91,59 & 25, & 28,9 & 205,24 & \begin{tabular}{ll|}
114,78 \\
\end{tabular} & \begin{tabular}{|l|l|}
123,02 \\
\end{tabular} & 133,82 \\
\hline Lissotriton helveticus & 31TDH90 & 17,00 & 130,04 & 80,65 & 33,43 & 5452,04 & 259,87 & $22,4<-3$ & 237,38 & 119,93 & 201,55 & 201, & 6 & 750,58 & 95,23 & 35,71 & $22,8 \quad 2=0$ & 229,15 | & 150,32 & $\mid 154,35$ & 172,62 \\
\hline Lissotriton helveticus & 31TEG02 & 28,00 & 159,86 & 72,57 & 32,57 & 5126,33 & 275 & 56 & 219,14 & 170, & \begin{tabular}{|l|l|l|}
218,33 \\
\end{tabular} & 227, & 97,29 & \begin{tabular}{|c|c|}
631,48 \\
\end{tabular} & 102,14 & 21,71 & 35, & 225,67 & \begin{tabular}{|c|}
106,76 \\
\end{tabular} & \begin{tabular}{|l|l|}
137,62 \\
\end{tabular} & 139,43 \\
\hline Lissotriton helveticus & 31TEG03 & 93,00 & 153,07 & 72,72 & 32,65 & 5129,58 & 269,70 & 50,30 & 219,40 & \begin{tabular}{|l|l|}
164,14 \\
\end{tabular} & 219,05 & 220,85 & 91,19 & \begin{tabular}{|c|}
659,64 \\
\end{tabular} & 100,74 & 24,89 & 31,94 & 226,71 & 118,30 & \begin{tabular}{ll|}
144,85 \\
\end{tabular} & 143,42 \\
\hline Lissotriton helveticus & 31TEG04 & 100,00 & 156,39 & 74,26 & 33,10 & 5126,21 & 273,53 & 52,28 & 221,25 & \begin{tabular}{|l|l|}
167,27 \\
\end{tabular} & 222,84 & 223,95 & 94,16 & 632,72 & 98,18 & 23,59 & 32,44 & 219,16 & \begin{tabular}{|c|}
112,16 \\
\end{tabular} & \begin{tabular}{|c|}
137,79 \\
\end{tabular} & 137,12 \\
\hline Lissotriton helveticus & 31TEG05 & 101,00 & 159,00 & 76,01 & 33,36 & 156,9 & 277. & 53,2 & 224,33 & 169, & 225, & 226, & 95 & 606 & 95,44 & 22,60 & 32, & 211 & 10 & \begin{tabular}{ll|}
130,96 \\
\end{tabular} & 130,71 \\
\hline Lissotriton helveticus & 31TEG06 & 97,00 & & & & if & 27 & 51 & 227,39 & 168 & 22 & 226,54 & & \begin{tabular}{|l|l|}
597,79 \\
\end{tabular} & 93,37 & 22,87 & 32, & 207,20 & 107,21 & \begin{tabular}{|c|}
128,67 \\
\end{tabular} & 128, \\
\hline Lissotriton helveticus & 31TEG07 & 99,00 & 158,76 & 79,15 & 33,82 & 5266,93 & 280,93 & \begin{tabular}{|l|l|}
50,05 \\
\end{tabular} & 230,89 & \begin{tabular}{ll|}
168,66 \\
\end{tabular} & 227,07 & 227,46 & \begin{tabular}{|c|}
93,87 \\
\end{tabular} & $\begin{array}{l}582,46 \\
\end{array}$ & 91,29 & 22,05 & 32,32 & 202,72 & \begin{tabular}{|c|}
103,44 \\
\end{tabular} & \begin{tabular}{ll|}
119,33 \\
\end{tabular} & 126,14 \\
\hline Lissotriton helveticus & 31TEG08 & 101,00 & 156,38 & 80,48 & 33,99 & 5305,64 & 280,52 & 46,90 & 233,62 & 166,31 & 225,23 & 225,66 & 90,90 & $\begin{array}{l}587,55 \\
\end{array}$ & 90,46 & 22,33 & 31,40 & 202,46 & \begin{tabular}{|l|}
103,81 \\
\end{tabular} & $\begin{array}{l}119,66 \\
19\end{array}$ & 129,73 \\
\hline Lissotriton helveticus & 31TEG13 & 37,00 & 159,26 & 74,63 & 33,92 & 4974,95 & 273,68 & 56,92 & 216,76 & 170,61 & 210,58 & 225,08 & $\begin{array}{l}99,42 \\
\end{array}$ & 587,89 & 94,26 & 19,53 & \begin{tabular}{|l|l|}
35,63 \\
\end{tabular} & \begin{tabular}{|l|l|}
211,92 \\
\end{tabular} & 100,21 & 130,21 & 126,39 \\
\hline Lissotrit & & 82,00 & & & & & & & & 16 & 218 & 223, & 98, & 581 . & 92,08 & 19,95 & & & 101 & 129,57 & 12 \\
\hline Pelobates cultripes & 29SMC77 & 7,00 & 165,36 & 77,64 & 41,14 & 3779,50 & 268,8 & 83,14 & 185,71 & $\begin{array}{l}125,50 \\
\end{array}$ & 210,64 & 215,21 & 118,00 & 717,43 & 110,43 & 4,00 & 64,07 & \begin{tabular}{|c|}
323,64 \\
\end{tabular} & \begin{tabular}{|c|}
30,07 \\
\end{tabular} & 32,79 & 306, \\
\hline Pelobates cultripes & 29SMC86 & 60,00 & 166,21 & 81,36 & 41,33 & 3924,44 & 276,58 & 82,44 & 194,15 & 125,29 & 213,76 & 218,67 & \begin{tabular}{|c|}
117,97 \\
\end{tabular} & 698,01 & 106,28 & 3,82 & \begin{tabular}{|l|l|}
63,62 \\
\end{tabular} & 313,06 & 29,58 & 32,19 & 299,45 \\
\hline
\end{tabular}




\begin{tabular}{|c|c|c|c|c|c|c|c|c|c|c|c|c|c|c|c|c|c|c|c|c|c|}
\hline TAXON & UTM & $\mathrm{km2}$ & BIO1 & B102 & B103 & B104 & B105 & B106 & B107 & B108 & B109 & BIO10 & BIO11 & B1012 & BIO13 & BIO14 & BIO15 & BIO16 & BIO17 & BIO18 & BI019 \\
\hline Pelobates cultripes & 29SMC87 & 85,00 & 166,33 & 80,39 & 41,04 & 3928,81 & 275,72 & 82,47 & 193,25 & 125,15 & 213,91 & 218,71 & 117,74 & 709,73 & 108,26 & 3,85 & 63,78 & 318,88 & 29,62 & 32,39 & 304,79 \\
\hline Pelobates cultripes & 29SMC96 & 101,00 & 166,61 & 83,55 & 41,10 & 4057,78 & 281,52 & 81,08 & 200,44 & 124,31 & 216,16 & 221,07 & \begin{tabular}{|l|l|}
116,95 \\
\end{tabular} & 689,66 & 104,09 & 3,57 & 63,35 & 308,21 & \begin{tabular}{|l|l|}
28,87 \\
\end{tabular} & 31,62 & 296,61 \\
\hline Pelobates cultripes & 29SMD63 & 9,00 & 153,06 & 59,78 & 41,09 & 3022,06 & 226,25 & 82,44 & 143,81 & 121,75 & $\begin{array}{l}188,06 \\
1\end{array}$ & \begin{tabular}{l|l|l|}
190,53 \\
\end{tabular} & \begin{tabular}{l|l|l|}
113,19 \\
\end{tabular} & 692,31 & 114,81 & 4,00 & 62,66 & 310,81 & 29,66 & 34,88 & 285,31 \\
\hline Pelobates cultripes & 29SMD65 & 11,00 & 152,83 & 53,46 & 41,63 & 2683,38 & 214,13 & 87,29 & \begin{tabular}{l|l|}
126,83 \\
\end{tabular} & \begin{tabular}{l|l|}
125,54 \\
\end{tabular} & $\begin{array}{l}183,25 \\
18\end{array}$ & \begin{tabular}{l|l|}
185,29 \\
\end{tabular} & \begin{tabular}{l|l|l|}
117,13 \\
\end{tabular} & 638,17 & 110,50 & 3,42 & 63,04 & 284,83 & 26,96 & 34,38 & 259,42 \\
\hline Pelobates cultripes & 29SMD73 & 101,00 & 153,51 & 62,06 & 41,03 & 3133,32 & 231,06 & 81,41 & \begin{tabular}{|l|l|}
149,66 \\
\end{tabular} & 120,85 & \begin{tabular}{|l|l|}
190,32 \\
\end{tabular} & \begin{tabular}{ll|}
193,01 \\
\end{tabular} & $\begin{array}{ll}112,66 \\
\end{array}$ & \begin{tabular}{|c|}
696,19 \\
\end{tabular} & 114,21 & 4,00 & \begin{tabular}{|l|l|}
62,63 \\
\end{tabular} & 311,64 & 29,42 & 34,60 & 288,44 \\
\hline Pelobates cultripes & 29SMD75 & 89,00 & 151,32 & 57,80 & 41,23 & 2903,17 & 220,92 & 82,61 & 138,31 & 121,57 & 185,03 & 187,33 & $\begin{array}{l}113,25 \\
\end{array}$ & 677,61 & 113,71 & 3,95 & \begin{tabular}{l|l}
62,35 \\
\end{tabular} & 300,55 & 29,35 & \begin{tabular}{l|l}
35,85 \\
\end{tabular} & 277,62 \\
\hline Pelobates cultripes & 29SMD98 & 58,00 & 154,47 & 68,99 & 42,01 & 3275,73 & 239,79 & 77,49 & \begin{tabular}{ll|}
162,30 \\
\end{tabular} & 119,74 & \begin{tabular}{|l|l|}
193,37 \\
\end{tabular} & \begin{tabular}{ll|}
195,76 \\
\end{tabular} & 111,73 & 752,49 & 116,18 & 5,30 & 59,35 & 321,62 & 37,58 & 44,10 & 307,90 \\
\hline Pelobates cultripes & 29SMD99 & 35,00 & 152,45 & 70,03 & 42,11 & 3291,15 & 238,72 & 74,76 & \begin{tabular}{ll|}
163,96 \\
\end{tabular} & \begin{tabular}{ll|}
117,54 \\
\end{tabular} & $\begin{array}{l}191,64 \\
194\end{array}$ & \begin{tabular}{|l|l|}
194,07 \\
\end{tabular} & $\begin{array}{ll}109,53 \\
\end{array}$ & 788,54 & 119,77 & 6,00 & 58,43 & \begin{tabular}{|l|l|}
334,07 \\
\end{tabular} & 41,22 & 47,77 & 321,45 \\
\hline Pelobates cultripes & 295NB13 & 51,00 & 165,90 & 86,91 & 44,25 & 3706,64 & 276,06 & 81,89 & \begin{tabular}{|l|l|}
194,17 \\
\end{tabular} & \begin{tabular}{l|l|l|}
129,33 \\
\end{tabular} & 211,51 & 215,80 & \begin{tabular}{l|l|}
121,01 \\
\end{tabular} & 513,94 & 82,24 & 1,00 & 68,10 & 240,26 & 18,46 & 19,60 & 229,58 \\
\hline Pelobates cultripes & 29SNB14 & 19,00 & 166,42 & 87,92 & 44,00 & 3803,89 & 279,44 & 81,19 & 198,25 & 128,75 & 213,33 & 217,72 & 120,36 & 522,64 & 82,56 & 1,00 & 67,69 & 243,06 & 18,89 & 19,89 & 232,81 \\
\hline Pelobates cultripes & 29SNB16 & 24,00 & 167,33 & 88,92 & 43,73 & 3885,90 & 282,76 & 81,06 & 201,69 & 128,55 & 215,29 & 219,73 & $\begin{array}{ll}120,39 \\
\end{array}$ & 539,57 & 83,76 & 1,00 & \begin{tabular}{|c|}
66,53 \\
\end{tabular} & 248,24 & 20,00 & 21,00 & 238,41 \\
\hline Pelobates cultripes & 29SNB21 & 101,00 & 166,71 & 86,81 & 43,34 & 3809,92 & 278,55 & 80,58 & \begin{tabular}{|l|l|}
197,97 \\
\end{tabular} & \begin{tabular}{|l|l|}
129,16 \\
\end{tabular} & 214,36 & 218,16 & $\begin{array}{ll}120,69 \\
\end{array}$ & \begin{tabular}{ll|l}
498,75 \\
\end{tabular} & 80,82 & 0,90 & \begin{tabular}{|c|}
69,59 \\
\end{tabular} & 237,30 & 16,71 & \begin{tabular}{|l|l|}
17,97 \\
\end{tabular} & 225,62 \\
\hline Pelobates cultripes & 29SNB23 & 101,00 & 160,57 & 89,23 & 43,49 & 3904,89 & 276,69 & 73,70 & 202,99 & \begin{tabular}{|l|l|l|}
122,19 \\
\end{tabular} & \begin{tabular}{|l|}
209,27 \\
\end{tabular} & 213,56 & \begin{tabular}{|l|l|}
113,87 \\
\end{tabular} & \begin{tabular}{ll|l}
548,35 \\
\end{tabular} & 86,14 & 1,15 & 67,36 & 254,48 & 20,17 & 21,04 & 244,38 \\
\hline Pelobates cultripes & 29SNB24 & 100,00 & 162,44 & 89,79 & 43,41 & 3953,88 & 280,03 & 75,26 & 204,76 & 123,45 & 211,84 & 216,11 & \begin{tabular}{ll|}
115,18 \\
\end{tabular} & 546,36 & 85,42 & 1,08 & \begin{tabular}{ll|l}
67,06 \\
\end{tabular} & 252,79 & \begin{tabular}{|l|l|}
20,07 \\
\end{tabular} & 20,88 & 242,88 \\
\hline Pelobates cultripes & 29SNB25 & 100,00 & 164,72 & 90,25 & 43,24 & 3981,16 & 283,08 & $\begin{array}{ll}77,15 \\
\end{array}$ & 205,94 & 125,25 & 214,24 & 218,62 & \begin{tabular}{l|l|l|}
116,82 \\
\end{tabular} & 543,22 & 84,29 & 1,00 & 66,7 & 250,47 & 20,04 & 20,94 & 240,79 \\
\hline Pelobates cultripes & 29SNB26 & 101,00 & 167,37 & 90,54 & 43,07 & 4006,83 & 286,40 & 79,38 & 207,03 & 127,37 & 217,05 & 221,60 & \begin{tabular}{l|l|}
119,02 \\
\end{tabular} & 539,28 & 83,16 & 1,06 & 66,34 & 247,82 & 20,04 & 21,07 & 238,29 \\
\hline Pelobates cultripes & 29SNB28 & 101,00 & 163,45 & 91,99 & 42,92 & 4134,08 & 286,67 & 74,44 & 212,23 & \begin{tabular}{ll|l}
121,86 \\
\end{tabular} & $\begin{array}{ll}214,92 \\
\end{array}$ & 219,54 & \begin{tabular}{ll|}
113,86 \\
1
\end{tabular} & 584,01 & 88,30 & 2,00 & 64,69 & 263,26 & 23,58 & 24,30 & 255,08 \\
\hline Pelobates cultripes & 29SNB30 & 26,00 & 171,04 & 87,22 & 42,22 & 3973,35 & 285,61 & 82,09 & 203,52 & \begin{tabular}{|l|l|}
131,74 \\
\end{tabular} & 221,13 & 224,74 & \begin{tabular}{ll|l}
123,26 \\
\end{tabular} & 482,91 & 78,78 & 0,48 & 70,65 & 233,09 & \begin{tabular}{ll|l}
14,83 \\
\end{tabular} & 16,48 & 220,22 \\
\hline Pelobates cultripes & 29SNB31 & 100,00 & 169,93 & 88,04 & 42,32 & 3993,05 & 285,92 & 80,82 & 205,09 & \begin{tabular}{ll|}
130,58 \\
\end{tabular} & 220,37 & 224,08 & 121,95 & 491,29 & \begin{tabular}{|l|l|}
79,47 \\
\end{tabular} & 0,87 & \begin{tabular}{l|l}
69,85 \\
\end{tabular} & 235,53 & 15,71 & \begin{tabular}{l|l|}
17,27 \\
\end{tabular} & 223,19 \\
\hline Pelobates cultripes & 29SNB37 & 100,00 & 164,94 & 93,73 & 42,83 & 4219,59 & 290,82 & 74,07 & 216,75 & 122,57 & \begin{tabular}{|l|l|}
217,72 \\
\end{tabular} & 222,23 & \begin{tabular}{ll|}
114,44 \\
\end{tabular} & 561,68 & 85,97 & 1,82 & 65,17 & 254,92 & 22,07 & 22,89 & 246,65 \\
\hline Pelobates cultripes & 29SNB39 & 100,00 & 165,48 & 94,48 & 42,38 & 4301,43 & 293,85 & \begin{tabular}{ll|}
74,15 \\
\end{tabular} & 219,70 & 122,07 & 219,27 & 223,98 & 114,02 & 576,49 & 86,88 & 2,00 & 64,22 & 258,47 & 23,19 & 24,02 & 251,19 \\
\hline Pelobates cultripes & 29SNB40 & 40,00 & 169,94 & 88,87 & 42,02 & 4031,70 & 286,43 & 79,40 & \begin{tabular}{|l|l|}
207,02 \\
\end{tabular} & 130,30 & $\begin{array}{l}221,06 \\
\end{array}$ & \begin{tabular}{|l|l|}
224,83 \\
\end{tabular} & \begin{tabular}{|l|l|}
121,79 \\
\end{tabular} & 494,32 & 81,45 & 1,00 & 69,98 & 238,64 & \begin{tabular}{l|l|}
15,89 \\
\end{tabular} & \begin{tabular}{ll|}
17,36 \\
\end{tabular} & 225,43 \\
\hline Pelobates cultripes & 29SNB45 & 101,00 & 165,68 & 94,29 & 42,55 & 4266,08 & 292,32 & 73,34 & 218,98 & 122,99 & \begin{tabular}{|l|l|}
219,44 \\
\end{tabular} & 223,80 & \begin{tabular}{|l|l|l|}
114,73 \\
\end{tabular} & 538,78 & 84,63 & 1,02 & \begin{tabular}{|c|}
66,67 \\
\end{tabular} & 248,75 & $\begin{array}{l}19,45 \\
\end{array}$ & 20,42 & 239,24 \\
\hline Pelobates cultripes & 29SNB47 & 100,00 & 163,18 & 96,28 & 42,48 & 4369,40 & 293,99 & 70,04 & 223,95 & 119,40 & \begin{tabular}{|l|l|}
218,06 \\
\end{tabular} & 222,73 & \begin{tabular}{|l|l|}
111,14 \\
\end{tabular} & 569,30 & 87,22 & 2,00 & \begin{tabular}{|c|}
64,67 \\
\end{tabular} & 257,01 & 22,82 & 23,42 & 249,30 \\
\hline Pelobates cultripes & 29SNB48 & 101,00 & 167,66 & 96,33 & 42,62 & 4369,44 & 298,26 & 74,38 & 223,87 & 123,46 & 222,40 & 226,92 & 115,25 & 551,81 & 83,96 & 2,00 & 64,54 & 248,81 & 21,95 & 22,84 & 241,24 \\
\hline Pelobates cultripes & 29SNB49 & 101,00 & 168,13 & 96,77 & 42,39 & 4402,72 & 299,73 & 74,62 & 225,11 & 123,45 & 223,21 & 227,86 & 115,34 & 557,31 & 84,01 & 2,00 & 64,01 & 249,32 & 22,72 & 23,49 & 242,42 \\
\hline Pelobates cultripes & 29SNB57 & 101,00 & 165,13 & 98,47 & 42,25 & 4481,33 & 299,41 & 69,77 & 229,64 & $\begin{array}{ll}119,95 \\
\end{array}$ & \begin{tabular}{ll|}
221,66 \\
\end{tabular} & 226,18 & \begin{tabular}{ll|}
111,69 \\
\end{tabular} & 554,76 & 85,12 & 1,99 & 64,53 & 250,30 & 21,91 & 22,56 & 242,74 \\
\hline Pelobates cultripes & 29SNB58 & 100,00 & 167,38 & 98,91 & 42,36 & 4491,59 & 302,26 & 72,00 & 230,26 & 121,99 & 223,90 & 228,48 & 113,80 & \begin{tabular}{|l|l|}
548,53 \\
\end{tabular} & 83,37 & 2,00 & \begin{tabular}{ll|}
64,49 \\
\end{tabular} & 246,13 & 21,50 & 22,24 & 239,15 \\
\hline Pelobates cultripes & 29SNB59 & 100,00 & 168,86 & 99,21 & 42,32 & 4520,42 & 304,48 & 73,29 & 231,19 & 122,86 & \begin{tabular}{|l|l|}
225,62 \\
\end{tabular} & \begin{tabular}{|l|l|}
230,19 \\
\end{tabular} & $\begin{array}{ll}114,75 \\
\end{array}$ & 547,27 & 82,53 & 2,00 & 63,86 & 244,05 & 22,02 & 22,64 & 237,48 \\
\hline Pelobates cultripes & 29SNB64 & 100,00 & 158,55 & 97,46 & 42,01 & 4485,71 & 291,07 & 62,47 & 228,60 & \begin{tabular}{|l|l|}
114,12 \\
\end{tabular} & \begin{tabular}{|l|l|}
215,45 \\
\end{tabular} & 219,80 & \begin{tabular}{|l|}
105,29 \\
\end{tabular} & 576,21 & 91,25 & 1,79 & \begin{tabular}{l|l|}
65,55 \\
\end{tabular} & 263,75 & 21,95 & 23,02 & 254,29 \\
\hline Pelobates cultripes & 29SNB66 & 101,00 & 162,98 & 99,69 & 42,06 & 4555,55 & 299,11 & 66,03 & 233,08 & 117,41 & \begin{tabular}{|l|l|}
220,63 \\
\end{tabular} & 225,06 & 108,82 & 559,86 & 86,75 & 1,99 & \begin{tabular}{ll|}
64,56 \\
\end{tabular} & 253,15 & 21,71 & 22,47 & 245,11 \\
\hline Pelobates cultripes & 295NB67 & 100,00 & 165,05 & 100,68 & 42,10 & 4589,97 & 302,86 & 67,74 & 235,12 & 118,94 & 223,03 & 227,53 & 110,40 & 553,32 & 84,75 & 2,00 & 64,32 & 248,44 & 21,63 & 22,47 & 241,14 \\
\hline Pelobates cultripes & 29SNB68 & 101,00 & 164,04 & 101,89 & 42,18 & 4647,18 & 304,28 & 66,41 & 237,87 & \begin{tabular}{l|l|}
117,29 \\
\end{tabular} & 222,77 & 227,32 & \begin{tabular}{ll|}
108,81 \\
\end{tabular} & 564,32 & 85,29 & 2,00 & \begin{tabular}{l|l}
63,15 \\
\end{tabular} & \begin{tabular}{l|l}
250,55 \\
\end{tabular} & \begin{tabular}{l|l}
23,05 \\
\end{tabular} & 23,58 & 244,48 \\
\hline Pelobates cultripes & 29SNB69 & 101,00 & 167,56 & 102,06 & 42,17 & 4654,46 & 307,85 & 69,73 & 238,13 & 120,29 & \begin{tabular}{|l|l|}
226,15 \\
\end{tabular} & 230,81 & 111,92 & 549,62 & 82,76 & 2,00 & 63,20 & 243,19 & 22,15 & 23,03 & 237,45 \\
\hline Pelobates cultripes & 29SNB75 & 101,00 & 159,78 & 100,28 & 42,00 & 4621,93 & 297,04 & 61,54 & 235,50 & 113,35 & 218,43 & 222,83 & \begin{tabular}{l|l|}
105,05 \\
\end{tabular} & 572,95 & 89,41 & 2,00 & \begin{tabular}{l|l|}
64,65 \\
\end{tabular} & 259,20 & 22,04 & 23,10 & 250,47 \\
\hline Pelobates cultripes & $295 N B 77$ & 101,00 & 162,11 & 103,12 & 42,01 & 4726,24 & 304,26 & 62,65 & 241,60 & 114,45 & 221,96 & 226,48 & 106,06 & 566,85 & 86,19 & 2,00 & 63,50 & 252,11 & 22,82 & 23,23 & 245,35 \\
\hline Pelobates cultripes & 29SNB78 & 100,00 & 163,24 & 104,39 & 42,08 & 4765,14 & 307,41 & 63,36 & 244,05 & 115,13 & 223,53 & 228,26 & 106,63 & 564,42 & 85,12 & 2,00 & 63,00 & 248,94 & 23,12 & 23,48 & 243,17 \\
\hline Pelobates cultripes & 29SNB80 & 97,00 & 169,36 & 92,45 & 42,75 & 4192,89 & 288,39 & 74,36 & 214,03 & 128,18 & 222,39 & 226,50 & \begin{tabular}{ll|}
119,50 \\
\end{tabular} & 515,13 & 88,79 & 1,00 & 69,74 & 249,99 & 15,82 & 18,36 & 234,58 \\
\hline Pelobates cultripes & 29SNB83 & 99,00 & 153,72 & 98,40 & 41,99 & 4596,25 & 288,04 & 55,56 & 232,47 & \begin{tabular}{ll|}
108,30 \\
\end{tabular} & 212,29 & 216,57 & $\begin{array}{ll}99,42 \\
\end{array}$ & $\begin{array}{ll}603,65 \\
\end{array}$ & 95,3 & 2,03 & $\begin{array}{l}64,86 \\
\end{array}$ & 274,47 & 22,96 & 4,69 & 264,03 \\
\hline Pelobates cultripes & $295 N B 84$ & 101,00 & 156,82 & 99,72 & 41,99 & 4649,05 & 293,62 & 58,02 & 235,60 & 110,58 & 215,99 & 220,47 & 101,90 & 587,33 & 91,97 & 2,00 & 64,52 & 265,77 & 22,60 & 24,20 & 255,97 \\
\hline Pelobates cultripes & 29SNB85 & 101,00 & 160,15 & 101,33 & 42,00 & 4701,10 & 299,33 & 60,68 & 238,64 & \begin{tabular}{|l|l|}
113,07 \\
\end{tabular} & \begin{tabular}{|l|l|}
219,98 \\
\end{tabular} & 224,36 & \begin{tabular}{|l|l|}
104,50 \\
\end{tabular} & 569,56 & 88,36 & 2,00 & 64,34 & 256,54 & 21,87 & \begin{tabular}{|l|}
23,07 \\
\end{tabular} & 247,50 \\
\hline Pelobates cultripes & 29SNB86 & 100,00 & 162,07 & 103,04 & 42,00 & 4757,32 & 303,96 & 61,80 & 242,16 & 114,11 & 222,48 & 226,92 & 105,67 & 561,37 & 85,89 & 2,00 & 63,65 & 250,74 & 22,00 & 23,10 & 242,69 \\
\hline Pelobates cultripes & 29SNB87 & 101,00 & 164,19 & 104,66 & 42,02 & 4802,14 & 308,43 & 63,30 & 245,14 & 115,60 & \begin{tabular}{|l|l|}
225,09 \\
\end{tabular} & \begin{tabular}{l|l|}
229,45 \\
\end{tabular} & \begin{tabular}{|l|l|}
107,14 \\
\end{tabular} & 552,20 & 83,83 & 2,00 & 63,11 & \begin{tabular}{|l|l|}
244,63 \\
\end{tabular} & 22,16 & 23,00 & 237,50 \\
\hline Pelobates cultripes & 29SNB88 & 101,00 & 164,83 & 106,41 & 42,05 & 4854,87 & 311,95 & 63,2 & 248,70 & 115,54 & 226,35 & 230,92 & \begin{tabular}{|l|l|}
107,07 \\
\end{tabular} & 551,99 & 83,25 & 2,00 & 62,32 & 242,05 & 2,81 & 23,29 & 236,15 \\
\hline Pelobates cultripes & $295 N B 94$ & 100,00 & 159,33 & 99,98 & 41,80 & 4709,88 & 296,68 & 59,39 & 237,29 & 112,16 & 219,24 & 223,63 & \begin{tabular}{|l|l|l|}
103,63 \\
\end{tabular} & 571,80 & 89,02 & 2,00 & 64,30 & 258,27 & 21,49 & 23,73 & 247,61 \\
\hline Pelobates cultripes & 29SNB95 & 100,00 & 162,10 & 101,68 & 41,85 & 4764,64 & 301,97 & 61,28 & \begin{tabular}{|l|l|}
240,69 \\
\end{tabular} & \begin{tabular}{ll|}
114,21 \\
\end{tabular} & 222,62 & 226,94 & \begin{tabular}{ll|}
105,44 \\
\end{tabular} & 557,84 & 85,81 & 2,00 & 63,79 & \begin{tabular}{l|l}
250,25 \\
\end{tabular} & 21,36 & 23,25 & 240,45 \\
\hline Pelobates cultripes & 295NB96 & 101,00 & 163,94 & 103,58 & 42,00 & 4820,32 & 306,60 & 62,39 & 244,21 & \begin{tabular}{l|l|l|l|}
115,39 \\
\end{tabular} & $\begin{array}{l}225,06 \\
\end{array}$ & \begin{tabular}{|l|l|}
229,47 \\
\end{tabular} & \begin{tabular}{ll|l}
106,53 \\
\end{tabular} & 548,79 & 83,65 & 2,00 & 63,29 & 244,15 & 21,60 & 23,07 & 235,36 \\
\hline Pelobates cultripes & 29SNB97 & 100,00 & 164,92 & 105,55 & 42,00 & 4874,85 & 310,72 & 62,35 & 248,37 & 115,44 & 226,73 & 231,23 & \begin{tabular}{|l|l|}
106,64 \\
\end{tabular} & 545,94 & 82,66 & 2,00 & 62,55 & 240,46 & 21,97 & 23,29 & 232,84 \\
\hline Pelobates cultripes & 29SNB98 & 100,00 & 166,44 & 107,51 & 42,05 & 4933,26 & 315,14 & 63,07 & 252,06 & 116,25 & 228,91 & 233,37 & \begin{tabular}{|l|}
107,37 \\
\end{tabular} & 539,69 & 81,21 & 2,00 & \begin{tabular}{l|l|}
61,85 \\
\end{tabular} & 235,36 & 22,26 & 23,41 & 228,93 \\
\hline Pelobates cultripes & 29SNB99 & 101,00 & 165,62 & 110,00 & 42,07 & 5015,02 & 318,32 & \begin{tabular}{|l|l|l|}
61,18 \\
\end{tabular} & 257,14 & 114,36 & 229,15 & 233,73 & 105 & 547,67 & 81,68 & 2,00 & 61,23 & 235,78 & 23,44 & 23,94 & 231,03 \\
\hline Pelobates cultripes & 295NC06 & 92,00 & 166,43 & 85,60 & 41,05 & 4169,39 & 285,32 & $\begin{array}{l}79,35 \\
\end{array}$ & 205,97 & \begin{tabular}{|l|l|}
122,99 \\
\end{tabular} & 217,60 & 222,47 & \begin{tabular}{|l|}
115,64 \\
\end{tabular} & \begin{tabular}{|l|l|}
681,47 \\
\end{tabular} & 101,62 & 3,41 & \begin{tabular}{l|l}
63,05 \\
\end{tabular} & 302,61 & 28,84 & 31,25 & 293,11 \\
\hline Pelobates cultripes & 29SNC07 & 101,00 & 169,51 & 84,83 & 40,99 & 4161,27 & 287,38 & 82,44 & 204,94 & \begin{tabular}{l|l|}
125,92 \\
\end{tabular} & 220,59 & 225,31 & $\begin{array}{ll}118,66 \\
\end{array}$ & 667,01 & 99,49 & 3,01 & 63,32 & 296,84 & 27,18 & 30,14 & 287,32 \\
\hline Pelobates cultripes & 29SNC08 & 88,00 & 170,53 & 83,66 & 40,89 & 4135,33 & 286,57 & 83,89 & 202,68 & $127, \underline{C}$ & 221,21 & 225,76 & 119,78 & 664,00 & 99, & 3,0 & $63,2,2-2$ & 295, & 26,97 & 30,01 & 285,61 \\
\hline Pelobates cultripes & $29 \mathrm{SNC1}$ & 101,00 & 170, & 85,57 & 40,95 & 4216,61 & 289 & 82,38 & 207, & 126 & 222 & 226 & 118 & 654, & 96,99 & 3,00 & $62, \varepsilon$ & 288,89 & 27,13 & 30,05 & 280 \\
\hline Pelobates cultripes & 29SNC19 & 100,00 & 169,45 & 84,33 & 40,73 & 4178,78 & 286,88 & 81,82 & 205,06 & 125,35 & \begin{tabular}{|l|l|}
220,79 \\
\end{tabular} & \begin{tabular}{l|l|}
225,15 \\
\end{tabular} & \begin{tabular}{|l|}
117,87 \\
\end{tabular} & 663,76 & 98,49 & 3,00 & 62,52 & 292,10 & 27,61 & 30,92 & 284,15 \\
\hline Pelobates cultripes & 29SNC21 & 101,00 & 164,38 & 92,12 & 42,16 & 4247,06 & 290,22 & 74,66 & 215,56 & \begin{tabular}{|l|l|}
121,27 \\
\end{tabular} & 217,10 & 221,97 & \begin{tabular}{|l|l|}
113,42 \\
\end{tabular} & 612,68 & 91,38 & 2,49 & 63,49 & 272,22 & \begin{tabular}{l|l}
25,95 \\
\end{tabular} & 26,81 & 265,08 \\
\hline Pelobates cultripes & 29SNC22 & 99,00 & 166,10 & 91,82 & 42,02 & 4275,52 & 292,11 & 76,33 & 215,78 & 122,47 & \begin{tabular}{|l|l|}
219,16 \\
\end{tabular} & \begin{tabular}{|l|}
224,04 \\
\end{tabular} & \begin{tabular}{ll|}
114,58 \\
\end{tabular} & \begin{tabular}{|l|l|}
614,17 \\
\end{tabular} & 91,45 & 2,67 & 63,12 & 272,23 & 6,19 & 27,32 & 265,21 \\
\hline Pelobate & $295 \mathrm{NC23}$ & 101,00 & & 91, & 42,0 & 4281,82 & & 78, & 215, & & 221, & 226,66 & 116 & 608 & 90,47 & 2,99 & \begin{tabular}{|c|}
63,12 \\
\end{tabular} & 269 & 25,78 & 27,64 & \\
\hline Pelobates cultripes & 29 SNC24 & 100,00 & 170,19 & 90,79 & 41,82 & 4295,96 & 295,24 & 80,06 & 215,18 & \begin{tabular}{ll|}
125,66 \\
\end{tabular} & 223,30 & 228,07 & $117,87 \mid$ & 612,17 & 90,74 & 2,98 & 62,43 & $270,48 \mid$ & 26,14 & 27,79 & 263 \\
\hline Pelobates cultripes & 29SNC25 & 72,00 & 171,37 & 90,26 & 41,50 & 4305,01 & 296,38 & 81,59 & 214,79 & 126,64 & 224,69 & 229,51 & 119,16 & 611,59 & 90,23 & 3,00 & 62,83 & 269,90 & 25,77 & 27,76 & 263,10 \\
\hline
\end{tabular}




\begin{tabular}{|c|c|c|c|c|c|c|c|c|c|c|c|c|c|c|c|c|c|c|c|c|c|}
\hline TAXON & UTM & $\mathrm{km} 2$ & B101 & B102 & $\mathrm{BIO3}$ & BIO4 & B105 & B106 & B107 & B108 & B109 & B1010 & BIO11 & BIO12 & B1013 & BIO14 & BIO15 & B1016 & B1017 & B1018 & B1019 \\
\hline Pelobates cultripes & 29SNC26 & 88,00 & 170,97 & 89,48 & 41,11 & 4314,14 & 295,55 & 81,21 & 214,34 & 126,11 & 224,43 & 229,03 & 118,54 & 625,67 & 92,01 & 3,00 & 62,56 & 275,11 & 26,84 & 29,01 & 268,52 \\
\hline Pelobates cultripes & 29SNC27 & 101,00 & 170,20 & 88,60 & 40,99 & 4323,06 & 294,15 & 80,47 & 213,68 & 125,06 & 223,61 & 228,18 & 117,38 & 639,31 & 94,12 & 3,00 & 62,43 & 280,42 & 27,36 & 29,82 & 274,05 \\
\hline Pelobates cultripes & 29 SNC29 & 100,00 & 169,06 & 86,49 & 40,86 & 4278,31 & 290,27 & 80,32 & 209,94 & 124,19 & 222,01 & 226,24 & 116,70 & 658,33 & 97,10 & 3,03 & 61,99 & 287,19 & 28,26 & 31,05 & 280,91 \\
\hline Pelobates cultripes & 29SNC31 & 101,00 & 161,27 & 94,95 & 42,00 & 4402,58 & 292,56 & 69,61 & 222,95 & 116,77 & 216,36 & 221,20 & 108,72 & 624,36 & 92,71 & 2,89 & 62,71 & 274,96 & 27,25 & 27,68 & 269,36 \\
\hline Pelobates cultripes & 29SNC32 & 101,00 & 164,58 & $\begin{array}{l}94,37 \\
\end{array}$ & 41,92 & \begin{tabular}{ll|l|}
4412,68 \\
\end{tabular} & 295,47 & 72,80 & 222,67 & 119,62 & 219,70 & 224,62 & \begin{tabular}{|l|l|}
111,69 \\
\end{tabular} & \begin{tabular}{|c|}
614,58 \\
\end{tabular} & 90,98 & 2,73 & 62,64 & 270,49 & 26,43 & 27,17 & 264,92 \\
\hline Pelobates cultripes & 29SNC33 & 100,00 & 167,77 & 93,79 & 41,93 & 4408,51 & 297,79 & 76,01 & 221,78 & 122,43 & 222,68 & 227,53 & 114,64 & 605,45 & 89,46 & 2,95 & 62,79 & 266,27 & 25,92 & 26,94 & 260,68 \\
\hline Pelobates cultripes & $295 N C 34$ & 101,00 & 169,72 & 93,09 & 41,86 & 4404,57 & 299,00 & 78,24 & 220,76 & 124,28 & 224,49 & 229,21 & 116,51 & 603,04 & 88,72 & 2,98 & 62,63 & 264,73 & 25,86 & 26,98 & 259,18 \\
\hline Pelobates cultripes & 29 SNC35 & 101,00 & 171,03 & 92,25 & 41,48 & 4404,83 & 299,52 & 79,46 & 220,05 & 125,40 & 225,77 & 230,49 & 117,50 & 604,24 & 88,76 & 3,00 & 62,41 & 264,68 & 25,77 & 27,49 & 259,25 \\
\hline Pelobates cultripes & 29SNC36 & 100,00 & 169,00 & 91,56 & \begin{tabular}{ll|}
41,06 \\
\end{tabular} & 4431,00 & 297,64 & 77,78 & 219,86 & 122,84 & 224,17 & 228,71 & 115,32 & 627,90 & 92,08 & 3,00 & 61,85 & 273,39 & 27,58 & 29,37 & 268,51 \\
\hline Pelobates cultripes & 29SNC37 & 101,00 & 169,03 & 90,66 & 40,99 & 4427,78 & 296,69 & 77,94 & 218,75 & 122,70 & 224,05 & 228,61 & 115,18 & 636,97 & 93,47 & 3,05 & 61,64 & 276,64 & 28,14 & 30,01 & 271,91 \\
\hline Pelobates cultripes & $295 N C 38$ & 100,00 & 167,84 & 89,72 & 40,97 & 4423,35 & 294,69 & 76,97 & 217,72 & 121,60 & 222,86 & 227,25 & 113,91 & 653,12 & 95,80 & 3,45 & 61,27 & 282,41 & 29,44 & 31,45 & 277,99 \\
\hline Pelobates cultripes & 29SNC39 & 100,00 & 168,15 & 88,67 & 40,81 & 4385,91 & 293,38 & 77,73 & 215,65 & 122,21 & 222,70 & 227,00 & 114,55 & 657,82 & 96,56 & 3,71 & 61,08 & 283,95 & 29,97 & 32,20 & 279,29 \\
\hline Pelobates cultripes & $295 N C 40$ & 101,00 & 167,25 & 97,05 & \begin{tabular}{ll|l}
42,15 \\
\end{tabular} & 4438,80 & 300,13 & 73,75 & 226,38 & 122,15 & 222,81 & 227,46 & 114,11 & 570,75 & 85,50 & 2,00 & 63,50 & 253,58 & 23,46 & 24,21 & 247,48 \\
\hline Pelobates cultripes & 29SNC41 & 101,00 & 166,46 & 97,10 & 42,00 & 4485,43 & 300,43 & 72,71 & 227,71 & 120,71 & 222,62 & 227,24 & 112,62 & 584,59 & 86,96 & 2,10 & 63,03 & 257,83 & 24,48 & 25,09 & 252,44 \\
\hline Pelobates cultripes & 29SNC42 & 99,00 & 168,70 & 96,55 & 42,00 & \begin{tabular}{ll|l}
4483,66 \\
\end{tabular} & 302,16 & 75,09 & 227,07 & 122,67 & 224,64 & 229,38 & 114,78 & 580,33 & 85,94 & 2,06 & 62,96 & 255,20 & 24,26 & 25,13 & 250,04 \\
\hline Pelobates cultripes & 29 SNC44 & 101,00 & 169,99 & 95,22 & 41,79 & 4509,82 & 302,72 & 76,65 & 226,07 & 123,49 & 226,24 & 231,00 & 115,48 & 591,50 & 86,65 & 2,87 & 61,89 & 257,60 & 25,84 & 27,04 & 253,18 \\
\hline Pelobates cultripes & 29 SNC45 & 101,00 & 169,94 & 94,46 & 41,41 & 4514,58 & 302,27 & 76,89 & 225,38 & 123,17 & 226,18 & 230,97 & 115,35 & 601,31 & 87,88 & 3,00 & 61,71 & 260,69 & 26,58 & 27,74 & 256,66 \\
\hline Pelobates cultripes & $295 N C 46$ & 100,00 & 168,48 & 93,61 & 41,02 & 4534,77 & 300,59 & 75,62 & 224,97 & 121,42 & 225,07 & 229,66 & 113,51 & 619,70 & 90,45 & 3,03 & 61,34 & 267,23 & 27,81 & 29,05 & 263,86 \\
\hline Pelobates cultripes & 29SNC47 & 100,00 & 167,73 & 92,62 & \begin{tabular}{|l|l|}
40,97 \\
\end{tabular} & 4524,31 & 299,07 & 75,36 & 223,71 & 120,67 & 224,19 & 228,77 & 112,91 & 635,36 & 92,66 & 3,44 & 60,82 & 272,81 & 29,39 & 30,81 & 269,64 \\
\hline Pelobates cultrips & 29SNC49 & 101,00 & 167,49 & 90,72 & \begin{tabular}{|l|l|}
40,48 \\
\end{tabular} & 4504,72 & 296,56 & 75,55 & 221.01 & $\mid 120,28$ & 223,71 & 227,97 & $|112,67|$ & 655,11 & 95,53 & 3,96 & 60,30 & 279,75 & 31,13 & 32.90 & 276,80 \\
\hline Pelobates cultripes & 29SNC50 & 101,00 & 169,36 & 99,40 & 42,16 & 4546,86 & 305,86 & 73,78 & 232,08 & 122,96 & 226,42 & 231,14 & 114,82 & 551,54 & 82,7 & 2,00 & 63,51 & 244,19 & 22,46 & 23,32 & 238,44 \\
\hline Pelobates cultripes & 29SNC51 & 101,00 & 169,44 & 99,28 & 42,04 & 4569,18 & 306,46 & 73,87 & 232,59 & 122,67 & 226,81 & 231,38 & 114,65 & 560,00 & 83,21 & 2,00 & 62,58 & 245,94 & 23,75 & 24,40 & 240,90 \\
\hline Pelobates cultripes & 29SNC52 & 101,00 & 169,67 & $\begin{array}{ll}98,88 \\
\end{array}$ & 42,01 & \begin{tabular}{|l|l|}
4587,13 \\
\end{tabular} & 306,68 & 74,25 & 232,43 & 122,60 & 227,16 & 231,83 & $\begin{array}{ll}114,48 \\
\end{array}$ & 566,97 & 83,56 & 2,08 & 62,27 & 247,49 & 24,29 & 24,99 & 243,05 \\
\hline Pelobates cultripes & 29 SNC53 & 100,00 & 170,04 & 98,17 & 41,97 & 4596,44 & 306,70 & 74,80 & 231,89 & 122,87 & 227,55 & 232,26 & 114,58 & 573,44 & 83,86 & 2,58 & 61,79 & 248,75 & 25,34 & 26,21 & 244,83 \\
\hline Pelobates cultripes & 29 SNC54 & 101,00 & 168,58 & 97,49 & 41,65 & 4619,20 & 305,30 & 73,76 & 231,54 & 121,07 & 226,41 & 231,19 & 113,01 & 590,22 & 85,94 & 2,99 & 61,12 & 254,27 & 26,74 & 27,45 & 251,14 \\
\hline Pelobates cultripes & 29SNC55 & 100,00 & 168,90 & 96,51 & 41,20 & 4621,95 & 304,91 & 74,40 & 230,51 & 121,21 & 226,82 & 231,37 & 113,07 & 597,31 & 86, & 3,00 & 60,85 & 256,22 & 27,24 & 28,15 & 253,45 \\
\hline Pelobates cultripes & 29SNC56 & 101,00 & 164,47 & 95,36 & 40,94 & 4653,64 & 300,76 & 70,51 & 230,25 & \begin{tabular}{|l|l|}
116,51 \\
\end{tabular} & $\begin{array}{l}222,78 \\
226\end{array}$ & 227,54 & 108,55 & 636,12 & $\begin{array}{l}0,0318 \\
92,18\end{array}$ & 3,69 & $\begin{array}{ll}60,01 \\
6\end{array}$ & 270,33 & 30,59 & 31,18 & 268,80 \\
\hline Pelobates cultripes & 29SNC57 & 100,00 & 163,63 & 94,28 & 40,87 & 4652,67 & 298,97 & 70,09 & 228,88 & 115,47 & 221,89 & 226,65 & 107,55 & 653,05 & 94,55 & 4,00 & 59,70 & 276,30 & 32,10 & 32,64 & 275,18 \\
\hline Pelobates cultripes & 29 SNC58 & 101,00 & 166,18 & 93,38 & 40,73 & 4621,51 & 299,98 & 72,89 & 227,09 & 118,19 & 224,19 & 228,68 & 110,35 & 646,13 & 93,50 & 4,00 & 59,70 & 273,34 & 31,76 & 32,74 & 271,86 \\
\hline Pelobates cultripes & 29 SNC59 & 101,00 & 166,11 & 92,51 & 40,31 & 4606,06 & 298,89 & 73,02 & 225,86 & 118,06 & 223,91 & 228,27 & 110,24 & 657,11 & 95,19 & 4,00 & 59,58 & 277,46 & 32,31 & 33,59 & 275,99 \\
\hline Pelobates cultripes & 29 SNC60 & 100,00 & 168,91 & 102,19 & 42,14 & 4666,86 & 309,80 & 71,14 & 238,66 & 121,42 & 227,67 & 232,32 & 113,08 & 548,16 & 81,95 & 2,00 & 62,98 & 240,78 & 22,67 & 23,01 & 235,76 \\
\hline Pelobates cultripes & $295 N C 61$ & 100,00 & 169,39 & 102,09 & $\begin{array}{l}42,14 \\
42,06\end{array}$ & 4689,62 & 310,75 & 71,73 & $\begin{array}{l}50,000 \\
239,02\end{array}$ & \begin{tabular}{|l|}
121,44 \\
121,4
\end{tabular} & 228,44 & 233,05 & 113,19 & 5402,32 & $\begin{array}{l}1,1,83 \\
81\end{array}$ & 2,00 & $\begin{array}{ll}62,34 \\
62\end{array}$ & 240,81 & 23,25 & 23,92 & 236,45 \\
\hline Pelobates cultripes & 29SNC62 & 101,00 & 169,70 & $\begin{array}{ll}101,47 \\
\end{array}$ & 42,00 & 4702,51 & 310,90 & 72,32 & 238,58 & 121,60 & 228,84 & 233,60 & 113,19 & 557,38 & 81,73 & 2,03 & 61,72 & 241,28 & 24,33 & 24,76 & 237,62 \\
\hline Pelobates cultripes & 29 SNC63 & 100,00 & 169,43 & 100,65 & \begin{tabular}{|l|l|}
41,97 \\
\end{tabular} & 4709,57 & 310,18 & 72,45 & 237,73 & 120,91 & 228,61 & 233,21 & 112,84 & 567,75 & 82,31 & 2,86 & 60,67 & 243,66 & 26,02 & 26,75 & 240,76 \\
\hline Pelobates cultripes & 29 SNC65 & 101,00 & 165,21 & 98,42 & 41,09 & 4744,75 & 305,35 & 69,42 & 235,94 & 116,34 & 224,94 & 229,67 & 108,29 & 609,86 & 87,75 & 3,01 & 60,04 & 257,88 & 29,32 & 29,53 & 256,77 \\
\hline Pelobates cultripes & $295 \mathrm{~N} C 67$ & 101,00 & 160,92 & 95,55 & 40,51 & 4762,73 & 299,50 & 66,41 & 233,08 & 108,31 & 221,06 & 225,57 & 103,85 & 660,70 & 94,83 & 4,00 & 58,89 & 276,39 & 33,88 & 33,97 & 276,32 \\
\hline Pelobates cultripes & $295 \mathrm{NC} 68$ & 101,00 & 103,25 & \begin{tabular}{|c|}
94,70 \\
94,70
\end{tabular} & 40,31 & 4730,67 & 300,30 & \begin{tabular}{|c|c|}
68,96 \\
\end{tabular} & \begin{tabular}{|l|}
231,34 \\
234
\end{tabular} & \begin{tabular}{|l|}
$111,72,1$ \\
110
\end{tabular} & 222,91 & $\mid$\begin{tabular}{|l|}
227,37 \\
\end{tabular} & \begin{tabular}{|l|}
106,33 \\
1060
\end{tabular} & 6000,62 & $\begin{array}{l}4,405 \\
94,41 \\
\end{array}$ & 4,00 & $\begin{array}{ll}0,0,05 \\
58,85\end{array}$ & \begin{tabular}{|l|}
274,96 \\
27
\end{tabular} & $\begin{array}{l}30,00 \\
33,71\end{array}$ & $\begin{array}{l}34,14 \\
34\end{array}$ & 274,80 \\
\hline Pelobates cultripes & 29SNC69 & 100,00 & 165,62 & 94,16 & 40,24 & 4717,41 & 301,63 & 71,25 & 230,38 & 115,59 & 224,87 & 229,36 & 108,58 & 652,73 & 93,69 & 4,00 & 58,75 & 272,66 & 33,34 & 34,18 & 272,37 \\
\hline Pelobates cultripes & 29SNC71 & 100,00 & 167,97 & 105,13 & 42,01 & 4818,71 & 314,16 & 68,10 & 246,06 & 118,71 & 228,77 & 233,40 & 110,28 & 553,44 & 81,62 & 2,00 & 61,39 & 238,80 & 23,73 & 24,02 & 235,39 \\
\hline Pelobates cultripes & $29 \mathrm{SNC72}$ & 101,00 & 168,99 & 104,16 & 42,00 & 4819,09 & 314,36 & 69,59 & 244,77 & 119,59 & 229,74 & 234,33 & 111,15 & 554,55 & 80, & 2,28 & 61,04 & 237,65 & 24,72 & 25,06 & 234,67 \\
\hline Pelobates cultripes & 29 SNC73 & 101,00 & 167,30 & 103,29 & 41,94 & 4840,16 & 312,68 & 68,40 & 244,28 & 117,58 & 228,25 & 23 & 109,32 & 571,18 & 81, & 3,0 & 59,96 & 242,07 & 27,26 & 27,38 & 240,14 \\
\hline 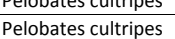 & 295NC74 & $\begin{array}{l}101,00 \\
101,00\end{array}$ & $\begin{array}{l}10,50 \\
164,58\end{array}$ & $\begin{array}{l}101,83 \\
101,83\end{array}$ & 41 & $\begin{array}{l}484,10 \\
4855,15\end{array}$ & $\begin{array}{l}31,00 \\
309,36\end{array}$ & $\begin{array}{l}0,404 \\
66,51 \\
\end{array}$ & \begin{tabular}{|l|}
242,84 \\
242,8
\end{tabular} & $\begin{array}{l}114,73 \\
114,3\end{array}$ & $\mid$\begin{tabular}{|l|l|l|l|l|}
226,27 \\
\end{tabular} & \begin{tabular}{|l|}
230,53 \\
230
\end{tabular} & $\begin{array}{l}109,32 \\
106,55 \\
\end{array}$ & | & $\begin{array}{l}1,49 \\
84,98 \\
\end{array}$ & $\begin{array}{l}3,000 \\
3,00\end{array}$ & 59,50 & \begin{tabular}{|l|}
250,03 \\
250
\end{tabular} & $\begin{array}{l}21,20 \\
28,86\end{array}$ & $\begin{array}{l}2,306 \\
28,86\end{array}$ & $\begin{array}{l}240,14 \\
249,31\end{array}$ \\
\hline Pelobates cultripes & 29 SNC75 & 100,00 & 164,53 & 100,09 & 41,03 & 4838,18 & 307,66 & 67,28 & 240,38 & 114,29 & 226,21 & 230,19 & 106,54 & 604,28 & 86,00 & 3,00 & 59,13 & 252,46 & 30,18 & 30,18 & 252,28 \\
\hline Pelobates cultripes & $295 N C 76$ & 101,00 & 160,29 & 98,06 & 40,77 & 4851,99 & 302,55 & 64,27 & 238,27 & 104,42 & 223,43 & 226,39 & 102,36 & 641,73 & 91,18 & 3,81 & 58,25 & 266,81 & 33,29 & 33,29 & 266,81 \\
\hline Pelobates cultripes & 29SNC78 & 99,00 & 160,21 & 95,62 & 40,11 & 4836,39 & 300,15 & 65,21 & 234,94 & 102,41 & 222,25 & 225 & 102,35 & 669,04 & 95, & 4,02 & 57,86 & 77,31 & 35,75 & 35,75 & 277,31 \\
\hline Pelobates cultripes & 295NC79 & 101,00 & 163,50 & $\begin{array}{l}0,20 \\
95,29 \\
\end{array}$ & 40,00 & 4 & 302,59 & $\begin{array}{l}0,2115 \\
68,15\end{array}$ & 234,43 & \begin{tabular}{|l|}
106,34 \\
10,41
\end{tabular} & 224,34 & 22 & 10 & 6599,75 & $\begin{array}{l}0,148 \\
93,87 \\
\end{array}$ & $\begin{array}{l}4,0,00 \\
4,4\end{array}$ & 57,83 & 273,29 & 35,38 & 35,75 & 273,29 \\
\hline Pelobates cultripes & $29 \mathrm{SNC} 80$ & 101,00 & 165,24 & 108,90 & 42,22 & 4951,82 & 316,80 & 62,73 & 254,06 & 114,69 & 227,97 & 232,64 & 106,17 & 558,11 & 82, & 2,06 & 61,14 & 239,67 & 24,29 & 24,41 & 236,34 \\
\hline Pelobates cultripes & $29 \mathrm{SNC} 81$ & 101,00 & 165,59 & 108,62 & 42,09 & 4964,21 & 317,28 & 63,29 & 253,99 & 114,89 & 228,42 & 233,08 & 106,27 & 561,88 & 82,25 & 2,18 & 60,46 & 239,21 & 25,24 & 25,36 & 236,65 \\
\hline Pelobates cultripes & 29 SNC82 & 99,00 & 167,03 & 107,19 & 42,01 & 4950,75 & 317,14 & 65,50 & 251,64 & 116,11 & 229,61 & 234,29 & 107,79 & 559,42 & 80,96 & 2,64 & 60,02 & 236,69 & 26,40 & 26,50 & 234,41 \\
\hline Pelobates cultripes & 29 SNC83 & 101,00 & 165,01 & 105,72 & 41,8 & 4963,12 & 314,42 & 64,19 & 250,23 & 113,99 & 228,62 & 232,37 & 105,65 & 577,32 & 82,20 & 3,00 & 59,25 & 41,88 & 28,08 & 28,08 & 240,77 \\
\hline Pelobates cultripes & 29SNC84 & 101,00 & 103,01 & $\begin{array}{l}103,66 \\
103\end{array}$ & $\frac{41}{41}$ & $\frac{4}{4}$ & 311,42 & $\begin{array}{l}64,15 \\
63,87 \\
\end{array}$ & \begin{tabular}{|l|}
247,52 \\
\end{tabular} & \begin{tabular}{|l|}
112,01 \\
12,01
\end{tabular} & $\begin{array}{l}220,0<2 \\
227,62\end{array}$ & \begin{tabular}{|l|}
230,76 \\
\end{tabular} & \begin{tabular}{|l|}
104,360 \\
\end{tabular} & 593,24 & $\begin{array}{l}\mid c, 2,0 \\
83,70\end{array}$ & $\frac{3,0}{3,0}$ & $\begin{array}{l}58,25 \\
58,59\end{array}$ & \begin{tabular}{|l|}
$241,0,40$ \\
246
\end{tabular} & $\begin{array}{l}20,00 \\
29,81\end{array}$ & \begin{tabular}{|l|}
29,810 \\
291
\end{tabular} & 246,24 \\
\hline Pelobates cultripes & 29SNC85 & 100,00 & 163,64 & 101,55 & 41,01 & 4935,13 & 309,45 & 65,10 & 244,36 & 108,31 & 227,21 & 230,59 & 104,60 & 598,99 & 84,16 & 3,00 & 58,12 & 247,69 & 30,76 & 30,76 & 247,69 \\
\hline Pelobates cultripes & 29 SNC86 & 100,00 & 161,19 & $\begin{array}{l}99,26 \\
99\end{array}$ & 40,70 & 4930,57 & 305,38 & 63,90 & 241,49 & \begin{tabular}{|l|l|}
102,56 \\
\end{tabular} & \begin{tabular}{|l|}
226,06 \\
\end{tabular} & 228,18 & 102,29 & $\mid 624,39$ & $\begin{array}{l}\mid 4,101 \\
87,51\end{array}$ & 3,77 & 57,59 & 257,09 & 33,38 & 33,38 & 257,09 \\
\hline Pelobates cultripes & 29 SNC87 & 100,00 & 157,48 & 97,19 & 40,03 & 4938,52 & 300,59 & 61,44 & 239,15 & 98,67 & 223,75 & 224,75 & 98,67 & 661,51 & 92,89 & 4,07 & 57,07 & 271,88 & 36,14 & 36,14 & 271,88 \\
\hline Pelobates cultripes & 29 SNC88 & 101,00 & 158,80 & 96,51 & 39,9 & 4931,32 & 301,25 & 62,78 & 238,47 & 100,02 & 224,18 & 225 & 100,02 & 667,61 & 93,90 & 4,19 & 56,95 & 274,30 & 36,84 & 36,84 & 27 \\
\hline Pelobates cultripes & $\begin{array}{l}295 N C 89 \\
\end{array}$ & $\begin{array}{l}100,00 \\
100\end{array}$ & $\begin{array}{l}150,00 \\
163,08\end{array}$ & $\begin{array}{l}0,11 \\
96,52 \\
\end{array}$ & | & 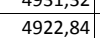 & 304,76 & $\begin{array}{l}2,10 \\
66,54 \\
\end{array}$ & \begin{tabular}{|l|}
238,417 \\
238,22 \\
\end{tabular} & \begin{tabular}{|l|l|}
104,04 \\
\end{tabular} & \begin{tabular}{|l|}
225,79 \\
225
\end{tabular} & \begin{tabular}{|l|}
229,75 \\
224
\end{tabular} & \begin{tabular}{|l|l|}
$103,99<9$ \\
\end{tabular} & | & $\begin{array}{l}3,10 \\
92,12 \\
\end{array}$ & $\begin{array}{l}4,15 \\
4,03 \\
\end{array}$ & $\begin{array}{ll}57,18 \\
57,18\end{array}$ & \begin{tabular}{|l|}
268,90 \\
\end{tabular} & $\begin{array}{l}30,04 \\
36,06\end{array}$ & $\begin{array}{l}0,044 \\
36,14 \\
\end{array}$ & 268,90 \\
\hline Pelobates cultripes & 29 SNC90 & 100,00 & 163,67 & 112,38 & 42,31 & 5089,53 & 320,41 & 58,57 & 261,84 & 111,71 & 228,54 & 232,88 & 103,12 & 562,60 & 82,93 & 2,10 & 60,35 & 238,93 & 25,01 & 25,10 & 235,98 \\
\hline Pelobat & 295NC91 & 100,00 & 164,76 & 111.73 & 42,12 & 5095,89 & 321,09 & 60,14 & 260.95 & 112.42 & 229,47 & 233.99 & $\mid 103.97$ & 560.86 & 81.73 & 2.19 & 59,75 & 236,43 & 26,09 & 26,09 & 234,05 \\
\hline Pelobates cultripes & 29SNC93 & 100,00 & 163,36 & 107,68 & 41,78 & 5076,10 & 316,32 & 60,82 & 255,49 & 111, & 228, & 232,37 & 102 & 580,06 & 81,76 & 3,00 & 58,43 & 240 & 28,79 & 28,79 & 239,58 \\
\hline Pelobates cultripes & 29 SNC95 & 101,00 & 162,26 & 102,82 & 40,99 & 5036,47 & 310,58 & 62,31 & 248,27 & 103,86 & 228,90 & 230,65 & 102,00 & 598,80 & 83,23 & 3,07 & 57,54 & 245,44 & 31,23 & 31,23 & 245,44 \\
\hline
\end{tabular}




\begin{tabular}{|c|c|c|c|c|c|c|c|c|c|c|c|c|c|c|c|c|c|c|c|c|c|}
\hline TAXON & UTM & $\mathrm{km} 2$ & B101 & B102 & $\mathrm{BIO3}$ & B104 & B105 & B106 & B107 & B108 & B109 & B1010 & BIO11 & BIO12 & B1013 & BIO14 & BIO15 & B1016 & B1017 & 81018 & B1019 \\
\hline Pelobates cultripes & 29SNC96 & 100,00 & 161,72 & 100,41 & 40,40 & 5014,36 & 307,90 & 63,07 & 244,83 & 101,64 & 227,53 & 229,77 & 101,64 & 610,86 & 84,42 & 3,90 & 56,55 & 248,98 & 33,86 & 33,86 & 248,98 \\
\hline Pelobates cultripes & 29SNC97 & 101,00 & 160,32 & 98,67 & 40,00 & 5013,92 & 305,33 & 62,47 & 242,87 & 100,35 & 227,13 & 228,47 & 100,35 & 630,48 & 87,14 & 4,00 & 56,21 & 256,55 & 35,39 & 35,39 & 256,55 \\
\hline Pelobates cultripes & 29SNC98 & 101,00 & 160,41 & 97,95 & 40,00 & 5019,94 & 305,06 & 62,60 & 242,46 & 100,33 & 226,64 & 228,62 & 100,33 & 646,31 & 89,76 & 4,01 & 56,42 & 263,36 & 36,37 & 36,37 & 263,36 \\
\hline Pelobates cultripes & 29SNC99 & 100,00 & 162,60 & 97,82 & 39,99 & 5028,22 & 307,13 & 64,41 & 242,72 & 102,16 & 226,96 & 230,84 & 102,16 & 649,82 & 90,50 & 4,00 & 56,37 & 264,99 & 36,64 & 36,65 & 264,99 \\
\hline Pelobates cultripes & 29SND00 & 86,00 & 168,99 & 80,29 & 40,89 & \begin{tabular}{|l|l|}
3998,73 \\
\end{tabular} & 279,15 & 84,05 & 195,10 & 126,88 & 217,88 & 221,80 & 119,13 & 669,94 & 101,14 & 3,00 & 62,94 & 296,62 & 27,01 & 30,94 & 286,32 \\
\hline Pelobates cultripes & 29SND02 & 101,00 & 164,16 & 76,69 & 40,82 & 3826,01 & 267,79 & 81,53 & 186,27 & 123,76 & 210,72 & 214,20 & 116,05 & 686,86 & 105,02 & 3,44 & 62,06 & 302,33 & 29,19 & 33,27 & 290,53 \\
\hline Pelobates cultripes & 29SND11 & 101,00 & 168,36 & 81,61 & 40,94 & 4048,53 & 280,49 & 82,40 & 198,09 & 125,47 & 217,97 & 221,82 & 118,03 & 666,83 & 99,99 & 3,01 & 62,14 & 292,33 & 28,04 & 31,66 & 283,46 \\
\hline Pelobates cultripes & 29SND12 & 101,00 & 166,69 & 80,13 & 40,82 & 3974,29 & 276,01 & 81,52 & 194,50 & 124,59 & 215,32 & $\begin{array}{l}218,92 \\
21,9\end{array}$ & 117,01 & 675,43 & \begin{tabular}{|r|}
101,78 \\
\end{tabular} & 3,45 & 61,80 & 295,13 & 29,08 & 32,92 & 285,80 \\
\hline Pelobates cultripes & 29SND13 & 100,00 & 162,92 & 79,09 & 40,77 & 3927,40 & 270,65 & 78,49 & 192,16 & 121,42 & 211,05 & 214,49 & 113,77 & 702,38 & 105,55 & 4,00 & 61,02 & 304,83 & 31,85 & 35,66 & 295,47 \\
\hline Pelobates cultripes & 29SND17 & 101,00 & 140,89 & 77,42 & 40,20 & \begin{tabular}{|l|l|}
3896,44 \\
\end{tabular} & 247,82 & 57,69 & 190,13 & 100,32 & 189,19 & 192,27 & 92,55 & 923,35 & 136,53 & 7,84 & 57,81 & 387,36 & 51,57 & 54,11 & 380,57 \\
\hline Pelobates cultripes & 29SND18 & 100,00 & 150,32 & 77,86 & 41,17 & 3751,52 & 253,42 & 66,79 & 186,64 & 110,63 & 196,26 & 199,05 & 102,79 & 842,71 & 124,44 & 6,59 & 57,92 & 354,03 & 45,62 & 49,85 & 346,48 \\
\hline Pelobates cultripes & 29SND20 & 100,00 & 168,46 & 85,41 & 40,66 & 4240,96 & 287,78 & 79,95 & 207,83 & 123,80 & 220,89 & 224,97 & 116,20 & 665,77 & 98,32 & 3,52 & 61,55 & 289,62 & 29,26 & 32,28 & 283,13 \\
\hline Pelobates cultripes & 29SND21 & 101,00 & 168,28 & 84,36 & 40,69 & 4184,02 & 285,37 & 80,20 & 205,17 & 124,08 & 219,84 & 223,76 & 116,43 & 668,57 & 98,90 & 3,69 & 61,35 & 290,17 & 29,67 & 32,85 & 283,33 \\
\hline Pelobates cultripes & 29SND22 & 100,00 & 167,60 & 83,33 & 40,74 & 4124,58 & 282,55 & 80,19 & 202,35 & 123,82 & 218,37 & 222,03 & 116,25 & 674,42 & 99,93 & 3,95 & 61,12 & 291,85 & 30,32 & 33,83 & 284,68 \\
\hline Pelobates cultripes & 29SND24 & 100,00 & 164,81 & 81,94 & \begin{tabular}{|l|l|}
40,97 \\
\end{tabular} & 4020,68 & 276,34 & 78,16 & 198,18 & 122,04 & 214,24 & 217,55 & 114,29 & 700,91 & 103,93 & 4,00 & 60,20 & 300,66 & 33,15 & 36,90 & 293,36 \\
\hline Pelobates cultripes & 29 SND26 & 101,00 & 159,71 & 81,56 & 41,01 & 3964,80 & 269,88 & 73,31 & 196,58 & 117,48 & 208,47 & 211,54 & 109,77 & 756,41 & 111,66 & 5,06 & 58,96 & 320,51 & 38,33 & 42,25 & 313,91 \\
\hline Pelobates cultripes & 29SND27 & 101,00 & 147,54 & 81,31 & 40,44 & 4037,86 & 260,08 & 61,37 & 198,71 & 105,03 & 197,73 & 200,82 & 97,41 & 880,62 & 129,94 & 7,08 & 57,73 & 368,51 & 48,65 & 51,27 & 363,81 \\
\hline Pelobates cultripes & 29SND28 & 101,00 & 144,18 & 81,60 & 40,51 & 4038,77 & 257,03 & 57,77 & 199,26 & 101,73 & 194,40 & 197,49 & 93,99 & \begin{tabular}{|l|l|}
927,78 \\
\end{tabular} & 136,62 & 7,98 & 57,12 & 385,76 & 53,21 & 55,56 & 381,90 \\
\hline Pelobates cultripes & 29SND30 & 101,00 & 168,25 & 87,76 & 40,79 & 4347,72 & 291,76 & 78,26 & 213,50 & 122,54 & 222,27 & 226,40 & 114,98 & 663,01 & 97,42 & 3,95 & 60,75 & 285,61 & 30,54 & 32,95 & 280,85 \\
\hline Pelobates cultrips & 29SND31 & 100,00 & 167,67 & 86,84 & $40,60 \mid$ & 4312.47 & 289,58 & 78,11 & 211,47 & $\mid 122,13$ & 221,16 & 225,22 & $\mid 114,66$ & 672,53 & 98,92 & 3,92 & 60,59 & 289,03 & 31,02 & 33,73 & 284,16 \\
\hline Pelobates cultripes & 29SND34 & 100,00 & 166,83 & 85,17 & 40,92 & 4174,14 & 283,97 & 77,71 & 206,26 & 122,48 & 218,47 & 221,85 & 114,71 & 695,73 & 102,21 & 4,03 & 59,65 & 296,03 & 33,76 & 37,29 & 290,63 \\
\hline Pelobates cultripes & $29 \mathrm{SND} 36$ & 101,00 & 163,01 & 85,30 & 40,99 & 4139,85 & 279,47 & 73,62 & 205,86 & 118,69 & 214,20 & 217,29 & 110,95 & 745,59 & \begin{tabular}{|l|l|}
109,38 \\
\end{tabular} & 5,01 & 58,52 & 313,82 & 38,47 & 41,99 & 309,20 \\
\hline Pelobates cultripes & 29SND38 & 101,00 & 154,11 & 86,06 & 40,92 & 4160,23 & 272,22 & \begin{tabular}{|l|l|}
64,23 \\
\end{tabular} & 207,99 & 109,68 & 205,85 & 208,84 & \begin{tabular}{|l|l|}
101,98 \\
\end{tabular} & 852,33 & 124,75 & 6,88 & 57,12 & 353,53 & 48,20 & 50,95 & 350,97 \\
\hline Pelobates cultripes & 29 SND40 & 100,00 & 168,20 & 89,94 & 40,42 & 4473,58 & 295,80 & 76,41 & 219,39 & 121,14 & 223,95 & 228,03 & 113,50 & 657,81 & 96,03 & 4,00 & 60,04 & 280,67 & 31,31 & 33,32 & 277,32 \\
\hline Pelobates cultripes & 29SND41 & 101,00 & 168,65 & 89,19 & 40,51 & 4432,78 & 294,78 & 77,14 & 217,64 & 121,91 & 223,91 & 227,95 & 114,21 & 662,52 & 96,85 & 4,00 & 60,02 & 282,14 & 31,64 & 34,01 & 278,72 \\
\hline Pelobates cultripes & 29SND44 & 100,00 & 163,98 & 87,84 & 40,42 & 4365,45 & 287,47 & 72,59 & 214,88 & 117,42 & 218,27 & 221,88 & 109,75 & 727,36 & 106,51 & 4,88 & 58,87 & 306,26 & 37,05 & 39,69 & 303,29 \\
\hline Pelobates cultripes & $295 N D 46$ & 101,00 & 166,58 & 88,53 & 40,98 & 4293,35 & 288,52 & 74,46 & 214,05 & \begin{tabular}{|l|l|}
120,34 \\
\end{tabular} & 219,92 & 223,14 & 112,81 & 727,41 & 106,05 & $\begin{array}{l}4,000 \\
5,03\end{array}$ & 58,10 & 304,27 & 38,17 & 41,38 & 301,09 \\
\hline Pelobates cultripes & 29SND51 & 100,00 & 168,79 & 91,31 & 40,28 & 4550,32 & 298,81 & 75,55 & 223,27 & 120,76 & 225,68 & 229,68 & 112,94 & 660,12 & 95,85 & 4,00 & 59,32 & 278,45 & 32,50 & 34,38 & 276,43 \\
\hline Pelobates cultripes & 29 SND54 & 100,00 & 163,62 & 90,20 & 40,02 & 4533,12 & 292,51 & 70,56 & 221,95 & 115,70 & 220,47 & 224,08 & 107,92 & 735,01 & 107,10 & 5,02 & 58,32 & 306,96 & 38,58 & 40,59 & 305,63 \\
\hline Pelobates cultripes & 29 SND55 & 100,00 & 162,59 & 90,29 & 40,09 & 4516,73 & 291,27 & 69,36 & 221,91 & 114,68 & 219,35 & 222,82 & 107,06 & 757,73 & 110,34 & 5,54 & 57,69 & 315,09 & 41,03 & 43,10 & 314,16 \\
\hline Pelobates cultripes & 29SND60 & 100,00 & 167,56 & 93,60 & 40,16 & 4693,55 & 302,33 & 73,11 & 229,22 & 118,44 & 226,51 & 230,75 & 110,51 & 652,08 & 93,74 & 4,00 & 58,75 & 272,51 & 33,19 & 34,41 & 271,85 \\
\hline Pelobates cultripes & 29SND61 & 100,00 & 168,42 & 93,18 & 40,17 & 4 & 302,26 & 73,77 & \begin{tabular}{|l|l|}
228,49 \\
\end{tabular} & \begin{tabular}{|l|}
119,18 \\
\end{tabular} & \begin{tabular}{|l|}
227,10 \\
221
\end{tabular} & $\begin{array}{ll}231,18 \\
\end{array}$ & 111,43 & 659,02 & \begin{tabular}{|l|}
94,87 \\
94
\end{tabular} & 4,00 & 58,62 & 275,31 & $\begin{array}{ll}33,64 \\
33\end{array}$ & $\begin{array}{l}35,414 \\
5,16\end{array}$ & 274,36 \\
\hline Pelobates cultripes & 29SND62 & 100,00 & 166,34 & 92,62 & 40,02 & 4682,53 & 300,06 & 71,66 & 228,40 & 116,55 & 225,23 & 229,08 & 109,13 & 689,45 & 99,47 & 4,62 & 58,18 & 287,12 & 36,23 & 37,75 & 286,52 \\
\hline Pelobates cultripes & 29 SND65 & 101,00 & 162,54 & 92,21 & 39,99 & 4676,03 & 296,03 & 67,49 & 228,53 & 110,27 & 221,56 & 225,14 & 105,29 & 763,63 & 110,71 & 5,94 & 57,23 & 315,68 & 42.68 & 44,36 & 315,62 \\
\hline Pelobates cultripes & 29 SND66 & 101,00 & 165,61 & 93,09 & 40,11 & 4654,14 & 298,53 & 69,45 & 229,09 & 114,68 & 224,13 & 227,40 & 108,00 & 751,99 & 108,81 & 5,59 & 57,07 & 310,31 & 41,83 & 44,10 & 310,05 \\
\hline Pelobates cultripes & 29 SND70 & 101,00 & 166,85 & 95,14 & 40,07 & 4804,47 & 305,03 & 70,95 & 234,08 & 113,76 & 227,38 & 231,65 & 108,60 & 651,19 & 92,75 & 4,00 & 57,94 & 269,61 & 34,63 & 35,48 & 269,59 \\
\hline Pelobates cultripes & 29SND71 & 100,00 & $\begin{array}{l}10,03,11 \\
168,1\end{array}$ & $\begin{array}{l}90,14 \\
94,80\end{array}$ & 40,01 & $\begin{array}{l}4049,47 \\
479,65\end{array}$ & 305,51 & $\begin{array}{l}, 1,85 \\
71,85\end{array}$ & \begin{tabular}{|l|}
233,66 \\
23,6
\end{tabular} & $\begin{array}{l}\mid 11,, 0,48 \\
116,\end{array}$ & 228,52 & 232,59 & $\begin{array}{l}109,66 \\
109,0\end{array}$ & $\mid$ & $\begin{array}{l}2,17 \\
93,77\end{array}$ & $\begin{array}{l}4,001 \\
4,01\end{array}$ & 57,93 & \begin{tabular}{|l|}
271,99 \\
270
\end{tabular} & $\begin{array}{l}34,003 \\
34,92 \\
\end{array}$ & $\begin{array}{l}0,40 \\
36,13 \\
\end{array}$ & 271,84 \\
\hline Pelobates cultripes & 29SND72 & 101,00 & 167,56 & 94,45 & 40,00 & 4800,62 & 304,86 & 71,40 & 233,45 & 115,69 & 228,11 & 232,07 & 109,13 & 676,64 & 96,79 & 4,45 & 57,64 & 279,63 & 36,56 & 37,84 & 279,55 \\
\hline Pelobates cultripes & 29SND73 & 101,00 & 166,31 & 94,13 & 39,99 & 4803,72 & 303,41 & 70,01 & 233,40 & 113,13 & 226,98 & 230,79 & 107,78 & 701,93 & 100,70 & 4,97 & 57,44 & 289,84 & 38,35 & 39,74 & 289,81 \\
\hline Pelobates cultripes & 29 SND76 & 101,00 & 166,34 & 94,80 & 39,87 & 4805,36 & 303,58 & 68,38 & 235,21 & 111,06 & 227,19 & 230,44 & 107,33 & 748,79 & 107,79 & 5,66 & 56,58 & 307,78 & 42,49 & 44,37 & 307,73 \\
\hline Pelobates cultripes & 29 SND80 & 101,00 & 166,63 & 96,48 & 40,6 & 4914,35 & 307,64 & 69,17 & 238,47 & 107,97 & 228,70 & 23 & 107,09 & 646,56 & 91,1 & 4,00 & 57,21 & 265,65 & 35,67 & 36,13 & 265,65 \\
\hline 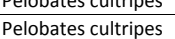 & 29SND81 & $\begin{array}{l}101,00 \\
101,00\end{array}$ & $\begin{array}{l}10,085 \\
168,40\end{array}$ & $\begin{array}{l}90,460 \\
96,43\end{array}$ & 40 & $\begin{array}{l}491,435 \\
491,53 \\
\end{array}$ & $\begin{array}{l}30,04 \\
308,99\end{array}$ & 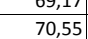 & \begin{tabular}{|l|}
238,47 \\
238,44
\end{tabular} & \begin{tabular}{|l|l|}
$113,75 / 7$ \\
\end{tabular} & $\frac{2 L 8,0}{230,43}$ & $\mid$\begin{tabular}{|l}
$23 L, y 1$ \\
234,46
\end{tabular} & \begin{tabular}{|l|l|l|l|l|l|}
108,68 \\
\end{tabular} & \begin{tabular}{|l|}
$640,50,91$ \\
649
\end{tabular} & $\begin{array}{l}1,14 \\
91,89 \\
\end{array}$ & $\begin{array}{l}4,00 \\
4,05 \\
\end{array}$ & $\begin{array}{ll}37,21 \\
57,22\end{array}$ & \begin{tabular}{|l|}
267,05 \\
267,05
\end{tabular} & $\begin{array}{l}3,001 \\
35,42 \\
\end{array}$ & $\begin{array}{l}0,15 \\
36,48 \\
\end{array}$ & $\begin{array}{l}2003,05 \\
267,05\end{array}$ \\
\hline Pelobates cultripes & 29SND82 & 100,00 & 166,25 & 95,78 & 39,86 & 4933,50 & 307,14 & 68,68 & 238,46 & 107,86 & 228,73 & 232,66 & 106,37 & 683,16 & 97,01 & 4,95 & 56,91 & 280,67 & 38,24 & 39,23 & 280,67 \\
\hline Pelobates cultripes & 29SND85 & 99,00 & 163,36 & 95,07 & 39,14 & 4975,53 & 304,82 & 65,19 & 239,63 & 103,05 & 226,75 & 230,31 & 103,01 & 759,23 & 109,09 & 5,89 & 56,40 & 311,86 & 43,72 & 44,89 & 311,86 \\
\hline Pelobates cultripes & 29SND90 & 100,00 & 165,34 & 97,75 & 39,97 & 5033,34 & 309,49 & 66,49 & 243,01 & 104,96 & 229,23 & 233,44 & 104,66 & 649,0 & 90,68 & 4,6 & 56,50 & 264,87 & 36,60 & 36,92 & 264,87 \\
\hline Pelobates cultripes & 29SND91 & 100,00 & 165,52 & 97,41 & 39,74 & 5042,61 & 309,69 & $\begin{array}{l}6,478 \\
66,78 \\
\end{array}$ & $\begin{array}{l}43,2,92 \\
242\end{array}$ & 105,51 & 229,67 & 233,77 & 10 & 6 666, & $\begin{array}{l}03,51 \\
93\end{array}$ & $\frac{4,}{4,}$ & 56,51 & \begin{tabular}{|l|}
272,06 \\
\end{tabular} & 38,02 & 38,47 & 272,06 \\
\hline Pelobates cultripes & 29SND92 & 100,00 & 167,01 & 97,38 & 39,53 & 5049,72 & 311,14 & 67,58 & 243,55 & 108,42 & 231,32 & 235,16 & 105,97 & 672 & 94,69 & 4,91 & 56,41 & 274,65 & 38,37 & 39,36 & 274,65 \\
\hline Pelobates cultripes & 29SND93 & 100,00 & 166,58 & 97,03 & 39,23 & 5067,16 & 310,69 & 67,06 & 243,63 & $\begin{array}{l}107,18 \\
\end{array}$ & 231,19 & 234,92 & 105,31 & 693,44 & 98,05 & 5,00 & 56,36 & 283,46 & 39,40 & 40,47 & 283,46 \\
\hline Pelobates cultripes & 29 SND94 & 100,00 & 164,63 & 96,36 & 39,00 & 5094,30 & 309,10 & 65,31 & 243,79 & 103,10 & 229,80 & 233,27 & 103,05 & 729,34 & 103,74 & 5,38 & 56,13 & 298,24 & 42,26 & 43,34 & 298,24 \\
\hline Pelobates cultripes & 29SND95 & 101,00 & 164,40 & 96,29 & 38,97 & 5107,33 & 308,97 & 64,56 & 244,41 & 102,61 & 229,69 & 233 & 102,46 & 749,64 & 107,05 & 5,86 & 56,03 & 306,62 & 43,75 & 44,92 & 306,62 \\
\hline Pelobates cultripes & 29SND97 & 100,00 & 103,404 & $\begin{array}{l}90,251 \\
96,61\end{array}$ & $\begin{array}{l}30, \\
38,\end{array}$ & 5152,31 & 309,19 & $\begin{array}{l}62,41 \\
62,41\end{array}$ & \begin{tabular}{|l|}
2446,78 \\
\end{tabular} & \begin{tabular}{|l|}
101,27 \\
10,0
\end{tabular} & 229,80 & \begin{tabular}{|l|}
232,76 \\
230
\end{tabular} & $\begin{array}{l}100,99 \\
10,9\end{array}$ & $\begin{array}{l}7499,04 \\
\end{array}$ & 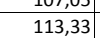 & $\frac{3,00}{6,22}$ & 55,85 & \begin{tabular}{|l|}
322,31 \\
32,3
\end{tabular} & \begin{tabular}{|l|l|}
46,76 \\
46,
\end{tabular} & $\begin{array}{ll}44,03 \\
48,03\end{array}$ & 322,31 \\
\hline Pelobates cultripes & 29SNE10 & 101,00 & 155,98 & 79,34 & 42,57 & 3622,00 & 256,06 & 71,49 & 184,58 & 116,98 & 199,76 & 202,30 & 109,14 & 821,60 & 119,97 & 6,60 & 56,95 & 341,94 & 45,99 & 51,55 & 334,68 \\
\hline Pelobates cultripes & 29SNE11 & 101.00 & 155,21 & 80,06 & $\mid 42,88$ | & 3601,97 & 254,96 & 70,29 & 184,66 & 116,16 & 198,65 & 201,09 & $\mid 108,34$ & 845,97 & 122,64 & $7,29 \mid$ & 56,16 & 349,90 & 48.92 & 54,74 & 343,15 \\
\hline Pelobates cultripes & 29SNE12 & 101,00 & 154,19 & 80,64 & 43,08 & 3581,21 & 253,36 & 68,70 & 184,66 & 115,14 & 197,19 & 199,53 & 107,27 & 874,10 & 125,94 & 7,94 & 55,56 & 359,32 & 52,16 & 58,23 & 353,13 \\
\hline Pelobates cultripes & 29SNE22 & 101,00 & 156,45 & 86,16 & 43,0 & 3801,99 & 264,73 & 66,96 & 197,77 & 114,81 & 202,60 & 205 & 107,05 & 877,24 & 125,73 & 8,03 & 55,11 & 358,35 & 53,36 & 58,58 & 354,81 \\
\hline Pelobates cultripes & $\begin{array}{l}\text { 2SSNNE } \\
\text { 290 }\end{array}$ & $\begin{array}{l}101,00 \\
100\end{array}$ & $\begin{array}{l}150,45 \\
155,32\end{array}$ & $\begin{array}{l}0,100 \\
91,90\end{array}$ & $\begin{array}{l}43,06 \\
41,29\end{array}$ & $\begin{array}{l}300,193 \\
4330,14\end{array}$ & $\begin{array}{l}280,15 \\
280,92\end{array}$ & $\begin{array}{l}0,00 \\
61,01 \\
\end{array}$ & 219,91 & \begin{tabular}{|l|}
104,81 \\
101
\end{tabular} & \begin{tabular}{|l|}
209,47 \\
\end{tabular} & \begin{tabular}{|l|}
212,15 \\
215
\end{tabular} & $\begin{array}{l}100,99 \\
100\end{array}$ & \begin{tabular}{|l|l|l|l|}
894,76 \\
\end{tabular} & \begin{tabular}{|l|l|}
129,51 \\
1295
\end{tabular} & $\frac{0,004}{7,94}$ & $\begin{array}{l}55,11 \\
55,79\end{array}$ & \begin{tabular}{|l|l|}
365,99 \\
365,9
\end{tabular} & $\begin{array}{l}5,14 \\
54,14 \\
\end{array}$ & \begin{tabular}{|l|l|}
56,40 \\
56,49
\end{tabular} & $\begin{array}{l}3034,01 \\
365,92 \\
\end{array}$ \\
\hline Pelobates cultripes & 29SPBO0 & 100,00 & 168,65 & 91,91 & \begin{tabular}{|l|l|}
41,97 \\
\end{tabular} & 4323,17 & 288,65 & 71,93 & 216,72 & 125,49 & 223,02 & 227,16 & 116,65 & 520,02 & 86,18 & 1,01 & 68,52 & 247,88 & 15,63 & 19,26 & 231,80 \\
\hline Pelobates cultripes & 29SPB03 & 101,00 & 158,06 & 98,16 & 41,13 & 4706,17 & 292,82 & 57,77 & 235,05 & 110,68 & 217,75 & 221.95 & 101.91 & $579,27 \mid$ & 90,05 & 1.99 & 64.43 & 262.06 & 21.21 & 24,19 & 249.89 \\
\hline Pelobates cultripes & 29SPB04 & 101,00 & 162,26 & 99,50 & 41,29 & 747,51 & 299,03 & 61,25 & 237,78 & 114,29 & 222, & 226,65 & 105 & 555,11 & 85,60 & 1,98 & 64,07 & 250 & 20,58 & 23,46 & 238,41 \\
\hline Pelobates cultripes & 29SPB05 & 100,00 & 163,97 & 101,37 & 41,34 & 4816,27 & 303,75 & 62,08 & 241,66 & 115,01 & 224,98 & 229,16 & $\begin{array}{ll}106,18 \\
\end{array}$ & 546,64 & 83,50 & 2,00 & 63,37 & 244,04 & 20,84 & 23,48 & 233,34 \\
\hline
\end{tabular}




\begin{tabular}{|c|c|c|c|c|c|c|c|c|c|c|c|c|c|c|c|c|c|c|c|c|c|}
\hline TAXON & UTM & $\mathrm{km} 2$ & B101 & B102 & $\mathrm{BIO3}$ & BIO4 & B105 & B106 & B107 & B108 & 8109 & B1010 & BIO11 & BIO12 & 81013 & BIO14 & BIO15 & B1016 & B1017 & B1018 & B1019 \\
\hline Pelobates cultripes & 29SPB06 & 101,00 & 166,78 & 103,09 & 41,77 & 4864,45 & 308,96 & 64,24 & 244,73 & 117,18 & 228,35 & 232,62 & 108,45 & 531,27 & 80,81 & 1,99 & 62,92 & 235,55 & 20,77 & 23,04 & 225,63 \\
\hline Pelobates cultripes & 29SPB07 & 101,00 & 166,32 & 105,44 & 41,88 & 4943,26 & 312,49 & 62,73 & 249,76 & 115,83 & 229,00 & 233,25 & 107,03 & 535,87 & 80,73 & 2,00 & 62,05 & 234,58 & 21,63 & 23,64 & 226,01 \\
\hline Pelobates cultripes & 29SPB08 & 100,00 & 167,55 & 107,56 & 41,97 & 5003,47 & 316,84 & 62,99 & 253,84 & 116,34 & 230,95 & 235,25 & 107,44 & 530,96 & 79,44 & 2,00 & 61,50 & 230,09 & 21,97 & 23,82 & 222,77 \\
\hline Pelobates cultripes & 29SPB09 & 100,00 & 166,65 & 110,11 & 42,02 & 5078,42 & 319,97 & 61,01 & 258,96 & 114,61 & 231,07 & 235,43 & 105,78 & 538,22 & 79,76 & 2,00 & 60,83 & 230,49 & 23,08 & 24,19 & 224,76 \\
\hline Pelobates cultripes & 29SPB14 & 100,00 & 164,15 & 98,47 & 40,99 & \begin{tabular}{|l|l|}
4808,23 \\
\end{tabular} & 300,24 & 62,28 & 237,96 & 114,95 & \begin{tabular}{|l|l|}
224,83 \\
\end{tabular} & 228,98 & 106,16 & 543,03 & 83,13 & 1,86 & 63,62 & 243,27 & 19,80 & 23,49 & 230,58 \\
\hline Pelobates cultripes & 29SPB15 & 101,00 & 166,02 & 100,20 & 41,00 & 4869,35 & 304,94 & 63,33 & 241,61 & 115,96 & 227,46 & 231,61 & 107,26 & 532,74 & 81,03 & 1,93 & 63,12 & 236,72 & 20,00 & 23,43 & 224,84 \\
\hline Pelobates cultripes & 29SPB16 & 100,00 & 169,62 & 101,78 & 41,12 & 4908,01 & 310,38 & 66,19 & 244,19 & 118,84 & 231,52 & 235,58 & 110,12 & 514,27 & 77,93 & 1,73 & 62,67 & 227,15 & 19,65 & 22,79 & 215,99 \\
\hline Pelobates cultripes & 29SPB17 & 100,00 & 168,05 & 104,46 & 41,20 & 5005,48 & 313,51 & 63,50 & 250,01 & 116,38 & 231,39 & 235,43 & 107,52 & 524,31 & 78,49 & 1,98 & 61,72 & 228,42 & 21,01 & 23,75 & 218,70 \\
\hline Pelobates cultripes & 29SPB18 & 101,00 & 168,43 & 106,74 & 41,49 & 5064,67 & 317,17 & 62,97 & 254,19 & 116,14 & 232,58 & 236,60 & 107,19 & 524,31 & 77,78 & 2,00 & 60,91 & 225,94 & 21,78 & 23,97 & 217,52 \\
\hline Pelobates cultripes & 29SPB19 & 100,00 & 168,67 & 108,60 & 41,74 & 5121,81 & 320,40 & 62,43 & 257,97 & 115,63 & 233,61 & 237,66 & 106,71 & 525,02 & 77,21 & 2,00 & 60,35 & 223,97 & 22,44 & 24,26 & 216,79 \\
\hline Pelobates cultripes & 29SPB23 & 101,00 & 168,25 & 94,56 & 40,32 & 4735,29 & 298,46 & 67,19 & 231,27 & 119,61 & 227,77 & 231,71 & 110,66 & 519,73 & 80,23 & 1,19 & 64,47 & 234,68 & 17,37 & 22,16 & 219,59 \\
\hline Pelobates cultripes & 29SPB24 & 100,00 & 165,69 & 97,05 & 40,46 & 4849,47 & 300,64 & 63,40 & 237,24 & 115,70 & 226,89 & 230,83 & 107,08 & 533,69 & 81,11 & 1,86 & 63,31 & 237,35 & 19,21 & 23,72 & 223,55 \\
\hline Pelobates cultripes & 29SPB25 & 100,00 & 169,33 & 98,40 & 40,57 & 4894,24 & 306,29 & 66,31 & 239,97 & 118,59 & 231,09 & 234,90 & 110,06 & 513,84 & 77,78 & 1,62 & 62,78 & 227,38 & 18,76 & 23,11 & 214,10 \\
\hline Pelobates cultripes & 29SPB26 & 101,00 & 169,08 & 100,77 & 40,72 & 4972,45 & 309,87 & 64,94 & 244,93 & 117,62 & 231,85 & 235,79 & 108,74 & 516,25 & 77,31 & 1,88 & 61,94 & 225,79 & 19,77 & 23,69 & 213,66 \\
\hline Pelobates cultripes & 29SPB27 & 100,00 & 167,14 & 103,45 & 40,86 & 5076,86 & 312,47 & 61,61 & 250,86 & 114,53 & 231,33 & 235,27 & 105,58 & 528,04 & 78,16 & 2,00 & 61,08 & 228,12 & 21,14 & 24,51 & 217,42 \\
\hline Pelobates cultripes & 29SPB28 & 100,00 & 167,52 & 105,62 & 40,98 & 5143,11 & 316,07 & 60,92 & 255,16 & 113,99 & 232,69 & 236,56 & 105,07 & 527,53 & 77,44 & 2,00 & 60,50 & 225,69 & 21,84 & 24,69 & 216,24 \\
\hline Pelobates cultripes & 29SPB29 & 101,00 & 167,13 & 107,53 & 41,02 & 5203,95 & 318,63 & 59,81 & 258,82 & 112,92 & 233,18 & 237,07 & 103,92 & 531,36 & 77,24 & 2,00 & 59,86 & 225,10 & 22,59 & 25,19 & 216,82 \\
\hline Pelobates cultripes & 29SPB31 & 58,00 & 174,81 & 88,67 & 40,00 & 4559,20 & 295,23 & 75,87 & 219,36 & 127,54 & 231,51 & 235,26 & 118,59 & 486,49 & 76,64 & 1,00 & 65,94 & 222,86 & 14,03 & 19,99 & 205,03 \\
\hline Pelobates cultripes & 29SPB32 & 101,00 & 173,23 & 90,13 & 39,87 & 4653,86 & 296,81 & 73,27 & 223,54 & 124,94 & 231,23 & 234,90 & 115,92 & 493,39 & 76,86 & 1,00 & 65,25 & 224,21 & 14,76 & 20,66 & 206,99 \\
\hline Pelobates cultripes & 29SPB33 & 100,00 & 172,24 & 92,08 & 39,85 & 4756,22 & 299,82 & 71,13 & 228,69 & 122,83 & 231,68 & 235,45 & 113,82 & 497,26 & 76,39 & 1,00 & 64,32 & 223,32 & 15,71 & 21,49 & 206,86 \\
\hline Pelobates cultripes & 29SPB34 & 101,00 & 170,86 & 94,32 & 39,90 & 4859,98 & 302,54 & 68,46 & 234,07 & 120,14 & 231,78 & 235,50 & 111,38 & 504,14 & 76,4 & 1,1 & 63,32 & 223,70 & 16,99 & 22,58 & 208,22 \\
\hline Pelobates cultripes & 29SPB36 & 99,00 & 171,07 & 98,97 & 40,02 & 5027,06 & 310,27 & 66,23 & 244,03 & 118,48 & 234,36 & 238,01 & 109,54 & 504,43 & 74,85 & 1,80 & 61,47 & 219,22 & 19,03 & 23,80 & 205,73 \\
\hline Pelobates cultripes & 29SPB37 & 101,00 & 168,89 & 101,83 & 40,13 & 5123,45 & 312,79 & 62,74 & 250,05 & 115,32 & 233,65 & 237,34 & 106,44 & 517,24 & 75,86 & 2,00 & 60,68 & 222,11 & 20,43 & 24,79 & 209,98 \\
\hline Pelobates cultripes & 29SPB38 & 100,00 & 165,74 & 104,48 & 40,26 & 5217,51 & 314,11 & 58,52 & 255,59 & 111,43 & 231,94 & 235,57 & 102,43 & 536,33 & 77,76 & 2,00 & 60,14 & 227,63 & 22,05 & 25,60 & 217,14 \\
\hline Pelobates cultripes & 29SPB39 & 100,00 & 165,47 & 106,32 & 40,48 & 5275,48 & 316,66 & 57,26 & 259,40 & 110,34 & 232,63 & 236,23 & 101,60 & 539,62 & 77,46 & 2,16 & 59,39 & 226,96 & 23,19 & 26,27 & 217,56 \\
\hline Pelobates cultripes & 29SPB41 & 45,00 & 175,94 & 86,66 & 39,08 & 4616,81 & 295,17 & 76,89 & 218,28 & 127,66 & 233,08 & 236,77 & 118,75 & 478,98 & 74,8 & 1,00 & 66,06 & 217,60 & 13,19 & 20,19 & 199,08 \\
\hline Pelobates cultripes & 29SPB42 & 100,00 & 174,39 & 87,81 & 39,07 & 4705,30 & 296,40 & 74,27 & 222,13 & $\begin{array}{ll}125,04 \\
\end{array}$ & 232,76 & 236,31 & 116,11 & |486,66 & 74,96 & $\begin{array}{l}1,00 \\
1,00\end{array}$ & 65,00 & 218,79 & $\begin{array}{l}14,07 \\
14,\end{array}$ & 21,01 & 200,46 \\
\hline Pelobates cultripes & 29SPB43 & 100,00 & 171,07 & 90,36 & 39,05 & 4835,05 & 298,26 & 69,46 & 228,80 & 120,41 & 231,39 & 234,94 & 111,54 & 503,00 & 76,14 & 1,00 & 63,58 & 223,05 & 15,97 & 22,78 & 205,61 \\
\hline Pelobates cultripes & 29SPB44 & 100,00 & 168,94 & 93,08 & 39,08 & 4953,04 & 301,00 & 65,92 & 235,08 & 116,97 & 230,92 & 234,64 & 108,21 & 514,36 & 76,65 & 1,65 & 62,62 & 225,14 & 17,70 & 24,14 & 208,76 \\
\hline Pelobates cultripes & 29SPB45 & 101,00 & 167,17 & 95,93 & 39,15 & 5057,97 & 303,87 & 62,46 & 241,41 & 114,03 & 230,75 & 234,29 & 105,23 & 524,81 & 77,31 & 1,95 & 61,65 & 227,20 & 19,13 & 25,01 & 212,03 \\
\hline Pelobates cultripes & 29SPB46 & 101,00 & 170,38 & 97,69 & 39,49 & 5097,67 & 309,21 & 64,66 & 244,55 & 116,60 & 234,40 & 237,99 & 107,66 & 508,40 & 74,47 & 2,00 & 61,12 & 218,77 & 19,17 & 24,74 & 204,27 \\
\hline Pelobates cultripes & 29SPB47 & 100,00 & 168,88 & 100,49 & 39,82 & 5191,89 & 311,99 & $\begin{array}{l}4,100 \\
61,96 \\
\end{array}$ & $\begin{array}{l}250,03 \\
\end{array}$ & $\begin{array}{l}114,28 \\
\end{array}$ & 234,42 & 237,89 & 105,12 & 517,01 & 75,01 & 2,00 & $\frac{1,12}{60,66}$ & 220,39 & 20,28 & 25,11 & 207,22 \\
\hline Pelobates cultripes & 29SPB49 & 100,00 & 166,50 & 105,08 & 40,00 & 5340,31 & 316,69 & 57,41 & 259,28 & 110,07 & 234,41 & 237,71 & 101,40 & 532,89 & 75,91 & 2,06 & 59,35 & 223,19 & 22,59 & 26,21 & 212,30 \\
\hline Pelobates cultripes & 29SPB51 & & & & & & & & & & & & & & & & & & & & \\
\hline Pelobates cultripes & 29SPB52 & 100,00 & 175,19 & 85,50 & 38,19 & 33,32 & 295,72 & 74,92 & 220,80 & 124,69 & 233,97 & 237,43 & 115,81 & 482,36 & 73,92 & 1,00 & 64,48 & 214,43 & 13,55 & 21,57 & 194,99 \\
\hline Pelobates cultripes & 29SPB53 & 101,00 & 172,90 & 87,90 & 38,16 & 4887,35 & 298,20 & 71,02 & 227,18 & 121,10 & 233,55 & 236,92 & 112,13 & 493,46 & 74,73 & 1,01 & 63,42 & 216,54 & 15,33 & 23,12 & 197,79 \\
\hline Pelobates cultripes & \begin{tabular}{|l|}
$295 P B 54$ \\
2958
\end{tabular} & 101,00 & 170,45 & $\begin{array}{l}1,00,94 \\
90,4\end{array}$ & $\frac{0,10}{38,30}$ & $\begin{array}{l}40007,82 \\
5007\end{array}$ & 300,94 & $\begin{array}{l}1,, 04 \\
66,97 \\
\end{array}$ & \begin{tabular}{|l|}
233,97 \\
2310
\end{tabular} & \begin{tabular}{|l|}
117,41 \\
117
\end{tabular} & 232,94 & \begin{tabular}{|l|}
236,36 \\
236
\end{tabular} & \begin{tabular}{|l|l|l|l|l|}
108,48 \\
\end{tabular} & $\begin{array}{l}506,40 \\
506,42\end{array}$ & 75,65 & $\begin{array}{l}1,1,51 \\
1,1\end{array}$ & $\begin{array}{ll}62,28 \\
62,2\end{array}$ & $\begin{array}{l}219,73 \\
219,7\end{array}$ & $\begin{array}{l}17,00 \\
17,0\end{array}$ & $\frac{25,12}{24,36}$ & 202,13 \\
\hline Pelobates cultripes & 29SPB55 & 99,00 & 166,69 & 94,61 & 38,71 & 5134,48 & 303,20 & 61,36 & 241,84 & 112,48 & 231,25 & 234,60 & 103,59 & 528,04 & 77,56 & 2,00 & 61,28 & 226,42 & 19,01 & 25,85 & 210,22 \\
\hline Pelobates cultripes & 29SPB56 & 100,00 & 168,05 & 96,89 & 38,95 & 5204,47 & 307,65 & 61,30 & 246,35 & 112,94 & 233,58 & 236,92 & 103,94 & 520,95 & 76,11 & 2,00 & 60,74 & 221.98 & $\mid 19,40$ & 25,68 & 206,68 \\
\hline Pelobates cultripes & 29SPB57 & 100,00 & 168,52 & 99,30 & 39,05 & 5265,48 & 311,35 & 60,62 & 250,73 & 112,74 & 235,06 & 238,25 & 103,76 & 519,26 & 75,34 & 2,00 & 60,09 & 219,62 & 20,12 & 25,82 & 205,28 \\
\hline Pelobates cultripes & 29SPB62 & 100,00 & 176,32 & 82,94 & 37,30 & 4827,46 & 295,47 & 75,96 & 219,51 & 124,72 & 235,65 & 238 & 115,88 & 476,06 & 73, & 1,00 & 64,06 & 209,23 & 13,14 & 22,10 & 188,61 \\
\hline Pelobates cultripes & 29SPB63 & 100,00 & 173,50 & 85,69 & 37,29 & 4955,21 & 297,65 & 71,32 & 226,33 & 120,63 & $\begin{array}{l}234,78 \\
23,0\end{array}$ & 237,93 & 111,59 & 490,51 & 75,08 & 1,01 & 62,88 & 213,02 & 14,88 & 23,59 & 193,09 \\
\hline Pelobates cultripes & 29SPB64 & 100,00 & 171,35 & 89,14 & 37,69 & 5074,96 & 300,92 & 67,29 & 233,63 & 117,19 & 234,48 & 237,69 & 108,34 & 502,45 & 75,84 & 1,52 & 62,03 & 215,97 & 16,64 & 24,62 & 197,18 \\
\hline Pelobates cultripes & 29SPB65 & 101,00 & 170,61 & 92,24 & 37,94 & 5171,80 & 304,69 & 64,81 & 239,88 & 115,30 & 235,21 & 238,42 & 106,43 & 507,57 & 75,85 & 1,94 & 61,13 & 216,36 & 17,85 & 25,54 & 198,55 \\
\hline Pelobates cultripes & 29SPB66 & 100,00 & 167,46 & 96,09 & 38,26 & 5281,79 & 307,19 & 59,68 & 247,51 & 111,22 & 233,90 & 237 & 102,17 & 526,75 & 77,38 & 2,00 & 60,41 & 222,67 & 19,45 & 26,22 & 206,49 \\
\hline Pelobates cultripes & 29SPB67 & 101,00 & 167,34 & 98,94 & 38, & 5365,73 & 310,9 & 58,12 & 252,87 & $\begin{array}{l}110,08 \\
11\end{array}$ & 235,12 & 238,06 & 101,04 & 527,78 & 76,87 & 2,00 & 59,80 & 221,55 & 20,25 & 26,49 & 206,39 \\
\hline Pelobates cultripes & 29SPB68 & 99,00 & 161,51 & 102,50 & 38,98 & 5475,86 & 310,95 & 50,86 & 260,09 & 103,49 & 237 & 234,26 & 94,64 & 565,09 & 80,49 & 2,59 & 58,77 & 234,47 & 24,03 & 29,36 & 221,11 \\
\hline Pelobates cultripes & 29SPB71 & 11,00 & 178,00 & 79,38 & 36,38 & 4854,08 & 293,31 & 77,85 & 215,46 & 125,85 & 236,69 & 240,08 & \begin{tabular}{|l|}
116,31 \\
\end{tabular} & 471,38 & 74,15 & 1,00 & 64,08 & 205,62 & 12,00 & 22,00 & 183,46 \\
\hline Pelobates cultripes & 29SPB72 & 100,00 & 177,28 & 80,30 & 36,32 & 4889,62 & 294,83 & 76,74 & 218,10 & 124,96 & 237,14 & 240,23 & 115,76 & 471,86 & 74,05 & 1,00 & 63,85 & 205,10 & 12,65 & 22,54 & 183,14 \\
\hline Pelobates cultripes & 29SPB73 & 101,00 & 176,50 & 82,76 & 36,45 & 5001,32 & 298,23 & 74,25 & 223,98 & 123,65 & 237,87 & 240,98 & 113,67 & 476,04 & 74,01 & 1,00 & 63,01 & 204,82 & 13,89 & 23,71 & 183,47 \\
\hline Pelobates cultripes & 29SPB74 & 100,00 & 174 & $\begin{array}{l}0,1,77 \\
86,7\end{array}$ & 30, & 511, 5 & 301 & 70,11 & \begin{tabular}{|l|}
231,86 \\
\end{tabular} & \begin{tabular}{|l|}
119,42 \\
19,
\end{tabular} & \begin{tabular}{|l|}
237,91 \\
\end{tabular} & \begin{tabular}{|l|}
240,89 \\
240
\end{tabular} & $\begin{array}{l}110,45 \\
110\end{array}$ & $\mid \begin{array}{l}\mid 780,04 \\
487,26\end{array}$ & $\begin{array}{l}74,01 \\
74,79\end{array}$ & $\begin{array}{l}1,003 \\
1,03\end{array}$ & $\frac{3,01}{62,14}$ & $\begin{array}{l}208,15 \\
208,15\end{array}$ & $\begin{array}{l}15,20 \\
15,20\end{array}$ & $\mid \begin{array}{l}\mid 24,11 \\
24,17\end{array}$ & $\begin{array}{l}10,47 \\
187,95\end{array}$ \\
\hline Pelobates cultripes & 29SPB75 & 100,00 & 173,17 & 90,78 & 37,35 & 5223,84 & 306,17 & 66,62 & 239,55 & 116,95 & 238,22 & 241,18 & 108,03 & 497,01 & 75,20 & 1,71 & 61,08 & 210,63 & 16,92 & 25,31 & 191,71 \\
\hline Pelobates cultripes & 29 SPB76 & 101.00 & 172,13 & 94,68 & 37,97 & 5322,15 & 310,30 & 63,59 & 246,72 & 115,01 & 238.91 & $\mid 241,79$ & $\mid$\begin{tabular}{|c|}
105,99 \\
\end{tabular} & 504,11 & 75,30 & 1,99 & 60,38 & 212,14 & 18,20 & 25,85 & 194,57 \\
\hline Pelobates cultripes & 29SPB78 & 101,00 & 163,20 & 102,44 & 38,68 & 5548,81 & 313,16 & 51,22 & 261,94 & 104,07 & 233,97 & 236,76 & 95,18 & 557,05 & 79,98 & 2,45 & 58,67 & 230,14 & 23,44 & 29,16 & 215,80 \\
\hline Pelobates cultripes & $29 \mathrm{SPB} 81$ & 49,00 & 177,89 & 79,56 & 36,00 & 4901,23 & 294,59 & 76,90 & 217,69 & 136,93 & 238,02 & 241,00 & 116,18 & 476,69 & 75,25 & 1,00 & 63,82 & 206,57 & 12,51 & 22,87 & 18 \\
\hline Pelobates cultripes & 29SPB82 & 101,00 & 177,98 & 79,33 & 35,82 & 4964,47 & 295,56 & 76,60 & 218,96 & $\begin{array}{ll}144,32 \\
\end{array}$ & 238,62 & 241,52 & 115,22 & $\begin{array}{ll}472,48 \\
\end{array}$ & 74,62 & 1,00 & 63,57 & 203,23 & 12,62 & 23,47 & 180,27 \\
\hline Pelobates cultripes & $295 P B 83$ & 99,00 & 177,82 & 81,79 & 35,97 & 5067,99 & 299,41 & 74,67 & 224,73 & 146,24 & 239,98 & 242,83 & $\begin{array}{l}113,78 \\
\end{array}$ & 473,24 & 74,27 & 1,00 & 62,87 & 202,07 & 13,64 & 23,87 & 179,64 \\
\hline Pelobates cultripes & 29SPB84 & 101,00 & 174,38 & 87,23 & 36,64 & 5210,35 & 303,54 & 68,52 & 235,02 & 120,05 & 239,13 & 241,89 & 109,09 & 493,86 & 76,00 & 1,26 & 61,76 & 209,21 & 15,46 & 24,91 & 188,50 \\
\hline Pelobates cultripes & 29SPB85 & 100,00 & 172,92 & 91,72 & 37,08 & 5321,27 & 307,98 & 64,69 & 243,29 & 115,49 & 239,49 & 242 & 106,45 & 504,88 & 76,49 & 1,83 & 61,00 & 212 & 17,19 & 25,68 & 193,27 \\
\hline Pelobates cultripes & $29 \mathrm{SPB} 86$ & 100,00 & 169,77 & 96,12 & 37,83 & 5442,40 & 311,10 & 59,32 & 251,78 & 111,16 & 238,45 & 241,03 & 102,23 & 523,43 & 77,89 & 2,00 & 60,25 & 218,73 & 18,97 & 26,66 & 201, \\
\hline
\end{tabular}




\begin{tabular}{|c|c|c|c|c|c|c|c|c|c|c|c|c|c|c|c|c|c|c|c|c|c|}
\hline TAXON & UTM & $\mathrm{km} 2$ & BIO1 & B102 & $\mathrm{BIO3}$ & BIO4 & B105 & B106 & 8107 & 8108 & 8109 & B1010 & BIO11 & BIO12 & 81013 & B1014 & BIO15 & B1016 & B1017 & B1018 & B1019 \\
\hline Pelobates cultripes & 29SPB89 & 100,00 & 153,82 & 106,46 & 38,23 & 5757,84 & 312,54 & 38,85 & 273,69 & 92,73 & 228,07 & 230,59 & 83,71 & 620,39 & 86,93 & 3,43 & 57,47 & 252,59 & 28,53 & 33,33 & 239,85 \\
\hline Pelobates cultripes & 29SPB90 & & & & & & & & & & & & & & & & & & & & \\
\hline Pelobates cultripes & 29SPB91 & 91,00 & 176,63 & 82,44 & 36,29 & 4991,09 & 297,27 & 73,43 & 223,85 & 129,05 & 238,21 & 241,18 & 113,96 & 495,43 & 77,43 & 1,00 & 63,73 & 213,67 & 13,84 & 23,77 & 191,63 \\
\hline Pelobates cultripes & 29SPB92 & 101,00 & 176,34 & 83,35 & 36,08 & 5092,33 & 299,59 & 72,02 & 227,57 & 134,69 & 239,17 & 242,06 & 112,29 & $\begin{array}{l}493,55 \\
\end{array}$ & 77,15 & 1,00 & 63,20 & 211,19 & 14,05 & 24,00 & 189,05 \\
\hline Pelobates cultripes & 29SPB93 & 100,00 & 178,35 & 85,09 & 36,17 & 5167,99 & 304,21 & 72,76 & 231,45 & \begin{tabular}{|l|l|}
147,42 \\
\end{tabular} & 242,25 & 244,99 & 113,29 & 482,24 & 75,46 & 1,00 & 62,70 & 205,42 & 14,09 & 24,00 & 183,32 \\
\hline Pelobates cultripes & 29SPB94 & 101,00 & 174,68 & 89,65 & 36,78 & 5315,18 & 307,38 & 66,53 & 240,84 & 122,55 & 241,05 & 243,73 & 108,15 & 502,46 & 77,16 & 1,28 & 61,65 & 212,05 & 15,74 & 24,94 & 191,58 \\
\hline Pelobates cultripes & 29SPB95 & 99,00 & 169,82 & 94,92 & 37,18 & 5462,90 & 310,08 & 58,89 & 251,19 & 110,79 & 238,72 & 241,25 & 101,85 & 531,43 & 79,77 & 2,00 & 60,74 & 222,38 & 18,52 & 26,68 & 203,61 \\
\hline Pelobates cultripes & 29SPB96 & 100,00 & 169,28 & 98,16 & 37,82 & 5549,99 & 313,89 & 56,72 & 257,17 & 109,34 & 239,57 & 242,12 & 100,46 & 534,59 & 79,41 & 2,00 & 60,10 & 222,36 & 19,56 & 27,16 & 204,72 \\
\hline Pelobates cultripes & 29SPB99 & 100,00 & 152,23 & 107,69 & 38,00 & 5848,46 & 313,92 & 35,78 & 278,14 & 90,23 & 227,96 & 230,29 & 81,17 & 635,97 & 88,77 & 3,60 & 57,37 & 257,79 & 29,35 & 34,22 & 245,06 \\
\hline Pelobates cultripes & 29SPC01 & 100,00 & 165,98 & 111,91 & 42,01 & 5165,10 & 322,97 & 59,96 & 263,01 & 112,77 & 231,50 & 236,05 & 104,19 & 549,03 & 79,49 & 2,02 & 59,40 & 230,39 & 25,61 & 25,86 & 226,94 \\
\hline Pelobates cultripes & 29SPC02 & 101,00 & 166,33 & 110,50 & 41,87 & 5160,53 & 322,00 & 60,85 & 261,15 & 112,99 & 231,84 & 236,18 & 104,34 & 552,50 & 78,82 & 2,58 & 58,68 & 229,86 & 26,91 & 27,28 & 227,05 \\
\hline Pelobates cultripes & 29SPC03 & 101,00 & 160,69 & 108,62 & 41,23 & 5185,48 & 316,10 & 56,55 & 259,55 & 107,39 & 227,90 & 231,14 & 98,85 & 592,32 & 82,64 & 3,04 & 57,66 & 243,29 & 30,44 & 30,45 & 242,18 \\
\hline Pelobates cultripes & 29SPC04 & 100,00 & 161,82 & 106,48 & 41,04 & 5164,14 & 314,94 & 58,80 & 256,14 & \begin{tabular}{l|}
108,27 \\
\end{tabular} & 229,01 & 231,91 & 100,14 & 589,98 & 81,44 & 3,02 & 57,23 & 241,04 & 30,93 & 30,93 & 240,44 \\
\hline Pelobates cultripes & 29SPC05 & 101,00 & 163,99 & 104,51 & 40,97 & 5131,42 & 314,60 & 61,82 & 252,78 & 109,97 & 230,79 & 233,51 & 102,35 & 583,41 & 80,05 & 3,00 & 57,05 & 237,34 & 31,10 & 31,10 & 236,97 \\
\hline Pelobates cultripes & 29SPC07 & 101,00 & 162,37 & 101,10 & 40,03 & 5119,50 & 310,44 & 61,96 & 248,48 & 101,92 & 229,31 & 231,74 & 100,87 & 613,08 & 83,86 & 4,00 & 55,95 & 247,58 & 35,10 & 35,10 & 247,58 \\
\hline Pelobates cultripes & 29SPC08 & 100,00 & 160,69 & 99,94 & 39,98 & 5139,34 & 308,49 & 60,77 & 247,72 & 99,37 & 228,08 & 230,42 & 99,08 & 640,14 & 87,99 & 4,12 & 55,88 & 258,78 & 36,81 & 36,81 & 258,78 \\
\hline Pelobates cultripes & 29SPC09 & 100,00 & 162,42 & 99,67 & 39,97 & 5141,97 & 309,99 & 62,39 & 247,60 & 101,25 & 228,39 & 232,14 & 100,70 & 646,09 & 89,10 & 4,17 & 55,93 & 261,45 & 37,30 & 37,32 & 261,45 \\
\hline Pelobates cultripes & 29SPC10 & 101,00 & 168,64 & 109,86 & 41,74 & 5166,21 & 322,54 & 61,98 & 260,56 & 115,16 & 234,22 & 238,31 & 106,22 & 527,47 & 76,84 & 2,00 & 59,79 & 222,91 & 23,19 & 24,74 & 216,76 \\
\hline Pelobates cultripes & 29SPC12 & 99,00 & 167,73 & 109,94 & 41,19 & 5225,10 & 323,02 & 60,97 & 262,05 & 113,38 & 234,04 & 238,20 & 104,57 & 540,49 & 76,70 & 2,27 & 58,39 & 224,17 & 26,18 & 27,20 & 219,97 \\
\hline Pelobates cultripes & $29 S P C 13$ & 101,00 & 160,51 & 109,02 & 41,00 & 5282,23 & 317,10 & 54,79 & 262,31 & 105,93 & 228.42 & 232,21 & 97,33 & 589,14 & 81,72 & 3,00 & 57,24 & 240,98 & 30,63 & 30,77 & 238,69 \\
\hline Pelobates cultripes & 29SPC15 & 99,00 & 165,51 & 106,22 & 40,89 & 5234,90 & 318,45 & 60,80 & 257,65 & 110,85 & 232,12 & 236,15 & 102,37 & 570,58 & 77,63 & 3,01 & 56,58 & 231,28 & 30,94 & 31,19 & 229,58 \\
\hline Pelobates cultripes & 29SPC17 & 99,00 & 163,81 & 103,55 & 40,05 & 5233,55 & 314,91 & 60,52 & 254,39 & 108,59 & 230,76 & 234,53 & 100,84 & 601,24 & 81,32 & 4,00 & 55,57 & 241,35 & 34,91 & 34,91 & 240,92 \\
\hline Pelobates cultripes & 29SPC18 & 101,00 & 160,60 & 102,15 & 39,90 & 5255,88 & 311,74 & 58,30 & 253,45 & 102,59 & 228,97 & 231,89 & $\begin{array}{l}97,68 \\
\end{array}$ & \begin{tabular}{|c|}
638,67 \\
\end{tabular} & 86,96 & 4,34 & 55,44 & 256,29 & 37,43 & 37,43 & 256,26 \\
\hline Pelobates cultripes & 29SPC19 & 101,00 & 161,79 & 101,60 & 39,82 & 5264,89 & 312,60 & 59,40 & 253,21 & 104,32 & 229,51 & 233,04 & 98,68 & 646,77 & 88,31 & 4,52 & 55,33 & 259,77 & 38,18 & 38,21 & 259,71 \\
\hline Pelobates cultripes & 29SPC20 & 100,00 & 167,25 & 108,79 & 41,00 & 5254,52 & 320,84 & 59,51 & 261,33 & 112,50 & 233,96 & 237,92 & 103,49 & 532,54 & 76,72 & 2,00 & 59,38 & 223,71 & 23,36 & 25,51 & 216,45 \\
\hline Pelobates cultripes & 29SPC21 & 100,00 & 168,08 & 109,25 & 41,01 & 5274,95 & 322,74 & 60,09 & 262,65 & 113,04 & 235,19 & 238,98 & 104,03 & 530,51 & 75,64 & 2,06 & 58,64 & 220,93 & 24,62 & 26,39 & 214,45 \\
\hline Pelobates cultripes & $295 P C 22$ & 101,00 & 168,42 & 109,29 & 40,99 & 5297,34 & 323,47 & $\begin{array}{l}0,32 \\
60,32 \\
\end{array}$ & 263,15 & 113,02 & 235,75 & 239,61 & 104,16 & 533,19 & 75,13 & 2,37 & 58,07 & 220,33 & 25,82 & 27,36 & 214,65 \\
\hline Pelobates cultripes & $295 P C 23$ & 100,00 & 165,26 & 109,13 & 40,97 & 5331,75 & 321,37 & 57,58 & 263,80 & 109,62 & 233,19 & 237,03 & 100,88 & 556,98 & 77,25 & 3,00 & 57,18 & 227,79 & 28,54 & 29,44 & 223,46 \\
\hline Pelobates cultripes & 29SPC27 & 101,00 & 163,06 & 105,66 & 40,00 & 5364,20 & 317,54 & 57,23 & 260,31 & 106,79 & 231,86 & 235,42 & 98,44 & 602,02 & 80,68 & 4,00 & 55,12 & 240,99 & 35,23 & 35,36 & 239,16 \\
\hline Pelobates cultripes & $295 \mathrm{SC} 28$ & 100,00 & 159,59 & 104,11 & 39,72 & 5380,03 & 313,91 & 54,76 & 259,15 & 102,98 & 229,49 & 232,40 & 95,14 & 642,65 & 86,77 & 4,51 & 54,97 & 256,99 & 38,20 & 38,24 & 255,93 \\
\hline Pelobates cultripes & 29SPC30 & 101,00 & 166,07 & 107,70 & 40,62 & 5327,15 & 319,31 & 57,17 & 262,14 & 110,25 & 233,87 & 237,53 & 101,40 & 538,07 & 76,59 & 2,32 & 58,83 & 224,42 & 24,33 & 27,07 & 215,93 \\
\hline Pelobates cultripes & 29SPC31 & 100,00 & 166,25 & 108,74 & 40,75 & 5373,15 & 321,21 & 56,92 & 264,29 & $\begin{array}{l}109,87 \\
10,25\end{array}$ & 234,71 & 238,28 & 101,01 & 540,34 & 75,98 & 2,89 & $\begin{array}{ll}5,064 \\
57,64\end{array}$ & 223,15 & $\begin{array}{l}24,13 \\
26,13\end{array}$ & 28,48 & 215,62 \\
\hline Pelobates cultripes & 29SPC32 & 100,00 & 168,44 & 108,99 & 40,68 & 5377,66 & 323,78 & 58,78 & 265,00 & 111,72 & 236,88 & 240,46 & 103,10 & 530,80 & 74,13 & 2,80 & 57,45 & 218,09 & 26,20 & 28,24 & 211,01 \\
\hline Pelobates cultripes & 29SPC34 & 101,00 & 167,87 & 109,05 & 40,35 & 5414,99 & 324,48 & 58,33 & 266,15 & 110,67 & 236,92 & 240,31 & 102,11 & 542,35 & 74,31 & 3,00 & 56,41 & 220,05 & 28,47 & 29,80 & 214,46 \\
\hline Pelobates cultripes & 29SPC35 & 100,00 & 167,02 & 108,80 & 40,12 & 5433,43 & 323,99 & 57,58 & 266,41 & 109,55 & 236,34 & 239,79 & 101,03 & 553,34 & 75,23 & 3,16 & 55,95 & 223,18 & 30,26 & 31,26 & 218,25 \\
\hline Pelobates cultripes & $295 \mathrm{SC} 36$ & 101,00 & 164,36 & 108,31 & 40,00 & 5467,16 & 321,97 & 55,28 & 266,69 & 106,72 & 234,42 & 237,79 & 98,15 & 577,66 & 77,96 & 3,98 & 55,18 & 231,45 & 33,13 & 33,78 & 227,34 \\
\hline Pelobates cultripes & 29SPC37 & 100,00 & 165,27 & 107,92 & 40,00 & 5472,45 & 322,58 & 56,23 & 266,34 & 107,39 & 235,64 & 238,79 & 98,97 & 581,16 & 78,36 & 4,00 & 54,85 & 232,22 & 34,01 & 34,58 & 228,44 \\
\hline Pelobates cultripes & 29SPC40 & 101,00 & 164,01 & 106,92 & 40,01 & 5409,63 & 317,65 & 54,14 & 263,51 & 107,14 & 233,05 & 236,42 & 98,43 & 550,22 & 77,29 & 2,92 & 57,95 & 227,62 & 25,75 & 28,88 & 218,07 \\
\hline Pelobates cultripes & 29SPC41 & 100,00 & 166,05 & 108,00 & 40,01 & 5437,09 & 321,08 & 55,40 & 265,69 & 108,56 & 235,40 & 238,69 & 99,84 & 540,63 & 75,50 & 3,00 & 57,42 & 222,30 & 26,20 & 29,02 & 213,41 \\
\hline Pelobates cultripes & $29 S P C 42$ & 100,00 & 168,63 & 108,80 & 40,06 & 5456,22 & 324,43 & 57,49 & 266,93 & 110,51 & 238,29 & 241,35 & 102,19 & 527,43 & 73,36 & 2,99 & 56,99 & 215,81 & 26,20 & 28,86 & 207,36 \\
\hline Pelobates cultripes & 29SPC43 & 101,00 & 167,88 & 109,24 & 40,02 & 5501,38 & 325,44 & 56,36 & 269,08 & 109,36 & 238,23 & 241 & 100,77 & 533,92 & 73,76 & 3,00 & 56,68 & 217,10 & 27,27 & 29,37 & 209,34 \\
\hline Pelobates cultripes & \begin{tabular}{|l}
$295 \mathrm{PC} 43$ \\
$29 \mathrm{PC} 44$
\end{tabular} & $\begin{array}{l}100,00 \\
100,0\end{array}$ & $\begin{array}{l}10,00 \\
168,91\end{array}$ & $\begin{array}{l}1099,24 \\
109,81\end{array}$ & $\begin{array}{ll}40,02 \\
40,04\end{array}$ & \begin{tabular}{|l}
3501,30 \\
5516,29
\end{tabular} & 327,01 & $\begin{array}{l}0,300 \\
57,07\end{array}$ & $\begin{array}{l}269,90 \\
2694\end{array}$ & $\begin{array}{l}110,10 \\
110\end{array}$ & \begin{tabular}{|l|}
230,25 \\
239,67 \\
\end{tabular} & $\begin{array}{l}241,44 \\
242,44 \\
\end{array}$ & 101,43 & $\begin{array}{l}353,92 \\
531,63\end{array}$ & $\begin{array}{l}\mid 73,10 \\
73,28\end{array}$ & $\begin{array}{l}3,000 \\
3,00\end{array}$ & $\begin{array}{l}0,00 \\
56,19\end{array}$ & 215,10 & $\begin{array}{l}27,82 \\
27,82\end{array}$ & \begin{tabular}{|l|}
29,73 \\
29
\end{tabular} & $\begin{array}{l}200,34 \\
207,85\end{array}$ \\
\hline Pelobates cultripes & 29SPC45 & 100,00 & 168,72 & 109,90 & 40,02 & 5520,70 & 327,46 & 56,84 & 270,62 & 109,73 & 239,59 & 242,28 & 101,23 & 536,43 & 73,75 & 3,02 & 55,77 & 215,92 & 28,96 & 30,40 & 209,14 \\
\hline Pelobates cultripes & 29SPC49 & 101,00 & 165,01 & 109,48 & 39,91 & 5613,73 & 325,70 & 53,33 & 272,37 & 105,11 & 237,55 & 240,08 & 96,82 & 595,18 & 80,41 & 4,58 & 53,77 & 236,19 & 36,72 & 37,23 & 231,34 \\
\hline Pelobates cultripes & 29SPC51 & 101,00 & 167,10 & 107,59 & 39,88 & 5507,90 & 322,31 & 55,03 & 267,28 & $\begin{array}{l}108,55 \\
\end{array}$ & 237,41 & 240,46 & 99,80 & 533,46 & 74,70 & 3,00 & 57,20 & 18,51 & 25,75 & 29,11 & 208,22 \\
\hline Pelobates cultripes & 29SPC52 & 100,00 & 168,43 & 108,65 & 39,99 & 5543,99 & 325,30 & 55,72 & 269,58 & \begin{tabular}{|l|}
109,37 \\
\end{tabular} & 239,34 & 242 & 100,59 & 526,22 & 73,52 & 3,00 & 56,66 & 214,39 & 26,14 & 29,12 & 204,65 \\
\hline Pelobates cultripes & 29SPC53 & 100,00 & 166,86 & 109,71 & 39,99 & 5586,67 & 325,93 & 53,65 & 272,28 & \begin{tabular}{|l|}
107,14 \\
\end{tabular} & 238,44 & 241,20 & 98,53 & 537,68 & 74,58 & 3,00 & 56,35 & 217,67 & 27,47 & 29,91 & 208,80 \\
\hline Pelobates cultripes & 29SPC54 & 100,00 & 167,86 & 110,35 & 40,00 & 5602,91 & 327,94 & 54,27 & 273,67 & $\begin{array}{l}107,78 \\
\end{array}$ & 239,81 & 242,30 & 99,23 & 534,37 & 73,98 & 3,03 & 55,77 & 215,26 & 28,15 & 30,24 & 206,77 \\
\hline Pelobates cultripes & 29SPC56 & 100,00 & 166,97 & 111,41 & 39,97 & 5663,56 & 329,39 & 52,77 & 276,63 & 106,25 & 240,07 & 242,45 & 97,86 & 546,35 & 75,01 & 3,92 & 54,31 & 217,49 & 31,92 & 33,19 & 209,91 \\
\hline Pelobates cultripes & 29SPC58 & 100,00 & 168,60 & 112,24 & 39,97 & 5700,35 & 332,14 & 53,08 & 279,07 & 107,03 & 242,20 & 244 & 98,73 & 546,20 & 75,06 & 4,00 & 53,57 & 216,33 & 33,25 & 34,09 & 208,90 \\
\hline Pelobates cultripes & 295PC59 & 100,00 & $\frac{100}{167}$ & $\frac{112}{112}$ & 39,84 & | 5728,25 & 331,77 & $\begin{array}{l}3,106 \\
51,96 \\
\end{array}$ & 279,81 & $\begin{array}{l}105,68 \\
105\end{array}$ & \begin{tabular}{|l|}
241,69 \\
240
\end{tabular} & \begin{tabular}{|l|}
243,64 \\
243
\end{tabular} & \begin{tabular}{|l|l|}
97,36 \\
97
\end{tabular} & 5402,54 & $\begin{array}{l}70,00 \\
76,98\end{array}$ & $\begin{array}{l}4,400 \\
4,17\end{array}$ & 53,42 & \begin{tabular}{|l|}
222,29 \\
22,2
\end{tabular} & $\begin{array}{l}35,25 \\
35,05 \\
\end{array}$ & $\begin{array}{l}4,450 \\
35,62\end{array}$ & 215,23 \\
\hline Pelobates cultripes & 29SPC61 & 100,00 & 162,79 & 107,89 & 39,17 & 5622,32 & 320,55 & 49,19 & 271,36 & 103,19 & 234,95 & 237,86 & 94,22 & 558,30 & 78,06 & 3,08 & 56,97 & 227,34 & 26,79 & 30,50 & 216,45 \\
\hline Pelobates cultripes & 29SPC62 & 100,00 & 167,16 & 108,97 & 39,37 & 5633,15 & 325,76 & 52,92 & 272,84 & 107,02 & 239,42 & 241,86 & 98,14 & 532,84 & 74,71 & 3,00 & 56,49 & 216,13 & 26,27 & 29,60 & 205,40 \\
\hline Pelobates cultripes & 29SPC63 & 101,00 & 165,10 & 110,21 & 39,51 & 5678,03 & 326,27 & 50,42 & 275,85 & 104,51 & 238,20 & 240,63 & 95,64 & 545,39 & 75,90 & 3,00 & 56,10 & 219,89 & 27,74 & 30,49 & 209,94 \\
\hline Pelobates cultripes & $29 S P C 64$ & 101,00 & 165,09 & 111,09 & 39,43 & 5713,22 & 327,85 & 49,66 & 278,20 & $\begin{array}{l}104,05 \\
\end{array}$ & 23 & 247 & 95,33 & 546,52 & 75,67 & 3,30 & 55,16 & 218,88 & 29,32 & 31,59 & 209,42 \\
\hline Pelobates cultripes & $\begin{array}{l}295 \mathrm{SPC} 67 \\
29 \mathrm{P}\end{array}$ & $\begin{array}{l}100,00 \\
100\end{array}$ & $\begin{array}{l}10,03,22 \\
163,22\end{array}$ & 1112,86 & $\begin{array}{l}35,45 \\
39,25\end{array}$ & 5799,65 & 329,68 & $\begin{array}{l}4,, 00 \\
46,44 \\
\end{array}$ & \begin{tabular}{|l|}
283,24 \\
283
\end{tabular} & \begin{tabular}{|l|l|l|l}
101,10 \\
\end{tabular} & \begin{tabular}{|l|}
238,40 \\
238
\end{tabular} & \begin{tabular}{|l|}
240,30 \\
240
\end{tabular} & \begin{tabular}{l|l|}
92,42 \\
92,
\end{tabular} & $\begin{array}{l}540,52 \\
565,42\end{array}$ & 77,51 & $\begin{array}{l}3,10 \\
4,10\end{array}$ & $\begin{array}{l}5,10 \\
53,61\end{array}$ & \begin{tabular}{|l|}
223,34 \\
223
\end{tabular} & \begin{tabular}{|l|l|}
34,08 \\
34
\end{tabular} & \begin{tabular}{|l|}
1,353 \\
35,10
\end{tabular} & 20214,86 \\
\hline Pelobates cultripes & 29SPC68 & 101,00 & 165,88 & 113,77 & 39,39 & 5827,84 & 333,01 & 48,04 & 284,97 & 102,98 & 241,62 & 243,26 & 94,45 & 550,29 & 75,81 & 4,00 & 53,27 & 216,66 & 33,90 & 34,73 & 207,97 \\
\hline Pelobates cultripes & 29SPC70 & 100,00 & 161,09 & 106,73 & 38,95 & 5675,07 & 318,19 & 46,80 & 271,38 & 100,66 & 233,89 & 236,54 & 91,70 & 571,07 & 80,41 & 3,15 & 57,24 & 232,70 & 26,59 & 31,03 & 220,35 \\
\hline Pelobates cultripes & 29SPC71 & 101,00 & 158,40 & 108,44 & 38,92 & 5732,58 & 318,87 & 43,40 & 275,47 & 97,48 & 232,29 & 234 & 88,52 & 587,30 & 81,78 & 3,33 & 56,56 & 237,71 & 28,70 & 32,39 & 226, \\
\hline Pelobates cultripes & 29SPC72 & 100,00 & 165,22 & 109,58 & 39,03 & 5735,12 & 326,20 & 49,42 & 276,78 & 103,68 & 239,04 & 241,32 & 95,01 & 543,63 & 76,32 & 3,01 & 56,35 & 219,52 & 26,65 & 30,28 & 208,00 \\
\hline
\end{tabular}




\begin{tabular}{|c|c|c|c|c|c|c|c|c|c|c|c|c|c|c|c|c|c|c|c|c|c|}
\hline TAXON & UTM & $\mathrm{km} 2$ & B101 & B102 & $\mathrm{BIO3}$ & BIO4 & B105 & B106 & B107 & B108 & B109 & B1010 & BIO11 & BIO12 & 81013 & BIO14 & BIO15 & B1016 & B1017 & B1018 & B1019 \\
\hline Pelobates cultripes & 29SPC75 & 100,00 & 160,62 & 112,54 & 38,99 & 5859,96 & 327,79 & 43,08 & 284,70 & 97,82 & 236,75 & 238,66 & 89,31 & 570,99 & 78,47 & 4,01 & 54,31 & 226,36 & 32,31 & 34,26 & 216,50 \\
\hline Pelobates cultripes & 29SPC77 & 99,00 & 161,64 & 113,86 & 39,01 & 5906,86 & 330,81 & 43,08 & 287,73 & 97,98 & 238,62 & 240,14 & 89,56 & 564,18 & 77,44 & 4,05 & 53,31 & 221,79 & 34,09 & 35,34 & 212,05 \\
\hline Pelobates cultripes & 29SPC78 & 101,00 & 164,72 & 114,89 & 39,01 & 5922,38 & 334,61 & 44,63 & 289,98 & 100,47 & 241,89 & 243,01 & 92,16 & 543,85 & 75,06 & 4,00 & 52,70 & 213,05 & 33,86 & 34,86 & 202,97 \\
\hline Pelobates cultripes & 29SPC79 & 99,00 & 166,67 & 115,78 & 39,06 & 5948,78 & 337,34 & 45,49 & 291,85 & 101,73 & 244,35 & 245,09 & 93,47 & 531,21 & 73,60 & 4,00 & 52,15 & 207,08 & 34,50 & 35,24 & 196,76 \\
\hline Pelobates cultripes & 29SPC80 & 101,00 & 154,66 & 107,93 & 38,41 & 5795,37 & 315,84 & 39,03 & 276,81 & 93,23 & 229,63 & 232,06 & 84,21 & 614,21 & 85,61 & 3,64 & 56,86 & 248,62 & 29,24 & 33,59 & 236,45 \\
\hline Pelobates cultripes & 29SPC81 & 99,00 & 159,18 & 109,25 & 38,81 & 5818,30 & 321,64 & 42,67 & 278,97 & 97,08 & 234,43 & 236,60 & 88,26 & 583,86 & 81,56 & 3,29 & 56,41 & 235,44 & 28,32 & 32,34 & 223,32 \\
\hline Pelobates cultripes & 29SPC82 & 101,00 & 160,19 & 110,52 & 38,84 & 5854,69 & 324,58 & 42,86 & 281,71 & 97,50 & 235,97 & 238,01 & 88,63 & 575,40 & 80,09 & 3,43 & 55,90 & 230,86 & 28,88 & 32,50 & 219,15 \\
\hline Pelobates cultripes & 29SPC83 & 100,00 & 162,91 & 111,65 & 38,96 & 5873,63 & 328,54 & 44,51 & 284,04 & 99,78 & 238,88 & 240,86 & 91,00 & 557,23 & 77,57 & 3,32 & 55,43 & 222,59 & 28,81 & 32,01 & 210,99 \\
\hline Pelobates cultripes & $295 P C 86$ & 100,00 & 156,27 & 113,57 & 38,80 & 5976,05 & 326,95 & 37,27 & 289,67 & 92,08 & 234,28 & 235,96 & 83,77 & 595,57 & 81,03 & 4,27 & 53,38 & 233,99 & 35,05 & 36,73 & 223,79 \\
\hline Pelobates cultripes & 29SPC87 & 101,00 & 159,43 & 114,49 & 38,96 & 6000,35 & 331,08 & 39,33 & 291,75 & 94,80 & 237,95 & 239,14 & 86,38 & 570,55 & 78,01 & 4,14 & 52,95 & 223,31 & 34,51 & 36,02 & 212,68 \\
\hline Pelobates cultripes & 29SPC88 & 100,00 & 163,88 & 115,66 & 39,00 & 5993,57 & 335,55 & 42,50 & 293,05 & 98,77 & 242,25 & 243,16 & 90,53 & 537,45 & 74,13 & 4,00 & 52,71 & 209,84 & 33,10 & 34,49 & 198,71 \\
\hline Pelobates cultripes & 29SPC90 & 100,00 & 155,39 & 109,04 & 38,17 & 5882,69 & 318,88 & 38,08 & 280,80 & 92,63 & 231,65 & 233,82 & 83,79 & 613,37 & 85,57 & 3,45 & 56,86 & 247,51 & 28,96 & 33,52 & 234,93 \\
\hline Pelobates cultripes & 29SPC91 & 101,00 & 158,57 & 110,27 & 38,30 & 5915,33 & 323,67 & 40,32 & 283,35 & 95,27 & 235,23 & 237,27 & 86,32 & 589,82 & 82,32 & 3,35 & 56,42 & 237,01 & 28,48 & 32,65 & 224,46 \\
\hline Pelobates cultripes & 29SPC92 & 99,00 & 153,35 & 111,44 & 38,22 & 5977,65 & 321,58 & 34,63 & 286,95 & 89,59 & 231,15 & 233,13 & 80,78 & 621,02 & 85,31 & 3,99 & 55,51 & 247,66 & 31,83 & 35,31 & 236,26 \\
\hline Pelobates cultripes & 29SPC93 & 101,00 & 159,94 & 112,53 & 38,63 & 5969,28 & 328,46 & 40,33 & 288,14 & 95,84 & 237,50 & 239,16 & 87,01 & 576,55 & 79,75 & 3,52 & 55,27 & 229,36 & 29,91 & 33,20 & 217,51 \\
\hline Pelobates cultripes & 29SPC96 & 100,00 & 150,56 & 113,48 & 38,09 & 6081,97 & 323,90 & 31,03 & 292,87 & 85,66 & 230,35 & 231,96 & 77,15 & 631,10 & 84,78 & 4,83 & 53,20 & 246,78 & 37,25 & 38,97 & 236,59 \\
\hline Pelobates cultripes & 29SPC97 & 100,00 & 160,76 & 115,31 & 38,64 & 6068,26 & 333,90 & 38,94 & 294,96 & 95,06 & 240,01 & 241,08 & 86,54 & 555,76 & 76,01 & 4,06 & 53,00 & 216,93 & 32,91 & 34,71 & 205,42 \\
\hline Pelobates cultripes & 29SPC98 & 100,00 & 163,77 & 115,99 & 38,94 & 6055,62 & 337,09 & 41,36 & 295,74 & 97,97 & 242,82 & 243,82 & 89,72 & 531,38 & 72,98 & 4,00 & 52,47 & 206,67 & 32,15 & 34,00 & 194,75 \\
\hline Pelobates cultripes & 29SPD00 & 101,00 & 164,58 & 99,37 & 39,79 & 5146,66 & 311,81 & 64,14 & 247,67 & 103,56 & 230,05 & 234,15 & 102,51 & 650,04 & 89,94 & 4,54 & 55,90 & 263,25 & 37,71 & 38,10 & 263,25 \\
\hline Pelobates cultrips & 29SPD01 & 101,00 & 164,77 & 98,75 & 39,30 & 5155,83 & 311,99 & 64,27 & 247,72 & $\mid 104,12$ & 230,51 & 234,52 & $\mid 102,75$ & 667,05 & 92,81 & 5,00 & 55,91 & 270,59 & 38,92 & 39,36 & 270,59 \\
\hline Pelobates cultripes & 29SPD02 & 100,00 & 167,21 & 98,91 & 39,28 & 5169,43 & 314,35 & 66,14 & 248,21 & 109,00 & 233,19 & 236,94 & 104,65 & 665,74 & 92,82 & 4,97 & 55,84 & 270,11 & 38,65 & 39,55 & 270,11 \\
\hline Pelobates cultripes & 29SPD05 & 100,00 & 164,19 & 97,09 & 38,45 & 5241,36 & 311,97 & 63,09 & 248,88 & 101,06 & 231,63 & 234,92 & 100,91 & 747,79 & \begin{tabular}{|c|}
106,27 \\
\end{tabular} & 5,92 & 55,64 & 304,62 & 44,26 & 45,40 & 304,62 \\
\hline Pelobates cultripes & 29SPD06 & 101,00 & 162,42 & 96,54 & 38,07 & 5278,41 & 310,58 & $\begin{array}{ll}61,03 \\
\end{array}$ & 249,54 & $\begin{array}{l}98,67 \\
\end{array}$ & 230,34 & 233,67 & \begin{tabular}{|c|c|}
98,67 \\
\end{tabular} & 781,05 & 111,75 & 6,01 & 55,70 & 318,61 & 46,15 & 47,22 & 318,61 \\
\hline Pelobates cultripes & $29 S P D 10$ & 100,00 & 161,34 & 100,52 & 39,30 & 5273,02 & 312,03 & 59,57 & 252,46 & 102,42 & 228,95 & 232,85 & 98,11 & 669,64 & 92,03 & 4,97 & 55,26 & 269,45 & 39,96 & 40,06 & 269,45 \\
\hline Pelobates cultripes & 29SPD11 & 101,00 & 164,59 & 100,59 & 39,14 & 5276,51 & 314,93 & 62,16 & 252,77 & 107,17 & 232,23 & 235,88 & 101,03 & 662,80 & 91,24 & 5,00 & 55,36 & 266,99 & 39,18 & 39,92 & 266,87 \\
\hline Pelobates cultripes & 29SPD12 & 100,00 & 166,36 & 100,31 & 39,03 & 5282,65 & 316,66 & 63,77 & 252,89 & 110,21 & 234,10 & 237,65 & 102,66 & 666,77 & 92,1 & 5,00 & 55,42 & 268,94 & 39,34 & 40,14 & 268,71 \\
\hline Pelobates cultripes & 29SPD13 & 100,00 & 165,32 & 99,37 & 38,84 & 5312,71 & 315,68 & 63,01 & 252,67 & $\begin{array}{l}107,43 \\
\end{array}$ & 233,46 & 237,16 & 101,29 & 694,89 & 96,87 & 5,21 & 55,44 & 280,93 & $\begin{array}{l}41,01 \\
41,01\end{array}$ & $\begin{array}{l}42,06 \\
42,06\end{array}$ & 280,87 \\
\hline Pelobates cultripes & 29SPD14 & 101,00 & 165,21 & 98,75 & 38,55 & 5330,92 & 315,60 & 62,83 & 252,77 & 106,32 & 233,90 & 237,29 & 101,11 & 714,56 & 100,17 & 5,54 & 55,28 & 289,08 & 42,56 & 43,73 & 289,07 \\
\hline Pelobates cultripes & $29 S P D 15$ & 99,00 & 162,46 & 97,29 & 38,02 & 5371,46 & 312,91 & 60,64 & 252,27 & 98,53 & 231,79 & 235,15 & 97,96 & 757,44 & 107,32 & 5,99 & 55,27 & 307,57 & 45,20 & 46,33 & 307,57 \\
\hline Pelobates cultripes & $29 S P D 16$ & 100,00 & 161,78 & 96,94 & 37,96 & 5407,71 & 312,48 & 59,44 & 253,04 & 96,84 & 231,64 & 234,87 & 96,84 & 780,17 & 111,29 & 6,00 & 55,41 & 317,28 & 46,43 & 47,58 & 317,28 \\
\hline Pelobates cultripes & 29SPD17 & 100,00 & 162,40 & 97,18 & 37,83 & 5441,73 & 313,80 & 59,03 & 254,77 & 97,30 & 232,95 & 235,84 & 96,87 & 787,81 & 112,55 & 6,00 & 55,10 & 319,82 & 47,48 & 48,64 & 319,82 \\
\hline Pelobates cultripes & 29SPD19 & 100,00 & 163,73 & 98,30 & 37,49 & 5511,66 & 316,45 & 57,86 & 258,59 & $\begin{array}{l}99,38 \\
90\end{array}$ & \begin{tabular}{|l|}
235,47 \\
\end{tabular} & \begin{tabular}{|l|}
237,44 \\
\end{tabular} & $\begin{array}{l}0,0,75 \\
96,75\end{array}$ & \begin{tabular}{|c|}
798,04 \\
\end{tabular} & \begin{tabular}{|l|l|l|l|l|}
114,38 \\
\end{tabular} & $6,0,44$ & 54,99 & \begin{tabular}{|l|}
322,98 \\
328
\end{tabular} & $\begin{array}{l}41,46 \\
48,53 \\
\end{array}$ & $\begin{array}{l}40,049 \\
49,92 \\
\end{array}$ & 322,95 \\
\hline Pelobates cultripes & 29SPD22 & 100,00 & 166,06 & 102,14 & 39,02 & 5404,88 & 319,60 & 61,34 & 258,25 & 109,06 & 235,63 & 238,95 & 100,95 & 661,05 & 90,44 & 5,06 & 54,90 & 265,60 & 39,65 & 40,57 & 264,47 \\
\hline Pelobates cultripes & 29SPD24 & 100,00 & 163,64 & 99,38 & 38,08 & 5448,06 & 316,78 & 60,27 & 256,51 & 106,05 & 234,11 & 237,44 & 98,42 & 720,95 & 100,47 & 5,90 & 54,74 & 290,40 & 43,93 & 45,10 & 290,08 \\
\hline Pelobates cultripes & $29 S P D 25$ & 101,00 & 160,69 & 97,33 & 37,76 & 5474,17 & 313,32 & 58,49 & 254,84 & 98,78 & 231,64 & 235,06 & 95,46 & 766,08 & 108,18 & 6,11 & 55,04 & 309,96 & 46,21 & 47,49 & 309,96 \\
\hline Pelobates cultripes & $29 S P D 26$ & 101,00 & 160,01 & 96,71 & 37,40 & 5512,44 & 312,78 & 57,41 & 255,37 & 95,55 & 231,52 & 234,88 & 94,22 & 787,61 & 111,94 & 6,14 & 55,06 & 319,04 & 47,62 & 48,89 & 319,04 \\
\hline Pelobates cultripes & $\begin{array}{l}\text { 29SPD27 } \\
\end{array}$ & 100,00 & 101,47 & $\begin{array}{ll}07,11 \\
97,40\end{array}$ & 37,06 & $\begin{array}{l}551,44^{2} \\
5567,\end{array}$ & 315,33 & $\frac{1,141}{57,12}$ & 258,21 & \begin{tabular}{|c|c|}
98,03 \\
98,0
\end{tabular} & \begin{tabular}{|l|}
233,97 \\
23,5
\end{tabular} & \begin{tabular}{|l|}
236,64 \\
23,0
\end{tabular} & $\begin{array}{ll}44,2< \\
94,68\end{array}$ & \begin{tabular}{|l|}
784,94 \\
\end{tabular} & \begin{tabular}{|l|}
111,68 \\
111,68
\end{tabular} & $\frac{0,14 \mid}{6,06}$ & $\begin{array}{l}54,80 \\
54,87\end{array}$ & \begin{tabular}{|l|}
317,364 \\
\end{tabular} & $\begin{array}{l}4,7,71 \\
47,4\end{array}$ & $\begin{array}{l}40,03 \\
48,92\end{array}$ & 317,33 \\
\hline Pelobates cultripes & 29SPD28 & 101,00 & 163,53 & 98,34 & 37,12 & 5619,06 & 318,43 & 57,26 & 261,16 & 101,12 & 236,92 & 238,95 & 95,64 & 774,94 & 110,22 & 5,99 & 54,79 & 312,52 & 47,14 & 48,58 & 312,37 \\
\hline Pelobates cultripes & 29SPD29 & 101,00 & 165,74 & 99,41 & 37,31 & 5638,23 & 320,90 & 57,92 & 262,98 & 103,96 & 239,38 & 240,89 & 97,06 & 762,84 & 108,38 & 5,99 & 54,66 & 306,90 & 46,46 & 48,16 & 306,55 \\
\hline Pelobates cultripes & 29SPD30 & 100,00 & 161,50 & 105,37 & 39,15 & 5515,50 & 318,91 & 54,19 & 264,71 & 103,47 & 232,66 & 236,00 & 95,16 & 649,40 & 87,17 & 5,00 & 54,22 & 259,03 & 39,70 & 40,00 & 256,64 \\
\hline Pelobates cultripes & 29SPD31 & 101,00 & 164,08 & 105,16 & 39,06 & 5516,52 & 321,40 & 56,66 & 264,73 & 105,84 & 235,25 & 238,34 & 97,68 & 647,09 & 86,6 & 5,00 & 54,20 & 258,42 & 39,55 & 40,13 & 255,93 \\
\hline Pelobates cultripes & $29 S P D 32$ & 101,00 & 164,90 & 104,14 & 38,5 & 5524,03 & 321,94 & 57,97 & 263,97 & 106,51 & 236,26 & 239,30 & 98,44 & 659,01 & 89,18 & 5,07 & 54,34 & \begin{tabular}{|l|}
263,67 \\
\end{tabular} & 40,15 & 41,02 & 261,42 \\
\hline Pelobates cultripes & 29SPD33 & 100,00 & 162,66 & 101,92 & 38,40 & 5533,15 & 318,94 & 57,36 & 261,57 & 104,52 & 234,36 & 237,56 & 96,38 & 699,47 & 95,88 & 5,75 & 54,18 & 280,39 & 43,21 & \begin{tabular}{ll|}
44,24 \\
\end{tabular} & 278,84 \\
\hline Pelobates cultripes & 29SPD34 & 101,00 & 160,24 & 99,30 & 37,85 & 5550,93 & 315,39 & 56,72 & 258,67 & 102,24 & 232,29 & 235,74 & 94,27 & 740,95 & 103,04 & 6,14 & 54,40 & 298,01 & 45,47 & 46,65 & 297,21 \\
\hline Pelobates cultripes & 29SPD35 & 100,00 & 150,96 & 93,90 & 36,71 & 5549,48 & 303,30 & 51,48 & 251,82 & 87,76 & 223,30 & 227,27 & 86,22 & 847,69 & 120,82 & 7,24 & 54,84 & 343,56 & 52,06 & 53,06 & 343,56 \\
\hline Pelobates cultripes & 29SPD36 & 101,00 & 153, & 94,90 & 36,77 & 5604,19 & 307,60 & 52,43 & 255,18 & 91,66 & 227,18 & 230,49 & $\begin{array}{l}0,25 \\
87,92\end{array}$ & $\begin{array}{l}831,12 \\
831,\end{array}$ & \begin{tabular}{|l|l|}
118,49 \\
\end{tabular} & $6,2,95$ & 54,64 & 336,25 & 51,13 & 52,08 & 336,14 \\
\hline Pelobates cultripes & 29SPD37 & 100,00 & 162 & 98,66 & 37,05 & 5674 & 318,45 & 56,13 & 262,32 & $\begin{array}{r}101,76 \\
\end{array}$ & 236,42 & 238,79 & 94,20 & 758,86 & 106, & 5,99 & 54,36 & 305,26 & 46,45 & 47,80 & 304,45 \\
\hline Pelobates cultripes & 29SPD38 & 101,00 & 162,82 & 98,87 & 36,98 & 5732,46 & 319,80 & 55,39 & 264,41 & 101,39 & 237,89 & 239,77 & 93,75 & 761,73 & 107,66 & 5,93 & 54,35 & 305,98 & 46,83 & 48,18 & 305,15 \\
\hline Pelobates cultripes & $29 S P D 39$ & 101,00 & 163,06 & 99,01 & 36,69 & 5777,13 & 320,64 & 54,43 & 266,21 & 100,55 & 238,81 & 240,35 & 93,17 & 767,51 & 108,81 & 5,99 & 54,15 & 307,94 & 47,38 & 48,78 & 307,06 \\
\hline Pelobates cultripes & $29 S P D 40$ & 100,00 & 160,85 & 107,88 & 39,32 & 5634,39 & 321,61 & 50,65 & 270,96 & 101,18 & 233,86 & 236,68 & 93,03 & 641,53 & 85,81 & 5,19 & 53,71 & 70 & 40,13 & 40,43 & 250,73 \\
\hline Pelobates cultripes & 29SPD41 & 100,00 & $\begin{array}{l}10,03,43 \\
162,43\end{array}$ & $\begin{array}{l}107,00 \\
107,64\end{array}$ & 39 & \begin{tabular}{|l|}
5644,46 \\
564,46
\end{tabular} & 323,51 & 50,29 & $\begin{array}{l}271,22 \\
\end{array}$ & \begin{tabular}{|l|}
102,49 \\
10,0
\end{tabular} & \begin{tabular}{|l|}
235,740 \\
235
\end{tabular} & \begin{tabular}{|l|}
238,270 \\
\end{tabular} & $\begin{array}{ll}30,25 \\
94,25\end{array}$ & \begin{tabular}{|l|l|}
645,10 \\
640
\end{tabular} & $\begin{array}{l}80,01 \\
86,31\end{array}$ & $\begin{array}{l}3,1,02 \\
5,02\end{array}$ & 53,74 & 256,50 & $\begin{array}{l}40,13 \\
40,14\end{array}$ & $\begin{array}{l}40,45 \\
40,61 \\
\end{array}$ & 252,58 \\
\hline Pelobates cultripes & $29 S P D 42$ & 100,00 & 164,73 & 107,12 & 39,01 & 5646,44 & 325,62 & 54,64 & 270,98 & 104,53 & 238,01 & 240,52 & 96,53 & 643,72 & 86,33 & 5,01 & 53,71 & 256,23 & 39,98 & 40,80 & 252,39 \\
\hline Pelobates cultripes & 29SPD43 & 99,00 & 163,16 & 104,89 & 38,67 & \begin{tabular}{|l|}
5647,58 \\
\end{tabular} & 323,13 & 54,71 & 268,42 & \begin{tabular}{|l|l|}
103,38 \\
\end{tabular} & $\begin{array}{l}236,58 \\
230\end{array}$ & 239,30 & $\begin{array}{ll}05,26 \\
95\end{array}$ & \begin{tabular}{|l|l|l|l|}
675,98 \\
\end{tabular} & \begin{tabular}{|l|}
91,26 \\
\end{tabular} & 5,35 & 53,69 & 269,65 & 42,25 & 43,30 & 266,46 \\
\hline Pelobates cultripes & 29SPD44 & 101,00 & 155,18 & 99,28 & 37,57 & 5640,11 & 312,16 & 51,31 & 260,85 & 96,60 & 228,72 & 232,15 & 88,58 & 767,07 & 106,42 & 6,42 & 54,01 & 307,69 & 47,74 & 48,74 & 306,19 \\
\hline Pelobates cultripes & $29 S P D 45$ & 99,00 & 145,56 & 94,44 & 36,50 & 5659,10 & 300,09 & 44,74 & 255,35 & 86,12 & 220,27 & 223 & 79,69 & 866,89 & 122,89 & 7,64 & 54,20 & 348,96 & 54,20 & 54,73 & 348,5 \\
\hline Pelobates cultripes & \begin{tabular}{|l|}
$295 \mathrm{PSD} 46$ \\
$29 P D$
\end{tabular} & \begin{tabular}{|c|}
100,00 \\
100
\end{tabular} & $\begin{array}{l}14,50 \\
156,64\end{array}$ & $\begin{array}{l}44,44 \\
97,92\end{array}$ & $\begin{array}{l}0,050 \\
36,98\end{array}$ & 5 & 313,60 & $\begin{array}{ll}44,1 / 85 \\
51,85\end{array}$ & $\begin{array}{l}261,75 \\
261 \\
\end{array}$ & $\begin{array}{l}\mid l 0,112 \\
96,79 \\
\end{array}$ & \begin{tabular}{|l|}
231,46 \\
231
\end{tabular} & \begin{tabular}{|l|}
234,36 \\
234
\end{tabular} & $\begin{array}{l}5,80 \\
88,84\end{array}$ & \begin{tabular}{|l|}
$779,79,71$ \\
\end{tabular} & \begin{tabular}{|l|}
109,38 \\
109,38
\end{tabular} & $\begin{array}{l}\frac{644}{6,38} \\
\end{array}$ & 54,05 & \begin{tabular}{|l|}
313,09 \\
3130
\end{tabular} & $\begin{array}{ll}4,, 40 \\
48,41\end{array}$ & $\begin{array}{l}4,135 \\
49,55 \\
\end{array}$ & $\begin{array}{l}340,51 \\
311,72 \\
\end{array}$ \\
\hline Pelobates cultripes & 29SPD47 & 100,00 & 161,78 & 99,90 & 37,00 & 5777,09 & 320,23 & 53,95 & 266,28 & 100,13 & 237,49 & 239,55 & 92,44 & 738,82 & 103,05 & 5,96 & 53,79 & 295,82 & 45,84 & 47,24 & 293,69 \\
\hline Pelobates cultripes & 29SPD48 & 100,00 & 163,51 & 100,30 & 37,01 & 5812,85 & 322,29 & 54,38 & 267,91 & 100,95 & 239,86 & 241,48 & 93,31 & 729,76 & 101,92 & 5,83 & 53,78 & 291,85 & 45,22 & 46,76 & 289,49 \\
\hline Pelobates cultripes & 29SPD49 & 99,00 & 164,02 & 100,39 & 36,89 & 5853,23 & 323,01 & 53,88 & 269,13 & 100,56 & 240,91 & 242 , & 93, & 730,46 & 102,34 & 5,78 & 53,71 & 291,92 & 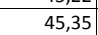 & 46,81 & 289,43 \\
\hline Pelobates cultripes & 29SPD53 & 101,00 & 162,51 & 107,88 & 38,71 & 5768,06 & 326,25 & $\begin{array}{l}50,88 \\
\end{array}$ & 275,37 & $\begin{array}{l}100,99 \\
\end{array}$ & 237,82 & 239,95 & 92,98 & 656,75 & 87,85 & 5,19 & 52,99 & 260,40 & 41,79 & $\begin{array}{l}42,66 \\
426\end{array}$ & 255,47 \\
\hline
\end{tabular}




\begin{tabular}{|c|c|c|c|c|c|c|c|c|c|c|c|c|c|c|c|c|c|c|c|c|c|}
\hline TAXON & UTM & $\mathrm{km} 2$ & B101 & B102 & $\mathrm{BIO3}$ & B104 & B105 & B106 & B107 & B108 & B109 & BIO10 & BIO11 & BIO12 & 81013 & BIO14 & BIO15 & B1016 & B1017 & BIO18 & B1019 \\
\hline Pelobates cultripes & 29SPD55 & 101,00 & 155,24 & 100,88 & 37,30 & 5793,53 & 315,14 & 48,08 & 267,07 & 94,52 & 231,21 & 233,80 & 86,40 & 749,56 & 103,06 & 6,22 & 53,30 & 298,95 & 47,35 & 48,26 & 295,74 \\
\hline Pelobates cultripes & 29SPD56 & 101,00 & 157,86 & 100,85 & 37,00 & 5829,21 & 317,95 & 49,67 & 268,29 & 96,27 & 234,37 & 236,51 & 88,25 & 735,80 & 101,26 & 6,06 & 53,23 & 293,24 & 46,52 & 47,58 & 289,84 \\
\hline Pelobates cultripes & 29SPD57 & 100,00 & 158,85 & 100,45 & 36,94 & 5864,96 & 318,85 & 50,03 & 268,81 & 96,40 & 235,90 & 237,80 & 88,58 & 735,08 & 101,59 & 6,03 & 53,27 & 292,83 & 46,55 & 47,62 & 289,41 \\
\hline Pelobates cultripes & 29SPD58 & 101,00 & 160,07 & 100,45 & 36,76 & 5897,48 & 320,11 & 50,25 & 269,86 & 96,85 & 237,75 & 239,16 & 89,13 & 729,97 & 101,25 & 5,89 & 53,19 & 290,69 & 45,96 & 47,07 & 287,24 \\
\hline Pelobates cultripes & 29SPD59 & 101,00 & 163,90 & 101,51 & 36,84 & 5918,49 & 324,06 & 52,29 & 271,77 & 99,59 & 241,73 & 242,68 & 92,03 & 700,88 & $\begin{array}{l}96,96 \\
\end{array}$ & 5,47 & 53,10 & 278,58 & 43,96 & 45,45 & 274,74 \\
\hline Pelobates cultripes & 29SPD62 & 100,00 & 165,88 & 114,38 & 39,38 & 5882,08 & 334,61 & 48,07 & 286,54 & 101,80 & 242,73 & 243,80 & 93,97 & 590,70 & 79,85 & 4,86 & 52,16 & 231,85 & 38,45 & 39,20 & 224,20 \\
\hline Pelobates cultripes & 29SPD63 & 99,00 & 165,28 & 111,71 & 39,01 & 5881,51 & 332,24 & 49,14 & 283,10 & 101,48 & 242,15 & 243,45 & 93,61 & 608,40 & 81,64 & 4,91 & 52,16 & 239,24 & 39,44 & 40,35 & 232,05 \\
\hline Pelobates cultripes & 29SPD64 & 101,00 & 163,57 & 108,86 & 38,40 & 5889,68 & 329,05 & 49,39 & 279,66 & 100,14 & 240,79 & 242,18 & 92,22 & 634,25 & 84,37 & 5,02 & 52,28 & 249,93 & 40,92 & 41,94 & 243,47 \\
\hline Pelobates cultripes & 29SPD65 & 99,00 & 159,07 & 105,07 & 37,66 & 5905,09 & 322,77 & 47,30 & 275,47 & 96,15 & 236,66 & 238,35 & 88,16 & 682,61 & \begin{tabular}{c|c|}
91,35 \\
\end{tabular} & 5,51 & 52,42 & 269,79 & 43,77 & 44,68 & 264,17 \\
\hline Pelobates cultripes & 29SPD66 & 100,00 & 155,77 & 102,29 & 36,99 & 5927,89 & 318,27 & 45,51 & 272,75 & 92,83 & 233,73 & 235,56 & 84,82 & 719,31 & 97,68 & 5,96 & 52,67 & 284,73 & 46,32 & 47,04 & 279,75 \\
\hline Pelobates cultripes & 29SPD67 & 100,00 & 160,17 & 102,90 & 37,00 & 5953,39 & 322,70 & 48,59 & 274,10 & 96,39 & 238,64 & 239,99 & 88,50 & 689,63 & 93,57 & 5,52 & 52,62 & 272,83 & 43,92 & 45,00 & 267,58 \\
\hline Pelobates cultripes & 29SPD68 & 100,00 & 162,31 & 102,78 & 37,01 & 5974,32 & 324,56 & 49,86 & 274,70 & 97,69 & 240,99 & 242,01 & 89,96 & 677,68 & 92,17 & 5,34 & 52,48 & 267,94 & 43,03 & 44,25 & 262,65 \\
\hline Pelobates cultripes & 29SPD69 & 99,00 & 163,36 & 102,63 & 36,88 & 5985,69 & 325,23 & 50,46 & 274,77 & 98,32 & 242,23 & 242,91 & 90,58 & 672,44 & 91,76 & 5,20 & 52,53 & 265,70 & 42,64 & 44,03 & 260,42 \\
\hline Pelobates cultripes & 29SPD70 & 101,00 & 168,47 & 116,41 & 39,00 & 5985,76 & 339,92 & 46,32 & 293,60 & 102,76 & 246,63 & 247,24 & 94,58 & 521,55 & 72,42 & 4,00 & 51,71 & 202,79 & 34,94 & 35,31 & 192,28 \\
\hline Pelobates cultripes & 29SPD71 & 100,00 & 168,40 & 116,38 & \begin{tabular}{l|l|}
39,05 \\
\end{tabular} & 5976,06 & 339,55 & 46,77 & 292,79 & 102,82 & 246,31 & 247,10 & 94,75 & 533,62 & 73,51 & 4,00 & 51,58 & 207,55 & 35,67 & 36,27 & 197,40 \\
\hline Pelobates cultripes & $29 S P D 72$ & 101,00 & 167,95 & 115,53 & 39,09 & 5969,52 & 338,12 & 47,37 & 290,75 & 102,45 & 245,99 & 246,49 & 94,50 & 549,09 & 74,84 & 4,03 & 51,63 & 214,01 & 36,08 & 36,81 & 204,42 \\
\hline Pelobates cultripes & $29 S P D 73$ & 100,00 & 164,64 & 112,88 & 38,83 & 5980,29 & 333,86 & 46,27 & 287,60 & 99,49 & 242,99 & 243,82 & 91,55 & 586,46 & 78,71 & 4,75 & 51,56 & 228,94 & 38,45 & 39,36 & 220,19 \\
\hline Pelobates cultripes & 29SPD74 & 101,00 & 160,95 & 109,50 & 38,06 & 5989,27 & 328,78 & 45,17 & 283,62 & 96,34 & 239,74 & 240,83 & 88,44 & 626,49 & 83,05 & 5,03 & 51,66 & 245,22 & 40,97 & 41,77 & 237,36 \\
\hline Pelobates cultripes & 29SPD75 & 100,00 & 160,41 & 107,47 & 37,79 & 6004,66 & 327,26 & 45,64 & 281,61 & 95,76 & 239,45 & 240,56 & 87,78 & 640,06 & 84,48 & 5,02 & 51,79 & 250,86 & 41,51 & 42,46 & 243,36 \\
\hline Pelobates cultripes & 29SPD77 & 100,00 & 163,55 & 105,60 & 37,01 & 6029,43 & 328,94 & 49,05 & 279,88 & 98,36 & 243,08 & 243,80 & 90,37 & 630,06 & 83,43 & 4,99 & 51,70 & 246,92 & 40,79 & 42,02 & 239,72 \\
\hline Pelobates cultripes & 29SPD78 & 101,00 & 163,18 & 104,46 & 36,98 & 6042,43 & 327,73 & 48,82 & 278,91 & 97,58 & 242,86 & 243,48 & 89,67 & 638,86 & 85,3 & 4,99 & 51,72 & 250,58 & 41,22 & 42,48 & 243,70 \\
\hline Pelobates cultripes & 29SPD79 & 100,00 & 164,08 & 103,93 & 36,99 & 6046,74 & 328,12 & 49,56 & 278,56 & 98,21 & 243,88 & 244,25 & 90,47 & 634,59 & 85,11 & 4,96 & 51,67 & 248,84 & 40,90 & 42,10 & 242,06 \\
\hline Pelobates cultripes & 29SPD80 & 100,00 & 166,48 & 116,63 & 39,00 & \begin{tabular}{|l|l|}
6016,54 \\
\end{tabular} & 338,82 & 43,80 & 295,03 & 101,63 & 244,73 & 245,60 & 92,25 & 515,78 & 71,39 & 4,00 & 51,66 & 200,01 & 33,50 & 34,65 & 188,28 \\
\hline Pelobates cultripes & 29SPD81 & 100,00 & 167,66 & 116,18 & 39,00 & 6007,36 & 339,61 & 45,34 & 294,27 & 101,59 & 245,93 & 246,56 & 93,46 & 517,34 & 71,18 & 4,00 & 51,31 & 200,32 & 33,97 & 35,08 & 188,84 \\
\hline Pelobates cultripes & $29 S P D 82$ & 100,00 & 167,14 & 115,38 & 38,95 & 6039,30 & 339,05 & 45,73 & 293,31 & 101,06 & 246,31 & 246,66 & 93,00 & 532,86 & 72,48 & 4,00 & 51,25 & 206,41 & 35,04 & 35,95 & 195,55 \\
\hline Pelobates cultripes & 29SPD84 & 100,00 & 164,51 & 111,56 & 38,02 & 6072,79 & 334,88 & 45,70 & 289,18 & 98,41 & 244,35 & 244,90 & 90,37 & 571,99 & 76,07 & 4,41 & 51,20 & 222,03 & 37,21 & 38,09 & 212,37 \\
\hline Pelobates cultripes & 29SPD87 & 100,00 & 162,66 & 106,46 & 37,01 & 6105,22 & 330,23 & 46,67 & 283,56 & $\begin{array}{l}\mid 0,4,46 \\
96,46\end{array}$ & 243,22 & 243,79 & 88,46 & 606,97 & 79,40 & $\begin{array}{l}4,4+95 \\
4,95\end{array}$ & 50,99 & 235,81 & $\mid \begin{array}{l}\mid r, 21 \\
40,01\end{array}$ & 41,02 & 227,34 \\
\hline Pelobates cultripes & 29SPD89 & 100,00 & 160,42 & 104,07 & 36,61 & 6124,59 & 326,65 & 45,32 & 281,34 & 93,82 & 241,47 & 241,73 & 86,14 & 627,26 & 83,17 & 5,00 & 51,11 & 244,16 & 41,07 & 41,74 & 236,20 \\
\hline Pelobates cultripes & $29 S P D 90$ & 100,00 & 167,01 & 116,32 & 38,96 & 6058,01 & 340,22 & 44,05 & 296,17 & 103,28 & 245,93 & 246,77 & 92,34 & 505,06 & 69,48 & 4,00 & 51,58 & 195,03 & 31,97 & 33,93 & 182,48 \\
\hline Pelobates cultripes & 29SPD92 & 101,00 & 166,57 & 115,02 & 38,25 & 6110,81 & 339,87 & 44,49 & 295,38 & 99,69 & 246,75 & 247,13 & 91,56 & 521,76 & 70,39 & 4,00 & 50,93 & 200,92 & 33,93 & 34,98 & 189,26 \\
\hline Pelobates cultripes & 29SPD98 & 101,00 & 158,49 & 105,22 & 36,24 & 6194,16 & 327,42 & 42,24 & 285,18 & 91,57 & 240,63 & 240,91 & 83,50 & 608,33 & 79,12 & 4,98 & 50,55 & 234,68 & 40,44 & 40,87 & 225,43 \\
\hline Pelobates cultripes & 29SPD99 & 100,00 & 158,30 & 104,49 & 30,24 & 6195,90 & 326,29 & $\begin{array}{l}42,27 \\
42,27 \\
\end{array}$ & \begin{tabular}{|l|}
284,01 \\
\end{tabular} & $\begin{array}{ll}10,98 \\
90\end{array}$ & \begin{tabular}{|l|}
240,64 \\
\end{tabular} & \begin{tabular}{|l|}
240,69 \\
\end{tabular} & $\begin{array}{l}3,27 \\
83,27\end{array}$ & \begin{tabular}{|l|l|}
610,56 \\
\end{tabular} & 79,83 & 5,00 & $\begin{array}{ll}50,47 \\
\end{array}$ & 235,55 & $\begin{array}{l}0,4,64 \\
40,64\end{array}$ & 40,75 & 226,44 \\
\hline Pelobates cultripes & 29SPE10 & 100,00 & 159,18 & 97,18 & $\begin{array}{l}36,95 \\
\end{array}$ & 5576,36 & 312,60 & 53,12 & 259,48 & 91,49 & 232,06 & 233,77 & 91,49 & 854,46 & 123,62 & 6,97 & 54,95 & 346,49 & 52,60 & 53,47 & 346,49 \\
\hline Pelobates cultripes & 29SPE12 & 100,00 & 151,78 & 95,52 & 36,56 & 5580,80 & 303,98 & 46,12 & 257,86 & 84,14 & 225,44 & 226,36 & 84,14 & 943,37 & 138,41 & 8,12 & 55,08 & 383,08 & 58.69 & 59,05 & 383,08 \\
\hline Pelobates cultripes & 29SPE20 & 100,00 & 159,02 & 97,11 & 36,27 & 5736,83 & 315,15 & 51,62 & 263,53 & 91,49 & 234,44 & 235,76 & 89,70 & 838,95 & 120,98 & 6,83 & 54,74 & 338,78 & 51,89 & 52,70 & 338,73 \\
\hline Pelobates cultripes & 29SPE21 & 100,00 & 157,59 & 97,04 & 36,15 & 5765,61 & 313,94 & 49,60 & 264,34 & 88,08 & 233,56 & 234,55 & 87,85 & 858,44 & 124,23 & 7,02 & 54,74 & 346,39 & 53,52 & 54,15 & 346,39 \\
\hline Pelobates cultripes & 29SPE22 & 100,00 & 153,76 & $\begin{array}{l}96,17 \\
96,17\end{array}$ & 36,13 & $\begin{array}{l}3703,01,76 \\
5741\end{array}$ & 308,91 & $\begin{array}{l}3,00 \\
46,21 \\
\end{array}$ & 262,70 & $\begin{array}{l}80,00 \\
84,23 \\
\end{array}$ & 229,40 & \begin{tabular}{|l|}
230,39 \\
230
\end{tabular} & \begin{tabular}{l|l}
84,23 \\
84,23
\end{tabular} & \begin{tabular}{|l|}
9000,23 \\
90,4
\end{tabular} & $\begin{array}{l}124,25 \\
131,32\end{array}$ & $\begin{array}{l}7,043 \\
7,73\end{array}$ & 54,81 & \begin{tabular}{|l|}
$360,70,70$ \\
\end{tabular} & \begin{tabular}{|l|l|}
56,48 \\
56
\end{tabular} & $\begin{array}{l}45,110 \\
56,78\end{array}$ & 363,70 \\
\hline Pelobates cultripes & 29SPE30 & 100,00 & 165,01 & 99,91 & 36,85 & 5785,91 & 322,58 & 55,11 & 267,47 & 101,66 & 240,95 & 241,99 & 94,62 & 754,97 & 106,97 & 6,00 & 54,14 & 302,59 & 46,47 & 48,13 & 301,33 \\
\hline Pelobates cultripes & 29SPE31 & 101,00 & 157,49 & 97,29 & 36,01 & 5870,90 & 315,45 & 48,45 & 267,00 & 91,57 & 234,94 & 235,83 & 86,60 & 833,36 & 120,00 & 6,90 & 54,25 & \begin{tabular}{|l|l|}
334,68 \\
\end{tabular} & 52,14 & 52,80 & 334,45 \\
\hline Pelobates cultripes & 29SPE32 & 100,00 & 155,12 & 96,91 & 36,01 & 5844,35 & 312,09 & 46,21 & 265,88 & 88,22 & 232,29 & 232,95 & 84,38 & 856,54 & 123,96 & 7,15 & 54,26 & 343,94 & 53,86 & 54,35 & 343,80 \\
\hline Pelobates cultripes & 29SPE40 & 101,00 & 164,31 & 100,45 & 36,85 & 5868,35 & 323,23 & 53,36 & 269,86 & 100,41 & 241,48 & 242,36 & 92,96 & 733,33 & 103,07 & 5, & 53,64 & 292,77 & 45,60 & 47,25 & 290,38 \\
\hline Pelobates cultripes & 29SPE41 & 100,00 & 163,53 & 100,25 & 36,75 & 5876,42 & 322,10 & 52,19 & 269,90 & \begin{tabular}{|l|l|}
99,20 \\
90
\end{tabular} & 240,77 & 241,49 & 91,83 & 744,16 & 105,12 & 6,05 & 53,53 & 296,93 & 46,41 & 48,04 & 294,75 \\
\hline Pelobates cultripes & 29SPE42 & 99,00 & 156,54 & 97,94 & 36,04 & 5903,14 & 314,45 & 46,30 & 268,15 & 92,15 & 234,38 & 234,94 & 84,72 & 808,24 & 115,72 & 6,78 & 53,88 & 322,90 & 50,98 & 51,71 & 321,60 \\
\hline Pelobates cultripes & 29SPE50 & 100,00 & 163,77 & 101,27 & 36,87 & 5932,29 & 323,69 & 51,76 & 271,94 & 99,08 & 241,85 & 242,54 & 91,55 & 705,68 & 98,12 & 5,53 & 53,11 & 280,54 & 44,12 & 45,66 & 276,80 \\
\hline Pelobates cultripes & 29SPE51 & 101,00 & 162,83 & 100,88 & 36,68 & 5941,95 & 322,45 & 50,59 & 271,86 & 97,88 & 241,23 & 241,63 & 90,42 & 716,97 & 100,21 & 5,8 & 53,12 & 284,78 & 45,20 & 46,64 & 281,24 \\
\hline Pelobates cultripes & 29SPE52 & 101,00 & 157,55 & 99,13 & 36,10 & 5958,68 & 316, & 46,10 & 270,33 & 92,54 & 236,26 & 236,52 & $\begin{array}{l}00,445 \\
84,95\end{array}$ & 761,84 & \begin{tabular}{|l|}
107,67 \\
\end{tabular} & $\frac{6,4}{6,1}$ & 53 & 302,85 & $\begin{array}{ll}48,50 \\
48,50\end{array}$ & $\begin{array}{ll}49,19 \\
49,\end{array}$ & 300,00 \\
\hline Pelobates cultripes & 29SPE60 & 101,00 & 160,83 & 101,30 & 36,43 & 6005,53 & 322,03 & 48,31 & 273,71 & 95,56 & 240,07 & 240,54 & 87,79 & 697,13 & 96,08 & 5,66 & 52,50 & 275,62 & 44,60 & 45,66 & 270,71 \\
\hline Pelobates cultripes & 29SPE61 & 99,00 & 159,52 & 100,65 & 36,13 & 6011,88 & 320,19 & 46,94 & 273,24 & 94,04 & 238,99 & 239,26 & 86,33 & 709,88 & 98,39 & 5,94 & 52,45 & 280,56 & 45,79 & 46,52 & 275,97 \\
\hline Pelobates cultripes & 29SPE62 & 100,00 & 155,44 & 99,42 & 36,04 & 6016,15 & 315,34 & 43,59 & 271,75 & 90,01 & 235,19 & 235,31 & 82,29 & 739,68 & 103,40 & 6,29 & 52,52 & 292,50 & 48,01 & 48,30 & 288,25 \\
\hline Pelobates cultripes & 29SPE70 & 101,00 & 160,68 & 102,50 & 36,39 & 6061,68 & 323,93 & 46,84 & 277,09 & 94,72 & 240,89 & 241,08 & 86,94 & 661,91 & 89, & 5,25 & 51,91 & 259,85 & 42,67 & 43,48 & 253,48 \\
\hline Pelobates cultripes & 29SPE71 & 100,00 & $\begin{array}{l}10,00 \\
159,82\end{array}$ & 101,92 & 36 & $\begin{array}{l}6000,100 \\
606,58\end{array}$ & 322 & $\begin{array}{l}40,04 \\
45,97 \\
\end{array}$ & $\begin{array}{l}27,, 34 \\
276,\end{array}$ & $\begin{array}{ll}4,1 / 2 \\
93,66\end{array}$ & \begin{tabular}{|l|}
240,05 \\
240
\end{tabular} & \begin{tabular}{|l|}
240,17 \\
240
\end{tabular} & $\begin{array}{l}0,34,82 \\
85,4\end{array}$ & $\mid \begin{array}{l}\mid 001, y 1 \\
670,65\end{array}$ & $\begin{array}{l}03,10 \\
91,49\end{array}$ & $\frac{1,2}{5,4}$ & $\begin{array}{ll}1,1,84 \\
51,84\end{array}$ & \begin{tabular}{|l|}
263,00 \\
263,29 \\
\end{tabular} & $\begin{array}{l}42,306 \\
43,56\end{array}$ & $\begin{array}{l}45,406 \\
44,06\end{array}$ & $\begin{array}{l}253,40 \\
257,20\end{array}$ \\
\hline Pelobates cultripes & 29SPE72 & 101,00 & 157,64 & 101,21 & 36,08 & 6065,15 & 319,49 & 44,06 & 275,43 & 91,42 & 237,94 & 238,00 & 83,62 & 684,95 & 93,96 & 5,83 & 51,77 & 268,81 & 45,03 & 45,28 & 262,93 \\
\hline Pelobates cultripes & 29SPE80 & 100,00 & 161,60 & 103,86 & 36,56 & 6119,63 & 326,96 & 46,28 & 280,68 & 94,92 & 242,58 & 242,65 & 87,03 & 621,49 & 82,74 & 5,02 & 51,02 & 241.96 & 40,81 & 41.16 & 234,20 \\
\hline Pelobates cultripes & 29SPE81 & 100,00 & 160,04 & 103,15 & 36,37 & 6120,16 & 324,52 & 44,95 & 279,57 & 93,18 & 240,99 & 241,01 & 85,30 & 632,97 & 84,87 & 5,11 & 51,11 & 246,61 & 41,57 & 41,67 & 239,18 \\
\hline Pelobates cultripes & 29SPE90 & 101,00 & 161,53 & 104,82 & 36,31 & 6179,27 & 328,69 & 45,03 & 283,66 & 94,00 & 243,44 & 243,47 & 86,17 & 590,59 & 77 & 4,79 & 50,34 & 227,83 & 39,41 & 39,47 & 218 \\
\hline Pelobates cultripes & $\begin{array}{l}295 \text { PSE92 } \\
\text { 295 }\end{array}$ & $\begin{array}{l}101,00 \\
100\end{array}$ & 158,55 & $\begin{array}{l}103,02 \\
103,70\end{array}$ & $\begin{array}{l}30,11 \\
36,20\end{array}$ & 6167,91 & $\begin{array}{l}32,05 \\
324,27\end{array}$ & $\begin{array}{l}42,50 \\
42,50 \\
\end{array}$ & \begin{tabular}{|l|}
281,77 \\
\end{tabular} & $\begin{array}{l}4,00 \\
90,89 \\
\end{array}$ & \begin{tabular}{|l|}
240,40 \\
\end{tabular} & \begin{tabular}{|l|}
240,40 \\
240
\end{tabular} & $\begin{array}{l}80,11 \\
83,11 \\
\end{array}$ & \begin{tabular}{|c|}
606,08 \\
600
\end{tabular} & 80,10 & $\begin{array}{ll}4, / 12 \\
5,12\end{array}$ & 50,16 & \begin{tabular}{|l|}
234,10 \\
230
\end{tabular} & $\begin{array}{l}30,88 \\
40,8\end{array}$ & $\begin{array}{l}30,88 \\
40,4\end{array}$ & $\begin{array}{l}210,05 \\
225,58\end{array}$ \\
\hline Pelobates cultripes & 29SQA19 & 10,00 & 178,00 & 87,00 & 37,00 & 4992,64 & 302,64 & 72,00 & 230,64 & 136,73 & 240,55 & 243,45 & 115,64 & 523,27 & 80,91 & 1,00 & 64,91 & 227,91 & 14,00 & 22,00 & 207,55 \\
\hline Pelobates cultripes & 29SQA26 & & & & & & & & & & & & & & & & & & & & \\
\hline Pelobates cultripes & 29SQA29 & 85,00 & 178,83 & 87,79 & 37,13 & 27,68 & 1,23 & 72,22 & 2 & 43,22 & 41,99 & 245 & 116,11 & 528,25 & 81,26 & 1,00 & 64,74 & 03 & 14,15 & 22,00 & 210,30 \\
\hline Pelobates cultripes & 29SQA35 & 24,00 & 177,69 & 83,83 & 38,69 & 4534,21 & 291,17 & 77,52 & 213,66 & 155,45 & 234,41 & 238,17 & 122,10 & 557,24 & 92,62 & 0,00 & 67,28 & 248,90 & 12,69 & 20,00 & 230,62 \\
\hline
\end{tabular}




\begin{tabular}{|c|c|c|c|c|c|c|c|c|c|c|c|c|c|c|c|c|c|c|c|c|c|}
\hline TAXON & UTM & $\mathrm{km} 2$ & B101 & B102 & $\mathrm{BIO3}$ & BIO4 & B105 & B106 & B107 & B108 & B109 & B1010 & BIO11 & BIO12 & 81013 & BIO14 & BIO15 & B1016 & B1017 & B1018 & B1019 \\
\hline Pelobates cultripes & 29SQA36 & 95,00 & 177,07 & 84,66 & 38,31 & 4649,30 & 293,27 & 75,19 & 218,08 & 153,02 & 235,24 & 238,90 & 119,87 & 554,28 & 90,71 & 0,00 & 66,75 & 246,68 & 13,00 & 20,40 & 228,02 \\
\hline Pelobates cultripes & 29SQA37 & 70,00 & 177,22 & 84,36 & 37,45 & 4807,11 & 296,27 & 74,12 & 222,15 & 152,46 & 237,56 & 241,03 & 117,86 & 551,16 & 87,79 & 0,53 & 65,83 & 242,48 & 13,59 & 21,43 & 223,57 \\
\hline Pelobates cultripes & 29SQA39 & 100,00 & 178,93 & 88,43 & 37,01 & 5120,94 & 306,79 & 71,23 & 235,55 & 143,96 & 243,43 & 246,48 & 115,26 & 540,45 & 82,58 & 1,00 & 64,61 & 233,88 & 14,96 & 22,00 & 214,68 \\
\hline Pelobates cultripes & 29SQA43 & 19,00 & 179,33 & 70,04 & 35,96 & 4462,26 & 279,67 & 86,48 & 193,19 & 158,41 & 234,30 & 238,67 & 123,78 & 609,26 & 105,11 & 0,93 & 68,96 & 264,70 & 11,96 & 22,00 & 248,44 \\
\hline Pelobates cultripes & 29SQA44 & 26,00 & 179,26 & 71,10 & 35,90 & \begin{tabular}{|l|l|}
4487,74 \\
\end{tabular} & 281,03 & 85,62 & 195,41 & 157,85 & 234,28 & 238,97 & 123,28 & 601,95 & 100,23 & 0,38 & 68,10 & 258,90 & 11,90 & 21,03 & 243,23 \\
\hline Pelobates cultripes & 29SQA45 & 69,00 & 176,93 & 76,35 & 36,36 & 4649,63 & 286,27 & 79,15 & 207,12 & 153,94 & 234,81 & 238,93 & 119,44 & 587,01 & 95,92 & 0,38 & 66,81 & 255,15 & 13,02 & 21,31 & 237,94 \\
\hline Pelobates cultripes & 29SQA46 & 101,00 & 175,51 & 79,22 & 36,27 & 4778,15 & 290,15 & 74,90 & 215,25 & 151,44 & 235,35 & 239,28 & 116,57 & 579,61 & 92,91 & 0,65 & 66,18 & 252,08 & 13,88 & 21,77 & 234,53 \\
\hline Pelobates cultripes & 29SQA48 & 99,00 & 177,43 & 83,96 & 36,08 & 5077,41 & 301,60 & 72,08 & 229,52 & 148,23 & 241,44 & 244,77 & 114,47 & 561,33 & 86,13 & 1,00 & 65,01 & 241,91 & 15,03 & 22,02 & 223,48 \\
\hline Pelobates cultripes & 29SQA52 & & & & & & & & & & & & & & & & & & & & \\
\hline Pelobates cultripes & 29SQA53 & 100,00 & 177,64 & 70,43 & 35,65 & 4493,07 & 279,11 & 84,29 & 194,82 & 143,26 & 232,93 & 237,52 & 121,50 & 635,77 & 110,43 & 1,00 & 69,06 & 277,45 & 13,16 & 23,23 & 262,34 \\
\hline Pelobates cultripes & 29SQA54 & 93,00 & 177,06 & 70,42 & 34,92 & 4627,92 & 281,23 & 82,24 & 198,99 & 149,73 & 234,27 & 238,95 & 119,38 & 623,61 & 105,06 & 1,00 & 68,15 & 269,05 & 13,48 & 23,19 & 253,37 \\
\hline Pelobates cultripes & 29SQA55 & 100,00 & 176,14 & 71,50 & 34,46 & 4748,96 & 283,85 & 79,40 & 204,45 & 150,89 & 235,24 & 239,52 & 117,14 & 611,03 & 99,24 & 1,00 & 67,15 & 261,72 & 14,25 & 22,82 & 245,79 \\
\hline Pelobates cultripes & 29SQA56 & 100,00 & $\begin{array}{ll}173,87 \\
\end{array}$ & 72,93 & 33,94 & 4924,18 & 286,72 & 74,69 & 212,03 & 144,30 & 235,60 & 239,56 & 112,85 & 606,72 & 95,02 & 1,00 & 65,93 & 257,52 & 15,55 & 23,43 & 241,52 \\
\hline Pelobates cultripes & 29SQA60 & & & & & & & & & & & & & & & & & & & & \\
\hline Pelobates cultripes & 29SQA61 & 69,00 & 173,72 & 74,04 & 37,77 & 4251,75 & 275,40 & 81,89 & 193,51 & 129,78 & 226,25 & 230,55 & 120,81 & $\begin{array}{l}723,45 \\
\end{array}$ & \begin{tabular}{|l|l|}
126,98 \\
\end{tabular} & 0,92 & 71,45 & 326,94 & 14,62 & 23,06 & 313,23 \\
\hline Pelobates cultripes & 29SQA62 & 96,00 & 173,91 & 72,69 & 36,69 & 4381,85 & 276,29 & 80,88 & 195,42 & 128,33 & 228,08 & 232,35 & 119,18 & 703,15 & 122,12 & 1,00 & 70,45 & 313,64 & 14,39 & 23,54 & 299,47 \\
\hline Pelobates cultripes & 29SQA63 & 91,00 & 174,26 & 71,55 & 35,73 & 4530,08 & 278,14 & 80,13 & 198,02 & 127,05 & 230,42 & 234,79 & 117,85 & 680,79 & 116,33 & 1,00 & 69,49 & 299,66 & 14,39 & 23,80 & 284,77 \\
\hline Pelobates cultripes & 29SQA64 & 82,00 & 173,11 & $\begin{array}{l}11,150 \\
71,60\end{array}$ & $\begin{array}{l}34,75 \\
34,77\end{array}$ & 4 & 280,25 & $\begin{array}{l}\mid 70,15 \\
77,27 \\
\end{array}$ & \begin{tabular}{|l|}
$202,98<$ \\
\end{tabular} & $\begin{array}{l}123,76 \\
\end{array}$ & $\begin{array}{l}\mid 50,44 \\
231,64\end{array}$ & 235,93 & \begin{tabular}{|l|l|l|l|l|l|}
114,68 \\
\end{tabular} & $\mid 6007,31$ & \begin{tabular}{|l|}
111,07 \\
111,07
\end{tabular} & $\begin{array}{l}1,000 \\
1,00\end{array}$ & $\begin{array}{l}58,47 \\
68,47\end{array}$ & \begin{tabular}{|l|}
289,70 \\
\end{tabular} & \begin{tabular}{|l|l|}
14,793 \\
14,
\end{tabular} & 24,00 & 274,71 \\
\hline Pelobates cultripes & 29SQA65 & 87,00 & 173,45 & 71,17 & 33,89 & 4832,19 & 282,94 & 76,20 & 206,74 & 123,52 & 233,76 & 237,93 & 113,34 & 646,16 & 104,12 & 1,00 & 67,41 & 276,87 & 15,43 & 23,97 & 261,60 \\
\hline Pelobates cultrips & 2950A66 & 81,00 & 172,10 & 71,69 & 33,18 & 5004,39 & 285,84 & 72,94 & 212.90 & 120,75 & 234,93 & 238,95 & 110,16 & 634,60 & 98,66 & 1,00 & 66,61 & 268.96 & 16,27 & 24,00 & 253,05 \\
\hline Pelobates cultripes & 29SQA68 & 77,00 & 174,05 & 82,09 & 34,77 & 5281,10 & 301,26 & 68,74 & 232,53 & 117,69 & 241,00 & 244,45 & 108,83 & 609,35 & 92,02 & 1,00 & 65,39 & 258,86 & 17,01 & 23,36 & 241,70 \\
\hline Pelobates cultripes & 29SQBOO & 46,00 & 176,74 & 85,34 & 37,00 & 5008,82 & 299,92 & 71,94 & 227,98 & 123,20 & 239,08 & 242,08 & 114,04 & 511,26 & 79,38 & 1,00 & 64,36 & 221,58 & 14,00 & 23,00 & 200,42 \\
\hline Pelobates cultripes & 29SQB01 & 100,00 & 177,03 & 85,80 & 36,91 & 5086,65 & 301,93 & 71,36 & 230,57 & 128,89 & 240,26 & 243,19 & 113,39 & 505,93 & 78,73 & 1,00 & 63,83 & 218,10 & 14,01 & 23,13 & 196,75 \\
\hline Pelobates cultripes & 29SQB02 & 100,00 & 175,71 & 87,83 & 36,78 & 5211,77 & 304,69 & 68,22 & 236,47 & 121,68 & 240,67 & 243,42 & 110,32 & 511,72 & 79,20 & 1,00 & 63,09 & 218,53 & 14,72 & 23,99 & 197,38 \\
\hline Pelobates cultripes & $29 \mathrm{SQBO3}$ & 100,00 & 176,62 & 90,04 & 36,92 & 5313,06 & 309,19 & 67,62 & 241,57 & 130,20 & 243,06 & 245,67 & 110,08 & 505,56 & 78,12 & 1,00 & 62,66 & 214,59 & 15,01 & 23,97 & 193,80 \\
\hline Pelobates cultripes & 29SQB04 & 100,00 & 175,53 & 93,32 & 37,02 & 5425,44 & 312,93 & 64,53 & 248,41 & 120,14 & 243,71 & 246,19 & 107,63 & 511,63 & 78,33 & 1,29 & 61,96 & 215,68 & 16,04 & 24,62 & 195,76 \\
\hline Pelobates cultripes & $29 \mathrm{SQB05}$ & 101,00 & 169,79 & 97,85 & 37,29 & 5573,42 & 314,27 & 56,43 & \begin{tabular}{|l|}
257,84 \\
\end{tabular} & $\begin{array}{l}109,60 \\
\end{array}$ & \begin{tabular}{|l|}
240,50 \\
\end{tabular} & 242,85 & 100,61 & 543,49 & 81,20 & 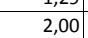 & 60,59 & 226,67 & 19,23 & 27,11 & 208,41 \\
\hline Pelobates cultripes & 29SQB06 & 101,00 & 165,53 & 101,65 & 37,97 & 5683,37 & 315,98 & 50,49 & 265,49 & 104,53 & 238,24 & 240,44 & 95,45 & 566,49 & 83,17 & 2,01 & 59,96 & 234,53 & 21,17 & 28,32 & 217,67 \\
\hline Pelobates cultripes & 29SQB07 & 100,00 & 164,82 & 104,21 & 38,00 & 5762,46 & 319,25 & 48,34 & 270,91 & 102,79 & 238,75 & 240,87 & 93,82 & 569,38 & 82,77 & 2,29 & 59,36 & 234,26 & 22,28 & 28,82 & 218,29 \\
\hline Pelobates cultripes & 29SQB08 & 100,00 & 163,17 & 106,56 & 38,00 & 5835,67 & 321,68 & 45,53 & 276,15 & 100,43 & 238,34 & 240,40 & 91,52 & 576,80 & 82,82 & 2,68 & 58,52 & 235,69 & 23,96 & 29,93 & 220,70 \\
\hline Pelobates cultripes & 29SQB09 & 101,00 & 149,98 & 109,34 & 38,00 & 5955,40 & 315,23 & 31,79 & 283,43 & 86,71 & 227,37 & 229,53 & 77,75 & 655,52 & 90,98 & 3,83 & 57,21 & 264,65 & 30,41 & 35,23 & 252,11 \\
\hline Pelobates cultripes & 29SQB10 & 96,00 & 177,80 & 87,58 & 37,01 & 5066,93 & 303,78 & 71,44 & \begin{tabular}{|l|}
232,34 \\
\end{tabular} & \begin{tabular}{|l|}
130,63 \\
\end{tabular} & 241,16 & \begin{tabular}{|l|}
244,08 \\
25
\end{tabular} & 114,66 & 518,74 & 80,20 & $\begin{array}{l}3,000 \\
1,00\end{array}$ & $\begin{array}{ll}64,27 \\
64,\end{array}$ & \begin{tabular}{|l|}
224,79 \\
22,0
\end{tabular} & \begin{tabular}{|l|l}
14,00 \\
14
\end{tabular} & $\begin{array}{ll}3,22,93 \\
223\end{array}$ & 204,25 \\
\hline Pelobates cultripes & 29SQB11 & 100,00 & 178,60 & 89,13 & 37,01 & 5175,99 & 307,72 & 70,57 & 237,15 & 130,95 & 243,40 & 246,23 & 113,90 & 513,12 & 79,52 & 1,00 & 63,83 & 220,93 & 14,38 & 23,00 & 200,28 \\
\hline Pelobates cultripes & 29SQB12 & 99,00 & 177,09 & 91,82 & 37,01 & 5318,58 & 311,16 & 67,03 & 244,13 & 119,89 & 244,00 & 246,56 & 110,55 & 519,52 & 80,10 & 1,00 & 63,16 & 221,75 & 15,04 & 23,39 & 201,42 \\
\hline Pelobates cultripes & 29SQB13 & 101,00 & 175,23 & 94,79 & 37,05 & 5452,54 & 314,19 & 62,94 & 251,25 & 116,11 & 244,04 & 246,46 & 107,10 & 528,76 & 80,87 & 1,01 & 62,52 & 224,05 & 15,94 & 24,02 & 204,34 \\
\hline Pelobates cultripes & 29SQB14 & 100,00 & 177,04 & 97,18 & 37,40 & 5528,40 & 319,21 & 63,27 & 255,94 & 117,12 & 247,02 & 249,25 & 108,02 & 518,64 & 79,16 & 1,11 & 62,08 & 218,60 & 16,14 & 24,15 & 199,43 \\
\hline Pelobates cultripes & 29SQB15 & 100,00 & 171,39 & 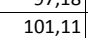 & 37,85 & $562,1,57$ & 320,21 & $\begin{array}{l}5,24 \\
55,58 \\
\end{array}$ & \begin{tabular}{|l|}
264,75 \\
\end{tabular} & \begin{tabular}{|l|}
110,05 \\
112
\end{tabular} & $\begin{array}{l}\mid 241,0< \\
243,75 \\
\end{array}$ & 245,90 & \begin{tabular}{|l|}
101,01 \\
101
\end{tabular} & $\begin{array}{l}540,045 \\
548,55\end{array}$ & $\begin{array}{l}51,87 \\
81\end{array}$ & $\begin{array}{l}1,11 \\
1,99 \\
\end{array}$ & $\begin{array}{l}2,0,71 \\
60,1\end{array}$ & \begin{tabular}{|l|}
228,6707 \\
\end{tabular} & $\begin{array}{l}19,41 \\
19,4\end{array}$ & 26,72 & $\begin{array}{l}25,45 \\
210,85\end{array}$ \\
\hline Pelobates cultripes & 29SQB16 & 99,00 & 168,83 & 104,02 & 38,00 & 5771,93 & 322,70 & 51,44 & 271,26 & 106,39 & 242,73 & 244,82 & 97,38 & 560,74 & 82,61 & 2,01 & 60,17 & 232,12 & 20,69 & 27,51 & 215,31 \\
\hline Pelobates cultripes & 29SQB20 & 100,00 & 179,04 & 89,73 & 37,08 & 5151,40 & 308,35 & 70,87 & 237,48 & 134,68 & 243,99 & 246,81 & 114,96 & 524,89 & 80,86 & 1,00 & 64,52 & 227,17 & 14,90 & 22.01 & 207,32 \\
\hline Pelobates cultripes & 29SQB21 & 101,00 & 179,80 & 92,42 & 37,20 & 5285,69 & 313,51 & 69,27 & 244,24 & 131,97 & 246,44 & 249,12 & 113,76 & 522,48 & 80,46 & 1,00 & 63,68 & 224,48 & 15,00 & 22,31 & 204,82 \\
\hline Pelobates cultripes & 29SQB22 & 100,00 & 178,30 & 95,58 & 37,40 & 5428,78 & 317,33 & 65,47 & 251,87 & 119,33 & 247,04 & 249,51 & 110,55 & 529,87 & 81,28 & 1,00 & 63,28 & 226,09 & 15,47 & 22,99 & 206,78 \\
\hline 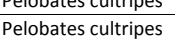 & $\frac{\mid 295024}{29 S Q B 24}$ & 100,00 & $\begin{array}{l}17,50,60 \\
175,60\end{array}$ & 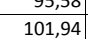 & $\frac{3,40}{37,95}$ & \begin{tabular}{|l|}
4420,10 \\
5673,27
\end{tabular} & 325,06 & $\begin{array}{l}5,34 \\
58,67 \\
\end{array}$ & \begin{tabular}{|l|}
266,40 \\
2660
\end{tabular} & \begin{tabular}{|l|}
114,06 \\
114,06
\end{tabular} & \begin{tabular}{|l|}
248,11 \\
248,
\end{tabular} & $\mid$\begin{tabular}{|l|}
2450,25 \\
250
\end{tabular} & \begin{tabular}{|l|l|l|l|l|}
104,99 \\
\end{tabular} & | & $\begin{array}{l}1,26 \\
81,97 \\
\end{array}$ & $\begin{array}{l}1,100 \\
1,36\end{array}$ & $\begin{array}{l}3,20 \\
61,76\end{array}$ & \begin{tabular}{|l|}
228,44 \\
22,4
\end{tabular} & $\begin{array}{l}18,41 \\
18,02 \\
\end{array}$ & $\begin{array}{l}24,99 \\
24,\end{array}$ & $\begin{array}{l}200,10 \\
210,41\end{array}$ \\
\hline Pelobates cultripes & 29SQB31 & 100,00 & 180,39 & 95,44 & 37,43 & 5399,35 & 319,24 & 67,63 & 251,61 & 121,85 & 248,92 & 251,55 & 113,18 & 535,35 & 82,11 & 1,00 & 63,83 & 229,68 & 15,20 & 22,00 & 210,79 \\
\hline Pelobates cultripes & 29SQB32 & 100,00 & 179,88 & 99,43 & 37,81 & 5541,95 & 324,76 & 64,30 & 260,46 & 119,66 & 250,41 & 252,84 & 110,82 & 540,01 & 82,50 & 1,00 & 63,43 & 230,37 & 16,01 & 22,43 & 212,05 \\
\hline Pelobates cultripes & 29SQB33 & 100,00 & 178,05 & 103,27 & 37,99 & 5681,46 & 329,20 & 60,05 & 269,14 & 116,39 & 250,78 & 252,92 & 107,42 & 549,83 & 83,33 & 1,00 & 62,64 & 32,79 & 17,50 & 23,88 & 215,05 \\
\hline Pelobates cultripes & 29SQB39 & 100,00 & 163,07 & 115,24 & 38,00 & 6172,04 & 336,21 & 38,54 & 297,66 & \begin{tabular}{|l|l|}
96,41 \\
\end{tabular} & 243,54 & 244 & $\begin{array}{l}67,38 \\
\end{array}$ & \begin{tabular}{|l|l|}
601,53 \\
\end{tabular} & 84,57 & 2,78 & 58,19 & 242,94 & 25,49 & 30,41 & 229,54 \\
\hline Pelobates cultripes & $295 Q B A$ & 101,00 & 181,47 & 103,41 & 37,99 & 5658,01 & 332,43 & 63,26 & 269,18 & 119,88 & 253,93 & 256,14 & 110,99 & 551,11 & 83,89 & 1,00 & 63,41 & 235,04 & 16,67 & 22,57 & 217,58 \\
\hline Pelobates cultripes & $29 \mathrm{SQB} 43$ & 100,00 & 180,23 & 108,01 & 38,05 & 5804,21 & 338,22 & 59,06 & 279,16 & 117,10 & 254,92 & 256,92 & 108,11 & 558,84 & 84,54 & 1,00 & 62,92 & 237,05 & 17,80 & 23,23 & 220,29 \\
\hline Pelobates cultripes & 29SQB44 & 101,00 & 180,49 & 111,05 & 38,36 & 5900,58 & 342,96 & 57,41 & 285,55 & 116,18 & 256,64 & 258,40 & 107,23 & 556,03 & 83,69 & 1,12 & 62,60 & 234,70 & 18,32 & 23,41 & 218,49 \\
\hline Pelobates cultripes & 29SQB45 & 99,00 & 179,99 & 113,45 & 38,61 & 5980,75 & 346,22 & 55,51 & 290,71 & 114,92 & 257,41 & 259,01 & 105,74 & 555,42 & 82,92 & 1,41 & 61,79 & 232,99 & 18,81 & 24,00 & 217,38 \\
\hline Pelobates cultripes & $\begin{array}{l}295 \mathrm{COB45} \\
20 \mathrm{~S}\end{array}$ & $\begin{array}{l}500,00 \\
100\end{array}$ & 182 & \begin{tabular}{|l|}
107,75 \\
\end{tabular} & 38, & 5772,57 & 330,22 & \begin{tabular}{|c|c|c|}
61,60 \\
6
\end{tabular} & \begin{tabular}{|l|}
278,00 \\
\end{tabular} & \begin{tabular}{|l|}
119,54 \\
119,5
\end{tabular} & \begin{tabular}{|l|}
256,69 \\
\end{tabular} & \begin{tabular}{|l|}
258,72 \\
\end{tabular} & \begin{tabular}{|l|}
110,67 \\
10,
\end{tabular} & 565,4L1 & $\begin{array}{l}8<, 32 \\
85,81\end{array}$ & $\begin{array}{l}\frac{1,41}{1,00} \\
\end{array}$ & $\begin{array}{ll}1,73 \\
63,65\end{array}$ & \begin{tabular}{|l|}
241,42 \\
\end{tabular} & $\begin{array}{l}10,01 \\
17,54 \\
\end{array}$ & 22,50 & 224,85 \\
\hline Pelobates cultripes & 29SQB55 & 100,00 & 182,80 & 117,92 & 38,98 & 6077,18 & 354,84 & 55,47 & 299,36 & 116,50 & 261,79 & 263,16 & 107,47 & 559,71 & 83,53 & 1,13 & 62,24 & 235,80 & 18,43 & 23,01 & 221,17 \\
\hline Pelobates cultripes & $295 \mathrm{SQB56}$ & 100,00 & 176,11 & 118,63 & 38,93 & 6163,05 & 350,68 & 48,61 & 302,07 & 109,00 & 256,31 & 257,66 & 100,02 & 582,65 & 85 & $\begin{array}{l}1,1,97 \\
1,97\end{array}$ & $\begin{array}{l}2,24 \\
61,03\end{array}$ & 242,14 & $\begin{array}{l}0,45 \\
20,77 \\
\end{array}$ & 25,32 & 228,14 \\
\hline Pelobates cultripes & 29SQB58 & 100,00 & 164,45 & 119,16 & 38,45 & 6288,16 & 342,96 & 37,21 & 305,74 & 96,54 & 246,97 & 248,00 & 87,55 & 621,15 & 87,10 & 2,57 & 59,09 & 252,23 & 24,62 & 29,52 & 239,62 \\
\hline Pelobates cultripes & 29SQB62 & 62,00 & 182,98 & 110,49 & 38, & 5832,79 & 343,73 & 61,26 & 282,48 & 119,58 & 258,21 & 260 & 110,66 & 575,13 & 87,33 & 1,00 & 63,97 & 246,17 & 17,90 & 22,00 & 22 \\
\hline Pelobates cultripes & $295 \mathrm{SQB64}$ & 54,00 & 184,91 & 120,33 & 39,01 & 6101,45 & 359,34 & 55,90 & 303,44 & $\begin{array}{l}118,35 \\
\end{array}$ & 264,13 & 265,64 & 109,23 & 571,64 & 86,08 & 1,00 & 63,33 & 243,27 & 18,19 & 22,17 & 228,95 \\
\hline Pelobates cultripes & 29SQB67 & 43,00 & 170,53 & 120,97 & 38,97 & 6280,84 & 349,67 & 42,23 & 307,44 & 102,34 & 252,81 & 253,81 & 93,31 & 608,03 & 86,59 & 2,00 & 60,22 & 249,81 & 22,67 & 27,20 & 236,97 \\
\hline Pelobate & $29 S Q C 02$ & 101.00 & 150,90 & 112.55 & 3800 & 6064.71 & 322.05 & 30.95 & 291.10 & 86,38 & 230.08 & 231.97 & 77.51 & 638.97 & 87,25 & 4,11 & 55,41 & 253,83 & 32.80 & 36,32 & 242,32 \\
\hline Pelobates cultripes & $2950 C 03$ & 100,00 & 153,97 & 113,52 & 38,06 & 6079,14 & 326,21 & 33,28 & 292,93 & 88,97 & 233,47 & 235 & 80, & 615,00 & 83,99 & 3,99 & 54,92 & 243,32 & 32,25 & 35,44 & 231,67 \\
\hline Pelobates cultripes & $2950 C 05$ & 100,00 & 151,69 & 114,27 & 38,05 & 6140,97 & 326,38 & 30,66 & 295,72 & 85,99 & 232,26 & 233,59 & 77,36 & 622,94 & 83,87 & 4,57 & 53,71 & 243,87 & 35,20 & 37,55 & 232,90 \\
\hline
\end{tabular}




\begin{tabular}{|c|c|c|c|c|c|c|c|c|c|c|c|c|c|c|c|c|c|c|c|c|c|}
\hline TAXON & UTM & $\mathrm{km} 2$ & B101 & B102 & $\mathrm{BIO3}$ & 8104 & B105 & B106 & B107 & B108 & B109 & BIO10 & BIO11 & BIO12 & 81013 & BIO14 & BIO15 & B1016 & B1017 & BIO18 & B1019 \\
\hline Pelobates cultripes & 29SQC08 & 100,00 & 164,01 & 116,26 & 38,37 & 6131,33 & 339,36 & 40,56 & 298,80 & 97,22 & 244,24 & 244,91 & 88,97 & 527,93 & 71,91 & 4,00 & 52,35 & 204,44 & 31,31 & 33,87 & 192,13 \\
\hline Pelobates cultripes & $29 \mathrm{SQC13}$ & 100,00 & 157,54 & 114,97 & 38,01 & 6161,86 & 331,80 & 34,74 & 297,06 & 91,12 & 238,20 & 239,41 & 82,41 & 594,93 & 81,35 & 3,71 & 55,09 & 234,82 & 30,46 & 33,99 & 222,73 \\
\hline Pelobates cultripes & $295 Q C 14$ & 101,00 & 159,23 & 115,59 & 38,01 & 6171,35 & 334,37 & 35,95 & 298,41 & 92,41 & 239,95 & 241,13 & 83,86 & 579,12 & 79,00 & 3,69 & 54,64 & 227,61 & 30,38 & 33,67 & 215,52 \\
\hline Pelobates cultripes & 29SQC15 & 100,00 & 153,88 & 115,50 & 38,00 & 6216,08 & 330,77 & 31,06 & 299,71 & 87,03 & 235,64 & 236,60 & 78,50 & 607,10 & 81,63 & 4,19 & 53,79 & 236,94 & 33,57 & 36,28 & 225,45 \\
\hline Pelobates cultripes & 29SQC16 & 100,00 & 158,39 & 116,15 & 38,01 & $\begin{array}{ll}6218,94 \\
\end{array}$ & 335,43 & 34,82 & 300,61 & 91,30 & 240,07 & 241,02 & $\begin{array}{l}82,66 \\
\end{array}$ & 573,53 & 77,26 & 4,05 & 53,32 & 222,97 & 32,25 & 34,93 & 211,15 \\
\hline Pelobates cultripes & $29 \mathrm{SQC20}$ & 100,00 & 158,69 & 114,03 & 38,00 & 6141,20 & 330,86 & 35,80 & 295,06 & 92,59 & 238,82 & 240,27 & 83,67 & 610,75 & 84,96 & 3,20 & 57,20 & 244,88 & 27,67 & 32,37 & 231,93 \\
\hline Pelobates cultripes & $295 Q C 21$ & 100,00 & 145,29 & 114,35 & 38,00 & 6208,92 & 321,02 & 23,04 & 297,98 & 79,29 & 227,01 & 228,47 & 70,48 & 684,79 & 92,50 & 4,51 & 55,84 & 271,28 & 34,24 & 38,10 & 260,10 \\
\hline Pelobates cultripes & $29 \mathrm{SQC23}$ & 101,00 & 156,44 & 116,22 & 38,00 & 6236,16 & 333,51 & 32,47 & 301,04 & 89,36 & 238,35 & 239,41 & 80,62 & 605,30 & 82,13 & 3,85 & 55,16 & 238,15 & 30,84 & 34,48 & 226,19 \\
\hline Pelobates cultripes & $2950 C 24$ & 99,00 & 155,97 & 116,59 & 38,00 & 6269,81 & 334,19 & 31,82 & 302,37 & 88,53 & 238,37 & 239,35 & 79,85 & 601,12 & 80,98 & 3,94 & 54,55 & 235,10 & 31,61 & 34,93 & 223,33 \\
\hline Pelobates cultripes & $29 S Q C 25$ & 100,00 & $\begin{array}{ll}154,87 \\
\end{array}$ & 116,72 & 38,00 & 6296,31 & 333,94 & \begin{tabular}{|l|l|}
30,57 \\
\end{tabular} & 303,37 & 86,94 & 237,62 & 238,51 & 78,50 & \begin{tabular}{|c|}
601,18 \\
\end{tabular} & 80,36 & 4,00 & 53,84 & 233,81 & 32,68 & 35,64 & 222,19 \\
\hline Pelobates cultripes & $29 \mathrm{SQC27}$ & 100,00 & 160,26 & 117,09 & 38,00 & 6298,64 & 339,64 & 35,21 & 304,44 & 92,04 & 243,19 & 243,81 & 83,50 & 555,99 & 74,05 & 4,00 & 52,60 & 214,13 & 31,88 & 34,19 & 202,09 \\
\hline Pelobates cultripes & $29 \mathrm{SQC28}$ & 101,00 & 162,42 & 117,04 & 38,00 & 6296,73 & 341,58 & 37,15 & 304,44 & 93,96 & 245,39 & 245,72 & 85,55 & 537,24 & 71,40 & 3,97 & 52,31 & 206,15 & 31,56 & 33,13 & 193,92 \\
\hline Pelobates cultripes & $295 Q C 30$ & 100,00 & 153,54 & 115,83 & 38,00 & 6238,75 & 329,83 & 29,25 & 300,58 & 86,61 & 235,49 & 236,64 & 77,72 & 646,89 & 88,68 & 3,60 & 56,96 & 258,16 & 29,81 & 34,28 & 246,06 \\
\hline Pelobates cultripes & 29SQC31 & 101,00 & 143,35 & 115,71 & 37,99 & 6285,63 & 321,80 & 20,01 & 301,79 & 76,51 & 226,30 & 227,65 & 67,74 & 700,80 & 93,93 & 4,65 & 55,87 & 276,69 & 34,98 & 38,88 & 265,89 \\
\hline Pelobates cultripes & 29SQC32 & 100,00 & 150,07 & 116,82 & 38,00 & 6311,19 & 329,47 & 25,56 & 303,92 & 82,63 & 233,28 & 234,30 & 73,90 & 652,92 & 87,76 & 4,06 & 55,58 & 257,04 & 32,41 & 36,21 & 245,72 \\
\hline Pelobates cultripes & $295 Q C 35$ & 100,00 & 153,54 & 117,59 & 38,00 & 6363,24 & 335,03 & 28,24 & 306,79 & 85,10 & 237,65 & 238,31 & 76,50 & 609,65 & 80,58 & 4,00 & 54,00 & 236,09 & 32,50 & 35,71 & 224,86 \\
\hline Pelobates cultripes & $29 \mathrm{SQC37}$ & 100,00 & 160,43 & 117,97 & 38,00 & 6361,74 & 341,86 & 34,42 & 307,44 & 91,44 & 244,49 & 244,74 & 82,93 & 555,56 & 73,23 & 3,90 & 52,90 & 213,13 & 31,30 & 33,37 & 201,28 \\
\hline Pelobates cultripes & $29 \mathrm{SQC} 38$ & 100,00 & 163,23 & 117,86 & 38,00 & 6367,95 & 344,36 & 36,86 & 307,50 & 93,88 & 247,29 & 247,38 & 85,35 & 532,76 & 70,17 & 3,44 & 52,54 & 203,66 & 30,08 & 31,66 & 191,64 \\
\hline Pelobates cultripes & 29SQC39 & 101,00 & 165,75 & 117,51 & \begin{tabular}{|l|l|}
37,97 \\
\end{tabular} & 6367,88 & 346,27 & 39,30 & 306,97 & 96,22 & 249,75 & 249,85 & 87,54 & 511,19 & 67,20 & 3,08 & 52,34 & 194,91 & 28,83 & 30,27 & 182,78 \\
\hline Pelobates cultrips & $2950 \mathrm{C} 41$ & 99,00 & 150,44 & 117,83 & 38,00 & 6353,23 & 331,26 & 24,82 & 306,44 & 82.53 & 234,27 & 235,31 & 73,66 & 662.91 & 89,17 & 3,90 & 56,33 & 261,88 & 31,52 & 35,70 & 250,75 \\
\hline Pelobates cultripes & 29SQC44 & 99,00 & 152,18 & 118,55 & 37,99 & 6422,21 & 335,51 & 25,57 & 309,93 & 83,18 & 237,18 & 237,71 & 74,32 & 627,23 & 82,93 & 4,00 & 54,74 & 243,43 & 32,07 & 35,38 & 232,45 \\
\hline Pelobates cultripes & $2950 C 45$ & 101,00 & 155,37 & 118,87 & 38,00 & 6435,91 & 338,99 & 28,40 & 310,59 & 85,98 & 240,62 & 240,92 & 77,21 & 600,77 & 79,28 & 3,96 & 54,09 & 231,94 & 31,57 & 34,04 & 220,74 \\
\hline Pelobates cultripes & $29 S Q C 46$ & 100,00 & 159,70 & 119,06 & \begin{tabular}{|l|l}
37,99 \\
\end{tabular} & \begin{tabular}{|l|l|l|}
6443,91 \\
\end{tabular} & 343,06 & 32,26 & 310,81 & 89,84 & 244,80 & 244,96 & 81,12 & 569,21 & 75,04 & 3,69 & 53,64 & 218,71 & 30,47 & 32,42 & 207,26 \\
\hline Pelobates cultripes & $29 S Q C 47$ & 99,00 & 162,97 & 118,88 & 37,99 & 6437,15 & 345,94 & 35,39 & 310,55 & 92,87 & 248,00 & 248,04 & 84,26 & 542,14 & 71,52 & 3,23 & 53,43 & 207,59 & 29,09 & 30,04 & 195,96 \\
\hline Pelobates cultripes & $29 \mathrm{SQC48}$ & 101,00 & 164,45 & 118,63 & 37,97 & 6434,42 & 347,13 & 37,04 & 310,09 & 94,36 & 249,40 & 249,46 & 85,73 & 525,70 & 69,10 & 3,06 & 52,98 & 200,26 & 28,72 & 29,29 & 188,50 \\
\hline Pelobates cultripes & 29SQC49 & 99,00 & 163,25 & 117,95 & 37,60 & 6448,65 & 346,10 & 36,12 & 309,98 & 92,98 & 248,56 & 248,66 & 84,46 & 523,97 & 68,4 & 3,31 & 52,23 & 198,42 & 29,73 & 30,41 & 186,63 \\
\hline Pelobates cultripes & $29 \mathrm{SQC51}$ & 100,00 & 157,25 & 120,01 & 38,00 & $\begin{array}{l}6413,78 \\
6413\end{array}$ & 340,24 & 29,40 & $\begin{array}{l}310,84 \\
\end{array}$ & 88,09 & $\begin{array}{l}40,00 \\
241,84\end{array}$ & 242,56 & 79,16 & 631,14 & 85,14 & 3,27 & 56,28 & 249,59 & 28,48 & 32,89 & 238,35 \\
\hline Pelobates cultripes & 29SQC52 & 100,00 & 158,74 & 120,32 & 38,00 & 6435,63 & 342,47 & 30,48 & 311,99 & 89,27 & 243,72 & 244,24 & 80,33 & 613,54 & 82,38 & 3,19 & 56,22 & 241,10 & 28,37 & 32,57 & 229,94 \\
\hline Pelobates cultripes & $295 Q C 54$ & 100,00 & 153,33 & 119,90 & 38,00 & 6489,27 & 338,89 & 25,67 & 313,23 & 83,50 & 239,37 & 239,85 & 74,71 & 623,19 & 82,50 & 4,00 & 54,77 & 241,07 & 31,37 & 34,32 & 230,40 \\
\hline Pelobates cultripes & $29 S Q C 55$ & 100,00 & 158,21 & 120,08 & 38,00 & 6492,21 & 343,57 & 29,89 & 313,68 & 87,86 & 244,27 & 244,42 & 79,23 & 588,23 & 77,81 & 3,70 & 54,34 & 226,40 & 30,18 & 32,39 & 215,47 \\
\hline Pelobates cultripes & 29 SQD00 & 99,00 & 167,55 & 116,21 & 38,22 & 6138,98 & 342,32 & 43,67 & 298,65 & 100,11 & 247,71 & 248,38 & 91,98 & 499,93 & 67,99 & 3,50 & 51,91 & 192,61 & 30,54 & 32,59 & 180,11 \\
\hline Pelobates cultripes & 29SQD07 & 100,00 & 160,93 & 107,44 & 30,62 & 6257,25 & 332,73 & $\begin{array}{ll}4,59 \\
42,5\end{array}$ & 290,13 & \begin{tabular}{|c|c|}
93,20 \\
90
\end{tabular} & \begin{tabular}{|l|}
243,99 \\
\end{tabular} & \begin{tabular}{|l|}
244,13 \\
240
\end{tabular} & 85,12 & 562,46 & 72,17 & $\begin{array}{l}4,35 \\
40\end{array}$ & 49,91 & \begin{tabular}{|l|}
214,50 \\
\end{tabular} & $\begin{array}{l}\mid 0,374 \\
37,65\end{array}$ & \begin{tabular}{|l|l|}
37,91 \\
\end{tabular} & 203,80 \\
\hline Pelobates cultripes & 29SQD08 & 100,00 & 157,66 & 105,80 & 36,10 & 6268,10 & 328,62 & 40,38 & 288,23 & 89,93 & 241,04 & 241,07 & 81,84 & 585,14 & 75,05 & 4,93 & 49,95 & 223,42 & 39,58 & 39,63 & 213,04 \\
\hline Pelobates cultripes & 29SQD10 & 101,00 & 167,45 & 116,22 & 38,00 & 6218,46 & 344,03 & 42,74 & 301,30 & 99,34 & 248,95 & 249,36 & 91,18 & 500,52 & 67,19 & 3,2 & 51,61 & 191,99 & 29,68 & 31.50 & 179,40 \\
\hline Pelobates cultripes & 29SQD14 & 100,00 & 158,51 & 110,98 & 36,95 & 6316,54 & 334,69 & 37,68 & 297,01 & 90,14 & 242,30 & 242,41 & 81,98 & 553,40 & 70,99 & 4,25 & 50,08 & 209,54 & 36,45 & 36,77 & 197,87 \\
\hline Pelobates cultripes & 29SQD17 & 100,00 & 159,88 & 107,54 & 36,00 & 6335,02 & 333,55 & 40,64 & 292,92 & 91,31 & 244,13 & 244,13 & 83,15 & 544,58 & 68,94 & 4,05 & 49,74 & 205,57 & 36,49 & 36,51 & 194,10 \\
\hline Pelobates cultripes & $\frac{29 S Q D 20}{29 S}$ & 99,00 & $\begin{array}{l}13,00 \\
165,92\end{array}$ & 116,54 & 37,99 & $\begin{array}{l}6350,064 \\
63064\end{array}$ & 344,73 & $\begin{array}{l}40,70 \\
40,70\end{array}$ & $\begin{array}{l}204,03 \\
304\end{array}$ & \begin{tabular}{|l|l|}
97,01 \\
97
\end{tabular} & \begin{tabular}{|l|}
249,04 \\
249,04
\end{tabular} & $\begin{array}{l}449,12 \\
249,12\end{array}$ & \begin{tabular}{|l|l|}
83,66 \\
88,6
\end{tabular} & | & $\frac{00,34 \mid}{66,95}$ & $\begin{array}{l}4,200 \\
3,20\end{array}$ & 51,86 & \begin{tabular}{|l|}
193,22 \\
\end{tabular} & $\begin{array}{l}0,49 \\
29,84 \\
\end{array}$ & $\begin{array}{l}0,51 \\
30,62\end{array}$ & $\begin{array}{l}194,10 \\
180,89\end{array}$ \\
\hline Pelobates cultripes & 29SQD21 & 101,00 & 167,54 & 115,88 & 37,93 & 6306,67 & 345,66 & 42,66 & 302,99 & 98,62 & 250,56 & 250,69 & 90,15 & 493,85 & 65,03 & 3,03 & 51,52 & 187,80 & 29,46 & 30,62 & 175,35 \\
\hline Pelobates cultripes & 29SQD22 & 99,00 & 166,10 & 114,86 & 37,35 & 6329,11 & 344,38 & 41,63 & 302,75 & 96,99 & 249,73 & 249,83 & 88,67 & 500,07 & 65,06 & 3,38 & 50,77 & 189,08 & 31,18 & 31,49 & 176,83 \\
\hline Pelobates cultripes & 29SQD23 & 100,00 & 162,78 & 113,37 & 37,00 & 6357,80 & 341,02 & 39,52 & 301,50 & 93,64 & 247,12 & 247,14 & 85,36 & 515,75 & 66,36 & 4,00 & 50,40 & 194,20 & 32,93 & 33,12 & 182,06 \\
\hline Pelobates cultripes & 29 SQD26 & 101,00 & 159,38 & 108,83 & 36,05 & 6397,50 & 335,77 & 38,95 & 296,82 & 90,23 & 244,69 & 244,69 & 82,14 & 526,93 & 67,03 & 4,02 & 49,63 & 196,72 & 35,47 & 35,47 & 184,62 \\
\hline 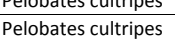 & $\begin{array}{l}295 \text { Q } \\
290200\end{array}$ & $\begin{array}{l}\quad 10,100 \\
99,00\end{array}$ & $\begin{array}{l}13,50,44 \\
160,44\end{array}$ & $\begin{array}{l}10,65 \\
107,57 \\
\end{array}$ & 30,05 & $\begin{array}{l}\mid \\
6372,07 \\
63720\end{array}$ & 3354,12 & \begin{tabular}{|l|l|}
30,552 \\
40,5
\end{tabular} & $\begin{array}{l}290,626 \\
293,60 \\
\end{array}$ & $\begin{array}{l}0,23 \\
91,04 \\
\end{array}$ & \begin{tabular}{|l|}
244,34 \\
245,34
\end{tabular} & $\begin{array}{l}244,39 \\
245,34\end{array}$ & \begin{tabular}{|l|l|}
82,97 \\
82,9
\end{tabular} & | 520,934 & $\begin{array}{l}61,03 \\
64,45\end{array}$ & $\begin{array}{l}4,402 \\
4,02 \\
\end{array}$ & $\begin{array}{l}44,03 \\
48,64 \\
\end{array}$ & $\begin{array}{l}190,1 / 2 \\
191,95 \\
\end{array}$ & $\begin{array}{l}3,44 \\
35,61 \\
\end{array}$ & $\begin{array}{l}35,41 \\
35,61\end{array}$ & $\begin{array}{l}184,02 \\
180,30\end{array}$ \\
\hline Pelobates cultripes & 29SQD31 & 100,00 & 165,92 & 116,10 & 37,53 & 6383,78 & 346,06 & 40,36 & 305,70 & 96,25 & 250,19 & 250,23 & 87,68 & 499,24 & 64,97 & 3,08 & 51,30 & 188,50 & 29,97 & 30,39 & 176,32 \\
\hline Pelobates cultripes & 29SQD32 & 99,00 & 163,79 & 115,06 & $\begin{array}{l}37,05 \\
\end{array}$ & 6406,58 & 344,01 & 38,80 & 305,22 & 94,02 & 248,83 & 248,84 & 85,67 & 506,41 & 65,30 & 3,67 & 50,66 & 190,02 & 31,50 & 31,52 & 177,81 \\
\hline Pelobates cultripes & 29SQD36 & 100,00 & 158,56 & 109,69 & 36,00 & 6453,55 & 336,64 & 37,03 & 299,60 & 88,73 & 244,68 & 244,68 & 80,45 & 515,19 & 66,6 & 4,06 & 49,25 & 190,48 & 34,98 & 34,98 & 178,10 \\
\hline Pelobates cultripes & 29SQD39 & 99,00 & 158,01 & 108,29 & 36,00 & 64520,54 & 333,4 & 37,18 & 296,26 & $\begin{array}{l}88,09 \\
88,09 \\
\end{array}$ & 243,70 & 243,70 & $\begin{array}{l}\mid 79,96 \\
79,9\end{array}$ & 505,57 & $62, \varepsilon$ & 4,44 & 48,10 & $\begin{array}{l}186,62 \\
\end{array}$ & $\begin{array}{l}35,82 \\
35,82\end{array}$ & 35,82 & 174,49 \\
\hline Pelobates cultripes & $29 \mathrm{SQD}$ & 100,00 & 167,40 & 116,77 & 37,13 & 6444,88 & 349 & 40,70 & 308,41 & 96,92 & 252,81 & 252,81 & 88,49 & 488,53 & 63,47 & 3,01 & 51,48 & 183,45 & 28,49 & 28,51 & 171,45 \\
\hline Pelobates cultripes & $29 S Q D 42$ & 101,00 & 163,45 & 115,65 & 37,00 & 6467,77 & 345,24 & 37,56 & $\begin{array}{l}307,68 \\
\end{array}$ & 92,97 & 249,25 & 249,25 & 84,56 & 501,69 & 64,52 & 3,59 & 50,63 & 187,05 & 30,86 & 30,86 & 175,00 \\
\hline Pelobates cultripes & 29 SQD43 & 101,00 & 161,52 & 114,56 & 37,00 & 6485,11 & 343,00 & 36,40 & 306,60 & 90,96 & 247,73 & 247,73 & 82,47 & 504,86 & 64,52 & 3,99 & 50,27 & 187,34 & 32,06 & 32,06 & 175,22 \\
\hline Pelobates cultripes & 29SQD46 & 101,00 & 158,61 & 111,09 & 36,02 & 6493,81 & 338,07 & 35,56 & 302,51 & 88,12 & 245,17 & 245,17 & 79,77 & 501,75 & 64,84 & 4,00 & 48,76 & 184,06 & 34,20 & 34,20 & 171,66 \\
\hline Pelobates cultripes & 29SQD47 & $\begin{array}{l}100,00 \\
100\end{array}$ & 130,01 & 1110,70 & $\begin{array}{l}30,0< \\
36,07\end{array}$ & | 64577,91 & 339,36 & $\begin{array}{l}3,00 \\
37,98 \\
\end{array}$ & \begin{tabular}{|l|}
301,38 \\
301
\end{tabular} & $\begin{array}{l}00,12 \\
90,34 \\
\end{array}$ & \begin{tabular}{|l|}
247,32 \\
24,3
\end{tabular} & \begin{tabular}{|l|}
247,32 \\
24,3
\end{tabular} & 82,02 & $\begin{array}{l}01,05 \\
484,05\end{array}$ & $\begin{array}{l}64,04 \\
62,15\end{array}$ & 4,00 & $\begin{array}{ll}48,10 \\
48,47\end{array}$ & $\begin{array}{l}177,120 \\
177\end{array}$ & $\begin{array}{l}4,20 \\
33,49 \\
\end{array}$ & $\begin{array}{l}34,20 \\
3,49\end{array}$ & $\begin{array}{l}1 / 1,00 \\
164,73\end{array}$ \\
\hline Pelobates cultripes & 29SQD49 & 101,00 & 157,11 & 109,50 & 36,00 & 6458,45 & 334,03 & 35,16 & 298,87 & 86,68 & 243,30 & 243,30 & 78,69 & 490,88 & 61,05 & 4,54 & 47,59 & 179,34 & 35,49 & 35,49 & 166,93 \\
\hline Pelobates cultripes & 29SQD55 & 82,00 & 156,69 & 113,12 & 36,23 & 6542,17 & 338,71 & 32,22 & 306,49 & 85,59 & 244,25 & 244,25 & 77,52 & 505,80 & 65,25 & 4,08 & 48,90 & $\mid 184,66$ & 34,11 & 34.11 & 172,52 \\
\hline Pelobates cultripes & 29 SQD56 & 87,00 & 157,94 & 112,30 & 36,01 & 6536,19 & 338,98 & 33,71 & 305,27 & 86,92 & 245,25 & 245,25 & 78,64 & 492,20 & 63,35 & 4,02 & 48,53 & 179,17 & 33,79 & 33,79 & 166,85 \\
\hline Pelobates cultripes & 29SQD57 & 80,00 & 160,28 & 111,88 & 36,03 & 6511,11 & 340,08 & 36,26 & 303,83 & 89,31 & 247,30 & 247,30 & 81,00 & 474,24 & 60,62 & 4,00 & 48,02 & 172,21 & 33,12 & 33,12 & 155 \\
\hline Pelobates cultripes & $\begin{array}{l}295 Q D 558 \\
29 S Q\end{array}$ & $\begin{array}{l}0,00 \\
72,00\end{array}$ & $\begin{array}{l}10,20 \\
159,68 \\
\end{array}$ & $\begin{array}{l}111,00 \\
111,35\end{array}$ & $\begin{array}{l}30,05 \\
36,05\end{array}$ & | $6511,110,86$ & 338,00 & \begin{tabular}{|l|l|}
30,23 \\
36,23
\end{tabular} & $\begin{array}{l}02,303 \\
302,36 \\
\end{array}$ & $\begin{array}{l} \\
89,04 \\
89,0 \\
\end{array}$ & \begin{tabular}{|l|}
246,51 \\
240
\end{tabular} & \begin{tabular}{|l|}
246,51 \\
240
\end{tabular} & $\begin{array}{l}1,00 \\
80,72 \\
\end{array}$ & | $47,40,35$ & $\begin{array}{l}50,0<2 \\
59,39\end{array}$ & 4,00 & $\begin{array}{ll}40,062 \\
47,57\end{array}$ & \begin{tabular}{|l|}
170,54 \\
170
\end{tabular} & \begin{tabular}{|l|l|}
33,51 \\
33
\end{tabular} & $\begin{array}{l}3,12 \\
33,51\end{array}$ & $\begin{array}{l}15,014 \\
158,14\end{array}$ \\
\hline Pelobates cultripes & 29SQE00 & 101,00 & 161,64 & 105,82 & 36,28 & 6236,36 & 330,84 & 43,91 & 286,93 & 93,55 & 244,43 & 244,43 & 85,63 & 559,13 & 71,91 & 4,71 & 49,55 & 213,51 & 37,99 & 37,99 & 203,48 \\
\hline Pelobates cultripes & 29SQE11 & 101,00 & 157,74 & 105,92 & 36,02 & 6286,97 & 328,03 & 39,43 & 288,61 & 89,15 & 241,37 & 241,37 & 81,21 & 550,67 & 70,10 & 5,05 & 48,66 & 208,12 & 38,66 & 38,66 & 197,41 \\
\hline Pelobates cultripes & 29SQE12 & 101,00 & 159,51 & 106,20 & 36,38 & 6265,51 & 328,80 & 40,89 & 287, & 90,55 & 242, & 242, & 82 & 537,63 & 68,69 & 4,94 & 48,43 & 203,31 & 37,95 & 37,95 & 192 \\
\hline Pelobates cultripes & 29SQE20 & 100,00 & 159,87 & 107,36 & 36,06 & 6349,34 & 332,51 & 40,08 & 292,43 & 90,46 & 244,42 & 244,42 & 82,45 & 516,13 & 64,99 & 4,44 & 48,31 & 192,92 & 36,32 & 36,33 & 181,32 \\
\hline
\end{tabular}




\begin{tabular}{|c|c|c|c|c|c|c|c|c|c|c|c|c|c|c|c|c|c|c|c|c|c|}
\hline TAXON & UTM & $\mathrm{km} 2$ & B101 & B102 & $\mathrm{BIO3}$ & B104 & B105 & B106 & B107 & B108 & B109 & BIO10 & BIO11 & BIO12 & 81013 & BIO14 & BIO15 & B1016 & B1017 & B1018 & B1019 \\
\hline Pelobates cultripes & 29SQE30 & 100,00 & 160,68 & 108,58 & 36,06 & 6384,78 & 334,81 & 39,60 & 295,20 & 90,75 & 245,78 & 245,78 & 82,71 & 488,52 & 60,88 & 4,24 & 47,79 & 180,53 & 34,82 & 34,82 & 168,60 \\
\hline Pelobates cultripes & 29SQE40 & 100,00 & 159,59 & 109,72 & 36,16 & 6430,23 & 335,48 & 37,50 & 297,98 & 89,04 & 245,33 & 245,33 & 81,16 & 473,60 & 58,51 & 4,28 & 47,20 & 172,99 & 34,49 & 34,49 & 160,75 \\
\hline Pelobates cultripes & 29SQE50 & 70,00 & 159,94 & 110,91 & 36,59 & 6450,74 & 336,84 & 36,84 & 300,00 & 89,39 & 246,15 & 246,15 & 81,11 & 456,27 & 56,13 & 4,02 & 46,66 & 165,05 & 33,50 & 33,50 & 152,85 \\
\hline Pelobates cultripes & 29SQE51 & 63,00 & 158,98 & 110,69 & 36,68 & 6427,51 & 334,89 & 36,06 & 298,83 & 88,21 & 244,68 & 244,68 & 80,34 & 454,36 & 55,83 & 4,50 & 46,13 & 164,21 & 34,23 & 34,23 & 151,88 \\
\hline Pelobates cultripes & 29SQE52 & 66,00 & 155,05 & 110,34 & 36,55 & \begin{tabular}{ll|l}
6425,27 \\
\end{tabular} & 330,51 & 32,56 & 297,95 & 84,20 & 240,69 & 240,69 & 76,57 & 463,73 & 57,01 & 5,01 & 45,64 & 167,40 & 36,06 & 36,06 & 154,87 \\
\hline Pelobates cultripes & 29тMH90 & 6,00 & 148,43 & 58,79 & 38,79 & 3288,93 & 229,93 & 80,50 & 149,43 & 115,14 & 189,36 & 191,43 & 106,64 & 1150,64 & 161,21 & 25,29 & 46,07 & 461,43 & 107,86 & 131,50 & 415,43 \\
\hline Pelobates cultripes & 29TMH91 & 46,00 & 146,53 & 59,04 & 38,62 & 3311,15 & 229,18 & 78,01 & 151,16 & 113,22 & 187,59 & 189,99 & 104,65 & 1143,04 & 161,42 & 26,24 & 45,56 & 458,00 & 110,67 & 134,49 & 409,85 \\
\hline Pelobates cultripes & 29TMH92 & 25,00 & 141,23 & 60,49 & 38,14 & 3378,23 & 227,51 & 71,47 & 156,05 & 107,72 & 183,44 & 185,91 & 99,12 & 1175,86 & 168,47 & 28,44 & 44,98 & 469,60 & 117,91 & 141,35 & 420,91 \\
\hline Pelobates cultripes & 29TMH93 & 45,00 & 142,97 & 60,38 & 38,58 & 3303,65 & 228,01 & 73,36 & 154,65 & 110,67 & 183,91 & 186,81 & 101,71 & 1081,97 & 153,14 & 26,94 & 44,01 & 431,12 & 113,87 & 138,10 & 376,59 \\
\hline Pelobates cultripes & 29TMH94 & 96,00 & 134,43 & 62,32 & 38,30 & 3383,03 & 224,15 & 63,56 & 160,59 & 101,66 & 176,79 & 179,88 & 92,99 & 1163,86 & 165,96 & 30,57 & 43,29 & 460,44 & 125,92 & 149,26 & 407,56 \\
\hline Pelobates cultripes & 29TNE14 & 94,00 & 153,37 & 80,69 & 43,99 & 3489,40 & 249,04 & 67,60 & 181,44 & 114,96 & 194,89 & 196,96 & 106,94 & 915,43 & 130,14 & 8,93 & 54,31 & 372,73 & 57,22 & 64,43 & 366,66 \\
\hline Pelobates cultripes & 29TNE15 & 95,00 & 152,10 & 79,87 & 44,23 & 3433,91 & 244,94 & 66,57 & 178,37 & 114,04 & 192,57 & 194,69 & 106,07 & 940,82 & 132,95 & 9,80 & 53,87 & 381,66 & 60,01 & 67,97 & 375,23 \\
\hline Pelobates cultripes & 29TNE17 & 40,00 & 151,00 & 77,70 & \begin{tabular}{|l|l|}
44,97 \\
\end{tabular} & 3321,38 & 237,20 & 65,97 & 171,23 & 113,99 & 189,58 & 191,34 & 105,62 & 973,01 & 136,21 & 10,34 & 53,00 & 393,07 & \begin{tabular}{l|l}
63,24 \\
\end{tabular} & 72,89 & 385,45 \\
\hline Pelobates cultripes & 29TNE26 & 100,00 & 152,32 & 84,16 & $\begin{array}{l}44,45 \\
\end{array}$ & 3581,52 & 250,69 & 63,32 & 187,37 & 112,44 & 194,77 & 196,81 & 104,39 & 969,56 & 136,02 & 10,03 & 53,09 & 390,74 & 63,01 & 70,94 & 385,71 \\
\hline Pelobates cultripes & 29TNE27 & 100,00 & 150,94 & 81,77 & 44,72 & 3491,93 & 244,10 & 63,03 & 181,07 & 111,95 & 191,99 & 193,90 & 103,76 & 988,28 & 138,04 & 10,85 & 52,79 & 397,95 & 65,18 & 74,10 & 391,49 \\
\hline Pelobates cultripes & 29TNE28 & 101,00 & 149,73 & 78,91 & 45,04 & 3384,36 & 236,65 & 63,11 & 173,54 & 111,73 & 189,05 & 190,76 & 103,37 & 1002,72 & 139,53 & 11,00 & 52,55 & 403,88 & 66,14 & 76,54 & 395,56 \\
\hline Pelobates cultripes & 29TNE29 & 91,00 & 148,62 & 76,34 & 45,23 & 3286,96 & 230,02 & 63,25 & 166,77 & 111,66 & 186,35 & 187,93 & 103,07 & 1017,60 & 140,94 & 11,13 & 52,35 & 410,05 & 67,19 & 78,96 & 399,81 \\
\hline Pelobates cultripes & 29TNE37 & 100,00 & 151,92 & 88,12 & 44,21 & 3760,17 & 256,36 & 59,47 & 196,88 & 109,94 & 196,99 & 198,97 & 101,90 & 999,56 & 139,38 & 11,00 & 52,72 & 400,87 & 66,69 & 74,56 & 396,25 \\
\hline Pelobates cultripes & 29TNE45 & 101,00 & 159,50 & 98,46 & 43,90 & 4164,52 & 283,32 & 60,82 & 222,49 & 108,75 & 210,58 & 212,78 & 105,32 & 936,35 & 130,70 & 9,70 & 52,90 & 374,25 & 62,54 & 67,44 & 374,14 \\
\hline Pelobates cultripes & 29TNF20 & 39,00 & 148,11 & 75,99 & 45,39 & 3278,87 & 228,40 & 62,72 & 165,68 & 111,24 & 185,74 & 187,30 & 102,70 & 1033,57 & 142,44 & 11,91 & 52,02 & 416,51 & 68,59 & 81,88 & 404,38 \\
\hline Pelobates cultripes & 29TNF21 & 42,00 & 147,88 & 78,33 & 45,13 & 3371,42 & 232,38 & 61,15 & \begin{tabular}{|l|l|}
171,23 \\
\end{tabular} & 110,42 & 187,18 & 188,83 & 101,85 & 1056,40 & $\mid 144,77$ & 12,05 & 52,00 & 425,88 & 70,18 & 84,85 & 411,62 \\
\hline Pelobates cultripes & 29TNF26 & 68,00 & 143,71 & 84,72 & 45,01 & 3658,17 & 241,52 & 55,50 & 186,02 & 99,99 & 188,56 & 190,46 & 97,07 & 1215,52 & 165,55 & 15,08 & 51,03 & 482,21 & 83,56 & 100,72 & 480,78 \\
\hline Pelobates cultripes & 29TNF27 & 83,00 & 143,39 & 83,67 & 44,84 & \begin{tabular}{ll|}
3665,84 \\
\end{tabular} & 241,48 & 56,50 & 184,98 & 98,16 & 188,60 & 190,35 & 96,94 & 1229,74 & 168,04 & 15,06 & 51,32 & 488,82 & 83,48 & 101,82 & 488,58 \\
\hline Pelobates cultripes & 29TNF30 & 97,00 & 149,38 & 82,52 & 44,75 & 3564,68 & 241,69 & 59,15 & 182,54 & 109,24 & 191,41 & $\begin{array}{l}193,03 \\
\end{array}$ & 100,90 & 1039,18 & 143,20 & 11,86 & 52,06 & 418,81 & 69,12 & 81,84 & 406,13 \\
\hline Pelobates cultripes & 29TNF31 & 101,00 & 148,07 & 83,26 & 44,69 & 3597,97 & 241,68 & 57,46 & 184,22 & 107,87 & 190,73 & 192,50 & 99,47 & 1065,36 & 146,05 & 12,24 & 52,00 & 429,98 & 71,06 & 85,21 & 414,46 \\
\hline Pelobates cultripes & 29TNF32 & 101,00 & 145,57 & 84,92 & 44,51 & 3682,73 & 242,81 & 53,91 & 188,90 & 104,71 & 189,77 & 191,53 & 96,39 & 1108,58 & 151,23 & 13,26 & 51,97 & 448,35 & 74,67 & 90,24 & 429,45 \\
\hline Pelobates cultripes & 29TNF33 & 100,00 & 143,08 & 86,64 & 44,26 & 3769,42 & 244,08 & $\begin{array}{l}50,32 \\
5\end{array}$ & \begin{tabular}{|l|}
193,75 \\
\end{tabular} & \begin{tabular}{|l|l|}
101,57 \\
\end{tabular} & 188,84 & 190,75 & 93,44 & $\begin{array}{l}1153,38 \\
1150\end{array}$ & 156,89 & 14,21 & 51,96 & $\mid 467,44$ & 78,42 & 95,49 & $\begin{array}{l}42,44,94 \\
444,94\end{array}$ \\
\hline Pelobates cultripes & 29TNF35 & 101,00 & 143,79 & 89,17 & 44,34 & 3853,99 & 248,86 & 50,08 & 198,78 & 101,82 & 191,19 & 193,23 & 93,92 & 1176,16 & 162,85 & 15,00 & 51,60 & 476,56 & 80,52 & 100,90 & 450,62 \\
\hline Pelobates cultripes & 29TNF41 & 101,00 & 142,38 & 89,36 & 43,37 & 3991,40 & 250,94 & 47,24 & 203,70 & 98,11 & 191,25 & 193,01 & 90,04 & 1145,99 & 159,30 & 13,48 & 52,06 & 462,52 & 77,32 & 89,31 & 448,96 \\
\hline Pelobates cultripes & 29TNF50 & 101,00 & 139,58 & 92,61 & 42,17 & 4304,23 & 258,99 & 41,99 & 217,01 & 92,04 & 193,36 & 195,11 & 84,30 & 1181,11 & 167,89 & 13,43 & 52,76 & 475,58 & 79,54 & 87,48 & 468,92 \\
\hline Pelobates cultripes & 29TNF70 & 100,00 & 131,12 & 93,82 & 39,84 & 4794,23 & 263,60 & 31,18 & 232,42 & 74,29 & 193,10 & 194,21 & 71,49 & 1276,03 & 187,97 & 13,92 & 54,17 & 515,51 & 84,71 & 88,05 & 514,91 \\
\hline Pelobates cultripes & 29TNG09 & & & & & & & & $202,4 \mathrm{C}$ & & & & & & & (10,5 & 4,17 & & $04,1 / 1$ & & \\
\hline Pelobates cultripes & 29TNG13 & 86,00 & 140,49 & 72,13 & 41,64 & 3603,62 & 234,13 & 62,90 & 171,23 & 100,04 & 185,70 & 187,01 & 95,30 & $\mid 1358,91$ & \begin{tabular}{|l|l|}
189,08 \\
\end{tabular} & 19,68 & 51,07 & 544,43 & 96,92 & 119,11 & 541,84 \\
\hline Pelobates cultripes & 29TNG15 & 101,00 & 132,16 & 69,72 & 40,14 & 3685,33 & 227,32 & 55,75 & 171,56 & 93,81 & 178,93 & 180,33 & 86,39 & 1509,91 & 227,25 & 27,33 & 50,50 & 609,48 & $\begin{array}{r}119,62 \\
\end{array}$ & 138,03 & 604,19 \\
\hline Pelobates cultripes & 29TNG17 & 33,00 & 149,14 & 62,22 & 38,97 & 3510,00 & 234,61 & 76,97 & 157,64 & 112,28 & 193,11 & 194,33 & 104,31 & \begin{tabular}{|l|}
1294,33 \\
\end{tabular} & 179,89 & 25,03 & 48,31 & 519,61 & 107,44 & 128,50 & 486,56 \\
\hline Pelobates cultripes & 29TNG19 & 57,00 & 145,12 & 59,99 & 37,97 & 3519,84 & 230,93 & 75,11 & 155,82 & 108,43 & 189,61 & 191,00 & 100,84 & 1316,97 & 192,33 & 28,91 & 47,32 & 528,09 & 117,50 & 139,10 & 493,80 \\
\hline Pelobates cultripes & 29TNG27 & 80,00 & 142,23 & 66,90 & 39,02 & 3729,91 & 235,55 & 66,17 & 169,38 & 100,94 & 189,67 & 190,59 & 95,20 & 1456,53 & 226,75 & 28,89 & 50,29 & 590,88 & 119,23 & 137,56 & 576,63 \\
\hline Pelobates cultripes & 29TNG32 & 101,00 & 142,57 & 82,02 & 41,84 & 3972,07 & 249,88 & 55,81 & 194,06 & 98,75 & 192,74 & 193,71 & 92,50 & 1300,19 & 180,92 & 17,88 & 51,01 & 516,76 & 92,01 & 111,91 & 515,34 \\
\hline Pelobates cultripes & 29TNG36 & 101,00 & 144,76 & 73,61 & 39,76 & 3928,62 & 246,38 & 62,98 & 183,40 & 101,35 & 194,70 & 195,47 & 95,00 & \begin{tabular}{|l|}
1380,58 \\
\end{tabular} & 213,07 & 25,50 & 50,08 & 554,99 & 110,69 & 128,51 & 543,54 \\
\hline Pelobates cultripes & 29TNG59 & 100,00 & 113,55 & 80,92 & 38,7 & 4310,81 & 231,79 & 25,08 & 206,71 & 67,71 & 170,02 & 171,45 & 62,24 & 1509,61 & 226,36 & 35,67 & 46,38 & 586,61 & 144,05 & 155,97 & 575,97 \\
\hline Pelobates cultripes & 29TNG73 & 100,00 & 115,12 & 89,06 & 38, & 4792,36 & 245 & 18,81 & 226,53 & 61,56 & 177,89 & 178,53 & 57,06 & 1389,96 & 190,55 & 24,75 & 48,83 & 543,13 & 116,06 & 122,88 & 540,40 \\
\hline 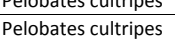 & 29TNG83 & 100,00 & $\begin{array}{r}11,12 \\
95,35\end{array}$ & $\begin{array}{l}5,, 50 \\
82,54\end{array}$ & $\begin{array}{l}30, \\
36,\end{array}$ & $\begin{array}{l}49,250 \\
4825,88 \\
\end{array}$ & 224 & \begin{tabular}{|l|}
4,018 \\
4,18
\end{tabular} & $\begin{array}{l}220,35 \\
220,77 \\
\end{array}$ & $\begin{array}{l} \\
39,97 \\
397\end{array}$ & $\mid$\begin{tabular}{|l}
$\mid 159,69$ \\
159,66
\end{tabular} & 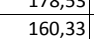 & $\begin{array}{l}1,00 \\
38,78 \\
\end{array}$ & \begin{tabular}{|l|}
1502,90 \\
1502,75
\end{tabular} & \begin{tabular}{|l|}
$199,53,67$ \\
199
\end{tabular} & $\begin{array}{l}29,19 \\
29,19\end{array}$ & $\begin{array}{l}44,03 \\
48,38 \\
\end{array}$ & \begin{tabular}{|l|l|}
587,88 \\
587
\end{tabular} & \begin{tabular}{|l|}
130,81 \\
130
\end{tabular} & $\begin{array}{l}134,50 \\
134,52\end{array}$ & $\begin{array}{l}54,40 \\
587,87\end{array}$ \\
\hline Pelobates cultripes & 29TNG93 & 100,00 & 96,32 & 83,47 & 36,63 & 4929,91 & 228,39 & 3,62 & 224,77 & 39,17 & 162,07 & 162,53 & 38,30 & 1441,20 & 190,75 & 27,84 & 48,34 & 563,31 & 125,34 & 128,21 & 563,31 \\
\hline Pelobates cultripes & 29TNG94 & 100,00 & 104,76 & 86,30 & 37,24 & 4947,62 & 237,78 & 9,36 & 228,42 & 50,88 & 170,56 & 170,87 & 45,91 & 1358,63 & 181,85 & 26,28 & 47,98 & 528,21 & 118,26 & 122,51 & 528,04 \\
\hline Pelobates cultripes & 29TNHOO & 16,00 & 147,29 & 59,00 & 38,4 & 3400,52 & 230,67 & 78,95 & 151,71 & 112,29 & 190,24 & 191,67 & 104,38 & 1225,90 & 74,48 & 26,5 & 46,81 & 491,57 & 111,81 & 134,71 & 450,57 \\
\hline Pelobates cultripes & 29TNH10 & 61,00 & $\begin{array}{l}14,2,39 \\
146,39\end{array}$ & 60,06 & 37,5 & 35019,36 & 232,27 & 76,11 & 156,16 & 109,72 & $\begin{array}{l}190,75 \\
\end{array}$ & & \begin{tabular}{|l|}
101,94 \\
\end{tabular} & 1275,06 & 185, & 28, & 46,99 & 509,45 & $\begin{array}{l}111,210 \\
116,28 \\
\end{array}$ & \begin{tabular}{|l|}
138,47 \\
\end{tabular} & 472,93 \\
\hline Pelobates cultripes & 29TNH & 40,00 & 14 & 60,45 & 37,82 & 3518,47 & 233,20 & 75,68 & 157,53 & 109,97 & 190,80 & 192,50 & 102,30 & 1241,93 & 180,28 & 28,89 & 46,24 & 494,43 & 116,57 & 139,20 & 455,66 \\
\hline Pelobates cultripes & 29TPE15 & 99,00 & 129,26 & 87,30 & 35,12 & 5467,14 & 273,53 & 28,66 & $\begin{array}{l}244,87 \\
\end{array}$ & 63,75 & 202,52 & 202,53 & 63,75 & 1199,32 & 181,90 & 11,09 & 55,96 & 490,30 & 73,40 & 73,40 & 490,30 \\
\hline Pelobates cultripes & 29TPE23 & 100,00 & 136,93 & 89,41 & 34,98 & 5655,55 & 286,47 & 34,08 & 252,39 & 69,31 & 212,77 & 212,88 & 69,31 & 1072,25 & 160,25 & 9,60 & 55,52 & 436,33 & 65,86 & 65,86 & 436,33 \\
\hline Pelobates cultripes & 29TPE26 & 101,00 & 103,49 & 76,74 & 32,4 & 5450,47 & 240,55 & 9,06 & 231,49 & 40,44 & 177,45 & 177,47 & 40,44 & 1460,65 & 224,47 & 13,97 & 56,51 & 598,38 & 87,92 & 88,13 & 598,38 \\
\hline Pelobates cultripes & 29TPE33 & $\begin{array}{l}101,00 \\
100\end{array}$ & 15 & 96 & 35 & $\begin{array}{l}340,4,4 ! \\
5812,66\end{array}$ & 307,4 & \begin{tabular}{|l|}
$4,30,36$ \\
43
\end{tabular} & $\begin{array}{l}261,44 \\
264,08 \\
\end{array}$ & $\begin{array}{l}40,34 \\
84,32\end{array}$ & \begin{tabular}{|l|}
228,71 \\
\end{tabular} & 22 & $\begin{array}{l}40,444 \\
81,34\end{array}$ & \begin{tabular}{|l|}
440,000 \\
887,47 \\
\end{tabular} & $\begin{array}{l}\mid 24,49 \\
129,32\end{array}$ & $\mid \frac{\mid c, 51}{7,58}$ & 54,42 & \begin{tabular}{|l|}
356,64 \\
356
\end{tabular} & $\begin{array}{l}56,06 \\
56,\end{array}$ & $\begin{array}{ll}00,13 \\
56,28\end{array}$ & $\begin{array}{l}350,50 \\
356,61\end{array}$ \\
\hline Pelobates cultripes & 29TPE34 & 100,00 & 144,07 & 93,37 & 35,58 & 5763,97 & 297,00 & 37,53 & 259,47 & 74,25 & 220,63 & 220,80 & 74,25 & 963,29 & \begin{tabular}{|l|l|}
142,08 \\
\end{tabular} & 8,48 & 54,82 & 388,56 & 60,65 & 60,78 & 388,56 \\
\hline Pelobates cultripes & 29TPE35 & 100,00 & 142,56 & 93,42 & 35,63 & 5737,22 & 294,59 & 35,97 & 258,62 & 72,78 & 218,54 & 218,67 & 72,78 & 976,71 & 144,52 & 8,80 & 54,84 & 394,12 & 61.76 & 61,99 & 394,12 \\
\hline Pelobates cultripes & 29TPE43 & 101,00 & 153,35 & 97,14 & 35,97 & 5887,56 & 310,18 & 43,60 & 266,59 & 89,12 & 231,20 & 231,48 & 81,69 & 837,38 & 120,72 & 7,00 & 53,85 & 334,35 & 53,38 & 53,65 & 333,63 \\
\hline Pelobates cultripes & 29TPE44 & 100,00 & 149 & 96,03 & 35,86 & 5860,33 & 304 & 40,37 & 264,60 & 84,59 & 226,95 & 227 & 78,09 & 871,44 & 126,58 & 7,52 & 54,06 & 348,36 & 55,63 & 55,78 & 347 \\
\hline Pelobates cultripes & $\begin{array}{l}\text { 29TPE45 } \\
\end{array}$ & $\begin{array}{l}101,00 \\
100\end{array}$ & $\begin{array}{l}14,40 \\
142,38 \\
\end{array}$ & $\begin{array}{l}0,305 \\
93,54\end{array}$ & $\begin{array}{l}35,00 \\
35,41\end{array}$ & $\begin{array}{l}58024,43 \\
582,4\end{array}$ & 295,68 & $\begin{array}{l}4,313 \\
34,92 \\
\end{array}$ & \begin{tabular}{|l|}
260,76 \\
\end{tabular} & 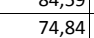 & \begin{tabular}{|l|}
219,54 \\
210
\end{tabular} & |219,65 & $\begin{array}{l}\mid 0,05 \\
71,49 \\
\end{array}$ & \begin{tabular}{|l|l|l|l|l|l|}
934,96 \\
\end{tabular} & \begin{tabular}{|l|l|}
137,33 \\
120,0
\end{tabular} & $\begin{array}{l}, 324 \\
8,42 \\
\end{array}$ & 54,35 & $\begin{array}{l}40,30 \\
374,92 \\
\end{array}$ & $\begin{array}{l}5,00 \\
59,48\end{array}$ & | 59,00 & $\begin{array}{l}34,, 50 \\
374,91 \\
\end{array}$ \\
\hline Pelobates cultripes & 29TPE46 & 99,00 & 140,79 & 93,71 & 35,62 & 5799,87 & 293,41 & 33,34 & 260,08 & 71,02 & 217,52 & 217,64 & 70,04 & 944,75 & 139,10 & 8,62 & 54,33 & 378,87 & 60,64 & 61,32 & 378,87 \\
\hline Pelobates cultripes & 29TPE53 & 100,00 & 151,91 & 97,36 & 35,85 & 5953,50 & 309,70 & 41,55 & 268,15 & 87,23 & 230,81 & 231,01 & 79,58 & 808,77 & 115,52 & 6,97 & 53,33 & 321,81 & 52,04 & 52,23 & 319,62 \\
\hline Pelobates cultripes & 29TPE54 & 100,00 & 147,75 & 95,98 & 35,62 & 5933,51 & 304,19 & 38,06 & 266,1 & 83,16 & 226 , & 226 , & 75, & 844,05 & 121,51 & 7,38 & 53,61 & 335,96 & 54,66 & 54,79 & 334 \\
\hline Pelobates cultripes & 29TPE55 & 100,00 & 139,99 & 93,16 & 35,09 & 5892,53 & 294,01 & 32,20 & 261,81 & 76,16 & 218,11 & 218,19 & 68,40 & 909,11 & 132,39 & 8,41 & 53,90 & 362,66 & 58,54 & 59,38 & 361,92 \\
\hline
\end{tabular}




\begin{tabular}{|c|c|c|c|c|c|c|c|c|c|c|c|c|c|c|c|c|c|c|c|c|c|}
\hline TAXON & UTM & $\mathrm{km} 2$ & B101 & B102 & $\mathrm{BIO3}$ & BIO4 & B105 & B106 & B107 & B108 & B109 & B1010 & BIO11 & BIO12 & B1013 & BIO14 & BIO15 & B1016 & B1017 & BIO18 & B1019 \\
\hline Pelobates cultripes & 29TPE56 & 101,00 & 128,25 & 88,22 & 34,20 & 5835,14 & 278,60 & 23,79 & 254,82 & 62,95 & 205,80 & 206,08 & 57,84 & 1007,41 & 148,40 & 9,62 & 54,15 & 403,27 & 64,49 & 67,35 & 403,21 \\
\hline Pelobates cultripes & 29TPE57 & 100,00 & 122,18 & 85,75 & 33,73 & 5797,09 & 270,24 & 19,26 & 250,98 & 53,93 & 199,19 & 199,57 & 52,20 & 1057,68 & 156,75 & 10,24 & 54,34 & 424,65 & 67,76 & 71,56 & 424,64 \\
\hline Pelobates cultripes & 29TPE58 & 101,00 & 120,47 & 85,76 & 33,81 & 5774,86 & 268,03 & 17,55 & 250,48 & 51,08 & 196,97 & 197,58 & 50,51 & 1064,41 & 157,89 & 10,49 & 54,30 & 427,55 & 68,80 & 72,51 & 427,55 \\
\hline Pelobates cultripes & 29TPE63 & 100,00 & 147,31 & 96,56 & 35,56 & 6005,60 & 305,46 & 37,25 & 268,21 & 82,40 & 227,14 & 227,18 & 74,60 & 805,58 & 114,23 & 7,23 & 52,82 & 319,18 & 52,55 & 52,87 & 315,84 \\
\hline Pelobates cultripes & 29TPE64 & 101,00 & 148,18 & \begin{tabular}{|l|l|}
97,18 \\
\end{tabular} & 35,78 & \begin{tabular}{ll|}
5989,67 \\
\end{tabular} & 305,84 & 37,38 & 268,45 & 82,93 & 227,58 & 227,62 & 75,21 & 797,19 & 113,21 & 7,17 & 52,86 & 315,68 & 52,29 & 52,49 & 312,48 \\
\hline Pelobates cultripes & \begin{tabular}{|l|} 
29TPE65 \\
\end{tabular} & 100,00 & 129,91 & 90,14 & 34,26 & 5929,70 & 283,01 & 23,91 & 259,10 & 66,46 & 208,92 & 209,16 & 58,67 & 944,84 & 136,77 & 9,21 & 53,25 & 375,78 & 61,54 & 63,95 & 373,87 \\
\hline Pelobates cultripes & 29TPE66 & 100,00 & 121,79 & 86,97 & 33,72 & 5881,62 & 272,26 & 17,83 & 254,43 & 59,20 & 200,18 & 200,57 & 51,21 & 1009,52 & 147,16 & 10,10 & 53,46 & 402,21 & 65,82 & 69,68 & 400,97 \\
\hline Pelobates cultripes & 29TPE67 & 101,00 & 125,29 & 89,10 & 34,18 & 5888,96 & 276,66 & 19,84 & 256,83 & 61,99 & 203,34 & 203,90 & 54,13 & $\begin{array}{r}971,07 \\
\end{array}$ & 141,31 & 9,83 & 53,26 & \begin{tabular}{|l|}
386,21 \\
\end{tabular} & 64,13 & 66,99 & 385,15 \\
\hline Pelobates cultripes & 29TPE68 & 99,00 & 124,21 & 89,65 & 34,41 & 5871,67 & 275,38 & 18,51 & 256,87 & 60,36 & 201,86 & 202,53 & 53,08 & 971,17 & 141,44 & 9,89 & 53,21 & 386,12 & 64,70 & 67,43 & 385,41 \\
\hline Pelobates cultripes & 29TPE69 & 101,00 & 123,25 & 90,59 & 34,72 & 5856,27 & 274,74 & 17,18 & 257,56 & 58,81 & 200,55 & 201,39 & 52,01 & 969,08 & 141,09 & 10,03 & 53,06 & 385,06 & 65,36 & 67,80 & 384,65 \\
\hline Pelobates cultripes & 29TPE73 & 100,00 & 150,30 & 98,84 & 35,77 & 6062,09 & 310,71 & 38,27 & 272,44 & 84,43 & 230,77 & 230,80 & 76,58 & 739,65 & 102,88 & 6,62 & 51,89 & 290,90 & 49,06 & 49,23 & 285,78 \\
\hline Pelobates cultripes & 29TPE76 & 101,00 & 116,20 & 87,38 & 33,60 & 5936,45 & 267,97 & 12,02 & 255,95 & 53,37 & 195,55 & 196,01 & 45,46 & 998,94 & 143,22 & 10,53 & 52,42 & 395,43 & 67,06 & 71,63 & 392,21 \\
\hline Pelobates cultripes & 29TPE77 & 100,00 & 122,37 & 90,04 & 34,30 & 5945,46 & 275,26 & 16,19 & 259,07 & 58,62 & 201,30 & 201,94 & 50,77 & 938,22 & 134,22 & \begin{tabular}{|l|}
9,98 \\
\end{tabular} & 52,23 & 370,92 & 63,72 & 66,87 & 367,88 \\
\hline Pelobates cultripes & \begin{tabular}{|l|} 
29TPE78 \\
\end{tabular} & 101,00 & 123,45 & 91,55 & 34,80 & 5941,90 & 276,94 & 16,45 & 260,49 & 59,43 & 202,15 & 202,87 & 51,50 & 917,39 & 131,03 & 9,84 & 52,04 & 362,22 & 63,19 & 65,75 & 359,37 \\
\hline Pelobates cultripes & 29TPE79 & 99,00 & 124,77 & 93,29 & 35,09 & 5934,79 & 279,08 & 16,71 & 262,37 & 60,47 & 203,18 & 204,08 & 52,60 & 896,75 & 127,89 & 9,73 & 51,82 & 353,66 & 62,66 & 64,50 & 351,17 \\
\hline Pelobates cultripes & 29TPE86 & 100,00 & 117,60 & 90,52 & 34,02 & 6008,49 & 272,64 & 11,27 & 261,36 & 53,76 & 197,92 & 198,45 & 45,95 & 928,26 & 130,25 & 10,32 & 51,22 & 364,31 & 64,53 & 68,45 & 358,97 \\
\hline Pelobates cultripes & 29TPE87 & 100,00 & 124,01 & 93,18 & 34,67 & 6018,82 & 280,22 & 15,67 & 264,55 & 59,25 & 203,85 & 204,61 & 51,39 & 866,80 & 121,19 & 9,70 & 50,97 & 339,73 & 60,96 & 63,50 & 334,53 \\
\hline Pelobates cultripes & \begin{tabular}{|l|} 
29TPE88 \\
\end{tabular} & 100,00 & 124,78 & 94,46 & 35,08 & 6008,36 & 281,25 & 15,80 & 265,45 & 59,89 & 204,33 & 205,17 & 52,01 & 849,17 & 118,51 & 9,48 & 50,67 & 332,56 & 60,52 & 62,53 & 327,54 \\
\hline Pelobates cultripes & 29TPE89 & 101,00 & 124,13 & 95,26 & 35,25 & 5995,30 & 280,81 & 14,85 & 265,97 & 59,14 & 203,39 & 204,31 & 51,43 & 843,46 & 117,63 & 9,60 & 50,67 & 330,28 & 60,83 & 62,57 & 325,45 \\
\hline Pelobates cultripes & 29TPE93 & 100,00 & 159,60 & 104,03 & 36,55 & 6147,39 & 324,55 & 43,22 & 281,32 & 91,70 & 240,92 & 240,92 & 84,00 & 597,31 & 79,00 & 5,03 & 50,11 & 230,72 & 40,36 & 40,36 & 222,36 \\
\hline Pelobates cultripes & 29TPE95 & 100,00 & 133,71 & 97,47 & 35,24 & 6122,54 & 294,97 & 22,26 & 272,71 & 67,52 & 215,21 & 215,54 & 59,77 & 762,82 & 103,58 & 8,34 & 49,95 & 295,84 & 54,36 & 55,87 & 288,21 \\
\hline Pelobates cultripes & 29TPE97 & 101,00 & 123,33 & 95,54 & 35,03 & 6081,09 & 282,39 & 13,56 & 268,83 & 57,85 & 204,07 & 204,93 & 50,15 & 815,68 & 111,21 & 9,77 & 49,60 & 316,66 & 59,75 & 62,02 & 309,32 \\
\hline Pelobates cultripes & 29TPE98 & 100,00 & 128,77 & 98,03 & $\begin{array}{ll}35,72 \\
\end{array}$ & 6080,10 & 288,79 & 17,22 & 271,56 & 62,50 & 209,12 & 209,95 & 54,96 & 765,26 & 103,76 & 9,16 & 49,35 & 296,62 & 56,86 & 57,99 & 289,48 \\
\hline Pelobates cultripes & 29TPE99 & 100,00 & 129,38 & 99,10 & 35,98 & 6061,66 & 289,52 & 17,34 & 272,18 & 63,10 & 209,68 & 210,36 & 55,57 & 750,64 & 101,66 & 8,98 & 49,19 & 290,90 & 56,43 & 57,15 & 283,99 \\
\hline Pelobates cultripes & 29TPF30 & 101,00 & 138,54 & 97,73 & 37,13 & 5630,05 & 289,25 & 30,10 & 259,15 & 68,92 & 212,42 & 212,50 & 68,92 & 1001,01 & 149,52 & 9,60 & 54,78 & 403,99 & 64,84 & 65,10 & 403,99 \\
\hline Pelobates cultripes & 29TPF42 & 101,00 & 129,46 & 97,21 & 36,92 & 5693,92 & 281,22 & 21,12 & 260,10 & 59,25 & 204,42 & 204,60 & 59,25 & 1019,33 & 152,01 & 10,78 & 54,30 & 410,91 & 68,29 & 68,78 & 410,91 \\
\hline Pelobates cultripes & 29TPF50 & 100,00 & 126,65 & $\begin{array}{l}92,55 \\
92,\end{array}$ & 35,46 & 5783,08 & 277,61 & 19,91 & 257,70 & 55,85 & 202,85 & 203,38 & 55,85 & \begin{tabular}{|l|}
993,74 \\
\end{tabular} & \begin{tabular}{|l|l|}
146,73 \\
\end{tabular} & 10,17 & 53,88 & \begin{tabular}{|l|l|}
398,03 \\
\end{tabular} & $\begin{array}{l}0,25 \\
66,35 \\
\end{array}$ & $\begin{array}{ll}6,1,84 \\
\end{array}$ & 398,03 \\
\hline Pelobates cultripes & 29TPF51 & 101,00 & 131,64 & 96,88 & 36,43 & 5782,81 & 284,82 & 22,60 & 262,23 & 60,43 & 208,01 & 208,14 & 60,43 & 944,00 & 138,90 & 9,93 & 53,56 & 377,33 & 64,01 & 64,23 & 377,33 \\
\hline Pelobates cultripes & 29TPF56 & 100,00 & 139,49 & 105,69 & 38,59 & 5705,64 & 295,63 & 25,55 & 270,08 & 70,99 & 214,41 & 214,41 & 68,22 & 837,54 & 120,32 & 9,97 & 51,84 & 331,83 & 59,22 & 59,22 & 331,53 \\
\hline Pelobates cultripes & 29TPF57 & 101,00 & 134,38 & 105,98 & 38,67 & 5715,32 & 291,15 & 20,48 & 270,66 & 63,93 & 209,56 & 209,56 & 63,28 & 863,64 & 124,24 & 11,01 & 51,61 & 343,18 & 62,44 & 62,44 & 343,14 \\
\hline Pelobates cultripes & 29TPF59 & 101,00 & 140,06 & 107,68 & 39,02 & 5679,65 & 296,10 & 24,35 & 271,75 & 70,61 & 214,39 & 214,39 & 68,77 & 794,76 & 111,26 & 10,91 & 50,28 & 312,01 & 58,91 & 58,91 & 312,01 \\
\hline Pelobates cultripes & 29TPF60 & 100,00 & 126,95 & $\begin{array}{r}93,99 \\
93,09\end{array}$ & 35,55 & 5856,68 & 279,99 & $\begin{array}{l}4,935 \\
18,95 \\
\end{array}$ & 261,04 & $\begin{array}{ll}60,23 \\
6\end{array}$ & 204,05 & 204,72 & 55,29 & 931,01 & $\begin{array}{l}135,27 \\
15,0\end{array}$ & \begin{tabular}{|c|}
9,88 \\
9
\end{tabular} & 52,80 & $\begin{array}{l}36,310 \\
369\end{array}$ & $\begin{array}{l}0,31,92 \\
63,\end{array}$ & $\begin{array}{ll}6,18 \\
65,18\end{array}$ & 369,14 \\
\hline Pelobates cultripes & 29TPF61 & 100,00 & 132,16 & 97,93 & 36,39 & 5855,03 & 287,09 & 21,78 & 265,31 & 64,63 & 209,47 & 209,65 & 59,93 & 881,01 & 127,52 & 9,52 & 52,48 & 348,64 & 61,25 & 61,44 & 348,50 \\
\hline Pelobates cultripes & 29TPF62 & 100,00 & 131,94 & 99,50 & 36,82 & 5846,01 & 287,62 & 20,89 & 266,74 & 63,30 & 209,20 & 209,32 & 59,75 & 870,22 & 125,57 & 9,66 & 52,26 & 344,02 & 61,16 & 61,35 & 343,96 \\
\hline Pelobates cultripes & 29TPF63 & 101,00 & 134,25 & 101,94 & 37,38 & 5835,98 & 290,96 & 21,88 & 269,08 & 63,60 & 211,38 & 211,38 & 61,97 & 844,73 & 121,62 & 9,68 & 52,03 & 333,64 & 59,71 & 59,71 & 333,62 \\
\hline Pelobates cultripes & 29TPF66 & 100,00 & 138,95 & 106,55 & 38,53 & 5783,69 & 296,75 & 23,90 & 272,85 & 68,93 & 214,97 & 214,97 & 66,74 & 780,99 & 110,72 & 9,66 & 50,94 & 307,18 & 56,57 & 56,57 & 306,92 \\
\hline Pelobates cultripes & 29TPF68 & 101,00 & $\begin{array}{l}13,50,93 \\
125,92\end{array}$ & \begin{tabular}{|l|}
105,07 \\
10,0
\end{tabular} & 38,24 & | 5746,909 & 283,86 & \begin{tabular}{|l|l|}
12,69 \\
12
\end{tabular} & \begin{tabular}{|l|}
271,17 \\
271
\end{tabular} & $\mid \begin{array}{l}\mid c 0,35 \\
55,71\end{array}$ & \begin{tabular}{|l|}
201,92 \\
\end{tabular} & \begin{tabular}{|l|}
201,94 \\
\end{tabular} & $\begin{array}{l}54,87 \\
54\end{array}$ & \begin{tabular}{|l|}
847,90 \\
84,
\end{tabular} & \begin{tabular}{|l|l|}
119,58 \\
19
\end{tabular} & \begin{tabular}{|c|}
3,909 \\
11,95
\end{tabular} & $\begin{array}{l}0,0,01 \\
50,01\end{array}$ & \begin{tabular}{|l|}
334,57 \\
3
\end{tabular} & $\begin{array}{ll}65,86 \\
65,\end{array}$ & $\begin{array}{ll}0,5,90 \\
65\end{array}$ & 334,55 \\
\hline Pelobates cultripes & 29TPF70 & 101,00 & 126,52 & 95,46 & 35,48 & 5924,88 & 281,66 & 17,39 & 264,27 & 61,88 & 204,75 & 205,50 & 54,21 & 874,26 & 124,50 & 9,71 & 51,57 & 344,34 & 61,95 & 63,13 & 342,25 \\
\hline Pelobates cultripes & 29TPF71 & 100,00 & 127,17 & 97,36 & 36,08 & 5919,39 & 283,19 & 17,05 & 266,14 & 62,28 & 205,32 & 205,96 & 54,80 & 856,38 & 121,62 & 9,80 & 51,38 & 336,79 & 61,71 & 62,35 & 334,93 \\
\hline Pelobates cultripes & 29TPF72 & 100,00 & 127,59 & 99,08 & 36,53 & 5904,58 & 284,36 & 16,52 & 267,84 & 62,55 & 205,84 & 205,97 & 55,05 & 843,94 & 119,73 & 9,89 & 51,16 & 331,56 & 61,64 & 61,79 & 330,15 \\
\hline Pelobates cultripes & 29TPF73 & 100,00 & 133,46 & 102,44 & 37 & 5891,66 & 291,47 & 20,37 & 271,10 & 67,96 & 211,44 & 211,44 & 60,61 & 792,11 & 111,81 & 9,3 & 50,82 & 310,49 & 57,83 & 57,83 & 309,20 \\
\hline 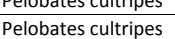 & 29TPF81 & 100,00 & $\begin{array}{l}13,4,40 \\
126,60\end{array}$ & $\begin{array}{r}102,44 \\
98,86\end{array}$ & $\begin{array}{ll}3 r, 2 \\
36,1\end{array}$ & \begin{tabular}{|l|}
5991,00 \\
5977,64
\end{tabular} & 2894,65 & $\begin{array}{l}0,215 \\
15,28 \\
\end{array}$ & \begin{tabular}{|l|}
269,37 \\
\end{tabular} & $\begin{array}{l}60,96 \\
60,96\end{array}$ & \begin{tabular}{|l|}
205,60 \\
205
\end{tabular} & $\begin{array}{l}206,194 \\
206\end{array}$ & $\begin{array}{l}00,01 \\
53,50\end{array}$ & \begin{tabular}{|l|}
$91,2,11$ \\
801,99
\end{tabular} & $\begin{array}{l}11,01,22 \\
111\end{array}$ & $\begin{array}{l}9,5 \\
9,5\end{array}$ & $\begin{array}{l}00,02 \\
50,05\end{array}$ & \begin{tabular}{|l|l|}
313,21 \\
313
\end{tabular} & $\begin{array}{l}3,1,83 \\
59,84\end{array}$ & $\begin{array}{l}30,03 \\
60,40\end{array}$ & $\begin{array}{l}30,20 \\
308,99\end{array}$ \\
\hline Pelobates cultripes & 29TPF82 & 100,00 & 131,03 & 101,63 & 36,88 & 5965,24 & 290,16 & 18,01 & 272,15 & 64,99 & 210,07 & 210,10 & 57,57 & 761,25 & 105,14 & 9,16 & 49,85 & 296,71 & 57,24 & 57,26 & 292,83 \\
\hline Pelobates cultripes & 29TPF83 & 101,00 & 129,88 & 102,77 & 37,09 & 5951,56 & 289,35 & 16,37 & 272,99 & 63,97 & 208,81 & 208,81 & 56,52 & 756,55 & 104,25 & 9,48 & 49,50 & 294,66 & 57,70 & 57,70 & 291,10 \\
\hline Pelobates cultripes & 29TPF90 & 100,00 & 128,32 & 100,02 & 36,06 & 6047,87 & 288,53 & 15,82 & 272,71 & 61,90 & 208,45 & 209,05 & 54,46 & 745,06 & 100,55 & 9,00 & 48,82 & 88,52 & 56,83 & 57,33 & 281,68 \\
\hline Pelobates cultripes & 29TPF92 & 100,00 & 125 , & \begin{tabular}{|l|}
101,71 \\
\end{tabular} & 36,70 & 6019,31 & 285, & 12,23 & 273,60 & $\begin{array}{ll}01,0,92 \\
58,9\end{array}$ & \begin{tabular}{|l|l|}
205,25 \\
\end{tabular} & \begin{tabular}{|l|}
205,49 \\
\end{tabular} & 51,56 & 742,40 & \begin{tabular}{|c|}
99,73 \\
99
\end{tabular} & $\begin{array}{ll}9,7 \\
, 7\end{array}$ & $\begin{array}{l}40,02 \\
48,30\end{array}$ & 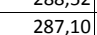 & $\begin{array}{ll}0,009 \\
58,92\end{array}$ & 59,10 & $\begin{array}{l}201,00 \\
280,79\end{array}$ \\
\hline Pelobates cultripes & 29TPF93 & 100,00 & 125,30 & 103,03 & 37,01 & 6001,13 & 286,26 & 11,60 & 274,66 & 59,07 & 205,17 & 205,17 & 51,65 & 728,21 & 97,39 & 9,94 & 47,86 & 281,22 & 58,88 & 58,88 & 275,19 \\
\hline Pelobates cultripes & 29TPF95 & 100,00 & 123,98 & 105,18 & 37,72 & 5972,06 & 285,81 & $\begin{array}{lll}9,47 \\
9\end{array}$ & 276,34 & 57,90 & 203,57 & 203,57 & 50,66 & 712,27 & 94,80 & 9,98 & 47,46 & $\begin{array}{l}274,87 \\
\end{array}$ & 58,80 & 58,80 & 269,70 \\
\hline Pelobates cultripes & 29TPF97 & 101,00 & 119,67 & 106,41 & 37,99 & 5930,73 & 282,07 & 4,67 & 277,39 & 53,80 & 198,61 & 198,61 & 46,65 & 718,31 & 95,14 & 11,02 & 46,70 & 276,97 & 61,95 & 61,95 & 272,98 \\
\hline Pelobates cultripes & 29TPF98 & 100,00 & 120,57 & 107,46 & 38,12 & 5908,98 & 283,11 & 5,07 & 278,03 & 54,57 & 199,09 & 199,09 & 47,67 & 701,41 & 92,47 & 11,18 & 46,30 & 270,26 & 61,39 & 61,39 & 266,71 \\
\hline Pelobates cultripes & 29TPG05 & 101,00 & 115 & $\begin{array}{r}01,40 \\
93,96\end{array}$ & $\begin{array}{l}30, \\
38,\end{array}$ & \begin{tabular}{|}
$\mid 500,30$ \\
5155,67
\end{tabular} & $\frac{20,11}{258,22}$ & $\begin{array}{l}, 0,84 \\
15,4\end{array}$ & \begin{tabular}{|l|}
242,38 \\
248
\end{tabular} & $\begin{array}{l}4,3 / 14 \\
63,14\end{array}$ & \begin{tabular}{|l|}
187,92 \\
18,
\end{tabular} & \begin{tabular}{|l|}
188,01 \\
198,
\end{tabular} & $\begin{array}{ll}57,21 \\
57\end{array}$ & $\mid$\begin{tabular}{l|l|}
$\mid 1153,20$ \\
1150
\end{tabular} & \begin{tabular}{|l|}
$22,4 !$ \\
156,06
\end{tabular} & $\frac{11,10}{22,16}$ & $\begin{array}{l}40,50 \\
47,08\end{array}$ & \begin{tabular}{|l|}
443,66 \\
\end{tabular} & \begin{tabular}{|l|}
100,34 \\
103
\end{tabular} & $\begin{array}{l}1,53 \\
101,71 \\
\end{array}$ & 440,77 \\
\hline Pelobates cultripes & 29TPG06 & 101,00 & 120,72 & 93,71 & 38,19 & 5132,34 & 258,02 & 16,47 & 241,55 & 63,99 & 188,26 & 188,35 & 58,39 & 1133,64 & 155,70 & 22,98 & 46,17 & 434,04 & 101,53 & 103,93 & 429,13 \\
\hline Pelobates cultripes & 29TPG15 & 99,00 & 117,40 & 94,81 & $\begin{array}{l}38,05 \\
\end{array}$ & 5235,88 & 258,51 & 12,64 & 245,87 & 59,84 & 186,75 & $\mid 186,77$ & 53,92 & 1115,37 & 149,09 & 21,82 & 46,89 & 429,50 & 97,90 & 99,06 & 427,21 \\
\hline Pelobates cultripes & 29TPG24 & 100,00 & 128,78 & 100,20 & 38,64 & 5413,35 & 274,57 & 18,36 & 256,21 & 68,08 & 199,94 & 199,94 & 62,10 & 972,87 & 127,05 & 17,39 & 47,39 & 374,59 & 81,45 & 81,45 & 372,83 \\
\hline Pelobates cultripes & 29TPG42 & 101,00 & 119,50 & 102,14 & 38,3 & 5551,84 & 272,26 & 8,95 & 263,32 & 51,70 & 193,03 & 193,03 & 51,39 & 962,54 & 131,89 & 16,71 & 48,75 & 378,48 & 79,34 & 79,34 & 378 \\
\hline Pelobates cultripes & 29TPG50 & 100,00 & 137,60 & $\begin{array}{l}107,47 \\
\end{array}$ & 39,01 & 5663,99 & 293,42 & 22,08 & 271,34 & 69,40 & 211,95 & 211,95 & 66,82 & 797,61 & 110,60 & $\begin{array}{ll}11,75 \\
\end{array}$ & 49,53 & 312,43 & 60,95 & 60,95 & 312,37 \\
\hline Pelobates cultripes & 29TPG69 & 100,00 & 109,58 & 99,72 & 38,42 & 5401,83 & 256,87 & 0,74 & 256,13 & 48,89 & 181,12 & 181,12 & 43,70 & 891,67 & 118,02 & 23,64 & 41,01 & 336,82 & 96,95 & 96,95 & 323,83 \\
\hline Pelobates cultripes & 29TPG73 & 100,00 & 111,26 & 105,36 & 38,08 & 5681,64 & 270,72 & $-1,27$ & 271,99 & 48,18 & 187,11 & 187,11 & 41,70 & 830,16 & 111,22 & 16,29 & 46,11 & 324,27 & 76,84 & 76,84 & 322,77 \\
\hline Pelobates cultripes & 29TPG84 & 100,00 & 101,08 & 104,58 & 38,04 & 5694,84 & 260,62 & $-10,39$ & 271,01 & 38,15 & 177, & 177 & 31, & 848,62 & 111,77 & 19,55 & 43 & 325,23 & 86,52 & 86,52 & 320 \\
\hline Pelobates cultripes & 29TPG93 & 100,00 & 114,11 & 109,10 & 38,82 & 5783,44 & 276,86 & $-1,48$ & 278,34 & 48,78 & 191,09 & 191,09 & 42,76 & 707,57 & 93,88 & 14,70 & 44,40 & 271,75 & 69,24 & 69,24 & 270,03 \\
\hline
\end{tabular}




\begin{tabular}{|c|c|c|c|c|c|c|c|c|c|c|c|c|c|c|c|c|c|c|c|c|c|}
\hline TAXON & UTM & $\mathrm{km} 2$ & B101 & B102 & $\mathrm{BIO3}$ & B104 & B105 & B106 & B107 & B108 & B109 & BIO10 & B1011 & BIO12 & B1013 & BIO14 & BIO15 & B1016 & B1017 & BIO18 & B1019 \\
\hline Pelobates cultripes & 29TPH20 & 100,00 & 128,59 & 94,28 & 38,67 & 5087,38 & 263,24 & 21,88 & 241,35 & 70,80 & 195,16 & 195,28 & 66,58 & 936,27 & 128,52 & 22,83 & 42,26 & 350,85 & 94,21 & 97,52 & 337,98 \\
\hline Pelobates cultripes & 29TPH21 & 100,00 & 131,78 & 93,25 & \begin{tabular}{|l|l|}
38,97 \\
\end{tabular} & 4996,08 & 263,61 & 26,14 & 237,47 & 75,01 & 196,99 & 197,21 & 70,90 & 914,56 & 125,36 & 22,94 & 41,58 & 340,74 & 94,05 & 100,10 & 325,66 \\
\hline Pelobates cultripes & 29TQE03 & 101,00 & 157,84 & 104,90 & 36,25 & 6197,98 & 324,68 & 40,68 & 284,00 & 89,63 & 240,05 & 240,05 & 81,88 & 573,08 & 74,32 & 5,06 & 49,47 & 219,34 & 39,70 & 39,70 & 209,86 \\
\hline Pelobates cultripes & 29TQE04 & 100,00 & 154,81 & 104,37 & 36,24 & 6192,69 & 321,03 & 38,01 & 283,02 & 86,55 & 237,01 & 237,01 & 78,85 & 586,07 & 76,24 & 5,54 & 48,99 & 224,24 & 41,44 & 41,44 & 214,93 \\
\hline Pelobates cultripes & 29TQE06 & 100,00 & 119,30 & 96,47 & \begin{tabular}{|l|l|}
34,97 \\
\end{tabular} & 6132,22 & 280,84 & 9,10 & 271,74 & 53,72 & 201,13 & 201,82 & 46,16 & \begin{tabular}{|l|l|}
805,73 \\
\end{tabular} & 107,34 & 10,19 & 48,41 & 309,67 & 60,69 & 63,48 & 300,38 \\
\hline Pelobates cultripes & 29TQE07 & 100,00 & 123,62 & 98,16 & 35,33 & 6135,20 & 285,67 & 12,02 & 273,65 & 57,43 & 204,98 & 205,92 & 49,78 & 759,97 & 100,67 & 9,58 & 48,27 & 291,79 & 57,97 & 59,88 & 282,52 \\
\hline Pelobates cultripes & 29TQE09 & 100,00 & 131,30 & 101,86 & 36,17 & 6116,52 & 294,27 & 17,42 & 276,85 & 64,19 & 212,74 & 212,94 & 56,78 & 685,57 & 89,87 & 8,81 & 47,62 & 262,67 & 54,02 & 54,22 & 253,71 \\
\hline Pelobates cultripes & 29TQE14 & 100,00 & 151,00 & 105,03 & 36,02 & 6245,07 & 319,05 & 33,85 & 285,20 & 82,28 & 234,02 & 234,02 & 74,70 & 573,23 & 73,34 & 6,00 & 47,74 & 216,81 & 42,50 & 42,50 & 206,36 \\
\hline Pelobates cultripes & 29TQE17 & 100,00 & 116,90 & 99,27 & 35,58 & 6162,49 & 280,77 & 5,20 & 275,57 & 50,61 & 198,90 & 199,93 & 43,24 & 757,81 & 97,69 & 10,55 & 46,63 & 287,30 & 60,86 & 63,32 & 276,08 \\
\hline Pelobates cultripes & 29TQE18 & 101,00 & 125,54 & 101,80 & 36,00 & 6169,60 & 290,29 & 11,75 & 278,54 & 58,30 & 207,24 & 208,30 & 51,04 & 686,06 & 88,32 & 9,12 & 46,56 & 260,12 & 55,46 & 56,49 & 249,12 \\
\hline Pelobates cultripes & 29TQE19 & 100,00 & 127,25 & 103,00 & 36,19 & 6162,70 & 292,13 & 12,80 & 279,33 & 59,83 & 209,15 & 209,75 & 52,47 & 661,92 & 85,14 & 9,13 & 46,17 & 250,62 & 54,62 & 55,15 & 239,65 \\
\hline Pelobates cultripes & 29TQE26 & 101,00 & 136,78 & 104,80 & 36,17 & 6252,37 & 305,10 & 20,15 & 284,95 & 68,32 & 220,21 & 220,43 & 60,87 & 600,82 & 76,44 & 7,80 & 46,06 & 224,75 & 48,41 & 48,75 & 212,96 \\
\hline Pelobates cultripes & 29TQE28 & 100,00 & 119,46 & 102,97 & 36,06 & 6199,91 & 286,09 & \begin{tabular}{|l|}
5,50 \\
5
\end{tabular} & 280,59 & 52,27 & \begin{tabular}{|l|}
201,76 \\
\end{tabular} & 202,81 & 44,99 & $\begin{array}{l}678,62 \\
\end{array}$ & 86,57 & $\begin{array}{l}1,1004 \\
10,04\end{array}$ & 44,90 & 253,79 & 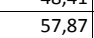 & 59,40 & 240,81 \\
\hline Pelobates cultripes & 29TQE29 & 100,00 & 116,36 & 103,20 & 36,24 & 6180,34 & 282,62 & 2,50 & 280,12 & 49,27 & 198,36 & 199,41 & 42,10 & 682,64 & 87,11 & 10,50 & 44,39 & 254,87 & 59,63 & 61,24 & 241,53 \\
\hline Pelobates cultripes & 29TQE43 & 100,00 & 153,78 & 109,25 & 36,69 & 6364,03 & 327,23 & 32,72 & 294,51 & 83,69 & 238,77 & 238,77 & 76,06 & 479,93 & 59,67 & 5,32 & 45,56 & 174,91 & 37,56 & 37,56 & 162,53 \\
\hline Pelobates cultripes & 29TQE48 & 99,00 & 117,99 & 107,09 & 36,82 & 6247,59 & 288,57 & 1,73 & 286,85 & 50,00 & 201,22 & 202,15 & 43,11 & 606,94 & 75,98 & 10,64 & 41,83 & 219,55 & 57,39 & 58,73 & 204,08 \\
\hline Pelobates cultripes & 29TQE49 & 100,00 & 111,13 & 106,74 & 36,98 & 6218,89 & 281,23 & $-3,86$ & 285,09 & 43,78 & 193,70 & 195,11 & 36,90 & 629,64 & 78,99 & 11,61 & 41,15 & 227,45 & 61,36 & 63,11 & 210,94 \\
\hline Pelobates cultripes & 29TQE53 & 60,00 & 149,80 & 109,92 & 36,70 & 6408,64 & 324,57 & $\begin{array}{ll}27,94 \\
\end{array}$ & 296,63 & 79,16 & 235,42 & 235,42 & 71,58 & 480,32 & 59,08 & 5,85 & 44,56 & 173,02 & 39,20 & 39,20 & 160,24 \\
\hline Pelobates cultripes & 29TQE55 & 57,00 & 150,76 & 110,57 & 37,00 & 6358,67 & 323,98 & 28,98 & 295,00 & 80,15 & 235,62 & 235,62 & 72,85 & 458,15 & 56,78 & 6,03 & 43,63 & 164,68 & 39,14 & 39,14 & 151,80 \\
\hline Pelobates cultripes & 29TQF02 & 100,00 & 122,89 & 103,03 & 36,92 & 6064,12 & 285,49 & 9,05 & 276,44 & 56,28 & 203,29 & 203,87 & 48,95 & 700,28 & 90,91 & 9,98 & 46,55 & 267,72 & 58,49 & 58,88 & 258,90 \\
\hline Pelobates cultripes & 29TQF05 & 99,00 & 122,03 & 106,32 & 37,58 & 6018,77 & 285,45 & 6,53 & 278,92 & 55,32 & 202,18 & 202,18 & 48,14 & 667,94 & 85,85 & 10,00 & 45,79 & 255,06 & 58,03 & 58,03 & 247,19 \\
\hline Pelobates cultripes & 29TQF06 & 100,00 & 125,29 & 107,78 & 38,01 & 6002,93 & 288,91 & 8,85 & 280,05 & 58,28 & 204,97 & 204,97 & 51,21 & 640,23 & 82,02 & 9,97 & 45,41 & 244,05 & 56,19 & 56,19 & 236,84 \\
\hline Pelobates cultripes & 29TQF07 & 100,00 & $\begin{array}{ll}124,47 \\
\end{array}$ & 108,48 & $\begin{array}{l}38,15 \\
\end{array}$ & 5975,92 & 288,21 & 7,85 & 280,36 & 57,62 & 203,80 & 203,80 & 50,69 & \begin{tabular}{|c|c|}
634,57 \\
\end{tabular} & 81,31 & 10,33 & 45,02 & 241,67 & 56,70 & 56,70 & 235,01 \\
\hline Pelobates cultripes & 29TQF08 & 100,00 & 119,33 & 108,56 & 38,17 & 5959,95 & 283,31 & 3,05 & 280,26 & 52,92 & 198,65 & 198,65 & 45,99 & 654,23 & 84,20 & 11,16 & 44,66 & 249,16 & 60,21 & 60,21 & 243,12 \\
\hline Pelobates cultripes & 29TQF10 & 99,00 & 123,20 & 103,09 & 36,52 & 6140,43 & 287,72 & 8,99 & 278,73 & 56,01 & 204,47 & 205,41 & 48,67 & 673,72 & 86,64 & 9,59 & 45,73 & 255,00 & 56,69 & 57,43 & 243,76 \\
\hline Pelobates cultripes & 29TQF11 & 100,00 & 123,25 & 104,14 & 36,98 & 6128,57 & 287,91 & 8,57 & 279,33 & 55,96 & 204,75 & 205,19 & 48,69 & 659,94 & 84,82 & 9,63 & 45,38 & 249,59 & 56,55 & 56,89 & 238,38 \\
\hline Pelobates cultripes & 29TQF12 & 100,00 & 122,99 & 105,13 & 37,00 & 6111,62 & 287,74 & $\begin{array}{l}7,87 \\
7,87\end{array}$ & $\begin{array}{l}279,87 \\
\end{array}$ & 55,62 & 204,36 & 204,60 & 48,39 & 647,71 & $\begin{array}{l}4,064 \\
83,04 \\
\end{array}$ & 9,79 & 44,91 & 244,60 & 56,76 & 56,92 & 233,47 \\
\hline Pelobates cultripes & 29TQF14 & 99,00 & 120,89 & 106,77 & 37,49 & 6081,66 & 286,01 & 5,07 & 280,95 & 53,65 & 201,93 & 201,93 & 46,56 & 633,33 & 80,74 & 10,00 & 44,27 & 238,69 & 57,48 & 57,48 & 227,90 \\
\hline Pelobates cultripes & 29TQF15 & 101,00 & 120,75 & 107,73 & 37,95 & 6071,48 & 286,05 & 4,44 & 281,61 & 53,44 & 201,50 & 201,50 & 46,21 & 621,94 & 79,17 & 10,14 & 43,99 & 234,15 & 57,15 & 57,15 & 223,71 \\
\hline Pelobates cultripes & 29TQF16 & 100,00 & 119,86 & 108,46 & 38,00 & 6049,59 & 285,22 & 3,36 & 281,85 & 52,53 & 200,33 & 200,33 & 45,51 & 616,45 & 78,70 & 10,64 & 43,43 & 231,63 & 58,12 & 58,12 & 221,61 \\
\hline Pelobates cultripes & 29TQF17 & 99,00 & 126,84 & 110,00 & 38,23 & 6022,16 & 292,13 & 8,85 & 283,28 & 59,28 & 206,62 & 206,62 & 52,31 & 571,63 & 73,31 & \begin{tabular}{|l|}
9,92 \\
\end{tabular} & 43,27 & 214,56 & 53,54 & 53,54 & 205,38 \\
\hline Pelobates cultripes & 29TQF18 & 100,00 & 122,60 & 110,21 & 38,40 & 6005,49 & 287,87 & $\begin{array}{l}, 0,76 \\
4,76\end{array}$ & \begin{tabular}{|l|}
283,11 \\
\end{tabular} & 55,36 & $\begin{array}{l}202,28 \\
202\end{array}$ & \begin{tabular}{|l|}
202,28 \\
\end{tabular} & $\begin{array}{ll}48,48 \\
\end{array}$ & 585,02 & $\begin{array}{l}75,58 \\
7,5\end{array}$ & \begin{tabular}{|c|}
10,69 \\
10,
\end{tabular} & $\begin{array}{ll}43,04 \\
43,2\end{array}$ & 219,49 & $\begin{array}{l}56,23 \\
56,23\end{array}$ & $\begin{array}{l}56,23 \\
56,\end{array}$ & 210,90 \\
\hline Pelobates cultripes & 29TQF19 & 100,00 & 118,95 & 110,37 & 38,70 & 5982,06 & 284,32 & 1,44 & 282,88 & 52,01 & 198,36 & 198,36 & 45,22 & 596,50 & 77,51 & 11,53 & 42,49 & 223,55 & 59,05 & 59,05 & 215,39 \\
\hline Pelobates cultripes & 29TQF20 & 100,00 & 122,60 & 105,19 & 36,93 & 6179,35 & 289,29 & 7,16 & 282,13 & 54,98 & 204,59 & 205,36 & 47,62 & 629,76 & 80,45 & 9,78 & 44,21 & 235,08 & 55,74 & 56,30 & 221,92 \\
\hline Pelobates cultripes & 29TQF22 & 100,00 & 122,91 & 107,17 & 37,21 & 6155,81 & 289,87 & 6,40 & 283,47 & 54,95 & 205,13 & 205,15 & 47,82 & 599,66 & 76,48 & 9,97 & 43,38 & 223,26 & 55,36 & 55,37 & 209,93 \\
\hline Pelobates cultripes & 29TQF24 & 101,00 & 119,11 & 108,31 & 37,93 & 6126,72 & 286,04 & 2,39 & 283,64 & 51,25 & 200,62 & 200,65 & 44,23 & 592,82 & 75,47 & 10,10 & 42,64 & 220,00 & 56,88 & 56,90 & 206,55 \\
\hline Pelobates cultripes & 29TQF25 & 100,00 & 118,78 & 109,07 & 38,00 & $\begin{array}{ll}0120,126 \\
6103,65\end{array}$ & 280,04 & $\begin{array}{l}2,3,81 \\
1,81\end{array}$ & 280,04 & \begin{tabular}{|l|l|}
51,01 \\
5
\end{tabular} & \begin{tabular}{|l|}
200,04 \\
\end{tabular} & \begin{tabular}{|l|}
200,04 \\
\end{tabular} & $\begin{array}{l}44,250 \\
44,07\end{array}$ & | & 74,56 & $\begin{array}{l}10,0,54 \\
10,\end{array}$ & $\begin{array}{l}42,204 \\
42,24\end{array}$ & \begin{tabular}{|l|}
215,88 \\
210
\end{tabular} & $\begin{array}{l}0,000 \\
56,95\end{array}$ & 56,95 & 202,80 \\
\hline Pelobates cultripes & 29TQF26 & 100,00 & 119,46 & 109,95 & 38,00 & 6093,24 & 286,79 & 1,91 & 284,88 & 51,71 & 200,57 & 200,57 & 44,79 & 566,95 & 72,83 & 10,62 & 41,69 & 209,51 & 56,51 & 56,51 & 196,92 \\
\hline Pelobates cultripes & 29TQF27 & 101,00 & 120,53 & 110,64 & 38,04 & 6077,37 & 287,51 & 2,25 & 285,26 & 52,64 & 201,23 & 201,23 & 45,72 & 554,0 & 71,52 & 10,61 & 41.49 & 204.46 & 55,79 & 55,79 & 192,65 \\
\hline Pelobates cultripes & 29TQF28 & 100,00 & 120,82 & 111,21 & 38,30 & 6056,09 & 287,94 & 2,60 & 285,34 & 53,22 & 201,28 & 201,28 & 46,19 & 543,86 & 70,42 & 10,86 & 41,16 & 200,26 & 55,77 & 55,77 & 188,94 \\
\hline Pelobates cultripes & 29TQF29 & 100,00 & 120,33 & 111,61 & 38,7 & 6032,92 & 287,25 & 1,88 & 285,36 & 52,66 & 200,29 & 200,29 & 45,80 & 541,55 & 70,40 & 11,25 & 40,85 & 199,19 & 56,50 & 56,50 & 188,40 \\
\hline 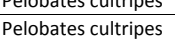 & 29TQF30 & 100,00 & $\begin{array}{l}12,53 \\
119,31\end{array}$ & $\begin{array}{l}111,01 \\
106,94\end{array}$ & 37,00 & $\begin{array}{l}003,292 \\
6208,17\end{array}$ & 2887,25 & $\begin{array}{l}, 00 \\
3,01 \\
\end{array}$ & $\begin{array}{l}284,90 \\
284 \\
\end{array}$ & $\begin{array}{l}32,00 \\
51,33\end{array}$ & \begin{tabular}{|l|}
201,75 \\
204
\end{tabular} & \begin{tabular}{|l|}
202,61 \\
201
\end{tabular} & $\begin{array}{l}43,00 \\
44,15 \\
\end{array}$ & \begin{tabular}{|c|}
341,33 \\
603,73
\end{tabular} & $\begin{array}{l}0,404 \\
76,57\end{array}$ & \begin{tabular}{|l|}
1,2506 \\
10,06
\end{tabular} & $\begin{array}{l}\mid 42,51 \\
42,51\end{array}$ & \begin{tabular}{|l|}
221,76 \\
22,
\end{tabular} & $\begin{array}{l}0,30 \\
56,64 \\
\end{array}$ & $\begin{array}{l}00,00 \\
57,28\end{array}$ & $\begin{array}{l}180,40 \\
206,68\end{array}$ \\
\hline Pelobates cultripes & 29TQF34 & 100,00 & 118,35 & 110,22 & 38,01 & 6155,54 & 287,30 & 0,83 & 286,47 & 50,35 & 200,59 & 200,59 & 43,27 & 549,21 & 70,31 & 10,36 & 41,10 & 200,35 & 56,01 & 56,01 & 184,51 \\
\hline Pelobates cultripes & 29TQF35 & 100,00 & 118,97 & 110,87 & 38,08 & 6142,17 & 287,85 & 0,92 & 286,92 & 50,75 & 200,85 & 200,85 & 43,79 & 533,91 & 68,62 & 10,49 & 40,59 & 194,06 & 55,55 & 55,55 & 178,62 \\
\hline Pelobates cultripes & 29TQF36 & 100,00 & 120,24 & 111,54 & 38,22 & 6129,71 & 289,00 & 1,76 & 287,24 & 52,16 & 201,72 & 201,72 & 45,03 & 517,40 & 66,80 & 10,2 & 40,33 & 187,67 & 54,43 & 54,43 & 172,97 \\
\hline Pelobates cultripes & 29TQF37 & 100,00 & 118,55 & 111,76 & 38,4 & 6114,85 & 287,34 & 0,26 & 287,08 & 51,81 & 199,80 & $\begin{array}{l}199,80 \\
\end{array}$ & 43,42 & 515,96 & $\begin{array}{l}66,70 \\
66,72\end{array}$ & 10, & \begin{tabular}{|l|l|}
39,88 \\
\end{tabular} & \begin{tabular}{|l|l|}
186,47 \\
\end{tabular} & 55,52 & 55,52 & 172,01 \\
\hline Pelobates cultripes & 29TQF38 & 100,00 & 117,16 & 112,03 & 38,93 & 6097,53 & 285,87 & $-0,68$ & 286,55 & 50,01 & 198,18 & 198,18 & 42,05 & 517,13 & 66,94 & 11,24 & 39,33 & 186,47 & 57,05 & 57,05 & 172,52 \\
\hline Pelobates cultripes & 29TQF39 & 101,00 & 117,53 & 112,34 & 38,95 & 6073,13 & 286,20 & $-0,80$ & 287,00 & 54,47 & 198,29 & 198,29 & 42,66 & 509,77 & 66,10 & 11,77 & 38,87 & 183,34 & 57,22 & 57,22 & 169,97 \\
\hline Pelobates cultripes & 29TQF40 & 100,00 & 116,70 & 108,66 & 37,23 & 6227,32 & 287,15 & $-0,06$ & 287,21 & 48,54 & 199,46 & 200,47 & 41,83 & 578,11 & 72,63 & 10,60 & 40,89 & 208,46 & 57,44 & 58,19 & 191,94 \\
\hline Pelobates cultripes & 29TQF41 & 100,00 & 120,12 & 110,06 & 37,78 & 6225,63 & 290,81 & 2,18 & 288,63 & 51,64 & 203,41 & 203,55 & 44,62 & 543,12 & 68,39 & 10,07 & 40,68 & 195,64 & 55,10 & 55,19 & 178,90 \\
\hline Pelobates cultripes & 29TQF42 & $\begin{array}{l}100,00 \\
100\end{array}$ & $\frac{121}{121}$ & 111,00 & 38 & $\begin{array}{l}02213,43 \\
6213,4\end{array}$ & 291,77 & $\begin{array}{l}2,10 \\
2,71\end{array}$ & \begin{tabular}{|l|}
289,000 \\
289
\end{tabular} & $\frac{\mid 1,04}{53,20}$ & \begin{tabular}{|l|}
204,21 \\
\end{tabular} & \begin{tabular}{|l|}
204,21 \\
\end{tabular} & $\begin{array}{l}44,0<2 \\
45,50\end{array}$ & $\begin{array}{l}\mid 522,19 \\
522,19\end{array}$ & $\begin{array}{l}0,03,12 \\
66,12\end{array}$ & $\mid 10,00$ & \begin{tabular}{|l|}
40,31 \\
40,31
\end{tabular} & \begin{tabular}{|l|}
187,54 \\
187
\end{tabular} & $\frac{5,10}{54,20}$ & 54,20 & 170,50 \\
\hline Pelobates cultripes & 29TQF44 & 99,00 & 118,41 & 112,01 & 38,09 & 6184,50 & 288,97 & 0,23 & 288,74 & 65,45 & 200,91 & 200,91 & 42,97 & 506,69 & 65,08 & 10,55 & 39,66 & 181,50 & 54,95 & 54,95 & 163,34 \\
\hline Pelobates cultripes & 29TQF45 & 99,00 & 120,27 & 112,72 & 38,18 & 6173,60 & 290,70 & 1.01 & 289,68 & 74,07 & 202,34 & 202,3 & 44.59 & $485,16 \mid$ & 62.58 & 10,14 & 39,43 & 173,62 & 53,39 & 53,39 & 155,40 \\
\hline Pelobates cultripes & 29TQF46 & 101,00 & 118,96 & 112,92 & 38,60 & 6153,76 & 289,35 & 0,24 & 289,11 & 76,52 & 200,76 & 200,76 & 43,42 & 481,04 & 62,11 & 10,63 & 38,93 & 171,84 & 54,16 & 54,16 & 153,67 \\
\hline Pelobates cultripes & 29TQF47 & 100,00 & 116,77 & 112,93 & $38, \varepsilon$ & 6141,71 & 287,25 & $-1,44$ & 288,68 & 76,17 & 198,53 & 198,53 & 41 & 481,72 & 62,16 & 11,00 & 38,46 & 171,64 & 55,31 & 55,31 & 15 \\
\hline Pelobates cultripes & 29TQF48 & 100,00 & 116,89 & 113,23 & 38,97 & 6130,25 & 286,98 & $-1,75$ & \begin{tabular}{|l|}
288,73 \\
\end{tabular} & 76,96 & 198,25 & 198,25 & 41,58 & 475,93 & $\begin{array}{l}61,37 \\
610\end{array}$ & $\begin{array}{ll}11,24 \\
11\end{array}$ & 37,99 & 169,20 & 55,66 & 55,66 & 151,72 \\
\hline Pelobates cultripes & 29TQF49 & 100,00 & 119,58 & 113,50 & 38,97 & 6115,42 & 289,29 & 0,01 & 289,29 & 80,05 & 200,47 & 200,48 & 43,96 & 459,76 & 59,24 & 11,05 & 37,64 & 163,38 & 54,36 & 54,37 & 146,34 \\
\hline Pelobate & 29TQF50 & 33,00 & 117,20 & 110,11 & 37.63 & 6238.59 & 288.82 & $-0,27$ & 289,09 & 48.91 & 20,27 & 201.05 & 42.04 & 550,61 & 68.77 & 10,71 & 39.96 & 195.88 & 56.96 & 57.45 & 178,63 \\
\hline Pelobates cultripes & 29TQF54 & 26,00 & 118,31 & 113,03 & 38,26 & 6183,91 & 289,74 & $-0,34$ & 290,09 & 78,5 & 200,80 & 200,80 & 42, & 483,09 & 62,06 & 10,69 & 39,00 & 172,43 & 54,46 & 54,46 & 151,34 \\
\hline Pelobates cultripes & 29TQF55 & 20,00 & 120,39 & 113,85 & 38,85 & 6201,03 & 291,73 & 0,48 & 291,24 & 80,33 & 202,91 & 202,91 & 44,55 & 462,15 & 59,55 & 10,12 & 38,76 & 165,27 & 52,79 & 52,79 & 143,82 \\
\hline
\end{tabular}




\begin{tabular}{|c|c|c|c|c|c|c|c|c|c|c|c|c|c|c|c|c|c|c|c|c|c|}
\hline TAXON & UTM & $\mathrm{km} 2$ & B101 & B102 & $\mathrm{BIO3}$ & B104 & B105 & B106 & B107 & B108 & B109 & BIO10 & BIO11 & BIO12 & 81013 & BIO14 & BIO15 & BIO16 & B1017 & BIO18 & B1019 \\
\hline Pelobates cultripes & 29TQF56 & 13,00 & 117,28 & 113,96 & 38,96 & 6187,16 & 288,52 & $-1,68$ & 290,20 & 77,16 & 199,72 & 199,72 & 41,68 & 466,84 & 60,20 & 11,00 & 38,12 & 166,48 & 54,76 & 54,76 & 145,08 \\
\hline Pelobates cultripes & 29TQG00 & 99,00 & 123,09 & 110,27 & 38,96 & 5918,68 & 286,88 & 5,41 & 281,47 & 56,58 & 201,70 & 201,70 & 49,72 & 619,22 & 80,70 & 11,43 & 44,19 & 235,64 & 58,29 & 58,29 & 230,85 \\
\hline Pelobates cultripes & 29TQG03 & 100,00 & 114,88 & 110,19 & 38,98 & 5844,04 & 278,26 & $-1,66$ & 279,92 & 49,20 & 192,60 & 192,60 & 42,71 & 654,32 & 86,67 & 14,58 & 42,81 & 247,97 & 66,98 & 66,98 & 243,35 \\
\hline Pelobates cultripes & 29TQG10 & 101,00 & 116,77 & 110,67 & 39,00 & 5974,82 & 282,16 & $-0,12$ & 282,28 & 50,13 & 196,21 & 196,21 & 43,23 & 602,56 & 78,66 & 12,23 & 42,09 & 225,51 & 61,11 & 61,11 & 217,74 \\
\hline Pelobates cultripes & 29TQG13 & 101,00 & 111,71 & 110,86 & 39,00 & 5909,07 & 276,33 & $-5,18$ & 281,51 & 45,45 & 190,29 & 190,29 & 38,81 & 625,53 & 82,37 & 15,30 & 40,67 & \begin{tabular}{|l|l|}
232,93 \\
\end{tabular} & 68,39 & 68,39 & 224,64 \\
\hline Pelobates cultripes & 29TQG20 & 100,00 & 116,37 & 111,62 & 38,94 & 6018,44 & 283,37 & $-1,28$ & 284,65 & 49,07 & 196,27 & 196,27 & 42,19 & 557,49 & 72,66 & 12,32 & 40,29 & 204,73 & 59,88 & 59,88 & 194,08 \\
\hline Pelobates cultripes & 29TQG22 & 100,00 & 112,56 & 111,70 & 38,98 & 5985,53 & 279,23 & $-5,25$ & 284,47 & 45,37 & 192,16 & 192,16 & 38,74 & 576,92 & 75,50 & 14,41 & 39,31 & 211,27 & 65,18 & 65,18 & 200,58 \\
\hline Pelobates cultripes & 29TQG23 & 100,00 & 110,98 & 111,77 & 38,99 & 5962,96 & 277,49 & $-6,65$ & 284,14 & 44,06 & 190,24 & 190,24 & 37,44 & 586,56 & 76,79 & \begin{tabular}{l|l|}
15,58 \\
\end{tabular} & 38,85 & 214,35 & 68,07 & 68,07 & 203,04 \\
\hline Pelobates cultripes & 29TQG28 & 99,00 & 90,53 & 108,82 & 38,88 & 5790,17 & 253,27 & $-23,63$ & 276,91 & 40,68 & 167,92 & 167,93 & 20,00 & 757,65 & 96,61 & 26,40 & 34,76 & 270,71 & 103,29 & 103,30 & 250,27 \\
\hline Pelobates cultripes & 29TQG30 & 99,00 & 118,24 & 112,71 & 38,98 & $\begin{array}{ll}6054,24 \\
\end{array}$ & 286,54 & $-0,55$ & 287,09 & 58,13 & 198,47 & 198,47 & 43,35 & 504,83 & 65,56 & 12,00 & 38,70 & 181,38 & 57,28 & 57,28 & 168,57 \\
\hline Pelobates cultripes & 29TQG31 & 99,00 & 114,43 & 112,67 & 39,00 & 6039,45 & 282,86 & $-4,10$ & 286,95 & 56,56 & 194,63 & 194,63 & 39,85 & 523,31 & 68,00 & 13,26 & 38,07 & 187,86 & 61,19 & 61,19 & 174,80 \\
\hline Pelobates cultripes & 29TQG32 & 101,00 & 115,15 & 112,95 & 39,00 & 6022,04 & 283,26 & $-3,62$ & 286,87 & 62,35 & 194,93 & 194,93 & 40,52 & 521,67 & 67,79 & 13,77 & 37,72 & \begin{tabular}{|l|l|}
187,15 \\
\end{tabular} & 62,19 & 62,19 & 173,83 \\
\hline Pelobates cultripes & 29TQG36 & 100,00 & 111,99 & 112,95 & 39,00 & 5944,72 & 278,49 & $-7,13$ & 285,62 & 73,74 & 190,64 & 190,64 & 38,05 & 562,72 & 72,66 & 17,69 & 36,04 & 203,73 & 73,84 & 73,84 & 183,80 \\
\hline Pelobates cultripes & 29TQG40 & 100,00 & 116,85 & 113,49 & \begin{tabular}{|l|l|}
38,97 \\
\end{tabular} & 6098,32 & 286,63 & $-2,42$ & 289,05 & 77,78 & 197,83 & 197,83 & 41,59 & 470,69 & 60,57 & 11,96 & 37,01 & 167,12 & 57,16 & 57,16 & 149,90 \\
\hline Pelobates cultripes & 29TQG42 & 95,00 & 113,63 & 113,73 & 38,99 & 6059,14 & 283,16 & $-5,64$ & 288,81 & 74,73 & 193,97 & 193,97 & 38,60 & 494,93 & 63,68 & 13,81 & 36,05 & $\begin{array}{l}176,35 \\
\end{array}$ & 62,64 & 62,64 & 158,34 \\
\hline Pelobates cultripes & 29TQG43 & 91,00 & 109,68 & 113,67 & 39,00 & 6041,99 & 279,31 & $-9,32$ & 288,63 & 71,14 & 189,93 & 189,93 & 34,99 & 522,63 & 67,10 & 15,60 & 35,67 & 186,39 & 68,06 & 68,06 & 167,33 \\
\hline Pelobates cultripes & 29TQG45 & 86,00 & 116,09 & 114,02 & 39,00 & 5989,02 & 284,02 & $-4,08$ & 288,09 & 78,02 & 195,22 & 195,22 & 41,51 & 506,24 & 64,85 & 15,65 & 35,28 & 182,75 & 67,67 & 67,67 & 160,55 \\
\hline Pelobates cultripes & 29TQG46 & 80,00 & 114,57 & 113,95 & 39,00 & 5963,28 & 282,04 & $-5,28$ & 287,32 & 76,54 & 193,27 & 193,27 & 40,03 & 523,95 & 66,95 & 17,08 & 34,98 & 189,85 & 71,64 & 71,64 & 165,34 \\
\hline Pelobates cultripes & 29TQH41 & 66,00 & 105,06 & 111,97 & 39,83 & 5716,76 & 267,24 & $-11,73$ & 278,96 & 69,57 & 180,51 & 180,51 & 33,90 & 643,94 & 84,24 & 26,08 & 32,41 & 233,54 & 99,70 & 99,70 & 193,78 \\
\hline Pelobates cultripes & 30STE59 & & & & & & & & & & & & & & & & & & & & \\
\hline Pelobates cultripes & 30STE68 & & & & & & & & & & & & & & & & & & & & \\
\hline Pelobates cultripes & 30STE69 & 90,00 & 166,92 & 83,47 & 39,98 & 4208,93 & 277,68 & 71,14 & 206,55 & 123,23 & 220,05 & 223,59 & 115,12 & 848,89 & 146,18 & 0,58 & 76,41 & \begin{tabular}{|l|}
404,67 \\
\end{tabular} & 13,56 & 22,34 & 401,74 \\
\hline Pelobates cultripes & 30STE79 & 80,00 & 165,85 & 86,17 & 40,60 & 4236,28 & 280,03 & 69,61 & 210,41 & 121,75 & 219,52 & 223,38 & 114,45 & 815,53 & 141,61 & 0,99 & 76,60 & \begin{tabular}{|l|l|}
396,23 \\
\end{tabular} & 13,03 & 22,71 & 390,32 \\
\hline Pelobates cultripes & 30STF30 & 17,00 & 172,45 & 75,41 & 38,41 & 4164,14 & 274,41 & 81,00 & 193,41 & 129,27 & 224,23 & 228,09 & 120,68 & 769,41 & 134,77 & 0,41 & 72,95 & 352,82 & 14,77 & 22,41 & 340,09 \\
\hline Pelobates cultripes & 30STF31 & 98,00 & 172,86 & 74,49 & 37,92 & 4225,17 & 274,71 & 80,89 & 193,82 & 129,00 & 225,26 & 229,20 & 120,17 & 756,80 & 131,74 & 0,44 & 72,26 & 344,73 & 14,59 & 22,62 & 331,52 \\
\hline Pelobates cultripes & 30STF32 & 90,00 & 172,06 & 73,73 & 36,93 & 4378,73 & 275,79 & 78,71 & \begin{tabular}{|l|l|}
197,08 \\
\end{tabular} & 126,41 & 226,50 & 230,49 & 117,51 & 741,70 & 127, & 1,00 & 71,14 & 333,93 & 15,08 & 23,50 & 320,08 \\
\hline Pelobates cultripes & 30STF33 & 90,00 & 171,30 & 73,63 & 35,99 & 4544,89 & 278,05 & 76,28 & 201,77 & \begin{tabular}{|l|l|}
123,77 \\
\end{tabular} & 228,06 & 232,17 & $\mid$ & 724,33 & $\mid 122,30$ & $\begin{array}{l}1,00 \\
1,00\end{array}$ & 70,20 & 322,57 & 15,14 & 23,99 & 307,85 \\
\hline Pelobates cultripes & 30STF34 & 90,00 & 171,41 & 73,47 & \begin{tabular}{|l|l|}
35,17 \\
\end{tabular} & 4698,44 & 280,66 & 74,99 & 205,66 & 122,05 & 230,19 & 234,29 & 113,12 & 700,70 & 115,90 & 1,00 & 69,12 & 308,26 & 15,67 & 24,01 & 292,74 \\
\hline Pelobates cultripes & 30STF35 & 81,00 & 172,92 & 73,12 & 34,53 & 4830,34 & 284,27 & 75,48 & 208,79 & 121,93 & 233,49 & 237,52 & 113,13 & 668,82 & 108,03 & 1,00 & 68,07 & 290,48 & 15,98 & 23,88 & 274,22 \\
\hline Pelobates cultripes & 30STF36 & 80,00 & 171,69 & 75,24 & 34,32 & 5009,00 & 288,16 & 71,81 & 216,35 & 118,67 & 234,80 & 238,68 & 109,86 & 657,79 & 103,48 & 1,00 & 67,23 & 283,17 & 16,55 & 23,91 & 266,49 \\
\hline Pelobates cultripes & 30STF40 & 79,00 & 170,05 & 77,24 & 38,86 & 4149,76 & 273,55 & 77,47 & 196,08 & 127,19 & 221,86 & 225,45 & 118,45 & 822,55 & 142,23 & 0,24 & 73,99 & 380,45 & 15,04 & 22,30 & 370,92 \\
\hline Pelobates cultripes & 30STF42 & 100,00 & 172,28 & 74,59 & 37,45 & 4314,16 & 275,88 & 79,09 & 196,79 & 127,13 & 226,17 & 229,93 & 118,57 & 768,15 & 131,09 & 0,67 & 71,80 & 349,92 & 15,67 & 22,89 & 335,87 \\
\hline Pelobates cultripes & 30STF43 & 100,00 & 171,37 & 75,07 & 36,61 & 4494,42 & 278,71 & 76,42 & 202,28 & 124,26 & 227,63 & 231,55 & 115,70 & 748,11 & 125,94 & 1,00 & 70,66 & \begin{tabular}{|l|l|}
337,59 \\
\end{tabular} & 15,96 & 23,63 & 322,29 \\
\hline Pelobates cultripes & 30STF44 & 100,00 & 170,27 & 76,41 & 36,06 & 4680,85 & 282,25 & 73,23 & 209,02 & 121,12 & 229,12 & 233,04 & 112,49 & 729,53 & 120,67 & 1,00 & 69,77 & 326,03 & 16,01 & 24,01 & 309,93 \\
\hline Pelobates cultripes & 30STF45 & 100,00 & 169,68 & 78,14 & 35,66 & 4861,25 & 286,50 & 70,68 & 215,82 & 118,62 & 231,10 & 234,95 & 109,92 & 708,52 & 114,95 & 1,00 & 68,80 & 313,47 & 16,20 & 24,13 & 296,85 \\
\hline Pelobates cultripes & 30STF46 & 100,00 & 172,40 & 79,32 & 35,49 & 4987,73 & 292,23 & 71,79 & 220,45 & 119,53 & 235,35 & 239,11 & 110,95 & 673,38 & 107,45 & 1,00 & 67,82 & 295,25 & 16,53 & 23,51 & 277,60 \\
\hline Pelobates cultripes & \begin{tabular}{|l} 
30STF47 \\
\end{tabular} & 100,00 & 171,66 & 83,90 & 35,81 & 5167,62 & 298,66 & $\begin{array}{ll}1,1,02 \\
68,02\end{array}$ & \begin{tabular}{|l|}
230,64 \\
230
\end{tabular} & \begin{tabular}{|l|}
116,63 \\
11,3
\end{tabular} & \begin{tabular}{|l|}
237,20 \\
23,0
\end{tabular} & \begin{tabular}{|l|}
240,68 \\
24,1
\end{tabular} & \begin{tabular}{|l|l|}
108,14 \\
10,03
\end{tabular} & \begin{tabular}{|c|}
662,66 \\
62,06
\end{tabular} & \begin{tabular}{|l|}
103,91 \\
103
\end{tabular} & $\begin{array}{l}1,000 \\
1,00\end{array}$ & $\begin{array}{ll}6,02,96 \\
6,\end{array}$ & 288,72 & $\mid \begin{array}{l}\mid 0,030 \\
17,01\end{array}$ & 23,58 & 271,04 \\
\hline Pelobates cultripes & 30STF48 & 100,00 & 171,85 & 89,53 & 36,60 & 5327,55 & 306,51 & 64,98 & 241,53 & 114,99 & 239,74 & 242,99 & 106,50 & 650,58 & 100,83 & 1,00 & 66,49 & 282,57 & 17,13 & 23,46 & 264,93 \\
\hline Pelobates cultripes & 30STF50 & 100,00 & 168,95 & 78,27 & 39,21 & 4103,92 & 272,40 & 75,62 & 196,79 & 126,26 & 220,38 & 223,74 & 117,77 & 855,68 & 146,48 & 0,21 & 74,96 & 398,75 & 15,01 & 22,30 & 392,21 \\
\hline Pelobates cultripes & 30STF51 & 100,00 & 167,76 & 78,74 & 38,64 & 4257,40 & 274,60 & 73,17 & 201,43 & 123,72 & 221,33 & 224,81 & 114,96 & 835,94 & 142,2 & 0,5 & 73,81 & 388,02 & 15,32 & 23,08 & 378,19 \\
\hline Pelobates cultripes & $\begin{array}{l}\text { 30STF52 } \\
\end{array}$ & 100,00 & 169,60 & 77,73 & 38,01 & 4336,43 & 276,87 & 74,98 & 201,89 & 124,45 & 224,16 & 227 & 116,00 & 802,55 & 136 & 0,8 & 72,62 & 371,01 & 15,89 & 23,25 & 357,32 \\
\hline Pelobates cultripes & 30STF53 & 100,00 & 171,09 & 77,64 & 37,41 & 4455,91 & 280,34 & 75,76 & $\begin{array}{ll}204,58 \\
\end{array}$ & 124,36 & 227,16 & 230,82 & 116,13 & 768,19 & 129 & 1,00 & 71,54 & 353,12 & 16,00 & 23,21 & 336,74 \\
\hline Pelobates cultripes & $\begin{array}{l}\text { 30STF54 } \\
\end{array}$ & 100,00 & 167,50 & 81,14 & 37,10 & 4709,99 & 284,60 & 68,95 & 215,66 & 118,41 & 227,11 & 230,79 & 109,68 & 760,61 & 125,99 & 1,00 & 70,60 & 346,04 & 16,13 & 24,07 & 329,51 \\
\hline Pelobates cultripes & 30STF55 & 100,00 & 165,22 & 84,72 & $\begin{array}{l}37,05 \\
\end{array}$ & 4918,91 & 289,35 & 63,82 & 225,53 & 113,95 & 227,76 & 231,43 & 105,18 & 749,39 & 121,80 & 1,00 & 69,44 & 337,26 & 17,08 & 24,59 & 320,86 \\
\hline Pelobates cultripes & 30STF56 & 100,00 & 169,24 & 85,20 & 36,8 & 5007,16 & 295,1 & 67,15 & 227,99 & 116,47 & 232,86 & 236 & 108,03 & 708,52 & 114,43 & 1,00 & 68,59 & 82 & 16,82 & 23,70 & 298,76 \\
\hline Pelobates cultripes & 30STF57 & 100,00 & 169,81 & $\begin{array}{l}89,20 \\
89,57\end{array}$ & 37,2 & 5177,85 & 302,2 & $\begin{array}{ll}64,88 \\
\end{array}$ & 237,41 & 114,88 & 235,72 & 239,06 & $\begin{array}{l}106,60 \\
\end{array}$ & 688,84 & 109 & 1,00 & 67,71 & 305,73 & $\begin{array}{l}17,10< \\
17,10\end{array}$ & 23,52 & 287,59 \\
\hline Pelobates cultripes & 30STF60 & 100,00 & 163,12 & 85,08 & 39,39 & 4376,18 & 278,43 & 65,18 & 213,25 & 118,40 & 218,60 & 222,23 & 109,53 & 853,79 & \begin{tabular}{|l|l|}
144,88 \\
\end{tabular} & 0,93 & 75,37 & 403,55 & 14,45 & 23,76 & 398,62 \\
\hline Pelobates cultripes & 30STF61 & 100,00 & 164,61 & 83,27 & 39,14 & 4365,90 & 278,12 & 67,86 & 210,26 & 120,64 & 219,93 & 223,56 & 111,16 & 840,99 & $\begin{array}{l}143,07 \\
\end{array}$ & 1,00 & 74,27 & 396,99 & 15,20 & 23,82 & 386,95 \\
\hline Pelobates cultripes & 30STF62 & 100,00 & 165,14 & 82,93 & 38,78 & 4449,51 & 279,79 & 68,02 & 211,77 & 119,86 & 221,57 & 225,24 & 110,77 & 820,39 & 138,76 & 1,00 & 73,24 & 384,86 & 15,59 & 23,91 & 371,59 \\
\hline Pelobates cultripes & 30STF63 & 100,00 & 164,08 & 84,68 & 38,34 & 4621,54 & 283,21 & 65,09 & 218,12 & 116,82 & 222,88 & 226,50 & 107,74 & 800,63 & 133,64 & 1,01 & 71,88 & 371,84 & 16,41 & 24,50 & 356,97 \\
\hline Pelobates cultripes & 30STF65 & 100,00 & 165 & $\begin{array}{l}84,000 \\
87,84\end{array}$ & $\begin{array}{l}30, \\
37,\end{array}$ & $\begin{array}{l}402,1,44 \\
4897,96\end{array}$ & 290,21 & $\begin{array}{l}3,030 \\
63,35 \\
\end{array}$ & \begin{tabular}{|l|}
228,62 \\
22,12
\end{tabular} & $\begin{array}{l}114,42 \\
114, \\
\end{array}$ & \begin{tabular}{|l|}
227,81 \\
221
\end{tabular} & \begin{tabular}{|l|}
231,30 \\
\end{tabular} & $\begin{array}{l}105,79 \\
105\end{array}$ & \begin{tabular}{|l|l|}
754,59 \\
\end{tabular} & \begin{tabular}{|l|}
$123,63,63$ \\
\end{tabular} & $\begin{array}{l}1,101 \\
1,03\end{array}$ & $\begin{array}{l}1,100 \\
69,99\end{array}$ & \begin{tabular}{|c|}
71,04 \\
344,99
\end{tabular} & \begin{tabular}{l|}
10,41 \\
16,89
\end{tabular} & 24,36 & $\begin{array}{l}327,48 \\
328\end{array}$ \\
\hline Pelobates cultripes & 30STF67 & 100,00 & 168,90 & 93,03 & 38,08 & 5159,38 & 304,42 & 63,52 & 240,91 & 114,46 & 234,91 & 238,07 & 106,27 & 702,95 & 113,37 & 1,00 & 68,34 & 316,61 & 17,09 & 23,46 & 297,82 \\
\hline Pelobates cultripes & 30STF70 & 100,00 & 170,76 & 82,27 & 40,56 & 4070,03 & 278,45 & 77,89 & 200,50 & $\mid 129,87$ & 222,10 & 225,97 & 121,34 & 806,82 & $|143,07|$ & 1,00 & 76,03 & 396,34 & $\mid 13,86$ & 22.01 & 381,87 \\
\hline Pelobates cultripes & 30STF71 & 100,00 & 168,40 & 83,23 & 40,00 & 4224,27 & 279,62 & 73,68 & 205,94 & 126,16 & 221,77 & 225,72 & 117,17 & 808,52 & 141,14 & 1,00 & 75,01 & 393,01 & 14,41 & 22,69 & 376,83 \\
\hline Pelobates cultripes & 30STF80 & 43,00 & 175,91 & 82,28 & 41,56 & 3927,69 & 281,94 & 86,09 & 195 & 137,66 & 225,39 & 229 & 129,36 & 749,14 & 138,61 & 1,00 & 76,92 & 382,69 & 13,02 & 20,77 & 358 \\
\hline Pelobates cultripes & \begin{tabular}{|l|} 
30STF81 \\
\end{tabular} & \begin{tabular}{|l|}
400,00 \\
100
\end{tabular} & 173,15 & $\begin{array}{l}2,200 \\
83,09\end{array}$ & $\begin{array}{l}41,00 \\
40,87\end{array}$ & $\begin{array}{l}352,103 \\
4074,54\end{array}$ & 282,17 & \begin{tabular}{l|l|}
80,160 \\
816
\end{tabular} & \begin{tabular}{|l|}
201,01 \\
204
\end{tabular} & \begin{tabular}{|l|}
133,03 \\
13,03
\end{tabular} & \begin{tabular}{|l|}
224,64 \\
22,6
\end{tabular} & \begin{tabular}{|l|}
228,83 \\
220
\end{tabular} & \begin{tabular}{|l|l|}
124,45 \\
120
\end{tabular} & \begin{tabular}{|l|}
$760,43,43$ \\
\end{tabular} & $\begin{array}{l}30,01 \\
137,52\end{array}$ & $\begin{array}{l}, 1,00 \\
1,0\end{array}$ & 75,86 & $\begin{array}{l}30,09 \\
382,20\end{array}$ & $\begin{array}{l}13,0<2 \\
13,55 \\
\end{array}$ & 21,39 & $\begin{array}{l}350,01 \\
358,96 \\
\end{array}$ \\
\hline Pelobates cultripes & 30STF82 & 100,00 & 173,59 & 83,40 & 40,32 & 4196,64 & 284,72 & 80,30 & 204,42 & $\begin{array}{l}131,67 \\
\end{array}$ & 226,76 & 230,81 & 123,30 & 749,50 & 133,75 & 1,00 & 74,76 & 371,99 & 14,12 & 21,54 & 348,06 \\
\hline Pelobates cultripes & 30STF90 & & & & & & & & & & & & & & & & & & & & \\
\hline Pelobates cultripes & 30STF91 & 39,00 & 17 & 33 & 41,17 & 17,94 & 4,50 & 85,06 & 4 & 06 & 22 & 231,21 & 128,54 & 719,27 & 131,94 & 1,00 & 76,06 & 92 & 13,00 & 20,62 & 341,06 \\
\hline Pelobates cultripes & 30STG40 & 100,00 & 178,80 & 101,57 & 38,31 & 5567,91 & 327,09 & 65,27 & 261,82 & 118,66 & 250,12 & 252,82 & 110,41 & 603,77 & 92,50 & 1,00 & 65,52 & 261,87 & 17,00 & 22,04 & 244 \\
\hline
\end{tabular}




\begin{tabular}{|c|c|c|c|c|c|c|c|c|c|c|c|c|c|c|c|c|c|c|c|c|c|}
\hline TAXON & UTM & $\mathrm{km} 2$ & B101 & B102 & $\mathrm{BIO3}$ & B104 & B105 & B106 & B107 & B108 & B109 & B1010 & BIO11 & BIO12 & B1013 & BIO14 & BIO15 & B1016 & B1017 & BIO18 & B1019 \\
\hline Pelobates cultripes & 30STG41 & 100,00 & 180,59 & 108,40 & 39,07 & 5727,80 & 336,93 & 62,84 & 274,09 & 118,44 & 254,23 & 256,61 & 110,24 & 594,63 & 90,80 & 1,00 & 64,95 & 257,31 & 17,29 & 22,00 & 240,40 \\
\hline Pelobates cultripes & 30STG48 & 100,00 & 174,66 & 123,03 & 39,00 & 6355,98 & 356,75 & 44,67 & 312,08 & 105,38 & 258,06 & 258,77 & 96,49 & 588,01 & 82,80 & 2,04 & 60,20 & 240,29 & 21,39 & 25,70 & 228,30 \\
\hline Pelobates cultripes & 30STG52 & 100,00 & 179,52 & 116,21 & 40,00 & 5879,30 & 345,52 & 58,86 & 286,67 & 115,59 & 255,52 & 257,48 & 107,74 & 601,59 & 91,87 & 1,00 & 64,81 & 260,75 & 17,60 & 21,60 & 244,58 \\
\hline Pelobates cultripes & 30STG59 & 100,00 & 162,75 & 123,58 & 38,49 & 6489,78 & 349,12 & 32,60 & 316,52 & 92,60 & 248,53 & 249,06 & 83,68 & 639,22 & 88,46 & 2,57 & 58,97 & 255,99 & 24,94 & 29,09 & 245,75 \\
\hline Pelobates cultripes & 30STG64 & 100,00 & 178,90 & 121,65 & 40,04 & \begin{tabular}{|l|l|}
6099,63 \\
\end{tabular} & 352,74 & 53,57 & 299,16 & 112,38 & 258,36 & 259,70 & 104,21 & 603,89 & 90,72 & 1,00 & 63,89 & 257,81 & 18,23 & 22,30 & 243,60 \\
\hline Pelobates cultripes & 30STG73 & 100,00 & 178,72 & 118,97 & 40,22 & 5955,20 & 348,24 & 57,16 & 291,08 & 114,01 & 256,09 & 257,47 & 106,22 & 607,86 & 94,16 & 1,00 & 65,12 & 263,69 & 16,46 & 21,33 & 248,35 \\
\hline Pelobates cultripes & 30STG79 & 100,00 & 158,45 & 124,13 & 38,25 & 6569,95 & 347,11 & 27,77 & 319,34 & 87,62 & 245,74 & 245,83 & 78,66 & 668,05 & 92,56 & 2,95 & 58,80 & 264,92 & 25,84 & 27,06 & 256,60 \\
\hline Pelobates cultripes & 30STG88 & 100,00 & 171,70 & 124,24 & 38,91 & 6496,07 & 357,21 & 40,91 & 316,29 & \begin{tabular}{|l|}
101,11 \\
\end{tabular} & 257,59 & 257,70 & 92,28 & 624,53 & 89,52 & 2,00 & 60,71 & 252,07 & 20,61 & 22,20 & 243,36 \\
\hline Pelobates cultripes & 30STG93 & 100,00 & 177,00 & 116,03 & 39,99 & 5944,39 & 343,43 & 55,99 & 287,44 & \begin{tabular}{|l|}
112,67 \\
\end{tabular} & 254,63 & 255,78 & 104,59 & 626,95 & 97,35 & 1,00 & 64,88 & 271,58 & 17,00 & 22,10 & 257,21 \\
\hline Pelobates cultripes & 30STH40 & 100,00 & 160,71 & 122,37 & 38,23 & 6479,99 & 346,34 & 31,07 & 315,27 & 90,63 & 246,38 & 246,83 & 81,72 & 633,15 & 86,42 & 2,97 & 58,00 & 251,74 & 26,43 & 30,23 & 241,17 \\
\hline Pelobates cultripes & 30STH41 & 100,00 & 160,59 & 122,44 & \begin{tabular}{|l|l|}
38,03 \\
\end{tabular} & 6501,08 & 346,94 & 30,69 & 316,24 & 90,13 & 246,60 & 246,97 & 81,27 & 623,32 & 84,59 & 3,05 & 57,23 & 245,85 & 26,93 & 30,72 & 235,46 \\
\hline Pelobates cultripes & 30STH42 & 100,00 & 151,34 & 121,54 & 37,99 & 6546,37 & 339,06 & 22,35 & 316,71 & 81,06 & 238,43 & 238,74 & 72,14 & 658,05 & 87,87 & 3,93 & 55,88 & 256,05 & 31,06 & 34,19 & 246,37 \\
\hline Pelobates cultripes & 30STH43 & 100,00 & 152,44 & 121,60 & 38,00 & 6564,90 & 340,64 & 23,11 & 317,53 & 81,97 & 239,73 & 240,03 & 72,92 & 641,43 & 85,26 & 4,01 & 55,44 & 247,99 & 30,97 & 34,01 & 238,21 \\
\hline Pelobates cultripes & 30STH46 & 100,00 & 155,29 & 120,92 & 37,69 & 6598,03 & 343,72 & 26,13 & 317,59 & 83,97 & 243,16 & 243,18 & 75,32 & 593,16 & 77,76 & 3,99 & 53,64 & 225,08 & 30,95 & 31,10 & 214,95 \\
\hline Pelobates cultripes & 30STH47 & 100,00 & 155,30 & 120,33 & 37,30 & 6604,54 & 343,48 & 26,08 & 317,40 & 83,89 & 243,26 & 243,27 & 75,19 & 581,81 & 75,87 & 4,00 & 53,02 & 219,34 & 31,45 & 31,55 & 209,07 \\
\hline Pelobates cultripes & 30STH50 & 100,00 & 154,55 & 122,76 & 38,00 & 6541,03 & 342,21 & 24,70 & 317,51 & 84,12 & 241,26 & 241,71 & 75,17 & 667,25 & 90,76 & 3,32 & 57,67 & 263,34 & 28,34 & 32,51 & 253,95 \\
\hline Pelobates cultripes & 30STH51 & 100,00 & 153,72 & 122,75 & 38,00 & 6576,28 & 342,43 & 23,63 & 318,80 & 82,89 & 241,05 & 241,33 & 74,09 & 661,33 & 89,25 & 3,54 & 56,83 & 258,68 & 29,39 & 32,99 & 249,47 \\
\hline Pelobates cultripes & 30STH52 & 100,00 & 154,26 & 122,84 & 38,00 & 6601,11 & 343,57 & 24,05 & 319,52 & 83,09 & 242,07 & 242,18 & 74,22 & 646,74 & 86,74 & 3,61 & 56,34 & 251,10 & 29,43 & 31,63 & 241,95 \\
\hline Pelobates cultripes & 30STH53 & 100,00 & 154,90 & 122,75 & 38,00 & 6617,85 & 344,73 & 24,51 & 320,22 & 83,45 & 243,01 & 243,06 & 74,60 & 631,86 & 84,23 & 3,78 & 55,64 & 243,45 & 29,58 & 30,37 & 234,31 \\
\hline Pelobates cultripes & 30STH61 & 100,00 & 152,05 & 123,47 & 38,00 & 6622.53 & 342,36 & 21,54 & 320,82 & 80,86 & 240,30 & 240,46 & 72.04 & 670,25 & 90,40 & 3,68 & 56,78 & 260,80 & 29,55 & 31.25 & 252,50 \\
\hline Pelobates cultripes & 30STH62 & 100,00 & 157,57 & 123,87 & 38,00 & 6630,11 & 347,98 & 26,14 & 321,84 & 85,75 & 245,83 & 245,90 & 76,93 & 634,27 & 85, & 3,25 & 56,54 & 245,70 & 27,79 & 28,80 & 237,15 \\
\hline Pelobates cultripes & 30STH63 & 100,00 & 157,68 & 123,72 & 38,00 & 6652,56 & 348,56 & 26,31 & 322,26 & 85,60 & 246,30 & 246,33 & 76,89 & 621,23 & 83,23 & 3,33 & 56,03 & 238,75 & 28,07 & 28,60 & 230,16 \\
\hline Pelobates cultripes & 30STH66 & 100,00 & 152,23 & 122,15 & 37,22 & 6697,95 & 343,97 & 21,39 & 322,58 & 79,81 & 241,83 & 241,83 & 71,41 & 607,75 & 80,32 & 4,09 & 53,43 & 227,41 & 31,95 & 31,95 & 218,64 \\
\hline Pelobates cultripes & \begin{tabular}{|l|}
30 STH67 \\
\end{tabular} & 100,00 & 153,41 & 121,93 & 37,29 & 6697,93 & 344,63 & 22,75 & 321,87 & 80,85 & 242,91 & 242,91 & 72,37 & 589,51 & 77,81 & 4,05 & 52,76 & 219,29 & 31,78 & 31,78 & 210,29 \\
\hline Pelobates cultripes & 30STH68 & 100,00 & 158,55 & 121,57 & 37,19 & 6686,85 & 349,00 & 27,63 & 321,37 & 85,77 & 247,87 & 247,87 & 77,34 & 551,79 & 72,81 & 3,78 & 52,64 & 204,48 & 29,63 & 29,63 & 195,11 \\
\hline Pelobates cultripes & 30STH69 & 100,00 & 160,45 & 120,86 & 37,00 & 6684,73 & 350,04 & 29,56 & 320,48 & 87,46 & 249,60 & 249,60 & 79,00 & 529,86 & 69, & 3,37 & 52,25 & 195,47 & 28,90 & 28,90 & 185,73 \\
\hline Pelobates cultripes & 30STH72 & 100,00 & 161,12 & 124,65 & 38,00 & 6671,75 & 352,56 & 28,79 & 323,77 & 88,78 & 249,95 & 249,95 & 79,81 & 621,28 & 84,23 & 3,12 & 57,01 & 239,88 & 26,17 & 26,17 & 232,06 \\
\hline Pelobates cultripes & 30STH75 & 100,00 & 155,29 & 123,65 & 37,63 & 6738,76 & 348,04 & 23,29 & 324,75 & 82,23 & 245,27 & 245,27 & 73,59 & 606,42 & 81,36 & 4,00 & 54,31 & 227,60 & 29,78 & 29,78 & 219,78 \\
\hline Pelobates cultripes & 30STH76 & 100,00 & 152,99 & 122,95 & 37,08 & 6744,62 & 346,10 & 21,23 & 324,86 & 80,04 & 243,23 & 243,23 & 71,27 & 602,77 & 80,62 & 4,09 & 53,45 & 224,19 & 31,37 & 31,37 & 216,19 \\
\hline Pelobates cultripes & 30STH77 & 100,00 & 153,77 & 122,52 & 37,05 & 6741,82 & 346,30 & 22,12 & 324,18 & 80,67 & 243,93 & 243,93 & 72,03 & 585,37 & 78,13 & 4,07 & 52,76 & 216,22 & 31,41 & 31,41 & 207,88 \\
\hline Pelobates cultripes & 30STH78 & 100,00 & 158,94 & 122,04 & \begin{tabular}{|l|l|}
37,07 \\
\end{tabular} & 6726,54 & 350,29 & 27,17 & 323,12 & 85,86 & 248,81 & 248,81 & 77,15 & 548,75 & 73,09 & 3,63 & 52,59 & 201,97 & 29,17 & 29,17 & 193,23 \\
\hline Pelobates cultripes & 30STH79 & 100,00 & 161,64 & 121,60 & 37,05 & 6709,72 & 352,14 & 29,99 & \begin{tabular}{|l|l|}
322,15 \\
\end{tabular} & $\begin{array}{l}3,006 \\
88,46\end{array}$ & \begin{tabular}{|l|}
251,24 \\
\end{tabular} & \begin{tabular}{|l|}
251,24 \\
250
\end{tabular} & 79,87 & 522,23 & $\begin{array}{l}0,3938 \\
69,\end{array}$ & 3,30 & 52,32 & \begin{tabular}{|l|l|}
191,36 \\
\end{tabular} & 28,09 & 28,09 & 182,27 \\
\hline Pelobates cultripes & 30STH80 & 100,00 & 159,47 & 124,72 & 38,00 & 6639,36 & 350,07 & 27,82 & 322,25 & 87,76 & 247,96 & 247,97 & 78,89 & 656,20 & 90,41 & 3,03 & 58,29 & 256,68 & 25,59 & 25,70 & 249,59 \\
\hline Pelobates cultripes & 30STH81 & 100,00 & 164,93 & 124,97 & 38,00 & 6662,85 & 355,81 & 32,29 & 323,52 & 92,55 & 253,64 & 253,64 & 83,63 & 622,20 & 85,72 & 2,64 & 58,18 & 241,91 & 23,87 & 23,87 & 234,87 \\
\hline Pelobates cultripes & 30STH88 & 100,00 & 155,86 & 122,67 & 37,00 & 6769,27 & 348,66 & 23,55 & 325,12 & 82,16 & 246,48 & 246,48 & 73,69 & 559,13 & 75,05 & 3,98 & 52,15 & 203,81 & 30,58 & 30,58 & 195,84 \\
\hline Pelobates cultripes & 30STH89 & 100,00 & 160,79 & 122,07 & 37,01 & 6751,70 & 352,34 & 28,51 & 323,83 & 87,16 & 251,17 & 251,17 & 78,56 & 523,03 & 69,94 & 3,46 & 52,02 & 189,93 & 28,30 & 28,30 & 181,55 \\
\hline Pelobates cultripes & 30STH91 & 100,00 & 163,51 & $\begin{array}{ll}124,07 \\
124,97\end{array}$ & 37,91 & 6701,95 & 355,13 & \begin{tabular}{|l|l|}
30,47 \\
3
\end{tabular} & \begin{tabular}{|l|}
224,606 \\
324,6
\end{tabular} & $\begin{array}{l}\mid l, 100 \\
90,71\end{array}$ & $\mid 252,71$ & $\mid$ & 81,61 & \begin{tabular}{|l|l|}
631,52 \\
632
\end{tabular} & $\begin{array}{l}3,744 \\
87,42\end{array}$ & 2,860 & 58,05 & \begin{tabular}{|l|}
243,73 \\
24,7
\end{tabular} & $\begin{array}{l}24,30 \\
240\end{array}$ & $\begin{array}{l}24,30 \\
24,30\end{array}$ & $\begin{array}{l}231,30 \\
237,81\end{array}$ \\
\hline Pelobates cultripes & 30STH95 & 100,00 & 154,11 & 124,24 & 37,09 & 6804,66 & 349,13 & 21,09 & 328,03 & 80,45 & 245,41 & 245,41 & 71,63 & 609,40 & 83,61 & 4,01 & 54,18 & 225,23 & 29,96 & 29,96 & 219,28 \\
\hline Pelobates cultripes & 30STH98 & 100,00 & 154,08 & 123,05 & 37,01 & 6809,59 & 348,09 & 21,13 & 326,96 & 79,90 & 245,35 & 245,35 & 71,55 & 563,20 & 76,05 & 4,14 & 51,94 & 203,41 & 31,01 & 31,01 & 196,29 \\
\hline Pelobates cultripes & 30STJ42 & 100,00 & 167,78 & 117,33 & 37,00 & 6552,41 & 351,55 & 39,67 & 311,88 & 95,93 & 254,79 & 254,79 & 87,54 & 471,53 & 60,81 & 3,00 & 50,65 & 173,96 & 28,00 & 28,00 & 162,49 \\
\hline Pelobates cultripes & 30STJ44 & 90,00 & 162,42 & 115,44 & 36,93 & 6560,68 & 345,72 & 35,69 & 310,02 & 90,72 & 249,89 & 249,89 & 82,45 & 479,24 & $61, \varepsilon \quad \gamma \quad>$ & 3,79 & 49,47 & 174,85 & 30,70 & 30,70 & 163,08 \\
\hline Pelobates cultripes & 30STJ45 & 90,00 & 155,14 & 114,11 & 36,52 & 6576,14 & 338,30 & 29,58 & 308,71 & 83,58 & $\begin{array}{l}243,04 \\
\end{array}$ & 243,04 & 75,36 & 505,07 & $\begin{array}{l}1,050 \\
65,06\end{array}$ & 4,2 & 48,59 & $\begin{array}{l}183,02 \\
\end{array}$ & 34,39 & 34,39 & 171,02 \\
\hline Pelobates cultripes & 30STJ46 & 81,00 & 155,51 & 113,32 & 36,25 & 6562,03 & 337,79 & 30,64 & 307,15 & 84,06 & 243,33 & 243,33 & 75,87 & 494,05 & 63,34 & 4,23 & 48,28 & 178,54 & 34,16 & 34,16 & 166,33 \\
\hline Pelobates cultripes & 30STJ47 & 80,00 & 158,34 & 112,88 & 36,33 & 6544,45 & 339,35 & 33,48 & 305,87 & 86,83 & 245,83 & 245,83 & 78,67 & 472,85 & 60,15 & 4,06 & 47,72 & 170,54 & 33,28 & 33,28 & 158,29 \\
\hline Pelobates cultripes & 30STJ48 & 80,00 & 157,30 & 112,20 & 36,16 & 6532,43 & 337,47 & 32,83 & 304,64 & 85,80 & 244,71 & 244,71 & 77,88 & 470,31 & 59,10 & 4, & 47,10 & 169,25 & 33,86 & 33,86 & 156,80 \\
\hline Pelobates cultripes & 30STJ49 & 71,00 & 156,13 & 111,76 & 36,26 & $\begin{array}{l}65305,03 \\
6505\end{array}$ & 335,34 & $\begin{array}{l}32,30 \\
32,39 \\
\end{array}$ & \begin{tabular}{|l|}
302,95 \\
\end{tabular} & $\begin{array}{l}85,06 \\
85,06\end{array}$ & 243,28 & 243,28 & 77,19 & |468,44 & 57,95 & 4,6 & 46,47 & $\begin{array}{l}168,19 \\
\end{array}$ & 34,86 & 34,86 & 155,72 \\
\hline Pelobates cultripes & 30STJ51 & 100,00 & 166,13 & 118,88 & 37,00 & 6600,50 & 352,20 & 36,54 & 315,66 & 93,81 & 254,05 & 254,05 & 85,33 & 485,22 & 62,98 & 3,0 & 51,23 & 178,56 & 28,03 & 28,03 & 167,71 \\
\hline Pelobates cultripes & 30STJ58 & 100,00 & 155,40 & 113,15 & 36,29 & 6552,72 & 336,67 & 30,22 & 306,45 & 83,61 & 243,05 & 243,05 & 75,49 & 467,24 & 58,29 & 4,77 & 46,49 & 166,39 & 34,67 & 34,67 & 153,99 \\
\hline Pelobates cultripes & 30STIS9 & 100,00 & 153,68 & 112,63 & 36,43 & 6536,26 & 333,96 & 28,91 & 305,05 & 82,08 & 241,23 & 241,23 & 74,07 & 466,74 & 57,20 & 4,98 & 45,69 & 165,74 & 35,83 & 35,83 & 153,15 \\
\hline Pelobates cultripes & 30STJ62 & 100,00 & 166,71 & 118,79 & 37,00 & 6630,30 & 352,93 & 36,76 & 316,17 & 93,99 & 255,07 & 255,07 & 85,52 & 466,96 & 60,83 & 3,00 & 50,72 & 169,80 & 27,38 & 27,38 & 159,24 \\
\hline Pelobates cultripes & 30STJ65 & 100,00 & 15 & 116,12 & 36,70 & 6632,08 & 340 & 27,62 & 313,01 & 83,03 & 244,19 & 244,19 & 74,88 & 484,69 & 61,93 & 4,40 & 47,61 & 172,52 & 33,67 & 33,67 & 161,03 \\
\hline Pelobates cultripes & 30STJ67 & 100,00 & 146,09 & 114,28 & 36,10 & 6615,83 & 330,29 & 20,18 & 310,11 & 74,11 & 235,11 & 235,11 & 66,36 & 505,77 & 62,89 & 5,54 & 45,92 & 178,34 & 38,77 & 38,77 & 165,94 \\
\hline Pelobates cultripes & 30 STJ69 & 100,00 & 148,10 & 113,43 & 36,43 & 6562,40 & 329,99 & 22,97 & \begin{tabular}{|l|l|}
307,02 \\
\end{tabular} & 76,38 & \begin{tabular}{|l|}
236,27 \\
\end{tabular} & \begin{tabular}{|l|}
236,27 \\
\end{tabular} & 60,73 & 475,96 & $\begin{array}{l}57,61 \\
5761\end{array}$ & 5,61 & 44,69 & \begin{tabular}{|l|}
166,87 \\
\end{tabular} & 38,15 & 38,15 & 154,07 \\
\hline Pelobates cultripes & 30STJ70 & 100,00 & 162,94 & 120,93 & 37,00 & 6711,61 & 352,53 & 31,34 & 321,19 & 89,45 & 252,49 & 252,49 & 80,99 & 503,63 & 66,61 & 3,16 & 51,62 & 183,48 & 27,84 & 27,84 & 174,04 \\
\hline Pelobates cultripes & 30STJ71 & 100,00 & 164,95 & 120,14 & 37,00 & 6683,93 & 353,31 & 33,90 & 319,41 & 91,52 & 254,01 & 254 & 83,24 & 482,22 & 63,35 & 3,01 & 51,07 & 174,78 & 27,49 & 27,49 & 164,96 \\
\hline Pelobates cultripes & 30STJ75 & $\begin{array}{l}100,00 \\
\end{array}$ & $\begin{array}{l}104,53 \\
156,64\end{array}$ & $\begin{array}{l}12,14 \\
117,10\end{array}$ & 36,93 & 6059,80 & $\begin{array}{l}353,51 \\
342,72 \\
\end{array}$ & \begin{tabular}{|l|l|}
27,78 \\
27
\end{tabular} & \begin{tabular}{|l|}
314,95 \\
314,
\end{tabular} & $\begin{array}{l}1,2< \\
83,69 \\
\end{array}$ & \begin{tabular}{|l|}
245,82 \\
245
\end{tabular} & $\begin{array}{l}54,01 \\
245,82 \\
\end{array}$ & $\begin{array}{l}3,24 \\
75,59 \\
\end{array}$ & \begin{tabular}{|l|l|l|l|l|l|}
470,78 \\
\end{tabular} & \begin{tabular}{|l|}
60,01 \\
601
\end{tabular} & $\begin{array}{l}3,24 \\
4,24 \\
\end{array}$ & $\begin{array}{l}1,001 \\
47,59\end{array}$ & \begin{tabular}{|l|}
166,20 \\
16,0
\end{tabular} & $\begin{array}{l}32,43 \\
32,63\end{array}$ & $\begin{array}{l}21,43 \\
32,63\end{array}$ & $\begin{array}{l}104,50 \\
154,99\end{array}$ \\
\hline Pelobates cultripes & 30STI78 & 100,00 & 149,32 & 115,03 & 36,47 & 6607,44 & 332,96 & 22,44 & 310,52 & 77,11 & 238,01 & 238,01 & 69,21 & 468,16 & 57,26 & 5,28 & 44,98 & 162,83 & 36,89 & 36,89 & 150,40 \\
\hline Pelobates cultripes & 30STJ79 & 100,00 & 145,83 & 114,40 & 36,55 & 6589,60 & 328,70 & 19,71 & 308,99 & 73,78 & 234,47 & 234,47 & 66,08 & 472,42 & 56,62 & 5,93 & 43,98 & 163,46 & 39,04 & 39,04 & 150,70 \\
\hline Pelobates cultripes & 30STJ80 & 100,00 & 162,30 & 121,46 & 37,00 & 6739,35 & 352,98 & 30,08 & 322,90 & 88,63 & 252, & 252,38 & 79,85 & 502,74 & 66,85 & 3,20 & 51,45 & 181,68 & 27,79 & 27,79 & 172,88 \\
\hline Pelobates cultripes & 30STJ81 & 100,00 & 163,48 & 120,86 & 37,00 & 6732,77 & 353,18 & 31,55 & 321,62 & 89,64 & 253,32 & 253,32 & 81,22 & 484,17 & 63,95 & 3,17 & 50,84 & 173,96 & 27,62 & 27,62 & 164,79 \\
\hline
\end{tabular}




\begin{tabular}{|c|c|c|c|c|c|c|c|c|c|c|c|c|c|c|c|c|c|c|c|c|c|}
\hline TAXON & UTM & $\mathrm{km} 2$ & B101 & B102 & $\mathrm{BIO3}$ & BIO4 & B105 & B106 & B107 & B108 & B109 & BIO10 & BIO11 & BIO12 & B1013 & BIO14 & BIO15 & B1016 & B1017 & B1018 & B1019 \\
\hline Pelobates cultripes & 30STI82 & 100,00 & 159,71 & 120,06 & 37,00 & 6722,78 & 349,14 & 28,61 & 320,54 & 86,01 & 249,70 & 249,70 & 77,87 & 486,66 & 63,75 & 3,78 & 49,62 & 173,27 & 29,86 & 29,86 & 163,70 \\
\hline Pelobates cultripes & 30STI85 & 100,00 & 156,96 & 117,95 & \begin{tabular}{|l|l|}
36,97 \\
\end{tabular} & $\begin{array}{l}6694,57 \\
\end{array}$ & 344,17 & 27,14 & 317,03 & 83,64 & 246,83 & 246,83 & 75,42 & 460,36 & 58,52 & 4,14 & 47,29 & 161,05 & 31,85 & 31,85 & 150,23 \\
\hline Pelobates cultripes & 30STJ90 & 100,00 & 160,49 & 121,98 & 37,00 & 6771,17 & 352,25 & 27,84 & 324,41 & 86,45 & 251,27 & 251,27 & 78,05 & 506,21 & 67,55 & 3,66 & 50,97 & 181,01 & 28,85 & 28,85 & 172,84 \\
\hline Pelobates cultripes & 30STJ91 & 100,00 & 160,67 & 121,29 & 37,00 & 6770,12 & 351,61 & 28,18 & 323,43 & 86,43 & 251,34 & 251,34 & 78,01 & 491,08 & 64,97 & 3,69 & 50,11 & 174,53 & 29,03 & 29,03 & 165,92 \\
\hline Pelobates cultripes & 30STJ92 & 100,00 & 162,71 & 120,71 & 37,00 & 6751,35 & 352,47 & 30,39 & 322,09 & 91,52 & 253,05 & 253,05 & 80,01 & 468,96 & 61,53 & 3,40 & 49,86 & 165,95 & 28,06 & 28,06 & 156,97 \\
\hline Pelobates cultripes & 30STJ93 & 100,00 & 161,94 & 119,95 & 37,00 & 6733,40 & 350,90 & 30,21 & 320,68 & 92,86 & 252,06 & 252,06 & 79,61 & 459,79 & 59,58 & 3,71 & 48,80 & 161,48 & 29,06 & 29,06 & 152,00 \\
\hline Pelobates cultripes & 30STJ96 & 100,00 & 141,01 & 117,50 & 36,58 & 6708,53 & 329,46 & 12,15 & 317,31 & 68,05 & 231,51 & 231,51 & 60,23 & 505,65 & 62,12 & 6,26 & 44,46 & 172,77 & 40,59 & 40,59 & 161,21 \\
\hline Pelobates cultripes & 30STJ99 & 100,00 & 144,12 & 116,00 & 36,92 & 6639,23 & 328,68 & 16,24 & 312,44 & 81,03 & 233,58 & 233,58 & 63,90 & 453,93 & 53,31 & 6,28 & 42,61 & 153,03 & 39,44 & 39,44 & 140,27 \\
\hline Pelobates cultripes & 30STK40 & 70,00 & 157,68 & 111,55 & 36,40 & 6477,31 & 335,56 & 33,93 & 301,63 & 86,53 & 244,31 & 244,31 & 78,84 & 455,27 & 55,76 & 4,71 & 46,00 & 163,25 & 34,57 & 34,57 & 150,81 \\
\hline Pelobates cultripes & 30STK41 & 70,00 & 160,83 & 111,62 & \begin{tabular}{|c|}
36,88 \\
\end{tabular} & 6438,31 & 337,22 & 37,00 & 300,22 & 89,67 & 246,68 & 246,68 & 81,92 & 435,49 & 53,34 & 4,25 & 45,75 & 156,26 & 32,98 & 32,98 & 143,93 \\
\hline Pelobates cultripes & 30STK50 & 100,00 & 156,29 & 112,45 & 36,60 & 6502,26 & 335,23 & 31,58 & 303,65 & 84,67 & 243,05 & 243,05 & 76,90 & 448,24 & 54,49 & 4,83 & 45,40 & 159,08 & 34,72 & 34,72 & 146,56 \\
\hline Pelobates cultripes & 30STK51 & 100,00 & 161,28 & 112,52 & 36,93 & 6469,97 & 338,53 & 36,40 & 302,13 & 89,56 & 247,40 & 247,40 & 81,93 & 420,85 & 51,29 & 4,13 & 45,34 & 149,64 & 32,44 & 32,44 & 137,23 \\
\hline Pelobates cultripes & 30STK52 & 100,00 & 161,90 & 112,44 & 37,00 & 6442,02 & 338,05 & 37,23 & 300,82 & 90,26 & 247,52 & 247,52 & 82,78 & 411,27 & 50,17 & 4,20 & 44,75 & 146,01 & 32,27 & 32,27 & 133,61 \\
\hline Pelobates cultripes & 30STK61 & 100,00 & 161,41 & 113,45 & 37,00 & 6464,10 & 339,30 & 35,73 & 303,57 & 89,90 & 247,71 & 247,71 & 82,00 & 405,86 & 49,08 & 4,07 & 44,62 & 142,62 & 31,97 & 31,97 & 130,32 \\
\hline Pelobates cultripes & 30STK62 & 100,00 & 161,23 & 113,17 & 37,00 & 6446,28 & 338,29 & 35,91 & 302,38 & 90,04 & 247,23 & 247,23 & 82,02 & 399,55 & 48,23 & 4,74 & 43,82 & $\mid 139,96$ & 32,74 & $\mid 32,74$ & 127,59 \\
\hline Pelobates cultripes & 30STK71 & 100,00 & 159,49 & 114,03 & 37,00 & 6506,11 & 338,62 & 32,78 & 305,84 & 94,35 & 246,32 & 246,32 & 79,77 & 400,66 & 47,97 & 4,71 & 43,70 & 138,88 & 32,83 & 32,83 & 126,42 \\
\hline Pelobates cultripes & 30STK72 & 100,00 & 160,40 & 114,00 & 37,00 & 6459,10 & 338,21 & 34,19 & 304,02 & 108,40 & 246,64 & 246,64 & 81,15 & 388,79 & 46,46 & 5,00 & 43,09 & 134,24 & 32,95 & 32,95 & 121,76 \\
\hline Pelobates cultripes & 30STK81 & 100,00 & 157,36 & 114,90 & 37,00 & 6538,47 & 337,27 & 30,14 & 307,14 & 109,29 & 244,77 & 244,77 & 77,19 & 397,06 & 46,97 & 5,00 & 43,09 & 135,98 & 33,42 & 33,42 & 123,21 \\
\hline Pelobates cultripes & 30STK82 & 100,00 & 159,99 & 114,49 & 37,00 & 6497,45 & 338,29 & 33,01 & 305,28 & 118,40 & 246,75 & 246,75 & 80,04 & 379,04 & 44,91 & 5,00 & 42,66 & 130,14 & 32,23 & 32,23 & 117,00 \\
\hline Pelobates cultripes & 30STK91 & 100,00 & 158,53 & 115,07 & 37,00 & 6558,74 & 338,88 & 30,31 & 308,57 & 116,44 & 246,30 & 246,30 & 78,05 & 382,92 & 44,90 & 5,00 & 42,83 & 130,80 & 32,58 & 32,58 & 117,11 \\
\hline Pelobates cultripes & 30STK92 & 100,00 & 158,97 & 115,00 & 37,00 & 6517,41 & 337,92 & 31,26 & 306,66 & 116,95 & 246,07 & 246,07 & 78,94 & 372,09 & 43,72 & 5,00 & 42,38 & 127,20 & 32,20 & 32,20 & 113,03 \\
\hline Pelobates cultripes & $\begin{array}{l}\text { 30SUF02 } \\
\end{array}$ & & & & & & & & & & & & & & & & & & & & \\
\hline Pelobates cultripes & 30SUF03 & 82,00 & 169,39 & 89,49 & \begin{tabular}{|l|l|}
40,47 \\
\end{tabular} & \begin{tabular}{|l|l|}
4467,10 \\
\end{tabular} & 290,21 & 71,31 & 218,90 & 125,21 & 226,56 & 230,21 & \begin{tabular}{|l|}
116,17 \\
\end{tabular} & 700,22 & 120,39 & 1,22 & 73,03 & 341,09 & 15,43 & 22,72 & 320,33 \\
\hline Pelobates cultripes & 30SUF13 & 41,00 & 177,76 & 86,60 & 40,55 & 4321,56 & 293,13 & 81,98 & 211,15 & 135,25 & 232,73 & 236,49 & 126,22 & 639,44 & 112,78 & 1,00 & 73,62 & 317,35 & 14,11 & 20,27 & 294,35 \\
\hline Pelobates cultripes & 30SUF14 & 100,00 & 164,25 & 93,61 & 40,05 & 4728,92 & 292,85 & 61,81 & 231,04 & 117,47 & 225,38 & 228,54 & 107,94 & 693,70 & 114,72 & 1,46 & 71,15 & 330,44 & 16,93 & 24,32 & 311,92 \\
\hline Pelobates cultripes & 30SUF24 & 94,00 & 168,45 & 92,06 & 40,05 & 4652,58 & 293,99 & 66,92 & 227,07 & 122,51 & 228,58 & 231,67 & 113,12 & 654,52 & 109,13 & 1,48 & 71,20 & 313,71 & 16,63 & 23,23 & 294,45 \\
\hline Pelobates cultripes & 30SUF27 & 100,00 & 147,31 & 105,57 & 39,00 & 5509,06 & 299,63 & 33,14 & 266,49 & | & $\begin{array}{l}220,22 \\
220\end{array}$ & 221,83 & \begin{tabular}{|l|l|}
81,75 \\
\end{tabular} & \begin{tabular}{|l|l|}
740,65 \\
\end{tabular} & 110,76 & $\begin{array}{l}3,400 \\
3,10\end{array}$ & 65,66 & \begin{tabular}{|l|}
327,50 \\
\end{tabular} & 23,41 & 30,92 & 314,60 \\
\hline Pelobates cultripes & 30SUF34 & 86,00 & 168,50 & 91,96 & 39,99 & 4679,37 & 294,07 & 66,24 & 227,83 & 122,48 & 229,17 & 232,01 & 113,01 & 630,40 & 103,78 & 1,59 & 70,51 & 301,26 & 16,97 & 23,19 & 282,53 \\
\hline Pelobates cultripes & 30SUF44 & 99,00 & 175,94 & 87,81 & 39,80 & 4528,52 & 294,53 & 75,85 & 218,68 & 131,70 & 234,36 & 237,40 & 122,17 & 584,84 & 98,22 & 1,33 & 71,14 & 283,83 & 16,13 & 21,07 & 263,71 \\
\hline Pelobates cultripes & 30SUF54 & 49,00 & 180,49 & 85,28 & 39,21 & 4478,44 & 295,30 & 80,95 & 214,34 & 136,74 & 238,13 & 241,05 & 127,16 & 556,48 & 94,54 & 1,16 & 71,26 & 271,38 & 15,97 & 20,07 & 250,74 \\
\hline Pelobates cultripes & 30SUF65 & 71,00 & 178,18 & 86,28 & 38,39 & 4686,09 & 296,79 & 75,63 & 221,16 & 131,94 & 239,13 & 241,45 & 122,25 & 553,97 & 93,95 & 1,93 & 69,95 & 265,73 & 17,57 & 21,24 & 245,09 \\
\hline Pelobates cultripes & \begin{tabular}{|l|}
30 SUF76 \\
\end{tabular} & 60,00 & 178,71 & $\begin{array}{l}80,200 \\
86,90\end{array}$ & 37,95 & 4863,15 & 300,02 & $\begin{array}{l}3,3,37 \\
73\end{array}$ & 226,66 & $\begin{array}{l}129,82 \\
129,\end{array}$ & 242,24 & \begin{tabular}{|l|}
244,01 \\
\end{tabular} & 120,51 & 525,85 & $\begin{array}{l}0,91 \\
87,91\end{array}$ & 2,07 & 67,84 & 246,26 & 17,54 & 21,09 & $\begin{array}{l}247,32 \\
227,32\end{array}$ \\
\hline Pelobates cultripes & 30SUF99 & 100,00 & 131,28 & 115,92 & 38,00 & 6159,14 & 307,14 & 6,72 & 300,42 & 67,43 & 214,93 & 214,93 & 58,55 & 651,95 & 87,41 & 7,08 & 55,91 & 259,09 & 33,13 & 33,13 & 251,82 \\
\hline Pelobates cultripes & 30SUG05 & 100,00 & 174,83 & 118,95 & 39,03 & 6223,51 & 349,01 & 49,08 & 299,93 & 107,51 & 256,89 & 257,21 & 98,96 & 636,42 & 95,56 & 1,52 & 63,53 & 266,32 & 17,58 & 22,12 & 255,99 \\
\hline Pelobates cultripes & 30SUG08 & 100,00 & 179,07 & 122,27 & 38,65 & 6465,53 & 361,50 & 48,51 & 312,99 & 108,69 & 264,57 & 264,59 & 99,60 & 606,15 & 88,31 & 1,66 & 61,55 & 243,76 & 17,82 & 18,13 & 236,68 \\
\hline Pelobates cultripes & 30SUG09 & 100,00 & 171,41 & 123,90 & 38,02 & 6601,14 & 359,11 & 39,39 & 319,72 & 99,62 & 259,17 & 259,17 & 90,60 & 629,89 & 89,50 & 2,11 & 60,41 & 248,30 & 20,38 & 20,38 & 242,66 \\
\hline Pelobates cultripes & \begin{tabular}{|l|} 
30SUG17 \\
30 G
\end{tabular} & 100,00 & $\begin{array}{l}17,41 \\
176,59\end{array}$ & 120,83 & 38,41 & 600026,45 & 357,16 & $\begin{array}{l}3,35 \\
46,85 \\
\end{array}$ & $\mid \begin{array}{l}\mid 1,7,2 \\
310,31\end{array}$ & \begin{tabular}{|c|}
106,78 \\
106,
\end{tabular} & $\mid 261,70$ & $\begin{array}{l}351,72 \\
2617\end{array}$ & $\begin{array}{l}90,700 \\
97,71\end{array}$ & \begin{tabular}{|l|l|}
630,39 \\
630
\end{tabular} & $\begin{array}{l}5,30 \\
92,22\end{array}$ & $\begin{array}{l}2,11 \\
2,00\end{array}$ & $\begin{array}{ll}62,09 \\
62\end{array}$ & \begin{tabular}{|l|}
254,40 \\
25,4
\end{tabular} & $\begin{array}{l}20,0 \\
18,00\end{array}$ & $\begin{array}{l}2,00 \\
18,23 \\
\end{array}$ & $\begin{aligned} 24,00 \\
248,02\end{aligned}$ \\
\hline Pelobates cultripes & 30SUG18 & 100,00 & 178,88 & 121,59 & 38,07 & 6495,44 & 361,50 & 48,04 & 313,46 & 108,01 & 264,87 & 264,87 & 98,88 & 614,41 & 89,36 & 2,00 & 61,87 & 245,13 & 17,57 & 17,57 & 239,64 \\
\hline Pelobates cultripes & 30SUG38 & 100,00 & 176,44 & 120,40 & 37,75 & 6576,82 & 360,40 & 44,73 & 315,68 & 106,72 & 264,12 & 264,12 & 95,58 & 632.80 & 93,53 & 2,01 & 62,00 & 248,47 & 17,71 & 17,71 & 245,31 \\
\hline Pelobates cultripes & 30SUG39 & 100,00 & 172,72 & 121,66 & 37,46 & 6673,92 & 360,28 & 39,74 & 320,55 & 103,10 & 261,75 & 261,75 & 90,77 & 634,97 & 94,36 & 2,40 & 60,84 & 247,91 & 19,40 & 19,40 & 242,96 \\
\hline Pelobates cultripes & 30 SUG 40 & 100,00 & 164,62 & 104,62 & 38,48 & 5666,15 & 316,75 & 48,21 & 268,55 & 105,23 & 239,72 & 240,42 & 96,60 & 643,79 & 97,35 & 2,44 & 64,83 & 283,87 & 20,00 & 25,60 & 268,63 \\
\hline 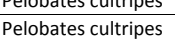 & $\begin{array}{l}050040 \\
30 S U G 49\end{array}$ & 100,00 & $\begin{array}{l}104,02 \\
177,84\end{array}$ & $\begin{array}{l}104,02 \\
119,92\end{array}$ & 37,05 & $\begin{array}{l}300,0110 \\
6641,07\end{array}$ & $\begin{array}{l}310, / 3 \\
362,81\end{array}$ & $\begin{array}{l}40,21 \\
45,38 \\
\end{array}$ & \begin{tabular}{|l|}
317,43 \\
31,4
\end{tabular} & \begin{tabular}{|l|}
108,48 \\
108,48
\end{tabular} & $\mid$\begin{tabular}{|l|l|l|l|}
266,49 \\
\end{tabular} & $\begin{array}{l}260,44 \\
266,49 \\
\end{array}$ & $\begin{array}{l}0,00 \\
96,15 \\
\end{array}$ & \begin{tabular}{|l|l|}
608,36 \\
608,36
\end{tabular} & $\begin{array}{l}1,33 \\
91,39 \\
\end{array}$ & $\begin{array}{l}2,244 \\
2,03\end{array}$ & $\begin{array}{l}4,303 \\
61,38 \\
\end{array}$ & \begin{tabular}{|l|}
238,32 \\
238,
\end{tabular} & $\begin{array}{l}20,00 \\
17,34\end{array}$ & $\begin{array}{l}2,30 \\
17,34 \\
\end{array}$ & $\begin{array}{l}208,03 \\
233,03\end{array}$ \\
\hline Pelobates cultripes & 30SUG53 & 100,00 & 170,54 & 108,60 & 37,96 & 6023,41 & 332,88 & 49,09 & 283,79 & 106,23 & 250,80 & 250,83 & 97,62 & 612,15 & 89,50 & 2,55 & 62,47 & 257,70 & 19,62 & 20,08 & 247,41 \\
\hline Pelobates cultripes & 30SUG65 & 100,00 & 163,63 & 113,17 & 37,00 & 6389,03 & 338,84 & 37,62 & 301,22 & 95,10 & 249,51 & 249,51 & 86,51 & 621,64 & 86,47 & 3,48 & 59,73 & 247,99 & 22,27 & 22,27 & 243,27 \\
\hline Pelobates cultripes & 30SUG71 & 100,00 & 151,62 & 110,58 & \begin{tabular}{|c|}
37,88 \\
\end{tabular} & 6072,57 & 318,97 & 29,47 & 289,50 & 87,29 & 233,57 & 233,57 & 79,09 & 616,86 & 87,21 & 4,57 & 59,53 & 255,86 & 25,25 & 25,25 & 245,22 \\
\hline Pelobates cultripes & 30SUG75 & 100,00 & 155,82 & 114,23 & 37,00 & 6483,09 & 334,9 & 29,28 & 305,67 & $\begin{array}{l}86,84 \\
86,\end{array}$ & 243,34 & 243,34 & 78,06 & 628,75 & \begin{tabular}{|l|l|l|l|}
85,66 \\
\end{tabular} & 4,59 & 57,93 & 245,89 & 25,79 & 25,79 & 242,22 \\
\hline Pelobates cultripes & 30SUG77 & 100,00 & 172,85 & 113,05 & 36,76 & 6504,26 & 349,80 & 45,24 & 304,56 & 104,92 & 260,04 & 260,04 & 93,80 & 576,88 & 81,82 & 3,05 & 59,29 & 224,69 & 19,93 & 19,93 & 221,81 \\
\hline Pelobates cultripes & 30SUG84 & 100,00 & 153,59 & 113,48 & 36,98 & 6436,52 & 331,44 & 27,62 & 303,83 & $\begin{array}{l}84,82 \\
8\end{array}$ & 240,74 & 240,74 & 76,60 & 607,21 & $\begin{array}{l}80,98 \\
80,9\end{array}$ & 4,97 & 57,11 & 237,89 & 26,17 & 26,17 & 233,38 \\
\hline Pelobates cultripes & 30SUG90 & 100,00 & 124,09 & 117,99 & 37,99 & 6306,11 & 305,62 & $-1,53$ & 307,15 & 58,80 & 210,03 & 210,03 & 49,98 & 696,79 & 91,66 & 8,28 & 54,52 & 269,74 & 38,04 & 38,04 & 264,54 \\
\hline Pelobates cultripes & 30SUG91 & 100,00 & 154,26 & 110,16 & 37,51 & 6085,34 & 321,24 & 31,49 & 289,75 & 89,03 & 236,53 & 236,53 & 81,49 & 549,58 & 78,58 & 4,79 & 58,01 & 02 & 24,42 & 24,42 & 214,44 \\
\hline Pelobates cultripes & 30SUHO3 & 100,00 & 156 & $\begin{array}{l}111,10 \\
124,97\end{array}$ & 37,22 & $\begin{array}{l}60012,24 \\
6812,88\end{array}$ & 351 & $\begin{array}{l}1,44 \\
22,94 \\
\end{array}$ & $\mid$\begin{tabular}{|l|l|}
328,90 \\
\end{tabular} & $\begin{array}{l}85,90 \\
84,97 \\
\end{array}$ & $\mid 248,16$ & \begin{tabular}{|l|}
248,16 \\
248
\end{tabular} & $\begin{array}{l}\mid l, 49 \\
73,96\end{array}$ & $\mid \begin{array}{l}\mid \\
629,18\end{array}$ & \begin{tabular}{|l|}
0,30 \\
88,10
\end{tabular} & $\begin{array}{ll}4,1 / 43 \\
3,43\end{array}$ & 56,14 & \begin{tabular}{|l|}
235,71 \\
23,1
\end{tabular} & $\begin{array}{l}24,4< \\
27,18\end{array}$ & $\begin{array}{l}24,44 \\
27,18\end{array}$ & 231,01 \\
\hline Pelobates cultripes & 30SUHO4 & 100,00 & 152,84 & 124,93 & 37,05 & 6831,90 & 348,81 & 19,41 & 329,40 & 81,84 & 244,76 & 244,76 & 70,04 & 628,36 & 87,41 & 3,97 & 54,82 & 232,80 & 29,55 & 29,55 & 227,64 \\
\hline Pelobates cultripes & 30SUH05 & 100,00 & 154,29 & 124,77 & 37,14 & 6832,25 & 350,07 & 20,79 & 329,28 & 83,11 & $\begin{array}{l}246,08 \\
\end{array}$ & 246,08 & 71,36 & $\begin{array}{l}606,60 \\
\end{array}$ & $\begin{array}{l}84,11 \\
84,11\end{array}$ & 4,00 & 54,17 & 222,77 & 29,59 & 29,59 & 217,47 \\
\hline Pelobates cultripes & 30SUHOG & 100,00 & 156,69 & 124,19 & 37,01 & 6840,76 & 351,82 & 22,84 & 328,98 & 84,58 & 248,40 & 248,40 & 73,47 & 581,11 & 80,24 & 3,99 & 53,46 & 211,54 & 29,10 & 29,10 & 206,06 \\
\hline Pelobates cultripes & 30SUH07 & 100,00 & 159,41 & 124,00 & 37,00 & 6836,97 & 353,94 & 25,40 & 328,54 & 85,75 & 251,04 & 251,04 & 76,13 & 553,36 & 76,10 & 3,42 & 53,17 & 200,52 & 27,60 & 27,60 & 194 \\
\hline Pelobates cultripes & $\begin{array}{l}\text { OSOSUHO8 } \\
30 \mathrm{~S}\end{array}$ & $\begin{array}{l}100,00 \\
\end{array}$ & $\begin{array}{l}15,41 \\
156,61\end{array}$ & $\begin{array}{l}123,00 \\
123,59\end{array}$ & 37,00 & | 60037,61 & 350,54 & $\begin{array}{l}22,84 \\
22,84 \\
\end{array}$ & \begin{tabular}{|l|}
$328,13,13$ \\
\end{tabular} & \begin{tabular}{|l|l|}
81,95 \\
81,9
\end{tabular} & $\begin{array}{l}241,443 \\
248,\end{array}$ & \begin{tabular}{|l|}
248,43 \\
\end{tabular} & $\begin{array}{l}\mid 0,15 \\
73,45\end{array}$ & \begin{tabular}{|l|l|}
549,13 \\
59,
\end{tabular} & $\begin{array}{l}0,10 \\
74,76\end{array}$ & $\begin{array}{l}3,44 \\
3,80\end{array}$ & $\begin{array}{l}52,03 \\
52,1\end{array}$ & \begin{tabular}{|l|}
197,04 \\
197
\end{tabular} & 29,49 & $\begin{array}{ll}29,40 \\
29,49\end{array}$ & $\begin{array}{l}54,05 \\
190,72\end{array}$ \\
\hline Pelobates cultripes & 30SUHO9 & 100,00 & 156,29 & 123,05 & 37,00 & 6827,99 & 350,39 & 22,76 & 327,62 & 81,72 & 247,94 & 247,94 & 73,39 & 533,95 & 72,05 & 4,00 & 51,27 & 190,05 & 30,05 & 30,05 & 183,17 \\
\hline Pelobates cultripes & 30SUH11 & 100,00 & 153,44 & 124,32 & 37,41 & 6790,20 & 347,48 & 20,28 & 327,20 & 82,93 & 244,46 & 244,46 & 71,11 & 668,52 & 94,50 & 3,88 & 56,90 & 253,99 & 27,99 & 27,99 & 249,24 \\
\hline Pelobates cultripes & 30SUH14 & 100,00 & 150,81 & 124,97 & 37,02 & 6860,81 & 347,49 & 17,3 & 330,15 & 80,42 & 243,28 & 243 & 67, & 632,93 & 88,78 & t & 54,50 & 234,54 & 30,24 & 30,24 & 228,31 \\
\hline Pelobates cultripes & 30SUH15 & 100,00 & 154,26 & 124,99 & 37,00 & 6858,90 & 350,54 & 20,44 & 330,10 & 83,81 & 246,70 & 246,70 & 71,17 & 603,60 & 84,48 & 4,00 & 54,14 & 221,67 & 29,30 & 29,30 & 215,70 \\
\hline
\end{tabular}




\begin{tabular}{|c|c|c|c|c|c|c|c|c|c|c|c|c|c|c|c|c|c|c|c|c|c|}
\hline TAXON & UTM & $\mathrm{km} 2$ & B101 & B102 & $\mathrm{BIO3}$ & BIO4 & B105 & B106 & B107 & B108 & B109 & BIO10 & BIO11 & BIO12 & B1013 & BIO14 & BIO15 & B1016 & B1017 & BIO18 & B1019 \\
\hline Pelobates cultripes & 30SUH16 & 100,00 & 156,14 & 124,60 & 37,00 & 6864,75 & 351,95 & 21,92 & 330,03 & 85,47 & 248,42 & 248,42 & 72,77 & 580,00 & 80,66 & 4,00 & 53,32 & 210,65 & 29,02 & 29,02 & 204,95 \\
\hline Pelobates cultripes & 30SUH17 & 100,00 & 159,76 & 124,03 & 37,00 & 6852,95 & 354,63 & 25,22 & 329,41 & 88,66 & 251,68 & 251,68 & 76,34 & 548,21 & 75,84 & 3,42 & 53,12 & 197,20 & 27,31 & 27,31 & 191,87 \\
\hline Pelobates cultripes & 30SUH18 & 100,00 & 160,50 & 123,94 & 37,00 & 6853,55 & 354,88 & 26,04 & 328,84 & 87,45 & 252,51 & 252,51 & 76,96 & \begin{tabular}{|c|}
528,38 \\
\end{tabular} & 72,45 & 3,32 & 52,48 & 188,55 & 27,29 & 27,29 & 183,01 \\
\hline Pelobates cultripes & 30SUH19 & 100,00 & 156,72 & 123,25 & 37,00 & 6850,13 & 351,13 & 22,66 & 328,47 & 82,51 & 248,74 & 248,74 & 73,43 & 527,22 & 71,32 & 3,82 & 51,09 & 186,22 & 29,49 & 29,49 & 180,06 \\
\hline Pelobates cultripes & 30SUH21 & 100,00 & 155,18 & 124,01 & \begin{tabular}{|l|l|}
37,13 \\
\end{tabular} & $\begin{array}{ll}6815,08 \\
\end{array}$ & 349,27 & 21,83 & 327,44 & 84,73 & 246,69 & 246,69 & 72,49 & 6600,60 & $\begin{array}{ll}94,63 \\
\end{array}$ & 3,78 & 57,17 & 251,76 & 27,13 & 27,13 & 245,69 \\
\hline Pelobates cultripes & $30 \mathrm{SUH} 22$ & 100,00 & 157,27 & 124,38 & \begin{tabular}{|l|l|}
37,08 \\
\end{tabular} & 6836,77 & 352,36 & 23,58 & 328,78 & 86,77 & 249,13 & 249,13 & 74,42 & 638,21 & 91,70 & 3,51 & 56,67 & 241,62 & 26,43 & 26,43 & 235,18 \\
\hline Pelobates cultripes & $30 \mathrm{SUH} 28$ & 100,00 & 159,77 & 124,01 & 37,00 & 6870,03 & 354,71 & 25,01 & 329,70 & 88,82 & 252,06 & 252,06 & 76,10 & 525,57 & 72,21 & 3,41 & 52,07 & 186,35 & 27,45 & 27,45 & 180,92 \\
\hline Pelobates cultripes & 30SUH30 & 100,00 & 162,30 & 122,87 & 37,04 & 6771,33 & 354,04 & 29,24 & 324,80 & 92,31 & 253,16 & 253,16 & 80,00 & 647,49 & $\begin{array}{ll}94,59 \\
\end{array}$ & 3,26 & 58,61 & 249,89 & 23,69 & 23,69 & 243,64 \\
\hline Pelobates cultripes & 30SUH31 & 100,00 & 159,11 & 123,50 & $\begin{array}{l}37,05 \\
\end{array}$ & 6820,64 & 352,68 & 25,53 & 327,15 & 88,65 & 250,72 & 250,72 & 76,22 & 643,77 & 93,65 & 3,54 & 57,47 & 246,45 & 25,46 & 25,46 & 239,30 \\
\hline Pelobates cultripes & 30SUH32 & 100,00 & 156,88 & 123,97 & 37,00 & 6859,15 & 351,87 & 22,99 & 328,88 & 86,10 & 249,13 & 249,13 & 73,61 & 635,38 & 92,01 & 3,77 & 56,51 & 240,96 & 26,70 & 26,70 & 233,23 \\
\hline Pelobates cultripes & 30SUH35 & 100,00 & 153,47 & 124,96 & 37,00 & 6914,82 & 350,41 & 18,82 & 331,59 & 82,61 & 246,64 & 246,64 & 69,85 & 595,47 & 84,36 & 4,00 & 53,71 & 218,63 & 29,03 & 29,03 & 210,82 \\
\hline Pelobates cultripes & 30SUH36 & 100,00 & 156,80 & 124,81 & 37,00 & 6903,97 & 353,21 & 21,85 & 331,37 & 86,01 & 249,63 & 249,63 & 72,98 & 566,97 & 79,78 & 3,86 & 53,20 & 205,78 & 28,44 & 28,44 & 198,61 \\
\hline Pelobates cultripes & 30SUH37 & 100,00 & 158,19 & 124,25 & 37,00 & 6893,18 & 353,98 & 23,16 & 330,82 & 87,52 & 250,85 & 250,85 & 74,40 & 543,75 & 75,72 & 3,51 & 52,56 & 194,90 & 27,77 & 27,77 & 188,42 \\
\hline Pelobates cultripes & 30SUH38 & 100,00 & 160,64 & 124,02 & 37,00 & 6885,64 & 355,60 & 25,47 & 330,13 & 89,97 & 253,13 & 253,13 & 76,72 & 517,02 & 71,21 & 3,28 & 52,03 & 182,91 & 26,94 & 26,94 & 177,24 \\
\hline Pelobates cultripes & 30SUH39 & 100,00 & 155,94 & 124,00 & 37,00 & 6899,70 & 351,46 & 21,01 & 330,45 & 85,36 & 248,87 & 248,87 & 72,04 & 516,53 & 69,93 & 3,90 & 50,60 & 179,69 & 29,56 & 29,56 & 174,11 \\
\hline Pelobates cultripes & $30 \mathrm{SUH} 40$ & 100,00 & 166,59 & 121,69 & 37,01 & 6766,19 & 356,73 & 33,38 & 323,35 & 96,41 & 257,32 & 257,32 & 83,97 & 627,45 & 92,90 & 3,00 & 58,99 & 243,12 & 22,05 & 22,05 & 235,93 \\
\hline Pelobates cultripes & $30 \mathrm{SUH} 41$ & 100,00 & 163,68 & 122,52 & 37,00 & 6815,77 & 355,97 & 29,91 & 326,06 & 93,17 & 255,18 & 255,18 & 80,68 & 621,48 & 91,61 & 3,31 & 57,85 & 238,69 & 23,62 & 23,62 & 230,69 \\
\hline Pelobates cultripes & 30SUH47 & 100,00 & 156,62 & 124,50 & 37,00 & 6912,72 & 352,90 & 21,42 & 331,48 & 85,87 & 249,65 & 249,65 & 72,71 & 541,91 & 75,45 & 3,73 & 52,08 & 193,57 & 28,44 & 28,44 & 186,43 \\
\hline Pelobates cultripes & 30SUH48 & 100,00 & 158,87 & 124,11 & 37,00 & 6901,36 & 354,40 & 23,56 & 330,84 & 88,28 & 251,73 & 251,73 & 75,01 & 516,26 & 70,91 & 3,53 & 51,42 & 181,79 & 27,87 & 27,87 & 175,64 \\
\hline Pelobates cultripes & 30SUH49 & 100,00 & 156,20 & 124,03 & 37,00 & 6904,72 & 351,85 & 21,02 & 330,83 & 85,84 & 249,25 & 249,25 & 72,32 & 508,38 & 68,64 & 3,86 & 50,16 & 176,05 & 29,40 & 29,40 & 170,30 \\
\hline Pelobates cultripes & 30SUH52 & 100,00 & 156,27 & 122,73 & 37,00 & 6888,54 & 350,98 & 22,63 & 328,35 & 85,45 & 249,04 & 249,04 & 72,88 & 619,82 & 90,5 & 3,96 & 55,71 & 235,00 & 27,16 & 27,16 & 225,29 \\
\hline Pelobates cultripes & 30SUH56 & 100,00 & 156,92 & 124,19 & 37,00 & 6927,64 & 353,20 & 21,55 & 331,65 & 85,88 & 250,18 & 250,18 & 72,80 & 550,41 & 77,53 & 3,89 & 52,44 & 198,71 & 28,34 & 28,34 & 190,68 \\
\hline Pelobates cultripes & 30SUH57 & 100,00 & 151,04 & 124,89 & 37,00 & 6933,85 & 348,32 & 15,91 & 332,42 & 80,23 & 244,52 & 244,52 & 67,21 & 552,66 & 76,26 & 4,34 & 50,95 & 195,91 & 31,15 & 31,15 & 188,14 \\
\hline Pelobates cultripes & 30SUH59 & 100,00 & 153,77 & 124,58 & 37,00 & 6913,86 & 349,99 & 18,56 & 331,43 & 100,63 & 247,06 & 247,06 & 70,13 & 508,30 & 68,12 & 4,05 & 49,48 & 175,65 & 30,44 & 30,44 & 168,93 \\
\hline Pelobates cultripes & 30SUH64 & 100,00 & 150,72 & 123,71 & 37,00 & 6944,50 & 347,86 & 16,61 & 331,26 & 79,53 & 244,57 & 244,57 & 67,15 & 596,67 & 85,45 & 4,58 & 52,90 & 220,07 & 30,67 & 30,67 & 209,74 \\
\hline Pelobates cultripes & 30SUH65 & 100,00 & 153,88 & 123,98 & 37,00 & 6938,73 & 350,60 & 19,02 & 331,58 & 82,97 & 247,51 & 247,51 & 69,97 & 568,39 & 80,8 & 4,03 & 52,71 & 207,44 & 29,00 & 29,00 & 198,00 \\
\hline Pelobates cultripes & 30SUH66 & 100,00 & $\begin{array}{l}147,00 \\
147,75\end{array}$ & 124,62 & 37,00 & \begin{tabular}{|l|l|}
6951,08 \\
\end{tabular} & 345,61 & 13,05 & 332,56 & 78,56 & $\begin{array}{l}241,74 \\
24\end{array}$ & $\begin{array}{l}241,74 \\
24\end{array}$ & 64,00 & 573,10 & $\begin{array}{l}0,006 \\
79,68\end{array}$ & 4,80 & 50,88 & 204,96 & 32,71 & 32,71 & 195,86 \\
\hline Pelobates cultripes & 30SUH67 & 100,00 & 149,16 & 124,99 & 37,00 & 6940,01 & 346,73 & 13,99 & 332,74 & 88,94 & 242,86 & 242,86 & 65,36 & 549,43 & 75,42 & 4,36 & 50,23 & \begin{tabular}{|l|}
194,17 \\
\end{tabular} & 32,05 & 32,05 & 185,56 \\
\hline Pelobates cultripes & 30SUH69 & 100,00 & 148,55 & 125,02 & 37,00 & 6936,00 & 345,94 & 13,06 & 332,88 & 116,64 & 242,25 & 242,25 & 64,80 & 517,39 & 68,56 & 4,43 & 48,32 & 179,27 & 32,96 & 32,96 & 169,88 \\
\hline Pelobates cultripes & 30SUH70 & 100,00 & 177,69 & 116,12 & 36,80 & 6647,14 & 359,74 & 47,10 & 312,63 & 108,78 & 266,65 & 266,65 & 96,31 & 544,59 & 80,35 & 2,31 & 58,69 & 210,57 & 18,35 & 18,35 & 204,07 \\
\hline Pelobates cultripes & 30SUH73 & 100,00 & 150,43 & 122,52 & 36,84 & 6938,53 & 346,58 & 16,95 & 329,64 & 79,37 & 244,26 & 244,26 & 66,90 & 603,05 & 87,12 & 4,85 & 53,18 & 224,50 & 30,80 & 30,80 & 213,05 \\
\hline Pelobates cultripes & 30SUH74 & 100,00 & 151,78 & 123,02 & 37,04 & 6941,81 & 348,19 & $\begin{array}{l}17,94 \\
17,\end{array}$ & 330,25 & 80,72 & \begin{tabular}{|l|}
245,66 \\
\end{tabular} & \begin{tabular}{|l|}
245,66 \\
\end{tabular} & 60,25 & 582,21 & $\begin{array}{l}1,12 \\
83,49 \\
\end{array}$ & 4, 4,44 & 52,59 & 214,36 & 30,20 & 30,20 & 203,55 \\
\hline Pelobates cultripes & 30SUH75 & 100,00 & 148,38 & 123,98 & 37,00 & 6945,49 & 345,76 & 14,17 & 331,59 & 81,12 & 242,28 & 242,28 & 64,94 & 577,95 & 81,45 & 4,75 & 51,44 & 209,36 & 32,20 & 32,20 & 198,97 \\
\hline Pelobates cultripes & 30SUH76 & 100,00 & 141,94 & 124,88 & 37,00 & 6962,21 & 340,69 & 7,44 & 333,25 & 90,01 & 236,19 & 236,19 & 58,53 & 583,66 & 80,33 & 5,47 & 49,59 & 208,01 & 35,86 & 35,86 & 197,16 \\
\hline Pelobates cultripes & 30SUH77 & 100,00 & 147,90 & 125,00 & 37,00 & 6946,68 & 345,71 & 12,77 & 332,94 & 101,20 & 241,78 & 241,78 & 64,02 & 543,49 & 74,16 & 4,66 & 49,51 & 192,43 & 32,81 & 32,81 & 181,97 \\
\hline Pelobates cultripes & 30SUH78 & 100,00 & 147,51 & 125,44 & 37,00 & 6943,53 & 345,35 & 11,86 & 333,49 & 101,89 & 241,28 & 241,28 & 63,78 & 527,11 & 70,51 & 4,52 & 48,64 & 184,42 & 33,20 & 33,20 & 174,00 \\
\hline Pelobates cultripes & 30SUH79 & 100,00 & 146,89 & 125,74 & 37,00 & 6936,43 & 344,63 & 10,99 & 333,64 & 126,48 & 240,77 & 240,77 & 63,22 & 511,78 & 67,01 & 4,52 & 47,64 & 178,23 & 33,67 & 33,67 & 166,41 \\
\hline Pelobates cultripes & 30SUH80 & 100,00 & 177,70 & 114,64 & 36,24 & 6641,40 & 358,53 & 48,07 & 310,46 & 108,80 & 266,67 & 266,67 & 96,51 & 528,09 & 77,71 & 2,45 & 58,08 & 203,85 & 18,58 & 18,58 & 196,87 \\
\hline Pelobates cultripes & 30SUH81 & 100,00 & 173,46 & 116,62 & 36,23 & 6739,70 & 358,49 & 42,42 & 316,07 & 103,77 & 263,92 & 263,92 & 91,24 & 537,50 & 79,71 & 2,97 & 57,01 & 206,38 & 20,59 & 20,59 & 197,35 \\
\hline Pelobates cultripes & 30SUH82 & 100,00 & 158,93 & 119,88 & 36,38 & 6896,57 & 351,39 & 26,70 & 324,69 & 88,28 & 252,11 & 252,11 & 75,77 & 578,24 & 85,17 & 4,16 & 54,55 & 218,97 & 26,85 & 26,85 & 207,22 \\
\hline Pelobates cultripes & 30SUH83 & 100,00 & 150,42 & 121,94 & 36,5 & 6952,54 & 346,31 & 17,11 & 329,19 & 79,19 & 244,50 & 244,50 & 66,77 & 593,26 & $85, \varepsilon$ & 4, & 52,75 & 220,49 & 31,11 & 31,11 & 208,25 \\
\hline Pelobates cultripes & \begin{tabular}{|l|} 
30SUHOH \\
304
\end{tabular} & 100,00 & $\begin{array}{l}\frac{13,42}{154,04} \\
\end{array}$ & $\begin{array}{l}121,94 \\
122,48\end{array}$ & 30,7 & $\begin{array}{l}6954,33,70 \\
6940\end{array}$ & $\begin{array}{l}340,51 \\
349,56\end{array}$ & $\frac{11,11}{20,06}$ & \begin{tabular}{|l|}
225,19 \\
329,49
\end{tabular} & \begin{tabular}{|l|l|}
33,92 \\
83,9
\end{tabular} & \begin{tabular}{|l|}
247,70 \\
247
\end{tabular} & \begin{tabular}{|l|}
247,70 \\
247
\end{tabular} & $\begin{array}{l}00,1 / 2 \\
70,27\end{array}$ & \begin{tabular}{|l|l|}
593,20 \\
563,59
\end{tabular} & \begin{tabular}{|l|}
80,90 \\
80,97
\end{tabular} & $\begin{array}{l}4,406 \\
4,26 \\
\end{array}$ & 52,13 & $\begin{array}{l}20,45 \\
207,25 \\
\end{array}$ & \begin{tabular}{|l|l|}
29,19 \\
29
\end{tabular} & $\begin{array}{l}30,11 \\
29,19\end{array}$ & $\begin{array}{l}0,25 \\
196,12\end{array}$ \\
\hline Pelobates cultripes & 30SUH85 & 100,00 & 141,49 & 124,08 & 37,00 & 6965,81 & 339,93 & 7,69 & 332,24 & 91,04 & 235,90 & 235,90 & 58,33 & 591,33 & 82,19 & 5,76 & 49,85 & 213,17 & 36,21 & 36,21 & 200,69 \\
\hline Pelobates cultripes & 30SUH86 & 100,00 & 145,59 & 124,74 & 37,00 & 6964,43 & 343,72 & 10,73 & 332,99 & 98,61 & 239,85 & 239,85 & 61,92 & 559,53 & 77,06 & 5,04 & 49,66 & 200,49 & 33,95 & 33,95 & 188,22 \\
\hline Pelobates cultripes & 30SUH87 & 100,00 & 146,01 & 125,26 & 37,00 & 6949,86 & 344,13 & 10,88 & 333,25 & 99,38 & 240,03 & 240,03 & 62,22 & 539,66 & 72,5 & 4, & 48,75 & 91,20 & 33,88 & 33,88 & 179,09 \\
\hline Pelobates cultripes & 30SUH88 & 100,00 & 144,92 & 125,94 & 37,00 & 6940,05 & 343,28 & 9,27 & 334,01 & $\begin{array}{r}107,70 \\
\end{array}$ & 238,79 & 238,79 & 61,38 & 525,05 & 69 & 4, & 47,69 & 184,06 & 34,63 & 34,63 & 171,40 \\
\hline Pelobates cultripes & 30SUH89 & 100,00 & 148,44 & 126,05 & 37,05 & 6923,10 & 345,99 & 12,38 & 333,61 & 131,37 & 242,10 & 242,10 & 64,94 & 493,66 & 63,99 & 4,09 & 47,51 & 172,80 & 32,73 & 32,73 & 159,31 \\
\hline Pelobates cultripes & 30SUH91 & 100,00 & 173,91 & 115,37 & 36,04 & 6737,19 & 357,76 & 43,66 & 314,10 & 104,35 & 264,36 & 264,36 & 91,91 & 522,34 & 77,31 & 3,08 & 56,38 & 200,06 & 20,91 & 20,91 & 190,64 \\
\hline Pelobates cultripes & 30SUH92 & 100,00 & 163,76 & 118,20 & 36,05 & 6865,54 & 353,73 & 32,17 & 321,56 & 93,18 & 256,31 & 256,31 & 80,76 & 550,32 & 81,49 & 3,78 & 54,71 & 208,74 & 24,99 & 24,99 & 196,92 \\
\hline Pelobates cultripes & 30SUH93 & 100,00 & 157,60 & 120,31 & 36,39 & 6920,18 & 350,89 & 25,01 & 25,88 & 91,03 & 251,12 & 251,12 & 74,21 & 557,10 & 81,35 & 4,24 & 53,21 & 207,95 & 27,88 & 27,88 & 195,62 \\
\hline Pelobates cultripes & 30SUH94 & 100,00 & 155 & 121,73 & 36,89 & $\begin{array}{ll}\mid 652027,27 \\
6927\end{array}$ & 349,65 & 21,51 & \begin{tabular}{|l|}
328,14 \\
32,14
\end{tabular} & $\mid$ & \begin{tabular}{|l|}
248,67 \\
241
\end{tabular} & \begin{tabular}{|l|}
248,67 \\
\end{tabular} & 71,53 & 5499,85 & $\begin{array}{l}\mid c 1,309 \\
78,94\end{array}$ & $\begin{array}{l}4,44 \\
4,31\end{array}$ & $\frac{3,21}{52,02}$ & \begin{tabular}{|l|}
202,57 \\
\end{tabular} & $\begin{array}{l}29,14 \\
29,14\end{array}$ & $\begin{array}{l}2,0,14 \\
29,\end{array}$ & $\begin{array}{l}1530,02 \\
190,15\end{array}$ \\
\hline Pelobates cultripes & 30SUH95 & 100,00 & 140,41 & 124,03 & 37,00 & 6966,58 & 338,94 & 6,78 & 332,16 & 92,96 & 235,03 & 235,03 & 57,38 & 584,27 & 80,83 & 5,92 & 49,15 & 211,03 & 37,01 & 37,01 & 196,48 \\
\hline Pelobates cultripes & 30SUH99 & 100,00 & $\begin{array}{l}14,46,58 \\
146,5\end{array}$ & 126,61 & 37,44 & 6909,73 & 344,29 & $\begin{array}{ll}, 10,52 \\
\end{array}$ & 333,77 & 129,35 & $\begin{array}{l}239,97 \\
\end{array}$ & 239,97 & 63,37 & 489,23 & $\begin{array}{l}62,0,42 \\
62\end{array}$ & 4,24 & 46,151 & $\begin{array}{l}171,92 \\
172\end{array}$ & 33,88 & 33,88 & 156,11 \\
\hline Pelobates cultripes & 30SUJoo & 100,00 & 159,71 & 122,47 & 37,00 & 6806,31 & 352,25 & 26,32 & 325,93 & 85,56 & 250,84 & 250,84 & 76,86 & 505,27 & 67,58 & 3,79 & 50,66 & 178,87 & 29,16 & 29,16 & 171,45 \\
\hline Pelobates cultripes & 30SUJO1 & 100,00 & 160,82 & 121,92 & 37,00 & 6783,25 & 352,34 & 27,82 & 324 & 89,92 & 251,71 & 251,71 & 78,15 & 485,01 & 64,20 & 3,49 & 50,32 & 170,88 & 28,56 & 28,56 & 162,9 \\
\hline Pelobates cultripes & $\begin{array}{l}3050302 \\
3050\end{array}$ & 100,00 & $\begin{array}{l}10,02 \\
159,36\end{array}$ & 121,10 & 37,00 & $\mid \begin{array}{l}\mid 670,20 \\
6790,35 \\
\end{array}$ & 350,54 & $\begin{array}{ll}26,64 \\
264\end{array}$ & \begin{tabular}{|l|l|}
323,95 \\
323
\end{tabular} & \begin{tabular}{|l|}
89,07 \\
89,0
\end{tabular} & \begin{tabular}{|l|}
250,54 \\
25
\end{tabular} & \begin{tabular}{|l|}
250,54 \\
25
\end{tabular} & $\begin{array}{l}0,15 \\
76,72\end{array}$ & \begin{tabular}{|l|}
403,01 \\
476,07
\end{tabular} & $\begin{array}{ll}62,28 \\
62,28\end{array}$ & $\begin{array}{l}0,449 \\
3,92\end{array}$ & $\begin{array}{ll}0,53 \\
49,00\end{array}$ & $\begin{array}{l}16,30,33 \\
166\end{array}$ & $\begin{array}{l}2,0,72 \\
29,2\end{array}$ & $\begin{array}{l}2,300 \\
29,72\end{array}$ & $\begin{array}{l}102,51 \\
157,84\end{array}$ \\
\hline Pelobates cultripes & 30SUJO3 & 100,00 & 158,62 & 120,52 & 37,00 & 6769,54 & 348,91 & 26,27 & 322,64 & 99,67 & 249,47 & 249,47 & 76,11 & 465,44 & 60,16 & 3,94 & 48,21 & 161,70 & 30,25 & 30,25 & 152,66 \\
\hline Pelobates cultripes & 30SUJ06 & 100,00 & 149,68 & 118,42 & 36,71 & 6729,45 & 337,97 & 19,17 & 318,81 & 90,45 & 240,28 & 240,28 & 68,12 & 459,66 & 56,62 & 5,14 & 44,90 & 155,97 & 35,53 & 35,53 & 145,01 \\
\hline Pelobates cultripes & 30SUJ10 & 100,00 & 160,25 & 122,95 & 37,00 & 6834,18 & 353,38 & 26,25 & 327,13 & 88,09 & 251, & 251, & 76 & 497,58 & 66,73 & 3,46 & 50,66 & 174,90 & 28,12 & 28,12 & 168, \\
\hline Pelobates cultripes & 30SUJ11 & 100,00 & 157,28 & 122,27 & 37,00 & 6821,56 & 350,13 & 23,83 & 326,31 & 87,09 & 248,91 & 248,91 & 74,36 & 493,68 & 65,26 & 4,00 & 49,40 & 171,72 & 30,24 & 30,24 & 164,36 \\
\hline
\end{tabular}




\begin{tabular}{|c|c|c|c|c|c|c|c|c|c|c|c|c|c|c|c|c|c|c|c|c|c|}
\hline TAXON & UTM & $\mathrm{km} 2$ & B101 & B102 & $\mathrm{BIO3}$ & BIO4 & B105 & B106 & B107 & B108 & 8109 & BIO10 & BIO11 & BIO12 & 81013 & BIO14 & BIO15 & B1016 & B1017 & B1018 & B1019 \\
\hline Pelobates cultripes & 30SUJ12 & 100,00 & 158,19 & 121,74 & 37,00 & 6812,73 & 350,10 & 25,05 & 325,05 & 103,86 & 249,71 & 249,71 & 75,26 & 474,85 & 61,96 & 3,89 & 48,81 & 164,18 & 29,88 & 29,88 & 156,28 \\
\hline Pelobates cultripes & 30SUJ13 & 100,00 & 156,64 & 121,00 & 37,00 & 6801,50 & 347,80 & 23,78 & 324,02 & 105,67 & 248,01 & 248,01 & 73,92 & 465,89 & 59,87 & 4,12 & 47,67 & 160,01 & 31,00 & 31,00 & 151,35 \\
\hline Pelobates cultripes & 30SUJ14 & 100,00 & 158,51 & 120,24 & 37,00 & 6776,48 & 348,22 & 25,77 & 322,45 & 113,71 & 249,50 & 249,50 & 75,81 & 446,28 & 56,61 & 4,03 & 47,15 & 153,15 & 30,48 & 30,48 & 143,51 \\
\hline Pelobates cultripes & 30SUJ15 & 100,00 & 156,77 & 119,64 & 36,98 & 6758,22 & 345,78 & 24,61 & 321,17 & 114,42 & 247,55 & 247,55 & 74,36 & 439,26 & 54,84 & 4,23 & 46,27 & 149,96 & 31,43 & 31,43 & 139,35 \\
\hline Pelobates cultripes & 30SUJ19 & 100,00 & 148,04 & $\begin{array}{lll}116,97 \\
\end{array}$ & 36,97 & 6669,21 & 333,37 & \begin{tabular}{|l|l|}
18,23 \\
\end{tabular} & 315,14 & $\begin{array}{ll}109,39 \\
\end{array}$ & \begin{tabular}{|l|l|}
237,87 \\
\end{tabular} & 237,87 & 67,00 & \begin{tabular}{|l|l|}
421,03 \\
\end{tabular} & 48,61 & 5,94 & 41,92 & 140,41 & 37,41 & 37,41 & 126,60 \\
\hline Pelobates cultripes & 30 SUJ 20 & 100,00 & 156,96 & 123,03 & 37,00 & 6860,53 & 351,14 & 22,51 & 328,63 & 86,62 & 249,08 & 249,08 & 73,57 & 503,85 & 67,41 & 3,88 & 50,11 & 174,82 & 29,59 & 29,59 & 168,86 \\
\hline Pelobates cultripes & 30SUJ21 & 100,00 & 150,90 & 122,81 & 37,00 & 6860,03 & 345,34 & 17,14 & 328,20 & 83,00 & 243,38 & 243,38 & 67,96 & 511,42 & 67,13 & 4,54 & 48,50 & 175,59 & 32,87 & 32,87 & 168,88 \\
\hline Pelobates cultripes & $\begin{array}{l}0 \text { SUJ } 22 \\
\end{array}$ & 100,00 & 154,62 & 122,09 & 37,00 & 6835,34 & 347,53 & 20,91 & 326,62 & $\begin{array}{ll}106,33 \\
10\end{array}$ & 246,51 & 246,51 & 71,58 & 481,43 & 62,50 & 4,12 & 48,03 & 164,49 & 31,29 & 31,29 & 157,19 \\
\hline Pelobates cultripes & 30SUJ23 & 100,00 & 154,21 & 121,51 & 37,00 & 6828,54 & 346,38 & 21,01 & 325,37 & 117,96 & 246,11 & 246,11 & 71,29 & 468,02 & 59,81 & 4,23 & 47,12 & 159,10 & 31,90 & 31,90 & 150,66 \\
\hline Pelobates cultripes & 30SUJ24 & 100,00 & 155,18 & 120,80 & 37,00 & 6806,05 & 346,03 & 22,25 & 323,78 & 119,90 & 246,76 & 246,76 & 72,42 & 450,64 & 56,65 & 4,29 & 46,35 & 153,20 & 31,85 & 31,85 & 143,24 \\
\hline Pelobates cultripes & 30 SUJ 26 & 100,00 & 152,32 & 119,27 & 36,81 & 6771,48 & 341,38 & 20,07 & 321,31 & 122,77 & 243,51 & 243,51 & 70,08 & 435,45 & 52,76 & 4,90 & 44,36 & 146,68 & 34,10 & 34,10 & 134,77 \\
\hline Pelobates cultripes & 30SUJ27 & 100,00 & 144,30 & 118,69 & 36,73 & 6749,11 & 333,08 & 13,26 & 319,82 & 127,03 & 235,39 & 235,39 & 62,75 & 450,37 & 53,29 & 5,94 & 42,70 & 150,73 & 38,40 & 38,40 & 136,93 \\
\hline Pelobates cultripes & 30SUJ28 & 100,00 & 144,97 & 117,94 & 36,74 & 6718,73 & 332,18 & 14,32 & 317,86 & 127,65 & 235,58 & 235,58 & 63,70 & 436,21 & 50,57 & 6,14 & 41,94 & 145,34 & 38,68 & 38,68 & 130,82 \\
\hline Pelobates cultripes & 30SUJ29 & 100,00 & 145,47 & 117,08 & 36,76 & 6683,31 & 331,32 & 15,28 & 316,03 & 122,78 & 235,70 & 235,70 & 64,65 & 422,31 & 48,16 & 6,32 & 41,13 & 140,39 & 38,88 & 38,88 & 124,91 \\
\hline Pelobates cultripes & 30SUJ30 & 100,00 & 155,59 & 123,52 & 37,00 & 6887,42 & 350,41 & 20,78 & 329,63 & 88,74 & 248,21 & 248,21 & 71,77 & 501,47 & 66,86 & 4,02 & 49,37 & 172,05 & 30,23 & 30,23 & 166,73 \\
\hline Pelobates cultripes & 30SUJ31 & 100,00 & 150,96 & 123,14 & 37,00 & 6882,02 & 345,94 & 16,56 & 329,38 & 115,15 & 243,83 & 243,83 & 67,74 & 502,99 & 65,85 & 4,31 & 48,20 & 171,38 & 32,64 & 32,64 & 164,81 \\
\hline Pelobates cultripes & 30SUJ32 & 100,00 & 151,82 & 122,74 & 37,00 & 6864,87 & 345,74 & 17,56 & 328,18 & 132,25 & 244,36 & 244,36 & 68,72 & 484,56 & 62,45 & 4,38 & 47,40 & 164,73 & 32,69 & 32,69 & 156,66 \\
\hline Pelobates cultripes & 30SUJ34 & 100,00 & 148,27 & 121,21 & 37,00 & 6833,84 & 340,65 & 15,19 & 325,46 & $\begin{array}{l}131,71 \\
\end{array}$ & 240,45 & 240,45 & 65,63 & 468,50 & 58,17 & 5,12 & 45,11 & 158,61 & 35,34 & 35,34 & 147,01 \\
\hline Pelobates cultripes & 30SUJ36 & 100,00 & 152,20 & 119,78 & 36,92 & 6784,40 & 341,57 & 19,43 & 322,15 & 134,07 & 243,51 & 243,51 & 69,69 & 428,59 & 51,38 & 4,99 & 43,87 & 144,37 & 34,22 & 34,22 & 131,29 \\
\hline Pelobates cultripes & 30SUJ37 & 100,00 & 144,70 & 119,00 & 36,75 & 6775,17 & 333,91 & 12,81 & 321,10 & 128,67 & 236,24 & 236,24 & 62,83 & 441,99 & 51,74 & 5,98 & 42,35 & 148,48 & 38,34 & 38,34 & 132,89 \\
\hline Pelobates cultripes & 30SUJ41 & 100,00 & 150,18 & 123,80 & 37,00 & 6888,35 & 345,62 & 15,44 & 330,18 & 133,39 & 243,10 & 243,10 & 66,82 & 497,24 & 64, & 4,4 & 47,59 & \begin{tabular}{|l|}
170,07 \\
\end{tabular} & 32,98 & 32,98 & 161,42 \\
\hline Pelobates cultripes & $\begin{array}{l}30 \mathrm{suJ} 43 \\
\end{array}$ & 100,00 & 145,44 & 122,64 & 37,00 & 6874,67 & 339,72 & 11,30 & 328,42 & 128,48 & 238,21 & 238,21 & 62,43 & 485,61 & 60,68 & 5,23 & 45,29 & 165,68 & 36,31 & 36,31 & 152,99 \\
\hline Pelobates cultripes & 30SUJ44 & 100,00 & 150,27 & 121,69 & 37,00 & \begin{tabular}{|l|l|}
6850,13 \\
\end{tabular} & 342,60 & 16,21 & 326,39 & 133,96 & 242,56 & 242,56 & 67,19 & \begin{tabular}{|l|l|}
455,08 \\
\end{tabular} & 56,06 & 4,84 & 45,04 & \begin{tabular}{ll|}
154,78 \\
\end{tabular} & 34,32 & 34,32 & \begin{tabular}{ll|l}
141,87 \\
\end{tabular} \\
\hline Pelobates cultripes & 30SUJ46 & 100,00 & 149,38 & 120,01 & 36,91 & 6803,76 & 339,39 & 16,32 & 323,06 & 133,49 & 241,15 & 241,15 & 66,78 & 431,73 & 51,15 & 5,34 & 43,24 & 146,16 & 35,74 & 35,74 & 130,47 \\
\hline Pelobates cultripes & 30SUJ47 & 100,00 & 139,20 & 119,04 & 36,58 & 6777,43 & 328,92 & 7,78 & 321,14 & 122,71 & 231,06 & 231,06 & 57,63 & 456,81 & 52,81 & 6,85 & 41,34 & 153,92 & 41,97 & 41,97 & 135,41 \\
\hline Pelobates cultripes & 30SUJ49 & 100,00 & 140,21 & 117,42 & \begin{tabular}{|c|}
36,08 \\
\end{tabular} & 6738,94 & 327,38 & 9,10 & 318,27 & \begin{tabular}{ll|}
124,44 \\
\end{tabular} & 231,39 & 231,39 & 58,99 & 427,31 & 49,60 & 6,98 & 39,94 & 142,94 & 41,89 & 41,89 & 123,03 \\
\hline Pelobates cultripes & \begin{tabular}{|l|l}
$305 U J 50$ \\
\end{tabular} & 100,00 & 148,90 & 124,47 & 37,00 & 6917,34 & 345,44 & \begin{tabular}{|c|}
13,79 \\
13
\end{tabular} & 331,64 & 128,63 & 242,25 & 242,25 & 65,34 & 509,58 & 66,83 & 4,47 & 47,94 & 175,40 & 33,10 & $\begin{array}{l}33,10 \\
33,10\end{array}$ & 166,39 \\
\hline Pelobates cultripes & 30SUJ51 & 100,00 & 150,69 & 124,01 & 37,00 & 6903,21 & 346,19 & 15,61 & 330,58 & 133,95 & 243,75 & 243,75 & 67,07 & 486,99 & 62,77 & 4,30 & 47,21 & 167,55 & 32,59 & 32,59 & 156,91 \\
\hline Pelobates cultripes & 30SUJ52 & 100,00 & 147,69 & 123,67 & 37,00 & 6888,11 & 342,84 & 12,90 & 329,94 & 130,79 & 240,73 & 240,73 & 64,54 & 482,92 & 60,95 & 4,93 & 45,89 & 165,87 & 34,88 & 34,88 & 153,01 \\
\hline Pelobates cultripes & 30SUJ55 & 100,00 & 146,73 & 121,31 & 37,00 & 6863,51 & 338,99 & 12,70 & 326,29 & 130,64 & 239,38 & 239,38 & 63,78 & 446,39 & 53,20 & 5,31 & 43,38 & 152,17 & 36,42 & 36,42 & 135,53 \\
\hline Pelobates cultripes & 30SUJ56 & 100,00 & 144,03 & 120,42 & 36,71 & 6835,28 & 335,41 & 10,61 & 324,80 & 127,69 & 236,51 & 236,51 & 61,60 & 443,45 & 51,75 & 5,95 & 42,22 & 150,82 & 38,71 & 38,71 & 132,20 \\
\hline Pelobates cultripes & \begin{tabular}{|l|l|}
$305 U J 57$ \\
3050
\end{tabular} & 100,00 & 132,87 & 119,36 & 36,71 & | 6787,24 & 323,47 & $\begin{array}{c}10,61 \\
1,64 \\
\end{array}$ & 321,84 & 115,81 & \begin{tabular}{|l|}
224,95 \\
\end{tabular} & 224,97 & 51,61 & $\begin{array}{l}443,407 \\
473,97 \\
\end{array}$ & 54,74 & $\begin{array}{l}3,79 \\
7,79\end{array}$ & $\begin{array}{l}42,24 \\
40,19\end{array}$ & $\begin{array}{l}160,11 \\
160\end{array}$ & 46,02 & $\begin{array}{l}0,11 \\
46,03 \\
\end{array}$ & 138,46 \\
\hline Pelobates cultripes & 30SUJ59 & 100,00 & 139,33 & 117,47 & 36,02 & 6758,71 & 326,81 & 7,85 & 318,96 & 123,33 & 230,97 & 230,97 & 57,93 & 426,18 & 49,96 & 7,13 & 39,41 & 142,91 & 42,85 & 42,85 & 121,35 \\
\hline Pelobates cultripes & 30SUJ60 & 100,00 & 144,95 & 125,02 & 37,00 & 6931,42 & 342,47 & 9,61 & 332,86 & 127,68 & 238,68 & 238,68 & 61,42 & 513,86 & 66,62 & 4,90 & 47,07 & 177,92 & 35,18 & 35,18 & 165,95 \\
\hline Pelobates cultripes & 30SUJ61 & 100,00 & 147,49 & 124,72 & 37,00 & 6918,40 & 343,85 & 11,91 & 331,94 & 130,79 & 240,96 & 240,96 & 63,70 & 489,01 & 62,27 & 4,62 & 46,51 & 169,13 & 34,19 & 34,19 & 155,95 \\
\hline Pelobates cultripes & 30SUJ62 & 100,00 & 149,63 & 123,97 & 37,00 & 6899,46 & 344,74 & 14,23 & 330,51 & 133,09 & 242,72 & 242,72 & 66,02 & 467,27 & 58,39 & 4,57 & 45,74 & 161,13 & 33,77 & 33,77 & 147,07 \\
\hline Pelobates cultripes & \begin{tabular}{|l|l}
3050363 \\
30503
\end{tabular} & 100,00 & $\begin{array}{l}14,05,25 \\
145,2\end{array}$ & 123,52 & 37,00 & $\begin{array}{l}0.53,409 \\
6890,92\end{array}$ & 340,28 & $\begin{array}{l}4,25 \\
10,49 \\
\end{array}$ & \begin{tabular}{|l|}
329,79 \\
329
\end{tabular} & 128,27 & 238,45 & $\begin{array}{l}242,1 / 2 \\
238,45\end{array}$ & $\begin{array}{l}60,0<4 \\
62,09\end{array}$ & $\begin{array}{l}40,27 \\
469,25 \\
\end{array}$ & 57,34 & 5, 4,25 & $\begin{array}{ll}4,1 / 38 \\
44,38\end{array}$ & $\begin{array}{l}161,49 \\
161\end{array}$ & 36,57 & $\begin{array}{ll}30,17 \\
6,57\end{array}$ & $\begin{array}{l}147,012 \\
45,12\end{array}$ \\
\hline Pelobates cultripes & 30SUJ64 & 100,00 & 145,08 & 122,74 & 37,00 & 6870,34 & 338,94 & 10,49 & 328,45 & 128,49 & 238,01 & 238,01 & 62,12 & 457,61 & 54,77 & 5,32 & 43,57 & 157,08 & 37,04 & 37,04 & 139,56 \\
\hline Pelobates cultripes & 30SUJ65 & 100,00 & 141,45 & 121,91 & 36,99 & 6863,46 & 334,63 & 7,48 & 327,16 & 124,84 & 234,37 & 234,37 & 58,69 & 459,14 & 53,75 & 5,96 & 42,35 & $\mid 157,07$ & 39,61 & 39,61 & 137,65 \\
\hline Pelobates cultripes & 30SUJ66 & 100,00 & 138,87 & 120,82 & 36,84 & 6853,41 & 330, & 5,46 & 325,52 & 122,02 & 231,64 & 231,64 & 56,39 & 456,53 & 52,59 & 6,61 & 41,24 & 155,54 & 41,78 & 41,78 & 134,68 \\
\hline Pelobates cultripes & 30SUJ67 & 100,00 & 133,27 & 119,57 & 36,5 & 6810,94 & 324,28 & 1,23 & 323,05 & 116,30 & 225,70 & 225,72 & 51,75 & 467,28 & 54,22 & 7,76 & 39,82 & 158,18 & 45,99 & 46,01 & 135,44 \\
\hline 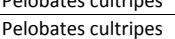 & $\begin{array}{l}305010 \\
3050\end{array}$ & 100,00 & $\begin{array}{l}13,27 \\
149,86\end{array}$ & 125,35 & 37,000 & $\begin{array}{l}08102,44 \\
692,91\end{array}$ & 34,28 & \begin{tabular}{r|}
, 25 \\
13,57 \\
\end{tabular} & $\begin{array}{l}33,05 \\
332,92 \\
\end{array}$ & $\begin{array}{l}110,00 \\
133,03 \\
\end{array}$ & $\begin{array}{l}243,10 \\
2432\end{array}$ & $\begin{array}{l}243,1 / 32 \\
2432\end{array}$ & \begin{tabular}{|l|l|}
66,07 \\
66
\end{tabular} & \begin{tabular}{|l|}
$40,1,20$ \\
485,27
\end{tabular} & $\begin{array}{l}34,2< \\
62,41\end{array}$ & $\begin{array}{l}, 104 \\
4,04\end{array}$ & $\begin{array}{l}35,02 \\
47,35\end{array}$ & \begin{tabular}{|l|}
$150,10,93$ \\
168
\end{tabular} & $\begin{array}{l}45,99 \\
32,20\end{array}$ & $\begin{array}{l}0,10 \\
32,20 \\
\end{array}$ & $\begin{array}{l}153,44 \\
156,07\end{array}$ \\
\hline Pelobates cultripes & 30SUJ71 & 100,00 & 150,08 & 125,08 & 37,00 & 6909,14 & 346,05 & 13,92 & 332,12 & 133,77 & 243,34 & 243,34 & 66,37 & \begin{tabular}{|l|l|}
469,68 \\
\end{tabular} & 59,18 & 4,21 & 46,36 & 163,15 & 32,79 & 32,79 & 148,78 \\
\hline Pelobates cultripes & 30SUJ73 & 100,00 & 140,36 & 124,17 & 37,00 & 6901,19 & 336,28 & 5,26 & 331,02 & 123,41 & 233,78 & 233,78 & 57,29 & 478,84 & 57,47 & 5,66 & 43,40 & 165,37 & 39,18 & 39,18 & 146,33 \\
\hline Pelobates cultripes & 30SUJ74 & 100,00 & 143,51 & 123,26 & 37,00 & 6884,85 & 337,84 & 8,47 & 329,36 & 126,77 & 236,64 & 236,64 & 60,49 & 455,14 & 53,60 & 5,38 & 42,92 & 56,66 & 37,91 & 37,91 & 137,36 \\
\hline Pelobates cultripes & 30suJ75 & 100,00 & 140,25 & 122,33 & 37,00 & $\begin{array}{l}60076,04 \\
6876,04 \\
\end{array}$ & 333,4 & 8,96 & 327,85 & 123,67 & 233,36 & 233,36 & $\begin{array}{l}57,40 \\
57,4\end{array}$ & 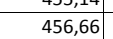 & 52,75 & 6 & 41,78 & 156,56 & 40,66 & 40,66 & 135,52 \\
\hline Pelobates cultripes & 30SUJ76 & 100,00 & 131 & 12 & 36,99 & 6845,36 & 324,71 & $-0,64$ & 325,36 & 114,22 & 224,64 & 224,64 & 49,95 & 478,72 & 55,45 & 7,72 & 40,05 & 163,20 & 46,50 & 46,50 & 139,57 \\
\hline Pelobates cultripes & $\begin{array}{l}0 \text { SUJ77 } \\
30\end{array}$ & 100,00 & 129,08 & 119,84 & 36,69 & 6811,62 & 320,59 & $-2,58$ & 323,17 & 111,64 & 221,71 & 221,73 & 47,82 & 479,38 & 56,10 & 8,50 & 38,99 & 162,42 & 49,09 & 49,11 & 137,63 \\
\hline Pelobates cultripes & 30SUJ78 & 100,00 & 129,47 & 118,53 & 36,27 & 6797,85 & 319,50 & $-1,77$ & 321,27 & 112,44 & 221,84 & 221,86 & 48,38 & 467,19 & 55,19 & 8,76 & 38,21 & 157,42 & 49,51 & 49,52 & 132,25 \\
\hline Pelobates cultripes & 30SUJ79 & 100,00 & 140,64 & 117,26 & 36,00 & 6813,01 & 328,23 & 8,23 & 319,99 & 124,71 & 232,97 & 232,97 & 58,34 & 417,31 & \begin{tabular}{l|l}
49,25 \\
\end{tabular} & 7,44 & 38,68 & 139,88 & 43,10 & 43,10 & 117,30 \\
\hline Pelobates cultripes & 305Uנ80 & 100,00 & $\frac{146}{146}$ & $\begin{array}{l}111,26 \\
126,21\end{array}$ & 37,15 & $\begin{array}{l}\mid 201012,49 \\
6912,49\end{array}$ & 343 & $\begin{array}{l}0,5 \\
10,46 \\
\end{array}$ & $\begin{array}{l}33,52 \\
333,5\end{array}$ & $\begin{array}{l}129,46 \\
\end{array}$ & \begin{tabular}{|l|}
240,11 \\
\end{tabular} & \begin{tabular}{|l|}
240,11 \\
\end{tabular} & $\begin{array}{l}30,344 \\
63,38\end{array}$ & | & $\begin{array}{l}45,25 \\
61,28 \\
\end{array}$ & $\frac{7,44}{4,30}$ & $\begin{array}{l}30,000 \\
46,40\end{array}$ & \begin{tabular}{|l|}
169,49 \\
169
\end{tabular} & 34,09 & $\begin{array}{l}3,10 \\
34,09 \\
\end{array}$ & 153,91 \\
\hline Pelobates cultripes & 30SUJ81 & 100,00 & 146,86 & 125,88 & 37,04 & 6901,70 & 343,59 & 10,77 & 332,83 & 130,04 & 240,18 & 240,18 & 63,61 & 470,88 & 58,30 & 4,47 & 45,48 & 164,25 & 34,40 & 34,40 & 147,42 \\
\hline Pelobates cultripes & 30SUJ82 & 100,00 & 142,16 & 125,58 & 37,00 & 6902,37 & 338,97 & 6,55 & 332,42 & 125,21 & 235,64 & 235,64 & 59,16 & \begin{tabular}{|l|l|}
475,08 \\
\end{tabular} & 57,40 & 5,16 & 44,01 & 165,12 & 37,56 & 37,56 & 146,14 \\
\hline Pelobates cultripes & 30SUJ83 & 100,00 & 143,81 & 124,75 & 37,00 & 6892,71 & 339,36 & 8,21 & 331,16 & 127,29 & 237,03 & 237,03 & 60,78 & 457,21 & 54,14 & 5,19 & 43,40 & 158,38 & 37,21 & 37,21 & 138,80 \\
\hline Pelobates cultripes & 30SUJ84 & 100,00 & 147 & 123,58 & 37,00 & 6891,58 & 341,06 & 11,29 & 329,77 & 130,97 & 240,20 & 244 & 63,63 & 435,05 & 50,60 & 5,04 & 43,12 & 150,06 & 36,03 & 36,03 & 130 \\
\hline Pelobates cultripes & $\begin{array}{l}3050048 \\
305 U 35\end{array}$ & 100,00 & $\begin{array}{l}14,10 \\
139,86\end{array}$ & $\begin{array}{l}122,50 \\
122,68\end{array}$ & 37,00 & | $68983,90 \mid$ & 333,48 & $\begin{array}{r}1,23 \\
5,15 \\
\end{array}$ & 328,33 & $\begin{array}{ll}123,22 \\
\end{array}$ & \begin{tabular}{|l|}
233,10 \\
230
\end{tabular} & \begin{tabular}{|l|}
233,10 \\
230
\end{tabular} & \begin{tabular}{|l|}
57,01 \\
57
\end{tabular} & \begin{tabular}{|l|}
452,03 \\
452,03
\end{tabular} & 50,20 & $\begin{array}{l}3,044 \\
6,18 \\
\end{array}$ & $\begin{array}{ll}43,1,36 \\
41,4\end{array}$ & $\begin{array}{l}154,99 \\
154\end{array}$ & $\begin{array}{l}30,140 \\
41,14\end{array}$ & $\begin{array}{l}30,13 \\
41,14 \\
\end{array}$ & 133,15 \\
\hline Pelobates cultripes & 30 SUJ86 & 100,00 & 139,18 & 121,51 & 37,00 & 6872,99 & 331,72 & 5,03 & 326,69 & 122,69 & 232,32 & 232,32 & 56,42 & 445,18 & 51,66 & 6,55 & 40,38 & 151,85 & 42,23 & 42,23 & 129,33 \\
\hline Pelobat & 30SUJ87 & 100,00 & 128,53 & 120,22 & 36,90 & 6825,34 & 320,44 & $-3,11$ & 323.55 & 111,06 & 221.42 & 221.42 & 47,25 & 476.95 & 56,08 & 8.54 & 38.63 & 161.68 & 49,58 & 49.58 & 136,07 \\
\hline Pelobates cultripes & 30 SUJ88 & 100,00 & 137,01 & 118,73 & 36,06 & 6843,51 & 326,82 & 3,88 & 322,94 & 120,65 & 229,86 & 229,8 & 54, & 436,48 & 51,38 & 7,67 & 38,58 & 147,06 & 45,13 & 45,13 & 123,42 \\
\hline Pelobates cultripes & $30 S U J 89$ & 100,00 & 141,21 & 117,18 & 36,00 & 6841,64 & 328,87 & 8,27 & 320,60 & 125,26 & 233,80 & 233,80 & 58,44 & 415,03 & 48,84 & 7,40 & 38,23 & 138,75 & 43,40 & 43,40 & 116,36 \\
\hline
\end{tabular}




\begin{tabular}{|c|c|c|c|c|c|c|c|c|c|c|c|c|c|c|c|c|c|c|c|c|c|}
\hline TAXON & UTM & $\mathrm{km} 2$ & B101 & B102 & $\mathrm{BIO3}$ & BIO4 & B105 & B106 & B107 & B108 & B109 & B1010 & BIO11 & BIO12 & B1013 & BIO14 & BIO15 & B1016 & B1017 & B1018 & B1019 \\
\hline Pelobates cultripes & 30SUJ90 & 100,00 & 147,43 & 126,93 & 37,81 & 6900,37 & 344,48 & 11,01 & 333,48 & 130,56 & 240,56 & 240,56 & 64,01 & 470,35 & 58,48 & 4,19 & 45,79 & 164,89 & 33,69 & 33,69 & 147,89 \\
\hline Pelobates cultripes & 30SUJ91 & 100,00 & 147,66 & 126,60 & $\begin{array}{l}37,53 \\
\end{array}$ & 6892,61 & 344,21 & 11,08 & 333,13 & 131,09 & 240,71 & 240,71 & 64,23 & 455,62 & 55,28 & 4,29 & 45,06 & 159,29 & 33,96 & 33,96 & 141,21 \\
\hline Pelobates cultripes & 30SUJ92 & 100,00 & 146,89 & 126,23 & 37,28 & 6888,05 & 342,90 & 10,26 & 332,64 & 130,50 & 239,83 & 239,83 & 63,38 & 447,19 & 53,12 & 4,36 & 44,15 & 155,79 & 34,83 & 34,83 & 136,70 \\
\hline Pelobates cultripes & 30SUJ94 & 100,00 & 144,67 & 124,35 & 37,00 & 6881,74 & 339,03 & 8,86 & 330,17 & 128,28 & 237,71 & 237,71 & 61,62 & 436,28 & 50,80 & 5,20 & 42,51 & 150,51 & 37,62 & 37,62 & 129,38 \\
\hline Pelobates cultripes & 30SUJ95 & 100,00 & 136,17 & 123,12 & 37,00 & \begin{tabular}{|l|l|}
6876,93 \\
\end{tabular} & 330,38 & 1,78 & 328,60 & 119,18 & 229,47 & 229,47 & 53,59 & 460,05 & 53,51 & 6,70 & 40,60 & 157,81 & 43,56 & 43,56 & 134,31 \\
\hline Pelobates cultripes & 30SUJ96 & 100,00 & 140,58 & 121,71 & 36,98 & 6881,84 & 332,97 & 5,60 & 327,37 & 124,21 & 233,66 & 233,66 & 57,52 & 435,73 & 50,77 & 6,36 & 40,32 & 148,64 & 41,68 & 41,68 & 125,90 \\
\hline Pelobates cultripes & 30SUJ97 & 100,00 & 132,15 & 120,44 & 36,84 & 6851,92 & 324,03 & $-0,53$ & 324,56 & 115,20 & 225,31 & 225,31 & 50,23 & 460,33 & 54,11 & 8,08 & 38,49 & 155,84 & 47,81 & 47,81 & 130,91 \\
\hline Pelobates cultripes & 30SUJ98 & 100,00 & 131,73 & 118,86 & 36,18 & 6842,66 & 322,13 & $-0,47$ & 322,60 & 114,83 & 224,72 & 224,73 & 49,97 & 454,45 & 53,69 & 8,53 & 37,87 & 152,77 & 48,75 & 48,75 & 127,88 \\
\hline Pelobates cultripes & 30SUJ99 & 100,00 & 137,42 & 117,29 & 36,00 & 6853,44 & 325,79 & 4,68 & 321,11 & 121,32 & 230,47 & 230,47 & 54,88 & 427,42 & 50,38 & 8,04 & 37,70 & 142,60 & 46,05 & 46,05 & 119,32 \\
\hline Pelobates cultripes & 30SUK00 & 100,00 & 154,22 & 116,00 & 36,98 & 6606,87 & 336,84 & 25,18 & 311,66 & 111,86 & 242,90 & 242,90 & 73,32 & 397,89 & 46,22 & 5,18 & 42,40 & 134,44 & 34,42 & 34,42 & 120,55 \\
\hline Pelobates cultripes & 30SUKO1 & 100,00 & 154,70 & 115,56 & 37,00 & 6570,73 & 335,95 & 26,02 & 309,94 & 112,48 & 242,89 & 242,89 & 74,18 & 386,27 & 44,60 & 5,27 & 41,76 & 130,38 & 34,47 & 34,47 & 115,88 \\
\hline Pelobates cultripes & 30SUKO2 & 100,00 & 157,32 & 115,00 & 37,00 & 6535,01 & 336,74 & 28,77 & 307,97 & 115,01 & 244,70 & 244,70 & 76,95 & 368,51 & 42,81 & 5,00 & 41,51 & 125,01 & 33,47 & 33,47 & 109,88 \\
\hline Pelobates cultripes & \begin{tabular}{|l|} 
30SUK10 \\
\end{tabular} & 100,00 & 155,03 & 116,19 & 36,88 & |6631,04 & 337,90 & 25,12 & 312,77 & $\mid$ & 243,99 & 243,99 & 73,90 & 387,96 & $\begin{array}{l}\mid \\
44,67 \\
420\end{array}$ & 5,10 & 41,97 & 130,74 & 33,97 & 33,97 & 116,10 \\
\hline Pelobates cultripes & 30SUK11 & 100,00 & 154,99 & 115,95 & 37,00 & 6596,19 & 336,55 & 25,81 & 310,74 & 112,56 & 243,61 & 243,61 & 74,08 & 378,55 & 43,34 & 5,32 & 41,05 & 127,47 & 34,37 & 34,37 & 111,92 \\
\hline Pelobates cultripes & 30SUK12 & 100,00 & 155,81 & 115,07 & 37,00 & 6556,55 & 335,75 & 26,94 & 308,82 & 113,23 & 243,57 & 243,57 & 75,22 & 366,27 & 42,02 & 5,35 & 40,46 & 123,19 & 34,38 & 34,38 & 107,31 \\
\hline Pelobates cultripes & 30 SUK20 & 100,00 & 152,34 & 116,41 & 36,72 & 6656,78 & 335,88 & 21,83 & 314,05 & 112,85 & 241,70 & 241,70 & 71,10 & 389,60 & 44,33 & 5,61 & 41,33 & 130,12 & 35,49 & 35,49 & 114,67 \\
\hline Pelobates cultripes & 30 SUK21 & 100,00 & 154,40 & 115,95 & 36,93 & 6627,13 & 336,39 & 24,47 & 311,92 & 111,71 & 243,48 & 243,48 & 73,37 & 373,45 & 42,32 & 5,56 & 40,64 & 125,13 & 34,54 & 34,54 & 109,02 \\
\hline Pelobates cultripes & 30SUK22 & 100,00 & 153,51 & 115,03 & 36,75 & 6590,10 & 334,04 & 24,14 & 309,90 & 110,88 & 241,71 & 241,71 & 72,60 & 366,62 & 41,84 & 6,00 & 40,20 & 122,49 & 35,40 & 35,40 & 105,70 \\
\hline Pelobates cultripes & 30SUK31 & 100,00 & 154,50 & 115,69 & 36,49 & 6643,90 & 336,36 & 23,79 & 312,57 & 113,64 & 243,60 & 243,60 & 73,10 & 368,84 & 41,88 & 5,61 & 40,27 & 123,02 & 35,06 & 35,06 & 106,35 \\
\hline Pelobates cultripes & 30SUK32 & 100,00 & 151,96 & 115,00 & 36,26 & $\mid 6621,24$ & 332.95 & 22,09 & 310,85 & 111,36 & 240,81 & 240,81 & 70,95 & 366,31 & 42,20 & 6,19 & 39,38 & $\mid 121,68$ & 36,48 & 36,48 & 104,07 \\
\hline Pelobates cultripes & 30SUK40 & 100,00 & 146,53 & 116,44 & 36,23 & 6706,19 & 331,25 & 15,48 & 315,77 & 129,94 & 236,95 & 236,95 & 65,07 & \begin{tabular}{|c|}
397,08 \\
\end{tabular} & $46, \mathrm{C}$ & 6,48 & 39,79 & 131,86 & 39,04 & 39,04 & 113,41 \\
\hline Pelobates cultripes & 30 SUK41 & 100,00 & 148,86 & 115,56 & 36,17 & 6671,69 & 331,60 & 18,05 & 313,56 & 126,31 & 238,56 & 238,56 & 67,48 & 380,72 & $\begin{array}{l}44,31 \\
4\end{array}$ & 6,51 & 39,38 & $\begin{array}{l}125,79 \\
\end{array}$ & 38,29 & 38,29 & 107,69 \\
\hline Pelobates cultripes & 30SUK42 & 100,00 & 153,17 & 114,75 & \begin{tabular}{|l|l|}
36,09 \\
\end{tabular} & $\begin{array}{ll}6644,08 \\
\end{array}$ & 333,95 & 22,73 & 311,21 & 112,53 & 242,41 & 242,41 & 71,86 & 359,77 & 41,62 & 6,11 & 39,30 & 119,29 & 36,19 & 36,19 & 101,33 \\
\hline Pelobates cultripes & 30SUK50 & 100,00 & 146,51 & 116,31 & 36,01 & 6737,53 & 331,38 & 14,77 & 316,62 & 131,71 & 237,39 & 237,39 & 64,44 & 394,60 & 45,99 & 6,64 & 39,18 & 131,05 & 39,60 & 39,60 & 111,67 \\
\hline Pelobates cultripes & 30SUK51 & 100,00 & 149,50 & 115,26 & 36,00 & 6702,48 & 332,43 & 18,28 & 314,14 & 128,10 & 239,76 & 239,76 & 67,73 & 376,64 & 43,95 & 6,52 & 38,94 & 124,28 & 38,22 & 38,22 & 105,82 \\
\hline Pelobates cultripes & 30SVF08 & 100,00 & 133,56 & 113,95 & 38,03 & 6023,94 & 304,68 & 10,38 & 294,30 & 71,01 & 215,36 & 215,38 & 62,47 & 616,68 & 84,1 & 7,03 & 55,93 & 246,27 & 32,40 & 32,95 & 237,63 \\
\hline Pelobates cultripes & 30SVF09 & 100,00 & 136,99 & 115,65 & 38,00 & 6143,62 & 311,83 & 11,90 & 299,92 & 72,73 & 220,46 & 220,46 & 64,20 & 596,54 & $\begin{array}{l}4,0,01 \\
80,\end{array}$ & 6,42 & 55,62 & 238,08 & 29,95 & 29,95 & 229,69 \\
\hline Pelobates cultripes & 30SVF18 & 100,00 & 126,82 & 117,46 & 38,02 & 6171,08 & 304,79 & 1,30 & 303,49 & 63,14 & 210,80 & 210,83 & 54,17 & 631,64 & 82,95 & 7,90 & 53,93 & 245,10 & 35,22 & 35,73 & 239,22 \\
\hline Pelobates cultripes & 30 SVG00 & 100,00 & 140,34 & 115,24 & 37,99 & 6202,73 & 315,66 & 15,01 & 300,65 & 74,86 & 224,61 & 224,61 & 66,69 & 582,23 & 79,01 & 6,38 & 55,46 & 231,74 & 29,46 & 29,46 & 222,61 \\
\hline Pelobates cultripes & 30 SVG 30 & 100,00 & 148,16 & 118,29 & 38,00 & 6278,06 & 326,89 & 19,56 & 307,33 & 81,36 & 233,53 & 233,53 & 73,22 & 479,05 & 64,55 & 5,64 & 53,49 & 187,07 & 24,65 & 24,65 & 178,29 \\
\hline Pelobates cultripes & 30 SVG32 & 100,00 & 155,35 & 116,17 & 37,27 & 6367,30 & 333,48 & 27,03 & 306,45 & 86,06 & 241,90 & 241,90 & 79,03 & 449,20 & 60,94 & 5,31 & 53,20 & 174,40 & 23,25 & 23,25 & 164,69 \\
\hline Pelobates cultripes & 30SVG43 & 100,00 & $\begin{array}{l}147,47 \\
147\end{array}$ & 119,11 & 37,00 & 6579,18 & 333,78 & 17,30 & \begin{tabular}{|l|l|}
316,48 \\
\end{tabular} & 78,58 & \begin{tabular}{|l|}
237,05 \\
23,0
\end{tabular} & \begin{tabular}{|l|}
237,05 \\
\end{tabular} & 69,25 & $\begin{array}{l}443,20 \\
511,75\end{array}$ & $\begin{array}{l}0,349 \\
66,96\end{array}$ & $\frac{6,32}{6,32}$ & 51,28 & $\begin{array}{l}186,44 \\
186\end{array}$ & 27,85 & 27,85 & 184,32 \\
\hline Pelobates cultripes & 30SVG82 & 100,00 & 137,17 & 117,37 & 37,33 & 6421,42 & 318,57 & 9,05 & 309,52 & 89,62 & 224,11 & 224,44 & 61,34 & 504,70 & 63,27 & 7,80 & 47,40 & $\mid 177,97$ & 34,45 & 40,80 & 172,27 \\
\hline Pelobates cultripes & 30SVG91 & 100,00 & 123,64 & 117,72 & 37,63 & 6400,30 & 305,85 & $-3,53$ & 309,38 & 75,38 & 210,51 & 211,27 & 48,91 & 561,19 & 69,47 & 10,75 & 44,90 & 196,42 & 44,97 & 52,32 & 186,69 \\
\hline Pelobates cultripes & 30SVG92 & 100,00 & 131,97 & 117,07 & 37,32 & 6407,26 & 312,95 & 4,42 & 308,53 & 84,12 & 218,78 & 219,35 & 56,67 & 518,62 & 64,18 & 8,86 & 45,68 & 181,84 & 38,77 & 46,37 & 173,32 \\
\hline Pelobates cultripes & 30SVH01 & 100,00 & 173,25 & 114,34 & 36,00 & 6739,98 & 356,56 & 43,78 & 312,78 & 103,74 & 263,86 & 263,86 & 91,44 & 511,77 & 75,83 & 3,23 & 55,60 & 195,58 & 21,62 & 21,62 & 185,27 \\
\hline Pelobates cultripes & $\begin{array}{l}\text { SOSVHO2 } \\
3 \text { VHOt }\end{array}$ & 100,00 & 166,13 & $\begin{array}{l}114,54 \\
116,79\end{array}$ & 36,00 & |6846,37 & 354,41 & $\begin{array}{l}45,10 \\
35,08\end{array}$ & \begin{tabular}{|l|}
319,33 \\
310
\end{tabular} & \begin{tabular}{|c|}
06,84 \\
96,84
\end{tabular} & \begin{tabular}{|l|}
$258,37,0$ \\
\end{tabular} & \begin{tabular}{|l|}
$258,37,3$ \\
\end{tabular} & $\begin{array}{ll}1,4431 \\
331\end{array}$ & 530,30 & $\begin{array}{l}70,03 \\
78,73\end{array}$ & $3,3,62$ & 54,40 & $\mid$ & $\begin{array}{l}21,024 \\
24,27\end{array}$ & $\begin{array}{l}12,202 \\
24,27 \\
\end{array}$ & $\begin{array}{l}10,27 \\
188,86\end{array}$ \\
\hline Pelobates cultripes & 30SVHO3 & 100,00 & 155,87 & 119,93 & 36,17 & 6936,06 & 349,27 & 23,47 & 325,80 & 103,94 & 249,62 & 249,62 & 72,41 & 553,67 & 80,94 & 4,54 & 52,48 & 207,08 & 29,00 & 29,00 & 192,78 \\
\hline Pelobates cultripes & 30SVH06 & 100,00 & 152,24 & 123,95 & 37,00 & 6927,25 & 348,01 & 17,46 & 330,55 & 105,68 & 245,73 & 245,73 & 68,59 & 511,84 & 70,05 & 4,21 & 49,41 & 184,61 & 30,80 & 30,80 & 170,22 \\
\hline Pelobates cultripes & 30SVH07 & 100,00 & 145,28 & 125,58 & 37,04 & 6933,85 & 342,96 & 10,19 & 332,77 & 98,85 & 239,11 & 239,11 & 61,93 & 519,53 & 68,96 & 4,83 & 47,56 & 184,41 & 34,67 & 34,67 & 169,24 \\
\hline Pelobates cultripes & 30SVH08 & 100,00 & 146,68 & 126,35 & 37,34 & 6917,47 & 344,27 & 10,82 & 333,44 & 123,90 & 240,12 & 240,12 & 63,49 & 495,58 & 64, & 4,3 & 46,88 & \begin{tabular}{|l|}
175,07 \\
\end{tabular} & 33,86 & 33,86 & 159,05 \\
\hline Pelobates cultripes & \begin{tabular}{|l|} 
SOSVINOS \\
$30 \mathrm{VH} 09$
\end{tabular} & 100,00 & $\begin{array}{l}14,00 \\
146,35\end{array}$ & $\begin{array}{l}120,33 \\
127,13\end{array}$ & 37, 37,87 & $\begin{array}{l}6911,41 \\
6903,11\end{array}$ & $\begin{array}{l}344,21 \\
343,78\end{array}$ & \begin{tabular}{|l|}
0,920 \\
9
\end{tabular} & \begin{tabular}{|l|}
$333,4,81$ \\
333
\end{tabular} & $\begin{array}{l}129,14 \\
129,14\end{array}$ & \begin{tabular}{|l|}
239,60 \\
232
\end{tabular} & \begin{tabular}{|l|}
239,12 \\
239,60
\end{tabular} & $\begin{array}{l}63,44 \\
63,14 \\
\end{array}$ & \begin{tabular}{|l}
493,50 \\
478,40
\end{tabular} & $\frac{0,4,-1}{60,0}$ & 4,1 & $\begin{array}{l}46,00 \\
46,07\end{array}$ & $\begin{array}{l}173,01 \\
168,82\end{array}$ & $\begin{array}{l}33,00 \\
33,85\end{array}$ & $\begin{array}{l}33,00 \\
33,85 \\
\end{array}$ & $\begin{array}{l}139,05 \\
151,16\end{array}$ \\
\hline Pelobates cultripes & 30SVH11 & 100,00 & 173,27 & 113,34 & 36,00 & 6740,93 & 355,86 & 44,18 & 311,68 & 103,58 & 263,83 & 263,83 & 91,41 & 500,60 & 74,46 & 3,27 & 55,22 & 191,21 & 21,66 & 21,66 & 180,09 \\
\hline Pelobates cultripes & 30SVH15 & 100,00 & 155,79 & 121,83 & 36,99 & 6898,91 & 349,23 & 22,23 & 327,01 & 109,29 & 248,88 & 248,88 & 72,53 & 506,77 & 70,68 & 4,16 & 50,15 & 85,38 & 29,49 & 29,49 & 170,10 \\
\hline Pelobates cultripes & 30SVH17 & 100,00 & 147,46 & 125,23 & 37,01 & 6913,02 & 344,08 & 12,32 & 31,76 & 104,38 & 240,95 & 240,95 & 64,36 & 499,75 & 65, & 4,5 & 47,34 & 77,79 & 33,55 & 33,55 & 161,52 \\
\hline Pelobates cultripes & 30SVH22 & 100,00 & 167,66 & 115,08 & 36,00 & 6811,41 & 353,58 & 37,68 & 315,90 & \begin{tabular}{|l|l|}
117,58 \\
\end{tabular} & 259,44 & 259,44 & 85,38 & 498,74 & $\begin{array}{l}73, \\
73,\end{array}$ & 3,6 & 53,34 & 188,84 & 24,08 & 24,08 & 174,98 \\
\hline Pelobates cultripes & $30 \mathrm{SVH} 25$ & 100,00 & 145,86 & 122,79 & 36,97 & 6929,03 & 341,56 & 12,40 & 329,17 & 98,79 & 239,69 & 239,69 & 62,92 & 532,36 & 72,99 & 5,5 & 48,12 & 193,73 & 35,29 & 35,29 & 175,10 \\
\hline Pelobates cultripes & $\begin{array}{l}30 \text { SVH26 } \\
\end{array}$ & 100,00 & 149,29 & 123,54 & 37,00 & 6905,60 & 344,42 & 15,08 & 329,34 & 102,72 & 242,76 & 242,76 & 66,32 & 502,27 & 67,41 & 4,82 & 47,70 & 180,86 & 33,34 & 33,34 & 163,47 \\
\hline Pelobates cultripes & 30 SVH27 & 100,00 & 148,80 & 124,78 & 37,01 & 6891,23 & 344,31 & 13,92 & 330,39 & 109,97 & 241,93 & 241,93 & 65,91 & 485,85 & 63,41 & 4,50 & 46,86 & 172,89 & 33,36 & 33,36 & 155,74 \\
\hline Pelobates cultripes & $30 \mathrm{SVH} 29$ & 100,00 & 145,92 & 127,20 & 37,97 & 6871,08 & 342,44 & 9,62 & 332,82 & 128,69 & 238,79 & 238,79 & 63,22 & 461,63 & 56,56 & 4,32 & 44,88 & 25 & 34,75 & 34,75 & 143,18 \\
\hline Pelobates cultripes & 30SVH35 & 100,00 & $\begin{array}{l}14,52,37 \\
140,3\end{array}$ & $\begin{array}{l}123,203 \\
123,03\end{array}$ & 37,00 & (601, 60,83 & 336,74 & $\begin{array}{l}3,02 \\
7,07 \\
\end{array}$ & 32 & \begin{tabular}{|c|c|}
20,009 \\
92,90
\end{tabular} & \begin{tabular}{|l|}
$234,50,5$ \\
\end{tabular} & \begin{tabular}{|l|}
$234,50,5$ \\
\end{tabular} & $\begin{array}{l}57,87 \\
57,8 \\
\end{array}$ & $\begin{array}{l}401,05 \\
542,59\end{array}$ & $\begin{array}{l}\mid 70,300 \\
73,30\end{array}$ & 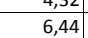 & $\begin{array}{l}44,00 \\
46,68\end{array}$ & \begin{tabular}{|l|}
196,41 \\
196,41
\end{tabular} & 38,99 & 38,99 & $\begin{array}{l}143,10 \\
175,76\end{array}$ \\
\hline Pelobates cultripes & $30 \mathrm{SVH} 36$ & 100,00 & 147,72 & 123,40 & 37,00 & 6898,34 & 342,58 & 13,64 & 328,94 & 101,11 & 241,08 & 241,08 & 64,94 & 497,93 & 66,21 & 5,07 & 46,86 & 178,98 & 34,49 & 34,49 & 160,34 \\
\hline Pelobates cultripes & 30 SVH 38 & 100,00 & 148,85 & 125,41 & 37,41 & 6858,53 & 343,64 & 13,66 & 329,98 & $\mid 131,73$ & 241,52 & 241,52 & 66,19 & 460,18 & 57,72 & 4,16 & 45,48 & $\mid 163,18$ & 33,46 & $\mid 33,46$ & 143,98 \\
\hline Pelobates cultripes & $30 \mathrm{SVH} 41$ & 100,00 & 172,06 & 112,09 & 36,00 & 6687,70 & 352,28 & 43,94 & 308,34 & 125,90 & 261,96 & 261,96 & 91,14 & 458,41 & 66,63 & 3,46 & 52,76 & 173,03 & 22,34 & 22,34 & 160,08 \\
\hline Pelobates cultripes & $30 \mathrm{SVH} 42$ & 100,00 & 168,91 & 114,17 & 36,00 & 6738,83 & 351,87 & 39,52 & 312,34 & 122,59 & 259,43 & 259,43 & 87,43 & 461,65 & 66,40 & 3,64 & 51,84 & 173,28 & 24,00 & 24,00 & 158 \\
\hline Pelobates cultripes & $30 \mathrm{SVH} 43$ & 100,00 & 163,33 & 116,73 & 36,05 & 6798,84 & 349,91 & 32,62 & 317,29 & $\begin{array}{ll}116,79 \\
\end{array}$ & 254,96 & 254,96 & 81,34 & 471,24 & 66,79 & 4,03 & 50,53 & $\begin{array}{l}175,58 \\
\end{array}$ & 26,70 & 26,70 & 158,96 \\
\hline Pelobates cultripes & $30 \mathrm{SVH} 44$ & 100,00 & 148,33 & 120,66 & 36,76 & 6890,83 & 341,28 & 15,92 & 325,37 & 100,84 & 241,58 & 241,58 & 65,94 & 515,72 & 70,99 & 5,67 & 47,88 & 189,17 & 34,67 & 34,67 & 168,88 \\
\hline Pelobate & $30 \mathrm{SVH} 46$ & 100,00 & 146,07 & 123,18 & 37,00 & 6878,33 & 340,31 & 12,33 & 327.98 & 99.86 & 239,18 & 239,18 & 63.76 & 494.85 & 65,02 & 5,43 & 45.99 & 177.10 & 36,01 & 36,01 & 157.28 \\
\hline Pelobates cultripes & 30SVH47 & 100,00 & 145,99 & 124,14 & 37,00 & 6870,11 & 340,45 & 11,56 & 328,90 & 119,88 & 238,96 & 238, & 63, & 480,10 & 61,46 & 5,12 & 45,32 & 170,58 & 36,08 & 36,08 & 150,46 \\
\hline Pelobates cultripes & 30SVH54 & 100,00 & 152,54 & 119,68 & 36,80 & 6830,84 & 342,73 & 20,42 & 322,31 & 105,50 & 244,79 & 244,79 & 70,64 & 485,61 & 65,96 & $\begin{array}{l}5,25 \\
5,25\end{array}$ & 47,56 & 177,26 & 32,77 & 32,77 & 157,69 \\
\hline
\end{tabular}




\begin{tabular}{|c|c|c|c|c|c|c|c|c|c|c|c|c|c|c|c|c|c|c|c|c|c|}
\hline TAXON & UTM & $\mathrm{km} 2$ & B101 & B102 & $\mathrm{BIO3}$ & BIO4 & B105 & B106 & B107 & B108 & B109 & BIO10 & BIO11 & BIO12 & 81013 & BIO14 & BIO15 & B1016 & B1017 & BIO18 & B1019 \\
\hline Pelobates cultripes & 30SVH56 & 100,00 & 144,76 & 122,97 & 37,00 & 6864,75 & 338,35 & 11,25 & 327,10 & 104,27 & 237,83 & 237,83 & 62,92 & 490,56 & 63,53 & 5,96 & 45,01 & 174,62 & 37,62 & 37,62 & 153,92 \\
\hline Pelobates cultripes & 30SVH59 & 100,00 & 144,79 & 124,84 & 37,39 & 6825,02 & 338,13 & 9,79 & 328,35 & 127,27 & 236,96 & 236,96 & 62,84 & 454,60 & 55,18 & 5,40 & 42,85 & 160,04 & 38,25 & 38,25 & 136,98 \\
\hline Pelobates cultripes & 30SVH64 & 100,00 & 154,19 & 119,16 & 36,95 & 6780,69 & 342,24 & 22,47 & 319,76 & 107,34 & 245,70 & 245,70 & 72,69 & 464,67 & 61,84 & 5,05 & 46,69 & 168,01 & 32,31 & 32,31 & 148,91 \\
\hline Pelobates cultripes & 30SVH65 & 100,00 & 145,01 & 121,56 & 37,00 & 6830,51 & 336,83 & 12,36 & 324,47 & 98,63 & 237,55 & 237,55 & 63,40 & 490,13 & 63,78 & 6,22 & 44,91 & 175,06 & 37,89 & 37,89 & 153,67 \\
\hline Pelobates cultripes & 30SVH74 & 100,00 & 156,35 & 118,46 & 37,00 & \begin{tabular}{|l|l|}
6713,76 \\
\end{tabular} & 341,89 & \begin{tabular}{|l|l|}
24,83 \\
\end{tabular} & 317,06 & \begin{tabular}{|l|l|}
109,79 \\
\end{tabular} & 246,80 & 246,80 & 75,59 & 4442,10 & 57,42 & 4,87 & 45,98 & 158,07 & 31,52 & 31,52 & 139,85 \\
\hline Pelobates cultripes & 30SVH75 & 100,00 & 148,09 & 120,87 & 37,00 & 6772,70 & 337,37 & 15,63 & 321,74 & 110,62 & 239,64 & 239,64 & 66,96 & 466,38 & 59,56 & 5,92 & 44,41 & 165,41 & 36,67 & 36,67 & 144,59 \\
\hline Pelobates cultripes & 30SVH76 & 100,00 & 142,16 & 122,42 & 37,00 & 6812,50 & 333,83 & 9,07 & 324,76 & 123,00 & 234,41 & 234,41 & 60,91 & 480,67 & 60,20 & 6,83 & 42,80 & 170,17 & 40,83 & 40,83 & 146,37 \\
\hline Pelobates cultripes & 30SVH81 & 100,00 & 159,91 & 114,97 & 36,91 & 6589,05 & 339,97 & 30,88 & 309,10 & 113,51 & 248,51 & 248,56 & 80,65 & 429,66 & 56,23 & 4,73 & 47,06 & 154,55 & 28,56 & 29,46 & 139,10 \\
\hline Pelobates cultripes & 30SVH83 & 100,00 & 152,89 & 118,31 & 37,00 & 6684,40 & 337,84 & 21,87 & 315,97 & 105,94 & 242,93 & 242,93 & 72,76 & 448,93 & 57,69 & 5,49 & 45,15 & 159,88 & 33,55 & 33,55 & 140,90 \\
\hline Pelobates cultripes & 30SVH94 & 100,00 & 149,32 & 119,44 & 37,01 & 6665,62 & 334,43 & 17,92 & 316,51 & 125,98 & 239,23 & 239,23 & 69,49 & 442,82 & 55,28 & 6,04 & 43,18 & 155,66 & 36,73 & 36,77 & 134,33 \\
\hline Pelobates cultripes & 30SVH95 & 100,00 & 143,64 & 121,02 & 37,12 & 6708,19 & 331,32 & 11,41 & 319,91 & 124,45 & 234,24 & 234,24 & 63,41 & 460,92 & 57,49 & 6,88 & 41,94 & 162,34 & 40,95 & 40,95 & 137,51 \\
\hline Pelobates cultripes & 30SVH97 & 100,00 & 139,67 & 122,69 & 37,56 & 6736,95 & 329,12 & 6,52 & 322,60 & $\begin{array}{ll}120,83 \\
\end{array}$ & 230,82 & 230,82 & 59,15 & 465,53 & 57,73 & 7,51 & 40,27 & 163,32 & 44,75 & 44,75 & 135,38 \\
\hline Pelobates cultripes & 30SVJ00 & 100,00 & $\begin{array}{lll}148,87 & \end{array}$ & 127,44 & 38,00 & 6881,30 & 345,65 & 11,99 & 333,65 & 132,29 & 241,78 & 241,78 & 65,87 & 452,13 & 55,12 & 4,00 & 45,43 & 158,93 & 32,90 & 32,90 & 140,79 \\
\hline Pelobates cultripes & 30SVJ01 & 100,00 & 145,96 & 127,77 & \begin{tabular}{|l|l|}
37,97 \\
\end{tabular} & 6873,92 & 342,90 & 8,98 & 333,92 & 129,55 & 238,77 & 238,77 & 63,01 & 448,95 & 53,61 & 4,16 & 44,37 & 157,40 & 34,68 & 34,68 & 137,48 \\
\hline Pelobates cultripes & $305 \mathrm{VJ} 02$ & 100,00 & 143,81 & 127,26 & 38,00 & 6880,20 & 340,49 & 7,06 & 333,44 & 127,11 & 236,74 & 236,74 & 60,84 & 446,77 & 53,00 & 4,54 & 43,43 & 156,01 & 36,44 & 36,44 & 134,77 \\
\hline Pelobates cultripes & 30SVJO3 & 100,00 & 142,10 & 126,30 & 37,46 & 6881,69 & 338,09 & 5,64 & 332,45 & 125,62 & 235,12 & 235,12 & 59,01 & 445,49 & 52,57 & 5,19 & 42,22 & 154,66 & 38,37 & 38,37 & 132,61 \\
\hline Pelobates cultripes & 30SVJ04 & 100,00 & 135,10 & 124,96 & \begin{tabular}{|l|l|}
37,05 \\
\end{tabular} & 6881,69 & 330,80 & 0,21 & 330,58 & 118,02 & 228,37 & 228,37 & 52,55 & 466,01 & 54,44 & 6,42 & 40,85 & 160,88 & 43,42 & 43,42 & 136,69 \\
\hline Pelobates cultripes & 30SVJ06 & 100,00 & 129,19 & 121,97 & 37,00 & 6851,31 & 322,54 & $-3,91$ & 326,45 & $\begin{array}{l}111,79 \\
\end{array}$ & 222,27 & 222,27 & 47,47 & 477,10 & 55,90 & 8,28 & 38,71 & 162,20 & 49,38 & 49,38 & 136,52 \\
\hline Pelobates cultripes & 30SVJ08 & 100,00 & 128,99 & 118,95 & 36,32 & 6836,28 & 319,54 & $-2,78$ & 322,32 & 111,71 & 221,98 & 222,00 & 47,55 & 465,26 & 54,82 & 9,07 & 37,28 & 155,83 & 51,08 & 51,10 & 130,69 \\
\hline Pelobates cultripes & 30SVJ09 & 100,00 & 139,00 & 117,17 & 36,00 & 6873,60 & 327,36 & 5,94 & 321,43 & 123,10 & 232,25 & 232,25 & 56,13 & 423,66 & 49,44 & 8,03 & 37,47 & 140,40 & 45,81 & 45,81 & 118,53 \\
\hline Pelobates cultripes & 30SVJ10 & 100,00 & 148,49 & 128,22 & 38,00 & 6857,95 & 344,86 & 11,30 & 333,56 & 132,17 & 240,94 & 240,94 & 65,41 & 442,34 & 53,4 & 4,00 & 44,74 & 155,84 & 33,31 & 33,31 & 136,15 \\
\hline Pelobates cultripes & 30SVJ11 & 100,00 & 147,16 & 128,77 & 38,00 & 6852,44 & 343,75 & 9,46 & 334,29 & 131,07 & 239,31 & 239,31 & 64,03 & 431,67 & 52,12 & 4,00 & 44,03 & 151,79 & 33,87 & 33,87 & 130,75 \\
\hline Pelobates cultripes & 30SVJ12 & 100,00 & 145,34 & 127,97 & 38,00 & \begin{tabular}{|l|l|}
6855,16 \\
\end{tabular} & $\begin{array}{lll}341,47 & \end{array}$ & 8,08 & 333,38 & 129,08 & 237,77 & 237,77 & 62,36 & \begin{tabular}{|l|l|}
430,18 \\
\end{tabular} & 51,64 & 4,23 & 43,15 & 150,32 & 35,40 & 35,40 & 128,68 \\
\hline Pelobates cultripes & 30SVJ13 & 100,00 & 143,91 & 126,68 & 37,89 & 6858,15 & 339,39 & 7,36 & 332,03 & 127,80 & 236,59 & 236,59 & 61,18 & 430,37 & 51,26 & 4,76 & 42,04 & 149,31 & 37,37 & 37,37 & 127,06 \\
\hline Pelobates cultripes & 30SVJ17 & 100,00 & 131,07 & 120,62 & 36,84 & 6857,65 & 322,85 & $-1,81$ & 324,66 & 114,03 & 224,17 & 224,17 & 49,04 & 461,86 & 54,09 & 8,49 & 37,81 & 155,32 & 49,35 & 49,35 & 130,82 \\
\hline Pelobates cultripes & 30SVJ18 & 100,00 & 131,14 & 119,15 & 36,31 & 6845,13 & 321,53 & $-1,08$ & 322,61 & 114,18 & 224,04 & 224,04 & 49,31 & 457,24 & 53, & 8,76 & 37,21 & 152,28 & 50,13 & 50,13 & 128,56 \\
\hline Pelobates cultripes & 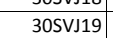 & 100,00 & 136,40 & 117,32 & 36,00 & |6863,28 & 324,79 & 3,71 & \begin{tabular}{|l|}
321,08 \\
\end{tabular} & 120,36 & 229,45 & 229,45 & 53,82 & 434,31 & 50,33 & 8,44 & 37,00 & 142,90 & 47,74 & 47,74 & 121,74 \\
\hline Pelobates cultripes & 30 SVJ20 & 100,00 & 147,62 & 128,19 & 38,00 & 6846,08 & 343,72 & 10,63 & 333,09 & 131,12 & 239,85 & 239,85 & 64,75 & 437,74 & 53,16 & 4,03 & 44,23 & 154,48 & 33,94 & 33,94 & 133,55 \\
\hline Pelobates cultripes & $30 \mathrm{SVJ} 23$ & 100,00 & 145,52 & 126,56 & 37,99 & 6840,83 & 340,04 & 8,74 & 331,30 & 129,61 & 237,74 & 237,74 & 62,74 & 420,08 & 50,24 & 4,60 & 42,20 & 145,53 & 36,85 & 36,85 & 123,39 \\
\hline Pelobates cultripes & 30 SVJ26 & 100,00 & 131,86 & 122,48 & 37,00 & 6854,60 & 324,92 & $-1,52$ & 326,44 & 114,67 & 224,86 & 224,86 & 49,79 & 461,87 & 53,92 & 7,87 & 38,37 & 156,21 & 48,18 & 48,18 & 131,69 \\
\hline Pelobates cultripes & 30 SVJ27 & 100,00 & 138,01 & 120,68 & 36,75 & 6871,08 & 329,10 & 3,85 & 325,25 & 121,88 & 230,97 & 230,97 & 55,32 & 434,99 & 50,34 & 7,21 & 38,25 & 145,27 & 44,89 & 44,89 & 123,82 \\
\hline Pelobates cultripes & $\begin{array}{l}0 \mathrm{SVJ} 28 \\
3\end{array}$ & 100,00 & 135,25 & 119,14 & 36,33 & 6859,47 & 325,16 & $\begin{array}{l}2,00 \\
2,30 \\
\end{array}$ & 322,87 & $\begin{array}{ll}118,00 \\
118,86\end{array}$ & \begin{tabular}{|l|}
228,19 \\
\end{tabular} & \begin{tabular}{|l|}
228,19 \\
\end{tabular} & 52,80 & \begin{tabular}{|l|l|}
442,13 \\
\end{tabular} & 51,11 & 8,18 & $\begin{array}{ll}37,29 \\
37,29\end{array}$ & $\begin{array}{l}146,24 \\
\end{array}$ & $\begin{array}{l}4,0,59 \\
47,5\end{array}$ & $\begin{array}{l}47,59 \\
47,59\end{array}$ & 124,93 \\
\hline Pelobates cultripes & 30 SVJ29 & 100,00 & 137,95 & 117,35 & 36,00 & 6861,37 & 325,99 & 5,17 & 320,82 & 122,23 & 230,87 & 230,87 & 55,37 & 430,23 & 49,26 & 8,04 & 37,27 & 140,51 & 46,49 & 46,49 & 121,50 \\
\hline Pelobates cultripes & 30 SVJ30 & 100,00 & 146,76 & 127,10 & 37,99 & 6842,75 & 342,09 & 10,56 & 331,53 & 130,08 & 239,26 & 239,26 & 64,42 & 438,42 & 53,29 & 4,09 & 43,92 & 154,52 & 34,53 & 34.53 & 133,05 \\
\hline Pelobates cultripes & 30 SVJ33 & 100,00 & 146,07 & 125,88 & 37,83 & 6835,78 & 339,76 & 9,77 & 329,99 & 130,11 & 238,23 & 238,23 & 63,47 & 417,42 & 49,97 & 4,87 & 41,82 & 144,18 & 37,16 & 37,16 & 122,00 \\
\hline Pelobates cultripes & 30 SVJ 34 & 100,00 & 136,18 & 125,01 & 37,16 & 6853,50 & 330,64 & 1,10 & 329,54 & 119,39 & 229,01 & 229,01 & 53,96 & \begin{tabular}{|l|l|}
451,78 \\
\end{tabular} & 53,40 & 6,54 & 39,76 & 154,97 & 44,15 & 44,15 & 130,48 \\
\hline Pelobates cultripes & |30SVJ44 & 100,00 & $\begin{array}{l}130,10 \\
134,94\end{array}$ & $\begin{array}{ll}124,01 \\
124,47\end{array}$ & 37,18 & $\mid 60337,59$ & 328,72 & $\begin{array}{l}1,10 \\
0,39 \\
\end{array}$ & 328,33 & $\begin{array}{ll}11,3,39 \\
117,92\end{array}$ & \begin{tabular}{|l|}
227,52 \\
27,5
\end{tabular} & \begin{tabular}{|l|}
227,52 \\
27,5
\end{tabular} & 52,91 & $\begin{array}{l}451,10 \\
457,44\end{array}$ & 53,83 & $\begin{array}{l}0,44 \\
7,13 \\
\end{array}$ & 39,26 & $\begin{array}{l}156,41 \\
15,4\end{array}$ & $\begin{array}{l}44,113 \\
46,03 \\
\end{array}$ & $\begin{array}{l}44,1,03 \\
46,03\end{array}$ & $\begin{array}{l}130,40 \\
131,50\end{array}$ \\
\hline Pelobates cultripes & 30 SVJ45 & 100,00 & 128,65 & 123,56 & 37,03 & 6835,67 & 322,47 & $-4,44$ & 326,91 & 111,14 & 221,50 & 221,50 & 47,35 & 478,31 & 55,59 & 8,50 & 37,84 & 162,32 & 50,98 & 50,98 & 136,15 \\
\hline Pelobates cultripes & 30SVJ54 & 100,00 & 144,27 & 123,68 & 37,15 & 6812,25 & 335,56 & 8,92 & 326,64 & 128,22 & 236,22 & 236,22 & 61,91 & 420,01 & 49,45 & 5,94 & 39.88 & $\mid 142,7$ & 40,63 & 40,63 & 121,01 \\
\hline Pelobates cultripes & 30 SVJ60 & 100,00 & 146,60 & 124,06 & 37,64 & 6791,43 & 337,84 & 11,36 & 326,48 & 129,55 & 237,93 & 237,93 & 64,54 & 433,45 & 52,76 & 5,2 & 41,85 & 151,32 & 37,87 & 37,87 & 128,27 \\
\hline Pelobates cultripes & 30 SVJ64 & 100,00 & 145,46 & 123,06 & 37,06 & 6786,10 & 335,44 & 10,40 & 325,05 & 129,29 & 236,99 & 236,99 & 63,45 & 415,23 & $48, \varepsilon$ & 6,0 & 39,58 & 140,40 & 40,97 & 40,97 & 118,88 \\
\hline 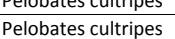 & $\begin{array}{l}3050404 \\
305 \mathrm{~V} 65 \\
\end{array}$ & 100,00 & $\begin{array}{l}14,40 \\
142,53 \\
\end{array}$ & $\begin{array}{l}12,00 \\
122,46\end{array}$ & $\begin{array}{l}37,00 \\
37,01\end{array}$ & $\begin{array}{l}0 / 8,0,10 \\
6797,50\end{array}$ & 332,44 & \begin{tabular}{|l|}
0,0401 \\
8
\end{tabular} & $\begin{array}{l}324,65 \\
324,61 \\
\end{array}$ & $\begin{array}{l}12,29 \\
126,37\end{array}$ & $\mid$\begin{tabular}{|l|}
234,29 \\
234,29
\end{tabular} & \begin{tabular}{|l|l|}
234,29 \\
234
\end{tabular} & $\begin{array}{l}30,45 \\
60,49 \\
\end{array}$ & \begin{tabular}{|l|}
422,73 \\
422,73
\end{tabular} & $\begin{array}{l}4,6, c \\
49,1\end{array}$ & $\begin{array}{l}0,00 \\
6,82\end{array}$ & $\begin{array}{l}35,50 \\
38,56\end{array}$ & $\begin{array}{l}140,404 \\
141,88 \\
\end{array}$ & \begin{tabular}{|l|}
43,16 \\
43,
\end{tabular} & $\begin{array}{l}40,191 \\
43,16\end{array}$ & $\begin{array}{l}1110,00 \\
120,14\end{array}$ \\
\hline Pelobates cultripes & 30 SVJ66 & 100,00 & 142,55 & 121,58 & 37,00 & 6801,44 & 331,60 & 8,51 & 323,09 & 126,80 & 234,23 & 234,23 & 60,47 & 420,51 & 48,24 & 7,00 & 38,27 & 139,51 & 43,66 & 43,66 & 119,16 \\
\hline Pelobates cultripes & 30 SVJ68 & 100,00 & 139,38 & 119,45 & 36,99 & 6792,24 & 326,91 & 6,43 & 320,48 & 121,76 & 230,94 & 230,94 & 57,30 & 429,52 & 48,12 & 8,10 & 36,96 & 139,14 & 46,72 & 46,72 & 121,38 \\
\hline Pelobates cultripes & 30SVJ76 & 100,00 & 143, & 121,29 & 37,03 & 6768,62 & 331,36 & 9,25 & 322,12 & 127,52 & 234,38 & 234,38 & 61,47 & 416,98 & 47,5 & 7,05 & 37,74 & 137,95 & 44,09 & 44,09 & 117,32 \\
\hline Pelobates cultripes & 30 SVJ77 & 100,00 & $\begin{array}{l}142,13 \\
142,13\end{array}$ & 120,53 & 37,00 & 6778,90 & 329, & 8,49 & 321,02 & 126,27 & 233,47 & 233,47 & $\begin{array}{l}1,40,07 \\
\end{array}$ & \begin{tabular}{|l|l|}
419,88 \\
\end{tabular} & 47, & 7,60 & 36,94 & 137,13 & $\begin{array}{l}44,50 \\
458\end{array}$ & 45,58 & 117,90 \\
\hline Pelobates cultripes & 30 SVJ86 & 100,00 & 140,81 & 121,76 & 37,16 & 6746,40 & 328,68 & 6,90 & 321,79 & 124,73 & 231,79 & 231,79 & 59,32 & 425,55 & 48,34 & 7,76 & 37,00 & 140,92 & 46,98 & 46,98 & 118,40 \\
\hline Pelobates cultripes & $\begin{array}{l}30 \mathrm{SV} J 97 \\
\end{array}$ & 100,00 & 140,27 & 120,99 & 37,04 & 6723,97 & 326,42 & 6,76 & 319,66 & 124,05 & 230,68 & 230,68 & 58,99 & 424,32 & 48,05 & 8,25 & 35,79 & 139,12 & 49,18 & 49,18 & 116,06 \\
\hline Pelobates cultripes & 30SVK10 & 100,00 & 139,54 & 115,28 & 35,74 & 6879,58 & 326,16 & 7,09 & 319,07 & 121,73 & 232,81 & 232,81 & 56,51 & 420,94 & 48,24 & 8,56 & 36,62 & 136,80 & 46,77 & 46,77 & 117,76 \\
\hline Pelobates cultripes & 30SVK42 & 100,00 & 143,69 & 112,19 & 35,34 & 6798,35 & 325,53 & 13,30 & 312,22 & 99,84 & 234,97 & 234,97 & 60,75 & 416,79 & 48,69 & 8,62 & 37,00 & 140,71 & 44,87 & 44,87 & 121,01 \\
\hline Pelobates cultripes & $\begin{array}{l}305 \mathrm{SW} 4 \mathrm{~s} \\
3\end{array}$ & 100,00 & $\frac{148}{148}$ & $\begin{array}{l}11,1,13 \\
111,22\end{array}$ & 37,23 & $\mid 6192,77$ & 317,25 & $\begin{array}{ll}1,30 \\
23,82\end{array}$ & $\begin{array}{l}52,2<4 \\
293,44\end{array}$ & $\begin{array}{r}502,47 \\
102\end{array}$ & \begin{tabular}{|l|}
231,48 \\
231
\end{tabular} & \begin{tabular}{|l|}
232,64 \\
\end{tabular} & $\begin{array}{l}\mid 0,13 \\
74,95\end{array}$ & 412,52 & $\begin{array}{l}40,05 \\
51,19\end{array}$ & $\frac{0,024}{6,22}$ & $\begin{array}{ll}3,00 \\
43,74\end{array}$ & \begin{tabular}{|l|}
139,83 \\
139,1
\end{tabular} & $\begin{array}{ll}44,01 \\
32,02\end{array}$ & 38,50 & 130,54 \\
\hline Pelobates cultripes & 30SWG48 & 100,00 & 133,42 & 116,38 & \begin{tabular}{|l|l|}
37,97 \\
\end{tabular} & 6375,05 & 310,23 & 5,79 & 304,44 & 112,25 & 219,40 & 220,26 & 58,35 & 472,79 & 60,70 & 9,84 & 38,89 & 161,44 & 47,91 & 51,92 & 137,14 \\
\hline Pelobates cultripes & 30SWG58 & 100,00 & 132,19 & 116,23 & $38,00 \mid$ & 6326,25 & 307,48 & 4.76 & 302,72 & 110,73 & 217,41 & 218,48 & 57,78 & 472,41 & 60,94 & 10,33 & 37,96 & 160,56 & 49,95 & 53,66 & 134,45 \\
\hline Pelobates cultripes & 30SWG59 & 100,00 & 132,38 & 117,02 & 38,00 & 6359,18 & 308,74 & 4,14 & 304,60 & 111,25 & 217,97 & 218,96 & 57,32 & 470,81 & 60,97 & 10,31 & 37,72 & 160,66 & 50,57 & 53,86 & 132,38 \\
\hline Pelobates cultripes & 30SWG88 & 100,00 & 139,40 & 114,28 & 38,41 & 6118,37 & 306,33 & 13,00 & 293,33 & 118 & 221,25 & 222 & 66,99 & 427,34 & 55,49 & 9,14 & 37,66 & 142,09 & 46,64 & 50,95 & 116,48 \\
\hline Pelobates cultripes & 30SWG96 & 100,00 & $\begin{array}{l}13,40 \\
144,29\end{array}$ & $\begin{array}{l}114,20 \\
110,90\end{array}$ & 年0,41 & 59040,80 & $\begin{array}{l}304,21 \\
304,21\end{array}$ & $\begin{array}{l}1,000 \\
20,36\end{array}$ & \begin{tabular}{|l|}
283,85 \\
283
\end{tabular} & \begin{tabular}{|l|l|}
118,84 \\
\end{tabular} & \begin{tabular}{|l|}
223,43 \\
220
\end{tabular} & \begin{tabular}{|l|}
225,23 \\
223
\end{tabular} & \begin{tabular}{|l|}
74,01 \\
745
\end{tabular} & | & $\begin{array}{l}30,45 \\
51,29\end{array}$ & $\begin{array}{l}3,144 \\
7,93\end{array}$ & $\begin{array}{l}38,00 \\
38,69\end{array}$ & \begin{tabular}{|l|}
132,37 \\
132,3
\end{tabular} & $\begin{array}{l}40,04 \\
41,16 \\
\end{array}$ & $\begin{array}{l}0,85 \\
46,88\end{array}$ & $\begin{array}{l}1110,40 \\
112,11\end{array}$ \\
\hline Pelobates cultripes & 30SWG98 & 100,00 & 148,92 & 113,06 & 38,88 & 5976,33 & 310,19 & 23,00 & 287,19 & 120,97 & 228,47 & 229,83 & 77,71 & 382,85 & 49,54 & 7,04 & 39,39 & 127,28 & 39,17 & 45,08 & 103,99 \\
\hline Pelobates cultripes & 30SWG99 & 100,00 & 141,93 & 115,04 & 38,85 & 6098,75 & 307,93 & 14,80 & 293,13 & 121,79 & 223,39 & 224,51 & 69,38 & 413,51 & 54,08 & 8,66 & 37,59 & 137,00 & 45,97 & 50,49 & 109,85 \\
\hline Pelobates cultripes & 30SWHOO & 100,00 & 135,70 & 118,81 & 37,07 & 6620,45 & 321,12 & 5,99 & 315,12 & 97,55 & 225,36 & 225, & 57, & 503,33 & 63,04 & 9,04 & 42,12 & 176,09 & 44 & 46,68 & 153,98 \\
\hline Pelobates cultripes & 30 SWHO4 & 100,00 & 153,38 & 118,44 & 37,31 & 6570,38 & 334,75 & 22,41 & 312,34 & 134,77 & 241,78 & 241,81 & 74,35 & 415,06 & 52,06 & 5,56 & 42,79 & 144,82 & 34,95 & 35,32 & 123,95 \\
\hline
\end{tabular}




\begin{tabular}{|c|c|c|c|c|c|c|c|c|c|c|c|c|c|c|c|c|c|c|c|c|c|}
\hline TAXON & UTM & $\mathrm{km} 2$ & B101 & B102 & $\mathrm{BIO3}$ & BIO4 & B105 & B106 & B107 & B108 & B109 & B1010 & BIO11 & BIO12 & 81013 & B1014 & BIO15 & B1016 & B1017 & B1018 & B1019 \\
\hline Pelobates cultripes & 30SWH17 & 100,00 & 134,64 & 122,57 & 38,00 & 6673,81 & 322,48 & 2,36 & 320,11 & 115,32 & 224,87 & 224,87 & 55,14 & 470,69 & 59,10 & 9,06 & 38,14 & 164,29 & 51,01 & 51,01 & 131,44 \\
\hline Pelobates cultripes & 30SWH23 & 100,00 & 135,81 & 119,95 & \begin{tabular}{|l|l|}
37,88 \\
\end{tabular} & 6573,86 & 319,58 & 5,31 & 314,27 & 115,67 & 224,68 & 224,79 & 57,81 & 473,78 & 60,36 & 9,25 & 39,12 & 164,77 & 48,83 & 49,47 & 135,25 \\
\hline Pelobates cultripes & 30SWH25 & 100,00 & 140,51 & 120,64 & 38,00 & 6580,19 & 324,05 & 8,96 & 315,09 & 121,21 & 229,27 & 229,33 & 61,99 & 444,95 & 56,81 & 7,98 & 39,07 & 154,85 & 46,07 & 46,40 & 125,01 \\
\hline Pelobates cultripes & 30SWH26 & 100,00 & 142,96 & 120,98 & 38,00 & 6576,61 & 326,16 & 10,95 & 315,21 & 123,99 & 231,54 & 231,55 & 64,16 & 431,01 & 54,96 & 7,51 & 39,07 & 149,84 & 44,83 & 44,90 & 120,01 \\
\hline Pelobates cultripes & 30SWH27 & 100,00 & 136,53 & 122,09 & 38,00 & 6621,28 & 322,34 & 4,31 & 318,03 & \begin{tabular}{|l|}
117,43 \\
\end{tabular} & 226,03 & 226,05 & 57,70 & 455,02 & 57,62 & 8,86 & 37,61 & \begin{tabular}{|l|l|}
158,18 \\
\end{tabular} & 50,57 & 50,66 & 124,84 \\
\hline Pelobates cultripes & 30SWH37 & 100,00 & 137,60 & 121,74 & 38,00 & 6574,66 & 321,26 & 5,33 & 315,93 & 118,44 & 226,15 & 226,18 & 58,94 & 443,36 & 56,69 & 8,84 & 37,12 & 153,45 & 50,73 & 51,05 & 119,20 \\
\hline Pelobates cultripes & 30SWH75 & 100,00 & 143,32 & 119,51 & 38,80 & 6318,92 & 317,40 & 12,58 & 304,82 & 124,51 & 228,17 & 228,31 & 67,60 & 402,00 & 53,56 & 8,37 & 37,06 & 136,37 & 48,75 & 49,31 & 101,49 \\
\hline Pelobates cultripes & 30 SWH 86 & 100,00 & 139,91 & 120,07 & 38,97 & 6323,97 & 314,17 & $\begin{array}{ll} & \\
9,01 \\
\end{array}$ & 305,16 & $\begin{array}{l}120,78 \\
\end{array}$ & 225,01 & 225,06 & 64,40 & 410,44 & 54,92 & 9,30 & 36,04 & 138,60 & 52,97 & 53,56 & $\begin{array}{l}99,77 \\
\end{array}$ \\
\hline Pelobates cultripes & 30SWH90 & 100,00 & 139,71 & 116,29 & \begin{tabular}{|l|}
38,98 \\
\end{tabular} & 6148,27 & 307,94 & 11,79 & 296,15 & 119,46 & 221,97 & 222,95 & 66,79 & 422,94 & 55,66 & 9,25 & 36,99 & 140,90 & 48,95 & 52,66 & 110,38 \\
\hline Pelobates cultripes & 30 SWJ22 & 100,00 & 133,82 & 123,21 & 38,00 & 6650,44 & 320,84 & 0,63 & 320,21 & 115,83 & 222,95 & 223,58 & 54,08 & 450,48 & 54,31 & 9,68 & 35,27 & 154,04 & 54,21 & 55,92 & 119,01 \\
\hline Pelobates cultripes & 30 SWJ44 & 100,00 & 138,99 & 122,42 & 38,15 & 6559,40 & 321,36 & 5,65 & 315,71 & 122,05 & 226,37 & 227,07 & 59,77 & 418,64 & 49,25 & 9,55 & 34,06 & 140,64 & 53,42 & 56,30 & 105,57 \\
\hline Pelobates cultripes & 30 SWJ55 & 100,00 & 137,90 & 122,05 & 38,07 & 6523,64 & 319,00 & 4,82 & 314,18 & 120,70 & 224,86 & 225,56 & 59,19 & 420,32 & 49,08 & 10,09 & 32,81 & 140,42 & 55,85 & 59,46 & 103,44 \\
\hline Pelobates cultripes & 30 SWJ65 & 100,00 & 136,36 & 122,01 & 38,46 & 6492,55 & 316,32 & 3,75 & 312,57 & 119,43 & 222,97 & 223,73 & 58,16 & 421,97 & 49,60 & 11,02 & 32,38 & 140,84 & 58,07 & 62,45 & 101,46 \\
\hline Pelobates cultripes & 30SWJ95 & 100,00 & 135,80 & 119,48 & 38,99 & 6356,69 & 309,21 & 4,95 & 304,25 & 125,53 & 220,64 & 221,02 & 59,32 & 416,92 & 49,31 & 12,31 & 31,38 & 136,82 & 62,93 & 68,19 & 92,83 \\
\hline Pelobates cultripes & 30SWJ98 & 100,00 & 124,07 & 119,64 & 38,88 & 6412,39 & 299,97 & $-6,04$ & 306,01 & 106,33 & 209,64 & 210,42 & 47,23 & 468,76 & 57,28 & 16,19 & 28,50 & 154,03 & 75,62 & 82,00 & 105,15 \\
\hline Pelobates cultripes & 30SWK10 & 100,00 & 127,28 & 120,63 & 37,75 & 6666,16 & 312,45 & $-3,96$ & 316,41 & 110,82 & 215,99 & 217,12 & 47,25 & 467,55 & 54,01 & 12,32 & 32,02 & 151,45 & 61,53 & 63,37 & 123,73 \\
\hline Pelobates cultripes & 30SWK82 & 100,00 & 110,53 & 121,79 & 38,60 & 6481,56 & 291,16 & $-21,05$ & 312,21 & 92,89 & 196,90 & 198,10 & 33,16 & 535,29 & 67,24 & 20,84 & 27,04 & 176,77 & 89,48 & 98,00 & 124,87 \\
\hline Pelobates cultripes & 30SXG08 & 100,00 & 151,93 & 113,00 & 39,05 & 5913,57 & 310,81 & 25,90 & 284,92 & 120,67 & 230,39 & 231,78 & 81,08 & 370,31 & 48,05 & 6,40 & 40,01 & 123,52 & 37,22 & 43,93 & 99,67 \\
\hline Pelobates cultripes & 30SXG17 & 100,00 & 160,87 & 110,77 & 39,68 & 5727,21 & 312,77 & 36,10 & 276,67 & 130,43 & 236,43 & 237,94 & 91,78 & 336,38 & 45,67 & 4,90 & 42,20 & 1117,44 & 30,48 & 39,09 & 92,01 \\
\hline Pelobates cultripes & 30SXG18 & 100,00 & 151,60 & 113,33 & 39,30 & 5891,02 & 309,77 & 25,39 & 284,39 & 120,49 & 229,70 & 231,13 & 81,06 & 373,52 & 48,68 & 6,68 & 39,81 & 125,42 & 38,17 & 45,46 & 99,34 \\
\hline Pelobates cultripes & 30 SXG28 & 100,00 & 150,61 & 113,57 & 39,63 & 5862,45 & 308,13 & 24,37 & 283,76 & 120,82 & 228,34 & 229,78 & 80,49 & 383,29 & 50,6 & 7,32 & 39,63 & 129,49 & 40,27 & 48,06 & 100,86 \\
\hline Pelobates cultripes & $30 \mathrm{~S} \times \mathrm{H} 12$ & 100,00 & 160,97 & 117,42 & 40,00 & 5947,23 & 321,29 & 31,01 & 290,28 & 128,20 & 239,56 & 240,31 & 88,66 & 337,19 & 46,14 & 5,14 & 41,70 & 114,03 & 34,47 & 42,27 & 84,77 \\
\hline Pelobates cultripes & $30 \mathrm{SXH13}$ & 100,00 & 163,85 & $\begin{array}{ll}117,87 \\
\end{array}$ & 40,00 & 5951,82 & 323,92 & 33,54 & 290,38 & 131,48 & 242,43 & 243,01 & 91,25 & 326,75 & 45,59 & 4,71 & 42,19 & \begin{tabular}{|l|l|}
111,07 \\
\end{tabular} & 33,41 & 40,68 & 80,99 \\
\hline Pelobates cultripes & $30 \mathrm{~S} \times \mathrm{H} 2 \mathrm{O}$ & 100,00 & 160,52 & 116,36 & 40,07 & 5859,28 & 318,01 & 31,53 & 286,48 & 128,67 & 237,89 & 238,85 & 89,54 & 342,41 & 47,22 & 5,10 & 42,01 & 117,74 & 33,39 & 42,79 & 88,05 \\
\hline Pelobates cultripes & $30 \mathrm{~S} \times \mathrm{H} 21$ & 100,00 & 156,96 & 117,32 & 40,01 & 5925,39 & 316,88 & 27,34 & 289,54 & 124,47 & 235,36 & 236,27 & 85,19 & 355,44 & 48,15 & 5,88 & 40,88 & 120,02 & 37,18 & 45,51 & 89,45 \\
\hline Pelobates cultripes & $30 \mathrm{~S} \times \mathrm{H} 22$ & 100,00 & 161,75 & 118,02 & 40,03 & 5912,38 & 321,08 & 31,27 & 289,82 & 129,47 & 239,76 & 240,55 & 89,86 & \begin{tabular}{|l|l|}
337,68 \\
\end{tabular} & 47, & 5,08 & 42,06 & 115,29 & 34,35 & 43,14 & 83,95 \\
\hline Pelobates cultripes & $30 \mathrm{SXH} 23$ & 100,00 & 166,99 & 118,20 & 40,32 & 5891,20 & 325,24 & 36,20 & \begin{tabular}{|l|}
289,04 \\
\end{tabular} & \begin{tabular}{|l|}
134,37 \\
\end{tabular} & 244,73 & 245,19 & $\begin{array}{l}5,04 \\
95,04\end{array}$ & 320,00 & 46,28 & $\begin{array}{l}4,30 \\
4,33\end{array}$ & 43,28 & 110,82 & 31,59 & 40,88 & 78,78 \\
\hline Pelobates cultripes & $30 \mathrm{SXH} 31$ & 100,00 & 163,71 & 118,16 & 40,51 & 5851,48 & 320,97 & 33,14 & 287,83 & 131,87 & 240,82 & 241,51 & 92,36 & 335,63 & 48,00 & 4,85 & 43,15 & 116,94 & 32,51 & 42,78 & 84,45 \\
\hline Pelobates cultripes & $30 \mathrm{~S} \times \mathrm{H} 36$ & 100,00 & 146,88 & 117,98 & 40,00 & 6050,49 & 310,16 & 17,26 & 292,90 & 125,80 & 227,36 & 228,03 & 74,01 & 395,32 & 51,84 & 9,04 & 36,91 & 127,41 & 52,43 & 56,84 & 90,37 \\
\hline Pelobates cultripes & 30 SXH37 & 100,00 & 143,78 & 117,68 & 39,80 & 6078,03 & 307,79 & 14,75 & 293,04 & 125,21 & 224,82 & 225,29 & 70,81 & 406,04 & 52,48 & 9,99 & 35,65 & 130,06 & 56,65 & 59,47 & 91,44 \\
\hline Pelobates cultripes & $30 \mathrm{~S} \times \mathrm{H} 42$ & 100,00 & 169,81 & 119,50 & 41,01 & 5798,55 & 325,57 & 37,98 & 287,59 & 138,33 & 245,83 & 246,50 & 98,54 & 319,48 & 48,45 & 3,99 & 45,53 & 114,22 & 29,29 & 42,20 & 78,85 \\
\hline Pelobates cultripes & $305 \times 1445$ & 100,00 & 153,31 & 117,88 & 40,10 & 5951,01 & 313,14 & 23,56 & \begin{tabular}{|l|}
289,58 \\
\end{tabular} & \begin{tabular}{|l|l|}
127,44 \\
\end{tabular} & \begin{tabular}{|l|}
232,03 \\
2320
\end{tabular} & 232,93 & $\begin{array}{ll}0,1,24 \\
\end{array}$ & \begin{tabular}{|l|l|l|l|l|}
378,31 \\
\end{tabular} & $\begin{array}{l}40,45 \\
52,56\end{array}$ & $\begin{array}{l}3,68 \\
7,68\end{array}$ & $\begin{array}{l}38,99 \\
38,9\end{array}$ & $\begin{array}{l}14,26,14 \\
126,\end{array}$ & 46,28 & 454,47 & 87,53 \\
\hline Pelobates cultripes & $30 \mathrm{SXH} 46$ & 100,00 & 148,49 & 117,36 & 39,99 & 5991,87 & 309,28 & 19,41 & 289,87 & 148,49 & 227,92 & 228,73 & 76,22 & 396,39 & 53,53 & 9,01 & 37,29 & 129,54 & 51,91 & 58,53 & 90,28 \\
\hline Pelobates cultripes & $30 \mathrm{SXH} 47$ & 100,00 & 139,29 & 116,61 & 39,69 & 6063,79 & 302,22 & 11,19 & 291,03 & 128,43 & 220,07 & 220,89 & 66,78 & 433,17 & 55,26 & 11,52 & 34,49 & 137,38 & 62,04 & 65,94 & 97,50 \\
\hline Pelobates cultripes & $30 \mathrm{~S} \times \mathrm{H} 48$ & 100,00 & 137,41 & 116,19 & 39,42 & 6078,15 & 300,53 & 9,62 & 290,91 & 130,16 & 218,48 & 219,18 & 64,59 & 439,88 & 55,64 & 12,19 & 33,73 & 139,74 & 65,08 & 68,10 & 97,91 \\
\hline Pelobates cultripes & $30 \mathrm{SXH51}$ & 100,00 & 176,58 & 120,63 & 41,65 & 5711,35 & 330,13 & 43,54 & 286,59 & 145,69 & 251,24 & 251,56 & 105,99 & 302,26 & 47,95 & 2,98 & 48,54 & 112,50 & 23,96 & 36,14 & 76,50 \\
\hline Pelobates cultripes & 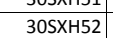 & 100,00 & $\begin{array}{l}17,50 \\
171,71\end{array}$ & $\begin{array}{l}12,03 \\
119,89\end{array}$ & 年11,05 & | 5754,33 & 326,11 & $\begin{array}{l}43,435 \\
39,55 \\
\end{array}$ & $280,56,56$ & \begin{tabular}{|l|}
140,78 \\
140,78
\end{tabular} & $\mid \begin{array}{l}\mid 51,24 \\
247,06\end{array}$ & $\begin{array}{l}247,60 \\
2470\end{array}$ & \begin{tabular}{|l|}
100,79 \\
100,59
\end{tabular} & $\begin{array}{l}30<, 20 \\
317,41\end{array}$ & | & $\begin{array}{l}2,300 \\
3,78\end{array}$ & $\begin{array}{ll}40,345 \\
46,59\end{array}$ & $\begin{array}{l}12,30,72 \\
115,\end{array}$ & 28,24 & $\begin{array}{l}0,14 \\
42,29\end{array}$ & $\begin{array}{l}0,50 \\
77,92\end{array}$ \\
\hline Pelobates cultripes & $30 \mathrm{SXH56}$ & 100,00 & 146,71 & 116,34 & 40,01 & 5950,56 & 305,92 & 18,71 & 287,21 & 155,11 & 225,60 & 226,49 & 75,18 & 411,71 & 56,05 & 9,79 & 36,74 & 135,81 & 54,56 & 62,28 & 93,67 \\
\hline Pelobates cultripes & $30 \mathrm{SXH57}$ & 100,00 & 141,69 & 115,62 & 39,89 & 5984,79 & 301,64 & $\begin{array}{ll}14,37 \\
\end{array}$ & 287,27 & 151,79 & 221,27 & 222,22 & 69,91 & 432,56 & 57,13 & 11,32 & 34,87 & 140,41 & 60,76 & 66,92 & 97,39 \\
\hline Pelobates cultripes & $30 \mathrm{~S} \times \mathrm{H} 60$ & 100,00 & 179,11 & 119,22 & 41,82 & 5622,63 & 329,72 & 47,06 & 282,67 & 149,38 & 252,55 & 252,93 & 109,56 & 298,01 & 48,85 & 2,73 & 49,87 & 114,67 & 22,28 & 37,67 & 76,57 \\
\hline Pelobates cultripes & $30 \mathrm{~S} \times \mathrm{H} 61$ & 100,00 & 176,46 & 119,74 & 41,7 & 5663,48 & 328,16 & 44,19 & 283,96 & 146,50 & 250,49 & 250,92 & 106,40 & 305,60 & 50, & 3,25 & 48,83 & 115,76 & 24,74 & 40,22 & 76,27 \\
\hline Pelobates cultripes & $30 \mathrm{SXH62}$ & 100,00 & 174,28 & 119,26 & 41,53 & 5689,21 & 326,38 & 42,57 & 283,81 & 144,11 & 248,62 & 249,25 & 104,05 & 311,99 & 51,08 & 3,57 & 47,87 & 116,82 & 27,08 & 42,08 & 75,82 \\
\hline Pelobates cultripes & 30SXH64 & 100,00 & 151,17 & 116,24 & 40,11 & \begin{tabular}{|l|l|}
5860,56 \\
\end{tabular} & 307,67 & 23,06 & 284,61 & $\mid 137,29$ & 228,65 & 229,75 & 80,54 & 401,33 & 57,18 & 8,61 & 38,69 & |137,03 & 48,79 & 59,51 & 93,54 \\
\hline Pelobates cultripes & $30 \mathrm{SXH66}$ & 100,00 & 149,38 & 115,34 & 40,01 & 5874,64 & 305,55 & 22,10 & 283,45 & 159,56 & 227,07 & 228,18 & 78,64 & 410,53 & 58,13 & 9,49 & 37,49 & 139,62 & 53,10 & 63,02 & 93,43 \\
\hline Pelobates cultripes & $30 \mathrm{SXH67}$ & 100,00 & 149,41 & 114,73 & 40,00 & 5872,88 & 305,05 & 22,55 & 282,49 & 159,75 & 227,07 & 228,20 & 78,63 & 411,25 & 58,21 & 9,72 & 37,14 & 40,16 & 54,33 & 63,98 & 92,81 \\
\hline Pelobates cultripes & 30SXH68 & 100,00 & 142,02 & 113,82 & 39,87 & 5933,7 & 298,99 & $\begin{array}{ll}2,3,03 \\
16,03\end{array}$ & 282,95 & 152,27 & 220,73 & 221,85 & $\begin{array}{l}0,030 \\
70,98\end{array}$ & $\begin{array}{l}441,100 \\
441,90\end{array}$ & 59,6 & \begin{tabular}{r|r|}
11,88 \\
11
\end{tabular} & 34,58 & $\begin{array}{l}140,62 \\
146,62\end{array}$ & $\begin{array}{l}62,88 \\
62,\end{array}$ & 70,57 & 98,86 \\
\hline Pelobates cultripes & $30 \mathrm{SXH71}$ & 100,00 & 178,63 & 116,88 & 41, & 5550,24 & 326,59 & 48,83 & 277,76 & 150,00 & 250,95 & 251,82 & 110,09 & 298,88 & 51,7 & 3,32 & 49,93 & 1117,47 & 24,25 & 41,11 & 73,47 \\
\hline Pelobates cultripes & 30SXH75 & 100,00 & 149,40 & 114,43 & 40,08 & \begin{tabular}{|l}
5814,46 \\
\end{tabular} & 303,77 & 22,72 & 281,06 & 156,23 & 226,13 & 227,51 & 79,30 & 419,80 & 60,28 & 9,59 & 37,78 & 144,82 & 52,92 & $\begin{array}{l}64,41 \\
64,1\end{array}$ & 96,90 \\
\hline Pelobates cultripes & $30 \mathrm{~S} \times \mathrm{H} 80$ & 100,00 & 174,23 & 113,75 & 41,06 & 5479,27 & 319,85 & 47,18 & 272,66 & 146,66 & 245,51 & 246,92 & 106,90 & 315,42 & 54,56 & 4,29 & 48,86 & 125,56 & 27,70 & 43,78 & 77,58 \\
\hline Pelobates cultripes & $30 \mathrm{~S} \times \mathrm{H} 81$ & 100,00 & 179,97 & 113,99 & 41,46 & 5444,26 & 324,12 & 52,53 & 271,60 & 159,36 & 250,52 & 251,79 & 112,64 & 292,76 & 53,77 & 3,42 & 52,47 & 119,63 & 24,24 & 41,31 & 70,22 \\
\hline Pelobates cultripes & \begin{tabular}{|l|}
$30 \mathrm{~S} \times \mathrm{SH} 8 \mathrm{1}$ \\
\end{tabular} & 100,00 & 15 & 111,85 & 40 & 57409,21 & 303,69 & $\begin{array}{l}2,3,32 \\
29,5\end{array}$ & $\begin{array}{l}274,37 \\
\end{array}$ & \begin{tabular}{|l|}
165,01 \\
16501
\end{tabular} & $\begin{array}{l}228,82 \\
228\end{array}$ & 230,47 & $\begin{array}{l}11,040 \\
85,08\end{array}$ & 419,51 & $\begin{array}{l}30,17 \\
63,23\end{array}$ & $\begin{array}{l}0,44 \\
9,43\end{array}$ & 38,47 & \begin{tabular}{|l|}
151,08 \\
151,08
\end{tabular} & $\begin{array}{l}\mid 4,24 \\
52,95\end{array}$ & $\begin{array}{l}41,11 \\
66,84\end{array}$ & 95,24 \\
\hline Pelobates cultripes & 30 XH88 & 100,00 & 148,49 & 111,03 & 39,90 & 5756,81 & 299,16 & 24,64 & 274,52 & 159,64 & 224,32 & 225,93 & 79,31 & 442,69 & 64,23 & 10,99 & 36,91 & 155,94 & 59,21 & 71,97 & 100,71 \\
\hline Pelobates cultripes & 30 SXH92 & 100,00 & 182,93 & 111,19 & 41,27 & 5337,78 & 322,79 & 57,58 & 265,22 & 195,09 & 251,56 & 253,29 & 116,55 & 288,90 & 56,03 & 3,51 & 54,63 & 123,30 & 24,35 & 42,49 & 67,24 \\
\hline Pelobates cultripes & 30SXH93 & 100,00 & 178,78 & 111,72 & 41,09 & 5400,40 & 320,62 & 53,39 & 267,23 & 191,18 & 248,55 & 250,44 & 112,20 & 309,93 & 57,72 & 4,22 & 51,72 & 128,54 & 28,58 & 46,75 & 71,09 \\
\hline Pelobates cultripes & 30 SXH94 & 100,00 & 170,06 & 112,04 & 41,00 & 5492,12 & 314,73 & 44,80 & 269,93 & 182,25 & 241,54 & 24 & 103,08 & 350,82 & 60,63 & 5,69 & 46,96 & 138,28 & 36,41 & 53,73 & 80,22 \\
\hline Pelobates cultripes & \begin{tabular}{|c|}
$305 \times J 05$ \\
30505
\end{tabular} & 100,00 & 135,89 & 1118,03 & 38, 38,99 & $\begin{array}{l}3450,112 \\
6306,92\end{array}$ & 306,59 & $\begin{array}{c}4,000 \\
6,05 \\
\end{array}$ & \begin{tabular}{|l|}
300,54 \\
300
\end{tabular} & \begin{tabular}{|l|l|}
151,47 \\
15,40
\end{tabular} & \begin{tabular}{|l|}
220,08 \\
224
\end{tabular} & \begin{tabular}{|l|}
220,45 \\
2240
\end{tabular} & $\begin{array}{r}50,00 \\
59,92\end{array}$ & $\begin{array}{l}30,02 \\
416,04\end{array}$ & $\begin{array}{l}40,10 \\
49,10\end{array}$ & \begin{tabular}{|c|}
0,250 \\
12,66
\end{tabular} & 31,06 & \begin{tabular}{|l|l|}
136,36 \\
136,36
\end{tabular} & $\begin{array}{l}30,41 \\
64,78\end{array}$ & $\begin{array}{l}30,13 \\
69,44 \\
\end{array}$ & $\begin{array}{l}0,24 \\
90,51\end{array}$ \\
\hline Pelobates cultripes & $30 \mathrm{SXJ} 29$ & 100,00 & 126,43 & 112,75 & 38,00 & 6289,60 & 291,53 & 0,37 & 291,16 & 144,61 & 210,27 & 210,82 & 51,06 & 446,32 & 55,21 & 17,49 & 28,18 & 145,12 & 80,79 & 84,38 & 91,66 \\
\hline Pelobates cultripes & $305 \times 130$ & 100,00 & 131,29 & 116,42 & 39,00 & 6170,28 & 297,46 & 3,50 & 293,96 & 127,35 & 214,25 & 214,35 & 57,77 & 454,16 & 55,76 & 13,91 & 31,75 & 145,20 & 71,55 & 71,69 & 99,33 \\
\hline Pelobates cultripes & $305 \times 131$ & 100,00 & 124,68 & 115,86 & 39,00 & 6219,28 & 292,20 & $-1,71$ & 293, & 124 & 208,66 & 208, & 51,00 & 481,85 & 57,84 & 16,12 & 30,18 & 15 & 78,00 & 78,19 & 104,80 \\
\hline Pelobates cultripes & $305 \times J 37$ & 100,00 & 129,43 & 112,05 & 38,30 & 6210,37 & 291,93 & 4,19 & 287,74 & 146,47 & 212,47 & 212,64 & 55,10 & 445,05 & 52,90 & 16,54 & 28,95 & 142,84 & 79,29 & 80,87 & 91,56 \\
\hline
\end{tabular}




\begin{tabular}{|c|c|c|c|c|c|c|c|c|c|c|c|c|c|c|c|c|c|c|c|c|c|}
\hline TAXON & UTM & $\mathrm{km2}$ & BIO1 & B102 & $\mathrm{BIO3}$ & B104 & B105 & B106 & B107 & B108 & B109 & BIO10 & BIO11 & $\overline{B 1012}$ & BIO13 & BIO14 & BIO15 & BIO16 & BIO17 & BIO18 & BIO19 \\
\hline Pelobates cultripes & 30SXJ38 & 100,00 & 124,98 & 111,35 & 38,03 & 6245,07 & 288,08 & 0,40 & 287,68 & 142,25 & 208,58 & 208,88 & 50,44 & 457,55 & 55,49 & 18,08 & 28,18 & 147,89 & 83,66 & 86,22 & 93,11 \\
\hline Pelobates cultripes & $30 \mathrm{SXJ46}$ & 100,00 & 140,77 & 109,92 & 38,90 & 6050,06 & 297,10 & 16,81 & 280,29 & \begin{tabular}{l|l}
150,23 \\
\end{tabular} & 221,32 & 221,66 & \begin{tabular}{|c|}
67,97 \\
\end{tabular} & $\begin{array}{l}413,15 \\
\end{array}$ & 52,03 & 13,81 & 31,29 & 132,51 & \begin{tabular}{ll|}
70,02 \\
\end{tabular} & \begin{tabular}{ll|}
72,27 \\
\end{tabular} & 85,21 \\
\hline Pelobates cultripes & 30 SXJ56 & 100,00 & 142,36 & 107,81 & 38,90 & 5975,50 & 294,88 & 20,05 & 274,84 & 151,12 & \begin{tabular}{l|l|}
221,59 \\
\end{tabular} & 222,31 & 70,39 & 417,13 & 54,42 & 13,94 & 31,68 & \begin{tabular}{ll|}
137,42 \\
\end{tabular} & 69,68 & 74,75 & 86,15 \\
\hline Pelobates cultripes & 30 SXJ66 & 100,00 & 137,73 & 106,27 & 38,63 & 5952,26 & 288,87 & 16,69 & \begin{tabular}{|l|l|}
272,18 \\
\end{tabular} & \begin{tabular}{ll|l}
146,89 \\
\end{tabular} & \begin{tabular}{l|l}
216,82 \\
\end{tabular} & 217,55 & 66,32 & 444,08 & 57,30 & 15,64 & 30,68 & 146,17 & 75,42 & 81,56 & 91,85 \\
\hline Pelobates cultripes & 30SXJ67 & 100,00 & 134,58 & 105,47 & 38,08 & 5986,80 & 286,09 & 14,12 & $271,97 \mid$ & $143,41 \mid$ & 214,29 & 214,93 . & 63,03 , & $449,14[$ & 56,28 & 16,73 & 29,75 | & $145,65 \mid$ & 79,29| & 84,23 . & 91,38 \\
\hline Pelobates cultripes & $30 \mathrm{SXJ86}$ & 100,00 & 143,03 & 101,81 & 38,50 & 5747,54 & 286,85 & 25,65 & 261,20 & 153,06 & 218,83 & 220,32 & 74,19 & 457,23 & 63,92 & 15,32 & 32,73 & 159,77 & \begin{tabular}{|l|l|}
72,87 \\
\end{tabular} & 85,12 & 97,37 \\
\hline Pelobates cultripes & 30SXJ89 & 100,00 & 151,22 & 97,45 & 38,00 & 5660,88 & 289,16 & 36,08 & 253,09 & \begin{tabular}{l|l|}
160,92 \\
\end{tabular} & 225,42 & 226,98 & 82,86 & 416,22 & 60,92 & 14,41 & 34,58 & \begin{tabular}{l|l}
150,62 \\
\end{tabular} & \begin{tabular}{ll|}
67,12 \\
\end{tabular} & 81,19 & 85,54 \\
\hline Pelobates cultripes & 30 XSJ91 & 100,00 & 154,65 & 105,88 & 39,80 & 5600,81 & 298,09 & 34,84 & 263,25 & \begin{tabular}{ll|}
166,33 \\
\end{tabular} & 227,97 & 230,00 & 87,14 & 446,79 & 68,62 & $\begin{array}{ll}11,06 \\
\end{array}$ & 38,44 & $\begin{array}{ll}165,52 \\
\end{array}$ & 58,81 & \begin{tabular}{l|l}
75,95 \\
\end{tabular} & 102,75 \\
\hline Pelobates cultripes & 30SXJ98 & 100,00 & 161,99 & 95,04 & 38,54 & 5418,89 & 292,97 & 49,34 & \begin{tabular}{|l|l|}
243,62 \\
\end{tabular} & 172,81 & \begin{tabular}{|l|l|}
232,29 \\
\end{tabular} & 234,62 & 96,34 & 414,44 & \begin{tabular}{ll|}
67,98 \\
\end{tabular} & 12,27 & 39,74 & $\begin{array}{l}160,49 \\
\end{array}$ & 58,30 & 78,11 & 90,18 \\
\hline Pelobates cultripes & 30SXJ99 & 100,00 & 156,57 & 94,70 & 38,02 & 5501,31 & 289,38 & 43,62 & 245,76 & \begin{tabular}{l|l|l|}
166,92 \\
\end{tabular} & 228,32 & 230,32 & 90,09 & 420,21 & 65,46 & 13,67 & 37,23 & 158,42 & 63,57 & 81,59 & 88,81 \\
\hline Pelobates cultripes & $305 \times K 22$ & 100,00 & 105,08 & 111,26 & 37,82 & 6372,31 & 272,03 & $-19,79$ & 291,83 & 123,10 & \begin{tabular}{|l|l|}
188,12 \\
\end{tabular} & \begin{tabular}{|l|l|l|l|}
191,08 \\
\end{tabular} & 29,40 & 520,37 & 67,76 & 24,79 & 26,65 & 173,16 & 101,24 & \begin{tabular}{ll|}
109,76 \\
\end{tabular} & 104,98 \\
\hline Pelobates cultripes & $305 \times K 32$ & 100,00 & 108,52 & 108,46 & 37,33 & 6339,29 & \begin{tabular}{|l|l|}
271,47 \\
\end{tabular} & $-14,69$ & 286,15 & 126,45 & 58,98 & \begin{tabular}{ll|l}
194,06 \\
\end{tabular} & 33,24 & 499,43 & 65,36 & 24,27 & 27,34 & \begin{tabular}{ll|}
167,26 \\
\end{tabular} & \begin{tabular}{|l|l|}
97,03 \\
\end{tabular} & \begin{tabular}{|l|}
107,17 \\
\end{tabular} & 97,07 \\
\hline Pelobates cultripes & 30 SXK40 & 100,00 & 116,01 & 107,73 & 37,78 & 6252,44 & 276,27 & $-6,16$ & 282,43 & \begin{tabular}{l|l|}
133,03 \\
\end{tabular} & 123,01 & 200,16 & \begin{tabular}{l|l}
41,92 \\
\end{tabular} & 485,12 & 60,79 & 22,01 & 27,28 & \begin{tabular}{|l|l|}
158,67 \\
\end{tabular} & $\begin{array}{l}94,35 \\
\end{array}$ & 98,94 & 95,01 \\
\hline Pelobates cultripes & 30 SXK41 & 100,00 & 113,97 & 106,82 & 37,28 & 6276,32 & 273,90 & $-7,82$ & 281,73 & \begin{tabular}{ll|}
131,38 \\
\end{tabular} & 40,80 & \begin{tabular}{l|l|l|}
198,58 \\
\end{tabular} & 39,77 & 483,34 & \begin{tabular}{l|l|}
61,95 \\
\end{tabular} & 22,85 & 27,58 & $\begin{array}{l}159,95 \\
\end{array}$ & \begin{tabular}{l|l}
92,75 \\
\end{tabular} & $\begin{array}{l}101,60 \\
\end{array}$ & 92,75 \\
\hline Pelobates cultripes & 30 SXK50 & 100,00 & 127,65 & 104,81 & 37,71 & 6135,18 & 281,71 & 6,70 & 275,01 & \begin{tabular}{l|l}
142,82 \\
\end{tabular} & \begin{tabular}{|c|}
92,14 \\
\end{tabular} & 209,82 & 54,41 & 442,77 & 54,5 & 19,12 & $28, \mathrm{c}$ & \begin{tabular}{ll|}
142,62 \\
\end{tabular} & 84,56 & 87,90 & 84,95 \\
\hline Pelobates cultripes & 30SXK61 & 100,00 & 121,73 & 102,01 & 37,02 & 6146,47 & 274,28 & 2,65 & 271,63 & 138,39 & 48,60 & 204,06 & 48,60 & 461,33 & 57,58 & 21,59 & 28,58 & \begin{tabular}{ll|}
148,96 \\
\end{tabular} & 86,06 & 95,50 & 86,06 \\
\hline Pelobates cultripes & 30 SXK72 & 100,00 & 95,77 & 100,65 & 36,45 & 6182,98 & 250,53 & $-21,31$ & 271,84 & \begin{tabular}{|l|l|}
111,17 \\
\end{tabular} & 23,68 & \begin{tabular}{|l|l|}
179,33 \\
\end{tabular} & 23,68 & 584,80 & 73,13 & 30,58 & 25,11 & \begin{tabular}{|l|l|}
189,64 \\
\end{tabular} & 113,11 & \begin{tabular}{|l|}
126,81 \\
\end{tabular} & 113,11 \\
\hline Pelobates cultripes & 30SXK90 & 100,00 & 137,15 & 96,17 & 37,23 & 5766,21 & 277,84 & 22,66 & 255,19 & 146,16 & 210,50 & 214,60 & 68,34 & 461,90 & 60,83 & 18,45 & 30,90 & 158,33 & 82,55 & 94,14 & 92,39 \\
\hline Pelobates cultripes & 30SXK91 & 100,00 & 118,16 & 97,05 & 36,70 & 5962,03 & 264,77 & 3,03 & 261,74 & 128,88 & 86,00 & $\begin{array}{l}198,45 \\
\end{array}$ & 47,94 & 516,47 & \begin{tabular}{l|l|l}
61,85 \\
\end{tabular} & 23,82 & 27,32 & \begin{tabular}{ll|}
164,19 \\
\end{tabular} & \begin{tabular}{|l|l}
99,90 \\
\end{tabular} & \begin{tabular}{|l|}
108,37 \\
\end{tabular} & 100,35 \\
\hline Pelobates cultripes & 30 XKK92 & 100,00 & 118,22 & 96,24 & 36,31 & 5976,35 & 264,32 & 3,29 & \begin{tabular}{|l|l|}
261,02 \\
\end{tabular} & \begin{tabular}{|l|l|}
129,84 \\
\end{tabular} & 58,95 & \begin{tabular}{ll|}
198,64 \\
\end{tabular} & 47,90 & 505,18 & 61,4 & 23,9 & 27,82 & 160,42 & \begin{tabular}{l|l}
95,62 \\
\end{tabular} & 107,63 & 95,73 \\
\hline Pelobates cultripes & $30 \mathrm{SYHO2}$ & 80,00 & 182,46 & 108,92 & 41,00 & 5276,77 & 320,21 & 59,09 & 261,13 & 195,28 & 250,29 & 252,49 & 117,35 & 297,04 & 58,03 & 4,00 & 54,71 & 128,71 & 26,03 & 44,69 & 68,70 \\
\hline Pelobates cultripes & 30SYHO4 & 100,00 & 173,90 & 109,71 & 41,00 & 5389,70 & 314,83 & 50,47 & 264,37 & \begin{tabular}{ll|l}
186,78 \\
\end{tabular} & 243,55 & \begin{tabular}{|l|}
245,87 \\
\end{tabular} & $\begin{array}{l}107,85 \\
1\end{array}$ & 346,29 & 62,24 & 5,29 & 49,14 & \begin{tabular}{|l|l|}
141,70 \\
\end{tabular} & $\begin{array}{l}34,85 \\
\end{array}$ & 53,52 & 78,97 \\
\hline Pelobates cultripes & 30SYHO6 & 100,00 & 144,42 & 108,84 & 39,61 & 5689,09 & 293,55 & 22,42 & 271,13 & 144,48 & 219,20 & 221,28 & 76,49 & \begin{tabular}{|l|l|}
486,58 \\
\end{tabular} & 69,47 & 12,40 & 36,53 & 172,01 & 63,57 & 78,33 & 115,60 \\
\hline Pelobates cultripes & 30SYH13 & 75,00 & 181,61 & 107,03 & 41,00 & 5237,53 & 317,59 & 59,90 & 257,70 & $\begin{array}{ll}194,88 \\
\end{array}$ & 248,67 & 251,29 & \begin{tabular}{|l|l|}
117,18 \\
\end{tabular} & 322,56 & 61,49 & 4,09 & 53,53 & \begin{tabular}{|l|l|}
139,03 \\
\end{tabular} & 29,04 & 48,90 & 75,25 \\
\hline Pelobates cultripes & 30SYH14 & 84,00 & 180,26 & 107,10 & 41,00 & 5257,41 & 316,59 & 58,60 & 257,99 & \begin{tabular}{l|l|}
193,68 \\
\end{tabular} & 247,77 & 250,42 & $\begin{array}{ll}115,62 \\
\end{array}$ & 336,75 & 63,1 & 4,36 & 52,08 & 143,41 & 31,77 & 51,94 & 77,46 \\
\hline Pelobates cultripes & 30SYH15 & 100,00 & 175,28 & 107,31 & 40,93 & 5313,91 & 313,30 & 53,72 & 259,57 & 188,76 & 243,76 & 246,37 & 110,37 & 366,35 & 65,66 & 5,46 & 49,10 & 151,58 & 37,05 & 57,48 & 84,94 \\
\hline Pelobates cultripes & 30 SYH16 & 100,00 & 159,20 & 107,47 & 40,10 & 5490,83 & 302,30 & 37,95 & 264,34 & 169,42 & 230,56 & 233,14 & $\begin{array}{l}92,89 \\
9\end{array}$ & 442,74 & \begin{tabular}{ll|l}
69,88 \\
\end{tabular} & 8,99 & \begin{tabular}{|l|l|l|}
41,99 \\
\end{tabular} & \begin{tabular}{ll|}
168,76 \\
\end{tabular} & 51,36 & \begin{tabular}{|l|}
70,57 \\
\end{tabular} & 106,53 \\
\hline Pelobates cultripes & 30 SYH 25 & 77,00 & 180,16 & 105,37 & 41,00 & 5215,02 & 314,92 & 60,07 & 254,85 & \begin{tabular}{|l|l|}
194,17 \\
\end{tabular} & 247,07 & \begin{tabular}{|l|l|}
250,04 \\
\end{tabular} & 116,15 & 369,19 & 67,10 & 4,91 & 51,03 & 156,33 & 34,86 & 57,50 & 89,25 \\
\hline Pelobates cultripes & 30 SYH26 & 100,00 & 162,06 & 105,68 & 40,10 & 5418,68 & 302,65 & 42,09 & 260,56 & \begin{tabular}{ll|}
164,62 \\
\end{tabular} & 232,30 & \begin{tabular}{|l|}
235,03 \\
\end{tabular} & 96,54 & 452,93 & 72,10 & 8,67 & 43,43 & \begin{tabular}{|l|}
176,14 \\
\end{tabular} & 50,53 & 71,93 & 112,25 \\
\hline Pelobates cultripes & 30SYJ07 & 100,00 & 166,40 & 93,37 & \begin{tabular}{l|l|}
38,95 \\
\end{tabular} & 5267,47 & 293,03 & 55,71 & 237,33 & 178,25 & 234,31 & 237,26 & \begin{tabular}{l|l|}
102,52 \\
\end{tabular} & 431,58 & 74,97 & 11,56 & \begin{tabular}{|l|l|}
43,03 \\
\end{tabular} & 173,01 & 55,33 & $\begin{array}{l}79,25 \\
\end{array}$ & 98,46 \\
\hline Pelobates cultripes & 30SYJ25 & 100,00 & 176,56 & 92,18 & 39,57 & 5054,61 & 297,92 & 67,46 & 230,45 & \begin{tabular}{l|l|}
190,01 \\
\end{tabular} & 240,95 & 244,55 & $\begin{array}{l}115,05 \\
115\end{array}$ & 446,92 & 82,85 & 8,90 & \begin{tabular}{l|l}
49,95 \\
\end{tabular} & \begin{tabular}{|l|l|}
189,43 \\
\end{tabular} & 48,38 & \begin{tabular}{ll|}
79,53 \\
\end{tabular} & 112,10 \\
\hline Pelobates cultripes & 30 SYJ26 & 99,00 & 175,54 & 89,83 & 39,25 & 5005,52 & 294,31 & 68,41 & 225,90 & 188,86 & 239,28 & 243,17 & \begin{tabular}{|l|l|}
114,93 \\
\end{tabular} & $\begin{array}{l}444,15 \\
\end{array}$ & 83,98 & 9,09 & $\begin{array}{l}50,35 \\
\end{array}$ & \begin{tabular}{|l|l|}
189,34 \\
\end{tabular} & \begin{tabular}{|l|l}
49,09 \\
\end{tabular} & 80,34 & 109,50 \\
\hline Pelobates cultripes & 30 SYJ28 & 100,00 & 171,52 & 87,47 & 38,46 & 5040,85 & 289,88 & 65,15 & 224,73 & \begin{tabular}{l|l|}
184,22 \\
\end{tabular} & 235,74 & 239,41 & \begin{tabular}{|l|l|}
110,39 \\
\end{tabular} & \begin{tabular}{|l|l|}
440,88 \\
\end{tabular} & 81,19 & 10,77 & \begin{tabular}{ll|}
47,69 \\
\end{tabular} & \begin{tabular}{|l|l|}
185,17 \\
\end{tabular} & 53,23 & 83,39 & 104,10 \\
\hline Pelobates cultripes & 30SYJ30 & 100,00 & 157,99 & 101,69 & 39,41 & 5412,07 & 295,78 & 41,07 & 254,72 & 133,98 & 228,08 & 230,92 & 92,74 & 524,14 & 80,05 & 10,99 & 41,91 & 203,56 & 60,87 & 87,18 & 136,38 \\
\hline Pelobates cultripes & 30SYJ32 & 100,00 & 168,37 & 98,61 & 39,62 & 5263,81 & 299,92 & 53,56 & 246,36 & 155,07 & \begin{tabular}{|l|l|}
236,04 \\
\end{tabular} & 239,10 & \begin{tabular}{|l|l|}
104,44 \\
\end{tabular} & 501,73 & 81,88 & 9,56 & 46,00 & 202,90 & 54,54 & 85,01 & 132,77 \\
\hline Pelobates cultripes & 30SYJ33 & 94,00 & 175,58 & 96,19 & 39,77 & 5151,25 & 302,46 & 62,88 & 239,58 & 175,71 & \begin{tabular}{|l|l|}
241,48 \\
\end{tabular} & 244,84 & \begin{tabular}{|l|l|}
112,74 \\
\end{tabular} & \begin{tabular}{|l|l|}
478,48 \\
\end{tabular} & 82,56 & 8,56 & \begin{tabular}{|l|l|}
49,07 \\
\end{tabular} & \begin{tabular}{|l|}
199,01 \\
\end{tabular} & \begin{tabular}{|l|}
49,47 \\
\end{tabular} & 81,90 & 127,13 \\
\hline Pelobates cultripes & 30 SYYJ35 & 37,00 & 177,22 & 91,78 & 39,26 & 5036,41 & 298,19 & 68,24 & 229,94 & 190,89 & 241,20 & 244,94 & \begin{tabular}{l|l|}
115,85 \\
\end{tabular} & 458,63 & 83,94 & 8,72 & 50,11 & \begin{tabular}{ll|}
194,61 \\
\end{tabular} & 48,72 & 81,63 & 117,43 \\
\hline Pelobates cultripes & 30 SYJ36 & 3,00 & 176,14 & 90,00 & 39,14 & 5001,71 & 295,57 & 69,00 & 226,57 & 189,57 & 240,00 & 243,86 & \begin{tabular}{ll|}
116,00 \\
\end{tabular} & 452,00 & 84,00 & 9,00 & 50,86 & $\begin{array}{l}192,86 \\
\end{array}$ & 49,00 & 82,00 & 113,57 \\
\hline Pelobates cultripes & 30SYJ41 & 92,00 & 178,72 & 99,65 & 39,99 & 5194,28 & 309,11 & 62,64 & 246,47 & 156,51 & \begin{tabular}{|l|l|}
244,90 \\
\end{tabular} & 248,08 & \begin{tabular}{ll|}
114,94 \\
\end{tabular} & 503,61 & 82,83 & 7,26 & 51,03 & 216,47 & 47,22 & 82,13 & 143,56 \\
\hline Pelobates cultripes & $30 \mathrm{YY} J 42$ & 37,00 & 179,44 & 97,85 & 39,97 & 5155,15 & 307,64 & 64,85 & 242,79 & 156,95 & 245,13 & 248,38 & 116,18 & \begin{tabular}{|l|l|}
491,85 \\
\end{tabular} & \begin{tabular}{|c|}
82,98 \\
\end{tabular} & 7,20 & 51,16 & 210,54 & 46,64 & 81,48 & 137,85 \\
\hline Pelobates cultripes & 30SYJ43 & 2,00 & \begin{tabular}{|l|}
179,67 \\
\end{tabular} & 96,50 & 40,00 & 5101,33 & 306,00 & 66,83 & 239,17 & \begin{tabular}{|l|l|l|l}
157,33 \\
\end{tabular} & \begin{tabular}{|l|l|}
244,83 \\
\end{tabular} & 248,00 & \begin{tabular}{|l|l|}
117,33 \\
\end{tabular} & \begin{tabular}{|l|l|}
484,17 \\
\end{tabular} & 83,00 & 8,00 & \begin{tabular}{|l|l|}
50,67 \\
\end{tabular} & 205,50 & 47,00 & 82,00 & 133,33 \\
\hline Pelobates cultripes & 30SYKO2 & 100,00 & 133,17 & 93,51 & 36,64 & 5766,06 & 272,32 & 19,80 & 252,52 & 141,83 & \begin{tabular}{l|l}
170,55 \\
\end{tabular} & 210,65 & 64,64 & 472,90 & 60,31 & 20,15 & 30,38 & 160,07 & 87,72 & $100,21 \mid$ & 92,38 \\
\hline Pelobates cultripes & 30SYK21 & 100,00 & 145,32 & 89,86 & 36,76 & 5470,59 & 276,20 & 34,98 & 241,22 & 155,35 & \begin{tabular}{|l|l|}
216,84 \\
\end{tabular} & \begin{tabular}{|l|l|}
219,06 \\
\end{tabular} & \begin{tabular}{ll|}
80,06 \\
\end{tabular} & \begin{tabular}{|l|l|}
483,17 \\
\end{tabular} & 68,68 & 17,47 & 33,96 & \begin{tabular}{|l|l|}
176,54 \\
\end{tabular} & 78,74 & $\begin{array}{l}98,83 \\
\end{array}$ & 102,43 \\
\hline Pelobates cultripes & 30 SYK30 & 100,00 & 167,69 & 85,61 & 37,08 & 105,08 & 287. & 60,99 & 226,56 & \begin{tabular}{|l|l|}
179,79 \\
\end{tabular} & 232,99 & 236,47 & \begin{tabular}{ll|}
105,86 \\
\end{tabular} & 442,63 & 74,27 & 12,40 & 43,1 & 180,40 & 58,61 & 87,77 & 100,94 \\
\hline Pelobates cultripes & 30SYK31 & 100,00 & 156,25 & 86,80 & 36,88 & 5275,68 & 281 & 48,02 & 233,10 & 167,22 & 224,50 & 227,43 & 93,01 & 466,86 & 71,02 & 15,19 & 37,94 & 179,61 & \begin{tabular}{|c|}
69,63 \\
\end{tabular} & 94,88 & 102,45 \\
\hline Pelobates cultripes & 30TTK43 & 60,00 & 149,16 & 110,74 & 36,88 & 6409,49 & 324,89 & 26,98 & 297,91 & 78,57 & 234,93 & 234,9 & 71, & \begin{tabular}{|l|l|}
468,07 \\
\end{tabular} & 57,26 & 5,87 & 44,11 & \begin{tabular}{|l|l}
167,16 \\
\end{tabular} & 38,90 & 38,90 & 154,18 \\
\hline Pelobates cultripes & 30TTK44 & 60,00 & 132,45 & 109,16 & 36,60 & 6377,70 & 307,43 & 12,65 & \begin{tabular}{|l|l|}
294,78 \\
\end{tabular} & 62,97 & 217,85 & 218,38 & 55,81 & 543,52 & 66,52 & 8,45 & \begin{tabular}{ll|}
42,58 \\
\end{tabular} & \begin{tabular}{|l|l|l|l|}
193,49 \\
\end{tabular} & 48,58 & 49,33 & 179,36 \\
\hline Pelobates cultripes & 30TTK56 & 100,00 & 125,09 & 110,34 & 36,99 & 6336,47 & 299,69 & 5,54 & 294,16 & \begin{tabular}{|l|l|}
55,85 \\
\end{tabular} & 209,65 & 210,40 & 48,89 & 532,56 & 65,03 & 9,79 & 40,50 & 186,53 & 52,18 & 52,97 & 171,06 \\
\hline Pelobates cultripes & 30TTK57 & 100,00 & 125,48 & 111,03 & 37,08 & 6317,04 & 299,69 & 5,65 & 294,04 & 56,32 & \begin{tabular}{|l|}
209,99 \\
\end{tabular} & 210,54 & 49,3 & 515,12 & 63,05 & 9,67 & 39,9 & 180,10 & 51,77 & 52,14 & 164,56 \\
\hline Pelobates cultripes & 30TTK58 & 100,00 & 125,15 & 111,64 & 37,57 & 6296,49 & 298,85 & 5,27 & 293,58 & 56,00 & 209,26 & 209,81 & 49,1 & 503,89 & 61,86 & 9,69 & 39,55 & 175,86 & 51,83 & 52,15 & 159,95 \\
\hline Pelobates cultripes & 30TTK59 & 100,00 & 118,74 & 111,53 & 37,89 & 6264,91 & 292,03 & 0,06 & 291,97 & \begin{tabular}{l|l}
50,05 \\
\end{tabular} & 202,19 & 203,01 & 43,41 & 522,27 & 64,35 & 10,65 & 38,81 & \begin{tabular}{l|l|}
182,02 \\
\end{tabular} & \begin{tabular}{|l|}
55,69 \\
\end{tabular} & 56,28 & 164,96 \\
\hline Pelobates cultripes & 30TTK63 & 100,00 & 151,82 & 112,81 & 37,00 & 6440,76 & 328,96 & 27,44 & 301,52 & 80,68 & \begin{tabular}{|l|l|}
238,04 \\
\end{tabular} & \begin{tabular}{|l|}
238,04 \\
\end{tabular} & 73,12 & 425,74 & 51,26 & 5,77 & \begin{tabular}{|l|l|}
42,79 \\
\end{tabular} & \begin{tabular}{ll|}
148,26 \\
\end{tabular} & 36,99 & 36,99 & 135,22 \\
\hline Pelobates cultripes & 30TTK68 & 100,00 & 121,72 & 112,60 & \begin{tabular}{|c|}
37,88 \\
\end{tabular} & 6290,36 & 296,40 & 1,58 & 294,82 & \begin{tabular}{|l|l|}
52,69 \\
\end{tabular} & 205,55 & 206,38 & 46,00 & 494,14 & 59,95 & 10,43 & 38,06 & 168, & 53,79 & 54,29 & 152,38 \\
\hline Pelobates cultripes & $30 \mathrm{TTK}$ & 100,00 & 11 & 112,76 & $38, \mathrm{C}$ & 255,50 & 290 & $-2,36$ & 293 & 54, & 199 & 200 & 41, & 504,86 & 61,34 & 11, & (3) & 171 & $\begin{array}{ll}56,85 \\
\end{array}$ & 57,70 & 154 \\
\hline Pelobates cultripes & 30TTK74 & 100,00 & 134,76 & 112,76 & 36,99 & 6418,78 & 312,39 & 11,83 & \begin{tabular}{|l|l|}
300,57 \\
\end{tabular} & 68,51 & 220,79 & 221,21 & 57,26 & 470,09 & 55,91 & 8,45 & 40,06 & $\begin{array}{l}159,85 \\
\end{array}$ & 46,18 & 46,69 & 145,14 \\
\hline Pelobates cultripes & 30TTK77 & 100,00 & 97,20 & 109,86 & 37,13 & 6246,57 & 272,49 & $-19,59$ & 292,07 & 30,34 & \begin{tabular}{|l|l|}
180,93 \\
\end{tabular} & \begin{tabular}{|l|}
182,39 \\
\end{tabular} & 24,13 & 626,00 & 74,51 & 15,30 & \begin{tabular}{l|l}
36,35 \\
\end{tabular} & 210,42 & \begin{tabular}{|l|}
70,67 \\
\end{tabular} & \begin{tabular}{ll|}
74,09 \\
\end{tabular} & 191,65 \\
\hline Pelobates cultripes & 30TTK78 & 100,00 & 114,63 & 112,80 & 37,91 & 6271,61 & 289,86 & $-4,61$ & \begin{tabular}{|l|l|}
294,47 \\
\end{tabular} & 55,68 & \begin{tabular}{|l|l|}
197,59 \\
\end{tabular} & $\begin{array}{l}199,56 \\
\end{array}$ & 39,69 & 504,84 & 60,39 & \begin{tabular}{ll|}
11,68 \\
\end{tabular} & 36,46 & 168,65 & $\begin{array}{l}57,96 \\
\end{array}$ & 59,24 & 151,39 \\
\hline Pelobat & $30 \pi T K$ & 100,00 & 104,01 & & 37,03 & 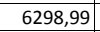 & 281 & $-14,76$ & 295, & 38, & 188, & 189 & 30,01 & 569,76 & 66,99 & 14, & & 188 & 65, & $67,68 \mid$ & 16 \\
\hline Pelobates cultripes & 30TTK87 & 100,00 & 112,29 & 112,73 & 37,60 & $6295,44]$ & 288,8 & $-7,63$ & 296,43 & 62,51 & $195,94[$ & 197,8 & 37,44 & 507,78 & 59,81 & $12,44[$ & 35,86 & 166,60 & 59,43 & 61,05 & 148 \\
\hline Pelobates cultripes & 30TTK88 & 100,00 & 115,08 & 113,70 & 37,98 & 6268,39 & 290,92 & $-5,17$ & 296,09 & 72,80 & \begin{tabular}{|l|l|}
197,78 \\
\end{tabular} & 200,01 & 40,13 & 480,61 & 56,77 & 11,78 & 35,36 & 157,37 & 57,66 & 58,97 & 139,60 \\
\hline
\end{tabular}




\begin{tabular}{|c|c|c|c|c|c|c|c|c|c|c|c|c|c|c|c|c|c|c|c|c|c|}
\hline TAXON & UTM & $\mathrm{km} 2$ & B101 & B102 & $\mathrm{BIO3}$ & BIO4 & B105 & B106 & B107 & B108 & B109 & BIO10 & B1011 & BIO12 & B1013 & BIO14 & BIO15 & B1016 & B1017 & BIO18 & B1019 \\
\hline Pelobates cultripes & 30тTК93 & 100,00 & 158,23 & 114,87 & 37,00 & 6478,21 & 336,17 & 31,10 & 305,07 & 116,45 & 244,77 & 244,77 & 78,48 & 365,64 & 43,12 & 5,03 & 41,74 & 124,73 & 32,99 & 32,99 & 110,07 \\
\hline Pelobates cultripes & 30TTK94 & 100,00 & 150,38 & 114,48 & 37,00 & 6451,97 & 328,03 & 24,12 & 303,91 & 108,28 & 236,77 & 236,78 & 71,27 & 381,23 & 44,71 & 6,37 & 39,86 & 128,30 & 37,38 & 37,38 & 113,13 \\
\hline Pelobates cultripes & 30TTK96 & 100,00 & 91,54 & 110,67 & 37,01 & 6268,13 & 268,93 & $-26,01$ & 294,93 & 33,22 & 176,05 & 177,31 & 18,89 & 629,13 & 73,17 & 17,20 & 34,74 & 204,69 & 75,06 & 79,02 & 184,84 \\
\hline Pelobates cultripes & 30TTK98 & 100,00 & 111,33 & 113,54 & 37,94 & 6252,65 & 287,35 & $-8,85$ & 296,19 & 70,37 & 194,08 & 196,31 & 37,04 & 480,69 & 57,37 & 12,67 & 34,32 & 155,03 & 60,19 & 61,95 & 135,37 \\
\hline Pelobates cultripes & 30TTK99 & 100,00 & 107,21 & $\begin{array}{lll}113,47 & \end{array}$ & 38,00 & $\begin{array}{ll}6202,06 \\
\end{array}$ & 282,46 & $-12,23$ & 294,69 & 67,18 & \begin{tabular}{|l|l|}
189,34 \\
\end{tabular} & 191,49 & 33,69 & 488,99 & 58,71 & 13,45 & 33,69 & 157,33 & 63,01 & 65,25 & 136,74 \\
\hline Pelobates cultripes & 30TTL40 & 39,00 & 117,22 & 110,80 & \begin{tabular}{|l|l|}
37,98 \\
\end{tabular} & 6241,55 & 289,36 & $-0,44$ & 289,80 & 48,96 & 200,42 & 201,29 & 42,09 & 537,40 & 66,89 & 10,84 & 39,51 & 189,65 & 56,73 & 57,22 & 172,22 \\
\hline Pelobates cultripes & 30TTL43 & 28,00 & 120,19 & 113,44 & 38,44 & 6210,08 & 292,31 & 0,81 & 291,50 & 80,14 & 203,31 & 203,31 & 44,75 & 477,17 & 61,00 & 10,00 & 39,67 & 169,92 & 53,00 & 53,00 & 149,11 \\
\hline Pelobates cultripes & 30TTL45 & 20,00 & 119,76 & 113,97 & 38,97 & 6206,59 & 291,48 & $\begin{array}{ll}, 0,07 \\
0,\end{array}$ & 291,41 & 79,59 & 202,28 & 202,28 & 43,86 & 458,03 & 59,00 & 10,34 & 38,24 & 163,90 & 53,28 & 53,28 & 141,10 \\
\hline Pelobates cultripes & 30TTL46 & 17,00 & 117,23 & 114,00 & 39,00 & 6179,09 & 288,50 & $-1,86$ & 290,36 & 77,09 & 199,50 & 199,50 & 41,55 & 461,64 & 59,36 & 11,00 & 38,05 & 164,77 & 54,86 & 54,86 & 142,27 \\
\hline Pelobates cultripes & 30TTL48 & 10,00 & 118,10 & 114,00 & 39,00 & 6146,50 & 288,90 & $-1,10$ & 290,00 & 78,30 & 199,70 & 199,70 & 42,60 & 444,90 & 57,00 & 11,00 & 37,30 & 157,80 & 54,00 & 54,00 & 137,20 \\
\hline Pelobates cultripes & 30TTL50 & 100,00 & 114,93 & 111,65 & 37,99 & 6240,78 & 287,90 & $-2,85$ & 290,75 & 47,54 & 197,78 & 199,05 & 40,02 & 528,61 & 65,29 & 11,17 & 38,41 & 183,98 & 57,94 & 58,66 & 166,05 \\
\hline Pelobates cultripes & 30TTL51 & 100,00 & 114,77 & 112,50 & 38,08 & 6230,42 & 287,68 & $-3,20$ & 290,88 & 64,41 & 197,93 & 198,57 & 39,84 & 514,20 & 63,74 & 11,21 & 38,14 & 179,09 & 57,85 & 58,21 & 160,08 \\
\hline Pelobates cultripes & 30TTL52 & 100,00 & 118,54 & 113,86 & 38,51 & 6232,96 & 291,42 & $-0,62$ & 292,05 & 78,26 & 201,92 & 201,92 & 42,90 & 480,01 & 60,34 & 10,69 & 38,36 & 168,97 & 54,94 & 54,94 & 147,61 \\
\hline Pelobates cultripes & 30TTL54 & 100,00 & 119,97 & 114,95 & \begin{tabular}{|l|l|}
38,97 \\
\end{tabular} & 6214,41 & 292,67 & 0,09 & 292,57 & 79,86 & 202,86 & 202,86 & 44,03 & 445,01 & 57,31 & 10,31 & 38,63 & 159,45 & 52,65 & 52,65 & 133,95 \\
\hline Pelobates cultripes & 30TTL55 & 100,00 & 119,49 & 114,99 & 39,00 & 6194,68 & 291,90 & $-0,15$ & 292,05 & 79,42 & 202,05 & 202,05 & 43,64 & 438,15 & 56,37 & 10,58 & 38,23 & 156,80 & 52,87 & 52,87 & 131,30 \\
\hline Pelobates cultripes & 30TTL56 & 100,00 & 115,04 & 114,44 & 39,00 & 6165,01 & 287,15 & $-3,84$ & 290,99 & 75,32 & 197,15 & 197,26 & 39,83 & 452,74 & 57,87 & 11,27 & 37,59 & 161,16 & 55,84 & 55,92 & 135,98 \\
\hline Pelobates cultripes & $\begin{array}{l}30 T T L 57 \\
\end{array}$ & 100,00 & 115,39 & 114,42 & 39,00 & 6158,74 & 287,28 & $-3,76$ & 291,04 & 75,66 & 197,18 & 197,42 & 40,06 & 444,03 & 56,61 & 11,27 & 37,08 & 157,38 & 55,33 & 55,47 & 133,44 \\
\hline Pelobates cultripes & 30TTL58 & 100,00 & 118,25 & 114,45 & 39,00 & 6157,61 & 289,66 & $-1,44$ & 291,09 & 78,51 & 199,50 & 199,90 & 42,43 & 426,35 & 54,25 & 10,94 & 36,63 & 150,60 & 53,39 & 53,63 & 128,16 \\
\hline Pelobates cultripes & 30TTL59 & 100,00 & 120,08 & 114,38 & 38,99 & \begin{tabular}{|l|l|l|}
6142,13 \\
\end{tabular} & 290,93 & $-0,17$ & 291,10 & 80,44 & 200,75 & 201,21 & 44,09 & 416,59 & 52,89 & 10,56 & 36,11 & 146,84 & 52,66 & 52,95 & 125,25 \\
\hline Pelobates cultripes & 30TTL60 & 100,00 & 114,36 & 113,21 & 38,01 & 6233,21 & 288,24 & $-4,33$ & 292,57 & 69,27 & 197,00 & 198,49 & 39,50 & 502,62 & 61,29 & 11,47 & 36,97 & 171,10 & 58,14 & 58,96 & 152,82 \\
\hline Pelobates cultripes & 30TTL61 & 100,00 & 113,50 & 113,97 & 38,46 & 6218,07 & 287,22 & $-5,21$ & 292,44 & 72,68 & 196,09 & 197,31 & 38,71 & 492,07 & 60,22 & 11,71 & 36,64 & 168,50 & 58,69 & 59,31 & 148,05 \\
\hline Pelobates cultripes & $\begin{array}{l}30 T T L 62 \\
\end{array}$ & 100,00 & 116,47 & 115,31 & 38,95 & 6219,87 & 290,42 & $-2,82$ & 293,24 & 76,27 & \begin{tabular}{|l|l|}
199,71 \\
\end{tabular} & 199,86 & 41,25 & 462,77 & 57,19 & 11,12 & 37,00 & 160,84 & 56,27 & 56,35 & 137,50 \\
\hline Pelobates cultripes & 30TTL63 & 100,00 & 119,51 & 116,51 & 39,01 & $\begin{array}{ll}6228,66 \\
\end{array}$ & 293,60 & $-0,62$ & 294,22 & 79,06 & 202,72 & 202,72 & 43,67 & 431,98 & 54,71 & 10,97 & 37,70 & 153,08 & 53,65 & 53,65 & 125,65 \\
\hline Pelobates cultripes & 30TTL64 & 100,00 & 120,29 & 116,82 & 39,05 & 6221,36 & 294,10 & $-0,18$ & 294,27 & 80,06 & 203,19 & 203,19 & 44,14 & 413,41 & 52,97 & 10,68 & 38,41 & 148,23 & 52,13 & 52,13 & 118,31 \\
\hline Pelobates cultripes & 30TTL65 & 100,00 & 118,88 & 116,50 & 39,01 & 6191,56 & 292,08 & $-1,21$ & 293,29 & 78,72 & 201,26 & 201,26 & 43,07 & 410,75 & 52,21 & 10,97 & 37,74 & 146,54 & 53,00 & 53,00 & 116,99 \\
\hline Pelobates cultripes & 30TTL66 & 100,00 & 114,36 & 115,74 & 39,00 & 6172,04 & 287,32 & $-5,11$ & 292,43 & 74,34 & 196,24 & 196,68 & 39,04 & 426,80 & 53,56 & 11,65 & 36,71 & 150,57 & 56,11 & 56,36 & 122,45 \\
\hline Pelobates cultripes & \begin{tabular}{|l|l|}
$30 T T L 67$ \\
\end{tabular} & 100,00 & 115,36 & 115,55 & 39,00 & 6155,89 & 287,85 & $\begin{array}{l}-4,14 \\
-4,08 \\
\end{array}$ & 291,93 & 75,61 & 196,41 & $\begin{array}{l}197,42 \\
\end{array}$ & 40,03 & 417,49 & 52,16 & $\begin{array}{l}11,57 \\
11,5\end{array}$ & \begin{tabular}{|l|l|}
36,18 \\
\end{tabular} & 146,45 & 55,03 & 55,53 & 119,99 \\
\hline Pelobates cultripes & 30TTL68 & 100,00 & 119,86 & 115,30 & 39,00 & 6157,26 & 291,68 & $-0,43$ & 292,11 & 80,01 & 199,99 & 201,51 & 43,94 & 390,48 & 48,65 & 10,34 & 35,71 & 136,31 & 51,33 & 52,09 & 111,71 \\
\hline Pelobates cultripes & 30TTL69 & 100,00 & 122,06 & 115,03 & 39,00 & 6155,46 & 293,29 & 0,89 & 292,40 & 82,50 & 201,72 & 203,25 & 45,71 & 378,28 & 47,02 & 9,83 & 35,32 & \begin{tabular}{|l|l|}
131,58 \\
\end{tabular} & 49,88 & 50,85 & 107,96 \\
\hline Pelobates cultripes & 30TTL70 & 100,00 & 118,69 & 114,98 & 38,57 & 6219,90 & 293,06 & $-1,30$ & 294,36 & 78,33 & 201,28 & 202,53 & 43,78 & 458,78 & 55,16 & 11,02 & 35,67 & 153,44 & 55,54 & 56,09 & 135,18 \\
\hline Pelobates cultripes & 30TTL71 & 100,00 & 115,19 & 115,41 & 38,99 & 6196,44 & 289,38 & $-4,39$ & 293,77 & 74,78 & 196,90 & 198,69 & 40,55 & 461,69 & 55,62 & 11,56 & 35,19 & 154,96 & 57,72 & 58,52 & 134,75 \\
\hline Pelobates cultripes & $\begin{array}{l}30 T T L 72 \\
\end{array}$ & 100,00 & 116,09 & 116,63 & 39,11 & 6185,27 & 290,35 & $\begin{array}{l}-3,85 \\
-3,85 \\
\end{array}$ & 294,19 & 75,68 & \begin{tabular}{|l|l|}
198,19 \\
\end{tabular} & \begin{tabular}{|l|}
199,27 \\
\end{tabular} & $\begin{array}{l}41,39 \\
41,3\end{array}$ & \begin{tabular}{|l|l|}
443,39 \\
\end{tabular} & $\begin{array}{l}5,306 \\
53,56\end{array}$ & $\begin{array}{ll}1,1,38 \\
11\end{array}$ & $\begin{array}{ll}35,13 \\
35\end{array}$ & $\begin{array}{l}150,09 \\
15,0\end{array}$ & 56,90 & $\begin{array}{ll}57,37 \\
50\end{array}$ & 127,97 \\
\hline Pelobates cultripes & 30TTL73 & 100,00 & 120,48 & 118,22 & 39,59 & 6217,77 & 295,16 & $-0,53$ & 295,68 & 79,94 & 203,51 & 203,67 & 44,79 & 414,32 & 50,82 & 10,99 & 35,68 & 142,51 & 53,90 & 53,97 & 118,64 \\
\hline Pelobates cultripes & 30TTL74 & 100,00 & 119,74 & 118,07 & 39,74 & 6189,04 & 293,94 & $-1,06$ & 295,01 & 79,43 & 202,52 & 202,54 & 44,36 & 397,47 & 49,66 & 10,92 & 36,87 & 139,32 & 53,40 & 53,40 & 109,99 \\
\hline Pelobates cultripes & 30TTL75 & 100,00 & 118,36 & 117,62 & 39,62 & 6170,04 & 292,09 & $-1,89$ & 293,97 & 78,08 & 200,76 & 200,92 & 43,20 & 394,29 & 49,00 & 11,00 & 36,49 & 137,82 & 53,90 & 53,96 & 108,48 \\
\hline Pelobates cultripes & $\begin{array}{l}30 T T L 76 \\
\end{array}$ & 100,00 & 115,98 & 116,93 & 39,04 & 6154,60 & 289,42 & $-4,00$ & 293,42 & 75,96 & 197,03 & 198,15 & 40,83 & 399,35 & 49,00 & 11,38 & 35,69 & 138,35 & 54,94 & 55,48 & 110,35 \\
\hline Pelobates cultripes & 30TTL77 & 100,00 & 115,30 & 116,42 & 39,02 & 6142,99 & 288,43 & $-4,77$ & 293,20 & 75,46 & 195,38 & 197,22 & 40,21 & 399,37 & 48,49 & 11,80 & 34,90 & 137,61 & 55,20 & 56,19 & 110,71 \\
\hline Pelobates cultripes & 30TTL78 & 100,00 & 119,71 & 116,10 & 39,00 & 6150,08 & 292,16 & $-0,90$ & 293,06 & 79,96 & 199,21 & 201,27 & 43,98 & 375,74 & 45,45 & 10,79 & 34,65 & 129,17 & 51,47 & 52,77 & 103,77 \\
\hline Pelobates cultripes & 30TTL82 & 100,00 & 117,57 & 117,17 & 39,34 & 6116,41 & 290,95 & $-2,46$ & 293,41 & 77,21 & $\begin{array}{l}197,13 \\
\end{array}$ & 200,08 & 43,72 & 421,53 & 50,03 & 11,24 & 33,00 & 137,38 & 56,54 & 57,75 & 118,50 \\
\hline Pelobates cultripes & 30TTL83 & 100,00 & 120,42 & 118,34 & 40,00 & 6087,64 & 293,26 & $-0,31$ & 293,57 & 79,91 & 199,28 & 202,43 & 46,64 & 400,26 & 47,40 & 11,00 & 32,46 & 130,21 & 54,99 & 56,17 & 111,81 \\
\hline Pelobates cultripes & 30TTL84 & 100,00 & 118,22 & 118,05 & 40,00 & 6094,94 & 291,11 & $-2,11$ & 293,22 & 77,77 & 197,44 & 200,09 & 44,13 & 395,58 & 47,83 & 11,05 & 33,18 & 130,74 & 55,48 & 56,54 & 108,39 \\
\hline Pelobates cultripes & 30TTL85 & 100,00 & 117,38 & 117,95 & 39,95 & 6110,75 & 290,40 & $\begin{array}{c}-3,05 \\
-3,05 \\
\end{array}$ & 293,45 & 76,89 & 196,71 & 199,36 & 43,06 & 390,23 & $47, \varepsilon$ & 11,2 & 33,78 & 130,64 & 55,23 & 56,36 & 105,81 \\
\hline Pelobates cultripes & 30TTL86 & 100,00 & 114,99 & 117,17 & 39,21 & 6118,82 & 288,09 & $-5,01$ & 293,10 & 74,80 & 194,29 & 196,82 & 40,29 & 395,85 & 48,46 & 11,95 & 33,60 & 132,92 & 56,56 & 57,97 & 107,10 \\
\hline Pelobates cultripes & 30TTL89 & 100,00 & 123,24 & 116,25 & 39,00 & 6124,41 & 295,14 & 1,65 & 293,49 & 83,91 & 202,13 & 204,34 & 47,36 & 358,89 & 42,33 & 10,93 & 33,26 & 121,55 & 50,74 & 52,56 & 97,16 \\
\hline Pelobates cultripes & 30TTL91 & 100,00 & 117,60 & 116,18 & 39,00 & 6136,11 & 291,29 & $-2,71$ & 294,00 & 77,22 & $\begin{array}{ll}197,47 \\
\end{array}$ & 200,64 & 43,65 & 418,35 & 50,18 & 11,39 & 32,73 & 133,71 & 56,42 & 58,07 & 115,02 \\
\hline Pelobates cultripes & 30TTL92 & 100,00 & 119,23 & 117,02 & 39,26 & \begin{tabular}{|c|c|}
6087,00 \\
\end{tabular} & 291,85 & $-1,21$ & 293,05 & 78,44 & 197,85 & 201 & 45,51 & \begin{tabular}{|l|}
402,74 \\
\end{tabular} & 48,6 & $\begin{array}{l}1,02 \\
11,02\end{array}$ & 31,95 & \begin{tabular}{|l|l|}
127,79 \\
\end{tabular} & 55,75 & 57,51 & 110,08 \\
\hline Pelobates cultripes & 30TTL93 & 100,00 & 119,44 & 117,50 & 39,96 & 6030,78 & 291,30 & $-0,79$ & 292,09 & 78,96 & 197,04 & 200,89 & 46,37 & 391,78 & 46,69 & $11, \mathrm{C}$ & 31,25 & 123,57 & 55,69 & 57,79 & 106,13 \\
\hline Pelobates cultripes & 30TTL94 & 100,00 & 117,14 & 117,62 & 39,89 & 6042,23 & 289,38 & $-2,95$ & 292,33 & 76,99 & 195,08 & 198,61 & 43,79 & 392,83 & 47,39 & 11,57 & 31,49 & 125,51 & 56,71 & 58,87 & 105,48 \\
\hline Pelobates cultripes & 30TTL97 & 100,00 & 120,42 & 117,03 & 39,03 & 6113,75 & 293,03 & $-0,62$ & 293,66 & 80,65 & 199,27 & 201,87 & 45,18 & 368,74 & 44,48 & 11,30 & 32,49 & 121,59 & 53,13 & 55,11 & 98,48 \\
\hline Pelobates cultripes & 30TTL98 & 100,00 & 120,71 & 117,00 & 39,00 & 6116,87 & 293,11 & $-0,66$ & 293,78 & 81,40 & 199,52 & 202,03 & 45,15 & 367,73 & 43,89 & 11,57 & 32,38 & 121,95 & 53,17 & 55,27 & 98,40 \\
\hline Pelobates cultripes & $30 T T L S$ & 100,00 & 12 & 116,79 & 39,00 & 52 & 295 & $\begin{array}{l}-0,00 \\
1,44 \\
\end{array}$ & $\begin{array}{l}293,85 \\
293\end{array}$ & $\begin{array}{l}1,40 \\
84,35 \\
\end{array}$ & 202,00 & \begin{tabular}{|l|}
204,42 \\
\end{tabular} & $\begin{array}{l}43,13 \\
47,40\end{array}$ & $\mid \begin{array}{l}\mid 361,10 \\
3610\end{array}$ & $\begin{array}{l}43,505 \\
42,50\end{array}$ & $\begin{array}{l}11,176 \\
11,65\end{array}$ & $\begin{array}{l}2,30 \\
32,23 \\
\end{array}$ & \begin{tabular}{|l|l|}
120,58 \\
\end{tabular} & 52,20 & $\begin{array}{l}5,24 \\
54,24\end{array}$ & $\begin{array}{l}9,40 \\
97,04\end{array}$ \\
\hline Pelobates cultripes & 30TTM54 & 90,00 & 116,40 & 114,82 & 39,00 & 6026,04 & 285,92 & $-4,15$ & 290,07 & 78,08 & $\begin{array}{l}196,07 \\
\end{array}$ & 196,07 & 41,31 & 472,40 & 59,91 & 14,77 & 34,46 & 169,34 & 64,79 & 64,79 & 145,21 \\
\hline Pelobates cultripes & 30TTM55 & 84,00 & 117,11 & 114,77 & 39,00 & 6000,72 & 285,95 & $-3,43$ & 289,39 & 78,98 & 196,27 & 196,27 & 42,17 & 481,39 & 60,98 & 15,51 & 34.29 & 173,54 & 66.96 & 66.96 & 147,86 \\
\hline Pelobates cultripes & 30TTM56 & 80,00 & 115,43 & 114,79 & 39,02 & 5976,23 & 283,90 & $-4,84$ & 288,73 & 77,50 & 194,25 & 194,25 & 40,71 & 500,38 & 63,39 & 16,95 & 34,12 & 181,13 & 71,15 & 71,15 & 153,10 \\
\hline Pelobates cultripes & 30TTM60 & 100,00 & 120,34 & 115,00 & 39,00 & 6131,49 & 291,38 & $-0,43$ & 291,81 & 80,93 & 199,72 & 201,24 & 44 & 389,94 & 48,50 & 10,63 & 34 & 135,93 & 52,24 & 53,13 & 112 \\
\hline Pelobates cultripes & 30TTM61 & 100,00 & 120,34 & 115,00 & 39,00 & 6111,14 & 291,01 & $-0,41$ & 291,42 & 80,98 & 200,24 & 200,94 & 44,43 & 400,67 & 49,91 & 11,19 & 34,43 & 140,49 & 54,41 & 54,76 & 116,63 \\
\hline Pelobates cultripes & 30TTM62 & 100,00 & 120,20 & 115,04 & 39,00 & 6087,90 & 290,52 & $-0,55$ & 291,06 & 81,15 & 200,17 & 200,39 & 44,52 & 413,72 & 51,54 & 12,11 & 34,03 & 145,85 & 57,31 & 57,43 & 121,43 \\
\hline Pelobate & 30TTM65 & 100,00 & 118,10 & 115,32 & 39,04 & 6004,03 & 287.45 & -2.96 & 290,41 & 80,33 & 197,26 & 197,26 & 42.92 & 459,7 & 57.50 & 15.53 & 33,32 & 165.03 & 66.84 & 66.84 & 136,30 \\
\hline Pelobates cultripes & 30TTM66 & 100,00 & 116,47 & 115,28 & 39,09 & 5983,55 & 285,57 & $-4,3$ & 289,88 & 78,7 & 195 & 195 & 41, & 479,97 & 60,65 & 17,05 & 33 & 173,27 & 71,19 & 71,19 & 142,10 \\
\hline Pelobates cultripes & 30TTM70 & 100,00 & 123,60 & 115,39 & 39,00 & 6134,25 & 294,63 & 1,73 & 292,90 & 84,40 & 202,34 & 204,45 & 47,04 & 363,72 & 44,02 & 10,25 & 33,86 & 125,23 & 50,36 & 51,65 & 100, \\
\hline
\end{tabular}




\begin{tabular}{|c|c|c|c|c|c|c|c|c|c|c|c|c|c|c|c|c|c|c|c|c|c|}
\hline TAXON & UTM & $\mathrm{km} 2$ & B101 & B102 & $\mathrm{BIO3}$ & BIO4 & B105 & B106 & B107 & B108 & 8109 & BIO10 & B1011 & BIO12 & 81013 & BIO14 & BIO15 & B1016 & B1017 & 81018 & B1019 \\
\hline Pelobates cultripes & 30TTM71 & 100,00 & 121,85 & 115,55 & 39,00 & 6114,96 & 292,99 & 0,33 & 292,66 & 82,69 & 200,34 & 202,35 & 45,68 & 381,07 & 46,33 & 11,31 & 33,39 & 132,14 & 53,70 & 54,66 & 107,03 \\
\hline Pelobates cultripes & 30TTM72 & 100,00 & 121,22 & 115,76 & 39,00 & 6085,42 & 292,07 & $-0,26$ & 292,33 & 82,42 & 200,30 & 201,51 & 45,26 & 396,00 & 48,23 & 12,26 & 33,17 & 138,25 & 56,89 & 57,44 & 112,25 \\
\hline Pelobates cultripes & 30TTM73 & 100,00 & 119,93 & 115,98 & 39,00 & 6054,20 & 290,56 & $-1,70$ & 292,26 & 81,61 & 199,49 & 199,75 & 44,16 & 413,48 & 50,49 & 13,51 & 32,68 & 145,36 & 60,75 & 60,88 & 118,08 \\
\hline Pelobates cultripes & 30TTM76 & 100,00 & 117,59 & 115,99 & 39,30 & 5980,07 & 287,18 & $-3,66$ & 290,84 & 80,61 & 196,48 & 196,48 & 42,61 & 461,07 & 58,07 & 17,05 & 32,64 & 165,55 & 71,11 & 71,11 & 132,08 \\
\hline Pelobates cultripes & 30TTM80 & 100,00 & 121,60 & 116,17 & 39,01 & 6115,09 & 293,37 & \begin{tabular}{|c|}
0,14 \\
\end{tabular} & 293,23 & 82,48 & 200,24 & 202,43 & 45,55 & 368,92 & 43,55 & 11,36 & 32,91 & 125,50 & 52,76 & 54,50 & 100,62 \\
\hline Pelobates cultripes & 30TTM83 & 100,00 & 121,46 & 116,04 & 39,00 & 6028,39 & 292,09 & $-0,39$ & 292,48 & 84,00 & 199,86 & 200,99 & 46,17 & 400,38 & 48,43 & 13,59 & 31,92 & 139,41 & 60,23 & 60,83 & 111,39 \\
\hline Pelobates cultripes & 30TTM84 & 100,00 & 119,90 & 116,05 & 39,03 & 6009,51 & 290,27 & $-2,04$ & 292,31 & 82,80 & 198,69 & 199,16 & 44,65 & 418,84 & 51,22 & 14,87 & 31,77 & 146,78 & 64,48 & 64,70 & 116,88 \\
\hline Pelobates cultripes & 30TTM86 & 100,00 & 118,72 & 116,01 & 39,16 & 5951,78 & 288,12 & $\begin{array}{l}-2,99 \\
-2,99 \\
\end{array}$ & 291,11 & 82,34 & 197,08 & \begin{tabular}{|l|l|}
197,08 \\
\end{tabular} & 43,80 & 448,88 & 56,30 & 17,25 & 31,89 & 159,88 & 71,49 & 71,49 & 125,12 \\
\hline Pelobates cultripes & 30TTM89 & 100,00 & 115,22 & 115,85 & \begin{tabular}{|l|l|}
39,87 \\
\end{tabular} & 5866,60 & 283,20 & $-6,04$ & 289,24 & 79,92 & 192,64 & 192,64 & 41,29 & 504,66 & 65,27 & 21,97 & 32,22 & 183,22 & 85,25 & 85,25 & 138,31 \\
\hline Pelobates cultripes & 30TTM92 & 100,00 & 120,89 & 116,64 & 39,00 & 6061,87 & 292,44 & $-1,17$ & 293,61 & 83,17 & 198,99 & 201,06 & 45,29 & 389,62 & 46,38 & 13,51 & 31,44 & 132,64 & 58,42 & 60,35 & 106,25 \\
\hline Pelobates cultripes & 30TTM93 & 100,00 & 121,63 & 116,31 & 39,02 & 6017,12 & 292,34 & $-0,49$ & 292,83 & 84,57 & 199,03 & 201,21 & 46,42 & 398,03 & 48,02 & 14,06 & 31,29 & 136,86 & 60,54 & 62,02 & 108,93 \\
\hline Pelobates cultripes & 30TTM98 & 100,00 & 115,31 & 115,94 & 39,65 & 5873,47 & 283,65 & $-6,28$ & 289,93 & 80,58 & 192,79 & 192,79 & 41,40 & 486,16 & 61,73 & 21,00 & 31,12 & 173,32 & 82,64 & 82,64 & 131,60 \\
\hline Pelobates cultripes & 30TTN52 & 60,00 & 100,86 & 111,71 & 40,00 & 5658,32 & 262,18 & $-14,77$ & 276,95 & 66,22 & 175,65 & 175,65 & 30,68 & 676,20 & 88,33 & 29,24 & 31,43 & 243,77 & 109,37 & 109,37 & 198,61 \\
\hline Pelobates cultripes & 30TTN61 & 100,00 & 109,29 & 114,10 & 39,99 & 5768,96 & 273,99 & $-9,38$ & 283,37 & 73,76 & 185,24 & 185,24 & 36,90 & 590,31 & 77,69 & 25,53 & 32,54 & 215,87 & 96,86 & 96,86 & 168,97 \\
\hline Pelobates cultripes & 30TTN63 & 100,00 & 97,88 & 110,95 & 40,00 & 5567,66 & 257,41 & $-16,42$ & 273,84 & 64,54 & 171,46 & 171,46 & 28,97 & 704,86 & 91,85 & 32,32 & 30,37 & 252,02 & 118,46 & 118,46 & 202,02 \\
\hline Pelobates cultripes & 30TTN64 & 100,00 & 88,79 & 108,26 & 40,01 & 5445,67 & 244,62 & $-22,48$ & 267,11 & 56,85 & 160,94 & 160,94 & 22,20 & 795,50 & 102,14 & 37,00 & 28,97 & 279,16 & 134,13 & 134,13 & 230,18 \\
\hline Pelobates cultripes & 30TTN71 & 100,00 & 108,29 & 115,51 & 39,98 & 5833,44 & 275,83 & $-11,51$ & 287,33 & 72,84 & 185,29 & 185,29 & 35,15 & 574,51 & 75,41 & 23,60 & 32,70 & 210,81 & 98,28 & 98,28 & 159,69 \\
\hline Pelobates cultripes & 30TTN72 & 100,00 & 101,50 & 113,74 & 39,99 & 5728,56 & 266,30 & $-16,17$ & 282,47 & 67,27 & 177,26 & 177,26 & 30,08 & 637,13 & 83,05 & 28,18 & 31,32 & 230,49 & 109,92 & 109,92 & 178,09 \\
\hline Pelobates cultripes & 30TTN81 & 100,00 & 112,09 & 115,44 & 39,99 & 5801,20 & 278,79 & $-8,02$ & 286,81 & 77,48 & 188,47 & 188,47 & 38,95 & 549,74 & 72,17 & 22,12 & 32,53 & 201,18 & 96,41 & 96,41 & 148,43 \\
\hline Pelobates cultripes & 30TTN82 & 100,00 & 108,29 & 114,24 & 40,00 & 5713,11 & 272,77 & $-10,27$ & 283,04 & 74,53 & 183,56 & 183,56 & 36,55 & 591,44 & 77,61 & 24,31 & 31,73 & 214,95 & $\begin{array}{ll}104,96 \\
\end{array}$ & 104,96 & 159,59 \\
\hline Pelobates cultripes & 30TTN90 & 100,00 & 115,60 & 114,52 & 39,93 & 5754,04 & 280,47 & $-4,69$ & 285,16 & 82,10 & 191,30 & 191,30 & 42,93 & 521,09 & 67,51 & 23,59 & 31,24 & 187,63 & 91,22 & 91,22 & 139,00 \\
\hline Pelobates cultripes & 30TTN91 & 100,00 & 112,42 & 114,10 & 39,99 & 5708,68 & 276,63 & $-6,76$ & 283,39 & 79,24 & 187,61 & 187,61 & 40,64 & 551,70 & 71,77 & 24,11 & 31,20 & 198,91 & 98,15 & 98,15 & 146,58 \\
\hline Pelobates cultripes & 30TTN92 & 100,00 & $\begin{array}{ll}107,67 \\
\end{array}$ & 113,09 & 40,00 & 5642,44 & 270,31 & \begin{tabular}{|l|l|}
$-10,03$ \\
\end{tabular} & 280,35 & 75,30 & \begin{tabular}{|l|}
182,14 \\
\end{tabular} & 182,14 & 36,94 & 595,94 & 77,47 & 26,22 & 30,55 & 213,70 & 107,31 & 107,31 & 158,62 \\
\hline Pelobates cultripes & 30TTN93 & 100,00 & 101,07 & 111,23 & 40,01 & 5538,27 & 260,69 & $-14,21$ & 274,90 & 69,69 & 174,09 & 174,09 & 32,15 & 658,48 & 84,97 & 31,07 & 29,28 & 233,02 & 119,10 & 119,10 & 176,86 \\
\hline Pelobates cultripes & 30TUK03 & 100,00 & 156,90 & 114,99 & 37,00 & 6503,86 & 335,39 & 28,88 & 306,51 & 114,68 & 243,94 & 243,94 & 76,89 & 361,34 & 42,13 & 5,25 & 40,71 & 122,40 & 33,81 & 33,81 & 106,76 \\
\hline Pelobates cultripes & 30TUK04 & 100,00 & 152,48 & 114,92 & 37,00 & 6473,37 & 330,21 & 25,06 & 305,15 & 110,58 & 239,14 & 239,14 & 72,90 & 365,59 & 42, & 6,31 & 39,21 & 122,56 & 36,52 & 36,52 & 106,51 \\
\hline Pelobates cultripes & 30TUK07 & 100,00 & $\begin{array}{l}76,40 \\
76,67\end{array}$ & 109,66 & 37,02 & 6199,42 & 253,59 & $-38,70$ & 292,29 & 15,36 & $\begin{array}{l}251,19 \\
161\end{array}$ & $\begin{array}{l}301,95 \\
161,5\end{array}$ & 5 & $\mid 693,74$ & 80,34 & $\begin{array}{l}0,1114 \\
21\end{array}$ & 32,93 & 222,01 & 87,41 & 93,44 & 200,16 \\
\hline Pelobates cultripes & 30TUK08 & 100,00 & 105,93 & 113,03 & 37,83 & 6234,50 & 282,07 & $-14,19$ & 296,26 & 64,14 & 188,86 & 190,86 & 32,37 & 495,59 & 60,24 & 14,20 & 33,61 & 157,74 & 64,29 & 66,78 & 136,18 \\
\hline Pelobates cultripes & 30TUK13 & 100,00 & 153,80 & 115,00 & 37,00 & 6529,68 & 332,82 & 25,31 & 307,51 & 111,49 & 241,18 & 241,18 & 73,63 & 362,19 & 41,65 & 5,97 & 39,65 & 121,37 & 35,44 & 35,44 & 104,84 \\
\hline Pelobates cultripes & 30TUK14 & 100,00 & 151,35 & 114,68 & 37,00 & 6499,67 & 329,40 & 23,35 & 306,06 & 109,40 & 238,49 & 238,49 & 71,49 & 361,03 & 41,78 & 6,41 & 38,95 & 120,26 & 36,98 & 36,98 & 103,24 \\
\hline Pelobates cultripes & 30TUK17 & 100,00 & 79,97 & 110,37 & 37,01 & 6204,22 & 257,10 & $-36,50$ & 293,60 & 31,32 & 164,45 & 165,12 & 9,03 & 648,18 & 77,16 & 20,45 & 32,38 & 203,69 & 84,44 & 89,93 & 181,01 \\
\hline Pelobates cultripes & 30TUK23 & 100,00 & 151,83 & 114,95 & 37,00 & 6558,41 & 331,25 & $\begin{array}{ll}23,05 \\
23,\end{array}$ & 308,19 & $\begin{array}{r}1,32 \\
109,52 \\
\end{array}$ & 239,88 & 239,88 & 71,45 & \begin{tabular}{|l|}
361,57 \\
\end{tabular} & 41,58 & $\begin{array}{r}6,45 \\
6,19 \\
\end{array}$ & 39,18 & $\begin{array}{l}120,32 \\
12,0\end{array}$ & 36,54 & 36,54 & 102,94 \\
\hline Pelobates cultripes & 30TUK24 & 100,00 & 148,45 & 114,23 & 37,00 & 6501,82 & 326,70 & 20,22 & 306,48 & 106,40 & 235,77 & 235,77 & 68,69 & 362,49 & 42,40 & 6,90 & 38,08 & 119,71 & 38,77 & 38,77 & 101,54 \\
\hline Pelobates cultripes & 30TUK29 & 100,00 & 97,39 & 111,69 & 37,25 & 6172,59 & 272,32 & $-22,07$ & 294,39 & 77,13 & 179,98 & 181,63 & 24,99 & 497,97 & 64,06 & 16,68 & 32,32 & 155,57 & 71,03 & 74,46 & 127,42 \\
\hline Pelobates cultripes & 30TUK33 & 100,00 & 148,26 & 114,36 & 36,68 & 6573,51 & 328,10 & 19,23 & 308,86 & 110,18 & 236,68 & 236,68 & 67,90 & 366,73 & 43,08 & 6,69 & 38,38 & 120,75 & 38,74 & 38,74 & 102,31 \\
\hline Pelobates cultripes & 30TUK34 & 100,00 & 146,30 & 113,97 & 36,92 & 6520,96 & 324,74 & 17,80 & 306,94 & 108,63 & 233,89 & 233,89 & 66,48 & 363,94 & 43,27 & 7,34 & 37,36 & 119,40 & 40,36 & 40,36 & 99,86 \\
\hline Pelobates cultripes & 30TUK35 & 100,00 & $\begin{array}{l}14,50,37 \\
129,\end{array}$ & 113,05 & 30 & 6435,29 & 307,23 & $\begin{array}{l}3,53 \\
3,53 \\
\end{array}$ & \begin{tabular}{|l|}
303,71 \\
\end{tabular} & $\begin{array}{l}10,02,52 \\
102,5\end{array}$ & 215,09 & \begin{tabular}{|l|}
216,31 \\
216,3
\end{tabular} & $\begin{array}{l}20,40 \\
51,82\end{array}$ & \begin{tabular}{|l|}
$408,73,73$ \\
\end{tabular} & $\begin{array}{l}43,27 \\
50,69\end{array}$ & $\mid \begin{array}{l}\mid, 342 \\
10,20\end{array}$ & $\begin{array}{ll}35,68 \\
35,0\end{array}$ & $\begin{array}{l}132,82 \\
132\end{array}$ & $\begin{array}{l}40,50 \\
50,62\end{array}$ & $\begin{array}{l}\quad 50,100 \\
51,16\end{array}$ & $\begin{array}{r}5,00 \\
108,39\end{array}$ \\
\hline Pelobates cultripes & 30TUK37 & 100,00 & 95,44 & 111,44 & 37,00 & 6240,27 & 272,10 & $-24,57$ & 296,67 & 77,51 & 179,49 & 180,74 & 22,86 & 520,51 & 67,05 & 16,80 & 32,78 & 165,76 & 72,71 & 76,01 & 133,20 \\
\hline Pelobates cultripes & 30TUK39 & 100,00 & 104,10 & 111,62 & 37,10 & 6184,29 & 278,08 & $-17,14$ & 295,22 & 97,69 & 186,34 & 188,11 & 30,71 & 449,96 & 60,10 & 15,34 & 32,89 & 142,87 & 66,47 & 69,05 & 109,53 \\
\hline Pelobates cultripes & 30TUK43 & 100,00 & 145,94 & 114,02 & 36,1 & 6601,61 & 326,07 & 16,37 & 309,70 & 117,03 & $\begin{array}{ll}234,62 \\
\end{array}$ & 234,62 & 65,32 & 370,04 & 44,08 & 7,20 & 37,97 & 121,24 & 40,37 & 40,37 & 101,62 \\
\hline Pelobates cultripes & 30TUK45 & 100,00 & 146,31 & 112,88 & 36,5 & 6512,57 & 323,18 & 17,87 & 305,31 & 107,34 & 233,69 & 233,69 & 66,26 & 353,29 & 42,5 & 7,55 & 37,12 & 115,64 & 40,71 & 40,71 & 94,95 \\
\hline Pelobates cultripes & $\begin{array}{l}30 \text { TUK49 } \\
\end{array}$ & 100,00 & 106,49 & 110,67 & 37,00 & 6192,96 & 279,53 & $-15,58$ & \begin{tabular}{|l|l|}
295,10 \\
\end{tabular} & 120,31 & 188,72 & 190,49 & 32,85 & 428,51 & 58,9 & 14,66 & 33,71 & 138,90 & 64,95 & 67,18 & 100,21 \\
\hline Pelobates cultripes & $\begin{array}{l}\text { 30TUK53 } \\
\end{array}$ & 100,00 & 150,74 & 113,37 & 36,00 & 6632,21 & 330,08 & 20,54 & 309,54 & $\begin{array}{l}109,54 \\
\end{array}$ & 239,77 & 239,77 & 69,22 & 357,35 & 42,01 & 6,85 & 38,16 & 117,52 & 38,30 & 38,30 & 98,42 \\
\hline Pelobates cultripes & 30TUK55 & 100,00 & 140,85 & 112,00 & 36,01 & 6541,56 & 318,01 & 12,68 & 305,33 & 110,79 & 228,88 & 228,88 & 60,92 & 365,31 & 44,80 & 8,45 & 35,97 & 118,38 & 44,29 & 44,29 & 96,25 \\
\hline Pelobates cultripes & 30TUK57 & 100,00 & 117,59 & 110,53 & 36,51 & 6344,52 & 292,32 & $-6,49$ & 298,81 & \begin{tabular}{ll|}
102,44 \\
\end{tabular} & 202,68 & 203 & 41 , & 410,25 & 4,77 & 12,60 & 34,25 & 62 & 58,94 & 59,81 & 98,93 \\
\hline Pelobates cultripes & $\begin{array}{l}\text { 30TUK59 } \\
\end{array}$ & 100,00 & 103,59 & 109,52 & 36,96 & 6183,07 & 275,94 & $\begin{array}{l}-17,90 \\
-17\end{array}$ & 29 & 121,31 & 186,10 & 18 & 30 & $\begin{array}{ll}432,48 \\
\end{array}$ & 60, & 15,26 & 34,09 & $\begin{array}{l}142,54 \\
142\end{array}$ & 67,51 & 69,93 & 97,73 \\
\hline Pelobates cultripes & 30TUKE & 100,00 & 151,11 & 112,77 & 36,00 & 6661,99 & 330,47 & 20,64 & 309,84 & 108,24 & 240,56 & 240,56 & 69,26 & 357,44 & 41,84 & 7,00 & 37,62 & 117,66 & 38,88 & 38,88 & 98,11 \\
\hline Pelobates cultripes & $\begin{array}{l}\text { 30TUK64 } \\
\end{array}$ & 100,00 & 143,47 & 111,86 & 36,00 & 6613,83 & 321,64 & 14,24 & 307,40 & 113,18 & 232,51 & 232,51 & 62,66 & 368,43 & 44,41 & 8,08 & 36,43 & 120,08 & 43,36 & 43,36 & 98,32 \\
\hline Pelobates cultripes & 30TUK65 & 100,00 & 132,66 & 111,17 & 36,00 & 6534,47 & 309,78 & 5,08 & 304,70 & 113,12 & 220,75 & 220,75 & 53,25 & 387,33 & 48,71 & 9,88 & 35,14 & 125,27 & 49,91 & 49,91 & 99,34 \\
\hline Pelobates cultripes & 30TUK66 & 100,00 & 113,97 & 110,31 & 36,34 & 6387,97 & 290,11 & $-9,62$ & 299,73 & 93,62 & 200,12 & 200,66 & 38,09 & 443,80 & 57,94 & 13,48 & 33,95 & 79 & 62,19 & 63,67 & 109,62 \\
\hline Pelobates cultripes & 30TUKद & 100,00 & 100,89 & 108,38 & 30,53 & |6170,98 & 272,44 & \begin{tabular}{|c|c|c|}
$-20,02$ \\
$-20,11$
\end{tabular} & 292,55 & \begin{tabular}{|l|}
118,39 \\
1180
\end{tabular} & $\begin{array}{l}203,14 \\
183,75 \\
\end{array}$ & \begin{tabular}{|l|}
184,77 \\
\end{tabular} & 280,19 & $\begin{array}{l}443,1,47 \\
447\end{array}$ & $\mid 62,70$ & $\begin{array}{l}\mid 0,460 \\
16,10\end{array}$ & $\begin{array}{l}34,16 \\
34,16\end{array}$ & $\begin{array}{l}143,15,82 \\
146,\end{array}$ & $\mid 70,40$ & $\begin{array}{l}73,012 \\
73,12\end{array}$ & $\begin{aligned} \quad 07,02 \\
97,69\end{aligned}$ \\
\hline Pelobates cultripes & 30TUK74 & 100,00 & 148,29 & 111,08 & 35,77 & 6661,16 & 326,08 & 18,42 & 307,66 & 106,53 & 237,77 & 237,77 & 66,49 & 360,88 & 42,33 & 7,73 & 36,76 & 118,60 & 41,34 & 41,34 & 97,94 \\
\hline Pelobates cultripes & 30TUK75 & 100,00 & 136,04 & 110,17 & $35,75 \mid$ & 6585,37 & 312,70 & 8,06 & 304,64 & 10 & 224,68 & 224,68 & 55,91 & 383,44 & 47,17 & $9,64 \mid$ & 35,07 & $\mid 123,98$ & 48,72 & 48,72 & 99,62 \\
\hline Pelobates cultripes & 30 TUK76 & 100,00 & 126,44 & 109,29 & 35,91 & 6486,12 & 301,51 & 0,41 & 301,10 & 104,01 & 213,75 & 214,03 & 48,02 & 399,10 & 51,13 & 11,25 & 34,41 & 128,63 & 54,68 & 54,91 & 99,41 \\
\hline Pelobates cultripes & 30TUK 7 & 100,00 & 128,57 & 108,45 & 35,97 & 6458,48 & 301,79 & 2,79 & 299,00 & 98,53 & 215,16 & 215,53 & 50, & 387,77 & 49,53 & 11,21 & 34,19 & 124,92 & 53,75 & 54,05 & 96 \\
\hline Pelobates cultripes & $\begin{array}{l}\text { 30TUK79 } \\
\end{array}$ & 100,00 & $\begin{array}{l}42,31 \\
95,53 \\
\end{array}$ & $\begin{array}{l}10,45 \\
107,68\end{array}$ & 36,53 & $\begin{array}{l}0450,40 \\
6167,27\end{array}$ & 267,01 & $\begin{array}{l}-2,1,95 \\
-23,5\end{array}$ & $\begin{array}{l}290,96 \\
\end{array}$ & \begin{tabular}{|r|}
111,88 \\
11,88
\end{tabular} & \begin{tabular}{|l|}
$21,10,89$ \\
178,
\end{tabular} & \begin{tabular}{|l|}
$217,, 39$ \\
179,49
\end{tabular} & $\begin{array}{l}30,05 \\
23,83\end{array}$ & \begin{tabular}{|l|l|}
475,36 \\
\end{tabular} & |l5, & $\begin{array}{l}\mid 1,11 \\
17,76\end{array}$ & $\begin{array}{l}4,119 \\
32,92\end{array}$ & \begin{tabular}{|l|}
156,51 \\
156,
\end{tabular} & 75,28 & $\begin{array}{l}34,030 \\
79,14\end{array}$ & $\begin{array}{r}5,10 \\
107,48\end{array}$ \\
\hline Pelobates cultripes & 30TUK85 & 100,00 & 145,18 & 109,17 & 35,10 & 6648,13 & 321,11 & 16,44 & 304,68 & 102,51 & 234,40 & 234,40 & 63,61 & 368,66 & 42,96 & 8,57 & 35,71 & 121,13 & 43,99 & 43,99 & 99,45 \\
\hline Pelobates cultripes & 30TUK86 & 100,00 & 133,66 & 108,22 & 35,36 & 6561,83 & 308,14 & 6,79 & 301,35 & 98,74 & 221,89 & 222,00 & 53,67 & 390,65 & 47,58 & 10,50 & 34,35 & 125,95 & 51,28 & 51,34 & 101,24 \\
\hline Pelobates cultripes & 30TUK87 & 100,00 & 133,51 & 107,34 & 35,38 & 6530,87 & 306,06 & 7,06 & 299,00 & 93,52 & 220,89 & 221,09 & 53, & 385,86 & 47,13 & 10,80 & 34,08 & 124,41 & 51,68 & 51,78 & 99,15 \\
\hline Pelobates cultripes & 30TUK88 & 100,00 & 120,92 & 106,42 & 35,70 & 6408,92 & 291,84 & $-2,97$ & 294,81 & 109,49 & 205,88 & 207,34 & 43,50 & 407,06 & 52,75 & 2,92 & 33,55 & 130,32 & 59,09 & 60,40 & 98,12 \\
\hline
\end{tabular}




\begin{tabular}{|c|c|c|c|c|c|c|c|c|c|c|c|c|c|c|c|c|c|c|c|c|c|}
\hline TAXON & UTM & $\mathrm{km} 2$ & B101 & B102 & $\mathrm{BIO3}$ & BIO4 & B105 & B106 & B107 & B108 & B109 & BIO10 & BIO11 & BIO12 & 81013 & BIO14 & BIO15 & B1016 & B1017 & BIO18 & B1019 \\
\hline Pelobates cultripes & 30TUK89 & 100,00 & 98,05 & 106,76 & 36,38 & 6211,20 & 268,70 & $-21,19$ & 289,90 & 113,77 & 181,84 & 182,58 & 25,62 & 478,86 & 64,70 & 17,80 & 32,27 & 155,90 & 74,58 & 78,62 & 110,54 \\
\hline Pelobates cultripes & 30TUK95 & 100,00 & 145,68 & 108,31 & 35,00 & 6683,45 & 321,35 & 16,88 & 304,47 & 102,77 & 235,29 & 235,29 & 63,46 & 376,91 & 43,02 & 8,79 & 35,68 & 124,77 & 44,47 & 44,47 & 103,72 \\
\hline Pelobates cultripes & 30TUK96 & 100,00 & 142,41 & 107,19 & 35,01 & 6629,52 & 316,24 & 14,88 & 301,36 & 100,00 & 231,30 & 231,30 & 60,84 & 380,83 & 44,26 & 9,53 & 35,10 & 125,81 & 46,72 & 46,72 & 103,71 \\
\hline Pelobates cultripes & 30TUK97 & 100,00 & 130,01 & 106,23 & 35,08 & 6535,23 & 302,11 & 4,72 & 297,39 & 91,01 & 217,24 & 217,90 & 50,46 & 406,46 & 48,70 & 11,65 & 33,54 & 131,35 & 54,53 & 54,97 & 105,93 \\
\hline Pelobates cultripes & 30TUK98 & 100,00 & 117,08 & 105,55 & 35,46 & \begin{tabular}{|l|l|}
6424,03 \\
\end{tabular} & 287,68 & $-5,43$ & 293,11 & $\begin{array}{l}92,36 \\
\end{array}$ & 202,24 & 203,76 & 39,80 & \begin{tabular}{|l|l|}
433,53 \\
\end{tabular} & 54,70 & 14,08 & 32,57 & 137,60 & 62,24 & 64,39 & 106,93 \\
\hline Pelobates cultripes & 30TUK99 & 100,00 & 96,32 & 106,41 & 36,45 & 6227,65 & 266,97 & $-21,79$ & 288,76 & 105,56 & 180,69 & 181,32 & 24,05 & 503,34 & 65,66 & 18,77 & 31,15 & 161,06 & 76,80 & 81,29 & 120,12 \\
\hline Pelobates cultripes & 30TUL01 & 100,00 & 116,99 & 115,61 & 38,79 & 6125,72 & 290,26 & $-4,01$ & 294,27 & 76,75 & 196,66 & 199,79 & 43,19 & 409,76 & 50,29 & 11,94 & 32,06 & 129,01 & 57,22 & 59,14 & 109,13 \\
\hline Pelobates cultripes & \begin{tabular}{|l|} 
30TULO3 \\
\end{tabular} & 100,00 & 118,01 & 116,63 & 39,36 & 6071,70 & 290,22 & $-2,33$ & 292,55 & 77,63 & 196,35 & 199,95 & 44,42 & 390,95 & 47,67 & 11,58 & 31,22 & 122,40 & 56,58 & 58,81 & 103,35 \\
\hline Pelobates cultripes & 30TUL04 & 100,00 & 118,51 & 116,89 & 39,44 & 6066,89 & 290,54 & $-2,02$ & 292,56 & 78,15 & 196,72 & 200,28 & 44,73 & 384,11 & 46,77 & 11,48 & 31,17 & 120,88 & 56,10 & 58,44 & 101,31 \\
\hline Pelobates cultripes & 30TUL05 & 100,00 & 119,92 & 117,01 & 39,21 & 6073,97 & 292,05 & $-0,88$ & 292,92 & 79,81 & 198,15 & 201,49 & 45,87 & 374,10 & 45,45 & 11,11 & 31,60 & 119,13 & 54,34 & 56,68 & 98,92 \\
\hline Pelobates cultripes & 30TUL07 & 100,00 & 120,47 & 117,01 & 39,03 & 6099,98 & 293,05 & $-0,56$ & 293,61 & 80,67 & 199,07 & 201,76 & 45,37 & 370,50 & 44,52 & 11,69 & 31,59 & 119,75 & 54,12 & 56,69 & 98,31 \\
\hline Pelobates cultripes & 30TUL08 & 100,00 & 121,23 & 117,00 & 39,00 & 6112,11 & 293,62 & $-0,21$ & 293,83 & 81,81 & 199,81 & 202,53 & 45,58 & 369,70 & 43,93 & 11,90 & 31,65 & 120,42 & 54,14 & 56,71 & 98,49 \\
\hline Pelobates cultripes & 30TUL09 & 100,00 & 124,48 & 117,00 & 39,01 & 6110,66 & 296,34 & 1,98 & $\begin{array}{ll}294,37 \\
\end{array}$ & 85,50 & 202,91 & 205,33 & 48,39 & 362,45 & 42,43 & 11,87 & 31,51 & 119,34 & 53,11 & 55,39 & 96,87 \\
\hline Pelobates cultripes & 30TUL12 & 100,00 & 115,75 & 115,13 & 38,71 & 6120,06 & 288,45 & $-5,24$ & 293,69 & 85,69 & 195,33 & 198,45 & 41,82 & 399,52 & 50,12 & 12,22 & 31,84 & 124,37 & 57,94 & 60,50 & 103,02 \\
\hline Pelobates cultripes & 30TUL13 & 100,00 & 117,23 & 115,59 & 38,98 & 6106,01 & 289,51 & $-3,42$ & 292,93 & 83,52 & 196,31 & 199,53 & 43,05 & 389,36 & 48,44 & 12,00 & 31,30 & 121,10 & 57,11 & 59,78 & 100,52 \\
\hline Pelobates cultripes & 30TUL14 & 100,00 & 119,47 & 116,01 & 39,00 & 6096,91 & 291,40 & $-1,53$ & 292,94 & 79,08 & 198,12 & 201,34 & 44,98 & 379,21 & 46,62 & 11,81 & 30,89 & 118,57 & 56,08 & 58,75 & 98,30 \\
\hline Pelobates cultripes & 30TUL15 & 100,00 & 120,68 & 116,36 & 39,02 & 6096,79 & 292,68 & $-0,61$ & 293,29 & 80,60 & 199,20 & 202,54 & 46,05 & 373,62 & 45,62 & 11,35 & 31,03 & 117,61 & 54,56 & 57,46 & 97,78 \\
\hline Pelobates cultripes & 30TUL16 & 100,00 & 121,14 & 116,50 & 39,06 & 6101,75 & 293,16 & $-0,21$ & 293,38 & 81,37 & 199,89 & 202,88 & 46,11 & 371,73 & 44,97 & 11,71 & 30,99 & 117,60 & 54,68 & 57,42 & 97,91 \\
\hline Pelobates cultripes & 30TUL23 & 100,00 & 116,90 & 114,53 & 38,55 & 6121,92 & 288,76 & $-4,31$ & 293,07 & 129,16 & 196,38 & 199,30 & 42,62 & 388,19 & 49,19 & 12,16 & 31,45 & 120,77 & 57,43 & 60,30 & 98,07 \\
\hline Pelobates cultrips & 30TUL24 & 100,00 & 119,42 & 114,94 & 38,87 & 6127,27 & 291,15 & $-1,90$ & 293,05 & 93,05 & $\mid 198,64$ & 201,77 & 44,47 & 379,32 & 47,25 . & 12,00 & 31,03 & $\mid 118,09$ & 56,54 & 59,31 & 97,02 \\
\hline Pelobates cultripes & 30TUL27 & 100,00 & 121,95 & 116,01 & 39,00 & 6121,77 & 293,83 & 0,06 & 293,77 & 82,36 & 200,81 & 203,47 & 46,22 & 375,81 & 45,01 & 12,00 & 30,34 & 118,29 & 55,65 & 58,75 & 99,25 \\
\hline Pelobates cultripes & $\begin{array}{l}\text { 30TUL36 } \\
\end{array}$ & 100,00 & 122,90 & 114,72 & 38,71 & 6153,03 & 294,14 & 0,59 & 293,55 & 83,43 & 202,46 & 205,13 & 46,99 & 375,59 & 45,42 & 12,00 & 30,11 & 117,00 & 55,89 & 58,94 & 97,66 \\
\hline Pelobates cultripes & 30TUL40 & 100,00 & 98,29 & 110,34 & 37,06 & 6137,15 & 271,00 & $-21,99$ & 292,99 & 115,20 & 180,48 & 181,82 & 26,00 & 459,96 & 62,84 & 16,79 & 32,74 & 148,90 & 70,95 & 74,44 & 108,01 \\
\hline Pelobates cultripes & 30TUL42 & 100,00 & 117,11 & 111,48 & 37,70 & 6190,93 & 287,91 & $-5,11$ & 293,03 & $\begin{array}{ll}137,87 \\
\end{array}$ & 198,17 & 200,36 & 42,06 & 385,70 & 50,87 & 13,01 & 32,17 & 123,17 & 59,00 & 61,30 & 92,32 \\
\hline Pelobates cultripes & 30TUL47 & 100,00 & 123,20 & 114,10 & 38,24 & 6176,62 & 294,00 & 0,69 & 293,31 & 83,98 & 203,08 & 205,38 & 46,46 & 385,30 & 45,72 & 12,04 & 30,30 & 120,18 & 56,13 & 60,02 & 101,96 \\
\hline Pelobates cultripes & \begin{tabular}{|l|} 
30TUL48 \\
\end{tabular} & 100,00 & 121,62 & 114,72 & 38,82 & 6148,09 & 292,76 & $-0,10$ & 292,86 & 82,72 & 201,16 & 203,36 & 45,36 & 396,06 & 46,36 & 12,66 & 29,93 & 123,46 & 57,60 & 62,23 & 106,48 \\
\hline Pelobates cultripes & \begin{tabular}{|l|l|l|l|l|l}
$30 T U L 49$ \\
\end{tabular} & 100,00 & 123,73 & 115,15 & 39,00 & $\mid 6132,16$ & 294,86 & $\begin{array}{l}-1,85 \\
1,85 \\
\end{array}$ & 293,01 & 85,12 & 202,97 & 204,89 & 47,32 & 397,40 & 46,06 & 12,77 & 29,75 & 124,49 & 57,33 & $\begin{array}{l}2,25 \\
61,80\end{array}$ & 108,98 \\
\hline Pelobates cultripes & 30TUL50 & 100,00 & 106,06 & 109,31 & 36,96 & 6168,92 & 277,19 & $-15,90$ & 293,08 & 124,70 & 188,09 & 189,54 & 32,53 & 414,73 & 58,77 & 15,01 & 34,32 & 137,72 & 65,86 & 68,31 & 92,25 \\
\hline Pelobates cultripes & 30TUL54 & 100,00 & 119,36 & 110,76 & 37,59 & 6209,85 & 288,73 & $-2,57$ & 291,29 & 140,60 & 200,38 & 202,50 & 43,13 & 386,54 & 49,22 & 12,74 & 31,26 & 122,31 & 57,77 & 61,86 & 95,20 \\
\hline Pelobates cultripes & 30TUL55 & 100,00 & 120,87 & 111,34 & 37,96 & 6203,96 & 290,23 & $-1,04$ & 291,27 & 139,61 & 201,57 & 203,75 & 44,41 & 386,99 & 48,02 & 12,09 & 31,04 & 120,80 & 56,94 & 61,18 & 97,56 \\
\hline Pelobates cultripes & 30TUL56 & 100,00 & 122,10 & 112,07 & 38,00 & 6182,96 & 291,54 & $-0,10$ & 291,64 & 108,31 & 202,33 & 204,53 & 45,69 & 388,29 & 47,19 & 12,05 & 30,90 & 120,47 & 56,23 & 61,05 & 100,49 \\
\hline Pelobates cultripes & $\begin{array}{l}\text { 30TUL57 } \\
\end{array}$ & 100,00 & 123,07 & 112,78 & 38,02 & 6181,97 & 293,06 & $\begin{array}{l}0,134 \\
0,34 \\
\end{array}$ & 292,72 & $\begin{aligned} 8,31,41 \\
\end{aligned}$ & \begin{tabular}{|l|l|}
203,18 \\
\end{tabular} & \begin{tabular}{|l|}
205,50 \\
\end{tabular} & \begin{tabular}{|l|}
46,37 \\
4,3
\end{tabular} & 391,90 & 46,43 & $\begin{array}{ll}12,03 \\
12\end{array}$ & 30,66 & $\begin{array}{l}121,94 \\
\end{array}$ & 56,41 & $\begin{array}{l}61,21 \\
61\end{array}$ & 103,59 \\
\hline Pelobates cultripes & 30TUL58 & 100,00 & 123,85 & 113,52 & 38,29 & 6158,24 & 294,08 & 1,67 & 292,41 & 85,56 & 203,82 & 205,75 & 47,39 & 397,03 & 46,06 & 12,08 & 30,10 & 123,65 & 56,97 & 61,73 & 106,99 \\
\hline Pelobates cultripes & 30TUL59 & 100,00 & 124,59 & 114,18 & 38,41 & 6141,55 & 294,91 & 2,19 & 292,73 & 86,62 & 203,97 & 205,89 & 47,84 & 403,19 & 46,57 & 12,84 & 29,82 & 125,94 & 57,73 & 62.66 & 110,59 \\
\hline Pelobates cultripes & 30TUL64 & 100,00 & 117,40 & 108,96 & 37,00 & 6222,52 & 285,39 & $-4,59$ & 289,98 & 137,95 & 198,67 & 200,66 & 41,32 & 399,51 & 50,89 & 13,03 & 31,45 & 127,01 & 60,01 & 64,75 & 97,43 \\
\hline Pelobates cultripes & 30TUL66 & 100,00 & 121,00 & 110,45 & 37,55 & 6210,75 & 289,58 & $-0,94$ & 290,52 & 122,36 & 201,98 & 204,01 & 44,47 & 398,79 & 48,28 & 12,53 & 30,18 & 123,56 & 58,21 & 63,56 & 102,40 \\
\hline Pelobates cultripes & 30TUL70 & 100,00 & 95,84 & 107,16 & $\frac{3,50}{36,46}$ & | $6213, / 54$ & $\begin{array}{l}20,50 \\
265,89\end{array}$ & \begin{tabular}{|c|c|c|c|}
$-23,49$ \\
$-23,4$
\end{tabular} & $\begin{array}{l}280,38 \\
289,38\end{array}$ & $\begin{array}{l}112,59 \\
112,5\end{array}$ & \begin{tabular}{|l|}
178,64 \\
1704
\end{tabular} & \begin{tabular}{|l|}
$179,37,3$ \\
\end{tabular} & $\begin{array}{l}44,413 \\
24,13\end{array}$ & $\begin{array}{l}350,13 \\
465,38\end{array}$ & $\begin{array}{l}40,00 \\
65,18\end{array}$ & $\begin{array}{l}\mid 1,, 35 \\
17,91 \\
\end{array}$ & 33,21 & $\begin{array}{l}154,68 \\
150\end{array}$ & $\begin{array}{l}\mid 70,21 \\
75,01\end{array}$ & $\begin{array}{l}79,26 \\
79,26\end{array}$ & 103,41 \\
\hline Pelobates cultripes & 30TUL72 & 100,00 & 110,81 & 106,15 & 36,19 & 6232,58 & 277,81 & $-10,92$ & 288,72 & 130,18 & 193,23 & 194,73 & 35,67 & 414,40 & 55,85 & 14,89 & 32,81 & 136,22 & 65,05 & 69,51 & 94,27 \\
\hline Pelobates cultripes & 30TUL73 & 100,00 & 114,46 & 106,51 & 36,45 & 6257,94 & 281,22 & \begin{tabular}{|c|}
$-7,24$ \\
\end{tabular} & 288,46 & $\begin{array}{l}134,77 \\
\end{array}$ & 196,88 & 198,54 & 38,53 & 411,88 & 53,39 & 13,91 & 31,75 & $\mid 132,72$ & 62.76 & 67,76 & 97,63 \\
\hline Pelobates cultripes & 30TUL74 & 100,00 & 118,27 & 107,23 & 36,81 & 6265,21 & 285,06 & $-3,55$ & 288,60 & 139,17 & 200,50 & 202,28 & 41,66 & 406,48 & 50,87 & 13,08 & 31,26 & 128,45 & 60,43 & 65,65 & 99,84 \\
\hline Pelobates cultripes & 30TUL75 & 100,00 & 120,59 & 107,99 & 37,00 & 6257,09 & 287,43 & $-1,29$ & 288,72 & 136,70 & 202,34 & 204,26 & 43,45 & 404,55 & 49,39 & 12,97 & 30,53 & $\begin{array}{l}126,07 \\
\end{array}$ & 59,21 & 64,94 & 101,82 \\
\hline 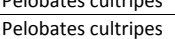 & \begin{tabular}{|l|} 
30TUL76 \\
\end{tabular} & 100,00 & $\begin{array}{l}121,59 \\
121,41\end{array}$ & 108,73 & 37,03 & | & 288,45 & $\begin{array}{l}-1,29 \\
-0,53\end{array}$ & $\begin{array}{l}280,1 / 2 \\
289,08 \\
\end{array}$ & $\begin{array}{l}1110,01 \\
111,75 \\
\end{array}$ & \begin{tabular}{|l|}
202,94 \\
204
\end{tabular} & \begin{tabular}{|l|}
204,71 \\
\end{tabular} & $\begin{array}{l}43,45 \\
44,49 \\
\end{array}$ & \begin{tabular}{|l|}
404,53 \\
405,92
\end{tabular} & $\begin{array}{l}49,39 \\
48,69 \\
\end{array}$ & $\begin{array}{l}L, 217 \\
12,92 \\
\end{array}$ & $\begin{array}{l}30,53 \\
30,21\end{array}$ & $\begin{array}{l}125,75 / \\
125\end{array}$ & \begin{tabular}{|l|l|}
58,90 \\
58,
\end{tabular} & $\begin{array}{l}04,44 \\
64,82\end{array}$ & $\begin{array}{l}101,82 \\
103,97\end{array}$ \\
\hline Pelobates cultripes & 30TUL77 & 100,00 & 122,47 & 109,62 & 37,13 & 6201,80 & 289,90 & $-0,06$ & 289,96 & 86,06 & 203,30 & 205,12 & 45,66 & 407,01 & 48,03 & 13,00 & 30,08 & 126,27 & 58,27 & 64,86 & 106,09 \\
\hline Pelobates cultripes & 30TUL79 & 100,00 & 116,90 & 111,40 & 37,96 & 6113,09 & 285,53 & $-5,35$ & 290,88 & 86,07 & 196,91 & 198,48 & 41,60 & 432,60 & 50,56 & 14,06 & 29,12 & 133,23 & 61,81 & 70,69 & 114,12 \\
\hline Pelobates cultripes & 30TUL80 & 100,00 & 92,66 & 106,66 & 36,56 & 6150,71 & 262,51 & $-25,10$ & 287,61 & 107,84 & 176,05 & 176,55 & 21,48 & 499,76 & 67,25 & 19 & 31,58 & 62,96 & 78,63 & 83,80 & 115,60 \\
\hline Pelobates cultripes & 30TUL81 & 100,00 & 105,88 & 104,96 & 35,6 & 6242,37 & 272,87 & $-14,65$ & $\begin{array}{l}287,52 \\
\end{array}$ & $\begin{array}{l}124,39 \\
\end{array}$ & $\begin{array}{l}189,19 \\
\end{array}$ & \begin{tabular}{|l|l|}
190,15 \\
\end{tabular} & 31,43 & 440,81 & 59,41 & 16 & 32,55 & 144,80 & 69,11 & $\begin{array}{ll}33,80 \\
\end{array}$ & 100,32 \\
\hline Pelobates cultripes & 30TUL82 & 100,00 & 113,51 & 104,40 & 35,99 & 6303,42 & 279,17 & $-7,94$ & 287,11 & 133,44 & 196,90 & 198,34 & 37,24 & 424,25 & 54,80 & 14,2 & 31,99 & 136,62 & 64,28 & 69,23 & 100,23 \\
\hline Pelobates cultripes & $\begin{array}{l}\text { 30TUL83 } \\
\end{array}$ & 100,00 & 116,33 & 104,58 & 36,00 & 6316,88 & 281,53 & $-5,29$ & 286,81 & 137,03 & 199,51 & 201,18 & 39,40 & 422,53 & 52,92 & 13,46 & 31,27 & 134,14 & 62,60 & 68,32 & 102,75 \\
\hline Pelobates cultripes & 30TUL84 & 100,00 & 116,68 & 105,21 & 36,05 & 6302,63 & 281,98 & $-4,68$ & 286,66 & 137,28 & 199,66 & 201,27 & 39,79 & 424,88 & 52,29 & 13,26 & 30,98 & 133,87 & 62,31 & 68,65 & 105,19 \\
\hline Pelobates cultripes & 30TUL85 & 100,00 & 118,67 & 106,09 & 36,48 & 6282,12 & 284,33 & $-2,83$ & 287,16 & 132,30 & 201,23 & 202,92 & 41,71 & 421,34 & \begin{tabular}{l|l}
50,85 \\
\end{tabular} & 13,09 & 30,66 & 131,34 & 61,16 & 67,74 & 106,22 \\
\hline Pelobates cultripes & \begin{tabular}{|l|l|l|l} 
30TUL86 \\
\end{tabular} & 100,00 & $\frac{112}{12}$ & 10 & 36 & $\begin{array}{ll}620,112 \\
6250,28\end{array}$ & 286,27 & $\begin{array}{l}-2,05 \\
-1,46\end{array}$ & \begin{tabular}{|l|}
287,74 \\
287
\end{tabular} & \begin{tabular}{|l|}
114,81 \\
11,8
\end{tabular} & \begin{tabular}{|l|}
202,20 \\
\end{tabular} & \begin{tabular}{|l|}
203,98 \\
\end{tabular} & $\begin{array}{l}41,1 / 2 \\
43,65\end{array}$ & $\begin{array}{l}421,34 \\
418,32\end{array}$ & $\begin{array}{l}0,000 \\
49,67\end{array}$ & $\mid \begin{array}{l}\mid 13,00 \\
13,00\end{array}$ & $\begin{array}{l}0,00 \\
30,17\end{array}$ & $\begin{array}{l}129,42 \\
129\end{array}$ & $\begin{array}{l}1,10 \\
60,27 \\
\end{array}$ & $\begin{array}{l}67,32 \\
67,4\end{array}$ & $\begin{array}{l}100,22 \\
107,17\end{array}$ \\
\hline Pelobates cultripes & 30TUL87 & 100,00 & 121,53 & 107,92 & 37,00 & 6219,24 & 287,56 & $-0,66$ & 288,22 & 85,59 & 202,69 & 204,38 & 44,64 & 417,66 & 49,00 & 13,00 & 29,88 & 129,37 & 59,88 & 67,24 & 108,07 \\
\hline Pelobates cultripes & 30TUL88 & 100,00 & 118,28 & 108,75 & 37,06 & 6172,89 & 284,97 & $-3,97$ & 288,95 & 106,98 & 199,23 & 200,66 & 42,14 & 430,05 & 50,49 & 13,62 & 29,58 & 132,71 & 61.48 & 70,13 & 111,92 \\
\hline Pelobates cultripes & 30TUL90 & 100,00 & 88,55 & 106,60 & 36,78 & 6147,86 & 258,66 & $-27,33$ & 285,99 & 96,43 & 172,41 & 172,71 & 18,22 & 541,27 & 69,75 & 20,88 & 30,08 & 172,62 & 83,43 & 88,12 & 130,46 \\
\hline Pelobates cultripes & 30TUL91 & 100,00 & 103,04 & 104,20 & 36,11 & 6268,38 & 269,75 & $-15,97$ & 285 & 120,93 & 187,10 & 18 & 28,96 & 474,41 & 61,07 & 16,82 & 31,16 & 152,40 & 72,34 & 78,09 & 112 \\
\hline Pelobates cultripes & \begin{tabular}{|l|} 
30TUL92 \\
30L
\end{tabular} & 100,00 & 110,04 & 102,63 & $\begin{array}{ll}35,11 \\
352\end{array}$ & $\begin{array}{l}\mid 020,030 \\
6364,53\end{array}$ & 276,80 & $\mid$\begin{tabular}{|c|c|}
$-8,16$ \\
$-8,16$
\end{tabular} & \begin{tabular}{|l|}
284,96 \\
284
\end{tabular} & \begin{tabular}{|l|}
131,29 \\
13,2
\end{tabular} & \begin{tabular}{|l|}
196,61 \\
196
\end{tabular} & \begin{tabular}{|l|l|}
198,26 \\
196
\end{tabular} & $\begin{array}{l}0,00 \\
35,66\end{array}$ & $\begin{array}{l}+49,41 \\
449,85 \\
\end{array}$ & $\begin{array}{l}\mid 51,717 \\
55,77\end{array}$ & $\begin{array}{l}10,36 \\
14,37 \\
\end{array}$ & $\begin{array}{l}1,1,18 \\
31,18\end{array}$ & $\begin{array}{l}142,48 \\
142,4\end{array}$ & $\begin{array}{l}2,34 \\
66,20\end{array}$ & $\begin{array}{l}72,4031 \\
72,41\end{array}$ & 109,86 \\
\hline Pelobates cultripes & 30TUL93 & 100,00 & 116,64 & 102,74 & 35,69 & 6377,58 & 280,39 & $-4,45$ & 284,83 & 129,84 & 200,68 & 202,26 & 39,11 & 440,48 & 53,17 & 13,25 & 30,98 & 137,89 & 63,39 & 69,84 & 110,16 \\
\hline Pelobate & 30TUL96 & 100,00 & 118,62 & 105,42 & 36,23 & 6282.53 & 283,42 & $-2,72$ & 286,14 & 101,18 & 201,27 & 202,77 & 41.50 & 433.54 & 50,89 & 13,13 & 30,22 & 134,16 & 61.92 & 69,65 & 111.47 \\
\hline Pelobates cultripes & 30TUL97 & 100,00 & 119,23 & 106,41 & 36,72 & 6233,07 & 284,23 & $-2,50$ & 286,73 & 91,11 & 200,99 & 202 & 42, & 432,63 & 50,53 & 13,55 & 29 & 133,64 & 62,01 & 70,22 & $111, \varepsilon$ \\
\hline Pelobates cultripes & 30TUM02 & 100,00 & 121,08 & 117,00 & 39,00 & 6043,71 & 292,43 & $-0,94$ & 293,37 & 83,58 & 198,70 & 200,97 & 45,49 & 392,60 & 46,74 & 14,08 & 30,80 & 132,01 & 59,13 & 61,87 & 106,46 \\
\hline
\end{tabular}




\begin{tabular}{|c|c|c|c|c|c|c|c|c|c|c|c|c|c|c|c|c|c|c|c|c|c|}
\hline TAXON & UTM & $\mathrm{km} 2$ & B101 & B102 & $\mathrm{BIO3}$ & B104 & B105 & B106 & B107 & B108 & B109 & B1010 & BIO11 & BIO12 & B1013 & BIO14 & BIO15 & B1016 & B1017 & BIO18 & B1019 \\
\hline Pelobates cultripes & зотUм03 & 100,00 & 120,97 & 116,78 & 39,21 & 6005,81 & 291,66 & $-1,18$ & 292,85 & 84,42 & 198,15 & 200,36 & 45,91 & 402,68 & 48,42 & 14,99 & 30,90 & 136,69 & 61,80 & 64,28 & 109,08 \\
\hline Pelobates cultripes & 30TUM06 & 100,00 & 118,18 & 115,99 & 39,44 & 5893,34 & 287,03 & $-3,74$ & 290,76 & 83,73 & 194,35 & 196,05 & 44,21 & 448,20 & 55,47 & 18,38 & 30,23 & 155,69 & 73,56 & 74,99 & 120,66 \\
\hline Pelobates cultripes & 30TUM07 & 100,00 & 115,87 & 115,88 & 39,41 & 5863,27 & 284,32 & $-6,15$ & 290,46 & 81,90 & 192,13 & 193,39 & 42,38 & 469,99 & 58,59 & 20,04 & 30,04 & 164,18 & 79,36 & 80,14 & 125,95 \\
\hline Pelobates cultripes & 30TUM27 & 100,00 & 117,38 & 114,55 & 39,09 & 5749,96 & 282,96 & $-4,90$ & 287,87 & 86,52 & 191,98 & 193,45 & 45,56 & 473,03 & 57,88 & 20,51 & 28,42 & 160,59 & 78,11 & 82,48 & 124,39 \\
\hline Pelobates cultripes & 30TUM28 & 100,00 & 116,00 & 113,62 & 39,21 & 5688,18 & 279,92 & $-5,54$ & 285,46 & 85,75 & 189,75 & 191,17 & 44,94 & \begin{tabular}{|l|l|}
494,83 \\
\end{tabular} & 61,05 & 22,19 & 28,15 & 169,00 & 83,81 & 87,49 & 129,43 \\
\hline Pelobates cultripes & 30TUM29 & 100,00 & 112,78 & 112,65 & 39,19 & 5631,06 & 275,25 & $-7,28$ & 282,52 & 83,09 & 185,99 & 187,28 & 42,63 & 525,30 & 65,14 & 24,28 & 27,92 & 179,86 & 91,29 & 94,23 & 137,08 \\
\hline Pelobates cultripes & 30TUM33 & 100,00 & 116,86 & 116,91 & 39,00 & 5964,17 & 287,89 & $-6,16$ & 294,05 & 82,65 & 194,20 & 196,15 & 42,60 & 435,02 & 51,10 & 16,41 & 28,95 & 140,78 & 65,07 & 72,13 & 117,56 \\
\hline Pelobates cultripes & 30TUM36 & 100,00 & 117,71 & 114,89 & 39,00 & 5767,21 & 284,04 & $-5,85$ & 289,89 & 87,57 & 192,61 & \begin{tabular}{|l|l|}
194,06 \\
\end{tabular} & 45,82 & 462,38 & 55,49 & $\begin{array}{l}19,68 \\
19,4\end{array}$ & 28,04 & 153,60 & 73,11 & 80,41 & 121,46 \\
\hline Pelobates cultripes & 30TUM40 & 100,00 & 122,15 & 115,78 & 39,00 & 6114,58 & 293,78 & 0,52 & 293,26 & 78,23 & 201,19 & 203,18 & 45,84 & 410,07 & 47,65 & 13,35 & 29,65 & 129,07 & 58,92 & 63,97 & 113,83 \\
\hline Pelobates cultripes & 30TUM44 & 100,00 & 119,96 & 115,96 & 39,00 & 5873,55 & 288,56 & $-4,79$ & 293,35 & 88,68 & 196,36 & 197,90 & 46,86 & 437,99 & 51,36 & 17,04 & 28,47 & 141,45 & 64,96 & 74,22 & 116,53 \\
\hline Pelobates cultripes & 30TUM45 & 100,00 & 119,78 & 115,23 & 39,00 & 5786,69 & 286,76 & $-4,92$ & 291,69 & 90,38 & 195,00 & 196,53 & 47,87 & 447,41 & 52,79 & 18,40 & 28,20 & 145,73 & 67,55 & 77,10 & 117,74 \\
\hline Pelobates cultripes & 30TUM46 & 100,00 & 118,20 & 114,43 & 39,00 & 5726,46 & 283,50 & $-6,18$ & 289,68 & 89,92 & 192,80 & 194,04 & 47,03 & 465,16 & 55,18 & 19,94 & 27,78 & 152,43 & 72,11 & 81,71 & 121,00 \\
\hline Pelobates cultripes & 30TUM49 & 100,00 & 109,31 & 110,90 & 39,00 & 5549,84 & 269,61 & \begin{tabular}{|c|}
$-10,74$ \\
-10
\end{tabular} & 280,35 & 82,26 & $\begin{array}{l}181,95 \\
\end{array}$ & $\begin{array}{l}182,82 \\
\end{array}$ & 40,77 & 548,23 & $\begin{array}{l}\mid 55,97 \\
65\end{array}$ & 25,72 & 26,17 & \begin{tabular}{|l|}
181,77 \\
\end{tabular} & $\begin{array}{l}\mid 2,11 \\
92,73 \\
\end{array}$ & $\begin{array}{l}0.1,1 \\
100,16\end{array}$ & 141,59 \\
\hline Pelobates cultripes & 30TUM50 & 100,00 & 124,34 & 114,90 & 38,89 & 6106,90 & 295,01 & 2,06 & 292,94 & 62,07 & 203,37 & 205,14 & 47,94 & 412,16 & 47,90 & 13,03 & 29,88 & 130,10 & 58,24 & 63,54 & 115,23 \\
\hline Pelobates cultripes & 30TUM56 & 100,00 & 119,70 & 113,90 & \begin{tabular}{|l|l|}
38,97 \\
\end{tabular} & 5683,32 & 283,72 & $-5,96$ & 289,69 & 93,62 & 193,73 & 194,98 & 49,34 & 462,42 & 54,10 & 19,69 & 27,77 & 149,64 & 69,88 & 82,09 & 118,81 \\
\hline Pelobates cultripes & 30TUM58 & 100,00 & 112,95 & 111,22 & 38,98 & 5561,76 & 273,43 & $-9,44$ & 282,87 & 87,28 & 185,75 & 186,54 & 44,39 & 520,03 & 61,52 & 23,71 & 26,27 & 169,80 & 84,27 & 94,75 & 133,20 \\
\hline Pelobates cultripes & 30TUM60 & 100,00 & 122,48 & 113,60 & 38,15 & 6089,17 & 292,07 & $-0,49$ & 292,56 & 86,07 & 201,70 & 203,24 & 46,55 & 419,17 & 48,36 & 13,43 & 29,68 & 131,25 & 58,86 & 66,41 & 114,57 \\
\hline Pelobates cultripes & 30TUM61 & 100,00 & 120,32 & 114,40 & \begin{tabular}{|l|l|}
38,47 \\
\end{tabular} & 6036,22 & 290,06 & $-3,31$ & 293,37 & 85,23 & 198,96 & 200,41 & 45,18 & 431,13 & 49,61 & 14,44 & 29,26 & 134,87 & 60,73 & 69,65 & 117,55 \\
\hline Pelobates cultripes & 30TUM64 & 100,00 & 116,19 & 115,26 & 38,27 & 5815,91 & 283,91 & $-11,75$ & 295,66 & 89,12 & 192,21 & 193,42 & 44,57 & 454,02 & 52,14 & 17,58 & 28,65 & 142,29 & 64,78 & 80,12 & 117,01 \\
\hline Pelobates cultripes & 30TUM68 & 100,00 & 114,51 & 110,01 & $38,80 \mid$ & 5524,72 & 273,23 & $-8,14$ & 281,38 & 90,16 & $\mid$\begin{tabular}{|l|l|}
186,78 \\
\end{tabular} & $\mid 187,56$ & 46,52 & 518,49| & 60,62 & 23,53 & 26,12 & 167.51 & 82,83 & 94.81 & 131,75 \\
\hline Pelobates cultripes & 30TUM70 & 100,00 & 120,65 & 112,09 & 38,00 & 6069,25 & 288,93 & $-2,75$ & 291,68 & 88,68 & 199,90 & 201,46 & 45,47 & 426,42 & 49,18 & 14,18 & 29,31 & 132,47 & 60,36 & 69,57 & 113,54 \\
\hline Pelobates cultripes & 30TUM99 & 100,00 & 112,43 & 102,95 & 38,00 & 5414,49 & 264,02 & $-3,80$ & 267,82 & 87,41 & 183,62 & 183,69 & 45,63 & 564,68 & 64,61 & 26,34 & 24,06 & 179,09 & 93,83 & 101,38 & 144,31 \\
\hline Pelobates cultripes & 30TUN01 & 100,00 & 111,04 & 112,70 & \begin{tabular}{|l|l|}
39,98 \\
\end{tabular} & 5628,60 & 272,93 & $-7,22$ & 280,16 & 79,47 & 185,17 & 185,17 & 40,30 & 563,92 & 72,45 & 26,71 & 29,77 & 199,85 & 101,55 & 101,55 & 148,49 \\
\hline Pelobates cultripes & 30TUN11 & 100,00 & 109,07 & 111,48 & 39,88 & 5567,29 & 269,32 & $-8,31$ & 277,63 & 78,70 & 182,48 & 182,55 & 39,53 & 576,87 & 73,10 & 27,93 & 28,45 & 201,05 & 104,75 & 104,80 & 151,04 \\
\hline Pelobates cultripes & 30TUN33 & 100,00 & 99,10 & 105,73 & 39,69 & 5295,84 & 250,86 & $-13,18$ & 264,04 & 72,29 & 168,86 & 169,11 & 33,99 & 687,41 & 85,03 & 34,75 & 25,42 & 231,73 & 126,50 & 127,49 & 180,19 \\
\hline Pelobates cultripes & 30TUN84 & 100,00 & 95,87 & 95,97 & 38,78 & 5037,41 & 235,94 & $-9,26$ & 245,21 & 72,10 & 163,01 & 163,01 & 34,63 & 773,53 & 91,48 & 38,99 & 22,55 & 250,52 & 141,46 & 141,46 & 205,00 \\
\hline Pelobates cultripes & 30TUN94 & 100,00 & 97,51 & 94,17 & 38,50 & 5005,21 & 235,48 & $-6,21$ & \begin{tabular}{|l|}
241,69 \\
\end{tabular} & 73,75 & $\begin{array}{l}164,15 \\
\end{array}$ & $\begin{array}{l}164,25 \\
\end{array}$ & 36,64 & 776,04 & $\begin{array}{l}1,406 \\
91,17 \\
\end{array}$ & 38,84 & 22,19 & 250,43 & 142,05 & 142,05 & 206,47 \\
\hline Pelobates cultripes & 30TVK04 & 100,00 & 141,82 & 108,82 & 35,00 & 6739,72 & 319,73 & 12,91 & 306,82 & 98,61 & 232,45 & 232,45 & 59,53 & 400,06 & 45,23 & 9,46 & 35,27 & 131,47 & 47,25 & 47,25 & 111,22 \\
\hline Pelobates cultripes & 30TVK05 & 100,00 & 140,83 & 107,49 & 35,00 & 6692,88 & 316,60 & 13,12 & 303,48 & 98,00 & 230,73 & 230,73 & 58,72 & 400,28 & 45,81 & 9,84 & 35,06 & 132,45 & 48,01 & 48,01 & 111,60 \\
\hline Pelobates cultripes & 30TVK06 & 100,00 & 142,47 & 106,21 & 35,00 & 6653,52 & 315,94 & 15,49 & 300,45 & 99,92 & 231,60 & 231,60 & 60,65 & 393,55 & 45,92 & 9,78 & 35,14 & 131,53 & 47,31 & 47,31 & 110,19 \\
\hline Pelobates cultripes & 30TVK07 & 100,00 & 138,22 & 105,19 & 35,00 & 6599,22 & 309,76 & 12,52 & 297,24 & 95,99 & 226,14 & 226,46 & 57,02 & 400,96 & 47,07 & 10,68 & 34,48 & 133,24 & 50,14 & 50,30 & 110,73 \\
\hline Pelobates cultripes & 30TVK08 & 100,00 & 124,39 & 104,41 & 35,06 & 6501,56 & 294,21 & $\begin{array}{c}1,24 \\
1,24 \\
\end{array}$ & 292,97 & 83,41 & \begin{tabular}{|l|}
209,89 \\
\end{tabular} & \begin{tabular}{|l|}
211,86 \\
\end{tabular} & $\begin{array}{ll}1,4,44 \\
45\end{array}$ & 432,64 & 51,12 & $\begin{array}{ll}13,14 \\
13\end{array}$ & $\begin{array}{l}34,406 \\
32,69\end{array}$ & \begin{tabular}{|l|}
139,51 \\
\end{tabular} & \begin{tabular}{|l|l|l|l|}
58,66 \\
\end{tabular} & $\begin{array}{ll}0,32 \\
60,32\end{array}$ & 113,69 \\
\hline Pelobates cultripes & 30TVK09 & 100,00 & 113,60 & 104,19 & 35,39 & 6407,64 & 282,44 & $-7,01$ & 289,45 & 85,27 & 198,75 & 200,05 & 36,88 & 464,05 & 56,18 & 15,15 & 31,66 & 147,87 & 65,86 & 69,08 & 118,12 \\
\hline Pelobates cultripes & 30TVK15 & 100,00 & 142,04 & 106,75 & \begin{tabular}{|l|l|}
34,97 \\
\end{tabular} & 6705,94 & 317,49 & 14,75 & 302,73 & 99,14 & 231,96 & 231,96 & 59,81 & 408,66 & 47,75 & 9,86 & 35,56 & 137,26 & 47,68 & 47,68 & 117,06 \\
\hline Pelobates cultripes & 30TVK17 & 100,00 & 138,91 & 104,25 & 34,96 & 6616,96 & 310,09 & 13,86 & 296,23 & 96,55 & 227,31 & 227,31 & 57,37 & 414,99 & 49,71 & 10,90 & 35,08 & 140,19 & 50,32 & 50,32 & 118,99 \\
\hline Pelobates cultripes & $\begin{array}{l}\text { 30TVK18 } \\
\end{array}$ & 100,00 & 131,85 & 103,41 & 34,97 & 6562,13 & 301,39 & 8,21 & 293,18 & 90,01 & 218,54 & 219,79 & 51,45 & 430,06 & 51,12 & 11,99 & 33,87 & 143,24 & 54,72 & 55,46 & 120,27 \\
\hline Pelobates cultripes & \begin{tabular}{|l|} 
30TVK19 \\
\end{tabular} & 100,00 & $\begin{array}{l}13,1,10 \\
122,10\end{array}$ & 103,03 & 35,01 & $\begin{array}{l}050,1,13 \\
6504,33\end{array}$ & 290,27 & $\begin{array}{l}0,21 \\
0,24 \\
\end{array}$ & 290,03 & $\begin{array}{l}0,010 \\
80,60\end{array}$ & \begin{tabular}{|l|}
207,63 \\
\end{tabular} & 209,40 & \begin{tabular}{l|l|}
43,13 \\
43
\end{tabular} & $\begin{array}{l}450,06 \\
452,22\end{array}$ & $\begin{array}{l}11,112 \\
52,58\end{array}$ & \begin{tabular}{|l|}
13,31 \\
13
\end{tabular} & \begin{tabular}{|l|l|}
32,24 \\
32,
\end{tabular} & \begin{tabular}{|l|}
$143,2,66$ \\
\end{tabular} & $\begin{array}{l}34,1 / 2 \\
60,58 \\
\end{array}$ & $\begin{array}{l}5,40 \\
63,19\end{array}$ & 121,45 \\
\hline Pelobates cultripes & 30TVK25 & 100,00 & 139,38 & 106,45 & 34,98 & 6697,34 & 314,71 & 13,08 & 301,62 & 96,42 & 229,10 & 229,10 & 57,26 & 428,35 & 50,99 & 10,36 & 36,03 & 145,21 & 49,27 & 49,27 & 125,76 \\
\hline Pelobates cultripes & 30TVK26 & 100,00 & 138,25 & 104,76 & 34,99 & 6657,59 & 311,19 & 13,42 & 297,77 & 95,62 & 227,21 & 227,21 & 56,31 & 433,86 & 52,36 & $\mid 10,97$ & 35,88 & 147,81 & 50,58 & 50,58 & 128,45 \\
\hline Pelobates cultripes & 30TVK27 & 100,00 & 135,36 & 103,56 & 34,97 & 6603,25 & 306,28 & 11,89 & 294,39 & 93,05 & 223,48 & 223,52 & 54,19 & 441,59 & 53,65 & 11,71 & 35,26 & 150,21 & 52,99 & 53,01 & 130,36 \\
\hline Pelobates cultripes & 30TVK28 & 100,00 & 134,52 & 102,71 & 34,77 & 6590,42 & 303,93 & 11,24 & 292,69 & 92,35 & 222,28 & 222,54 & 53,49 & 438,63 & 53,81 & 11,70 & 34,89 & 149,35 & 53,68 & 53,80 & 127,92 \\
\hline Pelobates cultripes & $\begin{array}{l}\text { 30TVK29 } \\
30 \text { T. }\end{array}$ & 100,00 & $\begin{array}{l}13,53,83 \\
123,\end{array}$ & $\begin{array}{l}102,11 \\
102,72\end{array}$ & 35,00 & $\begin{array}{l}\sigma_{0390,42} \\
6522,81\end{array}$ & 292,25 & $\begin{array}{r}1,44 \\
2,43 \\
\end{array}$ & $\begin{array}{l}228,, 39 \\
289,82\end{array}$ & \begin{tabular}{|l|}
82,35 \\
82,3
\end{tabular} & \begin{tabular}{|l|}
209,81 \\
20
\end{tabular} & $\frac{2 L L, 34}{211,40}$ & \begin{tabular}{|l|}
30,45 \\
44,65
\end{tabular} & \begin{tabular}{|l|}
$450,03,17$ \\
461,
\end{tabular} & $\begin{array}{l}35,101 \\
55,11\end{array}$ & $\begin{array}{l}11,0 \\
13,13\end{array}$ & $\begin{array}{l}4,, 50 \\
33,00 \\
\end{array}$ & \begin{tabular}{|l|}
152,183 \\
152,18
\end{tabular} & \begin{tabular}{|l|}
60,21 \\
606
\end{tabular} & $\begin{array}{ll}30,00 \\
62,15\end{array}$ & $\begin{array}{l}128,92 \\
28,16\end{array}$ \\
\hline Pelobates cultripes & 30TVK35 & 100,00 & 140,79 & 106,29 & 34,87 & 6709,03 & 316,27 & 14,32 & 301,95 & 97,58 & 230,45 & 230,45 & 58,30 & 432,71 & 53,08 & 10,14 & 37,05 & 149,43 & 48,10 & 48,10 & 129,22 \\
\hline Pelobates cultripes & 30TVK36 & 100,00 & 139,30 & 104,45 & 34,74 & 6663,92 & 312,32 & 14,42 & 297,90 & 96,29 & 228,15 & 228,15 & 57,02 & 441,51 & 54,98 & 10,73 & 37,02 & 153,39 & 49,58 & 49,58 & 133,44 \\
\hline Pelobates cultripes & 30TVK37 & 100,00 & 138,10 & 102,94 & 34,50 & 6626,82 & 309,23 & 14,46 & 294,77 & 95,56 & 226,59 & 226,59 & 56,19 & 444,80 & 56,12 & 11,12 & 36,95 & 155,32 & 50,47 & 50,47 & 134,92 \\
\hline Pelobates cultripes & $\begin{array}{l}\text { 30TVK38 } \\
\end{array}$ & 100,00 & 136,31 & 102,21 & 34 & $\begin{array}{ll}60202,03 \\
6603\end{array}$ & 306,29 & $\begin{array}{ll}13,06 \\
\end{array}$ & 293,23 & 93,77 & 224,52 & $\begin{array}{ll}224,52 \\
\end{array}$ & 54,94 & 4443,90 & 56,36 & \begin{tabular}{l|l}
11,18 \\
118
\end{tabular} & $\begin{array}{l}0,36,47 \\
36\end{array}$ & $\begin{array}{l}154,53 \\
15,3\end{array}$ & 51,94 & 51,94 & 132,50 \\
\hline Pelobates cultripes & $30 \mathrm{TVK}$ & 100,00 & 13 & 102,09 & $\begin{array}{l}34,58 \\
\end{array}$ & 6564,50 & 301,02 & 9,65 & 291,37 & 90,28 & 219,68 & 220,00 & 51,72 & 447,13 & 56,2 & 11,54 & 35,06 & 153,56 & 55,03 & 55,22 & 130,17 \\
\hline Pelobates cultripes & $\begin{array}{l}\text { 30TVK43 } \\
\end{array}$ & 100,00 & 146,90 & 110,28 & 35,02 & 6784,14 & 326,59 & 17,10 & 309,49 & $\begin{array}{r}103,19 \\
\end{array}$ & 237,63 & 237,63 & 63,67 & 408,17 & 49,26 & 8,35 & 37,78 & 140,62 & 42,91 & 42,91 & 120,14 \\
\hline Pelobates cultripes & 30TVK46 & 100,00 & 142,44 & 105,04 & 34,08 & 6722,08 & 317,54 & 15,72 & 301,82 & 99,19 & 232,04 & 232,04 & 59,47 & 433,65 & 56,45 & 9,89 & 38,66 & 154,29 & 46,01 & 46,01 & 131,79 \\
\hline Pelobates cultripes & 30TVK47 & 100,00 & 137,47 & 103,58 & 34,19 & 6659,03 & 310,34 & 12,61 & 200 & 94,24 & 226,32 & 226,32 & 55,21 & 449,72 & 58,83 & 10,81 & 38,01 & 159,53 & 49,71 & 49,71 & 136,32 \\
\hline Pelobates cultripes & $30 \mathrm{TVK}$ & 100,00 & 13 & 102 & 34,73 & 6603,20 & 305,15 & $\begin{array}{l}1,30 \\
11,37 \\
\end{array}$ & \begin{tabular}{|l|}
293,78 \\
\end{tabular} & $\begin{array}{l}4,24 \\
92,12\end{array}$ & $\begin{array}{l}222,82 \\
222 \\
\end{array}$ & $\begin{array}{l}222,82 \\
222\end{array}$ & \begin{tabular}{|l|l|}
53,66 \\
5
\end{tabular} & $\begin{array}{l}443,12,82 \\
442,\end{array}$ & $\begin{array}{l}50,03 \\
58,10\end{array}$ & $\begin{array}{l}\mid 0,01 \\
10,74 \\
\end{array}$ & 36,01 & \begin{tabular}{|l|}
155,84 \\
15,8
\end{tabular} & $\begin{array}{l}\mid 52,11 \\
52,14\end{array}$ & $\begin{array}{l}42,114 \\
52,14\end{array}$ & 130,55 \\
\hline Pelobates cultripes & 30TVK54 & 100,00 & 143,67 & 109,71 & 35,11 & 6755,05 & 322,69 & 15,08 & 307,61 & 99,94 & 233,95 & 233,95 & 60,92 & 420,95 & 52,77 & 9,08 & 37,83 & 147,14 & 44,87 & 44,87 & 124,71 \\
\hline Pelobates cultripes & 30TVK55 & 100,00 & 141,85 & 108,40 & 34,99 & 6738,40 & 319,77 & 14,16 & 305,61 & 98,29 & 231,79 & $\mid 231,79$ & 59,30 & 429,84 & 55,43 & 9,63 & 38,22 & 152.05 & 45,89 & 45,89 & 128,52 \\
\hline Pelobates cultripes & 30TVK57 & 100,00 & 140,80 & 106,21 & 34,44 & 6736,18 & 317,72 & 13,90 & 303,82 & 97,37 & 230,36 & 230,36 & 58,05 & 437,08 & 60,00 & 9,60 & 39,76 & 158,71 & 45,75 & 45,75 & 132,97 \\
\hline Pelobates cultripes & 30TVK59 & 100,00 & 135,08 & 104,62 & 34,94 & 6619,79 & 306,93 & 11,33 & 295,60 & 92,02 & 223,11 & 22 & 54,05 & 437,96 & 58,92 & 10,32 & 37,44 & 156,24 & 50,69 & 50,69 & 128 \\
\hline Pelobates cultripes & 30TVK63 & 100,00 & 141,18 & 112,37 & 36,00 & 6743,88 & 321,63 & 11,90 & 309,73 & 97,42 & $\begin{array}{l}231,27 \\
23\end{array}$ & 231,27 & 58,88 & 423,68 & 51,31 & $\begin{array}{c}2,18 \\
9,18\end{array}$ & 36,88 & 144,92 & 46,64 & 46,64 & 122,68 \\
\hline Pelobates cultripes & 30TVK68 & 100,00 & 136,47 & 108,46 & 35,96 & 6623,71 & 311,34 & 12,18 & 299,16 & 92,69 & 224,35 & 224,35 & 55,92 & 432,86 & 59,86 & 9,67 & 39,16 & 158,13 & 47,77 & 47,77 & 128,14 \\
\hline Pelobate & 30TVK69 & 100,00 & 130,82 & 105,62 & 35,28 & 6593,60 & 302,23 & 804 & 294,19 & 87.81 & 218,64 & 218,64 & 50.92 & 440,21 & 58.48 & 10.84 & 36,21 & 155,32 & 53,21 & 53,21 & 125,62 \\
\hline Pelobates cultripes & 30TVK76 & 100,00 & 127,98 & 110,16 & 36,00 & 6648,33 & 304,79 & 2,62 & 302,17 & 84,65 & 216,96 & 216,96 & 47,7 & 456,99 & 56,81 & 12,23 & 34 & 155 & 55,91 & 55,91 & 129,05 \\
\hline Pelobates cultripes & 30TVK77 & 100,00 & 127,52 & 108,89 & 36,00 & 6620,45 & 302,52 & 3,27 & 299,25 & 84,27 & 215,94 & 215,94 & 47,71 & 453,90 & 57,35 & 12,08 & 34,72 & 155,45 & 56,17 & 56,17 & 127 \\
\hline
\end{tabular}




\begin{tabular}{|c|c|c|c|c|c|c|c|c|c|c|c|c|c|c|c|c|c|c|c|c|c|}
\hline TAXON & UTM & $\mathrm{km} 2$ & B101 & B102 & $\mathrm{BIO3}$ & BIO4 & B105 & B106 & B107 & B108 & 8109 & BIO10 & BIO11 & BIO12 & 81013 & BIO14 & BIO15 & B1016 & B1017 & B1018 & B1019 \\
\hline Pelobates cultripes & 30TVK78 & 100,00 & 132,00 & 107,07 & 35,82 & 6613,92 & 304,40 & 8,54 & 295,86 & 88,89 & 220,03 & 220,03 & 52,04 & 431,48 & 56,53 & 10,85 & 35,91 & 151,10 & 52,36 & 52,36 & 120,87 \\
\hline Pelobates cultripes & 30TVK79 & 100,00 & 130,23 & 104,81 & 35,19 & 6592,21 & 299,79 & 7,80 & 291,99 & 87,36 & 218,03 & 218,03 & 50,57 & 428,29 & 55,77 & 10,97 & 34,90 & 148,50 & 54,04 & 54,04 & 117,38 \\
\hline Pelobates cultripes & 30TVK87 & 100,00 & 125,00 & 109,19 & 36,00 & 6611,96 & 299,33 & 1,01 & 298,32 & 82,09 & 213,40 & 213,40 & 45,56 & 453,26 & 54,74 & 12,95 & 32,86 & 150,36 & 59,67 & 59,67 & 123,08 \\
\hline Pelobates cultripes & 30TVL00 & 100,00 & 103,47 & 104,36 & 35,96 & 6315,89 & 271,61 & $-14,89$ & 286,50 & 97,34 & 188,25 & 189,18 & 29,18 & 495,14 & 61,23 & 17,16 & 30,66 & 156,36 & 73,01 & 77,93 & 122,97 \\
\hline Pelobates cultripes & 30TVL02 & 100,00 & 104,18 & 102,76 & 35,80 & 6328,72 & 269,13 & $-14,21$ & 283,34 & $\begin{array}{ll}120,89 \\
\end{array}$ & \begin{tabular}{|l|l|}
188,74 \\
\end{tabular} & 189,91 & 29,02 & 496,09 & 60,40 & 16,33 & 30,06 & 155,61 & 73,06 & 80,28 & 123,40 \\
\hline Pelobates cultripes & 30TVL03 & 100,00 & 111,68 & 101,23 & 35,18 & 6409,99 & 274,44 & $-7,84$ & 282,27 & 123,56 & 196,60 & 198,14 & 34,33 & 477,20 & 56,09 & 14,21 & 30,30 & 148,11 & 68,19 & 76,25 & 121,31 \\
\hline Pelobates cultripes & 30TVL05 & 100,00 & 116,57 & 103,03 & 35,97 & 6346,01 & 280,02 & $-3,86$ & 283,88 & 89,52 & 200,27 & 201,63 & 39,21 & 453,55 & 52,60 & 13,51 & 29,85 & 140,38 & 64,56 & 72,60 & 116,86 \\
\hline Pelobates cultripes & \begin{tabular}{|l|} 
30TVL06 \\
\end{tabular} & 100,00 & 116,71 & 104,10 & 36,00 & 6302,46 & 280,64 & $\begin{array}{l}-3,95 \\
-3,0 \\
\end{array}$ & 284,59 & 87,64 & 199,84 & 201,07 & 39,69 & 450,05 & 52,20 & 13,92 & 29,64 & $\begin{array}{l}138,92 \\
\end{array}$ & 64,53 & 72,95 & 115,98 \\
\hline Pelobates cultripes & 30TVL07 & 100,00 & 116,73 & 105,12 & 36,17 & 6250,86 & 281,10 & $-4,31$ & 285,42 & 94,92 & 199,00 & 200,28 & 40,25 & 447,60 & 51,91 & 14,11 & 29,45 & 137,76 & 64,35 & 73,21 & 115,57 \\
\hline Pelobates cultripes & 30TVL10 & 100,00 & 112,46 & 102,96 & 35,38 & 6427,44 & 279,75 & $-7,11$ & 286,86 & 80,22 & 197,93 & 199,25 & 35,60 & 478,21 & 56,21 & 15,01 & 30,94 & 150,99 & 67,21 & 71,88 & 123,97 \\
\hline Pelobates cultripes & 30TVL12 & 100,00 & 82,73 & 105,64 & 37,01 & 6128,99 & 251,27 & $-30,42$ & 281,69 & 86,58 & 166,66 & 167,03 & 13,17 & \begin{tabular}{|c|}
603,08 \\
\end{tabular} & 72,94 & 23,32 & 27,85 & 187,35 & 92,53 & 97,16 & 152,35 \\
\hline Pelobates cultripes & 30TVL14 & 100,00 & 107,35 & 102,19 & 35,99 & 6359,05 & 271,21 & $-11,09$ & 282,30 & 116,53 & 192,19 & 193,14 & 31,24 & 496,32 & 57,82 & 15,51 & 29,34 & 152,82 & 71,83 & 80,63 & 127,33 \\
\hline Pelobates cultripes & 30TVL15 & 100,00 & 111,79 & 102,60 & 36,00 & 6345,76 & 275,35 & $-7,64$ & 282,99 & 91,05 & 195,92 & 197,13 & 35,17 & 478,00 & 55,14 & 14,66 & 29,35 & 147,29 & 68,66 & 77,28 & 123,44 \\
\hline Pelobates cultripes & 30TVL16 & 100,00 & 115,36 & 103,26 & 36,00 & 6308,40 & 279,01 & $-4,90$ & 283,92 & 77,00 & 198,68 & 199,90 & 38,50 & 461,39 & 53,03 & 14,15 & 29,30 & 142,52 & 66,18 & 74,41 & 119,66 \\
\hline Pelobates cultripes & 30TVL17 & 100,00 & 115,73 & 104,16 & 36,00 & 6265,15 & 279,67 & $-4,48$ & 284,15 & 77,97 & 198,56 & 199,49 & 39,31 & 457,07 & 52,53 & 14,51 & 28,91 & 140,66 & 66,03 & 74,70 & 118,49 \\
\hline Pelobates cultripes & 30TVL18 & 100,00 & 115,06 & 104,96 & 36,06 & 6210,51 & 279,29 & $-5,45$ & 284,74 & 98,72 & 196,99 & 198,01 & 39,25 & 458,03 & 52,86 & 15,12 & 28,51 & 140,43 & 66,99 & 76,23 & 118,24 \\
\hline Pelobates cultripes & 30TVL20 & 100,00 & 116,65 & 102,55 & 35,13 & 6465,02 & 284,01 & $-3,38$ & 287,39 & 75,82 & 202,20 & 203,73 & 38,82 & 477,18 & 55,71 & 14,20 & 31,40 & 153,59 & 64,93 & 68,63 & 128,32 \\
\hline Pelobates cultripes & 30TVL21 & 100,00 & 84,19 & 106,10 & 36,89 & 6169,99 & 254,29 & $-29,16$ & 283,45 & 61,23 & 168,71 & 169,10 & 14,22 & 607,58 & 72,58 & 23,35 & 27,95 & 188,62 & 92,03 & 95,29 & 156,05 \\
\hline Pelobates cultripes & 30TVL24 & 100,00 & 93,79 & 104,32 & 36,48 & 6221,50 & 260,20 & $-21,89$ & 282,09 & 103,11 & 177,89 & 178,38 & 21,18 & 554,28 & 65,42 & 19,96 & 27,84 & 170,44 & 83,91 & 90,92 & 141,50 \\
\hline Pelobates cultripes & 30TVL25 & 100,00 & 108,37 & 102,99 & 35,99 & 6326,98 & 272,63 & $-10,23$ & 282,85 & 93,76 & 192,45 & 193,55 & 32,51 & 493,86 & 56,84 & 15,78 & 28,86 & 151,52 & 71,94 & 80,44 & 127,86 \\
\hline Pelobates cultripes & 30TVL26 & 100,00 & 112,70 & 103,07 & 36,00 & 6315,11 & 276,66 & $-6,85$ & 283,51 & 74,65 & 196,25 & \begin{tabular}{|l|}
197,43 \\
\end{tabular} & 36,25 & 475,34 & 54,32 & 15,05 & 28,77 & 146,19 & 69,14 & 77,29 & 123,50 \\
\hline Pelobates cultripes & 30TVL27 & 100,00 & 112,87 & 103,91 & 36,01 & 6262,71 & 276,90 & $-6,79$ & 283,69 & 86,03 & 195,63 & 196,50 & 36,60 & 471,66 & 54,16 & 15,43 & 28,28 & 144,47 & 69,39 & 77,94 & 122,11 \\
\hline Pelobates cultripes & 30TVL30 & 100,00 & 119,57 & 102,73 & 35,07 & 6498,95 & 287,51 & $-0,85$ & 288,36 & 77,69 & 205,32 & 206,90 & 41,19 & 476,05 & 56,83 & 13,65 & 32,14 & \begin{tabular}{|l|l|}
156,14 \\
\end{tabular} & 63,41 & 66,05 & 131,37 \\
\hline Pelobates cultripes & 30TVL31 & 100,00 & 112,12 & 103,04 & 35,52 & 6428,78 & 279,39 & $-6,72$ & 286,11 & 73,78 & 197,50 & 198,75 & 35,20 & 496,87 & 58,38 & 15,25 & 30,58 & 158,92 & 69,08 & 73,27 & 133,32 \\
\hline Pelobates cultripes & 30TVL32 & 100,00 & 89,33 & 105,67 & 36,72 & 6214,66 & 258,42 & $-25,45$ & 283,86 & 76,32 & 173,92 & 174,25 & 17,79 & 578,12 & 68,50 & 21,47 & 27,60 & 177,52 & 87,52 & 92,90 & 148,19 \\
\hline Pelobates cultripes & 30TVL33 & 100,00 & 93,59 & 104,76 & 36,51 & 6246,76 & 261,29 & $-22,01$ & 283,30 & 79,89 & 178,09 & 178,63 & 20,99 & 562,40 & 65,76 & 20,43 & 27,73 & 172,92 & 84,79 & 90,65 & 145,03 \\
\hline Pelobates cultripes & 30TVL34 & 100,00 & 86,44 & 105,55 & 36,82 & 6168,71 & 254,56 & $-27,94$ & 282,50 & 96,85 & 170,42 & 170,66 & 15,35 & 591,88 & 69,86 & 22,81 & 26,76 & 181,19 & $\begin{array}{l}4,1,63 \\
91,5\end{array}$ & $\begin{array}{l}97,38 \\
97,3\end{array}$ & 151,49 \\
\hline Pelobates cultripes & 30TVL35 & 100,00 & 104,34 & 103,59 & 36,00 & 6301,34 & 269,84 & $-13,51$ & 283,36 & 89,26 & 188,49 & 189,34 & 29,28 & 510,81 & 58,92 & 17,23 & 28,11 & 155,47 & 75,87 & 84,21 & 132,27 \\
\hline Pelobates cultripes & 30TVL40 & 100,00 & 127,79 & 102,91 & 35,01 & 6550,89 & 296,39 & 5,74 & 290,64 & 85,55 & 214,56 & 215,24 & 47,88 & 454,56 & 57,17 & 12,01 & 34,19 & 154,78 & 57,89 & 58,64 & 129,23 \\
\hline Pelobates cultripes & 30TVL41 & 100,00 & 120,84 & 102,69 & 35,08 & 6501,78 & 288,23 & 0,27 & 287,97 & 79,02 & 206,51 & 207,87 & 42,13 & 468,87 & 56,71 & 13,27 & 31,97 & 154,61 & 63,08 & 65,25 & 129,18 \\
\hline Pelobates cultripes & 30TVL42 & 100,00 & 106,04 & 103,99 & 36,08 & 6376,62 & 273,74 & $-11,87$ & 285,61 & 69,50 & 191,23 & 192,10 & 30,35 & 516,25 & 60,00 & 16,95 & 29,25 & 161,85 & 74,57 & 79,67 & 136,35 \\
\hline Pelobates cultripes & \begin{tabular}{|l|l|} 
30TVL43 \\
\end{tabular} & 100,00 & 109,23 & 103,29 & 36,00 & 6385,04 & 275,66 & $\begin{array}{r}-1,0,20 \\
\end{array}$ & \begin{tabular}{|l|}
284,86 \\
\end{tabular} & \begin{tabular}{|l|l|}
68,98 \\
50
\end{tabular} & 194,21 & 195,12 & $\begin{array}{ll}0,259 \\
32,98\end{array}$ & 499,32 & 56,90 & $\begin{array}{l}0,039 \\
15,97\end{array}$ & 29,15 & $\begin{array}{ll}155,92 \\
152\end{array}$ & 72,09 & 77,84 & 131,74 \\
\hline Pelobates cultripes & 30TVL46 & 100,00 & 108,25 & 103,93 & 36,01 & 6293,78 & 273,65 & $-10,18$ & 283,83 & 72,81 & 192,06 & 192,79 & 32,78 & 494,32 & 56,55 & 16,91 & 27,56 & 150,54 & 74,33 & 81,69 & 128,35 \\
\hline Pelobates cultripes & 30TVL47 & 100,00 & 110,21 & 104,01 & 36,01 & 6266,56 & 275,21 & $-8,54$ & 283,75 & 80,04 & 193,46 & 194,19 & 34,55 & 485,09 & 55,48 & 16,84 & 27,36 & 147,43 & 73,57 & 80,99 & 125,80 \\
\hline Pelobates cultripes & 30TVL50 & 100,00 & 133,14 & 103,39 & 35,00 & 6579,67 & 302,35 & 10,41 & 291,94 & 90,44 & 220,66 & 220,69 & 52,75 & 434,01 & 57,10 & 10,67 & 35,80 & 152,12 & 53,20 & 53,21 & 124,29 \\
\hline Pelobates cultripes & $\begin{array}{l}\text { 30TVL51 } \\
\end{array}$ & 100,00 & 128,43 & 102,74 & 35,00 & 6538,75 & 296,04 & 6,70 & 289,35 & 86,38 & 215,28 & 215,54 & 48,77 & 440,69 & 55,86 & 11,65 & 33,64 & 149,99 & 57,75 & 58,04 & 122,79 \\
\hline Pelobates cultripes & \begin{tabular}{|l|} 
30TVL52 \\
30
\end{tabular} & 100,00 & $\begin{array}{l}12,45 \\
119,14\end{array}$ & 103,05 & 35,49 & $\mid 6471,71$ & $\begin{array}{l}280,0406 \\
\end{array}$ & $\begin{array}{l}0,1 / 94 \\
-0,94 \\
\end{array}$ & \begin{tabular}{|l|}
286,99 \\
286,9
\end{tabular} & $\begin{array}{l}0,300 \\
77,81 \\
\end{array}$ & 204,20 & $\mid$ & $\begin{array}{ll}40,717 \\
40,94\end{array}$ & $\begin{array}{l}440,03 \\
466,92 \\
\end{array}$ & $\begin{array}{l}35,00 \\
55,77\end{array}$ & $\begin{array}{l}11,00 \\
13,73\end{array}$ & 31,05 & $\begin{array}{l}151,94 \\
151\end{array}$ & $\begin{array}{l}x, 1,03 \\
65,\end{array}$ & $\begin{array}{l}0,0744 \\
67,44\end{array}$ & 126,10 \\
\hline Pelobates cultripes & 30TVL53 & 100,00 & 109,88 & 103,92 & 36,06 & 6394,79 & 277,01 & $-8,73$ & 285,74 & 72,46 & 195,03 & 195,80 & 33,52 & 497,35 & 57,41 & 16,26 & 28,98 & 155,85 & 72,63 & 77,34 & 131,28 \\
\hline Pelobates cultripes & 30TVL54 & 100,00 & 97,28 & 105,44 & 36,44 & 6285,75 & 265,47 & $-19,77$ & 285,24 & 84,53 & 181,84 & 182,24 & 23,39 & 546,22 & 63,27 & 20,09 & 26,97 & 166,33 & 83,72 & 89,91 & 141,45 \\
\hline Pelobates cultripes & 30TVL55 & 100,00 & 76,54 & 107,27 & 37,39 & 6122,88 & 246,61 & $-37,30$ & 283,90 & 87,02 & 160,33 & 160,37 & 6,47 & 648,73 & 76,29 & 27,79 & 24,67 & 197,61 & 105,10 & 107,78 & 166,35 \\
\hline Pelobates cultripes & 30TVL57 & 100,00 & 104,72 & 105,03 & 36,17 & 6252,04 & 271,03 & $-13,48$ & 284,51 & 114,02 & 188,23 & 188,65 & 29,89 & 507,95 & 58,64 & 18,72 & 26,38 & 152,99 & 79,18 & 86,79 & 131,05 \\
\hline Pelobates cultripes & 30TVL59 & 100,00 & 108,00 & 105,03 & 36,61 & 6185,94 & 273,14 & $-10,25$ & 283,39 & 124,27 & 190,18 & 190,51 & 33,01 & 493,92 & 57,00 & 18,96 & 25,70 & 148,62 & 78,66 & 86,02 & 127,11 \\
\hline Pelobates cultripes & 30TVL60 & 100,00 & 126,06 & 104,05 & 35,02 & 6558,47 & 295,12 & 4,32 & 290,81 & 83,61 & 213,47 & 213,51 & 46,63 & 447,94 & 57,04 & 11,99 & 33,66 & 152,69 & 58,60 & 58,63 & 124,06 \\
\hline Pelobates cultripes & 30TVL61 & 100,00 & 121,44 & 103,71 & 35,33 & 6520,14 & 289,47 & 0,86 & 288,61 & 79,56 & 208,07 & 208,63 & 42,72 & 457,78 & 56,02 & 13,16 & 31,80 & 151,47 & 63,16 & 63,89 & 124,21 \\
\hline Pelobates cultripes & 30TVL62 & 100,00 & 122,19 & 103,14 & 35,32 & 6491,62 & 288,90 & 1,52 & 287,38 & 80,64 & 208,18 & 208,88 & 43,69 & $\begin{array}{l}450,45 \\
\end{array}$ & 54,49 & 13 & 31,25 & 7,72 & 63,30 & 64,48 & 120,74 \\
\hline Pelobates cultripes & 30TVL66 & 100,00 & 76,30 & 107,84 & $\begin{array}{l}37, \\
37,\end{array}$ & $\begin{array}{l}6411,961 \\
6191 \\
\end{array}$ & 246,56 & \begin{tabular}{|l|r|r|}
$-38,21$ \\
\end{tabular} & \begin{tabular}{|l|}
284,77 \\
\end{tabular} & \begin{tabular}{|l|l|}
90,68 \\
90
\end{tabular} & $\begin{array}{l}159,88 \\
150\end{array}$ & $\begin{array}{l}259,80 \\
159\end{array}$ & \begin{tabular}{|c|}
5,98 \\
5,08
\end{tabular} & $\begin{array}{l}4551,92 \\
651,92\end{array}$ & 76,56 & $\frac{15}{28}$ & 23,88 & $\begin{array}{l}198,39 \\
\end{array}$ & 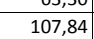 & $\begin{array}{l}0.4,40 \\
110,04 \\
\end{array}$ & 166,99 \\
\hline Pelobates cultripes & 30TVL67 & 100,00 & 100,57 & 106,06 & 36,81 & 6237,13 & 268,01 & $-17,44$ & 285,45 & 118,41 & 184,05 & 184,31 & 26,33 & 527,83 & 61,34 & 20,66 & 25,47 & 159,01 & 84,49 & 91,42 & 135,66 \\
\hline Pelobates cultripes & 30TVL70 & 100,00 & 124,57 & 103,99 & 35,16 & 6556,40 & 292,94 & 3,20 & 289,73 & 82,36 & 212,23 & 212,23 & 45,64 & 442,06 & 55,17 & 12,34 & 32,79 & 148,33 & 59,95 & 59,96 & 118,65 \\
\hline Pelobates cultripes & 30TVL71 & 100,00 & 120,88 & 103,79 & 35,43 & 6518,66 & 288,58 & 0,21 & 288,37 & 79,19 & 207,66 & 208,00 & 42,49 & 451,60 & 54,44 & 13,41 & 31,27 & 147,68 & 64,06 & 64,58 & 119,43 \\
\hline Pelobates cultripes & 30TVL72 & 100,00 & 117,74 & 104,08 & 35,80 & 6482,68 & 285,14 & $-2,35$ & 287,49 & 76,32 & 203,73 & 204,45 & 39,86 & 460,90 & 53,92 & 14,48 & 29,91 & 147,44 & 67,16 & 68,99 & 120,82 \\
\hline Pelobates cultripes & \begin{tabular}{|l} 
30TVL73 \\
\end{tabular} & 100,00 & $\frac{11}{11}$ & 104,90 & $\begin{array}{l}30, \\
36,\end{array}$ & 64024,90 & $\begin{array}{l}203,1 \\
280,0\end{array}$ & $\begin{array}{l}-7,50 \\
-7,36\end{array}$ & \begin{tabular}{|l|}
287,45 \\
287
\end{tabular} & 72,50 & \begin{tabular}{|l|}
297,80 \\
197,80
\end{tabular} & \begin{tabular}{|l|}
198,45 \\
\end{tabular} & $\begin{array}{l}35,00 \\
35,42\end{array}$ & $\begin{array}{l}400,50 \\
480,68\end{array}$ & 55,10 & $\begin{array}{l}14,460 \\
16,20\end{array}$ & 28,44 & $\begin{array}{l}149,45 \\
149\end{array}$ & $|72,21|$ & \begin{tabular}{|l|l|}
75,72 \\
\end{tabular} & $\begin{array}{l}125,02 \\
125,06\end{array}$ \\
\hline Pelobates cultripes & 30TVL80 & 100,00 & 128,46 & 102,32 & 35,07 & 6577,84 & 294,21 & 6,89 & 287,32 & 86,39 & 216,18 & 216,18 & 49,14 & 414,96 & 51,50 & 11,70 & 32,79 & 138,37 & 57,21 & 57,21 & 106,89 \\
\hline Pelobates cultripes & 30TVL81 & 100,00 & 125,82 & 102,84 & 35,13 & 6542.43 & 291,63 & 4,37 & 287,25 & 84,01 & 213,03 & 213,07 & 46,97 & 423,35 & 51,04 & $\mid 12.59$ & 31,28 & $\mid 138,47$ & 60,82 & 60,87 & 108,85 \\
\hline Pelobates cultripes & 30TVL82 & 100,00 & 121,66 & 103,83 & 35,64 & 6497,10 & 288,13 & 0,42 & 287,70 & 80,32 & 207,91 & 208,36 & 43,33 & 438,88 & 51,11 & 13,93 & 29,88 & 140,13 & 65,12 & 66,08 & 112,81 \\
\hline Pelobates cultripes & 30TVL83 & 100,00 & 113,14 & 105,61 & 36,07 & 6430,05 & 281,18 & $-7,22$ & 288,41 & 73,34 & 198,67 & 199,30 & 36,00 & 473,59 & 54,49 & 16,53 & 27,82 & 145,58 & 72,73 & 76,01 & 12 \\
\hline Pelobates cultripes & \begin{tabular}{|l|} 
30TVL97 \\
\end{tabular} & $\begin{array}{l}100,00 \\
\end{array}$ & $\begin{array}{r}11,14 \\
95,54\end{array}$ & 109,50 & $\begin{array}{ll}37,04 \\
37\end{array}$ & $\begin{array}{l}\mid 6433,001 \\
6239,01\end{array}$ & $\begin{array}{l}261,10 \\
266,14 \\
\end{array}$ & \begin{tabular}{|c|c|}
$-1,24,09$ \\
$-24,09$
\end{tabular} & $\begin{array}{l}290,412 \\
290,22\end{array}$ & $\frac{17,34}{113,26}$ & $\begin{array}{l}179,30 \\
\end{array}$ & \begin{tabular}{|l|l|}
179,44 \\
170
\end{tabular} & $\begin{array}{l}20,40 \\
21,46\end{array}$ & | & $\begin{array}{l}34,45 \\
65,73\end{array}$ & $\begin{array}{l}\mid 0,35 \\
24,58 \\
\end{array}$ & 23,43 & $\begin{array}{l}143,085 \\
168,52 \\
\end{array}$ & $\begin{array}{l}2,13 \\
94,61 \\
\end{array}$ & $\begin{array}{r}10,01,49 \\
101\end{array}$ & $\begin{array}{l}111,30 \\
141,73\end{array}$ \\
\hline Pelobates cultripes & \begin{tabular}{l|} 
30TVL99 \\
\end{tabular} & 100,00 & 112,22 & 108,10 & 37,00 & 6224,92 & 279,54 & $-8,33$ & 287,87 & $\begin{array}{ll}131,68 \\
\end{array}$ & $\begin{array}{l}194,76 \\
\end{array}$ & 194,99 & 36,66 & 480,92 & 56,55 & 20,60 & 23,92 & 144,70 & 82,34 & 87,35 & 122,43 \\
\hline Pelobates cultripes & 30TVM14 & 100,00 & 109,34 & 106,34 & 37,00 & 5863,51 & 271,63 & $-10,27$ & 281,90 & 118,32 & $\begin{array}{l}186,67 \\
\end{array}$ & 187,15 & 37,31 & 497,57 & 56,39 & 20,64 & 25,53 & 150,18 & 78,12 & 90,05 & 126,21 \\
\hline Pelobates cultripes & 30TVM24 & 100,00 & 109,50 & 104,90 & 37,00 & 5880,93 & 271,14 & $-8,71$ & 279,85 & \begin{tabular}{ll|l}
106,82 & \\
\end{tabular} & 187,10 & 187 & 37, & 498,61 & 56,35 & 20,91 & 25,01 & 149,86 & 79,75 & 89,26 & 12 \\
\hline Pelobates cultripes & 30TVM34 & 100,00 & 106,97 & 104,04 & 37,00 & 5908,60 & 268,39 & $-9,57$ & 277,97 & 121,96 & 185,07 & 185,15 & 34,46 & 511,04 & 57,86 & 22,09 & 24,09 & 152,90 & 83,91 & 91,86 & 130,41 \\
\hline
\end{tabular}




\begin{tabular}{|c|c|c|c|c|c|c|c|c|c|c|c|c|c|c|c|c|c|c|c|c|c|}
\hline TAXON & UTM & $\mathrm{km} 2$ & B101 & B102 & $\mathrm{BIO3}$ & BIO4 & B105 & B106 & B107 & B108 & B109 & B1010 & BIO11 & BIO12 & B1013 & BIO14 & BIO15 & B1016 & B1017 & BIO18 & B1019 \\
\hline Pelobates cultripes & 30TVM36 & 100,00 & 107,53 & 102,06 & 37,00 & 5790,03 & 265,81 & $-6,63$ & 272,44 & 79,54 & 183,78 & 183,81 & 35,90 & 526,94 & 58,12 & 24,18 & 23,20 & 157,04 & 88,99 & 92,82 & 134,78 \\
\hline Pelobates cultripes & 30TVM41 & 100,00 & 115,39 & 104,04 & 36,71 & $\begin{array}{l}6081,07 \\
\end{array}$ & 277,89 & $-3,05$ & 280,94 & 108,31 & 195,63 & 195,91 & 40,63 & 467,45 & 53,33 & 18,07 & 25,81 & 140,75 & 74,19 & 81,43 & 120,23 \\
\hline Pelobates cultripes & 30TVM42 & 100,00 & 111,55 & 104,21 & 36,99 & 6041,66 & 274,06 & $-6,11$ & 280,17 & 129,77 & 191,33 & 191,65 & 37,41 & 484,68 & 55,41 & 19,70 & 24,98 & 145,36 & 78,42 & 84,94 & 124,35 \\
\hline Pelobates cultripes & 30TVM43 & 100,00 & 107,22 & 104,07 & 37,00 & 5987,94 & 269,58 & $-9,39$ & 278,97 & 125,28 & 186,45 & 186,49 & 33,98 & 506,27 & 57,85 & 21,60 & 24,22 & 151,88 & 83,48 & 90,24 & 129,68 \\
\hline Pelobates cultripes & 30TVM46 & 100,00 & 102,56 & 102,01 & 37,00 & 5811,44 & 261,32 & \begin{tabular}{|c|}
$-10,13$ \\
\end{tabular} & 271,45 & 111,71 & 179,48 & 179,48 & 31,14 & 548,59 & 61,10 & 26,01 & 22,41 & 161,84 & 94,85 & 95,70 & 141,36 \\
\hline Pelobates cultripes & 30TVM50 & 100,00 & 110,55 & 104,77 & 36,84 & 6143,94 & 274,70 & $-7,78$ & 282,48 & 122,81 & 191,94 & 192,25 & 35,78 & 485,23 & 55,82 & 19,06 & 25,37 & 145,75 & 78,05 & 85,01 & 124,84 \\
\hline Pelobates cultripes & 30TVM56 & 100,00 & 97,36 & 102,37 & 37,11 & 5809,75 & 256,47 & $-14,40$ & \begin{tabular}{|l|l|}
270,87 \\
\end{tabular} & 113,70 & 174,64 & 174,64 & 26,77 & 579,32 & 64,67 & 28,43 & 21,82 & 170,90 & 102,09 & 102,18 & 150,45 \\
\hline Pelobates cultripes & 30 TVM 60 & 100,00 & 111,15 & 105,20 & 36,93 & 6157,40 & 275,67 & $\begin{array}{l}2,7,15 \\
\end{array}$ & 282,81 & 129,52 & 192,69 & 192,96 & 36,12 & 484,53 & 55,92 & 19,53 & 24,88 & 145,21 & 79,38 & 85,17 & 124,46 \\
\hline Pelobates cultripes & 30TVM70 & 100,00 & 112,55 & 105,87 & 36,98 & 6160,84 & 277,34 & $-6,28$ & 283,62 & 131,70 & 194,07 & 194,32 & 37,54 & 480,44 & 55,58 & 19,82 & 24,49 & 143,77 & 80,06 & 85,36 & 123,15 \\
\hline Pelobates cultripes & 30TVM73 & 100,00 & 98,56 & 105,98 & 37,12 & 5997,22 & 262,84 & $-17,20$ & 280,04 & 115,77 & 178,54 & 178,56 & 26,25 & 559,55 & 64,18 & 26,39 & 22,13 & 167,59 & 98,07 & 99,80 & 144,61 \\
\hline Pelobates cultripes & 30TVM80 & 100,00 & 110,79 & 107,04 & 37,00 & 6174,34 & 276,78 & $-8,55$ & 285,32 & 129,90 & 192,57 & 192,73 & 35,75 & 489,78 & 57,03 & 21,07 & 23,77 & 146,94 & 83,42 & 88,50 & 125,37 \\
\hline Pelobates cultripes & 30TVM81 & 100,00 & 107,37 & 107,21 & \begin{tabular}{|l|l|}
37,07 \\
\end{tabular} & 6121,69 & 273,23 & $-11,05$ & 284,28 & 125,88 & 188,52 & 188,66 & 33,26 & 509,37 & 59,19 & 22,79 & 23,06 & 152,96 & 88,11 & 93,40 & 130,80 \\
\hline Pelobates cultripes & 30TVM82 & 100,00 & 101,36 & 107,39 & 37,35 & 6056,29 & 267,30 & $-15,85$ & 283,15 & 119,08 & 182,21 & 182,22 & 28,29 & 543,64 & 62,84 & 25,53 & 22,24 & 163,19 & 95,59 & 99,04 & 140,21 \\
\hline Pelobates cultripes & 30TVM83 & 100,00 & 98,03 & 106,97 & $\begin{array}{l}37,55 \\
\end{array}$ & 6000,19 & 263,21 & $-18,06$ & 281,27 & 115,23 & 178,17 & 178,18 & 25,65 & 568,01 & 65,21 & 27,55 & 21,58 & 169,93 & 101,13 & 104,28 & 147,14 \\
\hline Pelobates cultripes & 30TVM90 & 100,00 & 109,67 & 108,41 & 37,01 & 6175,28 & 276,93 & $-10,38$ & 287,30 & 128,80 & 191,53 & 191,73 & 34,72 & 497,12 & 58,27 & 22,23 & 23,19 & 149,60 & 86,38 & 91,22 & $\begin{array}{ll}127,03 \\
\end{array}$ \\
\hline Pelobates cultripes & 30TVM91 & 100,00 & 105,88 & 108,52 & 37,18 & 6119,48 & 273,03 & $-13,45$ & 286,48 & 124,41 & 187,18 & 187,24 & 31,70 & 520,76 & 60,75 & 24,19 & 22,38 & 156,58 & 91,88 & 96,24 & 133,75 \\
\hline Pelobates cultripes & 30TVM92 & 100,00 & 100,07 & 108,72 & 37,73 & 6058,65 & 267,23 & $-17,95$ & 285,18 & 117,93 & 180,93 & 180,94 & 27,00 & 556,12 & 64,39 & 26,95 & 21,52 & 166,86 & 99,45 & 103,55 & 143,63 \\
\hline Pelobates cultripes & 30TVM93 & 100,00 & 95,84 & 108,37 & 37,98 & 6002,07 & 262,09 & $-20,98$ & 283,07 & 112,94 & 176,07 & 176,09 & 23,52 & 587,12 & 67,38 & 29,36 & 20,87 & 175,48 & 106,11 & 108,37 & 152,44 \\
\hline Pelobates cultripes & 30TVN03 & 100,00 & 98,08 & 94,63 & \begin{tabular}{|l|l|}
38,07 \\
\end{tabular} & 5091,35 & 238,07 & $-6,49$ & 244,56 & 73,30 & 165,73 & 165,91 & 36,01 & 748,90 & 86,70 & 37,29 & 21,95 & 239,08 & 135,73 & 135,79 & 199,06 \\
\hline Pelobates cultrips & 30TVN12 & 100,00 & 97,30 & 95,50 & 38,00 & 5209,78 & 240,46 & $-8,07$ & 248,53 & 71,01 & $\mid$\begin{tabular}{|l|}
166,72 \\
\end{tabular} & \begin{tabular}{|l|}
166,72 \\
\end{tabular} & 33,68 & 720,35 & 81,96 & 35,95 & 21,62 & 226,56 & $\mid 129,66$ & 129,66 & 190,89 \\
\hline Pelobates cultripes & 30TVN22 & 100,00 & 98,18 & 94,05 & 37,97 & 5211,92 & 239,98 & $-5,71$ & 245,69 & 71,22 & 167,44 & 167,58 & 34,47 & 722,47 & 81, & 35,99 & 21,27 & 226,16 & 130,84 & 130,90 & 192,53 \\
\hline Pelobates cultripes & 30TVN32 & 100,00 & 98,01 & 93,01 & 37,90 & 5220,81 & 238,88 & $-4,56$ & 243,45 & 70,10 & 167,05 & 167,62 & 34,19 & 729,61 & 81,65 & 36,42 & 21,10 & 226,93 & 132,83 & 133,19 & 196,12 \\
\hline Pelobates cultripes & 30TVN42 & 100,00 & 94,73 & 92,92 & \begin{tabular}{|l|l|}
37,97 \\
\end{tabular} & 5248,90 & 235,92 & $-6,76$ & 242,68 & 66,10 & 163,77 & 164,82 & 30,91 & 748,93 & 82,50 & 37,81 & 20,56 & 230,02 & 137,79 & 137,95 & 202,92 \\
\hline Pelobates cultripes & 30TWK58 & 100,00 & 118,81 & 115,73 & 37,71 & 6474,79 & 292,47 & $-11,08$ & 303,55 & 103,83 & 204,13 & 205,10 & 40,08 & 460,90 & 58,77 & 18,36 & 27,27 & 146,40 & 77,21 & 82,94 & 109,38 \\
\hline Pelobates cultripes & 30TWK75 & 100,00 & 109,20 & 120,60 & 38,14 & 6473,89 & 288,21 & $-22,43$ & 310,64 & 92,58 & 195,14 & 196,34 & 31,22 & 528,06 & 67,51 & 21,41 & 26,89 & 172,83 & 89,73 & 98,27 & 124,22 \\
\hline Pelobates cultripes & 30TWK83 & 100,00 & 102,58 & 120,26 & 38,17 & 6476,73 & 282,14 & $-27,89$ & 310,03 & 84,56 & 189,01 & 190,08 & 25,43 & 562,12 & 71,36 & 23,60 & 26,19 & 184,82 & 96,95 & 106,93 & 129,77 \\
\hline Pelobates cultripes & 30TWK87 & 100,00 & 91,65 & 114,86 & 37,95 & 6400,00 & 264,45 & $-36,16$ & 300,61 & \begin{tabular}{|l|l|}
106,94 \\
604
\end{tabular} & \begin{tabular}{|l|l|}
176,90 \\
\end{tabular} & 177,95 & 15,38 & 579,10 & 75,79 & 28,23 & 25,25 & $\begin{array}{l}188,82 \\
188,\end{array}$ & \begin{tabular}{|c|}
107,97 \\
\end{tabular} & 120,48 & 129,32 \\
\hline Pelobates cultripes & 30TWK99 & 100,00 & 85,59 & 111,09 & \begin{tabular}{|l|l|}
37,27 \\
\end{tabular} & 6324,33 & 252,81 & $-40,40$ & 293,21 & 104,34 & 169,66 & 170,64 & 9,83 & 589,39 & 78,67 & 31,47 & 25,33 & 196,45 & 116,27 & 130,66 & 127,00 \\
\hline Pelobates cultripes & 30TWL03 & 100,00 & 118,13 & 107,04 & 36,16 & 6446,04 & 286,24 & $-4,34$ & 290,58 & 86,60 & 203,59 & 204,21 & 40,31 & 446,77 & 52,88 & 16,51 & 27,15 & 134,88 & 71,42 & 74,17 & 111,64 \\
\hline Pelobates cultripes & 30TWL07 & 100,00 & 97,13 & 110,66 & 37,37 & 6252,88 & 268,36 & $-23,79$ & 292,15 & 115,05 & 180,97 & 181,10 & 22,64 & 549,99 & 65,41 & 24,94 & 23,07 & 167,04 & 95,15 & 102,44 & 139,62 \\
\hline Pelobates cultripes & 30TWL17 & 100,00 & 103,53 & 111,29 & 37,17 & 6279,43 & 274,65 & $-19,02$ & 293,67 & 122,61 & 187,15 & 187,58 & 28,16 & 519,04 & 62,40 & 23,79 & 23,10 & 158,25 & 91,01 & 97,74 & 130,71 \\
\hline Pelobates cultripes & 30TWL19 & 100,00 & 110,87 & 111,19 & 37,55 & 6229,64 & 280,75 & $-11,81$ & 292,56 & $\begin{array}{l}130,53 \\
130,5\end{array}$ & 193,55 & \begin{tabular}{|l|}
193,84 \\
\end{tabular} & 35,34 & \begin{tabular}{|l|}
490,44 \\
\end{tabular} & 58,62 & 22,78 & 22,84 & $\begin{array}{l}148,93 \\
140,\end{array}$ & $\begin{array}{l}1,10 \\
87,42\end{array}$ & $\begin{array}{ll}93,05 \\
\end{array}$ & 124,01 \\
\hline Pelobates cultripes & 30TWL22 & 100,00 & 109,82 & 111,17 & 37,00 & 6431,33 & 281,38 & $-14,88$ & 296,26 & 97,18 & 195,30 & $\begin{array}{l}196,03 \\
\end{array}$ & 32,79 & 484,43 & 59,43 & 20,47 & 25,62 & 148,23 & 80,99 & 86,33 & 118,82 \\
\hline Pelobates cultripes & 30TWL23 & 100,00 & 107,73 & 111,14 & 37,00 & 6395,07 & 279,09 & $-16,64$ & 295,73 & 117,25 & 192,73 & 193,40 & 30,99 & 492,52 & 60,48 & 21,39 & 25,13 & 150,85 & 83,67 & 89,55 & 120,92 \\
\hline Pelobates cultripes & 30TWL24 & 100,00 & 107,67 & 111,21 & 37,00 & 6371,25 & 278,73 & $-16,60$ & 295,33 & 127,47 & 192,42 & 192,95 & 31,09 & 491,85 & 60,39 & 21,70 & 24,67 & 150,90 & 84,58 & 90,68 & 121,06 \\
\hline Pelobates cultripes & 30 TWL26 & 100,00 & 105,36 & 111,83 & 37,18 & 6306,08 & 276,62 & $-18,44$ & 295,06 & 124,83 & 189,21 & 189,83 & 29,54 & 506,69 & 61,87 & 23,41 & 23,57 & 155,68 & 89,50 & 96,17 & 125,79 \\
\hline Pelobates cultripes & \begin{tabular}{|l|}
$30 T W L 27$ \\
\end{tabular} & 100,00 & $\begin{array}{l}103,26 \\
103,26\end{array}$ & $\begin{array}{l}11,03 \\
112,48\end{array}$ & 37,56 & | 65074,36 & 274,86 & $\begin{array}{l}-1.0,44 \\
-20,32 \\
\end{array}$ & 295,00 & \begin{tabular}{|l|}
122,43 \\
12,4
\end{tabular} & \begin{tabular}{|l|}
$189,21,79$ \\
186,
\end{tabular} & \begin{tabular}{|l|}
187,23 \\
187,23
\end{tabular} & 27,83 & \begin{tabular}{|l|l|}
520,87 \\
\end{tabular} & $\begin{array}{l}63,32 \\
63,32\end{array}$ & \begin{tabular}{|l|l|}
24,73 \\
$24+1$
\end{tabular} & 22,91 & $\begin{array}{l}159,920 \\
159,\end{array}$ & $\begin{array}{l}3,13 \\
93,13 \\
\end{array}$ & $\begin{array}{l}50,17 \\
100,17\end{array}$ & 130,19 \\
\hline Pelobates cultripes & 30TWL28 & 100,00 & 104,37 & 112,80 & 37,86 & 6240,78 & 276,01 & $-19,05$ & 295,06 & 123,50 & 187,44 & 187,69 & 29,20 & 519,80 & 62,82 & 25,08 & 22,39 & 159,21 & 93,81 & 100,57 & 130,73 \\
\hline Pelobates cultripes & 30TWL29 & 100,00 & 110,39 & 112,69 & 37,92 & 6226,97 & 281,09 & $-13,42$ & 294,51 & 130,14 & 192,90 & 193,25 & 34,77 & 495,23 & 59,73 & 23,86 & 22,44 & 151,22 & 89,90 & 95,86 & 124,86 \\
\hline Pelobates cultripes & 30TWL34 & 100,00 & 103,25 & 112,50 & 37,4 & 6352,49 & 274,90 & $-21,79$ & 296,68 & 122,84 & 187,75 & 188,19 & 26,94 & 512,13 & 63,82 & 24,03 & 24,14 & 159,32 & 90,44 & 98,01 & 124,74 \\
\hline Pelobates cultripes & 30TWL3 & 100, & 101,26 & 112,75 & 37, & 6319,27 & 272,95 & $-23,49$ & 296,44 & 120,55 & 185,24 & 185,87 & 25,27 & 523,95 & 65, & 25,26 & 23,49 & 96 & 93,88 & 101,78 & 128,29 \\
\hline 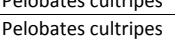 & \begin{tabular}{|c|}
$30 T W L 36$ \\
3
\end{tabular} & 100,00 & $\begin{array}{l}10,20 \\
100,93\end{array}$ & 1113,00 & $\begin{array}{l}37,11 \\
37,98\end{array}$ & 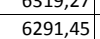 & 272,63 & $\begin{array}{l}-23,45 \\
-23,75\end{array}$ & $\begin{array}{l}290,34 \\
296,38 \\
\end{array}$ & \begin{tabular}{|l|}
120,11 \\
120
\end{tabular} & \begin{tabular}{|l|}
$183,24,61$ \\
184
\end{tabular} & $\begin{array}{l}183,01 \\
185,22 \\
\end{array}$ & $\begin{array}{l}\mid 25,24 \\
25,24\end{array}$ & 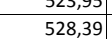 & $\begin{array}{ll}0 ., 4 \\
65,2\end{array}$ & $\begin{array}{l}3,20 \\
25,80\end{array}$ & $\begin{array}{l}23,49 \\
23,01\end{array}$ & \begin{tabular}{|l|}
164,10 \\
1640
\end{tabular} & $\begin{array}{l}5,00 \\
95,48 \\
\end{array}$ & $\begin{array}{l}101,18 \\
103,54\end{array}$ & $\begin{array}{l}120,29 \\
130,21\end{array}$ \\
\hline Pelobates cultripes & 30TWL38 & 100,00 & 107,05 & 113,55 & 38,00 & 6243,97 & 278,66 & $-17,82$ & 296,47 & 126,84 & 189,90 & 190,27 & 31,47 & 506,42 & 62,06 & 24,94 & 22,58 & 156,39 & 92,73 & 99,67 & 126,17 \\
\hline Pelobates cultripes & 30TWL39 & 100,00 & 109,03 & 113,99 & 38,00 & 6221,73 & 280,64 & $-15,73$ & 296,38 & 128,99 & 191,51 & 191,92 & 33,55 & 503,57 & 61,23 & 25,10 & 22,12 & 154,73 & 92,94 & 99,47 & 126,49 \\
\hline Pelobates cultripes & 30TWL41 & 100,00 & 106,50 & 113,52 & 37,5 & 6418,01 & 278,90 & $-20,49$ & 299,39 & 114,28 & 191,60 & 192,40 & 29,29 & 499,84 & 63,39 & 22 & 25,43 & 57 & 86,91 & 94,42 & 119,41 \\
\hline Pelobates cultripes & $\begin{array}{l}30 \text { TWL47 } \\
\end{array}$ & 100,00 & 103,76 & 113,88 & 38,0 & $\begin{array}{l}\mid 6271,11 \\
6271\end{array}$ & 274,91 & $\begin{array}{l}-21,69 \\
-21,69\end{array}$ & 296,60 & 12 & 186,89 & 18 & 27,77 & $\begin{array}{l}4516,56 \\
516,5\end{array}$ & $\begin{array}{l}64,5 \\
64,5 \\
6\end{array}$ & 26 & 22,91 & $\begin{array}{l}161,68 \\
\end{array}$ & \begin{tabular}{|l|l|}
95,83 \\
\end{tabular} & $\begin{array}{r}104,09 \\
104\end{array}$ & 126,38 \\
\hline Pelobates cultripes & $30 \mathrm{TWL}$ & 100,00 & 107 & 114,02 & 38,00 & 6247,87 & 279,03 & $-17,74$ & 296,77 & 128,00 & 190,51 & $\begin{array}{l}191,08 \\
\end{array}$ & 31,85 & 501,45 & 62,4 & 25,29 & 22,61 & 156,52 & 93,48 & 101,12 & 123,39 \\
\hline Pelobates cultripes & 30TWL49 & 100,00 & 106,99 & 114,69 & 38,00 & 6217,22 & 278,67 & $-18,62$ & 297,29 & 126,85 & 189,35 & 189,79 & 31,42 & 514,24 & $\begin{array}{ll}63,20 \\
\end{array}$ & 26,27 & 22,00 & 159,39 & 96,54 & 104,10 & 128,16 \\
\hline Pelobates cultripes & 30TWL55 & 100,00 & 100,28 & 113,00 & 38,00 & 6305,38 & 270,42 & $-25,85$ & 296,27 & 120,17 & 183,82 & 184,44 & 24,16 & 523,34 & 67,03 & 26,47 & 23,74 & 166,91 & 97,78 & 107,47 & 124,24 \\
\hline Pelobates cultripes & 30TWL61 & 100,00 & 101,79 & 113,57 & 37,77 & 6377,40 & 272,29 & $-25,99$ & 298,28 & 122,08 & 186,20 & 187,18 & 24,97 & 514,26 & 67,48 & 24,75 & 25,52 & 25 & 94,57 & 104,59 & 118,06 \\
\hline Pelobates cultripes & $30 \mathrm{TW}$ & 100,00 & 99 & 112,50 & 37 & 6279,44 & 267,61 & $\begin{array}{l}-27,34 \\
-22,34\end{array}$ & \begin{tabular}{|l|}
294,95 \\
290
\end{tabular} & \begin{tabular}{|l|l|}
119,48 \\
119
\end{tabular} & $\begin{array}{l}\mid 180,200 \\
182,29\end{array}$ & 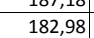 & 24,38 & 523,26 & $\begin{array}{l}1,406 \\
68,26\end{array}$ & $\mid 27,16$ & 24,29 & \begin{tabular}{|l|}
169,50 \\
\end{tabular} & $\begin{array}{l}4,313 \\
99,93 \\
\end{array}$ & 110,74 & $\begin{array}{l}110,00 \\
121,65\end{array}$ \\
\hline Pelobates cultripes & 30TWL68 & 100,00 & 112,19 & 112,81 & 38,00 & 6249,84 & 279,79 & $-14,71$ & 294,50 & 133,40 & 194,21 & 194,71 & 35,50 & 472,48 & 61,37 & 24,37 & 24,31 & 152,06 & 90,60 & 99,71 & 111,62 \\
\hline Pelobates cultripes & 30TWL70 & 100,00 & 91,25 & 113,37 & 37,78 & 6353,50 & 261,86 & $-35,97$ & 297,83 & 110,50 & $\begin{array}{l}175,78 \\
\end{array}$ & 176,58 & 15,10 & 567,06 & 74,54 & 28,58 & 25,04 & 185,02 & 106,81 & 119,27 & 128,13 \\
\hline Pelobates cultripes & 30TWL72 & 100,00 & 97,97 & 112,17 & 37,49 & 6323,04 & 265,56 & $-29,31$ & 294,87 & 118,24 & 181,43 & 182,42 & 21,56 & 523,62 & 69,92 & 26,82 & 25,62 & 172,54 & 100,47 & 112,13 & 117,24 \\
\hline Pelobates cultripes & 30TWL76 & 100,00 & 112,91 & 111,12 & 37,5 & 6278,00 & 277,68 & $-14,69$ & 292,37 & 134,77 & 195 & 195,79 & 35,59 & 452,82 & 61,1 & 23,25 & 26,56 & 149,84 & 87,80 & 97,69 & 102 \\
\hline Pelobates cultripes & $\begin{array}{l}30 \text { TWL82 } \\
\end{array}$ & 100,00 & 97,99 & 111,12 & 37,43 & $\mid \begin{array}{ll}\mid 629,10,36 \\
629\end{array}$ & 262,66 & $\begin{array}{l}-1,29,69 \\
-29,66\end{array}$ & $\begin{array}{l}292,32 \\
292,\end{array}$ & \begin{tabular}{|l|}
118,45 \\
118,4
\end{tabular} & \begin{tabular}{|l|}
180,81 \\
1981
\end{tabular} & $\begin{array}{l}181,82 \\
180,\end{array}$ & $\begin{array}{l}21,38 \\
21,3\end{array}$ & \begin{tabular}{|l|}
$515,71,71$ \\
\end{tabular} & $\begin{array}{l}1,115 \\
70,29 \\
\end{array}$ & \begin{tabular}{|l|}
27,27 \\
27
\end{tabular} & $\begin{array}{l}26,50 \\
26,64\end{array}$ & \begin{tabular}{|l|}
$173,04,13$ \\
\end{tabular} & \begin{tabular}{|l|}
101,80 \\
100
\end{tabular} & $\begin{aligned} 1,03 \\
114,38\end{aligned}$ & $\begin{array}{l}0.11,89 \\
111,89\end{array}$ \\
\hline Pelobates cultripes & 30TWL85 & 100,00 & 103,23 & 110,33 & 37,60 & 6248,02 & 266,10 & $-24,21$ & 290,31 & 124,35 & 184,99 & 185,88 & 26,57 & 489,99 & 67,06 & 26,40 & 26,77 & 164,80 & 97,84 & 109,98 & 107,51 \\
\hline Pelobates cultripes & 30TWL95 & 100,00 & 104,70 & 108,61 & \begin{tabular}{|l|l|}
37,03 \\
\end{tabular} & 6229,38 & 264,24 & $-22,89$ & 287,13 & 126,47 & 119,98 & 186,75 & 28,10 & 474,13 & 66,54 & 26,07 & 28,58 & 162,85 & 96,49 & 109,87 & 100,48 \\
\hline Pelobates cultripes & 30TWM03 & 100,00 & 93,98 & 109,78 & 38,00 & 6001,04 & 261,56 & $-23,63$ & 285,19 & 110, & 174 & 174 & 21, & 605,37 & 69,45 & 31,18 & 20,27 & 180,79 & 110,97 & 113,23 & 157, \\
\hline Pelobates cultripes & 30TWM11 & 100,00 & 103,61 & 112,07 & 38,00 & 6125,34 & 273,87 & $\begin{array}{l}-2,17,73 \\
\end{array}$ & 291,61 & 122,12 & 185,23 & 185,33 & 29,68 & 541,47 & 63,54 & 26,93 & 21,18 & 32 & 98,87 & 104,65 & 139,26 \\
\hline
\end{tabular}




\begin{tabular}{|c|c|c|c|c|c|c|c|c|c|c|c|c|c|c|c|c|c|c|c|c|c|}
\hline TAXON & UTM & $\mathrm{km} 2$ & BIO1 & B102 & $\mathrm{BIO3}$ & BIO4 & B105 & B106 & B107 & B108 & 8109 & B1010 & BIO11 & BIO12 & 81013 & BIO14 & BIO15 & B1016 & B1017 & B1018 & B1019 \\
\hline Pelobates cultripes & 30TWM12 & 100,00 & 97,65 & 111,98 & 38,00 & 6063,67 & 267,47 & $-22,53$ & 290,01 & 115,41 & 178,63 & 178,69 & 24,68 & 582,73 & 67,62 & 30,02 & 20,29 & 174,84 & 107,47 & 111,59 & 151,12 \\
\hline Pelobates cultripes & 30TWM13 & 100,00 & 96,87 & 111,31 & 38,04 & 6017,11 & 265,36 & $-22,23$ & 287,59 & 114,39 & 177,16 & 177,21 & 24,34 & 596,68 & 68,64 & 31,22 & 19,93 & 178,25 & 110,88 & 114,29 & 155,30 \\
\hline Pelobates cultripes & 30TWM23 & 100,00 & 100,11 & 113,02 & 38,18 & 6033,19 & 269,86 & $-20,79$ & 290,66 & 118,09 & 180,38 & 180,43 & 27,22 & 585,53 & 67,66 & 30,79 & 19,88 & 175,20 & 110,05 & 114,06 & 152,42 \\
\hline Pelobates cultripes & 30TWM31 & 100,00 & 103,45 & 115,62 & 38,23 & 6134,85 & 276,37 & $-20,69$ & 297,06 & 122,47 & 184,84 & 185,21 & 29,02 & 554,93 & 65,48 & 28,72 & 20,44 & 167,84 & 104,20 & 110,61 & 143,26 \\
\hline Pelobates cultripes & 30TWM32 & 100,00 & 100,33 & 115,52 & 38,74 & $\begin{array}{ll}6085,66 \\
\end{array}$ & 272,95 & $-22,71$ & 295,66 & \begin{tabular}{|l|l|}
118,86 \\
\end{tabular} & \begin{tabular}{|l|l|l|l|}
181,43 \\
\end{tabular} & 181,54 & 26,86 & 582,24 & 67,90 & 30,58 & 19,91 & 175,02 & \begin{tabular}{|l|}
110,07 \\
\end{tabular} & $\begin{array}{ll}115,38 \\
\end{array}$ & 151,54 \\
\hline Pelobates cultripes & 30TWM33 & 100,00 & 99,18 & 114,38 & 38,68 & 6035,13 & 269,98 & $-22,77$ & 292,75 & 117,33 & 179,49 & 179,60 & 26,17 & 597,93 & 69,21 & 31,78 & 19,53 & 179,08 & 113,60 & 119,15 & 155,93 \\
\hline Pelobates cultripes & 30TWM41 & 100,00 & 105,43 & 116,28 & 38,43 & 6140,06 & 278,34 & $-19,78$ & 298,12 & \begin{tabular}{ll|l}
124,92 \\
\end{tabular} & \begin{tabular}{ll|l}
186,82 & \\
\end{tabular} & 187,18 & 30,50 & 546,13 & 65,24 & 28,45 & 20,74 & 166,35 & 103,75 & 110,58 & 140,07 \\
\hline Pelobates cultripes & 30TWM42 & 100,00 & 103,64 & 116,72 & 38,95 & 6096,81 & 276,75 & $-20,97$ & 297,71 & 122,70 & 184,62 & 184,78 & 29,42 & 568,59 & 66,79 & 29,94 & 19,90 & 171,65 & 108,52 & 115,21 & 147,62 \\
\hline Pelobates cultripes & 30TWM43 & 100,00 & 101,79 & 115,45 & 38,91 & 6050,05 & 273,08 & $-21,62$ & 294,71 & 120,42 & 182,06 & 182,21 & 28,19 & 586,40 & 68,46 & 31,32 & 19,54 & 176,49 & 112,42 & 119,54 & 152,32 \\
\hline Pelobates cultripes & 30TWM50 & 100,00 & 107,07 & 115,01 & 38,01 & 6181,32 & 278,07 & $-18,90$ & 296,97 & 127,18 & 188,72 & 189,23 & 31,86 & 520,60 & 64,27 & 27,27 & 21,79 & 162,18 & 99,62 & 107,97 & 129,36 \\
\hline Pelobates cultripes & 30TWM51 & 100,00 & 106,51 & 115,54 & 38,41 & 6147,29 & 277,73 & $-19,11$ & 296,84 & 126,08 & 187,71 & 187,97 & 31,51 & 535,59 & 65,18 & 28,19 & 21,02 & 165,40 & 102,76 & 110,74 & 134,96 \\
\hline Pelobates cultripes & 30TWM52 & 100,00 & 101,71 & 115,63 & 38,63 & 6093,30 & 273,15 & $-22,72$ & 295,87 & 120,85 & 182,51 & 182,69 & 27,64 & 574,92 & 68,56 & 30,83 & 20,09 & 175,47 & 110,84 & 118,72 & 147,09 \\
\hline Pelobates cultripes & 30TWM60 & 100,00 & 104,44 & 114,17 & 38,01 & 6169,92 & 273,68 & $-21,68$ & 295,36 & $\begin{array}{ll}124,74 \\
\end{array}$ & 185,87 & 186,26 & 29,28 & 530,32 & 66,51 & 28,30 & 22,01 & 167,25 & 102,72 & 112,54 & 129,82 \\
\hline Pelobates cultripes & 30TWM63 & 100,00 & 91,97 & 112,84 & 38,32 & 6018,94 & 259,63 & $-30,03$ & 289,66 & 110,27 & \begin{tabular}{|l|l|}
171,93 \\
\end{tabular} & 172,04 & 19,11 & 640,81 & 75,90 & 35,53 & 19,41 & 195,60 & 124,72 & 131,51 & 163,30 \\
\hline Pelobates cultripes & 30TWM69 & 100,00 & \begin{tabular}{ll|l}
130,87 \\
\end{tabular} & 103,68 & 38,11 & 5811,44 & 280,87 & 13,60 & 267,27 & 151,81 & 205,82 & 205,84 & 57,84 & 516,60 & 59,99 & 28,08 & 20,37 & 156,31 & 103,10 & 106,02 & 123,92 \\
\hline Pelobates cultripes & 30TWM73 & 100,00 & 98,35 & 112,10 & 38,12 & 6048,86 & 264,16 & $-24,80$ & 288,95 & 117,78 & 178,12 & 178,32 & 24,46 & 600,17 & 72,80 & 33,19 & 20,39 & 185,91 & 117,19 & 126,24 & 150,12 \\
\hline Pelobates cultripes & 30TWM77 & 100,00 & 122,10 & 107,81 & 38,04 & 5973,97 & 279,65 & 1,33 & 278,32 & 143,23 & 199,55 & 199,65 & 47,51 & 536,37 & 63,52 & 28,69 & 20,92 & 163,45 & 103,33 & 108,63 & 133,39 \\
\hline Pelobates cultripes & 30TWM78 & 100,00 & 128,49 & 105,82 & 38,03 & 5904,04 & 282,21 & 9,08 & 273,14 & $\begin{array}{l}149,75 \\
\end{array}$ & 204,79 & 204,81 & 54,47 & 533,57 & 61,81 & 28,16 & 20,74 & 160,44 & 102,74 & 106,73 & 132,77 \\
\hline Pelobates cultripes & 30TWM79 & 100,00 & 131,83 & 103,92 & 38,15 & 5807,65 & 281,63 & 14,43 & 267,20 & 148,30 & 206,70 & 206,71 & 58,81 & 559,05 & 62,46 & 29,22 & 20,09 & 164,46 & 107,43 & 108,30 & $\begin{array}{ll}141,47 \\
\end{array}$ \\
\hline Pelobates cultrips & 30TWM80 & 100,00 & 100,41 & 111,41 & 38,00 & 6140,50 & 265,03 & $-24,86$ & 289,89 & 120,77 & 181,07 & \begin{tabular}{|l|l|}
181,43 \\
\end{tabular} & 25,11 & 542,10 & 70,08 & 29,99 & 23,26 & $\mid 175,30$ & 107,45 & 120,22 & 128,10 \\
\hline Pelobates cultripes & 30TWM81 & 100,00 & 95,19 & 111,13 & 38,00 & 6093,47 & 259,76 & $-28,84$ & 288,61 & 114,84 & 175,50 & 175,73 & 20,67 & 584,71 & 73,75 & 32,71 & 21,90 & 186,25 & 115,83 & 127,53 & 140,88 \\
\hline Pelobates cultripes & 30TWM83 & 100,00 & 102,29 & 111,08 & 38,01 & 6063,83 & 266,08 & $-21,32$ & 287,40 & 122,23 & 181,75 & 182,01 & 27,54 & 575,06 & 71,24 & 31,73 & 21,45 & $\begin{array}{l}180,48 \\
\end{array}$ & 112,34 & 123,17 & 141,63 \\
\hline Pelobates cultripes & 30TWM87 & 100,00 & 128,35 & 107,02 & $\begin{array}{ll}38,02 \\
\end{array}$ & 5975,87 & 284,11 & 7,13 & 276,98 & 149,45 & 205,52 & 205,54 & 53,25 & 532,35 & 62,14 & 27,45 & 21,42 & 160,02 & 100,23 & 104,59 & 134,85 \\
\hline Pelobates cultripes & 30TWM88 & 100,00 & 134,35 & 105,10 & 38,04 & 5889,37 & 286,21 & \begin{tabular}{ll|}
14,87 \\
\end{tabular} & 271,33 & 132,12 & 210,31 & 210,31 & 60,31 & 546,65 & 61,38 & 27,62 & 21,02 & 160,87 & 102,44 & 104,23 & 141,00 \\
\hline Pelobates cultripes & 30TWM89 & 100,00 & 131,38 & 104,44 & 38,28 & 5824,87 & 281,87 & 13,37 & 268,50 & 108,01 & 206,61 & 206,61 & 58,00 & 599,62 & 65,11 & 30,34 & 20,55 & 175,85 & 111,50 & 111,85 & 158,52 \\
\hline Pelobates cultripes & 30TWM91 & 100,00 & 87,84 & 108,99 & 37,95 & 6050,08 & 249,71 & $-35,05$ & 284,76 & 106,85 & 167,60 & 167,79 & 13,94 & 624,44 & 78,82 & 35,82 & 21,71 & 199,61 & 125,27 & 139,48 & 148,70 \\
\hline Pelobates cultripes & 30TWM93 & 100,00 & 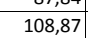 & 109,70 & 38,00 & 6087,02 & 270,50 & $\begin{array}{l}-15,03 \\
-15\end{array}$ & 285,53 & $\begin{array}{l}129,85 \\
100\end{array}$ & 188,27 & 188,40 & 33,36 & 539,83 & 60,31 & $\begin{array}{l}29,306 \\
290\end{array}$ & 22,86 & 171,31 & 104,81 & $\begin{array}{l}115,50 \\
150\end{array}$ & 130,99 \\
\hline Pelobates cultripes & 30TWM94 & 100,00 & 116,65 & 109,32 & 38,00 & 6088,93 & 277,28 & $-6,85$ & 284,12 & 138,12 & 195,80 & 195,84 & 40,77 & 518,92 & 65,08 & 27,44 & 23,06 & 163,27 & 99,03 & 108,04 & 127,24 \\
\hline Pelobates cultripes & 30TWM95 & 100,00 & 125,99 & 108,46 & 38,00 & 6076,73 & 284,75 & 2,67 & 282,08 & 148,08 & 204,72 & 204,73 & 49,95 & \begin{tabular}{|c|}
501,18 \\
\end{tabular} & 61,53 & 25,72 & 22,97 & 154,93 & 94,08 & 100,50 & 124,61 \\
\hline Pelobates cultripes & 30TWM96 & 100,00 & 131,71 & 107,23 & 38,00 & 6028,23 & 288,08 & 9,28 & 278,79 & 153,84 & 209,61 & 209,62 & 55,88 & 508,03 & 60,32 & 25,39 & 22,64 & 153,29 & 94,21 & 97,98 & 128,91 \\
\hline Pelobates cultripes & 30TWM97 & 100,00 & 135,62 & 105,89 & 38,00 & 5954,58 & 289,29 & \begin{tabular}{ll|}
14,64 \\
\end{tabular} & 274,65 & 134,12 & 212,38 & 212,38 & 60,68 & 530,99 & 60,56 & 26,04 & 22,04 & 156,61 & 97,62 & 99,75 & 138,13 \\
\hline Pelobates cultripes & 30TWM99 & 100,00 & $\begin{array}{ll}131,07 \\
131,07\end{array}$ & 104,91 & 38,25 & 5841,19 & 282,14 & $\begin{array}{l}4,343 \\
12,3 \\
\end{array}$ & 269,81 & $\begin{array}{r}35,75 \\
95,1\end{array}$ & 206,50 & \begin{tabular}{|l|}
206,50 \\
\end{tabular} & 57,70 & 635,06 & 70,00 & $\begin{array}{l}30,244 \\
31,24\end{array}$ & 21,29 & \begin{tabular}{|l|}
189,54 \\
\end{tabular} & \begin{tabular}{r|}
114,88 \\
114
\end{tabular} & \begin{tabular}{|l|l|}
115,15 \\
\end{tabular} & 174,14 \\
\hline Pelobates cultripes & 30TWN02 & 100,00 & 122,30 & 88,59 & 37,80 & 5134,56 & 253,13 & 21,27 & 231,85 & 92,57 & \begin{tabular}{|l|l|}
188,13 \\
\end{tabular} & 189,59 & 58,65 & 725,80 & 80,04 & 34,78 & 20,01 & 221,58 & 134,57 & 139,36 & 206,13 \\
\hline Pelobates cultripes & 30TWN20 & 100,00 & 126,10 & 96,62 & 38,00 & 5507,50 & 267,48 & 16,71 & 250,77 & 94,30 & 197,64 & 197,75 & 57,42 & 585,64 & 61,84 & 29,96 & 18,98 & 170,90 & 116,21 & 116,25 & 153,13 \\
\hline Pelobates cultripes & 30TWN40 & 100,00 & 128,64 & 100,21 & 38,06 & 5669,25 & 273,99 & 15,27 & 258,73 & 148,38 & 191,98 & 201,80 & 57,55 & 533,26 & 60,36 & 29,04 & 19,70 & 156,83 & 109,49 & 112,01 & 130,23 \\
\hline Pelobates cultripes & 30TWN60 & 100,00 & 128,49 & 102,42 & 38,65 & 5712,74 & 275,91 & 13,51 & 262,40 & 148,66 & 202,28 & 202,28 & 56,78 & 570,93 & 63,70 & 30,87 & 19,23 & 168,39 & 113,13 & 114,32 & 141,37 \\
\hline Pelobates cultripes & 30TWN70 & 100,00 & $\begin{array}{l}128,45 \\
128,26\end{array}$ & 103,05 & 3., 38,81 & 5722,17 & 276,35 & $\begin{array}{l}1,2,53 \\
12,5 \\
\end{array}$ & $\begin{array}{l}20,403,82 \\
263,8\end{array}$ & $\begin{array}{l}14,00 \\
117,08\end{array}$ & $\begin{array}{l}202,20 \\
202,17\end{array}$ & \begin{tabular}{|l|}
202,17 \\
\end{tabular} & $\begin{array}{ll}50,10 \\
56,39\end{array}$ & | & $\frac{63,0}{66,86}$ & $\begin{array}{l}30,014 \\
32,47\end{array}$ & $\begin{array}{l}19,25 \\
19,35\end{array}$ & \begin{tabular}{|l|}
180,75 \\
180,5
\end{tabular} & \begin{tabular}{|l|}
118,47 \\
118,4
\end{tabular} & $\begin{array}{l}118,62 \\
118,66\end{array}$ & $\begin{array}{l}141,21 \\
161,95\end{array}$ \\
\hline Pelobates cultripes & 30TWN80 & 100,00 & 129,95 & 103,38 & 38,72 & 5737,03 & 278,56 & 13,85 & 264,71 & 94,26 & 204,09 & 204,09 & 57,87 & 659,71 & 71,18 & 33,21 & 20,28 & 196,01 & 121,57 & 121,57 & 179,50 \\
\hline Pelobates cultripes & 30TWN90 & 100,00 & 130,41 & 103,87 & 38,51 & 5766,03 & 279,85 & 13,29 & 266,56 & 90,01 & 204,94 & 204,94 & 57,74 & 694,81 & 78,47 & 33,90 & 21,38 & 210,72 & $\mid 124,39$ & $\mid 124,39$ & 195,88 \\
\hline Pelobates cultripes & 30TXK08 & 100,00 & 77,03 & 109,66 & 37,08 & 6312,45 & 243,99 & $-46,97$ & 290,96 & 94,68 & 161,59 & 162,30 & 2,12 & 639,09 & 84,13 & 35,02 & 24,46 & 212,45 & 127,62 & 143,21 & 136,57 \\
\hline Pelobates cultripes & 30TXKO9 & 100, & 79, & 109,00 & 37,00 & 6294,38 & 244,64 & $-44,95$ & 289,60 & 97,81 & 162,42 & 164,38 & 4,53 & 617,75 & 82,3 & 34,29 & 25,07 & 206,99 & 124,88 & 140,40 & 130,87 \\
\hline 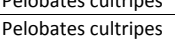 & \begin{tabular}{|l}
$30 T \times K 13$ \\
3017
\end{tabular} & 100,00 & $\begin{array}{l}103,18 \\
103,18\end{array}$ & $\begin{array}{l}10,00 \\
112,92\end{array}$ & 37,5 & $\begin{array}{l}0299,38 \\
6398,18 \\
\end{array}$ & $272,32,30$ & $\begin{array}{l}-4,4,35 \\
-23,34\end{array}$ & $\begin{array}{l}295,60 \\
295,6\end{array}$ & \begin{tabular}{r|}
121,64 \\
121
\end{tabular} & $\frac{10,42}{188,49}$ & \begin{tabular}{|l|}
184,50 \\
189,50
\end{tabular} & \begin{tabular}{|c|}
4,53 \\
27,14
\end{tabular} & $\mid$ & $\begin{array}{l}0,2, \\
69,3 \\
\end{array}$ & $\frac{34,2}{25,1}$ & 26,05 & \begin{tabular}{|l|}
200,99 \\
175,43
\end{tabular} & $\begin{array}{l}104,53 \\
101,53\end{array}$ & $\begin{array}{l}111,21 \\
111,21\end{array}$ & $\begin{array}{l}509,10 \\
109\end{array}$ \\
\hline Pelobates cultripes & $30 \mathrm{~T} \times \mathrm{K} 2$ & 100,00 & 84,80 & 105,77 & 36,99 & 6281,25 & 244,63 & $-38,76$ & 283,39 & 103,45 & 18,02 & 169,19 & 9,79 & 578,01 & 79,11 & 32,97 & 27,26 & 198,66 & 113,88 & 137,05 & 113,97 \\
\hline Pelobates cultripes & 30TXK29 & 100,00 & 85,15 & 105,01 & 36,99 & 6255,66 & 243,10 & $-38,75$ & 281,85 & 104,12 & 9,82 & 168,88 & 9,82 & 569,58 & 78,84 & 32,90 & 27,86 & 197,32 & 111,47 & 137,19 & 111,47 \\
\hline Pelobates cultripes & 30TXK36 & 100,00 & 89,36 & 105,15 & 36,5 & 6310,23 & 249,32 & $-33,01$ & 282,33 & 107,46 & 14,43 & 174,49 & 14,43 & 562,61 & 76,48 & 31, & 27,46 & 92,96 & 108,06 & 132,04 & 108,06 \\
\hline Pelobates cultripes & 30TXK37 & 100, & 9 & 103,75 & 36, & 6301,96 & 252,85 & $\frac{-3,01}{-26,35}$ & 279,20 & 115,90 & 21,12 & $\begin{array}{l}181,14 \\
\end{array}$ & $\begin{array}{l}21,1,12 \\
21\end{array}$ & 510,25 & 71, & 27 & 30,17 & 79,23 & 93,54 & 123,62 & 93,54 \\
\hline Pelobates cultripes & $30 \mathrm{TXK}$ & 100,00 & 95 & 102,94 & 36,5 & 6273,83 & 249,72 & $-28,17$ & 277,89 & 115,05 & 19,50 & 179,20 & 19,50 & 508,38 & 72,46 & 27,3 & 30,95 & 180,26 & 92,49 & 125,50 & 92,49 \\
\hline Pelobates cultripes & \begin{tabular}{|l|}
30 TXK39 \\
\end{tabular} & 100,00 & 96,64 & 102,03 & 36,50 & 6237,25 & 248,21 & $-27,50$ & 275,72 & $\begin{array}{l}117,08 \\
11,0\end{array}$ & 20,75 & 179,66 & 20,75 & 493,07 & 71,48 & 25,97 & 32,38 & 177,07 & 88,36 & 124,17 & 88,36 \\
\hline Pelobates cultripes & 30TXK45 & 100,00 & 100,83 & 103,15 & 36,74 & 6318,85 & 257,94 & $-20,10$ & 278,04 & 119,41 & 25,62 & 186,08 & 25,62 & 503,32 & 69,24 & 27,13 & 29,50 & 174,30 & 91,03 & 118,84 & 91,03 \\
\hline Pelobates cultripes & 30TXK46 & 100,00 & 100,39 & 102,03 & 36 , & 6310,30 & 255,61 & $-20,58$ & 276,19 & 119,41 & 25,17 & 185,30 & 25 & 494,29 & 69, & 26,03 & 30,70 & 173,50 & 87,49 & 119,83 & 87,49 \\
\hline Pelobates cultripes & $30 \mathrm{TXK} 4$ & 100,00 & 10 & 100,56 & 36 & | 6302,53 & 257,69 & $\begin{array}{l}-2,50 \\
-15,92\end{array}$ & $273,61 \mid$ & 125,56 & 29,86 & \begin{tabular}{|l|l|}
189,98 \\
189,0
\end{tabular} & 29,86 & $\begin{array}{l}454,23 \\
456,05\end{array}$ & $\frac{0,3,2}{66,0}$ & $\begin{array}{l}20,035 \\
22,62\end{array}$ & 33,51 & $\begin{array}{l}163,82 \\
162\end{array}$ & $\begin{array}{l}1,4,81 \\
76,81\end{array}$ & $\begin{array}{l}114,08 \\
114,08\end{array}$ & $\begin{array}{l}0,46,81 \\
76,8\end{array}$ \\
\hline Pelobates cultripes & 30TXK48 & 100,00 & 106,64 & 99,68 & 36,05 & 6268,44 & 255,85 & $-15,66$ & 271,51 & 127,33 & 30,49 & 190,24 & 30,49 & 442,42 & 65,35 & 21,40 & 35,04 & 161,32 & 73,19 & 113,16 & 73,19 \\
\hline Pelobates cultripes & 30TXK55 & 100,00 & 113,78 & 99,76 & 36,03 & 6306,82 & 267,17 & $-5,13$ & 272,30 & 132,75 & 38,54 & $\mid 198,56$ & 38.54 & 438,72 & 61,46 & 21,63 & 32,73 & $\mid 153,64$ & 73,11 & \begin{tabular}{|l|l|}
104,93 \\
\end{tabular} & 73,11 \\
\hline Pelobates cultripes & 30 TXK56 & 100,00 & 112,06 & 98,56 & 35,93 & 6318,25 & 264,44 & $-6,62$ & 271,06 & 131,48 & 36,42 & 196,96 & 36,42 & \begin{tabular}{|l|}
432,95 \\
\end{tabular} & 62,20 & 20,58 & 34,39 & 154,45 & 69,78 & 107,29 & 69,78 \\
\hline Pelobates cultripes & 30 TXK58 & 100,00 & 99 & 98,50 & 36, & 6242,60 & 248,40 & $-21,20$ & 269,60 & 118 & 24,26 & 18 & 24,26 & 484,26 & 69,93 & 24,02 & 33,15 & $173,81 \mid$ & 81,65 & 123,21 & 81 \\
\hline Pelobates cultripes & 30 TXK65 & 100,00 & 101,19 & 98,94 & 36,00 & 6251,87 & 254,13 & $-16,56$ & 270,68 & 118,92 & 27,25 & 185,38 & 27,25 & 510,44 & 69,27 & 26,68 & 29,66 & $\begin{array}{l}174,93 \\
\end{array}$ & 89,85 & 121,25 & 89,85 \\
\hline Pelobates cultripes & 30TXK77 & 100,00 & 88,03 & 97,19 & 36,00 & 6165,48 & 238,27 & $-29,22$ & 267,50 & 105,11 & 15,14 & 170,92 & 15,14 & 579,55 & 77,91 & 31,66 & 27,76 & 197,02 & 105,96 & 139,66 & 105,96 \\
\hline Pelobates cultripes & 30TXK83 & 100,00 & 106,31 & 97,56 & 36,03 & 6113,81 & 256,51 & $-9,25$ & 265,75 & $\begin{array}{ll}122,37 \\
\end{array}$ & 34,74 & 188,70 & 34,74 & 529,97 & 67,17 & 27,57 & 27,21 & 171,99 & 98,04 & $\begin{array}{ll}116,27 \\
\end{array}$ & 98,04 \\
\hline Pelobates cultripes & 30TXK93 & 100,00 & 115,89 & 95,69 & 36,00 & 6010,63 & 262,18 & 1,05 & 261,12 & 130,54 & 45,08 & 196,67 & 45,08 & 502,89 & 62,32 & 24,72 & 28 & 159,14 & 93,18 & 108,58 & 93,18 \\
\hline Pelobates cultripes & 30TXK95 & 100,00 & 108,05 & 94,79 & 35,99 & 6058,85 & 254,35 & $-6,84$ & 261,19 & 124,64 & 36,56 & 189,29 & 36,56 & 18,90 & 67,10 & 27,16 & 28,55 & 169,40 & 93,58 & 116,73 & 93,58 \\
\hline
\end{tabular}




\begin{tabular}{|c|c|c|c|c|c|c|c|c|c|c|c|c|c|c|c|c|c|c|c|c|c|}
\hline TAXON & UTM & $\mathrm{km2}$ & B101 & $\mathrm{B1O2}$ & $\mathrm{BIO3}$ & B104 & B105 & B106 & B107 & B108 & B109 & 81010 & B1011 & BIO12 & BIO13 & BIO14 & B1015 & BIO16 & BIO17 & BIO18 & B1019 \\
\hline Pelobates cultripes & 30TXK98 & 100,00 & 82,76 & 94,76 & 35,80 & 6063,78 & 230,25 & $-32,22$ & 262,47 & 98,75 & 11,65 & 164,31 & 11,65 & 634,63 & 82,64 & 35,73 & 25,51 & 209,67 & 120,22 & 148,25 & 120,22 \\
\hline Pelobates cultripes & 30TXL00 & 100,00 & 87,40 & 108,49 & 37,00 & 6279,95 & 249,65 & $-38,55$ & 288,19 & 106,84 & 120,01 & 171,49 & 11,81 & 564,10 & 77,31 & 31,40 & 26,81 & 192,40 & 115,47 & 130,72 & 116,72 \\
\hline Pelobates cultripes & 30TXL11 & 100,00 & 91,93 & 105,71 & 37,00 & 6228,03 & 248,16 & $-34,27$ & 282,43 & 112,37 & 15,75 & 174,65 & 15,75 & 523,98 & 74,38 & 30,10 & 29,51 & 184,00 & 102,93 & 127,41 & 102,93 \\
\hline Pelobates cultripes & 30TXL12 & 100,00 & 95,85 & 105,01 & 37,00 & 6202,83 & 249,54 & $-31,10$ & 280,64 & 117,09 & 26,91 & 177,72 & 19,57 & 497,81 & 71,90 & 28,04 & 30,91 & 176,99 & 96,26 & 122,93 & 96,50 \\
\hline Pelobates cultripes & 30TXL13 & 100,00 & 98,47 & 104,71 & 37,00 & $\begin{array}{ll}6186,85 \\
\end{array}$ & 251,01 & $-28,75$ & 279,77 & 120,31 & 31,71 & 179,94 & 22,29 & 482,34 & 70,19 & \begin{tabular}{|l|l|}
26,68 \\
\end{tabular} & 31,63 & 172,32 & 92,00 & 119,73 & 93,40 \\
\hline Pelobates cultripes & 30TXL14 & 100,00 & 99,84 & 104,72 & 37,00 & 6169,05 & 252,13 & $-27,52$ & 279,65 & 121,90 & 33,18 & 180,88 & 23,67 & 477,12 & 69,48 & 26,47 & 31,68 & 170,33 & 90,88 & 118,34 & 93,38 \\
\hline Pelobates cultripes & 30TXL20 & 100,00 & 90,82 & 103,97 & 36,94 & 6227,62 & 245,18 & $-34,25$ & 279,44 & 110,87 & 15,03 & 173,66 & 15,03 & 527,99 & 75,08 & \begin{tabular}{|l|l|}
29,67 \\
\end{tabular} & 30,20 & 186,55 & 100,45 & 130,35 & 100,45 \\
\hline Pelobates cultripes & 30TXL21 & 100,00 & 97,52 & 102,87 & 36,87 & 6191,58 & 247,66 & $-28,73$ & 276,39 & 119,02 & 26,43 & 179,32 & 21,33 & 482,29 & 70,89 & 25,56 & 33,13 & 174,63 & 88,47 & 122,35 & 88,61 \\
\hline Pelobates cultripes & $30 \mathrm{TXL22}$ & 100,00 & 99,03 & 102,34 & 36,82 & 6166,32 & 247,45 & $-27,74$ & 275,19 & 121,14 & 32,12 & 180,13 & 22,89 & 470,05 & 69,89 & 24,30 & 33,92 & 171,59 & 84,86 & 120,63 & 85,96 \\
\hline Pelobates cultripes & 30TXL23 & 100,00 & 101,91 & 102,08 & 36,85 & 6139,68 & 248,97 & $-25,49$ & 274,47 & 124,33 & 35,14 & 182,20 & 25,52 & 455,18 & 68,36 & 23,12 & 34,76 & 167,11 & 80,94 & 117,21 & 83,37 \\
\hline Pelobates cultripes & 30TXL24 & 100,00 & 96,83 & 102,61 & 36,90 & 6129,49 & 245,92 & $-29,65$ & 275,58 & 118,51 & 30,43 & 177,20 & 20,92 & 487,09 & 71,41 & 26,08 & 32,53 & 175,48 & 90,18 & 123,84 & 92,75 \\
\hline Pelobates cultripes & 30TXL30 & 100,00 & 102,60 & 100,66 & 36,42 & 6193,90 & 249,52 & $-22,81$ & 272,34 & 124,19 & 28,63 & 184,34 & 26,32 & 452,95 & 67,82 & 22,46 & 35,47 & 166,78 & 77,95 & 117,45 & 77,98 \\
\hline Pelobates cultripes & 30TXL31 & 100,00 & 104,71 & 99,65 & 36,29 & 6145,01 & 248,19 & $\begin{array}{l}-21,79 \\
-21,79\end{array}$ & 269,98 & $\begin{array}{l}127,27 \\
127,\end{array}$ & 37,75 & 185,23 & 28,40 & 435,22 & $\begin{array}{l}06,48 \\
66,\end{array}$ & 20,53 & 37,38 & 162,89 & 72,70 & 115,31 & 73,72 \\
\hline Pelobates cultripes & 30TXL32 & 100,00 & 102,32 & 99,48 & 36,27 & 6111,27 & 244,66 & $-24,75$ & 269,41 & 124,86 & 35,49 & 182,03 & 26,05 & 444,99 & 67,97 & 20,99 & 37,29 & 166,56 & 74,21 & 118,63 & 76,57 \\
\hline Pelobates cultripes & 30TXL33 & 100,00 & 100,56 & 99,81 & 36,35 & 6097,72 & 243,69 & $-26,50$ & 270,19 & 122,92 & 33,88 & 180,03 & 24,34 & 455,56 & 69,13 & 21,99 & 36,32 & 169,37 & 77,45 & 120,71 & 80,36 \\
\hline Pelobates cultripes & 30TXL35 & 100,00 & 106,74 & 100,94 & 36,57 & 6099,30 & 252,09 & $-20,23$ & 272,32 & 129,56 & 40,47 & 185,94 & 30,32 & 436,62 & 66,18 & 21,77 & 35,22 & 160,59 & 76,35 & 112,66 & 79,99 \\
\hline Pelobates cultripes & 30TXL40 & 100,00 & 98,19 & 99,03 & 36,00 & 6177,33 & 244,29 & $-25,42$ & 269,70 & 119,08 & 23,32 & 179,94 & 22,66 & 477,14 & 70,56 & 23,76 & 34,72 & 174,42 & 81,71 & 124,25 & 81,71 \\
\hline Pelobates cultripes & 30TXL41 & 100,00 & 97,45 & 98,44 & 36,00 & 6130,43 & 241,32 & $-27,00$ & 268,32 & 118,89 & 27,51 & 178,22 & 21,91 & 474,47 & 70,94 & 23,18 & 35,55 & 175,01 & 80,73 & 125,40 & 81,19 \\
\hline Pelobates cultripes & 30TXL49 & 100,00 & 134,22 & 104,51 & 36,86 & $\begin{array}{ll}6213,16 \\
\end{array}$ & 289,64 & 8,64 & 281,01 & 157,36 & 190,27 & 214,42 & 56,31 & 369,45 & 54,97 & 17,99 & 32,67 & 127,99 & 71,71 & 80,29 & 76,72 \\
\hline Pelobates cultripes & $30 \mathrm{TXL50}$ & 100,00 & 91,90 & 98.01 & 36,01 & $\mid 6162,41$ & 238,94 & $-29,51$ & 268,45 & 111,65 & 17,40 & $\mid 173,98$ & 17,40 & 515,99 & 74,51 & 26,49 & 32.53 & 185,27 & 89,94 & 132,90 & 89,94 \\
\hline Pelobates cultripes & 30TXL51 & 100,00 & 87,73 & 98,07 & 36,00 & 6124,77 & 234,65 & $-33,71$ & 268,35 & 107,34 & 13,52 & 169,11 & 13,46 & 539,12 & 77,24 & 28,50 & 31,44 & 192,34 & 96,55 & 138,61 & 96,55 \\
\hline Pelobates cultripes & 30TXL52 & 100,00 & 95,48 & 97,20 & 36,00 & 6089,01 & 238,10 & $-27,74$ & 265,83 & 116,36 & 26,76 & $\begin{array}{l}175,60 \\
\end{array}$ & 20,49 & 487,24 & 72,39 & 23,87 & 34,90 & 178,61 & 83,15 & 128,89 & 83,55 \\
\hline Pelobates cultripes & 30TXL60 & 100,00 & 94,83 & 96,48 & 36,00 & 6139,80 & 239,94 & $-25,42$ & 265,35 & 114,68 & 20,78 & 176,50 & 20,78 & 505,03 & 73,01 & 25,25 & 33,01 & 181,19 & 86,05 & 130,33 & 86,05 \\
\hline Pelobates cultripes & 30TXL61 & 100,00 & 90,23 & 96,60 & 35,99 & 6104,58 & 235,41 & $-30,41$ & 265,82 & 109,78 & 16,47 & 171,37 & 16,47 & 529,44 & 75,96 & 27,37 & 31,93 & 188,81 & 92,93 & 136,23 & 92,93 \\
\hline Pelobates cultripes & 30TXL62 & 100,00 & 93,88 & 96,39 & 36,00 & 6076,15 & 237,07 & $-27,70$ & 264,77 & 114,11 & 21,47 & 174,17 & 19,72 & 505,76 & 73,78 & 25,51 & 33,43 & 182,48 & 87,48 & 131,67 & 87,48 \\
\hline Pelobates cultripes & 30TXL63 & 100,00 & 90,23 & 96,66 & 36,00 & 6052,86 & 234,09 & $-31,12$ & 265,21 & 110,10 & 19,00 & 170,15 & 16,26 & 527,51 & 76,18 & 27,39 & 31,97 & 188,53 & 94,05 & 136,34 & 94,05 \\
\hline Pelobates cultripes & 30TXL65 & 100,00 & 107,50 & 97,78 & 36,00 & 6055,16 & 250,82 & $\frac{-1,12}{-16,10}$ & \begin{tabular}{|l|}
266,92 \\
\end{tabular} & 129,47 & 41,66 & 186,47 & 32,33 & 441,42 & $\begin{array}{l}0,10,32 \\
66\end{array}$ & 21,81 & 34,95 & 160,91 & 75,92 & 113,19 & 77,19 \\
\hline Pelobates cultripes & 30TXL66 & 100,00 & 112,34 & 99,02 & 36,03 & 6072,31 & 258,01 & $-11,55$ & 269,56 & 134,55 & 46,83 & 191,31 & 36,57 & 426,14 & 63,97 & 21,66 & 34,21 & 154,11 & 75,15 & 106,67 & 76,26 \\
\hline Pelobates cultripes & 30TXL68 & 100,00 & 123,29 & 101,80 & 36,25 & 6140,66 & 274,94 & $-0,96$ & 275,90 & 145,87 & 57,65 & 203,00 & 46,66 & 396,42 & 58,78 & 21,01 & 32,39 & 139,89 & 74,69 & 93,15 & 75,25 \\
\hline Pelobates cultripes & 30TXL69 & 100,00 & 131,13 & 103,27 & 36,36 & 6188,04 & 286,48 & 6,68 & 279,80 & 154,08 & 105,36 & 211,40 & 53,98 & 377,27 & 55,39 & 18,90 & 31,50 & 130,90 & 73,64 & 84,45 & 74,45 \\
\hline Pelobates cultripes & 30TXL70 & 100,00 & 91,62 & 95,82 & 35,95 & 6104,33 & 237,03 & $-26,92$ & 263,95 & 110,41 & 18,39 & 173,10 & 18,39 & 535,96 & 75,51 & 27,64 & 30,93 & 188,29 & 93,76 & 135,37 & 93,76 \\
\hline Pelobates cultripes & $\begin{array}{l}30 T X L 73 \\
\end{array}$ & 100,00 & $\begin{array}{l}1,102 \\
99,16\end{array}$ & $\begin{array}{l}95,91 \\
95,91\end{array}$ & 35 & $\mid 6045,63$ & 241,52 & $-22,07$ & \begin{tabular}{|l|l|}
263,58 \\
\end{tabular} & \begin{tabular}{|l|}
119,70 \\
\end{tabular} & $\begin{array}{l}\mid 0,030 \\
27,72\end{array}$ & 178,85 & $\begin{array}{ll}25,26 \\
25,2\end{array}$ & $\begin{array}{l}487,42 \\
48\end{array}$ & $\begin{array}{l}71,25 \\
71,2\end{array}$ & 24,47 & 33,50 & 174,96 & 83,98 & 125,23 & 83,98 \\
\hline Pelobates cultripes & 30TXL74 & 100,00 & 109,47 & 96,76 & 36,00 & 6044,27 & 252,24 & $-13,11$ & 265,36 & 131,08 & 42,85 & 188,66 & 34,88 & 439,68 & 65,54 & 21,57 & 34,89 & 158,99 & 74,79 & 111,64 & 74,89 \\
\hline Pelobates cultripes & 30TXL75 & 100,00 & 114,92 & 97,98 & 36,00 & 6066,83 & 259,62 & $-8,03$ & 267,65 & 136,97 & 48,13 & 194,08 & 39,80 & 419,59 & 62,66 & 20,99 & 34,60 & 151,11 & 72,50 & 104,34 & 72,64 \\
\hline Pelobates cultripes & 30TXL76 & 100,00 & 120,30 & 99,40 & 36,04 & 6087,55 & 267,63 & $-3,09$ & 270,72 & 142,67 & 52,88 & 199,61 & 44,59 & 403,03 & 60,00 & 20,77 & 33,93 & 143,90 & 71,35 & 97,52 & 71,46 \\
\hline Pelobates cultripes & 30TXL77 & 100,00 & 120,89 & 100,23 & 36,03 & 6099,63 & 270,27 & $-2,44$ & 272,71 & 143,32 & 52,76 & 200,37 & 45,11 & 404,11 & 59,66 & 21,35 & 32,80 & 143,03 & 73,46 & 96,21 & 73,56 \\
\hline Pelobates cultripes & $\begin{array}{l}\text { 30TXL78 } \\
\end{array}$ & 100,00 & $\begin{array}{l}123,03 \\
123,44\end{array}$ & 101,37 & 36,06 & $\begin{array}{ll}60319,33 \\
6193\end{array}$ & 275,03 & $\begin{array}{l}-2,44 \\
-0,11\end{array}$ & 275,14 & $\begin{array}{l}\mid 435,326 \\
145,86 \\
\end{array}$ & 52,43 & \begin{tabular}{|l|}
203,01 \\
\end{tabular} & $\begin{array}{l}43,112 \\
47,20\end{array}$ & \begin{tabular}{|l|l|}
399,68 \\
399,68
\end{tabular} & $\begin{array}{l}3,00 \\
58,42\end{array}$ & $\begin{array}{l}21,03 \\
21,03\end{array}$ & $\begin{array}{l}2,, 00 \\
31,61\end{array}$ & 13,05 & 74,40 & $\begin{array}{l}0,21 \\
93,08\end{array}$ & $\begin{array}{l}71,50 \\
74,68\end{array}$ \\
\hline Pelobates cultripes & 30TXL79 & 100,00 & 127,20 & 102,48 & 36,18 & 6146,71 & 281,60 & 3,56 & 278,04 & 149,99 & 54,67 & 207,17 & 50,63 & 391,98 & 56,46 & 20,06 & 30,52 & 135,25 & 75,40 & 88,81 & 75,40 \\
\hline Pelobates cultripes & 30TXL81 & 100,00 & 90,67 & 94,95 & 35,90 & 6049,47 & 235,18 & $-27,06$ & 262,24 & 109,03 & 18,25 & 171,36 & 18,25 & 555,37 & 77,05 & 29,46 & 29,80 & 191,96 & 99,52 & 138,05 & 99,52 \\
\hline Pelobates cultripes & 30TXL83 & 100,00 & 109,49 & 95,77 & 35,97 & 6035,23 & 252,01 & $-11,32$ & 263,33 & 130,29 & 36,04 & 188,90 & 35,78 & 452,96 & 66,15 & 22,27 & 33,96 & 161,12 & 76,89 & 112,97 & 76,89 \\
\hline Pelobates cultripes & $\begin{array}{l}30 T X L 84 \\
\end{array}$ & 100,00 & 115,72 & 96,93 & 36,00 & 6040,90 & 259,44 & \begin{tabular}{|l|}
$-6,17$ \\
\end{tabular} & 265,62 & 137,23 & 43,16 & 194,89 & 41,48 & 427,11 & 62,83 & 21,12 & 34,23 & 151,85 & 72,94 & 104,76 & 72,94 \\
\hline Pelobates cultripes & 30TXL85 & 100,00 & 116,66 & 97,82 & 36,00 & 6051,52 & 261,97 & $-5,50$ & 267,48 & 138,31 & 43,75 & $\begin{array}{l}195,76 \\
\end{array}$ & 42,05 & 424,05 & 62,31 & 21,52 & 33,57 & 150,21 & 73,66 & 102,92 & 73,66 \\
\hline Pelobates cultripes & 30TXL86 & 100,00 & 126,49 & 99,79 & 36,01 & 6088,22 & 275,16 & 2,99 & 272,17 & 148,82 & 52,40 & 205,93 & 51,04 & 391,26 & 57,25 & 20,01 & 33,19 & 137,14 & 69,25 & 91,28 & 69,25 \\
\hline Pelobates cultripes & \begin{tabular}{|l|}
$30 T X L 87$ \\
\end{tabular} & 100,00 & 132,95 & 101,34 & 36,00 & 6120,77 & 284,55 & 8,68 & 275,87 & 155,74 & 56,94 & 212,68 & 56,86 & 373,65 & 53,97 & 18,64 & 32,14 & 129,19 & 67,90 & 84,27 & 67,90 \\
\hline Pelobates cultripes & 30TXL88 & 100,00 & 134,58 & 102,23 & 36,03 & 6145,04 & 288,41 & 10,24 & 278,17 & 157,57 & 58,01 & 214,51 & 58,01 & 370,96 & 52,88 & 18,25 & 31,04 & 127,03 & 68,71 & 82,26 & 68,71 \\
\hline Pelobates cultripes & 30TXL89 & 100,00 & 136,03 & 103,14 & 36,15 & 6159,41 & 291,93 & 11,69 & 280,24 & 159,19 & 59,18 & 21 & 59,18 & 370,19 & 51, & 18,06 & 29,77 & 125,34 & 70,01 & 80,77 & 70,01 \\
\hline Pelobates cultripes & 30TXL91 & 100,00 & 92,79 & 94,06 & 35,91 & 6024,18 & 236,62 & $-24,29$ & 260,91 & 110,82 & 20,82 & 173,14 & 20,82 & 558,18 & 76,4 & 29,75 & 29,18 & 190,50 & 100,44 & 136,29 & 100,44 \\
\hline Pelobates cultripes & $\begin{array}{l}\text { 30TXL92 } \\
\end{array}$ & 100,00 & 108,34 & 94,90 & 35,97 & 6013,94 & 250,88 & $\begin{array}{l}-2,2,67 \\
-10,6\end{array}$ & 261,55 & $\begin{array}{l}128,18 \\
128\end{array}$ & 35,46 & 187,89 & 35,46 & 475,73 & 67,67 & 23,81 & 32,43 & 165,47 & 81,84 & 115,82 & 81,84 \\
\hline Pelobates cultripes & 30TXL93 & 100,00 & 119,24 & 96,28 & 35,99 & 6024,23 & 262,65 & $-1,61$ & 264,25 & 140,10 & 45,57 & 198,47 & 45,57 & 430,39 & 61,95 & 21,19 & 33,56 & 149,75 & 73,45 & 102,24 & 73,45 \\
\hline Pelobates cultripes & 30TXL94 & 100,00 & 121,7 & 97,31 & 36,00 & 6022,52 & 266,54 & 0,07 & 266,46 & 143,10 & 48,05 & 200 & 48,05 & 420,08 & 60,5 & 21,03 & 33,48 & 01 & 72,48 & 98,88 & 72,48 \\
\hline Pelobates cultripes & $30 \mathrm{TX}$ & 100,00 & 119 & 97,91 & 36,00 & 6025,98 & 265,34 & $-2,58$ & 267,92 & $14 \mathrm{C}$ & 45,32 & 198,40 & 45,32 & 428,44 & 61, & 21,84 & 32,63 & 148,84 & 75,02 & 101,15 & 75,02 \\
\hline Pelobates cultripes & $\begin{array}{l}30 T \times L 96 \\
\end{array}$ & 100,00 & 134,56 & 100,49 & 36,02 & 6076,06 & 284,31 & $\begin{array}{r}10,75 \\
\end{array}$ & 273,56 & 157,00 & 59,40 & 213,91 & 59,40 & 377,88 & 53,95 & 18,37 & 32,59 & 129,18 & 67,32 & 84,10 & 67,32 \\
\hline Pelobates cultripes & $\begin{array}{l}\text { 30TXL97 } \\
\end{array}$ & 100,00 & 139,50 & 101,88 & 36,10 & 6104,79 & 291,85 & 15,07 & 276,78 & 162,47 & 63,90 & 219,12 & 63,90 & 364,50 & $\begin{array}{l}51,29 \\
51,2\end{array}$ & 17,19 & 31,80 & 123,17 & 66,23 & $\begin{array}{l}49,08 \\
79,10\end{array}$ & 66,23 \\
\hline Pelobates cultripes & 30TXM01 & 100,00 & 95,38 & 108,00 & 37,85 & 6071,08 & 255,01 & $-28,10$ & 283,11 & 115,35 & 174,92 & 175,13 & 20,77 & 577,34 & 74,88 & 32,82 & 23,46 & 187,54 & 116,08 & 129,63 & 134,59 \\
\hline Pelobates cultripes & 30TXM03 & 100,00 & 119,16 & 108,53 & 37,97 & 6123,89 & 278,95 & $-5,19$ & 284,14 & 140,97 & 198,70 & 198 & 42,79 & 490,67 & 63,5 & 25,64 & 24,61 & 157,00 & 93,63 & 102,45 & 117,7 \\
\hline Pelobates cultripes & 30TXM05 & 100,00 & 133,34 & 107,29 & 37,99 & 6057,35 & 290,14 & \begin{tabular}{|c|}
10,14 \\
10
\end{tabular} & 279,99 & 155,39 & 211,64 & 211,64 & 57,25 & 485,86 & 59,23 & 23,80 & 23,70 & 148,22 & 89,40 & 92,39 & 122,30 \\
\hline Pelobates cultripes & 30TXM06 & 100,00 & 134,37 & 106,67 & 37,99 & 6021,66 & 289,83 & 12,23 & 277,60 & 155,06 & 212,27 & 212,27 & 58,71 & 513,80 & 60,26 & 25,03 & 22,90 & 152,93 & 93,81 & 95,71 & 132,79 \\
\hline Pelobate & 30TXM07 & 100,00 & 136.85 & 105.91 & $38,00 \mid$ & 5960,25 & 290,10 & 15,45 & 274,65 & 102.64 & 213,73 & 213,73 & 61,61 & 545,48 & 61,27 & 26,12 & 22.41 & 161.47 & 98.66 & 98.93 & 144.92 \\
\hline Pelobates cultripes & 30TXM09 & 100,00 & 131,31 & 105,03 & 38,08 & 5861,17 & 282,84 & 12,12 & 270,72 & 94,86 & 207,03 & 207 & 57 & 657,07 & 74,70 & 31,62 & 21,99 & 198,86 & 116,63 & 116,63 & 184,39 \\
\hline Pelobates cultripes & $30 \mathrm{TXM} 12$ & 100,00 & 117,64 & 107,61 & 37,63 & 6132,64 & 276,22 & $-6,61$ & 282,83 & 139,49 & 197,34 & 197,41 & 41,34 & \begin{tabular}{|l|}
477,46 \\
\end{tabular} & 63,91 & 25,09 & 26,04 & 156,16 & 92,14 & 101,36 & 111,16 \\
\hline
\end{tabular}




\begin{tabular}{|c|c|c|c|c|c|c|c|c|c|c|c|c|c|c|c|c|c|c|c|c|c|}
\hline TAXON & UTM & $\mathrm{km} 2$ & B101 & B102 & $\mathrm{BIO3}$ & BIO4 & B105 & B106 & B107 & B108 & B109 & B1010 & BIO11 & BIO12 & 81013 & BIO14 & BIO15 & B1016 & B1017 & BIO18 & B1019 \\
\hline Pelobates cultripes & 30TXM14 & 100,00 & 132,42 & 107,17 & 37,69 & 6099,90 & 289,75 & 8,56 & 281,19 & 154,72 & 211,33 & 211,37 & 55,81 & 466,15 & 59,06 & 22,67 & 24,96 & 145,23 & 85,77 & 88,68 & 114,99 \\
\hline Pelobates cultripes & 30TXM16 & 100,00 & 136,42 & 106,17 & 38,00 & 6012,49 & 291,15 & 14,39 & 276,76 & 134,60 & 213,97 & 213,97 & 60,58 & 516,44 & 60,18 & 24,55 & 23,20 & 152,87 & 93,38 & 95,00 & 134,77 \\
\hline Pelobates cultripes & 30TXM17 & 100,00 & 132,53 & 106,19 & 38,00 & 5976,67 & 286,65 & 11,06 & 275,59 & 102,39 & 209,63 & 209,63 & 57,17 & 567,05 & 63,84 & 27,16 & 22,45 & 167,42 & 101,85 & 102,41 & 152,02 \\
\hline Pelobates cultripes & 30TXM19 & 100,00 & 130,52 & 105,12 & 38,01 & 5871,83 & 282,08 & 10,50 & 271,58 & 94,28 & 206,24 & 206,24 & 56,29 & 673,35 & 77,95 & 31,95 & 22,21 & 205,12 & 118,55 & 118,55 & 191,28 \\
\hline Pelobates cultripes & 30TXM23 & 100,00 & 133,82 & $\begin{array}{ll}106,67 \\
\end{array}$ & 37,25 & 6133,99 & 291,05 & 9,61 & 281,44 & 156,30 & 213,06 & 213,06 & 56,85 & \begin{tabular}{|l|l|}
437,57 \\
\end{tabular} & 57,78 & 20,95 & 26,66 & 139,33 & 80,58 & 82,35 & 104,92 \\
\hline Pelobates cultripes & 30TXM24 & 100,00 & 138,28 & 106,28 & 37,48 & 6087,83 & 294,44 & 15,01 & 279,43 & 160,78 & 216,96 & 216,96 & 61,71 & 449,59 & 56,90 & 21,03 & 25,46 & 138,72 & 81,65 & 82,90 & 111,29 \\
\hline Pelobates cultripes & 30TXM26 & 100,00 & 132,34 & 106,18 & 37,95 & 6011,91 & 287,35 & 10,14 & 277,21 & 140,20 & 209,87 & 209,87 & 56,56 & 530,36 & 62,22 & 25,35 & 23,09 & 157,15 & 95,82 & 99,69 & 138,38 \\
\hline Pelobates cultripes & $30 \mathrm{TXM} 27$ & 100,00 & 133,69 & 105,99 & 38,00 & 5966,34 & 287,39 & 12,47 & 274,92 & \begin{tabular}{|l|}
96,91 \\
940
\end{tabular} & 210,66 & 210,66 & 58,58 & 564,81 & 63,52 & 26,71 & 22,52 & $\begin{array}{l}167,48 \\
\end{array}$ & 101,29 & 102,42 & 151,60 \\
\hline Pelobates cultripes & 30TXM30 & 100,00 & 133,31 & 105,50 & 37,00 & 6201,89 & 289,74 & 7,93 & 281,81 & 156,36 & 213,27 & 213,35 & 55,65 & 385,79 & 55,91 & 18,82 & 31,03 & 130,92 & 73,59 & 82,72 & 84,01 \\
\hline Pelobates cultripes & 30TXM33 & 100,00 & 138,50 & 106,01 & 37,01 & 6139,19 & 295,47 & 14,89 & 280,58 & 161,23 & 217,79 & 217,79 & 61,48 & 421,05 & 55,96 & 19,55 & 27,19 & 133,53 & 76,64 & 78,88 & 100,73 \\
\hline Pelobates cultripes & 30TXM35 & 100,00 & 127,31 & 106,02 & 37,54 & 6041,35 & 283,19 & 4,91 & 278,28 & 149,26 & 205,41 & 205,41 & 51,55 & 509,78 & 62,90 & 24,80 & 23,64 & 155,61 & 93,61 & 96,50 & 127,89 \\
\hline Pelobates cultripes & 30TXM36 & 100,00 & 129,18 & 106,00 & 37,92 & 6005,93 & 284,30 & 7,06 & 277,23 & 147,96 & 206,79 & 206,79 & 53,67 & 535,59 & 63,38 & 25,68 & 22,83 & 158,98 & 97,45 & 99,31 & 138,33 \\
\hline Pelobates cultripes & 30TXM37 & 100,00 & 129,39 & 105,94 & 38,00 & 5959,24 & 283,29 & 8,04 & 275,24 & 95,12 & 206,40 & 206,40 & 54,34 & 575,10 & 65,06 & 27,44 & 22,10 & 168,96 & 103,88 & 104,77 & 153,17 \\
\hline Pelobates cultripes & 30TXM38 & 100,00 & 127,53 & 105,31 & 38,00 & 5906,47 & 279,88 & 6,84 & 273,04 & 91,61 & 203,72 & 203,72 & 52,95 & 626,84 & 70,12 & 29,96 & 21,65 & 186,67 & 112,73 & 113,19 & 171,50 \\
\hline Pelobates cultripes & 30TXM40 & 100,00 & 136,26 & 105,00 & 36,99 & 6209,37 & 292,96 & 11,42 & 281,54 & 159,41 & 216,57 & 216,58 & 58,69 & 372,54 & 54,78 & 17,63 & 32,07 & 126,86 & 70,29 & 75,02 & 80,25 \\
\hline Pelobates cultripes & 30TXM42 & 100,00 & 139,63 & 105,96 & 37,00 & 6174,59 & 297,19 & 15,96 & 281,24 & 162,39 & 219,56 & 219,56 & 62,39 & 391,62 & 54,69 & 17,77 & 29,69 & 127,56 & 71,12 & 71,12 & 90,34 \\
\hline Pelobates cultripes & 30TXM45 & 100,00 & 134,59 & 105,80 & 37,72 & 6029,52 & 290,12 & 12,27 & 277,86 & 156,46 & 212,67 & 212,67 & 58,95 & 477,71 & 59,03 & 22,36 & 24,01 & 144,83 & 87,31 & 89,01 & 118,78 \\
\hline Pelobates cultripes & 30TXM49 & 100,00 & 111,52 & 104,06 & 38,12 & 5778,43 & 261,90 & $-6,27$ & 268,17 & 76,92 & 186,52 & 186,52 & 39,16 & 720,40 & 78,95 & 36,34 & 19,71 & 210,17 & 133,69 & 136,21 & 195,68 \\
\hline Pelobates cultripes & 30TXM50 & 100,00 & 127,07 & 103,95 & 36,92 & 6172,05 & 282,81 & 2,99 & 279,82 & 149,81 & 172,08 & 207,02 & 50,14 & 398,22 & 58,16 & 20,01 & 30,77 & 136,78 & 78,05 & 88,28 & 82,88 \\
\hline Pelobates cultripes & 30TXM51 & 100,00 & 139,49 & 105,15 & 37,00 & 6207,42 & 297,79 & 16,05 & 281,74 & 162,24 & 220,04 & 220,05 & 62,15 & 370,43 & 54,14 & 16,79 & 31,68 & 124,02 & 67,68 & 68,56 & 81,76 \\
\hline Pelobates cultripes & 30TXM53 & 100,00 & 132,01 & 105,19 & 37,00 & 6110,04 & 289,16 & 9,31 & 279,85 & 154,31 & 211,09 & 211,12 & 55,67 & 426,69 & 57, & 20,29 & 26,89 & 137,25 & 79,52 & 81,85 & 98,06 \\
\hline Pelobates cultripes & 30TXM54 & 100,00 & 131,54 & 105,22 & 37,02 & 6068,09 & 288,00 & 9,05 & 278,95 & 153,54 & 210,17 & 210,17 & 55,69 & 450,30 & 58,54 & 21,42 & 25,18 & 141,39 & 83,80 & 86,24 & 106,26 \\
\hline Pelobates cultripes & 30TXM55 & 100,00 & 130,65 & 105,09 & 37,32 & $\begin{array}{ll}6008,16 \\
\end{array}$ & 285,82 & 8,62 & 277,20 & 152,32 & 208,28 & 208,36 & 55,40 & \begin{tabular}{|l|l|}
481,03 \\
\end{tabular} & 59,89 & 22,92 & 23,46 & 146,85 & 89,62 & 92,53 & 116,77 \\
\hline Pelobates cultripes & 30TXM56 & 100,00 & 131,77 & 105,01 & 37,91 & 5949,14 & 285,46 & 10,50 & 274,96 & 153,61 & 208,60 & 208,63 & 57,17 & 509,43 & 60,64 & 24,06 & 22,18 & 151,01 & 94,66 & 98,75 & 127,41 \\
\hline Pelobates cultripes & 30TXM62 & 100,00 & 140,27 & 105,20 & 36,92 & 6196,80 & 299,27 & 16,77 & 282,50 & 163,26 & 220,23 & 220,33 & 62,77 & 378,15 & 52,03 & 17,40 & 27,95 & 123,81 & 70,57 & 75,92 & 82,54 \\
\hline Pelobates cultripes & 30TXM63 & 100,00 & 128,64 & 104,66 & 37,00 & 6080,80 & 285,52 & 6,23 & 279,29 & 150,99 & 207,27 & 207,39 & 52,65 & 429,19 & 57,69 & 20,81 & 25,96 & 138,63 & 82,14 & 88,34 & 95,42 \\
\hline Pelobates cultripes & 30TXM64 & 100,00 & 119,33 & 104,01 & 37,06 & 5984,79 & 273,83 & \begin{tabular}{|c|c|}
$-1,61$ \\
$-1,20$ \\
\end{tabular} & 275,44 & 140,75 & $\begin{array}{l}196,83 \\
\end{array}$ & \begin{tabular}{|l|}
196,96 \\
\end{tabular} & 44,60 & |484,83 & 62,92 & 24,45 & 23,75 & $\begin{array}{l}153,50 \\
150\end{array}$ & $\begin{array}{l}2,144 \\
94,64 \\
\end{array}$ & 102,13 & 110,14 \\
\hline Pelobates cultripes & 30TXM65 & 100,00 & 121,25 & 104,19 & 37,42 & 5940,58 & 275,03 & 0,62 & 274,40 & 142,57 & 198,01 & 198,11 & 46,95 & 503,56 & 63,01 & 25,09 & 22,43 & 155,19 & 97,32 & 103,62 & 118,05 \\
\hline Pelobates cultripes & 30TXM66 & 100,00 & 128,08 & 104,69 & 37,91 & 5906,69 & 281,10 & 7,36 & 273,74 & 149,54 & 204,25 & 204,33 & 53,87 & 508,92 & 60,97 & 24,51 & 21,57 & 151,79 & 97,01 & 100,58 & 123,64 \\
\hline Pelobates cultripes & 30TXM67 & 100,00 & 118,97 & 103,90 & 38,00 & 5817,41 & 270,15 & 0,01 & 270,13 & 139,65 & 194,19 & 194,25 & 46,15 & 572,81 & 66,77 & 28,48 & 20,11 & 168,26 & 110,30 & 114,96 & 141,91 \\
\hline Pelobates cultripes & 30TXM70 & 100,00 & 139,91 & 104,45 & 36,05 & 6233,91 & 299,11 & 15,36 & 283,75 & 163,46 & 148,13 & 220,96 & 62,00 & 362,75 & 50,22 & 17,38 & 28,79 & 122,03 & 71,01 & 77,63 & 71,93 \\
\hline Pelobates cultripes & 30TXM71 & 100,00 & 146,76 & 105,24 & 36,17 & $\mid 6257,39$ & 307,56 & 21,90 & 285,66 & $\begin{array}{l}170,51 \\
17\end{array}$ & $\begin{array}{l}\mid 227,09 \\
22,0\end{array}$ & \begin{tabular}{|l|}
227,87 \\
\end{tabular} & $\begin{array}{ll}68,17 \\
\end{array}$ & 356,92 & $\begin{array}{l}0,264 \\
46,94\end{array}$ & $\begin{array}{l}1,3656 \\
16,56\end{array}$ & 26,97 & $\begin{array}{l}116,55 \\
11,5\end{array}$ & \begin{tabular}{|c|c|}
69,08 \\
\end{tabular} & 73,65 & 72,93 \\
\hline Pelobates cultripes & 30TXM72 & 100,00 & 139,49 & 105,01 & \begin{tabular}{|l|l|}
36,78 \\
\end{tabular} & 6172,47 & 298,75 & 15,87 & 282,87 & 162,73 & 218,90 & 219,44 & 62,19 & 380,41 & 50,38 & 17,99 & 26,22 & 123,59 & 73,79 & 79,24 & 79,60 \\
\hline Pelobates cultripes & 30TXM73 & 100,00 & 131,66 & 104,51 & 37,00 & 6070,27 & 288,66 & 9,10 & 279,56 & 154,20 & 209,85 & 210,23 & 55,69 & 415,18 & 54,69 & 20,04 & 25,16 & 133,22 & 81,21 & 86,91 & 89,29 \\
\hline Pelobates cultripes & 30TXM75 & 100,00 & 122,42 & 103,73 & 37,22 & 5894,58 & 275,50 & 2,08 & 273,42 & 143,58 & 198,42 & 198,74 & 48,47 & 487,62 & 61,03 & 24,21 & 22,26 & 150,28 & 96,39 & 101,83 & 110,87 \\
\hline Pelobates cultripes & 30TXM76 & 100,00 & 124,55 & 103,96 & 37,89 & 5840,31 & 276,45 & 4,49 & 271,96 & 145,76 & 199,77 & 200,03 & 51,17 & 504,72 & 61,06 & 24,69 & 21,14 & 151,66 & 99,13 & 103,45 & 118,15 \\
\hline Pelobates cultripes & 30TXM79 & 100,00 & $\begin{array}{l}24,53 \\
94,27\end{array}$ & 100,14 & 38,01 & S578,12 & 239,18 & \begin{tabular}{r|}
$-2,4,06$ \\
$-20,06$
\end{tabular} & 259,24 & $\begin{array}{l}112,36 \\
112,3\end{array}$ & 166,83 & \begin{tabular}{|l|l|}
166,86 \\
\end{tabular} & $\begin{array}{l}1,11 \\
24,87\end{array}$ & 740,121 & $\begin{array}{l}1,00 \\
83,20\end{array}$ & \begin{tabular}{|l|}
40,77 \\
40,
\end{tabular} & $\begin{array}{l}21,14 \\
16,95\end{array}$ & $\begin{array}{l}51,200 \\
215,23\end{array}$ & $\begin{array}{l}35,102 \\
151,02\end{array}$ & 156,15 & $\begin{array}{l}118,1,56 \\
186,56\end{array}$ \\
\hline Pelobates cultripes & 30TXM80 & 100,00 & 145,28 & 104,63 & 36,21 & 6190,31 & 303,61 & 20,15 & 283,46 & 168,93 & 79,03 & 225,67 & 67,72 & 355,22 & 47,42 & 16,52 & 28,16 & 116,99 & 69,07 & 74,27 & 69,08 \\
\hline Pelobates cultripes & 30TXM81 & 100,00 & 144,28 & 104,85 & 36,36 & 6169,93 & 303,16 & 19,72 & 283,44 & 167,74 & 140,13 & 224,41 & 66,73 & 363,76 & 47,59 & 16,95 & 26,93 & 118,23 & 71,85 & 75,41 & 72,28 \\
\hline Pelobates cultripes & 30TXM82 & 100,00 & 139,35 & 104,73 & 36,89 & 6112,10 & 297,35 & $\begin{array}{ll}15,57 \\
\end{array}$ & 281,78 & 162,46 & 174,81 & 218,70 & 62,77 & 381,90 & 49,7 & 18,05 & 25,86 & 122,92 & 76,19 & 79,36 & 77,58 \\
\hline Pelobates cultripes & 30TXM83 & 100,00 & 136,28 & 104,68 & 37,0 & 6036,82 & 292,76 & 13,48 & 279,28 & 159,10 & 210,90 & 214,44 & 60,58 & 400,59 & 51,5 & 19,03 & 24,70 & 126,96 & 80,25 & 82,88 & 83,63 \\
\hline Pelobates cultripes & 30TXM84 & 100,00 & 133,34 & 104,30 & 37,08 & \begin{tabular}{|l|}
5953,49 \\
\end{tabular} & 288,14 & 11,68 & 276,45 & 155,49 & 209,82 & 210,30 & 58,63 & 422,34 & 53,5 & 20,11 & 23,76 & 131,74 & 84,71 & 86,98 & 90,53 \\
\hline Pelobates cultripes & 30TXM85 & 100,00 & 129,53 & 103,97 & 37,52 & 5870,70 & 282,41 & 8,86 & 273,55 & 151,40 & 204,97 & 205,53 & 55,79 & \begin{tabular}{|l|l|}
451,78 \\
\end{tabular} & 56,16 & 21,72 & 22,41 & 138,37 & 90,90 & 92,84 & 99,45 \\
\hline Pelobates cultripes & 30TXM86 & 100,00 & 124,99 & 103,48 & 37,99 & 5784,12 & 275,87 & 5,21 & 270,66 & 146,09 & 199,47 & 199,92 & 52,24 & 488,99 & 59,35 & 23,81 & 21,27 & 147,01 & 98,59 & 100,42 & 110,74 \\
\hline Pelobates cultripes & 30TXM87 & 100,00 & 118,97 & 102,86 & 38,00 & 5709,54 & 267,58 & 0,43 & 267,16 & 139,37 & 192,36 & 192,87 & 47,08 & 538,87 & 63,79 & 26,86 & 19,88 & 59,26 & 109,08 & 111,22 & 125,26 \\
\hline Pelobates cultripes & $30 \mathrm{TXM} 88$ & 100,00 & 112,24 & 102,10 & 38,1 & 5625,63 & 258,76 & $\begin{array}{c}-4,53 \\
-4,53 \\
\end{array}$ & 263,29 & \begin{tabular}{|l|l|}
132,04 \\
\end{tabular} & 184,71 & 185,06 & $\begin{array}{l}41,420 \\
41\end{array}$ & 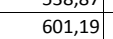 & 69 & $\begin{array}{l}30,70 \\
30,72\end{array}$ & 18,49 & 174,65 & $\begin{array}{l}122,07 \\
\end{array}$ & 124,87 & 143,51 \\
\hline Pelobates cultripes & 30TXM90 & 100,00 & 14 & 104 & 36,84 & 6119,99 & 302,47 & 21,05 & 281,42 & 169,23 & 69,32 & 225,45 & 69,32 & 356,85 & 47,36 & 16,40 & 28,47 & 116,04 & 68,17 & 73,87 & 68,17 \\
\hline Pelobates cultripes & 30TXM92 & 100,00 & 129,35 & 103,44 & 36,99 & 5994,92 & 284,30 & 6,92 & 277,38 & 151,60 & 54,36 & 207,39 & 54,36 & 404,14 & 53,86 & 19,69 & 26,35 & 131,16 & 79,34 & 86,07 & 79,34 \\
\hline Pelobates cultripes & 30TXM93 & 100,00 & 129,09 & 103,53 & 37,00 & 5941,32 & 283,25 & 7,50 & 275,75 & 151,18 & 76,57 & 206,39 & 54,61 & 412,78 & 53,98 & 19,98 & 25,28 & 131,66 & 82,86 & 86,85 & 82,89 \\
\hline Pelobates cultripes & $30 \mathrm{TXN}$ & 100,00 & 126,16 & 103,24 & 37,72 & 5788,91 & 277,59 & 6,25 & 271,34 & 147,70 & 190,51 & 201,40 & 53,52 & 449,38 & - & 21,78 & 22,87 & 07 & 92,75 & 93,08 & 95,25 \\
\hline Pelobates cultripes & $30 \mathrm{TX}$ & 100,00 & 12 & 102 & 37, & 5713,07 & 271,06 & 2,91 & 268,15 & 142,77 & 195,99 & 196,03 & 50,15 & 483,54 & 59,3 & 23,76 & 21,50 & 146,06 & 100,17 & 100,21 & 105,26 \\
\hline Pelobates cultripes & 30TXM97 & 100,00 & 117,48 & 102,31 & 38,00 & 5642,31 & 264,80 & $-0,18$ & 264,98 & 137,80 & 190,56 & $\begin{array}{ll}190,68 \\
\end{array}$ & 46,59 & 525,89 & 62,85 & 26,32 & 20,06 & 156,01 & 109,05 & 109,31 & 117,90 \\
\hline Pelobates cultripes & 30TXNOO & 100,00 & 127,58 & 104,76 & 38,30 & |5801,83 & 278,61 & 9,32 & 269,29 & $\begin{array}{l} \\
70,78 \\
\end{array}$ & 202,65 & 202,65 & 54,66 & 733,37 & $\begin{array}{l}82,00 \\
85,78\end{array}$ & $\begin{array}{l}35,25 \\
35,\end{array}$ & 22,26 & \begin{tabular}{|l|}
226,05 \\
\end{tabular} & 128,43 & 128,43 & 212,22 \\
\hline Pelobates cultripes & 30 TXN01 & 100,00 & 122,08 & 104,38 & 38,45 & 5749,16 & 272,88 & 5,07 & 267,82 & 58,33 & 196,59 & 196,59 & 49,94 & 823,10 & 98,48 & 39,67 & 22,73 & 259,36 & 142,68 & 142,68 & 244,35 \\
\hline Pelobates cultripes & 30TYKO3 & 100,00 & 121 & 93,96 & $36, \mathrm{C}$ & 5896,13 & 264,49 & 7,97 & 256 & 131,42 & 70,05 & 201,18 & 52,27 & 500,34 & 61,01 & 23,30 & 28,63 & 161,39 & 94,81 & 108,03 & 95, \\
\hline Pelobates cultripes & $\begin{array}{l}\text { 30TYKO4 } \\
30\end{array}$ & $\begin{array}{l}100,00 \\
\end{array}$ & 123,28 & $\begin{array}{ll}53,37 \\
93,\end{array}$ & $\begin{array}{l}30,01 \\
36,00\end{array}$ & $\begin{array}{l}5899,11 \\
5898\end{array}$ & $\begin{array}{l}264,45 \\
264,98\end{array}$ & $\begin{array}{l}9,50 \\
9,00\end{array}$ & \begin{tabular}{|l|}
250,98 \\
255
\end{tabular} & \begin{tabular}{|l|}
132,69 \\
132,
\end{tabular} & 57,10 & \begin{tabular}{|l|}
202,31 \\
201
\end{tabular} & $\begin{array}{ll}2,27 \\
53,42\end{array}$ & $\begin{array}{l}00,54 \\
485,57\end{array}$ & $\begin{array}{l}61,01 \\
60,07\end{array}$ & $\begin{array}{l}20,309 \\
22,98\end{array}$ & $\begin{array}{l}29,03 \\
29,46\end{array}$ & \begin{tabular}{|l|l|}
156,54 \\
15,5
\end{tabular} & \begin{tabular}{|l}
4,10 \\
90,19 \\
\end{tabular} & $\begin{array}{l}105,87 \\
105\end{array}$ & $\begin{array}{l}90,23 \\
90,\end{array}$ \\
\hline Pelobates cultripes & 30TYK26 & 100,00 & 100,24 & 92,26 & 35,75 & 5912,12 & 243,11 & $-12,43$ & 255,55 & 114,83 & 31,38 & 179,99 & 31,38 & 609,25 & 74,69 & 30,53 & 25,43 & 189,27 & 118,88 & 132,87 & 118,88 \\
\hline Pelobates cultripes & 30TYK53 & 60,00 & 165,35 & 83,90 & 36,00 & 5208,10 & 286,17 & 56,26 & 229,91 & 175,53 & 232,55 & 235,01 & 102,42 & 451,74 & 68,84 & 13,92 & 40,39 & 178,36 & 65,44 & 94,38 & 98,85 \\
\hline Pelobates cultripes & 30TYK54 & 60,00 & 153,71 & 86,33 & 36,02 & 5332,60 & 279,54 & 43,44 & 36,10 & 162, & 223,34 & 225,66 & 90 & 486,86 & 69,44 & 16,11 & 36,36 & 182,61 & 77,08 & $\begin{array}{ll}102,47 \\
\end{array}$ & 103 \\
\hline Pelobates cultripes & 30TYK55 & 50,00 & 149,13 & 87,66 & 36,01 & 5415,34 & 277,37 & 37,77 & 239,60 & 156,94 & 220,15 & 222,02 & 85,26 & 496,01 & 68,51 & 17,13 & 34,70 & 181,50 & 82,24 & 105,34 & 103 \\
\hline
\end{tabular}




\begin{tabular}{|c|c|c|c|c|c|c|c|c|c|c|c|c|c|c|c|c|c|c|c|c|c|}
\hline TAXON & UTM & $\mathrm{km} 2$ & BIO1 & B102 & $\mathrm{BIO3}$ & B104 & 8105 & B106 & B107 & 8108 & 8109 & B1010 & B1011 & B1012 & BIO13 & 81014 & B1015 & B1016 & B1017 & 81018 & 81019 \\
\hline Pelobates cultripes & 30TYL01 & 100,00 & 95,05 & 93,76 & 35,76 & 5986,23 & 238,47 & $-21,30$ & 259,77 & 112,71 & 23,67 & 174,78 & 23,67 & 564,13 & 76,12 & 30,37 & 28,37 & 189,44 & 102,78 & 134,63 & 102,78 \\
\hline Pelobates cultripes & \begin{tabular}{l|}
$30 T Y L 02$ \\
\end{tabular} & 100,00 & 108,92 & 94,52 & 36,00 & 5980,92 & 251,53 & $-9,03$ & 260,56 & 128,27 & 36,94 & 188,23 & 36,94 & 492,30 & 68,41 & 25,25 & 31,07 & 167,44 & 86,54 & 116,54 & 86,54 \\
\hline Pelobates cultripes & 30TYLO3 & 100,00 & 120,38 & 96,21 & 36,00 & 5988,00 & 264,03 & 0,13 & 263,90 & 140,84 & 47,60 & \begin{tabular}{|l|l|}
199,38 \\
\end{tabular} & 47,60 & 442,49 & $\begin{array}{l}62,33 \\
62,3\end{array}$ & 22,27 & 32,47 & 150,72 & 77,01 & \begin{tabular}{|l|}
102,17 \\
\end{tabular} & 77,01 \\
\hline Pelobates cultripes & 30TYL04 & 100,00 & 128,06 & 97,86 & 36,00 & 6000,80 & 273,61 & 6,32 & 267,29 & 149,40 & 54,93 & 206,99 & 54,88 & 414,35 & 58,48 & 20,44 & 32,87 & 140,48 & 72,46 & 93,32 & 72,46 \\
\hline Pelobates cultripes & 30TYL05 & 100,00 & 135,72 & 99,61 & 36,04 & 6025,13 & 283,62 & 12,59 & 271,03 & 157,66 & 61,97 & 214,66 & 61,74 & 388,46 & 54,65 & 18,39 & 32,93 & 130,68 & 68,50 & 85,03 & 68,50 \\
\hline Pelobates cultripes & 30TYL06 & 100,00 & 142,20 & 101,20 & 36,22 & 6042,49 & 292,40 & 18,20 & 274,20 & 164,69 & 68,48 & 221,25 & 67,81 & 368,36 & 51,33 & 16,74 & 32,70 & 122,58 & 65,86 & 78,34 & 65,86 \\
\hline Pelobates cultripes & 30TYL07 & 100,00 & 144,08 & 102,25 & 36,37 & 6057,12 & 296,00 & 19,68 & 276,32 & 167,03 & 69,18 & 223,23 & 69,18 & 362,62 & 50,07 & 16,34 & 31,95 & 120,05 & 65,58 & 76,32 & 65,58 \\
\hline Pelobates cultripes & 30TYL08 & 100,00 & 147,00 & 103,29 & 36,75 & 6075,08 & 300,51 & 22,25 & 278,27 & 170,25 & 71,66 & 226,18 & 71,66 & 355,77 & 48,37 & 15,92 & 31,24 & 116,53 & 65,40 & 73,91 & 65,40 \\
\hline Pelobates cultripes & 30TYL09 & 100,00 & 148,51 & 104,01 & 36,99 & 6077,60 & 303,15 & 23,56 & 279,59 & 171,91 & 72,67 & 227,53 & 72,67 & 353,00 & 47,32 & 15,67 & 30,28 & 114,69 & 65,39 & 72,80 & 65,39 \\
\hline Pelobates cultripes & 30TYL11 & 100,00 & 106,53 & 93,56 & 35,70 & 5941,94 & 248,77 & $-10,01$ & 258,77 & 124,49 & 35,74 & 185,55 & 35,74 & 528,69 & 70,90 & 27,69 & 29,27 & 174,84 & 95,94 & 121,62 & 95,94 \\
\hline Pelobates cultripes & 30TYL12 & 100,00 & 114,35 & 94,74 & 35,98 & 5948,82 & 256,97 & $-3,66$ & 260,62 & 133,53 & 42,95 & 193,27 & 42,95 & 488,99 & 66,71 & 25,01 & 30,69 & 162,80 & 87,40 & 111,36 & 87,40 \\
\hline Pelobates cultripes & 30TYL13 & 100,00 & 120,96 & 96,19 & 36,00 & 5955,15 & 264,72 & 1,18 & 263,54 & 140,97 & 49,06 & 199,65 & 49,06 & 458,44 & 63,28 & 22,79 & 31,53 & 153,08 & 81,40 & 103,08 & 81,40 \\
\hline Pelobates cultripes & \begin{tabular}{|l|}
$30 T Y L 14$ \\
\end{tabular} & 100,00 & 127,50 & 97,79 & 36,00 & 5971,89 & 273,09 & 6,11 & 266,98 & 148,28 & 55,17 & 206,20 & 55,06 & 431,76 & 59,89 & 20,81 & 32,13 & 143,95 & 76,56 & 95,36 & 76,56 \\
\hline Pelobates cultripes & 30TYL15 & 100,00 & 137,35 & 99,78 & 36,18 & 5990,26 & 285,10 & 14,33 & 270,77 & 159,05 & 65,33 & 215,87 & 64,22 & 398,05 & 55,03 & 18,12 & 32,69 & 131,48 & 70,89 & 84,97 & 70,89 \\
\hline Pelobates cultripes & 30TYL16 & 100,00 & 146,32 & 101,65 & 36,68 & 6010,72 & 296,19 & 22,16 & 274,02 & 168,23 & 78,09 & 224,96 & 72,52 & 370,77 & 50,68 & 16,07 & 32,89 & 120,83 & 66,73 & 76,48 & 66,73 \\
\hline Pelobates cultripes & 30TYL17 & 100,00 & 148,10 & 102,69 & 36,80 & 6032,76 & 299,68 & 23,34 & 276,34 & \begin{tabular}{|l|l|}
168,94 \\
\end{tabular} & 75,64 & 226,92 & 73,75 & 363,62 & 49,38 & 15,61 & 32,39 & 118,29 & 65,78 & 74,51 & 65,78 \\
\hline Pelobates cultripes & 30TYL18 & 100,00 & 147,57 & 103,69 & 37,00 & 6050,88 & 300,35 & 22,33 & 278,02 & 170,80 & 73,70 & 226,38 & 72,64 & 362,82 & 48,91 & 15,84 & 31,35 & 117,70 & 66,06 & 74,69 & 66,06 \\
\hline Pelobates cultripes & 30TYL22 & 100,00 & 121,20 & 95,16 & 36,00 & 5905,73 & 263,52 & 2,64 & 260,88 & 139,69 & 51,91 & 199,39 & 50,53 & 484,13 & 64,79 & 23,21 & 30,65 & 157,38 & 88,16 & 105,77 & 88,17 \\
\hline Pelobates cultripes & 30TYL23 & 100,00 & 129,53 & 96,95 & 36,01 & 5917,39 & 273,45 & 9,05 & 264,40 & 149,44 & 60,86 & 207,72 & 58,37 & 449,66 & 60,72 & 20,57 & 31,81 & 146,05 & 81,33 & 96,20 & 81,34 \\
\hline Pelobates cultripes & 30TYL24 & 100,00 & 134,76 & 98,59 & 36,18 & 5938,88 & 280,62 & 12,99 & 267,63 & 155,68 & 67,53 & 213,03 & 63,11 & 427,03 & 57,93 & 19,04 & 32,34 & 138,71 & 77,01 & 90,07 & 77,03 \\
\hline Pelobates cultripes & 30TYL25 & 100,00 & 142,00 & 100,52 & 36,74 & 5961,88 & 289,83 & 18,81 & 271,02 & 161,28 & 75,85 & 220,33 & 69,60 & 400,61 & 54,32 & 17,21 & 32,90 & 129,56 & 72,24 & 82,60 & 72,25 \\
\hline Pelobates cultripes & 30TYL26 & 100,00 & 147,16 & 102,06 & 36,92 & 5984,36 & \begin{tabular}{|l|l|}
296,88 \\
\end{tabular} & $\begin{array}{l}20,70 \\
22,70 \\
\end{array}$ & 274,18 & $\begin{array}{l}160,48 \\
106\end{array}$ & 82,08 & 225,53 & 73,97 & 381,64 & 51,51 & $\begin{array}{l}1,21,0 \\
16,0\end{array}$ & 33,10 & 123,42 & 68,83 & 77,54 & 68,86 \\
\hline Pelobates cultripes & 30TYL28 & 100,00 & 141,27 & 103,36 & 37,00 & 6026,76 & 293,91 & 16,48 & 277,43 & 163,92 & 67,06 & 220,09 & 66,99 & 387,27 & 52,42 & 17,14 & 31,11 & 125,88 & 70,01 & 80,77 & 70,01 \\
\hline Pelobates cultripes & 30TYL29 & 100,00 & 138,55 & 103,86 & 36,99 & 6033,03 & 292,02 & 13,74 & 278,28 & 161,56 & 63,97 & 217,26 & 63,97 & 391,10 & 52,82 & 17,75 & 30,19 & 127,30 & 70,85 & 82,48 & 70,85 \\
\hline Pelobates cultripes & 30TYL32 & 100,00 & 133,59 & 96,09 & 36,10 & 5848,65 & 275,59 & 13,99 & 261,60 & 140,98 & 69,86 & 210,97 & 63,95 & 464,46 & 60,79 & 19,82 & 31,84 & 149,59 & 85,77 & 97,49 & 86,31 \\
\hline Pelobates cultripes & $\begin{array}{l}30 \text { TYL33 } \\
\end{array}$ & 100,00 & 136,96 & 97,60 & 36,23 & 5872,92 & 280,81 & 16,10 & 264,72 & 144,41 & 73,30 & 214,55 & 66,74 & 447,91 & 59,08 & 18,85 & 32,32 & 144,72 & 82,19 & 92,25 & 82,85 \\
\hline Pelobates cultripes & 30TYL34 & 100,00 & 142,34 & 99,50 & 36, 36 & S901,58 & \begin{tabular}{|l|}
288,19 \\
28,1
\end{tabular} & $\begin{array}{l}10,102 \\
19,92\end{array}$ & $\begin{array}{l}268,27 \\
268,\end{array}$ & $\begin{array}{l}144,414 \\
146,99 \\
\end{array}$ & $\begin{array}{l}78,03 \\
78,78\end{array}$ & \begin{tabular}{|l|}
220,24 \\
224
\end{tabular} & 71,52 & $\begin{array}{l}44 l, y+ \\
423,89\end{array}$ & $\begin{array}{l}3,00 \\
56,32\end{array}$ & \begin{tabular}{l|l}
17,36 \\
17,36
\end{tabular} & $\begin{array}{ll}2,32,97 \\
32,9\end{array}$ & $\begin{array}{l}134,90 \\
137,90 \\
\end{array}$ & $\begin{array}{l}\mid 20,113 \\
76,94\end{array}$ & $\begin{array}{l}2,25 \\
85,89\end{array}$ & $\begin{array}{l}0,0,05 \\
77,94\end{array}$ \\
\hline Pelobates cultripes & 30TYL35 & 100,00 & 143,02 & 100,82 & 36,70 & 5940,71 & 290,94 & 19,49 & 271,45 & $\begin{array}{ll}150,37 \\
\end{array}$ & 78,90 & 221,16 & 71,21 & 414,94 & 55,39 & 17,11 & 32,87 & 134,25 & 75,32 & 83,91 & 75,83 \\
\hline Pelobates cultripes & 30TYL36 & 100,00 & 149,20 & 102,61 & 36,94 & 5967,16 & 298,83 & 24,44 & 274,39 & 153,92 & 85,32 & 227,44 & 76,60 & 390,97 & 52,10 & 15,74 & 33,37 & 128,10 & 70,41 & 78,03 & 71,10 \\
\hline Pelobates cultripes & 30TYL37 & 100,00 & 151,31 & 103,91 & 37,00 & 5995,37 & 302,51 & 25,69 & 276,82 & 157,30 & 86,81 & 229,77 & 77,99 & 379,98 & 50,51 & 15,35 & 33,08 & 124,24 & 68,44 & 75,90 & 68,99 \\
\hline Pelobates cultripes & 30TYL39 & 100,00 & 138,03 & 104,51 & 37,00 & 6031,40 & 291,85 & 12,97 & 278,88 & 161,19 & $\begin{array}{l}63,64 \\
63\end{array}$ & 216,90 & 63,64 & 403,20 & 54,17 & 18,13 & 30,51 & 130,85 & 72,66 & 85,02 & 72,66 \\
\hline Pelobates cultripes & \begin{tabular}{|l|l}
$30 T Y L 43$ \\
\end{tabular} & 100,00 & 133,19 & $\begin{array}{l}90,51 \\
97,27\end{array}$ & 36,27 & $\begin{array}{l}58554,53 \\
585,4\end{array}$ & \begin{tabular}{|l|}
271,900 \\
276,
\end{tabular} & $\begin{array}{ll}12,92 \\
12,9\end{array}$ & $\begin{array}{l}263,90 \\
2637\end{array}$ & \begin{tabular}{|l|l|}
138,21 \\
\end{tabular} & $\begin{array}{l}3,040 \\
69,69 \\
\end{array}$ & $\begin{array}{l}210,80 \\
210,8\end{array}$ & $\begin{array}{l}63,74 \\
63,74 \\
\end{array}$ & $\begin{array}{l}403,20 \\
481,13\end{array}$ & $\begin{array}{l}34,11 \\
62,31\end{array}$ & $\begin{array}{l}10,13 \\
19,97 \\
\end{array}$ & $\begin{array}{ll}0,151 \\
31,23\end{array}$ & $\begin{array}{l}154,15 \\
154 \\
\end{array}$ & $\begin{array}{l}2,000 \\
89,95 \\
\end{array}$ & $\begin{array}{l}5,020 \\
99,95 \\
\end{array}$ & $\begin{array}{l}12,00 \\
90,99\end{array}$ \\
\hline Pelobates cultripes & 30TYL44 & 100,00 & 140,32 & 99,42 & 36,68 & 5888,21 & 286,16 & 18,08 & 268,09 & $\begin{array}{l}143,57 \\
\end{array}$ & 76,69 & 218,13 & 70,13 & 450,49 & 58,86 & 18,01 & 32,39 & 146,43 & 82,97 & 90,82 & 84,47 \\
\hline Pelobates cultripes & 30TYL45 & 100,00 & 145,58 & 101,43 & 36,95 & 5916,80 & 293,39 & 21,75 & 271,64 & 149,00 & 81,82 & 223,47 & 74,58 & 426,60 & 56,07 & 16,75 & 33,06 & 139,95 & 77,66 & 84,61 & 79,26 \\
\hline Pelobates cultripes & 30TYL46 & 100,00 & 150,73 & 103,24 & 37,00 & 5957,93 & 300,52 & 25,43 & 275,08 & 153,39 & 86,88 & 228,96 & 78,75 & 402,34 & 52,94 & 15,59 & 33,55 & 133,19 & 72,40 & 78,88 & 74,04 \\
\hline Pelobates cultripes & 30TYL47 & 100,00 & 152,55 & 104,68 & 37,01 & 6001,37 & 304,22 & 26,26 & 277,96 & 155,34 & 88,44 & 231,15 & 79,55 & 388,64 & 51,21 & 15,34 & 33,43 & 128,15 & 69,58 & 76,82 & 70,90 \\
\hline Pelobates cultripes & 30TYL48 & 100,00 & 140,81 & 104,68 & 37,00 & 6037,27 & 294,13 & 14,99 & 279,14 & 162,67 & 69,21 & 219,93 & 66,72 & 414,60 & 55,17 & 17,81 & 30,88 & 133,07 & 75,60 & 85,93 & 75,63 \\
\hline Pelobates cultripes & 30TYL56 & 17,00 & 151,76 & 103,48 & 37,00 & 5963,08 & 301,56 & 26,04 & 275,52 & 154,04 & 87,64 & 229,96 & 79,96 & 409,40 & 53,44 & 15,52 & 33,96 & 136,36 & 73,64 & 79,40 & 75,88 \\
\hline Pelobates cultripes & 30TYM01 & 100,00 & 133,27 & 103,61 & 37,00 & 6003,54 & 287,89 & 10,21 & 277,68 & 155,81 & 58,41 & 211,50 & 58,41 & 390,14 & 52,38 & 18,70 & 27,95 & 127,22 & 73,48 & 83,02 & 73,48 \\
\hline Pelobates cultripes & 30TYM02 & 100,00 & 119,04 & 101,79 & 37,00 & 5880,27 & 270,87 & $-1,21$ & 272,07 & 140,31 & 45,86 & 195,83 & 45,86 & 436,98 & 58,78 & 22,03 & 26,51 & 142,13 & 83,77 & 95,42 & 83,77 \\
\hline Pelobates cultripes & 30TYM03 & 100,00 & 121,30 & 102,29 & 37,03 & 5829,62 & 272,96 & $\begin{array}{l}-1,21 \\
1,40\end{array}$ & 271,56 & \begin{tabular}{|l|}
142,63 \\
\end{tabular} & $\begin{array}{l}48,04 \\
48,45\end{array}$ & 197,35 & 48,45 & 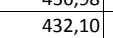 & 57,20 & 21,41 & 25,71 & $\begin{array}{l}138,24 \\
\end{array}$ & 84,15 & $\begin{array}{l}0,42,54 \\
92,\end{array}$ & 84,15 \\
\hline Pelobates cultripes & 30TYM06 & 100,00 & 119,42 & 102,02 & 38,00 & 5640,66 & 267,08 & 1,31 & 265,77 & 139,94 & 140,33 & 192,75 & 48,47 & 474,58 & 59,00 & 23,38 & 22,34 & 143,95 & 98,43 & 99,03 & 99,21 \\
\hline Pelobates cultripes & 30TYM07 & 100,00 & 114,41 & 101,49 & 38,01 & 5558,84 & 260,19 & $\begin{aligned}-1,59 \\
-1,99 \\
\end{aligned}$ & 262,17 & 134,43 & $\begin{array}{l}182,08 \\
182,0\end{array}$ & 186,63 & $\begin{array}{l}40,46 \\
44,68 \\
\end{array}$ & 517,81 & 62,85 & 26,10 & 20,67 & $\begin{array}{l}154,67 \\
\end{array}$ & \begin{tabular}{|r|}
108,79 \\
\end{tabular} & 108,83 & $\begin{aligned} 11,21,43 \\
111\end{aligned}$ \\
\hline Pelobates cultripes & 30TYM10 & 100,00 & 138,18 & 103,97 & 37,00 & 6015,59 & 292,35 & 14,01 & 278,34 & 161,16 & 63,17 & 216,51 & 63,17 & 382,09 & 51,42 & 17,67 & 29,34 & 124,46 & 70,11 & 80,60 & 70,11 \\
\hline Pelobates cultripes & 30TYM11 & 100,00 & 125,77 & 102,62 & 37,00 & 5933,21 & 278,42 & 3,96 & 274,46 & 147,69 & 51,95 & 203,28 & 51,95 & 418,11 & 56,35 & 20,45 & 27,92 & 136,35 & $\mid 77,60$ & 90,70 & 77,60 \\
\hline Pelobates cultripes & 30TYM16 & 100,00 & 120,28 & 102,10 & 38,00 & $\begin{array}{l}5539,21 \\
559,41\end{array}$ & \begin{tabular}{|l|}
267,16 \\
\end{tabular} & $\begin{array}{l}3,50 \\
2,13 \\
\end{array}$ & 265,03 & \begin{tabular}{|l|}
140,795 \\
140,
\end{tabular} & \begin{tabular}{|l|l|l|l|l}
50,66 \\
\end{tabular} & \begin{tabular}{|l|}
293,06 \\
193
\end{tabular} & $\begin{array}{l}1,39 \\
49,74 \\
\end{array}$ & \begin{tabular}{|l|l}
460,89 \\
460,89
\end{tabular} & $\begin{array}{l}50,83 \\
57,81\end{array}$ & $\begin{array}{l}20,45 \\
22,69\end{array}$ & 23,24 & \begin{tabular}{|l|}
140,17 \\
140,1
\end{tabular} & $\begin{array}{l}1,200 \\
92,80\end{array}$ & $\begin{array}{l}0,7 \\
96,65\end{array}$ & 92,80 \\
\hline Pelobates cultripes & 30TYM20 & 100,00 & 132,64 & 103,69 & 37,00 & 5998,09 & 286,11 & 8,73 & 277,38 & 155,39 & 58,21 & 210,96 & 58,21 & 405,59 & 54,66 & 19,10 & 29,19 & 132,05 & 73,81 & 86,84 & 73,81 \\
\hline Pelobates cultripes & 30TYM22 & 100,00 & 132,19 & 104,33 & 37,03 & 5924,70 & 285.49 & 890 & 276.59 & 154,73 & 57.99 & 209,31 & 57.99 & 405,34 & 53.59 & 19,24 & 27.73 & 129.82 & 75,04 & 86,23 & 75,04 \\
\hline Pelobates cultripes & 30 TYM24 & 100,00 & 128,66 & 103,96 & 37,82 & 5790,78 & 279,75 & 7,34 & 272,41 & 150,75 & 55,90 & 204,04 & 55,90 & 422,33 & 54,45 & 20,46 & 25,78 & 132,25 & 80,26 & 89,67 & 80,26 \\
\hline Pelobates cultripes & 30TYM26 & 100,00 & 114,57 & 101,09 & 38,00 & 5542,32 & 260,48 & $-1,73$ & 262,21 & 134,72 & $\begin{array}{ll}45,07 \\
4,\end{array}$ & 186,83 & 4 & 477,26 & 60 & 24 & 23,59 & $\begin{array}{l}146,04 \\
\end{array}$ & $\begin{array}{ll}90,28 \\
3,28\end{array}$ & 102,42 & 93,28 \\
\hline Pelobates cultripes & 30TYM33 & 100,00 & 134,14 & 105,67 & 37,61 & 5933,01 & 287,56 & 10,00 & 277,56 & $\begin{array}{l}157,45 \\
\end{array}$ & 59,48 & 211,13 & 59,48 & 414,51 & 53,65 & $\begin{array}{ll}19,94 \\
\end{array}$ & 26,74 & $\begin{array}{l}131,27 \\
\end{array}$ & $\begin{array}{l}\mid, 206 \\
76,99\end{array}$ & 年 & 76,99 \\
\hline Pelobates cultripes & 30TYM34 & 100,00 & 128,81 & 104,79 & 37,88 & 5843,16 & 280,60 & 6,17 & 274,43 & 151,32 & 55,13 & 204,69 & 55,13 & 434,10 & 55,61 & 21,29 & 25,61 & 136,36 & 81,52 & 93,95 & 81,52 \\
\hline Pelobates cultripes & 30TYM35 & 100,00 & 122,90 & 103,67 & 38,00 & 5744,74 & 272,47 & 2,21 & 270,26 & \begin{tabular}{|l|}
144,74 \\
\end{tabular} & 50,46 & 197,59 & 50,46 & 459,48 & 58,16 & 23,14 & 24,39 & 142,73 & 87,64 & 100,19 & 87,64 \\
\hline Pelobates cultripes & 31SBC49 & 100,00 & 174,19 & 100,95 & 39,64 & 5282,85 & 308,67 & 56,60 & 252,07 & 152,84 & 241,82 & 244, & 109,48 & 573,36 & 87,54 & 7,64 & 51,85 & 250,76 & 51,53 & 88,73 & 176,00 \\
\hline Pelobates cultripes & 31 SBC59 & 73,00 & 178,30 & 99,98 & 39,52 & 5248,02 & 311,31 & 60,82 & 250,49 & 157,60 & 245,06 & 248,11 & & 578,22 & 91,41 & 6,83 & 54,31 & 258,70 & 48,95 & 88,32 & 182,77 \\
\hline Pelobates cultripes & 31TBE43 & 42,00 & 168,69 & 83,80 & 36,00 & 5191,27 & 288,73 & 59,20 & 229,53 & 178,49 & 235,78 & 238,10 & 105,92 & $\begin{array}{l}450,08 \\
\end{array}$ & 69,67 & 13,00 & 41,61 & 180,04 & 63,59 & 94,02 & 98,96 \\
\hline Pelobates cultripes & 31TBE44 & 53,00 & 153,70 & 86,17 & 36,00 & 5322,66 & 279,40 & 43,45 & 235,94 & 162,33 & 223,42 & 225,59 & 90,90 & 497,59 & 71,08 & 16,06 & 36,24 & 186,84 & 77,97 & 104,35 & 107,06 \\
\hline Pelobates cultripes & 31TBE45 & 57,00 & 153,66 & 87,05 & 36,01 & 5360,26 & 280,27 & 42,42 & 237,85 & 161,39 & 223,80 & 225,93 & 90,54 & 493,76 & 69,85 & 16,15 & 36,06 & 184,06 & 79,28 & 104,61 & 104,30 \\
\hline Pelobates cultripes & 31TBE48 & 47,00 & 131,15 & 90,93 & 36,00 & 5643,69 & 266,31 & 17,18 & 249,13 & 137,00 & 203,74 & 207,20 & 65,56 & 547,07 & 67,10 & 21,13 & 30,26 & 183,33 & 101,84 & 117,48 & 110,67 \\
\hline Pelobates cultripes & 31TBE53 & & & & & & & & & & & & & & & & & & & & \\
\hline
\end{tabular}




\begin{tabular}{|c|c|c|c|c|c|c|c|c|c|c|c|c|c|c|c|c|c|c|c|c|c|}
\hline TAXON & UTM & $\mathrm{km2}$ & BIO1 & B102 & $\mathrm{BIO3}$ & B104 & B105 & B106 & B107 & B108 & B109 & BIO10 & BIO11 & B1012 & BIO13 & BIO14 & BIO15 & BIO16 & BIO17 & B1018 & BI019 \\
\hline Pelobates cultripes & 31TBE54 & 80,00 & 164,95 & 85,25 & 36,02 & 5226,37 & 287,26 & 54,61 & 232,65 & 173,45 & 233,00 & 235,31 & 103,00 & 473,82 & 71,71 & 13,63 & 39,91 & 185,67 & 69,66 & 99,72 & 103,14 \\
\hline Pelobates cultripes & 31TBE55 & 100,00 & 159,40 & 86,61 & 36,07 & 5294,17 & 284,20 & 48,04 & 236,16 & 166,89 & 228,64 & 230,73 & 97,16 & \begin{tabular}{ll|l}
490,98 \\
\end{tabular} & 71,74 & 14,86 & 37,91 & \begin{tabular}{|l|}
187,11 \\
\end{tabular} & 75,92 & 104,02 & 105,02 \\
\hline Pelobates cultripes & 31TBE65 & 61,00 & 169,18 & 86,34 & 36,36 & \begin{tabular}{|l|l|}
5208,07 \\
\end{tabular} & 291,59 & 57,66 & \begin{tabular}{|l|l|}
233,93 \\
\end{tabular} & \begin{tabular}{ll|}
176,24 \\
\end{tabular} & 237,21 & 239,49 & $\begin{array}{ll}108,25 \\
\end{array}$ & 475,79 & 73,49 & 12,71 & 41,21 & \begin{tabular}{|l|}
188,24 \\
\end{tabular} & 69,84 & 101,51 & 102,36 \\
\hline Pelobates cultripes & 31TBE77 & 99,00 & 164,72 & 88,66 & 36,73 & 5260,90 & 290,13 & 51,68 & 238,45 & 169,45 & 234,01 & 236,08 & \begin{tabular}{ll|}
105,05 \\
\end{tabular} & 515,23 & 77,21 & 13,70 & 39,55 & \begin{tabular}{ll|l}
197,66 \\
\end{tabular} & \begin{tabular}{|c|}
79,70 \\
\end{tabular} & $\begin{array}{ll}111,03 \\
\end{array}$ & 108,34 \\
\hline Pelobates cultripes & 31TBE87 & 15,00 & 170,22 & 89,00 & 37,00 _ & 5213,22 & 294,56 & $57,11 \mid$ & $237,44 \mid$ & $174,44 \mid$ & 239,00 & 241,00 & $111,67 \mid$ & 509,44 & 79,00 & 12,89 & 41,22 & 199,00 & 77,56 & 111,11 & 96,56 \\
\hline Pelobates cultripes & 31 TBF44 & 26,00 & 136,52 & 99,00 & 36,58 & 5870,97 & 282,06 & 14,76 & 267,30 & 139,88 & 72,73 & 214,24 & $\begin{array}{l}66,85 \\
\end{array}$ & 481,82 & 61,97 & 19,09 & 31,48 & 155,30 & 90,24 & 98,79 & 92,09 \\
\hline Pelobates cultripes & 31TBF51 & 100,00 & 112,71 & 92,11 & 35,72 & 5780,48 & 252,82 & $-1,59$ & 254,41 & 120,27 & 57,08 & 190,44 & 45,43 & \begin{tabular}{|l|l|}
610,58 \\
\end{tabular} & 74,07 & 26,67 & 26,86 & \begin{tabular}{ll|}
188,91 \\
\end{tabular} & \begin{tabular}{ll|}
122,06 \\
\end{tabular} & 131,81 & 122,89 \\
\hline Pelobates cultripes & 31 TBF54 & 99,00 & 140,39 & 99,64 & 36,83 & 5861,34 & 286,07 & 18,20 & 267,87 & \begin{tabular}{ll|}
143,16 \\
\end{tabular} & 76,75 & 218,07 & 71,29 & $\begin{array}{l}482,97 \\
\end{array}$ & 61,42 & 18,17 & 31,96 & \begin{tabular}{l|l|}
157,98 \\
\end{tabular} & \begin{tabular}{|l|l|}
90,49 \\
\end{tabular} & $\begin{array}{l}97,66 \\
\end{array}$ & 93,44 \\
\hline Pelobates cultripes & 31TBF59 & 100,00 & 143,56 & 107,13 & 37,00 & 6127,80 & 299,68 & 15,58 & 284,10 & \begin{tabular}{|l|l|}
167,14 \\
\end{tabular} & 74,32 & 223,41 & \begin{tabular}{ll|}
67,83 \\
\end{tabular} & 414,24 & \begin{tabular}{l|l}
54,45 \\
\end{tabular} & 17,95 & 30,49 & \begin{tabular}{|l|l|}
132,41 \\
\end{tabular} & 75,43 & 86,64 & 75,47 \\
\hline Pelobates cultripes & 31TBF61 & 99,00 & 109,30 & 90,92 & 35,52 & 5755,61 & 248,77 & $-3,78$ & 252,55 & $\begin{array}{ll}116,48 \\
\end{array}$ & \begin{tabular}{ll|}
146,49 \\
\end{tabular} & \begin{tabular}{|l|l|}
186,98 \\
\end{tabular} & 42,61 & \begin{tabular}{ll|l}
648,49 \\
\end{tabular} & $\begin{array}{l}76,95 \\
\end{array}$ & 28,02 & 25,89 & \begin{tabular}{|l|l|}
199,39 \\
\end{tabular} & \begin{tabular}{|l|}
130,34 \\
\end{tabular} & 138,81 & 133,36 \\
\hline Pelobates cultripes & 31TBF63 & 100,00 & 136,87 & 97,23 & 36,51 & 5786,36 & 279,66 & 16,86 & 262,80 & 139,95 & $\begin{array}{ll}196,36 \\
\end{array}$ & 214,02 & 69,52 & 531,63 & 65,19 & 19,19 & 31,10 & 174,12 & 100,18 & 113,19 & 106,70 \\
\hline Pelobates cultripes & 31TBF66 & 100,00 & 151,15 & 104,38 & 37,00 & 5977,35 & 301,79 & 24,80 & 276,99 & \begin{tabular}{l|l|l|l|}
153,03 \\
\end{tabular} & 86,90 & 229,76 & 79,66 & 436,73 & 55,95 & 15,89 & 33,54 & \begin{tabular}{ll|}
145,56 \\
\end{tabular} & 78,73 & 85,18 & 82,56 \\
\hline Pelobates cultripes & 31TBF67 & 100,00 & 147,35 & 105,65 & 37,01 & 6064,38 & 300,56 & 20,03 & 280,53 & 151,48 & 82,53 & 226,74 & 73,87 & 435,17 & \begin{tabular}{l|l|}
56,25 \\
\end{tabular} & 16,97 & \begin{tabular}{|l|l|}
32,07 \\
\end{tabular} & \begin{tabular}{|l|l|}
140,70 \\
\end{tabular} & \begin{tabular}{|l|}
79,07 \\
\end{tabular} & 86,45 & 81,33 \\
\hline Pelobates cultripes & 31TBF75 & 100,00 & 144,56 & 101,47 & 36,99 & 5904,87 & 292,23 & 20,69 & 271,54 & \begin{tabular}{ll|}
146,80 \\
\end{tabular} & 152,31 & 222,69 & \begin{tabular}{ll|}
75,06 \\
\end{tabular} & 498,08 & 61,53 & 17,34 & \begin{tabular}{|l|l|}
32,07 \\
\end{tabular} & \begin{tabular}{ll|}
163,84 \\
\end{tabular} & \begin{tabular}{|l|}
92,94 \\
\end{tabular} & 101,99 & 99,09 \\
\hline Pelobates cultripes & 31TBF76 & 100,00 & 151,21 & 104,35 & \begin{tabular}{l|l}
37,05 \\
\end{tabular} & 5991,01 & 301,78 & 24,64 & 277,14 & \begin{tabular}{|l|l|}
153,10 \\
\end{tabular} & 86,74 & 229,97 & 79,66 & 451,58 & 57,12 & 15,97 & 33,4 & 150,71 & 81,91 & 88,18 & 86,67 \\
\hline Pelobates cultripes & 31TBF77 & 101,00 & 148,88 & 106,04 & 37,03 & 6095,90 & 302,54 & 20,89 & 281,65 & 153,15 & 83,70 & 228,66 & 74,99 & 442,50 & 56,48 & 16,89 & \begin{tabular}{|l|}
32,27 \\
\end{tabular} & $\begin{array}{l}143,66 \\
\end{array}$ & 80,04 & 87,99 & 83,36 \\
\hline Pelobates cultripes & 31TBF78 & 100,00 & $\begin{array}{ll}149,66 \\
\end{array}$ & 107,88 & 37,05 & 6187,94 & 306,03 & 20,03 & 286,01 & $\begin{array}{ll}159,88 \\
\end{array}$ & 84,01 & 230,28 & 73,63 & 426,00 & 54,68 & 17,25 & 31,73 & \begin{tabular}{l|l|}
136,93 \\
\end{tabular} & 76,38 & 86,84 & 78,59 \\
\hline Pelobates cultripes & 31TBF83 & 101,00 & 154,13 & 97,79 & 37,09 & 5636,11 & 293,67 & 33,58 & 260,09 & 155,13 & 228,81 & 229,75 & $\begin{array}{l}90,46 \\
\end{array}$ & 533,66 & 71,59 & 15,66 & 35,76 & \begin{tabular}{|l|l|}
188,14 \\
\end{tabular} & $\begin{array}{l}1,76 \\
\end{array}$ & 115,07 & 106,59 \\
\hline Pelobates cultripes & 31 TBF85 & 101,00 & 142,05 & 100,12 & 36,88 & 5881,26 & 288,46 & 19,33 & 269,13 & \begin{tabular}{l|l}
144,82 \\
\end{tabular} & 217,74 & 220,00 & $\begin{array}{l}72,75 \\
\end{array}$ & 531,10 & 64,24 & 18,12 & 31,31 & \begin{tabular}{|l|l|}
172,97 \\
\end{tabular} & 98,56 & 109,81 & 108,51 \\
\hline Pelobates cultripes & 31TBF86 & 100,00 & 148,39 & 103,03 & 36,97 & 5982,27 & 297,99 & 22,86 & 275,14 & \begin{tabular}{l|l|l|}
150,98 \\
\end{tabular} & \begin{tabular}{l|l|}
118,25 \\
\end{tabular} & 227,11 & $\begin{array}{l}76,95 \\
\end{array}$ & \begin{tabular}{l|l}
480,05 \\
\end{tabular} & 59,84 & 16,85 & 32, & 158,42 & 88,56 & 96,58 & 94,17 \\
\hline Pelobates cultripes & 31TBF87 & 99,00 & 146,56 & 105,28 & 37,01 & 6113,84 & 299,91 & 19,08 & 280,83 & \begin{tabular}{l|l|}
150,82 \\
\end{tabular} & 81,16 & 226,53 & 72,37 & $\begin{array}{l}467,65 \\
\end{array}$ & 58,68 & 17,79 & 31,46 & \begin{tabular}{|l|l|}
149,93 \\
\end{tabular} & 86,02 & 94,01 & 89,59 \\
\hline Pelobates cultripes & 31TBF88 & 100,00 & 147,34 & 108,04 & 37,01 & 6253,64 & 304,80 & \begin{tabular}{l|l}
17,25 \\
\end{tabular} & 287,55 & 165,05 & 81,18 & 228,70 & $\begin{array}{ll}70,27 \\
\end{array}$ & 447,09 & 56,39 & 18,29 & 30,66 & \begin{tabular}{l|l|}
140,92 \\
\end{tabular} & 81,15 & 92,29 & 83,36 \\
\hline Pelobates cultripes & 31TBF89 & 100,00 & 153,62 & 110,83 & 37,14 & 6365,95 & 313,92 & 20,69 & 293,23 & $\begin{array}{ll}175,86 \\
\end{array}$ & 86,64 & 235,78 & 73,82 & 410,63 & 52,12 & 17,70 & \begin{tabular}{|l|l|}
31,02 \\
\end{tabular} & \begin{tabular}{l|l|}
130,95 \\
\end{tabular} & 72,10 & 87,34 & 73,76 \\
\hline Pelobates cultripes & 31TBF90 & 101,00 & 166,11 & 91,45 & \begin{tabular}{l|l|}
36,95 \\
\end{tabular} & 5296,97 & 294,19 & 50,89 & 243,29 & 167,91 & 236,18 & 238,11 & 106,50 & 549,27 & 82,41 & 13,79 & 40,63 & 208,34 & 88,54 & 121,87 & \begin{tabular}{|l|l|}
101,14 \\
\end{tabular} \\
\hline Pelobates cultripes & 31TBF91 & 99,00 & 167,58 & 93,52 & 37,26 & 5338,64 & 297,71 & 50,72 & 246,99 & \begin{tabular}{|l|l|}
168,19 \\
\end{tabular} & 238,26 & \begin{tabular}{|l|}
240,07 \\
\end{tabular} & 107,74 & 544,71 & 82,29 & 13,61 & \begin{tabular}{ll|}
40,87 \\
\end{tabular} & 207,22 & 88,10 & 121,40 & 98,81 \\
\hline Pelobates cultripes & 31TBF95 & 99,00 & 154,05 & 99,80 & 36,98 & 5812,87 & 297,87 & 31,06 & 266,81 & 156,35 & 221,29 & 231,13 & 85,82 & 504,44 & 64,91 & 15,38 & 34,84 & 173,88 & 88,90 & 109,29 & 102,07 \\
\hline Pelobates cultripes & 31TBF96 & 100,00 & 157,82 & 102,20 & 36,99 & 5922,54 & 304,71 & 32,44 & 272,26 & 160,45 & \begin{tabular}{|l|l|}
108,67 \\
\end{tabular} & 235,67 & 87,02 & 455,63 & 59,54 & 14,90 & \begin{tabular}{|c|}
35,59 \\
\end{tabular} & 158,33 & 80,41 & 99,20 & 87,44 \\
\hline Pelobates cultripes & 31TBF98 & 100,00 & 143,68 & 106,40 & 36,92 & 6260,13 & 300,11 & \begin{tabular}{|l|l|l|}
14,77 \\
\end{tabular} & 285,34 & 167,25 & 77,50 & 225,03 & 66,34 & 481,50 & 59,19 & 19,92 & 29,32 & \begin{tabular}{|l|l|l|}
150,18 \\
\end{tabular} & 89,43 & 100,59 & 91,37 \\
\hline Pelobates cultripes & 31тBF99 & 101,00 & 150,74 & $110,81$. & 37,00 & 6448,52. & 312,39 & 17,50 . & $294,89 \mid$ & $177,01 \mid$ & 83,19 [ & 233,87 & 69,58 & 432,38 & 54,02 & 19,18 & 30,09 ] & 138,39 & 76,89 ] & 94,13 & 78,06 \\
\hline Pelobates cultripes & 31TBG51 & 98,00 & 140,50 & 108,08 & 37,28 & 6144,25 & 297,68 & 12,34 & 285,34 & \begin{tabular}{|l|l|}
165,08 \\
\end{tabular} & \begin{tabular}{|l|l|}
63,47 \\
\end{tabular} & 220,31 & \begin{tabular}{|l|l|}
63,47 \\
\end{tabular} & 417,50 & 54,31 & 19,66 & 28,53 & 134,04 & 75,74 & 90,68 & 75,74 \\
\hline Pelobates cultripes & \begin{tabular}{|l|l} 
31TBG60 \\
\end{tabular} & 99,00 & 142,24 & 109,03 & 37,06 & 6230,79 & 300,97 & 12,59 & 288,37 & \begin{tabular}{|l|l|}
167,32 \\
\end{tabular} & 65,65 & 223,13 & \begin{tabular}{|l|l|}
64,47 \\
\end{tabular} & 425,82 & 55,24 & 19,53 & 29,18 & \begin{tabular}{|l|l|}
136,97 \\
\end{tabular} & \begin{tabular}{l|l}
77,25 \\
\end{tabular} & 92,28 & 77,25 \\
\hline Pelobates cultripes & 31TBG84 & 100,00 & 122,59 & 105,93 & 37,01 & 6166,65 & 278,31 & $-2,91$ & 281,22 & 146,39 & 44,41 & 202,31 & 44,41 & 573,46 & 68,98 & 31,92 & 22,78 & \begin{tabular}{ll|l}
181,56 \\
\end{tabular} & \begin{tabular}{|l|}
107,77 \\
\end{tabular} & 139,78 & 107,77 \\
\hline Pelobates cultripes & 31TBG90 & 99,00 & 152,19 & 113,57 & 37,03 & 6585,30 & 317,65 & 16,56 & \begin{tabular}{|l|l|}
301,09 \\
\end{tabular} & \begin{tabular}{|l|l|}
180,08 \\
\end{tabular} & 81,88 & 236,65 & \begin{tabular}{ll|l}
68,37 \\
\end{tabular} & 417,11 & 52,39 & 19,15 & 29,75 & $\begin{array}{l}136,25 \\
\end{array}$ & 73,12 & 94,92 & 73,43 \\
\hline Pelobates cultripes & 31TBG94 & 99,00 & 121,13 & 104,69 & 36,97 & 6185,15 & 276,28 & $-3,73$ & 280,01 & \begin{tabular}{l|l|}
144,80 \\
\end{tabular} & 42,76 & 201,11 & \begin{tabular}{ll|}
42,76 \\
\end{tabular} & \begin{tabular}{|l|l|}
607,27 \\
\end{tabular} & 72,09 & 33,76 & 22,4 & $\begin{array}{l}191,85 \\
\end{array}$ & \begin{tabular}{|l|l|}
114,17 \\
\end{tabular} & 150,78 & 114,17 \\
\hline Pelobates cultripes & 31TCF00 & 91,00 & 170,15 & 88,95 & 36,96 & 5216,73 & 294,89 & 56,82 & 238,07 & \begin{tabular}{|l|l|}
173,18 \\
\end{tabular} & 239,02 & 241,14 & 111,33 & 542,26 & 85,01 & 13,00 & 42,55 & 211,58 & \begin{tabular}{l|l|}
85,65 \\
\end{tabular} & 122,43 & 97,56 \\
\hline Pelobates cultripes & 31TCF01 & 91,00 & 169,24 & 90,59 & 37,01 & 5270,78 & 295,88 & 54,37 & 241,51 & \begin{tabular}{|l|l|}
171,44 \\
\end{tabular} & \begin{tabular}{|l|l}
238,53 \\
\end{tabular} & 240,62 & \begin{tabular}{ll|}
109,85 \\
\end{tabular} & 544,22 & 84,76 & 13,71 & $\begin{array}{l}42,07 \\
4\end{array}$ & 211,19 & 87,53 & 123,63 & 97,33 \\
\hline Pelobates cultripes & \begin{tabular}{|l|}
31 TCFO2 \\
\end{tabular} & 96,00 & 159,45 & 91,76 & 36,80 & 5411,50 & 290,13 & 43,73 & 246,40 & 161,96 & 230,93 & 232,68 & 98,68 & 572,99 & 83,03 & 14,95 & 38,52 & 211,12 & 92,86 & 123,94 & 113,35 \\
\hline Pelobates cultripes & 31 TCF03 & 100,00 & 155,72 & 93,07 & 36,66 & 5515,29 & 289,47 & 38,63 & 250,84 & 158,56 & 228,46 & 230,07 & 93,19 & 575,78 & 79,59 & 15,14 & 36,69 & 205,50 & 93,77 & 121,01 & 123,05 \\
\hline Pelobates cultripes & 31 TCF04 & 100,00 & 154,40 & 94,64 & 36,57 & 5617,50 & 291 & 35,83 & 255,28 & 157,61 & 228,30 & 229,60 & 89 & 554,93 & 74,48 & 15,61 & 35,8 & 194,72 & 93,81 & 118,16 & 116,40 \\
\hline Pelobates cultripes & 31TCFo9 & 100,00 & 146,17 & 107,88 & 36,88 & 6403,92 & 305,28 & \begin{tabular}{|l|l}
15,33 \\
\end{tabular} & 289,95 & 171,55 & 78,90 & 228,72 & 65,59 & 471,30 & 57,43 & 21,07 & 28,69 & 149,71 & 85,98 & 103,90 & 86,57 \\
\hline Pelobates cultripes & 31TCF10 & 64,00 & 169,45 & 86,30 & \begin{tabular}{l|l|}
36,35 \\
\end{tabular} & 5173,92 & 292,05 & 58,19 & 233,86 & $\begin{array}{ll}174,08 \\
\end{array}$ & 237,55 & 239,82 & 111,01 & 549,32 & 87,30 & 13,34 & 42,91 & 216,00 & 86,18 & \begin{tabular}{ll|}
124,69 \\
\end{tabular} & 98,97 \\
\hline Pelobates cultripes & 31TCF11 & 34,00 & 169,20 & 87,21 & 36,55 & 5197,79 & 292,89 & 57,21 & 235,68 & 173,32 & 237,71 & 239,98 & 110,73 & 549,23 & 87,16 & 14,00 & 42,80 & 215,45 & 87,46 & 125,54 & 98,16 \\
\hline Pelobates cultripes & 31 TCF20 & & & & & & & & & & & & & & & & & & & & \\
\hline Pelobates cultripes & 31 TCF35 & 101,00 & 157,66 & 81,96 & 34,79 & 32,40 & 281,05 & 48,75 & 232,30 & 166,51 & \begin{tabular}{|l|l|}
109,39 \\
\end{tabular} & 228,96 & 93,82 & \begin{tabular}{l|l|}
557,55 \\
\end{tabular} & 78,55 & 17,36 & 35,67 & 201,06 & 100,08 & 130,69 & 109,36 \\
\hline Pelobates cultripes & 31 TCF38 & 101,00 & 130,78 & 89,58 & 34,95 & 5816,48 & 269,14 & 16,21 & 252,92 & 138,87 & 64,10 & 207,49 & 59,81 & 621,44 & 70,68 & 26,14 & \begin{tabular}{l|l|}
26,05 \\
\end{tabular} & 190,56 & \begin{tabular}{|l|}
122,19 \\
\end{tabular} & 141,97 & 122,21 \\
\hline Pelobates cultripes & 31 TCF56 & 101,00 & 155 & 74,55 & 33,22 & 5207,45 & 272,43 & 52,23 & 220,20 & 166,81 & \begin{tabular}{ll|l}
167,68 \\
\end{tabular} & 224,6 & 92,09 & 566,00 & 74,36 & 19,01 & 32, & \begin{tabular}{|l|l|}
197,41 \\
\end{tabular} & \begin{tabular}{|l|}
104,13 \\
\end{tabular} & 134,60 & 119,22 \\
\hline Pelobates cultripes & 31TCF65 & 46,00 & 162,50 & 71,04 & 33,00 & 5050,68 & 274,52 & 62,36 & 212,16 & \begin{tabular}{l|l|}
175,04 \\
\end{tabular} & \begin{tabular}{ll|l}
227,02 \\
\end{tabular} & $\begin{array}{l}230,05 \\
\end{array}$ & \begin{tabular}{ll|}
101,48 \\
\end{tabular} & 558,36 & 77,79 & 18,38 & 34,71 & 201,48 & \begin{tabular}{l|l|}
99,46 \\
\end{tabular} & 134,50 & 120,18 \\
\hline Pelobates cultripes & \begin{tabular}{|l|}
31 TCF76 \\
\end{tabular} & 100,00 & 158,41 & 71,91 & 32,99 & 5151,24 & 272,81 & 57,54 & 215,27 & 170,21 & \begin{tabular}{|l|l|}
224,63 \\
\end{tabular} & 227,14 & 96,04 & 582,02 & 79,99 & 21,60 & 31,08 & 204,76 & 108,70 & 139,79 & 120,42 \\
\hline Pelobates cultripes & 31TCF86 & 91,00 & 159,65 & 71,41 & 32,97 & 5147,19 & 273,63 & 59,16 & 214,47 & 171,28 & 226,06 & 228,23 & 97, & 592,90 & 83,01 & 22,78 & 30,74 & 209,33 & 111,23 & 142,36 & 121,67 \\
\hline Pelobates cultripes & 31TCF87 & 99,00 & 154 & 72,64 & 32,94 & 5250 & 271,23 & 52, & 218,40 & 165,66 & 222,41 & 224,40 & 90,97 & 606,20 & 80,03 & 24,43 & 28,57 & 207,34 & 117,39 & 145,62 & 122,55 \\
\hline Pelobates cultripes & \begin{tabular}{|l|l|}
31 TCF99 \\
\end{tabular} & 100,00 & 150,56 & 74,29 & 32,61 & 5400,68 & 271,62 & 46,79 & 224,84 & 161,05 & 84,77 & 222,03 & 84,77 & \begin{tabular}{|l|l|}
616,26 \\
\end{tabular} & \begin{tabular}{|l|l|}
74,95 \\
\end{tabular} & 28,32 & 26,30 & 201,81 & $\begin{array}{ll}118,82 \\
\end{array}$ & 152,44 & 118,82 \\
\hline Pelobates cultripes & 31TCG00 & 101,00 & 150,62 & 112,15 & 37,00 & 6602,27 & 315,20 & 15,70 & 299,50 & 178,15 & 76,80 & 235,19 & 66,23 & 437,61 & 53,96 & 20,16 & 29,04 & \begin{tabular}{ll|}
142,76 \\
\end{tabular} & 77,21 & 101,21 & 77,22 \\
\hline Pelobates cultripes & 31TCG03 & 100,00 & 131,63 & 107,10 & \begin{tabular}{|c|}
36,88 \\
\end{tabular} & 6366,07 & 290 & 2,8 & 287,50 & $156, \varepsilon$ & 50,46 & 213,46 & \begin{tabular}{ll|}
50,46 \\
\end{tabular} & 551,20 & 66,24 & 28,90 & 24,4 & 177,22 & 100,41 & 137,19 & 100,41 \\
\hline Pelobates cultripes & $31 \mathrm{TCG}$ & 101,00 & 11 & 101 & 36 & 6139,49 & $2 / 0$ & $-4,6$ & 275 & 140 & 40, & 197. & 40, & 651,87 & 76,27 & 36,52 & 22, & 204,62 & 122,90 & 164,46 & 122 \\
\hline Pelobates cultripes & 31TCG05 & 101,00 & 113,19 & 100,43 & 36,55 & 6053,24 & 263,76 & \begin{tabular}{|l|}
$-7,62$ \\
\end{tabular} & \begin{tabular}{|l|l|}
271,38 \\
\end{tabular} & 135,18 & \begin{tabular}{|l|}
37,09 \\
\end{tabular} & 191,81 & 37,09 & 700,20 & 80,56 & 40,33 & 20,96 & 217,23 & 134,33 & 177,91 & 134,33 \\
\hline Pelobates cultripes & 31TCG10 & 100,00 & 148,09 & 106,57 & \begin{tabular}{l|l|}
36,55 \\
\end{tabular} & 6410,78 & 305,75 & \begin{tabular}{|l|l|}
17,94 \\
\end{tabular} & 287,81 & \begin{tabular}{l|l|l|l|l|}
173,48 \\
\end{tabular} & 74,81 & 230,39 & 66,60 & 474,01 & 56,88 & 22,27 & 28,30 & \begin{tabular}{|l|l|}
150,99 \\
\end{tabular} & 84,91 & $\begin{array}{ll}108,93 \\
\end{array}$ & 84,92 \\
\hline Pelobates cultripes & 31TCG12 & 101,00 & 145,60 & 108,07 & 36,81 & 6466,74 & 305,13 & \begin{tabular}{ll|}
14,48 \\
\end{tabular} & 290,65 & \begin{tabular}{|l|l|}
171,97 \\
\end{tabular} & \begin{tabular}{|l|l|l|}
62,63 \\
\end{tabular} & 228,31 & \begin{tabular}{ll|}
62,63 \\
\end{tabular} & 485,26 & 58,42 & 23,85 & 26,74 & \begin{tabular}{ll|}
156,84 \\
\end{tabular} & 85,61 & 118,50 & 85,61 \\
\hline Pelobate & $c G$ & 99, & 10 & & 35, & $5921, \mathrm{c}$ & & $-13,8$ & 261 & 121 & 28, & 179 & 28,49 & 793 & 90,01 & 46 & & 24 & 155,53 & 200,06 & 155 \\
\hline Pelobates cultripes & 31TCG22 & 100,00 & 144,19 & 102,99 & 36,11 & 6293,5 & 297, & \begin{tabular}{|l|l|l|}
17,28 \\
\end{tabular} & 280,26 & \begin{tabular}{|l|l|}
168,62 \\
\end{tabular} & 63,81 & 224,93 & 63,81 & 513,65 & $\begin{array}{ll}60,86 \\
\end{array}$ & 25,78 & 26,49 & \begin{tabular}{|l|l|}
163,31 \\
\end{tabular} & \begin{tabular}{|l|l}
90,99 \\
\end{tabular} & 125,23 & 90,99 \\
\hline Pelobates cultripes & 31TCG29 & 101,00 & 72,96 & 86,12 & \begin{tabular}{l|l|}
34,95 \\
\end{tabular} & 5607,02 & 209,42 & $-33,45$ & 242,88 & 88,30 & 7,88 & \begin{tabular}{|l|l|}
147,16 \\
\end{tabular} & 4,98 & 1052,25 & 113,75 & 67,49 & 15,78 & 309,17 & 223,17 & 259,37 & 223,46 \\
\hline
\end{tabular}




\begin{tabular}{|c|c|c|c|c|c|c|c|c|c|c|c|c|c|c|c|c|c|c|c|c|c|}
\hline TAXON & UTM & $\mathrm{km} 2$ & B101 & B102 & $\mathrm{BIO3}$ & B104 & B105 & B106 & B107 & B108 & B109 & BIO10 & B1011 & BIO12 & 81013 & BIO14 & BIO15 & B1016 & B1017 & B1018 & B1019 \\
\hline Pelobates cultripes & 31TCG31 & 101,00 & 144,05 & 96,82 & 35,74 & 6086,38 & 289,93 & 21,95 & 267,99 & 166,11 & 67,02 & 222,39 & 67,02 & 533,50 & 62,27 & 26,14 & 26,87 & 165,44 & 95,64 & 127,96 & 95,64 \\
\hline Pelobates cultripes & 31TCG33 & 100,00 & 136,32 & 97,96 & 35,89 & 6125,76 & 284,35 & 14,07 & 270,28 & 158,88 & 58,65 & 215,15 & 58,65 & 578,41 & 67,94 & 30,14 & 25,21 & 182,78 & 102,51 & 146,70 & 102,51 \\
\hline Pelobates cultripes & 31TCG34 & 100,00 & 126,66 & 96,48 & 35,73 & 6057,52 & 273,47 & 6,68 & 266,79 & 148,22 & 50,25 & 204,90 & 50,25 & 646,01 & 75,22 & 34,60 & 23,94 & 203,36 & 116,24 & 168,70 & 116,24 \\
\hline Pelobates cultripes & 31TCG41 & 100,00 & 139,26 & 91,73 & 35,06 & 5936,46 & 279,99 & 21,87 & 258,12 & 159,79 & 64,88 & 216,22 & 64,88 & 575,31 & 66,70 & 28,43 & 26,16 & 176,43 & 103,80 & 140,88 & 103,80 \\
\hline Pelobates cultripes & 31TCG42 & 99,00 & 138,89 & 93,20 & \begin{tabular}{|l|}
35,08 \\
\end{tabular} & 5983,99 & 281,33 & 20,20 & 261,13 & 159,89 & 63,45 & 216,18 & 63,45 & 577,85 & 67,41 & 30,03 & 25,98 & 179,55 & 102,43 & 144,34 & 102,43 \\
\hline Pelobates cultripes & 31TCG45 & 101,00 & 114,29 & 91,50 & 35,01 & 5901,49 & 256,68 & $-0,45$ & 257,13 & 133,68 & 40,92 & 191,16 & 40,92 & 741,55 & 85,76 & 39,78 & 23,26 & 232,24 & 134,15 & 198,86 & 134,15 \\
\hline Pelobates cultripes & 31TCG51 & 100,00 & 132,65 & 87,34 & 34,39 & 5814,95 & 269,45 & 19,29 & 250,15 & 151,20 & 60,71 & 208,69 & 60,71 & \begin{tabular}{|l|l|}
628,48 \\
\end{tabular} & 72,75 & 32,14 & 25,29 & 191,25 & 113,97 & 156,53 & 113,97 \\
\hline Pelobates cultripes & 31TCG55 & 100,00 & 122,96 & 90,48 & 34,96 & 5889,88 & 263,85 & 7,80 & 256,05 & 142,53 & 49,29 & $\begin{array}{l}199,42 \\
\end{array}$ & 49,29 & 693,17 & 81,14 & 35,47 & 25,08 & 219,27 & 120,52 & 189,14 & 120,52 \\
\hline Pelobates cultripes & 31TCG56 & 100,00 & 101,21 & 87,01 & 34,60 & 5759,90 & 239,94 & $-8,37$ & 248,31 & 118,44 & 30,82 & 177,04 & 30,82 & 836,70 & 95,76 & 46,51 & 21,94 & 258,07 & 156,10 & 221,74 & 156,10 \\
\hline Pelobates cultripes & 31TCG59 & 101,00 & 53,42 & 77,91 & \begin{tabular}{|l|l|}
33,18 \\
\end{tabular} & 5480,81 & 185,19 & $-46,43$ & 231,62 & 65,12 & 6,63 & 127,25 & $-10,71$ & 1162,71 & 125,42 & 76,56 & 14,33 & 334,58 & 253,12 & 273,89 & 255,58 \\
\hline Pelobates cultripes & 31TCG61 & 99,00 & 125,74 & 83,80 & 33,97 & 5727,71 & 259,95 & 15,87 & 244,08 & 143,41 & 55,75 & 201,19 & 55,75 & 683,17 & 78,92 & 35,98 & 24,29 & 206,36 & 124,60 & 171,33 & 124,60 \\
\hline Pelobates cultripes & 31TCG63 & 100,00 & 128,65 & 86,51 & 34,10 & 5808,17 & 265,45 & 16,13 & 249,32 & 147,04 & 56,57 & 204,41 & 56,57 & 667,53 & 78,55 & 33,57 & 25,63 & 208,33 & 115,35 & 175,76 & 115,35 \\
\hline Pelobates cultripes & 31TCG64 & 101,00 & 120,85 & 86,78 & 34,10 & 5815,49 & 258,77 & $\begin{array}{l}, 88 \\
8,88 \\
\end{array}$ & 249,89 & 139,11 & 48,99 & 196,76 & 48,99 & 712,98 & 84,27 & 35,55 & 25,45 & 224,98 & 122,59 & 192,38 & 122,59 \\
\hline Pelobates cultripes & 31TCG65 & 101,00 & 121,13 & 87,71 & 34,33 & 5831,24 & 259,73 & 8,37 & 251,36 & 139,89 & 48,66 & 197,02 & 48,66 & 711,34 & 84,13 & 35,08 & 25,96 & 226,18 & 120,89 & 196,85 & 120,89 \\
\hline Pelobates cultripes & 31TCG72 & 101,00 & 126,24 & 82,42 & 33,64 & 5699,56 & 259,27 & 17,33 & 241,95 & 142,78 & 56,45 & 201,25 & 56,45 & 699,37 & 81,27 & 35,29 & 24,88 & 212,50 & 122,24 & 180,40 & 122,24 \\
\hline Pelobates cultripes & 31TCG73 & 100,00 & 121,63 & 83,25 & 33,79 & 5723,55 & 256,15 & 12,41 & 243,74 & 138,51 & 51,61 & 196,92 & 51,61 & 720,62 & 85,22 & 35,85 & 25,23 & 224,42 & 124,60 & 191,02 & 124,60 \\
\hline Pelobates cultripes & 31TCG74 & 100,00 & 116,23 & 83,76 & 33,94 & 5734,19 & 251,71 & 7,01 & 244,69 & 133,10 & 46,16 & 191,64 & 46,16 & 752,23 & 89,30 & 37,21 & 25,30 & 236,62 & 129,29 & 203,23 & 129,29 \\
\hline Pelobates cultripes & 31TCG75 & 100,00 & 113,46 & 84,33 & 33,99 & 5744,27 & 249,75 & 4,17 & 245,58 & 130,70 & 43,18 & 188,87 & 43,18 & 767,56 & 90,93 & 38,16 & 25,40 & 242,60 & 131,87 & 211,41 & 131,87 \\
\hline Pelobates cultripes & 31TCG83 & 101,00 & 126,54 & 81,20 & \begin{tabular}{|l|l|}
33,17 \\
\end{tabular} & 5680,40 & 258,87 & 18,34 & 240,54 & 143,76 & 57,05 & 201,30 & 57,05 & 704,03 & 83,77 & 34,09 & 25,99 & 219,07 & 119,07 & 189,24 & 119,07 \\
\hline Pelobates cultripes & 31TCG84 & 101,00 & 127,57 & 82,38 & 33,35 & 5708,55 & 260,98 & 18,27 & 242,71 & 144,95 & 57,26 & 202,28 & 57,26 & 702,92 & 84,28 & 32,92 & 27,02 & 222,55 & 115,79 & 193,19 & 115,79 \\
\hline Pelobates cultripes & 31TCG90 & 101,00 & 136,36 & 75,89 & 32,62 & 5509,64 & 261,97 & 32,01 & 229,96 & 171,63 & 69,87 & 209,50 & 69,87 & 671,94 & 76,56 & 34,1 & 24,21 & 207,62 & 126,49 & 167,94 & 126,49 \\
\hline Pelobates cultripes & 31TCG92 & 100,00 & 140,33 & 78,33 & 32,96 & 5590,75 & 268,39 & 33,30 & 235,10 & 186,10 & 71,64 & 213,80 & 71,64 & 636,67 & 74,62 & 32,24 & 25,90 & 199,55 & 109,06 & 170,61 & 109,06 \\
\hline Pelobates cultripes & 31TCG95 & 101,00 & 111,81 & 80,22 & $\begin{array}{ll}33,02 \\
\end{array}$ & 5654,02 & 244,94 & 6,04 & 238,90 & 127,50 & 43,42 & 186,65 & 43,42 & 788,95 & 94,18 & 39,23 & 25,53 & 246,95 & 135,20 & 217,09 & 135,20 \\
\hline Pelobates cultripes & 31TCG96 & 101,00 & 83,33 & 77,80 & 32,93 & 5542,42 & 215,76 & $-16,57$ & 232,33 & 95,44 & 20,50 & 157,85 & 18,52 & 965,67 & 108,47 & 57,35 & 18,90 & 283,52 & 192,36 & 241,41 & 193,01 \\
\hline Pelobates cultripes & $31 \mathrm{TCH} 23$ & 101,00 & 39,35 & 77,48 & 33,21 & 5379,69 & 168,15 & $-61,19$ & 229,34 & 50,94 & 43,30 & 111,59 & $-24,16$ & 1278,98 & 134,37 & 86,22 & 12,74 & 363,34 & 286,52 & 294,29 & 297,12 \\
\hline Pelobates cultripes & 31TDF06 & 37,00 & 157,68 & 70,70 & 32,57 & 5176,48 & 272,55 & 58,09 & 214,45 & 168,68 & 224,93 & 226,84 & 95,61 & 632,00 & \begin{tabular}{|l|}
88,07 \\
\end{tabular} & 24,34 & 30,05 & 222,25 & 117,84 & 148,61 & 131,50 \\
\hline Pelobates cultripes & 31TDF07 & 100,00 & 148,43 & 71,25 & 32,08 & 5291,64 & 266,58 & 48,21 & 218,37 & $\begin{array}{l}159,33 \\
\end{array}$ & 217,47 & 219,19 & 85,31 & 668,64 & 85,49 & 27,15 & 27,00 & 223,53 & 127,41 & $\begin{array}{l}150,810 \\
155,86\end{array}$ & 139,43 \\
\hline Pelobates cultripes & 31TDF09 & 100,00 & 157,57 & 73,07 & 32,23 & 5337,48 & 276,76 & 54,45 & 222,32 & 168,05 & 93,54 & 228,09 & 92,38 & 597,40 & 76,89 & 27,83 & 27,82 & 201,93 & 114,38 & 150,33 & 114,39 \\
\hline Pelobates cultripes & 31TDF16 & & & & & & & & & & & & & & & & & & & & \\
\hline Pelobates cultripes & 31TDF17 & 101,00 & 160,92 & 70,50 & 32,28 & 5174,62 & 276,34 & 61,01 & 215,33 & 171,39 & 221,88 & 229,63 & 98,42 & 629,25 & 90,08 & 24,99 & 31,01 & 224,52 & 120,14 & 50,01 & 129,05 \\
\hline Pelobates cultripes & 31TDF27 & 85,00 & 166,22 & 70,16 & 32,17 & 5089,19 & 280,30 & 66,64 & 213,66 & 176,56 & 218,22 & 233,41 & 104,49 & 618,62 & 94,89 & 23,92 & 33,86 & 229,10 & 117,70 & 148,27 & 125,51 \\
\hline Pelobates cultripes & 31TDF28 & $\begin{array}{l}0,101,00 \\
100\end{array}$ & 158,99 & 70,16 & 31,69 & 5227,88 & 276,22 & $\begin{array}{l}0,04,85 \\
58,\end{array}$ & 217,37 & $\begin{array}{l}169,24 \\
\end{array}$ & 158,51 & \begin{tabular}{|l|}
228,43 \\
25,4
\end{tabular} & \begin{tabular}{|c|}
95,97 \\
95,40
\end{tabular} & $\begin{array}{l}626,99 \\
626\end{array}$ & 86,51 & 27,97 & 28,92 & 218,95 & 124,19 & $\begin{array}{l}150,21 \\
154,23 \\
\end{array}$ & 126,40 \\
\hline Pelobates cultripes & 31TDF29 & 101,00 & 159,89 & 70,96 & 31,86 & 5280,03 & 278,34 & 58,46 & 219,88 & 175,16 & 99,82 & 229,64 & 95,80 & \begin{tabular}{|l|l|}
601,07 \\
\end{tabular} & 80,09 & 29,35 & 28,43 & 206,58 & 115,70 & 153,82 & $\begin{array}{ll}116,03 \\
\end{array}$ \\
\hline Pelobates cultripes & 31TDF38 & 52,00 & 163,90 & 70,18 & \begin{tabular}{|l|l|}
32,17 \\
\end{tabular} & 5079,68 & 278,78 & 64,25 & 214,53 & 174,00 & 199,54 & 230,92 & 102,04 & 607,25 & 90,54 & 25,82 & 32,14 & 220,47 & 117.99 & 149,53 & 122,51 \\
\hline Pelobates cultripes & 31TDF39 & 99,00 & 159,05 & 70,45 & 31,72 & 5221,53 & 276,62 & 58,24 & 218,38 & 169,22 & 122,48 & 227,97 & 95,63 & 625,82 & 85,89 & 29,41 & 28,45 & 215,99 & 124,66 & 157,10 & 125,50 \\
\hline Pelobates cultripes & 31TDF49 & 74,00 & 155,34 & 69,84 & 31,34 & 5248,01 & 273,44 & 54,54 & 218,91 & 166,02 & 191,46 & 224,66 & 91,70 & 669,03 & 91,23 & 31,05 & 27,32 & 226,69 & 133,39 & 164,11 & 139,00 \\
\hline Pelobates cultripes & $\begin{array}{l}\text { 31TDF59 } \\
31 \text { Th }\end{array}$ & 14,00 & $\begin{array}{l}13,31,65 \\
161,65\end{array}$ & $\begin{array}{l}5,, 44 \\
69,94\end{array}$ & 31,41 & 5210,88 & 278,76 & $\begin{array}{ll}60,24 \\
60,4\end{array}$ & \begin{tabular}{|l|}
218,53 \\
\end{tabular} & \begin{tabular}{|l|l|}
$171,76<$ \\
\end{tabular} & 216,00 & 230,12 & $\begin{array}{l}91,10 \\
98,29\end{array}$ & $\begin{array}{l}6039,65 \\
649,65\end{array}$ & $\begin{array}{l}91,25 \\
96,41\end{array}$ & $\begin{array}{l}\mid 1,030 \\
27,29\end{array}$ & 30,94 & \begin{tabular}{|l|}
228,76 \\
22,7
\end{tabular} & \begin{tabular}{|l|}
121,53 \\
1235
\end{tabular} & \begin{tabular}{|l|}
155,41 \\
15,4
\end{tabular} & 138,59 \\
\hline Pelobates cultripes & 31TDG02 & 101,00 & 146,68 & 76,64 & 32,45 & 5543,49 & 272,71 & 40,25 & 232,46 & 195,43 & 78,39 & 219,41 & 78,39 & 612,12 & 72,23 & 31,38 & 26,17 & 196,17 & 103,62 & 166,15 & 103,62 \\
\hline Pelobates cultripes & 31TDG03 & 100,00 & 138,99 & 77,70 & 32,62 & 5595,96 & 267,33 & 32,06 & 235,27 & 185,64 & 70,21 & 212,47 & 70,21 & \begin{tabular}{|c|}
646,98 \\
\end{tabular} & 76,68 & 31,46 & 26,92 & 203,51 & $\begin{array}{l}105,68 \\
\end{array}$ & 179,85 & 105,68 \\
\hline Pelobates cultripes & 31TDG05 & 100,00 & 127,55 & 79,61 & 32,97 & 5659,60 & 259,13 & 19,95 & 239,18 & 144,45 & 58,10 & 201,78 & 58,10 & 706,09 & 86,06 & 32,36 & 28,71 & 225,31 & 111,86 & 203,49 & 111,86 \\
\hline Pelobates cultripes & 31TDG06 & 100,00 & 106,21 & 79,00 & 32, & 5609,13 & 238,65 & 2,26 & 236,39 & 121,23 & 39,69 & 180,73 & 38,92 & 829,94 & 97,73 & 43,36 & 24,43 & 255,93 & 147,61 & 225,40 & 147,75 \\
\hline 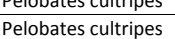 & $\begin{array}{l}\text { 31TDG10 } \\
31 \text { Do }\end{array}$ & 100,00 & $\begin{array}{l}10,21 \\
143,65\end{array}$ & $\frac{72,80}{72,82}$ & 31,4 & $\begin{array}{l}3000,15 \\
5436,23\end{array}$ & 263,03 & \begin{tabular}{|l|}
4,196 \\
41,19
\end{tabular} & \begin{tabular}{|l|}
225,27 \\
225
\end{tabular} & \begin{tabular}{|l|}
191,45 \\
191,40
\end{tabular} & $\begin{array}{l}35,, 59 \\
78,13\end{array}$ & $\mid \begin{array}{l}\mid 150,15 \\
215,81\end{array}$ & $\begin{array}{l}30,92 \\
78,13\end{array}$ & $\begin{array}{l}82,91,58 \\
661,58\end{array}$ & $\begin{array}{l}31,15 \\
76,92\end{array}$ & $\begin{array}{l}35,13 \\
35,13\end{array}$ & $\begin{array}{l}24,43 \\
24,4\end{array}$ & \begin{tabular}{|l|}
210,32 \\
21,35
\end{tabular} & \begin{tabular}{|l|}
$124,01,08$ \\
\end{tabular} & \begin{tabular}{|l|}
$253,40,04$ \\
170,0
\end{tabular} & $\begin{array}{l}14,, 13 \\
124,08\end{array}$ \\
\hline Pelobates cultripes & 31TDG11 & 100,00 & 130,92 & 73,96 & 32,00 & 5506,36 & 256,72 & 28,36 & 228,36 & 179,89 & 64,96 & 204,11 & 64,96 & 711,82 & 81,20 & 37,69 & 23,64 & 220,30 & 129,34 & 187,13 & 129,34 \\
\hline Pelobates cultripes & 31TDG12 & 101,00 & 138,82 & 74,97 & 31,99 & 5534,36 & 264,97 & 34,06 & 230,90 & 187,60 & 71,46 & 211,89 & 71,46 & 664,54 & 77,32 & 33,73 & 25,52 & 209,84 & 113,45 & 180,96 & 113,45 \\
\hline Pelobates cultripes & 31TDG15 & 101,00 & 123,04 & 77,90 & 32,4 & 5614,28 & 253,69 & 17,34 & 236,35 & 138,98 & 54,84 & 197,03 & 54,84 & 734,72 & 89,87 & 33,72 & 28,82 & 33,69 & 16,68 & 13,33 & 116,68 \\
\hline Pelobates cultripes & 31TDG16 & 100,00 & 109,61 & 78,14 & 32 & 5594,27 & 241,3 & $\begin{aligned} 5,940 \\
5,90\end{aligned}$ & 235,49 & \begin{tabular}{|l|}
124,73 \\
\end{tabular} & $\begin{array}{l}44,6468 \\
42,\end{array}$ & 183,93 & 42,52 & 816,30 & 97,07 & $\begin{array}{ll}41,02 \\
41,02\end{array}$ & 25,05 & \begin{tabular}{|l|l|}
253,79 \\
\end{tabular} & $\begin{array}{l}141,820 \\
\end{array}$ & 225,21 & 141,82 \\
\hline Pelobates cultripes & 31TDG20 & 100,00 & 152,94 & 71,68 & 31 & 5379,99 & 273,7 & 50,50 & 223,29 & 200,40 & 87,61 & 223,95 & 87,61 & 634,60 & 77,0 & 33,88 & 25,47 & 208,06 & 119,64 & 165,13 & 119,64 \\
\hline Pelobates cultripes & 31TDG22 & 99,00 & 125,49 & 73,69 & 31,92 & 5511,67 & 252,13 & 23,39 & 228,73 & 174,44 & 59,73 & \begin{tabular}{|l|l|}
198,87 \\
\end{tabular} & 59,73 & 746,68 & 87,10 & 38,10 & 23,96 & 229,79 & 133,40 & 201,19 & 133,40 \\
\hline Pelobates cultripes & 31TDG23 & 101,00 & 120,63 & 74,58 & 32,00 & 5523,95 & 248,55 & 18,30 & 230,24 & 167,35 & 54,73 & 194,10 & 54,73 & 769,68 & 90,82 & 38,58 & 24,64 & 234,97 & 134,90 & 209,82 & 134,90 \\
\hline Pelobates cultripes & 31TDG24 & 100,00 & 126,73 & 75,58 & 32,00 & 5574,07 & 255,26 & 22,19 & 233,07 & 149 & 59,32 & 200,34 & 59,32 & 739,43 & 89,01 & 0,7 & 27,42 & 37 & 121,26 & 10,88 & 121,26 \\
\hline Pelobates cultripes & 31TDG25 & 100,00 & 12 & 76 & $\begin{array}{ll}32, \\
32,\end{array}$ & 5584,37 & 250,2 & \begin{tabular}{|l|l|}
15,99 \\
\end{tabular} & \begin{tabular}{|l|}
234,26 \\
\end{tabular} & \begin{tabular}{|l|}
$135,76,7$ \\
\end{tabular} & $\begin{array}{l}53,10 \\
53,1\end{array}$ & \begin{tabular}{|l|}
194,30 \\
\end{tabular} & 53,10 & $\begin{array}{l}7730,45 \\
770,56\end{array}$ & $\begin{array}{l}93,01 \\
92,84\end{array}$ & $\begin{array}{l}34,1 / 1 \\
36,19\end{array}$ & 27,23 & $\mid \begin{array}{l}\mid 50,31,75 \\
241,75\end{array}$ & $\begin{array}{l}127,33 \\
127\end{array}$ & \begin{tabular}{|l|}
219,720 \\
\end{tabular} & $\begin{array}{l}121,20 \\
127,33\end{array}$ \\
\hline Pelobates cultripes & 31TDG26 & 101,00 & 110,29 & 77,01 & 32,33 & 5569,27 & 241,08 & 7,03 & 234,05 & 124,80 & 43,82 & 184,24 & 43,67 & 832,47 & 97,84 & 42,19 & 24,08 & 256,10 & 147,86 & 225,80 & 147,86 \\
\hline Pelobates cultripes & 31TDG27 & 101,00 & 99,41 & 77,17 & 32,82 & 5532,74 & 230,85 & $-1,67$ & 232,51 & 113,10 & 36,06 & 173,24 & 34,05 & 897,92 & 102,41 & 49,96 & 20,58 & 268,64 & 171,64 & 232.58 & 171,86 \\
\hline Pelobates cultripes & 31TDG30 & 100,00 & 157,83 & 71,01 & 31,53 & 5300,33 & 277,10 & 55,68 & 221,42 & 197,57 & 96,21 & 227,47 & 93,06 & \begin{tabular}{|c|}
632,38 \\
\end{tabular} & 82,25 & 31,86 & 26,59 & 212,42 & 124,07 & 160,28 & 124,09 \\
\hline Pelobates cultripes & 31TDG31 & 101,00 & 144,71 & 71,51 & $31, \mathrm{C}$ & 5430,91 & 267,32 & 42,09 & 225,23 & 192,77 & 78,92 & 216,44 & 78 & 701,68 & 81,71 & 38,45 & 23,28 & 223,49 & 133,61 & 182,06 & 133 \\
\hline Pelobates cultripes & 31TDG32 & 101,00 & 126,55 & 72,56 & 31,49 & 5485,82 & 252,29 & 24,87 & 227,42 & 175,21 & 61,18 & 199,62 & 61,18 & 777,76 & 87,68 & 41,15 & 22,50 & 238,41 & $\begin{array}{l}144,73 \\
\end{array}$ & 204,14 & 144,73 \\
\hline Pelobates cultripes & 31TDG33 & 100,00 & 127,01 & 73,42 & 31,53 & 5519,44 & 253,66 & 24,32 & 229,34 & 175,75 & 60,87 & 200,29 & 60,87 & 774,75 & 89,25 & 39,24 & 23,82 & 237,88 & 138,84 & 209,39 & 138,84 \\
\hline Pelobates cultripes & 31TDG34 & 101,00 & 129,94 & 74,44 & 31,72 & 5552,03 & 257,43 & 25,65 & 231,78 & 165,59 & 62,72 & 203,31 & 62,72 & 768,28 & 89,48 & 36,97 & 25,35 & 236,62 & 132,24 & 212,86 & 132,24 \\
\hline Pelobates cultripes & 31TDG35 & 100,00 & 124,92 & 75,47 & 31,97 & 5577,89 & 253,79 & 20,32 & 233,47 & 140,55 & 57, & 198, & 57 & 794,52 & 92,92 & 37,77 & 25,36 & 245,58 & 137,07 & 218,86 & 137,07 \\
\hline Pelobates cultripes & 31TDG36 & 100,00 & 114,79 & 76,19 & 32,08 & 5563,09 & 244,76 & 11,45 & 233,31 & 130,09 & 48,35 & 188,44 & 48,04 & 837,99 & $\mid 96,99$ & 42,20 & 23,51 & 256,19 & 151,28 & 225,56 & 151,35 \\
\hline
\end{tabular}




\begin{tabular}{|c|c|c|c|c|c|c|c|c|c|c|c|c|c|c|c|c|c|c|c|c|c|}
\hline TAXON & UTM & $\mathrm{km} 2$ & BIO1 & B102 & $B 103$ & BIO4 & B105 & B106 & B107 & B108 & B109 & B1010 & BIO11 & B1012 & BIO13 & B1014 & BIO15 & B1016 & B1017 & B1018 & 81019 \\
\hline Pelobates cultripes & 31TDG40 & 101,00 & 153,92 & 70,08 & 31,02 & 5322,70 & 273,35 & 51,94 & 221,41 & 184,27 & 153,09 & 224,08 & 89,16 & 686,11 & 89,72 & 33,67 & 25,24 & 226,52 & 139,44 & 169,65 & 141,06 \\
\hline Pelobates cultripes & 31TDG41 & 100,00 & 143,57 & 70,61 & 31,01 & 5418,05 & 265,73 & 41,25 & 224,47 & 191,17 & 83,61 & 215,19 & 78,09 & 744,65 & 88,99 & 40,05 & 22,43 & 234,86 & 148,77 & 186,25 & 148,81 \\
\hline Pelobates cultripes & 31TDG42 & 100,00 & 113,04 & 71,73 & 31,59 & 5434,21 & 238,94 & 14,74 & 224,20 & 152,19 & 57,00 & \begin{tabular}{|l|l|}
186,19 \\
\end{tabular} & 49,79 & \begin{tabular}{ll|l}
869,95 \\
\end{tabular} & 97,70 & \begin{tabular}{ll|l|}
48,67 \\
\end{tabular} & 20,16 & 260,21 & $\begin{array}{l}174,95 \\
\end{array}$ & 213,02 & 175,78 \\
\hline Pelobates cultripes & 31TDG43 & 101,00 & 120,79 & 72,53 & 31,36 & 5480,88 & 247,16 & 19,81 & 227,36 & 168,24 & 56,24 & $\begin{array}{l}193,96 \\
\end{array}$ & 55,80 & 841,38 & 93,61 & 44,30 & 21,43 & 251,91 & 161,19 & 215,44 & 161,25 \\
\hline Pelobates cultripes & 31TDG44 & 101,00 & 130,89 & 73,43 & $31,21 \mid$ & 5539,31 & 257,59 & $26,91 \mid$ & 230,68 & 168,05 & 63,87 & 204,03 & 63,87 & 819,11 & 91,15 & 40,15 & 22,82 & 246,08 & 151,03 & 214,89 & 151,03 \\
\hline Pelobates cultripes & 31TDG45 & 100,00 & 123,43 & 74,48 & 31,81 & 5541,19 & 251,55 & 19,82 & 231,73 & 138,59 & 56,68 & 196,77 & 56,65 & 844,31 & 94,95 & 41,38 & 22,77 & 254,73 & 155,64 & 222,07 & 155,64 \\
\hline Pelobates cultripes & 31TDG46 & 101,00 & 98,81 & 74,53 & 32,16 & 5461,29 & 227,98 & 0,29 & 227,69 & 123,23 & 38,16 & 172,11 & 35,25 & 935,05 & 102,41 & 54,20 & 18,70 & 269,63 & 188,71 & 229,59 & 189,68 \\
\hline Pelobates cultripes & 31TDG50 & 100,00 & 149,07 & 69,41 & 30,93 & 5340,44 & 268,83 & 47,51 & 221,32 & 172,34 & 184,93 & 219,62 & 84,45 & \begin{tabular}{|l|l|}
739,98 \\
\end{tabular} & 97,36 & 35,59 & 24,90 & 240,67 & 149,22 & \begin{tabular}{|c|}
177,14 \\
\end{tabular} & 156,74 \\
\hline Pelobates cultripes & 31TDG51 & 100,00 & 150,52 & 69,89 & 30,82 & 5412,19 & 271,39 & 47,10 & 224,29 & 175,65 & 190,74 & 221,70 & 84,58 & $\begin{array}{l}751,99 \\
\end{array}$ & $\begin{array}{l}97,13 \\
\end{array}$ & 37,05 & 23,69 & 241,22 & 152,85 & $\begin{array}{l}178,44 \\
\end{array}$ & 159,64 \\
\hline Pelobates cultripes & 31TDG52 & 100,00 & 121,05 & 70,84 & 31,14 & 5416,66 & 245,56 & 21,77 & 223,79 & \begin{tabular}{ll|}
158,67 \\
\end{tabular} & 73,56 & \begin{tabular}{|l|}
193,60 \\
\end{tabular} & 57,38 & 871,94 & 101,31 & 48,10 & 20,27 & 261,90 & 179,63 & 207,94 & 181,17 \\
\hline Pelobates cultripes & 31TDG53 & 101,00 & 120,29 & 71,75 & 31,31 & $\begin{array}{l}5454,72 \\
\end{array}$ & 245,94 & 19,90 & 226,03 & 168,79 & 56,34 & 193,21 & 55,81 & 879,46 & 97,58 & 47,86 & 20,11 & 259,23 & \begin{tabular}{ll|}
176,63 \\
\end{tabular} & 214,88 & 176,63 \\
\hline Pelobates cultripes & 31TDG56 & 101,00 & 126,48 & 74,94 & 31,73 & $\begin{array}{l}5552,87 \\
\end{array}$ & 254,68 & 21,49 & 233,19 & 143,13 & 59,32 & $\begin{array}{l}199,65 \\
\end{array}$ & 59,17 & 878,35 & 94,59 & 43,36 & 21,32 & 261,01 & $\begin{array}{l}171,38 \\
\end{array}$ & 218,56 & 171,39 \\
\hline Pelobates cultripes & 31TDG61 & 101,00 & 146,85 & 69,27 & 30,42 & 5401,26 & 267,46 & 44,08 & 223,38 & 169,79 & 194,63 & 218,05 & 81,26 & 781,72 & 103,63 & 37,41 & 24,57 & 249,46 & $\begin{array}{l}157,06 \\
\end{array}$ & 180,94 & 168,79 \\
\hline Pelobates cultripes & 31TDG62 & 101,00 & 149,18 & $\begin{array}{ll}69,89 \\
\end{array}$ & 30,11 & 5469,89 & 270,71 & 44,27 & 226,44 & 175,51 & 190,11 & 220,84 & 82,05 & 782,31 & \begin{tabular}{|l|l|}
103,47 \\
\end{tabular} & 38,13 & 24,38 & 247,74 & 157,19 & $\begin{array}{l}178,56 \\
\end{array}$ & 168,20 \\
\hline Pelobates cultripes & 31TDG63 & 100,00 & 134,37 & 70,82 & 30,71 & 5472,86 & 258,25 & 31,14 & 227,11 & 182,29 & 82,49 & 206,82 & 68,42 & 864,54 & $\begin{array}{l}102,08 \\
\end{array}$ & 45,97 & 21,14 & 257,04 & $\begin{array}{ll}178,28 \\
\end{array}$ & 202,84 & 178,94 \\
\hline Pelobates cultripes & 31TDG66 & 101,00 & 128,84 & 74,49 & 31,64 & 5531,15 & 256,26 & 23,76 & 232,50 & $\begin{array}{l}153,06 \\
\end{array}$ & 61,83 & 201,77 & 61,83 & $\begin{array}{l}877,56 \\
\end{array}$ & 97,45 & 45,15 & 20,81 & 255,27 & $\begin{array}{l}177,86 \\
\end{array}$ & 209,00 & 177,86 \\
\hline Pelobates cultripes & 31TDG67 & 100,00 & 137,40 & 76,11 & 31,80 & 5580,44 & $\begin{array}{l}265,66 \\
\end{array}$ & 29,24 & 236,41 & $\begin{array}{l}175,68 \\
\end{array}$ & 68,76 & 210,45 & 68,73 & 808,42 & 94,24 & \begin{tabular}{ll|}
42,97 \\
\end{tabular} & 21,05 & 236,38 & 165,84 & 188,53 & 165,85 \\
\hline Pelobates cultripes & 31TDG70 & & & & & & & & & & & & & & & & & & & & \\
\hline Pelobates cultripes & 31TDG71 & 99,00 & 156,87 & 69,51 & 30,60 & 5364,56 & 275,70 & 52,56 & 223,14 & 167,35 & 224,72 & 227,13 & $\begin{array}{l}90,86 \\
\end{array}$ & \begin{tabular}{ll|l}
711,45 \\
\end{tabular} & 107,54 & 29,23 & 30,94 & 243,24 & 129,62 & 160,29 & 156,59 \\
\hline Pelobates cultripes & 31TDG72 & 101,00 & 154,90 & 69,47 & 30,09 & 5459,06 & 275,20 & $\begin{array}{ll}48,78 \\
\end{array}$ & 226,42 & 165,21 & 225,52 & 226,12 & 87,35 & 736,21 & 108,20 & 31,73 & 28,88 & 244,81 & 137,61 & 161,82 & 162,07 \\
\hline Pelobates cultripes & 31TDG73 & 100,00 & 151,59 & 69,54 & $\begin{array}{l}29,97 \\
2\end{array}$ & 5553,31 & $\begin{array}{l}273,66 \\
\end{array}$ & 44,30 & 229,36 & 165,46 & 222,68 & 223,75 & 82,63 & 769,42 & 108,47 & 35,29 & 26,44 & 246,62 & 149,64 & 161,79 & 168,62 \\
\hline Pelobates cultripes & 31TDG75 & 101,00 & 138,71 & 72,55 & 30,92 & 5523,73 & 263,75 & 32,51 & 231,24 & 182,50 & 104,51 & 211,21 & 71,13 & $\begin{array}{l}832,95 \\
\end{array}$ & \begin{tabular}{|l|l|}
103,27 \\
\end{tabular} & 43,47 & 22,28 & 247,40 & $\begin{array}{l}173,37 \\
\end{array}$ & $\begin{array}{l}186,58 \\
\end{array}$ & 174,80 \\
\hline Pelobates cultripes & 31TDG76 & 100,00 & 143,13 & 74,41 & 31,20 & 5552,16 & 269,17 & 35,16 & 234,01 & 185,68 & 111,35 & 215,67 & 74,65 & 784,79 & 99,79 & 41,08 & 22,69 & 235,03 & 163,83 & 173,85 & 164,27 \\
\hline Pelobates cultripes & 31TDG77 & 100,00 & 138,85 & 75,89 & \begin{tabular}{l|l|l|}
31,95 \\
\end{tabular} & 5538,66 & 266,13 & 30,97 & 235,15 & 177,79 & 103,96 & 211,36 & 70,83 & \begin{tabular}{|l|l|}
782,67 \\
\end{tabular} & 97,23 & 41,56 & 21,97 & 231,89 & 164,30 & 174,28 & 164,77 \\
\hline Pelobates cultripes & 31TDG81 & 58,00 & 156,33 & $\begin{array}{ll}69,67 \\
\end{array}$ & 30,77 & 5324,65 & 274,68 & 52,23 & 222,45 & 166,76 & 221,85 & 226,11 & 91,01 & 700,06 & 108,3 & 27,85 & 32,13 & 241,39 & 125,74 & 155,80 & 153,82 \\
\hline Pelobates cultripes & 31TDG83 & 101,00 & 152,89 & 69,74 & 30,10 & 5483,13 & 273,79 & 46,21 & 227,58 & 163,03 & 223,94 & 224,33 & 85,14 & 738,58 & 109,55 & 31,46 & 29,01 & 243,75 & 137,25 & 159,43 & 163,03 \\
\hline Pelobates cultripes & 31TDG84 & 101,00 & 151,60 & 71,06 & \begin{tabular}{l|l|}
30,56 \\
\end{tabular} & 5502,87 & 273,56 & 44,03 & 229,53 & 161,75 & 222,87 & 223,26 & 83,40 & \begin{tabular}{|l|l|}
745,99 \\
\end{tabular} & \begin{tabular}{|l|l|}
107,99 \\
\end{tabular} & 33,42 & 27,63 & 240,70 & $\begin{array}{l}143,15 \\
\end{array}$ & $\begin{array}{l}156,73 \\
\end{array}$ & 162,27 \\
\hline Pelobates cultripes & 31TDG85 & 101,00 & 151,47 & 73,02 & 31,16 & 5489,76 & 274,51 & 43,28 & 231,23 & $\begin{array}{l}163,92 \\
\end{array}$ & 222,63 & 222,94 & 83,53 & $\begin{array}{l}727,58 \\
\end{array}$ & $\begin{array}{l}104,06 \\
\end{array}$ & 33,71 & 26,96 & 232,38 & $\begin{array}{l}143,45 \\
\end{array}$ & 154,74 & 155,45 \\
\hline Pelobates cultripes & 31TDG86 & 100,00 & 150,17 & 74,92 & 31,76 & 5484,51 & 274,44 & 41,47 & 232,96 & 160,93 & 221,32 & 221,62 & 82,25 & 708,14 & 99,79 & 33,60 & 26,14 & 224,22 & 142,91 & 150,56 & 149,80 \\
\hline Pelobates cultripes & 31TDG87 & 101,00 & 149,24 & 76,75 & 32,16 & 5487,27 & 274,86 & 39,84 & 235,02 & 160,05 & 216,56 & 220,80 & 81,28 & 689,46 & 96,19 & 32,82 & 25,71 & 217,65 & 140,02 & 146,09 & 146,16 \\
\hline Pelobates cultripes & 31TDG88 & 100,00 & 145,31 & 78,30 & 32,55 & 5499,28 & 272,62 & 35,72 & 236,90 & 157,99 & 205,09 & 217,05 & 77,44 & $\begin{array}{l}700,65 \\
\end{array}$ & 94,38 & 33,65 & 24,44 & 217,15 & 142,92 & \begin{tabular}{|l|l|}
147,29 \\
\end{tabular} & 151,21 \\
\hline Pelobates cultripes & 31TDG89 & 82,00 & 138,88 & 79,63 & 32,99 & 5506,15 & 267,94 & 29,75 & 238,19 & 152,98 & 186,80 & 211,01 & 71,29 & 724,75 & 93,55 & 35,45 & 22,99 & 219,97 & \begin{tabular}{|l|l|}
148,58 \\
\end{tabular} & \begin{tabular}{ll|}
152,88 \\
\end{tabular} & 159,90 \\
\hline Pelobates cultripes & 31TDG92 & 90,00 & 150,89 & 70,44 & 31,30 & 5265,40 & 268,98 & 47,70 & 221,29 & 161,82 & 218,54 & 220,26 & 86,91 & \begin{tabular}{ll|}
712,95 \\
\end{tabular} & $\begin{array}{l}106,85 \\
\end{array}$ & 28,68 & 30,50 & 240,38 & 130,56 & $\begin{array}{l}156,86 \\
\end{array}$ & 156,52 \\
\hline Pelobates cultripes & 31TDG93 & 101,00 & 149,48 & 71,06 & 31,22 & 5302,24 & 268,45 & 45,39 & 223,06 & 160,19 & 218,27 & 219,19 & 84,88 & 722,41 & $\begin{array}{l}106,15 \\
\end{array}$ & 30,10 & 29,09 & 238,99 & 135,13 & 158,25 & 157,90 \\
\hline Pelobates cultripes & 31TDG94 & 101,00 & 148,97 & 72,30 & \begin{tabular}{|l|l|}
31,68 \\
\end{tabular} & 5318,50 & 269,01 & 43,99 & 225,02 & 159,60 & 218,08 & 218,93 & 84,16 & 721,56 & 104,28 & 31,32 & 28,05 & 234,82 & 138,13 & 157,69 & 156,27 \\
\hline Pelobates cultripes & 31TDG96 & 101,00 & 154,32 & 76,03 & 32,57 & \begin{tabular}{|l|}
5354,37 \\
\end{tabular} & 276,69 & 46,32 & 230,38 & $\begin{array}{l}164,47 \\
\end{array}$ & 223,78 & 224,28 & 88,29 & \begin{tabular}{ll|}
645,72 \\
\end{tabular} & 96,88 & 27,87 & 29,30 & 214,89 & \begin{tabular}{ll|}
123,38 \\
\end{tabular} & $\begin{array}{l}138,33 \\
\end{array}$ & 136,76 \\
\hline Pelobates cultripes & 31TDG98 & 101,00 & 154,16 & 79,68 & 33,31 & 5404,67 & 279,85 & 43,98 & 235,87 & 163,77 & 224,38 & 224,69 & 87,42 & \begin{tabular}{|c|}
614,88 \\
\end{tabular} & 91,59 & 25,70 & 28,95 & 205,24 & \begin{tabular}{|l|l|}
114,78 \\
\end{tabular} & 123,02 & 133,82 \\
\hline Pelobates cultripes & 31TDG99 & 101,00 & 144,56 & 80,52 & 33,46 & 5443,28 & 272,35 & 34,86 & 237,48 & 151,97 & 215,52 & 215,81 & 77,70 & 669,90 & 92,67 & 29,61 & 25,82 & 213,72 & 128,84 & 135,24 & 149,82 \\
\hline Pelobates cultripes & 31TEG04 & 100,00 & 156,39 & 74,26 & 33,10 & 5126,21 & 273,5 & 52,28 & 221,25 & 167,27 & 222,84 & 223,95 & 94,16 & 632,72 & 98,18 & 23,59 & 32,44 & 19,16 & 12,16 & 137,79 & 137,12 \\
\hline Pelobates cultripes & 31TEG06 & 97,00 & 158,23 & 77,35 & 33,63 & 5215,84 & 278,52 & 51,12 & 227,39 & 168,48 & 225,83 & 226,54 & 94,18 & 597,79 & 93,37 & 22,87 & 32,11 & 207,20 & 107,21 & 128,67 & 128,37 \\
\hline Pelobates cultripes & 31TEG07 & 99,00 & 158,76 & 79,15 & 33,82 & 5266,93 & 280,93 & 50,05 & 230,89 & $\begin{array}{l}168,66 \\
\end{array}$ & \begin{tabular}{|l|}
227,07 \\
\end{tabular} & 227,46 & \begin{tabular}{ll|}
93,87 \\
\end{tabular} & $\begin{array}{l}582,46 \\
\end{array}$ & 91,29 & 22,05 & 32,32 & 202,72 & \begin{tabular}{|l|l|}
103,44 \\
\end{tabular} & $\begin{array}{l}119,33 \\
\end{array}$ & 126,14 \\
\hline Pelobates cultripes & 31TEG08 & 101,00 & 156,38 & 80,48 & 33,99 & 5305,64 & 280,52 & 46,90 & 233,62 & 166,31 & 225,23 & 225,66 & 90,90 & \begin{tabular}{|l|l}
587,55 \\
\end{tabular} & 90,46 & 22,33 & 31,40 & 202,46 & 103,81 & 119,66 & 129,73 \\
\hline Pelobates cultripes & 31TEG09 & 90,00 & 144,42 & 80,68 & 33,90 & 5361,71 & 271,10 & 35,65 & 235,45 & 153,62 & 214,34 & 214,71 & 78,84 & 656,66 & 92,80 & 27,31 & 27,12 & 213,79 & 121,92 & 133,07 & 148,59 \\
\hline Pelobates cultripes & 31TEG13 & 37,00 & 159,26 & 74,63 & 33,5 & 4974,95 & 273,6 & 56,92 & 216,76 & 170,61 & 210,58 & 225,08 & 99,42 & 587,89 & 94,26 & 19,53 & 35,63 & 11,92 & 00,21 & 130,21 & 126,39 \\
\hline Pelobates cultripes & 31TEG14 & 82,00 & 158 & 75,46 & 34 & 4968,86 & 273, & 55,60 & 217,57 & 169,46 & 218,00 & 223,94 & 98,45 & 581,97 & $92, \mathrm{C}$ & 19,95 & 34,63 & 207,98 & 101,27 & 129,57 & 123,84 \\
\hline Pelobates cultripes & 31TEG15 & 64,00 & 158 & 76,80 & 34, & \begin{tabular}{|l|}
5037,93 \\
\end{tabular} & 274,93 & 53,78 & 221,16 & 169,04 & 223,27 & 224,47 & 97,10 & 582,48 & 91,69 & 20,63 & 33,81 & 206,16 & \begin{tabular}{ll|}
102,02 \\
\end{tabular} & 127,89 & 124,51 \\
\hline Pelobates cultripes & 31TEG16 & 17,00 & 158,85 & 77,65 & 34,00 & \begin{tabular}{|l|}
5097,04 \\
\end{tabular} & 277,38 & 53,23 & 224,15 & 169,54 & 224,85 & 225,92 & $\begin{array}{l}96,69 \\
\end{array}$ & 576,65 & \begin{tabular}{|c|c|}
91,23 \\
\end{tabular} & $\mid 20,46$ & 33,62 & $\mid 204,23$ & \begin{tabular}{|c|}
100,58 \\
\end{tabular} & $\mid 125,35$ & 123,88 \\
\hline Pelobates cultripes & 31TEG18 & 92,00 & 150,02 & 80,18 & 34,19 & 5227,00 & 273,39 & 42,56 & 230,83 & 160,23 & 218,03 & 218,70 & 86,39 & 614,06 & 91,62 & 23,13 & 30,37 & 208,97 & 108,82 & 128,38 & 137,49 \\
\hline Pelodytes ibericus & 29SNB57 & 101,00 & 165,13 & 98,47 & 42,2 & 4481,33 & 299,41 & 69,77 & 229,64 & 119,95 & 221,66 & 226,18 & 111,69 & 554,76 & 85, & 1,99 & 64,53 & 250,30 & 21,91 & 22,56 & 242,74 \\
\hline Pelodytes ibericus & $29 \mathrm{SNE}$ & 100,00 & 167 & 98,91 & 42,36 & 4491,59 & 302 & 72,00 & 230,26 & 121,99 & 223,90 & 228,48 & 113,80 & 548,53 & 83,37 & 2,00 & 64,49 & 246,13 & 21,50 & 22,24 & 239,15 \\
\hline Pelodytes ibericus & 29SNB60 & 67,00 & 169,51 & 91,29 & \begin{tabular}{|l|l|l|l|l|}
42,87 \\
\end{tabular} & 4120,31 & 287,86 & 76,67 & 211,18 & 128,93 & 221,57 & 225,55 & 120,16 & 505,51 & 85,51 & 1,00 & 69,84 & 244,86 & 16,05 & 18,01 & 230,82 \\
\hline Pelodytes ibericus & 29SNB62 & 100,00 & 164,87 & 94,21 & \begin{tabular}{|l|l|}
42,18 &
\end{tabular} & 4299,61 & 290,15 & 70,25 & 219,91 & 122,35 & 219,43 & 223,56 & \begin{tabular}{|l|l|}
113,72 \\
\end{tabular} & 533,42 & 87,70 & 1,01 & 68,11 & 252,20 & 17,90 & \begin{tabular}{ll|l}
19,49 \\
\end{tabular} & 240,04 \\
\hline Pelodytes ibericus & 29SNB64 & 100,00 & 158,55 & 97,46 & 42,01 & 4485,71 & 291,07 & 62,47 & 228,60 & 114,12 & 215,45 & 219,80 & 105,29 & 576,21 & 91,25 & 1,79 & 65,55 & 263,75 & 21,95 & 23,02 & 254,29 \\
\hline Pelodytes ibericus & $29 \mathrm{SNBG}$ & 100,00 & 16 & 98,47 & & 4 & 296 & 65,55 & 230 & 117 & & 223 & 10 & 559,05 & 81, & 1,7 & 65,36 & 255,09 & 20,98 & 22,00 & 24 \\
\hline Pelodytes ibericus & 29SNB66 & 101,00 & 162,98 & 99,69 & 42,06 & 4555,55 & 299,11 & 66,03 & 233,08 & 117,41 & 220,63 & 225,06 & 108,82 & 559,86 & 86,75 & 1,99 & 64,56 & 253,15 & 21,71 & 22,47 & 245,11 \\
\hline Pelodytes ibericus & 29SNB67 & 100,00 & 165,05 & 100,68 & 42,10 & 4589,97 & 302,86 & 67,74 & 235,12 & 118,94 & 223,03 & 227,53 & 110,40 & 553,32 & 84,75 & 2,00 & 64,32 & 248,44 & 21,63 & 22,47 & 241,14 \\
\hline Pelodytes ibericus & 29SNB71 & 100,00 & 165,37 & 93,75 & \begin{tabular}{l|l}
42,25 \\
\end{tabular} & 4281,43 & 288,74 & 70,12 & 218,62 & 123,08 & 219,68 & 223,82 & 114,36 & 532,25 & 89,16 & 1,00 & 68,54 & 253,83 & 17,50 & $\begin{array}{ll}19,48 \\
\end{array}$ & 240,31 \\
\hline Pelodyte & 25 & 101,00 & & 95,96 & & 113, & 287. & 62, & & 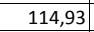 & & & & 571 & $92, \varepsilon \quad 2 \quad>$ & 1,49 & & 265 & 20,14 & 21,88 & 25 \\
\hline Pelodytes ibericus & 29SNB74 & 100,00 & 155,46 & 98,99 & 42,00 & 4582,57 & 290,88 & 57,98 & 232,90 & \begin{tabular}{|l|}
109,87 \\
\end{tabular} & $213,81]$ & 218,20 & 101,36 & \begin{tabular}{|l|l|}
595,08 \\
\end{tabular} & 93,54 & 2,00 & 64,75 & 269,91 & 23,20 & 24,36 & 260,62 \\
\hline Pelodytes ibericus & 29SNB75 & 101,00 & 159,78 & 100,28 & 42,00 & \begin{tabular}{|l|l|}
4621,93 \\
\end{tabular} & 297,04 & 61,54 & 235,50 & 113,35 & 218,43 & 222,83 & 105,05 & 572,95 & 89,41 & 2,00 & 64,65 & 259,20 & 22,04 & 23,10 & 250,47 \\
\hline
\end{tabular}




\begin{tabular}{|c|c|c|c|c|c|c|c|c|c|c|c|c|c|c|c|c|c|c|c|c|c|}
\hline TAXON & UTM & $\mathrm{km2}$ & B101 & $\mathrm{B1O2}$ & $\mathrm{BIO3}$ & $\mathrm{B104}$ & B105 & B106 & B107 & B108 & $\mathrm{BIO9}$ & 81010 & BIO11 & B1012 & BIO13 & 81014 & B1015 & B1O16 & B1017 & BIO18 & B1019 \\
\hline Pelodytes ibericus & 29SNB76 & 100,00 & 161,25 & 101,73 & 42,01 & 4676,71 & 301,01 & 62,32 & 238,69 & 114,21 & 220,53 & 224,98 & 105,82 & 567,53 & 87,48 & 2,00 & 63,97 & 254,77 & 22,03 & 23,01 & 247,03 \\
\hline Pelodytes ibericus & 29SNB77 & 101,00 & 162,11 & 103,12 & 42,01 & 4726,24 & 304,26 & 62,65 & 241,60 & 114,45 & 221,96 & 226,48 & 106,06 & 566,85 & 86,19 & 2,00 & 63,50 & 252,11 & 22,82 & 23,23 & 245,35 \\
\hline Pelodytes ibericus & 29 SNB78 & 100,00 & 163,24 & 104,39 & 42,08 & 4765,14 & 307,41 & 63,36 & 244,05 & 115,13 & 223,53 & 228,26 & 106,63 & 564,42 & 85,12 & 2,00 & 63,00 & 248,94 & 23,12 & 23,48 & 243,17 \\
\hline Pelodytes ibericus & 29SNB81 & 101,00 & 162,83 & 94,57 & 42,07 & 4366,06 & 287,94 & 66,33 & 221,61 & 119,65 & 218,25 & 222,48 & 111,04 & 548,10 & 91,22 & 1,09 & 67,97 & 259,42 & 18,07 & 20,46 & 245,71 \\
\hline Pelodytes ibericus & 29SNB82 & 101,00 & 157,12 & 96,63 & 41,94 & 4496,11 & 287,34 & 59,58 & 227,76 & 112,64 & 214,29 & 218,59 & 103,89 & 581,80 & 93,91 & 1,63 & 66,26 & 269,03 & 20,85 & 22,90 & 257,09 \\
\hline Pelodytes ibericus & 29SNB84 & 101,00 & 156,82 & 99,72 & 41,99 & 4649,05 & 293,62 & 58,02 & 235,60 & 110,58 & 215,99 & 220,47 & 101,90 & 587,33 & 91,97 & 2,00 & 64,52 & 265,77 & 22,60 & 24,20 & 255,97 \\
\hline Pelodytes ibericus & 29SNB85 & 101,00 & 160,15 & 101,33 & 42,00 & 4701,10 & 299,33 & 60,68 & 238,64 & 113,07 & 219,98 & 224,36 & 104,50 & 569,56 & 88,36 & 2,00 & 64,34 & 256,54 & 21,87 & 23,07 & 247,50 \\
\hline Pelodytes ibericus & \begin{tabular}{|l|}
$295 N B 86$ \\
\end{tabular} & 100,00 & 162,07 & 103,04 & 42,00 & 4757,32 & 303,96 & 61,80 & 242,16 & 114,11 & 222,48 & 226,92 & $\begin{array}{l}105,67 \\
\end{array}$ & 561,37 & 85,89 & 2,00 & 63,65 & 250,74 & 22,00 & 23,10 & 242,69 \\
\hline Pelodytes ibericus & 29SNB87 & 101,00 & 164,19 & 104,66 & 42,02 & 4802,14 & 308,43 & 63,30 & 245,14 & 115,60 & 225,09 & 229,45 & 107,14 & 552,20 & 83,83 & 2,00 & 63,11 & 244,63 & 22,16 & 23,00 & 237,50 \\
\hline Pelodytes ibericus & 29SNB89 & 100,00 & 165,90 & 107,83 & 42,29 & 4898,78 & 315,21 & 63,79 & 251,42 & 115,99 & 227,84 & 232,60 & 107,52 & 549,89 & 82,33 & 2,00 & 61,86 & 238,70 & 23,05 & 23,82 & 233,98 \\
\hline Pelodytes ibericus & 29SNB91 & 101,00 & 158,51 & 95,20 & 41,90 & 4472,75 & 285,95 & 60,85 & 225,10 & 114,12 & 215,32 & 219,49 & 105,46 & 573,59 & 93,32 & 1,59 & 66,76 & 267,24 & 19,59 & 22,46 & 253,81 \\
\hline Pelodytes ibericus & 29SNB92 & 100,00 & 150,90 & 97,38 & 41,39 & 4624,20 & 284,06 & 52,19 & 231,87 & 105,03 & 209,76 & 213,97 & 96,25 & 620,53 & 97,73 & 1,99 & 64,87 & 281,73 & 23,16 & 25,60 & 270,38 \\
\hline Pelodytes ibericus & 29SNB94 & 100,00 & 159,33 & 99,98 & 41,80 & 4709,88 & 296,68 & 59,39 & 237,29 & 112,16 & 219,24 & 223,63 & 103,63 & 571,80 & 89,02 & 2,00 & 64,30 & 258,27 & 21,49 & 23,73 & 247,61 \\
\hline Pelodytes ibericus & 29SNB95 & 100,00 & 162,10 & 101,68 & 41,85 & 4764,64 & 301,97 & 61,28 & 240,69 & 114,21 & 222,62 & 226,94 & 105,44 & 557,84 & 85,81 & 2,00 & 63,79 & 250,25 & 21,36 & 23,25 & 240,45 \\
\hline Pelodytes ibericus & 29SNB96 & 101,00 & 163,94 & 103,58 & 42,00 & 4820,32 & 306,60 & 62,39 & 244,21 & 115,39 & 225,06 & 229,47 & 106,53 & 548,79 & 83,65 & 2,00 & 63,29 & 244,15 & 21,60 & 23,07 & 235,36 \\
\hline Pelodytes ibericus & 29SNB97 & 100,00 & 164,92 & 105,55 & 42,00 & 4874,85 & 310,72 & 62,35 & 248,37 & 115,44 & 226,73 & 231,23 & 106,64 & 545,94 & 82,66 & 2,00 & 62,55 & 240,46 & 21,97 & 23,29 & 232,84 \\
\hline Pelodytes ibericus & 29SNB98 & 100,00 & 166,44 & 107,51 & 42,05 & 4933,26 & 315,14 & 63,07 & 252,06 & 116,25 & 228,91 & 233,37 & 107,37 & 539,69 & 81,21 & 2,00 & 61,85 & 235,36 & 22,26 & 23,41 & 228,93 \\
\hline Pelodytes ibericus & 29SNC32 & 101,00 & 164,58 & 94,37 & 41,92 & 4412,68 & 295,47 & 72,80 & 222,67 & 119,62 & 219,70 & 224,62 & 111,69 & 614,58 & 90,98 & 2,73 & 62,64 & 270,49 & 26,43 & 27,17 & 264,92 \\
\hline Pelodytes ibericus & 29SNC50 & 101,00 & 169,36 & 99,40 & 42,16 & 4546,86 & 305,86 & 73,78 & 232,08 & 122,96 & 226,42 & 231,14 & 114,82 & 551,54 & 82,71 & 2,00 & 63,51 & 244,19 & 22,46 & 23,32 & 238,44 \\
\hline Pelodytes ibericus & 29SNC51 & 101,00 & 169,44 & 99,28 & 42,04 & 4569,18 & 306,46 & 73,87 & 232.59 & $|122,67|$ & 226,81 & 231,38 & 114,65 & 560,00 & 83,21 & 2,00 & 62.58 & 245,94 & 23,75 & 24,40 & 240,90 \\
\hline Pelodytes ibericus & 29SNC54 & 101,00 & 168,58 & 97,49 & 41,65 & 4619,20 & 305,30 & 73,76 & 231,54 & 121,07 & 226,41 & 231,19 & 113,01 & 590,22 & 85, & 2,99 & 61,12 & 254,27 & 26,74 & 27,45 & 251,14 \\
\hline Pelodytes ibericus & 29 SNC55 & 100,00 & 168,90 & 96,51 & 41,20 & 4621,95 & 304,91 & 74,40 & 230,51 & 121,21 & 226,82 & 231,37 & \begin{tabular}{|l|l|}
113,07 \\
\end{tabular} & 597,31 & 86,69 & 3,00 & 60,85 & 256,22 & 27,24 & 28,15 & 253,45 \\
\hline Pelodytes ibericus & 29SNC56 & 101,00 & $\begin{array}{ll}164,47 \\
\end{array}$ & 95,36 & 40,94 & \begin{tabular}{|l|l|}
4653,64 \\
\end{tabular} & 300,76 & 70,51 & 230,25 & 116,51 & 222,78 & 227,54 & 108,55 & \begin{tabular}{|c|}
636,12 \\
\end{tabular} & 92,18 & 3,69 & 60,01 & 270,33 & 30,59 & 31,18 & 268,80 \\
\hline Pelodytes ibericus & 29 SNC60 & 100,00 & 168,91 & 102,19 & 42,14 & 4666,86 & 309,80 & 71,14 & 238,66 & 121,42 & 227,67 & 232,32 & 113,08 & 548,16 & 81,95 & 2,00 & 62,98 & 240,78 & 22,67 & 23,01 & 235,76 \\
\hline Pelodytes ibericus & 29 SNC63 & 100,00 & 169,43 & 100,65 & 41,97 & 4709,57 & 310,18 & 72,45 & 237,73 & 120,91 & 228,61 & 233,21 & 112,84 & 567,75 & 82,31 & 2,86 & 60,67 & 243,66 & 26,02 & 26,75 & 240,76 \\
\hline Pelodytes ibericus & 29SNC64 & 100,00 & 167,67 & 99,66 & 41,58 & 4728,05 & 308,14 & 71,10 & 237,04 & 118,99 & 227,06 & 231,73 & 110,79 & 586,38 & 84,6 & 2,98 & 60,50 & 249,87 & 27,36 & 27,77 & 247,77 \\
\hline \begin{tabular}{|l} 
Pelodytes ibericus \\
\end{tabular} & 29 SNC70 & 101,00 & 166,79 & 105,49 & $\begin{array}{l}42,09 \\
42,5\end{array}$ & 4809,92 & 312,99 & 66,70 & 246,29 & \begin{tabular}{|l|l|}
117,83 \\
\end{tabular} & 227,47 & 232,23 & 109,28 & 554,83 & $\begin{array}{l}4,, 57 \\
82,5\end{array}$ & 2,00 & 601,93 & 241,11 & 23,42 & 23,73 & 236,96 \\
\hline Pelodytes ibericus & $295 N C 72$ & 101,00 & 168,99 & 104,16 & 42,00 & 4819,09 & 314,36 & 69,59 & 244,77 & 119,59 & 229,74 & 234,33 & 111,15 & 554,55 & 80,84 & 2,28 & 61,04 & 237,65 & 24,72 & 25,06 & 234,67 \\
\hline Pelodytes ibericus & 29 SNC73 & 101,00 & 167,30 & 103,29 & 41,94 & 4840,16 & 312,68 & 68,40 & 244,28 & 117,58 & 228,25 & 233,07 & 109,32 & 571,18 & 81,99 & 3,00 & 59,96 & 242,07 & 27,26 & 27,38 & 240,14 \\
\hline Pelodytes ibericus & 29 SNC74 & 101,00 & 164,58 & 101,83 & 41,31 & 4855,15 & 309,36 & 66,51 & 242,84 & 114,73 & 226,27 & 230,53 & 106,55 & 594,93 & 84,98 & 3,00 & 59,55 & 250,03 & 28,86 & 28,86 & 249,31 \\
\hline Pelodytes ibericus & 29 SNC75 & 100,00 & 164,53 & 100,09 & 41,03 & 4838,18 & 307,66 & 67,28 & 240,38 & 114,29 & 226,21 & 230,19 & 106,54 & 604,28 & 86,00 & 3,00 & 59,13 & 252,46 & 30,18 & 30,18 & 252,28 \\
\hline \begin{tabular}{|l} 
Pelodytes ibericus \\
\end{tabular} & $295 N C 76$ & 101,00 & 160,29 & 98,06 & $\begin{array}{ll}40,77 \\
40,77\end{array}$ & $\begin{array}{ll}4030,100 \\
4851,99\end{array}$ & 302,55 & $\begin{array}{l}64,27 \\
640\end{array}$ & \begin{tabular}{|l|}
238,27 \\
\end{tabular} & $\begin{array}{l}104,42 \\
140\end{array}$ & \begin{tabular}{|l|}
223,43 \\
221
\end{tabular} & 226,39 & $\begin{array}{l}102,36 \\
\end{array}$ & $\begin{array}{l}641,73 \\
\end{array}$ & $\begin{array}{ll}91,18 \\
918\end{array}$ & 3,81 & 58,25 & 266,81 & $\begin{array}{l}30,100 \\
33,29\end{array}$ & 33,29 & 266,81 \\
\hline Pelodytes ibericus & 29SNC77 & 101,00 & 158,54 & 96,49 & 40,18 & 4855,58 & 299,73 & 63,38 & 236,35 & 100,76 & 222,23 & 224,66 & 100,60 & 666,05 & 94,64 & 4,08 & 57,82 & 276,19 & 35,39 & 35,39 & 276,19 \\
\hline Pelodytes ibericus & $29 \mathrm{SNC} 80$ & 101,00 & 165,24 & 108,90 & 42,22 & 4951,82 & 316,80 & 62,73 & 254,06 & 114,69 & 227,97 & 232,64 & 106,17 & 558,11 & 82,71 & 2,06 & 61,14 & 239,67 & 24,29 & 24,41 & 236,34 \\
\hline Pelodytes ibericus & 29 SNC81 & 101,00 & 165,59 & 108,62 & 42,09 & 4964,21 & 317,28 & 63,29 & 253,99 & 114,89 & 228,42 & 233,08 & 106,27 & \begin{tabular}{|c|}
561,88 \\
\end{tabular} & 82,25 & 2,18 & 60,46 & 239,21 & 25,24 & 25,36 & 236,65 \\
\hline Pelodytes ibericus & 29 SNC82 & 99,00 & 167,03 & 107,19 & 42,01 & 4950,75 & 317,14 & 65,50 & 251,64 & 116,11 & 229,61 & 234,29 & 107,79 & 559,42 & 80,96 & 2,64 & 60,02 & 236,69 & 26,40 & 26,50 & 234,41 \\
\hline Pelodytes ibericuu & $295 \mathrm{NC} 83$ & $\begin{array}{l}501,00 \\
101\end{array}$ & 165,01 & 105,72 & $44,1,89$ & $\begin{array}{l}450,1 / 12 \\
4963,12\end{array}$ & $31,4,42$ & $\begin{array}{l}3,10 \\
64,19 \\
\end{array}$ & $\begin{array}{l}250,23 \\
250\end{array}$ & \begin{tabular}{|l|l|l|l|l|}
113,99 \\
\end{tabular} & \begin{tabular}{|l|}
228,62 \\
28,
\end{tabular} & \begin{tabular}{|l|}
232,37 \\
\end{tabular} & 105,65 & $\begin{array}{l}3537,4 \mathrm{~T} \\
577,32\end{array}$ & $\begin{array}{l}\mid 00,20 \\
82,20\end{array}$ & $\frac{2,044}{3,00}$ & 59,25 & \begin{tabular}{|l|}
241,88 \\
240
\end{tabular} & $\begin{array}{l}0,40 \\
28,08\end{array}$ & $\begin{array}{l}28,00 \\
28,08\end{array}$ & $\begin{array}{l}254,41 \\
240,77\end{array}$ \\
\hline Pelodytes ibericus & 29SNC90 & 100,00 & 163,67 & 112,38 & 42,31 & 5089,53 & 320,41 & 58,57 & 261,84 & 111,71 & 228,54 & 232,88 & 103,12 & 562,60 & 82,93 & 2,10 & 60,35 & 238,93 & 25,01 & 25,10 & 235,98 \\
\hline Pelodytes ibericus & 29SNC94 & 100,00 & 161,65 & 105,11 & 41,13 & 5062,79 & 312,44 & 60,52 & 251,92 & 107,12 & 228,18 & 230,52 & 101,29 & 597,04 & 83,31 & 3,19 & 57,84 & 245,71 & 30,75 & 30,75 & 245,55 \\
\hline Pelodytes ibericus & 29SPB00 & 100,00 & 168,65 & 91,91 & 41,97 & 4323,17 & 288,65 & 71,93 & 216,72 & 125,49 & 223,02 & 227,16 & 116,65 & 520,02 & 86,18 & 1,01 & 68,52 & 247,88 & 15,63 & 19,26 & 231,80 \\
\hline Pelodytes ibericus & 29SPB01 & 101,00 & 162,03 & 94,36 & 41 , & 4497,07 & 288,29 & 63,89 & 224,40 & 117,19 & 218,91 & 223,10 & 108,31 & 555,68 & 89,50 & 1,30 & 66,64 & 258,63 & 18,44 & 21,93 & 244,09 \\
\hline Pelodytes ibericuu & 29SPBO4 & 101,00 & 162,26 & 99,50 & 41,29 & 4747,51 & 299,03 & $\begin{array}{l}61,25 \\
61,0\end{array}$ & 237,78 & 114,29 & 222,41 & 226,65 & 105,52 & 555,11 & 85,60 & 1,98 & 64,07 & 250,12 & 20,58 & 23,46 & 238,41 \\
\hline Pelodytes ibericus & 29SPB05 & 100,00 & 163,97 & 101,37 & 41,34 & 4816,27 & 303,75 & 62,08 & 241,66 & 115,01 & 224,98 & 229,16 & 106,18 & 546,64 & 83,50 & 2,00 & 63,37 & 244,04 & 20,84 & 23,48 & 233,34 \\
\hline Pelodytes ibericus & 29SPB06 & 101,00 & 166,78 & 103,09 & 41,77 & 4864,45 & 308,96 & 64,24 & 244,73 & 117,18 & 228,35 & 232,62 & 108,45 & 531,27 & 80,81 & 1,99 & 62,92 & 235,55 & 20,77 & 23,04 & 225,63 \\
\hline Pelodytes ibericus & 29SPB07 & 101,00 & 166,32 & 105,44 & 8 & 4943,26 & 312,49 & 62,73 & 249,76 & 115,83 & 229,00 & 233,25 & 107,03 & 535,87 & 80,7 & 2,00 & 62,05 & 234,58 & 21,63 & 23,64 & 226,01 \\
\hline \begin{tabular}{|l} 
Pelodytes ibericus \\
\end{tabular} & 29SPB08 & 100,00 & 167,55 & 107,56 & 4 & 5003,47 & 316,8 & 62,99 & 253,84 & $\begin{array}{l}116,34 \\
110\end{array}$ & 230,95 & 235,25 & 107,44 & 530,96 & $\begin{array}{l}79,44 \\
79,4\end{array}$ & 2,00 & 61,50 & \begin{tabular}{|l|}
230,09 \\
\end{tabular} & $\begin{array}{l}21,97 \\
21,97\end{array}$ & 23,82 & 222,77 \\
\hline Pelodytes ibericus & 29SPB09 & 100,00 & 166,65 & 110,11 & 42, & 5078,42 & 319,97 & 61,01 & 258,96 & 114,61 & 231,07 & 235,43 & 105,78 & 538,22 & 79,76 & 2,0 & 60,83 & 230,49 & 23,08 & 24,19 & 224,76 \\
\hline Pelodytes ibericus & 29SPB11 & 99,00 & 168,63 & 92,33 & 41,09 & 4481,92 & 291,86 & 70,19 & 221,67 & 123,23 & 224,88 & 228,95 & 114,35 & 520,10 & 83,18 & 1,01 & 66,93 & 242,62 & 16,15 & 20,50 & 226,66 \\
\hline Pelodytes ibericus & 29SPB13 & 100,00 & 163,67 & 96,69 & 40,97 & 4727,12 & 296,40 & 62,81 & 233,59 & 115,68 & 223,35 & 227,42 & 106,75 & 545,74 & 84,32 & 1,70 & 64,48 & 246,99 & 19,23 & 23,10 & 233,35 \\
\hline Pelodytes ibericus & 29SPB14 & 100,00 & 164,15 & 98,47 & 40,99 & 4808,23 & 300,24 & 62,28 & 237,96 & 114,95 & 224,83 & 228,98 & 106,16 & 543,03 & 83,13 & 1,86 & 63,62 & 243,27 & 19,80 & 23,49 & 230,58 \\
\hline Pelodytes ibericuu & 29SPB15 & 101,00 & 16 & $\begin{array}{l}50,41 \\
100,20\end{array}$ & $\begin{array}{l}40, \\
41,\end{array}$ & 35 & 304,9 & $\begin{array}{l}62,33 \\
63,33 \\
\end{array}$ & $\mid$\begin{tabular}{|l|}
241,61 \\
\end{tabular} & \begin{tabular}{|l|}
115,96 \\
15,
\end{tabular} & \begin{tabular}{|l|}
227,460 \\
227
\end{tabular} & \begin{tabular}{|l|}
231,610 \\
\end{tabular} & 107,26 & $\begin{array}{l}542,03 \\
532,74\end{array}$ & $\begin{array}{l}\mid 3,110 \\
81,03 \\
\end{array}$ & $\begin{array}{l}1,000 \\
1,93\end{array}$ & $\begin{array}{ll}63,12 \\
63,12\end{array}$ & \begin{tabular}{|l|}
236,72 \\
236,7
\end{tabular} & 20,00 & $\begin{array}{l}23,43 \\
23,43\end{array}$ & 224,84 \\
\hline Pelodytes ibericus & 29SPB16 & 100,00 & 169,62 & 101,78 & 41,12 & 4908,01 & 310,38 & 66,19 & 244,19 & 118,84 & 231,52 & 235,58 & 110,12 & 514,27 & 77,93 & 1,73 & 62,67 & 227,15 & 19,65 & 22,79 & 215,99 \\
\hline Pelodytes ibericuu & 29SPB17 & 100,00 & 168,05 & 104,46 & 41,20 & 5005,48 & 313,51 & $\begin{array}{ll}63,50 \\
\end{array}$ & 250,01 & $\begin{array}{l}116,38 \\
110,4\end{array}$ & $\begin{array}{l}231,39 \\
\end{array}$ & $\begin{array}{l}235,43 \\
230\end{array}$ & 107,52 & 524,31 & 78,49 & $\begin{array}{ll}1,1,98 \\
\end{array}$ & 61,72 & 228,42 & 21,01 & 23,75 & 218,70 \\
\hline Pelodytes ibericus & 29SPB18 & 101,00 & 168,43 & 106,74 & 41,49 & 5064,67 & 317,17 & 62,97 & 254,19 & 116,14 & 232,58 & 236,60 & 107,19 & 524,31 & 77,78 & 2,00 & 60,91 & 225,94 & 21,78 & 23,97 & 217,52 \\
\hline Pelodytes ibericus & 29SPB21 & 97,00 & 172,04 & 90,53 & 40,61 & 4512,68 & 293,65 & 73,35 & 220,30 & 125,89 & 228,34 & 23 & 11 & 501,29 & 79,80 & 1,00 & 66,59 & 232,37 & 14,78 & 20,05 & 215 \\
\hline Pelodytes ibericus & 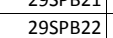 & \begin{tabular}{|c|}
100,00 \\
100
\end{tabular} & 166,31 & $\begin{array}{l}0,35 \\
93,15\end{array}$ & 40,013 & $\begin{array}{l}451,200 \\
4667,96\end{array}$ & $\begin{array}{l}293,03,92 \\
293,92\end{array}$ & $\begin{array}{l}3,3,12 \\
66,12\end{array}$ & \begin{tabular}{|l|}
227,81 \\
220
\end{tabular} & \begin{tabular}{|l|}
118,69 \\
1189
\end{tabular} & \begin{tabular}{|l|}
224,994 \\
\end{tabular} & \begin{tabular}{|l|}
228,93 \\
223
\end{tabular} & $\begin{array}{l}109,50 \\
109,63\end{array}$ & 531, & $\begin{array}{l}1,200 \\
82,62\end{array}$ & $\begin{array}{l}1,20 \\
1,25 \\
\end{array}$ & $\begin{array}{l}0,350 \\
65,03\end{array}$ & \begin{tabular}{|l|}
241,44 \\
241
\end{tabular} & $\begin{array}{l}17,10 \\
17,40\end{array}$ & $\begin{array}{l}22,36 \\
22,36\end{array}$ & $\begin{array}{l}21,43,77 \\
225,7\end{array}$ \\
\hline Pelodytes ibericus & 29SPB23 & 101,00 & 168,25 & 94,56 & 40,32 & 4735,29 & 298,46 & 67,19 & 231,27 & 119,61 & 227,77 & 231,71 & 110,66 & 519,73 & 80,23 & 1,19 & 64,47 & 234,68 & 17,37 & 22,16 & 219,59 \\
\hline Pelodytes ibericus & 29SPB24 & 100,00 & 165,69 & 97,05 & 40,46 & 4849,47 & 300,64 & 63,40 & 237.24 & 115,70 & 226.89 & 230.83 & 107.08 & 533.69 & 81.11 & 1.86 & 63,31 & 237.35 & 19,21 & 23,72 & 223,55 \\
\hline Pelodytes ibericus & 29SPB25 & 100,00 & 169,33 & 98,40 & 40,57 & 4894,24 & 306,29 & 66,31 & 239,97 & 118,59 & 231,09 & 234 & 110, & 513,84 & 77,78 & 1,62 & 62,78 & 227,38 & 18,76 & 23,11 & 214,10 \\
\hline Pelodytes ibericus & $29 \mathrm{SPB} 26$ & 101,00 & 169,08 & 100,77 & 40,72 & 4972,45 & 309,87 & 64,94 & 244,93 & 117,62 & 231,85 & 235,79 & 108,74 & 516,25 & 77,31 & 1,88 & 61,94 & 225,79 & 19,77 & 23,69 & 213,66 \\
\hline
\end{tabular}




\begin{tabular}{|c|c|c|c|c|c|c|c|c|c|c|c|c|c|c|c|c|c|c|c|c|c|}
\hline TAXON & UTM & $\mathrm{km} 2$ & BIO1 & B102 & $\mathrm{BIO3}$ & B104 & B105 & B106 & B107 & B108 & B109 & BIO10 & B1011 & BIO12 & B1013 & B1014 & 81015 & B1016 & BIO17 & B1018 & \begin{tabular}{|l|} 
B1019 \\
\end{tabular} \\
\hline Pelodytes ibericus & 29SPB27 & 100,00 & 167,14 & 103,45 & 40,86 & 5076,86 & 312,47 & 61,61 & 250,86 & 114,53 & 231,33 & $235,27 \mid$ & 105,58 & 528,04 & 78,16 & 2,00 & 61,08 & 228,12 & 21,14 & 24,51 & 217,42 \\
\hline Pelodytes ibericus & 29SPB28 & 100,00 & 167,52 & 105,62 & 40,98 & 5143,11 & 316,07 & 60,92 & 255,16 & 113,99 & 232,69 & 236,56 & 105,07 & 527,53 & 77,44 & 2,00 & 60,50 & 225,69 & 21,84 & 24,69 & 216,24 \\
\hline Pelodytes ibericus & 29SPB31 & 58,00 & 174,81 & 88,67 & 40,00 & 4559,20 & 295,23 & 75,87 & 219,36 & 127,54 & 231,51 & 235,26 & 118,59 & 486,49 & 76,64 & 1,00 & 65,94 & 222,86 & 14,03 & 19,99 & 205,03 \\
\hline Pelodytes ibericus & 29SPB32 & 101,00 & 173,23 & 90,13 & 39,87 & 4653,86 & 296,81 & 73,27 & 223,54 & 124,94 & 231,23 & 234,90 & 115,92 & 493,39 & 76,86 & 1,00 & 65,25 & 224,21 & 14,76 & 20,66 & 206,99 \\
\hline Pelodytes ibericus & 29SPB33 & 100,00 & 172,24 & 92,08 & 39,85 & 4756,22 & 299,82 & 71,13 & 228,69 & $\begin{array}{ll}122,83 \\
\end{array}$ & \begin{tabular}{|l|l|}
231,68 \\
\end{tabular} & 235,45 & 113,82 & 497,26 & 76,39 & 1,00 & 64,32 & 223,32 & 15,71 & 21,49 & 206,86 \\
\hline Pelodytes ibericus & 29SPB34 & 101,00 & 170,86 & 94,32 & 39,90 & 4859,98 & 302,54 & 68,46 & 234,07 & 120,14 & 231,78 & 235,50 & 111,38 & 504,14 & 76,40 & 1,15 & 63,32 & 223,70 & 16,99 & 22,58 & 208,22 \\
\hline Pelodytes ibericus & $295 P B 35$ & 101,00 & 169,60 & 96,90 & 39,96 & 4957,53 & 305,73 & 65,96 & 239,77 & 117,77 & 231,96 & 235,63 & 109,06 & 511,72 & 76,62 & 1,60 & 62,32 & 224,38 & 18,45 & 23,57 & 210,04 \\
\hline \begin{tabular}{|l} 
Pelodytes ibericus \\
\end{tabular} & 29SPB36 & \begin{tabular}{|l|}
99,00 \\
\end{tabular} & \begin{tabular}{|l|}
171,07 \\
\end{tabular} & $\begin{array}{ll}98,97 \\
8\end{array}$ & 40,02 & 5027,06 & 310,27 & 66,23 & 244,03 & 118,48 & 234,36 & 238,01 & 109,54 & 504,43 & $\begin{array}{l}70,825 \\
74,85\end{array}$ & 1,80 & $\begin{array}{l}61,47 \\
61,47\end{array}$ & 219,22 & $\begin{array}{l}19,403 \\
19,03\end{array}$ & 23,80 & 205,73 \\
\hline Pelodytes ibericus & 29SPB37 & 101,00 & 168,89 & 101,83 & 40,13 & 5123,45 & 312,79 & 62,74 & 250,05 & 115,32 & 233,65 & 237,34 & 106,44 & 517,24 & 75,86 & 2,00 & 60,68 & 222,11 & 20,43 & 24,79 & 209,98 \\
\hline Pelodytes ibericus & 29SPB38 & 100,00 & 165,74 & 104,48 & 40,26 & 5217,51 & 314,11 & 58,52 & 255,59 & \begin{tabular}{|l|l|}
111,43 \\
\end{tabular} & 231,94 & 235,57 & 102,43 & 536,33 & 77,76 & 2,00 & 60,14 & 227,63 & 22,05 & 25,60 & 217,14 \\
\hline Pelodytes ibericus & 29SPB42 & 100,00 & 174,39 & 87,81 & 39,07 & 4705,30 & 296,40 & 74,27 & 222,13 & 125,04 & 232,76 & 236,31 & 116,11 & 486,66 & 74,96 & 1,00 & 65,00 & 218,79 & 14,07 & 21,01 & 200,46 \\
\hline Pelodytes ibericus & 29SPB43 & 100,00 & 171,07 & 90,36 & 39,05 & 4835,05 & 298,26 & 69,46 & 228,80 & 120,41 & 231,39 & 234,94 & 111,54 & 503,00 & 76,14 & 1,00 & 63,58 & 223,05 & 15,97 & 22,78 & 205,61 \\
\hline Pelodytes ibericus & 29SPB44 & 100,00 & 168,94 & 93,08 & 39,08 & 4953,04 & 301,00 & 65,92 & 235,08 & 116,97 & 230,92 & 234,64 & 108,21 & 514,36 & 76,65 & 1,65 & 62,62 & 225,14 & 17,70 & 24,14 & 208,76 \\
\hline Pelodytes ibericus & 29SPB46 & 101,00 & 170,38 & 97,69 & 39,49 & 5097,67 & 309,21 & 64,66 & 244,55 & 116,60 & 234,40 & 237,99 & 107,66 & 508,40 & 74,47 & 2,00 & 61,12 & 218,77 & 19,17 & 24,74 & 204,27 \\
\hline Pelodytes ibericus & 29SPB47 & 100,00 & 168,88 & 100,49 & 39,82 & 5191,89 & 311,99 & 61,96 & 250,03 & 114,28 & 234,42 & 237,89 & 105,12 & 517,01 & 75,01 & 2,00 & 60,66 & 220,39 & 20,28 & 25,11 & 207,22 \\
\hline Pelodytes ibericus & 29SPB48 & 100,00 & 167,76 & 102,78 & 39,96 & 5275,35 & 314,51 & 59,57 & 254,94 & 112,04 & \begin{tabular}{|l|l|}
234,53 \\
\end{tabular} & 238,02 & 103,20 & 523,92 & 75,31 & 2,00 & 59,87 & 221,33 & 21,22 & 25,76 & 209,24 \\
\hline Pelodytes ibericus & $295 P B 49$ & 100,00 & 166,50 & 105,08 & 40,00 & 5340,31 & 316,69 & 57,41 & 259,28 & 110,07 & 234,41 & 237,71 & 101,40 & 532,89 & 75,91 & 2,06 & 59,35 & 223,19 & 22,59 & 26,21 & 212,30 \\
\hline Pelodytes ibericus & $29 S P B 52$ & 100,00 & 175,19 & 85,50 & 38,19 & 4763,32 & 295,72 & 74,92 & 220,80 & 124,69 & 233,97 & 237,43 & 115,81 & 482,36 & 73,92 & 1,00 & 64,48 & 214,43 & 13,55 & 21,57 & 194,99 \\
\hline Pelodytes ibericus & 29SPB53 & 101,00 & 172,90 & 87,90 & 38,16 & 4887,35 & 298,20 & 71,02 & 227,18 & 121,10 & 233,55 & 236,92 & 112,13 & 493,46 & 74,73 & 1,01 & 63,42 & 216,54 & 15,33 & 23,12 & 197,79 \\
\hline Pelodytes ibericus & 29SPB54 & 101,00 & 170,45 & 90,94 & 38,30 & 5007,82 & 300,94 & 66,97 & 233,97 & 117,41 & 232,94 & 236,36 & \begin{tabular}{|l|}
108,48 \\
\end{tabular} & 506,42 & 75,65 & 1,51 & 62,28 & 219,73 & 17,00 & 24,36 & 202,13 \\
\hline Pelodytes ibericus & 29SPB55 & 99,00 & 166,69 & 94,61 & 38,71 & 5134,48 & 303,20 & 61,36 & 241,84 & \begin{tabular}{|l|l|}
112,48 \\
\end{tabular} & 231,25 & 234,60 & 103,59 & 528,04 & 77,56 & 2,00 & 61,28 & 226,42 & 19,01 & 25,85 & 210,22 \\
\hline \begin{tabular}{|l} 
Pelodytes ibericus \\
\end{tabular} & 29SPB56 & 100,00 & 168,05 & $\begin{array}{l}94,015 \\
96,89\end{array}$ & 38,95 & 5204,47 & 307,65 & 61,30 & 246,35 & $\begin{array}{l}112,494 \\
112,94\end{array}$ & 233,58 & 236,92 & 103,94 & 520,95 & 76,11 & 2,00 & 60,74 & \begin{tabular}{|l|}
221,98 \\
221,98
\end{tabular} & 19,40 & 25,68 & 206,68 \\
\hline Pelodytes ibericus & 29SPB59 & 100,00 & 166,71 & 104,28 & 39,71 & 5416,16 & 316,71 & 56,52 & 260,20 & \begin{tabular}{|l|l|}
109,16 \\
\end{tabular} & 235,61 & 238,69 & 100,55 & 531,41 & 75,54 & 2,18 & 58,79 & 221,23 & 22,63 & 27,04 & 209,20 \\
\hline Pelodytes ibericus & $295 P B 62$ & 100,00 & 176,32 & 82,94 & 37,30 & 4827,46 & 295,47 & 75,96 & 219,51 & 124,72 & 235,65 & 238,97 & 115,88 & 476,06 & 73,79 & 1,00 & 64,06 & 209,23 & 13,14 & 22,10 & 188,61 \\
\hline Pelodytes ibericus & $295 P B 63$ & 100,00 & 173,50 & 85,69 & 37,29 & 4955,21 & 297,65 & 71,32 & 226,33 & 120,63 & 234,78 & 237,93 & 111,59 & 490,51 & 75,08 & 1,01 & 62,88 & 213,02 & 14,88 & 23,59 & 193,09 \\
\hline Pelodytes ibericus & $295 P B 64$ & 100,00 & 171,35 & 89,14 & 37,69 & 5074,96 & 300,92 & 67,29 & 233,63 & \begin{tabular}{|l|l|}
117,19 \\
\end{tabular} & 234,48 & 237,69 & 108,34 & 502,45 & 75,84 & 1,52 & 62,03 & 215,97 & 16,64 & 24,62 & 197,18 \\
\hline $\begin{array}{l}\text { Pelodytes ibericus } \\
\end{array}$ & 295PBP65 & 101,00 & $\mid \begin{array}{l}\mid 71,30 \\
170,61\end{array}$ & $\begin{array}{l}\mid l j, 14 \\
92,24\end{array}$ & $\begin{array}{l}37,95 \\
37,94\end{array}$ & 5171,80 & | & $\mid \begin{array}{ll}\mid l, 23 \\
64,81\end{array}$ & 239,03 & $\begin{array}{l}\mid 11,15 \\
115,30\end{array}$ & 235,21 & 238,42 & $\begin{array}{l}106,43 \\
\end{array}$ & $\mid$ & $\mid 75,85$ & $\begin{array}{l}1,1,94 \\
1,94\end{array}$ & $\mid \begin{array}{ll}02,1,13 \\
613\end{array}$ & 216,36 & $\begin{array}{l}10,04 \\
17,85\end{array}$ & $24,0<5$ & 198,55 \\
\hline Pelodytes ibericus & 29SPB66 & 100,00 & 167,46 & 96,09 & 38,26 & 5281,79 & 307,19 & 59,68 & 247,51 & 111,22 & 233,90 & 237,04 & $\mid 102,17$ & 526,75 & 77,38 & 2,00 & 60,41 & 222,67 & 19,45 & 26,22 & 206,49 \\
\hline Pelodytes ibericus & $295 \mathrm{SBG7}$ & 101,00 & 167,34 & 98,94 & 38,73 & 5365,73 & 310,99 & 58,12 & 252,87 & 110,08 & 235,12 & 238,06 & 101,04 & 527,78 & 76,87 & 2,00 & 59,80 & 221,55 & 20,25 & 26,49 & 206,39 \\
\hline Pelodytes ibericus & $295 P B 68$ & 99,00 & 161,51 & 102,50 & 38,98 & 5475,86 & 310,95 & 50,86 & 260,09 & 103,49 & 231,21 & 234,26 & 94,64 & 565,09 & 80,49 & 2,59 & 58,77 & 234,47 & 24,03 & 29,36 & 221,11 \\
\hline Pelodytes ibericus & $295 P B 72$ & 100,00 & 177,28 & 80,30 & 36,32 & 4889,62 & 294,83 & 76,74 & 218,10 & 124,96 & 237,14 & 240,23 & \begin{tabular}{|l|l|}
115,76 \\
\end{tabular} & 471,86 & 74,05 & 1,00 & 63,85 & 205,10 & 12,65 & 22,54 & 183,14 \\
\hline Pelodytes ibericus & 295PB73 & 101,00 & $\begin{array}{l}\mid 17,20 \\
176,50\end{array}$ & $\begin{array}{l}80,30 \\
82,76 \\
\end{array}$ & $\begin{array}{l}30,324 \\
36,45 \\
\end{array}$ & $\begin{array}{l}4000,102 \\
5001,32\end{array}$ & \begin{tabular}{|l|l|}
$298,03,23$ \\
29
\end{tabular} & 74,25 & $\begin{array}{l}210,10 \\
223,98\end{array}$ & $\begin{array}{l}123,50 \\
123,65\end{array}$ & $\mid 237,87$ & $\begin{array}{l}24,25 \\
240,98\end{array}$ & $\begin{array}{l}113,67 \\
113,67\end{array}$ & $\begin{array}{l}47,00 \\
476,04\end{array}$ & 74,01 & $\frac{1,00}{1,00}$ & | & \begin{tabular}{|l|l|}
204,82 \\
\end{tabular} & $\begin{array}{l}\mid 2,, 03 \\
13,89\end{array}$ & 23,71 & \begin{tabular}{|l|}
183,47 \\
183,47
\end{tabular} \\
\hline Pelodytes ibericus & $295 P B 74$ & 100,00 & 174,51 & 86,77 & 36,99 & 5116,97 & 301,96 & 70,11 & 231,86 & 119,42 & 237,91 & 240,89 & 110,45 & 487,26 & 74,79 & 1,03 & 62,14 & 208,15 & 15,20 & 24,17 & 187,95 \\
\hline Pelodytes ibericus & 29SPB75 & 100,00 & 173,17 & 90,78 & 37,35 & 5223,84 & 306,17 & 66,62 & 239,55 & $\begin{array}{ll}116,95 \\
\end{array}$ & 238,22 & 241,18 & 108,03 & 497,01 & 75,20 & 1,7 & 61,08 & 210,63 & 16,92 & 25,31 & 191,71 \\
\hline Pelodytes ibericus & $295 P B 76$ & 101,00 & 172,13 & 94,68 & 37,97 & 5322,15 & 310,30 & 63,59 & 246,72 & 115,01 & 238,91 & 241,79 & 105,99 & 504,11 & 75,30 & 1,99 & 60,38 & 212,14 & 18,20 & 25,85 & 194,57 \\
\hline Pelodytes ibericus & $295 P B 77$ & 100,00 & 169,75 & 98,39 & 38,18 & 5425,29 & 313,11 & 59,47 & 253,64 & \begin{tabular}{|l|l|l|l|}
111,36 \\
\end{tabular} & 238,29 & 241,06 & 102,64 & 517,79 & 76,19 & 2,01 & 59,74 & 216,32 & 19,64 & 26,46 & 200,12 \\
\hline Pelodytes ibericus & 29SPB78 & 101,00 & 163,20 & 102,44 & 38,68 & 5548,81 & 313,16 & 51,22 & 261,94 & 104,07 & 233,97 & 236,76 & 95,18 & 557,05 & 79,98 & 2,45 & 58,67 & 230,14 & 23,44 & 29,16 & 215,80 \\
\hline Pelodytes ibericus & 29SPB81 & 49,00 & 177,89 & 79,56 & 36,00 & 4901,23 & 294,59 & 76,90 & 217,69 & 136,93 & 238,02 & 241,00 & \begin{tabular}{|c|}
116,18 \\
\end{tabular} & 476,69 & 75,25 & 1,00 & 63,82 & 206,57 & 12,51 & 22,87 & 183,93 \\
\hline Pelodytes ibericus & $295 P B 82$ & 101,00 & 177,98 & 79,33 & 35,82 & 4964,47 & 295,56 & 76,60 & 218,96 & 144,32 & 238,62 & 241,52 & 115,22 & 472,48 & 74,62 & 1,00 & 63,57 & 203,23 & 12,62 & 23,47 & 180,27 \\
\hline Pelodytes ibericus & 29SPB83 & 99,00 & 177,82 & 81,79 & 35,97 & 5067,99 & 299,41 & 74,67 & 224,73 & 146,24 & 239,98 & 242,83 & 113,78 & 473,24 & 74,27 & 1,0 & 62,87 & 202,07 & 3,64 & 23,87 & 179,64 \\
\hline Pelodytes ibericus & 29SPB84 & 101,00 & 174,38 & 87,23 & 36,64 & 5210,35 & 303,54 & 68,52 & 235,02 & 140,24 & 239,13 & $\begin{array}{l}24,05 \\
241,89\end{array}$ & 109,09 & 493,24 & 76,00 & 1,26 & $\mid 61,76$ & 209,21 & 15,46 & 24,91 & 188,50 \\
\hline Pelodytes ibericus & $29 S P B 85$ & 100,00 & 172,92 & 91,72 & 37,08 & 5321,27 & 307,98 & 64,69 & 243,29 & 115,49 & 239,49 & 242,16 & 106,45 & 504,88 & 76,49 & 1,83 & 61,00 & 212,53 & 17,19 & 25,68 & 193,27 \\
\hline Pelodytes ibericus & 29SPB86 & 100,00 & 169,77 & 96,12 & 37,83 & 5442,40 & 311,10 & 59,32 & $\begin{array}{l}24,251,78 \\
251\end{array}$ & $\begin{array}{l}111,45 \\
111,16\end{array}$ & 238,45 & 241,03 & 102,23 & 523,43 & 77,89 & $\begin{array}{l}\frac{1,00}{2,00} \\
\end{array}$ & 60,25 & 218,73 & 18,97 & 26,66 & 201,01 \\
\hline Pelodytes ibericus & 29SPB87 & 100,00 & 168,34 & 99,61 & 38,00 & 5531,28 & 31 & 56,26 & 258,11 & 108,81 & 238,52 & 241,06 & $\begin{array}{l}99,98 \\
\end{array}$ & 531,65 & 78,12 & 2,02 & 59,57 & 220,72 & 20,46 & 27,36 & 204,23 \\
\hline Pelodytes ibericus & 29SPB88 & 100,00 & 162,84 & 103,31 & 38,20 & 5644,99 & 314,91 & 48,97 & 265,94 & 102,43 & 235,01 & 237,46 & 93,42 & 564,64 & 81,17 & 2,69 & 58,47 & 232,19 & 23,76 & 29,72 & 217,38 \\
\hline Pelodytes ibericus & 295PBP89 & 100,00 & $\begin{array}{l}102,04 \\
153,82 \\
\end{array}$ & $\mid$ & $\begin{array}{ll}30,20 \\
38,23\end{array}$ & 5757,84 & $\begin{array}{l}\mid 114,51 \\
312,54\end{array}$ & 38, 38,85 & 27273,69 & \begin{tabular}{|r|}
92,43 \\
92,73
\end{tabular} & \begin{tabular}{|l|}
228,07 \\
228
\end{tabular} & $\begin{array}{l}23,40 \\
230,59\end{array}$ & 83,71 & $\begin{array}{l}604,04 \\
620,39\end{array}$ & $\mid 86,93$ & $\begin{array}{l}2,053 \\
3,43\end{array}$ & S7,47 & | 252,59 & 28,53 & 33,33 & 239,85 \\
\hline Pelodytes ibericus & 29SPB91 & 91,00 & \begin{tabular}{|l|l|}
176,63 \\
\end{tabular} & 82,44 & 36,29 & 4991,09 & 297,27 & 73,43 & 223,85 & 129,05 & 238,21 & 241,18 & \begin{tabular}{|l|l|}
113,96 \\
\end{tabular} & 495,43 & 77,43 & 1,00 & 63,73 & 213,67 & 13,84 & 23,77 & 191,63 \\
\hline Pelodytes ibericus & 29SPB92 & 101,00 & 176,34 & 83,35 & 36,08 & 5092,33 & 299,59 & 72,02 & 227,57 & \begin{tabular}{ll|}
134,69 \\
\end{tabular} & 239,17 & 242,06 & 112,29 & 493,55 & 77,15 & 1,00 & 63,20 & 211,19 & 14,05 & 24,00 & 189,05 \\
\hline Pelodytes ibericus & $295 P B 93$ & 100,00 & 178,35 & 85,09 & 36,17 & 5167,99 & 304,21 & 72,76 & 231, & 147,42 & 242,25 & 244,99 & 113,29 & 482, & 75,46 & 1,0 & 62,7 & 205,42 & 14,09 & 24,00 & 183,32 \\
\hline Pelodytes ibericus & 29SPB94 & 101,00 & 17 & 8 & 36,78 & 315,18 & 307 & 66, & 240,84 & 122 & 241 & 243 & 108,15 & 502, & 77,16 & 1, & 61, & 212,05 & 15,74 & 24,94 & 191,58 \\
\hline Pelodytes ibericus & $295 P B 95$ & 99,00 & 169,82 & 94,92 & 37,18 & 5462,90 & 310,08 & 58,89 & 251,19 & 110,79 & 238,72 & 241,25 & 101,85 & 531,43 & 79,77 & $\frac{1,200}{2,00}$ & 60,74 & 222,38 & 18,52 & 26,68 & 203,61 \\
\hline Pelodytes ibericus & 29SPB96 & 100,00 & 169,28 & 98,16 & 37,82 & 5549,99 & 313,89 & 56,72 & 257,17 & 109,34 & 239,57 & 242,12 & 100,46 & 534,59 & 79,41 & 2,00 & 60,10 & 222,36 & 19,56 & 27,16 & 204,72 \\
\hline Pelodytes ibericus & 29SPB98 & 100,00 & 164,84 & 104,28 & 38,01 & 5721,95 & 318,91 & 49,21 & 269,70 & 103,34 & 238,19 & 240,41 & 94,44 & 558,94 & 80,74 & 2,51 & 58,66 & 229,30 & 23,06 & 29,22 & 214,00 \\
\hline Pelodytes iberic & 29SPB99 & 100,00 & 152,23 & 107,69 & 38,00 & 5848,46 & 313, & 35,78 & 278,14 & 90 & 227,96 & 230,29 & 81,17 & 635 & 88,77 & 3,60 & 57, & 257,79 & 29,35 & 34,22 & 245,06 \\
\hline Pelodytes ibericus & $295 \mathrm{SCO}$ & 16 & & & 41,87 & 5160,53 & & 60,85 & 261,15 & 112,99 & 231,84 & 236,18 & 104,34 & 552,50 & 78,82 & 2, & 58,68 & 229,86 & 26,91 & 27,28 & 227,05 \\
\hline Pelodytes ibericus & $295 \mathrm{PCO}$ & 101,00 & $\begin{array}{l}160,69 \\
\end{array}$ & 108,62 & 41,23 & 5185,48 & 316,10 & 56,55 & 259,55 & 107,39 & 227,90 & 231,14 & 98,85 & 592,32 & 82,64 & 3,04 & 57,66 & 243,29 & 30,44 & 30,45 & 242,18 \\
\hline Pelodytes ibericus & $295 \mathrm{SPC} 04$ & 100,00 & 161,82 & 106,48 & 41,04 & 5164,14 & 314,94 & 58,80 & 256,14 & 108,27 & 229,01 & 231,91 & 100,14 & \begin{tabular}{|c|}
589,98 \\
\end{tabular} & 81,44 & 3,02 & 57,23 & 241,04 & 30,93 & 30,93 & 240,44 \\
\hline Pelodytes ibericus & $295 \mathrm{SPC5}$ & 101,00 & 163,99 & 104,51 & 40,97 & 5131,42 & 14,60 & 61,82 & 252,78 & 109,97 & 230,79 & 233,51 & 102,35 & 583,41 & 80,05 & 3,00 & 57,05 & 237,34 & 31,10 & 31,10 & 236,9 \\
\hline Pelodytes ibericus & 29SPC12 & 99,00 & 167 & 109 & 41,1 & 5225,1 & 323 & 60,97 & 262,05 & 113 & 234,04 & 238 & 104 & 540 & 76,70 & 2,27 & 58,3 & 224 & 26,18 & 27,20 & 219 \\
\hline \begin{tabular}{|l} 
Pelodytes ibericus \\
\end{tabular} & $295 \mathrm{SC15}$ & 99,00 & 165,51 & 106,22 & $\begin{array}{ll}1,11 \\
40,89\end{array}$ & 5234,90 & \begin{tabular}{|l|l|}
318,45 \\
\end{tabular} & 60,80 & 257,65 & $\begin{array}{l}110,85 \\
110,85\end{array}$ & 232,12 & 236,15 & 102,37 & \begin{tabular}{|l|l|}
570,58 \\
\end{tabular} & 77,63 & 3,01 & 56,58 & 231,28 & $\begin{array}{l}30,94 \\
30,4\end{array}$ & 31,19 & 229,58 \\
\hline
\end{tabular}




\begin{tabular}{|c|c|c|c|c|c|c|c|c|c|c|c|c|c|c|c|c|c|c|c|c|c|}
\hline TAXON & UTM & $\mathrm{km} 2$ & BIO1 & B102 & $\mathrm{BIO3}$ & B104 & B105 & B106 & B107 & B108 & B109 & BIO10 & B1011 & BIO12 & B1013 & B1014 & 81015 & B1016 & BIO17 & B1018 & B1019 \\
\hline Pelodytes ibericus & $295 \mathrm{SP} 20$ & 100,00 & 167,25 & 108,79 & 41,00 & 5254,52 & 320,84 & 59,51 & 261,33 & 112,50 & 233,96 & 237,92 & 103,49 & 532,54 & 76,72 & 2,00 & 59,38 & 223,71 & 23,36 & 25,51 & 216,45 \\
\hline Pelodytes ibericus & 29SPC30 & 101,00 & 166,07 & 107,70 & 40,62 & 5327,15 & 319,31 & 57,17 & 262,14 & 110,25 & 233,87 & 237,53 & 101,40 & 538,07 & 76,59 & 2,32 & 58,83 & 224,42 & 24,33 & 27,07 & 215,93 \\
\hline Pelodytes ibericus & $295 \mathrm{SC} 36$ & 101,00 & 164,36 & 108,31 & 40,00 & 5467,16 & $\mid 321,97$ & 55,28 & 266,69 & 106,72 & 234,42 & 237,79 & $\begin{array}{l}98,15 \\
98,4\end{array}$ & 577,66 & 77,96 & 3,98 & $\begin{array}{l}5,0,18 \\
5,18\end{array}$ & 231,45 & 33,13 & 33,78 & 227,34 \\
\hline Pelodytes ibericus & 29SPC45 & 100,00 & 168,72 & 109,90 & 40,02 & 5520,70 & 327,46 & 56,84 & 270,62 & \begin{tabular}{|l|l|}
109,73 \\
\end{tabular} & 239,59 & 242,28 & 101,23 & 536,43 & 73,75 & 3,02 & 55,77 & 215,92 & 28,96 & 30,40 & 209,14 \\
\hline Pelodytes ibericus & 29SPC46 & 100,00 & 168,21 & 110,05 & 40,00 & 5541,22 & 327,67 & 56,19 & 271,48 & \begin{tabular}{|l|l|}
108,93 \\
\end{tabular} & 239,34 & 242,04 & \begin{tabular}{|l|l|}
100,49 \\
\end{tabular} & 546,01 & 74,72 & 3,51 & 55,06 & 218,49 & 31,15 & 32,31 & 212,21 \\
\hline Pelodytes ibericus & 29SPC54 & 100,00 & 167,86 & 110,35 & 40,00 & 5602,91 & 327,94 & 54,27 & 273,67 & 107,78 & 239,81 & 242,30 & 99,23 & 534,37 & 73,98 & 3,03 & 55,77 & 215,26 & 28,15 & 30,24 & 206,77 \\
\hline Pelodytes ibericus & $295 P C 55$ & 101,00 & 166,82 & 111,02 & 39,95 & 5639,14 & 328,46 & 52,88 & 275,58 & 106,43 & 239,38 & 241,86 & 97,84 & 543,21 & 74,81 & 3,39 & 54,97 & 217,40 & 30,10 & 31,80 & 209,48 \\
\hline Pelodytes ibericus & 29SPC58 & 100,00 & 168,60 & 112,24 & 39,97 & 5700,35 & 332,14 & 53,08 & 279,07 & 107,03 & 242,20 & 244,23 & 98,73 & 546,20 & 75,06 & 4,00 & 53,57 & 216,33 & 33,25 & 34,09 & 208,90 \\
\hline Pelodytes ibericus & $295 \mathrm{SP60}$ & 100,00 & 163,18 & 106,26 & 39,15 & 5569,55 & 317,99 & 50,66 & 267,33 & \begin{tabular}{ll|}
104,12 \\
\end{tabular} & 234,43 & 237,22 & 95,19 & 556,04 & 78,26 & 2,98 & 57,41 & 227,75 & 25,89 & 29,93 & 216,04 \\
\hline Pelodytes ibericus & 29SPC61 & 100,00 & 162,79 & 107,89 & 39,17 & 5622,32 & 320,55 & 49,19 & 271,36 & \begin{tabular}{|l|l|}
103,19 \\
\end{tabular} & 234,95 & 237,86 & 94,22 & 558,30 & 78,06 & 3,08 & 56,97 & 227,34 & 26,79 & 30,50 & 216,45 \\
\hline Pelodytes ibericus & $295 P C 68$ & 101,00 & 165,88 & 113,77 & 39,39 & $\begin{array}{ll}5827,84 \\
\end{array}$ & 333,01 & 48,04 & 284,97 & 102,98 & 241,62 & 243,26 & \begin{tabular}{l|l}
94,45 \\
\end{tabular} & 550,29 & 75,81 & 4,00 & 53,27 & 216,66 & 33,90 & 34,73 & 207,97 \\
\hline Pelodytes ibericus & $295 P C 70$ & 100,00 & 161,09 & 106,73 & 38,95 & 5675,07 & 318,19 & 46,80 & 271,38 & 100,66 & 233,89 & 236,54 & 91,70 & 571,07 & 80,41 & 3,15 & 57,24 & 232,70 & 26,59 & 31,03 & 220,35 \\
\hline Pelodytes ibericus & 29SPC71 & 101,00 & 158,40 & 108,44 & 38,92 & 5732,58 & 318,87 & 43,40 & 275,47 & 97,48 & 232,29 & 234,86 & 88,52 & 587,30 & 81,78 & 3,33 & 56,56 & 237,71 & 28,70 & 32,39 & 226,39 \\
\hline Pelodytes ibericus & 29SPC78 & 101,00 & 164,72 & 114,89 & 39,01 & 5922,38 & 334,61 & 44,63 & 289,98 & 100,47 & 241,89 & 243,01 & 92,16 & 543,85 & 75,06 & 4,00 & 52,70 & 213,05 & 33,86 & 34,86 & 202,97 \\
\hline Pelodytes ibericus & $295 \mathrm{SP} 80$ & 101,00 & 154,66 & 107,93 & 38,41 & 5795,37 & 315,84 & 39,03 & 276,81 & \begin{tabular}{|l|l|}
93,23 \\
\end{tabular} & 229,63 & 232,06 & 84,21 & 614,21 & 85,61 & 3,64 & 56,86 & 248,62 & 29,24 & 33,59 & 236,45 \\
\hline Pelodytes ibericus & $295 \mathrm{SP} 81$ & 99,00 & 159,18 & 109,25 & 38,81 & 5818,30 & 321,64 & 42,67 & 278,97 & \begin{tabular}{|l|l|}
97,08 \\
\end{tabular} & 234,43 & 236,60 & 88,26 & 583,86 & 81,56 & 3,29 & 56,41 & 235,44 & 28,32 & 32,34 & 223,32 \\
\hline Pelodytes ibericus & $295 P C 82$ & 101,00 & 160,19 & 110,52 & 38,84 & 5854,69 & 324,58 & 42,86 & 281,71 & 97,50 & 235,97 & 238,01 & 88,63 & 575,40 & 80,09 & 3,43 & 55,90 & 230,86 & 28,88 & 32,50 & 219,15 \\
\hline Pelodytes ibericus & 29SPC87 & 101,00 & 159,43 & 114,49 & 38,96 & 6000,35 & 331,08 & 39,33 & 291,75 & \begin{tabular}{|l|l|}
94,80 \\
\end{tabular} & 237,95 & 239,14 & 86,38 & 570,55 & 78,01 & 4,14 & 52,95 & 223,31 & 34,51 & 36,02 & 212,68 \\
\hline Pelodytes ibericus & $295 P C 90$ & 100,00 & 155,39 & 109,04 & 38,17 & 5882,69 & 318,88 & 38,08 & 280,80 & \begin{tabular}{|c|}
92,63 \\
\end{tabular} & 231,65 & 233,82 & 83,79 & 613,37 & 85,57 & 3,45 & 56,86 & 247,51 & 28,96 & 33,52 & 234,93 \\
\hline Pelodytes ibericus & $295 P C 92$ & 99,00 & 153,35 & 111,44 & 38,22 & 5977,65 & 321,58 & 34,63 & 286,95 & 89,59 & 231,15 & 233,13 & 80,78 & 621,02 & 85,31 & 3,99 & 55,51 & 247,66 & 31,83 & 35,31 & 236,26 \\
\hline Pelodytes ibericus & 29SPC98 & 100,00 & 163,77 & 115,99 & 38,94 & 6055,62 & 337,09 & 41,36 & 295,74 & 97,97 & 242,82 & 243,82 & 89,72 & 531,38 & 72,98 & 4,00 & 52,47 & 206,67 & 32,15 & 34,00 & 194,75 \\
\hline \begin{tabular}{|l} 
Pelodytes ibericus \\
\end{tabular} & 29SPD47 & 100,00 & \begin{tabular}{|l|l|}
161,78 \\
\end{tabular} & \begin{tabular}{|c|}
99,90 \\
99,
\end{tabular} & 37,00 & 5777,09 & 320,23 & 53,95 & 266,28 & 100,13 & 237,49 & 239,55 & 92,44 & 738,82 & 103,05 & 5,96 & 53,79 & 295,82 & 45,84 & 47,24 & 293,69 \\
\hline Pelodytes ibericus & 29SPD54 & 100,00 & 159,58 & 104,37 & 37,96 & 5772,25 & 321,21 & 50,21 & 271,00 & $\begin{array}{r}98,48 \\
\end{array}$ & 235,00 & 237,44 & 90,46 & 698,68 & 94,38 & 5,69 & 53,15 & 277,95 & 44,20 & 45,22 & 273,87 \\
\hline Pelodytes ibericus & $29 S P D 70$ & 101,00 & 168,47 & 116,41 & 39,00 & 5985,76 & 339,92 & 46,32 & 293,60 & 102,76 & 246,63 & 247,24 & 94,58 & 521,55 & 72,42 & 4,00 & 51,71 & 202,79 & 34,94 & 35,31 & 192,28 \\
\hline Pelodytes ibericus & 29SPD71 & 100,00 & 168,40 & 116,38 & 39,05 & 5976,06 & 339,55 & 46,77 & 292,79 & 102,82 & 246,31 & 247,10 & 94,75 & 533,62 & 73,51 & 4,00 & 51,58 & 207,55 & 35,67 & 36,27 & 197,40 \\
\hline Pelodytes ibericus & 29SPD72 & 101,00 & 167,95 & 115,53 & 39,09 & 5969,52 & 338,12 & 47,37 & 290,75 & \begin{tabular}{|l|l|}
102,45 \\
\end{tabular} & 245,99 & 246,49 & 94,50 & 549,09 & 74,84 & 4,03 & 51,63 & 214,01 & 36,08 & 36,81 & 204,42 \\
\hline Pelodytes ibericus & 29SPD74 & 101,00 & 160,95 & 109,50 & 38,06 & 5989,27 & 328,78 & 45,17 & 283,62 & 96,34 & 239,74 & 240,83 & 88,44 & \begin{tabular}{|l|l|}
626,49 \\
\end{tabular} & 83,05 & $\begin{array}{l}5,03 \\
\end{array}$ & 51,66 & 245,22 & 40,97 & 41,77 & 237,36 \\
\hline Pelodytes ibericus & 29SPD82 & 100,00 & 167,14 & 115,38 & 38,95 & 6039,30 & 339,05 & 45,73 & 293,31 & 101,06 & 246,31 & 246,66 & 93,00 & 532,86 & 72,48 & 4,00 & 51,25 & 206,41 & 35,04 & 35,95 & 195,55 \\
\hline Pelodytes ibericus & 29SPD83 & 100,00 & 164,86 & 113,41 & 38,41 & 6057,41 & 336,19 & 44,88 & 291,31 & \begin{tabular}{|l|l|}
98,84 \\
\end{tabular} & 244,34 & 244,99 & 90,78 & 559,73 & 75,01 & 4,28 & 51,20 & 216,95 & 36,56 & 37,66 & 206,87 \\
\hline Pelodytes ibericus & $29 S Q A 28$ & 14,00 & 178,46 & 86,77 & 37,23 & 4954,31 & 301,69 & 73,00 & 228,69 & 152,23 & 240,62 & 243,69 & 116,85 & 536,15 & 83,08 & 1,00 & 65,62 & 234,08 & 14,00 & 22,00 & 214,69 \\
\hline Pelodytes ibericus & 29SQA29 & 85,00 & 178,83 & 87,79 & 37,13 & 5027,68 & 304,23 & 72,22 & 232,02 & 143,22 & 241,99 & 245,02 & 116,11 & 528,25 & 81,26 & 1,00 & 64,74 & 230,03 & 14,15 & 22,00 & 210,30 \\
\hline Pelodytes ibericus & $\begin{array}{l}295 \mathrm{LAA3} 5 \\
2 \mathrm{SQA35}\end{array}$ & $\begin{array}{l}25,00 \\
24,00 \\
\end{array}$ & 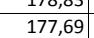 & $\begin{array}{l}\mid l, 1 / 1 \\
83,83\end{array}$ & $\begin{array}{l}1,15 \\
38,69 \\
\end{array}$ & $\begin{array}{l}3023,100 \\
453,21\end{array}$ & \begin{tabular}{|l|l|}
290,25 \\
291,17
\end{tabular} & 77,52 & $\begin{array}{l}23,04 \\
213,66\end{array}$ & $\begin{array}{l}4,2<5 \\
155,45\end{array}$ & $\begin{array}{l}24,39 \\
234,41\end{array}$ & $\begin{array}{l}2438,02 \\
238,17\end{array}$ & $\begin{array}{l}110,11 \\
122,10\end{array}$ & $\begin{array}{l}520,23 \\
557,24\end{array}$ & 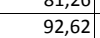 & $\begin{array}{l}1,000 \\
0,00\end{array}$ & $\begin{array}{ll}64,28 \\
67,28\end{array}$ & \begin{tabular}{|l|l|}
248,90 \\
248
\end{tabular} & $\begin{array}{l}\mid 4,13 \\
12,69\end{array}$ & 20,00 & 230,62 \\
\hline Pelodytes ibericus & 29SQA36 & 95,00 & 177,07 & 84,66 & 38,31 & 4649,30 & 293,27 & 75,19 & 218,08 & 153,02 & 235,24 & 238,90 & 119,87 & 554,28 & 90,71 & 0,00 & 66,75 & 246,68 & 13,00 & 20,40 & 228,02 \\
\hline Pelodytes ibericus & 29SQA37 & 70,00 & 177,22 & 84,36 & 37,45 & 4807,11 & 296,27 & 74,12 & 222,15 & 152,46 & 237,56 & 241,03 & 117,86 & 551,16 & 87,79 & 0,53 & 65,83 & 242,48 & 13,59 & 21,43 & 223,57 \\
\hline Pelodytes ibericus & 29SQA38 & 99,00 & 178,11 & 85,82 & 37,06 & 4961,88 & 301,15 & 73,00 & 228,15 & 152,06 & 240,71 & 243,84 & 116,70 & 544,02 & 84,41 & 1,0 & 65,20 & 236,98 & 14,46 & 22,00 & 217,83 \\
\hline Pelodytes ibericus & 29SQA39 & 100,00 & 178,93 & 88,43 & 37,01 & 5120,94 & 306,79 & 71,23 & 235,55 & 143,96 & 243,43 & 246,48 & 115,26 & 540,45 & 82,58 & 1,00 & 64,61 & 233,88 & 14,96 & 22,00 & 214,68 \\
\hline Pelodytes ibericus & 29SQA45 & 69,00 & 176,93 & 76,35 & 36,36 & 4649,63 & 286,27 & 79,15 & 207,12 & 153,94 & 234,81 & 238,93 & 119,44 & 587,01 & 95,92 & 0,38 & 66,81 & 255,15 & 13,02 & 21,31 & 237,94 \\
\hline Pelodytes ibericus & $29 S Q A 46$ & 101,00 & 175,51 & 79,22 & 36,27 & 4778,15 & 290,15 & 74,90 & 215,25 & 151,44 & 235,35 & 239,28 & 116,57 & 579,61 & 92,91 & 0,65 & 66,18 & 252,08 & 13,88 & 21,77 & 234,53 \\
\hline Pelodytes ibericus & 29SQA47 & 99,00 & 176,25 & 80,88 & 35,97 & 4931,20 & 295,24 & 73,49 & 221,75 & 150,49 & 238,23 & 241,92 & 115,29 & 568,75 & 88,95 & 0,97 & 65,60 & 246,05 & 14,79 & 21,97 & 227,88 \\
\hline Pelodytes ibericus & 29SQA48 & 99,00 & 177,43 & 83,96 & 36,08 & 5077,41 & 301,60 & 72,08 & 229,52 & 148,23 & 241,44 & 244,77 & 114,47 & 561,33 & 86,13 & 1,00 & 65,01 & 241,91 & 15,03 & 22,02 & 223,48 \\
\hline Pelodytes ibericus & 29SQA52 & & & & & & & & & & & & & & & & & & & & \\
\hline Pelodytes ibericus & 29SQA53 & 100,00 & 1777,64 & 70,43 & 35,65 & 4493,07 & 279,11 & 84,29 & 194,82 & 143,26 & 232,93 & 237,52 & 121,50 & 635,77 & 110,43 & 1,00 & 69,06 & 277,45 & 13,16 & 23,23 & 262,34 \\
\hline Pelodytes ibericus & 29SQA54 & 93,00 & 177,06 & 70,42 & 34,92 & 4627,92 & 281,23 & 82,24 & $\begin{array}{l}198,99 \\
\end{array}$ & $\begin{array}{l}49,203 \\
149,73\end{array}$ & 234,27 & 238,95 & 119,38 & 623,61 & 105,06 & 1,00 & 68,15 & 269,05 & 13,48 & 23,19 & 253,37 \\
\hline Pelodytes ibericus & 29SQA55 & 100,00 & 176,14 & 71,50 & 34,46 & 4748,96 & 283,85 & 79, & 204,45 & 150,89 & 235,24 & 239,52 & 117,14 & \begin{tabular}{|l|l|}
611,03 \\
\end{tabular} & 99,24 & 1,00 & 67,15 & 261,72 & 14,25 & 22,82 & 245,79 \\
\hline Pelodytes ibericus & 29SQA56 & 100,00 & 173,87 & 72,93 & 33,94 & 4924,18 & 286,72 & 74,69 & 212,03 & 144,30 & 235,60 & 239,56 & 112,85 & 606,72 & 95,02 & 1,00 & 65,93 & 257,52 & 15,55 & 23,43 & 241,52 \\
\hline Pelodytes ibericus & 29SQA57 & 100,00 & $\begin{array}{l}174,19 \\
174,\end{array}$ & 75,94 & 34,00 & $\begin{array}{l}4524,10 \\
5074,94\end{array}$ & $\begin{array}{l}\mid 000,1< \\
292,53 \\
\end{array}$ & 72,25 & $\begin{array}{l}21,03 \\
220,28\end{array}$ & $\begin{array}{l}144,56 \\
137,56\end{array}$ & $\begin{array}{l}23,001 \\
238,01\end{array}$ & $\begin{array}{l}\mid 241,78 \\
241\end{array}$ & $\begin{array}{l}11,03 \\
111,32\end{array}$ & $\begin{array}{l}590,1,55 \\
59,5\end{array}$ & $\begin{array}{l}30,0<3 \\
90,93\end{array}$ & $\begin{array}{l}1,000 \\
1,00\end{array}$ & $\begin{array}{l}65,40 \\
65,47\end{array}$ & | 252,01 & $\begin{array}{l}\mid l,, 30 \\
16,14\end{array}$ & $\begin{array}{l}23,45 \\
23,23\end{array}$ & 235,14 \\
\hline Pelodytes ibericus & 29SQA58 & 101,00 & 175,78 & 81,62 & 34,94 & 5197,06 & 300,87 & 70,73 & 230,14 & 126,74 & 241,48 & 244,90 & 111,45 & 585,37 & 88,62 & 1,00 & 65,05 & 248,94 & 16,59 & 22,96 & 231,55 \\
\hline Pelodytes ibericus & 29SQA61 & 69,00 & 173,72 & 74,04 & 37,77 & 4251,75 & 275,40 & 81,89 & 193,51 & \begin{tabular}{|l|l|}
129,78 \\
\end{tabular} & 226,25 & 230,55 & 120,81 & 723,45 & 126,98 & 0,92 & 71,45 & 326,94 & 14,62 & 23,06 & 313,23 \\
\hline Pelodytes ibericus & 29SQA63 & 91,00 & 174,26 & 71,55 & 35,73 & 4530,08 & 278,14 & 80 & 198 & 127,05 & 230,42 & 234,79 & 1117,85 & 680,79 & 116,33 & 1,0 & 69,49 & 299,66 & 14,39 & 23,80 & 284,77 \\
\hline Pelodytes ibericus & 29SQA64 & 82,00 & 17 & 71,6 & 34,77 & 4697,90 & 280,25 & 77 & 202,98 & 123, & 231 & 235,93 & 114,68 & 667 & 111,07 & 1,0 & 68, & 289,70 & 14,79 & 24,00 & 274,71 \\
\hline Pelodytes ibericus & 29SQA65 & 87,00 & 173,45 & 71,17 & 33,89 & 4832,19 & 282,94 & 76,20 & 206,74 & 123,52 & 233,76 & 237,93 & 113,34 & 646,16 & 104,12 & 1,00 & 67,41 & 276,87 & 15,43 & 23,97 & 261,60 \\
\hline Pelodytes ibericus & 29SQA66 & 81,00 & 172,10 & 71,69 & 33,18 & 5004,39 & 285,84 & 72,94 & 212,90 & 120,75 & 234,93 & 238,95 & 110,16 & 634,60 & 98,66 & 1,00 & 66,61 & 268,96 & 16,27 & 24,00 & 253,05 \\
\hline Pelodytes ibericus & 29SQA67 & 74,00 & 172,12 & 74,46 & 33,22 & 5156,09 & 291,14 & 70,57 & 220,57 & 117,32 & 237,22 & 241,03 & 108,40 & 622,43 & 94,41 & 1,00 & 65,77 & 262,61 & 17,00 & 23,99 & 245,97 \\
\hline Pelodytes iberic & 29SQA68 & 77,00 & 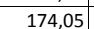 & 20 & 34,77 & 21 & 301,26 & 68,74 & 232,53 & 117,69 & 241,00 & 244,45 & 108,83 & 609 & 92,02 & $1, \mathrm{C}$ & 65,39 & 258,86 & 17,01 & 23,36 & 241,70 \\
\hline Pelodytes ibericus & 29SQA69 & 71,00 & & 89,5 & 36,24 & 5386,12 & & 68,35 & 243,82 & 119,56 & 245, & 248,96 & 110,91 & 592, & 89,20 & 1,1 & 65, & 252,94 & 17,00 & 23,00 & 235,42 \\
\hline Pelodytes ibericus & 29SQBO0 & 46,00 & 176,74 & 85,34 & 37,00 & 5008,82 & 299,92 & 71,94 & 227,98 & 123,20 & 239,08 & 242,08 & 114,04 & 511,26 & 79,38 & 1,00 & 64,36 & 221,58 & 14,00 & 23,00 & 200,42 \\
\hline Pelodytes ibericus & 29SQB01 & 100,00 & 177,03 & 85,80 & 36,91 & 5086,65 & 301,93 & 71,36 & 230,57 & 128,89 & 240,26 & 243,19 & 113,39 & 505,93 & 78,73 & 1,00 & 63,83 & 218,10 & 14,01 & 23,13 & 196,75 \\
\hline Pelodytes ibericus & $29 S Q B 02$ & 100,00 & 175,71 & 87,83 & 36,78 & 211,77 & 304,69 & 68,22 & 236,47 & 121,68 & 240,67 & 243,42 & 110,32 & 511,72 & 79,20 & 1,00 & 63,09 & 218,53 & 14,72 & 23,99 & 197,38 \\
\hline Pelodytes ibericus & 29SQB03 & 100,00 & 176 , & 90,04 & 36,9 & 312 & 300 & 67,62 & 241,5 & 130,20 & 243,06 & 245 & \begin{tabular}{|c|}
110,08 \\
\end{tabular} & 505 , & 78 , & 1,00 & 62, & 214 & 15,01 & 23,97 & 193 \\
\hline \begin{tabular}{|l} 
Pelodytes ibericus \\
\end{tabular} & 29SQBOA & 100,00 & 175,53 & 93,34 & 37,02 & 5425,44 & 312,93 & 64,53 & 248,41 & 120,14 & 243,71 & 246,19 & 107,63 & 511,63 & $\mid 78,33$ & 1,29 & 61,96 & $\begin{array}{l}214,5,68 \\
215\end{array}$ & $\begin{array}{l}\mid l, 0,04 \\
16,04\end{array}$ & 24,62 & $\begin{array}{l}195,00 \\
195,76\end{array}$ \\
\hline
\end{tabular}




\begin{tabular}{|c|c|c|c|c|c|c|c|c|c|c|c|c|c|c|c|c|c|c|c|c|c|}
\hline TAXON & UTM & $\mathrm{km} 2$ & BIO1 & B102 & $\mathrm{BIO3}$ & B104 & B105 & B106 & B107 & B108 & B109 & BIO10 & B1011 & BIO12 & B1013 & B1014 & 81015 & B1016 & B1017 & B1018 & B1019 \\
\hline Pelodytes ibericus & 29SQB05 & 101,00 & 169,79 & 97,85 & 37,29 & 5573,42 & 314,27 & 56,43 & 257,84 & 109,60 & 240,50 & 242,85 & 100,61 & 543,49 & 81,20 & 2,00 & 60,59 & 226,67 & 19,23 & 27,11 & 208,41 \\
\hline Pelodytes ibericus & 295QBOB & 101,00 & 165,53 & 101,65 & 37,97 & 5683,37 & 315,98 & 50,49 & 265,49 & \begin{tabular}{|l|l|l|}
104,53 \\
\end{tabular} & 238,24 & 240,44 & 95,45 & 566,49 & 83,17 & 2,01 & 59,96 & 234,53 & 21,17 & 28,32 & 217,67 \\
\hline Pelodytes ibericus & 295QBOB & 100,00 & 164,82 & 104,21 & 38,00 & 5762,46 & 319,25 & 48,34 & 270,91 & 102,79 & 238,75 & 240,87 & 93,82 & 569,38 & 82,77 & 2,29 & 59,36 & 234,26 & 22,28 & 28,82 & 218,29 \\
\hline Pelodytes ibericus & 29SQB08 & 100,00 & 163,17 & 106,56 & 38,00 & 5835,67 & 321,68 & 45,53 & \begin{tabular}{|l|l|}
276,15 \\
\end{tabular} & 100,43 & 238,34 & 240,40 & 91,52 & 576,80 & 82,82 & 2,68 & 58,52 & 235,69 & 23,96 & 29,93 & 220,70 \\
\hline Pelodytes ibericus & 29SQB09 & 101,00 & 149,98 & 109,34 & 38,00 & 5955,40 & 315,23 & 31,79 & 283,43 & 86,71 & 227,37 & 229,53 & 77,75 & 655,52 & 90,98 & 3,83 & 57,21 & 264,65 & 30,41 & 35,23 & 252,11 \\
\hline Pelodytes ibericus & 29SQB10 & 96,00 & 177,80 & 87,58 & 37,01 & 5066,93 & 303,78 & 71,44 & 232,34 & 130,63 & 241,16 & 244,08 & 114,66 & 518,74 & 80,20 & 1,00 & 64,27 & 224,79 & 14,00 & 22,93 & 204,25 \\
\hline Pelodytes ibericus & 29SQB11 & 100,00 & 178,60 & 89,13 & 37,01 & 5175,99 & 307,72 & 70,57 & 237,15 & 130,95 & 243,40 & 246,23 & 113,90 & 513,12 & 79,52 & 1,00 & 63,83 & 220,93 & 14,38 & 23,00 & 200,28 \\
\hline Pelodytes ibericus & 29SQB12 & 99,00 & 177,09 & 91,82 & 37,01 & 5318,58 & 311,16 & 67,03 & 244,13 & 119,89 & 244,00 & 246,56 & 110,55 & 519,52 & 80,10 & 1,00 & 63,16 & 221,75 & 15,04 & 23,39 & 201,42 \\
\hline Pelodytes ibericus & 29SQB13 & 101,00 & 175,23 & 94,79 & 37,05 & 5452,54 & 314,19 & 62,94 & 251,25 & 116,11 & 244,04 & 246,46 & 107,10 & 528,76 & 80,87 & 1,01 & 62,52 & 224,05 & 15,94 & 24,02 & 204,34 \\
\hline Pelodytes ibericus & 29SQB14 & 100,00 & 177,04 & 97,18 & 37,40 & 5528,40 & 319,21 & 63,27 & 255,94 & \begin{tabular}{ll|}
117,12 \\
\end{tabular} & 247,02 & 249,25 & 108,02 & 518,64 & 79,16 & 1,11 & 62,08 & 218,60 & 16,14 & 24,15 & 199,43 \\
\hline Pelodytes ibericus & 29SQB17 & 101,00 & 163,36 & 107,06 & 38,00 & 5877,79 & 322,84 & 44,57 & 278,27 & 99,97 & 239,10 & 241,08 & 90,98 & 589,06 & 85,03 & 2,50 & 59,22 & 241,64 & 23,35 & 29,53 & 226,20 \\
\hline Pelodytes ibericus & 29SQB19 & 99,00 & 151,81 & 111,03 & 38,00 & 6028,69 & 319,92 & 31,80 & 288,13 & 87,58 & 230,39 & 232,23 & 78,65 & 649,94 & 90,32 & 3,61 & 57,35 & 262,00 & 29,59 & 34,50 & 249,20 \\
\hline Pelodytes ibericus & 29SQB21 & 101,00 & 179,80 & 92,42 & 37,20 & 5285,69 & 313,51 & 69,27 & 244,24 & 131,97 & 246,44 & 249,12 & 113,76 & 522,48 & 80,46 & 1,00 & 63,68 & 224,48 & 15,00 & 22,31 & 204,82 \\
\hline Pelodytes ibericus & $29 S Q B 22$ & 100,00 & 178,30 & 95,58 & 37,40 & 5428,78 & 317,33 & 65,47 & 251,87 & 119,33 & 247,04 & 249,51 & 110,55 & 529,87 & 81,28 & 1,00 & 63,28 & 226,09 & 15,47 & 22,99 & 206,78 \\
\hline Pelodytes ibericus & 29SQB24 & 100,00 & 175,60 & 101,94 & 37,95 & 5673,27 & 325,06 & 58,67 & 266,40 & $\begin{array}{ll}114,06 \\
\end{array}$ & 248,11 & 250,25 & 104,99 & 543,60 & 81,97 & 1,36 & 61,76 & 228,44 & 18,02 & 24,99 & 210,41 \\
\hline Pelodytes ibericus & $29 S Q B 25$ & 99,00 & 170,63 & 105,14 & 37,99 & 5800,16 & 325,97 & 51,97 & 274,00 & 107,85 & 245,09 & 247,13 & 98,82 & 567,97 & 84,15 & 1,98 & 60,84 & 236,44 & 20,20 & 26,87 & 219,51 \\
\hline Pelodytes ibericus & 29SQB29 & 100,00 & 158,47 & 112,97 & 38,00 & 6098,34 & 328,68 & 36,09 & 292,59 & $\begin{array}{l}92,97 \\
\end{array}$ & 237,91 & 239,45 & 83,95 & 619,05 & 86,71 & 3,20 & 57,68 & 249,70 & 27,20 & 32,28 & 236,40 \\
\hline Pelodytes ibericus & $29 S Q B 35$ & 101,00 & 175,74 & 109,07 & 38,05 & 5890,17 & 336,24 & 54,13 & 282,11 & 111,61 & 251,58 & 253,33 & 102,63 & 558,45 & 83,11 & 1,74 & 61,18 & 233,21 & 19,53 & 25,44 & 216,83 \\
\hline Pelodytes ibericus & 29SQB37 & 100,00 & 165,23 & 112,90 & 38,01 & 6067,55 & 333,76 & 42,02 & 291,74 & 99,63 & 243,99 & 245,63 & 90,71 & 602,17 & 86,41 & 2,31 & 59,48 & 246,70 & 23,48 & 28,98 & 232,27 \\
\hline Pelodytes ibericus & 29SQB38 & 101,00 & 165,25 & 114,19 & 38,03 & 6120,83 & 336,06 & 41,25 & 294,81 & 99,12 & 244,91 & 246,42 & 90,10 & 596,49 & 84,86 & 2,55 & 58,82 & 242,79 & 24,17 & 29,42 & 228,80 \\
\hline Pelodytes ibericus & 29SQB43 & 100,00 & 180,23 & 108,01 & 38,05 & 5804,21 & 338,22 & 59,06 & 279,16 & \begin{tabular}{|c|}
117,10 \\
\end{tabular} & 254,92 & 256,92 & 108,11 & 558,84 & 84,54 & 1,00 & 62,92 & 237,05 & 17,80 & 23,23 & 220,29 \\
\hline \begin{tabular}{|l} 
Pelodytes ibericus \\
\end{tabular} & 295QB44 & 101,00 & $\begin{array}{l}180,49 \\
180,4\end{array}$ & 111,05 & 38,36 & 5900,58 & $\mid 342,96$ & 57,41 & 285,55 & $\begin{array}{l}116,18 \\
116,18\end{array}$ & 256,64 & 258,40 & \begin{tabular}{|l|l|}
107,23 \\
\end{tabular} & $\mid 556,03$ & 83,69 & $\begin{array}{l}1,12 \\
1,12\end{array}$ & 62,60 & 234,70 & 18,32 & 23,41 & 218,49 \\
\hline Pelodytes ibericus & 29SQB45 & 99,00 & 179,99 & 113,45 & 38,61 & 5980,75 & 346,22 & 55,51 & 290,71 & 114,92 & 257,41 & 259,01 & 105,74 & 555,42 & 82,92 & 1,41 & 61,79 & 232,99 & 18,81 & 24,00 & 217,38 \\
\hline Pelodytes ibericus & 29SQB54 & 100,00 & 179,52 & 116,15 & 38,86 & 6034,62 & 349,50 & 53,49 & 296,01 & 113,93 & 257,94 & 259,54 & 104,97 & 580,19 & 86,72 & 1,33 & 62,52 & 245,06 & 19,19 & 23,63 & 230,07 \\
\hline Pelodytes ibericus & 29SQB55 & 100,00 & 182,80 & 117,92 & 38,98 & 6077,18 & 354,84 & 55,47 & 299,36 & 116,50 & 261,79 & 263,16 & 107,47 & 559,71 & 83,53 & 1,13 & 62,24 & 235,80 & 18,43 & 23,01 & 221,17 \\
\hline Pelodytes ibericus & 295QB58 & 100,00 & 164,45 & 119,16 & 38,45 & 6288,16 & 342,96 & 37,21 & 305,74 & 96,54 & 246,97 & 248,00 & 87,55 & \begin{tabular}{|c|c|}
621,15 \\
\end{tabular} & 87,10 & 2,57 & 59,09 & 252,23 & 24,62 & 29,52 & 239,62 \\
\hline Pelodytes ibericus & $295 Q B 59$ & 100,00 & 161,72 & 119,53 & 38,08 & 6337,03 & 341,97 & 34,20 & 307,77 & 93,37 & \begin{tabular}{|l|l|}
244,95 \\
\end{tabular} & 245,92 & 84,36 & \begin{tabular}{ll|}
626,22 \\
\end{tabular} & 86,57 & 2,97 & 58,34 & 251,97 & 25,99 & 30,74 & 239,89 \\
\hline Pelodytes ibericus & $295 \mathrm{SaB63}$ & 57,00 & 184,32 & 116,90 & 39,00 & 5995,94 & 353,94 & 58,03 & 295,91 & \begin{tabular}{|l|l|}
119,06 \\
\end{tabular} & 262,14 & 263,82 & 110,10 & 574,31 & 86,98 & 1,00 & 63,84 & 245,33 & 18,05 & 22,11 & 230,18 \\
\hline Pelodytes ibericus & 29SQB699 & 40,00 & \begin{tabular}{|l|l|}
164,02 \\
\end{tabular} & 121,00 & 38,38 & 6377,10 & 346,10 & 35,40 & 310,70 & 95,05 & 247,85 & 248,63 & \begin{tabular}{|l|}
86,07 \\
\end{tabular} & 620,57 & 85,65 & 2,72 & 58,52 & 249,95 & 25,08 & 29,77 & 238,12 \\
\hline Pelodytes ibericus & $29 S Q C 00$ & 100,00 & 152,57 & 110,61 & 38,01 & 5987,54 & 319,70 & 33,50 & 286,20 & 88,75 & 230,46 & 232,42 & 79,85 & 634,96 & 88,02 & 3,70 & 56,71 & 255,20 & 30,10 & 34,59 & 242,76 \\
\hline Pelodytes ibericus & $295 \mathrm{Sac01}$ & 100,00 & 150,73 & 111,68 & 38,02 & 6030,24 & 320,13 & 31,31 & 288,82 & 86,57 & 229,46 & 231,34 & 77,71 & 643,26 & 88,33 & 4,06 & 56,03 & 256,93 & 31,92 & 35,85 & 245,11 \\
\hline Pelodytes ibericus & $295 \mathrm{SC} 10$ & $\begin{array}{l}101,00 \\
100\end{array}$ & \begin{tabular}{|l|l|}
157,87 \\
157
\end{tabular} & $\begin{array}{l}\mid 11,00 \\
112,11\end{array}$ & 38,00 & $\begin{array}{l}00052,92 \\
6052,92\end{array}$ & \begin{tabular}{|l|l|}
326,94 \\
326,5
\end{tabular} & | $31,7,77$ & $\begin{array}{l}200,02 \\
290,16\end{array}$ & $\begin{array}{l}00,31 \\
92,90\end{array}$ & $\begin{array}{l}23,40 \\
236,66\end{array}$ & 238,34 & 84,15 & $\begin{array}{l}64,20 \\
608,89\end{array}$ & $\begin{array}{l}80,03 \\
85,03 \\
\end{array}$ & $\begin{array}{l}4,200 \\
3,21\end{array}$ & $\begin{array}{l}0,0312 \\
57,12\end{array}$ & $\mid \begin{array}{l}\mid 244,71 \\
24,71\end{array}$ & 27, 27,85 & 32,59 & 2431,55 \\
\hline Pelodytes ibericus & $295 \mathrm{SCC} 11$ & 100,00 & 148,36 & 113,07 & 38,00 & 6121,03 & 320,93 & 27,46 & 293,47 & 83,27 & 228,53 & 230,22 & 74,29 & 662,73 & 90,34 & 4,26 & 56,03 & 263,69 & 32,92 & 36,88 & 252,11 \\
\hline Pelodytes ibericus & $29 S Q C 20$ & 100,00 & 158,69 & 114,03 & 38,00 & 6141,20 & 330,86 & 35,80 & 295,06 & \begin{tabular}{|c|}
92,59 \\
\end{tabular} & 238,82 & 240,27 & 83,67 & 610,75 & 84,96 & 3,20 & 57,20 & 244,88 & 27,67 & 32,37 & 231,93 \\
\hline Pelodytes ibericus & $29 S Q C 22$ & 100,00 & 152,88 & 115,44 & 38,00 & 6225,07 & 329,21 & 29,54 & 299,66 & 86,07 & 234,56 & 235,86 & 77,28 & 632,78 & 85,95 & 3,97 & 55,60 & 250,05 & 31,60 & 35,43 & 238,19 \\
\hline Pelodytes ibericus & $295 \mathrm{SQC23}$ & 101,00 & 156,44 & 116,22 & 38,00 & 6236,16 & 333,51 & 32,47 & 301,04 & 89,36 & 238,35 & 239,41 & 80,62 & 605,30 & 82,13 & 3,85 & 55,16 & 238,15 & 30,84 & 34,48 & 226,19 \\
\hline Pelodytes ibericus & $295 Q C 25$ & 100,00 & 154,87 & 116,72 & 38,00 & 6296,31 & 333,94 & 30,57 & 303,37 & 86,94 & 237,62 & 238,51 & 78,50 & 601,18 & 80,36 & 4,00 & 53,84 & 233,81 & 32,68 & 35,64 & 222,19 \\
\hline Pelodytes ibericus & $295 \mathrm{SC} 26$ & 100,00 & 157,30 & 117,01 & 38,00 & 6306,67 & 336,74 & 32,57 & 304,17 & 89,24 & 240,27 & 241,01 & 80,60 & 579,70 & 77,33 & 4,01 & 53,38 & 224,33 & 32,31 & 35,03 & 212,53 \\
\hline Pelodytes ibericus & $29 S Q C 37$ & 100,00 & 160,43 & 117,97 & 38,00 & 6361,74 & 341,86 & 34,42 & 307,44 & 91,44 & 244,49 & 244,74 & 82,93 & 555,56 & 73,23 & 3,90 & 52,90 & 213,13 & 31,30 & 33,37 & 201,28 \\
\hline Pelodytes ibericus & $29 S Q C 43$ & 99,00 & 153,59 & 118,71 & 38,00 & 6402,55 & 336,23 & 27,05 & 309,17 & 84,79 & 238,25 & 238,89 & 75,83 & 627,77 & 83,65 & 3,95 & 55,26 & 245,14 & 31,36 & 35,11 & 233,95 \\
\hline Pelodytes ibericus & $295 \mathrm{CC} 48$ & 101,00 & 164,45 & 118,63 & 37,97 & $\begin{array}{l}6434,42 \\
642,\end{array}$ & 347,13 & 37,04 & 310,09 & $\begin{array}{l}94,36 \\
94,36\end{array}$ & 249,40 & 249,46 & 85,73 & 525,70 & $\mid 69,10$ & 3,06 & 52,98 & 200,26 & 28,72 & 29,29 & 188,50 \\
\hline Pelodytes ibericus & $29 S Q C 54$ & 100,00 & 153,33 & 119,90 & 38,00 & 6489,27 & 338,89 & 25,67 & 313,23 & 83,50 & 239,37 & 239,85 & 74,71 & 623,19 & 82,50 & 4,00 & 54,77 & 241,07 & 31,37 & 34,32 & 230,40 \\
\hline Pelodytes ibericus & $2950<56$ & 99,00 & 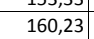 & 120,02 & 37,93 & 6499,58 & 345,58 & 31,79 & 313,79 & 89 & 246,42 & 246,50 & 81,13 & 566,80 & 74,75 & 3,33 & 53,84 & 216,93 & 29,53 & 31,24 & 205,91 \\
\hline Pelodytes ibericus & $29 S Q C 60$ & 32,00 & 155,24 & 120,45 & 38,00 & 6427,15 & 339,05 & 27, & 311, & 86,07 & 240,15 & 240,95 & 77,16 & 654,55 & 88,64 & 3,3 & 57,42 & 259,98 & 28,73 & 33,25 & 249,11 \\
\hline Pelodytes ibericus & 29SQD11 & 100,00 & 167,48 & 115,79 & 38,00 & 6236,47 & 344,04 & 43,37 & 300,67 & 99,24 & 249,51 & 249,55 & 90,87 & 497,77 & 66,39 & 3,17 & 51,52 & 190,39 & 30,01 & 30,95 & 277,96 \\
\hline Pelodytes ibericus & 29SQD21 & $\begin{array}{l}101,00 \\
\end{array}$ & \begin{tabular}{|l|}
167,54 \\
167
\end{tabular} & 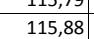 & 37,93 & \begin{tabular}{|l|l|}
$620,06,67$ \\
6307
\end{tabular} & \begin{tabular}{|l|l|}
344,04 \\
34566
\end{tabular} & 42, 42,66 & $\begin{array}{l}302,99 \\
302\end{array}$ & 98, 98,62 & $\begin{array}{l}24,30,56 \\
250,\end{array}$ & \begin{tabular}{|l|l|}
250,69 \\
250
\end{tabular} & $\begin{array}{l}90,15 \\
90,15\end{array}$ & | 493,85 & $\begin{array}{l}\mid 60,039 \\
65,03\end{array}$ & 3, 3 & $\begin{array}{ll}1,252 \\
51,52\end{array}$ & $\begin{array}{l}187,80 \\
187,\end{array}$ & $\begin{array}{l}30,01 \\
29,46\end{array}$ & 30,62 & 175,35 \\
\hline Pelodytes ibericus & $29 S Q D 22$ & 99,00 & 166,10 & 114,86 & 37,35 & 6329,11 & 344,38 & 41,63 & \begin{tabular}{|l|l}
302,75 \\
\end{tabular} & 96,99 & 249,73 & 249,83 & 88,67 & 500,07 & 65,06 & 3,38 & 50,77 & \begin{tabular}{|l|l|}
189,08 \\
\end{tabular} & 31,18 & 31,49 & 176,83 \\
\hline Pelodytes ibericus & 29SQD41 & 100,00 & 167,40 & 116,77 & 37,13 & 6444,88 & 349,11 & 40,70 & 308,41 & 96,92 & 252,81 & 252,81 & 88,49 & 488,53 & 63,47 & 3,01 & 51,48 & 183,45 & 28,49 & 28,51 & 171,45 \\
\hline Pelodytes ibericus & 29SQE32 & 100,00 & 157,19 & 108,24 & 36,26 & 6358,92 & 330,00 & 36,44 & 293,56 & 87,21 & 241 & 241,85 & 79,41 & 495,20 & 61,98 & 4, & 46,81 & 182,80 & 36,92 & 36,92 & 170,93 \\
\hline Pelodytes ibericus & 29SQE51 & 63,00 & 158,98 & 110,69 & 36,68 & 6427,51 & 334,89 & 36,06 & 298,83 & 88,21 & 244,68 & 244,68 & 80,34 & 454,36 & 55,83 & 4,50 & 46,13 & 164,21 & 34,23 & 34,23 & 151,88 \\
\hline Pelodytes ibericus & 30STE49 & & & & & & & & & & & & & & & & & & & & \\
\hline Pelodytes ibericus & 30STE59 & & & & & & & & & & & & & & & & & & & & \\
\hline Pelodytes ibericus & 30STE68 & & & & & & & & & & & & & & & & & & & & \\
\hline Pelodytes iberic & 30STE69 & 90,00 & 2 & 8 & 39,98 & 08,93 & 77,68 & 71,14 & 206,55 & 123,23 & 220,05 & 223,59 & 115,12 & 848,89 & 146,18 & 0,58 & 76,41 & 404,67 & 13,56 & 22,34 & 401,74 \\
\hline Pelodytes ibericus & 30STE79 & 80,00 & 165,85 & 86,17 & 40,60 & 4236,28 & 280,03 & 69,61 & 210,41 & 121,75 & 219,52 & 223,38 & 114,45 & 815,53 & 141,61 & 0,99 & 76,60 & 396,23 & 13,03 & 22,71 & 390,32 \\
\hline Pelodytes ibericus & 30STF 30 & 17,00 & 172,45 & 75,41 & 38,41 & 4164,14 & 274,41 & 81,00 & 193,41 & 129,27 & 224,23 & 228,09 & 120,68 & 769,41 & 134,77 & 0,41 & 72,95 & 352,82 & 14,77 & 22,41 & 340,09 \\
\hline Pelodytes ibericus & 30STF31 & 98,00 & 172,86 & 74,49 & 37,92 & 4225,17 & 274,71 & 80,89 & 193,82 & 129,00 & 225,26 & 229,20 & 120,17 & 756,80 & 131,74 & 0,44 & 72,26 & 344,73 & 14,59 & 22,62 & 331,52 \\
\hline Pelodytes ibericus & 30STF32 & 90,00 & 172,06 & 73,73 & 36,93 & 4378,73 & 275,79 & 78,71 & 197,08 & 126,41 & 226,50 & 230,49 & 117,51 & 741,70 & 127,34 & 1,00 & 71,14 & 333,93 & 15,08 & 23,50 & 320,08 \\
\hline Pelodytes ibericus & 30STF33 & 90,00 & 171, & & 35,9 & 150 & 278 & 76 & 201,77 & 123, & 228,06 & 232 & 114 & 724 & 122,30 & 1,00 & 70,20 & 322,57 & 15,14 & 23,99 & 307,85 \\
\hline \begin{tabular}{|l} 
Pelodytes ibericus \\
\end{tabular} & 30STF34 & 90,00 & 171,41 & 73,47 & 35,17 & 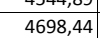 & 280,66 & 74,99 & 205,66 & 122,05 & 230,19 & 234,29 & \begin{tabular}{|l|}
113,12 \\
13
\end{tabular} & $\begin{array}{l}700,70 \\
\end{array}$ & 115,90 & 1,00 & $\frac{0,20}{69,12}$ & 308,26 & $\mid 15,67$ & 24,01 & 292,74 \\
\hline
\end{tabular}




\begin{tabular}{|c|c|c|c|c|c|c|c|c|c|c|c|c|c|c|c|c|c|c|c|c|c|}
\hline TAXON & UTM & $\mathrm{km2}$ & B101 & B1O2 & $\mathrm{BIO3}$ & B104 & B105 & B106 & 8107 & B108 & B109 & 81010 & B1011 & B1012 & B1013 & 81014 & B1015 & B1O16 & B1017 & B1018 & B1019 \\
\hline Pelodytes ibericus & 30STF35 & 81,00 & 172,92 & 73,12 & 34,53 & 4830,34 & 284,27 & 75,48 & 208,79 & 121,93 & 233,49 & 237,52 & 113,13 & 668,82 & 108,03 & 1,00 & 68,07 & 290,48 & 15,98 & 23,88 & 274,22 \\
\hline Pelodytes ibericus & 30STF36 & 80,00 & 171,69 & 75,24 & 34,32 & 5009,00 & 288,16 & 71,81 & 216,35 & 118,67 & 234,80 & 238,68 & 109,86 & 657,79 & 103,48 & 1,00 & 67,23 & 283,17 & 16,55 & 23,91 & 266,49 \\
\hline Pelodytes ibericus & 30STF39 & 70,00 & 176,77 & 91,58 & 36,60 & 5420,47 & 313,98 & 67,41 & 246,57 & 118,49 & 245,97 & 248,99 & 110,17 & 605,96 & 91,98 & 1,00 & 65,39 & 260,20 & 17,00 & 23,00 & 242,65 \\
\hline Pelodytes ibericus & 30STF40 & 79,00 & 170,05 & 77,24 & 38,86 & 4149,76 & 273,55 & 77,47 & 196,08 & 127,19 & 221,86 & 225,45 & 118,45 & 822,55 & 142,23 & 0,24 & 73,99 & 380,45 & 15,04 & 22,30 & 370,92 \\
\hline Pelodytes ibericus & 30STF41 & 100,00 & 172,72 & 74,78 & 38,32 & \begin{tabular}{ll|l|}
4162,68 \\
\end{tabular} & 273,71 & 80,79 & \begin{tabular}{ll|}
192,92 \\
\end{tabular} & 129,06 & \begin{tabular}{|l|l|}
224,63 \\
\end{tabular} & 228,16 & 120,80 & \begin{tabular}{|c|}
787,68 \\
\end{tabular} & 135,86 & 0,05 & 73,02 & 361,95 & 15,05 & 22,06 & 349,54 \\
\hline Pelodytes ibericus & 30STF42 & 100,00 & 172,28 & 74,59 & 37,45 & 4314,16 & 275,88 & 79,09 & 196,79 & 127,13 & 226,17 & 229,93 & 118,57 & 768,15 & 131,09 & 0,67 & 71,80 & 349,92 & 15,67 & 22,89 & 335,87 \\
\hline Pelodytes ibericus & 30STF43 & 100,00 & 171,37 & 75,07 & 36,61 & 4494,42 & 278,71 & 76,42 & 202,28 & 124,26 & \begin{tabular}{|l|l|}
227,63 \\
\end{tabular} & 231,55 & 115,70 & 748,11 & 125,94 & 1,00 & 70,66 & 337,59 & 15,96 & 23,63 & 322,29 \\
\hline Pelodytes ibericus & 30STF44 & 100,00 & 170,27 & 76,41 & 36,06 & 4680,85 & 282,25 & 73,23 & 209,02 & 121,12 & 229,12 & 233,04 & 112,49 & 729,53 & 120,67 & 1,00 & 69,77 & 326,03 & 16,01 & 24,01 & 309,93 \\
\hline Pelodytes ibericus & 30STF45 & 100,00 & 169,68 & 78,14 & 35,66 & 4861,25 & 286,50 & 70,68 & 215,82 & 118,62 & 231,10 & 234,95 & 109,92 & 708,52 & 114,95 & 1,00 & 68,80 & 313,47 & 16,20 & 24,13 & 296,85 \\
\hline Pelodytes ibericus & 30STF46 & 100,00 & 172,40 & 79,32 & \begin{tabular}{|l|l|}
35,49 \\
\end{tabular} & 4987,73 & 292,23 & 71,79 & 220,45 & 119,53 & 235,35 & 239,11 & 110,95 & 673,38 & 107,45 & 1,00 & 67,82 & 295,25 & 16,53 & 23,51 & 277,60 \\
\hline Pelodytes ibericus & 30STF47 & 100,00 & 171,66 & 83,90 & 35,81 & 5167,62 & 298,66 & 68,02 & 230,64 & 116,63 & 237,20 & 240,68 & 108,14 & 662,66 & 103,91 & 1,00 & 66,96 & 288,72 & 17,01 & 23,58 & 271,04 \\
\hline Pelodytes ibericus & 30STF50 & 100,00 & 168,95 & 78,27 & 39,21 & 4103,92 & 272,40 & 75,62 & 196,79 & 126,26 & 220,38 & 223,74 & 117,77 & 855,68 & $\begin{array}{ll}146,48 \\
\end{array}$ & 0,21 & 74,96 & 398,75 & 15,01 & 22,30 & 392,21 \\
\hline Pelodytes ibericus & 30STF51 & 100,00 & 167,76 & 78,74 & 38,64 & 4257,40 & 274,60 & 73,17 & 201,43 & 123,72 & 221,33 & 224,81 & 114,96 & 835,94 & 142,24 & 0,58 & 73,81 & 388,02 & 15,32 & 23,08 & 378,19 \\
\hline Pelodytes ibericus & 30STF52 & 100,00 & 169,60 & 77,73 & 38,01 & \begin{tabular}{ll|}
4336,43 \\
\end{tabular} & 276,87 & 74,98 & 201,89 & 124,45 & 224,16 & 227,73 & 116,00 & 802,55 & 136,23 & 0,89 & 72,62 & 371,01 & 15,89 & 23,25 & 357,32 \\
\hline Pelodytes ibericus & 30STF53 & 100,00 & 171,09 & 77,64 & 37,41 & 4455,91 & 280,34 & 75,76 & 204,58 & 124,36 & 227,16 & 230,82 & 116,13 & 768,19 & 129,70 & 1,00 & 71,54 & 353,12 & 16,00 & 23,21 & 336,74 \\
\hline Pelodytes ibericus & 30STF54 & 100,00 & 167,50 & 81,14 & 37,10 & 4709,99 & 284,60 & 68,95 & 215,66 & 118,41 & 227,11 & 230,79 & 109,68 & 760,61 & 125,99 & 1,00 & 70,60 & 346,04 & 16,13 & 24,07 & 329,51 \\
\hline Pelodytes ibericus & 30STF55 & 100,00 & 165,22 & 84,72 & \begin{tabular}{l|l|}
37,05 \\
\end{tabular} & 4918,91 & 289,35 & 63,82 & 225,53 & 113,95 & 227,76 & 231,43 & 105,18 & 749,39 & 121,80 & 1,00 & 69,44 & 337,26 & 17,08 & 24,59 & 320,86 \\
\hline Pelodytes ibericus & 30STF56 & 100,00 & 169,24 & 85,20 & 36,86 & 5007,16 & 295,14 & 67,15 & 227,99 & 116,47 & 232,86 & 236,40 & 108,03 & 708,52 & 114,43 & 1,00 & 68,59 & 316,82 & 16,82 & 23,70 & 298,76 \\
\hline Pelodytes ibericus & 30STF57 & 100,00 & 169,81 & 89,57 & 37,21 & 5177,85 & 302,29 & 64,88 & 237,41 & 114,88 & 235,72 & 239,06 & 106,60 & 688,84 & 109,76 & 1,00 & 67,71 & 305,73 & 17,10 & 23,52 & 287,59 \\
\hline Pelodytes ibericus & 30STF59 & 100,00 & 173,72 & 99,87 & \begin{tabular}{|l|l|}
38,37 \\
\end{tabular} & 5464,44 & 319,76 & 63,21 & 256,55 & 115,02 & 243,65 & 246,45 & 107,12 & 643,67 & 100,88 & 1,00 & 66,33 & 282,79 & 17,21 & 22,81 & 264,69 \\
\hline Pelodytes ibericus & 30STF60 & 100,00 & 163,12 & 85,08 & 39,39 & 4376,18 & 278,43 & 65,18 & 213,25 & 118,40 & 218,60 & 222,23 & 109,53 & 853,79 & \begin{tabular}{ll|}
144,88 \\
\end{tabular} & 0, & 75,37 & 403,55 & 14,45 & 23,76 & 398,62 \\
\hline Pelodytes ibericus & 30STF61 & 100,00 & 164,61 & 83,27 & 39,14 & 4365,90 & 278,12 & 67,86 & 210,26 & 120,64 & 219,93 & 223,56 & 111,16 & 840,99 & 143,07 & 1,00 & 74,27 & 396,99 & 15,20 & 23,82 & 386,95 \\
\hline Pelodytes ibericus & 30STF62 & 100,00 & 165,14 & \begin{tabular}{ll|}
82,93 \\
\end{tabular} & \begin{tabular}{|l|l|}
38,78 \\
\end{tabular} & \begin{tabular}{|l|l|}
4449,51 \\
\end{tabular} & 279,79 & 68,02 & 211,77 & 119,86 & 221,57 & 225,24 & 110,77 & 820,39 & 138,76 & 1,00 & 73,24 & 384,86 & 15,59 & 23,91 & 371,59 \\
\hline Pelodytes ibericus & 30STF63 & 100,00 & 164,08 & 84,68 & 38,34 & 4621,54 & 283,21 & 65,09 & 218,12 & 116,82 & 222,88 & 226,50 & 107,74 & 800,63 & 133,64 & 1,01 & 71,88 & 371,84 & 16,41 & 24,50 & 356,97 \\
\hline Pelodytes ibericus & 30STF64 & 100,00 & 153,75 & 92,74 & 38,40 & 5017,22 & 287,09 & 48,51 & 238,58 & 102,94 & 218,40 & 221,77 & 93,13 & 819,93 & 131,07 & 1,40 & 70,22 & 371,48 & 18,62 & 27,59 & 360,28 \\
\hline Pelodytes ibericus & 30STF65 & 100,00 & 165,30 & 87,84 & 37,91 & 4897,96 & 291,96 & 63,35 & 228,62 & 114,42 & 227,81 & 231,30 & 105,79 & 754,59 & 123,63 & 1,03 & 69,99 & 344,99 & 16,89 & 24,36 & 327,48 \\
\hline \begin{tabular}{|l} 
Pelodytes ibericus \\
\end{tabular} & 30STF66 & 100,00 & 165,34 & $\begin{array}{l}90,67 \\
90,4\end{array}$ & 37,88 & 5056,80 & 297,25 & $\begin{array}{ll}61,18 \\
61,\end{array}$ & \begin{tabular}{|l|}
236,06 \\
\end{tabular} & $\begin{array}{l}112,45 \\
112,4\end{array}$ & $\begin{array}{l}230,04 \\
\end{array}$ & 233,33 & \begin{tabular}{|l|l|}
103,99 \\
\end{tabular} & 737,02 & 119,37 & $\begin{array}{l}1,000 \\
1,00\end{array}$ & 69,04 & \begin{tabular}{|l|}
333,87 \\
\end{tabular} & 17,22 & 24,32 & 315,92 \\
\hline Pelodytes ibericus & 30STF67 & 100,00 & 168,90 & 93,03 & 38,08 & 5159,38 & 304,42 & 63,52 & 240,91 & 114,46 & 234,91 & 238,07 & 106,27 & 702,95 & 113,37 & 1,00 & 68,34 & 316,61 & 17,09 & 23,46 & 297,82 \\
\hline Pelodytes ibericus & 30STF69 & 100,00 & 172,93 & 102,83 & 39,14 & 5452,05 & 321,68 & 62,42 & 259,26 & 114,55 & 242,83 & 245,58 & 106,81 & 654,38 & 104,17 & 1,00 & 67,05 & 291,10 & 16,96 & 22,61 & 272,50 \\
\hline Pelodytes ibericus & 30STF70 & 100,00 & 170,76 & 82,27 & 40,56 & 4070,03 & 278,45 & 77,89 & 200,57 & 129,87 & 222,10 & 225,97 & 121,34 & 806,82 & 143,07 & 1,00 & 76,03 & 396,34 & 13,86 & 22,01 & 381,87 \\
\hline Pelodytes ibericus & 30STF71 & 100,00 & 168,40 & 83,23 & 40,00 & 4224,27 & 279,62 & 73,68 & 205,94 & 126,16 & 221,77 & 225,72 & 117,17 & 808,52 & 141,14 & 1,00 & 75,01 & 393,01 & 14,41 & 22,69 & 376,83 \\
\hline \begin{tabular}{|l} 
Pelodytes ibericus \\
\end{tabular} & 30STF72 & 100,00 & 166,30 & \begin{tabular}{|l|l|l|l|l|}
84,93 \\
\end{tabular} & 39,37 & 4410,77 & 282,35 & $\begin{array}{l}3,090 \\
69,29 \\
\end{array}$ & \begin{tabular}{|l|}
213,06 \\
\end{tabular} & \begin{tabular}{|l|l|}
121,98 \\
\end{tabular} & 222,38 & 226,13 & 112,89 & 800,83 & 137,35 & $\begin{array}{l}1,000 \\
1,00\end{array}$ & 73,74 & \begin{tabular}{|l|}
383,87 \\
\end{tabular} & 15,21 & 23,45 & 367,23 \\
\hline Pelodytes ibericus & 30STF73 & 100,00 & 163,52 & 87,45 & 39,04 & 4622,44 & 285,46 & 63,84 & 221,63 & 116,84 & 222,47 & 226,19 & 107,54 & 793,29 & 133,20 & 1,00 & 72,50 & 374,14 & 15,97 & 24,37 & 357,96 \\
\hline Pelodytes ibericus & 30STF75 & 100,00 & 157,73 & 94,24 & 38,77 & 5045,92 & 292,93 & 52,28 & 240,65 & 106,20 & 222,78 & 226,04 & 96,92 & 784,05 & 126,18 & 1,29 & 69,82 & 358,35 & 18,22 & 26,35 & 343,30 \\
\hline Pelodytes ibericus & 30STF76 & 100,00 & 162,57 & 94,47 & 38,71 & 5093,79 & 298,56 & 57,03 & 241,52 & 109,78 & 228,15 & 231,24 & 101,07 & 750,01 & 121,26 & 1,13 & 69,25 & 342,29 & 17,83 & 25,01 & 324,72 \\
\hline Pelodytes ibericus & $\begin{array}{l}\text { 30STF77 } \\
\end{array}$ & 100,00 & 158,26 & 99,27 & 38,87 & 5321,01 & 302,43 & 49,17 & 253,27 & 103,04 & 227,22 & 230,04 & 94,22 & 756,27 & 119,35 & 1,35 & 67,90 & 339,33 & 19,30 & 26,55 & 323,32 \\
\hline Pelodytes ibericuu & $\begin{array}{l}\text { 30STF79 } \\
\end{array}$ & 100,00 & $\begin{array}{l}130,20 \\
167,22\end{array}$ & $\begin{array}{l}304,85 \\
104,85\end{array}$ & 年0, & 5497,93 & 318,45 & $\begin{array}{l}45,57 \\
55,57\end{array}$ & $\begin{array}{l}263,24 \\
\end{array}$ & \begin{tabular}{|l|}
108,874 \\
\end{tabular} & 238,24 & 240,80 & \begin{tabular}{|l|}
$54,2<$ \\
100,88 \\
\end{tabular} & |580,97 & \begin{tabular}{|l|}
109,52 \\
\end{tabular} & $\begin{array}{l}1,130 \\
1,03\end{array}$ & 67,06 & \begin{tabular}{|l|l|}
308,04 \\
300,0
\end{tabular} & 17,85 & $\mid \begin{array}{l}\mid 2,330 \\
23,65\end{array}$ & 290,10 \\
\hline Pelodytes ibericus & 30STF80 & 43,00 & 175,91 & 82,28 & 41,56 & 3927,69 & 281,94 & 86,09 & 195,84 & 137,66 & 225,39 & 229,80 & 129,36 & 749,14 & 138,61 & 1,00 & 76,92 & 382,69 & 13,02 & 20,77 & 358,81 \\
\hline Pelodytes ibericus & 30STF81 & 100,00 & 173,15 & 83,09 & \begin{tabular}{|l|l|}
40,87 \\
\end{tabular} & 4074,54 & 282,17 & 81,16 & 201,01 & 133,03 & 224,64 & 228,83 & 124,45 & 760,43 & 137.52 & 1,00 & 75,86 & 382,20 & 13,55 & 21,39 & 358,96 \\
\hline Pelodytes ibericus & 30STF82 & 100,00 & 173,59 & 83,40 & 40,32 & 4196,64 & 284,72 & 80,30 & 204,42 & 131,67 & 226,76 & 230,81 & 123,30 & 749,50 & 133,75 & 1,00 & 74,76 & 371,99 & 14,12 & 21,54 & 348,06 \\
\hline Pelodytes ibericus & 30STF83 & 100,00 & 173,10 & 84,66 & 39,84 & 4358,86 & 287,95 & 77,71 & 210,25 & 129,07 & 228,36 & 232,25 & 120,63 & 739,53 & 129,64 & 1,00 & 73,58 & 361,28 & 14,88 & 21,88 & 337,73 \\
\hline Pelodytes ibericuu & 30STF84 & 100,00 & 159,27 & 93,11 & 39,21 & 4853,83 & 290,15 & 55,91 & 234,24 & 110,40 & 221,77 & 225,12 & 100,94 & 779,16 & 127,61 & 1,3 & 71,04 & 363,68 & 17,39 & 25,77 & 347,73 \\
\hline Pelodytes ibericus & 30STFE & 100,00 & 147,33 & 100,24 & 39,00 & 5242,53 & 291,33 & 37,85 & 253,47 & 94,49 & 215,79 & 218,57 & 84,58 & 816,53 & 126,63 & 2,14 & 68,67 & 367,17 & 21,33 & 30,02 & 356,10 \\
\hline Pelodytes ibericus & 30STF86 & 100,00 & 139,97 & 104,57 & 39,00 & 5481,88 & 291,96 & 26,83 & 265,13 & 84,45 & 212,01 & 214,44 & 74,54 & 840,73 & 126,14 & $2, \varepsilon$ & 66,86 & 369,18 & 24,63 & 33,24 & 359,97 \\
\hline Pelodytes ibericus & 30STF88 & 100,00 & 159,18 & 103,34 & 39,01 & 5441,13 & 308,69 & 47,81 & 260,88 & 102,47 & 229,94 & 232,45 & 93,75 & 739,03 & 116,06 & 1,46 & 67,26 & 330,99 & 19,64 & 26,47 & 314,51 \\
\hline Pelodytes ibericus & 30STF89 & 100,00 & 164,97 & 105,62 & 39,37 & 5509,10 & 317,27 & 52,51 & 264,76 & 106,85 & 236,40 & 238,74 & 98,66 & 703,42 & 111,41 & 1,05 & 67,10 & 314,99 & 18,34 & 24,40 & 297,42 \\
\hline Pelodytes ibericus & 30STF90 & & & & & & & & & & & & & & & & & & & & \\
\hline Pelodytes ibericus & 30STF91 & 39,00 & 176,17 & 83,33 & 41,17 & 4017,94 & 284,50 & 85,06 & \begin{tabular}{|l|}
199,44 \\
\end{tabular} & 137,06 & 226,75 & 231,21 & 128,54 & 719,27 & 131,94 & 1,00 & 76,06 & 365,92 & 13,00 & 20,62 & 341,06 \\
\hline Pelodytes ibericus & 30STF92 & 93,00 & 174,60 & 84,83 & 40,84 & 4174,83 & 286,67 & 81,19 & 205,48 & 133,55 & 227,43 & 231,57 & 124,91 & 713,66 & 128,04 & 1,00 & 74,88 & 357,33 & 13,87 & 21,17 & 333,13 \\
\hline Pelodytes ibericus & 30STF93 & 100,00 & 166,98 & 89,40 & 40,09 & 4514,49 & 288,77 & 68,36 & 220,41 & 122,21 & 224,76 & 22 & 113,05 & 735,55 & 125,81 & 1,13 & 72,92 & 18 & 15,45 & 23,38 & 336,01 \\
\hline Pelodytes ibericuu & 30 STFG & 100,00 & 15 & $\begin{array}{l}\mid 03,404 \\
94,59\end{array}$ & 39 & $\frac{4}{4}$ & $290,11,42$ & $\begin{array}{l}0,03,28 \\
55,\end{array}$ & $\begin{array}{l}23,414 \\
236,14\end{array}$ & $\begin{array}{l}\mid 22<, 21 \\
110,56\end{array}$ & \begin{tabular}{|l|}
221,89 \\
\end{tabular} & $\begin{array}{l}225,254 \\
226\end{array}$ & $\begin{array}{l}100,99 \\
100\end{array}$ & 759,01 & \begin{tabular}{|l|}
124,04 \\
124,04
\end{tabular} & $\begin{array}{l}\frac{1,113}{1,38} \\
\end{array}$ & 70,95 & $\mid$ & $\mid \begin{array}{l}17,45 \\
7,41\end{array}$ & $\begin{array}{l}25,68 \\
258\end{array}$ & 339,61 \\
\hline Pelodytes ibericus & 30STF96 & 100,00 & 140,76 & 105,24 & 39,02 & 5472,22 & 292,95 & 27,36 & 265,59 & 85,59 & 212,85 & 215,11 & 75,54 & 823,41 & 123,36 & 2,90 & 66,79 & 362,83 & 24,15 & 32,79 & 353,24 \\
\hline Pelodytes ibericuu & 30STF97 & 100,00 & 150,34 & $\begin{array}{l}103,86 \\
\end{array}$ & 39,00 & 5436,48 & 300,43 & 38,15 & 262,28 & \begin{tabular}{|l|l|}
94,78 \\
94,
\end{tabular} & 221,63 & 223,92 & 85,39 & $\mid 776,73$ & 119,36 & 2,20 & 67,05 & \begin{tabular}{|l|l|}
346,44 \\
\end{tabular} & 21,62 & 29,46 & 332,90 \\
\hline Pelodytes ibericus & 30STF98 & 100,00 & 156,77 & 104,40 & 39,06 & 5475,32 & 307,66 & 44,50 & 263,16 & 100,01 & 228,30 & 230,60 & 91,14 & 743,66 & 115,82 & 1,85 & 67,04 & 332,79 & 20,44 & 27,36 & 317,06 \\
\hline Pelodytes ibericus & 30STF99 & 100,00 & 162,62 & 106,09 & 39,23 & 5534,61 & 315,61 & 49,36 & 266,25 & 104,63 & 234,77 & 236,86 & 96,04 & 712,37 & 111,81 & 1,42 & 66,75 & 318,54 & 19,35 & 25,61 & 30 \\
\hline Pelodytes ibericus & 30STG43 & $\begin{array}{l}100,00 \\
\end{array}$ & $\begin{array}{l}102,02 \\
181,69\end{array}$ & $\begin{array}{l}119,12 \\
119,1\end{array}$ & | & | 6025,71 & $\begin{array}{l}31,01 \\
352,62\end{array}$ & $\begin{array}{l}5,30 \\
56,32\end{array}$ & \begin{tabular}{|l|}
296,30 \\
20
\end{tabular} & \begin{tabular}{|l|}
116,07 \\
116,0
\end{tabular} & 260,01 & $\begin{array}{l}25,00 \\
261,71\end{array}$ & \begin{tabular}{|r|}
107,65 \\
107
\end{tabular} & 592,01 & \begin{tabular}{|c|}
89,27 \\
89,27
\end{tabular} & $\begin{array}{l}\frac{1,44}{1,00} \\
\end{array}$ & $\begin{array}{l}00,1,06 \\
64,06\end{array}$ & \begin{tabular}{|l|}
253,86 \\
25,8
\end{tabular} & $\mid$ & \begin{tabular}{|l|l|}
22,01 \\
22
\end{tabular} & $\begin{array}{l}301,05 \\
238,95\end{array}$ \\
\hline Pelodytes ibericus & 30STG47 & 100,00 & 175,54 & 122,95 & 39,06 & 6315,07 & 356,46 & 45,87 & 310,59 & 106,78 & 258,24 & 259,07 & 97,82 & 593,90 & 84,53 & 1,76 & 60,90 & 245,11 & 20,94 & 25,34 & 232,64 \\
\hline Pelodytes ibericus & 30STG48 & 100,00 & 174,66 & 123,03 & 39,00 & 6355,98 & 356,75 & 44,67 & 312,08 & 105,38 & 258,06 & 258,77 & 96,49 & 588,01 & 82,80 & 2,04 & 60,20 & 240,29 & 21,39 & 25,70 & 228,30 \\
\hline Pelodytes ibericus & 30STG49 & 100,00 & 165,69 & 122,71 & 38,70 & 6434,94 & 349,90 & 35,92 & 313,99 & 95,88 & 250,41 & 251,07 & 87, & 620,24 & 85,77 & 2,65 & 58,86 & 249,59 & 24,31 & 29,03 & 238,44 \\
\hline Pelodytes ibericus & 30STG50 & 100,00 & 177,03 & 105,44 & 39,14 & 5583,52 & 329,56 & 63,59 & 265,97 & 116,68 & 248,59 & 251,21 & 108,93 & 618,46 & 96,50 & 1,00 & 66,22 & 271,26 & 16,58 & 21,61 & 253,39 \\
\hline
\end{tabular}




\begin{tabular}{|c|c|c|c|c|c|c|c|c|c|c|c|c|c|c|c|c|c|c|c|c|c|}
\hline TAXON & UTM & $\mathrm{km} 2$ & BIO1 & B102 & $\mathrm{BIO3}$ & B104 & B105 & B106 & B107 & B108 & B109 & BIO10 & B1011 & BIO12 & B1013 & B1014 & 81015 & B1016 & BIO17 & B1018 & B1019 \\
\hline Pelodytes ibericus & 30STG52 & 100,00 & 179,52 & 116,21 & 40,00 & 5879,30 & 345,52 & 58,86 & 286,67 & 115,59 & 255,52 & 257,48 & 107,74 & 601,59 & 91,87 & 1,00 & 64,81 & 260,75 & 17,60 & 21,60 & 244,58 \\
\hline Pelodytes ibericus & 30STG53 & 100,00 & 180,32 & 119,61 & 40,01 & 6004,94 & 350,80 & 56,53 & 294,27 & \begin{tabular}{|l|l|}
114,99 \\
\end{tabular} & 258,30 & 259,98 & 106,86 & \begin{tabular}{|l|l|}
598,05 \\
\end{tabular} & 90,15 & 1,00 & 64,34 & 257,19 & 18,00 & 22,09 & 242,00 \\
\hline Pelodytes ibericus & 30STG54 & 100,00 & $\begin{array}{l}\mid 178,92 \\
178,92\end{array}$ & $\mid 122,02$ & 40,00 & 6132,48 & 353,85 & 52,36 & 301,49 & $\mid 112,07$ & 258,86 & 260,17 & 103,72 & 603,02 & 89,54 & 1,00 & 63,51 & 256,85 & 18,41 & 22,61 & 242,78 \\
\hline Pelodytes ibericus & 30STG58 & 100,00 & 168,71 & 123,92 & 39,00 & 6427,23 & 353,35 & 38,44 & 314,92 & 99,08 & 253,38 & 254,00 & 90,12 & 621,32 & 87,25 & 2,01 & 59,98 & 252,34 & 22,64 & 27,19 & 241,33 \\
\hline Pelodytes ibericus & 30STG59 & 100,00 & 162,75 & 123,58 & 38,49 & 6489,78 & 349,12 & 32,60 & 316,52 & 92,60 & 248,53 & 249,06 & 83,68 & 639,22 & 88,46 & 2,57 & 58,97 & 255,99 & 24,94 & 29,09 & 245,75 \\
\hline Pelodytes ibericus & 30 STG60 & 100,00 & 174,76 & 108,79 & 39,92 & 5594,85 & 330,94 & 61,34 & 269,60 & 114,40 & 246,56 & 249,06 & 106,93 & 634,01 & 100,54 & 1,00 & 66,62 & 280,69 & 16,59 & 21,63 & 262,52 \\
\hline Pelodytes ibericus & 30STG61 & 100,00 & 176,62 & 114,36 & 40,43 & 5730,71 & 339,71 & 60,30 & 279,41 & 114,43 & 250,25 & 252,50 & 107,10 & 615,43 & 97,20 & 1,00 & 66,46 & 271,11 & 16,10 & 21,01 & 253,67 \\
\hline Pelodytes ibericus & 30STG68 & 100,00 & 168,27 & 124,46 & 38,92 & 6463,01 & 353,97 & 37,80 & 316,17 & 98,27 & 253,63 & 253,86 & 89,14 & 629,00 & 88,82 & 2,00 & 60,12 & 254,86 & 22,39 & 25,94 & 244,62 \\
\hline Pelodytes ibericus & 30STG69 & 100,00 & 158,30 & 123,72 & 38,13 & 6543,04 & 346,16 & 27,98 & 318,18 & \begin{tabular}{|l|l|}
87,73 \\
\end{tabular} & 245,06 & 245,34 & 78,92 & 664,30 & 91,73 & 2,86 & 58,72 & 264,30 & 26,15 & 28,46 & 255,15 \\
\hline Pelodytes ibericus & 30STG72 & 100,00 & 177,07 & 116,95 & 40,28 & 5847,54 & 343,72 & 58,04 & 285,68 & 113,66 & 252,76 & 254,48 & 106,05 & \begin{tabular}{|c|}
615,68 \\
\end{tabular} & 96,88 & 1,00 & 65,85 & 269,98 & 16,13 & 21,12 & 253,51 \\
\hline Pelodytes ibericus & 30STG73 & 100,00 & 178,72 & 118,97 & 40,22 & 5955,20 & 348,24 & 57,16 & 291,08 & 114,01 & 256,09 & 257,47 & 106,22 & 607,86 & 94,16 & 1,00 & 65,12 & 263,69 & 16,46 & 21,33 & 248,35 \\
\hline Pelodytes ibericus & 30 TTG85 & 100,00 & 176,23 & 121,39 & 39,94 & 6199,54 & 351,67 & 50,30 & 301,37 & 108,99 & 257,54 & 258,30 & 100,60 & 621,77 & 93,35 & 1,00 & 63,29 & 261,99 & 18,00 & 22,97 & 249,97 \\
\hline Pelodytes ibericus & 30STG94 & 100,00 & 176,66 & 118,32 & 39,97 & 6085,06 & 346,92 & 52,97 & 293,95 & 110,77 & 256,33 & 257,19 & 102,30 & 627,23 & 95,79 & 1,00 & 64,06 & 267,52 & 17,09 & 22,91 & 254,72 \\
\hline Pelodytes ibericus & 30STG95 & 100,00 & 176,31 & 120,07 & 39,50 & 6208,13 & 350,58 & 50,28 & 300,31 & 108,66 & 257,86 & 258,30 & 100,41 & 626,41 & 94,29 & 1,00 & 63,29 & 263,46 & 17,53 & 22,63 & 252,09 \\
\hline Pelodytes ibericus & 30STH40 & 100,00 & 160,71 & 122,37 & 38,23 & 6479,99 & 346,34 & 31,07 & 315,27 & \begin{tabular}{|l|l|}
90,63 \\
\end{tabular} & 246,38 & 246,83 & 81,72 & \begin{tabular}{|l|l|}
633,15 \\
\end{tabular} & 86,42 & 2,97 & 58,00 & 251,74 & 26,43 & 30,23 & 241,17 \\
\hline Pelodytes ibericus & 30STH43 & 100,00 & 152,44 & 121,60 & 38,00 & 6564,90 & 340,64 & 23,11 & 317,53 & \begin{tabular}{|l|l|}
81,97 \\
\end{tabular} & 239,73 & 240,03 & 72,92 & 641,43 & 85,26 & 4,01 & 55,44 & 247,99 & 30,97 & 34,01 & 238,21 \\
\hline Pelodytes ibericus & 30STH44 & 100,00 & 153,94 & 121,57 & 38,00 & 6575,79 & 342,36 & 24,53 & 317,83 & 83,12 & 241,33 & 241,64 & 74,22 & 622,99 & 82,48 & 4,00 & 54,88 & 239,42 & 30,72 & 33,11 & 229,57 \\
\hline Pelodytes ibericus & 30STH54 & 100,00 & 154,50 & 122,49 & 37,96 & 6634,03 & 344,70 & 23,91 & 320,79 & 82,82 & 243,02 & 243,02 & 74,04 & 621,54 & 82,39 & 4,00 & 55,00 & 237,79 & 30,11 & 30,11 & 228,58 \\
\hline Pelodytes ibericus & 30STH60 & 100,00 & 154,76 & 123,63 & 38,00 & 6584,50 & 343,96 & 24,34 & 319,62 & \begin{tabular}{|l|l|}
83,79 \\
\end{tabular} & 242,28 & 242,47 & 74,96 & 669,32 & 91,24 & 3,44 & 57,66 & 263,09 & 28,16 & 29,76 & 254,51 \\
\hline Pelodytes ibericus & 30STH70 & 100,00 & 151,81 & 123,86 & 38,00 & 6621,13 & 342,24 & 21,17 & 321,08 & 80,58 & 240,03 & 240,17 & 71,88 & 685,67 & 93,23 & 3,73 & 57,39 & 267,92 & 29,08 & 30,53 & 260,25 \\
\hline Pelodytes ibericus & 30STH88 & 100,00 & 155,86 & 122,67 & 37,00 & 6769,27 & 348,66 & 23,55 & 325,12 & 82,16 & 246,48 & 246,48 & 73,69 & 559,13 & 75,05 & 3,98 & 52,15 & 203,81 & 30,58 & 30,58 & 195,84 \\
\hline \begin{tabular}{|l} 
Pelodytes ibericus \\
\end{tabular} & 30STH89 & 100,00 & $\begin{array}{l}160,79 \\
160,0\end{array}$ & 122,07 & 37,01 & 6751,70 & 352,34 & 28,51 & 323,83 & $\begin{array}{l}82,16 \\
87,16 \\
\end{array}$ & $\begin{array}{l}24,40 \\
251,17\end{array}$ & $\begin{array}{l}24,41,17 \\
251\end{array}$ & 78,56 & 523,03 & 69,94 & 3,46 & 52,02 & |189,93 & 28,30 & 28,30 & 181,55 \\
\hline Pelodytes ibericus & 30STH97 & 100,00 & 159,33 & 123,80 & 37,09 & 6807,79 & 353,41 & 25,99 & 327,42 & 85,22 & 250,69 & 250,69 & 76,50 & 555,60 & 75,74 & 3,37 & 53,54 & 203,08 & 27,64 & 27,64 & 196,31 \\
\hline Pelodytes ibericus & 30STH98 & 100,00 & 154,08 & 123,05 & 37,01 & 6809,59 & 348,09 & 21,13 & 326,96 & 79,90 & 245,35 & 245,35 & 71,55 & 563,20 & 76,05 & 4,14 & 51,94 & 203,41 & 31,01 & 31,01 & 196,29 \\
\hline Pelodytes ibericus & 30STH99 & 100,00 & 157,95 & 122,70 & 37,00 & 6791,74 & 350,87 & 24,91 & 325,97 & 83,74 & 248,87 & 248,87 & 75,27 & 532,52 & 71,53 & 3,95 & 51,32 & 191,25 & 29,83 & 29,83 & 183,63 \\
\hline Pelodytes ibericus & 30STJ82 & 100,00 & 159,71 & 120,06 & 37,00 & 6722,78 & 349,14 & 28,61 & 320,54 & 86,01 & 249,70 & 249,70 & 77,87 & 486,66 & 63,75 & 3,78 & 49,62 & 173,27 & 29,86 & 29,86 & 163,70 \\
\hline $\begin{array}{l}\text { Pelodytes ibericus } \\
\end{array}$ & 30STJ90 & 100,00 & $\mid \begin{array}{l}\mid 5,1,1 \\
160,49\end{array}$ & $\begin{array}{l}\mid 21,06 \\
121,98\end{array}$ & 37,00 & $\begin{array}{l}072,11 \\
6771,17 \\
\end{array}$ & $\mid \begin{array}{l}34,1,25 \\
352,25\end{array}$ & 27,84 & 324,41 & $\begin{array}{l}80,01 \\
86,45\end{array}$ & 251,27 & 251,27 & 78,05 & $\begin{array}{l}40,06,21 \\
506,21\end{array}$ & $\mid \begin{array}{ll}67,55 \\
67,5\end{array}$ & 3, 3 & $\begin{array}{l}50,97 \\
50,97\end{array}$ & $\mid 181,01$ & 28,85 & 28,85 & 172,84 \\
\hline Pelodytes ibericus & 30STJ91 & 100,00 & 160,67 & 121,29 & 37,00 & 6770,12 & 351,61 & 28,18 & 323,43 & 86,43 & 251,34 & 251,34 & 78,01 & 491,08 & 64,97 & 3,69 & 50,11 & 174,53 & 29,03 & 29,03 & 165,92 \\
\hline Pelodytes ibericus & 30STJ92 & 100,00 & 162,71 & 120,71 & 37,00 & 6751,35 & 352,47 & 30,39 & 322,09 & 91,52 & 253,05 & 253,05 & 80,01 & 468,96 & 61,53 & 3,40 & 49,86 & 165,95 & 28,06 & 28,06 & 156,97 \\
\hline Pelodytes ibericus & 30STK71 & 100,00 & 159,49 & 114,03 & 37,00 & 6506,11 & 338,62 & 32,78 & 305,84 & 94,35 & 246,32 & 246,32 & 79,77 & 400,66 & 47,97 & 4,71 & 43,70 & 138,88 & 32,83 & 32,83 & 126,42 \\
\hline Pelodytes ibericus & 30SUF03 & 82,00 & 169,39 & 89,49 & 40,47 & 4467,10 & 290,21 & 71,31 & 218,90 & 125,21 & 226,56 & 230,21 & 116,17 & 700,22 & 120,39 & 1,22 & 73,03 & 341,09 & 15,43 & 22,72 & 320,33 \\
\hline Pelodytes ibericus & 30SUFO5 & $\begin{array}{l}0,2000 \\
100,00\end{array}$ & \begin{tabular}{|l|l|}
145,33 \\
145
\end{tabular} & \begin{tabular}{|l|}
0,45 \\
102,83
\end{tabular} & $\begin{array}{ll}40,49 \\
39,29\end{array}$ & 5290,31 & $\mid \begin{array}{l}\mid 290,21 \\
292,21\end{array}$ & $\begin{array}{l}31,1,25 \\
34,25\end{array}$ & 257,90 & \begin{tabular}{|l|l|}
92,33 \\
92,3
\end{tabular} & $\begin{array}{l}214,78 \\
214,78\end{array}$ & 217,25 & $\mid$ & $\begin{array}{l}0,2< \\
790,04\end{array}$ & \begin{tabular}{|l|l|}
120,53 \\
120
\end{tabular} & 2, 2,57 & $\begin{array}{l}5,303 \\
67,83 \\
\end{array}$ & \begin{tabular}{|l}
34,09 \\
354,48
\end{tabular} & $\begin{array}{l}\mid 22,45 \\
22,08\end{array}$ & $\begin{array}{ll}2 L, 1 / 2 \\
30,76\end{array}$ & $\begin{array}{l}32,53,39 \\
343,3\end{array}$ \\
\hline Pelodytes ibericus & 30SUF07 & 100,00 & 148,85 & 104,70 & 39,04 & 5460,91 & 299,82 & 35,93 & 263,89 & 93,13 & 220,67 & 222,81 & 83,66 & 769,43 & 117,27 & 2,48 & 66,68 & 342,70 & 22,23 & 30,04 & 329,43 \\
\hline Pelodytes ibericus & 30SUF08 & 100,00 & 151,01 & 106,04 & 39,03 & 5559,36 & 304,70 & 37,09 & 267,61 & 93,84 & 224,24 & 226,11 & 84,63 & 756,68 & 115,23 & 2,43 & 66,08 & 335,16 & 22,23 & 29,63 & 321,26 \\
\hline Pelodytes ibericus & 30SUF13 & 41,00 & 177,76 & 86,60 & 40,55 & 4321,56 & 293,13 & 81,98 & 211,15 & 135,25 & 232,73 & 236,49 & 126,22 & 639,44 & 112,78 & 1,00 & 73,62 & 317,35 & 14,11 & 20,27 & 294,35 \\
\hline Pelodytes ibericus & 30SUF15 & 100,00 & 137,05 & 106,49 & 39,38 & 5453,24 & 289,99 & 23,00 & 266,99 & 82,54 & 209,28 & 211,17 & 72,27 & 805,45 & 119,46 & 3,47 & 66,20 & 353,64 & 25,29 & 34,08 & 345,22 \\
\hline Pelodytes ibericus & 30SUF16 & 100,00 & 129,29 & 109,97 & 39,02 & 5681,03 & 290,17 & 12,23 & 277,94 & 71,73 & 205,11 & 206,59 & 61,96 & 839,94 & 121,57 & 4,46 & 64,32 & 360,19 & 29,42 & 38,14 & 352,82 \\
\hline Pelodytes ibericus & 30SUF17 & 100,00 & 139,45 & 108,08 & 39,01 & 5631,49 & 296,76 & 23,59 & 273,17 & 82,19 & 214,24 & 215,90 & 72,48 & 790,95 & 116,12 & 3,52 & 64,97 & 344,10 & 25,83 & 33,99 & 333,83 \\
\hline Pelodytes ibericus & 30SUF18 & 100,00 & 145,50 & 107,76 & 39,00 & 5650,69 & 302,14 & 29,69 & 272,45 & \begin{tabular}{|l|l|}
87,59 \\
\end{tabular} & 220,36 & 221,86 & 78,06 & 764,70 & 113,56 & 3,09 & 65,04 & 334,29 & 24,24 & 31,91 & 322,21 \\
\hline Pelodytes ibericus & 30SUF27 & 100,00 & 147,31 & 105,57 & 39,00 & 5509,06 & 299,63 & 33,1 & 266,49 & \begin{tabular}{|l|l}
91,15 \\
\end{tabular} & 220,22 & 221,83 & 81,75 & 740,65 & 110,76 & 3,10 & 65,66 & 327,50 & 23,41 & 30,92 & 314,60 \\
\hline Pelodytes ibericus & 30 SUF 28 & 100,00 & 154,73 & 104,85 & 39,0 & 5515,90 & 306,01 & 40,84 & 265,16 & 98,07 & 227,66 & 229,06 & 88,86 & 712,38 & 108,45 & 2,53 & 65,93 & 317,38 & $\begin{array}{l}21,41 \\
21,69\end{array}$ & 28,53 & 302,36 \\
\hline Pelodytes ibericus & 30SUF34 & 86,00 & 168,50 & 91,96 & 39,99 & 4679,37 & 294,07 & 66,24 & 227,83 & 122,48 & 229,17 & 232,01 & 113,01 & 630,40 & 103,78 & 1,59 & 70,51 & 301,26 & 16,97 & 23,19 & 282,53 \\
\hline Pelodytes ibericus & 30 SUF 35 & 100,00 & 158,75 & 97,82 & 39,57 & 5031,04 & 295,61 & 51,20 & 244,41 & 108,57 & 224,73 & 226,96 & \begin{tabular}{|c|c|}
98,93 \\
98,
\end{tabular} & $\begin{array}{l}671,78 \\
671,70\end{array}$ & 105,65 & 2,26 & 68,27 & 310,74 & 19,50 & 26,30 & 294,46 \\
\hline Pelodytes ibericus & 30SUF39 & 100,00 & 163,16 & 103,55 & 38,99 & 5526,19 & 312,55 & 49, & 263,52 & 105,89 & 236,23 & 237,36 & 97,02 & 666,41 & 102,47 & 2,11 & 65,86 & 298,11 & 20,08 & 26,09 & 281,61 \\
\hline Pelodytes ibericus & 30SUF44 & 99,00 & 175,94 & 87,81 & 39,80 & 4528,52 & 294,53 & 75,85 & 218,68 & 131,70 & 234,36 & 237,40 & 122,17 & 584,84 & 98,22 & 1,33 & 71,14 & 283,83 & 16,13 & 21,07 & 263,71 \\
\hline Pelodytes ibericus & 30SUF46 & \begin{tabular}{|c|}
100,00 \\
100
\end{tabular} & $\begin{array}{l}178,09 \\
178\end{array}$ & 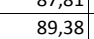 & $\begin{array}{l}35,00 \\
39,01\end{array}$ & 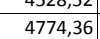 & \begin{tabular}{|l}
301,57 \\
301
\end{tabular} & $\begin{array}{l}74,88 \\
74,88 \\
\end{array}$ & $\begin{array}{l}21,06 \\
226,69\end{array}$ & 130,14 & $\begin{array}{l}2430,01 \\
240,01\end{array}$ & 242,55 & $\begin{array}{l}|l| l, 1\rangle \\
121,06\end{array}$ & $\mid 5905,38$ & \begin{tabular}{|l|}
00,22 \\
100,12
\end{tabular} & $\begin{array}{l}1,23 \\
1,28\end{array}$ & $\begin{array}{l}1,14 \\
70,45\end{array}$ & $\begin{array}{l}280,05 \\
285,75\end{array}$ & $\begin{array}{l}10,13 \\
16,65\end{array}$ & 21,29 & 263,75 \\
\hline Pelodytes ibericus & 30 SUF 47 & 100,00 & 173,28 & 93,60 & 38,83 & 5034,15 & 304,91 & 66,24 & 238,67 & 121,99 & 239,05 & 241,00 & 112,97 & 613,31 & 100,35 & 1,92 & 68,59 & 287,44 & 18,10 & 22,93 & 267,01 \\
\hline Pelodytes ibericus & 30SUF 48 & 100,00 & 164,32 & 99,91 & 38,79 & 5356,79 & 307,45 & 52,37 & 255,08 & $\begin{array}{ll}109,16 \\
\end{array}$ & 235,01 & 236,27 & 100,19 & 643,47 & 100,51 & 2,44 & 66,35 & 291,23 & 20,14 & 25,76 & 273,91 \\
\hline Pelodytes ibericus & 30SUF 49 & 100,00 & 161,69 & 103,47 & 38,72 & 5564,11 & 311,5 & 46 & 264,78 & 103,90 & 235,49 & 236,38 & 95,11 & 651,43 & 99,29 & 2,53 & 65,11 & 289,43 & 20,62 & 26,60 & 273,68 \\
\hline Pelodytes ibericus & 30SUF57 & 100,00 & 16 & 95,80 & 38,66 & 516 & 30 & 58, & 245 & 1 & 235 & 237,16 & 105,96 & 606 , & 97,54 & 2,2 & 67,11 & 279,59 & 19,05 & 24,16 & 260,99 \\
\hline Pelodytes ibericus & 30SUF58 & 100,00 & 161,08 & 101,12 & 38,52 & 5442,92 & 306,77 & 47,73 & 259,03 & 105,01 & 233,33 & 234,19 & 96,07 & 628,19 & 97,20 & 2,85 & 65,08 & 281,10 & 21,02 & 26,19 & 264,78 \\
\hline Pelodytes ibericus & $\begin{array}{l}30 \text { SUF59 } \\
\end{array}$ & 100,00 & 151,96 & 107,04 & 38,38 & 5743,58 & 309,15 & 34,31 & 274,84 & 92,37 & 228,85 & 229,23 & 83,52 & 661,30 & 97,48 & 3,74 & 62,77 & 285,63 & 23,96 & 28,66 & 272,52 \\
\hline Pelodytes ibericus & 30SUF65 & 71,00 & 178,18 & 86,28 & 38,39 & 4686,09 & 296,79 & 75,63 & 221,16 & 131,94 & 239,13 & 241,45 & 122,25 & 553,97 & 93,95 & 1,93 & 69,95 & 265,73 & 17,57 & 21,24 & 245,09 \\
\hline Pelodytes iberic & 30SUF66 & 100,00 & +2 & & 38,01 & 4749,54 & 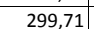 & $78, \mathrm{C}$ & 221, & 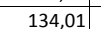 & 243,11 & 245 & 124,52 & 550,6 & 94,13 & 1, & 69,57 & 263,32 & 17,94 & 21,02 & 241,76 \\
\hline Pelodytes ibericus & 30SUF67 & 100,00 & 17 & & 38 & 5138, & & 61,14 & 242 & $11 /, 80$ & 238,01 & 239,35 & 108,82 & 573,92 & $\begin{array}{l}\mid 4,13 \\
93,08 \\
\end{array}$ & 2,34 & 66,71 & 264,25 & 18,82 & 23,33 & 245,63 \\
\hline Pelodytes ibericus & 30SUF68 & 100,00 & 160,01 & 101,65 & 38,30 & 5489,69 & 306,78 & 45,54 & 261,24 & 103,07 & 233,11 & 233,63 & 94,37 & 604,52 & 93,12 & 3,17 & 64,03 & 268,35 & 21,43 & 25,48 & 252,56 \\
\hline Pelodytes ibericus & 30SUF69 & 100,00 & 148,18 & 108,52 & 38,10 & 5824,46 & 308,79 & 29,03 & 279,76 & 87,60 & 226,42 & 226,51 & 78,91 & 649,50 & 94,31 & 4,30 & 61,40 & 276,40 & 25,32 & 26,83 & 264,26 \\
\hline Pelodytes ibericus & 30SUF76 & 60,00 & 178,71 & 86,90 & 37,95 & 4863,15 & 300,02 & 73,37 & 226,66 & 129,82 & 242,24 & 244,01 & 120,51 & 525,85 & 87,91 & 2,07 & 67,84 & 246,26 & 17,54 & 21,09 & 227,32 \\
\hline Pelodytes ibericus & 30SUF79 & 100,00 & . & 109 , & 38,06 & 5890, & & 26,14 & 283,45 & 84 & 225,82 & 225 & 76 & 629 & 90 & 4,67 & 60,19 & 264,72 & 26,09 & 26,35 & 253 \\
\hline \begin{tabular}{|l} 
Pelodytes ibericus \\
\end{tabular} & 30 SUF89 & 100,00 & $\begin{array}{l}138,18 \\
138,18\end{array}$ & 113,21 & 38,01 & 6037,40 & 308,46 & $\begin{array}{l}20,14 \\
15,46\end{array}$ & $\begin{array}{l}293,400 \\
293,00\end{array}$ & $\begin{array}{l}-34,05 \\
75,24 \\
\end{array}$ & $\begin{array}{l}219,029 \\
219,9\end{array}$ & 219,02 & 66,65 & \begin{tabular}{|l|l|}
639,85 \\
639
\end{tabular} & 80,60 & 5,89 & \begin{tabular}{|l|l|l|l|}
57,88 \\
\end{tabular} & 261,41 & 29,57 & 29,63 & 252,07 \\
\hline
\end{tabular}




\begin{tabular}{|c|c|c|c|c|c|c|c|c|c|c|c|c|c|c|c|c|c|c|c|c|c|}
\hline TAXON & UTM & $\mathrm{km} 2$ & BIO1 & B102 & $\mathrm{BIO3}$ & B104 & B105 & B106 & B107 & B108 & B109 & BIO10 & B1011 & BIO12 & B1013 & B1014 & 81015 & B1016 & B1017 & B1018 & B1019 \\
\hline Pelodytes ibericus & 30SUF98 & 100,00 & 164,71 & 100,24 & 38,00 & 5490,06 & 309,73 & 49,53 & 260,20 & 107,06 & 238,20 & 238,29 & 98,92 & 499,38 & 77,35 & 3,34 & 61,90 & 218,94 & 19,81 & 20,69 & 203,59 \\
\hline Pelodytes ibericus & 30SUF99 & 100,00 & 131,28 & 115,92 & 38,00 & 6159,14 & 307,14 & 6,72 & 300,42 & $\begin{array}{l}67,43 \\
\end{array}$ & 214,93 & 214,93 & 58,55 & \begin{tabular}{|l|l|}
651,95 \\
\end{tabular} & 87,41 & 7,08 & 55,91 & 259,09 & 33,13 & 33,13 & 251,82 \\
\hline Pelodytes ibericus & 30SUG03 & 100,00 & $\begin{array}{l}175,87 \\
\end{array}$ & \begin{tabular}{|l|l|l|l|l|}
114,48 \\
\end{tabular} & 39,79 & 5932,09 & 340,65 & 54,95 & 285,69 & $\mid \begin{array}{l}0,42,20 \\
112,\end{array}$ & 253,78 & 254,65 & $\mid$ & 635,93 & $\begin{array}{l}98,28 \\
98,28\end{array}$ & 1,00 & $\begin{array}{l}54,87 \\
64.8\end{array}$ & 274,76 & 17,00 & 22,97 & 260,99 \\
\hline Pelodytes ibericus & 30SUG19 & 100,00 & 170,83 & 123,41 & 38,00 & 6637,60 & 358,88 & 38,45 & 320,44 & 98,80 & 259,16 & 259,16 & 89,47 & 637,10 & 91,01 & 2,26 & 60,45 & 249,29 & 20,32 & 20,32 & 245,07 \\
\hline Pelodytes ibericus & 30 SUG20 & 100,00 & 158,31 & 108,00 & 38,99 & 5733,43 & 315,49 & 41,41 & 274,08 & \begin{tabular}{|l|l|}
98,67 \\
\end{tabular} & 234,24 & 235,27 & 89,62 & \begin{tabular}{|c|}
699,48 \\
\end{tabular} & 105,59 & 2,70 & 64,63 & 306,20 & 21,86 & 28,20 & 291,83 \\
\hline Pelodytes ibericus & 30 SUG 30 & 100,00 & 161,39 & 106,38 & 38,92 & 5693,89 & 316,09 & \begin{tabular}{|l|l|}
44,78 \\
\end{tabular} & 271,31 & 101,95 & 236,83 & 237,75 & 93,14 & 674,11 & 101,81 & 2,51 & 64,53 & 295,99 & 21,35 & 27,45 & 281,19 \\
\hline Pelodytes ibericus & 30SUG31 & 100,00 & 161,38 & 108,58 & 38,67 & 5841,32 & 320,60 & 42,83 & 277,77 & 99,99 & 238,97 & 239,58 & 91,20 & 673,64 & 100,65 & 2,64 & 63,81 & 291,63 & 21,31 & 27,21 & 278,18 \\
\hline Pelodytes ibericus & 30SUG36 & 100,00 & 174,02 & 116,99 & 37,99 & 6375,32 & 350,62 & 46,18 & 304,44 & 105,03 & 258,75 & 258,75 & 96,00 & 637,83 & 93,10 & 2,00 & 62,23 & 258,14 & 18,25 & 18,25 & 252,49 \\
\hline Pelodytes ibericus & 30SUG37 & 100,00 & 173,29 & 119,06 & 37,97 & 6501,13 & 354,58 & 43,41 & \begin{tabular}{|l|l|}
311,17 \\
\end{tabular} & \begin{tabular}{|l|}
103,03 \\
\end{tabular} & 259,91 & 259,91 & 93,59 & 642,11 & 92,83 & 2,01 & 61,93 & 255,04 & 18,79 & 18,79 & 251,26 \\
\hline Pelodytes ibericus & 30SUG38 & 100,00 & \begin{tabular}{ll|l}
176,44 \\
\end{tabular} & 120,40 & 37,75 & 6576,82 & 360,40 & 44,73 & 315,68 & 106,72 & 264,12 & 264,12 & 95,58 & 632,80 & 93,53 & 2,01 & 62,00 & 248,47 & 17,71 & 17,71 & 245,31 \\
\hline Pelodytes ibericus & 30SUG40 & 100,00 & 164,62 & 104,62 & 38,48 & 5666,15 & 316,75 & 48,21 & 268,55 & 105,23 & 239,72 & 240,42 & 96,60 & 643,79 & 97,35 & 2,44 & 64,83 & 283,87 & 20,00 & 25,60 & 268,63 \\
\hline Pelodytes ibericus & 30SUG41 & 100,00 & 163,92 & 107,10 & 38,08 & 5819,24 & 321,13 & 45,30 & 275,83 & 102,48 & 241,36 & 241,74 & 94,05 & 648,59 & 96,53 & 2,91 & 63,63 & 280,68 & 21,20 & 25,07 & 267,16 \\
\hline Pelodytes ibericus & 30SUG49 & 100,00 & 177,84 & 119,92 & 37,05 & 6641,07 & 362,81 & 45,38 & 317,43 & 108,48 & 266,49 & 266,49 & 96,15 & 608,36 & 91,39 & 2,03 & 61,38 & 238,32 & 17,34 & 17,34 & 233,03 \\
\hline Pelodytes ibericus & 30SUG50 & 100,00 & 164,66 & 103,90 & 38,05 & 5680,63 & 316,29 & 47,89 & 268,40 & \begin{tabular}{|l|l|}
105,03 \\
\end{tabular} & 240,25 & 240,61 & 96,56 & 622,40 & 93,90 & 2,99 & 63,95 & 273,02 & 20,50 & 25,05 & 257,99 \\
\hline Pelodytes ibericus & 30SUG51 & 100,00 & 162,12 & 107,03 & 38,00 & 5867,14 & 320,73 & 42,83 & 277,90 & 100,31 & 240,56 & 240,65 & \begin{tabular}{|l|l|}
91,79 \\
\end{tabular} & \begin{tabular}{|l|l|}
632,73 \\
\end{tabular} & 92,63 & 3,03 & 62,66 & 271,50 & 21,88 & 24,04 & 258,61 \\
\hline Pelodytes ibericus & 30SUG54 & 100,00 & 169,43 & 111,11 & 37,68 & 6182,19 & 337,53 & 45,85 & 291,68 & 103,08 & 251,95 & 251,95 & 94,54 & 619,52 & 89,40 & 2,85 & 61,66 & 255,64 & 20,03 & 20,03 & 247,58 \\
\hline Pelodytes ibericus & 30 SUG59 & 100,00 & 177,31 & $\mid 118,25$ & 37,00 & 6620,24 & 360,45 & 45,90 & 314,55 & 108,36 & 265,77 & 265,77 & 96,05 & 591,19 & 87,92 & 2,13 & 60,54 & 230,87 & 17,76 & 17,76 & 225,69 \\
\hline Pelodytes ibericus & 30SUG61 & 100,00 & 160,85 & 107,15 & 37,99 & 5906,79 & 320,53 & 41,13 & 279,40 & 98,45 & 240,06 & 240,08 & 90,04 & 611,66 & 89,09 & 3,27 & 61,66 & 260,49 & 22,17 & 22,45 & 247,99 \\
\hline Pelodytes ibericus & 30SUG62 & 100,00 & 166,75 & 106,91 & 37,78 & 5953,24 & 326,69 & 46,31 & 280,38 & \begin{tabular}{|l|l|}
103,38 \\
\end{tabular} & 246,45 & 246,45 & 95,07 & 598,20 & 86,39 & 3,00 & 61,96 & 253,34 & 20,42 & 20,42 & 241,88 \\
\hline Pelodytes ibericus & 30SUG70 & 100,00 & 153,02 & 108,60 & 38,00 & 5919,84 & 315,12 & 32,55 & 282,56 & 90,59 & 232,64 & 232,64 & 82,25 & 606,43 & 88,06 & 4,36 & 60,45 & 256,18 & 24,30 & 24,34 & 243,79 \\
\hline Pelodytes ibericus & 30SUG71 & 100,00 & 151,62 & 110,58 & 37,88 & 6072,57 & 318,97 & 29,47 & 289,50 & 87,29 & 233,57 & 233,57 & 79,09 & 616,86 & 87,21 & 4,57 & 59,53 & 255,86 & 25,25 & 25,25 & 245,22 \\
\hline \begin{tabular}{|l} 
Pelodytes ibericus \\
\end{tabular} & 30SUG75 & 100,00 & $\begin{array}{l}155,82 \\
15,2\end{array}$ & 114,23 & 37,00 & 6483,09 & 334,95 & 29,28 & 305,67 & 86,84 & 243,34 & 243,34 & 78,06 & 628,75 & \begin{tabular}{|l|l|l|}
85,66 \\
\end{tabular} & 4,59 & 57,93 & 245,89 & 25,79 & 25,79 & 242,22 \\
\hline Pelodytes ibericus & 30SUG76 & 100,00 & 167,93 & 112,70 & 36,94 & 6465,81 & 344,27 & 41,35 & 302,92 & 98,95 & 254,88 & 254,88 & 89,66 & 591,31 & 81,95 & 3,36 & 59,12 & 230,97 & 21,26 & 21,26 & 228,66 \\
\hline Pelodytes ibericus & 30SUG80 & 100,00 & 145,86 & 111,84 & 38,00 & 6057,58 & 314,52 & 23,17 & 291,35 & 81,99 & 227,83 & 227,83 & 73,82 & 607,50 & 85,53 & 5,29 & 58,42 & 250,28 & 26,89 & 26,89 & 239,62 \\
\hline Pelodytes ibericus & 30SUG81 & 100,00 & 153,52 & 110,27 & 37,74 & 6081,48 & 320,52 & 31,07 & 289,45 & 88,59 & 235,66 & 235,66 & 80,89 & 579,69 & 82,66 & 4,74 & 58,76 & 239,96 & 24,57 & 24,57 & 228,61 \\
\hline Pelodytes ibericus & 30 SUG84 & 100,00 & 153,59 & 113,48 & 36,98 & 6436,52 & 331,44 & 27,62 & \begin{tabular}{|l|l|}
303,83 \\
\end{tabular} & 84,82 & 240,74 & 240,74 & 76,60 & 607,21 & 80,98 & 4,97 & 57,11 & 237,89 & 26,17 & 26,17 & 233,38 \\
\hline $\begin{array}{l}\text { Pelodytes ibericus } \\
\end{array}$ & 30SUG90 & 100,00 & $\begin{array}{l}124,09 \\
124,09\end{array}$ & \begin{tabular}{|l|l|l|l|l|l|}
117,99 \\
\end{tabular} & $\begin{array}{l}30,00 \\
37,99\end{array}$ & $\begin{array}{l}0450,252 \\
6306,11\end{array}$ & $\begin{array}{l}351,44 \\
305,62\end{array}$ & $\begin{array}{c}2,02 \\
-1,53\end{array}$ & $\begin{array}{l}30,03 \\
307,15\end{array}$ & $\begin{array}{l}04,0< \\
58,80\end{array}$ & 2140,03 & 2140,03 & $\begin{array}{l}40,00 \\
49,98\end{array}$ & \begin{tabular}{|l|l|}
696,79 \\
696
\end{tabular} & $\begin{array}{l}00,90 \\
91,66 \\
\end{array}$ & 8,28 & $\begin{array}{l}54,52 \\
54,\end{array}$ & $\mid \begin{array}{l}\mid 5,1,03 \\
269,74\end{array}$ & 38,04 & 38,04 & $\begin{array}{l}\mid 264,54 \\
2640 \\
\end{array}$ \\
\hline Pelodytes ibericus & 30SUG91 & 100,00 & 154,26 & 110,16 & 37,51 & 6085,34 & 321,24 & 31,49 & 289,75 & 89,03 & 236,53 & 236,53 & 81,49 & 549,58 & 78,58 & 4,79 & 58,01 & 226,02 & 24,42 & 24,42 & 214,44 \\
\hline Pelodytes ibericus & 30SUG95 & 100,00 & 163,41 & 111,16 & 36,22 & $\begin{array}{l}\mid 600,134 \\
6471,75 \\
\end{array}$ & 339,35 & 37,74 & 301,61 & $\begin{array}{l}94,24 \\
94,24\end{array}$ & 250,87 & 250,87 & 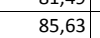 & 561,54 & 75,06 & 4,38 & 57,20 & 217,22 & 23,01 & 23,01 & 214,71 \\
\hline Pelodytes ibericus & 30SUG96 & 100,00 & 169,14 & 110,37 & 36,00 & 6498,94 & 344,60 & 43,37 & 301,23 & 102,06 & 256,68 & 256,68 & 90,79 & 550,85 & 76,01 & 3,79 & 57,74 & 213,36 & 21,20 & 21,20 & 210,45 \\
\hline Pelodytes ibericus & 30SUHO2 & 100,00 & 151,15 & 124,70 & 37,43 & 6797,93 & 346,13 & 18,10 & 328,02 & 79,88 & 242,27 & 242,27 & 68,97 & 665,09 & 92,69 & 3,96 & 56,19 & 250,52 & 29,42 & 29,42 & 245,90 \\
\hline Pelodytes ibericus & $\begin{array}{l}\text { SOSUHOS } \\
30 \text { U }\end{array}$ & 100,00 & $\begin{array}{l}13,1,29 \\
156,29\end{array}$ & $\begin{array}{l}\mid 22, i, 05 \\
123,05\end{array}$ & $\begin{array}{l}31,45 \\
37,00\end{array}$ & |6827,99 & \begin{tabular}{|l|}
350,39 \\
350,39
\end{tabular} & $\begin{array}{l}22,76 \\
22,76\end{array}$ & $\begin{array}{l}32,04 \\
327,62\end{array}$ & $\begin{array}{r}\quad 8,00 \\
81,72\end{array}$ & $242,24,94$ & 247,94 & | 73,379 & 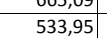 & $\begin{array}{l}\mid c, 095 \\
72,05\end{array}$ & 年, & \begin{tabular}{|l|l|}
51,27 \\
512
\end{tabular} & \begin{tabular}{|l|l|}
190,05 \\
1905
\end{tabular} & $\begin{array}{l}23,4 \mathrm{~L} \\
30,05\end{array}$ & $\begin{array}{l}23,42 \\
30,05\end{array}$ & $\begin{array}{l}43,, 0 \\
183,17 \\
\end{array}$ \\
\hline Pelodytes ibericus & 30SUH10 & 100,00 & 160,43 & 124,05 & 37,94 & 6743,60 & 352,50 & 27,41 & 325,09 & 89,12 & 250,70 & 250,70 & 78,31 & 659,05 & 93,60 & 3,05 & 58,55 & 253,14 & 24,49 & 24,49 & 249,34 \\
\hline Pelodytes ibericus & 30SUH19 & 100,00 & 156,72 & 123,25 & 37,00 & 6850,13 & 351,13 & 22,66 & 328,47 & 82,51 & 248,74 & 248,74 & 73,43 & 527,22 & 71,32 & 3,82 & 51,09 & 186,22 & 29,49 & 29,49 & 180,06 \\
\hline Pelodytes ibericus & $30 \mathrm{SUH} 21$ & 100,00 & 155,18 & 124,01 & 37,13 & 6815,08 & 349,27 & 21,83 & 327,44 & 84,73 & 246,69 & 246,69 & 72,49 & 660,60 & 94,63 & 3,78 & 57,17 & 251,76 & 27,13 & 27,13 & 245,69 \\
\hline Pelodytes ibericus & 30SUH22 & 100,00 & 157,27 & 124,38 & 37,08 & 6836,77 & 352,36 & 23,58 & 328,78 & 86,77 & 249,13 & 249,13 & 74,42 & 638,21 & 91,70 & 3,51 & 56,67 & 241,62 & 26,43 & 26,43 & 235,18 \\
\hline Pelodytes ibericus & $30 \mathrm{SUH} 25$ & 100,00 & 155,16 & 124,99 & 37,00 & 6879,92 & 351,62 & 20,82 & 330,80 & 84,49 & 247,76 & 247,76 & 71,97 & 596,25 & 84,09 & 3,99 & 54,09 & 219,10 & 28,85 & 28,85 & 212,30 \\
\hline Pelodytes ibericus & 30 SUH29 & 100,00 & 159,68 & 123,59 & 37,00 & 6866,72 & 354,01 & 24,97 & 329,04 & 89,87 & 251,91 & 251,91 & 76,03 & 509,45 & 69,12 & 3,47 & 51,26 & 178,71 & 27,92 & 27,92 & 173,23 \\
\hline Pelodytes ibericus & $30 \mathrm{SUH} 30$ & 100,00 & 162,30 & 122,87 & 37,04 & 6771,33 & 354,04 & 29,24 & 324,80 & 92,31 & 253,16 & 253,16 & 80,00 & 647,49 & 94,59 & 3,26 & 58,61 & 249,89 & 23,69 & 23,69 & 243,64 \\
\hline Pelodytes ibericus & 30SUH35 & 100,00 & 153,47 & 196 & 37,00 & 914,82 & 350,41 & 18 & 331,59 & 82,61 & 246,64 & 246,64 & 69,85 & 595,47 & 84,36 & 4,00 & 53,71 & 218,63 & 9,03 & 29,03 & 210,82 \\
\hline Pelodytes ibericus & 30SUH40 & 100,00 & 166,59 & , 69 & 37,01 & 6766,19 & $\mid 356,73$ & $\begin{array}{l}33,38 \\
33,38\end{array}$ & 323,35 & | 92,01 & 257,32 & 257,32 & 83,97 & 627,45 & 92,90 & 3,00 & 58,99 & 243,12 & 22,05 & 22,05 & 235,93 \\
\hline Pelodytes ibericus & $30 \mathrm{SUH} 42$ & 100,00 & 15 & 0 & 37,00 & 6866,91 & 354,13 & 25,70 & 328,43 & \begin{tabular}{|l|l|}
88,95 \\
\end{tabular} & 252,18 & 252,18 & 76,42 & \begin{tabular}{|l|l|}
618,63 \\
\end{tabular} & 90,50 & 3,56 & 56,64 & 235,22 & 25,44 & 25,44 & 226,66 \\
\hline Pelodytes ibericus & 30SUH61 & 100,00 & $\begin{array}{l}168,19 \\
\end{array}$ & 119,91 & 36,98 & 6799,46 & 357,62 & 35,53 & 322,10 & $\begin{array}{l}90,03 \\
98,02 \\
\end{array}$ & 259,55 & 259,55 & 85,31 & \begin{tabular}{|l|l|}
583,79 \\
\end{tabular} & 86,68 & 3,14 & 57,68 & 224,48 & 22,09 & 22,09 & 215,60 \\
\hline Pelodytes ibericus & $30 \mathrm{SUH} 70$ & 100,00 & 177,69 & 116,12 & 36,80 & 6647,14 & 359,74 & 47, & 312,63 & 108,78 & 266,65 & 266,65 & 96,31 & 544,59 & 80,35 & 2,31 & 58,69 & 210,57 & 18,35 & 18,35 & 204,07 \\
\hline Pelodytes ibericus & 30 SUH80 & 100,00 & 177,70 & 114,64 & 36,24 & 6641,40 & 358,53 & 48,07 & 310,46 & 108,80 & 266,67 & 266,67 & 96,51 & 528,09 & 77,71 & 2,45 & 58,08 & 203,85 & 18,58 & 18,58 & 196,87 \\
\hline Pelodytes ibericus & 30SUJ02 & 100,00 & 159,36 & $\begin{array}{l}141,04 \\
121,10\end{array}$ & 37,00 & $\begin{array}{l}60490,35 \\
6790 \\
\end{array}$ & | & 26, 264 & 323,405 & \begin{tabular}{|l|}
89,07 \\
\end{tabular} & 250,54 & 250,54 & $\begin{array}{l}30,01 \\
76,72\end{array}$ & \begin{tabular}{|l}
32,09 \\
476,07
\end{tabular} & $\begin{array}{ll}62,28 \\
6\end{array}$ & $\begin{array}{l}2,459 \\
3,92\end{array}$ & $\begin{array}{l}0,00 \\
49,00 \\
\end{array}$ & \begin{tabular}{|l|l|}
166,33 \\
166
\end{tabular} & $\begin{array}{l}29,50 \\
29,72\end{array}$ & $\begin{array}{l}29,50 \\
29,72\end{array}$ & 年 \\
\hline Pelodytes ibericus & 30SUJ11 & 100,00 & 157,28 & 122,27 & 37,00 & 6821,56 & 350,13 & 23,83 & 326,31 & \begin{tabular}{|l|l|}
87,09 \\
\end{tabular} & 248,91 & 248,91 & 74,36 & 493,68 & 65,26 & 4,00 & 49,40 & 171,72 & 30,24 & 30,24 & 164,36 \\
\hline Pelodytes ibericus & 30SUJ15 & 100,00 & 156,77 & 119,64 & 36,98 & 6758,22 & 345,78 & 24,61 & 321,17 & 114,42 & 247,55 & 247,55 & 74,36 & 439,26 & 54,84 & 4,23 & 46,27 & 149,96 & 31,43 & 31,43 & 139,35 \\
\hline Pelodytes ibericus & 30SVF08 & 100,00 & 56 & 3,95 & 38,03 & 6023,94 & 304,68 & 10,38 & 294,30 & 71 & 215,36 & 215,38 & 62,47 & 616,68 & 84,16 & 7,03 & 55,93 & 246,27 & 32,40 & 32,95 & 237,63 \\
\hline Pelodytes ibericus & 30SVF09 & 100,00 & 13 & 115,65 & 38, & 6143,62 & & $11, \varsigma$ & 299 & 72 & 220,46 & 220,46 & 64 & 596,54 & 80,01 & 6,42 & 55,62 & 238,08 & 29,95 & 29,95 & 229,69 \\
\hline Pelodytes ibericus & 30SVF18 & 100,00 & 126,82 & 117,46 & 38,02 & 6171,08 & 304,79 & 1,30 & 303,49 & 63,14 & 210,80 & 210,83 & 54,17 & 631,64 & 82,95 & 7,90 & 53,93 & 245,10 & 35,22 & 35,73 & 239,22 \\
\hline Pelodytes ibericus & 30SVF36 & 46,00 & 174,84 & 94,82 & 38,02 & 5184,26 & 309,11 & 63,31 & 245,80 & 120,82 & 243,44 & 244,08 & 112,26 & 362,41 & 53,00 & 2,33 & 60,03 & 157,21 & 14,16 & 17,56 & 146,72 \\
\hline Pelodytes ibericus & 30 SVF48 & 100,00 & 144,43 & 115,47 & 38,02 & 6075,72 & 316,82 & 18,45 & 298,38 & 81,20 & 226,66 & 226,66 & 72,07 & 482,90 & 65,27 & 5,73 & 53,36 & 187,41 & 25,48 & 25,48 & 181,11 \\
\hline Pelodytes iberic & 30SVF56 & 72,00 & $\begin{array}{ll}177,14 \\
\end{array}$ & 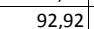 & 37,97 & 5138,75 & 308,87 & 66,64 & 242,23 & 124,12 & 244, & 245,98 & 115,02 & 323,9 & 46,7 & 2,07 & 58,29 & 137,38 & 12,52 & 17,56 & 129,49 \\
\hline Pelodytes ibericus & 30 SVF59 & 100,00 & & 12 & 37 & 6446,90 & & $-23,95$ & 336,25 & 45,38 & 192,09 & 192,42 & 29,21 & 717 & 89,99 & 14,93 & 46,53 & 256,12 & 59,06 & 62,18 & 247,05 \\
\hline Pelodytes ibericus & $\begin{array}{l}30 \text { SVF87 } \\
\end{array}$ & 100,00 & \begin{tabular}{|l|l}
148,05 \\
\end{tabular} & \begin{tabular}{|l|}
107,66 \\
\end{tabular} & 37,99 & 5823,31 & 308,04 & 27,55 & 280,49 & 89,11 & 226,04 & 227,34 & 79,09 & 421,66 & 55,24 & 5,26 & 51,20 & 156,62 & 24,17 & 31,90 & 153,55 \\
\hline Pelodytes ibericus & 30SVG02 & 100,00 & 150,38 & 113,64 & 37,05 & 6307,82 & 325,61 & 24,74 & 300,86 & \begin{tabular}{|l|}
82,49 \\
\end{tabular} & 236,10 & 236,10 & 75,05 & 546,70 & 74,73 & 5,65 & 55,64 & 217,00 & 26,42 & 26,42 & 207,91 \\
\hline Pelodytes ibericus & 30 SVG10 & 100,00 & 146,56 & 114,97 & 37,99 & 6181,29 & 320,53 & 20,79 & 299,74 & 80,53 & 230,58 & 230,58 & 72,92 & 519,77 & 71,88 & 5,83 & 55,21 & 208,73 & 26,13 & 26,13 & 197,66 \\
\hline Pelodytes ibericus & 30SVG12 & 100,00 & 10 & 114 & 37,13 & 6337,57 & 325 & 22,51 & 303,3 & 80,6 & 235,18 & 235,18 & 73, & 525, & 72 & 5,99 & 54,51 & 205,95 & 27,16 & 27,16 & 196,40 \\
\hline \begin{tabular}{|l} 
Pelodytes ibericus \\
\end{tabular} & 30SVG13 & 100,00 & 138,03 & 118,49 & 37,01 & 6573,18 & 324,53 & | & $\begin{array}{l}315,26 \\
3150\end{array}$ & $\mid 60,87$ & 227,57 & 227,57 & $\begin{array}{l}60,41 \\
60,05\end{array}$ & 604,05 & 78,08 & 7, 70 & 53,03 & 225,93 & 32,95 & 32,95 & 222,81 \\
\hline
\end{tabular}




\begin{tabular}{|c|c|c|c|c|c|c|c|c|c|c|c|c|c|c|c|c|c|c|c|c|c|}
\hline TAXON & UTM & $\mathrm{km} 2$ & B101 & B102 & $\mathrm{BIO3}$ & BIO4 & B105 & B106 & B107 & B108 & B109 & B1010 & B1011 & BIO12 & B1013 & BIO14 & BIO15 & B1016 & B1017 & B1018 & B1019 \\
\hline Pelodytes ibericus & 30SVG20 & 100,00 & 145,69 & 116,98 & 38,00 & 6252,42 & 322,93 & 18,24 & 304,69 & 78,98 & 230,76 & 230,76 & 71,08 & 505,76 & 68,07 & 6,06 & 53,89 & 199,54 & 26,34 & 26,34 & 189,76 \\
\hline Pelodytes ibericus & 30 SVG22 & 100,00 & 153,52 & 114,99 & 37,21 & 6338,62 & 330,23 & 26,31 & 303,92 & 84,42 & 239,78 & 239,78 & 77,80 & 473,18 & 65,41 & 5,45 & 54,03 & 185,84 & 24,53 & 24,53 & 175,09 \\
\hline Pelodytes ibericus & 30 SVG23 & 100,00 & 143,48 & 118,29 & 37,00 & 6569,32 & 329,22 & 14,20 & 315,02 & 73,80 & 232,93 & 232,93 & 65,32 & 558,01 & 71,92 & 6,87 & 52,63 & 208,01 & 30,10 & 30,10 & 204,63 \\
\hline Pelodytes ibericus & 30SVG24 & 100,00 & 144,54 & 117,80 & 36,96 & 6647,62 & 331,67 & 15,37 & 316,30 & 75,56 & 235,03 & 235,03 & 65,56 & 568,15 & 74,36 & 6,89 & 52,60 & 210,27 & 30,69 & 30,69 & 207,29 \\
\hline Pelodytes ibericus & 30SVG25 & 100,00 & 130,21 & 120,26 & 36,87 & $\begin{array}{ll}6743,06 \\
\end{array}$ & 322,75 & 0,62 & 322,12 & 61,14 & 222,23 & 222,23 & 50,70 & 642,81 & 86,59 & 8,94 & 50,67 & 236,40 & 39,79 & 39,79 & 228,93 \\
\hline Pelodytes ibericus & 30SVG34 & 100,00 & 139,93 & 119,43 & 36,99 & 6683,69 & 329,45 & 9,99 & 319,46 & 71,39 & 231,01 & 231,01 & 60,73 & 574,29 & 75,90 & 7,53 & 51,31 & 209,78 & 33,08 & 33,08 & 206,13 \\
\hline Pelodytes ibericus & 30 SVG40 & 100,00 & 145,38 & 119,73 & 38,00 & 6347,76 & 327,09 & 15,72 & 311,37 & 78,74 & 231,55 & 231,55 & 69,68 & 491,34 & 66,55 & 5,95 & 52,60 & 186,27 & 25,97 & 25,97 & 180,81 \\
\hline Pelodytes ibericus & \begin{tabular}{|l|l|}
30 SVG 43 \\
\end{tabular} & 100,00 & 147,47 & 119,11 & 37,00 & 6579,18 & 333,78 & 17,30 & 316,48 & 78,58 & 237,05 & 237,05 & 69,25 & 511,75 & 60,96 & 6,32 & 51,82 & 186,44 & 27,85 & 27,85 & 184,32 \\
\hline Pelodytes ibericus & 30SVG49 & 100,00 & $\begin{array}{lll}171,87 \\
\end{array}$ & 109,65 & 35,37 & 6671,28 & 350,31 & 45,36 & 304,95 & 114,53 & 261,52 & 261,52 & 91,38 & 475,47 & 70,42 & 3,79 & 54,19 & 181,92 & 21,97 & 21,97 & 169,90 \\
\hline Pelodytes ibericus & 30SVG51 & 100,00 & 137,77 & 120,31 & 37,80 & 6468,57 & 323,32 & 7,91 & 315,41 & 72,75 & 225,69 & 225,71 & 61,08 & 533,14 & 69,61 & 7,34 & 50,53 & 192,97 & 31,75 & 32,01 & 190,72 \\
\hline Pelodytes ibericus & 30SVG52 & 100,00 & 121,04 & 121,37 & 37,53 & 6577,65 & 311,27 & $-8,14$ & 319,41 & 69,02 & 210,81 & 210,84 & 44,02 & 627,20 & 80,32 & 10,60 & 47,88 & 223,75 & 44,60 & 45,24 & 217,73 \\
\hline Pelodytes ibericus & 30SVG59 & 100,00 & 171,17 & 110,18 & 35,92 & 6609,16 & 348,34 & 44,54 & 303,81 & 124,97 & 259,99 & 259,99 & 91,48 & 451,57 & 64,77 & 3,78 & 52,74 & 169,93 & 22,11 & 22,11 & 158,86 \\
\hline Pelodytes ibericus & 30SVG61 & 100,00 & 112,41 & 121,28 & 37,86 & 6532,90 & 301,90 & $-16,22$ & 318,13 & 62,72 & 201,56 & 201,79 & 36,41 & 659,49 & 82,80 & 12,84 & 46,09 & 233,59 & 52,19 & 55,75 & 224,71 \\
\hline Pelodytes ibericus & 30SVG62 & 100,00 & 122,76 & 120,85 & 37,48 & 6557,57 & 311,71 & $-6,24$ & 317,96 & 74,06 & 212,14 & 212,21 & 45,92 & 605,29 & 77,14 & 10,41 & 47,20 & 215,44 & 43,91 & 45,90 & 207,94 \\
\hline Pelodytes ibericus & 30SVG78 & 100,00 & 161,60 & 112,72 & 36,18 & 6559,96 & 339,99 & 34,07 & 305,92 & 115,06 & 249,91 & 249,92 & 82,82 & 443,93 & 60,16 & 4,71 & 49,69 & 162,60 & 25,75 & 25,97 & $\begin{array}{l}150,93 \\
\end{array}$ \\
\hline Pelodytes ibericus & 30SVHO1 & 100,00 & 173,25 & 114,34 & 36,00 & 6739,98 & 356,56 & 43,78 & 312,78 & 103,74 & 263,86 & 263,86 & 91,44 & 511,77 & 75,83 & 3,23 & 55,60 & 195,58 & 21,62 & 21,62 & 185,27 \\
\hline Pelodytes ibericus & 30SVH11 & 100,00 & 173,27 & 113,34 & 36,00 & 6740,93 & 355,86 & 44,18 & 311,68 & 103,58 & 263,83 & 263,83 & 91,41 & 500,60 & 74,46 & 3,27 & 55,22 & 191,21 & 21,66 & 21,66 & 180,09 \\
\hline Pelodytes ibericus & $30 \mathrm{SVH} 22$ & 100,00 & 167,66 & 115,08 & 36,00 & 6811,41 & 353,58 & 37,68 & 315,90 & $\begin{array}{l}117,58 \\
\end{array}$ & 259,44 & 259,44 & 85,38 & 498,74 & 73,72 & 3,62 & 53,34 & 188,84 & 24,08 & 24,08 & 174,98 \\
\hline Pelodytes ibericus & 30 SVH34 & 100,00 & 153,79 & 120,08 & 36,59 & 6892,22 & 345,85 & 21,45 & 324,40 & 106,64 & 246,91 & 246,91 & 71,05 & 508,68 & 71,43 & 4,85 & 49,44 & 188,17 & 31,19 & 31,19 & 169,55 \\
\hline Pelodytes ibericus & $30 \mathrm{SVH} 41$ & 100,00 & 172,06 & 112,09 & 36,00 & 6687,70 & 352,28 & 43,94 & 308,34 & 125,90 & 261,96 & 261,96 & 91,14 & 458,41 & 66,63 & 3,46 & 52,76 & 173,03 & 22,34 & 22,34 & 160,08 \\
\hline Pelodytes ibericus & $30 \mathrm{SVH} 42$ & 100,00 & 168,91 & 114,17 & 36,00 & 6738,83 & 351,87 & 39,52 & 312,34 & 122,59 & 259,43 & 259,43 & 87,43 & 461,65 & 66,40 & 3,64 & 51,84 & 173,28 & 24,00 & 24,00 & 158,57 \\
\hline Pelodytes ibericus & $30 \mathrm{SVH} 43$ & 100,00 & 163,33 & 116,73 & 36,05 & 6798,84 & 349,91 & 32,62 & 317,29 & 116,79 & 254,96 & 254,96 & 81,34 & 471,24 & 66,79 & 4,03 & 50,53 & $\begin{array}{l}175,58 \\
\end{array}$ & 26,70 & 26,70 & 158,96 \\
\hline Pelodytes ibericus & $30 \mathrm{SVH} 44$ & 100,00 & 148,33 & 120,66 & 36,76 & \begin{tabular}{|l|l|}
6890,83 \\
\end{tabular} & 341,28 & \begin{tabular}{|l|l|}
15,92 \\
\end{tabular} & 325,37 & 100,84 & 241,58 & 241,58 & 65,94 & 515,72 & 70,99 & 5,67 & 47,88 & 189,17 & \begin{tabular}{|l|l|}
34,67 \\
\end{tabular} & 34,67 & 168,88 \\
\hline Pelodytes ibericus & $30 \mathrm{SVH} 53$ & 100,00 & 163,20 & 116,49 & 36,24 & 6752,17 & 348,31 & 32,62 & 315,69 & 116,77 & 254,13 & 254,13 & 81,79 & 455,50 & 63,27 & 4,01 & 49,48 & 168,26 & 26,90 & 26,90 & 151,61 \\
\hline Pelodytes ibericus & 30SVH54 & 100,00 & 152,54 & 119,68 & 36,80 & 6830,84 & 342,73 & 20,42 & 322,31 & 105,50 & 244,79 & 244,79 & 70,64 & 485,61 & 65,96 & 5,25 & 47,56 & 177,26 & 32,77 & 32,77 & 157,69 \\
\hline Pelodytes ibericus & 30SVH64 & 100,00 & 154,19 & 119,16 & 36,95 & 6780,69 & 342,24 & 22,47 & 319,76 & 107,34 & 245,70 & 245,70 & 72,69 & 464,67 & 61,8 & 5,05 & 46,69 & 168,01 & 32,31 & 32,31 & 148,91 \\
\hline Pelodytes ibericus & 30SVH74 & 100,00 & 156,35 & 118,46 & 37,00 & 6713,76 & 341,89 & 24,83 & 317,06 & $\begin{array}{l}109,79 \\
\end{array}$ & 246,80 & 246,80 & 75,59 & 4442,10 & $\begin{array}{l}1,1,44 \\
57,42\end{array}$ & 4,87 & 45,98 & \begin{tabular}{|l|}
158,07 \\
\end{tabular} & 31,52 & $\begin{array}{ll}2,31,52 \\
\end{array}$ & 139,85 \\
\hline Pelodytes ibericus & 30SVH75 & 100,00 & 148,09 & 120,87 & 37,00 & 6772,70 & 337,37 & 15,63 & 321,74 & 110,62 & 239,64 & 239,64 & 66,96 & 466,38 & 59,56 & 5,92 & 44,41 & 165,41 & 36,67 & 36,67 & 144,59 \\
\hline Pelodytes ibericus & 30 SVH81 & 100,00 & 159,91 & 114,97 & 36,91 & 6589,05 & 339,97 & 30,88 & 309,10 & 113,51 & 248,51 & 248,56 & 80,65 & 429,66 & 56,23 & 4,73 & 47,06 & 154,55 & 28,56 & 29,46 & 139,10 \\
\hline Pelodytes ibericus & 30SVH83 & 100,00 & 152,89 & 118,31 & 37,00 & 6684,40 & 337,84 & 21,87 & 315,97 & 105,94 & 242,93 & 242,93 & 72,76 & 448,93 & 57,69 & 5,49 & 45,15 & 159,88 & 33,55 & 33,55 & 140,90 \\
\hline Pelodytes ibericus & $30 \mathrm{SVH} 92$ & 100,00 & 154,53 & 116,88 & 37,00 & 6587,96 & 336,01 & 24,53 & 311,47 & 108,27 & 243,29 & 243,34 & 75,54 & 431,61 & 54,32 & 5,40 & 44,88 & 152,25 & 32,54 & 33,10 & 134,77 \\
\hline Pelodytes ibericus & 30SWG09 & 100,00 & 121,09 & 120,41 & 37,09 & 6669,44 & 310,41 & \begin{tabular}{|l|l|}
$-8,41$ \\
\end{tabular} & $\begin{array}{l}318,82 \\
318\end{array}$ & 79, & \begin{tabular}{|l|}
211,79 \\
213
\end{tabular} & \begin{tabular}{|l|}
212,10 \\
\end{tabular} & 43,19 & \begin{tabular}{|l|l|} 
\\
574,48
\end{tabular} & $\begin{array}{l}24,325 \\
71,75\end{array}$ & $\mid \frac{1,40}{12,40}$ & 40,50 & \begin{tabular}{|l|}
199,80 \\
\end{tabular} & 56,02 & 58,31 & 174,50 \\
\hline Pelodytes ibericus & 30SWG20 & 100,00 & $\begin{array}{lll}131,47 & \end{array}$ & 111,31 & 37,74 & 6116,16 & 300,77 & 8,53 & 292,24 & 81,84 & 213,68 & 215,52 & 59,95 & 487,65 & 61,24 & 9,45 & 43,62 & 166,63 & 40,55 & 47,17 & 158,65 \\
\hline Pelodytes ibericus & 30SWG39 & 100,00 & 122,08 & 119,02 & 37,76 & 6531,97 & 305,88 & $-6,37$ & 312,25 & 99,95 & 210,69 & 211,26 & 45,77 & 538,32 & 68,69 & 12,72 & 37,90 & 185,42 & 58,18 & 61,05 & 155,37 \\
\hline Pelodytes ibericus & 30SWG59 & 100,00 & 132,38 & 117,02 & 38,00 & 6359,18 & 308,74 & 4,14 & 304,60 & 111,25 & 217,97 & 218,96 & 57,32 & 470,81 & 60,97 & 10,31 & 37,72 & 160,66 & 50,57 & 53,86 & 132,38 \\
\hline Pelodytes ibericus & 30SWHOO & 100,00 & 135,70 & 118,81 & 37,07 & 6620,45 & 321,12 & 5,99 & 315,12 & 97,55 & 225,36 & 225,55 & 57,45 & 503,33 & 63,04 & 9,04 & 42,12 & 176,09 & 44,77 & 46,68 & 153,98 \\
\hline $\begin{array}{l}\text { Pelodytes ibericus } \\
\end{array}$ & 30 SWH30 & 100,00 & 102,13 & $\begin{array}{l}11,0,01 \\
120,83\end{array}$ & 37,45 & $\begin{array}{l}\mid 6020,45 \\
6632,01\end{array}$ & $\begin{array}{l}291,12 \\
291,64\end{array}$ & \begin{tabular}{|l|l|}
$-26,36$ \\
-26,
\end{tabular} & \begin{tabular}{|l|}
318,00 \\
312
\end{tabular} & $\begin{array}{l}\mid 1,130 \\
78,76\end{array}$ & \begin{tabular}{|l|}
192,94 \\
192,
\end{tabular} & \begin{tabular}{|l|}
193,40 \\
13,0
\end{tabular} & $\begin{array}{ll}17,45 \\
25,83\end{array}$ & $\begin{array}{l}303,53 \\
644,83\end{array}$ & $\begin{array}{l}3,, 34 \\
81,33 \\
\end{array}$ & \begin{tabular}{|c|}
18,94 \\
184
\end{tabular} & $\begin{array}{l}4,11 \\
34,79\end{array}$ & $\begin{array}{l}121,03 \\
221\end{array}$ & $\begin{array}{l}44,111 \\
79,58\end{array}$ & $\begin{array}{l}40,12 \\
80,12\end{array}$ & $\begin{array}{l}15,50 \\
181,02\end{array}$ \\
\hline Pelodytes ibericus & 30SWH33 & 100,00 & 115,28 & 121,64 & 37,99 & 6624,59 & 303,36 & $-14,60$ & 317,95 & 93,55 & 205,45 & 205,58 & 37,90 & 563,74 & 71,58 & 14,55 & 35,49 & 195,09 & 67,78 & 68,03 & 155,56 \\
\hline Pelodytes ibericus & 30SWH34 & 100,00 & 127,64 & 121,06 & 37,99 & 6585,76 & 312,86 & $-2,88$ & 315,74 & $\begin{array}{r}107,04 \\
\end{array}$ & 216,92 & 217,02 & 50,06 & 499,64 & 63,86 & 11,34 & 36,86 & 173,19 & 57,30 & 57,69 & 137,60 \\
\hline Pelodytes ibericus & 30SWH35 & 100,00 & 135,10 & 120,94 & 38,00 & 6562,45 & 318,66 & 3,99 & 314,68 & 115,32 & 223,75 & 223,83 & 57,18 & 461,17 & 59,19 & 9,41 & 37,62 & 159,92 & 51,44 & 51,82 & 126,39 \\
\hline Pelodytes ibericus & 30SWH44 & 100,00 & 120,14 & 121,30 & 38,00 & 6578,54 & 305,68 & $-10,05$ & 315,73 & 98,81 & 209,57 & 209,66 & 42,99 & 529,28 & 67,71 & 13,53 & 35,21 & 182,61 & 64,91 & 65,25 & 142,30 \\
\hline Pelodytes ibericus & 30 SWH65 & 100,00 & 137,79 & 120,16 & 38,44 & 6408,61 & 315,40 & 7,05 & 308,36 & \begin{tabular}{|l|}
118,61 \\
\end{tabular} & 224,08 & 224,23 & 61,37 & 430,13 & 56,60 & 9,38 & 36,48 & \begin{tabular}{|l|l|}
146,97 \\
\end{tabular} & 52,01 & 52,64 & 110,77 \\
\hline Pelodytes nov. & 29SMC69 & 100,00 & 147,96 & 70,09 & 41,09 & 3488,38 & 238,79 & 70,50 & 168,29 & 111,22 & 189,22 & 193,04 & 102,87 & 825,55 & 127,97 & 5,09 & 64,31 & 370,27 & 36,55 & 38,54 & 344,46 \\
\hline Pelodytes nov. & 29SMC78 & 84,00 & 158,27 & 75,36 & 41,23 & 3702,77 & 257,79 & 77,44 & 180,35 & 119,08 & 202,40 & 206,80 & 111,26 & 771,92 & 120,92 & 4,01 & 64,95 & 348,70 & 31,93 & 34,07 & 328,03 \\
\hline Pelodytes nov. & 29SMC79 & 100,00 & 150,21 & 73,67 & 40,95 & 3685,18 & 248,04 & 70,05 & 177,99 & 111,34 & 194,26 & 198,41 & 103,30 & 825,94 & 28,66 & 4,5 & 64,91 & 71,05 & 34,95 & 36,68 & 348,66 \\
\hline $\begin{array}{l}\text { Pelodytes nov. } \\
\text { Polus }\end{array}$ & $295 \mathrm{SMC} 85$ & 48,00 & 162,61 & 81,58 & 41,70 & 3901,56 & 272,91 & 79,16 & 193,75 & $\begin{array}{l}122,18 \\
128\end{array}$ & 209,94 & 214,84 & 114,66 & 712,75 & $\begin{array}{l}108,22 \\
\end{array}$ & 3,94 & 63,17 & 318,22 & 31,22 & 33,31 & 304,73 \\
\hline Pelodytes nov. & 29SMC88 & 76,00 & 164,78 & 79,29 & 40,77 & 3947,81 & 273,54 & 81,14 & 192,41 & 123,28 & 212,72 & 217,34 & 115,89 & 731,80 & 111,36 & 3,84 & 63,98 & 328,19 & 30,27 & 32,97 & 314,90 \\
\hline Pelodytes nov. & $295 M C 89$ & 101,00 & 162,23 & 77,29 & 40,59 & 3890,32 & 267,64 & 79,42 & 188,21 & 121,02 & 209,27 & 213,48 & 113,54 & 744,37 & 113,05 & 3,82 & 64,03 & 333,09 & 30,62 & 33,27 & 318,85 \\
\hline Pelodytes nov. & 29SMC95 & 57,00 & 161,90 & 83,83 & 41,27 & 4053,90 & 277,25 & 76,73 & 200,52 & 120,01 & 211,56 & 216,45 & 112,46 & 712,24 & 107,07 & 3,97 & 62,97 & 316,56 & 31,18 & 33,15 & 305,23 \\
\hline Pelodytes nov. & 29SMC96 & 101,00 & 166,61 & 83,55 & 41,10 & 4057,78 & 281,52 & 81,08 & 200,44 & 124,31 & 216,16 & 221,07 & 116,95 & 689,66 & 104,09 & 3,57 & 63,35 & 21 & 28,87 & 31,62 & 296,61 \\
\hline Pelodytes nov. & 29SMD60 & 71,00 & $\frac{100}{150}$ & $\frac{63,305}{67,85}$ & $\frac{41,05}{41,05}$ & 3399,25 & \begin{tabular}{|l|}
237,06 \\
23,0
\end{tabular} & $\begin{array}{l}1,00 \\
73,70\end{array}$ & \begin{tabular}{|l|}
163,436 \\
\end{tabular} & \begin{tabular}{|l|}
$114,29,5$ \\
\end{tabular} & \begin{tabular}{|l|}
190,23 \\
\end{tabular} & \begin{tabular}{|l|}
193,60 \\
\end{tabular} & \begin{tabular}{|l|}
105,75 \\
105
\end{tabular} & $\begin{array}{l}\mid 203,00 \\
791,66\end{array}$ & \begin{tabular}{|l|}
123,77 \\
123,7
\end{tabular} & 4,56 & $\begin{array}{l}0,350 \\
64,30\end{array}$ & \begin{tabular}{|l|}
350,212 \\
356,92
\end{tabular} & $\begin{array}{l}20,01 \\
33,85\end{array}$ & $\begin{array}{l}31,0<4 \\
36,46\end{array}$ & 330,30 \\
\hline Pelodytes nov. & 29SMD62 & 49,00 & 153,55 & 62,03 & 41,17 & 3118,04 & 230,41 & 81,46 & 148,96 & 120,92 & 189,85 & 192,73 & 112,63 & 711,70 & 116,22 & 4,00 & 63,09 & 320,32 & 30,14 & 34,77 & 294,68 \\
\hline Pelodytes nov. & 29SMD63 & 9,00 & 153,06 & 59,78 & 41.09 & 3022,06 & 226,25 & 82.44 & $\mid 143,81$ & $\begin{array}{ll}121,75 \\
\end{array}$ & 188,06 & 190,53 & \begin{tabular}{|l|l|}
113,19 \\
\end{tabular} & 692,31 & 114,81 & 4,00 & 62.66 & 310,81 & 29,66 & 34,88 & 285,31 \\
\hline Pelodytes nov. & $295 M D 70$ & 101,00 & 148,41 & 71,26 & 40,70 & 3610,41 & 242,95 & 69,60 & 173,35 & 110,39 & 191,61 & 195,28 & 102,18 & 819,75 & 125,51 & 4,69 & 64,12 & 366,94 & 35,28 & 37,52 & 344,42 \\
\hline Pelodytes nov. & 29SMD72 & 101,00 & 154 & 65,05 & 40,89 & 3286,66 & 237,07 & 79,81 & 157,26 & 119,81 & 193,07 & 196,04 & 111,54 & 718,24 & 115,57 & 4,02 & 63,12 & 322,51 & 30,11 & 34,39 & 299 \\
\hline Pelodytes nov. & 29SMD73 & $\begin{array}{l}101,00 \\
100\end{array}$ & $\begin{array}{l}13,2,20 \\
153,51\end{array}$ & $\begin{array}{l}03,00 \\
62,06\end{array}$ & $\begin{array}{l}40,03 \\
41,03\end{array}$ & $\begin{array}{l}320,000 \\
3133,32\end{array}$ & 231,06 & \begin{tabular}{|l|l|}
81,41 \\
\end{tabular} & \begin{tabular}{|l|}
149,66 \\
149,
\end{tabular} & \begin{tabular}{|l|}
120,85 \\
12,0
\end{tabular} & $\begin{array}{l}190,32 \\
190, \\
\end{array}$ & \begin{tabular}{|l|}
193,01 \\
\end{tabular} & $\begin{array}{l}112,64 \\
112,66\end{array}$ & $\begin{array}{l}\mid 10,24 \\
696,19\end{array}$ & \begin{tabular}{|l|}
114,21 \\
114
\end{tabular} & $\begin{array}{ll}4,00 \\
4,00\end{array}$ & $\begin{array}{l}3,12 \\
62,63\end{array}$ & \begin{tabular}{|l|}
311,64 \\
31,4
\end{tabular} & $\begin{array}{l}30,11 \\
29,42\end{array}$ & \begin{tabular}{|l|}
34,60 \\
34,6
\end{tabular} & 288,44 \\
\hline Pelodytes nov. & $295 M D 74$ & 88,00 & 151,73 & 59,61 & 41,06 & 3010,96 & 224,95 & 81,51 & 143,43 & 120,61 & 186,91 & 189,33 & 112,29 & 688,41 & 114,38 & 3,95 & 62,44 & 306,73 & 29,59 & 35,33 & 283,54 \\
\hline Pelodytes $n$ & 29SMD75 & 89,00 & 151,32 & 57.80 & 41.23 & 2903,17 & 220.92 & 82.61 & 138,31 & $\mid 121.57$ & 185.03 & 187,33 & 113,25 & 677.61 & 113,71 & 3.95 & 62.35 & 300,55 & 29,35 & 35.85 & 277,62 \\
\hline Pelodytes nov & 29SMD93 & 101,00 & 152,29 & 71,58 & 40,51 & 3628,03 & 248,35 & 73,27 & $175, \mathrm{C}$ & 114,35 & 196,21 & 199 & 106 & 760,12 & 116,88 & 4,63 & 61,56 & 333,05 & 34,29 & 38,16 & 318,27 \\
\hline Pelodytes nov. & 29SMD98 & 58,00 & 154,47 & 68,99 & 42,01 & 3275,73 & 239,79 & 77,49 & 162,30 & 119,74 & 193,37 & 195,76 & 111,73 & 752,49 & 116,18 & 5,30 & 59,35 & 321,62 & 37,58 & 44,10 & 307,90 \\
\hline
\end{tabular}




\begin{tabular}{|c|c|c|c|c|c|c|c|c|c|c|c|c|c|c|c|c|c|c|c|c|c|}
\hline TAXON & UTM & $\mathrm{km2}$ & B101 & $\mathrm{B1O2}$ & $\mathrm{BIO3}$ & $\mathrm{B104}$ & B105 & B106 & B107 & B108 & $\mathrm{BIO9}$ & 81010 & B1011 & B1012 & BIO13 & 81014 & B1015 & B1O16 & B1017 & B1018 & B1019 \\
\hline Pelodytes nov. & 29SMD99 & 35,00 & 152,45 & 70,03 & 42,11 & 3291,15 & 238,72 & 74,76 & 163,96 & 117,54 & 191,64 & 194,07 & 109,53 & 788,54 & 119,77 & 6,00 & 58,43 & 334,07 & 41,22 & 47,77 & 321,45 \\
\hline Pelodytes nov. & 29SNB12 & 83,00 & 163,34 & 86,34 & 44,66 & 3628,14 & 271,70 & 80,42 & 191,27 & 128,07 & 207,95 & 212,23 & 119,51 & 516,43 & 83,19 & 1,00 & 68,47 & 241,95 & 18,35 & 19,41 & 231,30 \\
\hline Pelodytes nov. & 29 SNB13 & 51,00 & 165,90 & 86,91 & 44,25 & 3706,64 & 276,06 & 81,89 & 194,17 & 129,33 & 211,51 & 215,80 & 121,01 & 513,94 & 82,24 & 1,00 & 68,10 & 240,26 & 18,46 & 19,60 & 229,58 \\
\hline Pelodytes nov. & 29SNB14 & 19,00 & 166,42 & 87,92 & 44,00 & 3803,89 & 279,44 & 81,19 & 198,25 & 128,75 & 213,33 & 217,72 & 120,36 & 522,64 & 82,56 & 1,00 & 67,69 & 243,06 & 18,89 & 19,89 & 232,81 \\
\hline Pelodytes nov. & 29SNB16 & 24,00 & 167,33 & 88,92 & 43,73 & 3885,90 & 282,76 & 81,06 & 201,69 & 128,55 & 215,29 & 219,73 & 120,39 & 539,57 & 83,76 & 1,00 & 66,53 & 248,24 & 20,00 & 21,00 & 238,41 \\
\hline Pelodytes nov. & 29SNB21 & 101,00 & 166,71 & 86,81 & 43,34 & 3809,92 & 278,55 & 80,58 & 197,97 & 129,16 & 214,36 & 218,16 & 120,69 & 498,75 & 80,82 & 0,90 & 69,59 & 237,30 & 16,71 & 17,97 & 225,62 \\
\hline Pelodytes nov. & 29SNB22 & 101,00 & 159,48 & 88,59 & \begin{tabular}{|l|l|}
43,57 \\
\end{tabular} & 3863,33 & 274,21 & 73,06 & 201,15 & 121,65 & 207,70 & 211,89 & 113,22 & 545,39 & 86,20 & 1,08 & 67,90 & 254,36 & 19,78 & 20,69 & 243,97 \\
\hline Pelodytes nov. & 29SNB23 & 101,00 & 160,57 & 89,23 & 43,49 & 3904,89 & 276,69 & 73,70 & 202,99 & 122,19 & 209,27 & 213,56 & 113,87 & 548,35 & 86,14 & 1,15 & 67,36 & 254,48 & 20,17 & 21,04 & 244,38 \\
\hline Pelodytes nov. & 29SNB24 & 100,00 & 162,44 & 89,79 & 43,41 & 3953,88 & 280,03 & 75,26 & 204,76 & 123,45 & 211,84 & 216,11 & 115,18 & 546,36 & 85,42 & 1,08 & 67,06 & 252,79 & 20,07 & 20,88 & 242,88 \\
\hline Pelodytes nov. & 29SNB25 & 100,00 & 164,72 & 90,25 & 43,24 & 3981,16 & 283,08 & 77,15 & 205,94 & 125,25 & 214,24 & 218,62 & 116,82 & 543,22 & 84,29 & 1,00 & 66,73 & 250,47 & 20,04 & 20,94 & 240,79 \\
\hline Pelodytes nov. & 29SNB27 & 101,00 & 164,85 & 91,51 & 43,02 & 4077,94 & 286,17 & 76,15 & 210,02 & 124,01 & 215,44 & 219,99 & 115,74 & 565,10 & 86,24 & 1,72 & 65,40 & 256,79 & 22,20 & 22,99 & 248,03 \\
\hline Pelodytes nov. & 29SNB28 & 101,00 & 163,45 & 91,99 & 42,92 & 4134,08 & 286,67 & 74,44 & 212,23 & 121,86 & 214,92 & 219,54 & 113,86 & 584,01 & 88,30 & 2,00 & 64,69 & 263,26 & 23,58 & 24,30 & 255,08 \\
\hline Pelodytes nov. & 29SNB29 & 101,00 & 164,16 & 92,20 & 42,84 & 4175,37 & 288,44 & 74,92 & 213,52 & 122,01 & 216,06 & 220,71 & 113,97 & 590,88 & 88,76 & 2,00 & 64,15 & 265,09 & 24,11 & 24,86 & 257,27 \\
\hline Pelodytes nov. & 29SNB30 & 26,00 & 171,04 & 87,22 & 42,22 & 3973,35 & 285,61 & 82,09 & 203,52 & 131,74 & 221,13 & 224,74 & 123,26 & 482,91 & 78,78 & 0,48 & 70,65 & 233,09 & 14,83 & 16,48 & 220,22 \\
\hline Pelodytes nov. & 29SNB31 & 100,00 & 169,93 & 88,04 & 42,32 & 3993,05 & 285,92 & 80,82 & 205,09 & 130,58 & 220,37 & 224,08 & 121,95 & 491,29 & 79,47 & 0,87 & 69,85 & 235,53 & 15,71 & 17,27 & 223,19 \\
\hline Pelodytes nov. & 29 SNB32 & 100,00 & 157,21 & 90,43 & 42,89 & 4051,06 & 276,71 & 68,08 & 208,63 & 117,62 & 208,32 & 212,39 & 109,04 & 568,47 & 89,90 & 1,46 & 67,30 & 263,84 & 21,14 & 22,08 & 253,54 \\
\hline Pelodytes nov. & $29 \mathrm{SNB} 33$ & 101,00 & 153,17 & 91,73 & 42,96 & 4104,42 & 275,13 & 63,85 & 211,28 & 113,12 & 205,01 & 209,21 & 104,51 & 597,67 & 93,49 & 1,78 & 66,16 & 273,78 & 23,43 & 24,04 & 264,44 \\
\hline Pelodytes nov. & 29SNB34 & 100,00 & 160,98 & 91,92 & 42,89 & 4116,92 & 283,24 & 71,08 & 212,15 & 120,35 & 212,75 & 217,05 & 111,80 & 557,87 & 87,50 & 1,29 & 66,59 & 257,51 & 20,82 & 21,67 & 247,82 \\
\hline Pelodytes nov. & 29SNB35 & 101,00 & 167,48 & 91,98 & 42,96 & 4111,58 & 289,42 & 77,29 & 212,13 & 126,46 & 219,01 & 223,26 & 118,07 & 528,77 & 82,62 & 1,01 & 67,01 & 244,88 & 19,08 & 20,13 & 235,08 \\
\hline \begin{tabular}{|l} 
Pelodytes nov. \\
\end{tabular} & 295NB37 & 100,00 & 164,94 & 93,73 & 42,83 & 4219,59 & 290,82 & 74,07 & 216,75 & $\mid 122.57$ & $\mid 217,72$ & 222,23 & $\mid 114,44$ & 561,68 & 85,97 & 1,82 & 65,17 & 254,92 & 22.07 & 22,89 & 246,65 \\
\hline Pelodytes nov. & 29SNB39 & 100,00 & 165,48 & 94,48 & 42,38 & 4301,43 & 293,85 & 74,15 & 219,70 & 122,07 & 219,27 & 223,98 & 114,02 & 576,49 & 86,88 & 2,00 & 64,22 & 258,47 & 23,19 & 24,02 & 251,19 \\
\hline Pelodytes nov. & 29 SNB41 & 101,00 & 170,42 & 89,54 & 42,32 & 4071,24 & 288,31 & 79,58 & 208,73 & 130,01 & 221,89 & 225,72 & 121,66 & 494,19 & 80,91 & 1,00 & 69,76 & 237,45 & 15,99 & 17,53 & 224,66 \\
\hline Pelodytes nov. & 29SNB42 & 101,00 & 163,34 & 91,49 & 42,31 & 4153,20 & 284,97 & 71,88 & 213,09 & 122,27 & 215,89 & 219,81 & 113,77 & 536,63 & 86,44 & 1,15 & 68,24 & 252,48 & 18,58 & $\begin{array}{ll}19,76 \\
\end{array}$ & 241,22 \\
\hline Pelodytes nov. & 29SNB43 & 100,00 & 158,19 & 93,15 & 42,49 & 4219,30 & 282,90 & 66,29 & 216,61 & 116,56 & 211,49 & 215,67 & 108,04 & 570,05 & 90,55 & 1,33 & 66,86 & 263,84 & 21,04 & 21,89 & 253,89 \\
\hline Pelodytes nov. & 29SNB44 & 101,00 & 165,33 & 93,32 & $\begin{array}{l}42,45 \\
\end{array}$ & 4231,12 & 290,31 & 73,10 & 217,20 & 123,17 & 218,62 & 222,87 & 114,75 & 534,47 & 84,80 & 1,00 & 67,20 & 248,69 & 18,80 & 19,94 & 238,53 \\
\hline Pelodytes nov. & 29SNC05 & 13,00 & 170,30 & 85,90 & 41,70 & 4110,10 & 287,80 & 83,50 & 204,30 & 127,60 & 220,80 & 225,50 & 120,40 & 644,60 & 96,70 & 3,10 & 63,80 & 287,90 & 26,40 & 29,30 & 277,70 \\
\hline Pelodytes nov. & 29SNC18 & 101,00 & 170,36 & 85,57 & 40,95 & 4216,61 & 289,75 & $\begin{array}{ll}8,38 \\
82,38\end{array}$ & 207,36 & 126,20 & 222,34 & 226,68 & 118,63 & 654,34 & 96,199 & 3,00 & 62,89 & 288,89 & 27,13 & 30,05 & 280,95 \\
\hline Pelodytes nov. & $295 N C 20$ & 100,00 & 163,43 & 92,33 & 42,46 & 4224,95 & 288,91 & 73,92 & 214,99 & 120,64 & 215,90 & 220,69 & 112,66 & 606,74 & 90,73 & 2,30 & 63,70 & 270,56 & 25,52 & 26,30 & 263,18 \\
\hline Pelodytes nov. & 29 SNC21 & 101,00 & 164,38 & 92,12 & 42,16 & 4247,06 & 290,22 & 74,66 & 215,56 & 121,27 & 217,10 & 221,97 & 113,42 & 612,68 & 91,38 & 2,49 & 63,49 & 272,22 & 25,95 & 26,81 & 265,08 \\
\hline Pelodytes nov. & 29 SNC22 & 99,00 & 166,10 & 91,82 & 42,02 & 4275,52 & 292,11 & 76,33 & 215,78 & 122,47 & 219,16 & 224,04 & 114,58 & 614,17 & 91,45 & 2,67 & 63,12 & 272,23 & 26,19 & 27,32 & 265,21 \\
\hline Pelodytes nov. & $29 \mathrm{SNC} 30$ & 100,00 & 164,80 & 94,76 & 42,16 & 4339,40 & 294,27 & 73,09 & 221,18 & 120,82 & 218,96 & 223,73 & 112,79 & 591,55 & 88,55 & 2,06 & 63,69 & 263,40 & 24,27 & 24,90 & 256,82 \\
\hline $\begin{array}{l}\text { Pelodytes nov. } \\
\end{array}$ & $295 N C 31$ & 101,00 & 161,27 & 94,95 & 42,00 & 4 & 292,56 & 69,61, & 222,95 & \begin{tabular}{|l|}
116,77 \\
1202
\end{tabular} & 216,36 & 221,20 & 108,72 & 624,36 & $\begin{array}{l}0,030 \\
92,71 \\
\end{array}$ & 2,89 & 62,71 & \begin{tabular}{|l|}
274,96 \\
\end{tabular} & $\begin{array}{l}24,25 \\
27,25 \\
\end{array}$ & 27,68 & 269,36 \\
\hline Pelodytes nov. & $295 N C 32$ & 101,00 & 164,58 & 94,37 & 41,92 & 4412,68 & 295,47 & 72,80 & 222,67 & 119,62 & 219,70 & 224,62 & 111,69 & 614,58 & 90,98 & 2,73 & 62,64 & 270,49 & 26,43 & 27,17 & 264,92 \\
\hline \begin{tabular}{|l} 
Pelodytes nov. \\
.
\end{tabular} & 29 SNC33 & 100,00 & 167,77 & 93,79 & 41,93 & 4408,51 & 297,79 & 76,01 & 221,78 & 122,43 & 222,68 & 227,53 & 114,64 & 605,45 & 89,46 & 2,95 & 62,79 & 266,27 & 25,92 & 26,94 & 260,68 \\
\hline Pelodytes nov. & 29 SNC40 & 101,00 & 167,25 & 97,05 & 42,15 & 4438,80 & 300,13 & 73,75 & 226,38 & 122,15 & 222,81 & 227,46 & 114,11 & 570,75 & 85,50 & 2,00 & 63,50 & 253,58 & 23,46 & 24,21 & 247,48 \\
\hline Pelodytes nov. & 29SNC41 & 101,00 & 166,46 & 97,10 & 42,00 & 4485,43 & 300,43 & 72,71 & 227,71 & 120,71 & 222,62 & 227,24 & 112,62 & 584,59 & 86,96 & 2,10 & 63,03 & 257,83 & 24,48 & 25,09 & 252,44 \\
\hline Pelodytes nov. & $295 N C 42$ & 99,00 & $\begin{array}{l}10,40 \\
168,70\end{array}$ & $\begin{array}{l}96,55 \\
96,55\end{array}$ & 42,00 & $\begin{array}{l}4400,435 \\
448,66\end{array}$ & 302,16 & $\begin{array}{l}2,1,09 \\
75,\end{array}$ & \begin{tabular}{|l|}
227,07 \\
\end{tabular} & \begin{tabular}{|l|}
122,67 \\
1207
\end{tabular} & \begin{tabular}{|l|}
224,64 \\
224
\end{tabular} & \begin{tabular}{|l|}
229,38 \\
\end{tabular} & $\begin{array}{l}114,0< \\
114,78\end{array}$ & $\begin{array}{l}584,33 \\
580,33\end{array}$ & $\begin{array}{l}0,30 \\
85,94\end{array}$ & 2,06 & $\begin{array}{ll}3,02,96 \\
6\end{array}$ & \begin{tabular}{|l|}
255,20 \\
250
\end{tabular} & $\begin{array}{l}4,40 \\
24,26\end{array}$ & 25,13 & $\begin{array}{l}25,40,04 \\
250,04\end{array}$ \\
\hline Pelodytes nov. & 29SNC44 & 101,00 & 169,99 & 95,22 & 41,79 & 4509,82 & 302,72 & 76,65 & 226,07 & 123,49 & 226,24 & 231,00 & 115,48 & 591,50 & 86,65 & 2,87 & 61,89 & 257,60 & 25,84 & 27,04 & 253,18 \\
\hline Pelodytes nov. & 29SNC45 & 101,00 & 169,94 & 94,46 & 41,41 & 4514,58 & 302,27 & 76,89 & 225,38 & 123,17 & 226,18 & 230,97 & 115,35 & 601,31 & 87,88 & 3,00 & 61,71 & 260,69 & 26,58 & 27,74 & 256,66 \\
\hline Pelodytes nov. & $295 N C 46$ & 100,00 & 168,48 & 93,61 & 41,02 & 4534,77 & 300,59 & 75,62 & 224,97 & 121,42 & 225,07 & 229,66 & 113,51 & 619,70 & 90,45 & 3,03 & 61,34 & 267,23 & 27,81 & 29,05 & 263,86 \\
\hline Pelodytes nov. & 29SND03 & 101,00 & 160,54 & 75,24 & 40,72 & 3756,82 & 261,73 & 78,79 & 182,94 & 120,86 & 206,23 & 209,56 & 113,18 & 707,24 & 108,25 & 3,99 & 61,58 & 309,55 & 31,18 & 35,44 & 297,42 \\
\hline Pelodytes nov. & 29SND06 & $\begin{array}{l}101,00 \\
101,00\end{array}$ & $\begin{array}{l}10,54 \\
149,04\end{array}$ & $\frac{73,24}{73,22}$ & $\begin{array}{l}40,1 / 2 \\
40,77\end{array}$ & $\begin{array}{l}3 / 5,028 \\
363,73 \\
\end{array}$ & $\begin{array}{l}201,15 \\
246,47\end{array}$ & $\mid \frac{\mid 0,179}{68,94}$ & \begin{tabular}{|l|}
$177,54,54$ \\
\end{tabular} & \begin{tabular}{|l|}
111,00 \\
1100
\end{tabular} & \begin{tabular}{|l|}
193,27 \\
193,27
\end{tabular} & \begin{tabular}{|l|}
196,21 \\
196,21
\end{tabular} & \begin{tabular}{|l|}
103,07 \\
103
\end{tabular} & \begin{tabular}{|l|}
806,23 \\
806
\end{tabular} & \begin{tabular}{|l|}
121,74 \\
121,74
\end{tabular} & $\begin{array}{l}3,994 \\
5,64\end{array}$ & $\begin{array}{l}01,130 \\
59,51\end{array}$ & \begin{tabular}{|l|}
345,03 \\
345,03
\end{tabular} & \begin{tabular}{|l|}
1,10 \\
40,37 \\
\end{tabular} & $\begin{array}{l}3,444 \\
44,62\end{array}$ & $\begin{array}{l}295,42 \\
333,78\end{array}$ \\
\hline Pelodytes nov. & 29SND10 & 101,00 & 169,07 & 82,95 & 40,83 & 4115,42 & 283,87 & 82,42 & 201,45 & 125,60 & 219,60 & 223,64 & 118,22 & 664,85 & 99,11 & 3,00 & 62,31 & 292,12 & 27,81 & 31,06 & 283,75 \\
\hline Pelodytes nov. & 29SND16 & 100,00 & 153,84 & 77,45 & 40,77 & 3808,84 & 257,99 & 70,53 & 187,46 & 113,59 & 200,48 & 203,54 & 105,87 & 788,12 & 117,47 & 5,51 & 59,16 & 335,49 & 39,89 & 43,88 & 326,82 \\
\hline Pelodytes nov. & 29SND17 & 101,00 & 140,89 & 77,42 & 40,20 & 3896,44 & 247,82 & 57,69 & 190,13 & 100,32 & 189,19 & 192,27 & 92,55 & 923,35 & 36,53 & 7,84 & 57,81 & 387,36 & 51,57 & 54,11 & 380,57 \\
\hline $\begin{array}{l}\text { Pelodytes nov. } \\
\end{array}$ & 29SND18 & 100,00 & $\begin{array}{l}150,32 \\
150\end{array}$ & 77,86 & 41,1, & 3751,52 & 253,42 & $\begin{array}{ll}66,79 \\
\end{array}$ & 186,64 & 110,63 & 196,26 & \begin{tabular}{|l|l|}
199,05 \\
\end{tabular} & \begin{tabular}{|c|}
102,79 \\
120
\end{tabular} & 842,71 & 124,44 & 6,594 & 57,92 & 354,03 & 45,62 & $\begin{array}{l}4,11 \\
49,85 \\
\end{array}$ & 346,48 \\
\hline Pelodytes nov. & 29SND19 & 100,00 & 155,32 & 78,63 & 41,99 & 3664,69 & 256,27 & 71,28 & 184,99 & 116,06 & 199,79 & 202,38 & 108,15 & 810,80 & 119,14 & 6,25 & 57,62 & 339,55 & 44,17 & 49,25 & 331,81 \\
\hline Pelodytes nov. & 29 SND24 & 100,00 & 164,81 & 81,94 & 40,97 & 4020,68 & 276,34 & 78,16 & 198,18 & 122,04 & 214,24 & 217,55 & 114,29 & 700,91 & 103,93 & 4,00 & 60,20 & 300,66 & 33,15 & 36,90 & 293,36 \\
\hline Pelodytes nov. & 29 SND25 & 101,00 & 161,26 & 81,61 & 40,91 & 3997,80 & 272,25 & 74,87 & 197,38 & 118,84 & 210,46 & 213,58 & 111,06 & 735,20 & 108,67 & 4,79 & 59,47 & 313,26 & 36,15 & 39,89 & 306,39 \\
\hline Pelodytes nov. & 29 SND26 & 101,00 & 159,71 & 81,56 & 41,01 & 3964,80 & 269,88 & 73,31 & 196,58 & 117,48 & 208,47 & 211,54 & 109,77 & 756,41 & 111,66 & 5,06 & 58,96 & 320,51 & 38,33 & 42,25 & 313,91 \\
\hline Pelodytes nov. & 29SND27 & $\begin{array}{l}101,00 \\
100\end{array}$ & $\begin{array}{l}13,1+14 \\
147,54\end{array}$ & $\begin{array}{l}1,30 \\
81,31\end{array}$ & $\begin{array}{l}4+1, \\
40,\end{array}$ & $\begin{array}{l}3503,400 \\
403,86\end{array}$ & $\begin{array}{l}20,00 \\
260,08\end{array}$ & $\begin{array}{l}3,1,37 \\
61,\end{array}$ & \begin{tabular}{|l|}
198,71 \\
19,0
\end{tabular} & \begin{tabular}{|l|}
105,03 \\
150
\end{tabular} & \begin{tabular}{|l|}
200,4717 \\
197,73
\end{tabular} & $\begin{array}{l}200,82 \\
20,\end{array}$ & 97,41 & $\begin{array}{l}500,61 \\
880,62\end{array}$ & \begin{tabular}{|l|}
129,94 \\
129
\end{tabular} & $\begin{array}{l}3,000 \\
7,08\end{array}$ & $50,57,73$ & \begin{tabular}{|l|}
368,51 \\
3685
\end{tabular} & \begin{tabular}{|l|l}
48,65 \\
48,65
\end{tabular} & $\begin{array}{l}42,23 \\
51,27 \\
\end{array}$ & 363,81 \\
\hline Pelodytes nov. & 29SND28 & 101,00 & 144,18 & 81,60 & 40,51 & 4038,77 & 257,03 & 57,77 & 199,26 & 101,73 & 194,40 & 197,49 & 93,99 & 927,78 & 136,62 & 7,98 & 57,12 & 385,76 & 53,21 & 55,56 & 381,90 \\
\hline Pelodytes nov. & 29 SND29 & 99,00 & 151,13 & 82,99 & \begin{tabular}{ll|l}
41,45 \\
\end{tabular} & 3942,27 & 261,95 & 63,73 & $\mid 198,22$ & 109,08 & 199,74 & 202,52 & 101,35 & 876,15 & 128,23 & $7,39 \mid$ & 56,91 & 363,50 & 50,06 & 53,62 & 359,24 \\
\hline Pelodytes nov. & 29 SND34 & 100,00 & 166,83 & 85,17 & 40,92 & 4174,14 & 283,97 & 77,71 & 206,26 & 122,48 & 218,47 & 221,85 & 114,71 & 695,73 & 102,21 & 4,03 & 59,65 & 296,03 & 33,76 & 37,29 & 290,63 \\
\hline Pelodytes nov. & 29 SND35 & 101,00 & 166,06 & 85,14 & 40,9 & 4148,63 & 282,49 & 76,77 & 205,72 & 121,66 & 217 & 220 & 113,93 & 709,63 & 104,27 & 4,45 & 59,05 & 300,66 & 35,14 & 38,83 & 295 \\
\hline Pelodytes nov. & $29 \mathrm{SND} 36$ & 101,00 & 163,01 & 85,30 & 40,99 & 4139,85 & 279,47 & 73,62 & 205,86 & 118,69 & 214,20 & 217,29 & 110,95 & 745,59 & \begin{tabular}{|l|}
109,38 \\
\end{tabular} & 5,01 & 58,52 & 313,82 & 38,47 & 41,99 & 309,20 \\
\hline $\begin{array}{l}\text { Pelodytes nov. } \\
\end{array}$ & 29SND37 & 100,00 & 157,30 & 85,38 & 40,79 & 4154,40 & 274,52 & 67,86 & 206,66 & 112,97 & 208,89 & 211,94 & 105,38 & 810,35 & 118,84 & 6,19 & 57,83 & 338,33 & 44,14 & 47,12 & 334,79 \\
\hline Pelodytes nov. & 29SND38 & 101,00 & 154,11 & 86,06 & 40,92 & 4160,23 & 272,22 & 64,23 & 207,99 & 109,68 & 205,85 & 208,84 & 101,98 & 852,33 & 124,75 & 6,88 & 57,12 & 353,53 & 48,20 & 50,95 & 350,97 \\
\hline \begin{tabular}{|l} 
Pelodytes nov. \\
.
\end{tabular} & 29SND39 & 101,00 & 153,96 & 87,16 & 41,14 & 4137,05 & 272,16 & 63,43 & 208,73 & 109,60 & 205,40 & 208,28 & 102 & 870,46 & 126,93 & 7,33 & 56,63 & 359,14 & 50,47 & 53,44 & 357,18 \\
\hline Pelodytes nov. & 29 SND45 & 101,00 & 165,76 & 88,03 & 40,78 & 4321,19 & 288,15 & 74,32 & 213,82 & 119,42 & 219,42 & 222,85 & 111,97 & 723,74 & 105,79 & 4,87 & 58,48 & 304,00 & 37,37 & 40,32 & 300,70 \\
\hline
\end{tabular}




\begin{tabular}{|c|c|c|c|c|c|c|c|c|c|c|c|c|c|c|c|c|c|c|c|c|c|}
\hline TAXON & UTM & $\mathrm{km2}$ & B101 & B1O2 & $\mathrm{BIO3}$ & B104 & B105 & B106 & B107 & B108 & B109 & 81010 & B1011 & BIO12 & BIO13 & BIO14 & BIO15 & B1O16 & B1017 & BIO18 & B1019 \\
\hline Pelodytes nov. & 29SND46 & 101,00 & 166,58 & 88,53 & 40,98 & 4293,35 & 288,52 & 74,46 & 214,05 & 120,34 & 219,92 & 223,14 & 112,81 & 727,41 & 106,05 & 5,03 & 58,10 & 304,27 & 38,17 & 41,38 & 301,09 \\
\hline Pelodytes nov. & 29SND55 & 100,00 & 162,59 & 90,29 & $\begin{array}{ll}40,09 \\
\end{array}$ & \begin{tabular}{ll|}
4516,73 \\
\end{tabular} & 291,27 & 69,36 & 221,91 & 114,68 & 219,35 & 222,82 & 107,06 & 757,73 & 110,34 & 5,54 & 57,69 & 315,09 & 41,03 & 43,10 & 314,16 \\
\hline Pelodytes nov. & 29SND61 & 100,00 & 168,42 & 93,18 & 40,17 & 4677,65 & 302,26 & 73,77 & 228,49 & 119,18 & 227,10 & 231,18 & 111,43 & 659,02 & 94,87 & 4,00 & 58,62 & 275,31 & 33,64 & 35,16 & 274,36 \\
\hline Pelodytes nov. & 29SND71 & 100,00 & 168,11 & 94,80 & 40,01 & 4798,65 & 305,51 & 71,85 & 233,66 & 116,48 & 228,52 & 232,59 & 109,66 & 657,29 & 93,77 & 4,01 & 57,93 & 271,99 & 34,92 & 36,13 & 271,84 \\
\hline Pelodytes nov. & 29SND80 & 101,00 & 166,63 & \begin{tabular}{|l|l|}
96,48 \\
\end{tabular} & 40,00 & $\begin{array}{ll}4914,35 \\
\end{array}$ & 307,64 & \begin{tabular}{|c|}
69,17 \\
\end{tabular} & 238,47 & 107,97 & 228,70 & 232,91 & 107,09 & 646,56 & 91,14 & 4,00 & 57,21 & 265,65 & 35,67 & 36,13 & 265,65 \\
\hline Pelodytes nov. & 29SNE32 & 100,00 & 153,67 & 90,88 & 42,44 & 4083,90 & 272,45 & 60,72 & 211,73 & 106,56 & 204,07 & 206,71 & 101,62 & 929,17 & 133,19 & 8,90 & 54,84 & 377,49 & 58,40 & 61,82 & 376,70 \\
\hline Pelodytes nov. & 29SPD00 & 101,00 & 164,58 & 99,37 & 39,79 & 5146,66 & 311,81 & 64,14 & 247,67 & 103,56 & 230,05 & 234,15 & 102,51 & 650,04 & 89,94 & 4,54 & 55,90 & 263,25 & 37,71 & 38,10 & 263,25 \\
\hline Pelodytes nov. & 29SPD01 & 101,00 & 164,77 & 98,75 & 39,30 & 5155,83 & 311,99 & 64,27 & 247,72 & 104,12 & 230,51 & 234,52 & \begin{tabular}{|l|l|}
102,75 \\
\end{tabular} & 667,05 & 92,81 & 5,00 & 55,91 & 270,59 & 38,92 & 39,36 & 270,59 \\
\hline Pelodytes nov. & 29SPD03 & 101,00 & 167,25 & 98,55 & 39,03 & 5191,98 & 314,55 & 65,88 & 248,68 & 109,20 & 233,68 & 237,16 & 104,42 & 682,99 & 95,73 & 5,00 & 55,90 & 277,45 & 39,46 & 40,56 & 277,45 \\
\hline Pelodytes nov. & 29SPD10 & 100,00 & 161,34 & 100,52 & 39,30 & 5273,02 & 312,03 & 59,57 & 252,46 & 102,42 & 228,95 & 232,85 & 98,11 & 669,64 & 92,03 & 4,97 & 55,26 & 269,45 & 39,96 & 40,06 & 269,45 \\
\hline Pelodytes nov. & $29 \mathrm{SPD} 13$ & 100,00 & 165,32 & 99,37 & 38,84 & 5312,71 & 315,68 & 63,01 & 252,67 & 107,43 & 233,46 & 237,16 & 101,29 & 694,89 & 96,87 & 5,21 & 55,44 & 280,93 & 41,01 & 42,06 & 280,87 \\
\hline Pelodytes nov. & 29SPD15 & 99,00 & 162,46 & 97,29 & 38,02 & 5371,46 & 312,91 & 60,64 & 252,27 & 98,53 & 231,79 & 235,15 & 97,96 & 757,44 & 107,32 & 5,99 & 55,27 & 307,57 & 45,20 & 46,33 & 307,57 \\
\hline Pelodytes nov. & 29SPD17 & 100,00 & 162,40 & 97,18 & 37,83 & 5441,73 & 313,80 & 59,03 & 254,77 & 97,30 & 232,95 & 235,84 & 96,87 & 787,81 & 112,55 & 6,00 & 55,10 & 319,82 & 47,48 & 48,64 & 319,82 \\
\hline Pelodytes nov. & 29SPD19 & 100,00 & 163,73 & 98,30 & $\begin{array}{l}37,49 \\
\end{array}$ & 5511,66 & 316,45 & 57,86 & 258,59 & 99,38 & 235,47 & 237,44 & 96,75 & 798,04 & 114,38 & 6,44 & 54,99 & 322,98 & 48,53 & 49,92 & 322,95 \\
\hline Pelodytes nov. & 29TNE14 & 94,00 & 153,37 & 80,69 & 43,99 & 3489,40 & 249,04 & 67,60 & 181,44 & 114,96 & 194,89 & 196,96 & 106,94 & 915,43 & 130,14 & 8,93 & 54,31 & 372,73 & 57,22 & 64,43 & 366,66 \\
\hline Pelodytes nov. & 29TNE15 & 95,00 & 152,10 & 79,87 & 44,23 & 3433,91 & 244,94 & 66,57 & 178,37 & 114,04 & 192,57 & 194,69 & 106,07 & 940,82 & 132,95 & 9,80 & 53,87 & 381,66 & 60,01 & 67,97 & 375,23 \\
\hline Pelodytes nov. & $\begin{array}{l}\text { 29TNE17 } \\
\end{array}$ & 40,00 & 151,00 & 77,70 & 44,97 & 3321,38 & 237,20 & 65,97 & 171,23 & 113,99 & 189,58 & 191,34 & 105,62 & 973,01 & 136,21 & 10,34 & 53,00 & 393,07 & 63,24 & 72,89 & 385,45 \\
\hline Pelodytes nov. & 29TNE24 & 101,00 & 157,05 & 86,34 & 43,98 & 3694,57 & 261,43 & 67,16 & 194,27 & 116,16 & 201,40 & 203,60 & 108,25 & 901,97 & 127,53 & 8,99 & 53,98 & 365,32 & 57,08 & 63,58 & 361,36 \\
\hline Pelodytes nov. & 29TNE26 & 100,00 & 152,32 & 84,16 & \begin{tabular}{|l|l|l}
44,45 & \\
\end{tabular} & 3581,52 & 250,69 & 63,32 & 187,37 & 112,44 & 194,77 & 196,81 & 104,39 & 969,56 & 136,02 & 10,03 & 53,09 & 390,74 & 63,01 & 70,94 & 385,71 \\
\hline Pelodytes nov. & 29TNE27 & 100,00 & 150,94 & 81,77 & 44,72 & 3491,93 & 244,10 & 63,03 & 181,07 & 111,95 & 191,99 & 193,90 & 103,76 & 988,28 & 138,04 & 10,85 & 52,79 & 397,95 & 65,18 & 74,10 & 391,49 \\
\hline Pelodytes nov. & 29TNE28 & 101,00 & 149,73 & 78,91 & 45,04 & 3384,36 & 236,65 & 63,11 & 173,54 & 111,73 & 189,05 & 190,76 & 103,37 & 1002,72 & 139,53 & 11,00 & 52,55 & 403,88 & 66,14 & 76,54 & 395,56 \\
\hline Pelodytes nov. & 29TNE34 & 100,00 & 158,71 & 92,86 & 43,79 & 3959,58 & 274,19 & 64,23 & 209,97 & 114,31 & 206,84 & 209,11 & 106,97 & 911,58 & 128,28 & 9,09 & 53,73 & $\begin{array}{l}366,69 \\
\end{array}$ & 58,88 & 64,19 & 365,55 \\
\hline Pelodytes nov. & 29TNE36 & 101,00 & 153,32 & 90,79 & \begin{tabular}{ll|l}
44,05 & \\
\end{tabular} & 3857,75 & 263,38 & 59,66 & 203,71 & 110,21 & \begin{tabular}{|l|}
199,93 \\
\end{tabular} & 201,99 & 102,41 & 984,04 & 137,65 & 10,85 & 52,91 & 394,26 & 65,75 & 72,21 & 391,82 \\
\hline Pelodytes nov. & 29TNE37 & 100,00 & 151,92 & 88,12 & 44,21 & 3760,17 & 256,36 & 59,47 & 196,88 & 109,94 & 196,99 & 198,97 & 101,90 & 999,56 & 139,38 & 11,00 & 52,72 & 400,87 & 66,69 & 74,56 & 396,25 \\
\hline Pelodytes nov. & 29TNE43 & 100,00 & 152,01 & 96,88 & 42,29 & 4334,80 & 280,95 & 54,54 & 226,42 & 97,23 & 206,12 & 208,63 & 97,14 & 988,34 & 140,82 & 10,21 & 53,90 & 399,77 & 65,27 & 67,43 & 399,77 \\
\hline Pelodytes nov. & \begin{tabular}{|l|} 
29TNE45 \\
\end{tabular} & 101,00 & 159,50 & 98,46 & 43,90 & 4164,52 & 283,32 & 60,82 & 222,49 & 108,75 & 210,58 & 212,78 & 105,32 & 936,35 & 130,70 & 9,70 & 52,90 & 374,25 & 62,54 & 67,44 & 374,14 \\
\hline Pelodytes nov. & 29TNE46 & 100,00 & 155,75 & 90,92 & 43,75 & 4129,05 & 276,81 & $\begin{array}{l}0,069 \\
57,49\end{array}$ & 219,32 & 107,60 & 206,33 & 208,40 & \begin{tabular}{|l|l|}
101,84 \\
\end{tabular} & 981,31 & 136,99 & $\frac{1,10}{10,65}$ & 52,63 & 391,48 & 66,27 & 71,75 & 391,01 \\
\hline Pelodytes nov. & 29TNF20 & 39,00 & 148,11 & 75,99 & 45,39 & 3278,87 & 228,40 & 62,72 & 165,68 & 111,24 & 185,74 & 187,30 & 102,70 & 1033,57 & 142,44 & 11,91 & 52,02 & 416,51 & 68,59 & 81,88 & 404,38 \\
\hline Pelodytes nov. & 29TNF21 & 42,00 & 147,88 & 78,33 & 45,13 & 3371,42 & 232,38 & 61,15 & 171,23 & 110,42 & 187,18 & 188,83 & 101,85 & 1056,40 & 144,77 & 12,05 & 52,00 & 425,88 & 70,18 & 84,85 & 411,62 \\
\hline Pelodytes nov. & 29TNF25 & 28,00 & 144,51 & 85,81 & 44,94 & 3674,23 & 243,21 & 54,34 & 188,87 & 104,47 & 189,36 & 191,38 & 97,09 & 1183,21 & 162,30 & 14,83 & 51,15 & 472,75 & 81,40 & 99,72 & 460,91 \\
\hline Pelodytes nov. & 29TNF27 & 83,00 & 143,39 & 83,67 & 44,84 & 3665,84 & 241,48 & 56,50 & 184,98 & 98,16 & 188,60 & 190,35 & 96,94 & 1229,74 & 168,04 & 15,06 & 51,32 & 488,82 & 83,48 & 101,82 & 488,58 \\
\hline Pelodytes nov. & 29TNF30 & $\begin{array}{l}3,00 \\
97,00\end{array}$ & 149,38 & 82,52 & 44, 44,75 & 3564,68 & $\begin{array}{l}241,40 \\
241,69\end{array}$ & 59,15 & \begin{tabular}{|l|l|}
182,54 \\
\end{tabular} & \begin{tabular}{|l|}
109,24 \\
\end{tabular} & $\begin{array}{l}190,41,41 \\
\end{array}$ & 193,03 & \begin{tabular}{|r|}
100,90 \\
\end{tabular} & 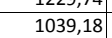 & \begin{tabular}{|l|}
143,20 \\
\end{tabular} & 111,86 & 52,06 & \begin{tabular}{|l|}
$418,81,81$ \\
\end{tabular} & $\begin{array}{l}5,4,12 \\
69,12\end{array}$ & $\begin{array}{r}1,04 \\
81,84 \\
\end{array}$ & $\begin{array}{l}40,50,13 \\
40,13\end{array}$ \\
\hline Pelodytes nov. & 29TNF31 & 101,00 & 148,07 & 83,26 & 44,69 & 3597,97 & 241,68 & 57,46 & 184,22 & 107,87 & 190,73 & 192,50 & 99,47 & 1065,36 & 146,05 & 12,24 & 52,00 & 429,98 & 71,06 & 85,21 & 414,46 \\
\hline Pelodytes nov. & 29TNF32 & 101,00 & 145,57 & 84,92 & 44,51 & 3682,73 & 242,81 & 53,91 & 188,90 & 104,71 & 189,77 & 191,53 & 96,39 & 1108,58 & 151,23 & 13,26 & 51,97 & 448,35 & 74,67 & 90,24 & 429,45 \\
\hline Pelodytes nov. & 29TNF33 & 100,00 & 143,08 & 86,64 & 44,26 & 3769,42 & 244,08 & 50,32 & 193,75 & 101,57 & 188,84 & 190,75 & 93,44 & 1153,38 & 156,89 & 14,21 & 51,96 & 467,44 & 78,42 & 95,49 & 444,94 \\
\hline Pelodytes nov. & 29TNF34 & 101,00 & 142,93 & 88,24 & 44,24 & 3832,79 & 246,60 & 49,26 & 197,34 & 100,95 & 189,74 & 191,72 & 92,80 & 1169,53 & 160,71 & 14,84 & 51,92 & 475,06 & 79,95 & 99,15 & 447,97 \\
\hline Pelodytes nov. & 29TPE43 & 101,00 & 153,35 & $\begin{array}{l}00,44 \\
97,14\end{array}$ & 35,97| & 5887,56 & 3140,18 & \begin{tabular}{|l|l|}
43,60 \\
43,0
\end{tabular} & \begin{tabular}{|l|}
266,59 \\
\end{tabular} & \begin{tabular}{|l|}
89,12 \\
89,
\end{tabular} & $\mid \begin{array}{l}\mid 03,1,4 \\
231,20\end{array}$ & 231,48 & $\begin{array}{ll}2,1,69 \\
81,69\end{array}$ & \begin{tabular}{|l|l|}
837,38 \\
\end{tabular} & \begin{tabular}{|l|}
120,72 \\
120,1
\end{tabular} & $\frac{14,04}{7,00}$ & $\begin{array}{l}1,25 \\
53,85 \\
\end{array}$ & \begin{tabular}{|l|}
434,35 \\
334
\end{tabular} & 53,38 & 53,65 & 333,63 \\
\hline Pelodytes punctatus & 29SNB50 & 53,00 & 169,96 & 90,04 & 42,66 & 4078,11 & 287,31 & 78,29 & 209,03 & 129,89 & 221,61 & 225,40 & 121,07 & 498,30 & 83,10 & 1,00 & 69,81 & 240,94 & 15,86 & 17,74 & 227,43 \\
\hline Pelodytes punctatus & 29SNB52 & 101,00 & 164,37 & 92,97 & 42,21 & 4241,13 & 288,17 & 71,28 & 216,89 & 122,52 & 218,10 & 222,13 & 113,81 & 533,03 & 86,93 & 1,00 & 68,19 & 251,74 & 17,99 & 19,46 & 240,04 \\
\hline Pelodytes punctatus & 29SNB53 & 100,00 & 164,55 & 94,13 & 42,08 & 4297,53 & 290,68 & 70,92 & 219,76 & 121,89 & 218,86 & 223,08 & 113,30 & 535,86 & 86,47 & 1,00 & 67,62 & 251,14 & 18,31 & 19,68 & 240,12 \\
\hline Pelodytes punctatus & 29 SNB54 & 101,00 & 161,55 & 95,59 & 42,24 & 4358,38 & 290, & 67,43 & 223,11 & 118,29 & 216,73 & 220,94 & 109,71 & 557,76 & 88,5 & 1,26 & 66,41 & 257,43 & 20,39 & 21,41 & 247,70 \\
\hline Pelodytes punctatus & $295 N C 19$ & 100,00 & 169,45 & 84,33 & 40,7 & 4178,78 & 286,88 & 81,82 & 205,06 & 125,35 & 220,79 & 225,15 & 117,87 & 663,76 & 98,49 & 3,00 & $\begin{array}{l}02,52 \\
62,\end{array}$ & 292,10 & 27,61 & 30,92 & 284,15 \\
\hline Pelodytes punctatus & 29SND04 & 100,00 & 159,03 & 74,02 & 40,93 & 3672,60 & 257,33 & 78,10 & 179,23 & 120,14 & 203,57 & 206,64 & 112,38 & 713,86 & 109,86 & 4,02 & 61,19 & 311,14 & 31,96 & 36,53 & 298,65 \\
\hline Pelodytes punctatus & 29SNE22 & 101,00 & 156,45 & 86,16 & 43,06 & 3801,99 & 264,73 & 66,96 & 197,77 & 114,81 & 202,60 & 205,01 & 107,05 & 877,24 & 125,73 & 8,03 & 55,11 & 58,35 & 53,36 & 58,58 & 354,81 \\
\hline Pelodytes punctatus & 29SPD12 & 100,00 & 166,36 & 100,31 & 39,03 & 5282,65 & 316,66 & 63,77 & 252,89 & 110,21 & 234,10 & 237,65 & 102,66 & 666,77 & 92, & 5,00 & 55 & 68,94 & 39,34 & 40,14 & 268,71 \\
\hline $\begin{array}{l}\text { Pelodytes punctatus } \\
\end{array}$ & 29SPD14 & 101,00 & 165,21 & 98,75 & 38,5 & 5330,92 & 315 & 62,83 & 252,77 & $\mid 106,32$ & 233,90 & 237,29 & $\begin{array}{l}101,11 \\
101,0\end{array}$ & 714,56 & $\mid$\begin{tabular}{|c|}
100,17 \\
\end{tabular} & 5,54 & \begin{tabular}{|l|l|}
55,28 \\
\end{tabular} & \begin{tabular}{|l|}
289,08 \\
\end{tabular} & 42,56 & 43,73 & 289,07 \\
\hline Pelodytes punctatus & 29SPD16 & 100,00 & 161 & 96,94 & 37,96 & 5407,71 & 312 & 59,44 & 253,04 & 96,84 & 231,64 & 234,87 & 96,84 & 780,17 & 111,29 & 6,00 & 55,41 & 317,28 & 46,43 & 47,58 & 317,28 \\
\hline Pelodytes punctatus & $29 S P D 35$ & 100,00 & 150,96 & 93,90 & 36,71 & 5549,48 & 303,30 & 51,48 & 251,82 & 87,76 & 223,30 & 227,27 & 86,22 & 847,69 & 120,82 & 7,24 & 54,84 & 343,56 & 52,06 & 53,06 & 343,56 \\
\hline Pelodytes punctatus & $29 S P D 36$ & 101,00 & 153,98 & 94,90 & 36,77 & 5604,19 & 307,60 & 52,43 & 255,18 & 91,66 & 227,18 & 230,49 & 87,92 & 831,12 & 118,49 & 6,95 & 54,64 & 336,25 & 51,13 & 52,08 & 336,14 \\
\hline Pelodytes punctatus & $29 S P D 46$ & 100,00 & 156,64 & 97,92 & 36,9 & 5715,55 & 313,60 & 51,85 & 261,75 & 96,79 & 231,46 & 234,36 & 88,84 & 779,71 & 109,38 & 6,38 & 54,05 & 313,09 & 48,41 & 49,55 & 311,72 \\
\hline Pelodytes punctatus & 29SPD60 & 100,00 & 168 & \begin{tabular}{|l|}
115,08 \\
115
\end{tabular} & $\begin{array}{l}30, \\
39,\end{array}$ & S867,40 & 337,01 & $\begin{array}{ll}1,030 \\
49,50\end{array}$ & \begin{tabular}{|l|}
287,52 \\
\end{tabular} & \begin{tabular}{|c|}
104,80 \\
10,5
\end{tabular} & \begin{tabular}{|l|}
245,21 \\
240
\end{tabular} & \begin{tabular}{|l|}
246,19 \\
246
\end{tabular} & $\begin{array}{l}00,044 \\
96,54\end{array}$ & 544,56 & $\begin{array}{l} \\
75,00 \\
750\end{array}$ & $\begin{array}{l}, 503 \\
4,03\end{array}$ & 52,36 & \begin{tabular}{|l|}
213,40 \\
21,0
\end{tabular} & $\begin{array}{l}0,45 \\
35,45\end{array}$ & $\begin{array}{l}45,35 \\
35,99\end{array}$ & 204,68 \\
\hline Pelodytes punctatus & 29SPD61 & 100,00 & 167,71 & 115,31 & 39,86 & 5882,00 & 336,11 & 48,61 & 287,49 & 103,42 & 244,34 & 245,41 & 95,43 & 563,84 & 77,06 & 4,32 & 52,19 & 220,94 & 36,92 & 37,50 & 212,62 \\
\hline $\begin{array}{l}\text { Pelodytes punctatus } \\
\text { S }\end{array}$ & 29SQA39 & 100,00 & 178,93 & 88,43 & 37,01 & 5120,94 & 306,79 & $\begin{array}{l}0,01,23 \\
71\end{array}$ & 235,55 & \begin{tabular}{|l|l|}
143,96 \\
\end{tabular} & 243,43 & \begin{tabular}{|l|}
246,48 \\
24,4
\end{tabular} & \begin{tabular}{|c|}
115,26 \\
115
\end{tabular} & 540,45 & 82,58 & 1,00 & 64,,61 & 233,88 & \begin{tabular}{|l|l}
14,96 \\
14
\end{tabular} & 22,00 & 214,68 \\
\hline Pelodytes punctatus & 29TNE33 & 101,00 & 158,16 & 92,64 & 43,21 & 4010,56 & 275,56 & 64,01 & 211,56 & 112,29 & 207,16 & 209,62 & 106,24 & 902,78 & 127,94 & 8,74 & 54,15 & 364,73 & 57,45 & 61,96 & 363,85 \\
\hline Pelodytes punctatus & 29TNE35 & 101,00 & 155,88 & 92,45 & 44, & 3919,27 & 269,56 & 61,58 & 207,99 & 112,19 & 203,42 & 205,66 & 104,51 & 950,94 & 133,34 & 9,92 & 53,16 & 381,31 & 62,81 & 68,60 & 379 \\
\hline Pelodytes punctatus & $\begin{array}{l}\text { 30SUH78 } \\
305\end{array}$ & $\begin{array}{l}100,00 \\
100\end{array}$ & $\begin{array}{l}13,00 \\
147,51\end{array}$ & 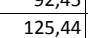 & 37,00 & 6974, & $\begin{array}{l}30,50,35 \\
345,5\end{array}$ & $\begin{array}{l}1,10 \\
11,86 \\
\end{array}$ & \begin{tabular}{|l|l|}
333,49 \\
3
\end{tabular} & \begin{tabular}{|l|}
101,89 \\
101
\end{tabular} & \begin{tabular}{|l|}
241,28 \\
241
\end{tabular} & \begin{tabular}{|l|}
241,28 \\
24
\end{tabular} & \begin{tabular}{|c|c|}
63,78 \\
63
\end{tabular} & $\mid \begin{array}{l}\mid 520,5411 \\
\end{array}$ & $\mid \begin{array}{l}\mid c 30,34 \\
70,51\end{array}$ & $\begin{array}{l}4,52 \\
4,52\end{array}$ & $\begin{array}{l}5,104 \\
48,64 \\
\end{array}$ & \begin{tabular}{|l|}
$01,1,11$ \\
184,42 \\
\end{tabular} & $\begin{array}{l}2,01 \\
33,20 \\
\end{array}$ & 30,20 & 174,00 \\
\hline Pelodytes punctatus & 30SUH87 & 100,00 & 146,01 & 125,26 & 37,00 & 6949,86 & 344,13 & 10,88 & 333,25 & 99,38 & 240,03 & 240,03 & 62,22 & 539,66 & 72,92 & 4,84 & 48,75 & 191,20 & 33,88 & 33,88 & 179,09 \\
\hline Pelodytes punctatus & 30SUH98 & 100,00 & 147,00 & 125,99 & 37,00 & 6930,67 & 344,96 & 11,24 & 333,72 & 118,62 & 240,77 & 240,77 & 63,63 & 505,15 & 66,19 & 4,32 & 47,51 & 177,79 & 33,52 & 33,52 & 163,80 \\
\hline Pelodytes punctat & 30SUJ52 & 100,00 & 147,69 & 123,67 & 37,00 & 6888,11 & 342,84 & 12,90 & 329,94 & 130,79 & 240, & 240,73 & 64 & 482,92 & 60,95 & 4,93 & 45 & 165,87 & 34,88 & 34,88 & 153,01 \\
\hline Pelodytes punctatus & 30SUJ62 & 100,00 & 149,63 & 123,97 & 37,00 & 6899,46 & 344,74 & 14,23 & 330,51 & 133,09 & 242,72 & 242,72 & 66,02 & 467,27 & 58,39 & 4,57 & 45,74 & 161,13 & 33,77 & 33,77 & 147, \\
\hline
\end{tabular}




\begin{tabular}{|c|c|c|c|c|c|c|c|c|c|c|c|c|c|c|c|c|c|c|c|c|c|}
\hline TAXON & UTM & $\mathrm{km} 2$ & BIO1 & B102 & $\mathrm{B1O3}$ & B104 & B105 & B106 & B107 & B108 & B109 & B1010 & B1011 & BIO12 & B1013 & BIO14 & B1015 & B1016 & B1017 & B1018 & B1019 \\
\hline Pelodytes punctatus & $305 U J 63$ & 100,00 & 145,25 & 123,52 & 37,00 & 6890,92 & 340,28 & 10,49 & 329,79 & 128,27 & 238,45 & 238,45 & 62,09 & 469,25 & 57,34 & 5,25 & 44,38 & 161,49 & 36,57 & 36,57 & 145,12 \\
\hline Pelodytes punctatus & 30SUJ71 & 100,00 & 150,08 & 125,08 & 37,00 & 6909,14 & 346,05 & 13,92 & 332,12 & 133,77 & 243,34 & 243,34 & 66,37 & 469,68 & 59,18 & 4,21 & 46,36 & 163,15 & 32,79 & 32,79 & 148,78 \\
\hline Pelodytes punctatus & $30 \mathrm{SUJ72}$ & 100,00 & 144,93 & 124,86 & 37,00 & 6910,35 & 341,01 & 9,19 & 331,82 & 128,45 & 238,29 & 238,29 & 61,42 & 474,52 & 58,32 & 4,97 & 44,83 & 164,41 & 36,07 & 36,07 & 147,54 \\
\hline Pelodytes punctatus & 30 SUJ75 & 100,00 & 140,25 & 122,33 & 37,00 & 6876,04 & 333,81 & 5,96 & 327,85 & 123,67 & 233,36 & 233,36 & 57,40 & 456,66 & 52,75 & 6,19 & 41,78 & 156,56 & 40,66 & 40,66 & 135,52 \\
\hline Pelodytes punctatus & 30 SUJ76 & 100,00 & \begin{tabular}{ll|}
131,62 \\
\end{tabular} & 121,11 & 36,99 & 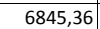 & 324,71 & $-0,64$ & 325,36 & 114,22 & 224,64 & 224,64 & 49,95 & 478,72 & 55,45 & 7,72 & 40,05 & 163,20 & 46,50 & 46,50 & 139,57 \\
\hline Pelodytes punctatus & 30 SUI83 & 100,00 & 143,81 & 124,75 & 37,00 & 6892,71 & 339,36 & 8,21 & 331,16 & 127,29 & 237,03 & 237,03 & 60,78 & 457,21 & 54,14 & 5,19 & 43,40 & 158,38 & 37,21 & 37,21 & 138,80 \\
\hline Pelodytes punctatus & 30 SUJ 84 & 100,00 & 147,10 & 123,58 & 37,00 & 6891,58 & 341,06 & 11,29 & 329,77 & 130,97 & 240,20 & 240,20 & 63,63 & 435,05 & 50,60 & 5,04 & 43,12 & 150,06 & 36,03 & 36,03 & 130,50 \\
\hline Pelodytes punctatus & 30 SUJ85 & 100,00 & 139,86 & 122,68 & 37,00 & 6883,90 & 333,48 & 5,15 & 328,33 & 123,22 & 233,10 & 233,10 & 57,01 & 452,03 & 52,22 & 6,18 & 41,36 & 154,99 & 41,14 & 41,14 & 133,15 \\
\hline Pelodytes punctatus & 30 SUJ 87 & 100,00 & 128,53 & 120,22 & 36,90 & 6825,34 & 320,44 & $-3,11$ & 323,55 & 111,06 & 221,42 & 221,42 & 47,25 & 476,95 & 56,08 & 8,54 & 38,63 & \begin{tabular}{|c|}
161,68 \\
\end{tabular} & 49,58 & 49,58 & 136,07 \\
\hline \begin{tabular}{|l} 
Pelodytes punctatus \\
\end{tabular} & 30SUJ91 & 100,00 & 147,66 & 126,60 & 37,53 & 6892,61 & 344,21 & $\mid 11,08$ | & 333,13 & 131,09 & 240,71 & 240,71 & 64,23 & 455,62 & 55,28 & 4,29 & 45,06 & 159,29 & 33,96 & 33,96 & 141,21 \\
\hline Pelodytes punctatus & 30 SUJ92 & 100,00 & 146,89 & 126,23 & 37,28 & 6888,05 & 342,90 & 10,26 & 332,64 & 130,50 & 239,83 & 239,83 & 63,38 & 447,19 & 53,12 & 4,36 & 44,15 & 155,79 & 34,83 & 34,83 & 136,70 \\
\hline Pelodytes punctatus & 30 SUJ95 & 100,00 & 136,17 & 123,12 & 37,00 & 6876,93 & 330,38 & 1,78 & 328,60 & 119,18 & 229,47 & 229,47 & 53,59 & 460,05 & 53,51 & 6,70 & 40,60 & 157,81 & 43,56 & 43,56 & 134,31 \\
\hline $\begin{array}{l}\text { Pelodytes punctatus } \\
\end{array}$ & 30 SUJ98 & 100,00 & 131,73 & 118,86 & 36,18 & 6842,66 & 322,13 & 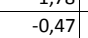 & 322,60 & 114,83 & 224,72 & 224,73 & 49,97 & 454,45 & 53,69 & 8,53 & $\begin{array}{l}37,87 \\
37\end{array}$ & $\mid$ & 48,75 & 48,75 & 127,88 \\
\hline Pelodytes punctatus & 30SUK12 & 100,00 & 155,81 & 115,07 & 37,00 & 6556,55 & 335,75 & 26,94 & 308,82 & 113,23 & 243,57 & 243,57 & 75,22 & 366,27 & 42,02 & 5,35 & 40,46 & 123,19 & 34,38 & 34,38 & 107,31 \\
\hline Pelodytes punctatus & 30 SVHO5 & 100,00 & 144,87 & 123,50 & 37,00 & 6956,21 & 342,06 & 11,07 & 330,99 & 97,66 & 239,15 & 239,15 & 61,62 & 557,74 & 77,28 & 5,44 & 49,29 & 202,56 & 34,99 & 34,99 & 186,84 \\
\hline Pelodytes punctatus & 30 SVHO8 & 100,00 & 146,68 & 126,35 & 37,34 & 6917,47 & 344,27 & 10,82 & 333,44 & 123,90 & 240,12 & 240,12 & 63,49 & 495,58 & 64,12 & 4,31 & 46,88 & 175,07 & 33,86 & 33,86 & 159,05 \\
\hline Pelodytes punctatus & 30SVHO9 & 100,00 & 146,35 & 127,13 & 37,87 & 6903,11 & 343,78 & 9,97 & 333,81 & 129,14 & 239,60 & 239,60 & 63,14 & 478,40 & 60,09 & 4,12 & 46,07 & 168,82 & 33,85 & 33,85 & 151,16 \\
\hline Pelodytes punctatus & 30SVH17 & 100,00 & $\begin{array}{l}14,37,46 \\
147,4\end{array}$ & 125,23 & 37,01 & $\begin{array}{l}-6931,02 \\
6913,02\end{array}$ & 344,08 & 12,32 & \begin{tabular}{|l|l|}
331,71 \\
331,76
\end{tabular} & \begin{tabular}{|l|}
104,38 \\
104,
\end{tabular} & 240,95 & 240,95 & $\mid 64,36$ & $\begin{array}{ll}470,40 \\
499,75\end{array}$ & $\begin{array}{l}60,039 \\
65,82\end{array}$ & $4,4,52$ & $\begin{array}{ll}40,36 \\
47,34 \\
\end{array}$ & $\begin{array}{l}10,02 \\
177,79\end{array}$ & 33,55 & 33,55 & $\begin{array}{l}13,10 \\
161,52\end{array}$ \\
\hline Pelodytes punctatus & 30SVH18 & 100,00 & 141,26 & 126,56 & 37,49 & 6920,60 & 339,46 & 5,81 & 333,64 & 122,40 & 234,95 & 234,95 & 58,32 & 507,36 & 64,76 & 5,18 & 45,75 & 179,45 & 37,25 & 37,25 & 160,72 \\
\hline Pelodytes punctatus & 30 SVH 38 & 100,00 & 148,85 & 125,41 & 37,41 & 6858,53 & 343,64 & 13,66 & 329,98 & 131,73 & 241,52 & 241,52 & 66,19 & 460,18 & 57,72 & 4,16 & 45,48 & 163,18 & 33,46 & 33,46 & 143,98 \\
\hline Pelodytes punctatus & $30 \mathrm{SVH} 46$ & 100,00 & 146,07 & 123,18 & 37,00 & 6878,33 & 340,31 & 12,33 & 327,98 & 99,86 & 239,18 & 239,18 & 63,76 & 494,85 & 65,02 & 5,43 & 45,99 & 177,10 & 36,01 & 36,01 & 157,28 \\
\hline Pelodytes punctatus & 30 SVH 48 & 100,00 & 146,49 & 124,96 & 37,16 & 6857,76 & 340,81 & 11,58 & 329,23 & 128,84 & 239,18 & 239,18 & 63,97 & 464,11 & 57,69 & 5,01 & 44,44 & 164,26 & 35,99 & 35,99 & 143,41 \\
\hline Pelodytes punctatus & $30 \mathrm{SVH} 49$ & 100,00 & 147,50 & 125,45 & 37,46 & 6835,61 & 341,49 & $\begin{array}{ll}11,92 \\
\end{array}$ & 329,56 & 130,52 & 239,71 & 239,71 & 65,16 & 447,70 & 54,38 & 4,81 & 43,65 & 157,62 & 35,58 & 35,58 & 136,44 \\
\hline $\begin{array}{l}\text { Pelodytes punctatus } \\
\end{array}$ & $30 \mathrm{SVH} / 5$ & 100,00 & 145,01 & 121,56 & 37,00 & 6830,51 & 336,83 & 12,36 & 324,47 & 98,63 & 237,55 & 237,55 & 63,40 & 490,13 & 63,78 & 6,22 & 44,91 & 175,06 & 37,89 & 37,89 & 153,67 \\
\hline Pelodytes punctatus & 30 SVH75 & 100,00 & 148,09 & 120,87 & 37,00 & 6772,70 & 337,37 & 15,63 & 321,74 & 110,62 & 239,64 & 239,64 & 66,96 & 466,38 & 59,56 & 5,92 & 44,41 & 165,41 & 36,67 & 36,67 & 144,59 \\
\hline Pelodytes punctatus & 30 SVH76 & 100,00 & 142,16 & 122,42 & 37,00 & 6812,50 & 333,83 & 9,07 & 324,76 & 123,00 & 234,41 & 234,41 & 60,91 & 480,67 & 60,20 & 6,83 & 42,80 & 170,17 & 40,83 & 40,83 & 146,37 \\
\hline Pelodytes punctatus & 30 SVH78 & 100,00 & 143,55 & 123,34 & 37,31 & 6789,82 & 334,83 & $\begin{array}{l}, 0,47 \\
\end{array}$ & 325,36 & 125,28 & 235,28 & 235,28 & $\begin{array}{ll}62,08 \\
\end{array}$ & 457,77 & 56,10 & $\frac{0,00}{6,16}$ & $\begin{array}{ll}41,93 \\
41\end{array}$ & $\mid 161,07$ & 40,42 & 40,42 & 136,31 \\
\hline Pelodytes punctatus & $30 \mathrm{SVJ} 00$ & 100,00 & \begin{tabular}{|l|l|}
148,87 \\
\end{tabular} & \begin{tabular}{ll|l}
127,44 \\
\end{tabular} & 38,00 & 6881,30 & 345,65 & 11,99 & 333,65 & 132,29 & 241,78 & 241,78 & 65,87 & 452,13 & 55,12 & 4,00 & 45,43 & 158,93 & 32,90 & 32,90 & 140,79 \\
\hline Pelodytes punctatus & $30 \mathrm{SVJ} 01$ & 100,00 & 145,96 & 127,77 & 37,97 & 6873,92 & 342,90 & 8,98 & 333,92 & 129,55 & 238,77 & 238,77 & 63,01 & 448,95 & 53,61 & 4,16 & 44,37 & 157,40 & 34,68 & 34,68 & 137,48 \\
\hline Pelodytes punctatus & $30 \mathrm{SVJO2}$ & 100,00 & 143,81 & 127,26 & 38,00 & 6880,20 & 340,49 & 7,06 & 333,44 & 127,11 & 236,74 & 236,74 & 60,84 & 446,77 & 53,00 & 4,54 & 43,43 & 156,01 & 36,44 & 36,44 & 134,77 \\
\hline Pelodytes punctatus & $30 \mathrm{SVJ} 06$ & 100,00 & 129,19 & 121,97 & 37,00 & 6851,31 & 322,54 & $-3,91$ & 326,45 & 111,79 & 222,27 & 222,27 & 47,47 & 477,10 & 55,90 & 8,28 & 38,71 & 162,20 & 49,38 & 49,38 & 136,52 \\
\hline Pelodytes punctatus & $30 \mathrm{SVJ08}$ & 100,00 & 128,99 & 118,95 & 36,32 & $\begin{array}{ll}6036,28 \\
6836\end{array}$ & 319,54 & $-2,78$ & 322,32 & $\frac{111,71}{111,71}$ & \begin{tabular}{|l|l|}
221,98 \\
\end{tabular} & 222,00 & 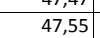 & 465,26 & 54,82 & $\begin{array}{ll}, 2,07 \\
9,07\end{array}$ & $\begin{array}{ll}30,112 \\
37,28\end{array}$ & 155,83 & $\begin{array}{l}41,08 \\
51,08\end{array}$ & 51,10 & 130,69 \\
\hline Pelodytes punctatus & 30SVJ11 & 100,00 & 147,16 & 128,77 & 38,00 & 6852,44 & 343,75 & 9,46 & 334,29 & 131,07 & 239,31 & 239,31 & 64,03 & 431,67 & 52,12 & 4,00 & 44,03 & 151,79 & 33,87 & 33,87 & 130,75 \\
\hline Pelodytes punctatus & $30 \mathrm{SVJ13}$ & 100,00 & 143,91 & 126,68 & 37,89 & 6858,15 & 339,39 & 7,36 & 332,03 & 127,80 & 236,59 & 236,59 & 61,18 & 430,37 & 51,26 & 4,76 & 42,04 & 149,31 & 37,37 & 37,37 & 127,06 \\
\hline Pelodytes punctatus & 30 SVJ15 & 100,00 & 133,32 & 123,81 & 37,00 & 6870,43 & 327,87 & $-0,78$ & 328,66 & 116,26 & 226,57 & 226,57 & 51,09 & 461,95 & 54,07 & 7,1 & 39,51 & \begin{tabular}{|c|}
158,08 \\
\end{tabular} & 45,73 & 45,73 & 133,26 \\
\hline Pelodytes punctatus & 30 SVJ17 & 100,00 & 131,07 & 120,62 & 36,84 & 6857,65 & 322,85 & $-1,81$ & 324,66 & 114,03 & 224,17 & 224,17 & 49,04 & 461,86 & 54,09 & 8,49 & 37,81 & 155,32 & 49,35 & 49,35 & 130,82 \\
\hline Pelodytes punctatus & 30 SVJ18 & $\begin{array}{l}100,00 \\
\end{array}$ & 131,14 & $\begin{array}{ll}12,02 \\
119,15\end{array}$ & $\begin{array}{l}30,044 \\
36,31\end{array}$ & $\begin{array}{ll}6054,035 \\
6845,13\end{array}$ & 321,53 & $\begin{array}{l}-1,01 \\
-1,08\end{array}$ & $\begin{array}{ll}324,006 \\
322,61\end{array}$ & \begin{tabular}{|l|}
$114,18,18$ \\
\end{tabular} & $\mid$\begin{tabular}{|l|}
224,04 \\
224
\end{tabular} & 224,04 & $\begin{array}{ll}435,04 \\
49,31\end{array}$ & $\begin{array}{l}\mid 40,00 \\
457,24\end{array}$ & $\begin{array}{ll}4,, 43 \\
53,43\end{array}$ & $\begin{array}{l}0,45 \\
8,76\end{array}$ & $\begin{array}{ll}37,21 \\
37\end{array}$ & 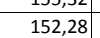 & 50,13 & $\mid \begin{array}{ll}45,130 \\
50,13\end{array}$ & 13,04 \\
\hline $\begin{array}{l}\text { Pelodytes punctatus } \\
\end{array}$ & 30 SVJ 20 & 100,00 & 147,62 & 128,19 & 38,00 & 6846,08 & 343,72 & 10,63 & 333,09 & 131,12 & 239,85 & 239,85 & 64,75 & 437,74 & 53,16 & 4,03 & 44,23 & 154,48 & 33,94 & 33,94 & 133,55 \\
\hline Pelodytes punctatus & $30 \mathrm{SVJ} 22$ & 100,00 & 146,95 & 127,78 & 38,00 & 6837,73 & 342,15 & 9,75 & 332,40 & 130,93 & 239,15 & 239,15 & 64,08 & 418,04 & 50,58 & 4,00 & 43,23 & 146,07 & 34,69 & 34,69 & 124,21 \\
\hline Pelodytes punctatus & $30 \mathrm{SVJ} 23$ & 100,00 & 145,52 & 126,56 & 37,99 & 6840,83 & 340,04 & 8,74 & 331,30 & 129,61 & 237,74 & 237,74 & 62,74 & 420,08 & 50,24 & 4,60 & 42,20 & 145,53 & 36,85 & 36,85 & 123,39 \\
\hline Pelodytes punctatus & 30 SVJ31 & 100,00 & 72 & 127,21 & 38,00 & 6832,17 & 342,24 & 11,03 & 331,21 & 131,45 & 239,79 & 239,79 & $65, \mathrm{C}$ & 423,81 & 51,49 & 4,00 & 43,30 & 148,81 & 34,42 & 34,42 & 126,96 \\
\hline $\begin{array}{l}\text { Pelodytes punctatus } \\
\end{array}$ & $\frac{50505313}{305 J 33}$ & 100,00 & $\begin{array}{l}141,1 / 2 \\
146,07 \\
\end{array}$ & $\begin{array}{l}12,21,88 \\
125,8\end{array}$ & $\begin{array}{l}30,00 \\
37,83 \\
\end{array}$ & $\begin{array}{ll}0.32,11 \\
6835,78\end{array}$ & $34,2,76$ & \begin{tabular}{|r|}
$\mid r, 03$ \\
9,77
\end{tabular} & $\mid \begin{array}{ll}351,21 \\
329,99\end{array}$ & $\mid \begin{array}{l}\mid 11,43 \\
130,11\end{array}$ & $\frac{\mid 35,, 95}{238,23}$ & $\mid \begin{array}{l}\mid 23,19 \\
238,23\end{array}$ & $\mid \begin{array}{l}\mid 23,03 \\
63,47\end{array}$ & $\begin{array}{l}423,01 \\
417,42\end{array}$ & $\begin{array}{l}\mid c 1,49 \\
49,97 \\
\end{array}$ & $4,4,87$ & $\begin{array}{l}43,30 \\
41,82\end{array}$ & $\begin{array}{l}148,01 \\
144,18\end{array}$ & $\begin{array}{l}34,4 c \\
37,16\end{array}$ & 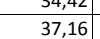 & $\begin{array}{l}120,90 \\
122,00\end{array}$ \\
\hline Pelodytes punctatus & $30 \mathrm{VVJ} 34$ & 100,00 & 136,18 & 125,01 & 37,16 & 6853,50 & 330,64 & 1,10 & 329,54 & 119,39 & 229,01 & 229,01 & 53,96 & 451,78 & 53,40 & 6,54 & 39,76 & 154,97 & 44,15 & 44,15 & 130,48 \\
\hline Pelodytes punctatus & $30 \mathrm{SVJ} 38$ & 100,00 & 137,88 & 119,14 & 36,31 & 6851,14 & 327,05 & 4,58 & 322,47 & 121,71 & 230,52 & 230,52 & 55,31 & 434,18 & 49,52 & 7,94 & 37,38 & 142,45 & 46,40 & 46,40 & 123,18 \\
\hline Pelodytes punctatus & $30 \mathrm{SVJ} 43$ & 100,00 & 146,62 & 125,01 & 37,4 & 823,15 & 339,09 & 10,59 & 328,50 & 130,47 & 238,72 & 238,72 & 64,20 & 415,36 & 49,60 & 5,00 & 41,53 & 142,82 & 37,42 & 37,42 & 121,07 \\
\hline Pelodytes punctatus & $30 \mathrm{SVJ44}$ & 100,00 & $\begin{array}{ll}134,94 \\
1340\end{array}$ & 124,47 & 37,1 & 6837,59 & 328,72 & 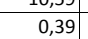 & 328,33 & $\frac{11}{11}$ & 227,52 & 227,52 & 52,91 & 457,44 & 53,83 & 7,13 & \begin{tabular}{|l|l|}
39,26 \\
\end{tabular} & $\begin{array}{l}42,02 \\
156,41 \\
\end{array}$ & 46,03 & 46,03 & 131,50 \\
\hline $\begin{array}{l}\text { Pelodytes punctatus } \\
\end{array}$ & 30 SVJ45 & 100,00 & 128,65 & 123 & 37,03 & 6835,67 & 322,47 & $-4,44$ & 326,91 & 111,14 & 221,50 & 221,50 & 47,35 & 478,31 & 55,59 & 8,50 & 37,84 & 162,32 & 50,98 & 50,98 & 136,15 \\
\hline Pelodytes punctatus & 30 SVJ54 & 100,00 & 144,27 & 123,68 & 37,15 & 6812,25 & 335,56 & 8,92 & 326,64 & 128,22 & 236,22 & 236,22 & 61,91 & 420,01 & 49,45 & 5,94 & 39,88 & 142,70 & 40,63 & 40,63 & 121,01 \\
\hline Pelodytes punctatus & 30 SVJ65 & 100,00 & 142,53 & 122,46 & 37,01 & 6797,50 & 332,62 & 8,01 & 324,61 & 126,37 & 234,29 & 234,29 & 60,49 & 422,73 & 49,10 & 6,82 & 38,56 & 141,88 & 43,16 & 43,16 & 120,14 \\
\hline Pelodytes punctatus & $30 \mathrm{SVJ} 68$ & 100,00 & 139,38 & 119,45 & 36,99 & 6792,24 & 26,91 & 6,43 & 320,48 & 121,76 & 230,94 & 230,94 & 57,30 & 429,52 & 48,12 & 8,10 & 36,96 & 139,14 & 46,72 & 46,72 & 121,38 \\
\hline Pelodytes punctatus & $30 \mathrm{SVJ71}$ & 10 & $\frac{14}{14}$ & 1 & 38 & 6772,19 & $\frac{524}{334}$ & $\begin{array}{l}9,43 \\
9,42\end{array}$ & 325,49 & $\begin{array}{ll}126,92 \\
126,\end{array}$ & $\mid 235,44$ & 235,44 & $\frac{3 r, 30}{62,34}$ & | 433,31 & $\begin{array}{ll}40,12 \\
52,40\end{array}$ & $\frac{0,10}{6,15}$ & $\begin{array}{l}0,40 \\
40,42\end{array}$ & $\mid \begin{array}{l}\mid 350,22 \\
150,2\end{array}$ & $\begin{array}{ll}40,1,24 \\
41,34\end{array}$ & 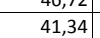 & $\begin{array}{ll}125,30 \\
125\end{array}$ \\
\hline $\begin{array}{l}\text { Pelodytes punctatus } \\
\end{array}$ & 30 SVJ75 & 100,00 & 144,96 & 122,00 & 37,01 & 6776,05 & 333,15 & 10,24 & 322,91 & 129,05 & 236,03 & 236,03 & 62,79 & 414,24 & 48,00 & 6,75 & 38,26 & 138,93 & 42,70 & 42,70 & 116,81 \\
\hline Pelodytes punctatus & 30 SVJ76 & 100,00 & 143,29 & 121,29 & 37,03 & 6768,62 & 331,36 & 9,25 & 322,12 & 127,52 & 234,38 & 234,38 & 61,47 & 416,98 & 47,55 & 7,05 & 37,74 & 137,95 & 44,09 & 44,09 & 117,32 \\
\hline Pelodytes punctatus & 30 SVI77 & 100,00 & 142,13 & 120,53 & 37,00 & 6778,90 & 329,51 & 8,49 & 321,02 & 126,27 & 233,47 & 233,47 & 60,07 & 419,88 & 47,05 & 7,60 & 36,94 & 137,13 & 45,58 & 45,58 & 117,90 \\
\hline Pelodytes punctatus & 30 SVI78 & 100 & 141 & 11 & 37,00 & 6769,87 & 327,47 & 7,95 & 319,52 & 121,23 & 232,09 & 232,09 & 58,94 & 422,44 & 47,01 & 8,00 & 36,31 & 136,81 & 46,45 & 46,45 & 11 \\
\hline Pelodytes punctatus & $\frac{305510}{305 J 83}$ & $\begin{array}{l}100,00 \\
\end{array}$ & $\begin{array}{ll}141,06 \\
144,75\end{array}$ & 1122,99 & $\begin{array}{ll}37,607 \\
37,6\end{array}$ & $\begin{array}{ll}0703,01 \\
673,62\end{array}$ & 333,31 & $\mid \frac{1,90}{10,16}$ & 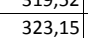 & \begin{tabular}{|l|}
128,24 \\
128,2
\end{tabular} & \begin{tabular}{|l|l|}
235,38 \\
253
\end{tabular} & 235,38 & 60,24, & $\begin{array}{l}42,2,44 \\
417,82\end{array}$ & $\begin{array}{l}41,01 \\
49,56 \\
\end{array}$ & 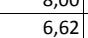 & $\begin{array}{l}30,21 \\
39,22\end{array}$ & \begin{tabular}{|l|}
342,01 \\
142,08
\end{tabular} & $\begin{array}{l}40,45 \\
42,68\end{array}$ & $\begin{array}{l}42,45 \\
42,68\end{array}$ & $\begin{array}{ll}1118,04 \\
118,05\end{array}$ \\
\hline Pelodytes punctatus & $30 \mathrm{SVJ} 85$ & 100,00 & 143,96 & 122,00 & 37,15 & 6750,31 & 331,81 & 9,66 & 322,16 & 128,12 & 234,82 & 234,82 & 62,24 & 415,35 & 48,00 & 7,00 & 37,99 & 139,01 & 44,36 & 44,36 & 116,04 \\
\hline Pelodytes punctatus & $30 \mathrm{SVJ} 86$ & 100,00 & 140,81 & 121,76 & 37,16 & 6746,40 & 328,68 & 6,90 & 321,79 & 124,73 & 231,79 & 231,79 & 59,32 & 425,55 & 48,34 & 7,76 & 37,00 & 140,92 & 46,98 & 46,98 & 118,40 \\
\hline Pelodytes punctatus & $30 \mathrm{SVJ} 91$ & 100,00 & 137, & 123,8 & 37,99 & 6745,7 & 327,5 & 3,47 & 324,06 & 119,60 & 228,68 & 228,68 & 56,69 & 452,03 & 54,69 & 7,90 & 38,25 & 156,15 & 48,22 & 48,22 & 12 \\
\hline Pelodytes punctatus & 30 SVJ92 & 100,00 & 142,75 & 123,03 & 37,95 & 6712,64 & 331,08 & 8,64 & 322,45 & 125,73 & 33,26 & 233,26 & 61,86 & 426,77 & 51,09 & 7,06 & 38,14 & 146,14 & 45,13 & 45,13 & 119,23 \\
\hline
\end{tabular}




\begin{tabular}{|c|c|c|c|c|c|c|c|c|c|c|c|c|c|c|c|c|c|c|c|c|c|}
\hline TAXON & $\overline{\text { UTM }}$ & $\mathrm{km} 2$ & BIO1 & $\mathrm{BIO2}$ & 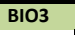 & 8104 & B105 & 8106 & B107 & B108 & B109 & BIO10 & BIO11 & BIO12 & BIO13 & BIO14 & BIO15 & B1016 & $\begin{array}{ll}1017 \\
17\end{array}$ & BIO18 & BIO19 \\
\hline Pelodytes punctatus & 30SVJ96 & 100,00 & 140,72 & 121,75 & 37,59 & 6723,46 & 327,53 & 6,95 & 320,58 & 124,70 & 231,31 & 231,31 & 59,56 & 423,62 & 48,05 & 8,03 & 36,39 & 140,24 & 48,18 & 48,18 & 116,52 \\
\hline Pelodytes punctatus & 30SVK32 & 100,00 & 148,20 & 111,54 & 35,01 & 6826,51 & $\begin{array}{ll}329,53 \\
\end{array}$ & 17,08 & 312,45 & 104,25 & 239,90 & 239,90 & 64,68 & 399,91 & 46,23 & 8,15 & 37,33 & 134,99 & 42,58 & 42,58 & 115,87 \\
\hline Pelodytes punctatus & 30SWG06 & 100,00 & $\begin{array}{ll}146,83 \\
\end{array}$ & 114,45 & 37,00 & 6411,38 & 323,90 & 19,77 & 304,13 & 99,96 & 233,36 & 233,69 & 70,77 & 448,55 & 55,63 & 6,58 & 45,28 & 156,92 & 33,01 & 38,71 & 145,03 \\
\hline Pelodytes punctatus & 30SWG29 & 100,00 & 110,30 & 120,44 & 37,52 & 6619,50 & 298,79 & $-18,26$ & 317,05 & 87,32 & 200,58 & 201,02 & 33,63 & 610,67 & 77,00 & 16,02 & 37,12 & 210,14 & 68,94 & \begin{tabular}{|c|}
70,97 \\
\end{tabular} & 177,13 \\
\hline Pelodytes punctatus & 30SWG39 & 100,00 & 122,08 & 119,02 & 37,76 & 6531,97 & 305,88 & $-6,37$ & 312,25 & 99,95 & 210,69 & 211,26 & 45,77 & 538,32 & 68,69 & 12,72 & 37,90 & 185,42 & 58,18 & 61,05 & 155,37 \\
\hline Pelodytes punctatus & 30SWG58 & 100,00 & 132,19 & 116,23 & 38,00 & 6326,25 & 307,48 & 4,76 & 302,72 & 110,73 & 217,41 & 218,48 & 57,78 & 472,41 & 60,94 & 10,33 & 37,96 & 160,56 & 49,95 & 53,66 & 134,45 \\
\hline Pelodytes punctatus & 30SWG59 & 100,00 & 132,38 & 117,02 & 38,00 & 6359,18 & 308,74 & 4,14 & 304,60 & 111,25 & 217,97 & 218,96 & 57,32 & 470,81 & 60,97 & 10,31 & 37,72 & 160,66 & 50,57 & 53,86 & 132,38 \\
\hline Pelodytes punctatus & 30SWG63 & 100,00 & 156,89 & 102,82 & 38,00 & 5690,49 & 305,92 & 38,53 & 267,39 & 127,10 & 232,02 & \begin{tabular}{|l|l|}
234,47 \\
\end{tabular} & 89,07 & 341,99 & 42,68 & 4,76 & 42,92 & \begin{tabular}{ll|l}
116,86 \\
\end{tabular} & 27,22 & 33,63 & 105,29 \\
\hline Pelodytes punctatus & 30SWG68 & 100,00 & 129,05 & 116,26 & 38,00 & 6309,61 & 303,79 & 1,58 & 302,21 & 107,38 & 214,05 & 215,21 & \begin{tabular}{l|l|l}
54,92 & \\
\end{tabular} & 483,47 & 62,64 & 11,28 & 36,86 & 163,72 & 53,81 & 56,95 & 134,88 \\
\hline Pelodytes punctatus & 30SWG78 & 100,00 & 131,36 & 115,47 & 38,00 & 6238,93 & 303,27 & 4,73 & 298,54 & 110,07 & 215,20 & 216,39 & 57,86 & 468,90 & 60,81 & 11,01 & 36,76 & 157,61 & 52,91 & 56,30 & 128,90 \\
\hline Pelodytes punctatus & 30SWG81 & 100,00 & 160,25 & 97,70 & 37,99 & 5419,57 & 300,41 & 46,09 & 254,32 & 132,88 & 231,18 & 234,46 & $\begin{array}{l}95,96 \\
\end{array}$ & 321,14 & 41,36 & 4,22 & 43,86 & 113,80 & 24,71 & 31,51 & 99,92 \\
\hline Pelodytes punctatus & 30SWG88 & 100,00 & 139,40 & 114,28 & 38,41 & 6118,37 & 306,33 & 13,00 & 293,33 & 118,91 & 221,25 & 222,57 & 66,99 & 427,34 & 55,49 & 9,14 & 37,66 & 142,09 & 46,64 & 50,95 & 116,48 \\
\hline Pelodytes punctatus & 30SWG89 & 100,00 & 136,07 & 115,69 & 38,32 & 6195,29 & 305,93 & 8,76 & 297,17 & 115,41 & 219,16 & 220,26 & \begin{tabular}{|c|}
62,78 \\
\end{tabular} & 441,31 & 57,66 & 9,91 & 36,84 & 147,62 & 50,23 & 53,73 & 118,40 \\
\hline Pelodytes punctatus & 30SWG94 & 100,00 & 163,11 & 103,32 & 38,81 & 5556,14 & 307,90 & 44,17 & 263,73 & 134,09 & 236,01 & 238,39 & $\begin{array}{l}96,45 \\
\end{array}$ & 317,65 & 42,44 & 4,03 & 43,36 & 112,63 & 25,60 & 33,18 & 93,60 \\
\hline Pelodytes punctatus & 30SWG95 & 100,00 & 144,93 & 109,42 & 38,49 & 5887,40 & 302,58 & $\begin{array}{l}21,95 \\
\end{array}$ & 280,62 & 117,33 & 223,08 & \begin{tabular}{l|l}
225,15 \\
\end{tabular} & 75,07 & 399,68 & 50,58 & 7,75 & 39,07 & 132,26 & 39,84 & 45,79 & 112,91 \\
\hline Pelodytes punctatus & 30SWG96 & 100,00 & 144,29 & 110,90 & 38,65 & 5940,80 & 304,21 & 20,36 & 283,85 & 118,84 & 223,43 & 225,23 & 74,01 & 402,57 & 51,29 & 7,93 & 38,69 & 132,37 & 41,16 & 46,88 & 112,11 \\
\hline Pelodytes punctatus & 30SWG97 & 100,00 & 151,15 & 111,36 & 38,95 & 5907,51 & 309,48 & 26,44 & 283,05 & 121,44 & 229,52 & 231,13 & 80,52 & 372,18 & 47,73 & 6,42 & 39,93 & 124,09 & 36,34 & \begin{tabular}{|c|}
42,69 \\
\end{tabular} & 103,01 \\
\hline Pelodytes punctatus & 30SWG98 & 100,00 & 148,92 & 113,06 & 38,88 & 5976,33 & 310,19 & 23,00 & 287,19 & 120,97 & 228,47 & 229,83 & 77,71 & 382,85 & 49,54 & 7,04 & 39,39 & 127,28 & 39,17 & 45,08 & 103,99 \\
\hline Pelodytes punctatus & 30SWG99 & 100,00 & 141,93 & 115,04 & 38,85 & 6098,75 & 307,93 & 14,80 & 293,13 & 121,79 & 223,39 & 224,51 & 69,38 & 413,51 & 54,08 & 8,66 & 37,59 & 137,00 & 45,97 & 50,49 & 109,85 \\
\hline Pelodytes punctatus & 30SWHOO & 100,00 & 135,70 & 118,81 & 37,07 & 6620,45 & 321,12 & 5,99 & 315,12 & 97,55 & 225,36 & 225,55 & \begin{tabular}{l|l|l}
57,45 & \\
\end{tabular} & 503,33 & 63,04 & 9,04 & 42, & 176,09 & 44,77 & 46,68 & 153,98 \\
\hline Pelodytes punctatus & 30 SWH20 & 100,00 & 97,98 & 121,82 & 37,70 & 6678,92 & 289,86 & $-30,73$ & 320,59 & 74,45 & 189,41 & 189,81 & 21,11 & 674,38 & 84,46 & 19,71 & 35,07 & 231,49 & 82,36 & 82,62 & 191,90 \\
\hline Pelodytes punctatus & 30SWH30 & 100,00 & 102,13 & 120,83 & 37,45 & 6632,01 & 291,64 & $-26,36$ & 318,00 & 78,76 & 192,94 & \begin{tabular}{|c|}
193,40 \\
\end{tabular} & 25,83 & 644,83 & 81,33 & 18,94 & 34,79 & 221,03 & 79,58 & 80,12 & 181,02 \\
\hline Pelodytes punctatus & 30SWH31 & 100,00 & 108,29 & 121,08 & 37,73 & 6625,97 & 297,12 & $-20,70$ & 317,82 & 85,36 & 198,76 & \begin{tabular}{|c|}
199,10 \\
\end{tabular} & 31,57 & 606,90 & 76,87 & 16,75 & 35,28 & 209,08 & 73,52 & 73,98 & 169,73 \\
\hline Pelodytes punctatus & 30SWH35 & 100,00 & 135,10 & 120,94 & 38,00 & 6562,45 & 318,66 & 3,99 & 314,68 & 115,32 & 223,75 & 223,83 & 57,18 & 461,17 & 59,19 & 9,41 & 37,62 & 159,92 & 51,44 & 51,82 & 126,39 \\
\hline Pelodytes punctatus & 30SWH36 & 100,00 & 126,54 & 122,05 & 38,00 & 6610,75 & 312,94 & $-4,77$ & 317,70 & 106,23 & 216,08 & 216,18 & 48,37 & 497,56 & 63,25 & 11,47 & 36,08 & 172,49 & 58,95 & 59,70 & 134,27 \\
\hline Pelodytes punctatus & 30 SWH40 & 100,00 & 111,35 & 119,94 & 37,86 & 6555,71 & 296,98 & $-17,14$ & 314,12 & 88,53 & 200,57 & 201,16 & 35,33 & 587,22 & 74,95 & 16,23 & 35,18 & 201,40 & 71,21 & 72,18 & 163,32 \\
\hline Pelodytes punctatus & 30SWH41 & 100,00 & 104,01 & 120,89 & 37,87 & 6607,13 & 292,17 & $-24,69$ & 316,87 & 80,68 & 194,50 & $\begin{array}{l}194,73 \\
\end{array}$ & 27,95 & 624,24 & 79,20 & $\begin{array}{l}18,58 \\
\end{array}$ & 33,92 & 213,93 & 79,32 & 79,43 & 171,15 \\
\hline Pelodytes punctatus & 30SWH44 & 100,00 & 120,14 & 121,30 & 38,00 & 6578,54 & 305,68 & $-10,05$ & 315,73 & \begin{tabular}{l|l|}
98,81 \\
\end{tabular} & 209,57 & 209,66 & 42,99 & 529,28 & 67,71 & 13,53 & 35,21 & 182,61 & 64,91 & 65,25 & 142,30 \\
\hline Pelodytes punctatus & 30SWH50 & 100,00 & 120,56 & 118,94 & 38,00 & 6466,86 & 302,08 & $-7,79$ & 309,87 & 98,62 & 208,15 & 208,87 & 44,98 & 530,73 & 68,54 & 13,60 & 35,69 & 181,69 & 62,95 & 64,42 & 146,11 \\
\hline Pelodytes punctatus & 30SWH61 & 100,00 & 108,09 & 119,62 & 37,93 & 6511,14 & 291,89 & $-19,90$ & 311,79 & 85,27 & 197,10 & \begin{tabular}{|c|}
197,38 \\
\end{tabular} & 32,68 & 592,88 & 75,97 & 18,10 & 33,04 & 201,65 & 78,14 & 78,20 & 157,47 \\
\hline Pelodytes punctatus & 30SWH62 & 100,00 & 122,64 & 119,54 & 38,00 & 6448,83 & 303,26 & $-6,08$ & 309,34 & 101,19 & 210,08 & 210,48 & \begin{tabular}{ll|}
47,03 \\
\end{tabular} & 510,83 & 66,39 & 13,34 & 34,84 & 174,56 & 63,86 & 64,27 & 135,26 \\
\hline Pelodytes punctatus & 30SWH65 & 100,00 & 137,79 & 120,16 & 38,44 & 6408,61 & 315,40 & \begin{tabular}{l|l}
7,05 \\
\end{tabular} & 308,36 & 118,61 & 224,08 & 224,23 & 61,37 & 430,13 & 56,60 & 9,38 & 36,48 & 146,97 & 52,01 & 52,64 & 110,77 \\
\hline Pelodytes punctatus & 30SWH71 & 100,00 & 119,08 & 118,76 & 38,03 & 6412,77 & 298,25 & $-8,89$ & 307,14 & 97,06 & 205,94 & 206,61 & 44,11 & 528,87 & 68,66 & 14,74 & 34,00 & 179,50 & 67,99 & 68,50 & 138,95 \\
\hline Pelodytes punctatus & 30SWH72 & 100,00 & 116,62 & 119,38 & 38,00 & 6439,80 & 297,18 & $-11,63$ & 308,81 & 94,75 & 204,30 & 204,62 & 41,43 & 539,06 & 69,85 & 15,50 & 33,44 & 183,02 & 71,05 & 71,07 & 140,00 \\
\hline Pelodytes punctatus & 30SWH75 & 100,00 & 143,32 & 119,51 & 38,80 & 6318,92 & 317,40 & 12,58 & 304,82 & 124,51 & 228,17 & 228,31 & 67,60 & 402,00 & 53,56 & 8,37 & 37,06 & 136,37 & 48,75 & 49,31 & 101,49 \\
\hline Pelodytes punctatus & 30SWH77 & 100,00 & 123,18 & 121,17 & 38,41 & \begin{tabular}{ll|}
6470,92 \\
\end{tabular} & 304,12 & $-7,16$ & 311,29 & 102,78 & 210,74 & \begin{tabular}{|l|}
210,77 \\
\end{tabular} & 46,77 & 489,06 & 63,27 & 13,52 & 33,29 & \begin{tabular}{ll|l}
166,43 \\
\end{tabular} & 65,67 & 68,23 & 120,31 \\
\hline \begin{tabular}{|l} 
Pelodytes punctatus \\
\end{tabular} & 30SWH79 & 100,00 & 133,24 & 121,32 & 38,83 & 6439,17 & 311,94 & 1,64 & 310,29 & 114,21 & 219,74 & 219,90 & 56,27 & 434,73 & 56,71 & 10,95 & 34,25 & 147,48 & 57,51 & 61,62 & 104,15 \\
\hline Pelodytes punctatus & 30SWH80 & 100,00 & 134,74 & 116,71 & 38,58 & 6236,81 & 306,19 & \begin{tabular}{l|l}
6,65 \\
\end{tabular} & 299,54 & 114,16 & 218,45 & 219,43 & 60,74 & 447,71 & 58,71 & 10,38 & 36,28 & 150,32 & 52,66 & 55,54 & 118,30 \\
\hline Pelodytes punctatus & 30SWH82 & 100,00 & 123,14 & 79 & 38,38 & 366,40 & 300,15 & $-5,17$ & 305,32 & 101,86 & 209,27 & 209, & 48,48 & 502,28 & 65,59 & 13,7 & 33,91 & 169,65 & 65,89 & 66,19 & 128,66 \\
\hline Pelodytes punctatus & 30SWH83 & 100,00 & 127,20 & 13 & 38,56 & 6355,33 & 303,63 & $-1,80$ & 305,43 & 106,50 & 213,11 & 213,46 & 52,27 & 479,97 & 63,04 & 12,64 & 34,44 & 162,31 & 62,58 & 62,96 & 121,56 \\
\hline Pelodytes punctatus & 30SWH86 & 100,00 & 139,91 & 120,07 & 38,97 & 6323,97 & 31 & 9,01 & 305,16 & 120,78 & 225,01 & 225,06 & 64,40 & 410,44 & 54,92 & 9,30 & 36,04 & 138,60 & 52,97 & 53,56 & 99,77 \\
\hline Pelodytes punctatus & 30SWH90 & 100,00 & 139,71 & 116,29 & 38,98 & 6148,27 & 307,94 & 11,79 & 296,15 & 119,46 & 221,97 & \begin{tabular}{l|l}
222,95 \\
\end{tabular} & 66,79 & 422,94 & 55,66 & 9,25 & 36,99 & 140,90 & 48,95 & 52,66 & 110,38 \\
\hline Pelodytes punctatus & 30SWH92 & 100,00 & 137,53 & 117,82 & 38,78 & 6220,34 & 308,26 & 8,64 & 299,62 & 117,55 & 220,95 & 221,68 & \begin{tabular}{|c|}
63,68 \\
\end{tabular} & 433,09 & 57,22 & 10,15 & 36,25 & 144,87 & 53,48 & 55,89 & $\begin{array}{ll}109,89 \\
\end{array}$ \\
\hline Pelodytes punctatus & 30SWH95 & 100,00 & 150,41 & 84 & 39,1 & 175,10 & 8,85 & 19,76 & 299,09 & 132,24 & 232,81 & 233,03 & 75,8 & 370,24 & 49,90 & 7,2 & 38,1 & 123,54 & 45,03 & 46,55 & 90,10 \\
\hline Pelodytes punctatus & 30SWH96 & 100,00 & 146,16 & 4 & 39,0 & 6231,48 & 316,62 & 15,25 & 301,38 & 127,58 & 229,58 & 229,75 & 71,2 & 384,08 & 51,70 & 8, & 37,09 & 128,34 & 49,41 & 50,04 & 91,68 \\
\hline \begin{tabular}{|l} 
Pelodytes punctatus \\
\end{tabular} & 30 SWJo0 & 100,00 & 133,64 & 123,97 & 37,98 & 6738,74 & 323,58 & 0,03 & 323,55 & 115,06 & 224,59 & 224,63 & 53,19 & 468,19 & 57,16 & 9,00 & 37,27 & 162,41 & 51,96 & 52,12 & 129,69 \\
\hline Pelodytes punctatus & 30SWJ06 & 100,00 & 141,19 & 121,88 & 37,88 & 6682,22 & 326,79 & 7,55 & 319,24 & 125,00 & 231,17 & 231,17 & $\begin{array}{l}60,55 \\
\end{array}$ & 419,66 & 47,80 & 8,17 & 35,69 & 139,11 & 49,30 & 49,30 & 113,53 \\
\hline Pelodytes punctatus & 30SWJ15 & 100,00 & 141,64 & 122,00 & 38,00 & 6662,83 & 326,70 & 7,86 & 318,84 & 125,15 & 230,81 & 231,25 & 60,91 & 417,19 & 48,00 & 8,08 & 35,97 & 139,83 & 49,29 & 49,64 & 111,50 \\
\hline Pelodytes punctatus & 30 SWJ22 & 100,00 & 133,82 & 123,21 & 38,00 & 6650,44 & 320,84 & 0,63 & 320,21 & 115,83 & 222,95 & 223,58 & 54,08 & 450,48 & 54,31 & 9,68 & 35,27 & 154,04 & 54,21 & 55,92 & 119,01 \\
\hline \begin{tabular}{|l} 
Pelodytes punctatus \\
\end{tabular} & 30 SWJ30 & 100,00 & 12 & 12 & 38,0 & 6630,43 & 315,81 & $-3,09$ & 318,89 & 110,17 & 218,38 & 218,71 & 49,96 & 471,51 & 58,39 & 10,96 & 34,82 & 162,29 & 57,77 & 60,31 & 123,33 \\
\hline \begin{tabular}{|l} 
Pelodytes punctatus \\
\end{tabular} & 30 SWJ32 & 100,00 & 133,69 & 123,08 & 38,00 & 6622,39 & 319,42 & 0,57 & 318,85 & 115,71 & 222,40 & 223,21 & 54,51 & 446,43 & 54,08 & 10,01 & 34,77 & 152,31 & 55,09 & 57,58 & 115,66 \\
\hline Pelodytes punctatus & 30SWJ41 & 100,00 & 126,03 & 123,10 & 38,06 & 6601,84 & 312,03 & $-5,62$ & 317,64 & 106,86 & 214,97 & 215,51 & 47,59 & 477,60 & 58,75 & 11,99 & 33,60 & 163,49 & 61,18 & 65,34 & 121,45 \\
\hline Pelodytes punctatus & 30SWJ42 & 100,00 & 131,83 & 123,01 & 38,05 & 6587,52 & 316,54 & $-0,47 \mid$ & 317,01 & 113,56 & 220,20 & 220,78 & 53,18 & 449,84 & 54,76 & 10, & $33,4,4,2>3$ & 153,20 & 57,27 & 60,92 & 113,88 \\
\hline Pelodytes punctatus & $30 \mathrm{SWJ}$ & 100 & & & 38, & 6551, & & $-3,77$ & 315,32 & 108, & 215,92 & 216,2 & 49,6 & 467,37 & 58,79 & 11 , & 33 & 159,86 & 60,48 & 64,90 & $11 \epsilon$ \\
\hline Pelodytes punctatus & 30SWJ51 & 100,00 & 128,77 & 122,86 & 38,44 & 6557,40 & 312,57 & $-2,92$ & 315,49 & 109,92 & 216,97 & 217,32 & 50,64 & 460,01 & 57,16 & 11,66 & 33,52 & 156,84 & 59,95 & 64,64 & 114,24 \\
\hline Pelodytes punctatus & 30SWJ52 & 100,00 & 133,79 & 122,73 & 38,44 & 6540,52 & 316,21 & 1,21 & 315,00 & 115,63 & 221,32 & 221,88 & 55,37 & 436,92 & \begin{tabular}{l|l|}
53,67 \\
\end{tabular} & 10,58 & 33,69 & 148,18 & 56,80 & 61,01 & 107,97 \\
\hline Pelodytes punctatus & 30SWJ59 & 100,00 & 127,01 & 123,13 & 38,41 & 6551,42 & 310,42 & $-5,79$ & 316,21 & 110,01 & 214,11 & \begin{tabular}{|l|l|}
215,17 \\
\end{tabular} & 48,17 & 471,94 & 56,39 & 13,88 & 30,06 & 156,34 & 67,69 & 72,37 & 117,24 \\
\hline Pelodyte & $30 \mathrm{SWJ}$ & $100, \mathrm{C}$ & & & 38, & 012 & & $-6,04$ & F & 106, & 209,64 & 210 & 47, & 468 & 57 & 16 & 28, & & 75,62 & 82,00 & \\
\hline Pelodytes punctatus & 30SWJ99 & 100,0 & 118,33 & 119,86 & 38,51 & 6436,01 & 295,44 & $-11,94$ & 307,38 & 100,21 & 204,26 & 205,12 & 41,34 & 494,68 & 61,08 & 18,13 & 27,68 & 162,79 & 81,62 & 88,84 & 111,42 \\
\hline Pelodytes punctatus & 30SWK10 & 100,00 & 127,28 & 120,63 & 37,75 & 6666,16 & 312,45 & $-3,96$ & 316,41 & 110,82 & 215,99 & 217,12 & 47,25 & 467,55 & 54,01 & 12,32 & 32,02 & 151,45 & 61,53 & 63,37 & 123,73 \\
\hline
\end{tabular}




\begin{tabular}{|c|c|c|c|c|c|c|c|c|c|c|c|c|c|c|c|c|c|c|c|c|c|}
\hline TAXON & UTM & $\mathrm{km} 2$ & BIO1 & $\mathrm{B1O2}$ & $\mathrm{BIO3}$ & 8104 & B105 & B106 & B107 & B108 & B109 & BIO10 & B1011 & BIO12 & B1013 & B1014 & 81015 & B1016 & BIO17 & B1018 & $\begin{array}{ll}\text { B1019 } \\
\end{array}$ \\
\hline Pelodytes punctatus & 30SWK12 & 100,00 & 124,11 & 119,03 & 37,44 & 6643,19 & 307,64 & $-5,88$ & 313,52 & 107,91 & 212,52 & 213,62 & 44,65 & 474,90 & 54,89 & 13,53 & 31,11 & 151,70 & 64,56 & 66,55 & 125,21 \\
\hline Pelodytes punctatus & 30 SWK30 & 100,00 & 128,39 & 122,10 & 38,00 & 6612,87 & 312,56 & $-3,83$ & 316,39 & \begin{tabular}{|l|l|}
111,76 \\
\end{tabular} & 216,24 & 217,35 & 48,82 & 463,96 & 54,65 & 12,93 & 31,00 & 151,84 & 63,84 & 66,83 & 119,37 \\
\hline Pelodytes punctatus & 30sWK32 & 100,00 & 122,24 & 121,29 & 38,00 & 6597,13 & 306,10 & $\begin{array}{l}-9,65 \\
-9,25 \\
\end{array}$ & 315,34 & 105,83 & 210,04 & 211,08 & 43,24 & 486,06 & 57,70 & 14,90 & 29,81 & 157,86 & 69,45 & 73,17 & 124,60 \\
\hline Pelodytes punctatus & $305 \times 606$ & 100,00 & 154,71 & 109,33 & 39,05 & 5775,40 & 308,06 & 31,32 & 276,74 & 124,32 & 230,99 & 232,88 & 85,58 & 357,89 & 46,59 & 5,82 & 40,90 & 122,11 & 33,55 & 40,85 & 99,85 \\
\hline Pelodytes punctatus & 30SXG07 & 100,00 & 157,85 & 110,81 & 39,21 & 5790,11 & 311,88 & 33,35 & 278,53 & \begin{tabular}{|l|}
126,88 \\
\end{tabular} & 234,36 & 235,93 & 88,32 & 345,32 & 45,54 & 5,28 & 41,50 & 118,36 & 31,96 & 39,56 & 95,20 \\
\hline Pelodytes punctatus & $305 \times G 08$ & 100,00 & 151,93 & 113,00 & 39,05 & 5913,57 & 310,81 & 25,90 & 284,92 & 120,67 & 230,39 & 231,78 & \begin{tabular}{|c|}
81,08 \\
\end{tabular} & 370,31 & 48,05 & 6,40 & 40,01 & 123,52 & 37,22 & 43,93 & 99,67 \\
\hline Pelodytes punctatus & $30 \mathrm{~S} \times \mathrm{G} 15$ & 100,00 & 164,24 & 106,18 & 39,19 & 5558,26 & 309,92 & 43,11 & 266,81 & 135,26 & 237,14 & 239,29 & 97,39 & 320,81 & 44,07 & 4,30 & 43,36 & 115,13 & 26,66 & 35,56 & 91,47 \\
\hline Pelodytes punctatus & 30 XSG17 & 100,00 & 160,87 & 110,77 & 39,68 & 5727,21 & 312,77 & 36,10 & 276,67 & 130,43 & 236,43 & 237,94 & $\begin{array}{l}91,78 \\
\end{array}$ & 336,38 & 45,67 & 4,90 & 42,20 & 117,44 & 30,48 & 39,09 & 92,01 \\
\hline Pelodytes punctatus & 30 XSG18 & 100,00 & 151,60 & 113,33 & 39,30 & 5891,02 & 309,77 & 25,39 & 284,39 & \begin{tabular}{|l|l|}
120,49 \\
\end{tabular} & 229,70 & 231,13 & 81,06 & 373,52 & 48,68 & 6,68 & 39,81 & 125,42 & 38,17 & 45,46 & 99,34 \\
\hline Pelodytes punctatus & 30SXG19 & 100,00 & 137,75 & 115,23 & 39,00 & 6059,27 & 302,45 & 10,86 & 291,59 & 113,05 & 218,54 & 219,89 & 65,82 & $\begin{array}{l}438,75 \\
\end{array}$ & 56,95 & 10,43 & 36,39 & 144,39 & 52,37 & 57,23 & 113,23 \\
\hline Pelodytes punctatus & 30 XKG25 & 100,00 & 155,85 & 107,76 & 39,13 & 5647,52 & 305,13 & 33,72 & 271,41 & 126,53 & 230,18 & 232,29 & 88,24 & 358,72 & 47,48 & 5,86 & 41,38 & 125,83 & 33,14 & 41,58 & 100,24 \\
\hline $\begin{array}{l}\text { Pelodytes punctatus } \\
\end{array}$ & $30 \mathrm{SXG26}$ & 100,00 & 160,43 & 109,38 & 39,67 & 5650,78 & 309,95 & 36,90 & 273,06 & 130,81 & 234,73 & 236,59 & 92,43 & 341,46 & 46,58 & 5,14 & 42,40 & 120,97 & 30,62 & 39,83 & 94,29 \\
\hline Pelodytes punctatus & $305 \times 628$ & 100,00 & 150,61 & 113,57 & 39,63 & 5862,45 & 308,13 & 24,37 & 283,76 & 120,82 & 228,34 & 229,78 & 80,49 & 383,29 & 50,60 & 7,32 & 39,63 & 129,49 & 40,27 & 48,06 & 100,86 \\
\hline Pelodytes punctatus & $305 \times G 29$ & 100,00 & 135,25 & 115,02 & 39,09 & 6045,20 & 299,51 & 8,79 & 290,73 & 110,42 & 215,94 & 217,42 & 63,70 & 455,83 & 58,89 & 11,65 & 35,79 & 149,59 & 56,40 & 61,37 & 116,24 \\
\hline Pelodytes punctatus & 30SXG37 & 100,00 & 170,68 & 111,53 & 40,27 & 5575,54 & 318,12 & 45,05 & 273,07 & 141,30 & 243,66 & 245,13 & 102,73 & 308,52 & 45,40 & 3,31 & 45,62 & 114,05 & 24,54 & 35,88 & 84,61 \\
\hline Pelodytes punctatus & 30SXG39 & 100,00 & 159,56 & 115,53 & 40,17 & 5803,77 & 315,15 & 31,25 & 283,89 & 128,48 & 236,18 & 237,14 & 89,25 & 351,11 & 48,74 & 5,53 & 42,01 & 122,20 & 34,09 & 44,18 & 91,23 \\
\hline Pelodytes punctatus & 30 SXG58 & 100,00 & 166,45 & 114,37 & 40,78 & 5636,22 & 316,64 & 38,75 & 277,88 & 136,84 & 240,20 & 241,47 & 97,68 & 335,43 & 49,68 & 4,56 & 44,66 & 123,39 & 29,46 & 42,21 & 88,57 \\
\hline Pelodytes punctatus & $305 \times 669$ & 100,00 & 167,66 & 116,15 & 41,02 & 5638,52 & 318,49 & 38,72 & 279,77 & 138,34 & \begin{tabular}{|l|l|}
241,47 \\
\end{tabular} & 242,52 & $\begin{array}{l}98,66 \\
\end{array}$ & 335,36 & 51,44 & 4,60 & 45,19 & 124,75 & 29,79 & 43,90 & 86,18 \\
\hline Pelodytes punctatus & 30 XSG96 & 69,00 & 179,66 & 103,47 & 40,45 & 5139,44 & 313,11 & 60,37 & 252,74 & 155,30 & 245,58 & 248,07 & 116,57 & 314,34 & 53,02 & 3,88 & 50,74 & 133,41 & 23,84 & 38,22 & 87,56 \\
\hline Pelodytes punctatus & $30 \mathrm{~S} \times \mathrm{HOO}$ & 100,00 & 137,24 & 116,32 & 39,00 & 6130,20 & 304,91 & 9,46 & 295,45 & 116,88 & 219,31 & 220,40 & 64,64 & 435,36 & 57,07 & 10,12 & 36,11 & 144,12 & 52,19 & 56,02 & 111,97 \\
\hline Pelodytes punctatus & $30 \mathrm{SXHO4}$ & 100,00 & 157,30 & 118,10 & 39,75 & 6065,95 & 321,49 & 26,75 & 294,74 & 134,09 & 237,81 & 238,18 & 83,81 & 346,90 & 46,75 & 5,89 & 40,07 & 114,89 & 38,99 & 43,45 & 84,99 \\
\hline Pelodytes punctatus & $30 \mathrm{~S} \times \mathrm{H} 10$ & 100,00 & $\begin{array}{l}34,76 \\
143,1\end{array}$ & $\begin{array}{ll}116,03 \\
16,03\end{array}$ & 39,24 & 6040,71 & 307,85 & 15,79 & 292,06 & 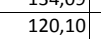 & 224,36 & 225,40 & $\begin{array}{l}\mid c 0,01 \\
71,79 \\
\end{array}$ & 4408,06 & 53,51 & 8,69 & 37,64 & $\begin{array}{l}134,36 \\
134,\end{array}$ & $\begin{array}{l}47,08 \\
47,\end{array}$ & 52,55 & 104,28 \\
\hline Pelodytes punctatus & 30SXH11 & 100,00 & 153,60 & 116,98 & 39,91 & 5982,88 & 315,57 & 24,52 & 291,05 & 124,31 & 232,96 & 233,94 & 81,49 & 365,12 & 48,54 & 6,44 & 39,89 & 121,22 & 39,21 & 46,06 & 92,68 \\
\hline Pelodytes punctatus & $30 \mathrm{~S} \times \mathrm{H} 12$ & 100,00 & 160,97 & 117,42 & 40,00 & 5947,23 & 321,29 & 31,01 & 290,28 & 128,20 & 239,56 & 240,31 & 88,66 & 337,19 & 46,14 & 5,14 & 41,70 & 114,03 & 34,47 & 42,27 & 84,77 \\
\hline Pelodytes punctatus & $30 \mathrm{~S} \times \mathrm{H} 13$ & 100,00 & 163,85 & 117,87 & 40,00 & 5951,82 & 323,92 & 33,54 & 290,38 & 131,48 & 242,43 & 243,01 & 91,25 & 326,75 & 45,59 & 4,71 & 42,19 & 111,07 & 33,41 & 40,68 & 80,99 \\
\hline $\begin{array}{l}\text { Pelodytes punctatus } \\
\end{array}$ & 30 SXH15 & 100,00 & 157,33 & 118,67 & 39,99 & 6041,73 & 320,72 & 26,74 & 293,99 & 130,91 & 237,50 & 237,97 & 83,89 & 347,87 & 47,04 & 6,10 & 39,93 & 114,83 & 40,63 & 44,60 & 82,83 \\
\hline Pelodytes punctatus & $\frac{505 \times H 13}{30 \mathrm{XH}}$ & 100,00 & $\begin{array}{l}\mid 5,, 53 \\
160,52\end{array}$ & $\mid \begin{array}{l}\mid 116,0,36 \\
116\end{array}$ & $\begin{array}{l}30,07 \\
40,0\end{array}$ & $\begin{array}{l}504+1,13 \\
5859,28\end{array}$ & $\mid \begin{array}{ll}320,1<, 01 \\
3181\end{array}$ & 31,53 & 286,48 & | & 237,89 & 238,85 & 89,54 & $\begin{array}{l}34,0 \\
342,41\end{array}$ & $\begin{array}{l}41,04 \\
47,22\end{array}$ & 5,0 & | & \begin{tabular}{|l|l|l|l|l|}
117,74 \\
\end{tabular} & 33, 30,39 & 42,79 & $\begin{array}{ll}82,030 \\
88,05\end{array}$ \\
\hline Pelodytes punctatus & $30 \mathrm{~S} \times \mathrm{H} 21$ & 100,00 & 156,96 & 117,32 & 40,01 & 5925,39 & 316,88 & 27,34 & 289,54 & 124,47 & 235,36 & 236,27 & 85,19 & 355,44 & 48,15 & 5,88 & 40,88 & 120,02 & 37,18 & 45,51 & 89,45 \\
\hline Pelodytes punctatus & $30 \mathrm{SXH} 22$ & 100,00 & 161,75 & 118,02 & 40,03 & 5912,38 & 321,08 & 31,27 & 289,82 & \begin{tabular}{|l|}
129,47 \\
\end{tabular} & 239,76 & 240,55 & 89,86 & 337,68 & 47,16 & 5,08 & 42,06 & 115,29 & 34,35 & 43,14 & 83,95 \\
\hline Pelodytes punctatus & $30 \mathrm{~S} \times \mathrm{H} 23$ & 100,00 & 166,99 & 118,20 & 40,32 & 5891,20 & 325,24 & 36,20 & 289,04 & 134,37 & 244,73 & 245,19 & 95,04 & 320,00 & 46,28 & 4,33 & 43,28 & 110,82 & 31,59 & 40,88 & 78,78 \\
\hline Pelodytes punctatus & $30 \mathrm{SXH} 31$ & 100,00 & 163,71 & 118,16 & 40,51 & 5851,48 & 320,97 & 33,14 & 287,83 & 131,87 & 240,82 & 241,51 & 92,36 & 335,63 & 48,00 & 4,85 & 43,15 & 116,94 & 32,51 & 42,78 & 84,45 \\
\hline Pelodytes punctatus & 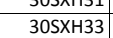 & 100,00 & $\mid \begin{array}{l}\mid 03,1,1 \\
168,96\end{array}$ & $\begin{array}{l}118,109 \\
118,92\end{array}$ & $\begin{array}{l}40,31 \\
40,94 \\
\end{array}$ & $\begin{array}{l}501,406 \\
5848,79\end{array}$ & | & 37,70 & $\begin{array}{l}20,03 \\
288,17\end{array}$ & $\begin{array}{l}\mid l 1,0 \prime \\
137,05\end{array}$ & $\begin{array}{l}24,02 \\
246,03\end{array}$ & 246,49 & 97,40 & $\begin{array}{l}\mid c 5,05 \\
317,30\end{array}$ & $\begin{array}{ll}40,00 \\
47,37\end{array}$ & 4,400 & $\begin{array}{l}4,15 \\
44,38 \\
\end{array}$ & $\mid \begin{array}{l}\mid 111,84 \\
11185\end{array}$ & 30,50 & 4 & $\begin{array}{ll}4,475 \\
77,54\end{array}$ \\
\hline Pelodytes punctatus & $30 \mathrm{~S} \times \mathrm{H} 36$ & 100,00 & 146,88 & 117,98 & 40,00 & 6050,49 & 310,16 & 17,26 & 292,90 & 125,80 & 227,36 & 228,03 & 74,01 & 395,32 & 51,84 & 9,04 & 36,91 & 127,41 & 52,43 & 56,84 & 90,37 \\
\hline Pelodytes punctatus & $30 \mathrm{SXH37}$ & 100,00 & 143,78 & 117,68 & 39,80 & 6078,03 & 307,79 & 14,75 & 293,04 & 125,21 & 224,82 & 225,29 & 70,81 & 406,04 & 52,48 & 9,99 & 35,65 & 130,06 & 56,65 & 59,47 & 91,44 \\
\hline Pelodytes punctatus & $30 \mathrm{~S} \times \mathrm{H} 38$ & 100,00 & 137,55 & 117,26 & 39,2 & 6126,10 & 302,96 & 9,10 & 293,86 & 118,36 & 219,49 & 219,99 & 64,43 & 429,92 & 54,45 & 11,7 & 33,95 & 137,54 & 63,85 & 64,80 & 95,74 \\
\hline Pelodytes punctatus & $30 \mathrm{SXH43}$ & 100,00 & 164,89 & 118,93 & 40,86 & 5849,01 & 322,05 & 33,71 & 288,34 & 133,06 & 241,92 & 242,58 & 93,44 & 336,60 & 49,91 & 5,00 & 43,68 & 117,83 & 34,13 & 45,94 & 81,16 \\
\hline Pelodytes punctatus & $30 \mathrm{SXH} 45$ & 100,00 & 153,31 & 117,88 & 40,10 & 5951,01 & 313,14 & 23,56 & 289,58 & 127,44 & 232,03 & 232,93 & 81,24 & 378,31 & 52,56 & 7,68 & 38,99 & 126,14 & 46,28 & 54,47 & 87,53 \\
\hline \begin{tabular}{|l} 
Pelodytes punctatus \\
\end{tabular} & 30 SXH55 & 100,00 & 149,62 & 116,87 & 40,09 & 5924,36 & 308,35 & 21,08 & 287,27 & 144,40 & 228,17 & 229,04 & 78,28 & 401,15 & 55,61 & 8,96 & 37,98 & 133,87 & 50,79 & 59,59 & 92,51 \\
\hline Pelodytes punctatus & $30 \mathrm{SXH58}$ & 100,00 & 142,56 & 115,13 & 39,85 & 5982,00 & 301,74 & 15,49 & 286,25 & 152,41 & 222,02 & 222,81 & 70,77 & 428,47 & 56,95 & 11,25 & 34,88 & 140,04 & 61,05 & 67,12 & 95,49 \\
\hline Pelodytes punctatus & $30 \mathrm{~S} \times \mathrm{H} 64$ & 100,00 & 151,17 & 5,24 & 40,11 & 860,56 & 307,67 & 23,06 & 284,61 & 137,29 & 228,65 & 229,75 & 80,54 & 401,33 & 57,18 & 8,61 & 38,69 & 137,03 & 48,79 & 59,51 & 93,54 \\
\hline $\begin{array}{l}\text { Pelodytes punctatus } \\
\end{array}$ & $30 \mathrm{SXH} 66$ & 100,00 & 149,38 & 5,34 & 40,01 & 5874,64 & 305,55 & 22,10 & 283,45 & 159,56 & 227,07 & 228,18 & 78,6 & 4 & 58,13 & $\begin{array}{l}9,019 \\
\end{array}$ & 37,49 & 139,62 & 53,10 & 63,02 & 93,43 \\
\hline Pelodytes punctatus & $30 \mathrm{SXH68}$ & 100,00 & 14 & 82 & 39,87 & 5933,72 & 298,99 & 16,03 & 282,95 & 152,27 & 220,73 & 221,85 & 70,5 & 441,90 & 59,60 & 11,88 & 34,58 & 146,62 & 62,88 & 70,57 & 98,86 \\
\hline Pelodytes punctatus & 30 SXH69 & 100,00 & \begin{tabular}{|l|l|l|l|l|}
134,60 \\
\end{tabular} & 112,94 & 39,23 & 5987,64 & 292,94 & $\begin{array}{l}9,0,47 \\
\end{array}$ & 283,47 & 144,47 & 214,34 & 215,40 & 63,29 & 472,17 & 60,75 & 14,14 & 32,32 & 152,42 & \begin{tabular}{|l|}
71,63 \\
71,63
\end{tabular} & 77,29 & 10,75 \\
\hline Pelodytes punctatus & $30 \mathrm{~S} \times \mathrm{H} 70$ & 100,00 & 174,36 & 6,30 & 41,38 & 5564,22 & 322,79 & 45,05 & 277,75 & 145,70 & 246,91 & 247,90 & 105,84 & 314,42 & 52,30 & 3,89 & 48,16 & 121,95 & 26,56 & 42,57 & 78,83 \\
\hline Pelodytes punctatus & $30 \mathrm{~S} \times \mathrm{H} 75$ & 100,00 & 149,40 & 114,43 & 40,08 & 5814,46 & 303,77 & 22,72 & 281,06 & 156,23 & 226,13 & 227,51 & 79,30 & 419,80 & 60,28 & 9,59 & 37,78 & 144,82 & 52,92 & 64,41 & 96,90 \\
\hline Pelodytes punctatus & 305XH87 & 100,00 & $\begin{array}{l}435,40 \\
153,86\end{array}$ & $\begin{array}{l}14,45 \\
111,85 \\
\end{array}$ & $\begin{array}{ll}40,00 \\
40,23\end{array}$ & 5709,21 & $\begin{array}{ll}303,69 \\
303\end{array}$ & 29,32 & $\begin{array}{l}201,00 \\
274,37\end{array}$ & $\begin{array}{l}365,01 \\
165,01\end{array}$ & $\begin{array}{l}228,13 \\
2282\end{array}$ & $\mid 230,47$ & 85,08 & $\begin{array}{l}41,00 \\
419,51\end{array}$ & $\begin{array}{l}\mid c 0,20 \\
63,23 \\
\end{array}$ & 9,43 & $\begin{array}{ll}38,86 \\
38,86\end{array}$ & $\begin{array}{l}44,02 \\
151,08 \\
\end{array}$ & 52,92 & $\begin{array}{ll}64,41 \\
664\end{array}$ & 90,90 \\
\hline $\begin{array}{l}\text { Pelodytes punctatus } \\
\end{array}$ & $30 \mathrm{~S} \times \mathrm{H} 88$ & 100,00 & 148,49 & 111,03 & 39,90 & 5756,81 & 299,16 & 24,64 & 274,52 & 159,64 & 224,32 & 225,93 & 79,31 & 442,69 & 64,23 & 10,99 & 36,91 & 155,94 & 59,21 & 71,97 & 100,71 \\
\hline Pelodytes punctatus & $30 \mathrm{SXH92}$ & 100,00 & 182,93 & 111,19 & 41,27 & 5337,78 & 322,79 & 57,58 & 265,22 & \begin{tabular}{|l|l|}
195,09 \\
\end{tabular} & 251,56 & 253,29 & 116,55 & 288,90 & 56,03 & 3,51 & 54,63 & 123,30 & 24,35 & 42,49 & 67,24 \\
\hline Pelodytes punctatus & $30 \mathrm{SXH93}$ & 100,00 & 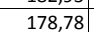 & 111,72 & 41,09 & 5400,40 & 320 & 53, & 267,23 & 191,1 & 248 & 250,44 & 112 & 309, & 57,72 & 4, & 51,72 & 128,54 & 28,58 & 46,75 & 71,09 \\
\hline Pelodytes punctatus & $30 \mathrm{~S} \times \mathrm{H} 94$ & 100,00 & 17 & 112 & 41,00 & 549 & & 44 & 269 & 182 & 241,54 & 243,40 & 103 & 350,8 & 60,63 & 5,69 & 46,96 & 138,28 & 36,41 & 53,73 & 80,2 \\
\hline Pelodytes punctatus & $30 \mathrm{~S} \times \mathrm{H} 96$ & 100,00 & 148,28 & 110,82 & 40,10 & 5709,03 & 298,50 & 24,74 & 273,76 & 156,32 & 223,42 & 225,22 & 79,91 & 452,91 & 66,12 & $\mid$ & 37,57 & 160,68 & 58,26 & 72,30 & 105,57 \\
\hline \begin{tabular}{|l} 
Pelodytes punctatus \\
\end{tabular} & 30 SXH97 & 100,00 & 140,39 & 109,89 & 39,67 & 5779,53 & 292,01 & 17,73 & 274,28 & 148,18 & 216,67 & 218,58 & 71,50 & 489,68 & 67,88 & 13,31 & 34,66 & 168,39 & 67,32 & 79,84 & 113,96 \\
\hline Pelodytes punctatus & $30 \mathrm{~S} \times \mathrm{H} 98$ & 100,00 & 144,32 & 109,36 & 39,72 & 5737,64 & 294,20 & 22,01 & 272,20 & 155,50 & 219,91 & 221,75 & 75,75 & 475,68 & 67,75 & 12,47 & 35,70 & 166,80 & 64,63 & 78,26 & 110,11 \\
\hline Pelodytes punctatus & $30 \mathrm{SXH99}$ & 100,00 & 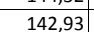 & 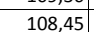 & 39,56 & 5746,21 & 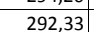 & 21,17 & 271,16 & 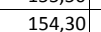 & 218,71 & 220,58 & 74,29 & 482,94 & 68,26 & 13,1 & & 168,86 & 67,18 & 80,69 & 111,19 \\
\hline Pelodytes punctatus & $305 \times J 01$ & 100 & & & 39 & 6264 & & 10,43 & 300,64 & 157, & 224,55 & 224,62 & 65, & 391 & 51,29 & 10, & 34,92 & 132,68 & 56,14 & 59,14 & 85,05 \\
\hline Pelodytes punctatus & $30 \mathrm{~s} \times 103$ & 100,00 & 141,64 & 118,23 & 39,00 & 6262,27 & 311,12 & 11,56 & 299,56 & 159,29 & 225,27 & 225,43 & 66,05 & 391,23 & 48,32 & 10,75 & 33,55 & 129,99 & 58,16 & 62,01 & 85,15 \\
\hline Pelodytes punctatus & $305 \times 108$ & 100,00 & 122,13 & 117,97 & 38,70 & 6381,62 & 295,58 & $-6,56$ & 302,14 & 104,82 & 207,47 & 208,10 & 45,69 & 473,02 & 57,98 & 17,31 & 28,02 & 154,30 & 79,13 & 85,51 & 103,34 \\
\hline Pelodytes punctatus & $305 \times 109$ & 100,00 & 120,42 & 17,75 & 38,44 & 6394,95 & 293,89 & $-8,44$ & 302,32 & 102,88 & 205,79 & 206,61 & 43,75 & 1701 & 59,40 & 18,10 & 27,64 & 156,27 & 81,62 & 88,12 & 104,53 \\
\hline Pelodytes punctatus & $305 \times J 29$ & 100,00 & & 112 & 38,0 & 6289 & 291 & 0,3 & 291,16 & 144,6 & 210,27 & 210,82 & 51,06 & 446 & 55 & 17,49 & 28,18 & 14 & 80,79 & 84,38 & 91 \\
\hline Pelodytes punctatus & $305 \times 337$ & 100,00 & 129,43 & 112,05 & 38,30 & 6210,37 & 291,93 & 4,19 & 287,74 & 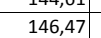 & 212,47 & 212,64 & 55,10 & \begin{tabular}{l|l}
$44,52,05$ \\
445
\end{tabular} & $\frac{52,21}{52,90}$ & 16,54 & 28,95 & $\begin{array}{l}\mid 42,14 \\
142,84 \\
\end{array}$ & 79,29 & $\begin{array}{l}80,87 \\
80,8\end{array}$ & 91,56 \\
\hline
\end{tabular}




\begin{tabular}{|c|c|c|c|c|c|c|c|c|c|c|c|c|c|c|c|c|c|c|c|c|c|}
\hline TAXON & UTM & $\mathrm{km} 2$ & BIO1 & $\mathrm{B1O2}$ & $\mathrm{BIO3}$ & 8104 & B105 & B106 & B107 & B108 & B109 & BIO10 & B1011 & BIO12 & B1013 & B1014 & 81015 & B1016 & BIO17 & B1018 & $\begin{array}{ll}\text { B1O19 } \\
\end{array}$ \\
\hline Pelodytes punctatus & $305 \times J 38$ & 100,00 & 124,98 & 111,35 & 38,03 & 6245,07 & 288,08 & 0,40 & 287,68 & 142,25 & 208,58 & 208,88 & 50,44 & 457,55 & 55,49 & 18,08 & 28,18 & 147,89 & 83,66 & 86,22 & 93,11 \\
\hline Pelodytes punctatus & $305 \times 140$ & 100,00 & 132,93 & 115,13 & 39,00 & 6113,63 & 296,21 & 5,99 & 290,22 & 121,67 & 214,54 & 215,18 & 59,95 & 455,80 & 55,78 & 13,94 & 31,92 & 143,52 & 72,06 & 73,11 & 99,41 \\
\hline $\begin{array}{l}\text { Pelodytes punctatus } \\
\end{array}$ & $30 \mathrm{SXJ46}$ & 100,00 & 140,77 & 109,92 & 38,90 & 6050,06 & 297,10 & 16,81 & 280,29 & 150,23 & 221,32 & 221,66 & 67,97 & 413,15 & 52,03 & 13,81 & 31,29 & 132,51 & 70,02 & 72,27 & 85,21 \\
\hline Pelodytes punctatus & $30 \mathrm{SXJ47}$ & 100,00 & 132,63 & 109,71 & 38,28 & 6132,50 & 290,92 & 8,77 & 282,15 & 147,91 & 214,44 & 214,60 & 59,05 & 437,66 & 52,14 & 16,21 & 29,32 & 138,60 & 78,77 & 79,29 & 89,08 \\
\hline Pelodytes punctatus & $30 \mathrm{SXJ49}$ & 100,00 & 122,53 & 108,38 & 37,99 & 6213,33 & 282,04 & $-0,13$ & 282,17 & \begin{tabular}{|l|l|}
139,53 \\
\end{tabular} & 202,60 & 205,97 & 48,61 & 465,00 & 56,91 & 19,70 & 27,76 & 150,18 & 89,13 & 90,91 & 92,11 \\
\hline Pelodytes punctatus & $305 \times J 52$ & 100,00 & 129,60 & 112,21 & 38,96 & 6071,79 & 289,74 & 5,25 & 284,49 & 131,89 & 210,86 & 211,45 & 57,43 & 478,03 & 58,38 & 16,09 & 30,25 & 151,48 & 78,93 & 81,26 & 102,80 \\
\hline Pelodytes punctatus & $30 \mathrm{SXJ53}$ & 100,00 & 132,83 & 111,44 & 38,99 & 6054,51 & 291,36 & 8,81 & 282,55 & 143,03 & 213,66 & 214,39 & 60,61 & 461,08 & 57,05 & 15,37 & 30,49 & 146,18 & 76,52 & 79,16 & 98,14 \\
\hline Pelodytes punctatus & $305 \times J 56$ & 100,00 & 142,36 & 107,81 & 38,90 & 5975,50 & 294,88 & 20,05 & 274,84 & 151,12 & 221,59 & 222,31 & 70,39 & 417,13 & 54,42 & 13,94 & 31,68 & 137,42 & 69,68 & 74,75 & 86,15 \\
\hline Pelodytes punctatus & $305 \times J 57$ & 100,00 & 135,43 & 107,41 & 38,28 & 6046,96 & 289,62 & 13,45 & 276,17 & \begin{tabular}{|l|l}
144,99 \\
\end{tabular} & \begin{tabular}{|l|l|}
215,97 \\
\end{tabular} & 216,39 & 62,89 & 435,39 & 53,66 & 15,97 & 29,95 & 139,20 & 77,11 & 80,02 & 88,35 \\
\hline Pelodytes punctatus & $305 \times 158$ & 100,00 & 127,50 & 106,93 & 37,98 & 6110,70 & 283,45 & 5,91 & 277,54 & 142,05 & 209,36 & 209,55 & 54,73 & 458,52 & 54,60 & 18,52 & 28,35 & 144,68 & 85,95 & 86,95 & 91,62 \\
\hline Pelodytes punctatus & $30 \mathrm{SXJ59}$ & 100,00 & 120,95 & 106,30 & 37,90 & 6167,78 & 277,81 & $-0,17$ & 277,97 & 137,32 & 163,31 & 203,76 & 47,78 & 477,04 & 57,77 & 20,75 & 27,53 & 152,52 & 92,88 & 93,98 & 93,77 \\
\hline Pelodytes punctatus & $305 \times J 61$ & 100,00 & 137,99 & 111,40 & 39,21 & 5952,97 & 293,82 & 13,92 & 279,90 & 147,24 & \begin{tabular}{|l|l|}
217,15 \\
\end{tabular} & 218,16 & 66,81 & 456,65 & 59,88 & 13,80 & 32,50 & 149,99 & 70,42 & 76,63 & 99,55 \\
\hline Pelodytes punctatus & $305 \times J 62$ & 100,00 & 140,55 & 110,31 & 39,25 & 5927,19 & 294,52 & 17,05 & 277,47 & 150,31 & 219,21 & 220,26 & 69,46 & 446,74 & 59,58 & 13,52 & 32,87 & 148,61 & 69,04 & 75,92 & 96,71 \\
\hline Pelodytes punctatus & $305 \times J 66$ & 100,00 & 137,73 & 106,27 & 38,63 & 5952,26 & 288,87 & 16,69 & 272,18 & 146,89 & 216,82 & 217,55 & 66,32 & 444,08 & 57,30 & 15,64 & 30,68 & 146,17 & 75,42 & 81,56 & 91,85 \\
\hline Pelodytes punctatus & $305 \times 167$ & 100,00 & 134,58 & 105,47 & 38,08 & 5986,80 & 286,09 & 14,12 & 271,97 & 143,41 & 214,29 & 214,93 & 63,03 & 449,14 & 56,28 & 16,73 & 29,75 & 145,65 & 79,29 & 84,23 & 91,38 \\
\hline Pelodytes punctatus & $305 \times 168$ & 100,00 & 122,35 & 105,18 & 37,93 & 6098,75 & 276,92 & 2,28 & 274,63 & \begin{tabular}{ll|}
136,46 \\
\end{tabular} & 203,99 & 204,38 & 50,08 & 487,44 & 57,57 & 20,5 & 27,48 & 153,17 & 92,86 & 94,41 & 97,42 \\
\hline Pelodytes punctatus & $305 \times 169$ & 100,00 & 130,08 & 103,49 & 37,92 & 6039,47 & 281,31 & 10,47 & 270,84 & 141,93 & 203,62 & 210,93 & 58,12 & 452,30 & 55,16 & 18,70 & 29,05 & 145,00 & 85,51 & 88,67 & 88,76 \\
\hline Pelodytes punctatus & $30 \mathrm{~S} \times \mathrm{J} 70$ & 100,00 & 137,53 & 110,71 & 39,32 & 5904,00 & 291,80 & 14,12 & 277,68 & 147,94 & 215,93 & 217,18 & 67,21 & 472,94 & 62,96 & 14,05 & 32,67 & 157,32 & 71,03 & 79,28 & 105,05 \\
\hline Pelodytes punctatus & $30 \mathrm{SXJ71}$ & 100,00 & 129,27 & 109,91 & 39,00 & 5973,05 & 285,19 & 6,64 & 278,55 & 139,33 & 208,87 & 210,05 & 58,50 & 504,70 & 63,75 & 16,71 & 30,28 & 162,69 & 80,68 & 86,76 & 111,01 \\
\hline Pelodytes punctatus & $30 \mathrm{SXJ73}$ & 100,00 & 134,74 & 107,78 & 38,92 & 5912,92 & 287,08 & 13,31 & 273,78 & 144,68 & 213,34 & 214,45 & 64,27 & 479,66 & 62,49 & 15,88 & 30,90 & 158,43 & 77,23 & 84,66 & 103,68 \\
\hline Pelodytes punctatus & $305 \times J 74$ & 100,00 & 144,64 & 106,00 & 38,97 & 5808,97 & 292,51 & 24,30 & 268,21 & 154,66 & 221,46 & 222,71 & 74,91 & 443,42 & 61,79 & 13,75 & 33,54 & 153,08 & 68,48 & 78,70 & 95,51 \\
\hline Pelodytes punctatus & $305 \times 176$ & 100,00 & \begin{tabular}{|l|l|}
136,34 \\
\end{tabular} & 104,40 & 38,32 & 5894,38 & 285,41 & 24,80 & 268,53 & 145,73 & 214,62 & 215,66 & 65 & 462,44 & 60,29 & 16,51 & 30,46 & $\begin{array}{l}154,06 \\
154\end{array}$ & 78,14 & 86,10 & 96,48 \\
\hline Pelodytes punctatus & $30 \mathrm{SXJ77}$ & 100,00 & 129,46 & 103,84 & 38,05 & 5965,21 & 280,00 & 10,43 & 269,57 & 138,84 & \begin{tabular}{ll|}
208,95 \\
\end{tabular} & 209,79 & 58,54 & 479,80 & 59,22 & 18,64 & 28,75 & 155,00 & 85,94 & 91,66 & 98,22 \\
\hline Pelodytes punctatus & $305 \times \mathrm{X} 78$ & 100,00 & 134,17 & 102,25 & 37,95 & 5919,14 & 282,15 & 16,04 & 266,11 & 144,01 & 212,92 & 213,66 & 63,56 & 458,25 & 58,45 & 17,81 & 29,83 & 151,35 & 81,92 & 88,97 & 92,58 \\
\hline Pelodytes punctatus & $30 \mathrm{~S} \times \mathrm{X} 80$ & 100,00 & 144,00 & 109,08 & 39,48 & 5785,34 & 294,12 & 21,79 & 272,33 & 154,88 & 220,38 & 221,94 & 74,64 & 463,92 & 65,44 & 12,84 & 34,78 & 161,16 & 66,09 & 78,03 & 104,46 \\
\hline $\begin{array}{l}\text { Pelodytes punctatus } \\
\end{array}$ & $305 \times J 81$ & 100,00 & 139,38 & 108,16 & 39,12 & 5823,71 & 290,00 & 17,87 & 272,13 & 150,14 & 216,53 & 217,97 & 69,86 & 480,55 & 65,73 & 14,34 & 32,98 & 164,05 & 71,62 & 82,44 & 107,25 \\
\hline Pelodytes punctatus & $\begin{array}{l}305 \times 182 \\
305 \times 1\end{array}$ & 100,00 & $\mid$ & $\begin{array}{l}\mid 0,106,86 \\
106\end{array}$ & 39,12 & 5781,11 & 291,03 & 22,04 & 268,99 & $\mid 353,31$ & 219,00 & 220,57 & $\begin{array}{l}-73,00 \\
73,45\end{array}$ & 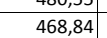 & $\mid \begin{array}{ll}65,57 \\
65\end{array}$ & $\mid \frac{14,340}{13,90}$ & \begin{tabular}{|c|c|}
33,69 \\
330
\end{tabular} & $\begin{array}{l}\mid 004,03 \\
162,69\end{array}$ & $\begin{array}{l}69,0<2 \\
69,65\end{array}$ & $\begin{array}{l}0<, 44 \\
81,45\end{array}$ & $\begin{array}{l}104,05 \\
104\end{array}$ \\
\hline Pelodytes punctatus & $305 \times 185$ & 100,00 & 151,95 & 102,27 & 38,99 & 5649,61 & 293,41 & 34,26 & 259,15 & \begin{tabular}{|c|}
162,57 \\
\end{tabular} & 226,08 & 227,78 & 83,80 & 435,08 & 65,18 & 12,88 & 35,90 & 158,16 & 63,79 & 78,46 & 94,93 \\
\hline Pelodytes punctatus & $305 \times 186$ & 100,00 & 143,03 & 101,81 & 38,50 & 5747,54 & 286,85 & 25,65 & 261,20 & 153,06 & 218,83 & 220,32 & 74,19 & 457,23 & 63,92 & 15,32 & 32,73 & 159,77 & 72,87 & 85,12 & 97,37 \\
\hline Pelodytes punctatus & $30 \mathrm{SXX87}$ & 100,00 & 134,47 & 101,46 & 38,03 & 5847,57 & 280,78 & 17,18 & 263,60 & 143,95 & 212,11 & 213,25 & 64,92 & 477,32 & 62,23 & 17,79 & 30,15 & 160,24 & 82,06 & 91,49 & 99,19 \\
\hline Pelodytes punctatus & $305 \times 189$ & 100,00 & 151,22 & 97,45 & 38,00 & 5660,88 & 289,16 & 36,08 & 253,09 & $\begin{array}{l}160,92 \\
160,9\end{array}$ & 225,42 & 226,98 & 82,86 & 416,22 & 60,92 & 14,41 & 34,58 & 150,62 & 67,12 & 81,19 & 85,54 \\
\hline Pelodytes punctatus & $\begin{array}{l}305 \times 990 \\
30509\end{array}$ & 100,00 & $\begin{array}{l}\mid 151,2< \\
153,25\end{array}$ & $\mid$\begin{tabular}{|c|}
107,17 \\
107
\end{tabular} & 39,81 & 50030,23 & $\begin{array}{l}\mid 209,10 \\
298,25 \\
\end{array}$ & 32,30 & 265,05 & \begin{tabular}{l|l}
10,52 \\
164,95
\end{tabular} & 227,01 & 228,96 & $\begin{array}{l}02,00 \\
85,40\end{array}$ & $\begin{array}{l}410,2< \\
449,15\end{array}$ & $\begin{array}{l}\mid c 0,3< \\
68,17 \\
\end{array}$ & $\begin{array}{l}4,41 \\
11,03 \\
\end{array}$ & \begin{tabular}{|c|}
34,19 \\
38,19
\end{tabular} & 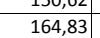 & $\begin{array}{l}0,12, \\
58,95\end{array}$ & $\mid 75,35$ & $\mid$\begin{tabular}{|c|}
103,51 \\
103,51
\end{tabular} \\
\hline Pelodytes punctatus & $305 \times J 91$ & 100,00 & 154,65 & 105,88 & 39,80 & 5600,81 & 298,09 & 34,84 & 263,25 & 166,33 & 227,97 & 230,00 & 87,14 & 446,79 & 68,62 & 11,06 & 38,44 & 165,52 & 58,81 & 75,95 & 102,75 \\
\hline Pelodytes punctatus & $30 \mathrm{SXJ95}$ & 100,00 & 154,12 & 100,07 & 38,95 & 5546,10 & 291,99 & 38,17 & 253,82 & 165,20 & 226,60 & 228,75 & 87,31 & 447,85 & 69,32 & 12,82 & 37,47 & 166,93 & 63,14 & 81,01 & 100,04 \\
\hline Pelodytes punctatus & $305 \times 196$ & 100,00 & 159,01 & 97,91 & 38,9 & 5464,39 & 293,27 & & 248,46 & 170,22 & 230,17 & 232,46 & 92,96 & 432,22 & 69,69 & 12,2 & 39,07 & 165,26 & 59,58 & 78,93 & 96,29 \\
\hline Pelodytes punctatus & $305 \times 197$ & 100,00 & 157,92 & 96,72 & 38,69 & 5480,10 & 291,59 & 44,24 & 247,35 & 168,84 & 229,31 & 231,46 & 91,61 & 430,08 & 68,64 & 12,78 & 38,43 & 163,54 & 61,12 & 80,02 & 94,32 \\
\hline Pelodytes punctatus & $305 \times 198$ & 100,00 & 161,99 & 95,04 & 38,54 & 5418,89 & 292,97 & 49,34 & 243,62 & 172,81 & 232,29 & 234,62 & 96,34 & 414,44 & 67,98 & 12,27 & 39,74 & 160,49 & 58,30 & 78,11 & 90,18 \\
\hline \begin{tabular}{|l} 
Pelodytes punctatus \\
\end{tabular} & $305 \times 1999$ & 100,00 & 156,57 & 94,70 & 38,02 & 5501,31 & 289,38 & 43,62 & 245,76 & 166,92 & 228,32 & 230,32 & 90,09 & 420,21 & 65,46 & 13,67 & 37,23 & 158,42 & 63,57 & 81,59 & 88,81 \\
\hline Pelodytes punctatus & $305 \times 12$ & 100,00 & 107,80 & 113,86 & 37,99 & 6396,03 & 277,60 & $-18,99$ & 296,59 & 126,32 & 193,10 & 194,14 & 31,64 & 514,64 & 66,77 & 23,34 & 26,70 & 169,85 & 96,73 & 105,32 & 107,11 \\
\hline Pelodytes punctatus & $305 \times K 22$ & 100,00 & 08 & 26 & 37,82 & 72,31 & 272,03 & $-19,79$ & 291,83 & 123,10 & 188,12 & 191,08 & 29,40 & 520,37 & 67,76 & 24,7 & 26,65 & 173,16 & 101,24 & 109,76 & 104,98 \\
\hline $\begin{array}{l}\text { Pelodytes punctatus } \\
\end{array}$ & 305XK31 & 100,00 & 113,36 & 109,34 & 37,76 & 6319,51 & 276,69 & $-10,14$ & 286,82 & 131,17 & $\begin{array}{l}140,04 \\
140,1\end{array}$ & 198,55 & 38,41 & 486,33 & 62,48 & 22,50 & 27,36 & 161,19 & \begin{tabular}{|l|}
94,60 \\
\end{tabular} & 101,05 & 年, \\
\hline Pelodytes punctatus & $305 \times 332$ & 100,00 & 10 & 108,46 & 37,33 & 6339,29 & 271,47 & $-14,69$ & \begin{tabular}{|l|l|}
286,15 \\
\end{tabular} & \begin{tabular}{|l|l|}
126,45 \\
\end{tabular} & 58,98 & 194,06 & 33,24 & 499,43 & 65,36 & 24,27 & 27,34 & 167,26 & 97,03 & 107,17 & 97,07 \\
\hline Pelodytes punctatus & $305 \times K 40$ & 100,00 & 116,01 & 107,73 & 37,78 & 6252,44 & 276,27 & $-6,16$ & 282,43 & $\begin{array}{l}133,03 \\
133,45\end{array}$ & $\begin{array}{r}123,01 \\
123,01\end{array}$ & 200,16 & 41,92 & 485,12 & 60,79 & 22,01 & 27,28 & 158,67 & 94,35 & 98,94 & 95,01 \\
\hline Pelodytes punctatus & $305 \times K 42$ & 100,00 & 116,05 & 105,51 & 37,03 & 6277,06 & 274,28 & $-5,51$ & 279,79 & 133,90 & 41,45 & 200,47 & 41,45 & 464,69 & 60,71 & 22,55 & 28,61 & 155,38 & 86,90 & 99,96 & 86,90 \\
\hline Pelodytes punctatus & $305 \times 550$ & 100,00 & 127,65 & 104,81 & 37,71 & 135,18 & 281,71 & 6,70 & 275,01 & 142,82 & 92,14 & 209,82 & 54,41 & 442,77 & 54,53 & 19,12 & 28,90 & 142,62 & 84,56 & 87,90 & 84,95 \\
\hline Pelodytes punctatus & 30SXK71 & 100,00 & $\begin{array}{l}116,02 \\
116,\end{array}$ & \begin{tabular}{|l|}
100,51 \\
100,53
\end{tabular} & 36,95 & $\begin{array}{ll}0131,100 \\
612,56\end{array}$ & \begin{tabular}{|l|l|}
261,73 \\
\end{tabular} & $\begin{array}{c}-1,27 \\
-1,27\end{array}$ & 269,01 & $\begin{array}{l}14,02 \\
131,13\end{array}$ & $\begin{array}{ll}32,14 \\
43,85\end{array}$ & $\begin{array}{l}00,02 \\
198,16\end{array}$ & $\begin{array}{l}34,41 \\
43,85\end{array}$ & 495,53 & $\begin{array}{ll}41,02 \\
61,\end{array}$ & $\begin{array}{l}23,12 \\
23,65\end{array}$ & 27,54 & $\begin{array}{l}42,0< \\
158,38 \\
\end{array}$ & $\begin{array}{l}04,50 \\
93,56 \\
\end{array}$ & \begin{tabular}{|l|}
01,302 \\
103,52
\end{tabular} & $\begin{array}{ll}93,56 \\
93,5\end{array}$ \\
\hline $\begin{array}{l}\text { Pelodytes punctatus } \\
\end{array}$ & $305 \times K 72$ & 100,00 & 95,77 & 100,65 & 36,45 & 6182,98 & 250,53 & $-21,31$ & 271,84 & 111,17 & 23,68 & 179,33 & 23,68 & 584,80 & 73,13 & 30,58 & 25,11 & 189,64 & 113,11 & 126,81 & 113,11 \\
\hline Pelodytes punctatus & $305 \times 180$ & 100,00 & 133,40 & 98,33 & 37,20 & 5881,55 & 277,88 & 17,42 & 260,45 & 142,60 & 180,96 & 212,31 & 63,21 & 457,53 & 58,17 & 18,99 & 29,97 & 152,34 & 84,32 & 93,37 & 89,68 \\
\hline Pelodytes punctatus & $305 \times K 81$ & 100,00 & 107,43 & 99,34 & 36,75 & 6087,26 & 258,7 & $-8,79$ & 267,52 & 121 & 36,15 & 189,55 & 36,15 & 548,46 & 66,48 & $26, \varepsilon$ & 25,90 & 173,45 & 106,31 & 115,03 & 106,31 \\
\hline Pelodytes punctatus & $305 \times K 82$ & 100,00 & 95,14 & 99,06 & 36,21 & 135,27 & 247 & $-20, \varepsilon$ & 268 & 110 & 23 & 178,07 & 23, & 600,15 & 73,97 & 31, & 24,62 & 192,01 & 117,01 & 128,30 & 117,01 \\
\hline Pelodytes punctatus & $305 \times K 90$ & 100,00 & 137,15 & 96,17 & 37,23 & 5766,21 & 277,84 & 22,66 & 255,19 & 146,16 & 210,50 & 214,60 & 68,34 & 461,90 & 60,83 & 18,45 & 30,90 & 158,33 & 82,55 & 94,14 & 92,39 \\
\hline \begin{tabular}{|l} 
Pelodytes punctatus \\
\end{tabular} & $305 \times K 91$ & 100,00 & 118,16 & 97,05 & 36,70 & 5962,03 & 264,77 & 3,03 & 261,74 & 128,88 & 86 & 198,45 & 47,94 & 516,47 & 61,85 & 23,82 & 27,32 & 164,19 & 99,90 & 108,37 & 100,35 \\
\hline Pelodytes punctatus & $305 \times K 92$ & 100,00 & 118,22 & 96,24 & 36,31 & 5976,35 & 264,32 & 3,29 & 261,02 & 129,84 & 58,95 & 198,64 & 47,90 & 505,18 & 61,45 & 23,95 & 27,82 & 160,42 & 95,62 & 107,63 & 95,73 \\
\hline Pelodytes punctat & 30SYH05 & 100,00 & & 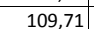 & 40,85 & 5465,29 & 309,8 & 43,6 & 266 & 4 & 237,69 & 240 & 100,20 & 20 & 64 & 6,7 & 45 & 151,15 & 41, & 60,32 & 89,22 \\
\hline $\begin{array}{l}\text { Pelodytes punctatus } \\
\end{array}$ & 30SYHO6 & 100,00 & & & 39,61 & 5689, & & 22,42 & 271,13 & 144, & 219,20 & 221,28 & $\begin{array}{l}76,40 \\
76,49 \\
\end{array}$ & 486,58 & 69,47 & $0,12,10$ & $\begin{array}{ll}36,53 \\
36,53\end{array}$ & 172,01 & $63,57 \mid$ & 78,33 & 115,60 \\
\hline Pelodytes punctatus & 30SYHO8 & 100,00 & 133,87 & 107,45 & 39,09 & 5786,82 & 284,80 & 13,19 & 271,61 & 144,48 & 210,39 & 212,43 & 65,38 & 534,69 & 71,73 & 15,72 & 32,70 & 181,60 & 76,45 & 89,32 & 125,78 \\
\hline Pelodytes punctatus & 30SYHO9 & 100,00 & 148,30 & 106,84 & 39,64 & 5640,08 & 294,15 & 27,77 & 266,38 & 160,23 & 222,30 & 224,45 & 80,64 & 481,97 & 70,89 & 12,15 & 37,05 & 174,40 & 63,64 & 80,44 & 113,50 \\
\hline Pelodytes punctatus & 30SYH13 & 75,00 & 181,61 & 107,03 & 41,00 & 237,53 & 170 & 59,90 & 257,70 & 194,88 & 248,67 & 251,29 & 117,18 & 322,56 & 61,49 & 4,09 & 53,53 & 139,03 & 29,04 & 48,90 & 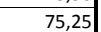 \\
\hline Pelodytes punctatus & 30SYH14 & 84,00 & & 107, & 41,0 & 5257, & 316 & 58,6 & 257,99 & 193, & 207 & 250 & 115,62 & 336 & 63, & 4,36 & 52,08 & 143,41 & 31,77 & 51,94 & \\
\hline Pelodytes punctatus & 30 SYH15 & 100,00 & $\begin{array}{l}175,28 \\
175,2\end{array}$ & 107,31 & 40,93 & 5313,91 & 313,30 & 53,72 & 259,57 & $\begin{array}{l}188,76 \\
188\end{array}$ & 243,76 & 246,37 & \begin{tabular}{|l|l|l|l|l|l|}
110,37 \\
\end{tabular} & 366,35 & 65,66 & 5,46 & \begin{tabular}{|l|l|}
49,10 \\
\end{tabular} & $\begin{array}{l}\mid 430,41 \\
151,58 \\
\end{array}$ & 37,05 & 57,48 & 84,94 \\
\hline
\end{tabular}




\begin{tabular}{|c|c|c|c|c|c|c|c|c|c|c|c|c|c|c|c|c|c|c|c|c|c|}
\hline TAXON & UTM & $\mathrm{km} 2$ & BIO1 & $\mathrm{B1O2}$ & $\mathrm{BIO3}$ & 8104 & B105 & B106 & B107 & B108 & B109 & BIO10 & B1011 & BIO12 & B1013 & B1014 & 81015 & B1016 & BIO17 & B1018 & 81019 \\
\hline Pelodytes punctatus & 30SYH16 & 100,00 & 159,20 & 107,47 & 40,10 & 5490,83 & 302,30 & 37,95 & 264,34 & 169,42 & 230,56 & 233,14 & 92,89 & 442,74 & 69,88 & 8,99 & 41,99 & 168,76 & 51,36 & 70,57 & 106,53 \\
\hline Pelodytes punctatus & 30SYH17 & 100,00 & 137,58 & 106,62 & 39,14 & 5704,24 & 286,43 & 17,54 & 268,89 & 126,61 & 212,69 & 215,01 & 69,98 & 534,91 & 73,47 & 14,70 & 34,32 & 186,51 & 72,75 & 87,84 & 129,03 \\
\hline Pelodytes punctatus & 30SYH18 & 100,00 & 135,72 & \begin{tabular}{|c|c|c|}
105,93 \\
\end{tabular} & 39,01 & 5715,70 & 284,32 & 16,26 & 268,07 & 135,22 & 211,13 & 213,36 & 68,11 & 545,95 & 74,34 & 15,54 & 33,65 & 189,00 & 76,09 & $\begin{array}{ll}91,16 \\
91,16\end{array}$ & 130,99 \\
\hline Pelodytes punctatus & 30SYH19 & 100,00 & 140,82 & 105,29 & 39,20 & 5663,73 & 287,27 & 21,68 & 265,59 & 149,01 & 215,32 & 217,56 & 73,55 & 529,39 & 74,34 & 14,42 & 35,07 & 187,23 & 72,32 & 89,16 & 126,96 \\
\hline Pelodytes punctatus & 30SYH24 & 13,00 & 181,85 & 105,46 & 41,00 & 5196,85 & 316,00 & 61,77 & 254,23 & \begin{tabular}{|l|l|}
196,08 \\
\end{tabular} & 248,23 & 251,23 & 118,00 & 352,31 & 65,31 & 4,23 & 52,23 & 151,00 & 32,31 & 54,23 & 84,31 \\
\hline Pelodytes punctatus & $30 \mathrm{SYH} 25$ & 77,00 & 180,16 & 105,37 & 41,00 & 5215,02 & 314,92 & 60,07 & 254,85 & 194,17 & 247,07 & 250,04 & 116,15 & 369,19 & 67,10 & 4,91 & 51,03 & 156,33 & 34,86 & 57,50 & 89,25 \\
\hline Pelodytes punctatus & $30 \mathrm{SYH} 26$ & 100,00 & 162,06 & 105,68 & 40,10 & 5418,68 & 302,65 & 42,09 & 260,56 & 164,62 & 232,30 & 235,03 & 96,54 & 452,93 & 72,10 & 8,67 & 43,43 & 176,14 & 50,53 & 71,93 & 112,25 \\
\hline Pelodytes punctatus & 30SYH27 & 100,00 & 138,36 & 105,00 & 39,08 & 5652,75 & 285,28 & 19,41 & 265,87 & 113,91 & 212,66 & 215,09 & 71,39 & 550,86 & 75,99 & 14,68 & 34,98 & 195,63 & 73,13 & 90,20 & 135,87 \\
\hline Pelodytes punctatus & $30 \mathrm{SYH} 28$ & 100,00 & 143,83 & 104,61 & 39,25 & 5600,58 & 288,71 & 25,05 & 263,66 & 129,31 & 217,22 & 219,66 & 77,15 & 534,83 & 76,21 & 13,50 & 36,49 & 193,59 & 69,20 & 88,25 & 132,28 \\
\hline Pelodytes punctatus & $30 \mathrm{SYH} 29$ & 100,00 & 157,11 & 103,99 & 39,83 & 5462,54 & 297,39 & 38,60 & 258,79 & 160,71 & 228,11 & 230,76 & 91,36 & \begin{tabular}{|c|}
495,67 \\
\end{tabular} & 76,34 & 10,57 & 41,07 & 189,27 & 58,63 & 81,85 & 124,46 \\
\hline Pelodytes punctatus & 30SYH36 & 76,00 & 172,53 & 104,27 & 40,29 & 5282,72 & 308,81 & 53,31 & 255,50 & 157,76 & 240,39 & 243,27 & 108,08 & 439,99 & 73,14 & 6,73 & 47,77 & 180,04 & 43,50 & 68,74 & 114,51 \\
\hline Pelodytes punctatus & 30SYH37 & 100,00 & 156,46 & 103,95 & 39,66 & 5443,78 & 297,10 & 37,91 & 259,19 & 131,88 & 227,12 & 229,92 & 90,96 & 507,02 & 76,68 & 10,34 & 41,72 & 195,70 & 57,87 & 81,19 & 130,93 \\
\hline \begin{tabular}{|l} 
Pelodytes punctatus \\
\end{tabular} & $30 \mathrm{YHH} 38$ & 100,00 & 130,60 & 102,73 & 38,43 & 5683,61 & 277,40 & 13,50 & 263,90 & 103,87 & $\begin{array}{l}205,45 \\
\end{array}$ & 208,02 & 63,76 & \begin{tabular}{|c|}
603,69 \\
\end{tabular} & 79,85 & 17,44 & 33,08 & 211,11 & 83,60 & 100,75 & 150,39 \\
\hline Pelodytes punctatus & 30SYH47 & 100,00 & 161,13 & 102,73 & 39,57 & 5376,77 & 299,46 & 43,28 & 256,17 & 137,70 & 230,58 & 233,57 & 96,22 & 517,59 & 78,54 & 9,54 & 44,19 & 206,86 & 55,42 & 81,62 & 139,68 \\
\hline Pelodytes punctatus & $30 \mathrm{SYH} 49$ & 100,00 & 147,75 & 101,29 & 38,85 & 5494,05 & 288,34 & 31,16 & 257,18 & \begin{tabular}{|l|}
123,03 \\
\end{tabular} & 219,25 & 222,17 & 82,22 & 568,60 & 81,47 & 13,02 & 38,90 & 215,42 & 69,06 & 93,62 & 149,08 \\
\hline Pelodytes punctatus & 30SYH59 & 100,00 & 165,68 & 101,14 & 39,39 & 5336,27 & 301,81 & 48,57 & 253,24 & 143,14 & 234,28 & 237,34 & 100,95 & 555,96 & 83,49 & 9,23 & 46,88 & 230,87 & 56,25 & 88,41 & 159,20 \\
\hline Pelodytes punctatus & $30 \mathrm{SYJ02}$ & 100,00 & 169,80 & 101,78 & 40,00 & 5352,22 & 304,00 & 52,88 & 251,12 & 182,31 & 238,94 & 241,55 & 104,55 & 424,42 & 72,88 & 8,66 & 44,99 & 170,37 & 48,57 & 72,18 & 101,98 \\
\hline Pelodytes punctatus & 30SYJ05 & 100,00 & 166,41 & 96,64 & 39,28 & 5302,08 & 296,17 & 53,60 & 242,58 & 178,57 & 234,92 & 237,66 & 102,14 & 436,16 & 75,19 & 10,58 & 43,50 & 174,36 & 53,81 & 77,63 & 102,01 \\
\hline Pelodytes punctatus & 30SYJ06 & 100,00 & 165,44 & 95,01 & 39,01 & 5293,51 & 293,86 & 53,87 & 239,99 & 177,42 & 233,86 & 236,68 & 101,27 & 438,06 & 75,39 & 11,25 & 42,87 & 174,73 & 55,44 & 79,30 & 101,17 \\
\hline Pelodytes punctatus & 30SYJ07 & 100,00 & 166,40 & 93,37 & 38,95 & 5267,47 & 293,03 & 55,71 & 237,33 & \begin{tabular}{ll|}
178,25 \\
\end{tabular} & 234,31 & 237,26 & 102,52 & 431,58 & 74,97 & 11,56 & 43,03 & 173,01 & 55,33 & 79,25 & 98,46 \\
\hline Pelodytes punctatus & 30SYJ08 & 100,00 & 167,01 & 92,15 & 38,61 & 5261,87 & 292,83 & 56,86 & 235,97 & 178,53 & 234,81 & 237,69 & 103,18 & 421,74 & 73,28 & 11,57 & 42,99 & 169,44 & 55,16 & 78,88 & 94,67 \\
\hline Pelodytes punctatus & 30SYJ11 & 100,00 & | 169,64 & 102,15 & 40,01 & 5328,99 & 304,21 & 52,64 & 251,57 & $\mid$ & 238,42 & 241,24 & 104,81 & 445,22 & 75,33 & 8,56 & 45,40 & \begin{tabular}{|l|l|}
179,08 \\
\end{tabular} & 49,42 & 74,85 & 110,63 \\
\hline \begin{tabular}{|l} 
Pelodytes punctatus \\
\end{tabular} & 30SYJ12 & 100,00 & 175,42 & 99,84 & 40,01 & 5239,15 & 305,98 & 59,97 & 246,01 & 188,69 & 242,74 & 245,67 & 111,35 & 431,18 & 76,26 & 8,03 & 47,87 & 178,21 & 46,04 & 73,26 & 107,94 \\
\hline Pelodytes punctatus & 30 SYJ14 & 100,00 & 175,11 & 95,80 & 39,95 & 5162,86 & 301,05 & 63,02 & 238,03 & 188,26 & 241,27 & 244,49 & 112,14 & 434,26 & 78,86 & 8,61 & 48,27 & 181,00 & 47,58 & 75,66 & 107,15 \\
\hline Pelodytes punctatus & 30 SYJ15 & 100,00 & 170,39 & 94,29 & 39,39 & 5182,47 & 295,91 & 59,55 & 236,36 & 183,27 & 236,85 & 240,14 & 107,42 & 446,90 & 79,84 & \begin{tabular}{|c|c|}
10,05 \\
\end{tabular} & 46,41 & 183,66 & 51,78 & 79,39 & 108,19 \\
\hline $\begin{array}{l}\text { Pelodytes punctatus } \\
\end{array}$ & 30 SYJ16 & 100,00 & 171,46 & 92,07 & 39,13 & 5121,67 & 294,22 & 62,56 & 231,66 & \begin{tabular}{|l|l|}
184,23 \\
\end{tabular} & 237,18 & 240,61 & \begin{tabular}{|l|l|}
109,48 \\
\end{tabular} & 442,56 & 80,93 & 10,23 & 47,32 & 183,66 & 51,43 & 79,50 & 106,04 \\
\hline Pelodytes punctatus & 30SYJ17 & 100,00 & \begin{tabular}{|l|l|l|l|}
170,87 \\
\end{tabular} & $\begin{array}{l}\mid c, 013 \\
90,37\end{array}$ & $\begin{array}{ll}39,00 \\
39,00\end{array}$ & 5 & $\mid \begin{array}{l}\mid 294,2< \\
292,25\end{array}$ & $\begin{array}{l}\mid c 2,90 \\
62,94\end{array}$ & 229,31 & $\begin{array}{l}104,25 \\
183,49\end{array}$ & 236,36 & 2399,79 & \begin{tabular}{|l|}
108,94 \\
108,9
\end{tabular} & $\begin{array}{l}442,301 \\
441,61\end{array}$ & $\begin{array}{l}80,95 \\
80,99 \\
\end{array}$ & $\mid 0,205$ & \begin{tabular}{c|c|}
46,75 \\
46,5
\end{tabular} & $\begin{array}{l}\mid 003,00 \\
183,14\end{array}$ & $\mid \begin{array}{l}52,74 \\
52,74\end{array}$ & 80,69 & 104,02 \\
\hline Pelodytes punctatus & 30 SYJ18 & 100,00 & 167,99 & 89,79 & 38,51 & 5159,09 & 290,30 & 59,94 & 230,36 & \begin{tabular}{|c|c|}
180,15 \\
\end{tabular} & 234,19 & 237,46 & 105,51 & 438,38 & 77,94 & 11,82 & 44,56 & 179,09 & 55,45 & 82,12 & 100,81 \\
\hline $\begin{array}{l}\text { Pelodytes punctatus } \\
\end{array}$ & 30SYJ19 & 100,00 & 155,37 & 90,99 & 37,79 & 5357,42 & 283,63 & 45,56 & 238,07 & $\begin{array}{l}166,40 \\
166,40\end{array}$ & 224,88 & 227,57 & | & 458,99 & 72,35 & 14,63 & 38,07 & 175,92 & 67,17 & 89,65 & 100,94 \\
\hline Pelodytes punctatus & 30 SYJ21 & 100,00 & 165,65 & 101,30 & 39,79 & 5339,22 & 300,55 & 49,14 & 251,41 & 176,73 & 234,67 & 237,43 & 100,84 & 481,21 & 78,40 & 9,51 & 44,28 & \begin{tabular}{|c|}
190,88 \\
\end{tabular} & 54,07 & 80,95 & 122,79 \\
\hline Pelodytes punctatus & 30 SYJ22 & 100,00 & 168,81 & 99,36 & 39,81 & 5279,18 & 300,68 & 53,71 & 246,97 & 182,04 & 236,77 & 239,79 & 104,65 & 475,11 & 79,52 & 9,31 & 45,55 & 191,42 & 52,57 & 80,87 & 121,54 \\
\hline Pelodytes punctatus & $305 Y J 23$ & $\begin{array}{l}100,00 \\
\end{array}$ & \begin{tabular}{|l|}
173,01 \\
173,90
\end{tabular} & $\begin{array}{l}30,01 \\
97,01\end{array}$ & $\begin{array}{l}35,11 \\
39,91 \\
\end{array}$ & 5186,52 & \begin{tabular}{|l|}
301,71 \\
301
\end{tabular} & $\begin{array}{l}3,1,73 \\
60,73\end{array}$ & $\begin{array}{l}240,57 \\
240,98\end{array}$ & $\begin{array}{l}\mid 0,0,04 \\
187,31\end{array}$ & 240,30 & $\begin{array}{l}243,48 \\
243\end{array}$ & \begin{tabular}{|l|}
110,50 \\
110,50
\end{tabular} & | 460,11 & $\begin{array}{l}30,59 \\
80,\end{array}$ & 8,63 & \begin{tabular}{|c|}
48,03 \\
48,03
\end{tabular} & \begin{tabular}{|l|}
190,34 \\
190,34
\end{tabular} & $42,3,35$ & $\begin{array}{l}\mid l 0,01 \\
79,16\end{array}$ & $\begin{array}{ll}12,34,22 \\
118,2\end{array}$ \\
\hline Pelodytes punctatus & 30SYJ25 & 100,00 & 176,56 & 92,18 & 39,57 & 5054,61 & 297,92 & 67,46 & 230,45 & 190,01 & 240,95 & 244,55 & 115,05 & 446,92 & 82,85 & 8,90 & 49,95 & 189,43 & 48,38 & 79,53 & 112,10 \\
\hline Pelodytes punctatus & 30SYJ27 & 100,00 & 173,96 & 87,97 & 39,00 & 4986,04 & 290,95 & 68,09 & 222,85 & 187,11 & 237,27 & 241,28 & 113,45 & 441,73 & 84,26 & 9,91 & 50,22 & 188,59 & 50,72 & 82,28 & 106,80 \\
\hline Pelodytes punctatus & 30 SYJ 29 & 100,00 & 160,16 & 88,68 & 37,70 & 5226,04 & 284,34 & 52,04 & 232,30 & 171,93 & 227,54 & 230,65 & 97,17 & 462 & 75,74 & 13,71 & 40,62 & 182,64 & 63,83 & 90,03 & 104,77 \\
\hline Pelodytes punctatus & 30 SYJ30 & 100,00 & 157,99 & 101,69 & 39,41 & 5412,07 & 295,78 & 41,07 & 254,72 & 133,98 & 228,08 & 230,92 & 92,74 & 524,14 & 80,05 & 10,99 & 41,91 & 203,56 & 60,87 & 87,18 & 136,38 \\
\hline Pelodytes punctatus & 30 SYJ31 & 100,00 & 165,65 & 100,49 & 39,72 & 5323,01 & 300,06 & 49,58 & 250,49 & 150,78 & 234,32 & 237,24 & 101,08 & 508,10 & 80,91 & 9,80 & 44,84 & 203,56 & 55,90 & 85,08 & 134,45 \\
\hline \begin{tabular}{|l} 
Pelodytes punctatus \\
\end{tabular} & $30 \mathrm{SYJ} 32$ & 100,00 & 168,37 & 98,61 & 39,62 & 5263,81 & 299,92 & 53,56 & 246,36 & 155,07 & 236,04 & 239,10 & 104,44 & 501,73 & 81,88 & 9,56 & 46,00 & 202,90 & 54,54 & 85,01 & 132,77 \\
\hline Pelodytes punctatus & 30 SYJ40 & 100,00 & 167,35 & 101,01 & 39,65 & 5315,62 & 302,27 & 50 & 251,75 & 144,27 & 235,75 & 238,78 & 102,67 & 530,74 & 82,46 & 9,23 & 46,43 & 218,19 & 55,11 & 86,49 & 147,33 \\
\hline Pelodytes punctatus & 30SYKO0 & 100,00 & 139,41 & 94,26 & 37,1 & 5666,42 & 277,01 & 26,49 & 250,53 & 148,94 & 214,20 & 215,70 & 71,98 & 472,11 & 64,15 & 18,16 & 31,70 & 165,66 & 1,42 & 95,94 & 96,76 \\
\hline $\begin{array}{l}\text { Pelodytes punctatus } \\
\end{array}$ & 30SYKO1 & 100,00 & 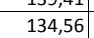 & 94,06 & 36,9 & 5741,43 & 273,68 & 21,12 & 252,56 & $\mid \begin{array}{l}143,61 \\
143,61\end{array}$ & 209,48 & 211,81 & 66,34 & 477,33 & 61,79 & 19, & 30,41 & 163,17 & $\begin{array}{l}\mid 81,4 \mathrm{~s} \\
86,90\end{array}$ & 99,28 & 95,21 \\
\hline Pelodytes punctatus & 30SYK10 & 100,00 & 14 & 92,15 & 37,02 & 5547,72 & 277,29 & & 245,38 & 153,64 & 216,17 & 218,25 & 77,29 & 479,42 & 67,76 & 17, & 33,16 & 173,14 & 78,71 & 96,77 & 101,15 \\
\hline Pelodytes punctatus & 30SYK12 & 100,00 & $\begin{array}{l}134,40 \\
134,80\end{array}$ & 92,09 & 36,45 & 5682,40 & 271,49 & 22,29 & 249,21 & 143,69 & 208,88 & 211,21 & 67,34 & 486,30 & 63,02 & 19,95 & 30,71 & 167,47 & 88,44 & $\mid 102,36$ & 97,31 \\
\hline Pelodytes punctatus & 30 SYK 20 & 100,00 & 160,35 & 87,92 & 37,24 & 5238,23 & 284,38 & 52,25 & 232 & 171,66 & 227,90 & 230,92 & 97,21 & 451,01 & 72,79 & 13,91 & 39,85 & 177,48 & 64,00 & 89,53 & 100,12 \\
\hline Pelodytes punctatus & 30 SYK22 & 100,00 & 141,91 & 89,99 & 36,3 & 5542,24 & 274,33 & 30,88 & 243,45 & 151,30 & 214,58 & 216,54 & 75,93 & 483,39 & 66,07 & 18,39 & 32,69 & 172,99 & 82,58 & 100,81 & 99,84 \\
\hline Pelodytes punctatus & 30SYK31 & 100,00 & $\begin{array}{l}\mid 41+, 1,1 \\
156,25\end{array}$ & $\begin{array}{l}\mid 86,80 \\
86,80\end{array}$ & 36,8 & 5275,68 & $\begin{array}{l}281,33 \\
281,12\end{array}$ & $\begin{array}{l}3,00 \\
48,02\end{array}$ & 233,40 & $\begin{array}{l}13,30 \\
167,22\end{array}$ & 224,50 & 227,43 & $\begin{array}{l}93,01 \\
3,1\end{array}$ & $\begin{array}{l}40,39 \\
466,86\end{array}$ & $\begin{array}{ll}00,01 \\
71,02\end{array}$ & $\begin{array}{l}0,39 \\
15,19\end{array}$ & \begin{tabular}{|c|}
32,909 \\
37,2
\end{tabular} & 17, & 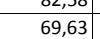 & \begin{tabular}{|l|r|}
94,88 \\
94
\end{tabular} & \begin{tabular}{r|r|}
102,45 \\
102,4
\end{tabular} \\
\hline $\begin{array}{l}\text { Pelodytes punctatus } \\
\end{array}$ & $30 \mathrm{SYK} 32$ & 100,00 & 160,29 & 85,89 & 36,64 & 5244,68 & 283,74 & 51,95 & 231,79 & \begin{tabular}{|l|}
170,88 \\
\end{tabular} & 227,87 & 230,75 & 97,07 & 446,44 & 68,37 & 14,57 & 38,74 & \begin{tabular}{|l|l|l|l}
173,66 \\
\end{tabular} & 66,49 & 91,97 & 96,40 \\
\hline Pelodytes punctatus & $305 Y K 42$ & 100,00 & 168,88 & 83,31 & 36,31 & 5093,37 & 287,97 & 61,97 & 226,00 & 180,32 & 233,98 & 237,25 & 107,00 & 432,64 & 68,52 & 13,02 & 41,82 & 174,65 & 59,97 & 89,27 & 95,79 \\
\hline Pelodytes punctatus & 30 SYK52 & 57,00 & 171,46 & 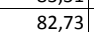 & 36,0 & 5099,43 & 289,4 & 63,70 & 225,76 & 182 & 236,61 & 239,70 & 109,33 & 435,60 & 69,0 & 12, & 42,66 & 177,43 & 58,92 & 89,85 & 97,71 \\
\hline Pelodytes punctatus & $30 \pi T L$ & 100,00 & 12 & 11 & 38 & 614 & 290 & $-0,17$ & 291, & 80, & 200 & 201 & $\begin{array}{l}44,09 \\
44\end{array}$ & 416 & 52,89 & 10, & 36,11 & 146,84 & 52,66 & 52,95 & 125,25 \\
\hline Pelodytes punctatus & 30TTL68 & 100,00 & 119,86 & 115,30 & 39,00 & 6157,26 & 291,68 & $-0,43$ & 292,11 & 80,01 & 199,99 & 201,51 & 43,94 & 390,48 & 48,65 & 10,34 & 35,71 & 136,31 & 51,33 & 52,09 & 111,71 \\
\hline \begin{tabular}{|l} 
Pelodytes punctatus \\
\end{tabular} & $\begin{array}{l}30 T T L 69 \\
\end{array}$ & 100,00 & 122,06 & 115,03 & 39,00 & 6155,46 & 293,29 & 0,89 & 292,40 & 82,50 & 201,72 & 203,25 & 45,71 & 378,28 & 47,02 & 9,83 & 35,32 & 131,58 & 49,88 & 50,85 & 107,96 \\
\hline Pelodytes punctatus & 30TTM70 & 100,00 & 123,60 & 115,39 & 39,00 & 6134,25 & 294,63 & 1,73 & 292,90 & 84,40 & 202,34 & 204,45 & 47,04 & 363,72 & 44,02 & 10,25 & 33,86 & 125,23 & 50,36 & 51,65 & 100,75 \\
\hline Pelodytes punctati & 30TTM & 100,00 & 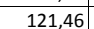 & 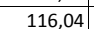 & 39,00 & 6028 & 292,0 & $-0,39$ & 292,48 & 84,00 & 199,86 & 200,99 & 46,17 & 400,38 & 48,43 & 13,5 & 31,92 & 139,41 & 60,23 & 60,83 & 111,39 \\
\hline Pelodytes punctatus & $3011 \mathrm{M}$ & 10 & & & 39 & 581 & 28 & $-6,28$ & 289 & 80,58 & 192, & 192,79 & 41,40 & 486, & 61, & 21, & 31,12 & 17 & 82,64 & 82,64 & 131,60 \\
\hline Pelodytes punctatus & 30TTN80 & 100,00 & $\begin{array}{l}113,69 \\
13\end{array}$ & 115,72 & 39,90 & 5842,43 & 281,21 & $\mid-7,17$ & 288,38 & 78,73 & 190,70 & 190,70 & 39,93 & 525,78 & 68,56 & 22,37 & 32,40 & 191,86 & 90,45 & 90,45 & 143,16 \\
\hline Pelodytes punctatus & 30TTN93 & 100,00 & 101,07 & 111,23 & 40,01 & 5538,27 & 260,69 & $-14,21$ & 274,90 & 69,69 & 174,09 & 174,09 & 32,15 & 658,48 & 84,97 & 31,07 & 29,28 & 233,02 & 119,10 & 119,10 & 176,86 \\
\hline Pelodytes punctatus & 30TTN94 & 100,00 & 93,59 & 108,77 & 40,01 & 418,02 & 249,74 & $-18,79$ & 268,53 & 63,35 & 165,26 & 165,26 & 26,95 & 733,11 & 93,67 & 36,51 & 27,87 & 255,42 & 132,52 & 132,52 & 199,38 \\
\hline Pelodytes & 30TUL38 & 100,00 & 122, & 115 & 39,0 & 139 & 293 & 0,19 & 293,44 & 82, & 201,31 & 203,60 & 45,82 & 386 & 45 & 12 , & 30,30 & 121,43 & 56,31 & 60,28 & 10 \\
\hline Pelodytes punctatus & 30TUL58 & 100,00 & $\begin{array}{ll}123,85 \\
\end{array}$ & 113,52 & 38,29 & 6158,24 & \begin{tabular}{|l|l|}
294,08 \\
\end{tabular} & 1,67 & 292,41 & $\begin{array}{l}82,0< \\
85,56\end{array}$ & 203,82 & 205,75 & $\begin{array}{l}45,0< \\
47,39 \\
\end{array}$ & \begin{tabular}{|l|l|}
397,03 \\
39
\end{tabular} & $\begin{array}{l}45,06 \\
46,06 \\
\end{array}$ & $\begin{array}{ll}212,08 \\
\end{array}$ & 30,10 & $\begin{array}{l}123,45 \\
123,65\end{array}$ & 56,97 & $\begin{array}{ll}61,73 \\
1,20\end{array}$ & 106,99 \\
\hline
\end{tabular}




\begin{tabular}{|c|c|c|c|c|c|c|c|c|c|c|c|c|c|c|c|c|c|c|c|c|c|}
\hline TAXON & UTM & $\mathrm{km} 2$ & BIO1 & $\mathrm{B1O2}$ & $\mathrm{BIO3}$ & 8104 & B105 & B106 & B107 & B108 & B109 & BIO10 & B1011 & BIO12 & B1013 & B1014 & 81015 & B1016 & BIO17 & B1018 & B1019 \\
\hline Pelodytes punctatus & 30TUL66 & 100,00 & 121,00 & 110,45 & 37,55 & 6210,75 & 289,58 & $-0,94$ & 290,52 & 122,36 & 201,98 & 204,01 & 44,47 & 398,79 & 48,28 & 12,53 & 30,18 & 123,56 & 58,21 & 63,56 & 102,40 \\
\hline Pelodytes punctatus & 30TUL68 & 100,00 & 120,22 & 112,10 & 38,00 & 6155,96 & 289,66 & $-1,80$ & 291,46 & 89,52 & 200,49 & 202,26 & 44,09 & 412,94 & 48,45 & 13,33 & 29,75 & 127,68 & 59,46 & 65,96 & 109,44 \\
\hline Pelodytes punctatus & 30TUL69 & 100,00 & $\mid 122,60$ & 112,92 & 38,06 & 6127,94 & 292,03 & $-0,01$ & 292,04 & 85,78 & 202,30 & 203,99 & 46,31 & 412,80 & 477,56 & 13,17 & 29,66 & 128,49 & 58,56 & 65,24 & 111,82 \\
\hline Pelodytes punctatus & 30TUL78 & 100,00 & 120,36 & 110,48 & 37,54 & 6159,98 & 288,13 & $-2,19$ & 290,31 & 96,41 & 200,69 & 202,44 & 44,06 & 417,91 & 48,99 & 13,38 & 29,81 & 129,16 & 59,82 & 67,49 & 109,73 \\
\hline Pelodytes punctatus & 30TUL79 & 100,00 & 116,90 & 111,40 & 37,96 & 6113,09 & 285,53 & $-5,35$ & 290,88 & \begin{tabular}{|l|l|}
86,07 \\
\end{tabular} & 196,91 & \begin{tabular}{|l|l|}
198,48 \\
\end{tabular} & 41,60 & 432,60 & 50,56 & 14,06 & 29,12 & 133,23 & 61,81 & 70,69 & 114,12 \\
\hline Pelodytes punctatus & 30TUL89 & 100,00 & 115,78 & 109,77 & 37,20 & 6117,25 & 282,95 & $-6,84$ & 289,78 & 126,76 & 196,10 & 197,42 & 40,47 & 440,64 & 51,64 & 14,72 & 28,99 & 135,42 & 63,55 & 73,62 & 114,46 \\
\hline Pelodytes punctatus & 30TUL91 & 100,00 & 103,04 & 104,20 & 36,11 & 6268,38 & 269,75 & $-15,97$ & 285,72 & 120,93 & 187,10 & 187,99 & 28,96 & 474,41 & 61,07 & 16,82 & 31,16 & 152,40 & 72,34 & 78,09 & 112,79 \\
\hline Pelodytes punctatus & 30TUMO0 & 100,00 & 121,52 & 117,00 & 39,00 & 6099,22 & 293,63 & $-0,48$ & 294,12 & \begin{tabular}{|l|l|}
82,95 & \\
\end{tabular} & 199,86 & 202,31 & 45,59 & 376,10 & 44,12 & 12,70 & 31,45 & 124,40 & 55,38 & 58,17 & 101,02 \\
\hline Pelodytes punctatus & 30TUM02 & 100,00 & 121,08 & 117,00 & 39,00 & 6043,71 & 292,43 & $-0,94$ & 293,37 & \begin{tabular}{|c|}
83,58 \\
\end{tabular} & 198,70 & 200,97 & 45,49 & 392,60 & 46,74 & 14,08 & 30,80 & 132,01 & 59,13 & 61,87 & 106,46 \\
\hline Pelodytes punctatus & 30TUM06 & 100,00 & 118,18 & 115,99 & 39,44 & 5893,34 & 287,03 & $-3,74$ & 290,76 & \begin{tabular}{|c|}
83,73 \\
\end{tabular} & $\begin{array}{l}194,35 \\
\end{array}$ & 196,05 & 44,21 & 448,20 & 55,47 & 18,38 & 30,23 & 155,69 & 73,56 & 74,99 & 120,66 \\
\hline Pelodytes punctatus & 30TUM12 & 100,00 & 120,33 & 117,00 & 39,04 & 6027,55 & 291,77 & $-1,68$ & 293,45 & 83,54 & 197,97 & 200,15 & 45,17 & 401,44 & 47,66 & 14,76 & 30,04 & 132,89 & 60,66 & 64,34 & 108,45 \\
\hline Pelodytes punctatus & 30TUM13 & 100,00 & 120,75 & 116,94 & 39,21 & 5977,65 & 291,32 & $-1,57$ & 292,89 & 85,24 & 197,89 & 199,78 & 46,04 & 408,67 & 48,88 & 15,53 & 29,84 & 136,65 & 62,41 & 66,12 & 110,30 \\
\hline Pelodytes punctatus & 30TUM14 & 100,00 & 119,74 & 116,61 & 39,38 & 5942,53 & 289,71 & $-2,67$ & 292,38 & 85,06 & 196,49 & 198,33 & 45,33 & 421,78 & 50,84 & 16,58 & 29,67 & 142,10 & 65,79 & 69,43 & 113,40 \\
\hline Pelodytes punctatus & 30TUM17 & 100,00 & 117,29 & 115,08 & 39,24 & 5806,82 & 284,13 & $-4,69$ & 288,82 & 84,79 & 192,30 & 194,02 & 44,52 & 469,07 & 58,02 & 20,24 & 29,21 & 161,68 & 78,54 & 80,92 & 124,26 \\
\hline Pelodytes punctatus & 30TUM18 & 100,00 & 114,87 & 114,51 & 39,26 & 5750,62 & 280,61 & $-6,58$ & 287,19 & 83,02 & 189,36 & \begin{tabular}{|l|}
190,87 \\
\end{tabular} & 42,83 & 493,50 & 61,48 & 22,02 & 29,04 & 170,85 & 84,79 & 86,58 & 130,20 \\
\hline Pelodytes punctatus & 30TUM20 & 100,00 & 120,71 & 116,99 & 39,00 & 6089,06 & 292,77 & $-1,37$ & 294,14 & 82,76 & $\mid 199,27$ & 201,29 & 44,73 & 394,51 & 46,10 & 13,34 & 30,16 & 126,82 & 58,12 & 62,25 & 106,86 \\
\hline Pelodytes punctatus & 30TUM22 & 100,00 & 116,34 & 117,00 & 39,00 & 6033,32 & 288,63 & $-5,76$ & 294,39 & 80,11 & 194,44 & 196,61 & 41,35 & 421,60 & 49,58 & 15,54 & 29,37 & 136,94 & 63,37 & 68,72 & 114,20 \\
\hline Pelodytes punctatus & 30TUM27 & 100,00 & 117,38 & 114,55 & 39,09 & 5749,96 & 282,96 & $-4,90$ & 287,87 & 86,52 & 191,98 & 193,45 & 45,56 & 473,03 & 57,88 & 20,51 & 28,42 & 160,59 & 78,11 & 82,48 & 124,39 \\
\hline Pelodytes punctatus & 30TUM33 & 100,00 & 116,86 & 116,91 & 39,00 & 5964,17 & 287,89 & $-6,16$ & 294,05 & \begin{tabular}{l|l|}
82,65 \\
\end{tabular} & 194,20 & 196,15 & 42,60 & 435,02 & 51,10 & 16,41 & 28,95 & 140,78 & 65,07 & 72,13 & 117,56 \\
\hline Pelodytes punctatus & 30TUM43 & 100,00 & 115,33 & 116,54 & 39,00 & 5937,94 & 286,39 & $-7,99$ & 294,38 & 82,39 & 192,84 & 194,41 & 41,83 & 445,14 & 51,89 & 16,70 & 28,48 & 142,24 & 65,52 & 74,47 & 119,81 \\
\hline Pelodytes punctatus & 30TUM45 & 100,00 & 119,78 & 115,23 & 39,00 & 5786,69 & 286,76 & $-4,92$ & 291,69 & 90,38 & 195,00 & 196,53 & 47,87 & 447,41 & 52,79 & 18, & 28,20 & 145,73 & 67,55 & 77,10 & 117,74 \\
\hline Pelodytes punctatus & 30 TUM 46 & 100,00 & $\begin{array}{l}118,20 \\
118\end{array}$ & $\begin{array}{ll}114,43 \\
14,4\end{array}$ & 39,00 & 5726,46 & 283,50 & $-6,18$ & 289,68 & 89,92 & 192,80 & 194,04 & |47,03 & 464,416 & 55,18 & 19,94 & 27,78 & 152,43 & 72,11 & 81,71 & 121,00 \\
\hline \begin{tabular}{|l} 
Pelodytes punctatus \\
\end{tabular} & 30TUM50 & 100,00 & 124,34 & 114,90 & 38,89 & 6106,90 & 295,01 & 2,06 & 292,94 & \begin{tabular}{|c|c|}
62,07 \\
\end{tabular} & 203,37 & 205,14 & 47,94 & 412,16 & 47,90 & 13,03 & 29,88 & 130,10 & 58,24 & 63,54 & 115,23 \\
\hline Pelodytes punctatus & 30TUM51 & 100,00 & 122,95 & 115,51 & 38,98 & 6066,38 & 293,71 & 0,46 & 293,25 & 63,90 & 201,60 & 203,15 & 46,92 & 423,85 & 49,38 & 13,88 & 29,50 & 134,49 & 59,79 & 66,21 & 119,16 \\
\hline Pelodytes punctatus & 30TUM54 & 100,00 & 118,23 & 115,84 & 38,94 & 5842,82 & 286,59 & $-7,87$ & 294,45 & 89,16 & 194,26 & 195,91 & 45,86 & 446,61 & 51,50 & 17,21 & 28,76 & 142,14 & 64,70 & 76,95 & 117,39 \\
\hline $\begin{array}{l}\text { Pelodytes punctatus } \\
\end{array}$ & 30TUM55 & 100,00 & 120,99 & 114,95 & 38,98 & 5756,24 & 287,11 & $-5,64$ & 292,75 & 93,99 & 195,90 & \begin{tabular}{|l|l|}
197,43 \\
\end{tabular} & 49,67 & 446,02 & 51,90 & 18,06 & 28,31 & 143,43 & 65,46 & 77,75 & 115,77 \\
\hline Pelodytes punctatus & 30TUM56 & 100,00 & 119,70 & \begin{tabular}{|l|l|l|l|}
113,90 \\
\end{tabular} & $\begin{array}{l}30,00 \\
38,97 \\
\end{array}$ & 5683,32 & $\mid \begin{array}{l}\mid 28,1,71 \\
283,72\end{array}$ & $\begin{array}{l}-5,04 \\
-5,96\end{array}$ & 289,69 & 93,,62 & 193,73 & $\begin{array}{l}194,43 \\
194,98\end{array}$ & 年 49,34 & $\begin{array}{l}44,02,42 \\
462,4\end{array}$ & $\mid \frac{54,10}{54,10}$ & $\begin{array}{l}0,000 \\
19,69\end{array}$ & 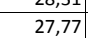 & \begin{tabular}{|l|}
449,45 \\
149,64
\end{tabular} & $\begin{array}{l}-63,40 \\
69,88\end{array}$ & 82,09 & 118,81 \\
\hline Pelodytes punctatus & 30TUM60 & 100,00 & 122,48 & 113,60 & 38,15 & 6089,17 & 292,07 & $-0,49$ & 292,56 & \begin{tabular}{|c|}
86,07 \\
\end{tabular} & 201,70 & 203,24 & 46,55 & 419,17 & 48,36 & 13,43 & 29,68 & 131,25 & 58,86 & 66,41 & 114,57 \\
\hline $\begin{array}{l}\text { Pelodytes punctatus } \\
\end{array}$ & 30TUM62 & 100,00 & $\mid 122,40$ & 114,68 & 38,59 & $\begin{array}{l}5961,61 \\
5961, \\
\end{array}$ & 291,22 & $\begin{array}{l}-2,43 \\
-2,43\end{array}$ & 293,65 & $\begin{array}{l}90,03 \\
90,55\end{array}$ & 200,06 & 201,50 & 48,14 & 428,31 & 49,35 & 14,77 & 29,23 & 135,19 & $\begin{array}{l}50,00 \\
59,98\end{array}$ & 70,13 & 115,71 \\
\hline Pelodytes punctatus & 30TUM64 & 100,00 & 116,19 & 115,26 & 38,27 & 5815,91 & 283,91 & $-11,75$ & 295,66 & 89,12 & 192,21 & 193,42 & 44,57 & 454,02 & 52,14 & 17,58 & 28,65 & 142,29 & 64,78 & 80,12 & 117,01 \\
\hline Pelodytes punctatus & 30TUM68 & 100,00 & 114,51 & 110,01 & 38,80 & 5524,72 & 273,23 & $-8,14$ & 281,38 & 90,16 & 186,78 & 187,56 & 46,52 & 518,49 & 60,62 & 23,53 & 26,12 & 167,51 & 82,83 & 94,81 & 131,75 \\
\hline Pelodytes punctatus & \begin{tabular}{|l|}
$30 T U M 69$ \\
300
\end{tabular} & 100,00 & \begin{tabular}{|l|l|l|l|l}
111,43 \\
\end{tabular} & $\mid \begin{array}{l}\mid 108,16 \\
108,16\end{array}$ & $\begin{array}{l}30,00 \\
38,76 \\
\end{array}$ & 5459,13 & $\begin{array}{l}267,25 \\
267,92\end{array}$ & - $-8,51$ & $\begin{array}{l}201,30 \\
276,42\end{array}$ & $80,8,93$ & \begin{tabular}{|l|l|}
183,06 \\
183
\end{tabular} & $\begin{array}{l}\mid \\
183,58\end{array}$ & 年0,34, & \begin{tabular}{|l|l|}
551,94 \\
551,94
\end{tabular} & $\begin{array}{ll}60,0201 \\
65,01\end{array}$ & $\mid \begin{array}{l}\mid 25,76 \\
25\end{array}$ & $\begin{array}{l}20,12 \\
25,35 \\
\end{array}$ & \begin{tabular}{|l|}
179,23 \\
\end{tabular} & $\begin{array}{l}02,05 \\
91,25\end{array}$ & \begin{tabular}{|c|}
101,51 \\
101,52
\end{tabular} & $\begin{array}{ll}140,89 \\
140,\end{array}$ \\
\hline Pelodytes punctatus & 30TUM70 & 100,00 & 120,65 & 112,09 & 38,00 & 6069,25 & 288,93 & $-2,75$ & 291,68 & \begin{tabular}{|c|}
88,68 \\
\end{tabular} & 199,90 & 201,46 & 45,47 & 426,42 & 49,18 & 14,18 & 29,31 & 132,47 & 60,36 & 69,57 & 113,54 \\
\hline Pelodytes punctatus & 30TUM72 & 100,00 & 118,17 & 113,46 & 38,02 & 5946,90 & 286,29 & $-7,18$ & 293,47 & 94,90 & 195,99 & 197,31 & 44,71 & 440,20 & 50,73 & 15,58 & 28,85 & 136,36 & 62,00 & 74,74 & 115,50 \\
\hline Pelodytes punctatus & 30TUM74 & 100,00 & 121,31 & 113,99 & 38,00 & 5780,65 & 286,95 & $-7,65$ & 294,60 & 103,09 & 196,71 & 197,91 & 50,21 & 438,37 & 50,55 & 16, & 29,02 & 136,96 & 61,24 & 77,77 & 111,05 \\
\hline Pelodytes punctatus & 30TUM76 & 100,00 & 118,33 & 112,23 & 38,03 & 5644,23 & 280,66 & $-9,05$ & 289,70 & 95,17 & \begin{tabular}{|l|l|l|}
192,05 \\
\end{tabular} & 193,00 & 49,30 & 471,03 & 53,46 & 20,07 & 27,54 & 148,38 & 69,53 & 85,92 & 117,91 \\
\hline Pelodytes punctatus & 30TUM81 & 100,00 & 116,95 & 111,21 & 37,90 & 6006,65 & 284,05 & $-7,19$ & 291,23 & 108,06 & 195,69 & 196,92 & 42,89 & 443,65 & 51,36 & 15,47 & 28,75 & 136,57 & 63,39 & 75,42 & 115,59 \\
\hline \begin{tabular}{|l} 
Pelodytes punctatus \\
\end{tabular} & 30TUM 85 & 100,00 & 117,19 & 111,39 & 38,00 & 5721,58 & 280,28 & $-9,41$ & 289,69 & 94,97 & 192,09 & \begin{tabular}{|l|l|}
192,98 \\
\end{tabular} & 47,09 & 466,69 & 53,01 & 19,09 & 27,68 & 144,82 & 68,30 & 84,67 & 117,12 \\
\hline Pelodytes punctatus & 30TUM91 & 100,00 & 115,85 & 109,53 & 37,30 & 6011,67 & 281,66 & $-7,52$ & 289,18 & 121,26 & 194,78 & 195,85 & 41,82 & 450,98 & 52,22 & 15,98 & 28,32 & 138,54 & 65,35 & 77,33 & 116,20 \\
\hline Pelodytes punctatus & 30TUNO0 & 100,00 & 113,28 & 113,74 & 39,77 & 5700,10 & 277,23 & $-6,27$ & 283,50 & 81,03 & 188,47 & 188,47 & 41,84 & 531,77 & 67,99 & 24,8 & 30,01 & 188,38 & 94,56 & 94,56 & 140,40 \\
\hline $\begin{array}{l}\text { Pelodytes punctatus } \\
\end{array}$ & 30TUNO2 & 100,00 & 106,83 & $\mid 11,48$ & 40,00 & 5549,11 & 266,75 & $\begin{array}{l}\mid-9,47 \\
-9,4\end{array}$ & 276,22 & 76,01 & $\begin{array}{l}180,08 \\
180,0\end{array}$ & $\begin{array}{l}180,08 \\
180,0\end{array}$ & 37, & 606,52 & 77,94 & 29,7 & 29,16 & 213,89 & 110,31 & $\mid 110,31$ & 159,96 \\
\hline Pelodytes punctatus & 30TUN61 & 100,00 & 103,72 & 104,85 & 38,99 & 5328,17 & 255,71 & $-11,23$ & 266,94 & 79, & 174,02 & 174,09 & 38,44 & 631,21 & 75,10 & 30,81 & 24,13 & 205,94 & \begin{tabular}{|l|}
109,97 \\
\end{tabular} & \begin{tabular}{|l|l|}
115,17 \\
\end{tabular} & 163,11 \\
\hline Pelodytes punctatus & $\begin{array}{l}\text { 30TUN73 } \\
3\end{array}$ & 100,00 & $\begin{array}{r}25,15 \\
95,15\end{array}$ & \begin{tabular}{|c|c|}
99,400 \\
99,90
\end{tabular} & 38,93 & 5169,28 & 240,88 & -13,69 & 254,58 & 70,69 & 163,85 & 163,85 & 32,27 & $|733,92|$ & 86,87 & 37,00 & 22,96 & 237,79 & 132,46 & 132,82 & 192,86 \\
\hline Pelodytes punctatus & 30TUN83 & 100,00 & 97,92 & 97,97 & 38,61 & 5124,45 & 241,13 & $-9,80$ & 250,94 & 73,74 & 166,08 & 166,08 & 35,36 & 729,99 & 85,87 & 36,48 & 22,68 & 235,61 & 131,57 & 131,59 & 192,01 \\
\hline Pelodytes punctatus & 30 TUN84 & 100,00 & 95,87 & 95,97 & 38,78 & 5037,41 & 235,94 & $-9,26$ & 245,21 & 72,10 & 163,01 & 163,01 & 34,63 & 773,53 & 91,48 & 38,99 & 22,55 & 250,52 & 141,46 & 141,46 & 205,00 \\
\hline Pelodytes punctatus & 30TUN90 & 100,00 & \begin{tabular}{|c|}
109,22 \\
109
\end{tabular} & 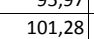 & $\begin{array}{ll}30,10 \\
38,00\end{array}$ & 5337,25 & $\mid \begin{array}{l}25,34,43 \\
258\end{array}$ & $\begin{array}{l}-4,20 \\
-2,49\end{array}$ & $\begin{array}{l}24,21 \\
262,92\end{array}$ & 84,31 & $\begin{array}{l}179,01 \\
179,54\end{array}$ & \begin{tabular}{|l|}
179,57 \\
\end{tabular} & $\begin{array}{l}34,03 \\
43,42\end{array}$ & 602,44 & $\begin{array}{l}\mid 1,40 \\
69,40\end{array}$ & 28,63 & \begin{tabular}{|l|l|}
23,47 \\
23,
\end{tabular} & $\begin{array}{ll}301,90 \\
191\end{array}$ & \begin{tabular}{|l|l|l|l|}
102,63 \\
\end{tabular} & $\begin{array}{l}41,40 \\
104,81 \\
\end{array}$ & $\begin{array}{ll}155,11 \\
155\end{array}$ \\
\hline $\begin{array}{l}\text { Pelodytes punctatus } \\
\end{array}$ & $\begin{array}{l}\text { 30TUN93 } \\
\end{array}$ & 100,00 & 101,05 & 95,72 & 38,19 & 5085,48 & 241,52 & $-4,99$ & 246,51 & \begin{tabular}{|l|l|}
76,96 \\
\end{tabular} & 168,68 & 168,68 & 38,88 & 728,04 & 85,35 & 35,99 & 22,53 & 234,67 & 131,51 & 131,51 & 192,18 \\
\hline Pelodytes punctatus & 30 TUN94 & 100,00 & 97,51 & 94,17 & 38,50 & 5005,21 & 235,48 & $-6,21$ & 241,69 & 73,75 & \begin{tabular}{l|l|l}
164,15 \\
\end{tabular} & 164,25 & 36,64 & 776,04 & 91,17 & 38,84 & 22,19 & 250,43 & 142,05 & 142,05 & 206,47 \\
\hline Pelodytes punctatus & 30TUN95 & 100,00 & 78,28 & 94,44 & 38,47 & 5046,53 & 218,6 & $-23,58$ & 242,26 & 53,5 & 146 & 146,33 & $18, \mathrm{C}$ & 901,17 & 103,65 & 46, & 21, & 285,22 & 166,28 & 166,34 & 244,29 \\
\hline Pelodytes punctatus & $\begin{array}{l}30 \text { TVK35 } \\
3\end{array}$ & 100,00 & 140,79 & $\mid 106,29$ & 34,87 & 6709,03 & & 14 & 301,95 & 97, & 230 & 230,45 & 58 & 1 & $\begin{array}{l}53,08 \\
53\end{array}$ & 10, & 37,05 & 149,43 & 48,10 & 48,10 & 129, \\
\hline Pelodytes punctatus & 30TVK43 & 100,00 & 146,90 & 110,28 & 35,02 & 6784,14 & 326,59 & 17,10 & 309,49 & 103,19 & 237,63 & 237,63 & 63,67 & 408,17 & 49,26 & $\mid 8,35$ & 37,78 & 140,62 & 42,91 & 42,91 & 120,14 \\
\hline \begin{tabular}{|l} 
Pelodytes punctatus \\
\end{tabular} & 30TVK44 & 100,00 & 143,44 & 108,56 & 34,99 & 6760,64 & 321,77 & 15,10 & 306,66 & 99,78 & 233,83 & 233,83 & 60,45 & 423,37 & 52,28 & 9,23 & 37,69 & 146,93 & 45,40 & 45,40 & 125,90 \\
\hline Pelodytes punctatus & 30 TVK45 & 100,00 & 141,73 & 106,88 & 34,73 & 6731,84 & 318,44 & 14,64 & 303,80 & \begin{tabular}{|c|}
98,28 \\
\end{tabular} & 231,64 & 231,64 & 58,98 & 432,94 & 54,79 & 9,89 & 37,89 & 151,93 & 46,67 & 46,67 & 130,14 \\
\hline Pelodytes punctatus & 30TVK46 & 100,00 & 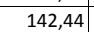 & 10 & 34,08 & 6722,08 & 317 & 15,72 & 301,82 & 99,19 & 232,04 & 232,04 & 59,47 & 433,6 & 56,45 & 9,8 & 38,66 & 154,29 & 46,01 & 46,01 & 131,79 \\
\hline Pelodytes punctatus & 30TVK55 & 100,00 & & & 34, & 6738,40 & & 14,16 & 305,61 & 98,29 & 231,79 & 231,79 & 59,3 & 429,84 & 55,43 & g, & 38,22 & 152,05 & 45,89 & 45,89 & 128 \\
\hline Pelodytes punctatus & 30TVK56 & 100,00 & 142,59 & 107,10 & $\begin{array}{ll}4,73 \\
34,73\end{array}$ & 6737,97 & 319,71 & 15,12 & 304,59 & \begin{tabular}{l|l}
99,05 \\
99
\end{tabular} & 232,33 & 232,33 & 59,72 & 429,50 & 57,37 & 9,44 & 39,30 & 154,57 & 44,76 & 44,76 & 129,99 \\
\hline Pelodytes punctatus & 30TVK57 & 100,00 & 140,80 & 106,21 & 34,44 & 6736,18 & 317,72 & 13,90 & 303,82 & 97,37 & 230,36 & 230,36 & \begin{tabular}{|c|c|}
58,05 \\
\end{tabular} & 437,08 & 60,00 & 9,60 & 39,76 & 158,71 & 45,75 & 45,75 & 132,97 \\
\hline Pelodytes punctatus & 30TVK64 & 100,00 & 135,64 & 111,39 & 35,88 & 6717,81 & 315,40 & 7,72 & 307,68 & 91,90 & 225,52 & 225,52 & 54,00 & 443,15 & 54,57 & 10,44 & 36,41 & 151,81 & 50,33 & 50,33 & 128,69 \\
\hline Pelodytes $\mathrm{p}$ & 30TVK65 & 100,00 & 136 & 110 & 35,5 & 6706,47 & & 9,29 & 305,54 & 92 & 225,97 & 225 & 54,7 & 441 & 56 & 10,42 & 37,09 & 154,02 & 49,42 & 49,42 & $12 \mathrm{c}$ \\
\hline Pelodytes punctatus & 30TVK67 & 100,00 & $\begin{array}{ll}137,19 \\
30\end{array}$ & \begin{tabular}{|l|l|}
109,24 \\
\end{tabular} & 35,68 & 6661,03 & 313,95 & 11,86 & 302,08 & 93,44 & 225,66 & 225,66 & 56,13 & 4346,79 & $\begin{array}{ll}59,65 \\
59,5\end{array}$ & 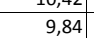 & 39,03 & $\begin{array}{l}, 34,0<2 \\
158,62\end{array}$ & $\begin{array}{l}47,44 \\
47,44 \\
\end{array}$ & $\begin{array}{l}47,424 \\
47,44\end{array}$ & 130,13 \\
\hline
\end{tabular}




\begin{tabular}{|c|c|c|c|c|c|c|c|c|c|c|c|c|c|c|c|c|c|c|c|c|c|}
\hline TAXON & UTM & $\mathrm{km} 2$ & BIO1 & B102 & $\mathrm{BIO3}$ & B104 & B105 & B106 & B107 & B108 & B109 & 81010 & BIO11 & B1012 & B1013 & B1014 & BIO15 & BIO16 & B1017 & B1018 & B1019 \\
\hline Pelodytes punctatus & 30TVK73 & 100,00 & 141,02 & 113,14 & 36,00 & 6727,66 & 321,23 & 11,60 & 309,64 & 97,50 & 230,97 & 230,97 & 59,09 & 419,19 & 50,42 & 9,30 & 36,39 & 142,58 & 47,14 & 47,14 & 119,64 \\
\hline Pelodytes punctatus & 30TVK75 & 100,00 & 133,78 & 111,15 & 36,00 & 6683,05 & 311,94 & 6,99 & 304,95 & 90,26 & 223,04 & 223,04 & 52,85 & 440,63 & 54,90 & 11,08 & 35,72 & 151,22 & 51,74 & 51,74 & 125,60 \\
\hline Pelodytes punctatus & 30 TVK76 & 100,00 & 127,98 & 110,16 & 36,00 & 6648,33 & 304,79 & 2,62 & 302,17 & 84,65 & 216,96 & 216,96 & 47,77 & 456,99 & 56,81 & 12,23 & 34,59 & 155,52 & 55,91 & 55,91 & 129,05 \\
\hline Pelodytes punctatus & 30TVK77 & 100,00 & 127,52 & 108,89 & 36,00 & 6620,45 & 302,52 & 3,27 & 299,25 & 84,27 & 215,94 & 215,94 & 47,71 & 453,90 & 57,35 & 12,08 & 34,72 & 155,45 & 56,17 & 56,17 & 127,52 \\
\hline Pelodytes punctatus & 30TVK78 & 100,00 & 132,00 & 107,07 & 35,82 & 6613,92 & 304,40 & 8,54 & 295,86 & 88,89 & 220,03 & 220,03 & 52,04 & \begin{tabular}{|c|}
431,48 \\
\end{tabular} & 56,53 & 10,85 & 35,91 & 151,10 & 52,36 & 52,36 & 120,87 \\
\hline Pelodytes punctatus & 30TVK79 & 100,00 & 130,23 & 104,81 & 35,19 & 6592,21 & 299,79 & 7,80 & 291,99 & 87,36 & 218,03 & 218,03 & 50,57 & 428,29 & 55,77 & 10,97 & 34,90 & 148,50 & 54,04 & 54,04 & 117,38 \\
\hline Pelodytes punctatus & 30TVK84 & 100,00 & 136,38 & 112,93 & 36,00 & 6688,14 & 315,22 & 8,16 & 307,06 & 93,16 & 225,78 & 225,78 & 55,40 & 427,51 & 51,14 & 10,45 & 35,06 & 143,71 & 50,99 & 50,99 & 119,44 \\
\hline Pelodytes punctatus & 30 TVK85 & 100,00 & 130,92 & 111,85 & 36,04 & 6663,29 & 308,86 & 3,97 & 304,89 & 87,80 & 220,08 & 220,08 & 50,55 & 442,93 & 53,19 & 11,81 & 34,14 & 148,08 & 54,91 & 54,91 & 122,79 \\
\hline Pelodytes punctatus & 30TVK86 & 100,00 & 129,06 & 110,40 & 36,00 & 6643,83 & 305,12 & 3,24 & 301,89 & 85,92 & 217,78 & 217,78 & 48,93 & 445,04 & 54,00 & 12,35 & 33,79 & 149,01 & 56,37 & 56,37 & 122,41 \\
\hline Pelodytes punctatus & 30TVK87 & 100,00 & 125,00 & 109,19 & 36,00 & 6611,96 & 299,33 & 1,01 & 298,32 & 82,09 & 213,40 & 213,40 & $\begin{array}{c}45,56 \\
\end{array}$ & 453,26 & 54,74 & 12,95 & 32,86 & 150,36 & 59,67 & 59,67 & 123,08 \\
\hline Pelodytes punctatus & 30TVK88 & 100,00 & 121,64 & 107,84 & 35,95 & 6583,24 & 294,27 & $-0,88$ & 295,15 & 79,05 & 209,83 & 209,84 & 42,75 & $\begin{array}{l}458,95 \\
\end{array}$ & 54,87 & 13,65 & 32,03 & 150,42 & 62,90 & 62,91 & 122,69 \\
\hline Pelodytes punctatus & 30TVK93 & 100,00 & 133,88 & 115,16 & 36,72 & 6682,34 & 314,40 & 4,33 & 310,06 & 91,02 & 223,35 & 223,35 & 53,06 & 435,85 & 49,31 & |11,01 & 33,60 & $\mid 141,44$ & 54,57 & 54,57 & 119,15 \\
\hline Pelodytes punctatus & 30TVK94 & 100,00 & 138,49 & 113,19 & 36,39 & 6662,75 & 316,37 & 9,55 & 306,82 & 95,65 & 227,41 & 227,41 & $\begin{array}{l}57,56 \\
\end{array}$ & 415,14 & 48,55 & 10,29 & 34,43 & 137,83 & 50,81 & 50,81 & 113,59 \\
\hline Pelodytes punctatus & 30TVK95 & 100,00 & 132,32 & 112,24 & 36,18 & 6644,92 & 309,54 & 4,81 & 304,73 & 89,54 & 221,22 & 221,22 & 52,02 & 432,00 & 50,47 & 11,76 & 33,33 & $\begin{array}{l}142,08 \\
\end{array}$ & 55,31 & 55,31 & 117,16 \\
\hline Pelodytes punctatus & 30TVK98 & 100,00 & 124,56 & 108,02 & 36,03 & $\mid 6591,40$ & 296,51 & 0,65 & 295,86 & 82,17 & 212,64 & 212,74 & $\mid 45,40$ & $\mid 441,87$ & $\mid 51,74$ & $\mid 13,47$ & 31,56 & |143,03 & 61,68 & 61,82 & $\begin{array}{lll}115,46 \\
\end{array}$ \\
\hline Pelodytes punctatus & 30TVL09 & 100,00 & 114,39 & 106,79 & 36,99 & 6145,49 & 279,37 & $-7,09$ & 286,46 & 126,24 & 195,30 & 196,40 & 39,16 & 455,36 & 52,89 & 15,34 & 28,42 & 139,83 & 66,71 & 77,08 & 116,99 \\
\hline Pelodytes punctatus & 30TVL19 & 100,00 & 115,14 & 105,68 & 36,66 & 6155,45 & 279,34 & $-5,68$ & 285,02 & 107,13 & 196,25 & 197,19 & 39,82 & 457,84 & 52,77 & 15,62 & 27,99 & 140,09 & 67,60 & 77,27 & 117,99 \\
\hline Pelodytes punctatus & 30TVL45 & 100,00 & 94,63 & 105,17 & 36,48 & 6228,27 & 262,01 & $-21,67$ & 283,68 & 89,50 & 178,54 & 178,99 & 21,54 & 555,45 & 64,78 & 20,73 & 26,73 & 169,10 & 85,71 & 92,87 & 143,01 \\
\hline Pelodytes punctatus & 30TVL49 & 100,00 & 103,11 & 105,19 & 36,68 & 6153,76 & 268,55 & $-14,83$ & 283,38 & 119,62 & 185,19 & 185,55 & 29,06 & 512,73 & 59,46 & 19,73 & 25,87 & 155,59 & 80,97 & 90,08 & 131,61 \\
\hline Pelodytes punctatus & $30 T V L 58$ & 100,00 & 109,69 & 104,92 & 36,27 & 6237,29 & 274,93 & $-8,82$ & 283,75 & 114,42 & 192,60 & $\begin{array}{l}193,04 \\
\end{array}$ & $\mid 34,23$ & $\mid 486,60$ & 55,97 & $\mid 17,97$ & 26,23 & $\mid 146,29$ & 76,12 & 83,23 & 125,49 \\
\hline Pelodytes punctatus & 30TVL59 & 100,00 & 108,00 & 105,03 & 36,61 & 6185,94 & 273,14 & $-10,25$ & 283,39 & 124,27 & 190,18 & 190,51 & 33,01 . & 493,92 & 57,00 & 18,96 & 25,70 & 148,62 & 78,66 & 86,02 & 127,11 \\
\hline Pelodytes punctatus & 30TVL81 & 100,00 & 125,82 & 102,84 & 35,13 & 6542,43 & 291,63 & 4,37 & 287,25 & 84,01 & 213,03 & 213,07 & 46,97 & 423,35 & 51,04 & 12,59 & 31,28 & 138,47 & 60,82 & 60,87 & 108,85 \\
\hline Pelodytes punctatus & 30TVL87 & 100,00 & 94,49 & 108,47 & 37,00 & 6223,54 & 264,29 & $-24,13$ & 288,42 & 111,81 & 178,15 & 178,29 & 20,81 & 559,91 & 65,81 & 24,12 & 23,88 & 169,43 & 93,76 & 100,73 & 143,13 \\
\hline Pelodytes punctatus & 30TVL91 & 100,00 & 121,90 & 104,96 & 35,73 & 6522,61 & 289,31 & $-0,26$ & 289,56 & 80,44 & 208,64 & 208,92 & 43,39 & 436,13 & 50,64 & 14,20 & 29,76 & 137,75 & 65,45 & 66,21 & 110,47 \\
\hline Pelodytes punctatus & 30TVL93 & 100,00 & 115,93 & 106,16 & 36,04 & 6443,86 & 283,94 & $-5,49$ & 289,42 & 76,12 & 201,56 & 202,12 & 38,45 & 458,06 & 53,33 & 16,36 & 27,60 & 139,58 & 71,74 & 74,50 & 115,90 \\
\hline Pelodytes punctatus & 30TVL97 & 100,00 & 95,54 & 109,50 & 37,04 & 6239,01 & 266,14 & $-24,09$ & 290,22 & 113,26 & 179,30 & 179,44 & 21,46 & 556,16 & 65,73 & 24,58 & 23,43 & 168,52 & 94,61 & 101,49 & 141,73 \\
\hline Pelodytes punctatus & 30TVMO0 & 100,00 & 118,81 & 107,24 & 36,99 & 6078,68 & 283,24 & $-3,31$ & 286,55 & 100,38 & 198,68 & 199,69 & 43,94 & \begin{tabular}{|c|}
442,13 \\
\end{tabular} & 50,97 & 15,28 & 28,18 & 135,81 & 64,50 & 74,67 & 114,07 \\
\hline Pelodytes punctatus & 30TVM01 & 100,00 & 115,13 & 107,86 & 37,00 & 6026,62 & 279,86 & $-6,93$ & 286,79 & 120,48 & 194,45 & 195,32 & 41,08 & 457,26 & 52,80 & 16,45 & 27,97 & 139,88 & 67,56 & 78,95 & 117,33 \\
\hline Pelodytes punctatus & 30TVM09 & 100,00 & 111,43 & 101,12 & 37,86 & 5430,86 & 262,16 & $-2,76$ & 264,92 & 85,14 & 182,99 & 183,01 & 44,32 & 572,90 & 64,84 & 26,95 & 23,45 & 180,18 & 96,46 & 100,11 & 147,05 \\
\hline Pelodytes punctatus & 30TVM12 & 100,00 & 112,73 & 106,63 & 37,00 & 5981,48 & 276,42 & $-8,06$ & 284,48 & 123,04 & 191,60 & 192,36 & 39,31 & $\begin{array}{l}472,45 \\
\end{array}$ & 54,27 & 18,01 & 26,84 & 143,71 & 71,90 & 83,22 & 120,59 \\
\hline Pelodytes punctatus & 30TVM13 & 100,00 & 109,38 & 106,68 & 37,00 & 5922,03 & 272,75 & $-10,96$ & 283,71 & 126,07 & 187,56 & 188,06 & 36,77 & 489,73 & 56,10 & 19,60 & 25,91 & 148,47 & 75,88 & 87,71 & 124,53 \\
\hline Pelodytes punctatus & 30TVM14 & 100,00 & 109,34 & 106,34 & 37,00 & 5863,51 & 271,63 & $-10,27$ & 281,90 & 118,32 & 186,67 & 187,15 & 37,31 & 497,57 & 56,39 & 20,64 & 25,53 & 150,18 & 78,12 & 90,05 & 126,21 \\
\hline Pelodytes punctatus & 30TVM19 & 100,00 & 106,62 & 100,06 & 37,50 & 5472,88 & 257,88 & $-5,60$ & 263,48 & 78,68 & 178,90 & 178,90 & 39,00 & 591,22 & 65,97 & 28,41 & 22,67 & 183,39 & 101,23 & 103,29 & 152,37 \\
\hline Pelodytes punctatus & 30TVM23 & 100,00 & 109,67 & 105,44 & 37,00 & 5941,56 & 272,32 & $-9,19$ & 281,50 & 125,40 & 188,09 & 188,45 & 36,70 & 491,21 & 56,07 & 20,01 & 25,35 & 148,21 & 77,60 & 87,96 & 125,23 \\
\hline Pelodytes punctatus & 30 TVM24 & 100,00 & 109,50 & 104,90 & 37,00 & 5880,93 & 271,14 & $-8,71$ & 279,85 & 106,82 & 187,10 & 187,48 & 37,17 & 498,61 & 56,35 & 20,91 & 25,01 & 149,86 & 79,75 & 89,26 & 126,97 \\
\hline Pelodytes punctatus & 30 TVM29 & 100,00 & 103,68 & 98,99 & 37,13 & 5518,38 & 255,18 & $-6,58$ & 261,75 & 74,01 & 176,60 & 176,60 & 35,58 & 601,44 & 66,36 & 29,42 & 22,04 & 184,45 & 104,62 & 105,03 & 155,32 \\
\hline Pelodytes punctatus & 30TVM34 & 100,00 & 106,97 & 104,04 & 37,00 & 5908,60 & 268,39 & $-9,57$ & 277,97 & 121,96 & 185,07 & 185,15 & 34,46 & 511,04 & 57,86 & 22,09 & 24,09 & 152,90 & 83,91 & 91,86 & 130,41 \\
\hline Pelodytes punctatus & 30 TVM 40 & 100,00 & 113,46 & 104,42 & 36,52 & 6135,33 & 276,98 & $-5,46$ & 282,45 & 122,49 & 194,55 & 195,09 & 38,56 & 472,12 & 54,16 & 17,76 & 26,23 & 142,26 & 74,12 & 81,77 & 121,43 \\
\hline Pelodytes punctatus & 30TVM41 & 100,00 & 115,39 & 104,04 & 36,71 & 6081,07 & 277,89 & $-3,05$ & 280,94 & 108,31 & 195,63 & 195,91 & 40,63 & $\begin{array}{l}467,45 \\
\end{array}$ & 53,33 & 18,07 & 25,81 & 140,75 & 74,19 & 81,43 & 120,23 \\
\hline Pelodytes punctatus & 30TVM43 & 100,00 & 107,22 & 104,07 & 37,00 & 5987,94 & 269,58 & $-9,39$ & 278,97 & 125,28 & 186,45 & 186,49 & 33,98 & 506,27 & 57,85 & 21,60 & 24,22 & 151,88 & 83,48 & 90,24 & 129,68 \\
\hline Pelodytes punctatus & 30TVM49 & 100,00 & 102,13 & 97,24 & 37,12 & 5571,20 & 252,62 & $-4,45$ & 257,07 & 69,98 & 175,98 & 175,98 & 33,61 & 602,61 & 65,54 & 29,99 & 21,43 & 181,30 & 108,10 & 108,10 & 158,06 \\
\hline Pelodytes punctatus & 30 TVM50 & 100,00 & 110,55 & 104,77 & 36,84 & 6143,94 & 274,70 & $-7,78$ & 282,48 & 122,81 & 191,94 & 192,25 & 35,78 & 485,23 & 55,82 & 19,06 & 25,37 & 145,75 & 78,05 & 85,01 & 124,84 \\
\hline Pelodytes punctatus & 30TVM52 & 100,00 & 110,15 & 104,31 & 37,00 & 6051,09 & 272,95 & $-7,05$ & 280,00 & 128,69 & 190,22 & 190,32 & 36,14 & $\begin{array}{l}492,55 \\
\end{array}$ & 56,49 & 20,68 & 24,27 & 147,56 & 81,44 & 87,01 & 126,53 \\
\hline Pelodytes punctatus & 30TVM55 & 100,00 & 101,93 & 103,01 & 37,03 & 5877,10 & 262,16 & $-11,48$ & 273,65 & 118,18 & 179,87 & 179,87 & 30,22 & 547,68 & 61,75 & 25,84 & 22,42 & 162,52 & 95,08 & 96,40 & 141,54 \\
\hline Pelodytes punctatus & 30TVM56 & 100,00 & 97,36 & 102,37 & 37,11 & 5809,75 & 256,47 & $-14,40$ & 270,87 & 113,70 & 174,64 & 174 & 26 & 579,32 & \begin{tabular}{|c|c|}
64 \\
\end{tabular} & 28,43 & 21,82 & 170,90 & 102,09 & 102,18 & 150,45 \\
\hline Pelodytes punctatus & 30TVM64 & 100,00 & 95,36 & 104,86 & 37,20 & 5925,16 & 258,21 & $-18,69$ & 276,90 & 111,96 & 174,48 & 174 & 24,00 & $\begin{array}{l}577,95 \\
\end{array}$ & 65,75 & 27,61 & 22,01 & $\begin{array}{l}172,62 \\
\end{array}$ & 101,03 & 102,07 & 149,71 \\
\hline Pelodytes punctatus & $30 \mathrm{TVME}$ & 100,00 & 99,66 & 103,47 & 37,19 & 5877,67 & 260,07 & $-13,36$ & 273,44 & 116,60 & 177,81 & 177,81 & 28,24 & 565,63 & 63,77 & 27,44 & 21,85 & \begin{tabular}{ll|}
167,67 \\
\end{tabular} & 99,91 & 100,37 & $\begin{array}{ll}146,89 \\
\end{array}$ \\
\hline Pelodytes punctatus & 30TVM66 & 100,00 & 96,82 & 102,54 & 37,51 & 5810,34 & 255,69 & $-14,68$ & 270,37 & 112,97 & 174,30 & 174,30 & 26,32 & $\begin{array}{l}592,52 \\
\end{array}$ & 65,98 & 29,71 & 21,25 & $\begin{array}{l}174,32 \\
\end{array}$ & 105,92 & 105,92 & 154,79 \\
\hline Pelodytes punctatus & 30TVM70 & 100,00 & 112,55 & 105,87 & 36,98 & 6160,84 & 277,34 & $-6,28$ & 283,62 & 131,70 & 194,07 & 194,32 & 37,54 & 480,44 & 55,58 & 19,82 & 24,49 & 143,77 & 80,06 & 85,36 & 123,15 \\
\hline Pelodytes punctatus & 30TVM74 & 100,00 & 100,22 & 105,01 & 37,27 & 5943,49 & 262,73 & $-14,36$ & 77,09 & 117,38 & 179,39 & 17 & 28 & 559,96 & 73 & 26,99 & 8 & 78 & 99,11 & 100,65 & 145,18 \\
\hline Pelodytes punctatus & 30TVM81 & 100,00 & 107,37 & 107,21 & 37, & 6121,69 & 273,23 & $-11,05$ & 284,28 & 125,88 & 188,52 & 188,66 & 33,26 & 509,37 & 59,19 & 22,79 & 23,06 & 152,96 & 88,11 & 93,40 & 130,80 \\
\hline Pelodytes punctatus & 30TVM82 & 100,00 & 101,36 & 107,39 & 37,35 & 6056,29 & 267,30 & $-15,85$ & 283,15 & 119,08 & 182,21 & 182,22 & 28,29 & 543,64 & 62,84 & 25,53 & 22,24 & 163,19 & 95,59 & 99,04 & 140,21 \\
\hline Pelodytes punctatus & 30TVM91 & 100,00 & 105,88 & 108,52 & 37,18 & 6119,48 & 273,03 & $-13,45$ & 286,48 & 124,41 & 187,18 & 187,24 & 31,70 & 520,76 & 60,75 & 24,19 & 22,38 & 156,58 & 91,88 & 96,24 & 133,75 \\
\hline Pelodytes punctatus & 30TVM92 & 100,00 & 100,07 & 108,72 & 37,73 & 6058,65 & 267,23 & $-17,95$ & 285,18 & 117,93 & 180,93 & $\begin{array}{ll}180,94 \\
\end{array}$ & 27,00 & 556,12 & 64,39 & 26,95 & 21,52 & 166,86 & 99,45 & 103,55 & 143,63 \\
\hline Pelodytes punctatus & 30TVM98 & 100,00 & 91,12 & 101,98 & 38,00 & 5661,91 & 246,27 & $-18,21$ & 264,47 & 84,41 & 166 & 166 & 22,79 & 98 & 74,72 & 36,97 & & 20 & 130,80 & 80 & 18 \\
\hline Pelodytes punctatus & 30 TVN & 100,00 & & 98,85 & 37,97 & 5568,33 & 252,12 & $-5,18$ & 257,30 & 60,80 & 176,65 & 176,71 & 34,77 & 662,93 & $69,71]$ & 34,25 & 19,01 & 192,52 & 125,39 & 125,39 & 178,41 \\
\hline \begin{tabular}{|l} 
Pelodytes punctatus \\
\end{tabular} & 30TVNOO & 100,00 & 108,50 & 99,59 & 37,93 & 5349,25 & 256,73 & $-3,32$ & 260,05 & 82,66 & 179,20 & 179,20 & 42,52 & 609,08 & 69,48 & 29,05 & 23,06 & 192,55 & 104,69 & 105,56 & 157,47 \\
\hline Pelodytes punctatus & 30TVN01 & 100,00 & 105,02 & 97,94 & 38,00 & 5266,53 & 250,59 & $-4,35$ & 254,94 & 79,44 & 174,73 & 174,73 & 40,23 & 652,32 & 74,87 & 31,68 & 22,53 & 206,91 & 114,49 & 114,60 & 170,16 \\
\hline Pelodytes punctatus & 30TVN02 & 100,00 & 94,93 & 97,31 & 38,01 & 5225,65 & 240,01 & $-12,12$ & 252,13 & 69,28 & 164,63 & 164,63 & 31,41 & 724,43 & 82,86 & 36,32 & 21,84 & 228,54 & 129,62 & 129,62 & 191, \\
\hline Pelodytes punctatus & 30TVN03 & 100,00 & 98,08 & 94,63 & 38,07 & 5091,35 & 238,07 & $-6,49$ & 244,56 & 73,30 & 165,73 & 165,91 & 36,01 & 748,90 & 86,70 & 37,29 & 21,95 & 239,08 & 135,73 & 135,79 & 199,06 \\
\hline
\end{tabular}




\begin{tabular}{|c|c|c|c|c|c|c|c|c|c|c|c|c|c|c|c|c|c|c|c|c|c|}
\hline TAXON & UTM & $\mathrm{km} 2$ & B101 & $\mathrm{B1O2}$ & $\mathrm{BIO3}$ & B104 & B105 & B106 & B107 & B108 & B109 & 81010 & BI011 & BIO12 & B1013 & BIO14 & B1015 & B1016 & BIO17 & BIO18 & B1019 \\
\hline Pelodytes punctatus & $30 \mathrm{TVN} 10$ & 100,00 & 106,85 & 98,15 & 37,69 & 5371,47 & 254,56 & $-3,10$ & 257,66 & 79,73 & 177,87 & 177,87 & 40,46 & 618,46 & 69,84 & 29,82 & 22,42 & 193,83 & 107,60 & 107,86 & 160,68 \\
\hline Pelodytes punctatus & 30TVN12 & 100,00 & 97,30 & 95,50 & 38,00 & 5209,78 & 240,46 & $-8,07$ & 248,53 & 71,01 & 166,72 & 166,72 & 33,68 & 720,35 & 81,96 & 35,95 & 21,62 & 226,56 & 129,66 & 129,66 & 190,89 \\
\hline Pelodytes punctatus & 30TVN13 & 100,00 & 100,03 & 92,71 & 37,99 & 5074,66 & 237,86 & $-3,24$ & 241,09 & 74,87 & 167,07 & 167,61 & 37,92 & 750,81 & 86,35 & 37,08 & 21,81 & 239,05 & 136,11 & 136,80 & 200,91 \\
\hline Pelodytes punctatus & 30 TVN22 & 100,00 & 98,18 & 94,05 & 37,97 & 5211,92 & 239,98 & $-5,71$ & 245,69 & 71,22 & 167,44 & 167,58 & 34,47 & \begin{tabular}{|c|}
722,47 \\
\end{tabular} & 81,64 & 35,99 & 21,27 & 226,16 & 130,84 & 130,90 & 192,53 \\
\hline Pelodytes punctatus & 30TVN23 & 100,00 & 97,04 & 91,99 & 37,98 & 5098,92 & 234,97 & $-4,75$ & 239,73 & 70,94 & 164,45 & 165,11 & 34,86 & 768,87 & 87,30 & 38,34 & 21,30 & 242,35 & 140,32 & 140,99 & 207,25 \\
\hline Pelodytes punctatus & 30TVN30 & 100,00 & 99,40 & 96,63 & 37,33 & 5448,19 & 247,74 & $-7,01$ & 254,75 & 69,27 & 171,72 & 171,72 & 32,52 & 648,39 & 71,83 & 32,34 & 21,29 & \begin{tabular}{ll|}
198,45 \\
\end{tabular} & 115,93 & 115,93 & 170,14 \\
\hline Pelodytes punctatus & 30TVN31 & 100,00 & 96,78 & 95,23 & 37,79 & 5345,47 & 242,09 & $-7,86$ & 249,95 & \begin{tabular}{|c|c|}
67,83 \\
\end{tabular} & 167,90 & 167,90 & \begin{tabular}{|l|l|l}
31,47 & \\
\end{tabular} & 694,26 & 77,24 & 34,87 & 21,03 & 213,68 & 125,51 & 125,51 & 184,37 \\
\hline Pelodytes punctatus & 30 TVN32 & 100,00 & 98,01 & 93,01 & 37,90 & 5220,81 & 238,88 & $-4,56$ & 243,45 & 70,10 & 167,05 & 167,62 & 34,19 & 729,61 & 81,65 & 36,42 & 21,10 & 226,93 & 132,83 & 133,19 & 196,12 \\
\hline Pelodytes punctatus & 30TVN33 & 100,00 & 99,88 & 90,41 & 37,83 & 5087,54 & 235,72 & $-0,61$ & 236,32 & 73,30 & 166,10 & 167,68 & 37,62 & 768,08 & 86,51 & 37,99 & 21,23 & 241,69 & 139,82 & 141,61 & 209,01 \\
\hline Pelodytes punctatus & 30TVN40 & 100,00 & 100,81 & 95,65 & 37,49 & 5453,55 & 247,77 & $-3,97$ & 251,74 & 69,92 & 173,08 & 173,21 & 33,90 & 645,41 & 70,98 & 32,20 & 21,06 & 196,42 & 116,78 & 116,78 & 171,18 \\
\hline Pelodytes punctatus & 30TVN41 & 100,00 & 97,97 & 94,24 & 37,84 & 5348,75 & 242,03 & $-5,08$ & 247,11 & 68,22 & 168,75 & 169,27 & 32,69 & 695,17 & 76,59 & 34,88 & 20,91 & 212,73 & 126,85 & 126,95 & 186,38 \\
\hline Pelodytes punctatus & 30TVN42 & 100,00 & 94,73 & 92,92 & 37,97 & 5248,90 & 235,92 & $-6,76$ & 242,68 & 66,10 & 163,77 & 164,82 & 30,91 & 748,93 & 82,50 & 37,81 & 20,56 & 230,02 & 137,79 & 137,95 & 202,92 \\
\hline $\begin{array}{l}\text { Pelodytes punctatus } \\
\end{array}$ & 30TVN46 & 100,00 & \begin{tabular}{|c|}
101,68 \\
\end{tabular} & 82,19 & 37,70 & 4705,55 & 224,07 & 8 & 215,30 & 78,10 & 162,36 & 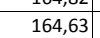 & 44,20 & 919,65 & \begin{tabular}{|c|c|}
105,53 \\
\end{tabular} & 44,48 & 22,03 & 295,47 & 164,43 & $\mid 174,03$ & 261,18 \\
\hline Pelodytes punctatus & 30TVN52 & 100,00 & 98,95 & 91,42 & 37,73 & 5221,31 & 237,64 & $-1,86$ & 239,51 & \begin{tabular}{|l|}
70,07 \\
\end{tabular} & \begin{tabular}{|l|}
167,23 \\
\end{tabular} & 168,60 & 35,30 & 749,14 & 81,75 & 37,43 & 20,46 & 229,92 & 137,40 & 139,13 & 205,45 \\
\hline Pelodytes punctatus & 30TVN55 & 100,00 & 113,55 & 80,20 & 37,16 & 4694,17 & 233,01 & 20,75 & 212,25 & 89,81 & 173,80 & 175,99 & 55,64 & 865,90 & 100,81 & 40,08 & 22,87 & 280,37 & \begin{tabular}{|c|}
151,47 \\
\end{tabular} & 163,42 & 249,80 \\
\hline Pelodytes punctatus & 30TVN56 & 100,00 & 106,14 & 80,16 & 37,35 & 4654,46 & 225,83 & 14,56 & 211,27 & 82,72 & 165,90 & 168,30 & 49,16 & 930,85 & 108,16 & 44,22 & 22,41 & 299,67 & 164,75 & 176,64 & 268,72 \\
\hline Pelodytes punctatus & 30TVN65 & 100,00 & 108,42 & 81,64 & 37,37 & 4761,87 & 230,73 & 15,28 & 215,45 & 82,29 & 169,62 & 171,90 & 50,06 & 889,65 & 102,73 & 42,10 & 21,96 & 283,26 & 157,77 & 168,31 & 257,69 \\
\hline Pelodytes punctatus & \begin{tabular}{|l|}
30 TVN70 \\
\end{tabular} & 100,00 & \begin{tabular}{|l|}
$100,4,58$ \\
\end{tabular} & $\begin{array}{l}\mid l 1,04 \\
94,92\end{array}$ & 37,86 & 5438,01 & 248,84 & $\begin{array}{r}r, 20 \\
0,10\end{array}$ & $\begin{array}{l}21,48,73 \\
248,73\end{array}$ & $\begin{array}{l}0<, 23 \\
73,09\end{array}$ & \begin{tabular}{|l|}
175,77 \\
\end{tabular} & $\begin{array}{l}17,, 60 \\
176,68\end{array}$ & 37,92 & $\begin{array}{l}600,09 \\
669,04\end{array}$ & \begin{tabular}{|l|}
70,87 \\
70,
\end{tabular} & 33,55 & $\begin{array}{l}1,100 \\
19,95 \\
\end{array}$ & $\begin{array}{l}20,20 \\
199,48 \\
\end{array}$ & 124,75 & \begin{tabular}{|l|}
125,08 \\
125
\end{tabular} & $\begin{array}{ll}23,02,08 \\
182,0\end{array}$ \\
\hline Pelodytes punctatus & 30TVN74 & 100,00 & 107,62 & 84,58 & 37,51 & 4912,95 & 234,44 & 12,03 & 222,40 & \begin{tabular}{|l|l|l}
74,75 & \\
\end{tabular} & 170,82 & 172,86 & 47,35 & 851,06 & 96,70 & 40,89 & 21,06 & 266,57 & 153,21 & 160,98 & 245,17 \\
\hline Pelodytes punctatus & 30TVN76 & 100,00 & 107,88 & 79,40 & 37,36 & 4649,58 & 226,83 & 17,28 & 209,55 & 67,34 & 167,40 & 169,86 & 51,09 & 964,32 & 112,88 & 45,46 & 22,21 & 308,11 & 170,29 & 183,10 & 285,22 \\
\hline Pelodytes punctatus & 30TVN81 & 100,00 & 109,16 & 92,28 & 37,84 & 5305,90 & 247,79 & 6,10 & 241,69 & 78,77 & 177,90 & 179,31 & 43,82 & 706,11 & 76,26 & 34, & 19,76 & 212,64 & 131,55 & 133,54 & 195,79 \\
\hline Pelodytes punctatus & 30TVN82 & 100,00 & 103,17 & 91,27 & 37,89 & 5220,71 & 240,35 & 2,42 & 237,93 & 60,00 & 170,94 & 172,61 & 39,31 & \begin{tabular}{|c|c|}
771,66 \\
\end{tabular} & 84,04 & 38,65 & 19,54 & 233,49 & 143,87 & 146,24 & 215,95 \\
\hline Pelodytes punctatus & 30TVN85 & 100,00 & 104,85 & 83,38 & 37,74 & 4828,90 & 229,94 & 11,22 & 218,72 & 54,11 & 166,92 & 169,21 & 45,99 & 924,90 & 105,84 & 44,83 & 20,84 & 290,18 & 167,04 & 175,80 & 270,28 \\
\hline $\begin{array}{l}\text { Pelodytes punctatus } \\
\end{array}$ & 30TVN90 & 100,00 & 115,81 & 94,12 & 37,79 & 5412,15 & 256,61 & 9,92 & 246,69 & \begin{tabular}{|l|l|}
84,13 \\
\end{tabular} & 185,79 & \begin{tabular}{|l|l|l|l|}
186,93 \\
\end{tabular} & 48,72 & 646,25 & 68,58 & 31,89 & 19,62 & 192,76 & 122,05 & 123,07 & 176,65 \\
\hline Pelodytes punctatus & 30TVN91 & 100,00 & 113,53 & 92,15 & 37,94 & 5299,28 & 251,10 & 10,04 & 241,07 & $\begin{array}{l}80,85 \\
\end{array}$ & 181,98 & 183,36 & 48,11 & 698,82 & 75,34 & 34,55 & 19,53 & 209,99 & 131,21 & 133,30 & 193,97 \\
\hline Pelodytes punctatus & 30TVN92 & 100,00 & 117,27 & 88,59 & 37,62 & 5141,02 & 249,09 & 16,71 & 232,37 & 86,20 & 183,32 & 184,93 & 53,60 & 738,05 & 81,65 & 35, & 20,21 & 225,82 & 135,85 & 140,65 & 209,57 \\
\hline Pelodytes punctatus & $\begin{array}{l}\text { 30TVN93 } \\
3\end{array}$ & 100,00 & 115,36 & 86,42 & 37,65 & 5019,65 & 244,13 & 17,40 & 226,73 & 80,67 & 179,86 & 181,60 & 53,52 & 797,27 & 89,48 & 38,23 & $\frac{20,41}{20,47}$ & 246,02 & $\begin{array}{l}145,48 \\
145\end{array}$ & 151,88 & 229,88 \\
\hline Pelodytes punctatus & 30TVN94 & 100,00 & 108,73 & 85,55 & 37,76 & 4938,92 & 236,51 & 12,67 & 223,84 & \begin{tabular}{|c|c|}
62,07 \\
\end{tabular} & 172,20 & 174,24 & 48,30 & 872,13 & 98,54 & 42,44 & 20,30 & 270,24 & 159,39 & 166,11 & 253,37 \\
\hline Pelodytes punctatus & 30TWK06 & 100,00 & 132,45 & 111,60 & 36,29 & 6620,05 & 307,21 & 4,89 & 302,31 & 90,06 & 220,83 & 220,83 & 52,19 & 422,20 & 48,04 & 12,28 & 32,21 & 136,34 & 57,04 & 57,04 & 111,09 \\
\hline Pelodytes punctatus & 30TWK14 & 100,00 & 120,81 & 116,91 & 37,10 & 6612,59 & 301,81 & $-7,68$ & 309,48 & 104,56 & 208,88 & 209,86 & 41,75 & 479,51 & 55,68 & 14,85 & 30,15 & 151,01 & 67,53 & 69,73 & 125,27 \\
\hline Pelodytes punctatus & 30TWK33 & 100,00 & 116,66 & 120,74 & 38,00 & 6585,14 & 300,33 & $-14,06$ & 314,40 & 100,01 & 204,55 & 205,58 & 38,06 & 505,99 & 60,53 & 16,58 & 29,01 & 163,99 & 74,23 & 78,88 & 129,05 \\
\hline Pelodytes punctatus & 30TWK49 & 100,00 & 106,46 & $\mid 115,14$ & 37,57 & 6454,86 & $\mid 281,33$ & $-21,36$ & 302,69 & $\begin{array}{r}90,44 \\
90\end{array}$ & $\begin{array}{l}202,08 \\
192,08\end{array}$ & $\mid$ & 28,95 & 510,99 & 60,31 & 21,77 & | 25,87 & 161,34 & 86,29 & $\begin{array}{l}93,58 \\
93,58\end{array}$ & 123,12 \\
\hline Pelodytes punctatus & 30TWK56 & 100,00 & 116,81 & 119,02 & 37,99 & 6505,19 & 295,14 & $-14,30$ & 309,44 & \begin{tabular}{|l|l|l|l|}
101,03 \\
\end{tabular} & 202,89 & 204,14 & 38,35 & 488,94 & 61,24 & 18,35 & 27,56 & 157,73 & 78,89 & 84,78 & 118,86 \\
\hline Pelodytes punctatus & 30TWK57 & 100,00 & 119,51 & 117,14 & 37,99 & 6488,75 & 295,10 & $-10,90$ & 306,00 & 104,30 & 205,19 & 206,31 & 40,91 & 466,33 & 58,95 & 17,86 & 27,57 & 149,15 & 76,57 & 81,97 & 111,85 \\
\hline Pelodytes punctatus & 30TWK58 & 100,00 & 118,81 & 115,73 & 37,71 & 6474,79 & 292,47 & $-11,0$ & 303,55 & 103,83 & 204,13 & 205,10 & 40,08 & 460,90 & 58,77 & 18,36 & 27,27 & 146,40 & 77,21 & 82,94 & 109,38 \\
\hline \begin{tabular}{|l} 
Pelodytes punctatus \\
\end{tabular} & 30TWK67 & 100,00 & 110,23 & 117,68 & 38,00 & 6460,58 & 286,09 & $-20,18$ & 306,27 & 94,21 & 195,76 & 196,93 & 32,25 & 505,56 & 64,96 & 21,13 & 26,69 & 162,87 & 86,71 & 94,60 & 118,85 \\
\hline Pelodytes punctatus & $\begin{array}{l}\text { 30TWK68 } \\
\end{array}$ & $\begin{array}{l}100,00 \\
\end{array}$ & \begin{tabular}{|l|l|l|l|}
106,73 \\
\end{tabular} & $\mid \begin{array}{l}\mid 11,00 \\
116,36\end{array}$ & 37,98 & $\begin{array}{ll}640,300 \\
644,07\end{array}$ & $\mid \frac{200,09}{281,06}$ & - & 303,84 & 92,12 & 192,05 & \begin{tabular}{|l|l|}
193,18 \\
193
\end{tabular} & 29,05 & 511,24 & \begin{tabular}{ll|l}
66,21 \\
\end{tabular} & $\begin{array}{l}21,15 \\
22,38\end{array}$ & \begin{tabular}{|l|l|}
26,24 \\
263
\end{tabular} & \begin{tabular}{|l|l|l|l|l|l|}
163,79 \\
\end{tabular} & $\begin{array}{l}80,1,1 \\
89,62\end{array}$ & $\begin{array}{ll}34,000 \\
98,37\end{array}$ & $\mid \begin{array}{l}119,02 \\
119,01\end{array}$ \\
\hline $\begin{array}{l}\text { Pelodytes punctatus } \\
\end{array}$ & 30TWK73 & 100,00 & 113,13 & 123,69 & 38,75 & 6497,97 & 295,96 & $-19,97$ & 315,93 & \begin{tabular}{|c|c|}
96,05 \\
\end{tabular} & 199,46 & 200,74 & 34,86 & 533,75 & 66,63 & 19,82 & 27,77 & 176,55 & 86,49 & 94,15 & 128,91 \\
\hline Pelodytes punctatus & 30TWK83 & 100,00 & 102,58 & 120,26 & 38,17 & 6476,73 & 282,14 & $-27,89$ & 310,03 & 84,56 & 189,01 & 190,08 & 25,43 & 562,12 & 71,36 & 23,60 & 26,19 & 184,82 & 96,95 & 106,93 & 129,77 \\
\hline Pelodytes punctatus & 30TWK84 & 100,00 & 96,47 & 36 & 38,01 & 57,47 & 274,20 & $-32,79$ & 306,99 & 78,13 & 182,81 & 183,78 & 19 & 580,26 & 74,21 & 25, & 25,51 & 189,63 & 102,94 & 114,16 & 132,22 \\
\hline Pelodytes punctatus & 30TWK85 & 100 & 95,1 & 117 & 38,00 & 6441,05 & 271 & $-33,7$ & 305,07 & 78,52 & 181,13 & 182,19 & 18,3 & 578 & 74,69 & 26 , & 25, & 188,32 & 104,36 & 115,87 & 131,04 \\
\hline $\begin{array}{l}\text { Pelodytes punctatus } \\
\end{array}$ & $\begin{array}{l} \\
30 T W K 86 \\
\end{array}$ & 100 & 88,7 & \begin{tabular}{|l|}
115,56 \\
1156
\end{tabular} & 30,30 & $\begin{array}{l}64414,97 \\
6414\end{array}$ & $\frac{271}{263}$ & $\begin{array}{l}-33,11 \\
-38,73\end{array}$ & $\begin{array}{l}\mid \\
302,05\end{array}$ & $\begin{array}{r}90,32 \\
92,32\end{array}$ & \begin{tabular}{|l|}
18,13 \\
174,60
\end{tabular} & $\begin{array}{l}\mid 02,19 \\
175,45\end{array}$ & $\begin{array}{l}10,30 \\
12,55\end{array}$ & \begin{tabular}{|c|c|}
$6 / 00,71$ \\
600,71
\end{tabular} & \begin{tabular}{|c|}
47,79 \\
77,74
\end{tabular} & 20,7 & $\begin{array}{l}23,31 \\
24,95 \\
\end{array}$ & $\begin{array}{l}180,32 \\
194,99\end{array}$ & \begin{tabular}{|l|l|l|l|l|l|}
110,73 \\
\end{tabular} & \begin{tabular}{|l|l|}
123,49 \\
123
\end{tabular} & 135,10 \\
\hline Pelodytes punctatus & $\begin{array}{l} \\
30 T W K 88 \\
\end{array}$ & 100,00 & 86,30 & 113,60 & 37,80 & 6367,38 & 257,78 & $-40,42$ & 298,21 & \begin{tabular}{|l|l|}
104,73 \\
\end{tabular} & 171,25 & 172,19 & 10,56 & \begin{tabular}{|l|l|}
599,53 \\
\end{tabular} & 78,42 & 30,40 & 24,72 & 196,11 & 113,56 & 127,13 & 133,66 \\
\hline Pelodytes punctatus & 30TWK93 & 100,00 & 102,88 & 118,10 & 38,03 & 6449,12 & 279,10 & $-26,4$ & 305,52 & 85,18 & \begin{tabular}{ll|}
188,95 \\
\end{tabular} & 190,01 & 25,99 & 549,82 & 70,66 & 24,09 & 26,09 & 180,04 & 98,38 & 108,40 & 122,41 \\
\hline Pelodytes punctatus & 30TWK94 & 100,00 & 92,23 &, 03 & $38, \mathrm{C}$ & 430,56 & 267,20 & $-35,36$ & 302,56 & 88,19 & \begin{tabular}{ll|}
178,35 \\
\end{tabular} & 179,33 & \begin{tabular}{ll|}
16,06 \\
\end{tabular} & 590,88 & 76,23 & 27, & 25, & 192,64 & \begin{tabular}{|c|}
108,68 \\
\end{tabular} & 120,74 & 130,77 \\
\hline Pelodytes punctatus & $30 \mathrm{TW}$ & & 92 & 23 & $38, \mathrm{C}$ & 6416,55 & 265,77 & $-35,2$ & 301,03 & 104,81 & 178,05 & 179,08 & 16,0 & 583 & 75,98 & 28, & 25,35 & 190,72 & 108,82 & 121,12 & 128,16 \\
\hline Pelodytes punctatus & 30TWK98 & 100 & 80,94 & 11 & 37,14 & 6340,80 & 250,10 & -44 & 294,66 & $\begin{array}{l}98,89 \\
\end{array}$ & \begin{tabular}{|c|}
165,63 \\
\end{tabular} & 166,52 & 5,5 & 622,34 & 81,77 & 32, & 24,56 & 205,50 & 121,34 & 136,15 & 135,74 \\
\hline Pelodytes punctatus & 30TWK99 & 100,00 & 85,59 & 111,09 & 37,27 & 6324,33 & 252,81 & $-40,40$ & 293,21 & 104,34 & 169,66 & 170,64 & 9,83 & 589,39 & 78,67 & 31,47 & 25,33 & 196,45 & 116,27 & 130,66 & 127,00 \\
\hline Pelodytes punctatus & 30TWL04 & 100,00 & 111,49 & 108,35 & 36,71 & 6393,51 & 280,81 & $-10,72$ & 291,53 & 108,95 & 196,57 & 196,98 & 34,78 & 476,03 & 56,68 & 18,80 & 25,92 & 142,80 & 77,88 & 82,26 & 119,36 \\
\hline Pelodytes punctatus & $\begin{array}{l}\text { 30TWL07 } \\
\end{array}$ & 100,00 & 97,13 & 110,66 & 37,37 & 252,88 & 268,36 & $-23,79$ & 292,15 & 115,05 & 180,97 & 181,10 & 22,64 & 549,99 & 65,41 & 24, & 23,07 & 167,04 & 95,15 & 102,44 & 139,62 \\
\hline Pelodytes punctatus & 30TWL14 & $\frac{10}{10}$ & 111 & & 37,00 & $\begin{array}{ll}025,400 \\
6393,14\end{array}$ & $\frac{200}{281}$ & -11,82 & 293,21 & $\begin{array}{l}1127,34 \\
127,34\end{array}$ & $\begin{array}{l}\mid 196,38 \\
196\end{array}$ & 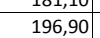 & $\frac{24,}{34,}$ & $\begin{array}{l}34,59 \\
475,03\end{array}$ & \begin{tabular}{l|l}
57,42 \\
57,4
\end{tabular} & \begin{tabular}{|l|l|}
19,64 \\
19,
\end{tabular} & 25,46 & $\begin{array}{l}\mid 01,04 \\
143,82\end{array}$ & $\mid 79,57$ & 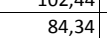 & $\begin{array}{ll}13,06 \\
117,86\end{array}$ \\
\hline $\begin{array}{l}\text { Pelodytes punctatus } \\
\end{array}$ & 30TWL15 & 100,00 & 106,60 & 110,39 & 37,01 & 6345,94 & 277,34 & $-16,30$ & 293,64 & 126,11 & 191,14 & 191,59 & 30,58 & 498,56 & 60,19 & 21,57 & 24,45 & 151,73 & 85,03 & 90,95 & 124,40 \\
\hline Pelodytes punctatus & \begin{tabular}{|l|} 
30TWL17 \\
\end{tabular} & 100,00 & 103,53 & 111,29 & 37,17 & 6279,43 & 274,65 & $-19,02$ & \begin{tabular}{|l|l|}
293,67 \\
\end{tabular} & 122,61 & \begin{tabular}{ll|}
187,15 \\
\end{tabular} & 187,58 & 28,16 & 519,04 & 62,40 & 23,79 & 23,10 & 158,25 & 91,01 & 97,74 & 130,71 \\
\hline Pelodytes punctatus & 30TWL23 & 100,00 & 107,73 & 111,14 & 37,00 & 6395,07 & 279,09 & $-16,64$ & 295,73 & 117,25 & 192,73 & 193,40 & 30,99 & 492,52 & 60,48 & 21,39 & 25,13 & 150,85 & 83,67 & 89,55 & 120,92 \\
\hline Pelodytes punctat & $30 \mathrm{TW}$ & 10 & 10 & 11 & 37,18 & 6306,08 & 276 & $-18,44$ & 295,06 & 124 & 189 & 189,83 & 29,54 & 506 & 61, & 23, & 23,57 & 155,68 & 89,50 & 96,17 & 12 \\
\hline Pelodytes punctatus & $\begin{array}{l}\text { 30TWL27 } \\
\end{array}$ & $\begin{array}{l}100,00 \\
\end{array}$ & \begin{tabular}{|l|}
103,26 \\
103
\end{tabular} & \begin{tabular}{|l|}
112,45 \\
112,48
\end{tabular} & | & $\begin{array}{ll}050,000 \\
6274,36\end{array}$ & $\begin{array}{l}\mid 27,0< \\
274,86\end{array}$ & $\begin{array}{l}-20,44 \\
-20,32\end{array}$ & $\begin{array}{l}295,00 \\
295,18\end{array}$ & $\begin{array}{l}\mid l 24,05 \\
122,43\end{array}$ & \begin{tabular}{|l|l|}
186,79 \\
186,2
\end{tabular} & \begin{tabular}{|l|l|l|l|l|l|l|}
187,23 \\
\end{tabular} & 27,83 & \begin{tabular}{|l|l|}
520,87 \\
20
\end{tabular} & $\begin{array}{l}\mid c 1,17 \\
63,32 \\
\end{array}$ & 24,43 & 22,91 & $\begin{array}{l}5,00 \\
159,92\end{array}$ & $\begin{array}{l}03,30 \\
93,13\end{array}$ & $\mid$\begin{tabular}{|c|c|}
100,17 \\
100
\end{tabular} & 130,19 \\
\hline Pelodytes punctatus & 30TWL33 & 100,00 & 103,81 & 112,51 & 37,22 & 6373,87 & 275,82 & \begin{tabular}{l|l|}
$-21,55$ \\
\end{tabular} & 297,37 & 123,36 & 188,46 & 189,08 & 27,23 & 510,20 & 63,66 & 23,53 & 24,61 & \begin{tabular}{|l|l|}
158,45 \\
\end{tabular} & 89,10 & 96,39 & 123,95 \\
\hline Pelodytes punctatus & 30TWL34 & 100,00 & 103,25 & 112,50 & 37,45 & 6352,49 & 274,90 & $-21,79$ & 296,68 & 122,84 & \begin{tabular}{|l|l|}
187,75 \\
\end{tabular} & 188,19 & 26,94 & 512,13 & 63,82 & 24,03 & 24,14 & 159,32 & 90,44 & 98,01 & 124,74 \\
\hline Pelodytes punctatus & 30TWL3 & 100,00 & 101, & 1 & 37,71 & 6319,27 & 272,9 & $-23,49$ & 296,44 & 120,55 & 185,24 & 185,87 & 25,27 & 523,95 & 65,03 & 25,26 & 23,49 & 162,96 & 93,88 & \begin{tabular}{|l|l|l|}
101,78 \\
\end{tabular} & 12 \\
\hline Pelodytes punctatus & 30TWL36 & 100,00 & 100,93 & 113,00 & 37,98 & 6291,45 & 272,63 & $-23,75$ & 296,38 & 120,11 & 184,61 & 185,22 & 25,24 & 528,39 & 65,26 & 25,80 & 23,01 & 164,10 & 95,48 & 103,54 & 130 \\
\hline
\end{tabular}




\begin{tabular}{|c|c|c|c|c|c|c|c|c|c|c|c|c|c|c|c|c|c|c|c|c|c|}
\hline TAXON & UTM & $\mathrm{km} 2$ & BIO1 & $\mathrm{BIO2}$ & 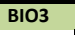 & 8104 & BIO5 & B106 & B107 & B108 & B109 & BIO10 & BIO11 & BIO12 & BIO13 & BIO14 & BIO15 & B1016 & $\begin{array}{ll}1017 \\
17\end{array}$ & BIO18 & BIO19 \\
\hline Pelodytes punctatus & 30TWL37 & 100,00 & 103,16 & 113,23 & 37,99 & 6272,93 & 274,97 & $-21,53$ & 296,50 & 122,53 & 186,64 & 186,98 & 27,49 & 520,99 & 64,03 & 25,62 & 22,73 & 161,25 & 94,88 & 102,47 & 129,11 \\
\hline Pelodytes punctatus & 30TWL38 & 100,00 & 107,05 & 113,55 & 38,00 & 6243,97 & 278,66 & $-17,82$ & 296,47 & 126,84 & 189,90 & $\begin{array}{l}190,27 \\
\end{array}$ & 31,47 & 506,42 & 62,06 & 24,94 & 22,58 & 156,39 & 92,73 & \begin{tabular}{|c|}
99,67 \\
\end{tabular} & 126,17 \\
\hline Pelodytes punctatus & 30TWL39 & 100,00 & 109,03 & 113,99 & 38,00 & 6221,73 & 280,64 & $-15,73$ & 296,38 & 128,99 & 191,51 & \begin{tabular}{ll|}
191,92 \\
\end{tabular} & 33,55 & 503,57 & 61,23 & 25,10 & 22,12 & 154,73 & 92,94 & \begin{tabular}{|c|}
99,47 \\
\end{tabular} & 126,49 \\
\hline Pelodytes punctatus & 30TWL42 & 100,00 & 103,18 & 113,13 & 37,28 & 6382,49 & 275,21 & $-23,22$ & 298,44 & 122,80 & \begin{tabular}{ll|}
187,86 \\
\end{tabular} & 188,62 & 26,21 & 512,75 & 65,03 & 23,88 & 24,88 & 161,17 & $\begin{array}{l}90,66 \\
\end{array}$ & 98,88 & 122,51 \\
\hline Pelodytes punctatus & 30TWL45 & 100,00 & 101,42 & 113,01 & 37,96 & 6313,14 & 272,55 & $-24,05$ & 296,60 & 120,94 & 185,25 & 185,75 & 25,16 & 521,14 & 65,67 & 25,74 & 23,55 & 163,99 & 95,18 & 103,92 & 125,89 \\
\hline Pelodytes punctatus & 30TWL47 & 100,00 & 103,76 & 113,88 & 38,00 & 6271,11 & 274,91 & $-21,69$ & 296,60 & 123,56 & 186,89 & 187,43 & 27,77 & 516,56 & 64,52 & 26,05 & 22,91 & \begin{tabular}{|l|l|}
161,68 \\
\end{tabular} & 95,83 & 104,09 & 126,38 \\
\hline Pelodytes punctatus & 30TWL48 & 100,00 & 107,87 & 114,02 & 38,00 & 6247,87 & 279,03 & $-17,74$ & 296,77 & 128,00 & 190,51 & \begin{tabular}{|l|l|}
191,08 \\
\end{tabular} & \begin{tabular}{ll|l}
31,85 \\
\end{tabular} & 501,45 & 62,41 & 25,29 & 22,61 & 156,52 & 93,48 & 101,12 & 123,39 \\
\hline Pelodytes punctatus & 30TWL49 & 100,00 & 106,99 & 114,69 & 38,00 & 6217,22 & 278,67 & $-18,62$ & 297,29 & 126,85 & 189,35 & \begin{tabular}{|c|}
189,79 \\
\end{tabular} & 31,42 & 514,24 & 63,20 & 26,27 & 22,00 & 159,39 & 96,54 & 104,10 & 128,16 \\
\hline Pelodytes punctatus & 30TWL51 & 100,00 & 106,28 & 113,61 & 37,56 & 6404,01 & 277,77 & $-21,32$ & 299,08 & 126,63 & 190,97 & \begin{tabular}{|c|}
191,94 \\
\end{tabular} & 28,86 & 497,92 & 64,29 & 22,93 & 25,53 & 158,24 & 88,77 & $\begin{array}{l}97,15 \\
\end{array}$ & 116,70 \\
\hline Pelodytes punctatus & 30TWL52 & 100,00 & 104,23 & 113,21 & 37,31 & 6375,36 & 275,06 & $-23,18$ & 298,23 & 124,50 & 188,55 & 189,52 & 27,03 & 504,13 & 65,19 & 23,91 & 25,12 & 160,82 & 91,22 & 100,04 & 118,13 \\
\hline Pelodytes punctatus & 30 TWL55 & 100,00 & 100,28 & 113,00 & 38,00 & 6305,38 & 270,42 & $-25,85$ & 296,27 & 120,17 & 183,82 & 184,44 & 24,16 & 523,34 & 67,03 & 26,47 & 23,74 & 166,91 & 97,78 & \begin{tabular}{|c|}
107,47 \\
\end{tabular} & 124,24 \\
\hline Pelodytes punctatus & 30TWL62 & 100,00 & 101,37 & 113,01 & 37,79 & 6352,98 & 271,03 & $-25,93$ & 296,96 & 121,79 & 185,60 & 186,39 & 24,84 & 512,22 & 67,35 & 25,23 & 25,26 & 166,09 & 95,40 & 105,62 & 117,44 \\
\hline Pelodytes punctatus & 30 TWL65 & 100,00 & 99,31 & 112,50 & 37,70 & 6279,44 & 267,61 & $-27,34$ & 294,95 & 119,48 & 182,29 & \begin{tabular}{ll|}
182,98 \\
\end{tabular} & 23,38 & 523,26 & 68,26 & 27,16 & 24,29 & 169,50 & \begin{tabular}{ll|}
99,93 \\
\end{tabular} & 110,74 & 121,65 \\
\hline Pelodytes punctatus & 30TWL67 & 100,00 & 115,46 & 112,12 & 37,82 & 6277,88 & 282,14 & $-11,88$ & 294,02 & 137,19 & 197,70 & \begin{tabular}{l|l|}
198,35 \\
\end{tabular} & \begin{tabular}{l|l|}
38,25 \\
\end{tabular} & 450,56 & 59,37 & 22,72 & 25,38 & 146,03 & 85,86 & 94,40 & 104,77 \\
\hline Pelodytes punctatus & 30TWL68 & 100,00 & 112,19 & 112,81 & 38,00 & 6249,84 & 279,79 & $-14,71$ & 294,50 & 133,40 & 194,21 & 194,71 & 35,50 & 472,48 & 61,37 & 24,37 & 24,31 & 152,06 & 90,60 & 99,71 & 111,62 \\
\hline Pelodytes punctatus & 30 TWL80 & 100,00 & 93,70 & 112,16 & 37,43 & 6338,13 & 261,37 & $-33,88$ & 295,25 & 113,39 & 177,54 & 178,62 & 17,14 & 547,11 & 73,40 & 28,23 & 25,82 & \begin{tabular}{l|l|}
181,65 \\
\end{tabular} & 106,07 & 118,79 & 119,77 \\
\hline Pelodytes punctatus & 30TWL90 & 100,00 & 89,55 & 110,45 & 37,31 & 6306,30 & 254,72 & $-37,08$ & 291,80 & 109,03 & 172,94 & \begin{tabular}{ll|}
173,98 \\
\end{tabular} & 13,40 & 560,82 & 76,00 & 30,19 & 26,20 & 188,81 & 112,05 & 126,10 & 119,52 \\
\hline Pelodytes punctatus & 30TWM06 & 100,00 & 91,56 & 106,05 & 38,00 & 5817,45 & 252,79 & $-21,79$ & 274,57 & 107,69 & 169,41 & 169,41 & 21,56 & 661,18 & 73,31 & 35,29 & 19,10 & \begin{tabular}{|c|}
193,37 \\
\end{tabular} & 124,01 & 124,21 & 174,34 \\
\hline Pelodytes punctatus & 30TWM08 & 100,00 & 89,97 & 103,04 & 38,06 & 5672,90 & 245,93 & $-20,14$ & 266,06 & 100,88 & 165,91 & 165,91 & 21,54 & 712,04 & 76,42 & 38,20 & 18,40 & 204,14 & 134,80 & 134,80 & 190,31 \\
\hline Pelodytes punctatus & 30TWM09 & 100,00 & 110,86 & 98,72 & 37,98 & 5573,69 & 258,66 & 1,7 & 256,95 & 78,18 & 184,26 & 184,34 & 42, & 629,40 & 66,34 & 32, & 18, & 182,56 & 120,69 & 120,69 & 168,21 \\
\hline Pelodytes punctatus & 30TWM10 & 100,00 & 108,22 & 111,68 & 37,99 & 6182,10 & 278,25 & $-14,00$ & 292,25 & 127,44 & 190,30 & 190,62 & 33,28 & 510,07 & 60,55 & 24,45 & 22,13 & 154,48 & 91,96 & 97,78 & 129,99 \\
\hline Pelodytes punctatus & 30TWM11 & 100,00 & 103,61 & 112,07 & 38,00 & 6125,34 & 273,87 & $-17,73$ & 291,61 & 122,12 & 185,23 & 185,33 & 29,68 & 541,47 & 63,54 & 26,93 & 21,18 & 163,32 & 98,87 & $\begin{array}{l}104,65 \\
\end{array}$ & 139,26 \\
\hline Pelodytes punctatus & 30TWM13 & 100,00 & 96,87 & 111,31 & 38,04 & 6017,11 & 265,36 & $-22,23$ & 287,59 & 114,39 & 177,16 & 177,21 & 24,34 & 596,68 & 68,64 & 31,22 & 19,93 & 178,25 & 110,88 & 114,29 & 155,30 \\
\hline Pelodytes punctatus & 30TWM15 & 100,00 & 68,97 & 107,08 & 38,02 & 5817,98 & 232,96 & $-43,81$ & 276,77 & 83,09 & 147,78 & \begin{tabular}{|c|}
147,78 \\
\end{tabular} & 0,49 & 794,58 & 87,97 & 44,08 & 18,21 & 233,03 & 149,38 & 149,38 & 209,87 \\
\hline Pelodytes punctatus & 30TWM19 & 100,00 & 120,28 & 98,44 & 37,98 & 5591,73 & 266,30 & 9,67 & 256,62 & 88,06 & 193,3 & \begin{tabular}{|c|}
193,38 \\
\end{tabular} & 50,78 & 581,66 & \begin{tabular}{c|}
62,07 \\
\end{tabular} & 29, & 19,11 & 168,78 & 113,38 & 113,42 & 152,68 \\
\hline Pelodytes punctatus & 30TWM22 & 100,00 & 96,86 & 113,61 & 38,16 & 6066,54 & 268,07 & $-24,41$ & 292,48 & 114,77 & 177,89 & 177,97 & 24,04 & 594,34 & 68,98 & 31,16 & 19,96 & 178,36 & 111,02 & 115,83 & 154,58 \\
\hline Pelodytes punctatus & 30TWM23 & 100,00 & 100,11 & 113,02 & 38,18 & 6033,19 & 269,86 & $-20,79$ & 290,66 & 118,09 & 180,38 & \begin{tabular}{ll|}
180,43 \\
\end{tabular} & 27,22 & 585,53 & 67,66 & 30,79 & 19,88 & 175,20 & $\begin{array}{l}110,05 \\
\end{array}$ & \begin{tabular}{ll|}
114,06 \\
\end{tabular} & 152,42 \\
\hline Pelodytes punctatus & 30TWM25 & 100,00 & 68,24 & 107,45 & 38,15 & 5819,86 & 232,22 & $-45,10$ & 277,32 & 82,59 & 147,03 & 147,03 & $-0,29$ & 807,14 & 89,42 & 45,16 & 17,94 & 236,86 & 153,03 & 153,23 & 212,90 \\
\hline Pelodytes punctatus & 30TWM26 & 100,00 & 88,12 & 108,23 & 38,21 & 5828,86 & 251,09 & $-27,02$ & 278,11 & 104,26 & 166,05 & $\begin{array}{l}166,05 \\
\end{array}$ & $\begin{array}{l}18,05 \\
\end{array}$ & 698,10 & 77,51 & 38,12 & 18,28 & 204,48 & 132,99 & 133,36 & 184,37 \\
\hline Pelodytes punctatus & 30TWM27 & 100,00 & 91,55 & 106,67 & 38,27 & 5774,84 & 251,68 & $-22,38$ & 274,06 & 107,79 & 168,63 & \begin{tabular}{|l|l|}
168,63 \\
\end{tabular} & 21,84 & 694,45 & 76,45 & 37,87 & 18,18 & 202,16 & 133,02 & 133,16 & 183,65 \\
\hline Pelodytes punctatus & 30TWM29 & 100,00 & 120,41 & 100,10 & 38,02 & 5642,81 & 268,08 & 8,30 & 259,78 & 117,56 & 194,07 & \begin{tabular}{|c|}
194,07 \\
\end{tabular} & 50,30 & 572,70 & 62,49 & 29,95 & 18,94 & 165,38 & 113,07 & 113,23 & 147,71 \\
\hline Pelodytes punctatus & 30TWM31 & 100,00 & 103,45 & 115,62 & 38,23 & 6134,85 & 276,37 & $-20,69$ & 297,06 & 122,47 & 184,84 & 185,21 & 29,02 & 554,93 & 65,48 & 28,72 & 20,44 & 167,84 & 104,20 & 110,61 & 143,26 \\
\hline Pelodytes punctatus & 30TWM32 & 100,00 & 100,33 & 115,52 & 38,74 & 6085,66 & 272,95 & $-22,71$ & 295,66 & 118,86 & 181,43 & 181,54 & 26,86 & 582,24 & 67,90 & 30,58 & 19,91 & 175,02 & 110,07 & \begin{tabular}{|c|}
115,38 \\
\end{tabular} & 151,54 \\
\hline Pelodytes punctatus & $30 \mathrm{TM}$ & 100,00 & 99,18 & 114,38 & 38,6 & 6035,13 & 269,98 & $-22,77$ & 292,75 & 117,33 & 179,49 & 179,60 & 26,17 & 597,93 & 69,21 & 31,7 & 19,53 & 179,08 & 113,60 & 119,15 & 155,93 \\
\hline Pelodytes punctatus & 30TWM34 & 100,00 & 85,60 & 111,58 & 38,56 & 5936,16 & 253,40 & $-32,75$ & 286,15 & 102,03 & 165,18 & 165,19 & $\begin{array}{l}14,49 \\
\end{array}$ & 689,98 & 78,33 & 37,81 & 18,55 & 204,94 & 131,59 & 133,87 & 180,82 \\
\hline Pelodytes punctatus & 30TWM38 & 100,00 & 101,31 & 105,51 & 38,45 & 5753,02 & 257,99 & $-12,79$ & 270,79 & 118,73 & 177,34 & $\begin{array}{l}177,35 \\
\end{array}$ & 31,06 & 658,51 & 72,71 & 35,99 & 18,21 & \begin{tabular}{|c|}
191,93 \\
\end{tabular} & 128,10 & 128,79 & 172,10 \\
\hline Pelodytes punctatus & 30TWM39 & 100,00 & 119,79 & 101,93 & 38,06 & 5702,21 & 269,49 & 6,12 & 263,36 & 138,85 & 194,02 & $\begin{array}{l}194,02 \\
\end{array}$ & 48,82 & 563,84 & 63,13 & 30,29 & 19,03 & 164,95 & 112,64 & 113,63 & 142,30 \\
\hline Pelodytes punctatus & $30 \mathrm{TWM} 40$ & 100,00 & 106,05 & 115,52 & $38, \mathrm{C}$ & 6179,69 & 278,45 & $-19,4$ & 297,90 & 125,65 & 187,90 & $\begin{array}{l}188,35 \\
\end{array}$ & 30,78 & 530,34 & 64,28 & 27,4 & 21,32 & 162,98 & 100,19 & 107,63 & 134,11 \\
\hline Pelodytes punctatus & 30TWM41 & 100,00 & 105,43 & & 38, & 140,06 & 278,34 & $-19,7$ & 298,12 & 124,92 & 186 & 187,18 & 30,5 & 546,13 & 65,24 & 28, & $0,1 / 4$ & 166,35 & $\begin{array}{l}103,75 \\
\end{array}$ & 1110,58 & 140,07 \\
\hline Pelodytes punctatus & 30TWM42 & 100,00 & 103,64 & 72 & 38,95 & 6096,81 & 276,75 & $-20,97$ & 297,71 & 122,70 & 184,62 & 184,78 & 29,42 & 568,59 & 66,79 & 29,5 & 19,90 & 171,65 & 108,52 & 115,21 & 147,62 \\
\hline Pelodytes punctatus & 30TWM43 & 100,00 & 101,79 & 1. & 38,91 & 6050,05 & 273,08 & $-21,62$ & 294,71 & 120,42 & 182,06 & 182,21 & 28,19 & 586,40 & 68,46 & 31,32 & 19,54 & 176,49 & \begin{tabular}{|c|}
112,42 \\
\end{tabular} & 119,54 & 152,32 \\
\hline Pelodytes punctatus & 30TWM44 & 100,00 & 91,01 & 112,88 & 38,79 & 5964,44 & 259,40 & $-29,18$ & 288,57 & 108,27 & 170,54 & \begin{tabular}{|c|}
170,55 \\
\end{tabular} & 19,05 & 662,31 & 75,82 & 36,30 & 18,65 & 197,60 & 127,36 & 131,80 & 173,05 \\
\hline Pelodytes punctatus & 30TWM48 & 100,00 & 105,81 & 106,21 & 38,58 & 5790,45 & 262,59 & $-9,79$ & 272,38 & 124,10 & 181,99 & \begin{tabular}{|c|}
181,99 \\
\end{tabular} & 34,73 & 631,48 & 70,85 & 34,7 & 18,56 & 185,93 & 123,74 & 124,95 & 162,81 \\
\hline Pelodytes punctatus & 30TWM49 & 100,00 & 126,24 & 5 & 38, & 8 & 76,19 & 10,4 & 265,72 & 146,67 & 195,92 & 200,91 & 54,01 & 508,37 & 59,42 & 27, & 0,34 & 153,06 & 104,01 & 107,40 & 122,04 \\
\hline Pelodytes punctatus & 30TWM50 & 100,00 & 10 & 1 & 38 & 618 & 278,07 & $-18,90$ & 296,97 & 127,18 & 188,72 & 189,23 & 31,86 & 520,60 & 64,27 & 27, & 21,79 & 162,18 & 99,62 & 107,97 & 129,36 \\
\hline \begin{tabular}{|l} 
Pelodytes punctatus \\
\end{tabular} & $30 \mathrm{TWN}$ & 100 & & & 38,41 & 6147,29 & 277,73 & $-19,11$ & 296,84 & 126,08 & 187 & \begin{tabular}{|l|l|}
187,97 \\
\end{tabular} & 31,51 & 535,59 & 65,18 & 28,19 & 21,02 & 165,40 & \begin{tabular}{ll|}
102,76 \\
\end{tabular} & 110,74 & 134,96 \\
\hline Pelodytes punctatus & 30TWM58 & 100,00 & 109,72 & 106,79 & 38,52 & 5832,45 & 266,50 & $-7,27$ & 273,77 & 128,72 & 186,08 & $\begin{array}{l}186,09 \\
\end{array}$ & 37,64 & 609,73 & 69,41 & 33,60 & 18,94 & 181,50 & \begin{tabular}{|c|}
119,68 \\
\end{tabular} & $\begin{array}{l}121,36 \\
\end{array}$ & 155,08 \\
\hline Pelodytes punctatus & 30TWM59 & 100,00 & 127,97 & 103,66 & 38,01 & 5820,68 & 278,78 & 10,88 & 267,90 & 148,81 & 191,49 & 203,04 & 54,83 & 495,98 & 59,03 & 27,62 & 20,81 & 152,26 & $\begin{array}{l}101,55 \\
\end{array}$ & 105,95 & 115,83 \\
\hline Pelodytes punctatus & 30TWM63 & 100,00 & 91,97 & 112,84 & 38,32 & 6018,94 & 259,63 & $-30,03$ & 289,66 & 110,27 & 171,93 & 172,04 & 19, & 640,81 & 75,90 & 35,53 & 19, & 195,60 & 124,72 & 131,51 & 163,30 \\
\hline \begin{tabular}{|l} 
Pelodytes punctatus \\
\end{tabular} & 30TWM67 & 100 & 105,56 & & 38,47 & 5898,47 & 265,38 & $-13,16$ & 278,54 & 124,65 & 183,04 & 183,08 & 32,9 & 625,73 & 71,84 & 34,36 & 19,22 & 187,22 & 121,40 & 124,74 & 160,55 \\
\hline \begin{tabular}{|l} 
Pelodytes punctatus \\
\end{tabular} & 30TWM68 & 100,00 & 114,52 & 106,87 & 38,35 & 5868,51 & 270,81 & $-3,59$ & 274,41 & 134,39 & 191,10 & 191,13 & \begin{tabular}{l|l|l}
41,65 \\
\end{tabular} & 589,48 & 67,82 & 32,29 & 19,56 & 176,80 & 115,20 & 118,20 & 148,52 \\
\hline Pelodytes punctatus & 30TWM69 & 100,00 & 130,87 & 103,68 & 38,11 & 5811,44 & 280,87 & 13,60 & 267,27 & 151,81 & 205,82 & 205,84 & 57,84 & 516,60 & 59,99 & 28,08 & 20,37 & 156,31 & 103,10 & 106,02 & 123,92 \\
\hline Pelodytes punctatus & 30TWM72 & 100,00 & 99,36 & 112,68 & 38,05 & 6087,58 & 266,03 & $-24,67$ & 290,70 & 119,00 & 179,66 & 179,81 & 25,04 & 578,93 & 71,36 & 31,90 & 21,09 & 181 & 113,30 & 123,71 & 202 \\
\hline Pelodytes punctatus & $30 \mathrm{TV}$ & 100 & & & 38,12 & 004 & & -24, & 288 & & & 178 & 24 & 600,17 & 72,80 & 33, & 20, & 18 & 117,19 & 126,24 & 150 \\
\hline Pelodytes punctatus & 30TWM74 & 100,00 & 104,64 & 111,38 & 38,15 & 6037,67 & 268,88 & $-18,07$ & 286,95 & 124,35 & 183,90 & \begin{tabular}{|l|}
184,07 \\
\end{tabular} & 30,39 & 579,31 & 70,04 & 31,70 & 20,70 & \begin{tabular}{|c|}
178,88 \\
\end{tabular} & 112,50 & 119,76 & 145,13 \\
\hline Pelodytes punctatus & 30TWM75 & 100,00 & 105,81 & 110,60 & 38,19 & 6005,52 & 268,75 & $-15,87$ & 284,62 & 125,63 & 184,67 & 184,71 & 31,91 & 589,35 & 70,32 & 32,27 & 20,32 & 180,49 & 114,13 & 120,21 & 148,72 \\
\hline Pelodytes punctatus & 30TWM76 & 100,00 & 108,27 & 109,80 & 38,40 & 5979,02 & 269,63 & $-12,52$ & 282,15 & 128,21 & 186,54 & 186,61 & 34,49 & 593,73 & 69,97 & 32,39 & 20,06 & 180,44 & 114,66 & 121,32 & 150,67 \\
\hline Pelody & OTV & & & & & & & 1,33 & $27 \varepsilon$ & & 100 & 199, & 47, & 536 & 63, & 28, & & & & & \\
\hline Pelodytes punctatus & $301 \mathrm{TV}$ & 100, & 128, & 105 & 38,03 & $5904, \mathrm{C} \quad \mathrm{F}$ & 282 & 9,08 & 273,14 & 149,75 & 204,79 & 204,81 & 54,47 & 533,5 & 61,81 & 28,16 & 20,74 & 160,44 & 102,74 & 106,73 & 132 \\
\hline Pelodytes punctatus & 30TWM79 & 100,00 & 131,83 & 103,92 & 38,15 & 5807,65 & 281,63 & 14,43 & 267,20 & 148,30 & 206,70 & 206,71 & 58,81 & 559,05 & 62,46 & 29,22 & 20,09 & 164,46 & 107,43 & 108,30 & 141,47 \\
\hline
\end{tabular}




\begin{tabular}{|c|c|c|c|c|c|c|c|c|c|c|c|c|c|c|c|c|c|c|c|c|c|}
\hline TAXON & UTM & $\mathrm{km} 2$ & BIO1 & B102 & $\mathrm{BIO3}$ & BIO4 & B105 & B106 & B107 & B108 & B109 & B1010 & BIO11 & BIO12 & B1013 & BIO14 & BIO15 & B1016 & B1017 & 81018 & B1019 \\
\hline Pelodytes punctatus & 30TWM81 & 100,00 & 95,19 & 111,13 & 38,00 & 6093,47 & 259,76 & $-28,84$ & 288,61 & 114,84 & 175,50 & 175,73 & 20,67 & 584,71 & 73,75 & 32,71 & 21,90 & 186,25 & 115,83 & 127,53 & 140,88 \\
\hline Pelodytes punctatus & 30TWM82 & 100,00 & 93,96 & 110,92 & 38,00 & 6058,28 & 258,25 & $-29,35$ & 287,60 & 113,12 & 173,90 & 173,96 & 19,82 & 607,35 & 75,29 & 34,08 & 21,12 & 191,30 & 119,85 & 131,13 & 148,50 \\
\hline Pelodytes punctatus & 30TWM83 & 100,00 & 102,29 & 111,08 & 38,01 & 6063,83 & 266,08 & $-21,32$ & 287,40 & 122,23 & 181,75 & 182,01 & 27,54 & 575,06 & 71,24 & 31,73 & 21,45 & 180,48 & 112,34 & 123,17 & 141,63 \\
\hline Pelodytes punctatus & 30TWM84 & 100,00 & 112,56 & 110,32 & 38,00 & 6074,30 & 274,85 & $-10,78$ & 285,63 & 133,44 & 191,83 & 191,95 & 37,15 & 536,46 & 66,46 & 28,88 & 22,09 & 167,91 & 103,46 & 111,82 & 132,19 \\
\hline Pelodytes punctatus & 30TWM85 & 100,00 & 120,81 & 109,32 & 38,00 & $\begin{array}{ll}6070,69 \\
\end{array}$ & 281,26 & $-2,30$ & 283,56 & 142,39 & \begin{tabular}{|l|}
199,63 \\
\end{tabular} & 199,70 & 45,06 & 512,43 & 63,00 & 27,03 & 22,39 & 159,30 & 97,77 & 106,13 & 126,51 \\
\hline Pelodytes punctatus & 30TWM86 & 100,00 & 114,20 & 109,04 & 38,09 & 6006,60 & 274,05 & $-7,30$ & 281,35 & 134,91 & 192,58 & 192,63 & 39,61 & 570,80 & 67,81 & 30,55 & 20,97 & 174,04 & 108,84 & 113,47 & 144,47 \\
\hline Pelodytes punctatus & 30TWM87 & 100,00 & 128,35 & 107,02 & 38,02 & 5975,87 & 284,11 & 7,13 & 276,98 & 149,45 & 205,52 & 205,54 & 53,25 & 532,35 & 62,14 & 27,45 & 21,42 & 160,02 & 100,23 & 104,59 & 134,85 \\
\hline Pelodytes punctatus & 30TWM88 & 100,00 & 134,35 & 105,10 & 38,04 & 5889,37 & 286,21 & 14,87 & 271,33 & 132,12 & 210,31 & 210,31 & 60,31 & 546,65 & 61,38 & 27,62 & 21,02 & $\begin{array}{ll}160,87 \\
\end{array}$ & 102,44 & 104,23 & 141,00 \\
\hline Pelodytes punctatus & 30TWM92 & 100,00 & 72,64 & 106,71 & 37,77 & 5954,64 & 233,16 & $-46,25$ & 279,41 & 89,69 & 152,01 & 152,06 & 0,86 & 739,71 & 89,38 & 43,41 & 19,55 & 230,16 & 148,20 & 155,56 & 180,58 \\
\hline Pelodytes punctatus & 30TWM94 & 100,00 & 116,65 & 109,32 & 38,00 & 6088,93 & 277,28 & $-6,85$ & 284,12 & 138,12 & 195,80 & 195,84 & 40,77 & 518,92 & 65,08 & 27,44 & 23,06 & 163,27 & 99,03 & 108,04 & 127,24 \\
\hline Pelodytes punctatus & 30TWM95 & 100,00 & 125,99 & 108,46 & 38,00 & 6076,73 & 284,75 & 2,67 & 282,08 & 148,08 & 204,72 & 204,73 & 49,95 & \begin{tabular}{|c|}
501,18 \\
\end{tabular} & 61,53 & 25,72 & 22,97 & 154,93 & 94,08 & 100,50 & 124,61 \\
\hline Pelodytes punctatus & 30TWM96 & 100,00 & 131,71 & 107,23 & 38,00 & 6028,23 & 288,08 & 9,28 & 278,79 & 153,84 & 209,61 & 209,62 & 55,88 & 508,03 & 60,32 & 25,39 & 22,64 & 153,29 & 94,21 & 97,98 & 128,91 \\
\hline Pelodytes punctatus & 30TWM97 & 100,00 & 135,62 & 105,89 & 38,00 & 5954,58 & 289,29 & 14,64 & 274,65 & 134,12 & 212,38 & 212,38 & 60,68 & 530,99 & 60,56 & 26,04 & 22,04 & 156,61 & 97,62 & 99,75 & 138,13 \\
\hline Pelodytes punctatus & 30TWM98 & 100,00 & 132,69 & 105,57 & \begin{tabular}{|l|l|}
38,03 \\
\end{tabular} & 5901,17 & 285,19 & 12,88 & 272,31 & 98,97 & 208,86 & 208,86 & 58,47 & 581,45 & 64,16 & 28,73 & 21,48 & 171,39 & 106,18 & 106,63 & 155,19 \\
\hline Pelodytes punctatus & 30TWM99 & 100,00 & 131,07 & 104,91 & 38,25 & 5841,19 & 282,14 & 12,33 & 269,81 & 95,75 & 206,50 & 206,50 & 57,70 & 635,06 & 70,00 & 31,24 & 21,29 & 189,54 & 114,88 & 115,15 & 174,14 \\
\hline Pelodytes punctatus & 30TWNOO & 100,00 & 120,38 & 94,44 & 37,97 & 5419,18 & 260,53 & 13,68 & 246,85 & 88,49 & 190,40 & 191,40 & 53,06 & 629,12 & 66,32 & 31,18 & 19,25 & 187,06 & 120,44 & 121,28 & 170,86 \\
\hline Pelodytes punctatus & 30TWN01 & 100,00 & 120,28 & 91,73 & 37,94 & 5288,90 & 256,13 & 16,42 & 239,71 & 88,03 & 188,49 & 189,70 & 54,88 & 677,58 & 72,94 & 33,23 & 19,58 & 203,86 & 128,09 & 130,50 & 187,86 \\
\hline Pelodytes punctatus & 30TWNO2 & 100,00 & 122,30 & 88,59 & 37,80 & 5134,56 & 253,13 & 21,27 & 231,85 & 92,57 & 188,13 & 189,59 & 58,65 & 725,80 & 80,04 & 34,78 & 20,01 & 221,58 & $\begin{array}{l}134,57 \\
\end{array}$ & 139,36 & 206,13 \\
\hline Pelodytes punctatus & 30TWNO3 & 100,00 & 116,25 & 87,55 & \begin{tabular}{|l|l|}
37,88 \\
\end{tabular} & 5049,03 & 246,02 & 17,38 & 228,64 & 76,28 & 181,08 & 182,81 & 54,08 & 797,32 & 88,72 & 38,69 & 19,84 & 243,94 & 147,58 & 152,84 & 229,04 \\
\hline Pelodytes punctatus & 30TWN04 & 100,00 & 108,15 & 86,93 & 37,99 & 4972,08 & 237,41 & 11,42 & 225,99 & 55,08 & 172,15 & 174,14 & 47,45 & 881,71 & 98,74 & 43,52 & 19,67 & 271,41 & 163,24 & 168,67 & 255,44 \\
\hline Pelodytes punctatus & 30TWN10 & 100,00 & 121,39 & 95,73 & 38,00 & 5462,53 & 262,62 & 13,45 & 249,18 & 88,99 & 192,30 & 192,78 & 53,50 & \begin{tabular}{|l|l|}
617,79 \\
\end{tabular} & 64,5 & 31, & 18,99 & 181,58 & 120,47 & 120,61 & 165,39 \\
\hline Pelodytes punctatus & 30TWN11 & 100,00 & 121,17 & 92,97 & 38,03 & 5325,25 & 258,05 & 16,19 & 241,87 & 87,30 & 189,92 & 190,83 & 55,10 & 671,24 & 71,31 & 33,48 & 19,01 & 200,12 & 129,18 & $\begin{array}{l}130,57 \\
\end{array}$ & 183,99 \\
\hline Pelodytes punctatus & 30TWN12 & 100,00 & \begin{tabular}{ll|}
116,42 \\
\end{tabular} & 91,61 & $\begin{array}{ll}38,06 \\
\end{array}$ & 5218,73 & 251,37 & 13,86 & 237,50 & 78,65 & \begin{tabular}{|l|l|}
183,78 \\
\end{tabular} & 185,01 & 51,99 & 741,39 & 80,05 & 37,07 & 18,90 & 222,10 & \begin{tabular}{|l|l|}
141,43 \\
\end{tabular} & 143,53 & 207,29 \\
\hline Pelodytes punctatus & 30TWN14 & 100,00 & 114,06 & 86,70 & 38,04 & 4951,83 & 242,09 & 17,31 & 224,79 & 60,66 & 177,48 & 179,45 & 53,44 & \begin{tabular}{|l|l|}
873,38 \\
\end{tabular} & 97,76 & 42,79 & 19,69 & 268,69 & 161,95 & 167,58 & 253,84 \\
\hline Pelodytes punctatus & 30TWN20 & 100,00 & 126,10 & 96,62 & 38,00 & 5507,50 & 267,48 & 16,71 & 250,77 & 94,30 & 197,64 & 197,75 & 57,42 & 585,64 & 61,84 & 29,96 & 18,98 & 170,90 & 116,21 & 116,25 & 153,13 \\
\hline Pelodytes punctatus & 30TWN21 & 100,00 & 110,79 & 96,77 & 38,36 & 5416,85 & 252,98 & 4,19 & 248,79 & 66,36 & 182,05 & 182,15 & 44,22 & 711,86 & 74,31 & 37,25 & 17,99 & 207,94 & 138,90 & 138,90 & 192,77 \\
\hline $\begin{array}{l}\text { Pelodytes punctatus } \\
\end{array}$ & 30TWN22 & 100,00 & 111,72 & 94,34 & 38,29 & 5288,91 & 250,19 & $\begin{array}{l}3,67 \\
7,67\end{array}$ & 242,52 & $\begin{array}{l}01,67 \\
61,6\end{array}$ & 180,75 & $\begin{array}{l}181,31 \\
181,\end{array}$ & 46,66 & 758,46 & $\begin{array}{l}80,55 \\
80,5\end{array}$ & 39,13 & 18,04 & 223,91 & 147,33 & 147,51 & 209,39 \\
\hline Pelodytes punctatus & 30TWN24 & 100,00 & 119,93 & 86,90 & 38,16 & 4940,64 & 247,10 & 22,81 & 224,29 & 66,12 & 182,88 & 184,78 & 59,15 & 862,41 & 95,99 & 42,06 & 19,59 & 264,73 & 160,61 & 165,94 & 250,16 \\
\hline Pelodytes punctatus & 30TWN30 & 100,00 & 127,14 & 98,39 & 38,01 & 5580,14 & 270,47 & 15,84 & 254,63 & 115,86 & 199,45 & 199,45 & 57,31 & 562,21 & 61,32 & 29,66 & 19,05 & 162,42 & 113,49 & 113,76 & 142,64 \\
\hline Pelodytes punctatus & 30TWN31 & 100,00 & 112,62 & 98,18 & 38,56 & 5463,45 & 255,92 & 4,41 & 251,51 & 69,11 & 184,18 & 184,18 & 45,19 & 698,07 & 73,03 & 37,09 & 17,75 & 201,94 & 137,27 & 137,27 & 186,42 \\
\hline Pelodytes punctatus & 30TWN33 & 100,00 & 103,56 & 94,58 & 38,90 & 5221,61 & 242,10 & 1,07 & 241,03 & 47,20 & 172,36 & 172,57 & 39,87 & 862,93 & 92,57 & 45,23 & 17,73 & 257,56 & 166,55 & 166,66 & 241,63 \\
\hline $\begin{array}{l}\text { Pelodytes punctatus } \\
\end{array}$ & 30TWN34 & 100,00 & 118,90 & 89,15 & 38,76 & 4985,27 & 248,45 & 20,54 & 227,91 & $\begin{array}{ll}64,53 \\
64\end{array}$ & 182,50 & \begin{tabular}{|l|l|}
184,28 \\
\end{tabular} & 57,72 & 871,82 & $\begin{array}{ll}2,63 \\
553\end{array}$ & $\begin{array}{l}3,25 \\
43,42\end{array}$ & 18,82 & 265,85 & \begin{tabular}{|l|l|}
165,05 \\
\end{tabular} & $\begin{array}{l}168,09 \\
\end{array}$ & $\begin{array}{l}24,05 \\
249,88 \\
\end{array}$ \\
\hline Pelodytes punctatus & 30TWN40 & 100,00 & 128,64 & 100,21 & 38,06 & 5669,25 & 273,99 & 15,27 & 258,73 & 148,38 & 191,98 & 201,80 & 57,55 & 533,26 & 60,36 & 29,04 & 19,70 & 156,83 & 109,49 & 112,01 & 130,23 \\
\hline Pelodytes punctatus & 30TWN41 & 100,00 & 113,05 & 99,65 & 38,75 & 5511,61 & 257,95 & 3,55 & 254,40 & 78,84 & 185,14 & 185,14 & 44,99 & 697,21 & 73,21 & 37,48 & 17,57 & 200,54 & 137,18 & 137,18 & 184,62 \\
\hline Pelodytes punctatus & 30TWN42 & 100,00 & 111,66 & 97,48 & 38,97 & 5372,17 & 253,22 & 4,92 & 248,30 & 55,80 & 182,10 & 182,10 & 45,54 & \begin{tabular}{|c|}
765,08 \\
\end{tabular} & 79,88 & 40,51 & 17,51 & 223,68 & 149,08 & 149,08 & 207,95 \\
\hline Pelodytes punctatus & 30TWN50 & 100,00 & 128,81 & 101,63 & 38,17 & 5707,35 & 275,59 & 14,16 & 261,43 & 149,29 & 178,54 & 202,48 & 57,20 & 531,73 & 60,97 & 29,42 & 19,74 & 159,20 & 108,66 & 111,32 & 127,16 \\
\hline Pelodytes punctatus & 30TWN60 & 100,00 & $\begin{array}{l}12,01 \\
128,49\end{array}$ & 102,42 & 38,65 & | 5712,74 & 275,91 & $\begin{array}{l}4,101 \\
13,51 \\
\end{array}$ & 262,40 & \begin{tabular}{|l|}
148,696 \\
148,6
\end{tabular} & \begin{tabular}{|l|}
$170,204,28$ \\
\end{tabular} & \begin{tabular}{|l|}
202,28 \\
202,
\end{tabular} & $\begin{array}{ll}56,78 \\
56\end{array}$ & |571,93 & $\begin{array}{l}60,70 \\
63,70\end{array}$ & $\begin{array}{l}\mid 3,44 \\
30,87 \\
\end{array}$ & 19,23 & \begin{tabular}{|l|}
168,39 \\
16,3
\end{tabular} & $\begin{array}{ll}113,13 \\
\end{array}$ & $\begin{array}{l}111,322 \\
114,32\end{array}$ & $\begin{array}{l}14,10 \\
141,37\end{array}$ \\
\hline Pelodytes punctatus & $30 \mathrm{TWNG}$ & 100,00 & 123,57 & 101,06 & 38,90 & 5586,07 & 268,85 & 11,30 & 257,55 & 97,75 & 195,97 & 195,97 & 53,90 & 664,02 & 70,13 & 35,35 & 18,29 & 191,84 & 129,09 & 129,09 & 173,33 \\
\hline Pelodytes punctatus & 30TWN63 & 100,00 & 103,32 & 97,94 & 39,01 & 5316,96 & 245,23 & $-2,27$ & 247,50 & 45,76 & 173,31 & 173,31 & 38,25 & 914,81 & 99,12 & 48,44 & 17,94 & 274,80 & 173,71 & 173,71 & 257,41 \\
\hline Pelodytes punctatus & 30TWN64 & 100,00 & 104,07 & 95,58 & 39,10 & 5166,61 & 242,19 & 1,56 & 240,63 & 48,36 & 172,21 & 172,21 & 41,03 & 984,99 & 108,32 & 51,52 & 18,30 & 300,55 & 186,36 & 186,36 & 281,81 \\
\hline Pelodytes punctatus & 30TWN70 & 100,00 & 128,26 & 103,05 & 38,8 & 5722,17 & 276,35 & 12,53 & 263,82 & 117,08 & 202,17 & 202 & 56,39 & 621,40 & $\begin{array}{l}06,86 \\
66,8 \\
\end{array}$ & 32,47 & 19,35 & $\begin{array}{l}180,75 \\
\end{array}$ & 118,47 & 118,66 & 161,95 \\
\hline Pelodytes punctatus & 30TWN71 & 100,00 & 122,45 & 101,95 & 38,5 & 5618,81 & 269,19 & 9,36 & 259,82 & 75,45 & 195,46 & 195,46 & 52,41 & 709,88 & 75,19 & $37, \mathrm{C}$ & 18,93 & 208,65 & 134,01 & 134,01 & 191,71 \\
\hline Pelodytes punctatus & 30TWN72 & 100,00 & 120,18 & 100,16 & 39,00 & 5473,56 & 264,10 & 10,08 & 254,02 & 59,92 & 191,43 & 191,43 & 52,22 & 795,65 & 86,12 & 40,98 & 18,93 & 239,09 & 148,78 & 148,78 & 221,42 \\
\hline Pelodytes punctatus & 30TWN74 & 100,00 & 100,62 & 96,62 & 39,21 & 5208,45 & 240,12 & $-2,82$ & 242,94 & 44,68 & 169,38 & 169,38 & 37,17 & $\begin{array}{l}1021,25 \\
\end{array}$ & 113,47 & 53,57 & 18,56 & 312,86 & 191,86 & 191,86 & 293,94 \\
\hline Pelodytes punctatus & 30TWN80 & 100,00 & 129,95 & 103,38 & 38,72 & 5737,03 & 278,56 & 13,85 & 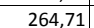 & 94,26 & 09 & 2 & 57,87 & 659,71 & 71,18 & 33 & 20,28 & 96,01 & 121,57 & 121,57 & 179,50 \\
\hline $\begin{array}{l}\text { Pelodytes punctatus } \\
\end{array}$ & 30TWN81 & 100,00 & 12 & 102,29 & 38 & 5634,65 & 274, & $\begin{array}{l}12,96 \\
12,96\end{array}$ & $\frac{26}{26}$ & 69,60 & $\frac{20}{20}$ & & 56,46 & 736,82 & 81,4 & & 20,25 & 222,85 & $\begin{array}{l}134,50 \\
\end{array}$ & 134,50 & 206,27 \\
\hline Pelodytes punctatus & $30 \mathrm{TWI}$ & 100,00 & 122,08 & 101,03 & 38,99 & 5523,64 & 267, & 10,41 & 256,87 & 61,07 & 193,86 & 193,86 & 53,14 & 830,67 & 93,74 & 41, & 20,33 & 255,99 & 150,78 & 150,78 & 238,30 \\
\hline Pelodytes punctatus & 30TWN84 & 100,00 & 91,57 & 97,49 & 39,01 & 5276,41 & 233,10 & $-13,28$ & 246,38 & 35,46 & 161,44 & 161,44 & 27,57 & $\begin{array}{r}1060,01 \\
\end{array}$ & 118,21 & 56,62 & 18,24 & 323,42 & 199,51 & 199,51 & 305,06 \\
\hline Pelodytes punctatus & 30TWN90 & 100,00 & 130,41 & 103,87 & 38,51 & 5766,03 & 279,85 & 13,29 & 266,56 & 90,01 & 204,94 & 204,94 & 57,74 & 694,81 & 78,47 & 33,90 & 21,38 & 10,72 & 124,39 & 124,39 & 195,88 \\
\hline Pelodytes punctatus & 30TWN91 & 100,00 & 129, & 102,72 & 38,78 & 5672,55 & 277,29 & 14,55 & 262,73 & 7,71 & 202,99 & 202 & 58,42 & 767,09 & 88,85 & 37,06 & 21,72 & 28 & 92 & 135,92 & 222,37 \\
\hline Pelodytes punctatus & $30 \mathrm{TW}$ & 100,00 & 12 & 10 & 38 & 5574,60 & 271,25 & 11,91 & 259,34 & 63,38 & 197,29 & 19 & 55,07 & 861,72 & \begin{tabular}{|l|}
101,88 \\
\end{tabular} & 41,6 & 22,23 & 272,79 & 151,59 & 151,59 & 255,62 \\
\hline Pelodytes punctatus & $\begin{array}{l}\text { 30TWN93 } \\
\end{array}$ & 100,00 & 114,54 & 100,49 & 39,01 & 5454,66 & 259,17 & 4,41 & 254,76 & 54,88 & 185,74 & 185,74 & 46,83 & 966,57 & 113,87 & 48,01 & 21,46 & 306,26 & 172,27 & 172,27 & 287,92 \\
\hline $\begin{array}{l}\text { Pelodytes punctatus } \\
\text { S }\end{array}$ & \begin{tabular}{|l|}
$30 T \times K 04$ \\
\end{tabular} & 100,00 & $\begin{array}{r}14,29 \\
91,29\end{array}$ & 113,85 & 37,81 & 6408,16 & 263,32 & \begin{tabular}{|c|c|}
$-4,41$ \\
$-35,17$
\end{tabular} & 298,49 & \begin{tabular}{|l|}
109,31 \\
\end{tabular} & $\begin{array}{l}177,06 \\
\end{array}$ & $\begin{array}{l}177,95 \\
\end{array}$ & $\begin{array}{l}40,50 \\
15,51\end{array}$ & 588,74 & 76,51 & $\begin{array}{l}28,84 \\
28,84\end{array}$ & 25,23 & $\begin{array}{l}193,61 \\
\end{array}$ & 111,69 & 123,91 & 126,51 \\
\hline Pelodytes punctatus & 30TXK05 & 100,00 & 85,42 & 112,53 & 37,48 & 6386,84 & 256,24 & $-40,19$ & 296,44 & 103,25 & 170,92 & 171,92 & 9,99 & 611,81 & 79,73 & 31,25 & 24,81 & 201,77 & 117,99 & 131,47 & 131,33 \\
\hline Pelodytes punctatus & 30TXKC & 100,00 & 79, & 111,37 & 37,1 & 6361,73 & 249,61 & $-44,79$ & 294,40 & 97,32 & 165,13 & 16 & 4,81 & 636 & 82,84 & 33,56 & 24,36 & 209,90 & 124,25 & 138,84 & 13 \\
\hline Pelodytes punctatus & 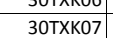 & 100,00 & 76,83 & 1110,40 & 年, & | $6301,1 / 15$ & 245,01 & $\begin{array}{l}-47,18 \\
-47,18\end{array}$ & \begin{tabular}{|l|}
292,56 \\
292,
\end{tabular} & $\begin{array}{l}1,325 \\
94,26 \\
\end{array}$ & \begin{tabular}{|l|}
161,80 \\
161
\end{tabular} & $\begin{array}{l}103,52,60 \\
162\end{array}$ & $\begin{array}{l}4,01 \\
1,99 \\
\end{array}$ & $\begin{array}{l}\mid \\
640,56,58\end{array}$ & $\begin{array}{l}<, 044 \\
84,44\end{array}$ & \begin{tabular}{|l|l|}
34,85 \\
34,8
\end{tabular} & 24,10 & \begin{tabular}{|l|}
213,76 \\
\end{tabular} & \begin{tabular}{l|}
127,65 \\
127
\end{tabular} & $\begin{array}{l}140,04 \\
142,93 \\
\end{array}$ & $\begin{array}{l}130,59,03 \\
39\end{array}$ \\
\hline Pelodytes punctatus & 30TXK08 & 100,00 & 77,03 & 109,66 & 37,08 & 6312,45 & 243,99 & $-46,97$ & 290,96 & 94,68 & 161,59 & 162,30 & 2,12 & 639,09 & 84,13 & 35,02 & 24,46 & 212,45 & 127,62 & 143,21 & 136,57 \\
\hline Pelodytes punctatus & 30TXK09 & 100,00 & 79,59 & 109,00 & 37,00 & 6294,38 & 244,64 & $-44,95$ & 289,60 & 97,81 & 162,42 & 164,38 & 4,53 & 617,75 & 82,36 & 34,29 & 25,07 & 206,99 & 124,88 & 140,40 & 130,87 \\
\hline Pelodytes punctatus & 30TXK13 & 100,00 & 103,18 & 112,92 & 37,95 & 6398,18 & 272,30 & $-23,34$ & 295,64 & 121,6 & 188 & 189 & 27,14 & 528,20 & 69,37 & 25,15 & 26 & 175 & 101,53 & 111,21 & 109,10 \\
\hline Pelodytes punctatus & 30TXK15 & 100,00 & 82,18 & 110,27 & 37,05 & 6359,69 & 250,24 & $-41,86$ & 292,10 & 99,40 & 166,42 & 168,26 & 7,14 & 624,09 & 81,44 & 3,05 & 24,62 & 207,10 & 123,55 & 137,40 & 131,11 \\
\hline
\end{tabular}




\begin{tabular}{|c|c|c|c|c|c|c|c|c|c|c|c|c|c|c|c|c|c|c|c|c|c|}
\hline TAXON & UTM & $\mathrm{km} 2$ & BIO1 & B102 & $\mathrm{BIO3}$ & 8104 & B105 & B106 & B107 & B108 & B109 & BIO10 & B1011 & BIO12 & B1013 & B1014 & 81015 & B1016 & BIO17 & BIO18 & \begin{tabular}{|l|}
$\mathrm{B} 1019$ \\
\end{tabular} \\
\hline Pelodytes punctatus & 30тХK16 & 100,00 & 80,38 & 109,45 & 37,00 & 6342,31 & 247,30 & $-43,47$ & 290,77 & 97,85 & 161,94 & 166,18 & 5,42 & 626,66 & 82,40 & 33,88 & 24,82 & 208,97 & 125,47 & 140,04 & 131,01 \\
\hline Pelodytes punctatus & 30TXK17 & 100,00 & 81,07 & 108,66 & 37,00 & 6320,35 & 246,23 & $-42,92$ & 289,15 & 98,94 & 129,53 & 166,37 & 6,01 & 614,81 & 81,79 & 33,82 & 25,33 & 206,54 & 124,02 & 139,62 & 127,34 \\
\hline Pelodytes punctatus & 30TXK18 & 100,00 & 75,69 & $\begin{array}{l}107,67 \\
\end{array}$ & 37,00 & 6288,67 & 239,92 & $-47,22$ & 287,14 & 93,29 & 120,62 & 160,59 & $\begin{array}{l}0,0125 \\
1,25 \\
\end{array}$ & $\mid 642,11$ & 84,96 & $\begin{array}{l}30,000 \\
36,08 \\
\end{array}$ & 24,72 & 215,03 & 130,37 & 147,04 & 134,20 \\
\hline Pelodytes punctatus & 30TXK19 & 100,00 & 83,36 & 107,15 & 37,00 & 6276,76 & 244,69 & $-41,06$ & 285,75 & 102,17 & 44,08 & \begin{tabular}{|c|}
167,57 \\
\end{tabular} & 8,08 & 586,94 & 80,05 & 33,30 & 26,64 & 200,45 & 118,56 & 137,53 & 119,29 \\
\hline Pelodytes punctatus & 30TXK23 & 100,00 & 100,11 & 110,21 & 37,39 & 6373,31 & 266,38 & $-24,35$ & 290,73 & 118,26 & \begin{tabular}{|c|}
146,67 \\
\end{tabular} & 186,21 & 24,56 & $\begin{array}{l}535,75 \\
\end{array}$ & 70,58 & 26,75 & 26,57 & \begin{tabular}{|c|}
179,48 \\
\end{tabular} & 105,99 & 116,16 & 107,35 \\
\hline Pelodytes punctatus & $30 T \times K 24$ & 100,00 & 93,48 & 109,31 & 37,07 & 6365,55 & 259,06 & $-30,55$ & 289,61 & 111,53 & 86,95 & 179,53 & 18,15 & 561,96 & 74,46 & 29,25 & 26,24 & 188,91 & \begin{tabular}{|c|}
111,88 \\
\end{tabular} & 124,59 & 112,80 \\
\hline Pelodytes punctatus & $30 T \times K 25$ & 100,00 & 87,44 & 108,39 & 37,00 & 6344,98 & 252,18 & $-36,29$ & 288,47 & 105,20 & 63,33 & 173,14 & 12,24 & 588,16 & 78,06 & 31,61 & 25,82 & 197,97 & 118,21 & 132,53 & 118,65 \\
\hline Pelodytes punctatus & $30 T \times K 26$ & 100,00 & 87,08 & 107,41 & 37,00 & 6329,36 & 250,13 & $-36,45$ & \begin{tabular}{|l|}
286,58 \\
\end{tabular} & 105,25 & \begin{tabular}{|c|}
49,88 \\
\end{tabular} & 172,45 & 11,81 & 580,73 & 78,10 & 31,95 & 26,41 & 197,09 & 115,44 & 133,34 & 115,90 \\
\hline Pelodytes punctatus & $30 T \times K 27$ & 100,00 & 90,92 & 106,46 & 36,99 & 6310,71 & 251,44 & $-33,16$ & 284,60 & 109,82 & \begin{tabular}{ll|}
15,49 \\
\end{tabular} & \begin{tabular}{|c|}
175,78 \\
\end{tabular} & 15,49 & 549,27 & 75,58 & 30,67 & 27,89 & 189,27 & 106,92 & 128,99 & \begin{tabular}{ll|}
106,92 \\
\end{tabular} \\
\hline Pelodytes punctatus & $30 T \times K 28$ & 100,00 & 84,80 & 105,77 & 36,99 & 6281,25 & 244,63 & $-38,76$ & 283,39 & 103,45 & 18,02 & 169,19 & 9,79 & 578,01 & 79,11 & 32,97 & 27,26 & 198,66 & 113,88 & 137,05 & 113,97 \\
\hline Pelodytes punctatus & 30T×K34 & 100,00 & 96,54 & 106,77 & 37,00 & 6341,71 & 258,65 & $-26,12$ & 284,78 & 114,40 & 23,29 & 182,16 & 21,10 & 541,29 & 72,33 & 28,84 & 27,11 & 183,53 & 104,59 & 122,41 & 104,60 \\
\hline $\begin{array}{l}\text { Pelodytes punctatus } \\
\end{array}$ & $30 T \times K 35$ & 100,00 & 91,11 & 105,96 & 37,00 & 6329,52 & 252,52 & $-31,06$ & 283,59 & 109,05 & 34,57 & 176,71 & 16,12 & 562,28 & 75,46 & 30,82 & 26,95 & 191,22 & 109,01 & 129,35 & 109,10 \\
\hline Pelodytes punctatus & $30 T \times K 36$ & 100,00 & 89,36 & 105,15 & 36,96 & \begin{tabular}{|c|c|c|}
6310,23 \\
\end{tabular} & 249,32 & $-33,01$ & 282,33 & 107,46 & \begin{tabular}{|l|l|l}
14,43 & \\
\end{tabular} & \begin{tabular}{|c|}
174,49 \\
\end{tabular} & 14,43 & 562,61 & 76,48 & 31,49 & 27,46 & $\begin{array}{l}192,96 \\
\end{array}$ & 108,06 & 132,04 & 108,06 \\
\hline Pelodytes punctatus & 30TXK37 & 100,00 & 96,51 & 103,75 & 36,84 & 6301,96 & 252,85 & $-26,35$ & 279,20 & 115,90 & 21,12 & 181,14 & 21,12 & \begin{tabular}{|l|l|}
510,25 \\
\end{tabular} & 71,81 & 27,73 & 30,17 & 179,23 & 93,54 & 123,62 & 93,54 \\
\hline Pelodytes punctatus & $30 \mathrm{~T} \times \mathrm{3} 3$ & 100,00 & 95,22 & 102,94 & 36,59 & 6273,83 & 249,72 & $-28,17$ & 277,89 & 115,05 & 19,50 & 179,20 & 19,50 & 508,38 & 72,46 & 27,36 & 30,95 & 180,26 & 92,49 & 125,50 & 92,49 \\
\hline Pelodytes punctatus & $30 \mathrm{~T} \times 39$ & 100,00 & 96,64 & 102,03 & 36,50 & 6237,25 & 248,21 & $-27,50$ & 275,72 & 117,08 & 20,75 & 179,66 & 20,75 & 493,07 & 71,48 & 25,97 & 32,38 & 177,07 & 88,36 & 124,17 & 88,36 \\
\hline Pelodytes punctatus & $30 T \times K 45$ & 100,00 & 100,83 & 103,15 & 36,74 & 6318,85 & 257,94 & $-20,10$ & 278,04 & 119,41 & 25,62 & 186,08 & 25,62 & 503,32 & 69,24 & 27,13 & 29,50 & 174,30 & 91,03 & 118,84 & 91,03 \\
\hline Pelodytes punctatus & 30TXK46 & 100,00 & 100,39 & 102,03 & 36,38 & 6310,30 & 255,61 & $-20,58$ & 276,19 & 119,41 & 25,17 & 185,30 & 25,17 & 494,29 & 69,28 & 26,03 & 30,70 & 173,50 & 87,49 & 119,83 & 87,49 \\
\hline Pelodytes punctatus & 30TXK47 & 100,00 & 105,58 & 100,56 & 36,06 & \begin{tabular}{|c|c|c|}
6302 \\
\end{tabular} & 257,69 & $-15,92$ & 273,61 & 125,56 & 29,86 & 189,98 & 29,86 & 456,05 & 66,08 & 22,62 & 33,51 & 163,82 & 76,81 & 114,08 & 76,81 \\
\hline Pelodytes punctatus & 30TXK48 & 100,00 & 106,64 & 99,68 & 36,05 & 6268,44 & 255,85 & $-15,66$ & 271,51 & 127,33 & 30,49 & 190,24 & 30,49 & 442,42 & 65,35 & 21,40 & 35,04 & 161,32 & 73,19 & 113,16 & 73,19 \\
\hline Pelodytes punctatus & $30 T \times K 49$ & 100,00 & 105,09 & 99,04 & 36,05 & 6222,95 & 251,72 & $-18,01$ & 269,73 & 126,24 & 29,09 & 187,64 & 29,09 & 443,49 & 66,29 & 21, & 35,94 & 163,25 & 73,09 & 115,32 & 73,09 \\
\hline Pelodytes punctatus & $30 T \times K 53$ & 100,00 & 104,61 & 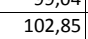 & 36,96 & 6278,89 & 261,26 & $-14,89$ & 276,15 & 122,03 & 30,58 & 189,31 & 30,58 & | & 67,23 & 26,95 & 28,05 & $\begin{array}{l}171,62 \\
171\end{array}$ & 93,89 & $\mid \frac{114,91}{214}$ & 93,89 \\
\hline Pelodytes punctatus & $30 \mathrm{TXK55}$ & 100,00 & 113,78 & 99,76 & 36,03 & 6306,82 & 267,17 & $-5,13$ & 272,30 & 132,75 & 38,54 & 198,56 & 38,54 & 438,72 & 61,46 & 21,63 & 32,73 & 153,64 & 73,11 & 104,93 & 73,11 \\
\hline Pelodytes punctatus & $30 T \times K 56$ & 100,00 & 112,06 & 98,56 & 35,93 & 6318,25 & 264,44 & $-6,62$ & 271,06 & 131,48 & 36,42 & 196,96 & 36,42 & 432,95 & 62,20 & 20,58 & 34,39 & 154,45 & 69,78 & 107,29 & 69,78 \\
\hline Pelodytes punctatus & $30 T \times K 57$ & 100,00 & 106,68 & 98,29 & 35,97 & 6290,38 & 257,41 & $-12,77$ & 270,18 & 126,34 & 31,34 & 191,11 & 31,34 & 450,32 & 65,32 & 21,55 & 34,45 & 162,01 & 73,28 & 113,87 & 73,28 \\
\hline Pelodytes punctatus & $30 T \times K 58$ & 100,00 & 99,21 & 98,50 & 36,00 & 6242,60 & 248,40 & $-21,20$ & 269,60 & 118,93 & 24,26 & 182,72 & 24,26 & 484,26 & 69,93 & 24,02 & 33,15 & 173,81 & 81,65 & 123,21 & 81,65 \\
\hline Pelodytes punctatus & $30 T \times K 59$ & 100,00 & 94,94 & 98,25 & 36,00 & 6198,18 & 243,00 & $-25,97$ & 268,97 & 114,45 & 20,13 & 177,62 & 20,13 & 503,23 & 72,60 & 25,45 & 32,69 & 180,55 & 86,46 & 128,89 & 86,46 \\
\hline Pelodytes punctatus & 30TXK63 & 100,00 & 82,82 & 102,00 & 36,40 & 6236,43 & 241,01 & $-35,06$ & 276,07 & 98,15 & 38,77 & 167,37 & 10,31 & 644,46 & 81,18 & 35,28 & 24,06 & 210,51 & 127,79 & 140,53 & 127,99 \\
\hline Pelodytes punctatus & 30TXK64 & 100,00 & 87,24 & 100,95 & 36,13 & 6239,38 & 243,50 & $-30,71$ & 274,21 & 103,31 & 23,44 & \begin{tabular}{|l|l|}
171,63 \\
\end{tabular} & 14,31 & 605,14 & 78,26 & 33,42 & 25,65 & 201,08 & \begin{tabular}{|c|}
116,08 \\
\end{tabular} & 137,66 & 116,18 \\
\hline Pelodytes punctatus & 30TXK65 & 100,00 & 101,19 & 98,94 & 36,00 & 6251,87 & 254,13 & $-16,56$ & 270,68 & 118,92 & 27,25 & 185,38 & 27,25 & 510,44 & 69,27 & 26,68 & 29,66 & 174,93 & 89,85 & 121,25 & 89,85 \\
\hline Pelodytes punctatus & 30TXK66 & 100,00 & 108,23 & 97,32 & 35,94 & 6269,53 & 259,48 & $-9,12$ & 268,61 & 126,95 & 33,81 & 192,60 & 33,81 & 458,11 & 64,67 & 22,13 & 33,10 & 161,26 & 74,98 & 112,78 & 74,98 \\
\hline Pelodytes punctatus & 30TXK67 & 100,00 & 104,56 & 96,94 & 35,79 & 6246,24 & 254,15 & $-13,47$ & 267,62 & 123,62 & 30,08 & 188,43 & 30,08 & 469,72 & 66,91 & 22,78 & 33,33 & 166,56 & 77,30 & 117,66 & 77,30 \\
\hline \begin{tabular}{|l} 
Pelodytes punctatus \\
\end{tabular} & 30TXK68 & 100,00 & 102,25 & 96,64 & 35,91 & 6212,39 & 249,82 & $-16,64$ & 266,47 & 121,72 & 27,74 & 185,44 & 27,74 & 474,20 & 68,32 & 22,89 & 33,66 & 169,64 & 78,10 & 120,54 & 78,10 \\
\hline Pelodytes punctatus & 30T×K69 & 100,00 & 100,38 & 96,35 & 35,97 & 6177,58 & 245,97 & $-19,36$ & 265,34 & 120,29 & 25,86 & 182,75 & 25,86 & 478,58 & 69,53 & 23,1 & 34,12 & 172,34 & 79,11 & 123,21 & 79,11 \\
\hline Pelodytes punctatus & 30TXK73 & 100,00 & 90,47 & 99,95 & 36,11 & 6192,30 & 245,25 & $-26,3$ & 271,55 & 106,12 & 20,42 & 174,21 & 18, & 604,95 & 76,52 & 32, & 25,01 & 197,56 & 116,88 & 134,35 & 116,88 \\
\hline Pelodytes punctatus & 30TXK74 & 100,00 & 91,00 & 99,13 & 36,01 & 6192,24 & 244,61 & $-25,81$ & 270,42 & 107,01 & 18,69 & 174,65 & 18,69 & 590,92 & 76,16 & 32,35 & 25,95 & 195,32 & 111,82 & 134,20 & 111,82 \\
\hline Pelodytes punctatus & $30 T \times K 75$ & 100,00 & 103,40 & 97,31 & 35,99 & 6193,90 & 254,00 & $-13,27$ & 267,27 & 120,72 & 30,15 & 186,71 & 30,15 & 508,76 & 68,34 & 26,39 & 29,45 & $\mid 172,57$ & 89,17 & 119,69 & 89,17 \\
\hline Pelodytes punctatus & 30TXK77 & 100,00 & 88,03 & 97,19 & 36,00 & 6165,48 & 238,27 & $-29,22$ & 267,50 & 105,11 & 15,14 & 170,92 & 15,14 & 579,55 & 77,91 & 31,66 & 27,76 & 197,02 & 105,96 & 139,66 & 105,96 \\
\hline Pelodytes punctatus & 30TXK78 & 100,00 & 86,79 & 96,62 & 35,98 & 6147,74 & 235,81 & $-30,66$ & 266,47 & 104,22 & 13,87 & 169,33 & 13,87 & 581,24 & 78,81 & 31,64 & 28,28 & 198,74 & 105,94 & 141,88 & 105,94 \\
\hline Pelodytes punctatus & $30 \mathrm{~T} \times \mathrm{K} 83$ & 100,00 & 106,31 & 97,56 & 36,03 & 13,81 & 256,51 & $-9,25$ & 265,75 & 122,37 & 34,74 & 188,70 & 34,74 & 529,97 & 67,17 & 27,57 & 7,21 & 171,99 & 98,04 & 116,27 & 98,04 \\
\hline $\begin{array}{l}\text { Pelodytes punctatus } \\
\end{array}$ & 30TXK86 & 100,00 & 102,09 & 95,56 & 35,84 & 6136,09 & 250,16 & $-13,75$ & 263,91 & 119,14 & 29,49 & 184,51 & 29,49 & 519,94 & 69,72 & 26,87 & 29,38 & 175,49 & 91,25 & 122,76 & 91,25 \\
\hline Pelodytes punctatus & 30TXK87 & 100,00 & 86,28 & 96,04 & 35,94 & 6125,23 & 235,37 & $-29,68$ & 265,04 & 102,63 & 14 & 168,73 & 14,27 & 603,92 & 79,63 & 33,52 & 26,50 & 202,00 & 112,33 & 142,80 & 112,33 \\
\hline Pelodytes punctatus & 30TXK88 & 100,00 & $\begin{array}{l}80,269 \\
86,99\end{array}$ & 95,60 & 35,78 & 6107,93 & 234,77 & $-29,32$ & 264,09 & 103,80 & 14,83 & 168,97 & 14,83 & \begin{tabular}{|l|l|}
591,79 \\
\end{tabular} & 79,21 & 32,33 & 27,40 & 199,92 & 108,56 & 142,45 & 108,56 \\
\hline Pelodytes punctatus & $30 T \times K 89$ & 100,00 & 89,89 & 95,19 & 35,86 & 6094,73 & 236,24 & $-26,91$ & 263,15 & 107,44 & 17,72 & 171,58 & 17,72 & 566,46 & 77,28 & 30,17 & 28,85 & 193,84 & 101,71 & 138,72 & 101,71 \\
\hline Pelodytes punctatus & 30TXK93 & 100,00 & 115,89 & 95,69 & 36,00 & 6010,63 & 262,18 & 1,05 & 261,12 & 130,54 & 45,08 & 196,67 & 45,08 & 502,89 & 62,32 & 24,72 & 28,11 & 159,14 & 93,18 & 108,58 & 93,18 \\
\hline Pelodytes punctatus & 30TXK95 & 100,00 & $\begin{array}{ll}108,05 \\
108,\end{array}$ & $\begin{array}{l}30,793 \\
94,79 \\
\end{array}$ & 35,95 & $\begin{array}{ll}6058,85 \\
6058\end{array}$ & | 254,35 & $\frac{\mid, 03}{-6,84}$ & 2601,19 & $\mid \begin{array}{l}\mid 50,34, \\
124,64\end{array}$ & 年3,00 & $\begin{array}{l}189,29 \\
\end{array}$ & $\begin{array}{l}43,00 \\
36,56 \\
\end{array}$ & 518,09 & \begin{tabular}{|c|}
$67,10<$ \\
67
\end{tabular} & 27,16 & $\begin{array}{l}20,11 \\
28,55 \\
\end{array}$ & $\mid \begin{array}{l}169,40 \\
\end{array}$ & $\begin{array}{l}93,58 \\
93,5\end{array}$ & $\begin{array}{l}116,73 \\
116,1\end{array}$ & $\begin{array}{l}3,10 \\
93,58 \\
\end{array}$ \\
\hline $\begin{array}{l}\text { Pelodytes punctatus } \\
\end{array}$ & $30 T \times K 96$ & 100,00 & 87,55 & 95,38 & 35,88 & 6087,28 & 236,15 & $-27,25$ & 263,40 & 103,18 & 16,42 & 169,58 & 16,42 & 620,63 & 79,56 & 34,40 & 25,38 & 202,81 & 117,91 & 141,56 & 117,91 \\
\hline Pelodytes punctatus & 30TXK98 & 100,00 & 82,76 & 94,76 & 35,80 & 6063,78 & 230,25 & $-32,22$ & 262,47 & 98,75 & 11,65 & 164,31 & 11,65 & 634,63 & 82,64 & 35,73 & 25,51 & 209,67 & 120,22 & 148,25 & 120,22 \\
\hline Pelodytes punctatus & $30 T \times L O 0$ & 100,00 & 87,40 & 108,49 & 37,00 & 6279,95 & 249,65 & $-38,55$ & 288,19 & 106,84 & 120,01 & 171,49 & 11 & 564,10 & 77,31 & 31, & 26,81 & 192,40 & 115,47 & 130,72 & 116,72 \\
\hline Pelodytes punctatus & 30TXL11 & 100,00 & 91, & 105,71 & 37, & & 24 & -34 & 282 & 112,37 & 15, & 174,65 & 15 & 523,98 & 74,38 & 30, & 29 & 184,00 & 102,93 & 127,41 & 102,93 \\
\hline Pelodytes punctatus & $30 \mathrm{~T} \times 12$ & 100,00 & 95,85 & 105,01 & 37,00 & 6202,83 & 249,54 & $\mid-31,10$ & 280,64 & 117,09 & 26,91 & 177,72 & 19,57 & 497,81 & 71,90 & 28,04 & 30,91 & 176,99 & 96,26 & 122,93 & 96,50 \\
\hline Pelodytes punctatus & 30TXL13 & 100,00 & 98,47 & 104,71 & 37,00 & 6186,85 & 251,01 & $-28,75$ & 279,77 & 120,31 & 31,71 & 179,94 & 22,29 & 482,34 & 70,19 & 26,68 & 31,63 & 172,32 & 92,00 & 119,73 & 93,40 \\
\hline Pelodytes punctatus & 30TXL14 & 100,00 & 99,84 & 104,72 & 37,00 & 6169,05 & 252,13 & $-27,52$ & 279,65 & 121,90 & 33,18 & 180,88 & 23,67 & 477,12 & 69,48 & 26,47 & 31,68 & 170,33 & 90,88 & 118,34 & 93,38 \\
\hline Pelodytes punctat & $30 \mathrm{~T} \times L 20$ & 100,00 & & , & 36,94 & 6227,62 & 2 & $-34,25$ & 279,44 & 7 & 15,03 & 173,66 & 15,03 & 527 & 75,08 & 29 & 30,20 & 186,55 & 100,45 & 130,35 & 100,45 \\
\hline Pelodytes punctatus & $30 \mathrm{~T} \times 21$ & 100 & & & 36, & 6191 & 241 & $-28,73$ & 276,39 & 1 & 26,43 & 179,32 & 21, & 482 & 70,89 & 25, & 33,13 & 174,63 & 88,47 & 122,35 & 88,61 \\
\hline Pelodytes punctatus & $30 T \times L 22$ & 100,00 & 99,03 & 102,34 & 36,82 & 6166,32 & 247,45 & $-27,74$ & 275,19 & $\begin{array}{ll}121,14 \\
\end{array}$ & 32,12 & 180,13 & 22,89 & 470,05 & 69,89 & 24,30 & 33,92 & 171,59 & 84,86 & 120,63 & 85,96 \\
\hline Pelodytes punctatus & $30 \mathrm{TXL23}$ & 100,00 & 101,91 & 102,08 & 36,85 & 6139,68 & 248,97 & $-25,49$ & 274,47 & 124,33 & 35,14 & 182,20 & 25,52 & 455,18 & 68,36 & 23,12 & 34,76 & 167,11 & 80,94 & 117,21 & 83,37 \\
\hline Pelodytes punctatus & $30 T \times L 24$ & 100,00 & 96,83 & 102,61 & 36,90 & 129,49 & 245,92 & $-29,65$ & 275,58 & 118,51 & 30,43 & 177,20 & 20,92 & 487,09 & 71,41 & 26,08 & 32,53 & \begin{tabular}{|l|l|}
175,48 \\
\end{tabular} & 90,18 & 123,84 & \\
\hline Pelodytes & $30 \mathrm{TXL}$ & 100,00 & 102, & 100 & 36, & 1 & 249 & $-22, \varepsilon$ & 272,34 & 9] & 28,63 & 184,34 & 26, & 452 & 67, & 22, & 35,47 & & 77,95 & 117,45 & \\
\hline Pelodytes punctatus & $30 T \times 131$ & 100,00 & 104,71 & $\begin{array}{l}39,65 \\
99,65 \\
\end{array}$ & $\begin{array}{l}0,429 \\
36,29 \\
\end{array}$ & 6145,01 & 248,19 & $\begin{array}{l}-21,79 \\
-21,79\end{array}$ & 269,98 & 127,27 & 37,75 & 185,23 & 28,40 & 435,22 & 66,48 & 20,53 & 37,38 & 162,89 & 72,70 & 115,31 & 73,72 \\
\hline
\end{tabular}




\begin{tabular}{|c|c|c|c|c|c|c|c|c|c|c|c|c|c|c|c|c|c|c|c|c|c|}
\hline TAXON & UTM & $\mathrm{km} 2$ & BIO1 & $\mathrm{B1O2}$ & $\mathrm{B1O3}$ & B104 & B105 & B106 & B107 & B108 & B109 & B1010 & BI011 & BIO12 & B1013 & B1014 & 81015 & B1016 & BIO17 & BIO18 & B1019 \\
\hline Pelodytes punctatus & 30TXL32 & 100,00 & 102,32 & 99,48 & 36,27 & 6111,27 & 244,66 & $-24,75$ & 269,41 & 124,86 & 35,49 & 182,03 & 26,05 & 444,99 & 67,97 & 20,99 & 37,29 & 166,56 & 74,21 & 118,63 & 76,57 \\
\hline Pelodytes punctatus & $30 T \times L 33$ & 100,00 & 100,56 & 99,81 & 36,35 & 6097,72 & 243,69 & $-26,50$ & 270,19 & 122,92 & 33,88 & 180,03 & 24,34 & 455,56 & 69,13 & 21,99 & 36,32 & 169,37 & 77,45 & 120,71 & 80,36 \\
\hline Pelodytes punctatus & $30 \mathrm{~T} \times 135$ & 100,00 & 106,74 & 100,94 & 36,57 & 6099,30 & 252,09 & $-20,23$ & 272,32 & 129,56 & \begin{tabular}{|l|l|}
40,47 \\
\end{tabular} & 185,94 & 30,32 & 436,62 & 66,18 & 21,77 & 35,22 & 160,59 & 76,35 & 112,66 & 79,99 \\
\hline Pelodytes punctatus & $30 T X L 40$ & 100,00 & 98,19 & 99,03 & 36,00 & 6177,33 & 244,29 & $-25,42$ & 269,70 & 119,08 & 23,32 & 179,94 & 22,66 & 477,14 & 70,56 & 23,76 & 34,72 & 174,42 & 81,71 & 124,25 & 81,71 \\
\hline Pelodytes punctatus & 30TXL41 & 100,00 & 97,45 & 98,44 & 36,00 & 6130,43 & 241,32 & $-27,00$ & 268,32 & 118,89 & 27,51 & 178,22 & 21,91 & 474,47 & 70,94 & 23,18 & 35,55 & 175,01 & 80,73 & 125,40 & 81,19 \\
\hline Pelodytes punctatus & $30 \mathrm{TXL43}$ & 100,00 & 103,52 & 97,70 & 36,03 & 6064,31 & 242,87 & $-22,97$ & 265,83 & \begin{tabular}{|l|l|}
126,45 \\
\end{tabular} & 37,18 & 182,36 & 27,64 & 437,57 & 67,50 & 19,82 & 38,29 & 165,04 & 70,36 & 118,27 & 73,68 \\
\hline Pelodytes punctatus & $30 T \times L 44$ & 100,00 & 99,57 & 98,60 & 36,16 & 6063,16 & 241,76 & $-26,03$ & 267,80 & \begin{tabular}{|l|l|}
121,83 \\
\end{tabular} & 33,31 & 178,59 & 23,97 & 462,21 & 69,90 & 22,22 & 35,83 & 171,22 & 78,36 & 122,62 & 81,31 \\
\hline Pelodytes punctatus & $30 T \times L 45$ & 100,00 & 103,29 & 99,36 & 36,30 & 6071,57 & 246,90 & $-22,48$ & 269,38 & 125,80 & 37,30 & 182,32 & 27,53 & 450,06 & 68,11 & 22,12 & 35,47 & 165,82 & 77,56 & 117,56 & 80,82 \\
\hline Pelodytes punctatus & $30 T X L 50$ & 100,00 & 91,90 & 98,01 & 36,01 & 6162,41 & 238,94 & $-29,51$ & 268,45 & \begin{tabular}{ll|l}
111,65 \\
\end{tabular} & 17,40 & 173,98 & 17,40 & 515,99 & 74,51 & 26,49 & 32,53 & \begin{tabular}{|c|}
185,27 \\
\end{tabular} & 89,94 & 132,90 & 89,94 \\
\hline Pelodytes punctatus & 30TXL51 & 100,00 & 87,73 & 98,07 & 36,00 & 6124,77 & 234,65 & $-33,71$ & 268,35 & 107,34 & 13,52 & 169,11 & 13,46 & 539,12 & 77,24 & 28,50 & 31,44 & 192,34 & 96,55 & 138,61 & 96,55 \\
\hline Pelodytes punctatus & $30 T \times L 52$ & 100,00 & 95,48 & 97,20 & 36,00 & 6089,01 & 238,10 & $-27,74$ & 265,83 & 116,36 & 26,76 & 175,60 & 20,49 & 487,24 & 72,39 & 23,87 & 34,90 & 178,61 & 83,15 & 128,89 & 83,55 \\
\hline Pelodytes punctatus & $30 \mathrm{TXL53}$ & 100,00 & 93,34 & 97,36 & 36,00 & 6066,05 & 236,19 & $-29,89$ & 266,08 & 114,21 & 26,24 & 173,12 & 18,58 & 500,72 & 73,83 & 25,11 & 34,01 & 182,28 & 87,26 & 131,60 & 88,09 \\
\hline $\begin{array}{l}\text { Pelodytes punctatus } \\
\end{array}$ & 30 TXL54 & 100,00 & 90,49 & 97,91 & 36,00 & 6048,23 & 234,72 & $-32,40$ & 267,12 & $\begin{array}{l}1114,21 \\
11,02\end{array}$ & 24,29 & 169,99 & $\begin{array}{l}10,006 \\
16,06\end{array}$ & 520,93 & 75,81 & 27,03 & 32,34 & \begin{tabular}{|l|l|}
187,29 \\
\end{tabular} & $\mid 93,71$ & 135,29 & 94,70 \\
\hline Pelodytes punctatus & $30 T \times L 60$ & 100,00 & 94,83 & 96,48 & 36,00 & 6139,80 & 239,94 & $-25,42$ & 265,35 & \begin{tabular}{|l|l|}
114,68 \\
\end{tabular} & 20,78 & 176,50 & 20,78 & 505,03 & 73,01 & 25,25 & 33,01 & 181,19 & 86,05 & 130,33 & 86,05 \\
\hline Pelodytes punctatus & 30TXL61 & 100,00 & 90,23 & 96,60 & 35,99 & 6104,58 & 235,41 & $-30,41$ & 265,82 & \begin{tabular}{|c|}
109,78 \\
\end{tabular} & \begin{tabular}{|l|l|l|}
16,47 & \\
\end{tabular} & \begin{tabular}{|l|l|}
171,37 \\
\end{tabular} & \begin{tabular}{|l|l|l|}
16,47 \\
\end{tabular} & 529,44 & 75,96 & 27,37 & 31,93 & 188,81 & 92,93 & 136,23 & 92,93 \\
\hline Pelodytes punctatus & $30 \mathrm{TXL62}$ & 100,00 & 93,88 & 96,39 & 36,00 & 6076,15 & 237,07 & $-27,70$ & 264,77 & 114,11 & 21,47 & 174,17 & 19,72 & 505,76 & 73,78 & 25,51 & 33,43 & \begin{tabular}{|l|}
182,48 \\
\end{tabular} & 87,48 & 131,67 & 87,48 \\
\hline Pelodytes punctatus & $30 T \times L 63$ & 100,00 & 90,23 & 96,66 & 36,00 & 6052,86 & 234,09 & $-31,12$ & 265,21 & 110,10 & 19,00 & 170,15 & 16,26 & 527,51 & 76,18 & 27,39 & 31,97 & 188,53 & $\begin{array}{l}94,05 \\
\end{array}$ & 136,34 & 94,05 \\
\hline Pelodytes punctatus & $30 T X L 64$ & 100,00 & 97,19 & 96,94 & 36,00 & 6042,81 & 240,17 & $-25,19$ & 265,35 & 118,09 & 31,02 & 176,54 & 22,75 & 489,91 & 72,06 & 24,70 & 33,49 & 176,98 & 85,80 & 126,94 & 86,37 \\
\hline Pelodytes punctatus & 30TXL65 & 100,00 & 107,50 & 97,78 & 36,00 & 6055,16 & 250,82 & $-16,10$ & 266,92 & \begin{tabular}{|l|l|}
129,47 \\
\end{tabular} & 41,66 & \begin{tabular}{|l|l|}
186,47 \\
\end{tabular} & 32,33 & 441,42 & 66,32 & 21,81 & 34,95 & 160,91 & 75,92 & 113,19 & 77,19 \\
\hline Pelodytes punctatus & $30 T \times L 68$ & 100,00 & 123,29 & 101,80 & 36,25 & 6140,66 & 274,94 & $-0,96$ & 275,90 & \begin{tabular}{|l|}
145,87 \\
\end{tabular} & 57,65 & 203,00 & 46,66 & 396,42 & 58,78 & 21,01 & 32,39 & 139,89 & 74,69 & 93,15 & 75,25 \\
\hline Pelodytes punctatus & $30 \mathrm{TXL70}$ & 100,00 & 91,62 & 95,82 & 35,95 & 6104,33 & 237,03 & $-26,92$ & 263,95 & 110,41 & 18,39 & 173,10 & 18,39 & 535,96 & 75,51 & 27,64 & 30,93 & 188,29 & 93,76 & 135,37 & 93,76 \\
\hline Pelodytes punctatus & 30TXL71 & 100,00 & 88,97 & 95,70 & 35,92 & 6076,17 & 234,03 & $-29,79$ & 263,82 & 107,70 & 15,86 & 169,95 & 15,86 & 549,70 & 77,34 & 28,97 & 30,47 & 192,75 & 97,80 & 139,05 & 97,80 \\
\hline Pelodytes punctatus & 30TXL72 & 100,00 & \begin{tabular}{|l|l|l|}
1013 \\
\end{tabular} & 95,36 & 35,98 & 6059,70 & 243,06 & $-19,58$ & 262,65 & \begin{tabular}{|c|}
121,64 \\
\end{tabular} & 27,75 & \begin{tabular}{|c|}
181,10 \\
\end{tabular} & 27,18 & 478,34 & 70,08 & 23,47 & 34,08 & $\begin{array}{ll}172,16 \\
\end{array}$ & 80,84 & 123,14 & 80,84 \\
\hline Pelodytes punctatus & $30 \mathrm{TXL73}$ & 100,00 & 99,16 & 95,91 & 35,99 & 6045,63 & 241,52 & $-22,07$ & 263,58 & 119,70 & 27,72 & 178,85 & 25,26 & 487,42 & 71,25 & 24,47 & 33,50 & 174,96 & 83,98 & 125,23 & 83,98 \\
\hline Pelodytes punctatus & $30 \mathrm{TXL74}$ & 100,00 & 109,47 & 96,76 & 36,00 & 6044,27 & 252,24 & $-13,11$ & 265,36 & 131,08 & 42,85 & 188,66 & 34,88 & 439,68 & 65,54 & 21,57 & 34,89 & 158,99 & 74,79 & 111,64 & 74,89 \\
\hline Pelodytes punctatus & $30 \mathrm{TXL75}$ & 100,00 & 114,92 & 97,98 & 36,0 & 6066,83 & 259,62 & $-8,03$ & 267,65 & 136,97 & 48,13 & 194,08 & 39,80 & 419,59 & 62,66 & 20,99 & 34,60 & 151,11 & 72,50 & 104,34 & 72,64 \\
\hline Pelodytes punctatus & 30TXL76 & 100,00 & 120,30 & 99,40 & 36,04 & 6087,55 & 267,63 & $\begin{array}{l}-3,09 \\
-3,09\end{array}$ & 270,72 & 142,67 & 52,88 & 199,61 & 44,59 & 403,03 & 60,00 & 20,77 & 33,93 & \begin{tabular}{|c|c|c|}
143,90 \\
\end{tabular} & 71,35 & 97,52 & 71,46 \\
\hline Pelodytes punctatus & $30 \mathrm{TXL77}$ & 100,00 & 120,89 & 100,23 & 36,03 & $\begin{array}{ll}6099,63 \\
\end{array}$ & 270,27 & $-2,44$ & 272,71 & 143,32 & 52,76 & 200,37 & 45,11 & 404,11 & 59,66 & 21,35 & 32,80 & 143,03 & 73,46 & 96,21 & 73,56 \\
\hline Pelodytes punctatus & $30 T \times L 78$ & 100,00 & 123,44 & 101,37 & 36,06 & 6119,33 & 275,03 & $-0,11$ & 275,14 & 145,86 & 52,43 & 203,01 & 47,20 & 399,68 & 58,42 & 21,03 & 31,61 & 139,80 & 74,66 & 93,08 & 74,68 \\
\hline Pelodytes punctatus & 30 TXL79 & 100,00 & 127,20 & 102,48 & 36,18 & 6146,71 & 281,60 & 3,56 & 278,04 & 149,99 & 54,67 & 207,17 & 50,63 & 391,98 & 56,46 & 20,06 & 30,52 & 135,25 & 75,40 & 88,81 & 75,40 \\
\hline Pelodytes punctatus & $30 T \times L 80$ & 100,00 & 92,12 & 94,93 & 35,88 & 6074,91 & 237,01 & $-25,42$ & 262,43 & 110,20 & 19,59 & 173,29 & 19,59 & 548,33 & 75,97 & 28,70 & 29,87 & 189,62 & 97,12 & 135,95 & 97,12 \\
\hline Pelodytes punctatus & $30 \mathrm{TXL} 81$ & 100,00 & \begin{tabular}{|l|l|}
90,67 \\
9,12
\end{tabular} & $\begin{array}{ll}34,95 \\
94,95\end{array}$ & $\frac{35,00}{35,90}$ & 6049,47 & $\mid 235,18$ & -27,06 & 262,24 & 109,03 & 18,25 & 171,36 & 18,25 & 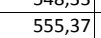 & 77,05 & 29,46 & 29,80 & \begin{tabular}{l|l}
$193,1,96$ \\
196
\end{tabular} & $\begin{array}{l}99,52 \\
99,5\end{array}$ & |138,05 & 99,52 \\
\hline Pelodytes punctatus & $30 T \times L 82$ & 100,00 & 105,61 & 95,06 & 36,00 & 6036,24 & 247,85 & $-14,08$ & 261,93 & 125,84 & 32,08 & 185,38 & 32,08 & 471,49 & 68,23 & 23,19 & 33,44 & $\mid 167,17$ & 79,96 & 118,27 & 79,96 \\
\hline Pelodytes punctatus & $30 T \times L 83$ & 100,00 & 109,49 & 95,77 & 35,97 & 6035,23 & 252,01 & $-11,32$ & 263,33 & 130,29 & 36,04 & 188,90 & 35,78 & 452,96 & 66,15 & 22,27 & 33,96 & 161,12 & 76,89 & 112,97 & 76,89 \\
\hline Pelodytes punctatus & $30 T \times L 84$ & 100,00 & 115,72 & 96,93 & 36,00 & 6040,90 & 259,44 & $-6,17$ & 265,62 & 137,23 & 43,16 & 194,89 & 41,48 & 427,11 & 62,83 & 21,12 & 34,23 & \begin{tabular}{|c|}
151,85 \\
\end{tabular} & 72,94 & 104,76 & 72,94 \\
\hline Pelodytes punctatus & 30TXL85 & 100,00 & 116,66 & 97,82 & 36,00 & 6051,52 & 261,97 & $-5,50$ & 267,48 & 138,31 & 43,75 & 195,76 & 42,05 & 424,05 & 62,31 & 21,52 & 33,57 & 150,21 & 73,66 & 102,92 & 73,66 \\
\hline Pelodytes punctatus & 30 TXL86 & $\begin{array}{l}100,00 \\
\end{array}$ & $\begin{array}{l}110,000 \\
126,49\end{array}$ & $\begin{array}{l}3 r, 0< \\
99,79\end{array}$ & $\begin{array}{ll}30,00 \\
36,01\end{array}$ & $\begin{array}{ll}60858,22 \\
6082\end{array}$ & $\mid 275,16$ & $\begin{array}{c}-2,509 \\
2,99\end{array}$ & $\begin{array}{l}201,40 \\
272,17\end{array}$ & $\begin{array}{l}130,31 \\
148,82\end{array}$ & 52,40 & 205,93 & 51,04 & $\begin{array}{l}424,03 \\
391,26\end{array}$ & $\begin{array}{l}\mid c 2,11 \\
57,25\end{array}$ & 20,01 & |33,19 & \begin{tabular}{|l|l|l}
137,14 \\
\end{tabular} & $\begin{array}{l}69,00 \\
69,25\end{array}$ & \begin{tabular}{|l|} 
\\
91,28
\end{tabular} & 69,25 \\
\hline $\begin{array}{l}\text { Pelodytes punctatus } \\
\end{array}$ & 30 TXL89 & 100,00 & 136,03 & 103,14 & 36,15 & 6159,41 & 291,93 & 11,69 & 280,24 & 159,19 & 59,18 & 216,21 & 59,18 & 370,19 & 51,84 & 18,06 & 29,77 & 125,34 & 70,01 & 80,77 & 70,01 \\
\hline Pelodytes punctatus & $30 \mathrm{~T} \times 190$ & 100,00 & 93,26 & 94,10 & 35,88 & 6037,54 & 237,51 & $-23,38$ & 260,88 & \begin{tabular}{ll|}
110,95 \\
\end{tabular} & 21,41 & 173,85 & 21,41 & 560,38 & 76,22 & 29,78 & 28,83 & \begin{tabular}{|c|}
190,28 \\
\end{tabular} & 100,83 & 135,84 & 100,83 \\
\hline Pelodytes punctatus & 30TXL91 & 100,00 & 92,79 & 94,06 & 35,91 & 6024,18 & 236,62 & $-24,29$ & 260,91 & 110,82 & 20,82 & 173,14 & 20,82 & 558,18 & 76,49 & 29, & 29,18 & 190,50 & 100,44 & 136,29 & 100,44 \\
\hline Pelodytes punctatus & 30TXL92 & 100,00 & 108,34 & 90 & 35,97 & 6013,94 & 250,8 & $-10,67$ & 261,55 & 128,18 & 35,4 & 187,89 & 35, & 475,73 & 67,67 & 23, & 32, & 165,47 & 81,84 & 115,82 & 81,84 \\
\hline Pelodytes punctatus & 30TXL93 & 100,00 & 119,24 & 96,28 & 35,99 & 6024,23 & 262,6 & $-1,61$ & 264,25 & $\mid 140,10$ & 45,5 & 198,47 & 45,5 & 430,39 & 61,95 & 21,19 & 33,56 & 149,75 & 73,45 & 102,24 & 73,45 \\
\hline Pelodytes punctatus & 30TXL94 & 100,00 & 121,76 & 97,31 & 36,00 & 6022,52 & 266,54 & 0,07 & 266,46 & $\begin{array}{l}143,10 \\
143\end{array}$ & 48,05 & 200,89 & 48,05 & 420,08 & 60,59 & 21,03 & 33,48 & 146,01 & 72,48 & $\begin{array}{l}98,88 \\
88,88 \\
\end{array}$ & 72,48 \\
\hline Pelodytes punctatus & $30 T \times L 95$ & 100,00 & 119,29 & 97,91 & 36,00 & 6025,98 & 265,34 & $-2,58$ & 267,92 & \begin{tabular}{|l|}
140,63 \\
\end{tabular} & 45,32 & 198,40 & 45,32 & 428,44 & 61,70 & 21,84 & 32,63 & 148,84 & 75,02 & \begin{tabular}{ll|}
101,15 \\
\end{tabular} & 75,02 \\
\hline Pelodytes punctatus & 30TXL96 & 100,00 & 156 & 100,49 & 36,02 & 6076,06 & 284,31 & 10,75 & 273,56 & 157,00 & 59,40 & 213,91 & 59,40 & 377,88 & 53, & 18, & 32,59 & 129,18 & 67,32 & 84,10 & 67,32 \\
\hline Pelodytes punctatus & 30TXL97 & 10 & 139,50 & 1,88 & 36,10 & 6104,79 & 291,85 & 15,07 & 276,78 & 162,47 & 63,90 & 219,12 & 63,90 & 364,50 & 51,29 & 17 & 31,80 & 123,17 & 66,23 & 79,08 & 66,23 \\
\hline Pelodytes punctatus & $30 T \times L 98$ & 100,00 & & 10 & 36,18 & 6118,22 & 296,53 & 17,65 & 278,88 & 165,50 & 66,35 & 222,14 & 66,35 & 358,47 & 49,68 & 16,66 & 30,96 & 119,94 & 66,09 & 76,27 & 66,09 \\
\hline Pelodytes punctatus & 30TXM02 & 100,00 & 100,94 & 108,08 & 37,93 & 6066,93 & 260,75 & $-22,31$ & 283,06 & 121,12 & \begin{tabular}{|r|r|}
180,29 \\
\end{tabular} & 180,39 & 26,02 & 566,20 & 72,63 & 31,53 & 23,29 & 181,91 & 112,00 & 124,01 & 134,25 \\
\hline Pelodytes punctatus & 30TXM03 & 100,00 & 119,16 & 108,53 & 37,97 & 6123,89 & 278,95 & $-5,19$ & 284,14 & 140,97 & 198,70 & 198,78 & 42,79 & 490,67 & 63,53 & 25,64 & 24,61 & 157,00 & 93,63 & \begin{tabular}{|c|c|}
102,45 \\
\end{tabular} & 117,71 \\
\hline Pelodytes punctatus & 30TXM05 & 100,00 & 133,34 & 107,29 & 37,99 & 6057,35 & 290,14 & 10,14 & 279,99 & 155,39 & 211,64 & 211,64 & 57,25 & 485,86 & 59, & 23,8 & 23,70 & 148,22 & 89,40 & 92,39 & 122,30 \\
\hline Pelodytes punctatus & 30TXM06 & 10 & & & $\begin{array}{ll}3,999 \\
37,99\end{array}$ & 602 & 289 & 12,23 & 277,60 & $\begin{array}{l}\mid 35,39 \\
155,06\end{array}$ & 212,27 & 212,27 & 58,71 & $\begin{array}{l}40,00 \\
513,80\end{array}$ & $\mid \frac{35,25}{60,26}$ & 25, & 22,90 & 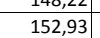 & 年33,401 & 95,71 & 132,79 \\
\hline $\begin{array}{l}\text { Pelodytes punctatus } \\
\end{array}$ & 30TXM07 & 100,00 & 136,85 & 105,91 & 38,00 & 5960,25 & 290,10 & 15,45 & 274,65 & 102,64 & 213,73 & 213,73 & 61,61 & 545,48 & 61,27 & 26,12 & 22,41 & 161,47 & 98,66 & 98,93 & 144,92 \\
\hline Pelodytes punctatus & 30 TXM08 & 100,00 & 134,51 & 105,33 & 38,00 & 5906,84 & 286,66 & 14,23 & 272,43 & 98,32 & 210,73 & 210,73 & 60,05 & 595,02 & 66,05 & 28,54 & 22,00 & \begin{tabular}{|l|l|}
178,07 \\
\end{tabular} & 106,76 & 106,98 & 162,32 \\
\hline Pelodytes punctatus & 30TXM09 & 100,00 & 131,31 & 105,03 & 38,08 & 5861,17 & 282,84 & 12,12 & 270,72 & 94,86 & 207,03 & 207,03 & 57,59 & 657,07 & 74,70 & 31,62 & 21,99 & 198,86 & 116,63 & 116,63 & 184,39 \\
\hline Pelodytes punctatus & $30 T X M$ & 100 & 11 & 10 & 37,63 & 613 & 27 & $-6,61$ & 282,83 & 139,49 & 197,34 & 197,41 & 41,34 & 477,46 & 63,91 & 25, & 26,04 & 156,16 & 92,14 & 101,36 & 11 \\
\hline Pelodytes punctatus & 30TXM13 & $\begin{array}{l}100,00 \\
\end{array}$ & 121,44 & \begin{tabular}{|l|}
107,69 \\
107
\end{tabular} & $\begin{array}{l}31,75 \\
37,73 \\
\end{array}$ & $\begin{array}{ll}013,2044 \\
6119,63\end{array}$ & $\begin{array}{l}\mid 270,2< \\
279,95\end{array}$ & $\begin{array}{l}-2,01 \\
-2,63\end{array}$ & $\begin{array}{l}20,03 \\
282,58\end{array}$ & $\begin{array}{l}\mid 35,43 \\
143,28\end{array}$ & 200,77 & 200,86 & 年14,94 & $\begin{array}{l}\mid 41,40 \\
481,73\end{array}$ & 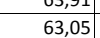 & $\mid 24,77$ & $\begin{array}{l}20,04 \\
25,32\end{array}$ & \begin{tabular}{|l|l|}
154,56 \\
\end{tabular} & $\begin{array}{ll}32,143 \\
91,31\end{array}$ & \begin{tabular}{|l|}
100,01 \\
\end{tabular} & $\begin{array}{l}11,10 \\
115,08\end{array}$ \\
\hline \begin{tabular}{|l} 
Pelodytes punctatus \\
\end{tabular} & 30TXM14 & 100,00 & 132,42 & 107,17 & 37,69 & 6099,90 & 289,75 & 8,56 & 281,19 & 154,72 & 211,33 & 211,37 & 55,81 & 466,15 & 59,06 & 22,67 & 24,96 & 145,23 & 85,77 & 88,68 & 114,99 \\
\hline Pelodytes punctatus & 30TXM15 & 100,00 & 137,34 & 106,54 & 37,96 & 6040,20 & 292,78 & 14,55 & 278,22 & 159,61 & 215,33 & 215,33 & 61,35 & 480,36 & 58,18 & 22,85 & 24,02 & 145,01 & 87,32 & 89,54 & 122,01 \\
\hline Pelodytes punctatus & $30 T \times M 1$ & 100,00 & 13 & 106,17 & 38,00 & 6012,4 & 291, & 14,39 & 276,76 & 134,60 & 213,97 & 213,97 & 60,58 & 516,44 & 60,1 & 24,55 & 23,20 & 152,87 & 93,38 & 95,00 & 13 \\
\hline Pelodytes punctatus & 30TXM17 & 100,00 & 132,53 & 106,19 & 38,00 & 5976,67 & 286,65 & 11,06 & 275,59 & 102,39 & 209,63 & 209,63 & 57,17 & 567,05 & 63,84 & 27,16 & 22,45 & 167,42 & 101,85 & 102,41 & 152 \\
\hline
\end{tabular}




\begin{tabular}{|c|c|c|c|c|c|c|c|c|c|c|c|c|c|c|c|c|c|c|c|c|c|}
\hline TAXON & UTM & $\mathrm{km} 2$ & BIO1 & $\mathrm{B1O2}$ & $\mathrm{BIO3}$ & 8104 & B105 & B106 & B107 & B108 & B109 & 81010 & B1011 & BIO12 & B1013 & B1014 & 81015 & B1016 & B1017 & B1018 & \begin{tabular}{|l|} 
B1019 \\
\end{tabular} \\
\hline Pelodytes punctatus & 30TXM18 & 100,00 & 130,54 & 105,84 & 38,00 & 5931,66 & 283,74 & 9,80 & 273,94 & 94,21 & 207,13 & 207,13 & 55,90 & 618,58 & 69,70 & 29,63 & 22,02 & 185,17 & 110,02 & 110,09 & 170,60 \\
\hline Pelodytes punctatus & 30TХM19 & 100,00 & 130,52 & 105,12 & 38,01 & 5871,83 & 282,08 & 10,50 & 271,58 & 94,28 & 206,24 & 206,24 & 56,29 & 673,35 & 77,95 & 31,95 & 22,21 & 205,12 & \begin{tabular}{l|l|}
118,55 \\
\end{tabular} & \begin{tabular}{ll|}
118,55 \\
\end{tabular} & 191,28 \\
\hline Pelodytes punctatus & $30 \mathrm{TXM} 23$ & 100,00 & 133,82 & $\mid \begin{array}{l}\mid 106,67 \\
\end{array}$ & 37,25 & 6133,99 & 291,05 & 9,61 & 281,44 & 156,30 & 213,06 & 213,06 & 56,85 & 437,57 & 57,78 & 20,95 & 26,66 & 139,33 & $\begin{array}{r}80,58 \\
80,\end{array}$ & 82,35 & 104,92 \\
\hline Pelodytes punctatus & 30TXM24 & 100,00 & 138,28 & 106,28 & 37,48 & 6087,83 & 294,44 & 15,01 & 279,43 & \begin{tabular}{|c|}
160,78 \\
\end{tabular} & 216,96 & 216,96 & 61,71 & 449,59 & 56,90 & 21,03 & 25,46 & 138,72 & 81,65 & 82,90 & 111,29 \\
\hline Pelodytes punctatus & 30TXM25 & 100,00 & 135,71 & 106,21 & 37,74 & 6045,86 & 291,28 & 12,96 & 278,32 & \begin{tabular}{|l|l|}
157,97 \\
\end{tabular} & 213,74 & 213,74 & 59,53 & \begin{tabular}{|l|l|}
487,17 \\
\end{tabular} & 59,36 & 23,02 & 24,15 & 147,02 & 88,34 & 90,45 & 123,83 \\
\hline Pelodytes punctatus & 30TXM26 & 100,00 & 132,34 & 106,18 & 37,95 & 6011,91 & 287,35 & 10,14 & 277,21 & 140,20 & 209,87 & 209,87 & 56,56 & 530,36 & 62,22 & 25,35 & 23,09 & 157,15 & 95,82 & 99,69 & 138,38 \\
\hline Pelodytes punctatus & 30TXM27 & 100,00 & 133,69 & 105,99 & 38,00 & 5966,34 & 287,39 & 12,47 & 274,92 & 96,91 & 210,66 & 210,66 & 58,58 & 564,81 & 63,52 & 26,71 & 22,52 & 167,48 & \begin{tabular}{|l|}
101,29 \\
\end{tabular} & 102,42 & 151,60 \\
\hline Pelodytes punctatus & 30TXM28 & 100,00 & 127,85 & 105,90 & 38,00 & 5923,58 & 280,96 & 7,13 & 273,82 & \begin{tabular}{l|l|l|}
91,65 & \\
\end{tabular} & 204,24 & 204,24 & 53,19 & 630,60 & 71,13 & 30,23 & 21,98 & 188,22 & 112,42 & 112,42 & 173,84 \\
\hline Pelodytes punctatus & 30 TXM29 & 100,00 & 126,49 & 105,21 & 38,02 & 5856,42 & 278,16 & 6,71 & 271,46 & 87,33 & 202,15 & 202,15 & 52,67 & 689,63 & 79,75 & 32,97 & 21,94 & 209,18 & \begin{tabular}{|l|l|}
122,07 \\
\end{tabular} & \begin{tabular}{|l|l|}
122,07 \\
\end{tabular} & 195,51 \\
\hline Pelodytes punctatus & 30TXM32 & 100,00 & 134,91 & 106,01 & 37,00 & 6158,24 & 292,16 & 10,49 & 281,66 & 157,51 & 214,41 & 214,42 & 57,63 & 410,03 & 56,70 & 19,42 & 28,87 & 133,87 & 75,70 & 79,25 & 94,99 \\
\hline Pelodytes punctatus & 30TXM35 & 100,00 & 127,31 & 106,02 & 37,54 & 6041,35 & 283,19 & 4,91 & 278,28 & 149,26 & 205,41 & 205,41 & 51,55 & 509,78 & 62,90 & 24,80 & 23,64 & 155,61 & 93,61 & 96,50 & 127,89 \\
\hline $\begin{array}{l}\text { Pelodytes punctatus } \\
\end{array}$ & $30 T \times M 36$ & 100,00 & 129,18 & 106,00 & 37,92 & 6005,93 & 284,30 & 7,06 & 277,23 & 147,96 & 206,79 & 206,79 & 53,67 & 535,59 & 63,38 & 25,68 & 22,83 & 158,98 & 97,45 & 99,31 & 138,33 \\
\hline Pelodytes punctatus & 30TXM37 & 100,00 & 129,39 & 105,94 & 38,00 & 5959,24 & 283,29 & 8,04 & 275,24 & \begin{tabular}{|c|}
95,12 \\
\end{tabular} & 206,40 & 206,40 & 54,34 & 575,10 & 65,06 & 27,44 & 22,10 & \begin{tabular}{|c|}
168,96 \\
\end{tabular} & \begin{tabular}{|c|}
103,88 \\
\end{tabular} & 104,77 & 153,17 \\
\hline Pelodytes punctatus & 30TХM39 & 100,00 & 124,96 & 104,99 & 38,09 & 5850,36 & 275,92 & 5,17 & 270,75 & 89,49 & 200,52 & 200,52 & 51,20 & 687,19 & 78,48 & 32,94 & 21,50 & 207,19 & 123,07 & 123,44 & 192,83 \\
\hline Pelodytes punctatus & 30TXM45 & 100,00 & 134,59 & 105,80 & 37,72 & 6029,52 & 290,12 & 12,27 & 277,86 & \begin{tabular}{ll|}
156,46 \\
\end{tabular} & 212,67 & 212,67 & 58,95 & 477,71 & 59,03 & 22,36 & 24,01 & 144,83 & 87,31 & 89,01 & 118,78 \\
\hline Pelodytes punctatus & 30TXM48 & 100,00 & 120,32 & 104,88 & 38,03 & 5861,92 & 272,18 & 0,66 & 271,51 & 84,90 & 196,10 & 196,10 & 46,53 & 641,09 & 70,74 & 31,44 & 20,65 & 187,44 & 117,89 & 119,70 & 171,65 \\
\hline Pelodytes punctatus & 30 XMM49 & 100,00 & 111,52 & 104,06 & 38,12 & 5778,43 & 261,90 & $-6,27$ & 268,17 & 76,92 & 186,52 & 186,52 & 39,16 & 720,40 & 78,95 & 36,34 & 19,71 & 210,17 & 133,69 & 136,21 & 195,68 \\
\hline Pelodytes punctatus & 30TXM50 & 100,00 & 127,07 & 103,95 & 36,92 & 6172,05 & 282,81 & 2,99 & 279,82 & 149,81 & \begin{tabular}{|c|}
172,08 \\
\end{tabular} & 207,02 & 50,14 & 398,22 & 58,16 & 20,01 & 30,77 & 136,78 & 78,05 & 88,28 & 82,88 \\
\hline Pelodytes punctatus & 30TXM53 & 100,00 & 132,01 & 105,19 & 37,00 & 6110,04 & 289,16 & 9,31 & 279,85 & 154,31 & 211,09 & 211,12 & 55,67 & 426,69 & 57,63 & 20,29 & 26,89 & 137,25 & 79,52 & 81,85 & 98,06 \\
\hline Pelodytes punctatus & 30TXM54 & 100,00 & 131,54 & 105,22 & 37,02 & 6068,09 & 288,00 & 9,05 & 278,95 & 153,54 & 210,17 & 210,17 & 55,69 & 450,30 & 58,54 & 21,42 & 25,18 & 141,39 & 83,80 & 86,24 & 106,26 \\
\hline Pelodytes punctatus & 30TXM56 & 100,00 & 131,77 & 105,01 & 37,91 & 5949,14 & 285,46 & 10,50 & 274,96 & 153,61 & 208,60 & 208,63 & 57,17 & 509,43 & 60,64 & 24,06 & 22,18 & 151,01 & 94,66 & 98,75 & 127,41 \\
\hline Pelodytes punctatus & 30TXM57 & 100,00 & 124,80 & \begin{tabular}{|l|l|}
104,84 \\
\end{tabular} & 38,00 & 5881,56 & $\begin{array}{l}278,40 \\
277,18 \\
\end{array}$ & 4,57 & 272,62 & 137,31 & 200,75 & 200,76 & 50,84 & 569,34 & $60,0,41$ & 27,60 & 20,89 & 165,63 & \begin{tabular}{|l|r|}
106,48 \\
\end{tabular} & \begin{tabular}{|c|c|}
109,27 \\
\end{tabular} & 145,84 \\
\hline Pelodytes punctatus & 30TXM58 & 100,00 & 113,90 & 103,95 & 38,00 & 5797,35 & 264,50 & $-4,35$ & 268,85 & 116,61 & 188,90 & 188,90 & 41,18 & 649,11 & 72,57 & 32,71 & 19,63 & 186,95 & 122,80 & 126,16 & 168,81 \\
\hline Pelodytes punctatus & 30TXM60 & 100,00 & 135,65 & 104,38 & 36,44 & 6225,17 & 293,69 & 11,31 & 282,38 & 158,78 & 207,07 & 216,32 & 58,02 & 371,20 & 53,65 & 17,91 & 30,35 & 126,58 & 71,97 & 79,83 & 76,02 \\
\hline Pelodytes punctatus & 30TXM62 & 100,00 & 140,27 & 105,20 & 36,92 & 6196,80 & 299,27 & 16,77 & 282,50 & 163,26 & 220,23 & 220,33 & 62,77 & 378,15 & 52,03 & 17,40 & 27,95 & 123,81 & 70,57 & 75,92 & 82,54 \\
\hline $\begin{array}{l}\text { Pelodytes punctatus } \\
\end{array}$ & 30 TXM64 & 100,00 & 119,33 & 104,01 & 37,06 & 5984,79 & 273,83 & $-1,61$ & 275,44 & 140,75 & 196,83 & 196,96 & 44,60 & 484,83 & 62,92 & 24,45 & 23,75 & 153,50 & 94,64 & 102,13 & 110,14 \\
\hline Pelodytes punctatus & 30TXM65 & 100,00 & $\mid \begin{array}{l}\mid 121,25 \\
121,25\end{array}$ & $\begin{array}{l}104,19 \\
104,19\end{array}$ & $\begin{array}{ll}37,40 \\
37,42\end{array}$ & 5940,58 & $\begin{array}{l}\mid 7,05 \\
275,03\end{array}$ & $\begin{aligned} 0,01 \\
0,62\end{aligned}$ & 274,40 & $\begin{array}{l}\mid l 4,73 \\
142,57\end{array}$ & $\begin{array}{l}19,03,01 \\
198,01\end{array}$ & \begin{tabular}{|l|l|}
198,11 \\
\end{tabular} & 44,00 & $\begin{array}{l}404,05 \\
503,56\end{array}$ & $\begin{array}{ll}63,01 \\
63,01\end{array}$ & $\begin{array}{l}24,45 \\
25,09\end{array}$ & 22,43 & $\begin{array}{l}\mid 355,19 \\
155\end{array}$ & 97,32 & \begin{tabular}{|l|}
103,62 \\
103
\end{tabular} & 118,05 \\
\hline Pelodytes punctatus & 30 TXM67 & 100,00 & 118,97 & 103,90 & 38,00 & 5817,41 & 270,15 & 0,01 & 270,13 & \begin{tabular}{|c|}
139,65 \\
\end{tabular} & \begin{tabular}{|l|}
194,19 \\
\end{tabular} & 194,25 & 46,15 & 572,81 & 66,77 & 28,48 & 20,11 & 168,26 & 110,30 & 114,96 & 141,91 \\
\hline Pelodytes punctatus & 30TXM68 & 100,00 & 109,32 & 102,91 & 38,01 & 5729,41 & 258,29 & $-7,86$ & 266,14 & 129,00 & 183,44 & 183,52 & 37,62 & 649,78 & 73,60 & 33,38 & 18,82 & 188,19 & 126,30 & 131,44 & 164,01 \\
\hline Pelodytes punctatus & $30 T \times M 70$ & 100,00 & 139,91 & 104,45 & 36,05 & 6233,91 & 299,11 & 15,36 & 283,75 & 163,46 & 148,13 & 220,96 & 62,00 & 362,75 & 50,22 & 17,38 & 28,79 & 122,03 & 71,01 & 77,63 & 71,93 \\
\hline Pelodytes punctatus & 30TXM71 & 100,00 & 146,76 & 105,24 & 36,17 & 6257,39 & 307,56 & 21,90 & 285,66 & 170,51 & 227,09 & 227,87 & 68,17 & 356,92 & 46,94 & 16,56 & 26,97 & 116,55 & \begin{tabular}{|c|}
69,08 \\
\end{tabular} & 73,65 & 72,93 \\
\hline Pelodytes punctatus & 30TXM72 & 100,00 & $\begin{array}{l}40,10 \\
139,49\end{array}$ & $\mid \begin{array}{l}105,01 \\
105\end{array}$ & $\begin{array}{l}30,111 \\
36,78\end{array}$ & 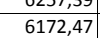 & | 298,75 & $\mid \frac{21,90}{15,87}$ & $\begin{array}{l}20,00 \\
282,87\end{array}$ & $\begin{array}{l}\mid 1 /, 71 \\
162,73\end{array}$ & 218,90 & $\mid \begin{array}{l}\mid 219,44 \\
219,44\end{array}$ & $\mid \frac{00,11}{62,19}$ & 年 & $\begin{array}{l}40,34 \\
50,38\end{array}$ & $\begin{array}{l}10,00 \\
17,99 \\
\end{array}$ & \begin{tabular}{|l|l|}
26,22 \\
\end{tabular} & \begin{tabular}{|l|l|}
123,59 \\
120
\end{tabular} & $\begin{array}{l}\mid 73,00 \\
73,79\end{array}$ & $\begin{array}{l}79,030 \\
79,24\end{array}$ & 79,60 \\
\hline Pelodytes punctatus & 30TXM74 & 100,00 & 123,39 & 103,77 & 37,03 & 5963,16 & 277,90 & 2,33 & 275,57 & 145,01 & 200,31 & 200,54 & 48,69 & 461,11 & 59,48 & 22,87 & 23,54 & 145,45 & 91,31 & 97,31 & 101,83 \\
\hline Pelodytes punctatus & 30TXM76 & 100,00 & 124,55 & 103,96 & 37,89 & 5840,31 & 276,45 & 4,49 & 271,96 & 145,76 & 199,77 & 200,03 & 51,17 & 504,72 & 61,06 & 24,69 & 21,14 & 151,66 & 99,13 & 103,45 & 118,15 \\
\hline Pelodytes punctatus & 30TXM77 & 100,00 & 114,39 & 102,89 & 38,00 & 5741,08 & 263,99 & $-3,34$ & 267,33 & 134,57 & 188,62 & 188,75 & 42,53 & 574,25 & 67,66 & 29,05 & 19,62 & 169,91 & 113,86 & 118,68 & 137,66 \\
\hline Pelodytes punctatus & $30 T \times M 78$ & 100,00 & 105,11 & 101,80 & 38,00 & 5660,68 & 252,52 & $-11,02$ & 263,54 & 124,45 & 178,48 & 178,66 & 34,44 & 651,86 & 74,57 & 34,13 & 18,21 & 189,92 & 130,24 & 135,19 & 159,73 \\
\hline Pelodytes punctatus & 30TXM79 & 100,00 & 94,27 & 100,14 & 38,01 & 5578,12 & 239,18 & $-20,06$ & 259,24 & 112,36 & 166,83 & 166,86 & 24,87 & 748,31 & 83,20 & 40,77 & 16,95 & 215,23 & 151,02 & 156,15 & 186,56 \\
\hline \begin{tabular}{|l} 
Pelodytes punctatus \\
\end{tabular} & $30 T \times M 80$ & 100,00 & 145,28 & 104,63 & 36,21 & 6190,31 & 303,61 & 20,15 & 283,46 & 168,93 & 79,03 & 225,67 & 67,72 & 355,22 & 47,42 & 16,52 & 28,16 & 116,99 & 69,07 & 74,27 & 69,08 \\
\hline Pelodytes punctatus & 30TXM82 & 100,00 & 139,35 & 104,73 & 36,89 & 6112,10 & 297,35 & 15,57 & 281,78 & 162,46 & 174,81 & 218,70 & 62,77 & 381,90 & 49,74 & 18,05 & 25,86 & 122,92 & 76,19 & 79,36 & 77,58 \\
\hline Pelodytes punctatus & 30TXM87 & 100,00 & 87 & 102,86 & 38,00 & 709,54 & 267,58 & 0,43 & 267,16 & 139,37 & 192,36 & 192,87 & 47,08 & 538,87 & 63,79 & 26,8 & 19,88 & 159,26 & 109,08 & 111,22 & 125,26 \\
\hline $\begin{array}{l}\text { Pelodytes punctatus } \\
\end{array}$ & 30 TXM92 & 100,00 & 35 & 103,44 & 36,99 & 5994,92 & 284,30 & 6,452 & 277,38 & 151,60 & 54,36 & 207,39 & 54,36 & 404,14 & 53,86 & 19,69 & 26,35 & 131,16 & $\begin{array}{l}79,34 \\
7\end{array}$ & \begin{tabular}{|l|}
86,07 \\
\end{tabular} & 79,34 \\
\hline Pelodytes punctatus & 30TXM97 & 100,00 & & 102,31 & 38,00 & 5642,31 & 264,80 & $-0,18$ & 264,98 & 137,80 & 190,56 & 190,68 & 46,59 & 525,89 & 62,85 & 26,32 & 20,06 & 156,01 & \begin{tabular}{ll|}
109,05 \\
\end{tabular} & 109,31 & 117,90 \\
\hline Pelodytes punctatus & 30TXNOO & 100,00 & $\begin{array}{l}\mid 127,58 \\
127\end{array}$ & \begin{tabular}{|l|l|}
104,76 \\
\end{tabular} & 38,30 & 5801,83 & 278,61 & 9,32 & 269,29 & $\begin{array}{l}70,78 \\
70,0\end{array}$ & 202,65 & 202,65 & 54,66 & 733,33 & 85,78 & 35,25 & 22,26 & 226,05 & 128,43 & 128,43 & 212,22 \\
\hline Pelodytes punctatus & $30 T X N 01$ & 100,00 & 08 & 104,38 & 38,45 & 5749,16 & 272,88 & 5,07 & 267,82 & 58 & 196,59 & 196,59 & 49,94 & 823,10 & 98,48 & 39,67 & 22,73 & 259,36 & 142,68 & 142,68 & 244,35 \\
\hline Pelodytes punctatus & $30 \mathrm{TXNO2}$ & 100,00 & 118,55 & 103,34 & 38,71 & 5664,61 & 267,93 & 3,58 & 264,35 & 56,29 & 192,16 & 192,16 & 47,55 & 908,59 & 110,43 & 43,78 & 23,08 & 291,15 & 156,75 & 156,75 & 274,93 \\
\hline Pelodytes punctatus & 30TXN03 & 100,00 & 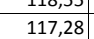 & \begin{tabular}{|l|}
101,84 \\
101
\end{tabular} & $\begin{array}{ll}30,11 \\
38,87\end{array}$ & 5563,04 & 264,31 & $\begin{array}{ll}3,30 \\
4,46\end{array}$ & 250,85 & 50,23 & $\begin{array}{l}18,, 71 \\
189,7\end{array}$ & $\begin{array}{l}18,, 71 \\
189,71\end{array}$ & $\begin{array}{l}47,30 \\
47,87\end{array}$ & $\begin{array}{l}30,39 \\
987,76\end{array}$ & $\mid \begin{array}{l}110,45 \\
121,64\end{array}$ & $\begin{array}{l}43,10 \\
47,40\end{array}$ & 23,51 & 321,10 & $\begin{array}{l}30,13 \\
170,42\end{array}$ & $\begin{array}{l}170,42 \\
170,1\end{array}$ & 303,38 \\
\hline $\begin{array}{l}\text { Pelodytes punctatus } \\
\end{array}$ & 30TXNO4 & 100,00 & 120,11 & 99,69 & 38,96 & 5424,70 & 263,16 & 9,95 & 253,21 & 60,57 & 190,76 & 190,76 & 52,43 & 1054,55 & 130,95 & 50,27 & 23,93 & 346,91 & \begin{tabular}{|l|l|l|}
182,97 \\
\end{tabular} & 182,97 & 327,25 \\
\hline Pelodytes punctatus & $30 \mathrm{TXN10}$ & 100,00 & 123,99 & 105,02 & 38,19 & 5829,79 & 275,63 & 5,1 & 270,50 & 65,01 & \begin{tabular}{|c|}
199,39 \\
\end{tabular} & 199,39 & 50,54 & 757,65 & 89,75 & 36,32 & 22,51 & 234,27 & 132,08 & 132,08 & 221,01 \\
\hline Pelodytes punctatus & $30 T X N 11$ & 100,00 & 4 & 104,39 & 38, & 5739,69 & 263,64 & $-3,9$ & 267,55 & 49 & 187,27 & 187,27 & 40 & 859,66 & 101,79 & 42, & 21 & 267,27 & 151,36 & 151,36 & 252,99 \\
\hline Pelodytes punctatus & $30 \mathrm{TXI}$ & 100,00 & 10 & 102 & 38, & 561 & 25 & -9, & 262 & 43, & 177 & 177,51 & 34 & 941 & 110,28 & 47 & 20,74 & 291,98 & 169,21 & 169,21 & 276,37 \\
\hline Pelodytes punctatus & 30 TXN13 & 100,00 & 118,26 & 102,80 & 38,63 & 5631,79 & 266,64 & 3,42 & 263,22 & 56,39 & \begin{tabular}{|c|c|}
191,36 \\
\end{tabular} & 191,36 & 47,70 & 996,28 & 125,80 & 47,05 & 24,63 & 327,85 & \begin{tabular}{|c|}
169,48 \\
\end{tabular} & 169,48 & 310,93 \\
\hline \begin{tabular}{|l} 
Pelodytes punctatus \\
\end{tabular} & 30TXN14 & 100,00 & 114,75 & 100,62 & 38,90 & 5484,35 & 259,12 & 3,13 & 255,99 & 54,69 & 186,16 & 186,16 & 46,05 & 1064,60 & 132,53 & 51,37 & 23,62 & 348,62 & 185,86 & 185,86 & 329,79 \\
\hline Pelodytes punctatus & $30 T \times N 20$ & 100,00 & 116,12 & 104,93 & 38,45 & 5801,88 & 267,64 & $-1,72$ & 269,35 & 55,99 & 191,37 & 191,37 & 43,40 & 782,81 & 91,30 & 38,45 & 21,42 & 238,41 & 138,98 & 138,98 & 225,49 \\
\hline Pelodytes p & 30 TXN21 & 100,00 & & 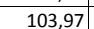 & 38,6 & 5720,06 & 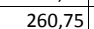 & $-5,38$ & 266,14 & 48,12 & 185,19 & 185,19 & 39,23 & 858 & 100 & 42, & 21 & & 153,29 & 153,29 & 250,21 \\
\hline Pelodytes punctatus & 30TX & & & & 38 & 557 & 25 & $-2,50$ & 260,15 & 50,36 & 183,84 & 183,84 & 41 & 988,25 & 120, & 48 & 22,30 & 315,84 & 175,14 & 175,14 & 299 \\
\hline Pelodytes punctatus & 30TXN24 & 100,00 & $\begin{array}{ll}105,82 \\
\end{array}$ & 100,25 & $\begin{array}{ll}38,97 \\
38,9\end{array}$ & 5446,53 & 249,11 & $-5,28$ & 254,39 & 46,76 & 176,99 & 176,99 & 37,91 & 1056,73 & 127,07 & 53,08 & 21,29 & 336,13 & 191,33 & 191,33 & 317,75 \\
\hline Pelodytes punctatus & 30TXN31 & 100,00 & 120,59 & 103,87 & 38,52 & 5721,66 & 268,99 & 2,92 & 266,06 & \begin{tabular}{|c|}
65,57 \\
\end{tabular} & $\begin{array}{l}194,55 \\
\end{array}$ & 194,55 & 48,45 & 814,16 & 96,60 & 39,15 & 21,72 & 252,33 & 145,09 & 145,09 & 238,28 \\
\hline Pelodytes punctatus & 30 TXN32 & 100,00 & 113,49 & 102,85 & 38,92 & 636,46 & 260,48 & $-2,03$ & 262,51 & 51,78 & 186,71 & 186,71 & 42,65 & 896,38 & 106,61 & 44,13 & 21,28 & 279,60 & 161,46 & 161,46 & 264,2 \\
\hline Pelodytes & $30 \mathrm{TXI}$ & $100, \mathrm{C}$ & & $101, \varepsilon$ & 38, & 5557 & 257 & $-1,0 \varepsilon$ & 258,92 & 52,09 & 185 & 18 & 43,1 & 960 & 11 & 47, & 21,58 & 303,97 & 173,33 & 173,33 & 28 \\
\hline Pelodytes punctatus & 30 TXN34 & 100,00 & 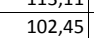 & $\begin{array}{l}\mid c 1,10 \\
99,88 \\
\end{array}$ & 39,00 & 5425,73 & 244,40 & $-8,06$ & 252,92 & 43,64 & 173,20 & \begin{tabular}{|l|l|}
173,20 \\
\end{tabular} & $\begin{array}{l}40,71 \\
34,78\end{array}$ & $\begin{array}{r}1043,23 \\
\end{array}$ & $\mid \begin{array}{l}\mid 122,91 \\
122,97\end{array}$ & 53,41 & $\begin{array}{l}\mid 1,000 \\
20,09 \\
\end{array}$ & 326,28 & \begin{tabular}{|l|l|}
193,20 \\
\end{tabular} & \begin{tabular}{|l|l|}
193,20 \\
\end{tabular} & 308,08 \\
\hline
\end{tabular}




\begin{tabular}{|c|c|c|c|c|c|c|c|c|c|c|c|c|c|c|c|c|c|c|c|c|c|}
\hline TAXON & UTM & $\mathrm{km} 2$ & BIO1 & $\mathrm{B1O2}$ & $\mathrm{BIO3}$ & 8104 & 8105 & B106 & B107 & B108 & B109 & BIO10 & BIO11 & BIO12 & BIO13 & B1014 & 81015 & B1016 & B1017 & B1018 & 81019 \\
\hline Pelodytes punctatus & 30TXN37 & & & & & & & & & & & & & & & & & & & & \\
\hline Pelodytes punctatus & 30TXN41 & 100,00 & 119,31 & 103,47 & 38,94 & 5672,28 & 266,17 & 1,97 & 264,20 & 81,03 & 192,59 & 192,59 & 47,78 & 796,64 & 92,31 & 38,74 & 20,62 & 243,00 & 145,39 & 145,78 & 228,46 \\
\hline Pelodytes punctatus & 30TXN42 & 100,00 & 107,87 & 101,97 & 38,86 & 5576,71 & 252,92 & $-6,84$ & 259,76 & 48,18 & 180,30 & 180,30 & 37,93 & 892,28 & $\mid \begin{array}{r}\mid 102,53 \\
\end{array}$ & 45,19 & 19,58 & 271,23 & 165,82 & $\begin{array}{l}465,88 \\
\end{array}$ & 255,72 \\
\hline Pelodytes punctatus & 30 TXN50 & 100,00 & 104,72 & 102,40 & 38,53 & 5650,83 & 251,56 & $-11,08$ & 262,63 & 76,05 & 178,11 & 178,11 & 34,09 & 777,70 & 84,18 & 40,27 & 18,30 & 225,41 & 148,41 & 150,99 & 209,58 \\
\hline Pelodytes punctatus & 30TXN51 & 100,00 & 108,88 & 102,45 & 38,88 & 5601,82 & 254,21 & $-6,87$ & 261,08 & 73,79 & 181,44 & 181,44 & 38,63 & 810,39 & 89,62 & 41,22 & 18,58 & 239,75 & $\mid 153,41$ & 154,05 & 224,22 \\
\hline Pelodytes punctatus & 30 TXN52 & 100,00 & 94,12 & 100,09 & 38,71 & 5497,32 & 237,15 & $-18,39$ & 255,54 & 40,05 & 165,93 & 165,93 & 25,84 & 916,59 & 99,80 & 49,03 & 17,30 & 267,96 & 177,47 & 177,65 & 251,91 \\
\hline Pelodytes punctatus & $30 T \times N 61$ & 100,00 & 103,46 & 101,43 & 38,79 & 5547,82 & 247,30 & $-11,17$ & 258,47 & 72,57 & 175,39 & 175,41 & 34,01 & 809,72 & 86,63 & 42,30 & 17,41 & 234,79 & 157,77 & 159,76 & 217,41 \\
\hline Pelodytes punctatus & 30TXN62 & 100,00 & 102,55 & 100,90 & 38,94 & 5489,47 & 244,74 & $-11,35$ & 256,10 & 66,79 & \begin{tabular}{|l|l|}
173,81 \\
\end{tabular} & 173,82 & 33,73 & \begin{tabular}{|l|l|}
857,75 \\
\end{tabular} & $\begin{array}{ll}92,71 \\
2,1\end{array}$ & 44,94 & $\begin{array}{ll}17,23 \\
17\end{array}$ & 250,88 & 167,34 & 168,63 & 233,86 \\
\hline Pelodytes punctatus & 30 TXN65 & 92,00 & 75,72 & 95,36 & 38,75 & 5277,87 & 211,78 & $-31,52$ & 243,30 & 20,16 & 145,08 & 145,08 & 10,64 & 1101,25 & 117,80 & 62,58 & 15,22 & 320,67 & 221,68 & 221,68 & 301,24 \\
\hline Pelodytes punctatus & 30 TXN83 & 100,00 & 75,68 & 95,40 & 38,34 & 5342,54 & 212,55 & $-33,13$ & 245,68 & 55,34 & 145,72 & 145,72 & 9,74 & 993,85 & 102,26 & 57,44 & 14,39 & 278,46 & 205,26 & 206,54 & 257,59 \\
\hline Pelodytes punctatus & 30 TXN90 & 100,00 & 93,84 & 99,07 & 38,37 & 5463,30 & 235,24 & $-19,39$ & 254,62 & 111,83 & 164,67 & 164,93 & 25,66 & 755,96 & 83,18 & 41,68 & 15,97 & 215,56 & 158,02 & 162,15 & 183,27 \\
\hline Pelodytes punctatus & 30 TXN91 & 100,00 & 94,57 & 99,19 & 38,74 & 5424,62 & 234,78 & $-18,37$ & 253,15 & 100,32 & 164,88 & 165,09 & 26,64 & 790,45 & 84,67 & 43,56 & 15,38 & 222,04 & 164,76 & 169,02 & 195,90 \\
\hline \begin{tabular}{|l} 
Pelodytes punctatus \\
\end{tabular} & 30TYK03 & 100,00 & 121,97 & 93,96 & 36,01 & 5896,13 & 264,49 & 7,97 & 256,52 & 131,42 & 70,05 & 201,18 & 52,27 & 500,34 & 61,01 & 23,30 & 28,63 & 161,39 & 94,81 & 108,03 & 95,10 \\
\hline Pelodytes punctatus & 30TYK05 & 100,00 & 100,61 & 94,21 & 35,98 & 6014,84 & 246,59 & $-13,39$ & 259,98 & 116,11 & 30,21 & 181,51 & 30,21 & 575,43 & 72,34 & 30,21 & 26,24 & 183,80 & 108,59 & 126,76 & 108,59 \\
\hline Pelodytes punctatus & 30TYK07 & 100,00 & 68,33 & 94,32 & 35,40 & 6042,30 & 217,98 & $-44,36$ & 262,34 & 82,14 & $-1,25$ & 150,22 & $-1,25$ & 753,29 & 92,79 & 42,78 & 21,72 & 239,41 & 152,74 & 163,50 & 152,74 \\
\hline Pelodytes punctatus & 30TYK08 & 100,00 & 75,69 & 93,84 & 35,46 & 6025,71 & 223,34 & $-37,81$ & 261,16 & 90,59 & 5,51 & \begin{tabular}{|l|l|}
156,97 \\
\end{tabular} & 5,51 & 697,84 & 87,99 & 39,66 & 23,44 & 224,99 & 137,49 & 155,86 & 137,49 \\
\hline Pelodytes punctatus & 30TYK13 & 100,00 & 133,52 & 91,90 & 36,12 & 5720,51 & 270,72 & 20,66 & 250,06 & \begin{tabular}{r|r|}
141,93 \\
\end{tabular} & 190,10 & 210,40 & 65,70 & 480,60 & 60,84 & 20,39 & 30,59 & 2163,49 & 89 & 102,94 & 94,05 \\
\hline Pelodytes punctatus & 30TYK15 & 100,00 & 107,86 & 92,99 & 35,94 & 5930,00 & 251,03 & $-5,59$ & 256,62 & 121,00 & 39,34 & 187,61 & 38,37 & 561,84 & 69,31 & 27,93 & 26,82 & 177,01 & 107,34 & 122,82 & 107,34 \\
\hline Pelodytes punctatus & 30TYK16 & 100,00 & 89,12 & 93,38 & 35,75 & 5989,60 & 234,93 & $-23,77$ & 258,70 & 103,82 & 19,38 & 169,94 & 19,38 & 647,59 & 80,16 & 34,49 & 24,11 & 204,66 & 126,70 & 141,65 & 126,70 \\
\hline Pelodytes punctatus & 30TYK18 & 100,00 & 82,81 & 92,92 & 35,28 & 5984,08 & 228,21 & $-30,54$ & 258,75 & 97,72 & 12,92 & 163,42 & 12,92 & 670,47 & 84,31 & 37,02 & 23,94 & 214,57 & 131,01 & 148,71 & 131,01 \\
\hline Pelodytes punctatus & 30TYK23 & 100,00 & 144,56 & 89,52 & 36,22 & 5531,22 & 276,12 & 33,26 & 242,86 & 153,56 & 217,08 & 218,90 & 78,57 & 466,90 & 64,05 & 17,85 & 33,37 & 167,93 & 80,47 & 98,66 & 94,84 \\
\hline Pelodytes punctatus & 30TYK24 & 100,00 & 128,92 & $\begin{array}{ll}91,07 \\
91,0\end{array}$ & 36,01 & 5715,12 & 265,81 & $\begin{array}{ll}30,21 \\
16,21\end{array}$ & 249,60 & 137,03 & 174,89 & 205,76 & 61,53 & 508,72 & 62,90 & 21,82 & 29,73 & \begin{tabular}{|l|l|}
170,49 \\
\end{tabular} & 96,40 & 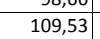 & 100,30 \\
\hline \begin{tabular}{|l} 
Pelodytes punctatus \\
\end{tabular} & 30TYK25 & 100,00 & 107,68 & 92,12 & 35,88 & 5869,38 & 249,48 & $-5,07$ & 254,55 & 118,68 & 48,43 & 186,86 & 39,12 & 584,87 & 70,64 & 28,20 & 26,23 & 183,42 & 114,63 & 126,74 & 114,80 \\
\hline Pelodytes punctatus & 30TYK26 & 100,00 & 100,24 & 92,26 & 35,75 & 5912,12 & 243,11 & $-12,43$ & 255,55 & 114,83 & 31,38 & 179,99 & 31,38 & 609,25 & 74,69 & 30,53 & 25,43 & 189,27 & 118,88 & 132,87 & 118,88 \\
\hline Pelodytes punctatus & 30TYK33 & 100,00 & 157,83 & 86,51 & 36,28 & 5315,71 & 282,90 & 48,26 & 234,65 & 167,63 & 226,74 & 229,22 & 93,87 & 445,78 & 66,24 & 15,17 & 37,56 & 170,38 & 69,38 & 93,29 & 93,96 \\
\hline $\begin{array}{l}\text { Pelodytes punctatus } \\
\end{array}$ & 30TYK34 & 100,00 & 142,37 & 88,91 & 36,01 & 5524,07 & 273,70 & 30,99 & 242,71 & 150,77 & 214,97 & 216,80 & 76,91 & 486,08 & 65,09 & 18,55 & 32,92 & 173,11 & 84,74 & 103,44 & 99,05 \\
\hline Pelodytes punctatus & 30TYK35 & 100,00 & 130,75 & $\begin{array}{l}00,11 \\
90,27\end{array}$ & $\begin{array}{ll}30,019 \\
35,99\end{array}$ & 5665,03 & 265,95 & 18,15 & 247,80 & 138,52 & \begin{tabular}{|l|l|l|l|l|}
179,23 \\
\end{tabular} & 206,90 & $\begin{array}{l}60,01 \\
64,04\end{array}$ & $\begin{array}{l}40,06 \\
516,23\end{array}$ & $\mid \begin{array}{l}\mid c 0,039 \\
64,66\end{array}$ & $\begin{array}{l}\mid 0,030 \\
21,47\end{array}$ & \begin{tabular}{|c|c|}
30,31 \\
30,1
\end{tabular} & $\mid$ & $\begin{array}{ll}04,7,4 \\
96,55\end{array}$ & \begin{tabular}{|l|}
111,27 \\
111,27
\end{tabular} & 102,75 \\
\hline Pelodytes punctatus & 30TYK36 & 100,00 & 120,48 & 90,97 & 35,82 & 5759,56 & 258,38 & 7,41 & 250,97 & 128,45 & 105,86 & 197,99 & 52,83 & 546,76 & 66,65 & 24,28 & 28,53 & 176,65 & 105,75 & 118,76 & 107,49 \\
\hline $\begin{array}{l}\text { Pelodytes punctatus } \\
\end{array}$ & 30TYK38 & 100,00 & 105,05 & 91,56 & 35,64 & 5850,46 & 245,73 & $\mid-7,82$ & 253,55 & $\begin{array}{l}119,73 \\
119,7\end{array}$ & $\begin{array}{l}30,006 \\
36,66\end{array}$ & 183,72 & 36,64 & 594,96 & 73,63 & 28,94 & $\frac{20,35}{26,24}$ & 184,55 & 115,64 & 129,85 & 115,64 \\
\hline Pelodytes punctatus & 30TYK43 & 100,00 & 160,71 & 85,01 & 36,01 & 5244,10 & 283,73 & 51,85 & 231,88 & 170,75 & 228,53 & 231,13 & 97,66 & 453,06 & 67,77 & 14,71 & 38,72 & 175,56 & 68,20 & 94,68 & 97,40 \\
\hline Pelodytes punctatus & 30TYK44 & 100,00 & 154,11 & 86,76 & 36,03 & 5356,39 & 280,45 & 43,74 & 236,70 & 162,89 & 224,01 & 226,19 & 90,39 & 469,68 & 67,13 & 16,07 & 36,26 & 175,98 & 75,34 & 99,29 & 98,57 \\
\hline Pelodytes punctatus & 30TYK46 & 100,00 & $\begin{array}{l}13,14 \\
135,10\end{array}$ & $\begin{array}{ll}80,10 \\
89,75\end{array}$ & $\begin{array}{l}30,05 \\
35,99 \\
\end{array}$ & $\begin{array}{l}5300,35 \\
5606,18\end{array}$ & 208,45 & 22,27 & 246,39 & \begin{tabular}{|l|}
142,35 \\
142,36
\end{tabular} & \begin{tabular}{|l|}
206,40 \\
\end{tabular} & 212,195 & $\begin{array}{l}60,23 \\
69,29\end{array}$ & $\begin{array}{l}\mid 40,00 \\
518,79\end{array}$ & $\begin{array}{l}\mid l, 13 \\
65,81 \\
\end{array}$ & $\mid 20,37$ & $\begin{array}{ll}30,31,31 \\
31\end{array}$ & \begin{tabular}{|l|l|}
177,99 \\
177
\end{tabular} & $\begin{array}{l}94,340 \\
94,90\end{array}$ & $\mid$\begin{tabular}{|c|}
111,56 \\
111,56
\end{tabular} & $\begin{aligned} 104,65 \\
104,65\end{aligned}$ \\
\hline Pelodytes punctatus & 30TYK47 & 100,00 & 121,71 & 90,79 & 35,97 & 5728,22 & 258,75 & 8,35 & 250,40 & 128,71 & 137,52 & 198,86 & 54,79 & 557,17 & 67,35 & 23,85 & 28,58 & 180,73 & 108,31 & 120,55 & 110,92 \\
\hline Pelodytes punctatus & 30TYK48 & 100,00 & 108,78 & 91,05 & 35,78 & 5802,24 & 248,13 & $-3,89$ & 252,02 & 117,16 & 45,72 & 186,98 & 41,16 & 602,38 & 72,99 & 27,83 & 26,31 & 186,16 & 119,52 & 130,85 & 119,58 \\
\hline Pelodytes punctatus & 30TYK49 & 100,00 & 112,81 & 91,67 & 35,87 & 5799,99 & 252,14 & $-1,10$ & 253,24 & 120,85 & 46,74 & 190,63 & 44,90 & 578,67 & 71,28 & 26, & 27,3 & 179,76 & 113,38 & 125,70 & 113,40 \\
\hline Pelodytes punctatus & 30TYK53 & 60,00 & 165,35 & 83,90 & 36,00 & 5208,10 & 286,17 & 56,26 & 229,91 & 175,53 & 232,55 & 235,01 & 102,42 & 451,74 & 68,84 & 13,92 & 40,39 & 178,36 & 65,44 & \begin{tabular}{|l|l|}
94,38 \\
\end{tabular} & 98,85 \\
\hline Pelodytes punctatus & 30TYK54 & 60,00 & 153,71 & 86,33 & 36,02 & 5332,60 & 279,54 & 43,44 & 236,10 & 162,32 & 223,34 & 225,66 & 90,49 & 486,86 & 69,44 & 16,11 & 36,36 & 182,61 & 77,08 & 102,47 & 103,82 \\
\hline \begin{tabular}{|l} 
Pelodytes punctatus \\
\end{tabular} & 30 TYK55 & 50,00 & 149,13 & 87,66 & 36,01 & 5415,34 & 277,37 & 37,77 & 239,60 & 156,94 & 220,15 & 222,02 & 85,26 & 496,01 & 68,51 & 17,13 & 34,70 & 181,50 & 82,24 & 105,34 & 103,52 \\
\hline Pelodytes punctatus & 30TYK57 & 50,00 & 132,20 & 90,22 & 35,99 & 5624,92 & 266,61 & 18,71 & 247,89 & 138,72 & 204,88 & 208,01 & 66,71 & 539,14 & 66,88 & 21,00 & 30,62 & 182,24 & 99,75 & 115,82 & 109,14 \\
\hline Pelodytes punctatus & 30TYK58 & 40,00 & 119,33 & 90,92 & 35,93 & 5731,61 & 256,69 & 5,82 & 250,87 & 125,82 & 149,34 & 196,54 & 52,54 & 578,41 & 69,30 & 24,5 & 28,00 & 185,54 & 113,25 & 124,67 & 116,23 \\
\hline $\begin{array}{l}\text { Pelodytes punctatus } \\
\end{array}$ & 30 TYK59 & 40,00 & 112,86 & 91,12 & 35,82 & 5774,23 & 251,69 & 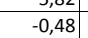 & 252,17 & 119,95 & $\begin{array}{c}14,394 \\
59,28\end{array}$ & 190,71 & 45,66 & 595,51 & 72,06 & 26, & 26,98 & 185,86 & 118,42 & $\mid 128,97$ & 118,77 \\
\hline Pelodytes punctatus & 30TYLO1 & 100,00 & 95,05 & 93,76 & 35,76 & 5986,23 & 238,47 & $-21,30$ & 259,77 & 112,71 & 23,67 & 174,78 & 23,67 & 564,13 & 76,12 & 30, & 28,37 & 189,44 & \begin{tabular}{|l|l|}
102,78 \\
\end{tabular} & 134,63 & 102,78 \\
\hline Pelodytes punctatus & 30TYLO2 & 100,00 & \begin{tabular}{rl|}
108,92 \\
10,0
\end{tabular} & 94,52 & 36,00 & 5980,92 & 251,53 & $-9,03$ & 260,56 & 128,27 & 36,94 & 188,23 & 36,94 & 492,30 & 68,41 & 25,25 & 31,07 & $\mid 167,44$ & 86,54 & 116,54 & 86,54 \\
\hline Pelodytes punctatus & 30TYLO3 & 100,00 & 120,38 & 96,21 & 36,00 & 5988,00 & 264,03 & 0,13 & 263,90 & 140,84 & 47,60 & 199,38 & 47,60 & 442,49 & 62,33 & 22,27 & 32,47 & 150,72 & 77,01 & 102,17 & 77,01 \\
\hline Pelodytes punctatus & 30TYLO4 & 100,00 & 128,06 & 97,86 & 36,00 & 6000,80 & 273,61 & 6,32 & 267,29 & 149,40 & 54,93 & 206,99 & 54,88 & 414,35 & 58,48 & 20,44 & 32,87 & 140,48 & 72,46 & 93,32 & 72,46 \\
\hline Pelodytes punctatus & 30 TYLO5 & 100,00 & $\begin{array}{ll}135,72,0 \\
\end{array}$ & $\begin{array}{l}99,60 \\
99,6\end{array}$ & 36,0 & $\begin{array}{ll}6025,13 \\
6025\end{array}$ & 283,62 & \begin{tabular}{r|r|r|}
12,59 \\
12
\end{tabular} & 27271,03 & \begin{tabular}{|l|}
157,406 \\
157,66
\end{tabular} & \begin{tabular}{|l|l|}
61,97 \\
61
\end{tabular} & 214,66 & $\begin{array}{l}34,00 \\
61,74\end{array}$ & $\begin{array}{l}414,33 \\
388,46\end{array}$ & $\begin{array}{l}50,40 \\
54,65\end{array}$ & $\begin{array}{l}0,44 \\
18,39 \\
\end{array}$ & $\begin{array}{ll}32,01 \\
32,93\end{array}$ & $\begin{array}{l}440,40 \\
130,68\end{array}$ & $\begin{array}{r}62,400 \\
68,50\end{array}$ & 85,03 & 68,400 \\
\hline $\begin{array}{l}\text { Pelodytes punctatus } \\
\end{array}$ & 30TYLO6 & 100,00 & 142,20 & 101,20 & 36,22 & 6042,49 & 292,40 & 18,20 & 274,20 & 164,69 & 68,48 & 221,25 & 67,81 & 368,36 & 51,33 & 16,74 & 32,70 & 122,58 & 65,86 & 78,34 & 65,86 \\
\hline Pelodytes punctatus & 30TYL07 & 100,00 & 144,08 & 102,25 & 36,37 & 6057,12 & 296,00 & 19,68 & 276,32 & 167,03 & 69,18 & 223,23 & 69,18 & 362,62 & 50,07 & 16,34 & 31,95 & 120,05 & 65,58 & 76,32 & 65,58 \\
\hline Pelodytes punctatus & 30TYLO8 & 100,00 & 147,00 & 103,29 & 36,75 & 6075,08 & 300,51 & 22,2 & 278,27 & 170 & 71,66 & 226,18 & 71,66 & 355 & 48,37 & 15, & 31, & 116,53 & 65,40 & 73,91 & 65,40 \\
\hline Pelodytes punctatus & 30TYL10 & 100,00 & 102 & 93,13 & 35,82 & 5950,25 & 244 & $-13,08$ & 257,92 & 120,08 & 32,05 & 181 & 32 & 552,67 & 72,99 & 29, & & 181,29 & 101,44 & 126,59 & 101,44 \\
\hline Pelodytes punctatus & 30TYL11 & 100,00 & 106,53 & 93,56 & 35,70 & 5941,94 & 248,77 & $-10,01$ & 258,77 & 124,49 & 35,74 & 185,55 & 35,74 & 528,69 & 70,90 & 27,69 & $\begin{array}{l}20,27 \\
29,27\end{array}$ & 174,84 & 95,94 & 121,62 & 95,94 \\
\hline \begin{tabular}{|l} 
Pelodytes punctatus \\
\end{tabular} & 30TYL12 & 100,00 & 114,35 & 94,74 & 35,98 & 5948,82 & 256,97 & \begin{tabular}{|c|c|c|}
$-3,66$ \\
\end{tabular} & 260,62 & 133,53 & 42,95 & 193,27 & 42,95 & 488,99 & 66,71 & 25,01 & 30,69 & 162,80 & 87,40 & 111,36 & 87,40 \\
\hline Pelodytes punctatus & 30TYL13 & 100,00 & 120,96 & 96,19 & 36,00 & 5955,15 & 264,72 & 1,18 & 263,54 & 140,97 & 49,06 & 199,65 & 49,06 & 458,44 & 63,28 & 22,79 & 31,53 & 153,08 & 81,40 & 103,08 & 81,40 \\
\hline Pelodytes punctat & 30TYL14 & 100,00 & 127 & 17 & 36,00 & 5971 & (7) & 6,11 & 266,98 & 8 & 55,17 & 206,20 & 55,06 & 431, & 59,8 & 20 & 32 & 143,95 & 76,56 & 95,36 & 76,56 \\
\hline $\begin{array}{l}\text { Pelodytes punctatus } \\
\end{array}$ & $30 \mathrm{TY}$ & 100,00 & & & 36 & 2990 & 285 & $\begin{array}{r}0,11 \\
14,33 \\
\end{array}$ & 270,77 & 159,05 & 65,33 & 215,87 & $\frac{3,0}{64,2}$ & 398,05 & 55,03 & 18, & 32,69 & $\mid 131,48$ & 70,89 & 84,97 & 70, \\
\hline Pelodytes punctatus & 30TYL16 & 100,00 & 146,32 & 101,65 & 36,68 & 6010,72 & 296,19 & 22,16 & 274,02 & 168,23 & 78,09 & 224,96 & 72,52 & 370,77 & 50,68 & 16,07 & 32,89 & 120,83 & 66,73 & 76,48 & 66,73 \\
\hline Pelodytes punctatus & 30TYL20 & 100,00 & 110,80 & 92,95 & 35,91 & 5895,90 & 251,75 & $-4,60$ & 256,35 & 128,26 & 40,93 & 189,42 & 40,93 & 535,13 & 69,78 & 26,77 & 28,71 & 172,13 & 99,11 & 118,94 & 99,11 \\
\hline Pelodytes punctatus & 30TYL21 & 100,00 & 123,69 & 94,50 & 36,00 & 5880,54 & 264,86 & 5,84 & 259,02 & 140,88 & 55,55 & 201,77 & 53,63 & 480,97 & 63,68 & 22,64 & 30,88 & 154,82 & 87,78 & 104,53 & - \\
\hline Pelodytes & $30 \mathrm{TYL}$ & 100,00 & 121 & & 36,0 & 5905, & 263 & 2,64 & 260,88 & 139,69 & 51,91 & 199,39 & 50,5 & 48 & 64 & 23, & 30,65 & 157,38 & 88,16 & 105,77 & $8 \varepsilon$ \\
\hline Pelodytes punctatus & 30TYL23 & 100,00 & 129,53 & 96,95 & 36,01 & 5917,39 & 273,45 & $\begin{array}{l}2,04 \\
9,05\end{array}$ & 264,40 & $\begin{array}{l}149,44 \\
\end{array}$ & 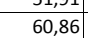 & 207,72 & $\mid$ & $\begin{array}{l}4049,13 \\
449,66\end{array}$ & $\begin{array}{ll}60,72 \\
\end{array}$ & $\mid$ & \begin{tabular}{|l|}
31,80 \\
31
\end{tabular} & $\begin{array}{l}146,05 \\
\end{array}$ & $\mid \begin{array}{l}\mid 80,1,33 \\
81,33\end{array}$ & 96,20 & 81,34 \\
\hline
\end{tabular}




\begin{tabular}{|c|c|c|c|c|c|c|c|c|c|c|c|c|c|c|c|c|c|c|c|c|c|}
\hline TAXON & UTM & $\mathrm{km} 2$ & BIO1 & B102 & $\mathrm{BIO3}$ & 8104 & B105 & B106 & B107 & B108 & B109 & BIO10 & B1011 & BIO12 & B1013 & B1014 & 81015 & B1016 & BIO17 & B1018 & 81019 \\
\hline Pelodytes punctatus & 30TYL24 & 100,00 & 134,76 & 98,59 & 36,18 & 5938,88 & 280,62 & 12,99 & 267,63 & 155,68 & 67,53 & 213,03 & 63,11 & 427,03 & 57,93 & 19,04 & 32,34 & 138,71 & 77,01 & 90,07 & 77,03 \\
\hline $\begin{array}{l}\text { Pelodytes punctatus } \\
\end{array}$ & 30TYL25 & 100,00 & 142,00 & 100,52 & 36,74 & 5961,88 & 289,83 & 18,81 & 271,02 & 161,28 & 75,85 & 220,33 & 69,60 & 400,61 & 54,32 & 17,21 & 32,90 & 129,56 & 72,24 & 82,60 & 72,25 \\
\hline $\begin{array}{l}\text { Pelodytes punctatus } \\
\end{array}$ & 30 TYL26 & 100,00 & 147,16 & 102,06 & 36,92 & 5984,36 & 296,88 & 22,70 & 274,18 & \begin{tabular}{|l|l|}
160,48 \\
\end{tabular} & 82,08 & 225,53 & 73,97 & 381,64 & 51,51 & 16,00 & 33,10 & 123,42 & 68,83 & 77,54 & 68,86 \\
\hline Pelodytes punctatus & 30 TYL30 & 100,00 & 118,61 & 93,06 & 35,99 & 5838,37 & 258,66 & 2,61 & 256,04 & 131,25 & 51,76 & 196,54 & 49,72 & 527,06 & 67,34 & 24,41 & 29,16 & 166,63 & 99,49 & 115,73 & 99,57 \\
\hline Pelodytes punctatus & 30TYL31 & 100,00 & 122,49 & 94,09 & 36,00 & 5848,88 & 263,37 & 5,04 & 258,33 & \begin{tabular}{|l|l|l|}
136,73 \\
\end{tabular} & 55,75 & 200,25 & 53,10 & 507,43 & 65,71 & 23,12 & 29,93 & 161,32 & 94,97 & 109,91 & 95,10 \\
\hline Pelodytes punctatus & 30TYL32 & 100,00 & 133,59 & 96,09 & 36,10 & 5848,65 & 275,59 & 13,99 & 261,60 & 140,98 & 69,86 & 210,97 & 63,95 & 464,46 & 60,79 & 19,82 & 31,84 & 149,59 & 85,77 & 97,49 & 86,31 \\
\hline Pelodytes punctatus & 30TYL33 & 100,00 & 136,96 & 97,60 & 36,23 & 5872,92 & 280,81 & 16,10 & 264,72 & 144,41 & 73,30 & 214,55 & 66,74 & 447,91 & 59,08 & 18,85 & 32,32 & 144,72 & 82,19 & 92,25 & 82,85 \\
\hline Pelodytes punctatus & 30TYL34 & 100,00 & 142,34 & 99,50 & 36,76 & 5901,58 & 288,19 & 19,92 & 268,27 & 146,99 & 78,78 & 220,24 & 71,52 & 423,89 & 56,32 & 17,36 & 32,97 & 137,90 & 76,94 & 85,89 & 77,94 \\
\hline Pelodytes punctatus & 30TYL35 & 100,00 & 143,02 & 100,82 & 36,70 & 5940,71 & 290,94 & 19,49 & 271,45 & \begin{tabular}{|l|}
150,37 \\
\end{tabular} & 78,90 & 221,16 & 71,21 & 414,94 & 55,39 & 17,11 & 32,87 & 134,25 & 75,32 & 83,91 & 75,83 \\
\hline Pelodytes punctatus & 30TYL40 & 100,00 & 109,39 & 91,87 & 35,70 & 5823,57 & 249,52 & $-4,65$ & 254,17 & 122,61 & 42,23 & 187,43 & 41,16 & 589,35 & 73,23 & 27,54 & 26,94 & 182,63 & 115,19 & 128,43 & 115,21 \\
\hline Pelodytes punctatus & 30TYL41 & 100,00 & 119,24 & 93,51 & 35,97 & 5819,53 & 259,90 & 2,94 & 256,97 & 129,11 & 54,79 & 196,99 & 50,72 & 543,12 & 68,61 & 24,24 & 28,79 & 170,06 & 104,42 & 117,63 & 104,67 \\
\hline Pelodytes punctatus & 30TYL43 & 100,00 & 133,19 & 97,27 & 36,27 & 5854,53 & 276,90 & 12,92 & 263,97 & 138,21 & 69,69 & 210,85 & 63,74 & 481,13 & 62,31 & 19,97 & 31,23 & 154,15 & 89,95 & 99,95 & 90,99 \\
\hline Pelodytes punctatus & $30 \mathrm{TYL50}$ & 39,00 & 110,93 & 91,70 & 35,70 & 5798,36 & 250,68 & $-2,77$ & 253,45 & \begin{tabular}{|c|}
120,29 \\
\end{tabular} & 45,79 & 188,80 & 43,29 & 598,38 & 73,23 & 27,07 & 26,75 & \begin{tabular}{|c|}
184,88 \\
\end{tabular} & 118,50 & 130,05 & 118,63 \\
\hline Pelodytes punctatus & 30TYL51 & 30,00 & 120,18 & 93,35 & 36,00 & 5791,27 & 260,47 & 4,02 & \begin{tabular}{|l|l|}
256,45 \\
\end{tabular} & 127,02 & 56,69 & 197,64 & 52,31 & 556,07 & 69,22 & 23,95 & 28,58 & 174,89 & 108,18 & 121,33 & 108,84 \\
\hline Pelodytes punctatus & 30TYM02 & 100,00 & 119,04 & 101,79 & 37,00 & 5880,27 & 270,87 & $-1,21$ & 272,07 & 140,31 & 45,86 & \begin{tabular}{|c|}
195,83 \\
\end{tabular} & 45,86 & 436,98 & 58,78 & 22,03 & 26,51 & 142,13 & 83,77 & 95,42 & 83,77 \\
\hline Pelodytes punctatus & 30TYM03 & 100,00 & 121,30 & 102,29 & 37,03 & 5829,62 & 272,96 & 1,40 & 271,56 & \begin{tabular}{|l|}
142,63 \\
\end{tabular} & 48,45 & 197,35 & $\begin{array}{l}48,45 \\
\end{array}$ & 432,10 & 57,20 & 21,41 & 25,71 & 138,24 & 84,15 & 92,54 & 84,15 \\
\hline Pelodytes punctatus & 30TYMO6 & 100,00 & 119,42 & 102,02 & 38,00 & 5640,66 & 267,08 & 1,31 & 265,77 & 139,94 & 140,33 & 192,75 & 48,47 & 474,58 & 59,00 & 23,38 & 22,34 & 143,95 & 98,43 & 99,03 & 99,21 \\
\hline Pelodytes punctatus & 30TYM07 & 100,00 & 114,41 & 101,49 & 38,01 & 5558,84 & 260,19 & $-1,99$ & 262,17 & \begin{tabular}{|l|l|}
134,43 \\
\end{tabular} & 182,08 & \begin{tabular}{|l|l|}
186,63 \\
\end{tabular} & 44,68 & 517,81 & 62,85 & 26,10 & 20,67 & \begin{tabular}{|l|l|}
154,67 \\
\end{tabular} & 108,79 & 108,83 & 111,43 \\
\hline Pelodytes punctatus & 30TYM08 & 100,00 & 88,36 & 97,26 & 37,60 & 5508,18 & 230,50 & $-24,23$ & 254,73 & 105,88 & 160,23 & 160,39 & 20,16 & 720,99 & 83,39 & 40,79 & 17,43 & 213,13 & 154,64 & 158,41 & 164,13 \\
\hline Pelodytes punctatus & 30TYM10 & 100,00 & 138,18 & 103,97 & 37,00 & 6015,59 & 292,35 & 14,01 & 278,34 & 161,16 & 63,17 & 216,51 & 63,17 & 382,09 & 51,42 & 17,67 & 29,34 & 124,46 & 70,11 & 80,60 & 70,11 \\
\hline Pelodytes punctatus & 30TYM11 & 100,00 & 125,77 & 102,62 & 37,00 & 5933,21 & 278,42 & 3,96 & 274,46 & \begin{tabular}{|c|}
147,69 \\
\end{tabular} & 51,95 & 203,28 & $\begin{array}{l}51,95 \\
\end{array}$ & 418,11 & 56,35 & 20,45 & 27,92 & 136,35 & 77,60 & 90,70 & 77,60 \\
\hline Pelodytes punctatus & 30TYM18 & 100,00 & 84,91 & $\begin{aligned} 2,2,38 \\
96,38 \\
\end{aligned}$ & 37,59 & 5494,60 & 226,17 & $\begin{array}{r}-27,16 \\
-276\end{array}$ & 253,33 & $\begin{array}{l}4,02,28 \\
102\end{array}$ & $\mid$\begin{tabular}{r|r|}
141,59 \\
\end{tabular} & 156,87 & $\begin{array}{l}17,03 \\
17,03\end{array}$ & 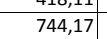 & 86,03 & 42,78 & 17,13 & 220,64 & 161,93 & $\begin{array}{r}, 167,48 \\
\end{array}$ & 166,72 \\
\hline Pelodytes punctatus & 30TYNOO & 100,00 & 89,01 & 97,77 & 38,10 & 5436,31 & 229,17 & $-23,37$ & 252,54 & \begin{tabular}{|c|}
106,64 \\
\end{tabular} & 159,62 & 159,92 & 21,38 & \begin{tabular}{|c|}
777,07 \\
\end{tabular} & 85,95 & 43,85 & 15,60 & 223,04 & 165,59 & 170,13 & 184,36 \\
\hline Pelodytes punctatus & 30TYN01 & 100,00 & 87,26 & 97,46 & 38,44 & 5402,29 & 226,07 & $-24,44$ & 250,51 & \begin{tabular}{|c|}
104,60 \\
\end{tabular} & 157,51 & 157,71 & 20,01 & 824,62 & 89,14 & 46,93 & 14,90 & 233,53 & 175,42 & \begin{tabular}{|c|}
179,88 \\
\end{tabular} & 199,54 \\
\hline Pelodytes punctatus & $31 \mathrm{SBC} 49$ & 100,00 & 174,19 & 100,95 & 39,64 & 5282,85 & 308,67 & 56,60 & 252,07 & 152,84 & 241,82 & 244,76 & 109,48 & 573,36 & 87,54 & 7,64 & 51,85 & 250,76 & 51,53 & 88,73 & 176,00 \\
\hline Pelodytes punctatus & $315 \mathrm{BC59}$ & 73,00 & 178,30 & 99,98 & 39,52 & 5248,02 & 311,31 & 60,82 & 250,49 & 157,60 & 245,06 & 248,11 & 113,73 & 578,22 & 91,41 & 6,83 & 54,31 & 258,70 & 48,95 & 88,32 & 182,77 \\
\hline Pelodytes punctatus & 31 SBD40 & 51,00 & 180,61 & 101,19 & 39,92 & 5239,28 & 313,91 & 62,61 & 251,30 & 159,51 & 247,30 & 250,34 & 115,92 & 572,82 & 90,86 & 7,14 & 54,59 & 256,71 & 48,90 & 88,87 & 180,37 \\
\hline Pelodytes punctatus & 31тBE 43 & 42,00 & 168,69 & 83,80 & 36,00 & 5191,27 & 288,73 & 59,20 & 229,53 & \begin{tabular}{|l|l|}
178,49 \\
\end{tabular} & 235,78 & 238,10 & 105,92 & 450,08 & 69,67 & 13,00 & 41,61 & 180,04 & 63,59 & 94,02 & 98,96 \\
\hline Pelodytes punctatus & 31TBE44 & 53,00 & 153,70 & 86,17 & 36,00 & 5322,66 & 279,40 & 43,45 & 235,94 & 162,33 & 223,42 & 225,59 & 90,90 & 497,59 & 71,08 & 16,06 & 36,24 & 186,84 & 77,97 & 104,35 & 107,06 \\
\hline Pelodytes punctatus & 31TBE45 & 57,00 & 153,66 & 87,05 & 36,01 & 5360,26 & 280,27 & 42,42 & 237,85 & 161,39 & 223,80 & 225,93 & 90,54 & 493,76 & 69,85 & 16,15 & 36,06 & 184,06 & 79,28 & 104,61 & 104,30 \\
\hline Pelodytes punctatus & 31TBE47 & 42,00 & 139,21 & 89,90 & 36,00 & 5553,37 & 271,91 & 25,73 & 246,19 & 145,64 & 212,67 & 214,06 & 74,59 & 527,90 & 68,06 & 19,19 & 32,11 & 183,50 & 93,84 & 112,96 & 108,14 \\
\hline Pelodytes punctatus & 31TBE48 & 47,00 & 131,15 & 90,93 & 36,00 & 5643,69 & 266,31 & 17,18 & 249,13 & 137,00 & 203,74 & 207,20 & 65,56 & 547,07 & 67,10 & 21,13 & 30,26 & 183,33 & 101,84 & 117,48 & 110,67 \\
\hline Pelodytes punctatus & 31TBE49 & 40,00 & 119,56 & 91,25 & 35,92 & 5731,29 & 257,22 & 5,59 & 251,63 & 125,81 & 145,69 & 196,73 & 52,88 & 581,34 & 69,86 & 24,46 & 28,17 & 185,85 & 113,97 & 125,36 & 116,83 \\
\hline Pelodytes punctatus & 31TBE53 & & & & & & & & & & & & & & & & & & & & \\
\hline Pelodytes punctatus & 31TBE54 & 80,00 & 4,95 & 25 & 36,02 & 26,37 & 26 & 54 & 232,65 & 45 & 00 & 235,31 & 03,00 & 82 & 71,71 & 13, & 39,91 & 67 & 69,66 & 99,72 & 103,14 \\
\hline Pelodytes punctatus & 31TBE55 & 100,00 & 159,40 & 86,61 & 36,07 & 5294,17 & 284,20 & 48,04 & 236,16 & 166,89 & 228,64 & 230,73 & 97,16 & 490,98 & 71,74 & 14,86 & 37,91 & 187,11 & 75,92 & 104,02 & 105,02 \\
\hline Pelodytes punctatus & 31TBE59 & 100,00 & 126,75 & 91,35 & 36,00 & 5672,10 & 263,16 & 12,45 & 250,71 & 132,39 & 198,51 & 203,30 & 61,11 & 573,99 & 69,69 & 22,45 & 29,45 & 188,32 & \begin{tabular}{|c|}
108,58 \\
\end{tabular} & 122,88 & 117,01 \\
\hline \begin{tabular}{|l} 
Pelodytes punctatus \\
\end{tabular} & 31тBE65 & 61,00 & 169,18 & 86,34 & 36,36 & 5208,07 & 291,59 & 57,66 & 233,93 & 176,24 & 237,21 & 239,49 & \begin{tabular}{|c|c|}
108,25 \\
\end{tabular} & 475,79 & 73,49 & 12,71 & 41,21 & 188,24 & 69,84 & 101,51 & 102,36 \\
\hline Pelodytes punctatus & 31тBE66 & 101,00 & 159,37 & 87,61 & 36,12 & 5304,93 & 285,12 & 47,15 & 237,97 & 165,57 & 229,12 & 231,24 & 98,10 & 510,59 & 74,43 & 14,72 & 37,96 & 193,39 & 79,62 & 108,70 & 108,96 \\
\hline Pelodytes punctatus & 31тBE67 & 99,00 & 74 & 89,09 & 36,22 & 395,38 & 51 & 38,61 & 241,91 & 157,12 & 223,05 & 224,85 & 89,94 & 532,26 & 74,02 & 16 , & 35,63 & 194,55 & 87,19 & 113,19 & 112,28 \\
\hline $\begin{array}{l}\text { Pelodytes punctatus } \\
\end{array}$ & 31TBE69 & \begin{tabular}{|r|r|}
101,00 \\
\end{tabular} & 148,92 & $\mid 92,00$ & 36,53 & 5502,09 & 281,72 & 33,28 & 248,44 & 152,69 & 221,81 & 223,33 & 86,35 & 535,42 & 71,96 & 16,89 & 34,60 & 190,29 & 91,55 & $\mid 114,38$ & 110,82 \\
\hline Pelodytes punctatus & 31TBE78 & 100,00 & 16 & 90,35 & 37, & 5309,51 & 290,76 & 49,03 & 241,74 & \begin{tabular}{ll|}
166,95 \\
\end{tabular} & 233,61 & 235,45 & 103,63 & 521,50 & 76,95 & 14,03 & 38,96 & 197,60 & 82,61 & 112,80 & 104,24 \\
\hline Pelodytes punctatus & 31TBE89 & 100,00 & 162,13 & 91,20 & 36,93 & 5325,69 & 290,57 & 47,15 & 243,42 & $\begin{array}{l}164,59 \\
\end{array}$ & 232,68 & 234,53 & 102,40 & 547,65 & 80,27 & 14,27 & 38,82 & 205,27 & $\mid 87,58$ & 118,50 & 103,46 \\
\hline Pelodytes punctatus & 31TBE99 & 42,00 & 163,34 & 90,17 & 36,85 & 5294,15 & 290 & 49,19 & 241,43 & 166,13 & 233,26 & 235,49 & 103,72 & 555,15 & 82,38 & 14,23 & 39,66 & 209,34 & 88,68 & 121,32 & 104,89 \\
\hline Pelodytes punctatus & $31 \mathrm{TBF} 40$ & 33,00 & 108,69 & 91,31 & 35,60 & 5789,89 & 248,31 & $-4,47$ & 252,78 & 118,67 & 43,71 & 186,73 & 41,31 & 616,76 & 74,91 & 27,93 & 26,22 & 189,78 & 123,22 & 133,71 & 123,42 \\
\hline Pelodytes punctatus & $31 \mathrm{TBF} 50$ & \begin{tabular}{|l|}
50,000 \\
100,0
\end{tabular} & $\begin{array}{l}111,46 \\
1116\end{array}$ & \begin{tabular}{|c|c|}
$1,1,01$ \\
91
\end{tabular} & 35,6 & 5761,27 & \begin{tabular}{|l|l|}
240,31 \\
250,48
\end{tabular} & $-\frac{-1,4 !}{-1,84}$ & 252,32 & $\begin{array}{l}1119,02 \\
11,02\end{array}$ & \begin{tabular}{|l|r|}
112,78 \\
12,1
\end{tabular} & $\begin{array}{l}180,13 \\
189,19 \\
\end{array}$ & $\begin{array}{l}41,31 \\
44,59\end{array}$ & 622,24 & 74,61 & 27,16 & 26,54 & $\begin{array}{l}\mid \\
193,39 \\
\end{array}$ & \begin{tabular}{|l|}
124,08 \\
124,
\end{tabular} & $\begin{array}{l}333,1+86 \\
133\end{array}$ & $\begin{array}{l}\mid 21,426 \\
126,29\end{array}$ \\
\hline $\begin{array}{l}\text { Pelodytes punctatus } \\
\end{array}$ & 31TBF51 & 100,00 & 112,71 & 92,11 & 35,72 & 5780,48 & 252,82 & $-1,59$ & 254,41 & 120,27 & 57,08 & 190,44 & 45,43 & 610,58 & 74,07 & 26,67 & 26,86 & 188,91 & 122,06 & 131,81 & 122,89 \\
\hline Pelodytes punctatus & 31TBF53 & 100,00 & 136,58 & 97,57 & 36,49 & 5812,02 & 280,01 & 16,22 & 263,80 & 139,80 & 80,42 & 213,90 & 68,49 & 507,23 & 63,65 & 19,22 & 31,35 & 165,47 & 96,33 & 106,67 & 99,39 \\
\hline Pelodytes punctatus & 31TBF54 & 99,00 & 140,39 & 99,64 & 36,83 & 5861,34 & 286,07 & 18,20 & 267 & 143 & 76,75 & 218,07 & 71,29 & 482,97 & 61, & 18 & 31, & 157,98 & 90,49 & 97,66 & 93,44 \\
\hline Pelodytes punctatus & 31TBF55 & 99,00 & 14 & 101,81 & 36 & 914,32 & 29 & 20, & 272 & 147 & 81 & 223,09 & 74,75 & 454,87 & 58, & 17 & 32,76 & 149,69 & 83,71 & 90,81 & 86,57 \\
\hline Pelodytes punctatus & 31TBF58 & 100,00 & 147,11 & 106,32 & 37,06 & 6087,26 & 301,49 & 19,42 & 282,06 & 160,37 & 81,35 & 226,64 & 72,42 & 411,32 & 53,87 & 16,99 & 31,73 & 132,36 & 74,40 & 83,85 & 75,21 \\
\hline \begin{tabular}{|l} 
Pelodytes punctatus \\
\end{tabular} & 31TBF59 & 100,00 & 143,56 & 107,13 & 37,00 & 6127,80 & 299,68 & 15,58 & 284,10 & 167,14 & 74,32 & 223,41 & 67,83 & 414,24 & 54,45 & 17,95 & 30,49 & 132,41 & 75,43 & 86,64 & 75,47 \\
\hline Pelodytes punctatus & 31TBF60 & 100,00 & 131,81 & 92,23 & 36,17 & 5648,64 & 268,52 & 16,45 & 252,08 & 136,55 & 206,01 & 207,95 & 66,86 & 576,26 & 70,87 & 21,04 & 30,52 & 191,29 & 106,43 & 122,69 & 118,72 \\
\hline Pelodytes puncta & 31TBF61 & 99,00 & & & 35,52 & 5755,61 & 210 & $-3,78$ & 252, & 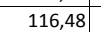 & 146,49 & 186,98 & 42,61 & 648, & 76 , & 20 & 25,89 & 199,39 & 130,34 & 138,81 & 133, \\
\hline Pelodytes punctatus & 31тBF62 & 101,00 & & & 36,04 & 5757 & 261 & 9,53 & 257,66 & 130,90 & 188,52 & 203, & 59,5 & 576,00 & 69,50 & 22, & 29,10 & 18 & 111,21 & 123,23 & 116 \\
\hline Pelodytes punctatus & $31 \mathrm{TBF}$ & 100,00 & 136,87 & 97,23 & 36,51 & 5786,36 & 279,66 & 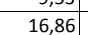 & 262,80 & 139,95 & 196,36 & 214,02 & 69,52 & 531,63 & 65,19 & 19,19 & 31,10 & 174,12 & 100,18 & 113,19 & 106,70 \\
\hline Pelodytes punctatus & 31TBF65 & 100,00 & 148,14 & 102,33 & 36,99 & 5906,11 & 296,24 & 23,44 & 272,80 & 150,01 & 86,07 & 226,12 & 78,34 & 464,28 & 58,74 & 16,47 & 33,28 & 154,86 & 85,46 & 93,14 & 89,80 \\
\hline Pelodytes punctatus & 31TBF71 & 101,00 & 132,77 & 92,82 & 36,20 & 5636,99 & 270,10 & 17,10 & 252,99 & 136,79 & 207,72 & 208,94 & 68,45 & 596,72 & 74,31 & 21,14 & 30,76 & 197,60 & 109,47 & 126,59 & 123,37 \\
\hline Pelodytes punctatus & 31TBF72 & 100,00 & 120 & & 35,8 & 5726 & 260 & 5,8 & 254,78 & 126,04 & 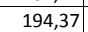 & 197 & 54 & 625 , & 75 , & 24 & 27,98 & 197,57 & 121,08 & 132,97 & $12 \mathrm{~s}$ \\
\hline Pelodytes punctatus & $31 \mathrm{TBF73}$ & 100,00 & 136,20 & 96,45 & 36,51 & 5760,37 & 278,20 & $\begin{array}{l}16,004 \\
16,94\end{array}$ & 261,26 & 139,32 & 212,64 & 213,25 & $\begin{array}{l}64,41 \\
69,49\end{array}$ & 559,53 & $60,67,84$ & $\begin{array}{l}19,63 \\
\end{array}$ & \begin{tabular}{|l|l|}
30,87 \\
\end{tabular} & 183,26 & $\begin{array}{l}103,73 \\
\end{array}$ & 118,88 & $\begin{array}{ll}114,94 \\
\end{array}$ \\
\hline
\end{tabular}




\begin{tabular}{|c|c|c|c|c|c|c|c|c|c|c|c|c|c|c|c|c|c|c|c|c|c|}
\hline TAXON & UTM & $\mathrm{km} 2$ & $\mathrm{BIO1}$ & $\mathrm{B1O2}$ & $\mathrm{BIO3}$ & B104 & B105 & B106 & B107 & B108 & B109 & 81010 & B1011 & B1012 & 81013 & 81014 & B1015 & B1016 & B1017 & $\mathrm{BIO18}$ & B1019 \\
\hline Pelodytes punctatus & 31TBF75 & 100,00 & 144,56 & 101,47 & 36,99 & 5904,87 & 292,23 & 20,69 & 271,54 & 146,80 & 152,31 & 222,69 & 75,06 & 498,08 & 61,53 & 17,34 & 32,07 & 163,84 & 92,94 & 101,99 & 99,09 \\
\hline Pelodytes punctatus & 31TBF76 & 100,00 & 151,21 & 104,35 & 37,05 & 5991,01 & 301,78 & 24,64 & 277,14 & 153,10 & 86,74 & 229,97 & 79,66 & 451,58 & 57,12 & 15,97 & 33,44 & 150,71 & 81,91 & 88,18 & 86,67 \\
\hline Pelodytes punctatus & 31TBF80 & 99,00 & 161,91 & 93,13 & 37,04 & 5377,75 & 292,75 & 45,29 & 247,46 & 163,14 & 233,20 & 234,91 & 101,67 & 550,62 & 80,09 & 14,42 & 38,54 & 204,72 & 89,35 & 119,45 & 103,11 \\
\hline Pelodytes punctatus & 31TBF84 & 99,00 & 147,68 & 98,95 & 36,85 & 5772,38 & 290,93 & 25,93 & 265,00 & 149,58 & 223,98 & 224,66 & 80,99 & 533,00 & 66,84 & 16,69 & 33,26 & 180,07 & 94,50 & 113,37 & 110,08 \\
\hline \begin{tabular}{|l} 
Pelodytes punctatus \\
\end{tabular} & 31TBF85 & 101,00 & 142,05 & 100,12 & 36,88 & 5881,26 & 288,46 & 19,33 & 269,13 & 144,82 & 217,74 & 220,00 & 72,75 & 531,10 & 64,24 & 18,12 & 31,31 & 172,97 & 98,56 & 109,81 & 108,51 \\
\hline Pelodytes punctatus & 31TBF87 & 99,00 & 146,56 & 105,28 & 37,01 & 6113,84 & 299,91 & 19,08 & 280,83 & 150,82 & 81,16 & 226,53 & 72,37 & 467,65 & 58,68 & 17,79 & 31,46 & 149,93 & 86,02 & 94,01 & 89,59 \\
\hline Pelodytes punctatus & 31TBF92 & 100,00 & 154,42 & 94,27 & 36,87 & 5503,33 & 289,07 & 36,95 & 252,12 & 156,01 & 227,38 & 228,80 & 92,66 & 574,65 & 78,97 & 15,66 & 36,24 & 204,95 & 95,11 & 121,81 & 114,87 \\
\hline Pelodytes punctatus & 31TBF93 & 100,00 & 149,18 & 95,28 & 36,69 & 5614,96 & 286,96 & 30,72 & 256,24 & $\begin{array}{l}151,58 \\
\end{array}$ & 223,56 & 224,74 & 85,42 & 572,98 & 74,83 & 16,53 & 34,38 & 197,79 & $\begin{array}{l}\mid 0,11 \\
97,31 \\
\end{array}$ & 120,03 & 120,59 \\
\hline Pelodytes punctatus & 31TBF94 & 101,00 & 158,05 & 98,10 & 36,99 & 5668,52 & 297,90 & 36,88 & 261,03 & 159,60 & 232,83 & 233,79 & 93,17 & 517,33 & 70,50 & 14,62 & 36,83 & 184,75 & 87,80 & 112,56 & 105,25 \\
\hline Pelodytes punctatus & 31TBF95 & 99,00 & 154,05 & 99,80 & 36,98 & 5812,87 & 297,87 & 31,06 & 266,81 & 156,35 & 221,29 & 231,13 & 85,82 & 504,44 & 64,91 & 15,38 & 34,84 & 173,88 & 88,90 & 109,29 & 102,07 \\
\hline Pelodytes punctatus & 31TBF96 & 100,00 & 157,82 & 102,20 & 36,99 & 5922,54 & 304,71 & 32,44 & 272,26 & 160,45 & 108,67 & 235,67 & 87,02 & 455,63 & 59,54 & 14,90 & 35,59 & 158,33 & 80,41 & 99,20 & 87,44 \\
\hline Pelodytes punctatus & 31TBF99 & 101,00 & 150,74 & 110,81 & 37,00 & 6448,52 & 312,39 & 17,50 & 294,89 & 177,01 & 83,19 & 233,87 & 69,58 & 432,38 & 54,02 & 19,18 & 30,09 & 138,39 & 76,89 & 94,13 & 78,06 \\
\hline $\begin{array}{l}\text { Pelodytes punctatus } \\
\end{array}$ & 31TBG54 & 87,00 & 133,04 & 107,32 & 37,95 & 6022,70 & 287,83 & $\begin{array}{l}7,08 \\
7,0 \\
\end{array}$ & 280,74 & 157,12 & 56,73 & 211,02 & 56,73 & 年 & 57,03 & 23,13 & $\begin{array}{l}24,92 \\
24,92\end{array}$ & 143,35 & 84,73 & 102,08 & 84,73 \\
\hline Pelodytes punctatus & 31TBH60 & 101,00 & 97,64 & 98,63 & 37,98 & 5582,82 & 238,54 & $-17,64$ & 256,18 & 117,12 & 34,65 & 170,18 & 27,44 & 786,31 & 86,23 & 47,05 & 15,98 & 229,72 & 170,56 & 186,30 & 170,95 \\
\hline Pelodytes punctatus & 31TCF04 & 100,00 & 154,40 & 94,64 & 36,57 & 5617,50 & 291,10 & 35,83 & 255,28 & 157,61 & 228,30 & 229,60 & 89,45 & 554,93 & 74,48 & 15,61 & 35,81 & 194,72 & 93,81 & 118,16 & 116,40 \\
\hline Pelodytes punctatus & 31TCF05 & 100,00 & 159,51 & 96,97 & 36,84 & 5707,16 & 298,92 & 38,62 & 260,29 & 162,82 & 205,02 & 235,38 & 92,45 & 502,93 & 68,89 & 14,89 & 36,64 & 179,87 & 87,99 & 112,60 & (n) \\
\hline Pelodytes punctatus & 31TCF07 & 101,00 & 142,31 & 100,70 & 36,31 & 6051,46 & 291,38 & 18,27 & 273,10 & 147,80 & 78,59 & 221,51 & 68,61 & 528,52 & 62,41 & 19,92 & 29,48 & 166,29 & 101,07 & 111,62 & 104,64 \\
\hline Pelodytes punctatus & 31TCF09 & 100,00 & 146,17 & 107,88 & 36,88 & 6403,92 & 305,28 & 15,33 & 289,95 & 171,55 & 78,90 & 228,72 & 65,59 & 471,30 & 57,43 & 21,07 & 28,69 & 149,71 & 85,98 & 103,90 & 86,57 \\
\hline Pelodytes punctatus & 31TCF13 & 95,00 & 155,01 & 89,43 & 36,08 & 5443,29 & 285,01 & 40,86 & 244,15 & 159,62 & 226,56 & 228,42 & 92,51 & 584,05 & 82,37 & 16,18 & 37,03 & 210,66 & 97,51 & 126,43 & 121,91 \\
\hline \begin{tabular}{|l|} 
Pelodytes punctatus \\
\end{tabular} & 31TCF14 & 99,00 & 141,43 & 90,34 & 35,86 & 5617,71 & 276,12 & 26,61 & 249,51 & $\mid 147,04$ & 215,30 & 216,78 & 75,68 & 614,80 & 76,57 & 18,80 & 31,62 & 204.52 & $\mid 107.99$ & 128,10 & 133,09 \\
\hline Pelodytes punctatus & 31TCF17 & 99,00 & 125,28 & 93,84 & 35,53 & 5901,09 & 268,66 & 7,94 & 260,72 & 133,01 & 61,14 & 203,30 & 54,08 & 630,37 & 72,59 & 26,30 & 25,89 & 190,87 & 126,36 & 138,57 & 127,53 \\
\hline Pelodytes punctatus & 31TCF 25 & 99,00 & 145,13 & 87,91 & 35,27 & 5575,42 & 277,06 & 31,92 & 245,14 & 152,12 & 204,07 & 219,64 & 78,86 & 593,26 & 75,52 & 19,18 & 31,89 & 200,03 & 108,90 & 130,00 & 122,54 \\
\hline Pelodytes punctatus & 31TCF27 & 100,00 & 120,60 & 89,93 & 35,00 & 5805,41 & 260,19 & 6,82 & 253,36 & 128,42 & 57,11 & 197,84 & 50,98 & 670,91 & 76,09 & 28,75 & 24,87 & 202,60 & 135,85 & 149,16 & 136,49 \\
\hline Pelodytes punctatus & 31TCF35 & 101,00 & 157,66 & 81,96 & 34,79 & 5332,40 & 281,05 & 48,75 & 232,30 & 166,51 & 109,39 & 228,96 & 93,82 & \begin{tabular}{r|r}
557,55 \\
\end{tabular} & 78,55 & 17,36 & 35,67 & 201,06 & 100,08 & 130,69 & 109,36 \\
\hline Pelodytes punctatus & 31TCF36 & 100,00 & 136,20 & 85,52 & 34,78 & 5605,32 & 267,82 & 25,11 & 242,71 & 144,68 & 167,76 & 210,99 & 68,99 & 624,55 & 74,92 & 22,99 & 28,69 & 202,11 & 121,90 & 139,31 & 128,05 \\
\hline Pelodytes punctatus & 31TCF39 & 100,00 & 133,43 & 91,90 & 35,08 & 5911,36 & 274,57 & 16,60 & 257,97 & 145,94 & 60,67 & 210,86 & 60,54 & 597,88 & 68,80 & 26,49 & 26,11 & 181,22 & 114,03 & 139,69 & 114,03 \\
\hline Pelodytes punctatus & 31TCF44 & 18,00 & 163,59 & 75,71 & 34,00 & 5096,00 & 279,18 & 59,82 & 219,35 & 174,12 & 114,35 & 232,00 & \begin{tabular}{|c|}
102,65 \\
\end{tabular} & 550,18 & 80,12 & 16,59 & 37,71 & 204,47 & 年, & 132,65 & 111,82 \\
\hline Pelodytes punctatus & 31TCF45 & 98,00 & 160,62 & 75,79 & 33,81 & 5147,51 & 277,23 & 56,59 & 220,64 & 171,42 & 103,96 & 229,48 & 98,64 & 553,08 & 77,58 & 17,17 & 36,42 & 201,01 & 97,92 & 132,79 & 113,60 \\
\hline Pelodytes punctatus & 31TCF55 & 69,00 & 160,04 & 71,70 & 33,01 & 5056,42 & 272,84 & 59,35 & 213,49 & 172,27 & 199,78 & 227,65 & 99,01 & 559,29 & 75,85 & 17,51 & 35,78 & 200,36 & 98,77 & 133,98 & 122,29 \\
\hline Pelodytes punctatus & 31TCF57 & 99,00 & 147,41 & 78,90 & 33,88 & 5423,19 & 270,97 & 40,84 & 230,14 & 157,99 & 100,81 & 219,44 & 81,40 & 581,84 & 72,51 & 21,21 & 29,63 & 194,63 & 112,55 & 136,12 & 117,33 \\
\hline Pelodytes punctatus & 31TCF65 & 46,00 & 162,50 & 71,04 & 33,00 & 5050,68 & 274,52 & 62,36 & 212,16 & 175,04 & 227,02 & 230,05 & 101,48 & 558,36 & 77,79 & 18,38 & 34,71 & 201,48 & 99,46 & 134,50 & 120,18 \\
\hline Pelodytes punctatus & 31TCFG6 & 100,00 & 154,23 & 73,09 & 33,01 & 5191,91 & 270,40 & 52,41 & 217,99 & \begin{tabular}{|l|l|l}
165,974 \\
\end{tabular} & 220,92 & 223,55 & $\begin{array}{l}1,40 \\
91,57 \\
\end{array}$ & 583,63 & 76,96 & 20,63 & \begin{tabular}{|c|c|}
31,16 \\
\end{tabular} & 202,41 & \begin{tabular}{|l|}
108,47 \\
\end{tabular} & 138,47 & 122,70 \\
\hline Pelodytes punctatus & 31TCF68 & 99,00 & 131,15 & 79,81 & 33,66 & 5559,16 & 259,21 & 24,77 & 234,45 & 141,26 & 64,97 & 205,27 & 64,24 & 666,55 & 75,62 & 29,08 & 25,12 & 208,11 & 131,83 & 156,38 & 131,86 \\
\hline Pelodytes punctatus & 31TCF75 & & & & & & & & & & & & & & & & & & & & \\
\hline Pelodytes punctatus & 31TCF76 & 100,00 & 158,41 & 71,91 & 32,99 & 51,24 & 272,81 & 57,54 & 215,27 & 170,21 & 224,63 & 227,14 & 96,04 & 582,02 & 79,99 & 21,60 & 31,08 & 204,76 & 108,70 &, 79 & 120,42 \\
\hline Pelodytes punctatus & 31TCF77 & 101,00 & 145,54 & 74,80 & 33,01 & 5344,03 & 265,69 & 42,47 & 223,23 & 156,52 & 193,43 & 216,74 & 81,12 & 627,43 & 78,06 & 25,09 & 27,47 & 208,00 & 123,24 & 148,06 & 127,46 \\
\hline Pelodytes punctatus & $\begin{array}{l}\text { 31TCF78 } \\
\end{array}$ & 101,00 & $\begin{array}{l}1430,54 \\
130,54\end{array}$ & 77,56 & 33,05 & 5504,74 & 256,71 & $\begin{array}{ll}26,05 \\
26,05\end{array}$ & $\mid 230,66$ & 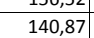 & $\begin{array}{l}150,45 \\
72,92 \\
\end{array}$ & 204,04 & $\begin{array}{l}61,124 \\
64,67\end{array}$ & $\begin{array}{l}\mid 2021,43 \\
687,65\end{array}$ & $\begin{array}{l}70,700 \\
77,72\end{array}$ & $\begin{array}{l}30,725 \\
30,72\end{array}$ & \begin{tabular}{|l|l|}
24,46 \\
\end{tabular} & \begin{tabular}{|l|}
214,6404 \\
\end{tabular} & \begin{tabular}{|l|}
$136,78,7$ \\
\end{tabular} & $\begin{array}{l}140,00 \\
162,16\end{array}$ & $\begin{array}{l}121,40 \\
136,81\end{array}$ \\
\hline Pelodytes punctatus & 31TCF79 & 100,00 & 128,91 & 78,91 & 33,06 & 5569,67 & 257,32 & 23,18 & 234,14 & 138,99 & 61,92 & 203,09 & 61,92 & 687,95 & 76,92 & 32,81 & 24,03 & 210,20 & 132,79 & 165,84 & 132,79 \\
\hline Pelodytes punctatus & 31TCF86 & 91,00 & 159,65 & 71,41 & 32,97 & 5147,19 & 273,63 & 59,16 & 214,47 & 171,28 & 226,06 & 228,23 & 97,46 & 592,90 & 83,01 & 22,78 & 30,74 & 209,33 & 111,23 & 142,36 & 121,67 \\
\hline Pelodytes punctatus & 31TCF87 & 99,00 & 154,53 & 72,64 & 32,94 & 5250,76 & 271,23 & 52,83 & 218,40 & 165,66 & 222,41 & 224,40 & 90,97 & 606,20 & 80,03 & 24,43 & 28,57 & 207,34 & 117,39 & 145,62 & 122,55 \\
\hline Pelodytes punctatus & 31TCF88 & 101,00 & 146,61 & 74,55 & 32,95 & 5379,89 & 267,30 & 43,24 & 224,06 & 157,43 & 124,63 & $21 \varepsilon$ & 81,53 & 630,24 & 76,94 & 26, & 26,52 & 206,60 & 124,75 & 151,34 & 125,14 \\
\hline $\begin{array}{l}\text { Pelodytes punctatus } \\
\end{array}$ & $\begin{array}{l}1 \text { L } \\
31 \text { TCF } 89 \\
\end{array}$ & $\begin{array}{l}101,00 \\
101,00\end{array}$ & $\begin{array}{l}14,01 \\
139,33 \\
\end{array}$ & $\begin{array}{l}74,35 \\
76,38\end{array}$ & $\begin{array}{l}32,95 \\
32,97\end{array}$ & $\begin{array}{l}35 / 8,09 \\
5485,22\end{array}$ & $26,53,93$ & $\begin{array}{l}3,24 \\
34,78 \\
\end{array}$ & \begin{tabular}{|l|}
229,15 \\
220
\end{tabular} & \begin{tabular}{|l|}
149,73 \\
149,7
\end{tabular} & \begin{tabular}{|l|}
124,03 \\
72,92
\end{tabular} & $\frac{\mid 20,17}{212,16}$ & $\begin{array}{l}1,33 \\
72,92 \\
\end{array}$ & $\mid \begin{array}{l}\mid c 30,24 \\
652,83\end{array}$ & $\begin{array}{l}70,94 \\
74,95\end{array}$ & $\begin{array}{l}20,00 \\
30,19\end{array}$ & $\begin{array}{l}2,352 \\
25,02\end{array}$ & $\begin{array}{l}200,00 \\
205,62\end{array}$ & $\begin{array}{ll}126,215 \\
126,2\end{array}$ & $\begin{aligned} 151,34 \\
158,68\end{aligned}$ & $\begin{array}{l}12,14 \\
126,21\end{array}$ \\
\hline Pelodytes punctatus & 31TCF96 & 63,00 & 162,17 & 71,02 & 32,93 & 5135,33 & 275,55 & 61,89 & 213,65 & 173,63 & 228,45 & 230,55 & 100,06 & 597,04 & 85,61 & 22,81 & 31,43 & 213,67 & 111,73 & 143,07 & 122,33 \\
\hline Pelodytes punctatus & 31TCF97 & 101,00 & 155,44 & 71,73 & 32,62 & 5239,23 & 271,63 & 54,42 & 217,21 & 166,41 & 223,38 & 225,25 & 92,23 & 620,28 & 82,75 & 25,01 & 28,58 & 213,10 & 119,15 & 48,12 & 126,26 \\
\hline Pelodytes punctatus & 31TCF98 & 100,00 & 154,06 & 72,97 & 32,69 & 5317,90 & 272,40 & 51,77 & 220,63 & 164,93 & 143,72 & 224,68 & 89,57 & 613,12 & 78,77 & 26,30 & 27,63 & 06,61 & 71 & 49,15 & 121,59 \\
\hline Pelodytes punctatus & 31TCG04 & 101,00 & 118,09 & 101,98 & 36,4 & |6139,49 & 270,8 & $-4,66$ & 275,52 & \begin{tabular}{|l|l|}
140,83 \\
\end{tabular} & \begin{tabular}{|c|c|}
44,75 \\
40,75
\end{tabular} & $\begin{array}{ll}197,62 \\
\end{array}$ & 40,75 & $\mid \begin{array}{l}\mid 651,87 \\
\end{array}$ & 76,27 & & 22,10 & 204,62 & 122,90 & 164,46 & 122,90 \\
\hline Pelodytes punctatus & 31TCG05 & 101,00 & 113 & 100,43 & 36,55 & 6053,24 & 263,76 & $-7,62$ & 271,38 & 135,18 & 37,09 & 191,81 & 37,09 & 700,20 & 80,56 & 40 & 20,96 & 217,23 & 134,33 & 177,91 & 134,33 \\
\hline Pelodytes punctatus & 31TCG06 & 100,00 & 107,47 & 98,54 & 36,54 & 5951,47 & 255,26 & $\frac{-11,17}{-117}$ & 266,43 & 128,46 & 32,85 & 184,80 & 32,85 & 762,64 & 85,91 & 45,06 & 19,62 & 233,25 & 149,42 & 195,38 & 149,42 \\
\hline Pelodytes punctatus & 31TCG11 & 100,00 & 148,88 & 108,25 & 36,80 & 6481,73 & 308,54 & 17,17 & 291,36 & 175,20 & 66,22 & 231,77 & 65,83 & 466,93 & 56,24 & 22,36 & 27,81 & 150,37 & 82,35 & 110,83 & 82,35 \\
\hline Pelodytes punctatus & $31 \mathrm{TCG} 13$ & 100,00 & 134,26 & 104,94 & 36,54 & 6324,92 & 290,34 & 6,70 & 283,64 & 158,86 & 53,53 & 215,44 & 53,53 & 557,00 & 66,26 & 29,01 & 24,74 & 38 & 100,51 & 139,94 & 100,51 \\
\hline Pelodytes punctatus & 31TCG14 & 100,00 & 115 & 100,30 & 36 & 6 & 270, & $\begin{array}{ll}0,1744 \\
-2,44\end{array}$ & \begin{tabular}{|l|}
272,82 \\
272,
\end{tabular} & \begin{tabular}{|l|l|}
141,630 \\
\end{tabular} & \begin{tabular}{l|l}
42,18 \\
42,1
\end{tabular} & \begin{tabular}{|l|}
198,448 \\
\end{tabular} & \begin{tabular}{l|l}
42,18 \\
42,
\end{tabular} & | & $\begin{array}{l}30,20 \\
77,33\end{array}$ & $\begin{array}{l}\mid 3,010 \\
36,82\end{array}$ & 22,38 & \begin{tabular}{|l|}
208,670 \\
\end{tabular} & \begin{tabular}{|l|}
$123,72,1$ \\
\end{tabular} & 170,29 & 123,72 \\
\hline $\begin{array}{l}\text { Pelodytes punctatus } \\
\end{array}$ & 31TCG15 & 99,00 & 101,89 & 95,01 & 35,75 & 5921,92 & 247,70 & $-13,87$ & 261,58 & 121,46 & 28,49 & 179,32 & 28,49 & 793,30 & 90,01 & 46,81 & 19,97 & 242,68 & 155,53 & 200,06 & 155,53 \\
\hline $\begin{array}{l}\text { Pelodytes punctatus } \\
\end{array}$ & 31TCG16 & \begin{tabular}{|r|r|}
101,00 \\
\end{tabular} & 105,52 & 96,40 & 36,16 & 5926,78 & 251,74 & $-11,38$ & 263,12 & 125,83 & $\begin{array}{ll}20,1,49 \\
31,49\end{array}$ & 182,73 & $\begin{array}{ll}20,4,4 \\
31,49\end{array}$ & 796,46 & 89,31 & $\begin{array}{l}|c|, 10 \\
46,46 \\
\end{array}$ & 19,72 & 243,61 & $\begin{array}{l}154,88 \\
15,0\end{array}$ & 207,47 & 154,88 \\
\hline Pelodytes punctatus & 31TCG18 & 101,00 & 95,11 & 93,72 & 36,10 & 5789,82 & 237,62 & $-18,57$ & 256,19 & 114,02 & 23,29 & 170,75 & 23,17 & 912,47 & 98,85 & 55,75 & 17,54 & 271,84 & 186,17 & 234,07 & 186,17 \\
\hline Pelodytes punctatus & 31 TCG24 & 100,00 & 119,50 & 97,78 & 35,88 & 6070 & 268 & $-0,65$ & 268,75 & 140 & 43,20 & 198 & 43,20 & 679,44 & 78,79 & 37,49 & 22,68 & 212,84 & 125,75 & 175,27 & 125 \\
\hline Pelodytes punctatus & 31TCG25 & $\begin{array}{l}101,00 \\
100\end{array}$ & 113,46 & $\begin{array}{l}91,10 \\
96,40\end{array}$ & $\begin{array}{l}35,00 \\
35,79 \\
\end{array}$ & $\begin{array}{l}6002,89 \\
6002\end{array}$ & 260,44 & $\begin{array}{l}-2,05 \\
-4,72 \\
\end{array}$ & \begin{tabular}{|l|}
260,117 \\
265,17
\end{tabular} & \begin{tabular}{|l|l|}
134,30 \\
130
\end{tabular} & $\begin{array}{ll}38,32 \\
38,\end{array}$ & $\begin{array}{l}191,44 \\
1911\end{array}$ & $\begin{array}{ll}38,32 \\
38,3\end{array}$ & $\begin{array}{l}731,44 \\
731,19\end{array}$ & 83,64 & $\begin{array}{l}1,434 \\
41,37 \\
\end{array}$ & $\begin{array}{l}22,00 \\
21,60\end{array}$ & \begin{tabular}{|l|}
226,89 \\
22,1
\end{tabular} & \begin{tabular}{|c|}
137,85 \\
13,1
\end{tabular} & 190,11 & 137,85 \\
\hline Pelodytes punctatus & 31 TCG26 & 100,00 & 121,80 & 99,03 & 36,10 & 6058,95 & 270,30 & 0,71 & 269,59 & 144,06 & 44,99 & 200,04 & 44,99 & 689,62 & 78,65 & 38,37 & 21,92 & 215,45 & 127,89 & 183,79 & 127,89 \\
\hline Pelodytes punctatus & 31TCG28 & 99,00 & 85,87 & 89,44 & 35,39 & 5711,95 & 225,33 & $-23,97$ & 249,30 & 102,84 & 15,88 & 160,93 & 15,79 & 965,62 & 105,61 & 59,56 & 17,35 & 287,94 & 197,62 & 245,02 & 197,62 \\
\hline Pelodytes punctatus & 31TCG37 & 101,00 & 105,48 & 92,90 & 35,55 & 5864,52 & 248,53 & $-8,86$ & 257,39 & $124, \varepsilon$ & 32,59 & 181 & 32,59 & 822,30 & 92,24 & 46,80 & 20,57 & 252 & 156,84 & 221,14 & 156,84 \\
\hline Pelodytes punctatus & 31TCG44 & 100,00 & 131,50 & 94,24 & 35,22 & 6007,63 & 275,71 & 12,66 & 263,05 & 152,78 & 55,70 & 209,05 & 55,70 & 26,31 & 73,35 & 62 & 25,01 & 197,87 & 109,67 & 665,11 & 109, \\
\hline
\end{tabular}




\begin{tabular}{|c|c|c|c|c|c|c|c|c|c|c|c|c|c|c|c|c|c|c|c|c|c|}
\hline TAXON & UTM & $\mathrm{km2}$ & B101 & $\mathrm{B1O2}$ & $\mathrm{BIO3}$ & B104 & B105 & B106 & B107 & B108 & B109 & 81010 & B1011 & B1O12 & B1013 & 81014 & B1015 & B1O16 & B1017 & B1018 & B1019 \\
\hline Pelodytes punctatus & 31TCG45 & 101,00 & 114,29 & 91,50 & 35,01 & 5901,49 & 256,68 & $-0,45$ & 257,13 & 133,68 & 40,92 & 191,16 & 40,92 & 741,55 & 85,76 & 39,78 & 23,26 & 232,24 & 134,15 & 198,86 & 134,15 \\
\hline Pelodytes punctatus & 31TCG46 & 100,00 & 97,35 & 88,30 & 34,84 & 5776,11 & 237,24 & $-12,70$ & 249,94 & 114,72 & 26,74 & 173,27 & 26,74 & 863,40 & 97,85 & 49,07 & 20,60 & 264,79 & 164,38 & 227,18 & 164,38 \\
\hline Pelodytes punctatus & 31TCG47 & 100,00 & 73,25 & 83,05 & 34,10 & 5610,93 & 209,02 & $-30,90$ & 239,92 & 87,44 & 7,54 & 148,02 & 6,28 & \begin{tabular}{|l|}
1023,62 \\
\end{tabular} & 112,84 & 64,09 & 16,84 & 302,60 & 211,83 & 249,96 & 211,91 \\
\hline Pelodytes punctatus & 31TCG50 & 100,00 & 125,20 & 85,47 & 34,08 & 5757,16 & 260,77 & 14,22 & 246,55 & 141,68 & 54,95 & 201,17 & 54,95 & 672,70 & 77,02 & 33,49 & 24,15 & 201,27 & 126,60 & 163,08 & 126,60 \\
\hline Pelodytes punctatus & 31TCG53 & 100,00 & 133,98 & 90,15 & 34,92 & 5900,41 & 273,85 & $\begin{array}{ll}18,03 \\
\end{array}$ & \begin{tabular}{ll|}
255,82 \\
\end{tabular} & \begin{tabular}{|l|l|}
153,91 \\
\end{tabular} & 60,08 & 210,46 & 60,08 & 622,11 & 72,87 & 31,93 & 25,73 & 194,46 & 108,20 & 161,22 & 108,20 \\
\hline Pelodytes punctatus & 31TCG54 & 100,00 & 128,47 & 90,52 & 34,94 & 5904,12 & 269,06 & 12,75 & 256,31 & 148,32 & 54,50 & 204,86 & 54,50 & 656,86 & 77,26 & 33,38 & 25,45 & 207,43 & 113,50 & 175,72 & 113,50 \\
\hline Pelodytes punctatus & 31TCG55 & 100,00 & 122,96 & 90,48 & 34,96 & 5889,88 & 263,85 & 7,80 & 256,05 & 142,53 & 49,29 & 199,42 & 49,29 & \begin{tabular}{|c|}
693,17 \\
\end{tabular} & 81,14 & 35,47 & 25,08 & 219,27 & 120,52 & \begin{tabular}{|l|l|}
189,14 \\
\end{tabular} & 120,52 \\
\hline Pelodytes punctatus & \begin{tabular}{|l|}
31 TCG57 \\
\end{tabular} & 101,00 & 93,94 & 86,16 & 34,51 & 5718,43 & 231,94 & $-14,21$ & 246,15 & $\begin{array}{l}110,49 \\
\end{array}$ & 24,77 & 169,36 & 24,33 & \begin{tabular}{|l|l|}
890,55 \\
\end{tabular} & \begin{tabular}{|l|l|l|l|l|}
100,86 \\
\end{tabular} & 51,10 & 20,70 & 272,21 & $\begin{array}{l}170,57 \\
\end{array}$ & 235,88 & 170,58 \\
\hline Pelodytes punctatus & 31TCG61 & 99,00 & 125,74 & 83,80 & 33,97 & 5727,71 & 259,95 & 15,87 & 244,08 & 143,41 & 55,75 & 201,19 & 55,75 & 683,17 & 78,92 & 35,98 & 24,29 & 206,36 & 124,60 & 171,33 & 124,60 \\
\hline Pelodytes punctatus & 31TCG63 & 100,00 & 128,65 & 86,51 & 34,10 & 5808,17 & 265,45 & 16,13 & 249,32 & 147,04 & 56,57 & 204,41 & 56,57 & 667,53 & 78,55 & 33,57 & 25,63 & 208,33 & 115,35 & 175,76 & 115,35 \\
\hline Pelodytes punctatus & 31TCG64 & 101,00 & 120,85 & 86,78 & 34,10 & 5815,49 & 258,77 & 8,88 & 249,89 & 139,11 & 48,99 & 196,76 & 48,99 & 712,98 & 84,27 & 35,55 & 25,45 & 224,98 & 122,59 & 192,38 & 122,59 \\
\hline Pelodytes punctatus & 31TCG65 & 101,00 & 121,13 & 87,71 & 34,33 & 5831,24 & 259,73 & 8,37 & 251,36 & 139,89 & 48,66 & 197,02 & 48,66 & 711,34 & 84,13 & 35,08 & 25,96 & 226,18 & 120,89 & 196,85 & 120,89 \\
\hline Pelodytes punctatus & 31TCG67 & 100,00 & 99,70 & 85,67 & 34,39 & 5726,07 & 237,23 & $-8,64$ & 245,87 & \begin{tabular}{l|l|}
116,54 \\
\end{tabular} & 30,30 & 175,10 & 29,84 & 851,07 & 97,52 & 47,29 & 22,18 & 262,35 & 158,57 & 229,13 & 158,57 \\
\hline Pelodytes punctatus & 31TCG69 & 100,00 & 81,66 & 83,19 & 34,16 & 5613,66 & 217,09 & $-22,99$ & 240,08 & 96,70 & 20,97 & 156,14 & 14,08 & 984,49 & 109,60 & 59,94 & 18,40 & 294,83 & 197,92 & 252,69 & 198,74 \\
\hline Pelodytes punctatus & 31TCG71 & 101,00 & 127,45 & 81,27 & 33,46 & 5665,09 & 259,12 & 19,54 & 239,58 & 161,52 & 58,44 & 202,31 & 58,44 & 687,89 & 79,31 & 35,96 & 24,35 & 207,74 & 124,61 & 174,50 & 124,61 \\
\hline Pelodytes punctatus & 31TCG72 & 101,00 & 126,24 & 82,42 & 33,64 & 5699,56 & 259,27 & 17,33 & 241,95 & 142,78 & 56,45 & 201,25 & 56,45 & 694,37 & 81,27 & 35,29 & 24,88 & 212,50 & 122,24 & 180,40 & 122,24 \\
\hline Pelodytes punctatus & 31TCG73 & 100,00 & 121,63 & 83,25 & 33,79 & 5723,55 & 256,15 & 12,41 & 243,74 & 138,51 & 51,61 & 196,92 & 51,61 & 720,62 & 85,22 & 35,85 & 25,23 & 224,42 & 124,60 & 191,02 & 124,60 \\
\hline Pelodytes punctatus & 31TCG74 & 100,00 & 116,23 & 83,76 & 33,94 & 5734,19 & 251,71 & 7,01 & 244,69 & 133,10 & 46,16 & 191,64 & 46,16 & 752,23 & 89,30 & 37,21 & 25,30 & 236,62 & 129,29 & 203,23 & 129,29 \\
\hline Pelodytes punctatus & 31TCG75 & 100,00 & 113,46 & 84,33 & 33,99 & 5744,27 & 249,75 & 4,17 & 245,58 & 130,70 & 43,18 & 188,87 & 43,18 & 767,56 & 90,93 & 38,16 & 25,40 & 242,60 & 131,87 & 211,41 & $\begin{array}{ll}131,87 \\
\end{array}$ \\
\hline Pelodytes punctatus & 31TCG76 & 101,00 & 82,16 & 80,14 & 33,41 & 5598,00 & 216,28 & $-20,41$ & 236,68 & 95,78 & 19,20 & 157,11 & 15,95 & 964,72 & 108,32 & 56,96 & 19,15 & 286,27 & 192,24 & 241,99 & 192,74 \\
\hline Pelodytes punctatus & 31TCG78 & 101,00 & 85,85 & 82,15 & 33,85 & 5619,35 & 220,94 & \begin{tabular}{|l|l|}
$-18,18$ \\
\end{tabular} & 239,12 & 100,67 & 23,43 & 160,50 & 18,55 & 949,62 & 106,95 & 56,21 & 19,49 & 285,60 & 186,85 & 246,24 & 187,27 \\
\hline Pelodytes punctatus & 31TCG80 & 100,00 & 142,39 & 77,58 & 33,01 & 5522,76 & 268,04 & 36,43 & 231,61 & 182,38 & 74,93 & 215,34 & 74,93 & 629,71 & 73,18 & $\begin{array}{ll}30,88 \\
30\end{array}$ & 25,36 & 197,39 & 117,18 & $\begin{array}{l}157,80 \\
\end{array}$ & 117,18 \\
\hline Pelodytes punctatus & 31TCG82 & 100,00 & 125,96 & 80,09 & 33,02 & \begin{tabular}{|l|}
5639,63 \\
\end{tabular} & 257,04 & 18,88 & 238,16 & 152,77 & 57,31 & 200,52 & 57,31 & 705,59 & 82,69 & 35,65 & 24,78 & 215,71 & 123,66 & 185,27 & 123,66 \\
\hline Pelodytes punctatus & 31TCG84 & 101,00 & 127,57 & 82,38 & 33,35 & 5708,55 & 260,98 & 18,27 & 242,71 & 144,95 & 57,26 & 202,28 & 57,26 & 702,92 & 84,28 & 32,92 & 27,02 & 222,55 & 115,79 & 193,19 & 115,79 \\
\hline Pelodytes punctatus & 31TCG87 & 99,00 & 67,24 & 77,10 & 32,93 & 5503,48 & 199,44 & $-31,32$ & 230,76 & 78,97 & 13,91 & 141,54 & 3,51 & \begin{tabular}{|l|}
1068,36 \\
\end{tabular} & 117,04 & 67,59 & 16,05 & 307,45 & 224,74 & 256,98 & 226,27 \\
\hline Pelodytes punctatus & 31TCG88 & 100,00 & 63,33 & 76,98 & 32,89 & 5497,30 & 195,29 & $-35,57$ & 230,86 & 73,67 & 28,23 & 137,52 & $-0,41$ & 1098,87 & 119,62 & 68,98 & 15,87 & 316,04 & 231,11 & 263,61 & 235,88 \\
\hline $\begin{array}{l}\text { Pelodytes punctatus } \\
\end{array}$ & 31TCG90 & 101,00 & 136,36 & 75,89 & 32,62 & 5509,64 & 261,97 & 32,01 & 229,96 & \begin{tabular}{|l|}
171,63 \\
\end{tabular} & $\begin{array}{l}20,25 \\
69,87\end{array}$ & 209,50 & $\begin{array}{l}0,4,87 \\
69\end{array}$ & 671,94 & $\begin{array}{l}76,56 \\
\end{array}$ & 34,14 & 24,21 & 207,62 & \begin{tabular}{|l|l|l|l|l|l|}
126,49 \\
\end{tabular} & $\begin{array}{l}167,94 \\
\end{array}$ & 126,49 \\
\hline Pelodytes punctatus & 31TCG95 & 101,00 & 111,81 & 80,22 & 33,02 & 5654,02 & 244,94 & \begin{tabular}{r|}
6,04 \\
\end{tabular} & 238,90 & 127,50 & 43,42 & 186,65 & 43,42 & 788,95 & 94,18 & 39,23 & 25,53 & 246,95 & 135,20 & 217,09 & 135,20 \\
\hline Pelodytes punctatus & 31TCG97 & 100,00 & 71,85 & 76,80 & 32,78 & 5500,74 & 203,82 & $-26,53$ & 230,35 & 81,58 & 21,96 & 146,11 & 8,09 & $\begin{array}{l}1042,29 \\
\end{array}$ & 114,65 & 64,51 & 16,80 & 300,67 & 216,33 & 253,16 & 218,34 \\
\hline Pelodytes punctatus & 31TCG98 & 101,00 & 64,66 & 76,27 & 32,77 & 5478,46 & 196,19 & $-33,27$ & 229,46 & 73,71 & 26,64 & 138,66 & 1,43 & 1092,72 & 118,86 & 68,90 & 15,71 & 312,52 & 231,01 & 261,60 & 235,04 \\
\hline Pelodytes punctatus & 31TCG99 & 99,00 & 73,05 & 78,05 & 33,11 & 5513,07 & 205,46 & $-26,95$ & 232,41 & 85,52 & 20,57 & 146,93 & 8,37 & 1043,01 & 114,88 & 64,81 & 16,92 & 303,95 & 215,59 & 257,31 & 218,58 \\
\hline $\begin{array}{l}\text { Pelodytes punctatus } \\
\end{array}$ & 31TCH23 & 101,00 & 39,35 & 77,48 & $\frac{3,11}{33,21}$ & 5379,69 & 168,15 & $\begin{array}{l}-61,19 \\
-619\end{array}$ & 229,34 & \begin{tabular}{|l|l|}
50,94 \\
5
\end{tabular} & 43,30 & $\begin{array}{l}111,59 \\
1109\end{array}$ & \begin{tabular}{|c|c|}
$-24,16$ \\
-24
\end{tabular} & \begin{tabular}{|l|l|l|l|l|l}
1278,98 \\
\end{tabular} & \begin{tabular}{|l|}
134,37 \\
134
\end{tabular} & $\begin{array}{l}4,, 22 \\
86,2\end{array}$ & 12,74 & \begin{tabular}{|l|l|}
363,34 \\
\end{tabular} & $\begin{array}{l}286,52 \\
286\end{array}$ & 294,29 & 297,12 \\
\hline Pelodytes punctatus & 31TDF06 & 37,00 & 157,68 & 70,70 & 32,57 & 5176,48 & 272,55 & 58,09 & 214,45 & 168,68 & 224,93 & 226,84 & 95,61 & 632,00 & 88,07 & 24,34 & 30,05 & 222,25 & 117,84 & 148,61 & 131,50 \\
\hline Pelodytes punctatus & 31TDF07 & 100,00 & 148,43 & 71,25 & 32,08 & 5291,64 & 266,58 & 48,21 & 218,37 & 159,33 & 217,47 & 219,19 & 85,31 & 668,64 & 85,49 & 27,15 & 27,00 & 223,53 & 127,41 & 155,86 & 139,43 \\
\hline Pelodytes punctatus & 31TDF08 & 101,00 & 149,24 & 72,06 & 32,09 & 5339,18 & 268,69 & 47,90 & 220,79 & 159,90 & 173,09 & 220,30 & 85,04 & 650,99 & 81,38 & 28,46 & 26,38 & 215,60 & 128,65 & 156,33 & 131,18 \\
\hline Pelodytes punctatus & 31TDF16 & & & & & & & & & & & & & & & & & & & & \\
\hline Pelodytes punctatus & 31TDF17 & 101,00 & 160,92 & 70,50 & 32,28 & 5174,62 & 276,34 & 61,01 & 215,33 & 171,39 & 221,88 & 229,63 & 98,42 & 629,25 & $\begin{array}{l}90,08 \\
\end{array}$ & 24,99 & 31,01 & 224,52 & 120,14 & 150,01 & 129,05 \\
\hline Pelodytes punctatus & 31TDF18 & 99,00 & 160,91 & 71,10 & 32,03 & 5239,75 & 277,92 & 59,79 & 218,13 & 171,23 & 130,82 & 230,38 & 97,46 & 609,35 & 84,18 & 26,58 & 29,69 & 213,79 & 118,71 & 150,19 & 120,98 \\
\hline Pelodytes punctatus & 31TDF19 & 101,00 & 158,29 & 71,93 & 31,99 & 5322,04 & 277,37 & 55,97 & 221,40 & 169,71 & 96,54 & 228,56 & 93,61 & 602,55 & 78,29 & 29,03 & 27,86 & 204,69 & 115,31 & 153,16 & 115,54 \\
\hline Pelodytes punctatus & 31TDF27 & 85,00 & 166,22 & 70,16 & 32,17 & 5089,19 & 280,30 & 66,64 & 213,66 & 176,56 & 218,22 & 233,41 & 104,49 & 618,62 & 94,89 & 23,92 & 33,86 & 229,10 & 117,70 & 148,27 & 125,51 \\
\hline Pelodytes punctatus & 31TDF28 & 101,00 & 158,99 & 70 & 31,69 & 5227,88 & 276,22 & 58,85 & 217,37 & 169,24 & 158,51 & 228,43 & $\begin{array}{l}95,97 \\
\end{array}$ & 626,99 & 86,51 & 27,97 & 28,92 & 218,95 & 124,19 & 154,23 & 126,40 \\
\hline Pelodytes punctatus & 31TDF29 & 101,00 & 159,89 & 70,96 & 31,86 & 5280,03 & 278,34 & 58,46 & 219,88 & 175,16 & 99,82 & 229,64 & 95,80 & 601,07 & 80,0 & 29,35 & 28,43 & 206,58 & 115,70 & 153,82 & 116,03 \\
\hline Pelodytes punctatus & 31TDF38 & 52,00 & 163,90 & 70,18 & 32,17 & 5079,68 & 278,78 & 64,25 & 214,53 & 174,00 & 199,54 & 230,92 & 102,04 & 607,25 & 90,54 & 25,82 & 32,14 & 220,47 & 117,99 & 149,53 & 122,51 \\
\hline Pelodytes punctatus & 31TDF39 & 99,00 & 159,05 & 70,45 & 31,72 & 5221,53 & 276,62 & 58,24 & 218,38 & 169,22 & 122,48 & 227,97 & 95,63 & 625,82 & 85,89 & 29,41 & 28,45 & 215,99 & 124,66 & 157,10 & 125,50 \\
\hline Pelodytes punctatus & 31TDF49 & 74,00 & 155,34 & 69,84 & 31,34 & 5248,01 & 273,44 & 54,54 & 218,91 & 166,02 & 191,46 & 224,66 & 91,70 & 669,03 & 91,23 & 31,05 & 27,32 & 26,69 & 133,39 & 164,11 & 139,00 \\
\hline $\begin{array}{l}\text { Pelodytes punctatus } \\
\end{array}$ & $\begin{array}{l}\text { 31TDF59 } \\
\end{array}$ & 14,00 & 161,65 & $\begin{array}{l}69,94 \\
694\end{array}$ & 3 & \begin{tabular}{|l|}
5210,88 \\
\end{tabular} & 278,76 & $\begin{array}{ll}60,24 \\
\end{array}$ & 218,53 & $\begin{array}{l}171,76 \\
\end{array}$ & 216,00 & 230,12 & 98,29 & 649,65 & 96, & 27,29 & 30,94 & 228,76 & $\begin{array}{l}121,53 \\
\end{array}$ & 155,41 & 138,59 \\
\hline Pelodytes punctatus & 31TDG00 & 100,00 & 14 & 74,17 & 32,10 & 5444,61 & 269,96 & 43,25 & 226,71 & 187,89 & 81,00 & 219,13 & 81,00 & 632,84 & 75,08 & 32,5 & 25,41 & 202,78 & 118,11 & 161,49 & 118,11 \\
\hline Pelodytes punctatus & 31TDG01 & 101,00 & 148,37 & 75,39 & 32,31 & 5488,51 & 272,64 & 43,17 & 229,47 & 196,91 & 81,18 & 220,65 & 81,18 & 613,92 & 72,77 & 32,55 & 25,69 & 197,42 & 109,00 & 162,21 & 109,00 \\
\hline Pelodytes punctatus & 31TDG02 & 101,00 & 146,68 & 76,64 & 32,45 & 5543,49 & 272,71 & 40,25 & 232,46 & 195,43 & 78,39 & 219,41 & 78,39 & 612,12 & 72,23 & 31,38 & 26,17 & 196,17 & 103,62 & 166,15 & 103,62 \\
\hline Pelodytes punctatus & 31TDG03 & 100,00 & 138,99 & 77,70 & 32,62 & 5595,96 & 267,33 & 32,06 & 235,27 & 185,64 & 70,21 & 212,47 & 70,21 & \begin{tabular}{|c|}
646,98 \\
\end{tabular} & 76, & 31,46 & 26,92 & 03,51 & 05,68 & 179,85 & 105,68 \\
\hline Pelodytes punctatus & 31TDG05 & 100,00 & $\frac{12}{12}$ & 79,61 & $\frac{52}{32}$ & |5659,60 & 255 & $\begin{array}{l}2,00 \\
19,95 \\
\end{array}$ & \begin{tabular}{|l|}
239,18 \\
239
\end{tabular} & $\begin{array}{l}144,45 \\
144\end{array}$ & $\begin{array}{ll}58,10 \\
\end{array}$ & \begin{tabular}{|l|}
201,78 \\
\end{tabular} & 58,10 & 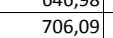 & $86, c$ & $\frac{1,4}{32,3}$ & $\begin{array}{l}28,72 \\
28,71\end{array}$ & \begin{tabular}{|l|}
225,31 \\
22,1
\end{tabular} & $\begin{array}{l}111,86 \\
110\end{array}$ & $\begin{array}{l}103,49 \\
203\end{array}$ & $\begin{array}{l}1031,80 \\
11,86\end{array}$ \\
\hline Pelodytes punctatus & 31TDG06 & 100,00 & 106,21 & 79,00 & 32,99 & 5609,13 & 238,65 & 2,26 & 236,39 & 121,23 & 39,69 & 180,73 & 38,92 & 829,94 & 97,73 & 43,36 & 24,43 & 255,93 & 147,61 & 225,40 & 147,75 \\
\hline $\begin{array}{l}\text { Pelodytes punctatus } \\
\text { S }\end{array}$ & 31TDG07 & 101,00 & 97,75 & 79,20 & 33,01 & 5585,81 & 230,65 & $\begin{array}{l}2,2<0 \\
-4,96\end{array}$ & 235,61 & 112,18 & 32,50 & \begin{tabular}{|l|l|}
172,05 \\
\end{tabular} & 31,12 & 884,39 & 102,25 & 48,81 & 21,83 & 268,99 & \begin{tabular}{|l|l|}
165,19 \\
\end{tabular} & 234,06 & 165,33 \\
\hline Pelodytes punctatus & 31TDG08 & 101,00 & 67,80 & 75,83 & 32,65 & 5466,88 & 199,08 & $-29,52$ & 228,60 & 74,25 & 25,33 & 141,74 & 4,84 & 1075,86 & 116,99 & 67,49 & 15,94 & 307,24 & 226,72 & 258,04 & 230,88 \\
\hline Pelodytes punctatus & 31TDG09 & 101,00 & 88,07 & 79,57 & 33 & 5552,21 & 221,40 & $-13,35$ & 23 & 102,11 & 28,74 & 162,03 & 22,14 & 952,05 & 107,28 & 56,50 & 18,73 & 284,35 & 188,33 & 243,10 & 185 \\
\hline Pelodytes punctatus & $\begin{array}{l}\text { 31TDG10 } \\
31 \text { D }\end{array}$ & $\begin{array}{l}100,00 \\
100\end{array}$ & $\begin{array}{l}0,0301 \\
143,65\end{array}$ & 72,82 & $\begin{array}{l}30,42 \\
31,99 \\
\end{array}$ & $\mid 5436,23$ & 266,45 & \begin{tabular}{|l|l}
$-11,19$ \\
41,5
\end{tabular} & $\begin{array}{l}225,27 \\
225 \\
\end{array}$ & $\begin{array}{l}191,40 \\
191\end{array}$ & $\begin{array}{l}20,1 / 4 \\
78,13\end{array}$ & \begin{tabular}{|l|}
215,81 \\
210
\end{tabular} & $\begin{array}{l}22,4,13 \\
78,13\end{array}$ & $\begin{array}{l}\mid c 32,05 \\
661,58\end{array}$ & \begin{tabular}{|l|}
76,20 \\
76,92
\end{tabular} & $\begin{array}{l}30,13 \\
35,13\end{array}$ & $\begin{array}{l}10,15 \\
24,44\end{array}$ & \begin{tabular}{|l|}
210,32 \\
21,30
\end{tabular} & \begin{tabular}{|l|l|}
124,08 \\
1240
\end{tabular} & \begin{tabular}{|l|}
$273,0,04$ \\
170,
\end{tabular} & $\begin{array}{l}10,34 \\
124,08 \\
\end{array}$ \\
\hline Pelodytes punctatus & 31TDG11 & 100,00 & 130,92 & 73,96 & 32,00 & 5506,36 & 256,72 & 28,36 & 228,36 & 179,89 & 64,96 & 204,11 & 64,96 & 711,82 & 81,20 & 37,69 & 23,64 & 220,30 & 129,34 & 187,13 & 129,34 \\
\hline Pelodytes & 31TDG15 & 101.00 & 123,04 & 77,90 & 3241 & 5614,28 & 253,69 & 17,34 & 236,35 & 138.98 & 54,84 & \begin{tabular}{|c|}
197.03 \\
\end{tabular} & 54,84 & 734.72 & 89,87 & 33,72 & 28.82 & 233,69 & 116,68 & 213,33 & 116,68 \\
\hline Pelodytes punctatus & 31TDG16 & 100,00 & 109,61 & 78,14 & 32,94 & 5594,27 & 241,39 & 5,90 & 235,49 & 124, & 42,68 & 183,93 & 42, & 816,30 & 97,07 & 41,02 & 25 & 253,79 & 141,82 & 225,21 & 141,82 \\
\hline Pelodytes punctatus & 31TDG17 & 100,00 & 92,30 & 77,43 & 32,98 & 5530,63 & 224,15 & $-7,93$ & 232,07 & 105,48 & 30,03 & 166,30 & 27,32 & 927,47 & 105,12 & 53,59 & 19,78 & 274,98 & 80,58 & 37,38 & 181, \\
\hline
\end{tabular}




\begin{tabular}{|c|c|c|c|c|c|c|c|c|c|c|c|c|c|c|c|c|c|c|c|c|c|}
\hline TAXON & UTM & $\mathrm{km} 2$ & BIO1 & B102 & $\mathrm{BIO3}$ & B104 & B105 & B106 & B107 & B108 & B109 & 81010 & B1011 & BIO12 & B1013 & BIO14 & BIO15 & BIO16 & B1017 & BIO18 & B1019 \\
\hline Pelodytes punctatus & 31TDG18 & 98,00 & 62,33 & 74,21 & 32,38 & 5421,81 & 192,68 & $-33,11$ & 225,79 & 60,52 & 21,32 & 135,92 & 0,71 & 1113,96 & 119,15 & 70,54 & 14,95 & 312,34 & 240,85 & 260,57 & 245,94 \\
\hline Pelodytes punctatus & 31TDG19 & 44,00 & 74,09 & 76,62 & 32,84 & 5468,72 & 205,63 & $-23,84$ & 229,47 & 82,36 & 21,98 & 147,66 & 10,64 & 1044,01 & 113,79 & 65,48 & 16,03 & 299,40 & 218,83 & 252,53 & 222,53 \\
\hline Pelodytes punctatus & 31TDG20 & 100,00 & 152,94 & 71,68 & 31,71 & 5379,99 & 273,79 & 50,50 & 223,29 & 200,40 & 87,61 & 223,95 & 87,61 & 634,60 & 77,02 & 33,88 & 25,47 & 208,06 & 119,64 & 165,13 & 119,64 \\
\hline Pelodytes punctatus & 31TDG21 & 101,00 & 134,01 & 72,64 & 31,69 & 5474,85 & 258,67 & 31,96 & 226,71 & 182,80 & 68,49 & 206,92 & 68,49 & 718,32 & 81,31 & 38,66 & 23,28 & 224,13 & 132,51 & 188,93 & 132,51 \\
\hline Pelodytes punctatus & 31TDG22 & 99,00 & 125,49 & 73,69 & 31,92 & 5511,67 & 252,13 & 23,39 & 228,73 & 174,44 & 59,73 & 198,87 & 59,73 & 746,68 & 87,10 & 38,10 & 23,96 & 229,79 & 133,40 & 201,19 & 133,40 \\
\hline Pelodytes punctatus & 31TDG23 & 101,00 & 120,63 & 74,58 & 32,00 & 5523,95 & 248,55 & 18,30 & 230,24 & 167,35 & 54,73 & 194,10 & 54,73 & 769,68 & 90,82 & 38,58 & 24,64 & 234,97 & 134,90 & 209,82 & 134,90 \\
\hline Pelodytes punctatus & 31TDG24 & 100,00 & 126,73 & 75,58 & 32,00 & 5574,07 & 255,26 & 22,19 & 233,07 & 149,77 & 59,32 & 200,34 & 59,32 & 739,43 & 89,01 & 34,71 & 27,42 & 230,37 & 121,26 & 210,88 & 121,26 \\
\hline Pelodytes punctatus & 31TDG25 & 100,00 & 120,53 & 76,48 & 32,00 & 5584,37 & 250,26 & 15,99 & 234,26 & 135,76 & 53,10 & 194,30 & 53,10 & 770,56 & 92,84 & 36,19 & 27,23 & 241,75 & 127,33 & 219,72 & 127,33 \\
\hline Pelodytes punctatus & 31TDG26 & 101,00 & 110,29 & 77,01 & 32,33 & 5569,27 & 241,08 & 7,03 & 234,05 & 124,80 & 43,82 & 184,24 & 43,67 & 832,47 & 97,84 & 42,19 & 24,08 & 256,10 & 147,86 & 225,80 & 147,86 \\
\hline Pelodytes punctatus & 31TDG27 & 101,00 & 99,41 & 77,17 & 32,82 & 5532,74 & 230,85 & $-1,67$ & 232,51 & 113,10 & 36,06 & 173,24 & 34,05 & 897,92 & 102,41 & 49,96 & 20,58 & 268,64 & 171,64 & 232,58 & 171,86 \\
\hline Pelodytes punctatus & 31TDG28 & 100,00 & 71,10 & 74,64 & 32,52 & 5429,70 & 201,55 & $-24,87$ & 226,41 & 71,42 & 28,10 & 144,59 & 9,08 & \begin{tabular}{ll|}
1066,16 \\
\end{tabular} & 114,64 & 66,61 & 15,65 & 301,19 & 226,87 & 252,25 & 231,73 \\
\hline Pelodytes punctatus & 31TDG30 & 100,00 & 157,83 & 71,01 & 31,53 & 5300,33 & 277,10 & 55,68 & 221,42 & 197,57 & 96,21 & 227,47 & 93,06 & 632,38 & 82,25 & 31,86 & 26,59 & 212,42 & $\mid 124,07$ & 160,28 & 124,09 \\
\hline Pelodytes punctatus & 31TDG31 & 101,00 & 144,71 & 71,51 & 31,09 & 5430,91 & 267,32 & 42,09 & 225,23 & \begin{tabular}{|c|}
192,77 \\
\end{tabular} & 78,92 & 216,44 & 78,92 & 701,68 & 81,71 & 38,45 & 23,28 & 223,49 & 133,61 & 182,06 & 133,61 \\
\hline Pelodytes punctatus & 31TDG32 & 101,00 & 126,55 & 72,56 & 31,49 & 5485,82 & 252,29 & 24,87 & 227,42 & 175,21 & 61,18 & $\begin{array}{l}199,62 \\
\end{array}$ & 61,18 & 777,76 & 87,68 & 41,15 & 22,50 & 238,41 & 144,73 & 204,14 & 144,73 \\
\hline Pelodytes punctatus & 31TDG33 & 100,00 & 127,01 & 73,42 & 31,53 & 5519,44 & 253,66 & 24,32 & 229,34 & 175,75 & 60,87 & 200,29 & 60,87 & 774,75 & 89,25 & 39,24 & 23,82 & 237,88 & 138,84 & 209,39 & 138,84 \\
\hline Pelodytes punctatus & 31TDG34 & 101,00 & 129,94 & 74,44 & 31,72 & 5552,03 & 257,43 & 25,65 & 231,78 & 165,59 & 62,72 & 203,31 & 62,72 & 768,28 & 89,48 & 36,97 & 25,35 & 236,62 & 132,24 & 212,86 & 132,24 \\
\hline Pelodytes punctatus & 31TDG35 & 100,00 & 124,92 & 75,47 & 31,97 & 5577,89 & 253,79 & 20,32 & 233,47 & 140,55 & 57,43 & 198,57 & 57,43 & 794,52 & 92,92 & 37,77 & 25,36 & 245,58 & 137,07 & 218,86 & 137,07 \\
\hline Pelodytes punctatus & 31TDG36 & 100,00 & 114,79 & 76,19 & 32,08 & 5563,09 & 244,76 & 11,45 & 233,31 & 130,09 & 48,35 & 188,44 & 48,04 & 837,99 & 96,99 & 42,20 & 23,51 & 256,19 & 151,28 & 225,56 & 151,35 \\
\hline Pelodytes punctatus & 31TDG37 & 101,00 & 107,25 & 76,76 & 32,33 & 5546,01 & 238,00 & 4,78 & 233,22 & 121,53 & 42,10 & 180,97 & 41,12 & 876,42 & $\begin{array}{l}99,70 \\
\end{array}$ & 46,81 & 21,35 & 263,89 & \begin{tabular}{|c|}
165,67 \\
\end{tabular} & 227,95 & 165,95 \\
\hline Pelodytes punctatus & 31TDG38 & 101,00 & 73,34 & 74,25 & $\mid 32,47$ & 5414,20 & 203,41 & $-22,12$ & 225,52 & \begin{tabular}{|c|c|}
68,72 \\
\end{tabular} & 37,31 & $\mid 146,73$ & $\mid 11,69$ & $\mid 1057,84$ & 112,89 & 64,87 & 15,93 & 300,44 & 226,13 & 248,49 & 231,54 \\
\hline Pelodytes punctatus & 31TDG40 & 101,00 & 153,92 & 70,08 & 31,02 & 5322,70 & 273,35 & 51,94 & 221,41 & 184,27 & 153,09 & 224,08 & 89,16 & 686,11 & 89,72 & 33,67 & 25,24 & 226,52 & 139,44 & 169,65 & 141,06 \\
\hline Pelodytes punctatus & 31TDG41 & 100,00 & 143,57 & 70,61 & 31,01 & 5418,05 & 265,73 & 41,25 & 224,47 & 191,17 & 83,61 & 215,19 & 78,09 & 744,65 & 88,99 & 40,05 & 22,43 & 234,86 & 148,77 & 186,25 & 148,81 \\
\hline Pelodytes punctatus & 31TDG42 & 100,00 & 113,04 & 71,73 & 31,59 & 5434,21 & 238,94 & 14,74 & 224,20 & 152,19 & 57,00 & 186,19 & 49,79 & 869,95 & 97,70 & 48,67 & 20,16 & 260,21 & 174,95 & 213,02 & 175,78 \\
\hline Pelodytes punctatus & 31TDG43 & 101,00 & 120,79 & 72,53 & 31,36 & 5480,88 & 247,16 & 19,81 & 227,36 & 168,24 & 56,24 & 193,96 & 55,80 & 841,38 & 93,61 & 44,30 & 21,43 & 251,91 & 161,19 & 215,44 & 161,25 \\
\hline Pelodytes punctatus & 31TDG44 & 101,00 & 130,89 & 73,43 & 31,21 & 5539,31 & 257,59 & 26,91 & 230,68 & 168,05 & 63,87 & 204,03 & 63,87 & 819,11 & 91,15 & 40,15 & 22,82 & 246,08 & 151,03 & 214,89 & 151,03 \\
\hline Pelodytes punctatus & 31TDG45 & 100,00 & 123,43 & 74,48 & 31,81 & 5541,19 & 251,55 & 19,82 & 231,73 & 138,59 & 56,68 & 196,77 & 56,65 & 844,31 & 94,95 & 41,38 & 22,77 & 254,73 & 155,64 & 222,07 & 155,64 \\
\hline Pelodytes punctatus & 31TDG46 & 101,00 & 98,81 & 74,53 & 32,16 & 5461,29 & 227,98 & 0,29 & 227,69 & 123,23 & 38,16 & 172,11 & 35,25 & 935,05 & 102,41 & 54,20 & 18,70 & 269,63 & 188,71 & 229,59 & 189,68 \\
\hline Pelodytes punctatus & 31TDG47 & 100,00 & 107,07 & 76,01 & 32,18 & 5516,90 & 237,20 & 5,42 & 231,79 & 122,12 & 43,70 & $\begin{array}{l}180,49 \\
\end{array}$ & 41,55 & 899,99 & 99,75 & 49,27 & 19,80 & 265,71 & 176,79 & 226,44 & 177,02 \\
\hline Pelodytes punctatus & 31TDG48 & 99,00 & 90,22 & 75,53 & 32,75 & 5453,60 & 220,57 & $\begin{array}{l}-7,82 \\
\end{array}$ & 228,39 & 99,62 & 32,26 & 163,59 & 26,84 & 975,65 & 105,37 & 59,03 & 17,02 & 278,09 & 203,11 & 234,79 & 205,54 \\
\hline Pelodytes punctatus & 31TDG50 & 100,00 & 149,07 & 69,41 & 30,93 & 5340,44 & 268,83 & 47,51 & 221,32 & 172,34 & 184,93 & 219,62 & 84,45 & 739,98 & 97,36 & 35,59 & 24,90 & 240,67 & 149,22 & 177,14 & 156,74 \\
\hline Pelodytes punctatus & 31TDG51 & 100,00 & 150,52 & 69,89 & 30,82 & 5412,19 & 271,39 & 47,10 & 224,29 & 175,65 & 190,74 & 221,70 & 84,58 & 751,99 & 97,13 & 37,05 & 23,69 & 241,22 & 152,85 & 178,44 & 159,64 \\
\hline Pelodytes punctatus & 31TDG52 & 100,00 & 121,05 & 70,84 & 31,14 & 5416,66 & 245,56 & 21,77 & 223,79 & 158,67 & 73,56 & 193,60 & 57,38 & 871,94 & 101,31 & 48,10 & 20,27 & 261,90 & 179,63 & 207,94 & 181,17 \\
\hline Pelodytes punctatus & 31TDG53 & 101,00 & 120,29 & 71,75 & 31,31 & 5454,72 & 245,94 & 19,90 & 226,03 & 168,79 & 56,34 & 193,21 & 55,81 & 879,46 & 97,58 & 47,86 & 20,11 & 259,23 & 176,63 & 214,88 & 176,63 \\
\hline Pelodytes punctatus & 31TDG54 & 100,00 & 125,16 & 72,61 & 31,28 & 5493,16 & 251,46 & 22,80 & 228,67 & 159,72 & 59,79 & 198,10 & 59,49 & 882,49 & 96,36 & 45,17 & 20,85 & 259,02 & 173,86 & 217,20 & 173,90 \\
\hline Pelodytes punctatus & 31TDG55 & 101,00 & 112,93 & 73,61 & 31,78 & 5470,40 & 240,58 & 12,28 & 228,29 & 146,27 & 49,85 & 185,97 & 48,41 & 911,09 & 98,75 & 49,15 & 19,85 & 264,80 & 182,35 & 222,98 & 182,41 \\
\hline Pelodytes punctatus & 31TDG56 & 101,00 & 126,48 & 74,94 & 31,73 & 5552,87 & 254,68 & 21,49 & 233,19 & 143,13 & 59,32 & 199,65 & 59,17 & 878,35 & 94,59 & 43,36 & 21,32 & 261,01 & 171,38 & 218,56 & 171,39 \\
\hline Pelodytes punctatus & 31TDG57 & 100,00 & 129,29 & 76,38 & 31,96 & 5582,05 & 258,48 & 22,78 & 235,70 & 147,30 & 61,07 & 202,62 & 61,07 & 845,98 & 92,13 & 42,93 & 20,88 & 250,54 & 166,34 & 210,12 & 166,34 \\
\hline Pelodytes punctatus & 31TDG60 & 61,00 & 154,39 & 69,16 & 30,85 & 5341,51 & 273,27 & 51,57 & 221,70 & 165,06 & 219,98 & 224,61 & 89,12 & 727,44 & 103,91 & 31,62 & 28,39 & 244,78 & 137,27 & 168,24 & 159,08 \\
\hline Pelodytes punctatus & 31TDG61 & 101,00 & 146,85 & 69,27 & 30,42 & 5401,26 & 267,46 & 44,08 & 223,38 & 169,79 & $\begin{array}{l}194,63 \\
\end{array}$ & 218,05 & 81,26 & 781,72 & 103,63 & 37,41 & 24,57 & 249,46 & 157,06 & 180,94 & 168,79 \\
\hline Pelodytes punctatus & 31TDG62 & 101,00 & 149,18 & 69,89 & 30,11 & 5469,89 & 270,71 & 44,27 & 226,44 & 175,51 & 190,11 & 220,84 & 82,05 & 782,31 & 103,47 & 38,13 & 24,38 & 247,74 & 157,19 & 178,56 & 168,20 \\
\hline Pelodytes punctatus & 31TDG63 & 100,00 & 134,37 & 70,82 & 30,71 & 5472,86 & 258,25 & 31,14 & 227,11 & 182,29 & 82,49 & 206,82 & 68,42 & 864,54 & 102,08 & 45,97 & 21,14 & 257,04 & 178,28 & 02,84 & 178,94 \\
\hline Pelodytes punctatus & 31TDG65 & 100,00 & 134,61 & 73,08 & 31,10 & 5543,73 & 260,82 & 29,16 & 231,66 & 171,21 & 67,05 & 207,58 & 67,05 & 869,24 & 99,53 & 44,63 & 21,17 & 253,62 & 177,00 & 205,04 & 177,00 \\
\hline Pelodytes punctatus & 31TDG66 & 101,00 & 128,84 & 74,49 & 31,64 & 5531,15 & 256,26 & 23,76 & 232,50 & 153,06 & 61,83 & 201,77 & 61,83 & 877,56 & 97,45 & 45,15 & 20,81 & 255,27 & 177,86 & 209,00 & 177,86 \\
\hline Pelodytes punctatus & 31TDG67 & 100,00 & 137,40 & 76,11 & 31,80 & 5580,44 & 265,66 & 29,24 & 236,41 & 175,68 & 68,76 & 210,45 & 68,73 & 808,42 & 94,24 & 42,97 & 21,05 & 236,38 & 165,84 & 188,53 & 165,85 \\
\hline Pelodytes punctatus & 31TDG68 & 86,00 & 114,42 & 76,43 & 32,34 & 5500,76 & 243,88 & 11,05 & 232,83 & 134,60 & 51,47 & 187,37 & \begin{tabular}{ll|}
48,63 \\
\end{tabular} & 893,25 & $\begin{array}{l}96,76 \\
\end{array}$ & 50,69 & 18,58 & 255,03 & $\begin{array}{l}186,61 \\
\end{array}$ & 211,05 & 187,34 \\
\hline Pelodytes punctatus & 31TDG70 & & & & & & & & & & & & & & & & & & & & \\
\hline Pelodytes punctatus & 31TDG71 & 99,00 & 156,87 & 69,51 & 30,60 & 5364,56 & 275,70 & 52,56 & 223,14 & 167,35 & 224,72 & 227,13 & 90,86 & 711,45 & 107,54 & 29,23 & 30,94 & 243,24 & $\begin{array}{l}129,62 \\
\end{array}$ & 160,29 & 156,59 \\
\hline Pelodytes punctatus & 31TDG72 & 101,00 & 154,90 & 69,47 & 30,09 & 5459,06 & 275,20 & 48,78 & 226,42 & 165,21 & 225,52 & 226,12 & 87,35 & 736,21 & 108,20 & 31,73 & 28,88 & 244,81 & 137,61 & 161,82 & 162,07 \\
\hline Pelodytes punctatus & 31TDG73 & 100,00 & 151,59 & 69,54 & 29,97 & 5553,31 & 273,66 & 44,30 & 229,36 & 165,46 & 222,68 & 223,75 & 82,63 & 769,42 & 108,47 & 35,29 & 26,44 & 246,62 & 149,64 & 61,79 & 168,62 \\
\hline Pelodytes punctatus & 31TDG74 & 101,00 & 148,67 & 70,75 & $30, \mathrm{C}$ & 5587,62 & 272,30 & 40,82 & 231,48 & 15 & 209,99 & 22. & 79 & 785 & 106,68 & 38,35 & 24 & 16 & 67 & 67,53 & 169,21 \\
\hline Pelodytes punctatus & 31TDG75 & 101,00 & 13 & 72 & 30,9 & 5523,73 & 263,75 & 32,51 & 231,24 & 182,50 & 104,51 & 21 & 71 & 832,95 & 103,27 & $4: 3$ & 22,28 & 247,40 & 173,37 & 186,58 & 174 \\
\hline Pelodytes punctatus & 31TDG76 & 100,00 & 143,13 & 74,41 & 31,20 & 5552,16 & 269,17 & 35,16 & 234,01 & 185,68 & 111,35 & 215,67 & 74,65 & 784,79 & 99,79 & 41,08 & 22,69 & 235,03 & 163,83 & 173,85 & 164,27 \\
\hline $\begin{array}{l}\text { Pelodytes punctatus } \\
\end{array}$ & 31TDG77 & 100,00 & 138,85 & 75,89 & 31,95 & 5538,66 & 266,13 & 30,97 & 235,15 & 177,79 & 103,96 & 211,36 & 70,83 & 782,67 & 97,23 & 41,56 & 21,97 & 231,89 & 164,30 & 174,28 & 164,77 \\
\hline Pelodytes punctatus & 31TDG78 & 93,00 & 127,93 & 77,01 & 32,06 & 5514,09 & 256,73 & 21,64 & 235,10 & 166,72 & 73,70 & 200,46 & 60,95 & 827,53 & 96,41 & 45,54 & 20,13 & 238,31 & 175,62 & 187,78 & 175,90 \\
\hline Pelodytes punctatus & 31TDG81 & 58,00 & 156,33 & 69,67 & 30,7 & 5324,65 & 274,68 & 52,23 & 222,45 & 166,76 & 221,85 & & 91 & 700,06 & 108,38 & & & & 74 & 80 & 15 \\
\hline Pelodytes punctatus & 31TDG83 & 101,00 & & 69,74 & 30 & 5483,13 & 273,79 & 46,21 & 227,58 & 163,03 & 223,94 & 22 & 85,14 & 738,58 & 109,55 & 31,46 & 29,01 & 243,75 & 137,25 & 159,43 & 163,03 \\
\hline \begin{tabular}{|l} 
Pelodytes punctatus \\
\end{tabular} & 31TDG84 & 101,00 & 151,60 & 71,06 & 30,56 & 5502,87 & 273,56 & 44,03 & 229,53 & 161,75 & 222,87 & 223,26 & 83,40 & 745,99 & 107,99 & 33,42 & 27,63 & 240,70 & 143,15 & 156,73 & 162,27 \\
\hline Pelodytes punctatus & 31TDG85 & 101,00 & 151,47 & 73,02 & 31,16 & 5489,76 & 274,51 & 43,28 & 231,23 & 163,92 & 222,63 & 222,94 & 83,53 & 727,58 & 104,06 & 33,71 & 26,96 & 232,38 & 143,45 & 154,74 & 155,45 \\
\hline Pelodytes pu & 31TDG86 & 100,00 & 150,17 & 74,92 & 31,76 & 5484,51 & 274,44 & 41,47 & 232,96 & 160,93 & 221,32 & 221,62 & 82, & 708,14 & 99,79 & 33,60 & 26,14 & 224 & 142,91 & 150,56 & 149,80 \\
\hline Pelodytes punctatus & 31TDG87 & 101,00 & 149,24 & 76,75 & 32,16 & 5487,27 & 274,86 & 39,84 & 235,02 & 160,05 & 216,56 & 220,80 & 81,28 & 689,46 & 96,19 & 32,82 & 25,71 & 217,65 & 140,02 & 146,09 & 146,16 \\
\hline
\end{tabular}




\begin{tabular}{|c|c|c|c|c|c|c|c|c|c|c|c|c|c|c|c|c|c|c|c|c|c|}
\hline TAXON & UTM & $\mathrm{km} 2$ & B101 & B102 & $\mathrm{BIO3}$ & BIO4 & B105 & B106 & B107 & B108 & 8109 & B1010 & BIO11 & BIO12 & BIO13 & BIO14 & BIO15 & B1016 & B1017 & B1018 & B1019 \\
\hline Pelodytes punctatus & 31TDG88 & 100,00 & 145,31 & 78,30 & 32,55 & 5499,28 & 272,62 & 35,72 & 236,90 & 157,99 & 205,09 & 217,05 & 77,44 & 700,65 & 94,38 & 33,65 & 24,44 & 217,15 & 142,92 & 147,29 & 151,21 \\
\hline Pelodytes punctatus & 31TDG89 & 82,00 & 138,88 & 79,63 & 32,99 & 5506,15 & 267,94 & 29,75 & 238,19 & 152,98 & 186,80 & 211,01 & 71,29 & 724,75 & 93,55 & 35,45 & 22,99 & 219,97 & 148,58 & 152,88 & 159,90 \\
\hline Pelodytes punctatus & 31TDG92 & 90,00 & 150,89 & 70,44 & 31,30 & 5265,40 & 268,98 & 47,70 & 221,29 & 161,82 & 218,54 & 220,26 & 86,91 & 712,95 & 106,85 & 28,68 & 30,50 & 240,38 & 130,56 & 156,86 & 156,52 \\
\hline Pelodytes punctatus & 31TDG93 & 101,00 & 149,48 & 71,06 & 31,22 & 5302,24 & 268,45 & 45,39 & 223,06 & 160,19 & 218,27 & 219,19 & 84,88 & 722,41 & 106,15 & 30,10 & 29,09 & 238,99 & 135,13 & 158,25 & 157,90 \\
\hline Pelodytes punctatus & 31TDG94 & 101,00 & 148,97 & 72,30 & 31,68 & 5318,50 & 269,01 & 43,99 & 225,02 & 159,60 & 218,08 & 218,93 & 84,16 & 721,56 & \begin{tabular}{|l|}
104,28 \\
\end{tabular} & 31,32 & 28,05 & 234,82 & \begin{tabular}{|l|l|}
138,13 \\
\end{tabular} & 157,69 & 156,27 \\
\hline Pelodytes punctatus & 31TDG96 & 101,00 & 154,32 & 76,03 & 32,57 & 5354,37 & 276,69 & 46,32 & 230,38 & \begin{tabular}{ll|l}
164,47 &
\end{tabular} & 223,78 & 224,28 & 88,29 & 645,72 & 96,88 & 27,87 & 29,30 & 214,89 & 123,38 & 138,33 & 136,76 \\
\hline Pelodytes punctatus & 31TDG97 & 101,00 & 154,91 & 77,94 & 32,98 & 5376,61 & 278,77 & 45,78 & 232,99 & 164,75 & 224,66 & 225,07 & 88,52 & 620,55 & 93,45 & 26,50 & 29,39 & 207,71 & 118,15 & $\begin{array}{lll}129,83 \\
\end{array}$ & 131,77 \\
\hline Pelodytes punctatus & 31TDG98 & 101,00 & 154,16 & 79,68 & 33,31 & 5404,67 & 279,85 & 43,98 & 235,87 & 163,77 & 224,38 & 224,69 & 87,42 & 614,88 & 91,59 & 25,70 & 28,95 & 205,24 & $\begin{array}{l}114,78 \\
114,7\end{array}$ & 123,02 & 133,82 \\
\hline Pelodytes punctatus & 31TDG99 & 101,00 & 144,56 & 80,52 & 33,46 & 5443,28 & 272,35 & 34,86 & 237,48 & 151,97 & 215,52 & 215,81 & 77,70 & 669,90 & 92,67 & 29,61 & 25,82 & 213,72 & 128,84 & 135,24 & 149,82 \\
\hline Pelodytes punctatus & 31TDHOO & 28,00 & 50,10 & 74,04 & 32,22 & 5406,83 & 179,99 & $-45,96$ & 225,95 & $\begin{array}{ll}54,34 \\
\end{array}$ & 38,71 & 123,44 & $-11,53$ & 1195,66 & 126,85 & 77,40 & 13,68 & 334,47 & 260,85 & 277,01 & 270,95 \\
\hline Pelodytes punctatus & 31TDH90 & 17,00 & 130,04 & 80,65 & 33,43 & 5452,04 & 259,87 & 22,49 & 237,38 & 119,93 & 201,55 & 201,87 & 63,90 & 750,58 & 95,23 & 35,71 & 22,82 & 229,15 & 150,32 & 154,35 & 172,62 \\
\hline Pelodytes punctatus & 31TEG03 & 93,00 & 153,07 & 72,72 & 32,65 & 5129,58 & 269,70 & 50,30 & 219,40 & 164,14 & 219,05 & 220,85 & 91,19 & 659,64 & 100,74 & 24,89 & 31,94 & 226,71 & 118,30 & 144,85 & 143,42 \\
\hline Pelodytes punctatus & 31TEG04 & 100,00 & 156,39 & 74,26 & 33,10 & 5126,21 & 273,53 & 52,28 & 221,25 & 167,27 & 222,84 & 223,95 & 94,16 & 632,72 & 98,18 & 23,59 & 32,44 & 219,16 & 112,16 & 137,79 & 137,12 \\
\hline Pelodytes punctatus & 31TEG05 & 101,00 & 159,00 & 76,01 & 33,36 & 5156,94 & 277,61 & 53,28 & 224,33 & 169,69 & 225,81 & 226,69 & 95,95 & 606,38 & 95,44 & 22,60 & 32,90 & 211,53 & 107,01 & 130,96 & 130,71 \\
\hline Pelodytes punctatus & 31TEG07 & 99,00 & 158,76 & 79,15 & 33,82 & 5266,93 & 280,93 & 50,05 & 230,89 & 168,66 & 227,07 & 227,46 & 93,87 & 582,46 & 91,29 & 22,05 & 32,32 & 202,72 & 103,44 & 119,33 & 126,14 \\
\hline Pelodytes punctatus & 31TEG08 & 101,00 & 156,38 & 80,48 & 33,99 & 5305,64 & 280,52 & 46,90 & 233,62 & 166,31 & 225,23 & 225,66 & 90,90 & 587,55 & 90,46 & 22,33 & 31,40 & 202,46 & 103,81 & 119,66 & 129,73 \\
\hline Pelodytes punctatus & 31TEG09 & 90,00 & 144,42 & 80,68 & 33,90 & 5361,71 & 271,10 & 35,65 & 235,45 & 153,62 & 214,34 & 214,71 & 78,84 & 656,66 & 92,80 & 27,31 & 27,12 & 213,79 & 121,92 & 133,07 & 148,59 \\
\hline Pelodytes punctatus & 31TEG13 & 37,00 & 159,26 & 74,63 & 33,92 & 4974,95 & 273,68 & 56,92 & 216,76 & \begin{tabular}{|l|}
170,61 \\
\end{tabular} & 210,58 & 225,08 & 99,42 & 587,89 & 94,26 & 19,53 & 35,63 & 211,92 & 100,21 & 130,21 & 126,39 \\
\hline Pelodytes punctatus & 31TEG14 & 82,00 & 158,10 & 75,46 & 34,12 & 4968,86 & 273,17 & 55,60 & 217,57 & 169,46 & 218,00 & 223,94 & 98,45 & 581,97 & 92,08 & 19,95 & 34,63 & 207,98 & 101,27 & 129,57 & 123,84 \\
\hline Pelodytes punctatus & 31TEG15 & 64,00 & 158,06 & 76,80 & 34,23 & 5037,93 & 274,93 & 53,78 & 221,16 & 169,04 & 223,27 & 224,47 & 97,10 & 582,48 & 91,69 & 20,63 & 33,81 & 206,16 & 102,02 & 127,89 & 124,51 \\
\hline Pelodytes punctatus & 31TEG16 & 17,00 & 158,85 & 77,65 & 34,00 & 5097,04 & 277,38 & 53,23 & 224,15 & \begin{tabular}{|l|l|}
169,54 \\
\end{tabular} & 224,85 & 225,92 & 96,69 & 576,65 & 91,23 & 20,46 & 33,62 & 204,23 & 100,58 & 125,35 & 123,88 \\
\hline Pelodytes punctatus & $\begin{array}{l}\text { 31TEG17 } \\
\end{array}$ & 27,00 & 152,47 & 79,42 & 34,11 & 5163,58 & 274,11 & 45,63 & 228,47 & 162,74 & 219,58 & 220,32 & 89,89 & 597,79 & 91,05 & 21,89 & 31,53 & 206,53 & 105,05 & 127,42 & 132,21 \\
\hline Pelodytes punctatus & 31TEG18 & 92,00 & 150,02 & 80,18 & 34,19 & 5227,00 & 273,39 & 42,56 & 230,83 & 160,23 & 218,03 & 218,70 & 86,39 & $\begin{array}{ll}614,06 \\
\end{array}$ & 91,62 & 23,13 & 30,37 & 208,97 & 108,82 & $\begin{array}{ll}128,38 \\
\end{array}$ & 137,49 \\
\hline Pelodytes punctatus & 31TEG28 & 31,00 & 152,98 & 80,93 & 34,83 & 5170,83 & 275,50 & 45,63 & 229,88 & 163,23 & 220,27 & 220,98 & 90,05 & 588,20 & 90,30 & 20,48 & 32,55 & 205,35 & 99,82 & 120,45 & 132,93 \\
\hline Pelodytes punctatus & 31TEHOO & 8,00 & 143,60 & 82,49 & 34,11 & 5406,03 & 272,29 & 33,72 & 238,57 & 147,51 & 214,13 & 214,46 & 77,38 & 656,68 & 91,94 & 26,81 & 27,44 & 213,72 & 119,09 & 127,74 & 152,85 \\
\hline Pelophylax perezi & 29SMC69 & 100,00 & 147,96 & 70,09 & 41,09 & 3488,38 & 238,79 & 70,50 & 168,29 & 111,22 & 189,22 & 193,04 & 102,87 & 825,55 & 127,97 & \begin{tabular}{|l|}
5,09 \\
\end{tabular} & 64,31 & 370,27 & 36,55 & 38,54 & 344,46 \\
\hline Pelophylax perezi & $295 \mathrm{SMC} 78$ & 84,00 & 158,27 & 75,36 & 41,23 & 3702,77 & 257,79 & 77,44 & $\begin{array}{l}180,35 \\
\end{array}$ & \begin{tabular}{|l|}
119,08 \\
119
\end{tabular} & 202,40 & 206,80 & $\mid$ & 771,92 & 120,92 & 4,01 & 64,95 & 348,70 & $\begin{array}{ll}0,31,93 \\
31\end{array}$ & $\begin{array}{l}34,07 \\
34\end{array}$ & 328,03 \\
\hline Pelophylax perezi & 29SMC79 & 100,00 & 150,21 & 73,67 & 40,95 & 3685,18 & 248,04 & 70,05 & 177,99 & 111,34 & 194,26 & 198,41 & 103,30 & 825,94 & 128,66 & 4,51 & 64,91 & 371,05 & 34,95 & 36,68 & 348,66 \\
\hline Pelophylax perezi & $29 \mathrm{SMC} 85$ & 48,00 & 162,61 & 81,58 & 41,70 & 3901,56 & 272,91 & 79,16 & 193,75 & 122,18 & 209,94 & 214,84 & 114,66 & 712,75 & 108,22 & 3,94 & 63,17 & 318,22 & 31,22 & 33,31 & 304,73 \\
\hline Pelophylax perezi & $295 M C 86$ & 60,00 & 166,21 & 81,36 & 41,33 & 3924,44 & 276,58 & 82,44 & 194,15 & 125,29 & 213,76 & 218,67 & 117,97 & 698,01 & 106,28 & 3,82 & 63,62 & 313,06 & 29,58 & 32,19 & 299,45 \\
\hline Pelophylax perezi & 29SMC87 & 85,00 & 166,33 & 80,39 & 41,04 & 3928,81 & 275,72 & 82,47 & 193,25 & 125,15 & 213,91 & 218,71 & 117,74 & 709,73 & 108,26 & 3,85 & 63,78 & 318,88 & 29,62 & 32,39 & 304,79 \\
\hline Pelophylax perezi & $295 \mathrm{MC} 88$ & 76,00 & 164,78 & $\mid \begin{array}{l}\mid c 0,25 \\
79,29\end{array}$ & $\begin{array}{l}40,77 \\
40,77\end{array}$ & 3947,81 & 273,54 & $\begin{array}{l}2,41,14 \\
814\end{array}$ & 192,41 & 123,28 & $\begin{array}{l}212,72 \\
212\end{array}$ & 217,34 & 115,89 & 731,80 & 1111,36 & 3,84 & $\begin{array}{ll}63,98 \\
63\end{array}$ & \begin{tabular}{|l|}
328,19 \\
328
\end{tabular} & 30,27 & 32,97 & 314,90 \\
\hline Pelophylax perezi & 29SMC89 & 101,00 & 162,23 & 77,29 & 40,59 & 3890,32 & 267,64 & 79,42 & 188,21 & 121,02 & 209,27 & 213,48 & 113,54 & 744,37 & 113,05 & 3,82 & 64,03 & 333,09 & 30,62 & 33,27 & 318,85 \\
\hline Pelophylax perezi & 29SMC95 & 57,00 & 161,90 & 83,83 & 41,27 & 4053,90 & 277,25 & 76,73 & 200,52 & 120,01 & 211,56 & 216,45 & 112,46 & 712,24 & 107,07 & 3,97 & 62,97 & 316,56 & 31,18 & 33,15 & 305,23 \\
\hline Pelophylax perezi & 29SMC96 & 101,00 & 166,61 & 83,55 & 41,10 & 4057,78 & 281,52 & 81,08 & 200,44 & 124,31 & 216,16 & 221,07 & 116,95 & 689,66 & 104,09 & 3,57 & 63,35 & 308,21 & 28,87 & 31,62 & 296,61 \\
\hline Pelophylax perezi & 29SMC97 & 83,00 & 169,59 & 82,84 & 41,01 & 4055,47 & 283,64 & 84,10 & 199,54 & 127,08 & 219,11 & 223,74 & 119,69 & 677,60 & 102,26 & 3,02 & 63,56 & 303,42 & 27,61 & 30,84 & 291,77 \\
\hline Pelophylax perezi & $295 \mathrm{MC} 98$ & $\begin{array}{l}3,00 \\
24,00\end{array}$ & $\begin{array}{l}10,50,45 \\
170,4\end{array}$ & $\begin{array}{l}8<, 04 \\
81,76 \\
\end{array}$ & 40,95 & $\begin{array}{l}4050,4)^{4} \\
4050,98\end{array}$ & $\begin{array}{l}200,04 \\
283,33\end{array}$ & $\begin{array}{l}4,10 \\
84,93 \\
\end{array}$ & \begin{tabular}{|l|}
198,40 \\
\end{tabular} & $\begin{array}{l}127,79 \\
127\end{array}$ & 219,11 & 224,26 & \begin{tabular}{|l|}
120,24 \\
124
\end{tabular} & $\begin{array}{l}675,07 \\
67\end{array}$ & \begin{tabular}{|l|l|l|l|l|l|}
101,98 \\
\end{tabular} & $\begin{array}{l}3,004 \\
3,05\end{array}$ & $\begin{array}{l}3,50 \\
63,52\end{array}$ & $\begin{array}{l}03,42 \\
301,95 \\
\end{array}$ & $\begin{array}{l}27,12 \\
27,12\end{array}$ & $\begin{array}{l}30,04 \\
30,50\end{array}$ & 290,71 \\
\hline Pelophylax perezi & 29SMD60 & 71,00 & 150,13 & 67,85 & 41,05 & 3399,25 & 237,06 & 73,70 & 163,36 & 114,29 & 190,23 & 193,60 & 105,75 & 791,66 & 123,77 & 4,56 & 64,30 & 356,92 & 33,85 & 36,46 & 330,30 \\
\hline Pelophylax perezi & 29SMD61 & 56,00 & 151,29 & 65,25 & 41,09 & 3287,54 & 233,99 & 76,85 & 157,14 & 116,75 & 189,82 & 193,05 & 108,30 & 756,94 & 120,51 & 4,18 & 63,64 & 340,78 & 32,10 & 35,60 & 314,88 \\
\hline Pelophylax perezi & 29SMD62 & 49,00 & 153,55 & 62,03 & 41,17 & 3118,04 & 230,41 & 81,46 & 148,96 & 120,92 & 189,85 & 192,73 & 112,63 & 711,70 & 116,22 & 4,00 & 63,09 & 320,32 & 30,14 & 34,77 & 294,68 \\
\hline Pelophylax perezi & $29 \mathrm{SMD} 6$ & 9,00 & 153,06 & 59,78 & 41,09 & 3022,06 & 226,25 & 82,44 & 143,81 & 121,75 & 188,06 & 190,53 & 113,19 & 692,31 & 114,81 & 4,00 & 62,66 & 310,81 & 29,66 & 34,88 & 285,31 \\
\hline Pelophylax perezi & 295MD70 & $\begin{array}{r}9,000 \\
101,00\end{array}$ & $\begin{array}{l}13,080 \\
148,41\end{array}$ & $\begin{array}{l}35,16 \\
71,26\end{array}$ & $\begin{array}{l}40,70 \\
40,70\end{array}$ & \begin{tabular}{|l|}
362,00 \\
3610,41
\end{tabular} & 242,25 & 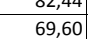 & $\begin{array}{l}114,01 \\
173,35 \\
\end{array}$ & $\begin{array}{l}11,1 / 39 \\
110,39 \\
\end{array}$ & $\begin{array}{l}10,01,61 \\
191,61\end{array}$ & \begin{tabular}{|l|l|}
195,28 \\
195
\end{tabular} & \begin{tabular}{|l|l|l|l|l|}
102,18 \\
\end{tabular} & $\begin{array}{l}09 L, 51 \\
819,75 \\
\end{array}$ & \begin{tabular}{|l|}
114,01 \\
125,51
\end{tabular} & $\begin{array}{l}4,409 \\
4,69\end{array}$ & $\begin{array}{l}6,060 \\
64,12\end{array}$ & $\begin{array}{l}50,01 \\
366,94 \\
\end{array}$ & $\begin{array}{l}2,00 \\
35,28 \\
\end{array}$ & $\begin{array}{l}4,00 \\
37,52 \\
\end{array}$ & $\begin{array}{l}28,51 \\
344,42 \\
\end{array}$ \\
\hline Pelophylax perezi & 29SMD71 & 100,00 & 150,71 & 68,40 & 40,60 & 3472,66 & 240,14 & 73,81 & 166,34 & 114,08 & 192,05 & 195,36 & 105,94 & 776,94 & 121,19 & 4,36 & 63,53 & 348,12 & 33,01 & 36,16 & 325,55 \\
\hline Pelophylax perezi & 29SMD72 & 101,00 & 154,26 & 65,05 & 40,89 & 3286,66 & 237,07 & 79,81 & 157,26 & 119,81 & 193,07 & 196,04 & 111,54 & 718,24 & 115,57 & 4,02 & 63,12 & 22,51 & 30,11 & 34,39 & 299,55 \\
\hline Pelophylax perezi & 29SMD73 & 101,00 & 153,51 & 62,06 & 41,03 & 3133,32 & 231,06 & 81,41 & 149,66 & 120,85 & 190,32 & 193,01 & 112,66 & 696,19 & 114,21 & 4,00 & 62,63 & 64 & 29,42 & 34,60 & 288,44 \\
\hline Pelophylax perezi & $295 M D 74$ & 88,00 & 151,73 & 59,61 & 4 & 3010,96 & 224,95 & \begin{tabular}{|l|l|}
81,51 \\
\end{tabular} & $\begin{array}{l}143,43 \\
\end{array}$ & 120,61 & 186,91 & 189,33 & 112,29 & 688,41 & \begin{tabular}{|l|}
114,38 \\
114,38
\end{tabular} & $\begin{array}{l}3,905 \\
3,95\end{array}$ & 62,44 & 306,73 & 29,59 & 35,33 & 283,54 \\
\hline Pelophylax perezi & $29 \mathrm{SMD}$ & 89,00 & 15. & 57,80 & 41 & 2903,17 & 220,92 & 82,61 & 138,31 & $\begin{array}{ll}121,57 \\
\end{array}$ & 185,03 & 187,33 & 113,25 & 677,61 & 113,71 & 3,95 & 62,35 & 300,55 & 29,35 & 35,85 & 277,62 \\
\hline Pelophylax perezi & $295 M D 80$ & 101,00 & 155,19 & 74,75 & 40,26 & 3803,25 & 256,91 & 73,98 & 182,93 & 115,18 & 201,22 & 205,14 & 107,34 & 778,76 & 117,50 & 4,20 & 63,64 & 346,89 & 32,86 & 35,49 & 330,61 \\
\hline Pelophylax perezi & 29SMD81 & 101,00 & 150,37 & 72,32 & 40,14 & 3700,78 & 248,21 & 70,74 & 177,47 & 111,64 & 195,10 & 198,73 & 103,66 & 795,14 & 120,81 & 4,60 & 62,82 & 352,42 & 34,73 & 37,59 & 335,04 \\
\hline Pelophylax perezi & 29SMD82 & 101,00 & 153,03 & 69,44 & 40,40 & 3534,30 & 244,96 & 75,42 & 169,54 & 116,00 & 195,51 & $19 \varepsilon$ & 108,01 & 749,30 & 116,86 & 4,18 & 62,60 & 333,04 & 32,12 & 35,86 & 314,60 \\
\hline Pelophylax perezi & 29SMDE & $\begin{array}{l}100,00 \\
100\end{array}$ & 15 & $\begin{array}{l}60,44 \\
66,84 \\
\end{array}$ & $\frac{40}{40}$ & 3384 & 239,50 & $\frac{7,44}{77,50}$ & \begin{tabular}{|l|}
162,39 \\
\end{tabular} & $\begin{array}{l}1117,72 \\
1170\end{array}$ & $\begin{array}{ll}193,51,62 \\
193,62\end{array}$ & $\begin{array}{l}196,54 \\
\end{array}$ & $\begin{array}{l}109,72 \\
109,1\end{array}$ & $\begin{array}{l}\mid 425,80 \\
7258\end{array}$ & $\begin{array}{l}\mid 110,0,35 \\
115\end{array}$ & $\frac{4,1}{4,1}$ & $\begin{array}{l}62,31 \\
62\end{array}$ & $\begin{array}{l}350,04 \\
322,08 \\
\end{array}$ & \begin{tabular}{|l|l|l|}
31,21 \\
\end{tabular} & $\begin{array}{l}35,00 \\
35,70\end{array}$ & 303,04 \\
\hline Pelophylax perezi & 29SMD84 & 101,00 & 154,34 & 64,55 & 40,99 & 3237,16 & 236,09 & 80,47 & 155,62 & 120,55 & 192,73 & 195,36 & 112,40 & 698,05 & 113,05 & 4,00 & 62,10 & 309,29 & 30,02 & 35,43 & 289,73 \\
\hline Pelophylax perezi & 29SMD85 & 99,00 & 153,92 & 63,22 & 41,25 & 3141.44 & 232.59 & 81,14 & 151,45 & 121,16 & 190,92 & $\mid$\begin{tabular}{|c|}
193,39 \\
\end{tabular} & 113,04 & $|693,97|$ & $|113,00|$ & 4,06 & 61.81 & $\mid 305,79$ & 30,54 & 36.53 & 286,46 \\
\hline Pelophylax perezi & 29SMD86 & 79,00 & 154,64 & 62,85 & 41,60 & 3081,51 & 231,56 & 82,21 & 149,35 & 122,49 & 190,84 & 193,19 & 114,37 & 691,11 & 112,46 & 4,04 & 61,43 & 302,84 & 30,71 & 37,30 & 284,19 \\
\hline Pelophylax perezi & $295 \mathrm{MD}$ & 17,00 & 155,55 & 63,89 & 41,92 & 3097,29 & 233,29 & 82,21 & 151,08 & 123 & 191,87 & 194 & 11 & 698,42 & 112,39 & 4,13 & 60,89 & 303,76 & 32,03 & 38,92 & 286 \\
\hline Pelophylax perezi & 29SMD90 & 83,00 & $\begin{array}{l}13,53 \\
162,53\end{array}$ & $\begin{array}{l}3,05 \\
77,54 \\
\end{array}$ & 40,45 & $\begin{array}{l}3051,25 \\
39182\end{array}$ & 268,93 & $\begin{array}{l}2,2<1 \\
79,41\end{array}$ & $\begin{array}{l}189,52 \\
189\end{array}$ & $\begin{array}{l}121,24 \\
121\end{array}$ & 210,21 & \begin{tabular}{|l|}
214,18 \\
218
\end{tabular} & \begin{tabular}{|l|}
113,53 \\
113
\end{tabular} & $\begin{array}{l} \\
723,444 \\
\end{array}$ & \begin{tabular}{|l|}
109,03 \\
109
\end{tabular} & 年,150 & $\begin{array}{l}0,03 \\
63,15\end{array}$ & \begin{tabular}{|l|l|}
321,26 \\
3
\end{tabular} & $\begin{array}{l}2,005 \\
30,05 \\
\end{array}$ & $\begin{array}{l}3,21 \\
33,21 \\
\end{array}$ & $\begin{array}{l}200,54 \\
308,79\end{array}$ \\
\hline Pelophylax perezi & 29SMD91 & 101,00 & 156,95 & 75,62 & 40,22 & 3847,59 & 260,60 & 75,08 & 185,53 & 116,65 & 203,88 & 207,54 & 108,80 & 750,88 & 113,34 & 4,19 & 62,47 & 331,62 & 32,32 & 35,53 & 318,31 \\
\hline Pelophylax perezi & 29SMD92 & 101,00 & 156,43 & 73,36 & 40,42 & 3718,49 & 255,45 & 76,15 & 179,30 & 117,38 & 201,57 & 204,95 & 109,56 & 738,14 & 113,18 & 4,07 & 62,29 & 325,77 & 31,79 & 35,54 & 311,36 \\
\hline Pelophylax perezi & 29SMD93 & 101,00 & 152,29 & 71,58 & 40,51 & 3628,03 & 248,35 & 73,2 & 175,08 & 114,35 & 196,21 & 199 & 106, & 760,12 & \begin{tabular}{|l|l|}
116,88 \\
\end{tabular} & 63 & 61,56 & 333 & 34,29 & 38,16 & 318, \\
\hline Pelophylax perezi & 29SMD94 & 100,00 & 154,66 & 69,63 & 40,84 & 3484,84 & 245,83 & 77,01 & 68,82 & 118,17 & 196,54 & 199,51 & 110,10 & 725,66 & 113,71 & 4,11 & 61,57 & 318,32 & 32,08 & 36,79 & 302,73 \\
\hline
\end{tabular}




\begin{tabular}{|c|c|c|c|c|c|c|c|c|c|c|c|c|c|c|c|c|c|c|c|c|c|}
\hline TAXON & UTM & $\mathrm{km} 2$ & B101 & B102 & $\mathrm{BIO3}$ & B104 & B105 & B106 & B107 & B108 & B109 & B1010 & BIO11 & BIO12 & 81013 & BIO14 & BIO15 & B1016 & B1017 & B1018 & B1019 \\
\hline Pelophylax perezi & 29SMD95 & 101,00 & 154,16 & 68,46 & 41,02 & 3399,61 & 242,54 & 77,46 & 165,08 & 118,55 & 194,88 & 197,66 & 110,52 & 724,99 & 114,07 & 4,23 & 61,16 & 316,49 & 32,79 & 38,09 & 300,91 \\
\hline Pelophylax perezi & 29SMD96 & 101,00 & 153,52 & 67,99 & 41,25 & 3337,48 & 240,05 & 77,19 & 162,86 & 118,46 & 193,38 & 195,98 & 110,44 & 732,84 & 115,06 & 4,58 & 60,60 & 317,84 & 34,29 & 40,05 & 302,60 \\
\hline Pelophylax perezi & 29SMD97 & 92,00 & 153,65 & 67,96 & 41,64 & 3283,66 & 238,79 & 77,36 & 161,43 & 119,03 & 192,74 & 195,21 & 111,05 & 740,74 & 115,77 & 4,83 & 60,01 & 319,21 & 35,65 & 41,78 & 304,47 \\
\hline Pelophylax perezi & 29SMD98 & 58,00 & 154,47 & 68,99 & 42,01 & 3275,73 & 239,79 & 77,49 & 162,30 & 119,74 & \begin{tabular}{|l|}
193,37 \\
\end{tabular} & 195,76 & 111,73 & 752,49 & 116,18 & 5,30 & 59,35 & 321,62 & 37,58 & 44,10 & 307,90 \\
\hline Pelophylax perezi & 29SMD99 & 35,00 & 152,45 & 70,03 & 42,11 & 3291,15 & 238,72 & 74,76 & 163,96 & 117,54 & 191,64 & $\begin{array}{l}194,07 \\
\end{array}$ & 109,53 & 788,54 & 119,77 & 6,00 & 58,43 & 334,07 & 41,22 & 47,77 & 321,45 \\
\hline Pelophylax perezi & 29SNA99 & 53,00 & 172,39 & 90,87 & 42,93 & 4136,21 & 287,45 & 77,59 & 209,86 & 131,51 & 224,27 & 228,45 & 123,00 & 502,21 & 86,95 & 1,00 & 70,80 & 245,73 & 14,27 & 17,51 & 228,90 \\
\hline Pelophylax perezi & 29SNB12 & 83,00 & 163,34 & 86,34 & 44,66 & 3628,14 & 271,70 & 80,42 & \begin{tabular}{|l|l|}
191,27 \\
\end{tabular} & 128,07 & 207,95 & 212,23 & 119,51 & 516,43 & 83,19 & 1,00 & 68,47 & 241,95 & 18,35 & 19,41 & 231,30 \\
\hline Pelophylax perezi & 29SNB13 & 51,00 & 165,90 & 86,91 & 44,25 & 3706,64 & 276,06 & 81,89 & 194,17 & 129,33 & 211,51 & 215,80 & 121,01 & 513,94 & 82,24 & 1,00 & 68,10 & 240,26 & 18,46 & 19,60 & 229,58 \\
\hline Pelophylax perezi & 29SNB14 & 19,00 & 166,42 & 87,92 & 44,00 & 3803,89 & 279,44 & 81,19 & 198,25 & 128,75 & 213,33 & 217,72 & 120,36 & 522,64 & 82,56 & 1,00 & 67,69 & 243,06 & 18,89 & 19,89 & 232,81 \\
\hline Pelophylax perezi & 29SNB16 & 24,00 & 167,33 & 88,92 & 43,73 & 3885,90 & 282,76 & 81,06 & 201,69 & 128,55 & 215,29 & 219,73 & 120,39 & 539,57 & 83,76 & 1,00 & 66,53 & 248,24 & 20,00 & 21,00 & 238,41 \\
\hline Pelophylax perezi & 29SNB17 & 20,00 & 167,92 & 89,56 & 43,36 & 3939,44 & 285,08 & 81,17 & 203,92 & 128,25 & 216,47 & 221,03 & 120,08 & 549,53 & 84,28 & 1,56 & 65,78 & 250,86 & 21,03 & 22,08 & 241,44 \\
\hline Pelophylax perezi & 29SNB19 & 31,00 & 168,49 & 90,07 & 43,00 & 4041,32 & 288,02 & 80,83 & 207,20 & 127,34 & 218,22 & 222,93 & 119,46 & 569,29 & 86,15 & 2,00 & 64,95 & 257,37 & 22,49 & 23,78 & 248,22 \\
\hline Pelophylax perezi & 29SNB21 & 101,00 & 166,71 & 86,81 & 43,34 & 3809,92 & 278,55 & 80,58 & $\begin{array}{l}197,97 \\
\end{array}$ & 129,16 & 214,36 & 218,16 & 120,69 & 498,75 & 80,82 & 0,90 & 69,59 & 237,30 & 16,71 & 17,97 & 225,62 \\
\hline Pelophylax perezi & 29SNB22 & 101,00 & 159,48 & 88,59 & 43,57 & 3863,33 & 274,21 & 73,06 & 201,15 & 121,65 & 207,70 & 211,89 & 113,22 & 545,39 & 86,20 & 1,08 & 67,90 & 254,36 & 19,78 & 20,69 & 243,97 \\
\hline Pelophylax perezi & 29SNB23 & 101,00 & 160,57 & 89,23 & 43,49 & 3904,89 & 276,69 & 73,70 & 202,99 & 122,19 & 209,27 & 213,56 & 113,87 & 548,35 & 86,14 & 1,15 & 67,36 & 254,48 & 20,17 & 21,04 & 244,38 \\
\hline Pelophylax perezi & 29 SNB24 & 100,00 & 162,44 & 89,79 & 43,41 & 3953,88 & 280,03 & 75,26 & 204,76 & 123,45 & 211,84 & 216,11 & 115,18 & 546,36 & 85,42 & 1,08 & 67,06 & 252,79 & 20,07 & 20,88 & 242,88 \\
\hline Pelophylax perezi & 29 SNB25 & 100,00 & 164,72 & 90,25 & 43,24 & 3981,16 & 283,08 & 77,15 & 205,94 & 125,25 & 214,24 & 218,62 & 116,82 & 543,22 & 84,29 & 1,00 & 66,73 & 250,47 & 20,04 & 20,94 & 240,79 \\
\hline Pelophylax perezi & 29SNB26 & 101,00 & 167,37 & 90,54 & 43,07 & 4006,83 & 286,40 & 79,38 & 207,03 & 127,37 & 217,05 & 221,60 & 119,02 & 539,28 & 83,16 & 1,06 & 66,34 & 247,82 & 20,04 & 21,07 & 238,29 \\
\hline Pelophylax perezi & 29SNB27 & 101,00 & 164,85 & 91,51 & 43,02 & $\begin{array}{lll}4077,94 \\
\end{array}$ & 286,17 & 76,15 & 210,02 & 124,01 & 215,44 & 219,99 & 115,74 & 565,10 & 86,24 & 1,72 & 65,40 & 256,79 & 22,20 & 22,99 & 248,03 \\
\hline Pelophylax perezi & 29SNB28 & 101,00 & 163,45 & 91,99 & 42,92 & 4134,08 & 286,67 & 74,44 & 212,23 & 121,86 & 214,92 & 219,54 & $\mid 113,86$ & 584,01 & 88,30 & 2,00 & 64,69 & 263,26 & 23,58 & 24,30 & 255,08 \\
\hline Pelophylax perezi & $295 N B 29$ & 101,00 & 164,16 & 92,20 & 42,84 & 4175,37 & 288,44 & 74,92 & 213,52 & 122,01 & 216,06 & 220,71 & 113,97 & \begin{tabular}{|c|}
590,88 \\
\end{tabular} & 88,76 & 2,00 & 64,15 & 265,09 & 24,11 & 24,86 & 257,27 \\
\hline Pelophylax perezi & $29 \mathrm{SNB} 30$ & 26,00 & 171,04 & 87,22 & 42,22 & 3973,35 & 285,61 & 82,09 & 203,52 & 131,74 & 221,13 & 224,74 & 123,26 & 482,91 & 78,78 & 0,48 & 70,65 & 233,09 & 14,83 & 16,48 & 220,22 \\
\hline Pelophylax perezi & 29SNB31 & 100,00 & 169,93 & 88,04 & 42,32 & 3993,05 & 285,92 & $\begin{array}{l}80,82 \\
\end{array}$ & 205,09 & 130,58 & 220,37 & 224,08 & 121,95 & \begin{tabular}{|l|l|}
491,29 \\
\end{tabular} & 79,47 & 0,87 & 69,85 & 235,53 & 15,71 & 17,27 & 223,19 \\
\hline Pelophylax perezi & 29 SNB32 & 100,00 & 157,21 & 90,43 & 42,89 & 4051,06 & 276,71 & 68,08 & 208,63 & 117,62 & 208,32 & 212,39 & 109,04 & 568,47 & 89,90 & 1,46 & 67,30 & 263,84 & 21,14 & 22,08 & 253,54 \\
\hline Pelophylax perezi & 29 SNB33 & 101,00 & 153,17 & 91,73 & 42,96 & 4104,42 & 275,13 & 63,85 & 211,28 & 113,12 & 205,01 & 209,21 & 104,51 & 597,67 & 93,49 & 1,78 & 66,16 & 273,78 & 23,43 & 24,04 & 264,44 \\
\hline Pelophylax perezi & 29SNB34 & 100,00 & 160,98 & 91,92 & 42,89 & 4116,92 & 283,24 & 71,08 & 212,15 & 120,35 & 212,75 & 217,05 & 111,80 & 557,87 & 87,50 & 1,29 & 66,59 & 257,51 & 20,82 & 21,67 & 247,82 \\
\hline Pelophylax perezi & 29 SNB35 & 101,00 & 167,48 & $\begin{array}{ll}91,92 \\
91,98\end{array}$ & 42,96 & 4111,58 & 289,42 & 77,29 & 212,13 & 126,46 & 219,01 & 223,26 & 118,07 & 528,77 & 82,62 & $\begin{array}{l}1,251 \\
1,01\end{array}$ & 67,01 & \begin{tabular}{|l|l|}
244,88 \\
\end{tabular} & $\begin{array}{l}20,02 \\
19,08\end{array}$ & 20,13 & $\begin{array}{l}24,02 \\
235,08 \\
\end{array}$ \\
\hline Pelophylax perezi & 29 SNB36 & 101,00 & 165,93 & 92,97 & 42,95 & 4165,94 & 289,95 & 75,37 & 214,58 & 124,09 & 217,99 & 222,40 & 115,90 & 546,52 & 84,50 & 1,23 & 66,02 & 250,43 & 20,62 & 21,50 & 241,41 \\
\hline Pelophylax perezi & 29SNB37 & 100,00 & 164,94 & 93,73 & 42,83 & 4219,59 & 290,82 & 74,07 & 216,75 & 122,57 & 217,72 & 222,23 & 114,44 & \begin{tabular}{|l|l|}
561,68 \\
\end{tabular} & 85,97 & 1,82 & 65,17 & 254,92 & 22,07 & 22,89 & 246,65 \\
\hline Pelophylax perezi & 29SNB38 & 101,00 & 165,56 & 94,17 & 42,70 & 4258,45 & 292,73 & 74,44 & 218,29 & 122,77 & 218,79 & 223,35 & 114,49 & 567,57 & 86,11 & 2,00 & 64,57 & 256,00 & 22,76 & 23,43 & 248,21 \\
\hline Pelophylax perezi & 29SNB39 & 100,00 & 165,48 & 94,48 & 42,38 & 4301,43 & 293,85 & 74,15 & 219,70 & 122,07 & 219,27 & 223,98 & 114,02 & 576,49 & 86,88 & 2,00 & 64,22 & 258,47 & 23,19 & 24,02 & 251,19 \\
\hline Pelophylax perezi & 29SNB40 & 40,00 & $\begin{array}{l}169,90 \\
169,94\end{array}$ & \begin{tabular}{|l|l|}
48,87 \\
\end{tabular} & $\begin{array}{ll}42,03 \\
42,02\end{array}$ & $\begin{array}{l}45031,70 \\
4031,70\end{array}$ & 286,43 & 79,40 & 207,02 & \begin{tabular}{|l|}
130,30 \\
\end{tabular} & \begin{tabular}{|l|}
221,06 \\
\end{tabular} & \begin{tabular}{|l|}
224,83 \\
\end{tabular} & $\begin{array}{l}121,79 \\
121,\end{array}$ & $\begin{array}{l}494,32 \\
\end{array}$ & $\begin{array}{l}80,00 \\
81,45\end{array}$ & 2,00 & $\begin{array}{ll}69,98 \\
69\end{array}$ & 238,64 & 15,89 & $\begin{array}{l}24,0<4 \\
17,36\end{array}$ & 225,43 \\
\hline Pelophylax perezi & 29SNB41 & 101,00 & 170,42 & 89,54 & 42,32 & 4071,24 & 288,31 & 79,58 & 208,73 & 130,01 & 221,89 & 225,72 & 121,66 & 494,19 & 80,91 & 1,00 & 69,76 & 237,45 & 15,99 & 17,53 & 224,66 \\
\hline Pelophylax perezi & 29 SNB42 & 101,00 & 163,34 & 91,49 & 42,31 & 4153,20 & 284,97 & 71,88 & 213,09 & 122,27 & 215,89 & 219,81 & 113,77 & 536,63 & 86,44 & 1,15 & 68,24 & 252,48 & 18,58 & 19,76 & 241,22 \\
\hline Pelophylax perezi & 29SNB43 & 100,00 & 158,19 & 93,15 & 42,49 & 4219,30 & 282,90 & 66,29 & 216,61 & 116,56 & 211,49 & 215,67 & 108,04 & 570,05 & 90,55 & 1,33 & 66,86 & 263,84 & 21,04 & 21,89 & 253,89 \\
\hline Pelophylax perezi & 295 NB44 & 101,00 & 165,33 & 93,32 & 42,45 & 4231,12 & 290,31 & 73,10 & 217,20 & 123,17 & 218,62 & 222,87 & 114,75 & 534,47 & 84,80 & 1,00 & 67,20 & 248,69 & 18,80 & 19,94 & 238,53 \\
\hline Pelophylax perezi & 295NB45 & $\begin{array}{l}101,00 \\
100\end{array}$ & $\begin{array}{l}10,530 \\
165,68\end{array}$ & $\begin{array}{ll}30,25 \\
94,29\end{array}$ & 42,45 & $\begin{array}{l}4251,12 \\
4266,08\end{array}$ & 292,32 & 73,34 & $\begin{array}{ll}21,12,98 \\
\end{array}$ & \begin{tabular}{|l|}
122,99 \\
\end{tabular} & $\begin{array}{l}190,0<4 \\
219,44 \\
\end{array}$ & \begin{tabular}{|l|}
223,80 \\
\end{tabular} & $\begin{array}{l}144,73 \\
114,7\end{array}$ & |538,78 & $\begin{array}{l}84,00 \\
84,63\end{array}$ & $\begin{array}{l}1,002 \\
1,02\end{array}$ & $\begin{array}{l}6,206 \\
66,67\end{array}$ & $\begin{array}{l}\mid 420,03 \\
248,75\end{array}$ & $\begin{array}{l}10,00 \\
19,45\end{array}$ & 20,42 & 239,24 \\
\hline Pelophylax perezi & 29SNB46 & 100,00 & 161,56 & 95,68 & 42,42 & 4340,36 & 291,18 & 68,73 & 222,45 & 118,32 & 216,23 & 220,75 & 109,95 & 570,36 & 88,19 & 1,79 & 65,12 & 258,97 & 22,44 & 23,13 & 250,85 \\
\hline Pelophylax perezi & 29SNB47 & 100,00 & 163,18 & 96,28 & 42,48 & 4369,40 & 293,99 & 70,04 & 223,95 & 119,40 & 218,06 & 222,73 & 111,14 & 569,30 & 87,22 & 2,00 & 64,67 & 257,01 & 22,82 & 23,42 & 249,30 \\
\hline Pelophylax perezi & 29SNB48 & 101,00 & 167,66 & 96,33 & 42,62 & 4369,44 & 298,26 & 74,38 & 223,87 & 123,46 & 222,40 & 226,92 & 115,25 & 551,81 & 83,96 & 2,00 & 64,54 & 248,81 & 21,95 & 22,84 & 241,24 \\
\hline Pelophylax perezi & 29SNB49 & 101,00 & 168,13 & 96,77 & 42 & 4402,72 & 299,73 & 74,62 & 225,11 & 123,45 & 223,21 & 227,86 & 115,34 & 557,31 & 84,01 & 2,00 & 64,01 & 249,32 & 22,72 & 23,49 & 242,42 \\
\hline Pelophylax perezi & 29SNB50 & 53,00 & 169,96 & 90,04 & 42,66 & 4078,11 & 287,31 & 78,29 & \begin{tabular}{|l|}
209,03 \\
\end{tabular} & 129,89 & 221,61 & 225,40 & 121,07 & 498,30 & 83,10 & 1,00 & 69,81 & 240,94 & 15,86 & 17,74 & 227,43 \\
\hline Pelophylax perezi & 29SNB51 & 100,00 & 169,62 & 90,95 & 42,34 & 4135,12 & 289,13 & 77,28 & 211,85 & 128,81 & 221,94 & 225,75 & 120,05 & 502,62 & 83,26 & 1,00 & 69,36 & 241,57 & 16,27 & 18,05 & 228,53 \\
\hline Pelophylax perezi & 29SNB52 & 101,00 & 164,37 & 92,97 & 42,21 & 4241,13 & 288,17 & 71,28 & 216,89 & 122,52 & 218,10 & 222,13 & 113,81 & 533,03 & 86,93 & 1,00 & 68,19 & 251,74 & 17,99 & 19,46 & 240,04 \\
\hline Pelophylax perezi & 29SNB53 & 100,00 & 164,55 & 94,13 & 42,08 & 4297,53 & 290,68 & 70,92 & 219,76 & 121,89 & 218,86 & 223,08 & 113,30 & 535,86 & 86,47 & 1,00 & 67,62 & 251,14 & 18,31 & 19,68 & 240,12 \\
\hline Pelophylax perezi & 29 SNB54 & 101,0 & 161,55 & 95,59 & 4 & 4358,38 & 290,54 & 67,43 & 223,11 & 118,29 & 216,73 & 220,94 & & 557,76 & 88,57 & 1,26 & 66,41 & 257,43 & 20,39 & 21,41 & 247,70 \\
\hline Pelophylax perezi & $29 \mathrm{SNB}$ & 100,00 & 162 & 96,57 & 42,24 & 4398,71 & 293,67 & 68,26 & 225,41 & 118,99 & 218,50 & 222,80 & 110,58 & 555,57 & 87,30 & 1,36 & 65,95 & 254,66 & 20,70 & 21,57 & 245,62 \\
\hline Pelophylax perezi & 295NB56 & 101,00 & 159,93 & 97,96 & 42,07 & 4473,81 & 293,72 & 64,86 & 228,86 & 115,26 & 216,56 & 221,03 & 106,94 & 579,15 & 89,53 & 2,00 & 64,59 & 261,53 & 23,14 & 23,72 & 253,80 \\
\hline Pelophylax perezi & 29 SNB57 & 101,00 & 165,13 & 98,47 & 42,25 & 4481,33 & 299,41 & 69,77 & 229,64 & 119,95 & 221,66 & 226,18 & 111,69 & 554,76 & 85,12 & 1,99 & 64,53 & 250,30 & 21,91 & 22,56 & 242,74 \\
\hline Pelophylax perezi & 29 SNB58 & 100,00 & 167,38 & 98,91 & 42,36 & 4491,59 & 302,26 & 72,00 & 230,26 & 121,99 & 223,90 & 228,48 & 113,80 & 548,53 & 83,37 & 2,00 & 64,49 & 246,13 & 21,50 & 22,24 & 239,15 \\
\hline Pelophylax perezi & $29 \mathrm{SNB}$ & 100,00 & 168,86 & \begin{tabular}{|l|l|}
99,21 \\
9,1
\end{tabular} & 42, & 年4520,42 & 304,48 & $\begin{array}{l}2,00 \\
73,29\end{array}$ & \begin{tabular}{|l|}
231,19 \\
231
\end{tabular} & \begin{tabular}{|l|l|}
122,86 \\
\end{tabular} & $\begin{array}{l}225,62 \\
226\end{array}$ & \begin{tabular}{|l|}
230,19 \\
230
\end{tabular} & $\begin{array}{l}114,75 \\
114,0\end{array}$ & $\begin{array}{l}540,53 \\
547,27\end{array}$ & $\begin{array}{l}80,37 \\
82,53\end{array}$ & 2,00 & $\begin{array}{ll}6,4,86 \\
63,86\end{array}$ & \begin{tabular}{|l|}
240,1305 \\
244,05
\end{tabular} & $\begin{array}{l}21,00 \\
22,02\end{array}$ & $\frac{22,44}{22,64}$ & 237,48 \\
\hline Pelophylax perezi & 29SNB60 & 67,00 & 169,51 & 91,29 & 42,87 & 4120,31 & 287,86 & 76,67 & 211,18 & 128,93 & 221,57 & 225,55 & 120,16 & 505,51 & 85,51 & 1,00 & 69,84 & 244,86 & 16,05 & 18,01 & 230,82 \\
\hline Pelophylax perezi & 29 SNB61 & 101,00 & 168,60 & 92,44 & 42,55 & 4200,03 & 289,83 & 74,99 & 214,85 & 127,13 & 221,86 & 225,84 & 118,45 & 511,83 & 85,67 & 1,00 & 69,11 & 245,74 & $\mid 16,66$ & 18,50 & 232,36 \\
\hline Pelophylax perezi & 29 SNB62 & 100,00 & 164,87 & 94,21 & 42,18 & 4299,61 & 290,15 & 70,25 & 219,91 & 122,35 & 219,43 & 223,56 & 113,72 & 533,42 & 87,70 & 1,01 & 68,11 & 252,20 & 17,90 & 19,49 & 240,04 \\
\hline Pelophylax perezi & 29SNB63 & 101 & 160,97 & 95, & 42,07 & 4400,78 & 290,09 & 65,53 & 224,56 & 117,48 & 216,88 & 22 & 108 & 558,03 & 89,99 & 1,27 & 66,82 & 259,41 & 19,80 & 21,14 & 248,62 \\
\hline Pelophylax perezi & 29 SNB64 & 100,00 & 158,55 & 97,46 & 42,01 & 4485,71 & 291,07 & 62,47 & 228,60 & 114,12 & 215,45 & 219,80 & 105,29 & 576,21 & 91,25 & 1,79 & 65,55 & 263,75 & 21,95 & 23,02 & 254,29 \\
\hline Pelophylax perezi & 29SNB65 & 100,00 & 162,17 & 98,47 & 42,03 & 4511,04 & 296,07 & 65,55 & 230,53 & 117,11 & 219,31 & 223,70 & 108,42 & 559,05 & 87,77 & 1,70 & 65,36 & 255,09 & 20,98 & 22,00 & 246,12 \\
\hline Pelophylax & 29SNB66 & 101,00 & 162.98 & 99,69 & 4206 & 4555.55 & 299,11 & 66,03 & 233.08 & 117.41 & 220,63 & 225,06 & 108.82 & 559.86 & 86,75 & 1.99 & 64.56 & 253,15 & 21,71 & 22,47 & 245,11 \\
\hline Pelophylax perezi & 29SNB67 & 100,00 & 165,05 & 100,68 & 42,10 & 589,97 & 302,86 & 67,74 & 235,12 & 118, & 223,03 & 227,53 & 110 & 553,32 & 84,75 & 2,00 & 64,32 & 248,44 & 21,63 & 22,47 & 241,14 \\
\hline Pelophylax perezi & 29SNB68 & 101,00 & 164,04 & 101,89 & 42,18 & 4647,18 & 304,28 & 66,41 & 237,87 & 117,29 & 222,77 & 227,32 & 108,81 & 564,32 & 85,29 & 2,00 & 63,15 & 250,55 & 23,05 & 23,58 & 244,48 \\
\hline
\end{tabular}




\begin{tabular}{|c|c|c|c|c|c|c|c|c|c|c|c|c|c|c|c|c|c|c|c|c|c|}
\hline TAXON & UTM & $\mathrm{km} 2$ & B101 & B102 & $\mathrm{BIO3}$ & B104 & B105 & B106 & B107 & B108 & B109 & B1010 & BIO11 & BIO12 & B1013 & BIO14 & BIO15 & B1016 & B1017 & BIO18 & B1019 \\
\hline Pelophylax perezi & 29SNB69 & 101,00 & 167,56 & 102,06 & 42,17 & 4654,46 & 307,85 & 69,73 & 238,13 & 120,29 & 226,15 & 230,81 & 111,92 & 549,62 & 82,76 & 2,00 & 63,20 & 243,19 & 22,15 & 23,03 & 237,45 \\
\hline Pelophylax perezi & 29SNB70 & 63,00 & 170,56 & 91,99 & 42,83 & 4150,31 & 289,13 & 76,40 & 212,73 & 129,72 & 223,10 & 227,19 & 121,14 & 505,07 & 86,61 & 1,00 & 70,08 & 245,50 & 15,78 & 17,89 & 230,74 \\
\hline Pelophylax perezi & 29 SNB71 & 100,00 & 165,37 & 93,75 & 42,25 & 4281,43 & 288,74 & 70,12 & 218,62 & 123,08 & 219,68 & 223,82 & 114,36 & 532,25 & 89,16 & 1,00 & 68,54 & 253,83 & 17,50 & 19,48 & 240,31 \\
\hline Pelophylax perezi & 29SNB72 & 101,00 & 158,56 & 95,96 & 42,03 & 4413,77 & 287,27 & 62,45 & 224,82 & 114,93 & 214,69 & 218,96 & 106,39 & 571,05 & 92,86 & 1,49 & 66,85 & 265,98 & 20,14 & 21,88 & 254,31 \\
\hline Pelophylax perezi & 29SNB73 & 101,00 & 155,11 & 97,55 & 42,01 & 4511,24 & 287,61 & 58,42 & 229,19 & 110,50 & 212,56 & 216,92 & $\begin{array}{l}102,06 \\
\end{array}$ & 594,00 & 94,58 & 1,85 & 65,52 & 272,01 & 22,33 & 23,79 & 261,73 \\
\hline Pelophylax perezi & 29SNB74 & 100,00 & 155,46 & 98,99 & 42,00 & 4582,57 & 290,88 & 57,98 & 232,90 & 109,87 & 213,81 & 218,20 & 101,36 & 595,08 & 93,54 & 2,00 & 64,75 & 269,91 & 23,20 & 24,36 & 260,62 \\
\hline Pelophylax perezi & 29SNB75 & 101,00 & 159,78 & 100,28 & 42,00 & 4621,93 & 297,04 & 61,54 & 235,50 & 113,35 & 218,43 & 222,83 & 105,05 & 572,95 & 89,41 & 2,00 & 64,65 & 259,20 & 22,04 & 23,10 & 250,47 \\
\hline Pelophylax perezi & \begin{tabular}{|l|}
$295 N B 76$ \\
\end{tabular} & 100,00 & 161,25 & 101,73 & 42,01 & 4676,71 & 301,01 & 62,32 & 238,69 & 114,21 & 220,53 & 224,98 & 105,82 & 567,53 & \begin{tabular}{l|l}
87,48 \\
\end{tabular} & 2,00 & 63,97 & 254,77 & 22,03 & 23,01 & 247,03 \\
\hline Pelophylax perezi & 29SNB77 & 101,00 & 162,11 & 103,12 & 42,01 & 4726,24 & 304,26 & 62,65 & 241,60 & 114,45 & 221,96 & 226,48 & 106,06 & 566,85 & 86,19 & 2,00 & 63,50 & 252,11 & 22,82 & 23,23 & 245,35 \\
\hline Pelophylax perezi & 29SNB78 & 100,00 & 163,24 & 104,39 & \begin{tabular}{|l|l|}
42,08 \\
\end{tabular} & 4765,14 & 307,41 & 63,36 & 244,05 & 115,13 & 223,53 & 228,26 & 106,63 & 564,42 & 85,12 & 2,00 & 63,00 & 248,94 & 23,12 & 23,48 & 243,17 \\
\hline Pelophylax perezi & 29SNB79 & 100,00 & 166,09 & 105,06 & 42,25 & 4779,42 & 311,19 & 66,12 & 245,07 & 117,61 & 226,48 & 231,18 & 109,12 & 553,21 & 83,07 & 2,00 & 62,53 & 242,47 & 22,90 & 23,34 & 237,38 \\
\hline Pelophylax perezi & 29SNB80 & 97,00 & 169,36 & 92,45 & 42,75 & 4192,89 & 288,39 & 74,36 & 214,03 & 128,18 & 222,39 & 226,50 & 119,50 & 515,13 & 88,79 & 1,00 & 69,74 & 249,99 & 15,82 & 18,36 & 234,58 \\
\hline Pelophylax perezi & 29SNB81 & 101,00 & 162,83 & 94,57 & \begin{tabular}{|l|l|}
42,07 \\
\end{tabular} & 4366,06 & 287,94 & 66,33 & 221,61 & 119,65 & 218,25 & 222,48 & 111,04 & 548,10 & 91,22 & 1,09 & 67,97 & 259,42 & 18,07 & 20,46 & 245,71 \\
\hline Pelophylax perezi & 29SNB82 & 101,00 & 157,12 & 96,63 & 41,94 & 4496,11 & 287,34 & 59,58 & 227,76 & 112,64 & 214,29 & 218,59 & 103,89 & 581,80 & 93,91 & 1,63 & 66,26 & 269,03 & 20,85 & 22,90 & 257,09 \\
\hline Pelophylax perezi & 29SNB83 & 99,00 & 153,72 & 98,40 & 41,99 & 4596,25 & 288,04 & 55,56 & 232,47 & 108,30 & 212,29 & 216,57 & 99,42 & 603,65 & 95,34 & 2,03 & 64,86 & 274,47 & 22,96 & 24,69 & 264,03 \\
\hline Pelophylax perezi & 29 SNB84 & 101,00 & 156,82 & 99,72 & 41,99 & 4649,05 & 293,62 & 58,02 & 235,60 & 110,58 & 215,99 & 220,47 & 101,90 & 587,33 & 91,97 & 2,00 & 64,52 & 265,77 & 22,60 & 24,20 & 255,97 \\
\hline Pelophylax perezi & 29 SNB85 & 101,00 & 160,15 & 101,33 & 42,00 & 4701,10 & 299,33 & 60,68 & 238,64 & 113,07 & 219,98 & 224,36 & 104,50 & 569,56 & 88,36 & 2,00 & 64,34 & 256,54 & 21,87 & 23,07 & 247,50 \\
\hline Pelophylax perezi & 29SNB86 & 100,00 & 162,07 & 103,04 & 42,00 & 4757,32 & 303,96 & 61,80 & 242,16 & 114,11 & 222,48 & 226,92 & 105,67 & 561,37 & 85,89 & 2,00 & 63,65 & 250,74 & 22,00 & 23,10 & 242,69 \\
\hline Pelophylax perezi & 29SNB87 & 101,00 & 164,19 & 104,66 & 42,02 & \begin{tabular}{ll|}
4802,14 \\
\end{tabular} & 308,43 & 63,30 & 245,14 & 115,60 & 225,09 & 229,45 & 107,14 & 552,20 & 83,83 & 2,00 & 63,11 & 244,63 & 22,16 & 23,00 & 237,50 \\
\hline Pelophylax perezi & 29SNB88 & 101,00 & 164,83 & 106,41 & $\begin{array}{l}42,05 \\
\end{array}$ & 4854,87 & 311,95 & 63,26 & 248,70 & 115,54 & 226,35 & 230,92 & 107,07 & 551,99 & 83,25 & 2,00 & 62,32 & 242,05 & 22,81 & 23,29 & 236,15 \\
\hline Pelophylax perezi & 29SNB89 & 100,00 & 165,90 & 107,83 & 42,29 & 4898,78 & 315,21 & 63,79 & 251,42 & 115,99 & 227,84 & 232,60 & 107,52 & 549,89 & 82, & 2,00 & 61,86 & 238,70 & 23,05 & 23,82 & 233,98 \\
\hline Pelophylax perezi & 29 SNB90 & 101,00 & 167,65 & 92,61 & 42,31 & 4268,22 & 287,80 & 71,63 & 216,17 & 125,45 & 221,67 & 225,81 & 116,87 & 525,16 & 88,98 & 1,00 & 69,10 & 252,34 & 16,11 & 19,09 & 236,77 \\
\hline Pelophylax perezi & 29SNB91 & 101,00 & 158,51 & 95,20 & 41,90 & 4472,75 & 285,95 & 60,85 & 225,10 & 114,12 & 215,32 & 219,49 & 105,46 & 573,59 & 93,32 & 1,59 & 66,76 & 267,24 & 19,59 & 22,46 & 253,81 \\
\hline Pelophylax perezi & 29 SNB92 & 100,00 & 150,90 & 97,38 & 41,39 & 4624,20 & 284,06 & 52,19 & 231,87 & 105,03 & 209,76 & 213,97 & 96,25 & 620,53 & 97,73 & 1,99 & 64,87 & 281,73 & 23,16 & 25,60 & 270,38 \\
\hline Pelophylax perezi & 29 SNB93 & 101,00 & 154,65 & 98,68 & 41,62 & 4663,30 & 289,92 & 55,33 & 234,59 & 108,13 & 214,02 & 218,37 & 99,52 & 599,00 & 93,82 & 2,02 & 64,50 & 271,15 & 22,54 & 24,85 & 260,13 \\
\hline Pelophylax perezi & 29SNB94 & 100,00 & 159,33 & 99,98 & 41,80 & 4709,88 & 296,68 & 59,39 & 237,29 & 112,16 & 219,24 & 223,63 & 103,63 & 571,80 & 89,02 & 2,00 & 64,30 & 258,27 & 21,49 & 23,73 & 247,61 \\
\hline Pelophylax perezi & 29 SNB95 & 100,00 & 162,10 & 101,68 & 年11,85 & 4764,64 & 301,97 & $\frac{61,28}{601,}$ & 240,69 & 114,21 & 222,62 & 226,94 & 105,44 & 557,84 & 85,81 & 2,00 & 63,79 & 250,25 & 21,36 & 23,25 & 240,45 \\
\hline Pelophylax perezi & 29 SNB96 & 101,00 & 163,94 & 103,58 & 42,00 & 4820,32 & 306,60 & 62,39 & 244,21 & 115,39 & 225,06 & 229,47 & 106,53 & 548,79 & 83,65 & 2,00 & 63,29 & 244,15 & 21,60 & 23,07 & 235,36 \\
\hline Pelophylax perezi & 29SNB97 & 100,00 & 164,92 & 105,55 & 42,00 & 4874,85 & 310,72 & 62,35 & 248,37 & 115,44 & 226,73 & 231,23 & 106,64 & 545,94 & 82,66 & 2,00 & 62,55 & 240,46 & 21,97 & 23,29 & 232,84 \\
\hline Pelophylax perezi & 29SNB98 & 100,00 & 166,44 & 107,51 & 42,05 & 4933,26 & 315,14 & 63,07 & 252,06 & 116,25 & 228,91 & 233,37 & 107,37 & 539,69 & 81,21 & 2,00 & 61,85 & 235,36 & 22,26 & 23,41 & 228,93 \\
\hline Pelophylax perezi & 29SNB99 & 101,00 & 165,62 & 110,00 & 42,07 & 5015,02 & 318,32 & 61,18 & 257,14 & 114,36 & 229,15 & 233,73 & 105,83 & 547,67 & $\begin{array}{ll}81,68 \\
\end{array}$ & 2,00 & 61,23 & 235,78 & 23,44 & 23,94 & 231,03 \\
\hline Pelophylax perezi & $295 \mathrm{NCO5}$ & 13,00 & 170,30 & 85,90 & 42, 41,70 & 4110,10 & 287,80 & $\begin{array}{l}1,10 \\
83,50 \\
\end{array}$ & 204,30 & \begin{tabular}{|l|}
127,60 \\
12,0
\end{tabular} & \begin{tabular}{|l|}
220,80 \\
\end{tabular} & 225,50 & 120,40 & $\begin{array}{l}644,60 \\
\end{array}$ & $\begin{array}{l}1,06 \\
96,70 \\
\end{array}$ & 2,10 & $\begin{array}{ll}1,2,80 \\
63,80\end{array}$ & 287,90 & 26,40 & 29,30 & 277,70 \\
\hline Pelophylax perezi & 29SNC06 & 92,00 & 166,43 & 85,60 & \begin{tabular}{l|l|l|l|}
41,05 \\
\end{tabular} & 4169,39 & 285,32 & 79,35 & 205,97 & 122,99 & 217,60 & 222,47 & 115,64 & 681,47 & 101,62 & 3,41 & 63,05 & 302,61 & 28,84 & 31,25 & 293,11 \\
\hline Pelophylax perezi & 29SNC07 & 101,00 & 169,51 & 84,83 & 40,99 & 4161,27 & 287,38 & 82,44 & 204,94 & 125,92 & 220,59 & 225,31 & 118,66 & 667,01 & 99,49 & 3,01 & 63,32 & 296,84 & 27,18 & 30,14 & 287,32 \\
\hline Pelophylax perezi & 29 SNC08 & 88,00 & 170,53 & 83,66 & 40,89 & 4135,33 & 286,57 & 83,89 & 202,68 & 127,01 & 221,21 & 225,76 & 119,78 & 664,00 & 99,33 & 3,00 & 63,24 & 295,24 & 26,97 & 30,01 & 285,61 \\
\hline Pelophylax perezi & 29 SNCO9 & 44,00 & 169,96 & 82,41 & 40,92 & 4094,55 & 283,96 & 83,82 & 200,14 & 126,75 & 220,06 & 224,33 & 119,35 & 666,27 & 99,81 & 3,00 & 63,11 & 295,30 & 27,00 & 30,45 & 285,77 \\
\hline Pelophylax perezi & 29SNC10 & 74,00 & 168,25 & $\begin{array}{ll}82,49 \\
89,65\end{array}$ & 42,91 & $\begin{array}{l}4034,53 \\
404,68\end{array}$ & $\begin{array}{l}200,50 \\
287,78\end{array}$ & $\begin{array}{l}30,78 \\
80,78\end{array}$ & \begin{tabular}{|l|}
207,00 \\
\end{tabular} & \begin{tabular}{|l|l|}
127,19 \\
\end{tabular} & \begin{tabular}{|l|}
218,07 \\
\end{tabular} & \begin{tabular}{|l|}
222,81 \\
228
\end{tabular} & \begin{tabular}{|l|}
119,20 \\
19,0
\end{tabular} & \begin{tabular}{|l|}
583,03 \\
\end{tabular} & \begin{tabular}{|l|l|}
37,01 \\
87,85
\end{tabular} & 2,00 & $\begin{array}{l}3,11 \\
64,57\end{array}$ & \begin{tabular}{|l|}
262,35 \\
265
\end{tabular} & 23,98 & $\begin{array}{l}0,45 \\
24,99\end{array}$ & 253,35 \\
\hline Pelophylax perezi & $295 N C 14$ & 18,00 & 171,34 & 89,19 & 41,84 & 4214,47 & 293,56 & 82,31 & 211,25 & 127,59 & 223,09 & 228,06 & 119,66 & 612,06 & 91,03 & 3,00 & 63,09 & 271,59 & 26,00 & 28,00 & 263,56 \\
\hline Pelophylax perezi & 29SNC15 & 36,00 & 171,75 & 88,25 & 41,64 & 4206,15 & 292,96 & 83,02 & 209,94 & 127,92 & 223,30 & 228,25 & 120,13 & 620,98 & 92,36 & 3,00 & 63,06 & 275,83 & 26,00 & 28,26 & 267,51 \\
\hline Pelophylax perezi & $295 N C 16$ & 88,00 & 171,19 & 87,51 & 41,15 & 4225,15 & 292,32 & 82,74 & 209,58 & 127,11 & 223,20 & 227,95 & 119,56 & 635,06 & 94,05 & 3,00 & 62,94 & 281,42 & 26,54 & 29,02 & 273,28 \\
\hline Pelophylax perezi & 29SNC17 & 101,00 & 170,53 & 86,68 & 41,6 & 4232,24 & 291,12 & 82,37 & 208,75 & 126,37 & 222,68 & 227 & 118,88 & 648,25 & $95, \varepsilon$ & 3,00 & 62,78 & 286,50 & 27,00 & 29,86 & 278,50 \\
\hline Pelophylax perezi & 29 SNC18 & 101,00 & 170,36 & 85,57 & 40,95 & 4216,61 & 289,75 & 82,38 & 207,36 & 126,20 & 222,34 & 226,68 & 118,63 & 654,34 & |96,99 & 3,00 & 62,89 & 288,89 & 27,13 & 30,05 & 280,95 \\
\hline Pelophylax perezi & 29SNC19 & 100,00 & 169,45 & 84,33 & 40,73 & 4178,78 & 286,88 & 81,82 & 205,06 & 125,35 & 220,79 & 225,15 & 117,87 & 663,76 & 98,49 & 3,00 & 62,52 & 292,10 & 27,61 & 30,92 & 284,15 \\
\hline Pelophylax perezi & $295 N C 20$ & 100,00 & 163,43 & 92,33 & 42,46 & 4224,95 & 288,91 & 73,92 & 214,99 & 120,64 & 215,90 & 220,69 & 112,66 & 606,74 & 90,73 & 2,30 & 63,70 & 270,56 & 25,52 & 26,30 & 263,18 \\
\hline Pelophylax perezi & $295 N C 21$ & 101,00 & 164,38 & 92,12 & 42, & 4247,06 & 290,22 & 74,66 & 215,56 & 121,27 & 217,10 & 221,97 & 113,42 & 612,68 & 91,3 & 2,49 & 63,49 & 272,22 & 25,95 & 26,81 & 265,08 \\
\hline Pelophylax perezi & $295 \mathrm{NC22}$ & 99,00 & 166,10 & 91,82 & 4 & 4275,52 & 292,11 & 76,33 & 215,78 & 122,47 & 219,16 & 224,04 & \begin{tabular}{|l|l|l|l|l|}
114,58 \\
\end{tabular} & \begin{tabular}{|l|l|}
614,17 \\
\end{tabular} & $\begin{array}{l}1,46 \\
91,45 \\
\end{array}$ & 2,6 & 63,12 & 272,23 & 26,19 & 27,32 & 265,21 \\
\hline Pelophylax perezi & 29SNC23 & 101,00 & 168,86 & 91,32 & 42,00 & 4281,82 & 294,32 & 78,88 & 215,44 & 124,77 & 221,79 & 226,66 & 116,93 & 608,71 & 90,47 & 2,99 & 63,12 & 269,53 & 25,78 & 27,64 & 262,48 \\
\hline Pelophylax perezi & $295 N C 24$ & 100,00 & 170,19 & 90,79 & 41,82 & 4295,90 & 295,24 & 80,06 & 215,18 & 125,66 & 223,30 & 228,07 & 117,87 & 612,17 & 90,74 & 2,98 & 62,43 & 270,48 & 26,14 & 27,79 & 263,54 \\
\hline Pelophylax perezi & 29 SNC25 & 72,00 & 171,37 & 90,26 & 41,50 & 4305,01 & 296,38 & 81,59 & 214,79 & 126,64 & 224,69 & 229,51 & 119,16 & 611,59 & 90,23 & 3,00 & 62,83 & 269,90 & 25,77 & 27,76 & 263,10 \\
\hline Pelophylax perezi & 29 SNC26 & 88,00 & 170,97 & 89,48 & 41,11 & 4314,14 & 295,55 & 81,21 & 214,34 & 126,11 & 224,43 & 229,03 & 118,54 & 625,67 & 92,01 & 3,00 & 62,56 & 275,11 & 26,84 & 29,01 & 268,52 \\
\hline Pelophylax perezi & $295 \mathrm{NC2}$ & \begin{tabular}{|l|}
00,000 \\
101,00
\end{tabular} & 170 & $\begin{array}{l}80,400 \\
88,60\end{array}$ & 46 & 06 & 294,15 & $\begin{array}{l}1,12 \\
80,47 \\
\end{array}$ & \begin{tabular}{|l|}
213,68 \\
\end{tabular} & \begin{tabular}{|l|}
125,06 \\
125,1
\end{tabular} & \begin{tabular}{|l|}
223,61 \\
223,51
\end{tabular} & $\mid 228,18$ & \begin{tabular}{|l|}
117,38, \\
11,3
\end{tabular} & \begin{tabular}{|l|l|}
639,31 \\
\end{tabular} & $\begin{array}{l}2,11,12 \\
94,12\end{array}$ & 3,00 & $\begin{array}{l}2,3,43 \\
62,43\end{array}$ & \begin{tabular}{|l|}
280,42 \\
28,1
\end{tabular} & $\begin{array}{l}\mid 2,0,44 \\
27,36\end{array}$ & 29,82 & $\begin{array}{l}20,34 \\
274,05\end{array}$ \\
\hline Pelophylax perezi & $295 N C 28$ & 101,00 & 169,01 & 87,66 & 40,97 & 4313,12 & 291,96 & 79,80 & 212,16 & 123,92 & 222,42 & 226,85 & 116,38 & 654,50 & 96,47 & 3,00 & 62,12 & 286,12 & 28,15 & 30,59 & 279,97 \\
\hline Pelophylax perezi & 29 SNC29 & 100,00 & 169,06 & 86,49 & 40,86 & 4278,31 & 290,27 & 80,32 & 209,9 & $\begin{array}{l}124,19 \\
\end{array}$ & 222,01 & 226,24 & 116,70 & 658,33 & 97,10 & 3,03 & 61,99 & 287.19 & 28.26 & 31,05 & 280,91 \\
\hline Pelophylax perezi & 29 SNC30 & 100,00 & 164,80 & 94,76 & 42,16 & 4339,40 & 294,27 & 73,09 & 221,18 & 120,82 & 218,96 & 223,73 & 112,79 & 591,55 & 88,55 & 2,06 & 63,69 & 263,40 & 24,27 & 24,90 & 256,82 \\
\hline Pelophylax perezi & 29 SNC31 & 101,00 & 161,27 & 94,95 & 42, & 4402,58 & 292,56 & 69,61 & 222,95 & 116 & 216,36 & 22 & $10 \varepsilon$ & 624,36 & 92,71 & 2,89 & 62,71 & 274,96 & 27,25 & 27,68 & 269 \\
\hline Pelophylax perezi & 29SNC32 & $\begin{array}{l}101,00 \\
100\end{array}$ & $\begin{array}{l}101,27 \\
164,58\end{array}$ & $\begin{array}{l}4,35 \\
94,37\end{array}$ & $\begin{array}{l}42,06 \\
41,92\end{array}$ & $\begin{array}{l}44012,60 \\
4412,68\end{array}$ & $\begin{array}{l}29,55,47 \\
295,4\end{array}$ & \begin{tabular}{|l|l|}
72,80 \\
7
\end{tabular} & \begin{tabular}{|l|}
222,67 \\
22,6
\end{tabular} & $\begin{array}{l}119,62 \\
117\end{array}$ & 219,70 & \begin{tabular}{|l|}
224,62 \\
220
\end{tabular} & \begin{tabular}{l|l}
111,69 \\
$111 / 2$
\end{tabular} & \begin{tabular}{|l|l|}
614,58 \\
6140
\end{tabular} & $\begin{array}{l}\mid c, 1 / 1 \\
90,98 \\
\end{array}$ & $2,2,73$ & $\begin{array}{ll}2,1 / 64 \\
62,64\end{array}$ & \begin{tabular}{|l|}
270,49 \\
\end{tabular} & $\begin{array}{l}2,25 \\
26,43 \\
\end{array}$ & $\begin{array}{l}27,17 \\
27\end{array}$ & $\begin{array}{l}200,00 \\
264,92\end{array}$ \\
\hline Pelophylax perezi & 29SNC33 & 100,00 & 167,77 & 93,79 & 41,93 & 4408,51 & 297,79 & 76,01 & 221,78 & 122,43 & 222,68 & 227,53 & 114,64 & 605,45 & 89,46 & 2,95 & 62,79 & 266,27 & 25,92 & 26,94 & 260,68 \\
\hline Pelophylax perezi & 29SNC34 & 101,00 & 169,72 & 93,09 & 41,86 & 4404,57 & 299,00 & 78,24 & 220,76 & 124,28 & 224,49 & 229,21 & 116,51 & 603,04 & 88,72 & 2,98 & 62,63 & 264,73 & 25,86 & 26,98 & 259,18 \\
\hline Pelophylax perezi & 29SNC35 & 101,00 & 171,03 & 92,25 & 41,48 & 4404,83 & 299,52 & 79,46 & 220,05 & 125,40 & 225,7 & 230 & 117 & 604,24 & 88,76 & 3,00 & 62,41 & 264,68 & 25,77 & 27,49 & 259 \\
\hline Pelophylax perezi & $295 \mathrm{NC} 36$ & 100,00 & 169,00 & 91,56 & 41,06 & 4431,00 & 297,64 & 77,78 & 219,86 & 122,84 & 224,17 & 228,71 & 115,32 & 627,90 & 92,08 & 3,00 & 61,85 & 273,39 & 27,58 & 29,37 & 268,51 \\
\hline
\end{tabular}




\begin{tabular}{|c|c|c|c|c|c|c|c|c|c|c|c|c|c|c|c|c|c|c|c|c|c|}
\hline TAXON & UTM & $\mathrm{km2}$ & BIO1 & B102 & $\mathrm{BIO3}$ & B104 & B105 & B106 & B107 & B108 & B109 & BIO10 & BIO11 & B1012 & BIO13 & BIO14 & BIO15 & BIO16 & BIO17 & B1018 & BlO19 \\
\hline Pelophylax perezi & 29SNC37 & 101,00 & 169,03 & 90,66 & 40,99 & 4427,78 & 296,69 & 77,94 & 218,75 & 122,70 & 224,05 & 228,61 & 115,18 & 636,97 & 93,47 & 3,05 & 61,64 & 276,64 & 28,14 & 30,01 & 271,91 \\
\hline Pelophylax perezi & 29 SNC38 & 100,00 & 167,84 & 89,72 & 40,97 & 4423,35 & 294,69 & \begin{tabular}{|l|l|}
76,97 \\
\end{tabular} & 217,72 & \begin{tabular}{|l|l|}
121,60 \\
1
\end{tabular} & 222,86 & 227,25 & 113,91 & 653,12 & 95,80 & 3,45 & 61,27 & 282,41 & 29,44 & 31,45 & 277,99 \\
\hline Pelophylax perezi & 29SNC39 & 100,00 & 168,15 & 88,67 & 40,81 & 4385,91 & 293,38 & 77,73 & 215,65 & 122,21 & 222,70 & 227,00 & \begin{tabular}{l|l|}
114,55 \\
\end{tabular} & 657,82 & 96,56 & 3,71 & 61,08 & 283,95 & \begin{tabular}{|l|l|}
29,97 \\
\end{tabular} & 32,20 & 279,29 \\
\hline Pelophylax perezi & 29SNC40 & 101,00 & 167,25 & 97,05 & 42,15 & 4438,80 & 300,13 & 73,75 & 226,38 & 122,15 & 222,81 & 227,46 & 114,11 & 570,75 & 85,50 & 2,00 & 63,50 & 253,58 & 23,46 & 24,21 & 247,48 \\
\hline Pelophylax perezi & 29SNC41 & 101,00 & 166,46 & 97,10 & 42,00 & 4485,43 & 300,43 & 72,71 & 227,71 & 120,71 & \begin{tabular}{|l|l|}
222,62 \\
\end{tabular} & 227,24 & 112,62 & 584,59 & 86,96 & 2,10 & \begin{tabular}{|l|l|l|}
63,03 \\
\end{tabular} & 257,83 & 24,48 & 25,09 & 252,44 \\
\hline Pelophylax perezi & 29SNC42 & 99,00 & 168,70 & 96,55 & 42,00 & 4483,66 & 302,16 & 75,09 & 227,07 & 122,67 & 224,64 & 229,38 & 114,78 & 580,33 & 85,94 & 2,06 & \begin{tabular}{ll|l}
62,96 \\
\end{tabular} & 255,20 & 24,26 & 25,13 & 250,04 \\
\hline Pelophylax perezi & 29 SNC43 & 101,00 & 169,53 & 95,90 & 42,00 & 4501,04 & 302,69 & 76,17 & 226,52 & 123,27 & 225,75 & 230,51 & 115,38 & 585,04 & 86,01 & 2,62 & 62,24 & 255,76 & 25,29 & 26,29 & 251,02 \\
\hline Pelophylax perezi & 29SNC44 & 101,00 & 169,99 & 95,22 & 41,79 & 4509,82 & 302,72 & \begin{tabular}{l|l}
76,65 \\
\end{tabular} & 226,07 & \begin{tabular}{ll|}
123,49 \\
\end{tabular} & 226,24 & 231,00 & \begin{tabular}{|l|l|}
115,48 \\
\end{tabular} & 591,50 & \begin{tabular}{l|l|}
86,65 \\
\end{tabular} & 2,87 & \begin{tabular}{ll|}
61,89 \\
\end{tabular} & 257,60 & 25,84 & 27,04 & 253,18 \\
\hline Pelophylax perezi & 29SNC45 & 101,00 & 169,94 & 94,46 & 41,41 & 4514,58 & 302,27 & 76,89 & 225,38 & \begin{tabular}{|l|l|}
123,17 \\
\end{tabular} & 226,18 & \begin{tabular}{|l|l|}
230,97 \\
\end{tabular} & 115,35 & 601,31 & 87,88 & 3,00 & 61,71 & 260,69 & 26,58 & 27,74 & 256,66 \\
\hline Pelophylax perezi & 29SNC46 & 100,00 & 168,48 & 93,61 & 41,02 & 4534,77 & 300,59 & 75,62 & 224,97 & 121,42 & $225,07 \mid$ & 229,66 & 113,51 & 619,70 & 90,45 & 3,03 & $61,34[$ & 267,23 & $27,81 \mid$ & 29,05 & 263,86 \\
\hline Pelophylax perezi & 29SNC47 & 100,00 & 167,73 & 92,62 & \begin{tabular}{ll|}
40,97 \\
\end{tabular} & 4524,31 & 299,07 & 75,36 & 223,71 & 120,67 & \begin{tabular}{|l|l|}
224,19 \\
\end{tabular} & 228,77 & 112,91 & 635,36 & 92,66 & 3,44 & \begin{tabular}{ll|}
60,82 \\
\end{tabular} & 272,81 & 29,39 & 30,81 & 269,64 \\
\hline Pelophylax perezi & 29SNC48 & 101,00 & 167,37 & 91,63 & 40,88 & \begin{tabular}{ll|}
4518,73 \\
\end{tabular} & 297,60 & 75,26 & 222,34 & \begin{tabular}{|l|l|}
120,13 \\
\end{tabular} & \begin{tabular}{|l|l|}
223,69 \\
\end{tabular} & 228,17 & \begin{tabular}{l|l}
112,45 \\
\end{tabular} & 647,64 & 94,44 & 3,90 & 60,49 & 277,18 & 30,66 & 32,10 & 274,15 \\
\hline Pelophylax perezi & 29SNC49 & 101,00 & 167,49 & 90,72 & 40,48 & 4504,72 & 296,56 & 75,55 & 221,01 & 120,28 & 223,71 & 227,97 & \begin{tabular}{|l|l|}
112,67 \\
\end{tabular} & 655,11 & 95,53 & 3,96 & 60,30 & 279,75 & 31,13 & 32,90 & 276,80 \\
\hline Pelophylax perezi & 29SNC50 & 101,00 & 169,36 & 99,40 & 42,16 & 4546,86 & 305,86 & 73,78 & 232,08 & \begin{tabular}{ll|}
122,96 \\
\end{tabular} & \begin{tabular}{|l|l|}
226,42 \\
\end{tabular} & 231,14 & \begin{tabular}{ll|}
114,82 \\
\end{tabular} & 551,54 & 82,71 & 2,00 & 63,51 & 244,19 & 22,46 & 23,32 & 238,44 \\
\hline Pelophylax perezi & 29SNC51 & 101,00 & 169,44 & 99,28 & 42,04 & 4569,18 & 306,46 & 73,87 & 232,59 & \begin{tabular}{|l|l|}
122,67 \\
\end{tabular} & 226,81 & 231,38 & \begin{tabular}{l|l|}
114,65 \\
\end{tabular} & 560,00 & 83,21 & 2,00 & 62,5 & 245,94 & \begin{tabular}{|l|l|}
23,75 \\
\end{tabular} & 24,40 & 240,90 \\
\hline Pelophylax perezi & 29SNC52 & 101,00 & 169,67 & 98,88 & 42,01 & 4587,13 & 306,68 & 74,25 & 232,43 & 122,60 & \begin{tabular}{|l|l|}
227,16 \\
\end{tabular} & 231,83 & \begin{tabular}{|l|l|}
114,48 \\
\end{tabular} & 566,97 & 83,56 & 2,08 & \begin{tabular}{|l|}
62,27 \\
\end{tabular} & \begin{tabular}{|l|l|}
247,49 \\
\end{tabular} & 24,29 & 24,99 & 243,05 \\
\hline Pelophylax perezi & 29SNC53 & 100,00 & 170,04 & 98,17 & 41,97 & 4596,44 & 306,70 & 74,80 & 231,89 & \begin{tabular}{|l|l|}
122,87 \\
\end{tabular} & 227,55 & 232,26 & \begin{tabular}{|l|l|}
114,58 \\
\end{tabular} & 573,44 & 83,86 & 2,58 & \begin{tabular}{|l|l|}
61,79 \\
\end{tabular} & \begin{tabular}{|l|l|}
248,75 \\
\end{tabular} & 25,34 & 26,21 & 244,83 \\
\hline Pelophylax perezi & 29SNC54 & 101,00 & 168,58 & 97,49 & 41,65 & 4619,20 & 305,30 & 73,76 & 231,54 & 121,07 & 226,41 & 231,19 & 113,01 & 590,22 & 85,94 & 2,99 & 61,12 & 254,27 & 26,74 & 27,45 & 251,14 \\
\hline Pelophylax perezi & 29SNC55 & 100,00 & 168,90 & 96,51 & 41,20 & 4621,95 & 304,91 & 74,40 & 230,51 & 121,21 & \begin{tabular}{|l|l|}
226,82 \\
\end{tabular} & \begin{tabular}{|l|l|}
231,37 \\
\end{tabular} & \begin{tabular}{|l|}
113,07 \\
\end{tabular} & 597,31 & 86,69 & 3,00 & \begin{tabular}{l|l}
60,85 \\
\end{tabular} & 256,22 & 27,24 & 28,15 & 253,45 \\
\hline Pelophylax perezi & 29SNC56 & 101,00 & 164,47 & 95,36 & 40,94 & 4653,64 & 300,76 & 70,51 & 230,25 & \begin{tabular}{ll|}
116,51 \\
\end{tabular} & 222,78 & 227,54 & $\begin{array}{ll}108,55 \\
\end{array}$ & 636,12 & 92,18 & 3,69 & 60,0 & 270,33 & 30,59 & 31,18 & 268,80 \\
\hline Pelophylax perezi & \begin{tabular}{|l|}
$295 N C 57$ \\
\end{tabular} & 100,00 & 163,63 & 94,28 & 40,87 & 4652,67 & 298,97 & 70,09 & 228,88 & 115,47 & 221,89 & 226,65 & \begin{tabular}{|l|l|}
107,55 \\
\end{tabular} & \begin{tabular}{|l|l|}
653,05 \\
\end{tabular} & \begin{tabular}{l|l|}
94,55 \\
\end{tabular} & 4,00 & 59,70 & 276,30 & 32,10 & 32,64 & 275,18 \\
\hline Pelophylax perezi & 29SNC58 & 101,00 & 166,18 & 93,38 & 40,73 & 4621,51 & 299,98 & 72,89 & \begin{tabular}{|l|l|}
227,09 \\
\end{tabular} & \begin{tabular}{|l|l|l|l|}
118,19 \\
\end{tabular} & \begin{tabular}{|l|l|}
224,19 \\
\end{tabular} & 228,68 & $\begin{array}{l}110,35 \\
10\end{array}$ & 646,13 & 93,50 & 4,00 & 59,70 & 273,34 & 31,76 & 32,74 & 271,86 \\
\hline Pelophylax perezi & 29SNC59 & 101,00 & 166,11 & 92,51 & 40,31 & 4606,06 & 298,89 & 73,02 & 225,86 & \begin{tabular}{ll|}
118,06 \\
\end{tabular} & \begin{tabular}{|l|}
223,91 \\
\end{tabular} & 228,27 & 110,24 & 657,11 & 95,19 & 4,00 & \begin{tabular}{|l|l|}
59,58 \\
\end{tabular} & 277,46 & 32,31 & 33,59 & 275,99 \\
\hline Pelophylax perezi & 29SNC60 & 100,00 & 168,91 & 102,19 & 42,14 & 4666,86 & 309,80 & 71,14 & 238,66 & 121,42 & 227,67 & 232,32 & 113,08 & 548,16 & \begin{tabular}{l|l|}
81,95 \\
\end{tabular} & 2,00 & \begin{tabular}{|l|l|}
62,98 \\
\end{tabular} & 240,78 & 22,67 & 23,01 & 235,76 \\
\hline Pelophylax perezi & 29SNC61 & 100,00 & 169,39 & 102,09 & 42,06 & 4689,62 & 310,75 & 71,73 & 239,02 & 121,44 & 228,44 & 233,05 & 113,19 & 552,32 & 81,83 & 2,00 & 62,34 & 240,81 & 23,25 & 23,92 & 236,45 \\
\hline Pelophylax perezi & 29 SNC62 & 101,00 & 169,70 & 101,47 & 42,00 & 4702,51 & 310,90 & 72,32 & 238,58 & 121,60 & 228,84 & 233,60 & 113,19 & 557,38 & 81,73 & 2,03 & 61,72 & 241,28 & 24,33 & 24,76 & 237,62 \\
\hline Pelophylax perezi & 29SNC63 & 100,00 & 169,43 & 100,65 & \begin{tabular}{|l|l|}
41,97 \\
\end{tabular} & 4709,57 & 310,18 & 72,45 & 237,73 & 120,91 & 228,61 & 233,21 & \begin{tabular}{|l|l|}
112,84 \\
\end{tabular} & $\begin{array}{l}567,75 \\
\end{array}$ & 82,31 & 2,86 & \begin{tabular}{ll|l}
60,67 & \\
\end{tabular} & 243,66 & 26,02 & 26,75 & 240,76 \\
\hline Pelophylax perezi & 29SNC64 & 100,00 & \begin{tabular}{ll|}
167,67 \\
\end{tabular} & 99,66 & \begin{tabular}{|l|l|}
41,58 \\
\end{tabular} & 4728,05 & 308,14 & 71,10 & 237,04 & \begin{tabular}{|l|l|}
118,99 \\
\end{tabular} & 227,06 & 231,73 & 110,79 & 586,38 & 84,68 & 2,98 & 60,50 & 249,87 & 27,36 & 27,77 & 247,77 \\
\hline Pelophylax perezi & 29SNC65 & 101,00 & 165,21 & 98,42 & 41,09 & 4744,75 & 305,35 & 69,42 & 235,94 & 116,34 & 224,94 & 229,67 & 108,29 & 609,86 & 87,75 & 3,01 & 60,04 & 257,88 & 29,32 & 29,53 & 256,77 \\
\hline Pelophylax perezi & 29SNC66 & 100,00 & 163,32 & 96,95 & 40,96 & 4748,38 & 302,52 & 68,20 & 234,32 & 113,71 & \begin{tabular}{|l|}
223,07 \\
\end{tabular} & 227,75 & 106,26 & \begin{tabular}{|c|}
633,58 \\
\end{tabular} & $\begin{array}{l}90,95 \\
\end{array}$ & 3,66 & \begin{tabular}{|l|}
59,27 \\
\end{tabular} & 266,10 & 31,68 & 31,91 & 265,71 \\
\hline Pelophylax perezi & 29SNC67 & 101,00 & 160,92 & 95,55 & 40,51 & 4762,73 & 299,50 & 66,41 & 233,08 & 108,31 & 221,06 & 225,57 & 103,85 & 660,70 & 94,83 & 4,00 & 58,89 & 276,39 & 33,88 & 33,97 & 276,32 \\
\hline Pelophylax perezi & 29SNC68 & 101,00 & 163,25 & 94,70 & 40,31 & 4730,67 & 300,30 & 68,96 & 231,34 & \begin{tabular}{ll|}
111,72 \\
\end{tabular} & 222,91 & 227,37 & 106,33 & 657,62 & 94,41 & 4,00 & \begin{tabular}{l|l|l|}
58,85 \\
\end{tabular} & 274,96 & 33,71 & 34,14 & 274,80 \\
\hline Pelophylax perezi & 29SNC69 & 100,00 & 165,62 & 94,16 & 40,24 & 4717,41 & 301,63 & 71,25 & 230,38 & \begin{tabular}{ll|}
115,59 \\
\end{tabular} & 224,87 & 229,36 & 108,58 & 652,73 & 93,69 & 4,00 & \begin{tabular}{l|l}
58,75 \\
\end{tabular} & 272,66 & 33,34 & 34,18 & 272,37 \\
\hline Pelophylax perezi & 29 SNC70 & 101,00 & 166,79 & 105,49 & 42,09 & 4809,92 & 312,99 & 66,70 & 246,29 & $\begin{array}{ll}117,83 \\
\end{array}$ & 227,47 & 232,23 & 109,28 & 554,83 & 82,57 & 2,00 & \begin{tabular}{|l|l|}
61,93 \\
\end{tabular} & 241,11 & 23,42 & 23,73 & 236,96 \\
\hline Pelophylax perezi & 29SNC71 & 100,00 & 167,97 & 105,13 & 42,01 & 4818,71 & 314,16 & 68,10 & 246,06 & 118,71 & 228,77 & 233,40 & 110,28 & 553,44 & 81,62 & 2,00 & 61,39 & 238,80 & 23,73 & 24,02 & 235,39 \\
\hline Pelophylax perezi & 29SNC72 & 101,00 & 168,99 & 104,16 & 42,00 & 4819,09 & 314,36 & 69,59 & 244,77 & \begin{tabular}{|l|l|}
119,59 \\
\end{tabular} & 229,74 & 234,33 & 111,15 & \begin{tabular}{|l|l}
554,55 \\
\end{tabular} & 80,84 & 2,28 & \begin{tabular}{|l|l|}
61,04 \\
\end{tabular} & 237,65 & 24,72 & 25,06 & 234,67 \\
\hline Pelophylax perezi & $295 N C 73$ & 101,00 & 167,30 & 103,29 & 41,94 & 4840,16 & 312,68 & 68,40 & 244,28 & 117,58 & \begin{tabular}{|l|l|}
228,25 \\
\end{tabular} & 233,07 & 109,32 & 571,18 & 81,99 & 3,00 & 59,96 & 242,07 & 27,26 & 27,38 & 240,14 \\
\hline Pelophylax perezi & 29SNC74 & 101,00 & 164,58 & 101,83 & 41,31 & 4855,15 & 309,36 & 66,51 & 242,84 & 114,73 & 226,27 & 230,53 & $\begin{array}{ll}106,55 \\
\end{array}$ & 594,93 & 84,98 & 3,00 & \begin{tabular}{l|l}
59,55 \\
\end{tabular} & 250,03 & 28,86 & 28,86 & 249,31 \\
\hline Pelophylax perezi & 29SNC75 & 100,00 & 164,53 & 100,09 & 41,03 & 4838,18 & 307,66 & 67,28 & 240,38 & \begin{tabular}{ll|}
114,29 \\
\end{tabular} & 226,21 & 230,19 & 106,54 & 604,28 & 86,00 & 3,00 & 59,13 & 252,46 & 0,18 & 0,18 & 252,28 \\
\hline Pelophylax perezi & $295 N C 76$ & 101,00 & 160,29 & 98,06 & 40,77 & 4851,99 & 302,55 & 64,27 & 238,27 & 104,42 & 223,43 & 226,39 & 102,36 & \begin{tabular}{|l|l|}
641,73 \\
\end{tabular} & 91,18 & 3,81 & 58,25 & 266,81 & 33,29 & 33,29 & 266,81 \\
\hline Pelophylax perezi & 29SNC77 & 101,00 & 158,54 & 96,49 & \begin{tabular}{ll|}
40,18 \\
\end{tabular} & 4855,58 & 299,73 & 63,38 & 236,35 & \begin{tabular}{|l|l|}
100,76 \\
\end{tabular} & 222,23 & 224,66 & 100,60 & \begin{tabular}{ll|l|}
666,05 \\
\end{tabular} & 94,64 & 4,08 & 57,82 & 276,19 & 35,39 & 35,39 & 276,19 \\
\hline Pelophylax perezi & $295 N C 78$ & 99,00 & 160,21 & 95,62 & 40,11 & 4836,39 & 300,15 & 65,21 & 234,94 & 102,41 & \begin{tabular}{l|l|}
222,25 \\
\end{tabular} & 225,85 & 102,35 & 669,04 & 95,14 & 4,02 & 57,86 & 277,31 & 35,75 & 35,75 & 277,31 \\
\hline Pelophylax perezi & 29SNC79 & 101,00 & 163,50 & 95,29 & 40,00 & 4822,36 & 302,59 & \begin{tabular}{l|l}
68,15 \\
\end{tabular} & 234,43 & 106,34 & 224,34 & 228,70 & 105,38 & $\begin{array}{ll}659,75 \\
\end{array}$ & 93,87 & 4,00 & \begin{tabular}{|l|l|}
57,83 \\
\end{tabular} & 273,29 & 35,38 & \begin{tabular}{l|l}
35,75 \\
\end{tabular} & 273,29 \\
\hline Pelophylax perezi & 29SNC80 & 101,00 & 165,24 & 108,90 & 42,22 & 4951,82 & 316,80 & 62,73 & 254,06 & \begin{tabular}{ll|}
114,69 \\
\end{tabular} & 227,97 & 232,64 & 106 & 558,11 & 82,71 & 2,06 & 61,1 & 239,67 & 4,29 & 4,41 & 236,34 \\
\hline Pelophylax perezi & $29 S N C 81$ & 101,00 & 165,59 & 108,62 & 42,09 & 4964,21 & 317,28 & 63,29 & 253,99 & 114,89 & 228,42 & 233,08 & 106,27 & \begin{tabular}{|l|l|l|}
561,88 \\
\end{tabular} & 82,25 & 2,18 & 60,46 & 239,21 & 25,24 & 25,36 & 236,65 \\
\hline Pelophylax perezi & 29SNC82 & 99,00 & 167,03 & & 42,01 & 4950,75 & 317,14 & 65,50 & 251,64 & 116,11 & 229,61 & 234,29 & 107,7 & 559,42 & 80,96 & 2,64 & $\begin{array}{ll}60,02 \\
\end{array}$ & 236,69 & 26,40 & 26,50 & 234,41 \\
\hline Pelophylax perezi & 29 SNC83 & 101,00 & 165,01 & 105,72 & \begin{tabular}{l|l|}
41,89 \\
\end{tabular} & 4963,12 & 314,42 & 64,19 & \begin{tabular}{|l|l|}
250,23 \\
\end{tabular} & \begin{tabular}{l|l|l|l|l|}
113,99 \\
\end{tabular} & $\begin{array}{ll}228,62 \\
\end{array}$ & 232,37 & \begin{tabular}{ll|}
105,65 \\
\end{tabular} & 577,32 & 82,20 & 3,00 & \begin{tabular}{l|l|}
59,25 \\
\end{tabular} & 241,88 & 28,08 & 28,08 & 240,77 \\
\hline Pelophylax perezi & 29SNC84 & 101,00 & 163,50 & 103,66 & 41,22 & 4958,27 & 311,40 & 63,87 & 247,52 & 112,01 & 227,62 & 230,76 & 104,36 & 593,24 & 83,70 & 3,01 & 58,59 & 246,40 & 29,81 & 29,81 & 246,24 \\
\hline Pelophylax perezi & 29SNC85 & 100,00 & 163,64 & 101,55 & 41,01 & 4935,13 & 309,45 & 65,10 & 244,36 & 108,31 & 227,21 & 230,59 & 104,60 & 598,99 & 84,16 & 3,00 & 58,12 & 247,69 & 30,76 & 30,76 & 247,69 \\
\hline Pelophylax perezi & $295 N C 86$ & 100,00 & 161,19 & 99,26 & 40,70 & 4930,57 & 305,38 & 63,90 & 241,49 & 102,56 & 226,06 & 228,18 & 102,29 & 624,39 & 87,51 & 3,77 & 57,59 & 257,09 & 33,38 & 33,38 & 257,09 \\
\hline Pelophylax perezi & 29SNC87 & 100,00 & 157,48 & 97,19 & 40,03 & 4938,52 & 300,59 & 61,44 & 239,15 & $\begin{array}{ll}98,67 \\
\end{array}$ & \begin{tabular}{|l|l}
223,75 \\
\end{tabular} & 224,75 & \begin{tabular}{|l|}
98,67 \\
\end{tabular} & 661,51 & 92,89 & 4,07 & \begin{tabular}{|l|l|}
57,07 \\
\end{tabular} & 271,88 & 36,14 & 36,14 & 271,88 \\
\hline Pelophylax perezi & 29SNC88 & 101,00 & 158,80 & 96,51 & 39,99 & 4931,32 & 301,25 & \begin{tabular}{|l|l|}
62,78 \\
\end{tabular} & 238,47 & \begin{tabular}{l|l|}
100,02 \\
\end{tabular} & 224,18 & 225,94 & 100,02 & 667,61 & 93,90 & 4,19 & \begin{tabular}{l|l}
56,95 \\
\end{tabular} & 274,30 & 36,84 & 36,84 & 274,30 \\
\hline Pelophylax perezi & 29SNC89 & 100,00 & 163,08 & 96,52 & 40,01 & 4922,84 & 304,76 & 66,54 & 238,22 & \begin{tabular}{|l|l|}
104,04 \\
\end{tabular} & 225,79 & 229,75 & 103,99 & 654,01 & 92,12 & 4,03 & 57,18 & 268,90 & 36,06 & 36,14 & 268,90 \\
\hline Pelophylax perezi & $295 N C S$ & 100,00 & 163,67 & 112,38 & 42 , & 5089,53 & 320 & 58, & 261, & $1 I 1$ & 228,54 & 232,88 & 103 & 562,60 & 82,93 & 2,10 & 60, & 238,93 & 25, & 25,10 & 235 \\
\hline Pelophylax perezi & 29SNC91 & 100,00 & 164,76 & 111,73 & 42,12 & 5095,89 & 321,09 & 60,14 & 260,95 & 112,42 & 229,47 & 233,99 & \begin{tabular}{|l|}
103,97 \\
\end{tabular} & 560,86 & 81,73 & 2,19 & \begin{tabular}{l|l|}
59,75 \\
\end{tabular} & 236,43 & 26,09 & 26,09 & 234,05 \\
\hline Pelophylax perezi & 29SNC92 & 101,00 & 165,37 & 109,80 & 42,00 & 5080,16 & 319,78 & $\begin{array}{ll}61,63 \\
\end{array}$ & 258,15 & \begin{tabular}{l|l|}
113,12 \\
\end{tabular} & 230,16 & 234,41 & 104,70 & 562,89 & 80,75 & 2,80 & 59,01 & 235,45 & 27,29 & 27,30 & 233,49 \\
\hline Pelophylax perezi & 29SNC93 & 100,00 & 163,36 & 107,68 & 41,78 & 5076,10 & 316,32 & \begin{tabular}{ll|}
60,82 \\
\end{tabular} & \begin{tabular}{|l|l|}
255,49 \\
\end{tabular} & \begin{tabular}{|l|l|}
111,17 \\
\end{tabular} & \begin{tabular}{|l|}
228,91 \\
\end{tabular} & 232,37 & \begin{tabular}{|l|l|}
102,78 \\
\end{tabular} & 580,06 & 81,76 & 3,00 & 58,43 & 240,55 & 28,79 & 28,79 & 239,58 \\
\hline Pelophyla & 29SNC94 & 100,00 & 161,65 & 105,11 & 411 & 5062 & 312 & & 251, & & 228, & 230,52 & 101,29 & 597,04 & 83, & 3,19 & 57,84 & 245 & 30,75 & 30,75 & \\
\hline Pelophylax perezi & 29SNC95 & 101,00 & 162,26 & 102,82 & 40,99 & 5036,47 & 310,5 & 62,3 & 248,27 & $103,86[$ & 228,90 & 230,65 & 102,00 & 598,80 & 83,23 & 3,07 & 57,54 & 245,44 & 31,23 & 31,23 & 245, \\
\hline Pelophylax perezi & 29SNC96 & 100,00 & 161,72 & 100,41 & 40,40 & 5014,36 & 307,90 & \begin{tabular}{|l|l|}
63,07 \\
\end{tabular} & \begin{tabular}{|l|l|}
244,83 \\
\end{tabular} & \begin{tabular}{|l|l|}
101,64 \\
\end{tabular} & 227,53 & 229,77 & 101,64 & 610,86 & 84,42 & 3,90 & \begin{tabular}{|l|l|}
56,55 \\
\end{tabular} & 248,98 & 33,86 & 33,86 & 248,98 \\
\hline
\end{tabular}




\begin{tabular}{|c|c|c|c|c|c|c|c|c|c|c|c|c|c|c|c|c|c|c|c|c|c|}
\hline TAXON & UTM & $\mathrm{km2}$ & B101 & $\mathrm{B1O2}$ & $\mathrm{BIO3}$ & $\mathrm{B104}$ & B105 & B106 & B107 & B108 & B109 & 81010 & B1011 & B1012 & 81013 & 81014 & B1015 & B1016 & B1017 & BIO18 & B1019 \\
\hline Pelophylax perezi & 29SNC97 & 101,00 & 160,32 & 98,67 & 40,00 & 5013,92 & 305,33 & 62,47 & 242,87 & 100,35 & 227,13 & 228,47 & 100,35 & 630,48 & 87,14 & 4,00 & 56,21 & 256,55 & 35,39 & 35,39 & 256,55 \\
\hline Pelophylax perezi & 29SNC98 & 101,00 & 160,41 & 97,95 & 40,00 & 5019,94 & 305,06 & 62,60 & 242,46 & 100,33 & 226,64 & 228,62 & 100,33 & 646,31 & 89,76 & 4,01 & 56,42 & 263,36 & 36,37 & 36,37 & 263,36 \\
\hline Pelophylax perezi & 29 SNC99 & 100,00 & 162,60 & 97,82 & 39,99 & 5028,22 & 307,13 & 64,41 & 242,72 & 102,16 & 226,96 & 230,84 & 102,16 & 649,82 & 90,50 & 4,00 & 56,37 & 264,99 & 36,64 & 36,65 & 264,99 \\
\hline Pelophylax perezi & 29SND00 & 86,00 & 168,99 & 80,29 & 40,89 & 3998,73 & 279,15 & 84,05 & 195,10 & 126,88 & 217,88 & 221,80 & 119,13 & 669,94 & 101,14 & 3,00 & 62,94 & 296,62 & 27,01 & 30,94 & 286,32 \\
\hline Pelophylax perezi & 29SND01 & 100,00 & $\begin{array}{ll}167,07 \\
\end{array}$ & 78,62 & 40,80 & 3916,19 & 274,05 & 83,15 & 190,90 & \begin{tabular}{|l|l|}
125,68 \\
\end{tabular} & 214,87 & 218,61 & $\begin{array}{l}118,06 \\
\end{array}$ & $\begin{array}{ll}673,62 \\
\end{array}$ & 102,52 & 3,04 & 62,79 & 298,01 & 27,32 & 31,21 & 286,83 \\
\hline Pelophylax perezi & 29SND02 & 101,00 & 164,16 & 76,69 & 40,82 & 3826,01 & 267,79 & 81,53 & 186,27 & 123,76 & 210,72 & 214,20 & 116,05 & 686,86 & 105,02 & 3,44 & 62,06 & 302,33 & 29,19 & 33,27 & 290,53 \\
\hline Pelophylax perezi & 29SND03 & 101,00 & 160,54 & 75,24 & 40,72 & 3756,82 & 261,73 & 78,79 & 182,94 & 120,86 & 206,23 & 209,56 & 113,18 & 707,24 & 108,25 & 3,99 & 61,58 & 309,55 & 31,18 & 35,44 & 297,42 \\
\hline Pelophylax perezi & 29SND04 & 100,00 & 159,03 & 74,02 & 40,93 & 3672,60 & 257,33 & 78,10 & 179,23 & 120,14 & 203,57 & 206,64 & 112,38 & 713,86 & 109,86 & 4,02 & 61,19 & 311,14 & 31,96 & 36,53 & 298,65 \\
\hline Pelophylax perezi & 29SND05 & 101,00 & 155,97 & 73,29 & \begin{tabular}{|l|l|}
40,97 \\
\end{tabular} & 3622,09 & 252,84 & 75,74 & 177,10 & 117,80 & 199,97 & 202,88 & 109,98 & 738,07 & 113,12 & 4,51 & 60,61 & 319,44 & 34,41 & 39,11 & 307,22 \\
\hline Pelophylax perezi & 29SND06 & 101,00 & 149,04 & 73,22 & 40,77 & 3633,73 & 246,47 & 68,94 & 177,54 & 111,00 & 193,27 & 196,21 & 103,07 & 806,23 & 121,74 & 5,64 & 59,51 & 345,03 & 40,37 & 44,62 & 333,78 \\
\hline Pelophylax perezi & 29SND07 & 100,00 & 150,55 & 72,97 & 41,12 & 3560,35 & 245,85 & 70,64 & 175,21 & 112,96 & 193,75 & 196,39 & 105,14 & 801,02 & 121,01 & 5,78 & 59,06 & 341,15 & 40,96 & 45,75 & 329,98 \\
\hline Pelophylax perezi & 29SND08 & 101,00 & 154,16 & 73,18 & 41,81 & 3476,62 & 247,18 & 74,14 & 173,04 & 117,32 & 195,93 & 198,56 & 109,29 & 778,49 & 117,54 & 5,62 & 58,76 & 330,55 & 39,95 & 45,65 & 319,44 \\
\hline Pelophylax perezi & 29SND09 & 101,00 & 152,42 & 73,80 & $\begin{array}{l}42,05 \\
\end{array}$ & 3457,76 & 245,39 & 72,05 & 173,34 & 115,68 & 193,97 & 196,45 & 107,71 & 810,14 & 120,76 & 6,13 & 57,97 & 341,25 & 43,40 & 49,26 & 330,91 \\
\hline Pelophylax perezi & 29SND10 & 101,00 & 169,07 & 82,95 & 40,83 & 4115,42 & 283,87 & 82,42 & 201,45 & 125,60 & 219,60 & 223,64 & 118,22 & 664,85 & 99,11 & 3,00 & 62,31 & 292,12 & 27,81 & 31,06 & 283,75 \\
\hline Pelophylax perezi & 29SND11 & 101,00 & 168,36 & 81,61 & 40,94 & 4048,53 & 280,49 & 82,40 & 198,09 & 125,47 & 217,97 & 221,82 & 118,03 & 666,83 & 99,99 & 3,01 & 62,14 & 292,33 & 28,04 & 31,66 & 283,46 \\
\hline Pelophylax perezi & 29 SND12 & 101,00 & 166,69 & 80,13 & 40,82 & 3974,29 & 276,01 & 81,52 & 194,50 & 124,59 & 215,32 & 218,92 & 117,01 & 675,43 & \begin{tabular}{|l|l|}
101,78 \\
\end{tabular} & 3,45 & 61,80 & 295,13 & 29,08 & 32,92 & 285,80 \\
\hline Pelophylax perezi & 29 SND13 & 100,00 & 162,92 & 79,09 & 40,77 & 3927,40 & 270,65 & 78,49 & 192,16 & 121,42 & 211,05 & 214,49 & 113,77 & 702,38 & 105,55 & 4,00 & 61,02 & 304,83 & 31,85 & 35,66 & 295,47 \\
\hline Pelophylax perezi & 29SND14 & 100,00 & 161,86 & 78,18 & 40,90 & 3854,03 & 267,09 & 77,92 & 189,18 & 120,97 & 208,90 & 212,05 & 113,22 & 710,49 & 107,10 & 4,05 & 60,74 & 307,14 & 32,71 & 36,83 & 297,57 \\
\hline Pelophylax perezi & 29SND15 & 100,00 & 159,96 & 77,63 & 40,96 & 3799,61 & 263,78 & 76,55 & 187,23 & 119,64 & 206,39 & 209,51 & 112,04 & 727,13 & 109,49 & 4,44 & 60,20 & 312,69 & 34,41 & 38,76 & 303,14 \\
\hline Pelophylax perezi & 29SND16 & 100,00 & 153,84 & 77,45 & $\mid 40,77$ | & 3808,84 & 257,99 & 70,53 & $\mid 187,46$ & $\mid$\begin{tabular}{|l|l|}
113,59 \\
\end{tabular} & 200,48 & 203,54 & $|105,87|$ & 788,12 & $\mid 117.47$ & 5,51 & 59,16 & 335,49 & 39,89 & 43,88 & 326,82 \\
\hline Pelophylax perezi & 29SND17 & 101,00 & 140,89 & 77,42 & 40,20 & 3896,44 & 247,82 & 57,69 & 190,13 & 100,32 & 189,19 & 192,27 & 92,55 & 923,35 & 136,53 & 7,84 & 57,81 & 387,36 & 51,57 & 54,11 & 380,57 \\
\hline Pelophylax perezi & 29SND18 & 100,00 & 150,32 & 77,86 & 41,17 & 3751,52 & 253,42 & 66,79 & 186,64 & 110,63 & 196,26 & 199,05 & \begin{tabular}{|r|r|}
102,79 \\
\end{tabular} & 842,71 & 124,44 & 6,59 & 57,92 & 354,03 & 45,62 & 49,85 & 346,48 \\
\hline Pelophylax perezi & 29SND19 & 100,00 & 155,32 & 78,63 & \begin{tabular}{|l|l|}
41,99 \\
\end{tabular} & 3664,69 & 256,27 & 71,28 & 184,99 & 116,06 & 199,79 & 202,38 & 108,15 & 810,80 & 119,14 & 6,25 & 57,62 & 339,55 & 44,17 & 49,25 & 331,81 \\
\hline Pelophylax perezi & 29SND20 & 100,00 & 168,46 & 85,41 & 40,66 & 4240,96 & 287,78 & 79,95 & 207,83 & 123,80 & 220,89 & 224,97 & 116,20 & 665,77 & 98,32 & 3,52 & 61,55 & 289,62 & 29,26 & 32,28 & 283,13 \\
\hline Pelophylax perezi & 29SND21 & 101,00 & 168,28 & 84,36 & 40,69 & 4184,02 & 285,37 & 80,20 & 205,17 & 124,08 & 219,84 & 223,76 & 116,43 & 668,57 & 98,90 & 3,69 & 61,35 & 290,17 & 29,67 & 32,85 & 283,33 \\
\hline Pelophylax perezi & 29SND22 & 100,00 & 167,60 & 83,33 & 40,74 & 4124,58 & 282,55 & 80,19 & 202,35 & 123,82 & 218,37 & 222,03 & 116,25 & 674,42 & 99,93 & 3,95 & 61,12 & 291,85 & 30,32 & 33,83 & 284,68 \\
\hline Pelophylax perezi & 29SND23 & 101,00 & 166,88 & 82,44 & 40,89 & 4062,76 & 279,72 & $\frac{\mid 0,130}{79,88}$ & 199,84 & \begin{tabular}{|l|l|}
123,67 \\
\end{tabular} & 216,86 & 220,34 & 116,05 & 680,99 & \begin{tabular}{|c|}
101,13 \\
13
\end{tabular} & 4,00 & $\begin{array}{ll}1,12 \\
60,87\end{array}$ & 293,59 & $\mid \begin{array}{l}\mid 31,14 \\
31,\end{array}$ & $\begin{array}{l}34,84 \\
34,\end{array}$ & 286,27 \\
\hline Pelophylax perezi & 29SND24 & 100,00 & 164,81 & 81,94 & 40,97 & 4020,68 & 276,34 & 78,16 & 198,18 & 122,04 & 214,24 & 217,55 & 114,29 & 700,91 & 103,93 & 4,00 & 60,20 & 300,66 & 33,15 & 36,90 & 293,36 \\
\hline Pelophylax perezi & 29 SND25 & 101,00 & 161,26 & 81,61 & 40,91 & 3997,80 & 272,25 & 74,87 & 197,38 & 118,84 & 210,46 & 213,58 & 111,06 & 735,20 & 108,67 & 4,79 & 59,47 & 313,26 & 36,15 & 39,89 & 306,39 \\
\hline Pelophylax perezi & 29 SND26 & 101,00 & 159,71 & 81,56 & 41,01 & 3964,80 & 269,88 & 73,31 & 196,58 & 117,48 & 208,47 & 211,54 & 109,77 & 756,41 & 111,66 & 5,06 & 58,96 & 320,51 & 38,33 & 42,25 & 313,91 \\
\hline Pelophylax perezi & 29SND27 & 101,00 & 147,54 & 81,31 & 40,44 & 4037,86 & 260,08 & 61,37 & 198,71 & 105,03 & 197,73 & 200,82 & 97,41 & 880,62 & 129,94 & 7,08 & 57,73 & 368,51 & 48,65 & 51,27 & 363,81 \\
\hline Pelophylax perezi & $295 N D 28$ & 101,00 & 144,18 & 81,60 & 40,51 & 4038,77 & 257,03 & 57,77 & $\begin{array}{l}199,26 \\
\end{array}$ & $\begin{array}{l}101,73 \\
\end{array}$ & $\begin{array}{l}194,40 \\
\end{array}$ & \begin{tabular}{|l|}
$200,0<2$ \\
197,49 \\
\end{tabular} & $\begin{array}{ll}13,4+99 \\
33\end{array}$ & $\begin{array}{l}927,78 \\
927\end{array}$ & 136,62 & $\begin{array}{l}7,906 \\
7,98\end{array}$ & 57,12 & \begin{tabular}{|l|}
385,76 \\
\end{tabular} & 53,21 & 55,56 & 381,90 \\
\hline Pelophylax perezi & 29SND29 & 99,00 & 151,13 & 82,99 & \begin{tabular}{|l|l|l|}
41,45 \\
\end{tabular} & 3942,27 & 261,95 & 63,73 & 198,22 & 109,08 & 199,74 & 202,52 & 101,35 & 876,15 & 128,23 & 7,39 & 56,91 & 363,50 & 50,06 & 53,62 & 359,24 \\
\hline Pelophylax perezi & 29 SND30 & 101,00 & 168,25 & 87,76 & 40,79 & 4347,72 & 291,76 & 78,26 & 213,50 & 122,54 & 222,27 & 226,40 & 114,98 & 663,01 & 97,42 & 3,9 & 60,75 & 285,61 & 30,54 & 32.95 & 280,85 \\
\hline Pelophylax perezi & 29SND31 & 100,00 & 167,67 & 86,84 & 40,60 & 4312,47 & 289,58 & 78,11 & 211,47 & 122,13 & 221,16 & 225,22 & 114,66 & 672,53 & 98,92 & 3,92 & 60,59 & 289,03 & 31,02 & 33,73 & 284,16 \\
\hline Pelophylax perezi & $29 \mathrm{SND} 32$ & 101,00 & 166,77 & 86,02 & 40,55 & 4269,76 & 287,08 & 77,51 & 209,56 & 121,58 & 219,75 & 223,47 & 114,09 & 684,15 & \begin{tabular}{|c|}
100,70 \\
\end{tabular} & 4,00 & 60,36 & 293,18 & 31,87 & 34,80 & 288,13 \\
\hline Pelophylax perezi & 29SND33 & 101,00 & 10,117 & 85,45 & 年 40,62 & 42228,31 & 284,64 & $\begin{array}{l}1,101 \\
76,75\end{array}$ & \begin{tabular}{|l|}
207,89 \\
20
\end{tabular} & \begin{tabular}{|l|}
120,97 \\
127
\end{tabular} & 218,22 & $\begin{array}{l}\mid 221,79 \\
221,79\end{array}$ & \begin{tabular}{|l|}
113,41 \\
11,03
\end{tabular} & $\begin{array}{l}604,13 \\
697,75\end{array}$ & 102,69 & 4,40 & $\begin{array}{l}0,090 \\
59,87\end{array}$ & \begin{tabular}{|l|}
297,75 \\
2910
\end{tabular} & $\begin{array}{l}1,0 \\
33,50 \\
\end{array}$ & $\begin{array}{l}34,00 \\
36,59\end{array}$ & $\begin{array}{l}200,13 \\
292,63\end{array}$ \\
\hline Pelophylax perezi & 29SND34 & 100,00 & 166,83 & 85,17 & 40,92 & 4174,14 & 283,97 & 77,71 & 206,26 & 122,48 & 218,47 & 221,85 & 114,71 & 695,73 & 102,21 & 4,03 & 59,65 & 296,03 & 33,76 & 37,29 & 290,63 \\
\hline Pelophylax perezi & 29SND35 & 101,00 & 166,06 & 85,14 & \begin{tabular}{|l|l|}
40,97 \\
\end{tabular} & 4148,63 & 282,49 & 76,77 & 205,72 & 121,66 & 217,32 & 220,53 & 113,93 & 709,63 & 104,27 & 4,45 & 59,05 & 300,66 & 35,14 & 38,83 & 295,42 \\
\hline Pelophylax perezi & 29SND36 & 101,00 & 163,01 & 85,30 & 40,99 & 4139,85 & 279,47 & 73,62 & 205,86 & 118,69 & 214,20 & 217,29 & 110,95 & 745,59 & \begin{tabular}{|l|l|}
109,38 \\
\end{tabular} & 5,01 & 58,52 & 313,82 & 38,47 & 41,99 & 309,20 \\
\hline Pelophylax perezi & 29 SND37 & 100,00 & 157,30 & 85,38 & 40,79 & 4154,40 & 274,52 & 67,86 & 206,66 & 112,97 & 208,89 & 211,94 & 105,38 & 810,35 & 118,84 & 6,19 & 57,83 & 338,33 & 44,14 & 47,12 & 334,79 \\
\hline Pelophylax perezi & 29 SND38 & 101,00 & 154,11 & 86,06 & 40,92 & 4160,23 & 272,22 & $\begin{array}{ll}64,23 \\
\end{array}$ & 207,99 & 109,68 & 205,85 & 208,84 & 101,98 & 852,33 & 124,75 & 6,88 & 57,12 & 353,53 & 48,20 & 50,95 & 350,97 \\
\hline Pelophylax perezi & 29SND39 & 101,00 & 153,96 & 87,16 & 41,14 & 4137,05 & 272,16 & 63,43 & 208,73 & 109,60 & 205,40 & 208,28 & 102,00 & 870,46 & 126,93 & 7,33 & 56,63 & 359,14 & 50,47 & 53,44 & 357,18 \\
\hline Pelophylax perezi & 29SND40 & 100,00 & 168,20 & 89,94 & 40,42 & 4473,58 & 295,80 & 76,41 & 219,39 & 121,14 & 223,95 & 228,03 & 113,50 & 657,81 & 96,03 & 4,00 & 60,04 & 280,67 & 31,31 & 33,32 & 277,32 \\
\hline Pelophylax perezi & 29SND41 & 101,00 & 168,65 & 89,19 & 40,5 & 4432,78 & 294,78 & 77,14 & 217,64 & 121,91 & 223,91 & 227,95 & 114,21 & 662,52 & 96,85 & 4,00 & 60,02 & 282,14 & 31,64 & 34,01 & 278,72 \\
\hline Pelophylax perezi & $295 N D 42$ & 101,00 & 165,60 & 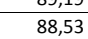 & 4 & 4423,03 & 291,1 & 74,42 & 216,71 & \begin{tabular}{|l|l|}
118,99 \\
\end{tabular} & \begin{tabular}{|l|}
220,79 \\
\end{tabular} & 224,66 & 11 & \begin{tabular}{|l|l|}
694,78 \\
\end{tabular} & \begin{tabular}{|r|}
101,68 \\
\end{tabular} & $\begin{array}{l}4,13 \\
4,13 \\
\end{array}$ & 59,47 & $\begin{array}{l}294,52 \\
294,\end{array}$ & $\begin{array}{l}3,1,99 \\
33,99\end{array}$ & 36,29 & 291,45 \\
\hline Pelophylax perezi & 29SND43 & 101,00 & 165,55 & 88,08 & 40,38 & 4386,48 & 289,87 & 74,40 & 215,47 & 119,04 & 220,25 & 223,94 & 111,32 & 704,16 & 103,05 & 4, & 59,20 & 297,69 & 35,20 & 37,73 & 294,37 \\
\hline Pelophylax perezi & 29 SND44 & 100,00 & 163,98 & 87,84 & 40,42 & 4365,45 & 287,47 & 72,59 & 214,88 & 117,42 & 218,27 & 221,88 & 109,75 & 727,36 & 106,51 & 4,88 & 58,87 & 306,26 & 37,05 & 39,69 & 303,29 \\
\hline Pelophylax perezi & 29 SND45 & 101,00 & 165,76 & 88,03 & 40,78 & 4321,19 & 288,15 & 74,32 & 213,82 & 119,42 & 219,42 & 222,85 & 111,97 & 723,74 & 105,79 & 4,87 & 58,48 & 304,00 & 37,37 & 40,32 & 300,70 \\
\hline Pelophylax perezi & 29 SND46 & 101,00 & 166,58 & 88,53 & 40,98 & 4293,35 & 288,52 & 74,46 & 214,05 & 120,34 & 219,92 & 223 & 112,81 & 727,41 & 106,05 & 5,03 & 58,10 & 27 & 38,17 & 41,38 & 301,09 \\
\hline Pelophylax perezi & 29SND47 & 101,00 & 163 & $\begin{array}{l}80,0305 \\
89,05\end{array}$ & 40 & $\begin{array}{l}42509,41 \\
4309,4\end{array}$ & 285 & $\begin{array}{l}74,40 \\
70,68\end{array}$ & \begin{tabular}{|l|}
215,21 \\
\end{tabular} & \begin{tabular}{|l|}
116,77 \\
11,7
\end{tabular} & \begin{tabular}{|l|}
216,77 \\
216,
\end{tabular} & \begin{tabular}{|l|}
219,84 \\
214
\end{tabular} & \begin{tabular}{|l|}
109,16 \\
109,1
\end{tabular} & $\begin{array}{l}772,41 \\
770,68\end{array}$ & 1112,25 & 5,77 & 57,55 & $\begin{array}{l}320,32 \\
32,\end{array}$ & | & $\begin{array}{l}44,00 \\
45,06\end{array}$ & 318,06 \\
\hline Pelophylax perezi & 29 SND48 & 100,00 & 160,19 & 89,82 & 41,00 & 4310,84 & 283,68 & 67,29 & 216,38 & 113,66 & 213,89 & 216,89 & 106,16 & 813,88 & 118,38 & 6,42 & 56,90 & 336,12 & 46,13 & 48,98 & 334,85 \\
\hline Pelophylax perezi & $295 N D 49$ & 101,00 & 159,09 & $\begin{array}{l}0,02 \\
90,97\end{array}$ & 41,13 & 4312,25 & 283,37 & 65,34 & 218,03 & 111,86 & $\begin{array}{l}212,82 \\
212\end{array}$ & \begin{tabular}{|l|}
215,70 \\
\end{tabular} & 104,90 & $\begin{array}{l}840,45 \\
840,45\end{array}$ & $\begin{array}{l}121,77 \\
121,0\end{array}$ & $\begin{array}{l}0,4,01 \\
7,4\end{array}$ & 56,19 & $\begin{array}{l}345,12 \\
345\end{array}$ & 49,12 & 51,90 & 344,49 \\
\hline Pelophylax perezi & 29 SND50 & 101,00 & 167,79 & 91,83 & 40,21 & 4577,92 & 299,08 & 74,61 & 224,47 & 119,69 & 225,07 & 229,25 & 111,94 & 656,23 & 95,12 & 4,00 & 59,42 & 277,02 & 32,25 & 33,94 & 275,19 \\
\hline Pelophylax perezi & 29 SND51 & 100,00 & 168,79 & 91,31 & 40,2 & 4550,32 & 298,81 & 75,55 & 223,27 & 120,76 & 225,68 & 229 & 112,94 & 660,12 & 95,85 & 4,00 & 59,32 & 278,45 & 32,50 & 34,38 & 276,43 \\
\hline Pelophylax perezi & $\begin{array}{l}\text { 29SND552 } \\
\end{array}$ & $\begin{array}{l}101,00 \\
100\end{array}$ & $\begin{array}{l}100,15 \\
165,51\end{array}$ & $\begin{array}{l}1,11 \\
90,66\end{array}$ & $\begin{array}{l}40,20 \\
40,03\end{array}$ & $\begin{array}{l}450,025 \\
4560,99\end{array}$ & $\begin{array}{l}290,01 \\
295,47\end{array}$ & $\begin{array}{l}3,35 \\
72,48 \\
\end{array}$ & \begin{tabular}{|l|}
222,99 \\
227
\end{tabular} & $\begin{array}{l}117,32 \\
117\end{array}$ & \begin{tabular}{|l|}
222,660 \\
\end{tabular} & \begin{tabular}{|l|}
226,66 \\
226
\end{tabular} & $\begin{array}{l}109,70 \\
109,0\end{array}$ & $\begin{array}{l}\mid \\
6900,99 \\
\end{array}$ & $\mid$ & $\begin{array}{l}4,406 \\
4,66 \\
\end{array}$ & $\begin{array}{l}58,82 \\
58,8\end{array}$ & \begin{tabular}{|l|}
292,10 \\
292,10
\end{tabular} & $\begin{array}{ll}2,3006 \\
35,66\end{array}$ & $\begin{array}{l}4,30 \\
37,49\end{array}$ & $\begin{array}{l}270,45 \\
290,59\end{array}$ \\
\hline Pelophylax perezi & 29SND53 & 100,00 & 164,97 & 90,36 & 40,04 & 4544,14 & 294,20 & 71,92 & 222,29 & 116,87 & 221,92 & 225,62 & 109,24 & 712,40 & 103,62 & 4,94 & 58,43 & 298,19 & 37,14 & 39,10 & 296,69 \\
\hline Pelophylax perezi & 29SND54 & 100,00 & 163,62 & 90,20 & 40,02 & 4533,12 & 292.51 & 70.56 & 221.95 & 115,70 & 220,47 & 224,08 & 107.92 & 735.01 & 107.10 & 5,02 & 58.32 & 306.96 & 38.58 & 40,59 & 305,63 \\
\hline Pelophylax perezi & 29SND55 & 100,00 & 162,59 & 90,29 & 40,09 & 116,73 & 291,27 & 69,36 & 221,9 & 114,68 & 219, & 222,82 & 107 & 757,73 & 110,34 & 5,54 & 57,69 & 315,09 & 41,03 & 43,10 & 314,16 \\
\hline Pelophylax perezi & 29 SND56 & 100,00 & 164,14 & 90,99 & 40,28 & 4499,20 & 292,42 & 70,03 & 222,39 & 115,91 & 220,46 & 223,79 & 108,37 & 758,66 & 110,26 & 5,55 & 57,46 & 314,56 & 41,55 & 43,99 & 313,51 \\
\hline
\end{tabular}




\begin{tabular}{|c|c|c|c|c|c|c|c|c|c|c|c|c|c|c|c|c|c|c|c|c|c|}
\hline TAXON & UTM & $\mathrm{km} 2$ & B101 & B102 & $\mathrm{BIO3}$ & B104 & B105 & B106 & B107 & B108 & B109 & B1010 & BIO11 & BIO12 & B1013 & BIO14 & BIO15 & BIO16 & B1017 & B1018 & B1019 \\
\hline Pelophylax perezi & 29SND57| & 101,00 & 163,58 & 91,65 & 40,52 & 4487,99 & 292,20 & 68,96 & 223,24 & 114,77 & 219,93 & 223,01 & 107,82 & 778,36 & 112,98 & 5,93 & 57,09 & 321,51 & 43,46 & 45,93 & 320,79 \\
\hline Pelophylax perezi & 29SND58 & 99,00 & 160,41 & 92,24 & 40,51 & 4511,64 & 290,14 & 65,14 & 224,99 & 108,50 & 217,14 & 220,11 & 104,43 & 823,70 & 119,57 & 6,61 & 56,51 & \begin{tabular}{|l|l|}
338,98 \\
\end{tabular} & 47,61 & 49,76 & 338,68 \\
\hline Pelophylax perezi & 29 SND59 & 101,00 & 155,63 & 92,85 & 40,48 & 4542,00 & 286,69 & 60,08 & 226,61 & 100,20 & 212,94 & 215,92 & 99,49 & 886,67 & 128,71 & 7,65 & 56,03 & 363,69 & 53,16 & 54,72 & 363,69 \\
\hline Pelophylax perezi & 29SND60 & 100,00 & 167,56 & 93,60 & 40,16 & 4693,55 & 302,33 & 73,11 & 229,22 & 118,44 & 226,51 & 230,75 & 110,51 & 652,08 & 93,74 & 4,00 & 58,75 & 272,51 & 33,19 & 34,41 & 271,85 \\
\hline Pelophylax perezi & 29SND61 & 100,00 & 168,42 & 93,18 & 40,17 & 4677,65 & 302,26 & 73,77 & 228,49 & 119,18 & 227,10 & 231,18 & 111,43 & 659,02 & 94,87 & 4,00 & 58,62 & 275,31 & 33,64 & 35,16 & 274,36 \\
\hline Pelophylax perezi & 29SND62 & 100,00 & 166,34 & 92,62 & 40,02 & 4682,53 & 300,06 & 71,66 & 228,40 & 116,55 & 225,23 & 229,08 & 109,13 & 689,45 & 99,47 & 4,62 & 58,18 & 287,12 & 36,23 & 37,75 & 286,52 \\
\hline Pelophylax perezi & 29SND63 & 101,00 & 164,31 & 92,28 & 39,99 & \begin{tabular}{ll|}
4680,84 \\
\end{tabular} & 298,07 & 69,76 & 228,31 & 114,41 & 223,45 & 227,20 & 107,21 & 718,88 & 103,97 & 5,00 & 57,95 & 298,56 & 38,39 & 39,92 & 298,32 \\
\hline Pelophylax perezi & 29SND64 & 100,00 & 163,53 & 92,14 & 39,99 & 4671,31 & 296,93 & 68,86 & 228,06 & 112,76 & 222,46 & 226,16 & 106,44 & 739,71 & 107,19 & 5,24 & 57,64 & 306,74 & $\begin{array}{l}0,06 \\
40,0\end{array}$ & 41,67 & 306,59 \\
\hline Pelophylax perezi & 29SND65 & 101,00 & 162,54 & 92,21 & 39,99 & 4676,03 & 296,03 & 67,49 & 228,53 & 110,27 & 221,56 & 225,14 & 105,29 & 763,63 & 110,71 & 5,94 & 57,23 & 315,68 & 42,68 & 44,36 & 315,62 \\
\hline Pelophylax perezi & 29SND66 & 101,00 & 165,61 & 93,09 & 40,11 & 4654,14 & 298,53 & 69,45 & 229,09 & $\begin{array}{l}114,68 \\
\end{array}$ & 224,13 & 227,40 & 108,00 & 751,99 & 108,81 & 5,59 & 57,07 & 310,31 & 41,83 & 44,10 & 310,05 \\
\hline Pelophylax perezi & 29SND67 & 100,00 & 162,12 & 93,45 & 40,02 & 4683,37 & 296,33 & 65,63 & 230,70 & 106,61 & 221,41 & 224,52 & 104,51 & 799,38 & 115,80 & 6,27 & 56,69 & 329,00 & 45,86 & 47,63 & 328,94 \\
\hline Pelophylax perezi & 29SND68 & 101,00 & 159,67 & 93,99 & 40,01 & 4703,47 & 294,69 & 62,56 & 232,14 & 102,14 & 219,35 & 222,32 & 101,68 & 838,90 & 121,61 & 6,79 & 56,21 & 344,67 & 49,30 & 50,85 & 344,67 \\
\hline Pelophylax perezi & 29SND69 & 100,00 & 156,26 & 94,39 & 39,99 & 4724,42 & 292,26 & 58,78 & 233,49 & 98,11 & 216,29 & 219,20 & 98,11 & 888,65 & 129,02 & 7,71 & 55,92 & 364,47 & 53,76 & 54,91 & 364,47 \\
\hline Pelophylax perezi & 29SND70 & 101,00 & 166,85 & 95,14 & 40,07 & 4804,47 & 305,03 & 70,95 & 234,08 & 113,76 & 227,38 & 231,65 & 108,60 & 651,19 & 92,75 & 4,00 & 57,94 & 269,61 & 34,63 & 35,48 & 269,59 \\
\hline Pelophylax perezi & 29SND71 & 100,00 & 168,11 & 94,80 & 40,01 & 4798,65 & 305,51 & 71,85 & 233,66 & 116,48 & 228,52 & 232,59 & 109,66 & 657,29 & 93,77 & 4,01 & 57,93 & $271,99 \mid$ & 34,92 & 36,13 & 271,84 \\
\hline Pelophylax perezi & 29 SND72 & 101,00 & 167,56 & 94,45 & 40,00 & 4800,62 & 304,86 & 71,40 & 233,45 & 115,69 & 228,11 & 232,07 & 109,13 & 676,64 & 96,79 & 4,45 & 57,64 & 279,63 & 36,56 & 37,84 & 279,55 \\
\hline Pelophylax perezi & 29 SND73 & 101,00 & 166,31 & 94,13 & 39,99 & 4803,72 & 303,41 & 70,01 & 233,40 & 113,13 & 226,98 & 230,79 & 107,78 & 701,93 & 100,70 & 4,97 & 57,44 & 289,84 & 38,35 & 39,74 & 289,81 \\
\hline Pelophylax perezi & 29SND74 & 101,00 & 163,90 & 93,73 & 39,83 & 4823,81 & 301,46 & 67,69 & 233,77 & 106,79 & 225,15 & 228,75 & 105,49 & 737,46 & 106,23 & 5,32 & 57,22 & 304,37 & 41,04 & 42,31 & 304,37 \\
\hline Pelophylax perezi & 29SND75 & 100,00 & 164,11 & 93,99 & 39,71 & 4828,13 & 301,70 & 67,27 & 234,44 & 106,90 & 225,40 & 228,76 & 105,26 & 751,74 & 108,35 & 5,77 & 56,91 & \begin{tabular}{|l|l|}
309,75 \\
\end{tabular} & 42,51 & 43,99 & 309,75 \\
\hline Pelophylax perezi & 29SND76 & 101,00 & 166,34 & 94,80 & 39,87 & 4805,36 & 303,58 & 68,38 & 235,21 & 111,06 & 227,19 & 230,44 & 107,33 & 748,79 & 107,79 & 5,66 & 56,58 & \begin{tabular}{|l|l|}
307,78 \\
\end{tabular} & 42,49 & 44,37 & 307,73 \\
\hline Pelophylax perezi & 29SND77 & 101,00 & 163,16 & 94,90 & 39,62 & 4845,10 & 301,51 & 64,80 & 236,71 & 105,01 & 224,73 & 227,83 & 103,70 & 794,91 & 114,82 & 6,29 & 56,23 & 326,38 & 46,21 & 47,79 & 326,38 \\
\hline Pelophylax perezi & 29SND78 & 100,00 & 156,18 & 94,27 & 39,20 & 4899,09 & 295,88 & 58,04 & 237,84 & 96,54 & 218,78 & 221,83 & 96,54 & 877,66 & \begin{tabular}{|l|l|}
127,63 \\
\end{tabular} & 7,38 & 56,02 & 360,54 & 52,64 & 53,34 & 360,54 \\
\hline Pelophylax perezi & 29SND79 & 101,00 & 153,58 & 94,51 & 39,06 & 4917,92 & 293,90 & 55,02 & 238,88 & 93,68 & 216,89 & 219,49 & 93,68 & 919,63 & 133,97 & 8,12 & 55,83 & 377,20 & 56,25 & 56,71 & 377,20 \\
\hline Pelophylax perezi & 29SND80 & 101,00 & 166,63 & 96,48 & 40,00 & 4914,35 & 307,64 & 69,17 & 238,47 & 107,97 & 228,70 & 232,91 & 107,09 & 646,56 & 91,14 & 4,00 & 57,21 & 265,65 & 35,67 & 36,13 & 265,65 \\
\hline Pelophylax perezi & 29SND81 & 101,00 & 168,40 & 96,43 & 40,00 & 4914,53 & 308,99 & 70,55 & 238,44 & 113,75 & 230,43 & 234,46 & 108,68 & 649,91 & 91,89 & 4,05 & 57,22 & 267,05 & 35,42 & 36,48 & 267,05 \\
\hline Pelophylax perezi & 29SND82 & 100,00 & 166,25 & 95,78 & 39,86 & 4933,50 & 307,14 & 68,68 & 238,46 & 107,86 & 228,73 & 232,66 & 106,37 & 683,16 & 97,01 & 4,95 & 56,91 & 280,67 & 38,24 & 39,23 & 280,67 \\
\hline \begin{tabular}{|l|} 
Pelophylax perezi \\
\end{tabular} & 29SND83 & 101,00 & 165,65 & 95,47 & 39,54 & 4946,11 & 306,57 & $\begin{array}{l}6,904 \\
67,94 \\
\end{array}$ & 238,62 & 106,90 & 228,45 & 232,34 & 105,62 & 704,76 & $\mid$\begin{tabular}{|c|}
100,50 \\
\end{tabular} & 5,00 & 56,88 & 289,71 & $\begin{array}{l}30,34,38 \\
39\end{array}$ & $\begin{array}{l}40,52 \\
40,52\end{array}$ & 289,71 \\
\hline Pelophylax perezi & 29SND84 & 101,00 & 166,20 & 95,57 & 39,56 & 4949,48 & 307,08 & 67,86 & 239,22 & 107,46 & 229,05 & 232,68 & 105,90 & 717,25 & 102,55 & 5,08 & 56,79 & 294,66 & 40,21 & 41,54 & 294,66 \\
\hline Pelophylax perezi & 29 SND85 & 99,00 & 163,36 & 95,07 & 39,14 & 4975,53 & 304,82 & 65,19 & 239,63 & 103,05 & 226,75 & 230,31 & 103,01 & 759,23 & 109,09 & 5,89 & 56,40 & 311,86 & 43,72 & 44,89 & 311,86 \\
\hline Pelophylax perezi & 29SND86 & 100,00 & 164,90 & 95,70 & 39,27 & 4975,12 & 306,28 & 65,64 & 240,64 & 105,07 & 228,30 & 231,51 & 104,17 & 762,81 & 109,64 & 5,84 & 56,31 & 312,88 & 43,97 & 45,47 & 312,88 \\
\hline Pelophylax perezi & 29SND87 & 101,00 & 163,28 & 95,93 & 39,23 & 5002,83 & 305,49 & 63,42 & 242,07 & 102,54 & 227,23 & 230,24 & 102,16 & 794,42 & 114,52 & 6,29 & 56,04 & 325,44 & 46,72 & 48,10 & 325,44 \\
\hline \begin{tabular}{|l|} 
Pelophylax perezi \\
\end{tabular} & 29SND88 & 99,00 & 154,56 & 94,24 & 38,52 & 5066,11 & 297,74 & $\begin{array}{l}5,44 \\
55,48 \\
\end{array}$ & \begin{tabular}{|l|}
242,26 \\
\end{tabular} & $\mid 93,30$ & 220,01 & \begin{tabular}{|l|}
222,74 \\
\end{tabular} & 俄, & 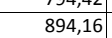 & $\begin{array}{l}130,22 \\
130,\end{array}$ & $\begin{array}{l}, 25 \\
7,64 \\
\end{array}$ & 55,91 & $\mid 366,97$ & $\begin{array}{l}34,09 \\
54,0\end{array}$ & $\begin{array}{l}34,40 \\
54,49\end{array}$ & 366,97 \\
\hline Pelophylax perezi & 29SND89 & 101,00 & 153,44 & 94,66 & 38,42 & 5085,55 & 297,12 & 53,67 & 243,45 & 91,82 & 219,37 & 221,80 & 91,82 & 921,40 & 134,45 & 8,01 & 55,71 & 377,72 & 56,39 & 56,68 & 377,72 \\
\hline Pelophylax perezi & 29SND90 & 100,00 & 165,34 & 97,75 & 39,97 & 5033,34 & 309,49 & 66,49 & 243,01 & 104,96 & 229,23 & 233,44 & 104,66 & 649,04 & 90,68 & 4,01 & 56,50 & 264,87 & 36,60 & 36,92 & 264,87 \\
\hline Pelophylax perezi & 29SND91 & 100,00 & 165,52 & 97,41 & 39,74 & 5042,61 & 309,69 & 66,78 & 242,92 & 105,51 & 229,67 & 233,77 & 104,78 & 666,33 & 93,51 & 4,71 & 56,51 & 272,06 & 38,02 & 38,47 & 272,06 \\
\hline Pelophylax perezi & 29SND92 & 100,00 & 167,01 & 97,38 & 39,53 & 5049,72 & 311,14 & 67,58 & 243,55 & 108,42 & 231,32 & 235,16 & 105,97 & 672,80 & 94,69 & 4,91 & 56,41 & 274,65 & 38,37 & 39,36 & 274,65 \\
\hline Pelophylax perezi & 29SND93 & 100,00 & 10,01 & $\begin{array}{l}1,00 \\
97,03\end{array}$ & $\frac{39,23}{39,23}$ & 5067,16 & 31,14 & $\begin{array}{l}67,06 \\
67,\end{array}$ & \begin{tabular}{|l|}
243,63 \\
\end{tabular} & \begin{tabular}{|l|}
$107,4<$ \\
107,18
\end{tabular} & \begin{tabular}{|l|}
231,192 \\
231
\end{tabular} & $\begin{array}{l}53,10 \\
234,92 \\
\end{array}$ & \begin{tabular}{|l|}
105,31 \\
105
\end{tabular} & \begin{tabular}{|l|l|}
693,44 \\
\end{tabular} & \begin{tabular}{|l|}
48,03 \\
98,05
\end{tabular} & 5,00 & $\begin{array}{l}0,46 \\
56,36\end{array}$ & 283,46 & $\begin{array}{l}30,017 \\
39,40\end{array}$ & $\begin{array}{l}30,40 \\
40,47 \\
\end{array}$ & 283,46 \\
\hline Pelophylax perezi & 29SND94 & 100,00 & 164,63 & 96,36 & 39,00 & 5094,30 & 309,10 & 65,31 & 243,79 & 103,10 & 229,80 & 233,27 & 103,05 & 729,34 & 103,74 & 5,38 & 56,13 & 298,24 & 42,26 & 43,34 & 298,24 \\
\hline Pelophylax perezi & 29SND95 & 101,00 & 164,40 & 96,29 & 38,97 & 5107,33 & 308,97 & 64,56 & 244,41 & 102,61 & 229,69 & 233,08 & 102,46 & 749,64 & 107,05 & 5,86 & 56,03 & 306,62 & 43,75 & 44,92 & 306,62 \\
\hline Pelophylax perezi & 29SND96 & 101,00 & 161,90 & 95,79 & 38,71 & 5140,64 & 307,12 & 61,99 & 245,13 & 99,61 & 227,89 & 231,10 & 99,61 & 788,45 & 113,31 & 6,03 & 55,97 & 322,89 & 46,10 & 47,06 & 322,89 \\
\hline Pelophylax perezi & 29SND97 & 100,00 & 163,64 & 96,61 & 38,69 & 5152,31 & 309,19 & 62,41 & 246,78 & 101,27 & 229,80 & 232 & 100,99 & 789,01 & 113,33 & 6,22 & 55,85 & 322,31 & 46,76 & 48,03 & 322,31 \\
\hline Pelophylax perezi & 29SND98 & 101,00 & 159,65 & $\begin{array}{l}96,07 \\
96\end{array}$ & 38,20 & 5204,60 & 306,12 & 58,25 & $\begin{array}{l}40,107 \\
247,87\end{array}$ & 96,60 & 226,80 & 229,56 & (96,60 & 842,70 & 121,84 & 6,97 & 55,70 & 344,44 & 50,83 & 51,66 & 344,44 \\
\hline Pelophylax perezi & 29SND99 & 100,00 & 157,27 & 95,94 & 38,03 & 5233,99 & 304,20 & 55,38 & 248,82 & 93,83 & 224,97 & 227,49 & 93,83 & 880,99 & 127,97 & 7,45 & 55,45 & 360,06 & 53,78 & 54,41 & 360,06 \\
\hline Pelophylax perezi & 29SNE01 & 71,00 & 155,54 & 75,36 & 43,04 & 3391,56 & 246,96 & 73,98 & 172,98 & 118,78 & 195,81 & 198,16 & 110,94 & 820,20 & 120,06 & 6,99 & 56,68 & 341,42 & 46,29 & 53,10 & 331,97 \\
\hline Pelophylax perezi & 29SNE02 & 37,00 & 154,45 & 76,67 & 43,41 & 3404,48 & 246,83 & 72,06 & 174,77 & 117,64 & 195,06 & 197,29 & 109,50 & 851,18 & 123,02 & 7,56 & 55,97 & 351,79 & 49,67 & 56,62 & 343,38 \\
\hline Pelophylax perezi & 29SNE10 & 101,00 & 155,98 & 79,34 & 4 & 36022,00 & 256,0 & 71,49 & 184,58 & $\begin{array}{l}116,98 \\
11,0\end{array}$ & $\begin{array}{l}199,76 \\
\end{array}$ & 202 & 10 & \begin{tabular}{|l|}
821,60 \\
31,0
\end{tabular} & $\begin{array}{l}119, \\
119,\end{array}$ & 6,60 & 56,95 & 341,94 & 45,99 & 51,55 & $\begin{array}{l}34,34,68 \\
334\end{array}$ \\
\hline Pelophylax perezi & 29SNE11 & 101,00 & 155,21 & 80,06 & 42,88 & 3601,97 & 254,96 & 70,29 & 184,66 & 116,16 & 198,65 & 201,09 & 108,34 & 845,97 & 122,64 & 7,29 & 56,16 & 349,90 & 48,92 & 54,74 & 343,15 \\
\hline Pelophylax perezi & 29SNE12 & 101,00 & 154,19 & 80,64 & 43,08 & 3581,21 & 253,36 & 68,70 & 184,66 & 115,14 & 197,19 & 199,53 & 107,27 & 874,10 & 125,94 & 7,94 & 55,56 & 359,32 & 52,16 & 58,23 & 353,13 \\
\hline Pelophylax perezi & 29SNE20 & 101,00 & 152,52 & 84,09 & 41,92 & 3904,09 & 262,92 & 64,42 & 198,50 & 110,37 & 200,48 & 203,16 & 102,82 & 879,72 & 128,01 & 7,63 & 56,25 & 363,10 & 51,42 & 55,46 & 359,14 \\
\hline Pelophylax perezi & 29SNE21 & 100,00 & 154,41 & 85,30 & 42,49 & 3858,25 & 264,11 & 65,67 & 198,45 & 112,57 & 201,62 & 204,18 & 104,94 & 879,25 & 127,02 & 7,92 & 55,83 & 05 & 52,38 & 56,89 & 357,44 \\
\hline Pelophylax perezi & 29SNE22 & 101,00 & 156,45 & 80,16 & $\begin{array}{l}42, \\
43,\end{array}$ & $\begin{array}{l}3050,25 \\
3801,99\end{array}$ & 264 & $\begin{array}{l}3,06 \\
66,96 \\
\end{array}$ & \begin{tabular}{|l|}
$197,77,7$ \\
\end{tabular} & \begin{tabular}{|l|}
114,81 \\
114
\end{tabular} & $\begin{array}{l}202,60 \\
200\end{array}$ & \begin{tabular}{|l|}
205,01 \\
\end{tabular} & \begin{tabular}{|l|}
107,05 \\
107,05
\end{tabular} & $\mid$\begin{tabular}{|l|l|}
877,24 \\
\end{tabular} & \begin{tabular}{|l|l|l|l|l|l|}
125,73 \\
\end{tabular} & 8,03 & $\begin{array}{l}55,11 \\
55,11\end{array}$ & 351,035 & $\begin{array}{l}52,30 \\
53,36\end{array}$ & $\begin{array}{l}50,05 \\
58,58\end{array}$ & 354,81 \\
\hline Pelophylax perezi & 29SNE30 & 100,00 & 151,17 & 88,04 & 41,29 & 4146,76 & 270,31 & 60,08 & 210,23 & 106,59 & 202,74 & 205,56 & 99,05 & 915,09 & 132,98 & 8,19 & 55,99 & 375,21 & 54,94 & 57,61 & 374,22 \\
\hline Pelophylax perezi & 29SNE31 & 101,00 & 153,26 & 89,56 & 41.83 & 4109,00 & 272,14 & 61,12 & 211,03 & $\mid 107,35$ & 204,18 & 20682 & 101,14 & 913,92 & $\mid 131.86$ & 8,50 & 55,35 & 373,01 & 56,08 & 59,22 & 372,06 \\
\hline Pelophylax perezi & 29SNE32 & 100,00 & 153,67 & 90,88 & 42,44 & 4083,90 & 272,45 & 60,72 & 211,73 & 106,56 & 204,07 & 206,71 & 101,62 & 929,17 & 133,19 & 8,90 & 54,84 & 377,49 & 58,40 & 61,82 & 376,70 \\
\hline Pelophylax perezi & 29SNE40 & 101,00 & 155,32 & 91,90 & 41,29 & 4330,14 & 280,92 & 61,01 & 219,91 & 104,81 & 209,47 & 212 & 100,99 & 894 & 129,51 & 7,94 & 55,79 & 365,99 & 54,14 & 56,49 & 365,9 \\
\hline Pelophylax perezi & 29SNE41 & 101,00 & 152,76 & 93,14 & 41,49 & 4345,88 & 279,68 & $\begin{array}{l}1,65 \\
57,65\end{array}$ & 222,03 & 年, & 207,16 & 209,86 & 98,28 & 939,08 & \begin{tabular}{|l|l|}
135,46 \\
\end{tabular} & 8,86 & 55,12 & 382,81 & 58,79 & 60,79 & 382,81 \\
\hline Pelophylax perezi & 29SNE42 & 100,00 & 150,50 & 94,55 & 41,80 & 4357,86 & 278,69 & 54,41 & 224,29 & 95,73 & 205,08 & 207,75 & 95,73 & 981,85 & 141,10 & 9,75 & 54,39 & 398,97 & 63,27 & 65,08 & 398,97 \\
\hline Pelophylax perezi & 29SNE50 & 101,00 & 152,49 & 93,64 & 40,52 & 4559,42 & 284,73 & 56,28 & 228,45 & 96,01 & 210,15 & 213,00 & 96,01 & 936,03 & 135,86 & 8,58 & 55,59 & 383,17 & 57,83 & 59,04 & 383,17 \\
\hline Pelophylax perezi & 29SNE51 & 101,00 & 150,79 & 94,81 & 40,71 & 4567,43 & 283,90 & 53,75 & 230,15 & 94,13 & 208,58 & 211 , & 94, & 971,58 & 140,67 & 9,29 & 54 & 396,61 & 61,51 & 62,51 & 396,61 \\
\hline Pelophylax perezi & 29SNE52 & 100,00 & 145,71 & 94,36 & 40,55 & 4572,50 & 278,62 & 48,77 & 229,86 & 89,08 & 204,36 & 206,28 & 89,08 & 1042,81 & \begin{tabular}{|l|}
151,36 \\
\end{tabular} & 10,45 & 54,69 & 424,94 & 67,24 & 68,03 & 424,94 \\
\hline
\end{tabular}




\begin{tabular}{|c|c|c|c|c|c|c|c|c|c|c|c|c|c|c|c|c|c|c|c|c|c|}
\hline TAXON & UTM & $\mathrm{km} 2$ & B101 & B102 & $\mathrm{BIO3}$ & BIO4 & B105 & B106 & B107 & B108 & B109 & B1010 & B1011 & BIO12 & B1013 & BIO14 & BIO15 & BIO16 & B1017 & B1018 & B1019 \\
\hline Pelophylax perezi & 29SNE60 & 100,00 & 156,03 & 95,70 & 40,18 & 4727,17 & 292,76 & 57,48 & 235,28 & 97,60 & 216,06 & 218,82 & 97,60 & 909,29 & 131,69 & 8,14 & 55,40 & 371,90 & 56,08 & 57,23 & 371,90 \\
\hline Pelophylax perezi & 29SNE61 & 100,00 & 151,40 & 95,90 & \begin{tabular}{l|l|l}
40,15 \\
\end{tabular} & 4750,56 & 289,01 & 52,56 & 236,45 & 92,84 & 211,99 & 214,58 & 92,84 & 973,54 & 141,32 & 9,16 & 55,04 & 397,64 & 61,64 & 62,21 & 397,64 \\
\hline Pelophylax perezi & 29SNE62 & 100,00 & 141,47 & 93,16 & 39,39 & 4773,60 & 277,94 & 44,03 & 233,92 & 83,16 & 204,14 & 205,27 & 83,16 & 1091,31 & 160,04 & 10,87 & 54,99 & 445,90 & 69,95 & 70,01 & 445,90 \\
\hline Pelophylax perezi & 29SNE70 & 101,00 & 154,33 & 95,89 & 39,32 & 4917,30 & 295,29 & 54,54 & 240,75 & 94,07 & 217,36 & 219,94 & 94,07 & 929,76 & 135,19 & 8,27 & 55,35 & \begin{tabular}{|l|l|}
380,43 \\
\end{tabular} & 57,70 & 58,26 & 380,43 \\
\hline Pelophylax perezi & 29SNE71 & 100,00 & 147,42 & \begin{tabular}{|l|l|}
94,63 \\
\end{tabular} & \begin{tabular}{|l|l|}
38,97 \\
\end{tabular} & $\begin{array}{lll}4938,86 \\
\end{array}$ & 288,14 & 48,14 & 240,01 & 87,19 & 211,97 & 213,50 & 87,19 & 1016,43 & 148,84 & 9,58 & 55,22 & \begin{tabular}{|l|l|}
415,88 \\
\end{tabular} & 63,99 & 64,14 & 415,88 \\
\hline Pelophylax perezi & 29SNE72 & 101,00 & 147,01 & 95,68 & 39,19 & 4934,79 & 287,99 & 46,80 & 241,19 & 86,58 & 211,29 & 212,84 & 86,58 & 1037,05 & 151,67 & 10,03 & 55,00 & 423,37 & 66,27 & 66,45 & 423,37 \\
\hline Pelophylax perezi & 29SNE80 & 101,00 & 147,36 & 93,38 & 38,00 & 5105,65 & 290,68 & 48,02 & 242,66 & 85,73 & 214,97 & 216,08 & 85,73 & 999,48 & 146,99 & 9,09 & 55,62 & 409,81 & 61,75 & 61,78 & 409,81 \\
\hline Pelophylax perezi & 29SNE81 & 100,00 & 139,59 & 91,18 & 37,40 & 5112,34 & 281,58 & 41,21 & 240,36 & 78,28 & 208,20 & 208,53 & 78,28 & 1095,12 & 162,51 & 10,33 & 55,64 & 449,06 & 67,73 & 67,73 & 449,06 \\
\hline Pelophylax perezi & 29SNE82 & 101,00 & 142,45 & 93,26 & \begin{tabular}{l|l|l}
37,95 \\
\end{tabular} & 5101,60 & 285,13 & 42,50 & 242,63 & 80,70 & 210,18 & 210,85 & 80,70 & 1080,88 & 159,84 & 10,28 & 55,32 & 442,08 & 67,84 & 67,92 & 442,08 \\
\hline Pelophylax perezi & 29SNE90 & 100,00 & 144,25 & 91,88 & 37,01 & 5263,55 & 289,66 & 44,62 & 245,03 & 81,28 & 214,68 & 215,34 & 81,28 & 1026,81 & 151,79 & 9,32 & 55,69 & 420,93 & 63,00 & 63,03 & 420,93 \\
\hline Pelophylax perezi & 29SNE91 & 100,00 & 133,40 & 88,25 & 36,15 & 5252,89 & 276,32 & 35,82 & 240,49 & 71,19 & 204,67 & 204,67 & 71,19 & 1151,78 & 172,48 & 10,85 & 55,87 & $\begin{array}{l}472,69 \\
\end{array}$ & 70,36 & 70,36 & 472,69 \\
\hline Pelophylax perezi & 29SNE92 & 100,00 & 141,13 & 92,11 & 37,01 & 5261,34 & 286,09 & 40,61 & 245,48 & 77,82 & 211,52 & 211,83 & 77,82 & 1085,70 & 161,39 & 10,10 & 55,59 & 444,37 & 67,32 & 67,38 & 444,37 \\
\hline Pelophylax perezi & 29SPB00 & 100,00 & 168,65 & 91,91 & \begin{tabular}{|l|l|}
41,97 \\
\end{tabular} & 4323,17 & 288,65 & 71,93 & 216,72 & 125,49 & 223,02 & 227,16 & 116,65 & 520,02 & 86,18 & 1,01 & 68,52 & 247,88 & 15,63 & 19,26 & 231,80 \\
\hline Pelophylax perezi & 29SPB01 & 101,00 & 162,03 & 94,36 & 41,61 & \begin{tabular}{|l|l|}
4497,07 \\
\end{tabular} & 288,29 & 63,89 & 224,40 & 117,19 & 218,91 & 223,10 & 108,31 & 555,68 & 89,50 & 1,30 & 66,64 & 258,63 & 18,44 & 21,93 & 244,09 \\
\hline Pelophylax perezi & 29SPB02 & 100,00 & 156,21 & 96,72 & $\begin{array}{ll}41,06 \\
\end{array}$ & 4645,49 & 288,15 & 56,77 & 231,38 & 109,81 & 215,06 & 219,32 & 100,94 & 589,35 & 92,50 & 1,92 & 64,92 & 268,40 & 21,17 & 24,40 & 255,58 \\
\hline Pelophylax perezi & 29SPB03 & 101,00 & 158,06 & 98,16 & 41,13 & 4706,17 & 292,82 & 57,77 & 235,05 & 110,68 & 217,75 & 221,95 & 101,91 & 579,27 & 90,05 & 1,99 & 64,43 & 262,06 & 21,21 & 24,19 & 249,89 \\
\hline Pelophylax perezi & 29SPB04 & 101,00 & 162,26 & 99,50 & 41,29 & 4747,51 & 299,03 & 61,25 & 237,78 & 114,29 & 222,41 & 226,65 & 105,52 & 555,11 & 85,60 & 1,98 & 64,07 & 250,12 & 20,58 & 23,46 & 238,41 \\
\hline Pelophylax perezi & 29SPB05 & 100,00 & 163,97 & 101,37 & 41,34 & 4816,27 & 303,75 & 62,08 & 241,66 & 115,01 & 224,98 & 229,16 & 106,18 & 546,64 & 83,50 & 2,00 & 63,37 & 244,04 & 20,84 & 23,48 & 233,34 \\
\hline Pelophylax perezi & 29SPB06 & 101,00 & 166,78 & 103,09 & \begin{tabular}{|l|l|}
41,77 \\
\end{tabular} & 4864,45 & 308,96 & 64,24 & 244,73 & 117,18 & 228,35 & 232,62 & 108,45 & 531,27 & 80,81 & 1,99 & 62,92 & 235,55 & 20,77 & 23,04 & 225,63 \\
\hline Pelophylax perezi & 29SРB07 & 101,00 & 166,32 & 105,44 & $\mid 41.88$ & 4943,26 & 312,49 & 62,73 & 249,76 & 115,83 & 229,00 & 233,25 & 107,03 & 535,87 & 80,73 & 2,00 & 62.05 & 234,58 & 21,63 & 23,64 & 226,01 \\
\hline Pelophylax perezi & 29SPB08 & 100,00 & 167,55 & 107,56 & \begin{tabular}{|l|l|}
41,97 \\
\end{tabular} & 5003,47 & 316,84 & 62,99 & 253,84 & 116,34 & 230,95 & 235,25 & 107,44 & 530,96 & 79,44 & 2,00 & 61,50 & 230,09 & 21,97 & 23,82 & 222,77 \\
\hline Pelophylax perezi & 29SPB09 & 100,00 & 166,65 & 110,11 & 42,02 & 5078,42 & 319,97 & 61,01 & $\begin{array}{l}258,96 \\
25,\end{array}$ & 114,61 & 231,07 & 235,43 & 105,78 & 538,22 & 79,76 & 2,00 & 60,83 & 230,49 & 23,08 & 24,19 & 224,76 \\
\hline Pelophylax perezi & 29SPB10 & 83,00 & 172,73 & 90,49 & \begin{tabular}{|l|l|}
41,49 \\
\end{tabular} & \begin{tabular}{|l|l|}
4345,16 \\
\end{tabular} & 291,22 & 75,65 & 215,57 & 128,91 & 227,13 & 231,16 & 120,17 & 499,02 & 81,41 & 1,00 & 68,00 & 236,81 & 14,28 & 18,78 & 220,00 \\
\hline Pelophylax perezi & 29SPB11 & 99,00 & 168,63 & 92,33 & 41,09 & 4481,92 & 291,86 & 70,19 & 221,67 & 123,23 & 224,88 & 228,95 & 114,35 & 520,10 & 83,18 & 1,01 & 66,93 & 242,62 & 16,15 & 20,50 & 226,66 \\
\hline Pelophylax perezi & 29SPB12 & 101,00 & 159,55 & 95,59 & 40,93 & 4684,63 & 290,54 & 59,33 & 231,21 & 112,27 & 218,81 & 222,92 & 103,22 & 570,01 & 88,50 & 1,90 & 64,84 & 258,87 & 19,90 & 23,92 & 244,94 \\
\hline Pelophylax perezi & 29SPB13 & 100,00 & 163,67 & 96,69 & 40,97 & 4727,12 & 296,40 & 62,81 & 233,59 & 115,68 & 223,35 & 227,42 & 106,75 & 545,74 & 84,32 & 1,70 & 64,48 & 246,99 & 19,23 & 23,10 & 233,35 \\
\hline \begin{tabular}{|l|} 
Pelophylax perezi \\
\end{tabular} & 29SPB14 & 100,00 & 164,15 & 98,47 & 40,99 & 4808,23 & 300,24 & $\begin{array}{ll}62,28 \\
62\end{array}$ & \begin{tabular}{|l|}
237,96 \\
\end{tabular} & 114,95 & 224,83 & 228,98 & 106,16 & 543,03 & $\begin{array}{l}84,32 \\
83,13\end{array}$ & 1,86 & 63,62 & 243,27 & 19,80 & 23,49 & 230,58 \\
\hline Pelophylax perezi & 29SPB15 & 101,00 & 166,02 & 100,20 & 41,00 & 4869,35 & 304,94 & 63,33 & 241,61 & 115,96 & 227,46 & 231,61 & 107,26 & 532,74 & 81,03 & 1,93 & 63,12 & 236,72 & 20,00 & 23,43 & 224,84 \\
\hline Pelophylax perezi & 29SPB16 & 100,00 & 169,62 & 101,78 & 41,12 & 4908,01 & 310,38 & 66,19 & 244,19 & 118,84 & 231,52 & 235,58 & 110,12 & 514,27 & 77,93 & 1,73 & 62,67 & 227,15 & 19,65 & 22,79 & 215,99 \\
\hline Pelophylax perezi & 29SPB17 & 100,00 & 168,05 & 104,46 & 41,20 & 5005,48 & 313,51 & 63,50 & 250,01 & 116,38 & 231,39 & 235,43 & 107,52 & 524,31 & 78,49 & 1,98 & 61,72 & 228,42 & 21,01 & 23,75 & 218,70 \\
\hline Pelophylax perezi & 29SPB18 & 101,00 & 168,43 & 106,74 & 41,49 & 5064,67 & 317,17 & 62,97 & 254,19 & 116,14 & 232,58 & 236,60 & 107,19 & 524,31 & 77,78 & 2,00 & 60,91 & 225,94 & 21,78 & 23,97 & 217,52 \\
\hline \begin{tabular}{|l|} 
Pelophylax perezi \\
\end{tabular} & 29SPB19 & 100,00 & 168,67 & 108,60 & 年1, 41,74 & 5121,81 & 320,40 & \begin{tabular}{|c|}
62,43 \\
62
\end{tabular} & 257,97 & $\begin{array}{l}115,63 \\
15,\end{array}$ & 233,61 & 237,66 & 106,71 & \begin{tabular}{|l|l|}
525,02 \\
\end{tabular} & 77,21 & 2,00 & 60,35 & 223,97 & 22,44 & 24,26 & 216,79 \\
\hline Pelophylax perezi & 29SPB20 & 11,00 & 174,00 & 89,13 & 41,00 & 4376,00 & 292,25 & 77,00 & 215,25 & 129,75 & 228,88 & 232,88 & 121,00 & 490,25 & 79,25 & 1,00 & 68,00 & 231,00 & 14,00 & 19,00 & 213,38 \\
\hline Pelophylax perezi & 29SPB21 & 97,00 & 172,04 & 90,53 & 40,61 & 4512,68 & 293,65 & 73,35 & 220,30 & 125,89 & 228,34 & 232,29 & 116,95 & 501,29 & 79,80 & 1,00 & 66,59 & 232,37 & 14,78 & 20,05 & 215,44 \\
\hline Pelophylax perezi & 29SPB22 & 100,00 & 166,31 & 93,15 & 40,33 & 4667,96 & 293,92 & 66,12 & 227,81 & 118,69 & 224,99 & 228,93 & 109,63 & 531,05 & 82,62 & 1,25 & 65,03 & 241,44 & 17,40 & 22,36 & 225,77 \\
\hline Pelophylax perezi & 29SPB23 & 101,00 & 168,25 & 94,56 & 40,32 & 4735,29 & 298,46 & 67,19 & 231,27 & 119,61 & 227,77 & 231,71 & 110,66 & 519,73 & 80,23 & $\begin{array}{l}1,19 \\
\end{array}$ & 64,47 & 234,68 & 17,37 & 22,16 & 219,59 \\
\hline Pelophylax perezi & 29SPB24 & 100,00 & $\begin{array}{l}10,25 \\
165,69\end{array}$ & \begin{tabular}{|c|}
4,300 \\
97,05
\end{tabular} & 年 40,46 & 4849,47 & $\begin{array}{l}350,40 \\
300,64\end{array}$ & $\begin{array}{l}63,40 \\
63,10\end{array}$ & 237,24 & $\mid$ & 226,89 & $\begin{array}{l}230,83 \\
230,1\end{array}$ & 107,08 & 533,69 & \begin{tabular}{ll|}
81,11 \\
81,
\end{tabular} & $\begin{array}{l}, 19 \\
1,86\end{array}$ & $\begin{array}{ll}63,31 \\
63,\end{array}$ & $\begin{array}{l}2354,00 \\
237,35\end{array}$ & $\mid 19,21$ & 23,72 & 223,55 \\
\hline Pelophylax perezi & 29SPB25 & 100,00 & 169,33 & 98,40 & 40,57 & 4894,24 & 306,29 & 66,31 & 239,97 & 118,59 & 231,09 & 234,90 & 110,06 & 513,84 & 77,78 & 1,62 & 62,78 & 227,38 & 18,76 & 23,11 & 214,10 \\
\hline Pelophylax perezi & 29SPB26 & 101,00 & 169,08 & 100,77 & 40,72 & 4972,45 & 309,87 & 64,94 & 244,93 & 117,62 & 231,85 & 235,79 & 108,74 & 516,25 & 77,31 & 1,88 & 61,94 & 225,79 & 19,77 & 23,69 & 213,66 \\
\hline Pelophylax perezi & 29SPB27 & 100,00 & 167,14 & 103,45 & 40,86 & 5076,86 & 312,47 & 61,61 & 250,86 & 114,53 & 231,33 & 235,27 & 105,58 & 528,04 & 78,16 & 2,00 & 61,08 & 228,12 & 21,14 & 24,51 & 217,42 \\
\hline Pelophylax perezi & 29SPB28 & 100,00 & 167,52 & 105,62 & 40,9 & 5143,11 & 316,07 & 60,92 & 255,16 & 113,99 & 232,69 & 236,56 & 105,07 & 527,53 & 77,44 & 2,00 & 60,50 & 225,69 & 21,84 & 24,69 & 216,24 \\
\hline Pelophylax perezi & 29SPB29 & 101,00 & 167,13 & $\begin{array}{l}107,53 \\
\end{array}$ & 41 & 5203,95 & 318,63 & 59,81 & 258,82 & 112,92 & 233,18 & 237,07 & 103,92 & 531,36 & 77,24 & 2,00 & 59,86 & 225,10 & 22,59 & 25,19 & 216,82 \\
\hline Pelophylax perezi & 29SPB31 & 58,00 & 174,81 & 88,67 & 40,00 & 4559,20 & 295,23 & 75,87 & 219,36 & 127,54 & 231,51 & 235,26 & 118,59 & 486,49 & 76,64 & 1,00 & 65,94 & 222,86 & 14,03 & 19,99 & 205,03 \\
\hline Pelophylax perezi & 29SPB32 & 101,00 & 173,23 & 90,13 & 39,87 & 4653,86 & 296,81 & 73,27 & 223,54 & 124,94 & 231,23 & 234,90 & 115,92 & 493,39 & 76,86 & 1,00 & 65,25 & 224,21 & 14,76 & 20,66 & 206,99 \\
\hline Pelophylax perezi & 29SPB33 & 100,00 & 172,24 & 92,08 & 39,8 & 4756,22 & 299,82 & 71,13 & 228,69 & 122,83 & 231,68 & 235,45 & 113,82 & 497,26 & 76,39 & 1,00 & 64,32 & 223,32 & 15,71 & 21,49 & 206,86 \\
\hline Pelophylax perezi & 29SPB34 & 101,00 & 170,86 & $\begin{array}{l}2,30 \\
94,32 \\
\end{array}$ & $\begin{array}{l}39, \\
39,\end{array}$ & 4859,98 & 302,54 & $\begin{array}{ll}68,46 \\
\end{array}$ & \begin{tabular}{|l|}
234,07 \\
\end{tabular} & $\begin{array}{l}120,14 \\
12,0\end{array}$ & 231,78 & 235 & 111,38 & $\begin{array}{l}504,14 \\
\end{array}$ & 76,40 & $\begin{array}{l}1,00 \\
1,15\end{array}$ & 63,32 & 223,70 & $\begin{array}{l}16,119 \\
\end{array}$ & 22,58 & 208,22 \\
\hline Pelophylax perezi & 29SPB35 & 101,00 & 169,60 & 96,90 & 39,96 & 4957,53 & 305,73 & 65,96 & 239,77 & 117,77 & 231,96 & 235,63 & 109,06 & 511,72 & 76,62 & 1,60 & 62,32 & 224,38 & 18,45 & 23,57 & 210,04 \\
\hline Pelophylax perezi & 29SPB36 & 99,00 & 171,07 & 98,97 & 40,02 & 5027,06 & 310,27 & 66,23 & 244,03 & 118,48 & 234,36 & 238,01 & 109,54 & 504,43 & 74,85 & 1,80 & 61,47 & 219,22 & $\begin{array}{l}19,03 \\
19,0\end{array}$ & 23,80 & 205,73 \\
\hline Pelophylax perezi & 29SPB37 & 101,00 & 168,89 & 101,83 & 40,13 & 5123,45 & 312,79 & 62,74 & 250,05 & 115,32 & 233,65 & 237,34 & 106,44 & 517,24 & 75,86 & 2,00 & 60,68 & 222,11 & 20,43 & 24,79 & 209,98 \\
\hline Pelophylax perezi & 29SPB38 & 100,00 & 165,74 & 104,48 & 40,26 & 5217,51 & 314,11 & 58,52 & 255,59 & 111,43 & 231,94 & 235 & 102,43 & 536,33 & 77,76 & 2,00 & 60,14 & 227,63 & 22,05 & 25,60 & 217,14 \\
\hline Pelophylax perezi & \begin{tabular}{|l|}
$295 \mathrm{SPB} 39$ \\
\end{tabular} & 100,00 & 165 & $\begin{array}{l}104,40 \\
106,32 \\
\end{array}$ & $\begin{array}{l}40, \\
40,\end{array}$ & 5 & 316,66 & $\frac{50,26}{57,26}$ & \begin{tabular}{|l|}
259,40 \\
259
\end{tabular} & \begin{tabular}{|l|}
110,34 \\
110,
\end{tabular} & 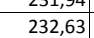 & $\mid 236,23$ & 101,60 & \begin{tabular}{|l|}
539,62 \\
539,6
\end{tabular} & $\begin{array}{l}71,1,46 \\
\end{array}$ & $\begin{array}{l}, 00 \\
2,16\end{array}$ & $\begin{array}{l}0,144 \\
59,39\end{array}$ & $\begin{array}{l}226,05 \\
226,96\end{array}$ & $\begin{array}{l}22,303 \\
23,19\end{array}$ & $\begin{array}{l}26,27 \\
260\end{array}$ & 217,14 \\
\hline Pelophylax perezi & $295 \mathrm{SB} 41$ & 45,00 & 175,94 & 86,66 & 39,08 & 4616,81 & 295,17 & 76,89 & 218,28 & 127,66 & 233,08 & 236,77 & 118,75 & 478,98 & 74,89 & 1,00 & 66,06 & 217,60 & 13,19 & 20,19 & 199,08 \\
\hline Pelophylax perezi & 29SPB42 & \begin{tabular}{|l|}
100,00 \\
\end{tabular} & 174,39 & 87,81 & 39,07 & 4705,30 & 296,40 & 74,27 & 222,13 & $\begin{array}{ll}125,04 \\
\end{array}$ & $\begin{array}{l}232,76 \\
232\end{array}$ & 236,31 & 116,11 & |486,66 & $\begin{array}{l}74,909 \\
74,96\end{array}$ & $\begin{array}{l}, 00 \\
1,00\end{array}$ & 65,00 & 218,79 & $\begin{array}{l}14,07 \\
14,0\end{array}$ & 21,01 & 200,46 \\
\hline Pelophylax perezi & 29SPB43 & 100,00 & 171,07 & 90,36 & 39,05 & 4835,05 & 298,26 & 69,46 & 228,80 & 120,41 & 231,39 & 234,94 & 111,54 & 503,00 & 76,14 & 1,00 & 63,58 & 223,05 & 15,97 & 22,78 & 205,61 \\
\hline Pelophylax perezi & 29SPB44 & 100,00 & 168,94 & 93,08 & 39,08 & 4953,04 & 301,00 & 65,92 & 235,08 & 116,97 & 230,92 & 23 & 10 & 514,36 & 76,65 & 1,65 & 62,62 & 225,14 & 17,70 & 24,14 & 208 \\
\hline Pelophylax perezi & 29SPB45 & $\begin{array}{l}101,00 \\
100\end{array}$ & $\begin{array}{l}100,54 \\
167,17\end{array}$ & \begin{tabular}{|l|l}
95,93 \\
95
\end{tabular} & 39,00 & | 50505,97 & 303,87 & \begin{tabular}{|l|l|}
62,46 \\
62
\end{tabular} & \begin{tabular}{|l|}
241,41 \\
\end{tabular} & \begin{tabular}{|l|}
114,03 \\
14,03
\end{tabular} & $\begin{array}{l}230,75 \\
230,75\end{array}$ & \begin{tabular}{|l|}
234,294 \\
\end{tabular} & 105,23 & \begin{tabular}{|l|}
524,81 \\
\end{tabular} & $\begin{array}{l}\mid 0,05 \\
77,31\end{array}$ & $\begin{array}{l}, 05 \\
1,95 \\
\end{array}$ & 62,026 & $\mid 227,20$ & $\begin{array}{ll}19,13 \\
19\end{array}$ & 24,01 & $\begin{array}{l}200,10 \\
212,03\end{array}$ \\
\hline Pelophylax perezi & 29SPB46 & 101,00 & 170,38 & 97,69 & 39,49 & 5097,67 & 309,21 & 64,66 & 244,55 & 116,60 & 234,40 & 237,99 & 107,66 & 508,40 & 74,47 & 2,00 & 61,12 & 218,77 & 19,17 & 24,74 & 204,27 \\
\hline Pelophylax perezi & 29SPB47 & 100,00 & 168,88 & 100,49 & 39,82 & 5191,89 & 311,99 & 61,96 & 250,03 & 114,28 & 234,42 & 237,89 & 105,12 & 517,01 & 75,01 & 2,00 & 60,66 & 220,39 & 20,28 & 25,11 & 207,22 \\
\hline Pelophylax perezi & 29SPB48 & 100,00 & 167,76 & 102,78 & 39,96 & 5275,35 & 314,51 & 59,57 & 254,94 & 112,04 & 234, & 238,02 & 103 & 523,92 & 75,31 & 2,00 & 59,87 & 221,33 & 21,22 & 25,76 & 209,24 \\
\hline Pelophylax perezi & 29SPB49 & 100,00 & 166,50 & 105,08 & 40,00 & 5340,31 & 316,69 & 57,41 & 259,28 & $\begin{array}{l}110,07 \\
\end{array}$ & 234,41 & 237,71 & 101,40 & 532,89 & 75,91 & 2,06 & 59,35 & 223,19 & 22,59 & 26,21 & 212,30 \\
\hline
\end{tabular}




\begin{tabular}{|c|c|c|c|c|c|c|c|c|c|c|c|c|c|c|c|c|c|c|c|c|c|}
\hline TAXON & UTM & $\mathrm{km} 2$ & BIO1 & BIO2 & $\mathrm{BIO3}$ & BIO4 & BIO5 & B106 & B107 & B108 & 8109 & BIO10 & BIO11 & BIO12 & 81013 & BIO14 & BIO15 & B1016 & B1017 & B1018 & 81019 \\
\hline Pelophylax perezi & 29SPB51 & & & & & & & & & & & & & & & & & & & & \\
\hline Pelophylax perezi & 29SPB52 & 100,00 & 175,19 & 85,50 & 38,19 & 4763,32 & 295,72 & 74,92 & 220,80 & 124,69 & 233,97 & 237,43 & 115,81 & 482,36 & 73,92 & 1,00 & 64,48 & 214,43 & 13,55 & 21,57 & $\begin{array}{l}194,99 \\
197,70\end{array}$ \\
\hline Pelophylax perezi & 29SPB53 & 101,00 & 172,90 & 87,90 & 38,16 & 4887,35 & 298,20 & 71,02 & 227,18 & 121,10 & 233,55 & 236,92 & 112,13 & $\begin{array}{l}493,46 \\
\end{array}$ & 74,73 & 1,01 & 63,42 & 216,54 & 15,33 & 23,12 & 197,79 \\
\hline Pelophylax perezi & 29SPB54 & 101,00 & 170,45 & 90,94 & 38,30 & 5007,82 & 300,94 & 66,97 & 233,97 & 117,41 & 232,94 & 236,36 & 108,48 & 506,42 & 75,65 & 1,51 & 62,28 & 219,73 & 17,00 & 24,36 & 202,13 \\
\hline Pelophylax perezi & 29SPB55 & 99,00 & 166,69 & 94,61 & 38,71 & 5134,48 & 303,20 & 61,36 & 241,84 & 112,48 & 231,25 & 234,60 & 103,59 & 528,04 & 77,56 & 2,00 & 61,28 & 226,42 & 19,01 & 25,85 & 210,22 \\
\hline Pelophylax perezi & 29SPB56 & 100,00 & 168,05 & 96,89 & 38,95 & 5204,47 & 307,65 & 61,30 & 246,35 & $\begin{array}{ll}112,94 \\
\end{array}$ & 233,58 & 236,92 & 103,94 & 520,95 & 76,11 & 2,00 & 60,74 & 221,98 & 19,40 & 25,68 & 206,68 \\
\hline Pelophylax perezi & 29SPB57 & 100,00 & 168,52 & 99,30 & 39,05 & 5265,48 & 311,35 & 60,62 & 250,73 & 112,74 & 235,06 & 238,25 & 103,76 & 519,26 & 75,34 & 2,00 & 60,09 & 219,62 & 20,12 & 25,82 & 205,28 \\
\hline Pelophylax perezi & 29SPB58 & 101,00 & 165,17 & 102,30 & 39,26 & 5365,91 & 312,87 & 56,02 & 256,85 & $\begin{array}{l}108,46 \\
\end{array}$ & 233,42 & 236,58 & 99,60 & 539,10 & 77,02 & 2,18 & 59,31 & 225,79 & 22,22 & 27,10 & 212,91 \\
\hline Pelophylax perezi & 29SPB59 & 100,00 & 166,71 & 104,28 & 39,71 & $\begin{array}{l}5416,16 \\
\end{array}$ & 316,71 & 56,52 & 260,20 & 109,16 & 235,61 & 238,69 & 100,55 & 531,41 & 75,54 & 2,18 & 58,79 & 221,23 & 22,63 & 27,04 & 209,20 \\
\hline Pelophylax perezi & 29SPB62 & 100,00 & 176,32 & 82,94 & 37,30 & 4827,46 & 295,47 & 75,96 & 219,51 & \begin{tabular}{ll|}
124,72 \\
\end{tabular} & 235,65 & 238,97 & 115,88 & $\begin{array}{l}476,06 \\
\end{array}$ & 73,79 & 1,00 & 64,06 & 209,23 & 13,14 & 22,10 & 188,61 \\
\hline Pelophylax perezi & 29SPB63 & 100,00 & 173,50 & 85,69 & 37,29 & \begin{tabular}{|l|}
4955,21 \\
\end{tabular} & 297,65 & 71,32 & $\begin{array}{l}226,33 \\
\end{array}$ & $\begin{array}{ll}120,63 \\
\end{array}$ & 234,78 & 237,93 & 111,59 & 490,51 & 75,08 & 1,01 & 62,88 & 213,02 & 14,88 & 23,59 & 193,09 \\
\hline Pelophylax perezi & 29SPB64 & 100,00 & 171,35 & 89,14 & 37,69 & 5074,96 & 300,92 & 67,29 & $\begin{array}{ll}233,63 \\
\end{array}$ & 117,19 & $\begin{array}{ll}234,48 \\
\end{array}$ & \begin{tabular}{|l|l|}
237,69 \\
\end{tabular} & \begin{tabular}{|l|l|}
108,34 \\
\end{tabular} & \begin{tabular}{l|l|}
502,45 \\
\end{tabular} & 75,84 & 1,52 & 62,03 & 215,97 & 16,64 & 24,62 & 197,18 \\
\hline Pelophylax perezi & 29SPB65 & 101,00 & 170,61 & 92,24 & 37,94 & 5171,80 & 304,69 & 64,81 & 239,88 & 115,30 & 235,21 & 238,42 & $\mid 106,43$ & 507,57 & 75,85 & 1,94 & 61,13 & 216,36 & 17,85 & 25,54 & 198,55 \\
\hline Pelophylax perezi & 29SPB66 & 100,00 & 167,46 & 96,09 & 38,26 & 5281,79 & 307,19 & 59,68 & 247,51 & 111,22 & 233,90 & 237,04 & 102,17 & 526,75 & 77,38 & 2,00 & 60,41 & 222,67 & 19,45 & 26,22 & 206,49 \\
\hline Pelophylax perezi & 29SPB67 & 101,00 & 167,34 & 98,94 & 38,73 & 5365,73 & 310,99 & 58,12 & 252,87 & \begin{tabular}{|l|l|}
110,08 \\
\end{tabular} & 235,12 & 238,06 & $\begin{array}{l}101,04 \\
\end{array}$ & \begin{tabular}{|l|l|}
527,78 \\
\end{tabular} & 76,87 & 2,00 & 59,80 & 221,55 & 20,25 & 26,49 & 206,39 \\
\hline Pelophylax perezi & 29SPB68 & 99,00 & 161,51 & 102,50 & 38,98 & \begin{tabular}{|l|l|}
5475,86 \\
\end{tabular} & 310,95 & 50,86 & 260,09 & $\begin{array}{l}103,49 \\
\end{array}$ & 231,21 & 234,26 & \begin{tabular}{ll|l}
94,64 \\
\end{tabular} & 565,09 & 80,49 & 2,59 & 58,77 & 234,47 & 24,03 & 29,36 & 221,11 \\
\hline Pelophylax perezi & 29SPB69 & 101,00 & 160,85 & 104,80 & 39,03 & 5543,35 & $\begin{array}{l}313,78 \\
\end{array}$ & 49,17 & 264,61 & \begin{tabular}{|l|l|}
102,18 \\
\end{tabular} & 231,74 & \begin{tabular}{|l|l|}
234,69 \\
\end{tabular} & 93,30 & 569,54 & 80,36 & 2,99 & 57,97 & 234,49 & 25,62 & \begin{tabular}{l|l}
30,24 \\
\end{tabular} & 222,24 \\
\hline Pelophylax perezi & 29SPB71 & 11,00 & 178,00 & 79,38 & 36,38 & 4854,08 & 293,31 & 77,85 & 215,46 & 125,85 & 236,69 & 240,08 & \begin{tabular}{|l|l|}
116,31 \\
\end{tabular} & 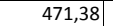 & 74,15 & 1,00 & 64,08 & 205,62 & 12,00 & 22,00 & 183,46 \\
\hline Pelophylax perezi & 29SPB72 & 100,00 & 177,28 & 80,30 & 36,32 & 4889,62 _ & 294,83 & 76,74 & 218,10 & 124,96 & 237,14 & 240,23 & 115,76 & 471,86 & 74,05 & 1,00 & 63,85 & 205,10 & 12,65 & 22,54 & 183,14 \\
\hline Pelophylax perezi & 29SPB73 & 101,00 & 176,50 & 82,76 & 36,45 & 5001,32 & 298,23 & 74,25 & 223,98 & 123,65 & 237,87 & 240,98 & 113,67 & 476,04 & 74,01 & 1,00 & 63,01 & 204,82 & 13,89 & 23,71 & 183,47 \\
\hline Pelophylax perezi & 29SPB74 & 100,00 & 174,51 & 86,77 & 36,99 & 5116,97 & 301,96 & 70,11 & 231,86 & $\begin{array}{ll}119,42 \\
\end{array}$ & 237,91 & 240,89 & 110,45 & $\begin{array}{l}487,26 \\
\end{array}$ & 74,79 & 1,03 & 62,14 & 208,15 & 15,20 & 24,17 & 187,95 \\
\hline Pelophylax perezi & 29SPB75 & 100,00 & 173,17 & 90,78 & 37,35 & 5223,84 & 306,17 & \begin{tabular}{ll|}
66,62 \\
\end{tabular} & 239,55 & $\begin{array}{ll}116,95 \\
\end{array}$ & $\begin{array}{ll}238,22 \\
\end{array}$ & 241,18 & $\begin{array}{l}108,03 \\
\end{array}$ & $\begin{array}{l}497,01 \\
\end{array}$ & 75,20 & 1,71 & 61,08 & 210,63 & 16,92 & 25,31 & 191,71 \\
\hline Pelophylax perezi & 29SPB76 & 101,00 & 172,13 & 94,68 & 37,97 & 5322,15 & 310,30 & 63,59 & 246,72 & 115,01 & 238,91 & 241,79 & 105,99 & 504,11 & 75,30 & 1,99 & 60,38 & 212,14 & 18,20 & 25,85 & 194,57 \\
\hline Pelophylax perezi & 29SPB77 & 100,00 & 169,75 & $\begin{array}{l}98,39 \\
\end{array}$ & 38,18 & 5425,29 & 313,11 & 59,47 & 253,64 & 111,36 & 238,29 & 241,06 & \begin{tabular}{ll|}
102,64 \\
\end{tabular} & 517,79 & 76,19 & 2,01 & 59,74 & 216,32 & 19,64 & 26,46 & 200,12 \\
\hline Pelophylax perezi & 29SPB78 & 101,00 & 163,20 & 102,44 & 38,68 & 5548,81 & 313,16 & 51,22 & 261,94 & 104,07 & 233,97 & 236,76 & 95,18 & 557,05 & 79,98 & 2,45 & 58,67 & 230,14 & 23,44 & 29,16 & 215,80 \\
\hline Pelophylax perezi & 29SPB79 & 100,00 & 158,60 & 105,26 & 38,94 & 5641,23 & 313,68 & 45,54 & 268,14 & 98,76 & 231,00 & 233,69 & 89,80 & 585,79 & 82,62 & 3,10 & 57,73 & 239,91 & 26,44 & 31,26 & 227,16 \\
\hline Pelophylax perezi & 29SPB81 & 49,00 & 177,89 & 79,56 & 36,00 & 4901,23 & 294,59 & 76,90 & 217,69 & 136,93 & 238,02 & 241,00 & 116,18 & $\begin{array}{l}476,69 \\
\end{array}$ & 75,25 & 1,00 & 63,82 & 206,57 & 12,51 & 22,87 & $\begin{array}{l}183,93 \\
\end{array}$ \\
\hline Pelophylax perezi & 29SPB82 & 101,00 & 177,98 & 79,33 & 35,82 & 4964,47 & 295,56 & 76,60 & 218,96 & 144,32 & 238,62 & 241,52 & 115,22 & $\begin{array}{l}472,48 \\
\end{array}$ & 74,62 & 1,00 & 63,57 & 203,23 & 12,62 & 23,47 & 180,27 \\
\hline Pelophylax perezi & 29SPB83 & 99,00 & 177,82 & 81,79 & 35,97 & 5067,99 & 299,41 & 74,67 & 224,73 & \begin{tabular}{|l|l|}
146,24 \\
\end{tabular} & 239,98 & 242,83 & \begin{tabular}{|l|l|}
113,78 \\
\end{tabular} & 473,24 & 74,27 & 1,00 & 62,87 & 202,07 & 13,64 & 23,87 & 179,64 \\
\hline Pelophylax perezi & 29SPB84 & 101,00 & $\begin{array}{ll}174,38 \\
\end{array}$ & 87,23 & 36,64 & 5210,35 & $\begin{array}{l}303,54 \\
\end{array}$ & $\begin{array}{ll}68,52 \\
\end{array}$ & $\begin{array}{ll}235,02 \\
\end{array}$ & $\begin{array}{ll}120,05 \\
\end{array}$ & \begin{tabular}{|l|l|}
239,13 \\
\end{tabular} & 241,89 & $\begin{array}{l}109,09 \\
\end{array}$ & $\begin{array}{l}493,86 \\
4\end{array}$ & 76,00 & 1,26 & 61,76 & 209,21 & 15,46 & 24,91 & 188,50 \\
\hline Pelophylax perezi & 29SPB85 & 100,00 & $\begin{array}{l}172,92 \\
\end{array}$ & 91,72 & 37,08 & \begin{tabular}{|l|}
5321,27 \\
\end{tabular} & $\begin{array}{ll}307,98 \\
\end{array}$ & 64,69 & 243,29 & 115,49 & 239,49 & 242,16 & 106,45 & $\begin{array}{l}504,88 \\
\end{array}$ & 76,49 & 1,83 & 61,00 & 212,53 & 17,19 & 25,68 & 193,27 \\
\hline Pelophylax perezi & 29SPB86 & 100,00 & 169,77 & 96,12 & 37,83 & 5442,40 & 311,10 & 59,32 & 251,78 & 111,16 & 238,45 & 241,03 & 102,23 & 523,43 & 77,89 & 2,00 & 60,25 & 218,73 & 18,97 & 26,66 & 201,01 \\
\hline Pelophylax perezi & 29SPB87 & 100,00 & 168,34 & 99,61 & 38,00 & 5531,28 & 314,37 & 56,26 & 258,11 & 108,81 & 238,52 & 241,06 & $\begin{array}{ll}99,98 \\
\end{array}$ & $\begin{array}{l}531,65 \\
\end{array}$ & 78,12 & 2,02 & 59,57 & 220,72 & 20,46 & 27,36 & 204,23 \\
\hline Pelophylax perezi & 29SPB88 & 100,00 & 162,84 & 103,31 & 38,20 & 5644,99 & 314,91 & 48,97 & 265,94 & 102,43 & 235,01 & 237,46 & 93,42 & 564,64 & 81,1 & 2,69 & 58,47 & 232,19 & 23,76 & 29,72 & 217,38 \\
\hline Pelophylax perezi & 29SPB89 & 100,00 & 153,82 & 106,46 & 38,23 & \begin{tabular}{|l|}
5757,84 \\
\end{tabular} & \begin{tabular}{ll|}
312,54 \\
\end{tabular} & 38,85 & 273,69 & 92,73 & 228,07 & 230,59 & 83,71 & 620,39 & 86,93 & 3,43 & 57,47 & 252,59 & 28,53 & 33,33 & 239,85 \\
\hline Pelophylax perezi & 29SPB90 & & & & & & & & & & & & & & & & & & & & \\
\hline Pelophylax perezi & 29SPB91 & 91,00 & 176,63 & $\begin{array}{ll}82,44 \\
\end{array}$ & 36,29 & 4991,09 & 297,27 & 73,43 & 223,85 & 129,05 & 238,21 & 241,18 & $\begin{array}{l}113,96 \\
\end{array}$ & \begin{tabular}{|l|l|}
495,43 \\
\end{tabular} & 77,43 & 1,00 & 63,73 & 213,67 & 13,84 & 23,77 & 191,63 \\
\hline Pelophylax perezi & 29SPB92 & 101,00 & 176,34 & 83,35 & 36,08 & 5092,33 & 299,59 & 72,02 & 227,57 & 134,69 & 239,17 & 242,06 & 112,29 & 493,55 & 77, & 1,00 & 63,20 & 211,19 & 14,05 & 24,00 & 189,05 \\
\hline Pelophylax perezi & 29SPB93 & 100,00 & 178,35 & 85,09 & 36,17 & 5167,99 & 304,21 & 72,76 & 231,45 & 147,42 & 242,25 & 244,99 & 113,29 & 482,24 & 75,46 & 1,00 & 62,70 & 205,42 & 14,09 & 24,00 & 183,32 \\
\hline Pelophylax perezi & 29SPB94 & 101,00 & 174,68 & 89,65 & 36,78 & 5315,18 & 307,38 & 66,53 & 240,84 & 122,55 & 241,05 & 243,73 & 108,15 & $\begin{array}{l}502,46 \\
\end{array}$ & 77,16 & 1,28 & 61,65 & 212,05 & 15,74 & \begin{tabular}{|l|l}
24,94 \\
\end{tabular} & 191,58 \\
\hline Pelophylax perezi & 29SPB95 & 99,00 & 169,82 & $\begin{array}{ll}94,92 \\
\end{array}$ & 37,18 & \begin{tabular}{|l|}
5462,90 \\
\end{tabular} & $\begin{array}{l}310,08 \\
\end{array}$ & 58,89 & 251,19 & 110,79 & 238,72 & 241,25 & 101,85 & 531,43 & 79,77 & 2,00 & 60,74 & 222,38 & 18,52 & 26,68 & 203,61 \\
\hline Pelophylax perezi & 29SPB96 & 100,00 & 169,28 & $\begin{array}{ll}98,16 \\
\end{array}$ & 37,82 & 5549,99 & $\begin{array}{l}313,89 \\
\end{array}$ & 56,72 & 257,17 & \begin{tabular}{|l|l|}
109,34 \\
\end{tabular} & 239,57 & 242,12 & 100,46 & $\begin{array}{l}534,59 \\
\end{array}$ & 79,41 & 2,00 & 60,10 & 222,36 & 19,56 & 27,16 & 204,72 \\
\hline Pelophylax perezi & 29SPB97 & 100,00 & 170,11 & 100,77 & 38,00 & 5609,81 & 317,98 & 56,11 & 261,87 & 109,56 & 241,47 & 243,77 & 100,57 & \begin{tabular}{|l|l|}
529,92 \\
\end{tabular} & 78,18 & 2,00 & 59,68 & 219,39 & 20,10 & 27,11 & 202,56 \\
\hline Pelophylax perezi & 29SPB98 & 100,00 & 164,84 & 104,28 & 38,01 & 5721,95 & 318,91 & 49,21 & 269,70 & 103,34 & 238,19 & 240,41 & \begin{tabular}{ll|}
94,44 \\
\end{tabular} & 558,94 & 80,74 & 2,51 & 58,66 & 229,30 & 23,06 & 29,22 & 214,00 \\
\hline Pelophylax perezi & 29SPB99 & 100,00 & 152,23 & 107,69 & 38,00 & 5848,46 & 313,92 & 35,78 & 278,14 & 90,23 & 227,96 & 230,29 & 81,17 & 635,97 & 88,77 & 3,60 & 57,37 & 257,79 & 29,35 & 34,22 & 245,06 \\
\hline Pelophylax perezi & 29SPC00 & 101,00 & 165,29 & 112,18 & 42,05 & 5145,05 & 322,05 & 59,05 & 263,01 & 112,51 & 230,68 & 235,07 & 103,90 & 548,84 & 80,47 & 2,00 & 59,99 & 232,29 & 24,28 & 25,03 & 228,07 \\
\hline Pelophylax perezi & 29SPC01 & 100,00 & 165,98 & 111,91 & 42,01 & 5165,10 & 322,97 & $\begin{array}{l}59,96 \\
\end{array}$ & 263,01 & \begin{tabular}{|l|l|}
112,77 \\
\end{tabular} & 231,50 & 236,05 & $\begin{array}{l}104,19 \\
\end{array}$ & $\begin{array}{l}549,03 \\
\end{array}$ & 79,49 & 2,02 & 59,40 & 230,39 & 25,61 & 25,86 & 226,94 \\
\hline Pelophylax perezi & 29SPC02 & 101,00 & 166,33 & 110,50 & 41,87 & 5160,53 & 322,00 & 60,85 & 261,15 & 112,99 & 231,84 & 236,18 & 104,34 & 552,50 & 78,82 & 2,58 & 58,68 & 229,86 & 26,91 & 27,28 & 227 \\
\hline Pelophylax perezi & 29SPC03 & 101,00 & 160,69 & 108,62 & 41,23 & $\begin{array}{l}5185,48 \\
\end{array}$ & 316,10 & 56,55 & 259,55 & $\begin{array}{l}107,39 \\
\end{array}$ & 227,90 & 231,14 & 98,85 & 592,32 & 82,64 & 3,04 & 57,66 & 243,29 & 30,44 & 30,45 & 242,18 \\
\hline Pelophylax perezi & 29SPC04 & 100,00 & 161,82 & 106,48 & 41,04 & 5164,14 & \begin{tabular}{ll|}
314,94 \\
\end{tabular} & 58,80 & \begin{tabular}{|l|l|}
256,14 \\
\end{tabular} & \begin{tabular}{|l|l|}
108,27 \\
\end{tabular} & 229,01 & 231,91 & $\begin{array}{l}100,14 \\
\end{array}$ & 589,98 & 81,44 & 3,02 & 57,23 & 241,04 & $\begin{array}{ll}30,93 \\
\end{array}$ & \begin{tabular}{l|l}
30,93 \\
\end{tabular} & 240,44 \\
\hline Pelophylax perezi & 29SPC05 & 101,00 & 163,99 & 104,51 & 40,97 & 5131,42 & $\begin{array}{l}314,60 \\
\end{array}$ & $\begin{array}{ll}61,82 \\
\end{array}$ & 252,78 & $\begin{array}{l}109,97 \\
\end{array}$ & 230,79 & 233,51 & $\begin{array}{l}102,35 \\
\end{array}$ & 583,41 & 80,05 & 3,00 & 57,05 & 237,34 & 31,10 & 31,10 & 236,97 \\
\hline Pelophylax perezi & 29SPC06 & 100,00 & 163,16 & 102,61 & 40,53 & 5122,15 & 312,29 & 62,04 & 250,25 & 105,59 & 229,36 & 232,55 & 101,71 & 596,58 & 81,61 & 3,75 & 56,34 & 241,45 & 33,24 & 33,24 & 241,42 \\
\hline Pelophylax perezi & 29SPC07 & 101,00 & 162,37 & 101,10 & 40,03 & 5119,50 & 310,44 & 61,96 & 248,48 & 101,92 & 229,31 & 231 & 100,87 & 613,08 & 83, & 4,00 & 55,95 & 247,58 & 35,10 & 35,10 & 24 \\
\hline Pelophylax perezi & 29SPC08 & 100,00 & 160,69 & $\begin{array}{ll}99,94 \\
\end{array}$ & 39,98 & 5 & 308,49 & 60,77 & & \begin{tabular}{|l|l|}
99,37 \\
\end{tabular} & 228,08 & 230,42 & $\begin{array}{ll}99,08 \\
\end{array}$ & 640,14 & 87, & 4,12 & 55,88 & 258,78 & 36,81 & 36,81 & 258,78 \\
\hline Pelophylax perezi & 29SPC09 & 100,00 & 162,42 & $\begin{array}{ll}99,67 \\
\end{array}$ & 39,97 & \begin{tabular}{|l|}
5141,97 \\
\end{tabular} & 309,99 & 62,39 & 247,60 & 101,25 & 228,39 & 232,14 & 100,70 & 646,09 & 89,10 & 4,17 & 55,93 & 261,45 & 37,30 & 37,32 & 261,45 \\
\hline Pelophylax perezi & 29SPC10 & 101,00 & \begin{tabular}{ll|}
168,64 \\
\end{tabular} & 109,86 & 41,74 & 5166,21 & 322,54 & $\begin{array}{ll}61,98 \\
\end{array}$ & 260,56 & 115,16 & 234,22 & 238,31 & 106,22 & \begin{tabular}{|l|l|}
527,47 \\
\end{tabular} & 76,84 & 2,00 & 59,79 & 222,91 & 23,19 & 24,74 & 216,76 \\
\hline Pelophylax perezi & 29SPC11 & 101,00 & 167,94 & 110,49 & 41,60 & 5210,14 & 323,28 & 61,00 & 262,28 & 113,82 & 234,09 & 238,19 & 105,04 & 534,53 & 76,94 & 2,02 & 59,23 & 223,80 & 24,49 & 25,59 & 218, \\
\hline Pelophy & 12 & 99,00 & 16 & 18 & 41, & 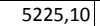 & 2 & 0,97 & 62, & 8 & 14 & & 104 & 540,49 & 76 & 2,27 & 58,39 & 224,17 & 26,18 & 27,20 & 21 \\
\hline Pelophylax perezi & 29SPC13 & 101,00 & 160,51 & 109,02 & 41,00 & 5282,23 & 317,10 & 54,79 & 262,31 & 105,93 & 228,42 & 232,21 & 97,33 & 589,14 & 81,72 & 3,00 & 57,24 & 240,98 & $\begin{array}{ll}30,63 \\
\end{array}$ & 30,77 & 238, \\
\hline Pelophylax perezi & 29SPC14 & 101,00 & 162,18 & 107,55 & 40,99 & 5257,45 & 316,92 & 57,16 & 259,76 & 107,77 & 229,61 & 233,36 & 99,09 & 584,99 & 80,21 & 3,18 & 56,79 & 237,86 & 31,36 & 31,48 & 236,03 \\
\hline
\end{tabular}




\begin{tabular}{|c|c|c|c|c|c|c|c|c|c|c|c|c|c|c|c|c|c|c|c|c|c|}
\hline TAXON & UTM & $\mathrm{km} 2$ & B101 & B102 & $\mathrm{BIO3}$ & B104 & B105 & B106 & 8107 & B108 & 8109 & B1010 & BIO11 & BIO12 & B1013 & BIO14 & BIO15 & B1016 & B1017 & B1018 & B1019 \\
\hline Pelophylax perezi & 29SPC15 & 99,00 & 165,51 & 106,22 & 40,89 & 5234,90 & 318,45 & 60,80 & 257,65 & 110,85 & 232,12 & 236,15 & 102,37 & 570,58 & 77,63 & 3,01 & 56,58 & 231,28 & 30,94 & 31,19 & 229,58 \\
\hline Pelophylax perezi & 29SPC16 & 101,00 & 164,63 & 104,87 & $\begin{array}{l}40,48 \\
\end{array}$ & 5233,01 & 316,59 & 60,68 & 255,91 & 109,99 & 231,29 & 235,31 & 101,53 & 584,22 & 79,00 & 3,59 & 56,01 & 235,55 & 32,65 & 32,69 & 234,44 \\
\hline Pelophylax perezi & 29SPC17 & 99,00 & 163,81 & 103,55 & $\begin{array}{ll}40,05 \\
\end{array}$ & 5233,55 & 314,91 & 60,52 & 254,39 & 108,59 & 230,76 & 234,53 & 100,84 & 601,24 & 81,32 & 4,00 & 55,57 & 241,35 & 34,91 & 34,91 & 240,92 \\
\hline Pelophylax perezi & 29SPC18 & 101,00 & 160,60 & 102,15 & 39,90 & 5255,88 & 311,74 & 58,30 & 253,45 & 102,59 & 228,97 & 231,89 & 97,68 & 638,67 & 86,96 & 4,34 & 55,44 & 256,29 & 37,43 & 37,43 & 256,26 \\
\hline Pelophylax perezi & 29SPC19 & 101,00 & 161,79 & 101,60 & 39,82 & 5264,89 & 312,60 & 59,40 & 253,21 & 104,32 & 229,51 & 233,04 & 98,68 & 646,77 & 88,31 & 4,52 & 55,33 & 259,77 & 38,18 & 38,21 & 259,71 \\
\hline Pelophylax perezi & 29SPC20 & 100,00 & 167,25 & 108,79 & 41,00 & 5254,52 & 320,84 & 59,51 & 261,33 & 112,50 & 233,96 & 237,92 & 103,49 & 532,54 & 76,72 & 2,00 & 59,38 & 223,71 & 23,36 & 25,51 & 216,45 \\
\hline Pelophylax perezi & 29SPC21 & 100,00 & 168,08 & 109,25 & 41,01 & 5274,95 & 322,74 & 60,09 & 262,65 & 113,04 & 235,19 & 238,98 & 104,03 & 530,51 & 75,64 & 2,06 & 58,64 & 220,93 & 24,62 & 26,39 & 214,45 \\
\hline Pelophylax perezi & 29SPC22 & 101,00 & 168,42 & 109,29 & 40,99 & 5297,34 & 323,47 & 60,32 & 263,15 & 113,02 & 235,75 & 239,61 & 104,16 & 533,19 & 75,13 & 2,37 & 58,07 & 220,33 & 25,82 & 27,36 & 214,65 \\
\hline Pelophylax perezi & 29SPC23 & 100,00 & 165,26 & 109,13 & \begin{tabular}{|l|l|}
40,97 \\
\end{tabular} & 5331,75 & 321,37 & 57,58 & 263,80 & 109,62 & 233,19 & 237,03 & 100,88 & 556,98 & 77,25 & 3,00 & 57,18 & 227,79 & 28,54 & 29,44 & 223,46 \\
\hline Pelophylax perezi & 29SPC24 & 100,00 & 165,85 & 108,43 & 40,86 & 5334,76 & 321,51 & 58,32 & 263,18 & 109,86 & 233,76 & 237,63 & 101,18 & 558,27 & 76,57 & 3,00 & 56,60 & 226,87 & 29,57 & 30,35 & 223,10 \\
\hline Pelophylax perezi & $29 \mathrm{SPC} 25$ & 101,00 & 165,01 & 107,59 & 40,39 & 5344,68 & 320,41 & 58,02 & 262,39 & 109,00 & 233,26 & 236,94 & 100,45 & 569,88 & 77,21 & 3,12 & 55,98 & 230,09 & 31,34 & 31,72 & 227,01 \\
\hline Pelophylax perezi & 29SPC26 & 100,00 & 163,38 & 106,58 & 40,03 & 5357,52 & 318,45 & 57,03 & 261,42 & 107,29 & 231,94 & 235,68 & 98,68 & 588,79 & 78,97 & 3,99 & 55,43 & 236,50 & 33,58 & 33,74 & 234,22 \\
\hline Pelophylax perezi & 29SPC28 & 100,00 & 159,59 & 104,11 & 39,72 & 5380,03 & 313,91 & 54,76 & 259,15 & 102,98 & 229,49 & 232,40 & 95,14 & 642,65 & 86,77 & 4,51 & 54,97 & 256,99 & 38,20 & 38,24 & 255,93 \\
\hline Pelophylax perezi & 29SPC29 & 100,00 & 158,40 & 102,98 & 39,39 & 5393,15 & 312,64 & 54,31 & 258,34 & 102,07 & 228,38 & 231,60 & 94,01 & 668,10 & 90,58 & 5,07 & 54,64 & 267,01 & 40,43 & 40,47 & 266,42 \\
\hline Pelophylax perezi & 29SPC30 & 101,00 & 166,07 & 107,70 & \begin{tabular}{ll|}
40,62 \\
\end{tabular} & 5327,15 & 319,31 & 57,17 & 262,14 & 110,25 & 233,87 & 237,53 & 101,40 & 538,07 & 76,59 & 2,32 & 58,83 & 224,42 & 24,33 & 27,07 & 215,93 \\
\hline Pelophylax perezi & 29SPC31 & 100,00 & 166,25 & 108,74 & 40,75 & 5373,15 & 321,21 & 56,92 & 264,29 & 109,87 & 234,71 & 238,28 & 101,01 & 540,34 & 75,98 & 2,89 & 57,64 & 223,15 & 26,13 & 28,48 & 215,62 \\
\hline Pelophylax perezi & $29 \mathrm{SPC} 32$ & 100,00 & 168,44 & 108,99 & 40,68 & 5377,66 & 323,78 & 58,78 & 265,00 & 111,72 & 236,88 & 240,46 & 103,10 & 530,80 & 74,13 & 2,80 & 57,45 & 218,09 & 26,20 & 28,24 & 211,01 \\
\hline Pelophylax perezi & 29SPC33 & 100,00 & 168,65 & 109,01 & 40,48 & 5392,90 & 324,63 & 58,97 & 265,66 & 111,64 & 237,36 & 240,86 & 103,12 & 533,38 & 73,80 & 2,99 & 56,89 & 217,75 & 27,26 & 28,95 & 211,42 \\
\hline Pelophylax perezi & 29SPC34 & 101,00 & $\begin{array}{ll}167,87 \\
\end{array}$ & 109,05 & 40,35 & 5414,99 & 324,48 & 58,33 & 266,15 & 110,67 & 236,92 & 240,31 & 102,11 & 542,35 & 74,31 & 3,00 & 56,41 & 220,05 & 28,47 & 29,80 & 214,46 \\
\hline Pelophylax perezi & 29SPC35 & 100,00 & 167,02 & 108,80 & 40,12 & 5433,43 & 323,99 & 57,58 & 266,41 & 109,55 & 236,34 & 239,79 & 101,03 & 553,34 & 75,23 & 3,16 & 55,95 & 223,18 & 30,26 & 31,26 & 218,25 \\
\hline Pelophylax perezi & 29SPC36 & 101,00 & 164,36 & 108,31 & 40,00 & 5467,16 & 321,97 & 55,28 & 266,69 & \begin{tabular}{|l|l|}
106,72 \\
\end{tabular} & 234,42 & 237,79 & 98,15 & 577,66 & 77,9 & 3,98 & 55,18 & 231,45 & 33,13 & 33,78 & 227,34 \\
\hline Pelophylax perezi & 29SPC37 & 100,00 & 165,27 & 107,92 & 40,00 & 5472,45 & 322,58 & 56,23 & 266,34 & 107,39 & 235,64 & 238,79 & 98,97 & 581,16 & 78,36 & 4,00 & 54,85 & 232,22 & 34,01 & 34,58 & 228,44 \\
\hline Pelophylax perezi & 29SPC38 & 100,00 & 162,29 & 106,91 & 39,89 & 5492,93 & 319,66 & 54,09 & 265,57 & 104,35 & 233,02 & 236,21 & 95,88 & 614,36 & 82,31 & 4,41 & 54,57 & 244,89 & 36,96 & 37,18 & 241,92 \\
\hline Pelophylax perezi & 29SPC39 & 101,00 & 158,32 & 105,42 & 39,32 & 5511,46 & 315,80 & 51,43 & 264,37 & 100,70 & 229,73 & 232,91 & 92,33 & 658,86 & 88,45 & 5,04 & 54,28 & 262,54 & 40,31 & 40,40 & 260,37 \\
\hline Pelophylax perezi & $29 \mathrm{SPC} 40$ & 101,00 & 164,01 & 106,92 & 40,01 & 5409,63 & 317,65 & 54,14 & 263,51 & 107,14 & 233,05 & 236,42 & 98,43 & 550,22 & 77,29 & 2,92 & 57,95 & 227,62 & 25,75 & 28,88 & 218,07 \\
\hline Pelophylax perezi & 29SPC41 & 100,00 & 166,05 & 108,00 & 40,01 & 5437,09 & 321,08 & 55,40 & 265,69 & 108,56 & 235,40 & 238,69 & 99,84 & 540,63 & 75,50 & 3,00 & 57,42 & 222,30 & 26,20 & 29,02 & 213,41 \\
\hline Pelophylax perezi & $295 P C 42$ & 100,00 & 168,63 & 108,80 & 40,06 & 5456,22 & 324,43 & 57,49 & $\begin{array}{l}266,93 \\
2\end{array}$ & 110,51 & 238,29 & 241,35 & \begin{tabular}{|l|}
102,19 \\
\end{tabular} & 527,43 & 73,36 & 2,99 & 56,99 & 215,81 & 26,20 & 28,86 & 207,36 \\
\hline Pelophylax perezi & 29SPC43 & 101,00 & 167,88 & 109,24 & 40,02 & 5501,38 & 325,44 & 56,36 & 269,08 & 109,36 & 238,23 & 241,34 & 100,77 & 533,92 & 73,76 & 3,00 & 56,68 & 217,10 & 27,27 & 29,37 & 209,34 \\
\hline Pelophylax perezi & 29SPC44 & 100,00 & 168,91 & 109,81 & 40,04 & 5516,29 & 327,01 & 57,07 & 269,94 & 110,10 & 239,67 & 242,44 & 101,43 & 531,63 & 73,28 & 3,00 & 56,19 & 215,10 & 27,82 & 29,73 & 207,85 \\
\hline Pelophylax perezi & $295 P C 46$ & 100,00 & 168,21 & 110,05 & 40,00 & 5541,22 & 327,67 & 56,19 & 271,48 & 108,93 & 239,34 & 242,04 & 100,49 & 546,01 & 74,72 & 3,51 & 55,06 & 218,49 & 31,15 & 32,31 & 212,21 \\
\hline Pelophylax perezi & 29SPC47 & 101,00 & 167,52 & 110,02 & 40,00 & 5572,71 & 327,53 & 55,35 & 272,18 & 107,90 & 239,20 & 241,86 & 99,60 & 557,72 & 76,07 & 3,98 & 54,43 & 222,23 & 32,93 & 33,83 & 216,36 \\
\hline Pelophylax perezi & 29SPC48 & 100,00 & 166,22 & 109,81 & 39,98 & 5599,39 & 326,71 & 54,12 & 272,59 & 106,36 & 238,41 & 241,00 & $\begin{array}{ll}58,04 \\
98\end{array}$ & 575,10 & 78,17 & $\begin{array}{l}3,08 \\
4,08\end{array}$ & 54,29 & 228,73 & 34,55 & $\begin{array}{l}\mid 3,00 \\
35,15 \\
\end{array}$ & 223,27 \\
\hline Pelophylax perezi & 29SPC49 & 101,00 & 165,01 & 109,48 & 39,91 & 5613,73 & 325,70 & 53,33 & 272,37 & 105,11 & 237,55 & 240,08 & 96,82 & 595,18 & 80,41 & 4,58 & 53,77 & 236,19 & 36,72 & 37,23 & 231,34 \\
\hline Pelophylax perezi & 29SPC50 & 100,00 & 165,21 & 106,32 & 39,84 & 5479,81 & 318,78 & 54,19 & 264,59 & 107,29 & 235,18 & 238,30 & 98,45 & 542,76 & 76,27 & 2,7 & 57,73 & 223,62 & 25,01 & 28,78 & 212,74 \\
\hline Pelophylax perezi & 29SPC51 & 101,00 & 167,10 & 107,59 & 39,88 & 5507,90 & 322,31 & 55,03 & 267,28 & 108,55 & 237,41 & 240,46 & 99,80 & 533,46 & 74,70 & 3,00 & 57,20 & 218,51 & 25,75 & 29,11 & 208,22 \\
\hline Pelophylax perezi & 29SPC52 & 100,00 & 168,43 & 108,65 & 39,99 & 5543,99 & 325,30 & 55,72 & 269,58 & 109,37 & 239,34 & 242,17 & 100,59 & 526,22 & 73,52 & 3,00 & 56,66 & 214,39 & 26,14 & 29,12 & 204,65 \\
\hline Pelophylax perezi & 29SPC53 & 100,00 & $\begin{array}{l}10,45 \\
166,86\end{array}$ & $\begin{array}{l}109,05 \\
109,71\end{array}$ & 39,99 & 5586,67 & 325,93 & 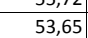 & $\begin{array}{l}272,28 \\
272\end{array}$ & $\begin{array}{l}107,14 \\
\end{array}$ & 238,44 & \begin{tabular}{|l|}
241,20 \\
\end{tabular} & \begin{tabular}{|c|}
98,53 \\
98,5
\end{tabular} & \begin{tabular}{|l|l|}
537,68 \\
\end{tabular} & $\begin{array}{l}7,3,58 \\
74,58\end{array}$ & 3,00 & 56,00 & \begin{tabular}{|l|}
217,67 \\
217,6
\end{tabular} & $\mid 27,47$ & 29,91 & 208,80 \\
\hline Pelophylax perezi & 29SPC54 & 100,00 & 167,86 & 110,35 & 40,00 & 5602,91 & 327,94 & 54,27 & 273,67 & 107,78 & 239,81 & 242,30 & 99,23 & 534,37 & 73,98 & 3,03 & 55,77 & 215,26 & 28,15 & 30,24 & 206,77 \\
\hline Pelophylax perezi & 29SPC55 & 101,00 & 166,82 & 111,02 & $\begin{array}{ll}39,95 \\
\end{array}$ & 5639,14 & 328,46 & 52,88 & 275,58 & 106,43 & 239,38 & 241,86 & 97,84 & 543,21 & 74,81 & 3,39 & 54,97 & 217,40 & 30,10 & 31,80 & 209,48 \\
\hline Pelophylax perezi & 29SPC56 & 100,00 & 166,97 & 111,41 & 39,97 & 5663,56 & 329,39 & 52,77 & 276,63 & 106,25 & 240,07 & 242,45 & 97,86 & 546,35 & 75,01 & 3,92 & 54,31 & 217,49 & 31,92 & 33,19 & 209,91 \\
\hline Pelophylax perezi & 29SPC57 & 100,00 & 168,13 & 111,79 & 39,96 & 5684,87 & 331,09 & 53,09 & 278,00 & 106,93 & 241,54 & 24 & 98,65 & 543,91 & 74, & 3,9 & 53,94 & 215,79 & 32,57 & 33,71 & 208,22 \\
\hline Pelophylax perezi & 29SPC58 & 100,00 & 168,60 & 112,24 & 39,97 & 5700,35 & 332,14 & 53,08 & 279,07 & 107,03 & 242,20 & 244,23 & 98,73 & 546,20 & 75,06 & 4,00 & 53,57 & 216,33 & 33,25 & 34,09 & 208,90 \\
\hline Pelophylax perezi & 29SPC59 & 100,00 & 167,52 & 112,36 & 39,84 & 5728,25 & 331,77 & 51,96 & 279,81 & 105,68 & 241,69 & 243,64 & 97,36 & 562,54 & 76,98 & 4,17 & 53,42 & 222,29 & 35,05 & 35,62 & 215,23 \\
\hline Pelophylax perezi & 29SPC60 & 100,00 & 163,18 & 106,26 & 39,15 & 5569,55 & 317,99 & 50,66 & 267,33 & 104,12 & 234,43 & 237,22 & 95,19 & 556,04 & 78,26 & 2,98 & 57,41 & 227,75 & 25,89 & 29,93 & 216,04 \\
\hline Pelophylax perezi & 29SPC61 & 100,00 & 162,79 & 107,89 & 39,17 & 5622,32 & 320,55 & 49,19 & 271,36 & 103,19 & 234,95 & 237,86 & 94,22 & 558,30 & 78,06 & 3,08 & 56,97 & 227,34 & 26,79 & 30,50 & 216,45 \\
\hline Pelophylax perezi & 29SPC62 & 100,00 & 167,16 & 108,97 & 39,37 & 5633,15 & 325,76 & 52,92 & 272,84 & $\begin{array}{l}107,02 \\
\end{array}$ & 239,42 & 241,86 & $\begin{array}{l}4,2< \\
98,14 \\
\end{array}$ & 532,84 & 74, & 3,00 & 56,49 & 216,13 & 26,27 & 29,60 & 205,40 \\
\hline Pelophylax perezi & 29SPC63 & 101,00 & 165,10 & 110,21 & 39,51 & 5678,03 & 326,27 & 50,42 & 275,85 & 104,51 & 238,20 & 240,63 & 95,64 & 545,39 & 75,90 & 3,00 & 56,10 & 219,89 & 27,74 & 30,49 & 209,94 \\
\hline Pelophylax perezi & 29SPC64 & 101,00 & 165,09 & 111,09 & 39,43 & 5713,22 & 327,85 & 49,66 & 278,20 & 104,05 & $\begin{array}{l}238,78 \\
\end{array}$ & 241,18 & 95,33 & 546,52 & 75,67 & 3,30 & 55,16 & 218,88 & 29,32 & 31,59 & 209,42 \\
\hline Pelophylax perezi & 29SPC65 & 99,00 & 164,63 & 111,94 & 39,49 & 5746,92 & 328,91 & 48,54 & 280,37 & 103,08 & 238,90 & 241,08 & 94,49 & 551,15 & 75,98 & 3,93 & 54,29 & 219,39 & 31,55 & 33,24 & 210,27 \\
\hline Pelophylax perezi & $29 S P C 66$ & 101,00 & 163,96 & 112,50 & 39,32 & 5777,11 & 329,45 & 47,39 & 282,05 & 102,15 & 238,82 & 240,75 & 93,51 & 556,83 & 76,5 & 4,01 & 54,10 & 220,64 & 32,59 & 34,07 & 211,91 \\
\hline Pelophylax perezi & 29SPC67 & $\begin{array}{l}100,00 \\
100\end{array}$ & 163 & 1112,86 & 39 & 5799,65 & 32 & \begin{tabular}{|l|l}
46,44 \\
46,
\end{tabular} & $\begin{array}{l}283,24 \\
283\end{array}$ & \begin{tabular}{|l|}
101,10 \\
10,15
\end{tabular} & \begin{tabular}{|l|}
238,40 \\
238
\end{tabular} & \begin{tabular}{|l|}
240,30 \\
\end{tabular} & \begin{tabular}{l|l}
32,42 \\
92,4
\end{tabular} & \begin{tabular}{|l|}
560,405 \\
5652
\end{tabular} & $\mid 77,51$ & $\begin{array}{l}4,110 \\
4,10\end{array}$ & 53,61 & $\mid$\begin{tabular}{|l|}
223,34 \\
223
\end{tabular} & $\begin{array}{l}32,03 \\
34,08\end{array}$ & $\begin{array}{l}34,170 \\
35,10\end{array}$ & 214,86 \\
\hline Pelophylax perezi & 29SPC68 & 101,00 & 165,88 & 113,77 & 39,39 & 5827,84 & 333,01 & 48,04 & 284,97 & 102,98 & 241,62 & 243,26 & 94,45 & 550,29 & 75,81 & 4,00 & 53,27 & 216,66 & 33,90 & 34,73 & 207,97 \\
\hline Pelophylax perezi & 29SPC69 & 100,00 & 168,82 & 114,62 & 39,47 & 5851,69 & 336,48 & 49,70 & $\begin{array}{l}286,78 \\
\end{array}$ & 105,11 & $\begin{array}{l}244,84 \\
244\end{array}$ & 246,10 & $\begin{array}{l}96,77 \\
96,7\end{array}$ & 535,56 & $\begin{array}{l}74,10 \\
74,10\end{array}$ & 4,00 & 52,84 & 210,37 & 33,94 & 34,49 & 201,39 \\
\hline Pelophylax perezi & 29SPC70 & 100,00 & 161,09 & 106,73 & 38,95 & 5675,07 & 318,19 & 46,80 & 271,38 & 100,66 & 233,89 & 236,54 & 91,70 & 571,07 & 80,41 & 3,15 & 57,24 & 232,70 & 26,59 & 31,03 & 220,3 \\
\hline Pelophylax perezi & $29 S P C 71$ & 101,00 & 158,40 & 108,44 & 38,5 & 5732,58 & 318,87 & 43,40 & 275,47 & 97,48 & 232,29 & 234,86 & 88,52 & 587,30 & 81,78 & 3,33 & 56,56 & 237,71 & 28,70 & 32,39 & 226 \\
\hline Pelophylax perezi & \begin{tabular}{|l|}
$295 P C 72$ \\
$29 S P C$
\end{tabular} & $\begin{array}{l}100,00 \\
100\end{array}$ & $\begin{array}{ll}150,40 \\
165,22\end{array}$ & $\begin{array}{l}1009,44 \\
10,58\end{array}$ & 年 & 5735,12 & 326,20 & $\begin{array}{l}5,404 \\
49,42 \\
\end{array}$ & $\begin{array}{l}27,46,78 \\
276,\end{array}$ & \begin{tabular}{r|}
103,68 \\
103
\end{tabular} & \begin{tabular}{|l|}
239,04 \\
239
\end{tabular} & \begin{tabular}{|l|}
241,32 \\
241
\end{tabular} & $\begin{array}{l}0,325 \\
95,01 \\
\end{array}$ & \begin{tabular}{|l|l|}
543,63 \\
\end{tabular} & $\begin{array}{l}\mid c 1,10 \\
76,32\end{array}$ & 年, & $\begin{array}{l}0,56,35 \\
56,5\end{array}$ & \begin{tabular}{|l|}
219,52 \\
21,1
\end{tabular} & $\frac{20,0}{26,65}$ & $\begin{array}{l}2,33 \\
30,28 \\
\end{array}$ & \begin{tabular}{|l|}
208,00 \\
\end{tabular} \\
\hline Pelophylax perezi & 29SPC73 & 100,00 & 164,62 & 110,88 & 39,01 & 5774,34 & 327,87 & 47,88 & 279,99 & 102,55 & 239,21 & 241,35 & 94,00 & 546,35 & 76,21 & 3,05 & 55,68 & 219,18 & 27,99 & 31,12 & 208,24 \\
\hline Pelophylax perezi & 29SPC74 & 100,00 & 162,33 & 111,87 & 39,01 & 5819,58 & 327,60 & 45,12 & 282,49 & 99,79 & 237,63 & 239,69 & 91,24 & 560,86 & 77,53 & 3,71 & 54,81 & 223,50 & 30,66 & 33,10 & 213,25 \\
\hline Pelophylax perezi & $29 S P C 75$ & 100,00 & 160,62 & 112,54 & 38,99 & 5859,96 & 327,79 & 43,08 & 284,70 & 97,82 & 236,75 & 238,6 & 89, & 570,99 & 78,47 & 4,01 & 54,31 & 226,36 & 32,31 & 34,26 & 216 \\
\hline Pelophylax perezi & 29SPC76 & 101,00 & 159,65 & 113,05 & 39,00 & 5884,03 & 28,04 & 41,70 & 286,34 & 96,49 & 236,10 & 238,09 & 88,08 & 578,22 & 79,15 & 4,05 & 53,77 & 228,21 & 33,88 & 35,32 & 218,64 \\
\hline
\end{tabular}




\begin{tabular}{|c|c|c|c|c|c|c|c|c|c|c|c|c|c|c|c|c|c|c|c|c|c|}
\hline TAXON & UTM & $\mathrm{km2}$ & B101 & $\mathrm{B1O2}$ & $\mathrm{BIO3}$ & B104 & B105 & B106 & B107 & B108 & $\mathrm{BIO9}$ & 81010 & B1011 & BIO12 & BIO13 & 81014 & B1015 & B1O16 & B1017 & B1018 & B1019 \\
\hline Pelophylax perezi & 29SPC77 & 99,00 & 161,64 & 113,86 & 39,01 & 5906,86 & 330,81 & 43,08 & 287,73 & 97,98 & 238,62 & 240,14 & 89,56 & 564,18 & 77,44 & 4,05 & 53,31 & 221,79 & 34,09 & 35,34 & 212,05 \\
\hline Pelophylax perezi & 29SPC80 & 101,00 & 154,66 & 107,93 & 38,41 & 5795,37 & 315,84 & 39,03 & 276,81 & 93,23 & 229,63 & 232,06 & 84,21 & 614,21 & 85,61 & 3,64 & 56,86 & 248,62 & 29,24 & 33,59 & 236,45 \\
\hline Pelophylax perezi & $29 \mathrm{SPC} 81$ & 99,00 & 159,18 & 109,25 & 38,81 & 5818,30 & 321,64 & 42,67 & 278,97 & 97,08 & 234,43 & 236,60 & 88,26 & 583,86 & 81,56 & 3,29 & 56,41 & 235,44 & 28,32 & 32,34 & 223,32 \\
\hline Pelophylax perezi & 29SPC82 & 101,00 & 160,19 & 110,52 & 38,84 & 5854,69 & 324,58 & 42,86 & 281,71 & 97,50 & 235,97 & 238,01 & 88,63 & 575,40 & 80,09 & 3,43 & 55,90 & 230,86 & 28,88 & 32,50 & 219,15 \\
\hline Pelophylax perezi & 29SPC83 & 100,00 & 162,91 & 111,65 & 38,96 & 5873,63 & 328,54 & 44,51 & 284,04 & 99,78 & 238,88 & 240,86 & 91,00 & 557,23 & 77,57 & 3,32 & 55,43 & 222,59 & 28,81 & 32,01 & 210,99 \\
\hline Pelophylax perezi & 29SPC84 & 101,00 & 157,50 & 112,40 & 38,91 & 5936,03 & 326,01 & 39,01 & 286,99 & 93,97 & 234,75 & 236,48 & 85,22 & 589,00 & 80,89 & 4,03 & 54,68 & 233,65 & 32,11 & 34,68 & 222,91 \\
\hline Pelophylax perezi & 29SPC85 & 100,00 & 154,08 & 112,77 & 38,61 & 5968,82 & 324,12 & 35,77 & 288,36 & 90,35 & 231,94 & 233,88 & 81,75 & 611,60 & 83,11 & 4,36 & 53,93 & 241,21 & 34,97 & 36,92 & 231,16 \\
\hline Pelophylax perezi & $295 P C 86$ & 100,00 & 156,27 & 113,57 & 38,80 & 5976,05 & 326,95 & 37,27 & 289,67 & 92,08 & 234,28 & 235,96 & 83,77 & 595,57 & \begin{tabular}{|l|l|}
81,03 \\
\end{tabular} & 4,27 & 53,38 & 233,99 & 35,05 & 36,73 & 223,79 \\
\hline Pelophylax perezi & 29SPC87 & 101,00 & 159,43 & 114,49 & 38,96 & 6000,35 & 331,08 & 39,33 & 291,75 & 94,80 & 237,95 & 239,14 & 86,38 & 570,55 & 78,01 & 4,14 & 52,95 & 223,31 & 34,51 & 36,02 & 212,68 \\
\hline Pelophylax perezi & 29SPC90 & 100,00 & 155,39 & 109,04 & 38,17 & 5882,69 & 318,88 & 38,08 & 280,80 & 92,63 & 231,65 & 233,82 & 83,79 & 613,37 & 85,57 & 3,45 & 56,86 & 247,51 & 28,96 & 33,52 & 234,93 \\
\hline Pelophylax perezi & 29SPC91 & 101,00 & 158,57 & 110,27 & 38,30 & 5915,33 & 323,67 & 40,32 & 283,35 & 95,27 & 235,23 & 237,27 & 86,32 & 589,82 & 82,32 & 3,35 & 56,42 & 237,01 & 28,48 & 32,65 & 224,46 \\
\hline Pelophylax perezi & 29SPC92 & 99,00 & 153,35 & 111,44 & 38,22 & 5977,65 & 321,58 & 34,63 & 286,95 & 89,59 & 231,15 & 233,13 & 80,78 & 621,02 & 85,31 & 3,99 & 55,51 & 247,66 & 31,83 & 35,31 & 236,26 \\
\hline Pelophylax perezi & 29SPC93 & 101,00 & 159,94 & 112,53 & 38,63 & 5969,28 & 328,46 & 40,33 & 288,14 & 95,84 & 237,50 & 239,16 & 87,01 & 576,55 & 79,75 & 3,52 & 55,27 & 229,36 & 29,91 & 33,20 & 217,51 \\
\hline Pelophylax perezi & 29SPC94 & 99,00 & 158,64 & 113,32 & 38,53 & 6010,83 & 329,04 & 38,53 & 290,51 & 93,99 & 236,90 & 238,53 & 85,32 & 581,60 & 79,89 & 3,74 & 54,58 & 230,01 & 31,40 & 34,26 & 218,55 \\
\hline Pelophylax perezi & 29SPC95 & 101,00 & 153,03 & 113,44 & 38,21 & 6051,86 & 325,26 & 33,25 & 292,01 & 88,29 & 232,23 & 233,77 & 79,68 & $\mid 615,80$ & 83,41 & 4,51 & 53,75 & 241,99 & 35,09 & 37,22 & 231,30 \\
\hline Pelophylax perezi & 29SPC96 & 100,00 & 150,56 & 113,48 & 38,09 & 6081,97 & 323,90 & 31,03 & 292,87 & 85,66 & 230,35 & 231,96 & 77,15 & 631,10 & 84,78 & 4,83 & 53,20 & 246,78 & 37,25 & 38,97 & 236,59 \\
\hline Pelophylax perezi & $295 P C 97$ & 100,00 & 160,76 & 115,31 & 38,64 & 6068,26 & 333,90 & 38,94 & 294,96 & 95,06 & 240,01 & 241,08 & 86,54 & 555,76 & 76,01 & 4,06 & 53,00 & 216,93 & 32,91 & 34,71 & 205,42 \\
\hline Pelophylax perezi & 29SPC99 & 100,00 & 165,35 & 116,18 & 38,94 & 6062,52 & 338,82 & 42,56 & 296,26 & 99,26 & 244,25 & 245,25 & 90,75 & 516,90 & 71,06 & 4,00 & 51,87 & 200,16 & 32,14 & 34,00 & 187,97 \\
\hline Pelophylax perezi & 29SPD00 & 101,00 & 164,58 & 99,37 & 39,79 & 5146,66 & 311,81 & 64,14 & 247,67 & 103,56 & 230,05 & 234,15 & 102,51 & 650,04 & 89,94 & 4,54 & 55,90 & 263,25 & 37,71 & 38,10 & 263,25 \\
\hline Pelophylax perezi & 29SPD01 & 101,00 & 164,77 & 98,75 & 39,30 & 5155,83 & 311,99 & 64,27 & 247,72 & 104,12 & 230,51 & 234,52 & 102,75 & 667,05 & 92,81 & 5,00 & 55,91 & 270,59 & 38,92 & 39,36 & 270,59 \\
\hline Pelophylax perezi & 29SPD02 & 100,00 & 167,21 & 98,91 & 39,28 & 5169,43 & 314,35 & 66,14 & 248,21 & 109,00 & 233,19 & 236,94 & 104,65 & 665,74 & 92,82 & 4,9 & 55,84 & 270,11 & 38,65 & 39,55 & 270,11 \\
\hline Pelophylax perezi & 29SPD03 & 101,00 & 167,25 & 98,55 & 39,03 & 5191,98 & 314,55 & 65,88 & 248,68 & 109,20 & 233,68 & 237,16 & 104,42 & 682,99 & $\begin{array}{l}2,75 \\
95,73 \\
\end{array}$ & 5,00 & 55,90 & 277,45 & 39,46 & 40,56 & 277,45 \\
\hline Pelophylax perezi & 29SPD04 & 101,00 & 167,18 & 98,12 & 39,00 & 5207,99 & 314,58 & 65,51 & 249,07 & 108,01 & 233,88 & 237,27 & 104,14 & 701,80 & 98,94 & 5,02 & 55,98 & 285,48 & 40,41 & 41,68 & 285,48 \\
\hline Pelophylax perezi & $29 \mathrm{SPD} 05$ & 100,00 & 164,19 & 97,09 & 38,45 & 5241,36 & 311,97 & 63,09 & 248,88 & 101,06 & 231,63 & 234,92 & 100,91 & 747,79 & 106,27 & 5,92 & 55,64 & 304,62 & 44,26 & 45,40 & 304,62 \\
\hline Pelophylax perezi & 29SPD06 & 101,00 & 162,42 & 96,54 & 38,07 & 5278,41 & 310,58 & 61,03 & 249,54 & 98,67 & 230,34 & 233,67 & 98,67 & 781,05 & 111,75 & 6,01 & 55,70 & 318,61 & 46,15 & 47,22 & 318,61 \\
\hline Pelophylax perezi & 29SPD07 & 100,00 & 163,07 & 96,93 & 38,15 & 5303,94 & 311,69 & 60,67 & 251,02 & 99,04 & 231,54 & 234,37 & 98,93 & 789,75 & 113,19 & 6,18 & 55,53 & 321,77 & 47,18 & 48,37 & 321,77 \\
\hline Pelophylax perezi & 29SPD08 & 101,00 & 164,65 & 97,86 & 38,19 & 5326,48 & 313,87 & $\begin{array}{l}0,86 \\
60,86\end{array}$ & 253,01 & 100,50 & 233,51 & 235,92 & 99,80 & 788,15 & $\mid 112,94$ & $\frac{0,100}{6,20}$ & 55,25 & 320,35 & 47,34 & $\begin{array}{l}48,77 \\
48,7\end{array}$ & 320,35 \\
\hline Pelophylax perezi & 29SPD09 & 101,00 & 161,29 & 97,32 & 37,86 & 5371,68 & 311,23 & 57,29 & 253,94 & 96,06 & 230,99 & 233,26 & 96,06 & 833,96 & 120,30 & 6,85 & 55,16 & 339,27 & 50,81 & 51,89 & 339,27 \\
\hline Pelophylax perezi & 29SPD11 & 101,00 & 164,59 & 100,59 & 39,14 & 5276,51 & 314,93 & 62,16 & 252,77 & 107,17 & 232,23 & 235,88 & 101,03 & 662,80 & 91,24 & 5,00 & 55,36 & 266,99 & 39,18 & 39,92 & 266,87 \\
\hline Pelophylax perezi & $29 S P D 12$ & 100,00 & 166,36 & 100,31 & 39,03 & 5282,65 & 316,66 & 63,77 & 252,89 & 110,21 & 234,10 & 237,65 & 102,66 & 666,77 & 92,14 & 5,00 & 55,42 & 268,94 & 39,34 & 40,14 & 268,71 \\
\hline Pelophylax perezi & $29 \mathrm{SPD} 13$ & 100,00 & 165,32 & 99,37 & 38,84 & 5312,71 & 315,68 & 63,01 & 252,67 & 107,43 & 233,46 & 237,16 & 101,29 & 694,89 & 96,87 & 5,21 & 55,44 & 280,93 & 41,01 & 42,06 & 280,87 \\
\hline Pelophylax perezi & 29SPD14 & 101,00 & 165,21 & 98,75 & 38,04 & 5330,92 & 315,60 & $\begin{array}{l}62,83 \\
62\end{array}$ & \begin{tabular}{|l|}
252,77 \\
\end{tabular} & $\begin{array}{l}106,32 \\
10,45\end{array}$ & 233,90 & 237,29 & 101,11 & \begin{tabular}{|l|l|}
714,56 \\
\end{tabular} & \begin{tabular}{|r|}
100,17 \\
\end{tabular} & 5,54 & 55,28 & \begin{tabular}{|l|l|}
289,08 \\
\end{tabular} & 42,56 & $\begin{array}{l}42,00 \\
43,73 \\
\end{array}$ & 289,07 \\
\hline Pelophylax perezi & 29SPD15 & 99,00 & 162,46 & 97,29 & 38,02 & 5371,46 & 312,91 & 60,64 & 252,27 & 98,53 & 231,79 & 235,15 & 97,96 & 757,44 & 107,32 & 5,99 & 55,27 & 307,57 & 45,20 & 46,33 & 307,57 \\
\hline Pelophylax perezi & 29SPD16 & 100,00 & 161,78 & 96,94 & 37,96 & 5407,71 & 312,48 & 59,44 & 253,04 & 96,84 & 231,64 & 234,87 & 96,84 & 780,17 & 111,29 & 6,00 & 55,41 & 317,28 & 46,43 & 47,58 & 317,28 \\
\hline Pelophylax perezi & 29SPD17 & 100,00 & 162,40 & 97,18 & 37,83 & 5441,73 & 313,80 & 59,03 & 254,77 & 97,30 & 232,95 & 235,84 & 96,87 & 787,81 & 112,55 & 6,00 & 55,10 & 319,82 & 47,48 & 48,64 & 319,82 \\
\hline Pelophylax perezi & 29SPD18 & 100,00 & 165,73 & 98,61 & 37,78 & 5466,37 & 317,80 & 60,42 & 257,38 & 102,76 & 236,73 & 238,93 & 99,37 & 766,83 & 109,26 & 6,00 & 55,04 & 310,27 & 46,09 & 47,75 & 310,24 \\
\hline Pelophylax perezi & $\begin{array}{l}\text { 29SPPD19 } \\
\text { 29SP }\end{array}$ & 100,00 & $\begin{array}{l}103,173 \\
163,73\end{array}$ & $\begin{array}{l}0,0,01 \\
98,30\end{array}$ & $\begin{array}{ll}37,10 \\
3,49\end{array}$ & $\begin{array}{l}54011,66 \\
5511,6\end{array}$ & 31,00 & $\begin{array}{ll}57,86 \\
57\end{array}$ & \begin{tabular}{|l|}
258,59 \\
\end{tabular} & \begin{tabular}{|l|}
99,38 \\
99,0
\end{tabular} & \begin{tabular}{|l|}
235,47 \\
\end{tabular} & $\mid$ & $\begin{array}{l}95,73 \\
96,75\end{array}$ & \begin{tabular}{|l|}
798,0404 \\
\end{tabular} & \begin{tabular}{|l|}
114,38 \\
14,0
\end{tabular} & $0,0,44$ & $\begin{array}{l}54,049 \\
54,99\end{array}$ & $\mid \begin{array}{l}\mid 10,27 \\
322,98\end{array}$ & $\begin{array}{l}40,05 \\
48,53\end{array}$ & $\begin{array}{ll}49,92 \\
49,92\end{array}$ & 322,24 \\
\hline Pelophylax perezi & 29SPD20 & 100,00 & 159,85 & 102,48 & 39,07 & 5401,49 & 313,94 & 55,83 & 258,10 & 103,21 & 229,40 & 233,08 & 95,22 & 674,09 & 91,73 & 5,03 & 54,81 & 269,90 & 40,77 & 40,90 & 269,22 \\
\hline Pelophylax perezi & 29SPD21 & 100,00 & 164,55 & 102,79 & 39,06 & 5396,16 & 318,34 & 59,78 & 258,56 & 107,75 & 233,89 & 237,44 & 99,64 & 654,05 & 88,96 & 5,00 & 54,91 & 262,27 & 39,32 & 39,95 & 261,14 \\
\hline Pelophylax perezi & 29SPD22 & 100,00 & 166,06 & 102,14 & 39,02 & 5404,88 & 319,60 & 61,34 & 258,25 & 109,06 & 235,63 & 238,95 & 100,95 & 661,05 & 90,44 & 5,06 & 54,90 & 265,60 & \begin{tabular}{l|l}
39,65 \\
\end{tabular} & 40,57 & 264,47 \\
\hline Pelophylax perezi & $29 S P D 23$ & 101,00 & 162,56 & 99,87 & 38,44 & 5420,56 & 315,60 & 59,50 & 256,09 & 105,28 & 232,51 & 236,07 & 97,74 & 712,61 & 98,85 & 5,84 & 54,81 & 286,88 & 43,34 & 44,26 & 286,62 \\
\hline Pelophylax perezi & 29SPD24 & 100,00 & 163,64 & 99,38 & 38,08 & 5448,06 & 316,78 & 60,27 & 256,51 & 106,05 & 234,11 & 237,44 & 98,42 & 720,95 & $\begin{array}{r}100,47 \\
\end{array}$ & 5,90 & 54,74 & 290,40 & 43,93 & 45,10 & 290,08 \\
\hline Pelophylax perezi & $29 S P D 25$ & 101,00 & 160,69 & 97,33 & 37,76 & 5474,17 & 313,32 & 58,49 & 254,84 & 98,78 & 231,64 & 235,06 & 95,46 & 766,08 & 108,18 & 6,11 & 55,04 & 309,96 & 46,21 & 47,49 & 309,96 \\
\hline Pelophylax perezi & 29SPD26 & 101,00 & 160,01 & 96,71 & 37,40 & 5512,44 & 312,78 & 57,41 & 255,37 & 95,55 & 231,52 & 234,88 & 94,22 & 787,61 & 111,94 & 6,14 & 55,06 & 319,04 & 47,62 & 48,89 & 319,04 \\
\hline Pelophylax perezi & 29SPD27 & 100,00 & $\begin{array}{lll}161,47 \\
\end{array}$ & 97,40 & 37,06 & 5567,78 & 315,3 & 57,12 & 258,21 & 98,03 & 233,97 & 236,64 & 94,68 & 784,94 & 111,68 & 6,06 & 54,87 & 317,36 & 47,71 & 48,92 & 317,33 \\
\hline Pelophylax perezi & 29SPD28 & 101,00 & 163,53 & 98,34 & 37, & \begin{tabular}{|l}
5619,06 \\
\end{tabular} & 318, & 57,26 & $\begin{array}{l}261,16 \\
2616\end{array}$ & \begin{tabular}{|l|}
101,12 \\
10,12
\end{tabular} & 236,92 & 238,95 & 95,64 & \begin{tabular}{|l|l|}
774,94 \\
\end{tabular} & 110,22 & 5,99 & 54,79 & 312,52 & 47,14 & 年48,58 & 312,37 \\
\hline Pelophylax perezi & 29SPD29 & 101,00 & 165,74 & 99,41 & 37,31 & 5638,23 & 320,90 & 57,92 & 262,98 & 103,96 & 239,38 & 240,89 & 97,06 & 762,84 & 108,38 & 5,99 & 54,66 & 306,90 & 46,46 & 48,16 & 306,55 \\
\hline Pelophylax perezi & 29SPD30 & 100,00 & 161,50 & 105,37 & 39,15 & 5515,50 & 318,91 & 54,19 & 264,71 & 103,47 & 232,66 & 236,00 & 95,16 & 649,40 & 87,17 & 5,00 & 54,22 & 259,03 & 39,70 & 40,00 & 256,64 \\
\hline Pelophylax perezi & 29SPD31 & 101,00 & 164,08 & 105,16 & 39,06 & 5516,52 & 321,40 & 56,66 & 264,73 & 105,84 & 235,25 & 238,34 & 97,68 & 647,09 & 86,94 & 5,00 & 54,20 & 258,42 & 39,55 & 40,13 & 255,93 \\
\hline Pelophylax perezi & $29 S P D 32$ & 101,00 & 164,90 & 104,14 & 38,99 & 5524,03 & 321,94 & 57,97 & 263,97 & 106,51 & 236,26 & 239,30 & 98,44 & 659,01 & 89,18 & 5,07 & 54,34 & 263,67 & 40,15 & 41,02 & 261,42 \\
\hline Pelophylax perezi & $\begin{array}{l}\text { 29SPDS33 } \\
\text { 29SP }\end{array}$ & 100,00 & 162,66 & 101,92 & $\begin{array}{l}30, \\
38,\end{array}$ & \begin{tabular}{|l}
$52,033,15$ \\
5535
\end{tabular} & 318 & 57,36 & \begin{tabular}{|l|}
261,57 \\
267
\end{tabular} & \begin{tabular}{|l|}
104,52 \\
10,51
\end{tabular} & 234,36 & \begin{tabular}{|l|}
237,56 \\
237
\end{tabular} & $\begin{array}{l}0,44 \\
96,38 \\
\end{array}$ & \begin{tabular}{|l|}
699,47 \\
699,4
\end{tabular} & $\begin{array}{l}\mid c 5,10 \\
95,88\end{array}$ & 5,75 & 54,18 & \begin{tabular}{|l|}
280,39 \\
280
\end{tabular} & | 43,21 & $\begin{array}{l}1,0<4 \\
44,24 \\
\end{array}$ & 278,84 \\
\hline Pelophylax perezi & $295 P D 34$ & 101,00 & 160,24 & 99,30 & 37,85 & 5550,93 & 315,39 & 56,72 & 258,67 & 102,24 & 232,29 & 235,74 & 94,27 & 740,95 & \begin{tabular}{|l|}
103,04 \\
\end{tabular} & 6,14 & 54,40 & 298,01 & 45,47 & 46,65 & 297,21 \\
\hline Pelophylax perezi & 29SPD35 & 100,00 & 150,96 & 93,90 & 36,71 & 5549,48 & 303,30 & 51,48 & 251,82 & \begin{tabular}{|c|c|c|}
87,76 \\
\end{tabular} & 223,30 & 227,27 & 86,22 & 847,69 & $\begin{array}{l}120,82,8 \\
\end{array}$ & $\frac{0,144}{7,24}$ & 54,84 & 343,56 & $\begin{array}{l}45,47 \\
52,06\end{array}$ & $\begin{array}{l}43,06 \\
53,06\end{array}$ & 343,56 \\
\hline Pelophylax perezi & $29 S P D 36$ & 101,00 & 153,98 & 94,90 & 36,77 & 5604,19 & 307,60 & 52,43 & 255,18 & 91,66 & 227,18 & 230,49 & 87,92 & 831,12 & 118,49 & 6,95 & 54,64 & 336,25 & 51,13 & 52,08 & 336,14 \\
\hline Pelophylax perezi & $29 S P D 37$ & 100,00 & 162,36 & 98,66 & 37,05 & 5674,95 & 318,45 & 56,13 & 262,32 & 101,76 & 236,42 & 238,79 & 94,20 & 758,86 & 106,97 & 5,99 & 54,36 & 305,26 & 46,45 & 47,80 & 304,45 \\
\hline Pelophylax perezi & $\begin{array}{l}\text { 29SPD38 } \\
\text { 29SP }\end{array}$ & $\begin{array}{l}101,00 \\
100\end{array}$ & $\begin{array}{l}102,50 \\
162,82\end{array}$ & $\begin{array}{ll}98,80 \\
98,87\end{array}$ & $\begin{array}{l}30,03 \\
36,98\end{array}$ & $\mid 5732,46$ & $\begin{array}{l}31,49,40 \\
319,80\end{array}$ & $\begin{array}{l}0,15 \\
55,39 \\
\end{array}$ & \begin{tabular}{|l|}
264,42 \\
264
\end{tabular} & \begin{tabular}{|l|}
101,39 \\
10
\end{tabular} & $\begin{array}{l}30,44 \\
237,89 \\
\end{array}$ & \begin{tabular}{|l|}
239,77 \\
230
\end{tabular} & $\begin{array}{l}4,20 \\
93,75 \\
\end{array}$ & \begin{tabular}{|l|}
761,730 \\
\end{tabular} & \begin{tabular}{|l|}
107,66 \\
100
\end{tabular} & $\begin{array}{l}3,93 \\
5,93 \\
\end{array}$ & 54,35 & \begin{tabular}{|l|}
305,98 \\
305
\end{tabular} & 460,83 & $\begin{array}{l}4,100 \\
48,18 \\
\end{array}$ & $\begin{array}{l}304,45 \\
305,15\end{array}$ \\
\hline Pelophylax perezi & 29SPD39 & 101,00 & 163,06 & 99,01 & 36,69 & 5777,13 & 320,64 & 54,43 & 266,21 & 100,55 & 238,81 & 240,35 & 93,17 & 767,51 & 108,81 & 5,99 & 54,15 & 307,94 & 47,38 & 48,78 & 307,06 \\
\hline Pelophylax perezi & 29SPD40 & 100,00 & 160.85 & 107.88 & 39.32 & 5634,39 & 321.61 & 50,65 & 270.96 & $\mid 101.18$ & 233.86 & 236,68 & 93,03 & 641.53 & 85.81 & $5,19 \mid$ & 53.71 & 254,70 & 40,13 & 40,43 & 250,73 \\
\hline Pelophylax perezi & 29SPD41 & 100,00 & 162,43 & 107,64 & 39,01 & 5644,46 & 323,51 & 52,29 & 271,2 & 102,49 & 235, & 238,27 & 94, & 645,10 & 86,31 & 5,02 & 53,74 & 256,50 & 40,14 & 40,61 & 252,58 \\
\hline Pelophylax perezi & 29SPD42 & 100,00 & 164,73 & 107,12 & 39,01 & 5646,44 & 325,62 & 54,64 & 270,98 & 104,53 & 238,01 & 240,52 & 96,53 & 643,72 & 86,33 & 5,01 & 53,71 & 256,23 & 39,98 & 40,80 & 252,39 \\
\hline
\end{tabular}




\begin{tabular}{|c|c|c|c|c|c|c|c|c|c|c|c|c|c|c|c|c|c|c|c|c|c|}
\hline TAXON & UTM & $\mathrm{km} 2$ & B101 & B102 & $\mathrm{BIO3}$ & B104 & B105 & B106 & B107 & B108 & B109 & BIO10 & BIO11 & BIO12 & B1013 & BIO14 & BIO15 & B1016 & B1017 & BIO18 & B1019 \\
\hline Pelophylax perezi & 29SPD43 & 99,00 & 163,16 & 104,89 & 38,67 & 5647,58 & 323,13 & 54,71 & 268,42 & 103,38 & 236,58 & 239,30 & 95,26 & 675,98 & 91,26 & 5,35 & 53,69 & 269,65 & 42,25 & 43,30 & 266,46 \\
\hline Pelophylax perezi & 29SPD44 & 101,00 & 155,18 & 99,28 & 37,57 & 5640,11 & 312,16 & 51,31 & 260,85 & 96,60 & 228,72 & 232,15 & 88,58 & 767,07 & 106,42 & 6,42 & 54,01 & 307,69 & 47,74 & 48,74 & 306,19 \\
\hline Pelophylax perezi & $29 S P D 45$ & 99,00 & 145,56 & 94,44 & 36,50 & 5659,10 & 300,09 & 44,74 & 255,35 & 86,12 & 220,27 & 223,39 & 79,69 & 866,89 & 122,89 & 7,64 & 54,20 & 348,96 & 54,20 & 54,73 & 348,51 \\
\hline Pelophylax perezi & 29SPD46 & 100,00 & 156,64 & 97,92 & 36,98 & 5715,55 & 313,60 & 51,85 & 261,75 & 96,79 & 231,46 & 234,36 & 88,84 & 779,71 & 109,38 & 6,38 & 54,05 & 313,09 & 48,41 & 49,55 & 311,72 \\
\hline Pelophylax perezi & 29SPD47 & 100,00 & 161,78 & 99,90 & 37,00 & 5777,09 & 320,23 & 53,95 & 266,28 & 100,13 & 237,49 & 239,55 & 92,44 & 738,82 & 103,05 & 5,96 & 53,79 & 295,82 & 45,84 & 47,24 & 293,69 \\
\hline Pelophylax perezi & 29SPD48 & 100,00 & 163,51 & 100,30 & 37,01 & 5812,85 & 322,29 & 54,38 & 267,91 & 100,95 & 239,86 & 241,48 & 93,31 & 729,76 & 101,92 & 5,83 & 53,78 & 291,85 & 45,22 & 46,76 & 289,49 \\
\hline Pelophylax perezi & 29SPD49 & 99,00 & 164,02 & 100,39 & 36,89 & 5853,23 & 323,01 & 53,88 & 269,13 & 100,56 & 240,91 & 242,15 & 93,07 & 730,46 & 102,34 & 5,78 & 53,71 & 291,92 & 45,35 & 46,81 & 289,43 \\
\hline Pelophylax perezi & 29SPD50 & 101,00 & 161,35 & 110,94 & 39,34 & 5753,36 & 325,81 & 47,58 & 278,22 & \begin{tabular}{|l|l|}
99,84 \\
\end{tabular} & 236,19 & 238,25 & 91,60 & 621,37 & \begin{tabular}{|l|}
83,68 \\
\end{tabular} & 5,08 & 53,01 & 245,32 & 39,71 & 39,97 & 239,52 \\
\hline Pelophylax perezi & 29SPD51 & 100,00 & 164,01 & 111,44 & 39,36 & 5761,51 & 328,97 & 49,73 & 279,23 & 102,11 & 239,04 & 240,87 & 93,99 & 614,70 & 82,82 & 4,99 & 52,89 & 242,76 & 39,40 & 39,88 & 236,78 \\
\hline Pelophylax perezi & 29SPD52 & 101,00 & 166,26 & 111,13 & 39,15 & 5767,16 & 331,38 & 51,92 & 279,45 & 104,00 & 241,34 & 243,14 & 96,06 & 610,44 & 82,21 & 4,99 & 52,86 & 241,30 & 38,96 & 39,79 & 235,35 \\
\hline Pelophylax perezi & 29SPD53 & 101,00 & 162,51 & 107,88 & 38,71 & 5768,06 & 326,25 & 50,88 & 275,37 & 100,99 & 237,82 & 239,95 & 92,98 & 656,75 & 87,85 & 5,19 & 52,99 & 260,40 & 41,79 & 42,66 & 255,47 \\
\hline Pelophylax perezi & 29SPD54 & 100,00 & 159,58 & 104,37 & 37,96 & 5772,25 & 321,21 & 50,21 & 271,00 & 98,48 & 235,00 & 237,44 & 90,46 & 698,68 & 94,38 & 5,69 & 53,15 & 277,95 & 44,20 & 45,22 & 273,87 \\
\hline Pelophylax perezi & 29SPD55 & 101,00 & 155,24 & 100,88 & 37,30 & 5793,53 & 315,14 & 48,08 & 267,07 & 94,52 & 231,21 & 233,80 & 86,40 & 749,56 & 103,06 & 6,22 & 53,30 & 298,95 & 47,35 & 48,26 & 295,74 \\
\hline Pelophylax perezi & 29SPD56 & 101,00 & 157,86 & 100,85 & 37,00 & 5829,21 & 317,95 & 49,67 & 268,29 & 96,27 & 234,37 & 236,51 & 88,25 & 735,80 & 101,26 & 6,06 & 53,23 & 293,24 & 46,52 & 47,58 & 289,84 \\
\hline Pelophylax perezi & 29SPD58 & 101,00 & 160,07 & 100,45 & 36,76 & 5897,48 & 320,11 & 50,25 & 269,86 & 96,85 & 237,75 & 239,16 & 89,13 & 729,97 & 101,25 & 5,89 & 53,19 & 290,69 & 45,96 & 47,07 & 287,24 \\
\hline Pelophylax perezi & $29 S P D 59$ & 101,00 & 163,90 & 101,51 & 36,84 & 5918,49 & 324,06 & 52,29 & 271,77 & 99,59 & 241,73 & 242,68 & 92,03 & 700,88 & 96,96 & 5,47 & 53,10 & 278,58 & 43,96 & 45,45 & 274,74 \\
\hline Pelophylax perezi & $29 S P D 60$ & 100,00 & 168,81 & 115,08 & 39,66 & 5867,40 & 337,01 & 49,50 & 287,52 & 104,80 & 245,21 & 246,19 & 96,54 & 544,56 & 75,00 & 4,03 & 52,36 & 213,40 & 35,45 & 35,99 & 204,68 \\
\hline Pelophylax perezi & 29SPD61 & 100,00 & 167,71 & 115,31 & 39,86 & 5882,00 & 336,11 & 48,61 & 287,49 & 103,42 & 244,34 & 245,41 & 95,43 & 563,84 & 77,06 & 4,32 & 52,19 & 220,94 & 36,92 & 37,50 & 212,62 \\
\hline Pelophylax perezi & 29SPD62 & 100,00 & 165,88 & 114,38 & 39,38 & 5882,08 & 334,61 & 48,07 & 286,54 & 101,80 & 242,73 & 243,80 & 93,97 & 590,70 & 79,85 & 4,86 & 52,16 & 231,85 & 38,45 & 39,20 & 224,20 \\
\hline Pelophylax perezi & 29SPD63 & 99,00 & 165,28 & 111,71 & 39,01 & 5881.51 & 332,24 & 49,14 & 283,10 & $\mid$\begin{tabular}{|l|}
101.48 \\
\end{tabular} & 242,15 & 243,45 & 93,61 & 608,40 & 81,64 & 4,91 & 52.16 & 239,24 & 39,44 & 40,35 & 232,05 \\
\hline Pelophylax perezi & 29SPD64 & 101,00 & 163,57 & 108,86 & 38,40 & 5889,68 & 329,05 & 49,39 & 279,66 & 100,14 & 240,79 & 242,18 & 92,22 & 634,25 & 84,37 & 5,02 & 52,28 & 249,93 & 40,92 & 41,94 & 243,47 \\
\hline Pelophylax perezi & $29 S P D 65$ & 99,00 & 159,07 & 105,07 & 37,66 & 5905,09 & 322,77 & 47,30 & 275,47 & \begin{tabular}{|c|}
96,15 \\
96
\end{tabular} & 236,66 & 238,35 & 88,16 & 682,61 & 91,35 & 5,51 & 52,42 & 269,79 & 43,77 & 44,68 & 264,17 \\
\hline Pelophylax perezi & 29SPD66 & 100,00 & 155,77 & 102,29 & 36,99 & 5927,89 & 318,27 & 45,51 & 272,75 & 92,83 & 233,73 & 235,56 & 84,82 & 719,31 & $\begin{array}{l}97,68 \\
\end{array}$ & 5,96 & 52,67 & 284,73 & 46,32 & 47,04 & 279,75 \\
\hline Pelophylax perezi & 29SPD67 & 100,00 & 160,17 & 102,90 & 37,00 & 5953,39 & 322,70 & 48,59 & 274,10 & 96,39 & 238,64 & 239,99 & 88,50 & 689,63 & 93,57 & 5,52 & 52,62 & 272,83 & 43,92 & 45,00 & 267,58 \\
\hline Pelophylax perezi & 29SPD68 & 100,00 & 162,31 & 102,78 & 37,01 & 5974,32 & 324,56 & 49,86 & 274,70 & 97,69 & 240,99 & 242,01 & 89,96 & 677,68 & 92,17 & 5,34 & 52,48 & 267,94 & 43,03 & 44,25 & 262,65 \\
\hline Pelophylax perezi & 29SPD69 & 99,00 & 163,36 & 102,63 & 36,88 & 5985,69 & 325,23 & 50,46 & 274,77 & 98,32 & 242,23 & 242,91 & 90,58 & 672,44 & 91,76 & 5,20 & 52,53 & 265,70 & 42,64 & 44,03 & 260,42 \\
\hline Pelophylax perezi & 29SPD70 & 101,00 & 168,47 & 116,41 & 39,00 & 5985,76 & 339,92 & 40,32 & 293,60 & \begin{tabular}{|r|}
102,76 \\
\end{tabular} & \begin{tabular}{|l|}
246,63 \\
\end{tabular} & \begin{tabular}{|l|}
247,24 \\
\end{tabular} & 94,58 & 521,55 & $\frac{1,10}{72,42}$ & 4,00 & 51,71 & 202,79 & $\begin{array}{l}42,34 \\
34,94 \\
\end{array}$ & 35,31 & 192,28 \\
\hline Pelophylax perezi & 29SPD71 & 100,00 & 168,40 & 116,38 & 39,05 & 5976,06 & 339,55 & 46,77 & 292,79 & 102,82 & 246,31 & 247,10 & 94,75 & 533,62 & 73,51 & 4,00 & 51,58 & 207,55 & 35,67 & 36,27 & 197,40 \\
\hline Pelophylax perezi & $29 S P D 72$ & 101,00 & 167,95 & 115,53 & 39,09 & 5969,52 & 338,12 & 47,37 & 290,75 & 102,45 & 245,99 & 246,49 & 94,50 & 549,09 & 74,84 & 4,03 & 51,63 & 214,01 & 36,08 & 36,81 & 204,42 \\
\hline Pelophylax perezi & $29 S P D 73$ & 100,00 & 164,64 & 112,88 & 38,83 & 5980,29 & 333,86 & 46,27 & 287,60 & 99,49 & 242,99 & 243,82 & 91,55 & 586,46 & 78,71 & 4,75 & 51,56 & 228,94 & 38,45 & 39,36 & 220,19 \\
\hline Pelophylax perezi & $29 S P D 74$ & 101,00 & 160,95 & 109,50 & 38,06 & 5989,27 & 328,78 & 45,17 & 283,62 & 96,34 & 239,74 & 240,83 & 88,44 & 626,49 & 83,05 & 5,03 & 51,66 & 245,22 & 40,97 & 41,77 & 237,36 \\
\hline Pelophylax perezi & 29SPD75 & 100,00 & 160,41 & 107,47 & 37,79 & 6004,66 & 327,26 & 年 & \begin{tabular}{|l|}
281,61 \\
281
\end{tabular} & $\begin{array}{l}00,3476 \\
95,76\end{array}$ & \begin{tabular}{|l|}
239,45 \\
\end{tabular} & \begin{tabular}{|l|}
240,56 \\
240
\end{tabular} & $\begin{array}{l}0,474 \\
87,78 \\
\end{array}$ & \begin{tabular}{|l|l|}
640,06 \\
\end{tabular} & $\begin{array}{l}34,48 \\
84,\end{array}$ & 5,02 & 51,79 & $\begin{array}{l}250,86 \\
25,2\end{array}$ & 41,51 & 42,46 & 243,36 \\
\hline Pelophylax perezi & $295 P D 76$ & 101,00 & 158,10 & 105,10 & 37,02 & 6021,02 & 323,91 & 44,77 & 279,14 & 93,63 & 237,60 & 238,68 & 85,63 & 665,40 & 88,27 & 5,44 & 51,81 & 261,00 & 43,29 & 44,05 & 254,05 \\
\hline Pelophylax perezi & 29SPD77 & 100,00 & 163,55 & 105,60 & 37,01 & 6029,43 & 328,94 & 49,05 & 279,88 & 98,36 & 243,08 & 243,80 & 90,37 & 630,06 & 83,43 & 4,99 & 51,70 & 246,92 & 40,79 & 42,02 & 239,72 \\
\hline Pelophylax perezi & 29SPD78 & 101,00 & 163,18 & 104,46 & 36,98 & 6042,43 & 327,73 & 48,82 & 278,91 & 97,58 & 242,86 & 243,48 & 89,67 & 638,86 & 85,31 & 4,99 & 51,72 & 250,58 & 41,22 & 42,48 & 243,70 \\
\hline Pelophylax perezi & $295 P D 79$ & 100,00 & 164,08 & 103,93 & 36,99 & 6046,74 & 328,12 & 49,56 & 278,56 & 98,21 & 243,88 & 244,25 & 90,47 & 634,59 & 85,11 & 4,96 & 51,67 & 248,84 & 40,90 & 42,10 & 242,06 \\
\hline Pelophylax perezi & 29SPD80 & 100,00 & $\begin{array}{l}10,060 \\
166,48\end{array}$ & 116,63 & 39,00 & $\begin{array}{l}0040,16,54 \\
601,\end{array}$ & 338,82 & $\begin{array}{l}3,30 \\
43,80\end{array}$ & \begin{tabular}{|l|}
295,03 \\
\end{tabular} & 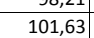 & \begin{tabular}{|l|}
$244,73,3$ \\
\end{tabular} & \begin{tabular}{|l|}
245,60 \\
\end{tabular} & $\begin{array}{ll}0,474 \\
92,25\end{array}$ & \begin{tabular}{|l|l|}
515,78 \\
515
\end{tabular} & $\begin{array}{l}\mid 03,11 \\
71,39\end{array}$ & 4,000 & 51,66 & \begin{tabular}{|l|}
200,01 \\
\end{tabular} & 33,50 & $\begin{array}{ll}42,10 \\
34,65\end{array}$ & $\begin{array}{l}24,00 \\
188,28\end{array}$ \\
\hline Pelophylax perezi & 29SPD81 & 100,00 & 167,66 & 116,18 & 39,00 & 6007,36 & 339,61 & 45,34 & 294,27 & 101,59 & 245,93 & 246,56 & 93,46 & 517,34 & 71,18 & 4,00 & 51,31 & 200,32 & 33,97 & 35,08 & 188,84 \\
\hline Pelophylax perezi & 29SPD83 & 100,00 & 164,86 & 113,41 & 38,41 & 6057,41 & 336,19 & 44,88 & 291,31 & 98,84 & 244,34 & 244,99 & 90,78 & 559,73 & 75,01 & 4,28 & 51,20 & 216,95 & 36,56 & 37,66 & 206,87 \\
\hline Pelophylax perezi & 29SPD84 & 100,00 & 164,51 & 111,56 & 38,02 & 6072,79 & 334,88 & 45,70 & 289,18 & 98,41 & 244,35 & 244,90 & 90,37 & 571,99 & 76,07 & 4,41 & 51,20 & 222,03 & 37,21 & 38,09 & 212,37 \\
\hline Pelophylax perezi & 29SPD85 & 100,00 & 162,03 & 109,12 & 37,66 & 6085,60 & 331,38 & 44,92 & 286,45 & $\begin{array}{l}96,06 \\
96,0\end{array}$ & 242,24 & 242,89 & 88,12 & 600,05 & 79,06 & 4,84 & 51,03 & 233,03 & 39,47 & 40,46 & 223,95 \\
\hline Pelophylax perezi & $29 S P D 86$ & 100,00 & 160,82 & 107,20 & 37,01 & 6100,64 & 329,33 & $\begin{array}{ll}44,68 \\
\end{array}$ & \begin{tabular}{|l|}
284,66 \\
\end{tabular} & 94,91 & 241,38 & 242,02 & 86,92 & $\begin{array}{l}614,69 \\
\end{array}$ & 80,48 & 4,97 & 51,01 & 238,84 & 40,42 & 41,25 & 230,18 \\
\hline Pelophylax perezi & 29SPD87 & 100,00 & 162,66 & 106,46 & 37,01 & 6105,22 & 330,23 & 46,67 & 283,56 & 96,46 & 243,22 & 243,79 & 88,46 & 606,97 & 79,40 & 4,95 & 50,99 & 235,81 & 40,01 & 41,02 & 227,34 \\
\hline Pelophylax perezi & 29SPD88 & 100,00 & 160,83 & 104,91 & 36,82 & 6114,80 & 327,59 & 45,66 & 281,93 & 94,69 & 241,76 & 242,15 & 86,66 & 623,56 & 82,11 & 5,00 & 51,16 & 242,62 & 40,83 & 41,62 & 234,50 \\
\hline Pelophylax perezi & 29SPD89 & 100,00 & 160,42 & 104,07 & 36,61 & 6124,59 & 326,65 & 45,32 & 281,34 & 93,82 & 241,47 & 241,73 & 86,14 & 627,26 & 83,17 & 5,00 & 51,11 & 244,16 & 41,07 & 41,74 & 236,20 \\
\hline Pelophylax perezi & $29 S P D 90$ & 100,00 & 167,01 & 116,32 & 38,96 & 6058,01 & 340,2 & 44,05 & 296,17 & 103,28 & 245,93 & 246,77 & 92,34 & 505,06 & 69,48 & 4,00 & 51,58 & 195,03 & 31,97 & 33,93 & 182,48 \\
\hline Pelophylax perezi & 29SPD94 & 101,00 & 162,61 & 111,41 & 37,79 & 6154,11 & 335,04 & 43,05 & 291,99 & 95,77 & 243,83 & 244,16 & 87,60 & 563,05 & 74,21 & 4,3 & 50,71 & 216,84 & 36,79 & 37,66 & 206,23 \\
\hline Pelophylax perezi & 29SPD95 & 100,00 & 161,11 & 109,48 & 37,20 & 6168,92 & 332,58 & 42,74 & 289,84 & 94,19 & 242,64 & 242,97 & 86,19 & 580,94 & 75,82 & 4,72 & 50,47 & 223,68 & 38,61 & 39,40 & 213,55 \\
\hline Pelophylax perezi & $29 S P D 96$ & 101,00 & 160,82 & 107,91 & 36,97 & 6178,85 & 331,39 & 43,34 & 288,05 & 93,88 & 242,63 & 242,93 & 85,88 & 586,53 & 76,25 & 4,64 & 50,48 & 226,01 & 38,76 & 39,28 & 216,13 \\
\hline Pelophylax perezi & 29SPD97 & 100,00 & 162,45 & 107,19 & 36,97 & 6180,94 & 332,20 & 45,06 & 287,14 & 95,38 & 244,22 & 244,52 & 87,40 & 580,10 & 75,34 & 4,52 & 50,45 & 223,50 & 38,32 & 39,01 & 213,86 \\
\hline Pelophylax perezi & $\begin{array}{l}\text { 29SPD99 } \\
\end{array}$ & 100,00 & $\frac{10,45}{158,30}$ & 104,49 & $\begin{array}{l}30, \\
36,\end{array}$ & $\begin{array}{ll}610,05,94 \\
6195,90\end{array}$ & 326 & $\begin{array}{l}5,270 \\
42,27 \\
\end{array}$ & \begin{tabular}{|l|}
284,01 \\
28,0
\end{tabular} & $\begin{array}{l}0,00 \\
90,98 \\
\end{array}$ & $\begin{array}{l}244,2< \\
240,64 \\
\end{array}$ & \begin{tabular}{|l|}
240,69 \\
240
\end{tabular} & $\begin{array}{l}1,404 \\
83,27 \\
\end{array}$ & \begin{tabular}{|l|l|l|l|l|}
610,56 \\
\end{tabular} & 79,83 & $\begin{array}{l}4,254 \\
5,00\end{array}$ & $\begin{array}{l}0,40,47 \\
50\end{array}$ & $\begin{array}{l}235,55 \\
230\end{array}$ & $\begin{array}{l}30,254 \\
40,64\end{array}$ & $\frac{30,01}{40,75}$ & $\begin{array}{l}21,00 \\
226,44\end{array}$ \\
\hline Pelophylax perezi & 29SPEOO & 100,00 & 156,61 & 96,31 & 37,36 & 5412,16 & 306,87 & 52,65 & 254,22 & 91,06 & 227,34 & 229,15 & 91,06 & 892,60 & 129,81 & 7,50 & 55,12 & 363,46 & 55,07 & 55,67 & 363,46 \\
\hline Pelophylax perezi & 29SPE01 & 101,00 & 148,83 & 94,02 & 36,76 & 5429,34 & 298,03 & 45,95 & $252.07 \mid$ & 83,36 & 220,92 & 221,77 & 83,36 & 983,23 & $\begin{array}{ll}144,85 \\
\end{array}$ & 8,69 & 55,36 & 401,42 & 60,77 & 60,98 & 401,42 \\
\hline Pelophylax perezi & 29SPE02 & 101,00 & 138,63 & 90,45 & 36,04 & 5409,04 & 285,24 & 37,94 & 247,30 & 73,95 & 211,46 & 211,53 & 73,95 & 1097,44 & 163,97 & 10,08 & 55,76 & 449,22 & 67,41 & 67,41 & 449,22 \\
\hline Pelophylax perezi & 29SPE10 & 100,00 & 159,18 & 97,18 & 36,95 & 5576,36 & 312,60 & 53,12 & 259,48 & 91,49 & 232,06 & 233,77 & 91,49 & 854,46 & 123,62 & 6,97 & 54,95 & 346,49 & 52,60 & 53,47 & 346 \\
\hline Pelophylax perezi & 29SPE11 & 101,00 & 157,91 & 97,35 & 36,95 & 5583,85 & 311,32 & 51,39 & 259,93 & 90,01 & 231,04 & 232,51 & 90,01 & 875,06 & $\begin{array}{ll}127,01 \\
\end{array}$ & 7,26 & 54,90 & 354,47 & 54,36 & 55,11 & 354,47 \\
\hline Pelophylax perezi & 29SPE12 & 100,00 & 151,78 & 95,52 & 36,56 & 5580,80 & 303,98 & 46,12 & 257,86 & 84,14 & 225,44 & 226,36 & 84,14 & 943,37 & 138,41 & 8,12 & 55,08 & 383,08 & 58,69 & 59,05 & 383,08 \\
\hline Pelophylax perezi & 29SPE20 & 100,00 & 159,02 & 97,11 & 36,27 & 5736,83 & 315,15 & 51,62 & 263,53 & 91,49 & 234,44 & 235,76 & 89,70 & 838,95 & 120,98 & 6,83 & 54,74 & 338,78 & 51,89 & 52,70 & 338,73 \\
\hline Pelophylax perezi & 29SPE21 & 100,00 & 157,59 & 97,04 & 36,15 & 5765,61 & 313,94 & 49,60 & 264,34 & 88,08 & 233,5 & 234 & 87, & 858,44 & 124,23 & 7,02 & 54,74 & 346,39 & 53,52 & 54,15 & 346,39 \\
\hline Pelophylax perezi & 29SPE22 & 100,00 & 153,76 & 96,17 & 36,13 & 5741,76 & 308,91 & 46,21 & 262,70 & 84,23 & 229,40 & 230,39 & 84,23 & 900,23 & 131,32 & 7,73 & 54,81 & 363,70 & 56,48 & 56,78 & 363,70 \\
\hline
\end{tabular}




\begin{tabular}{|c|c|c|c|c|c|c|c|c|c|c|c|c|c|c|c|c|c|c|c|c|c|}
\hline TAXON & UTM & $\mathrm{km2}$ & B101 & $\mathrm{B1O2}$ & $\mathrm{BIO3}$ & B104 & B105 & B106 & B107 & B108 & $\mathrm{BIO9}$ & B1010 & B1011 & B1O12 & BIO13 & 81014 & B1015 & B1O16 & B1017 & B1018 & B1019 \\
\hline Pelophylax perezi & 29SPE30 & 100,00 & 165,01 & 99,91 & 36,85 & 5785,91 & 322,58 & 55,11 & 267,47 & 101,66 & 240,95 & 241,99 & 94,62 & 754,97 & 106,97 & 6,00 & 54,14 & 302,59 & 46,47 & 48,13 & 301,33 \\
\hline Pelophylax perezi & 29SPE31 & 101,00 & 157,49 & 97,29 & 36,01 & 5870,90 & 315,45 & 48,45 & 267,00 & 91,57 & 234,94 & 235,83 & 86,60 & 833,36 & 120,00 & 6,90 & 54,25 & 334,68 & 52,14 & 52,80 & 334,45 \\
\hline Pelophylax perezi & 29SPE32 & 100,00 & 155,12 & 96,91 & 36,01 & 5844,35 & 312,09 & 46,21 & 265,88 & 88,22 & 232,29 & 232,95 & 84,38 & 856,54 & 123,96 & 7,15 & 54,26 & 343,94 & 53,86 & 54,35 & 343,80 \\
\hline Pelophylax perezi & 29SPE40 & 101,00 & 164,31 & 100,45 & 36,85 & 5868,35 & 323,23 & 53,36 & 269,86 & 100,41 & 241,48 & 242,36 & 92,96 & 733,33 & 103,07 & 5,98 & 53,64 & 292,77 & 45,60 & 47,25 & 290,38 \\
\hline Pelophylax perezi & 29SPE41 & 100,00 & 163,53 & 100,25 & 36,75 & 5876,42 & 322,10 & 52,19 & 269,90 & 99,20 & 240,77 & 241,49 & 91,83 & 744,16 & 105,12 & 6,05 & 53,53 & 296,93 & 46,41 & 48,04 & 294,75 \\
\hline Pelophylax perezi & 29SPE42 & 99,00 & 156,54 & 97,94 & 36,04 & 5903,14 & 314,45 & 46,30 & 268,15 & 92,15 & 234,38 & 234,94 & 84,72 & 808,24 & 115,72 & 6,78 & 53,88 & 322,90 & 50,98 & 51,71 & 321,60 \\
\hline Pelophylax perezi & 29SPE50 & 100,00 & 163,77 & 101,27 & 36,87 & 5932,29 & 323,69 & 51,76 & 271,94 & 99,08 & 241,85 & 242,54 & 91,55 & 705,68 & 98,12 & 5,53 & 53,11 & 280,54 & 44,12 & 45,66 & 276,80 \\
\hline Pelophylax perezi & 29SPE51 & 101,00 & 162,83 & 100,88 & 36,68 & 5941,95 & 322,45 & 50,59 & 271,86 & 97,88 & 241,23 & 241,63 & 90,42 & 716,97 & 100,21 & 5,86 & 53,12 & 284,78 & 45,20 & 46,64 & 281,24 \\
\hline Pelophylax perezi & 29SPE52 & 101,00 & 157,55 & 99,13 & 36,10 & 5958,68 & 316,43 & 46,10 & 270,33 & 92,54 & 236,26 & 236,52 & 84,95 & 761,84 & $\begin{array}{l}107,67 \\
\end{array}$ & 6,19 & 53,17 & 302,85 & 48,50 & 49,19 & 300,00 \\
\hline Pelophylax perezi & 29SPE60 & 101,00 & 160,83 & 101,30 & 36,43 & 6005,53 & 322,03 & 48,31 & 273,71 & 95,56 & 240,07 & 240,54 & 87,79 & 697,13 & 96,08 & 5,66 & 52,50 & 275,62 & 44,60 & 45,66 & 270,71 \\
\hline Pelophylax perezi & 29SPE61 & 99,00 & 159,52 & 100,65 & 36,13 & 6011,88 & 320,19 & 46,94 & 273,24 & 94,04 & 238,99 & 239,26 & 86,33 & 709,88 & 98,39 & 5,94 & 52,45 & 280,56 & 45,79 & 46,52 & 275,97 \\
\hline Pelophylax perezi & 29SPE62 & 100,00 & 155,44 & 99,42 & 36,04 & 6016,15 & 315,34 & 43,59 & 271,75 & 90,01 & 235,19 & 235,31 & 82,29 & 739,68 & 103,40 & 6,29 & 52,52 & 292,50 & 48,01 & 48,30 & 288,25 \\
\hline Pelophylax perezi & 29SPE70 & 101,00 & 160,68 & 102,50 & 36,39 & 6061,68 & 323,93 & 46,84 & 277,09 & 94,72 & 240,89 & 241,08 & 86,94 & 661,91 & 89,78 & 5,25 & 51,91 & 259,85 & 42,67 & 43,48 & 253,48 \\
\hline Pelophylax perezi & 29SPE71 & 100,00 & 159,82 & 101,92 & 36,35 & 6065,58 & 322,31 & 45,97 & 276,34 & 93,66 & 240,05 & 240,17 & 85,82 & 670,65 & 91,49 & 5,45 & 51,84 & 263,29 & 43,56 & 44,06 & 257,20 \\
\hline Pelophylax perezi & 29SPE72 & 101,00 & 157,64 & 101,21 & 36,08 & 6065,15 & 319,49 & 44,06 & 275,43 & 91,42 & 237,94 & 238,00 & 83,62 & $\begin{array}{l}684,95 \\
\end{array}$ & 93,96 & 5,83 & 51,77 & 268,81 & 45,03 & 45,28 & 262,93 \\
\hline Pelophylax perezi & 29SPE80 & 100,00 & 161,60 & 103,86 & 36,56 & 6119,63 & 326,96 & 46,28 & 280,68 & 94,92 & 242,58 & 242,65 & 87,03 & 621,49 & 82,74 & 5,02 & 51,02 & 241,96 & 40,81 & 41,16 & 234,20 \\
\hline Pelophylax perezi & 29SPE81 & 100,00 & 160,04 & 103,15 & 36,37 & 6120,16 & 324,52 & 44,95 & 279,57 & 93,18 & 240,99 & 241,01 & 85,30 & 632,97 & 84,87 & 5,11 & 51,11 & 246,61 & 41,57 & 41,67 & 239,18 \\
\hline Pelophylax perezi & 29SPE82 & 100,00 & 156,19 & 101,95 & 36,03 & 6125,07 & 319,99 & 41,74 & 278,25 & 89,41 & 237,48 & 237,48 & 81,48 & 657,45 & 88,73 & 5,76 & 50,90 & 256,01 & 44,06 & 44,06 & 248,87 \\
\hline Pelophylax perezi & 29SPE90 & 101,00 & 161,53 & 104,82 & 36,31 & 6179,27 & 328,69 & 45,03 & 283,66 & 94,00 & 243,44 & 243,47 & 86,17 & 590,59 & 77,21 & 4,79 & 50,34 & 227,83 & 39,41 & 39,47 & 218,83 \\
\hline Pelophylax perezi & 29SPE91 & 100,00 & 158,95 & 103,88 & 36,13 & 6177,81 & 325,38 & 42,89 & 282,49 & 91,39 & 240,88 & 240,89 & 83,55 & 606,26 & 79,87 & 5,05 & 50,38 & 234,12 & 40,67 & 40,69 & 225,45 \\
\hline Pelophylax perezi & 29SPE92 & 101,00 & 158,55 & 103,70 & 36,20 & 6167,91 & 324,27 & 42,50 & 281,77 & 90,89 & 240,40 & 240,40 & 83,11 & \begin{tabular}{|c|}
606,08 \\
\end{tabular} & 80,10 & 5,12 & 50,16 & 234,10 & 40,88 & 40,88 & 225,58 \\
\hline Pelophylax perezi & 29SQA19 & 10,00 & 178,00 & 87,00 & 37,00 & 4992,64 & 302,64 & 72,00 & 230,64 & $\begin{array}{r}136,73 \\
\end{array}$ & 240,55 & 243,45 & \begin{tabular}{|l|l|}
115,64 \\
\end{tabular} & 523,27 & 80,91 & 1,00 & 64,91 & 227,91 & 14,00 & 22,00 & 207,55 \\
\hline Pelophylax perezi & 29SQA26 & & & & & & & & & & & & & & & & & & & & \\
\hline Pelophylax perezi & 29SQA28 & 14,00 & 178,46 & 86,77 & 37,23 & 4954,31 & 301,69 & 73,00 & 228,69 & 152,23 & 240,62 & 243,69 & 116,85 & 536,15 & 83,08 & 1,00 & 65,62 & 234,08 & 14,00 & 22,00 & 214,69 \\
\hline Pelophylax perezi & 29SQA29 & 85,00 & 178,83 & 87,79 & 37,13 & 5027,68 & 304,23 & 72,22 & 232,02 & 143,22 & 241,99 & 245,02 & 116,11 & 528,25 & 81,26 & 1,00 & 64,74 & 230,03 & 14,15 & 22,00 & 210,30 \\
\hline Pelophylax perezi & 29SQA35 & 24,00 & 177,69 & 83,83 & 38,69 & 4534,21 & 291,17 & 77,52 & 213,66 & 155,45 & 234,41 & 238,17 & 122,10 & 557,24 & 92,62 & 0,00 & 67,28 & 248,90 & 12,69 & 20,00 & 230,62 \\
\hline Pelophylax perezi & $295 \mathrm{SA} 36$ & 95,00 & 177,07 & 84,66 & 38,31 & 4649,30 & 293,27 & 75,19 & 218,08 & $\begin{array}{l}153,02 \\
15,4\end{array}$ & $\begin{array}{l}235,24 \\
234\end{array}$ & 238,90 & 119,87 & 554,28 & $\begin{array}{l}2,0<1 \\
90,71\end{array}$ & 0,00 & $\begin{array}{l}06,20 \\
66,75\end{array}$ & 246,68 & 13,00 & 20,40 & 228,02 \\
\hline Pelophylax perezi & 29SQA37 & 70,00 & 177,22 & 84,36 & 37,45 & 4807,11 & 296,27 & 74,12 & 222,15 & 152,46 & 237,56 & 241,03 & 117,86 & 551,16 & 87,79 & 0,53 & 65,83 & 242,48 & 13,59 & 21,43 & 223,57 \\
\hline Pelophylax perezi & 29SQA38 & 99,00 & 178,11 & 85,82 & 37,06 & 4961,88 & 301,15 & 73,00 & 228,15 & 152,06 & 240,71 & 243,84 & 116,70 & 544,02 & 84,41 & 1,00 & 65,20 & 236,98 & 14,46 & 22,00 & 217,83 \\
\hline Pelophylax perezi & 29SQA39 & 100,00 & 178,93 & 88,43 & 37,01 & 5120,94 & 306,79 & 71,23 & 235,55 & 143,96 & 243,43 & 246,48 & 115,26 & 540,45 & 82,58 & 1,00 & 64,61 & 233,88 & 14,96 & 22,00 & 214,68 \\
\hline Pelophylax perezi & 29SQA43 & 19,00 & 179,33 & 70,04 & 35,96 & 4462,26 & 279,67 & 86,48 & 193,19 & 158,41 & 234,30 & 238,67 & 123,78 & 609,26 & 105,11 & 0,93 & 68,96 & 264,70 & 11,96 & 22,00 & 248,44 \\
\hline Pelophylax perezi & $29 \mathrm{SQA44}$ & 26,00 & 179,26 & 71,10 & 35,90 & 4487,74 & 281,03 & $\begin{array}{l}80,45 \\
85,62\end{array}$ & \begin{tabular}{|l|l}
195,41 \\
\end{tabular} & \begin{tabular}{|l|}
157,85 \\
\end{tabular} & $\begin{array}{l}234,28 \\
230\end{array}$ & \begin{tabular}{|l|}
238,97 \\
\end{tabular} & 123,28 & 601,95 & \begin{tabular}{|l|l|}
100,23 \\
\end{tabular} & 年, & 68,10 & 258,90 & $\begin{array}{l}11,90 \\
11,90\end{array}$ & 21,03 & 243,23 \\
\hline Pelophylax perezi & 29SQA45 & 69,00 & 176,93 & 76,35 & 36,36 & \begin{tabular}{|l|l|}
4649,63 \\
\end{tabular} & 286,27 & 79,15 & 207,12 & 153,94 & 234,81 & 238,93 & 119,44 & 587,01 & 95,92 & 0,38 & 66,81 & 255,15 & 13,02 & 21,31 & 237,94 \\
\hline Pelophylax perezi & $29 \mathrm{SQA46}$ & 101,00 & 175,51 & 79,22 & 36,27 & 4778,15 & 290,15 & 74,90 & 215,25 & 151,44 & 235,35 & 239,28 & 116,57 & 579,61 & 92,91 & 0,6 & 66,18 & 252,08 & 13,88 & 21,77 & 234,53 \\
\hline Pelophylax perezi & 29SQA47 & 99,00 & 176,25 & 80,88 & 35,97 & 4931,20 & 295,24 & 73,49 & 221,75 & 150,49 & 238,23 & 241,92 & 115,29 & 568,75 & 88,95 & 0,97 & 65,60 & 246,05 & 14,79 & 21,97 & 227,88 \\
\hline Pelophylax perezi & 29SQA48 & 99,00 & 177,43 & 83,96 & 36,08 & 5077,41 & 301,60 & 72,08 & 229,52 & 148,23 & 241,44 & 244,77 & 114,47 & 561,33 & 86,13 & 1,00 & 65,01 & 241,91 & 15,03 & 22,02 & 223,48 \\
\hline Pelophylax perezi & 29SQA49 & 101,00 & 178,51 & 88,45 & 36,54 & 5224,04 & 308,88 & 70,11 & 238,77 & 135,92 & 244,63 & 247,68 & 113,72 & 556,37 & 84,39 & 1,00 & 64,87 & 239,23 & 15,06 & 22,00 & 220,85 \\
\hline Pelophylax perezi & 29SQA52 & & & & & & & & & & & & & & & & & & & & \\
\hline Pelophylax perezi & 29SQA53 & 100,00 & 177,64 & 70,43 & 35,65 & \begin{tabular}{|l|l|}
4493,07 \\
\end{tabular} & 279,11 & 84,29 & 194,82 & 143,26 & 232,93 & 237,52 & 121,50 & 635,77 & 110,43 & 1,00 & 69,06 & 277,45 & 13,16 & 23,23 & 262,34 \\
\hline Pelophylax perezi & 29SQA54 & 93,00 & 177,06 & 70,42 & 34,92 & 4627,92 & 281,23 & 82,24 & 198,99 & 149,73 & 234,27 & 238,95 & 119,38 & 623,61 & 105,06 & 1,00 & 68,15 & 269,05 & 13,48 & 23,19 & 253,37 \\
\hline Pelophylax perezi & 29SQA55 & 100,00 & 176,14 & 71,50 & 34,46 & 4748,96 & 283,85 & 79,40 & 204,45 & 150,89 & 235,24 & 239,52 & 117,14 & 611,03 & 99,24 & 1,00 & 67,15 & 261,72 & 14,25 & 22,82 & 245,79 \\
\hline Pelophylax perezi & 29SQA56 & 100,00 & 173,87 & 72,93 & 33,94 & 4924,18 & 286,72 & 74,69 & 212,03 & 144,30 & 235,60 & 239,56 & 112,85 & 606,72 & 95,02 & 1,00 & 65,93 & 257,52 & 15,55 & 23,43 & 241,52 \\
\hline Pelophylax perezi & 29SQA57 & 100,00 & 174,19 & 75,94 & 34,00 & 5074,94 & 292,53 & 72,25 & 220,28 & 137,56 & 238,01 & 241,78 & 111,32 & 594,55 & 90,93 & 1,00 & 65,47 & 252,01 & 16,14 & 23,23 & 235,14 \\
\hline Pelophylax perezi & 29SQA58 & 101,00 & 175,78 & 81,62 & 34,94 & 5197,06 & 300,87 & 70,73 & 230,14 & 126,74 & 241,48 & 244,90 & 111,45 & 585,37 & 88,62 & 1,00 & 65,05 & 248,94 & 16,59 & 22,96 & 231,55 \\
\hline Pelophylax perezi & 29SQA59 & 100,00 & 177,81 & 88,22 & 36,01 & 5325,35 & 310,44 & 68,98 & 241,46 & 121,73 & 245,46 & 248,52 & 111,84 & 576,63 & 86,75 & 1,00 & 64,58 & 246,06 & 16,63 & 22,69 & 228,34 \\
\hline Pelophylax perezi & 29SQA60 & & & & & & & & & & & & & & & & & & & & \\
\hline Pelophylax perezi & 29SQA61 & 69,00 & 173,72 & 74,04 & 37,77 & 4251,75 & 275,40 & 81,89 & 193,51 & 129,78 & 226,25 & 230,55 & 120,81 & $\begin{array}{l}723,45 \\
\end{array}$ & 126,98 & 0, & 71,45 & 326,94 & 14,62 & 23,06 & 313,23 \\
\hline Pelophylax perezi & 29SQA62 & 96,00 & 173,91 & 72,69 & 36,69 & 4381,85 & 276,29 & 80,88 & $\begin{array}{l}195,42 \\
\end{array}$ & 128,33 & 228,08 & 232,35 & 119,18 & 703,15 & 122,12 & 1,00 & 70,45 & 313,64 & 14,39 & 23,54 & 299,47 \\
\hline Pelophylax perezi & 29SQA63 & 91,00 & 174,26 & 71,55 & 35,73 & 4530,08 & 278,14 & 80,13 & 198,02 & 127,05 & 230,42 & 234,79 & 117,85 & 680,79 & 116,33 & 1,00 & 69,49 & 299,66 & 14,39 & 23,80 & 284,77 \\
\hline Pelophylax perezi & 29SQA64 & 82,00 & 173,11 & 71,60 & 34,77 & 4697,90 & 280,25 & 77,27 & 202,98 & 123,76 & 231,64 & 235,93 & 114,68 & 667,31 & 111,07 & 1,00 & 68,47 & 289,70 & 14,79 & 24,00 & 274,71 \\
\hline Pelophylax perezi & 29SQA65 & 82,0 & 17 & $\begin{array}{ll}1,1,17 \\
71,\end{array}$ & 33,89 & 4 & 282 & 76,20 & \begin{tabular}{|l|}
206,74 \\
20,0
\end{tabular} & $\begin{array}{l}123,52 \\
\end{array}$ & \begin{tabular}{|l|}
233,764 \\
\end{tabular} & \begin{tabular}{|l|}
237,93 \\
237
\end{tabular} & \begin{tabular}{|l|}
113,34 \\
113
\end{tabular} & $\begin{array}{l}\mid c 0,1,11 \\
646,16\end{array}$ & \begin{tabular}{|l|}
104,12 \\
104
\end{tabular} & $\begin{array}{l}1,000 \\
1,00\end{array}$ & $\begin{array}{l}0,4,41 \\
67,41\end{array}$ & \begin{tabular}{|l|}
276,87 \\
27
\end{tabular} & $\begin{array}{l}4,15 \\
15,43 \\
\end{array}$ & 24,90 & 261,60 \\
\hline Pelophylax perezi & 29SQA66 & 81,00 & 172,10 & 71,69 & 33,18 & 5004,39 & 285,84 & 72,94 & 212,90 & 120,75 & 234,93 & 238,95 & 110,16 & 634,60 & 98,66 & 1,00 & 66,61 & 268,96 & 16,27 & 24,00 & 253,05 \\
\hline Pelophylax perezi & 29SQA67 & 74,00 & 172,12 & 74,46 & 33,22 & 5156,09 & 291,14 & 70,57 & 220,57 & 117,32 & 237,22 & 241,03 & 108,40 & 622,43 & $\begin{array}{l}94,41 \\
940\end{array}$ & 1,00 & 65,77 & 262,61 & 17,00 & 23,99 & 245,97 \\
\hline Pelophylax perezi & 29SQA68 & 77,00 & 174,05 & 82,09 & 34,77 & 5281,10 & 301,26 & 68,74 & 232,53 & 117,69 & 241,00 & 244,45 & 108,83 & 609,35 & 92,02 & 1,00 & 65,39 & 258,86 & 17,01 & 23,36 & 241,70 \\
\hline Pelophylax perezi & 29SQA69 & 71,00 & 177,33 & 89,51 & 36,24 & 538 & 312,16 & 68,35 & 243,82 & 119,56 & 245,90 & 248,96 & 11 & 592,09 & 89,20 & 1,00 & 65,02 & 252,94 & 17,00 & 23,00 & 235,42 \\
\hline Pelophylax perezi & 295QBOBO & 46,00 & 176,74 & $\begin{array}{l}5,34 \\
85,34 \\
\end{array}$ & $\begin{array}{l}30,24 \\
37,00\end{array}$ & 5008,82 & 291,10 & $\begin{array}{l}0,330 \\
71,94 \\
\end{array}$ & \begin{tabular}{|l|}
227,98 \\
227,98
\end{tabular} & \begin{tabular}{|l|l|}
123,20 \\
\end{tabular} & \begin{tabular}{|l|}
239,08 \\
230
\end{tabular} & \begin{tabular}{|l|}
242,08 \\
242,0
\end{tabular} & \begin{tabular}{|l|l|}
114,04 \\
11
\end{tabular} & $\begin{array}{l}532,03 \\
511,26\end{array}$ & $\begin{array}{l}3,20 \\
79,38\end{array}$ & $\begin{array}{l}, 1,00 \\
1,0\end{array}$ & $\begin{array}{l}03,04 \\
64,36\end{array}$ & \begin{tabular}{|l|}
221,58 \\
22,4
\end{tabular} & $\begin{array}{l}14,00 \\
14,00\end{array}$ & 23,00 & $\begin{array}{l}203,42 \\
200,42\end{array}$ \\
\hline Pelophylax perezi & 29SQB01 & 100,00 & 177,03 & 85,80 & 36,91 & 5086,65 & 301,93 & 71,36 & 230,57 & 128,89 & 240,26 & 243,19 & 113,39 & 505,93 & 78,73 & 1,00 & 63,83 & 218,10 & 14,01 & 23,13 & 196,75 \\
\hline Pelophylax perezi & 29SQB02 & 100,00 & 175,71 & 87,83 & 36,78 & 5211,77 & 304,69 & 68.22 & 236,47 & 121.68 & 240,67 & 243,42 & 110,32 & 511.72 & 79,20 & 1,00 & 63.09 & 218.53 & 14,72 & 23.99 & 197,38 \\
\hline Pelophylax perezi & 29SQB03 & 100,00 & 176,62 & 90,04 & 36,92 & 5313,06 & 309,19 & 67,62 & 241,57 & 130,20 & 243,06 & 245,67 & 110 & 505,56 & 78,12 & 1,00 & 62,66 & 214,59 & 15,01 & 23,97 & 193,80 \\
\hline Pelophylax perezi & 29SQB04 & 100,00 & 175,53 & 93,32 & 37,02 & 5425,44 & 312,93 & 64,53 & 248,41 & 120,14 & 243,71 & 246,19 & 107,63 & 511,63 & 78,33 & 1,29 & 61,96 & 215,68 & 16,04 & 24,62 & 195,76 \\
\hline
\end{tabular}




\begin{tabular}{|c|c|c|c|c|c|c|c|c|c|c|c|c|c|c|c|c|c|c|c|c|c|}
\hline TAXON & UTM & $\mathrm{km} 2$ & B101 & B102 & $\mathrm{BIO3}$ & B104 & B105 & B106 & B107 & B108 & 8109 & B1010 & BIO11 & BIO12 & 81013 & BIO14 & BIO15 & B1016 & B1017 & B1018 & B1019 \\
\hline Pelophylax perezi & 29SQB05 & 101,00 & 169,79 & 97,85 & 37,29 & 5573,42 & 314,27 & 56,43 & 257,84 & 109,60 & 240,50 & 242,85 & 100,61 & 543,49 & 81,20 & 2,00 & 60,59 & 226,67 & 19,23 & 27,11 & 208,41 \\
\hline Pelophylax perezi & 29SQB06 & 101,00 & 165,53 & 101,65 & \begin{tabular}{|l|l|}
37,97 \\
\end{tabular} & 5683,37 & 315,98 & 50,49 & 265,49 & 104,53 & 238,24 & 240,44 & 95,45 & 566,49 & 83,17 & 2,01 & 59,96 & 234,53 & 21,17 & 28,32 & 217,67 \\
\hline Pelophylax perezi & 29SQB07 & 100,00 & 164,82 & 104,21 & 38,00 & 5762,46 & 319,25 & 48,34 & 270,91 & 102,79 & 238,75 & 240,87 & 93,82 & 569,38 & 82,77 & 2,29 & 59,36 & 234,26 & 22,28 & 28,82 & 218,29 \\
\hline Pelophylax perezi & 29SQB08 & 100,00 & 163,17 & 106,56 & 38,00 & 5835,67 & 321,68 & 45,53 & 276,15 & 100,43 & 238,34 & 240,40 & 91,52 & 576,80 & 82,82 & 2,68 & 58,52 & 235,69 & 23,96 & 29,93 & 220,70 \\
\hline Pelophylax perezi & 29SQB09 & 101,00 & 149,98 & 109,34 & 38,00 & 5955,40 & 315,23 & 31,79 & \begin{tabular}{|l|l|}
283,43 \\
\end{tabular} & 86,71 & \begin{tabular}{|l|l|}
227,37 \\
\end{tabular} & 229,53 & 77,75 & 655,52 & $\begin{array}{l}90,98 \\
\end{array}$ & 3,83 & 57,21 & 264,65 & 30,41 & 35,23 & 252,11 \\
\hline Pelophylax perezi & 29SQB10 & 96,00 & 177,80 & 87,58 & 37,01 & 5066,93 & 303,78 & 71,44 & 232,34 & 130,63 & 241,16 & 244,08 & 114,66 & 518,74 & 80,20 & 1,00 & 64,27 & 224,79 & 14,00 & 22,93 & 204,25 \\
\hline Pelophylax perezi & 29SQB11 & 100,00 & 178,60 & 89,13 & 37,01 & 5175,99 & 307,72 & 70,57 & 237,15 & 130,95 & 243,40 & 246,23 & 113,90 & 513,12 & 79,52 & 1,00 & 63,83 & 220,93 & 14,38 & 23,00 & 200,28 \\
\hline Pelophylax perezi & 29SQB12 & 99,00 & 177,09 & 91,82 & 37,01 & 5318,58 & 311,16 & 67,03 & 244,13 & 119,89 & 244,00 & 246,56 & 110,55 & 519,52 & 80,10 & 1,00 & 63,16 & 221,75 & 15,04 & 23,39 & 201,42 \\
\hline Pelophylax perezi & 29SQB13 & 101,00 & 175,23 & 94,79 & $\begin{array}{l}37,05 \\
\end{array}$ & 5452,54 & 314,19 & 62,94 & 251,25 & 116,11 & 244,04 & 246,46 & 107,10 & 528,76 & 80,87 & 1,01 & 62,52 & 224,05 & 15,94 & 24,02 & 204,34 \\
\hline Pelophylax perezi & 29SQB14 & 100,00 & 177,04 & 97,18 & 37,40 & 5528,40 & 319,21 & \begin{tabular}{|l|l|}
63,27 \\
\end{tabular} & 255,94 & 117,12 & 247,02 & 249,25 & 108,02 & 518,64 & 79,16 & 1,11 & 62,08 & 218,60 & 16,14 & 24,15 & 199,43 \\
\hline Pelophylax perezi & 29SQB15 & 100,00 & 171,39 & 101,11 & $\begin{array}{l}37,85 \\
\end{array}$ & 5671,57 & 320,33 & 55,58 & 264,75 & 110,05 & 243,75 & 245,90 & 101,01 & 548,55 & 81,87 & 1,99 & 60,71 & 228,67 & 19,41 & 26,72 & 210,85 \\
\hline Pelophylax perezi & 29SQB16 & 99,00 & 168,83 & 104,02 & 38,00 & 5771,93 & 322,70 & 51,44 & 271,26 & 106,39 & 242,73 & 244,82 & 97,38 & 560,74 & 82,61 & 2,01 & 60,17 & 232,12 & 20,69 & 27,51 & 215,31 \\
\hline Pelophylax perezi & 29SQB17 & 101,00 & 163,36 & 107,06 & 38,00 & 5877,79 & 322,84 & 44,57 & 278,27 & 99,97 & 239,10 & 241,08 & 90,98 & 589,06 & 85,03 & 2,50 & 59,22 & 241,64 & 23,35 & 29,53 & 226,20 \\
\hline Pelophylax perezi & 29SQB18 & 100,00 & 159,01 & 109,34 & 38,00 & 5957,20 & 322,97 & 39,38 & 283,59 & 95,16 & 236,25 & 238,07 & 86,15 & 610,38 & 86,62 & 2,97 & 58,25 & 248,23 & 25,93 & 31,53 & 233,97 \\
\hline Pelophylax perezi & 29SQB19 & 99,00 & 151,81 & 111,03 & 38,00 & 6028,69 & 319,92 & 31,80 & 288,13 & 87,58 & 230,39 & 232,23 & 78,65 & 649,94 & 90,32 & 3,61 & 57,35 & 262,00 & 29,59 & 34,50 & 249,20 \\
\hline Pelophylax perezi & 29SQB20 & 100,00 & 179,04 & 89,73 & 37,08 & 5151,40 & 308,35 & 70,87 & 237,48 & 134,68 & 243,99 & 246,81 & 114,96 & 524,89 & 80,86 & 1,00 & 64,52 & 227,17 & 14,90 & 22,01 & 207,32 \\
\hline Pelophylax perezi & 29SQB21 & 101,00 & 179,80 & 92,42 & 37,20 & 5285,69 & 313,51 & 69,27 & 244,24 & 131,97 & 246,44 & 249,12 & 113,76 & 522,48 & 80,46 & 1,00 & 63,68 & 224,48 & 15,00 & 22,31 & 204,82 \\
\hline Pelophylax perezi & 29SQB22 & 100,00 & 178,30 & 95,58 & 37,40 & 5428,78 & 317,33 & 65,47 & 251,87 & 119,33 & 247,04 & 249,51 & 110,55 & 529,87 & 81,28 & 1,00 & 63,28 & 226,09 & 15,47 & 22,99 & 206,78 \\
\hline Pelophylax perezi & 29SQB23 & 100,00 & 175,58 & 99,15 & \begin{tabular}{|l|l|}
37,64 \\
\end{tabular} & 5576,75 & 320,65 & 60,34 & 260,32 & 115,05 & 246,60 & 248,85 & 106,15 & 544,32 & 82,68 & 1,00 & 62,51 & 230,34 & 16,86 & 24,24 & 211,68 \\
\hline Pelophylax perezi & 29SQB24 & 100,00 & 175,60 & 101,94 & $\begin{array}{l}37,95 \\
\end{array}$ & 5673,27 & 325,06 & 58,67 & 266,40 & 114,06 & 248,11 & 250,25 & 104,99 & 543,60 & 81,97 & 1,36 & 61,76 & 228,44 & 18,02 & 24,99 & 210,41 \\
\hline Pelophylax perezi & 29SQB25 & 99,00 & 170,63 & 105,14 & 37,99 & 5800,16 & 325,97 & 51,97 & 274,00 & 107,85 & 245,09 & 247,13 & 98,82 & 567,97 & 84 & 1,9 & 60,84 & 236,44 & 20,20 & 26,87 & 219,51 \\
\hline Pelophylax perezi & $29 S Q B 26$ & 101,00 & 165,03 & 108,10 & 38,00 & 5908,15 & 325,85 & 45,03 & 280,81 & 101,40 & 241,28 & 243,17 & 92,26 & 594,59 & 86,44 & 2,06 & 60,03 & 245,36 & 22,21 & 28,46 & 229,72 \\
\hline Pelophylax perezi & 29SQB27 & 100,00 & 162,82 & 109,90 & 38,00 & 5980,37 & 327,18 & $\begin{array}{lll}41,83 \\
\end{array}$ & 285,35 & 98,45 & 240,34 & 242,12 & 89,41 & \begin{tabular}{|c|c|}
602,57 \\
\end{tabular} & 86,51 & 2,57 & 59,20 & 246,70 & 24,01 & 29,90 & 231,84 \\
\hline Pelophylax perezi & 29SQB28 & 100,00 & 158,95 & 111,69 & 38,00 & 6054,53 & 326,96 & 37,32 & 289,64 & 94,01 & 237,72 & 239,36 & 85,00 & 619,95 & 87,61 & 2,99 & 58,42 & 251,77 & 26,12 & 31,53 & 237,91 \\
\hline Pelophylax perezi & 29SQB29 & 100,00 & 158,47 & 112,97 & 38,00 & 6098,34 & 328,68 & 36,09 & 292,59 & 92,97 & 237,91 & 239,45 & 83,95 & 619,05 & 86,71 & 3,20 & 57,68 & 249,70 & 27,20 & 32,28 & 236,40 \\
\hline Pelophylax perezi & 29SQB30 & 100,00 & 179,70 & 91,75 & \begin{tabular}{|l|l|}
37,03 \\
\end{tabular} & 5261,84 & 312,93 & 69,67 & 243,26 & 131,84 & 246,24 & 249,06 & 114,13 & 537,09 & 82,25 & 1,00 & 64,32 & 231,41 & 15,00 & 22,00 & 212,24 \\
\hline Pelophylax perezi & 29SQB31 & 100,00 & 180,39 & 95,44 & 37,43 & 5399,35 & 319,24 & 67,63 & 251,61 & \begin{tabular}{|l|}
121,85 \\
12,4
\end{tabular} & 248,92 & 251,55 & $\begin{array}{l}113,18 \\
118\end{array}$ & 535,35 & 82,11 & $\begin{array}{l}1,00 \\
1,00\end{array}$ & 63,83 & \begin{tabular}{|l|}
229,68 \\
29
\end{tabular} & 15,20 & 22,00 & 210,79 \\
\hline Pelophylax perezi & 29SQB32 & 100,00 & 179,88 & 99,43 & 37,81 & 5541,95 & 324,76 & 64,30 & 260,46 & 119,66 & 250,41 & 252,84 & 110,82 & 540,01 & 82,50 & 1,00 & 63,43 & 230,37 & 16,01 & 22,43 & 212,05 \\
\hline Pelophylax perezi & 29SQB33 & 100,00 & 178,05 & 103,27 & 37,99 & 5681,46 & 329,20 & 60,05 & 269,14 & 116,39 & 250,78 & 252,92 & 107,42 & 549,83 & 83,33 & 1,00 & 62,64 & 232,79 & 17,50 & 23,88 & 215,05 \\
\hline Pelophylax perezi & 29SQB34 & 100,00 & 179,52 & 106,17 & 38,01 & 5772,33 & 334,80 & 59,57 & 275,24 & 116,62 & 253,47 & 255,43 & 107,67 & 542,43 & 81,89 & 1,01 & 62,08 & 228,52 & 18,01 & 23,92 & 211,26 \\
\hline Pelophylax perezi & 29SQB35 & 101,00 & 175,74 & 109,07 & 38,05 & 5890,17 & 336,24 & 54,13 & 282,11 & 111,61 & 251,58 & 253,33 & 102,63 & 558,45 & 83,11 & 1,74 & 61,18 & 233,21 & 19,53 & 25,44 & 216,83 \\
\hline Pelophylax perezi & 29SQB36 & 100,00 & 170,21 & 111,26 & 38,03 & 5991,56 & 335,15 & \begin{tabular}{|l|}
47,61 \\
47,5
\end{tabular} & \begin{tabular}{|l|}
287,54 \\
\end{tabular} & \begin{tabular}{|l|l|l|l|l}
105,24 \\
\end{tabular} & \begin{tabular}{|l|}
247,70 \\
\end{tabular} & \begin{tabular}{|l|}
249,40 \\
\end{tabular} & $\begin{array}{l}02,23 \\
96,23\end{array}$ & \begin{tabular}{|l}
581,49 \\
581,49
\end{tabular} & 85,01 & 2,00 & $\begin{array}{ll}1,10 \\
60,50\end{array}$ & \begin{tabular}{|l|}
240,69 \\
\end{tabular} & 21,21 & 26,95 & 225,24 \\
\hline Pelophylax perezi & 29SQB37 & 100,00 & 165,23 & 112,90 & 38,01 & 6067,55 & 333,76 & 42,02 & 291,74 & 99,63 & 243,99 & 245,63 & 90,71 & 602,17 & 86,41 & 2,31 & 59,48 & 246,70 & 23,48 & 28,98 & 232,27 \\
\hline Pelophylax perezi & 29SQB38 & 101,00 & 165,25 & 114,19 & 38,03 & 6120,83 & 336,06 & 41,25 & 294,81 & 99,12 & 244,91 & 246,42 & 90,10 & 596,49 & 84,86 & 2,55 & 58,82 & 242,79 & 24,17 & 29,42 & 228,80 \\
\hline Pelophylax perezi & 29SQB39 & 100,00 & 163,07 & 115,24 & 38,00 & 6172,04 & 336,21 & 38,54 & 297,66 & 96,41 & 243,54 & 244,97 & 87,38 & 601,53 & 84,57 & 2,78 & 58,19 & 242,94 & 25,49 & 30,41 & 229,54 \\
\hline Pelophylax perezi & 29SQB40 & 99,00 & 179,69 & 93,24 & 37,00 & 5365,82 & 316,83 & 68,17 & 248,66 & 121,89 & 247,90 & 250,69 & \begin{tabular}{r|r|}
112,98 \\
\end{tabular} & 553,37 & 84,17 & 1,00 & 64,45 & 237,47 & 15,55 & 22,00 & 219,19 \\
\hline Pelophylax perezi & 29SQB41 & 100,00 & 180,84 & 98,40 & 37,65 & 5512,73 & 324,91 & 66,20 & 258,72 & 121,24 & 251,24 & 253,74 & 112,42 & 550,42 & 83,90 & 1,00 & 64,00 & 235,61 & 16,05 & 22,08 & 217,62 \\
\hline Pelophylax perezi & 29SQB42 & 101,00 & 181,47 & 103,41 & 37,99 & 5658,01 & 332,43 & 63,26 & 269,18 & 119,88 & 253,93 & 256,14 & 110,99 & 551,11 & 83,89 & 1,00 & 63,41 & 235,04 & 16,67 & 22,57 & 217,58 \\
\hline Pelophylax perezi & 29SQB43 & 100,00 & 180,23 & 108,01 & 38,05 & 5804,21 & 338,22 & 59,06 & 279,16 & 117,10 & 254,92 & 256,92 & 108,11 & 558,84 & 84,54 & 1,00 & 62,92 & 237,05 & 17,80 & 23,23 & 220,29 \\
\hline Pelophylax perezi & 29SQB44 & 101,00 & 180,49 & 111,05 & 38,36 & 5900,58 & 342,96 & 57,41 & 285,55 & 116,18 & 256,64 & 258,40 & 107,23 & 556,03 & 83,69 & 1,12 & 62,60 & 234,70 & 18,32 & 23,41 & 218,49 \\
\hline Pelophylax perezi & 29SQB45 & 99,00 & 179,99 & 113,45 & 38,61 & 5980,75 & 346,22 & 55,51 & 290,71 & 114,92 & 257,41 & 259,01 & 105,74 & 555,42 & 82,9 & 1,41 & 61,79 & 232,99 & 18,81 & 24,00 & 217,38 \\
\hline Pelophylax perezi & $29 S Q B 46$ & 99,00 & 173,66 & 115,02 & 38,40 & 6082,63 & 343,56 & 48,44 & 295,12 & 107,63 & 252,68 & 254,05 & 98,53 & 579,42 & 84,7 & 2,00 & 60,85 & 240,38 & 20,83 & 25,98 & 225,57 \\
\hline Pelophylax perezi & 29SQB47 & 101,00 & 169,77 & 116,00 & 38,36 & 6146,51 & 342,23 & 44,27 & 297,96 & 103,11 & 249,79 & 251,23 & 94,08 & 591,41 & 85,13 & 2,04 & 59,97 & 242,96 & 22,34 & 27,42 & 228,87 \\
\hline Pelophylax perezi & 29SQB48 & 99,00 & 165,34 & 116,84 & 38,20 & 6207,25 & 340,24 & 39,51 & 300,73 & 98,16 & 246,41 & 247,64 & 89,31 & 606,48 & 85,72 & 2,53 & 58,92 & 246,50 & 24,30 & 29,31 & 233,16 \\
\hline Pelophylax perezi & 29SQB49 & 99,00 & 160,27 & 117,41 & 38,07 & 6265,76 & 337,49 & 34,39 & 303,10 & 92,76 & 242,46 & 243,63 & 83,80 & 624,67 & 86,79 & 3,01 & 58,13 & 251,52 & 26,41 & 31,25 & 238,92 \\
\hline Pelophylax perezi & 29SQB50 & 101,00 & 179,57 & 95,10 & 37,05 & 5466,56 & 320,40 & $\begin{array}{l}4,05 \\
67,05 \\
\end{array}$ & 253,35 & 120,67 & 249,35 & \begin{tabular}{|l|}
252,07 \\
\end{tabular} & $\begin{array}{l}111,92 \\
1102\end{array}$ & 570,72 & $\begin{array}{l}80, \\
86,\end{array}$ & 1,00 & 60,35 & 243,91 & \begin{tabular}{|l|}
16,70 \\
16,70
\end{tabular} & 22,70 & 226,31 \\
\hline Pelophylax perezi & 29SQB51 & 100,00 & 181,28 & 101,57 & 37,78 & 5616,31 & 330,24 & 64,46 & 265,78 & 120,27 & 253,19 & 255,54 & 111,54 & 566,30 & 85,94 & 1,00 & 64,08 & 242,13 & 16,97 & 22,72 & 224,97 \\
\hline Pelophylax perezi & 295 QB52 & 100,00 & 182,30 & 107,75 & 38,14 & 5772,57 & 339,60 & 61,60 & 278,00 & 119,54 & 256,69 & 258,72 & 110,67 & 565,41 & 85,81 & 1,00 & 63,65 & 241,42 & 17,54 & 22,50 & 224,85 \\
\hline Pelophylax perezi & 29SQB53 & 100,00 & 181,30 & 113,02 & 38,63 & 5927,42 & 346,34 & 57,17 & 289,17 & 116,76 & 258,02 & 259,85 & 107,85 & 573,75 & 86,57 & 1,00 & 63,24 & 243,96 & 18,11 & 22,87 & 228,30 \\
\hline Pelophylax perezi & 29SQB54 & 100,00 & 179,52 & 116,15 & 38,86 & 6034,62 & 349,50 & 53,49 & 296,01 & 113,93 & 257,94 & 259,54 & 104,97 & 580,19 & 86,72 & 1,33 & 62,52 & 06 & 19,19 & 23,63 & 230,07 \\
\hline Pelophylax perezi & $295 Q B 5$ & 100,00 & 182,80 & $\begin{array}{l}111,10 \\
117,92\end{array}$ & 30,00 & 6 & 354,84 & $\begin{array}{l}5,44 \\
55,47 \\
\end{array}$ & \begin{tabular}{|l|}
299,36 \\
\end{tabular} & \begin{tabular}{|l|}
116,50 \\
11,5
\end{tabular} & \begin{tabular}{|l|}
261,79 \\
\end{tabular} & \begin{tabular}{|l|}
263,16 \\
\end{tabular} & \begin{tabular}{|l|}
107,47 \\
\end{tabular} & $\mid 550,71$ & $\begin{array}{l}00,1 / 2 \\
83,53\end{array}$ & $\frac{1,2}{1,1}$ & $\frac{2,252}{62,24}$ & \begin{tabular}{|l|}
235,80 \\
\end{tabular} & $\begin{array}{l}18,43 \\
18,1\end{array}$ & 23,01 & 221,17 \\
\hline Pelophylax perezi & $295 \mathrm{SQB56}$ & 100,00 & 176,11 & 118,63 & 38,93 & 6163,05 & 350,68 & 48,61 & 302,07 & 109,00 & 256,31 & 257,66 & 100,02 & 582,65 & 85,06 & 1,97 & 61,03 & 242,14 & 20,77 & 25,32 & 228,14 \\
\hline Pelophylax perezi & 29SQB57 & 100,00 & 171,79 & 119,16 & 38,85 & 6226,66 & 348,23 & \begin{tabular}{|l|l|}
44,11 \\
\end{tabular} & 304,11 & 104,11 & 253,04 & 254,23 & 95,11 & 594,15 & 85,23 & 2,00 & 60,20 & 244,31 & 22,15 & 26,90 & 230,84 \\
\hline Pelophylax perezi & 29SQB58 & 100,00 & 164,45 & 119,16 & 38,45 & 6288,16 & 342,96 & 37,21 & 305,74 & 96,54 & 246,97 & 248,00 & 87,55 & 621,15 & 87,10 & 2,57 & 59,09 & 252,23 & 24,62 & 29,52 & 239,62 \\
\hline Pelophylax perezi & 29SQB59 & 100,00 & 161,72 & 119,53 & 38,08 & 6337,03 & 341,97 & 34,20 & 307,77 & 93,37 & 244,95 & 245 & 84,36 & 626,22 & 86, & 2,97 & 58,34 & 251,97 & 25,99 & 30,74 & 239 \\
\hline Pelophylax perezi & $\begin{array}{l}295 \mathrm{COB} 60 \\
20\end{array}$ & 65,00 & $\begin{array}{l}101,1 / 2 \\
179,53\end{array}$ & $\begin{array}{l}1,50,98 \\
96\end{array}$ & 年, 30,24 & - 55325,91 & 323,05 & $\begin{array}{l}4,40 \\
66,35 \\
\end{array}$ & 256,70 & \begin{tabular}{|c|}
319,86 \\
119,86
\end{tabular} & \begin{tabular}{|l|}
250,19 \\
250
\end{tabular} & \begin{tabular}{|l|}
252,96 \\
256
\end{tabular} & \begin{tabular}{|l|}
111,27 \\
11,27
\end{tabular} & 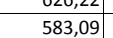 & $\begin{array}{l}0,571 \\
88,29\end{array}$ & (1,00 & $\begin{array}{l}0 ., 34 \\
64,75 \\
\end{array}$ & \begin{tabular}{|l|}
249,96 \\
\end{tabular} & \begin{tabular}{|l|l}
17,00 \\
17
\end{tabular} & $\begin{array}{l}0,1 / 73 \\
22,73\end{array}$ & $\begin{array}{l}23,05 \\
232,56\end{array}$ \\
\hline Pelophylax perezi & 29SQB61 & 66,00 & 181,26 & 103,97 & 38,03 & 5680,70 & 333,38 & 63,80 & 269,58 & 119,67 & 254,26 & 256,66 & 111,03 & 576,63 & 87,65 & 1,00 & 64,41 & 247,51 & 17,00 & 22,01 & 230,55 \\
\hline Pelophylax perezi & 29SQB62 & 62,00 & 182.98 & 110,49 & 38,71 & 5832,79 & 343,73 & 61.26 & 282.48 & 119.58 & 258.21 & 260,28 & $\begin{array}{ll}110,66 \\
\end{array}$ & 575.13 & 87,33 & 1,00 & 63.97 & 246,17 & 17,90 & 2200 & 229.97 \\
\hline Pelophylax perezi & 29SQB63 & 57,00 & 184,32 & 116,90 & 39,00 & 5995,94 & 353,94 & 58,03 & 295,91 & 119,06 & 262,14 & 263,82 & 110 & 574,31 & 86,98 & 1,00 & 63,84 & 245 & 18,05 & 22,11 & 230,18 \\
\hline Pelophylax perezi & $29 \mathrm{SQB64}$ & 54,00 & 184,91 & 120,33 & 39,01 & 6101,45 & 359,34 & 55,90 & 303,44 & 118,35 & 264,13 & 265,64 & 109,23 & 571,64 & 86,08 & 1,00 & $\begin{array}{l}63,33 \\
\end{array}$ & 243,27 & 18,19 & 22,17 & 228,95 \\
\hline
\end{tabular}




\begin{tabular}{|c|c|c|c|c|c|c|c|c|c|c|c|c|c|c|c|c|c|c|c|c|c|}
\hline TAXON & UTM & $\mathrm{km} 2$ & BIO1 & B102 & $B 103$ & BIO4 & B105 & B106 & B107 & B108 & B109 & B1010 & BIO11 & B1012 & BIO13 & B1014 & BIO15 & B1016 & B1017 & B1018 & 81019 \\
\hline Pelophylax perezi & 29SQB65 & 54,00 & 185,05 & 120,77 & 39,04 & 6134,68 & 360,27 & 56,13 & 304,14 & 118,00 & 264,73 & 266,16 & 108,92 & 561,39 & 83,79 & 1,00 & 62,83 & 237,35 & 18,06 & 22,06 & 223,32 \\
\hline Pelophylax perezi & 29SQB66 & 49,00 & 179,39 & 121,08 & 39,00 & 6213,04 & 356,69 & 50,47 & 306,22 & 111,55 & 260,39 & 261,53 & 102,69 & 576,55 & 84,32 & 1,69 & 61,45 & 240,57 & 19,96 & 24,26 & 226,99 \\
\hline Pelophylax perezi & 29SQB67 & 43,00 & 170,53 & $\begin{array}{l}120,97 \\
\end{array}$ & 38,97 & $\begin{array}{lll}6280,84 \\
\end{array}$ & \begin{tabular}{|l|l|}
349,67 \\
\end{tabular} & 42,23 & $\begin{array}{l}307,44 \\
\end{array}$ & 102,34 & 252,81 & 253,81 & 93,31 & $\begin{array}{l}608,03 \\
6\end{array}$ & 86,59 & 2,00 & 60,22 & 249,81 & 22,67 & 27,20 & 236,97 \\
\hline Pelophylax perezi & 29SQB68 & 45,00 & 165,08 & 120,71 & 38,64 & 6333,68 & 345,70 & 36,77 & 308,92 & 96,58 & 248,45 & 249,27 & 87,58 & 624,02 & 87,17 & 2,32 & 59,42 & 253,56 & 24,21 & 28,88 & 241,35 \\
\hline Pelophylax perezi & 29SQB69 & 40,00 & 164,02 & 121,00 & 38,38 . & 6377,10 & 346,10 & 35,40 & 310,70 & 95,05 & 247,85 & 248,63 & 86,07 & 620,57 & 85,65 & 2,72 & 58,52 & 249,95 & 25,08 & 29,77 & 238,12 \\
\hline Pelophylax perezi & 29SQC00 & 100,00 & 152,57 & 110,61 & 38,01 & 5987,54 & 319,70 & 33,50 & 286,20 & 88,75 & 230,46 & 232,42 & 79,85 & 634,96 & 88,02 & 3,70 & 56,71 & 255,20 & 30,10 & 34,59 & 242,76 \\
\hline Pelophylax perezi & 29SQC01 & 100,00 & 150,73 & 111,68 & 38,02 & 6030,24 & 320,13 & 31,31 & 288,82 & 86,57 & 229,46 & 231,34 & 77,71 & 643,26 & 88,33 & 4,06 & 56,03 & 256,93 & 31,92 & 35,85 & 245,11 \\
\hline Pelophylax perezi & 29SQC02 & 101,00 & 150,90 & 112,55 & 38,00 & 6064,71 & 322,05 & 30,95 & 291,10 & 86,38 & 230,08 & 231,97 & 77,51 & \begin{tabular}{|l|l|}
638,97 \\
\end{tabular} & 87,25 & 4,11 & 55,41 & 253,83 & 32,80 & 36,32 & 242,32 \\
\hline Pelophylax perezi & 29SQC04 & 100,00 & 162,19 & 114,61 & 38,27 & $\begin{array}{ll}6086,43 \\
\end{array}$ & 334,44 & 40,11 & 294,33 & $\begin{array}{l}96,37 \\
\end{array}$ & 241,55 & 242,96 & 87,75 & 558,28 & 76,98 & 3,34 & 54,69 & 220,37 & 29,30 & 32,56 & 208,18 \\
\hline Pelophylax perezi & 29SQC05 & 100,00 & 151,69 & 1114,27 & $\begin{array}{l}38,05 \\
\end{array}$ & \begin{tabular}{|l|l|l}
6140,97 \\
\end{tabular} & 326,38 & 30,66 & 295,72 & 85,99 & 232,26 & 233,59 & 77,36 & 622,94 & 83,87 & 4,57 & 53,71 & 243,87 & 35,20 & 37,55 & 232,90 \\
\hline Pelophylax perezi & 29SQC06 & 100,00 & 151,43 & 114,50 & 38,00 & 6152,60 & 326,90 & 30,33 & 296,57 & 85,56 & 232,32 & 233,59 & 77,10 & 619,90 & 83,06 & 4,68 & 53,24 & 241,60 & 36,05 & 38,10 & 230,70 \\
\hline Pelophylax perezi & $295 Q C 09$ & 101,00 & 165,31 & $\begin{array}{l}116,39 \\
\end{array}$ & 38,40 & 6139,80 & 340,59 & 41,61 & 298,98 & 98,23 & 245,51 & 246,18 & 89,80 & 516,38 & 70,23 & 3,88 & 51,95 & \begin{tabular}{|l|l|}
199,27 \\
\end{tabular} & 31,38 & 33,42 & 186,85 \\
\hline Pelophylax perezi & 29SQC10 & 101,00 & 157,87 & 112,11 & 38,00 & 6052,92 & 326,94 & 36,77 & 290,16 & 92,90 & 236,66 & 238,34 & 84,15 & 608,89 & 85,03 & 3,21 & 57,12 & 244,71 & 27,85 & 32,59 & 231,55 \\
\hline Pelophylax perezi & 29SQC11 & 100,00 & 148,36 & 1113,07 & 38,00 & 6121,03 & 320,93 & 27,46 & 293,47 & 83,27 & 228,53 & 230,22 & 74,29 & 662,73 & 90,34 & 4,26 & 56,03 & 263,69 & 32,92 & 36,88 & 252,11 \\
\hline Pelophylax perezi & 29SQC12 & 100,00 & 150,30 & $\begin{array}{ll}113,83 \\
\end{array}$ & 38,00 & 6146,70 & 324,17 & 28,77 & 295,39 & 84,84 & 230,91 & 232,48 & \begin{tabular}{|l|l|}
75,97 \\
\end{tabular} & \begin{tabular}{|l|l|}
644,97 \\
\end{tabular} & 87,7 & 4,05 & 55,47 & 255,49 & 32,72 & 36,30 & 243,86 \\
\hline Pelophylax perezi & $295 Q C 13$ & 100,00 & 157,54 & 114,97 & 38,01 & 6161,86 & 331,80 & $\begin{array}{ll}34,74 \\
\end{array}$ & 297,06 & 91,12 & 238,20 & 239,41 & 82,41 & \begin{tabular}{|l|l|}
594,93 \\
\end{tabular} & 81,35 & 3,71 & 55,09 & 234,82 & 30,46 & 33,99 & 222,73 \\
\hline Pelophylax perezi & 29SQC14 & 101,00 & 159,23 & 115,59 & 38,01 & 6171,35 & 334,37 & 35,95 & 298,41 & 92,41 & 239,95 & 241,13 & 83,86 & 579,12 & 79,00 & 3,69 & 54,64 & 227,61 & 30,38 & 33,67 & 215,52 \\
\hline Pelophylax perezi & $295 \mathrm{~S}$ C15 & 100,00 & 153,88 & 115,50 & 38,00 & 6216,08 & 330,77 & 31,06 & 299,71 & 87,03 & 235,64 & 236,60 & 78,50 & $\mid 607,10$ & 81,63 & 4,19 & 53,79 & 236,94 & 33,57 & 36,28 & 225,45 \\
\hline Pelophylax perezi & 295aC16 & 100,00 & 158,39 & 116,15 & 38,01 . & 6218,94 & 335,43 & 34,82 & 300,61 & 91,30 & 240,07 & 241,02 & 82,66 & 573,53 & 77,26 & 4,05 & 53,32 & 222,97 & 32,25 & 34,93 & 211,15 \\
\hline Pelophylax perezi & $295 Q C 20$ & 100,00 & 158,69 & 1114,03 & 38,00 & 6141,20 & 330,86 & 35,80 & 295,06 & 92,59 & 238,82 & 240,27 & \begin{tabular}{ll|}
83,67 \\
\end{tabular} & $\begin{array}{l}610,75 \\
\end{array}$ & 84,9 & 3,20 & 57,20 & 244,88 & 27,67 & 32,37 & 231,93 \\
\hline Pelophylax perezi & 29SQC21 & 100,00 & 145,29 & 114,35 & 38,00 & 6208,92 & 321,02 & 23,04 & 297,98 & 79,29 & 227,01 & 228,47 & 70,48 & $\begin{array}{l}684,79 \\
\end{array}$ & 92,50 & 4,51 & 55,84 & 271,28 & 34,24 & 38,10 & 260,10 \\
\hline Pelophylax perezi & $295 Q C 22$ & 100,00 & 152,88 & \begin{tabular}{ll|}
115,44 \\
\end{tabular} & 38,00 & $\begin{array}{ll}6225,07 \\
\end{array}$ & 329,21 & 29,54 & 299,66 & 86,07 & 234,56 & 235,86 & 77,28 & $\begin{array}{l}632,78 \\
\end{array}$ & 85,95 & 3,97 & 55,60 & 250,05 & 31,60 & 35,43 & 238,19 \\
\hline Pelophylax perezi & $295 \mathrm{~S}$ C23 & 101,00 & 156,44 & $\mid 116,22$ & 38,00 & 6236,16 & 333,51 & 32,47 & 301,04 & 89,36 & 238,35 & 239,41 & 80,62 & $\mid 605,30$ & 82,13 & 3,85 & 55,16 & 238,15 & 30,84 & 34,48 & 226,19 \\
\hline Pelophylax perezi & $2950<24$ & 99,00 & 155,97 & 116,59 & 38,00 & 6269,81 & 334,19 & 31,82 & 302,37 & 88,53 & 238,37 & 239,35 & 79,85 & 601,12 & 80,98 & 3,94 & 54,55 & 235,10 & 31,61 & 34,93 & 223,33 \\
\hline Pelophylax perezi & 29SQC25 & 100,00 & 154,87 & 116,72 & 38,00 & 6296,31 & 333,94 & 30,57 & 303,37 & 86,94 & 237,62 & 238,51 & 78,50 & 601,18 & 80,3 & 4,00 & 53,84 & 233,81 & 32,68 & 35,64 & 222,19 \\
\hline Pelophylax perezi & 29SQC28 & 101,00 & 162,42 & 117,04 & 38,00 & 6296,73 & 341,58 & 37,15 & 304,44 & 93,96 & 245,39 & 245,72 & 85,55 & 537,24 & 71,40 & 3,97 & 52,31 & 206,15 & 31,56 & 33,13 & 193,92 \\
\hline Pelophylax perezi & 29SQC29 & 99,00 & 163,70 & 116,98 & 37,99 & 6310,48 & 342,96 & 38,34 & 304,62 & 94,99 & 247,14 & 247,18 & 86,50 & 523,24 & 69,29 & 3,71 & 51,97 & 200,01 & 30,94 & 31,56 & 187,75 \\
\hline Pelophylax perezi & 29SQC30 & 100,00 & 153,54 & 115,83 & 38,00 & 6238,75 & 329,83 & 29,25 & 300,58 & 86,61 & 235,49 & 236,64 & 77,72 & $\begin{array}{l}646,89 \\
\end{array}$ & 88,68 & 3,60 & 56,96 & 258,16 & 29,81 & 34,28 & 246,06 \\
\hline Pelophylax perezi & 29SQC31 & 101,00 & 143,35 & 115,71 & 37,99 ] & 6285,63 & 321,80 & 20,01 & 301,79 & 76,51 & 226,30 & 227,65 & 67,74 & 700,80 & 93,93 & 4,65 & 55,87 & 276,69 & 34,98 & 38,88 & 265,89 \\
\hline Pelophylax perezi & 29SQC32 & 100,00 & $\begin{array}{lll}150,07 \\
\end{array}$ & 116,82 & 38,00 & 6311,19 & 329,47 & 25,56 & 303,92 & 82,63 & 233,28 & 234,30 & 73,90 & 652,92 & 87,76 & 4,06 & 55,58 & 257,04 & 32,41 & 36,21 & 245,72 \\
\hline Pelophylax perezi & 29SQC34 & 101,00 & 153,91 & 117,59 & 38,00 & 6343,62 & $\begin{array}{l}34,60 \\
\end{array}$ & 28,48 & 306,12 & 85,62 & 237,58 & 238,24 & 76,99 & \begin{tabular}{ll|l|}
616,08 \\
\end{tabular} & 82,05 & 4,00 & 54,58 & 239,90 & 32,05 & 35,34 & 228,58 \\
\hline Pelophylax perezi & 29SQC38 & 100,00 & 163,23 & 117,86 & 38,00 & 6367,95 & 344,36 & 36,86 & 307,50 & 93,88 & 247,29 & 247,38 & 85,35 & 532,76 & 70,17 & 3,44 & 52,54 & 203,66 & 30,08 & 31,66 & 191,64 \\
\hline Pelophylax perezi & 29SQC39 & 101,00 & 165,75 & 117,51 & \begin{tabular}{|l|l|}
37,97 \\
\end{tabular} & 6367,88 & 346,27 & 39,30 & 306,97 & 96,22 & 249,75 & 249,85 & 87,54 & 511,19 & 67,20 & 3,08 & 52,34 & 194,91 & 28,83 & 30,27 & 182,78 \\
\hline Pelophylax perezi & 29SQC40 & 101,00 & 158,58 & 118,01 & 38,01 & 6304,75 & 337,41 & 32,34 & 305,07 & \begin{tabular}{ll|}
90,67 \\
\end{tabular} & 241,28 & 242,38 & 81,72 & 626,43 & 86,06 & 3,03 & 57,45 & 250,37 & 27,34 & 32,01 & 238,25 \\
\hline Pelophylax perezi & 29SQC41 & 99,00 & 150,44 & 117,83 & 38,00 & 6353,23 & 331,26 & 24,82 & 306,44 & 82,53 & 234,27 & 235,31 & 73,66 & 662,91 & 89,17 & 3,90 & 56,33 & 261,88 & 31,52 & 35,70 & 250,75 \\
\hline Pelophylax perezi & 29SQC42 & 101,00 & 152,95 & \begin{tabular}{ll|}
118,39 \\
\end{tabular} & 38,00 & 6376,73 & $\begin{array}{l}344,71 \\
\end{array}$ & 26,75 & 307,97 & 84,57 & 237,21 & 237,92 & 75,77 & 640,44 & 85,79 & 3,86 & 55,69 & 251,67 & 31,08 & 35,10 & 240,44 \\
\hline Pelophylax perezi & 29SQC44 & 99,00 & 152,18 & 118,55 & 37,99 & 6422,21 & 335,51 & 25,57 & 309,93 & 83,18 & 237,18 & 237,71 & 74,32 & 627,23 & 82,93 & 4,00 & 54,74 & 243,43 & 32,07 & 35,38 & 232,45 \\
\hline Pelophylax perezi & 29SQC47 & 99,00 & 162,97 & 118,88 & 37,99 & 6437,15 & 345,94 & 35,39 & 310,55 & 92,87 & 248,00 & 248,04 & 84,26 & 542,14 & 71,52 & 3,23 & 53,43 & 207,59 & 29,09 & 30,04 & 195,96 \\
\hline Pelophylax perezi & 29SQC48 & 101,00 & 164,45 & 118,63 & \begin{tabular}{|l|l|}
37,97 \\
\end{tabular} & 6434,42 & 347,13 & 37,04 & 310,09 & 94,36 & 249,40 & 249,46 & 85,73 & 525,70 & 69,10 & 3,06 & 52,98 & 200,26 & 28,72 & 29,29 & 188,50 \\
\hline Pelophylax perezi & 29SQC49 & 99,00 & 163,25 & 117,95 & 37,60 & 6448,65 & 346,10 & 36,12 & 309,98 & 92,98 & 248,56 & 248,66 & 84,46 & 523,97 & 68,46 & 3,31 & 52,23 & $\begin{array}{l}198,42 \\
\end{array}$ & 29,73 & 30,41 & 186,63 \\
\hline Pelophylax perezi & 29SQC50 & 100,00 & 154,05 & 119,27 & 38,01 & 6389,85 & $\begin{array}{l}336,10 \\
\end{array}$ & 27,00 & 309,10 & 85,45 & 238,34 & 239,30 & 76,60 & $\begin{array}{l}656,46 \\
\end{array}$ & 88,95 & 3,43 & 57,26 & 260,95 & 29,22 & 33,80 & 249,81 \\
\hline Pelophylax perezi & 29SQC51 & 100,00 & 157,25 & 120,01 & 38,00 & 6413,78 & 340,24 & 29,40 & 310,84 & 88,09 & 241,84 & 242,56 & 79,16 & 631,14 & 85,14 & 3,27 & 56,81 & 249,59 & 28,48 & 32,89 & 238,35 \\
\hline Pelophylax perezi & 29SQC52 & 100,00 & 158,74 & 120,32 & 38,00 & 6435,63 & 342,47 & 30,48 & 311,99 & 89,27 & 243,72 & 244,24 & 80,33 & 613,54 & 82,38 & 3,19 & 56,22 & 241,10 & 28,37 & 32,57 & 229,94 \\
\hline Pelophylax perezi & 29SQC56 & 99,00 & 160,23 & 120,02 & $\begin{array}{ll}37,93 \\
\end{array}$ & 6499,58 & 345,5 & 31,79 & 313,79 & 89,49 & 246,42 & 246,50 & 81,13 & 566,80 & 74,75 & 3,33 & 53,84 & 216,93 & 29,53 & 31,24 & 205,91 \\
\hline Pelophylax perezi & 29SQC57 & 101,00 & 157,18 & 119,37 & 37,73 & 6509,74 & 342,79 & 29,19 & 313,61 & 86,55 & 243,60 & 243,67 & 77,96 & 573,23 & 74,97 & 3,87 & 53,01 & 217,74 & 31,36 & 32,25 & 206,81 \\
\hline \begin{tabular}{|l} 
Pelophylax perezi \\
\end{tabular} & $2950 C 58$ & 100,00 & 160,35 & 119,09 & \begin{tabular}{l|l|l}
37,65 \\
\end{tabular} & 6510,78 & 345,55 & 32,21 & 313,33 & 89,57 & 246,70 & 246,74 & 81,06 & 547,69 & 71,51 & 3,60 & 52,61 & 207,06 & 30,33 & 30,64 & 195,84 \\
\hline Pelophylax perezi & 29SQC59 & 100,00 & 160,74 & $\begin{array}{ll}118,62 \\
\end{array}$ & 37,32 & 6523,95 & 345,77 & $\begin{array}{ll}32,92 \\
\end{array}$ & 312,85 & 90,06 & 247,48 & 247,51 & 81,41 & 535,84 & $\begin{array}{l}69,69 \\
\end{array}$ & 3,57 & 52,03 & 201,52 & 30,46 & 30,61 & 190,22 \\
\hline Pelophylax perezi & $2950<60$ & 32,00 & 155,24 & 120,45 & 38,00 & 6427,15 & 339,05 & 27,25 & 311,80 & 86,07 & 240,15 & 240,95 & 77,16 & 654,55 & 88,64 & 3,35 & 57,42 & 259,98 & 28,73 & 33,25 & 249,1 \\
\hline Pelophylax perezi & 29SQC61 & 36,00 & 161,81 & 121,29 & 38,02 & 6448,65 & 345,96 & 32,98 & 312,98 & 92,10 & 246,90 & 247,63 & 83,29 & 611,21 & 82,88 & 3,02 & 57,23 & 242,10 & 26,58 & 31,02 & 230,92 \\
\hline Pelophylax perezi & $29 \mathrm{SOC}$ & 30,00 & 158,40 & 121,10 & 38,00 & 6484,80 & 343,60 & 29,48 & 314,13 & 88,45 & 244,20 & 244,60 & 79,50 & 619,28 & 83,18 & 3,25 & 56,40 & 242,82 & 28,33 & 32,40 & 232,15 \\
\hline Pelophylax perezi & 29SQC63 & 22,00 & 148,95 & 120,27 & \begin{tabular}{|l|}
37,98 \\
\end{tabular} & 6508,00 & 335,43 & 21,27 & 314,16 & 79,09 & 235,43 & 235,86 & 70,36 & 658,91 & 87,20 & 4,20 & 55,09 & 255,39 & 32,91 & 35,98 & 245,32 \\
\hline Pelophylax perezi & 29SQD02 & 99,00 & 165,92 & 114,71 & 38,00 & 6184,23 & 340,88 & 43,15 & 297,73 & 98,20 & 247,12 & 247,40 & 90,08 & 515,70 & 68,77 & 4,00 & 50,75 & \begin{tabular}{|l|l|}
197,38 \\
\end{tabular} & 33,19 & 34,14 & 185,29 \\
\hline Pelophylax perezi & 29SQD03 & 99,00 & 162,05 & 112,89 & \begin{tabular}{|c|}
37,65 \\
\end{tabular} & 6217,30 & 336,97 & 40,74 & 96,23 & 94,54 & 244,16 & 244,37 & 86,30 & 543,79 & 71,43 & 4,07 & 50,64 & 207,91 & 35,20 & 35,89 & 196,42 \\
\hline Pelophylax perezi & 29SQD04 & 101,00 & 162,14 & $\begin{array}{l}111,49 \\
\end{array}$ & 37, & 623 & 33 & 41,53 & 294,79 & 94,29 & 244,50 & 244,68 & 86,19 & 547,03 & 71,38 & 4,06 & 50,53 & 209,08 & 35,45 & 35,94 & 197,72 \\
\hline Pelophylax perezi & 29SQD05 & 99,00 & 159,20 & 109,38 & \begin{tabular}{|l|l|}
36,93 \\
\end{tabular} & \begin{tabular}{ll|l}
6248,82 \\
\end{tabular} & 332,70 & 40,15 & 292,56 & 91,71 & 242,11 & 242,33 & 83,56 & 570,26 & 73,62 & 4,45 & 50,23 & 217,73 & 37,80 & 38,31 & 206,77 \\
\hline Pelophylax perezi & 29SQD06 & 100,00 & 162,13 & 108,65 & 36,89 & 6249,81 & 334,75 & 43,05 & 291,70 & 94,37 & 244,94 & 245,01 & 86,27 & 553,42 & 71,32 & 4,17 & 50,11 & 211,10 & 36,57 & 36,87 & 200,20 \\
\hline Pelophylax perezi & 29SQD07 & 100,00 & 160,93 & 107,44 & 36,60 & 6257,25 & 332,73 & 42,59 & 290,13 & 93,20 & 243,99 & 244,13 & 85,12 & 562,46 & 72,17 & 4,35 & 49,91 & 214,50 & 37,65 & 37,91 & 203,80 \\
\hline Pelophylax per & 29SQD08 & 100,00 & 157. & 105,80 & 36,10 & 668,10 & 328, & 40,38 & 288,23 & 89,93 & 4 & 24 & 81 & 585,14 & 75,05 & 4,93 & & 22 & 39,58 & 39,63 & 213,04 \\
\hline Pelophylax perezi & 29SQD09 & 99,00 & 158,24 & 105,39 & 36,01 & $\begin{array}{ll}6260,37 \\
\end{array}$ & 328,33 & 40,89 & 287,44 & 90,36 & 241,45 & 241,47 & 82,33 & 580,27 & 74,52 & 4,97 & 49,78 & 221,52 & 39,41 & $\begin{array}{l}39,46 \\
\end{array}$ & 211,38 \\
\hline Pelophylax perezi & 29SQD13 & 101,00 & 161,91 & 112,93 & 37,27 & 6289,60 & 338,44 & 39,80 & 298,64 & 93,62 & 245,15 & 245,26 & 85,32 & 532,07 & 69,11 & 4,03 & 50,50 & 201,98 & 34,28 & 34,72 & 190,05 \\
\hline
\end{tabular}




\begin{tabular}{|c|c|c|c|c|c|c|c|c|c|c|c|c|c|c|c|c|c|c|c|c|c|}
\hline TAXON & UTM & $\mathrm{km2}$ & BIO1 & B102 & $\mathrm{BIO3}$ & B104 & B105 & B106 & B107 & B108 & B109 & BIO10 & BIO11 & BIO12 & BIO13 & BI014 & BIO15 & BIO16 & BIO17 & B1018 & BlO19 \\
\hline Pelophylax perezi & 29SQD14 & 100,00 & 158,51 & 110,98 & 36,95 & 6316,54 & 334,69 & 37,68 & 297,01 & 90,14 & 242,30 & 242,41 & 81,98 & 553,40 & 70,99 & 4,25 & 50,08 & 209,54 & 36,45 & 36,77 & 197,87 \\
\hline Pelophylax perezi & \begin{tabular}{|l|} 
29SQD15 \\
\end{tabular} & 100,00 & 160,22 & 109,91 & 36,91 & 6318,99 & 335,55 & 39,81 & 295,74 & $\begin{array}{l}1,89 \\
\end{array}$ & 244,16 & 244,19 & 83,61 & 543,83 & 69,39 & 4,14 & \begin{tabular}{ll|}
49,90 \\
\end{tabular} & 205,40 & 36,18 & 36,36 & 193,78 \\
\hline Pelophylax perezi & 29SQD16 & 100,00 & 161,86 & 108,93 & 36,45 & 6324,93 & 336,34 & 41,80 & 294,54 & 93,24 & 245,83 & 245,83 & 85,13 & 533,57 & 67,87 & 4,00 & 49,69 & 201,38 & 35,67 & 35,70 & 189,67 \\
\hline Pelophylax perezi & 29SQD17 & 100,00 & 159,88 & 107,54 & 36,00 & 6335,02 & 333,55 & 40,64 & \begin{tabular}{l|l|}
292,92 \\
\end{tabular} & 91,31 & 244,13 & 244,13 & 83,15 & \begin{tabular}{ll|}
544,58 \\
\end{tabular} & 68,94 & 4,05 & 49,74 & 205,57 & 36,49 & 36,51 & 194,10 \\
\hline Pelophylax perezi & \begin{tabular}{|l|} 
29SQD18 \\
\end{tabular} & 100,00 & 158,95 & 106,70 & 36,00 & 6328,08 & 331,75 & \begin{tabular}{|l|l|}
40,47 \\
\end{tabular} & 291,28 & \begin{tabular}{|c|}
90,38 \\
\end{tabular} & \begin{tabular}{|l|l|}
243,22 \\
\end{tabular} & 243,22 & 82,34 & 550,14 & 69,56 & 4,51 & 49,38 & 207,69 & 37,51 & 37,51 & 196,47 \\
\hline Pelophylax perezi & \begin{tabular}{|l|l|}
$29 S Q D 20$ \\
\end{tabular} & 99,00 & 165,92 & 116,54 & 37,99 & 6306,84 & 344,73 & 40,70 & \begin{tabular}{|l|}
304,03 \\
\end{tabular} & \begin{tabular}{ll|}
97,01 \\
\end{tabular} & 249,04 & 249,12 & 88,66 & \begin{tabular}{|l|}
506,59 \\
\end{tabular} & 66,95 & 3,20 & 51,86 & $\begin{array}{l}193,22 \\
\end{array}$ & 29,84 & 30,62 & 180,89 \\
\hline Pelophylax perezi & 29SQD21 & 101,00 & 167,54 & 115,88 & 37,93 & 6306,67 & 345,66 & 42,66 & 302,99 & 98,62 & \begin{tabular}{l|l|}
250,56 \\
\end{tabular} & 250,69 & $\begin{array}{l}90,15 \\
\end{array}$ & \begin{tabular}{l|l}
493,85 \\
\end{tabular} & 65,03 & 3,03 & 51,52 & $\begin{array}{l}187,80 \\
\end{array}$ & 29,46 & 30,62 & 175,35 \\
\hline Pelophylax perezi & 29SQD22 & 99,00 & 166,10 & 114,86 & \begin{tabular}{l|l|}
37,35 \\
\end{tabular} & 6329,11 & 344,38 & 41,63 & 302,75 & $\begin{array}{l}96,99 \\
\end{array}$ & 249,73 & 249,83 & $\begin{array}{l}88,67 \\
\end{array}$ & \begin{tabular}{|l|l|}
500,07 \\
\end{tabular} & \begin{tabular}{ll|l}
65,06 \\
\end{tabular} & 3,38 & \begin{tabular}{|l|l|}
50,77 \\
\end{tabular} & \begin{tabular}{|l|l|}
189,08 \\
\end{tabular} & 31,18 & 31,49 & 176,83 \\
\hline Pelophylax perezi & 29SQD23 & 100,00 & 162,78 & 113,37 & 37,00 & 6357,80 & 341,02 & 39,52 & 301,50 & \begin{tabular}{|c|}
93,64 \\
\end{tabular} & 247,12 & 247,14 & 85,36 & 515,75 & 66,36 & 4,00 & 50,40 & \begin{tabular}{|l|l|}
194,20 \\
\end{tabular} & 32,93 & 33,12 & 182,06 \\
\hline Pelophylax perezi & 295QD24 & 100,00 & 159,30 & 111,62 & 36,90 & 6383,19 & 337,20 & 37,28 & 299,93 & 90,30 . & 244,22 & 244,27 & 82,04 & 533,15 & 67,94 & 4,09 & 49,93 & 200,05 & 35,15 & 35,28 & 187,96] \\
\hline Pelophylax perezi & \begin{tabular}{|l|l|}
$29 S Q D 25$ \\
\end{tabular} & 100,00 & 161,08 & 110,50 & 36,56 & 6385,15 & 338,14 & 39,61 & 298,53 & \begin{tabular}{l|l|l}
91,93 \\
\end{tabular} & \begin{tabular}{|l|l|}
246,09 \\
\end{tabular} & 246,10 & 83,70 & 520,90 & 66,19 & 4,00 & 49,61 & 194,74 & 34,86 & 34,94 & 182,62 \\
\hline Pelophylax perezi & \begin{tabular}{|l|l|}
$29 S Q D 26$ \\
\end{tabular} & 101,00 & 159,38 & 108,83 & 36,05 & 6397,50 & 335,77 & \begin{tabular}{l|l}
38,95 \\
\end{tabular} & 296,82 & 90,23 & \begin{tabular}{|l|l|}
244,69 \\
\end{tabular} & 244,69 & 82,14 & \begin{tabular}{|l|l|}
526,93 \\
\end{tabular} & 67,03 & 4,02 & \begin{tabular}{|l|}
49,63 \\
\end{tabular} & $\begin{array}{l}196,72 \\
\end{array}$ & \begin{tabular}{|l|}
35,47 \\
\end{tabular} & \begin{tabular}{|l|}
35,47 \\
\end{tabular} & 184,62 \\
\hline Pelophylax perezi & 29SQD27 & 100,00 & 160,06 & 107,97 & 36,00 & 6397,26 & 335,49 & \begin{tabular}{l|l}
39,85 \\
\end{tabular} & 295,64 & 90,75 & 245,32 & 245,32 & 82,60 & 521,58 & \begin{tabular}{ll|l}
66,06 \\
\end{tabular} & 4,07 & 49,38 & $\begin{array}{ll}194,52 \\
\end{array}$ & 35,48 & 35,48 & 182,45 \\
\hline Pelophylax perezi & $\begin{array}{l}29 S Q D 28 \\
\end{array}$ & 101,00 & 162,73 & 108,12 & 36,03 & 6376,15 & 337,02 & 42,26 & 294,77 & 93,22 & 247,57 & \begin{tabular}{|l|l|}
247,57 \\
\end{tabular} & 85,14 & \begin{tabular}{|l|l|}
506,04 \\
\end{tabular} & 63,53 & 4,00 & \begin{tabular}{l|l}
48,92 \\
\end{tabular} & \begin{tabular}{ll|}
188,88 \\
\end{tabular} & \begin{tabular}{|l|l|}
34,67 \\
\end{tabular} & \begin{tabular}{|l|l}
34,67 \\
\end{tabular} & 177,03 \\
\hline Pelophylax perezi & $\begin{array}{l}\text { 29SQD29 } \\
\end{array}$ & 99,00 & 160,44 & 107,57 & 36,00 & 6372,07 & 334,12 & 40,52 & $293,60 \mid$ & 91,04 & 245,34 & 245,34 & 82,9 & 514,47 & $\begin{array}{l}64,45 \\
\end{array}$ & 4,02 & 48,64 & \begin{tabular}{|l|l|}
191,95 \\
\end{tabular} & 35,61 & 35,61 & 180,30 \\
\hline Pelophylax perezi & 295 QD32 & 99,00 & 163,79 & 115,06 & $\begin{array}{l}37,05 \\
\end{array}$ & 6406,58 & 344,01 & 38,80 & 305,22 & $\begin{array}{ll}94,02 \\
\end{array}$ & \begin{tabular}{|l|l}
248,83 \\
\end{tabular} & 248,84 & 85,67 & 506,41 & 65,30 & 3,67 & 50,66 & 190,02 & 31,50 & 31,52 & 177,81 \\
\hline Pelophylax perezi & 29SQD33 & 100,00 & 159,75 & 113,57 & 36,93 & 6431,24 & 339,81 & 35,92 & \begin{tabular}{|l|l|}
303,89 \\
\end{tabular} & \begin{tabular}{|l|l|}
90,02 \\
\end{tabular} & \begin{tabular}{|l|l|}
245,19 \\
\end{tabular} & 245,19 & 81,60 & \begin{tabular}{|l|l|}
523,70 \\
\end{tabular} & 66,91 & 4,03 & 50,19 & \begin{tabular}{|l|l|}
195,72 \\
\end{tabular} & 33,60 & 33,66 & 183,56 \\
\hline Pelophylax perezi & 29SQD34 & 100,00 & 158,26 & 112,18 & 36,66 & 6447,42 & 337,87 & 35,26 & 302,62 & 88,47 & \begin{tabular}{|l|l}
244,05 \\
\end{tabular} & 244,05 & 80,09 & 526,71 & 67,01 & 4,03 & 49,66 & $\begin{array}{l}195,96 \\
\end{array}$ & 34,72 & 34,72 & 183,75 \\
\hline Pelophylax perezi & 29SQD35 & 99,00 & 158,47 & 110,82 & 36,14 & 6450,33 & 337,36 & 36,26 & 301,10 & 88,72 & \begin{tabular}{|l|l|l|}
244,43 \\
\end{tabular} & 244,43 & 80,42 & \begin{tabular}{ll|}
519,96 \\
\end{tabular} & 66,67 & 4,00 & \begin{tabular}{|c|}
49,57 \\
\end{tabular} & \begin{tabular}{|l|}
192,81 \\
\end{tabular} & 34,79 & 34,79 & 180,51 \\
\hline Pelophylax perezi & 29SQD36 & 100,00 & 158,56 & 109,69 & 36,00 & 6453,55 & 336,64 & 37,03 & \begin{tabular}{|l|l|}
299,60 \\
\end{tabular} & 88,73 & 244,68 & 244,68 & 80,4 & 515,1 & 66,62 & 4,06 & \begin{tabular}{l|l}
49,25 \\
\end{tabular} & \begin{tabular}{ll|l}
190,48 \\
\end{tabular} & 34,98 & 34,98 & 178,10 \\
\hline Pelophylax perezi & \begin{tabular}{|l|}
$29 S Q D 37$ \\
\end{tabular} & 100,00 & 159,95 & 109,03 & 36,00 & 6446,34 & 337,11 & 38,68 & 298,43 & $\begin{array}{l}90,07 \\
\end{array}$ & \begin{tabular}{|l|l|}
246,03 \\
\end{tabular} & 246,03 & 81,86 & 502,86 & \begin{tabular}{|l|l|}
64,88 \\
\end{tabular} & 4,01 & 48,87 & 185,48 & 34,50 & 34,50 & 173,13 \\
\hline Pelophylax perezi & 29SQD38 & 100,00 & 162,23 & 109,03 & \begin{tabular}{ll|}
36,06 \\
\end{tabular} & 6418,17 & 338,20 & 40,89 & 297,31 & \begin{tabular}{|l|l|}
92,29 \\
\end{tabular} & 247,74 & 247,74 & 84,08 & $\begin{array}{lll}488,93 \\
\end{array}$ & 61,73 & 4,00 & 48,59 & \begin{tabular}{|l|l|}
180,47 \\
\end{tabular} & 33,92 & 33,92 & 168,29 \\
\hline Pelophylax perezi & 29SQD39 & 99,00 & 158,01 & 108,29 & 36,00 & 6420,54 & 333,44 & 37,18 & 296,26 & \begin{tabular}{|l|l|}
88,09 \\
\end{tabular} & \begin{tabular}{|l|l|}
243,70 \\
\end{tabular} & 243,70 & 79,96 & \begin{tabular}{|l|l|}
505,57 \\
\end{tabular} & 62,88 & 4,44 & 48,10 & $\begin{array}{ll}186,62 \\
\end{array}$ & 35,82 & 35,82 & 174,49 \\
\hline Pelophylax perezi & \begin{tabular}{|l|l|}
$29 S Q D 40$ \\
\end{tabular} & 100,00 & 167,71 & 117,67 & 37,59 & 6440,08 & 349,40 & 40,25 & 309,15 & 97,20 & 252,73 & 252,73 & 88,58 & 494,36 & 64,55 & 3,00 & 52,06 & \begin{tabular}{|l|l|}
186,50 \\
\end{tabular} & 28,03 & 28,13 & 174,54 \\
\hline Pelophylax perezi & 29SQD41 & 100,00 & 167,40 & 116,77 & 37,13 & 6444,88 & 349,11 & 40,70 & 308,41 & 96,92 & 252,81 & 252,81 & 88,49 & 488,5 & 63,47 & 3,01 & 51,4 & $\begin{array}{l}183,45 \\
\end{array}$ & 28,49 & 28,51 & 171,45 \\
\hline Pelophylax perezi & \begin{tabular}{|l|}
$295 Q D 42$ \\
\end{tabular} & 101,00 & 163,45 & 115,65 & 37,00 & 6467,77 & 345,24 & 37,56 & 307,68 & 92,97 & 249,25 & 249,25 & 84,56 & \begin{tabular}{|l|l|}
501,69 \\
\end{tabular} & 64,52 & 3,59 & 50,63 & \begin{tabular}{|l|l|}
187,05 \\
\end{tabular} & 30,86 & 30,86 & 175,00 \\
\hline Pelophylax perezi & 29SQD43 & 101,00 & 161,52 & 114,56 & 37,00 & 6485,11 & 343,00 & 36,40 & 306,60 & $\begin{array}{l}90,96 \\
\end{array}$ & 247,73 & 247,73 & $\begin{array}{l}82,47 \\
\end{array}$ & $\begin{array}{l}504,86 \\
\end{array}$ & 64,52 & 3,99 & \begin{tabular}{|l|l|}
50,27 \\
\end{tabular} & \begin{tabular}{|l|l|}
187,34 \\
\end{tabular} & 32,06 & 32,06 & 175,22 \\
\hline Pelophylax perezi & \begin{tabular}{|l|l|}
$29 S Q D 45$ \\
\end{tabular} & 101,00 & 156,92 & 111,98 & 36,18 & 6502,96 & 337,50 & 33,38 & 304,12 & 86,42 & 243,73 & 243,73 & 78,09 & 515,62 & 66,49 & 4,00 & 49,19 & \begin{tabular}{|l|l|}
189,75 \\
\end{tabular} & 34,48 & 34,48 & 177,47 \\
\hline Pelophylax perezi & \begin{tabular}{|l|}
$29 S Q D 46$ \\
\end{tabular} & 101,00 & 158,61 & 111,09 & 36,02 & 6493,81 & 338,07 & 35,56 & 302,51 & 88,12 & 245,17 & 245,17 & 79,77 & \begin{tabular}{|l|l|}
501,75 \\
\end{tabular} & 64,84 & $\begin{array}{l}4,00 \\
\end{array}$ & 48,76 & \begin{tabular}{ll|}
184,06 \\
\end{tabular} & 34,20 & 34,20 & 171,66 \\
\hline Pelophylax perezi & \begin{tabular}{|l|} 
29SQD47 \\
\end{tabular} & 100,00 & 160,86 & 110,70 & \begin{tabular}{|l|}
36,07 \\
\end{tabular} & 6477,91 & 339,36 & 37,98 & 301,38 & 90,34 & 247,32 & 247,32 & 82,02 & 484,05 & \begin{tabular}{ll|l}
62,15 \\
\end{tabular} & 4,00 & \begin{tabular}{|l|}
48,47 \\
\end{tabular} & \begin{tabular}{|l|l|}
177,12 \\
\end{tabular} & \begin{tabular}{|l|}
33,49 \\
\end{tabular} & 33,49 & 164,73 \\
\hline Pelophylax perezi & \begin{tabular}{|l|l|}
$29 S Q D 48$ \\
\end{tabular} & 101,00 & 161,55 & 110,35 & 36,08 & 6466,01 & 339,07 & 38,76 & 300,31 & $\begin{array}{l}90,95 \\
\end{array}$ & 247,84 & 247,84 & \begin{tabular}{c|c}
82,85 \\
\end{tabular} & 475,51 & 60,13 & 4,00 & 48,11 & 173,82 & 33,42 & 33,42 & 161,51 \\
\hline Pelophylax perezi & 29SQD49 & 101,00 & 157,11 & 109,50 & 36,00 & 6458,45 & 334,03 & 35,16 & 298,87 & 86,68 & 243,30 & 243,30 & 78,69 & 490,88 & 61,05 & 4,54 & 47,59 & 179,34 & 35,49 & 35,49 & 166,93 \\
\hline Pelophylax perezi & $\begin{array}{l}29 S Q D 50 \\
\end{array}$ & 100,00 & 165,70 & 118,08 & \begin{tabular}{l|l}
37,15 \\
\end{tabular} & 6507,03 & 349,50 & 37,54 & 311,96 & 94,54 & 251,86 & 251,86 & 85,97 & 502,35 & 65,33 & 3,00 & 51,91 & $\begin{array}{l}188,30 \\
\end{array}$ & 28,59 & 28,59 & 176,77 \\
\hline Pelophylax perezi & 29SQD52 & 92,00 & 167,44 & 116,65 & 37,00 & 6497,98 & 349,78 & 40,09 & 309,69 & \begin{tabular}{|l|l}
96,03 \\
\end{tabular} & 253,58 & 253,58 & 87,75 & $\begin{array}{ll}477,86 \\
\end{array}$ & 61,55 & 3,01 & 50,82 & 177,33 & 28,63 & 28,63 & 165,58 \\
\hline Pelophylax perezi & \begin{tabular}{|l|}
$29 S Q D 53$ \\
\end{tabular} & 97,00 & 165,47 & 115,63 & 37,00 & 6512,83 & 347,79 & 38,87 & 308,92 & \begin{tabular}{|l|}
94,19 \\
\end{tabular} & 252,03 & 252,03 & 85,84 & 479,56 & 61,44 & 3,16 & 50,23 & \begin{tabular}{ll|}
176,96 \\
\end{tabular} & 29,56 & 29,56 & 165,02 \\
\hline Pelophylax perezi & $295 Q D 54$ & 90,00 & 156,13 & 113,97 & 36,59 & 6540,17 & 338,76 & 31,17 & 307,59 & 85,11 & 243,50 & 243,50 & 76,94 & 517,89 & 66,59 & 4,21 & 49,36 & 189,84 & 34,20 & 34,20 & 177,86 \\
\hline Pelophylax perezi & $295 Q 055$ & 82,00 & 156,69 & 113,12 & 36,23 & 6542,17 & 338,71 & 32,22 & 306,49 & \begin{tabular}{|l|}
85,59 \\
\end{tabular} & \begin{tabular}{|l|l|}
244,25 \\
\end{tabular} & 244,25 & 77,52 & 505,80 & \begin{tabular}{l|l|}
65,25 \\
\end{tabular} & 4,08 & 48,90 & \begin{tabular}{|l|l|}
184,66 \\
\end{tabular} & 34,11 & 34,11 & 172,52 \\
\hline Pelophylax perezi & $\begin{array}{l}29 S Q D 56 \\
\end{array}$ & 87,00 & 157,94 & 112,30 & 36,01 & 6536,19 & 338,98 & 33,71 & 305,27 & 86,92 & 245,25 & 245,25 & 78,64 & 492,20 & 63,35 & 4,02 & 48,53 & \begin{tabular}{|l|l|}
179,17 \\
\end{tabular} & 33,79 & 33,79 & 166,85 \\
\hline Pelophylax perezi & \begin{tabular}{|l|}
$29 S Q D 57$ \\
\end{tabular} & 80,00 & 160,28 & 111,88 & 36,03 & 511,11 & 340,08 & 36,26 & 303,83 & 89,31 & 247,30 & 247,30 & 81,00 & 474,2 & 60,62 & 4,00 & $\begin{array}{ll}48,02 \\
\end{array}$ & 172,21 & 33,12 & 33,12 & 159,87 \\
\hline Pelophylax perezi & \begin{tabular}{|l|}
$29 S Q D 58$ \\
\end{tabular} & 72,00 & 159,68 & 111,35 & \begin{tabular}{l|l}
36,05 \\
\end{tabular} & 6490,86 & 338,59 & \begin{tabular}{l|l|}
36,23 \\
\end{tabular} & 302,36 & 89,04 & 246,51 & 246,51 & 80,72 & 470,35 & 59,39 & 4,00 & \begin{tabular}{|c|}
47,57 \\
\end{tabular} & 170,54 & 33,51 & 33,51 & 158,14 \\
\hline Pelophylax perezi & \begin{tabular}{|l|}
$29 S Q D 59$ \\
\end{tabular} & 77,00 & 158,03 & 110,91 & 36,04 & 6482,15 & 336,26 & 34,92 & 301,34 & \begin{tabular}{|l|l|}
87,37 \\
\end{tabular} & \begin{tabular}{|l|l|}
244,79 \\
\end{tabular} & 244,79 & 79,16 & \begin{tabular}{|l|l|}
471,49 \\
\end{tabular} & 58,59 & 4,33 & 47,20 & $\begin{array}{ll}170,65 \\
\end{array}$ & 34,29 & 34,29 & 158,17 \\
\hline Pelophylax perezi & 29SQEOO & 101,00 & 161,64 & 105,82 & 36,28 & 6236,36 & 330,84 & 43,91 & 286,93 & 93,55 & \begin{tabular}{|l|l|}
244,43 \\
\end{tabular} & 244,43 & 85,63 & 559,13 & 71,91 & 4,71 & \begin{tabular}{|l|l}
49,55 \\
\end{tabular} & 213,51 & 37,99 & 37,99 & 203,48 \\
\hline Pelophylax perezi & 29SQE01 & 99,00 & 160,30 & 105,32 & 36,15 & 6233,46 & 328,60 & 42,66 & 285,94 & \begin{tabular}{|c|}
92,10 \\
\end{tabular} & \begin{tabular}{|l|l|}
242,99 \\
\end{tabular} & 242,99 & 84,28 & 566,09 & 72,99 & 5,00 & 49,40 & \begin{tabular}{|l|l|}
216,25 \\
\end{tabular} & 38,86 & 38,86 & 206,46 \\
\hline Pelophylax perezi & 29SQE02 & 99,00 & 159,22 & 105,03 & 36,30 & 19,57 & \begin{tabular}{|l|}
326,95 \\
\end{tabular} & 41,93 & \begin{tabular}{|l|}
285,02 \\
\end{tabular} & $\begin{array}{l}91,05 \\
\end{array}$ & 241,83 & 241,83 & 83,1 & 568,5 & 73,55 & 5,00 & 49,3 & 217,29 & 39,12 & 39,12 & 207,64 \\
\hline Pelophylax perezi & \begin{tabular}{|l|}
$29 S Q E 10$ \\
\end{tabular} & 100,00 & 161,27 & 106,66 & 36,20 & 6291,10 & 332,27 & 42,40 & 289,87 & 92,50 & 244,82 & 244,82 & 84,4 & 533,2 & 67,80 & 4,52 & \begin{tabular}{|l|l|}
48,95 \\
\end{tabular} & 201,42 & 36,81 & 36,81 & 190,60 \\
\hline Pelophylax perezi & 29SQE11 & 101,00 & 157,74 & 105,92 & 36,02 & 6286,97 & 328,03 & 39,4 & 288,61 & 89,15 & 241,37 & 241,37 & 81,2 & \begin{tabular}{|l|}
550,67 \\
\end{tabular} & 70,10 & 5,05 & \begin{tabular}{ll|l}
48,66 \\
\end{tabular} & 208,12 & 38,66 & 38,66 & 197,41 \\
\hline Pelophylax perezi & 29SQE12 & 101,00 & 159,51 & 106,20 & 36,38 & 6265,51 & 328,80 & 40,89 & 287,91 & $\begin{array}{l}90,55 \\
\end{array}$ & 242,56 & 242,56 & 82,76 & \begin{tabular}{|l|l|}
537,63 \\
\end{tabular} & 68,69 & 4,94 & 48,43 & 203,31 & \begin{tabular}{l|l|l|}
37,95 \\
\end{tabular} & \begin{tabular}{l|l}
37,95 \\
\end{tabular} & 192,75 \\
\hline Pelophylax perezi & 29SQE20 & 100,00 & 159,87 & 107,36 & 36,06 & 6349,34 & 332,51 & 40,08 & 292,43 & \begin{tabular}{|l|l}
90,46 \\
\end{tabular} & 244,42 & 244,42 & 82,45 & 516,13 & 64,99 & 4,44 & 48,31 & 192,92 & 36,32 & 36,33 & 181,32 \\
\hline Pelophylax perezi & 29SQE21 & 100,00 & 154,50 & 106,46 & 36,05 & 6336,97 & 326,43 & 35,58 & 290,85 & 85,30 & 238,99 & 238,99 & 77,47 & \begin{tabular}{l|l}
541,05 \\
\end{tabular} & 68,05 & 5,17 & 47,80 & \begin{tabular}{|l|}
202,17 \\
\end{tabular} & 39,26 & 39,29 & 190,77 \\
\hline Pelophylax perezi & 29SQE22 & 99,00 & 161,24 & 107,65 & 36,48 & 6301,11 & 332,08 & 41,32 & 290,76 & 91,85 & 245,08 & 245,08 & 83,98 & 500,32 & 63,38 & 4,59 & 47,75 & 187,07 & 35,98 & 35,98 & 175,85 \\
\hline Pelophylax perezi & 29SQE30 & 100,00 & 160,68 & 108,58 & 36,06 & 6384,78 & 334,81 & 39,60 & 295,20 & \begin{tabular}{l|l}
90,75 \\
\end{tabular} & \begin{tabular}{|l|l|}
245,78 \\
\end{tabular} & 245,78 & 82,71 & \begin{tabular}{|l|l|}
488,52 \\
\end{tabular} & 60,88 & 4,24 & \begin{tabular}{|l|l|}
47,79 \\
\end{tabular} & 180,53 & 34,82 & 34,82 & 168,60 \\
\hline Pelophylax perezi & 29SQE31 & 100,00 & 151,70 & 107,43 & 35,99 & 6391,73 & 325,58 & 31,99 & 293,58 & 82,12 & 237,20 & 237,20 & 74,27 & 528,86 & \begin{tabular}{|l|l}
65,88 \\
\end{tabular} & 5,36 & 47,12 & \begin{tabular}{|l|l|}
195,34 \\
\end{tabular} & 39,53 & 39,53 & 183,23 \\
\hline Pelophylax perezi & 29SQE32 & 100,00 & 157,19 & 108,24 & 36,26 & 6358,92 & 330,00 & 36,44 & 293,56 & 87,21 & 241,85 & 241,85 & 79,41 & 495,20 & 61,98 & 4,9 & 46,8 & 182,80 & 36,92 & 36,92 & 170,93 \\
\hline Pelophylax perezi & 29SQE40 & 100,00 & 159,59 & 109, & 36,7 & 430 & 335 & 37, & 297, & 89, & 245 & 245 & 81 , & 473 & 58,51 & 4, & $47,20 \mid$ & \begin{tabular}{ll|}
172,99 \\
\end{tabular} & 34,49 & 34,49 & 160,75 \\
\hline Pelophylax perezi & 29SQE41 & 101,00 & 154,90 & 109,12 & 36,13 & 6419,67 & 330,21 & 33,53 & 296,68 & 84,60 & 240,72 & 240,72 & 76,87 & 489,60 & 60,49 & $\begin{array}{l}4,99 \\
\end{array}$ & 46,49 & \begin{tabular}{|l|l|}
178,67 \\
\end{tabular} & 36,92 & 36,92 & 166,26 \\
\hline Pelophylax perezi & 29SQE42 & 100,00 & 153,12 & 109,16 & 36,26 & 6395,85 & 327,66 & 32,03 & 295,63 & 82,96 & 238,64 & 238,64 & 75,36 & \begin{tabular}{|l|l|}
489,82 \\
\end{tabular} & 60,62 & 5,12 & 46,01 & \begin{tabular}{|l|l|}
178,57 \\
\end{tabular} & 37,77 & 37,77 & 166,24 \\
\hline Pelophylax perezi & 29SQE50 & 70,00 & 159,94 & 110,91 & 36,59 & 6450,74 & 336,84 & 36,84 & \begin{tabular}{|l|}
300,00 \\
\end{tabular} & 89,39 & \begin{tabular}{|l|l|}
246,15 \\
\end{tabular} & $\begin{array}{l}246,15 \\
\end{array}$ & 81,11 & \begin{tabular}{|l|l|}
456,27 \\
\end{tabular} & 56,13 & 4,02 & 46,66 & $\begin{array}{l}165,05 \\
\end{array}$ & 33,50 & 33,50 & 152,85 \\
\hline Pelophylax per & 29SQE51 & 63,00 & & 110,69 & 36,6 & 7 & & $36, \mathrm{C}$ & $298, \varepsilon$ & 88, & 244 & 24 & 80,34 & 454, & 55,83 & 4,50 & 461 & 164 & 34,23 & 34,23 & 151 \\
\hline Pelophylax perezi & 29SQE5 & 66,00 & 155,05 & 110,34 & 36,55 & 6425,27 & 330,5 & 32,56 & 297,95 & 84,20 & $240,69 \mid$ & 240,69 & 76,57 & 463,73 & 57,01 & $5,01[$ & 45,64 & 167,40 & 36,06 & 36,06 & 154, \\
\hline Pelophylax perezi & 29TMH76 & 18,00 & 142,36 & 59,45 & 39,14 & 3130,50 & 224,05 & 74,18 & 149,86 & 112,64 & 180,45 & 184,00 & 103,45 & 970,82 & 140,59 & 26,09 & 42,05 & 384,09 & 112,86 & 138,27 & 322,23 \\
\hline
\end{tabular}




\begin{tabular}{|c|c|c|c|c|c|c|c|c|c|c|c|c|c|c|c|c|c|c|c|c|c|}
\hline TAXON & UTM & $\mathrm{km} 2$ & B101 & B102 & $\mathrm{BIO3}$ & B104 & B105 & B106 & B107 & B108 & B109 & B1010 & BIO11 & BIO12 & B1013 & BIO14 & BIO15 & B1016 & B1017 & B1018 & B1019 \\
\hline Pelophylax perezi & 29TMH85 & 76,00 & 139,86 & 60,66 & 38,86 & 3227,67 & 224,58 & 70,50 & 154,08 & 109,07 & 179,49 & 182,91 & 99,89 & 1022,70 & 146,27 & 27,14 & 42,50 & 405,09 & 116,07 & 140,82 & 344,98 \\
\hline Pelophylax perezi & 29TMH87 & 60,00 & 143,94 & 60,09 & 39,43 & 3139,24 & 225,93 & 75,29 & 150,63 & 114,11 & 182,18 & 185,88 & 104,93 & 980,60 & 139,88 & 26,78 & 41,41 & 385,48 & 113,95 & 139,40 & 326,89 \\
\hline Pelophylax perezi & 29TMH90 & 6,00 & 148,43 & 58,79 & 38,79 & 3288,93 & 229,93 & 80,50 & 149,43 & 115,14 & 189,36 & 191,43 & 106,64 & 1150,64 & 161,21 & 25,29 & 46,07 & 461,43 & 107,86 & 131,50 & 415,43 \\
\hline Pelophylax perezi & 29TMH91 & 46,00 & 146,53 & 59,04 & 38,62 & 3311,15 & 229,18 & 78,01 & 151,16 & 113,22 & 187,59 & 189,99 & 104,65 & 1143,04 & 161,42 & 26,24 & 45,56 & 458,00 & 110,67 & 134,49 & 409,85 \\
\hline Pelophylax perezi & 29TMH92 & 25,00 & 141,23 & 60,49 & 38,14 & 3378,23 & 227,51 & 71,47 & 156,05 & 107,72 & 183,44 & 185,91 & 99,12 & \begin{tabular}{ll|}
1175,86 \\
\end{tabular} & 168,47 & 28,44 & 44,98 & 469,60 & 117,91 & 141,35 & 420,91 \\
\hline Pelophylax perezi & 29тMH93 & 45,00 & 142,97 & 60,38 & 38,58 & 3303,65 & 228,01 & 73,36 & 154,65 & 110,67 & 183,91 & 186,81 & 101,71 & 1081,97 & 153,14 & 26,94 & 44,01 & 431,12 & 113,87 & 138,10 & 376,59 \\
\hline Pelophylax perezi & 29TMH94 & 96,00 & 134,43 & 62,32 & 38,30 & 3383,03 & 224,15 & 63,56 & 160,59 & 101,66 & 176,79 & 179,88 & 92,99 & 1163,86 & 165,96 & 30,57 & 43,29 & 460,44 & 125,92 & 149,26 & 407,56 \\
\hline Pelophylax perezi & 29TMH95 & 101,00 & 132,06 & 62,84 & 38,29 & 3379,81 & 222,68 & 60,82 & 161,87 & $\begin{array}{l} \\
99,50 \\
\end{array}$ & 174,35 & $\begin{array}{l}177,58 \\
\end{array}$ & 90,84 & 1161,49 & 163,83 & 31,54 & 42,44 & 457,27 & $\begin{array}{l}129,28 \\
\end{array}$ & 152,73 & 403,12 \\
\hline Pelophylax perezi & 29TMH96 & 101,00 & 132,67 & 62,76 & 38,41 & 3336,99 & 222,47 & 61,55 & 160,92 & 100,76 & 174,14 & 177,72 & 91,95 & 1134,29 & 158,51 & 31,50 & 41,88 & 444,68 & 129,01 & 152,87 & 389,79 \\
\hline Pelophylax perezi & 29TMH97 & 100,00 & 138,07 & 61,86 & 38,93 & 3246,93 & 224,66 & 67,91 & 156,75 & 107,19 & 178,13 & 181,82 & 98,28 & 1062,28 & 147,82 & 29,67 & 41,14 & 415,54 & 122,71 & 147,29 & 360,00 \\
\hline Pelophylax perezi & 29TMH98 & 28,00 & 142,80 & 61,16 & 39,53 & 3177,18 & 226,53 & 73,42 & 153,11 & 112,60 & 181,80 & 185,62 & 103,67 & 1013,53 & 141,49 & 28,18 & 41,00 & 395,73 & 117,49 & 142,60 & 341,07 \\
\hline Pelophylax perezi & 29TNE13 & 97,00 & 154,79 & 80,80 & 43,68 & 3528,08 & 252,14 & 69,20 & 182,95 & 116,15 & 196,97 & 199,18 & 108,20 & 885,08 & 126,62 & 8,21 & 54,91 & 362,20 & 53,86 & 60,55 & 356,00 \\
\hline Pelophylax perezi & 29TNE14 & 94,00 & 153,37 & 80,69 & 43,99 & 3489,40 & 249,04 & 67,60 & 181,44 & 114,96 & 194,89 & 196,96 & 106,94 & 915,43 & 130,14 & 8,93 & 54,31 & 372,73 & 57,22 & 64,43 & 366,66 \\
\hline Pelophylax perezi & 29TNE15 & 95,00 & 152,10 & 79,87 & $\begin{array}{l}44,23 \\
\end{array}$ & 3433,91 & 244,94 & 66,57 & 178,37 & 114,04 & 192,57 & 194,69 & 106,07 & 940,82 & 132,95 & 9,80 & 53,87 & 381,66 & 60,01 & 67,97 & 375,23 \\
\hline Pelophylax perezi & 29TNE17 & 40,00 & 151,00 & 77,70 & \begin{tabular}{|l|l|l|}
44,97 & \\
\end{tabular} & 3321,38 & 237,20 & 65,97 & 171,23 & 113,99 & 189,58 & 191,34 & 105,62 & 973,01 & 136,21 & 10,34 & 53,00 & 393,07 & 63,24 & 72,89 & 385,45 \\
\hline Pelophylax perezi & 29TNE23 & 100,00 & 156,94 & 86,62 & 43,62 & 3755,01 & 263,74 & 67,06 & 196,68 & 115,60 & 202,23 & 204,55 & 107,75 & 889,55 & 126,60 & 8,44 & 54,58 & 361,68 & 55,13 & 60,88 & 358,13 \\
\hline Pelophylax perezi & 29TNE24 & 101,00 & 157,05 & 86,34 & \begin{tabular}{|c|}
43,98 \\
\end{tabular} & 3694,57 & 261,43 & 67,16 & 194,27 & 116,16 & 201,40 & 203,60 & 108,25 & 901,97 & 127,53 & 8,99 & 53,98 & 365,32 & 57,08 & 63,58 & 361,36 \\
\hline Pelophylax perezi & 29TNE25 & 101,00 & 153,77 & 85,81 & 44,09 & 3656,36 & 256,26 & 64,15 & 192,11 & 113,23 & 197,53 & 199,63 & 105,25 & 947,18 & 133,35 & 9,75 & 53,42 & 382,17 & 61,32 & 68,27 & 378,15 \\
\hline Pelophylax perezi & 29TNE26 & 100,00 & 152,32 & 84,16 & \begin{tabular}{|l|l|l}
44,45 & \\
\end{tabular} & 3581,52 & 250,69 & 63,32 & 187,37 & 112,44 & 194,77 & 196,81 & 104,39 & 969,56 & 136,02 & 10,03 & 53,09 & 390,74 & 63,01 & 70,94 & 385,71 \\
\hline Pelophylax perezi & 29TNE27 & 100,00 & 150,94 & 81,77 & 44,72 & 3491,93 & 244,10 & 63,03 & 181,07 & 111,95 & 191,99 & 193,90 & 103,76 & 988,28 & 138,04 & 10,85 & 52,79 & 397,95 & 65,18 & 74,10 & 391,49 \\
\hline Pelophylax perezi & 29TNE28 & 101,00 & 149,73 & 78,91 & 45,04 & 3384,36 & 236,65 & 63,11 & 173,54 & 111,73 & 189,05 & 190,76 & 103,37 & 1002,72 & 139,53 & 11,00 & 52,55 & 403,88 & 66,14 & 76,54 & 395,56 \\
\hline Pelophylax perezi & 29TNE29 & 91,00 & 148,62 & 76,34 & 45,23 & 3286,96 & 230,02 & 63,25 & 166,77 & 111,66 & 186,35 & 187,93 & 103,07 & 1017,60 & 140,94 & 11,13 & 52,35 & 410,05 & 67,19 & 78,96 & 399,81 \\
\hline Pelophylax perezi & 29TNE33 & 101,00 & 158,16 & 92,64 & 43,21 & 4010,56 & 275,56 & 64,01 & 211,56 & 112,29 & 207,16 & 209,62 & 106,24 & 902,78 & 127,94 & 8,74 & 54,15 & 364,73 & 57,45 & 61,96 & 363,85 \\
\hline Pelophylax perezi & 29TNE34 & 100,00 & 158,71 & 92,86 & 43,79 & 3959,58 & 274,19 & 64,23 & 209,97 & 114,31 & 206,84 & 209,11 & 106,97 & 911,58 & 128,28 & 9,09 & 53,73 & 366,69 & 58,88 & 64,19 & 365,55 \\
\hline Pelophylax perezi & 29TNE35 & 101,00 & 155,88 & 92,45 & 44,00 & 3919,27 & 269,56 & 61,58 & 207,99 & 112,19 & 203,42 & 205,66 & 104,51 & 950,94 & 133,34 & 9,92 & 53,16 & 381,31 & 62,81 & 68,60 & 379,90 \\
\hline Pelophylax perezi & 29TNE36 & 101,00 & 153,32 & 90,79 & 44,05 & 3857,75 & 263,38 & 59,66 & 203,71 & 110,21 & 199,93 & 201,99 & 102,41 & 984,04 & 137,65 & 10,85 & 52,91 & 394,26 & 65,75 & 72,21 & 391,82 \\
\hline \begin{tabular}{|l|} 
Pelophylax perezi \\
\end{tabular} & 29TNE37 & 100,00 & 151,92 & 88,12 & 44,21 & 3760,17 & 256,36 & 59,47 & \begin{tabular}{|l|l|}
196,88 \\
\end{tabular} & \begin{tabular}{|l|l|}
109,94 \\
\end{tabular} & \begin{tabular}{|l|l|}
196,99 \\
\end{tabular} & \begin{tabular}{|l|}
198,97 \\
\end{tabular} & $\begin{array}{l}101,90 \\
101,1\end{array}$ & \begin{tabular}{|l|l|}
999,56 \\
\end{tabular} & $\begin{array}{l}139,38 \\
\end{array}$ & 11,00 & 52,72 & 400,87 & 66,69 & $\begin{array}{l}74,26 \\
74,56\end{array}$ & 396,25 \\
\hline Pelophylax perezi & 29TNE38 & 100,00 & 151,17 & 85,28 & \begin{tabular}{|l|l|}
44,48 \\
\end{tabular} & 3655,62 & 249,50 & 59,88 & 189,62 & 110,04 & 194,48 & 196,30 & 101,87 & 1009,27 & 140,22 & 11,01 & 52,38 & 405,38 & 67,20 & 76,61 & 398,25 \\
\hline Pelophylax perezi & 29TNE39 & 101,00 & 149,99 & 83,28 & 44,75 & 3590,40 & 244,10 & 59,58 & 184,53 & 109,52 & 192,36 & 194,02 & 101,25 & 1023,95 & 141,72 & 11,49 & 52,18 & 411,92 & 68,18 & 79,27 & 402,06 \\
\hline Pelophylax perezi & 29TNE43 & 100,00 & 152,01 & 96,88 & 42,29 & 4334,80 & 280,95 & 54,54 & 226,42 & 97,23 & 206,12 & 208,63 & 97,14 & 988,34 & 140,82 & 10,21 & 53,90 & 399,77 & 65,27 & 67,43 & 399,77 \\
\hline Pelophylax perezi & 29TNE44 & 101,00 & 157,36 & 99,73 & 43,31 & 4271,78 & 286,11 & 58,28 & 227,83 & 102,93 & 210,29 & 212,65 & 102,55 & 952,53 & 133,76 & 10,00 & 53,12 & 382,72 & 63,82 & 67,21 & 382,71 \\
\hline \begin{tabular}{|l|} 
Pelophylax perezi \\
\end{tabular} & 29TNE45 & 101,00 & 159,50 & \begin{tabular}{|l|l|}
98,46 \\
\end{tabular} & | 43,90 & 4164,52 & 283,32 & $\begin{array}{ll}60,82 \\
60,\end{array}$ & 222,49 & \begin{tabular}{|l|l|}
108,75 \\
\end{tabular} & 210,58 & \begin{tabular}{|l|l|l|l|l|l|}
212,78 \\
\end{tabular} & $\begin{array}{l}105,32 \\
105\end{array}$ & \begin{tabular}{|l|l|}
936,35 \\
96
\end{tabular} & $\begin{array}{l}130,70 \\
\end{array}$ & 9,70 & 52,90 & $\begin{array}{l}374,25 \\
\end{array}$ & $\begin{array}{l}62,54 \\
62,54\end{array}$ & $\begin{array}{l}67,44 \\
67\end{array}$ & 374,14 \\
\hline Pelophylax perezi & 29TNE46 & 100,00 & 155,75 & 96,92 & 43,75 & 4129,05 & 276,81 & 57,49 & 219,32 & 107,60 & 206,33 & 208,40 & 101,84 & 981,31 & 136,99 & 10,65 & 52,63 & 391,48 & 66,27 & 71,75 & 391,01 \\
\hline Pelophylax perezi & 29TNE47 & 101,00 & 154,50 & 94,07 & 43,94 & 4033,16 & 269,87 & 57,67 & 212,19 & 109,24 & 203,70 & 205,62 & 101,39 & 992,43 & 138,39 & 10,73 & 52,51 & 396,70 & 66,59 & 73,58 & 393,77 \\
\hline Pelophylax perezi & 29TNE48 & 101,00 & 153,62 & 91,44 & 44,01 & 3947,35 & 263,56 & 57,81 & 205,75 & 109,17 & 201,37 & 203,17 & 101,12 & 1001,46 & 139,26 & 10,96 & 52,41 & 401,25 & 66,83 & 75,53 & 395,36 \\
\hline Pelophylax perezi & 29TNE49 & 100,00 & 151,63 & 89,81 & 43,97 & 3905,53 & 258,44 & 56,55 & 201,90 & 107,68 & 198,79 & 200,54 & 99,55 & 1025,40 & 142,39 & 11,30 & 52,40 & 412,01 & 68,11 & 78,33 & 403,22 \\
\hline Pelophylax perezi & $\begin{array}{l}\text { 29TNE53 } \\
\text { 29TE }\end{array}$ & 101,00 & $\begin{array}{l}151,83 \\
151,81\end{array}$ & $\begin{array}{l}3,01 \\
98,81 \\
\end{array}$ & 年 41,57 & $\begin{array}{l}35045,58 \\
4545\end{array}$ & 280,44 & \begin{tabular}{|l|l|l|}
52,19 \\
\end{tabular} & 234,65 & \begin{tabular}{|l|} 
\\
94,84
\end{tabular} & 209,36 & $\mid$ & $\begin{array}{ll}94,84 \\
94,8\end{array}$ & 1002,83 & \begin{tabular}{|l|}
$142,3,49$ \\
143
\end{tabular} & $\begin{array}{l}1,00 \\
10,28 \\
\end{array}$ & 53,94 & \begin{tabular}{|l|}
406,24 \\
40,2
\end{tabular} & $\begin{array}{l}00,11 \\
66,25\end{array}$ & $\begin{array}{l}\mid 0,303 \\
67,75 \\
\end{array}$ & $\begin{array}{l}40,24 \\
406,24\end{array}$ \\
\hline Pelophylax perezi & 29TNE54 & 101,00 & 156,27 & 102,18 & 42,50 & 4514,23 & 292,22 & 54,61 & 237,61 & 99,02 & 212,75 & 215,25 & 99,02 & 975,79 & 137,69 & 10,19 & 53,13 & 392,97 & 65,87 & 68,08 & 392,97 \\
\hline Pelophylax perezi & 29TNE55 & 99,00 & 150,55 & 100,13 & 42,22 & 4497,70 & 284,29 & 49,83 & 234,45 & 93,64 & 207,01 & 209,27 & 93,64 & 1043,22 & 148,06 & 11,27 & 53,18 & 419,77 & 70,97 & 73,17 & 419,77 \\
\hline Pelophylax perezi & 29TNE56 & 101,00 & 150,10 & 99,40 & 42,3 & 4444,24 & 281,01 & 49,47 & 231,54 & 93,55 & 205,67 & 207,82 & 93,41 & 1053,40 & 149,12 & 11,49 & 52,88 & 422,23 & 71,75 & 75,15 & 422,23 \\
\hline Pelophylax perezi & 29TNE57 & 101,00 & 148,69 & 97,64 & 42 & 4378,99 & 275,62 & 48,79 & 226,84 & 97,88 & 203,34 & 205,27 & 92,45 & 1070,57 & 151,49 & 11,72 & 52,86 & 28,03 & 72,49 & 77,32 & 427,56 \\
\hline Pelophylax perezi & $\begin{array}{l}\text { 29TNES } \\
\text { 29TNE58 }\end{array}$ & $\begin{array}{l}100,00 \\
100,0\end{array}$ & $\begin{array}{l}14,09 \\
146,09\end{array}$ & $\begin{array}{l}1,104 \\
95,18 \\
\end{array}$ & 42 & 4351,91, & 268,92 & \begin{tabular}{|l|l|}
40,29 \\
47,29
\end{tabular} & \begin{tabular}{|l|}
$221,63,63$ \\
22
\end{tabular} & $\begin{array}{l}1,00 \\
98,02 \\
\end{array}$ & \begin{tabular}{|l|}
$199,92,92$ \\
\end{tabular} & \begin{tabular}{|l|}
201,72 \\
201
\end{tabular} & $\begin{array}{l}2,45 \\
90,42 \\
\end{array}$ & \begin{tabular}{|l|l|l|l|l|l|}
1099,79 \\
\end{tabular} & \begin{tabular}{|l|}
151,499 \\
155,99
\end{tabular} & $\begin{array}{l}\mid 1,1 / 1 \\
12,10\end{array}$ & $\begin{array}{l}2,2,00 \\
52,83\end{array}$ & \begin{tabular}{|l|}
440,82 \\
440
\end{tabular} & $\begin{array}{l}\mid 2,4,5 \\
74,02\end{array}$ & $\begin{array}{l}1,25 \\
80,08 \\
\end{array}$ & $\begin{array}{l}42,38,16 \\
438\end{array}$ \\
\hline Pelophylax perezi & 29TNE59 & 101,00 & 145,60 & 94,24 & 42,64 & 4275,39 & 265,54 & 47,09 & 218,45 & 98,05 & 198,66 & 200,38 & 90,22 & 1107,62 & 156,50 & 12,31 & 52,68 & 444,74 & 74,34 & 82,05 & 439,23 \\
\hline Pelophylax perezi & 29TNE63 & 101,00 & 130,56 & 89,14 & 38,42 & 4769,88 & 264,01 & 35,22 & 228,79 & 72,92 & 194,23 & 194,62 & 72,92 & 1221,84 & 181,18 & 12,82 & 55,21 & 499,16 & 78,16 & 78,31 & 499,16 \\
\hline Pelophylax perezi & 29TNE64 & 100,00 & 155,81 & 101,81 & 41,50 & 4683,46 & 294,72 & 53,07 & 241,64 & 96,83 & 215,14 & 217,20 & 96,83 & 978,93 & 139,33 & 9,92 & 53,46 & 94,96 & 65,10 & 67,15 & 394,96 \\
\hline Pelophylax perezi & 29TNE65 & 101, & 154 & 102,10 & 41,7 & 4672,85 & 292 & 51,79 & 241,18 & 95,81 & 213,88 & 216,01 & 95,81 & 997,15 & 141,65 & 10,31 & 53,17 & $\begin{array}{l}401,08 \\
\end{array}$ & 66,87 & 69,43 & 401,08 \\
\hline Pelophylax perezi & 29TNEG & 100,00 & 156,09 & 101,84 & 42, & 4606,32 & 291,36 & 52,82 & 238,53 & 97,33 & 213,92 & 215,92 & 97,29 & 989,81 & 139,97 & 10,23 & 52,97 & 396,23 & 66,28 & 70,18 & 396,23 \\
\hline Pelophylax perezi & 29TNE67 & 100,00 & 151,69 & 99,91 & 42,00 & 4573,47 & 284,14 & 49,24 & 234,90 & 97,01 & 209,18 & 210,97 & 93,25 & 1039,96 & 147,79 & 10,93 & 53,01 & 415,86 & 69,58 & 74,15 & 415,82 \\
\hline Pelophylax perezi & 29TNE68 & 101,00 & 134,72 & 93,55 & 40,41 & 4632,53 & 264,80 & 36,08 & 228,72 & 80,31 & 194,14 & 195,64 & 76,89 & 1229,75 & 179,29 & 13,54 & 53,76 & 495,74 & 82,40 & 85,19 & 495,61 \\
\hline Pelophylax perezi & 29TNE69 & 101,00 & 128,02 & 91,01 & 39,8 & 4638,69 & 256,21 & 30,75 & 25,47 & 73,66 & 187,77 & 189,16 & 70,46 & 1311,34 & 192,53 & 14,74 & 54,03 & 92 & 88,13 & 90,71 & 529,25 \\
\hline Pelophylax perezi & $29 \mathrm{TNE}$ & 100,00 & $\frac{120}{130}$ & \begin{tabular}{|l|l|}
89,04 \\
\end{tabular} & 37 & 42 & 267,29 & $\begin{array}{l}34,13 \\
34,12\end{array}$ & \begin{tabular}{|l|}
233,17 \\
23,1
\end{tabular} & 71,19 & \begin{tabular}{|l|}
196,84 \\
\end{tabular} & \begin{tabular}{|l|}
196,95 \\
196,95
\end{tabular} & 71,19 & 年1223,43 & \begin{tabular}{|l|}
182,48 \\
182,
\end{tabular} & $\begin{array}{l}4,4,4 \\
12,4\end{array}$ & 55,44 & \begin{tabular}{|l|}
500,58 \\
\end{tabular} & $\begin{array}{l}00,13 \\
77,23\end{array}$ & $\begin{array}{ll}70,211 \\
77,23\end{array}$ & 500,58 \\
\hline Pelophylax perezi & 29TNE74 & 100,00 & 144,66 & 96,62 & 39,51 & 4909,73 & 284,97 & 43,52 & 241,46 & 84,22 & 208,62 & 209,88 & 84,22 & 1088,21 & 159,07 & 10,86 & 54,50 & 442,33 & 70,82 & 71,38 & 442,33 \\
\hline Pelophylax perezi & 29TNE75 & 101,00 & 154,08 & \begin{tabular}{|r|}
101,29 \\
\end{tabular} & 40,82 & 4855,81 & 295,17 & |49,96 & 245,21 & $\begin{array}{l}94,12 \\
93,12\end{array}$ & $\begin{array}{l}215,94 \\
215,4\end{array}$ & 217,84 & 93,12 & $\begin{array}{r}998,76 \\
9\end{array}$ & $\mid 143,36$ & \begin{tabular}{|l|}
9,90 \\
9,0
\end{tabular} & 53,72 & \begin{tabular}{|l|}
402,78 \\
\end{tabular} & 65,75 & 68,01 & 402,78 \\
\hline Pelophylax perezi & 29TNE76 & 101,00 & 154,06 & 101,53 & 41,08 & 4813,66 & 293,38 & 49,62 & 243,76 & 93,18 & 215,14 & 216,88 & 93,18 & 1005,56 & 143,97 & 9,99 & 53,47 & 404,01 & 66,34 & 69,56 & 404,01 \\
\hline Pelophylax perezi & 29TNE7 & 100,00 & 151,71 & 100,66 & 41,1 & 4778,52 & 288,89 & 47,59 & 241,30 & 91,92 & 212,30 & 213 & 91,08 & 1035,22 & 148,55 & 10,42 & 53,45 & 415,23 & 68,17 & 72,12 & 415 \\
\hline Pelophylax perezi & 29TNE78 & $\begin{array}{l}100,00 \\
\end{array}$ & $14,1 / 15$ & $\begin{array}{r}0,00 \\
99,57 \\
\end{array}$ & 年11,25 & 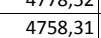 & $\begin{array}{l}20,03 \\
283,45\end{array}$ & $\begin{array}{l}4,, 56 \\
44,\end{array}$ & \begin{tabular}{|l|}
$231,30,88$ \\
238
\end{tabular} & $\begin{array}{l}1,2< \\
92,48 \\
\end{array}$ & 208,55 & \begin{tabular}{|l|}
209,97 \\
\end{tabular} & $\begin{array}{l}1,00 \\
87,76\end{array}$ & \begin{tabular}{|l|l|l|l|l|l|}
1076,81 \\
\end{tabular} & \begin{tabular}{|l|}
150,120 \\
155,12
\end{tabular} & $\begin{array}{l}10,44 \\
11,07 \\
\end{array}$ & $\begin{array}{l}53,45 \\
53,44\end{array}$ & \begin{tabular}{|l|}
431,68 \\
431,68
\end{tabular} & | & $\begin{array}{l}72,124 \\
75,54\end{array}$ & $\begin{array}{l}41,25 \\
431,42\end{array}$ \\
\hline Pelophylax perezi & 29TNE79 & 101,00 & 134,17 & 94,47 & 39,91 & 4800,60 & 267,62 & 33,70 & 233,92 & 76,77 & 196,11 & 197,26 & 74,32 & 1237,77 & 181,96 & 13,33 & 54,13 & 499,57 & 81,97 & 84,94 & 499,52 \\
\hline Pelophylax perezi & 29TNE83 & 100,00 & 136,83 & 91,53 & 37,62 & 5092,52 & 278,06 & 37,73 & 240,33 & 75,38 & 204,90 & 205,18 & 75,38 & 1153,36 & 171,78 & 11,27 & 55,46 & 471,89 & 72,49 & 72,49 & 471,89 \\
\hline Pelophylax perezi & 29TNE84 & 101,00 & 133,6 & 90,79 & 37,47 & 5087,30 & 273,82 & 34,7 & 239, & 72,27 & 201,6 & 201, & 72, & 1197,70 & 179,06 & 11,86 & 55 & 489,74 & 75,49 & 75,49 & 489,74 \\
\hline Pelophylax perezi & 29TNE85 & 100,00 & 147,50 & 97,92 & 39,26 & 5042,36 & 289,99 & 44,08 & 245,90 & 85,04 & 212,90 & 214,17 & 85,04 & 1059,06 & 55,04 & 10,29 & 54,51 & 429,45 & 68,30 & 69,66 & 429,45 \\
\hline
\end{tabular}




\begin{tabular}{|c|c|c|c|c|c|c|c|c|c|c|c|c|c|c|c|c|c|c|c|c|c|}
\hline TAXON & UTM & $\mathrm{km} 2$ & B101 & B102 & $\mathrm{BIO3}$ & B104 & B105 & B106 & B107 & B108 & B109 & B1010 & BIO11 & BIO12 & B1013 & BIO14 & BIO15 & BIO16 & B1017 & BIO18 & B1019 \\
\hline Pelophylax perezi & 29TNE87 & 101,00 & 151,38 & 100,69 & 40,36 & 4969,05 & 292,32 & 46,06 & 246,27 & 88,92 & 214,94 & 216,39 & 88,82 & 1027,25 & 148,92 & 9,93 & 53,91 & 413,26 & 66,69 & 70,08 & 413,26 \\
\hline Pelophylax perezi & 29TNE88 & 101,00 & 149,07 & 100,28 & 40,46 & 4943,27 & 288,54 & 43,95 & 244,59 & 88,11 & 212,25 & 213,54 & 86,67 & 1056,45 & 153,52 & 10,50 & 53,85 & 424,47 & 68,67 & 72,72 & 424,47 \\
\hline Pelophylax perezi & 29TNE89 & 99,00 & 143,28 & 98,96 & 40,16 & 4954,20 & 281,94 & 38,90 & 243,03 & 81,35 & 206,81 & 207,99 & 80,99 & 1124,35 & 164,80 & 11,31 & 54,06 & 452,74 & 73,25 & 77,10 & 452,74 \\
\hline Pelophylax perezi & 29TNE93 & 101,00 & 140,56 & 92,62 & 37,11 & 5261,71 & 285,37 & 39,35 & 246,03 & 77,01 & 210,76 & 211,08 & 77,01 & 1102,34 & 164,09 & 10,29 & 55,49 & 450,73 & 68,82 & 68,84 & 450,73 \\
\hline Pelophylax perezi & 29TNE96 & 100,00 & 144,25 & 96,90 & \begin{tabular}{|l|}
38,48 \\
\end{tabular} & 5194,21 & 288,55 & 39,98 & 248,56 & 80,12 & 211,84 & 212,90 & 80,12 & 1084,89 & 160,45 & 10,32 & 54,88 & 440,40 & 69,82 & 70,58 & 440,40 \\
\hline Pelophylax perezi & 29TNE97 & 100,00 & 147,75 & 99,20 & 39,25 & 5155,38 & 291,58 & 42,09 & 249,49 & 83,40 & 214,19 & 215,39 & 83,40 & 1050,55 & 154,38 & 9,97 & 54,49 & 424,55 & 67,60 & 69,74 & 424,55 \\
\hline Pelophylax perezi & 29TNE98 & 100,00 & 146,38 & 99,49 & 39,50 & 5130,69 & 289,32 & 40,54 & 248,78 & 82,20 & 212,43 & 213,62 & 82,20 & 1069,29 & 157,42 & 10,31 & 54,43 & 431,66 & 68,89 & 71,63 & 431,66 \\
\hline Pelophylax perezi & 29TNE99 & 101,00 & 143,90 & 99,38 & 39,62 & 5127,85 & 286,19 & 38,18 & 248,01 & 79,91 & 210,06 & 211,01 & 79,71 & 1097,89 & 162,19 & 10,71 & 54,52 & 443,23 & 70,70 & 73,80 & 443,23 \\
\hline Pelophylax perezi & 29TNF19 & 18,00 & 144,64 & 78,62 & 44,00 & 3569,05 & 239,07 & 62,36 & 176,71 & 99,81 & 188,74 & 190,24 & 99,81 & 1240,36 & 172,69 & 14,17 & 52,00 & 496,90 & 81,19 & 103,10 & 496,90 \\
\hline Pelophylax perezi & 29TNF20 & 39,00 & 148,11 & 75,99 & 45,39 & $\begin{array}{ll}3278,87 \\
\end{array}$ & 228,40 & 62,72 & 165,68 & 111,24 & 185,74 & 187,30 & 102,70 & 1033,57 & 142,44 & 11,91 & 52,02 & 416,51 & 68,59 & 81,88 & 404,38 \\
\hline Pelophylax perezi & 29TNF25 & 28,00 & 144,51 & 85,81 & 44,94 & 3674,23 & 243,21 & 54,34 & 188,87 & 104,47 & 189,36 & 191,38 & 97,09 & 1183,21 & 162,30 & 14,83 & 51,15 & 472,75 & 81,40 & 99,72 & 460,91 \\
\hline Pelophylax perezi & 29TNF26 & 68,00 & 143,71 & 84,72 & 45,01 & 3658,17 & 241,52 & 55,50 & 186,02 & 99,99 & 188,56 & 190,46 & 97,07 & 1215,52 & 165,55 & 15,08 & 51,03 & 482,21 & 83,56 & 100,72 & 480,78 \\
\hline Pelophylax perezi & 29TNF27 & 83,00 & 143,39 & 83,67 & 44,84 & 3665,84 & 241,48 & 56,50 & 184,98 & 98,16 & 188,60 & 190,35 & 96,94 & 1229,74 & 168,04 & 15,06 & 51,32 & 488,82 & 83,48 & 101,82 & 488,58 \\
\hline Pelophylax perezi & 29TNF28 & 101,00 & 142,97 & 82,67 & \begin{tabular}{|l|l|}
44,28 \\
\end{tabular} & 3688,89 & 241,72 & 57,07 & 184,65 & 96,45 & 188,66 & 190,33 & 96,40 & 1246,49 & 171,06 & 15,08 & 51,64 & 496,82 & 83,70 & 103,29 & 496,82 \\
\hline Pelophylax perezi & 29TNF29 & 100,00 & 143,40 & 81,55 & 43,81 & 3705,16 & 242,68 & 58,44 & 184,24 & 96,74 & 189,45 & 190,99 & 96,74 & 1253,60 & 172,57 & 14,95 & 51,94 & 500,80 & 83,10 & 104,21 & 500,80 \\
\hline Pelophylax perezi & 29TNF30 & 97,00 & 149,38 & 82,52 & 44,75 & 3564,68 & 241,69 & 59,15 & 182,54 & 109,24 & 191,41 & 193,03 & 100,90 & 1039,18 & 143,20 & 11,86 & 52,06 & 418,81 & 69,12 & 81,84 & 406,13 \\
\hline Pelophylax perezi & 29TNF31 & 101,00 & 148,07 & 83,26 & 44,69 & 3597,97 & 241,68 & 57,46 & 184,22 & 107,87 & 190,73 & 192,50 & 99,47 & 1065,36 & 146,05 & 12,24 & 52,00 & 429,98 & 71,06 & 85,21 & 414,46 \\
\hline Pelophylax perezi & 29TNF32 & 101,00 & 145,57 & 84,92 & 44,51 & 3682,73 & 242,81 & 53,91 & 188,90 & 104,71 & 189,77 & 191,53 & 96,39 & 1108,58 & 151,23 & 13,26 & 51,97 & 448,35 & 74,67 & 90,24 & 429,45 \\
\hline Pelophylax perezi & 29TNF33 & 100,00 & 143,08 & 86,64 & 44,26 & 3769,42 & 244,08 & 50,32 & 193,75 & 101,57 & 188,84 & 190,75 & 93,44 & 1153,38 & 156,89 & 14,21 & 51,96 & 467,44 & 78,42 & 95,49 & 444,94 \\
\hline Pelophylax perezi & 29TNF34 & 101,00 & 142,93 & 88,24 & 44,24 & 3832,79 & 246,60 & 49,26 & 197,34 & 100,95 & 189,74 & 191,72 & 92,80 & 1169,53 & 160,71 & 14,84 & 51,92 & 475,06 & 79,95 & 99,15 & 447,97 \\
\hline Pelophylax perezi & 29TNF35 & 101,00 & 143,79 & 89,17 & 44,3 & 3853,99 & 248,86 & 50,08 & 198,78 & 101,82 & 191,19 & 193,23 & 93,92 & 1176,16 & 162,85 & 15,00 & 51,60 & 476,56 & 80,52 & 100,90 & 450,62 \\
\hline Pelophylax perezi & 29TNF36 & 100,00 & 142,72 & 88,75 & 44,37 & 3874,54 & 248,10 & 50,30 & 197,80 & $\begin{array}{l}100,59 \\
\end{array}$ & 190,60 & $\begin{array}{l}192,54 \\
\end{array}$ & 93,19 & 1208,89 & $\begin{array}{l}165,64 \\
106\end{array}$ & 15,18 & 51,16 & 484,74 & 82,84 & 101,99 & 470,16 \\
\hline Pelophylax perezi & 29TNF37 & 101,00 & 143,27 & 87,78 & \begin{tabular}{|l|l|}
44,23 \\
\end{tabular} & 3880,42 & 248,43 & 52,12 & 196,31 & 100,95 & 191,39 & 193,10 & 93,98 & 1219,17 & 165,45 & 15,05 & 51,07 & 485,64 & 82,94 & $\begin{array}{ll}101,87 \\
\end{array}$ & 478,73 \\
\hline Pelophylax perezi & 29TNF38 & 101,00 & 142,52 & 86,87 & 43,81 & 3905,18 & 248,58 & 52,35 & 196,23 & 99,41 & 191,21 & 192,75 & 93,25 & 1241,90 & 168,32 & 15,31 & 51,18 & 493,36 & 84,21 & 103,44 & 490,86 \\
\hline Pelophylax perezi & 29TNF39 & 100,00 & 142,67 & 85,68 & 43,22 & 3921,25 & 249,19 & 53,49 & 195,69 & 97,62 & 191,73 & 193,13 & 93,16 & 1252,93 & 169,96 & 15,41 & 51,40 & 497,59 & 84,71 & 104,50 & 496,90 \\
\hline Pelophylax perezi & 29TNF40 & 100,00 & 147,44 & 89,30 & 43,83 & 3923,90 & 254,03 & 52,39 & 201,63 & 103,46 & 195,05 & 196,67 & 95,31 & 1079,18 & 149,73 & 12,26 & 52,06 & 434,59 & 72,22 & 83,50 & 423,05 \\
\hline Pelophylax perezi & 29TNF41 & 101,00 & 142,38 & 89,36 & | 43,37 & 3991,40 & 250,94 & $\begin{array}{ll}47,24 \\
47\end{array}$ & 203,70 & $\begin{array}{l}8,4,11 \\
98,\end{array}$ & 191,25 & 193,01 & $\begin{array}{l}90,04 \\
90,1\end{array}$ & \begin{tabular}{|l|l|l|l|}
1145,99 \\
\end{tabular} & 159,30 & $\begin{array}{ll}13,48 \\
\end{array}$ & 52,06 & 462,52 & 77,32 & 89,31 & 448,96 \\
\hline Pelophylax perezi & 29TNF42 & 100,00 & 139,86 & 89,98 & 43,29 & 4039,26 & 249,99 & 44,34 & 205,65 & 95,41 & 189,66 & 191,42 & 87,24 & 1184,27 & 164,08 & 14,18 & 52,01 & 478,82 & 80,25 & 93,42 & 462,77 \\
\hline Pelophylax perezi & 29TNF43 & 100,00 & 139,21 & 90,71 & 43,30 & 4069,14 & 250,59 & 43,39 & 207,20 & 94,59 & 189,62 & 191,44 & 86,51 & 1202,18 & 165,41 & 14,71 & 52,01 & 486,77 & 81,77 & 96,65 & 467,70 \\
\hline Pelophylax perezi & 29TNF44 & 101,00 & 145,19 & 91,73 & 43,95 & 4024,80 & 255,19 & 48,47 & 206,73 & 100,89 & 194,71 & 196,60 & 92,76 & 1143,15 & 155,45 & 13,92 & 51,95 & 463,79 & 77,06 & 95,12 & 439,23 \\
\hline Pelophylax perezi & 29TNF45 & 100,00 & 143,60 & 92,24 & 43,84 & 4070,49 & 255,27 & 46,97 & 208,31 & 98,94 & $\begin{array}{l}194,03 \\
\end{array}$ & 195,90 & 91,10 & 1174,73 & 159,85 & 14,55 & 51,68 & 475,51 & 79,77 & 98,42 & 452,40 \\
\hline Pelophylax perezi & 29TNF46 & 101,00 & 139,99 & $\begin{array}{l}92,24 \\
92,04\end{array}$ & 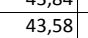 & $\begin{array}{l}40124,76 \\
412,76\end{array}$ & 253,26 & $\begin{array}{ll}44,26 \\
440\end{array}$ & \begin{tabular}{|l|}
208,99 \\
\end{tabular} & $\begin{array}{l}0,34,91 \\
\end{array}$ & $\begin{array}{l}191,59 \\
\end{array}$ & $\begin{array}{l}193,29 \\
\end{array}$ & 87,44 & 1229,65 & 167,21 & $\begin{array}{l}4,3,41 \\
15,\end{array}$ & 51,34 & 495,06 & 84,11 & 1001,93 & $\begin{array}{l}45,40 \\
478,38\end{array}$ \\
\hline Pelophylax perezi & 29TNF47 & 100,00 & 139,14 & 91,24 & 43,32 & \begin{tabular}{ll|}
4147,14 \\
\end{tabular} & 252,84 & 44,35 & 208,48 & 93,89 & 191,25 & 192,76 & 86,61 & 1253,11 & 169,91 & 15,81 & 51,14 & 501,37 & 86,32 & 103,48 & 491,26 \\
\hline Pelophylax perezi & 29TNF48 & 100,00 & 142,13 & 90,79 & $\begin{array}{l}43,15 \\
\end{array}$ & 4135,87 & 255,81 & 47,93 & 207,87 & 96,82 & 194,12 & 195,50 & 89,72 & 1230,59 & 165,88 & 15,35 & 51,02 & 490,29 & 84,29 & 102,44 & 483,04 \\
\hline Pelophylax perezi & 29TNF49 & 101,00 & 139,80 & 89,86 & 42,66 & $\begin{array}{ll}4175,54 \\
\end{array}$ & 254,55 & 46,33 & 208,22 & 94,19 & 192,55 & 193,76 & 87,19 & 1270,24 & 171,95 & 16,30 & 51,01 & 504,73 & 88,23 & 105,84 & 500,86 \\
\hline Pelophylax perezi & 29TNF50 & 101,00 & 139,58 & 92,61 & 42,17 & 4304,23 & 258,99 & 41,99 & 217,01 & 92,04 & 193,36 & 195,11 & 84,30 & 1181,11 & 167,89 & 13,43 & 52,76 & 475,58 & 79,54 & 87,48 & 468,92 \\
\hline Pelophylax perezi & 29TNF51 & 101,00 & 130,68 & 90,91 & 41,39 & 4383,84 & 251,56 & 34,36 & 217,20 & 83,11 & 186,06 & 187,79 & 75,27 & \begin{tabular}{|l|l|}
1291,53 \\
\end{tabular} & 185,22 & 15,29 & 52,99 & 520,41 & 88,04 & 94,96 & 515,26 \\
\hline Pelophylax perezi & 29TNF52 & 100,00 & 128,82 & 90,79 & 41,34 & 4388,35 & 249,56 & 32,56 & 217,00 & 80,65 & 184,49 & 186,10 & 73,51 & 1319,05 & 188,56 & 15,87 & 52,82 & 531,86 & 90,28 & 98,23 & 525,29 \\
\hline Pelophylax perezi & \begin{tabular}{|l|} 
29TNF53 \\
\end{tabular} & 101,00 & 139,12 & 93,95 & $\begin{array}{l}42,65 \\
\end{array}$ & 4304,01 & 258,06 & 40,55 & 217,52 & 91,75 & 192,97 & 194,65 & 83,83 & 1206,82 & 168,46 & 14,26 & 52,14 & 487,19 & 81,32 & 94,06 & 473,32 \\
\hline Pelophylax perezi & 29TNF54 & 101,00 & 143,24 & 94,76 & 43,1 & 4278,36 & 261,19 & 44,06 & 217,13 & 96,03 & 196,62 & 198,24 & 88,15 & 1165,91 & 160,49 & 13,81 & 51,97 & 470,68 & 78,26 & 93,43 & 453,65 \\
\hline Pelophylax perezi & 29TNF55 & 100,00 & 140,87 & 95,08 & 42 & 4326,04 & 260,24 & 41,73 & 218,51 & 93,30 & 195,21 & 196,68 & 85,53 & 1202,49 & 165,11 & $\begin{array}{l}14,53 \\
14,5\end{array}$ & 51,85 & 484,56 & 81,28 & 96,84 & 468,84 \\
\hline Pelophylax perezi & 29TNF56 & 101,00 & 139,94 & 95,13 & 42 & 4354,26 & 260,13 & 41,13 & 219,00 & 92,16 & \begin{tabular}{|l|}
194,79 \\
\end{tabular} & $\begin{array}{l}196,27 \\
\end{array}$ & 84,56 & 1221,82 & |166,99 & 14,6 & 51,64 & 490,56 & 83,17 & 98,86 & 477,69 \\
\hline Pelophylax perezi & $\begin{array}{l}\text { 29TNF57 } \\
\end{array}$ & 101,00 & 136,33 & 94,43 & 42,54 & 4395,62 & 257,89 & 38,43 & 219,46 & 88,25 & 192,09 & 193,38 & 80,76 & \begin{tabular}{|l|l|}
1271,83 \\
\end{tabular} & $\begin{array}{l}173,49 \\
\end{array}$ & 15,97 & 51,45 & 508,53 & 87,85 & 102,68 & 500,28 \\
\hline Pelophylax perezi & \begin{tabular}{|l|} 
29TNF58 \\
\end{tabular} & 100,00 & 142,10 & 94,36 & 42,68 & 4362,30 & 262,89 & 44,19 & 218,70 & 94,05 & 197,22 & 198,42 & 86,75 & 1212,75 & 162,86 & 15,06 & 51,03 & 482,85 & 83,48 & 99,97 & 474,72 \\
\hline Pelophylax perezi & 29TNF59 & 101,00 & 139,94 & 93,48 & 42,1 & 4393,00 & 261,73 & 42,64 & 219,10 & 91,63 & 195,73 & 196,85 & 84,56 & 1243,58 & 167,10 & 16,12 & 50,99 & 493,44 & 87,40 & 103,38 & 487,78 \\
\hline Pelophylax perezi & 29TNF60 & 100,00 & 135,03 & 94,39 & 4 & 4585,71 & 262,88 & 35,58 & 227,30 & 84,44 & 193,27 & 194,86 & 77,17 & 1237,64 & 179,24 & $\begin{array}{l}13,79 \\
13\end{array}$ & 53,37 & 4998,24 & 82,88 & 88,33 & 495,79 \\
\hline Pelophylax perezi & 29TNF61 & 100,00 & 135,59 & 94,12 & 41,30 & 4545,64 & 261,58 & 36,27 & 225,31 & 84,47 & 193,36 & 194,77 & 78,12 & 1233,48 & 177,66 & 13,94 & 53,23 & 497,11 & 82,71 & 89,56 & 492,25 \\
\hline Pelophylax perezi & 29TNF62 & 101,00 & 119,24 & 89,37 & 39,56 & 4648,32 & 246,04 & 23,36 & 222,68 & 65,19 & 179,50 & 180,74 & 62,13 & 1421,55 & 207,84 & 17,24 & 53,69 & 573,99 & 97,86 & 101,46 & 572,57 \\
\hline Pelophylax perezi & 29TNF63 & 100,00 & 137,18 & 96,37 & 41,92 & 4552,30 & 263,63 & 36,45 & 227,18 & 87,09 & 194,87 & 196,22 & 79,29 & 1227,80 & 174,69 & 14,04 & 52,72 & 494,00 & 82,05 & 92,22 & 486,62 \\
\hline Pelophylax perezi & 29TNFG4 & 100,00 & 139,87 & 96,89 & 42,2 & 4533,38 & 265,28 & 38,81 & 226,47 & 89,13 & 197,19 & 198,52 & 82,13 & 1200,42 & 169,04 & 13,86 & 52,38 & 482,70 & 80,33 & 92,20 & 473,27 \\
\hline Pelophylax perezi & 29TNF65 & 101,00 & $\frac{5}{14}$ & 97 & $\frac{42}{42}$ & $\begin{array}{ll}4535,30,34 \\
4548\end{array}$ & 267,20 & \begin{tabular}{|l|l|}
30,49 \\
39,4
\end{tabular} & \begin{tabular}{|l|}
227,70 \\
22,7
\end{tabular} & $\begin{array}{l}50,13 \\
90,78 \\
\end{array}$ & \begin{tabular}{|l|l|}
198,67 \\
\end{tabular} & \begin{tabular}{|l|}
$199,92,98$ \\
\end{tabular} & $\begin{array}{ll}82,15 \\
83,18\end{array}$ & \begin{tabular}{|l|l|l|l|l|l|}
1191,76 \\
\end{tabular} & \begin{tabular}{|l|}
$166,29,29$ \\
\end{tabular} & $\begin{array}{l}3,00 \\
13,82\end{array}$ & $\begin{array}{l}2,30 \\
52,13 \\
\end{array}$ & $\begin{array}{l}40,10 \\
478,12\end{array}$ & $\begin{array}{l}\mid l 0,53 \\
79,78\end{array}$ & $\begin{array}{l}25,20 \\
93,05\end{array}$ & 468,42 \\
\hline Pelophylax perezi & 29TNF66 & 100,00 & 140,95 & 98,10 & 42,56 & 4557,92 & 267,53 & 39,38 & 228,15 & 90,49 & 198,65 & 199,92 & 82,92 & 1198,66 & 165,92 & 14,16 & 51,88 & 479,50 & 80,88 & 94,69 & 470,84 \\
\hline Pelophylax perezi & $\begin{array}{l}\text { 29TNF67 } \\
\end{array}$ & 100,00 & 139,03 & 97,85 & 42,15 & 4589,24 & 266,73 & 37,67 & 229,06 & 88,29 & 197,36 & 198,49 & 80,91 & 1225,60 & 168,33 & $\mid 14,86$ & 51,72 & 488,61 & $|83,77|$ & 97.47 & 482,14 \\
\hline Pelophylax perezi & 29TNF68 & 101,00 & 137,90 & 97,23 & 41,97 & 4606,79 & 266,17 & 37,05 & 229,12 & 87,12 & 196,63 & 197,66 & 79,77 & 1240,93 & 168,44 & 15,51 & 51,33 & 492,91 & 86,19 & 99,84 & 488,19 \\
\hline Pelophylax perezi & 29TNF69 & 100,00 & 135,31 & 96,15 & 41, & 4630,85 & 264,13 & 35,32 & 228,80 & 83,85 & 194,67 & 195 & 77,28 & 1267,98 & 170,11 & 16,66 & 50,99 & 502,08 & 90,32 & 103,32 & 498,82 \\
\hline Pelophylax perezi & $\begin{array}{l}\text { 29TNF70 } \\
\end{array}$ & $\begin{array}{l}100,00 \\
\end{array}$ & $\begin{array}{l}13,51,12 \\
131,1\end{array}$ & $\begin{array}{l}0,11 \\
93,82\end{array}$ & | & $\begin{array}{l}405,050 \\
479,23\end{array}$ & 263,60 & $\begin{array}{l}3,132 \\
31,18 \\
\end{array}$ & \begin{tabular}{|l|}
$232,42,0$ \\
\end{tabular} & $\begin{array}{l} \\
74,29 \\
74,29\end{array}$ & \begin{tabular}{|l|}
193,10 \\
\end{tabular} & $\begin{array}{l}194,21 \\
194\end{array}$ & $\begin{array}{l}71,260 \\
71,49\end{array}$ & 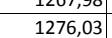 & \begin{tabular}{|l|l|l|l|}
187,97 \\
\end{tabular} & \begin{tabular}{l|}
13,902 \\
13,9
\end{tabular} & $\begin{array}{l}0,17 \\
54,17\end{array}$ & $50,0 \circ$ & $\begin{array}{l}0,32,71 \\
84,\end{array}$ & $\begin{array}{r}0,305 \\
88,05\end{array}$ & $\begin{array}{l}450,02 \\
514,91 \\
\end{array}$ \\
\hline Pelophylax perezi & 29TNF71 & 101,00 & 138,55 & 97,23 & 41,02 & 4748,50 & 270,65 & 36,33 & 234,32 & 84,96 & 199,28 & 200,42 & 78,59 & 1195,33 & 173,64 & 12,91 & 53,50 & 480,83 & 78,99 & 85,21 & 478,45 \\
\hline Pelophylax perezi & 29TNF72 & 100,00 & 124,75 & 93,12 & 39,79 & 4811,33 & 256,79 & 25,56 & 231,23 & 67,57 & 187,14 & 188,20 & 65,25 & 1354,86 & 199,64 & 15,47 & 54,07 & 547.42 & 91,22 & 94.88 & 546.90 \\
\hline Pelophylax perezi & 29TNF73 & 100,00 & 125,97 & 94,19 & 40,16 & 798,34 & 257,82 & 26,19 & 231,62 & 69,94 & $188, \mathrm{C}$ & 189,07 & 66, & 1340,38 & 195,83 & 15,66 & 53 & 540,51 & 90,73 & 95,98 & 538,99 \\
\hline Pelophylax perezi & 29TNF75 & 100,00 & 137,44 & 99,71 & 41,73 & 4775,34 & 270,14 & 34,08 & 236,05 & 82,59 & 198,39 & 199,50 & 77,09 & 1223,22 & 174,59 & 13,90 & 52,80 & 489,74 & 81,78 & 91,80 & 486,31 \\
\hline
\end{tabular}




\begin{tabular}{|c|c|c|c|c|c|c|c|c|c|c|c|c|c|c|c|c|c|c|c|c|c|}
\hline TAXON & UTM & $\mathrm{km} 2$ & B101 & B102 & $\mathrm{BIO3}$ & B104 & B105 & B106 & B107 & B108 & B109 & B1010 & B1011 & BIO12 & B1013 & BIO14 & BIO15 & B1016 & B1017 & BIO18 & B1019 \\
\hline Pelophylax perezi & 29TNF76 & 101,00 & 141,79 & 100,39 & 41,96 & 4748,21 & 274,06 & 37,90 & 236,17 & 87,98 & 202,21 & 203,32 & 81,53 & 1172,75 & 164,56 & 13,40 & 52,24 & 467,99 & 78,52 & 90,37 & 462,94 \\
\hline Pelophylax perezi & 29TNF77 & 100,00 & 139,96 & 100,63 & 41,82 & 4786,69 & 273,79 & 35,96 & 237,83 & 85,58 & 201,14 & 201,93 & 79,40 & 1195,50 & 166,38 & 14,04 & 52,04 & 475,06 & 81,10 & 92,96 & 472,06 \\
\hline Pelophylax perezi & 29TNF78 & 101,00 & 126,95 & 97,32 & 40,78 & 4844,60 & 261,42 & 25,75 & 235,68 & 68,04 & 189,60 & 190,52 & 66,83 & 1333,31 & 185,94 & 17,30 & 52,04 & 531,44 & 94,53 & 103,38 & 531,32 \\
\hline Pelophylax perezi & 29TNF79 & 101,00 & 124,43 & 95,81 & $\begin{array}{l}40,47 \\
\end{array}$ & 4841,80 & 258,19 & 24,30 & 233,89 & 65,58 & 187,19 & 188,09 & 64,62 & 1349,39 & 185,11 & 18,55 & 51,51 & 536,28 & 98,47 & 107,09 & 536,16 \\
\hline Pelophylax perezi & 29TNF80 & 101,00 & 137,26 & 97,59 & 39,95 & 4966,71 & 275,12 & 33,90 & 241,22 & 75,65 & 201,18 & 202,29 & 75,13 & 1195,95 & 176,73 & 12,38 & 54,37 & 482,82 & 78,28 & 81,81 & 482,81 \\
\hline Pelophylax perezi & 29TNF81 & 101,00 & 138,58 & 98,97 & 40,41 & 4957,04 & 276,29 & 34,33 & 241,95 & 78,33 & 202,15 & 203,23 & 76,25 & 1184,88 & 174,47 & 12,24 & 54,20 & 477,17 & 77,25 & 82,20 & 477,00 \\
\hline Pelophylax perezi & 29TNF82 & 100,00 & 133,58 & 98,23 & 40,21 & 4971,25 & 271,19 & 30,14 & 241,06 & 73,00 & 197,70 & 198,66 & 71,47 & 1244,51 & 184,08 & 13,26 & 54,36 & 502,42 & 81,71 & 86,36 & 502,12 \\
\hline Pelophylax perezi & 29TNF83 & 101,00 & 109,14 & 87,77 & 37,62 & 4975,93 & 242,62 & 12,70 & 229,92 & 49,47 & 175,17 & 175,58 & 49,22 & 1493,52 & 222,19 & 18,53 & 54,42 & 606,03 & \begin{tabular}{|c|}
102,49 \\
\end{tabular} & 103,59 & 606,01 \\
\hline Pelophylax perezi & 29TNF84 & 101,00 & 118,90 & 93,61 & 39,19 & 4982,55 & 254,88 & 19,09 & 235,79 & 58,28 & 184,21 & 184,84 & 57,85 & 1397,56 & 206,45 & 16,64 & 54,06 & 565,62 & 95,33 & 98,47 & 565,51 \\
\hline Pelophylax perezi & 29TNF85 & 100,00 & 136,01 & 101,39 & \begin{tabular}{|l|l|}
41,17 \\
\end{tabular} & 4965,90 & 274,28 & 30,99 & 243,29 & 75,89 & $\begin{array}{l}199,76 \\
\end{array}$ & 200,67 & 73,51 & 1222,05 & 177,54 & 13,56 & 53,63 & 490,55 & 81,16 & 89,01 & 489,57 \\
\hline Pelophylax perezi & 29TNF86 & 101,00 & 125,67 & 98,43 & 40,38 & 4998,73 & 264,11 & 23,07 & 241,04 & 64,83 & 190,54 & 191,36 & 63,74 & 1325,58 & 192,39 & 15,93 & 53,57 & 533,46 & 91,11 & 96,93 & 533,22 \\
\hline Pelophylax perezi & \begin{tabular}{|l|} 
29TNF87 \\
\end{tabular} & 101,00 & 135,01 & 101,65 & 41,07 & 4987,46 & 274,44 & 29,83 & 244,61 & 74,73 & 199,17 & 199,92 & 72,50 & 1223,35 & 174,13 & 14,38 & 52,84 & 488,05 & 83,36 & 92,32 & 487,44 \\
\hline Pelophylax perezi & 29TNF88 & 99,00 & 141,71 & 103,14 & 41,42 & $\begin{array}{ll}4974,24 \\
\end{array}$ & 281,45 & 35,06 & 246,39 & 83,10 & 205,58 & 206,22 & 78,92 & 1144,18 & 158,88 & 13,41 & 52,08 & 452,19 & 78,01 & 89,11 & 451,23 \\
\hline Pelophylax perezi & 29TNF89 & 101,00 & 138,03 & 102,06 & \begin{tabular}{l|l|l}
40,95 \\
\end{tabular} & 4999,15 & 277,95 & 31,91 & 246,04 & 78,21 & 202,41 & 202,92 & 75,17 & \begin{tabular}{ll|}
1176,14 \\
\end{tabular} & 161,05 & 14,66 & 51,68 & 463,52 & 82,57 & 92,81 & 463,14 \\
\hline Pelophylax perezi & 29TNF90 & 100,00 & 135,74 & 97,24 & 39,11 & 5140,79 & 277,09 & 31,58 & 245,51 & 71,87 & 202,41 & 203,33 & $|71,87|$ & $\mid 1192,29$ & $\mid 178,24$ & $\mid 11,99$ & 54,96 & 483,60 & 77,32 & 79,46 & 483,60 \\
\hline Pelophylax perezi & 29TNF91 & 100,00 & 132,75 & 97,32 & 39,23 & 5137,78 & 273,84 & 28,79 & 245,06 & 68,99 & 199,50 & 200,32 & 68,99 & 1228,40 & 184,01 & 12,60 & 55,01 & 498,40 & 79,94 & 82,35 & 498,40 \\
\hline Pelophylax perezi & 29TNF92 & 101,00 & 126,83 & 96,14 & 39,03 & 5143,95 & 267,40 & 23,92 & 243,48 & 63,31 & 193,92 & 194,57 & 63,31 & 1295,64 & 194,83 & 13,75 & 55,18 & 526,94 & 85,17 & 87,05 & 526,94 \\
\hline Pelophylax perezi & 29TNF93 & 100,00 & 112,22 & 89,85 & 37,50 & 5123,48 & 249,76 & 13,62 & 236,13 & 50,27 & 180,26 & 180,45 & 50,27 & 1440,64 & 216,60 & 16,93 & 55,02 & 587,21 & 97,41 & 97,51 & 587,21 \\
\hline Pelophylax perezi & 29TNF94 & 100,00 & 117,18 & 94,18 & \begin{tabular}{|l|l|}
38,63 \\
\end{tabular} & 5143,77 & 257,13 & 16,22 & 240,91 & 54,41 & 184,94 & 185,37 & 54,41 & 1388,86 & 207,75 & 16,25 & 54,85 & 564,88 & 94,28 & 95,58 & 564,88 \\
\hline Pelophylax perezi & 29TNF95 & 101,00 & 138,40 & 103,35 & 40,82 & 5122,49 & 281,31 & 31,16 & 250,14 & 75,40 & 204,41 & 205,04 & 74,01 & 1168,52 & 171,57 & 12,46 & 54,07 & 469,70 & 76,62 & 82,85 & 469,33 \\
\hline Pelophylax perezi & 29TNF96 & 100,00 & 122,41 & 99,04 & 39,60 & 5160,22 & 265,41 & 18,77 & 246,64 & 58,88 & 189,82 & 190,40 & 58,88 & 1327,04 & 195,32 & 16,05 & 54,19 & 536,19 & 91,36 & 95,12 & 536,19 \\
\hline Pelophylax perezi & 29TNF97 & 100,00 & 115,88 & 95,90 & 39,03 & 5136,17 & 257,03 & 14,56 & 242,47 & 53,35 & 183,44 & 183,91 & 53,35 & 1372,61 & 199,44 & 17,95 & 53,49 & 553,49 & 98,06 & 101,01 & 553,49 \\
\hline Pelophylax perezi & 29TNF98 & 101,00 & 121,02 & 98,41 & 39,61 & 5139,73 & 263,22 & 17,96 & 245,26 & 57,91 & 188,29 & \begin{tabular}{|l|}
188,76 \\
\end{tabular} & 57,91 & 1316,53 & 188,74 & 17,26 & 53,01 & 528,34 & 94,25 & 98,83 & 528,34 \\
\hline Pelophylax perezi & 29TNF99 & 100,00 & 135,05 & 103,43 & 40,67 & 5161,06 & 279,51 & 27,52 & 251,99 & 71,37 & 201,96 & 202,26 & 70,61 & 1168,49 & 163,49 & 14,49 & 52,32 & 463,38 & 81,88 & 88,21 & 463,32 \\
\hline Pelophylax perezi & 29TNG04 & & & & & & & & & & & & & & & & & & & & \\
\hline Pelophylax perezi & 29TNG11 & 68,00 & 142,97 & 75,17 & 42,97 & 66,09 & 236,70 & 63,82 & 172,88 & 98,36 & 187,37 & 188,68 & 98,36 & 288,24 & 180,59 & 15,17 & 52,45 & 18,55 & 83,56 & 108,22 & 518,55 \\
\hline Pelophylax perezi & 29TNG12 & 87,00 & 137,29 & 73,96 & 42,06 & 3627,14 & 232,43 & $\begin{array}{l}5,6262 \\
\end{array}$ & $\begin{array}{l}173,81 \\
17\end{array}$ & 92,83 & 182,87 & 184,29 & 92,14 & 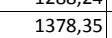 & 191,82 & 19,18 & 51,61 & 553,01 & $\begin{array}{l}0,3064 \\
96,64\end{array}$ & 118,57 & 552,97 \\
\hline Pelophylax perezi & 29TNG13 & 86,00 & 140,49 & 72,13 & 41,64 & 3603,62 & 234,13 & 62,90 & 171,23 & 100,04 & 185,70 & 187,01 & 95,30 & 1358,91 & 189,08 & 19,68 & 51,07 & 544,43 & 96,92 & 119,11 & 541,84 \\
\hline Pelophylax perezi & 29TNG14 & 99,00 & 141,35 & 69,97 & 41,01 & 3592,14 & 233,55 & 65,01 & 168,54 & 103,58 & 186,44 & 187,73 & 96,16 & 1368,59 & 193,12 & 21,54 & 50,70 & 549,61 & 101,51 & 122,99 & 542,04 \\
\hline Pelophylax perezi & 29TNG15 & 101,00 & 132,16 & 69,72 & 40,14 & 3685,33 & 227,32 & 55,75 & 171,56 & 93,81 & 178,93 & 180,33 & 86,39 & 1509,91 & 227,25 & 27,33 & 50,50 & 609,48 & 119,62 & 138,03 & 604,19 \\
\hline Pelophylax perezi & 29TNG16 & 63,00 & 144,91 & 65,38 & 39,81 & 3554,55 & 233,48 & 71,05 & 162,43 & 107,66 & 189,68 & 190,80 & 99,84 & 1361,27 & 195,80 & 24,69 & 49,54 & 549,03 & 108,17 & 128,84 & 528,42 \\
\hline Pelophylax perezi & 29TNG17 & 33,00 & 149,14 & $\frac{62,22}{62,22}$ & 38,97 & 3510,00 & 234,61 & 76,97 & $\begin{array}{l}152,454 \\
157,64\end{array}$ & $\begin{array}{l}112,28 \\
\end{array}$ & \begin{tabular}{|l|}
193,11 \\
\end{tabular} & 194,33 & \begin{tabular}{|l|}
104,31 \\
104
\end{tabular} & $\begin{array}{l}1294,33 \\
\end{array}$ & $\begin{array}{l}179,89 \\
\end{array}$ & 25,03 & $\mid 48,31$ & 519,61 & $\begin{array}{l}107,44 \\
\end{array}$ & 128,50 & 486,56 \\
\hline Pelophylax perezi & 29TNG18 & 45,00 & 144,43 & 61,74 & \begin{tabular}{|l|l|}
38,37 \\
\end{tabular} & 3541,20 & 231,42 & 73,05 & 158,37 & 107,44 & 189,24 & 190,36 & 99,57 & 1364,63 & 199,30 & 28,12 & 48,48 & 549,64 & 116,34 & 136,83 & 520,34 \\
\hline Pelophylax perezi & 29TNG19 & 57,00 & 145,12 & 59,99 & \begin{tabular}{|l|l|}
37,97 \\
\end{tabular} & 3519,84 & 230,93 & 75,11 & 155,82 & 108,43 & 189,61 & 191,00 & 100,84 & 1316,97 & 192,33 & 28,91 & 47,32 & 528,09 & 117,50 & 139,10 & 493,80 \\
\hline Pelophylax perezi & 29TNG20 & 101,00 & 138,63 & 80,62 & 42,90 & 3774,84 & 239,93 & 54,36 & 185,56 & 91,40 & 185,97 & 187,32 & 91,40 & 1326,01 & 182,29 & 16,74 & 51,84 & 531,55 & 89,82 & 110,74 & 531,55 \\
\hline Pelophylax perezi & 29TNG21 & 100,00 & 140,46 & 79,05 & 42,58 & 3766,11 & 241,19 & 57,32 & 183,88 & 93,37 & 187,78 & 188,95 & 93,37 & 1319,70 & 182,44 & 16,80 & 51,79 & 528,80 & 89,38 & 111,32 & 528,80 \\
\hline Pelophylax perezi & 29TNG22 & 101,00 & $\begin{array}{l}14,40 \\
137,87\end{array}$ & 77,71 & 年 41,84 & 3802,67 & 239,14 & 55,51 & \begin{tabular}{|l|}
183,60 \\
183,63
\end{tabular} & $\begin{array}{l}\mid 3,13 \\
92,15\end{array}$ & \begin{tabular}{|l|}
185,93 \\
185,0
\end{tabular} & \begin{tabular}{|l|}
187,09 \\
187,09
\end{tabular} & $\begin{array}{l}30,017 \\
90,40\end{array}$ & $\begin{array}{l}1364,18 \\
1364\end{array}$ & \begin{tabular}{|l|}
$182,4,74$ \\
189,7
\end{tabular} & $\begin{array}{l}0,0,11 \\
19,1\end{array}$ & $\begin{array}{l}\mid 1,1,39 \\
51,0\end{array}$ & $\begin{array}{l}540,00 \\
5454\end{array}$ & $\begin{array}{l}3,30 \\
96,55 \\
\end{array}$ & 111,25 & $\begin{array}{l}520,00 \\
545,41\end{array}$ \\
\hline Pelophylax perezi & 29TNG23 & 100,00 & 133,12 & 76,64 & 41,04 & 3855,64 & 235,53 & 51,17 & 184,36 & 88,49 & 182,12 & 183,32 & 85,21 & 1450,79 & 209,92 & 22,81 & 50,88 & 581,76 & 108,37 & 126,68 & 581,25 \\
\hline Pelophylax perezi & 29TNG24 & 99,00 & 142,72 & 73,68 & 40,92 & 3762,67 & 240,82 & 62,56 & 178,27 & 101,27 & 190,16 & 191,21 & 95,21 & 1360,54 & 195,29 & 21,41 & 50,56 & 545,50 & 101,24 & 121,49 & 538,65 \\
\hline Pelophylax perezi & 29TNG25 & 101,00 & 142,44 & 71,61 & 40,21 & 3755,29 & 239,25 & 63,49 & 175,77 & 101,68 & 189,94 & 190,94 & 95,01 & 1394,60 & 206,60 & 23,94 & 50,39 & 561,40 & 107,55 & 126,99 & 552,19 \\
\hline Pelophylax perezi & 29TNG26 & 100,00 & 137,42 & 70,38 & 39,69 & 3792,18 & 234,78 & 59,26 & 175,52 & 95,03 & 185,76 & 186,73 & 89,89 & 1494,19 & 233,27 & 28,30 & 50,67 & 605,16 & 120,03 & 137,69 & 598,49 \\
\hline Pelophylax perezi & 29TNG27 & 80,00 & 142,23 & 66,90 & 39,02 & 3729,91 & 235,55 & 66,17 & 169,38 & 100,94 & \begin{tabular}{|l|l|}
189,67 \\
\end{tabular} & 190,59 & 95,20 & |1456,53 & 226,75 & $28, \varepsilon$ & 50,29 & 590,88 & 119,23 & 137,56 & 576,63 \\
\hline Pelophylax perezi & 29TNG28 & 86,00 & 139,17 & 65,44 & 38,37 & 3735,36 & 232,63 & 64,36 & 168,28 & 99,83 & 186,87 & 187,97 & 92,44 & \begin{tabular}{|l|}
1463,59 \\
1405
\end{tabular} & 227,46 & 31,15 & 49,23 & 589,78 & 125,44 & 144,09 & 572,35 \\
\hline Pelophylax perezi & 29TNG29 & 72,00 & 142,90 & 62,57 & 37,89 & 3707,49 & 233,27 & 70,12 & 163,15 & 103,57 & 190,24 & 191,12 & 96,35 & 1394,43 & 212,13 & 30,94 & 48,26 & 558,48 & 122,62 & 142,96 & 533,75 \\
\hline Pelophylax perezi & 29TNG30 & 100,00 & 142,44 & 84,53 & 42,87 & 3938,87 & 249 & 54,16 & 195,22 & 95,44 & 191,86 & 193,10 & 92,81 & 1270,66 & 172,69 & 15,94 & 51,41 & 505,15 & 86,42 & 106,61 & 504,88 \\
\hline Pelophylax perezi & 29TNG31 & 101,00 & 138,13 & 83,65 & 4 & 3997,59 & 246 & 50,50 & $\mid$ & $\begin{array}{l}90,32 \\
90,32\end{array}$ & $\begin{array}{l}188,70 \\
\end{array}$ & 189,82 & 88,05 & 1338,81 & \begin{tabular}{|l|l|}
185,48 \\
\end{tabular} & & $\begin{array}{l}1,41,15 \\
51\end{array}$ & 533,35 & $\begin{array}{l}0,4435 \\
94,35 \\
\end{array}$ & 113,34 & 533,25 \\
\hline Pelophylax perezi & 29TNG32 & 101,00 & 142 & 82,02 & 41, & 3972,07 & 249 & 55,81 & 194,06 & 98,75 & 192,74 & 19 & 92,50 & 1300,19 & 180,92 & 17, & 51,01 & 516,76 & 92,01 & 111,91 & 515,34 \\
\hline Pelophylax perezi & 29TNG33 & 100,00 & 128,02 & 80,92 & 40,79 & 4087,55 & 238,12 & 41,92 & 196,20 & 79,68 & 180,45 & $\begin{array}{l}181,48 \\
\end{array}$ & 77,39 & 1483,19 & 217,87 & 24,47 & 50,58 & 592,61 & \begin{tabular}{r|r|}
114,75 \\
\end{tabular} & 129,94 & 592,45 \\
\hline Pelophylax perezi & 29TNG34 & 100,00 & 130,47 & 79,59 & 40,55 & 4068,19 & 239,44 & 45,08 & 194,36 & 84,61 & 182,58 & 183,56 & 79,95 & 1482,56 & 223,25 & 25,55 & 50,53 & 593,07 & 116,73 & 132,15 & 591,82 \\
\hline Pelophylax perezi & 29TNG35 & 100,00 & 145,15 & 76,03 & 40,07 & 3941,12 & 248, & 61,79 & 186,88 & 101,87 & 195,09 & 195,83 & 95 , & 1342,05 & 200,47 & 22,86 & 50,10 & 537,04 & 104,42 & 122,88 & 526,61 \\
\hline Pelophylax perezi & 29TNG36 & $\begin{array}{l}101,00 \\
100\end{array}$ & $\frac{144}{144}$ & 73,61 & 39 & 3928,62 & $\frac{24 c}{246}$ & $\begin{array}{ll}62,98 \\
621\end{array}$ & \begin{tabular}{|l|}
183,40 \\
183,4
\end{tabular} & \begin{tabular}{|l|}
101,35 \\
101
\end{tabular} & \begin{tabular}{|l|}
194,70 \\
194,0
\end{tabular} & \begin{tabular}{|l|}
195,47 \\
1950
\end{tabular} & $\begin{array}{ll}30,11 \\
95,00\end{array}$ & \begin{tabular}{|l|l|l|l|l|l|}
1380,58 \\
\end{tabular} & \begin{tabular}{|l|}
213,07 \\
\end{tabular} & 25,5 & $\begin{array}{ll}50,08 \\
50\end{array}$ & $\mid \begin{array}{l}551,049 \\
554,99\end{array}$ & $\begin{array}{l}110,69 \\
11,69\end{array}$ & $\begin{array}{l}12,00 \\
128,51\end{array}$ & 543,51 \\
\hline Pelophylax perezi & 29TNG37 & 100,00 & 139,44 & 72,37 & 39,17 & 3952,22 & 241,01 & 58,61 & 182,39 & 95,37 & 190,05 & 190,83 & 89,86 & \begin{tabular}{|l|}
1472,17 \\
\end{tabular} & 236,44 & 29,55 & 50,39 & 593,97 & 122,06 & 138,70 & 586,24 \\
\hline Pelophylax perezi & 29TNG38 & 88,00 & 139,79 & 70,11 & 38,73 & 3935,64 & 239,20 & $\begin{array}{l}60,43 \\
60\end{array}$ & $\begin{array}{l}178,77 \\
\end{array}$ & $\begin{array}{l}97,45 \\
97\end{array}$ & $\begin{array}{l}190,29 \\
\end{array}$ & \begin{tabular}{|l|}
191,03 \\
\end{tabular} & $\begin{array}{l}90,000 \\
90,49\end{array}$ & \begin{tabular}{|l|}
1461,61 \\
\end{tabular} & 233,79 & 31,05 & 49,66 & 586,56 & 124,93 & 141,71 & 575,20 \\
\hline Pelophylax perezi & 29TNG39 & 101,00 & 136,77 & 68,86 & 38,12 & 3933,53 & 236,40 & 58,27 & 178,13 & 94,66 & 187,42 & 188,34 & 87,94 & 1478,41 & 235,28 & 33,27 & 48,80 & 590,26 & 130,99 & 148,84 & 576,22 \\
\hline Pelophylax perezi & 29 TNG 40 & 101,00 & 145,85 & 88,48 & 42,5 & 4128,39 & 258,94 & 53,25 & 205,69 & 100,52 & 197,76 & 198,85 & 93, & 1208,74 & 163,53 & 15,25 & 50,98 & 478,58 & 83,25 & 102,33 & 474 \\
\hline Pelophylax perezi & 29TNG41 & 100,00 & 138,67 & 87,77 & 41,79 & 4212,47 & 254,27 & 46,55 & 207,72 & $\begin{array}{ll}92,38 \\
92\end{array}$ & 192,13 & $\begin{array}{ll}193,18 \\
\end{array}$ & 85,67 & 1304,64 & \begin{tabular}{|l|l|}
181,44 \\
\end{tabular} & 18,13 & 50,77 & 517,18 & 94,26 & 111,32 & 514,42 \\
\hline Pelophylax perezi & 29TNG42 & 100,00 & 137,73 & 86,50 & 41,29 & 4229,46 & 253,40 & 46,41 & 206,99 & 90,97 & 191,60 & 192,52 & 84,68 & 1324,39 & 187,27 & 19,51 & 50,38 & 524,80 & 98,47 & 114,94 & 521,03 \\
\hline Pelophylax perezi & 29TNG43 & 101,00 & 137,51 & 85,64 & 40,89 & 4235,56 & 253,34 & 46,66 & 206,68 & 91,15 & 191,53 & 192,29 & 84,30 & 1342,99 & 195,19 & 21,10 & 50,03 & 532,19 & 103,16 & 118,92 & 527,01 \\
\hline Pelophylax perezi & 29TNG44 & 100,00 & 130,60 & 84,27 & 40,4 & 4270,75 & 246,88 & 40,75 & 206,14 & 84,49 & 185 & 186 & 77 & 1431,34 & 214,47 & 24,88 & 49 & 567 & 115,32 & 129,11 & 563 \\
\hline Pelophylax perezi & 29TNG45 & 101,00 & 142,30 & 82,14 & 40,13 & 4197,28 & 255,32 & 53,36 & 201,96 & 96,35 & 195,81 & 196,38 & 89,24 & 1323,49 & 199,84 & 23,13 & 49,47 & 524,75 & 106,82 & 122,21 & 513,46 \\
\hline
\end{tabular}




\begin{tabular}{|c|c|c|c|c|c|c|c|c|c|c|c|c|c|c|c|c|c|c|c|c|c|}
\hline TAXON & UTM & $\mathrm{km} 2$ & B101 & B102 & $\mathrm{BIO3}$ & B104 & B105 & B106 & B107 & B108 & B109 & BIO10 & BIO11 & BIO12 & B1013 & BIO14 & BIO15 & BIO16 & B1017 & B1018 & B1019 \\
\hline Pelophylax perezi & 29TNG46 & 101,00 & 143,29 & 80,28 & 39,91 & 4175,75 & 254,49 & 55,52 & 198,96 & 97,62 & 196,56 & 197,13 & 90,47 & 1332,85 & 205,65 & 24,82 & 49,20 & 528,98 & 110,47 & 125,52 & 515,79 \\
\hline Pelophylax perezi & 29TNG48 & 100,00 & 128,16 & 78,41 & \begin{tabular}{|l|l|}
39,08 \\
\end{tabular} & 4198,61 & 239,79 & 41,84 & 197,95 & 83,04 & 182,58 & 183,64 & 76,66 & $\begin{array}{l}1502,07 \\
\end{array}$ & 239,28 & 32,79 & 48,85 & 595,05 & 133,86 & $\begin{array}{ll}147,87 \\
\end{array}$ & 587,57 \\
\hline Pelophylax perezi & 29TNG49 & 101,00 & 125,64 & 77,56 & 38,85 & 4165,73 & 237,61 & 39,97 & 197,64 & 81,13 & 179,86 & 181,09 & 75,07 & 1508,88 & 237,59 & 34,66 & 47,92 & 594,55 & 138,65 & 153,11 & 584,39 \\
\hline Pelophylax perezi & 29TNG50 & 101,00 & 140,38 & 92,44 & 41,82 & 4400,09 & 262,18 & 43,75 & 218,44 & 91,96 & 196,36 & 197,28 & 84,86 & 1243,80 & 168,81 & 16,54 & 50,69 & \begin{tabular}{|l|l|}
492,03 \\
\end{tabular} & 88,82 & 104,69 & 487,03 \\
\hline Pelophylax perezi & 29TNG51 & 100,00 & 138,16 & 91,40 & 41,41 & 4425,39 & 260,50 & 42,19 & 218,31 & 89,59 & 194,64 & 195,49 & 82,54 & $\begin{array}{ll}1274,66 \\
\end{array}$ & 176,06 & \begin{tabular}{|l|l|}
17,98 \\
\end{tabular} & 50,29 & 503,34 & 93,86 & 109,01 & 498,60 \\
\hline Pelophylax perezi & 29TNG52 & 100,00 & 130,71 & 89,65 & 40,70 & 4468,95 & 253,57 & 35,99 & 217,57 & 81,64 & 188,20 & 188,95 & 75,02 & 1357,70 & 191,48 & 21,14 & 49,95 & 535,88 & 104,88 & 117,86 & 532,10 \\
\hline Pelophylax perezi & 29TNG53 & 101,00 & 131,96 & 89,04 & 40,50 & 4465,45 & 254,88 & 37,47 & 217,42 & 83,37 & 189,44 & 190,19 & 76,41 & \begin{tabular}{|l|l|}
1345,19 \\
\end{tabular} & 193,52 & 21,98 & 49,53 & 529,65 & 106,91 & 119,50 & 523,62 \\
\hline Pelophylax perezi & 29TNG54 & 101,00 & 107,50 & 82,47 & 38,62 & 4465,10 & 228,68 & 18,35 & 210,33 & 60,80 & 166,06 & $\begin{array}{l}167,06 \\
\end{array}$ & 54,06 & 1555,27 & 221,33 & 30,16 & 48,53 & 611,15 & 134,21 & 142,65 & 608,70 \\
\hline Pelophylax perezi & 29TNG56 & 101,00 & 134,95 & 86,64 & 39,84 & 4443,65 & 256,33 & 41,37 & 214,96 & 86,19 & 192,04 & 192,69 & 79,37 & 1329,41 & 202,14 & 25,73 & 48,28 & 520,27 & 115,85 & 126,77 & 506,14 \\
\hline Pelophylax perezi & 29TNG58 & 99,00 & 113,23 & 81,48 & 38,81 & $\begin{array}{lll}4356,27 \\
\end{array}$ & 232,03 & 24,34 & 207,69 & 66,96 & 170,34 & 171,53 & 61,18 & 1517,29 & 227,58 & 34,32 & 47,03 & 591,85 & 141,42 & 152,52 & 583,34 \\
\hline Pelophylax perezi & 29TNG59 & 100,00 & 113,55 & 80,92 & 38,72 & 4310,81 & 231,79 & 25,08 & 206,71 & 67,71 & 170,02 & 171,45 & 62,24 & 1509,61 & 226,36 & \begin{tabular}{|c|}
35,67 \\
\end{tabular} & 46,38 & 586,61 & 144,05 & 155,97 & 575,97 \\
\hline Pelophylax perezi & 29TNG60 & 100,00 & 134,74 & 95,32 & 41,24 & 4644,93 & 263,68 & 35,02 & 228,66 & 83,36 & 194,34 & 195,08 & 76,56 & 1273,15 & 170,29 & 17,49 & 50,72 & 502,46 & 92,99 & 105,74 & 499,23 \\
\hline Pelophylax perezi & 29TNG61 & 101,00 & 129,52 & 92,96 & 40,52 & 4652,63 & 257,84 & 31,49 & 226,34 & 76,71 & 189,55 & 190,32 & 71,80 & 1320,79 & 179,13 & 19,68 & 50,09 & 520,45 & 100,31 & 111,37 & 517,43 \\
\hline Pelophylax perezi & 29TNG62 & 101,00 & 115,32 & 87,95 & 39,30 & 4647,57 & 241,85 & 21,15 & 220,70 & 62,37 & 176,03 & 176,82 & 58,84 & 1450,71 & 198,80 & 24,52 & 49,68 & 571,37 & 116,97 & 125,53 & 570,44 \\
\hline Pelophylax perezi & 29TNG63 & 100,00 & 123,83 & 90,23 & 39,73 & 4660,90 & 251,54 & 27,50 & 224,04 & 72,50 & 184,36 & 185,01 & 66,47 & 1369,05 & 192,82 & 23,31 & 49,05 & 536,57 & 111,71 & 121,10 & 531,94 \\
\hline Pelophylax perezi & 29TNG64 & 101,00 & 110,77 & 85,49 & 38,75 & 4618,93 & 235,92 & 18,21 & 217,71 & 61,90 & 171,38 & 172,25 & 55,21 & 1481,37 & 208,95 & 28,14 & 48,52 & 579,94 & 126,96 & 135,08 & 577,66 \\
\hline Pelophylax perezi & 29TNG65 & 100,00 & 104,96 & 83,10 & 38,21 & 4573,78 & 228,97 & 14,35 & 214,62 & 57,06 & 165,27 & 166,23 & 50,52 & 1523,45 & 215,64 & \begin{tabular}{l|l|}
31,05 \\
\end{tabular} & 47,71 & 594,87 & 135,51 & 143,03 & 591,62 \\
\hline Pelophylax perezi & 29TNG66 & 100,00 & 132,97 & 90,07 & 39,70 & 4650,79 & 259,97 & 35,22 & 224,75 & 81,72 & 193,13 & 193,56 & 75,17 & 1269,36 & 188,81 & 24,75 & 47,50 & 491,39 & 112,81 & 122,05 & 476,26 \\
\hline Pelophylax perezi & 29TNG67 & 101,00 & 131,55 & 88,09 & 39,38 & $\begin{array}{lll}4616,44 \\
\end{array}$ & 255,96 & 34,71 & 221,25 & 80,76 & 191,40 & 191,92 & 74,53 & 1285,02 & 193,17 & 26,55 & 47,19 & 496,80 & 116,35 & 126,10 & 482,80 \\
\hline Pelophylax perezi & 29TNG68 & 101,00 & 125,16 & 85,59 & $\begin{array}{l}38,95 \\
\end{array}$ & 4545,41 & 247,24 & 30,58 & 216,66 & 75,50 & 184,41 & 185,20 & 69,87 & 1345,60 & 201,85 & 29,79 & 46,67 & 519,66 & 125,28 & 137,12 & 507,16 \\
\hline Pelophylax perezi & 29TNG70 & 100,00 & 125,96 & 95,39 & 40,34 & 4836,55 & 259,46 & 25,65 & 233,80 & 69,04 & 188,61 & 189,35 & 66,06 & 1323,33 & 177,65 & 18,87 & 50,92 & 523,00 & 98,51 & 107,73 & 522,32 \\
\hline Pelophylax perezi & 29TNG71 & 101,00 & 123,47 & 93,49 & 39,85 & 4824,53 & 255,95 & 24,26 & 231,69 & 67,47 & 186,21 & 186,93 & 64,12 & 1335,23 & 178,47 & 20,38 & 50,23 & 525,75 & 102,88 & 111,40 & 524,43 \\
\hline Pelophylax perezi & 29TNG72 & 100,00 & 97,65 & 83,12 & \begin{tabular}{|l|l|}
37,48 \\
\end{tabular} & $\begin{array}{lll}4745,83 \\
\end{array}$ & 225,53 & 6,75 & 218,78 & 42,20 & 160,59 & 161,38 & 41,58 & 1545,54 & 206,22 & 28,51 & 49,13 & $\begin{array}{l}607,76 \\
\end{array}$ & 130,75 & 134,74 & 607,72 \\
\hline Pelophylax perezi & 29TNG73 & 100,00 & 115,12 & 89,06 & 38,83 & 4792,36 & 245,33 & 18,81 & 226,53 & 61,56 & 177,89 & 178,53 & 57,06 & 1389,96 & 190,55 & 24,75 & 48,83 & 543,13 & 116,06 & 122,88 & 540,40 \\
\hline Pelophylax perezi & 29TNG74 & 100,00 & 118,22 & 89,85 & 39,04 & 4792,53 & 248,44 & 20,96 & 227,47 & 66,63 & 181,05 & 181,57 & 60,02 & 1355,98 & 189,64 & 24,99 & 48,16 & 527,67 & 115,35 & 123,03 & 523,51 \\
\hline Pelophylax perezi & 29TNG75 & 100,00 & 95,31 & 81,82 & 37,30 & 4670,94 & 221,61 & 5,29 & 216,32 & 47,01 & 157,29 & 158,27 & 40,48 & 1539,21 & 211,15 & 32,58 & 47,17 & 598,54 & 140,23 & 145,68 & 596,07 \\
\hline \begin{tabular}{|l|} 
Pelophylax perezi \\
\end{tabular} & 29TNG76 & 101,00 & 119,59 & 88,52 & 38,71 & 4750,27 & 247,99 & 22,54 & 225,45 & |68,06 & 181,81 & 182,36 & $\begin{array}{l}|c|, 404 \\
61,94\end{array}$ & \begin{tabular}{|l|l|}
1331,79 \\
\end{tabular} & $\begin{array}{l}191,78 \\
\end{array}$ & 27,01 & 47,14 & 514,88 & 119,36 & 127,88 & 506,72 \\
\hline Pelophylax perezi & 29TNG77 & 101,00 & 133,18 & 91,21 & 39,10 & 4819,46 & 261,81 & 31,66 & 230,15 & 79,49 & 195,82 & 196,10 & 73,70 & 1193,18 & 176,81 & 24,51 & 46,56 & 456,50 & 108,58 & 116,42 & 442,62 \\
\hline Pelophylax perezi & 29TNG78 & 100,00 & 139,06 & 89,04 & 38,86 & 4789,06 & 264,12 & 37,72 & 226,40 & 85,44 & 201,18 & 201,45 & 79,82 & \begin{tabular}{|l|}
1126,93 \\
\end{tabular} & 167,65 & 24,12 & 45,96 & 428,39 & 104,06 & 112,19 & 412,40 \\
\hline Pelophylax perezi & 29TNG80 & 101,00 & 112,87 & 91,32 & 38,75 & 4947,97 & 247,61 & 15,16 & 232,45 & 53,01 & 177,90 & 178,60 & 53,01 & 1400,14 & 192,11 & 21,42 & 51,11 & 556,51 & 107,68 & 112,99 & 556,51 \\
\hline Pelophylax perezi & 29TNG81 & 99,00 & 115,24 & 91,50 & 38,82 & 4947,70 & 249,65 & 16,98 & 232,68 & 55,94 & 180,29 & 180,76 & 55,18 & 1364,75 & 183,45 & 21,60 & 50,37 & 539,13 & 106,90 & 111,89 & 538,88 \\
\hline \begin{tabular}{|l|} 
Pelophylax perezi \\
\end{tabular} & 29TNG82 & 101,00 & 108,29 & 87,72 & $\begin{array}{l}30,02 \\
38,01\end{array}$ & 48996,41 & 240,41 & $\begin{array}{ll}12,73 \\
12,\end{array}$ & \begin{tabular}{|l|}
227,68 \\
22,0
\end{tabular} & $\begin{array}{l}59,93 \\
49\end{array}$ & $\begin{array}{ll}172,98 \\
\end{array}$ & $\begin{array}{l}173,49 \\
170\end{array}$ & 49,60 & 1410,36 & \begin{tabular}{|l|l|}
187,29 \\
\end{tabular} & 24,39 & 49,53 & 554,55 & 115,56 & 120,32 & 554,48 \\
\hline Pelophylax perezi & 29TNG83 & 100,00 & 95,35 & 82,54 & 36,89 & 4825,88 & 224,96 & 4,18 & 220,77 & 39,97 & 159,66 & 160,33 & 38,78 & 1502,75 & \begin{tabular}{|l|}
199,67 \\
\end{tabular} & 29,19 & 48,38 & \begin{tabular}{|l|l|}
587,88 \\
\end{tabular} & 130,81 & 134,52 & 587,87 \\
\hline Pelophylax perezi & 29TNG84 & 101,00 & 115,06 & 89,61 & 38,44 & 4900,82 & 247,18 & 17,13 & 230,05 & 62,29 & 179,62 & 180,01 & 55,89 & 1330,30 & 182,38 & 24,65 & 48,11 & 516,80 & 113,30 & 119,51 & 514,85 \\
\hline Pelophylax perezi & 29TNG85 & 101,00 & 110,38 & 87,58 & 38,09 & 4847,86 & 241,14 & 14,13 & 227,01 & 58,55 & 174,38 & 174,95 & 52,32 & 1362,59 & 188,53 & 27,05 & 47,48 & 528,30 & 120,16 & 126,83 & 525,43 \\
\hline Pelophylax perezi & 29TNG86 & 100,00 & 118,55 & 89,98 & 38,52 & 4887,39 & 249,84 & 19,15 & 230,69 & 65,38 & 182,86 & 183,30 & 59,50 & 1277,69 & 180,86 & 25,94 & 46,84 & 491,94 & 114,51 & 120,97 & 485,73 \\
\hline Pelophylax perezi & 29TNG87 & 100,00 & 131,52 & 92,63 & 38,90 & 4978,81 & 263,13 & 27,19 & 235,94 & 75,96 & 196,55 & 196,79 & 70,46 & 1135,81 & 164,80 & 23,53 & 46,00 & 431,70 & 103,51 & 109,38 & 420,30 \\
\hline Pelophylax perezi & 29TNG88 & 100,00 & 134,92 & 90,86 & 38,50 & 4962,84 & 263,78 & 30,42 & 233,36 & 79,33 & 199,65 & 199,84 & 74,12 & 1091,09 & 159,33 & 23,65 & 45,35 & \begin{tabular}{|l|l|}
411,98 \\
\end{tabular} & 101,28 & 106,87 & 399,33 \\
\hline Pelophylax perezi & 29TNG89 & 99,00 & 133,11 & 89,58 & $\begin{array}{l}38,65 \\
\end{array}$ & 4845,43 & 259,80 & 30,64 & 229,15 & 78,79 & 196,33 & 196,78 & 74,04 & 1116,15 & 163,64 & 25,52 & 44,91 & 420,88 & 106,30 & 116,78 & 407,68 \\
\hline Pelophylax perezi & 29TNG90 & 100,00 & 120,45 & 96,51 & 39,18 & 5118,80 & 260,85 & 17,93 & 242,93 & 57,81 & 187,52 & 187,92 & 57,81 & 1287,23 & 177,84 & 18,68 & 51,39 & 510,95 & 96,68 & 101,54 & 510,95 \\
\hline Pelophylax perezi & 29TNG91 & 101,00 & 106,49 & 88,55 & 37,63 & 5026,95 & 242,03 & 9,90 & 232,12 & 46,30 & 173,06 & 173,50 & 46,30 & 1386,53 & 188,86 & 23,03 & 50,32 & 548,86 & 111,20 & 114,51 & 548,86 \\
\hline Pelophylax perezi & 29TNG92 & $\begin{array}{l}101,00 \\
101,00\end{array}$ & $\begin{array}{l}104,45 \\
104,70\end{array}$ & $\begin{array}{l}80,350 \\
86,50\end{array}$ & 37, 37,29 & \begin{tabular}{|l|l|}
4987,78 \\
49878
\end{tabular} & 24,058 & $\begin{array}{l}, 9,44 \\
9,4\end{array}$ & \begin{tabular}{|l|}
229,12 \\
229,
\end{tabular} & $\begin{array}{l}40,30 \\
45,29 \\
\end{array}$ & \begin{tabular}{|l|}
170,90 \\
170
\end{tabular} & \begin{tabular}{|l|}
171,31 \\
171
\end{tabular} & $\begin{array}{l}40,20 \\
45,29 \\
\end{array}$ & \begin{tabular}{|l|l}
130,050 \\
1385,85
\end{tabular} & \begin{tabular}{|l|}
$180,00,38$ \\
185
\end{tabular} & 24,03 & $\begin{array}{ll}00,52 \\
49,44\end{array}$ & $\begin{array}{l}548,80 \\
545,62\end{array}$ & $\begin{array}{l}111,20 \\
114,51\end{array}$ & $\begin{array}{l}114,51 \\
117,69\end{array}$ & $\begin{array}{l}548,00 \\
545,62\end{array}$ \\
\hline Pelophylax perezi & 29TNG93 & 100,00 & 96,32 & 83,47 & 36,63 & 4929,91 & 228,39 & 3,62 & 224,77 & 39,17 & 162,07 & 162,53 & 38,30 & 1441,20 & 190,75 & 27,84 & 48,34 & 563,31 & 125,34 & 128,21 & 563,31 \\
\hline Pelophylax perezi & 29TNG94 & 100,00 & 104,76 & 86,30 & 37,24 & 4947,62 & 237,78 & 9,36 & 228,42 & 50,88 & 170,56 & 170,87 & 45,91 & 1358,63 & 181,85 & 26,28 & 47,98 & 28,21 & 118,26 & 122,51 & 528,04 \\
\hline Pelophylax perezi & 29TNG97 & 101,00 & 128,47 & 93,28 & 38,48 & 5077,27 & 262,36 & 22,92 & 239,45 & 71,72 & 194,96 & 195,08 & 66,47 & 1102,83 & 156,57 & 22,5 & 45,68 & 18,49 & 100,50 & 103,93 & 409,70 \\
\hline Pelophylax perezi & 29TNG98 & 101,00 & 13 & 92,45 & 37,8 & 5162,84 & 269,37 & 28,60 & 240,77 & 79,01 & 204,71 & 204,75 & 73,95 & \begin{tabular}{|l|l|}
989,93 \\
\end{tabular} & 142,03 & 21, & 44,79 & $\begin{array}{l} \\
370,10 \\
\end{array}$ & 91,71 & 93,81 & 359,00 \\
\hline Pelophylax perezi & 29TNG & 101,00 & 13 & 91,03 & 38, & 5016,64 & 264,07 & 28,52 & 235,55 & 77,88 & 199,94 & 200,11 & 73,24 & 1026,37 & 147,59 & 23,5 & 44,20 & 384,14 & 97,82 & 102,91 & 372,22 \\
\hline Pelophylax perezi & 29TNHOO & 16,00 & 147,29 & 59,00 & 38,48 & 3400,52 & 230,67 & 78,95 & 151,71 & 112,29 & 190,24 & \begin{tabular}{|l|l|}
191,67 \\
\end{tabular} & \begin{tabular}{|l|l|}
104,38 \\
\end{tabular} & 1225,90 & $\begin{array}{l}174,48 \\
\end{array}$ & 26,95 & 46,81 & 491,57 & 111,81 & 134,71 & 450,57 \\
\hline Pelophylax perezi & 29TNHO1 & 40,00 & 144,58 & 59,91 & 38,18 & 3389,01 & 229,52 & 75,00 & 154,52 & 110,27 & 186,96 & 189,12 & 101,96 & 1190,85 & 170,30 & 27,81 & 45,66 & 475,97 & 115,04 & 138,49 & 430,70 \\
\hline Pelophylax perezi & 29TNHO2 & 97,00 & 132,26 & 63,14 & 37,98 & 3521,94 & 224,76 & 60,48 & 164,28 & 97,19 & 177,01 & 179,36 & 89,11 & 1311,65 & 191,91 & 32,75 & 44,97 & 73 & 131,71 & 153,40 & 479,06 \\
\hline Pelophylax perezi & $29 T N$ & 72,00 & 14 & 62 & 38 & 34441,65 & 229,47 & $\begin{array}{l}68,97 \\
68,97 \\
\end{array}$ & \begin{tabular}{|l|}
$164,50,50$ \\
160
\end{tabular} & $\mid$\begin{tabular}{|c|}
106,00 \\
10,0
\end{tabular} & \begin{tabular}{|l|}
183,51 \\
\end{tabular} & \begin{tabular}{|l|l|}
186,10 \\
\end{tabular} & $\begin{array}{l}\mid c 5,11 \\
97,60\end{array}$ & 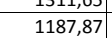 & \begin{tabular}{|l|}
170,53 \\
170
\end{tabular} & 29,84 & $\begin{array}{ll}44,38 \\
445\end{array}$ & \begin{tabular}{|l|l|}
470,94 \\
\end{tabular} & 121,46 & 144,58 & 424,12 \\
\hline Pelophylax perezi & 29TNH04 & 98,00 & 137,01 & 63,14 & 38,09 & 3452,36 & 228,38 & 64,98 & 163,40 & 103,02 & 180,45 & 183,28 & 94,56 & 1187,81 & 169,67 & 31,04 & 43,51 & 468,51 & 125,83 & 148,93 & 420,04 \\
\hline Pelophylax perezi & 29TNHO5 & 99,00 & 130,21 & 64,82 & 38,15 & 3496,92 & 225,11 & 57,22 & 167,89 & 96,18 & 174,38 & 177,55 & 87,89 & 1236,42 & 176,17 & 33,76 & 42,70 & 484,35 & 135,19 & 157,82 & 436,14 \\
\hline Pelophylax perezi & 29TNH06 & 101,00 & 130,82 & 64,73 & 38,44 & 3443,75 & 224,58 & 58,12 & 166,45 & 97,50 & 174,06 & 177,48 & 89,05 & 1201,01 & 168,81 & 33,56 & 41,93 & 468,53 & 134,43 & 157,51 & 418,84 \\
\hline Pelophylax perezi & 29TNHC & 101,00 & 135,56 & 63,77 & 38,5 & 3340,52 & 225,72 & 63,71 & 162,01 & 103,33 & 176,99 & 180 & 94,75 & 1124,75 & 155,33 & 31,65 & 41,14 & 437,83 & 128,10 & 152,02 & 386 \\
\hline Pelophylax perezi & \begin{tabular}{l|} 
29TNH08 \\
\end{tabular} & 81,00 & $\begin{array}{l}13,50 \\
139,86\end{array}$ & 62,83 & 39,45 & 3245,91 & 226,120 & $\begin{array}{l}3,11,94 \\
68,4 \\
\end{array}$ & \begin{tabular}{|l|}
152,01 \\
157,55 \\
\end{tabular} & \begin{tabular}{|l|}
108,65 \\
1085
\end{tabular} & \begin{tabular}{|l|}
179,71 \\
179,
\end{tabular} & \begin{tabular}{|l|l|}
183,68 \\
180
\end{tabular} & \begin{tabular}{|l|l|}
99,93 \\
99
\end{tabular} & \begin{tabular}{|l|l|l|l|l|l|}
1066,54 \\
\end{tabular} & \begin{tabular}{|l|}
146,17 \\
146,17
\end{tabular} & 势, & $\begin{array}{l}1,14 \\
40,82\end{array}$ & \begin{tabular}{|l}
45,05 \\
414,13
\end{tabular} & 122,84 & 147,26 & $\begin{array}{l}300,01 \\
363,35\end{array}$ \\
\hline Pelophylax perezi & 29TNHO9 & 36,00 & 140,84 & 62,53 & 39,81 & 3197,92 & 225,89 & 70,47 & 155,42 & 110,27 & 179,88 & 184,00 & \begin{tabular}{|l|}
101,47 \\
\end{tabular} & 1046,33 & 142,86 & \begin{tabular}{|l|l|}
29,83 \\
\end{tabular} & 40,06 & 404,94 & 121,86 & 146,55 & 354,73 \\
\hline Pelophylax perezi & 29TNH10 & 61,00 & 146,39 & 60,06 & 37,91 & 3519,36 & 232,27 & 76,11 & 156,16 & 109,72 & 190,75 & 192,23 & 101,94 & 1275,06 & 185,37 & 28,73 & 46,99 & 509,45 & 116,28 & 138,47 & 472,93 \\
\hline Pelophylax perezi & $29 \mathrm{TNH}$ & 40,00 & 146,34 & 60,45 & 37,82 & 3518,47 & 233,20 & 75,68 & 57, & 109,9 & 190,80 & 192 & 102 & \begin{tabular}{|l|l|}
1241,93 \\
\end{tabular} & 180,28 & 28,89 & 46,24 & 494 & 116,57 & 139,20 & 455 \\
\hline Pelophylax perezi & 29TNH12 & 80,00 & 143,85 & 61,84 & 37,90 & 3527,18 & 233,33 & 72,06 & 161,27 & 107,84 & 188,46 & 190,54 & 99,85 & 1225,40 & 177,83 & 29,87 & 45,22 & 485,94 & 119,86 & 142,71 & 444,59 \\
\hline
\end{tabular}




\begin{tabular}{|c|c|c|c|c|c|c|c|c|c|c|c|c|c|c|c|c|c|c|c|c|c|}
\hline TAXON & UTM & $\mathrm{km} 2$ & B101 & B102 & $\mathrm{BIO3}$ & B104 & B105 & B106 & B107 & B108 & B109 & BIO10 & BIO11 & BIO12 & B1013 & BIO14 & BIO15 & BIO16 & B1017 & B1018 & B1019 \\
\hline Pelophylax perezi & 29TNH13 & 101,00 & 134,28 & 65,16 & 37,83 & 3618,45 & 230,51 & 60,17 & 170,34 & 97,99 & 180,32 & 182,90 & 90,05 & 1306,88 & 191,55 & 33,69 & 44,61 & 514,94 & 132,93 & 154,63 & 475,23 \\
\hline Pelophylax perezi & 29TNH14 & 100,00 & 133,17 & 66,01 & \begin{tabular}{|l|l|}
37,97 \\
\end{tabular} & 3607,29 & 230,45 & 58,59 & 171,85 & 97,29 & 178,97 & 181,81 & 89,22 & 1284,45 & 186,08 & 34,10 & 43,76 & 503,35 & 134,48 & 156,51 & 461,63 \\
\hline Pelophylax perezi & 29TNH15 & 101,00 & 131,49 & 66,60 & $\begin{array}{l}38,05 \\
\end{array}$ & 3585,35 & 229,44 & 56,70 & 172,74 & 96,06 & 176,92 & 180,04 & 88,01 & 1269,31 & 181,60 & 34,69 & 42,87 & 494,86 & 136,62 & 158,82 & 451,55 \\
\hline Pelophylax perezi & 29TNH16 & 100,00 & 129,53 & 66,99 & 38,23 & 3553,02 & 227,55 & 54,86 & 172,69 & 94,82 & 174,47 & 177,92 & 86,69 & 1258,25 & 177,72 & 35,39 & 41,99 & 487,99 & 139,03 & 161,37 & 443,71 \\
\hline Pelophylax perezi & 29TNH18 & 99,00 & 138,18 & 64,56 & 39,53 & 3317,71 & 227,61 & 66,00 & 161,61 & 106,04 & 179,15 & 183,05 & 97,47 & 1106,27 & 150,80 & 31,46 & 40,66 & 427,34 & 126,22 & 150,06 & 380,75 \\
\hline Pelophylax perezi & 29TNH19 & 64,00 & 140,89 & 63,56 & 39,93 & 3223,95 & 227,11 & 69,77 & 157,34 & 109,84 & 180,43 & 184,43 & 101,17 & 1059,58 & 143,29 & 30,28 & 40,01 & 408,67 & 122,48 & 146,75 & 361,63 \\
\hline Pelophylax perezi & 29TNH20 & 100,00 & 140,04 & 63,04 & 37,60 & 3718,64 & 232,42 & \begin{tabular}{ll|}
66,87 \\
\end{tabular} & 165,55 & 101,01 & 187,74 & 188,88 & 93,81 & 1395,50 & 212,46 & 32,47 & 47,52 & 556,28 & 127,28 & 147,77 & 529,68 \\
\hline Pelophylax perezi & 29TNH21 & 101,00 & 143,07 & 62,99 & 37,73 & 3680,33 & 234,96 & 69,79 & 165,16 & 104,60 & 190,07 & 191,50 & 97,21 & 1313,98 & 195,41 & 31,39 & 46,36 & 520,52 & 123,46 & 145,06 & 488,04 \\
\hline Pelophylax perezi & 29TNH22 & 98,00 & 142,56 & 64,37 & 37,83 & 3673,06 & 236,45 & 68,27 & 168,18 & 104,48 & 189,39 & 191,20 & 97,00 & 1282,23 & 189,18 & 31,60 & 45,59 & 505,62 & 124,06 & 145,95 & 470,89 \\
\hline Pelophylax perezi & 29TNH23 & 100,00 & 140,69 & 65,81 & 37,91 & 3675,02 & 236,85 & 65,44 & 171,42 & 102,96 & 187,49 & 189,76 & 95,38 & 1268,02 & 185,23 & 32,23 & 44,81 & 497,28 & 126,63 & 148,60 & 460,75 \\
\hline Pelophylax perezi & 29TNH24 & 101,00 & 139,46 & 66,85 & 38,14 & 3657,53 & 237,04 & 63,64 & 173,40 & 102,32 & 185,96 & 188,60 & 94,54 & 1247,55 & 180,10 & 32,75 & 43,93 & 486,78 & 128,33 & 150,59 & 448,39 \\
\hline Pelophylax perezi & 29TNH25 & 101,00 & 134,22 & 68,49 & 38,02 & 3679,17 & 235,07 & 57,13 & 177,94 & 97,31 & 180,95 & 184,04 & 89,61 & 1277,87 & 182,81 & 34,92 & 42,98 & 495,32 & 135,80 & 157,76 & 456,50 \\
\hline Pelophylax perezi & 29TNH26 & 101,00 & 129,38 & $\mid 69,40$ & 38,11 & 3658,94 & 231,39 & 52,28 & 179,10 & 93,09 & 175,81 & $\begin{array}{l}179,24 \\
\end{array}$ & $\begin{array}{l}85,42 \\
85\end{array}$ & 1295,09 & \begin{tabular}{|l|l|}
183,16 \\
\end{tabular} & 36,61 & $\begin{array}{l}42,07 \\
42,07\end{array}$ & 499,18 & $\begin{array}{l}141,72 \\
\end{array}$ & $\begin{array}{l}163,38 \\
\end{array}$ & 459,85 \\
\hline Pelophylax perezi & 29TNH27 & 100,00 & 129,17 & 68,83 & 38,77 & 3574,89 & 228,79 & 53,35 & 175,45 & 94,07 & 174,25 & 178,02 & 86,21 & 1259,95 & 175,62 & 36,27 & 41,11 & 484,03 & 140,94 & 162,85 & 443,55 \\
\hline Pelophylax perezi & 29TNH28 & 101,00 & 138,15 & 66,22 & 39,76 & 3371,93 & 229,55 & 64,80 & 164,75 & 105,12 & 179,97 & 183,87 & 96,86 & $\begin{array}{l}1124,24 \\
\end{array}$ & 152,92 & 32,00 & 40,55 & 432,17 & 126,98 & 150,29 & 389,89 \\
\hline Pelophylax perezi & 29TNH29 & 39,00 & 138,94 & 65,60 & 40,11 & 3300,89 & 227,96 & 66,33 & 161,63 & 106,78 & 179,56 & 183,64 & 98,28 & 1096,42 & 147,44 & 31,46 & 39,97 & 420,50 & 125,51 & 149,00 & 378,18 \\
\hline Pelophylax perezi & 29TNH30 & 101,00 & 136,38 & 68,31 & 37,86 & 3916,51 & 236,40 & 58,16 & 178,24 & 94,75 & 186,93 & 188,06 & 88,14 & 1444,96 & 225,06 & 34,07 & 47,76 & 572,47 & 132,50 & 151,25 & 553,08 \\
\hline Pelophylax perezi & 29TNH31 & 100,00 & 135,63 & 69,05 & 37,66 & 3905,13 & 237,49 & 56,52 & 180,97 & 94,42 & 186,07 & 187,56 & 87,79 & $\begin{array}{l}1419,43 \\
\end{array}$ & 217,60 & 34,79 & 46,73 & 558,64 & 134,36 & 153,66 & 535,47 \\
\hline Pelophylax perezi & 29TNH33 & 101,00 & 140,89 & 68,88 & \begin{tabular}{|l|l|}
37,78 \\
\end{tabular} & 3814,67 & 241,68 & 61,72 & 179,97 & 101,09 & 189,69 & 191,86 & 94,03 & 1286,69 & 188,93 & 32,96 & 44,87 & 500,80 & 127,77 & 149,09 & 469,14 \\
\hline Pelophylax perezi & 29TNH34 & 100,00 & 137.98 & 70,61 & $37,67 \mid$ & 3829,36 & 242,21 & 57,25 & $\mid 184.96$ & 98,68 & $\mid 186,96$ & $\mid 189,58$ & 91,35 & 1297,37 & $\mid 188,15$ & 34,52 & 43,99 & 501,72 & $\mid 132,89$ & $\mid 154,22$ & 468,82 \\
\hline Pelophylax perezi & 29TNH35 & 101,00 & 132,84 & 72,28 & 37,68 & 3838,58 & 240,40 & 50,95 & 189,45 & 94,15 & 182,04 & 185,10 & 86,75 & 1326,75 & 190,10 & 36,64 & 43,10 & 509,81 & 140,19 & 161,30 & 476,37 \\
\hline Pelophylax perezi & 29TNH36 & 101,00 & 129,84 & 72,27 & 38,05 & 3774,65 & 236,38 & 49,07 & 187,31 & 92,04 & 178,03 & 181,37 & 84,62 & 1317,82 & 186,12 & 37,45 & 42,10 & 504,27 & 143,19 & 164,27 & 469,58 \\
\hline Pelophylax perezi & 29TNH37 & 101,00 & 127,82 & 71,68 & \begin{tabular}{|l|l|}
38,69 \\
\end{tabular} & 3685,61 & 231,99 & 48,85 & 183,14 & 91,12 & \begin{tabular}{ll|}
174,58 \\
\end{tabular} & 178,31 & 83,80 & 1296,43 & 180,66 & 37,63 & 41,15 & 494,57 & 144,29 & 165,38 & 458,65 \\
\hline Pelophylax perezi & 29TNH38 & 100,00 & 130,25 & 69,90 & 39,58 & 3529,25 & 228,82 & 54,21 & 174,62 & 95,40 & 174,66 & 178,55 & 87,84 & 1225,75 & 167,86 & 35,84 & 40,29 & 467,01 & 138,82 & 160,53 & 429,77 \\
\hline Pelophylax perezi & 29TNH39 & 66,00 & 137,72 & 67,21 & 40,50 & 3335,65 & 228,27 & 64,37 & 163,90 & 104,80 & 178,85 & 182,93 & 96,84 & 1111,28 & 148,76 & 32,07 & 39,82 & 423,65 & 126,76 & 149,62 & 385,50 \\
\hline Pelophylax perezi & $29 \mathrm{TNH} 40$ & 101,00 & 124,43 & 76,64 & 38,40 & 4126,21 & 236,23 & 39,22 & 197,01 & 80,58 & 178,19 & 179,63 & 74,68 & 1499,32 & 232,05 & 36,10 & 47,05 & 587,15 & 141,93 & 157,16 & 573,21 \\
\hline Pelophylax perezi & 29TNH41 & 99,00 & 124,50 & 76,53 & 38,28 & 4087,47 & 236,72 & 39,20 & $\begin{array}{l}197,52 \\
\end{array}$ & 81,28 & $\begin{array}{l}177,72 \\
\end{array}$ & 179,47 & 75,52 & 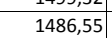 & 227,30 & 37,16 & 46,14 & 578,92 & $\begin{array}{l}144,31 \\
141,\end{array}$ & 160,36 & 561,84 \\
\hline Pelophylax perezi & $29 \mathrm{TNH} 42$ & 100,00 & 132,13 & 74,96 & \begin{tabular}{|l|l|}
37,98 \\
\end{tabular} & 4042,12 & 242,29 & 47,15 & 195,13 & 89,34 & 184,54 & 186,42 & 83,32 & 1407,67 & 212,28 & 35,99 & 45,57 & 545,52 & 138,23 & 156,49 & 523,46 \\
\hline Pelophylax perezi & 29 TNH 43 & 101,00 & 140,12 & 72,87 & 37,98 & 3953,22 & 246,17 & 56,53 & 189,64 & 98,34 & 190,91 & 193,06 & 91,84 & 1293,19 & 190,16 & 33,42 & 44,74 & 499,02 & 128,68 & 149,06 & 471,50 \\
\hline Pelophylax perezi & 29TNH44 & 99,00 & 134,34 & 75,62 & 37,50 & 4016,51 & 247,01 & 47,82 & 199,18 & 92,76 & 186,25 & 188,81 & 86,23 & 1354,82 & 196,79 & 36,70 & 43,95 & 518,70 & 139,25 & 159,31 & 490,94 \\
\hline Pelophylax perezi & 29TNH45 & 100,00 & 133,85 & 75,41 & 37,71 & 3948,35 & 245,54 & 48,08 & 197,45 & 93,39 & 184,49 & 187,60 & 86,62 & 1327,24 & 189,42 & 36,86 & 42,92 & 505,97 & 139,84 & 160,39 & 476,27 \\
\hline Pelophylax perezi & 29TNH46 & 100,00 & 133,61 & 74,17 & 38,49 & 3807,22 & 241,03 & $\begin{array}{l}50,75 \\
50,0\end{array}$ & $\begin{array}{l}190,27 \\
\end{array}$ & \begin{tabular}{|l|l|}
94,78 \\
9
\end{tabular} & \begin{tabular}{|l|}
182,11 \\
\end{tabular} & 185,54 & $\begin{array}{l}0,0<2 \\
87,87\end{array}$ & $\begin{array}{l}1277,88 \\
127,4\end{array}$ & \begin{tabular}{|l|}
179,38 \\
179,38
\end{tabular} & 36,11 & $\begin{array}{ll}42,96 \\
41,96\end{array}$ & 486,11 & \begin{tabular}{|l|}
137,91 \\
13,4
\end{tabular} & \begin{tabular}{|l|l|}
158,76 \\
\end{tabular} & 454,57 \\
\hline Pelophylax perezi & 29TNH47 & 101,00 & 129,79 & 73,67 & 39,01 & 3726,10 & 235,43 & 48,83 & 186,61 & 92,02 & 177,26 & 180,80 & 85,29 & 1276,81 & 177,09 & 37,02 & 41,03 & 484,24 & 141,41 & 162,11 & 451,80 \\
\hline Pelophylax perezi & 29TNH48 & 99,00 & 130,64 & 71,90 & 39,94 & 3580,81 & 231,16 & 52,91 & 178,25 & 94,65 & 175,87 & 179,58 & 87,62 & \begin{tabular}{|l|}
1222,47 \\
\end{tabular} & 166,76 & 35,87 & 40,09 & 463,07 & 138,08 & 159,15 & 429,36 \\
\hline Pelophylax perezi & 29TNH49 & 99,00 & 138,44 & 68,49 & 41,26 & 3334,69 & 228,73 & 64,79 & 163,94 & 105,25 & 179,57 & 183,74 & 97,48 & 1091,49 & 144,73 & 31,59 & 39,26 & 413,86 & 124,45 & 146,72 & 379,25 \\
\hline Pelophylax perezi & 29TNH50 & 101,00 & 115,81 & 80,39 & 38,78 & 4246,05 & 232,99 & 27,72 & 205,27 & 70,53 & 171,45 & 172,95 & 65,34 & 1493,95 & 224,52 & 36,57 & 45,84 & 578,78 & 145,19 & 158,22 & 565,92 \\
\hline Pelophylax perezi & 29TNH53 & $\begin{array}{l}101,00 \\
100\end{array}$ & 136,01 & $\mid \frac{\mid 0,37}{77,41}$ & 38,54 & $\begin{array}{l}424,0495 \\
40495\end{array}$ & 247,69 & \begin{tabular}{|l|l|}
49,24 \\
\end{tabular} & \begin{tabular}{|l|}
198,45 \\
19,4
\end{tabular} & \begin{tabular}{|c|c|}
93,11 \\
93
\end{tabular} & $\mid \begin{array}{l}\mid 11,45,96 \\
188,\end{array}$ & \begin{tabular}{|l|l|}
191,10 \\
\end{tabular} & \begin{tabular}{|l|l|}
87,81 \\
\end{tabular} & \begin{tabular}{|l|}
14501,01 \\
1301
\end{tabular} & \begin{tabular}{|l|}
191,18 \\
1918
\end{tabular} & $\begin{array}{l}30,07 \\
34,0\end{array}$ & $\begin{array}{l}45,04 \\
44,30\end{array}$ & $\begin{array}{l}490,10 \\
497,36\end{array}$ & \begin{tabular}{|l|}
130,92 \\
130,
\end{tabular} & $\begin{array}{l}149,73 \\
149,7 \\
\end{array}$ & 473,88 \\
\hline Pelophylax perezi & 29TNH54 & 100,00 & 137,07 & 77,10 & 38,52 & 3993,02 & 247,76 & 50,07 & 197,69 & 94,62 & 188,50 & 191,06 & 89,04 & 1279,09 & 184,57 & 34,47 & 43,47 & 486,83 & 131,67 & 151,22 & 461,07 \\
\hline Pelophylax perezi & 29TNH55 & 101,00 & 132,55 & 77,84 & 38,55 & 3952,98 & 244,93 & 45,58 & 199,35 & 91,08 & 183,42 & 186,37 & 85,47 & 1311,62 & 186,78 & 36,64 & 42,66 & 496,98 & 138,85 & 158,30 & 470,35 \\
\hline Pelophylax perezi & 29TNH56 & 101,00 & 131,83 & 76,71 & 38,90 & 3858,57 & 241,48 & 46,94 & 194,54 & 91,76 & 181,28 & 184,54 & 85,86 & 1281,64 & 179,77 & 36,54 & 41,76 & 484,46 & 138,73 & 158,58 & 456,12 \\
\hline Pelophylax perezi & $\begin{array}{l}\text { 29TNH57 } \\
\end{array}$ & 100,00 & 129,49 & 75,79 & 39,47 & 3760,92 & 236,42 & 46,84 & 189,58 & 90,69 & 177,58 & 181,00 & 84,70 & 1264,25 & 174,91 & 36,84 & 40,79 & 476,82 & 140,23 & 160,14 & 447,24 \\
\hline Pelophylax perezi & 29TNH58 & 101,00 & $\begin{array}{l}12,46,43 \\
136,43\end{array}$ & $\mid \frac{\mid 1,2,19}{72,36}$ & $\frac{3,4}{40,7}$ & 3553,90 & 2334,25 & $\begin{array}{l}40,04 \\
58,55 \\
\end{array}$ & \begin{tabular}{|l|}
175,70 \\
175,0
\end{tabular} & \begin{tabular}{|l|}
90,0903 \\
100,03
\end{tabular} & \begin{tabular}{|l|}
181,02 \\
181,02
\end{tabular} & \begin{tabular}{l|l}
184,780 \\
184,
\end{tabular} & $\begin{array}{l}4,10 \\
93,25 \\
\end{array}$ & $\mid$\begin{tabular}{|l|l|l|l|l|l|}
1141,24 \\
\end{tabular} & \begin{tabular}{|l|}
154,04 \\
154
\end{tabular} & $\begin{array}{l}30,04 \\
33,02\end{array}$ & $\begin{array}{l}49,19 \\
39,87\end{array}$ & $\begin{array}{l}41 / 0,82 \\
430,70\end{array}$ & \begin{tabular}{|l|}
128,01 \\
125
\end{tabular} & \begin{tabular}{|l|}
149,14 \\
149,16
\end{tabular} & $\begin{array}{l}44,24 \\
399,31 \\
\end{array}$ \\
\hline Pelophylax perezi & 29TNH59 & 98,00 & 140,77 & 69,91 & 41,80 & 3381,91 & 231,80 & 66,23 & 165,56 & 106,31 & 182,51 & 186,54 & 99,09 & 1058,70 & 139,63 & 30,57 & 39,04 & 399,41 & 120,42 & 142,28 & 367,09 \\
\hline Pelophylax perezi & 29TNH60 & 100,00 & 118,94 & 83,20 & 38,98 & 4353,18 & 238,48 & 27,84 & 210,64 & 71,76 & 175,90 & 177,36 & 67,11 & 1409,20 & 210,16 & 34,42 & 45,45 & 541,88 & 137,56 & 150,38 & 528,85 \\
\hline Pelophylax perezi & 29TNH61 & 101,00 & 119, & 82,67 & 39,1 & 4262,34 & 238,07 & 29,73 & 208,34 & 73,64 & 175,70 & 177,29 & 69,46 & 1400,04 & 207,77 & 35,43 & 44,95 & 536,38 & 139,36 & 153,01 & 521,48 \\
\hline Pelophylax perezi & 29TNH62 & 101,00 & 126 & 8 & 39,6 & $\begin{array}{ll}420,42,87 \\
4147\end{array}$ & 242,07 & 37,06 & 205,01 & 81,27 & 180,62 & 182,46 & 77,59 & $\begin{array}{l}1348,88 \\
1348\end{array}$ & \begin{tabular}{|l|l|}
199,73 \\
\end{tabular} & \begin{tabular}{l|l|}
34,98 \\
34
\end{tabular} & 44,38 & 514,25 & $\begin{array}{l}135,83 \\
\end{array}$ & 151,36 & 496,63 \\
\hline Pelophylax perezi & 29TNH & 100,00 & 127,69 & 81,29 & 39,80 & 4046,96 & 241,44 & 39,35 & 202,09 & 83,45 & 180,25 & 182,44 & 79,89 & 1331,88 & 194,42 & 35,6 & 43,65 & 505,65 & 137,02 & 153,53 & 485,67 \\
\hline Pelophylax perezi & 29TNH64 & 101,00 & 133,27 & 80,09 & 39,73 & 3986,03 & 244,84 & 45,28 & 199,56 & 89,76 & 184,79 & 187,14 & 85,81 & 1267,58 & 182,28 & 34,57 & 42,88 & 479,13 & 132,16 & 150,26 & 456,27 \\
\hline Pelophylax perezi & 29TNH65 & 101,00 & 130,40 & 79,78 & 39,77 & 3917,78 & 241,68 & 43,59 & 198,09 & 88,21 & 181,02 & 183,65 & 84,03 & 1279,46 & 181,47 & 35,99 & 42,05 & 482,16 & 136,82 & 155,12 & 457,82 \\
\hline Pelophylax perezi & 29TNH66 & 101,00 & 129,58 & 78,71 & 39,87 & 3857,86 & 239,18 & 44,01 & 195,17 & 88,47 & 179,21 & 182,21 & 83,81 & 1260,61 & 176,24 & 36,25 & 41,21 & 474,02 & 137,71 & 156,45 & 447,92 \\
\hline Pelophylax perezi & 29TNH67 & $\begin{array}{l}100,00 \\
100\end{array}$ & 12 & \begin{tabular}{|l|l|l|}
77,79 \\
\end{tabular} & 40 & $\begin{array}{l}305,100 \\
3800,28\end{array}$ & 234 & $\begin{array}{l}4,3,32 \\
42,\end{array}$ & 19 & $\begin{array}{l}80,471 \\
86,01 \\
\end{array}$ & \begin{tabular}{|l|l|l|l|l|}
174,86 \\
\end{tabular} & \begin{tabular}{|l|}
178,211 \\
178,03
\end{tabular} & \begin{tabular}{l|l}
31,18 \\
81,1
\end{tabular} & \begin{tabular}{|l|l|}
1264,47 \\
1264
\end{tabular} & \begin{tabular}{|l|}
174,59 \\
174
\end{tabular} & \begin{tabular}{|c|c|}
37,33 \\
37
\end{tabular} & $\begin{array}{ll}4,212 \\
40,38\end{array}$ & 474,41 & \begin{tabular}{|l|}
141,641 \\
141
\end{tabular} & \begin{tabular}{|l|}
160,31 \\
160
\end{tabular} & $\begin{array}{l}44,56 \\
446,85\end{array}$ \\
\hline Pelophylax perezi & 29TNH68 & 101,00 & 134,85 & 74,68 & 40,77 & 3631,25 & 235,43 & 54,60 & 180,83 & 96,81 & 180,73 & 184,20 & 90,95 & 1139,74 & 153,76 & 33,40 & 39,51 & 427,46 & 128,78 & 149,04 & 397,92 \\
\hline Pelophylax perezi & 29TNH69 & 95,00 & 138,76 & 72,50 & 41,54 & 3500,36 & 233,97 & 61,39 & 172,57 & 102,55 & 182,52 & 186,15 & 95,99 & 1070,00 & 141,51 & 31.45 & 38,83 & 401,11 & 122,61 & 143,65 & 370,04 \\
\hline Pelophylax perezi & 29TNH70 & 101,00 & 121,99 & 85,74 & 39,01 & 4488,05 & 244,15 & 27,49 & 216,65 & 72,54 & 180,79 & 181,86 & 68,41 & 1311,15 & 193,43 & 31,86 & 44,90 & 500,27 & 128,43 & 141,17 & 487,17 \\
\hline Pelophylax perezi & 29TNH71 & 99,00 & 118 & 84, & 39,2 & 4357,75 & 238,68 & 26,08 & 212 & 70,47 & 175,35 & 176,65 & 66,72 & 1346,03 & 196,75 & 34,18 & 44,25 & 512,73 & 135,22 & 148,12 & 498 \\
\hline Pelophylax perezi & $\begin{array}{l}\text { 29TNH72 } \\
\end{array}$ & $\begin{array}{l}500,00 \\
100\end{array}$ & $\begin{array}{l}110,10 \\
120,88\end{array}$ & $\begin{array}{l}84,11 \\
84,11 \\
\end{array}$ & 39,24 & 4 & 238,74 & \begin{tabular}{|l|}
30,06 \\
30,
\end{tabular} & \begin{tabular}{|l|}
208,68 \\
\end{tabular} & $\begin{array}{l}0,4,28 \\
74,28\end{array}$ & \begin{tabular}{|l|l|}
176,17 \\
\end{tabular} & $\begin{array}{l}177,82 \\
177\end{array}$ & $\begin{array}{ll}71,15 \\
71,15\end{array}$ & $\begin{array}{l}\mid 54,050 \\
1325,34\end{array}$ & \begin{tabular}{|l|l|}
192,94 \\
\end{tabular} & \begin{tabular}{|l|}
34,76 \\
34,7
\end{tabular} & $\begin{array}{l}4,250 \\
43,67\end{array}$ & 502,72 & \begin{tabular}{|l|}
$135,75,75$ \\
135
\end{tabular} & \begin{tabular}{|l|}
140,12 \\
149,76 \\
\end{tabular} & $\begin{array}{l}450,31 \\
486,41 \\
\end{array}$ \\
\hline Pelophylax perezi & 29TNH74 & 99,00 & 132,39 & 81,96 & 40,60 & 3987,50 & 243,52 & 43,78 & 199,74 & 88,08 & 184,03 & 186,11 & 85,16 & 1213,25 & 173,05 & 33,25 & 42,24 & 455,95 & 127,77 & 145,03 & 434,40 \\
\hline Pelophyla & 29TNH76 & 100,00 & 123,45 & 80,75 & 40,48 & 391396 & 234,63 & 37.28 & 197.35 & 81.06 & 174,02 & 176,74 & 77,42 & 1263,07 & 175.84 & 36.85 & 40,71 & 472.81 & 140,15 & 157,23 & 448,44 \\
\hline Pelophylax perezi & 29TNH77 & 100,00 & 122,67 & 79,66 & 40,36 & 3855,55 & 232,35 & 37,6 & 194,7 & 81,38 & 172,28 & 175 & 77 & 1252,18 & 172,13 & 37,44 & 39,90 & 467,53 & 142,08 & 159,52 & 441,33 \\
\hline Pelophylax perezi & 29TNH78 & 100,00 & 125,41 & 78,00 & 40,75 & 3774,11 & 231,87 & 42,35 & 189,52 & 85,45 & 173,73 & 176,95 & 80,70 & 1203,79 & 163,01 & 36,49 & 39,10 & 448,58 & 138,77 & 157,20 & 420 \\
\hline
\end{tabular}




\begin{tabular}{|c|c|c|c|c|c|c|c|c|c|c|c|c|c|c|c|c|c|c|c|c|c|}
\hline TAXON & UTM & $\mathrm{km} 2$ & B101 & B102 & $\mathrm{BIO3}$ & BIO4 & B105 & B106 & B107 & B108 & B109 & B1010 & BIO11 & BIO12 & B1013 & BIO14 & BIO15 & B1016 & B1017 & B1018 & B1019 \\
\hline Pelophylax perezi & 29TNH79 & 101,00 & 127,95 & 76,35 & 40,99 & 3677,10 & 230,73 & 46,82 & 183,90 & 89,37 & 174,66 & 178,06 & 84,01 & 1160,08 & 154,75 & 35,67 & 38,39 & 431,51 & 135,97 & 155,20 & 401,73 \\
\hline Pelophylax perezi & 29TNH82 & 100,00 & 116,25 & 85,54 & 39,56 & 4367,94 & 237,33 & 23,49 & 213,84 & 68,15 & 173,50 & 175,03 & 64,72 & 1291,08 & 184,62 & 34,22 & 42,98 & 487,78 & 134,11 & 147,04 & 472,19 \\
\hline Pelophylax perezi & 29TNH84 & 100,00 & 127,03 & 83,97 & 40,56 & 4104,26 & 241,13 & 36,61 & 204,52 & 81,13 & 180,29 & 182,31 & 78,65 & 1198,23 & 169,39 & 33,26 & 41,66 & 448,57 & 128,19 & 144,12 & 428,34 \\
\hline Pelophylax perezi & 29TNH85 & 101,00 & 121,53 & 83,23 & 40,44 & 4063,13 & 235,80 & 32,57 & 203,23 & 76,88 & 174,31 & 176,45 & 73,91 & 1235,25 & 172,50 & 35,55 & 40,89 & 461,64 & 135,93 & 151,63 & 439,92 \\
\hline Pelophylax perezi & 29TNH86 & 101,00 & 115,94 & 82,36 & 40,29 & \begin{tabular}{ll|l|}
4041,46 \\
\end{tabular} & 230,32 & 28,34 & 201,98 & 72,10 & 168,44 & \begin{tabular}{ll|}
170,87 \\
\end{tabular} & 68,70 & \begin{tabular}{ll|}
1270,44 \\
\end{tabular} & 175,37 & 37,83 & 39,99 & 473,87 & 143,78 & 159,12 & 450,46 \\
\hline Pelophylax perezi & 29TNH87 & 100,00 & 120,24 & 81,21 & 40,53 & 3948,06 & 231,67 & 33,64 & 198,03 & 77,44 & 171,24 & 173,84 & 73,78 & 1223,72 & 167,01 & 37,04 & 39,34 & 454,95 & 140,50 & 157,10 & 429,47 \\
\hline Pelophylax perezi & 29TNH88 & 101,00 & 120,39 & 79,96 & 40,75 & 3879,56 & 229,84 & 35,39 & 194,45 & 78,82 & 170,37 & 173,09 & 74,51 & 1209,88 & 163,08 & 37,42 & 38,62 & 448,59 & 141,75 & 158,84 & 421,24 \\
\hline Pelophylax perezi & 29TNH89 & 100,00 & 118,54 & 78,92 & 40,75 & 3828,43 & 226,61 & 34,99 & 191,62 & 77,91 & 167,77 & 170,85 & 73,56 & \begin{tabular}{|l|}
1211,67 \\
\end{tabular} & 161,56 & 38,36 & 37,93 & 448,19 & 144,90 & 162,40 & 419,19 \\
\hline Pelophylax perezi & 29TNH90 & 100,00 & 122,24 & 89,38 & 38,96 & 4753,56 & 249,93 & 22,45 & 227,48 & 69,16 & 184,61 & 185,24 & 65,15 & 1166,68 & 166,79 & 28,45 & 43,87 & 440,45 & 115,60 & 126,20 & 428,22 \\
\hline Pelophylax perezi & 29TNH91 & 101,00 & 118,31 & 88,03 & 39,00 & 4616,37 & 244,04 & 21,27 & 222,77 & 67,07 & 178,96 & 179,91 & 63,44 & 1205,83 & 171,39 & 30,83 & 43,10 & 454,83 & 123,06 & 135,26 & 441,25 \\
\hline Pelophylax perezi & 29TNH93 & 100,00 & 120,09 & 86,50 & 39,86 & 4380,79 & 240,84 & 26,01 & 214,82 & 71,35 & 177,34 & 178,84 & 68,32 & 1192,53 & 167,75 & 32,62 & 41,76 & 446,68 & 127,21 & 141,04 & 429,09 \\
\hline Pelophylax perezi & 29TNH94 & 101,00 & 120,48 & 85,68 & 40,00 & 4286,38 & 239,28 & 27,86 & 211,42 & 72,89 & 176,37 & 178,07 & 69,93 & 1187,30 & 165,77 & 33,41 & 41,03 & 443,28 & 129,30 & 143,69 & 423,85 \\
\hline Pelophylax perezi & 29TNH95 & 101,00 & 120,38 & 84,72 & 40,10 & \begin{tabular}{|l|l|}
4199,03 \\
\end{tabular} & 237,33 & 29,28 & 208,05 & 73,99 & 175,04 & 176,95 & 70,86 & 1186,55 & 164,11 & 34,36 & 40,28 & 441,78 & 132,04 & 146,98 & 420,39 \\
\hline Pelophylax perezi & 29TNH96 & 101,00 & 121,63 & 83,64 & 40,42 & 4105,72 & 236,21 & 32,01 & 204,20 & 76,47 & 174,88 & 177,02 & 73,10 & 1172,85 & 160,54 & 34,80 & 39,63 & 435,42 & 133,02 & 148,72 & 411,98 \\
\hline Pelophylax perezi & 29TNH97 & 100,00 & 122,66 & 82,42 & 40,76 & 4034,11 & 235,08 & 34,51 & 200,57 & 78,55 & 174,71 & 177,24 & 74,77 & 1155,42 & 156,30 & 35,05 & 38,88 & 427,68 & 133,61 & 150,03 & 402,29 \\
\hline Pelophylax perezi & 29TNH98 & 101,00 & 121,27 & 81,36 & 40,79 & 3959,32 & 232,09 & 34,47 & 197,61 & 78,34 & 172,28 & 174,98 & 74,29 & 1159,91 & 155,18 & 36,09 & 38,11 & 428,21 & 137,12 & 153,85 & 401,04 \\
\hline Pelophylax perezi & 29TNH99 & 100,00 & 121,31 & 80,24 & 40,97 & 3889,75 & 230,11 & 36,08 & 194,03 & 79,50 & 171,34 & 174,06 & 75,10 & 1152,55 & 152,47 & 36,63 & 37,43 & 424,45 & 138,80 & 156,01 & 395,57 \\
\hline Pelophylax perezi & 29TNJ40 & 18,00 & 140,90 & 67,00 & 41,90 & 3225,38 & 226,97 & 68,62 & 158,34 & 109,17 & 180,34 & 184,66 & 101,00 & 1040,24 & 135,86 & 30,03 & 39,00 & 394,31 & 119,52 & 142,10 & 359,59 \\
\hline Pelophylax perezi & 29TNJ50 & 35,00 & 140,32 & 69,33 & 42,05 & 3314,98 & 229,41 & 66,90 & 162,51 & 106,79 & 181,08 & 185,25 & 99,56 & 1041,52 & 135,65 & 30,56 & 38,54 & 392,02 & 120,49 & 142,51 & 359,29 \\
\hline Pelophylax perezi & 29TNJ51 & 48,00 & 137,32 & 69,06 & 42,18 & 3289,25 & 226,38 & 64,58 & 161,79 & 104,32 & 177,74 & 182,08 & 96,99 & 1053,97 & 136,43 & 32,00 & 37,81 & 395,00 & 125,51 & 147,40 & 360,88 \\
\hline Pelophylax perezi & 29TNJ52 & 12,00 & 139,57 & 68,29 & 42,50 & 3239,32 & 226,61 & 67,61 & 159,00 & 107,07 & 179,29 & 183,57 & 99,82 & 1024,82 & 132,75 & 31,04 & 37,57 & 383,82 & 122,86 & 145,32 & 348,71 \\
\hline Pelophylax perezi & 29TNJ60 & 66,00 & 138,42 & 71,58 & 41,92 & 3427,75 & 231,34 & 62,74 & 168,59 & 103,12 & 181,05 & 184,86 & 96,42 & 1051,61 & 137,08 & 31,55 & 38,09 & $\begin{array}{l}393,14 \\
393\end{array}$ & 123,14 & $\begin{array}{l}144,39 \\
\end{array}$ & 360,99 \\
\hline Pelophylax perezi & 29TNJ61 & 82,00 & 138,78 & 70,46 & 42,23 & 3350,75 & 229,34 & 64,74 & 164,60 & 104,63 & 180,27 & 184,22 & 97,70 & 1035,07 & 133,93 & 31,48 & 37,61 & 386,40 & 123,21 & 144,96 & 352,94 \\
\hline Pelophylax perezi & 29TNJ62 & 77,00 & 138,50 & 69,71 & 42,42 & 3311,98 & 227,83 & 65,35 & 162,48 & 104,89 & 179,31 & 183,41 & 97,82 & 1028,44 & 132,74 & 31,91 & 37,02 & 383,10 & 124,55 & 146,55 & 348,41 \\
\hline Pelophylax perezi & 29TNJ72 & 101,00 & 133,10 & 72,15 & 42,08 & 3432,01 & 226,92 & 57,35 & 169,57 & 97,92 & 175,90 & 179,71 & 91,45 & 1067,50 & 137,07 & 34,02 & 36,65 & 394,97 & 131,15 & 152,16 & 360,88 \\
\hline Pelophylax perezi & \begin{tabular}{|l|} 
29TNJ73 \\
\end{tabular} & 59,00 & 136,04 & 70,98 & 42,29 & 3368,61 & 227,33 & 61,57 & 165,76 & \begin{tabular}{|c|}
101,66 \\
\end{tabular} & 177,81 & 181,81 & 95,03 & 1033,72 & 133,07 & 33,30 & 36,18 & 381,82 & 128,65 & 150,28 & 346,35 \\
\hline Pelophylax perezi & 29TNJ91 & 101,00 & 119,44 & 78,01 & 44,06 & 3765,45 & 224,70 & 37,15 & 187,55 & 79, & 167,50 & $\begin{array}{l}170,67 \\
1707\end{array}$ & 74,70 & \begin{tabular}{|l|l|}
1154,74 \\
\end{tabular} & $\mid 149,70$ & 38,31 & 36,17 & \begin{tabular}{|l|l|}
423,15 \\
\end{tabular} & $\begin{array}{l}144,50 \\
\end{array}$ & $\begin{array}{l}162,42 \\
162\end{array}$ & 391,05 \\
\hline Pelophylax perezi & 29TNJ93 & 92,00 & 133,74 & 73,98 & 41,97 & 3525,79 & 229,64 & 55,54 & 174,11 & 96,84 & 177,87 & 181,48 & 91,05 & \begin{tabular}{|l|}
1025,37 \\
\end{tabular} & 131,62 & 34,11 & 35,33 & 374,76 & 130,39 & 150,86 & 339,41 \\
\hline Pelophylax perezi & 29TNJ94 & 26,00 & 139,35 & 72,33 & 42,44 & 3429,44 & 231,53 & 63,05 & 168,49 & 103,72 & 181,98 & 185,72 & 97,65 & 980,72 & 127,09 & 32,65 & 35,09 & 358,56 & 125,33 & 146,77 & 322,12 \\
\hline Pelophylax perezi & 29TPE03 & 99,00 & 143,31 & 93,20 & 36,73 & 5412,20 & 291,02 & 40,40 & 250,62 & 77,86 & 215,25 & 215,73 & 77,86 & 1056,32 & 156,96 & 9,67 & 55,29 & 430,96 & 65,84 & 65,92 & 430,96 \\
\hline Pelophylax perezi & 29TPE04 & 101,00 & 133,29 & 89,19 & 35,94 & 5376,00 & 277,60 & 32,75 & 244,84 & 68,79 & 205,28 & 205,44 & 68,79 & 1173,62 & 176,92 & 10,95 & 55,84 & 480,06 & 72,32 & 72,34 & 480,06 \\
\hline Pelophylax perezi & 29TPE05 & 101,00 & 126,58 & $\begin{array}{ll}3,12 \\
86,64\end{array}$ & 35,51 & 5336,17 & 268,16 & 27,58 & \begin{tabular}{|l|}
240,57 \\
\end{tabular} & $\mid 62,81$ & $\begin{array}{l}198,19 \\
\end{array}$ & \begin{tabular}{|l|}
198,24 \\
\end{tabular} & $\begin{array}{ll}62,81 \\
\end{array}$ & $\mid \begin{array}{l}1256,14 \\
125,\end{array}$ & \begin{tabular}{|l|l|}
190,94 \\
\end{tabular} & $\mid$ & $\begin{array}{l}56,04 \\
56,14\end{array}$ & 514,50 & 76,92 & 76,93 & 514,50 \\
\hline Pelophylax perezi & 29TPE06 & 100,00 & 135,12 & 91,66 & 36,74 & 5328,00 & 278,88 & 32,86 & 246,03 & 70,31 & 205,51 & 205,99 & 70,31 & 1164,94 & 175,36 & 11,03 & 55,58 & 475,27 & 73,03 & 73,29 & 475,27 \\
\hline Pelophylax perezi & \begin{tabular}{|l|} 
29TPE07 \\
\end{tabular} & 101,00 & 141,90 & 96,20 & 37,94 & 5321,55 & 287,46 & 36,82 & 250,64 & 76,22 & 211,36 & 212,15 & 76,22 & 1091,34 & 162,71 & 10,26 & 55,15 & 443,22 & 69,66 & 70,37 & 443,22 \\
\hline Pelophylax perezi & 29TPE08 & 100,00 & 144,63 & 98,44 & 38,54 & 5297,72 & 290,27 & 38,25 & 252,02 & 78,79 & 213,46 & 214,23 & 78,79 & 1062,03 & 157,71 & 9,92 & 54,88 & 429,93 & 67,87 & 69,61 & 429,93 \\
\hline Pelophylax perezi & $\begin{array}{l}\text { 29TPEO9 } \\
\end{array}$ & 100,00 & 139,40 & 97,45 & 38,44 & 5293,84 & 284,18 & 33,86 & 250,32 & 73,69 & 208,42 & 209,06 & 73,69 & 1121,11 & 167,79 & 10,81 & 55,10 & 454,88 & 72,02 & 73,49 & 454,88 \\
\hline Pelophylax perezi & 29TPE13 & 101,00 & 138,06 & $\begin{array}{l}90,21 \\
90,21\end{array}$ & $\begin{array}{l}0,454 \\
35,47\end{array}$ & $\begin{array}{l}5254,1,54 \\
554\end{array}$ & 280,10 & $\begin{array}{l}3,00 \\
35,83 \\
\end{array}$ & \begin{tabular}{|l|}
250,45 \\
250
\end{tabular} & $\begin{array}{l}\mid 5,1,63 \\
71\end{array}$ & \begin{tabular}{|l|}
212,30 \\
212
\end{tabular} & 212,50 & $\begin{array}{l}70,605 \\
71,63\end{array}$ & $\mid$ & \begin{tabular}{|l|l|}
163,14 \\
106
\end{tabular} & \begin{tabular}{r|}
9,87 \\
9,87
\end{tabular} & 55,65 & \begin{tabular}{|l|}
$444,77,7$ \\
\end{tabular} & $\begin{array}{l}2,064 \\
66,97 \\
\end{array}$ & $\begin{array}{l}3,49 \\
66,98 \\
\end{array}$ & $\begin{array}{l}454,00 \\
444,77 \\
\end{array}$ \\
\hline Pelophylax perezi & 29TPE14 & 101,00 & 143,73 & 93,64 & 36,32 & 5535,10 & 293,33 & 39,08 & 254,25 & 76,45 & 217,15 & 217,53 & 76,45 & 1033,99 & 153,73 & 9,37 & 55,26 & 420,45 & 64,75 & 64,79 & 420,45 \\
\hline Pelophylax perezi & 29TPE15 & 99,00 & 129,26 & 87,30 & 35,12 & 5467,14 & 273,53 & 28,66 & 244,87 & 63,75 & 202,52 & 202,53 & 63,75 & 1199,32 & 181,90 & 11,09 & 55,96 & 490,30 & 73,40 & 73,40 & 490,30 \\
\hline Pelophylax perezi & 29TPE16 & 100,00 & 89,37 & 73,79 & 32,38 & 5308,01 & 222,81 & $-1,45$ & 224,25 & 29,35 & 162,23 & 162,23 & 29,35 & 1627,76 & 249,32 & 17,25 & 56,10 & 663,37 & 100,90 & 100,90 & 663,37 \\
\hline Pelophylax perezi & 29TPE17 & 100,00 & 105,52 & 77,94 & 33,30 & 5333,84 & 240,87 & 11,12 & 229,75 & 43,46 & 177,77 & 177,83 & 43,46 & 1488,39 & 230,10 & 14,23 & 56,81 & 610,46 & 89,59 & 89,68 & 610,46 \\
\hline Pelophylax perezi & 29TPE18 & 101,00 & 138,06 & 94,81 & 37,17 & F436,40 & 284,38 & 32,78 & 251,60 & 71,02 & 209,38 & 209,73 & 71,02 & $\begin{array}{l}1101,46 \\
\end{array}$ & 165,42 & 10,36 & 55,31 & 447,47 & 70,05 & 70,65 & 447,47 \\
\hline Pelophylax perezi & 29TPE19 & 101,00 & 138,73 & 96,68 & 37,72 & 5420,53 & 285,38 & 32,53 & 252,85 & 71,60 & 209,64 & 209,95 & 71,60 & \begin{tabular}{|c|}
1094,17 \\
\end{tabular} & 164,30 & 10,36 & 55,31 & 444,18 & 69,92 & 70,79 & 444,18 \\
\hline Pelophylax perezi & 29TPE23 & 100,00 & 136,93 & 89,41 & 34,98 & 5655,55 & 286,47 & 34,08 & 252,39 & 69,31 & 212,77 & 212,88 & 69,31 & 1072,25 & 160,25 & 9,60 & 55,52 & 436,33 & 65,86 & 65,86 & 436,33 \\
\hline Pelophylax perezi & 29TPE24 & 100,00 & 142,68 & 92,77 & 35,65 & 5654,12 & 293,58 & 37,45 & 256,12 & 74,19 & 217,73 & 218,05 & 74,19 & 1014,30 & 150,67 & 8,95 & 55,21 & 11,38 & 63,29 & 63,31 & 411,38 \\
\hline Pelophylax perezi & 29TPE25 & 101,00 & 137,34 & 90,80 & 35, & 5606,22 & 285,74 & 33,34 & 252,40 & 69,51 & 211,78 & 212,03 & 69,51 & 1075,73 & 161,29 & $\begin{array}{l}9,7 \\
9,7 \\
\end{array}$ & 55,46 & 437,30 & $\begin{array}{ll}66,83 \\
663\end{array}$ & $\begin{array}{l}66,87 \\
66,\end{array}$ & 437,30 \\
\hline Pelophylax perezi & 29TPE26 & 101,00 & 103,49 & 76,74 & 32,49 & 5450,47 & 240,55 & 9,06 & 231,49 & 40,44 & 177,45 & 177,47 & 40,44 & 1460,65 & 224,47 & 13,9 & 56,51 & 598,38 & 87,92 & 88,13 & 598,38 \\
\hline Pelophylax perezi & 29TPE27 & 100,00 & 106,99 & 77,23 & 32,68 & 5450,44 & 243,96 & 11,69 & 232,27 & 43,10 & 180,52 & 180,54 & 43,10 & 1421,80 & 219,17 & 13,32 & 56,76 & 583,80 & 85,34 & 86,46 & 583,80 \\
\hline Pelophylax perezi & 29TPE28 & 100,00 & 115,82 & 82,63 & 34,00 & 5469,42 & 255,98 & 17,15 & 238,83 & 50,50 & 188,84 & 188,97 & 50,50 & 1311,44 & 200,81 & 12,45 & 56,23 & 537,03 & 80,49 & 82,35 & 537,03 \\
\hline Pelophylax perezi & 29TPE29 & 101,00 & 140,71 & 97,32 & 37,40 & 5537,38 & 289,73 & 33,15 & 256,58 & 72,15 & 213,23 & 213,42 & 72,15 & 1031,62 & 154,36 & 9,59 & 55,08 & 417,47 & 65,82 & 66,46 & 417,47 \\
\hline Pelophylax perezi & 29TPE33 & $\begin{array}{l}101,00 \\
100\end{array}$ & 15 & 96 & 35 & $\mid$ & 307,44 & $\begin{array}{l}3,15 \\
43,36\end{array}$ & \begin{tabular}{|l|}
$\mid 264,08$ \\
264,0
\end{tabular} & $\begin{array}{ll}2,313 \\
84,32\end{array}$ & $\mid \begin{array}{l}\mid l 3,230 \\
228,71\end{array}$ & \begin{tabular}{|l|}
229,21 \\
22,
\end{tabular} & 81,34 & $\begin{array}{r}887,47 \\
887\end{array}$ & $\begin{array}{l}129,320 \\
129,3\end{array}$ & $\begin{array}{l}3,351 \\
7,58\end{array}$ & $\begin{array}{l}54,40 \\
54,42\end{array}$ & \begin{tabular}{|l|}
$456,64 \mid$ \\
3564
\end{tabular} & $\begin{array}{l}5,026 \\
56,06\end{array}$ & $\begin{array}{l}0,40 \\
56,28\end{array}$ & $\begin{array}{l}41,46,61 \\
356,61\end{array}$ \\
\hline Pelophylax perezi & 29TPE34 & 100,00 & 144,07 & 93,37 & 35,58 & 5763,97 & 297,00 & 37,53 & 259,47 & 74,25 & 220,63 & 220,80 & 74,25 & 963,29 & 142,08 & 8,48 & 54,82 & 388,56 & 60,65 & 60,78 & 388,56 \\
\hline Pelophylax perezi & 29TPE35 & 100,00 & 142,56 & 93,42 & 35,63 & 5737,22 & 294,59 & 35,97 & 258,62 & 72,78 & 218,54 & 218,67 & 72,78 & 976,71 & 144,52 & 8,80 & 54,84 & 394.12 & 61.76 & 61.99 & 394,12 \\
\hline Pelophylax perezi & 29TPE36 & 101,00 & 139,74 & 92,73 & 35,61 & 5699,14 & 290,19 & 33,56 & 256,64 & 70,23 & 215,06 & 215,18 & 70,23 & 1004,28 & 149,39 & 9,13 & 54,98 & 405,67 & 63,55 & 64,08 & 405,67 \\
\hline Pelophylax perezi & 29TPE37 & 100,00 & 126,44 & 86,62 & 34,39 & 5632,12 & 272,12 & 24,14 & 247,98 & 58,40 & 201,32 & 201,39 & 58,40 & 1136,45 & 171,51 & 10,64 & 55,48 & 461,98 & 70,81 & 73,01 & 46 \\
\hline Pelophylax perezi & 29TPE38 & $\begin{array}{l}101,00 \\
100\end{array}$ & $\begin{array}{l}120,44 \\
108,42 \\
\end{array}$ & $\begin{array}{ll}77,78 \\
77,78\end{array}$ & 32,55 & $\begin{array}{l}502,112 \\
5536,88\end{array}$ & 247,27 & \begin{tabular}{|l|}
11,75 \\
114
\end{tabular} & \begin{tabular}{|l|}
235,51 \\
231
\end{tabular} & $\begin{array}{l}30,404 \\
42,64 \\
\end{array}$ & $\begin{array}{l}21,22 \\
182,53 \\
\end{array}$ & \begin{tabular}{|l|}
21,239 \\
182,68 \\
\end{tabular} & $\begin{array}{l}30,404 \\
42,64\end{array}$ & \begin{tabular}{|l|l|l|l|l|}
1323,69 \\
\end{tabular} & \begin{tabular}{|l|}
202,22 \\
201
\end{tabular} & \begin{tabular}{|l|}
12,645 \\
12,
\end{tabular} & $\begin{array}{l}5,40 \\
56,09\end{array}$ & \begin{tabular}{|l|}
541,51 \\
545
\end{tabular} & $\begin{array}{l}, 01,32 \\
81,32\end{array}$ & $\begin{array}{l}3,01 \\
87,37 \\
\end{array}$ & $\begin{array}{l}401,50 \\
541,51 \\
\end{array}$ \\
\hline Pelophylax perezi & 29TPE39 & 99,00 & 129,36 & 90,95 & 35,62 & 5612,20 & 276,53 & 24,79 & 251,73 & 60,76 & 203,41 & 203,57 & 60,76 & 1096,85 & 165,15 & 10,54 & 55,27 & 444,89 & 69,91 & 71,83 & 444,89 \\
\hline Pelophylax perezi & 29TPE43 & 101,00 & 153,35 & 97,14 & 35,97 & 5887,56 & 310,18 & 43,60 & 266,59 & 89,12 & 231,20 & 231,48 & 81,69 & 837,38 & 120,72 & 7,00 & 53,85 & 334,35 & 53,38 & 53,65 & 333,63 \\
\hline Pelophylax perezi & 29TPE44 & 100,00 & 149,48 & 96,03 & 35,86 & 5860,33 & 304,97 & 40,37 & 264,60 & 84,5 & 226,95 & 227 & 78, & 871,44 & 126,58 & 7,52 & 54,06 & 348,36 & 55,63 & 55,78 & 347,93 \\
\hline Pelophylax perezi & 29TPE45 & 101,00 & 142,38 & 93,54 & 35,41 & 5824,43 & 295,68 & 34,92 & 260,76 & 74,84 & 219,54 & 219,65 & 71,49 & 934,96 & 137,33 & 8,42 & 54,35 & 374,92 & 59,48 & 59,90 & 374,91 \\
\hline
\end{tabular}




\begin{tabular}{|c|c|c|c|c|c|c|c|c|c|c|c|c|c|c|c|c|c|c|c|c|c|}
\hline TAXON & UTM & $\mathrm{km} 2$ & BIO1 & BIO2 & $B 103$ & BIO4 & B105 & B106 & B107 & B108 & B109 & B1010 & BIO11 & BIO12 & BIO13 & B1014 & BIO15 & B1016 & B1017 & B1018 & B1019 \\
\hline Pelophylax perezi & 29TPE46 & 99,00 & 140,79 & 93,71 & 35,62 & 5799,87 & 293,41 & 33,34 & 260,08 & 71,02 & 217,52 & 217,64 & 70,04 & 944,75 & 139,10 & 8,62 & 54,33 & 378,87 & 60,64 & 61,32 & 378,87 \\
\hline Pelophylax perezi & 29TPE47 & 101,00 & 132,53 & 90,33 & 34,91 & 5754,58 & 282,24 & 27,16 & 255,08 & 62,33 & 208,59 & 208,83 & 62,33 & 1017,71 & 151,31 & 9,63 & 54,73 & 409,90 & 64,86 & 66,79 & 409,90 \\
\hline Pelophylax perezi & 29TPE48 & 99,00 & 117,54 & 82,71 & 33,32 & 5674,60 & 261,50 & 16,91 & 244,60 & 48,96 & $\begin{array}{l}192,78 \\
\end{array}$ & \begin{tabular}{|l|}
193,24 \\
\end{tabular} & 48,96 & $\begin{array}{l}1155,77 \\
\end{array}$ & \begin{tabular}{|l|l|}
173,94 \\
\end{tabular} & 11,18 & 55,15 & 468,54 & 73,04 & \begin{tabular}{ll|}
77,68 \\
\end{tabular} & 468,54 \\
\hline Pelophylax perezi & 29TPE49 & 101,00 & 125,55 & 88,94 & 34,86 & 5693,66 & \begin{tabular}{|l|l|}
273,09 \\
\end{tabular} & 21,39 & 251,70 & 56,06 & 200,71 & 201,07 & 56,06 & 1071,79 & 160,32 & 10,53 & 54,81 & 432,91 & 69,15 & 71,71 & 432,91 \\
\hline Pelophylax perezi & 29TPE53 & 100,00 & 151,91 & 97,36 & 35,85 . & 5953,50 & 309,70 & 41,55 & 268,15 , & 87,23 & 230,81 & 231,01 & 79,58 & 808,77 & 115,52 & 6,97 & 53,33 & 321,81 & 52,04 & 52,23 & 319,62 \\
\hline Pelophylax perezi & 29TPE54 & 100,00 & 147,75 & 95,98 & 35,62 & 5933,51 & 304,19 & 38,06 & 266,13 & 83,16 & 226,32 & 226,50 & 75,69 & 844,05 & 121,51 & 7,38 & 53,61 & 335,96 & 54,66 & 54,79 & 334,47 \\
\hline Pelophylax perezi & 29TPE55 & 100,00 & 139,99 & 93,16 & 35,09 & 5892,53 & 294,01 & 32,20 & 261,81 & 76,16 & 218,11 & 218,19 & 68,40 & 909,11 & 132,39 & 8,41 & 53,90 & 362,66 & 58,54 & 59,38 & 361,92 \\
\hline Pelophylax perezi & 29TPE56 & 101,00 & 128,25 & 88,22 & 34,20 & 5835,14 & 278,60 & 23,79 & 254,82 & 62,95 & 205,80 & 206,08 & 57,84 & 1007,41 & \begin{tabular}{|l|l|}
148,40 \\
\end{tabular} & 9,62 & 54,15 & 403,27 & 64,49 & 67,35 & 403,21 \\
\hline Pelophylax perezi & 29TPE57 & 100,00 & 122,18 & 85,75 & 33,73 & $\begin{array}{l}5797,09 \\
\end{array}$ & 270,24 & 19,26 & 250,98 & \begin{tabular}{|l|l}
53,93 \\
\end{tabular} & 199,19 & $\begin{array}{l}199,57 \\
\end{array}$ & 52,20 & $\begin{array}{l}1057,68 \\
\end{array}$ & $\begin{array}{l}156,75 \\
\end{array}$ & 10,24 & 54,34 & $\begin{array}{l}424,65 \\
\end{array}$ & 67,76 & 71,56 & 424,64 \\
\hline Pelophylax perezi & 29TPE58 & 101,00 & \begin{tabular}{ll|l}
120,47 \\
\end{tabular} & 85,76 & 33,81 & 5774,86 & \begin{tabular}{|l|}
268,03 \\
\end{tabular} & 17,55 & \begin{tabular}{|l|l|}
250,48 \\
\end{tabular} & 51,08 & \begin{tabular}{|l|l|}
196,97 \\
\end{tabular} & \begin{tabular}{ll|}
197,58 \\
\end{tabular} & 50,51 & 1064,41 & 157,89 & 10,49 & 54,30 & 427,55 & 68,80 & 72,51 & 427,55 \\
\hline Pelophylax perezi & 29TPE59 & 100,00 & 119,76 & 86,90 & 34,11 & 5766,20 & 267,68 & 16,35 & 251,34 & 49,78 & 196,01 & 196,68 & 49,78 & 1061,22 & 157,39 & 10,70 & 54,14 & 426,26 & 69,47 & 72,85 & 426,26 \\
\hline Pelophylax perezi & 29TPE63 & 100,00 & 147,31 & 96,56 & 35,56 & 6005,60 & 305,46 & 37,25 & 268,21 & 82,40 & 227,14 & 227,18 & 74,60 & 805,58 & \begin{tabular}{|l|l|}
114,23 \\
\end{tabular} & 7,23 & 52,82 & 319,18 & 52,55 & 52,87 & 315,84 \\
\hline Pelophylax perezi & 29TPE64 & 101,00 & 148,18 & 97,18 & 35,78 & 5989,67 & 305,84 & 37,38 & 268,45 & 82,93 & 227,58 & 227,62 & 75,21 & 797,19 & 113,21 & 7,17 & 52,86 & \begin{tabular}{|l|}
315,68 \\
\end{tabular} & 52,29 & 52,49 & 312,48 \\
\hline Pelophylax perezi & 29TPE65 & 100,00 & 129,91 & 90,14 & 34,26 & 5929,70 & 283,01 & 23,91 & 259,10 & $\begin{array}{l}66,46 \\
\end{array}$ & 208,92 & 209,16 & \begin{tabular}{ll|}
58,67 \\
\end{tabular} & 944,84 & 136,77 & 9,21 & 53,25 & \begin{tabular}{|l|l|}
375,78 \\
\end{tabular} & 61,54 & \begin{tabular}{ll|}
63,95 \\
\end{tabular} & 373,87 \\
\hline Pelophylax perezi & 29TPE66 & 100,00 & 121,79 & 86,97 & 33,72 & $\begin{array}{l}5881,62 \\
\end{array}$ & $\begin{array}{l}272,26 \\
\end{array}$ & $\begin{array}{ll}17,83 \\
\end{array}$ & 254,43 & 59,20 & 200,18 & 200,57 & 51,21 & \begin{tabular}{ll|l}
1009,52 \\
\end{tabular} & $\begin{array}{l}147,16 \\
\end{array}$ & 10,10 & 53,46 & 402,21 & 65,82 & \begin{tabular}{ll|}
69,68 \\
\end{tabular} & 400,97 \\
\hline Pelophylax perezi & 29TPE67 & 101,00 & 125,29 & 89,10 & \begin{tabular}{ll|}
34,18 \\
\end{tabular} & \begin{tabular}{|l|}
5888,96 \\
\end{tabular} & $\begin{array}{l}276,66 \\
\end{array}$ & 19,84 & 256,83 & 61,99 & 203,34 & 203,90 & 54,13 & \begin{tabular}{|l|l|}
971,07 \\
\end{tabular} & 141,31 & 9,83 & 53,26 & 386,21 & 64,13 & 66,99 & 385,15 \\
\hline Pelophylax perezi & 29TPE68 & 99,00 & 124,21 & 89,65 & 34,41 & 5871,67 & 275,38 & 18,51 & 256,87 & 60,36 & 201,86 & 202,53 & 53,08 & $\begin{array}{l}971,17 \\
91\end{array}$ & 141,44 & 9,89 & 53,21 & 386,12 & 64,70 & 67,43 & 385,41 \\
\hline Pelophylax perezi & 29TPE69 & 101,00 & 123,25 & 90,59 & \begin{tabular}{|c|c|}
34,72 \\
\end{tabular} & 5856,27 & 274,74 & 17,18 & 257,56 & 58,81 & 200,55 & 201,39 & 52,01 & \begin{tabular}{|l|l|}
969,08 \\
\end{tabular} & $\mid 141,09$ & \begin{tabular}{|c|c|}
10,03 \\
\end{tabular} & 53,06 & 385,06 & 65,36 & 67,80 & 384,65 \\
\hline Pelophylax perezi & 29TPE73 & 100,00 & 150,30 & 98,84 & 35,77 & 6062,09 & 310,71 & 38,27 & 272,44 & 84,43 & 230,77 & 230,80 & 76,58 & $\begin{array}{l}739,65 \\
\end{array}$ & \begin{tabular}{ll|}
102,88 \\
\end{tabular} & 6,62 & 51,89 & 290,90 & 49,06 & 49,23 & 285,78 \\
\hline Pelophylax perezi & 29TPE74 & 100,00 & 151,09 & 99,45 & 35,99 & $\begin{array}{l}6044,12 \\
\end{array}$ & 311,10 & 38,55 & 272,55 & 85,01 & 231,27 & 231,27 & 77,25 & 730,10 & $\begin{array}{l}101,60 \\
\end{array}$ & 6,54 & 51,86 & 286,93 & \begin{tabular}{ll|}
48,63 \\
\end{tabular} & $\begin{array}{l}48,65 \\
\end{array}$ & 281,99 \\
\hline Pelophylax perezi & 29TPE75 & 99,00 & 135,54 & 94,15 & 34,92 & 6008,58 & 292,03 & 26,54 & 265,49 & 70,70 & 215,39 & 215,63 & 62,83 & 847,52 & $\begin{array}{l}119,95 \\
\end{array}$ & 8,43 & 52,10 & 334,35 & 56,87 & 58,58 & 330,22 \\
\hline Pelophylax perezi & 29TPE76 & 101,00 & 116,20 & 87,38 & 33,60 & 5936,45 & \begin{tabular}{|l|l|}
267,97 \\
\end{tabular} & 12,02 & \begin{tabular}{|l|l|}
255,95 \\
\end{tabular} & 53,37 & 195,55 & $\begin{array}{l}196,01 \\
\end{array}$ & 45,46 & $\begin{array}{l}998,94 \\
\end{array}$ & 143,22 & 10,53 & 52,42 & $\begin{array}{l}395,43 \\
\end{array}$ & 67,06 & 71,63 & 392,21 \\
\hline Pelophylax perezi & 29TPE77 & 100,00 & 122,37 & 90,04 & 34,30 & 5945,46 & $\begin{array}{l}275,26 \\
\end{array}$ & 16,19 & \begin{tabular}{|l|}
259,07 \\
\end{tabular} & 58,62 & 201,30 & 201,94 & 50,77 & 938,22 & 134,22 & 9,98 & 52,23 & 370,92 & 63,72 & 66,87 & 367,88 \\
\hline Pelophylax perezi & 29TPE78 & 101,00 & 123,45 & 91,55 & 34,80 ] & 5941,90 & 276,94 & 16,45 & 260,49 & 59,43 & 202,15 & 202,87 & 51,50 & 917,39 & 131,03 & 9,84 & 52,04 & 362,22 & 63,19 & 65,75 & 359,37 \\
\hline Pelophylax perezi & 29TPE79 & 99,00 & 124,77 & 93,29 & 35,09 & 5934,79 & 279,08 & 16,71 & 262,37 & \begin{tabular}{|c|}
60,47 \\
\end{tabular} & 203,18 & 204,08 & 52,60 & 896,75 & 127,89 & 9,73 & 51,82 & 353,66 & $\begin{array}{l}62,66 \\
\end{array}$ & 64,50 & 351,17 \\
\hline Pelophylax perezi & 29TPE83 & 100,00 & 155,39 & 101,75 & \begin{tabular}{l|l}
36,05 \\
\end{tabular} & 6107,25 & 318,29 & 40,92 & 277,37 & 88,51 & 236,29 & 236,29 & 80,65 & 662,07 & 89,77 & 5,86 & 50,92 & 258,07 & 44,53 & 44,53 & 251,09 \\
\hline Pelophylax perezi & 29TPE84 & 101,00 & 146,87 & 99,36 & 35,82 & 6104,88 & 308,40 & 33,98 & \begin{tabular}{|l|l|}
274,42 \\
\end{tabular} & 80,31 & 227,97 & 228,03 & 72,56 & \begin{tabular}{|l|l|}
717,78 \\
\end{tabular} & 98,46 & 6,86 & 51,03 & 280,18 & 49,20 & 49,35 & 273,80 \\
\hline Pelophylax perezi & 29TPE85 & 101,00 & 126,42 & 93,40 & 34,64 & 6044,36 & 283,86 & 18,13 & 265,73 & 61,90 & 207,17 & 207,49 & 54,01 & 867,71 & 120,90 & 9,38 & 51,16 & 339,84 & 60,08 & 62,81 & 334,06 \\
\hline Pelophylax perezi & 29TPE86 & 100,00 & 117,60 & 90,52 & 34,02 & 6008,49 & 272,64 & 11,27 & 261,36 & 53,76 & 197,92 & 198,45 & 45,95 & 928,26 & 130,25 & 10,32 & 51,22 & 364,31 & 64,53 & 68,45 & 358,97 \\
\hline Pelophylax perezi & 29TPE87 & 100,00 & 124,01 & 93,18 & \begin{tabular}{|l|l|}
34,67 \\
\end{tabular} & 6018,82 & 280,22 & 15,67 & 264,55 & 59,25 & 203,85 & 204,61 & 51,39 & 866,80 & 121,19 & 9,70 & 50,97 & 339,73 & 60,96 & 63,50 & 334,53 \\
\hline Pelophylax perezi & 29TPE88 & 100,00 & 124,78 & 94,46 & \begin{tabular}{|l|}
35,08 \\
\end{tabular} & 6008,36 & 281,25 & 15,80 & \begin{tabular}{|l|l|}
265,45 \\
\end{tabular} & 59,89 & 204,33 & 205,17 & 52,01 & 849,17 & 118,51 & 9,48 & 50,67 & 332,56 & 60,52 & 62,53 & 327,54 \\
\hline Pelophylax perezi & 29TPE89 & 101,00 & 124,13 & 95,26 & $\begin{array}{l}35,25 \\
\end{array}$ & 5995,30 & 280,81 & 14,85 & \begin{tabular}{|l|l|}
265,97 \\
\end{tabular} & 59,14 & 203,39 & 204,31 & 51,43 & 843,46 & \begin{tabular}{|l|l|}
117,63 \\
\end{tabular} & 9,60 & 50,67 & 330,28 & 60,83 & 62,57 & 325,45 \\
\hline Pelophylax perezi & 29TPE93 & 100,00 & 159,60 & 104,03 & \begin{tabular}{l|l}
36,55 \\
\end{tabular} & 6147,39 & 324,55 & 43,22 & 281,32 & 91,70 & 240,92 & 240,92 & 84,00 & 597,31 & 79,00 & 5,03 & 50,11 & 230,72 & $\begin{array}{l}40,36 \\
\end{array}$ & 40,36 & 222,36 \\
\hline Pelophylax perezi & 29TPE94 & 99,00 & 150,74 & 101,88 & \begin{tabular}{l|l}
36,05 \\
\end{tabular} & 6149,45 & 314,58 & 35,85 & \begin{tabular}{|l|l|}
278,73 \\
\end{tabular} & 83,35 & 232,37 & 232,43 & 75,59 & 651,22 & 87,12 & 6,18 & 50,01 & 251,82 & 45,26 & 45,42 & 243,87 \\
\hline Pelophylax perezi & 29TPE95 & 100,00 & 133,71 & 97,47 & 35,24 & 6122,54 & 294,97 & 22,26 & 272,71 & 67,52 & 215,21 & 215,54 & 59,77 & 762,82 & \begin{tabular}{|l|l|}
103,58 \\
\end{tabular} & 8,34 & 49,95 & 295,84 & 54,36 & 55,87 & 288,21 \\
\hline Pelophylax perezi & 29TPE96 & 100,00 & 121,66 & 94,40 & 34,79 & 6085,22 & 280,54 & 12,66 & 267,88 & 56,49 & 202,72 & 203,40 & 48,71 & $\begin{array}{l}839,86 \\
\end{array}$ & \begin{tabular}{|l|l|}
114,81 \\
\end{tabular} & 9,92 & 49,81 & 326,27 & 60,70 & 63,49 & 318,88 \\
\hline Pelophylax perezi & 29TPE97 & 101,00 & 123,33 & 95,54 & $\begin{array}{l}35,03 \\
\end{array}$ & 6081,09 & 282,39 & 13,56 & 268,83 & 57,85 & 204,07 & 204,93 & 50,15 & \begin{tabular}{|l|l|}
815,68 \\
\end{tabular} & 111,21 & 9,77 & 49,60 & 316,66 & 59,75 & 62,02 & 309,32 \\
\hline Pelophylax perezi & 29TPE98 & 100,00 & 128,77 & 98,03 & 35,72 & 6080,10 & 288,79 & 17,22 & 271,56 & 62,50 & 209,12 & 209,95 & 54,96 & 765,26 & 103,76 & 9,1 & 49,35 & 296,62 & 56,86 & 57,99 & 289,48 \\
\hline Pelophylax perezi & 29TPE99 & 100,00 & 129,38 & 99,10 & 35,9 & \begin{tabular}{ll|l|}
6061,66 \\
\end{tabular} & 289,52 & 17,34 & 272,18 & 63,10 & 209,68 & 210,36 & 55,57 & 750,64 & $\begin{array}{l}101,66 \\
\end{array}$ & 8,98 & 49,19 & 290,90 & 56,43 & 57,15 & 283,99 \\
\hline Pelophylax perezi & 29TPF00 & 101,00 & 139,06 & 98,71 & 38,8 & 5279,84 & 283,75 & 32,90 & 250,85 & 73,23 & 207,69 & 208,26 & 73,23 & 1127,70 & 168,86 & 10,94 & 55,06 & 457,17 & 72,42 & 74,61 & 457,17 \\
\hline Pelophylax perezi & 29TPF01 & 100,00 & 128,78 & $\begin{array}{ll}95,58 \\
\end{array}$ & 38,14 & 5282,38 & 272,01 & 24,88 & \begin{tabular}{|l|l|}
247,14 \\
\end{tabular} & \begin{tabular}{|l|l|}
63,64 \\
\end{tabular} & $\begin{array}{l}197,92 \\
\end{array}$ & $\begin{array}{l}198,34 \\
\end{array}$ & \begin{tabular}{ll|}
63,64 \\
\end{tabular} & $\begin{array}{l}1241,40 \\
\end{array}$ & \begin{tabular}{l|l|}
187,92 \\
\end{tabular} & 12,69 & 55,62 & $\begin{array}{l}505,95 \\
\end{array}$ & 80,76 & 81,46 & 505,95 \\
\hline Pelophylax perezi & 29TPF02 & 100,00 & 120,33 & 92,91 & 37,62 & 5265,34 & 262,17 & 18,53 & 243,64 & 55,99 & 189,91 & 190,07 & 55,99 & 1328,52 & 201,64 & 14,36 & 55,81 & 542,65 & 87,32 & 87,58 & 542,65 \\
\hline Pelophylax perezi & 29TPF03 & 101,00 & 113,74 & 90,97 & 37, & 5258,84 & 254,54 & 13,44 & 241,10 & 50,04 & 183,61 & 183,69 & 50,04 & $\begin{array}{l}1387,50 \\
\end{array}$ & 209,98 & 15,89 & 55,33 & 566,60 & 92,49 & 92,91 & 566,60 \\
\hline Pelophylax perezi & 29TPF04 & 100,00 & 128,77 & 101,16 & 39,5 & 5306,69 & 275,1 & 22,47 & 252,72 & 62,85 & 197,94 & 198,38 & 62,85 & 1242,10 & 187,23 & 13,26 & 55,32 & 505,25 & 81,75 & 84,25 & 505,25 \\
\hline Pelophylax perezi & 29TPF05 & 100,00 & 142,96 & 106,65 & 40,8 & 5279,31 & 290,9 & 32,77 & 258,16 & 78,24 & 210,95 & 211,44 & 76,34 & $\begin{array}{l}1091,92 \\
\end{array}$ & $\begin{array}{l}161,79 \\
\end{array}$ & 10,5 & 54,62 & 439,34 & 70,24 & 76,22 & 439,25 \\
\hline Pelophylax perezi & 29TPF06 & 100,00 & 141,31 & 108,38 & $\begin{array}{ll}40,93 \\
\end{array}$ & 5312,79 & 291,76 & 30,46 & 261,30 & 79,60 & 209,92 & 210,29 & 74,38 & \begin{tabular}{|l|}
1113,87 \\
\end{tabular} & 165,33 & 11,38 & 54,92 & 449,72 & 71,98 & 77,73 & 448,75 \\
\hline Pelophylax perezi & 29TPF07 & 101,00 & 129,25 & 104,96 & \begin{tabular}{|l|l|}
40,17 \\
\end{tabular} & 5320,59 & 279,02 & 21,27 & 257,75 & 69,15 & 198,58 & $\begin{array}{l}198,93 \\
\end{array}$ & 63,25 & $\begin{array}{l}1223,92 \\
\end{array}$ & $\mid 181,16$ & 14,12 & 54,73 & $\mid$\begin{tabular}{|l|l|}
496,20 \\
\end{tabular} & 82,95 & 87,13 & 494,77 \\
\hline Pelophylax perezi & 29TPF08 & 100,00 & 108,66 & 93,52 & 38,00 & 5223,34 & 250,90 & 8,30 & 242,61 & 45,75 & 178,02 & 178,18 & 45,68 & $\begin{array}{l}1370,44 \\
\end{array}$ & 197,65 & 19,63 & 52,80 & 551,13 & 101,85 & 103,26 & 551,12 \\
\hline Pelophylax perezi & 29TPF09 & 100,00 & 111,77 & 94,08 & 38,18 & 5213,47 & 253,83 & 10,63 & 243,20 & 48,68 & 180,74 & 180,98 & 48,68 & \begin{tabular}{|l|}
1325,43 \\
\end{tabular} & 188,43 & 19,36 & 52,06 & 530,87 & 99,87 & \begin{tabular}{|l|l|}
101,47 \\
\end{tabular} & 530,87 \\
\hline Pelophylax perezi & 29TPF10 & 100,00 & 136 & 97,26 & 37, & 5414,49 & 282,79 & 29,94 & 252,85 & 69,04 & 207,02 & 207,27 & 69,04 & $\begin{array}{l}1121,47 \\
\end{array}$ & 169,00 & 10,83 & 55,29 & 455,61 & 72,08 & 72,82 & 455,61 \\
\hline Pelophylax perezi & 29TPF11 & 100,00 & $\begin{array}{ll}128,63 \\
\end{array}$ & 95,37 & $\begin{array}{l}37,60 \\
\end{array}$ & \begin{tabular}{|l|}
5404,76 \\
\end{tabular} & 274,24 & 23,95 & \begin{tabular}{|l|l|}
250,29 \\
\end{tabular} & 62,05 & \begin{tabular}{|l|}
199,63 \\
\end{tabular} & 199,88 & 62,05 & $\begin{array}{l}1200,90 \\
\end{array}$ & 182,25 & 12,14 & 55,80 & $\mid 489,67$ & 77,94 & 78,26 & 489,67 \\
\hline Pelophylax perezi & 29TPF12 & 100,00 & 118,88 & 91,96 & 36,84 & 5385,78 & 262,58 & 16,65 & 245,93 & 53,27 & 190,27 & 190,32 & 53,27 & 1295,22 & 197,19 & 13,90 & 55,95 & 529,52 & 84,37 & 85,12 & 529,52 \\
\hline Pelophylax perezi & 29TPF13 & 101,00 & 121,03 & 95,23 & 37,6 & \begin{tabular}{|l|l|}
5397,58 \\
\end{tabular} & 266,55 & 17,10 & \begin{tabular}{|l|l|}
249,45 \\
\end{tabular} & 54,91 & 192,27 & 192 & 54 & 1270,64 & \begin{tabular}{ll|}
192,82 \\
\end{tabular} & 13 & 55,64 & 518 & 83,82 & 84,37 & 518 \\
\hline Pelophylax perezi & 29TPF14 & 100,00 & 124 & 99,18 & 38 & 541 & 272, & 18, & 253,77 & 57,77 & 195,61 & 195 & 57 & 1234 & 186 & 13 & 55,38 & 502,96 & 82,15 & 83,12 & 502 \\
\hline Pelophylax perezi & 29TPF15 & 100,00 & 140,38 & 106,18 & 40,16 & 5405,68 & 290,95 & 29,63 & 261,32 & 73,99 & 210,42 & 210,69 & 72,49 & $\begin{array}{l}1074,86 \\
\end{array}$ & 160,31 & 10,99 & 54,83 & 433,77 & 69,73 & 73,32 & 433,71 \\
\hline Pelophylax perezi & 29TPF16 & \begin{tabular}{|l|l}
101,00 \\
\end{tabular} & \begin{tabular}{|l|}
133,02 \\
\end{tabular} & \begin{tabular}{|l|l|}
106,93 \\
\end{tabular} & \begin{tabular}{|c|c|}
40,08 \\
\end{tabular} & 5451,47 & $\mid 286,04$ & 22,66 & $\mid 263,38$ & 70,80 & 203,93 & 204,22 & 65,01 & $\mid 1150,71$ & 172,83 & \begin{tabular}{|l|l|}
12,42 \\
\end{tabular} & 55,22 & 467,60 & 76,12 & 78,60 & 466,91 \\
\hline Pelophylax perezi & 29TPF17 & 99,00 & 124,80 & 103,41 & 39,44 & 5430,11 & 275,66 & 16,91 & 258,75 & 60,08 & 195,94 & 196,20 & 57,73 & 1205,82 & \begin{tabular}{|l|l|}
179,03 \\
\end{tabular} & 14,42 & 54,47 & 488,74 & 83,17 & 84,79 & 488,54 \\
\hline Peloph & 29TPF18 & 101,00 & 1118,4 & 98 & 38 & 5 & 264 & 11 & 252 & 51, & 77 & 187 & 51 & $\mid 1252,20$ & 182 & $\mid 16,84$ & & 505,01 & 90,84 & 91,97 & 50 \\
\hline Pelophylax perezi & 29TPF19 & 101,00 & 113,80 & 96,73 & 38,31 & 5336,32 & 259,53 & 10,18 & \begin{tabular}{|l|l|}
249,36 \\
\end{tabular} & 48,93 & 184,38 & 184,5 & 48,93 & \begin{tabular}{l|l}
1255,75 \\
\end{tabular} & $\begin{array}{l}179,85 \\
\end{array}$ & 18,12 & 52,30 & 503,68 & \begin{tabular}{|l|l|}
94,08 \\
\end{tabular} & 94,80 & 503,68 \\
\hline Pelophylax perezi & 29TPF20 & 100,00 & 131,99 & 94,76 & 36,96 & 5520,84 & 279,47 & 26,29 & 253,18 & 63,93 & 204,61 & 204,73 & 63,93 & 1119,52 & $\begin{array}{l}169,25 \\
\end{array}$ & 10,95 & 55,43 & 455,27 & 72,09 & 72,60 & 455,27 \\
\hline
\end{tabular}




\begin{tabular}{|c|c|c|c|c|c|c|c|c|c|c|c|c|c|c|c|c|c|c|c|c|c|}
\hline TAXON & UTM & $\mathrm{km} 2$ & B101 & B102 & $\mathrm{BIO3}$ & B104 & B105 & B106 & B107 & B108 & B109 & B1010 & BIO11 & BIO12 & B1013 & BIO14 & BIO15 & BIO16 & B1017 & BIO18 & B1019 \\
\hline Pelophylax perezi & 29TPF21 & 101,00 & 126,21 & 93,56 & 36,68 & 5513,60 & 272,97 & 21,53 & 251,44 & 58,52 & 198,83 & 198,97 & 58,52 & 1172,13 & 177,94 & 11,92 & 55,70 & 477,64 & 75,95 & 76,74 & 477,64 \\
\hline Pelophylax perezi & 29TPF22 & 100,00 & 123,09 & 94,03 & \begin{tabular}{|l|l}
36,88 \\
\end{tabular} & 5506,71 & 269,90 & 18,45 & 251,45 & 55,53 & 195,71 & 195,79 & 55,53 & 1199,46 & 182,05 & 12,66 & 55,60 & 488,99 & 78,61 & 79,60 & 488,99 \\
\hline Pelophylax perezi & 29TPF23 & 100,00 & 126,79 & 98,25 & 37,87 & 5516,59 & 275,90 & 19,95 & 255,94 & 58,64 & 199,26 & 199,34 & 58,64 & 1160,35 & 175,66 & 12,24 & 55,32 & 472,38 & 76,56 & 77,15 & 472,38 \\
\hline Pelophylax perezi & 29TPF24 & 101,00 & 126,75 & 100,17 & 38,32 & 5518,90 & 277,01 & 19,14 & 257,87 & 58,60 & 199,25 & 199,32 & 58,60 & 1155,55 & 174,45 & 12,59 & 55,08 & 469,91 & 77,07 & 77,46 & 469,91 \\
\hline Pelophylax perezi & 29TPF25 & 100,00 & 140,51 & 106,44 & 39,69 & 5513,85 & 293,37 & 28,59 & 264,78 & 71,32 & 212,18 & 212,25 & 71,32 & \begin{tabular}{|l|l|}
1019,19 \\
\end{tabular} & 151,94 & 10,54 & 54,60 & 410,81 & $\begin{array}{ll}66,63 \\
\end{array}$ & \begin{tabular}{|l|l|}
67,38 \\
\end{tabular} & 410,81 \\
\hline Pelophylax perezi & 29TPF26 & 100,00 & 140,98 & 107,60 & 39,89 & 5514,54 & 294,66 & 28,42 & 266,25 & 73,20 & 212,58 & 212,65 & 71,78 & 1005,65 & 149,08 & 10,67 & 54,36 & 404,49 & 66,37 & 67,06 & 404,46 \\
\hline Pelophylax perezi & \begin{tabular}{|l|} 
29TPF27 \\
\end{tabular} & 101,00 & 127,74 & 104,65 & 39,24 & 5523,54 & 281,02 & 17,96 & 263,06 & 61,29 & 200,19 & 200,25 & 59,37 & 1117,23 & 165,84 & 13,31 & 54,31 & 451,90 & 77,02 & 77,42 & 451,81 \\
\hline Pelophylax perezi & 29TPF28 & 101,00 & 124,70 & 103,28 & 39,13 & 5499,98 & 276,56 & 15,72 & 260,84 & 56,85 & \begin{tabular}{|l|}
197,01 \\
\end{tabular} & \begin{tabular}{|l|l|}
197,03 \\
\end{tabular} & 56,85 & $\begin{array}{l}1124,99 \\
1120\end{array}$ & 164,65 & 14,44 & 53,30 & 453,16 & 80,03 & 80,49 & 453,16 \\
\hline Pelophylax perezi & 29TPF29 & 100,00 & 119,33 & 100,64 & 38,58 & 5460,93 & 269,38 & 12,14 & 257,24 & 52,55 & 191,46 & 191,47 & 52,55 & 1147,42 & 165,13 & 16,19 & 52,33 & \begin{tabular}{|c|}
460,08 \\
\end{tabular} & 85,13 & 85,52 & 460,08 \\
\hline Pelophylax perezi & 29TPF30 & 101,00 & 138,54 & 97,73 & \begin{tabular}{|l|l|}
37,13 \\
\end{tabular} & 5630,05 & 289,25 & 30,10 & 259,15 & 68,92 & 212,42 & 212,50 & 68,92 & 1001,01 & 149,52 & 9,60 & 54,78 & 403,99 & 64,84 & 65,10 & 403,99 \\
\hline Pelophylax perezi & 29TPF31 & 100,00 & 122,01 & 91,03 & 35,81 & 5592,34 & 269,00 & 17,97 & 251,03 & 53,63 & 195,80 & 196,16 & 53,63 & 1153,91 & 174,51 & 11,85 & 55,18 & 469,29 & 75,12 & 77,18 & 469,29 \\
\hline Pelophylax perezi & 29TPF32 & 101,00 & 118,52 & 91,48 & 35,98 & 5579,90 & 265,56 & 14,68 & 250,89 & 50,49 & 192,24 & 192,61 & 50,49 & 1181,51 & 178,55 & 12,66 & 55,06 & 480,60 & 78,06 & 80,25 & 480,60 \\
\hline Pelophylax perezi & 29TPF33 & 101,00 & 117,67 & 93,44 & \begin{tabular}{|l|l|}
36,47 \\
\end{tabular} & 5576,81 & 265,92 & 13,04 & 252,89 & 49,59 & 191,29 & 191,61 & 49,59 & 1180,34 & 177,86 & 13,10 & 54,92 & 479,81 & 79,46 & 81,04 & 479,81 \\
\hline Pelophylax perezi & 29TPF34 & 100,00 & 123,76 & 98,46 & \begin{tabular}{|l|l|}
37,58 \\
\end{tabular} & 5598,62 & 274,87 & 16,29 & 258,58 & 54,90 & 197,58 & 197,69 & 54,90 & 1117,24 & 167,71 & 12,54 & 54,69 & \begin{tabular}{|l|l|}
453,09 \\
\end{tabular} & 75,71 & 76,31 & 453,09 \\
\hline Pelophylax perezi & 29TPF35 & 101,00 & 137,94 & 105,49 & \begin{tabular}{l|l|}
39,15 \\
\end{tabular} & 5607,72 & 292,31 & 25,79 & 266,52 & 67,82 & 211,25 & 211,27 & 67,82 & 982,27 & 146,01 & 10,54 & 54,18 & \begin{tabular}{|l|l|}
395,49 \\
\end{tabular} & 65,43 & 65,51 & 395,49 \\
\hline Pelophylax perezi & 29TPF36 & 100,00 & 136,08 & 105,63 & 39,20 & 5593,92 & 290,39 & 23,96 & 266,43 & 66,31 & 209,21 & 209,21 & 66,31 & 987,88 & 145,90 & 11,16 & 53,79 & 397,09 & 67,05 & 67,16 & 397,09 \\
\hline Pelophylax perezi & 29TPF37 & 101,00 & 136,96 & 106,85 & 39,44 & 5597,15 & 291,74 & 23,96 & 267,78 & 66,93 & 209,96 & 209,98 & 66,93 & 970,32 & 142,26 & 11,30 & 53,38 & \begin{tabular}{|c|}
388,98 \\
\end{tabular} & 66,55 & 66,61 & 388,98 \\
\hline Pelophylax perezi & 29TPF38 & 99,00 & 135,86 & 107,09 & 39,57 & 5593,05 & 290,65 & 22,66 & 267,99 & 66,02 & 208,89 & 208,89 & 66,02 & 963,54 & 139,80 & 11,88 & 52,75 & 385,04 & 67,49 & 67,52 & 385,04 \\
\hline Pelophylax perezi & 29TPF39 & 101,00 & 128,98 & 104,90 & \begin{tabular}{|l|}
39,08 \\
\end{tabular} & 5570,40 & 282,66 & 17,49 & 265,18 & 60,08 & 202,29 & 202,29 & 60,08 & 1002,01 & 143,85 & \begin{tabular}{|l|l|}
13,58 \\
\end{tabular} & 51,97 & 400,05 & 73,12 & 73,12 & 400,05 \\
\hline Pelophylax perezi & 29TPF40 & 100,00 & 133,53 & 95,41 & 36,31 & 5720,40 & 284,69 & 25,68 & 259,01 & 63,05 & 208,84 & 209,07 & 63,05 & 991,53 & 147,47 & 9,75 & 54,42 & 398,90 & 65,13 & \begin{tabular}{|c|}
65,67 \\
\end{tabular} & 398,90 \\
\hline Pelophylax perezi & 29TPF41 & 100,00 & 130,09 & 95,51 & 36,44 & 5704,54 & 281,07 & 22,43 & 258,64 & 59,81 & 205,16 & 205,40 & 59,81 & 1019,40 & 152,10 & 10,5 & 54,47 & 410,99 & 67,65 & 68,26 & 410,99 \\
\hline Pelophylax perezi & 29TPF42 & 101,00 & 129,46 & 97,21 & 36,92 & 5693,92 & 281,22 & 21,12 & 260,10 & 59,25 & 204,42 & 204,60 & 59,25 & 1019,33 & 152,01 & 10,78 & 54,30 & 410,91 & 68,29 & \begin{tabular}{|l|}
68,78 \\
\end{tabular} & 410,91 \\
\hline Pelophylax perezi & 29TPF43 & 100,00 & $\begin{array}{ll}128,47 \\
\end{array}$ & 98,78 & \begin{tabular}{|l|l|}
37,29 \\
\end{tabular} & 5690,11 & 281,10 & \begin{tabular}{|c|}
19,51 \\
\end{tabular} & 261,59 & 58,25 & 203,40 & 203,53 & 58,25 & 1018,61 & 151,77 & \begin{tabular}{|l|}
11,11 \\
\end{tabular} & 54,11 & \begin{tabular}{|l|l|}
410,75 \\
\end{tabular} & 69,20 & 69,37 & 410,75 \\
\hline Pelophylax perezi & 29TPF44 & 100,00 & 132,75 & 102,47 & 38,08 & 5697,92 & 287,24 & 21,71 & 265,53 & 62,03 & 207,71 & 207,71 & 62,03 & 972,21 & 144,25 & 10,68 & 53,94 & 391,00 & 66,10 & 66,10 & 391,00 \\
\hline Pelophylax perezi & 29TPF45 & 100,00 & 140,70 & 105,77 & 38,89 & 5667,42 & 295,95 & 27,37 & 268,58 & 70,06 & 214,86 & 214,86 & 69,73 & 898,03 & 131,61 & 9,86 & 53,24 & 358,68 & 60,80 & 60,80 & 358,68 \\
\hline Pelophylax perezi & 29TPF46 & 101,00 & 123,35 & 101,60 & 38,00 & 5663,76 & 277,73 & 13,58 & 264,15 & 53,73 & 198,39 & 198,39 & 53,73 & 1028,48 & 151,52 & 12,73 & 53,08 & 413,96 & 73,53 & 73,53 & 413,96 \\
\hline Pelophylax perezi & 29TPF47 & 99,00 & 132,70 & 105,43 & 38,83 & 5659,92 & 288,25 & 20,00 & 268,25 & 62,32 & \begin{tabular}{|l|}
207,06 \\
\end{tabular} & \begin{tabular}{|l|}
207,06 \\
\end{tabular} & 62,32 & $\begin{array}{r}038,61 \\
938\end{array}$ & 136,65 & 11,66 & 52,49 & 375,35 & 66,55 & |66,55 & 375,35 \\
\hline Pelophylax perezi & \begin{tabular}{|l|} 
29TPF48 \\
\end{tabular} & 101,00 & 140,12 & 107,65 & 39,32 & 5646,39 & 295,76 & 25,48 & 270,27 & 69,34 & 214,06 & 214,06 & 69,34 & 865,86 & 123,90 & \begin{tabular}{|c|}
10,87 \\
\end{tabular} & 51,73 & \begin{tabular}{|c|}
343,18 \\
\end{tabular} & 61,50 & 61,50 & 343,18 \\
\hline Pelophylax perezi & 29TPF49 & 100,00 & 137,42 & 106,91 & 39,23 & 5629,61 & 292,32 & 23,10 & 269,23 & 67,23 & 211,12 & 211,12 & 66,99 & 873,61 & 123,63 & 11,76 & 51,03 & 345,28 & 63,87 & 63,87 & 345,28 \\
\hline Pelophylax perezi & 29TPF50 & 100,00 & 126,65 & 92,55 & 35,46 & 5783,08 & 277,61 & 19,91 & 257,70 & 55,85 & 202,85 & 203,38 & 55,85 & 993,74 & 146,73 & 10,17 & 53,88 & 398,03 & 66,35 & 67,84 & 398,03 \\
\hline Pelophylax perezi & 29TPF51 & 101,00 & 131,64 & 96,88 & 36,43 & 5782,81 & 284,82 & 22,60 & 262,23 & 60,43 & 208,01 & 208,14 & 60,43 & 944,00 & 138,90 & 9,93 & 53,56 & 377,33 & 64,01 & 64,23 & 377,33 \\
\hline Pelophylax perezi & 29TPF52 & 100,00 & 137,54 & 101,08 & 37,46 & 5779,03 & 292,46 & 25,97 & 266,49 & 65,88 & 213,69 & 213,69 & 65,70 & 888,20 & 129,97 & 9,39 & 53,19 & 353,77 & 60,27 & 60,27 & 353,77 \\
\hline Pelophylax perezi & 29TPF53 & 100,00 & 141,10 & 103,66 & 38,12 & 5763,83 & 296,81 & 28,05 & 268,76 & 69,62 & 216,60 & 216,60 & 69,12 & 850,97 & 123,81 & 9,14 & 52,78 & \begin{tabular}{|l|l|}
337,87 \\
\end{tabular} & 57,88 & 57,88 & 337,83 \\
\hline Pelophylax perezi & 29TPF54 & 101,00 & 142,68 & 105,21 & 38,51 & 5744,58 & 298,77 & 28,79 & 269,97 & 72,03 & 217,84 & 217,84 & 70,80 & 832,23 & 120,63 & 9,06 & 52,52 & 329,99 & 56,84 & 56,84 & 329,90 \\
\hline Pelophylax perezi & 29TPF55 & 100,00 & 143,81 & 106,25 & 38,74 & 5720,69 & 300,02 & 29,27 & 270,76 & 74,26 & 218,64 & 218,64 & 72,02 & 814,43 & 117,22 & 9,14 & 52,12 & 322,14 & 56,22 & 56,22 & 321,98 \\
\hline Pelophylax perezi & 29TPF56 & 100,00 & 139,49 & 105,69 & 38,59 & 5705,64 & 295,63 & 25,55 & 270,08 & 70,99 & 214,41 & 214,41 & 68,22 & 837,54 & 120,32 & 9,97 & 51,84 & 331,83 & 59,22 & 59,22 & 331,53 \\
\hline Pelophylax perezi & 29TPF57 & 101,00 & $\begin{array}{l}13,43,38 \\
134,38\end{array}$ & 105,98 & 30,67| & 5715,32 & 291,15 & $\begin{array}{l}3,035 \\
20,48\end{array}$ & \begin{tabular}{|l|}
270,66 \\
\end{tabular} & $\frac{\mid 0,99}{63,93}$ & \begin{tabular}{|l|}
209,56 \\
\end{tabular} & \begin{tabular}{|l|}
209,56 \\
\end{tabular} & $\begin{array}{ll}60,2<2 \\
63,28\end{array}$ & 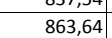 & \begin{tabular}{|l|}
124,24 \\
124,24
\end{tabular} & $\begin{array}{r}31,01 \\
11,01\end{array}$ & $\begin{array}{l}1,104 \\
51,61\end{array}$ & | & $\begin{array}{l}30,2<4 \\
62,44 \\
\end{array}$ & \begin{tabular}{|l|l|l|l|}
62,44 \\
6
\end{tabular} & 343,14 \\
\hline Pelophylax perezi & 29TPF58 & 99,00 & 136,87 & 107,07 & 38,82 & 5702,16 & 293,58 & 22,00 & 271,58 & 65,83 & 211,69 & 211,69 & 65,64 & 829,85 & 117,91 & 11,02 & 50,93 & 327,95 & 60,81 & 60,81 & 327,95 \\
\hline Pelophylax perezi & 29TPF59 & 101,00 & 140,06 & 107,68 & 39,02 & 5679,65 & 296,10 & 24,35 & 271,75 & 70,61 & 214,39 & 214,39 & 68,77 & 794,76 & 111,26 & 10,91 & 50,28 & 312,01 & 58,91 & 58,91 & 312,01 \\
\hline Pelophylax perezi & 29TPF60 & 100,00 & 126,95 & 93,99 & 35,55 & 5856,68 & 279,99 & 18,95 & 261,04 & 60,23 & 204,05 & 204,72 & 55,29 & 931,01 & 135,27 & 9,88 & 52,80 & \begin{tabular}{|l|l|}
369,36 \\
\end{tabular} & 63,92 & \begin{tabular}{|c|}
65,18 \\
\end{tabular} & 369,14 \\
\hline Pelophylax perezi & 29TPF61 & 100,00 & 132,16 & 97,93 & 36,39 & 5855,03 & 287,09 & 21,78 & 265,31 & 64,63 & 209,47 & 209,65 & 59,93 & 881,01 & 127,52 & 9,5 & 52,48 & 348,64 & 61,25 & 61,44 & 348,50 \\
\hline Pelophylax perezi & 29TPF62 & 100,00 & $\frac{132}{131}$ & $\begin{array}{l}99,50 \\
9,50\end{array}$ & 30,4 & F8546,01 & 287,62 & \begin{tabular}{|l|}
20,89 \\
20
\end{tabular} & \begin{tabular}{|l|}
$263,31,74$ \\
266,
\end{tabular} & $\begin{array}{l}64,35 \\
63,30 \\
\end{array}$ & \begin{tabular}{|l|}
209,20 \\
2017
\end{tabular} & \begin{tabular}{|l|}
209,32 \\
2093
\end{tabular} & $\begin{array}{l}39,93 \\
59,75 \\
\end{array}$ & $\begin{array}{l}801,01 \\
870,22 \\
\end{array}$ & $\begin{array}{l}127,525 \\
125,57\end{array}$ & $\begin{array}{l}, 32 \\
9,66\end{array}$ & 52,40 & $\begin{array}{l}48,04 \\
344,02\end{array}$ & $\begin{array}{l}61,23 \\
61,16 \\
\end{array}$ & $\begin{array}{l}0,44,35 \\
61,35\end{array}$ & $\begin{array}{l}348,30 \\
343,96\end{array}$ \\
\hline Pelophylax perezi & \begin{tabular}{|l|} 
29TPF63 \\
\end{tabular} & 101,00 & 134,25 & 101,94 & \begin{tabular}{|c|}
37,38 \\
\end{tabular} & 5835,98 & 290,96 & 21,88 & 269,08 & 63,60 & 211,38 & 211,38 & 61,97 & 844,73 & 121,62 & 9,68 & 52,03 & 333,64 & 59,71 & 59,71 & 333,62 \\
\hline Pelophylax perezi & 29TPF64 & 99,00 & 141,58 & 105,17 & 38,20 & 5807,07 & 298,94 & 27,17 & 271,77 & 72,58 & 217,82 & 217,82 & 69,07 & 782,20 & 111,55 & 8,88 & 51,52 & 307,77 & 55,02 & 55,02 & 307,29 \\
\hline Pelophylax perezi & $\begin{array}{l}\text { 29TPF65 } \\
\end{array}$ & 101,00 & 133,16 & 104,27 & 37,5 & 5804,01 & 290,69 & 19,73 & 270,97 & 62,06 & 209,68 & 209,68 & 61,14 & 831,42 & 118,91 & 10,1 & 51,36 & 28,13 & 60,39 & 60,39 & 328,13 \\
\hline Pelophylax perezi & 29TPF66 & 100,00 & 138,95 & 106,55 & 38, & 5783,69 & 296,75 & 23,90 & 272,85 & $\begin{array}{ll}68,93 \\
\end{array}$ & \begin{tabular}{|l|}
214,97 \\
\end{tabular} & 214,97 & 66,74 & \begin{tabular}{|l|l|}
780,99 \\
\end{tabular} & \begin{tabular}{|l|}
110,72 \\
110,1
\end{tabular} & $\begin{array}{c}9,1,6 \\
9,6\end{array}$ & 50,94 & $\begin{array}{l}300,18 \\
307,18\end{array}$ & $\begin{array}{l}56,57 \\
5,5\end{array}$ & \begin{tabular}{|l|}
56,57 \\
\end{tabular} & 306,92 \\
\hline Pelophylax perezi & \begin{tabular}{|l|} 
29TPF67 \\
\end{tabular} & 100,00 & 138,89 & 107,36 & 38,83 & 5764,51 & 296,72 & 23,36 & 273,36 & 69,09 & 214,57 & 214,57 & 66,78 & 768,30 & 108,26 & 9,93 & 50,41 & \begin{tabular}{|c|}
301,58 \\
\end{tabular} & 56,62 & 56,62 & 301,41 \\
\hline Pelophylax perezi & 29TPF68 & 101,00 & 125,92 & 105,07 & 38,24 & 5746,97 & 283,86 & 12,69 & 271,17 & 55,71 & 201,92 & 201,94 & 54,87 & 847,90 & 119,58 & 11,95 & 50,01 & 334,57 & 65,86 & 65,90 & 334,55 \\
\hline Pelophylax perezi & 29TPF69 & 100,00 & 124,72 & 105,60 & 38,38 & 5737,43 & 282,95 & 11,12 & 271,83 & 53,84 & 200,67 & 200,69 & 53,80 & 842,56 & 118,37 & 12,49 & 49,51 & 332,58 & 66,68 & 66,71 & 332,58 \\
\hline Pelophylax perezi & 29TPF70 & 101,00 & 126,52 & 95,46 & 35,4 & 5924,88 & 281,66 & 17,39 & 264,27 & 61,88 & 204,75 & 205,50 & 54,21 & 874,26 & 124,50 & 9,71 & 51,57 & 34 & 61,95 & 63,13 & 342,25 \\
\hline Pelophylax perezi & 29TPF71 & 100,00 & 12 & $\begin{array}{l}30,40 \\
97,36\end{array}$ & 36,6 & $\begin{array}{l}592,400 \\
5919,39\end{array}$ & 280,00 & $\begin{array}{l}1,035 \\
17,05 \\
\end{array}$ & \begin{tabular}{|l|}
266,14 \\
\end{tabular} & $\begin{array}{l}1,20 \\
62,28 \\
\end{array}$ & \begin{tabular}{|l|}
205,32 \\
\end{tabular} & 205,96 & \begin{tabular}{|l|l|}
54,80 \\
5
\end{tabular} & \begin{tabular}{|l|l|}
856,38 \\
\end{tabular} & $\begin{array}{l}124,302 \\
121,62\end{array}$ & $\begin{array}{l}, 1+1 \\
9,80\end{array}$ & $\begin{array}{l}1,31 \\
51,38\end{array}$ & $\begin{array}{l}344,54 \\
336,79\end{array}$ & $\begin{array}{l}61,713 \\
61\end{array}$ & \begin{tabular}{|l|l|l|l|}
62,35 \\
\end{tabular} & $\begin{array}{l}34,25 \\
334,93 \\
\end{array}$ \\
\hline Pelophylax perezi & 29TPF72 & 100,00 & 127,59 & 99,08 & 36,53 & 5904,58 & 284,36 & 16,52 & 267,84 & 62,55 & 205,84 & 205,97 & 55,05 & 843,94 & \begin{tabular}{|l|l|}
119,73 \\
\end{tabular} & 9,89 & 51,16 & 331,56 & 61,64 & \begin{tabular}{|l|l|}
61,79 \\
\end{tabular} & 330,15 \\
\hline Pelophylax perezi & 29TPF73 & 100,00 & 133,46 & 102,44 & 37,27 & 5891,66 & 291,47 & 20,37 & 271,10 & 67,96 & 211,44 & 211,44 & 60,61 & $\mid 792,11$ & 111,81 & \begin{tabular}{|l|}
9,37 \\
9,37
\end{tabular} & 50,82 & 310,49 & 57,83 & \begin{tabular}{|l|l|}
57,83 \\
\end{tabular} & 309,20 \\
\hline Pelophylax perezi & 29TPF74 & 101,00 & 141,89 & 105,77 & 38,07 & 5862,92 & 300,65 & 26,54 & 274,11 & 75,85 & 218,98 & 218,98 & 68,70 & 723,89 & 101,04 & 8,58 & & 282,67 & 52,56 & 52,56 & 280,76 \\
\hline Pelophylax perezi & 29TPF75 & 99,00 & 134,33 & 105,26 & 37,9 & 5864,59 & 293,29 & 19,66 & 273,63 & 67,46 & 21 & 21 & 61,42 & 765,39 & 107,37 & 9,63 & 50,20 & 299,43 & 57,12 & 57,12 & 298 \\
\hline Pelophylax perezi & 29TPF76 & 101,00 & 133,84 & 105,95 & 38,20 & 5841,09 & 292,79 & 18,91 & 273,88 & 66,99 & 210,85 & 210,86 & 61,26 & 757,77 & $\begin{array}{l}105,79 \\
\end{array}$ & 9,82 & 49,82 & 296,32 & 57,40 & 57,40 & 295,41 \\
\hline Pelophylax perezi & 29TPF77 & 100,00 & 137,67 & 107,68 & 38,62 & 5820,77 & 296,98 & 21,54 & 275,44 & 71,36 & 214,26 & 214,26 & 64,96 & 721,04 & 99,86 & 9,74 & 49,31 & 281,24 & 54,96 & 54,96 & 280,28 \\
\hline Pelophylax perezi & 29TPF78 & 100,00 & 129,88 & 107,05 & 38,40 & 580903 & 289,73 & 14,60 & 275,14 & 62,27 & 206,69 & 206,69 & 57,73 & 759.94 & 105.55 & 10,85 & 49,07 & 297.53 & 59.92 & 59.92 & 297,20 \\
\hline Pelophylax perezi & 29TPF79 & 100,00 & 123,01 & 106,30 & 38,32 & 5778,23 & 282,90 & 8,87 & 274,03 & 54,38 & 199,62 & 199 & 51, & 793,80 & 109,92 & 12,11 & 48 & 311,30 & 65,06 & 65,08 & 311,22 \\
\hline Pelophylax perezi & 29TPF80 & 100,00 & 124,54 & 96,64 & 35,69 & 5984,11 & 281,57 & 14,38 & 267,19 & 59,31 & 203,48 & 204,49 & 51,68 & 829,57 & 115,42 & | & 50,31 & 324,36 & 60,92 & 62,19 & 319,90 \\
\hline
\end{tabular}




\begin{tabular}{|c|c|c|c|c|c|c|c|c|c|c|c|c|c|c|c|c|c|c|c|c|c|}
\hline TAXON & UTM & $\mathrm{km} 2$ & B101 & B102 & $\mathrm{BIO3}$ & B104 & B105 & B106 & B107 & B108 & B109 & B1010 & BIO11 & BIO12 & 81013 & BIO14 & BIO15 & BIO16 & B1017 & B1018 & B1019 \\
\hline Pelophylax perezi & 29TPF81 & 100,00 & 126,60 & 98,86 & 36,16 & 5977,64 & 284,65 & 15,28 & 269,37 & 60,96 & 205,60 & 206,19 & 53,50 & 801,99 & 111,22 & 9,53 & 50,05 & 313,21 & 59,84 & 60,40 & 308,99 \\
\hline Pelophylax perezi & 29TPF82 & 100,00 & 131,03 & 101,63 & \begin{tabular}{|l|l}
36,88 \\
\end{tabular} & 5965,24 & 290,16 & 18,01 & 272,15 & 64,99 & 210,07 & 210,10 & 57,57 & 761,25 & 105,14 & 9,16 & 49,85 & 296,71 & 57,24 & 57,26 & 292,83 \\
\hline Pelophylax perezi & 29TPF83 & 101,00 & 129,88 & 102,77 & 37,09 & 5951,56 & 289,35 & 16,37 & 272,99 & 63,97 & 208,81 & 208,81 & 56,52 & 756,55 & 104,25 & 9,48 & 49,50 & 294,66 & 57,70 & 57,70 & 291,10 \\
\hline Pelophylax perezi & 29TPF84 & 99,00 & 136,85 & 105,53 & 37,81 & 5927,83 & 296,95 & 21,49 & 275,46 & 70,53 & 215,16 & 215,16 & 63,22 & 702,12 & 96,03 & 8,77 & 49,13 & 272,78 & 53,29 & 53,29 & 269,14 \\
\hline Pelophylax perezi & 29TPF85 & 101,00 & 133,76 & 105,84 & $\begin{array}{l}37,90 \\
\end{array}$ & 5913,94 & 294,04 & 18,42 & 275,63 & 67,60 & 211,91 & 211,91 & 60,34 & 713,10 & 97,54 & 9,38 & 48,85 & 277,16 & 55,33 & 55,33 & 274,08 \\
\hline Pelophylax perezi & 29TPF86 & 100,00 & 126,57 & 105,56 & 37,85 & 5900,58 & 287,13 & 11,93 & 275,19 & 60,90 & 204,84 & 204,84 & 53,61 & 744,61 & 101,80 & 10,30 & 48,49 & 289,46 & 59,65 & 59,65 & 287,21 \\
\hline Pelophylax perezi & \begin{tabular}{|l|} 
29TPF87 \\
\end{tabular} & 99,00 & 128,44 & 106,95 & \begin{tabular}{|l|l|}
38,07 \\
\end{tabular} & 5880,29 & 289,34 & 12,93 & 276,42 & 62,64 & 206,21 & 206,21 & 55,45 & 721,95 & 98,36 & 10,32 & 48,11 & 280,52 & 58,36 & 58,36 & 278,59 \\
\hline Pelophylax perezi & 29TPF88 & 101,00 & 131,27 & 108,01 & 38,51 & 5851,74 & 291,97 & 14,96 & 277,01 & 65,44 & 208,61 & 208,61 & 58,38 & 695,99 & 94,18 & 10,34 & $\begin{array}{l}47,79 \\
47\end{array}$ & 270,13 & 56,85 & 56,85 & 268,09 \\
\hline Pelophylax perezi & 29TPF89 & 100,00 & 127,67 & 108,27 & 38,52 & 5831,94 & 288,98 & 11,46 & 277,52 & 62,03 & 204,89 & 204,89 & 55,23 & 706,50 & 95,57 & 11,02 & 47,46 & 274,56 & 59,14 & 59,14 & 273,30 \\
\hline Pelophylax perezi & 29TPF90 & 100,00 & 128,32 & 100,02 & 36,06 & \begin{tabular}{|l|l|}
6047,87 \\
\end{tabular} & 288,53 & 15,82 & 272,71 & 61,90 & 208,45 & 209,05 & 54,46 & 745,06 & 100,55 & 9,00 & 48,82 & 288,52 & 56,83 & 57,33 & 281,68 \\
\hline Pelophylax perezi & 29TPF91 & 101,00 & 127,38 & 101,04 & 36,35 & 6036,27 & 287,82 & 14,43 & 273,39 & 60,91 & 207,49 & 207,84 & 53,55 & 739,90 & 99,64 & 9,21 & 48,60 & 286,37 & 57,43 & 57,71 & 279,78 \\
\hline Pelophylax perezi & 29TPF94 & 100,00 & 127,14 & 104,70 & 37,31 & 5992,22 & 288,67 & 12,45 & 276,22 & 60,62 & 206,74 & 206,74 & 53,35 & 706,35 & 94,23 & 9,63 & 47,70 & 272,59 & 57,28 & 57,28 & 267,10 \\
\hline Pelophylax perezi & 29TPF95 & 100,00 & 123,98 & 105,18 & 37,72 & 5972,06 & 285,81 & 9,47 & 276,34 & 57,90 & 203,57 & 203,57 & 50,66 & 712,27 & 94,80 & 9,98 & 47,46 & 274,87 & 58,80 & 58,80 & 269,70 \\
\hline Pelophylax perezi & 29TPF96 & 100,00 & 125,79 & 106,55 & 38,02 & 5947,17 & 287,79 & 10,27 & 277,52 & 59,50 & 204,76 & 204,76 & 52,34 & 691,95 & 91,70 & 10,15 & 47,00 & 266,69 & 57,95 & 57,95 & 261,99 \\
\hline Pelophylax perezi & \begin{tabular}{|l|} 
29TPF97 \\
\end{tabular} & 101,00 & 119,67 & 106,41 & 37,99 & 5930,73 & 282,07 & 4,67 & 277,39 & 53,80 & 198,61 & 198,61 & 46,65 & 718,31 & 95,14 & 11,02 & 46,70 & $276,97 \mid$ & 61,95 & 61,95 & 272,98 \\
\hline Pelophylax perezi & 29TPF98 & 100,00 & 120,57 & 107,46 & 38,12 & 5908,98 & 283,11 & 5,07 & 278,03 & 54,57 & 199,09 & 199,09 & 47,67 & 701,41 & 92,47 & 11,18 & 46,30 & 270,26 & 61,39 & 61,39 & 266,71 \\
\hline Pelophylax perezi & 29TPF99 & 100,00 & 130,68 & 109,56 & 38,84 & 5876,27 & 292,54 & 13,18 & 279,36 & 64,36 & 208,23 & 208,23 & 57,49 & 638,01 & 83,60 & 10,49 & 46,07 & 245,56 & 55,23 & 55,23 & 241,94 \\
\hline Pelophylax perezi & 29TPG00 & 101,00 & 128,55 & 101,51 & 39,68 & 5268,55 & 274,20 & 21,32 & 252,88 & 63,34 & 197,31 & 197,49 & 63,30 & $\mid 1164,34$ & 161,88 & 15,93 & 51,68 & 461,28 & 85,32 & 88,02 & 461,28 \\
\hline Pelophylax perezi & 29TPG01 & 100,00 & 111,76 & 92,42 & 37,99 & 5168,72 & 251,69 & 11,49 & 240,20 & 49,41 & 180,21 & 180,35 & 49,41 & 1289,31 & 176,79 & 20,77 & 50,47 & 510,67 & 101,87 & 103,85 & 510,67 \\
\hline Pelophylax perezi & 29TPG02 & 100,00 & 106,85 & 88,80 & 37,21 & 5111,32 & 244,26 & 9,02 & 235,24 & 45,71 & 174,80 & 174,99 & 45,71 & 1310,86 & 176,48 & 22,83 & 49,52 & 516,13 & 107,83 & 110,31 & 516,13 \\
\hline Pelophylax perezi & 29TPG03 & 101,00 & 100,34 & 86,02 & 36,70 & 5053,09 & 235,86 & 4,79 & 231,07 & 40,97 & 167,75 & 168,01 & 40,55 & 1349,43 & 178,69 & 25,66 & 48,45 & 527,55 & 116,37 & 118,48 & 527,53 \\
\hline Pelophylax perezi & 29TPG04 & 100,00 & 105,08 & 88,21 & 37,23 & 5064,05 & 241,28 & 7,38 & 233,90 & 49,16 & 172,41 & $\begin{array}{l}172,65 \\
\end{array}$ & 44,73 & \begin{tabular}{|l|}
1295,86 \\
1396
\end{tabular} & 171,56 & 25,20 & 47,82 & 502,97 & 113,33 & 115,43 & 502,81 \\
\hline Pelophylax perezi & 29TPG05 & 101,00 & 119,89 & 93,96 & 38,26 & 5155,67 & 258,22 & 15,84 & 242,38 & 63,14 & 187,92 & 188,01 & 57,21 & 1153,20 & 156,06 & 22,16 & 47,08 & 443,66 & 100,34 & $\mid 101,71$ & 440,77 \\
\hline Pelophylax perezi & 29TPG06 & 101,00 & 120,72 & 93,71 & 38,19 & 5132,34 & 258,02 & 16,47 & 241,55 & 63,99 & 188,26 & 188,35 & 58,39 & 1133,64 & 155,70 & 22,98 & 46,17 & 434,04 & 101,53 & 103,93 & 429,13 \\
\hline Pelophylax perezi & 29TPG07 & 100,00 & 123,10 & 93,56 & 38,15 & 5116,46 & 259,22 & 18,05 & 241,17 & 66,16 & 190,42 & 190,56 & 60,93 & 1099,61 & 152,97 & 23,37 & 45,42 & 418,36 & 101,12 & 104,45 & 411,31 \\
\hline Pelophylax perezi & 29TPG08 & 101,00 & 122,86 & 92,65 & 38,09 & 5064,76 & 257,47 & 18,36 & 239,11 & 66,42 & 189,60 & 189,72 & 61,56 & 1094,30 & 153,24 & 24,48 & 44,66 & 414,44 & 103,56 & 107,31 & 405,74 \\
\hline Pelophylax perezi & 29TPG10 & 100,00 & 126,91 & 102,29 & 39,40 & 5384,67 & 275,27 & 18,51 & $\mid 256,76$ & $\begin{array}{l}0,42,43 \\
60\end{array}$ & 197,61 & \begin{tabular}{|l|l|}
197,66 \\
\end{tabular} & 60,43 & 1124,66 & $\mid 158,03$ & 15,63 & 51,73 & $\mid 446,89$ & $\begin{array}{l}2,, 92 \\
82\end{array}$ & $\begin{array}{l}83,49 \\
83\end{array}$ & 446,89 \\
\hline Pelophylax perezi & 29TPG11 & 100,00 & 130,59 & 102,55 & 39,37 & 5379,72 & 278,26 & 21,08 & 257,18 & 63,94 & 201,00 & 201,04 & 63,94 & 1069,72 & 146,26 & 15,45 & 50,64 & 420,48 & 80,50 & 80,87 & 420,48 \\
\hline Pelophylax perezi & 29TPG12 & 100,00 & 115,84 & 95,37 & 38,04 & 5283,63 & 259,08 & 11,91 & 247,16 & 51,65 & 185,68 & 185,71 & 51,65 & 1176,26 & 158,86 & 19,73 & 49,55 & 462,11 & 95,00 & 95,45 & 462,11 \\
\hline Pelophylax perezi & 29TPG13 & 101,00 & 114,59 & 94,29 & 37,88 & 5258,16 & 256,75 & 11,16 & 245,59 & 51,08 & 184,25 & 184,28 & 50,83 & 1171,31 & 155,10 & 20,77 & 48,71 & 457,27 & 97,45 & 97,95 & 457,27 \\
\hline Pelophylax perezi & 29TPG14 & 101,00 & 113,99 & 93,88 & 37,92 & 5231,74 & 255,38 & 10,69 & 244,69 & 55,23 & $\begin{array}{ll}183,38 \\
\end{array}$ & 183,44 & 50,77 & 1159,41 & 152,44 & 21,83 & 47,73 & 449,20 & 99,54 & 100,49 & 449,09 \\
\hline Pelophylax perezi & 29TPG16 & 101,00 & 115,22 & $\begin{array}{l}93,66 \\
93,6\end{array}$ & 37,91 & 5183,58 & 254,83 & $\begin{array}{l}0,11,28 \\
11\end{array}$ & 243,54 & 58,25 & \begin{tabular}{|l|l|}
183,88 \\
1030
\end{tabular} & \begin{tabular}{|l|}
183,96 \\
\end{tabular} & 52,68 & $\mid \begin{array}{l}1123,78 \\
1123\end{array}$ & $\mid$ & 23,44 & $\begin{array}{ll}45,97 \\
45\end{array}$ & $\begin{array}{l}4431,18 \\
431,18\end{array}$ & \begin{tabular}{|c|}
102,31 \\
10,4
\end{tabular} & \begin{tabular}{|l|}
103,57 \\
\end{tabular} & 427,11 \\
\hline Pelophylax perezi & 29TPG17 & 99,00 & 118,91 & 94,17 & 38,01 & 5173,19 & 257,53 & 13,69 & 243,84 & 61,46 & 187,16 & 187,19 & 56,20 & 1081,36 & 147,99 & 23,39 & 45,11 & 412,32 & 100,59 & 101,89 & 406,09 \\
\hline Pelophylax perezi & 29TPG20 & 100,00 & 116,55 & 98,57 & 38,25 & 5422,90 & 264,90 & 10,39 & 254,51 & 50,42 & 188,25 & 188,27 & 50,42 & 1146,33 & 161,59 & 17,49 & 51,15 & 456,30 & 88,32 & 88,41 & 456,30 \\
\hline Pelophylax perezi & 29TPG21 & 101,00 & 126,25 & 102,04 & 38,88 & 5451,82 & 275,59 & 16,75 & 258,84 & 59,06 & 197,96 & 197,96 & 59,06 & 1047,46 & 144,56 & 15,91 & 50,38 & 412,99 & 80,47 & 80,47 & 412,99 \\
\hline Pelophylax perezi & 29TPG22 & 101,00 & 133,16 & 103,27 & 39,01 & 5460,32 & 282,04 & 21,44 & 260,59 & 66,48 & 204,71 & 204,71 & 65,46 & 970,41 & 130,05 & 15,04 & 49,31 & 377,52 & 75,53 & 75,53 & 377,52 \\
\hline Pelophylax perezi & 29TPG23 & 100,00 & $\begin{array}{l}13,10 \\
128,44\end{array}$ & 100,89 & 38,75 & $\begin{array}{l}340,0,26,73 \\
542,\end{array}$ & 270,045 & \begin{tabular}{|l|l|}
18,16 \\
\end{tabular} & \begin{tabular}{|l|}
257,20 \\
\end{tabular} & 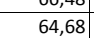 & \begin{tabular}{|l|}
199,68 \\
\end{tabular} & \begin{tabular}{|l|}
$199,68,1$ \\
\end{tabular} & $\begin{array}{l}3,404 \\
61,42\end{array}$ & \begin{tabular}{|l|}
793,41 \\
993,4
\end{tabular} & $\mid$ & $\begin{array}{l}10,04 \\
16,78\end{array}$ & $\begin{array}{l}45,38 \\
48,38\end{array}$ & 385,02 & $\begin{array}{l}3,030 \\
80,62\end{array}$ & $\begin{array}{l}1,030 \\
80,62\end{array}$ & 384,57 \\
\hline Pelophylax perezi & 29TPG24 & 100,00 & 128,78 & 100,20 & 38,64 & 5413,35 & 274,57 & 18,36 & 256,21 & 68,08 & 199,94 & 199,94 & 62,10 & 972,87 & 127,05 & 17,39 & 47,39 & 374,59 & 81,45 & 81,45 & 372,83 \\
\hline Pelophylax perezi & 29TPG25 & 100,00 & 120,04 & 97,11 & 38,12 & 5336,47 & 263,87 & 12,51 & 251,36 & 60,75 & 190,56 & 190,56 & 54,99 & \begin{tabular}{|c|}
1034,95 \\
\end{tabular} & 137,25 & 20,39 & 46,61 & 398,36 & 91,23 & 91,43 & 395,74 \\
\hline Pelophylax perezi & 29TPG26 & 101,00 & 105,01 & 92,90 & 37,58 & 5216,32 & 246,69 & 2,59 & 244,09 & 48,25 & 174,52 & 174,57 & 42,60 & 1153,25 & 153,62 & 25,51 & 45,44 & 443,06 & 108,79 & 109,53 & 438,97 \\
\hline Pelophylax perezi & 29TPG28 & 101,00 & 102,96 & 91,96 & 37,8 & 5109,11 & 242,32 & 1,67 & 240,65 & 47,18 & 170,96 & 171,02 & 42,07 & 1159,66 & \begin{tabular}{|l|l|}
156,59 \\
\end{tabular} & 27,99 & 43,84 & 442,53 & 115,48 & 117,44 & 435,04 \\
\hline Pelophylax perezi & 29TPG30 & 101,00 & 129,20 & 104,36 & 38,86 & 5549,78 & 281,83 & 17,57 & 264,26 & 60,49 & 202,10 & 202,10 & 60,49 & 983,61 & 138,69 & 14,19 & 51,07 & 390,06 & (73,76 & 73,76 & 390,06 \\
\hline Pelophylax perezi & 29TPG31 & 99,00 & 119,83 & 101,17 & 38,41 & 5507,86 & 270,92 & 10,81 & 260,12 & 52,25 & 192,70 & 192,70 & 52,25 & 1040,03 & \begin{tabular}{|l|l|l|l|l}
144,93 \\
\end{tabular} & 16,75 & 50,13 & 412,02 & 81,99 & 81,99 & 412,02 \\
\hline Pelophylax perezi & 29TPG32 & 100,00 & 121,65 & 101,25 & 38,42 & 5496,12 & 272,07 & 11,98 & 260,09 & 54,58 & 194,31 & 194,31 & 54,26 & 1006,25 & 137,16 & 16,95 & 49,15 & 395,01 & 81,34 & 81,34 & 395,01 \\
\hline Pelophylax perezi & 29TPG33 & 100,00 & 121,95 & 100,70 & 38,3 & 5475,42 & 271,29 & 12,10 & 259,19 & 57,53 & 194,34 & 194,34 & 54,80 & 986,87 & 131,60 & 17,61 & 48,16 & 84,05 & 82,26 & 82,26 & 383,95 \\
\hline Pelophylax perezi & 29TPG34 & 101,00 & 119,10 & 99,36 & 38,7 & $\begin{array}{l}5438,34 \\
543,35\end{array}$ & 267,03 & 10,11 & 256,92 & 58,52 & \begin{tabular}{|l|}
191,03 \\
\end{tabular} & $\begin{array}{l}191,03 \\
\end{array}$ & 52,56 & $\begin{array}{l}996,47 \\
\end{array}$ & $\begin{array}{l}130,92 \\
130,\end{array}$ & 19,09 & $\begin{array}{l}40,10 \\
47,19 \\
\end{array}$ & 385,91 & 86,18 & 86,18 & 385,02 \\
\hline Pelophylax perezi & 29TPG & 101,00 & 108,30 & 95,95 & 37,66 & 5353,04 & 254,26 & 3,04 & 251,22 & 49,68 & 179,55 & 179,55 & 43,77 & \begin{tabular}{|c|}
1075,13 \\
\end{tabular} & 141,59 & 22,7 & 46,07 & \begin{tabular}{|l|l|}
415,19 \\
\end{tabular} & 98,62 & 98,63 & 412,73 \\
\hline Pelophylax perezi & 29TPG37 & 100,00 & 81,18 & 89,85 & 36,97 & 5161,60 & 223,24 & $-16,66$ & 239,90 & 26,61 & 150,66 & 150,77 & 20,92 & 1289,79 & 168,92 & 33,27 & 43,10 & 490,73 & $\begin{array}{r}134,79 \\
\end{array}$ & 135,32 & 482,99 \\
\hline Pelophylax perezi & 29TPG38 & 100,00 & 96,75 & 92,85 & 37,72 & 5178,34 & 238,76 & $-4,64$ & 243,39 & 40,47 & 165,90 & 165,96 & 35,20 & 1152,50 & 153,75 & 28,99 & 43,10 & 438,96 & 118,41 & 119,17 & 430,55 \\
\hline Pelophylax perezi & 29TPG40 & 100,00 & 139,68 & 107,25 & 39, & 5619,81 & 294,02 & 24,54 & 269,48 & 69,90 & 213,18 & 213,18 & 69,41 & 839 & 116,78 & 11,78 & 50,19 & 329,39 & 62,42 & 62,42 & 329,39 \\
\hline Pelophylax perezi & 29TPG41 & 100,00 & 13 & 105,64 & 38 & | $561,03,97$ & 286,01 & $\begin{array}{l}4,434 \\
18,46\end{array}$ & \begin{tabular}{|l|}
267,55 \\
267
\end{tabular} & $\begin{array}{l}63,01 \\
63,0\end{array}$ & \begin{tabular}{|l|}
205,82 \\
250
\end{tabular} & \begin{tabular}{|l|}
205,82 \\
25
\end{tabular} & \begin{tabular}{l|l}
62,58 \\
62,5
\end{tabular} & \begin{tabular}{|l|}
880,38 \\
880,
\end{tabular} & $\mid$ & $\begin{array}{l}1,1,70 \\
13,71\end{array}$ & \begin{tabular}{|l|l|}
49,58 \\
49
\end{tabular} & $\mid 345,71$ & $\begin{array}{l}62,42,32 \\
68,\end{array}$ & $\begin{array}{ll}62,42,32 \\
68,\end{array}$ & $\begin{array}{l}34,53,69 \\
345,69\end{array}$ \\
\hline Pelophylax perezi & 29TPG42 & 101,00 & 119,50 & 102,14 & 38,32 & 5551,84 & 272,26 & 8,95 & 263,32 & 51,70 & 193,03 & 193,03 & 51,39 & 962,54 & 131,89 & 16,71 & 48,75 & \begin{tabular}{|c|}
378,48 \\
\end{tabular} & 79,34 & 79,34 & 378,47 \\
\hline Pelophylax perezi & 29TPG43 & 100,00 & 117,15 & 101,03 & 38,13 & 5522,05 & 268,85 & 7,27 & 261,57 & 52,89 & 190,41 & 190,41 & 49,60 & 966,51 & 130,02 & 18,09 & 47,76 & 377,38 & 82,60 & 82,60 & 377,30 \\
\hline Pelophylax perezi & 29TPG44 & 100,00 & 113,68 & 99,82 & 38,01 & 5485,88 & 264,16 & 4,66 & 259,50 & 52,80 & 186,67 & 186,67 & 46,81 & 981,93 & \begin{tabular}{|l|}
129,95 \\
\end{tabular} & 19,66 & 46,90 & 381,73 & 87,10 & 87,10 & 380,84 \\
\hline Pelophylax perezi & 29TPG46 & 100,00 & 98,28 & 95,56 & 37,5 & 5354,62 & 245,40 & $-5,79$ & 251,19 & 39,99 & 169,93 & 165 & 34 & 1090,34 & 143,81 & 25,79 & 44,43 & 418,90 & 107,37 & 107,37 & 413,87 \\
\hline Pelophylax perezi & $\begin{array}{l}\text { 29TPG47 } \\
\end{array}$ & $\begin{array}{l}101,00 \\
100\end{array}$ & $\begin{array}{l}8,200 \\
87,27\end{array}$ & $\begin{array}{ll}53,12 \\
93,0\end{array}$ & | & $\begin{array}{l}5357,02 \\
5272,05\end{array}$ & $\begin{array}{l}24,42,57 \\
232,\end{array}$ & \begin{tabular}{|c|c|}
$-2,13,80$ \\
$-13,80$
\end{tabular} & \begin{tabular}{|l|}
246,38 \\
2419
\end{tabular} & | & \begin{tabular}{|l|l|}
158,08 \\
15,0
\end{tabular} & $\begin{array}{l}158,12 \\
158,12\end{array}$ & $\begin{array}{l}4,214 \\
25,08\end{array}$ & $\begin{array}{l}1178,80 \\
1178,80\end{array}$ & $\begin{array}{l}43,01 \\
154,82 \\
\end{array}$ & 30,25 & $\begin{array}{l}44,45 \\
43,01 \\
\end{array}$ & $\begin{array}{l}4+10,90 \\
449,01\end{array}$ & \begin{tabular}{|l|l|}
123,01 \\
\end{tabular} & \begin{tabular}{|l|l|}
123,16 \\
\end{tabular} & $\begin{array}{l}41,01 \\
441,24\end{array}$ \\
\hline Pelophylax perezi & 29TPG48 & 100,00 & 108,67 & 96,86 & 37,97 & 5314,99 & 253,42 & 2,25 & 251,18 & 49,64 & 179,27 & 179,29 & 44,47 & 997,65 & 133,38 & 24,48 & 42,97 & 380,02 & 101,32 & 101,38 & 371,02 \\
\hline Pelophylax perezi & 29TPG49 & 101,00 & 118,67 & 97,49 & 38,41 & 5283,64 & 261,09 & 10,54 & 250,55 & 58,99 & 188,28 & 188,28 & 54,20 & 919,91 & 123,69 & 22,59 & 42,35 & 348,53 & 93,97 & 93,97 & 337,24 \\
\hline Pelophylax perezi & 29TPG50 & 100,00 & 137,60 & 107,47 & 39,01 & 5663,99 & 293,42 & 22,08 & 271, & 69,40 & 211, & 211 & 66, & 797,61 & 110,60 & 11,75 & 49 & 312 & 60 & 60,95 & 312,37 \\
\hline Pelophylax perezi & 29TPG51 & 100,00 & 135,10 & 106,82 & 38,97 & 5652,70 & 290,36 & 19,93 & 270,43 & 68,85 & 209,35 & 209,35 & 64,65 & 802,20 & 109,94 & 12,67 & 48,85 & 313,40 & 63,25 & 63,25 & 313,23 \\
\hline
\end{tabular}




\begin{tabular}{|c|c|c|c|c|c|c|c|c|c|c|c|c|c|c|c|c|c|c|c|c|c|}
\hline TAXON & UTM & $\mathrm{km} 2$ & B101 & B102 & $\mathrm{BIO3}$ & B104 & B105 & B106 & B107 & B108 & B109 & B1010 & BIO11 & BIO12 & B1013 & BIO14 & BIO15 & BIO16 & BIO17 & BIO18 & B1019 \\
\hline Pelophylax perezi & 29TPG52 & 99,00 & 126,28 & 105,19 & 38,73 & 5629,65 & 281,48 & 12,63 & 268,85 & 59,49 & 200,62 & 200,62 & 56,60 & 851,88 & 116,31 & 14,69 & 48,20 & 333,63 & 70,27 & 70,27 & 333,50 \\
\hline Pelophylax perezi & 29TPG53 & 101,00 & 118,10 & 103,22 & 38,19 & 5593,68 & 272,73 & 6,29 & 266,44 & 54,78 & 192,35 & 192,35 & 49,42 & 897,29 & 121,15 & \begin{tabular}{|l|l|}
16,78 \\
\end{tabular} & 47,42 & 350,83 & 77,64 & 77,64 & 350,43 \\
\hline Pelophylax perezi & 29TPG54 & 100,00 & 112,14 & 101,49 & 37,99 & 5549,06 & 265,44 & 2,10 & 263,34 & 50,57 & 186,01 & 186,01 & 44,43 & 933,69 & 123,73 & 19,01 & 46,45 & 363,30 & 84,68 & 84,68 & 361,72 \\
\hline Pelophylax perezi & 29TPG55 & 101,00 & 101,87 & 98,62 & 37,70 & 5478,45 & 253,21 & $-4,90$ & 258,12 & 41,72 & 175,11 & 175,11 & 35,82 & 1007,10 & 132,54 & 22,70 & 45,05 & 389,16 & 96,94 & 96,94 & 385,59 \\
\hline Pelophylax perezi & 29TPG56 & 100,00 & 103,96 & 98,97 & \begin{tabular}{|l|l|}
37,87 \\
\end{tabular} & 5460,41 & 254,30 & $-3,50$ & 257,80 & 43,58 & \begin{tabular}{|l|}
176,87 \\
\end{tabular} & \begin{tabular}{|l|}
176,87 \\
\end{tabular} & 37,96 & 984,56 & 130,35 & 23,21 & 44,33 & 378,83 & 97,03 & 97,03 & 373,37 \\
\hline Pelophylax perezi & 29TPG57 & 100,00 & 107,87 & 99,36 & 38,03 & 5437,69 & 257,09 & $-0,42$ & 257,51 & 47,28 & 180,21 & 180,21 & 41,88 & 949,49 & 126,52 & 22,96 & 43,53 & 363,96 & 95,28 & 95,28 & 356,65 \\
\hline Pelophylax perezi & 29TPG58 & 99,00 & 113,24 & 99,55 & 38,22 & 5409,77 & 260,71 & 4,08 & 256,63 & 52,44 & 184,97 & 184,97 & 47,33 & 906,05 & 121,16 & 22,17 & 42,81 & 345,63 & 92,32 & 92,32 & 336,18 \\
\hline Pelophylax perezi & 29TPG59 & 101,00 & 120,87 & 99,39 & 38,56 & 5362,54 & 265,42 & 10,95 & 254,47 & 59,95 & 191,56 & 191,56 & 55,12 & 854,10 & 114,17 & 21,06 & 41,95 & 323,58 & 88,29 & 88,29 & 311,47 \\
\hline Pelophylax perezi & 29TPG60 & 100,00 & 123,07 & 105,87 & 38,38 & 5712,51 & 281,58 & 9,35 & 272,23 & 52,57 & 198,73 & 198,73 & 52,53 & 838,83 & 117,23 & 13,04 & 49,09 & 331,15 & 67,94 & 67,94 & 331,15 \\
\hline Pelophylax perezi & 29TPG61 & 101,00 & 124,66 & 106,28 & 38,58 & 5691,35 & 282,65 & \begin{tabular}{|l|l|}
10,37 \\
\end{tabular} & 272,28 & 56,10 & 199,97 & 199,97 & 54,20 & 816,66 & 112,80 & 13,43 & 48,38 & 321,04 & 67,43 & 67,43 & 320,98 \\
\hline Pelophylax perezi & 29TPG62 & 101,00 & 117,17 & 104,76 & 38,23 & 5659,64 & 274,68 & 4,41 & 270,26 & 52,34 & 192,27 & 192,27 & 47,48 & 857,09 & 117,25 & 15,25 & 47,61 & 336,34 & 74,11 & 74,11 & 336,18 \\
\hline Pelophylax perezi & 29TPG63 & 100,00 & 112,97 & 103,74 & 38,15 & 5628,42 & 269,69 & 1,35 & 268,34 & 50,38 & 187,93 & 187,93 & 44,10 & 878,27 & 118,15 & 16,94 & 46,75 & 343,20 & 79,00 & 79,00 & 342,17 \\
\hline Pelophylax perezi & 29TPG64 & 100,00 & 104,22 & 101,47 & 37,91 & 5587,04 & 259,60 & $-4,87$ & 264,47 & 42,66 & 178,99 & 178,99 & 36,56 & 935,40 & 123,39 & 19,90 & 45,50 & 363,13 & 88,84 & 88,84 & 360,58 \\
\hline Pelophylax perezi & 29TPG65 & 100,00 & 91,21 & 98,25 & $\begin{array}{l}37,45 \\
\end{array}$ & 5510,92 & 244,11 & $-14,60$ & 258,71 & 31,40 & 165,31 & 165,32 & 25,41 & \begin{tabular}{ll|}
1036,29 \\
\end{tabular} & 135,29 & 25,12 & 43,62 & 396,79 & 105,96 & 106,01 & 391,05 \\
\hline Pelophylax perezi & 29TPG66 & 100,00 & 85,32 & 97,01 & 37,38 & 5459,42 & 236,65 & $-19,18$ & 255,84 & 26,37 & 158,82 & 158,85 & 20,53 & \begin{tabular}{|l|l|}
1082,19 \\
\end{tabular} & 140,94 & $\begin{array}{l}28,45 \\
\end{array}$ & 42,32 & 410,84 & 115,68 & 115,73 & 402,63 \\
\hline Pelophylax perezi & 29TPG67 & 101,00 & 90,62 & 98,13 & 37,76 & 5449,74 & 241,65 & $-15,01$ & 256,66 & 31,18 & 163,81 & 163,81 & 25,53 & 1033,16 & 135,57 & 27,56 & 41,95 & 391,99 & 111,28 & 111,28 & 382,79 \\
\hline Pelophylax perezi & 29TPG68 & 101,00 & 95,38 & 98,77 & 37,99 & 5429,41 & 245,36 & $-11,17$ & 256,53 & 35,56 & 168,01 & 168,01 & 30,21 & 994,16 & 131,08 & 26,93 & 41,40 & 376,34 & 108,56 & 108,56 & 365,59 \\
\hline Pelophylax perezi & 29TPG69 & 100,00 & 109,58 & 99,72 & 38,42 & 5401,83 & 256,87 & 0,74 & 256,13 & 48,89 & $\begin{array}{l}181,12 \\
\end{array}$ & 181,12 & 43,70 & 891,67 & 118,02 & 23,64 & 41,01 & 336,82 & 96,95 & 96,95 & 323,83 \\
\hline Pelophylax perezi & 29TPG70 & 101,00 & 120,49 & 106,61 & 38,23 & 5758,56 & 281,01 & 6,19 & 274,81 & 50,93 & 197,05 & 197,05 & 49,40 & 797,41 & 110,24 & 12,70 & 48,25 & 313,45 & 66,84 & 66,84 & 313,45 \\
\hline Pelophylax perezi & 29TPG71 & 99,00 & 106,29 & 103,38 & 37,79 & 5709,64 & 265,63 & $-4,35$ & 269,98 & 41,02 & $\mid 182,72$ & $\mid 182,73$ & 36,85 & 887,24 & 120,34 & $\mid 15,88$ | & 47,03 & 346,53 & 79,77 & 79,77 & 346,12 \\
\hline Pelophylax perezi & 29TPG72 & 100,00 & 104,66 & 103,39 & 37,88 & 5685,59 & 263,66 & $-5,85$ & 269,52 & 42,04 & 180,79 & 180,80 & 35,52 & 889,11 & 119,21 & 17,01 & 46,29 & 346,30 & 82,30 & 82,30 & 345,29 \\
\hline Pelophylax perezi & 29TPG73 & 100,00 & 111,26 & 105,36 & 38,08 & 5681,64 & 270,72 & $-1,27$ & 271,99 & 48,18 & 187,11 & 187,11 & 41,70 & 830,16 & 111,22 & 16,29 & 46,11 & 324,27 & 76,84 & 76,84 & 322,77 \\
\hline Pelophylax perezi & 29TPG74 & 100,00 & 102,89 & 103,19 & 37,94 & 5639,26 & 260,53 & $-7,56$ & 268,10 & 40,61 & 178,40 & 178,40 & 34,42 & 888,01 & 117,14 & \begin{tabular}{|l|l|}
19,58 \\
\end{tabular} & 44,67 & 343,11 & 87,15 & 87,15 & 339,61 \\
\hline Pelophylax perezi & 29TPG75 & 101,00 & 85,19 & 98,99 & 37,41 & 5559,49 & 239,74 & $-21,08$ & 260,82 & 25,02 & 159,90 & 160,06 & 18,98 & 1030,75 & 133,59 & 26,48 & 42,22 & 390,72 & 110,32 & 110,63 & 382,84 \\
\hline Pelophylax perezi & 29TPG76 & 100,00 & 69,20 & 95,75 & \begin{tabular}{|l|l|}
37,03 \\
\end{tabular} & 5474,24 & 221,21 & $-33,69$ & 254,90 & 11,21 & 143,07 & 143,32 & 5,10 & 1166,78 & 148,91 & 33,61 & 40,03 & 435,09 & 133,11 & 134,16 & 423,21 \\
\hline Pelophylax perezi & 29TPG77 & 100,00 & 72,02 & 96,50 & 37,33 & 5454,39 & 223,74 & \begin{tabular}{|l|}
$-31,34$ \\
\end{tabular} & 255,08 & 13,92 & 145,64 & 145,74 & 7,94 & 1141,30 & 146,33 & 33,84 & 39,61 & 424,73 & 132,61 & 133,18 & 411,98 \\
\hline Pelophylax perezi & 29TPG78 & 99,00 & 84,24 & 98,73 & 37,94 & 5461,01 & 235,92 & $-21,51$ & 257,42 & 24,81 & 157,54 & $\begin{array}{l}157,55 \\
\end{array}$ & 19,16 & 1035,81 & \begin{tabular}{|l|l|}
134,64 \\
\end{tabular} & 30,25 & 39,76 & 387,35 & 119,61 & 119,70 & $\begin{array}{l}371,30 \\
374,39\end{array}$ \\
\hline Pelophylax perezi & 29TPG79 & 101,00 & 115,29 & 102,23 & 38,71 & 5504,49 & 264,82 & 3,55 & 261,28 & 52,63 & 187,88 & 187,88 & 47,61 & 798,91 & 105,84 & 21,01 & 40,71 & 302,25 & 87,53 & 87,53 & 288,56 \\
\hline Pelophylax perezi & 29TPG80 & 100,00 & 121,05 & 107,95 & 38,31 & 5805,80 & 283,05 & 5,75 & 277,30 & 55,69 & 198,22 & 198,22 & 49,43 & 736,72 & 99,75 & 12,07 & 47,20 & 287,01 & 63,76 & 63,76 & 286,57 \\
\hline Pelophylax perezi & 29TPG81 & 100,00 & 112,63 & 106,89 & 38,07 & 5769,69 & 274,83 & $-0,95$ & 275,78 & 47,70 & 189,63 & 189,63 & 41,79 & 781,52 & 105,21 & 13,80 & 46,54 & 304,45 & 70,73 & 70,73 & 304,31 \\
\hline Pelophylax perezi & 29TPG82 & 101,00 & 115,92 & 108,05 & 38,48 & 5741,87 & 278,21 & 1,19 & 277,01 & 49,20 & 192,39 & 192,39 & 45,23 & 751,50 & 101,08 & 13,75 & 46,42 & 293,71 & 68,50 & 68,50 & 293,50 \\
\hline Pelophylax perezi & 29TPG83 & 100,00 & 114,34 & 107,76 & 38,40 & 5717,94 & 275,96 & $\begin{array}{c}-1,14 \\
-0,14 \\
\end{array}$ & 276,10 & $\begin{array}{ll}49,76 \\
40\end{array}$ & 190,63 & 190,63 & $\begin{array}{ll}43,99 \\
43,9\end{array}$ & 756,43 & \begin{tabular}{|l|l|}
100,89 \\
\end{tabular} & 14,92 & $\begin{array}{ll}40,45 \\
45,71\end{array}$ & 294,30 & 71,12 & $\begin{array}{l}0,1,12 \\
71,\end{array}$ & 293,56 \\
\hline Pelophylax perezi & 29TPG84 & 100,00 & 101,08 & 104,58 & 38,04 & 5694,84 & 260,62 & $-10,39$ & 271,01 & 38,15 & 177,42 & 177,42 & 31,99 & 848,62 & 111,77 & $\begin{array}{l}19,55 \\
\end{array}$ & 43,67 & 325,23 & 86,52 & 86,52 & 320,86 \\
\hline Pelophylax perezi & 29TPG85 & 99,00 & 90,22 & 102,10 & 37,74 & 5649,05 & 247,58 & $-18,81$ & 266,39 & 28,47 & 166,10 & 166,16 & 22,38 & 931,97 & 121,43 & 24,22 & 41,70 & 352,40 & 101,25 & 101,38 & 344,17 \\
\hline Pelophylax perezi & 29TPG86 & 101,00 & 80,34 & 100,06 & 37,57 & 5586,05 & 235,83 & $-26,54$ & 262,37 & 19,98 & 155,48 & 155,64 & 13,90 & 1015,72 & 130,94 & 29,10 & 40,06 & 379,28 & 116,18 & 116,72 & 367,84 \\
\hline Pelophylax perezi & 29TPG87 & 100,00 & 60,76 & 96,29 & 37,14 & 5479,39 & 213,40 & $-41,90$ & 255,30 & 3,18 & 134,78 & 135,09 & $-3,08$ & 1192,08 & 150,36 & 37,89 & 37,67 & 436,76 & 145,06 & 146,84 & 421,17 \\
\hline Pelophylax perezi & 29TPG88 & 101,00 & 75,96 & $\begin{array}{l}0,20 \\
99,19\end{array}$ & 37,83 & 5498,03 & 229,16 & $\begin{array}{l}-4,29,65 \\
-295\end{array}$ & \begin{tabular}{|l|}
258,81 \\
28,
\end{tabular} & \begin{tabular}{|l|}
$, 16,66$ \\
16,66
\end{tabular} & \begin{tabular}{|l|}
149,91 \\
149,
\end{tabular} & \begin{tabular}{|l|l|}
149,95 \\
1495
\end{tabular} & \begin{tabular}{|l|l|}
$-30,69$ \\
10,69
\end{tabular} & 1056,83 & \begin{tabular}{|l|}
135,57 \\
157
\end{tabular} & 32,94 & 38,18 & $\begin{array}{l}450,10 \\
389,90\end{array}$ & 128,19 & $\begin{array}{l}14,04,45 \\
128,45\end{array}$ & $\begin{array}{l}421,17 \\
374,70\end{array}$ \\
\hline Pelophylax perezi & 29TPG90 & 101,00 & 125,92 & 109,62 & 38,7 & 5856,70 & 288,50 & 8,71 & 279,79 & 60,02 & 203,44 & 203,44 & 53,20 & 655,17 & 85,95 & 11,25 & 45,79 & 252,45 & 58,32 & 58,32 & 249,87 \\
\hline Pelophylax perezi & 29TPG91 & 100,00 & 118,94 & 109,38 & 38,64 & 5827,16 & 282,27 & 2,54 & 279,73 & 53,38 & 196,21 & 196,21 & 46,87 & 687,62 & 90,57 & 12,47 & 45,58 & 265,21 & 63,42 & 63,42 & 264,07 \\
\hline Pelophylax perezi & 29TPG92 & 100,00 & 117,79 & 109,49 & 38,73 & 5801,07 & 281,12 & 1,55 & 279,58 & 51,24 & 194,91 & 194,91 & 45,98 & 690,75 & 91,31 & 13,20 & 45,22 & 266,29 & 65,12 & 65,12 & 265,58 \\
\hline Pelophylax perezi & 29TPG93 & 100,00 & 114,11 & 109,10 & 38,8 & 5783,44 & 276,86 & $\begin{array}{l}-1,48 \\
-1,40 \\
\end{array}$ & 278,34 & 48,78 & 191,09 & 191,09 & 42,76 & 707,57 & $\begin{array}{ll}1,33,88 \\
\end{array}$ & 14,70 & 44,40 & 271,75 & 69,24 & 69,24 & 270,03 \\
\hline Pelophylax perezi & 29TPG94 & 101,00 & 11 & 108,34 & 38, & 5772,11 & 272,62 & $-4,27$ & 276,90 & 45,99 & 187,51 & 187,51 & 39,68 & 726,49 & 96,60 & 16,5 & 43,40 & 277,94 & 73,92 & 73,92 & 274,29 \\
\hline Pelophylax perezi & 29TPG95 & 101,00 & 102,24 & 106,49 & 38,29 & 5749,81 & 262,78 & $-11,04$ & 273,82 & 38,15 & 179,12 & 179,12 & 32,12 & 781,86 & 103,44 & 20,04 & 41,76 & 296,35 & 84,39 & 84,39 & 288,95 \\
\hline Pelophylax perezi & 29TPG96 & 100,00 & 97,20 & 105,45 & 38,22 & 5715,20 & 256,35 & $-15,01$ & 271,35 & 33,71 & 173,68 & 173,68 & 27,75 & 820,67 & 107,87 & 22,87 & 40,53 & 308,33 & 92,64 & 92,64 & 298,22 \\
\hline Pelophylax perezi & 29TPG97 & 100,00 & 73,90 & 100,69 & 37,7 & 5591,12 & 229,81 & $-32,99$ & 262,80 & 13,84 & 149,23 & 149,36 & 7,62 & 1021,92 & 130,38 & 32,26 & 37,71 & 88 & 125,27 & 125,90 & 359,55 \\
\hline Pelophylax perezi & 29TPHOO & 101,00 & 125,61 & 90,94 & 38,5 & 4901,53 & 255,8 & 22,76 & 233,04 & $\begin{array}{l}70,594 \\
70,5\end{array}$ & \begin{tabular}{|l|}
189,97 \\
\end{tabular} & \begin{tabular}{|l|}
190,31 \\
\end{tabular} & \begin{tabular}{r|r|}
66,55 \\
\end{tabular} & 1067,43 & 150,45 & 25, & 43,21 & 400,80 & 106,02 & 114,20 & 388,56 \\
\hline Pelophylax perezi & 29TPH02 & 99,00 & 12 & 89,12 & 39, & 4652,13 & 251,70 & 27,49 & 224,21 & 74,29 & 187,64 & 188,44 & 70,94 & 1066,92 & 149,59 & 27,96 & 41,88 & 398,26 & 111,13 & 125,05 & 382,20 \\
\hline Pelophylax perezi & 29TPHO3 & $\begin{array}{r}101,00 \\
100\end{array}$ & 122,39 & 88,14 & 39,68 & 4526,51 & 245,68 & 25,57 & 220,12 & 71,62 & 181,60 & 182,66 & 68,41 & 1110,45 & 154,52 & 30,34 & 41,20 & 414,15 & 119,09 & 132,83 & 396,58 \\
\hline Pelophylax perezi & 29TPH06 & 100,00 & 122,37 & 85,04 & 40,24 & 4221,63 & 238,92 & 30,56 & 208,36 & 75,70 & 177,15 & 178,95 & 72,04 & 1114,61 & 150,96 & 33,28 & 38,97 & 412,09 & 127,86 & 143,18 & 388,61 \\
\hline Pelophylax perezi & 29TPH07 & 100,00 & 123,13 & 83,78 & 40,52 & 4121,32 & 237,34 & 33,13 & 204,21 & 77,79 & 176,53 & 178,70 & 74,12 & 1106,65 & 148,29 & 33,80 & 38,24 & 408,04 & 129,36 & 145,35 & 382,48 \\
\hline Pelophylax perezi & 29TPH08 & 100,00 & $\frac{12}{12}$ & $\begin{array}{l}3,10 \\
82,49\end{array}$ & $\frac{40}{40}$ & $\begin{array}{l}412,252 \\
4047,40\end{array}$ & 236,2 & $\begin{array}{l}3,13 \\
36,13 \\
\end{array}$ & \begin{tabular}{|l|}
200,11 \\
20,1
\end{tabular} & 80,26 & 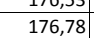 & 179,07 & 76,20 & \begin{tabular}{|l|l|l|l|l|l|}
1090,69 \\
\end{tabular} & \begin{tabular}{|l|}
140,251 \\
144,51
\end{tabular} & 34,03 & 37,66 & 4000,97 & 129,85 & $\begin{array}{l}14,50 \\
146,52\end{array}$ & $\begin{array}{l}30,40 \\
373,57\end{array}$ \\
\hline Pelophylax perezi & 29TPH09 & 100,00 & 122,75 & 81,56 & 40,98 & 3966,66 & 232,91 & 35,86 & \begin{tabular}{|l|l|}
197,05 \\
\end{tabular} & 79,73 & 173,76 & 176,37 & 75,50 & \begin{tabular}{|l|}
1103,86 \\
\end{tabular} & 144,75 & 35,37 & 36,96 & 404,69 & 134,34 & 151,17 & 375,61 \\
\hline Pelophylax perezi & 29TPH10 & 101,00 & 132,16 & 92,85 & 38,48 & 5032,68 & 264,12 & $\begin{array}{ll}3,06 \\
25,98\end{array}$ & 238,14 & 75,15 & $\begin{array}{l}197,94 \\
196\end{array}$ & \begin{tabular}{|l|l|}
198,04 \\
\end{tabular} & 70,82 & $\begin{array}{l}953,14 \\
9\end{array}$ & 132,65 & 22,92 & 42,71 & 355,93 & 94,51 & 98,62 & 343,08 \\
\hline Pelophylax perezi & 29TPH12 & 100,00 & 118,21 & 90,44 & 39,02 & 4755,97 & 247,19 & 18,30 & 228,90 & 65,00 & 180,68 & 181,38 & 61,27 & 1085,40 & 149,81 & 29,07 & 41,33 & 405,99 & 115,62 & 127,23 & 390,25 \\
\hline Pelophylax perezi & 29TPH13 & 101,00 & 119,95 & 89,56 & 39,2 & 4654,25 & 246,39 & 21,29 & 225,10 & 67,82 & 180,91 & 18 & 64,29 & 1074,00 & 147,45 & 29,69 & 40,64 & 400,06 & 116,88 & 129,88 & 38 \\
\hline Pelophylax perezi & 29TPH14 & $\begin{array}{l}100,00 \\
100\end{array}$ & 127,77 & $\begin{array}{l}3,300 \\
88,45\end{array}$ & 39, 39 & $\begin{array}{l}4034,25 \\
4530,25\end{array}$ & $\begin{array}{l}240,53 \\
250,04\end{array}$ & \begin{tabular}{|l|l|}
30,10 \\
30
\end{tabular} & \begin{tabular}{|l|l|}
219,94 \\
\end{tabular} & $\begin{array}{l}1,0<4 \\
76,72\end{array}$ & \begin{tabular}{|l|}
186,71 \\
186,1
\end{tabular} & \begin{tabular}{|l|l|}
187,88 \\
\end{tabular} & $\begin{array}{l}4,23 \\
73,19 \\
\end{array}$ & $\begin{array}{l}1014,92 \\
\end{array}$ & \begin{tabular}{|l|}
138,48 \\
138,48
\end{tabular} & 28,44 & $\begin{array}{l}34,044 \\
39,90\end{array}$ & $\begin{array}{l}30,00 \\
375,81\end{array}$ & $\begin{array}{l}11,00,00 \\
111,82\end{array}$ & $\begin{array}{l}12,00 \\
126,42\end{array}$ & $\begin{array}{l}30,25 \\
355,63\end{array}$ \\
\hline Pelophylax perezi & 29TPH16 & 101,00 & 125,04 & 86,30 & 40,07 & 4330,92 & 243,26 & 31,13 & 212,13 & 76,77 & 181,15 & 182,83 & 73,01 & 1042,90 & 139,56 & 31,21 & 38,41 & 383,96 & 120,74 & 136,01 & 359,84 \\
\hline Pelophyla & 29TPH17 & 100,00 & 126.18 & 84,96 & 40,36 & 4216.44 & 241,65 & 34,25 & 207,40 & 79,44 & 180,65 & 182,65 & 75,51 & 1038.06 & 137.45 & 31.90 & 37.78 & 381.03 & 122,60 & 138,47 & 354.94 \\
\hline Pelophylax perezi & 29TPH18 & 101,00 & 125,68 & 83,80 & 40,68 & 4123,85 & 238,95 & 35,24 & 203,71 & 80,25 & 178,80 & 180 & 76, & 1044,09 & 136,94 & 32,81 & 37,04 & 382,20 & 125,76 & 142,04 & 354,40 \\
\hline Pelophylax perezi & 29TPH19 & 100,00 & 123,57 & 82,76 & 40,98 & 4058,01 & 235,39 & 34,93 & 200,46 & 79,42 & 175,75 & 178,19 & 74,90 & 1060,94 & 137,80 & 34,36 & 36,39 & 387,31 & 130,66 & 147,15 & 357,73 \\
\hline
\end{tabular}




\begin{tabular}{|c|c|c|c|c|c|c|c|c|c|c|c|c|c|c|c|c|c|c|c|c|c|}
\hline TAXON & UTM & $\mathrm{km} 2$ & B101 & B102 & $\mathrm{BIO3}$ & BIO4 & B105 & B106 & B107 & B108 & 8109 & B1010 & BIO11 & BIO12 & 81013 & BIO14 & BIO15 & B1016 & B1017 & B1018 & B1019 \\
\hline Pelophylax perezi & 29TPH20 & 100,00 & 128,59 & 94,28 & 38,67 & 5087,38 & 263,24 & 21,88 & 241,35 & 70,80 & 195,16 & 195,28 & 66,58 & 936,27 & 128,52 & 22,83 & 42,26 & 350,85 & 94,21 & 97,52 & 337,98 \\
\hline Pelophylax perezi & 29TPH21 & 100,00 & 131,78 & 93,25 & 38,97 & 4996,08 & 263,61 & 26,14 & 237,47 & 75,01 & 196,99 & 197,21 & 70,90 & 914,56 & \begin{tabular}{|l|}
125,36 \\
\end{tabular} & 22,94 & 41,58 & 340,74 & 94,05 & 100,10 & 325,66 \\
\hline Pelophylax perezi & 29TPH22 & 99,00 & 124,49 & 92,23 & 39,00 & 4876,32 & 255,17 & 21,55 & 233,62 & 69,34 & 188,35 & 188,78 & 65,41 & 978,94 & 133,70 & 25,94 & 40,88 & 364,82 & 104,40 & 114,61 & 348,37 \\
\hline Pelophylax perezi & 29TPH23 & 101,00 & 119,56 & 91,15 & 39,07 & 4762,91 & 248,70 & 19,16 & 229,53 & 66,02 & 181,97 & 182,57 & 62,19 & 1024,94 & 139,16 & 28,49 & 40,09 & 381,25 & 112,89 & 125,25 & 363,04 \\
\hline Pelophylax perezi & 29TPH24 & 99,00 & 125,55 & \begin{tabular}{|l|l|}
89,93 \\
\end{tabular} & 39,68 & \begin{tabular}{ll|}
4642,18 \\
\end{tabular} & 250,82 & 26,28 & 224,54 & 73,35 & $\begin{array}{ll}185,99 \\
\end{array}$ & 186,97 & 69,51 & \begin{tabular}{|c|}
983,58 \\
\end{tabular} & \begin{tabular}{|l|l|}
132,48 \\
\end{tabular} & 27,91 & 39,24 & 363,67 & 110,25 & 124,13 & 342,92 \\
\hline Pelophylax perezi & 29TPH25 & 100,00 & 126,69 & 88,78 & 40,00 & 4525,55 & 249,07 & 29,25 & 219,82 & 75,85 & 185,51 & 186,73 & 72,08 & 981,64 & 131,10 & 28,68 & 38,56 & 361,47 & 112,42 & 126,98 & 338,67 \\
\hline Pelophylax perezi & 29TPH26 & 100,00 & 121,66 & 87,84 & 40,00 & $\begin{array}{ll}4444,56 \\
\end{array}$ & 243,07 & 26,02 & 217,05 & 71,93 & \begin{tabular}{|l|l|l|}
179,43 \\
\end{tabular} & 180,73 & 68,04 & $\begin{array}{l}1026,71 \\
\end{array}$ & 136,01 & 31,28 & 37,83 & 377,12 & 121,13 & 135,50 & 352,61 \\
\hline Pelophylax perezi & 29TPH27 & 100,00 & 123,01 & 86,66 & 40,23 & 4337,90 & 241,68 & 29,27 & 212,41 & 74,82 & 179,25 & 180,94 & 70,80 & 1019,81 & 133,69 & 31,80 & 37,10 & 373,07 & 122,70 & 137,63 & 346,56 \\
\hline Pelophylax perezi & 29TPH30 & 100,00 & 125,13 & 95,64 & 38,73 & 5150,07 & 262,55 & 17,90 & 244,65 & 66,68 & \begin{tabular}{|l|l|}
192,63 \\
\end{tabular} & 192,70 & 62,20 & 918,66 & 124,73 & 22,65 & 41,96 & 345,25 & 93,92 & 95,44 & 332,19 \\
\hline Pelophylax perezi & 29TPH31 & 101,00 & 119,04 & 94,44 & 38,82 & 5059,74 & 255,30 & 14,04 & 241,25 & 62,01 & 185,63 & 185,73 & 57,79 & 967,60 & 131,02 & 25,32 & 41,14 & 362,64 & 102,89 & 105,66 & 347,87 \\
\hline Pelophylax perezi & 29TPH32 & 101,00 & 111,82 & 93,24 & 38,93 & 4954,82 & 246,85 & 9,55 & 237,30 & 56,42 & 177,15 & 177,45 & 52,28 & 1029,96 & 138,71 & 28,51 & 40,24 & 384,92 & 113,70 & 120,04 & 368,31 \\
\hline Pelophylax perezi & 29TPH33 & 100,00 & 118,60 & 92,65 & 39,09 & 4857,10 & 250,24 & 16,57 & 233,68 & 63,89 & 182,29 & 182,76 & 59,89 & 983,53 & 132,01 & 27,70 & 39,46 & 365,39 & 110,18 & 120,45 & 346,38 \\
\hline Pelophylax perezi & 29TPH34 & 101,00 & 122,50 & 91,58 & 39,55 & 4743,04 & 250,87 & 21,83 & 229,04 & 69,08 & 184,43 & 185,11 & 65,12 & 961,03 & \begin{tabular}{|l|l|}
127,96 \\
\end{tabular} & 27,78 & 38,70 & 354,84 & 109,87 & 122,43 & 333,48 \\
\hline Pelophylax perezi & 29TPH35 & 101,00 & 118,79 & 90,60 & 39,82 & 4643,16 & 245,49 & 20,12 & 225,38 & 66,82 & 179,40 & 180,40 & 62,86 & \begin{tabular}{|l|l|}
996,47 \\
\end{tabular} & 131,71 & 30,01 & 37,94 & 366,67 & 117,26 & 130,42 & 343,40 \\
\hline Pelophylax perezi & 29TPH36 & 100,00 & 116,71 & 89,59 & 39,98 & 4558,89 & 241,60 & 19,71 & 221,89 & 65,93 & 176,12 & 177,35 & 61,98 & 1019,44 & 133,61 & 31,76 & 37,13 & 373,52 & 122,99 & 136,32 & 348,31 \\
\hline Pelophylax perezi & 29TPH40 & 100,00 & 122,17 & 96,97 & 38,64 & 5220,98 & 262,21 & 14,28 & 247,94 & 62,99 & 190,75 & 190,76 & 58,29 & 893,50 & 120,14 & 22,50 & 41,55 & 336,45 & 93,20 & 93,37 & 322,83 \\
\hline Pelophylax perezi & 29TPH42 & 99,00 & 98,73 & 93,70 & 38,60 & 5033,63 & 237,43 & $-2,60$ & 240,03 & 43,30 & 165,53 & 165,70 & 38,78 & \begin{tabular}{|l|}
1084,12 \\
\end{tabular} & 143,75 & 31,77 & 39,41 & 404,36 & 124,83 & 128,62 & 386,95 \\
\hline Pelophylax perezi & 29TPH44 & 99,00 & 109,30 & 93,09 & 39,19 & 4862,07 & 242,56 & 8,30 & 234,26 & 54,97 & 173,19 & 173,70 & 50,86 & \begin{tabular}{|l|}
1015,57 \\
\end{tabular} & 133,86 & 30,74 & 37,96 & 375,15 & 120,36 & 129,85 & 353,36 \\
\hline Pelophylax perezi & 29TPH45 & 100,00 & 111,85 & 92,25 & 39,68 & 4763,05 & 242,47 & 11,89 & 230,58 & 58,62 & 174,21 & 174,95 & 54,51 & \begin{tabular}{|l|}
1003,77 \\
\end{tabular} & 131,25 & 31,17 & 37,17 & 368,70 & 121,41 & 132,90 & 344,71 \\
\hline Pelophylax perezi & 29TPH48 & 101,00 & 117,97 & 88,31 & 40,36 & 4404,92 & 239,19 & 23,24 & 215,96 & 69,26 & 175,12 & 176,65 & 64,93 & 993,69 & 127,02 & 33,38 & 34,98 & 359,06 & 127,50 & 141,46 & 328,68 \\
\hline Pelophylax perezi & 29TPH51 & 100,00 & 92,45 & 95,33 & 38,24 & 5173,82 & 235,67 & $-10,10$ & 245,76 & 35,76 & 161,46 & 161,51 & 30,84 & 1078,35 & 141,86 & 31,88 & 39,27 & 402,52 & 125,19 & 125,91 & 386,28 \\
\hline Pelophylax perezi & 29TPH55 & 101,00 & 115,59 & 93,60 & 39,80 & 4824,02 & 247,23 & 14,03 & 233,20 & 61,30 & 178,62 & 179,20 & 57,08 & 937,10 & 121,15 & 29,23 & 36,63 & 342,96 & 114,97 & 125,70 & 317,72 \\
\hline Pelophylax perezi & 29TPH56 & 100,00 & 112,59 & 92,57 & 39,92 & 4721,95 & 242,36 & 12,91 & 229,45 & 59,88 & 174,30 & 175,10 & 55,56 & $\begin{array}{l}969,45 \\
\end{array}$ & 124,37 & 31,62 & 35,72 & 352,59 & 122,46 & 134,51 & 325,18 \\
\hline Pelophylax perezi & 29TPH58 & 99,00 & 111,89 & 90,21 & 40,17 & 4511,60 & 236,79 & 15,61 & 221,18 & 62,19 & 170,64 & 171,93 & 57,57 & \begin{tabular}{|l|}
1001,05 \\
\end{tabular} & 128,05 & 34,69 & 34,26 & 360,09 & 131,93 & 144,69 & 328,66 \\
\hline Pelophylax perezi & 29TPH63 & 100,00 & 96,65 & 96,45 & 38,91 & 5119,07 & 238,28 & $-6,57$ & 244,86 & 39,94 & 164,49 & 164,55 & 35,18 & 1010,04 & 131,23 & 31,90 & 37,11 & 372,28 & 124,46 & 125,75 & 350,78 \\
\hline Pelophylax perezi & 29TPH67 & 100,00 & 111,40 & 92,64 & 40,16 & 4672,44 & 240,37 & 12,48 & 227,89 & 59,48 & 172,27 & 173,21 & 54,89 & 959,28 & 123,40 & 33,20 & 34,14 & 344,70 & 127,14 & 138,91 & 313,97 \\
\hline Pelophylax perezi & 29TPH68 & 100,00 & 112,91 & 91,50 & 40,35 & 4561,33 & 239,10 & 15,52 & 223,58 & 62,99 & 172,22 & 173,42 & 57,89 & |963,04 & 124,25 & 34,13 & 33,53 & 344,15 & 129,85 & $\begin{array}{l}142,22 \\
140\end{array}$ & 311,33 \\
\hline Pelophylax perezi & 29TPH70 & 99,00 & 120,04 & 101,98 & 38,92 & 5464,69 & 267,27 & 7,93 & 259,34 & 57,30 & 191,79 & 191,79 & 52,47 & 768,84 & 101,73 & 20,23 & 40,17 & 290,06 & 85,34 & 85,34 & 274,12 \\
\hline Pelophylax perezi & 29TPH71 & 100,00 & 113,94 & 100,82 & 38,97 & 5392,16 & 260,03 & 3,76 & 256,27 & 52,37 & 184,91 & 184,91 & 47,68 & 816,87 & 107,39 & 22,93 & 39,03 & 305,75 & 94,65 & 94,65 & 287,50 \\
\hline Pelophylax perezi & 29TPH72 & 100,00 & 106,85 & 99,74 & 38,99 & 5300,89 & 251,67 & $-0,98$ & 252,65 & 46,96 & 176,72 & 176,72 & 42,12 & 876,57 & 114,23 & 26,39 & 37,74 & 324,95 & 106,04 & 106,04 & 304,42 \\
\hline Pelophylax perezi & 29TPH73 & 101,00 & 86,82 & 97,28 & 38,88 & 5179,44 & 231,19 & $-16,28$ & 247,47 & 30,10 & 155,82 & 155,92 & 25,01 & \begin{tabular}{|l|}
1044,37 \\
\end{tabular} & 133,86 & 35,11 & 35,84 & 381,04 & 134,58 & 135,46 & 358,23 \\
\hline Pelophylax perezi & 29TPH76 & 100,00 & $\begin{array}{l}0,02,21 \\
110,21\end{array}$ & $\begin{array}{ll}1,260 \\
95,48\end{array}$ & $\begin{array}{l}30,00 \\
40,02\end{array}$ & 4853,39 & 243,99 & $\begin{array}{r}, 24 \\
8,24\end{array}$ & 235,75 & 55,87 & $\begin{array}{l}173,04 \\
173,58\end{array}$ & \begin{tabular}{|l|}
174,10 \\
\end{tabular} & 51,26 & | & $\begin{array}{l}118,62 \\
118,6\end{array}$ & 31,57 & 34,05 & 329,48 & $\begin{array}{l}121,99 \\
129\end{array}$ & \begin{tabular}{|l|}
131,67 \\
\end{tabular} & 299,50 \\
\hline Pelophylax perezi & 29TPH77 & 101,00 & 109,22 & 93,94 & 40,19 & 4735,34 & 240,26 & 9,41 & 230,85 & 57,06 & 171,00 & 171,77 & 51,94 & 943,31 & 121,95 & 33,73 & 33,37 & 336,65 & 128,55 & 139,42 & 304,64 \\
\hline Pelophylax perezi & 29TPH78 & 100,00 & 114,42 & 92,48 & 40,65 & 4583,52 & 241,15 & 16,33 & 224,81 & 67,71 & $\begin{array}{ll}173,87 \\
\end{array}$ & 175,05 & 58,89 & 927,82 & 120,75 & 33,81 & 32,65 & 328,82 & 128,45 & 140,50 & 294,39 \\
\hline Pelophylax perezi & 29TPH80 & 101,00 & 115,40 & 103,38 & 38,97 & 5547,08 & 265,72 & 2,60 & 263,12 & 51,78 & 188,51 & 188,51 & 46,90 & 754,35 & 99,32 & 20,75 & 39,45 & 283,55 & 87,01 & 87,01 & 266,77 \\
\hline Pelophylax perezi & 29TPH83 & 101,00 & 103,10 & 100,38 & 39,18 & 5272,73 & 248,04 & $-4,25$ & 252,29 & 43,77 & 172,58 & 172,58 & 38,79 & 876,14 & \begin{tabular}{|c|}
113,19 \\
\end{tabular} & 28,54 & 35,80 & 320,06 & 112,79 & 112,79 & 295,79 \\
\hline Pelophylax perezi & 29TPH84 & 99,00 & 84,45 & $\begin{array}{r}0,50 \\
98,01 \\
\end{array}$ & $\frac{39,10}{39,11}$ & 5161,57 & 228,83 & \begin{tabular}{|l|l|}
$--18,65$ \\
$-18,65$
\end{tabular} & 247,48 & $\begin{array}{ll}28,11 \\
28\end{array}$ & 153,10 & \begin{tabular}{|l|l|l|l|l|}
153,23 \\
\end{tabular} & $\begin{array}{l}20,80 \\
22,80\end{array}$ & \begin{tabular}{|l|}
$0 /, 14$ \\
1035,10
\end{tabular} & $\mid$ & $\begin{array}{l}20,34 \\
37,17\end{array}$ & 34,15 & 372,30 & $\begin{array}{l}140,47 \\
140\end{array}$ & \begin{tabular}{|l|l|l|l|}
142,00 \\
\end{tabular} & 346,19 \\
\hline Pelophylax perezi & 29TPH91 & 100,00 & 123,96 & 104,01 & 39,00 & 5549,99 & 273,22 & 9,52 & 263,70 & 59,34 & 196,45 & 196,45 & 54,78 & 671,06 & 89,20 & 18,55 & 38,11 & 250,52 & 80,57 & 80,57 & 229,55 \\
\hline Pelophylax perezi & 29TPH92 & 100,00 & 115,93 & 103,31 & 39,17 & 5449,94 & 263,76 & 3,94 & 259,82 & 53,38 & 187,38 & 187,38 & 48,47 & 733,35 & 96,86 & 22,12 & 36,71 & 270,19 & 92,33 & 92,33 & 246,59 \\
\hline Pelophylax perezi & 29TPH93 & 101,00 & 107,31 & 102,32 & 39,65 & 5336,26 & 253,68 & $-1,99$ & 255,66 & 46,81 & 177,48 & 177,48 & 41,85 & 807,54 & 105,61 & 26,68 & 35,10 & 293,24 & 106,52 & 106,52 & 267,56 \\
\hline Pelophylax perezi & 29TPJ02 & 101,00 & 123,80 & 77,64 & 41,36 & 3730,50 & 226,94 & 41,71 & 185,24 & 84,33 & 171,23 & 174,39 & 79,08 & 1089,72 & 138,96 & 36,99 & 35,12 & 396,56 & 139,64 & 158,09 & 362,56 \\
\hline Pelophylax perezi & $\begin{array}{l}\text { 29TPJ03 } \\
\text { 29T2 }\end{array}$ & $\begin{array}{l}101,00 \\
101,00\end{array}$ & $\begin{array}{l}127,00 \\
127,49\end{array}$ & $\begin{array}{l}11,04 \\
76,06\end{array}$ & $\begin{array}{l}41,60 \\
41,66\end{array}$ & | 3640,31 & 227,42 & $\begin{array}{l}4,1,19 \\
47,19\end{array}$ & $\begin{array}{l}180,24 \\
180,23 \\
\end{array}$ & \begin{tabular}{|l|}
84,25 \\
89,29 \\
\end{tabular} & $\begin{array}{l}1 / 1,25 \\
173,45\end{array}$ & \begin{tabular}{|l|}
176,91 \\
176,9
\end{tabular} & \begin{tabular}{|l|}
83,71 \\
83
\end{tabular} & $\begin{array}{l}1057,71 \\
1057\end{array}$ & \begin{tabular}{|l|}
135,904 \\
135,04
\end{tabular} & $\begin{array}{l}30,95 \\
36,25\end{array}$ & 34,12 & \begin{tabular}{|l|}
384,150 \\
384,15
\end{tabular} & $\begin{array}{l}139,04 \\
137,13 \\
\end{array}$ & \begin{tabular}{|l|l|}
156,459 \\
156
\end{tabular} & $\begin{array}{l}30,50 \\
348,63\end{array}$ \\
\hline Pelophylax perezi & 29TPJ04 & 56,00 & 137,36 & 73,90 & 42,15 & \begin{tabular}{|l|l|}
3514,50 \\
\end{tabular} & 232,05 & 58,87 & $\begin{array}{l}173,18 \\
\end{array}$ & 100,53 & 181,14 & 184,83 & 94,53 & \begin{tabular}{|l|l|}
981,99 \\
\end{tabular} & 127,14 & 33,35 & 34,81 & 356,73 & 127,39 & 148,12 & 319,92 \\
\hline Pelophylax perezi & \begin{tabular}{|l|} 
29TPJ13 \\
\end{tabular} & 90,00 & 132,24 & 76,74 & 41,84 & 3674,46 & 232,24 & 50,79 & 181,45 & 93,37 & 178,62 & 181,91 & 87,82 & 1000,76 & 128,78 & 34,41 & 34,42 & 361,84 & 130,66 & 149,97 & 325,86 \\
\hline Pelophylax perezi & 29TPJ21 & 100,00 & 120,79 & 81,71 & 41,1 & 3971,63 & 230,49 & 34,14 & 196,35 & 77,94 & 171,70 & 174,29 & 73,26 & 1057,61 & 134,68 & 36,63 & 34,61 & 381,88 & 137,79 & 154,38 & 348,21 \\
\hline Pelophylax perezi & 29TPJ22 & 101,00 & 128,39 & 79,59 & 41,46 & 3830,80 & 233,22 & 43,66 & 189,56 & 87,41 & 177,09 & 180,01 & 82,31 & \begin{tabular}{l|l|}
1008,09 \\
\end{tabular} & 129,29 & 35,01 & 34,31 & 363,16 & 132,31 & 150,16 & 327,92 \\
\hline Pelophylax perezi & 29TPJ24 & & & & & & & & & & & & & & & & & & & & \\
\hline Pelophylax perezi & 29TPJ31 & 100,00 & 135,22 & 81,16 & 41,29 & 3932,80 & 241,41 & $\begin{array}{ll}47,83 \\
\end{array}$ & 193,58 & 92,40 & 185,17 & 187,79 & 87,18 & 929,59 & 120,41 & 31,68 & 34,24 & 333,90 & 121,13 & 138,70 & 299,17 \\
\hline Pelophylax perezi & 29TPJ32 & 91,00 & 136,61 & 79,53 & 41,78 & 3831,15 & 239,88 & 51,33 & 188,55 & 95,22 & 185,06 & 187,84 & 89,85 & 927,72 & 120,65 & 32,12 & 33,99 & 332,50 & 122,39 & 40,73 & 296,34 \\
\hline Pelophylax perezi & 29TPJ40 & 101,00 & 128,17 & 84,57 & 41,07 & 4134,92 & 240,82 & 37,28 & 54 & 82,84 & 181,01 & 183,25 & 77,93 & 945,88 & 122,14 & 32,70 & 34,02 & 338,76 & 124,47 & 140,34 & 304,66 \\
\hline Pelophylax perezi & 29TPJ51 & 98,00 & $\frac{13}{13}$ & 82 & $\begin{array}{l}41, \\
41,\end{array}$ & 3,40 & 244 & $\begin{array}{l}1,200 \\
47,71\end{array}$ & \begin{tabular}{|l|}
2196,96 \\
\end{tabular} & \begin{tabular}{|l|}
$0<, 04$ \\
101,82 \\
\end{tabular} & $\begin{array}{l}10,101,53 \\
187,53\end{array}$ & \begin{tabular}{|l|}
190,06 \\
190,06
\end{tabular} & $\begin{array}{l}87,89 \\
87\end{array}$ & $\begin{array}{l}43,00 \\
881,10\end{array}$ & $\mid \begin{array}{l}\mid 2,15,75 \\
115,75\end{array}$ & 31,25 & 33,10 & \begin{tabular}{|l|l|}
312,48 \\
310
\end{tabular} & 119,11 & \begin{tabular}{|l|}
$135,91,9$ \\
\end{tabular} & 270,00 \\
\hline Pelophylax perezi & 29TPJ52 & 41,00 & 139,23 & 81,22 & 41,72 & 3912,25 & 244,14 & 51,68 & 192,46 & 111,51 & 188,72 & 191,29 & 91,29 & 874,91 & 115,40 & 31,32 & 32,94 & 309,83 & 119,20 & 136,62 & 271,68 \\
\hline Pelophylax perezi & 29TPJ61 & 101,00 & 128,73 & 85,00 & 41,49 & 4095,14 & 240,69 & 38,16 & 202,54 & \begin{tabular}{|c|}
$1+1,10$ \\
93,10
\end{tabular} & $\begin{array}{l}180,98 \\
\end{array}$ & 183,27 & 79,05 & 912,44 & 119,82 & 33,86 & 32,17 & \begin{tabular}{|l|}
321,09 \\
3
\end{tabular} & 127,55 & $\begin{array}{l}142,96 \\
142\end{array}$ & 282,41 \\
\hline Pelophylax perezi & 29TPJ62 & 54,00 & 139,54 & 81,85 & 41,87 & 3920,14 & 244,99 & 51,45 & 193,54 & 117,69 & 189,06 & 191,73 & 91,50 & 858,44 & 114,06 & 31,57 & 32,26 & 302,67 & 119,81 & 136,55 & 261,82 \\
\hline Pelophylax perezi & 29TPJ71 & 100,00 & 120 & 87, & 41, & 418 & 236,81 & 29,09 & 207 & 87,25 & 17 & 176,78 & 70,42 & 941,81 & 123,60 & 36,55 & 31,16 & 328,99 & 136,06 & 150,07 & 288 \\
\hline Pelophylax perezi & 29TQE03 & $\begin{array}{l}101,00 \\
100\end{array}$ & 157,84 & \begin{tabular}{|l|}
104,90 \\
10,0
\end{tabular} & $\begin{array}{l}41,45 \\
36,25 \\
\end{array}$ & $\begin{array}{ll}4101,10 \\
6197,98\end{array}$ & $\begin{array}{l}230,01 \\
324,68 \\
\end{array}$ & \begin{tabular}{|l|l|}
40,68 \\
405
\end{tabular} & \begin{tabular}{|l|l|}
284,00 \\
\end{tabular} & $\begin{array}{l}1,25 \\
89,63 \\
\end{array}$ & $\begin{array}{l}14,030 \\
240,05 \\
\end{array}$ & 240,05 & \begin{tabular}{l|l|l|l|l|}
81,88 \\
\end{tabular} & $\begin{array}{l}341,01 \\
573,08\end{array}$ & \begin{tabular}{|l|}
74,00 \\
74,32
\end{tabular} & $\begin{array}{c}30,03 \\
5,06 \\
\end{array}$ & $\begin{array}{l}1,10 \\
49,47\end{array}$ & \begin{tabular}{|l|l|}
219,34 \\
213
\end{tabular} & $\begin{array}{l}30,00 \\
39,70\end{array}$ & $\begin{array}{l}30,70 \\
39,70\end{array}$ & $\begin{array}{l}200,45 \\
209,86\end{array}$ \\
\hline Pelophylax perezi & 29TQE04 & 100,00 & 154,81 & 104,37 & 36,24 & 6192,69 & 321,03 & 38,01 & 283,02 & 86,55 & 237,01 & 237,01 & 78,85 & 586,07 & 76,24 & 5,54 & 48,99 & 224,24 & 41,44 & 41,44 & 214,93 \\
\hline Pelophyla & 29TQE05 & 101,00 & 138.92 & 100,86 & 35,66 & 6179,17 & 303,34 & 24,93 & 278,40 & 71,73 & 221,24 & 221.47 & 63.98 & 681.18 & 89,82 & 7.55 & 48.70 & 261.17 & 50,10 & 50.85 & 25198 \\
\hline Pelophylax perezi & 29TQE06 & 100,00 & 119,30 & 96,47 & 34,97 & 6132,22 & 280,84 & 9,10 & 271,74 & 53,72 & 201,13 & 201, & 46, & 805,73 & 107,34 & 10,19 & 48,41 & 309,67 & 60,69 & 63,48 & 300,38 \\
\hline Pelophylax perezi & 29TQE07 & 100,00 & 123,62 & 98,16 & 35,33 & 135,20 & 285,67 & 12,02 & 273,65 & 57,43 & 204,98 & 205,92 & 49,78 & 759,97 & \begin{tabular}{|l|l|}
100,67 \\
\end{tabular} & $\begin{array}{l}9,2,58 \\
9,58\end{array}$ & 48,27 & 291,79 & 57,97 & 59,88 & 282 \\
\hline
\end{tabular}




\begin{tabular}{|c|c|c|c|c|c|c|c|c|c|c|c|c|c|c|c|c|c|c|c|c|c|}
\hline TAXON & UTM & $\mathrm{km2}$ & BIO1 & B102 & $\mathrm{BIO3}$ & B104 & B105 & B106 & B107 & B108 & B109 & BIO10 & BIO11 & B1012 & BIO13 & BIO14 & BIO15 & BIO16 & BIO17 & BIO18 & BlO19 \\
\hline Pelophylax perezi & 29TQE08 & 99,00 & 125,47 & 99,36 & 35,85 & 6122,78 & 287,60 & 13,15 & 274,45 & 58,98 & 206,49 & 207,47 & 51,45 & 736,57 & 97,22 & 9,29 & 48,01 & 282,68 & 56,92 & 58,27 & 273,55 \\
\hline Pelophylax perezi & 29TQE09 & 100,00 & 131,30 & 101,86 & 36,17 & 6116,52 & 294,27 & 17,42 & 276,85 & 64,19 & 212,74 & 212,94 & 56,78 & $\begin{array}{l}685,57 \\
\end{array}$ & 89,87 & 8,81 & \begin{tabular}{ll|}
47,62 \\
\end{tabular} & 262,67 & 54,02 & 54,22 & 253,71 \\
\hline Pelophylax perezi & 29TQE13 & 100,00 & 156,33 & 105,69 & 36,17 & 6251,36 & 324,88 & 38,28 & 286,60 & 87,52 & 239,41 & 239,41 & 79,80 & \begin{tabular}{|l|l|}
550,07 \\
\end{tabular} & 70,36 & 5,31 & 48,23 & 208,15 & 39,49 & 39,49 & 197,77 \\
\hline Pelophylax perezi & 29TQE14 & 100,00 & 151,00 & 105,03 & 36,02 & 6245,07 & 319,05 & 33,85 & 285,20 & 82,28 & $\begin{array}{ll}234,02 \\
\end{array}$ & 234,02 & 74,70 & 573,23 & 73,34 & 6,00 & 47,74 & 216,81 & 42,50 & 42,50 & 206,36 \\
\hline Pelophylax perezi & 29TQE15 & 100,00 & 146,55 & 104,35 & 36,06 & 6231,45 & 313,85 & 29,86 & \begin{tabular}{|l|l|}
283,99 \\
\end{tabular} & 78,17 & \begin{tabular}{|l|l|}
229,47 \\
\end{tabular} & 229,52 & 70,50 & 592,07 & 76,03 & 6,48 & 47,61 & 224,16 & 44,50 & 44,61 & 213,74 \\
\hline Pelophylax perezi & 29TQE16 & 100,00 & 126,83 & 100,71 & 35,60 & 6194,17 & 292,02 & 13,50 & 278,52 & \begin{tabular}{|l|l|l|}
59,89 \\
\end{tabular} & 209,38 & 209,97 & 52,39 & 705,71 & 90,99 & 9,18 & 47,08 & 267,62 & 55,30 & 56,81 & 256,77 \\
\hline Pelophylax perezi & 29TQE17 & 100,00 & 116,90 & 99,27 & 35,58 & 6162,49 & 280,77 & 5,20 & 275,57 & 50,61 & \begin{tabular}{l|l|l|}
198,90 \\
\end{tabular} & $\begin{array}{l}199,93 \\
\end{array}$ & 43,24 & 757,81 & 97,69 & 10,55 & 46,63 & 287,30 & 60,86 & 63,32 & 276,08 \\
\hline Pelophylax perezi & 29TQE18 & 101,00 & 125,54 & 101,80 & 36,00 & 6169,60 & 290,29 & \begin{tabular}{l|l}
11,75 \\
\end{tabular} & 278,54 & 58,30 & 207,24 & 208,30 & 51,04 & \begin{tabular}{ll|l}
686,06 \\
\end{tabular} & 88,32 & 9,12 & 46,56 & 260,12 & 55,46 & 56,49 & 249,12 \\
\hline Pelophylax perezi & 29TQE19 & 100,00 & 127,25 & 103,00 & 36,19 & 6162,70 & 292,13 & 12,80 & 279,33 & \begin{tabular}{|l|l}
59,83 \\
\end{tabular} & 209,15 & $\begin{array}{l}209,75 \\
2\end{array}$ & \begin{tabular}{|l|l|}
52,47 \\
\end{tabular} & 661,92 & 85,14 & 9,13 & 46,17 & 250,62 & 54,62 & 55,15 & 239,65 \\
\hline Pelophylax perezi & 29TQE23 & 101,00 & 158,39 & 107,25 & 36,63 & 6291,53 & 328,72 & 38,90 & 289,82 & $89,09[$ & 242,02 & 242,02 & 81,28 & 510,27 & 64,77 & 5,10 & 47,50 & 190,83 & $37,41 \mid$ & 37,41 & 179,67 \\
\hline Pelophylax perezi & 29TQE24 & 99,00 & 149,99 & 106,28 & 36,22 & 6291,31 & 319,92 & 31,59 & 288,33 & \begin{tabular}{|l|}
80,97 \\
\end{tabular} & \begin{tabular}{|l|}
233,87 \\
\end{tabular} & 233,87 & 73,29 & 545,39 & 69,12 & 5,95 & 46,76 & 203,85 & $\begin{array}{ll}41,63 \\
\end{array}$ & 41,63 & 192,54 \\
\hline Pelophylax perezi & 29TQE25 & 100,00 & 144,28 & 105,56 & 36,23 & 6274,53 & 313,42 & 26,70 & 286,71 & 75,50 & \begin{tabular}{|l|l|}
227,90 \\
\end{tabular} & 227,97 & \begin{tabular}{ll|l}
67,85 \\
\end{tabular} & 568,92 & 72,27 & 6,71 & 46,51 & 212,81 & 44,44 & 44,51 & 201,38 \\
\hline Pelophylax perezi & 29TQE26 & 101,00 & 136,78 & 104,80 & \begin{tabular}{|l|}
36,17 \\
\end{tabular} & 6252,37 & 305,10 & 20,15 & 284,95 & 68,32 & 220,21 & 220,43 & \begin{tabular}{ll|l}
60,87 \\
\end{tabular} & 600,82 & 76,44 & 7,80 & \begin{tabular}{ll|}
46,06 \\
\end{tabular} & 224,75 & 48,41 & \begin{tabular}{l|l}
48,75 \\
\end{tabular} & 212,96 \\
\hline Pelophylax perezi & 29TQE27 & 100,00 & 115,21 & 101,46 & 35,89 & 6193,50 & 281,50 & 2,46 & \begin{tabular}{|l|l|}
279,03 \\
\end{tabular} & 48,61 & \begin{tabular}{ll|l}
197,91 \\
\end{tabular} & $\begin{array}{l}198,74 \\
\end{array}$ & 41,40 & 724,32 & 92,23 & 10,95 & 45,11 & 270,80 & 61,14 & 63,60 & 257,91 \\
\hline Pelophylax perezi & 29TQE28 & 100,00 & 119,46 & 102,97 & \begin{tabular}{ll|}
36,06 \\
\end{tabular} & 6199,91 & 286,09 & 5,50 & \begin{tabular}{|l|l|}
280,59 \\
\end{tabular} & 52,27 & \begin{tabular}{|l|l|}
201,76 \\
\end{tabular} & 202,81 & \begin{tabular}{ll|}
44,99 \\
\end{tabular} & 678,62 & 86,57 & 10,04 & 44, & 253,79 & \begin{tabular}{|l|l|}
57,87 \\
\end{tabular} & 59,40 & 240,81 \\
\hline Pelophylax perezi & 29TQE29 & 100,00 & 116,36 & 103,20 & 36,24 & 6180,34 & 282,62 & 2,50 & 280,12 & 49,27 & 198,36 & 199,41 & 42,10 & 682,64 & 87,11 & 10,50 & 44,39 & 254,87 & 59,63 & 61,24 & 241,53 \\
\hline Pelophylax perezi & 29TQE33 & 100,00 & 159,17 & 108,60 & 36,74 & 6323,18 & 330,81 & 38,28 & 292,54 & 89,22 & 243,18 & 243,18 & 81,60 & \begin{tabular}{ll|}
480,89 \\
\end{tabular} & 60,47 & 5,00 & 46,54 & \begin{tabular}{|l|}
177,64 \\
\end{tabular} & 36,23 & 36,23 & 165,88 \\
\hline Pelophylax perezi & 29TQE35 & 99,00 & 149,72 & 108,06 & 36,90 & 6304,32 & 320,61 & 30,16 & 290,45 & 80,12 & 233,76 & 233,76 & 72,64 & 508,86 & 64,10 & 6,03 & 45,44 & 187,75 & 40,64 & 40,64 & 175,75 \\
\hline Pelophylax perezi & 29TQE36 & 101,00 & 141,63 & 107,36 & 36,79 & 6292,12 & 312,02 & 22,93 & \begin{tabular}{|l|}
289,09 \\
\end{tabular} & 72,36 & 225,59 & 225,64 & 65,01 & 539,11 & 67,97 & 7,11 & 44,88 & $\begin{array}{l}198,78 \\
\end{array}$ & \begin{tabular}{|l|l|}
44,67 \\
\end{tabular} & 44,72 & 186,33 \\
\hline Pelophylax perezi & 29TQE37 & 99,00 & 132,68 & 106,64 & 36,72 & 6260,68 & 302,26 & 15,30 & 286,96 & 64,04 & 216,10 & 216,41 & 56,71 & 576,18 & 72,79 & 8,43 & 44,1 & 212,34 & \begin{tabular}{l|l}
9,52 \\
\end{tabular} & \begin{tabular}{ll|}
49,99 \\
\end{tabular} & 199,15 \\
\hline Pelophylax perezi & 29TQE38 & 100,00 & 110,46 & 103,62 & 36,32 & 6198,67 & 278,44 & $-3,04$ & 281,49 & 43,78 & 193,30 & 194,22 & 36,73 & \begin{tabular}{|l|l|}
697,16 \\
\end{tabular} & 88,05 & 11,78 & \begin{tabular}{|l|l|}
43,03 \\
\end{tabular} & 256,34 & 63,16 & 65,78 & 241,57 \\
\hline Pelophylax perezi & 29TQE39 & 101,00 & 109,91 & 104,34 & 36,66 & 6188,14 & 277,81 & $-3,78$ & \begin{tabular}{l|l|}
281,59 \\
\end{tabular} & 43,16 & $\begin{array}{l}192,28 \\
1\end{array}$ & $\begin{array}{l}193,47 \\
193\end{array}$ & 36,11 & 681,21 & 86,15 & 11,77 & 42,58 & 250,19 & 63,12 & 65,34 & 234,95 \\
\hline Pelophylax perezi & 29TQE43 & 100,00 & 153,78 & 109,25 & 36,69 & 6364,03 & 327,23 & 32,72 & 294,51 & 83,69 & 238,77 & 238,77 & 76,06 & \begin{tabular}{|l|l|}
479,93 \\
\end{tabular} & 59,67 & 5,32 & $\begin{array}{l}45,56 \\
\end{array}$ & $\mid 174,91$ & 37,56 & 37,56 & 162,53 \\
\hline Pelophylax perezi & 29TQE44 & 100,00 & 152,58 & 109,43 & 36,98 & 6344,64 & 325,43 & 31,54 & 293,89 & 82,55 & 237,27 & 237,27 & 74,89 & 477,37 & $\begin{array}{l}5,45 \\
\end{array}$ & 5,67 & 45,00 & \begin{tabular}{ll|}
173,76 \\
\end{tabular} & 38,39 & 38,39 & 161,35 \\
\hline Pelophylax perezi & 29TQE45 & 100,00 & 151,61 & 109,59 & 37,00 & 6324,97 & 323,68 & 30,62 & 293,06 & 81,56 & \begin{tabular}{|l|l|}
235,82 \\
\end{tabular} & 235,82 & 74,03 & 473,99 & 59,14 & 5,99 & 44,33 & 172,29 & \begin{tabular}{|l|}
39,09 \\
\end{tabular} & 39,09 & 159,80 \\
\hline Pelophylax perezi & \begin{tabular}{l|}
$29 T Q E 46$ \\
\end{tabular} & 100,00 & 146,14 & 109,54 & 36,99 & 6308,07 & 317,85 & 25,67 & 292,17 & 76,37 & 230,16 & 230,17 & 69,01 & 487,99 & 61,03 & 6,55 & 43,85 & \begin{tabular}{|l|l|}
177,18 \\
\end{tabular} & 41,57 & 41,57 & 164,23 \\
\hline Pelophylax perezi & 29TQE47 & 101,00 & 140,64 & 109,38 & 37,03 & 6294,98 & 312,04 & 20,83 & 291,21 & 71,06 & \begin{tabular}{|l|l|}
224,69 \\
\end{tabular} & $\begin{array}{l}224,75 \\
\end{array}$ & \begin{tabular}{ll|}
63,78 \\
\end{tabular} & \begin{tabular}{l|l}
502,05 \\
\end{tabular} & \begin{tabular}{ll|l}
62,86 \\
\end{tabular} & 7,40 & 43,31 & \begin{tabular}{ll|}
182,16 \\
\end{tabular} & \begin{tabular}{ll|}
44,17 \\
\end{tabular} & 44,21 & 168,79 \\
\hline Pelophylax perezi & 29TQE48 & 99,00 & 117,99 & 107,09 & 36,82 & 6247,59 & 288,57 & 1,73 & 286,85 & 50,00 & \begin{tabular}{|l|l|}
201,22 \\
\end{tabular} & $\begin{array}{l}202,15 \\
2\end{array}$ & 43,11 & $\begin{array}{ll}606,94 \\
\end{array}$ & 75,98 & 10,64 & 41,83 & 219,55 & 57,39 & 58,73 & 204,08 \\
\hline Pelophylax perezi & 29TQE49 & 100,00 & 111,13 & 106,74 & 36,98 & 6218,89 & 281,23 & $-3,86$ & 285,09 & 43,78 & \begin{tabular}{|l|l|}
193,70 \\
\end{tabular} & 195,11 & 36,90 & 629,64 & 78,99 & 11,61 & \begin{tabular}{|l|l|}
41,15 \\
\end{tabular} & 227,45 & \begin{tabular}{ll|}
61,36 \\
\end{tabular} & 63,11 & 210,94 \\
\hline Pelophylax perezi & 29TQE53 & 60,00 & 149,80 & 109,92 & 36,70 & 6408,64 & 324,57 & 27,94 & 296,63 & 79,16 & \begin{tabular}{|l|l|}
235,42 \\
\end{tabular} & 235,42 & 71,58 & 480,32 & 59,08 & 5,85 & 44,56 & \begin{tabular}{ll|}
173,02 \\
\end{tabular} & 39,20 & 39,20 & 160,24 \\
\hline Pelophylax perezi & 29TQE54 & 53,00 & 143,79 & 109,60 & 36,76 & 6381,46 & 318,09 & 22,92 & 295,17 & 73,69 & 229,20 & 229,32 & 66,36 & \begin{tabular}{l|l}
499,15 \\
\end{tabular} & 61,49 & 6,79 & 43,84 & 179,41 & 42,44 & 42,54 & 166,18 \\
\hline Pelophylax perezi & 29TQE55 & 57,00 & 150,76 & 110,57 & 37,00 & 6358,67 & 323,98 & 28,98 & 295,00 & 80,15 & 235,62 & 235,62 & 72,85 & \begin{tabular}{|l|l|}
458,15 \\
\end{tabular} & 56,78 & 6,03 & 43,63 & $\begin{array}{ll}164,68 \\
\end{array}$ & 39,14 & 39,14 & 151,80 \\
\hline Pelophylax perezi & 29TQE56 & 50,00 & 137,16 & 109,69 & 36,99 & 6325,01 & 310,13 & \begin{tabular}{|l|l|}
17,17 \\
\end{tabular} & 292,96 & 67,55 & 221,57 & 221,77 & 60,39 & \begin{tabular}{|l|l|}
507,69 \\
\end{tabular} & 62,88 & 7,87 & 42,52 & \begin{tabular}{ll|}
181,96 \\
\end{tabular} & 45,81 & 46,01 & 168,04 \\
\hline Pelophylax perezi & 29TQE57 & 42,00 & 139,19 & 110,38 & 37,06 & 6308,52 & 311,71 & \begin{tabular}{|l|l|}
18,79 \\
\end{tabular} & 292,92 & 69,40 & 223,40 & 223,47 & 62,26 & 486,51 & 60,44 & 7,65 & 42,35 & 174,30 & 44,42 & $\begin{array}{l}44,45 \\
\end{array}$ & 160,43 \\
\hline Pelophylax perezi & 29TQE58 & 47,00 & 134,90 & 110,69 & 37,23 & 6298,43 & 307,31 & \begin{tabular}{|l|l|l|}
14,87 \\
\end{tabular} & 292,44 & 65,49 & 219,16 & 219,25 & 58,23 & 493,18 & 61,34 & 8,28 & 41,59 & \begin{tabular}{ll|}
176,15 \\
\end{tabular} & \begin{tabular}{|l|l|}
46,67 \\
\end{tabular} & 46,74 & 161,74 \\
\hline Pelophylax perezi & 29TQE59 & 40,00 & 109,11 & 107,80 & 37,02 & 6220,82 & 280,18 & $-6,55$ & 286,74 & \begin{tabular}{ll|l}
41,68 \\
\end{tabular} & \begin{tabular}{|l|l|}
191,77 \\
\end{tabular} & \begin{tabular}{|l|l|}
193,17 \\
\end{tabular} & 35,12 & 618,22 & 76,86 & 12,17 & 39,94 & 220,18 & \begin{tabular}{ll|}
62,66 \\
\end{tabular} & 64,60 & 203,06 \\
\hline Pelophylax perezi & 29TQF00 & 101,00 & 125,68 & 101,47 & 36,07 & 6098,83 & 288,05 & 12,26 & 275,78 & \begin{tabular}{|l|l|}
58,74 \\
\end{tabular} & 206,51 & 207,12 & 51,41 & \begin{tabular}{|l|}
708,92 \\
\end{tabular} & $\begin{array}{l}92,76 \\
\end{array}$ & 9,30 & 47,33 & 271,62 & 56,76 & 57,37 & 262,61 \\
\hline Pelophylax perezi & 29TQF01 & 99,00 & 123,27 & 101,93 & \begin{tabular}{|l|l|}
36,47 \\
\end{tabular} & 6078,89 & 285,48 & \begin{tabular}{l|l}
9,88 \\
\end{tabular} & 275,60 & 56,65 & 203,79 & 204,45 & 49,18 & \begin{tabular}{|l|l|}
712,59 \\
\end{tabular} & 93,04 & 9,86 & 47,03 & 272,95 & 58,21 & 58,77 & 263,94 \\
\hline Pelophylax perezi & 29TQF02 & 100,00 & 122,89 & 103,03 & 36,92 & 6064,12 & 28 & 9,05 & 276,44 & 56,28 & 203,29 & 203,87 & 48,9 & 700,28 & 90,91 & 9,98 & o, & 267,72 & 8,49 & 58,88 & 258,90 \\
\hline Pelophylax perezi & \begin{tabular}{|l|}
$29 T Q F 03$ \\
\end{tabular} & 100,00 & 124,36 & 104,55 & 37,03 & 6050,11 & 287,38 & 9,67 & 277,71 & 57,40 & 204,96 & 204,97 & 50,19 & \begin{tabular}{|l|l|}
679,25 \\
\end{tabular} & 87,93 & 9,80 & 46,31 & 259,57 & 57,41 & 57,42 & 251,08 \\
\hline Pelophylax perezi & 29TQF04 & 101,00 & 123,46 & 105,54 & \begin{tabular}{l|l|}
37,25 \\
\end{tabular} & 6028,68 & 286,61 & 8,46 & 278,16 & \begin{tabular}{|l|l|}
56,72 \\
\end{tabular} & \begin{tabular}{|l|l|}
203,73 \\
\end{tabular} & 203,73 & \begin{tabular}{l|l|}
49,45 \\
\end{tabular} & \begin{tabular}{|l|l|}
672,08 \\
\end{tabular} & 86,70 & 9,91 & \begin{tabular}{|l|}
45,98 \\
\end{tabular} & 256,68 & 57,71 & 57,71 & 248,53 \\
\hline Pelophylax perezi & 29TQF05 & 99,00 & 122,03 & 106,32 & 37,58 & 6018,77 & 285,45 & 6,53 & 278,92 & 55,32 & 202,18 & 202,18 & 48,14 & 667,94 & \begin{tabular}{l|l|}
85,85 \\
\end{tabular} & 10,00 & 45,79 & 255,06 & \begin{tabular}{|l|l}
58,03 \\
\end{tabular} & 58,03 & 247,19 \\
\hline Pelophylax perezi & 29TQF06 & 100,00 & 125,29 & 107,78 & 38,01 & 6002,93 & 288,91 & 8,85 & 280,05 & 58,28 & \begin{tabular}{|l|}
204,97 \\
\end{tabular} & \begin{tabular}{|l|}
204,97 \\
\end{tabular} & 51,21 & 640,23 & 82,02 & 9,97 & 45,41 & \begin{tabular}{l|l|}
244,05 \\
\end{tabular} & 56,19 & 56,19 & 236,84 \\
\hline Pelophylax perezi & 29TQF07 & 100,00 & 124,47 & 108,48 & 38,15 & 5975,92 & 288,21 & \begin{tabular}{l|l}
7,85 \\
\end{tabular} & 280,36 & 57,62 & 203,80 & 203,80 & 50,69 & \begin{tabular}{|c|}
634,57 \\
\end{tabular} & 81,31 & 10,33 & $\begin{array}{ll}45,02 \\
\end{array}$ & \begin{tabular}{|l|l|}
241,67 \\
\end{tabular} & 56,70 & 56,70 & 235,01 \\
\hline Pelophylax perezi & \begin{tabular}{|l|l|}
$29 T Q F 08$ \\
\end{tabular} & 100,00 & 119,33 & 108,56 & 38,17 & 5959,95 & 28 & 3,05 & 280,26 & 52,92 & 198,65 & 198,65 & 45,99 & 654,23 & 84,20 & 11,16 & 44,66 & 249,16 & 60,21 & 60,21 & 243,12 \\
\hline Pelophylax perezi & 29TQF09 & 101,00 & 126,93 & 110,16 & 38,94 & 5930,54 & 290,50 & 9,14 & 281,36 & 60,20 & 205,50 & 205,50 & 53,32 & 605,30 & 78,18 & 10,60 & 44,49 & 230,27 & 55,42 & 55,42 & 224,78 \\
\hline Pelophylax perezi & 29TQF10 & 99,00 & 123,20 & 103,09 & 36,52 & 6140,43 & 287,72 & 8,99 & 278,73 & 56,01 & \begin{tabular}{|l|l|}
204,47 \\
\end{tabular} & 205,41 & \begin{tabular}{|l|l|}
48,67 \\
\end{tabular} & 673,72 & 86,64 & 9,59 & 45,73 & 255,00 & \begin{tabular}{l|l|}
56,69 \\
\end{tabular} & 57,43 & 243,76 \\
\hline Pelophylax perezi & 29TQF11 & 100,00 & 123,25 & 104,14 & 36,98 & 6128,57 & 287,91 & 8,57 & 279,33 & 55,96 & \begin{tabular}{|l|l|}
204,75 \\
\end{tabular} & 205,19 & 48,69 & 659,94 & 84,82 & 9,63 & 45,38 & 249,59 & 56,55 & 56,89 & 238,38 \\
\hline Pelophylax perezi & 29TQF12 & 100,00 & 122,99 & 105,13 & 37,00 & 6111,62 & 287,74 & 7,87 & 279,87 & 55,62 & 204,36 & 204,60 & 48,39 & 647,71 & 83,04 & 9,79 & 44,91 & 244,60 & 56,76 & 56,92 & 233,47 \\
\hline Pelophylax perezi & \begin{tabular}{|l|l|l}
$29 T Q F 13$ \\
\end{tabular} & 101,00 & 123,01 & 106,11 & 37,06 & 6095,12 & 287,97 & 7,33 & 280,65 & 55,72 & 204,13 & 204,15 & 48,44 & 634,82 & 81,18 & 9,91 & 44,66 & 239,46 & 56,57 & 56,58 & 228,54 \\
\hline Pelophylax perezi & 29TQF14 & 99,00 & 120,89 & 106,77 & 37,49 & 6081,66 & 286,01 & 5,07 & 280,95 & $\begin{array}{l}53,65 \\
\end{array}$ & 201,93 & 201,93 & 46,56 & 633,33 & 80,74 & 10,00 & \begin{tabular}{|l|l|}
44,27 \\
\end{tabular} & 238,69 & 57,48 & 57,48 & 227,90 \\
\hline Pelophylax perezi & 29TQF15 & 101,00 & 120,75 & 107,73 & \begin{tabular}{l|l|}
37,95 \\
\end{tabular} & 6071,48 & 286,05 & \begin{tabular}{ll|}
4,44 \\
\end{tabular} & 281,61 & 53,44 & 201,50 & 201,50 & 46,21 & 621,94 & 79,17 & 10,14 & \begin{tabular}{|l|}
43,99 \\
\end{tabular} & 234,15 & \begin{tabular}{|l|l|}
57,15 \\
\end{tabular} & \begin{tabular}{l|l}
57,15 \\
\end{tabular} & 223,71 \\
\hline Pelophylax perezi & 29TQF16 & 100,00 & 119,86 & 108,46 & 38,00 & 6049,59 & 285,22 & 3,36 & 281,85 & 52,53 & 200,33 & 200,33 & 45,51 & $\begin{array}{l}616,45 \\
\end{array}$ & 78,70 & 10,64 & 43,43 & 231,63 & 58,12 & 58,12 & 221,61 \\
\hline Pelophylax perezi & 29TQF & 99,00 & 126 , & 110,00 & 38,2 & 6022 & 292 & 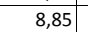 & 283 & 59, & 206 & 206 & 52, & 571,63 & 73,3 & 9,92 & 43, & 214 & 53,54 & 53,54 & 205 \\
\hline Pelophylax perezi & 29TQF18 & 100,00 & 122,60 & 110,21 & 38,40 & 6005,49 & 287,87 & 4,76 & 283,11 & 55,36 & 202,28 & 202,28 & 48,48 & 585,02 & 75,58 & 10,69 & 43,04 & 219,49 & 56,23 & 56,23 & 210,90 \\
\hline Pelophylax perezi & 29TQF19 & 100,00 & 118,95 & 110,37 & 38,70 & 5982,06 & 284,32 & 1,44 & 282,88 & 52,01 & \begin{tabular}{ll|}
198,36 \\
\end{tabular} & 198,36 & 45,22 & 596,50 & 77,51 & 11,53 & 42,49 & 223,55 & \begin{tabular}{l|l|l|}
59,05 \\
\end{tabular} & \begin{tabular}{l|l}
59,05 \\
\end{tabular} & 215,39 \\
\hline Pelophylax perezi & 29TQF20 & 100,00 & 122,60 & 105,19 & 36,93 & 6179,35 & 289,29 & 7,16 & \begin{tabular}{|l|l|}
282,13 \\
\end{tabular} & 54,98 & \begin{tabular}{|l|l|}
204,59 \\
\end{tabular} & 205,36 & 47,62 & 629,76 & 80,45 & 9,78 & 44,21 & 235,08 & 55,74 & 56,30 & 221,92 \\
\hline Pelophy & 29TQF2 & 101,00 & 123,91 & 106,41 & 37,00 & 6166,18 & & 772 (7) & 283, & 55,99 & \begin{tabular}{|l|l|}
206,19 \\
\end{tabular} & 206,34 & 48,80 & \begin{tabular}{|c|}
606,68 \\
\end{tabular} & 77,50 & 9,49 & $4388>>$ & 226,22 & 54,70 & 54,79 & 213 \\
\hline Pelophylax perezi & 29TQF22 & 100,00 & 122,91 & 107,17 & 37,21 & $6155,81 \mid$ & 289,8 & 6,40 & 283,47 & \begin{tabular}{|l|l|}
54,95 \\
\end{tabular} & 205,13 & 205,15 & 47,82 & 599,66 & 76,48 & 9,97 & 43,38 & 223,26 & 55,36 & 55,37 & 209,93 \\
\hline Pelophylax perezi & 29TQF23 & 100,00 & 121,07 & 107,80 & 37,57 & 6138,42 & 288,02 & 4,50 & 283,52 & 53,12 & 202,86 & 202,95 & 46,11 & 594,91 & 75,73 & 9,97 & 42,97 & 221,11 & 56,01 & 56,09 & 207,68 \\
\hline
\end{tabular}




\begin{tabular}{|c|c|c|c|c|c|c|c|c|c|c|c|c|c|c|c|c|c|c|c|c|c|}
\hline TAXON & UTM & $\mathrm{km} 2$ & B101 & B102 & $\mathrm{BIO3}$ & B104 & B105 & B106 & B107 & B108 & B109 & BIO10 & B1011 & BIO12 & B1013 & BIO14 & BIO15 & B1016 & B1017 & B1018 & B1019 \\
\hline Pelophylax perezi & 29TQF24 & 101,00 & 119,11 & 108,31 & 37,93 & 6126,72 & 286,04 & 2,39 & 283,64 & 51,25 & 200,62 & 200,65 & 44,23 & 592,82 & 75,47 & 10,10 & 42,64 & 220,00 & 56,88 & 56,90 & 206,55 \\
\hline Pelophylax perezi & 29TQF25 & 100,00 & 118,78 & 109,07 & 38,00 & 6103,65 & 285,76 & 1,81 & 283,94 & 51,01 & 200,04 & 200,04 & 44,07 & 582,67 & 74,56 & 10,54 & 42,24 & 215,88 & 56,95 & 56,95 & 202,80 \\
\hline Pelophylax perezi & 29TQF26 & 100,00 & 119,46 & 109,95 & 38,00 & 6093,24 & 286,79 & 1,91 & 284,88 & 51,71 & 200,57 & 200,57 & 44,79 & 566,95 & 72,83 & 10,62 & 41,69 & 209,51 & 56,51 & 56,51 & 196,92 \\
\hline Pelophylax perezi & 29TQF27 & 101,00 & 120,53 & 110,64 & 38,04 & 6077,37 & 287,51 & 2,25 & 285,26 & 52,64 & 201,23 & 201,23 & 45,72 & 554,07 & 71,52 & 10,61 & 41,49 & 204,46 & 55,79 & 55,79 & 192,65 \\
\hline Pelophylax perezi & 29TQF28 & 100,00 & 120,82 & 111,21 & 38,30 & 6056,09 & 287,94 & 2,60 & 285,34 & 53,22 & 201,28 & 201,28 & 46,19 & 543,86 & 70,42 & $\begin{array}{ll}10,86 \\
\end{array}$ & 41,16 & 200,26 & 55,77 & 55,77 & 188,94 \\
\hline Pelophylax perezi & 29TQF29 & 100,00 & 120,33 & 111,61 & 38,78 & 6032,92 & 287,25 & 1,88 & 285,36 & 52,66 & 200,29 & 200,29 & 45,80 & 541,55 & 70,40 & 11,25 & 40,85 & 199,19 & 56,50 & 56,50 & 188,40 \\
\hline Pelophylax perezi & 29TQF30 & 100,00 & 119,31 & 106,94 & 37,00 & 6208,17 & 287,95 & 3,01 & 284,94 & 51,33 & 201,75 & 202,61 & 44,15 & 603,73 & 76,57 & 10,06 & 42,51 & 221,76 & 56,64 & 57,28 & 206,68 \\
\hline Pelophylax perezi & 29TQF31 & 99,00 & 122,05 & 108,26 & 37,16 & 6197,09 & 290,82 & $\begin{array}{ll}4,97 \\
4,9\end{array}$ & 285,84 & 53,83 & 204,93 & 205,01 & 46,73 & 573,46 & 72,70 & 10,00 & 42,23 & 210,20 & 55,09 & 55,15 & 195,05 \\
\hline Pelophylax perezi & 29TQF32 & 101,00 & 122,84 & 109,25 & 37,61 & 6182,62 & 291,85 & 5,21 & 286,64 & 54,53 & 205,46 & 205,46 & 47,40 & 553,92 & 70,25 & 10,00 & 41,88 & 202,84 & 53,95 & 53,95 & 187,61 \\
\hline Pelophylax perezi & 29TQF34 & 100,00 & 118,35 & 110,22 & 38,01 & \begin{tabular}{ll|}
6155,54 \\
\end{tabular} & 287,30 & 0,83 & 286,47 & 50,35 & 200,59 & 200,59 & 43,27 & 549,21 & 70,31 & 10,36 & 41,10 & 200,35 & 56,01 & 56,01 & 184,51 \\
\hline Pelophylax perezi & 29TQF35 & 100,00 & 118,97 & 110,87 & 38,08 & 6142,17 & 287,85 & 0,92 & 286,92 & 50,75 & 200,85 & 200,85 & 43,79 & 533,91 & 68,62 & 10,49 & 40,59 & 194,06 & 55,55 & 55,55 & 178,62 \\
\hline Pelophylax perezi & 29TQF36 & 100,00 & 120,24 & 111,54 & 38,22 & 6129,71 & 289,00 & 1,76 & 287,24 & 52,16 & 201,72 & 201,72 & 45,03 & 517,40 & 66,80 & 10,28 & 40,33 & $\begin{array}{l}187,67 \\
\end{array}$ & 54,43 & 54,43 & 172,97 \\
\hline Pelophylax perezi & 29TQF37 & 100,00 & 118,55 & 111,76 & 38,46 & 6114,85 & 287,34 & 0,26 & 287,08 & 51,81 & 199,80 & 199,80 & 43,42 & 515,96 & 66,72 & 10,98 & 39,88 & 186,47 & 55,52 & 55,52 & 172,01 \\
\hline Pelophylax perezi & 29TQF38 & 100,00 & 117,16 & 112,03 & \begin{tabular}{|l|l|}
38,93 \\
\end{tabular} & 6097,53 & 285,87 & $-0,68$ & 286,55 & 50,01 & 198,18 & 198,18 & 42,05 & 517,13 & 66,94 & 11,24 & 39,33 & 186,47 & 57,05 & 57,05 & 172,52 \\
\hline Pelophylax perezi & 29TQF39 & 101,00 & 117,53 & 112,34 & \begin{tabular}{l|l|}
38,95 \\
\end{tabular} & 6073,13 & 286,20 & $-0,80$ & 287,00 & 54,47 & 198,29 & 198,29 & 42,66 & 509,77 & 66,10 & \begin{tabular}{|c|}
11,77 \\
\end{tabular} & 38,87 & 183,34 & 57,22 & 57,22 & 169,97 \\
\hline Pelophylax perezi & 29TQF40 & 100,00 & 116,70 & 108,66 & 37,23 & 6227,32 & 287,15 & $-0,06$ & 287,21 & 48,54 & 199,46 & 200,47 & 41,83 & 578,11 & 72,63 & 10,60 & 40,89 & 208,46 & 57,44 & 58,19 & 191,94 \\
\hline Pelophylax perezi & 29TQF41 & 100,00 & 120,12 & 110,06 & 37,78 & 6225,63 & 290,81 & 2,18 & 288,63 & 51,64 & 203,41 & 203,55 & 44,62 & 543,12 & 68,39 & 10,07 & 40,68 & 195,64 & 55,10 & 55,19 & 178,90 \\
\hline Pelophylax perezi & 29TQF42 & 100,00 & 121,21 & 111,03 & 38,00 & 6213,43 & 291,77 & 2,71 & 289,06 & 53,20 & 204,21 & 204,21 & 45,50 & 522,19 & 66,12 & 10,00 & 40,31 & 187,54 & 54,20 & 54,20 & 170,50 \\
\hline Pelophylax perezi & 29TOF44 & 99,00 & 118,41 & 112,01 & 38,09 & 6184,50 & 288,97 & 0,23 & 288,74 & 65,45 & 200,91 & 200,91 & 42,97 & 506,69 & 65,08 & $\begin{array}{ll}10,55 \\
\end{array}$ & 39,66 & 181,50 & 54,95 & 54,95 & 163,34 \\
\hline Pelophylax perezi & 29TQF45 & 99,00 & 120,27 & 112,72 & 38,18 & 6173,60 & 290,70 & 1,01 & 289,68 & 74,07 & 202,34 & 202,34 & 44,59 & 485,16 & 62,58 & 10,14 & 39,43 & 173,62 & 53,39 & 53,39 & 155,40 \\
\hline Pelophylax perezi & 29TQF46 & 101,00 & 118,96 & 112,92 & 38,60 & 6153,76 & 289,35 & 0,24 & 289,11 & 76,52 & 200,76 & 200,76 & 43,42 & 481,04 & 62,11 & 10,63 & 38,93 & 171,84 & 54,16 & 54,16 & 153,67 \\
\hline Pelophylax perezi & 29TQF47 & 100,00 & 116,77 & 112,93 & 38,80 & 6141,71 & 287,25 & $\begin{array}{l}-1,44 \\
-1,44 \\
\end{array}$ & 288,68 & 76,17 & 198,53 & 198,53 & 41,46 & 481,72 & $\begin{array}{ll}62,16 \\
\end{array}$ & 11,00 & 38,46 & 171,64 & 55,31 & 55,31 & 153,66 \\
\hline Pelophylax perezi & 29TQF48 & 100,00 & 116,89 & 113,23 & \begin{tabular}{|l|l|}
38,97 \\
\end{tabular} & 6130,25 & 286,98 & $-1,75$ & 288,73 & 76,96 & 198,25 & 198,25 & 41,58 & 475,93 & 61,37 & \begin{tabular}{|l|}
11,24 \\
\end{tabular} & 37,99 & 169,20 & 55,66 & 55,66 & 151,72 \\
\hline Pelophylax perezi & 29TQF49 & 100,00 & 119,58 & 113,50 & 38,97 & 6115,42 & 289,29 & 0,01 & 289,29 & 80,05 & 200,47 & 200,48 & 43,96 & 459,76 & 59,24 & 11,05 & 37,64 & 163,38 & 54,36 & 54,37 & 146,34 \\
\hline Pelophylax perezi & 29TQF50 & 33,00 & 117,20 & 110,11 & 37,63 & 6238,59 & 288,82 & $-0,27$ & 289,09 & 48,91 & 200,27 & 201,05 & 42,04 & 550,61 & 68,77 & 10,71 & 39,96 & 195,89 & 56,96 & 57,45 & 178,63 \\
\hline Pelophylax perezi & 29TQF51 & 36,00 & 117,76 & 111,09 & 38,00 & 6228,51 & 289,45 & $-0,02$ & 289,47 & 49,35 & 200,98 & 201,33 & 42,56 & 530,89 & 66,45 & 10,80 & 39,60 & 188,53 & 56,38 & 56,60 & 170,73 \\
\hline Pelophylax perezi & 29TQF55 & 20,00 & 120,39 & 113,85 & 38,85 & 6201,03 & $\begin{array}{l}291,45 \\
291,73 \\
\end{array}$ & 0,48 & 291,24 & 80,33 & 202,91 & 202,91 & 44,55 & 462,15 & 50,55 & 10,12 & 38,76 & $\begin{array}{l}165,27 \\
165\end{array}$ & 52,79 & 52,79 & 143,82 \\
\hline Pelophylax perezi & 29TQF56 & 13,00 & 117,28 & 113,96 & 38,96 & 6187,16 & 288,52 & $-1,68$ & 290,20 & 77,16 & 199,72 & 199,72 & 41,68 & 466,84 & 60,20 & 11,00 & 38,12 & 166,48 & 54,76 & 54,76 & 145,08 \\
\hline Pelophylax perezi & 29TQF59 & 4,00 & 119,55 & 114,00 & 39,00 & 6127,82 & 289,64 & $-0,36$ & 290,00 & 80,00 & 200,64 & 200,64 & 43,91 & 438,91 & 56,27 & 10,73 & 36,91 & 155,64 & 53,36 & 53,36 & 136,09 \\
\hline Pelophylax perezi & 29TQG00 & 99,00 & 123,09 & 110,27 & 38,96 & 5918,68 & 286,88 & 5,41 & 281,47 & 56,58 & 201,70 & 201,70 & 49,72 & 619,22 & 80,70 & 11,43 & 44,19 & 235,64 & 58,29 & 58,29 & 230,85 \\
\hline Pelophylax perezi & 29TQG01 & 101,00 & 120,16 & 110,37 & 39,00 & 5890,61 & 283,96 & 2,77 & 281,19 & 54,07 & 198,46 & 198,46 & 47,29 & 630,02 & 82,67 & 12,21 & 43,76 & 239,57 & 60,81 & 60,81 & 235,47 \\
\hline Pelophylax perezi & 29TQG02 & 100,00 & 118,31 & 110,55 & 39,00 & 5867,35 & 282,03 & 1,14 & \begin{tabular}{|l|l|}
280,89 \\
\end{tabular} & 52,36 & $\begin{array}{l}196,31 \\
19,40\end{array}$ & 196,31 & 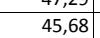 & 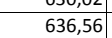 & $\begin{array}{l}2,010 \\
84,01\end{array}$ & 13,14 & 43,33 & \begin{tabular}{|l|}
241,71 \\
\end{tabular} & $\begin{array}{l}0,0107 \\
63,07\end{array}$ & $\begin{array}{l}0,0107 \\
63,07\end{array}$ & 237,84 \\
\hline Pelophylax perezi & 29TQG03 & 100,00 & 114,88 & 110,19 & \begin{tabular}{|l|}
38,98 \\
\end{tabular} & 5844,04 & 278,26 & $-1,66$ & 279,92 & 49,20 & 192,60 & 192,60 & 42,71 & 654,32 & 86,67 & \begin{tabular}{|l|l|}
14,58 \\
\end{tabular} & 42,81 & 247,97 & 66,98 & 66,98 & 243,35 \\
\hline Pelophylax perezi & 29TQG04 & 99,00 & 107,72 & 109,04 & 38,75 & 5831,01 & 270,54 & $-7,80$ & 278,34 & 42,36 & 185,45 & 185,45 & 36,15 & \begin{tabular}{|l|l|}
697,38 \\
\end{tabular} & 92,22 & 17,25 & $\begin{array}{l}42,55 \\
41,55\end{array}$ & 262,69 & 75,26 & 75,26 & 255,74 \\
\hline Pelophylax perezi & 29TQG05 & 99,00 & 104,21 & 108,35 & 38,61 & 5812,30 & 266,16 & $-10,78$ & 276,93 & 39,18 & 181,82 & 181,82 & 33,12 & 720,31 & 95,06 & 19,42 & 40,52 & 270,01 & 80,76 & 80,76 & 260,84 \\
\hline Pelophylax perezi & 29TQG06 & 101,00 & 97,59 & 107,19 & 38,63 & 5777,70 & 258,37 & $-16,03$ & 274,40 & 33,35 & 174,90 & 174,90 & 27,26 & 770,14 & 100,90 & 22,35 & 39,27 & 286,20 & 90,40 & 90,40 & 274,29 \\
\hline Pelophylax perezi & 29TQG07 & 100,00 & 75,27 & 102,87 & 38,12 & 5659,24 & 233,23 & $-33,33$ & 266,56 & 14,21 & 151,42 & 151,61 & 7,86 & 961,33 & 122,26 & 31,36 & 36,71 & 349,51 & 121,47 & 122,08 & 332,88 \\
\hline Pelophylax perezi & 29TQG10 & 101,00 & 116,77 & 110,67 & 39,00 & 5974,82 & 282,16 & $-0,12$ & 282,28 & 50,13 & 196,21 & 196,21 & 43,23 & 602,56 & 78,66 & 12,23 & 42,09 & 225,51 & 61,11 & 61,11 & 217,74 \\
\hline Pelophylax perezi & 29TQG11 & 99,00 & 115,18 & 110,82 & \begin{tabular}{|c|}
38,98 \\
\end{tabular} & 5954,86 & 280,36 & $-1,87$ & 282,23 & 48,68 & \begin{tabular}{l|l}
194,38 \\
\end{tabular} & 194,38 & 41,81 & 608,24 & 79,75 & 13,07 & 41,70 & 227,39 & 63,06 & $\begin{array}{ll}63,06 \\
\end{array}$ & 219,83 \\
\hline Pelophylax perezi & 29TQG12 & 100,00 & 111,25 & 110,62 & 38,97 & 5928,59 & 276,26 & $-5,44$ & 281,70 & 44,90 & 190,13 & 190,13 & 38,21 & 629,53 & 82,72 & 14,56 & 41,12 & 234,74 & 67,54 & 67,54 & 226,96 \\
\hline Pelophylax perezi & 29 TQG13 & 101,00 & 111,71 & 110,86 & 39,00 & 5909,07 & 276,33 & $-5,18$ & 281,51 & 45,45 & 190,29 & 190,29 & 38,81 & 625,53 & 82,37 & 15,30 & 40,67 & 232,93 & 68,39 & 68,39 & 224,64 \\
\hline Pelophylax perezi & $\begin{array}{l}29 \text { TQG14 } \\
290\end{array}$ & $\begin{array}{l}100,00 \\
100,0\end{array}$ & $\begin{array}{l}11,11 \\
106,12\end{array}$ & $\begin{array}{l}111,80 \\
110,05\end{array}$ & 38,00 & $\begin{array}{l}3909,00 \\
584\end{array}$ & 270,36 & \begin{tabular}{|c|c|}
$-30,14$ \\
$-10,14$
\end{tabular} & \begin{tabular}{|l|}
280,50 \\
280
\end{tabular} & \begin{tabular}{|l|}
40,25 \\
40,21
\end{tabular} & \begin{tabular}{|l|l|}
184,73 \\
\end{tabular} & 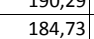 & $\begin{array}{l}30,01 \\
33,77\end{array}$ & \begin{tabular}{|l|l|}
623,20 \\
662,20
\end{tabular} & 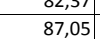 & $\begin{array}{l}\mid 2,30 \\
17,70\end{array}$ & \begin{tabular}{|l|l|}
39,73 \\
39,
\end{tabular} & \begin{tabular}{|l|}
245,46 \\
245
\end{tabular} & $\begin{array}{l}0,39 \\
75,48 \\
\end{array}$ & $\begin{array}{l}0,39 \\
75,48 \\
\end{array}$ & $\begin{array}{l}224,04 \\
235,49\end{array}$ \\
\hline Pelophylax perezi & 29TQG15 & 100,00 & 106,85 & 110,18 & 38,99 & 5876,78 & 270,54 & $-9,53$ & 280,07 & 40,80 & 185,13 & 185,13 & 34,51 & 658,88 & 86,64 & 18,55 & 39,18 & 243,62 & 76,94 & 76,94 & 232,45 \\
\hline Pelophylax perezi & 29TQG16 & 100,00 & 100,74 & 109,21 & 38,89 & 5841,69 & 263,66 & $-14,63$ & 278,29 & 35,43 & 178,66 & 178,66 & 29,22 & 704,69 & 92,02 & 21,13 & 38,13 & 258,67 & 85,76 & 85,76 & 245,22 \\
\hline Pelophylax perezi & 29TQG18 & 100,00 & 80,36 & 105,43 & 38,57 & 5693,88 & 239,67 & $-30,51$ & 270,17 & 18,24 & 156,74 & 156,79 & 11 , & 880,15 & 111,79 & 30,29 & 35,26 & 16,01 & 117,00 & 117,16 & 297,01 \\
\hline Pelophylax perezi & 29TQG20 & 100,00 & 116,37 & 111,62 & 38,94 & 6018,44 & 283,37 & \begin{tabular}{|l|l|}
$-1,28$ \\
\end{tabular} & 284,65 & \begin{tabular}{|l|}
49,07 \\
\end{tabular} & 196,27 & 196,27 & 42,19 & 557,49 & \begin{tabular}{|c|c|}
72,66 \\
\end{tabular} & 12,32 & \begin{tabular}{l|}
50,29 \\
40,
\end{tabular} & 204,73 & 然1, & $\begin{array}{ll}59,88 \\
59\end{array}$ & 194,08 \\
\hline Pelophylax perezi & 29TQG21 & 101,00 & 113,17 & 111,51 & 38,93 & 6004,49 & 280,10 & $-4,34$ & 284,44 & 46,17 & 193,10 & 193,10 & 39,30 & 572,97 & 74,83 & 13,54 & 39,72 & 210,03 & 63,41 & 63,41 & 199,39 \\
\hline Pelophylax perezi & 29TQG22 & 100,00 & 112,56 & 111,70 & 38,98 & 5985,53 & 279,23 & $-5,25$ & 284,47 & 45,37 & 192,16 & 192,16 & 38,74 & 576,92 & 75,50 & 14,41 & 39,31 & 211,27 & 65,18 & 65,18 & 200,58 \\
\hline Pelophylax perezi & $29 \mathrm{TQG23}$ & 100,00 & 110,98 & 111,77 & 38,99 & 5962,96 & 277,49 & $-6,65$ & 284,14 & 44,06 & 190,24 & 190,24 & 37,44 & 586,56 & 76,79 & 15,58 & 38,85 & 214,35 & 68,07 & 68,07 & 203,04 \\
\hline Pelophylax perezi & 29TQG24 & 99,00 & 106,53 & 111,31 & 38,98 & 5942,33 & 272,67 & $-10,62$ & 283,29 & 40,28 & 185,74 & 185,74 & 33,40 & 617,64 & 80,63 & 17,53 & 38,15 & 224,86 & 74,17 & 74,17 & 212,30 \\
\hline Pelophylax perezi & $299 \mathrm{TQG25}$ & $\begin{array}{l}501,00 \\
101\end{array}$ & 11 & $\begin{array}{l}111,51 \\
111,69\end{array}$ & 年0, 39,00 & 5924,36 & 275,84 & \begin{tabular}{|c|c|}
$-1,0,58$ \\
$-7,58$
\end{tabular} & \begin{tabular}{|l|}
283,42 \\
283
\end{tabular} & $\begin{array}{l}40,260 \\
47,51\end{array}$ & \begin{tabular}{|l|}
189,06 \\
18,4
\end{tabular} & \begin{tabular}{|l|}
$189,06,4$ \\
189,06
\end{tabular} & 36,88 & $\mid 598,86$ & $\mid \begin{array}{l}\mid 70,3031 \\
78,31\end{array}$ & 17,36 & $\begin{array}{l}30,113 \\
37,81\end{array}$ & \begin{tabular}{|l|}
$217,92,0$ \\
\end{tabular} & 72,90 & 72,90 & 204,71 \\
\hline Pelophylax perezi & 29 TQG26 & 100,00 & 107,80 & 111,40 & 39,00 & 5903,09 & 272,74 & $-9,90$ & 282,63 & 53,23 & 186,34 & 186,34 & 34,78 & 619,73 & 80,76 & 18,88 & 37,12 & 224,81 & 77,87 & 77,87 & 209,72 \\
\hline Pelophylax perezi & 29TQG27 & 101,00 & 96,95 & 110,01 & 38,90 & 5850,44 & 261,05 & $-18,67$ & 279,72 & 45,32 & $\begin{array}{l}175,08 \\
\end{array}$ & \begin{tabular}{l|l|}
175,08 \\
\end{tabular} & 25,39 & 700,54 & $\begin{array}{l}90,10 \\
90,26\end{array}$ & 23,14 & 35,87 & \begin{tabular}{|l|}
251,96 \\
\end{tabular} & 92,35 & 92,35 & 234,13 \\
\hline Pelophylax perezi & 29TQG30 & 99,00 & 118,24 & 112,71 & 38,98 & 6054,24 & 286,54 & $-0,55$ & 287,09 & 58,13 & 198,47 & 198,47 & 43,35 & 504,83 & 65,56 & 12,00 & 38,70 & 181,38 & 57,28 & 57,28 & 168,57 \\
\hline Pelophylax perezi & 29TQG31 & 99,00 & 114,43 & 112,67 & 39,00 & 6039,45 & 282,86 & $-4,10$ & 286,95 & 56,56 & 194,63 & 194,63 & 39,85 & 523,31 & 68,00 & 13,26 & 38,07 & 187,86 & 61,19 & 61,19 & 174 \\
\hline Pelophylax perezi & $\begin{array}{l}29 \mathrm{TQG} 32 \\
\end{array}$ & \begin{tabular}{|l|}
101,00 \\
100
\end{tabular} & 1145,15 & 1112,95 & 39,00 & $\begin{array}{ll}6022,04 \\
6022,04\end{array}$ & $\begin{array}{l}20,00 \\
283,26\end{array}$ & $\begin{array}{l}-3,10 \\
-3,62\end{array}$ & \begin{tabular}{|l|}
286,87 \\
28,8 \\
\end{tabular} & $\begin{array}{l}30,30 \\
62,35 \\
\end{array}$ & \begin{tabular}{|l|}
194,93 \\
194
\end{tabular} & \begin{tabular}{|l|}
194,93 \\
193
\end{tabular} & $\begin{array}{l}30,03 \\
40,52\end{array}$ & \begin{tabular}{|l|}
521,67 \\
527
\end{tabular} & $\begin{array}{l}0,000 \\
67,79 \\
\end{array}$ & $\begin{array}{l}\mid 3,20 \\
13,77\end{array}$ & $\begin{array}{l}37,72 \\
37,\end{array}$ & \begin{tabular}{|l|}
187,15 \\
18,0
\end{tabular} & $\begin{array}{l}1,115 \\
62,19 \\
\end{array}$ & $\begin{array}{l}\mid l, 11 \\
62,19 \\
\end{array}$ & $\begin{array}{l}1 / 14,00 \\
173,83\end{array}$ \\
\hline Pelophylax perezi & 29TQG33 & 100,00 & 109,75 & 112,69 & 38,99 & 6005,46 & 277,86 & $-8,55$ & 286,41 & 60,00 & 189,58 & 189,58 & 35,59 & 555,71 & 72,08 & 15,75 & 37,15 & 199,17 & 68,57 & 68,57 & 184,91 \\
\hline Pelophylax perezi & 29TQG34 & 100,00 & 109,08 & 112,74 & 38,97 & 5982,61 & 276,92 & $-9,39$ & 286,31 & 65,83 & 188,59 & 188.59 & 35,17 & 564.89 & 73.18 & 16,72 & 36,65 & 202.73 & 71,26 & 71,26 & 187,20 \\
\hline Pelophylax perezi & 29TQG35 & 100,00 & 113,57 & 113,09 & 39,00 & 5964,48 & 280,43 & $-5,71$ & 286,14 & 74,89 & 192, & 192 & 39 & 547,40 & 70,94 & 16,45 & 36 & 197,66 & 69,83 & 69,83 & 180,30 \\
\hline Pelophylax perezi & 29 TQG36 & 100,00 & 111,99 & 112,95 & 39,00 & 5944,72 & 278,49 & $-7,13$ & 285,62 & 73,74 & 190,64 & 190,64 & 38,05 & 562,72 & 72,66 & 17,69 & 36,04 & 203,73 & 73,84 & 73,84 & 183,80 \\
\hline
\end{tabular}




\begin{tabular}{|c|c|c|c|c|c|c|c|c|c|c|c|c|c|c|c|c|c|c|c|c|c|}
\hline TAXON & UTM & $\mathrm{km} 2$ & B101 & B102 & $\mathrm{BIO3}$ & B104 & B105 & B106 & B107 & B108 & B109 & BIO10 & B1011 & BIO12 & 81013 & BIO14 & BIO15 & B1016 & B1017 & B1018 & B1019 \\
\hline Pelophylax perezi & 29TQG37 & 100,00 & 107,03 & 112,53 & 39,00 & 5911,25 & 273,25 & $-11,47$ & 284,72 & 69,31 & 185,40 & 185,40 & 33,77 & 599,10 & 77,00 & 20,05 & 35,24 & 216,74 & 81,45 & 81,45 & 193,97 \\
\hline Pelophylax perezi & 29TQG40 & 100,00 & 116,85 & 113,49 & \begin{tabular}{|l|l|}
38,97 \\
\end{tabular} & 6098,32 & 286,63 & $-2,42$ & 289,05 & 77,78 & 197,83 & 197,83 & 41,59 & 470,69 & 60,57 & 11,96 & 37,01 & 167,12 & 57,16 & 57,16 & 149,90 \\
\hline Pelophylax perezi & 29TQG41 & 98,00 & 116,63 & 113,70 & 39,00 & 6077,83 & 286,10 & $-2,87$ & 288,97 & 77,60 & 197,19 & 197,19 & 41,35 & 474,35 & 61,05 & 12,53 & 36,55 & 168,65 & 58,62 & 58,62 & 151,31 \\
\hline Pelophylax perezi & 29TQG43 & 91,00 & 109,68 & 113,67 & 39,00 & 6041,99 & 279,31 & $-9,32$ & 288,63 & 71,14 & 189,93 & 189,93 & 34,99 & 522,63 & 67,10 & 15,60 & 35,67 & 186,39 & 68,06 & 68,06 & 167,33 \\
\hline Pelophylax perezi & 29TQG44 & 87,00 & 113,50 & 113,96 & 39,00 & \begin{tabular}{|l|l|}
6017,14 \\
\end{tabular} & 282,27 & $-6,12$ & 288,39 & 75,18 & 193,18 & \begin{tabular}{|l|}
193,18 \\
\end{tabular} & 38,84 & 510,74 & 65,61 & 15,50 & 35,49 & 183,36 & 67,18 & 67,18 & 163,04 \\
\hline Pelophylax perezi & 29TQG45 & 86,00 & 116,09 & 114,02 & 39,00 & 5989,02 & 284,02 & $-4,08$ & 288,09 & 78,02 & 195,22 & 195,22 & 41,51 & 506,24 & 64,85 & 15,65 & 35,28 & 182,75 & 67,67 & 67,67 & 160,55 \\
\hline Pelophylax perezi & 29TQG46 & 80,00 & 114,57 & 113,95 & 39,00 & 5963,28 & 282,04 & $-5,28$ & 287,32 & 76,54 & 193,27 & 193,27 & 40,03 & 523,95 & 66,95 & 17,08 & 34,98 & 189,85 & 71,64 & 71,64 & 165,34 \\
\hline Pelophylax perezi & 29TQG47 & 75,00 & 110,56 & 113,81 & 39,00 & 5933,95 & 278,12 & $-8,62$ & 286,74 & 72,76 & 189,15 & 189,15 & 36,70 & 553,25 & 70,70 & 19,14 & 34,52 & 200,81 & 77,97 & 77,97 & 173,41 \\
\hline Pelophylax perezi & 29TQG48 & 76,00 & 111,49 & 113,62 & 39,21 & 5898,32 & 277,62 & $-7,67$ & 285,29 & 73,80 & 189,35 & 189,35 & 37,83 & 563,03 & 72,64 & 20,12 & 34,14 & 205,08 & 81,08 & 81,08 & 174,74 \\
\hline Pelophylax perezi & 29TQHO1 & 100,00 & 111,83 & 105,68 & 39,02 & 5588,74 & 264,79 & $-1,94$ & 266,74 & 48,26 & 185,37 & 185,37 & 42,65 & 713,22 & 93,71 & 22,38 & 36,39 & 261,24 & 91,88 & 91,88 & 239,47 \\
\hline Pelophylax perezi & 29TQHO4 & 100,00 & 93,47 & 102,08 & 39,79 & 5265,62 & 240,36 & $-13,48$ & 253,84 & 43,81 & 163,13 & 163,14 & 29,65 & 894,39 & 115,39 & 33,59 & 32,65 & 317,06 & 127,51 & 127,59 & 287,97 \\
\hline Pelophylax perezi & 29TQH12 & 101,00 & 109,52 & 106,53 & 39,84 & 5511,58 & 262,08 & $-3,35$ & 265,42 & 74,24 & 182,02 & 182,02 & 41,22 & 714,61 & 94,32 & 24,98 & 34,18 & 257,79 & 99,18 & 99,18 & 229,73 \\
\hline Pelophylax perezi & 29TQH20 & 100,00 & 96,09 & 108,97 & 39,01 & 5707,80 & 256,39 & $-18,26$ & 274,66 & 59,38 & 171,92 & 171,92 & 26,08 & 737,99 & 94,79 & 26,95 & 33,87 & 264,59 & 104,28 & 104,28 & 238,53 \\
\hline Pelophylax perezi & 29TQH21 & 99,00 & 90,49 & 107,60 & 39,20 & 5617,95 & 248,60 & $-21,87$ & 270,47 & 53,99 & 165,27 & 165,27 & 21,89 & 794,80 & \begin{tabular}{|l|l|}
101,78 \\
\end{tabular} & 30,23 & 32,91 & 282,67 & 115,17 & 115,17 & 254,36 \\
\hline Pelophylax perezi & 29тQH26 & 100,00 & 67,82 & 99,91 & 39,58 & 5166,21 & 214,59 & $-35,04$ & 249,64 & 28,79 & 136,77 & 136,99 & 6,55 & 1070,76 & 133,82 & 46,89 & 28,95 & 367,11 & 168,84 & 170,41 & 332,03 \\
\hline Pelophylax perezi & 29TQH27 & 100,00 & 82,73 & 100,29 & 40,40 & 5017,34 & 225,37 & $-20,01$ & 245,38 & 50,25 & 149,06 & 149,50 & 22,69 & 987,79 & 126,24 & 43,63 & 28,73 & 340,24 & 157,60 & 162,62 & 298,65 \\
\hline Pelophylax perezi & 29TQH30 & 101,00 & 105,34 & 111,31 & 39,43 & 5755,78 & 267,51 & $-11,20$ & 278,71 & 69,03 & 181,46 & 181,46 & 33,96 & 647,92 & 84,30 & 24,21 & 33,58 & 234,91 & 94,58 & 94,58 & 202,69 \\
\hline Pelophylax perezi & 29TQH36 & 100,00 & 63,68 & 100,41 & 39,56 & 5201,10 & 211,47 & $-39,53$ & 251,01 & 22,61 & 133,22 & 133,42 & 2,10 & 1080,66 & 134,02 & 48,65 & 28,20 & 368,40 & 174,22 & $\begin{array}{r}175,09 \\
\end{array}$ & 331,37 \\
\hline Pelophylax perezi & $29 \mathrm{TQH} 40$ & 62,00 & 109,52 & 112,79 & 39,82 & 5784,23 & 273,06 & $\begin{array}{r}-8,42 \\
\end{array}$ & 281,48 & 73,07 & 185,82 & 185,82 & 37,25 & 601,74 & 78,75 & 23,27 & 33,20 & 219,38 & 90,83 & 90,83 & 182,55 \\
\hline Pelophylax perezi & 29TQH44 & 55,00 & 85,53 & 106,75 & 39,96 & 5416,52 & 239,67 & $-24,34$ & 264,01 & 53,52 & 157,49 & 157,49 & 19,69 & 842,54 & 107,92 & 37,39 & 29,48 & 295,18 & 136,52 & 136,52 & 251,94 \\
\hline Pelophylax perezi & 29TQJ00 & 100,00 & 113,08 & 92,84 & 41,78 & 4381,67 & 236,87 & 17,31 & 219,56 & 88,49 & 169,52 & 171,28 & 60,21 & 922,77 & 122,26 & 39,35 & 29,15 & 317,84 & 143,82 & 154,93 & 269,66 \\
\hline Pelophylax perezi & 29TQJ21 & 99,00 & 125,99 & 89,26 & 42,98 & 4019,27 & 239,73 & 34,48 & 205,25 & 105,42 & $\begin{array}{l}176,76 \\
\end{array}$ & 179,55 & 77,59 & 879,09 & 119,14 & 40,58 & 28,35 & 298,48 & 145,41 & 156,50 & 237,74 \\
\hline Pelophylax perezi & 29TQJ32 & 74,00 & 134,23 & 83,35 & 43,00 & \begin{tabular}{|l|l|}
3796,84 \\
\end{tabular} & 238,70 & 46,89 & 191,82 & 116,10 & 181,84 & 185,14 & 88,38 & 858,30 & 117,33 & 40,27 & 28,58 & 290,85 & 144,00 & 156,31 & 226,00 \\
\hline Pelophylax perezi & $\begin{array}{l}\text { 30STE49 } \\
\end{array}$ & & & & & & & & & & & & & & & & & & & & \\
\hline Pelophylax perezi & 30STE59 & & & & & & & & & & & & & & & & & & & & \\
\hline Pelophylax perezi & 30STE68 & & & & & & & & & & & & & & & & & & & & \\
\hline Pelophylax perezi & \begin{tabular}{|l|l|} 
30STE69 \\
\end{tabular} & 90,00 & 166,92 & 83,47 & 39,98 & 4208,93 & 277,68 & 71,14 & 206,55 & 123,23 & 220,05 & 223,59 & 115,12 & 848,89 & \begin{tabular}{|l|l|}
146,18 \\
\end{tabular} & 0,58 & 76,41 & 404,67 & 13,56 & 22,34 & 401,74 \\
\hline Pelophylax perezi & 30STE79 & 80,00 & 165,85 & 86,17 & 40,60 & 4236,28 & 280,03 & 69,61 & 210,41 & 121,75 & 219,52 & 223,38 & 114,45 & 815,53 & 141,61 & 0,99 & 76,60 & 396,23 & 13,03 & 22,71 & 390,32 \\
\hline Pelophylax perezi & 30STF30 & 17,00 & 172,45 & 75,41 & 38,41 & 4164,14 & 274,41 & 81,00 & 193,41 & 129,27 & 224,23 & 228,09 & 120,68 & 769,41 & 134,77 & 0,41 & 72,95 & 352,82 & 14,77 & 22,41 & 340,09 \\
\hline Pelophylax perezi & 30STF31 & 98,00 & 172,86 & 74,49 & 37,92 & 4225,17 & 274,71 & 80,89 & 193,82 & 129,00 & 225,26 & 229,20 & 120,17 & 756,80 & 131,74 & 0,44 & 72,26 & 344,73 & 14,59 & 22,62 & 331,52 \\
\hline Pelophylax perezi & $\begin{array}{l}\text { 30STF32 } \\
\end{array}$ & 90,00 & 172,06 & 73,73 & 36,93 & 4378,73 & 275,79 & 78,71 & $\begin{array}{l}197,08 \\
\end{array}$ & 126,41 & 226,50 & 230,49 & 117,51 & 741,70 & 127,34 & 1,00 & 71,14 & 333,93 & 15,08 & 23,50 & 320,08 \\
\hline Pelophylax perezi & 30STF33 & 90,00 & 171,30 & 73,63 & 35,99 & 4544,89 & 278,05 & $\begin{array}{ll}76,28 \\
\end{array}$ & 201,77 & \begin{tabular}{|l|}
123,77 \\
\end{tabular} & 228,06 & \begin{tabular}{|l|}
232,17 \\
\end{tabular} & \begin{tabular}{|l|}
114,86 \\
114
\end{tabular} & 724,33 & $\mid 122,30$ & $\begin{array}{l}1,000 \\
1,00\end{array}$ & 70,20 & \begin{tabular}{|l|}
322,57 \\
\end{tabular} & 15,14 & 23,99 & 307,85 \\
\hline Pelophylax perezi & 30STF34 & 90,00 & 171,41 & 73,47 & \begin{tabular}{|l|l|}
35,17 \\
\end{tabular} & 4698,44 & 280,66 & 74,99 & 205,66 & 122,05 & 230,19 & 234,29 & 113,12 & 700,70 & 115,90 & 1,00 & 69,12 & 308,26 & 15,67 & 24,01 & 292,74 \\
\hline Pelophylax perezi & 30STF35 & 81,00 & 172,92 & 73,12 & 34,53 & 4830,34 & 284,27 & 75,48 & 208,79 & 121,93 & 233,49 & 237,52 & 113,13 & 668,82 & 108,03 & 1,00 & 68,07 & 290,48 & 15,98 & 23,88 & 274,22 \\
\hline Pelophylax perezi & 30STF36 & 80,00 & 171,69 & 75,24 & 34,32 & 5009,00 & 288,16 & 71,81 & 216,35 & 118,67 & 234,80 & 238,68 & 109,86 & 657,79 & 103,48 & 1,00 & 67,23 & 283,17 & 16,55 & 23,91 & 266,49 \\
\hline Pelophylax perezi & 30STF37 & 80,00 & 171,09 & 79,31 & 34,54 & 5179,89 & 294,31 & 68,23 & 226,07 & 116,02 & 236,66 & 240,31 & 107,31 & 647,85 & 99,81 & 1,00 & 66,34 & 277,40 & 17,04 & 24,05 & 260,46 \\
\hline Pelophylax perezi & 30STF38 & $\frac{10,00}{72,00}$ & 171,74 & 86,27 & 34,82 & 5325,61 & 303,23 & $\begin{array}{l}60,25 \\
65,21 \\
\end{array}$ & 238,02 & \begin{tabular}{|l|l|l|l|l|l|}
114,89 \\
\end{tabular} & 239,46 & \begin{tabular}{|l|}
242,79 \\
242,9
\end{tabular} & \begin{tabular}{|l|}
106,25 \\
106,5
\end{tabular} & $\begin{array}{l}\mid c 4 l, 05 \\
637,94\end{array}$ & $\begin{array}{l}93,01 \\
97,45\end{array}$ & $\begin{array}{l}1,000 \\
1,00\end{array}$ & $\begin{array}{l}0 ., 54 \\
65,84\end{array}$ & 273,76 & $\begin{array}{l}11,04 \\
17,25\end{array}$ & $\begin{array}{l}24,73 \\
23,73\end{array}$ & $\begin{array}{l}20,40,61 \\
256,61\end{array}$ \\
\hline Pelophylax perezi & 30STF39 & 70,00 & 176,77 & 91,58 & 36,60 & 5420,47 & 313,98 & 67,41 & 246,57 & 118,49 & 245,97 & 248,99 & 110,17 & 605,96 & 91,98 & 1,00 & 65,39 & 260,20 & 17,00 & 23,00 & 242,65 \\
\hline Pelophylax perezi & 30STF40 & 79,00 & 170,05 & 77,24 & 38,86 & 4149,76 & 273,55 & 77,47 & 196,08 & 127,19 & 221,86 & 225,45 & 118,45 & 822,55 & 142,23 & 0,24 & 73,99 & 380,45 & 15,04 & 22,30 & 370,92 \\
\hline Pelophylax perezi & 30STF41 & 100,00 & 172,72 & 74,78 & 38,32 & 4162,68 & 273,71 & 80,79 & 192,92 & 129,06 & 224,63 & 228,16 & 120,80 & 787,68 & 135,86 & 0,05 & 73,02 & 361,95 & 15,05 & 22,06 & 349,54 \\
\hline Pelophylax perezi & 30STF42 & 100,00 & 172,28 & 74,59 & 37,45 & 4314,16 & 275,88 & 79,09 & 196,79 & 127,13 & 226,17 & 229,93 & 118,57 & 768,15 & \begin{tabular}{|l|l|}
131,09 \\
\end{tabular} & 0,67 & 71,80 & 349,92 & 15,67 & 22,89 & 335,87 \\
\hline Pelophylax perezi & 30STF43 & 100,00 & 171,37 & 75,07 & 36,61 & 4494,42 & 278,71 & 76,42 & 202,28 & 124,26 & 227,63 & 231,55 & 115,70 & 748,11 & 125,94 & 1,00 & 70,66 & 337,59 & 15,96 & 23,63 & 322,29 \\
\hline Pelophylax perezi & 30STF44 & 100,00 & 170,27 & 76,41 & 36,06 & 4680,85 & 282,25 & 73,23 & 209,02 & 121,12 & 229,12 & 233,04 & 112,49 & 729,53 & 120,67 & 1,00 & 69,77 & 326,03 & 16,01 & 24,01 & 309,93 \\
\hline Pelophylax perezi & 30STF45 & 100,00 & 169,68 & 78,14 & 35,66 & 4861,25 & 286,50 & 70,68 & 215,82 & 118,62 & 231,10 & 234,95 & 109,92 & 708,52 & 114,95 & 1,00 & 68,80 & 313,47 & 16,20 & 24,13 & 296,85 \\
\hline Pelophylax perezi & 30STF46 & 100,00 & 172,40 & 79,32 & 35,49 & 4987,73 & 292,23 & 71,79 & 220,45 & 119,53 & 235,35 & 239,11 & 110,95 & $\begin{array}{l}673,38 \\
\end{array}$ & 107,45 & 1,00 & 67,82 & 95,25 & 16,53 & 23,51 & 277,60 \\
\hline Pelophylax perezi & 30STF47 & 100,00 & 171,66 & 83,90 & 35,8 & 5167,62 & 298,66 & 68,02 & 230,64 & 116,63 & 237,20 & \begin{tabular}{|l|}
240,68 \\
\end{tabular} & & 662,66 & \begin{tabular}{|l|}
103,91 \\
103
\end{tabular} & 1,00 & $\begin{array}{ll}66,96 \\
6\end{array}$ & 288,72 & 17,01 & 23,58 & 271,04 \\
\hline Pelophylax perezi & 30STF48 & 100,00 & 171,85 & 89,53 & 36,60 & 5327,55 & 306,51 & 64,98 & 241,53 & 114,99 & 239,74 & 242,99 & 106,50 & 650,58 & 100,83 & 1,00 & 66,49 & 282,57 & 17,13 & 23,46 & 264,93 \\
\hline Pelophylax perezi & 30STF49 & 100,00 & 174,80 & 95,45 & 37,42 & 5455,12 & 316,42 & 64,72 & 251,70 & 116,19 & 244,53 & 247,50 & 107,91 & 627,88 & $\begin{array}{l}96,63 \\
\end{array}$ & 1,00 & 65,80 & 272,34 & 17,22 & 22,89 & 254,65 \\
\hline Pelophylax perezi & 30STF50 & 100,00 & 168,95 & 78,27 & 39,21 & 4103,92 & 272,40 & 75,62 & 196,79 & 126,26 & 220,38 & 223,74 & 117,77 & 855,68 & \begin{tabular}{r|}
146,48 \\
\end{tabular} & 0,21 & 74,96 & 398,75 & 15,01 & 22,30 & 392,21 \\
\hline Pelophylax perezi & 30STF51 & 100,00 & 167,76 & 78,74 & 38,64 & 4257,40 & 274,60 & 73,17 & 201,43 & 123,72 & 221,33 & 224,81 & 114,96 & 835,94 & 142,24 & 0,58 & 73,81 & 388,02 & 15,32 & 23,08 & 378,19 \\
\hline Pelophylax perezi & \begin{tabular}{|l|l|} 
30STF52 \\
OST
\end{tabular} & 100,00 & 169,60 & 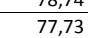 & 38,04 & $\begin{array}{l}423,4,40 \\
4336,43\end{array}$ & 276,87 & $\begin{array}{l}3,11 \\
74,98 \\
\end{array}$ & \begin{tabular}{|l|}
201,89 \\
\end{tabular} & \begin{tabular}{|l|l|}
124,45 \\
\end{tabular} & \begin{tabular}{|l|}
224,163 \\
224
\end{tabular} & \begin{tabular}{|l|}
227,73 \\
227
\end{tabular} & \begin{tabular}{|l|}
116,00 \\
116,00
\end{tabular} & 802,55 & \begin{tabular}{|l|}
136,23 \\
\end{tabular} & $\begin{array}{l}0,000 \\
0,89\end{array}$ & 72,62 & \begin{tabular}{|l|}
$371,01,01$ \\
\end{tabular} & $\begin{array}{l}15,32< \\
15,89\end{array}$ & $\begin{array}{l}23,25 \\
23,2 \\
\end{array}$ & 357,32 \\
\hline Pelophylax perezi & 30STF53 & 100,00 & 171,09 & 77,64 & 37,41 & 4455,91 & 280,34 & 75,76 & 204,58 & 124,36 & 227,16 & 230,82 & 116,13 & 768,19 & 129,70 & 1,00 & 71,54 & 353,12 & 16,00 & 23,21 & 336,74 \\
\hline Pelophylax perezi & 30STF54 & 100,00 & 167,50 & 81,14 & 37,10 & 4709,99 & 284,60 & 68,95 & 215,66 & $\begin{array}{l}118,41 \\
11,4\end{array}$ & 227,11 & $\begin{array}{l}230,79 \\
230\end{array}$ & 109,68 & 760,61 & 125,99 & 1,00 & 70,60 & \begin{tabular}{|l|}
346,04 \\
34,0
\end{tabular} & 16,13 & 24,07 & 329,51 \\
\hline Pelophylax perezi & 30STF55 & 100,00 & 165,22 & 84,72 & 37,05 & 4918,91 & 289,35 & 63,82 & 225,53 & 113,95 & 227,76 & 231,43 & 105,18 & 749,39 & 121,80 & 1,00 & 69,44 & 337,26 & 17,08 & 24,59 & 320,86 \\
\hline Pelophylax perezi & 30STF56 & 100,00 & 169,24 & 85,20 & 36,86 & 5007,16 & 295,14 & 67,15 & 227,99 & 116,47 & 232,86 & 236,40 & 108 & 708,52 & 114,43 & 1,00 & 68,59 & 316,82 & 16,82 & 23,70 & 298 \\
\hline Pelophylax perezi & 30STF57 & 100,00 & 169,81 & 89,57 & 37,21 & 5177,85 & 302,29 & $\begin{array}{ll}64,88 \\
\end{array}$ & 237,41 & 114,88 & 235,72 & 239,06 & 106,60 & 688,84 & 109,76 & 1,00 & 67,71 & 305,73 & 17,10 & 23,52 & 287,59 \\
\hline Pelophylax perezi & 30STF58 & 100,00 & 171,08 & 94,41 & 37,79 & 5328,45 & 310,34 & 63,45 & 246,89 & 114,27 & 239,19 & 242,22 & 106,05 & 667,79 & 105,33 & 1,00 & 66,99 & 294,63 & 17,19 & 23,25 & 276,42 \\
\hline Pelophylax perezi & 30STF59 & 100,00 & 173,72 & 99,87 & 38,37 & 5464.44 & 319,76 & 63,21 & 256.55 & 115,02 & 243,65 & 246,45 & 107.12 & $|643,67|$ & 100.88 & 1,00 & 66.33 & 282.79 & 17,21 & 2281 & 264,69 \\
\hline Pelophylax perezi & 30STF60 & 100,00 & 163,12 & 85,08 & 39,39 & 4376,18 & 278,43 & 65,18 & 213,25 & 118,40 & 218,60 & 222 & 109 & 853,79 & 144,88 & 0,93 & 75,37 & 403,55 & 14,45 & 23,76 & 398,62 \\
\hline Pelophylax perezi & 30STF61 & 100,00 & 164,61 & 83,27 & 39,14 & 4365,90 & 278,12 & 67,86 & 210,26 & 120,64 & 219,93 & 223,56 & 111,16 & 840,99 & \begin{tabular}{|l|l|}
143,07 \\
\end{tabular} & 1,00 & 74,27 & 396,99 & 15,20 & 23,82 & 386,95 \\
\hline
\end{tabular}




\begin{tabular}{|c|c|c|c|c|c|c|c|c|c|c|c|c|c|c|c|c|c|c|c|c|c|}
\hline TAXON & UTM & $\mathrm{km} 2$ & B101 & B102 & $\mathrm{BIO3}$ & BIO4 & B105 & B106 & B107 & B108 & B109 & B1010 & BIO11 & BIO12 & B1013 & BIO14 & BIO15 & B1016 & B1017 & BIO18 & B1019 \\
\hline Pelophylax perezi & 30STF62 & 100,00 & 165,14 & 82,93 & 38,78 & 4449,51 & 279,79 & 68,02 & 211,77 & 119,86 & 221,57 & 225,24 & 110,77 & 820,39 & 138,76 & 1,00 & 73,24 & 384,86 & 15,59 & 23,91 & 371,59 \\
\hline Pelophylax perezi & 30STF63 & 100,00 & 164,08 & 84,68 & 38,34 & 4621,54 & 283,21 & 65,09 & 218,12 & 116,82 & 222,88 & 226,50 & 107,74 & 800,63 & 133,64 & 1,01 & 71,88 & 371,84 & 16,41 & 24,50 & 356,97 \\
\hline Pelophylax perezi & 30STF64 & 100,00 & 153,75 & 92,74 & 38,40 & 5017,22 & 287,09 & 48,51 & 238,58 & 102,94 & 218,40 & 221,77 & 93,13 & 819,93 & 131,07 & 1,40 & 70,22 & 371,48 & 18,62 & 27,59 & 360,28 \\
\hline Pelophylax perezi & 30STF65 & 100,00 & 165,30 & 87,84 & 37,91 & \begin{tabular}{ll|}
4897,96 \\
\end{tabular} & 291,96 & 63,35 & 228,62 & 114,42 & 227,81 & 231,30 & 105,79 & 754,59 & 123,63 & 1,03 & 69,99 & 344,99 & 16,89 & 24,36 & 327,48 \\
\hline Pelophylax perezi & 30STF66 & 100,00 & 165,34 & 90,67 & \begin{tabular}{|l|}
37,88 \\
\end{tabular} & 5056,80 & 297,25 & 61,18 & 236,06 & 112,45 & 230,04 & 233,33 & 103,99 & 737,02 & 119,37 & 1,00 & 69,04 & 333,87 & 17,22 & 24,32 & 315,92 \\
\hline Pelophylax perezi & 30STF67 & 100,00 & 168,90 & 93,03 & 38,08 & 5159,38 & 304,42 & 63,52 & 240,91 & 114,46 & 234,91 & 238,07 & 106,27 & 702,95 & 113,37 & 1,00 & 68,34 & 316,61 & 17,09 & 23,46 & 297,82 \\
\hline Pelophylax perezi & 30STF68 & 100,00 & $\begin{array}{lll}171,47 \\
\end{array}$ & 97,29 & 38,64 & 5297,85 & 312,87 & \begin{tabular}{ll|}
63,87 \\
\end{tabular} & 249,01 & 115,13 & 239,32 & 242,31 & 107,15 & 674,89 & 108,22 & 1,00 & 67,69 & 302,13 & 17,01 & 23,00 & 283,13 \\
\hline Pelophylax perezi & \begin{tabular}{|l|} 
30STF69 \\
\end{tabular} & 100,00 & 172,93 & 102,83 & 39,14 & 5452,05 & 321,68 & 62,42 & 259,26 & 114,55 & 242,83 & 245,58 & 106,81 & 654,38 & 104,17 & 1,00 & 67,05 & 291,10 & 16,96 & 22,61 & 272,50 \\
\hline Pelophylax perezi & 30STF70 & 100,00 & 170,76 & 82,27 & 40,56 & 4070,03 & 278,45 & 77,89 & 200,57 & 129,87 & 222,10 & 225,97 & 121,34 & 806,82 & 143,07 & 1,00 & 76,03 & 396,34 & 13,86 & 22,01 & 381,87 \\
\hline Pelophylax perezi & 30STF71 & 100,00 & 168,40 & 83,23 & 40,00 & 4224,27 & 279,62 & 73,68 & 205,94 & 126,16 & 221,77 & 225,72 & 117,17 & 808,52 & 141,14 & 1,00 & 75,01 & 393,01 & 14,41 & 22,69 & 376,83 \\
\hline Pelophylax perezi & 30STF72 & 100,00 & 166,30 & 84,93 & 39,37 & 4410,77 & 282,35 & 69,29 & 213,06 & 121,98 & 222,38 & 226,13 & 112,89 & 800,83 & 137,35 & 1,00 & 73,74 & 383,87 & 15,21 & 23,45 & 367,23 \\
\hline Pelophylax perezi & 30STF73 & 100,00 & 163,52 & 87,45 & 39,04 & 4622,44 & 285,46 & 63,84 & 221,63 & 116,84 & 222,47 & 226,19 & 107,54 & 793,29 & 133,20 & 1,00 & 72,50 & 374,14 & 15,97 & 24,37 & 357,96 \\
\hline Pelophylax perezi & 30STF74 & 100,00 & 158,09 & 92,03 & \begin{tabular}{|l|l|}
38,87 \\
\end{tabular} & 4898,94 & 288,79 & 54,41 & 234,38 & 108,48 & 221,05 & 224,46 & 98,97 & 797,05 & 129,72 & 1,23 & 70,83 & 367,79 & 17,65 & 26,06 & 353,45 \\
\hline Pelophylax perezi & 30STF75 & 100,00 & 157,73 & 94,24 & 38,77 & 5045,92 & 292,93 & 52,28 & 240,65 & 106,20 & 222,78 & 226,04 & 96,92 & 784,05 & 126,18 & 1,29 & 69,82 & 358,35 & 18,22 & 26,35 & 343,30 \\
\hline Pelophylax perezi & 30STF76 & 100,00 & 162,57 & 94,47 & 38,71 & 5093,79 & 298,56 & 57,03 & 241,52 & 109,78 & 228,15 & 231,24 & 101,07 & 750,01 & 121,26 & 1,13 & 69,25 & 342,29 & 17,83 & 25,01 & 324,72 \\
\hline Pelophylax perezi & 30STF77 & 100,00 & 158,26 & 99,27 & 38,87 & 5321,01 & 302,43 & 49,17 & 253,27 & 103,04 & 227,22 & 230,04 & 94,22 & 756,27 & 119,35 & 1,35 & 67,90 & 339,33 & 19,30 & 26,55 & 323,32 \\
\hline Pelophylax perezi & 30STF78 & 100,00 & 164,69 & 100,93 & 38,99 & 5369,97 & 310,85 & 55,05 & 255,80 & 108,20 & 233,97 & 236,78 & 99,91 & 714,16 & 113,74 & 1,04 & 67,65 & 320,81 & 18,01 & 24,51 & 302,89 \\
\hline Pelophylax perezi & 30STF79 & 100,00 & 167,22 & 104,85 & 39,29 & 5497,93 & 318,80 & 55,57 & 263,24 & 108,87 & 238,24 & 240,80 & 100,88 & 689,97 & 109,52 & 1,03 & 67,06 & 308,04 & 17,85 & 23,65 & 290,10 \\
\hline Pelophylax perezi & 30STF80 & 43,00 & 175,91 & 82,28 & 41,56 & 3927,69 & 281,94 & 86,09 & 195,84 & 137,66 & 225,39 & 229,80 & 129,36 & 749,14 & 138,61 & 1,00 & 76,92 & 382,69 & 13,02 & 20,77 & 358,81 \\
\hline Pelophylax perezi & 30STF81 & 100,00 & 173,15 & 83,09 & \begin{tabular}{|l|l|}
40,87 \\
\end{tabular} & 4074,54 & 282,17 & 81,16 & 201,01 & 133,03 & 224,64 & 228,83 & 124,45 & 760,43 & 137,52 & 1,00 & 75,86 & 382,20 & 13,55 & 21,39 & 358,96 \\
\hline Pelophylax perezi & 30STF82 & 100,00 & 173,59 & 83,40 & 40,32 & $\begin{array}{ll}4196,64 \\
\end{array}$ & 284,72 & 80,30 & 204,42 & \begin{tabular}{|l|}
131,67 \\
\end{tabular} & 226,76 & 230,81 & 123,30 & 749,50 & 133,75 & 1,00 & 74,76 & 371,99 & 14,12 & 21,54 & 348,06 \\
\hline Pelophylax perezi & 30STF83 & 100,00 & 173,10 & 84,66 & 39,84 & 4358,86 & 287,95 & 77,71 & 210,25 & 129,07 & 228,36 & 232,25 & 120,63 & 739,53 & 129,64 & 1,00 & 73,58 & 361,28 & 14,88 & 21,88 & 337,73 \\
\hline Pelophylax perezi & 30STF84 & 100,00 & 159,27 & 93,11 & 39,21 & \begin{tabular}{|l|l|}
4853,83 \\
\end{tabular} & 290,15 & 55,91 & 234,24 & 110,40 & 221,77 & 225,12 & 100,94 & 779,16 & 127,61 & 1,32 & 71,04 & 363,68 & 17,39 & 25,77 & 347,73 \\
\hline Pelophylax perezi & 30STF85 & 100,00 & 147,33 & 100,24 & 39,00 & 5242,53 & 291,33 & 37,85 & 253,47 & 94,49 & 215,79 & 218,57 & 84,58 & 816,53 & 126,63 & 2,14 & 68,67 & 367,17 & 21,33 & 30,02 & 356,10 \\
\hline Pelophylax perezi & 30STF86 & 100,00 & 139,97 & 104,57 & 39,00 & 5481,88 & 291,96 & 26,83 & 265,13 & 84,45 & 212,01 & 214,44 & 74,54 & 840,73 & 126,14 & 2,85 & 66,86 & 369,18 & 24,63 & 33,24 & 359,97 \\
\hline Pelophylax perezi & 30STF87 & 100,00 & 144,08 & 105,08 & 39,00 & 5527,88 & 297,17 & 30,56 & 266,61 & 87,53 & 216,61 & 219,03 & 77,99 & 815,38 & 123,04 & 2,60 & 66,53 & 358,10 & 23,87 & 31,97 & 346,90 \\
\hline Pelophylax perezi & 30STF88 & 100,00 & 159,18 & 103,34 & 39,01 & 5441,13 & 308,69 & 47,81 & 260,88 & \begin{tabular}{|l|}
102,47 \\
\end{tabular} & 229,94 & 232,45 & 93,75 & 739,03 & 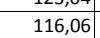 & 2,40 & $\begin{array}{l}67,26 \\
67\end{array}$ & 330,99 & $\begin{array}{l}3,04 \\
19,64 \\
\end{array}$ & 26,47 & 314,51 \\
\hline Pelophylax perezi & 30STF89 & 100,00 & 164,97 & 105,62 & 39,37 & 5509,10 & 317,27 & 52,51 & 264,76 & 106,85 & 236,40 & 238,74 & 98,66 & 703,42 & 111,41 & 1,05 & 67,10 & 314,99 & 18,34 & 24,40 & 297,42 \\
\hline Pelophylax perezi & 30STF91 & 39,00 & 176,17 & 83,33 & 41,17 & 4017,94 & 284,50 & 85,06 & 199,44 & 137,06 & 226,75 & 231,21 & 128,54 & 719,27 & 131,94 & 1,00 & 76,06 & 365,92 & 13,00 & 20,62 & 341,06 \\
\hline Pelophylax perezi & 30STF92 & 93,00 & 174,60 & 84,83 & 40,84 & 4174,83 & 286,67 & 81,19 & 205,48 & 133,55 & 227,43 & 231,57 & 124,91 & 713,66 & 128,04 & 1,00 & 74,88 & 357,33 & 13,87 & 21,17 & 333,13 \\
\hline Pelophylax perezi & 30STF93 & 100,00 & 166,98 & 89,40 & 40,09 & 4514,49 & 288,77 & 68,36 & 220,41 & 122,21 & 224,76 & 228,44 & 113,05 & 735,55 & 125,81 & 1,13 & 72,92 & 356,18 & 15,45 & 23,38 & 336,01 \\
\hline Pelophylax perezi & 30STF94 & 100,00 & 159,15 & $\begin{array}{l}90,445 \\
94,59\end{array}$ & 39,62 & 4860,97 & 291,42 & 55,28 & \begin{tabular}{|l|}
236,14 \\
\end{tabular} & \begin{tabular}{|l|l|l|l|l|}
110,56 \\
\end{tabular} & 221,89 & \begin{tabular}{|l|}
225,26 \\
\end{tabular} & 100,99 & 759,01 & \begin{tabular}{|l|}
124,04 \\
1240
\end{tabular} & $\begin{array}{l}1,150 \\
1,38\end{array}$ & 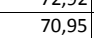 & \begin{tabular}{|l|}
355,90 \\
\end{tabular} & $\begin{array}{l}17,41 \\
17,41\end{array}$ & 25,68 & 339,61 \\
\hline Pelophylax perezi & 30STF95 & 100,00 & 151,72 & 99,36 & 39,19 & 5148,58 & 293,22 & 43,49 & 249,72 & 99,93 & 218,81 & 221,64 & 90,19 & 783,50 & 123,22 & 1,91 & 69,12 & 357,32 & 19,93 & 28,33 & 343,75 \\
\hline Pelophylax perezi & 30STF96 & 100,00 & 140,76 & 105,24 & 39,02 & 5472,22 & 292,95 & 27,36 & 265,59 & 85,59 & 212,85 & 215,11 & 75,54 & 823,41 & 123,36 & 2,90 & 66,79 & 362,83 & 24,15 & 32,79 & 353,24 \\
\hline Pelophylax perezi & 30STF97 & 100,00 & 150,34 & 103,86 & 39,00 & 5436,48 & 300,43 & 38,15 & 262,28 & 94,78 & 221,63 & 223,92 & 85,39 & 776,73 & 119,36 & 2,20 & 67,05 & 346,44 & 21,62 & 29,46 & 332,90 \\
\hline Pelophylax perezi & $\begin{array}{l}\text { 30STF98 } \\
\end{array}$ & 100,00 & 156,77 & 104,40 & 39,06 & 5475,32 & 307,66 & 44,50 & 263,16 & 100,01 & 228,30 & 230,60 & 91,14 & 743,66 & 115,82 & 1,85 & 67,04 & 332,79 & 20,44 & 27,36 & 317,06 \\
\hline Pelophylax perezi & 30STF99 & 100,00 & 162,62 & 106,09 & 39,23 & 5534,61 & 315,61 & 49,36 & 266,25 & $\begin{array}{l}104,63 \\
\end{array}$ & 234,77 & 236,86 & 96,04 & 712,37 & 111,81 & 1,42 & 66,75 & 318,54 & 19,35 & 25,61 & 301,63 \\
\hline Pelophylax perezi & 30STG32 & 60,00 & 182,06 & 112,51 & 38,99 & 5872,88 & 344,91 & 59,87 & 285,04 & 118,18 & 258,01 & 260,02 & 109,61 & 584,96 & 88,69 & 1,00 & 64,39 & 250,94 & 18,00 & 22,00 & 235,08 \\
\hline Pelophylax perezi & 30STG33 & 60,00 & 183,77 & 118,47 & 39,22 & 6020,89 & 355,07 & 57,33 & 297,74 & 118,25 & 262,02 & 263,72 & 109,45 & 581,70 & 87,93 & 1,00 & $\begin{array}{l}63,67 \\
\end{array}$ & 248,97 & 18,00 & 22,00 & 234,15 \\
\hline Pelophylax perezi & 30STG34 & 56,00 & 185,45 & 121,81 & 39,35 & 6122,18 & 361,35 & 56,06 & 305,29 & 118,62 & 264,96 & 266,55 & 109,75 & 574,53 & 86,42 & 1,00 & 63,36 & 244,78 & 18,00 & 22,00 & 230,79 \\
\hline Pelophylax perezi & 30STG36 & 50,00 & 179,75 & 122,09 & 39,04 & 6222,42 & 358,25 & 50,54 & 307,72 & 111,81 & 261,12 & 262,19 & 103,03 & 579,31 & 84,54 & 1,48 & 61,61 & 241,93 & 19,79 & 23,93 & 228,63 \\
\hline Pelophylax perezi & 30STG37 & 47,00 & 169,10 & 121,56 & 39,00 & 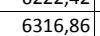 & 349,56 & 40,54 & 309,02 & 100,75 & 251,86 & 253,03 & $\begin{array}{l}91,75 \\
91\end{array}$ & 617,83 & 87,48 & 2,6 & 60,30 & 253,56 & 22,98 & 27,44 & 241,08 \\
\hline Pelophylax perezi & $\begin{array}{l}\text { 30STG39 } \\
\end{array}$ & 40,00 & 170,22 & 122,02 & 38,84 & 6377,82 & 352,44 & 40,78 & 311,65 & 100,87 & 253,89 & 254,67 & 91,93 & 593,58 & 82,44 & 2,22 & 59,20 & 239,95 & 22,91 & 27,60 & 228,11 \\
\hline Pelophylax perezi & 30STG40 & 100,00 & 178,80 & 101,57 & 38,31 & 5567,91 & 327,09 & 65,27 & 261,82 & 118,66 & 250,12 & 252,82 & 110,41 & 603,77 & 92,50 & 1,00 & 65,52 & 261,87 & 17,00 & 22,04 & 244,38 \\
\hline Pelophylax perezi & 30STG41 & 100,00 & 180,59 & 108,40 & 39,0 & 5727,80 & 336,93 & 62,84 & 274,09 & 118,44 & 254,23 & 256,61 & 110,24 & 594,63 & 90,80 & 1,00 & 64,95 & 257,31 & 17,29 & 22,00 & 240,40 \\
\hline Pelophylax perezi & 30STG42 & 100,00 & 180,63 & 114,50 & 39,5 & 5890,94 & 345,09 & 58,84 & 286,25 & $\begin{array}{l}116,67 \\
110,4\end{array}$ & 256,97 & 258,86 & 108,30 & 595,41 & $\begin{array}{l}0,003 \\
90,39 \\
\end{array}$ & 1,00 & \begin{tabular}{|l|l|}
64,33 \\
\end{tabular} & 256,53 & $\begin{array}{ll}18,00 \\
18\end{array}$ & 22,00 & 240,59 \\
\hline Pelophylax perezi & 30STG43 & 100,00 & 181,69 & 119,12 & 39,88 & 6025,71 & 352,62 & 56,32 & 296,30 & 116,07 & 260,01 & 261,71 & 107,65 & 592,01 & 89,27 & 1,00 & 64,06 & 253,86 & 18,01 & 22,01 & 238,95 \\
\hline Pelophylax perezi & $\begin{array}{l}\text { 30STG44 } \\
\end{array}$ & 100,00 & 183,53 & 121,81 & 39,90 & 6117,17 & 358,86 & 55,53 & 303,33 & 116,78 & 263,25 & 264,59 & 108,12 & 581,99 & 87,18 & 1,00 & 63,46 & 248,29 & 18,00 & 22,00 & 234,10 \\
\hline Pelophylax perezi & 30STG45 & 100,00 & 183,83 & 122,90 & 39,83 & 6180,29 & 361,25 & 54,79 & 306,46 & 116,39 & 264,59 & 265,65 & 107,65 & 573,19 & 84,99 & 1,00 & 63,01 & 242,74 & 18,00 & 22,00 & 229,10 \\
\hline Pelophylax perezi & 30STG46 & 100,00 & 182,42 & 122,99 & 39,41 & 6229,88 & 361,25 & 53,28 & 307,97 & 114,58 & 264,03 & 264,75 & 105,65 & 570,93 & 83,33 & 1,17 & 62,17 & 24 & 18,65 & 22,78 & 226,07 \\
\hline Pelophylax perezi & \begin{tabular}{|l|}
30 STG 47 \\
\end{tabular} & 100,00 & $\begin{array}{l}10,42 \\
175,54\end{array}$ & 122,95 & 39 & $\begin{array}{l}62315,0 \\
6315,07\end{array}$ & 356,46 & $\begin{array}{l}5,80 \\
45,87 \\
\end{array}$ & \begin{tabular}{|l|l|}
310,59 \\
\end{tabular} & \begin{tabular}{|l|}
106,78 \\
10,7
\end{tabular} & \begin{tabular}{|l|}
258,24 \\
\end{tabular} & \begin{tabular}{|l|}
259,07 \\
\end{tabular} & $\begin{array}{l}00,3 \\
97,82 \\
\end{array}$ & 593,90 & $\begin{array}{l}\mid 20,35 \\
84,53 \\
\end{array}$ & $\begin{array}{l}1,116 \\
1,76\end{array}$ & $\begin{array}{l}2,11 \\
60,90\end{array}$ & \begin{tabular}{|l|}
245,11 \\
24,4
\end{tabular} & $\begin{array}{l}10,00 \\
20,94\end{array}$ & $\begin{array}{ll}25,34 \\
25\end{array}$ & 232,64 \\
\hline Pelophylax perezi & 30STG48 & 100,00 & 174,66 & 123,03 & 39,00 & 6355,98 & 356,75 & 44,67 & 312,08 & 105,38 & 258,06 & 258,77 & 96,49 & 588,01 & 82,80 & 2,04 & 60,20 & 240,29 & 21,39 & 25,70 & 228,30 \\
\hline Pelophylax perezi & 30STG49 & 100,00 & 165,69 & 122,71 & 38,70 & 6434,94 & 349,90 & 35,92 & 313,99 & $\begin{array}{l}\mid 95,88 \\
95,\end{array}$ & 250,41 & 251,07 & $\begin{array}{l}0,4,03 \\
87,03\end{array}$ & $\mid 620,24$ & $\begin{array}{l}2,0,77 \\
85,7\end{array}$ & $2,2,65$ & 58,86 & 249,59 & 24,31 & 29,03 & 238,44 \\
\hline Pelophylax perezi & 30STG50 & 100,00 & 177,03 & 105,44 & 39,14 & 5583,52 & 329,56 & 63,59 & 265,97 & 116,68 & 248,59 & 251,21 & 108,93 & 618,46 & 96,50 & 1,00 & 66,22 & 271,26 & 16,58 & 21,61 & 253,39 \\
\hline Pelophylax perezi & 30STG53 & 100,00 & 180,32 & 119,61 & 40,01 & 6004,94 & 350,80 & 56,53 & 294,27 & 114,99 & 258,30 & 259 & 106,86 & 598,05 & 90,15 & 1,00 & 64,34 & 257,19 & 18,00 & 22,09 & 242 \\
\hline Pelophylax perezi & 30STG55 & 100,00 & 181,37 & 123,03 & 39,98 & 6195,43 & 358,79 & 53,10 & 305,69 & 113,67 & 262,20 & 263,24 & 105,06 & 586,47 & 86 & 1,00 & 63,07 & 248,40 & 18,00 & 22,19 & 234,90 \\
\hline Pelophylax perezi & 30STG56 & 100,00 & 183,18 & 123,41 & 39,64 & 6237,61 & 361,81 & 53,85 & 307,96 & 115,05 & 264,77 & 265,45 & 106,17 & 571,86 & 83,34 & 1,00 & 62,52 & 240,11 & 18,05 & 22,14 & 227,19 \\
\hline Pelophylax perezi & 30STG57 & 100,00 & 178,89 & 124,02 & 39,27 & 6320,81 & 360,30 & 48,86 & 311,45 & 110,09 & 261,71 & 262,37 & 100,99 & 584,72 & 83,77 & 1,46 & 61,38 & 241,95 & 19,40 & 23,80 & 229,87 \\
\hline Pelophylax perezi & 30STG58 & 100,00 & 168,71 & 123,92 & 39,00 & 6427,23 & 353,35 & 38,44 & 314,9 & 99,08 & 253,38 & 254 & 90, & 621,32 & 87,25 & 2,01 & 59,98 & 252,34 & 22,64 & 27,19 & 241,33 \\
\hline Pelophylax perezi & 30STG59 & 100,00 & 162,75 & 123,58 & 38,49 & 6489,78 & 349,12 & 32,60 & 316,52 & 92,60 & 248,53 & 249,06 & 83,68 & 639,22 & 88,46 & 2,57 & 58,97 & 255,99 & 24,94 & 29,09 & 245,75 \\
\hline
\end{tabular}




\begin{tabular}{|c|c|c|c|c|c|c|c|c|c|c|c|c|c|c|c|c|c|c|c|c|c|}
\hline TAXON & UTM & $\mathrm{km} 2$ & B101 & B102 & $\mathrm{BIO3}$ & B104 & B105 & B106 & B107 & B108 & B109 & B1010 & BIO11 & BIO12 & 81013 & BIO14 & BIO15 & B1016 & B1017 & BIO18 & B1019 \\
\hline Pelophylax perezi & 30STG60 & 100,00 & 174,76 & 108,79 & 39,92 & 5594,85 & 330,94 & 61,34 & 269,60 & 114,40 & 246,56 & 249,06 & 106,93 & 634,01 & 100,54 & 1,00 & 66,62 & 280,69 & 16,59 & 21,63 & 262,52 \\
\hline Pelophylax perezi & 30STG61 & 100,00 & 176,62 & 114,36 & 40,43 & 5730,71 & 339,71 & 60,30 & 279,41 & 114,43 & 250,25 & 252,50 & 107,10 & 615,43 & 97,20 & 1,00 & 66,46 & 271,11 & 16,10 & 21,01 & 253,67 \\
\hline Pelophylax perezi & 30STG62 & 100,00 & 178,73 & 117,33 & 40,37 & 5855,19 & 345,65 & 59,25 & 286,41 & 117,71 & 254,33 & 256,22 & 107,43 & 603,73 & 94,25 & 1,00 & 65,71 & 263,97 & 16,18 & 21,00 & 247,31 \\
\hline Pelophylax perezi & 30STG63 & 100,00 & 180,16 & 119,63 & 40,22 & 5968,07 & 350,24 & 57,68 & 292,57 & 115,11 & 257,60 & 259,05 & 107,25 & 598,96 & 91,77 & 1,00 & 64,90 & 259,06 & 17,01 & 21,23 & 243,64 \\
\hline Pelophylax perezi & 30STG64 & 100,00 & 178,90 & 121,65 & 40,04 & \begin{tabular}{|l|l|}
6099,63 \\
\end{tabular} & 352,74 & 53,57 & 299,16 & 112,38 & 258,36 & 259,70 & 104,21 & \begin{tabular}{|l|l|}
603,89 \\
\end{tabular} & 90,72 & 1,00 & 63,89 & 257,81 & 18,23 & 22,30 & 243,60 \\
\hline Pelophylax perezi & 30STG65 & 100,00 & 178,83 & 122,93 & 40,00 & 6199,52 & 355,76 & 51,74 & 304,01 & 111,36 & 259,92 & 260,95 & 102,95 & 600,30 & 88,96 & 1,00 & 63,12 & 253,72 & 18,10 & 22,79 & 240,55 \\
\hline Pelophylax perezi & 30STG66 & 100,00 & 182,21 & 123,29 & 39,99 & 6235,86 & 360,32 & 53,61 & 306,71 & 113,96 & 263,74 & 264,51 & 105,26 & 580,38 & 85,29 & 1,00 & 62,51 & 243,32 & 18,00 & 22,10 & 230,78 \\
\hline Pelophylax perezi & \begin{tabular}{|l|}
30 STG67 \\
\end{tabular} & 100,00 & 175,46 & 124,19 & 39,23 & 6358,80 & 357,91 & 45,78 & 312,14 & 106,27 & 259,13 & 259,64 & $\begin{array}{l}97,48 \\
97\end{array}$ & 605,06 & 87,20 & 1,63 & 61,45 & 249,46 & 19,86 & 24,03 & 238,20 \\
\hline Pelophylax perezi & 30STG68 & 100,00 & 168,27 & 124,46 & 38,92 & 6463,01 & 353,97 & 37,80 & 316,17 & 98,27 & 253,63 & 253,86 & 89,14 & 629,00 & 88,82 & 2,00 & 60,12 & 254,86 & 22,39 & 25,94 & 244,62 \\
\hline Pelophylax perezi & 30STG69 & 100,00 & 158,30 & 123,72 & 38,13 & \begin{tabular}{|l|l|}
6543,04 \\
\end{tabular} & 346,16 & 27,98 & 318,18 & 87,73 & 245,06 & 245,34 & 78,92 & 664,30 & 91,73 & 2,86 & 58,72 & 264,30 & 26,15 & 28,46 & 255,15 \\
\hline Pelophylax perezi & 30STG70 & 100,00 & 171,25 & 109,52 & 39,94 & 5615,85 & 328,45 & 57,40 & 271,05 & 111,07 & 243,65 & 245,95 & 103,34 & 659,12 & 104,64 & 1,01 & 66,65 & 292,77 & 17,48 & 22,87 & 274,92 \\
\hline Pelophylax perezi & 30STG71 & 100,00 & 175,13 & 113,89 & 40,27 & 5719,97 & 337,59 & 58,99 & 278,60 & 113,35 & 248,85 & 251,01 & 105,91 & 629,15 & 100,05 & 1,00 & 66,39 & 278,57 & 16,39 & 21,41 & 261,01 \\
\hline Pelophylax perezi & 30STG72 & 100,00 & 177,07 & 116,95 & 40,28 & 5847,54 & 343,72 & 58,04 & 285,68 & 113,66 & 252,76 & 254,48 & 106,05 & 615,68 & 96,88 & 1,00 & 65,85 & 269,98 & 16,13 & 21,12 & 253,51 \\
\hline Pelophylax perezi & 30STG73 & 100,00 & 178,72 & 118,97 & 40,22 & 5955,20 & 348,24 & 57,16 & 291,08 & 114,01 & 256,09 & 257,47 & 106,22 & 607,86 & 94,16 & 1,00 & 65,12 & 263,69 & 16,46 & 21,33 & 248,35 \\
\hline Pelophylax perezi & 30STG74 & 100,00 & 179,84 & 120,65 & 40,05 & 6056,41 & 351,84 & 55,69 & 296,15 & 113,80 & 258,72 & 259,93 & 105,75 & 603,07 & 91,89 & 1,00 & 64,22 & 258,35 & 17,49 & 22,00 & 244,27 \\
\hline Pelophylax perezi & 30STG76 & 100,00 & 181,00 & 122,99 & 39,97 & 6246,53 & 358,77 & 53,08 & 305,69 & 112,95 & 262,77 & 263,46 & 104,16 & 590,59 & 87,52 & 1,00 & 62,71 & 247,14 & 17,77 & 22,23 & 235,14 \\
\hline Pelophylax perezi & 30STG77 & 100,00 & 176,89 & 123,78 & 39,27 & 6357,19 & 358,43 & 47,43 & 311,00 & 107,58 & 260,53 & 260,91 & 98,78 & 603,82 & 87,85 & 1,46 & 61,70 & 248,68 & 19,14 & 23,60 & 237,96 \\
\hline Pelophylax perezi & 30STG78 & 100,00 & 168,50 & 124,56 & 38,92 & 6485,80 & 354,55 & 37,93 & 316,62 & 98,37 & 254,24 & 254,40 & 89,27 & 633,13 & 89,94 & 2,00 & 60,40 & 255,87 & 21,89 & 24,68 & 246,41 \\
\hline Pelophylax perezi & 30STG79 & 100,00 & 158,45 & 124,13 & 38,25 & 6569,95 & 347,11 & 27,77 & 319,34 & 87,62 & 245,74 & 245,83 & 78,66 & 668,05 & $\begin{array}{l}92,56 \\
\end{array}$ & 2,95 & 58,80 & 264,92 & 25,84 & 27,06 & 256,60 \\
\hline Pelophylax perezi & 30STG80 & 100,00 & 167,54 & 109,06 & 39,83 & 5630,22 & 324,68 & 53,19 & 271,49 & 107,61 & 240,60 & 242,74 & 99,61 & 682,44 & 107,70 & 1,00 & 66,50 & 303,31 & 18,04 & 23,71 & 286,10 \\
\hline Pelophylax perezi & 30STG81 & 100,00 & 170,50 & 112,65 & 39,99 & 5754,78 & 332,39 & 53,71 & 278,68 & 108,88 & 245,23 & 247,12 & 100,98 & 660,95 & 103,85 & 1,00 & 65,99 & 291,38 & 17,70 & 23,10 & 274,78 \\
\hline Pelophylax perezi & $\begin{array}{l}\text { 30STG82 } \\
\end{array}$ & 100,00 & 174,71 & 115,52 & 40,01 & 5849,26 & 340,04 & 55,75 & 284,29 & $\begin{array}{l}111,67 \\
\end{array}$ & 250,75 & 252,36 & 103,77 & 635,29 & $\begin{array}{l}99,57 \\
\end{array}$ & 1,00 & 65,56 & 278,16 & 17,04 & 22,36 & 262,19 \\
\hline Pelophylax perezi & 30STG84 & 100,00 & $\begin{array}{ll}178,47 \\
\end{array}$ & 119,55 & 40,00 & $\begin{array}{lll}6065,93 \\
\end{array}$ & 349,58 & 54,61 & 294,97 & 112,69 & 257,68 & 258,66 & 104,36 & 613,71 & 93,91 & 1,00 & 64,34 & 262,69 & 17,10 & 22,24 & 249,12 \\
\hline Pelophylax perezi & 30STG85 & 100,00 & 176,23 & 121,39 & 39,94 & 6199,54 & 351,67 & 50,30 & 301,37 & 108,99 & 257,54 & 258,30 & 100,60 & 621,77 & 93,35 & 1,00 & 63,29 & 261,99 & 18,00 & 22,97 & 249,97 \\
\hline Pelophylax perezi & 30STG86 & 100,00 & 178,99 & 122,24 & 39,78 & 6266,13 & 356,57 & 51,29 & 305,28 & 110,92 & 261,29 & 261,69 & 102,17 & 605,48 & 90,01 & 1,00 & 62,75 & 252,48 & 17,68 & 22,53 & 241,26 \\
\hline Pelophylax perezi & 30STG88 & 100,00 & 171,70 & 124,24 & 38,91 & 6496,07 & 357,21 & 40,91 & 316,29 & 101,11 & 257,59 & 257,70 & 92,28 & 624,53 & 89,52 & 2,00 & 60,71 & 252,07 & 20,61 & 22,20 & 243,36 \\
\hline Pelophylax perezi & 30STG89 & 100,00 & 165,30 & 124,77 & 38,45 & 6580,47 & 353,79 & $\begin{array}{l}33,74 \\
33,\end{array}$ & 320,05 & \begin{tabular}{|l|l|}
93,88 \\
901
\end{tabular} & 252,60 & 252,63 & 85,04 & $\mid 643,30$ & 90,31 & 2,47 & 59,56 & 255,34 & 23,07 & $\begin{array}{l}23,72 \\
23,72\end{array}$ & 247,64 \\
\hline Pelophylax perezi & 30STG90 & 100,00 & 162,42 & 109,08 & 39,31 & 5685,62 & 320,47 & 46,95 & 273,52 & 102,55 & 236,79 & 238,63 & 94,09 & 706,63 & \begin{tabular}{|r|}
109,79 \\
\end{tabular} & 1,59 & 66,01 & 312,36 & 19,64 & 25,89 & 296,33 \\
\hline Pelophylax perezi & 30STG91 & 100,00 & 168,78 & 111,41 & 39,80 & 5755,98 & 329,38 & 51,78 & 277,60 & 107,57 & 243,88 & 245,63 & 99,31 & 672,11 & 105,18 & 1,06 & 65,85 & 296,47 & 18,01 & 23,59 & 280,25 \\
\hline Pelophylax perezi & 30STG92 & 100,00 & 174,72 & 113,71 & 40,00 & 5824,79 & 337,78 & 55,98 & 281,80 & 112,22 & 250,71 & 252,10 & 104,10 & 641,05 & 100,45 & 1,00 & 65,68 & 280,99 & 17,00 & 22,49 & 265,39 \\
\hline Pelophylax perezi & 30STG93 & 100,00 & 177,00 & 116,03 & 39,99 & 5944,39 & 343,43 & 55,99 & 287,44 & 112,67 & 254,63 & 255,78 & 104,59 & 626,95 & 97,35 & 1,00 & 64,88 & 271,58 & 17,00 & 22,10 & 257,21 \\
\hline Pelophylax perezi & 30STG94 & 100,00 & 176,66 & 118,32 & 39,97 & 6085,06 & $\begin{array}{l}34,45 \\
346,92\end{array}$ & \begin{tabular}{|l|l|}
52,97 \\
\end{tabular} & \begin{tabular}{|l|}
293,95 \\
\end{tabular} & \begin{tabular}{|l|}
110,77 \\
\end{tabular} & $\begin{array}{l}256,33 \\
\end{array}$ & 257,19 & 102,30 & 627,23 & 95,79 & $\begin{array}{l}1,000 \\
1,00\end{array}$ & 64,06 & $\begin{array}{l}267,52 \\
\end{array}$ & 17,09 & 22,91 & 254,72 \\
\hline Pelophylax perezi & 30STG95 & 100,00 & 176,31 & 120,07 & 39,50 & 6208,13 & 350,58 & 50,28 & 300,31 & 108,66 & 257,86 & 258,30 & 100,41 & 626,41 & 94,29 & 1,00 & 63,29 & 263,46 & 17,53 & 22,63 & 252,09 \\
\hline Pelophylax perezi & 30STG96 & 100,00 & 177,84 & 121,31 & 39,14 & 6287,33 & 355,09 & 50,04 & 305,05 & 109,46 & 260,51 & 260,79 & 100,73 & 616,07 & 91,77 & 1,00 & 62,92 & 255,89 & 17,31 & 20,45 & 245,68 \\
\hline Pelophylax perezi & 30STG97 & 100,00 & 180,20 & 122,08 & 39,01 & 6349,77 & 359,43 & 50,93 & 308,51 & 111,03 & 263,92 & 264,04 & 101,95 & 600,20 & 88,64 & 1,05 & 62,49 & 246,44 & 17,11 & 19,23 & 237,14 \\
\hline Pelophylax perezi & $\begin{array}{l}\text { 30STG98 } \\
\end{array}$ & 100,00 & 173,99 & 123,66 & 38,80 & 6501,44 & 358,65 & 43,13 & 315,52 & 103,21 & 260,03 & 260,10 & 94,35 & 621,06 & 89,58 & 1,93 & 61,14 & 250,08 & 19,47 & 20,25 & 242,25 \\
\hline Pelophylax perezi & \begin{tabular}{|l} 
30STG99 \\
3050
\end{tabular} & 100,00 & 168,38 & $\begin{array}{l}12,00 \\
124,53\end{array}$ & $\begin{array}{ll}38,18 \\
38,0\end{array}$ & $\begin{array}{l}0500,144 \\
659,17\end{array}$ & 356,69 & $\begin{array}{l}3,15 \\
36,42 \\
\end{array}$ & \begin{tabular}{|l|l|}
320,27 \\
320
\end{tabular} & \begin{tabular}{|l|}
03,21 \\
96,58
\end{tabular} & $\mid 256,00$ & \begin{tabular}{|l|}
256,02 \\
\end{tabular} & $\begin{array}{l}4,35 \\
87,88\end{array}$ & $\begin{array}{l}621,069 \\
634,99\end{array}$ & $\begin{array}{l}\mid \\
89,69 \\
89,69\end{array}$ & $\begin{array}{l}\frac{1,350}{2,26} \\
\end{array}$ & $\begin{array}{l}1,144 \\
59,99\end{array}$ & $\begin{array}{l}251,330 \\
\end{array}$ & 21,56 & $\begin{array}{l}21,25 \\
21,75\end{array}$ & $\begin{array}{l}24,25 \\
244,56\end{array}$ \\
\hline Pelophylax perezi & 30STH30 & 38,00 & 162,02 & 121,69 & 38,05 & 6437,09 & 346,07 & 32,84 & 313,24 & 92,33 & 246,85 & 247,60 & 83,40 & 623,24 & 85,07 & 2,93 & 57,98 & 248,53 & 26,09 & 30,42 & 237,40 \\
\hline Pelophylax perezi & 30STH40 & 100,00 & 160,71 & 122,37 & 38,23 & 6479,99 & 346,34 & 31,07 & 315,27 & 90,63 & 246,38 & 246,83 & 81,72 & 633,15 & 86,42 & 2,97 & 58,00 & 251,74 & 26,43 & 30,23 & 241,17 \\
\hline Pelophylax perezi & 30STH41 & 100,00 & 160,59 & 122,44 & 38,03 & 6501,08 & 346,94 & 30,69 & 316,24 & 90,13 & 246,60 & 246,97 & 81,27 & 623,32 & 84,59 & 3,05 & 57,23 & 245,85 & 26,93 & 30,72 & 235,46 \\
\hline Pelophylax perezi & 30STH42 & 100,00 & 151,34 & 121,54 & 37,99 & 6546,37 & 339,06 & 22,35 & 316,71 & 81,06 & 238,43 & 238,74 & 72,14 & 658,05 & 87,87 & 3,93 & 55,88 & 256,05 & 31,06 & 34,19 & 246,37 \\
\hline Pelophylax perezi & 30STH43 & 100,00 & 152,44 & 121,60 & 38,00 & 6564,90 & 340,64 & 23,11 & 317,53 & 81,97 & \begin{tabular}{|l|}
239,73 \\
\end{tabular} & 240,03 & 72,92 & 641,43 & 85,26 & 4,0 & 55,44 & 247,99 & 30,97 & 34,01 & 238,21 \\
\hline Pelophylax perezi & 30STH44 & 100,00 & 153,94 & 121,57 & 38,00 & 6575,79 & 342,36 & 24,53 & 317,83 & 83,12 & 241,33 & 241,64 & 74,22 & 622,99 & 82,48 & 4,00 & 54,88 & 239,42 & 30,72 & 33,11 & 229,57 \\
\hline Pelophylax perezi & 30STH45 & 100,00 & 156,29 & 121,34 & 37,90 & 6582,55 & 344,70 & 26,89 & 317,80 & 85,22 & 243,84 & 243,96 & 76,47 & 599,57 & 79,15 & 3,77 & 54,35 & 229,14 & 30,18 & 31,53 & 219,06 \\
\hline Pelophylax perezi & 30STH46 & 100,00 & 155,29 & 120,92 & 37,6 & 6598,03 & 343,72 & 26,13 & 317,59 & 83,97 & 243,16 & 243,18 & 75,32 & 593,16 & 77,76 & 3,5 & 53,64 & 225,08 & 30,95 & 31,10 & 214,95 \\
\hline Pelophylax perezi & 30STH47 & 100,00 & 155,30 & 120,33 & 37, & 6604,54 & 343,48 & 26,08 & 317,40 & 83,89 & 243,26 & 24 & 75,19 & 581,81 & 75,87 & 4 & 53,02 & 219,34 & 31,45 & 31,55 & 209,07 \\
\hline Pelophylax perezi & 30STH48 & 100,00 & 157,44 & 119,95 & 37,17 & 6597,95 & 344,99 & 28,26 & 316,73 & 85,84 & 245,26 & 245,27 & 77,32 & 561,16 & 72,90 & 3,99 & 52,53 & 210,48 & 31,05 & 31,16 & 199,90 \\
\hline Pelophylax perezi & 30STH49 & 100,00 & 161,22 & 119,45 & 37,07 & 6578,13 & 347,86 & 32,22 & 315,64 & 89,57 & 248,72 & 248,72 & 80,99 & 532,09 & 69,07 & 3,46 & 52,21 & $\begin{array}{l}198,78 \\
\end{array}$ & 29,68 & 29,68 & 187,99 \\
\hline Pelophylax perezi & 30STH50 & 100,00 & 154,55 & 122,76 & 38,00 & 6541,03 & 342,21 & 24,70 & 317,51 & 84,12 & 241,26 & 241,71 & 75,17 & 667,25 & 90,76 & 3,32 & 57,67 & 263,34 & 28,34 & 32,51 & 253,95 \\
\hline Pelophylax perezi & 30STH51 & 100,00 & 153,72 & 122,75 & 38,00 & 6576,28 & 342,43 & 23,63 & 318,80 & 82,89 & 241,05 & 241,33 & 74,09 & 661,33 & 89,25 & 3,54 & 56,83 & 258,68 & 29,39 & 32,99 & 249,47 \\
\hline Pelophylax perezi & $\begin{array}{l}\text { 30STH52 } \\
30 \text { TH }\end{array}$ & 100,00 & 154 & 122,84 & $\begin{array}{l}30, \\
38,\end{array}$ & . 65001,11 & 343,57 & $\begin{array}{l}24,05 \\
24,0\end{array}$ & $\begin{array}{l}10,00 \\
319,52 \\
\end{array}$ & 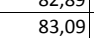 & \begin{tabular}{|l|}
242,07 \\
240
\end{tabular} & \begin{tabular}{|l|}
242,183 \\
242
\end{tabular} & $\begin{array}{l}74,22 \\
74,2\end{array}$ & $\begin{array}{l}\mid 001,33 \\
646,74\end{array}$ & 86,74 & 3, 3,61 & $\begin{array}{ll}5,0,34 \\
5,34\end{array}$ & \begin{tabular}{|l|}
$251,10,10$ \\
\end{tabular} & \begin{tabular}{|l|l|}
29,43 \\
\end{tabular} & $\begin{array}{ll}32,153 \\
31,63\end{array}$ & $\begin{array}{l}24,41,95 \\
241\end{array}$ \\
\hline Pelophylax perezi & \begin{tabular}{|l|}
30 STH53 \\
\end{tabular} & 100,00 & 154,90 & 122,75 & 38,00 & 6617,85 & 344,73 & 24,51 & 320,22 & 83,45 & 243,01 & 243,06 & 74,60 & 631,86 & 84,23 & 3,78 & 55,64 & 243,45 & 29,58 & 30,37 & 234,31 \\
\hline Pelophylax perezi & 30STH54 & 100,00 & 154,50 & 122,49 & 37,96 & 6634,03 & 344,70 & 23,91 & \begin{tabular}{|l|l|l|l|l|}
320,79 \\
\end{tabular} & $\begin{array}{l}3,, 45 \\
82,82\end{array}$ & \begin{tabular}{|l|}
243,02 \\
\end{tabular} & 243,02 & 74,04 & 621,54 & 82,39 & 4,00 & 55,00 & \begin{tabular}{|l|}
237,79 \\
\end{tabular} & 30,11 & 30,11 & 228,58 \\
\hline Pelophylax perezi & 30STH55 & 100,00 & 155,17 & 122,07 & 37,85 & 6633,65 & 344,99 & 24,61 & 320,37 & 83,29 & 243,63 & 243,64 & 74,65 & 606,76 & 79,93 & 3,98 & 54,26 & 230,53 & 30,33 & 30,50 & 221,18 \\
\hline Pelophylax perezi & 30STH56 & 100,00 & 156,51 & 121,87 & 37,81 & 6632,01 & 346,29 & 26,18 & $32 C$ & 84,64 & 244,90 & 244,91 & 76,15 & 588,28 & 77,20 & 3,90 & 53,72 & 222,09 & 30,26 & 30,38 & 212 \\
\hline Pelophylax perezi & \begin{tabular}{|c|} 
30STH57 \\
\end{tabular} & $\begin{array}{l}100,00 \\
\end{array}$ & $\begin{array}{l}150,51 \\
158,29\end{array}$ & $\begin{array}{l}121,01 \\
121,34\end{array}$ & $\begin{array}{l}37,01 \\
37,48 \\
\end{array}$ & 60335,21 & $\begin{array}{l}34,29 \\
347,64\end{array}$ & $\begin{array}{l}2,0,06 \\
28,06\end{array}$ & \begin{tabular}{|l|l|}
319,58 \\
31
\end{tabular} & $\begin{array}{l}44,04 \\
86,25 \\
\end{array}$ & \begin{tabular}{|l|}
246,79 \\
249
\end{tabular} & \begin{tabular}{|l|}
246,79 \\
249
\end{tabular} & $\begin{array}{l}\mid 0,115 \\
77,69\end{array}$ & | & 74,11 & $\begin{array}{l}3,07 \\
3,67 \\
\end{array}$ & $\begin{array}{ll}53,1 / 32 \\
53,2\end{array}$ & \begin{tabular}{|l|}
212,71 \\
213
\end{tabular} & $\begin{array}{l}0,290 \\
29,75 \\
\end{array}$ & $\begin{array}{l}0,30 \\
29,75\end{array}$ & 202,91 \\
\hline Pelophylax perezi & 30STH58 & 100,00 & 160,03 & 120,83 & 37,06 & 6641,15 & 348,80 & 29,68 & 319,12 & 87,60 & 248,34 & 248,34 & 79,01 & 546,29 & 71,27 & 3,55 & 52,77 & 203,87 & 29,41 & 29,41 & 193,80 \\
\hline Pelophylax perezi & 30STH59 & 100,00 & 158,08 & 120,01 & 37,01 & 6644,11 & 346,61 & 28,50 & 318,10 & 85,85 & 246,69 & 246,69 & 77,37 & 543,94 & 70,90 & 3,76 & 51,89 & 201,49 & 30,76 & 30,76 & 191,24 \\
\hline Pelophylax perezi & 30STH60 & 100,00 & 154,76 & 123,63 & 38,00 & 6584,50 & 343,96 & 24,34 & 319, & 83,79 & 242,2 & 242, & 74 & 669,32 & 91,24 & 3,44 & 57,66 & 263,09 & 28,16 & 29,76 & 254,51 \\
\hline Pelophylax perezi & 30STH61 & 100,00 & 152,05 & 123,47 & 38,00 & 6622,53 & 342,36 & 21,54 & 320,82 & 80,86 & 240,30 & 240,46 & 72,04 & 670,25 & 90,40 & 3,68 & 56,78 & 260,80 & 29,55 & 31,25 & 252, \\
\hline
\end{tabular}




\begin{tabular}{|c|c|c|c|c|c|c|c|c|c|c|c|c|c|c|c|c|c|c|c|c|c|}
\hline TAXON & UTM & $\mathrm{km2}$ & BIO1 & B102 & $\mathrm{BIO3}$ & B104 & B105 & B106 & B107 & B108 & B109 & BIO10 & BIO11 & $\overline{B 1012}$ & BIO13 & BIO14 & BIO15 & BIO16 & BIO17 & B1018 & BlO19 \\
\hline Pelophylax perezi & 30STH62 & 100,00 & 157,57 & 123,87 & 38,00 & 6630,11 & 347,98 & 26,14 & 321,84 & 85,75 & 245,83 & 245,90 & 76,93 & 634,27 & 85,54 & 3,25 & 56,54 & 245,70 & 27,79 & 28,80 & 237,15 \\
\hline Pelophylax perezi & 30STH63 & 100,00 & 157,68 & 123,72 & 38,00 & 6652,56 & 348,56 & 26,31 & 322,26 & 85,60 & 246,30 & 246,33 & 76,89 & 621,23 & 83,23 & 3,33 & 56,03 & 238,75 & 28,07 & 28,60 & 230,16 \\
\hline Pelophylax perezi & 30STH64 & 100,00 & 154,32 & 123,17 & 37,97 & 6682,70 & 345,85 & 23,28 & 322,57 & 82,10 & 243,38 & 243,40 & 73,25 & 623,00 & 82,64 & 4,00 & 54,93 & 236,89 & 30,16 & 30,75 & 228,46 \\
\hline Pelophylax perezi & 30STH65 & 100,00 & 154,76 & 122,96 & 37,73 & 6691,52 & 346,54 & 23,53 & 323,01 & 82,50 & 243,94 & 243,94 & 73,56 & 607,96 & 80,52 & 4,00 & 54,32 & 229,53 & 30,39 & 30,42 & 221,02 \\
\hline Pelophylax perezi & 30STH67 & 100,00 & 153,41 & 121,93 & 37,29 & 6697,93 & 344,63 & 22,75 & 321,87 & $\begin{array}{l}80,85 \\
\end{array}$ & \begin{tabular}{|l|}
242,91 \\
\end{tabular} & 242,91 & 72,37 & 589,51 & 77,81 & 4,05 & 52,76 & 219,29 & 31,78 & 31,78 & 210,29 \\
\hline Pelophylax perezi & 30STH68 & 100,00 & 158,55 & 121,57 & 37,19 & 6686,85 & 349,00 & 27,63 & 321,37 & 85,77 & 247,87 & 247,87 & 77,34 & 551,79 & 72,81 & 3,78 & 52,64 & 204,48 & 29,63 & 29,63 & 195,11 \\
\hline Pelophylax perezi & 30STH69 & 100,00 & 160,45 & 120,86 & 37,00 & 6684,73 & 350,04 & 29,56 & \begin{tabular}{|l|l|}
320,48 \\
\end{tabular} & 87,46 & \begin{tabular}{|l|l|}
249,60 \\
\end{tabular} & 249,60 & 79,00 & 529,86 & 69,74 & 3,37 & \begin{tabular}{l|l}
52,25 \\
\end{tabular} & $\begin{array}{l}195,47 \\
\end{array}$ & 28,90 & 28,90 & 185,73 \\
\hline Pelophylax perezi & 30STH70 & 100,00 & 151,81 & 123,86 & 38,00 & 6621,13 & 342,24 & 21,17 & \begin{tabular}{|l|l|}
321,08 \\
\end{tabular} & 80,58 & \begin{tabular}{|l|l}
240,03 \\
\end{tabular} & \begin{tabular}{|l|}
240,17 \\
\end{tabular} & 71,88 & $\begin{array}{l}685,67 \\
\end{array}$ & 93,23 & 3,73 & 57,39 & \begin{tabular}{|l|l|}
267,92 \\
\end{tabular} & 29,08 & 30,53 & 260,25 \\
\hline Pelophylax perezi & 30STH71 & 100,00 & 159,14 & 124,55 & 38,00 & 6644,97 & 350,01 & 27,44 & 322,57 & 87,29 & \begin{tabular}{ll|}
247,66 \\
\end{tabular} & $\begin{array}{l}247,69 \\
\end{array}$ & 78,43 & \begin{tabular}{ll|}
642,25 \\
\end{tabular} & 87,52 & 3,21 & 57,40 & \begin{tabular}{|l|l|}
249,90 \\
\end{tabular} & 26,60 & 26,83 & 242,09 \\
\hline Pelophylax perezi & 30STH72 & 100,00 & 161,12 & 124,65 & 38,00 & 6671,75 & 352,56 & 28,79 & 323,77 & 88,78 . & $249,95[$ & 249,95 & 79,81 & 621,28 & 84,23 & 3,12 & $57,01 \mid$ & 239,88 & 26,17 & 26,17 & 232,06 \\
\hline Pelophylax perezi & 30STH73 & 100,00 & 157,96 & 124,19 & 38,00 & 6695,41 & 350,16 & 25,70 & 324,46 & 85,29 & \begin{tabular}{|l|l|}
247,26 \\
\end{tabular} & 247,26 & 76,62 & 621,96 & 83,71 & 3,38 & 55,96 & 237,66 & 27,83 & 27,83 & 229,96 \\
\hline Pelophylax perezi & 30STH74 & 100,00 & 154,56 & 123,97 & \begin{tabular}{|c|}
37,97 \\
\end{tabular} & 6724,35 & 347,42 & 22,71 & 324,71 & 81,68 & \begin{tabular}{|l|l|}
244,42 \\
\end{tabular} & 244,42 & 73,12 & \begin{tabular}{ll|l|}
623,88 \\
\end{tabular} & 83,69 & 3,98 & \begin{tabular}{|l|l|}
54,97 \\
\end{tabular} & 235,97 & 29,66 & 29,66 & 228,38 \\
\hline Pelophylax perezi & 30STH75 & 100,00 & 155,29 & 123,65 & 37,63 & 6738,76 & 348,04 & 23,29 & 324,75 & 82,23 & 245,27 & 245,27 & 73,59 & \begin{tabular}{ll|}
606,42 \\
\end{tabular} & 81,36 & 4,00 & 54,31 & 227,60 & 29,78 & 29,78 & 219,78 \\
\hline Pelophylax perezi & 30STH76 & 100,00 & 152,99 & 122,95 & \begin{tabular}{|l|}
37,08 \\
\end{tabular} & 6744,62 & 346,10 & 21,23 & 324,86 & 80,04 & 243,23 & 243,23 & \begin{tabular}{|l|l|}
71,27 \\
\end{tabular} & \begin{tabular}{|l|l|}
602,77 \\
\end{tabular} & 80,62 & 4,09 & \begin{tabular}{l|l}
53,45 \\
\end{tabular} & 224,19 & 31,37 & 31,37 & 216,19 \\
\hline Pelophylax perezi & 30STH77 & 100,00 & 153,77 & 122,52 & \begin{tabular}{l|l}
37,05 \\
\end{tabular} & 6741,82 & 346,30 & 22,12 & 324,18 & \begin{tabular}{|l|}
80,67 \\
\end{tabular} & 243,93 & 243,93 & 72,03 & 585,37 & 78,13 & 4,07 & 52,76 & 216,22 & 31,41 & 31,41 & 207,88 \\
\hline Pelophylax perezi & 30STH78 & 100,00 & 158,94 & 122,04 & \begin{tabular}{|l|}
37,07 \\
\end{tabular} & 6726,54 & 350,29 & 27,17 & 323,12 & 85,86 & \begin{tabular}{|l|}
248,81 \\
\end{tabular} & 248,81 & $\begin{array}{l}77,15 \\
\end{array}$ & $\begin{array}{l}548,75 \\
\end{array}$ & 73,09 & 3,63 & 52,59 & \begin{tabular}{|l|}
201,97 \\
\end{tabular} & \begin{tabular}{|l|}
29,17 \\
\end{tabular} & 29,17 & 193,23 \\
\hline Pelophylax perezi & 30STH80 & 100,00 & 159,47 & 124,72 & 38,00 & 6639,36 & 350,07 & 27,82 & 322,25 & 87,76 & \begin{tabular}{|l|l|}
247,96 \\
\end{tabular} & \begin{tabular}{|l|l|}
247,97 \\
\end{tabular} & 78,89 & 656,20 & 90,41 & 3,03 & 58,29 & 256,68 & 25,59 & 25,70 & 249,59 \\
\hline Pelophylax perezi & 30STH81 & 100,00 & 164,93 & $\begin{array}{l}124,97 \\
\end{array}$ & 38,00 & 6662,85 & 355,81 & 32,29 & 323,52 & 92,55 & 253,64 & 253,64 & 83,63 & 622,20 & 85,72 & 2,64 & 58,18 & 241,91 & 23,87 & 23,87 & 234,87 \\
\hline Pelophylax perezi & 30STH82 & 100,00 & 160,47 & 124,88 & 37,99 & 6717,64 & 353,05 & 27,63 & 325,43 & 87,61 & \begin{tabular}{|l|l|}
250,08 \\
\end{tabular} & 250,08 & 78,63 & 626,84 & 85,41 & 3,14 & \begin{tabular}{l|l}
57,05 \\
\end{tabular} & 240,49 & 26,13 & 26,13 & 233,82 \\
\hline Pelophylax perezi & 30STH83 & 100,00 & 152,89 & 124,35 & 37,89 & 6749,92 & 346,89 & 20,61 & 326,28 & 79,97 & 243,25 & 243,25 & 71,3 & $\begin{array}{ll}644,83 \\
\end{array}$ & 87,63 & 3,99 & 55, & 243,88 & 29,88 & 29,88 & 237,43 \\
\hline Pelophylax perezi & 30STH84 & 100,00 & 153,50 & 124,19 & 37,58 & 6762,58 & 347,76 & \begin{tabular}{|l|l|}
21,15 \\
\end{tabular} & 326,61 & 80,31 & 244,01 & 244,01 & 71,78 & 628,24 & 85,36 & 4,01 & \begin{tabular}{|l|l}
54,83 \\
\end{tabular} & 235,77 & 30,01 & 30,01 & 229,16 \\
\hline Pelophylax perezi & 30STH85 & 100,00 & 153,88 & 124,01 & 37,63 & \begin{tabular}{ll|}
6775,67 \\
\end{tabular} & 347,84 & 21,45 & \begin{tabular}{|l|l|}
326,39 \\
\end{tabular} & 80,45 & \begin{tabular}{|l|l|}
244,69 \\
\end{tabular} & 244,69 & \begin{tabular}{l|l|}
72,05 \\
\end{tabular} & 611,90 & 83,02 & 4,00 & 54,14 & 227,90 & 30,21 & 30,21 & 221,07 \\
\hline Pelophylax perezi & 30STH86 & 100,00 & 156,58 & 123,79 & \begin{tabular}{|l|l|}
37,37 \\
\end{tabular} & 6782,16 & 350,26 & 23,82 & 326,44 & 82,86 & 247,33 & 247,33 & 74,38 & 585,63 & 79,31 & 3,89 & 53,74 & 216,73 & 29,32 & 29,32 & 209,48 \\
\hline Pelophylax perezi & 30STH87 & 100,00 & 153,78 & 123,07 & 37,00 & 6781,37 & 347,53 & 21,35 & 326,18 & 80,12 & 244,73 & 244,73 & 71,63 & 582,79 & 78,53 & 4,11 & 52,72 & 213,69 & 31,03 & 31,03 & 206,22 \\
\hline Pelophylax perezi & 30STH88 & 100,00 & 155,86 & 122,67 & 37,00 & 6769,27 & 348,66 & 23,55 & 325,12 & 82,16 & 246,48 & 246,48 & 73,69 & 559,13 & $\begin{array}{l}75,05 \\
\end{array}$ & 3,98 & 52,15 & 203,81 & 30,58 & 30,58 & 195,84 \\
\hline Pelophylax perezi & \begin{tabular}{|l|l|}
$30 S T H 89$ \\
\end{tabular} & 100,00 & 160,79 & 122,07 & 37,01 & 6751,70 & 352,34 & 28,51 & \begin{tabular}{|l|l|}
323,83 \\
\end{tabular} & 87,16 & 251,17 & 251,17 & 78,56 & \begin{tabular}{|l|l|}
523,03 \\
\end{tabular} & 69,94 & 3,46 & 52,02 & \begin{tabular}{|l|l|}
189,93 \\
\end{tabular} & 28,30 & 28,30 & 181,55 \\
\hline Pelophylax perezi & 30STH90 & 100,00 & 165,87 & 124,90 & 38,01 & 6649,20 & 356,02 & 33,41 & 322,61 & 93,65 & 254,33 & 254,33 & 84,77 & \begin{tabular}{|l|l|}
634,47 \\
\end{tabular} & 88,36 & 2,52 & \begin{tabular}{l|l}
59,05 \\
\end{tabular} & 247,76 & 22,97 & 22,97 & 241,61 \\
\hline Pelophylax perezi & 30STH91 & 100,00 & 163,51 & 124,97 & 37,99 & 6701,95 & 355,13 & \begin{tabular}{|l|l|}
30,47 \\
\end{tabular} & 324,66 & 90,71 & 252,71 & 252,71 & 81,61 & 631,52 & 87,42 & 2,86 & \begin{tabular}{l|l|}
58,05 \\
\end{tabular} & 243,73 & 24,30 & 24,30 & 237,81 \\
\hline Pelophylax perezi & 30STH94 & 100,00 & 155,75 & 124,84 & 37,59 & 6791,60 & 350,71 & 22,55 & 328,16 & 82,34 & \begin{tabular}{|l|l|}
246,94 \\
\end{tabular} & 246,94 & 73,25 & \begin{tabular}{|l|l|}
617,97 \\
\end{tabular} & 85,14 & 3,79 & 55,09 & 230,59 & 28,66 & 28,66 & 224,83 \\
\hline Pelophylax perezi & 30STH95 & 100,00 & 154,11 & 124,24 & 37,09 & 6804,66 & 349,13 & 21,09 & 328,03 & $\begin{array}{l}80,45 \\
\end{array}$ & 245,41 & 245,41 & 71,63 & 609,40 & 83,61 & 4,01 & 54,18 & 225,23 & 29,96 & 29,96 & 219,28 \\
\hline Pelophylax perezi & 30STH97 & 100,00 & 159,33 & 123,80 & 37,09 & 6807,79 & 353,41 & 25,99 & \begin{tabular}{|l|l|}
327,42 \\
\end{tabular} & 85,22 & \begin{tabular}{|l|l|}
250,69 \\
\end{tabular} & 250,69 & 76,50 & 555,60 & 75,74 & 3,37 & 53,54 & 203,08 & 27,64 & 27,64 & 196,31 \\
\hline Pelophylax perezi & 30STH98 & 100,00 & 154,08 & 123,05 & 37,01 & 6809,59 & 348,09 & 21,13 & 326,96 & 79,90 & 245,35 & 245,35 & \begin{tabular}{ll|l}
71,55 \\
\end{tabular} & 563,20 & 76,05 & 4,14 & 51,94 & 203,41 & 31,01 & 31,01 & 196,29 \\
\hline Pelophylax perezi & 30STJ40 & 100,00 & 164,92 & 118,90 & 37,14 & 6555,99 & 350,43 & 36,02 & 314,41 & 93,29 & 252,11 & 252,11 & 84,69 & 503,79 & 65,32 & 3,11 & 51,78 & \begin{tabular}{ll|}
187,58 \\
\end{tabular} & 28,46 & 28,46 & 176,44 \\
\hline Pelophylax perezi & 30STJ42 & 100,00 & 167,78 & 117,33 & 37,00 & 6552,41 & 351,55 & 39,67 & 311,88 & \begin{tabular}{|c|}
95,93 \\
\end{tabular} & 254,79 & 254,79 & 87,54 & 471,53 & 60,81 & 3,00 & 50,65 & 173,96 & 28,00 & 28,00 & 162,49 \\
\hline Pelophylax perezi & 30STJ43 & 91,00 & 165,71 & 116,47 & 37,00 & 6546,46 & 349,03 & 38,01 & \begin{tabular}{|l|}
311,02 \\
\end{tabular} & 93,88 & 252,67 & 252,67 & 85,50 & 472,84 & 60,88 & 3,12 & 50,02 & 173,15 & 28,96 & 28,96 & 161,63 \\
\hline Pelophylax perezi & 30STJ45 & 90,00 & 155,14 & 114,11 & 36,52 & 6576,14 & 338,30 & 29,58 & 308,71 & 83,58 & \begin{tabular}{|l|l|}
243,04 \\
\end{tabular} & 243,04 & 75,36 & 505,07 & 65,06 & 4,28 & 48,59 & \begin{tabular}{|l|l|}
183,02 \\
\end{tabular} & 34,39 & 34,39 & 171,02 \\
\hline Pelophylax perezi & 30STJ46 & 81,00 & 155,51 & 113,32 & \begin{tabular}{l|l}
36,25 \\
\end{tabular} & 6562,03 & 337,79 & 30,64 & 307,15 & 84,06 & 243,33 & 243,33 & 75,87 & 494,05 & 63,34 & 4,23 & 48,28 & 178,54 & 34,16 & 34,16 & 166,33 \\
\hline Pelophylax perezi & 30STJ47 & 80,00 & 158,34 & 112,88 & 36,33 & 6544,45 & 339,35 & 33,48 & 305,87 & 86,83 & 245,83 & 245,83 & 78,67 & \begin{tabular}{ll|}
472,85 \\
\end{tabular} & 60,15 & 4,06 & 47,72 & \begin{tabular}{|l|l|}
170,54 \\
\end{tabular} & 33,28 & 33,28 & 158,29 \\
\hline Pelophylax perezi & 30STJ48 & 80,00 & 157,30 & 112,20 & 36,16 & 532,43 & 337,47 & 32,83 & 304,64 & 85,80 & 244,71 & 244,71 & 77,88 & 470,31 & 59,10 & 4,17 & 47,10 & $\begin{array}{l}169,25 \\
\end{array}$ & $\begin{array}{l}3,86 \\
\end{array}$ & 33,86 & 156,80 \\
\hline Pelophylax perezi & 30STJ49 & 71,00 & 156,13 & 111,76 & 36,26 & 6505,03 & 335,34 & 32,39 & 302,95 & 85,06 & 243,28 & 243,28 & 77,19 & 468,44 & 57,95 & 4,65 & 46,47 & 168,19 & 34,86 & 34,86 & 155,72 \\
\hline Pelophylax perezi & 30STJ50 & 100,00 & 163,18 & 119,64 & 37,01 & 6621,01 & 350,36 & 33,55 & 316,80 & $\begin{array}{l}90,76 \\
\end{array}$ & \begin{tabular}{|l|l|}
251,32 \\
\end{tabular} & 251,32 & \begin{tabular}{|l|l|}
82,37 \\
\end{tabular} & 509,18 & 66,27 & 3,17 & 51,72 & \begin{tabular}{|l|l|}
188,16 \\
\end{tabular} & 28,62 & 28,62 & 177,60 \\
\hline Pelophylax perezi & 30STJ52 & 100,00 & 167,62 & 117,97 & 37,00 & 6582,42 & 352,50 & $\begin{array}{l}38,25 \\
\end{array}$ & 314,25 & 95,18 & 254,94 & 254,94 & $\begin{array}{l}86,75 \\
\end{array}$ & 469,10 & 60,64 & 3,00 & 50,56 & 171,66 & \begin{tabular}{l|l}
27,95 \\
\end{tabular} & 27,95 & 160,63 \\
\hline Pelophylax perezi & \begin{tabular}{|l|}
30 STJ53 \\
\end{tabular} & 100,00 & 166,45 & 117,24 & 37,00 & 6592,93 & 350,83 & 37,91 & \begin{tabular}{|l|l|}
312,92 \\
\end{tabular} & \begin{tabular}{|l|l|}
94,09 \\
\end{tabular} & \begin{tabular}{|l|l|}
254,25 \\
\end{tabular} & 254,25 & 85,66 & 462,89 & 59,97 & 3,01 & 50,18 & 168,80 & 28,12 & 28,12 & 157,63 \\
\hline Pelophylax perezi & 30STJ54 & 100,00 & $162, \mathrm{C}$ & 116,30 & 36,99 & 593,86 & 346,44 & 34,30 & 312,14 & 89,98 & \begin{tabular}{|l|l}
250,05 \\
\end{tabular} & 250,05 & 81,69 & 473,01 & 61,11 & 3,76 & 49,12 & 171,18 & 0,61 & 30,61 & 159,60 \\
\hline Pelophylax perezi & \begin{tabular}{|l|l|}
30 STIS7 \\
\end{tabular} & 100,00 & 15 & 56 & 36,34 & 6576,88 & 335,72 & \begin{tabular}{|l|}
27,88 \\
\end{tabular} & 307,84 & 81,56 & 241,36 & 241,36 & 73,40 & 485,68 & \begin{tabular}{|l|l|}
61,27 \\
\end{tabular} & 4,99 & 46,87 & 173,18 & \begin{tabular}{|l|l}
35,75 \\
\end{tabular} & \begin{tabular}{|c|}
35,75 \\
\end{tabular} & 160,91 \\
\hline Pelophylax perezi & 30STJ58 & 100,00 & 155,40 & 113,15 & 36,29 & 6552,72 & 336,67 & 30,22 & 306,45 & 83,61 & 243,05 & 243,05 & 75,49 & 467,24 & 58,29 & 4,77 & 46,49 & \begin{tabular}{|l|l|}
166,39 \\
\end{tabular} & \begin{tabular}{|l|l|}
34,67 \\
\end{tabular} & 34,67 & 153,99 \\
\hline Pelophylax perezi & 30STJ59 & 100,00 & 153,68 & 112,63 & 36,43 & 6536,26 & 333,96 & 28,91 & 305,05 & 82,08 & 241,23 & 241,23 & \begin{tabular}{|l|l|}
74,07 \\
\end{tabular} & 466,74 & 57,20 & 4,98 & \begin{tabular}{l|l|}
45,69 \\
\end{tabular} & \begin{tabular}{|l|l|}
165,74 \\
\end{tabular} & \begin{tabular}{|l|}
35,83 \\
\end{tabular} & 35,83 & 153,15 \\
\hline Pelophylax perezi & 30STJ60 & 100,00 & 162,60 & 120,19 & 37,01 & 6670,16 & 351,09 & 32,07 & 319,02 & 89,56 & 251,53 & 251,53 & 81,13 & 507,73 & 66,73 & 3,06 & 51,73 & 186,28 & 28,21 & 28,21 & 176,27 \\
\hline Pelophylax perezi & 30STJ61 & 100,00 & 165,51 & 119,52 & 37,00 & 6647,77 & 352,82 & 35,38 & 317,43 & 92,67 & 254,06 & 254,06 & 84,1 & 483,15 & 63,18 & 3,00 & 51,24 & \begin{tabular}{|l|l|}
176,44 \\
\end{tabular} & 27,62 & 27,62 & 166,13 \\
\hline Pelophylax perezi & \begin{tabular}{|l|l|}
$30 S T J 62$ \\
\end{tabular} & 100,00 & 166,71 & 118,79 & 37,00 & 6630,30 & 352,93 & 36,76 & 316,17 & 93,99 & 255,07 & 255,07 & 85,52 & 466,96 & 60,83 & 3,00 & 50,72 & 169,80 & 27,38 & 27,38 & 159,24 \\
\hline Pelophylax perezi & 30STJ63 & 100,00 & 165,26 & 117,98 & 37,00 & 6625,51 & 350,97 & 35,78 & 315,19 & 92,52 & 253,61 & 253,61 & 84,17 & 462,88 & 60,12 & 3,09 & 49,94 & 167,34 & 28,19 & 28,19 & 156,48 \\
\hline Pelophylax perezi & 30STJ64 & 100,00 & 162,51 & 117,17 & 37,00 & 6632,60 & 347,78 & 33,68 & 314,10 & 89,64 & \begin{tabular}{|l|l|}
251,03 \\
\end{tabular} & 251,03 & 81,49 & 464,40 & 59,96 & 3,73 & 48,80 & $\begin{array}{ll}166,62 \\
\end{array}$ & 29,91 & 29,91 & 155,51 \\
\hline Pelophylax perezi & 30STJ66 & 100,00 & 144,41 & 114,81 & 36,21 & 6629,29 & 329,64 & 18,39 & 311,25 & 72,59 & 233,64 & 233,64 & \begin{tabular}{|c|}
64,67 \\
\end{tabular} & 524,45 & 65,76 & 5,75 & 46,24 & \begin{tabular}{|l|}
185,41 \\
\end{tabular} & 39,55 & 39,55 & 173,24 \\
\hline Pelophylax perezi & 30ST. & 100,00 & 146 & & 36,7 & 6615 & 330 & 20,1 & & & 235 & 235 & 66, & 505,77 & 62,89 & 5,54 & 45, & 178,34 & 38,77 & 38,77 & \\
\hline Pelophylax perezi & 30STJ69 & 100,00 & 148,10 & 113,43 & 36,43 & 6562,40 & 329,99 & 22,97 & \begin{tabular}{|l|}
307,02 \\
\end{tabular} & 76,38 & 236,27 & 236,27 & 68,73 & 475,96 & 57,61 & 5,61 & \begin{tabular}{|l|l}
44,69 \\
\end{tabular} & \begin{tabular}{|l|l|}
166,87 \\
\end{tabular} & \begin{tabular}{|l|l|}
38,15 \\
\end{tabular} & 38,15 & 154,07 \\
\hline Pelophylax perezi & \begin{tabular}{|l|l|}
$30 S T J 70$ \\
\end{tabular} & 100,00 & 162,94 & 120,93 & 37,00 & 6711,61 & 352,53 & 31,34 & \begin{tabular}{|l|l|}
321,19 \\
\end{tabular} & \begin{tabular}{l|l|l}
89,45 \\
\end{tabular} & 252,49 & 252,49 & 80,99 & 503,63 & 66,61 & 3,16 & 51,62 & \begin{tabular}{|l|l|}
183,48 \\
\end{tabular} & 27,84 & 27,84 & 174,04 \\
\hline Pelophylax perezi & 30STJ71 & 100,00 & 164,95 & 120,14 & 37,00 & 6683,93 & 353,31 & 33,90 & 319,41 & $\begin{array}{l}91,52 \\
\end{array}$ & \begin{tabular}{|l|}
254,01 \\
\end{tabular} & 254,01 & 83,24 & 482,22 & 63,35 & 3,01 & \begin{tabular}{|l|l|l|}
51,07 \\
\end{tabular} & \begin{tabular}{|l|l|}
174,78 \\
\end{tabular} & 27,49 & 27,49 & 164,96 \\
\hline Pelophylax per & $30 \mathrm{STJ7}$ & 100,00 & 16 & & 37,00 & 680 & 250 & & 318,44 & 91, & 253, & 253, & 82 & $\begin{array}{l}471,15 \\
\end{array}$ & 61,59 & 3,05 & 50,33 & & 27,75 & 27,75 & 15 \\
\hline Pelophylax perezi & \begin{tabular}{|l|l|}
30 STI73 \\
\end{tabular} & 100,00 & 165,03 & 118,73 & 37,00 & 6656,6 & 351,7 & 34,71 & 317,04 & 91,92 & 253,87 & 253,87 & 83,65 & 457,19 & 59,44 & 3,02 & 49,79 & 163,93 & 27,85 & 27,85 & 153,66 \\
\hline Pelophylax perezi & 30STJ74 & 100,00 & 162,17 & 117,93 & 37,00 & 6665,46 & 348,56 & 32,45 & 316,11 & \begin{tabular}{|l|l|}
89,02 \\
\end{tabular} & 251,31 & 251,31 & 80,81 & 458,88 & 59,24 & 3,78 & 48,81 & 163,27 & 29,70 & 29,70 & 152,46 \\
\hline
\end{tabular}




\begin{tabular}{|c|c|c|c|c|c|c|c|c|c|c|c|c|c|c|c|c|c|c|c|c|c|}
\hline TAXON & UTM & $\mathrm{km} 2$ & B101 & B102 & $\mathrm{BIO3}$ & BIO4 & B105 & B106 & B107 & B108 & B109 & B1010 & B1011 & BIO12 & B1013 & BIO14 & BIO15 & B1016 & B1017 & B1018 & B1019 \\
\hline Pelophylax perezi & 30STJ76 & 100,00 & 140,27 & 115,77 & 36,36 & 6661,01 & 326,81 & 13,58 & 313,23 & 68,12 & 230,10 & 230,10 & 60,34 & 531,60 & 65,98 & 6,25 & 45,55 & 185,83 & 41,36 & 41,36 & 173,77 \\
\hline Pelophylax perezi & 30STJ77 & 100,00 & 147,64 & 115,50 & 36,43 & 6635,54 & 332,56 & 20,52 & 312,04 & 75,32 & 236,87 & 236,87 & 67,48 & 485,83 & 60,11 & 5,42 & 45,44 & 169,46 & 37,52 & 37,52 & 157,28 \\
\hline Pelophylax perezi & 30STJ78 & 100,00 & 149,32 & 115,03 & 36,47 & 6607,44 & 332,96 & 22,44 & 310,52 & 77,11 & 238,01 & 238,01 & 69,21 & 468,16 & 57,26 & 5,28 & 44,98 & 162,83 & 36,89 & 36,89 & 150,40 \\
\hline Pelophylax perezi & 30STJ79 & 100,00 & 145,83 & 114,40 & 36,55 & 6589,60 & 328,70 & 19,71 & 308,99 & 73,78 & 234,47 & 234,47 & 66,08 & 472,42 & 56,62 & 5,93 & 43,98 & 163,46 & 39,04 & 39,04 & 150,70 \\
\hline Pelophylax perezi & 30STI80 & 100,00 & 162,30 & 121,46 & 37,00 & 6739,35 & 352,98 & 30,08 & 322,90 & 88,63 & 252,38 & 252,38 & 79,85 & 502,74 & 66,85 & 3,20 & 51,45 & 181,68 & 27,79 & 27,79 & 172,88 \\
\hline Pelophylax perezi & 30STJ81 & 100,00 & 163,48 & 120,86 & 37,00 & 6732,77 & 353,18 & 31,55 & 321,62 & 89,64 & 253,32 & 253,32 & 81,22 & 484,17 & 63,95 & 3,17 & 50,84 & 173,96 & 27,62 & 27,62 & 164,79 \\
\hline Pelophylax perezi & 30STI82 & 100,00 & 159,71 & 120,06 & 37,00 & 6722,78 & 349,14 & 28,61 & 320,54 & 86,01 & 249,70 & 249,70 & 77,87 & 486,66 & 63,75 & 3,78 & 49,62 & 173,27 & 29,86 & 29,86 & 163,70 \\
\hline Pelophylax perezi & 30STJ83 & 100,00 & 164,26 & 119,30 & 37,00 & 6693,97 & 351,82 & 33,32 & 318,50 & 91,13 & 253,90 & 253,90 & 82,54 & 454,95 & 59,16 & 3,09 & 49,66 & 161,80 & 27,59 & 27,59 & 151,82 \\
\hline Pelophylax perezi & 30STI84 & 100,00 & 160,99 & 118,71 & 36,98 & 6691,07 & 348,55 & 30,58 & 317,97 & 87,68 & 250,68 & 250,68 & 79,21 & 455,58 & 58,58 & 3,95 & 48,18 & 160,46 & 30,10 & 30,10 & 150,10 \\
\hline Pelophylax perezi & 30STJ86 & 100,00 & 140,42 & 116,69 & 36,62 & 6683,16 & 327,95 & 12,71 & 315,23 & 67,77 & 230,58 & 230,58 & 60,09 & 519,05 & 64,15 & 6,31 & 44,92 & 179,38 & 41,07 & 41,07 & 167,52 \\
\hline Pelophylax perezi & 30STJ87 & 100,00 & 139,50 & 116,00 & 36,29 & 6660,10 & 326,07 & 12,18 & 313,89 & 67,07 & 229,44 & 229,44 & 59,43 & 510,14 & 62,04 & 6,55 & 44,22 & 175,34 & 41,84 & 41,84 & 162,97 \\
\hline Pelophylax perezi & 30STI88 & 100,00 & 139,32 & 115,41 & 36,44 & 6633,73 & 324,53 & 12,55 & 311,98 & 67,20 & 228,75 & 228,76 & 59,59 & 498,80 & 59,71 & 6,71 & 43,49 & 170,82 & 42,19 & 42,20 & 158,02 \\
\hline Pelophylax perezi & 30STI89 & 100,00 & 147,49 & 115,24 & 36,63 & 6605,04 & 331,02 & 20,20 & 310,82 & 75,09 & 236,35 & 236,35 & 67,44 & 452,42 & 53,79 & 5,80 & 43,54 & 154,66 & 37,88 & 37,88 & 141,99 \\
\hline Pelophylax perezi & 30STJ90 & 100,00 & 160,49 & 121,98 & 37,00 & 6771,17 & 352,25 & 27,84 & 324,41 & 86,45 & 251,27 & 251,27 & 78,05 & 506,21 & 67,55 & 3,66 & 50,97 & 181,01 & 28,85 & 28,85 & 172,84 \\
\hline Pelophylax perezi & 30STJ92 & 100,00 & 162,71 & 120,71 & 37,00 & 6751,35 & 352,47 & 30,39 & 322,09 & 91,52 & 253,05 & 253,05 & 80,01 & 468,96 & 61,53 & 3,40 & 49,86 & 165,95 & 28,06 & 28,06 & 156,97 \\
\hline Pelophylax perezi & 30STJ93 & 100,00 & 161,94 & 119,95 & 37,00 & 6733,40 & 350,90 & 30,21 & 320,68 & 92,86 & 252,06 & 252,06 & 79,61 & 459,79 & 59,58 & 3,71 & 48,80 & 161,48 & 29,06 & 29,06 & 152,00 \\
\hline Pelophylax perezi & 30STI94 & 100,00 & 158,84 & 119,27 & 37,00 & 6728,99 & 347,22 & 27,64 & 319,58 & 86,10 & 248,96 & 248,96 & 76,88 & 458,23 & 58,68 & 4,08 & 47,70 & 159,69 & 30,84 & 30,84 & 149,71 \\
\hline Pelophylax perezi & 30STJ95 & 100,00 & 151,63 & 118,54 & 36,72 & 6729,74 & 340,22 & 21,33 & 318,89 & 78,04 & 242,05 & 242,05 & 69,90 & 472,72 & 59,57 & 4,74 & 46,27 & 163,10 & 34,22 & 34,22 & 152,54 \\
\hline Pelophylax perezi & 30STJ96 & 100,00 & 141,01 & 117,50 & \begin{tabular}{|l|}
36,58 \\
\end{tabular} & 6708,53 & 329,46 & 12,15 & 317,31 & 68,05 & 231,51 & 231,51 & 60,23 & 505,65 & 62,12 & 6,26 & 44,46 & 172,77 & 40,59 & 40,59 & 161,21 \\
\hline Pelophylax perezi & 30STJ97 & 100,00 & 127,72 & 116,23 & 36,51 & $\mid 6662,72$ & 315,44 & 1.45 & 313,99 & 55,93 & 218,06 & 218,12 & 48,59 & 552,82 & 65,80 & 8,28 & 42,71 & $\mid 187,37$ & 48,65 . & 48,73 & 174,55 \\
\hline Pelophylax perezi & 30STJ98 & 100,00 & 132,35 & 115,84 & 36,44 & 6643,61 & 318,84 & 5,84 & 313,00 & 60,65 & 222,37 & 222,40 & 53,04 & 517,27 & 60,93 & 7,7 & 42,39 & 174,55 & 46,10 & 46,14 & 161,46 \\
\hline Pelophylax perezi & 30STJ99 & 100,00 & 144,12 & 116,00 & 36,92 & 6639,23 & 328,68 & 16,24 & 312,44 & 81,03 & 233,58 & 233,58 & 63,90 & 453,93 & 53,31 & 6,28 & 42,61 & 153,03 & 39,44 & 39,44 & 140,27 \\
\hline Pelophylax perezi & 30STK40 & 70,00 & 157,68 & 111,55 & \begin{tabular}{|l|l|}
36,40 \\
\end{tabular} & 6477,31 & 335,56 & \begin{tabular}{|l|l|}
33,93 \\
\end{tabular} & 301,63 & 86,53 & 244,31 & 244,31 & 78,84 & 455,27 & 55,76 & 4,71 & 46,00 & 163,25 & 34,57 & 34,57 & 150,81 \\
\hline Pelophylax perezi & 30STK41 & 70,00 & 160,83 & 111,62 & 36,88 & 6438,31 & 337,22 & 37,00 & 300,22 & 89,67 & 246,68 & 246,68 & 81,92 & 435,49 & 53,34 & 4,25 & 45,75 & 156,26 & 32,98 & 32,98 & 143,93 \\
\hline Pelophylax perezi & 30STK42 & 61,00 & 159,72 & 111,47 & 37,00 & 6405,93 & 335,10 & 36,22 & 298,88 & 88,79 & 244,95 & 244,95 & 80,91 & 433,38 & 53,14 & 4,72 & 45,05 & 155,24 & 33,98 & 33,98 & 142,80 \\
\hline Pelophylax perezi & 30STK50 & 100,00 & 156,29 & 112,45 & 36,60 & 6502,26 & 335,23 & 31,58 & 303,65 & 84,67 & 243,05 & 243,05 & 76,90 & 448,24 & 54, & 4,83 & 45,40 & 159,08 & 34,72 & 34,72 & 146,56 \\
\hline Pelophylax perezi & 30STK51 & 100,00 & 161,28 & 112,45 & 36,93 & 6469,97 & 338,53 & 36,40 & 302,13 & 89,56 & 247,40 & 247,40 & 81,93 & $\mid 420,85$ & 51,29 & 年, 4,13 & 45,34 & \begin{tabular}{|l|l|}
149,64 \\
\end{tabular} & 32,44 & 32,44 & 137,23 \\
\hline Pelophylax perezi & 30STK52 & 100,00 & 161,90 & 112,44 & 37,00 & 6442,02 & 338,05 & 37,23 & 300,82 & 90,26 & 247,52 & 247,52 & 82,78 & 411,27 & 50,17 & 4,20 & 44,75 & 146,01 & 32,27 & 32,27 & 133,61 \\
\hline Pelophylax perezi & 30STK60 & 100,00 & 157,27 & 113,56 & 36,92 & 6518,93 & 336,98 & 31,42 & 305,56 & 85,42 & 244,50 & 244,50 & 77,66 & 429,95 & 51,95 & 4,62 & 44,91 & 150,92 & 33,77 & 33,77 & 138,42 \\
\hline Pelophylax perezi & 30STK61 & 100,00 & 161,41 & 113,45 & 37,00 & 6464,10 & 339,30 & 35,73 & 303,57 & 89,90 & 247,71 & 247,71 & 82,00 & 405,86 & 49,08 & 4,07 & 44,62 & 142,62 & 31,97 & 31,97 & 130,32 \\
\hline Pelophylax perezi & 30STK62 & 100,00 & 161,23 & 113,17 & 37,00 & 6446,28 & 338,29 & 35,91 & 302,38 & 90,04 & 247,23 & 247,23 & 82,02 & 399,55 & 48,23 & 4,74 & 43,82 & 139,96 & 32,74 & 32,74 & 127,59 \\
\hline Pelophylax perezi & 30STK70 & 100,00 & 155,58 & 114,38 & 36,93 & 6548,73 & 336,36 & \begin{tabular}{|l|l|}
28,76 \\
\end{tabular} & \begin{tabular}{|l|}
307,60 \\
30,0
\end{tabular} & 80,64 & 243,10 & 243,10 & $\begin{array}{ll}75,64 \\
75,64\end{array}$ & \begin{tabular}{|l|l|}
423,57 \\
\end{tabular} & $\begin{array}{l}0,20 \\
50,69\end{array}$ & 4,94 & $\begin{array}{l}43,02 \\
44,09\end{array}$ & \begin{tabular}{|l|}
146,71 \\
\end{tabular} & 34,22 & 34,22 & 134,25 \\
\hline Pelophylax perezi & 30STK71 & 100,00 & 159,49 & 114,03 & 37,00 & 6506,11 & 338,62 & 32,78 & 305,84 & 94,35 & 246,32 & 246,32 & 79,77 & 400,66 & 47,97 & 4,71 & 43,70 & 138,88 & 32,83 & 32,83 & 126,42 \\
\hline Pelophylax perezi & 30STK72 & 100,00 & 160,40 & 114,00 & 37,00 & 6459,10 & 338,21 & 34,19 & 304,02 & 108,40 & 246,64 & 246,64 & 81,15 & 388,79 & 46,46 & 5,00 & 43,09 & 134,24 & 32,95 & 32,95 & 121,76 \\
\hline Pelophylax perezi & 30STK80 & 100,00 & 154,11 & 115,03 & 36,92 & 6563,75 & 335,78 & 26,85 & 308,93 & 96,75 & 242,10 & 242,10 & 74,02 & 417,37 & 49,41 & 5,16 & 43,39 & 142,80 & 34,71 & 34,71 & 130,20 \\
\hline Pelophylax perezi & $\begin{array}{l}\text { 30STK81 } \\
\end{array}$ & 100,00 & 157,36 & 114,90 & 37,00 & 6538,47 & 337,27 & 30,14 & 307,14 & 109,29 & 244,77 & 244,77 & 77,19 & 397,06 & 46,97 & 5,00 & 43,09 & 135,98 & 33,42 & 33,42 & 123,21 \\
\hline Pelophylax perezi & 30STK82 & 100,00 & 159,99 & 114,49 & 37,00 & 6497,45 & 338,29 & 33,01 & 305,28 & 118,40 & 246,75 & 246,75 & 80,04 & 379,04 & 44,91 & 5,00 & 42,66 & 130,14 & 32,23 & 32,23 & 117,00 \\
\hline Pelophylax perezi & 30STK90 & 100,00 & 154,91 & 115,74 & 36,95 & 6592,40 & 337,13 & 26,57 & 310,57 & 112,30 & 243,39 & 243,39 & 74,49 & 403,36 & 47,36 & 5,11 & 42,98 & 137,03 & 34,03 & 34,03 & 123,97 \\
\hline Pelophylax perezi & 30STK91 & 100,00 & 158,53 & 115,07 & 37,00 & 6558,74 & 338,88 & 30,31 & 308,57 & 116,44 & 246,30 & 246,30 & 78,05 & 382,92 & 44,90 & 5,00 & 42,83 & 130,80 & 32,58 & 32,58 & 117,11 \\
\hline Pelophylax perezi & 30STK92 & 100,00 & 158,97 & 115,00 & 37,00 & 6517,41 & 337,92 & 31,26 & 306,66 & 116,95 & 246,07 & 246,07 & 78,94 & 372,09 & 43,72 & 5,00 & 42,38 & 127,20 & 32,20 & 32,20 & 113,03 \\
\hline Pelophylax perezi & $\begin{array}{l}\text { 30SUF02 } \\
\end{array}$ & & & & & & & & & & & & & & & & & & & & \\
\hline Pelophylax perezi & 30SUF03 & 82,00 & 169,39 & 89,49 & \begin{tabular}{|l|l|}
40,47 \\
\end{tabular} & 4467,10 & 290,21 & 71,31 & 218,90 & 125,21 & 226,56 & 230,21 & 1116,17 & 700,22 & 120,39 & 1,22 & 73,03 & 341,09 & 15,43 & 22,72 & 320,33 \\
\hline Pelophylax perezi & 30SUF04 & 100,00 & 150,08 & 99,70 & 39,78 & 5072,33 & 290,43 & 42,10 & 248,32 & 99,75 & 216,34 & 219,17 & 89,69 & 772,31 & 120,92 & 2,11 & 69,39 & 353,55 & 20,02 & 28,71 & 341,47 \\
\hline Pelophylax perezi & 30SUF05 & 100,00 & 145,33 & 102,83 & 39,29 & 5290,31 & 292,21 & 34,25 & 257,95 & 92,33 & 214,78 & 217,25 & 82,33 & 790,04 & 120,53 & 2,57 & 67,83 & 354,48 & 22,08 & 30,76 & 343,39 \\
\hline Pelophylax perezi & 30SUF06 & 100,00 & 141,85 & 105,55 & 39,09 & 5464,68 & 294,05 & 28,43 & 265,62 & 86,67 & 213,94 & 216,01 & 76,81 & 802,06 & 120,23 & 3,02 & 66,62 & 54,21 & 24,06 & 32,49 & 343,76 \\
\hline Pelophylax perezi & $\begin{array}{l}\text { 30SUF07 } \\
\end{array}$ & 100,00 & $\begin{array}{l}148,85 \\
148,85\end{array}$ & 104,70 & 39,04 & 5460,91 & 299,82 & 35,93 & \begin{tabular}{|l|}
263,89 \\
\end{tabular} & \begin{tabular}{ll|}
93,13 \\
\end{tabular} & 220,67 & 222,81 & 83,66 & 769,43 & 117,27 & 2,48 & 60,62 & \begin{tabular}{|l|}
342,70 \\
\end{tabular} & 22,23 & 30,04 & 329,43 \\
\hline Pelophylax perezi & 30SUF08 & 100,00 & 151,01 & 106,04 & 39,03 & 5559,36 & 304,70 & 37,09 & 267,61 & 93,84 & 224,24 & 226,11 & 84,63 & 756,68 & 115,23 & 2,4 & 66,08 & 335,16 & 22,23 & 29,63 & 321,26 \\
\hline Pelophylax perezi & $\begin{array}{l}\text { 30SUFO9 } \\
\end{array}$ & 100,00 & 153,81 & 107,61 & 39,00 & 5651,03 & 310,21 & 38,57 & 271,64 & 95,21 & 228,32 & 229,94 & 86,20 & 742,10 & 112,92 & 2,29 & 65,64 & 326,77 & 22,01 & 28,98 & 312,48 \\
\hline Pelophylax perezi & 30SUF13 & 41,00 & 177,76 & 86,60 & 40,55 & 4321,56 & 293,13 & 81,98 & 211,15 & 135,25 & 232,73 & 236,49 & 126,22 & 639,44 & 112,78 & 1,00 & 73,62 & 317,35 & 14,11 & 20,27 & 294,35 \\
\hline Pelophylax perezi & 30SUF14 & 100,00 & 164,25 & 93,61 & 40,05 & 4728,92 & 292,85 & 61,81 & 231,04 & 117,47 & 225,38 & 228,54 & 107,94 & 693,70 & 114,72 & 1,46 & 71,15 & 44 & 16,93 & 24,32 & 311,92 \\
\hline Pelophylax perezi & 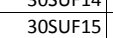 & 100,00 & 13 & $\begin{array}{r}3,01 \\
106,49\end{array}$ & 年 39,38 & \begin{tabular}{|l|}
$4 / 2,53,24$ \\
453,24
\end{tabular} & 289 & \begin{tabular}{|l|l|}
23,00 \\
\end{tabular} & \begin{tabular}{|l|}
261,049 \\
266,99
\end{tabular} & $\begin{array}{l}\mid 11,44 \\
82,54 \\
\end{array}$ & \begin{tabular}{|l|}
209,28 \\
\end{tabular} & \begin{tabular}{|l|}
211,17 \\
217
\end{tabular} & $\mid$ & 805,45 & \begin{tabular}{|l|l|l|l|l|}
119,46 \\
\end{tabular} & $\begin{array}{l}1,400 \\
3,47\end{array}$ & $\frac{1,10}{66,20}$ & \begin{tabular}{|l|}
$350,4,64$ \\
353
\end{tabular} & 25,29 & $\begin{array}{l}24,02 \\
34,08\end{array}$ & 341,22 \\
\hline Pelophylax perezi & 30SUF16 & 100,00 & 129,29 & 109,97 & 39,02 & 5681,03 & 290,17 & 12,23 & 277,94 & 71,73 & 205,11 & 206,59 & 61,96 & 839,94 & 121,57 & 4,46 & 64,32 & 360,19 & 29,42 & 38,14 & 352,82 \\
\hline Pelophylax perezi & 30SUF17 & 100,00 & 139,45 & 108,08 & 39,01 & 5631,49 & 296,76 & 23,59 & 273,17 & 82,19 & $\begin{array}{l}214,24 \\
21,4\end{array}$ & 215,90 & 72,48 & $\mid 790,95$ & 116,12 & 3, 3,52 & 64,97 & 344,10 & 25,83 & 33,99 & 333,83 \\
\hline Pelophylax perezi & 30SUF18 & 100,00 & 145,50 & 107,76 & 39,00 & 5650,69 & 302,14 & 29,69 & 272,45 & 87,59 & 220,36 & 221,86 & 78,06 & 764,70 & 113,56 & 3,09 & 65,04 & 334,29 & 24,24 & 31,91 & 322,21 \\
\hline Pelophylax perezi & 30SUF19 & 100,00 & 153,66 & 107,43 & 39,00 & 5652,85 & 309,79 & 38,03 & 271,76 & 95,08 & 228,48 & 229 & 86,25 & 731,08 & 110,58 & 2,50 & 65,31 & 321,66 & 22,23 & 29,17 & 307 \\
\hline Pelophylax perezi & 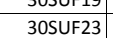 & 7,00 & $\begin{array}{l}13,00 \\
179,83\end{array}$ & 86,00 & 40,33 & | & 294,00 & \begin{tabular}{|l|l|}
83,603 \\
83,67
\end{tabular} & 210,33 & \begin{tabular}{|r|}
137,33 \\
137
\end{tabular} & \begin{tabular}{|l|}
234,50 \\
234
\end{tabular} & \begin{tabular}{|l|}
238,17 \\
238
\end{tabular} & \begin{tabular}{|l|}
00,20 \\
128,17 \\
\end{tabular} & \begin{tabular}{|l|}
613,00 \\
61,0
\end{tabular} & \begin{tabular}{|l|}
107,83 \\
107
\end{tabular} & $\begin{array}{l}, 00 \\
1,00\end{array}$ & $\begin{array}{l}3,15 \\
73,33\end{array}$ & \begin{tabular}{|l|}
304,170 \\
\end{tabular} & $\begin{array}{l}2 L, 25 \\
14,00\end{array}$ & $\begin{array}{l}\mid c, 111 \\
19,83\end{array}$ & $\begin{array}{l}281,67 \\
281,67\end{array}$ \\
\hline Pelophylax perezi & 30SUF24 & 94,00 & 168,45 & 92,06 & 40,05 & 4652,58 & 293,99 & 66,92 & 227,07 & 122,51 & 228,58 & 231,67 & 113,12 & 654,52 & 109,13 & 1,48 & 71,20 & 313,71 & 16,63 & 23,23 & 294,45 \\
\hline Pelophylax perezi & 30SUF25 & 100,00 & 151,94 & 100,82 & 39,72 & 5156,42 & 294,15 & 42,55 & 251,60 & 100,47 & 219,74 & 221,94 & 90,62 & 720,34 & 111,42 & 2.52 & 67.90 & 328.08 & 20,82 & 28,60 & 314,10 \\
\hline Pelophylax perezi & 30 SUF26 & 100,00 & 139,10 & 106,50 & 39,10 & 5504,40 & 293,23 & 24,74 & 268,49 & 83,18 & 212,2 & 213 & 73, & 778,80 & 115,34 & 3,84 & 65,27 & 341,04 & 26,48 & 34,36 & 329,79 \\
\hline Pelophylax perezi & 30SUF27 & 100,00 & 147,31 & 105,57 & 39,00 & 5509,06 & 299,63 & 33,14 & 266,49 & 91,15 & 220,22 & 221,83 & 81,75 & 740,65 & $\mid 110,76$ & 3,10 & 65,66 & 327,50 & 23,41 & 30,92 & 314,60 \\
\hline
\end{tabular}




\begin{tabular}{|c|c|c|c|c|c|c|c|c|c|c|c|c|c|c|c|c|c|c|c|c|c|}
\hline TAXON & UTM & $\mathrm{km} 2$ & B101 & B102 & $\mathrm{BIO3}$ & B104 & B105 & B106 & B107 & B108 & B109 & BIO10 & BIO11 & BIO12 & B1013 & BIO14 & BIO15 & BIO16 & B1017 & BIO18 & B1019 \\
\hline Pelophylax perezi & 30SUF28 & 100,00 & 154,73 & 104,85 & 39,00 & 5515,90 & 306,01 & 40,84 & 265,16 & 98,07 & 227,66 & 229,06 & 88,86 & 712,38 & 108,45 & 2,53 & 65,93 & 317,38 & 21,69 & 28,53 & 302,36 \\
\hline Pelophylax perezi & 30SUF29 & 100,00 & 159,16 & 105,45 & 39,00 & 5574,05 & 311,62 & 44,54 & 267,08 & 101,34 & 232,83 & 234,14 & 92,55 & 696,91 & 106,71 & 2,18 & 65,71 & 309,96 & 20,84 & 27,23 & 294,31 \\
\hline Pelophylax perezi & 30SUF34 & 86,00 & 168,50 & 91,96 & 39,99 & 4679,37 & 294,07 & 66,24 & 227,83 & 122,48 & 229,17 & 232,01 & 113,01 & 630,40 & 103,78 & 1,59 & 70,51 & 301,26 & 16,97 & 23,19 & 282,53 \\
\hline Pelophylax perezi & 30SUF35 & 100,00 & 158,75 & 97,82 & 39,57 & 5031,04 & 295,61 & 51,20 & 244,41 & 108,57 & 224,73 & 226,96 & 98,93 & 671,78 & 105,65 & 2,26 & 68,27 & \begin{tabular}{|l|}
310,74 \\
\end{tabular} & 19,50 & 26,30 & 294,46 \\
\hline Pelophylax perezi & 30SUF36 & 100,00 & 168,44 & 94,62 & 39,09 & 4960,52 & 300,68 & 62,44 & 238,24 & 118,42 & 233,11 & 235,40 & \begin{tabular}{|r|}
109,13 \\
\end{tabular} & 645,01 & 104,60 & 1,90 & 69,21 & 303,24 & 18,20 & 23,92 & 283,39 \\
\hline Pelophylax perezi & 30SUF37 & 100,00 & 154,78 & 102,31 & 39,00 & 5375,08 & 301,58 & 42,60 & 258,97 & 100,04 & 225,88 & 227,42 & 90,71 & 694,24 & 106,26 & 2,77 & 66,19 & 311,65 & 21,86 & 28,57 & 296,34 \\
\hline Pelophylax perezi & 30SUF38 & 100,00 & 161,50 & 101,88 & 38,99 & 5404,44 & 307,68 & 49,02 & 258,66 & 105,83 & 232,80 & 234,28 & 96,89 & 671,02 & 103,93 & 2,26 & 66,48 & 303,10 & 20,13 & 26,24 & 286,15 \\
\hline Pelophylax perezi & 30SUF39 & 100,00 & 163,16 & 103,55 & 38,99 & 5526,19 & 312,55 & 49,03 & 263,52 & 105,89 & 236,23 & 237,36 & 97,02 & 666,41 & 102,47 & 2,11 & 65,86 & 298,11 & 20,08 & 26,09 & 281,61 \\
\hline Pelophylax perezi & 30SUF43 & & & & & & & & & & & & & & & & & & & & \\
\hline Pelophylax perezi & 30SUF44 & 99,00 & 175,94 & 87,81 & 39,80 & 4528,52 & 294,53 & 75,85 & 218,68 & 131,70 & 234,36 & 237,40 & 122,17 & 584,84 & 98,22 & 1,33 & 71,14 & 283,83 & 16,13 & 21,07 & 263,71 \\
\hline Pelophylax perezi & 30SUF45 & 100,00 & 168,58 & 92,63 & 39,20 & 4834,96 & 296,72 & 63,92 & 232,80 & 120,46 & 231,56 & 233,94 & 111,00 & 617,16 & 100,64 & 2,04 & 69,42 & \begin{tabular}{|l|l|}
291,88 \\
\end{tabular} & 17,94 & 23,56 & 272,80 \\
\hline Pelophylax perezi & 30SUF46 & 100,00 & 178,09 & 89,38 & 39,01 & 4774,36 & 301,57 & 74,88 & 226,69 & 130,14 & 240,01 & 242,55 & 121,06 & 595,38 & 100,12 & 1,28 & 70,45 & 285,75 & 16,65 & 21,29 & 263,75 \\
\hline Pelophylax perezi & 30SUF47 & 100,00 & 173,28 & 93,60 & 38,83 & 5034,15 & 304,91 & 66,24 & 238,67 & 121,99 & 239,05 & 241,00 & 112,97 & 613,31 & 100,35 & 1,92 & 68,59 & 287,44 & 18,10 & 22,93 & 267,01 \\
\hline Pelophylax perezi & 30SUF48 & 100,00 & 164,32 & 99,91 & 38,79 & 5356,79 & 307,45 & 52,37 & 255,08 & 109,16 & 235,01 & 236,27 & 100,19 & 643,47 & 100,51 & 2,44 & 66,35 & 291,23 & 20,14 & 25,76 & 273,91 \\
\hline Pelophylax perezi & 30SUF49 & 100,00 & 161,69 & 103,47 & 38,72 & 5564,11 & 311,51 & 46,74 & 264,78 & 103,90 & 235,49 & 236,38 & 95,11 & 651,43 & 99,29 & 2,53 & 65,11 & 289,43 & 20,62 & 26,60 & 273,68 \\
\hline Pelophylax perezi & 30SUF54 & 49,00 & 180,49 & 85,28 & 39,21 & 4478,44 & 295,30 & 80,95 & 214,34 & 136,74 & 238,13 & 241,05 & 127,16 & 556,48 & 94,54 & 1,16 & 71,26 & 271,38 & 15,97 & 20,07 & 250,74 \\
\hline Pelophylax perezi & 30SUF55 & 100,00 & 166,07 & 93,57 & 39,03 & 4922,22 & 296,25 & 59,76 & 236,49 & 117,03 & 230,54 & 232,58 & 107,47 & 602,98 & 97,23 & 2,34 & 68,10 & 281,26 & 19,05 & 24,29 & 263,55 \\
\hline Pelophylax perezi & 30SUF56 & 100,00 & 179,54 & 87,59 & 38,50 & 4770,36 & 300,70 & 76,10 & 224,60 & 131,76 & 241,54 & 243,85 & 122,45 & 574,20 & 97,38 & 1,66 & 70,02 & 275,22 & 17,46 & 21,11 & 253,32 \\
\hline Pelophylax perezi & 30SUF57 & 100,00 & 167,71 & 95,80 & 38,66 & 5165,28 & 303,53 & 58,40 & 245,13 & 115,01 & 235,71 & 237,16 & 105,96 & 606,67 & 97,54 & 2,26 & 67,11 & 279,59 & 19,05 & 24,16 & 260,99 \\
\hline Pelophylax perezi & 30SUF58 & 100,00 & 161,08 & 101,12 & 38,52 & 5442,92 & 306,77 & 47,73 & 259,03 & 105,01 & 233,33 & 234,19 & 96,07 & 628,19 & 97,20 & 2,85 & 65,08 & 281,10 & 21,02 & 26,19 & 264,78 \\
\hline Pelophylax perezi & 30SUF59 & 100,00 & 151,96 & 107,04 & 38,38 & 5743,58 & 309,15 & 34,31 & 274,84 & 92,37 & 228,85 & 229,23 & 83,52 & 661,30 & 97,48 & 3,74 & 62,77 & 285,63 & 23,96 & 28,66 & 272,52 \\
\hline Pelophylax perezi & $\begin{array}{l}30 \text { SUF65 } \\
\end{array}$ & 71,00 & 178,18 & 86,28 & 38,39 & 4686,09 & 296,79 & 75,63 & 221,16 & 131,94 & 239,13 & 241,45 & 122,25 & 553,97 & 93,95 & 1,93 & 69,95 & 265,73 & 17,57 & 21,24 & 245,09 \\
\hline Pelophylax perezi & 30SUF66 & 100,00 & 181,38 & 85,40 & \begin{tabular}{|l|l|}
38,01 \\
\end{tabular} & 4749,54 & 299,71 & 78,08 & 221,63 & 134,01 & 243,11 & 245,35 & 124,52 & 550,63 & \begin{tabular}{|c|}
94,13 \\
\end{tabular} & 1,94 & 69,57 & \begin{tabular}{|l|l|}
263,32 \\
\end{tabular} & 17,94 & 21,02 & 241,76 \\
\hline Pelophylax perezi & 30SUF67 & 100,00 & 170,32 & 93,93 & 38,20 & 5138,18 & 303,49 & 61,14 & 242,35 & 117,80 & 238,01 & 239,35 & 108,82 & 573,92 & 93,08 & 2,34 & 66,71 & 264,25 & 18,82 & 23,33 & 245,63 \\
\hline Pelophylax perezi & 30SUF68 & 100,00 & 160,01 & 101,65 & 38,30 & 5489,69 & 306,78 & 45,54 & 261,24 & 103,07 & 233,11 & 233,63 & 94,37 & 604,52 & 93,12 & 3,17 & 64,03 & 268,35 & 21,43 & 25,48 & 252,56 \\
\hline Pelophylax perezi & 30SUF69 & 100,00 & 148,18 & 108,52 & 38,10 & 5824,46 & 308,79 & 29,03 & 279,76 & 87,60 & 226,42 & 226,51 & 78,91 & 649,50 & 94,31 & 4,30 & 61,40 & 276,40 & 25,32 & 26,83 & 264,26 \\
\hline Pelophylax perezi & \begin{tabular}{|l|}
30 SUF76 \\
\end{tabular} & 60,00 & 178,71 & 86,90 & 37,95 & 4863,15 & 300,02 & 73,37 & 226,66 & $\begin{array}{l}129,82 \\
\end{array}$ & 242,24 & \begin{tabular}{|l|}
244,01 \\
\end{tabular} & $\mid$\begin{tabular}{|l|}
120,51 \\
121
\end{tabular} & 525,85 & $\begin{array}{l}\mid 87,91 \\
87\end{array}$ & 2,07 & $\begin{array}{l}01,4,84 \\
67,\end{array}$ & 246,26 & 17,54 & 21,09 & 227,32 \\
\hline Pelophylax perezi & 30SUF77 & 100,00 & 159,55 & 100,20 & 38,38 & 5393,29 & 303,62 & 46,13 & 257,50 & 104,07 & 231,38 & 231,93 & 95,20 & 575,35 & 88,88 & 3,26 & 63,66 & 255,70 & 21,20 & 24,50 & 240,32 \\
\hline Pelophylax perezi & 30SUF78 & 100,00 & 153,56 & 105,24 & 38,18 & 5646,55 & 307,16 & 36,49 & 270,67 & 94,86 & 229,24 & 229,34 & 86,25 & 595,17 & 89,12 & 3,87 & 61,92 & 258,15 & 22,98 & 24,53 & 244,17 \\
\hline Pelophylax perezi & 30SUF79 & 100,00 & 146,45 & 109,68 & 38,06 & 5890,52 & 309,60 & 26,14 & 283,45 & 84,89 & 225,82 & 225,82 & 76,33 & 629,21 & 90,48 & 4,67 & 60,19 & 264,72 & 26,09 & 26,35 & 253,12 \\
\hline Pelophylax perezi & 30SUF86 & 60,00 & 174,85 & 90,24 & 38,04 & 4988,76 & 301,67 & 67,22 & 234,45 & \begin{tabular}{|l|}
124,08 \\
\end{tabular} & 240,53 & 241,71 & 115,09 & 496,94 & 80,94 & 2,22 & 65,88 & 228,36 & 17,27 & 20,95 & 211,64 \\
\hline Pelophylax perezi & \begin{tabular}{|l|}
30 SUF87 \\
\end{tabular} & 100,00 & 159,96 & 100,69 & 38,35 & 5423,32 & 304,65 & $\begin{array}{l}\mid 1,25 \\
45,79 \\
\end{array}$ & 258,86 & $\begin{array}{l}103,82, \\
13\end{array}$ & 232,49 & \begin{tabular}{|l|}
232,70 \\
\end{tabular} & 年, & 539,94 & $\begin{array}{l}00,24 \\
83,27 \\
\end{array}$ & 3,36 & $\begin{array}{l}62,74 \\
62\end{array}$ & 238,61 & 20,62 & 22,90 & 223,51 \\
\hline Pelophylax perezi & 30SUF88 & 100,00 & 161,41 & 101,54 & 38,05 & 5530,29 & 308,63 & 45,94 & 262,69 & 103,62 & 235,46 & 235,54 & 95,27 & 539,06 & 83,10 & 3,43 & 62,29 & 236,67 & 20,83 & 21,66 & 221,22 \\
\hline Pelophylax perezi & 30SUF89 & 100,00 & 138,18 & 113,21 & 38,01 & 6037,40 & 308,46 & 15,46 & 293,00 & 75,24 & 219,99 & 219,99 & 66,65 & 639,85 & 88,60 & 5,89 & 57,88 & 261,41 & 29,57 & 29,63 & 252,07 \\
\hline Pelophylax perezi & 30SUF96 & 57,00 & 178,52 & 89,16 & 38,00 & 4952,90 & 303,42 & 71,34 & 232,08 & 127,89 & 243,63 & 244,81 & 119,07 & 456,51 & 73,92 & 2,04 & 65,26 & 209,08 & 15,84 & 19,48 & 193,53 \\
\hline Pelophylax perezi & $\begin{array}{l}\text { 30SUF97 } \\
\end{array}$ & 100,00 & 175,94 & 91,94 & 37,94 & 5114,45 & 306,17 & 66,45 & 239,72 & 123,09 & 243,52 & 244,29 & 114,42 & \begin{tabular}{|l|l|}
464,87 \\
\end{tabular} & 74,74 & 2,26 & 64,55 & 210,69 & 16,53 & 20,02 & 194,90 \\
\hline Pelophylax perezi & \begin{tabular}{|l|}
30 SUF98 \\
\end{tabular} & 100,00 & 164,71 & 100,24 & 38,00 & $\begin{array}{l}5414,40,06 \\
5490\end{array}$ & 309,73 & $\begin{array}{l}0,495 \\
49,53 \\
\end{array}$ & \begin{tabular}{|l|}
260,20 \\
\end{tabular} & \begin{tabular}{|l|l|}
107,06 \\
127
\end{tabular} & \begin{tabular}{|l|}
238,20 \\
238,2
\end{tabular} & \begin{tabular}{|l|}
238,29 \\
\end{tabular} & \begin{tabular}{|l|}
$1+4,424$ \\
98,92
\end{tabular} & \begin{tabular}{|l|l|}
499,38 \\
499,38
\end{tabular} & 77,35 & $\begin{array}{l}3,20 \\
3,34\end{array}$ & $\begin{array}{l}4,, 930 \\
61,90 \\
\end{array}$ & $\begin{array}{l}218,09 \\
218,94\end{array}$ & \begin{tabular}{|l|}
19,813 \\
19,8
\end{tabular} & $\begin{array}{l}20,04 \\
20,69\end{array}$ & 203,59 \\
\hline Pelophylax perezi & 30SUF99 & 100,00 & 131,28 & 115,92 & 38,00 & 6159,14 & 307,14 & 6,72 & 300,42 & 67,43 & 214,93 & 214,93 & 58,55 & 651,95 & 87,41 & 7,08 & 55,91 & 259,09 & 33,13 & 33,13 & 251,82 \\
\hline Pelophylax perezi & 30SUG00 & 100,00 & 161,31 & 108,74 & 39,13 & 5694,42 & 318,83 & 45,36 & 273,47 & 101,53 & 236,13 & 237,63 & 92,80 & 707,84 & 109,19 & 1,94 & 65,68 & 312,33 & 20,30 & 26,57 & 296,84 \\
\hline Pelophylax perezi & 30SUG01 & 100,00 & 166,71 & 110,68 & 39,27 & 5775,27 & 326,71 & 49,14 & 277,56 & 105,37 & 242,43 & 243,84 & 97,01 & 680,99 & 105,53 & 1,53 & 65,47 & 299,20 & 18,94 & 24,81 & 283,82 \\
\hline Pelophylax perezi & 30SUG02 & 100,00 & 173,47 & 112,27 & 39,68 & 5833,07 & 335,08 & 54,56 & 280,52 & 110,91 & 249,81 & 250,97 & 102,64 & 648,46 & 101,11 & 1,00 & 65,43 & 283,83 & 17,03 & 22,98 & 268,80 \\
\hline Pelophylax perezi & $\begin{array}{l}\text { OSOSOSOL } \\
30 \text { SUG03 }\end{array}$ & 100,00 & $\begin{array}{l}17,45,87 \\
175,87\end{array}$ & $\begin{array}{l}111,27 \\
114,48\end{array}$ & $\begin{array}{l}39,08 \\
39,79\end{array}$ & $\begin{array}{l}30332,09 \\
5932,09\end{array}$ & 3430,65 & \begin{tabular}{|l|l|}
54,95 \\
54,95
\end{tabular} & \begin{tabular}{|l|}
280,52 \\
285,69 \\
\end{tabular} & \begin{tabular}{|l|}
112,201 \\
112
\end{tabular} & $\mid$\begin{tabular}{|l|}
2453,78 \\
25,8
\end{tabular} & $\mid 254,65$ & $\begin{array}{l}102,04,90 \\
103,90\end{array}$ & \begin{tabular}{|l|}
$640,40,93$ \\
635
\end{tabular} & \begin{tabular}{|l|}
01,11 \\
98,28
\end{tabular} & $\frac{1,00}{1,00}$ & $\begin{array}{l}3,45 \\
64,87 \\
\end{array}$ & $\begin{array}{l}283,85 \\
274,76\end{array}$ & $\begin{array}{l}1,05 \\
17,00 \\
\end{array}$ & $\begin{array}{l}2,50 \\
22,97\end{array}$ & $\begin{array}{l}200,00 \\
260,99\end{array}$ \\
\hline Pelophylax perezi & 30SUG04 & 100,00 & 174,68 & 117,00 & 39,43 & 6094,71 & 344,37 & 51,05 & 293,32 & 109,03 & 254,87 & 255,42 & 100,49 & 639,99 & 97,29 & 1,29 & 64,03 & 271,75 & 17,62 & 22,87 & 259,88 \\
\hline Pelophylax perezi & 30SUG05 & 100,00 & 174,83 & 118,95 & 39,03 & 6223,51 & 349,01 & 49,08 & 299,93 & 107,51 & 256,89 & 257,21 & 98,96 & 636,42 & 95,56 & 1,52 & 63,53 & 266,32 & 17,58 & 22,12 & 255,99 \\
\hline Pelophylax perezi & 30SUG06 & 100,00 & 177,07 & 120,20 & 39,00 & 6308,46 & 354,11 & 49,54 & 304,57 & 108,70 & 260,46 & 260 & 100,03 & 624,19 & 92,89 & 1,2 & 62,82 & 257,88 & 17,40 & 18,85 & 248,75 \\
\hline Pelophylax perezi & 30SUG07 & 100,00 & 178,95 & 121,29 & 38,99 & 6379,80 & 358,43 & $\mid 49,71$ & $\begin{array}{l}08,72 \\
308,7\end{array}$ & 109,61 & 263,26 & 263,31 & 100,66 & 612,95 & $\begin{array}{l}2,00 \\
90,28 \\
\end{array}$ & 1,5 & $\begin{array}{l}62,29 \\
62,\end{array}$ & 249,83 & 17,50 & $\begin{array}{l}18,0,83 \\
\end{array}$ & $\begin{array}{l}241,77 \\
241,7\end{array}$ \\
\hline Pelophylax perezi & 30SUG08 & 100,00 & 179,07 & 122,27 & 38,65 & 6465,53 & 361,50 & 48,51 & 312,99 & 108,69 & 264,57 & 264,59 & 99,60 & 606,15 & 88,31 & 1,66 & 61,55 & 243,76 & 17,82 & 18,13 & 236,68 \\
\hline Pelophylax perezi & 30SUG09 & 100,00 & 171,41 & 123,90 & 38,02 & 6601,14 & 359,11 & 39,39 & 319,72 & 99,62 & 259,17 & 259,17 & 90,60 & 629,89 & 89,50 & 2,11 & 60,41 & 248,30 & 20,38 & 20,38 & 242,66 \\
\hline Pelophylax perezi & 30SUG10 & 100,00 & 159,24 & 108,45 & 39,01 & 5718,69 & 316,76 & 42,82 & 273,95 & 99,60 & 234,76 & 235,98 & 90,61 & 707,58 & 107,98 & 2,08 & 65,19 & 311,06 & 20,88 & 27,25 & 296,25 \\
\hline Pelophylax perezi & 30SUG11 & 100,00 & 162,22 & 110,26 & 39,00 & 5826,52 & 322,81 & 43,99 & 278,81 & 100,68 & 239,15 & 240,24 & 92,25 & 694,13 & 105,64 & 2,07 & 64,74 & 302,36 & 20,58 & 26,74 & 288,19 \\
\hline Pelophylax perezi & 30SUG12 & 100,00 & 171 & 11 & 39,06 & $\begin{array}{l}302,067,53 \\
5867,\end{array}$ & 332,19 & \begin{tabular}{|l|l|}
51,71 \\
51
\end{tabular} & \begin{tabular}{|l|}
280,47 \\
\end{tabular} & \begin{tabular}{|l|}
108,360 \\
\end{tabular} & \begin{tabular}{|l|}
248,19 \\
248
\end{tabular} & \begin{tabular}{|l|}
249,15 \\
244
\end{tabular} & $\begin{array}{ll}2,25,96 \\
99,\end{array}$ & \begin{tabular}{|l|l|}
657,01 \\
65,01
\end{tabular} & \begin{tabular}{|l|}
101,29 \\
101,0
\end{tabular} & $\frac{1,01}{1,70}$ & $\begin{array}{l}64,4 / 98 \\
64\end{array}$ & $\begin{array}{l}30<, 30 \\
285,91\end{array}$ & $\begin{array}{l}0,0,27 \\
18,2\end{array}$ & $\frac{20,14}{24,20}$ & $\begin{array}{l}20,19 \\
271,83\end{array}$ \\
\hline Pelophylax perezi & 30SUG13 & 100,00 & 174,70 & 113,11 & 39,04 & 5956,19 & 338,53 & 53,39 & 285,14 & 110,82 & 253,09 & 253,78 & 102,18 & 640,77 & 98,39 & 1,38 & 64,44 & 275,81 & 17,38 & 23,21 & 262,82 \\
\hline Pelophylax perezi & 30SUG15 & 100,00 & 176,83 & 117,18 & 38,98 & 6195,92 & 349,00 & 51,24 & \begin{tabular}{|l|}
297,76 \\
\end{tabular} & \begin{tabular}{|l|l|}
109,89 \\
\end{tabular} & 258,59 & 258,86 & $\begin{array}{l}101,00 \\
\end{array}$ & 631,30 & $\begin{array}{l}0,33 \\
94,82 \\
\end{array}$ & 1,59 & 63,29 & 263,54 & $\begin{array}{ll}17,38 \\
170\end{array}$ & 20,48 & 253,87 \\
\hline Pelophylax perezi & 30 SUG16 & 100,00 & 177,14 & 119,05 & 38,87 & 6319,29 & 353,65 & 49,57 & 304,07 & 108,73 & 260,71 & 260,80 & 99,67 & 628,85 & 93,36 & 1,74 & 62,61 & 258,14 & 17,54 & 19,01 & 250,19 \\
\hline Pelophylax perezi & 30SUG17 & 100,00 & 176,59 & 120,83 & 38,41 & 6426,45 & 357,16 & 46,85 & 310,31 & 106,78 & 261,70 & 26 & 97,71 & 630,39 & 92,22 & 2,00 & 62,09 & 254,40 & 18,00 & 18,23 & 248,02 \\
\hline Pelophylax perezi & \begin{tabular}{|l|}
$3050 \mathrm{~s} 18$ \\
3
\end{tabular} & $\begin{array}{l}100,00 \\
\end{array}$ & $\begin{array}{l}17,59, \\
178,88\end{array}$ & $\begin{array}{l}12,03 \\
121,59\end{array}$ & | $30,4+07$ & $\begin{array}{ll}642,05,43 \\
649,44\end{array}$ & 361,50 & \begin{tabular}{|l|l}
48,004 \\
48,04
\end{tabular} & \begin{tabular}{|l|}
313,46 \\
316
\end{tabular} & \begin{tabular}{|l|}
108,01 \\
10,0
\end{tabular} & \begin{tabular}{|l|}
264,87 \\
\end{tabular} & \begin{tabular}{|l|}
264,87 \\
264
\end{tabular} & \begin{tabular}{l|l|}
98,88 \\
9
\end{tabular} & \begin{tabular}{|l|l|}
614,41 \\
614
\end{tabular} & $\begin{array}{l}2,2<2 \\
89,36 \\
\end{array}$ & 2,00 & $\begin{array}{l}2,309 \\
61,87 \\
\end{array}$ & $\begin{array}{l}2534,40 \\
245,13\end{array}$ & $\begin{array}{l}17,57 \\
17\end{array}$ & $\begin{array}{l}17,57 \\
17,57\end{array}$ & $\begin{array}{l}240,02 \\
239,64\end{array}$ \\
\hline Pelophylax perezi & 30SUG19 & 100,00 & 170,83 & 123,41 & 38,00 & 6637,60 & 358,88 & 38,45 & 320,44 & 98,80 & 259,16 & 259,16 & 89,47 & 637,10 & 91,01 & 2,26 & 60,45 & 249,29 & 20,32 & 20,32 & 245,07 \\
\hline Pelophylax perezi & 30 SUG20 & 100,00 & 158,31 & 108,00 & 38,99 & 5733,43 & 315,49 & 41,41 & 274,08 & 98,67 & 234,24 & 235,27 & 89,62 & 699,48 & 105,59 & 2,70 & 64,63 & 306,20 & 21,86 & 28,20 & 291,83 \\
\hline Pelophylax perezi & 30SUG21 & 100,00 & 165,14 & 108,67 & 38,99 & 5785,97 & 323,27 & 47,4 & 275,80 & 104,26 & 241,60 & 242, & 95, & 673,90 & 102,79 & 2,01 & 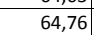 & 294,47 & 19,90 & 25,88 & 280,05 \\
\hline Pelophylax perezi & 30SUG22 & 100,00 & 168,04 & 110,52 & 38,99 & 5893,31 & 329,24 & 48,40 & 280,84 & 105,42 & 245,97 & 246,65 & 96,92 & 662,55 & 100,60 & 2,05 & 64,31 & 286,27 & 19,50 & 25,26 & 273,05 \\
\hline
\end{tabular}




\begin{tabular}{|c|c|c|c|c|c|c|c|c|c|c|c|c|c|c|c|c|c|c|c|c|c|}
\hline TAXON & UTM & $\mathrm{km} 2$ & B101 & B102 & $\mathrm{BIO3}$ & BIO4 & B105 & B106 & B107 & B108 & 8109 & BIO10 & BIO11 & BIO12 & 81013 & BIO14 & BIO15 & B1016 & B1017 & BIO18 & B1019 \\
\hline Pelophylax perezi & 30SUG23 & 100,00 & 172,70 & 112,00 & 38,96 & 5984,88 & 336,31 & 51,34 & 284,97 & 108,78 & 251,66 & 252,20 & 99,99 & 645,07 & 97,92 & 2,00 & 63,92 & 275,95 & 18,41 & 23,51 & 263,90 \\
\hline Pelophylax perezi & 30 SUG25 & 100,00 & 177,11 & 115,70 & \begin{tabular}{|l|l|}
38,47 \\
\end{tabular} & 6197,34 & 348,18 & 51,59 & 296,60 & 110,24 & 259,11 & 259,20 & 101,24 & 629,42 & 94,16 & 1,99 & 63,18 & 261,45 & 17,47 & 18,83 & 252,76 \\
\hline Pelophylax perezi & 30 SUG26 & 100,00 & 174,32 & 118,30 & 38,05 & 6364,71 & 351,55 & 46,19 & 305,35 & 105,34 & 258,78 & 258,78 & 96,44 & 641,77 & 94,36 & 2,00 & 62,40 & 261,26 & 18,11 & 18,20 & 254,61 \\
\hline Pelophylax perezi & 30SUG27 & 100,00 & 176,12 & 119,83 & 38,00 & 6461,01 & 356,74 & 46,04 & 310,70 & 106,12 & 261,92 & 261,92 & 96,58 & 635,43 & 92,68 & 2,00 & 62,12 & 254,70 & 17,76 & 17,76 & 249,60 \\
\hline Pelophylax perezi & 30SUG28 & 100,00 & 178,36 & 121,08 & 38,00 & \begin{tabular}{|l|l|}
6541,79 \\
\end{tabular} & 361,68 & 46,69 & 314,99 & 106,93 & 265,16 & 265,16 & 97,76 & 623,62 & 90,72 & 2,00 & 62,02 & 246,41 & 17,23 & 17,23 & 242,49 \\
\hline Pelophylax perezi & 30SUG29 & 100,00 & 171,23 & 122,66 & 37,88 & 6667,74 & 359,38 & 38,34 & 321,03 & 100,62 & 260,12 & 260,12 & 89,40 & 638,74 & 92,99 & 2,38 & 60,78 & 248,38 & 19,95 & 19,95 & 244,96 \\
\hline Pelophylax perezi & 30SUG30 & 100,00 & 161,39 & 106,38 & 38,92 & 5693,89 & 316,09 & 44,78 & 271,31 & 101,95 & 236,83 & 237,75 & 93,14 & 674,11 & 101,81 & 2,51 & 64,53 & 295,99 & 21,35 & 27,45 & 281,19 \\
\hline Pelophylax perezi & 30SUG31 & 100,00 & 161,38 & 108,58 & 38,67 & 5841,32 & 320,60 & 42,83 & 277,77 & \begin{tabular}{|l|l|}
99,99 \\
\end{tabular} & 238,97 & 239,58 & 91,20 & 673,64 & |100,65 & 2,64 & 63,81 & 291,63 & 21,31 & 27,21 & 278,18 \\
\hline Pelophylax perezi & 30SUG32 & 100,00 & 159,56 & 111,25 & 38,29 & 6008,58 & 324,64 & 38,62 & 286,03 & 96,04 & 239,62 & 239,98 & 87,44 & 680,73 & 100,01 & 2,95 & 62,84 & 289,04 & 22,29 & 26,61 & 277,57 \\
\hline Pelophylax perezi & 30SUG33 & 100,00 & 170,43 & 111,18 & \begin{tabular}{|l|l|}
38,29 \\
\end{tabular} & 6014,66 & 334,47 & 48,73 & 285,74 & 106,37 & 250,28 & 250,43 & 97,68 & 644,45 & 96,44 & 2,01 & 63,51 & 273,78 & 19,10 & 22,07 & 262,59 \\
\hline Pelophylax perezi & 30SUG34 & 100,00 & 175,81 & 112,36 & 38,18 & 6089,49 & 341,99 & 52,48 & 289,51 & 110,43 & 256,49 & 256,55 & 101,55 & 626,32 & 93,86 & 2,00 & 63,44 & 263,17 & 17,58 & 19,36 & 253,45 \\
\hline Pelophylax perezi & 30SUG35 & 100,00 & 176,11 & 114,54 & 38,01 & 6221,43 & 347,04 & 50,63 & 296,41 & 109,01 & 258,59 & 258,60 & 100,05 & 627,36 & 93,04 & 2,00 & 63,01 & 259,12 & 17,49 & 17,59 & 251,28 \\
\hline Pelophylax perezi & 30SUG36 & 100,00 & 174,02 & 116,99 & 37,99 & 6375,32 & 350,62 & 46,18 & 304,44 & 105,03 & 258,75 & 258,75 & 96,00 & 637,83 & 93,10 & 2,00 & 62,23 & 258,14 & 18,25 & 18,25 & 252,49 \\
\hline Pelophylax perezi & 30SUG37 & 100,00 & 173,29 & 119,06 & \begin{tabular}{|l|l|}
37,97 \\
\end{tabular} & 6501,13 & 354,58 & 43,41 & 311,17 & 103,03 & 259,91 & 259,91 & 93,59 & 642,11 & 92,83 & 2,01 & 61,93 & 255,04 & 18,79 & 18,79 & 251,26 \\
\hline Pelophylax perezi & 30SUG38 & 100,00 & 176,44 & 120,40 & 37,75 & 6576,82 & 360,40 & 44,73 & 315,68 & 106,72 & 264,12 & 264,12 & 95,58 & 632,80 & 93,53 & 2,01 & 62,00 & 248,47 & 17,71 & 17,71 & 245,31 \\
\hline Pelophylax perezi & 30SUG39 & 100,00 & 172,72 & 121,66 & 37,46 & 6673,92 & 360,28 & 39,74 & 320,55 & 103,10 & 261,75 & 261,75 & 90,77 & 634,97 & 94,36 & 2,40 & 60,84 & 247,91 & 19,40 & 19,40 & 242,96 \\
\hline Pelophylax perezi & 30SUG40 & 100,00 & 164,62 & 104,62 & 38,48 & 5666,15 & 316,75 & 48,21 & 268,55 & 105,23 & 239,72 & 240,42 & 96,60 & 643,79 & 97,35 & 2,44 & 64,83 & 283,87 & 20,00 & 25,60 & 268,63 \\
\hline Pelophylax perezi & 30SUG41 & 100,00 & 163,92 & 107,10 & 38,08 & 5819,24 & 321,13 & 45,30 & 275,83 & 102,48 & 241,36 & 241,74 & 94,05 & 648,59 & 96,53 & 2,91 & 63,63 & 280,68 & 21,20 & 25,07 & 267,16 \\
\hline Pelophylax perezi & 30SUG42 & 100,00 & 166,52 & 108,48 & 38,01 & 5933,72 & 327,02 & 46,30 & 280,72 & 103,47 & 245,39 & 245,58 & 94,90 & 641,69 & 95,17 & 2,56 & 63,31 & 274,66 & 20,23 & 22,79 & 262,42 \\
\hline Pelophylax perezi & 30SUG43 & 100,00 & 171,84 & 109,44 & 38,01 & $\mid 6006,52$ & 334,15 & 50,38 & 283,77 & $\mid 107,65$ & 251,63 & 251,71 & 99,12 & 624,99 & 92,97 & 2,10 & 63,18 & 265,05 & 18,86 & 20,31 & 254,21 \\
\hline Pelophylax perezi & 30SUG44 & 100,00 & 172,34 & 111,65 & 38,00 & 6139,10 & 339,58 & 48,64 & 290,94 & 106,45 & 254,03 & 254,10 & 97,77 & 626,83 & 92,21 & 2,15 & 62,63 & 260,99 & 18,94 & 19,48 & 252,20 \\
\hline Pelophylax perezi & 30 SUG 45 & 100,00 & 173,85 & 113,65 & 37,96 & 6261,89 & 345,24 & 48,10 & 297,14 & 106,35 & 257,18 & 257,18 & 97,48 & 624,27 & 91,20 & 2,05 & 62,30 & 255,65 & 18,35 & 18,35 & 248,82 \\
\hline Pelophylax perezi & 30SUG46 & 100,00 & 173,01 & 115,77 & $\begin{array}{l}37,69 \\
\end{array}$ & 6390,71 & 349,22 & 45,24 & 303,99 & 104,06 & 258,29 & 258,29 & 94,97 & 629,66 & 90,83 & 2,29 & 61,69 & 253,01 & 18,80 & 18,80 & 248,18 \\
\hline Pelophylax perezi & 30SUG48 & 100,00 & 176,47 & 118,81 & 37,23 & 6575,07 & 359,06 & 45,15 & 313,91 & 107,69 & 264,08 & 264,08 & 95,61 & 620,24 & 91,78 & 2,03 & 61,67 & 243,40 & 17,58 & 17,58 & 239,99 \\
\hline Pelophylax perezi & 30SUG49 & 100,00 & 177,84 & 119,92 & $\begin{array}{l}37,05 \\
\end{array}$ & 6641,07 & 362,81 & 45,38 & 317,43 & 108,48 & 266,49 & 266,49 & 96,15 & 608,36 & 91,39 & 2,03 & 61,38 & 238,32 & 17,34 & 17,34 & 233,03 \\
\hline Pelophylax perezi & 30SUG50 & 100,00 & 164,66 & 103,90 & 38,05 & 5680,63 & 316,29 & 47,89 & 268,40 & 105,03 & 240,25 & 240,61 & 96,56 & 622,40 & 93,9 & 2,99 & 63,95 & 273,02 & 20,50 & 25,05 & 257,99 \\
\hline Pelophylax perezi & 30SUG52 & 100,00 & 167,80 & 107,27 & 37,99 & 5920,05 & 327,06 & 47,73 & 279,34 & \begin{tabular}{|l|l|}
104,98 \\
\end{tabular} & $\begin{array}{l}246,79 \\
240\end{array}$ & \begin{tabular}{|l|}
246,83 \\
\end{tabular} & 96,37 & 618,11 & 90,78 & 2,81 & 62,80 & \begin{tabular}{|l|}
263,87 \\
\end{tabular} & 20,13 & 20,95 & 251,85 \\
\hline Pelophylax perezi & 30SUG54 & 100,00 & 169,43 & 111,11 & 37,68 & 6182,19 & 337,53 & 45,85 & 291,68 & 103,08 & 251,95 & 251,95 & 94,54 & 619,52 & 89,40 & 2,85 & 61,66 & 255,64 & 20,03 & 20,03 & 247,58 \\
\hline Pelophylax perezi & 30SUG55 & 100,00 & 170,56 & 112,87 & 37,33 & 6300,87 & 342,64 & 45,02 & 297,62 & 102,83 & 254,71 & 254,71 & 94,03 & 619,35 & 88,62 & 2,86 & 61,12 & 251,06 & 20,03 & 20,03 & 245,03 \\
\hline Pelophylax perezi & 30SUG56 & 100,00 & 172,76 & 114,40 & 37,12 & 6397,20 & 348,01 & 45,56 & 302,45 & 103,79 & 258,24 & 258,24 & 94,82 & 614,39 & 87,47 & 2,53 & 61,03 & 245,24 & 19,16 & 19,16 & 241,01 \\
\hline Pelophylax perezi & 30SUG57 & 100,00 & 176,82 & 115,35 & \begin{tabular}{|c|}
37,08 \\
\end{tabular} & 6451,29 & 353,91 & 48,21 & 305,70 & 107,37 & 262,91 & 262,91 & 97,94 & 600,80 & 86,33 & 2,02 & 61,42 & 236,98 & 17,28 & 17,28 & 234,25 \\
\hline Pelophylax perezi & 30SUG58 & 100,00 & 174,33 & 117,37 & 37,00 & 6577, & 356,15 & \begin{tabular}{|l|l|}
44,03 \\
44,
\end{tabular} & 312,11 & \begin{tabular}{|l|l|}
105,81 \\
\end{tabular} & \begin{tabular}{|l|}
262,29 \\
\end{tabular} & \begin{tabular}{|l|}
262,29 \\
\end{tabular} & $\begin{array}{ll}93,83 \\
\end{array}$ & 609,07 & 89,21 & 2,52 & $\begin{array}{ll}1,42 \\
60,53\end{array}$ & 238,13 & $\begin{array}{l}19,02 \\
19,02\end{array}$ & $\begin{array}{l}11,20 \\
19,02\end{array}$ & 234,34 \\
\hline Pelophylax perezi & 30SUG59 & 100,00 & 177,31 & 118,25 & 37,00 & 6620,24 & 360,45 & 45,90 & 314,55 & 108,36 & 265,77 & 265,77 & 96,05 & 591,19 & 87,92 & 2,13 & 60,54 & 230,87 & 17,76 & 17,76 & 225,69 \\
\hline Pelophylax perezi & 30 SUG60 & 100,00 & 161,05 & 105,06 & 38,00 & 5764,34 & 315,83 & 43,04 & 272,78 & 100,34 & 238,06 & 238,18 & 91,94 & 607,87 & 90,73 & 3,27 & 62,49 & 263,13 & 21,77 & 23,36 & 249,10 \\
\hline Pelophylax perezi & 30SUG61 & 100,00 & 160,85 & 107,15 & 37,99 & 5906,79 & 320,53 & 41,13 & 279,40 & 98,45 & 240,06 & 240,08 & 90,04 & 611,66 & 89,09 & 3,27 & 61,66 & 260,49 & 22,17 & 22,45 & 247,99 \\
\hline Pelophylax perezi & 30SUG62 & 100,00 & 166,75 & 106,91 & 37,78 & 5953,24 & 326,69 & 46,31 & 280,38 & \begin{tabular}{r|r|}
103,38 \\
\end{tabular} & 246,45 & 246,45 & 95,07 & 598,20 & 86,39 & 3,00 & 61,96 & 253,34 & 20,42 & 20,42 & 241,88 \\
\hline Pelophylax perezi & \begin{tabular}{|l|}
050002 \\
30 UGG3
\end{tabular} & 100,00 & 165,01 & 109,44 & 37,39 & 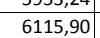 & 330,89 & $\begin{array}{l}40,3156 \\
42,56\end{array}$ & \begin{tabular}{|l|}
288,33 \\
28,3
\end{tabular} & \begin{tabular}{|}
99,67 \\
99,6 \\
\end{tabular} & 247,00 & \begin{tabular}{|l|}
247,00 \\
240
\end{tabular} & $\begin{array}{ll}0,1,44 \\
91\end{array}$ & | & 80,851 & 3,27 & $\begin{array}{l}1,50,98 \\
60,\end{array}$ & \begin{tabular}{|l|}
252,16 \\
25,16
\end{tabular} & $\frac{\mid 0,44}{21,25}$ & 21,25 & $\begin{array}{l}241,00 \\
242,99\end{array}$ \\
\hline Pelophylax perezi & 30SUG64 & 100,00 & 166,05 & 110,95 & \begin{tabular}{|l|l|}
37,07 \\
\end{tabular} & 6241,95 & 335,71 & 41,93 & 293,78 & 99,02 & 249,73 & 249,73 & 90,74 & 609,53 & 85,97 & 3,18 & 60,58 & 248,72 & 21,10 & 21,10 & 241,49 \\
\hline Pelophylax perezi & 30SUG66 & 100,00 & 168,88 & 113,75 & 37,00 & 6442,65 & 345,35 & 41,78 & 303,57 & 99,54 & 255,26 & 255,26 & 90,73 & 608,13 & 85,05 & 3,13 & 59,89 & 239,79 & 20,77 & 20,77 & 236,57 \\
\hline Pelophylax perezi & 30SUG67 & 100,00 & 174,88 & 114,20 & 37,00 & 6477,71 & 351,75 & 46,71 & 305,04 & 106,12 & 261,42 & 261,42 & 95,62 & 588,70 & 83,95 & 2,59 & 60,24 & 230,25 & 18,75 & 18,75 & 227,96 \\
\hline Pelophylax perezi & 30SUG68 & 100,00 & 174,37 & 115,71 & 37,00 & 6574,85 & 354,79 & 44,93 & 309,86 & 106,15 & 262,43 & 262,43 & 94,10 & 588,76 & 85,6 & 2,83 & 59,68 & 229,52 & 19,57 & 19,57 & 225,41 \\
\hline Pelophylax perezi & $\begin{array}{l}050006 \\
30 \text { UGG69 }\end{array}$ & 100,00 & $\begin{array}{l}17,31 \\
176,63\end{array}$ & $111, / 12$ & 37,00 & 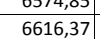 & 358,19 & $\begin{array}{l}4,, 53 \\
46,02\end{array}$ & \begin{tabular}{|l|}
312,54 \\
31,54
\end{tabular} & \begin{tabular}{|l|}
107,87 \\
107
\end{tabular} & $\begin{array}{l}20,45,08 \\
265,08\end{array}$ & \begin{tabular}{|l|}
$262,45,08$ \\
\end{tabular} & $\begin{array}{l}4,10 \\
95,63 \\
\end{array}$ & \begin{tabular}{|l|l|}
5700,101 \\
574,91
\end{tabular} & $\begin{array}{l}80,6 \\
84,7\end{array}$ & 2,235 & $\begin{array}{l}59,00 \\
59,89\end{array}$ & \begin{tabular}{|l|}
223,89 \\
223,
\end{tabular} & $\begin{array}{l}18,28 \\
18,28\end{array}$ & $\begin{array}{ll}18,28 \\
18,\end{array}$ & $\begin{array}{l}22,41,41 \\
218,58\end{array}$ \\
\hline Pelophylax perezi & 30SUG70 & 100,00 & 153,02 & 108,60 & 38,00 & 5919,84 & 315,12 & 32,55 & 282,56 & 90,59 & 232,64 & 232,64 & 82,25 & 606,43 & 88,06 & 4,36 & 60,45 & 256,18 & 24,30 & 24,34 & 243,79 \\
\hline Pelophylax perezi & 30SUG71 & 100,00 & 151,62 & 110,58 & \begin{tabular}{|c|}
37,88 \\
\end{tabular} & 6072,57 & 318,97 & 29,47 & 289,50 & 87,29 & 233,57 & 233,57 & 79,09 & 616,86 & 87,21 & 4,57 & 59,53 & 255,86 & 25,25 & 25,25 & 245,22 \\
\hline Pelophylax perezi & 30SUG73 & 100,00 & 160,62 & 110,39 & 37,03 & 6209,98 & 329,74 & 37,22 & 292,52 & 94,11 & 244,16 & 244,16 & 86,08 & 598,01 & 82, & $3, \varepsilon$ & 59,53 & 244,13 & 22,91 & 22,91 & 235,89 \\
\hline Pelophylax perezi & 30SUG74 & 100,00 & 155,15 & 113,29 & 37,00 & 6391,20 & 331,4 & 29,64 & 301,81 & $\begin{array}{l}84,1+9 \\
86,90\end{array}$ & 241,43 & 241,43 & $\begin{array}{l}78,57 \\
78,5\end{array}$ & \begin{tabular}{|l|l|}
624,57 \\
\end{tabular} & $\begin{array}{ll}84, \\
84,\end{array}$ & 4, & 58,31 & 247,93 & 25,42 & 25,42 & 242,53 \\
\hline Pelophylax perezi & 30SUG75 & 100,00 & 155,82 & 114,23 & 37,00 & 6483,09 & 334,95 & 29,28 & 305,67 & 86,84 & 243,34 & 243,34 & 78,06 & 628,75 & 85,66 & 4,59 & 57,93 & 245,89 & 25,79 & 25,79 & 242,22 \\
\hline Pelophylax perezi & 30SUG76 & 100,00 & 167,93 & 112,70 & 36,94 & 6465,81 & 344,27 & 41,35 & 302,92 & 98,95 & 254,88 & 254,88 & 89,66 & 591,31 & 81,95 & 3,36 & 59,12 & 230,97 & 21,26 & 21,26 & 228,66 \\
\hline Pelophylax perezi & 30SUG77 & 100,00 & 172,85 & 113,05 & 36,76 & 6504,26 & 349,80 & 45,24 & 304,56 & 104,92 & 260,04 & 260,04 & 93,80 & \begin{tabular}{|c|}
576,88 \\
\end{tabular} & 81,82 & 3,05 & 59,29 & 224,69 & 19,93 & 19,93 & 221,81 \\
\hline Pelophylax perezi & 30SUG78 & 100,00 & 172,73 & 114,57 & 36,69 & 6593,64 & 352,94 & 43,79 & 309,15 & 104,53 & 261,20 & 261,20 & 92,47 & 576,82 & 83,54 & 3,06 & 58,88 & 224,57 & 20,27 & 20,27 & 219,54 \\
\hline Pelophylax perezi & 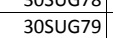 & 100,00 & 174,32 & 1145,61 & 36, & 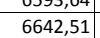 & $\begin{array}{l}352,1 \\
356,\end{array}$ & $\begin{array}{l}4,, 43 \\
44,43\end{array}$ & \begin{tabular}{|l|}
311,80 \\
31,0
\end{tabular} & \begin{tabular}{|l|}
105,50 \\
1050
\end{tabular} & $\begin{array}{l}263,37 \\
\end{array}$ & 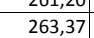 & $\begin{array}{ll}2,43,36 \\
93,\end{array}$ & $\begin{array}{l}560,028 \\
566,28\end{array}$ & $\begin{array}{l}80,34 \\
83,23\end{array}$ & 2,84 & $\begin{array}{l}0,0,00 \\
58,80\end{array}$ & \begin{tabular}{|l|}
220,16 \\
22,16
\end{tabular} & \begin{tabular}{|l|l|}
19,61 \\
\end{tabular} & $\begin{array}{l}2,21 \\
19,61\end{array}$ & 213,69 \\
\hline Pelophylax perezi & 30SUG80 & 100,00 & 145,86 & 111,84 & 38,00 & 6057,58 & 314,52 & 23,17 & 291,35 & 81,99 & 227,83 & 227,83 & 73,82 & 607,50 & 85,53 & 5,29 & 58,42 & 250,28 & 26,89 & 26,89 & 239,62 \\
\hline Pelophylax perezi & 30SUG81 & 100,00 & 153,52 & 110,27 & 37,74 & 6081,48 & 320,52 & 31,07 & 289,45 & 88,59 & 235,66 & 235,66 & 80,89 & 579,69 & 82,66 & 4,74 & 58,76 & 239,96 & 24.57 & 24.57 & 228,61 \\
\hline Pelophylax perezi & 30SUG82 & 100,00 & 160,03 & 108,95 & 37,09 & 6113,47 & 325,95 & 37,62 & 288,34 & 94,39 & 242,38 & 242,38 & 86,69 & 565,50 & 80,03 & 4,05 & 59,18 & 233,26 & 22,71 & 22,71 & 222,88 \\
\hline Pelophylax perezi & 30SUG83 & 100,00 & 146,88 & 114,40 & 37,0 & 6387,08 & 324,88 & 21,16 & 303,71 & 78,95 & 233,39 & 233,39 & 70,75 & 626,14 & 83,73 & 5,68 & 56,84 & 246,76 & 28,60 & 28,60 & 240,6 \\
\hline Pelophylax perezi & 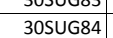 & $\begin{array}{l}100,00 \\
\end{array}$ & $\begin{array}{l}14,00 \\
153,59\end{array}$ & 1113,48 & 36,01 & $\begin{array}{l}030,160 \\
6436,52\end{array}$ & 331,44 & $\begin{array}{l}1,10 \\
27,62\end{array}$ & \begin{tabular}{|l|}
303,83 \\
303,1
\end{tabular} & $\begin{array}{l}0,35 \\
84,82 \\
\end{array}$ & \begin{tabular}{|l|}
240,74 \\
240
\end{tabular} & \begin{tabular}{|l|}
240,74 \\
240
\end{tabular} & $\mid 76,60$ & $\mid \begin{array}{l}\mid 620,14 \\
607,21\end{array}$ & $\begin{array}{l}\mid 00,15 \\
80,98\end{array}$ & $\begin{array}{l}, 000 \\
4,97\end{array}$ & $\begin{array}{l}0,04 \\
57,11\end{array}$ & \begin{tabular}{|l|}
237,89 \\
2370
\end{tabular} & $\begin{array}{l}26,17 \\
26,0\end{array}$ & $\begin{array}{l}26,17 \\
26,17\end{array}$ & $\begin{array}{l}24,05 \\
233,38 \\
\end{array}$ \\
\hline Pelophylax perezi & 30SUG85 & 100,00 & 148,31 & 115,62 & 36,83 & 6568,63 & 331,42 & 20,96 & 310,46 & 80,28 & 237,43 & 237,43 & 69,99 & 636,94 & 86,21 & 5,68 & 56,18 & 244,56 & 29,24 & 29,24 & 241,33 \\
\hline Pelophylax perezi & 30SUG86 & 100,00 & 166,49 & 112,03 & 36,32 & 6502,36 & 343,51 & 40,11 & 303,40 & 98,99 & 254,17 & 254,17 & 87,96 & 578,36 & 80,01 & 3,79 & 58,17 & 224,45 & 22,03 & 22,03 & 221,88 \\
\hline Pelophylax perezi & 30SUG87 & 100,00 & 172,88 & 111,81 & 36,27 & 6513,82 & 349,27 & 46,05 & 303,21 & 105,54 & 260,41 & 260, & 93, & 558,44 & 79,02 & 3,06 & 58 & 217,10 & 20,09 & 20,09 & 213,61 \\
\hline Pelophylax perezi & 30SUG88 & 100,00 & 173,66 & 112,90 & 36,15 & 6590,31 & 352,58 & 45,80 & 306,78 & $\begin{array}{l}105,69 \\
\end{array}$ & 262,17 & 262,17 & 93,69 & 556,08 & 80,42 & 3,00 & 58,36 & 216,38 & 20,06 & 20,06 & 210,75 \\
\hline
\end{tabular}




\begin{tabular}{|c|c|c|c|c|c|c|c|c|c|c|c|c|c|c|c|c|c|c|c|c|c|}
\hline TAXON & UTM & $\mathrm{km} 2$ & B101 & B102 & $\mathrm{BIO3}$ & B104 & B105 & B106 & B107 & B108 & B109 & BIO10 & BIO11 & BIO12 & B1013 & BIO14 & BIO15 & B1016 & B1017 & BIO18 & B1019 \\
\hline Pelophylax perezi & 30SUG89 & 100,00 & 173,58 & 114,20 & 36,08 & 6659,54 & 355,01 & 44,55 & 310,46 & 104,81 & 263,07 & 263,07 & 92,59 & 553,14 & 81,26 & 3,00 & 57,99 & 214,98 & 20,16 & 20,16 & 207,47 \\
\hline Pelophylax perezi & 30SUG90 & 100,00 & 124,09 & 117,99 & 37,99 & 6306,11 & 305,62 & $-1,53$ & 307,15 & 58,80 & 210,03 & 210,03 & 49,98 & 696,79 & 91,66 & 8,28 & 54,52 & 269,74 & 38,04 & 38,04 & 264,54 \\
\hline Pelophylax perezi & 30SUG91 & 100,00 & 154,26 & 110,16 & 37,51 & 6085,34 & 321,24 & 31,49 & 289,75 & 89,03 & 236,53 & 236,53 & 81,49 & 549,58 & 78,58 & 4,79 & 58,01 & 226,02 & 24,42 & 24,42 & 214,44 \\
\hline Pelophylax perezi & 30SUG92 & 100,00 & 153,51 & 111,81 & 37,11 & 6234,93 & 325,26 & 29,25 & 296,01 & 86,55 & 237,92 & 237,92 & 78,91 & 561,34 & 77,69 & 5,05 & 57,17 & 226,44 & 25,16 & 25,16 & 217,01 \\
\hline Pelophylax perezi & 30SUG93 & 100,00 & 149,08 & 114,18 & 37,00 & \begin{tabular}{|l|l|}
6403,34 \\
\end{tabular} & 327,12 & 23,01 & 304,10 & 80,62 & 235,97 & 235,97 & 72,76 & 592,08 & 78,83 & 5,62 & 56,10 & 232,11 & 27,61 & 27,61 & 225,90 \\
\hline Pelophylax perezi & 30SUG94 & 100,00 & 154,81 & 113,20 & 36,90 & 6460,44 & 332,98 & 28,65 & 304,33 & 85,55 & 242,41 & 242,41 & 77,56 & 581,53 & 76,64 & 5,13 & 56,41 & 225,90 & 25,89 & 25,89 & 221,69 \\
\hline Pelophylax perezi & 30SUG95 & 100,00 & 163,41 & 111,16 & 36,22 & 6471,75 & 339,35 & 37,74 & 301,61 & 94,24 & 250,87 & 250,87 & 85,63 & 561,54 & 75,06 & 4,38 & 57,20 & 217,22 & 23,01 & 23,01 & 214,71 \\
\hline Pelophylax perezi & 30SUG96 & 100,00 & 169,14 & 110,37 & 36,00 & 6498,94 & 344,60 & 43,37 & 301,23 & \begin{tabular}{|r|}
102,06 \\
\end{tabular} & 256,68 & 256,68 & 90,79 & 550,85 & 76,01 & 3,79 & 57,74 & 213,36 & 21,20 & 21,20 & 210,45 \\
\hline Pelophylax perezi & 30SUG97 & 100,00 & 170,74 & 111,06 & 36,00 & 6573,88 & 348,21 & 44,16 & 304,05 & 103,03 & 259,23 & 259,23 & 91,30 & 551,62 & 78,58 & 3,55 & 57,69 & 214,80 & 21,00 & 21,00 & 209,27 \\
\hline Pelophylax perezi & 30SUG98 & 100,00 & 174,07 & 111,48 & 36,00 & 6596,45 & 352,12 & 46,86 & 305,26 & 105,95 & 262,70 & 262,70 & 94,11 & 539,69 & 78,25 & 3,07 & 57,72 & 210,20 & 20,13 & 20,13 & 203,50 \\
\hline Pelophylax perezi & 30SUG99 & 100,00 & 174,24 & 112,71 & 36,00 & 6657,41 & 354,55 & 45,97 & 308,58 & 105,44 & 263,70 & 263,70 & 93,38 & 537,01 & 79,08 & 3,06 & 57,43 & 208,75 & 20,22 & 20,22 & 200,42 \\
\hline Pelophylax perezi & 30SUHOO & 100,00 & 165,63 & 124,63 & 38,00 & 6680,67 & 356,48 & 32,82 & 323,66 & 93,24 & 254,76 & 254,76 & 84,18 & 638,97 & 89,64 & 2,68 & 59,13 & 247,83 & 22,80 & 22,80 & 242,89 \\
\hline Pelophylax perezi & 30SUHO1 & 100,00 & 161,68 & 124,97 & \begin{tabular}{|l|l|}
37,98 \\
\end{tabular} & 6747,20 & 354,36 & 28,29 & 326,07 & 88,75 & 251,77 & 251,77 & 79,41 & 640,75 & 89,85 & 3,03 & 58,01 & 245,15 & 24,70 & 24,70 & 240,57 \\
\hline Pelophylax perezi & 30SUHO3 & 100,00 & 156,72 & 124,97 & 37,22 & 6812,88 & 351,83 & 22,94 & 328,90 & 84,97 & 248,16 & 248,16 & 73,96 & 629,18 & 88,10 & 3,43 & 56,14 & 235,71 & 27,18 & 27,18 & 231,01 \\
\hline Pelophylax perezi & 30SUHO4 & 100,00 & 152,84 & 124,93 & \begin{tabular}{l|l|l|}
37,05 \\
\end{tabular} & 6831,90 & 348,81 & 19,41 & 329,40 & 81,84 & 244,76 & 244,76 & 70,04 & 628,36 & 87,41 & 3,97 & 54,82 & 232,80 & 29,55 & 29,55 & 227,64 \\
\hline Pelophylax perezi & 30SUHO5 & 100,00 & 154,29 & 124,77 & 37,14 & 6832,25 & 350,07 & 20,79 & 329,28 & 83,11 & 246,08 & 246,08 & 71,36 & 606,60 & 84,11 & 4,00 & 54,17 & 222,77 & 29,59 & 29,59 & 217,47 \\
\hline Pelophylax perezi & 30SUHO6 & 100,00 & 156,69 & 124,19 & 37,01 & 6840,76 & 351,82 & 22,84 & 328,98 & 84,58 & 248,40 & 248,40 & 73,47 & 581,11 & 80,24 & 3,99 & 53,46 & 211,54 & 29,10 & 29,10 & 206,06 \\
\hline Pelophylax perezi & 30SUH08 & 100,00 & 156,61 & 123,59 & 37,00 & 6837,61 & 350,97 & 22,84 & 328,13 & 81,95 & 248,43 & 248,43 & 73,45 & 549,13 & 74,76 & 3,80 & 52,03 & 197,04 & 29,49 & 29,49 & 190,72 \\
\hline Pelophylax perezi & 30SUHO9 & 100,00 & 156,29 & 123,05 & 37,00 & 6827,99 & 350,39 & 22,76 & 327,62 & 81,72 & 247,94 & 247,94 & 73,39 & 533,95 & 72,05 & 4,00 & 51,27 & 190,05 & 30,05 & 30,05 & 183,17 \\
\hline Pelophylax perezi & $30 \mathrm{SUH} 10$ & 100,00 & 160,43 & 124,05 & 37,94 & 6743,60 & 352,50 & 27,41 & 325,09 & 89,12 & 250,70 & 250,70 & 78,31 & 659,05 & 93,60 & 3,05 & 58,55 & 253,14 & 24.49 & 24.49 & 249,34 \\
\hline Pelophylax perezi & 30SUH11 & 100,00 & 153,44 & 124,32 & 37,41 & 6790,20 & 347,48 & 20,28 & 327,20 & 82,93 & 244,46 & 244,46 & 71,11 & 668,52 & 94,50 & 3,88 & 56,90 & 253,99 & 27,99 & 27,99 & 249,24 \\
\hline Pelophylax perezi & 30SUH12 & 100,00 & 152,39 & 124,68 & 37,23 & 6821,05 & 347,75 & 19,14 & 328,61 & 81,93 & 243,99 & 243,99 & 69,83 & 657,64 & 92,90 & 3,98 & 56,20 & 247,94 & 28,79 & 28,79 & 242,44 \\
\hline Pelophylax perezi & 30SUH13 & 100,00 & 154,20 & 124,93 & \begin{tabular}{|l|l|}
37,09 \\
\end{tabular} & \begin{tabular}{|l|l|}
6841,54 \\
\end{tabular} & 350,06 & 20,50 & 329,56 & 83,68 & 246,18 & 246,18 & 71,38 & 636,21 & 89,85 & 3,75 & 55,83 & 238,13 & 28,24 & 28,24 & 232,44 \\
\hline Pelophylax perezi & 30SUH14 & 100,00 & 150,81 & 124,97 & 37,02 & 6860,81 & 347,49 & 17,34 & 330,15 & 80,42 & 243,28 & 243,28 & 67,93 & 632,93 & 88,78 & 4,17 & 54,50 & 234,54 & 30,24 & 30,24 & 228,31 \\
\hline Pelophylax perezi & 30SUH15 & 100,00 & 154,26 & 124,99 & 37,00 & 6858,90 & 350,54 & 20,44 & 330,10 & 83,81 & 246,70 & 246,70 & 71,17 & 603,60 & 84,48 & 4,00 & 54,14 & 221,67 & 29,30 & 29,30 & 215,70 \\
\hline Pelophylax perezi & 30SUH16 & 100,00 & 156,14 & 124,60 & 37,00 & 6864,75 & 351,95 & 21,92 & 330,03 & 85,47 & 248,42 & 248,42 & 72,77 & 580,00 & 80, & 4,00 & 53,32 & 210,65 & 29,02 & 29,02 & 204,95 \\
\hline Pelophylax perezi & 30SUH17 & 100,00 & 159,76 & 124,03 & 37,00 & 6852,95 & 354,63 & 25,22 & $\begin{array}{l}329,41 \\
32\end{array}$ & 88,66 & $\begin{array}{l}40,1,68 \\
251,68\end{array}$ & \begin{tabular}{l|}
251,68 \\
258
\end{tabular} & 76,34 & 548,21 & 75,84 & $\begin{array}{l}3,40 \\
3,42\end{array}$ & 53,12 & 197,20 & 27,31 & 27,31 & 191,87 \\
\hline Pelophylax perezi & 30SUH18 & 100,00 & 160,50 & 123,94 & 37,00 & 6853,55 & 354,88 & 26,04 & 328,84 & 87,45 & 252,51 & 252,51 & 76,96 & 528,38 & 72,45 & 3,32 & 52,48 & 188,55 & 27,29 & 27,29 & 183,01 \\
\hline Pelophylax perezi & 30SUH19 & 100,00 & 156,72 & 123,25 & 37,00 & 6850,13 & 351,13 & 22,66 & 328,47 & 82,51 & 248,74 & 248,74 & 73,43 & 527,22 & 71,32 & 3,82 & 51,09 & 186,22 & 29,49 & 29,49 & 180,06 \\
\hline Pelophylax perezi & $30 \mathrm{SUH} 2 \mathrm{O}$ & 100,00 & 164,69 & 123,62 & 37,62 & 6753,70 & 356,12 & 31,21 & 324,91 & 94,63 & 255,00 & 255,00 & 82,13 & 645,91 & 93,62 & 2,86 & 59,03 & 248,81 & 22,74 & 22,74 & 244,30 \\
\hline Pelophylax perezi & $30 \mathrm{SUH} 21$ & 100,00 & 155,18 & 124,01 & 37,13 & 6815,08 & 349,27 & 21,83 & 327,44 & 84,73 & 246,69 & 246,69 & 72,49 & 660,60 & 94,63 & 3,78 & 57,17 & 251,76 & 27,13 & 27,13 & 245,69 \\
\hline Pelophylax perezi & 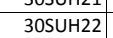 & 100,00 & $\begin{array}{l}157,27 \\
157\end{array}$ & 124,38 & 37,08 & 6836,77 & 352,36 & 23,58 & \begin{tabular}{|l|}
328,78 \\
\end{tabular} & $\begin{array}{l}4,7,77 \\
86,\end{array}$ & \begin{tabular}{|l|}
249,13 \\
\end{tabular} & \begin{tabular}{|l|}
249,13 \\
\end{tabular} & 74,42 & $\begin{array}{ll}638,21 \\
\end{array}$ & $\begin{array}{l}4,1,70 \\
91\end{array}$ & 3,51 & 56,67 & 241,62 & 26,43 & 26,43 & $\begin{array}{l}2435,18 \\
235\end{array}$ \\
\hline Pelophylax perezi & $30 \mathrm{SUH} 23$ & 100,00 & 149,64 & 124,64 & 37,01 & 6867,08 & 346,31 & 16,29 & 330,03 & 79,18 & 242,11 & 242,11 & 66,75 & 647,95 & 91,83 & 4,34 & 54,98 & 242,28 & 30,37 & 30,37 & 235,08 \\
\hline Pelophylax perezi & $30 \mathrm{SUH} 24$ & 100,00 & 152,59 & 124,99 & 37,00 & 6879,76 & 349,49 & 18,78 & 330,70 & 82,04 & 245,28 & 245,28 & 69,63 & 621,17 & 88,01 & 4,03 & 54,46 & 230,47 & 29,16 & 29,16 & 223,26 \\
\hline Pelophylax perezi & 30 SUH 25 & 100,00 & 155,16 & 124,99 & 37,00 & 6879,92 & 351,62 & 20,82 & 330,80 & 84,49 & 247,76 & 247,76 & 71,97 & 596,25 & 84,09 & 3,99 & 54,09 & 219,10 & 28,85 & 28,85 & 212,30 \\
\hline Pelophylax perezi & 30SUH26 & 100,00 & 157,27 & 124,76 & 37,00 & 6887,23 & 353,44 & 22,57 & 330,86 & 86,49 & 249,83 & 249,83 & 73,66 & 571,73 & 80,10 & 3,89 & 53,37 & 207,64 & 28,53 & 28,53 & 201,17 \\
\hline Pelophylax perezi & $\begin{array}{l}305 \mathrm{SOH} 27 \\
30 \mathrm{~s}\end{array}$ & 100,00 & 157,73 & $\begin{array}{l}124,16 \\
124,17\end{array}$ & 37,00 & $\begin{array}{ll}0.000,25 \\
6876,54\end{array}$ & 353,64 & \begin{tabular}{|l|l|}
23,18 \\
\end{tabular} & \begin{tabular}{|l|}
330,46 \\
330
\end{tabular} & $\begin{array}{l}\mid \frac{80,45}{87,20} \\
\end{array}$ & \begin{tabular}{|l|}
250,21 \\
250
\end{tabular} & \begin{tabular}{|l|}
250,21 \\
250
\end{tabular} & 74,31 & 550,77 & $\begin{array}{l}\mid 70,0,50 \\
76,5\end{array}$ & $\begin{array}{l}3,097 \\
3,67\end{array}$ & 52,70 & \begin{tabular}{|l|}
197,75 \\
197
\end{tabular} & $\begin{array}{l}28,21 \\
28,\end{array}$ & $\begin{array}{l}28,50 \\
28,21\end{array}$ & 191,68 \\
\hline Pelophylax perezi & $30 \mathrm{SUH} 28$ & 100,00 & 159,77 & 124,01 & 37,00 & 6870,03 & 354,71 & 25,01 & 329,70 & 88,82 & 252,06 & 252,06 & 76,10 & 525,57 & 72,21 & 3,41 & 52,07 & 186,35 & 27,45 & 27,45 & 180,92 \\
\hline Pelophylax perezi & $30 \mathrm{SUH} 29$ & 100,00 & 159,68 & 123,59 & 37,00 & 6866,72 & 354,01 & 24,97 & 329,04 & 89,87 & 251,91 & 251,91 & 76,03 & 509,45 & 69,12 & 3,47 & 51,26 & 178,71 & 27,92 & 27,92 & 173,23 \\
\hline Pelophylax perezi & $30 \mathrm{SUH} 30$ & 100,00 & 162,30 & 122,87 & 37,04 & 6771,33 & 354,04 & 29,24 & 324,80 & 92,31 & 253,16 & 253,16 & 80,00 & 647,49 & 94,59 & 3,26 & 58,61 & 249,89 & 23,69 & 23,69 & 243,64 \\
\hline Pelophylax perezi & 30SUH31 & 100,00 & 159,11 & 123,50 & 37,05 & 6820,64 & 352,68 & 25,53 & 327,15 & 88,65 & 250,72 & 250,72 & 76,22 & 643,77 & 93,65 & 3,54 & 57,47 & 246,45 & 25,46 & 25,46 & 239,30 \\
\hline Pelophylax perezi & \begin{tabular}{|l} 
OSOSUH31 \\
$30 \mathrm{SUH}$
\end{tabular} & 100,00 & $\begin{array}{l}13,11 \\
156,88 \\
\end{array}$ & $\begin{array}{l}123,50 \\
123,97\end{array}$ & 37,00 & $\begin{array}{l}0820,064 \\
6859,15\end{array}$ & $\begin{array}{l}33,08 \\
351,87\end{array}$ & \begin{tabular}{|l|}
22,99 \\
22,5
\end{tabular} & \begin{tabular}{|l|}
328,88 \\
32,15
\end{tabular} & \begin{tabular}{|l|}
80,03 \\
86,10
\end{tabular} & \begin{tabular}{|l|}
249,13 \\
249
\end{tabular} & $\begin{array}{l}240,1 / 1 \\
249\end{array}$ & \begin{tabular}{|l|}
$73,2,61$ \\
73
\end{tabular} & \begin{tabular}{|l|l|}
635,38 \\
635,3
\end{tabular} & \begin{tabular}{|l|}
92,03 \\
92,01
\end{tabular} & $\begin{array}{l}3,344 \\
3,77\end{array}$ & $\begin{array}{ll}3,4,51 \\
56,51\end{array}$ & \begin{tabular}{|l|}
240,456 \\
240,96
\end{tabular} & $\begin{array}{l}2,400 \\
26,70\end{array}$ & 26,40 & $\begin{array}{l}235,30 \\
233,23\end{array}$ \\
\hline Pelophylax perezi & 30SUH33 & 100,00 & 155,03 & 124,15 & 37,00 & 6882,36 & 351,03 & 20,96 & 330,08 & 84,19 & 247,63 & 247,63 & 71,67 & 625,04 & 89,89 & 3,97 & 55,43 & 234,58 & 27,97 & 27,97 & 226,59 \\
\hline Pelophylax perezi & 30SUH34 & 100,00 & 152,05 & 124,73 & 37,00 & 6907,64 & 348,98 & 17,85 & 331,13 & 81,11 & 245,16 & 245,16 & 68,66 & 617,62 & 87,99 & 4,11 & 54,31 & 229,10 & 29,42 & 29,42 & 220,93 \\
\hline Pelophylax perezi & 30SUH35 & 100,00 & 153,47 & 124,96 & 37,00 & 6914,82 & 350,41 & 18,82 & 331,59 & 82,61 & 246,64 & 246,64 & 69,85 & 595,47 & 84,36 & 4,00 & 53,71 & 218,63 & 29,03 & 29,03 & 210,82 \\
\hline Pelophylax perezi & 30SUH36 & 100,00 & 156,80 & 124,81 & 37,00 & $\begin{array}{ll}6903,97 \\
6903\end{array}$ & 353, & 21,85 & \begin{tabular}{|l|l|}
331,37 \\
\end{tabular} & \begin{tabular}{|l|l|}
86,01 \\
\end{tabular} & 249,63 & 249,63 & $\begin{array}{l}3,, 90 \\
72,\end{array}$ & |566,97| & $\begin{array}{l}79,78 \\
79,7\end{array}$ & $\begin{array}{ll}3,3,86 \\
3\end{array}$ & 53,20 & 205,78 & 28,44 & 28,44 & 198,61 \\
\hline Pelophylax perezi & 30SUH37 & 100,00 & 158 & 124,25 & 37,00 & 6893,18 & 353,98 & 23,16 & 330,82 & 87,52 & 250,85 & 250,85 & 74,40 & 543,75 & 75,72 & 3,51 & 52,56 & 194,90 & 27,77 & 27,77 & 188,42 \\
\hline Pelophylax perezi & 30 SUH 38 & 100,00 & 160,64 & 124,02 & 37,00 & 6885,64 & 355,60 & 25,47 & $\begin{array}{l}330,13 \\
330\end{array}$ & 89,97 & 253,13 & 253,13 & 76,72 & 517,02 & 71,21 & 3,28 & 52,03 & 182,91 & 26,94 & 26,94 & 177,24 \\
\hline Pelophylax perezi & 30SUH39 & 100,00 & 155,94 & 124,00 & 37,00 & 6899,70 & 351,46 & 21,01 & 330,45 & 85,36 & 248,87 & 248,87 & 72,04 & 516,53 & 69,93 & 3,90 & 50,60 & 179,69 & 29,56 & 29,56 & 174,11 \\
\hline Pelophylax perezi & $30 \mathrm{SUH} 40$ & 100,00 & 166,59 & 121,69 & 37,01 & 6766,19 & 356,73 & 33,38 & 323,35 & 96,41 & 257,32 & 257,32 & 83,97 & 627,45 & 92,90 & 3,00 & 58,99 & 243,12 & 22,05 & 22,05 & 235,93 \\
\hline Pelophylax perezi & 30SUH41 & 100,00 & $\begin{array}{l}100,53 \\
163,68\end{array}$ & $\begin{array}{l}121,03 \\
122,52\end{array}$ & 37,00 & 681 & 355,97 & $\begin{array}{l}3,300 \\
29,91 \\
\end{array}$ & \begin{tabular}{|l|}
326,06 \\
32,0
\end{tabular} & \begin{tabular}{l|l}
93,17 \\
93,1
\end{tabular} & \begin{tabular}{|l|}
255,18 \\
25,18
\end{tabular} & $\begin{array}{l}255,18 \\
252\end{array}$ & $\begin{array}{l}30,68 \\
80,\end{array}$ & \begin{tabular}{|l|l|}
621,48 \\
\end{tabular} & $\begin{array}{l}32,100 \\
91,61 \\
\end{array}$ & 3,31 & 57,85 & \begin{tabular}{|l|}
238,69 \\
238,69
\end{tabular} & $\begin{array}{l}23,03 \\
23,62\end{array}$ & $\begin{array}{l}23,62 \\
23,62\end{array}$ & 230,69 \\
\hline Pelophylax perezi & $30 \mathrm{SUH} 42$ & 100,00 & 159,93 & 123,20 & 37,00 & 6866,91 & 354,13 & 25,70 & 328,43 & 88,95 & 252,18 & 252,18 & 76,42 & 618,63 & 90,50 & 3,56 & 56,64 & 235,22 & 25,44 & 25,44 & 226,66 \\
\hline Pelophylax perezi & $30 \mathrm{SUH} 43$ & 100,00 & 154,47 & 123,89 & 37,00 & 6906,66 & 350,66 & 20,31 & 330,36 & 83,37 & 247,52 & 247,52 & 70,86 & 619,21 & 89,46 & 3,99 & 55,09 & 232,34 & 28.04 & 28.04 & 223,41 \\
\hline Pelophylax perezi & $30 \mathrm{SUH} 44$ & 100,00 & 151,10 & 124,14 & 37,00 & 6935,14 & 348,41 & 16,70 & 331,71 & 79,95 & 244,71 & 244,71 & 67,39 & 613,34 & 87,64 & 4,10 & 53,95 & 227,34 & 29,66 & 29,66 & 218,34 \\
\hline Pelophylax perezi & 30 SUH 45 & 100,00 & 153,57 & 124,49 & 37,00 & 6930,52 & 350,69 & 18,71 & 331,98 & 82,64 & 247,05 & 247,05 & 69,74 & 587,65 & 83,48 & 4,00 & 53,46 & 215,42 & 28,93 & 28,93 & 206 \\
\hline Pelophylax perezi & 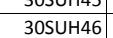 & $\begin{array}{l}100,00 \\
\end{array}$ & $\begin{array}{l}157,91 \\
157,91\end{array}$ & $\begin{array}{l}124,45 \\
124,35\end{array}$ & 37,00 & $\begin{array}{l}0530,1252 \\
6911,92\end{array}$ & 354,04 & $\frac{\mid 0,11}{22,60}$ & \begin{tabular}{|l|l|}
331,45 \\
331,4
\end{tabular} & 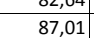 & \begin{tabular}{|l|}
250,81 \\
251
\end{tabular} & \begin{tabular}{|l|}
250,81 \\
251
\end{tabular} & \begin{tabular}{|l|l|}
73,84 \\
\end{tabular} & \begin{tabular}{|l|l|}
555,28 \\
\end{tabular} & $\begin{array}{l}\mid c 5,400 \\
78,31\end{array}$ & $\begin{array}{l}4,00 \\
3,76 \\
\end{array}$ & $\begin{array}{l}35,40 \\
52,91\end{array}$ & \begin{tabular}{|l|}
201,13 \\
20
\end{tabular} & \begin{tabular}{|l|l}
27,90 \\
27
\end{tabular} & $\begin{array}{l}27,90 \\
27,90\end{array}$ & $\begin{array}{l}20,53 \\
193,54\end{array}$ \\
\hline Pelophylax perezi & $30 \mathrm{SUH} 47$ & 100,00 & 156,62 & 124,50 & 37,00 & 6912,72 & 352,90 & 21,42 & 331,48 & 85,87 & 249,65 & 249,65 & 72,71 & 541,91 & 75,45 & 3,73 & 52,08 & 193,57 & 28,44 & 28,44 & 186,43 \\
\hline Pelophylax perezi & 30SUH48 & 100,00 & 158,87 & 124,11 & 37,00 & 6901,36 & 354,40 & 23,56 & 330,84 & 88,28 & 251,73 & 251,73 & 75,01 & 516,26 & 70,91 & 3,53 & 51,42 & 181,79 & 27,87 & 27,87 & 175,64 \\
\hline Pelophylax perezi & $30 \mathrm{SUH} 49$ & 100,00 & 156,20 & 124,03 & 37,00 & 6904,72 & 351,85 & 21,02 & 330,83 & 85,84 & 249,25 & 249,2 & 72, & 508,38 & 68,64 & 3,86 & 50,16 & 176,05 & 29,40 & 29,40 & 170,30 \\
\hline Pelophylax perezi & 30 SUH50 & 100,00 & 175,19 & 119,49 & 37,00 & 6695,72 & 361,25 & 42,80 & 318,44 & 105,48 & 264,70 & 264,70 & 93,00 & 587,42 & 87,73 & 2,28 & 59,74 & 228,21 & 18,78 & 18,78 & 221,46 \\
\hline
\end{tabular}




\begin{tabular}{|c|c|c|c|c|c|c|c|c|c|c|c|c|c|c|c|c|c|c|c|c|c|}
\hline TAXON & UTM & $\mathrm{km2}$ & BIO1 & B102 & $\mathrm{BIO3}$ & B104 & B105 & B106 & B107 & B108 & B109 & BIO10 & BIO11 & $\overline{B 1012}$ & BIO13 & BIO14 & BIO15 & BIO16 & BIO17 & BIO18 & BIO19 \\
\hline Pelophylax perezi & 30SUH52 & 100,00 & 156,27 & 122,73 & 37,00 & 6888,54 & 350,98 & 22,63 & 328,35 & 85,45 & 249,04 & 249,04 & 72,88 & 619,82 & 90,50 & 3,96 & 55,71 & 235,00 & 27,16 & 27,16 & 225,29 \\
\hline Pelophylax perezi & 30SUH53 & 100,00 & 151,46 & 123,55 & 37,00 & 6923,90 & 347,84 & $\begin{array}{l}17,35 \\
\end{array}$ & 330,49 & 80,16 & \begin{tabular}{|l|l}
244,83 \\
\end{tabular} & 244,83 & 67,78 & 620,32 & 89,50 & 4,44 & $\begin{array}{l}54,35 \\
\end{array}$ & 232,18 & 29,65 & 29,65 & 222,21 \\
\hline Pelophylax perezi & 30SUH54 & 100,00 & 150,88 & 123,99 & 37,00 & 6938,76 & 347,95 & 16,38 & 331,58 & 79,54 & \begin{tabular}{ll|l}
244,46 \\
\end{tabular} & 244,46 & $\begin{array}{l}67,07 \\
6\end{array}$ & 605,83 & 86,74 & 4,39 & 53,43 & 224,08 & 30,25 & 30,25 & 214,33 \\
\hline Pelophylax perezi & 30SUH55 & 100,00 & 154,13 & 124,04 & 37,00 & 6932,63 & 350,89 & 19,13 & 331,76 & 83,23 & 247,52 & 247,52 & 70,19 & 577,22 & 82,19 & 4,02 & 53,10 & 211,24 & 28,82 & 28,82 & 202,25 \\
\hline Pelophylax perezi & $\begin{array}{l}30 S U H 56 \\
\end{array}$ & 100,00 & 156,92 & 124,19 & 37,00 & 6927,64 & 353,20 & 21,55 & 331,65 & 85,88 & \begin{tabular}{|l|l|}
250,18 \\
\end{tabular} & 250,18 & 72,80 & 550,41 & 77,53 & 3,89 & 52,44 & \begin{tabular}{|l|l|}
198,71 \\
\end{tabular} & 28,34 & 28,34 & $\begin{array}{ll}190,68 \\
\end{array}$ \\
\hline Pelophylax perezi & \begin{tabular}{|l|}
$30 S U H 57$ \\
\end{tabular} & 100,00 & 151,04 & 124,89 & 37,00 & 6933,85 & 348,32 & 15,91 & 332,42 & 80,23 & 244,52 & 244,52 & 67,21 & 552,66 & 76,26 & 4,34 & \begin{tabular}{l|l}
50,95 \\
\end{tabular} & \begin{tabular}{|l|l|}
195,91 \\
\end{tabular} & 31,15 & 31,15 & 188,14 \\
\hline Pelophylax perezi & \begin{tabular}{|l|}
$30 S U H 58$ \\
\end{tabular} & 100,00 & 155,92 & 124,62 & 37,00 & 6916,51 & 352,13 & 20,50 & 331,63 & 87,59 & 249,11 & 249,11 & 72,13 & 518,13 & 70,77 & 3,93 & 50,58 & \begin{tabular}{|l|l|}
181,39 \\
\end{tabular} & 29,22 & 29,22 & 174,72 \\
\hline Pelophylax perezi & $\begin{array}{l}30 \text { SUH59 } \\
\end{array}$ & 100,00 & 153,77 & 124,58 & 37,00 & 6913,86 & 349,99 & 18,56 & 331,43 & \begin{tabular}{l|l|}
100,63 \\
\end{tabular} & 247,06 & 247,06 & 70,13 & 508,30 & 68,12 & 4,05 & 49,48 & $\begin{array}{l}175,65 \\
\end{array}$ & 30,44 & 30,44 & 168,93 \\
\hline Pelophylax perezi & $\begin{array}{l}30 \mathrm{SUH} 60 \\
\end{array}$ & 100,00 & 176,86 & 117,71 & 36,99 & 6667,53 & 360,79 & 45,29 & 315,51 & $\begin{array}{ll}107,58 \\
\end{array}$ & \begin{tabular}{|l|l|}
266,04 \\
\end{tabular} & 266,04 & 95,12 & 564,16 & 83,75 & 2,28 & 59,33 & 218,60 & 18,40 & 18,40 & 212,14 \\
\hline Pelophylax perezi & 30SUH61 & 100,00 & 168,19 & 119,91 & \begin{tabular}{|l|}
36,98 \\
\end{tabular} & 6799,46 & 357,62 & \begin{tabular}{|l|l}
35,53 \\
\end{tabular} & 322,10 & $\begin{array}{l}98,02 \\
\end{array}$ & 259,55 & 259,55 & 85,31 & 583,79 & 86,68 & 3,14 & 57,68 & 224,48 & 22,09 & 22,09 & 215,60 \\
\hline Pelophylax perezi & \begin{tabular}{|l|l|}
$30 S U H 63$ \\
\end{tabular} & 100,00 & 151,72 & 122,97 & 37,00 & 6927,43 & 347,90 & 18,08 & \begin{tabular}{|l|}
329,83 \\
\end{tabular} & $\begin{array}{l}80,69 \\
\end{array}$ & 245,28 & 245,28 & 68,30 & 609,03 & 88,09 & 4,53 & 53,90 & 227,54 & 29,81 & 29,81 & 216,79 \\
\hline Pelophylax perezi & $\begin{array}{l}30 S U H 64 \\
\end{array}$ & 100,00 & 150,72 & 123,71 & 37,00 & 6944,50 & 347,86 & 16,61 & 331,26 & 79,53 & 244,57 & 244,57 & $\begin{array}{l}67,15 \\
\end{array}$ & 596,67 & $\begin{array}{l}85,45 \\
\end{array}$ & 4,58 & 52,90 & 220,07 & 30,67 & 30,67 & 209,74 \\
\hline Pelophylax perezi & 30SUH65 & 100,00 & 153,88 & 123,98 & 37,00 & 6938,73 & 350,60 & \begin{tabular}{l|l|l|}
19,02 \\
\end{tabular} & 331,58 & 82,97 & 247,51 & 247,51 & \begin{tabular}{|l|l|}
69,97 \\
\end{tabular} & 568,39 & 80,88 & 4,03 & 52,71 & 207,44 & 29,00 & 29,00 & 198,00 \\
\hline Pelophylax perezi & $\begin{array}{l}30 S U H 66 \\
\end{array}$ & 100,00 & 147,75 & 124,62 & 37,00 & 6951,08 & 345,61 & \begin{tabular}{l|l}
13,05 \\
\end{tabular} & 332,56 & 78,56 & 241,74 & 241,74 & 64,00 & 573,10 & 79,68 & 4,80 & 50,88 & \begin{tabular}{ll|}
204,96 \\
\end{tabular} & 32,71 & 32,71 & 195,86 \\
\hline Pelophylax perezi & 30SUH67 & 100,00 & 149,16 & 124,99 & 37,00 & 6940,01 & 346,73 & \begin{tabular}{l|l|l|l|}
13,99 \\
\end{tabular} & 332,74 & 88,94 & \begin{tabular}{|l|l|}
242,86 \\
\end{tabular} & 242,86 & 65,36 & 549,43 & 75,42 & 4,36 & 50,2 & \begin{tabular}{|c|}
194,17 \\
\end{tabular} & \begin{tabular}{l|l|}
32,05 \\
\end{tabular} & \begin{tabular}{l|l|}
32,05 \\
\end{tabular} & 185,56 \\
\hline Pelophylax perezi & \begin{tabular}{|l|}
$30 S U H 68$ \\
\end{tabular} & 100,00 & 153,25 & 124,97 & 37,00 & 6928,40 & 350,03 & \begin{tabular}{|l|l|l|}
17,89 \\
\end{tabular} & 332,15 & 104,50 & \begin{tabular}{|l|l|}
246,76 \\
\end{tabular} & 246,76 & \begin{tabular}{|c|}
69,48 \\
\end{tabular} & 517,11 & 70,02 & 4,09 & \begin{tabular}{|l|l|}
49,73 \\
\end{tabular} & $\begin{array}{ll}180,85 \\
\end{array}$ & \begin{tabular}{|l|}
30,47 \\
\end{tabular} & \begin{tabular}{|l|}
30,47 \\
\end{tabular} & 172,72 \\
\hline Pelophylax perezi & $\begin{array}{l}30 S U H 69 \\
\end{array}$ & 100,00 & 148,55 & 125,02 & 37,00 & 6936,00 & 345,94 & \begin{tabular}{ll|}
13,06 \\
\end{tabular} & 332,88 & \begin{tabular}{|l|l|}
116,64 \\
\end{tabular} & 242,25 & 242,25 & 64,80 & 517,39 & 68,56 & 4,43 & 48,32 & \begin{tabular}{|l|}
179,27 \\
\end{tabular} & 32,96 & 32,96 & 169,88 \\
\hline Pelophylax perezi & 30SUH70 & 100,00 & 177,69 & 116,12 & 36,80 & 6647,14 & 359,74 & 47,10 & 312,63 & 108,78 & 266,65 & 266,65 & 96,31 & 544,59 & 80,35 & 2,31 & 58,69 & 210,57 & 18,35 & 18,35 & 204,07 \\
\hline Pelophylax perezi & $\begin{array}{l}30 S U H 71 \\
\end{array}$ & 100,00 & 173,71 & 117,85 & 36,75 & 6743,01 & 359,66 & 42,01 & 317,65 & \begin{tabular}{|l|l|}
103,97 \\
\end{tabular} & \begin{tabular}{|l|l|}
264,08 \\
\end{tabular} & 264,08 & 91,19 & 550,19 & 81,64 & 2,86 & 57,58 & 211,40 & 20,33 & 20,33 & 203,06 \\
\hline Pelophylax perezi & $\begin{array}{l}30 S U H 73 \\
\end{array}$ & 100,00 & 150,43 & 122,52 & 36,84 & 6938,53 & 346,58 & \begin{tabular}{l|l}
16,95 \\
\end{tabular} & 329,64 & 79,37 & \begin{tabular}{ll|}
244,26 \\
\end{tabular} & 244,26 & 66,9 & $\begin{array}{l}603,05 \\
\end{array}$ & 87,12 & 4,8 & 53, & 224,50 & 30,80 & 30,80 & 213,05 \\
\hline Pelophylax perezi & $\begin{array}{l}30 S U H 74 \\
\end{array}$ & 100,00 & 151,78 & 123,02 & 37,00 & 6941,81 & 348,19 & 17,94 & 330,25 & 80,72 & 245,66 & 245,66 & 68,25 & 582,21 & 83,49 & 4,44 & 52,59 & 214,36 & 30,20 & 30,20 & 203,55 \\
\hline Pelophylax perezi & $\begin{array}{l}30 S U H 75 \\
\end{array}$ & 100,00 & 148,38 & 123,98 & 37,00 & 6945,49 & 345,76 & \begin{tabular}{|l|l|l|}
14,17 \\
\end{tabular} & \begin{tabular}{|l|l|}
331,59 \\
\end{tabular} & 81,12 & 242,28 & 242,28 & 64,94 & $\begin{array}{l}577,95 \\
\end{array}$ & 81,45 & 4,75 & 51,44 & 209,36 & 32,20 & 32,20 & 198,97 \\
\hline Pelophylax perezi & $\begin{array}{l}30 S U H 76 \\
\end{array}$ & 100,00 & 141,94 & 124,88 & 37,00 & 6962,21 & 340,69 & 7,44 & 333,25 & $\begin{array}{l}90,01 \\
\end{array}$ & \begin{tabular}{|l|l|}
236,19 \\
\end{tabular} & 236,19 & 58,53 & 583,66 & 80,33 & 5,47 & \begin{tabular}{|l|l|}
49,59 \\
\end{tabular} & \begin{tabular}{|l|}
208,01 \\
\end{tabular} & 35,86 & 35,86 & $\begin{array}{ll}197,16 \\
\end{array}$ \\
\hline Pelophylax perezi & \begin{tabular}{|l|}
$30 S U H 77$ \\
\end{tabular} & 100,00 & 147,90 & 125,00 & 37,00 & 6946,68 & 345,71 & 12,77 & 332,94 & 101,20 & 241,78 & 241,78 & \begin{tabular}{ll|}
64,02 \\
\end{tabular} & 543,49 & 74,16 & 4,66 & 49,51 & \begin{tabular}{|l|l|}
192,43 \\
\end{tabular} & 32,81 & 32,81 & 181,97 \\
\hline Pelophylax perezi & $\begin{array}{l}30 S U H 78 \\
\end{array}$ & 100,00 & 147,51 & 125,44 & 37,00 & 6943,53 & 345,35 & 11,86 & 333,49 & \begin{tabular}{|l|l|l|l|}
101,89 \\
\end{tabular} & 241,28 & 241,28 & 63,78 & 527,11 & 70,51 & 4,52 & 48,64 & $\begin{array}{ll}184,42 \\
\end{array}$ & 33,20 & 33,20 & 174,00 \\
\hline Pelophylax perezi & \begin{tabular}{|l|}
30 SUH79 \\
\end{tabular} & 100,00 & 146,89 & 125,74 & 37,00 & 6936,43 & 344,63 & 10,99 & 333,64 & 126,48 & 240,77 & 240,77 & 63,22 & \begin{tabular}{|l|l|}
511,78 \\
\end{tabular} & 67,01 & 4,52 & 47,64 & \begin{tabular}{|l|l|}
178,23 \\
\end{tabular} & 33,67 & 33,67 & 166,41 \\
\hline Pelophylax perezi & $\begin{array}{l}30 S U H 80 \\
\end{array}$ & 100,00 & 177,70 & 114,64 & 36,24 & 6641,40 & 358,53 & \begin{tabular}{ll|l}
48,07 \\
\end{tabular} & 310,46 & 108,80 & 266,67 & \begin{tabular}{|l|l|}
266,67 \\
\end{tabular} & 96,51 & 528,09 & 77,71 & 2,45 & 58,08 & \begin{tabular}{l|l|}
203,85 \\
\end{tabular} & 18,58 & 18,58 & \begin{tabular}{ll|l|}
196,87 \\
\end{tabular} \\
\hline Pelophylax perezi & 30SUH81 & 100,00 & 173,46 & 116,62 & 36,23 & \begin{tabular}{|l|l|}
6739,70 \\
\end{tabular} & 358,49 & 42,42 & 316,07 & \begin{tabular}{|l|}
103,77 \\
\end{tabular} & 263,92 & 263,92 & 91,24 & 537,50 & 79,71 & 2,97 & 57,01 & 206,38 & 20,59 & 20,59 & 197,35 \\
\hline Pelophylax perezi & $\begin{array}{l}30 S U H 82 \\
\end{array}$ & 100,00 & 158,93 & 119,88 & 36,38 & 6896,57 & 351,39 & 26,70 & \begin{tabular}{|l|}
324,69 \\
\end{tabular} & 88,28 & 252,11 & 252,11 & 75,77 & 578,24 & 85,17 & 4,16 & \begin{tabular}{l|l|}
54,55 \\
\end{tabular} & 218,97 & 26,85 & 26,85 & 207,22 \\
\hline Pelophylax perezi & \begin{tabular}{|l|l|}
$30 S U H 83$ \\
\end{tabular} & 100,00 & 150,42 & 121,94 & 36,52 & 6952,54 & 346,31 & 17,11 & 329,19 & \begin{tabular}{|c|}
79,19 \\
\end{tabular} & \begin{tabular}{|l|l|}
244,50 \\
\end{tabular} & 244,50 & 66,77 & 593,26 & 85,86 & 4,98 & 52,75 & 220,49 & 31,11 & 31,11 & 208,25 \\
\hline Pelophylax perezi & 30SUH84 & 100,00 & 154,04 & 122,48 & 36,91 & 6943,70 & 349,56 & 20,06 & 329,49 & \begin{tabular}{ll|}
83,92 \\
\end{tabular} & 247,77 & 247,77 & 70,27 & 563,59 & 80,97 & 4,26 & 52,42 & 207,25 & 29,19 & 29,19 & 196,12 \\
\hline Pelophylax perezi & $\begin{array}{l}30 S U H 85 \\
\end{array}$ & 100,00 & 141,49 & 124,08 & 37,00 & 6965,81 & 339,93 & 7,69 & 332,24 & \begin{tabular}{|l|l|}
91,04 \\
\end{tabular} & 235,90 & 235,90 & 58,33 & 591,33 & 82,19 & 5,76 & \begin{tabular}{l|l|}
49,85 \\
\end{tabular} & 213,17 & 36,21 & 36,21 & 200,69 \\
\hline Pelophylax perezi & $\begin{array}{l}30 S U H 86 \\
\end{array}$ & 100,00 & 145,59 & 124,74 & 37,00 & 6964,43 & 343,72 & 10,73 & 332,99 & 98,61 & 239,85 & 239,85 & \begin{tabular}{l|l|l|}
61,92 \\
\end{tabular} & 559,53 & \begin{tabular}{ll|}
77,06 \\
\end{tabular} & 5,04 & \begin{tabular}{ll|}
49,66 \\
\end{tabular} & 200,49 & \begin{tabular}{l|l}
33,95 \\
\end{tabular} & \begin{tabular}{l|l}
33,95 \\
\end{tabular} & 188,22 \\
\hline Pelophylax perezi & 30SUH87 & 100,00 & 146,01 & 125,26 & 37,00 & 6949,86 & 344,13 & \begin{tabular}{|l|l|}
10,88 \\
\end{tabular} & 333,25 & \begin{tabular}{|l|l|}
99,38 \\
\end{tabular} & \begin{tabular}{|l|l|}
240,03 \\
\end{tabular} & 240,03 & 62,22 & 539,66 & 72,92 & 4,84 & 48,75 & 191,20 & 33,88 & 33,88 & 179,09 \\
\hline Pelophylax perezi & \begin{tabular}{|l|}
$30 S U H 88$ \\
\end{tabular} & 100,00 & 144,92 & 125,94 & 37,00 & 6940,05 & 343,28 & 9,27 & 334,01 & \begin{tabular}{|l|l|}
107,70 \\
\end{tabular} & \begin{tabular}{|l|l|}
238,79 \\
\end{tabular} & 238,79 & 61,38 & 525,05 & 69,43 & 4,77 & 47,69 & \begin{tabular}{ll|}
184,06 \\
\end{tabular} & \begin{tabular}{|l|}
34,63 \\
\end{tabular} & 34,63 & 171,40 \\
\hline Pelophylax perezi & \begin{tabular}{|l|}
$30 S U H 89$ \\
\end{tabular} & 100,00 & 148,44 & 126,05 & 37,05 & 6923,10 & 345,99 & 12,38 & 333,61 & 131,37 & \begin{tabular}{|l|l|}
242,10 \\
\end{tabular} & 242,10 & 64,94 & 493,66 & 63,99 & 4,09 & 47,51 & 172,80 & 32,73 & 32,73 & 159,31 \\
\hline Pelophylax perezi & $\begin{array}{l}30 \text { SUH9O } \\
\end{array}$ & 100,00 & 176,26 & 113,60 & 36,00 & 6676,15 & 357,25 & 47,11 & 310,14 & 107,19 & 265,76 & 265,76 & 94,81 & 521,21 & 76,92 & 2,81 & 57,10 & 201,13 & 19,64 & 19,64 & 192,75 \\
\hline Pelophylax perezi & 30SUH91 & 100,00 & 173,91 & 115,37 & 36,04 & 6737,19 & 357,76 & 43,66 & 314,10 & 104,35 & 264,36 & 264,36 & 91,91 & 522,34 & 77,31 & 3,08 & 56,38 & 200,06 & 20,91 & 20,91 & 190,64 \\
\hline Pelophylax perezi & $\begin{array}{l}30 \text { SUH92 } \\
\end{array}$ & 100,00 & \begin{tabular}{|l|l|}
163,76 \\
\end{tabular} & 118,20 & $\begin{array}{l}36,05 \\
\end{array}$ & 6865,54 & 353,73 & 32,17 & 321,56 & \begin{tabular}{|c|}
93,18 \\
\end{tabular} & 256,31 & 256,3 & 80,7 & 550,32 & 81,49 & 3,7 & 54,7 & 208,74 & ti & 4,99 & 196,92 \\
\hline Pelophylax perezi & 30SUH93 & 100,00 & 157,60 & 120,31 & 36,39 & 6920,18 & 350,89 & 25,01 & 325,88 & 91,03 & 251,12 & 251,12 & 74,21 & 557,10 & \begin{tabular}{|l|l|}
81,35 \\
\end{tabular} & 4,24 & 53,21 & 207,95 & 27,88 & 27,88 & 195,62 \\
\hline Pelophylax perezi & 30SUH94 & 100,00 & 155,04 & 121,73 & 36,89 & 6927,27 & 349,65 & 21,51 & 328,14 & \begin{tabular}{|l|}
100,29 \\
\end{tabular} & $248,67 \mid$ & \begin{tabular}{|l|l|}
248,67 \\
\end{tabular} & 71,53 & \begin{tabular}{l|l|}
549,85 \\
\end{tabular} & 78,94 & 4,31 & 52,02 & 202,57 & 29,14 & 29,14 & 190,15 \\
\hline Pelophylax perezi & \begin{tabular}{l|l}
30 SUH95 \\
\end{tabular} & 100,00 & 140,41 & 124,03 & 37,00 & 6966,58 & 338,94 & 6,78 & 332,16 & 92,96 & 235,03 & 235,03 & 57,38 & 584,27 & 80,83 & 5,92 & \begin{tabular}{|l|l}
49,15 \\
\end{tabular} & 211,03 & 37,01 & 37,01 & 196,48 \\
\hline Pelophylax perezi & \begin{tabular}{|l|}
$30 S U H 96$ \\
\end{tabular} & 100,00 & 146,94 & 124,51 & 37,00 & 6950,51 & 344,40 & 12,19 & 332,21 & \begin{tabular}{l|l|}
100,02 \\
\end{tabular} & \begin{tabular}{|l|l|}
240,92 \\
\end{tabular} & 240,92 & 63,40 & 542,94 & 74,48 & 4,81 & 49,26 & $\begin{array}{l}195,16 \\
\end{array}$ & 33,37 & 33,37 & 181,33 \\
\hline Pelophylax perezi & \begin{tabular}{|l|}
$30 S U H 97$ \\
\end{tabular} & 100,00 & 146,86 & 125,39 & 37,00 & 38,87 & 344,56 & 11,62 & 332,94 & 100,52 & 240,75 & 240,75 & \begin{tabular}{|l|l|}
63,27 \\
\end{tabular} & 525,40 & 70,56 & 4,64 & 48,40 & 186,60 & 3,58 & 3,58 & 173,00 \\
\hline Pelophylax perezi & \begin{tabular}{|l|}
30 SUHA \\
\end{tabular} & 100,00 & 147,00 & 125,99 & 37,00 & 6930,67 & 344,96 & 11,24 & 333,72 & 118,62 & 240,77 & 240,77 & 63,63 & 505,15 & 66,19 & 4,32 & 47,51 & $\begin{array}{l}177,79 \\
\end{array}$ & 33,52 & 33,52 & 163,80 \\
\hline Pelophylax perezi & \begin{tabular}{|l|l}
$30 S U H 99$ \\
\end{tabular} & 100,00 & 146,58 & 126,61 & 37,44 & 6909,73 & 344,29 & 10,52 & 333,77 & 129,35 & 239,97 & 239,97 & 63,3 & 489,23 & 62,42 & 4,24 & 46,61 & \begin{tabular}{|l|l|}
171,92 \\
\end{tabular} & 33,88 & 33,88 & 156,11 \\
\hline Pelophylax perezi & 30SUJ00 & 100,00 & 159,71 & 122,47 & 37,00 & 6806,31 & 352,25 & 26,32 & \begin{tabular}{|l|l|}
325,93 \\
\end{tabular} & $\begin{array}{l}85,56 \\
\end{array}$ & \begin{tabular}{|l|l|}
250,84 \\
\end{tabular} & 250,84 & 76,86 & \begin{tabular}{|l|}
505,27 \\
\end{tabular} & 67,58 & 3,79 & \begin{tabular}{ll|l}
50,66 \\
\end{tabular} & \begin{tabular}{|l|l|}
178,87 \\
\end{tabular} & 29,16 & 29,16 & 171,45 \\
\hline Pelophylax perezi & 30SUJ01 & 100,00 & 160,82 & 121,92 & 37,00 & 6783,25 & 352,34 & 27,82 & 324,52 & \begin{tabular}{|l|l|}
89,92 \\
\end{tabular} & 251,71 & 251,71 & 78,15 & 485,01 & 64,20 & 3,49 & 50,32 & \begin{tabular}{|l|l|}
170,88 \\
\end{tabular} & 28,56 & 28,56 & 162,91 \\
\hline Pelophylax perezi & 30 SUJ02 & 100,00 & 159,36 & 121,10 & 37,00 & 6790,35 & 350,59 & 26,64 & 323,95 & \begin{tabular}{|l|}
89,07 \\
\end{tabular} & 250,54 & 250,54 & 76,72 & \begin{tabular}{|l|l|}
476,07 \\
\end{tabular} & 62,28 & 3,92 & 49,00 & $\begin{array}{ll}166,33 \\
\end{array}$ & 29,72 & 29,72 & 157,84 \\
\hline Pelophylax perezi & 305UJ03 & 100,00 & 158,62 & 120,52 & 37,00 & 6769,54 & 348,91 & 26,27 & 322,64 & 99,67 & 249,47 & 249,47 & 76,11 & 465,44 & 60,16 & 3,94 & 48,21 & \begin{tabular}{|l|l|}
161,70 \\
\end{tabular} & 30,25 & 30,25 & 152,66 \\
\hline Pelophylax perezi & 30 SUJ04 & 100,00 & 156,92 & 119,92 & 37,00 & 6755,07 & 346,35 & 25,01 & 321,34 & 102,60 & 247,57 & 247,57 & 74,59 & \begin{tabular}{|l|l}
458,75 \\
\end{tabular} & 58,51 & 4,14 & $\begin{array}{ll}47,32 \\
\end{array}$ & \begin{tabular}{|l|l|}
158,13 \\
\end{tabular} & 31,29 & 31,29 & 148,60 \\
\hline Pelophylax perezi & 30 SUJ05 & 100,00 & 153,83 & 119,08 & 36,97 & 6740,80 & 342,60 & 22,66 & 319,95 & \begin{tabular}{ll|}
96,68 \\
\end{tabular} & 244,34 & 244,34 & 71,93 & 457,30 & 57,37 & 4,52 & $\begin{array}{l}46,15 \\
\end{array}$ & \begin{tabular}{ll|l}
156,56 \\
\end{tabular} & 33,04 & 33,04 & 146,30 \\
\hline Pelophylax perezi & 30SUJ06 & 100,00 & 149,68 & 118,42 & 36,71 & 6729,45 & 337,97 & 19,17 & 318,81 & \begin{tabular}{|l|l|}
90,45 \\
\end{tabular} & 240,28 & 240,28 & 68,12 & 459,66 & 56,62 & 5,14 & 44,90 & \begin{tabular}{|l|}
155,97 \\
\end{tabular} & \begin{tabular}{|l|}
35,53 \\
\end{tabular} & 35,53 & 145,01 \\
\hline Pelophylax perezi & $30 \mathrm{SU}$ & 100,00 & 135 & 117 & 36,7 & 6696 & 323 & 7,2 & & 68, & 226 & 226,28 & 55, & 503,10 & 60,02 & 7,08 & 42, & 168,60 & 43,59 & 43,59 & 156,38 \\
\hline Pelophylax perezi & 30SUJ08 & 100,00 & 137,04 & 116,82 & 36,70 & 6673,35 & 323,89 & 8,81 & 315,09 & 77,53 & 227,21 & 227,23 & 56,81 & 486,26 & 57,10 & 7,11 & 42,11 & 162,30 & 43,28 & 43,30 & 149,61 \\
\hline Pelophylax perezi & \begin{tabular}{|l|l|}
30 UJJ09 \\
\end{tabular} & 100,00 & 145,21 & 116,46 & 36,88 & 6640,38 & 330,17 & 16,56 & 313,60 & 96,42 & 234,72 & 234,72 & 64,74 & 440,33 & 51,25 & 6,19 & 42,26 & 147,34 & \begin{tabular}{|l|}
38,79 \\
\end{tabular} & 38,79 & 134,21 \\
\hline Pelophylax perezi & 30SUJ10 & 100,00 & 160,25 & 122,95 & 37,00 & 6834,18 & 353,38 & 26,25 & 327,13 & \begin{tabular}{|l|l|}
88,09 \\
\end{tabular} & \begin{tabular}{|l|l|}
251,96 \\
\end{tabular} & 251,96 & 76,84 & \begin{tabular}{|l|l|}
497,58 \\
\end{tabular} & 66,73 & 3,46 & 50,66 & \begin{tabular}{ll|}
174,90 \\
\end{tabular} & 28,12 & 28,12 & 168,17 \\
\hline Pelophylax pe & 30SUJ11 & 100,00 & 728 & & 37,00 & 27 & 250 & 23,8 & 326, & \begin{tabular}{ll|}
87,09 \\
\end{tabular} & 248, & 248, & 74,36 & 493,68 & 65,26 & 4,00 & 49,40 & $\begin{array}{ll}171,72 \\
\end{array}$ & 4 & 0,24 & 16 \\
\hline Pelophylax perezi & 30SUI12 & 100,00 & 158,19 & 121,74 & 37,00 & 6812,7 & 350,1 & 25,05 & 325,05 & 103,86 & 249,71 & 249,7 & 75,26 & 474,85 & 61,96 & 3,89 & 48,81 & 164,18 & 29,88 & 29,88 & 156,28 \\
\hline Pelophylax perezi & 30SUJ13 & 100,00 & 156,64 & 121,00 & 37,00 & 6801,50 & 347,80 & 23,78 & 324,02 & 105,67 & 248,01 & 248,01 & 73,92 & 465,89 & 59,87 & 4,12 & \begin{tabular}{|l|l}
47,67 \\
\end{tabular} & 160,01 & 31,00 & 31,00 & 151,35 \\
\hline
\end{tabular}




\begin{tabular}{|c|c|c|c|c|c|c|c|c|c|c|c|c|c|c|c|c|c|c|c|c|c|}
\hline TAXON & UTM & $\mathrm{km} 2$ & B101 & B102 & $\mathrm{BIO3}$ & B104 & B105 & B106 & B107 & B108 & B109 & BIO10 & BIO11 & BIO12 & B1013 & BIO14 & BIO15 & B1016 & B1017 & B1018 & B1019 \\
\hline Pelophylax perezi & 30SUJ14 & 100,00 & 158,51 & 120,24 & 37,00 & 6776,48 & 348,22 & 25,77 & 322,45 & 113,71 & 249,50 & 249,50 & 75,81 & 446,28 & 56,61 & 4,03 & 47,15 & 153,15 & 30,48 & 30,48 & 143,51 \\
\hline Pelophylax perezi & 30SUJ15 & 100,00 & 156,77 & 119,64 & \begin{tabular}{|l|}
36,98 \\
\end{tabular} & 6758,22 & 345,78 & 24,61 & 321,17 & 114,42 & 247,55 & 247,55 & 74,36 & 439,26 & 54,84 & 4,23 & 46,27 & 149,96 & 31,43 & 31,43 & 139,35 \\
\hline Pelophylax perezi & 30SUJ16 & 100,00 & 150,71 & 118,95 & 36,93 & 6750,22 & 339,48 & 19,53 & 319,95 & 112,31 & 241,65 & 241,65 & 68,87 & 447,62 & 54,79 & 4,97 & 44,69 & 150,97 & 34,73 & 34,73 & 139,90 \\
\hline Pelophylax perezi & 30SUJ17 & 100,00 & 144,12 & 118,10 & $\begin{array}{l}36,65 \\
\end{array}$ & 6722,19 & 332,29 & 13,95 & 318,35 & 112,25 & 234,75 & 234,75 & 62,97 & 459,73 & 54,85 & 6,05 & 42,98 & 153,58 & 38,86 & 38,86 & 141,30 \\
\hline Pelophylax perezi & 30SUJ18 & 100,00 & 139,00 & 117,31 & 36,77 & 6694,77 & 326,16 & 9,66 & 316,50 & 112,17 & 229,44 & 229,45 & 58,38 & 467,38 & 54,50 & 6,79 & 41,90 & 155,04 & 41,88 & 41,89 & 141,82 \\
\hline Pelophylax perezi & 30SUJ19 & 100,00 & 148,04 & 116,97 & 36,97 & 6669,21 & 333,37 & 18,23 & 315,14 & 109,39 & 237,87 & 237,87 & 67,00 & 421,03 & 48,61 & 5,94 & 41,92 & 140,41 & 37,41 & 37,41 & 126,60 \\
\hline Pelophylax perezi & 30SUJ20 & 100,00 & 156,96 & 123,03 & 37,00 & 6860,53 & 351,14 & 22,51 & 328,63 & 86,62 & 249,08 & 249,08 & 73,57 & 503,85 & 67,41 & 3,88 & 50,11 & 174,82 & 29,59 & 29,59 & 168,86 \\
\hline Pelophylax perezi & 30SUJ21 & 100,00 & 150,90 & 122,81 & 37,00 & 6860,03 & 345,34 & 17,14 & 328,20 & 83,00 & 243,38 & 243,38 & 67,96 & 511,42 & $\begin{array}{l}67,13 \\
\end{array}$ & 4,54 & 48,50 & 175,59 & 32,87 & 32,87 & 168,88 \\
\hline Pelophylax perezi & 30 SUJ 22 & 100,00 & 154,62 & 122,09 & 37,00 & 6835,34 & 347,53 & 20,91 & 326,62 & 106,33 & 246,51 & 246,51 & 71,58 & 481,43 & 62,50 & 4,12 & 48,03 & 164,49 & 31,29 & 31,29 & 157,19 \\
\hline Pelophylax perezi & 30SUJ23 & 100,00 & 154,21 & 121,51 & 37,00 & \begin{tabular}{ll|}
6828,54 \\
\end{tabular} & 346,38 & 21,01 & 325,37 & 117,96 & 246,11 & 246,11 & 71,29 & 468,02 & 59,81 & 4,23 & 47,12 & 159,10 & 31,90 & 31,90 & 150,66 \\
\hline Pelophylax perezi & 30SUJ24 & 100,00 & 155,18 & 120,80 & 37,00 & 6806,05 & 346,03 & 22,25 & 323,78 & 119,90 & 246,76 & 246,76 & 72,42 & 450,64 & 56,65 & 4,29 & 46,35 & 153,20 & 31,85 & 31,85 & 143,24 \\
\hline Pelophylax perezi & 30SUJ25 & 100,00 & 154,72 & 120,04 & 36,99 & 6787,16 & 344,53 & 21,95 & 322,58 & 120,57 & 246,02 & 246,02 & 72,17 & 439,75 & 54,41 & 4,44 & 45,49 & 148,96 & 32,50 & 32,50 & 138,06 \\
\hline Pelophylax perezi & 30SUJ26 & 100,00 & 152,32 & 119,27 & 36,81 & 6771,48 & 341,38 & 20,07 & 321,31 & 122,77 & 243,51 & 243,51 & 70,08 & 435,45 & 52,76 & 4,90 & 44,36 & 146,68 & 34,10 & 34,10 & 134,77 \\
\hline Pelophylax perezi & 30SUJ27 & 100,00 & 144,30 & 118,69 & 36,73 & 6749,11 & 333,08 & 13,26 & 319,82 & 127,03 & 235,39 & 235,39 & 62,75 & 450,37 & 53,29 & 5,94 & 42,70 & 150,73 & 38,40 & 38,40 & 136,93 \\
\hline Pelophylax perezi & 30SUJ28 & 100,00 & 144,97 & 117,94 & 36,74 & 6718,73 & 332,18 & 14,32 & 317,86 & 127,65 & 235,58 & 235,58 & 63,70 & 436,21 & 50,57 & 6,14 & 41,94 & 145,34 & 38,68 & 38,68 & 130,82 \\
\hline Pelophylax perezi & 30 SUJ29 & 100,00 & 145,47 & 117,08 & 36,76 & 6683,31 & 331,32 & 15,28 & 316,03 & 122,78 & 235,70 & 235,70 & 64,65 & 422,31 & 48,16 & 6,32 & 41,13 & 140,39 & 38,88 & 38,88 & 124,91 \\
\hline Pelophylax perezi & 30SUJ30 & 100,00 & 155,59 & 123,52 & 37,00 & 6887,42 & 350,41 & 20,78 & 329,63 & 88,74 & 248,21 & 248,21 & 71,77 & 501,47 & 66,86 & 4,02 & 49,37 & 172,05 & 30,23 & 30,23 & 166,73 \\
\hline Pelophylax perezi & 30SUJ31 & 100,00 & 150,96 & 123,14 & 37,00 & 6882,02 & 345,94 & 16,56 & 329,38 & 115,15 & 243,83 & 243,83 & 67,74 & 502,99 & 65,85 & 4,31 & 48,20 & 171,38 & 32,64 & 32,64 & 164,81 \\
\hline Pelophylax perezi & 30SUJ32 & 100,00 & 151,82 & 122,74 & 37,00 & \begin{tabular}{ll|l}
6864,87 \\
\end{tabular} & 345,74 & 17,56 & 328,18 & 132,25 & 244,36 & 244,36 & 68,72 & 484,56 & 62,45 & 4,38 & 47,40 & 164,73 & 32,69 & 32,69 & 156,66 \\
\hline Pelophylax perezi & 30SUJ33 & 100,00 & 149,19 & 122,03 & 37,00 & 6854,45 & 342,55 & 15,48 & 327,07 & 131,88 & 241,58 & 241,58 & 66,27 & 479,43 & 60,62 & 4,86 & 46,07 & 162,71 & 34,47 & 34,47 & 152,56 \\
\hline Pelophylax perezi & 30SUJ34 & 100,00 & 148,27 & 121,21 & 37,00 & \begin{tabular}{|l|l|}
6833,84 \\
\end{tabular} & 340,65 & 15,19 & 325,46 & \begin{tabular}{|l|l|}
131,71 \\
\end{tabular} & 240,45 & 240,45 & 65,63 & 468,50 & 58,1 & 5,12 & 45,11 & 158,61 & 35,34 & 35,34 & 147,01 \\
\hline Pelophylax perezi & 30SUJ35 & 100,00 & 152,93 & 120,36 & 37,00 & 6810,05 & 343,39 & 19,86 & 323,53 & 133,26 & 244,65 & 244,65 & 70,08 & 439,24 & 53,72 & 4,65 & $\begin{array}{l}44,76 \\
44,\end{array}$ & 148,41 & 33,46 & 33,46 & 136,42 \\
\hline Pelophylax perezi & 30SUJ36 & 100,00 & 152,20 & 119,78 & 36,92 & 6784,40 & 341,57 & \begin{tabular}{|l|l|}
19,43 \\
\end{tabular} & 322,15 & \begin{tabular}{|l|}
134,07 \\
\end{tabular} & 243,51 & 243,51 & 69,69 & 428,59 & 51,38 & 4,99 & 43,87 & 144,37 & 34,22 & 34,22 & 131,29 \\
\hline Pelophylax perezi & 30SUJ37 & 100,00 & 144,70 & 119,00 & 36,75 & 6775,17 & 333,91 & 12,81 & 321,10 & 128,67 & 236,24 & 236,24 & 62,83 & 441,99 & 51,74 & 5,98 & 42,35 & 148,48 & 38,34 & 38,34 & 132,89 \\
\hline Pelophylax perezi & 30SUJ38 & 100,00 & 131,12 & 117,91 & 36,48 & 6727,14 & 319,99 & 1,57 & 318,42 & 114,04 & 222,45 & 222,45 & 50,72 & 480,95 & 55,18 & 8,10 & 40,09 & 160,68 & 46,89 & 46,89 & 141,54 \\
\hline Pelophylax perezi & 30SUJ39 & 100,00 & 138,86 & 117,22 & 36,46 & 6705,00 & 325,71 & 8,61 & 317,10 & 122,84 & 229,62 & 229,62 & 58,14 & 437,96 & 50,3 & 7,14 & 40,21 & 146,02 & 42,50 & 42,50 & 127,45 \\
\hline Pelophylax perezi & 30 SUJ40 & 100,00 & 152,11 & 124,00 & 37,00 & 6903,59 & 347,91 & $\begin{array}{ll}17,13 \\
\end{array}$ & 330,78 & $\begin{array}{l}115,87 \\
112,8\end{array}$ & \begin{tabular}{|l|}
245,17 \\
\end{tabular} & \begin{tabular}{|l|}
245,17 \\
\end{tabular} & 68,48 & 506,47 & $\begin{array}{l}0,03 \\
67,03\end{array}$ & 4,21 & $\begin{array}{l}\mid 48,74 \\
48,\end{array}$ & \begin{tabular}{|l|}
173,362 \\
\end{tabular} & 31,73 & 31,73 & 166,86 \\
\hline Pelophylax perezi & 30SUJ41 & 100,00 & 150,18 & 123,80 & 37,00 & 6888,35 & 345,62 & 15,44 & 330,18 & 133,39 & 243,10 & 243,10 & 66,82 & 497,24 & 64,62 & 4,46 & 47,59 & 170,07 & 32,98 & 32,98 & 161,42 \\
\hline Pelophylax perezi & 30 SUJ 42 & 100,00 & 146,07 & 123,11 & 37,00 & 6891,55 & 341,34 & 11,74 & 329,60 & 129,14 & 239,19 & 239,19 & 62,95 & 497,35 & 63,27 & 5,08 & 46,15 & 169,92 & 35,59 & 35,59 & 158,83 \\
\hline Pelophylax perezi & 30SUJ43 & 100,00 & 145,44 & 122,64 & 37,00 & 6874,67 & 339,72 & 11,30 & 328,42 & 128,48 & 238,21 & 238,21 & 62,43 & 485,61 & 60,68 & 5,23 & 45,29 & 165,68 & 36,31 & 36,31 & 152,99 \\
\hline Pelophylax perezi & 30SUJ44 & 100,00 & 150,27 & 121,69 & 37,00 & 6850,13 & 342,60 & 16,21 & 326,39 & 133,96 & 242,56 & 242,56 & 67,19 & 455,08 & 56,06 & 4,84 & 45,04 & $\begin{array}{ll}154,78 \\
\end{array}$ & 34,32 & 34,32 & 141,87 \\
\hline Pelophylax perezi & 30SUJ45 & 100,00 & 150,62 & 120,88 & 36,99 & 6831,53 & 341,75 & $\begin{array}{l}17,01 \\
17\end{array}$ & 324,75 & $\begin{array}{l}134,62 \\
1340\end{array}$ & \begin{tabular}{|l|}
242,70 \\
\end{tabular} & \begin{tabular}{|l|}
242,70 \\
\end{tabular} & 67,85 & \begin{tabular}{|l|}
440,17 \\
40,0
\end{tabular} & 53,18 & $\begin{array}{l}4,4049 \\
4,99\end{array}$ & \begin{tabular}{|l|}
44,07 \\
440
\end{tabular} & \begin{tabular}{|l|}
149,37 \\
\end{tabular} & 34,59 & $\begin{array}{l}34,525 \\
34,59\end{array}$ & 135,15 \\
\hline Pelophylax perezi & 30SUJ46 & 100,00 & 149,38 & 120,01 & 36,91 & 6803,76 & 339,39 & 16,32 & 323,06 & 133,49 & 241,15 & 241,15 & 66,78 & 431,73 & 51,15 & 5,34 & 43,24 & 146,16 & 35,74 & 35,74 & $\begin{array}{ll}130,47 \\
\end{array}$ \\
\hline Pelophylax perezi & 30SUJ47 & 100,00 & 139,20 & 119,04 & \begin{tabular}{|c|}
36,58 \\
\end{tabular} & 6777,43 & 328,92 & 7,78 & 321,14 & 122,71 & 231,06 & 231,06 & 57,63 & 456,81 & 52,81 & 6,85 & 41,34 & 153,92 & 41,97 & 41,97 & 135,41 \\
\hline Pelophylax perezi & 30SUJ48 & 100,00 & 128,70 & 118,21 & 36,60 & 6735,84 & 318,01 & $-0,92$ & 318,93 & 111,44 & 220,25 & 220,25 & 48,31 & 482,80 & 55,92 & 8,52 & 39,42 & 161,99 & 48,59 & 48,59 & 140,19 \\
\hline Pelophylax perezi & $\begin{array}{l}305 U J 49 \\
\end{array}$ & 100,00 & 140,21 & 117,42 & 36,08 & 6738,94 & 327,38 & 9,10 & 318,27 & 124,44 & 231,39 & 231,39 & 58,99 & 427,31 & 49,60 & 6,98 & 39,94 & 142,94 & 41,89 & 41,89 & 123,03 \\
\hline Pelophylax perezi & \begin{tabular}{|l|l}
$305 U J 50$ \\
3050
\end{tabular} & 100,00 & $\frac{14,21}{148,90}$ & 1124,47 & 37,00 & $\begin{array}{l}6915,7,34 \\
6917,\end{array}$ & 345,44 & \begin{tabular}{|c|}
, 100 \\
13,79 \\
\end{tabular} & \begin{tabular}{|l|}
331,64 \\
331
\end{tabular} & $\begin{array}{l}128,63 \\
\end{array}$ & | 242,25 & \begin{tabular}{|l|}
242,25 \\
242
\end{tabular} & | & | 509,58 & $\begin{array}{l}56,80 \\
66,83\end{array}$ & $\begin{array}{l}0,300 \\
4,47\end{array}$ & \begin{tabular}{|l|l|}
47,94 \\
47
\end{tabular} & \begin{tabular}{|l|}
$174,4,40$ \\
\end{tabular} & $\begin{array}{l}41,09 \\
33,10\end{array}$ & $\begin{array}{l}4,305 \\
33,10\end{array}$ & $\begin{array}{l}12,0639 \\
166,39\end{array}$ \\
\hline Pelophylax perezi & 30SUJ51 & 100,00 & 150,69 & 124,01 & 37,00 & 6903,21 & 346,19 & 15,61 & 330,58 & 133,95 & 243,75 & 243,75 & 67,07 & 486,99 & 62,77 & 4,30 & 47,21 & 167,55 & 32,59 & 32,59 & 156,91 \\
\hline Pelophylax perezi & 30SUJ52 & 100,00 & 147,69 & 123,67 & 37,00 & 6888,11 & 342,84 & 12,90 & 329,94 & 130,79 & 240,73 & 240,73 & 64,54 & 482,92 & 60,95 & 4,93 & 45,89 & 165,87 & 34,88 & 34,88 & 153,01 \\
\hline Pelophylax perezi & 30SUJ53 & 100,00 & 149,64 & 122,92 & 37,00 & 6866,68 & 343,38 & 14,90 & 328,48 & 133,16 & 242,41 & 242,41 & 66,54 & 462,56 & 57,40 & 4,74 & 45,35 & 158,46 & 34,27 & 34,27 & 144,74 \\
\hline Pelophylax perezi & 30SUJ54 & 100,00 & 147,92 & 122,07 & 37,00 & 6864,75 & 340,99 & 13,44 & 327,55 & 131,67 & 240,57 & 240,57 & 64,81 & 455,88 & 55,47 & 5,07 & 44,39 & 155,87 & 35,52 & 35,52 & 140,57 \\
\hline Pelophylax perezi & 30 SUJ55 & 100,00 & 146,73 & 121,31 & 37,00 & 6863,51 & 338,99 & 12,70 & 326,29 & 130,64 & 239,38 & 239,38 & 63,78 & 446,39 & 53,20 & 5,3 & 43,38 & 152,17 & 36,42 & 36,42 & 135,53 \\
\hline Pelophylax perezi & 30SUJ56 & 100,00 & 144,03 & 120,42 & 36,71 & 6835,28 & 335,41 & 10,61 & 324,80 & 127,69 & 236,51 & 236,51 & 61,60 & 443,45 & 51,75 & 5,95 & 42,22 & 150,82 & 38,71 & 38,71 & 132,20 \\
\hline Pelophylax perezi & 30SUJ57 & 100,00 & 132,87 & 119,36 & 36,71 & \begin{tabular}{ll|}
6787,24 \\
\end{tabular} & 323,47 & $\begin{array}{ll}1,64 \\
\end{array}$ & 321,84 & 115,81 & 224,95 & 224,97 & 51,61 & 473,97 & 54,74 & 7,79 & 40,19 & 160,11 & 46,02 & 46,03 & 138,46 \\
\hline Pelophylax perezi & 30SUJ58 & 100,00 & 131,10 & 118,38 & 36,48 & 6761,15 & 320,51 & 0,67 & 319,85 & 114,06 & 222,93 & 222,93 & 50,26 & 467,69 & 54,6 & 8,2 & 39,29 & 157,42 & 47,50 & 47,50 & 134,38 \\
\hline Pelophylax perezi & 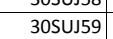 & 100,00 & 139,33 & $\begin{array}{l}117,40 \\
117,47\end{array}$ & 36,402 & 6758,71 & 326, & 7,85 & $\begin{array}{l}318,96 \\
\end{array}$ & 123,33 & 230,97 & 230,97 & 57,93 & $\begin{array}{l}426,18 \\
426,\end{array}$ & $\begin{array}{l}4,90,96 \\
\end{array}$ & $\frac{1,2}{7,1}$ & 39,41 & 142,91 & 42,85 & 42,85 & 121,35 \\
\hline Pelophylax perezi & 30SUJ61 & 100,00 & 147,49 & 124,72 & 37,00 & 6918,40 & 343,85 & 11,91 & 331,94 & 130,79 & 240,96 & 240,96 & 63,70 & 489,01 & 62,27 & 4,6 & 46,51 & 169,13 & 34,19 & 34,19 & 155,95 \\
\hline Pelophylax perezi & $\begin{array}{l}30 \mathrm{~s} U \mathrm{~J} 62 \\
\end{array}$ & 100,00 & 149,63 & 123,97 & 37,00 & 6899,46 & 344,74 & 14,23 & 330,51 & 133,09 & 242,72 & 242,72 & 66,02 & 467,27 & 58,39 & 4,57 & 45,74 & 161,13 & 33,77 & 33,77 & 147,07 \\
\hline Pelophylax perezi & 30SUJ63 & 100,00 & 145,25 & 123,52 & 37,00 & 6890,92 & 340,28 & 10,49 & 329,79 & 128,27 & 238,45 & 238,45 & 62,09 & 469,25 & 57,34 & 5,25 & 44,38 & 161,49 & 36,57 & 36,57 & 145,12 \\
\hline Pelophylax perezi & 30SUJ64 & 100,00 & 145,08 & 122,74 & 37,00 & 6870,34 & 338,94 & 10,49 & 328,45 & 128,49 & 238,01 & 238,01 & 62,12 & 457,61 & 54 & 5,32 & 43,57 & 157,08 & 37,04 & 37,04 & 139,56 \\
\hline Pelophylax perezi & \begin{tabular}{|l}
3050064 \\
30505
\end{tabular} & 100,00 & $\begin{array}{l}14,00 \\
141,45\end{array}$ & 12 & 36,99 & $\begin{array}{l}600,353,46 \\
6863,4\end{array}$ & 334 & $\begin{array}{l}0,45 \\
7,48 \\
\end{array}$ & \begin{tabular}{|l|}
$327,4,16$ \\
\end{tabular} & $\begin{array}{l}124,84 \\
124,8\end{array}$ & \begin{tabular}{|l|}
234,37 \\
234
\end{tabular} & \begin{tabular}{|l|}
234,37 \\
234
\end{tabular} & $\begin{array}{l}02,124 \\
58,69\end{array}$ & \begin{tabular}{|l}
$\mid$ \\
$459,14,14$
\end{tabular} & 53,75 & $\begin{array}{l}3,256 \\
5,96\end{array}$ & $\begin{array}{l}42,35 \\
42,35\end{array}$ & \begin{tabular}{|l|}
157,07 \\
15
\end{tabular} & 39,61 & $\begin{array}{l}31,, 44 \\
39,61\end{array}$ & 137,65 \\
\hline Pelophylax perezi & 30SUJ66 & 100,00 & 138,87 & 120,82 & 36,84 & 6853,41 & 330,98 & 5,46 & 325,52 & 122,02 & 231,64 & 231,64 & 56,39 & 456,53 & 52,59 & 6,61 & 41,24 & 155,54 & 41,78 & 41,78 & 134,68 \\
\hline Pelophylax perezi & 30SUJ67 & 100,00 & 133,27 & 119,57 & 36,55 & 6810,94 & 324,28 & 1,23 & 323,05 & 116,30 & 225,70 & 225,72 & 51,75 & 467,28 & 54,22 & 7,76 & 39,82 & $\mid$\begin{tabular}{|l|l|}
158,18 \\
\end{tabular} & 45,99 & 46,01 & 135,44 \\
\hline Pelophylax perezi & 30 SUJ68 & 100,00 & 127,92 & 118,44 & 36,46 & 6771,95 & 317,75 & $-2,49$ & 320,25 & 110,53 & 220,03 & 220,03 & 47,24 & 475,21 & 56,03 & 8,85 & 38,49 & 160,12 & 49,94 & 49,94 & 135,27 \\
\hline Pelophylax perezi & 30 SUJ69 & 100,00 & 138,46 & 117,39 & 36,06 & 6776,79 & 326,03 & 6,79 & 319,24 & 122,33 & 230,29 & 230,29 & 56,83 & 426,07 & 50,24 & 7,51 & 38,77 & 142,88 & 43,81 & 43,81 & $12 C$ \\
\hline Pelophylax perezi & 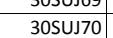 & $\begin{array}{l}100,00 \\
\end{array}$ & $\begin{array}{l}150,40 \\
149,86\end{array}$ & 125,35 & 30,0 & 6926,91 & 346,50 & \begin{tabular}{|c|}
0,13 \\
13,57 \\
\end{tabular} & \begin{tabular}{|l|}
132,249 \\
332,92
\end{tabular} & \begin{tabular}{|l|}
133,03 \\
133,03
\end{tabular} & \begin{tabular}{|l|}
243,32 \\
243
\end{tabular} & \begin{tabular}{|l|}
243,32 \\
243
\end{tabular} & $\begin{array}{l}0,03 \\
66,07 \\
\end{array}$ & \begin{tabular}{|l|l|}
485,27 \\
45
\end{tabular} & $\frac{\mid 0,24}{62,41}$ & $\begin{array}{l}4,01 \\
4,04 \\
\end{array}$ & $\begin{array}{ll}0,117 \\
47,35\end{array}$ & \begin{tabular}{|l|}
$14 L 8,93$ \\
168
\end{tabular} & $\begin{array}{l}43,01 \\
32,20\end{array}$ & $\begin{array}{l}43,20 \\
32,20\end{array}$ & $\begin{array}{l}121,20 \\
156,07\end{array}$ \\
\hline Pelophylax perezi & 30SUJ71 & 100,00 & 150,08 & 125,08 & 37,00 & 6909,14 & 346,05 & 13,92 & 332,12 & 133,77 & 243,34 & 243,34 & 66,37 & 469,68 & 59,18 & 4,21 & 46,36 & 163,15 & 32,79 & 32,79 & 148,78 \\
\hline Pelophylax perezi & 30SUJ72 & 100,00 & 144,93 & 124.86 & 37,00 & 6910.35 & 341,01 & 9.19 & 331.82 & 128.45 & 238,29 & 238.29 & 61.42 & 474.52 & 58.32 & 4.97 & 44.83 & 164.41 & $36,07 \mid$ & 36,07 & 147.54 \\
\hline Pelophylax perezi & 30SUJ73 & 100,00 & 140,36 & 124,17 & 37,00 & 6901,19 & 336,28 & 5,26 & $331, \mathrm{C}$ & 123,41 & 233, & 233 & 57 & 478,84 & 57,47 & 5,66 & 43,40 & 165 & 39,18 & 39,18 & 146,33 \\
\hline Pelophylax perezi & 30SUJ74 & 100,00 & 143,51 & 123,26 & 37,00 & 6884,85 & 337,84 & 8,47 & 329,36 & 126,77 & 236,64 & 236,64 & 60,49 & 455,14 & 53,60 & 5,38 & 42,92 & 156,66 & 37,91 & 37,91 & 137,36 \\
\hline
\end{tabular}




\begin{tabular}{|c|c|c|c|c|c|c|c|c|c|c|c|c|c|c|c|c|c|c|c|c|c|}
\hline TAXON & UTM & $\mathrm{km} 2$ & B101 & B102 & $\mathrm{BIO3}$ & B104 & B105 & B106 & B107 & B108 & 8109 & B1010 & BIO11 & BIO12 & B1013 & BIO14 & BIO15 & B1016 & B1017 & BIO18 & B1019 \\
\hline Pelophylax perezi & 30SUJ75 & 100,00 & 140,25 & 122,33 & 37,00 & 6876,04 & 333,81 & 5,96 & 327,85 & 123,67 & 233,36 & 233,36 & 57,40 & 456,66 & 52,75 & 6,19 & 41,78 & 156,56 & 40,66 & 40,66 & 135,52 \\
\hline Pelophylax perezi & 30SUJ76 & 100,00 & 131,62 & 121,11 & 36,99 & 6845,36 & 324,71 & $-0,64$ & 325,36 & 114,22 & 224,64 & 224,64 & 49,95 & 478,72 & 55,45 & 7,72 & 40,05 & 163,20 & 46,50 & 46,50 & 139,57 \\
\hline Pelophylax perezi & 30SUJ77 & 100,00 & 129,08 & 119,84 & 36,69 & 6811,62 & 320,59 & $-2,58$ & 323,17 & 111,64 & 221,71 & 221,73 & 47,82 & 479,38 & 56,10 & 8,50 & 38,99 & 162,42 & 49,09 & 49,11 & 137,63 \\
\hline Pelophylax perezi & 30SUJ78 & 100,00 & 129,47 & 118,53 & 36,27 & 6797,85 & 319,50 & $-1,77$ & 321,27 & 112,44 & 221,84 & 221,86 & 48,38 & 467,19 & 55,19 & 8,76 & 38,21 & 157,42 & 49,51 & 49,52 & 132,25 \\
\hline Pelophylax perezi & 30SUJ79 & 100,00 & 140,64 & 117,26 & 36,00 & 6813,01 & 328,23 & 8,23 & 319,99 & \begin{tabular}{|l|l|}
124,71 \\
\end{tabular} & 232,97 & 232,97 & 58,34 & 417,31 & 49,25 & 7,44 & 38,68 & 139,88 & 43,10 & 43,10 & 117,30 \\
\hline Pelophylax perezi & 30SUJ80 & 100,00 & 146,51 & 126,21 & 37,15 & 6912,49 & 343,98 & 10,46 & 333,52 & 129,46 & 240,11 & 240,11 & 63,38 & 484,96 & 61,28 & 4,30 & 46,40 & 169,49 & 34,09 & 34,09 & 153,91 \\
\hline Pelophylax perezi & 30SUJ81 & 100,00 & 146,86 & 125,88 & 37,04 & 6901,70 & 343,59 & 10,77 & 332,83 & \begin{tabular}{|l|l|}
130,04 \\
\end{tabular} & 240,18 & 240,18 & 63,61 & 470,88 & 58,30 & 4,47 & 45,48 & 164,25 & 34,40 & 34,40 & 147,42 \\
\hline Pelophylax perezi & $\begin{array}{l}30 \mathrm{SU} J 82 \\
\end{array}$ & 100,00 & 142,16 & 125,58 & 37,00 & 6902,37 & 338,97 & 6,55 & 332,42 & 125,21 & 235,64 & 235,64 & 59,16 & 475,08 & 57,40 & 5,16 & 44,01 & 165,12 & 37,56 & 37,56 & 146,14 \\
\hline Pelophylax perezi & 30SUJ84 & 100,00 & 147,10 & 123,58 & 37,00 & 6891,58 & 341,06 & 11,29 & 329,77 & 130,97 & 240,20 & 240,20 & 63,63 & 435,05 & 50,60 & 5,04 & 43,12 & 150,06 & 36,03 & 36,03 & 130,50 \\
\hline Pelophylax perezi & 30SUJ85 & 100,00 & 139,86 & 122,68 & 37,00 & 6883,90 & 333,48 & 5,15 & 328,33 & 123,22 & 233,10 & 233,10 & 57,01 & 452,03 & 52,22 & 6,18 & 41,36 & 154,99 & 41,14 & 41,14 & 133,15 \\
\hline Pelophylax perezi & 30SUJ86 & 100,00 & 139,18 & 121,51 & 37,00 & 6872,99 & 331,72 & 5,03 & 326,69 & 122,69 & 232,32 & 232,32 & 56,42 & 445,18 & 51,66 & 6,55 & 40,38 & 151,85 & 42,23 & 42,23 & 129,33 \\
\hline Pelophylax perezi & 30SUJ87 & 100,00 & 128,53 & 120,22 & 36,90 & 6825,34 & 320,44 & $-3,11$ & 323,55 & 111,06 & 221,42 & 221,42 & 47,25 & 476,95 & 56,08 & 8,54 & 38,63 & 161,68 & 49,58 & 49,58 & 136,07 \\
\hline Pelophylax perezi & 30SUJ88 & 100,00 & 137,01 & 118,73 & 36,06 & 6843,51 & 326,82 & 3,88 & 322,94 & 120,65 & 229,86 & 229,86 & 54,64 & 436,48 & 51,38 & 7,67 & 38,58 & 147,06 & 45,13 & 45,13 & 123,42 \\
\hline Pelophylax perezi & 30SUJ89 & 100,00 & 141,21 & 117,18 & 36,00 & 6841,64 & 328,87 & 8,27 & 320,60 & 125,26 & 233,80 & 233,80 & 58,44 & 415,03 & 48,84 & 7,40 & 38,23 & 138,75 & 43,40 & 43,40 & 116,36 \\
\hline Pelophylax perezi & 30SUJ90 & 100,00 & 147,43 & 126,93 & 37,81 & 6900,37 & 344,48 & 11,01 & 333,48 & 130,56 & 240,56 & 240,56 & 64,01 & 470,35 & 58,48 & 4,19 & 45,79 & 164,89 & 33,69 & 33,69 & 147,89 \\
\hline Pelophylax perezi & 30SUJ91 & 100,00 & 147,66 & 126,60 & 37,53 & 6892,61 & 344,21 & 11,08 & 333,13 & 131,09 & 240,71 & 240,71 & 64,23 & 455,62 & 55,28 & 4,29 & 45,06 & 159,29 & 33,96 & 33,96 & 141,21 \\
\hline Pelophylax perezi & 30SUJ92 & 100,00 & 146,89 & 126,23 & 37,28 & 6888,05 & 342,90 & 10,26 & 332,64 & 130,50 & 239,83 & 239,83 & 63,38 & 447,19 & 53,12 & 4,36 & 44,15 & 155,79 & 34,83 & 34,83 & 136,70 \\
\hline Pelophylax perezi & 30SUJ93 & 100,00 & 145,83 & 125,46 & 37,05 & 6882,95 & 341,08 & 9,45 & 331,63 & $\begin{array}{ll}129,68 \\
\end{array}$ & 238,78 & 238,78 & 62,57 & 441,07 & 51,63 & 4,78 & 43,28 & 153,05 & 36,04 & 36,04 & 132,92 \\
\hline Pelophylax perezi & 30SUJ94 & 100,00 & 144,67 & 124,35 & 37,00 & \begin{tabular}{ll|}
6881,74 \\
\end{tabular} & 339,03 & 8,86 & 330,17 & 128,28 & 237,71 & 237,71 & 61,62 & 436,28 & 50,80 & 5,20 & 42,51 & 150,51 & 37,62 & 37,62 & 129,38 \\
\hline Pelophylax perezi & 30SUJ95 & 100,00 & 136,17 & 123,12 & 37,00 & 6876,93 & 330,38 & 1,78 & 328,60 & 119,18 & 229,47 & 229,47 & 53,59 & 460,05 & 53,51 & 6,70 & 40,60 & 157,81 & 43,56 & 43,56 & 134,31 \\
\hline Pelophylax perezi & 30SUJ96 & 100,00 & 140,58 & 121,71 & 36,98 & \begin{tabular}{|l|l|}
6881,84 \\
\end{tabular} & 332,97 & 5,60 & 327,37 & 124,21 & 233,66 & 233,66 & 57,52 & 435,73 & 50,77 & 6,36 & 40,32 & 148,64 & 41,68 & 41,68 & 125,90 \\
\hline Pelophylax perezi & 30SUJ97 & 100,00 & 132,15 & 120,44 & 36,84 & 6851,92 & 324,03 & $-0,53$ & 324,56 & 115,20 & 225,31 & 225,31 & 50,23 & 460,33 & 54,11 & 8,08 & 38,49 & 155,84 & 47,81 & 47,81 & 130,91 \\
\hline Pelophylax perezi & 30SUJ98 & 100,00 & 131,73 & 118,86 & \begin{tabular}{|l|}
36,18 \\
\end{tabular} & $\begin{array}{ll}6842,66 \\
\end{array}$ & 322,13 & $-0,47$ & 322,60 & \begin{tabular}{|l|l|}
114,83 \\
\end{tabular} & 224,72 & 224,73 & 49,97 & $\begin{array}{l}454,45 \\
\end{array}$ & 53,69 & 8,53 & 37,87 & 152,77 & 48,75 & 48,75 & 127,88 \\
\hline Pelophylax perezi & 30SUJ99 & 100,00 & 137,42 & 117,29 & 36,00 & 6853,44 & 325,79 & 4,68 & 321,11 & 121,32 & 230,47 & 230,47 & 54,88 & 427,42 & 50,38 & 8,04 & 37,70 & 142,60 & 46,05 & 46,05 & 119,32 \\
\hline Pelophylax perezi & 30SUKOO & 100,00 & 154,22 & 116,00 & 36,98 & 6606,87 & 336,84 & 25,18 & 311,66 & 111,86 & 242,90 & 242,90 & 73,32 & 397,89 & 46,22 & 5,18 & 42,40 & 134,44 & 34,42 & 34,42 & 120,55 \\
\hline Pelophylax perezi & 30SUKO1 & 100,00 & 154,70 & 115,56 & 37,00 & 6570,73 & 335,95 & 26,02 & 309,94 & 112,48 & 242,89 & 242,89 & 74,18 & 386,27 & 44,60 & 5,27 & 41,76 & 130,38 & 34,47 & 34,47 & 115,88 \\
\hline Pelophylax perezi & 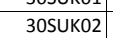 & 100,00 & 157,32 & 115,00 & 37,00 & 6535,01 & 336,74 & 28,77 & $\begin{array}{l}307,97 \\
\end{array}$ & 115,01 & \begin{tabular}{|l|}
244,70 \\
\end{tabular} & \begin{tabular}{|l|}
244,70 \\
\end{tabular} & 76,95 & 368,51 & 42,81 & 5,00 & 41,51 & 125,01 & 33,47 & 33,47 & 109,88 \\
\hline Pelophylax perezi & 30SUK10 & 100,00 & 155,03 & 116,19 & 36,88 & 6631,04 & 337,90 & 25,12 & 312,77 & 112,80 & 243,99 & 243,99 & 73,90 & 387,96 & 44,67 & 5,10 & 41,97 & 130,74 & 33,97 & 33,97 & 116,10 \\
\hline Pelophylax perezi & 30SUK11 & 100,00 & 154,99 & 115,95 & 37,00 & 6596,19 & 336,55 & 25,81 & 310,74 & 112,56 & 243,61 & 243,61 & 74,08 & 378,55 & 43,34 & 5,32 & 41,05 & 127,47 & 34,37 & 34,37 & 111,92 \\
\hline Pelophylax perezi & 30SUK12 & 100,00 & 155,81 & 115,07 & 37,00 & 6556,55 & 335,75 & 26,94 & 308,82 & 113,23 & 243,57 & 243,57 & 75,22 & 366,27 & 42,02 & 5,35 & 40,46 & 123,19 & 34,38 & 34,38 & 107,31 \\
\hline Pelophylax perezi & 30 SUK20 & 100,00 & 152,34 & 116,41 & 36,72 & 6656,78 & 335,88 & 21,83 & 314,05 & 112,85 & 241,70 & 241,70 & 71,10 & 389,60 & 44,33 & 5,61 & 41,33 & 130,12 & 35,49 & 35,49 & 114,67 \\
\hline Pelophylax perezi & 30SUK21 & 100,00 & 154,40 & 115,95 & 36,93 & 6627,13 & 336,39 & $\begin{array}{l}24,47 \\
24,\end{array}$ & 311,92 & $\begin{array}{l}11,, 71 \\
111\end{array}$ & 243,48 & 243,48 & 73,37 & 373,45 & $\begin{array}{l}44,32 \\
42,32\end{array}$ & 5,56 & \begin{tabular}{|l|l|}
40,64 \\
40
\end{tabular} & 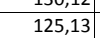 & $\begin{array}{l}30,445 \\
34,54 \\
\end{array}$ & $\begin{array}{l}34,54 \\
34,54\end{array}$ & 109,02 \\
\hline Pelophylax perezi & 30 SUK22 & 100,00 & 153,51 & 115,03 & 36,75 & 6590,10 & 334,04 & 24,14 & 309,90 & 110,88 & 241,71 & 241,71 & 72,60 & 366,62 & 41,84 & 6,00 & 40,20 & 122,49 & 35,40 & 35,40 & 105,70 \\
\hline Pelophylax perezi & 30SUK30 & 100,00 & 150,69 & 116,42 & 36,44 & 6677,44 & 334,52 & 19,78 & 314,74 & 120,12 & 240,44 & 240,44 & 69,27 & 389,56 & 44,33 & 5,99 & 40,58 & 129,62 & $3,6,67 \mid$ & 36,67 & 113,05 \\
\hline Pelophylax perezi & 30SUK31 & 100,00 & 154,50 & 115,69 & 36,49 & 6643,90 & 336,36 & 23,79 & 312,57 & 113,64 & 243,60 & 243,60 & 73,10 & 368,84 & 41,88 & 5,61 & 40,27 & 123,02 & 35,06 & 35,06 & 106,35 \\
\hline Pelophylax perezi & 30SUK32 & 100,00 & 151,96 & 115,00 & 36,26 & 6621,24 & 332,95 & 22,09 & 310,85 & 111,36 & 240,81 & 240,81 & 70,95 & 366,31 & 42,20 & 6,19 & 39,38 & $\begin{array}{ll}121,68 \\
\end{array}$ & 36,48 & 36,48 & 104,07 \\
\hline Pelophylax perezi & $\begin{array}{l}30 \mathrm{SUK} 40 \\
\end{array}$ & 100,00 & 146,53 & 1116,44 & 30,23 & 60206,19 & 331,25 & $\begin{array}{l}2,35 \\
15,48 \\
\end{array}$ & $\begin{array}{l}315,77 \\
315,0\end{array}$ & $\begin{array}{l}11,1,90 \\
129,94\end{array}$ & \begin{tabular}{|l|}
236,95 \\
236
\end{tabular} & \begin{tabular}{|l|}
236,95 \\
236,95
\end{tabular} & $\begin{array}{l}0,030 \\
65,07\end{array}$ & | & $\begin{array}{ll}46,01 \\
46,0\end{array}$ & $\begin{array}{ll}0,151 \\
6,48\end{array}$ & $\begin{array}{l}3,30 \\
39,79 \\
\end{array}$ & \begin{tabular}{|l|}
131,860 \\
13
\end{tabular} & $\begin{array}{l}30,400 \\
39,04\end{array}$ & $\begin{array}{l}0,40 \\
39,04\end{array}$ & 113,41 \\
\hline Pelophylax perezi & 30SUK41 & 100,00 & 148,86 & 115,56 & 36,17 & 6671,69 & 331,60 & 18,05 & 313,56 & 126,31 & 238,56 & 238,56 & 67,48 & 380,72 & 44,31 & 6,51 & 39,38 & 125,79 & 38,29 & 38,29 & 107,69 \\
\hline Pelophylax perezi & 30SUK42 & 100,00 & 153,17 & 114,75 & 36,09 & 6644,08 & 333,95 & 22,73 & 311,21 & 112,53 & 242,41 & 242,41 & 71,86 & 359,77 & 41,62 & 6,11 & 39,30 & 119,29 & 36,19 & 36,19 & 101,33 \\
\hline Pelophylax perezi & 30SUK50 & 100,00 & 146,51 & 116,31 & 36,01 & 6737,53 & 331,38 & 14,77 & 316,62 & 131,71 & 237,39 & 237,39 & 64,44 & 394,60 & 45,99 & 6,64 & 39,18 & 131,05 & 39,60 & 39,60 & 111,67 \\
\hline Pelophylax perezi & $\begin{array}{l}30 \text { SUK51 } \\
\end{array}$ & 100,00 & 149,50 & 115,26 & 36,00 & 6702,48 & 332,43 & 18,28 & 314,14 & 128,10 & 239,76 & 239,76 & 67,73 & 376,64 & 43,5 & 6, & 38,94 & 124,28 & 38,22 & 38,22 & 105,82 \\
\hline Pelophylax perezi & 30 SUK52 & 100,00 & 152,38 & 114,18 & 36,00 & 6671,95 & 333,40 & 21,64 & 311,76 & $\begin{array}{l}112,48 \\
\end{array}$ & 242,03 & 242,03 & 70,64 & 359,69 & 4 & 6,3 & 38,75 & \begin{tabular}{|l|}
119,06 \\
11,06
\end{tabular} & $\begin{array}{l}30,26 \\
36,95 \\
\end{array}$ & 36,95 & 100,44 \\
\hline Pelophylax perezi & 30SUK60 & 100,00 & 145,95 & 116,11 & 36,00 & 6769,99 & 331,10 & 13,71 & 317,39 & 130,61 & 237,25 & 237,25 & 63,46 & 394,45 & 46,21 & 6,86 & 38,87 & 131,01 & 40,37 & 40,37 & 110,80 \\
\hline Pelophylax perezi & 30SUK61 & 100,00 & 151,96 & 114,77 & 36,00 & 6730,75 & 334,60 & 20,13 & 314,47 & 125,33 & 242,56 & 242,56 & 69,63 & 368,95 & 42,88 & 6,08 & 39,14 & 121,83 & 37,05 & 37,05 & 103,62 \\
\hline Pelophylax perezi & 30SUK70 & 100,00 & 146,87 & 115,74 & 36,00 & \begin{tabular}{ll|l}
6797,84 \\
\end{tabular} & 332,01 & 14,21 & 317,80 & 131,20 & 238,62 & 238,62 & 64,13 & 390,90 & 45,72 & 6,90 & 38,59 & 129,60 & 40,41 & 40,41 & 109,35 \\
\hline Pelophylax perezi & 30 SUK80 & 100,00 & 149,30 & 115,40 & 35,95 & 6835,18 & 334,28 & $\begin{array}{l}4,1219 \\
16,19\end{array}$ & 318,09 & 128,56 & 241,51 & \begin{tabular}{|l|}
241,51 \\
\end{tabular} & 65,95 & 384,66 & $\begin{array}{ll}43,1 / 25 \\
44,56\end{array}$ & 6 , & 38,52 & 127,14 & $\begin{array}{l}40,41 \\
39,66 \\
\end{array}$ & 39,66 & 107,63 \\
\hline Pelophylax perezi & 30 SUK90 & 100,00 & 143,16 & 115,31 & 35,81 & 6860,69 & 329,16 & 10,21 & 318,95 & 127,38 & 235,93 & 235,93 & 60,10 & 404,49 & 47,19 & $7, \varepsilon$ & 37,34 & 133,31 & 43,97 & 43,97 & 112,35 \\
\hline Pelophylax perezi & 30SUK91 & 100,00 & 150,90 & 113,42 & 35,24 & 6847,36 & 334,12 & 17,96 & 316,15 & 119,18 & 243,29 & 243,29 & 67,14 & 377,12 & 43,17 & 7,22 & 37,55 & 123,31 & 40,33 & 40,33 & 105,06 \\
\hline Pelophylax perezi & 30SUK92 & 100,00 & 148,53 & 112,13 & 35,00 & 6827,01 & 330,25 & 16,51 & 313,74 & 108,64 & 240,51 & 240,51 & 65,15 & 379,70 & 43,46 & 7,86 & 36,69 & \begin{tabular}{l|l|}
123,68 \\
\end{tabular} & 42,23 & 42,23 & 104,96 \\
\hline Pelophylax perezi & 30SVF06 & 32,00 & 182,14 & 88,44 & 38,00 & 4926,03 & 305,81 & 75,25 & 230,56 & 131,58 & 246,78 & 248,14 & 122,78 & 418,61 & 67,00 & 2,00 & 64,61 & 190,67 & 14,67 & 18,11 & 176,56 \\
\hline Pelophylax perezi & \begin{tabular}{|l|}
30 SVF07 \\
\end{tabular} & $\begin{array}{l}2,200 \\
100,00\end{array}$ & $\begin{array}{l}10,14 \\
167,91\end{array}$ & $\begin{array}{l}00,44 \\
97,84\end{array}$ & 38,12 & 5325,12 & 307,01 & $\begin{array}{l}54,626 \\
54,66\end{array}$ & \begin{tabular}{|l|}
252,93 \\
\end{tabular} & $\begin{array}{ll}13,50 \\
112,35\end{array}$ & $\begin{array}{l}238,92 \\
238,92\end{array}$ & \begin{tabular}{|l|}
239,17 \\
234
\end{tabular} & \begin{tabular}{|l|l|}
103,99 \\
120
\end{tabular} & \begin{tabular}{|l|}
410,01 \\
454,88
\end{tabular} & $\begin{array}{l}10,73 \\
70\end{array}$ & 2,98 & 64,86 & \begin{tabular}{|l|}
201,03 \\
\end{tabular} & $\begin{array}{l}14,910 \\
17,95\end{array}$ & $\begin{array}{l}\frac{10,11}{19,37} \\
\end{array}$ & 186,34 \\
\hline Pelophylax perezi & 30SVF08 & 100,00 & 133,56 & 113,95 & 38,03 & 6023,94 & 304,68 & 10,38 & 294,30 & 71,01 & 215,36 & 215,38 & 62,47 & 616,68 & 84,16 & 7,03 & 55,93 & 246,27 & 32,40 & 32,95 & 237,63 \\
\hline Pelophylax perezi & 30SVF09 & 100,00 & 136,99 & 115,65 & 38,00 & 6143,62 & 311,83 & 11,90 & 299,92 & $\begin{array}{l}1,1,0 \\
72,73\end{array}$ & 220,46 & 220,46 & $\mid 64,20$ & 596,54 & $\begin{array}{l}4,100 \\
80,01\end{array}$ & 6,42 & 55,62 & \begin{tabular}{|l|}
238,08 \\
\end{tabular} & $\begin{array}{l}29,9495 \\
29\end{array}$ & 29,95 & 229,69 \\
\hline Pelophylax perezi & 30 SVF16 & & & & & & & & & & & & & & & & & & & & \\
\hline Pelophylax perezi & 30SVF17 & 100,00 & 159,46 & 103,53 & 38,19 & 5540,32 & 309,17 & 42,39 & 266,78 & 101,41 & 233,86 & 233 & 93, & 458,48 & 67,69 & 3,80 & 59,34 & 196,04 & 19,99 & 20,58 & 183,33 \\
\hline Pelophylax perezi & $\begin{array}{l}\text { 30SVF18 } \\
30 \text { SF }\end{array}$ & $\begin{array}{l}100,00 \\
\end{array}$ & $\begin{array}{l}13,40 \\
126,82\end{array}$ & 117,46 & 38,02 & $\begin{array}{ll}344,25 \\
6171,08\end{array}$ & 304,79 & $\begin{array}{r}1,30 \\
1,30 \\
\end{array}$ & \begin{tabular}{|l|}
303,49 \\
300
\end{tabular} & $\begin{array}{r}|r|, 4,14 \\
63,14\end{array}$ & \begin{tabular}{|l|}
210,80 \\
\end{tabular} & \begin{tabular}{|l|}
210,83 \\
210
\end{tabular} & $\begin{array}{l}54,17 \\
54,17\end{array}$ & $\begin{array}{l}500,40 \\
631,64\end{array}$ & \begin{tabular}{|l|}
82,95 \\
82,95
\end{tabular} & $\begin{array}{l}3,000 \\
7,90\end{array}$ & $\begin{array}{l}53,44 \\
53,93\end{array}$ & \begin{tabular}{|l|}
245,10 \\
240
\end{tabular} & $\begin{array}{l}35,22 \\
5,2\end{array}$ & $\begin{array}{l}0,00 \\
35,73\end{array}$ & $\begin{array}{l}20,030 \\
239,22\end{array}$ \\
\hline Pelophylax perezi & 30SVF19 & 100,00 & 139,25 & 116,15 & 38,00 & 6168,30 & 314,74 & \begin{tabular}{ll|}
13,34 \\
\end{tabular} & 301,40 & 74,45 & 223,03 & 223,03 & 65,97 & 561,14 & 75,10 & 6,36 & 54,89 & 222,64 & 28,74 & 28,74 & 214,12 \\
\hline Pelophylax perezi & 30SVF26 & & & & & & & & & & & & & & & & & & & & \\
\hline Pelophylax perezi & 30SVF27 & 100,00 & 14 & 30 & 38,16 & 70,76 & 6,13 & 19,53 & 31 & 0,52 & 0,65 & 220,71 & 71, & 34,35 & 72,65 & 6,17 & 55,57 & 213,17 & 28,24 & 29,07 & 205 , \\
\hline Pelophylax perezi & 30 SVF28 & 100,00 & 132,77 & 117,33 & 38,04 & 6163,82 & 309,87 & 6,88 & 302,99 & 69,12 & 216,59 & 216,59 & 59,94 & 577,46 & 76,14 & 7,13 & 53,57 & 224,27 & 31,52 & 31,52 & 218 \\
\hline
\end{tabular}




\begin{tabular}{|c|c|c|c|c|c|c|c|c|c|c|c|c|c|c|c|c|c|c|c|c|c|}
\hline TAXON & UTM & $\mathrm{km2}$ & BIO1 & B102 & $\mathrm{BIO3}$ & B104 & B105 & B106 & B107 & B108 & B109 & BIO10 & BIO11 & B1012 & BIO13 & BIO14 & BIO15 & BIO16 & B1017 & B1018 & BlO19 \\
\hline Pelophylax perezi & 30SVF29 & 100,00 & 135,92 & 117,76 & 38,00 & 6238,52 & 314,48 & 9,06 & 305,41 & 70,73 & 220,70 & 220,70 & 62,00 & 564,20 & 74,42 & 6,97 & 53,54 & 218,67 & 30,59 & 30,59 & 211,99 \\
\hline Pelophylax perezi & 30SVF36 & 46,00 & 174,84 & 94,82 & 38,02 & 5184,26 & 309,11 & 63,31 & 245,80 & \begin{tabular}{l|l}
120,82 \\
\end{tabular} & 243,44 & 244,08 & \begin{tabular}{ll|}
112,26 \\
\end{tabular} & 362,41 & 53,00 & 2,33 & $\begin{array}{ll}60,03 \\
\end{array}$ & \begin{tabular}{|l|}
157,21 \\
\end{tabular} & 14,16 & \begin{tabular}{ll|}
17,56 \\
\end{tabular} & 146,72 \\
\hline Pelophylax perezi & 30SVF37 & 100,00 & 154,58 & 107,92 & 38,13 & 5726,31 & 312,32 & 34,15 & 278,18 & 94,73 & 231,64 & 231,68 & 86,07 & 441,92 & 61,35 & 4,36 & 56,31 & \begin{tabular}{|l|}
180,91 \\
\end{tabular} & 21,02 & 21,48 & 171,45 \\
\hline Pelophylax perezi & $305 V F 38$ & 100,00 & 127,31 & 118,64 & 38,00 & 6235,23 & 307,54 & \begin{tabular}{l|l}
0,59 \\
\end{tabular} & 306,95 & 63,47 & 212,11 & 212,11 & 53,92 & 596,31 & 77,20 & 8,08 & \begin{tabular}{l|l|}
52,06 \\
\end{tabular} & 225,13 & 35,01 & 35,01 & 221,38 \\
\hline Pelophylax perezi & 30SVF46 & 39,00 & 176,27 & 94,16 & 38,00 & 5177,69 & 309,59 & 64,71 & 244,88 & 122,35 & \begin{tabular}{|l|l|}
244,45 \\
\end{tabular} & 245,33 & 113,53 & 341,96 & 49,25 & 2,31 & 59,10 & \begin{tabular}{|l|l|}
146,37 \\
\end{tabular} & \begin{tabular}{|l|l|}
13,47 \\
\end{tabular} & \begin{tabular}{|l|l|}
17,37 \\
\end{tabular} & 137,31 \\
\hline Pelophylax perezi & 30SVF47 & 100,00 & 159,54 & 105,76 & 38,09 & 5649,02 & 313,34 & 40,31 & 273,04 & 100,56 & 235,24 & 235,39 & 91,74 & 405,70 & 56,34 & 3,81 & 56,20 & $\begin{array}{l}165,65 \\
\end{array}$ & 18,68 & 20,10 & 157,14 \\
\hline Pelophylax perezi & 30SVF48 & 100,00 & 144,43 & 115,47 & 38,02 & 6075,72 & 316,82 & 18,45 & 298,38 & 81,20 & 226,66 & 226,66 & \begin{tabular}{|l|l|}
72,07 \\
\end{tabular} & 482,90 & 65,27 & 5,73 & 53,36 & $\begin{array}{l}187,41 \\
\end{array}$ & 25,48 & 25,48 & 181,11 \\
\hline Pelophylax perezi & 30SVF49 & 100,00 & 144,52 & 117,92 & 38,00 & 6222,36 & 322,06 & 16,38 & 305,67 & $\begin{array}{ll}79,48 \\
\end{array}$ & \begin{tabular}{|l|l|}
228,90 \\
\end{tabular} & 228,90 & 70,24 & \begin{tabular}{ll|}
488,69 \\
\end{tabular} & 66,22 & 5,89 & 52,86 & \begin{tabular}{ll|}
187,38 \\
\end{tabular} & 25,87 & \begin{tabular}{|l|l|}
25,87 \\
\end{tabular} & 181,41 \\
\hline Pelophylax perezi & 30SVF56 & 72,00 & 177,14 & 92,92 & \begin{tabular}{|l|l|}
37,97 \\
\end{tabular} & 5138,75 & 308,87 & \begin{tabular}{ll|}
66,64 \\
\end{tabular} & 242,23 & \begin{tabular}{l|l|}
124,12 \\
\end{tabular} & 244,73 & 245,98 & \begin{tabular}{l|l|l|}
115,02 \\
\end{tabular} & 323,99 & \begin{tabular}{ll|}
46,75 \\
\end{tabular} & 2,07 & 58,29 & $\begin{array}{l}137,38 \\
\end{array}$ & 12,52 & 17,56 & 129,49 \\
\hline Pelophylax perezi & 30SVF57 & 100,00 & 159,37 & 105,05 & $38,01[$ & 5647,74 & 312,63 & 40,51 & 272,12 & 100,78 & 234,96 & $235,27[$ & $\begin{array}{l}91,68 \\
\end{array}$ & 398,57 & 54,91 & 3,90 & 55,24 & 159,44 & 19,14 & 22,90 & 152,46 \\
\hline Pelophylax perezi & 30 SVF58 & 100,00 & 151,65 & 111,24 & 38,00 & 5928,96 & 316,66 & 28,35 & 288,31 & \begin{tabular}{ll|}
89,96 \\
\end{tabular} & \begin{tabular}{|l|l|}
231,53 \\
\end{tabular} & 231,60 & \begin{tabular}{l|l|l|}
80,85 \\
\end{tabular} & 437,84 & 59,44 & 5,03 & 53,48 & \begin{tabular}{|l|l|}
169,94 \\
\end{tabular} & 22,82 & 24,13 & 163,64 \\
\hline Pelophylax perezi & 30 SVF59 & 100,00 & 104,01 & 121,17 & 37,92 & 6446,90 & 292,30 & $-23,95$ & 316,25 & 45,38 & \begin{tabular}{|l|l|}
192,09 \\
\end{tabular} & \begin{tabular}{l|l}
192,42 \\
\end{tabular} & 29,21 & 717,51 & 89,99 & 14,93 & 46,53 & 256,12 & \begin{tabular}{|l|l|}
59,06 \\
\end{tabular} & 62,18 & 247,05 \\
\hline Pelophylax perezi & 30SVF66 & & & & & & & & & & & & & & & & & & & & \\
\hline Pelophylax perezi & 30SVF67 & 100,00 & 138,51 & 113,04 & 38,00 & 6002,14 & \begin{tabular}{|l|l|}
307,75 \\
\end{tabular} & \begin{tabular}{l|l}
14,95 \\
\end{tabular} & 292,80 & 77,56 & 219,50 & 220,01 & 67,56 & $\begin{array}{l}494,65 \\
\end{array}$ & 64,81 & 6,81 & 51,52 & \begin{tabular}{|l|l|}
184,87 \\
\end{tabular} & \begin{tabular}{l|l}
29,65 \\
\end{tabular} & 36,48 & 181,19 \\
\hline Pelophylax perezi & 30SVF68 & 100,00 & 145,95 & 111,88 & 38,00 & 5986,90 & 313,21 & 22,53 & \begin{tabular}{|l|l|}
290,68 \\
\end{tabular} & 85,22 & 226,68 & \begin{tabular}{|l|l|}
226,92 \\
\end{tabular} & 74,84 & 459,45 & \begin{tabular}{ll|}
61,02 \\
\end{tabular} & 5,88 & 51,92 & \begin{tabular}{l|l}
172,95 \\
\end{tabular} & \begin{tabular}{|l|l|}
26,35 \\
\end{tabular} & \begin{tabular}{|l|l|}
31,35 \\
\end{tabular} & 168,28 \\
\hline Pelophylax perezi & 30 SVF69 & 100,00 & 72,97 & 122,82 & 37,61 & 6587,29 & 267,50 & $-54,97$ & 322,48 & 21,67 & 163,66 & 164,27 & $-2,03$ & 900,79 & \begin{tabular}{|l|l|}
109,13 \\
\end{tabular} & 25,20 & 41,06 & 314,29 & \begin{tabular}{|l|l}
93,63 \\
\end{tabular} & 97,06 & 292,93 \\
\hline Pelophylax perezi & 30SVF76 & & & & & & & & & & & & & & & & & & & & \\
\hline Pelophylax perezi & 30SVF77 & 100,00 & 141,47 & 111,78 & 38,00 & 5970,81 & 308,71 & 18,41 & 290,30 & 80,95 | & 221,84 & 222,72 & 70,96 & 465,72 & 60,90 & 6,16 & 51,14 & \begin{tabular}{|l|l|}
172,79 \\
\end{tabular} & 27,34 & \begin{tabular}{|l|}
35,47 \\
\end{tabular} & 169,90 \\
\hline Pelophylax perezi & 30SVF78 & 100,00 & 137,54 & 114,66 & 38,00 & 6125,11 & 310,65 & 12,40 & 298,25 & 77,14 & 220,24 & 220,87 & \begin{tabular}{l|l}
65,25 \\
\end{tabular} & 491,79 & \begin{tabular}{l|l}
63,45 \\
\end{tabular} & 7,00 & 50,06 & $\begin{array}{l}179,05 \\
\end{array}$ & \begin{tabular}{|l|}
30,47 \\
\end{tabular} & 38,11 & 176,57 \\
\hline Pelophylax perezi & 30SVF79 & 100,00 & 84,24 & 121,90 & \begin{tabular}{l|l|}
37,75 \\
\end{tabular} & 6536,23 & 276,12 & $-43,49$ & 319,61 & 33,94 & 173,84 & 174,68 & 9,40 & 816,99 & 99,13 & 21,72 & 41,68 & 285,37 & 81,84 & 86,32 & 266,44 \\
\hline Pelophylax perezi & 30 SVF 86 & 30,00 & 171,17 & 93,81 & 37,69 & 5251,89 & 306,11 & \begin{tabular}{l|l}
59,75 \\
\end{tabular} & 246,36 & 117,72 & 240,14 & 242,11 & \begin{tabular}{|l|l|}
107,92 \\
\end{tabular} & \begin{tabular}{|l|l|}
311,67 \\
\end{tabular} & 43,47 & 2,33 & 55,06 & 124,75 & 13,64 & 19,44 & 119,36 \\
\hline Pelophylax perezi & 30SVF87 & 100,00 & 148,05 & 107,66 & \begin{tabular}{l|l|}
37,99 \\
\end{tabular} & 5823,31 & 308,04 & 27,55 & \begin{tabular}{|l|l|l|}
280,49 \\
\end{tabular} & 89,11 & \begin{tabular}{|l|l|}
226,04 \\
\end{tabular} & 227,34 & 79,09 & 421,66 & 55,24 & 5,26 & 51,20 & \begin{tabular}{ll|l}
156,62 \\
\end{tabular} & \begin{tabular}{|l|l|}
24,17 \\
\end{tabular} & 31,90 & 153,55 \\
\hline Pelophylax perezi & 30SVF88 & 100,00 & 136,35 & 113,95 & 37,99 & 6115,76 & 308,71 & 11,71 & 297,00 & \begin{tabular}{ll|}
75,72 \\
\end{tabular} & \begin{tabular}{|l|l|}
218,92 \\
\end{tabular} & \begin{tabular}{|l|l|}
219,85 \\
\end{tabular} & \begin{tabular}{|l|l|l|}
64,42 \\
\end{tabular} & 487,39 & 61,85 & 7,22 & \begin{tabular}{|l|l|l|}
49,04 \\
\end{tabular} & \begin{tabular}{|l|}
174,61 \\
\end{tabular} & 31,39 & 39,77 & 172,74 \\
\hline Pelophylax perezi & 30SVF89 & 100,00 & 112,96 & 118,39 & \begin{tabular}{|l|l|}
37,97 \\
\end{tabular} & 6356,66 & 295,94 & $-13,57$ & 309,51 & $\begin{array}{ll}60,76 \\
\end{array}$ & \begin{tabular}{|l|l|}
199,37 \\
\end{tabular} & 200,30 & 39,15 & \begin{tabular}{ll|}
628,47 \\
\end{tabular} & 77,78 & 13,18 & $\begin{array}{ll}45,06 \\
\end{array}$ & 221,29 & 52,71 & \begin{tabular}{l|l}
59,65 \\
\end{tabular} & 211,40 \\
\hline Pelophylax perezi & 30SVF96 & 31,00 & 172,63 & 91,29 & 37,20 & 5181,34 & 304,29 & 62,76 & 241,54 & 120,05 & 240,20 & 242,66 & \begin{tabular}{l|l|l|}
110,12 \\
\end{tabular} & 296,85 & 41,29 & 2,17 & 54,78 & \begin{tabular}{|l|l|}
117,63 \\
\end{tabular} & \begin{tabular}{l|l}
13,05 \\
\end{tabular} & 18,63 & 112,80 \\
\hline Pelophylax perezi & $305 V F 97$ & 100,00 & 157,29 & 101,36 & 37,74 & 5594,42 & 306,41 & 40,82 & 265,58 & 100,68 & 231,47 & 233,33 & 90,53 & 366,20 & 48,44 & 3,94 & 51,79 & \begin{tabular}{|l|l|}
137,63 \\
\end{tabular} & 19,61 & 26,57 & 134,02 \\
\hline Pelophylax perezi & 30SVF98 & 100,00 & 154,21 & 104,91 & 37,83 & 5767,85 & 309,91 & 35,00 & 274,91 & $\begin{array}{l}95,56 \\
\end{array}$ & \begin{tabular}{|l|l|}
231,09 \\
\end{tabular} & 232,62 & 85,49 & 383,14 & 50,11 & 4,41 & \begin{tabular}{|l|l|}
50,69 \\
\end{tabular} & $\begin{array}{l}141,25 \\
\end{array}$ & 21,40 & 28,81 & 138,01 \\
\hline Pelophylax perezi & 30SVF99 & 100,00 & 137,76 & 111,74 & 37,86 & 6080,67 & \begin{tabular}{|l|l|}
307,06 \\
\end{tabular} & 14,40 & 292,67 & 82,08 & 219,58 & \begin{tabular}{|l|l|}
220,73 \\
\end{tabular} & \begin{tabular}{|c|}
66,13 \\
\end{tabular} & 477,34 & 60,49 & 7,68 & 47,77 & 169,92 & 33,42 & 40,98 & 164,84 \\
\hline Pelophylax perezi & 30 SVG00 & 100,00 & 140,34 & 115,24 & 37,99 & 6202,73 & 315,66 & 15,01 & 300,65 & 74,86 & 224,61 & 224,61 & \begin{tabular}{|c|}
66,69 \\
\end{tabular} & 582,23 & 79,01 & 6,38 & 55,46 & 231,74 & 29,46 & 29,46 & 222,61 \\
\hline Pelophylax perezi & 30SVG01 & 100,00 & 158,93 & 109,21 & 37,43 & 6048,53 & 323,79 & 36,26 & 287,53 & 93,18 & \begin{tabular}{|l|l|}
240,85 \\
\end{tabular} & \begin{tabular}{l|l|}
240,85 \\
\end{tabular} & \begin{tabular}{|l|l|}
86,47 \\
\end{tabular} & 493,41 & 72,84 & 4,53 & 57,51 & 204,53 & 22,43 & 22,43 & 190,89 \\
\hline Pelophylax perezi & 30SVG02 & 100,00 & 150,38 & 113,64 & \begin{tabular}{l|l|}
37,05 \\
\end{tabular} & 6307,82 & 325,61 & 24,74 & 300,86 & 82,49 & 236,10 & 236,10 & $\begin{array}{ll}75,05 \\
\end{array}$ & 546,70 & 74,73 & 5,65 & 55,64 & 217,00 & 26,42 & 26,42 & 207,91 \\
\hline Pelophylax perezi & 30SVG03 & 100,00 & 144,25 & 116,31 & 37,00 & 6493,53 & \begin{tabular}{|l|l|}
326,55 \\
\end{tabular} & 16,71 & 309,84 & 75,08 & 232,55 & 232,55 & \begin{tabular}{l|l}
66,95 \\
\end{tabular} & 591,22 & 77,10 & 6,41 & 54,50 & 226,69 & 29,73 & 29,73 & 221,93 \\
\hline Pelophylax perezi & 30SVG04 & 100,00 & 153,14 & 113,90 & 36,66 & 6516,42 & 333,25 & 26,35 & 306,90 & 83,34 & 241,63 & 241,63 & 75,37 & 567,18 & 73,69 & 5,63 & 55,34 & 216,96 & 26,66 & 26,66 & 213,60 \\
\hline Pelophylax perezi & 30SVG05 & 100,00 & 160,37 & 111,84 & 36,06 & 6553,34 & \begin{tabular}{|l|l|}
339,08 \\
\end{tabular} & 34,10 & 304,97 & 92,30 & 249,14 & 249,14 & 81,81 & 554,87 & 74,29 & 4,92 & 55,97 & 212,51 & $\begin{array}{l}24,45 \\
\end{array}$ & 24,45 & 209,51 \\
\hline Pelophylax perezi & 30SVG06 & 100,00 & 159,20 & 112,65 & 36,05 & 6647,09 & 340,97 & 32,25 & 308,72 & 91,17 & 249,27 & 249,27 & 79,61 & 574,35 & 80,27 & 5,09 & 55,89 & \begin{tabular}{|l|l|}
221,47 \\
\end{tabular} & 25,64 & 25,64 & 215,16 \\
\hline Pelophylax perezi & 30SVG07 & 100,00 & 168,36 & 110,49 & 35,88 & 6646,22 & 347,64 & 41,99 & 305,65 & 100,01 & 258,01 & 258,01 & 88,29 & 551,40 & 79,78 & 4,04 & 57,01 & 215,75 & 22,23 & 22,23 & 207,42 \\
\hline Pelophylax perezi & 30SVG08 & 100,00 & 171,91 & 110,63 & 35,73 & 6666,36 & 351,30 & 45,10 & 306,20 & 103,21 & 261,64 & 261,64 & 91,40 & 539,60 & 79,57 & 3,61 & 57,24 & 211,39 & 21,10 & 21,10 & 201,90 \\
\hline Pelophylax perezi & 30SVG09 & 100,00 & 173,32 & 111,54 & 35,91 & 6694,79 & 353,79 & 45,67 & \begin{tabular}{|l|}
308,12 \\
\end{tabular} & 104,30 & 263,36 & 263,36 & 92,20 & 530,16 & 78,97 & 3,19 & \begin{tabular}{|l|l|}
56,99 \\
\end{tabular} & 206,95 & 20,62 & 20,62 & 196,72 \\
\hline Pelophylax perezi & 30SVG10 & 100,00 & 146,56 & 97 & 37,99 & 81,29 &, 53 & 20,79 & 299,74 & 80,53 & 230,58 & 230,5 & 72,9 & 519,77 & 71,88 & 5,83 & 55,21 & 208,73 & 6,13 & 6,13 & 197,66 \\
\hline Pelophylax perezi & 30SVG11 & 100,00 & 156,80 & 111,43 & 37,70 & 6116,14 & \begin{tabular}{|l|}
325,09 \\
\end{tabular} & 32,39 & 292,70 & 89,82 & 239,79 & 239,79 & 83,49 & 465,79 & 69,00 & 4,91 & 56,07 & 191,06 & 22,99 & 22,99 & 176,59 \\
\hline Pelophylax perezi & 30SVG12 & 100,00 & 149,03 & \begin{tabular}{ll|}
114,67 \\
\end{tabular} & 37,13 & 6337,57 & 325,89 & 22,51 & 303,38 & \begin{tabular}{ll|}
80,62 \\
\end{tabular} & \begin{tabular}{|l|l|}
235,18 \\
\end{tabular} & 235,18 & 73,41 & 525,07 & 72,16 & 5,99 & 54,51 & 205,95 & 27,16 & 27,16 & 196,40 \\
\hline Pelophylax perezi & 30SVG13 & 100,00 & 138,03 & 118,49 & 37,01 & 6573,18 & 324,53 & 9,28 & 315,26 & 68,87 & 227,57 & 227,57 & 60,05 & $\begin{array}{ll}604,05 \\
\end{array}$ & 78,08 & 7,40 & 53,03 & 225,93 & 32,95 & 32,95 & 222,81 \\
\hline Pelophylax perezi & 30SVG14 & 100,00 & 143,62 & 117,40 & 36,89 & 6630,32 & 330,15 & 14,90 & 315,25 & 75,28 & 233,90 & 233,90 & \begin{tabular}{|l|l|l|l|}
64,83 & \\
\end{tabular} & \begin{tabular}{l|l|}
589,65 \\
\end{tabular} & 77,39 & 6,85 & \begin{tabular}{|l|l|}
53,37 \\
\end{tabular} & 220,12 & 31,00 & 31,00 & 217,41 \\
\hline Pelophylax perezi & 30SVG15 & 100,00 & 153,21 & 114,31 & 36,15 & 588,71 & 337,18 & 25,51 & 311,67 & 85,32 & 243,65 & 243,65 & 73,77 & 567,08 & 76,80 & 5,90 & 54,41 & 214,94 & 27,50 & 27,50 & 210,31 \\
\hline Pelophylax perezi & 30SVG16 & 100,00 & 156,32 & 1. & 35,89 & 6725,89 & 340,77 & 29,01 & 311,77 & 87,56 & \begin{tabular}{|l|l|}
247,53 \\
\end{tabular} & 247,53 & \begin{tabular}{|l|l|}
75,98 \\
\end{tabular} & 573,85 & 81,39 & 5,70 & 54,92 & 221,15 & 27,11 & 27,11 & 212,48 \\
\hline Pelophylax perezi & 30SVG17 & 100,00 & 157 & 112,85 & 35,48 & 6784,96 & 343,38 & 30,41 & 312,97 & 88,40 & 249,78 & 249,78 & 76,8 & 581,42 & 85,36 & 5,54 & 55,32 & 226,36 & 27,17 & 27,17 & 214,31 \\
\hline Pelophylax perezi & 30SVG18 & 100,00 & 169,51 & 109,81 & 35,04 & 6741,25 & 350,59 & 43,18 & 307,41 & \begin{tabular}{|l|l|l|l|l|}
100,09 \\
\end{tabular} & \begin{tabular}{l|l|}
260,53 \\
\end{tabular} & 260,53 & 88,44 & 545,42 & 82,57 & 4,19 & $\begin{array}{ll}56,62 \\
\end{array}$ & \begin{tabular}{l|l}
215,55 \\
\end{tabular} & 22,63 & 22,63 & 202,51 \\
\hline Pelophylax perezi & 30 SVG20 & 100,00 & 145,69 & 116,98 & 38,00 & 6252,42 & 322,93 & 18,24 & \begin{tabular}{|l|}
304,69 \\
\end{tabular} & \begin{tabular}{|l|l|}
78,98 \\
\end{tabular} & 230,76 & 230,76 & 71,0 & 505,76 & 68,07 & 6,06 & 53,89 & 199,54 & 26,34 & 26,34 & 189,76 \\
\hline Pelophylax perezi & 30SVG21 & 100,00 & 156,34 & 113,11 & 37,95 & 6152,04 & 326,59 & 30,64 & 295,95 & 88,38 & \begin{tabular}{|l|l|}
239,92 \\
\end{tabular} & 239,92 & 82,5 & $\begin{array}{ll}432,45 \\
\end{array}$ & 64,77 & 4,80 & 55,33 & 176,44 & 22,57 & 22,57 & 160,84 \\
\hline Pelophylax perezi & 30SVG22 & 100,00 & 153,52 & 114,99 & 37,21 & 6338,62 & 330,23 & 26,31 & 303,92 & 84,42 & 239,78 & 239,78 & 77,8 & 473,18 & 65,41 & 5,45 & 54,03 & 185,84 & 24,53 & 24,53 & 175,09 \\
\hline Pelophylax perezi & 30 SVG23 & 100,00 & 143,48 & 118,29 & 37,00 & 6569,32 & 329,22 & 14,20 & \begin{tabular}{|l|l|}
315,02 \\
\end{tabular} & 73,80 & 232,93 & 232,93 & 65,32 & 558,01 & 71,92 & 6,87 & \begin{tabular}{|l|l}
52,63 \\
\end{tabular} & 208,01 & 30,10 & 30,10 & 204,63 \\
\hline Pelophylax perezi & 30SVG24 & 100,00 & 144,54 & 117,80 & 36,96 & 6647,62 & 331,67 & \begin{tabular}{|l|l|l|}
15,37 \\
\end{tabular} & 316,30 & 75,56 & \begin{tabular}{|l|l|}
235,03 \\
\end{tabular} & \begin{tabular}{|l|}
235,03 \\
\end{tabular} & 65,56 & 568,15 & 74,36 & 6,89 & 52,60 & 210,27 & \begin{tabular}{|l|}
30,69 \\
\end{tabular} & 30,69 & 207,29 \\
\hline Pelophylax perezi & 30SVG25 & 100,00 & 130,21 & 120,26 & 36,87 & $\begin{array}{ll}6743,06 \\
\end{array}$ & 322,75 & 0,62 & 322,12 & \begin{tabular}{|c|}
61,14 \\
\end{tabular} & 222,23 & 222,23 & 50,70 & 642,81 & 86,59 & 8,94 & 50,67 & 236,40 & 39,79 & 39,79 & 228,93 \\
\hline Pelophylax perezi & 30 SVG26 & 100,00 & & 118,47 & 36, & 193 & $32 \mathrm{~s}$ & 8,5 & 321 & 69, & 230, & 230 & 57, & 620,03 & 85,90 & 8,01 & 51,60 & 230,96 & 36,29 & 36,29 & 221,40 \\
\hline Pelophylax perezi & 30SVG27 & 100,00 & 149,35 & 114,96 & 35,68 & 6835,44 & 338,37 & 21,04 & 317,34 & \begin{tabular}{|c|}
80,48 \\
\end{tabular} & 242,35 & 242,35 & 68,20 & 594,90 & 86,50 & 6,71 & 53,41 & 227,54 & 31,52 & 31,52 & 214,63 \\
\hline Pelophylax perezi & 30SVG28 & 100,00 & 167,47 & 109,58 & 35,04 & 6784,30 & 349,56 & 41,31 & 308,25 & 97,45 & 259,05 & \begin{tabular}{|l|l}
259,05 \\
\end{tabular} & 86,04 & 545,37 & 83,71 & 4,61 & 56,18 & 215,71 & 23,85 & 23,85 & 200,56 \\
\hline Pelophylax perezi & 30SVG29 & 100,00 & 174,29 & 109,27 & 35,11 & \begin{tabular}{ll|}
6698,83 \\
\end{tabular} & 353,26 & \begin{tabular}{|l|l|}
47,97 \\
\end{tabular} & \begin{tabular}{|l|}
305,29 \\
\end{tabular} & \begin{tabular}{|l|l|}
105,10 \\
\end{tabular} & 264,34 & 264,34 & 93,33 & 504,78 & 76,38 & 3,57 & 56,17 & \begin{tabular}{|l|l|}
197,27 \\
\end{tabular} & 21,01 & 21,01 & 184,84 \\
\hline Pelophylax per & 30 SVG30 & 100,00 & & & 38,0 & 6278,06 & & 19,5 & 307 & 81, & 20 & 233 & 73,22 & \begin{tabular}{l|l}
479,05 \\
\end{tabular} & 64,55 & 5,64 & 53,49 & \begin{tabular}{|l|}
187,07 \\
\end{tabular} & & \begin{tabular}{l|l}
24,65 \\
\end{tabular} & $17 \varepsilon$ \\
\hline Pelophylax perezi & 30SVG31 & 100,00 & 156,21 & 115,40 & 37,99 & 6220,1 & 330,04 & 28,66 & 301,38 & $87,92[$ & 240,69 & 240,69 & 81,49 & \begin{tabular}{|l|l|}
421,63 \\
\end{tabular} & 60,03 & 5,01 & $54,07]$ & 168,55 [ & 21,97 & 21,97 & 155,25 \\
\hline Pelophylax perezi & 30SVG32 & 100,00 & 155,35 & 116,17 & 37,27 & 6367,30 & 333,48 & 27,03 & 306,45 & \begin{tabular}{|l|l|}
86,06 \\
\end{tabular} & 241,90 & 241,90 & 79,03 & 449,20 & 60,94 & 5,31 & 53,20 & 174,40 & 23,25 & 23,25 & 164,69 \\
\hline
\end{tabular}




\begin{tabular}{|c|c|c|c|c|c|c|c|c|c|c|c|c|c|c|c|c|c|c|c|c|c|}
\hline TAXON & UTM & $\mathrm{km} 2$ & BIO1 & B102 & $B 103$ & BIO4 & B105 & B106 & B107 & B108 & B109 & B1010 & BIO11 & BIO12 & BIO13 & BIO14 & BIO15 & B1016 & B1017 & B1018 & 81019 \\
\hline Pelophylax perezi & 30SVG33 & 100,00 & 145,52 & 118,63 & 37,00 & 6567,88 & 331,36 & 15,78 & 315,57 & 76,20 & 235,00 & 235,00 & 67,37 & 530,49 & 68,97 & 6,75 & 52,08 & 196,18 & 29,18 & 29,18 & 192,47 \\
\hline Pelophylax perezi & 30SVG34 & 100,00 & 139,93 & 119,43 & 36,99 & 6683,69 & 329,45 & 9,99 & 319,46 & 71,39 & 231,01 & 231,01 & 60,73 & 574,29 & 75,90 & 7,53 & 51,31 & 209,78 & 33,08 & 33,08 & 206,13 \\
\hline Pelophylax perezi & 30SVG35 & 100,00 & 126,20 & 121,18 & 36,97 & 6752,57 & 319,85 & $-3,67$ & 323,52 & 64,45 & 218,48 & 218,48 & 46,92 & 644,41 & 86,30 & 9,73 & 49,36 & 234,17 & 42,64 & 42,64 & 225,70 \\
\hline Pelophylax perezi & 30SVG36 & 100,00 & 132,62 & 119,55 & 36,53 & 6795,28 & 325,48 & 2,86 & 322,62 & 75,23 & 225,41 & 225,41 & 52,59 & \begin{tabular}{ll|l}
626,85 \\
\end{tabular} & 85,85 & 9,01 & 50,08 & 230,35 & 40,13 & 40,13 & 219,61 \\
\hline Pelophylax perezi & 30SVG37 & 100,00 & 162,55 & 110,80 & 35,25 , & 6759,06 & 345,47 & 36,00 & 309,47 & 95,21 & 254,03 & 254,03 & 81,78 & 537,45 & 80,05 & $5,21]$ & 54,72 & 208,61 & 25,54 & 25,54 & 195,53 \\
\hline Pelophylax perezi & 30SVG38 & 100,00 & 172,59 & 108,24 & 35,04 & 6691,36 & 350,72 & 47,06 & 303,66 & 103,34 & 262,76 & 262,76 & 92,04 & 500,91 & 75,67 & 3,99 & 55,81 & 195,89 & 21,58 & 21,58 & 183,27 \\
\hline Pelophylax perezi & 30SVG39 & 100,00 & 174,79 & 108,88 & 35,10 & 6664,34 & 352,41 & 48,55 & 303,86 & 105,84 & 264,30 & 264,30 & 94,21 & 482,79 & 72,16 & 3,47 & 55,40 & 186,60 & 20,73 & 20,73 & 175,18 \\
\hline Pelophylax perezi & 30SVG40 & 100,00 & 145,38 & 119,73 & 38,00 & 6347,76 & 327,09 & 15,72 & 311,37 & 78,74 & 231,55 & 231,55 & 69,68 & 491,34 & 66,55 & \begin{tabular}{l|l}
5,95 \\
\end{tabular} & 52,60 & \begin{tabular}{|l|l|}
186,27 \\
\end{tabular} & 25,97 & 25,97 & 180,81 \\
\hline Pelophylax perezi & 30SVG41 & 100,00 & 153,30 & $\begin{array}{ll}119,43 \\
\end{array}$ & 37,94 & 6373,83 & \begin{tabular}{|l|l|}
334,49 \\
\end{tabular} & 23,04 & 311,45 & 85,31 & 239,83 & 239,83 & 76,87 & 453,80 & 62,06 & 5,21 & 53,01 & \begin{tabular}{|l|l|}
173,27 \\
\end{tabular} & 22,75 & 22,75 & 166,64 \\
\hline Pelophylax perezi & 30SVG42 & 100,00 & 148,23 & 119,59 & 37,30 & $\begin{array}{ll}6503,29 \\
\end{array}$ & 333,06 & 17,69 & 315,37 & 79,29 & 236,58 & 236,58 & 70,59 & \begin{tabular}{|l|l|}
494,17 \\
\end{tabular} & 65,33 & 6,06 & 52,03 & 182,97 & 26,45 & 26,45 & 179,08 \\
\hline Pelophylax perezi & 30SVG43 & 100,00 & \begin{tabular}{ll|l}
147,47 \\
\end{tabular} & 119,11 & 37,00 & 6579,18 & 333,78 & 17,30 & 316,48 & 78,58 & 237,05 & 237,05 & 69,25 & 511,75 & 66,96 & 6,32 & 51,82 & 186,44 & 27,85 & 27,85 & 184,32 \\
\hline Pelophylax perezi & 30SVG44 & 100,00 & 139,33 & 119,77 & 37,00 & \begin{tabular}{ll|l}
6682,62 \\
\end{tabular} & 329,05 & 9,07 & 319,98 & 79,28 & 230,30 & 230,30 & 60,18 & 564,60 & 74,91 & 7,68 & 50,60 & 204,73 & 33,72 & 33,72 & 200,23 \\
\hline Pelophylax perezi & 30SVG45 & 100,00 & 136,11 & 119,86 & 36,88 & 6743,93 & 327,60 & 5,93 & 321,68 & 83,75 & 228,09 & 228,09 & 56,45 & \begin{tabular}{|l|l|}
587,08 \\
\end{tabular} & 79,14 & 8,34 & 49,90 & 214,21 & 36,75 & 36,75 & 205,80 \\
\hline Pelophylax perezi & 30SVG46 & 100,00 & 143,98 & 1117,51 & 36,36 & 6768,92 & 333,58 & 14,49 & 319,08 & 91,27 & 236,06 & 236,06 & 63,70 & $\begin{array}{l}566,46 \\
\end{array}$ & 78,63 & 7,38 & 50,98 & 209,87 & 33,53 & 33,53 & 199,33 \\
\hline Pelophylax perezi & 30SVG47 & 100,00 & 147,62 & 116,10 & 35,98 & 6802,55 & 336,55 & \begin{tabular}{|l|l|}
18,67 \\
\end{tabular} & 317,88 & 93,94 & 239,99 & 239,99 & $\begin{array}{ll}66,83 \\
\end{array}$ & 562,77 & 80,0 & 6,99 & 51,40 & 211,26 & 32,76 & 32,76 & 197,56 \\
\hline Pelophylax perezi & 30SVG48 & 100,00 & 160,46 & 112,17 & 35,26 & 6796,60 & 345,24 & 32,91 & 312,34 & 105,88 & 252,39 & 252,39 & 79,30 & 527,44 & 78,75 & 5,40 & 53,53 & 202,94 & 26,89 & 26,89 & 187,64 \\
\hline Pelophylax perezi & 30SVG49 & 100,00 & 171,87 & 109,65 & 35,37 & 6671,28 & 350,31 & 45,36 & 304,95 & 114,53 & 261,52 & 261,52 & 91,38 & $\begin{array}{l}475,47 \\
\end{array}$ & 70,42 & 3,79 & 54,19 & \begin{tabular}{ll|}
181,92 \\
\end{tabular} & 21,97 & 21,97 & 169,90 \\
\hline Pelophylax perezi & 30SVG50 & 100,00 & 111,64 & 121,25 & \begin{tabular}{l|l|l|}
37,95 \\
\end{tabular} & 6483,53 & 300,34 & $-16,90$ & 317,23 & 53,95 & 200,07 & 200,32 & 36,09 & 673,94 & 85,04 & 12,65 & 47,20 & 240,43 & 51,48 & 55,05 & 233,93 \\
\hline Pelophylax perezi & 30SVG51 & 100,00 & 137,77 & 120,31 & 37,80 & 6468,57 & 323,32 & 7,91 & 315,41 & 72,75 & 225,69 & 225,71 & 61,08 & 533,14 & 69,61 & 7,34 & 50,53 & \begin{tabular}{|l|l|}
192,97 \\
\end{tabular} & 31,75 & 32,01 & 190,72 \\
\hline Pelophylax perezi & 30SVG52 & 100,00 & 121,04 & 121,37 & 37,53 & 6577,65 & 311,27 & $-8,14$ & 319,41 & 69,02 & 210,81 & 210,84 & 44,02 & 627,20 & 80,3 & 10,60 & 47,88 & 223,75 & 44,60 & 45,24 & 217,73 \\
\hline Pelophylax perezi & 30SVG53 & 100,00 & 132,54 & 120,41 & 37,09 & $\begin{array}{ll}6610,03 \\
\end{array}$ & 321,70 & 2,59 & 319,11 & 79,42 & 222,59 & 222,61 & 54,58 & 576,19 & 74,64 & 8,94 & 49,04 & 206,32 & 38,22 & 38,56 & 200,98 \\
\hline Pelophylax perezi & 30SVG54 & 100,00 & 143,99 & \begin{tabular}{ll|}
119,14 \\
\end{tabular} & 37,00 & 6641,52 & \begin{tabular}{|l|l|}
332,01 \\
\end{tabular} & $\begin{array}{ll}13,67 \\
\end{array}$ & 318,34 & 94,65 & 234,34 & 234,34 & 65,17 & $\begin{array}{l}527,69 \\
\end{array}$ & 69,98 & 6,98 & 50,44 & 190,85 & 31,01 & 31,01 & 186,00 \\
\hline Pelophylax perezi & 30SVG55 & 100,00 & 134,70 & 120,19 & 37,00 & \begin{tabular}{|l|l|l|}
6727,44 \\
\end{tabular} & 325,86 & 4,20 & 321,66 & 86,12 & 226,34 & 226,34 & 55,16 & 576,79 & 77,16 & 8,54 & 48,93 & 209,65 & 37,73 & 37,73 & 199,31 \\
\hline Pelophylax perezi & 30SVG56 & 100,00 & 135,86 & 119,61 & 36,73 & 6767,58 & 327,38 & 5,70 & 321,69 & 87,11 & 227,97 & 227,97 & 55,90 & 579,11 & 78,55 & 8,52 & 48,84 & 211,90 & 38,31 & 38,31 & 198,88 \\
\hline Pelophylax perezi & 30SVG57 & 100,00 & 119,51 & 121,43 & \begin{tabular}{|l|l|}
36,87 \\
\end{tabular} & 6806,40 & 314,62 & $-10,48$ & 325,10 & \begin{tabular}{ll|}
69,97 \\
\end{tabular} & 212,57 & 212,58 & 40,06 & 653,93 & 86,56 & 11,92 & 45,99 & 235,78 & 51,76 & 51,94 & 217,53 \\
\hline Pelophylax perezi & 30SVG58 & 100,00 & 148,94 & 115,90 & 36,12 & 6782,17 & 336,74 & 19,89 & 316,85 & 100,73 & 240,96 & 240,96 & 68,35 & $\begin{array}{l}539,85 \\
\end{array}$ & 76,30 & 6,80 & 50,24 & 201,74 & 32,99 & 32,99 & 185,82 \\
\hline Pelophylax perezi & 30SVG59 & 100,00 & 171,17 & 110,18 & 35,92 & 6609,16 & 348,34 & 44,54 & 303,81 & 124,97 & 259,99 & 259,99 & 91,48 & \begin{tabular}{|l|l|}
451,57 \\
\end{tabular} & 64,77 & 3,78 & 52,74 & $\begin{array}{ll}169,93 \\
\end{array}$ & 22,11 & 22,11 & 158,86 \\
\hline Pelophylax perezi & 30SVG60 & 100,00 & 71,10 & 123,12 & $\begin{array}{l}37,55 \\
\end{array}$ & 6632,43 & 267,01 & $-57,13$ & 324,14 & 20,08 & 162,51 & 163,00 & $-4,30$ & \begin{tabular}{|l|l|}
913,97 \\
\end{tabular} & 110,84 & 26,09 & 40,48 & 318,17 & 96,84 & 99,76 & 294,48 \\
\hline Pelophylax perezi & 30SVG61 & 100,00 & 112,41 & 121,28 & 37,86 & 6532,90 & 301,90 & $-16,22$ & 318,13 & 62,72 & 201,56 & 201,79 & 36,41 & 659,49 & 82,80 & 12,84 & 46,09 & 233,59 & 52,19 & 55,75 & 224,71 \\
\hline Pelophylax perezi & 30SVG62 & 100,00 & 122,76 & 120,85 & \begin{tabular}{|l|}
37,48 \\
\end{tabular} & 6557,57 & 311,71 & $-6,24$ & 317,96 & 74,06 & 212,14 & 212,21 & 45,92 & 605,29 & 77,14 & 10,41 & 47,20 & 215,44 & 43,91 & 45,90 & 207,94 \\
\hline Pelophylax perezi & 30SVG63 & 100,00 & 122,08 & 121,11 & 37,19 & 6612,23 & 312,55 & $-7,40$ & 319,95 & 73,26 & 212,25 & 212,32 & 44,72 & \begin{tabular}{|l|l|}
613,89 \\
\end{tabular} & 78,69 & 10,86 & 46,73 & 218,94 & 45,77 & 47,06 & 208,89 \\
\hline Pelophylax perezi & 30SVG64 & 100,00 & 136,36 & 119,84 & 37,00 & 6636,61 & 325,11 & 6,08 & 319,03 & 88,25 & 226,72 & 226,73 & 57,94 & 547,77 & 71,86 & $\begin{array}{l}8,15 \\
\end{array}$ & 48,48 & 197,16 & 35,97 & 36,09 & 188,69 \\
\hline Pelophylax perezi & 30SVG65 & 100,00 & 135,93 & 119,71 & 37,00 & 6691,84 & 325,60 & 5,58 & 320,03 & 87,42 & 226,97 & 226,97 & 56,80 & 556,57 & 73,86 & 8,38 & 48,16 & 201,59 & 37,38 & 37,38 & 190,13 \\
\hline Pelophylax perezi & 30SVG66 & 100,00 & 137,12 & 1119,37 & 36,88 & 6732,43 & 327,30 & 6,80 & 320,50 & 88,49 & 228,65 & 228,65 & 57,50 & 556,55 & 74,74 & 8,29 & 48,10 & 202,79 & 37,60 & 37,60 & 189,02 \\
\hline Pelophylax perezi & 30SVG67 & 100,00 & 132,71 & 119,32 & \begin{tabular}{|l|l}
36,68 \\
\end{tabular} & 6757,97 & 323,71 & 2,81 & 320,90 & 83,86 & 224,71 & 224,71 & 53,13 & 581,53 & 77,70 & 9,48 & 47,01 & 211,09 & 42,71 & 42,82 & 194,21 \\
\hline Pelophylax perezi & 30SVG68 & 100,00 & 152,33 & 115,31 & 36,18 & \begin{tabular}{|l|l|l|}
6711,34 \\
\end{tabular} & $\begin{array}{l}337,47 \\
\end{array}$ & 23,54 & 313,94 & $\begin{array}{l}104,62 \\
\end{array}$ & 243,16 & 243,16 & 72,34 & 504,23 & 70,05 & 6,20 & 49,64 & \begin{tabular}{ll|}
186,92 \\
\end{tabular} & 30,95 & 30,95 & $\begin{array}{ll}171,88 \\
\end{array}$ \\
\hline Pelophylax perezi & 30SVG69 & 100,00 & 170,19 & 110,63 & 36,00 & 6543,41 & 346,04 & 43,41 & 302,63 & 124,30 & 258,14 & 258,14 & 91,29 & 430,62 & 59,77 & 3,66 & 51,49 & 159,45 & 22,26 & 22,37 & 148,99 \\
\hline Pelophylax perezi & 30SVG71 & 100,00 & 92,18 & 122,05 & \begin{tabular}{l|l|l}
37,65 \\
\end{tabular} & 6588,12 & 284,81 & $-36,15$ & 320,96 & 41,94 & 182,41 & 183,06 & 16,58 & \begin{tabular}{|l|l|}
767,78 \\
\end{tabular} & 94,10 & 19,05 & 42,08 & 269,11 & 73,90 & 78,55 & 250,38 \\
\hline Pelophylax perezi & 30SVG72 & 100,00 & 131,32 & 119,24 & \begin{tabular}{|l|l|}
37,27 \\
\end{tabular} & 6501,60 & 316,88 & 2,31 & 314,58 & 83,27 & 219,66 & 219,80 & 54,84 & 548,03 & 69,45 & 8,87 & 47,55 & $\begin{array}{l}194,36 \\
\end{array}$ & 38,15 & \begin{tabular}{l|l|}
40,92 \\
\end{tabular} & 187,99 \\
\hline Pelophylax perezi & 30SVG73 & 100,00 & 134,85 & 119,13 & 37,06 & 6544,22 & 320,85 & 5,49 & 315,36 & 86,77 & 223,70 & 223,81 & 57,65 & 535,35 & 68,68 & 8,34 & 47,65 & 190,71 & 36,62 & 38,49 & 182,96 \\
\hline Pelophylax perezi & 30SVG74 & 100,00 & 139,94 & \begin{tabular}{ll|}
118,44 \\
\end{tabular} & 37,00 & $\begin{array}{ll}6572,61 \\
\end{array}$ & 325,67 & 10,28 & 315,39 & 92,14 & 229,21 & 229,23 & \begin{tabular}{ll|}
62,07 \\
\end{tabular} & \begin{tabular}{ll|}
516,92 \\
\end{tabular} & 67,15 & 7,63 & 47,99 & 185,14 & 34,32 & 35,44 & 176,46 \\
\hline Pelophylax perezi & 30SVG75 & 100,00 & \begin{tabular}{|l|l|}
137,38 \\
\end{tabular} & 118,94 & 37,00 & 6634,40 & 324,88 & 7,42 & 317,47 & 89,10 & 227,53 & 227,55 & 58,95 & 534,26 & 69,94 & 8,20 & 47,38 & \begin{tabular}{|l|l|}
192,19 \\
\end{tabular} & 36,90 & \begin{tabular}{|c|c|}
37,68 \\
\end{tabular} & 180,31 \\
\hline Pelophylax perezi & 30SVG76 & 100,00 & 139,21 & 118,62 & 37,00 & 6671,63 & 326,99 & 9,16 & 317,82 & 90,94 & 229,79 & 229,79 & 60,30 & 530,29 & 70,12 & 7,98 & 47,31 & \begin{tabular}{|l|l|}
191,77 \\
\end{tabular} & 36,68 & 36,73 & 177,96 \\
\hline Pelophylax perezi & 30SVG77 & 100,00 & 145,97 & 116,83 & 36,6 & 6663,67 & 331,46 & 16,71 & 314,75 & 98,09 & 236,19 & 236,21 & 66,75 & 506,15 & 67,71 & 7,02 & 47,99 & 184,15 & 33,73 & 34,28 & 169,86 \\
\hline Pelophylax perezi & 30SVG78 & 100,00 & 161,60 & 112,72 & 36,18 & 6559,96 & 339,99 & 34,07 & 305,92 & 115,06 & 249,91 & 249,92 & 82,82 & 443,93 & 60,16 & 4,71 & 49,69 & 162,60 & 25,75 & 25,97 & 150,93 \\
\hline Pelophylax perezi & $30 \mathrm{SVG}$ & 100,00 & 168,21 & 111,19 & 36,14 & 6497,86 & 343,14 & 41,24 & 301,89 & 122,41 & 255,39 & 255,42 & 89,80 & 416,60 & 56,08 & 3,86 & 49,86 & 151,84 & 23,30 & 23,59 & 141,36 \\
\hline Pelophylax perezi & 30SVG81 & 100,00 & 117,90 & \begin{tabular}{ll|}
119,38 \\
\end{tabular} & $\begin{array}{ll}37,68 \\
\end{array}$ & $\begin{array}{ll}6463,46 \\
\end{array}$ & 303,60 & $\begin{array}{ll}-9,92 \\
\end{array}$ & 313,52 & \begin{tabular}{ll|l}
69,14 \\
\end{tabular} & 205,87 & 206,44 & 42,78 & 604,33 & 74,68 & \begin{tabular}{l|l|}
11,93 \\
\end{tabular} & 45,00 & 212,65 & 48,99 & 55,84 & 202,19 \\
\hline Pelophylax perezi & 30SVG82 & 100,00 & 137,17 & 117,37 & 37,33 & 6421,42 & 318,57 & 9,05 & 309,52 & 89,62 & 224,11 & 224,44 & 61,34 & 504,70 & 63,27 & 7,80 & 47,40 & 177,97 & 34,45 & 40,80 & 172,27 \\
\hline Pelophylax perezi & 30SVG83 & 100,00 & 144,03 & 116,31 & 37,00 & 6424,32 & 324,13 & 15,93 & 308,20 & 96,98 & 230,86 & 231,19 & 67,69 & 476,49 & 60,29 & 6,71 & 48,16 & 168,45 & 30,90 & 35,47 & 162,76 \\
\hline Pelophylax perezi & $30 \mathrm{SVG}$ & 100,00 & 146,12 & 115,93 & 37,00 & 6460,65 & 326,48 & 18,02 & 308,47 & 98,95 & 233,46 & 233,65 & 69,32 & 472,62 & 60,39 & 6,55 & 47,95 & 167,88 & 30,62 & 33,53 & 160,47 \\
\hline Pelophylax perezi & 30SVG85 & 100,00 & 140,54 & \begin{tabular}{|l|}
117,37 \\
\end{tabular} & 37,00 & \begin{tabular}{|l|l|}
6548,81 \\
\end{tabular} & 324,38 & 11,65 & 312,73 & 92,73 & 229,30 & 229,42 & 63,09 & 503,91 & \begin{tabular}{ll|}
64,87 \\
\end{tabular} & \begin{tabular}{|c|}
7,67 \\
\end{tabular} & 46,85 & $\begin{array}{ll}179,86 \\
\end{array}$ & 35,31 & 37,92 & 168,24 \\
\hline Pelophylax perezi & 30SVG86 & 100,00 & 147,12 & 116,06 & 37,00 & 6551,86 & 329,27 & 18,45 & 310,82 & 99,57 & 235,67 & 235,73 & 69,33 & 479,10 & 62,33 & 6,66 & 47,36 & 171,90 & 32,13 & 33,97 & 160,06 \\
\hline Pelophylax perezi & 30SVG87 & 100,00 & 151,08 & 115,10 & 36,94 & 6555,31 & 332,01 & 22,66 & 309,36 & 103,88 & 239,61 & 239,64 & 72,95 & \begin{tabular}{ll|}
465,92 \\
\end{tabular} & 60,94 & 6,13 & 47,49 & \begin{tabular}{|l|l|}
167,68 \\
\end{tabular} & 30,89 & 32,69 & 154,99 \\
\hline Pelophylax perezi & 305 & 100 & 163,67 & 111,76 & 36,8 & 6 & 33 & 36,77 & 301,36 & 1117,71 & 250,17 & 250,25 & 86,18 & 414,9 & 54,20 & 4,3 & 48,68 & 149,10 & 24,87 & 26,67 & 139,02 \\
\hline Pelophylax perezi & 30SVG89 & 100,00 & 164,75 & 112,11 & \begin{tabular}{|l|}
36,78 \\
\end{tabular} & 6463,34 & 339,70 & 37,53 & 302,17 & 118,98 & 251,51 & 251,55 & 86,95 & 411,70 & 53,87 & 4,17 & 48,48 & 148,10 & 24,91 & 25,92 & 136,85 \\
\hline Pelophylax perezi & 30SVG90 & 100,00 & 85,83 & 121,31 & \begin{tabular}{|l|l|}
37,58 \\
\end{tabular} & 6557,77 & 277,24 & $-41,90$ & 319,14 & 35,25 & 175,59 & $\begin{array}{l}176,67 \\
\end{array}$ & 10,81 & 786,80 & $\begin{array}{l}97,22 \\
\end{array}$ & 22,23 & 39,53 & 273,08 & 83,72 & 87,56 & 248,57 \\
\hline Pelophylax perezi & 30SVG91 & 100,00 & 123,64 & 117,72 & $\begin{array}{ll}37,63 \\
\end{array}$ & 6400,30 & 305,85 & $-3,53$ & 309,38 & 75,38 & 210,51 & 211,27 & 48,91 & 561,19 & 69,47 & 10,75 & 44,90 & 196,42 & 44,97 & 52,32 & 186,69 \\
\hline Pelophylax pe & 30SVG92 & 100, & & 117 & 37, & 6407, & 312 & 4,42 & 8 & 84, & 8 & & 56, & 518 & 64,18 & 8 & 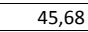 & 18 & $3 \varepsilon$ & $46,37]$ & 173,32 \\
\hline Pelophylax perezi & 30SVG93 & 100,00 & 129,06 & 118,02 & \begin{tabular}{|l|}
37,19 \\
\end{tabular} & 6480,29 & 312,71 & 1,07 & 311,64 & 80,73 & 216,99 & 217,51 & 53,1 & 538,44 & 66,96 & 9,71 & 44,88 & $\begin{array}{l}189,25 \\
\end{array}$ & 42,22 & 48,92 & 177,36 \\
\hline Pelophylax perezi & 30SVG94 & 100,00 & 137,81 & 116,80 & \begin{tabular}{|l|l|}
37,03 \\
\end{tabular} & 6468,53 & 319,42 & 9,71 & 309,71 & 90,09 & 225,38 & 225,91 & 61,62 & $\begin{array}{l}497,66 \\
\end{array}$ & 62,30 & 8,00 & 45,82 & 175,46 & 36,53 & \begin{tabular}{|l|}
43,52 \\
\end{tabular} & 164,63 \\
\hline
\end{tabular}




\begin{tabular}{|c|c|c|c|c|c|c|c|c|c|c|c|c|c|c|c|c|c|c|c|c|c|}
\hline TAXON & UTM & $\mathrm{km} 2$ & B101 & B102 & $\mathrm{BIO3}$ & B104 & B105 & B106 & B107 & B108 & B109 & BIO10 & BIO11 & BIO12 & B1013 & BIO14 & BIO15 & B1016 & B1017 & BIO18 & B1019 \\
\hline Pelophylax perezi & 30SVG95 & 100,00 & 151,79 & 113,35 & 37,00 & 6370,99 & 327,12 & 25,09 & 302,03 & 105,32 & 237,60 & 237,94 & 75,87 & 436,68 & 54,84 & 5,77 & 47,27 & 153,81 & 28,69 & 34,02 & 145,86 \\
\hline Pelophylax perezi & 30SVG96 & 100,00 & 153,87 & 113,10 & 37,00 & 6394,29 & 329,22 & 27,06 & 302,16 & 107,45 & 239,94 & 240,28 & 77,50 & 432,02 & 54,56 & 5,47 & 47,16 & 152,66 & 28,46 & 33,47 & 143,34 \\
\hline Pelophylax perezi & 30SVG97 & 100,00 & 154,25 & 113,49 & 36,99 & 6438,83 & 330,70 & 26,98 & 303,72 & 107,68 & 240,95 & 241,14 & 77,26 & \begin{tabular}{|l|l|}
434,65 \\
\end{tabular} & 55,14 & 5,55 & 46,94 & 154,05 & 29,32 & 33,38 & 142,86 \\
\hline Pelophylax perezi & 30SVG98 & 100,00 & 138,54 & 117,48 & 37,01 & 6605,31 & 323,07 & 9,57 & 313,50 & 90,52 & 227,97 & 228,16 & 60,40 & 507,78 & 64,38 & 8,58 & 44,35 & 179,71 & 41,02 & 43,36 & 161,53 \\
\hline Pelophylax perezi & 30SVG99 & 100,00 & 148,60 & 115,92 & 37,00 & \begin{tabular}{|l|l|}
6562,74 \\
\end{tabular} & 329,82 & 20,00 & 309,82 & 101,51 & 237,17 & 237,29 & 70,40 & 463,21 & 59,05 & 6,64 & 45,31 & 164,47 & 34,75 & 36,81 & 148,06 \\
\hline Pelophylax perezi & 30SVHO1 & 100,00 & 173,25 & 114,34 & 36,00 & 6739,98 & 356,56 & 43,78 & 312,78 & 103,74 & 263,86 & 263,86 & 91,44 & 511,77 & 75,83 & 3,23 & 55,60 & 195,58 & 21,62 & 21,62 & 185,27 \\
\hline Pelophylax perezi & 30SVHO2 & 100,00 & 166,13 & 116,79 & 36,00 & $\begin{array}{ll}6846,37 \\
\end{array}$ & 354,41 & 35,08 & 319,33 & 96,84 & 258,37 & 258,37 & 83,31 & 530,30 & 78,73 & 3,62 & 54,44 & 201,04 & 24,27 & 24,27 & 188,86 \\
\hline Pelophylax perezi & \begin{tabular}{|l|l|l|l|l}
$30 \mathrm{SVHO}$ \\
\end{tabular} & 100,00 & 155,87 & 119,93 & 36,17 & 6936,06 & 349,27 & 23,47 & 325,80 & $\begin{array}{r}103,94 \\
\end{array}$ & 249,62 & 249,62 & 72,41 & 553,67 & 80,94 & 4,54 & 52,48 & 207,08 & 29,00 & 29,00 & 192,78 \\
\hline Pelophylax perezi & 30SVH04 & 100,00 & 152,67 & 121,54 & 36,70 & 6943,12 & 347,59 & 19,47 & 328,12 & 105,63 & 246,53 & 246,53 & 69,13 & 547,43 & 78,34 & 4,60 & 51,14 & 202,35 & 30,55 & 30,55 & 187,44 \\
\hline Pelophylax perezi & 30SVH05 & 100,00 & 144,87 & 123,50 & 37,00 & 6956,21 & 342,06 & 11,07 & 330,99 & 97,66 & 239,15 & 239,15 & 61,62 & 557,74 & 77,28 & 5,44 & 49,29 & 202,56 & 34,99 & 34,99 & 186,84 \\
\hline Pelophylax perezi & 30SVH06 & 100,00 & 152,24 & 123,95 & 37,00 & 6927,25 & 348,01 & 17,46 & 330,55 & 105,68 & 245,73 & 245,73 & 68,59 & 511,84 & 70,05 & 4,21 & 49,41 & 184,61 & 30,80 & 30,80 & 170,22 \\
\hline Pelophylax perezi & 30SVH07 & 100,00 & 145,28 & 125,58 & 37,04 & 6933,85 & 342,96 & 10,19 & 332,77 & 98,85 & 239,11 & 239,11 & 61,93 & 519,53 & 68,96 & 4,83 & 47,56 & 184,41 & 34,67 & 34,67 & 169,24 \\
\hline Pelophylax perezi & 30SVH08 & 100,00 & 146,68 & 126,35 & 37,34 & 6917,47 & 344,27 & 10,82 & 333,44 & 123,90 & 240,12 & 240,12 & 63,49 & 495,58 & 64,12 & 4,31 & 46,88 & 175,07 & 33,86 & 33,86 & 159,05 \\
\hline Pelophylax perezi & 30SVHO9 & 100,00 & 146,35 & 127,13 & \begin{tabular}{|l|l|}
37,87 \\
\end{tabular} & 6903,11 & 343,78 & 9,97 & 333,81 & 129,14 & 239,60 & 239,60 & 63,14 & 478,40 & 60,09 & 4,12 & 46,07 & 168,82 & 33,85 & 33,85 & 151,16 \\
\hline Pelophylax perezi & $30 \mathrm{SVH} 10$ & 100,00 & 177,28 & 111,16 & 35,96 & 6661,47 & 356,09 & 49,61 & 306,48 & 108,35 & 266,54 & 266,54 & 96,29 & 491,86 & 72,84 & 3,00 & 55,99 & 189,31 & 20,07 & 20,07 & 179,62 \\
\hline Pelophylax perezi & 30SVH11 & 100,00 & 173,27 & 113,34 & 36,00 & 6740,93 & 355,86 & 44,18 & 311,68 & 103,58 & 263,83 & 263,83 & 91,41 & 500,60 & 74,46 & 3,27 & 55,22 & 191,21 & 21,66 & 21,66 & 180,09 \\
\hline Pelophylax perezi & $30 \mathrm{SVH} 12$ & 100,00 & 165,95 & 116,11 & 36,00 & 6846,00 & 353,68 & 35,44 & 318,24 & 105,58 & 258,18 & 258,18 & 83,22 & 519,72 & 77,25 & 3,74 & 53,92 & 197,10 & 24,62 & 24,62 & 183,63 \\
\hline Pelophylax perezi & 30SVH13 & 100,00 & 163,29 & 117,95 & 36,05 & 6870,86 & 352,93 & 31,71 & 321,22 & 115,03 & 255,89 & 255,89 & 80,25 & 515,05 & 75,36 & 3,79 & 52,75 & 193,19 & 25,86 & 25,86 & 179,25 \\
\hline Pelophylax perezi & 30SVH14 & 100,00 & 157,62 & 120,27 & 36,56 & \begin{tabular}{ll|}
6901,44 \\
\end{tabular} & 350,06 & 24,96 & 325,10 & 110,93 & 250,79 & 250,79 & 74,49 & 518,31 & 74,11 & 4,22 & 51,24 & 192,18 & 28,63 & 28,63 & 176,88 \\
\hline Pelophylax perezi & 30SVH15 & 100,00 & 155,79 & 121,83 & 36,99 & 6898.91 & 349,23 & 22,23 & 327.01 & $\mid 109,29$ & 248,88 & 248,88 & 72.53 & 506,77 & 70,68 & 4,16 & 50,15 & $\mid \begin{array}{l}185,38 \\
\end{array}$ & 29,49 & 29,49 & 170,10 \\
\hline Pelophylax perezi & 30SVH16 & 100,00 & 151,04 & 123,69 & 37,00 & 6916,59 & 346,40 & 16,60 & 329,79 & 104,47 & 244,47 & 244,47 & 67,67 & 505,62 & 68,5 & 4,41 & 48,62 & 182,34 & 31,85 & 31,85 & 166,40 \\
\hline Pelophylax perezi & 30SVH17 & 100,00 & 147,46 & 125,23 & 37,01 & 6913,02 & 344,08 & 12,32 & 331,76 & 104,38 & 240,95 & 240,95 & 64,36 & 499,75 & 65,82 & 4,52 & 47,34 & $\begin{array}{l}177,79 \\
\end{array}$ & 33,55 & 33,55 & 161,52 \\
\hline Pelophylax perezi & 30SVH18 & 100,00 & 141,26 & 126,56 & \begin{tabular}{|l|l|}
37,49 \\
\end{tabular} & 6920,60 & 339,46 & 5,81 & 333,64 & 122,40 & 234,95 & 234,95 & 58,32 & 507,36 & $\begin{array}{ll}64,76 \\
\end{array}$ & 5,18 & 45,75 & 179,45 & 37,25 & 37,25 & 160,72 \\
\hline Pelophylax perezi & 30SVH19 & 100,00 & 143,09 & 127,54 & \begin{tabular}{l|l|}
37,95 \\
\end{tabular} & 6904,06 & 340,91 & 6,75 & 334,16 & 125,67 & 236,47 & 236,47 & 60,09 & 480,86 & 59,54 & 4,61 & 45,19 & 169,93 & 35,97 & 35,97 & 150,17 \\
\hline Pelophylax perezi & $30 \mathrm{SVH} 21$ & 100,00 & 175,23 & 112,19 & 36,00 & 6708,16 & 355,88 & 46,71 & 309,18 & 107,21 & 265,28 & 265,28 & 93,80 & 478,04 & 70,70 & 3,01 & 54,79 & 181,60 & 20,69 & 20,69 & 170,99 \\
\hline Pelophylax perezi & $30 \mathrm{SVH} 22$ & 100,00 & 167,66 & 115,08 & 36,00 & 6811,41 & 353,58 & 37,68 & 315,90 & $\begin{array}{l}17,58 \\
\end{array}$ & 259,44 & 259,44 & 85,38 & 498,74 & 73,7 & 3,62 & 53,34 & 188,84 & 24,08 & 24,08 & 174,98 \\
\hline Pelophylax perezi & 30SVH23 & 100,00 & 159,30 & 118,18 & 36,02 & 6893,52 & 349,99 & 27,74 & 322,25 & 112,12 & 252,44 & 252,44 & $\begin{array}{l}70,30 \\
76,32\end{array}$ & $\mid 517,86$ & 75,42 & $\begin{array}{l}3,064 \\
4,36\end{array}$ & 51,70 & \begin{tabular}{|l|}
$194,73,7$ \\
\end{tabular} & 28,09 & 28,09 & 177,84 \\
\hline Pelophylax perezi & 30 SVH24 & 100,00 & 155,16 & 120,19 & \begin{tabular}{|l|l|}
36,47 \\
\end{tabular} & 6904,58 & 347,68 & 22,64 & 325,04 & 108,23 & 248,43 & 248,43 & 72,14 & 515,62 & 73,10 & 4,60 & 50,27 & 191,16 & 30,13 & 30,13 & 173,88 \\
\hline Pelophylax perezi & 30 SVH 25 & 100,00 & 145,86 & 122,79 & 36,97 & 6929,03 & 341,56 & 12,40 & 329,17 & 98,79 & 239,69 & 239,69 & 62,92 & 532,36 & 72,99 & 5,53 & 48,12 & 193,73 & 35,29 & 35,29 & 175,10 \\
\hline Pelophylax perezi & 30 SVH 26 & 100,00 & 149,29 & 123,54 & 37,00 & 6905,60 & 344,42 & 15,08 & 329,34 & 102,72 & 242,76 & 242,76 & 66,32 & 502,27 & 67,41 & 4,82 & 47,70 & 180,86 & 33,34 & 33,34 & 163,47 \\
\hline Pelophylax perezi & $30 \mathrm{SVH} 27$ & 100,00 & 148,80 & 124,78 & 37,01 & 6891,23 & 344,31 & 13,92 & 330,39 & 109,97 & 241,93 & 241,93 & 65,91 & 485,85 & 63,41 & 4,50 & 46,86 & 172,89 & 33,36 & 33,36 & 155,74 \\
\hline Pelophylax perezi & 30SVH29 & 100,00 & $\begin{array}{l}140,00 \\
145,92\end{array}$ & 127,20 & 37,97 & 6871,08 & 342,44 & $\begin{array}{l}5,62 \\
9,6\end{array}$ & $\begin{array}{l}332,82 \\
330\end{array}$ & \begin{tabular}{|l|l|}
128,69 \\
\end{tabular} & \begin{tabular}{|l|}
238,79 \\
\end{tabular} & \begin{tabular}{|l|}
238,79 \\
231,5
\end{tabular} & $\begin{array}{l}63,22 \\
63\end{array}$ & \begin{tabular}{|l|l|}
$40,01,63$ \\
461,6
\end{tabular} & $\begin{array}{l}0,414 \\
56,56\end{array}$ & 4,32 & $\begin{array}{ll}4,60 \\
4488\end{array}$ & \begin{tabular}{|l|l|}
163,25 \\
16,0
\end{tabular} & $\begin{array}{l}34,75 \\
34,\end{array}$ & 34,75 & 143,18 \\
\hline Pelophylax perezi & 30SVH31 & 100,00 & 174,42 & 111,81 & \begin{tabular}{|l|l|}
35,97 \\
\end{tabular} & 6694,98 & 354,43 & 46,19 & 308,23 & 120,97 & 264,31 & 264,31 & 93,27 & 464,98 & 68,30 & 3,05 & 54,04 & 176,06 & 21,03 & 21,03 & 164,68 \\
\hline Pelophylax perezi & 30 SVH32 & 100,00 & 171,49 & 113,88 & 36,00 & 6739,60 & 354,18 & 42,16 & 312,03 & 125,20 & 262,05 & 262,05 & 89,90 & 467,04 & 68,03 & 3,12 & 52,92 & 175,95 & 22,52 & 22,52 & 162,79 \\
\hline Pelophylax perezi & 30SVH33 & 100,00 & 163,99 & 116,79 & 36,00 & 6826,59 & 351,34 & 33,03 & 318,31 & 117,36 & 255,90 & 255,90 & 81,46 & \begin{tabular}{|c|}
484,88 \\
\end{tabular} & 69,84 & 3,89 & 51,35 & 181,73 & 26,11 & 26,11 & 165,59 \\
\hline Pelophylax perezi & 30SVH34 & 100,00 & 153,79 & 120,08 & 36,59 & 6892,22 & 345,85 & 21,45 & 324,40 & 106,64 & 246,91 & 246,91 & 71,05 & 508,68 & 71,43 & 4,85 & 49,44 & 188,17 & 31,19 & 31,19 & 169,55 \\
\hline Pelophylax perezi & $\begin{array}{l}30 \mathrm{SVH} 35 \\
\end{array}$ & 100,00 & $\begin{array}{l}13,153 \\
140,37\end{array}$ & $\begin{array}{l}123,00 \\
123,03\end{array}$ & 37,00 & $\begin{array}{l}0.03,2,24 \\
6930,83\end{array}$ & $\begin{array}{l}34,05 \\
336,74\end{array}$ & \begin{tabular}{|l|l|}
7,07 \\
7,0
\end{tabular} & \begin{tabular}{|l|}
329,67 \\
326
\end{tabular} & \begin{tabular}{|c|}
100,04 \\
92,90
\end{tabular} & \begin{tabular}{|l|}
234,50 \\
2340
\end{tabular} & \begin{tabular}{|l|}
234,50 \\
23,5
\end{tabular} & $\begin{array}{l}1,, 03 \\
57,87\end{array}$ & 542,59 & $\begin{array}{l}11,45 \\
73,30\end{array}$ & $\begin{array}{l}4,00 \\
6,44\end{array}$ & $\begin{array}{l}44,44 \\
46,68\end{array}$ & \begin{tabular}{|l|}
196,41 \\
196,41
\end{tabular} & \begin{tabular}{|l|l|}
38,99 \\
38
\end{tabular} & $\begin{array}{l}1,11 \\
38,99\end{array}$ & $\begin{array}{l}105,75 \\
175,76\end{array}$ \\
\hline Pelophylax perezi & $30 \mathrm{SVH} 36$ & 100,00 & 147,72 & 123,40 & 37,00 & 6898,34 & 342,58 & 13,64 & 328,94 & 101,11 & 241,08 & 241,08 & 64,94 & 497,93 & 66,21 & 5,07 & 46,86 & 178,98 & 34,49 & 34,49 & 160,34 \\
\hline Pelophylax perezi & 30SVH37 & 100,00 & 147,75 & 124,45 & 37,01 & 6881,14 & 342,70 & 13,11 & 329,59 & 114,63 & 240,86 & 240,86 & 65,12 & 481,28 & 62,21 & 4,71 & 46,21 & 171,07 & 34,39 & 34,39 & 152,79 \\
\hline Pelophylax perezi & 30SVH38 & 100,00 & 148,85 & 125,41 & 37,41 & 6858,53 & 343,64 & 13,66 & 329,98 & 131,73 & 241,52 & 241,52 & 66,19 & \begin{tabular}{|l|l|}
460,18 \\
\end{tabular} & 57,72 & 4,16 & 45,48 & 163,18 & 33,46 & 33,46 & 143,98 \\
\hline Pelophylax perezi & $30 \mathrm{SVH} 40$ & 100,00 & 174,85 & 110,15 & 35,5 & 6627,02 & 352,03 & 47,89 & 304,14 & 122,42 & 263,74 & 263,74 & 94,66 & 450,93 & 65,43 & 3,1 & 53,62 & 170,19 & 20,72 & 20,72 & 159,75 \\
\hline Pelophylax perezi & $30 \mathrm{SVH} 41$ & 100,00 & 172,06 & 112,09 & 36,00 & 6687,70 & 352,28 & 43,94 & 308,34 & 125,90 & 261,96 & 261,96 & 91,14 & 458,41 & $\begin{array}{l}6,63,63 \\
\end{array}$ & 3,46 & 52,76 & $\begin{array}{l}173,03 \\
\end{array}$ & 22,34 & 22,34 & 160,08 \\
\hline Pelophylax perezi & $30 \mathrm{SVH} 42$ & 100,00 & 168,91 & 114,17 & 36,00 & 6738,83 & 351,87 & 39,52 & 312,34 & 122,59 & 259,43 & 259,43 & 87,43 & 461,65 & 66,40 & 3,64 & 51,84 & 173,28 & 24,00 & 24,00 & 158,57 \\
\hline Pelophylax perezi & $30 \mathrm{SVH} 43$ & 100,00 & 163,33 & 116,73 & 36,05 & \begin{tabular}{|l|l|}
6798,84 \\
\end{tabular} & 349,91 & 32,62 & 317,29 & 116,79 & 254,96 & 254,96 & 81,34 & 471,24 & 66,79 & 4,03 & 50,53 & 175,58 & 26,70 & 26,70 & 158,96 \\
\hline Pelophylax perezi & $30 \mathrm{SVH} 44$ & 100,00 & 148,33 & 120,66 & 36,76 & 6890,83 & 341,28 & 15,92 & 325,37 & 100,84 & 241,58 & 241,58 & 65,94 & 515,72 & 70,99 & 5,67 & 47,88 & 89,17 & 34,67 & 34,67 & 168,88 \\
\hline Pelophylax perezi & 30SVH45 & 100,00 & $\begin{array}{l}135,75 \\
135,5\end{array}$ & 123,29 & 37,00 & $\begin{array}{l}69015,99 \\
6915\end{array}$ & $\begin{array}{l}34,20 \\
332,29\end{array}$ & $\begin{aligned} 3,01 \\
3,01 \\
\end{aligned}$ & 329,29 & \begin{tabular}{|c|}
0,040 \\
87,90
\end{tabular} & 229,84 & 229,84 & 53,68 & 550,14 & 72,97 & 7,40 & 45,32 & \begin{tabular}{|l|l|}
197,48 \\
\end{tabular} & 42,56 & 42,56 & $\begin{array}{l}175,34 \\
175,34\end{array}$ \\
\hline Pelophylax perezi & $30 \mathrm{SVH} 46$ & 100,00 & 146,07 & 123,18 & 37,00 & 6878,33 & 340,31 & 12,33 & 327,98 & 99,86 & 239,18 & 239,18 & 63,76 & 494,85 & 65,02 & 5,43 & 45,99 & 177,10 & 36,01 & 36,01 & 157,28 \\
\hline Pelophylax perezi & \begin{tabular}{|l|l|}
30 SVH47 \\
\end{tabular} & 100,00 & 145,99 & 124,14 & 37,00 & 6870,11 & 340,45 & 11,56 & 328,90 & \begin{tabular}{r|}
119,88 \\
\end{tabular} & 238,96 & 238,96 & 63,64 & 480,10 & 61,46 & 5,12 & 45,32 & 170,58 & 36,08 & 36,08 & 150,46 \\
\hline Pelophylax perezi & $30 \mathrm{SVH} 48$ & 100,00 & 146,49 & 124,96 & 37,16 & 6857,76 & 340,81 & 11,58 & 329,23 & 128,84 & 239,18 & 239,18 & 63,97 & 464,11 & 57,69 & 5,01 & 44,44 & 164,26 & 35,99 & 35,99 & 143,41 \\
\hline Pelophylax perezi & $30 \mathrm{SVH} 49$ & 100,00 & 147,50 & 125,45 & 37,46 & 6835,61 & 341,49 & 11,92 & 329,56 & 130,52 & 239,71 & 239,71 & 65,16 & 447,70 & 54,38 & 4,81 & 43,65 & 157,62 & 35,58 & 35,58 & 136,44 \\
\hline Pelophylax perezi & $\begin{array}{l}30 \mathrm{SVH} 50 \\
3\end{array}$ & 100,00 & 164,82 & $\frac{2 x}{11}$ & 36,00 & $\begin{array}{l}0.53,014 \\
6714,47\end{array}$ & 346,88 & $\begin{array}{ll}1,25 \\
36,63\end{array}$ & \begin{tabular}{|l|l|}
310,25 \\
\end{tabular} & \begin{tabular}{|l|}
117,82 \\
117
\end{tabular} & $\mid$ & \begin{tabular}{|l|}
255,25 \\
25,1
\end{tabular} & $\begin{array}{l}\mid \\
84,05 \\
\end{array}$ & 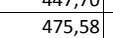 & $\begin{array}{l}34,50 \\
68,54 \\
\end{array}$ & $\begin{array}{l}4,014 \\
4,43\end{array}$ & $\begin{array}{l}4,03 \\
51,68\end{array}$ & \begin{tabular}{|l|}
$179,36<$ \\
\end{tabular} & $\begin{array}{l}3,00 \\
25,53 \\
\end{array}$ & $\begin{array}{l}\frac{13,00}{25,53} \\
\end{array}$ & 164,36 \\
\hline Pelophylax perezi & $30 \mathrm{SVH} 51$ & 100,00 & 170,07 & 112,55 & 36,00 & 6660,25 & 349,90 & 41,69 & 308,21 & 123,95 & 259,56 & 259,56 & 89,53 & 446,53 & 63,47 & 3,60 & 51,54 & 166,90 & 23,22 & 23,22 & 153,44 \\
\hline Pelophylax perezi & 30 SVH52 & 100,00 & 170,28 & 113,68 & 36,05 & 6664,14 & 350,71 & 41,16 & 309,55 & $\mid 124,24$ & 259,68 & 259,68 & 89,45 & 436,84 & 61.14 & 3,31 & 50,87 & $\mid 161,84$ & 23,39 & 23,39 & 148,33 \\
\hline Pelophylax perezi & 30SVH53 & 100,00 & 163,20 & 116,49 & 36,24 & 6752,17 & 348,31 & 32,62 & 315,69 & 116,77 & 254,13 & 254,13 & 81,79 & 455,50 & 63,27 & 4,01 & 49,48 & 168,26 & 26,90 & 26,90 & 151,61 \\
\hline Pelophylax perezi & 30SVH54 & 100,00 & 152,54 & 119,68 & 36,80 & 6830,84 & 342,73 & 20,42 & 322,31 & 105,50 & 244,79 & 244,79 & 70,64 & 485,61 & 65,96 & 5,25 & 47,56 & 177,26 & 32,77 & 32,77 & 15 \\
\hline Pelophylax perezi & $\begin{array}{l}30 \mathrm{SVH} 555 \\
\end{array}$ & $\begin{array}{l}100,00 \\
\end{array}$ & $\begin{array}{l}13,54 \\
144,77\end{array}$ & 1121,90 & $\begin{array}{l}30,00 \\
37,00\end{array}$ & $\begin{array}{l}6050,094 \\
6869,73\end{array}$ & 338,06 & $\begin{array}{l}0,44 \\
11,91 \\
\end{array}$ & \begin{tabular}{|l|l|}
326,15 \\
32,1
\end{tabular} & \begin{tabular}{|l|}
97,47 \\
97
\end{tabular} & \begin{tabular}{|l|}
237,79 \\
23,7
\end{tabular} & \begin{tabular}{|l|}
237,79 \\
23,7
\end{tabular} & 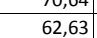 & \begin{tabular}{|l}
403,01 \\
502,61
\end{tabular} & $\begin{array}{l}6,30 \\
66,60 \\
\end{array}$ & $\frac{3,25}{6,10}$ & $\begin{array}{ll}45,87 \\
45,\end{array}$ & $\begin{array}{l}180,92 \\
182\end{array}$ & $\begin{array}{l}32,113 \\
37,33 \\
\end{array}$ & $\begin{array}{l}32,111 \\
37,33\end{array}$ & $\begin{array}{l}151,03 \\
159,71\end{array}$ \\
\hline Pelophylax perezi & 30 SVH56 & 100,00 & 144,76 & 122,97 & 37,00 & 6864,75 & 338,35 & 11,25 & 327,10 & 104,27 & 237,83 & 237,83 & 62,92 & 490,56 & 63,53 & 5,96 & 45,01 & 174,62 & 37,62 & 37,62 & 153,92 \\
\hline Pelophylax perezi & 30SVH57 & 100,00 & 146,16 & 123,48 & 37,01 & 6850.53 & 339,36 & 11.95 & 327.41 & 127.02 & 238,77 & 238,77 & 63,90 & 471.66 & 59,66 & 5,38 & 44,42 & 167,22 & 36.88 & 36.88 & 146,25 \\
\hline Pelophylax perezi & 30SVH58 & 100,00 & 146,40 & 124,25 & 37,12 & 6837,86 & 339,53 & 11,86 & 327,67 & 128,63 & 238,77 & 238, & 64,06 & 458,37 & 56,50 & 5,18 & 43,79 & 162,01 & 36,71 & 36,71 & 140,19 \\
\hline Pelophylax perezi & 30SVH59 & 100,00 & 144,79 & 124,84 & 37,39 & 6825,02 & 338,13 & 9,79 & 328,35 & 127,27 & 236,96 & 236,96 & 62,84 & 454,60 & 55,18 & 5,40 & 42,85 & 160,04 & 38,25 & 38,25 & 136,98 \\
\hline
\end{tabular}




\begin{tabular}{|c|c|c|c|c|c|c|c|c|c|c|c|c|c|c|c|c|c|c|c|c|c|}
\hline TAXON & UTM & $\mathrm{km} 2$ & B101 & B102 & $\mathrm{BIO3}$ & BIO4 & B105 & B106 & B107 & B108 & B109 & B1010 & B1011 & BIO12 & 81013 & BIO14 & BIO15 & B1016 & B1017 & BIO18 & B1019 \\
\hline Pelophylax perezi & 30SVH60 & 100,00 & 162,46 & 113,54 & 36,01 & 6671,92 & 344,00 & 34,08 & 309,92 & 115,57 & 252,36 & 252,36 & 82,38 & 462,21 & 64,74 & 4,69 & 50,18 & 171,91 & 26,73 & 26,73 & 156,73 \\
\hline Pelophylax perezi & 30 SVH61 & 100,00 & 161,65 & 114,69 & 36,03 & 6700,25 & 344,56 & 32,49 & 312,06 & 114,79 & 251,90 & 251,90 & 81,13 & 460,62 & 64,02 & 4,58 & 49,55 & 170,56 & 27,51 & 27,51 & 154,40 \\
\hline Pelophylax perezi & 30SVH62 & 100,00 & 164,73 & 114,86 & 36,16 & 6674,53 & 346,68 & 35,18 & 311,50 & 118,38 & 254,51 & 254,51 & 84,26 & 441,02 & 60,50 & 4,08 & 49,19 & 162,05 & 26,24 & 26,24 & 146,58 \\
\hline Pelophylax perezi & 30SVH63 & 100,00 & 164,47 & 116,01 & 36,64 & 6684,56 & 347,21 & 34,17 & 313,04 & 118,42 & 254,30 & 254,30 & 83,66 & 433,40 & 58,56 & 3,93 & 48,54 & 157,97 & 26,50 & 26,50 & 142,27 \\
\hline Pelophylax perezi & 30SVH64 & 100,00 & 154,19 & 119,16 & 36,95 & $\begin{array}{ll}6780,69 \\
\end{array}$ & 342,24 & 22,47 & 319,76 & 107,34 & 245,70 & 245,70 & 72,69 & \begin{tabular}{|l|l|}
464,67 \\
\end{tabular} & 61,84 & 5,05 & 46,69 & 168,01 & 32,31 & 32,31 & 148,91 \\
\hline Pelophylax perezi & 30SVH65 & 100,00 & 145,01 & 121,56 & 37,00 & 6830,51 & 336,83 & 12,36 & 324,47 & 98,63 & 237,55 & 237,55 & 63,40 & 490,13 & 63,78 & 6,22 & 44,91 & 175,06 & 37,89 & 37,89 & 153,67 \\
\hline Pelophylax perezi & 30 SVH66 & 100,00 & 143,03 & 122,68 & 37,00 & 6836,81 & 335,70 & 9,75 & 325,95 & 116,32 & 235,58 & 235,58 & 61,51 & 486,52 & 62,02 & 6,23 & 43,92 & 172,68 & 39,25 & 39,25 & 150,32 \\
\hline Pelophylax perezi & \begin{tabular}{|l|l|}
30 SVH67 \\
\end{tabular} & 100,00 & 145,63 & 123,05 & 37,01 & 6821,12 & 337,65 & 11,86 & 325,78 & 127,34 & 237,73 & 237,73 & 63,69 & $\begin{array}{l}465,95 \\
465\end{array}$ & 58,14 & 5,86 & 43,54 & 164,86 & 38,03 & 38,03 & 142,61 \\
\hline Pelophylax perezi & 30SVH69 & 100,00 & 146,29 & 124,01 & 37,65 & 6792,17 & 337,92 & 11,67 & 326,24 & 128,97 & 237,93 & 237,93 & 64,61 & 442,55 & 53,97 & 5,37 & 42,74 & 155,66 & 37,81 & 37,81 & 132,21 \\
\hline Pelophylax perezi & 30SVH70 & 100,00 & 163,49 & 113,30 & 36,27 & 6589,86 & 342,51 & 35,32 & 307,18 & 117,14 & 252,12 & 252,14 & 84,23 & 435,80 & 58,97 & 4,42 & 48,99 & 159,37 & 26,10 & 26,45 & 145,56 \\
\hline Pelophylax perezi & 30SVH71 & 100,00 & 158,31 & 115,52 & 36,50 & 6665,09 & 341,10 & 28,90 & 312,20 & 111,62 & 248,20 & 248,20 & 78,44 & 454,27 & 61,34 & 5,01 & 48,06 & 165,90 & 29,30 & 29,35 & 149,21 \\
\hline Pelophylax perezi & 30SVH72 & 100,00 & 159,66 & 115,97 & 36,73 & 6665,73 & 342,40 & 29,73 & 312,66 & 113,17 & 249,38 & 249,38 & 79,49 & 443,50 & 59,31 & 4,74 & 47,62 & 161,06 & 29,03 & 29,03 & 144,19 \\
\hline Pelophylax perezi & 30SVH73 & 100,00 & 158,57 & 117,19 & 36,92 & 6693,90 & 342,66 & 27,94 & 314,72 & 112,08 & 248,70 & 248,70 & 78,07 & 440,84 & 58,22 & 4,71 & 46,95 & 159,03 & 29,90 & 29,90 & 141,52 \\
\hline Pelophylax perezi & 30 SVH74 & 100,00 & 156,35 & 118,46 & 37,00 & 6713,76 & 341,89 & 24,83 & 317,06 & 109,79 & 246,80 & 246,80 & 75,59 & 442,10 & 57,42 & 4,87 & 45,98 & 158,07 & 31,52 & 31,52 & 139,85 \\
\hline Pelophylax perezi & 30SVH75 & 100,00 & 148,09 & 120,87 & 37,00 & 6772,70 & 337,37 & \begin{tabular}{ll|}
15,63 \\
\end{tabular} & 321,74 & 110,62 & 239,64 & 239,64 & 66,96 & 466,38 & 59,56 & 5,92 & 44,41 & 165,41 & 36,67 & 36,67 & 144,59 \\
\hline Pelophylax perezi & 30SVH76 & 100,00 & 142,16 & 122,42 & 37,00 & 6812,50 & 333,83 & 9,07 & 324,76 & 123,00 & 234,41 & 234,41 & 60,91 & 480,67 & 60,20 & 6,83 & 42,80 & 170,17 & 40,83 & 40,83 & 146,37 \\
\hline Pelophylax perezi & 30SVH78 & 100,00 & 143,55 & 123,34 & 37,31 & 6789,82 & 334,83 & 9,47 & 325,36 & 125,28 & 235,28 & 235,28 & 62,08 & 457,77 & 56,10 & 6,16 & 41,93 & 161,07 & 40,42 & 40,42 & 136,31 \\
\hline Pelophylax perezi & 30SVH79 & 100,00 & 142,29 & 124,04 & 37,87 & 6792,63 & 333,87 & 8,03 & 325,84 & 124,32 & 234,12 & 234,12 & 60,79 & 453,68 & 55,35 & 6,31 & 41,55 & 159,05 & 41,42 & 41,42 & 133,61 \\
\hline Pelophylax perezi & 30 SVH80 & 100,00 & 165,92 & 112,52 & 36,74 & 6487,59 & 341,30 & 38,10 & 303,20 & 120,27 & 252,95 & 252,99 & 87,56 & 406,50 & 53,04 & 4,08 & 48,16 & 145,92 & 24,94 & 25,74 & 133,91 \\
\hline Pelophylax perezi & 30SVH81 & 100,00 & 159,91 & 114,97 & 36.91 & 6589,05 & 339,97 & 30,88 & $\mid 309,10$ & 113,51 & 248,51 & 248,56 & 80,65 & 429,66 & 56,23 & 4,73 & 47,06 & 154,55 & 28.56 & 29,46 & 139,10 \\
\hline Pelophylax perezi & 30 SVH82 & 100,00 & 160,16 & 115,77 & 36,99 & 6603,46 & 340,81 & $\begin{array}{ll}30,47 \\
\end{array}$ & 310,34 & 113,89 & 248,95 & 248,96 & 80,58 & 424,64 & 55, & 4,6 & 46,62 & 151,94 & 28,97 & 29,23 & 135,88 \\
\hline Pelophylax perezi & 30SVH83 & 100,00 & 152,89 & 118,31 & 37,00 & 6684,40 & 337,84 & 21,87 & 315,97 & 105,94 & 242,93 & 242,93 & 72,76 & 448,93 & 57,69 & 5,49 & 45,15 & 159,88 & 33,55 & 33,55 & 140,90 \\
\hline Pelophylax perezi & 30SVH84 & 100,00 & 151,55 & 119,32 & 37,00 & \begin{tabular}{|l|l|}
6704,51 \\
\end{tabular} & 337,58 & 19,89 & 317,69 & 108,82 & 241,97 & 241,97 & 71,14 & 447,91 & 56,74 & 5,63 & 44,35 & 158,38 & 34,87 & 34,87 & 138,63 \\
\hline Pelophylax perezi & 30 SVH 85 & 100,00 & 146,29 & 120,92 & 37,01 & 6742,36 & 334,64 & 13,91 & 320,72 & 123,55 & 237,31 & 237,31 & 65,56 & 461,99 & 57,69 & 6,39 & 43,18 & 163,03 & 38,59 & 38,59 & 140,59 \\
\hline Pelophylax perezi & 30SVH87 & 100,00 & 139,49 & 123,06 & 37,12 & 6786,70 & 330,69 & 6,01 & 324,68 & 120,62 & 231,38 & 231,38 & 58,45 & 474,48 & 58,55 & 7,18 & 41,23 & 167,08 & 43,86 & 43,86 & 140,26 \\
\hline Pelophylax perezi & 30SVH88 & 100,00 & 141,78 & 123,04 & 37,28 & 6771,16 & 332,17 & 7,86 & 324,31 & 123,02 & 233,21 & 233,21 & 60,82 & 458,14 & 56,45 & 6,96 & 41,01 & 160,90 & 42,93 & 42,93 & 134,25 \\
\hline Pelophylax perezi & $\begin{array}{l}30 \text { SVH89 } \\
\end{array}$ & 100,00 & 140,90 & 123,53 & 37,70 & 6775,70 & 331,73 & $\begin{array}{l}7,00 \\
7,22\end{array}$ & \begin{tabular}{|l|}
324,51 \\
\end{tabular} & $\begin{array}{l}122,73 \\
120\end{array}$ & \begin{tabular}{|l|}
232,59 \\
232
\end{tabular} & 232,59 & 59,84 & $\mid 453,45$ & 55,56 & $\begin{array}{l}7,05 \\
7,05\end{array}$ & 40,45 & 158,53 & \begin{tabular}{|l|l|}
43,93 \\
4
\end{tabular} & $\begin{array}{l}43,93 \\
43,93\end{array}$ & 131,40 \\
\hline Pelophylax perezi & 30SVH90 & 100,00 & 157,60 & 114,58 & 37,00 & 6514,66 & 335,62 & 29,21 & 306,41 & 111,28 & 245,21 & 245,31 & 79,36 & 423,56 & 53,86 & 5,10 & 46,10 & 150,25 & 29,61 & 31,51 & 135,57 \\
\hline Pelophylax perezi & 30SVH91 & 100,00 & 157,54 & 115,40 & 37,00 & 6535,99 & 336,60 & 28,51 & 308,10 & 111,21 & 245,42 & 245,54 & 79,16 & 422,17 & 53,42 & 5,06 & 45,63 & 149,34 & 30,23 & 31,69 & 133,69 \\
\hline Pelophylax perezi & 30SVH92 & 100,00 & 154,53 & 116,88 & 37,00 & 6587,96 & 336,01 & 24,53 & 311,47 & 108,27 & 243,29 & 243,34 & 75,54 & 431,61 & 54,32 & 5,40 & 44,88 & 152,25 & 32,54 & 33,10 & 134,77 \\
\hline Pelophylax perezi & 30SVH93 & 100,00 & 154,94 & 117,56 & 37,00 & 6602,10 & 336,82 & 24,36 & 312,46 & 111,42 & 243,77 & 243,82 & 75,61 & 425,90 & 53,23 & 5,27 & 44,41 & 149,47 & 32,83 & 33,28 & 131,48 \\
\hline Pelophylax perezi & 30SVH94 & 100,00 & 149,32 & 119,44 & 37,01 & 6665,62 & 334,43 & $\begin{array}{l}4,30 \\
17,92 \\
\end{array}$ & 316,51 & \begin{tabular}{|l|l|l|l|l|}
125,98 \\
\end{tabular} & 239,23 & \begin{tabular}{|l|}
239,23 \\
230
\end{tabular} & 69,49 & 442,82 & 55,28 & 6,04 & 443,18 & \begin{tabular}{|l|}
155,66 \\
\end{tabular} & \begin{tabular}{|l|}
$2,0,73$ \\
36,3
\end{tabular} & $\begin{array}{l}30,200 \\
36,77\end{array}$ & 134,33 \\
\hline Pelophylax perezi & 30SVH95 & 100,00 & 143,64 & 121,02 & 37,12 & 6708,19 & 331,32 & 11,41 & 319,91 & 124,45 & 234,24 & 234,24 & 63,41 & 460,92 & 57,49 & 6,88 & 41,94 & 162,34 & 40,95 & 40,95 & 137,51 \\
\hline Pelophylax perezi & 30SVH96 & 100,00 & 142,46 & 121,82 & 37,42 & 6720,53 & 330,88 & 9,75 & 321,13 & 123,38 & 233,27 & 233,27 & 62,18 & 459,70 & 57,23 & 7,12 & 41,27 & 161,69 & 42,24 & 42,24 & 135,50 \\
\hline Pelophylax perezi & 30SVH97 & 100,00 & 139,67 & 122,69 & 37,56 & 6736,95 & 329,12 & 6,52 & 322,60 & 120,83 & 230,82 & 230,82 & 59,15 & 465,53 & 57,73 & 7,51 & 40,27 & 163,32 & 44,75 & 44,75 & 135,38 \\
\hline Pelophylax perezi & 30SVH98 & 100,00 & 139,86 & 122,99 & 37,83 & 6736,23 & 329,23 & 6,42 & 322,81 & 121,03 & 230,88 & 230,88 & 59,26 & 458,89 & 56,75 & 7,38 & 39,95 & 160,64 & 45,17 & 45,17 & 132,16 \\
\hline Pelophylax perezi & 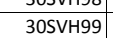 & 100,00 & $\begin{array}{l}13,00 \\
139,69\end{array}$ & $\begin{array}{ll}12,53,08 \\
123,08\end{array}$ & $\begin{array}{l}37,05 \\
37,79\end{array}$ & $\mid 6748,69$ & 329,19 & $\begin{array}{l}0,42 \\
6,02\end{array}$ & \begin{tabular}{|l|}
323,1717 \\
323,17
\end{tabular} & $\begin{array}{l}\mid 21,03 \\
121,15 \\
\end{array}$ & $\mid$\begin{tabular}{|l|}
230,91 \\
230
\end{tabular} & \begin{tabular}{|l|}
230,91 \\
230
\end{tabular} & $\begin{array}{l}35,20 \\
58,94\end{array}$ & $\begin{array}{l}450,03 \\
453,36\end{array}$ & 50,73 & $\begin{array}{l}7,00 \\
7,39\end{array}$ & 39,36 & \begin{tabular}{|l|}
$158,10,10$ \\
\end{tabular} & $\begin{array}{l}4,11 \\
45,71 \\
\end{array}$ & $\begin{array}{l}44,11 \\
45,71\end{array}$ & $\begin{array}{l}15,10 \\
129,19\end{array}$ \\
\hline Pelophylax perezi & 30SVJO0 & 100,00 & 148,87 & 127,44 & 38,00 & 6881,30 & 345,65 & 11,99 & 333,65 & 132,29 & 241,78 & 241,78 & 65,87 & 452,13 & 55,12 & 4,00 & 45,43 & 158,93 & 32,90 & 32,90 & 140,79 \\
\hline Pelophylax perezi & 30SVJ01 & 100,00 & 145,96 & 127,77 & 37,97 & 6873,92 & 342,90 & 8,98 & 333,92 & 129,55 & 238,77 & 238,77 & 63,01 & 448,95 & 53,61 & 4,16 & 44,37 & 157,40 & 34,68 & 34,68 & 137,48 \\
\hline Pelophylax perezi & 30SVJO2 & 100,00 & 143,81 & 127,26 & 38,00 & 6880,20 & 340,49 & 7,06 & 333,44 & 127,11 & 236,74 & 236,74 & 60,84 & 446,77 & 53,00 & 4,5 & 43,43 & 156,01 & 36,44 & 36,44 & 134,77 \\
\hline Pelophylax perezi & $\begin{array}{l}30 \mathrm{SVJ} 04 \\
\end{array}$ & 100,00 & 135,10 & 124,96 & 37,05 & 6881,69 & 330,80 & 0,21 & 330,58 & 118,02 & 228,37 & 228,37 & 52,55 & 466,01 & 54,44 & 6,4 & 40,85 & 160,88 & 43,42 & 43,42 & 136,69 \\
\hline Pelophylax perezi & 30 SVJ05 & 100,00 & 130,97 & 123,47 & 37,00 & 6870,26 & 325,77 & $-2,56$ & 328,33 & 113,57 & 224,31 & 224,31 & 48,85 & 475,61 & 55,56 & 7,50 & 39,55 & 162,95 & 47,10 & 47,10 & 137,71 \\
\hline Pelophylax perezi & 30SVJ06 & 100,00 & 129,19 & 121,97 & 37,00 & 6851,31 & 322,54 & $-3,91$ & 326,45 & 111,79 & 222,27 & 222,27 & 47,47 & 477,10 & 55,90 & 8,28 & 38,71 & 162,20 & 49,38 & 49,38 & 136,52 \\
\hline Pelophylax perezi & 30SVJ07 & 100,00 & 131,62 & 120,57 & 36,83 & 6862,95 & 323,58 & $-1,03$ & 324,61 & 114,59 & 224,92 & 224,92 & 49,54 & 460,03 & 54,08 & 8,21 & 38,10 & 155,29 & 48,46 & 48,46 & 130,47 \\
\hline Pelophylax perezi & 30SVJ08 & 100,00 & 128,99 & 118,95 & 36,32 & 6836,28 & 319,54 & $-2,78$ & 322,32 & 1,71 & 221,98 & 222,00 & 47,55 & 465,26 & 54,8 & 9,07 & 37,28 & 55,83 & 51,08 & 51,10 & 130,69 \\
\hline Pelophylax perezi & $\begin{array}{l}305 \mathrm{~s} J 09 \\
\end{array}$ & 100,00 & 139,00 & 117,17 & 36,00 & | $68073,60 \mid$ & 327,36 & 5,94 & 321,43 & 123,10 & 232,25 & 232,25 & 56,13 & $\begin{array}{l}423,66 \\
423,66\end{array}$ & 49,4 & 8,03 & 37,47 & $\begin{array}{l}140,40 \\
140\end{array}$ & 45,81 & 45,81 & 118,53 \\
\hline Pelophylax perezi & 30SVJ11 & 100,00 & 147,16 & 128,77 & 38,00 & 6852,44 & 343,75 & 9,46 & 334,29 & 131,07 & 239,31 & 239,31 & 64,03 & 431,67 & 52, & 4,00 & 44,03 & 151,79 & 33,87 & 33,87 & 130,75 \\
\hline Pelophylax perezi & $\begin{array}{l}0 \text { SVJ12 } \\
\end{array}$ & 100,00 & 145,34 & 127,97 & 38,00 & 6855,16 & 341,47 & 8,08 & 333,38 & 129,08 & 237,77 & 237,77 & 62,36 & 430,18 & 51,64 & 4,23 & 43,15 & 150,32 & 35,40 & 35,40 & 128,68 \\
\hline Pelophylax perezi & 30SVJ13 & 100,00 & 143,91 & 126,68 & 37,89 & 6858,15 & 339,39 & 7,36 & 332,03 & 127,80 & 236,59 & 236,59 & 61,18 & 430,37 & 51,26 & 4,76 & 42,04 & 149,31 & 37,37 & 37,37 & 127,06 \\
\hline Pelophylax perezi & 30SVJ14 & 100,00 & 138,22 & 125,37 & 37,23 & 6874,87 & 333,56 & 2,55 & 331,01 & 121,61 & 231,30 & 231,30 & 55,50 & 448,08 & 52,82 & 5,88 & 40,84 & 54 & 41,71 & 41,71 & 130,77 \\
\hline Pelophylax perezi & $\frac{30 \mathrm{SVJ}}{305}$ & 100,00 & 130,24 & 12 & 37, & \begin{tabular}{|l|l|}
6870,43 \\
\end{tabular} & 327,87 & $\begin{array}{c}-, 50, \\
-0,78 \\
\end{array}$ & \begin{tabular}{|l|}
328,66 \\
32,6
\end{tabular} & \begin{tabular}{|l|}
116,261 \\
\end{tabular} & \begin{tabular}{|l|}
226,57 \\
220
\end{tabular} & \begin{tabular}{|l|}
226,57 \\
20
\end{tabular} & 51,09 & $\begin{array}{l}440,00 \\
461,95 \\
\end{array}$ & 54, & $\frac{3,00}{7,10}$ & $\begin{array}{l}30,04 \\
39,51\end{array}$ & \begin{tabular}{|l|}
158,08 \\
158,0
\end{tabular} & \begin{tabular}{|l|l|}
45,73 \\
45
\end{tabular} & $\begin{array}{l}44,1 / 73 \\
45,73\end{array}$ & 133,26 \\
\hline Pelophylax perezi & 30SVJ16 & 100,00 & 125,61 & 122,16 & 37,00 & 6838,57 & 319,31 & $-6,62$ & 325,93 & 107,87 & 218,67 & 218,67 & 44,38 & 488,71 & 57,26 & 8,93 & 37,88 & 165,76 & 52,09 & 52,09 & 139,21 \\
\hline Pelophylax perezi & 30SVJ17 & 100,00 & 131,07 & 120,62 & 36,84 & 6857,65 & 322,85 & $-1,81$ & 324,66 & 114,03 & $\begin{array}{l}224,17 \\
22,1\end{array}$ & 224,17 & $\begin{array}{l}49,04 \\
49,04\end{array}$ & 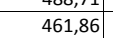 & 54,09 & 8,49 & 37,81 & 155,32 & 49,35 & 49,35 & 130,82 \\
\hline Pelophylax perezi & 30SVJ18 & 100,00 & 131,14 & 119,15 & 36,31 & 6845,13 & 321,53 & $-1,08$ & 322,61 & 114,18 & 224,04 & 224,04 & 49,31 & 457,24 & 53,43 & 8,76 & 37,21 & 152,28 & 50,13 & 50,13 & 128,56 \\
\hline Pelophylax perezi & 30SVJ19 & 100,00 & 136,40 & 117,32 & 36,00 & 6863,28 & 324,79 & 3,71 & 321,08 & 120,36 & 229,45 & 229,45 & 53,82 & 434,31 & 50,33 & 8,44 & 37,00 & 142,90 & 47,74 & 47,74 & 12 \\
\hline Pelophylax perezi & $305 \mathrm{~V} 220$ & $\begin{array}{l}100,00 \\
\end{array}$ & $\begin{array}{l}150,40 \\
147,62\end{array}$ & 128,19 & 38,00 & $\begin{array}{l}\mid c 00,200 \\
6846,08\end{array}$ & 343,72 & \begin{tabular}{|c|c|}
10,63 \\
10,
\end{tabular} & \begin{tabular}{|l|}
333,09 \\
330
\end{tabular} & \begin{tabular}{|l|}
131,12 \\
130
\end{tabular} & \begin{tabular}{|l|}
239,85 \\
239
\end{tabular} & \begin{tabular}{|l|}
239,85 \\
239
\end{tabular} & $\begin{array}{l}30,02 \\
64,75 \\
\end{array}$ & $\begin{array}{l}354,51 \\
437,74\end{array}$ & $\begin{array}{l}50,53 \\
53,16\end{array}$ & $\begin{array}{l}0,44^{4} \\
4,03\end{array}$ & $\begin{array}{ll}1,200 \\
4,23\end{array}$ & \begin{tabular}{|l|}
154,480 \\
154
\end{tabular} & \begin{tabular}{|l|l|}
33,94 \\
33
\end{tabular} & $\begin{array}{ll}1,1 / 4 \\
33,94\end{array}$ & 133,55 \\
\hline Pelophylax perezi & 30 SVJ22 & 100,00 & 146,95 & 127,78 & 38,00 & 6837,73 & 342,15 & 9,75 & 332,40 & 130,93 & 239,15 & 239,15 & 64,08 & 418,04 & 50,58 & 4,00 & 43,23 & 146,07 & 34,69 & 34,69 & 124,21 \\
\hline Pelophylax perezi & 30 SVJ23 & 100,00 & 145,52 & 126.56 & 37,99 & 6840,83 & 340,04 & 874 & 331,30 & 129,61 & 237,74 & 237,74 & 62.74 & 420.08 & 50,24 & 4,60 & 42,20 & 145.53 & 36.85 & 36.85 & 123,39 \\
\hline Pelophylax perezi & 30 SVJ24 & 100,00 & 139,28 & 125,41 & 37,44 & 6862,47 & 334,05 & 3,54 & 330,51 & 122,87 & 232,12 & 232,12 & 56,73 & 440,29 & 52,10 & 5,83 & 40,52 & 151 & 41,41 & 41,41 & 127,94 \\
\hline Pelophylax perezi & $30 \mathrm{SV} J 25$ & 100,00 & 134,07 & 123,99 & 37,01 & 6863,34 & 328,14 & $-0,46$ & 328,60 & 117,11 & 227,11 & 227,11 & 51,84 & 456,90 & 53,47 & $\begin{array}{l}7,008 \\
7,08\end{array}$ & 39,26 & 155,95 & 45,73 & 45,73 & 131,37 \\
\hline
\end{tabular}




\begin{tabular}{|c|c|c|c|c|c|c|c|c|c|c|c|c|c|c|c|c|c|c|c|c|c|}
\hline TAXON & UTM & $\mathrm{km} 2$ & B101 & B102 & $\mathrm{BIO3}$ & B104 & B105 & B106 & B107 & B108 & B109 & BIO10 & B1011 & BIO12 & B1013 & BIO14 & BIO15 & B1016 & B1017 & B1018 & B1019 \\
\hline Pelophylax perezi & 30 SVJ26 & 100,00 & 131,86 & 122,48 & 37,00 & 6854,60 & 324,92 & $-1,52$ & 326,44 & 114,67 & 224,86 & 224,86 & 49,79 & 461,87 & 53,92 & 7,87 & 38,37 & 156,21 & 48,18 & 48,18 & 131,69 \\
\hline Pelophylax perezi & 30SVJ27 & 100,00 & 138,01 & 120,68 & 36,75 & 6871,08 & 329,10 & 3,85 & 325,25 & 121,88 & 230,97 & 230,97 & 55,32 & 434,99 & 50,34 & 7,21 & 38,25 & 145,27 & 44,89 & 44,89 & 123,82 \\
\hline Pelophylax perezi & $30 \mathrm{SVJ} 28$ & 100,00 & 135,25 & 119,14 & 36,33 & 6859,47 & 325,16 & 2,30 & 322,87 & 118,86 & 228,19 & 228,19 & 52,80 & 442,13 & 51,11 & 8,18 & 37,29 & 146,24 & 47,59 & 47,59 & 124,93 \\
\hline Pelophylax perezi & $305 \mathrm{~V} J 29$ & 100,00 & 137,95 & 117,35 & 36,00 & 6861,37 & 325,99 & 5,17 & 320,82 & 122,23 & 230,87 & 230,87 & 55,37 & 430,23 & 49,26 & 8,04 & 37,27 & 140,51 & 46,49 & 46,49 & 121,50 \\
\hline Pelophylax perezi & $30 \mathrm{SV} / 30$ & 100,00 & 146,76 & 127,10 & \begin{tabular}{|l|l|}
37,99 \\
\end{tabular} & 6842,75 & 342,09 & 10,56 & 331,53 & 130,08 & 239,26 & 239,26 & 64,42 & 438,42 & 53,29 & 4,09 & 43,92 & 154,52 & 34,53 & 34,53 & 133,05 \\
\hline Pelophylax perezi & 30 SVJ32 & 100,00 & 147,26 & 126,73 & 38,00 & 6819,47 & 341,26 & 10,77 & 330,49 & 131,51 & 239,21 & 239,21 & 64,75 & 418,02 & 50,40 & 4,12 & 42,60 & 145,18 & 35,91 & 35,91 & 123,62 \\
\hline Pelophylax perezi & 30SVJ33 & 100,00 & 146,07 & 125,88 & 37,83 & 6835,78 & 339,76 & 9,77 & 329,99 & 130,11 & 238,23 & 238,23 & 63,47 & 417,42 & 49,97 & 4,87 & 41,82 & 144,18 & 37,16 & 37,16 & 122,00 \\
\hline Pelophylax perezi & 30SVJ34 & 100,00 & 136,18 & 125,01 & 37,16 & 6853,50 & 330,64 & 1,10 & 329,54 & 119,39 & 229,01 & 229,01 & 53,96 & 451,78 & 53,40 & 6,54 & 39,76 & 154,97 & 44,15 & 44,15 & 130,48 \\
\hline Pelophylax perezi & $305 \mathrm{~V} J 35$ & 100,00 & 133,50 & 123,81 & 37,00 & 6852,51 & 327,30 & $-0,71$ & 328,01 & 116,49 & 226,45 & 226,45 & 51,56 & 458,12 & 53,57 & 7,31 & 39,04 & 155,94 & 46,49 & 46,49 & 131,32 \\
\hline Pelophylax perezi & $305 \mathrm{SV} 36$ & 100,00 & 135,57 & 122,39 & 37,00 & 6858,08 & 328,01 & 1,46 & 326,55 & 118,81 & 228,45 & 228,45 & 53,19 & \begin{tabular}{|l|l|}
446,68 \\
\end{tabular} & 51,84 & 7,35 & 38,52 & 150,40 & 46,07 & 46,07 & 127,53 \\
\hline Pelophylax perezi & 30SVJ37 & 100,00 & 139,10 & 120,68 & 36,88 & 6864,69 & 329,58 & 4,81 & 324,77 & 123,21 & 231,79 & 231,79 & 56,30 & 431,93 & 49,58 & 7,11 & 38,28 & 143,32 & 44,71 & 44,71 & 122,90 \\
\hline Pelophylax perezi & 30 SVJ42 & 100,00 & 147,07 & 125,73 & 37,80 & 6824,05 & 340,22 & 11,03 & 329,18 & 130,93 & 239,08 & 239,08 & 64,71 & 419,65 & 50,44 & 4,93 & 41,76 & 145,29 & 36,93 & 36,93 & 123,44 \\
\hline Pelophylax perezi & 30SVJ43 & 100,00 & 146,62 & 125,01 & $\begin{array}{l}37,45 \\
\end{array}$ & 6823,15 & 339,09 & 10,59 & 328,50 & 130,47 & 238,72 & 238,72 & 64,20 & 415,36 & 49,60 & 5,00 & 41,53 & 142,82 & 37,42 & 37,42 & 121,07 \\
\hline Pelophylax perezi & 30SVJ44 & 100,00 & 134,94 & 124,47 & \begin{tabular}{|l|}
37,18 \\
\end{tabular} & 6837,59 & 328,72 & 0,39 & 328,33 & 117,92 & 227,52 & 227,52 & 52,91 & 457,44 & 53,83 & 7,13 & 39,26 & 156,41 & 46,03 & 46,03 & 131,50 \\
\hline Pelophylax perezi & $305 \mathrm{VJ} 45$ & 100,00 & 128,65 & 123,56 & 37,03 & 6835,67 & 322,47 & $-4,44$ & 326,91 & 111,14 & 221,50 & 221,50 & 47,35 & 478,31 & 55,59 & 8,50 & 37,84 & 162,32 & 50,98 & 50,98 & 136,15 \\
\hline Pelophylax perezi & 30 SVJ46 & 100,00 & 138,17 & 122,27 & 37,00 & 6842,14 & 329,49 & 3,76 & 325,73 & 121,55 & 230,58 & 230,58 & 55,69 & 437,42 & 50,53 & 7,14 & 38,40 & 146,42 & 45,07 & 45,07 & 124,66 \\
\hline Pelophylax perezi & 30SVJ47 & 100,00 & 139,74 & 120,62 & 36,98 & 6842,33 & 329,47 & 5,55 & 323,92 & 123,77 & 231,86 & 231,86 & 57,08 & 430,01 & 49,10 & 7,06 & 38,04 & 142,10 & 44,89 & 44,89 & 122,19 \\
\hline Pelophylax perezi & 30 SVJ48 & 100,00 & 140,14 & 119,09 & \begin{tabular}{|l|l|}
36,47 \\
\end{tabular} & 6835,67 & 328,65 & 6,76 & 321,89 & 123,19 & 232,41 & 232,41 & 57,61 & 427,09 & 48,18 & 7,86 & 37,47 & 139,05 & 45,62 & 45,62 & 121,21 \\
\hline Pelophylax perezi & 30SVJ49 & 100,00 & 140,49 & 117,41 & 36,00 & 6837,43 & 327,53 & 7,89 & 319,64 & 105,80 & 232,76 & 232,76 & 57,93 & 425,16 & 47,43 & 8,03 & 37,04 & 138,04 & 45,75 & 45,75 & 121,16 \\
\hline Pelophylax perezi & 30SVI51 & 100,00 & 146,97 & 125,01 & 37,74 & 6819,39 & 339,39 & 11,22 & 328,17 & 130,10 & 238,76 & 238,76 & 64,74 & 426,66 & 51,64 & 5,00 & 42,08 & 148,41 & 37,15 & 37,15 & 126,10 \\
\hline Pelophylax perezi & $305 \mathrm{~V} J 54$ & 100,00 & 144,27 & 123,68 & 37,15 & 6812,25 & 335,56 & 8,92 & 326,64 & 128,22 & 236,22 & 236,22 & 61,91 & 420,01 & 49, & 5,94 & 39,88 & 142,70 & 40,63 & 40,63 & 121,01 \\
\hline Pelophylax perezi & $305 \mathrm{VJ} 55$ & 100,00 & 138,96 & 123,14 & 37,03 & 6822,71 & 330,55 & 4,48 & 326,07 & 122,39 & 231,19 & 231,19 & 56,86 & $\begin{array}{l}436,58 \\
\end{array}$ & 50,83 & 7,02 & 38,73 & 147,13 & 44,65 & 44,65 & 124,51 \\
\hline Pelophylax perezi & 30SVJ56 & 100,00 & 141,14 & 121,81 & 37,00 & \begin{tabular}{|l|l|}
6824,03 \\
\end{tabular} & 331,22 & 6,81 & 324,42 & 124,94 & 233,10 & 233,10 & 58,76 & 426,60 & 49,15 & 7,00 & 38,18 & 142,00 & 43,97 & 43,97 & 121,56 \\
\hline Pelophylax perezi & 30 SVJ60 & 100,00 & 146,60 & 124,06 & 37,64 & 6791,43 & 337,84 & 11,36 & 326,48 & 129,55 & 237,93 & 237,93 & 64,54 & 433,45 & 52,76 & 5,24 & 41,85 & 151,32 & 37,87 & 37,87 & 128,27 \\
\hline Pelophylax perezi & 30 SVJ61 & 100,00 & 146,27 & 124,13 & 37,63 & 6800,42 & 337,58 & 11,04 & 326,54 & 129,70 & 237,86 & 237,86 & 64,06 & 426,94 & 51,61 & 5,36 & 41,60 & 148,29 & 38,40 & 38,40 & 125,17 \\
\hline Pelophylax perezi & 30 SVJ65 & 100,00 & 142,53 & 122,46 & 37,01 & 6797,50 & 332,62 & 8,01 & 324,61 & 126,37 & 234,29 & 234,29 & 60,49 & 422,73 & 49, & 6,82 & 38,56 & 141,88 & 43,16 & 43,16 & 120,14 \\
\hline Pelophylax perezi & $305 \mathrm{~S} J 66$ & 100,00 & 142,55 & 121,58 & 37,00 & 6801,44 & 331,60 & 8,01 & \begin{tabular}{|l|}
323,09 \\
\end{tabular} & 126,80 & 234,23 & 234,23 & 60,40 & 420,51 & 48,24 & $\begin{array}{l}0,02 \\
7,00\end{array}$ & 38,27 & $\begin{array}{l}139,51 \\
\end{array}$ & 43,66 & 43,66 & 119,16 \\
\hline Pelophylax perezi & 30 SVJ70 & 100,00 & 145,14 & 123,99 & 37,99 & 6779,11 & 335,90 & 10,46 & 325,44 & 127,62 & 236,54 & 236,54 & 63,40 & 436,02 & 53,00 & 6,00 & 40,94 & 151,82 & 40,34 & 40,34 & 127,27 \\
\hline Pelophylax perezi & 30 SVJ72 & 100,00 & 145,55 & 123,73 & 37,74 & 6768,12 & 335,58 & 10,77 & 324,81 & 128,68 & 236,65 & 236,65 & 63,76 & 422,14 & 50,55 & 6,00 & 39,81 & 144,96 & 40,98 & 40,98 & 121,29 \\
\hline Pelophylax perezi & 30 SVJ75 & 100,00 & 144,96 & 122,00 & 37,01 & 6776,05 & 333,15 & 10,24 & 322,91 & 129,05 & 236,03 & 236,03 & 62,79 & 414,24 & 48,00 & 6,75 & 38,26 & 138,93 & 42,70 & 42,70 & 116,81 \\
\hline Pelophylax perezi & 30SVJ76 & 100,00 & 143,29 & 121,29 & 37,03 & 6768,62 & 331,36 & 9,25 & 322,12 & 127,52 & 234,38 & 234,38 & 61,47 & \begin{tabular}{|l|l|l|}
416,98 \\
\end{tabular} & 47,55 & 7,05 & 37,74 & 137,95 & 44,09 & 44,09 & 117,32 \\
\hline Pelophylax perezi & 30SVJ77 & 100,00 & 142,13 & 120,53 & 37,00 & 6778,90 & 329,51 & 8,49 & \begin{tabular}{|l|}
321,02 \\
3212
\end{tabular} & \begin{tabular}{|l|l|}
126,27 \\
\end{tabular} & 233,47 & \begin{tabular}{|l|}
233,47 \\
\end{tabular} & $\begin{array}{ll}10,417 \\
60,07\end{array}$ & \begin{tabular}{|l|l|}
419,88 \\
419,8
\end{tabular} & | & 7,60 & 36,94 & 年137,13 & 445,58 & $\begin{array}{l}44,53 \\
45,5\end{array}$ & 117,90 \\
\hline Pelophylax perezi & 30SVJ78 & 100,00 & 141,08 & 119,51 & 37,00 & \begin{tabular}{|l|l|}
6769,87 \\
\end{tabular} & 327,47 & 7,95 & 319,52 & 121,23 & 232,09 & 232,09 & 58,94 & 422,44 & 47,01 & 8,00 & 36,31 & 136,81 & 46,45 & 46,45 & 118,64 \\
\hline Pelophylax perezi & 30 SVJ80 & 100,00 & 140,69 & 123,88 & 37,93 & 6766,96 & 331,26 & 6,62 & 324,64 & 122,67 & 231,94 & 231,94 & 59,36 & 449,30 & 54,72 & 7,00 & 39,91 & 156,41 & 44,36 & 44,36 & 129,07 \\
\hline Pelophylax perezi & 30 SVJ85 & 100,00 & 143,96 & 122,00 & 37,15 & 6750,31 & 331,81 & 9,66 & 322,16 & 128,12 & 234,82 & 234,82 & 62,24 & 415,35 & 48,00 & 7,00 & 37,99 & 139,01 & 44,36 & 44,36 & 116,04 \\
\hline Pelophylax perezi & 30 SVJ86 & 100,00 & 140,81 & 121,76 & 37,16 & 6746,40 & 328,68 & 6,90 & 321,79 & 124,73 & 231,79 & 231,79 & 59,32 & 425,55 & 48,34 & 7,76 & 37,00 & $\begin{array}{l}140,92 \\
\end{array}$ & 46,98 & 46,98 & 118,40 \\
\hline Pelophylax perezi & \begin{tabular}{|l|}
$305 V J 87$ \\
3050
\end{tabular} & 100,00 & $\begin{array}{l}14,01 \\
141,18\end{array}$ & $\begin{array}{l}121,10 \\
120,79\end{array}$ & 37,01 & 6743,01 & 327,89 & $\begin{array}{l}0,04 \\
7,84 \\
\end{array}$ & \begin{tabular}{|l|l|}
220,05 \\
320
\end{tabular} & \begin{tabular}{|l|}
124,94 \\
124,94
\end{tabular} & $\mid \begin{array}{l}\mid 231,94 \\
21,9\end{array}$ & $\mid 231,94$ & $\begin{array}{l}35,327 \\
59,87\end{array}$ & \begin{tabular}{|l|l|}
421,58 \\
421,58
\end{tabular} & $\begin{array}{l}40,34 \\
47,50\end{array}$ & 8,00 & 36,32 & $\begin{array}{l}130,12 \\
138,12\end{array}$ & $\begin{array}{l}40,50 \\
47,05\end{array}$ & $\begin{array}{l}40,05 \\
47,05\end{array}$ & $\begin{array}{l}110,40 \\
117,12\end{array}$ \\
\hline Pelophylax perezi & 30SVJ90 & 100,00 & 137,31 & 123,81 & \begin{tabular}{|l|l|}
37,97 \\
\end{tabular} & 6755,60 & 327,59 & 3,46 & 324,12 & 119,08 & 228,68 & 228,68 & 56,43 & 457,68 & 55,81 & 7,90 & 38,51 & 158,96 & 47,99 & 47,99 & 129,13 \\
\hline Pelophylax perezi & 30SVJ92 & 100,00 & 142,75 & 123,03 & $\begin{array}{l}37,95 \\
\end{array}$ & \begin{tabular}{ll|}
6712,64 \\
\end{tabular} & 331,08 & 8,64 & 322,45 & 125,73 & 233,26 & 233,26 & 61,86 & 426,77 & 51,09 & 7,06 & 38,14 & 146,14 & 45,13 & 45,13 & 119,23 \\
\hline Pelophylax perezi & 30 SVJ95 & 100,00 & 143,69 & 122,00 & 37,86 & $\begin{array}{ll}6707,67 \\
\end{array}$ & 330,29 & 9,75 & 320,54 & 127,69 & 233,91 & 233,91 & 62,46 & 414,76 & 47,81 & 7,21 & 37,31 & 138,81 & 45,64 & 45,64 & 114,32 \\
\hline Pelophylax perezi & 30SVJ96 & 100,00 & 140,72 & 121,75 & 37,59 & 6723,46 & 327,53 & 6,95 & 320,58 & 124,70 & 231,31 & 231,31 & 59,56 & 423,62 & 48,05 & 8,03 & 36,39 & 140,24 & 48,18 & 48,18 & 116,52 \\
\hline Pelophylax perezi & 30SVKO0 & 100,00 & 142,08 & 115,15 & 35,59 & 6885,85 & 328,40 & 8,99 & 319,41 & 126,45 & 235,29 & 235,29 & 58,85 & 410,00 & 47,49 & 8,07 & 36,99 & 134,34 & 45,10 & 45,10 & 114,06 \\
\hline Pelophylax perezi & 30SVKO1 & 100,00 & 149,04 & 113,12 & 35,00 & 6882,69 & 332,72 & 15,98 & 316,74 & 117,76 & 242,08 & 242,08 & 65,22 & 385,81 & 43,97 & 7,68 & 36,92 & 125,51 & 42,08 & 42,08 & 107,56 \\
\hline Pelophylax perezi & 30SVK10 & 100,00 & 139,54 & 115,28 & 35,74 & 6879,58 & 326,16 & 7,09 & 319,07 & 121,73 & 232,81 & 232,81 & 56,51 & 420,94 & 48,24 & 8,56 & 36,62 & 136,80 & 46,77 & 46,77 & 117,76 \\
\hline Pelophylax perezi & 30SVK12 & 100,00 & 148,27 & 111,28 & 35,00 & 6865,56 & 329,97 & 16,42 & 313,55 & 104,12 & 240,69 & 240,69 & 64,36 & 390,71 & 44,21 & 8,18 & 36,43 & 128,62 & 43,23 & 43,23 & 110,14 \\
\hline Pelophylax perezi & 30SVK21 & 100,00 & $\begin{array}{l}149,35 \\
149\end{array}$ & 112,96 & 35,06 & $\begin{array}{ll}6871,38 \\
6871\end{array}$ & 332,62 & $\begin{array}{l}0,46 \\
16,78 \\
\end{array}$ & |315,84 & $\begin{array}{l}105,12 \\
\end{array}$ & 241,92 & 241,92 & 65,45 & 392,59 & \begin{tabular}{|l|l|}
44,66 \\
442
\end{tabular} & $\begin{array}{l}0,106 \\
7,59\end{array}$ & 37,04 & $\begin{array}{ll}129,84 \\
\end{array}$ & 4 & $\begin{array}{l}41,85 \\
41,5 \\
\end{array}$ & 111,98 \\
\hline Pelophylax perezi & 30SVK22 & 100,00 & 149,90 & 111,27 & 35,00 & 6847,68 & 331,14 & 18,29 & 312,85 & 105,72 & 241,91 & 241,91 & 65,97 & 390,97 & 44,78 & 7,99 & 36,77 & 130,69 & 42,15 & 42,15 & 112,01 \\
\hline Pelophylax perezi & 30SVK31 & 100,00 & 146,79 & 113,32 & 35,32 & 6849,82 & 330,11 & 14,84 & 315,27 & 102,71 & 238,96 & 238,96 & 63,23 & 403,49 & 45,93 & 7,89 & 37,22 & 134,38 & 42,99 & 42,99 & 115,95 \\
\hline Pelophylax perezi & 30 SVK32 & 100,00 & 148,20 & 111,54 & 35,01 & 6826,51 & 329,53 & 17,08 & 312,45 & 104,25 & 239,90 & 239,90 & 64,68 & 399,91 & 46,23 & 8,15 & 37,33 & 134,99 & 42,58 & 42,58 & 115,87 \\
\hline Pelophylax perezi & $30 \mathrm{SVK} 40$ & 100,00 & 143,46 & 115,60 & 36,00 & 6829,75 & 328,63 & 11,20 & 317,43 & 99,51 & 235,32 & 235,32 & 60,50 & 415,52 & 46,59 & 8,00 & 37,13 & 136,82 & 44,46 & 44,46 & 118,98 \\
\hline Pelophylax perezi & 305VK41 & 100,00 & $\begin{array}{l}14,40 \\
142,28\end{array}$ & $\begin{array}{l}1113,00 \\
113,99\end{array}$ & 35,88 & 6815,05 & 326,08 & $\begin{array}{l}1,20 \\
11,25 \\
\end{array}$ & \begin{tabular}{|l|}
$314,82,8$ \\
\end{tabular} & \begin{tabular}{|l|l|}
98,38 \\
98,
\end{tabular} & \begin{tabular}{|l|}
234,01 \\
234
\end{tabular} & \begin{tabular}{|l|}
234,01 \\
2340
\end{tabular} & 59,56 & | & $\begin{array}{l}40,33 \\
47,72 \\
\end{array}$ & $\begin{array}{l}0,004 \\
8,47\end{array}$ & $\begin{array}{ll}3,1,13 \\
36,83\end{array}$ & $\begin{array}{l}130,0<2 \\
139,45 \\
\end{array}$ & $\begin{array}{l}444,40 \\
45,42\end{array}$ & $\begin{array}{l}44,404 \\
45,42\end{array}$ & $\begin{array}{l}110,50 \\
120,79\end{array}$ \\
\hline Pelophylax perezi & 30SVK42 & 100,00 & 143,69 & 112,19 & 35,34 & 6798,35 & 325,53 & 13,30 & 312,22 & 99,84 & 234,97 & 234,97 & 60,75 & 416,79 & 48,69 & 8,62 & 37,00 & 140,71 & 44,87 & 44,87 & 121,01 \\
\hline Pelophylax perezi & 30SVK50 & 100,00 & 141,80 & 116,19 & 36,00 & 6809,98 & 326,92 & 9,91 & 317,01 & 98,08 & 233,49 & 233,49 & 59,15 & 420,79 & 47,14 & 8,24 & 36,94 & 138,66 & 45,49 & 45,49 & 120,36 \\
\hline Pelophylax perezi & 30 SVK51 & 100,00 & 137,96 & 114,91 & 36,00 & 6787,16 & 322,16 & 7,38 & 314,78 & 94,31 & 229,40 & 229,40 & 55,82 & 434,20 & 49,43 & 9,05 & 36,12 & 143,43 & 48,20 & 48,20 & 124,39 \\
\hline Pelophylax perezi & 30SVK70 & 100,00 & 136,90 & 117,44 & 36,87 & 6761,28 & 321,82 & 5,38 & 316,44 & 93,44 & 227,84 & 227,84 & 55,18 & 435,76 & 48,33 & 9,24 & 35,39 & 141,32 & 50,07 & 50,07 & 122 \\
\hline Pelophylax perezi & 30SVK72 & 100,00 & 135,36 & 114,94 & 36,16 & 6738,88 & 317,93 & 5,55 & 312,38 & 91,84 & 225,73 & 225,73 & 53,86 & 439,48 & 50,73 & 10,01 & 35,34 & 145,48 & 51,10 & 51,10 & 124,22 \\
\hline Pelophylax perezi & 30SVK90 & 100,00 & 134,84 & 118,64 & 37,00 & 6711,92 & 319,23 & 3,06 & 316,16 & 114,06 & 224,96 & 224,96 & 53,60 & 439,73 & 49,30 & 10,10 & 34,20 & 140,18 & 53,80 & 53,80 & 120,42 \\
\hline Pelophylax perezi & 30SWF06 & 31,00 & 178,38 & 85,78 & 36,97 & 4976,35 & 301,83 & 72,30 & 229,52 & 128,25 & 242,68 & 245,75 & 118,15 & 266,20 & 37,42 & 1,63 & 55,30 & 106,15 & 11,02 & 16,27 & 100,95 \\
\hline Pelophylax perezi & 30SWF07 & 100,00 & 162,90 & 96,33 & 37,43 & 5421,05 & 303,66 & 49,63 & 254,0 & 108,33 & 234,18 & 236,65 & 98, & 329,34 & 43,60 & 3,15 & 51,93 & 124,36 & 17,06 & 23,40 & 120,34 \\
\hline Pelophylax perezi & 30SWF08 & 100,00 & 137,34 & 109,31 & 37,88 & 5970,86 & 302,06 & 15,92 & 286,14 & 82,48 & 217,38 & 219,10 & 67,16 & 467,47 & 59,30 & 7,89 & 47,35 & 165,75 & 33,92 & 41,08 & 160,40 \\
\hline
\end{tabular}




\begin{tabular}{|c|c|c|c|c|c|c|c|c|c|c|c|c|c|c|c|c|c|c|c|c|c|}
\hline TAXON & UTM & $\mathrm{km} 2$ & B101 & B102 & $\mathrm{BIO3}$ & BIO4 & B105 & B106 & B107 & B108 & B109 & B1010 & BIO11 & BIO12 & B1013 & BIO14 & BIO15 & B1016 & B1017 & B1018 & B1019 \\
\hline Pelophylax perezi & 30SWF09 & 100,00 & 132,55 & 112,59 & 37,86 & 6128,55 & 303,78 & 8,78 & 294,99 & 78,87 & 215,13 & 216,48 & 60,73 & 494,66 & 61,90 & 8,66 & 46,15 & 172,67 & 37,08 & 44,53 & 167,55 \\
\hline Pelophylax perezi & 30SWF16 & 78,00 & 179,02 & 83,11 & \begin{tabular}{|l|}
36,68 \\
\end{tabular} & 4880,61 & 298,99 & 74,88 & 224,12 & 130,31 & 241,62 & 245,35 & 120,06 & 253,58 & 35,65 & 1,23 & 55,12 & 100,56 & 10,29 & 15,34 & 95,39 \\
\hline Pelophylax perezi & 30SWF17 & 100,00 & 151,18 & 99,22 & 37,40 & 5556,79 & 298,51 & 36,55 & 261,96 & 98,95 & 224,63 & 227,24 & 85,36 & 387,70 & 50,30 & 5,71 & 49,20 & 140,50 & 26,11 & 32,34 & 135,14 \\
\hline Pelophylax perezi & 30SWF19 & 100,00 & 130,46 & 111,75 & 37,81 & 6109,05 & 300,50 & 7,40 & 293,10 & 78,34 & 212,63 & 214,39 & 58,97 & 498,17 & 62,45 & 9,34 & 44,82 & 172,25 & 39,73 & 46,65 & 165,68 \\
\hline Pelophylax perezi & 30SWF26 & 98,00 & 179,60 & 80,83 & 36,15 & \begin{tabular}{ll|l|}
4808,28 \\
\end{tabular} & 296,48 & 76,88 & 219,60 & 131,95 & 240,91 & 245,09 & \begin{tabular}{|l|}
121,53 \\
\end{tabular} & 242,97 & 34,06 & 1,00 & 54,81 & 95,87 & 10,02 & 15,00 & 90,52 \\
\hline Pelophylax perezi & 30 SWF29 & 100,00 & 145,65 & 104,86 & \begin{tabular}{|c|}
37,57 \\
\end{tabular} & 5826,32 & 302,48 & 26,71 & 275,76 & 91,43 & 223,29 & 225,54 & 76,95 & 406,06 & 50,43 & 6,11 & 46,27 & 140,37 & 28,82 & 35,61 & 136,85 \\
\hline Pelophylax perezi & 30 SWF36 & 34,00 & 180,41 & 79,20 & 36,05 & 4752,23 & 294,80 & 79,02 & 215,77 & 133,45 & 240,84 & 245,05 & 123,07 & 234,66 & 32,57 & 1,00 & 54,66 & 91,84 & 10,00 & 15,00 & 86,34 \\
\hline Pelophylax perezi & $\begin{array}{l}30 \text { SWF37 } \\
\end{array}$ & 87,00 & 167,73 & 88,00 & 36,67 & 5132,04 & 296,56 & 60,19 & 236,36 & 116,87 & 234,14 & 237,92 & 106,30 & 287,17 & 37,22 & 2,64 & 50,52 & $\begin{array}{r}105,88 \\
\end{array}$ & 16,01 & 21,44 & 101,28 \\
\hline Pelophylax perezi & 30SWF38 & 100,00 & 142,22 & 104,11 & 37,77 & 5781,32 & 297,62 & 24,26 & 273,36 & 88,74 & 219,12 & 221,81 & 74,32 & 415,66 & 51,95 & 6,74 & 45,49 & 142,97 & 30,94 & 37,60 & 139,01 \\
\hline Pelophylax perezi & 30SWF39 & 100,00 & 160,39 & 95,69 & \begin{tabular}{|l|l|}
37,13 \\
\end{tabular} & 5459,98 & 301,24 & 47,45 & 253,79 & 119,38 & 232,06 & 235,10 & 95,45 & 323,93 & 39,69 & 3,71 & 47,44 & 114,23 & 20,68 & 26,78 & 110,24 \\
\hline Pelophylax perezi & 30SWF47 & 40,00 & 171,80 & 84,11 & 36,39 & 4984,22 & 295,09 & 67,17 & 227,93 & 139,22 & 235,78 & 240,20 & 112,19 & 260,81 & 34,20 & 2,11 & 49,87 & 96,44 & 14,78 & 19,85 & 90,93 \\
\hline Pelophylax perezi & 30SWF48 & 100,00 & 167,45 & 88,45 & 36,80 & 5150,72 & 297,08 & 59,96 & 237,12 & 132,02 & 234,32 & 238,16 & 106,17 & 281,43 & 36,18 & 2,70 & 48,55 & 102,15 & 16,97 & 22,57 & 96,69 \\
\hline Pelophylax perezi & 30SWF49 & 100,00 & 168,05 & 90,03 & 36,93 & 5222,22 & 299,62 & 59,06 & 240,56 & 142,15 & 235,85 & 239,51 & 105,63 & 281,36 & 35,90 & 2,58 & 47,82 & 101,46 & 17,24 & 22,94 & 95,53 \\
\hline Pelophylax perezi & 30SWF57 & 35,00 & 180,43 & 78,35 & 36,03 & 4722,03 & 294,35 & 80,46 & 213,89 & 158,62 & 240,24 & 245,16 & 123,86 & 220,24 & 31,65 & 1,00 & 51,08 & 85,03 & 11,95 & 16,97 & 76,14 \\
\hline Pelophylax perezi & 30 SWF58 & 100,00 & 172,02 & 84,87 & \begin{tabular}{|l|l|}
36,67 \\
\end{tabular} & 4991,31 & 295,91 & 67,38 & 228,53 & 147,44 & 236,24 & 240,65 & 112,60 & 257,20 & 34,58 & 2,17 & 49,02 & 95,14 & 15,54 & 21,12 & 87,52 \\
\hline Pelophylax perezi & 30SWF59 & 100,00 & 147,86 & 100,32 & 37,53 & 5634,95 & 296,31 & 32,21 & 264,09 & 106,88 & 222,25 & 225,46 & 81,54 & 380,63 & 47,31 & 6,18 & 44,01 & 129,35 & 29,97 & 36,03 & 123,23 \\
\hline Pelophylax perezi & 30SWF67 & 65,00 & 179,98 & 79,82 & 36,63 & 4714,35 & 294,94 & 79,64 & 215,30 & 158,40 & 239,82 & 244,83 & 123,90 & 225,80 & 32,51 & 1,07 & 51,71 & 87,95 & 12,02 & 18,04 & 77,76 \\
\hline Pelophylax perezi & 30SWF68 & 100,00 & 171,50 & 85,66 & 36,96 & 4987,16 & 295,83 & 66,57 & 229,26 & 147,73 & 235,65 & 240,14 & 112,24 & 260,08 & 35,26 & 2,28 & 48,56 & 96,64 & 16,01 & 22,06 & 87,50 \\
\hline Pelophylax perezi & 30SWF69 & 100,00 & 144,29 & 101,58 & 37,77 & 5675,91 & 294,55 & 27,91 & 266,64 & 107,48 & 219,46 & 222,52 & 77,78 & 397,01 & 49,25 & 6,94 & 42,90 & 132,95 & 32,81 & 38,94 & 126,45 \\
\hline Pelophylax perezi & 30 SWF76 & 41,00 & 175,49 & 81,61 & 36,94 & 4769,35 & 292,80 & 73,86 & 218,94 & 153,98 & 236,18 & 241,18 & 118,84 & 247,45 & 33,71 & 1,67 & 50,75 & 94,73 & 13,35 & 19,71 & 85,75 \\
\hline Pelophylax perezi & 30SWF77 & 100,00 & 176,22 & 82,23 & 36,96 & 4798,15 & 294,35 & 74,02 & 220,33 & 154,27 & 237,42 & 242,31 & 119,29 & 244,06 & 34, & 1,71 & 50,29 & 93,95 & 13,52 & 19,92 & 83,53 \\
\hline Pelophylax perezi & 30SWF78 & 100,00 & 175,00 & 84,50 & 37,00 & 4891,20 & 296,34 & 71,05 & 225,29 & 152,16 & 237,72 & 242,35 & 116,86 & 249,27 & 34,99 & 2,00 & 49,12 & 95,04 & 14,89 & 21,39 & 83,71 \\
\hline Pelophylax perezi & 30SWF79 & 100,00 & 163,15 & 92,40 & \begin{tabular}{|l|l|}
37,41 \\
\end{tabular} & 5242,14 & 297,03 & 53,20 & 243,83 & 137,36 & 231,33 & 235,22 & 101,06 & 302,16 & 39,06 & 3,46 & 46,01 & 108,60 & 21,05 & 27,49 & 98,20 \\
\hline Pelophylax perezi & 30SWF87 & 57,00 & 175,68 & 83,45 & 37,00 & 4821,32 & 294,83 & 72,54 & 222,29 & 153,54 & 237,12 & 242,00 & 118,32 & \begin{tabular}{|l|l|}
251,78 \\
\end{tabular} & 34,87 & 1,79 & 50,59 & 97,13 & 13,96 & 20,78 & 85,87 \\
\hline Pelophylax perezi & 30SWF88 & 97,00 & 173,50 & 86,06 & 37,04 & 4928,89 & 296,35 & 68,35 & 228,00 & 150,29 & 236,65 & 241,17 & 114,74 & 260,41 & 36,10 & 2,00 & 49,24 & 99,37 & 15,50 & 22,37 & 86,88 \\
\hline Pelophylax perezi & 30SWF89 & 100,00 & 171,15 & 89,01 & 37,33 & 5051,64 & 298,24 & 63,49 & 234,75 & 146,85 & 236,22 & 240,41 & 110,95 & 270,72 & 37,31 & 2,34 & 47,94 & 101,80 & 17,16 & 24,09 & 88,43 \\
\hline Pelophylax perezi & 30SWF99 & 88,00 & 176,42 & 87,67 & 37,69 & 4938,62 & 299,72 & $\begin{array}{l}69,77 \\
69\end{array}$ & 229,94 & $\begin{array}{l}153,11 \\
150,0\end{array}$ & \begin{tabular}{|l|}
239,69 \\
\end{tabular} & \begin{tabular}{|l|}
243,92 \\
\end{tabular} & 117,31 & 256,69 & $\begin{array}{l}36,65 \\
36,1\end{array}$ & 2,07 & 49,15 & \begin{tabular}{|l|}
99,56 \\
\end{tabular} & 15,48 & 22,94 & $\begin{array}{l}84,13 \\
84,13\end{array}$ \\
\hline Pelophylax perezi & 30SWG01 & 100,00 & 126,27 & 116,22 & 37,69 & 6332,87 & 305,31 & $-0,05$ & 305,36 & 78,27 & 211,95 & 213,03 & 52,25 & 535,98 & 66,84 & 10,32 & 44,31 & 186,33 & 43,44 & 50,73 & 176,52 \\
\hline Pelophylax perezi & 30SWG02 & 100,00 & 118,62 & 118,01 & 37,52 & 6441,29 & 302,00 & $-8,44$ & 310,44 & 69,90 & 206,17 & 207,05 & 43,79 & 581,40 & 72,56 & 12,42 & 42,76 & 202,16 & 51,45 & 57,94 & 187,32 \\
\hline Pelophylax perezi & 30SWG03 & 100,00 & 112,13 & 119,29 & 37,38 & 6521,42 & 298,87 & $-15,51$ & 314,38 & 62,80 & 200,97 & 201,69 & 36,74 & 620,72 & 77,48 & 14,42 & 41,36 & 215,71 & 58,83 & 64,42 & 196,34 \\
\hline Pelophylax perezi & 30SWG05 & 100,00 & 150,64 & 112,52 & 37,01 & 6310,40 & 323,64 & 24,64 & 298,99 & \begin{tabular}{r|r|}
104,28 \\
\end{tabular} & 235,48 & 236,06 & 75,49 & 427,50 & 52,55 & |5,91 & 46,10 & 148,82 & 29,76 & 36,66 & 140,36 \\
\hline Pelophylax perezi & 30 SWG06 & 100,00 & 146,83 & 114,45 & 37,00 & 6411,38 & 323,90 & \begin{tabular}{|l|}
19,77 \\
194
\end{tabular} & 304,13 & \begin{tabular}{|l|}
99,96 \\
99,0
\end{tabular} & \begin{tabular}{|l|}
233,36 \\
236
\end{tabular} & $\begin{array}{l}233,69 \\
\end{array}$ & 70,77 & 4448,55 & 55,63 & 6,58 & $\begin{array}{ll}45,28 \\
45,10\end{array}$ & $\begin{array}{l}140,020 \\
156,92 \\
\end{array}$ & 33,01 & 38,71 & $\begin{array}{l}140,03 \\
145\end{array}$ \\
\hline Pelophylax perezi & 30SWG07 & 100,00 & $\begin{array}{ll}139,87 \\
\end{array}$ & 116,56 & 37,01 & 6514,90 & 321,19 & 11,47 & 309,72 & 92,14 & 227,87 & 228,22 & 62,84 & 484,39 & 60,38 & 8,08 & 43,87 & 169,69 & 39,10 & 43,90 & 153,57 \\
\hline Pelophylax perezi & 30SWG08 & 100,00 & 114,83 & 120,64 & 37,04 & 6665,08 & 304,94 & $-14,35$ & 319,29 & 66,73 & 205,73 & 205,99 & 37,30 & 607,25 & 75,59 & 14,07 & 39,93 & 210,27 & 61,06 & 63,95 & 184,67 \\
\hline Pelophylax perezi & 30SWG09 & 100,00 & 121,09 & 120,41 & 37,09 & 6669,44 & 310,41 & $-8,41$ & 318,82 & 79,84 & 211,79 & 212,10 & 43,19 & 574,48 & 71,75 & 12,40 & 40,50 & 199,80 & 56,02 & 58,31 & 174,50 \\
\hline Pelophylax perezi & 30SWG10 & 100,00 & 103,26 & 118,05 & 37,69 & 6418,95 & 287,19 & \begin{tabular}{|l|l|}
$-22,94$ \\
\end{tabular} & 310,14 & 53,60 & 190,52 & 191,94 & 29,32 & 663,94 & 83,67 & 17,52 & 40,18 & 228,83 & 67,81 & 72,75 & 208,69 \\
\hline Pelophylax perezi & 30SWG11 & 100,00 & 132,20 & $\begin{array}{ll}113,03 \\
113,16\end{array}$ & 37,64 & $\begin{array}{l}-6410,03,22 \\
6208,\end{array}$ & 305,95 & $\frac{-2,244}{8,40}$ & \begin{tabular}{|l|}
297,55 \\
\end{tabular} & $\begin{array}{l}30,00 \\
85,38\end{array}$ & $\begin{array}{l}1,00,52 \\
216,56 \\
\end{array}$ & 218,04 & 60,21 & \begin{tabular}{|l|l|}
489,8486 \\
\end{tabular} & $\begin{array}{l}3,1,16 \\
61,1\end{array}$ & \begin{tabular}{r|}
1,325 \\
8,98
\end{tabular} & $\begin{array}{l}40,100 \\
44,23\end{array}$ & \begin{tabular}{|l|}
$168,0,36$ \\
\end{tabular} & $\begin{array}{l}1,01 \\
39,18\end{array}$ & 46,19 & $\begin{array}{l}20,00,45 \\
60,4\end{array}$ \\
\hline Pelophylax perezi & 30SWG12 & 100,00 & 101,44 & 119,38 & 37,42 & 6512,31 & 288,48 & $-25,79$ & 314,27 & 51,48 & 190,12 & 191,34 & 26,44 & 673,90 & 84,83 & 18,07 & 39,16 & 232,05 & 70,73 & 75,03 & 208,34 \\
\hline Pelophylax perezi & 30SWG13 & 100,00 & 99,91 & 119,76 & 37,30 & 6547,08 & 288,19 & $-27,56$ & 315,75 & 49,82 & 189,21 & 190,23 & 24,62 & 683,86 & 85,86 & 18,71 & 38,55 & 234,97 & 73,59 & 77,43 & 209,17 \\
\hline Pelophylax perezi & 30SWG15 & 100,00 & 143,41 & 113,58 & 37,11 & 6319,60 & 317,77 & 17,28 & 300,49 & 96,60 & 228,55 & 229,30 & 68,56 & 448,80 & 55,77 & 7,20 & 44,06 & 154,73 & 35,01 & 41,78 & 143,45 \\
\hline Pelophylax perezi & 30SWG16 & 100,00 & 149,42 & 112,81 & 37,04 & 6306,94 & 321,98 & 23,26 & 298,72 & 103,02 & 234,14 & 234,83 & 74,31 & 423,79 & 52,47 & 6,21 & 44,50 & 145,99 & 31,96 & 38,55 & 135,13 \\
\hline Pelophylax perezi & 30SWG17 & 100,00 & 141,90 & 115,60 & 37,02 & 6435,08 & 320,18 & 13,97 & 306,21 & 94,70 & 228,68 & 229,28 & 65,69 & 460,74 & 57,71 & 7,59 & 43,16 & 159,51 & 37,77 & |43,53 & 144,05 \\
\hline Pelophylax perezi & 30SWG18 & 100,00 & 124,05 & 119,03 & 37,19 & 6575,96 & 309,64 & $-4,69$ & 314,32 & 88,28 & 213,40 & 213,81 & 47,07 & 549,98 & 69,08 & 11,94 & 40,32 & 190,03 & 53,89 & 57,21 & 166,22 \\
\hline Pelophylax perezi & 30SWG19 & 100,00 & 102,99 & 121,55 & 37,25 & 6684,30 & 294,93 & $-25,91$ & 320,84 & 79,69 & 194,39 & 194,80 & 25,85 & 658,50 & 82,24 & 17,84 & 37,02 & 226,52 & 74,95 & 76,55 & 192,90 \\
\hline Pelophylax perezi & 30SWG20 & 100,00 & 131,47 & 111,31 & 37,74 & 6116,16 & 300,77 & 8,53 & 292,24 & 81,84 & 213,68 & 215,52 & 59,95 & 487,65 & 61,2 & 9,2 & 43,62 & 66,63 & 40,55 & 47,17 & 158,65 \\
\hline Pelophylax perezi & 30 SWG21 & 100,00 & 126,21 & 112,80 & 37,52 & 6201,71 & 298,98 & 2,32 & 296,66 & $\begin{array}{l}\mid 76,06 \\
76,0\end{array}$ & \begin{tabular}{|l|}
209,87 \\
\end{tabular} & 211,48 & 53,91 & | 521,88 & $\frac{65,}{65,}$ & 11, & 42,31 & $\begin{array}{l}177,94 \\
\end{array}$ & 47,53 & 53,39 & $\begin{array}{l}165,77 \\
165,0\end{array}$ \\
\hline Pelophylax perezi & 30SWG22 & 100,00 & 101 & 118,70 & \begin{tabular}{|c|}
37,38 \\
\end{tabular} & 6485,48 & 286,99 & $-25,45$ & 312,44 & 51,23 & 189,61 & 190,87 & 26,50 & 668,34 & 84, & 18,64 & 38,13 & 228,60 & 72,73 & 76,59 & 203,33 \\
\hline Pelophylax perezi & 30SWG25 & 100,00 & 148,54 & 111,22 & 37,23 & 6192,77 & 317,25 & 23,82 & 293,44 & \begin{tabular}{|l|}
102,47 \\
\end{tabular} & 231,48 & 232,64 & 74,95 & 412,52 & 51,19 & $\begin{array}{r}6,22 \\
6,5\end{array}$ & 43,74 & 139,83 & 32,02 & 38,50 & 130,54 \\
\hline Pelophylax perezi & 30SWG26 & 100,00 & 150,31 & 111,76 & 37,27 & 6217,77 & 319,74 & 24,91 & 294,83 & 104,48 & 233,65 & 234,60 & 76,27 & \begin{tabular}{|l|l|}
407,45 \\
\end{tabular} & 50,71 & 5,99 & 43,55 & 138,21 & 31,82 & 38,17 & 127,79 \\
\hline Pelophylax perezi & 30SWG27 & 100,00 & 143,06 & 114,67 & 37,3 & 6352,62 & 318,23 & 15,94 & 302,29 & 105,84 & 228,60 & 229,33 & 67,80 & 443,23 & 55,81 & 7,42 & 42,33 & 151,55 & 37,64 & 43,30 & 136,21 \\
\hline Pelophylax perezi & 30SWG28 & 100,00 & 130 & $\frac{11}{11}$ & 37, & 64994,73 & 312 & $\frac{\mid 2,34}{2,30}$ & \begin{tabular}{|l|}
310,10 \\
310
\end{tabular} & \begin{tabular}{|l|}
107,79 \\
107,4
\end{tabular} & $\begin{array}{l}218,55 \\
2100\end{array}$ & \begin{tabular}{|l|}
219,213 \\
219
\end{tabular} & $\begin{array}{ll}1,300 \\
4,36\end{array}$ & $\begin{array}{l}443,25 \\
504,53\end{array}$ & $\begin{array}{l}3,01 \\
64,02 \\
\end{array}$ & \begin{tabular}{|l|}
1,424 \\
10,30
\end{tabular} & $\begin{array}{l}44,53 \\
40,24\end{array}$ & \begin{tabular}{|l|}
173,95 \\
17,50
\end{tabular} & | $41,04,5$ & $\begin{array}{l}32,80 \\
52,84\end{array}$ & 151,06 \\
\hline Pelophylax perezi & 30SWG29 & 100,00 & 110,30 & 120,44 & 37,52 & 6619,50 & 298,79 & $-18,26$ & 317,05 & 87,32 & 200,58 & 201,02 & 33,63 & 610,67 & 77,00 & 16,02 & 37,12 & 210,14 & 68,94 & 70,97 & 177,13 \\
\hline Pelophylax perezi & 30 SWG31 & 100,00 & 116,82 & 114,07 & 37,57 & 6265,03 & 292,50 & $\begin{array}{l}-10,20 \\
-7,49 \\
\end{array}$ & 299,99 & \begin{tabular}{l|l}
67,82 \\
67,
\end{tabular} & 201,51 & 203,23 & $\begin{array}{ll}44,28 \\
445\end{array}$ & 570,07 & 72,29 & \begin{tabular}{l|l}
14,36 \\
14
\end{tabular} & 40,05 & \begin{tabular}{|l|}
193,01 \\
\end{tabular} & 57,89 & 62,74 & 175,77 \\
\hline Pelophylax perezi & 30SWG32 & 100,00 & 108,31 & 116,88 & 37,58 & 6403,72 & 289,88 & $-17,44$ & 307,32 & 58,95 & 195,25 & 196,76 & 34,38 & 619,90 & 78,99 & 16,83 & 38,24 & 210,41 & 66,78 & 70,91 & 187,42 \\
\hline Pelophylax perezi & 30SWG33 & 100,00 & 135,56 & 112,17 & 37,69 & 6190,07 & 306,04 & 11,34 & 294,70 & 88,76 & 218,78 & 220,29 & 62,79 & 463,58 & 58,39 & 8,76 & 41,95 & 156,30 & 40,33 & 46,45 & 144,90 \\
\hline Pelophylax perezi & 30SWG35 & $\begin{array}{l}100,00 \\
\end{array}$ & $\begin{array}{l}137,90 \\
137,91\end{array}$ & 1113,41 & 37, 33 & $\begin{array}{l}6105,02 \\
6255,02\end{array}$ & 30,044 & $\begin{array}{l}1,34 \\
12,36 \\
\end{array}$ & \begin{tabular}{|l|}
298,08 \\
\end{tabular} & \begin{tabular}{|l|}
104,23 \\
10,2
\end{tabular} & $\begin{array}{l}222,05 \\
222,05\end{array}$ & \begin{tabular}{|l|}
223,26 \\
223
\end{tabular} & $\begin{array}{l}2,17 \\
64,15 \\
\end{array}$ & \begin{tabular}{|l}
403,30 \\
455,59
\end{tabular} & $\begin{array}{l}30,35 \\
57,55 \\
\end{array}$ & $\begin{array}{l}0,10 \\
8,47 \\
\end{array}$ & $\begin{array}{l}41,155 \\
41,45\end{array}$ & $\begin{array}{l}154,0303 \\
150\end{array}$ & | 40,45 & $\begin{array}{l}40,45 \\
46,23 \\
\end{array}$ & $\begin{array}{l}1449,74 \\
139,7\end{array}$ \\
\hline Pelophylax perezi & 30SWG37 & 100,00 & 142,67 & 114,20 & 37,86 & 6298,67 & 315,76 & 15,97 & 299,80 & 120,83 & 227,31 & 228,16 & 67,95 & 435,64 & 55,24 & 7,52 & 41,38 & 148,18 & 38,60 & 44,01 & 131,43 \\
\hline Pelophylax perezi & 30SWG38 & 100,00 & 134,64 & 116,67 & 37,80 & 6414,44 & 312,78 & 6,73 & 306,05 & 113,44 & 221,11 & 221,89 & 58,84 & 474,94 & 60,64 & 9,41 & 39,96 & 162,93 & 45,98 & 50,41 & 140,35 \\
\hline Pelophylax perezi & 30SWG39 & 100,00 & 122,08 & 119,02 & 37,76 & 6531,97 & 305,88 & $-6,37$ & 312,25 & 99,95 & 210,69 & 211, & 45, & 538,32 & 68,69 & 12,72 & 37,90 & 185 & 58,18 & 61,05 & 155,37 \\
\hline Pelophylax perezi & 30SWG40 & 100,00 & 152,15 & 100,91 & 37,54 & 5671,06 & 301,24 & 35,71 & 265,53 & 115,63 & 227,13 & 229,90 & 85,04 & 362,27 & 44,10 & 5,15 & 44,74 & $\begin{array}{ll}122,92 \\
122,9\end{array}$ & 26,55 & 32,86 & 118,51 \\
\hline
\end{tabular}




\begin{tabular}{|c|c|c|c|c|c|c|c|c|c|c|c|c|c|c|c|c|c|c|c|c|c|}
\hline TAXON & UTM & $\mathrm{km} 2$ & B101 & B102 & $\mathrm{BIO3}$ & BIO4 & B105 & B106 & B107 & B108 & B109 & B1010 & BIO11 & BIO12 & 81013 & BIO14 & BIO15 & BIO16 & BIO17 & B1018 & B1019 \\
\hline Pelophylax perezi & 30SWG41 & 100,00 & 121,78 & 112,29 & 37,66 & 6180,22 & 293,31 & $-1,59$ & 294,90 & 74,71 & 204,99 & 206,92 & 50,00 & 535,18 & 67,99 & 13,07 & 39,90 & 179,45 & 53,83 & 58,79 & 163,96 \\
\hline Pelophylax perezi & 30SWG42 & 100,00 & 108,77 & 116,04 & 37,70 & 6363,33 & 288,35 & $-16,43$ & 304,78 & 69,62 & 194,99 & 196,67 & 35,45 & 611,50 & 78,24 & 17,09 & 37,39 & 206,11 & \begin{tabular}{|l|l|}
67,97 \\
\end{tabular} & 71,68 & 182,05 \\
\hline Pelophylax perezi & 30SWG43 & 100,00 & 143,50 & 108,73 & 37,84 & 6021,64 & 306,44 & 21,31 & 285,14 & 105,51 & 223,97 & 225,81 & 72,36 & 415,18 & 51,79 & 7,17 & 42,11 & 137,89 & 35,13 & 41,23 & 129,15 \\
\hline Pelophylax perezi & 30SWG44 & 100,00 & 125,28 & 114,48 & 37,88 & 6292,01 & 300,34 & 0,19 & 300,14 & 101,58 & 210,23 & 211,67 & 51,86 & 514,18 & 65,61 & 11,80 & 39,21 & 173,75 & \begin{tabular}{ll|}
51,62 \\
\end{tabular} & 56,37 & 154,16 \\
\hline Pelophylax perezi & 30SWG47 & 100,00 & 136,35 & 115,08 & \begin{tabular}{ll|}
37,94 \\
\end{tabular} & $\begin{array}{ll}6313,04 \\
\end{array}$ & 310,58 & \begin{tabular}{|c|}
9,37 \\
\end{tabular} & 301,21 & 115,42 & 221,29 & 222,34 & 61,70 & 458,22 & 58,59 & 9,09 & 39,72 & 155,74 & 44,40 & 49,13 & 134,84 \\
\hline Pelophylax perezi & 30SWG48 & 100,00 & 133,42 & 116,38 & \begin{tabular}{|l|l|}
37,97 \\
\end{tabular} & 6375,05 & 310,23 & 5,79 & 304,44 & 112,25 & 219,40 & 220,26 & 58,35 & 472,79 & 60,70 & 9,84 & 38,89 & 161,44 & 47,91 & 51,92 & 137,14 \\
\hline Pelophylax perezi & 30SWG49 & 100,00 & 122,95 & 118,41 & 37,96 & 6475,62 & 304,59 & $-5,06$ & 309,65 & 100,98 & 210,68 & 211,39 & 47,27 & 526,21 & 67,58 & 12,72 & 37,10 & 180,48 & 58,56 & 61,17 & 149,34 \\
\hline Pelophylax perezi & 30SWG50 & 100,00 & 157,90 & 97,31 & 37,46 & 5502,16 & 300,28 & 43,97 & 256,31 & 129,80 & 230,17 & 233,28 & 92,68 & 329,08 & 40,29 & 4,23 & 45,03 & 114,02 & 23,50 & 29,72 & 107,16 \\
\hline Pelophylax perezi & 30SWG51 & 100,00 & 135,59 & 107,66 & $\begin{array}{ll}37,92 \\
\end{array}$ & 5960,92 & 297,10 & 14,97 & 282,13 & 101,08 & 215,22 & 217,60 & 65,88 & 450,66 & 56,53 & 9,29 & 41,14 & 149,65 & 41,48 & 47,14 & 139,36 \\
\hline Pelophylax perezi & 30SWG52 & 100,00 & 118,74 & 113,35 & 37,86 & 6231,44 & 291,99 & $-5,15$ & 297,14 & 94,74 & 202,79 & 204,69 & 46,57 & 548,09 & 70,14 & 14,23 & 38,14 & 183,59 & 58,63 & 62,94 & 163,17 \\
\hline Pelophylax perezi & 30SWG53 & 100,00 & 151,59 & 105,21 & 37,97 & 5832,13 & 306,55 & 31,64 & 274,91 & 121,75 & 229,11 & 231,27 & 82,44 & 370,07 & 45,47 & 5,61 & 42,53 & 123,97 & 30,08 & 36,27 & 114,67 \\
\hline Pelophylax perezi & 30SWG54 & 100,00 & 132,58 & 112,34 & 37,99 & 6168,66 & 301,99 & 8,19 & 293,80 & 110,74 & 215,41 & 217,17 & 60,34 & 468,70 & 59,65 & 9,99 & 39,40 & 156,86 & 45,81 & 50,90 & 139,75 \\
\hline Pelophylax perezi & $\begin{array}{l}30 S W G 56 \\
\end{array}$ & 100,00 & 121,43 & 116,06 & 37,92 & 6350,07 & 298,60 & $-4,86$ & 303,46 & 98,91 & 207,23 & 208,45 & 47,40 & 531,51 & 68,21 & 13,40 & 37,08 & 179,99 & \begin{tabular}{|l|l|}
58,83 \\
\end{tabular} & 62,27 & 152,71 \\
\hline Pelophylax perezi & 30SWG57 & 100,00 & 135,03 & 114,82 & 38,00 & 6267,46 & 307,81 & 8,50 & 299,31 & 113,81 & 219,26 & 220,45 & 61,03 & 458,12 & 58,86 & 9,54 & 38,80 & 154,95 & 46,52 & 50,82 & 132,23 \\
\hline Pelophylax perezi & 30SWG58 & 100,00 & 132,19 & 116,23 & 38,00 & 6326,25 & 307,48 & 4,76 & 302,72 & 110,73 & 217,41 & 218,48 & 57,78 & 472,41 & 60,94 & 10,33 & 37,96 & 160,56 & \begin{tabular}{l|l|l}
49,95 \\
\end{tabular} & 53,66 & 134,45 \\
\hline Pelophylax perezi & 30SWG59 & 100,00 & 132,38 & 117,02 & 38,00 & 6359,18 & 308,74 & 4,14 & 304,60 & 111,25 & 217,97 & 218,96 & 57,32 & 470,81 & 60,97 & 10,31 & 37,72 & 160,66 & 50,57 & 53,86 & 132,38 \\
\hline Pelophylax perezi & 30SWG60 & 100,00 & 156,21 & 97,80 & $\begin{array}{l}37,75 \\
\end{array}$ & 5499,91 & 298,91 & 42,09 & 256,82 & 128,22 & 228,41 & 231,70 & 91,19 & 335,54 & 40,97 & 4,48 & 44,29 & 116,20 & 24,87 & 31,24 & 107,69 \\
\hline Pelophylax perezi & 30SWG61 & 100,00 & 143,49 & 104,67 & 37,99 & 5807,31 & 298,15 & 24,66 & 273,49 & 116,26 & 220,59 & 223,24 & 75,18 & 403,63 & 49,97 & 7,29 & 41,69 & 134,36 & 35,11 & 41,08 & 124,97 \\
\hline Pelophylax perezi & 30SWG62 & 100,00 & 141,01 & 106,89 & \begin{tabular}{|l|l|}
37,97 \\
\end{tabular} & 5903,09 & 299,60 & 20,50 & 279,10 & 115,58 & 219,66 & 222,04 & 71,64 & 418,46 & 52,33 & 7,97 & 40,81 & 138,42 & 37,92 & 43,70 & 127,56 \\
\hline Pelophylax perezi & 30SWG63 & 100,00 & 156,89 & 102,82 & 38,00 & 5690,49 & 305,92 & 38,53 & 267,39 & 127,10 & 232,02 & 234,47 & 89,07 & 341,99 & 42,68 & 4,76 & 42,92 & 116,86 & 27,22 & 33,63 & 105,29 \\
\hline Pelophylax perezi & 30SWG65 & 100,00 & 129,95 & 113,35 & 38,00 & 6193,44 & 300,41 & 5,10 & 295,31 & 108,03 & 213,16 & 214,82 & 57,55 & 479,40 & 61,47 & 10,97 & 37,88 & 160,57 & 50,27 & 54,67 & 138,60 \\
\hline Pelophylax perezi & 30SWG66 & 100,00 & 119,94 & 115,46 & 37,88 & 6316,01 & 295,73 & $-5,88$ & 301,61 & 97,31 & 205,27 & 206,60 & 46,37 & 536,43 & 68,96 & 14,37 & 36,18 & 180,68 & 62,16 & 65,17 & 151,16 \\
\hline Pelophylax perezi & 30SWG67 & 100,00 & 126,68 & 115,62 & 37,99 & 6300,59 & 301,27 & 0,18 & 301,08 & 104,79 & 211,59 & 212,89 & 52,99 & 496,44 & \begin{tabular}{ll|}
64,07 \\
\end{tabular} & 12,06 & 36,76 & 167,64 & 55,44 & 58,80 & 139,53 \\
\hline Pelophylax perezi & 30SWG68 & 100,00 & 129,05 & 116,26 & 38,00 & 6309,61 & 303,79 & 1,58 & 302,21 & 107,38 & 214,05 & 215,21 & 54,92 & 483,47 & 62,64 & 11,28 & 36,86 & 163,72 & 53,81 & 56,95 & 134,88 \\
\hline Pelophylax perezi & 30SWG69 & 100,00 & 125,43 & 117,41 & 38,00 & 6367,87 & 302,64 & $-2,10$ & 304,74 & 103,67 & 211,35 & 212,27 & 50,73 & 501,81 & 65,10 & 12,45 & 36,06 & 170,50 & 58,49 & 60,77 & 137,84 \\
\hline Pelophylax perezi & 30SWG70 & 100,00 & 159,69 & 95,97 & \begin{tabular}{|l|l|}
37,87 \\
\end{tabular} & 5393,61 & 298,73 & 47,05 & 251,69 & 132,57 & 230,19 & 233,77 & 95,87 & 318,72 & 40,32 & 4,03 & 44,51 & 112,52 & 23,47 & 29,96 & 101,64 \\
\hline Pelophylax perezi & 30SWG71 & 100,00 & 152,69 & 100,67 & 37,95 & 5599,65 & 299,15 & 36,47 & 262,69 & 124,80 & 226,48 & 229,51 & 86,54 & 355,43 & $\begin{array}{l}44,14 \\
44,14\end{array}$ & $\begin{array}{l}4,45 \\
5,45\end{array}$ & 42,76 & 121,56 & \begin{tabular}{|l|}
28,99 \\
\end{tabular} & 35,29 & 110,29 \\
\hline Pelophylax perezi & 30SWG72 & 100,00 & 151,10 & 103,10 & 38,00 & 5694,17 & 300,88 & 32,95 & 267,92 & 122,01 & 226,39 & 229,08 & 83,76 & 365,64 & 45,43 & 5,86 & 41,93 & 123,62 & 30,96 & 37,22 & 111,62 \\
\hline Pelophylax perezi & 30SWG73 & 100,00 & 162,92 & 100,54 & 38,01 & 5537,90 & 306,48 & 46,31 & 260,16 & 134,02 & 235,66 & 238,38 & 96,78 & 313,27 & 40,85 & 3,78 & 43,80 & 110,31 & 23,94 & 30,75 & 95,97 \\
\hline Pelophylax perezi & 30SWG74 & 100,00 & 151,97 & 106,00 & 38,00 & 5797,69 & 305,59 & 31,41 & 274,17 & 122,64 & 228,80 & 231,01 & 83,10 & 364,66 & 45,64 & 5,83 & 41,41 & 122,48 & 31,96 & 38,14 & 108,35 \\
\hline Pelophylax perezi & 30SWG75 & 100,00 & 131,21 & 112,51 & 38,00 & 6137,04 & 299,15 & 6,73 & 292,42 & 109,45 & 213,48 & 215,27 & 59,23 & 470,07 & 60,27 & 10,93 & 37,49 & 156,36 & 50,31 & 54,71 & 133,99 \\
\hline Pelophylax perezi & 30SWG77 & 100,00 & 125,93 & 115,18 & 37,97 & $\mid 6262,87$ & 298,96 & $\begin{array}{c}-0,24 \\
-0,24 \\
\end{array}$ & 299,21 & \begin{tabular}{|l|l|}
103,99 \\
\end{tabular} & $\begin{array}{l}210,25 \\
210,0\end{array}$ & 211,69 & 52,67 & \begin{tabular}{|l|l|}
498,77 \\
\end{tabular} & $\begin{array}{l}60,27 \\
64,43\end{array}$ & \begin{tabular}{l|l|}
12,68 \\
12
\end{tabular} & 36,12 & 167,36 & 57,72 & \begin{tabular}{l|l}
60,85 \\
60
\end{tabular} & 137,99 \\
\hline Pelophylax perezi & 30SWG78 & 100,00 & 131,36 & 115,47 & 38,00 & 6238,93 & 303,27 & 4,73 & 298,54 & 110,07 & 215,20 & 216,39 & 57,86 & 468,90 & 60,81 & 11,01 & 36,76 & 157,61 & 52,91 & 56,30 & 128,90 \\
\hline Pelophylax perezi & 30SWG79 & 100,00 & 128,27 & 116,74 & 38,01 & 6304,95 & 302,71 & 1,07 & 301,64 & 106,82 & 213,16 & 214,17 & 54,13 & 483,07 & 62,92 & 11,84 & 36,05 & 163,21 & 56,64 & 59,17 & 130,85 \\
\hline Pelophylax perezi & 30SWG80 & 100,00 & 165,59 & 93,54 & 37,88 & 5247,23 & 299,58 & 54,39 & 245,19 & 139,68 & 233,77 & 237,46 & 103,20 & 295,56 & 39,35 & 3,23 & 45,72 & 107,79 & 20,76 & 27,63 & 94,16 \\
\hline Pelophylax perezi & 30SWG81 & 100,00 & 160,25 & 97,70 & 37,99 & 5419,57 & 300,41 & 46,09 & 254,32 & 132,88 & 231,18 & 234,46 & 95,96 & 321,14 & 41,36 & 4,22 & 43,86 & 113,80 & 24,71 & 31,51 & 99,92 \\
\hline Pelophylax perezi & 30SWG82 & 100,00 & 161,55 & 99,23 & 38,00 & 5469,05 & 303,05 & 46,01 & 257,04 & 133,45 & 233,16 & 236,22 & 96,45 & 317,63 & 41,41 & 4,06 & 43,88 & 112,54 & 24,57 & 31,51 & 97,51 \\
\hline Pelophylax perezi & 30SWG83 & 100,00 & 167,74 & 99,16 & 38,06 & 5423,78 & 307,43 & 51,92 & 255,51 & 139,93 & 238,62 & 241,43 & 102,65 & 294,92 & 40,18 & 3,23 & 44,63 & 106,63 & 21,77 & 29,06 & 90,01 \\
\hline Pelophylax perezi & 30SWG85 & 100,00 & 137,80 & 110,88 & 38,03 & 6014,57 & 300,68 & 14,06 & 286,62 & $\begin{array}{l}114,78 \\
\end{array}$ & 218,07 & 220,00 & 66,92 & 434,69 & 55,43 & 9,35 & 38,06 & 143,19 & 45,24 & 50,28 & 123,24 \\
\hline Pelophylax perezi & 30SWG86 & 100,00 & 140,42 & 111,71 & 38,09 & 6034,16 & 303,80 & 15,93 & 287,87 & 118,89 & 220,95 & 222,72 & 69,15 & 421,27 & 53,94 & 8,70 & 38,35 & 138,72 & 43,68 & 48,79 & 118,18 \\
\hline Pelophylax perezi & 30SWG87 & 100,00 & 134,92 & 113,63 & 38,1 & 6122,39 & 302,26 & $\begin{array}{l}9,58 \\
9\end{array}$ & 292,68 & 113,04 & 216,92 & 218,50 & 62,80 & 449,87 & 58,1 & 10,33 & 37,11 & 149,45 & 49,95 & 54,15 & 123,74 \\
\hline Pelophylax perezi & 30SWG88 & 100,00 & 139,40 & 114,28 & 38, & 6118,37 & 306,33 & 13,00 & 293,33 & 118,91 & 221,25 & 222,57 & 66,99 & 427,34 & 55,49 & 9,14 & 37,66 & 142,09 & |46,64 & 50,95 & 116,48 \\
\hline Pelophylax perezi & $\begin{array}{l}30 \text { SWG } \\
\end{array}$ & 100,00 & 136,07 & 115,69 & 38,32 & 6195,29 & 305,93 & 8,76 & 297,17 & 115,41 & 219,16 & 220,26 & 62,78 & 441,31 & 57,66 & 9,91 & 36,84 & 147,62 & 50,23 & 53,73 & 118,40 \\
\hline Pelophylax perezi & 30SWG90 & 100,00 & 162,44 & 95,17 & 37,99 & 5294,62 & 298,41 & 50,19 & 248,22 & 136,31 & 231,38 & 235,03 & 99,61 & 314,14 & 41,14 & 3,89 & 45,13 & 113,73 & 23,25 & 30,41 & 98,76 \\
\hline Pelophylax perezi & 30SWG91 & 100,00 & 176,51 & 92,11 & 38,00 & 5085,30 & 304,70 & 66,04 & 238,67 & 151,54 & 242,00 & 245,68 & 115,30 & 260,83 & 37,7 & 2,7 & 48,35 & 100,20 & 16,46 & 24,27 & 82,80 \\
\hline Pelophylax perezi & 30SWG92 & 100,00 & 175 & 94,86 & 38,7 & 5187,80 & 307,08 & 62,62 & 244,47 & 149,29 & 242,43 & 245,73 & 112,84 & 267,15 & 3 & 2,2 & 47,30 & 101,38 & 17,62 & 25,55 & 83,10 \\
\hline Pelophylax perezi & 30 SWG & 100,00 & 168,13 & 99,49 & 38,34 & 5395,51 & 307,27 & 52,05 & 255,22 & 140,55 & 238,50 & 241,33 & 103,29 & 295,93 & 40, & 3,30 & 44,89 & 107,88 & 21,99 & 29,78 & 89,43 \\
\hline Pelophylax perezi & 30SWG94 & 100,00 & 163,11 & 103,32 & 38,81 & 5556,14 & 307,90 & 44,17 & 263,73 & $\begin{array}{l}134,09 \\
\end{array}$ & 236,01 & 238,39 & $\begin{array}{l}96,45 \\
96,\end{array}$ & 317,65 & 42,44 & 4,03 & 43,36 & 112,63 & 25,60 & 33,18 & 93,60 \\
\hline Pelophylax perezi & 30SWG95 & 100,00 & 144,93 & 109,42 & 38,49 & 5887,40 & 302,58 & 21,95 & 280,62 & 117,33 & 223,08 & 225,15 & 75,07 & 399,68 & 50,58 & 7,75 & 39,07 & 132,26 & 39,84 & 45,79 & 112,91 \\
\hline Pelophylax perezi & 30SWG96 & 100,00 & 144,29 & 110,90 & 38,65 & 5940,80 & 304,21 & 20,36 & 283,85 & 118,84 & 223,43 & 225,23 & 74,01 & 402,57 & 51,2 & 7,93 & 38,69 & 132,37 & 41,16 & 46,88 & 112,11 \\
\hline Pelophylax perezi & 30SWG9 & 100,00 & $\frac{14}{15}$ & 11 & 38 & $\begin{array}{l}594,00 \\
590,51\end{array}$ & 309 & $\begin{array}{l}26,44 \\
26,4\end{array}$ & \begin{tabular}{|l|}
283,050 \\
283
\end{tabular} & \begin{tabular}{|l|}
121,44 \\
12,4
\end{tabular} & $\begin{array}{l}229,52 \\
225\end{array}$ & $\mid 231,13$ & $\begin{array}{l}4,015 \\
80,52\end{array}$ & \begin{tabular}{|l|}
372,18 \\
372
\end{tabular} & $\begin{array}{l}\mid 1,25 \\
47,73\end{array}$ & $\begin{array}{l}6,153 \\
6,42\end{array}$ & $\begin{array}{l}30,0093 \\
39,93\end{array}$ & 124,09 & 年1,10 & $\begin{array}{l}40,60 \\
42,69\end{array}$ & $\begin{array}{l}11,11 \\
103,01\end{array}$ \\
\hline Pelophylax perezi & 30SWG98 & 100,00 & 148,92 & 113,06 & 38,88 & 5976,33 & 310,19 & 23,00 & 287,19 & 120,97 & 228,47 & 229,83 & 77,71 & 382,85 & 49,54 & 7,04 & 39,39 & 127,28 & 39,17 & 45,08 & 103,99 \\
\hline Pelophylax perezi & 30SWG99 & 100,00 & 141,93 & 115,04 & 38,85 & 6098,75 & 307,93 & 14,80 & 293,13 & 121,79 & 223,39 & 224,51 & 69,38 & 413,51 & 54,08 & 8,66 & 37.59 & 137,00 & 45,97 & 50,49 & 109,85 \\
\hline Pelophylax perezi & 30SWHOO & 100,00 & 135,70 & 118,81 & 37,07 & 6620,45 & 321,12 & 5,99 & 315,12 & 97,55 & 225,36 & 225,55 & 57,45 & 503,33 & 63,04 & 9,04 & 42,12 & 176,09 & 44,77 & 46,68 & 153,98 \\
\hline Pelophylax perezi & 30SWHO1 & 100,00 & 131,25 & 119,80 & 37,0 & 6658,89 & 318,57 & 1,16 & 317,42 & 100,95 & 221,56 & 22 & 52,66 & 522,87 & 65,45 & 10,09 & 41,08 & 182,81 & 49,46 & 50,68 & 157,44 \\
\hline Pelophylax perezi & $\begin{array}{l}30 \text { SWHO2 } \\
\end{array}$ & $\begin{array}{l}100,00 \\
\end{array}$ & $\begin{array}{l}13,25 \\
144,42\end{array}$ & 1118,63 & | & 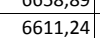 & 328,17 & \begin{tabular}{|l|}
1,10 \\
14,06
\end{tabular} & \begin{tabular}{|l|}
314,11 \\
314,
\end{tabular} & \begin{tabular}{|l|l|}
115,59 \\
110
\end{tabular} & \begin{tabular}{|l|}
233,70 \\
233
\end{tabular} & \begin{tabular}{|l|}
233,81 \\
231
\end{tabular} & $\begin{array}{ll}65,58 \\
658\end{array}$ & \begin{tabular}{|l|}
$459,73,7$ \\
4
\end{tabular} & $\mid \begin{array}{l}\mid 50,45 \\
57,65\end{array}$ & $\mid 7,20$ & $\begin{array}{l}1,00 \\
42,47\end{array}$ & $\begin{array}{l}10,01 \\
160,87\end{array}$ & $\begin{array}{l}49,40 \\
39,82 \\
\end{array}$ & $\begin{array}{l}0,00 \\
40,88 \\
\end{array}$ & $\begin{array}{l}131,49 \\
139,07\end{array}$ \\
\hline Pelophylax perezi & 30SWHO3 & 100,00 & 152,16 & 117,87 & 37,10 & 6566,44 & 333,27 & 21,56 & 311,71 & 127,42 & 240,51 & 240,57 & 73,34 & 424,25 & 53,19 & 5,88 & 43,00 & 147,95 & 35,37 & 36,05 & 127,97 \\
\hline Pelophylax perezi & 30SWHO4 & 100,00 & 153,38 & 118,44 & 37,31 & 6570,38 & 334,75 & 22,41 & 312,34 & 134,77 & 241,78 & 241,81 & 74,35 & 415,06 & 52,06 & 5,56 & 42,79 & 144,82 & \begin{tabular}{|l|l|}
34,95 \\
\end{tabular} & 35,32 & 123,95 \\
\hline Pelophylax perezi & 30SWHO5 & 100,00 & 146,81 & 120,28 & 37,49 & 6636,79 & 331,49 & 14,79 & 316,69 & 128,08 & 236,2 & 236 & 67 & 437,31 & 54,96 & 6,57 & 41 & 153,16 & 39,79 & 39,86 & 128,39 \\
\hline Pelophylax perezi & 30SWHO6 & 100,00 & 138,07 & 121,96 & 37,75 & 6697,72 & 326,27 & 5,68 & 320,59 & 118,73 & 228,64 & 228,64 & 58,33 & 468,66 & 58,71 & 8,10 & 39,86 & 164,30 & 46,44 & 46,44 & 135,13 \\
\hline
\end{tabular}




\begin{tabular}{|c|c|c|c|c|c|c|c|c|c|c|c|c|c|c|c|c|c|c|c|c|c|}
\hline TAXON & UTM & $\mathrm{km} 2$ & B101 & B102 & $\mathrm{BIO3}$ & BIO4 & B105 & B106 & 8107 & B108 & B109 & B1010 & BIO11 & BIO12 & 81013 & BIO14 & BIO15 & B1016 & B1017 & B1018 & B1019 \\
\hline Pelophylax perezi & 30SWH08 & 100,00 & 135,94 & 123,06 & 37,92 & 6721,55 & 325,14 & 2,68 & 322,45 & 117,01 & 226,79 & 226,79 & 55,60 & 467,67 & 58,10 & 8,45 & 38,56 & 163,34 & 49,23 & 49,23 & 131,95 \\
\hline Pelophylax perezi & 30SWHO9 & 100,00 & 134,57 & 123,45 & 37,88 & 6738,96 & 324,19 & 1,06 & 323,14 & 115,69 & 225,62 & 225,62 & 54,10 & 468,23 & 57,77 & 8,75 & 38,11 & 163,12 & 50,86 & 50,86 & 130,85 \\
\hline Pelophylax perezi & 30SWH10 & 100,00 & 119,81 & 120,31 & 37,38 & 6638,95 & 308,01 & $-9,60$ & 317,61 & 94,93 & 210,08 & 210,42 & 42,17 & 569,87 & 71,55 & 13,20 & 38,99 & 197,38 & 59,80 & 61,74 & 168,19 \\
\hline Pelophylax perezi & 30SWH11 & 100,00 & 134,09 & 119,02 & 37,29 & \begin{tabular}{ll|l}
6587,66 \\
\end{tabular} & 318,37 & 4,40 & 313,97 & 111,43 & 223,24 & 223,42 & 56,20 & 498,22 & 62,81 & 9,64 & 40,51 & 173,14 & 48,17 & 50,10 & 147,80 \\
\hline Pelophylax perezi & 30SWH12 & 100,00 & 134,78 & $\begin{array}{ll}119,67 \\
\end{array}$ & 37,38 & 6609,19 & 319,85 & 4,54 & 315,31 & 114,20 & 224,19 & 224,34 & 56,55 & \begin{tabular}{|l|l|}
491,51 \\
\end{tabular} & $\begin{array}{ll}62,07 \\
\end{array}$ & 9,38 & 40,19 & 171,31 & 48,13 & 49,49 & 144,39 \\
\hline Pelophylax perezi & 30SWH13 & 100,00 & 136,64 & 120,31 & 37,53 & 6623,65 & 322,19 & 5,76 & 316,43 & 116,56 & 226,25 & 226,32 & 58,05 & 478,28 & 60,61 & 8,73 & 40,08 & 167,22 & 46,82 & 47,43 & 139,38 \\
\hline Pelophylax perezi & 30SWH14 & 100,00 & 148,97 & 119,01 & 37,71 & 6557,42 & 330,43 & 17,86 & 312,57 & 130,21 & 237,24 & 237,24 & 70,45 & 422,51 & 53,51 & 6,37 & 41,31 & 147,08 & 38,62 & 38,94 & 123,22 \\
\hline Pelophylax perezi & 30 SWH15 & 100,00 & 147,25 & 119,94 & 37,88 & 6586,56 & 330,12 & 15,63 & 314,48 & 128,62 & 235,99 & 235,99 & 68,25 & 425,55 & 53,92 & 6,58 & $\begin{array}{l}40,75 \\
40\end{array}$ & 148,32 & 40,22 & 40,28 & 122,72 \\
\hline Pelophylax perezi & 30SWH16 & 100,00 & 143,69 & 121,04 & 37,97 & 6623,49 & 328,40 & 11,49 & 316,91 & 124,80 & 233,03 & 233,03 & 64,38 & 435,98 & 55,13 & 7,22 & 39,76 & 152,02 & 43,33 & 43,33 & 123,95 \\
\hline Pelophylax perezi & 30SWH17 & 100,00 & 134,64 & 122,57 & 38,00 & 6673,81 & 322,48 & 2,36 & 320,11 & 115,32 & 224,87 & 224,87 & 55,14 & 470,69 & 59,10 & 9,06 & 38,14 & 164,29 & 51,01 & 51,01 & 131,44 \\
\hline Pelophylax perezi & 30SWH20 & 100,00 & 97,98 & 121,82 & 37,70 & 6678,92 & 289,86 & $-30,73$ & 320,59 & 74,45 & 189,41 & 189,81 & 21,11 & 674,38 & 84,46 & 19,71 & 35,07 & 231,49 & 82,36 & 82,62 & 191,90 \\
\hline Pelophylax perezi & 30SWH21 & 100,00 & 108,66 & 121,42 & 37,75 & 6662,13 & 298,65 & $-20,64$ & 319,29 & 85,88 & 199,53 & 199,80 & 31,31 & 615,27 & 77,37 & 16,50 & 36,18 & 212,34 & 72,30 & 72,93 & 175,07 \\
\hline Pelophylax perezi & 30SWH22 & 100,00 & 129,43 & 120,05 & 37,79 & 6589,29 & 314,54 & $-0,47$ & 315,01 & 108,49 & 218,69 & 218,97 & 51,83 & 507,32 & 64,45 & 10,86 & 38,66 & 176,13 & 53,73 & 54,77 & 145,49 \\
\hline Pelophylax perezi & 30SWH23 & 100,00 & 135,81 & 119,95 & 37,88 & 6573,86 & 319,58 & 5,31 & 314,27 & 115,67 & 224,68 & 224,79 & 57,81 & 473,78 & 60,36 & 9,25 & 39,12 & 164,77 & 48,83 & 49,47 & 135,25 \\
\hline Pelophylax perezi & 30SWH24 & 100,00 & 144,52 & 119,50 & 37,97 & 6537,57 & 326,10 & 13,49 & 312,61 & 125,46 & 232,60 & 232,66 & 66,33 & \begin{tabular}{|l|l|}
431,48 \\
\end{tabular} & 55,08 & 7,33 & 39,93 & 149,76 & 42,48 & 42,80 & 123,02 \\
\hline Pelophylax perezi & 30SWH25 & 100,00 & 140,51 & 120,64 & 38,00 & 6580,19 & 324,05 & 8,96 & 315,09 & 121,21 & 229,27 & 229,33 & 61,99 & 444,95 & 56,81 & 7,98 & 39,07 & 154,85 & 46,07 & 46,40 & 125,01 \\
\hline Pelophylax perezi & 30SWH26 & 100,00 & 142,96 & 120,98 & 38,00 & 6576,61 & 326,16 & 10,95 & 315,21 & 123,99 & 231,54 & 231,55 & 64,16 & 431,01 & 54,96 & 7,51 & 39,07 & 149,84 & 44,83 & 44,90 & 120,01 \\
\hline Pelophylax perezi & 30SWH27 & 100,00 & 136,53 & 122,09 & 38,00 & 6621,28 & 322,34 & 4,31 & 318,03 & 117,43 & 226,03 & 226,05 & 57,70 & 455,02 & 57,62 & 8,86 & 37,61 & 158,18 & 50,57 & 50,66 & 124,84 \\
\hline Pelophylax perezi & 30SWH28 & 100,00 & 130,82 & 122,95 & 38,00 & 6646,01 & 318,52 & $-1,10$ & 319,62 & 111,49 & 220,70 & 220,86 & 51,95 & 476,01 & 59,69 & 9,92 & 36,66 & 165,36 & 54,88 & 55,57 & 128,99 \\
\hline Pelophylax perezi & 30SWH30 & 100,00 & 102,13 & 120,83 & 37,45 & 6632,01 & 291,64 & $-26,36$ & 318,00 & 78,76 & 192,94 & 193,40 & 25,83 & 644,83 & 81,33 & 18,94 & 34,79 & 221,03 & 79,58 & 80,12 & 181,02 \\
\hline Pelophylax perezi & 30SWH31 & 100,00 & 108,29 & 121,08 & 37,73 & 6625,97 & 297,12 & $-20,70$ & 317,82 & 85,36 & 198,76 & 199,10 & 31,57 & 606,90 & 76,87 & 16,75 & 35,28 & 209,08 & 73,52 & 73,98 & 169,73 \\
\hline Pelophylax perezi & 30SWH32 & 100,00 & 114,08 & 121,17 & 37,90 & 6616,64 & 301,82 & $-15,40$ & 317,22 & 91,90 & 204,23 & 204,44 & 36,99 & 573,92 & 72,88 & 15,03 & 35,73 & 198,20 & 68,40 & 68,88 & 159,72 \\
\hline Pelophylax perezi & 30SWH33 & 100,00 & 115,28 & 121,64 & 37,99 & 6624,59 & 303,36 & $-14,60$ & 317,95 & 93,55 & 205,45 & 205,58 & 37,90 & 563,74 & 71,58 & 14,55 & 35,49 & 195,09 & 67,78 & 68,03 & 155,56 \\
\hline Pelophylax perezi & 30SWH34 & 100,00 & 127,64 & 121,06 & 37,99 & 6585,76 & 312,86 & $-2,88$ & 315,74 & \begin{tabular}{l|l|}
107,04 \\
\end{tabular} & 216,92 & 217,02 & 50,06 & 499,64 & 63,86 & 11,34 & 36,86 & 173,19 & 57,30 & 57,69 & 137,60 \\
\hline Pelophylax perezi & 30SWH35 & 100,00 & 135,10 & 120,94 & 38,00 & 6562,45 & 318,66 & 3,99 & 314,68 & 115,32 & 223,75 & 223,83 & 57,18 & 461,17 & 59,19 & 9,41 & 37,62 & 159,92 & 51,44 & 51,82 & 126,39 \\
\hline Pelophylax perezi & 30SWH36 & 100,00 & 126,54 & 122,05 & 38,00 & 6610,75 & 312,94 & $-4,77$ & 317,70 & $\begin{array}{ll}106,23 \\
\end{array}$ & 216,08 & 216,18 & 48,37 & 497,56 & 63,25 & 11,47 & 36,08 & 172,49 & 58,95 & 59,70 & 134,27 \\
\hline Pelophylax perezi & 30SWH37 & 100,00 & 137,60 & 121,74 & 38,00 & 6574,66 & 321,26 & 5,33 & 315,93 & $\begin{array}{l}118,44 \\
\end{array}$ & 226,15 & 226,18 & 58,94 & 4443,36 & 56,69 & \begin{tabular}{|c|}
8,84 \\
8,84
\end{tabular} & 37,12 & 153,45 & 50,73 & 51,05 & 119,20 \\
\hline Pelophylax perezi & 30SWH40 & 100,00 & 111,35 & 119,94 & 37,86 & 6555,71 & 296,98 & $-17,14$ & 314,12 & 88,53 & 200,57 & 201,16 & 35,33 & 587,22 & 74,95 & 16,23 & 35,18 & 201,40 & 71,21 & 72,18 & 163,32 \\
\hline Pelophylax perezi & 30SWH41 & 100,00 & 104,01 & 120,89 & 37,87 & 6607,13 & 292,17 & $-24,69$ & 316,87 & 80,68 & 194,50 & 194,73 & 27,95 & 624,24 & 79,20 & 18,58 & 33,92 & 213,93 & 79,32 & 79,43 & 171,15 \\
\hline Pelophylax perezi & 30SWH42 & 100,00 & 117,07 & 120,59 & 37,97 & 6569,31 & 302,61 & $-12,38$ & 314,99 & 94,95 & 206,40 & 206,77 & 40,55 & 550,65 & 70,50 & 14,42 & 35,34 & 189,73 & 66,72 & 67,18 & 150,78 \\
\hline Pelophylax perezi & 30SWH43 & 100,00 & 126,58 & 120,40 & 37,99 & 6533,06 & 309,88 & $-3,61$ & 313,49 & 105,78 & 215,07 & 215,37 & 49,71 & 500,56 & 64,43 & 11,81 & 36,40 & 172,66 & 58,66 & 59,34 & 136,50 \\
\hline Pelophylax perezi & 30 SWH44 & 100,00 & 120,14 & 121,30 & 38,00 & 6578,54 & 305,68 & \begin{tabular}{|c|c|}
$-10,05$ \\
-10
\end{tabular} & $\begin{array}{l}315,73 \\
31,4\end{array}$ & $\begin{array}{l}98,81 \\
9\end{array}$ & 209,57 & 209,66 & \begin{tabular}{|l|l|}
42,99 \\
4
\end{tabular} & 529,28 & 67,71 & \begin{tabular}{l|l}
13,53 \\
13
\end{tabular} & 35,21 & $\begin{array}{l}182,61 \\
\end{array}$ & $\begin{array}{ll}6,, 91 \\
64\end{array}$ & $\frac{65,25}{65,25}$ & 142,30 \\
\hline Pelophylax perezi & 30SWH45 & 100,00 & 122,26 & 121,51 & 38,00 & 6578,14 & 307,64 & $-8,31$ & 315,95 & 101,38 & 211,55 & 211,58 & 44,91 & 515,95 & 65,98 & 13,00 & 35,23 & 178,04 & 63,34 & 64,24 & 137,55 \\
\hline Pelophylax perezi & 30 SWH46 & 100,00 & 115,51 & 122,13 & 38,00 & 6610,28 & 302,89 & $-14,96$ & 317,85 & 94,21 & 205,38 & 205,49 & 38,10 & 545,61 & 69,02 & 14,80 & 33,92 & 188,01 & 69,40 & 70,86 & 143,76 \\
\hline Pelophylax perezi & 30 SWH47 & 100,00 & 121,31 & 122,45 & 38,00 & 6603,47 & 307,74 & $-9,66$ & 317,40 & 100,72 & 210,66 & 210,88 & 43,54 & 512,44 & 64,99 & 13,08 & 34,31 & 176,73 & 64,28 & 66,55 & 134,06 \\
\hline Pelophylax perezi & 30SWH50 & 100,00 & 120,56 & 118,94 & 38,00 & 6466,86 & 302,08 & $-7,79$ & 309,87 & 98,62 & 208,15 & 208,87 & 44,98 & 530,73 & 68,54 & 13,60 & 35,69 & 181,69 & 62,95 & 64,42 & 146,11 \\
\hline Pelophylax perezi & 30SWH51 & 100,00 & $\begin{array}{l}12,50 \\
102,68\end{array}$ & 1120,33 & 37,85 & $\begin{array}{l}040,000 \\
6578,31\end{array}$ & 280,40 & $\mid-25,73$ & \begin{tabular}{|l|}
315,19 \\
315
\end{tabular} & $\begin{array}{l}\mid 70,0<4 \\
79,39\end{array}$ & \begin{tabular}{|l|}
192,83 \\
192,
\end{tabular} & \begin{tabular}{|l|}
193,01 \\
\end{tabular} & $\begin{array}{l}44,90 \\
26,90\end{array}$ & $\begin{array}{l}350,13 \\
627,86\end{array}$ & $\begin{array}{l}\mid 00,54 \\
79,82\end{array}$ & $\begin{array}{l}10,50 \\
19,57\end{array}$ & $\begin{array}{l}32,97 \\
32,97\end{array}$ & \begin{tabular}{|l|}
214,10 \\
21,0
\end{tabular} & $\begin{array}{l}2,359 \\
82,39 \\
\end{array}$ & $\begin{array}{l}4,44 \\
82,44 \\
\end{array}$ & $\begin{array}{l}140,11 \\
169,05\end{array}$ \\
\hline Pelophylax perezi & 30SWH52 & 100,00 & 116,10 & 120,35 & 38,00 & 6533,21 & 300,31 & $-12,83$ & 313,14 & 94,07 & 205,03 & 205,38 & 40,06 & 548,71 & 70,60 & 14,86 & 34,53 & 188,31 & 68,69 & 68,93 & 147,66 \\
\hline Pelophylax perezi & 30SWH53 & 100,00 & 123,01 & 120,28 & 38,00 & 6502,48 & 305,49 & $-6,56$ & 312,05 & \begin{tabular}{r|}
101,84 \\
\end{tabular} & 211,27 & 211,45 & 46,66 & 513,34 & 66,25 & 13,13 & 35,28 & 176,21 & 63,08 & 63,49 & 137,18 \\
\hline Pelophylax perezi & 30SWH54 & 100,00 & 131,29 & 120,31 & 38,04 & 6476,47 & 312,01 & 1,13 & 310,89 & 110,88 & 218,81 & 218,99 & 54,62 & 468,32 & 60,97 & 10,81 & 36,17 & 161,00 & 56,14 & 56,56 & 124,16 \\
\hline Pelophylax perezi & 30SWH55 & 100,00 & 121,66 & 121,17 & 38,03 & 6532,07 & 305,32 & $-8,37$ & 313,69 & 100,71 & 210,34 & 210,44 & 44,90 & 514,17 & 65,99 & 13,58 & 34,55 & 176,47 & 65,08 & 66,08 & 134,49 \\
\hline Pelophylax perezi & \begin{tabular}{|l|}
305 SWH56 \\
3056
\end{tabular} & 100,00 & $\begin{array}{l}12,00 \\
117,42\end{array}$ & $\begin{array}{l}121,17 \\
121,80\end{array}$ & $\begin{array}{l}38,00 \\
38,00\end{array}$ & $\begin{array}{l}6536,08,34 \\
6564\end{array}$ & $\begin{array}{l}30,52 \\
302,79\end{array}$ & \begin{tabular}{|c|c|}
$-0,31,63$ \\
$-12,63$
\end{tabular} & $\begin{array}{l}31,, 45 \\
315,42\end{array}$ & $\begin{array}{r}10, / 1 \\
96,35 \\
\end{array}$ & $\mid \frac{\mid 10,34}{206,74}$ & $\begin{array}{l}20,44,80 \\
206\end{array}$ & $\begin{array}{l}44,53 \\
40,5\end{array}$ & $\mid$ & $\begin{array}{l}\mid c 3,99 \\
67,58\end{array}$ & $\begin{array}{ll}31,4,6 \\
14,6\end{array}$ & 33,55 & \begin{tabular}{|l|}
$182,10,10$ \\
\end{tabular} & $\begin{array}{l}3,300 \\
68,66\end{array}$ & $\begin{array}{l}0,00 \\
70,37 \\
\end{array}$ & $\begin{array}{l}134,49 \\
137,23\end{array}$ \\
\hline Pelophylax perezi & 30SWH57 & 100,00 & 114,82 & 122,09 & 38,00 & 6587,10 & 300,95 & $-15,36$ & 316,31 & 93,56 & 204,25 & 204,32 & 37,72 & 539,45 & 68,25 & 15,29 & 32,92 & 185,07 & 70,97 & 73,38 & 138,21 \\
\hline Pelophylax perezi & 30SWH59 & 100,00 & 129,59 & 122,39 & 38,30 & 6539,40 & 312,89 & $-1,79$ & 314,68 & 110,51 & 217,68 & 218,04 & 51,72 & 460,34 & 58,64 & 11,23 & 34,25 & 157,76 & 58,58 & 62,27 & 115,81 \\
\hline Pelophylax perezi & 30SWH60 & 100,00 & 124,15 & 118,25 & 38,00 & 6404,44 & 302,79 & $-3,59$ & 306,38 & 102,50 & 210,65 & 211,57 & 49,02 & 506,06 & 65,76 & 12,7 & 35,65 & 172,45 & 60,49 & 62,05 & 137,26 \\
\hline Pelophylax perezi & 30 SWH61 & 100,00 & 108,09 & 119,62 & 37,93 & 65411,14 & 291,8 & \begin{tabular}{|c|c|}
$-19,90$ \\
-19
\end{tabular} & $\begin{array}{l}311,79 \\
3\end{array}$ & 85,27 & 197,10 & 19 & $\begin{array}{l}35,626 \\
32,68\end{array}$ & 592,88 & 75,6 & 18, & 33,04 & 201,65 & $\begin{array}{l}0,4714 \\
78,14\end{array}$ & 78,20 & 157,47 \\
\hline Pelophylax perezi & $30 \mathrm{SWHE}$ & 100,00 & 122 & 119,54 & 38,00 & 6448,83 & 303,26 & $-6,08$ & 309,34 & 101,19 & 210,08 & 210,48 & 47,03 & 510,83 & 66,39 & 13,34 & 34,84 & 174,56 & 63,86 & 64,27 & 135,26 \\
\hline Pelophylax perezi & 30SWH63 & 100,00 & 130,89 & 119,69 & 38,07 & 6418,81 & 309,65 & 1,35 & 308,30 & 110,42 & 217,51 & 217,96 & 54,92 & 467,12 & 61,21 & 11,03 & 35,84 & 159,75 & 56,89 & 57,26 & 122,81 \\
\hline Pelophylax perezi & 30SWH64 & 100,00 & 143,58 & 119,04 & 38,44 & 6357,51 & 318,63 & 13,18 & 305,45 & 124,52 & 228,84 & 229,14 & 67,52 & \begin{tabular}{|c|}
406,88 \\
\end{tabular} & 53,85 & 8,03 & 37,66 & 138,73 & 46,86 & 47,79 & 106,31 \\
\hline Pelophylax perezi & 30SWH65 & 100,00 & 137,79 & 120,16 & 38,44 & 6408,61 & 315,40 & 7,05 & 308,36 & 118,61 & 224,08 & 224,23 & 61,37 & 430,13 & 56,60 & 9,38 & 36,48 & 97 & 52,01 & 52,64 & 110,77 \\
\hline Pelophylax perezi & 30SWH66 & 100,00 & 125 & $\begin{array}{l}121,10 \\
121,30\end{array}$ & 38, & \begin{tabular}{|l|}
64990,78 \\
6
\end{tabular} & 307,5 & $\begin{array}{c}-4,69 \\
-4,69 \\
\end{array}$ & $\begin{array}{l}312,25 \\
3120\end{array}$ & $\begin{array}{l}105,67 \\
105\end{array}$ & \begin{tabular}{|l|}
213,69 \\
2130
\end{tabular} & 21 & \begin{tabular}{|l|}
49,07 \\
4
\end{tabular} & $\begin{array}{l}580,15 \\
483,00\end{array}$ & $\begin{array}{l}00,200 \\
62,73\end{array}$ & $\mid \begin{array}{r}\mid, 2,05 \\
12,45\end{array}$ & 30,40 & $\begin{array}{l}140,47,2 \\
165,\end{array}$ & $\begin{array}{l}2,101 \\
62,13 \\
\end{array}$ & $\begin{array}{l}2,044 \\
63,59 \\
\end{array}$ & 122,54 \\
\hline Pelophylax perezi & 30SWH67 & 100,00 & 121,15 & 121,71 & 38,09 & 6519,50 & 304,16 & $-9,30$ & 313,46 & 100,49 & 209,50 & 209,64 & 44,39 & 503,36 & 64,59 & 13,88 & 33,23 & \begin{tabular}{|l|l|}
172,13 \\
\end{tabular} & 66,52 & 69,38 & 126,38 \\
\hline Pelophylax perezi & 30SWH68 & 100,00 & 120,79 & 121,99 & 38,05 & 6529,85 & 304,34 & $\begin{array}{l}-9,69 \\
-9,69\end{array}$ & 314,03 & $\begin{array}{l}100,02 \\
\end{array}$ & 209,21 & 209,41 & 43,87 & 500,94 & 63,86 & $\begin{array}{l}13,006 \\
13,86\end{array}$ & 32,85 & $\begin{array}{l}171,14 \\
171\end{array}$ & $\begin{array}{l}0,71 \\
66,71\end{array}$ & 70,40 & 124,62 \\
\hline Pelophylax perezi & 30 SWH70 & 100,00 & 129,57 & 117,44 & 38,03 & 6318,67 & 304,54 & 1,52 & 303,03 & 108,62 & 214,68 & 215,58 & 55,08 & 475,33 & 62,10 & 11,50 & 35,89 & 160,92 & 56,41 & 58,56 & 127,24 \\
\hline Pelophylax perezi & $30 S W H 71$ & 100,00 & 119,08 & 118,76 & 38,03 & 6412,77 & 298,25 & $-8,89$ & 307,14 & 97,06 & 205,94 & 206 & 44,11 & 528,87 & 68,66 & 14,74 & 34,00 & 179,50 & 67,99 & 68,50 & 13 \\
\hline Pelophylax perezi & $\begin{array}{l}305 W H 72 \\
305\end{array}$ & $\begin{array}{l}100,00 \\
\end{array}$ & $\begin{array}{l}111,00 \\
116,62\end{array}$ & $\begin{array}{l}110,190 \\
119,38\end{array}$ & $\begin{array}{l}30,030 \\
38,00\end{array}$ & 6439,80 & $\begin{array}{l}290,25 \\
297,18\end{array}$ & \begin{tabular}{|c|c|}
$-0,03$ \\
$-11,63$
\end{tabular} & \begin{tabular}{|l|}
308,81 \\
\end{tabular} & $\begin{array}{l}1,00 \\
94,75 \\
\end{array}$ & \begin{tabular}{|l|}
204,30 \\
\end{tabular} & \begin{tabular}{|l|}
204,62 \\
\end{tabular} & $\begin{array}{l}44,114 \\
41,43\end{array}$ & | & $\begin{array}{l}00,00 \\
69,85 \\
\end{array}$ & \begin{tabular}{|l|}
15,50 \\
15,4
\end{tabular} & $\begin{array}{ll}43,40 \\
33,44\end{array}$ & $\begin{array}{l}183,02 \\
180\end{array}$ & $\begin{array}{l}1,1,05 \\
71\end{array}$ & $\begin{array}{l}0,00 \\
71,07 \\
\end{array}$ & $\begin{array}{l}150,50 \\
140,00\end{array}$ \\
\hline Pelophylax perezi & 30SWH73 & 100,00 & 122,36 & 119,87 & 38,13 & 6426,94 & 301,87 & $-6,58$ & 308,45 & 101,08 & 209,64 & 209,83 & 47,00 & 505,47 & 65,92 & 13,66 & 34,00 & 171,94 & 65,78 & 65,79 & 129,99 \\
\hline Pelophylax perezi & 30SWH74 & 100,00 & 141,05 & 119,23 & 38,77 & 6329,09 & 315,33 & 10,57 & 304,76 & 121,84 & 225,88 & 226,24 & 65,34 & 414,05 & 55,10 & 8,77 & 36,85 & 140,58 & 50,00 & 50,60 & 105,82 \\
\hline Pelophylax perezi & 30SWH75 & 100,00 & 143,32 & 119,51 & 38,80 & 6318,92 & 317,40 & 12,58 & 304,8 & 124, & 228,17 & 228, & 67, & 402,00 & 53,56 & 8,37 & 37,06 & 136,37 & 48,75 & 49,31 & 101,49 \\
\hline Pelophylax perezi & 30 SWH76 & 100,00 & 132,95 & 120,81 & 38,82 & 6408,51 & 311,01 & 2,16 & 308,85 & 113,34 & 219,48 & 219,49 & 56,69 & 444,69 & 58,68 & 10,75 & 35,01 & 151,40 & 57,19 & 58,24 & 110,40 \\
\hline
\end{tabular}




\begin{tabular}{|c|c|c|c|c|c|c|c|c|c|c|c|c|c|c|c|c|c|c|c|c|c|}
\hline TAXON & UTM & $\mathrm{km} 2$ & B101 & B102 & $\mathrm{BIO3}$ & BIO4 & B105 & B106 & B107 & B108 & B109 & B1010 & BIO11 & BIO12 & 81013 & BIO14 & BIO15 & B1016 & B1017 & BIO18 & B1019 \\
\hline Pelophylax perezi & 30SWH77 & 100,00 & 123,18 & 121,17 & 38,41 & 6470,92 & 304,12 & $-7,16$ & 311,29 & 102,78 & 210,74 & 210,77 & 46,77 & 489,06 & 63,27 & 13,52 & 33,29 & 166,43 & 65,67 & 68,23 & 120,31 \\
\hline Pelophylax perezi & 30SWH78 & 100,00 & 119,50 & 121,59 & 38,33 & 6494,99 & 301,59 & $-10,78$ & 312,37 & 98,80 & 207,46 & 207,51 & 43,04 & 504,06 & 64,44 & 14,59 & 32,28 & 171,28 & 69,07 & 72,55 & 122,98 \\
\hline Pelophylax perezi & 30 SWH80 & 100,00 & 134,74 & 116,71 & 38,58 & 6236,81 & 306,19 & 6,65 & 299,54 & 114,16 & 218,45 & 219,43 & 60,74 & 447,71 & 58,71 & 10,38 & 36,28 & 150,32 & 52,66 & 55,54 & 118,30 \\
\hline Pelophylax perezi & 30SWH81 & 100,00 & 133,70 & 117,66 & 38,62 & 6270,47 & 306,62 & 5,01 & 301,61 & 113,16 & 217,97 & 218,81 & 59,57 & 450,95 & 59,38 & 10,58 & 35,94 & 152,00 & 54,51 & 56,62 & 117,47 \\
\hline Pelophylax perezi & 30SWH82 & 100,00 & 123,14 & 118,79 & 38,38 & 6366,40 & 300,15 & $-5,17$ & 305,32 & \begin{tabular}{|l|}
101,86 \\
\end{tabular} & 209,27 & 209,86 & 48,48 & 502,28 & 65,59 & 13,74 & 33,91 & 169,65 & 65,89 & 66,19 & 128,66 \\
\hline Pelophylax perezi & 30SWH83 & 100,00 & 127,20 & 119,13 & 38,56 & 6355,33 & 303,63 & $-1,80$ & 305,43 & 106,50 & 213,11 & 213,46 & 52,27 & 479,97 & 63,04 & 12,64 & 34,44 & 162,31 & 62,58 & 62,96 & 121,56 \\
\hline Pelophylax perezi & 30SWH84 & 100,00 & 141,39 & 119,12 & 38,93 & 6275,90 & 313,94 & 11,17 & 302,77 & 122,32 & 225,54 & 225,87 & 66,34 & 411,11 & 54,83 & 8,93 & 36,70 & 138,72 & 50,65 & 51,52 & 103,15 \\
\hline Pelophylax perezi & 30 SWH 85 & 100,00 & 148,53 & 118,95 & 39,00 & 6241,77 & 319,29 & 17,79 & 301,50 & 130,34 & 231,99 & 232,27 & 73,44 & 377,51 & 50,75 & 7,36 & 37,82 & 126,92 & 45,61 & 46,44 & 93,48 \\
\hline Pelophylax perezi & 30SWH86 & 100,00 & 139,91 & 120,07 & 38,97 & 6323,97 & 314,17 & 9,01 & 305,16 & 120,78 & 225,01 & 225,06 & 64,40 & 410,44 & 54,92 & 9,30 & 36,04 & 138,60 & 52,97 & 53,56 & 99,77 \\
\hline Pelophylax perezi & 30SWH87 & 100,00 & 130,85 & 120,71 & 38,95 & 6393,79 & 308,12 & 0,47 & 307,66 & 111,27 & 217,19 & 217,21 & 55,06 & 448,12 & 59,10 & 11,66 & 34,21 & 151,61 & 60,12 & 62,05 & 107,57 \\
\hline Pelophylax perezi & 30SWH90 & 100,00 & 139,71 & 116,29 & 38,98 & 6148,27 & 307,94 & 11,79 & 296,15 & 119,46 & 221,97 & 222,95 & 66,79 & 422,94 & 55,66 & 9,25 & 36,99 & 140,90 & 48,95 & 52,66 & 110,38 \\
\hline Pelophylax perezi & 30SWH91 & 100,00 & 141,29 & 117,12 & 38,93 & 6162,53 & 309,87 & 12,71 & 297,16 & 121,52 & 223,81 & 224,52 & 67,92 & 415,86 & 54,98 & 9,03 & 37,18 & 138,75 & 48,73 & 52,23 & 107,13 \\
\hline Pelophylax perezi & 30SWH92 & 100,00 & 137,53 & 117,82 & 38,78 & 6220,34 & 308,26 & 8,64 & 299,62 & 117,55 & 220,95 & 221,68 & 63,68 & 433,09 & 57,22 & 10,15 & 36,25 & 144,87 & 53,48 & 55,89 & 109,89 \\
\hline Pelophylax perezi & 30SWH93 & 100,00 & 141,58 & 118,42 & 39,03 & 6211,47 & 311,88 & 11,96 & 299,92 & 122,12 & 224,78 & 225,34 & 67,37 & 411,29 & 54,77 & 9,06 & 36,84 & 137,69 & 50,45 & 52,65 & 103,01 \\
\hline Pelophylax perezi & 30SWH94 & 100,00 & 152,20 & 118,30 & 39,15 & 6143,11 & 319,57 & 21,88 & 297,69 & 133,95 & 234,10 & 234,45 & 78,05 & 365,16 & 49,16 & 6,70 & 38,84 & 121,72 & 42,36 & 44,79 & 90,51 \\
\hline Pelophylax perezi & 30SWH95 & 100,00 & 150,41 & 118,84 & 39,14 & 6175,10 & 318,85 & 19,76 & 299,09 & 132,24 & 232,81 & 233,03 & 75,88 & 370,24 & 49,90 & 7,21 & 38,17 & 123,54 & 45,03 & 46,55 & 90,10 \\
\hline Pelophylax perezi & 30SWH96 & 100,00 & 146,16 & 119,44 & 39,02 & 6231,48 & 316,62 & 15,25 & 301,38 & 127,58 & 229,58 & 229,75 & 71,24 & \begin{tabular}{|l|l|}
384,08 \\
\end{tabular} & 51,70 & 8,15 & 37,09 & 128,34 & 49,41 & 50,04 & 91,68 \\
\hline Pelophylax perezi & 30SWH97 & 100,00 & 137,70 & 120,01 & 39,00 & 6308,39 & 311,18 & 6,87 & 304,30 & 118,44 & 222,62 & 222,62 & 62,31 & 415,08 & 55,55 & 10,15 & 35,33 & 139,23 & 55,92 & 57,06 & 97,45 \\
\hline Pelophylax perezi & 30SWJ01 & 100,00 & 135,83 & 123,65 & 38,00 & 6718,88 & 324,97 & 2,06 & 322,91 & 117,75 & 226,59 & 226,64 & 55,40 & 454,33 & 55,12 & 8,55 & 37,33 & 156,72 & 50,76 & 50,82 & 125,18 \\
\hline Pelophylax perezi & 30 SWJ02 & 100,00 & 138,45 & 123,25 & 38,00 & 6704,66 & 326,68 & 4.44 & 322,24 & 120,94 & 228,87 & 228,95 & 57,98 & 440,06 & 52,78 & 8,14 & 37,16 & $\mid 150,69$ & 49,34 & 49,43 & 120,67 \\
\hline Pelophylax perezi & 305WJ06 & 100,00 & 141,19 & 121,88 & 37,88 & 6682,22 & 326,79 & 7,55 & 319,24 & 125,00 & 231,17 & 231,17 & 60,55 & 419,66 & 47,80 & 8,17 & 35,69 & 139,11 & 49,30 & 49,30 & 113,53 \\
\hline Pelophylax perezi & 30SWJ07 & 100,00 & 138,27 & 121,39 & 37,40 & 6693,20 & 324,12 & 4,90 & 319,22 & 122,05 & 228,10 & 228,25 & 57,68 & 429,80 & 48,92 & 9,08 & 34,97 & $\begin{array}{l}141,21 \\
\end{array}$ & 51,73 & 51,88 & 116,28 \\
\hline Pelophylax perezi & 30SWJ10 & 100,00 & 133,74 & 123,38 & 38,00 & 6685,27 & 322,20 & \begin{tabular}{|c|}
0,64 \\
\end{tabular} & 321,56 & 115,28 & 223,74 & 224,19 & 53,98 & 461,31 & 56,75 & 9,04 & 36,79 & 159,66 & 52,44 & 53,18 & 125,69 \\
\hline Pelophylax perezi & 30SWJ11 & 100,00 & 132,95 & 123,77 & 38,00 & 6688,70 & 321,48 & $-0,02$ & 321,50 & 114,59 & 222,89 & 223,38 & 53,13 & \begin{tabular}{|l|l|}
461,69 \\
\end{tabular} & 56,23 & 9,45 & 36,06 & 159,09 & 53,73 & 54,64 & 124,72 \\
\hline Pelophylax perezi & 30 SWJ25 & 100,00 & 140,69 & 122,05 & 38,00 & 6627,31 & 325,09 & 7,04 & 318,05 & 123,91 & 229,06 & 229,84 & 60,76 & 418,63 & 48,04 & 8,94 & 34,96 & 140,03 & 51,64 & 52,42 & 109,46 \\
\hline Pelophylax perezi & 30 SWJ26 & 100,00 & 139,34 & 122,00 & 38,00 & 6638,15 & 323,77 & 5,79 & 317,98 & 122,66 & 227,61 & 228,66 & 59,20 & 422,04 & 48,65 & 9,17 & 34,31 & 140,25 & 52,52 & 53,75 & 110,55 \\
\hline Pelophylax perezi & 30 SWJ30 & 100,00 & 128,96 & 123,06 & 38,00 & 6630,43 & 315,81 & $\begin{array}{r}-3,09 \\
-3,10\end{array}$ & 318,89 & 110,17 & 218,38 & 218,71 & 49,96 & 4771,51 & 58,39 & 10,96 & 34,82 & $\begin{array}{l}162,29 \\
162\end{array}$ & 57,77 & $\begin{array}{l}0,31 \\
60,31\end{array}$ & 123,33 \\
\hline Pelophylax perezi & 30 SWJ31 & 100,00 & 128,17 & 123,36 & 38,01 & 6632,26 & 315,34 & $-3,90$ & 319,24 & 109,36 & 217,53 & 218,01 & 49,30 & 472,30 & 57,84 & 11,16 & 34,40 & 162,02 & 58,61 & 61,64 & 122,75 \\
\hline Pelophylax perezi & 30 SWJ32 & 100,00 & 133,69 & 123,08 & 38,00 & 6622,39 & 319,42 & 0,57 & 318,85 & 115,71 & 222,40 & 223,21 & 54,51 & 446,43 & 54,08 & 10,01 & 34,77 & 152,31 & 55,09 & 57,58 & 115,66 \\
\hline Pelophylax perezi & 30 SWJ48 & 100,00 & 128,28 & 123,04 & 38,01 & 6587,38 & 312,77 & $-4,47$ & 317,24 & 111,47 & 216,01 & 216,95 & 49,06 & 465,45 & 55,03 & 12,82 & 31,04 & 154,44 & 64,16 & 68,21 & 117,49 \\
\hline Pelophylax perezi & 30 SWJ50 & 100,00 & 127,69 & 122,77 & 38,37 & 6551,86 & 311,55 & $-3,77$ & 315,32 & 108,62 & 215,92 & 216,22 & 49,68 & 467,37 & 58,79 & 11,88 & 33,73 & 159,86 & 60,48 & 64,90 & 116,82 \\
\hline Pelophylax perezi & 30 SWJ51 & 100,00 & 128,77 & 122,86 & 38,44 & 6557,40 & 312,57 & $-2,92$ & \begin{tabular}{|l|l|}
315,49 \\
\end{tabular} & \begin{tabular}{|l|}
$109,92,2$ \\
\end{tabular} & |216,97 & 217,32 & 50,64 & 460,01 & 57,16 & \begin{tabular}{l|l}
$1,1,66$ \\
11
\end{tabular} & 33,52 & \begin{tabular}{|l|}
156,84 \\
15,0
\end{tabular} & $\begin{array}{l}0,496 \\
59,95\end{array}$ & $\begin{array}{ll}64,64 \\
\end{array}$ & 114,24 \\
\hline Pelophylax perezi & 30SWJ58 & 100,00 & 128,65 & 123,07 & 38,53 & 6547,10 & 311,84 & $-3,84$ & 315,68 & 111,64 & 215,87 & 216,81 & 49,99 & 462,92 & 55,10 & 13,25 & 30,64 & 153,75 & 65,49 & 70,16 & 114,59 \\
\hline Pelophylax perezi & 30SWJ59 & 100,00 & 127,01 & 123,13 & 38,41 & 6551,42 & 310,42 & $-5,79$ & 316,21 & 110,01 & 214,11 & 215,17 & 48,17 & 471,94 & 56,39 & 13,88 & 30,06 & 156,34 & 67,69 & 72,37 & 117,24 \\
\hline Pelophylax perezi & 30 SWJ62 & 100,00 & 138,03 & 121,89 & 38,58 & 6483,92 & 317,54 & 5,41 & 312,13 & 120,22 & 224,68 & 225,21 & 60,16 & 413,27 & 51,48 & 9,97 & 33,99 & 139,39 & 54,32 & 58,86 & 99,42 \\
\hline Pelophylax perezi & $\begin{array}{l}30 \text { SWJ68 } \\
\end{array}$ & 100,00 & 128,73 & 122,84 & 38,70 & 6520,25 & 310,60 & $-3,58$ & 314,18 & 111,75 & 215,49 & 216,51 & 50,20 & 460,01 & 55,18 & 13,64 & 30,08 & 152,64 & 66,99 & 72,01 & 111,45 \\
\hline Pelophylax perezi & 30 SWJ69 & 100,00 & 128,54 & 122,96 & 38,79 & 6519,52 & 310,29 & $-4,11$ & 314,40 & 111,79 & 215,14 & 216,25 & 49,88 & 462,64 & 55,71 & 13,89 & 29,87 & 153,09 & 68,06 & 72,87 & 112,60 \\
\hline Pelophylax perezi & 305WJ73 & 100,00 & 139,85 & 121,01 & 38,91 & 6432,06 & 316,79 & 7,47 & 309,32 & 122,52 & 225,70 & 226,13 & 62,48 & 401,63 & 49,43 & 10,00 & 33,68 & 134,13 & 54,66 & 59,55 & 93,92 \\
\hline Pelophylax perezi & 30SWJ74 & 100,00 & 137,99 & 121,12 & 38,83 & 6441,73 & 315,46 & 5,58 & 309,88 & 120,61 & 223,82 & 224,39 & 60,43 & 411,07 & 48,99 & 10,77 & 32,52 & 136,67 & 57,20 & 62,14 & 96,07 \\
\hline Pelophylax perezi & 30 SWJ75 & 100,00 & 136,66 & 121,39 & 38,79 & 6450,91 & 314,45 & 4,13 & 310,32 & 119,44 & 222,53 & 223,25 & 58,82 & 417,61 & 49,28 & 11,19 & 31,94 & 138,79 & 59,12 & 63,97 & 97,91 \\
\hline Pelophylax perezi & 30SWJ76 & 100,00 & 134,61 & 121,55 & 38,82 & 6462,91 & 313,02 & 2,20 & 310,82 & 117,55 & 220,68 & 221,38 & 56,69 & 428,03 & 50,88 & 12,09 & 31,03 & 141,85 & 61,89 & 66,78 & 100,57 \\
\hline Pelophylax perezi & 30SWJ77 & 100,00 & 128,87 & 122,03 & 38, & 6483,01 & 308,72 & $-3,01$ & 311,73 & 111,45 & 215,26 & 215,97 & 50,74 & 454,88 & 54,52 & $\begin{array}{ll}13,78 \\
\end{array}$ & 29,97 & $\begin{array}{l}150,85 \\
151,0\end{array}$ & $\begin{array}{ll}07,42 \\
67\end{array}$ & 73,20 & 107,28 \\
\hline Pelophylax perezi & 30 SWJ82 & 100,00 & 141,60 & 120,25 & 38,99 & 6360,39 & 315,90 & 9,92 & 305,98 & 140,59 & 226,51 & 226,81 & 64,90 & 391,05 & 49,97 & 9,95 & 34,44 & 130,69 & 53,97 & 59,14 & 88,66 \\
\hline Pelophylax perezi & 30 SWJ84 & 100,00 & 138,64 & 120,26 & 38,88 & 6389,12 & 313,60 & 6,79 & 306,81 & 121,05 & 223,71 & 224,19 & 61,56 & 405,77 & 48,75 & 10,81 & 32,57 & 134,10 & 57,99 & 63,25 & 92,36 \\
\hline Pelophylax perezi & 30 SWJ85 & 100,00 & 135,73 & 120,58 & 38,91 & 6404,92 & 311, & 3,90 & 307,65 & 118,14 & 221,08 & 221,61 & 58,52 & 419,01 & 49,58 & 11 & 31,51 & 38,48 & 61,30 & 66,62 & 95,69 \\
\hline Pelophylax perezi & \begin{tabular}{|l|}
30 SWJ 87 \\
\end{tabular} & 100,00 & 130,41 & 120,87 & 38 & $\begin{array}{l}6430,03 \\
6430 \\
\end{array}$ & 307, & $\begin{array}{l}-0,75 \\
-0,5 \\
\end{array}$ & 308,38 & $\begin{array}{l}112,97 \\
112\end{array}$ & 216,07 & $\begin{array}{l}216,85 \\
216,8\end{array}$ & 53,01 & \begin{tabular}{|l|l|}
444,45 \\
\end{tabular} & 53,49 & 13 & 29,74 & $\begin{array}{l}146,54 \\
140\end{array}$ & 67,81 & 73,46 & $\begin{aligned} 102,09 \\
\end{aligned}$ \\
\hline Pelophylax perezi & 30SWJ96 & 100,00 & 132,25 & 119,58 & 38,97 & 6377,11 & 306,53 & 1,43 & 305,10 & 114,64 & 217,40 & 217,82 & 55,66 & 432,70 & 51,7 & 13,42 & 30,30 & 141,95 & 66,74 & 72,16 & 96,69 \\
\hline Pelophylax perezi & \begin{tabular}{|l|}
30 SWJg9 \\
\end{tabular} & 100,00 & 118,33 & 119,86 & 38,51 & 6436,01 & 295,44 & \begin{tabular}{|l|l|}
$-11,94$ \\
$-1,4$
\end{tabular} & 307,38 & 100,21 & 204,26 & 205,12 & 41,34 & 494,68 & 61,08 & 18,13 & 27,68 & $\begin{array}{l}162,79 \\
\end{array}$ & 81,62 & 88,84 & 111,42 \\
\hline Pelophylax perezi & 30SWKO0 & 100,00 & 132,31 & 119,43 & 37,07 & 6687,66 & 316,81 & 0,61 & 316,19 & 116,15 & 221,89 & 222,30 & 51,86 & 447,76 & 50,90 & 10,93 & 33,16 & 143,58 & 56,99 & 57,34 & 120,51 \\
\hline Pelophylax perezi & 30SWKO1 & 100,00 & 129,76 & 118,74 & 37,04 & 6681,85 & 313,66 & $-0,85$ & 314,51 & 113,12 & 219,06 & 219,66 & 49,36 & 455,79 & 51,75 & 11,65 & 32,54 & 84 & 59,03 & 59,56 & 122,38 \\
\hline Pelophylax perezi & 30SWKO2 & 100,00 & 128 & $\begin{array}{ll}110,1 / 4 \\
117,82\end{array}$ & 37, & | 600068,49 & 311 & $\begin{array}{l}-2,05 \\
-1,07 \\
\end{array}$ & \begin{tabular}{|l|}
312,57 \\
31,5
\end{tabular} & \begin{tabular}{|l|}
107,97 \\
10,12
\end{tabular} & 217,75 & \begin{tabular}{|l|}
218,23 \\
\end{tabular} & \begin{tabular}{|l|l|}
48,46 \\
480
\end{tabular} & | & 51,77 & \begin{tabular}{l|}
1,203 \\
12,18
\end{tabular} & 32,41 & \begin{tabular}{|l|}
$144,, 25$ \\
144
\end{tabular} & $\begin{array}{l}50,01 \\
601\end{array}$ & $\begin{array}{l}50,53 \\
603\end{array}$ & $\begin{array}{l}12,>0 \\
122,55\end{array}$ \\
\hline Pelophylax perezi & 30SWK10 & 100,00 & 127,28 & 120,63 & 37,75 & 6666,16 & 312,45 & $-3,96$ & 316,41 & 110,82 & 215,99 & 217,12 & 47,25 & 467,55 & 54,01 & 12,32 & 32,02 & 151,45 & 61,53 & 63,37 & 123,73 \\
\hline Pelophylax perezi & 30SWK11 & 100,00 & 127,21 & 119,86 & 37,71 & $\begin{array}{l}6654,59 \\
\end{array}$ & 311,46 & $\begin{array}{l}-3,37 \\
-3,37 \\
\end{array}$ & \begin{tabular}{|l|}
314,83 \\
\end{tabular} & \begin{tabular}{|l|l|}
110,91 \\
\end{tabular} & 215,81 & 216,84 & 47,49 & 464,80 & 53,60 & 12,60 & 31,68 & $\begin{array}{l}149,25 \\
\end{array}$ & $\begin{array}{ll}1,32,02 \\
\end{array}$ & 63,58 & 122,94 \\
\hline Pelophylax perezi & 30SWK12 & 100,00 & 124,11 & 119,03 & 37,44 & 6643,19 & 307,64 & $-5,88$ & 313,52 & 107,91 & 212,52 & 213,62 & 44,65 & 474,90 & 54,89 & 13,53 & 31,11 & 151,70 & 64,56 & 66,55 & 125,21 \\
\hline Pelophylax perezi & 30SWK21 & 100,00 & 126 & 120,70 & 38,00 & 6626,87 & 310,87 & $-4,46$ & 315,33 & 110,69 & 214,99 & 215 & 47 & 467,38 & 54,53 & 13,16 & 31,07 & 151,26 & 63,78 & 66,23 & 12 \\
\hline Pelophylax perezi & $\begin{array}{l}30 \text { SWK22 } \\
306\end{array}$ & $\begin{array}{l}100,00 \\
\end{array}$ & $\begin{array}{l}12,05 \\
125,56\end{array}$ & $\begin{array}{l}12,19,97 \\
119\end{array}$ & $\begin{array}{l}0,00 \\
37,98 \\
\end{array}$ & $\begin{array}{l}\mid 6020,0,3 \\
6623,30\end{array}$ & 308,77 & $\begin{array}{l}-2,40 \\
-5,27\end{array}$ & \begin{tabular}{|l|l|}
314,04 \\
314
\end{tabular} & \begin{tabular}{|l|}
109,49 \\
109
\end{tabular} & \begin{tabular}{|l|}
213,51 \\
2145
\end{tabular} & \begin{tabular}{|l|}
214,71 \\
214,
\end{tabular} & $\begin{array}{l}4,, 12 \\
45,99\end{array}$ & \begin{tabular}{|l|}
$40,, 50,67$ \\
469,
\end{tabular} & $\begin{array}{l}54,502 \\
54,92\end{array}$ & $\begin{array}{l}\mid 0,101 \\
13,59 \\
\end{array}$ & $\begin{array}{l}1,101 \\
30,66\end{array}$ & \begin{tabular}{|l|}
151,05 \\
15,05
\end{tabular} & $\begin{array}{l}3,10 \\
65,05 \\
\end{array}$ & $\begin{array}{l}6,250 \\
67,47\end{array}$ & $\begin{array}{l}121,04 \\
122,26\end{array}$ \\
\hline Pelophylax perezi & 30SWK30 & 100,00 & 128,39 & 122,10 & 38,00 & 6612,87 & 312,56 & $-3,83$ & 316,39 & 111,76 & 216,24 & 217,35 & 48,82 & 463,96 & 54,65 & 12,93 & 31,00 & 151,84 & 63,84 & 66,83 & 119,37 \\
\hline Pelophylax perezi & 30SWK31 & 100,00 & 124,82 & 121,86 & 38,00 & 6607,94 & 309,05 & $-7,18$ & 316,23 & 108,18 & 212,70 & 213,74 & 45,54 & 477,86 & 56,53 & 14,01 & 30,42 & 155,92 & 67,05 & 70,51 & 122,71 \\
\hline Pelophylax perezi & 30SWK32 & 100,00 & 122,24 & 121,29 & 38,00 & 6597,13 & 306,10 & $-9,25$ & 315,34 & 105,83 & 210,04 & 211 , & 43, & 486,06 & 57,70 & 14,90 & 29,81 & 157,86 & 69,45 & 73,17 & 124,60 \\
\hline Pelophylax perezi & 30SWK41 & 100,00 & 122,46 & 122,80 & 38,01 & 6583,14 & 306,92 & $\begin{array}{l}-10,08 \\
-10,\end{array}$ & 317,00 & $\begin{array}{l}105,83 \\
\end{array}$ & 209,96 & 211,16 & 43,49 & 490,88 & 58,69 & 15,08 & 29,70 & $\begin{array}{l}161,28 \\
161,28\end{array}$ & \begin{tabular}{|l|l|}
70,79 \\
\end{tabular} & 75,39 & 124,37 \\
\hline
\end{tabular}




\begin{tabular}{|c|c|c|c|c|c|c|c|c|c|c|c|c|c|c|c|c|c|c|c|c|c|}
\hline TAXON & UTM & $\mathrm{km} 2$ & B101 & B102 & $\mathrm{BIO3}$ & BIO4 & B105 & B106 & B107 & B108 & 8109 & BIO10 & BIO11 & BIO12 & B1013 & BIO14 & BIO15 & B1016 & B1017 & BIO18 & B1019 \\
\hline Pelophylax perezi & 30SWK51 & 100,00 & 122,02 & 123,62 & 38,35 & 6555,28 & 306,19 & $-10,90$ & 317,08 & 105,10 & 209,21 & 210,29 & 43,23 & 495,65 & 59,82 & 15,66 & 29,29 & 163,62 & 73,20 & 78,48 & 123,90 \\
\hline Pelophylax perezi & 30SWK52 & 100,00 & 116,43 & 123,60 & 38,21 & $\begin{array}{l}6551,48 \\
\end{array}$ & 301,21 & $-16,38$ & 317,58 & 99,40 & 203,56 & 204,86 & 37,84 & 519,30 & 63,09 & 17,45 & 28,70 & 171,20 & 78,46 & 84,58 & 129,87 \\
\hline Pelophylax perezi & 30SWK61 & 100,00 & 119,79 & 123,89 & 38,56 & 6530,47 & 303,82 & $-13,36$ & 317,18 & 102,45 & 206,68 & 207,85 & 41,37 & 506,33 & 61,71 & 16,84 & 28,71 & 167,69 & 77,09 & 83,29 & 124,54 \\
\hline Pelophylax perezi & 30SWK62 & 100,00 & 118,32 & 124,13 & 38,55 & 6525,96 & 302,51 & $-15,08$ & 317,60 & 101,30 & 205,01 & 206,36 & 39,88 & 514,53 & 63,03 & 17,47 & 28,62 & \begin{tabular}{|l|l|}
170,18 \\
\end{tabular} & 79,20 & 85,58 & 127,06 \\
\hline Pelophylax perezi & 30SWK70 & 100,00 & 119,55 & 123,14 & 38,94 & 6504,62 & 301,82 & \begin{tabular}{|c|}
$-13,16$ \\
\end{tabular} & \begin{tabular}{|l|l|}
314,97 \\
\end{tabular} & \begin{tabular}{|l|}
102,07 \\
\end{tabular} & 206,11 & 207,18 & 41,53 & 503,21 & 61,60 & 17,08 & 28,29 & \begin{tabular}{|l|l|}
166,87 \\
\end{tabular} & 78,19 & 84,97 & 120,53 \\
\hline Pelophylax perezi & 30SWK72 & 100,00 & 114,84 & 123,94 & 38,78 & 6504,07 & 298,22 & $-18,23$ & 316,45 & 97,64 & 201,27 & 202,55 & 36,71 & 529,12 & 65,56 & 19,03 & 27,95 & 175,45 & 84,35 & 91,78 & 128,03 \\
\hline Pelophylax perezi & 30SWK80 & 100,00 & 113,99 & 121,85 & 38,65 & 6483,76 & 294,69 & $-17,24$ & 311,93 & 95,93 & 200,63 & 201,60 & 36,80 & 520,77 & 64,36 & 19,13 & 27,34 & 172,34 & 84,60 & 92,57 & 121,23 \\
\hline Pelophylax perezi & 30 SWK81 & 100,00 & 110,82 & 121,81 & 38,53 & 6483,51 & 291,80 & \begin{tabular}{|l|l|}
$-20,39$ \\
\end{tabular} & 312,19 & 92,95 & 197,45 & 198,55 & 33,73 & 534,36 & 66,63 & 20,43 & 27,09 & 176,77 & 88,24 & 96,72 & 124,56 \\
\hline Pelophylax perezi & 30SWK82 & 100,00 & 110,53 & 121,79 & 38,60 & $\begin{array}{l}6481,56 \\
\end{array}$ & 291,16 & $-21,05$ & 312,21 & 92,89 & 196,90 & 198,10 & 33,16 & 535,29 & 67,24 & 20,84 & 27,04 & 176,77 & 89,48 & 98,00 & 124,87 \\
\hline Pelophylax perezi & 30SWK90 & 100,00 & 116,58 & 119,88 & 38,45 & 6443,29 & 293,81 & $-13,81$ & 307,62 & 98,66 & 202,56 & 203,46 & 39,53 & 501,62 & 62,54 & 18,95 & 27,31 & 165,01 & 84,10 & 91,51 & 113,06 \\
\hline Pelophylax perezi & 30SWK91 & 100,00 & 114,45 & 119,77 & 38,44 & 6445,08 & 291,52 & $-16,03$ & 307,55 & 96,69 & 200,27 & 201,36 & 37,24 & 509,50 & 64,22 & 19,90 & 27,16 & 167,62 & 86,79 & 94,59 & 114,72 \\
\hline Pelophylax perezi & 30SWK92 & 100,00 & 111,82 & 119,45 & 38,27 & 6446,76 & 288,67 & $-18,55$ & 307,22 & 94,28 & 197,75 & 198,81 & 34,66 & 517,63 & 65,91 & 20,95 & 26,86 & 170,08 & 89,76 & 98,07 & 116,28 \\
\hline Pelophylax perezi & 30SXG00 & 22,00 & 177,38 & 90,29 & 38,00 & 4995,43 & 302,86 & 68,57 & 234,29 & 153,43 & 241,62 & $\begin{array}{l}245,48 \\
240\end{array}$ & $\begin{array}{l}117,48 \\
17,0\end{array}$ & 259,38 & $\begin{array}{l}3,61,62 \\
37\end{array}$ & 2,14 & 48,76 & 100,86 & $\begin{array}{l}3,05 \\
16,05\end{array}$ & 24,00 & 83,14 \\
\hline Pelophylax perezi & 30 XSG01 & 50,00 & 180,97 & 91,21 & 38,06 & 4995,75 & 306,45 & 71,09 & 235,36 & 156,82 & 245,13 & 248,81 & 120,57 & 250,03 & 37,21 & 2,03 & 49,72 & 98,54 & 15,19 & 23,28 & 79,87 \\
\hline Pelophylax perezi & $30 \mathrm{SXG02}$ & 91,00 & 179,73 & 94,34 & 38,73 & 5102,44 & 308,78 & 67,37 & 241,41 & 154,57 & 245,46 & 248,79 & 117,92 & 256,57 & 38,31 & 2,04 & 48,58 & 100,13 & 15,94 & 24,59 & 79,92 \\
\hline Pelophylax perezi & $305 \times G 03$ & 100,00 & 171,10 & 99,29 & 38,84 & 5329,23 & 308,21 & 55,03 & 253,19 & 144,08 & 240,42 & 243,24 & 106,86 & 288,73 & 40,82 & 2,97 & 45,78 & 107,49 & 20,84 & 29,28 & 87,01 \\
\hline Pelophylax perezi & $30 \mathrm{SXG04}$ & 100,00 & 166,78 & 102,84 & 38,98 & 5472,15 & 308,97 & 48,11 & 260,86 & 138,57 & 238,39 & 240,78 & 100,93 & 306,03 & 42,30 & 3,57 & 44,33 & 111,04 & 23,83 & 32,17 & 89,97 \\
\hline Pelophylax perezi & 30SXG05 & 100,00 & 159,90 & 106,58 & 38,99 & 5646,30 & 308,39 & 38,58 & 269,81 & 130,17 & 234,18 & 236,40 & 92,16 & 334,54 & 44,43 & 4,76 & 42,45 & 117,23 & 28,87 & 36,72 & 95,59 \\
\hline Pelophylax perezi & $305 \times$ X06 & 100,00 & 154,71 & 109,33 & 39,05 & 5775,40 & 308,06 & 31,32 & 276,74 & 124,32 & 230,99 & 232,88 & 85,58 & 357,89 & 46,59 & 5,82 & 40,90 & 122,11 & 33,55 & 40,85 & 99,85 \\
\hline Pelophylax perezi & $305 \times 607$ & 100,00 & 157,85 & 110,81 & 39,21 & 5790,11 & 311,88 & 33,35 & 278,53 & $\mid 126,88$ & 234,36 & 235,93 & 88,32 & 345,32 & 45,54 & 5,28 & 41,50 & 118,36 & 31.96 & 39.56 & 95,20 \\
\hline Pelophylax perezi & 30SXG08 & 100,00 & 151,93 & 113,00 & 39,05 & 5913,57 & 310,81 & 25,90 & 284,92 & 120,67 & 230,39 & 231,78 & 81,08 & 370,31 & $48, \mathrm{c}$ & 6,40 & 40,01 & 123,52 & 37,22 & 43,93 & 99,67 \\
\hline Pelophylax perezi & 30 XX09 & 100,00 & 142,73 & 114,96 & 38,99 & 6051,80 & 307,07 & 15,66 & 291,41 & 122,28 & 223,36 & 224,67 & 70,64 & 410,66 & 53,64 & 8,66 & 37,56 & 135,18 & 46,12 & 51,16 & 107,71 \\
\hline Pelophylax perezi & 30 SXG12 & 12,00 & $\begin{array}{ll}176,47 \\
\end{array}$ & 96,60 & 38,93 & 5177,47 & 308,33 & 62,20 & 246,13 & 150,80 & 243,40 & 246,40 & 113,73 & 271,33 & 39,87 & 2,47 & 47,87 & \begin{tabular}{|l|}
104,73 \\
\end{tabular} & 17,87 & 26,67 & 83,27 \\
\hline Pelophylax perezi & 30 XG13 & 77,00 & 177,22 & 98,53 & 39,01 & 5218,30 & 310,74 & 61,50 & 249,24 & 150,96 & 244,65 & 247,50 & 113,88 & 271,97 & 40,23 & 2,32 & 47,83 & 104,89 & 18,07 & 27,37 & 82,33 \\
\hline Pelophylax perezi & $30 S \times G 14$ & 100,00 & 169,89 & 102,74 & 39,03 & 5405,75 & 310,13 & 51,13 & 259,00 & 142,17 & 240,30 & 242,78 & 104,59 & 298,53 & 42,45 & 3,26 & 45,36 & 110,75 & 22,45 & 31,53 & 87,54 \\
\hline Pelophylax perezi & 30SXG15 & 100,00 & 164,24 & 106,18 & 39,19 & 5558,26 & 309,92 & 43,11 & 266,81 & 135,26 & 237,14 & 239,29 & 97,39 & 320,81 & 44,07 & 4,30 & 43,36 & 115,13 & 26,66 & 35,56 & 91,47 \\
\hline Pelophylax perezi & 305XG16 & 100,00 & 167,10 & 107,93 & 39,82 & 5582,04 & 313,74 & $\begin{array}{l}43,1156 \\
44,56\end{array}$ & \begin{tabular}{|l|}
269,18 \\
\end{tabular} & $\begin{array}{l}137,78 \\
13,0\end{array}$ & 240,38 & 242,22 & 99,66 & 311,22 & 43,68 & 4,04 & 43,83 & 112,11 & 25,76 & 35,06 & 87,63 \\
\hline Pelophylax perezi & 30SXG17 & 100,00 & 160,87 & 110,77 & 39,68 & 5727,21 & 312,77 & 36,10 & $\begin{array}{l}276,67 \\
\end{array}$ & 130,43 & 236,43 & 237,94 & 91,78 & 336,38 & 45,67 & 4,90 & 42,20 & 117,44 & 30,48 & 39,09 & 92,01 \\
\hline Pelophylax perezi & 30 XG18 & 100,00 & 151,60 & 113,33 & 39,30 & 5891,02 & 309,77 & 25,39 & 284,39 & 120,49 & 229,70 & 231,13 & 81,06 & 373,52 & 48,68 & 6,68 & 39,81 & 125,42 & 38,17 & 45,46 & 99,34 \\
\hline Pelophylax perezi & 30 XG19 & 100,00 & 137,75 & 115,23 & 39,00 & 6059,27 & 302,45 & 10,86 & 291,59 & 113,05 & 218,54 & 219,89 & 65,82 & 438,75 & 56,95 & 10,43 & 36,39 & 144,39 & 52,37 & 57,23 & 113,23 \\
\hline Pelophylax perezi & $30 S \times G 24$ & 92,00 & 174,82 & 102,19 & 39,44 & 5312,10 & 312,18 & 56,31 & 255,86 & 147,92 & 243,68 & 246,19 & 110,24 & 286,39 & 42,23 & 2,73 & 47,11 & 109,56 & 20,19 & 30,23 & 84,23 \\
\hline Pelophylax perezi & 30 SXG25 & 100,00 & 155,85 & 107,76 & 39,13 & 5647,52 & 305,13 & $\begin{array}{ll}3,72 \\
33,72\end{array}$ & 271,41 & \begin{tabular}{|l|l|}
126,53 \\
\end{tabular} & \begin{tabular}{|l|}
230,18 \\
230
\end{tabular} & \begin{tabular}{|l|}
232,29 \\
\end{tabular} & 88,24 & 358,72 & $\begin{array}{ll}47,48 \\
47,48\end{array}$ & 5,86 & 441,38 & $\begin{array}{ll}125,83 \\
\end{array}$ & 33,14 & $\begin{array}{l}0,25 \\
41,58\end{array}$ & $\begin{array}{l}0,25 \\
100,24\end{array}$ \\
\hline Pelophylax perezi & 30 XSG26 & 100,00 & 160,43 & 109,38 & 39,67 & 5650,78 & 309,95 & 36,90 & 273,06 & 130,81 & 234,73 & 236,59 & 92,43 & 341,46 & 46,58 & 5,14 & 42,40 & 120,97 & 30,62 & 39,83 & 94,29 \\
\hline Pelophylax perezi & 30 XX27 & 100,00 & 165,69 & 110,98 & 39,92 & 5649,69 & 315,10 & 40,62 & 274,48 & 135,95 & 239,87 & 241,26 & 97,10 & 322,84 & 45,60 & 4,13 & 43,86 & 115,58 & 27,64 & 37,69 & 88,31 \\
\hline Pelophylax perezi & 30 XG28 & 100,00 & 150,61 & 113,57 & 39,63 & 5862,45 & 308,13 & 24,37 & 283,76 & 120,82 & 228,34 & 229,78 & 80,49 & 383,29 & 50,60 & 7,32 & 39,63 & 129,49 & 40,27 & 48,06 & 100,86 \\
\hline Pelophylax perezi & 30 SXG29 & 100,00 & 135,25 & 115,02 & 39,09 & 6045,20 & 299,51 & 8,79 & 290,73 & 110,42 & 215,94 & 217,42 & 63,70 & 455,83 & 58,89 & 11,65 & 35,79 & 149,59 & 56,40 & 61,37 & 116,24 \\
\hline Pelophylax perezi & $30 \mathrm{SXG34}$ & & & & & & & & & & & & & & & & & & & & \\
\hline Pelophylax perezi & 30SXG35 & & & & & & & & & & & & & & & & & & & & \\
\hline Pelophylax perezi & $305 \times$ X36 & 100,00 & 163,48 & 109,57 & 39,90 & 5591,43 & 311,36 & 39,76 & 271,60 & 134,42 & \begin{tabular}{|l|l|}
236,87 & \\
\end{tabular} & 238,66 & 95,97 & 334,28 & 46,94 & 4,62 & 43,48 & 120,96 & 28,96 & 39,17 & 92,25 \\
\hline Pelophylax perezi & 30SXG37 & 100,00 & 170,68 & 111,53 & 40,27 & 5575,54 & 318,12 & 45,05 & 273,07 & 141,30 & 243,66 & 245,13 & 102,73 & 308,52 & 45,40 & 3,31 & 45,62 & 114,05 & 24,54 & 35,88 & 84,61 \\
\hline Pelophylax perezi & 30SXG38 & 100,00 & 169,85 & 113,70 & 40,50 & 5651,02 & 319,95 & 42,49 & 277,46 & 139,68 & 243,88 & 245,08 & 100,80 & 313,13 & 45,82 & 3,62 & 45,34 & 113,96 & 25,87 & 37,57 & 84,12 \\
\hline Pelophylax perezi & $30 S \times G 39$ & 100,00 & 159,56 & 115,53 & 40 & 5803,77 & 315,15 & 31,25 & 283,89 & 128,48 & 236,18 & 237,14 & 89,25 & 351,11 & 48,74 & 5,53 & 42,01 & 122,20 & 34,09 & 44,18 & 91,23 \\
\hline Pelophylax perezi & $30 \mathrm{SXG45}$ & 37,00 & 180,25 & 105,52 & 40,13 & 5290,22 & 317,84 & 59,00 & 258,84 & 153,41 & 248,70 & 250,67 & 115,27 & 280,03 & 43,71 & 2,29 & 49,06 & 110,81 & 18,92 & 30,92 & 80,59 \\
\hline Pelophylax perezi & $30 S X G 46$ & 100,00 & 175,81 & 108,60 & 40,23 & 5416,03 & 318,05 & 52,29 & 265,77 & 148,03 & 246,27 & 248,01 & 109,54 & 295,79 & 45,27 & 3,00 & 47,43 & 114,08 & 21,68 & 33,89 & 83,13 \\
\hline Pelophylax perezi & 30 XSG47 & 100,00 & 172,94 & 111,85 & 40,56 & 5532,49 & 319,31 & 46,91 & 272,40 & 144,11 & 245,13 & 246,59 & 105,23 & 305,51 & 6,25 & 3,09 & 46,83 & 15,35 & 23,46 & 35,78 & 83,79 \\
\hline Pelophylax perezi & 30SXG48 & 100,00 & 168,86 & 114,22 & 40,80 & \begin{tabular}{|l}
5636,87 \\
563
\end{tabular} & 318, & \begin{tabular}{|l|l|}
41,24 \\
\end{tabular} & 277,64 & \begin{tabular}{|l|l|}
139,06 \\
\end{tabular} & 242,74 & \begin{tabular}{|l|}
243,87 \\
\end{tabular} & 100,05 & 322,31 & $\begin{array}{l}47,63 \\
47,6\end{array}$ & 3,6 & 45,31 & 1118,31 & 27,14 & 39,47 & 85,99 \\
\hline Pelophylax perezi & $30 S \times G 49$ & 100,00 & 172,06 & 116,70 & 40,96 & 5678,09 & 323,75 & 42,29 & 281,46 & 141,68 & 246,43 & 247,30 & 102,42 & 311,38 & 46,99 & 3,44 & 46,39 & 114,59 & 25,34 & 38,59 & 81,97 \\
\hline Pelophylax perezi & $\begin{array}{l}305 \times G 56 \\
\end{array}$ & 98,00 & 171,96 & 108,98 & 40,13 & 5436,36 & 315,16 & 48,31 & 266,85 & 144,31 & 242,72 & 244,52 & 105,62 & 314,30 & 47,59 & 3,67 & 46,46 & 120,64 & 24,58 & 37,03 & 87,22 \\
\hline Pelophylax perezi & 30 XG57 & 100,00 & 173,81 & 111,92 & 40,83 & 5492,58 & 319,26 & 47,78 & 271,48 & 145,46 & 245,48 & 246,82 & 106,53 & 308,34 & 47,58 & 3,15 & 47,48 & 118,35 & 23,42 & 36,66 & 84,32 \\
\hline Pelophylax perezi & 30 XG58 & 100,00 & 166,45 & 114,37 & 40,78 & 5636,22 & 316,64 & 38,75 & 277,88 & 136,84 & 240,20 & 241, & 97,68 & 335,43 & 49 , & 4,56 & 44,66 & 123,39 & 29,46 & 42,21 & 88,57 \\
\hline Pelophylax perezi & $\begin{array}{l}30 \text { SXG59 } \\
3 \times 69\end{array}$ & 100,00 & 16 & $\frac{11}{11}$ & $\frac{40}{40}$ & \begin{tabular}{|l|}
5702,91 \\
5701
\end{tabular} & 318,04 & $\begin{array}{ll}36,713 \\
36,84\end{array}$ & $\begin{array}{l}282,08 \\
282,\end{array}$ & \begin{tabular}{|l|}
$136,12,1$ \\
13,
\end{tabular} & $\begin{array}{l}241,15 \\
242\end{array}$ & \begin{tabular}{|l|}
242,01 \\
\end{tabular} & $\begin{array}{l}1,00 \\
96,73 \\
\end{array}$ & | & $\begin{array}{l}50,04 \\
50,0\end{array}$ & $\begin{array}{l}4,300 \\
4,80\end{array}$ & $\begin{array}{ll}44,89 \\
44,\end{array}$ & $\begin{array}{l}122,95 \\
12,9\end{array}$ & $\begin{array}{l}3,40 \\
30,47\end{array}$ & $\begin{array}{ll}4,2,63 \\
43,63\end{array}$ & $\begin{array}{l}8,200 \\
87,60\end{array}$ \\
\hline Pelophylax perezi & $305 \times G 66$ & 99,00 & 171,91 & 108,54 & 40,41 & 5396,95 & 314,02 & 48,69 & 265,33 & $\begin{array}{l}144,73 \\
\end{array}$ & 242,11 & 243,93 & 106,05 & 320,93 & 49,26 & 3,93 & 46,67 & 124,97 & 25,52 & 38,41 & 88,75 \\
\hline Pelophylax perezi & 305XG67 & \begin{tabular}{|c|}
100,00 \\
\end{tabular} & 176,16 & 111,23 & 40,48 & F423,55 & 319,54 & $\begin{array}{ll}50,73 \\
\end{array}$ & 268,80 & $\begin{array}{l}148,60 \\
\end{array}$ & \begin{tabular}{|l|}
246,62 \\
\end{tabular} & \begin{tabular}{|l|}
248,09 \\
\end{tabular} & \begin{tabular}{|l|}
109,50 \\
\end{tabular} & 306,58 & 48,77 & 3,15 & 47,94 & 120,43 & 23,23 & $\begin{array}{l}37,23 \\
37,2\end{array}$ & 83,56 \\
\hline Pelophylax perezi & 30 XX68 & 100,00 & 173,81 & 114,23 & 41,00 & 5529,79 & 320,91 & 45,89 & 275,02 & 145,26 & 245,95 & 246,99 & 105,85 & 314,45 & 49,66 & 3,56 & 47,42 & 121,11 & 25,01 & 39,50 & 83,37 \\
\hline Pelophylax perezi & 30 XKG9 & 100,00 & 167,66 & 116,15 & 41, & 5638,52 & 318,49 & 38,72 & 279,77 & 138,34 & 241,47 & 242 & 98,66 & 335,36 & 51,44 & 4,60 & 45,19 & 124,75 & 29,79 & 43,90 & 86,18 \\
\hline Pelophylax perezi & 30 XXG76 & 86,00 & 179,86 & 106,64 & 40,80 & 5252,99 & 317,07 & 57,88 & 259,19 & | 153,89 & 247,61 & 249,56 & $\begin{array}{l}115,17 \\
1100\end{array}$ & 300,50 & 49,40 & 3,09 & 50,35 & 123,67 & 21,62 & 35,51 & 84,13 \\
\hline Pelophylax perezi & 30 XSG77 & 100,00 & 180,15 & 109,34 & 40,99 & 5321,32 & 319,97 & 56,12 & 263,84 & 153,61 & 248,97 & 250,64 & 114,68 & 299,15 & 49,98 & 3,00 & 50,05 & 122,11 & 22,14 & 36,73 & 81,47 \\
\hline Pelophylax perezi & 30SXG79 & 100,00 & 172,11 & 114,82 & 41,00 & 5538,27 & 319,84 & 44,04 & 275,80 & 143,75 & 244,36 & 245,53 & 104,17 & 323,20 & 52,45 & 4,23 & 46,96 & 125,00 & 27,66 & 42,76 & 82,68 \\
\hline Pelophylax perezi & 30 SXG86 & 94,00 & 178,55 & 105,16 & 40,65 & 5208,12 & 314,32 & 57,88 & 256,44 & 153,40 & 245,6 & 247 & 114 & 311,91 & 51,57 & 3,66 & 49,66 & 129,58 & 23,65 & 37,63 & 86,85 \\
\hline Pelophylax perezi & 30SXG87 & 97,00 & 181,96 & 107,12 & 41,00 & 5230,09 & 318,66 & 59,74 & 258,92 & 156,48 & 249,40 & 251,29 & 117,44 & 300,34 & 51,78 & 3,09 & 50,84 & 126,12 & 22,50 & 36,88 & 81,84 \\
\hline
\end{tabular}




\begin{tabular}{|c|c|c|c|c|c|c|c|c|c|c|c|c|c|c|c|c|c|c|c|c|c|}
\hline TAXON & UTM & $\mathrm{km} 2$ & B101 & B102 & $\mathrm{BIO3}$ & B104 & B105 & B106 & B107 & B108 & B109 & B1010 & B1011 & BIO12 & B1013 & BIO14 & BIO15 & B1016 & B1017 & BIO18 & B1019 \\
\hline Pelophylax perezi & $30 S \times G 88$ & 100,00 & 180,62 & 109,68 & 41,00 & 5307,32 & 320,20 & 56,40 & 263,80 & 154,52 & 249,17 & 250,83 & 115,18 & 303,26 & 52,86 & 3,86 & 49,99 & 125,84 & 24,05 & 39,32 & 80,08 \\
\hline Pelophylax perezi & 30 SXG96 & 69,00 & 179,66 & 103,47 & \begin{tabular}{l|l|l}
40,45 \\
\end{tabular} & 5139,44 & 313,11 & 60,37 & 252,74 & 155,30 & 245,58 & 248,07 & 116,57 & 314,34 & 53,02 & 3,88 & 50,74 & 133,41 & 23,84 & 38,22 & 87,56 \\
\hline Pelophylax perezi & 30 XG97 & 13,00 & 182,75 & 104,45 & 40,95 & 5133,95 & 316,20 & 62,65 & 253,55 & 158,25 & 248,55 & 250,90 & 119,50 & 305,05 & 53,45 & 3,55 & 52,10 & \begin{tabular}{|l|}
131,05 \\
\end{tabular} & 22,90 & 37,40 & 83,55 \\
\hline Pelophylax perezi & 30SXG98 & 46,00 & 182,58 & 107,61 & 41,00 & 5218,21 & 319,30 & 60,05 & 259,25 & 157,23 & 249,51 & 251,54 & 118,05 & 302,33 & 54,46 & 4,00 & 51,30 & 128,58 & 24,37 & 39,88 & 79,21 \\
\hline Pelophylax perezi & 30SXG99 & 79,00 & 180,58 & 109,37 & 41,00 & 5288,47 & 319,70 & $\begin{array}{ll}56,83 \\
\end{array}$ & 262,87 & 155,03 & 248,88 & 250,73 & 115,47 & 298,50 & 54,94 & 4,00 & 52,17 & 126,64 & 24,59 & 40,65 & 75,11 \\
\hline Pelophylax perezi & $30 \mathrm{~S} \times \mathrm{HOO}$ & 100,00 & 137,24 & 116,32 & 39,00 & 6130,20 & 304,91 & 9,46 & 295,45 & 116,88 & 219,31 & 220,40 & 64,64 & 435,36 & 57,07 & 10,12 & 36,11 & 144,12 & 52,19 & 56,02 & 111,97 \\
\hline Pelophylax perezi & $30 \mathrm{SXH}$ & 100,00 & 151,39 & 116,77 & 39,44 & 6040,76 & 315,11 & 22,50 & 292,61 & 128,53 & 231,71 & 232,53 & 78,78 & 372,17 & 49,41 & 6,80 & 39,20 & \begin{tabular}{|l|l|}
123,07 \\
\end{tabular} & 40,48 & 46,20 & 95,36 \\
\hline Pelophylax perezi & 30SXHO3 & 100,00 & 159,70 & 117,63 & 39,90 & 6014,01 & 322,24 & 29,60 & 292,64 & 132,09 & 239,51 & 239,92 & 86,75 & 339,37 & 45,99 & 5,39 & 40,88 & 113,35 & 36,12 & 42,16 & 84,78 \\
\hline Pelophylax perezi & $30 \mathrm{SXHO4}$ & 100,00 & 157,30 & 118,10 & 39,75 & 6065,95 & 321,49 & 26,75 & 294,74 & 134,09 & 237,81 & 238,18 & 83,81 & 346,90 & 46,75 & 5,89 & 40,07 & 114,89 & 38,99 & 43,45 & 84,99 \\
\hline Pelophylax perezi & $30 \mathrm{SXH07}$ & 100,00 & 141,71 & 119,43 & 39,01 & 6233,71 & 312,12 & 11,10 & 301,02 & 122,98 & 225,34 & 225,46 & 67,07 & 399,46 & 53,55 & 9,48 & 36,12 & 132,63 & 54,67 & 55,28 & 92,22 \\
\hline Pelophylax perezi & $30 \mathrm{~S} \times \mathrm{H} 08$ & 100,00 & 135,18 & 119,70 & 39,00 & 6288,88 & 307,47 & 4,86 & 302,62 & 115,81 & 219,69 & 219,73 & 60,03 & 424,28 & 56,12 & 11,18 & 34,43 & 140,84 & 59,71 & 61,71 & 96,69 \\
\hline Pelophylax perezi & $30 \mathrm{SXH10}$ & 100,00 & 143,76 & 116,03 & 39,24 & 6040,71 & 307,85 & 15,79 & 292,06 & 120,10 & 224,36 & 225,40 & 71,79 & 408,06 & 53,51 & 8,69 & 37,64 & 134,36 & 47,08 & 52,55 & 104,28 \\
\hline Pelophylax perezi & $30 \mathrm{SXH11}$ & 100,00 & 153,60 & 116,98 & 39,91 & 5982,88 & 315,57 & 24,52 & 291,05 & 124,31 & 232,96 & 233,94 & 81,49 & 365,12 & 48,54 & 6,44 & 39,89 & 121,22 & 39,21 & 46,06 & 92,68 \\
\hline Pelophylax perezi & $30 \mathrm{SXH12}$ & 100,00 & 160,97 & 117,42 & 40,00 & 5947,23 & 321,29 & 31,01 & 290,28 & 128,20 & 239,56 & 240,31 & 88,66 & 337,19 & 46,14 & 5,14 & 41,70 & 114,03 & 34,47 & 42,27 & 84,77 \\
\hline Pelophylax perezi & $30 \mathrm{SXH13}$ & 100,00 & 163,85 & 1117,87 & 40,00 & 5951,82 & 323,92 & 33,54 & 290,38 & 131,48 & 242,43 & 243,01 & 91,25 & 326,75 & 45,59 & 4,71 & 42,19 & \begin{tabular}{|l|l|}
111,07 \\
\end{tabular} & 33,41 & 40,68 & 80,99 \\
\hline Pelophylax perezi & $30 \mathrm{~S} \times \mathrm{H} 14$ & 100,00 & 160,29 & 118,20 & 39,97 & 6002,46 & 322,25 & 29,85 & 292,40 & 128,42 & 239,85 & 240,23 & 87,23 & 338,39 & 46,36 & 5,46 & 41,05 & 113,10 & 37,17 & 42,51 & 82,03 \\
\hline Pelophylax perezi & $30 \mathrm{~S} \times \mathrm{H} 15$ & 100,00 & 157,33 & 118,67 & 39,99 & 6041,73 & 320,72 & 26,74 & 293,99 & 130,91 & 237,50 & 237,97 & 83,89 & 347,87 & 47,04 & 6,10 & 39,93 & 114,83 & 40,63 & 44,60 & 82,83 \\
\hline Pelophylax perezi & $30 \mathrm{SXH18}$ & 100,00 & 137,11 & 118,97 & 39,00 & 6231,74 & 306,90 & 7,16 & 299,73 & 118,08 & 220,88 & 220,88 & 62,67 & 418,91 & 55,03 & 11,02 & 34,61 & 137,60 & 60,27 & 60,84 & 94,20 \\
\hline Pelophylax perezi & $30 \mathrm{SXH} 20$ & 100,00 & 160,52 & 116,36 & \begin{tabular}{|l|l|}
40,07 \\
\end{tabular} & 5859,28 & 318,01 & 31,53 & 286,48 & 128,67 & 237,89 & 238,85 & 89,54 & 342,41 & 47,22 & 5,10 & 42,01 & 1117,74 & 33,39 & 42,79 & 88,05 \\
\hline Pelophylax perezi & $30 \mathrm{~S} \times \mathrm{H} 22$ & 100,00 & 161,75 & 118,02 & 40,03 & 5912,38 & 321,08 & 31,27 & 289,82 & $\mid 129,47$ & 239,76 & 240,55 & 89,86 & $\mid 337,68$ & 47,16 & 5,08 & 42,06 & $\mid 115,29$ & 34,35 & 43,14 & 83,95 \\
\hline Pelophylax perezi & $30 \mathrm{SXH} 23$ & 100,00 & 166,99 & 118,20 & 40,32 & 5891,20 & 325,24 & 36,20 & 289,04 & 134,37 & 244,73 & 245,19 & 95,04 & 320,00 & 46,28 & 4,3 & 43,28 & 110,82 & 31,59 & 40,88 & 78,78 \\
\hline Pelophylax perezi & $30 \mathrm{~S} \times \mathrm{H} 24$ & 100,00 & 158,82 & 118,82 & 40,12 & 5978,28 & 320,22 & 28,14 & 292,08 & 126,72 & 238,04 & 238,46 & 86,12 & 347,20 & 47,89 & 5,93 & 40,63 & \begin{tabular}{|l|l|}
116,18 \\
\end{tabular} & 38,84 & 45,43 & 83,17 \\
\hline Pelophylax perezi & $30 \mathrm{SXH} 26$ & 100,00 & 152,54 & 118,53 & 40,00 & 6042,06 & 315,78 & 22,14 & 293,64 & 126,31 & 232,79 & 233,29 & 79,33 & \begin{tabular}{|l|}
368,38 \\
\end{tabular} & 48,94 & 7,50 & 38,25 & 119,71 & 46,63 & \begin{tabular}{|l|l|}
51,08 \\
\end{tabular} & 84,98 \\
\hline Pelophylax perezi & $30 \mathrm{~S} \times \mathrm{H} 29$ & 100,00 & 132,69 & 117,84 & 39,00 & 6208,59 & 301,35 & 3,95 & 297,40 & 124,30 & 216,37 & 216,38 & 58,81 & 442,33 & 56,26 & 12,94 & 32,83 & 143,66 & 66,91 & 67,28 & 97,77 \\
\hline Pelophylax perezi & $30 \mathrm{~S} \times \mathrm{H} 30$ & 100,00 & 163,99 & 117,15 & 40,55 & 5806,50 & 320,01 & 34,19 & 285,81 & 132,64 & 240,55 & 241,29 & 93,27 & 333,58 & 47,67 & 4,60 & 43,46 & 117,17 & 31,16 & 41,92 & 85,57 \\
\hline Pelophylax perezi & $30 \mathrm{SXH} 31$ & 100,00 & 163,71 & 118,16 & 40,51 & 5851,48 & 320,97 & 33,14 & 287,83 & 131,87 & 240,82 & 241,51 & 92,36 & 335,63 & 48,00 & 4,85 & 43,15 & 116,94 & 32,51 & 42,78 & 84,45 \\
\hline Pelophylax perezi & $30 \mathrm{SXH} 32$ & 100,00 & 156,38 & 118,17 & 40,27 & 5922,60 & 316,39 & 26,29 & 290,10 & $\begin{array}{l}125,14 \\
12,1\end{array}$ & $\begin{array}{l}234,82 \\
230\end{array}$ & \begin{tabular}{|l|}
235,47 \\
\end{tabular} & 84,64 & 363,01 & $\begin{array}{l}50,08 \\
50,0\end{array}$ & 6.,43 & $\begin{array}{ll}40,77 \\
40,15\end{array}$ & 122,75 & 39,51 & 48, 48 & $\begin{array}{l}89,01 \\
\end{array}$ \\
\hline Pelophylax perezi & $30 \mathrm{SXH33}$ & 100,00 & 168,96 & 118,92 & 40,94 & 5848,79 & 325,87 & 37,70 & 288,17 & 137,05 & 246,03 & 246,49 & 97,40 & 317,30 & 47,37 & 4,12 & 44,38 & 111,85 & 30,50 & 41,24 & 77,54 \\
\hline Pelophylax perezi & $30 \mathrm{~S} \times \mathrm{H} 34$ & 100,00 & 163,03 & 118,92 & 40,78 & 5905,04 & 321,92 & 32,18 & 289,73 & 130,41 & 240,97 & 241,51 & 91,01 & 336,90 & 48,69 & 5,25 & 42,42 & 115,52 & 36,00 & 45,22 & 80,27 \\
\hline Pelophylax perezi & $30 \mathrm{~S} \times \mathrm{H} 35$ & 100,00 & 153,01 & 118,34 & 40,13 & 5995,92 & 314,72 & 22,88 & 291,85 & 122,76 & 232,63 & 233,05 & 80,42 & 373,44 & 50,75 & 7,56 & 38,94 & 123,15 & 45,81 & 51,91 & 86,98 \\
\hline Pelophylax perezi & $30 \mathrm{~S} \times \mathrm{H} 36$ & 100,00 & 146,88 & 117,98 & 40,00 & 6050,49 & 310,16 & 17,26 & 292,90 & 125,80 & 227,36 & 228,03 & 74,01 & 395,32 & 51,84 & 9,04 & 36,91 & 127,41 & 52,43 & 56,84 & 90,37 \\
\hline Pelophylax perezi & 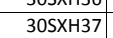 & 100,00 & $\begin{array}{l}143,00 \\
143,78\end{array}$ & \begin{tabular}{|l|}
117,68 \\
11,30
\end{tabular} & 39,80 & 6078,03 & 307,79 & $\begin{array}{l}14,75 \\
14,0\end{array}$ & 293,04 & 125,21 & $\begin{array}{l}224,82 \\
\end{array}$ & \begin{tabular}{|l|}
225,29 \\
\end{tabular} & 70,81 & | & $\begin{array}{l}1,, 44 \\
52,48\end{array}$ & 9,99 & 35,65 & $\begin{array}{l}130,06 \\
130,41\end{array}$ & $\begin{array}{l}5,4,65 \\
56,5\end{array}$ & 50,047 & 91,44 \\
\hline Pelophylax perezi & $30 \mathrm{SXH} 38$ & 100,00 & 137,55 & 117,26 & 39,29 & 6126,10 & 302,96 & 9,10 & 293,86 & 118,36 & 219,49 & 219,99 & 64,43 & 429,92 & 54,45 & 11,76 & 33,95 & 137,54 & 63,85 & 64,80 & 95,74 \\
\hline Pelophylax perezi & $30 \mathrm{~S} \times \mathrm{H} 39$ & 100,00 & 132,66 & 116,85 & 39,02 & 6157,21 & 298,93 & 4,77 & 294,16 & 114,38 & 215,22 & 215,60 & 59,30 & 449,99 & 56,06 & 13,26 & 32,57 & 143,89 & 69,54 & 69,70 | & 99,27 \\
\hline Pelophylax perezi & $30 \mathrm{~S} \times \mathrm{H} 40$ & 100,00 & 170,94 & 118,49 & \begin{tabular}{l|l}
41,05 \\
\end{tabular} & 5741,97 & 324,94 & 39,75 & 285,19 & 139,95 & 246,27 & 246,95 & 100,42 & 315,08 & 47,42 & 3,53 & 46,19 & 114,44 & 26,56 & 38,82 & 81,21 \\
\hline Pelophylax perezi & $30 \mathrm{SXH} 41$ & 100,00 & 171,99 & 119,47 & 40,97 & 5769,64 & 326,82 & 40,00 & 286,82 & 140,71 & 247,56 & 248,23 & 101,04 & 311,89 & 47,45 & 3,45 & 46,32 & 112,96 & 26,67 & 39,47 & 78,94 \\
\hline Pelophylax perezi & $\begin{array}{l}30 \mathrm{~S} \times \mathrm{SH} 4 \mathrm{H} \\
\end{array}$ & 100,00 & 169,81 & \begin{tabular}{|l|}
119,50 \\
119,5
\end{tabular} & 年 41,01 & $\begin{array}{ll}5703,044 \\
579,55\end{array}$ & 325,57 & $\begin{array}{l}40,00 \\
37,98 \\
\end{array}$ & \begin{tabular}{|l|}
$287,50<$ \\
287
\end{tabular} & $\begin{array}{l}40,1,1 \\
138,33 \\
\end{array}$ & \begin{tabular}{|l|}
245,83 \\
240
\end{tabular} & \begin{tabular}{|l|}
246,5050 \\
\end{tabular} & \begin{tabular}{|l|}
101,04 \\
98,54
\end{tabular} & | & $\begin{array}{l}1,45 \\
48,45 \\
\end{array}$ & $3,3,99$ & 40,54 & $\begin{array}{l}14,, 00 \\
114,22\end{array}$ & $\begin{array}{l}0,01 \\
29,29 \\
\end{array}$ & $\begin{array}{l}3,41 \\
42,20\end{array}$ & 78,85 \\
\hline Pelophylax perezi & $30 \mathrm{SXH} 43$ & 100,00 & 164,89 & 118,93 & 40,86 & 5849,01 & 322,05 & 33,71 & 288,34 & 133,06 & 241,92 & 242,58 & 93,44 & 336,60 & 49,91 & 5,00 & 43,68 & 117,83 & 34,13 & 45,94 & 81,16 \\
\hline Pelophylax perezi & $30 \mathrm{~S} \times \mathrm{H} 45$ & 100,00 & 153,31 & 117,88 & 40,10 & 5951,01 & 313,14 & 23,56 & 289,58 & 127,44 & 232,03 & 232,93 & 81,24 & 378,31 & 52,56 & 7,68 & 38,99 & 126,14 & 46,28 & 54,47 & 87,53 \\
\hline Pelophylax perezi & $30 \mathrm{SXH} 46$ & 100,00 & 148,49 & 117,36 & 39,99 & 5991,87 & 309,28 & 19,41 & 289,87 & 148,49 & 227,92 & 228,73 & 76,22 & \begin{tabular}{|c|}
396,39 \\
\end{tabular} & 53,53 & 9,01 & 37,29 & 129,54 & 51,91 & 58,53 & 90,28 \\
\hline Pelophylax perezi & 30 SXH47 & 100,00 & 139,29 & 116,61 & 39,69 & 6063,79 & 302,22 & 11,19 & 291,03 & 128,43 & 220,07 & 220,89 & 66,78 & 433,17 & 55,26 & 11,52 & 34,49 & 137,38 & 62,04 & 65,94 & 97,50 \\
\hline Pelophylax perezi & 30 SXH50 & 100,00 & 177,76 & 120 & 41,70 & 5681,36 & 330,25 & 45,01 & 285,24 & 147,28 & 252,02 & 252,39 & 107,44 & 299,05 & 47,22 & 2,59 & 49,04 & 112,32 & 22,37 & 35,57 & 77,64 \\
\hline Pelophylax perezi & 30SXH51 & 100,00 & 176,58 & |120,63 & 41,65 & 5711,35 & 330,13 & 43,54 & 286,59 & 145,69 & 251,24 & 251,56 & 105,99 & 302,26 & 47,95 & 2,98 & 48,54 & 112,50 & 23,96 & 36,14 & 76,50 \\
\hline Pelophylax perezi & $30 \mathrm{SXH52}$ & 100,00 & 171,71 & 119,89 & 41,05 & 5754,33 & 326,11 & 39,55 & 286,56 & 140,78 & 247,06 & 247,60 & 100,79 & 317,41 & 49,66 & 3,78 & 46,59 & 115,72 & 28,24 & 42,29 & 77,92 \\
\hline Pelophylax perezi & $30 \mathrm{SXH53}$ & 100,00 & 152,10 & 117,47 & 40,34 & 5896,20 & 310,52 & 22,78 & 287,74 & 120,85 & 230,07 & 230,98 & 80,87 & 391,85 & 54,71 & 8,7 & 39,48 & \begin{tabular}{|l|l|}
132,68 \\
\end{tabular} & 46,29 & 56,29 & 93,03 \\
\hline Pelophylax perezi & 30SXH54 & 100,00 & 156,87 & $\begin{array}{l}\mid 117,74 \\
117,4\end{array}$ & 40,52 & 5866,33 & 314,0 & 27,24 & 286,82 & 133,13 & 234,34 & 235,11 & 85,81 & 370,83 & \begin{tabular}{|l|l|}
53,79 \\
\end{tabular} & 6,5 & $\begin{array}{ll}40,52 \\
0,52\end{array}$ & $\begin{array}{l}127,31 \\
\end{array}$ & $\begin{array}{l}2,57 \\
42,5 \\
\end{array}$ & 53,45 & 86,72 \\
\hline Pelophylax perezi & $30 \mathrm{SXH55}$ & 100,00 & 149,62 & 116,87 & 40,09 & 5924,36 & 308,35 & 21,08 & 287,27 & 144,40 & 228,17 & 229,04 & 78,28 & 401,15 & 55,6 & 8,96 & 37,98 & 133,87 & 50,79 & 59,59 & 92,51 \\
\hline Pelophylax perezi & 30SXH56 & 100,00 & 146,71 & 116,34 & 40,01 & 5950,56 & 305,92 & 18,71 & 287,21 & 155,11 & 225,60 & 226,49 & 75,18 & 411,71 & 56,05 & 9,79 & 36,74 & 135,81 & 54,56 & \begin{tabular}{|l|}
62,28 \\
\end{tabular} & 93,67 \\
\hline Pelophylax perezi & 30 SXH57 & 100,00 & 141,69 & 115,62 & 39,89 & 5984,79 & 301,64 & 14,37 & 287,27 & 151,79 & 221,27 & 222,22 & 69,91 & 432,56 & 57,13 & 11,32 & 34,87 & 140,41 & 60,76 & 66,92 & 97,39 \\
\hline Pelophylax perezi & $30 \mathrm{SXH} 58$ & 100,00 & 142,56 & 115,13 & 39,85 & 5982,00 & 301,74 & 15,49 & 286,25 & 152,41 & 222,02 & 222,81 & 70,77 & 428,47 & 56,95 & 11,25 & 34,88 & 140,04 & 61,05 & 67,12 & 95,49 \\
\hline Pelophylax perezi & $\begin{array}{l}30 \mathrm{~S} \times \mathrm{H}+60 \\
\end{array}$ & 100,00 & $\begin{array}{l}14,50 \\
179,11\end{array}$ & $\frac{119}{119}$ & 年, 41,82 & 5622,63 & 329 & \begin{tabular}{l|l}
0,454 \\
47,06
\end{tabular} & \begin{tabular}{|l|}
282,67 \\
282
\end{tabular} & \begin{tabular}{|l|}
149,38 \\
149,38
\end{tabular} & $\begin{array}{l}22,0<2 \\
252,55 \\
\end{array}$ & \begin{tabular}{|l|}
252,93 \\
\end{tabular} & $\mid$ & | 2980,01 & $\begin{array}{l}0,83 \\
48,85 \\
\end{array}$ & $\mid \frac{\mid 1,25}{2,73}$ & $\begin{array}{l}4,000 \\
49,87\end{array}$ & \begin{tabular}{|l|}
$140,04,67$ \\
\end{tabular} & $\begin{array}{l}1,03 \\
22,28\end{array}$ & | 37,67 & $\begin{array}{l}3,45 \\
76,57\end{array}$ \\
\hline Pelophylax perezi & $30 \mathrm{SXH61}$ & 100,00 & 176,46 & 119,74 & 41,76 & 5663,48 & 328,16 & 44,19 & 283,96 & 146,50 & 250,49 & 250,92 & 106,40 & 305,60 & 50,02 & 3,25 & 48,83 & 115,76 & 24,74 & 40,22 & 76,27 \\
\hline Pelophylax perezi & $30 \mathrm{SXH62}$ & 100,00 & 174,28 & 119,26 & 41,53 & 5689,21 & 326,38 & 42,57 & 283,81 & 144,11 & 248,62 & 249,25 & 104,05 & 311.99 & 51,08 & 3,57 & 47,87 & 116,82 & 27,08 & 42,08 & 75,82 \\
\hline Pelophylax perezi & $30 \mathrm{~S} \times \mathrm{H} 63$ & 100,00 & 161,50 & 117,55 & 40,83 & 5777,43 & 316,01 & 31,80 & 284,21 & 136,03 & 237,48 & 238,43 & 91,17 & 359,28 & 54,51 & 6,15 & 42,88 & 127,51 & 38,40 & 51,64 & 84,96 \\
\hline Pelophylax perezi & $30 \mathrm{SXH64}$ & 100,00 & 151,17 & 116,24 & 40,11 & 5860,56 & 307,67 & 23,06 & 28 & 137,29 & 228,65 & 225 & 80 & 401,33 & 57,18 & 8,61 & 38,69 & 137,03 & 48,79 & 59,51 & 93,54 \\
\hline Pelophylax perezi & $30 \mathrm{~S} \times \mathrm{H} 66$ & 100,00 & 149,38 & 115,34 & 40,01 & 5874,64 & 305,55 & 22,10 & 283,45 & 159,56 & 227,07 & 228,18 & 78,64 & 410,53 & 58,13 & $\begin{array}{ll}, 499 \\
9\end{array}$ & 37,49 & 139,62 & 53,10 & 63,02 & 93,43 \\
\hline Pelophylax perezi & 30 SXH67 & 100,00 & 149,41 & 114,73 & 40,00 & 5872,88 & 305,05 & 22,55 & 282,49 & 159,75 & 227,07 & 228,20 & 78,63 & 411,25 & 58,21 & 9,72 & 37,14 & 140,16 & 54,33 & \begin{tabular}{|l|l|}
63,98 \\
\end{tabular} & 92,81 \\
\hline Pelophylax perezi & $30 \mathrm{SXH68}$ & 100,00 & 142,02 & 113,82 & 39,87 & 5933,72 & 298,99 & 16,03 & 282,95 & 152,27 & 220,73 & 221,85 & 70,98 & 441,90 & 59,60 & 11,88 & 34,58 & 146,62 & 62,88 & 70,57 & 98,86 \\
\hline Pelophylax perezi & $30 \mathrm{SXH69}$ & 100,00 & 134,60 & 112,94 & 39,23 & $\begin{array}{ll}5987,64 \\
\end{array}$ & 292,94 & 9,4 & 283,4 & 144, & 214, & 215 & 63, & \begin{tabular}{|l|l|}
472,17 \\
\end{tabular} & 60,75 & 14,14 & 32,32 & 152 & 71,63 & 77,29 & 104,7 \\
\hline Pelophylax perezi & $30 \mathrm{SXH70}$ & 100,00 & 174,36 & 116,30 & 41,38 & 5564,22 & 322,79 & 45,05 & 277,75 & 145,70 & 246,91 & 247,90 & 105,84 & 314,42 & 52,30 & 3,89 & 48,16 & 121,95 & 26,56 & 42,57 & 78,83 \\
\hline
\end{tabular}




\begin{tabular}{|c|c|c|c|c|c|c|c|c|c|c|c|c|c|c|c|c|c|c|c|c|c|}
\hline TAXON & UTM & $\mathrm{km} 2$ & B101 & B102 & $\mathrm{BIO3}$ & B104 & B105 & B106 & B107 & B108 & B109 & B1010 & BIO11 & BIO12 & B1013 & BIO14 & BIO15 & B1016 & B1017 & BIO18 & B1019 \\
\hline Pelophylax perezi & 30SXH71 & 100,00 & 178,63 & 116,88 & 41,76 & 5550,24 & 326,59 & 48,83 & 277,76 & 150,00 & 250,95 & 251,82 & 110,09 & 298,88 & 51,72 & 3,32 & 49,93 & 117,47 & 24,25 & 41,11 & 73,47 \\
\hline Pelophylax perezi & $30 \mathrm{SXH72}$ & 100,00 & 177,32 & 117,13 & \begin{tabular}{|l|l|l|}
41,63 \\
\end{tabular} & 5578,35 & 325,76 & 47,36 & 278,40 & 163,10 & 250,02 & 250,90 & 108,56 & 303,84 & 52,70 & 3,46 & 49,61 & 117,92 & 26,08 & 43,02 & 72,70 \\
\hline Pelophylax perezi & $30 \mathrm{~S} \times \mathrm{H73}$ & 100,00 & 163,55 & 116,26 & 40,89 & 5699,90 & 315,38 & 34,92 & 280,47 & 164,81 & 238,28 & 239,44 & 94,13 & 357,52 & 56,34 & 6,06 & 43,71 & 130,13 & 37,74 & 52,36 & 83,97 \\
\hline Pelophylax perezi & $30 \mathrm{SXH74}$ & 100,00 & 150,28 & 114,87 & 40,22 & 5806,56 & 304,90 & 23,32 & 281,59 & 147,41 & 226,90 & 228,33 & 80,41 & 414,01 & 59,64 & 9,21 & 38,53 & 142,92 & 50,85 & 62,55 & 96,60 \\
\hline Pelophylax perezi & $30 \mathrm{SXH75}$ & 100,00 & 149,40 & 114,43 & \begin{tabular}{|l|l|}
40,08 \\
\end{tabular} & 5814,46 & 303,77 & 22,72 & 281,06 & 156,23 & 226,13 & 227,51 & 79,30 & 419,80 & 60,28 & 9,59 & 37,78 & 144,82 & 52,92 & 64,41 & 96,90 \\
\hline Pelophylax perezi & $30 \mathrm{SXH76}$ & 100,00 & 142,36 & 113,50 & 39,83 & 5868,98 & 297,99 & 16,76 & 281,22 & 146,74 & 220,05 & 221,49 & 72,16 & 452,18 & 61,99 & 11,76 & 35,44 & 151,84 & 61,42 & 71,16 & 103,74 \\
\hline Pelophylax perezi & $30 \mathrm{SXH77}$ & 100,00 & 150,55 & 113,32 & 40,03 & 5800,73 & 303,51 & 24,84 & 278,67 & 161,39 & 227,08 & 228,47 & 80,60 & 418,66 & 60,84 & 9,78 & 37,63 & 146,12 & 54,44 & 65,97 & 94,93 \\
\hline Pelophylax perezi & 30 SXH80 & 100,00 & 174,23 & 113,75 & 41,06 & 5479,27 & 319,85 & 47,18 & 272,66 & 146,66 & 245,51 & 246,92 & $\begin{array}{r}106,90 \\
\end{array}$ & 315,42 & 54,56 & 4,29 & 48,86 & 125,56 & 27,70 & 43,78 & 77,58 \\
\hline Pelophylax perezi & $30 \mathrm{SXH} 81$ & 100,00 & 179,97 & 113,99 & 41,46 & 5444,26 & 324,12 & 52,53 & 271,60 & 159,36 & 250,52 & 251,79 & 112,64 & 292,76 & 53,77 & 3,42 & 52,47 & 119,63 & 24,24 & 41,31 & 70,22 \\
\hline Pelophylax perezi & $30 \mathrm{SXH} 82$ & 100,00 & 180,74 & 114,12 & \begin{tabular}{|l|l|}
41,63 \\
\end{tabular} & 5454,53 & 324,83 & 53,30 & 271,53 & 190,49 & 251,38 & 252,86 & 113,27 & 293,09 & 54,26 & 3,24 & 52,47 & 119,61 & 24,64 & 42,30 & 68,99 \\
\hline Pelophylax perezi & $30 \mathrm{~S} \times \mathrm{H} 83$ & 100,00 & 168,56 & 114,31 & 41,02 & 5579,27 & 316,39 & 41,38 & 275,01 & 175,92 & 241,35 & 242,81 & 100,41 & 344,30 & 57,59 & 5,64 & 46,19 & 131,40 & 35,20 & 51,27 & 80,19 \\
\hline Pelophylax perezi & $30 \mathrm{SXH} 84$ & 100,00 & 159,57 & 113,83 & 40,78 & 5663,92 & 309,71 & 32,99 & 276,72 & 168,58 & 233,78 & 235,32 & 90,85 & 384,87 & 60,29 & 7,46 & 42,07 & 141,05 & 43,71 & 58,50 & 89,33 \\
\hline Pelophylax perezi & 30 XXH85 & 100,00 & 156,23 & 113,31 & 40,58 & 5696,90 & 306,83 & 30,39 & 276,44 & 167,71 & 230,98 & 232,68 & 87,20 & 401,97 & 61,46 & 8,33 & 40,48 & 145,36 & 47,87 & 62,07 & 92,82 \\
\hline Pelophylax perezi & 30SXH87 & 100,00 & 153,86 & 111,85 & 40,23 & 5709,21 & 303,69 & 29,32 & 274,37 & 165,01 & 228,82 & 230,47 & 85,08 & 419,51 & 63,23 & 9,43 & 38,86 & 151,08 & 52,95 & 66,84 & 95,90 \\
\hline Pelophylax perezi & $30 \mathrm{SXH} 88$ & 100,00 & 148,49 & 111,03 & 39,90 & 5756,81 & 299,16 & 24,64 & 274,52 & 159,64 & 224,32 & 225,93 & 79,31 & 442,69 & 64,23 & 10,99 & 36,91 & 155,94 & 59,21 & 71,97 & 100,71 \\
\hline Pelophylax perezi & $30 \mathrm{~S} \times \mathrm{H} 89$ & 100,00 & 148,21 & 110,09 & 39,95 & 5750,68 & 298,07 & 25,22 & 272,85 & 159,33 & 223,96 & 225,60 & 79,03 & 446,46 & 64,77 & 11,42 & 36,43 & 157,67 & 60,70 & 73,58 & 101,23 \\
\hline Pelophylax perezi & $30 \mathrm{~S} \times \mathrm{H} 90$ & 100,00 & 179,64 & 110,48 & 41,03 & 5337,68 & 320,01 & 54,99 & 265,02 & 160,94 & 248,46 & 250,44 & 113,81 & 293,90 & 55,32 & 3,97 & 53,07 & 124,36 & 24,82 & 41,74 & 71,05 \\
\hline Pelophylax perezi & 30SXH91 & 100,00 & 180,85 & 111,16 & 41,18 & 5349,22 & 321,50 & 55,73 & 265,77 & 189,96 & 249,89 & 251,66 & 114,82 & 288,62 & 55,62 & 3,80 & 54,55 & 122,54 & 24,43 & 42,02 & 67,75 \\
\hline Pelophylax perezi & 30SXH92 & 100,00 & 182,93 & 111,19 & \begin{tabular}{|l|l|}
41,27 \\
\end{tabular} & 5337,78 & 322,79 & 57,58 & 265,22 & 195,09 & 251,56 & 253,29 & 116,55 & 288,90 & 56,03 & 3,51 & 54,63 & 123,30 & 24,35 & 42,49 & 67,24 \\
\hline Pelophylax perezi & $30 \mathrm{SXH93}$ & 100,00 & 178,78 & 111,72 & 41,09 & 5400,40 & 320,62 & 53,39 & 267,23 & $\mid$\begin{tabular}{|l|}
191.18 \\
\end{tabular} & 248,55 & 250,44 & $\mid 112,20$ & 309,93 & 57,72 & 4,22 & 51,72 & 128,54 & 28.58 & $46,75 \mid$ & 71,09 \\
\hline Pelophylax perezi & 30 XXH94 & 100,00 & 170,06 & 112,04 & 41,00 & 5492,12 & 314,73 & 44,80 & 269,93 & 182,25 & 241,54 & 243,40 & 103,08 & 350,82 & 60,63 & 5,69 & 46,96 & 138,28 & 36,41 & 53,73 & 80,22 \\
\hline Pelophylax perezi & 30 SXH95 & 100,00 & 162,30 & 111,57 & 40,77 & 5574,44 & 308,95 & 37,72 & 271,23 & 172,71 & 235,08 & 237,00 & 94,60 & 389,55 & 62,99 & 7,53 & 43,21 & 147,42 & 44,34 & 60,79 & 89,86 \\
\hline Pelophylax perezi & 30SXH96 & 100,00 & 148,28 & 110,82 & 40,10 & 5709,03 & 298,50 & 24,74 & 273,76 & 156,32 & 223,42 & 225,22 & 79,91 & 452,91 & 66,12 & 10,99 & 37,57 & 160,68 & 58,26 & 72,30 & 105,57 \\
\hline Pelophylax perezi & 30 SXH97 & 100,00 & 140,39 & 109,89 & 39,67 & 5779,53 & 292,01 & 17,73 & 274,28 & 148,18 & 216,67 & 218,58 & 71,50 & 489,68 & 67,88 & 13,31 & 34,66 & 168,39 & 67,32 & 79,84 & 113,96 \\
\hline Pelophylax perezi & $30 \mathrm{SXH98}$ & 100,00 & 144,32 & 109,36 & 39,72 & 5737,64 & 294,20 & 22,01 & 272,20 & 155,50 & 219,91 & 221,75 & 75,75 & 475,68 & 67,75 & 12,47 & 35,70 & 166,80 & 64,63 & 78,26 & 110,11 \\
\hline Pelophylax perezi & 30SXH99 & 100,00 & 142,93 & 108,45 & 39,56 & 5746,21 & 292,33 & 21,17 & 271,16 & 154,30 & 218,71 & 220,58 & 74,29 & 482,94 & 68,26 & 13,15 & 34,97 & 168,86 & 67,18 & 80,69 & 111,19 \\
\hline Pelophylax perezi & |305XJ09 & 100,00 & 120,42 & 117,75 & 38,44 & 6394,95 & 293,89 & $-8,44$ & 302,32 & $\begin{array}{l}102,88 \\
10,0\end{array}$ & $\begin{array}{l}205,79 \\
\end{array}$ & 206,61 & 43,75 & $\begin{array}{l}479,12 \\
479,4\end{array}$ & 59,40 & 18,10 & 27,64 & $\begin{array}{l}156,27 \\
\end{array}$ & 81,62 & 88,12 & 104,53 \\
\hline Pelophylax perezi & 30 XXJ19 & 100,00 & 123,78 & 115,25 & 38,13 & 6342,05 & 292,98 & $-3,72$ & 296,70 & 135,69 & 208,34 & 209,01 & 47,72 & 460,06 & 57,08 & 17,71 & 27,87 & 149,62 & 80,81 & 85,97 & 97,18 \\
\hline Pelophylax perezi & $30 \mathrm{SXJ} 20$ & 100,00 & 131,74 & 117,49 & 39,00 & 6221,58 & 300,28 & 3,13 & 297,16 & 143,39 & 215,42 & 215,42 & 57,42 & 444,72 & 55,84 & 13,37 & 32,31 & 144,85 & 68,35 & 68,76 & 97,31 \\
\hline Pelophylax perezi & $305 \times 126$ & 100,00 & 140,74 & 113,79 & 38,99 & 6168,73 & 303,37 & 13,85 & 289,52 & 157,58 & 222,91 & 223,06 & 66,30 & 401,84 & 48,33 & 12,80 & 31,27 & 128,56 & 66,98 & 67,74 & 84,39 \\
\hline Pelophylax perezi & $305 \times 127$ & 100,00 & 135,49 & 113,62 & 38,55 & 6222,47 & 299,38 & 8,49 & 290,89 & 153,20 & 218,48 & 218,69 & 60,57 & 418,58 & 49,97 & 14,38 & 29,99 & 134,59 & 71,86 & 73,58 & 87,35 \\
\hline Pelophylax perezi & $305 \times 128$ & 100,00 & $\begin{array}{l}129,43 \\
129,83\end{array}$ & 113,20 & 38,18 & $\begin{array}{l}6262,01 \\
6262,\end{array}$ & 294,62 & $\begin{array}{l}0,43 \\
3,43 \\
\end{array}$ & \begin{tabular}{|l|l|}
291,19 \\
\end{tabular} & $\begin{array}{l}147,66 \\
140\end{array}$ & $\begin{array}{l}213,38 \\
213\end{array}$ & \begin{tabular}{|l|}
213,73 \\
\end{tabular} & 54,72 & \begin{tabular}{|l|l|}
437,58 \\
470
\end{tabular} & 53,12 & $\begin{array}{l}\mid 4,36 \\
16,26 \\
\end{array}$ & 28,87 & $\begin{array}{l}141,52 \\
\end{array}$ & $\begin{array}{l}1,100 \\
77,37 \\
\end{array}$ & 80,19 & $\begin{array}{l}0,56 \\
90,65\end{array}$ \\
\hline Pelophylax perezi & $305 \times 129$ & 100,00 & 126,43 & 112,75 & 38,00 & 6289,60 & 291,53 & 0,37 & 291,16 & 144,61 & 210,27 & 210,82 & 51,06 & 446,32 & 55,21 & 17,49 & 28,18 & 145,12 & 80,79 & 84,38 & 91,66 \\
\hline Pelophylax perezi & $305 \times 130$ & 100,00 & 131,29 & 116,42 & 39,00 & 6170,28 & 297,46 & 3,50 & 293,96 & 127,35 & 214,25 & 214,35 & 57,77 & 454,16 & 55,76 & 13,91 & 31,75 & 145,20 & 71,55 & \begin{tabular}{|l|l|}
71,69 \\
\end{tabular} & 99,33 \\
\hline Pelophylax perezi & $305 \times 135$ & 100,00 & 142,52 & 112,52 & 39,00 & 6093,07 & 302,14 & 16,90 & 285,25 & 155,35 & 223,78 & 223,99 & 69,16 & 403,19 & 50,40 & 12,57 & 31,85 & 129,24 & 66,36 & 67,54 & 84,77 \\
\hline Pelophylax perezi & $305 \times 136$ & 100,00 & 141,98 & 111,71 & 38,92 & 6101,21 & 301,05 & 16,47 & 284,58 & 154,50 & 223,22 & 223,39 & 68,34 & 402,47 & 50,05 & 12,97 & 31,48 & 128,76 & 67,55 & 68,61 & 83,69 \\
\hline Pelophylax perezi & $305 \times 137$ & 100,00 & $\begin{array}{l}141,50 \\
129,43\end{array}$ & $\begin{array}{ll}111,1 / 1 \\
112,05\end{array}$ & 30 & $\begin{array}{l}0101,21 \\
6210,37\end{array}$ & 291,93 & $\begin{array}{r}0,417 \\
4,19\end{array}$ & \begin{tabular}{|l|}
287,74 \\
28,4
\end{tabular} & \begin{tabular}{|l|}
146,47 \\
140
\end{tabular} & \begin{tabular}{|l|}
212,47 \\
$212<$
\end{tabular} & $\mid 212,64$ & $\begin{array}{l}0,34,10 \\
55\end{array}$ & \begin{tabular}{|l|l|}
445,05 \\
44,5
\end{tabular} & $\begin{array}{l}50,900 \\
52,90\end{array}$ & $\begin{array}{l}16,54 \\
16,5 \\
\end{array}$ & $\begin{array}{l}1,40 \\
28,95\end{array}$ & $\begin{array}{l}142,84 \\
140\end{array}$ & $\begin{array}{l}79,29 \\
79,\end{array}$ & $\begin{array}{l}\mid l o, 01 \\
80,87\end{array}$ & $\begin{array}{l}01,03 \\
91,56\end{array}$ \\
\hline Pelophylax perezi & $305 \times 138$ & 100,00 & 124,98 & 111,35 & 38,03 & 6245,07 & 288,08 & 0,40 & 287,68 & 142,25 & 208,58 & 208,88 & 50,44 & 457,55 & 55,49 & 18,08 & 28,18 & 147,89 & 83,66 & 86,22 & 93,11 \\
\hline Pelophylax perezi & $305 \times 339$ & 100,00 & 119,33 & 110,82 & 38,00 & 6279,90 & 283,03 & $-4,71$ & 287,74 & 136,68 & 203,39 & 203,80 & 44,63 & 475,85 & 58,88 & 20,06 & 27,44 & 155,07 & 89,13 & 93,15 & 96,12 \\
\hline Pelophylax perezi & $305 \times 140$ & 100,00 & 132,93 & 115,13 & 39,00 & 6113,63 & 296,21 & 5,99 & 290,22 & 121,67 & 214,54 & 215,18 & 59,95 & 455,80 & 55,78 & 13,94 & 31,92 & 143,52 & 72,06 & 73,11 & 99,41 \\
\hline Pelophylax perezi & $305 \times 143$ & 100,00 & 133,74 & 113,07 & 39,00 & 6112,01 & 294,95 & 8,18 & 286,77 & 148,23 & 215,41 & 215,81 & 60,73 & 446,48 & 54,29 & 14,56 & 30,90 & 140,62 & 74,33 & 75,01 & 94,71 \\
\hline Pelophylax perezi & $305 \times 145$ & 100,00 & 147,24 & 110,23 & 39,00 & 5982,31 & 301,92 & 23,03 & 278,89 & 156,40 & 226,66 & 227,11 & 74,90 & 395,45 & 52,44 & 11,9 & 33,08 & 130,62 & 63,16 & \begin{tabular}{|l|l|}
67,46 \\
\end{tabular} & 82,81 \\
\hline Pelophylax perezi & $305 \times 146$ & 100,00 & 140,77 & 109,92 & 38,90 & 6050,06 & 297,10 & 16,81 & 280,29 & 150,23 & 221,32 & 221,66 & 67,97 & 413,15 & 52,03 & 13,81 & 31,29 & 132,51 & 70,02 & 72,27 & 85,21 \\
\hline Pelophylax perezi & $305 \times J 47$ & 100,00 & 132,63 & 109,71 & 38,28 & 6132,50 & 290,92 & 8,77 & 282,15 & 147,91 & 214,44 & 214,60 & 59,05 & 437,66 & 52,14 & 16,21 & 29,32 & 138,60 & 78,77 & 79,29 & 89,08 \\
\hline Pelophylax perezi & $305 \times 148$ & 100,00 & 126,77 & 109,15 & 38,01 & 6183,54 & 286,05 & 3,45 & 282,60 & 143,61 & 209,52 & 209,62 & 52,92 & 454,79 & 54,45 & 18,17 & 28,26 & 145,25 & 84,73 & 85,71 & 91,40 \\
\hline Pelophylax perezi & $305 \times 151$ & 100,00 & 133,18 & 112,97 & 39,00 & 6048,94 & 293,03 & 8,12 & 284,91 & \begin{tabular}{|l|}
139,41 \\
139,1
\end{tabular} & 213,86 & $\begin{array}{ll}214,76 \\
\end{array}$ & $\begin{array}{ll}61,01 \\
6\end{array}$ & 463,61 & 57,82 & $\begin{array}{l}10,110 \\
14,67 \\
\end{array}$ & $\begin{array}{l}31,29 \\
31,29\end{array}$ & $\begin{array}{l}146,88 \\
14,20\end{array}$ & 74,18 & . 77,11 & 100,44 \\
\hline Pelophylax perezi & $305 \times 152$ & 100,00 & 129,60 & 112,21 & 38,96 & 6071,79 & 289,74 & 5,25 & 284,49 & 131,89 & 210,86 & 211,45 & 57,43 & 478,03 & 58,38 & 16,09 & 30,25 & 151,48 & 78,93 & 81,26 & 102,80 \\
\hline Pelophylax perezi & $305 \times 153$ & 100,00 & 132,83 & 111,44 & 38,99 & 6054,51 & 291,36 & 8,81 & 282,55 & 143,03 & 213,66 & 214,39 & 60,61 & 461,08 & 57,05 & 15,37 & 30,49 & $\begin{array}{ll}146,18 \\
\end{array}$ & 76,52 & $\begin{array}{l}79,16 \\
\end{array}$ & 98,14 \\
\hline Pelophylax perezi & $305 \times 154$ & 100,00 & 138,76 & 110,19 & 39,02 & 6004,92 & 294,48 & 15,13 & 279,34 & 147,93 & 218,64 & 219,31 & 66,72 & 435,97 & 55,88 & 14,11 & 31,42 & 141,36 & 71,40 & 75,39 & 91,89 \\
\hline Pelophylax perezi & $305 \times 155$ & 100,00 & 148,64 & 108,27 & 39,01 & 5905,81 & 299,69 & 25,99 & 273,70 & 157,78 & 226,81 & 227,51 & 77,32 & 400,95 & 55,10 & 12,10 & 33,61 & 136,10 & 62,95 & 69,85 & 84,22 \\
\hline Pelophylax perezi & $305 \times 156$ & 100,00 & $\frac{144}{14}$ & 10 & $\begin{array}{l}35, \\
38,\end{array}$ & 59075,50 & 294 & $\begin{array}{l}20,05 \\
20,\end{array}$ & 274,84 & \begin{tabular}{|l|}
151,12 \\
151
\end{tabular} & \begin{tabular}{|l|}
221,591 \\
220
\end{tabular} & \begin{tabular}{|l|}
222,31 \\
\end{tabular} & 70,39 & \begin{tabular}{|l|l|}
417,13 \\
40,3
\end{tabular} & $\begin{array}{l}54,42 \\
54,42\end{array}$ & $\begin{array}{l}13,94 \\
13,4\end{array}$ & $\begin{array}{ll}30,01,68 \\
31,\end{array}$ & $\begin{array}{l}137,42 \\
1370\end{array}$ & $\begin{array}{l}69,68 \\
698\end{array}$ & 74, 74 & $\begin{array}{l}4,24 \\
86,15\end{array}$ \\
\hline Pelophylax perezi & 305XJ57 & 100,00 & 135,43 & 107,41 & 38,28 & 6046,96 & 289,62 & 13,45 & 276,17 & 144,99 & 215,97 & 216,39 & 62,89 & 435,39 & 53,66 & 15,97 & 29,95 & 139,20 & 77,11 & 80,02 & 88,35 \\
\hline Pelophylax perezi & $305 \times 158$ & 100,00 & $\begin{array}{l}127,50 \\
127,50\end{array}$ & 106,93 & 37,98 & 6110,70 & 283,45 & \begin{tabular}{|l|}
5,91 \\
5
\end{tabular} & 277,54 & \begin{tabular}{|l|}
142,05 \\
\end{tabular} & 209,36 & 209,55 & 54,73 & 458,52 & 54,60 & 18,52 & 28,35 & $\begin{array}{ll}144,68 \\
\end{array}$ & $\begin{array}{ll}85,95 \\
\end{array}$ & $\begin{array}{l}8,0,95 \\
86,9\end{array}$ & $\begin{array}{l}91,62 \\
91,62\end{array}$ \\
\hline Pelophylax perezi & $305 \times 159$ & 100,00 & 120,95 & 106,30 & 37,90 & 6167,78 & 277,81 & $-0,17$ & 277,97 & 137,32 & 163,31 & 203,76 & 47,78 & 477,04 & 57,77 & 20,75 & 27,53 & 152,52 & 92,88 & 93,98 & 93,77 \\
\hline Pelophylax perezi & $305 \times 161$ & 100,00 & 137,99 & 111,40 & 39,2 & 5952,97 & 293,82 & 13,92 & 279,90 & 147,24 & 217 & 21 & 66,81 & 456,65 & 59,88 & 13,80 & 32,50 & 149,99 & 70,42 & 76,63 & 99,5 \\
\hline Pelophylax perezi & $305 \times 162$ & 100,00 & 140,55 & 110,31 & 39,25 & 5927,19 & 294,52 & $\begin{array}{ll}17,05 \\
\end{array}$ & 277,47 & 150,31 & 219,21 & 220,26 & 69,46 & 446,74 & 59,58 & 13,52 & 32,87 & 148,61 & 69,04 & 75,92 & 96,71 \\
\hline Pelophylax perezi & $305 \times 163$ & 100,00 & 144,75 & 109,03 & 39,27 & 5877,77 & 296,22 & 22,16 & 274,06 & 154,58 & 222,55 & 223,61 & 74,08 & 430,61 & 59,06 & 12,83 & 33,59 & 146,08 & 66,01 & 74,06 & 92,64 \\
\hline Pelophylax perezi & $305 \times 164$ & 100,00 & 149,53 & 107,54 & 39,27 & 5826,07 & 298,32 & 27,84 & 270,48 & 159,32 & 226,47 & 227,62 & 79,22 & 412,81 & 58,55 & 12,10 & 34,66 & 143,23 & 62,50 & 71,75 & 88,25 \\
\hline Pelophylax perezi & $305 \times 165$ & 100,00 & 140,37 & 107,06 & 38,91 & 5923,89 & 291,50 & 19,09 & 272,4 & 149 & 218,99 & 219 & 69 & 438,99 & 58,03 & 14,58 & 31,61 & 146 & 71,97 & 78,82 & 92,03 \\
\hline Pelophylax perezi & $305 \times 166$ & 100,00 & 137,73 & 106,27 & 38,63 & 5952,26 & 288,87 & 16,69 & 272,18 & 146,89 & 216,82 & 217,55 & 66,32 & 444,08 & 57,30 & 15,64 & 30,68 & 146,17 & 75,42 & 81,56 & 91,85 \\
\hline
\end{tabular}




\begin{tabular}{|c|c|c|c|c|c|c|c|c|c|c|c|c|c|c|c|c|c|c|c|c|c|}
\hline TAXON & UTM & $\mathrm{km2}$ & B101 & $\mathrm{B1O2}$ & $\mathrm{BIO3}$ & B104 & B105 & B106 & B107 & B108 & B109 & 81010 & B1011 & BIO12 & BIO13 & 81014 & B1015 & B1016 & B1017 & BIO18 & B1019 \\
\hline Pelophylax perezi & 305XJ67| & 100,00 & 134,58 & 105,47 & 38,08 & 5986,80 & 286,09 & 14,12 & 271,97 & 143,41 & 214,29 & 214,93 & 63,03 & 449,14 & 56,28 & 16,73 & 29,75 & 145,65 & 79,29 & 84,23 & 91,38 \\
\hline Pelophylax perezi & $305 \times 168$ & 100,00 & 122,35 & 105,18 & 37,93 & 6098,75 & 276,92 & 2,28 & 274,63 & 136,46 & 203,99 & 204,38 & 50,08 & 487,44 & 57,57 & 20,50 & 27,48 & 153,17 & 92,86 & 94,41 & 97,42 \\
\hline Pelophylax perezi & $305 \times 169$ & 100,00 & 130,08 & 103,49 & 37,92 & 6039,47 & 281,31 & 10,47 & 270,84 & 141,93 & 203,62 & 210,93 & 58,12 & 452,30 & 55,16 & 18,70 & 29,05 & 145,00 & 85,51 & 88,67 & 88,76 \\
\hline Pelophylax perezi & $305 \times 170$ & 100,00 & 137,53 & 110,71 & 39,32 & 5904,00 & 291,80 & 14,12 & 277,68 & 147,94 & 215,93 & 217,18 & 67,21 & 472,94 & 62,96 & 14,05 & 32,67 & 157,32 & 71,03 & 79,28 & 105,05 \\
\hline Pelophylax perezi & $305 \times J 71$ & 100,00 & 129,27 & 109,91 & 39,00 & 5973,05 & 285,19 & 6,64 & 278,55 & \begin{tabular}{|l|l|}
139,33 \\
\end{tabular} & 208,87 & 210,05 & 58,50 & 504,70 & 63,75 & 16,71 & 30,28 & 162,69 & 80,68 & 86,76 & 111,01 \\
\hline Pelophylax perezi & $305 \times \mathrm{J} 72$ & 100,00 & 135,05 & 108,85 & 39,00 & 5916,15 & 288,28 & 13,03 & 275,26 & 145,11 & 213,66 & 214,93 & 64,58 & 480,25 & 62,86 & 15,44 & 31,38 & 158,73 & 75,77 & 83,35 & 104,77 \\
\hline Pelophylax perezi & $305 \times 173$ & 100,00 & 134,74 & 107,78 & 38,92 & 5912,92 & 287,08 & 13,31 & 273,78 & $\begin{array}{lll}144,68 \\
\end{array}$ & 213,34 & 214,45 & 64,27 & 479,66 & 62,49 & 15,88 & 30,90 & 158,43 & 77,23 & 84,66 & 103,68 \\
\hline Pelophylax perezi & $305 \times 174$ & 100,00 & 144,64 & 106,00 & 38,97 & 5808,97 & 292,51 & 24,30 & 268,21 & 154,66 & 221,46 & 222,71 & 74,91 & 443,42 & 61,79 & 13,75 & 33,54 & $\begin{array}{l}153,08 \\
\end{array}$ & 68,48 & 78,70 & 95,51 \\
\hline Pelophylax perezi & $305 \times 175$ & 100,00 & 139,39 & 105,26 & 38,74 & 5863,84 & 288,17 & 19,44 & 268,74 & 149,05 & 217,05 & 218,16 & 69,21 & 457,30 & 61,21 & 15,39 & 31,63 & 154,40 & 74,34 & 83,16 & 96,96 \\
\hline Pelophylax perezi & $305 \times 176$ & 100,00 & 136,34 & 104,40 & 38,32 & 5894,38 & 285,41 & 16,88 & 268,53 & 145,73 & 214,62 & 215,66 & 65,99 & 462,44 & 60,29 & 16,51 & 30,46 & 154,06 & 78,14 & 86,10 & 96,48 \\
\hline Pelophylax perezi & $305 \times 177$ & 100,00 & 129,46 & 103,84 & 38,05 & 5965,21 & 280,00 & 10,43 & 269,57 & 138,84 & 208,95 & 209,79 & 58,54 & 479,80 & 59,22 & 18,64 & 28,75 & 155,00 & 85,94 & 91,66 & 98,22 \\
\hline Pelophylax perezi & $305 \times 178$ & 100,00 & 134,17 & 102,25 & 37,95 & 5919,14 & 282,15 & 16,04 & 266,11 & 144,01 & 212,92 & 213,66 & 63,56 & 458,25 & 58,45 & 17,81 & 29,83 & 151,35 & 81,92 & 88,97 & 92,58 \\
\hline Pelophylax perezi & 305XJ79 & 100,00 & 145,16 & 100,16 & 37,99 & 5811,26 & 288,28 & 27,86 & 260,41 & $\begin{array}{l}154,01 \\
\end{array}$ & 221,87 & 222,82 & 75,13 & 417,16 & 56,96 & 15,33 & 32,41 & 144,09 & 71,62 & 81,59 & 83,63 \\
\hline Pelophylax perezi & $305 \times 180$ & 100,00 & 144,00 & 109,08 & 39,48 & 5785,34 & 294,12 & 21,79 & 272,33 & 154,88 & 220,38 & 221,94 & 74,64 & 463,92 & 65,44 & 12,84 & 34,78 & 161,16 & 66,09 & 78,03 & 104,46 \\
\hline Pelophylax perezi & $305 \times 81$ & 100,00 & 139,38 & 108,16 & 39,12 & 5823,71 & 290,00 & 17,87 & 272,13 & $\mid 150,14$ & 216,53 & $\mid 217,97$ & $\mid 69,86$ & 480,55 & 65,73 & $\mid 14,34$ & 32,98 & 164,05 & $\mid 71,62$ & 82,44 & 107,25 \\
\hline Pelophylax perezi & $305 \times 182$ & 100,00 & 142,61 & 106,86 & 39,12 & 5781,11 & 291,03 & 22,04 & 268,99 & 153,31 & 219,00 & 220,57 & 73,45 & 468,84 & 65,57 & 13,90 & 33,69 & 162,69 & 69,65 & 81,45 & 104,05 \\
\hline Pelophylax perezi & $305 \times 183$ & 100,00 & 143,86 & 105,54 & 39,10 & 5758,33 & 290,70 & 24,10 & 266,60 & 154,37 & 219,85 & 221,39 & 74,88 & 464,10 & 65,49 & 13,98 & 33,84 & 162,18 & 69,61 & 81,77 & 102,29 \\
\hline Pelophylax perezi & $305 \times 184$ & 100,00 & 143,71 & 104,29 & 39,00 & 5747,43 & 289,46 & 24,87 & 264,59 & 154,15 & 219,55 & 221,15 & 75,00 & 462,29 & 65,19 & 14,37 & 33,59 & 161,71 & 70,50 & 82,78 & 100,98 \\
\hline Pelophylax perezi & $305 \times 185$ & 100,00 & 151,95 & 102,27 & 38,99 & 5649,61 & 293,41 & 34,26 & 259,15 & 162,57 & 226,08 & 227,78 & 83,80 & 435,08 & 65,18 & 12,88 & 35,90 & 158,16 & 63,79 & 78,46 & 94,93 \\
\hline Pelophylax perezi & $305 \times 186$ & 100,00 & 143,03 & 101,81 & 38,50 & 5747,54 & 286,85 & 25,65 & 261,20 & 153,06 & 218,83 & 220,32 & 74,19 & 457,23 & 63,92 & 15,32 & 32,73 & 159,77 & 72,87 & 85,12 & 97,37 \\
\hline Pelophylax perezi & $305 \times 187$ & 100,00 & $\begin{array}{ll}134,47 \\
\end{array}$ & 101,46 & 38,03 & 5847,57 & 280,78 & 17,18 & 263,60 & 143,95 & 212,11 & 213,25 & 64,92 & 477,32 & 62,23 & 17,79 & 30,15 & 160,24 & 82,06 & 91,49 & 99,19 \\
\hline Pelophylax perezi & $305 \times 188$ & 100,00 & 150,47 & 98,58 & 38,21 & 5662,01 & 289,49 & 34,89 & 254,60 & 160,34 & 224,78 & 226,36 & 82,20 & 425,20 & 62,30 & 14,31 & 34,76 & 153,35 & 67,35 & 81,33 & 88,84 \\
\hline Pelophylax perezi & $305 \times 189$ & 100,00 & 151,22 & 97,45 & 38,00 & 5660,88 & 289,16 & 36,08 & 253,09 & 160,92 & 225,42 & 226,98 & 82,86 & 416,22 & 60,92 & 14,41 & 34,58 & 150,62 & 67,12 & 81,19 & 85,54 \\
\hline Pelophylax perezi & $305 \times 190$ & 100,00 & 153,25 & 107,17 & 39,81 & 5630,23 & 298,25 & 32,30 & 265,95 & 164,95 & 227,01 & 228,96 & 85,40 & 449,15 & 68,17 & 11,03 & 38,19 & 164,83 & 58,95 & 75,35 & 103,51 \\
\hline Pelophylax perezi & $305 \times 191$ & 100,00 & 154,65 & 105,88 & 39,80 & 5600,81 & 298,09 & 34,84 & 263,25 & 166,33 & 227,97 & 230,00 & 87,14 & 446,79 & 68,62 & 11,06 & 38,44 & 165,52 & 58,81 & 75,95 & 102,75 \\
\hline Pelophylax perezi & $305 \times 192$ & 100,00 & 157,11 & 104,43 & 39,78 & 5563,59 & 298,29 & 38,17 & 260,11 & 168,70 & 229,72 & 231,88 & 89,87 & 440,43 & 69,03 & 10,91 & 39,15 & 165,36 & 57,65 & 75,60 & 101,15 \\
\hline Pelophylax perezi & $305 \times 193$ & 100,00 & 161,82 & 102,37 & 39,76 & 5482,65 & 299,51 & 44,50 & 255,01 & $\begin{array}{l}173,54 \\
\end{array}$ & 233,14 & 235,41 & $\begin{array}{l}95,32 \\
95,32\end{array}$ & \begin{tabular}{|l|l|}
428,66 \\
\end{tabular} & $\begin{array}{l}69,86 \\
\end{array}$ & 10,31 & 40,90 & $\begin{array}{l}165,05 \\
\end{array}$ & 54,69 & 74,34 & $\begin{array}{l}98,67 \\
98\end{array}$ \\
\hline Pelophylax perezi & $305 \times 194$ & 100,00 & 154,36 & 101,60 & 39,15 & 5556,76 & 293,62 & 37,51 & 256,10 & 165,70 & 227,05 & 229,12 & 87,33 & 448,82 & 69,43 & 12,38 & 37,73 & 167,25 & 62,05 & 79,83 & 101,26 \\
\hline Pelophylax perezi & $305 \times 195$ & 100,00 & 154,12 & 100,07 & 38,95 & 5546,10 & 291,99 & 38,17 & 253,82 & 165,20 & 226,60 & 228,75 & 87,31 & 447,85 & 69,32 & 12,82 & 37,47 & 166,93 & 63,14 & 81,01 & 100,04 \\
\hline Pelophylax perezi & $305 \times 196$ & 100,00 & 159,01 & 97,91 & 38,99 & 5464,39 & 293,27 & 44,80 & 248,46 & 170,22 & 230,17 & 232,46 & 92,96 & 432,22 & 69,69 & 12,20 & 39,07 & 165,26 & 59,58 & 78,93 & 96,29 \\
\hline Pelophylax perezi & $305 \times 197$ & 100,00 & 157,92 & 96,72 & 38,69 & 5480,10 & 291,59 & 44,24 & 247,35 & 168,84 & 229,31 & 231,46 & 91,61 & $\begin{array}{l}430,08 \\
\end{array}$ & 68,64 & 12,78 & 38,43 & 163,54 & 61,12 & 80,02 & 94,32 \\
\hline Pelophylax perezi & $305 \times 198$ & 100,00 & 161,99 & 95,04 & 38,54 & 5418,89 & 292,97 & |49,34 & 243,62 & $\begin{array}{l}172,81 \\
\end{array}$ & 232,29 & $\begin{array}{l}234,62 \\
2340\end{array}$ & $\begin{array}{ll}1,10 \\
96,34\end{array}$ & \begin{tabular}{|l|l|}
414,44 \\
4
\end{tabular} & $\begin{array}{l}0,049 \\
67,98 \\
\end{array}$ & 12,27 & 30,74 & $\begin{array}{l}160,49 \\
\end{array}$ & 58,30 & $\begin{array}{l}00,02 \\
78,11\end{array}$ & $\begin{array}{l}40,18 \\
90,5\end{array}$ \\
\hline Pelophylax perezi & 30SXJ99 & 100,00 & 156,57 & 94,70 & 38,02 & 5501,31 & 289,38 & 43,62 & 245,76 & 166,92 & 228,32 & 230,32 & 90,09 & 420,21 & 65,46 & 13,67 & 37,23 & 158,42 & 63,57 & 81,59 & 88,81 \\
\hline Pelophylax perezi & 30 XKK00 & 100,00 & 117,03 & 117,58 & 38,22 & 6405,90 & 290,68 & $-11,81$ & 302,48 & 99,08 & 202,55 & 203,36 & 40,19 & 491,68 & 61,76 & 19,42 & 27,18 & 160,49 & 85,47 & 92,59 & 107,13 \\
\hline Pelophylax perezi & 30 XXK01 & 100,00 & 113,84 & 117,21 & 38,05 & 6418,00 & 287,49 & $-15,02$ & 302,51 & 99,80 & 199,50 & 200,48 & 36,92 & 502,00 & 63,86 & 20,64 & 26,94 & 164,00 & 88,99 & 96,66 & 108,97 \\
\hline Pelophylax perezi & 30SXK10 & 100,00 & 119,41 & 114,96 & 38,03 & 6364,99 & 289,05 & $-7,86$ & 296,91 & 134,11 & 204,31 & 205,06 & 43,17 & 474,57 & 59,86 & 19,29 & 27,44 & 154,89 & 85,25 & 91,36 & 99,81 \\
\hline Pelophylax perezi & 30SXK11 & 100,00 & 112,66 & 114,56 & 38,00 & 6389,70 & 282,94 & $-14,45$ & 297,39 & 129,78 & 197,94 & 198,83 & 36,42 & 499,21 & 63,90 & 21,56 & 26,85 & $\begin{array}{l}163,73 \\
\end{array}$ & 91,80 & 99,37 & 104,68 \\
\hline Pelophylax perezi & 30SXK12 & 100,00 & 107,80 & 113,86 & 37,99 & 6396,03 & 277,60 & $-18,99$ & 296,59 & $\begin{array}{l}126,32 \\
\end{array}$ & 193,10 & 194,14 & 31,64 & 514,64 & 66,77 & 23,34 & 26,70 & 169,85 & 96,73 & 105,32 & 107,11 \\
\hline Pelophylax perezi & $305 \times K 20$ & 100,00 & 118,83 & 112,53 & 38,00 & 6329,76 & 285,25 & $-6,66$ & 291,91 & 136,98 & 203,38 & 204,00 & 43,37 & 472,28 & 59,64 & 19,96 & 27,46 & 154,90 & 87,86 & $\begin{array}{r}93,14 \\
9\end{array}$ & 96,35 \\
\hline Pelophylax perezi & $30 \mathrm{SXK21}$ & 100,00 & 105,33 & 112,06 & 37,97 & 6370,31 & 273,35 & $-19,68$ & 293,03 & 123,00 & 190,63 & 191,50 & 29,87 & 527,39 & 67,49 & 24,47 & 26,25 & 174,19 & 100,69 & 108,91 & 107,95 \\
\hline Pelophylax perezi & 30 SXK30 & 100,00 & 117,71 & 110,05 & 37,95 & 6293,58 & 280,91 & $-6,02$ & 286,93 & 135,21 & 201,84 & 202,31 & 42,81 & 476,10 & 60,00 & 20,90 & 27,42 & 156,32 & 91,20 & 95,71 & 94,79 \\
\hline Pelophylax perezi & $305 \times K 32$ & 100,00 & 108,52 & 108,46 & 37,33 & 6339,29 & 271,47 & $-14,69 \mid$ & 286,15 & $\begin{array}{l}126,45 \\
\end{array}$ & 58,98 & 194,06 & 33,24 & 499,43 & 65,36 & 24,27 & 27,34 & 167,26 & 97,03 & 107,17 & 97,07 \\
\hline Pelophylax perezi & $30 S \times K 40$ & 100,00 & 116,01 & 107,73 & 37,78 & 6252,44 & 276,27 & $-6,16$ & 282,43 & 133,03 & 123,01 & 200,16 & 41,92 & 485,12 & 60,79 & 22,01 & 27,28 & 158,67 & 94,35 & 98,94 & 95,01 \\
\hline Pelophylax perezi & 30SXK41 & 100,00 & 113,97 & 106,82 & 37,28 & 6276,32 & 273,90 & $-7,82$ & 281,73 & 131,38 & 40,80 & 198,58 & 39,77 & 483,34 & 61,95 & 22,85 & 27,58 & 159,95 & 92,75 & 101,60 & 92,75 \\
\hline Pelophylax perezi & $305 \times K 42$ & 100,00 & 116,05 & 105,51 & 37,03 & 6277,06 & 274,28 & $-5,51$ & 279,79 & 133,90 & 41,45 & 200,47 & 41,45 & 464,69 & 60,71 & 22,55 & 28,61 & 155,38 & 86,90 & 99,96 & 86,90 \\
\hline Pelophylax perezi & $30 \mathrm{SKK}$ & 100, & 127,65 & 104,81 & 37, & 6135 & 281,71 & 6,70 & 275,01 & 142,82 & 92,14 & 209,82 & 54,41 & 442,77 & 54,53 & 19 & 28,90 & 142,62 & 84,56 & 87,90 & 84,95 \\
\hline Pelophylax perezi & $305 \times K 5$ & 100,00 & 121,03 & 104,12 & 37,22 & 619 & 276,05 & 0,70 & 275,35 & $\begin{array}{l}137,93 \\
\end{array}$ & 48,32 & 204,10 & 47,33 & 458,95 & 57,95 & 21,34 & 28,56 & 149,92 & 86,45 & 95,23 & 86,45 \\
\hline Pelophylax perezi & 30 XKK52 & 100,00 & 116,95 & 103,14 & 37,03 & 6232,40 & 272,18 & $-2,82$ & 275,00 & 134,51 & 42,97 & 200,73 & 42,97 & 464,15 & 60,12 & 22,83 & 28,82 & 154,08 & 85,43 & 100,12 & 85,43 \\
\hline Pelophylax perezi & 30 SXK60 & 100,00 & 133,08 & 102,24 & 37,55 & 6028,01 & 282,71 & 13,90 & 268,81 & 144,14 & 135,44 & 213,70 & 61,01 & 432,27 & 53,45 & 18,14 & 29,76 & 139,75 & 81,08 & 85,84 & 82,95 \\
\hline Pelophylax perezi & 30 XXK61 & 100,00 & 121,73 & 102,01 & 37,02 & 6146,47 & 274,28 & 2,65 & 271,63 & 138,39 & 48,60 & 204,06 & 48,60 & 461,33 & 57,58 & 21,59 & 28,58 & 148,96 & 86,06 & 95,50 & 86,06 \\
\hline Pelophylax perezi & $\frac{305 \mathrm{NXKG}}{30 \mathrm{~K}}$ & 100,00 & $\frac{10}{10}$ & 101,78 & 36, & $\mid 61418,09$ & 261,26 & \begin{tabular}{|c|}
$-2,03$ \\
$-12,13$ \\
\end{tabular} & $\begin{array}{l}271,3050 \\
270\end{array}$ & \begin{tabular}{|l|}
122,72 \\
122
\end{tabular} & $\begin{array}{l}40,00 \\
32,84\end{array}$ & \begin{tabular}{|l|}
190,04 \\
\end{tabular} & $\begin{array}{ll}40,00 \\
32,84\end{array}$ & \begin{tabular}{|l|l|}
520,18 \\
520
\end{tabular} & $\begin{array}{l}1,30 \\
66,47 \\
\end{array}$ & $\begin{array}{l}\mid 1,35 \\
26,72\end{array}$ & $\begin{array}{l}27,06 \\
27,06\end{array}$ & $\begin{array}{l}170,30 \\
171,32 \\
\end{array}$ & $\begin{array}{l}0,000 \\
97,31\end{array}$ & $\begin{aligned} 113,83 \\
113,80\end{aligned}$ & $\begin{array}{l}0,0,31 \\
97,3\end{array}$ \\
\hline Pelophylax perezi & 30 XKK70 & 100,00 & 129,53 & 100,59 & 37,27 & 5995,70 & 277,80 & 11,79 & 266,01 & 140,13 & 119,53 & 209,80 & 58,06 & 456,08 & 56,17 & 19,62 & 29,24 & 147,22 & 85,81 & 92,48 & 88,02 \\
\hline Pelophylax perezi & 30 SXK71 & 100,00 & 116,02 & 100,53 & 36,95 & 6112,56 & 267,73 & $-1,27$ & 269,01 & 131,13 & 43,85 & 198,16 & 43,85 & 495,53 & 61,02 & 23,65 & 27,54 & 158,38 & 93,56 & 103,52 & 93,56 \\
\hline Pelophylax perezi & 30 SXK72 & 100,00 & 95,77 & 100,65 & 36,45 & 6182,98 & 250,53 & $-21,31$ & 271,84 & 111,17 & 23,68 & 179,33 & 23,68 & 584,80 & 73,13 & 30,58 & 25,11 & 189,64 & 113,11 & 126,81 & 113,11 \\
\hline Pelophylax perezi & 30 XKK80 & 100,00 & 133,40 & 98,33 & 37,20 & 5881,55 & 277,88 & 17,42 & 260,45 & 142,60 & 180,96 & 212 & 63,21 & 457,53 & 58,17 & 18,99 & 29,97 & 152,34 & 84,32 & 93,37 & 89 \\
\hline Pelophylax perezi & 30 SXK81 & 100,00 & 107,43 & 99,34 & 36,75 & 6087,26 & 258,74 & $-8,79$ & 267,52 & 121,45 & $\begin{array}{l}30,15 \\
36,15\end{array}$ & 189,55 & 36,15 & 548,46 & 66,48 & 26,89 & 25,90 & 173,45 & 106,31 & 115,03 & 106,31 \\
\hline Pelophylax perezi & 30SXK82 & 100,00 & 95,14 & 99,06 & 36,21 & 6135,27 & 247,94 & $-20,86$ & 268,79 & 110,04 & 23,55 & 178,07 & 23,55 & 600,15 & 73,97 & 31,18 & 24,62 & 192,01 & 117,01 & 128,30 & 117,01 \\
\hline Pelophylax perezi & 30SXK90 & 100,00 & 137,15 & 96,17 & 37,23 & 5766,21 & 277,84 & 22,66 & 255,19 & 146,16 & 210,50 & 214,60 & 68,34 & 461,90 & 60,83 & 18,45 & 30,90 & 158,33 & 82,55 & 94,14 & 92,39 \\
\hline Pelophylax perezi & 30SXK91 & 100,00 & 118,16 & 97,05 & 36,70 & 5962,03 & 264,77 & 3,03 & 261,74 & 128,88 & 86,00 & 198, & 47, & 516,47 & 61,85 & 23,82 & 27,32 & 164,19 & 99,90 & 108,37 & 100, \\
\hline Pelophylax perezi & $30 \mathrm{~S} \times \mathrm{K} 92$ & 100,00 & 118,22 & 96,24 & 36,31 & 5976,35 & 264,32 & 3,29 & 261,02 & 129,84 & 58,95 & 198,64 & 47,90 & 505,18 & 61,45 & 23,95 & 27,82 & 160,42 & 95,62 & 107,63 & 95,73 \\
\hline
\end{tabular}




\begin{tabular}{|c|c|c|c|c|c|c|c|c|c|c|c|c|c|c|c|c|c|c|c|c|c|}
\hline TAXON & UTM & $\mathrm{km2}$ & BIO1 & B102 & $\mathrm{BIO3}$ & BIO4 & B105 & B106 & B107 & B108 & B109 & BIO10 & BIO11 & $\overline{B 1012}$ & BIO13 & BIO14 & BIO15 & BIO16 & BIO17 & B1018 & BlO19 \\
\hline Pelophylax perezi & 30SYHOO & 33,00 & 182,53 & 108,27 & 41,02 & 5246,55 & 319,78 & 59,71 & 260,06 & 182,18 & 250,04 & 252,10 & 117,90 & 282,22 & 56,12 & 3,96 & 56,27 & 124,12 & 23,45 & 41,18 & 66,90 \\
\hline Pelophylax perezi & 30SYH01 & 62,00 & 182,16 & 108,79 & 41,00 & \begin{tabular}{|l|}
5270,48 \\
\end{tabular} & 320,05 & \begin{tabular}{|l|l|}
58,99 \\
\end{tabular} & 261,06 & \begin{tabular}{l|l|l|}
194,93 \\
\end{tabular} & \begin{tabular}{|l|l|}
249,99 \\
\end{tabular} & 252,12 & 117,15 & 286,90 & 56,79 & 4,00 & 55,98 & $\begin{array}{l}125,45 \\
1\end{array}$ & 24,32 & 42,38 & 67,05 \\
\hline Pelophylax perezi & 30SYHO2 & 80,00 & $\begin{array}{ll}182,46 \\
\end{array}$ & 108,92 & 41,00 & 5276,77 & 320,21 & 59,09 & 261,13 & $\begin{array}{ll}195,28 \\
\end{array}$ & \begin{tabular}{|l|l|}
250,29 \\
\end{tabular} & 252,49 & 117,35 & 297,04 & \begin{tabular}{ll|l}
58,03 \\
\end{tabular} & 4,00 & 54,71 & \begin{tabular}{|l|}
128,71 \\
\end{tabular} & 26,03 & 44,69 & 68,70 \\
\hline Pelophylax perezi & 30SYHO3 & 100,00 & 181,04 & 109,05 & 41,01 & 5301,23 & 319,32 & 57,70 & 261,62 & \begin{tabular}{l|l|l|l|l}
194,00 \\
\end{tabular} & 249,20 & 251,55 & 115,75 & 311,40 & 59,62 & 4,00 & 53,46 & \begin{tabular}{|l|l|}
133,19 \\
\end{tabular} & 28,22 & 47,27 & 71,40 \\
\hline Pelophylax perezi & 30SYHO4 & 100,00 & 173,90 & 109,71 & 41,00 & 5389,70 & 314,83 & 50,47 & 264,37 & \begin{tabular}{|l|l|}
186,78 \\
\end{tabular} & 243,55 & 245,87 & \begin{tabular}{l|l}
107,85 \\
\end{tabular} & 346,29 & 62,24 & 5,29 & 49,14 & \begin{tabular}{|l|l|}
141,70 \\
\end{tabular} & \begin{tabular}{l|l|}
34,85 \\
\end{tabular} & 53,52 & 78,97 \\
\hline Pelophylax perezi & 30SYHO5 & 100,00 & 166,77 & 109,71 & \begin{tabular}{l|l}
40,85 \\
\end{tabular} & 5465,29 & 309,83 & \begin{tabular}{|l|l|}
43,67 \\
\end{tabular} & 266,15 & 179,36 & 237,69 & 240,01 & 100,20 & \begin{tabular}{l|l}
384,95 \\
\end{tabular} & 64,88 & 6,78 & 45,22 & 151,15 & \begin{tabular}{|l|l|}
41,97 \\
\end{tabular} & 60,32 & 89,22 \\
\hline Pelophylax perezi & 30SYH06 & 100,00 & 144,42 & 108,84 & 39,61 & 5689,09 & 293,55 & 22,42 & 271,13 & \begin{tabular}{ll|l}
144,48 \\
\end{tabular} & 219,20 & 221,28 & 76,49 & 486,58 & 69,47 & 12,40 & 36,53 & 172,01 & 63,57 & 78,33 & 115,60 \\
\hline Pelophylax perezi & 30SYH07 & 100,00 & 145,51 & 108,53 & 39,83 & 5677,36 & 293,93 & 23,77 & 270,16 & \begin{tabular}{|l|l|}
156,67 \\
\end{tabular} & 220,10 & 222,15 & 77,61 & 484,35 & 69,80 & 12,21 & 36,42 & $\begin{array}{l}172,25 \\
\end{array}$ & \begin{tabular}{l|l}
63,45 \\
\end{tabular} & 78,80 & 114,59 \\
\hline Pelophylax perezi & 30SYH08 & 100,00 & 133,87 & 107,45 & 39,09 & 5786,82 & 284,80 & 13,19 & 271,61 & $\begin{array}{ll}144,48 \\
\end{array}$ & \begin{tabular}{|l|l|}
210,39 \\
\end{tabular} & 212,43 & 65,38 & 534,69 & 71,73 & 15,72 & 32,70 & \begin{tabular}{ll|}
181,60 \\
\end{tabular} & 76,45 & 89,32 & 125,78 \\
\hline Pelophylax perezi & 30SYHO9 & 100,00 & 148,30 & 106,84 & 39,64 & 5640,08 & 294,15 & $27,77 \mid$ & 266,38 & 160,23 & 222,30 & 224,45 & 80,64 & 481,97 & 70,89 & 12,15 & 37,05 & 174,40 & 63,64 & 80,44 & 113,50 \\
\hline Pelophylax perezi & 30SYH13 & 75,00 & 181,61 & 107,03 & 41,00 & 5237,53 & 317,59 & 59,90 & 257,70 & $\begin{array}{ll}194,88 \\
\end{array}$ & 248,67 & 251,29 & 117,18 & 322,56 & 61,49 & 4,09 & 53,53 & \begin{tabular}{|l|l|}
139,03 \\
\end{tabular} & 29,04 & 48,90 & 75,25 \\
\hline Pelophylax perezi & 30SYH14 & 84,00 & 180,26 & 107,10 & 41,00 & 5257,41 & 316,59 & 58,60 & 257,99 & \begin{tabular}{ll|}
193,68 \\
\end{tabular} & 247,77 & 250,42 & 115,62 & 336,75 & 63,16 & 4,36 & 52,08 & 143,41 & 31,77 & 51,94 & 77,46 \\
\hline Pelophylax perezi & 30SYH15 & 100,00 & 175,28 & 107,31 & 40,93 & 5313,91 & 313,30 & 53,72 & 259,57 & \begin{tabular}{ll|}
188,76 \\
\end{tabular} & 243,76 & \begin{tabular}{|l|l|}
246,37 \\
\end{tabular} & \begin{tabular}{|l|}
110,37 \\
\end{tabular} & 366,35 & 65,66 & 5,46 & \begin{tabular}{|l|l}
49,10 \\
\end{tabular} & \begin{tabular}{ll|}
151,58 \\
\end{tabular} & \begin{tabular}{l|l}
37,05 \\
\end{tabular} & 57,48 & 84,94 \\
\hline Pelophylax perezi & 30 SYH16 & 100,00 & 159,20 & 107,47 & 40,10 & 5490,83 & 302,30 & \begin{tabular}{l|l}
37,95 \\
\end{tabular} & 264,34 & $\begin{array}{ll}169,42 \\
\end{array}$ & 230,56 & 233,14 & 92,89 & 442,74 & 69,88 & 8,99 & \begin{tabular}{ll|}
41,99 \\
\end{tabular} & $\begin{array}{l}168,76 \\
\end{array}$ & 51,36 & \begin{tabular}{ll|}
70,57 \\
\end{tabular} & 106,53 \\
\hline Pelophylax perezi & 30SYH17 & 100,00 & 137,58 & 106,62 & 39,14 & 5704,24 & 286,43 & 17,54 & 268,89 & 126,61 & \begin{tabular}{|l|l|}
212,69 \\
\end{tabular} & 215,01 & \begin{tabular}{ll|l}
69,98 \\
\end{tabular} & 534,91 & 73,47 & 14,7 & 34,3 & 186,51 & \begin{tabular}{|l|l|}
72,75 \\
\end{tabular} & 87,84 & 129,03 \\
\hline Pelophylax perezi & 30SYH18 & 100,00 & 135,72 & 105,93 & 39,01 & 5715,70 & 284,32 & 16,26 & 268,07 & 135,22 & \begin{tabular}{|l|l|}
211,13 \\
\end{tabular} & 213,36 & 68,11 & $\begin{array}{l}545,95 \\
\end{array}$ & 74,34 & 15,54 & 33,65 & 189,00 & \begin{tabular}{ll|}
76,09 \\
\end{tabular} & 91,16 & 130,99 \\
\hline Pelophylax perezi & 30SYH19 & 100,00 & 140,82 & 105,29 & 39,20 & 5663,73 & 287,27 & 21,68 & 265,59 & 149,01 & 215,32 & 217,56 & 73,55 & 529,39 & 74,34 & 14,42 & \begin{tabular}{|l|l|}
35,07 \\
\end{tabular} & \begin{tabular}{l|l|}
187,23 \\
\end{tabular} & 72,32 & 89,16 & 126,96 \\
\hline Pelophylax perezi & 30 SYH24 & 13,00 & 181,85 & 105,46 & 41,00 & 5196,85 & 316,00 & 61,77 & 254,23 & \begin{tabular}{|l|l|}
196,08 \\
\end{tabular} & 248,23 & 251,23 & 118,00 & 352,31 & 65,31 & 4,23 & 52,23 & 151,00 & 32,31 & 54,23 & 84,31 \\
\hline Pelophylax perezi & 30 SYH25 & 77,00 & 180,16 & 105,37 & 41,00 & 5215,02 & 314,92 & 60,07 & 254,85 & \begin{tabular}{|l|l|}
194,17 \\
\end{tabular} & 247,07 & 250,04 & \begin{tabular}{ll|}
116,15 \\
\end{tabular} & 369,19 & 67,10 & 4,91 & 51,03 & \begin{tabular}{ll|}
156,33 \\
\end{tabular} & 34,86 & 57,50 & 89,25 \\
\hline Pelophylax perezi & 30 SYH26 & 100,00 & 162,06 & 105,68 & 40,10 & 5418,68 & 302,65 & 42,09 & 260,56 & \begin{tabular}{l|l|l|}
164,62 \\
\end{tabular} & 232,30 & 235,03 & 96,5 & \begin{tabular}{|l|l}
452,93 \\
\end{tabular} & 72,10 & 8,67 & 43, & 176,14 & 50,53 & $\begin{array}{ll}71,93 \\
\end{array}$ & 112,25 \\
\hline Pelophylax perezi & 30 SYH 27 & 100,00 & 138,36 & 105,00 & 39,08 & 5652,75 & 285,28 & 19,41 & 265,87 & 113,91 & 212,66 & 215,09 & 71,39 & 550,86 & 75,99 & 14,68 & 34,98 & 195,63 & 73,13 & 90,20 & 135,87 \\
\hline Pelophylax perezi & 30 SYH28 & 100,00 & 143,83 & 104,61 & \begin{tabular}{l|l|}
39,25 \\
\end{tabular} & 5600,58 & 288,71 & \begin{tabular}{|l|l|}
25,05 \\
\end{tabular} & 263,66 & 129,31 & \begin{tabular}{l|l|}
217,22 \\
\end{tabular} & 219,66 & $\begin{array}{l}77,15 \\
\end{array}$ & 534,83 & 76,21 & 13,50 & 36,49 & $\begin{array}{l}193,59 \\
1\end{array}$ & 69,20 & 88,25 & 132,28 \\
\hline Pelophylax perezi & 30 SYH 29 & 100,00 & 157,11 & 103,99 & \begin{tabular}{|l|l|}
39,83 \\
\end{tabular} & 5462,54 & 297,39 & 38,60 & 258,79 & 160,71 & 228,11 & 230,76 & 91,36 & 495,67 & 76,34 & 10,57 & \begin{tabular}{l|l}
41,07 \\
\end{tabular} & \begin{tabular}{|l|}
189,27 \\
\end{tabular} & \begin{tabular}{|l|l|}
58,63 \\
\end{tabular} & \begin{tabular}{l|l|}
81,85 \\
\end{tabular} & 124,46 \\
\hline Pelophylax perezi & 30SYH35 & 1,00 & 182,50 & 104,00 & 41,00 & 5186,50 & 316,00 & 63,50 & 252,50 & \begin{tabular}{|l|l|}
197,00 \\
\end{tabular} & 249,00 & 252,00 & 119,00 & 385,00 & 69,00 & 5,00 & 52,00 & 164,00 & 34,50 & 60,00 & 98,00 \\
\hline Pelophylax perezi & $30 \mathrm{SYH} 36$ & 76,00 & 172,53 & 104,27 & 40,29 & 5282,72 & 308,81 & 53,31 & 255,50 & 157,76 & 240,39 & \begin{tabular}{|l|}
243,27 \\
\end{tabular} & 108,0 & 439,99 & 73,14 & 6,73 & 47,77 & \begin{tabular}{l|l|}
180,04 \\
\end{tabular} & 43,50 & 68,74 & 114,51 \\
\hline Pelophylax perezi & 30SYH37 & 100,00 & 156,46 & 103,95 & 39,66 & 5443,78 & 297,10 & 37,91 & 259,19 & 131,88 & 227,12 & 229,92 & 90,96 & 507,02 & 76,68 & 10,34 & 41,72 & 195,70 & 57,87 & 81,19 & 130,93 \\
\hline Pelophylax perezi & $30 \mathrm{SYH} 38$ & 100,00 & 130,60 & 102,73 & 38,43 & 5683,61 & 277,40 & 13,50 & 263,90 & \begin{tabular}{|l|l|}
103,87 \\
\end{tabular} & 205,45 & 208,02 & \begin{tabular}{ll|}
63,76 \\
\end{tabular} & \begin{tabular}{ll|l}
603,69 \\
\end{tabular} & 79,85 & 17,44 & 33,08 & 211,11 & 83,60 & 100,75 & 150,39 \\
\hline Pelophylax perezi & $30 \mathrm{SYH} 39$ & 100,00 & 144,33 & 102,50 & \begin{tabular}{l|l}
38,95 \\
\end{tabular} & 5554,15 & 286,91 & 27,00 & 259,91 & 118,71 & 216,85 & 219,56 & 78,26 & 557,31 & 79,22 & 13,79 & 36,98 & 204,92 & 71,13 & 92,80 & 141,15 \\
\hline Pelophylax perezi & 30 SYH46 & 30,00 & 180,65 & 102,84 & 40,40 & 5191,81 & 313,65 & 62,23 & 251,42 & \begin{tabular}{|l|l|}
158,72 \\
\end{tabular} & 246,81 & 249,93 & 116,88 & 444,02 & 74,65 & 5,37 & \begin{tabular}{|l|l|}
51,47 \\
\end{tabular} & 191,30 & 39,09 & 67,95 & 123,14 \\
\hline Pelophylax perezi & 30SYH47 & 100,00 & 161,13 & 102,73 & 39,57 & 5376,77 & 299,46 & 43,28 & 256,17 & 137,70 & \begin{tabular}{|l|l|}
230,58 \\
\end{tabular} & 233,57 & 96,22 & 517,59 & 78,54 & 9,54 & 44,19 & 206,86 & 55,42 & 81,62 & 139,68 \\
\hline Pelophylax perezi & 30SYH48 & 100,00 & 147,95 & 101,86 & 39,00 & 5496,58 & 289,23 & 30,96 & 258,27 & \begin{tabular}{|l|l|}
123,39 \\
\end{tabular} & 219,55 & 222,47 & 82,43 & 565,97 & 80,80 & 12,82 & \begin{tabular}{|l|}
39,29 \\
\end{tabular} & 214,74 & 68,09 & 92,00 & 148,93 \\
\hline Pelophylax perezi & \begin{tabular}{|l|l|}
30 SYH49 \\
\end{tabular} & 100,00 & 147,75 & 101,29 & 38,85 & 5494,05 & 288,34 & 31,16 & 257,18 & 123,03 & 219,25 & 222,17 & 82,22 & 568,60 & 81,47 & 13,02 & 38,90 & 215,42 & 69,06 & 93,62 & 149,08 \\
\hline Pelophylax perezi & 30SYH57 & 71,00 & 178,86 & 101,94 & 40,00 & 5217,23 & 312,31 & 60,79 & 251,52 & \begin{tabular}{ll|}
157,38 \\
\end{tabular} & \begin{tabular}{|l|l|}
245,42 \\
\end{tabular} & 248,61 & \begin{tabular}{ll|}
114,68 \\
\end{tabular} & 492,36 & 78,70 & 6,12 & 51,98 & \begin{tabular}{l|l}
214,95 \\
\end{tabular} & \begin{tabular}{l|l}
42,95 \\
\end{tabular} & 75,21 & 143,88 \\
\hline Pelophylax perezi & 30SYH58 & 100,00 & 160,29 & 101,03 & 39,26 & 5370,17 & 297,63 & 43,41 & 254,21 & 137,30 & 229,64 & 232,68 & 95,54 & 554,42 & 82,17 & 9,95 & 44,69 & 224,76 & 58,50 & 87,69 & 155,10 \\
\hline Pelophylax perezi & 30SYH59 & 100,00 & 165,68 & 101,14 & 39,39 & 5336,27 & 301,81 & 48,57 & 253,24 & 143,14 & 234,28 & 237,34 & 100,95 & 555,96 & 83,49 & 9,23 & 46,88 & 230,87 & 56,25 & 88,41 & 159,20 \\
\hline Pelophylax perezi & $\begin{array}{l}30 \mathrm{SY} J 00 \\
\end{array}$ & 100,00 & 155,61 & 105,66 & 39,80 & 5555,91 & 298,20 & 35,92 & 262,28 & 167,72 & 228,19 & 230,44 & 88,69 & 460,32 & 71,19 & 10,76 & 39,49 & 172,56 & 58,32 & 77,35 & 108,73 \\
\hline Pelophylax perezi & 30SYJo1 & 100,00 & 165,16 & 103,69 & \begin{tabular}{|c|}
39,98 \\
\end{tabular} & 5425,32 & 302,72 & \begin{tabular}{ll|}
46,92 \\
\end{tabular} & 255,79 & 177,70 & 235,58 & 238,01 & \begin{tabular}{|c|}
99,28 \\
\end{tabular} & 435,34 & 72,06 & 9,13 & 43,17 & $\begin{array}{ll}170,82 \\
\end{array}$ & 51,37 & 73,43 & 104,19 \\
\hline Pelophylax perezi & 30SYJ02 & 100,00 & 169,80 & 101,78 & 40,00 & 5352,22 & 304,00 & 52,88 & 251,12 & 182,31 & 238,94 & 241,55 & 104,5 & 424,42 & 72,88 & 8,66 & 44,99 & \begin{tabular}{|l|l|}
170,37 \\
\end{tabular} & 48,57 & 72,18 & 101,98 \\
\hline Pelophylax perezi & 30SYJ03 & 100,00 & 168,71 & 100,05 & 39,94 & $\begin{array}{l}37,45 \\
\end{array}$ & 301 & 53,23 & 248,16 & \begin{tabular}{|l|l|l|l|}
181,09 \\
\end{tabular} & 237,61 & 240,26 & 103,62 & 429,98 & 73,90 & 9,23 & 44,47 & 172,31 & 0,47 & 74,18 & 102,75 \\
\hline Pelophylax perezi & 30SYJO4 & 100,00 & 164,61 & 98,55 & 39,45 & 5354,88 & 297,08 & 50,29 & 246,79 & 176,84 & 233,95 & 236,69 & 99,77 & 442,46 & 74,50 & 10,55 & 42,74 & 174,80 & 54,69 & 77,86 & 104,31 \\
\hline Pelophylax perezi & 30SYJ05 & 100,00 & 166,41 & 96,64 & 39,28 & 5302,08 & 296,17 & 53,60 & 242,58 & 178,57 & \begin{tabular}{|l|l|}
234,92 \\
\end{tabular} & 237,66 & \begin{tabular}{|l|l|}
102,14 \\
\end{tabular} & 436,16 & 75,19 & 10,58 & 43,50 & 174,36 & 53,81 & 77,63 & 102,01 \\
\hline Pelophylax perezi & 30SYJ06 & 100,00 & 165,44 & 95,01 & 39,01 & 5293,51 & 293,86 & 53,87 & 239,99 & 177,42 & 233,86 & 236,68 & 101,27 & \begin{tabular}{|l|l|}
438,06 \\
\end{tabular} & 75,39 & 11,25 & 42,87 & 174,73 & 55,44 & 79,30 & 101,17 \\
\hline Pelophylax perezi & 30SYJ07 & 100,00 & 166,40 & 93,37 & \begin{tabular}{l|l|}
38,95 \\
\end{tabular} & 5267,47 & 293,03 & 55,71 & 237,33 & 178,25 & 234,31 & 237,26 & 102,52 & 431,58 & 74,97 & 11,56 & 43,03 & \begin{tabular}{|l|}
173,01 \\
\end{tabular} & 55,33 & \begin{tabular}{l|l}
79,25 \\
\end{tabular} & 98,46 \\
\hline Pelophylax perezi & 30SYJ08 & 100,00 & 167,01 & 92,15 & 38,61 & 261,87 & 292,83 & 56,8 & 235,97 & 178,53 & 234,81 & 237,69 & 103, & 421,74 & 73,28 & 11,57 & 42,99 & 169,44 & 6 & 78,88 & 94,67 \\
\hline Pelophylax perezi & 30SYJO9 & 100,00 & 16 & 92,08 & 37,99 & 5362,79 & 288,7 & 49,75 & 238,95 & 171,34 & 230,00 & 232,42 & 95, & 428,82 & 69,92 & 13,27 & 39,42 & 166,71 & 61,35 & 82,93 & 93,31 \\
\hline Pelophylax perezi & 30SYJ10 & 100,00 & 165,27 & 103,89 & 39,96 & 5405,59 & \begin{tabular}{ll|}
302,96 \\
\end{tabular} & 46,72 & 256,23 & 178,26 & 235,20 & 237,88 & $\begin{array}{l}99,58 \\
\end{array}$ & \begin{tabular}{ll|}
452,59 \\
\end{tabular} & 74,18 & 8,97 & 43,6 & $\begin{array}{l}178,25 \\
\end{array}$ & 51,70 & 75,32 & 111,40 \\
\hline Pelophylax perezi & 30SYJ11 & 100,00 & 169,64 & 102,15 & 40,01 & 5328,99 & 304,21 & 52,64 & 251,57 & 182,70 & 238,42 & 241,24 & \begin{tabular}{|l|}
104,81 \\
\end{tabular} & 445,22 & 75,33 & 8,56 & 45,40 & \begin{tabular}{|l|l|}
179,08 \\
\end{tabular} & 49,42 & \begin{tabular}{|l|l|}
74,85 \\
\end{tabular} & 110,63 \\
\hline Pelophylax perezi & 30SYJ12 & 100,00 & 175,42 & 99,84 & 40,01 & 5239,15 & 305,98 & 59,97 & 246,01 & \begin{tabular}{|l|l|}
188,69 \\
\end{tabular} & 242,74 & 245,67 & 111,35 & 431,18 & 76,26 & 8,03 & 47,87 & 178,21 & 46,04 & 73,26 & 107,94 \\
\hline Pelophylax perezi & 30SYJ13 & 100,00 & 176,74 & 97,73 & 40,00 & 5188,13 & 304, & 63,16 & 241,47 & \begin{tabular}{|l|l|}
189,93 \\
\end{tabular} & 243,33 & 246,34 & 113,46 & 427,88 & 77,39 & 8,01 & 48,8 & \begin{tabular}{|l|}
178,87 \\
\end{tabular} & 45,33 & 73,54 & 106,88 \\
\hline Pelophylax perezi & 30SYJ14 & 100,00 & 175 & 95,80 & 39,95 & 5162,86 & 301 & 63,02 & 238,03 & 188,26 & 241,27 & 244,49 & 112,14 & 434,26 & 78,86 & 8,61 & 48,27 & 181,00 & $\begin{array}{l}47,58 \\
\end{array}$ & 75,66 & 107,15 \\
\hline Pelophylax perezi & 30SYJ15 & 100,00 & 170,39 & 94,29 & 39,39 & 5182,47 & 295,91 & \begin{tabular}{l|l}
59,55 \\
\end{tabular} & 236,36 & 183,27 & \begin{tabular}{|l|l|}
236,85 \\
\end{tabular} & 240,14 & \begin{tabular}{ll|}
107,42 \\
\end{tabular} & 446,90 & 79,84 & 10,05 & 46,41 & \begin{tabular}{ll|}
183,66 \\
\end{tabular} & 51,78 & 79,39 & 108,19 \\
\hline Pelophylax perezi & 30SYJ16 & 100,00 & 171,46 & 92,07 & 39,13 & 5121,67 & 294,22 & 62,56 & 231,66 & \begin{tabular}{|l|l|l|l}
184,23 \\
\end{tabular} & 237,18 & 240,61 & \begin{tabular}{|l|l|}
109,48 \\
\end{tabular} & 442,56 & 80,93 & 10,23 & 47,32 & \begin{tabular}{ll|}
183,66 \\
\end{tabular} & 51,43 & 79,50 & 106,04 \\
\hline Pelophylax perezi & 30SYJ17 & 100,00 & 170,87 & 90,37 & 39,00 & 5111,14 & 292,25 & 62,94 & 229,31 & \begin{tabular}{|l|l|}
183,49 \\
\end{tabular} & 236,36 & 239,79 & 108,94 & 441,61 & 80,99 & 10,95 & 46, & \begin{tabular}{|l|l|}
183,14 \\
\end{tabular} & 52,74 & 80,69 & 104,02 \\
\hline Pelophylax perezi & $30 \mathrm{SY}$ & 100, & 167 & 89,79 & 38, & 5159 & 290 & 59, & 230 & 180 & 234 & 237 & 105 & 438,38 & 77,94 & 11,82 & 44, & \begin{tabular}{ll|}
179,09 \\
\end{tabular} & $\begin{array}{l}55,45 \\
\end{array}$ & 82,12 & 100 \\
\hline Pelophylax perezi & 30SYJ19 & 100,00 & 155,37 & 90,99 & 37,79 & 5357,42 & 283,63 & 45,56 & \begin{tabular}{|l|}
238,07 \\
\end{tabular} & 166,40 & 224,88 & 227,57 & 90,93 & 458,99 & 72,35 & 14,63 & \begin{tabular}{|l|}
38,07 \\
\end{tabular} & 175,92 & \begin{tabular}{|c|}
67,17 \\
\end{tabular} & 89,65 & 100,94 \\
\hline Pelophylax perezi & 30SYJ20 & 100,00 & 161,27 & 102,76 & 39,77 & 5409,64 & 299,06 & 43,64 & 255,43 & \begin{tabular}{ll|}
169,00 \\
\end{tabular} & 231,37 & 234,10 & $\begin{array}{l}95,89 \\
\end{array}$ & \begin{tabular}{ll|}
489,92 \\
\end{tabular} & 77,30 & 10,09 & \begin{tabular}{|l|l|}
42,53 \\
\end{tabular} & \begin{tabular}{|l|l}
190,19 \\
\end{tabular} & 56,71 & 81,62 & 124,09 \\
\hline Pelophylax perezi & 30SYJ21 & 100,00 & 165,65 & 101,30 & 39,79 & 5339,22 & 300,55 & \begin{tabular}{|l|}
49,14 \\
\end{tabular} & 251,41 & \begin{tabular}{|l|l|l|l|}
176,73 \\
\end{tabular} & \begin{tabular}{|l|l|}
234,67 \\
\end{tabular} & 237,43 & 100,84 & 481,21 & 78,40 & 9,51 & 44,28 & $\begin{array}{l}190,88 \\
\end{array}$ & \begin{tabular}{|l|l|l|}
54,07 \\
\end{tabular} & \begin{tabular}{l|l}
80,95 \\
\end{tabular} & 122,79 \\
\hline Pelophyl: & $30 \mathrm{SYJ} 2$ & 100,00 & & & 39,8 & 570 & & & 246, & 182, & 236 , & 239,79 & $.04,65$ & 475,11 & 79,52 & 1 & 45,5 & 191 & & \begin{tabular}{|l|l|}
80,87 \\
\end{tabular} & 121 \\
\hline Pelophylax perezi & \begin{tabular}{|l|l|}
$30 \mathrm{YYJJ23}$ \\
\end{tabular} & 100,00 & 173,90 & 97,01 & 39,91 & 5186,52 & 301 & 60,7 & 240,98 & 187,31 & 240,30 & 243,48 & 110,50 & \begin{tabular}{|l|l|}
460,88 \\
\end{tabular} & 80,59 & 8,63 & 48,03 & 190,34 & 49,35 & 79,16 & 118, \\
\hline Pelophylax perezi & 30SYJ24 & 100,00 & 177,52 & 94,45 & 39,91 & 5100,77 & 301,29 & \begin{tabular}{|l|l|}
66,09 \\
\end{tabular} & 235,20 & \begin{tabular}{|l|l|}
190,93 \\
\end{tabular} & 242,38 & 245,97 & 115,07 & $\begin{array}{l}448,85 \\
\end{array}$ & 81,69 & 8,05 & \begin{tabular}{|l|l|}
49,87 \\
\end{tabular} & 189,31 & \begin{tabular}{|l|}
47,05 \\
\end{tabular} & \begin{tabular}{|l|}
77,89 \\
\end{tabular} & 114,67 \\
\hline
\end{tabular}




\begin{tabular}{|c|c|c|c|c|c|c|c|c|c|c|c|c|c|c|c|c|c|c|c|c|c|}
\hline TAXON & UTM & $\mathrm{km} 2$ & B101 & B102 & $\mathrm{BIO3}$ & B104 & B105 & B106 & B107 & B108 & B109 & B1010 & BIO11 & BIO12 & B1013 & BIO14 & BIO15 & B1016 & B1017 & B1018 & B1019 \\
\hline Pelophylax perezi & 30SYJ25 & 100,00 & 176,56 & 92,18 & 39,57 & 5054,61 & 297,92 & 67,46 & 230,45 & 190,01 & 240,95 & 244,55 & 115,05 & 446,92 & 82,85 & 8,90 & 49,95 & 189,43 & 48,38 & 79,53 & 112,10 \\
\hline Pelophylax perezi & 30SYJ26 & 99,00 & 175,54 & 89,83 & 39,25 & 5005,52 & 294,31 & 68,41 & 225,90 & 188,86 & 239,28 & 243,17 & 114,93 & 444,15 & 83,98 & 9,09 & 50,35 & 189,34 & 49,09 & 80,34 & 109,50 \\
\hline Pelophylax perezi & 30 SYJ 27 & 100,00 & 173,96 & 87,97 & 39,00 & 4986,04 & 290,95 & 68,09 & 222,85 & 187,11 & 237,27 & 241,28 & 113,45 & 441,73 & 84,26 & 9,91 & 50,22 & 188,59 & 50,72 & 82,28 & 106,80 \\
\hline Pelophylax perezi & $30 \mathrm{SYJ} 28$ & 100,00 & 171,52 & 87,47 & 38,46 & 5040,85 & 289,88 & 65,15 & 224,73 & 184,22 & 235,74 & 239,41 & 110,39 & 440,88 & 81,19 & 10,77 & 47,69 & 185,17 & 53,23 & 83,39 & 104,10 \\
\hline Pelophylax perezi & 30SYJ29 & 100,00 & 160,16 & 88,68 & 37,70 & 5226,04 & 284,34 & 52,04 & 232,30 & \begin{tabular}{|l|l|}
171,93 \\
\end{tabular} & 227,54 & 230,65 & \begin{tabular}{|l|}
97,17 \\
\end{tabular} & 462,29 & 75,74 & 13,71 & 40,62 & 182,64 & 63,83 & $\begin{array}{ll}90,03 \\
\end{array}$ & 104,77 \\
\hline Pelophylax perezi & 30SYJ30 & 100,00 & 157,99 & 101,69 & 39,41 & 5412,07 & 295,78 & 41,07 & 254,72 & 133,98 & 228,08 & 230,92 & 92,74 & 524,14 & 80,05 & 10,99 & 41,91 & 203,56 & 60,87 & 87,18 & 136,38 \\
\hline Pelophylax perezi & 30SYJ31 & 100,00 & 165,65 & 100,49 & 39,72 & 5323,01 & 300,06 & 49,58 & 250,49 & 150,78 & 234,32 & 237,24 & 101,08 & 508,10 & 80,91 & 9,80 & 44,84 & 203,56 & 55,90 & 85,08 & 134,45 \\
\hline Pelophylax perezi & $30 \mathrm{SY} J 32$ & 100,00 & 168,37 & 98,61 & 39,62 & 5263,81 & 299,92 & 53,56 & 246,36 & 155,07 & 236,04 & 239,10 & 104,44 & 501,73 & 81,88 & 9,56 & 46,00 & 202,90 & 54,54 & 85,01 & 132,77 \\
\hline Pelophylax perezi & 30SYJ33 & 94,00 & 175,58 & 96,19 & 39,77 & 5151,25 & 302,46 & 62,88 & 239,58 & 175,71 & 241,48 & 244,84 & 112,74 & 478,48 & 82,56 & 8,56 & 49,07 & 199,01 & 49,47 & 81,90 & 127,13 \\
\hline Pelophylax perezi & 30 SYJ34 & 83,00 & 177,99 & 93,86 & 39,78 & 5079,17 & 301,41 & 67,27 & 234,14 & 191,76 & 242,68 & 246,17 & 115,93 & 465,64 & 83,37 & 8,01 & 50,42 & 196,55 & 47,74 & 80,94 & 122,39 \\
\hline Pelophylax perezi & 30 SYJ35 & 37,00 & 177,22 & 91,78 & 39,26 & 5036,41 & 298,19 & 68,24 & 229,94 & 190,89 & 241,20 & 244,94 & 115,85 & 458,63 & 83,94 & 8,72 & 50,11 & 194,61 & 48,72 & 81,63 & 117,43 \\
\hline Pelophylax perezi & 30 SYJ36 & 3,00 & 176,14 & 90,00 & 39,14 & 5001,71 & 295,57 & 69,00 & 226,57 & 189,57 & 240,00 & 243,86 & 116,00 & 452,00 & 84,00 & 9,00 & 50,86 & 192,86 & 49,00 & 82,00 & 113,57 \\
\hline Pelophylax perezi & 30SYJ37 & 4,00 & 175,00 & 87,00 & 39,00 & 4981,75 & 291,50 & 69,00 & 222,50 & 188,00 & 238,00 & 242,25 & 114,50 & 443,25 & 83,25 & 10,00 & 49,75 & 189,25 & 51,00 & 84,00 & 108,00 \\
\hline Pelophylax perezi & 30 SYJ38 & 40,00 & 174,18 & 86,54 & 38,47 & 4984,38 & 291,01 & 68,26 & 222,75 & 187,19 & 237,71 & 241,18 & 113,76 & 440,35 & 81,18 & 10,03 & 48,81 & 187,10 & 51,87 & 83,85 & 105,65 \\
\hline Pelophylax perezi & 30SYJ39 & 93,00 & 171,91 & 85,77 & 37,67 & 5036,25 & 289,90 & 65,66 & 224,24 & 184,57 & 236,06 & 239,78 & 110,72 & 440,55 & 77,82 & 11,16 & 46,32 & 184,18 & 54,45 & 85,56 & 103,47 \\
\hline Pelophylax perezi & 30 SYJ40 & 100,00 & 167,35 & 101,01 & 39,65 & 5315,62 & 302,27 & 50,52 & 251,75 & 144,27 & 235,75 & 238,78 & 102,67 & 530,74 & 82,46 & 9,23 & 46,43 & 218,19 & 55,11 & 86,49 & 147,33 \\
\hline Pelophylax perezi & 30SYJ41 & 92,00 & 178,72 & 99,65 & 39,99 & 5194,28 & 309,11 & 62,64 & 246,47 & 156,51 & 244,90 & 248,08 & 114,94 & 503,61 & 82,83 & 7,26 & 51,03 & 216,47 & 47,22 & 82,13 & 143,56 \\
\hline Pelophylax perezi & 30SYJ42 & 37,00 & 179,44 & 97,85 & 39,97 & 5155,15 & 307,64 & 64,85 & 242,79 & \begin{tabular}{l|}
156,95 \\
\end{tabular} & 245,13 & 248,38 & 116,18 & 491,85 & 82,98 & 7,20 & 51,16 & 210,54 & 46,64 & 81,48 & 137,85 \\
\hline Pelophylax perezi & $30 \mathrm{SYJ43}$ & 2,00 & 179,67 & 96,50 & 40,00 & 5101,33 & 306,00 & 66,83 & 239,17 & 157,33 & 244,83 & 248,00 & 117,33 & 484,17 & 83,00 & 8,00 & 50,67 & 205,50 & 47,00 & 82,00 & 133,33 \\
\hline Pelophylax perezi & $30 \mathrm{SY} 449$ & & & & & & & & & & & & & & & & & & & & \\
\hline Pelophylax perezi & 30 SYJ50 & 91,00 & 178,28 & 100,93 & 39,94 & 5233,66 & 310,87 & 60,86 & 250,01 & \begin{tabular}{|l|l|}
156,53 \\
\end{tabular} & 245,10 & 248,07 & 113,90 & 537,55 & 84,02 & 7,42 & 51,87 & 234,68 & 48,71 & 85,38 & 160,51 \\
\hline Pelophylax perezi & 30SYJ51 & 15,00 & 181,67 & 99,90 & 40,00 & 5192,90 & 312,10 & 64,86 & 247,24 & \begin{tabular}{|l|l|}
159,90 \\
\end{tabular} & 247,57 & 250,81 & 117,71 & 518,95 & 83,95 & 7,00 & 52,95 & 228,43 & 46,00 & 83,29 & 154,05 \\
\hline Pelophylax perezi & $30 \mathrm{SYJ60}$ & 0,00 & 181,57 & 101,00 & 40,00 & 5224,86 & 314,43 & 63,71 & 250,71 & 160,14 & 248,00 & 251,14 & 116,86 & 554,14 & 85,57 & 7,00 & 54,00 & 247,14 & 48,00 & 87,00 & 171,57 \\
\hline Pelophylax perezi & 30SYKO0 & 100,00 & 139,41 & 94,26 & 37,13 & 5666,42 & 277,01 & 26,49 & 250,53 & 148,94 & 214,20 & 215,70 & 71,98 & 472,11 & 64,15 & 18,16 & 31,70 & 165,66 & 81,42 & 95,94 & 96,76 \\
\hline Pelophylax perezi & 30SYKO1 & 100,00 & 134,56 & 94,06 & 36,96 & 5741,43 & 273,68 & 21,12 & 252,56 & 143,61 & 209,48 & 211,81 & 66,34 & 477,33 & 61,79 & 19,63 & 30,41 & 163,17 & 86,90 & 99,28 & 95,21 \\
\hline Pelophylax perezi & 30SYKO2 & 100,00 & 133,17 & 93,51 & 36,64 & 5766,06 & 272,32 & 19,80 & 252,52 & 141,83 & 170,55 & 210,65 & 64,64 & 472,90 & 60,31 & 20,15 & 30,38 & 160,07 & 87,72 & 100,21 & 92,38 \\
\hline Pelophylax perezi & 30SYK10 & 100,00 & 143,46 & 92,15 & 37,02 & 5547,72 & 277,29 & 31,91 & 245,38 & $\begin{array}{l}153,64 \\
153\end{array}$ & 216,17 & 218,25 & 77,29 & 479,42 & $\begin{array}{l}0,711 \\
67,76\end{array}$ & 17,51 & 33,16 & 173,14 & 78,71 & 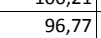 & 101,15 \\
\hline Pelophylax perezi & 30SYK11 & 100,00 & 149,50 & 90,61 & 36,97 & 5478,63 & 280,43 & 38,69 & 241,74 & 159,46 & 221,06 & 223,19 & 83,84 & 453,34 & 66,30 & 16,24 & 34,97 & 167,62 & 73,26 & 92,60 & 94,66 \\
\hline Pelophylax perezi & 30SYK12 & 100,00 & 134,80 & 92,09 & 36,45 & 5682,40 & 271,49 & 22,29 & 249,21 & 143,69 & 208,88 & 211,21 & 67,34 & 486,30 & 63,02 & 19,95 & 30,71 & 167,47 & 88,44 & 102,36 & 97,31 \\
\hline Pelophylax perezi & 30SYK20 & 100,00 & 160,35 & 87,92 & 37,24 & 5238,23 & 284,38 & 52,25 & 232,14 & 171,66 & 227,90 & 230,92 & 97,21 & 451,01 & 72,79 & 13,91 & 39,85 & 177,48 & 64,00 & 89,53 & 100,12 \\
\hline Pelophylax perezi & 30SYK21 & 100,00 & 145,32 & 89,86 & 36,76 & 5470,59 & 276,20 & 34,98 & 241,22 & 155,35 & 216,84 & 219,06 & 80,06 & 483,17 & 68,68 & 17,47 & 33,96 & 176,54 & 78,74 & 98,83 & 102,43 \\
\hline Pelophylax perezi & 30SYK22 & 100,00 & 141,91 & $\begin{array}{l}5,, 00 \\
89,99\end{array}$ & 36,38 & 5542,24 & 274,33 & $\begin{array}{l}4,30 \\
30,88 \\
\end{array}$ & 243,45 & \begin{tabular}{|l|}
151,30 \\
150
\end{tabular} & $\begin{array}{l}214,584 \\
214\end{array}$ & 216,54 & 75,93 & \begin{tabular}{|l|l|}
483,39 \\
\end{tabular} & $\begin{array}{l}0,000 \\
66,07 \\
\end{array}$ & $\begin{array}{l}\mid 1,, 47 \\
18,39\end{array}$ & 32,69 & \begin{tabular}{|l|}
172,99 \\
\end{tabular} & 82,58 & \begin{tabular}{|l|}
100,81 \\
100
\end{tabular} & $\begin{aligned} 99,45 \\
99,84\end{aligned}$ \\
\hline Pelophylax perezi & 30SYK30 & 100,00 & 167,69 & 85,61 & 37,08 & 5105,08 & 287,56 & 60,99 & 226,56 & 179,79 & 232,99 & 236,47 & 105,86 & 442,63 & 74,27 & 12,40 & 43,17 & 180,40 & 58,61 & 87,77 & 100,94 \\
\hline Pelophylax perezi & 30SYK31 & 100,00 & 156,25 & 86,80 & 36,88 & 5275,68 & 281,12 & 48,02 & 233,10 & 167,22 & 224,50 & 227,43 & 93,01 & 466,86 & 71,02 & 15,19 & 37,94 & 179,61 & 69,63 & 94,88 & 102,45 \\
\hline Pelophylax perezi & 30 SYK32 & 100,00 & 160,29 & 85,89 & 36,64 & 5244,68 & 283,74 & 51,95 & 231,79 & 170,88 & 227,87 & 230,75 & 97,07 & 446,44 & 68,37 & 14,57 & 38,74 & 173,66 & 66,49 & 91,97 & 96,40 \\
\hline Pelophylax perezi & $\begin{array}{l}30 \text { SYK } \\
\end{array}$ & 33,00 & 172,92 & 84,25 & 37,00 & 5035,57 & 290,78 & 66,69 & 224,10 & 185,51 & 236,98 & 240,76 & 111,71 & 434,41 & 74,12 & 11,29 & 45,12 & 180,96 & 54,69 & 86,20 & 100,75 \\
\hline Pelophylax perezi & 30SYK41 & 86,00 & 171,83 & 83,56 & 36,83 & 5049,79 & 289,73 & 65,27 & 224,45 & 183,75 & 236,14 & 239,53 & 110,35 & 432,37 & 71,21 & 12,03 & 43,70 & 177,79 & 56,71 & 87,44 & 98,35 \\
\hline Pelophylax perezi & 30SYK42 & 100,00 & 168,88 & 83,31 & 36,31 & 5093,37 & 287,97 & 61,97 & 226,00 & 180,32 & 233,98 & 237,25 & 107,00 & 432,64 & 68,52 & 13,02 & 41,82 & 174,65 & 59,97 & 89,27 & 95,79 \\
\hline Pelophylax perezi & 30SYK51 & 6,00 & 172,20 & 83,00 & 36,90 & 5063,60 & 290,00 & 65,90 & 224,10 & 184,20 & 236,90 & 240,90 & 111,00 & 436,90 & 70,60 & 12,00 & 43,40 & 179,00 & 57,90 & 89,00 & 99,20 \\
\hline Pelophylax perezi & 30SYK52 & 57,00 & 171,46 & 82,73 & 36,02 & 5099,43 & 289,46 & 63,70 & 225,76 & 182,67 & 236,61 & 239,70 & 109,33 & 435,60 & 69,07 & 12,52 & 42,66 & 177,43 & 58,92 & 89,85 & 97,71 \\
\hline Pelophylax perezi & \begin{tabular}{|l|}
$30 T T K 43$ \\
\end{tabular} & 60,00 & 149,16 & 110,74 & 36,88 & 6409,49 & 324,89 & 26,98 & 297,91 & 78,57 & 234,93 & 234,93 & $\begin{array}{l}1,07 \\
\end{array}$ & 468,07 & 57,26 & |5,87 & 44,11 & 167,16 & 38,90 & 38,90 & 154,18 \\
\hline Pelophylax perezi & 30TTK44 & 60,00 & 132,45 & 109,16 & 36,60 & 6377,70 & 307,43 & 12,65 & 294,78 & 62,97 & 217,85 & 218,38 & 55,81 & 543,52 & 66,52 & 8,45 & 42,58 & 193,49 & 48,58 & 49,33 & 179,36 \\
\hline Pelophylax perezi & 30TTK45 & 50,00 & 131,76 & 109,35 & 36,72 & 6352,00 & 305,94 & 12,08 & 293,86 & 62,33 & 216,75 & 217,14 & 55,19 & 538,41 & 66,14 & 8,77 & 42,37 & 191,61 & 49,05 & 49,87 & 177,23 \\
\hline Pelophylax perezi & 30TTK46 & 50,00 & 135,01 & 110,26 & 36,96 & 6344,70 & 308,87 & 14,62 & 294,25 & 65,34 & 219,75 & 220,12 & 58,21 & 503,96 & 62,09 & 8,23 & 41,86 & 178,99 & 46,81 & 47,03 & 164,68 \\
\hline Pelophylax perezi & 30TTK47 & 50,00 & 130,68 & 110,36 & 37,00 & 6328,70 & 304,17 & 10,70 & 293,48 & 61,23 & 215,45 & 215,70 & 54,12 & 511,74 & 63,16 & 8,91 & 41,23 & 81,62 & 49,12 & 49,30 & 166,80 \\
\hline Pelophylax perezi & 30TTK48 & 40,00 & 134,10 & 111,33 & 37,38 & 6306,80 & 307,13 & 13,61 & $\begin{array}{l}293,52 \\
293\end{array}$ & $\begin{array}{ll}64,43 \\
\end{array}$ & 218,56 & 218,64 & 57,33 & 483,51 & 59, & 8,43 & $\begin{array}{l}41,25 \\
40,90\end{array}$ & $\begin{array}{l}171,39 \\
\end{array}$ & 年 & 46,92 & 156,69 \\
\hline Pelophylax perezi & 30TTK4 & 40,00 & 115,98 & 109,66 & 37,29 & 6252,05 & 288,25 & $-1,39$ & 289,64 & 47,76 & 199,29 & 200,29 & 41,29 & 562,68 & 69, & 11,05 & 39,69 & 198,97 & 57,68 & 58,81 & 182,14 \\
\hline Pelophylax perezi & 30TTK53 & 100,00 & 147,35 & 111,49 & 36,97 & 6429,11 & 323,85 & 24,52 & 299,33 & 76,59 & 233,48 & 233,54 & 69,23 & 461,32 & 56,02 & 6,25 & 43,28 & 162,79 & 39,68 & 39,72 & 149,46 \\
\hline Pelophylax perezi & 30TTK54 & 100,00 & 126,02 & 109,80 & 36,64 & 6379,98 & 302,00 & 6,26 & 295,74 & 56,83 & 211,49 & 212,14 & 49,72 & 553,85 & 67,17 & 9,55 & 41,46 & 194,51 & 51,85 & 52,86 & 179,58 \\
\hline Pelophylax perezi & 30TTK55 & 100,00 & 108,84 & 107,86 & 36,47 & 6312,55 & 283,49 & $-7,86$ & 291,36 & 41,26 & 193,66 & 194,57 & 34,53 & 643,86 & 78,32 & 12,68 & 40,28 & 226,02 & 62,99 & 65,62 & 209,65 \\
\hline Pelophylax perezi & $30 T T K 5$ & $\begin{array}{l}100,00 \\
100\end{array}$ & $\frac{100}{125}$ & $\begin{array}{l}10,00 \\
110,34\end{array}$ & 30, & 年 & $\begin{array}{l}20,45 \\
299,69\end{array}$ & $\begin{aligned}-3,000 \\
5,54\end{aligned}$ & \begin{tabular}{|l|}
294,16 \\
\end{tabular} & $\begin{array}{l}41,20 \\
55,85 \\
\end{array}$ & \begin{tabular}{|l|}
209,65 \\
\end{tabular} & \begin{tabular}{|l|}
210,40 \\
\end{tabular} & $\begin{array}{l}4,35 \\
48,89 \\
\end{array}$ & \begin{tabular}{|l|l|}
532,56 \\
\end{tabular} & 65,6 & \begin{tabular}{|l|l|}
9,79 \\
9,7
\end{tabular} & $\begin{array}{l}40,20 \\
40,50\end{array}$ & \begin{tabular}{|l|}
$186,53,5$ \\
\end{tabular} & \begin{tabular}{|l|l|}
52,18 \\
5
\end{tabular} & $\begin{array}{l}5,2024 \\
52,97\end{array}$ & 171,06 \\
\hline Pelophylax perezi & 30TTK57 & 100,00 & 125,48 & 111,03 & 37,08 & 6317,04 & 299,69 & 5,65 & 294,04 & 56,32 & 209,99 & 210,54 & 49,34 & 515,12 & 63,05 & 9,67 & 39,93 & 180,10 & 51,77 & 52,14 & 164,56 \\
\hline Pelophylax perezi & 30TTK58 & 100,00 & 125,15 & 111,64 & 37,57 & 6296,49 & 298,85 & 5,27 & 293,58 & 56,00 & 209,26 & 209,81 & 49,13 & 503,89 & 61,86 & 9,699 & 39,55 & 175,86 & 51,83 & 52,15 & 159,95 \\
\hline Pelophylax perezi & 30TTK59 & 100,00 & 118,74 & 111,53 & 37,89 & 6264,91 & 292,03 & 0,06 & 291,97 & 50,05 & 202,19 & 203,01 & 43,41 & 522,27 & 64,35 & 10,65 & 38,81 & 182,02 & 55,69 & 56,28 & 164,96 \\
\hline Pelophylax perezi & 30TTK63 & 100,00 & 151,82 & 112,81 & 37,00 & 6440,76 & 328,96 & 27,44 & 301,52 & 80,68 & 238,04 & 238,04 & 73,12 & 425,74 & 51,26 & 5,77 & 42,79 & 148,26 & 36,99 & 36,99 & 135 \\
\hline Pelophylax perezi & 30TTK64 & 100,00 & 125,55 & 110,94 & 36,79 & 6392,01 & 302,50 & 4,83 & $\begin{array}{l}297,67 \\
\end{array}$ & 56,05 & 211,25 & 211,87 & 49,11 & 535,59 & 64,29 & 9,79 & 40,50 & 185,12 & 51,99 & 53,12 & 169,90 \\
\hline Pelophylax perezi & 30TTK65 & 100,00 & 113,49 & 109,94 & 36,78 & 6341,39 & 289,57 & $-5,24$ & 294,81 & 45,07 & 198,60 & 199,43 & 38,40 & 586,38 & 70,42 & 12,04 & 39,20 & 201,93 & 59,78 & 61,71 & 185,52 \\
\hline Pelophylax perezi & 30TTK66 & 100,00 & 79,21 & 106,14 & 36,41 & 6224,39 & 253,47 & $-34,09$ & 287,56 & 14,25 & 163,83 & 164,57 & 7,95 & 803,94 & 95,97 & 19,66 & 37,45 & 276,18 & 86,49 & 92,45 & 257,79 \\
\hline Pelophylax perezi & 30TTK67 & 100,00 & 109,14 & 110,24 & 37,07 & 6281,82 & 283,90 & $-8,71$ & 292,61 & 41,20 & 192, & 194 & 34 & 578,51 & 69,88 & 12,63 & 37,97 & 198,20 & 62,04 & 64,14 & 180,7 \\
\hline Pelophylax perezi & 30TTK68 & 100,00 & 121,72 & 112,60 & 37,88 & 6290,36 & 296,40 & 1,58 & 294,82 & 52,69 & 205,55 & 206,38 & 46,00 & 494,14 & 59,95 & 10,43 & 38,06 & 168,79 & 53,79 & 54,29 & 152,38 \\
\hline
\end{tabular}




\begin{tabular}{|c|c|c|c|c|c|c|c|c|c|c|c|c|c|c|c|c|c|c|c|c|c|}
\hline TAXON & UTM & $\mathrm{km2}$ & B101 & $\mathrm{B1O2}$ & $\mathrm{BIO3}$ & B104 & B105 & B106 & B107 & B108 & B109 & 81010 & B1011 & B1O12 & BIO13 & 81014 & B1015 & B1016 & B1017 & BIO18 & B1019 \\
\hline Pelophylax perezi & 30TTK69 & 100,00 & 116,55 & 112,76 & 38,00 & 6255,50 & 290,74 & $-2,36$ & 293,10 & 54,45 & 199,44 & 200,97 & 41,45 & 504,86 & 61,34 & 11,15 & 37,32 & 171,90 & 56,85 & 57,70 & 154,59 \\
\hline Pelophylax perezi & 30TTK73 & 100,00 & 156,65 & 113,84 & 37,00 & 6445,10 & 333,92 & 30,98 & 302,94 & 103,79 & 242,73 & 242,73 & 77,59 & 393,18 & 47,05 & 5,31 & 42,28 & 135,41 & 34,34 & 34,34 & 122,65 \\
\hline Pelophylax perezi & 30TTK74 & 100,00 & 134,76 & 112,76 & 36,99 & 6418,78 & 312,39 & 11,83 & 300,57 & 68,51 & 220,79 & 221,21 & 57,26 & 470,09 & 55,91 & 8,45 & 40,06 & 159,85 & 46,18 & 46,69 & 145,14 \\
\hline Pelophylax perezi & 30TTK75 & 100,00 & 81,44 & 107,65 & 36,44 & 6263,92 & 257,81 & $-33,16$ & 290,97 & 16,03 & 166,67 & 167,38 & 9,72 & 767,13 & 90,58 & 19,21 & 36,84 & 259,87 & 83,75 & 88,86 & 241,18 \\
\hline Pelophylax perezi & 30TTK76 & 100,00 & 91,53 & 108,77 & 36,79 & \begin{tabular}{|l|l|}
6260,14 \\
\end{tabular} & 267,27 & $-24,49$ & 291,75 & 25,18 & 175,92 & 177,06 & 18,91 & 680,86 & 80,72 & 16,69 & 36,68 & 229,91 & 75,34 & 79,58 & 211,18 \\
\hline Pelophylax perezi & 30TTK77 & 100,00 & 97,20 & 109,86 & 37,13 & 6246,57 & 272,49 & $-19,59$ & 292,07 & 30,34 & 180,93 & 182,39 & 24,13 & 626,00 & 74,51 & 15,30 & 36,35 & 210,42 & 70,67 & 74,09 & 191,65 \\
\hline Pelophylax perezi & 30TTK78 & 100,00 & 114,63 & 112,80 & 37,91 & 6271,61 & 289,86 & $-4,61$ & \begin{tabular}{|l|l|}
294,47 \\
\end{tabular} & 55,68 & 197,59 & 199,56 & 39,69 & 504,84 & 60,39 & 11,68 & 36,46 & 168,65 & 57,96 & 59,24 & 151,39 \\
\hline Pelophylax perezi & 30TाK79 & 100,00 & 116,93 & 113,89 & 38,05 & 6247,73 & 291,87 & \begin{tabular}{|l|l|}
$-2,66$ \\
\end{tabular} & 294,53 & 73,70 & $\begin{array}{l}199,32 \\
\end{array}$ & 201,36 & 41,94 & 479,76 & 57,49 & 11,22 & 36,02 & 159,91 & 56,53 & 57,49 & 142,51 \\
\hline Pelophylax perezi & 30TTK83 & 100,00 & 158,97 & 114,14 & 37,00 & $\begin{array}{ll}6461,66 \\
\end{array}$ & 336,39 & 32,36 & 304,03 & 117,50 & 245,23 & 245,23 & 79,43 & 373,42 & 44,45 & 5,01 & 42,10 & 128,14 & 32,99 & 32,99 & 114,34 \\
\hline Pelophylax perezi & 30TTK84 & 100,00 & 134,41 & 113,27 & 37,00 & 6425,82 & 312,65 & 10,59 & 302,07 & 81,47 & 220,52 & 220,95 & 56,82 & 456,62 & 53,71 & 8,67 & 39,33 & 153,00 & 46,50 & 47,06 & 137,83 \\
\hline Pelophylax perezi & 30TTK85 & 100,00 & 78,37 & 108,42 & 36,60 & 6264,29 & 255,69 & $-36,63$ & 292,32 & 13,03 & 163,74 & 164,41 & 6,90 & 760,19 & 88,73 & 20,16 & 35,67 & 253,42 & 86,09 & 91,79 & 233,99 \\
\hline Pelophylax perezi & 30TTK86 & 100,00 & 104,01 & 111,33 & 37,03 & 6298,99 & 281,10 & $-14,76$ & 295,86 & 38,62 & 188,25 & 189,81 & 30,01 & 569,76 & 66,99 & 14,01 & 36,09 & 188,25 & 65,19 & 67,68 & 169,77 \\
\hline Pelophylax perezi & 30TTK87 & 100,00 & 112,29 & 112,73 & 37,60 & 6295,44 & 288,80 & $-7,63$ & 296,43 & 62,51 & 195,94 & 197,81 & 37,44 & 507,78 & 59,81 & 12,44 & 35,86 & 166,60 & 59,43 & 61,05 & 148,84 \\
\hline Pelophylax perezi & 30TTK88 & 100,00 & 115,08 & 113,70 & \begin{tabular}{|l|l|}
37,98 \\
\end{tabular} & 6268,39 & 290,92 & $-5,17$ & 296,09 & 72,80 & 197,78 & 200,01 & 40,13 & 480,61 & 56,77 & 11,78 & 35,36 & 157,37 & 57,66 & 58,97 & 139,60 \\
\hline Pelophylax perezi & 30TтK89 & 100,00 & 114,12 & 114,19 & 38,01 & 6219,95 & 289,16 & $-5,91$ & 295,07 & 73,80 & 195,95 & 198,39 & 39,77 & \begin{tabular}{|c|}
472,86 \\
\end{tabular} & 55,95 & 11,97 & 34,69 & 154,65 & 58,43 & 59,90 & 136,11 \\
\hline Pelophylax perezi & 30TTK93 & 100,00 & 158,23 & 114,87 & 37,00 & 6478,21 & 336,17 & 31,10 & 305,07 & 116,45 & 244,77 & 244,77 & 78,48 & 365,64 & 43,12 & 5,03 & 41,74 & 124,73 & 32,99 & 32,99 & 110,07 \\
\hline Pelophylax perezi & 30TTK94 & 100,00 & 150,38 & 114,48 & 37,00 & 6451,97 & 328,03 & 24,12 & 303,91 & 108,28 & 236,77 & 236,78 & 71,27 & 381,23 & 44,71 & 6,37 & 39,86 & 128,30 & 37,38 & 37,38 & 113,13 \\
\hline Pelophylax perezi & 30TTK95 & 100,00 & 94,42 & 110,80 & 36,89 & 6314,75 & 272,60 & $-23,77$ & \begin{tabular}{l|}
296,37 \\
\end{tabular} & 36,90 & 179,93 & 180,69 & 21,05 & 643,16 & 74,43 & 17,05 & 35,56 & 210,75 & 74,63 & 78,42 & 191,89 \\
\hline Pelophylax perezi & 30TTK96 & 100,00 & 91,54 & 110,67 & 37,01 & \begin{tabular}{|l|l|}
6268,13 \\
\end{tabular} & 268,93 & $-26,01$ & 294,93 & 33,22 & 176,05 & 177,31 & 18,89 & 629,13 & 73,17 & 17,20 & 34,74 & 204,69 & 75,06 & 79,02 & 184,84 \\
\hline Pelophylax perezi & 30TTK97 & 100,00 & 99,04 & 111,70 & 37,34 & 6257,05 & 275,69 & $-19,61$ & 295,30 & 48,24 & 182,84 & 184,34 & 25,79 & 565,46 & 66,21 & 15,39 & 34,41 & 182,77 & 69,10 & 72,18 & 162,84 \\
\hline Pelophylax perezi & 30TTK98 & 100,00 & 111,33 & 113,54 & 37,94 & 6252,65 & 287,35 & $-8,85$ & 296,19 & 70,37 & 194,08 & 196,31 & 37,04 & 480,69 & 57,37 & \begin{tabular}{ll|}
12,67 \\
\end{tabular} & 34,32 & 155,03 & 60,19 & 61,95 & 135,37 \\
\hline Pelophylax perezi & 30TTK99 & 100,00 & 107,21 & 113,47 & 38,00 & 6202,06 & 282,46 & $-12,23$ & 294,69 & 67,18 & 189,34 & 191,49 & 33,69 & 488,99 & 58,71 & 13,45 & 33,69 & 157,33 & 63,01 & 65,25 & 136,74 \\
\hline Pelophylax perezi & 30TTL40 & 39,00 & 117,22 & 110,80 & \begin{tabular}{|l|l|}
37,98 \\
\end{tabular} & 6241,55 & 289,36 & $-0,44$ & 289,80 & 48,96 & 200,42 & 201,29 & 42,09 & 537,40 & 66,89 & 10,84 & 39,51 & 189,65 & 56,73 & 57,22 & 172,22 \\
\hline Pelophylax perezi & 30TTL42 & 30,00 & 120,48 & 112,93 & 38,05 & 6232,91 & 292,73 & 1,11 & 291,61 & 77,20 & 203,64 & 203,64 & 44,57 & 490,30 & 62,09 & 10,07 & 39,20 & 173,45 & 53,66 & 53,66 & 154,52 \\
\hline Pelophylax perezi & 30TTL43 & 28,00 & 120,19 & 113,44 & 38,44 & 6210,08 & 292,31 & 0,81 & 291,50 & 80,14 & 203,31 & 203,31 & 44,75 & 477,17 & 61,00 & 10,00 & 39,67 & 169,92 & 53,00 & 53,00 & 149,11 \\
\hline Pelophylax perezi & 30TTL45 & 20,00 & 119,76 & 113,97 & 38,97 & 6206,59 & 291,48 & 0,07 & 291,41 & 79,59 & 202,28 & 202,28 & 43,86 & 458,03 & 59,00 & 10,34 & 38,24 & 163,90 & 53,28 & 53,28 & 141,10 \\
\hline Pelophylax perezi & \begin{tabular}{|l|l|l|l|}
$30 T T L 6$ \\
\end{tabular} & 17,00 & 117,23 & 114,00 & 39,00 & $\mid 6179,09$ & 288,50 & $-1,86$ & 290,36 & 77,09 & \begin{tabular}{|l|}
199,50 \\
\end{tabular} & \begin{tabular}{|l|}
199,50 \\
\end{tabular} & 4 & 461,64 & 59,36 & 11,00 & $\begin{array}{l}30,45 \\
38,05\end{array}$ & $\begin{array}{l}164,77 \\
\end{array}$ & $\begin{array}{ll}54,26 \\
54,86\end{array}$ & $\begin{array}{l}54,86 \\
54,86\end{array}$ & 142,27 \\
\hline Pelophylax perezi & 30TTL50 & 100,00 & 114,93 & 111,65 & 37,99 & 6240,78 & 287,90 & $-2,85$ & 290,75 & 47,54 & $\begin{array}{l}197,78 \\
\end{array}$ & 199,05 & 40,02 & 528,61 & 65,29 & 11,17 & 38,41 & 183,98 & 57,94 & 58,66 & 166,05 \\
\hline Pelophylax perezi & 30TTL51 & 100,00 & 114,77 & 112,50 & 38,08 & 6230,42 & 287,68 & $-3,20$ & 290,88 & 64,41 & 197,93 & 198,57 & 39,84 & 514,20 & 63,74 & 11,21 & 38,14 & 179,09 & 57,85 & 58,21 & 160,08 \\
\hline Pelophylax perezi & 30TTL52 & 100,00 & 118,54 & 113,86 & 38,51 & 6232,96 & 291,42 & $-0,62$ & 292,05 & 78,26 & 201,92 & 201,92 & 42,90 & 480,01 & 60,34 & 10,69 & 38,36 & 168,97 & 54,94 & 54,94 & 147,61 \\
\hline Pelophylax perezi & 30TTL54 & 100,00 & 119,97 & 114,95 & 38,97 & 6214,41 & 292,67 & 0,09 & 292,57 & 79,86 & 202,86 & 202,86 & 44,03 & 445,01 & 57,31 & 10,31 & 38,63 & 159,45 & 52,65 & 52,65 & 133,95 \\
\hline Pelophylax perezi & 30TTL55 & 100,00 & 119,49 & 114,99 & 39,00 & $\begin{array}{l}6194,68 \\
6194\end{array}$ & 291,90 & $\begin{array}{c}-0,15 \\
-0,15 \\
\end{array}$ & 292,05 & 79,42 & \begin{tabular}{|l|}
202,05 \\
200
\end{tabular} & \begin{tabular}{|l|}
202,05 \\
\end{tabular} & $\begin{array}{ll}43,64 \\
43\end{array}$ & \begin{tabular}{|l|l|}
438,15 \\
438
\end{tabular} & $\begin{array}{l}56,37 \\
50\end{array}$ & \begin{tabular}{l|l}
10,58 \\
10
\end{tabular} & 38,23 & $\begin{array}{l}156,80 \\
15,4\end{array}$ & 52,87 & $\begin{array}{l}25,2,87 \\
5\end{array}$ & 131,30 \\
\hline Pelophylax perezi & 30TTL56 & 100,00 & 115,04 & 114,44 & 39,00 & 6165,01 & 287,15 & $-3,84$ & 290,99 & 75,32 & 197,15 & 197,26 & 39,83 & 452,74 & 57,87 & 11,27 & 37,59 & 161,16 & 55,84 & 55,92 & 135,98 \\
\hline Pelophylax perezi & \begin{tabular}{|l|}
$30 T T L 57$ \\
\end{tabular} & 100,00 & 115,39 & 114,42 & 39,00 & 6158,74 & 287,28 & $-3,76$ & 291,04 & 75,66 & 197,18 & 197,42 & 40,06 & 444,03 & 56,61 & 11,27 & 37,08 & 157,38 & 55,33 & 55,47 & 133,44 \\
\hline Pelophylax perezi & 30TTL58 & 100,00 & 118,25 & 114,45 & 39,00 & 6157,61 & 289,66 & $-1,44$ & 291,09 & 78,51 & 199,50 & 199,90 & 42,43 & 426,35 & 54,25 & 10,94 & 36,63 & 150,60 & 53,39 & 53,63 & 128,16 \\
\hline Pelophylax perezi & $\begin{array}{l}30 T T L 59 \\
\end{array}$ & 100,00 & 120,08 & 114,38 & 38,99 & 6142,13 & 290,93 & $-0,17$ & 291,10 & 80,44 & 200,75 & 201,21 & 44,09 & 416,59 & 52,89 & 10,56 & 36,11 & 146,84 & 52,66 & 52,95 & 125,25 \\
\hline Pelophylax perezi & 30TTL60 & 100,00 & 114,36 & 113,21 & 38,01 & 6233,21 & 288,24 & $-4,33$ & 292,57 & 69,27 & 197,00 & 198,49 & 39,50 & 502,62 & 61,29 & 11,47 & 36,97 & 171,10 & 58,14 & 58,96 & 152,82 \\
\hline Pelophylax perezi & 30TTL61 & 100,00 & 113,50 & 113,97 & 38,46 & 6218,07 & 287,22 & $-5,21$ & 292,44 & 72,68 & 196,09 & 197,31 & 38,71 & 492,07 & 60,22 & 11,71 & 36,64 & 168,50 & 58,69 & 59,31 & 148,05 \\
\hline Pelophylax perezi & 30TTL62 & 100,00 & 116,47 & 115,31 & 38,95 & 6219,87 & 290,42 & $-2,82$ & 293,24 & 76,27 & 199,71 & 199,86 & 41,25 & 462,77 & 57,19 & 11,12 & 37,00 & 160,84 & 56,27 & 56,35 & 137,50 \\
\hline Pelophylax perezi & 30TTL63 & 100,00 & 119,51 & 116,51 & 39,01 & 6228,66 & 293,60 & $-0,62$ & 294,22 & 79,06 & 202,72 & 202,72 & 43,67 & 431,98 & 54,71 & 10,97 & 37,70 & 153,08 & 53,65 & 53,65 & 125,65 \\
\hline Pelophylax perezi & 30TTL64 & 100,00 & 120,29 & 116,82 & 39,05 & 6221,36 & 294,10 & $-0,18$ & 294,27 & 80,06 & 203,19 & 203,19 & 44,14 & 413,41 & 52,97 & 10,68 & 38,41 & 148,23 & 52,13 & 52,13 & 118,31 \\
\hline Pelophylax perezi & 30TTL65 & 100,00 & 118,88 & 116,50 & 39,01 & 6191,56 & 292,08 & -1,21 & 293,29 & 78,72 & 201,26 & 201,26 & 43,07 & 410,75 & 52,21 & 10,97 & 37,74 & 146,54 & 53,00 & 53,00 & 116,99 \\
\hline Pelophylax perezi & 30TTL66 & 100,00 & 114,36 & 115,74 & 39,00 & 6172,04 & 287,32 & $-5,11$ & 292,43 & 74,34 & 196,24 & 196,68 & 39,04 & 426,80 & 53,56 & 11,65 & 36,71 & 150,57 & 56,11 & 56,36 & 122,45 \\
\hline Pelophylax perezi & \begin{tabular}{|l|}
$30 T T L 67$ \\
\end{tabular} & 100,00 & 115,36 & 115,55 & 39,00 & 6155,89 & 287,85 & $-4,08$ & 291,93 & 75,61 & 196,41 & 197,42 & 40,03 & 417,49 & 52,16 & 11,57 & 36,18 & 146,45 & 55,03 & 55,53 & 119,99 \\
\hline Pelophylax perezi & 30TTL68 & 100,00 & 119,86 & 115,30 & 39,00 & 6157,26 & 291,6 & $-0,43$ & 292,11 & 80,01 & 199,99 & 201,51 & 43,94 & 390,48 & 48,65 & 10,34 & 35,71 & 136,31 & 51,33 & 52,09 & 111,71 \\
\hline Pelophylax perezi & $30 T T L$ & 100,00 & 122,06 & 115,03 & 39,00 & 6155, & 293,2 & $\begin{array}{l}0,45 \\
0,89 \\
\end{array}$ & 292,40 & $\begin{array}{l}80,2,50 \\
82\end{array}$ & 201,72 & 20 & 45,71 & \begin{tabular}{|l|l|}
378,28 \\
\end{tabular} & $\begin{array}{l}40,002 \\
47,02\end{array}$ & 9, & 35,32 & $\begin{array}{l}131,58 \\
130\end{array}$ & \begin{tabular}{|l|l|}
49,88 \\
1,3
\end{tabular} & 50,85 & 107,96 \\
\hline Pelophylax perezi & 30 TTL70 & 100,00 & 118,69 & 114,98 & 38,57 & 6219,90 & 293,06 & $-1,30$ & 294,36 & 78,33 & 201,28 & 202,53 & 43,78 & 458,78 & 55,16 & 11,02 & 35,67 & 153,44 & 55,54 & 56,09 & 135,18 \\
\hline Pelophylax perezi & 30TTL71 & 100,00 & 115,19 & 115,41 & 38,99 & 6196,44 & 289,38 & $\begin{array}{l}-4,39 \\
-150\end{array}$ & 293,77 & 74,78 & 196,90 & 198,69 & 40,55 & 461,69 & 55,62 & 11,56 & 35,19 & 154,96 & 57,72 & 58,52 & 134,75 \\
\hline Pelophylax perezi & 30TTL72 & 100,00 & 116,09 & 116,63 & 39,11 & 6185,27 & 290,35 & $-3,85$ & 294,19 & 75,68 & 198,19 & 199,27 & 41,39 & 443,39 & 53,56 & 11,38 & 35,13 & 150,09 & 56,90 & 57,37 & 127,97 \\
\hline Pelophylax perezi & 30TTL73 & 100,00 & 120,48 & 118,22 & 39,59 & 6217,77 & 295,16 & $-0,53$ & 295,68 & 79,94 & 203,51 & 203,67 & 44,79 & 414,32 & 50,82 & 10,99 & 35,68 & 142,51 & 53,90 & 53,97 & 118,64 \\
\hline Pelophylax perezi & $30 T T L$ & 100,00 & 119 & $\frac{11}{11 \zeta}$ & 39,74 & $\frac{62189}{6189}$ & 293 & $\begin{array}{l}-1,06 \\
-1,06\end{array}$ & \begin{tabular}{|l|}
295,01 \\
\end{tabular} & 79,43 & \begin{tabular}{|l|}
202,52 \\
20,5
\end{tabular} & \begin{tabular}{|l|}
202,54 \\
\end{tabular} & $\begin{array}{ll}44,36 \\
44,3\end{array}$ & | & $\begin{array}{l}0,026 \\
49,66\end{array}$ & $\begin{array}{l}10,93 \\
10,92\end{array}$ & $\begin{array}{l}35,00 \\
36,87\end{array}$ & \begin{tabular}{|l|}
139,32 \\
139,3
\end{tabular} & 53,40 & 53,40 & $\begin{array}{l}110,04,99 \\
09,9\end{array}$ \\
\hline Pelophylax perezi & 30TTL75 & 100,00 & 118,36 & 117,62 & 39,62 & 6170,04 & 292,09 & $-1,89$ & 293,97 & 78,08 & 200,76 & 200,92 & 43,20 & 394,29 & 49,00 & 11,00 & 36,49 & 137,82 & 53,90 & 53,96 & 108,48 \\
\hline Pelophylax perezi & \begin{tabular}{|l|l|l|l|}
$30 T L 76$ \\
\end{tabular} & 100,00 & 115,98 & 116,93 & 39,04 & 6154,60 & 289,42 & $\begin{array}{l}-4,05 \\
-4,00 \\
\end{array}$ & 293,42 & 75,96 & $\begin{array}{l}197,03 \\
\end{array}$ & $\begin{array}{l}198,15 \\
\end{array}$ & 40,83 & 399,35 & 49,00 & 11,38 & 35,45 & 138,35 & 54,94 & 55,48 & 110,35 \\
\hline Pelophylax perezi & 30TTL77 & 100,00 & 115,30 & 116,42 & 39,02 & 6142,99 & 288,43 & $-4,77$ & 293,20 & 75,46 & 195,38 & 197,22 & 40,21 & 399,37 & 48,49 & 11,80 & 34,90 & 137,61 & 55,20 & 56,19 & 110,71 \\
\hline Pelophylax perezi & 30TTL78 & 100,00 & 119,71 & 116,10 & 39,00 & 6150,08 & 292,16 & $-0,90$ & 293,06 & 79,96 & 199,21 & 20 & 43,98 & 375,74 & 45,45 & 10,79 & 34,65 & 129,17 & 51,47 & 52,77 & 10 \\
\hline Pelophylax perezi & 30TTL79 & 100,00 & 123,62 & 115,62 & 39,00 & 6148,60 & 295,08 & 1,99 & 293,09 & 84,09 & 202,65 & 204,89 & 47,22 & 358,17 & 43,27 & 9,79 & 34,54 & 122,99 & 49,01 & 50,37 & 98,48 \\
\hline Pelophylax perezi & 30TTL80 & 100,00 & 116,94 & 115,38 & 38,70 & 6194,59 & 291,30 & $-3,28$ & 294,58 & 76,48 & $\begin{array}{l}198,09 \\
\end{array}$ & 200,76 & 42,40 & \begin{tabular}{|l|l|}
447,38 \\
\end{tabular} & 53,07 & 11,43 & 34,27 & 146,34 & 56,69 & 57,84 & 127,78 \\
\hline Pelophylax perezi & 30TTL81 & 100,00 & 119,77 & 116,53 & 39,00 & 6165,85 & 293,85 & $-0,93$ & 294,78 & 79,18 & 200,16 & 202,99 & 45,29 & 424,89 & 50,31 & 11,05 & 33,65 & 138,73 & 55,23 & 56,31 & 120,59 \\
\hline Pelophylax perezi & 30TTL82 & 100,00 & 117,57 & 117,17 & 39,34 & 6116,41 & 290,95 & $-2,46$ & 293,41 & 77,21 & 197,13 & $200, \mathrm{C}$ & 43, & 421,53 & 50,03 & 11,24 & 33,00 & 137,38 & 56,54 & 57,75 & 11 \\
\hline Pelophylax perezi & 30TTL83 & 100,00 & 120,42 & 118,34 & 40,00 & 6087,64 & 293,26 & $-0,31$ & 293,57 & 79,91 & 199,28 & 202,43 & 46,64 & 400,26 & 47,40 & 11,00 & 32,46 & 130,21 & 54,99 & 56,17 & 111,81 \\
\hline
\end{tabular}




\begin{tabular}{|c|c|c|c|c|c|c|c|c|c|c|c|c|c|c|c|c|c|c|c|c|c|}
\hline TAXON & UTM & $\mathrm{km} 2$ & B101 & B102 & $\mathrm{BIO3}$ & B104 & B105 & B106 & B107 & B108 & B109 & BIO10 & B1011 & BIO12 & B1013 & BIO14 & BIO15 & B1016 & B1017 & B1018 & B1019 \\
\hline Pelophylax perezi & 30TTL84 & 100,00 & 118,22 & 118,05 & 40,00 & 6094,94 & 291,11 & $-2,11$ & 293,22 & 77,77 & 197,44 & 200,09 & 44,13 & 395,58 & 47,83 & 11,05 & 33,18 & 130,74 & 55,48 & 56,54 & 108,39 \\
\hline Pelophylax perezi & 30TTL85 & 100,00 & 117,38 & 117,95 & $\begin{array}{l}39,95 \\
\end{array}$ & 6110,75 & 290,40 & $-3,05$ & 293,45 & 76,89 & 196,71 & 199,36 & 43,06 & 390,23 & 47,82 & 11,22 & 33,78 & 130,64 & 55,23 & 56,36 & 105,81 \\
\hline Pelophylax perezi & 30TTL86 & 100,00 & 114,99 & 117,17 & 39,21 & 6118,82 & 288,09 & $-5,01$ & 293,10 & 74,80 & 194,29 & 196,82 & 40,29 & 395,85 & 48,46 & 11,95 & 33,60 & 132,92 & 56,56 & 57,97 & 107,10 \\
\hline Pelophylax perezi & 30TTL87 & 100,00 & 117,45 & 117,01 & 39,01 & 6128,10 & 290,28 & $-3,02$ & 293,30 & 77,47 & 196,72 & 199,04 & 42,31 & 381,31 & 46,22 & 11,59 & 33,62 & 128,43 & 54,19 & 55,82 & 103,11 \\
\hline Pelophylax perezi & 30TTL88 & 100,00 & 120,04 & $\begin{array}{lll}116,87 & \end{array}$ & 39,00 & \begin{tabular}{|l|l|}
6129,04 \\
\end{tabular} & 292,54 & $-0,96$ & 293,50 & 80,56 & 199,23 & 201,35 & 44,43 & 369,22 & 44,14 & 11,29 & 33,43 & 124,61 & 52,34 & 54,01 & 99,94 \\
\hline Pelophylax perezi & 30TTL89 & 100,00 & 123,24 & 116,25 & 39,00 & 6124,41 & 295,14 & 1,65 & 293,49 & 83,91 & 202,13 & 204,34 & 47,36 & 358,89 & 42,33 & 10,93 & 33,26 & 121,55 & 50,74 & 52,56 & 97,16 \\
\hline Pelophylax perezi & 30TTL90 & 100,00 & 114,29 & 115,12 & 38,60 & 6168,75 & 288,58 & $-5,88$ & 294,46 & 74,00 & 195,12 & 197,74 & 40,25 & 442,18 & 53,26 & 12,10 & 33,22 & 141,85 & 58,34 & 60,13 & 122,18 \\
\hline Pelophylax perezi & 30TTL91 & 100,00 & 117,60 & 116,18 & 39,00 & 6136,11 & 291,29 & $-2,71$ & 294,00 & 77,22 & $\begin{array}{l}197,47 \\
\end{array}$ & 200,64 & 43,65 & 418,35 & 50,18 & 11,39 & 32,73 & 133,71 & 56,42 & 58,07 & 115,02 \\
\hline Pelophylax perezi & 30TTL93 & 100,00 & 119,44 & 117,50 & 39,96 & 6030,78 & 291,30 & $-0,79$ & 292,09 & 78,96 & 197,04 & 200,89 & 46,37 & 391,78 & 46,69 & 11,02 & 31,25 & 123,57 & 55,69 & 57,79 & 106,13 \\
\hline Pelophylax perezi & 30TTL94 & 100,00 & 117,14 & 117,62 & 39,89 & 6042,23 & 289,38 & $-2,95$ & 292,33 & 76,99 & $\begin{array}{l}195,08 \\
\end{array}$ & 198,61 & 43,79 & 392,83 & 47,39 & 11,57 & 31,49 & 125,51 & 56,71 & 58,87 & 105,48 \\
\hline Pelophylax perezi & 30TTL95 & 100,00 & 117,80 & 117,64 & 39,72 & 6069,91 & 290,40 & $-2,62$ & 293,02 & 77,74 & 196,23 & 199,40 & 44,09 & 383,52 & 46,63 & 11,36 & 32,12 & 124,15 & 55,46 & 57,44 & 102,38 \\
\hline Pelophylax perezi & 30TTL96 & 100,00 & 117,16 & 117,26 & 39,36 & 6097,63 & 290,05 & $-3,19$ & 293,24 & 77,09 & 196,05 & 198,89 & 42,75 & 382,61 & 46,59 & 11,75 & 32,22 & 124,92 & 55,61 & 57,70 & 102,01 \\
\hline Pelophylax perezi & 30TTL97 & 100,00 & 120,42 & 117,03 & 39,03 & 6113,75 & 293,03 & $-0,62$ & 293,66 & 80,65 & 199,27 & 201,87 & 45,18 & 368,74 & 44,48 & 11,30 & 32,49 & 121,59 & 53,13 & 55,11 & 98,48 \\
\hline Pelophylax perezi & 30TTL99 & 100,00 & 123,40 & 116,79 & 39,00 & 6113,62 & 295,29 & 1,44 & 293,85 & 84,35 & 202,00 & 204,42 & 47,40 & 361,10 & 42,50 & 11,65 & 32,23 & 120,58 & 52,20 & 54,24 & 97,04 \\
\hline Pelophylax perezi & 30TTM50 & 100,00 & 118,92 & 114,25 & 39,00 & 6119,15 & 289,53 & $-1,20$ & 290,73 & 79,56 & 199,50 & 199,86 & 43,12 & 425,39 & 54,04 & 11,10 & 35,80 & 150,07 & 54,46 & 54,70 & 128,83 \\
\hline Pelophylax perezi & 30TTM52 & 95,00 & 116,33 & 114,59 & 39,00 & 6081,45 & 286,63 & $-3,58$ & 290,21 & 77,34 & 196,83 & 196,83 & 40,68 & 452,17 & 57,37 & 13,01 & 34,89 & 160,40 & 60,13 & 60,13 & 138,52 \\
\hline Pelophylax perezi & 30TTM53 & 90,00 & 116,54 & 114,76 & 39,00 & 6052,98 & 286,48 & $-3,53$ & 290,01 & 77,97 & 196,54 & 196,54 & 41,24 & 461,58 & 58,57 & 13,78 & 34,71 & 164,57 & 62,22 & 62,22 & 141,87 \\
\hline Pelophylax perezi & 30TाM55 & 84,00 & 117,11 & 114,77 & 39,00 & 6000,72 & 285,95 & $-3,43$ & 289,39 & 78,98 & 196,27 & 196,27 & 42,17 & 481,39 & 60,98 & 15,51 & 34,29 & 173,54 & 66,96 & 66,96 & 147,86 \\
\hline Pelophylax perezi & 30TTM56 & 80,00 & 115,43 & 114,79 & 39,02 & 5976,23 & 283,90 & $-4,84$ & 288,73 & 77,50 & 194,25 & 194,25 & 40,71 & 500,38 & 63,39 & 16,95 & 34,12 & 181,13 & 71,15 & 71,15 & 153,10 \\
\hline Pelophylax perezi & 30TாM57 & 80,00 & 112,37 & 114,69 & 39,02 & 5954,96 & 280,73 & $-7,69$ & 288,41 & 74,69 & \begin{tabular}{|l|l|}
191,03 \\
\end{tabular} & \begin{tabular}{|l|l|}
191,03 \\
\end{tabular} & 37,87 & $|527,27|$ & 67,28 & $\mid 18,87$ & 33,90 & $\mid 191,45$ & 76,99 & 76,99 & 160,66 \\
\hline Pelophylax perezi & 30TTM58 & 72,00 & 113,88 & 114,43 & 39,27 & 5904,91 & 280,85 & $-5,97$ & 286,83 & 76,74 & 191,77 & 191,77 & 39,79 & 533,92 & 69,01 & 19,62 & 33,73 & 194,87 & 79,21 & 79,21 & 161,12 \\
\hline Pelophylax perezi & 30TTM59 & 70,00 & 113,74 & 114,05 & 39,83 & 5850,72 & 279,31 & $-5,75$ & 285,06 & 76,92 & 190,78 & 190,78 & 40,39 & 550,41 & $\begin{array}{l}71,79 \\
\end{array}$ & 21,13 & 33,42 & 201,25 & 83,59 & 83,59 & 164,39 \\
\hline Pelophylax perezi & 30TTM60 & 100,00 & 120,34 & 115,00 & 39,00 & $\begin{array}{lll}6131,49 \\
\end{array}$ & 291,38 & $-0,43$ & 291,81 & 80,93 & 199,72 & 201,24 & 44,30 & 389,94 & 48,50 & 10,63 & 34,65 & 135,93 & 52,24 & 53,13 & 112,21 \\
\hline Pelophylax perezi & 30TTM61 & 100,00 & 120,34 & 115,00 & 39,00 & 6111,14 & 291,01 & $-0,41$ & 291,42 & 80,98 & 200,24 & 200,94 & 44,43 & 400,67 & 49,91 & 11,19 & 34,43 & 140,49 & 54,41 & 54,76 & 116,63 \\
\hline Pelophylax perezi & 30TTM62 & 100,00 & 120,20 & 115,04 & 39,00 & 6087,90 & 290,52 & $-0,55$ & 291,06 & 81,15 & 200,17 & 200,39 & 44,52 & 413,72 & 51,54 & 12,11 & 34,03 & 145,85 & 57,31 & 57,43 & 121,43 \\
\hline Pelophylax perezi & 30TTM63 & 100,00 & 119,25 & 115,18 & 39,00 & 6062,60 & 289,37 & $-1,77$ & 291,14 & 80,81 & 199,31 & 199,31 & 43,73 & 429,64 & 53,58 & 13,31 & 33,78 & 152,42 & 60,47 & 60,47 & 126,97 \\
\hline Pelophylax perezi & 30TTM64 & 100,00 & 118,42 & 115,20 & 39,00 & 6033,58 & 288,30 & $-2,81$ & 291,11 & $\begin{array}{l}0,013 \\
80,39\end{array}$ & \begin{tabular}{|l|}
198,16 \\
\end{tabular} & \begin{tabular}{|l|}
198,16 \\
\end{tabular} & 43,04 & $\mid 445,77$ & $\begin{array}{l}55,58 \\
5,5\end{array}$ & \begin{tabular}{l|l|}
14,38 \\
13
\end{tabular} & 33,53 & \begin{tabular}{|l|}
159,09 \\
\end{tabular} & $\begin{array}{l}0,4,73 \\
63\end{array}$ & $\begin{array}{ll}0,743 \\
\end{array}$ & 132,16 \\
\hline Pelophylax perezi & 30TTM65 & 100,00 & 118,10 & 115,32 & 39,04 & 6004,03 & 287,45 & $-2,96$ & 290,41 & 80,33 & 197,26 & 197,26 & 42,92 & 459,71 & 57,50 & 15,53 & 33,32 & 165,03 & 66,84 & 66,84 & 136,30 \\
\hline Pelophylax perezi & 30TTM66 & 100,00 & 116,47 & 115,28 & 39,09 & 5983,55 & 285,57 & $-4,31$ & 289,88 & 78,71 & 195,43 & 195,43 & 41,65 & 479,97 & 60,65 & 17,05 & 33,31 & 173,27 & 71,19 & 71,19 & 142,10 \\
\hline Pelophylax perezi & 30TTM67 & 100,00 & 116,22 & 115,21 & 39,13 & 5958,63 & 284,64 & $-4,48$ & 289,11 & 78,81 & 194,82 & 194,82 & 41,64 & 493,36 & 63,05 & 18,19 & 33,27 & 179,10 & 74,47 & 74,47 & 145,43 \\
\hline Pelophylax perezi & 30TTM68 & 100,00 & 115,66 & 115,14 & 39,30 & 5920,82 & 283,44 & $-4,84$ & 288,27 & 78,75 & 193,59 & 193,59 & 41,14 & 510,51 & 65,92 & 19,61 & 33,18 & 186,15 & 78,70 & 78,70 & 149,35 \\
\hline Pelophylax perezi & 30TTM69 & 100,00 & 114,35 & 114,14 & 39,66 & 5869,97 & 281,20 & $\begin{array}{l}-6,0407 \\
-6,07\end{array}$ & \begin{tabular}{|l|}
287,28 \\
\end{tabular} & 77,94 & \begin{tabular}{|l|}
191,56 \\
\end{tabular} & \begin{tabular}{|l|}
191,56 \\
\end{tabular} & $\begin{array}{l}41,44 \\
40,43\end{array}$ & 531,65 & $\begin{array}{l}69,26 \\
69\end{array}$ & 21,31 & $\begin{array}{l}\mid 3,100 \\
33,10\end{array}$ & \begin{tabular}{|l|l|}
194,55 \\
\end{tabular} & 83,77 & 83,77 & 154,35 \\
\hline Pelophylax perezi & 30TTM70 & 100,00 & 123,60 & 115,39 & 39,00 & 6134,25 & 294,63 & 1,73 & 292,90 & 84,40 & 202,34 & 204,45 & 47,04 & 363,72 & 44,02 & 10,25 & 33,86 & 125,23 & 50,36 & 51,65 & 100,75 \\
\hline Pelophylax perezi & 30TTM71 & 100,00 & 121,85 & 115,55 & 39,00 & 6114,96 & 292,99 & 0,33 & 292,66 & 82,69 & 200,34 & 202,35 & 45,68 & 381,07 & 46,33 & 11,31 & 33,39 & 132,14 & 53,70 & 54,66 & 107,03 \\
\hline Pelophylax perezi & 30TTM72 & 100,00 & 121,22 & 115,76 & 39,00 & 6085,42 & 292,07 & $-0,26$ & 292,33 & 82,42 & 200,30 & 201,51 & 45,26 & 396,00 & 48,23 & 12,26 & 33,17 & 138,25 & 56,89 & 57,44 & 112,25 \\
\hline Pelophylax perezi & 30TTM73 & 100,00 & 119,93 & 115,98 & 39,00 & 6054,20 & 290,56 & $-1,70$ & 292,26 & 81,61 & 199,49 & 199,75 & 44,16 & 413,48 & 50,49 & 13,51 & 32,68 & 145,36 & 60,75 & 60,88 & 118,08 \\
\hline Pelophylax perezi & 30TTM75 & 100,00 & 119,06 & $\begin{array}{l}1115,50 \\
115,99\end{array}$ & 39,01 & $\begin{array}{l}6003,200 \\
600,19\end{array}$ & 289,02 & $-2,23$ & \begin{tabular}{|l|}
291,25 \\
\end{tabular} & \begin{tabular}{l|l|}
81,85 \\
81,8
\end{tabular} & \begin{tabular}{|l|}
198,19 \\
198,4
\end{tabular} & \begin{tabular}{|l|}
198,19 \\
\end{tabular} & $\begin{array}{l}44,10 \\
43,90\end{array}$ & \begin{tabular}{|l|}
441,94 \\
441,94
\end{tabular} & $\begin{array}{l}30,45 \\
55,03\end{array}$ & $\begin{array}{l}\mid 3,5,5 \\
15,57\end{array}$ & $\begin{array}{l}2,00 \\
32,62 \\
\end{array}$ & \begin{tabular}{|l|}
157,67 \\
157,6
\end{tabular} & $\mid \frac{00,15}{66,79}$ & $\begin{array}{l}0,000 \\
66,79\end{array}$ & $\begin{array}{l}110,00 \\
126,77\end{array}$ \\
\hline Pelophylax perezi & 30TTM76 & 100,00 & 117,59 & 115,99 & 39,30 & 5980,07 & 287,18 & $-3,66$ & 290,84 & 80,61 & 196,48 & 196,48 & 42,61 & 461,07 & 58,07 & 17,05 & 32,64 & 165,55 & 71,11 & 71,11 & 132,08 \\
\hline Pelophylax perezi & 30TTM77 & 100,00 & 116,78 & 116,00 & 39,48 & 5949,67 & 285,97 & $-4,49$ & 290,45 & 80,04 & 195,47 & 195,47 & 42,10 & 477,64 & 60,80 & 18,48 & 32,57 & 172,57 & 75,17 & 75,17 & 136,20 \\
\hline Pelophylax perezi & 30TTM78 & 100,00 & 115,38 & 116,00 & 39,77 & 5922,14 & 284,42 & $-5,63$ & 290,05 & 78,96 & 193,60 & 193,60 & 41,05 & 496,08 & 63,83 & 19,98 & 32,71 & 180,31 & 79,54 & 79,54 & 140,71 \\
\hline Pelophylax perezi & 30TTM79 & 100,00 & 114,03 & 115,95 & 39,95 & 5900,76 & 282,31 & $-7,13$ & 289,43 & 77,75 & 191,87 & 191,87 & 39,68 & 517,01 & 67,1 & 21, & 32,80 & 188,87 & 84,68 & 84,68 & 145,62 \\
\hline Pelophylax perezi & 30TTM80 & 100,00 & 121,60 & 116,17 & 39,01 & 6115,09 & 293,37 & 0,14 & 293,23 & 82,48 & 200,24 & 202,43 & 45,55 & 368,92 & $\begin{array}{l}, 1,55 \\
43,5\end{array}$ & 11,36 & 32,91 & 125,50 & 52,76 & 54,50 & 100,62 \\
\hline Pelophylax perezi & 30TTM81 & 100,00 & 121,71 & 116,06 & 39,00 & 6095,45 & 293,17 & 0,01 & 293,16 & 82,96 & 200,07 & 202,17 & 45,78 & 377,01 & 44,77 & 11,90 & 32,52 & 129,05 & 54,64 & 56,07 & 103,53 \\
\hline Pelophylax perezi & 30TTM82 & 100,00 & 121,96 & 116,00 & 39,00 & 6064,74 & 292,99 & $-0,03$ & 293,02 & 83,87 & 199,86 & 201,93 & 46,20 & 386,85 & 46,24 & 12,59 & 32,27 & 133,54 & 56,88 & 58,06 & 107,09 \\
\hline Pelophylax perezi & 30TTM83 & 100,00 & 121,46 & 116,04 & 39,00 & 6028,39 & 292,09 & $-0,39$ & 292,48 & 84,00 & 199,86 & 200,99 & 46,17 & 400,38 & 48,43 & 13,59 & 31,92 & 139,41 & 60,23 & 60,83 & 111,39 \\
\hline Pelophylax perezi & 30TाM84 & 100,00 & 119,90 & 116,05 & 39,03 & 6009,51 & 290,27 & $\begin{array}{l}-2,04 \\
-2,50\end{array}$ & 292,31 & 82,80 & \begin{tabular}{|l|}
198,69 \\
\end{tabular} & \begin{tabular}{|l|l|}
199,16 \\
\end{tabular} & $\begin{array}{l}44,65 \\
44,5 \\
\end{array}$ & 418,84 & $\begin{array}{l}40,1,22 \\
51,\end{array}$ & 14,8 & 31,77 & \begin{tabular}{|l|}
146,78 \\
\end{tabular} & $\begin{array}{l}60,458 \\
64,4\end{array}$ & $\begin{array}{l}0,030 \\
64,70 \\
\end{array}$ & 116,88 \\
\hline Pelophylax perezi & 30TTM85 & 100,00 & 119,63 & 116,05 & 39,03 & 5984,16 & 289,65 & $-1,88$ & 291,53 & 82,89 & 198,59 & 198,59 & 44,51 & 431,66 & 53 & $15, \mathrm{c}$ & 31,95 & 152,64 & 67,61 & 67,61 & 120,59 \\
\hline Pelophylax perezi & 30TTM86 & 100,00 & 118,72 & 116,01 & 39,16 & 5951,78 & 288,12 & $\begin{array}{l}-2,99 \\
-100\end{array}$ & 291,11 & 82,34 & $\begin{array}{l}197,08 \\
\end{array}$ & $\begin{array}{l}197,08 \\
\end{array}$ & 43,80 & 448,88 & 56,30 & 17,25 & 31,89 & 159,88 & 71,49 & 71,49 & 125,12 \\
\hline Pelophylax perezi & 30TTM87 & 100,00 & 117,81 & 116,00 & 39,49 & 5920,41 & 286,75 & $-3,75$ & 290,50 & 81,81 & 195,85 & 195,85 & 43,28 & 466,17 & 59,07 & 18,60 & 31,97 & 167,09 & 75,59 & 75,59 & 129,48 \\
\hline Pelophylax perezi & 30TTM88 & 100,00 & 116,48 & 116,00 & 39,73 & 5897,23 & 285,04 & $-4,91$ & 289,96 & 80,79 & 194,24 & 194,24 & 42,16 & 485,22 & 62,16 & 20,34 & 31,97 & 175,15 & 80,31 & 80,31 & 133,90 \\
\hline Pelophylax perezi & $30 \pi T N$ & 100,00 & $\frac{11}{11 !}$ & 115,06 & 39,87 & 586 & $\begin{array}{l}283, \\
283, \\
\end{array}$ & $\begin{array}{l}-2,51,04 \\
-6,04\end{array}$ & \begin{tabular}{|l|}
289,24 \\
28,4
\end{tabular} & $\mid \begin{array}{ll}\mid 79,92 \\
79,9\end{array}$ & \begin{tabular}{|l|}
192,64 \\
192,64
\end{tabular} & \begin{tabular}{|l|}
192,64 \\
192
\end{tabular} & $\begin{array}{l}42,10 \\
41,29\end{array}$ & 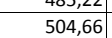 & $\begin{array}{l}62,10 \\
65,27 \\
\end{array}$ & $\begin{array}{l}\mid 21,97 \\
21,9\end{array}$ & $\begin{array}{l}1,21 \\
32,22 \\
\end{array}$ & \begin{tabular}{|l|}
183,22 \\
\end{tabular} & $\begin{array}{l}30,51 \\
85,25\end{array}$ & $\begin{array}{l}\mid c 0,5,1 \\
85,25\end{array}$ & 138,31 \\
\hline Pelophylax perezi & 30TTM91 & 100,00 & 120,45 & 116,80 & 39,02 & 6090,04 & 292,39 & $-1,20$ & 293,59 & 82,16 & 198,92 & 201,05 & 44,57 & 381,93 & 45,12 & 12,96 & 31,86 & 129,16 & 56,21 & 58,57 & 103,69 \\
\hline Pelophylax perezi & 30TTM92 & 100,00 & 120,89 & 116,64 & 39,00 & $\begin{array}{l}6061,87 \\
\end{array}$ & 292,44 & $\begin{array}{l}-1,27 \\
-1,17 \\
\end{array}$ & 293,61 & 83,17 & $\begin{array}{l}198,99 \\
\end{array}$ & $\begin{array}{l}201,06 \\
20\end{array}$ & 45,29 & 389,62 & $\begin{array}{l}45,12 \\
46,38 \\
\end{array}$ & 13,51 & $\begin{array}{l}1,1,40 \\
31,44\end{array}$ & 132,64 & 58,42 & 60,35 & 106,25 \\
\hline Pelophylax perezi & 30TTM93 & 100,00 & 121,63 & 116,31 & 39,02 & 6017,12 & 292,34 & $-0,49$ & 292,83 & 84,57 & 199,03 & 201,21 & 46,42 & 398,03 & 48,02 & 14,06 & 31,29 & 136,86 & 60,54 & 62,02 & 108,93 \\
\hline Pelophylax perezi & 30TTM94 & 100,00 & 120,15 & 116,45 & 39,17 & 5991,92 & 290,56 & $-1,88$ & 292,45 & 83,73 & 197,40 & 199,33 & 45 & 415,08 & 50,59 & 15,35 & 31,10 & 143,84 & 64,70 & 65,83 & 113 \\
\hline Pelophylax perezi & 30TTM95 & $\begin{array}{l}100,00 \\
\end{array}$ & $\begin{array}{l}12,15 \\
118,58 \\
\end{array}$ & $\begin{array}{l}1110,45 \\
116,32\end{array}$ & 39,22 & $\begin{array}{ll}59364,45 \\
5964\end{array}$ & 288,75 & $\begin{array}{l}-1,00 \\
-3,27 \\
\end{array}$ & \begin{tabular}{|l|}
292,02 \\
292,0
\end{tabular} & $\begin{array}{l}83,15 \\
82,68 \\
\end{array}$ & $\begin{array}{l}196,15 \\
196\end{array}$ & \begin{tabular}{|l|}
197,34 \\
193
\end{tabular} & $\begin{array}{l}43,13 \\
43,70\end{array}$ & \begin{tabular}{|l|}
432,88 \\
432,
\end{tabular} & $\begin{array}{l}\mid 50,33 \\
53,30\end{array}$ & \begin{tabular}{|l|}
16,613 \\
16,61
\end{tabular} & $\begin{array}{l}1,110 \\
31,18 \\
\end{array}$ & \begin{tabular}{|l|}
1451,15 \\
151,1
\end{tabular} & $\begin{array}{l}04,10 \\
69,25\end{array}$ & \begin{tabular}{|l|l|}
69,86 \\
69,86
\end{tabular} & $\begin{array}{l}1118,05 \\
118,58\end{array}$ \\
\hline Pelophylax perezi & 30TTM96 & 100,00 & 117,91 & 116,07 & 39,13 & 5937,17 & 287,51 & $-4,03$ & 291,53 & 82,30 & 196,05 & 196,30 & 43,35 & 448,11 & 55,80 & 17,87 & 31,11 & 157,64 & 73,34 & 73,50 & 122,49 \\
\hline Pelophylax perezi & 30TTM97 & 100,00 & 115.85 & 116,00 & 39,31 & 5914,77 & 285.15 & -5.94 & 291.08 & 80.58 & 193.93 & 193.93 & 41.69 & 469,21 & 58.95 & 19.56 & 30.93 & $\mid 166,19$ & 78,40 & 78.40 & 127.92 \\
\hline Pelophylax perezi & 30TTM98 & 100,00 & 115,31 & 115,94 & 39,65 & 5873,47 & 283,65 & $-6,28$ & 289,93 & 80,58 & 192, & 192 & 41, & 486,16 & 61,73 & 21,00 & 31 & 173 & 82,64 & 82,64 & 131,60 \\
\hline Pelophylax perezi & 30TTN53 & 58,00 & 93,44 & 109,66 & 39,99 & 5543,63 & 251,73 & $-19,50$ & 271,23 & 60,25 & 166,97 & 166,97 & 25,44 & 749,48 & 97,07 & 33,26 & $\begin{array}{l}30,23 \\
30,\end{array}$ & 266,40 & 122,49 & 122,49 & 220,42 \\
\hline
\end{tabular}




\begin{tabular}{|c|c|c|c|c|c|c|c|c|c|c|c|c|c|c|c|c|c|c|c|c|c|}
\hline TAXON & UTM & $\mathrm{km} 2$ & B101 & B102 & $\mathrm{BIO3}$ & BIO4 & B105 & B106 & B107 & B108 & B109 & BIO10 & BIO11 & BIO12 & B1013 & BIO14 & BIO15 & BIO16 & B1017 & BIO18 & B1019 \\
\hline Pelophylax perezi & 30TTN54 & 50,00 & 85,92 & 107,32 & 39,96 & 5432,77 & 240,95 & $-24,42$ & 265,37 & 54,00 & 157,99 & 157,99 & 19,85 & 827,83 & 105,94 & 37,45 & 29,26 & 289,86 & 136,27 & 136,33 & 244,65 \\
\hline Pelophylax perezi & 30TTN56 & 47,00 & 65,31 & 101,61 & 39,72 & 5231,31 & 214,28 & $-38,83$ & 253,11 & 31,13 & 135,35 & 135,42 & 3,28 & 1038,97 & 128,89 & 48,32 & 27,40 & 352,92 & 172,06 & 172,99 & 312,22 \\
\hline Pelophylax perezi & 30TTN60 & 100,00 & 112,30 & 114,63 & 39,92 & 5825,36 & 278,29 & $-7,38$ & 285,67 & 76,30 & 189,01 & 189,01 & 39,02 & 557,37 & 73,12 & 23,30 & 32,92 & 204,20 & 89,71 & 89,71 & 160,39 \\
\hline Pelophylax perezi & 30TTN61 & 100,00 & 109,29 & 114,10 & 39,99 & 5768,96 & 273,99 & $-9,38$ & 283,37 & 73,76 & 185,24 & 185,24 & 36,90 & 590,31 & 77,69 & 25,53 & 32,54 & 215,87 & 96,86 & 96,86 & 168,97 \\
\hline Pelophylax perezi & 30TTN62 & 100,00 & 104,34 & $\begin{array}{lll}112,87 & \end{array}$ & 40,00 & 5683,40 & 266,90 & $-12,56$ & 279,46 & 69,82 & 179,35 & 179,35 & 33,50 & 640,29 & 84,06 & 28,65 & 31,66 & 232,06 & 106,62 & 106,62 & 182,98 \\
\hline Pelophylax perezi & 30TTN63 & 100,00 & 97,88 & 110,95 & 40,00 & 5567,66 & 257,41 & $-16,42$ & 273,84 & 64,54 & 171,46 & 171,46 & 28,97 & 704,86 & 91,85 & 32,32 & 30,37 & 252,02 & 118,46 & 118,46 & 202,02 \\
\hline Pelophylax perezi & 30TTN64 & 100,00 & 88,79 & 108,26 & 40,01 & 5445,67 & 244,62 & $-22,48$ & 267,11 & 56,85 & 160,94 & 160,94 & 22,20 & 795,50 & 102,14 & 37,00 & 28,97 & 279,16 & 134,13 & \begin{tabular}{|l|l|}
134,13 \\
\end{tabular} & 230,18 \\
\hline Pelophylax perezi & 30TTN66 & 100,00 & 75,87 & 102,94 & 40,22 & 5193,28 & 223,88 & $-29,61$ & 253,49 & 46,30 & 144,83 & 144,96 & 13,51 & 955,68 & 120,26 & 45,30 & 27,28 & 325,99 & 161,73 & 162,86 & 279,55 \\
\hline Pelophylax perezi & 30TTN69 & 100,00 & 119,03 & 95,86 & 43,27 & 4250,99 & 241,90 & 22,63 & 219,26 & 97,51 & 173,16 & 175,43 & 67,69 & 853,09 & 115,27 & 42,55 & 27,79 & 287,22 & 149,88 & 157,86 & 220,65 \\
\hline Pelophylax perezi & 30TTN70 & 100,00 & 111,83 & 115,86 & 39,87 & 5876,95 & 279,96 & $-8,85$ & 288,81 & 76,08 & 189,31 & 189,31 & 37,82 & 541,07 & 70,76 & 23,03 & 32,95 & 198,52 & 90,65 & 90,65 & 151,22 \\
\hline Pelophylax perezi & 30TTN71 & 100,00 & 108,29 & 115,51 & 39,98 & 5833,44 & 275,83 & $-11,51$ & 287,33 & 72,84 & 185,29 & 185,29 & 35,15 & 574,51 & 75,41 & 23,60 & 32,70 & 210,81 & 98,28 & 98,28 & 159,69 \\
\hline Pelophylax perezi & 30TTN72 & 100,00 & 101,50 & 113,74 & 39,99 & 5728,56 & 266,30 & $-16,17$ & 282,47 & 67,27 & 177,26 & 177,26 & 30,08 & 637,13 & 83,05 & 28,18 & 31,32 & 230,49 & 109,92 & 109,92 & 178,09 \\
\hline Pelophylax perezi & 30TTN73 & 100,00 & 96,86 & 111,50 & 40,00 & 5591,34 & 257,71 & $-18,05$ & 275,76 & 63,91 & 170,84 & 170,84 & 27,56 & 694,81 & 90,14 & 32,83 & 29,98 & 247,84 & 120,24 & 120,24 & 195,01 \\
\hline Pelophylax perezi & 30TTN74 & 100,00 & 83,51 & 107,91 & 39,82 & 5452,56 & 240,04 & $-27,45$ & 267,49 & 52,10 & 155,92 & 155,92 & 17,04 & 818,40 & 103,75 & \begin{tabular}{|l|l|}
39,17 \\
\end{tabular} & 28,25 & 284,09 & 140,87 & \begin{tabular}{|l|l|}
140,88 \\
\end{tabular} & 234,68 \\
\hline Pelophylax perezi & 30TTN75 & 100,00 & 78,74 & 105,74 & 39,91 & 5340,06 & 231,84 & $-29,75$ & 261,59 & 48,48 & 149,70 & 149,71 & 14,15 & 879,32 & 110,85 & 42,46 & 27,29 & 302,26 & 151,78 & 151,81 & 252,92 \\
\hline Pelophylax perezi & 30TTN80 & 100,00 & 113,69 & 115,72 & 39,90 & 5842,43 & 281,21 & $-7,17$ & 288,38 & 78,73 & 190,70 & 190,70 & 39,93 & 525,78 & 68,56 & 22,37 & 32,40 & \begin{tabular}{|l|l|}
191,86 \\
\end{tabular} & 90,45 & $\begin{array}{l}90,45 \\
\end{array}$ & 143,16 \\
\hline Pelophylax perezi & 30TTN81 & 100,00 & 112,09 & 115,44 & 39,99 & 5801,20 & 278,79 & $-8,02$ & 286,81 & 77,48 & 188,47 & 188,47 & 38,95 & 549,74 & 72,17 & 22,12 & 32,53 & 201,18 & 96,41 & 96,41 & 148,43 \\
\hline Pelophylax perezi & 30TTN82 & 100,00 & 108,29 & 114,24 & 40,00 & 5713,11 & 272,77 & $-10,27$ & 283,04 & 74,53 & 183,56 & 183,56 & 36,55 & 591,44 & 77,61 & 24,31 & 31,73 & 214,95 & 104,96 & 104,96 & 159,59 \\
\hline Pelophylax perezi & 30TTN83 & 100,00 & 100,81 & 111,97 & 40,01 & 5578,91 & 261,61 & $-14,78$ & 276,39 & 68,47 & 174,49 & 174,49 & 31,46 & 662,58 & 86,12 & 30,41 & 30,02 & 236,55 & 117,88 & \begin{tabular}{|l|l|}
117,88 \\
\end{tabular} & 180,73 \\
\hline Pelophylax perezi & 30TTN84 & 100,00 & 93,04 & 109,27 & 40,02 & 5449,02 & 249,85 & $-19,49$ & 269,34 & 62,02 & 165,11 & 165,11 & 25,95 & 741,51 & 95,24 & 36,19 & 28,41 & 259,91 & 131,66 & 131,66 & 204,84 \\
\hline Pelophylax perezi & 30TTN88 & 100,00 & 110,02 & 98,86 & 42,09 & \begin{tabular}{|l|l|}
4609,07 \\
\end{tabular} & 240,93 & 8,93 & 232,00 & 86,32 & 169,63 & 170,88 & 53,76 & 820,57 & 109,09 & 41,97 & 27,09 & 279,84 & 148,35 & 155,84 & 213,51 \\
\hline Pelophylax perezi & 30TTN90 & 100,00 & 115,60 & 114,52 & 39,93 & 5754,04 & 280,47 & $-4,69$ & 285,16 & 82,10 & 191,30 & 191,30 & 42,93 & 521,09 & 67,51 & 23,59 & 31,24 & 187,63 & $\begin{array}{l}91,22 \\
91,0\end{array}$ & 91,22 & 139,00 \\
\hline Pelophylax perezi & 30TTN91 & 100,00 & 112,42 & 114,10 & 39,99 & 5708,68 & 276,63 & $-6,76$ & 283,39 & 79,24 & 187,61 & 187,61 & 40,64 & 551,70 & 71,77 & 24,11 & 31,20 & \begin{tabular}{|l|l|}
198,91 \\
\end{tabular} & 98,15 & $\begin{array}{l}98,15 \\
\end{array}$ & 146,58 \\
\hline Pelophylax perezi & 30TTN92 & 100,00 & 107,67 & 113,09 & 40,00 & 5642,44 & 270,31 & $-10,03$ & 280,35 & 75,30 & 182,14 & 182,14 & 36,94 & 595,94 & 77,47 & 26,22 & 30,55 & 213,70 & 107,31 & 107,31 & 158,62 \\
\hline Pelophylax perezi & 30TTN93 & 100,00 & 101,07 & 111,23 & 40,01 & 5538,27 & 260,69 & $-14,21$ & 274,90 & 69,69 & 174,09 & 174,09 & 32,15 & 658,48 & 84,97 & \begin{tabular}{|c|}
31,07 \\
\end{tabular} & 29,28 & 233,02 & 119,10 & 119,10 & 176,86 \\
\hline Pelophylax perezi & 30TTN94 & 100,00 & 93,59 & 108,77 & 40,01 & 5418,02 & 249,74 & $-18,79$ & 268,53 & 63,35 & 165,26 & 165,26 & 26,95 & 733,11 & 93,67 & 36,51 & 27,87 & 255,42 & 132,52 & 132,52 & 199,38 \\
\hline Pelophylax perezi & $30 \pi T P 60$ & 100,00 & 129,66 & 89,93 & 43,73 & 3918,14 & 241,79 & 38,42 & 203,37 & \begin{tabular}{|l|l|}
111,05 \\
\end{tabular} & 178,84 & 181,95 & 82,53 & 850,03 & $\mid$\begin{tabular}{|l|}
116,32 \\
\end{tabular} & 42,40 & 28,38 & 284,03 & \begin{tabular}{|l|l|}
149,06 \\
\end{tabular} & 158,09 & 214,18 \\
\hline Pelophylax perezi & 30TTP71 & 100,00 & 132,88 & 81,76 & 42,68 & 3781,16 & 235,44 & 46,17 & 189,27 & 115,82 & 180,43 & 183,86 & 87,43 & 850,84 & 116,50 & 42,31 & 28,38 & 285,73 & 149,56 & 160,26 & 214,32 \\
\hline Pelophylax perezi & 30TTP73 & & & & & & & & & & & & & & & & & & & & \\
\hline Pelophylax perezi & 30TTP80 & 100,00 & 126,93 & 86,91 & 42,80 & 3981,43 & 237,32 & 36,17 & 201,14 & 108,64 & 177,37 & 180,30 & 78,91 & 843,78 & 114,67 & 42,99 & 27,94 & 283,30 & 151,37 & 160,74 & 211,27 \\
\hline Pelophylax perezi & 30TUK03 & 100,00 & 156,90 & 114,99 & 37,00 & 6503,86 & 335,39 & 28,88 & 306,51 & 114,68 & 243,94 & 243,94 & 76,89 & 361,34 & 42,13 & 5,25 & 40,71 & 122,40 & 33,81 & 33,81 & 106,76 \\
\hline Pelophylax perezi & 30TUK04 & 100,00 & 152,48 & 114,92 & 37,00 & 64 & 330,21 & $\begin{array}{l}25,06 \\
25,06\end{array}$ & \begin{tabular}{|l|l|}
305,15 \\
\end{tabular} & $\begin{array}{l}140,58 \\
110\end{array}$ & \begin{tabular}{|l|}
239,14 \\
23
\end{tabular} & \begin{tabular}{|l|}
239,14 \\
\end{tabular} & 72,90 & \begin{tabular}{|l|l|}
365,59 \\
\end{tabular} & $\begin{array}{l}42,15 \\
42,55 \\
\end{array}$ & $\frac{\mid, 25}{6,31}$ & 39,21 & 122,56 & $\begin{array}{l}3,01 \\
36,52 \\
\end{array}$ & 36,52 & 106,51 \\
\hline Pelophylax perezi & 30TUK05 & 100,00 & 91,60 & 111,19 & 36,98 & 6312,57 & 270,40 & $-26,92$ & 297,31 & 37,66 & 177,25 & 178,03 & 18,63 & 640,32 & 74,19 & 17,84 & 34,65 & 206,66 & 76,97 & 80,68 & 186,89 \\
\hline Pelophylax perezi & $\begin{array}{l}\text { 30TUKOG } \\
\end{array}$ & 100,00 & 80,47 & 110,13 & 36,98 & 6240,22 & 258,27 & $-35,89$ & 294,16 & 23,13 & 165,30 & 166,20 & 9,04 & 683,23 & 79,23 & 20,24 & 33,51 & 219,28 & 84,51 & 89,35 & 198,20 \\
\hline Pelophylax perezi & 30TUK07 & 100,00 & 76,67 & 109,66 & 37,02 & 6199,42 & 253,59 & $-38,70$ & 292,29 & 15,36 & 161,19 & 161,95 & 5,96 & 693,74 & 80,34 & 21,14 & 32,93 & 222,01 & 87,41 & 93,44 & 200,16 \\
\hline Pelophylax perezi & $\begin{array}{l}\text { 30TUK08 } \\
\end{array}$ & 100,00 & 105,93 & 113,03 & 37,83 & 6234,50 & 282,07 & $-14,19$ & 296,26 & 64,14 & 188,86 & 190,86 & 32,37 & 495,59 & 60,24 & 14,20 & 33,61 & 157,74 & 64,29 & 66,78 & 136,18 \\
\hline Pelophylax perezi & 30TUK13 & 100,00 & 153,80 & 115,00 & 37,00 & 6529,68 & 332,82 & 25,31 & 307,51 & 111,49 & 241,18 & 241,18 & 73,63 & 362,19 & 41,65 & 5,97 & 39,65 & 121,37 & 35,44 & 35,44 & 104,84 \\
\hline Pelophylax perezi & 30TUK14 & 100,00 & 151,35 & 114,68 & 37,00 & 6499,67 & 329,40 & 23,35 & 306,06 & 109,40 & 238,49 & 238,49 & 71,49 & 361,03 & 41,78 & 6,41 & 38,95 & 120,26 & 36,98 & 36,98 & 103,24 \\
\hline Pelophylax perezi & 30TUK15 & 100,00 & 107,17 & 112,56 & 37,00 & 6357,38 & 286,19 & $-14,32$ & 300,52 & 71,97 & 192,81 & 193,76 & 32,42 & 526,62 & 62,91 & \begin{tabular}{|c|}
14,19 \\
\end{tabular} & 34,84 & 168,06 & 64,68 & 66,84 & 147,18 \\
\hline Pelophylax perezi & 30TUK16 & 100,00 & 82,40 & 110,78 & 37,00 & 6241,99 & 260,71 & $-34,80$ & 295,51 & 35,77 & 167,32 & 168,13 & 10,85 & 646,15 & 76,49 & 19,65 & 32,89 & 203,86 & 82,49 & 87,53 & 181,66 \\
\hline Pelophylax perezi & 30TUK17 & 100,00 & 79,97 & 110,37 & 37,01 & 6204,22 & 257,10 & $-36,50$ & 293,60 & 31,32 & 164,45 & 165,12 & 9,03 & 648,18 & 77,16 & 20,45 & 32,38 & 203,69 & 84,44 & 89,93 & 181,01 \\
\hline Pelophylax perezi & $\begin{array}{l}\text { 30TUK18 } \\
30 \text { Th }\end{array}$ & 100,00 & 85,68 & $\begin{array}{ll}1110,51 \\
110,95\end{array}$ & $\frac{37,01}{37,17}$ & $\begin{array}{l}0248,2<2 \\
6184,79 \\
\end{array}$ & 261,81 & $\begin{array}{l}-3,0,63 \\
-31,63 \\
\end{array}$ & \begin{tabular}{|l|}
293,40 \\
293,44
\end{tabular} & $\begin{array}{l}1,32 \\
40,94 \\
\end{array}$ & \begin{tabular}{|l|}
$164,45,28$ \\
\end{tabular} & \begin{tabular}{|l|}
1703,12 \\
170,44
\end{tabular} & \begin{tabular}{r|}
5,05 \\
14,40
\end{tabular} & \begin{tabular}{|l|l|}
6400,66 \\
600
\end{tabular} & $\begin{array}{l}1,10 \\
72,73\end{array}$ & $\begin{array}{l}\mid 0,45 \\
19,18\end{array}$ & $\begin{array}{l}32,50 \\
32,23\end{array}$ & \begin{tabular}{|l|l|}
188,44 \\
188,44
\end{tabular} & $\begin{array}{l}84,44 \\
80,13 \\
\end{array}$ & \begin{tabular}{|l|}
85,09 \\
85,09
\end{tabular} & $\begin{array}{l}181,01 \\
164,78\end{array}$ \\
\hline Pelophylax perezi & 30TUK19 & 100,00 & 92,96 & 111,70 & 37,53 & 6162,45 & 268,20 & $-25,55$ & 293,75 & 55,26 & 175,56 & 177,18 & 21,10 & 536,76 & 66,86 & 17,20 & 32,19 & 168,07 & 73,77 & 77,81 & 143,09 \\
\hline Pelophylax perezi & 30TUK23 & 100,00 & 151,83 & 114,95 & 37,00 & 6558,41 & 331,25 & 23,05 & 308,19 & 109,52 & 239,88 & 239,88 & 71,45 & 361,57 & 41,58 & 6,19 & 39,18 & 120,32 & 36,54 & 36,54 & 102,94 \\
\hline Pelophylax perezi & 30TUK24 & 100,00 & 148,45 & 114,23 & 37,00 & 6501,82 & 326,70 & 20,22 & 306,48 & 106,40 & 235,77 & 235,77 & 68,69 & 362,49 & 42,40 & 6,90 & 38,08 & 119,71 & 38,77 & 38,77 & 101,54 \\
\hline Pelophylax perezi & 30 TUK25 & 100,00 & 135,47 & 113,90 & 37,00 & 6441,15 & 313,42 & 9,08 & 304,35 & 104,99 & 222,13 & 222 & 57,18 & 389,31 & 47,34 & 8,90 & 36,26 & 126,13 & 46,22 & 46,31 & 105,63 \\
\hline Pelophylax perezi & 30 TUK26 & 100,00 & 94 & 111,68 & 37,00 & 6277,75 & 272,94 & $-24,75$ & 297,69 & 72,72 & 179,80 & 180,69 & 21,95 & 555,93 & 68,55 & 16,80 & 33,22 & 175,91 & 73,17 & 76,48 & 149,86 \\
\hline Pelophylax perezi & $\begin{array}{l}\text { 30TUK27 } \\
\end{array}$ & 100,00 & 89,82 & 111,24 & 37,00 & 6224,85 & 266,71 & $-28,78$ & 295,48 & 70,00 & 173,92 & 174,90 & 17,89 & 566,20 & 70,59 & 18,04 & 32,43 & 178,04 & 76,65 & 80,72 & 150,68 \\
\hline Pelophylax perezi & 30TUK28 & 100,00 & 80,02 & 110,48 & 37,01 & 6176,16 & 256,19 & $-36,62$ & 292,81 & 47,95 & 163,94 & 164,79 & 9,42 & 625,94 & 76,25 & 21,04 & 31,64 & 195,47 & 85,60 & 91,35 & 169,35 \\
\hline Pelophylax perezi & 30TUK29 & 100,00 & 97,39 & 111,69 & 37,25 & 6172,59 & 272,32 & $-22,07$ & 294,39 & 77,13 & 179,98 & 181,63 & 24,99 & 497,97 & 64,06 & 16,68 & 32,32 & 155,57 & 71,03 & 74,46 & 127,42 \\
\hline Pelophylax perezi & 30TUK & 100,00 & 148,26 & 11 & 36,68 & 6573 & 328,10 & 19,23 & 308,86 & 110,18 & 236,68 & 236,68 & 67,90 & 366,73 & 43,08 & 6,69 & 38,38 & \begin{tabular}{|l|l|}
120,75 \\
\end{tabular} & 38,74 & 38,74 & 102,31 \\
\hline Pelophylax perezi & 30TUK34 & 100,00 & 146,30 & 113,97 & 36,92 & 6520,96 & 324,74 & 17,80 & 306,94 & 108,63 & 233,89 & 233,89 & 66,48 & 363,94 & 43,27 & 7,34 & 37,36 & 119,40 & 40,36 & 40,36 & 99,86 \\
\hline Pelophylax perezi & 30 TUK35 & 100,00 & 129,37 & 113,05 & 36,90 & 6435,29 & 307,23 & 3,53 & 303,71 & 102,52 & 215,81 & 216,31 & 51,82 & 408,73 & 50,69 & 10,20 & 35,68 & 132,82 & 50,62 & 51,16 & 108,39 \\
\hline Pelophylax perezi & 30 TUK36 & 100,00 & 90,23 & 111,35 & 37,00 & 6263,98 & 268,25 & $-29,08$ & 297,34 & 71,25 & 175,15 & 175,99 & 18,05 & 568,18 & 71,19 & 17,99 & 32,66 & 180,80 & 77,02 & 80,79 & 149,91 \\
\hline Pelophylax perezi & 30TUK37 & 100,00 & 95,44 & 111,44 & 37,00 & 6240,27 & 272,10 & $-24,57$ & 296,67 & 77,51 & 179,49 & 180,74 & 22,86 & 520,51 & 67,05 & 16,80 & 32,78 & 165,76 & 72,71 & 76,01 & 13 \\
\hline Pelophylax perezi & $\begin{array}{l}\text { 30TUK38 } \\
\end{array}$ & 100,00 & $\begin{array}{l}35,44 \\
85,05\end{array}$ & 111,44 & 37,00 & $\begin{array}{l}0247,24 \\
6175,64\end{array}$ & 261,01 & $\begin{array}{l}-24,31 \\
-32,71 \\
\end{array}$ & \begin{tabular}{|l|}
$293,72,7$ \\
\end{tabular} & $\begin{array}{l}\mid 11,11 \\
65,94\end{array}$ & \begin{tabular}{|l|}
168,71 \\
168,4
\end{tabular} & \begin{tabular}{|l|}
$169,74,68$ \\
\end{tabular} & $\begin{array}{l}2,300 \\
13,97 \\
\end{array}$ & \begin{tabular}{|c|}
576,70 \\
576,0
\end{tabular} & $\begin{array}{l}\mid 7,, 305 \\
72,81\end{array}$ & $\begin{array}{l}\mid 0,0,0 \\
19,77\end{array}$ & $\begin{array}{l}20,1,65 \\
31,65\end{array}$ & \begin{tabular}{|l|}
181,17 \\
181
\end{tabular} & $\begin{array}{l}1,1 / 1 \\
81,46\end{array}$ & 80,51 & $\begin{array}{l}150,20 \\
149,94\end{array}$ \\
\hline Pelophylax perezi & $\begin{array}{l}\text { 30TUK39 } \\
\end{array}$ & 100,00 & 104,10 & 111,62 & 37,10 & 6184,29 & 278,08 & $\begin{array}{l}-17,14 \\
\end{array}$ & 295,22 & 97,69 & 186,34 & 188,11 & 30,71 & 449,96 & 60,10 & 15,34 & 32,89 & 142,87 & 66,47 & 69,05 & 109,53 \\
\hline Pelophylax perezi & 30TUK43 & 100,00 & 145,94 & 114,02 & 36,11 & 6601,61 & 326,07 & 16,37 & 309,70 & 117,03 & 234,62 & 234,62 & 65,32 & 370,04 & 44,08 & 7,20 & 37,97 & \begin{tabular}{|l|l|}
121,24 \\
\end{tabular} & 40,37 & 40,37 & 101,6 \\
\hline Pelophylax perezi & 30TUK44 & 100,00 & 137,53 & 113,39 & 36,27 & 6544,31 & 316,55 & 9,15 & 307,40 & 116, & 225,59 & 225, & 57, & 384,04 & 47,22 & 8,61 & 36,50 & 125,24 & 45,59 & 45,61 & 102,2 \\
\hline Pelophylax perezi & 30TUK45 & 100,00 & 146,31 & 112,88 & 36,51 & 6512,57 & 23,18 & $\begin{array}{r}17,87 \\
17\end{array}$ & 305,31 & 107,34 & 233,69 & 233,69 & 66,26 & 353,29 & 42,51 & $\mid$ & 37,12 & 115,64 & 40,71 & 40,71 & $\begin{array}{r}0,26 \\
94,95\end{array}$ \\
\hline
\end{tabular}




\begin{tabular}{|c|c|c|c|c|c|c|c|c|c|c|c|c|c|c|c|c|c|c|c|c|c|}
\hline TAXON & UTM & $\mathrm{km} 2$ & B101 & B102 & $\mathrm{BIO3}$ & BIO4 & B105 & B106 & B107 & B108 & B109 & B1010 & BIO11 & BIO12 & B1013 & BIO14 & BIO15 & B1016 & B1017 & B1018 & B1019 \\
\hline Pelophylax perezi & 30TUK46 & 100,00 & 100,93 & 111,37 & 36,83 & 6305,77 & 278,33 & $-20,28$ & 298,61 & 82,70 & 186,21 & 186,97 & 27,26 & 508,86 & 65,08 & 15,92 & 33,13 & 163,43 & 70,14 & 72,82 & 130,45 \\
\hline Pelophylax perezi & 30TUK47 & 100,00 & 114,25 & 111,30 & 36,96 & 6312,72 & 289,66 & $-9,22$ & 298,88 & 98,77 & 198,49 & 199,77 & 38,77 & 421,32 & 56,28 & 12,95 & 34,11 & 136,14 & 60,19 & 61,26 & 102,46 \\
\hline Pelophylax perezi & 30TUK48 & 100,00 & 88,76 & 110,42 & 37,00 & 6176,06 & 264,24 & $-29,81$ & 294,05 & 71,09 & 172,36 & 173,36 & 17,44 & 539,78 & 70,30 & 18,85 & 31,91 & 171,63 & 78,73 & 83,12 & 134,92 \\
\hline Pelophylax perezi & 30TUK49 & 100,00 & 106,49 & 110,67 & 37,00 & \begin{tabular}{ll|}
6192,96 \\
\end{tabular} & 279,53 & $-15,58$ & 295,10 & 120,31 & 188,72 & 190,49 & 32,85 & 428,51 & 58,98 & 14,66 & 33,71 & 138,90 & 64,95 & 67,18 & 100,21 \\
\hline Pelophylax perezi & 30TUK53 & 100,00 & 150,74 & $\begin{array}{ll}113,37 \\
\end{array}$ & 36,00 & 6632,21 & 330,08 & 20,54 & 309,54 & 109,54 & 239,77 & 239,77 & 69,22 & 357,35 & 42,01 & 6,85 & 38,16 & 117,52 & 38,30 & 38,30 & 98,42 \\
\hline Pelophylax perezi & 30TUK54 & 100,00 & 131,14 & 112,60 & 36,09 & 6545,57 & 310,48 & 3,62 & 306,87 & 113,72 & 219,40 & 219,58 & 52,15 & 401,54 & 50,23 & 9,73 & 35,69 & 130,93 & 49,81 & 49,99 & 104,96 \\
\hline Pelophylax perezi & 30TUK55 & 100,00 & 140,85 & 112,00 & 36,01 & 6541,56 & 318,01 & 12,68 & 305,33 & 110,79 & 228,88 & 228,88 & 60,92 & 365,31 & 44,80 & 8,45 & 35,97 & 118,38 & 44,29 & 44,29 & 96,25 \\
\hline Pelophylax perezi & $\begin{array}{l}30 T U K 56 \\
\end{array}$ & 100,00 & 118,29 & 111,17 & 36,41 & 6398,64 & 294,72 & $-5,92$ & 300,64 & 92,11 & 204,53 & 204,95 & 41,94 & 438,19 & 55,93 & 12, 12,85 & 34,18 & 141,45 & 59,34 & 60,68 & 111,31 \\
\hline Pelophylax perezi & 30TUK57 & 100,00 & 117,59 & 110,53 & 36,51 & 6344,52 & 292,32 & $-6,49$ & 298,81 & 102,44 & 202,68 & 203,47 & 41,46 & 410,25 & 54,77 & 12,60 & 34,25 & 132,62 & 58,94 & 59,81 & 98,93 \\
\hline Pelophylax perezi & 30TUK58 & 100,00 & 96,35 & 109,92 & 36,98 & \begin{tabular}{|l|l|}
6196,46 \\
\end{tabular} & 270,65 & $-23,76$ & 294,41 & 85,99 & 179,84 & 180,83 & 24,11 & 484,28 & 65,80 & 16,94 & 32,88 & 156,43 & 73,19 & 76,41 & 114,71 \\
\hline Pelophylax perezi & 30TUK59 & 100,00 & 103,59 & 109,52 & 36,96 & 6183,07 & 275,94 & $-17,90$ & 293,85 & 121,31 & 186,10 & 187,49 & 30,31 & 432,48 & 60,85 & 15,26 & 34,09 & 142,54 & 67,51 & 69,93 & 97,73 \\
\hline Pelophylax perezi & 30TUK63 & 100,00 & 151,11 & 112,77 & 36,00 & 6661,99 & 330,47 & 20,64 & 309,84 & 108,24 & 240,56 & 240,56 & 69,26 & 357,44 & 41,84 & 7,00 & 37,62 & 117,66 & 38,88 & 38,88 & 98,11 \\
\hline Pelophylax perezi & 30TUK64 & 100,00 & 143,47 & 111,86 & 36,00 & 6613,83 & 321,64 & 14,24 & 307,40 & 113,18 & 232,51 & 232,51 & 62,66 & 368,43 & 44,41 & 8,08 & 36,43 & 120,08 & 43,36 & 43,36 & 98,32 \\
\hline Pelophylax perezi & 30TUK65 & 100,00 & 132,66 & 111,17 & 36,00 & 6534,47 & 309,78 & 5,08 & 304,70 & 113,12 & 220,75 & 220,75 & 53,25 & 387,33 & 48,71 & 9,88 & 35,14 & 125,27 & 49,91 & 49,91 & 99,34 \\
\hline Pelophylax perezi & 30TUK66 & 100,00 & 113,97 & 110,31 & 36,34 & 6387,97 & 290,11 & $-9,62$ & 299,73 & 93,62 & 200,12 & 200,66 & 38,09 & 443,80 & 57,94 & 13,48 & 33,95 & 143,79 & 62,19 & 63,67 & 109,62 \\
\hline Pelophylax perezi & 30TUK67 & 100,00 & 115,18 & 109,57 & 36,26 & 6353,57 & 289,42 & $-8,52$ & 297,94 & 99,45 & 200,54 & 201,23 & 39,29 & 424,64 & 56,42 & 13,34 & 33,94 & 137,14 & 61,37 & 62,58 & 102,34 \\
\hline Pelophylax perezi & 30TUK68 & 100,00 & 112,38 & 108,73 & 36,22 & 6287,41 & 284,87 & $-10,69$ & 295,57 & 119,11 & 196,26 & 197,41 & 37,17 & 413,36 & 57,04 & 13,77 & 34,30 & 134,88 & 62,91 & 64,32 & 94,84 \\
\hline Pelophylax perezi & 30TUK69 & 100,00 & 100,89 & 108,38 & 36,53 & 6170,98 & 272,44 & $-20,11$ & 292,55 & 118,39 & 183,75 & 184,77 & 28,19 & 441,47 & 62,70 & 16,10 & 34,16 & 146,82 & 70,40 & 73,12 & 97,69 \\
\hline Pelophylax perezi & 30TUK73 & 100,00 & 149,81 & 112,07 & 35,82 & 6700,78 & 329,16 & 19,16 & 310,00 & 106,77 & 239,81 & 239,81 & 67,62 & 362,88 & 42,42 & 7,16 & 37,32 & 119,15 & 40,05 & 40,05 & 99,37 \\
\hline Pelophylax perezi & 30TUK74 & 100,00 & 148,29 & 111,08 & 35,77 & 6661,16 & 326,08 & 18,42 & 307,66 & $\mid 106,53$ & 237,77 & $237,77 \mid$ & 66.49 & 360,88 & 42,33 & 7,73 & 36,76 & $|118,60|$ & 41,34 & 41,34 & 97,94 \\
\hline Pelophylax perezi & 30TUK75 & 100,00 & 136,04 & 110,17 & 35,75 & 6585,37 & 312,70 & 8,06 & 304,64 & 107,44 & 224,68 & 224,68 & 55,91 & 383,44 & 47,1 & 9,64 & 35,07 & 123,98 & 48,72 & 48,72 & 99,62 \\
\hline Pelophylax perezi & 30 TUK76 & 100,00 & 126,44 & 109,29 & 35,91 & 6486,12 & 301,51 & 0,41 & 301,10 & 104,01 & 213,75 & 214,03 & 48,02 & 399,10 & 51,13 & 11,25 & 34,41 & 128,63 & 54,68 & 54,91 & 99,41 \\
\hline Pelophylax perezi & 30TUK77 & 100,00 & 128,57 & 108,45 & \begin{tabular}{|l|l|}
35,97 \\
\end{tabular} & $\begin{array}{lll}6458,48 \\
\end{array}$ & 301,79 & 2,79 & 299,00 & $\begin{array}{l}98,53 \\
\end{array}$ & 215,16 & 215,53 & 50,03 & 387,77 & 49,53 & 11,21 & 34,19 & 124,92 & 53,75 & 54,05 & 96,10 \\
\hline Pelophylax perezi & 30TUK78 & 100,00 & 110,91 & 107,58 & 35,99 & 6295,12 & 282,65 & $-11,84$ & 294,49 & 120,68 & 194,87 & 196,09 & 35,86 & 419,20 & 58,01 & 14,20 & 34,27 & 137,62 & 64,45 & 66,14 & 95,07 \\
\hline Pelophylax perezi & 30TUK85 & 100,00 & 145,18 & 109,17 & 35,10 & 6648,13 & 321,11 & 16,44 & 304,68 & 102,51 & 234,40 & 234,40 & 63,61 & 368,66 & 42,96 & 8,57 & 35,71 & 121,13 & 43,99 & 43,99 & 99,45 \\
\hline Pelophylax perezi & 30TUK86 & 100,00 & 133,66 & 108,22 & 35,36 & 6561,83 & 308,14 & 6,79 & 301,35 & 98,74 & 221,89 & 222,00 & 53,67 & 390,65 & 47,58 & 10,50 & 34,35 & 125,95 & 51,28 & 51,34 & 101,24 \\
\hline Pelophylax perezi & $\begin{array}{l}\text { 30TUK87 } \\
\end{array}$ & 100,00 & 133,51 & 107,34 & 35,38 & 6530,87 & 306,06 & 7,06 & 299,00 & 93,52 & $\begin{array}{l}220,89 \\
228\end{array}$ & 221,09 & 53,58 & 385,86 & $\begin{array}{l}47,13 \\
470\end{array}$ & 10,80 & 34,08 & 124,41 & $\begin{array}{l}\mid 1,1,68 \\
51,68\end{array}$ & 51,78 & 99,15 \\
\hline Pelophylax perezi & 30TUK88 & 100,00 & 120,92 & 106,42 & 35,70 & 6408,92 & 291,84 & $-2,97$ & 294,81 & 109,49 & 205,88 & 207,34 & 43,50 & 407,06 & 52,75 & 12,92 & 33,55 & 130,32 & 59,09 & 60,40 & 98,12 \\
\hline Pelophylax perezi & 30TUK89 & 100,00 & 98,05 & 106,76 & 36,38 & 6211,20 & 268,70 & $-21,19$ & 289,90 & 113,77 & 181,84 & 182,58 & 25,62 & 478,86 & 64,70 & 17,80 & 32,27 & 155,90 & 74,58 & 78,62 & 110,54 \\
\hline Pelophylax perezi & 30TUK94 & 100,00 & 143,14 & 109,56 & 35,00 & 6725,91 & 321,14 & 13,71 & 307,44 & 100,04 & 233,56 & 233,56 & 60,79 & 386,98 & 44,44 & 8,99 & 35,52 & 126,62 & 45,84 & 45,84 & 105,94 \\
\hline Pelophylax perezi & 30TUK95 & 100,00 & 145,68 & 108,31 & 35,00 & 6683,45 & 321,35 & 16,88 & 304,47 & 102,77 & 235,29 & 235,29 & 63,46 & 376,91 & 43,02 & 8,79 & 35,68 & 124,77 & 44,47 & 44,47 & 103,72 \\
\hline Pelophylax perezi & \begin{tabular}{|l|l|}
30 TUK96 \\
\end{tabular} & 100,00 & 142,41 & 107,19 & 35,01 & $\begin{array}{l}60029,52 \\
6629\end{array}$ & 316,24 & $\begin{array}{l}0,00 \\
14,88 \\
\end{array}$ & \begin{tabular}{|l|}
301,36 \\
\end{tabular} & 100,00 & 231,30 & 231,30 & $\begin{array}{l}60,84 \\
60\end{array}$ & \begin{tabular}{|l|l|}
380,83 \\
\end{tabular} & $\begin{array}{l}4,26 \\
44,26 \\
\end{array}$ & 9,53 & 35,10 & \begin{tabular}{|l|}
125,81 \\
\end{tabular} & 46,72 & 46,72 & 103,71 \\
\hline Pelophylax perezi & 30TUK97 & 100,00 & 130,01 & 106,23 & \begin{tabular}{|l|}
35,08 \\
\end{tabular} & 6535,23 & 302,11 & 4,72 & 297,39 & 91,01 & 217,24 & 217,90 & 50,46 & 406,46 & 48,70 & 11,65 & 33,54 & 131,35 & 54,53 & 54,97 & 105,93 \\
\hline Pelophylax perezi & 30TUK98 & 100,00 & 117,08 & 105,55 & 35,46 & 6424,03 & 287,68 & $-5,43$ & 293,11 & 92,36 & 202,24 & 203,76 & 39,80 & 433,53 & 54,70 & 14,08 & 32,57 & 137,60 & 62,24 & 64,39 & 106,93 \\
\hline Pelophylax perezi & 30TUK99 & 100,00 & 96,32 & 106,41 & 36,45 & 6227,65 & 266,97 & $-21,79$ & 288,76 & 105,56 & 180,69 & 181,32 & 24,05 & 503,34 & 65,66 & 18,77 & 31,15 & 161,06 & 76,80 & 81,29 & 120,12 \\
\hline Pelophylax perezi & 30TULOO & 100,00 & 110,18 & 114,28 & 38,09 & 6167,10 & 284,62 & $-10,15$ & 294,77 & 70,03 & $\begin{array}{l}191,37 \\
\end{array}$ & 193,92 & 36,64 & 447,81 & 55,41 & 13,05 & 32,65 & 141,66 & 61,14 & 63,42 & 119,99 \\
\hline Pelophylax perezi & 30TUL01 & 100,00 & $\begin{array}{l}110,10 \\
116,99\end{array}$ & $\begin{array}{l}114,20 \\
115,61\end{array}$ & 30,79 & 6125,72 & 290,02 & $-4,01$ & 294,27 & $\mid 76,75$ & \begin{tabular}{|l|}
196,66 \\
196
\end{tabular} & $\begin{array}{l}199,792 \\
199,7\end{array}$ & $\begin{array}{l}0,04 \\
43,19\end{array}$ & \begin{tabular}{|l}
$441,01,76$ \\
409,7
\end{tabular} & $\begin{array}{l}0,414 \\
50,29 \\
\end{array}$ & $\begin{array}{l}\mid 3,030 \\
11,94\end{array}$ & 32,06 & \begin{tabular}{|l|}
$129,01,01$ \\
\end{tabular} & $\begin{array}{l}\mid 1,14 \\
57,22\end{array}$ & $\begin{array}{l}5,444 \\
59,14\end{array}$ & 109,13 \\
\hline Pelophylax perezi & 30TUL03 & 100,00 & 118,01 & 116,63 & 39,36 & 6071,70 & 290,22 & $-2,33$ & 292,55 & 77,63 & 196,35 & 199,95 & 44,42 & 390,95 & 47,67 & 11,58 & 31,22 & 122,40 & 56,58 & 58,81 & 103,35 \\
\hline Pelophylax perezi & 30TUL04 & 100,00 & 118,51 & 116,89 & 39,44 & 6066,89 & 290,54 & $-2,02$ & 292,56 & 78,15 & 196,72 & 200,28 & 44,73 & 384,11 & 46,77 & 11,48 & 31,17 & 120,88 & 56,10 & 58,44 & 101,31 \\
\hline Pelophylax perezi & 30TUL05 & 100,00 & 119,92 & 117,01 & 39,21 & 6073,97 & 292,05 & $-0,88$ & 292,92 & 79,81 & 198,15 & 201,49 & 45,87 & 374,10 & 45,45 & 11,11 & 31,60 & 119,13 & 54,34 & 56,68 & 98,92 \\
\hline Pelophylax perezi & 30TUL06 & 100,00 & 120,28 & 117,02 & 39,1 & 6083,57 & 292,61 & $\begin{array}{l}-, 0,73 \\
-0,73\end{array}$ & 293,34 & 80,51 & 198,68 & 201,75 & 45,65 & 371,36 & 44,96 & 11,37 & 31,54 & 119,15 & 54,14 & 56,68 & 98,24 \\
\hline Pelophylax perezi & 30TUL07 & 100,00 & 120,47 & 117,01 & 39,03 & 6099,98 & 293,05 & $-0,56$ & 293,61 & 80,67 & 199,07 & 201,76 & 45,37 & 370,50 & 44,52 & 11,69 & 31,59 & 119,75 & 54,12 & 56,69 & 98,31 \\
\hline Pelophylax perezi & 30TULO9 & 100,00 & 124,48 & 117,00 & 39,01 & 6110,66 & 296,34 & 1,98 & 294,37 & 85,50 & 202,91 & 205,33 & 48,39 & 362,45 & 42,43 & 11,87 & 31,51 & 119,34 & 53,11 & 55,39 & 96,87 \\
\hline Pelophylax perezi & 30TUL11 & 100,00 & 112,50 & 114,35 & 38,20 & 6142,97 & 285,96 & $-8,51$ & 294,47 & 77,47 & 193,01 & 195,76 & 38,67 & 418,29 & 52,93 & 12,89 & 32,10 & 130,44 & 59,94 & 62,39 & 107,87 \\
\hline Pelophylax perezi & 30TUL12 & 100,00 & 115,75 & 115,13 & 38,71 & 6120,06 & 288,45 & $-5,24$ & 293,69 & 85,69 & 195,33 & 198,45 & 41,82 & 399,52 & 0,12 & 12,22 & 31,84 & 124,37 & 57,94 & 60,50 & 103,02 \\
\hline Pelophylax perezi & 30TUL13 & 100,00 & 117,23 & 115,59 & 38,98 & 6106,01 & 289 & $\begin{array}{l}-3,24 \\
-3,42 \\
\end{array}$ & 292,93 & $\begin{array}{l}83,52 \\
83,5\end{array}$ & \begin{tabular}{|l|l|}
196,31 \\
\end{tabular} & 19 & $\begin{array}{l}1,0<2 \\
43,05 \\
\end{array}$ & \begin{tabular}{|l|l|}
389,36 \\
\end{tabular} & $\begin{array}{ll}0,414 \\
484\end{array}$ & $\begin{array}{l}2,2,0 \\
12,0\end{array}$ & 31,30 & \begin{tabular}{|l|}
121,10 \\
\end{tabular} & 57,11 & 59,78 & 100,52 \\
\hline Pelophylax perezi & 30TUL14 & 100,00 & 119,47 & 116,01 & 39,00 & 6096,91 & 291,40 & $-1,53$ & 292,94 & 79,08 & 198,12 & 201,34 & 44,98 & 379,21 & 46,62 & 11,8 & 30,89 & 118,57 & 56,08 & 58,75 & 98,30 \\
\hline Pelophylax perezi & 30TUL15 & 100,00 & 120,68 & 116,36 & 39,02 & 6096,79 & 292,68 & $-0,61$ & 293,29 & 80,60 & 199,20 & 202,54 & 46,05 & 373,62 & 45,62 & 11,35 & 31,03 & 117,61 & 54,56 & 57,46 & 97,78 \\
\hline Pelophylax perezi & 30TUL16 & 100,00 & 121,14 & 116,50 & 39,06 & 6101,75 & 293,16 & $-0,21$ & 293,38 & 81,37 & 199,89 & 202,88 & 46,11 & 371,73 & 44,97 & 11,71 & 30,99 & 117,60 & 54,68 & 57,42 & 97,91 \\
\hline Pelophylax perezi & 30TUL18 & 100,00 & 123,31 & 116,90 & 39,00 & 6114,50 & 295,28 & 1,28 & 293,99 & 83,96 & 201,97 & 204,40 & 47,29 & 368,44 & 43,48 & 11,85 & 31,01 & 118,60 & 53,89 & 56,66 & 98,44 \\
\hline Pelophylax perezi & $30 \mathrm{TU}$ & 100,00 & $\frac{129}{99}-10$ & $\frac{112}{112}$ & 37,90 & 6148,64 & 273, & $\begin{array}{l}-1,20 \\
-19,95 \\
\end{array}$ & \begin{tabular}{|l|}
293,84 \\
\end{tabular} & $\begin{array}{l}30,97 \\
96,97 \\
\end{array}$ & 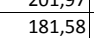 & $\begin{array}{l}204,404 \\
183,42 \\
\end{array}$ & $\begin{array}{l}41,25 \\
27,20\end{array}$ & \begin{tabular}{|l|}
$400,45,32$ \\
\end{tabular} & $\begin{array}{l}35,400 \\
61,68\end{array}$ & $\begin{array}{l}11,039 \\
15,97\end{array}$ & $\frac{1,01}{32,11}$ & \begin{tabular}{|l|}
148,31 \\
140
\end{tabular} & | & $\begin{array}{l}\mid 20,00 \\
72,51\end{array}$ & $\begin{array}{r}50,44 \\
120,04\end{array}$ \\
\hline Pelophylax perezi & 30TUL21 & 100,00 & 108,61 & 113,21 & 38,00 & 6144,71 & 281,79 & $-12,28$ & 294,07 & 127,77 & 189,54 & 191,95 & 35,27 & 426,13 & 55,39 & 13,99 & 32,14 & 133,37 & 62,80 & 65,65 & 106,39 \\
\hline Pelophylax perezi & 30TUL22 & 100,00 & 113,64 & 113,85 & 38,04 & $\mid 6132,68$ & 286,00 & $\begin{array}{r}-7,79 \\
-7,\end{array}$ & 293,79 & 130,43 & \begin{tabular}{|l|}
193,77 \\
\end{tabular} & $\begin{array}{l}196,52 \\
\end{array}$ & 39,75 & |401,84 & 51,69 & $\mid 12,96$ & 31,82 & $\mid 125,55$ & 59,50 & $\begin{array}{ll}62,28 \\
\end{array}$ & 100,61 \\
\hline Pelophylax perezi & 30TUL23 & 100,00 & 116,90 & 114,53 & 38,55 & 6121,92 & 288,76 & $-4,31$ & 293,07 & 129,16 & 196,38 & 199,30 & 42,62 & 388,19 & 49,19 & 12,16 & 31,45 & 120,77 & 57,43 & 60,30 & 98,07 \\
\hline Pelophylax perezi & 30TUL24 & 100,00 & 119 & 114,94 & 38,87 & 6127,27 & 291,15 & $-1,90$ & 293,05 & 93,05 & 198,64 & 201 & 44,47 & 379,32 & 47,25 & 12,00 & 31,03 & 118,09 & 56,54 & 59,31 & 97 \\
\hline Pelophylax perezi & 30TUL25 & 100,00 & 120,94 & 115,34 & 39,00 & 6132,99 & 292,69 & $-0,53$ & 293,22 & 80,93 & 200,23 & 203,11 & 45,72 & $\begin{array}{l}374,95 \\
\end{array}$ & 46,05 & 11,99 & 30,37 & \begin{tabular}{|l|l|}
117,06 \\
\end{tabular} & 55,76 & 58,77 & 97,00 \\
\hline Pelophylax perezi & 30TUL27 & 100,00 & 121,95 & 116,01 & 39,00 & 6121,77 & 293,83 & 0,06 & 293,77 & 82,36 & 200,81 & 203,47 & 46,22 & 375,81 & 45,01 & 12,00 & 30,34 & 118,29 & 55,65 & 58,75 & 99,25 \\
\hline Pelophylax perezi & 30TUL29 & 100,00 & 124,35 & 116.46 & 39,00 & 6110,26 & 295,87 & 1.75 & 294.12 & 85,78 & 202.97 & 205,22 & 47.91 & 377.03 & 44,03 & 12,18 & 30.50 & 120.93 & 54,84 & 58.46 & 101.84 \\
\hline Pelophylax perezi & 30TUL30 & 100,00 & 95,80 & 111,23 & 37,54 & 6133,05 & 269,38 & $-23,46$ & 292,84 & 103,8 & 177, & 179,37 & 23, & 485,58 & 64,25 & 17,28 & 32,02 & 153 & 72,46 & 76,43 & 119,35 \\
\hline Pelophylax perezi & 30TUL32 & 100,00 & 114,95 & 112,78 & 38,00 & 6158,72 & 286,66 & $-6,86$ & 293,52 & $\begin{array}{l}135,48 \\
\end{array}$ & 195,63 & 197,95 & 40,37 & 393,73 & 51,45 & 13,05 & 32,16 & 124,57 & 59,27 & 61,92 & 96,10 \\
\hline
\end{tabular}




\begin{tabular}{|c|c|c|c|c|c|c|c|c|c|c|c|c|c|c|c|c|c|c|c|c|c|}
\hline TAXON & UTM & $\mathrm{km2}$ & BIO1 & B102 & $\mathrm{BIO3}$ & B104 & B105 & B106 & B107 & B108 & B109 & BIO10 & BIO11 & BIO12 & BIO13 & BIO14 & BIO15 & BIO16 & BIO17 & BIO18 & BI019 \\
\hline Pelophylax perezi & 30TUL36 & 100,00 & 122,90 & 114,72 & 38,71 & 6153,03 & 294,14 & 0,59 & 293,55 & 83,43 & 202,46 & 205,13 & 46,99 & 375,59 & 45,42 & 12,00 & 30,11 & 117,00 & 55,89 & 58,94 & 97,66 \\
\hline Pelophylax perezi & 30TUL38 & 100,00 & 122,01 & 115,66 & 39,00 & 6139,48 & 293,63 & 0,19 & 293,44 & 82,82 & 201,31 & 203,60 & 45,82 & 386,17 & 45,38 & 12,31 & 30,30 & \begin{tabular}{|l|l|l|}
121,43 \\
\end{tabular} & 56,31 & 60,28 & 103,48 \\
\hline Pelophylax perezi & 30TUL39 & 100,00 & 124,29 & $\begin{array}{l}115,97 \\
\end{array}$ & 39,00 & 6127,98 & 295,91 & 2,29 & \begin{tabular}{|l|l|}
293,62 \\
\end{tabular} & 85,70 & 203,32 & 205,50 & \begin{tabular}{ll|}
47,89 \\
\end{tabular} & 385,62 & 44,94 & 12,25 & 30,20 & 122,30 & 55,58 & 59,60 & 105,06 \\
\hline Pelophylax perezi & 30TUL40 & 100,00 & 98,29 & 110,34 & 37,06 & 6137,15 & 271,00 & $-21,99$ & 292,99 & \begin{tabular}{l|l|}
115,20 \\
\end{tabular} & \begin{tabular}{ll|l}
180,48 \\
\end{tabular} & \begin{tabular}{l|l|}
181,82 \\
\end{tabular} & 26,00 & \begin{tabular}{ll|l}
459,96 \\
\end{tabular} & 62,84 & 16,79 & 32,74 & \begin{tabular}{ll|}
148,90 \\
\end{tabular} & $\begin{array}{ll}70,95 \\
\end{array}$ & 74,44 & 108,01 \\
\hline Pelophylax perezi & 30TUL41 & 100,00 & 110,84 & 110,94 & 37,20 & 6171,97 & 282,27 & $-11,04$ & 293,30 & 130,51 & \begin{tabular}{|l|l|}
192,27 \\
\end{tabular} & \begin{tabular}{|l|l|l|}
194,19 \\
\end{tabular} & 36,58 & 403,66 & 54,89 & 14,22 & \begin{tabular}{|l|}
33,07 \\
\end{tabular} & \begin{tabular}{l|l|}
130,92 \\
\end{tabular} & \begin{tabular}{|l|l|l|}
62,23 \\
\end{tabular} & \begin{tabular}{l|l|}
64,93 \\
\end{tabular} & 94,35 \\
\hline Pelophylax perezi & 30TUL42 & 100,00 & 117,11 & 111,48 & 37,70 & 6190,93 & 287,91 & $-5,11$ & 293,03 & 137,87 & \begin{tabular}{|l|l|}
198,17 \\
\end{tabular} & 200,36 & 42,06 & 385,70 & 50,87 & 13,01 & 32,17 & 123,17 & 59,00 & 61,30 & 92,32 \\
\hline Pelophylax perezi & 30TUL48 & 100,00 & 121,62 & 114,72 & 38,82 & 6148,09 & 292,76 & $-0,10$ & 292,86 & 82,72 & 201,16 & 203,36 & $\begin{array}{l}45,36 \\
\end{array}$ & \begin{tabular}{ll|}
396,06 \\
\end{tabular} & 46,36 & 12,66 & 29,93 & \begin{tabular}{ll|}
123,46 \\
\end{tabular} & 57,60 & 62,23 & 106,48 \\
\hline Pelophylax perezi & 30TUL49 & 100,00 & 123,73 & 115,15 & 39,00 & 6132,16 & 294,86 & 1,85 & 293,01 & 85,12 & 202,97 & 204,89 & 47,32 & \begin{tabular}{|l|l|}
397,40 \\
\end{tabular} & \begin{tabular}{ll|}
46,06 \\
\end{tabular} & 12,77 & 29,75 & \begin{tabular}{|l|l|}
124,49 \\
\end{tabular} & 57,33 & 61,80 & 108,98 \\
\hline Pelophylax perezi & 30TUL50 & 100,00 & 106,06 & 109,31 & \begin{tabular}{ll|}
36,96 \\
\end{tabular} & 6168,92 & 277,19 & $-15,90$ & \begin{tabular}{|l|l|}
293,08 \\
\end{tabular} & 124,70 & $\begin{array}{l}188,09 \\
\end{array}$ & \begin{tabular}{l|l|}
189,54 \\
\end{tabular} & 32,53 & 414,73 & 58,77 & 15,01 & 34,32 & $\begin{array}{l}137,72 \\
\end{array}$ & 65,86 & 68,31 & 92,25 \\
\hline Pelophylax perezi & 30TUL51 & 100,00 & 111,96 & 109,47 & 36,99 & 6186,67 & 282,21] & $-10,26$ & 292,47 & 131,75 & 193,70 & 195,51 & 37,53 & 397,01 & 54,77 & 14,28 & 33,63 & 130,34 & 62,25 & 64,91 . & 90,30 \\
\hline Pelophylax perezi & 30TUL52 & 100,00 & 117,23 & 109,92 & 37,11 & 6205,52 & 286,90 & $-5,14$ & 292,04 & 137,77 & \begin{tabular}{|l|l|}
198,64 \\
\end{tabular} & 200,75 & 41,84 & 385,60 & 51,36 & 13,13 & 32,48 & 124,47 & \begin{tabular}{|l|l|}
59,16 \\
\end{tabular} & \begin{tabular}{|l|l|}
62,07 \\
\end{tabular} & 90,53 \\
\hline Pelophylax perezi & 30TUL54 & 100,00 & 119,36 & 110,76 & 37,59 & 6209,85 & 288,73 & $-2,57$ & 291,29 & \begin{tabular}{ll|}
140,60 \\
\end{tabular} & 200,38 & 202,50 & 43,13 & 386,54 & 49,22 & 12,74 & 31,26 & 122,31 & 57,77 & 61,86 & 95,20 \\
\hline Pelophylax perezi & 30TUL56 & 100,00 & 122,10 & 112,07 & 38,00 & 6182,96 & 291,54 & $-0,10$ & 291,64 & 108,31 & 202,33 & 204,53 & 45,69 & 388,29 & 47,19 & 12,05 & 30,90 & \begin{tabular}{|l|l|}
120,47 \\
\end{tabular} & 56,23 & \begin{tabular}{l|l}
61,05 \\
\end{tabular} & 100,49 \\
\hline Pelophylax perezi & 30TUL57 & 100,00 & 123,07 & 112,78 & 38,02 & 6181,97 & 293,06 & 0,34 & \begin{tabular}{|l|}
292,72 \\
\end{tabular} & 84,41 & \begin{tabular}{|l|l|}
203,18 \\
\end{tabular} & 205,50 & 46,37 & 391,90 & 46,43 & 12,03 & 30,66 & \begin{tabular}{l|l|}
121,94 \\
\end{tabular} & 56,41 & 61,21 & 103,59 \\
\hline Pelophylax perezi & 30TUL58 & 100,00 & 123,85 & 113,52 & 38,29 & 6158,24 & 294,08 & 1,67 & 292,41 & 85,56 & \begin{tabular}{|l|l|}
203,82 \\
\end{tabular} & 205,75 & 47, & 397,03 & 46,06 & 12,08 & 30,10 & 123,65 & 56,97 & 61,73 & 106,99 \\
\hline Pelophylax perezi & 30TUL59 & 100,00 & 124,59 & 114,18 & 38,41 & 6141,55 & 294,91 & 2,19 & 292,73 & 86,62 & \begin{tabular}{|l|}
203,97 \\
\end{tabular} & \begin{tabular}{|l|l|}
205,89 \\
\end{tabular} & 47,84 & \begin{tabular}{|l|l|}
403,19 \\
\end{tabular} & 46,57 & 12,84 & 29,82 & \begin{tabular}{|l|l|}
125,94 \\
\end{tabular} & 57,73 & 62,66 & 110,59 \\
\hline Pelophylax perezi & 30TUL60 & 100,00 & 104,58 & 107,76 & 36,22 & 6148,58 & 274,42 & $-17,22$ & 291,64 & 122,81 & $\begin{array}{l}186,65 \\
\end{array}$ & \begin{tabular}{|l|l|}
187,74 \\
\end{tabular} & 31,39 & \begin{tabular}{ll|l}
412,56 \\
\end{tabular} & 60,01 & 15,35 & 35,14 & \begin{tabular}{|l|l|}
139,47 \\
\end{tabular} & \begin{tabular}{|l|l|}
67,69 \\
\end{tabular} & \begin{tabular}{ll|}
70,06 \\
\end{tabular} & 87,97 \\
\hline Pelophylax perezi & 30TUL61 & 100,00 & 109,68 & 107,73 & 36,43 & 6183,77 & 278,66 & $-12,53$ & 291,19 & 128,92 & \begin{tabular}{|l|l|}
191,70 \\
\end{tabular} & 193,16 & $\begin{array}{l}35,45 \\
\end{array}$ & 401,21 & 56,55 & 14,90 & 34,20 & 133,92 & 64,43 & 67,35 & 88,12 \\
\hline Pelophylax perezi & 30TUL62 & 100,00 & 115,15 & 107,97 & 36,73 & 6226,64 & 283,59 & $-7,01$ & 290,59 & \begin{tabular}{ll|}
135,39 \\
\end{tabular} & $\begin{array}{l}197,16 \\
19\end{array}$ & \begin{tabular}{|l|l|l|}
198,98 \\
\end{tabular} & 39,81 & 393,84 & 52,96 & 13,83 & 32,93 & 128,41 & 61,14 & \begin{tabular}{ll|}
64,47 \\
\end{tabular} & 90,91 \\
\hline Pelophylax perezi & 30TUL63 & 100,00 & 116,76 & 108,44 & 36,98 & 6228,86 & 284,87 & $-5,48$ & 290,36 & \begin{tabular}{l|l|}
137,23 \\
\end{tabular} & $\begin{array}{l}198,50 \\
\end{array}$ & 200,40 & 40,9 & 395,52 & 51,62 & 13,19 & 32, & 127,21 & 60,18 & 64,31 & 94,06 \\
\hline Pelophylax perezi & $\begin{array}{l}30 \text { TUL66 } \\
\end{array}$ & 100,00 & 121,00 & 110,45 & \begin{tabular}{l|l}
37,55 \\
\end{tabular} & 6210,75 & 289,58 & $-0,94$ & 290,52 & 122,36 & 201,98 & 204,01 & 44,47 & 398,79 & \begin{tabular}{|l|l|}
48,28 \\
\end{tabular} & 12,53 & 30,18 & 123,56 & 58,21 & 63,56 & 102,40 \\
\hline Pelophylax perezi & 30TUL67 & 100,00 & 122,54 & 111,32 & 37,93 & 6189,27 & 291,36 & $-0,03$ & \begin{tabular}{|l|l|l|}
291,39 \\
\end{tabular} & $\begin{array}{ll}90,32 \\
\end{array}$ & 203,01 & $\begin{array}{l}204,96 \\
\end{array}$ & 45,99 & \begin{tabular}{l|l|}
399,58 \\
\end{tabular} & 47,35 & 12,35 & \begin{tabular}{l|l|}
30,15 \\
\end{tabular} & $\begin{array}{l}123,99 \\
\end{array}$ & 57,42 & 63,21 & 104,70 \\
\hline Pelophylax perezi & 30TUL69 & 100,00 & 122,60 & 112,92 & 38,06 & 6127,94 & 292,03 & $-0,01$ & 292,04 & 85,78 & 202,30 & \begin{tabular}{|l|l|}
203,99 \\
\end{tabular} & 46,31 & 412,80 & 47,56 & 13,17 & 29,66 & \begin{tabular}{|l|l|}
128,49 \\
\end{tabular} & 58,56 & 65,24 & 111,82 \\
\hline Pelophylax perezi & \begin{tabular}{|l|}
$30 T U L 70$ \\
\end{tabular} & 100,00 & 95,84 & 107,16 & 36,46 & 6136,64 & 265,89 & $-23,49$ & 289,38 & \begin{tabular}{ll|}
112,59 \\
\end{tabular} & $\begin{array}{l}178,64 \\
\end{array}$ & \begin{tabular}{|l|l|}
179,37 \\
\end{tabular} & 24,13 & 465,38 & 65,18 & 17,91 & 33,21 & 154,68 & 75,01 & 79,26 & 103,41 \\
\hline Pelophylax perezi & 30TUL71 & 100,00 & 106,17 & 106,36 & 36,08 & 6191,89 & 274,05 & $-15,29$ & 289,34 & 124,98 & 188,57 & 189,81 & 32,22 & 418,26 & 58,89 & 15,86 & \begin{tabular}{l|l}
34,05 \\
\end{tabular} & \begin{tabular}{|l|l|}
140,14 \\
\end{tabular} & \begin{tabular}{|l|l}
67,73 \\
\end{tabular} & 71,37 & 91,20 \\
\hline Pelophylax perezi & 30TUL72 & 100,00 & 110,81 & 106,15 & 36,19 & 6232,58 & 277,81 & $-10,92$ & 288,72 & 130,18 & 193,23 & \begin{tabular}{|l|l|}
194,73 \\
\end{tabular} & 35,67 & 414,40 & 55,85 & 14,89 & 32,81 & 136,22 & 65,05 & 69,51 & 94,27 \\
\hline Pelophylax perezi & 30TUL73 & 100,00 & 114,46 & 106,51 & \begin{tabular}{l|l}
36,45 \\
\end{tabular} & 6257,94 & 281,22 & \begin{tabular}{|l|l|}
$-7,24$ \\
\end{tabular} & 288,46 & 134,77 & $\begin{array}{l}196,88 \\
\end{array}$ & \begin{tabular}{l|l|}
198,54 \\
\end{tabular} & 38,53 & \begin{tabular}{ll|l}
411,88 \\
\end{tabular} & 53,39 & 13,91 & 31,75 & \begin{tabular}{l|l|}
132,72 \\
\end{tabular} & \begin{tabular}{ll|}
62,76 \\
\end{tabular} & 67,76 & 97,63 \\
\hline Pelophylax perezi & 30TUL74 & 100,00 & 118,27 & 107,23 & 36,81 & 6265,21 & 285,06 & $-3,55$ & 288,60 & \begin{tabular}{|l|l|}
139,17 \\
\end{tabular} & 200,50 & 202,28 & 41,66 & 406,48 & 50,87 & 13,08 & 31,26 & $\begin{array}{ll}128,45 \\
\end{array}$ & \begin{tabular}{|l|l|}
60,43 \\
\end{tabular} & 65,65 & 99,84 \\
\hline Pelophylax perezi & 30TUL77 & 100,00 & 122,47 & 109,62 & 37,13 & 6201,80 & 289,90 & $-0,06$ & 289,96 & 86,06 & 203,30 & \begin{tabular}{|l|}
205,12 \\
\end{tabular} & 45,66 & 407,01 & 48,03 & 13,00 & 30,08 & \begin{tabular}{|l|}
126,27 \\
\end{tabular} & 58,27 & 64,86 & 106,09 \\
\hline Pelophylax perezi & 30TUL79 & 100,00 & 116,90 & 111,40 & 37,96 & 6113,09 & 285,53 & $-5,35$ & 290,88 & \begin{tabular}{|l|}
86,07 \\
\end{tabular} & \begin{tabular}{|l|l|}
196,91 \\
\end{tabular} & \begin{tabular}{|l|l|l|}
198,48 \\
\end{tabular} & 41,60 & 432,60 & 50,56 & 14,06 & 29,12 & 133,23 & 61,81 & 70,69 & 114,12 \\
\hline Pelophylax perezi & 30TUL80 & 100,00 & 92,66 & 106,66 & 36,56 & 6150,71 & 262,51 & $-25,10$ & 287,61 & 107,84 & \begin{tabular}{l|l|}
176,05 \\
\end{tabular} & 176,55 & 21,48 & 499,76 & 67,25 & 19,42 & 31,58 & 162,96 & \begin{tabular}{|l|l|}
78,63 \\
\end{tabular} & 83,80 & 115,60 \\
\hline Pelophylax perezi & 30TUL81 & 100,00 & 105,88 & 104,96 & 35,99 & 6242,37 & 272,87 & $-14,65$ & 287,52 & 124,39 & \begin{tabular}{|l|l|}
189,19 \\
\end{tabular} & $\begin{array}{l}190,15 \\
\end{array}$ & 31,43 & 440,81 & 59,41 & 16,20 & 32,55 & 144,80 & 69,11 & 73,87 & 100,32 \\
\hline Pelophylax perezi & 30TUL82 & 100,00 & 113,51 & 104,40 & 35,99 & 6303,42 & 279,17 & $-7,94$ & 287,11 & 133,44 & $\begin{array}{l}196,90 \\
1\end{array}$ & \begin{tabular}{|l|l|}
198,34 \\
\end{tabular} & 37,24 & \begin{tabular}{l|l}
424,25 \\
\end{tabular} & 54,80 & 14,23 & 31,99 & $\begin{array}{ll}136,62 \\
\end{array}$ & 64,28 & 69,23 & 100,23 \\
\hline Pelophylax perezi & 30TUL87 & 100,00 & 121,53 & 107,92 & 37,00 & 6219,24 & 287,56 & $-0,66$ & 288,22 & 85,59 & \begin{tabular}{|l|l|}
202,69 \\
\end{tabular} & 204,38 & 44,6 & \begin{tabular}{|l|l|}
417,66 \\
\end{tabular} & 49,00 & 13,00 & 29,88 & 129,37 & 59,88 & 67,24 & 108,07 \\
\hline Pelophylax perezi & 30TUL89 & 100,00 & 115,78 & 109,77 & 37,20 & 6117,25 & 282,95 & $-6,84$ & 289,78 & \begin{tabular}{ll|}
126,76 \\
\end{tabular} & \begin{tabular}{|l|l|}
196,10 \\
\end{tabular} & \begin{tabular}{|l|l|}
197,42 \\
\end{tabular} & 40,47 & 440,64 & 51,64 & 14,72 & 28,99 & \begin{tabular}{|l|l|}
135,42 \\
\end{tabular} & $\begin{array}{ll}63,55 \\
\end{array}$ & 73,62 & 114,46 \\
\hline Pelophylax perezi & 30TUL90 & 100,00 & 88,55 & 106,60 & 36,78 & 6147,86 & 258,66 & $-27,33$ & \begin{tabular}{|l|}
285,99 \\
\end{tabular} & 96,43 & 172,41 & 172,71 & 18,22 & 541,27 & 69,75 & 20,88 & \begin{tabular}{|l|}
30,08 \\
\end{tabular} & $\begin{array}{ll}172,62 \\
\end{array}$ & \begin{tabular}{|l|l|}
83,43 \\
\end{tabular} & 88,12 & 130,46 \\
\hline Pelophylax perezi & 30TUL91 & 100,00 & 103,04 & 104,20 & 36,11 & 6268,38 & 269,75 & $-15,97$ & 285,72 & 120,93 & 187,10 & \begin{tabular}{|l|l|}
187,99 \\
\end{tabular} & 28,96 & 474,41 & 61,07 & 16,82 & 31,16 & 152,40 & 72,34 & 78,09 & 112,79 \\
\hline Pelophylax perezi & 30TUL94 & 100,00 & 117,12 & 103,36 & 35,95 & 6352,82 & 280,98 & $-3,91$ & 284,89 & 125,22 & 200,77 & 202,35 & 39,72 & \begin{tabular}{ll|}
439,99 \\
\end{tabular} & 52,49 & 13,18 & 30,68 & \begin{tabular}{|l|l|l|}
137,03 \\
\end{tabular} & \begin{tabular}{ll|}
63,16 \\
\end{tabular} & 70,18 & 111,11 \\
\hline Pelophylax perezi & 30TUL98 & 100,00 & 117,03 & 107,34 & 36,97 & 183,03 & 282,61 & $-4,76$ & 287,37 & \begin{tabular}{ll|}
112,48 \\
\end{tabular} & \begin{tabular}{ll|}
198,30 \\
\end{tabular} & \begin{tabular}{ll|}
199,66 \\
\end{tabular} & 41,1 & 440,27 & 51,47 & 14,2 & 29,06 & $\begin{array}{ll}135,63 \\
\end{array}$ & 63,50 & 72,80 & 113,82 \\
\hline Pelophylax perezi & 30TUM00 & 100,00 & 121,52 & 117,00 & 39,00 & 6099,22 & 293,63 & $-0,48$ & 294,12 & 82,95 & \begin{tabular}{|l|l|}
199,86 \\
\end{tabular} & 202,31 & 45,59 & \begin{tabular}{|l|}
376,10 \\
\end{tabular} & 44,12 & 12,70 & \begin{tabular}{|l|l|}
31,45 \\
\end{tabular} & 124,40 & 55,38 & 58,17 & 101,02 \\
\hline Pelophylax perezi & 30TUM01 & 100,00 & 119 & 117,00 & 39,00 & 6081,99 & 291,62 & $-2,32$ & 293,94 & \begin{tabular}{|l|l|}
81,27 \\
\end{tabular} & \begin{tabular}{|l|l|}
197,82 \\
\end{tabular} & \begin{tabular}{|l|l|}
200,03 \\
\end{tabular} & 43, & 390,11 & 46,00 & 13,86 & \begin{tabular}{|l|}
30,87 \\
\end{tabular} & 129,80 & 58,25 & 61,39 & 105,43 \\
\hline Pelophylax perezi & 30TUM02 & 100,00 & 121,08 & 117,00 & 39,00 & 6043,71 & 292,43 & $-0,94$ & 293,37 & 83,58 & 198,70 & 200,97 & 45,49 & 392,60 & 46,74 & 14,08 & 30,80 & 132,01 & \begin{tabular}{|l|l}
59,13 \\
\end{tabular} & \begin{tabular}{|l|l|}
61,87 \\
\end{tabular} & 106,46 \\
\hline Pelophylax perezi & 30TUM04 & 100,00 & 120,97 & 116,40 & 39,29 & 5966,85 & 290,96 & $-1,11$ & 292,07 & 85,40 & \begin{tabular}{|l|l|}
197,87 \\
\end{tabular} & $\begin{array}{l}199,85 \\
\end{array}$ & 46,33 & 413,75 & 50,18 & 15,69 & 30,44 & \begin{tabular}{|l|l|}
141,44 \\
\end{tabular} & \begin{tabular}{|c|}
64,64 \\
\end{tabular} & 66,80 & 111,96 \\
\hline Pelophylax perezi & 30TUM05 & 100,00 & 118,77 & 116,27 & 39,11 & 941,20 & 288,57 & $-3,38$ & 291,95 & 83,72 & \begin{tabular}{|l|l|}
195,41 \\
\end{tabular} & \begin{tabular}{|l|l|}
197,28 \\
\end{tabular} & 44, & 433,29 & 52,94 & 17,20 & 30,2 & 149,11 & 9,51 & 71,34 & 117,04 \\
\hline Pelophylax perezi & 30TUM06 & 100,00 & 18 & 11 & 39,44 & 5893,34 & 287,03 & $-3,74$ & 290,76 & 83,73 & 194,35 & 196,05 & 44 & 448,20 & 55,47 & 18,38 & 30, & \begin{tabular}{|l|l|l|}
155,69 \\
\end{tabular} & 73,56 & 74,99 & 120,66 \\
\hline Pelophylax perezi & 30TUM07 & 100,00 & 115,87 & 115,88 & 39,41 & 5863,27 & 284,32 & $-6,15$ & 290,46 & 81,90 & \begin{tabular}{l|l|l|}
192,13 \\
\end{tabular} & \begin{tabular}{|l|l|}
193,39 \\
\end{tabular} & 42,38 & \begin{tabular}{l|l|}
469,99 \\
\end{tabular} & 58,59 & 20,04 & 30,04 & $\begin{array}{ll}164,18 \\
\end{array}$ & \begin{tabular}{ll|}
79,36 \\
\end{tabular} & 80,14 & 125,95 \\
\hline Pelophylax perezi & 30TUM09 & 100,00 & 113,76 & 114,72 & 39,50 & 5767,30 & 279,73 & $-7,10$ & 286,83 & 80,94 & 189,89 & 189,89 & 41,24 & \begin{tabular}{|l|l|}
510,43 \\
\end{tabular} & 64,72 & 23,28 & 30,11 & 180,32 & 89,68 & 89,68 & 135,52 \\
\hline Pelophylax perezi & 30TUM11 & 100,00 & 118,37 & 117,00 & 39,00 & 6073,24 & 290,72 & $-3,53$ & 294,26 & 80,71 & \begin{tabular}{|l|l|}
196,67 \\
\end{tabular} & \begin{tabular}{|l|l|}
199,01 \\
\end{tabular} & 42,72 & 399,96 & 47,04 & 14,32 & 30,24 & 131,10 & 59,76 & 63,84 & 108,02 \\
\hline Pelophylax perezi & 30TUM13 & 100,00 & 120,75 & 116,94 & 39,21 & 5977,65 & 291,32 & $-1,57$ & \begin{tabular}{|l|}
292,89 \\
\end{tabular} & 85,24 & \begin{tabular}{|l|l|}
197,89 \\
\end{tabular} & \begin{tabular}{|l|l|}
199,78 \\
\end{tabular} & 46,0 & 408,67 & 48,88 & 15,53 & 29,84 & 136,65 & 62,41 & 66,12 & 110,30 \\
\hline Pelophylax perezi & 30TUM14 & 100,00 & 119,74 & 116,61 & 39,38 & 594 & 289,71 & $-2,67$ & 292,38 & 85,06 & 196,49 & 198,33 & 45,33 & 421,78 & 50,84 & 16,58 & 29,67 & 142,10 & \begin{tabular}{|l|l|}
65,79 \\
\end{tabular} & 69,43 & 113,40 \\
\hline Pelophylax perezi & 30TUM15 & 100,00 & 119,22 & 116,09 & 39,10 & 5907,52 & 288,30 & $\begin{array}{l}-3,32 \\
\end{array}$ & 291,62 & 85,19 & $\begin{array}{ll}195,62 \\
\end{array}$ & \begin{tabular}{|l|l|}
197,24 \\
\end{tabular} & 45,13 & \begin{tabular}{|l|l|}
434,67 \\
\end{tabular} & \begin{tabular}{|l|l|}
52,85 \\
\end{tabular} & 17,52 & 29,52 & \begin{tabular}{|l|l|}
147,70 \\
\end{tabular} & 69,14 & 72,57 & 116,46 \\
\hline Pelophylax perezi & 30TUM16 & 100,00 & 118,70 & 115,79 & 39,37 & 5856,60 & 286,73 & $-3,77$ & 290,50 & 85,25 & \begin{tabular}{|l|l|}
194,20 \\
\end{tabular} & $\begin{array}{l}196,06 \\
\end{array}$ & 45,19 & \begin{tabular}{ll|}
449,58 \\
\end{tabular} & 55,12 & 18,70 & 29,39 & 153,91 & 73,29 & 76,26 & 119,81 \\
\hline Pelophylax perezi & 30TUM17 & 100,00 & 117,29 & 115,08 & 39,24 & 5806,82 & 284,13 & $-4,69$ & 288,82 & \begin{tabular}{|l|}
84,79 \\
\end{tabular} & \begin{tabular}{|l|l|}
192,30 \\
\end{tabular} & \begin{tabular}{ll|}
194,02 \\
\end{tabular} & 44,52 & 469,07 & 58,02 & 20,24 & 29,2 & 161,68 & 78,54 & 80,92 & 124,26 \\
\hline Pelophylax perezi & $30 T \mathrm{~T}$ & 100,00 & 114 & 114 & 39,2 & 575 & 280 & $-6,5$ & 287 & 83 & 189, & 190 & 42 & 493,50 & 61,48 & & 29,04 & 170,85 & 84, & 86,58 & 130,20 \\
\hline Pelophylax perezi & 30TUM19 & 100,00 & 112,08 & 113,84 & 39,45 & 5711,47 & 276,81 & $-8,39$ & 285,20 & 80,59 & \begin{tabular}{|l|l|}
186,43 \\
\end{tabular} & 187,57 & 40,66 & 521,27 & 65,33 & 24,05 & 28,83 & \begin{tabular}{|l|l|}
181,12 \\
\end{tabular} & \begin{tabular}{|l|l|}
91,78 \\
\end{tabular} & 92,82 & 137,14 \\
\hline Pelophylax perezi & 30TUM20 & 100,00 & 120,71 & 116,99 & 39,00 & 6089,06 & 292,77 & $-1,37$ & 294,14 & 82,76 & \begin{tabular}{|l|l|}
199,27 \\
\end{tabular} & 201,29 & 44,73 & 394,51 & 46,10 & 13,34 & 30,16 & 126,82 & 58,12 & \begin{tabular}{l|l|}
62,25 \\
\end{tabular} & 106,86 \\
\hline Pelophylax perezi & 30TUM22 & 100,00 & 116,34 & 117,00 & 39,00 & 6033,32 & 288,63 & $-5,76$ & 294,39 & 80,11 & \begin{tabular}{|l|l|}
194,44 \\
\end{tabular} & \begin{tabular}{ll|}
196,61 \\
\end{tabular} & \begin{tabular}{l|l}
41,35 \\
\end{tabular} & 421,60 & 49,58 & 15,54 & \begin{tabular}{|l|l|}
29,37 \\
\end{tabular} & \begin{tabular}{|l|l|}
136,94 \\
\end{tabular} & \begin{tabular}{|l|l|}
63,37 \\
\end{tabular} & 68,72 & 114,20 \\
\hline Pelophyla & 30TUM23 & 100, & & & 39, & & & $-2,26$ & $293, \mathrm{C}$ & 85, & 197, & 199,12 & 45,63 & \begin{tabular}{|l|l|}
417,02 \\
\end{tabular} & 49, & & & 137 & 63, & 68,10 & 112, \\
\hline Pelophylax perezi & 30TUM24 & 100,00 & 118,63 & 116,41 & 39,05 & 5919,12 & 288,5 & $-4,22$ & 292,76 & $84,93[$ & 195,36 & 197,06 & 44,6 & 431,28 & $51,5$. & 17,28 & $29,09 \mid$ & $143,01 \mid$ & 66,56 & 71,83 & 115 \\
\hline Pelophylax perezi & 30TUM25 & 100,00 & 118,05 & 116,00 & 39,00 & 5875,11 & 286,80 & $-5,09$ & 291,90 & 85,13 & 194,26 & 195,84 & 44,66 & 443,61 & 53,41 & 18,29 & 28,99 & 148,39 & 69,82 & 75,11 & 118,03 \\
\hline
\end{tabular}




\begin{tabular}{|c|c|c|c|c|c|c|c|c|c|c|c|c|c|c|c|c|c|c|c|c|c|}
\hline TAXON & UTM & $\mathrm{km} 2$ & B101 & B102 & $\mathrm{BIO3}$ & B104 & B105 & B106 & B107 & B108 & B109 & BIO10 & BIO11 & BIO12 & B1013 & BIO14 & BIO15 & B1016 & B1017 & B1018 & B1019 \\
\hline Pelophylax perezi & 30TUM26 & 100,00 & 117,05 & 115,38 & 39,03 & 5819,70 & 284,64 & $-5,93$ & 290,57 & 85,09 & 192,47 & 194,16 & 44,41 & 459,45 & 55,68 & 19,51 & 28,57 & 154,73 & 74,14 & 79,14 & 121,54 \\
\hline Pelophylax perezi & 30TUM27 & 100,00 & 117,38 & 114,55 & 39,09 & 5749,96 & 282,96 & $-4,90$ & 287,87 & 86,52 & 191,98 & 193,45 & 45,56 & 473,03 & 57,88 & 20,51 & 28,42 & 160,59 & 78,11 & 82,48 & 124,39 \\
\hline Pelophylax perezi & 30TUM28 & 100,00 & 116,00 & 113,62 & 39,21 & 5688,18 & 279,92 & $-5,54$ & 285,46 & 85,75 & 189,75 & 191,17 & 44,94 & 494,83 & 61,05 & 22,19 & 28,15 & 169,00 & 83,81 & 87,49 & 129,43 \\
\hline Pelophylax perezi & 30TUM29 & 100,00 & 112,78 & 112,65 & 39,19 & 5631,06 & 275,25 & $-7,28$ & 282,52 & 83,09 & 185,99 & 187,28 & 42,63 & 525,30 & 65,14 & 24,28 & 27,92 & 179,86 & 91,29 & 94,23 & 137,08 \\
\hline Pelophylax perezi & 30TUM31 & 100,00 & 117,58 & 116,93 & 39,00 & \begin{tabular}{|l|l|}
6063,27 \\
\end{tabular} & 289,83 & $-4,33$ & 294,16 & 80,52 & \begin{tabular}{|l|}
196,14 \\
\end{tabular} & \begin{tabular}{|l|}
198,07 \\
\end{tabular} & 42,13 & 419,81 & 48,93 & \begin{tabular}{|l|l|}
14,67 \\
\end{tabular} & 29,27 & 133,56 & 61,70 & 67,52 & 114,77 \\
\hline Pelophylax perezi & 30TUM32 & 100,00 & 116,04 & 117,00 & 39,00 & 6025,13 & 288,00 & $-6,39$ & 294,39 & 79,98 & 194,07 & 196,12 & 41,03 & 430,89 & 50,41 & 15,72 & 29,08 & 138,06 & 63,74 & 70,54 & 117,22 \\
\hline Pelophylax perezi & 30TUM33 & 100,00 & 116,86 & 116,91 & 39,00 & 5964,17 & 287,89 & $-6,16$ & 294,05 & 82,65 & 194,20 & 196,15 & 42,60 & 435,02 & 51,10 & 16,41 & 28,95 & 140,78 & 65,07 & 72,13 & 117,56 \\
\hline Pelophylax perezi & 30TUM34 & 100,00 & 120,10 & 116,06 & 39,00 & 5897,92 & 289,35 & $-3,58$ & 292,93 & 87,40 & $\begin{array}{l}196,63 \\
\end{array}$ & 198,19 & 46,40 & 432,74 & 51,34 & $\begin{array}{l}01,1,1 \\
17,12\end{array}$ & 28,79 & 141,74 & 65,51 & 72,43 & 115,91 \\
\hline Pelophylax perezi & 30TUM35 & 100,00 & 119,29 & 115,69 & 39,01 & 5833,60 & 287,07 & $-4,72$ & 291,80 & 87,83 & 194,83 & 196,56 & 46,54 & 445,27 & 53,14 & 18,44 & 28,56 & 146,99 & 68,80 & 76,01 & 117,87 \\
\hline Pelophylax perezi & 30TUM36 & 100,00 & 117,71 & 114,89 & 39,00 & 5767,21 & 284,04 & $-5,85$ & 289,89 & 87,57 & 192,61 & 194,06 & 45,82 & 462,38 & 55,49 & 19,68 & 28,04 & 153,60 & 73,11 & 80,41 & 121,46 \\
\hline Pelophylax perezi & 30TUM37 & 100,00 & 116,17 & 114,03 & 39,00 & 5711,23 & 280,92 & $-6,76$ & 287,68 & 86,68 & 190,43 & 191,79 & 44,98 & 481,85 & 58,23 & 21,25 & 27,86 & 161,06 & 78,38 & 85,12 & 125,70 \\
\hline Pelophylax perezi & 30TUM38 & 100,00 & 114,84 & 112,86 & 39,01 & 5647,56 & 277,71 & $-6,86$ & 284,57 & 86,00 & 188,38 & 189,59 & 44,63 & 503,23 & 61,25 & 22,71 & 27,38 & 169,15 & 83,95 & 89,87 & 130,77 \\
\hline Pelophylax perezi & 30TUM39 & 100,00 & 112,70 & 111,60 & 39,02 & 5574,34 & 273,58 & $-7,33$ & 280,91 & 84,59 & 185,41 & 186,47 & 43,48 & 530,67 & 64,97 & 24,63 & 27,08 & 179,08 & 90,80 & 95,92 & 137,57 \\
\hline Pelophylax perezi & 30TUM40 & 100,00 & 122,15 & 115,78 & 39,00 & 6114,58 & 293,78 & 0,52 & 293,26 & 78,23 & 201,19 & 203,18 & 45,84 & 410,07 & 47,65 & 13,35 & 29,65 & 129,07 & 58,92 & 63,97 & 113,83 \\
\hline Pelophylax perezi & 30TUM41 & 100,00 & 116,48 & 116,22 & 39,00 & 6077,18 & 289,07 & $-5,09$ & 294,16 & 77,72 & $\begin{array}{l}195,67 \\
\end{array}$ & 197,33 & 41,18 & 432,19 & 50,04 & 14,91 & 29,02 & 135,79 & 62,79 & 69,55 & 119,23 \\
\hline Pelophylax perezi & 30TUM43 & 100,00 & 115,33 & 116,54 & 39,00 & 5937,94 & 286,39 & $-7,99$ & 294,38 & 82,39 & 192,84 & 194,41 & 41,83 & 445,14 & 51,89 & 16,70 & 28,48 & 142,24 & 65,52 & 74,47 & 119,81 \\
\hline Pelophylax perezi & 30TUM44 & 100,00 & 119,96 & 115,96 & 39,00 & 5873,55 & 288,56 & $-4,79$ & 293,35 & 88,68 & 196,36 & 197,90 & 46,86 & 437,99 & 51,36 & 17,04 & 28,47 & 141,45 & 64,96 & 74,22 & 116,53 \\
\hline Pelophylax perezi & 30TUM45 & 100,00 & 119,78 & 115,23 & 39,00 & 5786,69 & 286,76 & $-4,92$ & 291,69 & 90,38 & 195,00 & 196,53 & 47,87 & 447,41 & 52,79 & 18,40 & 28,20 & 145,73 & 67,55 & 77,10 & 117,74 \\
\hline Pelophylax perezi & 30TUM46 & 100,00 & 118,20 & 114,43 & 39,00 & 5726,46 & 283,50 & $-6,18$ & 289,68 & 89,92 & 192,80 & 194,04 & 47,03 & 465,16 & 55,18 & 19,94 & 27,78 & 152,43 & 72,11 & 81,71 & 121,00 \\
\hline Pelophylax perezi & 30TUM47 & 100,00 & 115,94 & 113,37 & 39,00 & 5664,99 & 279,62 & $-7,53$ & 287,15 & 88,30 & 189,80 & 191,02 & 45,72 & 487,52 & 58,13 & 21,51 & 27,29 & 160,58 & 77,79 & 86,99 & 126,13 \\
\hline Pelophylax perezi & $\begin{array}{l}30 \text { TUM48 } \\
\end{array}$ & 100,00 & 113,35 & 112,18 & 39,00 & 5604,36 & 275,24 & $-8,78$ & 284,02 & 86,09 & 186,47 & 187,52 & 43,78 & 513,62 & 61,56 & 23,37 & 26,75 & 169,87 & 84,42 & 92,81 & 132,54 \\
\hline Pelophylax perezi & 30TUM49 & 100,00 & 109,31 & 110,90 & 39,00 & 5549,84 & 269,61 & $-10,74$ & 280,35 & 82,26 & 181,95 & 182,82 & 40,77 & 548,23 & 65,97 & 25,72 & 26,17 & 181,77 & 92,73 & $\mid \begin{array}{r}\mid 100,16 \\
\end{array}$ & 141,59 \\
\hline Pelophylax perezi & 30TUM50 & 100,00 & 124,34 & 114,90 & \begin{tabular}{|l|l|}
38,89 \\
\end{tabular} & 6106,90 & 295,01 & 2,06 & 292,94 & 62,07 & 203,37 & 205,14 & 47,94 & 412,16 & 47,90 & 13,03 & 29,88 & 130,10 & 58,24 & 63,54 & 115,23 \\
\hline Pelophylax perezi & 30TUM51 & 100,00 & 122,95 & 115,51 & 38,98 & 6066,38 & 293,71 & 0,46 & 293,25 & 63,90 & 201,60 & 203,15 & 46,92 & 423,85 & 49,38 & 13,88 & 29,50 & 134,49 & 59,79 & 66,21 & 119,16 \\
\hline Pelophylax perezi & 30TUM55 & 100,00 & 120,99 & 114,95 & 38,98 & 5756,24 & 287,11 & $-5,64$ & 292,75 & 93,99 & 195,90 & 197,43 & 49,67 & 446,02 & 51,90 & 18,06 & 28,31 & 143,43 & 65,46 & 77,75 & 115,77 \\
\hline Pelophylax perezi & 30TUM56 & 100,00 & 119,70 & 113,90 & 38,97 & 5683,32 & 283,72 & $-5,96$ & 289,69 & 93,62 & 193,73 & 194,98 & 49,34 & 462,42 & 54,10 & 19,69 & 27,77 & 149,64 & 69,88 & 82,09 & 118,81 \\
\hline Pelophylax perezi & 30TUM57 & 100,00 & 115,86 & 112,71 & 39,00 & 5627,80 & 278,45 & $-8,25$ & \begin{tabular}{|l|}
286,70 \\
\end{tabular} & 90,00 & $\begin{array}{l}189,36 \\
\end{array}$ & $\begin{array}{l}190,38 \\
\end{array}$ & 46,43 & \begin{tabular}{|l|l|}
490,84 \\
490
\end{tabular} & 57,69 & 21,75 & 26,95 & \begin{tabular}{|l|}
159,46 \\
\end{tabular} & 76,90 & 88,51 & 125,72 \\
\hline Pelophylax perezi & 30TUM58 & 100,00 & 112,95 & 111,22 & 38,98 & 5561,76 & 273,43 & $-9,44$ & 282,87 & 87,28 & 185,75 & 186,54 & 44,39 & 520,03 & 61,52 & 23,71 & 26,27 & 169,80 & 84,27 & 94,75 & 133,20 \\
\hline Pelophylax perezi & 30TUM59 & 100,00 & 110,88 & 109,56 & 39,00 & 5495,01 & 268,95 & $-9,26$ & 278,22 & 85,30 & 182,86 & 183,40 & 43,01 & 548,82 & 65,37 & 25,64 & 25,81 & 180,01 & 91,50 & 100,58 & 140,82 \\
\hline Pelophylax perezi & 30TUM60 & 100,00 & 122,48 & 113,60 & 38,15 & 6089,17 & 292,07 & $-0,49$ & 292,56 & 86,07 & 201,70 & 203,24 & 46,55 & 419,17 & 48,36 & 13,43 & 29,68 & 131,25 & 58,86 & 66,41 & 114,57 \\
\hline Pelophylax perezi & 30TUM61 & 100,00 & 120,32 & 114,40 & 38,47 & 6036,22 & 290,06 & $-3,31$ & 293,37 & 85,23 & 198,96 & 200,41 & 45,18 & 431,13 & 49,61 & 14,44 & 29,26 & 134,87 & 60,73 & 69,65 & 117,55 \\
\hline Pelophylax perezi & $\begin{array}{l}\text { 30TUM63 } \\
\end{array}$ & 100,00 & 119,17 & 115,22 & 38,41 & 5885,32 & 287,68 & $\begin{array}{l}-7,51 \\
-7,44 \\
\end{array}$ & 295,12 & \begin{tabular}{l|l}
89,93 \\
89
\end{tabular} & \begin{tabular}{|l|}
195,93 \\
\end{tabular} & \begin{tabular}{|l|}
$200,4,41$ \\
\end{tabular} & 46,32 & $\mid \begin{array}{l}\mid 439,86 \\
439,8\end{array}$ & $\begin{array}{l}50,41 \\
50\end{array}$ & $\begin{array}{l}4,4,09 \\
16,0\end{array}$ & 29,01 & \begin{tabular}{|l|}
138,04 \\
130
\end{tabular} & 62,10 & $\begin{array}{l}75,25 \\
750\end{array}$ & 115,75 \\
\hline Pelophylax perezi & 30TUM64 & 100,00 & 116,19 & 115,26 & \begin{tabular}{|l|}
38,27 \\
\end{tabular} & 5815,91 & 283,91 & $-11,75$ & 295,66 & 89,12 & 192,21 & 193,42 & 44,57 & 454,02 & 52,14 & 17,58 & 28,65 & 142,29 & 64,78 & 80,12 & 117,01 \\
\hline Pelophylax perezi & 30TUM65 & 100,00 & 120,56 & 114,66 & 38,52 & 5723,75 & 285,82 & $-8,01$ & 293,82 & 95,88 & 194,97 & 196,42 & 50,15 & $\begin{array}{l}447,48 \\
\end{array}$ & 51,29 & 18,07 & 28,54 & 141,68 & 64,24 & 79,89 & 113,66 \\
\hline Pelophylax perezi & 30TUM66 & 100,00 & 118,44 & 113,53 & 38,58 & 5661,01 & 282,08 & $-8,95$ & 291,03 & 94,38 & 192,27 & 193,35 & 48,90 & 467,21 & 53,63 & 19,92 & 27,83 & 148,82 & 69,35 & 84,41 & 118,20 \\
\hline Pelophylax perezi & 30TUM67 & 100,00 & 116,04 & 111,89 & 38,72 & 5599,05 & 277,43 & $-8,96$ & 286,39 & 91,78 & 189,24 & 190,09 & 47,21 & 492,99 & 57,07 & 21,84 & 26,85 & 158,02 & 76,02 & 89,84 & 124,90 \\
\hline Pelophylax perezi & $\begin{array}{l}\text { 30TUM68 } \\
\end{array}$ & 100,00 & $\begin{array}{l}111,04,51 \\
114,51\end{array}$ & $\begin{array}{l}11,03 \\
110,01\end{array}$ & 38,80 & 5524,72 & 273,23 & $\begin{array}{ll}-0,50 \\
-8,14\end{array}$ & \begin{tabular}{|l|}
281,38 \\
281
\end{tabular} & $\begin{array}{l}1,16 \\
90,16 \\
\end{array}$ & \begin{tabular}{|l|}
$186,78,78$ \\
186,
\end{tabular} & $\begin{array}{l}187,56 \\
187\end{array}$ & $\begin{array}{l}41,14 \\
46,52\end{array}$ & 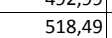 & $\begin{array}{ll}1,, 60 \\
60,62\end{array}$ & 23,53 & $\begin{array}{l}26,03 \\
26,12\end{array}$ & \begin{tabular}{|l|}
$167,0<5$ \\
167
\end{tabular} & $80,8<4$ & $\begin{array}{l}5,, 44 \\
94,81\end{array}$ & 131,75 \\
\hline Pelophylax perezi & 30TUME & 100,00 & 111,43 & 108,16 & 38,76 & 5459,33 & 267,92 & $-8,51$ & 276,42 & 86,93 & 183,06 & 183,58 & 44,34 & 551,94 & 65,01 & 25,76 & 25,35 & 179,23 & 91,25 & 101,52 & 140,89 \\
\hline Pelophylax perezi & 30TUM70 & 100,00 & 120,65 & 112,09 & 38,00 & 6069,25 & 288,93 & $-2,75$ & 291,68 & 88,68 & 199,90 & 201,46 & 45,47 & 426,42 & 49,18 & 14,18 & 29,31 & 132,47 & 60,36 & $\begin{array}{ll}69,57 \\
\end{array}$ & 113,54 \\
\hline Pelophylax perezi & 30TUM72 & 100,00 & 118,17 & 113,46 & 38,02 & 5946,90 & 286,29 & $-7,18$ & 293,47 & 94,90 & 195,99 & 197,31 & 44,71 & 440,20 & 50,73 & 15,58 & 28,85 & 136,36 & 62,00 & 74,74 & 115,50 \\
\hline Pelophylax perezi & 30TUM73 & 100,00 & 120,60 & 113,79 & 38,01 & 5866,47 & 287,42 & $-6,64$ & 294,06 & 99,05 & 197,23 & 198,49 & 48,18 & 436,93 & 50,23 & 15,99 & 28,97 & 136,12 & 61,21 & 75,53 & 113,04 \\
\hline Pelophylax perezi & \begin{tabular}{|l|} 
30TUM74 \\
\end{tabular} & 100,00 & $\begin{array}{l}121,31 \\
121,31\end{array}$ & $\begin{array}{l}111,199 \\
113,99\end{array}$ & 38,01 & $\begin{array}{l}3000,47 \\
5780,65\end{array}$ & $288,4 \mathrm{2}$ & 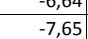 & $\begin{array}{l}294,60 \\
294,60\end{array}$ & $\mid$ & \begin{tabular}{|l|}
196,75 \\
196,71
\end{tabular} & \begin{tabular}{|l|}
$190,49,91$ \\
\end{tabular} & $\begin{array}{l}40,16 \\
50,21\end{array}$ & \begin{tabular}{|l|}
438,935 \\
438,37
\end{tabular} & $\begin{array}{l}30,23 \\
50,55 \\
\end{array}$ & $\begin{array}{l}0,39 \\
16,69 \\
\end{array}$ & $\begin{array}{l}29,02 \\
29,02\end{array}$ & \begin{tabular}{|l|l|}
136,96 \\
136,9
\end{tabular} & $\begin{array}{l}01,21 \\
61,24\end{array}$ & \begin{tabular}{|l|}
77,77 \\
77
\end{tabular} & $\begin{array}{l}113,04 \\
111,05\end{array}$ \\
\hline Pelophylax perezi & 30TUM75 & 100,00 & 118,92 & 113,79 & 38,02 & 5711,37 & 283,52 & $-10,29$ & 293,81 & 104,70 & 193,40 & 194,54 & 49,02 & 454,39 & 52,15 & 18,33 & 28,52 & 141,93 & 64,84 & 82,43 & 113,56 \\
\hline Pelophylax perezi & 30TUM76 & 100,00 & 118,33 & 112,23 & 38,03 & 5644,23 & 280,66 & $-9,05$ & 289,70 & 95,17 & 192,05 & 193,00 & 49,30 & 471,03 & 53,46 & 20,07 & 27,54 & 148,38 & 69,53 & 85,92 & 117,91 \\
\hline Pelophylax perezi & 30TUM77 & 100,00 & 117,27 & 110,45 & 38,12 & 5576,35 & 277,07 & $-7,69$ & 284,76 & 93,87 & 190,12 & 190,76 & 48,83 & 492,67 & 56,39 & 21 & 26,74 & 56,50 & 75,42 & 90,09 & 123,93 \\
\hline Pelophylax perezi & 30TUM78 & 100,00 & 114,83 & 108,54 & 38,2 & 5504, & 272,11 & $-7,24$ & 279,35 & $\begin{array}{l}90,1,16 \\
91\end{array}$ & 186,94 & 187,57 & $\begin{array}{l}40,30 \\
47,24 \\
\end{array}$ & 521,83 & $\begin{array}{l}0,33 \\
60,33\end{array}$ & 23 & 25,84 & $\begin{array}{l}166,99 \\
\end{array}$ & 82,90 & $\begin{array}{l}95,62 \\
95\end{array}$ & 132,06 \\
\hline Pelophylax perezi & 30TUM? & 100,00 & 111,89 & 106,71 & 38,25 & 5428,82 & 266,68 & $-7,42$ & 274,10 & 87,91 & 183,20 & 183,58 & 45,18 & 555,44 & 64,7 & 25,89 & 25,01 & 178,71 & 91,41 & 102,15 & 141,46 \\
\hline Pelophylax perezi & 30TUM80 & 100,00 & 118,00 & 110,56 & 37,59 & 6067,71 & 284,98 & $-5,22$ & 290,20 & \begin{tabular}{|l|}
105,01 \\
\end{tabular} & 197,54 & 198,71 & 43,04 & 437,78 & 50,68 & 14,66 & 28,99 & 135,09 & 62,41 & 72,84 & 114,67 \\
\hline Pelophylax perezi & 30TUM82 & 100,00 & 117,95 & 111,66 & 38,00 & 5940,03 & 284,48 & $-7,22$ & 291,70 & 106,45 & 195,72 & 196,94 & 44,73 & 443,83 & 51,25 & 15,91 & 28,60 & 136,89 & 63,27 & 76,37 & 114,72 \\
\hline Pelophylax perezi & 30TUM84 & 100,00 & 118,26 & 111,90 & 38,00 & 5791,12 & 282,80 & $-8,46$ & 291,26 & 108,32 & 194,12 & 195,13 & 47,18 & 453,26 & 52,05 & 17,63 & 28,31 & 140,44 & 65,07 & 80,87 & 114,54 \\
\hline Pelophylax perezi & 30TUN & 100,00 & 11 & 111,39 & 38,00 & 5721 & 280 & $-9,41$ & 289,69 & $\begin{array}{l}94,97 \\
94\end{array}$ & 192,09 & 192,98 & 47,09 & 466,69 & 53,01 & 19,09 & 27,68 & 144,82 & 68,30 & 84,67 & 117,12 \\
\hline Pelophylax perezi & 30TUM86 & 100,00 & 112,63 & 110,45 & 38,00 & 5660,24 & 274,55 & $-12,10$ & 286,66 & 87,77 & 186,88 & 187,64 & 43,37 & 496,62 & 55,80 & 21,52 & 26,70 & 154,33 & 75,32 & 91,19 & 124,66 \\
\hline Pelophylax perezi & 30TUM87 & 100,00 & 116,17 & 108,59 & 38,00 & 5572,34 & 274,58 & $-7,01$ & 281,59 & 92,07 & 189,17 & 189,63 & 47,62 & 501,96 & 56,91 & 22,37 & 26,03 & 158,15 & 77,71 & 91,85 & 126,35 \\
\hline Pelophylax perezi & 30TUM88 & 100,00 & 114,21 & 106,84 & 38,00 & 5498,59 & 270,20 & $-6,47$ & 276,67 & 90,12 & 186,30 & 186,76 & 46,57 & 528,80 & 60,47 & 24,17 & 25,22 & 167,67 & 84,56 & 96,95 & 133,87 \\
\hline Pelophylax perezi & 30TUN & 100,00 & 112,65 & 104,88 & 38,02 & 5418,04 & 265,75 & $-5,36$ & 271,10 & 88,43 & 183,75 & 184,00 & 45,94 & 558,20 & 64,41 & 25,91 & 24,59 & 178,22 & 91,90 & 102,24 & 142,23 \\
\hline Pelophylax perezi & $\begin{array}{l}\text { 30TUM90 } \\
\end{array}$ & $\begin{array}{l}100,00 \\
\end{array}$ & 1116,75 & $\begin{array}{l}104,00 \\
108,81\end{array}$ & 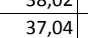 & $\begin{array}{l}3410,044 \\
6074,87\end{array}$ & 282,72 & $\begin{array}{l}-3,50 \\
-5,89 \\
\end{array}$ & 288,61 & \begin{tabular}{|l|}
00,45 \\
107,18 \\
\end{tabular} & \begin{tabular}{|l|}
196,63 \\
196,6
\end{tabular} & $\begin{array}{l}194,80 \\
197\end{array}$ & \begin{tabular}{|l|}
42,09 \\
42,0
\end{tabular} & \begin{tabular}{|l|l|}
444,94 \\
44,
\end{tabular} & $\begin{array}{l}4,41 \\
51,66\end{array}$ & \begin{tabular}{|l|}
15,19 \\
15
\end{tabular} & $\begin{array}{l}28,35 \\
28,65\end{array}$ & \begin{tabular}{|l|}
136,81 \\
13,28
\end{tabular} & $\begin{array}{ll}61,20 \\
64,21\end{array}$ & $\begin{array}{l}\mid c, 24 \\
75,12 \\
\end{array}$ & $\begin{array}{l}142,23 \\
115,16\end{array}$ \\
\hline Pelophylax perezi & $\begin{array}{l}\text { 30TUM91 } \\
\end{array}$ & 100,00 & 115,85 & 109,53 & 37,30 & 6011,67 & 281,66 & $-7,52$ & 289,18 & 121,26 & $\begin{array}{l}194,78 \\
\end{array}$ & $\begin{array}{l}195,85 \\
\end{array}$ & 41,82 & 450,98 & 52,22 & 15,98 & 28,32 & 138,54 & 65,35 & 77,33 & 116,20 \\
\hline Pelophylax perezi & 30TUM94 & 100,00 & 114,79 & 109,83 & 37,86 & 5811,28 & 278,43 & $-9,44$ & 287,87 & 103,26 & 191,17 & 192,00 & 43,48 & 470,52 & 53,73 & 18,77 & 27,21 & 144,45 & 69,83 & 84,41 & 119,03 \\
\hline Pelophylax perezi & 30TUM95 & 100,00 & 117,54 & 108,95 & 37,89 & 5730,65 & 278,82 & $-6,41$ & 285,23 & 92,02 & 192,58 & 193,36 & 46, & 472,01 & 52,98 & 19,47 & 26,93 & 146,03 & 70,81 & 84,98 & 119 , \\
\hline Pelophylax perezi & 30TUM96 & 100,00 & 113,27 & 108,10 & 37,92 & 5665,31 & 273,44 & $\begin{array}{l}-9,11 \\
-9,11 \\
\end{array}$ & 282,55 & 87,18 & 187,76 & 188,23 & 43,72 & 500,03 & 55,74 & 21,76 & 25,99 & 154,71 & 77,24 & 91,33 & 126,07 \\
\hline
\end{tabular}




\begin{tabular}{|c|c|c|c|c|c|c|c|c|c|c|c|c|c|c|c|c|c|c|c|c|c|}
\hline TAXON & UTM & $\mathrm{km2}$ & BIO1 & B102 & $\mathrm{BIO3}$ & B104 & B105 & B106 & BI07 & B108 & B109 & BIO10 & BIO11 & B1012 & BIO13 & BIO14 & BIO15 & BIO16 & BIO17 & BIO18 & BlO19 \\
\hline Pelophylax perezi & 30TUM97 & 100,00 & 114,96 & 106,42 & 37,96 & 5576,17 & 272,09 & $-5,85$ & 277,94 & 89,56 & 188,07 & 188,39 & 46,25 & 512,10 & 57,56 & 23,06 & 25,42 & 160,27 & 80,73 & 93,38 & 129,47 \\
\hline Pelophylax perezi & \begin{tabular}{|l|l|} 
30TUM98 \\
\end{tabular} & 100,00 & 114,23 & 104,75 & 38,00 & 5496,74 & 268,64 & $-4,47$ & 273,11 & 89,04 & 186,26 & 186,51 & 46,29 & 535,23 & 60,69 & 24,54 & 24,79 & \begin{tabular}{ll|}
168,63 \\
\end{tabular} & 86,63 & \begin{tabular}{ll|}
97,59 \\
\end{tabular} & 135,96 \\
\hline Pelophylax perezi & 30TUM99 & 100,00 & 112,43 & 102,95 & 38,00 & 5414,49 & 264,02 & $-3,80$ & 267,82 & 87,41 & \begin{tabular}{ll|}
183,62 \\
\end{tabular} & $\begin{array}{l}183,69 \\
\end{array}$ & \begin{tabular}{ll|}
45,63 \\
\end{tabular} & 564,68 & 64,61 & 26,34 & 24,06 & $\begin{array}{l}179,09 \\
\end{array}$ & 93,83 & \begin{tabular}{ll|}
101,38 \\
\end{tabular} & 144,31 \\
\hline Pelophylax perezi & 30TUNOO & 100,00 & 113,28 & 113,74 & 39,77 & 5700,10 & 277,23 & $-6,27$ & 283,50 & 81,03 & \begin{tabular}{|l|l|}
188,47 \\
\end{tabular} & $\begin{array}{l}188,47 \\
1\end{array}$ & 41,84 & 531,77 & 67,99 & 24,85 & 30,01 & \begin{tabular}{ll|}
188,38 \\
\end{tabular} & 94,56 & 94,56 & 140,40 \\
\hline Pelophylax perezi & 30TUN01 & 100,00 & 111,04 & 112,70 & 39,98 & 5628,60 & 272,93 & $-7,22$ & 280,16 & \begin{tabular}{|l|l|}
79,47 \\
\end{tabular} & \begin{tabular}{|l|l|}
185,17 \\
\end{tabular} & \begin{tabular}{|l|l|}
185,17 \\
\end{tabular} & 40,30 & $\begin{array}{ll}563,92 \\
\end{array}$ & 72,45 & 26,71 & 29,77 & \begin{tabular}{l|l|}
199,85 \\
\end{tabular} & $\begin{array}{l}101,55 \\
\end{array}$ & \begin{tabular}{l|l}
101,55 \\
\end{tabular} & 148,49 \\
\hline Pelophylax perezi & 30TUN02 & 100,00 & 106,83 & 111,48 & 40,00 & 5549,11 & 266,75 & $-9,47$ & 276,22 & 76,01 & \begin{tabular}{|l|l|l|}
180,08 \\
\end{tabular} & 180,08 & \begin{tabular}{l|l|l}
37,55 \\
\end{tabular} & 606,52 & 77,94 & 29,18 & 29,16 & 213,89 & 110,31 & 110,31 & 159,96 \\
\hline Pelophylax perezi & \begin{tabular}{|l|} 
30TUN03 \\
\end{tabular} & 100,00 & 103,34 & 109,88 & 40,00 & 5459,93 & 260,54 & $-11,11$ & 271,66 & 73,21 & \begin{tabular}{|l|l|}
175,34 \\
\end{tabular} & \begin{tabular}{|l|l|}
175,34 \\
\end{tabular} & 35,38 & 650,41 & 83,54 & 32,09 & 28,48 & 228,09 & 118,83 & 118,83 & 172,09 \\
\hline Pelophylax perezi & $\begin{array}{l}\text { 30TUN04 } \\
\end{array}$ & 100,00 & 96,16 & 107,92 & 39,99 & 5364,44 & 250,54 & $-16,02$ & 266,56 & \begin{tabular}{ll|}
66,93 \\
\end{tabular} & $\begin{array}{ll}167,02 \\
\end{array}$ & 167,02 & 30,00 & 718,23 & $\begin{array}{l}91,48 \\
\end{array}$ & 36,42 & 27,36 & \begin{tabular}{|l|l}
248,75 \\
\end{tabular} & $\begin{array}{l}131,44 \\
\end{array}$ & \begin{tabular}{l|l|}
131,44 \\
\end{tabular} & 192,26 \\
\hline Pelophylax perezi & $\begin{array}{l}\text { 30TUN06 } \\
\end{array}$ & 100,00 & 67,79 & 102,16 & 39,56 & 5215,84 & 217,31 & $-37,60$ & 254,91 & \begin{tabular}{ll|}
40,02 \\
\end{tabular} & $\begin{array}{l}137,45 \\
\end{array}$ & 137,62 & 5,61 & 963,07 & 117,60 & 49,21 & 24,66 & 320,48 & $\begin{array}{l}173,26 \\
\end{array}$ & \begin{tabular}{|l|l|}
173,77 \\
\end{tabular} & 271,29 \\
\hline Pelophylax perezi & 30TUN10 & 100,00 & 110,00 & 112,82 & 39,55 & 5650,92 & 272,87 & $-9,21$. & 282,08 & 78,96 & 184,15 | & 184,58 & 39,22 & 549,77 & 69,22 & 26,07 & 28,63 & 191,38 & 98,66 & 99,03 & 144,40 \\
\hline Pelophylax perezi & 30TUN11 & 100,00 & 109,07 & 111,48 & 39,88 & 5567,29 & 269,32 & $-8,31$ & 277,63 & 78,70 & 182,48 & \begin{tabular}{l|l|}
182,55 \\
\end{tabular} & 39,53 & 576,87 & 73,10 & 27,93 & 28,45 & 201,05 & \begin{tabular}{|l|}
104,75 \\
\end{tabular} & 104,80 & 151,04 \\
\hline Pelophylax perezi & \begin{tabular}{|l|} 
30TUN12 \\
\end{tabular} & 100,00 & 105,21 & 110,09 & 39,98 & 5484,01 & 263,13 & $-10,52$ & 273,65 & 75,65 & 177,55 & \begin{tabular}{ll|l}
177,55 \\
\end{tabular} & 36,96 & \begin{tabular}{|c|}
619,48 \\
\end{tabular} & 78,58 & 30,70 & 27,93 & 215,26 & \begin{tabular}{ll|}
113,46 \\
\end{tabular} & \begin{tabular}{ll|}
113,46 \\
\end{tabular} & 162,66 \\
\hline Pelophylax perezi & $\begin{array}{l}\text { 30TUN13 } \\
\end{array}$ & 100,00 & 98,49 & 108,60 & 39,99 & 5414,90 & 254,58 & $-15,25$ & 269,83 & $\begin{array}{ll}69,63 \\
\end{array}$ & \begin{tabular}{|l|l|}
170,10 \\
\end{tabular} & \begin{tabular}{|l|l|}
170,10 \\
\end{tabular} & 31,66 & 678,60 & 85,67 & 34,26 & 27,12 & \begin{tabular}{|l|l|}
233,87 \\
\end{tabular} & \begin{tabular}{l|l|}
124,96 \\
\end{tabular} & \begin{tabular}{ll|}
124,96 \\
\end{tabular} & 179,56 \\
\hline Pelophylax perezi & $\begin{array}{l}\text { 30TUN14 } \\
\end{array}$ & 100,00 & 91,91 & 106,65 & 39,90 & 5329,67 & 245,37 & $-19,25$ & 264,62 & 63,65 & \begin{tabular}{l|l|l|l|l|}
162,49 \\
\end{tabular} & \begin{tabular}{ll|}
162,50 \\
\end{tabular} & 26,67 & 743,89 & 93,24 & 37,99 & 26,26 & 253,88 & $\begin{array}{l}136,95 \\
\end{array}$ & \begin{tabular}{|l|l|}
137,00 \\
\end{tabular} & 199,17 \\
\hline Pelophylax perezi & $\begin{array}{l}\text { 30TUN16 } \\
\end{array}$ & 100,00 & 78,12 & 102,39 & 39,84 & 5167,15 & 226,15 & $-28,03$ & 254,18 & 51,17 & \begin{tabular}{|l|l|}
146,75 \\
\end{tabular} & \begin{tabular}{ll|}
147,05 \\
\end{tabular} & \begin{tabular}{l|l|}
15,97 \\
\end{tabular} & 888,69 & 109,61 & 45,98 & 24,75 & 297,35 & \begin{tabular}{|l|l|}
162,91 \\
\end{tabular} & \begin{tabular}{|l|l|}
163,98 \\
\end{tabular} & 243,87 \\
\hline Pelophylax perezi & 30TUN22 & 100,00 & 103,05 & 108,81 & 39,66 & 5432,62 & 259,46 & $-12,24$ & 271,70 & 74,61 & \begin{tabular}{|l|l|}
174,47 \\
\end{tabular} & 174,79 & 35,75 & \begin{tabular}{|l|l|}
634,62 \\
\end{tabular} & 79,38 & 31,56 & 26,73 & 217,08 & 116,31 & 116,92 & 166,18 \\
\hline Pelophylax perezi & \begin{tabular}{|l|} 
30TUN24 \\
\end{tabular} & 100,00 & 90,07 & 105,16 & 39,77 & 5281,60 & 241,81 & $-20,16$ & 261,97 & 62,69 & \begin{tabular}{|l|l|}
160,11 \\
\end{tabular} & \begin{tabular}{|l|l|}
160,14 \\
\end{tabular} & 25,69 & 760,14 & $\begin{array}{l}94,15 \\
\end{array}$ & 38,96 & 25,36 & \begin{tabular}{|l|l|}
256,25 \\
\end{tabular} & \begin{tabular}{|l|l|}
140,39 \\
\end{tabular} & \begin{tabular}{|l|}
140,77 \\
\end{tabular} & 203,05 \\
\hline Pelophylax perezi & $\begin{array}{l}30 T U N 25 \\
\end{array}$ & 100,00 & 83,33 & 103,26 & 39,81 & 5209,53 & 232,64 & $-24,53$ & 257,17 & 56,47 & \begin{tabular}{|l|l|}
152,47 \\
\end{tabular} & 152,62 & 20,19 & 828,77 & 101,93 & 42,87 & 24,62 & 277,06 & \begin{tabular}{|l|l|}
152,97 \\
\end{tabular} & \begin{tabular}{|l|l|}
153,39 \\
\end{tabular} & 224,02 \\
\hline Pelophylax perezi & 30TUN31 & 100,00 & 106,65 & 108,77 & 39,24 & 5442,33 & 263,13 & $-9,97$ & 273,10 & 79,18 & \begin{tabular}{ll|l}
177,90 \\
\end{tabular} & $\begin{array}{l}178,56 \\
\end{array}$ & 39,26 & 600,99 & 74,19 & 29,27 & 26,33 & 203,26 & $\begin{array}{l}107,56 \\
\end{array}$ & \begin{tabular}{l|l|}
110,53 \\
\end{tabular} & 156,07 \\
\hline Pelophylax perezi & 30TUN32 & 100,00 & 103,38 & 107,30 & 39,40 & 5369,91 & 257,61 & $-11,11$ & 268,72 & 76,31 & $\begin{array}{ll}173,92 \\
\end{array}$ & 174,31 & 37,1 & \begin{tabular}{ll|}
640,16 \\
\end{tabular} & 79,2 & 31,81 & 25, & 216,41 & 116,32 & 118,36 & 166,88 \\
\hline Pelophylax perezi & \begin{tabular}{|l|l|}
30 TUN33 \\
\end{tabular} & 100,00 & 99,10 & 105,73 & 39,69 & 5295,84 & 250,86 & $-13,18$ & 264,04 & 72,29 & 168,86 & 169,11 & 33,99 & 687,41 & 85,03 & 34,75 & 25,42 & 231,73 & 126,50 & 127,49 & 180,19 \\
\hline Pelophylax perezi & 30TUN35 & 100,00 & 83,84 & 102,02 & 39,59 & 5166,43 & 231,60 & $-23,32$ & 254,91 & 57,79 & $\begin{array}{l}152,46 \\
1\end{array}$ & \begin{tabular}{|l|l|}
152,70 \\
\end{tabular} & \begin{tabular}{l|l|l}
21,45 \\
\end{tabular} & 828,77 & 101,18 & 42,98 & 24,12 & 275,09 & \begin{tabular}{l|l|l|}
153,42 \\
\end{tabular} & \begin{tabular}{|l|l|}
153,77 \\
\end{tabular} & 222,86 \\
\hline Pelophylax perezi & $\begin{array}{l}30 T U N 36 \\
\end{array}$ & 100,00 & 81,83 & 100,10 & 39,74 & 5077,09 & 226,35 & $-23,31$ & 249,66 & 56,39 & \begin{tabular}{|l|l|}
149,19 \\
\end{tabular} & \begin{tabular}{|l|l|}
149,59 \\
\end{tabular} & 20,72 & 872,92 & \begin{tabular}{l|l}
106,65 \\
\end{tabular} & 45,55 & 23,93 & 289,19 & \begin{tabular}{|l|l|}
161,93 \\
\end{tabular} & \begin{tabular}{|l|l|}
162,79 \\
\end{tabular} & 235,85 \\
\hline Pelophylax perezi & $\begin{array}{l}30 \text { TUN40 } \\
\end{array}$ & 100,00 & 105,47 & 109,44 & 39,01 & 5488,89 & 263,70 & $-12,67$ & 276,37 & 78,60 & \begin{tabular}{ll|l}
177,50 \\
\end{tabular} & \begin{tabular}{|l|l|}
178,13 \\
\end{tabular} & 37,78 & 586,21 & 70,90 & 28,18 & 25,76 & \begin{tabular}{|l|l|}
194,83 \\
\end{tabular} & \begin{tabular}{|l|l|}
101,58 \\
\end{tabular} & \begin{tabular}{|l|l|}
107,87 \\
\end{tabular} & 151,79 \\
\hline Pelophylax perezi & 30TUN41 & 100,00 & 101,74 & 107,86 & 39,02 & 5420,32 & 257,66 & $-14,34$ & 271,99 & 75,09 & \begin{tabular}{l|l|}
173,02 \\
\end{tabular} & 173,41 & 35,02 & 627,36 & 76,11 & 30,86 & 25,2 & 208,63 & \begin{tabular}{|l|l|l|}
111,03 \\
\end{tabular} & \begin{tabular}{ll|}
116,13 \\
\end{tabular} & 163,18 \\
\hline Pelophylax perezi & \begin{tabular}{|l|}
30 TUN42 \\
\end{tabular} & 100,00 & 97,22 & 106,17 & 39,05 & 5354,13 & 250,99 & $-16,26$ & 267,24 & 70,70 & \begin{tabular}{|l|}
167,87 \\
\end{tabular} & 168,13 & 31,68 & 674,79 & 81,94 & 33,81 & 24,87 & 224,17 & \begin{tabular}{|l|l|}
121,51 \\
\end{tabular} & 124,96 & 176,68 \\
\hline Pelophylax perezi & $\begin{array}{l}\text { 30TUN43 } \\
\end{array}$ & 100,00 & 93,60 & 104,56 & 39,16 & 5282,69 & 244,86 & $-17,88$ & 262,73 & 67,40 & $\begin{array}{l}163,50 \\
\end{array}$ & $\begin{array}{l}163,55 \\
\end{array}$ & 29,04 & \begin{tabular}{|l|l|}
719,69 \\
\end{tabular} & 87,54 & 36,59 & \begin{tabular}{l|l}
24,45 \\
\end{tabular} & 238,82 & \begin{tabular}{|l|l|}
131,28 \\
\end{tabular} & \begin{tabular}{ll|}
133,60 \\
\end{tabular} & 189,55 \\
\hline Pelophylax perezi & 30TUN44 & 100,00 & 83,80 & 102,75 & 39,18 & 5232,73 & 233,68 & $-24,74$ & 258,42 & 57,72 & $\begin{array}{ll}153,55 \\
\end{array}$ & 153,56 & 20,65 & \begin{tabular}{|l|l|}
801,07 \\
\end{tabular} & 96,52 & 41,34 & 23,69 & 263,35 & \begin{tabular}{|l|l|}
146,87 \\
\end{tabular} & \begin{tabular}{|l|l|}
147,75 \\
\end{tabular} & 214,32 \\
\hline Pelophylax perezi & \begin{tabular}{|l|l|}
$30 T U N 45$ \\
\end{tabular} & 100,00 & 76,39 & 100,89 & 39,15 & 5173,28 & 224,06 & $-29,82$ & 253,88 & 50,36 & \begin{tabular}{|l|l|}
145,58 \\
\end{tabular} & $\begin{array}{l}145,65 \\
\end{array}$ & 14,36 & $\begin{array}{l}876,55 \\
\end{array}$ & \begin{tabular}{|l|l|}
104,95 \\
\end{tabular} & 45,73 & 23,18 & 286,34 & 161,28 & 161,54 & 237,51 \\
\hline Pelophylax perezi & \begin{tabular}{|l|l|}
$30 T U N 50$ \\
\end{tabular} & 100,00 & 108,18 & 107,94 & 39,00 & 5427,27 & 264,00 & $-9,95$ & 273,95 & 82,67 & 179,40 & \begin{tabular}{ll|}
179,86 \\
\end{tabular} & 41,34 & 581,56 & 69,70 & 27,79 & 25,18 & \begin{tabular}{|l|l|}
191,44 \\
\end{tabular} & 99,60 & \begin{tabular}{|l|}
107,21 \\
\end{tabular} & 149,70 \\
\hline Pelophylax perezi & 30TUN51 & 100,00 & 102,94 & 106,35 & 39,00 & 5369,64 & 256,83 & $-12,45$ & 269,28 & 77,30 & \begin{tabular}{|l|l|}
173,72 \\
\end{tabular} & 173,89 & 37,00 & 628,56 & 75,55 & 30,81 & 24,62 & 206,99 & 110,28 & \begin{tabular}{|l|l|}
115,75 \\
\end{tabular} & 162,79 \\
\hline Pelophylax perezi & 30TUN52 & 100,00 & 97,59 & 104,75 & 39,00 & 5309,83 & 249,49 & $-15,47$ & 264,96 & 71,96 & $\begin{array}{l}167,75 \\
\end{array}$ & 167,78 & 32,71 & 679,19 & 81,65 & 34,02 & 24,14 & 223,35 & 121,52 & 125,41 & 177,32 \\
\hline Pelophylax perezi & $\begin{array}{l}\text { 30TUN53 } \\
\end{array}$ & 100,00 & 92,94 & 103,02 & 39,01 & 5238,93 & 242,56 & $-17,49$ & 260,05 & \begin{tabular}{ll|}
67,53 \\
\end{tabular} & \begin{tabular}{l|l|}
162,39 \\
\end{tabular} & \begin{tabular}{ll|}
162,39 \\
\end{tabular} & 29,32 & \begin{tabular}{|l|l|}
730,08 \\
\end{tabular} & 87,81 & 37,11 & 23,85 & 239,81 & $\begin{array}{l}132,59 \\
\end{array}$ & \begin{tabular}{|l|l|}
134,37 \\
\end{tabular} & 192,08 \\
\hline Pelophylax perezi & \begin{tabular}{|l|}
$30 T U N 54$ \\
\end{tabular} & 100,00 & 75,20 & 101,38 & 39,01 & 5232,19 & 224,77 & $-31,92$ & 256,68 & \begin{tabular}{|l|l|}
49,17 \\
\end{tabular} & \begin{tabular}{|l|l|}
145,45 \\
\end{tabular} & $\begin{array}{l}145,45 \\
\end{array}$ & 12,64 & 858,34 & 101,26 & 44,68 & 22,6 & 277,25 & 156,33 & $\begin{array}{ll}156,65 \\
\end{array}$ & 231,81 \\
\hline Pelophylax perezi & \begin{tabular}{|l|l|}
$30 T U N 55$ \\
\end{tabular} & 100,00 & 67,09 & 99,61 & 38,96 & 5184,02 & 214,98 & $-37,53$ & 252,51 & $\begin{array}{l}40,85 \\
\end{array}$ & \begin{tabular}{|l|l|}
137,07 \\
\end{tabular} & \begin{tabular}{|l|}
137,07 \\
\end{tabular} & 5,56 & 938,72 & 109,96 & 49,34 & 22,30 & 301,20 & 171,41 & \begin{tabular}{|l|l|}
171,43 \\
\end{tabular} & 256,99 \\
\hline Pelophylax perezi & \begin{tabular}{|l|}
$30 T U N 60$ \\
\end{tabular} & 100,00 & $\begin{array}{r}107,78 \\
\end{array}$ & $\begin{array}{r}106,52 \\
\end{array}$ & 38,92 & 5388,48 & 261,99 & $-9,53$ & 271,52 & 83,11 & 178,64 & 178,98 & 41,52 & 589,75 & 69 & 28,18 & 24,79 & 192,11 & 100,31 & 108,56 & 151,41 \\
\hline Pelophylax perezi & 30TUN61 & 100,00 & 103,72 & 104,85 & 38,99 & 5328,17 & 255,71 & $-11,23$ & 266,94 & \begin{tabular}{l|l|}
79,01 \\
\end{tabular} & $\begin{array}{ll}174,02 \\
\end{array}$ & 174,09 & 38,44 & 631,21 & 75,10 & 30,81 & 24,13 & 205,94 & \begin{tabular}{|l|l|}
109,97 \\
\end{tabular} & \begin{tabular}{|l|l|}
115,17 \\
\end{tabular} & 163,11 \\
\hline Pelophylax perezi & 30TUN62 & 100,00 & 100,53 & 103,01 & 39,00 & 5256,10 & 249,99 & $-11,71$ & 261,70 & 75,86 & \begin{tabular}{|l|l|}
170,14 \\
\end{tabular} & \begin{tabular}{|l|l|}
170,17 \\
\end{tabular} & 36,2 & 672,64 & 80,35 & 33,38 & 23,89 & \begin{tabular}{|l|l|}
219,87 \\
\end{tabular} & $\begin{array}{ll}119,62 \\
\end{array}$ & \begin{tabular}{ll|}
122,53 \\
\end{tabular} & 174,97 \\
\hline Pelophylax perezi & $\begin{array}{l}\text { 30TUN63 } \\
\end{array}$ & 100,00 & 95,59 & 101,35 & 39,00 & 5191,21 & 242,75 & $-14,30$ & 257,06 & \begin{tabular}{|l|}
70,87 \\
\end{tabular} & 164,51 & $164, \mathrm{~s}$ & 32,3 & 724,91 & 86,66 & 36,6 & 23,4 & 236,82 & \begin{tabular}{|l|l|}
131,10 \\
\end{tabular} & \begin{tabular}{l|l|}
132,35 \\
\end{tabular} & 190,20 \\
\hline Pelophylax perezi & \begin{tabular}{|l|}
$30 T U N 64$ \\
\end{tabular} & 100,00 & 80,02 & 100,06 & 38,98 & 5184,33 & 28 & $-26,53$ & 253,81 & 54,72 & \begin{tabular}{|l|l|}
149,56 \\
\end{tabular} & 149,56 & 17,97 & 837,02 & 98,52 & 43,42 & 22,52 & 269,66 & 152,69 & 152,69 & 224,50 \\
\hline Pelophylax perezi & \begin{tabular}{|l|} 
30TUN65 \\
\end{tabular} & 100,00 & 69,90 & 98,53 & 38,94 & 5144,39 & 215,94 & $-34,28$ & 250,22 & 43,91 & \begin{tabular}{|l|l|}
139,24 \\
\end{tabular} & \begin{tabular}{|l|l|}
139,24 \\
\end{tabular} & 8,80 & 926,83 & 108,09 & 48,77 & 21,90 & 296,21 & \begin{tabular}{|l|l|}
169,89 \\
\end{tabular} & \begin{tabular}{|l|l|}
169,89 \\
\end{tabular} & 252,41 \\
\hline Pelophylax perezi & \begin{tabular}{|l|}
$30 T U N 68$ \\
\end{tabular} & 100,00 & 96,86 & 88,38 & 39,26 & 4626,31 & 222,21 & 0,02 & 222,19 & 75,25 & 157,31 & 158,81 & 40,88 & \begin{tabular}{|l|l|}
912,28 \\
\end{tabular} & 112,01 & 46,25 & 23,97 & 302,74 & 166,82 & 173,13 & 246,33 \\
\hline Pelophylax perezi & \begin{tabular}{|l|l|} 
30TUN69 \\
\end{tabular} & 100,00 & 117,26 & 81,33 & 39,36 & 4297,31 & 229,34 & 25,31 & 204,04 & 98,33 & \begin{tabular}{|l|l|l|l|}
172,43 & \\
\end{tabular} & \begin{tabular}{|l|l|}
174,63 \\
\end{tabular} & \begin{tabular}{|c|}
64,57 \\
\end{tabular} & \begin{tabular}{|l|l|}
870,67 \\
\end{tabular} & 110,78 & 42,19 & 25,82 & 296,73 & \begin{tabular}{|l|l|}
155,49 \\
\end{tabular} & \begin{tabular}{ll|l}
167,92 \\
\end{tabular} & 233,20 \\
\hline Pelophylax perezi & \begin{tabular}{|l|} 
30TUN71 \\
\end{tabular} & 100,00 & 103,74 & 103,20 & 38,6 & 300,40 & 254,0 & $-10,03$ & 264,13 & 79,26 & 173,72 & 173,73 & 38 & 638, & 75,21 & 31,10 & 3,84 & 206,53 & \begin{tabular}{|l|l|}
110,94 \\
\end{tabular} & \begin{tabular}{ll|}
114,36 \\
\end{tabular} & 165,02 \\
\hline Pelophylax perezi & \begin{tabular}{|l|}
30 TUN72 \\
\end{tabular} & 100,00 & 99,99 & 101,48 & 38,67 & 5232,63 & 248,0 & $-11,38$ & 259,38 & 75,58 & 169,40 & 169,40 & 36,0 & 682,09 & 80,68 & 33,80 & 23,22 & 221,05 & 120,96 & \begin{tabular}{|l|l|}
123,15 \\
\end{tabular} & 177,63 \\
\hline Pelophylax perezi & 30TUN73 & 100,00 & 95,15 & 99,90 & 38,93 & 5169,28 & 240,88 & $-13,69$ & 254,58 & \begin{tabular}{ll|}
70,69 \\
\end{tabular} & $\begin{array}{ll}163,85 \\
\end{array}$ & \begin{tabular}{l|l|}
163,85 \\
\end{tabular} & 32, & 733,92 & 86,87 & 37,00 & 22,96 & 237,79 & \begin{tabular}{ll|}
132,46 \\
\end{tabular} & 132,82 & 192,86 \\
\hline Pelophylax perezi & $\begin{array}{l}\text { 30TUN74 } \\
\end{array}$ & 100,00 & 89,82 & 98,09 & 38,98 & 5102,09 & 233,30 & $-16,41$ & 249,71 & 65,46 & $\begin{array}{l}157,94 \\
154\end{array}$ & \begin{tabular}{ll|l|}
157,94 \\
\end{tabular} & 28,13 & \begin{tabular}{|l|l|}
792,77 \\
\end{tabular} & 93,82 & 40,51 & 22,65 & $\begin{array}{l}256,46 \\
\end{array}$ & \begin{tabular}{|l|l|}
144,87 \\
\end{tabular} & $\begin{array}{l}144,87 \\
14\end{array}$ & 210,52 \\
\hline Pelophylax perezi & \begin{tabular}{|l|}
$30 T U N 82$ \\
\end{tabular} & 100,00 & 103,75 & 99,23 & 38,19 & 5181,73 & 248,67 & $-6,26$ & 254,93 & \begin{tabular}{|l|l|}
79,67 \\
\end{tabular} & $\begin{array}{ll}172,36 \\
\end{array}$ & 172,36 & 40,25 & 676,56 & 79,63 & 33,14 & 23,00 & 218,70 & 119,91 & \begin{tabular}{l|l|}
120,45 \\
\end{tabular} & 176,38 \\
\hline Pelophylax perezi & \begin{tabular}{|l|} 
30TUN83 \\
\end{tabular} & 100,00 & 97,92 & 97,97 & 38,61 & 5124,45 & 241, & $-9,80$ & 250,94 & 73,74 & \begin{tabular}{|l|l|}
166,08 \\
\end{tabular} & 166,08 & 35,36 & 729,99 & 85,87 & 36,48 & 22,68 & 235,61 & \begin{tabular}{|l|l|}
131,57 \\
\end{tabular} & \begin{tabular}{|l|l|}
131,59 \\
\end{tabular} & 192,01 \\
\hline Pelophylax perezi & 30TUNE & 100,00 & 95,87 & 95,97 & 38,78 & 5037,41 & 235 & $-9,26$ & 245,21 & 72,10 & 163,01 & 163,01 & 34,63 & 773,53 & 91,48 & 38,99 & 22,55 & 250,52 & 141,46 & 141,46 & 205,00 \\
\hline Pelophylax perezi & 30TUN88 & 100,00 & 112,28 & 82,25 & 38,92 & 4422,59 & 227,97 & 18,89 & \begin{tabular}{|l|}
209,08 \\
\end{tabular} & 92,69 & \begin{tabular}{|l|l|}
169,27 \\
\end{tabular} & \begin{tabular}{|l|l|}
171,39 \\
\end{tabular} & 58,07 & \begin{tabular}{|l|l|}
878,46 \\
\end{tabular} & \begin{tabular}{l|l|}
108,95 \\
\end{tabular} & 42,39 & \begin{tabular}{l|l}
24,85 \\
\end{tabular} & 296,31 & \begin{tabular}{|l|l|}
157,07 \\
\end{tabular} & \begin{tabular}{ll|}
168,16 \\
\end{tabular} & 237,92 \\
\hline Pelophylax perezi & \begin{tabular}{|l|}
$30 T U N 89$ \\
\end{tabular} & 100,00 & 127,09 & 75,33 & 38,78 & 4128,39 & 231,24 & 38,99 & 192,25 & 109,28 & $\begin{array}{ll}179,62 \\
\end{array}$ & 182,10 & 76,02 & 878,53 & 111,87 & 40,39 & 26,85 & \begin{tabular}{|l|l|}
303,48 \\
\end{tabular} & 152,44 & 170,10 & 239,38 \\
\hline Pelophylax perezi & \begin{tabular}{|l|} 
30TUN90 \\
\end{tabular} & 100,00 & 109,22 & 101,28 & 38,00 & 5337,25 & 258,43 & $-4,49$ & 262,92 & 84,31 & 179,54 & \begin{tabular}{|l|l|}
179,57 \\
\end{tabular} & 43,42 & 602,44 & 69,40 & 28,63 & 23, & 191,90 & \begin{tabular}{|l|}
102,63 \\
\end{tabular} & \begin{tabular}{|l|}
104,81 \\
\end{tabular} & 155,11 \\
\hline Pelophylax perezi & $30 \mathrm{TUI}$ & 100, & 106 & 99,36 & 38, & 524 & 252 & $-4,36$ & 257 & 82 & 176,04 & 176 & & 641 & 74,43 & 30,98 & 22, & 205 & 111,84 & \begin{tabular}{|l|l|}
112,18 \\
\end{tabular} & 166 \\
\hline Pelophylax perezi & \begin{tabular}{|l|}
$30 T U N 92$ \\
\end{tabular} & 100,00 & 101,90 & 97,83 & 38,05 & 5179,18 & 245,87 & $-6,59$ & 252,46 & \begin{tabular}{|c|}
77,36 \\
\end{tabular} & \begin{tabular}{|l|l|}
170,68 \\
\end{tabular} & 170,68 & 38,63 & 691,31 & 80,48 & 33,97 & 22,56 & 221,58 & 122,90 & 122,90 & 181,06 \\
\hline Pelophylax perezi & \begin{tabular}{|l|l|} 
30TUN93 \\
\end{tabular} & 100,00 & 101,05 & 95,72 & 38,19 & 5085,48 & 241,52 & $-4,99$ & 246,51 & $\begin{array}{ll}76,96 \\
\end{array}$ & \begin{tabular}{|l|l|}
168,68 \\
\end{tabular} & 168,68 & 38,88 & 728,04 & 85,35 & 35,99 & 22,53 & \begin{tabular}{|l|}
234,67 \\
\end{tabular} & 131,51 & 131,51 & 192,18 \\
\hline Pelophylax perezi & \begin{tabular}{|l|} 
30TUN94 \\
\end{tabular} & 100,00 & 97,51 & 94,17 & 38,50 & 5005,21 & 235,48 & $-6,21$ & 241,69 & 73,75 & \begin{tabular}{|l|l|l|}
164,15 \\
\end{tabular} & $\begin{array}{l}164,25 \\
\end{array}$ & 36,64 & 776,04 & 91,17 & 38,84 & 22,19 & 250,43 & \begin{tabular}{l|l|}
142,05 \\
\end{tabular} & \begin{tabular}{l|l|}
142,05 \\
\end{tabular} & 206,47 \\
\hline Pelophyl: & THN & 10 & 117, & 79,04 & $38.55-3$ & & & 25,87 & 202 & 97, & 172, & & & 887, & 109,93 & 41 & 25, & 300 & 156, & 170,18 & \\
\hline Pelophylax perezi & \begin{tabular}{|l|}
30 TUN99 \\
\end{tabular} & 100,00 & 129,86 & 72,59 & 38,23 & 4062,2 & 231, & 43,82 & 187,25 & 112,45 [ & $181,34 \mid$ & \begin{tabular}{|l|l|}
183,99 \\
\end{tabular} & 79,52 & 896,31 & 113,76 & 40,26 & $27,29 \mid$ & 311,29 & 153,49 & 173,86 & 247, \\
\hline Pelophylax perezi & 30TUP00 & 100,00 & 126,74 & 83,46 & 41,44 & 4057,12 & 235,08 & 36,23 & 198,85 & 108,39 & 178,43 & 181,14 & 77,34 & 829,34 & 111,57 & 41,76 & 27,54 & 281,62 & 149,04 & 159,96 & 210,49 \\
\hline
\end{tabular}




\begin{tabular}{|c|c|c|c|c|c|c|c|c|c|c|c|c|c|c|c|c|c|c|c|c|c|}
\hline TAXON & UTM & $\mathrm{km} 2$ & BIO1 & B102 & $B 103$ & BIO4 & B105 & B106 & B107 & B108 & B109 & B1010 & BIO11 & BIO12 & BIO13 & BIO14 & BIO15 & B1016 & B1017 & B1018 & 81019 \\
\hline Pelophylax perezi & 30TUP01 & 98,00 & 132,84 & 77,05 & 40,95 & 3870,73 & 232,49 & 46,63 & 185,86 & 115,81 & 181,85 & 184,96 & 85,62 & 834,29 & 112,99 & 41,12 & 27,93 & 284,33 & 147,81 & 160,77 & 212,72 \\
\hline Pelophylax perezi & 30TUP02 & 40,00 & 136,08 & 73,30 & 40,65 & 3764,03 & 230,71 & 52,45 & 178,26 & 119,80 & 183,68 & $\begin{array}{l}186,80 \\
\end{array}$ & 90,21 & 839,39 & 114,00 & 40,95 & 28,24 & 286,77 & 147,48 & $\begin{array}{l}161,79 \\
\end{array}$ & 215,03 \\
\hline Pelophylax perezi & 30TUP10 & 100,00 & 128,41 & 81,58 & \begin{tabular}{ll|}
40,93 \\
\end{tabular} & 4066,27 & 235,21 & 38,27 & 196,94 & 110,11 & 180,23 & 182,88 & 78,61 & \begin{tabular}{|l|l|}
820,87 \\
\end{tabular} & \begin{tabular}{|l|l|}
109,97 \\
\end{tabular} & 40,75 & 27,43 & 280,47 & $\begin{array}{l}146,78 \\
\end{array}$ & $\begin{array}{l}158,76 \\
\end{array}$ & 210,20 \\
\hline Pelophylax perezi & 30TUP20 & 100,00 & 134,88 & 77,88 & 40,29 & 3995,93 & 237,12 & 46,48 & 190,63 & 117,35 & 185,62 & 188,38 & 85,65 & 802,19 & $\begin{array}{l}107,72 \\
\end{array}$ & 38,63 & 27,90 & 276,54 & 141,34 & 155,20 & 206,81 \\
\hline Pelophylax perezi & 30TUP21 & 65,00 & 132,62 & 76,72 & 40,33 & 3942,74 & 233,28 & 45,64 & 187,64 & 115,31 & 182,62 & 185,54 & 84,31 & 833,38 & 111,64 & 40,50 & 27,68 & 286,53 & 147,33 & 161,81 & 215,78 \\
\hline Pelophylax perezi & 30TUP30 & 100,00 & 126,56 & 80,18 & 40,24 & 4107,21 & 233,28 & 36,55 & 196,73 & 108,50 & 178,94 & 181,48 & 76,06 & 836,94 & 110,50 & 40,98 & 27,01 & 287,16 & 149,31 & 162,56 & 217,93 \\
\hline Pelophylax perezi & 30TUP31 & 47,00 & 138,43 & 74,00 & 40,01 & 3894,79 & 235,65 & 52,49 & 183,16 & 121,57 & 187,60 & 190,48 & 90,33 & 816,59 & 109,47 & 38,40 & 28,28 & 283,51 & 141,96 & 158,43 & 213,59 \\
\hline Pelophylax perezi & $\begin{array}{l}\text { 30TUP70 } \\
\end{array}$ & 60,00 & 138,51 & 71,72 & 38,94 & 3944,71 & 235,56 & 53,15 & 182,42 & 121,71 & $\begin{array}{l}188,22 \\
\end{array}$ & $\begin{array}{l}190,99 \\
\end{array}$ & 89,35 & 851,58 & $\begin{array}{l}111,16 \\
\end{array}$ & 38,07 & 28,35 & 298,79 & $\begin{array}{l}145,09 \\
\end{array}$ & 165,69 & 231,25 \\
\hline Pelophylax perezi & 30TUP80 & 52,00 & 140,72 & 69,54 & 38,38 & 3892,03 & 235,48 & 57,06 & 178,42 & 124,28 & 189,84 & $\begin{array}{l}192,54 \\
\end{array}$ & 92,19 & 868,10 & \begin{tabular}{|l|l|}
112,90 \\
\end{tabular} & 37,91 & 28,77 & $\begin{array}{l}306,16 \\
\end{array}$ & $\begin{array}{l}146,00 \\
\end{array}$ & $\begin{array}{l}169,13 \\
\end{array}$ & 238,68 \\
\hline Pelophylax perezi & 30TVK03 & 100,00 & \begin{tabular}{ll|l}
145,97 \\
\end{tabular} & 110,20 & 35,00 & \begin{tabular}{|l|l|l|l|l|}
6806,34 \\
\end{tabular} & 325,77 & 15,20 & 310,57 & 102,11 & 237,57 & 237,57 & 62,60 & 390,10 & 44,01 & 8,79 & 36,03 & \begin{tabular}{|l|l|}
128,12 \\
\end{tabular} & 44,57 & 44,57 & $\begin{array}{ll}108,59 \\
\end{array}$ \\
\hline Pelophylax perezi & 30TVK04 & 100,00 & 141,82 & $\begin{array}{l}108,82 \\
\end{array}$ & 35,00 & 6739,72 & 319,73 & 12,91 & 306,82 & 98,61 & 232,45 & 232,45 & 59,53 & 400,06 & 45,23 & $\begin{array}{l}9,46 \\
\end{array}$ & 35,27 & \begin{tabular}{|l|l|}
131,47 \\
\end{tabular} & 47,25 & 47,25 & 111,22 \\
\hline Pelophylax perezi & 30TVK05 & 100,00 & 140,83 & 107,49 & 35,00 & 6692,88 & 316,60 & 13,12 & 303,48 & 98,00 & 230,73 & 230,73 & 58,72 & 400,28 & 45,81 & 9,84 & 35,06 & 132,45 & 48,01 & 48,01 & 111,60 \\
\hline Pelophylax perezi & 30TVK06 & 100,00 & 142,47 & 106,21 & 35,00 & 6653,52 & 315,94 & 15,49 & 300,45 & 99,92 & 231,60 & 231,60 & 60,65 & 393,55 & 45,92 & 9,78 & 35,14 & 131,53 & 47,31 & 47,31 & 110,19 \\
\hline Pelophylax perezi & 30TVK07 & 100,00 & 138,22 & 105,19 & 35,00 & 6599,22 & 309,76 & 12,52 & 297,24 & 95,99 & 226,14 & 226,46 & 57,02 & $\begin{array}{l}400,96 \\
\end{array}$ & 47,07 & 10,68 & 34,48 & 133,24 & 50,14 & 50,30 & 110,73 \\
\hline Pelophylax perezi & 30TVK08 & 100,00 & 124,39 & 104,41 & \begin{tabular}{ll|}
35,06 \\
\end{tabular} & 6501,56 & 294,21 & 1,24 & 292,97 & 83,41 & 209,89 & 211,86 & 45,44 & $\begin{array}{l}432,64 \\
\end{array}$ & 51,12 & 13,14 & 32,69 & 139,51 & $\begin{array}{l}58,66 \\
\end{array}$ & 60,32 & 113,69 \\
\hline Pelophylax perezi & 30TVK09 & 100,00 & 113,60 & 104,19 & \begin{tabular}{|l|}
35,39 \\
\end{tabular} & \begin{tabular}{|l|l|l|}
6407,64 \\
\end{tabular} & 282,44 & $-7,01$ & 289,45 & 85,27 & 198,75 & 200,05 & 36,88 & $\begin{array}{l}464,05 \\
\end{array}$ & 56,18 & 15,15 & 31,66 & \begin{tabular}{|l|l|}
147,87 \\
\end{tabular} & $\begin{array}{l}65,86 \\
\end{array}$ & 69,08 & 118,12 \\
\hline Pelophylax perezi & 30TVK13 & 100,00 & 145,24 & 109,73 & 35,00 & 6814,80 & 325,08 & 14,99 & 310,09 & $\begin{array}{l}101,44 \\
\end{array}$ & 236,94 & 236,94 & 61,94 & 399,49 & 45,21 & 8,85 & 36,09 & 132,32 & 45,10 & 45,10 & 113,19 \\
\hline Pelophylax perezi & 30TVK14 & 100,00 & 143,95 & 108,34 & 35,00 & 6764,50 & 321,63 & 15,06 & 306,57 & 100,59 & 234,79 & 234,79 & 61,20 & 403,45 & 46,28 & 9,30 & 35,95 & $|134,67|$ & 46,24 & 46,24 & $\begin{array}{ll}115,13 \\
\end{array}$ \\
\hline Pelophylax perezi & 30TVK15 & 100,00 & 142,04 & 106,75 & \begin{tabular}{|l|l|}
34,97 \\
\end{tabular} & \begin{tabular}{|l|l|l|}
6705,94 \\
\end{tabular} & 317,49 & 14,75 & 302,73 & $\begin{array}{l}99,14 \\
\end{array}$ & 231,96 & 231,96 & 59,81 & $\begin{array}{l}408,66 \\
\end{array}$ & 47,75 & $\begin{array}{l}9,86 \\
\end{array}$ & 35,56 & 137,26 & 47,68 & \begin{tabular}{ll|}
47,68 \\
\end{tabular} & 117,06 \\
\hline Pelophylax perezi & 30TVK16 & 100,00 & 139,82 & 105,44 & 34,99 & 6661,84 & 313,12 & 13,97 & 299,15 & 97,24 & 229,09 & 229,09 & 58,00 & \begin{tabular}{ll|}
414,38 \\
\end{tabular} & $49, \mathrm{C}$ & 10,47 & 35,36 & \begin{tabular}{ll|}
139,58 \\
\end{tabular} & $\begin{array}{l}49,25 \\
\end{array}$ & $\begin{array}{l}49,25 \\
\end{array}$ & 118,99 \\
\hline Pelophylax perezi & 30TVK17 & 100,00 & 138,91 & 104,25 & 34,96 & $\begin{array}{ll}6616,96 \\
\end{array}$ & 310,09 & 13,86 & 296,23 & 96,55 & 227,31 & 227,31 & 57,37 & \begin{tabular}{ll|l}
414,99 \\
\end{tabular} & 49,71 & $\begin{array}{l}10,90 \\
\end{array}$ & 35,08 & $\begin{array}{l}140,19 \\
\end{array}$ & 50,32 & 50,32 & 118,99 \\
\hline Pelophylax perezi & 30TVK18 & 100,00 & 131,85 & 103,41 & \begin{tabular}{|c|}
34,97 \\
\end{tabular} & 6562,13 & 301,39 & 8,21 & 293,18 & 90,01 & 218,54 & 219,79 & 51,45 & $\begin{array}{l}430,06 \\
4\end{array}$ & 51,12 & 11,99 & 33,87 & 143,24 & 54,72 & 55,46 & 120,27 \\
\hline Pelophylax perezi & 30TVK19 & 100,00 & 122,10 & 103,03 & 35,01 & 6504,33 & $\mid 290,27$ & 0,24 & 290,03 & 80,60 & 207,63 & 209,40 & 43,13 & 452,22 & 52,58 & $\mid 13,31$ & 32,24 & $\mid$\begin{tabular}{|l|l|}
146,66 \\
\end{tabular} & 60,58 & 63,19 & 121,45 \\
\hline Pelophylax perezi & 30TVK23 & 100,00 & 146,61 & 109,52 & 35,00 & 6808,27 & 326,06 & 16,59 & 309,47 & 102,75 & 238,05 & 238,05 & 63,21 & 402,47 & 46,38 & 8,66 & 36,64 & 135,25 & 44,18 & 44,18 & 116,12 \\
\hline Pelophylax perezi & 30TVK25 & 100,00 & 139,38 & 106,45 & 34,98 & $\begin{array}{ll}6697,34 \\
\end{array}$ & 314,71 & 13,08 & 301,62 & 96,42 & 229,10 & 229,10 & 57,26 & $\begin{array}{l}428,35 \\
\end{array}$ & 50,99 & \begin{tabular}{ll|}
10,36 \\
\end{tabular} & 36,03 & 145,21 & 49,27 & 49,27 & 125,76 \\
\hline Pelophylax perezi & 30TVK26 & 100,00 & 138,25 & 104,76 & 34,99 & 6657,59 & 311,19 & 13,42 & 297,77 & 95,62 & 227,21 & 227,21 & 56,31 & 433,86 & 52,36 & \begin{tabular}{ll|}
10,97 \\
\end{tabular} & 35,88 & 147,81 & 50,58 & 50,58 & 128,45 \\
\hline Pelophylax perezi & 30TVK27 & 100,00 & 135,36 & 103,56 & \begin{tabular}{|l|l|}
34,97 \\
\end{tabular} & 6603,25 & 306,28 & 11,89 & 294,39 & 93,05 & 223,48 & 223,52 & 54,19 & $\begin{array}{l}441,59 \\
\end{array}$ & 53,65 & 11,71 & 35,26 & 150,21 & 52,99 & 53,01 & 130,36 \\
\hline Pelophylax perezi & 30TVK28 & 100,00 & 134,52 & 102,71 & 34,77 & 6590,42 & 303,93 & 11,24 & 292,69 & 92,35 & 222,28 & 222,54 & 53,49 & \begin{tabular}{|l|l|}
438,63 \\
\end{tabular} & 53,81 & 11,70 & 34,89 & $\begin{array}{l}149,35 \\
\end{array}$ & 53,68 & 53,80 & 127,92 \\
\hline Pelophylax perezi & 30TVK29 & 100,00 & 123,83 & 102,72 & 35,00 & 6522,81 & 292,25 & 2,43 & 289,82 & 82,35 & 209,81 & 211,40 & 44,65 & 461,17 & 55,11 & 13,13 & 33,00 & 152,18 & 60,21 & 62,15 & 128,16 \\
\hline Pelophylax perezi & 30TVK33 & 100,00 & 144,05 & 109,81 & 35,00 & 6792,65 & 323,82 & 14,66 & 309,16 & 100,29 & 235,23 & 235,23 & 60,91 & 415,73 & 48,88 & 8,95 & 36,88 & 140,90 & 45,36 & 45,36 & 121,40 \\
\hline Pelophylax perezi & 30TVK35 & 100,00 & 140,79 & 106,29 & 34,87 & $\begin{array}{ll}6709,03 \\
\end{array}$ & 316,27 & 14,32 & 301,95 & 97,58 & 230,45 & 230,45 & 58,30 & 432,71 & 53,08 & 10,14 & 37,05 & $\begin{array}{l}149,43 \\
\end{array}$ & 48,10 & 48,10 & 129,22 \\
\hline Pelophylax perezi & 30TVK36 & 100,00 & 139,30 & 104,45 & 34,74 & 6663,92 & 312,32 & 14,42 & 297,90 & 96,29 & 228,15 & 228,15 & 57,02 & 441,51 & 54,98 & 10,73 & 37,02 & 153,39 & 49,58 & 49,58 & 133,44 \\
\hline Pelophylax perezi & 30TVK37 & 100,00 & 138,10 & 102,94 & 34,50 & 6626,82 & 309,23 & 14,46 & 294,77 & 95,56 & 226,59 & 226,59 & 56,19 & 444,80 & 56,12 & 11,12 & 36,95 & 155,32 & 50,47 & 50,47 & 134,92 \\
\hline Pelophylax perezi & 30TVK38 & 100,00 & 136,31 & 102,21 & 34,23 & 6602,03 & 306,29 & 13,06 & 293,23 & 93,77 & 224,52 & 224,52 & 54,94 & 443,90 & 56,36 & 11,18 & 36,47 & 154,53 & 51,94 & 51,94 & 132,50 \\
\hline Pelophylax perezi & 30TVK39 & 100,00 & 132,33 & 102,09 & 34,58 & 6564,50 & 301,02 & 9,65 & 291,37 & 90,28 & 219,68 & 220,00 & 51,72 & 447,13 & 56,23 & 11,54 & 35,06 & 153,56 & 55,03 & 55,22 & 130,17 \\
\hline Pelophylax perezi & 30TVK43 & 100,00 & 146,90 & 110,28 & 35,02 & \begin{tabular}{|l|l|l|l|}
6784,14 \\
\end{tabular} & 326,59 & 17,10 & 309,49 & 103,19 & 237,63 & 237,63 & 63,67 & $\begin{array}{l}408,17 \\
4\end{array}$ & 49,26 & 8,35 & 37,78 & 140,62 & 42,91 & 42,91 & 120,14 \\
\hline Pelophylax perezi & 30TVK44 & 100,00 & 143,44 & 108,56 & 34,99 & \begin{tabular}{|l|l|l|}
6760,64 \\
\end{tabular} & 321,77 & 15,10 & 306,66 & 99,78 & 233,83 & 233,83 & 60,45 & 423,37 & 52,28 & 9,23 & 37,69 & \begin{tabular}{|l|l|}
146,93 \\
\end{tabular} & 45,40 & 45,40 & 125,90 \\
\hline Pelophylax perezi & 30TVK45 & 100,00 & 141,73 & 106,88 & 34,73 & 6731,84 & 318,44 & 14,64 & 303,80 & 98,28 & 231,64 & 231,64 & 58,98 & 432,94 & 54,79 & $\begin{array}{l}9,89 \\
\end{array}$ & 37,89 & 151,93 & 46,67 & 46,67 & 130,14 \\
\hline Pelophylax perezi & 30TVK46 & 100,00 & 142,44 & 105,04 & 34,08 & 6722,08 & 317,5 & 15,72 & 301,82 & 99,19 & 232,04 & 232,04 & 59,47 & \begin{tabular}{ll|l}
433,65 \\
\end{tabular} & 56,45 & $\begin{array}{l}9,89 \\
\end{array}$ & 38,66 & 154,29 & 46,01 & 46,01 & 131,79 \\
\hline Pelophylax perezi & \begin{tabular}{|l|}
$30 T V K 47$ \\
\end{tabular} & 100,00 & 137,47 & 103,58 & 34,19 & 6659,03 & 310,34 & 12,61 & 297,73 & 94,24 & 226,32 & 226,32 & 55,21 & 449,72 & 58,83 & 10,81 & 38,01 & 159,53 & 49,71 & 49,71 & 136,32 \\
\hline Pelophylax perezi & 30TVK48 & 100,00 & 135,62 & 103,27 & \begin{tabular}{ll|}
34,38 \\
\end{tabular} & 6631,22 & 307,45 & 11,59 & 295,86 & 92,62 & 224,08 & 224,08 & 53,97 & $\begin{array}{l}449,55 \\
4\end{array}$ & 59,09 & 10,81 & 37,42 & \begin{tabular}{l|l|}
159,03 \\
\end{tabular} & 51,06 & 51,06 & 134,80 \\
\hline Pelophylax perezi & 30TVK49 & 100,00 & 134,81 & 102,96 & 34,73 & 6603,20 & 305,15 & 11,37 & 293,78 & 92,12 & 222,82 & 222,82 & 53,66 & \begin{tabular}{ll|}
442,82 \\
\end{tabular} & 58,10 & 10,74 & 36,60 & 155,84 & 52,14 & 52,14 & 130,55 \\
\hline Pelophylax perezi & 30TVK53 & 100,00 & 144,53 & 111,16 & 35,28 & 6768,78 & 324,73 & 14,94 & 309,79 & 100,76 & 235,02 & 235,02 & 61,71 & 415,71 & 50,65 & 8,66 & 37,63 & \begin{tabular}{|l|l|}
143,47 \\
\end{tabular} & 44,26 & 44,26 & 121,99 \\
\hline Pelophylax perezi & 30TVK54 & 100,00 & $\begin{array}{lll}143,67 \\
\end{array}$ & 109,71 & 35,7 & 6755,05 & 322,69 & 15,08 & 307,61 & 99,94 & 233,95 & 233,95 & 60,92 & 420,95 & 52,77 & $\begin{array}{l}9,08 \\
\end{array}$ & 37,83 & 147,14 & 44,87 & 44,87 & 124,71 \\
\hline Pelophylax perezi & 30TVK55 & 100,00 & 141, & 108,40 & 34,5 & 6738,40 & 319,77 & 14,16 & 305,61 & 98,29 & 231,79 & 231,79 & 59,30 & 429,84 & 55,43 & 9,63 & 38,22 & 152,05 & 45,89 & 45,89 & 128,52 \\
\hline Pelophylax perezi & 30TVK56 & 100,00 & 142 & 107,10 & 34,73 & 6737,97 & 319,71 & 15,12 & 304,59 & 99,05 & 232,33 & 232,33 & 59,72 & 429,50 & 57, & 9,44 & 39,30 & 154,57 & 44,76 & 44,76 & 129,99 \\
\hline Pelophylax perezi & 30TVK57 & 100,00 & 140,80 & 106,21 & 34,44 & 6736,18 & 317,72 & 13,90 & 303,82 & 97,37 & 230,36 & 230,36 & 58,05 & $\mid$\begin{tabular}{|l|l|}
437,08 \\
\end{tabular} & 60,00 & 9,60 & 39,76 & $\mid 158,71$ & 45,75 & \begin{tabular}{|c|c|}
45,75 \\
\end{tabular} & $\begin{array}{ll}132,97 \\
\end{array}$ \\
\hline Pelophylax perezi & 30TVK58 & 100,00 & 137,29 & 105,89 & 34,75 & 6671,55 & 312,08 & 12,03 & 300,05 & 93,89 & 225,91 & 225,91 & 55,51 & 441,80 & 60,58 & 10,14 & 38,73 & 159,91 & 48,39 & 48,39 & 132,82 \\
\hline Pelophylax perezi & 30TVK59 & 100,00 & 135,08 & 104,62 & 34,94 & 6619,79 & 306,93 & 11,33 & 295,60 & 92,02 & 223,11 & 223,11 & 54,05 & 437,96 & 58,92 & 10,32 & 37,44 & 156,24 & 50,69 & 50,69 & 128,61 \\
\hline Pelophylax perezi & $30 \mathrm{TVK}$ & 100,00 & 141,18 & 112,37 & $36, \mathrm{C}$ & 6743,88 & 321 & 11,90 & 309,73 & 97,42 & 231,27 & 231,27 & 58,88 & 423,68 & 51,31 & 9,18 & 36,88 & 144,92 & 46,64 & 46,64 & 122,68 \\
\hline Pelophylax perezi & 30TVK64 & 100,00 & \begin{tabular}{ll|}
135,64 \\
\end{tabular} & 111,39 & \begin{tabular}{|l|l|}
35,88 \\
\end{tabular} & \begin{tabular}{|l|l|}
6717,81 \\
\end{tabular} & 315,40 & 7,72 & 307,68 & 91,90 & 225,52 & 225,52 & 54,00 & $\begin{array}{l}443,15 \\
\end{array}$ & 54,57 & 10,44 & 36,41 & 151,81 & 50,33 & 50,33 & 128,69 \\
\hline Pelophylax perezi & 30TVK65 & 100,00 & 136,33 & 110,13 & 35,57 & $\mid 6706,47$ & 314,83 & 9,29 & 305,54 & $\mid 92,67$ & 225,97 & 225,97 & 54,79 & $\mid 441,00$ & 56,15 & $\mid 10,42$ & 37,09 & $\mid 154,02$ & $\mid 49,42$ & $\mid 49,42$ & 129,26 \\
\hline Pelophylax perezi & 30TVK66 & 100,00 & 135,15 & 109,35 & 35,54 & \begin{tabular}{|l|l|}
6682,24 \\
\end{tabular} & 312,59 & 9,16 & 303,44 & 91,49 & 224,27 & 224,27 & 53,89 & $\begin{array}{l}444,85 \\
\end{array}$ & 58,23 & 10,72 & 37,30 & 157,33 & 49,85 & 49,85 & 130,99 \\
\hline Pelophylax perezi & $30 \mathrm{TV}$ & 100 & 137 & 109,24 & 35,68 & 6661 & 31 & 11,86 & 302,08 & 93,44 & 225,66 & 225,66 & 56,13 & 436,79 & 59, & 9,84 & 39,03 & 158,62 & 47,44 & 47,44 & 130,13 \\
\hline Pelophylax perezi & 30TVK68 & 100,00 & 136,47 & 108,46 & $\begin{array}{l}35,96 \\
\end{array}$ & 6623,71 & 311,34 & 12,18 & 299,16 & 92,69 & 224,35 & 224,35 & 55,92 & 432,86 & 59,86 & 9,67 & 39,16 & 158,13 & 47,77 & 47,77 & 128,14 \\
\hline Pelophylax perezi & 30TVK69 & 100,00 & 130,82 & 105,62 & 35,28 & 6593,60 & 302,23 & 8,04 & 294,19 & 87,81 & 218,64 & 218,64 & 50,92 & 440,21 & 58,48 & 10,84 & 36,21 & $\begin{array}{l}155,32 \\
\end{array}$ & 53,21 & 53,21 & 125,62 \\
\hline Pelophylax perezi & 30TVK73 & 100,00 & 141,02 & 113,14 & 36,00 & 6727,66 & 321,23 & 11,60 & 309,64 & 97,50 & 230,97 & 230,97 & 59,09 & 419,19 & 50,42 & 9,30 & 36,39 & \begin{tabular}{ll|}
142,58 \\
\end{tabular} & 47,14 & 47,14 & 119,64 \\
\hline Pelophyl & $\overline{T V y}$ & 100, & & 112,49 & 36,00 & 702, & 312 & 5,0 & 07,55 & 8 & 22 & & 51 & 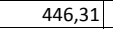 & 53 & 10,94 & $35>>>$ & 10 & 52,65 & 52,65 & 12 \\
\hline Pelophylax perezi & 30TVK75 & 100,00 & 133,78 & 111,15 & 36,00 & 6683,05 & 311,94 & 6,99 & 304,95 & 90,26 & 223,04 & 223, & 52,8 & \begin{tabular}{|l|l|}
440,63 \\
\end{tabular} & 54,90 & \begin{tabular}{|l|l|}
11,08 \\
\end{tabular} & 35,72 & $\begin{array}{l}151,22 \\
\end{array}$ & 51,74 & 51,74 & 125,60 \\
\hline Pelophylax perezi & 30TVK76 & 100,00 & 127,98 & 110,16 & 36,00 & 6648,33 & 304,79 & 2,62 & 302,17 & 84,65 & 216,96 & 216,96 & 47,77 & 456,99 & 56,81 & 12,23 & 34,59 & 155,52 & 55,91 & 55,91 & 129,05 \\
\hline
\end{tabular}




\begin{tabular}{|c|c|c|c|c|c|c|c|c|c|c|c|c|c|c|c|c|c|c|c|c|c|}
\hline TAXON & UTM & $\mathrm{km2}$ & B101 & $\mathrm{B1O2}$ & $\mathrm{BIO3}$ & B104 & B105 & B106 & B107 & B108 & B109 & 81010 & B1011 & B1O12 & BIO13 & 81014 & B1015 & B1016 & B1017 & BIO18 & B1019 \\
\hline Pelophylax perezi & 30TVK77| & 100,00 & 127,52 & 108,89 & 36,00 & 6620,45 & 302,52 & 3,27 & 299,25 & 84,27 & 215,94 & 215,94 & 47,71 & 453,90 & 57,35 & 12,08 & 34,72 & 155,45 & 56,17 & 56,17 & 127,52 \\
\hline Pelophylax perezi & 30TVK78 & 100,00 & 132,00 & 107,07 & 35,82 & 6613,92 & 304,40 & 8,54 & 295,86 & 88,89 & 220,03 & 220,03 & 52,04 & 431,48 & 56,53 & 10,85 & 35,91 & 151,10 & 52,36 & 52,36 & 120,87 \\
\hline Pelophylax perezi & 30TVK79 & 100,00 & 130,23 & 104,81 & 35,19 & 6592,21 & 299,79 & 7,80 & 291,99 & 87,36 & 218,03 & 218,03 & 50,57 & 428,29 & 55,77 & 10,97 & 34,90 & 148,50 & 54,04 & 54,04 & 117,38 \\
\hline Pelophylax perezi & 30TVK83 & 100,00 & 138,79 & 113,98 & 36,19 & 6701,32 & 318,91 & 9,42 & 309,49 & 95,62 & 228,52 & 228,52 & 57,55 & 421,78 & 49,56 & 9,79 & 35,27 & 141,03 & 49,49 & 49,49 & 118,06 \\
\hline Pelophylax perezi & 30TVK84 & 100,00 & 136,38 & 112,93 & 36,00 & \begin{tabular}{|l|l|}
6688,14 \\
\end{tabular} & 315,22 & 8,16 & 307,06 & \begin{tabular}{|c|}
93,16 \\
\end{tabular} & 225,78 & 225,78 & 55,40 & 427,51 & 51,14 & 10,45 & 35,06 & 143,71 & 50,99 & 50,99 & 119,44 \\
\hline Pelophylax perezi & 30TVK85 & 100,00 & 130,92 & 111,85 & 36,04 & 6663,29 & 308,86 & 3,97 & 304,89 & 87,80 & 220,08 & 220,08 & 50,55 & 442,93 & 53,19 & 11,81 & 34,14 & 148,08 & 54,91 & 54,91 & 122,79 \\
\hline Pelophylax perezi & 30TVK86 & 100,00 & 129,06 & 110,40 & 36,00 & 6643,83 & 305,12 & 3,24 & 301,89 & 85,92 & 217,78 & 217,78 & 48,93 & 445,04 & 54,00 & 12,35 & 33,79 & 149,01 & 56,37 & 56,37 & 122,41 \\
\hline Pelophylax perezi & $\begin{array}{l}\text { 30TVK87 } \\
\end{array}$ & 100,00 & 125,00 & 109,19 & 36,00 & 66 & 299,33 & 1,01 & 298,32 & 82,09 & 213,40 & 213,40 & 45,56 & 453,26 & 54,74 & 12,95 & 32,86 & 150,36 & 59,67 & 59,67 & 123,08 \\
\hline Pelophylax perezi & 30TVK88 & 100,00 & 121,64 & 107,84 & \begin{tabular}{l|l|l}
35,95 \\
\end{tabular} & 6583,24 & 294,27 & $-0,88$ & 295,15 & 79,05 & 209,83 & 209,84 & 42,75 & 458,95 & 54,87 & 13,65 & 32,03 & 150,42 & 62,90 & 62,91 & 122,69 \\
\hline Pelophylax perezi & 30TVK89 & 100,00 & 126,58 & 104,72 & 35,36 & 6585,39 & 295,38 & 4,42 & 290,96 & 84,21 & 214,39 & 214,50 & 47,38 & 431,15 & 53,18 & 12,27 & 32,92 & 143,65 & 58,45 & 58,59 & 113,28 \\
\hline Pelophylax perezi & 30TVK93 & 100,00 & 133,88 & 115,16 & 36,72 & 6682,34 & 314,40 & 4,33 & 310,06 & 91,02 & 223,35 & 223,35 & 53,06 & 435,85 & 49,31 & 11,01 & 33,60 & 141,44 & 54,57 & 54,57 & 119,15 \\
\hline Pelophylax perezi & 30TVK94 & 100,00 & 138,49 & 113,19 & 36,39 & 6662,75 & 316,37 & 9,55 & 306,82 & 95,65 & 227,41 & 227,41 & 57,56 & 415,14 & 48,55 & 10,29 & 34,43 & 137,83 & 50,81 & 50,81 & 113,59 \\
\hline Pelophylax perezi & 30TVK95 & 100,00 & 132,32 & 112,24 & 36,18 & 6644,92 & 309,54 & 4,81 & 304,73 & 89,54 & 221,22 & 221,22 & 52,02 & 432,00 & 50,47 & 11,76 & 33,33 & 142,08 & 55,31 & 55,31 & 117,16 \\
\hline Pelophylax perezi & 30TVL00 & 100,00 & 103,47 & 104,36 & 35,96 & 6315,89 & 271,61 & $-14,89$ & 286,50 & 97,34 & 188,25 & 189,18 & 29,18 & 495,14 & 61,23 & 17,16 & 30,66 & 156,36 & 73,01 & 77,93 & 122,97 \\
\hline Pelophylax perezi & 30TVL01 & 100,00 & 80,62 & 106,71 & 37,19 & 6073,35 & 250,45 & $-32,06$ & 282,52 & 83,05 & 164,19 & 164,30 & 12,32 & 595,66 & 74,22 & 23,49 & 28,36 & 187,09 & 91,97 & 95,44 & 147,75 \\
\hline Pelophylax perezi & 30TVL02 & 100,00 & 104,18 & 102,76 & 35,80 & 6328,72 & 269,13 & $-14,21$ & 283,34 & 120,89 & 188,74 & 189,91 & 29,02 & 496,09 & 60,40 & 16,33 & 30,06 & 155,61 & 73,06 & 80,28 & 123,40 \\
\hline Pelophylax perezi & 30TVL03 & 100,00 & 111,68 & 101,23 & 35,18 & 6409,99 & 274,44 & $-7,84$ & 282,27 & 123,56 & 196,60 & 198,14 & 34,33 & 477,20 & 56,09 & 14,21 & 30,30 & 148,11 & 68,19 & 76,25 & 121,31 \\
\hline Pelophylax perezi & 30TVL06 & 100,00 & 116,71 & 104,10 & 36,00 & 6302,46 & 280,64 & $-3,95$ & 284,59 & 87,64 & 199,84 & 201,07 & 39,69 & 450,05 & 52,20 & 13,92 & 29,64 & 138,92 & 64,53 & 72,95 & 115,98 \\
\hline Pelophylax perezi & 30TVL07 & 100,00 & 116,73 & 105,12 & 36,17 & 6250,86 & 281,10 & $-4,31$ & 285,42 & 94,92 & 199,00 & 200,28 & 40,25 & 447,60 & 51,91 & 14,11 & 29,45 & 137,76 & 64,35 & 73,21 & 115,57 \\
\hline Pelophylax perezi & 30TVL09 & 100,00 & 114,39 & 106,79 & 36,99 & 6145,49 & 279,37 & $-7,09$ & 286,46 & 126,24 & 195,30 & 196,40 & 39,16 & 455,36 & 52,89 & 15,34 & 28,42 & 139,83 & 66,71 & 77,08 & 116,99 \\
\hline Pelophylax perezi & 30TVL10 & 100,00 & 112,46 & 102,96 & 35,38 & 6427,44 & 279,75 & $-7,11$ & 286,86 & 80,22 & 197,93 & 199,25 & 35,60 & 478,21 & 56,21 & 15,01 & 30,94 & 150,99 & 67,21 & 71,88 & 123,97 \\
\hline Pelophylax perezi & 30TVL11 & 100,00 & 77,29 & 106,95 & 37,36 & 6068,16 & 247,71 & $-34,23$ & 281,95 & 70,78 & 161,14 & 161,28 & $\begin{array}{l}9,66 \\
9,6\end{array}$ & \begin{tabular}{|l|l|}
626,03 \\
\end{tabular} & $\begin{array}{l}76,40 \\
76\end{array}$ & 24,97 & 27,68 & 194,81 & 96,49 & 99,25 & 157,99 \\
\hline Pelophylax perezi & 30TVL12 & 100,00 & 82,73 & 105,64 & 37,01 & 6128,99 & 251,27 & $\begin{array}{l}-30,42 \\
\end{array}$ & 281,69 & 86,58 & 166,66 & $\begin{array}{ll}167,03 \\
\end{array}$ & 13,17 & \begin{tabular}{|c|}
603,08 \\
\end{tabular} & 72,94 & 23,32 & 27,85 & 187,35 & 92,53 & 97,16 & 152,35 \\
\hline Pelophylax perezi & 30TVL13 & 100,00 & 96,53 & 103,59 & 36,31 & 6254,86 & 262,27 & $-19,81$ & 282,08 & 112,64 & 180,82 & 181,56 & 23,29 & 537,20 & 64,27 & 18,65 & 28,74 & 166,76 & 80,23 & 87,89 & 135,82 \\
\hline Pelophylax perezi & 30TVL14 & 100,00 & 107,35 & 102,19 & 35,99 & 6359,05 & 271,21 & $-11,09$ & 282,30 & 116,53 & 192,19 & 193,14 & 31,24 & 496,32 & 57,82 & 15,51 & 29,34 & 152,82 & 71,83 & 80,63 & 127,33 \\
\hline Pelophylax perezi & 30TVL15 & 100,00 & 111,79 & 102,60 & 36,00 & 6345,76 & 275,35 & $-7,64$ & 282,99 & 91,05 & 195,92 & 197,13 & 35,17 & 478,00 & 55,14 & 14,66 & 29,35 & 147,29 & 68,66 & 77,28 & 123,44 \\
\hline \begin{tabular}{|l|} 
Pelophylax perezi \\
\end{tabular} & 30TVL16 & 100,00 & 115,36 & 103,26 & 36,00 & 6308,40 & 279,01 & $-4,90$ & 283,92 & 77,00 & \begin{tabular}{|l|l|}
198,68 \\
\end{tabular} & $\begin{array}{l}199,90 \\
\end{array}$ & 38,50 & 461,39 & 53,03 & 14,15 & 29,30 & 142,52 & 60,18 & 74,41 & 119,66 \\
\hline Pelophylax perezi & 30TVL17 & 100,00 & 115,73 & 104,16 & 36,00 & 6265,15 & 279,67 & $-4,48$ & 284,15 & 77,97 & 198,56 & 199,49 & 39,31 & 457,07 & 52,53 & 14,51 & 28,91 & 140,66 & 66,03 & 74,70 & 118,49 \\
\hline Pelophylax perezi & 30TVL18 & 100,00 & 115,06 & 104,96 & 36,06 & 6210,51 & 279,29 & $-5,45$ & 284,74 & 98,72 & 196,99 & 198,01 & 39,25 & 458,03 & 52,86 & 15,12 & 28,51 & 140,43 & 66,99 & 76,23 & 118,24 \\
\hline Pelophylax perezi & 30TVL19 & 100,00 & 115,14 & 105,68 & 36,66 & 6155,45 & 279,34 & $-5,68$ & 285,02 & 107,13 & 196,25 & 197,19 & 39,82 & 457,84 & 52,77 & 15,62 & 27,99 & 140,09 & 67,60 & 77,27 & 117,99 \\
\hline Pelophylax perezi & 30TVL20 & 100,00 & 116,65 & 102,55 & 35,13 & 6465,02 & 284,01 & $-3,38$ & 287,39 & 75,82 & 202,20 & 203,73 & 38,82 & \begin{tabular}{|l|l|}
477,18 \\
\end{tabular} & 55,71 & 14,20 & 31,40 & 153,59 & 64,93 & 68,63 & 128,32 \\
\hline \begin{tabular}{|l|} 
Pelophylax perezi \\
\end{tabular} & 30TVL21 & 100,00 & 84,19 & 106,10 & 36,89 & 6169,99 & 254,29 & -29,16 & 283,45 & $\begin{array}{ll}61,23 \\
61\end{array}$ & \begin{tabular}{|l|}
168,71 \\
168,0
\end{tabular} & 169,10 & $\begin{array}{ll}14,22 \\
14,2\end{array}$ & | & $\begin{array}{l}\mid 0,11 \\
72,58\end{array}$ & 23,35 & 27,95 & $\begin{array}{l}188,62 \\
\end{array}$ & \begin{tabular}{|l|l|}
92,03 \\
92,
\end{tabular} & $\begin{array}{l}5,0,29 \\
5,\end{array}$ & 156,05 \\
\hline Pelophylax perezi & 30TVL22 & 100,00 & 89,15 & 105,22 & 36,69 & 6195,81 & 257,50 & $-25,31$ & 282,81 & 82,82 & 173,58 & 173,95 & 18,03 & 575,22 & 68,69 & 21,29 & 27,97 & 177,58 & 86,99 & 92,20 & $\begin{array}{ll}146,47 \\
\end{array}$ \\
\hline Pelophylax perezi & 30TVL23 & 100,00 & 72,79 & 106,73 & 37,51 & 6045,02 & 242,56 & $-38,25$ & 280,81 & 68,29 & 156,35 & 156,48 & 5,44 & 658,42 & 78,70 & 27,16 & 26,32 & 202,81 & 103,42 & 105,63 & 167,97 \\
\hline Pelophylax perezi & 30TVL24 & 100,00 & 93,79 & 104,32 & 36,48 & 6221,50 & 260,20 & $-21,89$ & 282,09 & 103,11 & 177,89 & 178,38 & 21,18 & \begin{tabular}{|l|}
554,28 \\
\end{tabular} & 65,42 & 19,96 & 27,84 & 170,44 & 83,91 & 90,92 & 141,50 \\
\hline Pelophylax perezi & 30TVL25 & 100,00 & 108,37 & 102,99 & 35,99 & 6326,98 & 272,63 & $-10,23$ & 282,85 & $\begin{array}{l}93,76 \\
9\end{array}$ & 192,45 & 193,55 & 32,51 & 493,86 & 56,84 & 15,78 & 28,86 & 151,52 & 71,94 & 80,44 & 127,86 \\
\hline Pelophylax perezi & 30TVL26 & 100,00 & 112,70 & 103,07 & 36,00 & | $6320,515,11$ & 276,66 & $\begin{array}{l}-1.0,25 \\
-6,85 \\
\end{array}$ & \begin{tabular}{|l|}
$282,03,51$ \\
283
\end{tabular} & 74,65 & \begin{tabular}{|l|}
196,25 \\
196,25
\end{tabular} & \begin{tabular}{|l|l}
197,43 \\
197
\end{tabular} & $\begin{array}{l}32,11 \\
36,25\end{array}$ & $\begin{array}{l}453,00 \\
475,34\end{array}$ & $\begin{array}{l}50,04 \\
54,32\end{array}$ & $\begin{array}{l}\mid 0,10 \\
15,05\end{array}$ & $\begin{array}{l}28,00 \\
28,77\end{array}$ & $\begin{array}{l}146,19 \\
146,\end{array}$ & $\begin{array}{l}1,144 \\
69,14\end{array}$ & $\begin{array}{l}0,444 \\
77,29\end{array}$ & $\begin{array}{l}123,00 \\
123,50\end{array}$ \\
\hline Pelophylax perezi & 30TVL27 & 100,00 & 112,87 & 103,91 & 36,01 & 6262,71 & 276,90 & $-6,79$ & 283,69 & 86,03 & 195,63 & 196,50 & 36,60 & 471,66 & 54,16 & 15,43 & 28,28 & 144,47 & 69,39 & 77,94 & 122,11 \\
\hline Pelophylax perezi & 30TVL30 & 100,00 & 119,57 & 102,73 & \begin{tabular}{|l|l|}
35,07 \\
\end{tabular} & 6498,95 & 287,51 & $-0,85$ & 288,36 & 77,69 & 205,32 & 206,90 & 41,19 & 476,05 & 56,83 & 13,65 & 32,14 & 156,14 & 63,41 & 66,05 & 131,37 \\
\hline Pelophylax perezi & 30TVL31 & 100,00 & 112,12 & 103,04 & 35,52 & 6428,78 & 279,39 & $-6,72$ & 286,11 & 73,78 & 197,50 & 198,75 & 35,20 & 496,87 & 58,38 & 15,25 & 30,58 & 158,92 & 69,08 & 73,27 & 133,32 \\
\hline Pelophylax perezi & $\begin{array}{l}\text { 30TVL32 } \\
\end{array}$ & 100,00 & 89,33 & 105,67 & 36,72 & 6214,66 & 258,42 & $-25,45$ & 283,86 & 76,32 & 173,92 & 174,25 & 17,79 & 578,12 & 68,50 & 21,47 & 27,60 & $\begin{array}{l}177,52 \\
\end{array}$ & 87,52 & 92,90 & 148,19 \\
\hline Pelophylax perezi & 30TVL33 & 100,00 & 93,59 & 104,76 & 36,51 & 6246,76 & 261,29 & $-22,01$ & 283,30 & 79,89 & 178,09 & 178,63 & 20,99 & 562,40 & 65,76 & 20,2 & 27,73 & 172,92 & $\begin{array}{l}84,79 \\
\end{array}$ & 90,65 & 145,03 \\
\hline Pelophylax perezi & $\begin{array}{l}\text { 30TVL34 } \\
\end{array}$ & 100,00 & 86,44 & 105,55 & 36,82 & 6168,71 & 254,56 & $\begin{array}{l}-27,94 \\
-2,1\end{array}$ & 282,50 & 96,85 & 170,42 & 170,66 & 15,35 & 591,88 & 69,86 & 22,81 & 26,76 & 181,19 & 91,63 & 97,38 & 151,49 \\
\hline Pelophylax perezi & 30TVL35 & 100,00 & 104,34 & 103,59 & 36,00 & 6301,34 & 269,84 & $-13,51$ & 283,36 & 89,26 & 188,49 & 189,34 & 29,28 & 510,81 & 58,92 & 17,23 & 28,11 & 155,47 & 75,87 & 84,21 & 132,27 \\
\hline Pelophylax perezi & 30TVL37 & 100,00 & 107,35 & 104,11 & 36,11 & 6255,96 & 272,44 & $-11,06$ & 283,50 & 105,80 & 190,72 & 191,32 & 32,04 & \begin{tabular}{|l|l|}
494,47 \\
\end{tabular} & 56,99 & 17,06 & 27,40 & 150,43 & 74,52 & 83,17 & 127,57 \\
\hline Pelophylax perezi & 30TVL38 & 100,00 & 100,34 & 105,17 & 36,5 & 6175,10 & 266,0 & $-17,38$ & 283,42 & $\begin{array}{l}117,67 \\
\end{array}$ & 182,90 & $\begin{array}{l}183,32 \\
\end{array}$ & 26,50 & 522,24 & $\begin{array}{l}0,83 \\
60,83 \\
\end{array}$ & 19,44 & 26,54 & $\begin{array}{l}159,43 \\
\end{array}$ & 80,88 & $\begin{array}{l}90,116 \\
90,76\end{array}$ & 133,88 \\
\hline Pelophylax perezi & 30TVL39 & 100,00 & 107,55 & 104,97 & 36,42 & 6161,29 & 272,40 & $-11,12$ & 283,52 & 123,65 & 189,48 & 190,04 & 33,00 & 492,28 & 56,88 & 18,05 & 26,70 & 149,55 & 75,81 & 85,15 & 126,47 \\
\hline Pelophylax perezi & 30TVL40 & 100,00 & 127,79 & 102,91 & 35,01 & 6550,89 & 296,39 & 5,74 & 290,64 & 85,55 & 214,56 & 215,24 & 47,88 & 454,56 & 57,17 & 12,01 & 34,19 & 154,78 & 57,89 & 58,64 & 129,23 \\
\hline Pelophylax perezi & 30TVL41 & 100,00 & 120,84 & 102,69 & 35,08 & 6501,78 & 288,23 & 0,27 & 287,97 & 79,02 & 206,51 & 207,87 & 42,13 & 468,87 & 56,71 & 13,27 & 31,97 & 154,61 & 63,08 & 65,25 & 129,18 \\
\hline Pelophylax perezi & 30TVL42 & 100,00 & 106,04 & 103,99 & 36,08 & 6376,62 & 273,74 & $-11,87$ & 285,61 & 69,50 & 191,23 & 192,10 & 30,35 & 516,25 & 60,00 & 16,95 & 29,25 & 161,85 & 74,57 & 79,67 & 136,35 \\
\hline Pelophylax perezi & $\begin{array}{l}\text { 30TVL43 } \\
\end{array}$ & 100,00 & 109,23 & 103,29 & 36,00 & $\begin{array}{l}638,0204 \\
6385,04\end{array}$ & 275,66 & $\begin{array}{l}-1,0,20 \\
-9,20\end{array}$ & \begin{tabular}{|l|}
284,861 \\
284
\end{tabular} & $\begin{array}{l}58,98 \\
68,9\end{array}$ & $\begin{array}{l}194,21 \\
194\end{array}$ & $\begin{array}{l}195,12 \\
195\end{array}$ & $\begin{array}{ll}0,359 \\
32,98\end{array}$ & $\begin{array}{l}10,23 \\
499,32\end{array}$ & 56,90 & $\begin{array}{l}\mid 0,359 \\
15,97 \\
\end{array}$ & 29,15 & $\begin{array}{l}155,920 \\
152\end{array}$ & \begin{tabular}{|l|}
72,09 \\
\end{tabular} & 77,84 & $\begin{array}{l}130,03 \\
131,74\end{array}$ \\
\hline Pelophylax perezi & 30TVL44 & 100,00 & 95,01 & 105,03 & 36,40 & 6252,22 & 262,72 & $-21,24$ & 283,96 & 86,56 & 179,36 & 179,79 & 21,82 & 555,86 & 64,66 & 20,44 & 27,23 & 170,18 & 84,87 & 90,53 & 143,55 \\
\hline Pelophylax perezi & 30TVL45 & 100,00 & 94,63 & 105,17 & 36,48 & 6228,27 & 262,01 & $-21,67$ & 283,68 & 89,50 & 178,54 & 178,99 & 21,54 & 555,45 & 64,78 & 20,73 & 26,73 & 169,10 & 85,71 & 92.87 & 143,01 \\
\hline Pelophylax perezi & 30TVL46 & 100,00 & 108,25 & 103,93 & 36,01 & 6293,78 & 273,65 & $-10,18$ & 283,83 & 72,81 & 192,06 & 192,79 & 32,78 & 494,32 & 56,55 & 16,91 & 27,56 & 150,54 & 74,33 & 81,69 & 128,35 \\
\hline Pelophylax perezi & 30TVL47 & 100,00 & 110,21 & 104,01 & 36,01 & 6266,56 & 275,21 & $-8,54$ & 283,75 & 80,04 & 193,46 & 194,19 & 34,55 & 485,09 & 55,48 & 16,84 & 27,36 & 147,43 & 73,57 & 80,99 & 125 \\
\hline Pelophylax perezi & $\begin{array}{l}\text { 30TVL48 } \\
\text { 30 }\end{array}$ & $\begin{array}{l}100,00 \\
\end{array}$ & 104,21 & 104,90 & $\begin{array}{l}30,01 \\
36,47\end{array}$ & | 6200,16 & 270,21 & 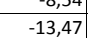 & \begin{tabular}{|l|}
283,56 \\
283
\end{tabular} & \begin{tabular}{|l|}
00,04 \\
117,58 \\
\end{tabular} & \begin{tabular}{|l|}
187,43 \\
187,4
\end{tabular} & \begin{tabular}{|l|}
187,73 \\
187,
\end{tabular} & \begin{tabular}{|l|l|}
29,86 \\
29,8
\end{tabular} & $\begin{array}{l}40,06,53 \\
506,53\end{array}$ & $\begin{array}{l}30,400 \\
58,59 \\
\end{array}$ & $\begin{array}{l}18,74 \\
18,77 \\
\end{array}$ & 26,41 & $\begin{array}{l}151,435 \\
153,38 \\
\end{array}$ & \begin{tabular}{|l|}
78,77 \\
78
\end{tabular} & $\begin{array}{l}80,49 \\
87,40\end{array}$ & $\begin{array}{l}12,00 \\
130,42\end{array}$ \\
\hline Pelophylax perezi & 30TVL49 & 100,00 & 103,11 & 105,19 & 36,68 & 6153,76 & 268,55 & $-14,83$ & 283,38 & 119,62 & 185,19 & 185,55 & 29,06 & 512,73 & 59,46 & 19,73 & 25,87 & 155,59 & 80,97 & 90,08 & 131,61 \\
\hline Pelophylax perezi & 30TVL50 & 100,00 & 133,14 & 103,39 & 35,00 & 6579,67 & 302,35 & 10,41 & 291,94 & 90,44 & 220,66 & 220,69 & 52,75 & 434,01 & 57,10 & 10,67 & 35,80 & 152,12 & 53,20 & 53,21 & 124,29 \\
\hline Pelophylax perezi & 30TVL51 & 100,00 & 128,43 & 102,74 & 35,00 & 6538,75 & 296,04 & 6,70 & 289,3 & 86,38 & 215,28 & 215,54 & 48, & 440,69 & 55,86 & 11,65 & 33,64 & 149 & 57,75 & 58,04 & 122,79 \\
\hline Pelophylax perezi & 30TVL52 & 100,00 & 119,14 & 103,05 & 35,49 & 6471,71 & 286,06 & $-0,94$ & 286,99 & 77,81 & 204,90 & 205,77 & 40,94 & 466,92 & 55,77 & 13,73 & 31,05 & 151,94 & 65,03 & 67,44 & 126, \\
\hline
\end{tabular}




\begin{tabular}{|c|c|c|c|c|c|c|c|c|c|c|c|c|c|c|c|c|c|c|c|c|c|}
\hline TAXON & UTM & $\mathrm{km2}$ & B101 & $\mathrm{B1O2}$ & $\mathrm{BIO3}$ & B104 & B105 & B106 & B107 & B108 & $\mathrm{BIO9}$ & 81010 & B1011 & B1O12 & BIO13 & 81014 & BIO15 & B1016 & B1017 & B1018 & B1019 \\
\hline Pelophylax perezi & 30TVL53 & 100,00 & 109,88 & 103,92 & 36,06 & 6394,79 & 277,01 & $-8,73$ & 285,74 & 72,46 & 195,03 & 195,80 & 33,52 & 497,35 & 57,41 & 16,26 & 28,98 & 155,85 & 72,63 & 77,34 & 131,28 \\
\hline Pelophylax perezi & 30TVL54 & 100,00 & 97,28 & 105,44 & 36,44 & 6285,75 & 265,47 & $-19,77$ & 285,24 & 84,53 & 181,84 & 182,24 & 23,39 & 546,22 & 63,27 & 20,09 & 26,97 & 166,33 & 83,72 & 89,91 & 141,45 \\
\hline Pelophylax perezi & 30TVL55 & 100,00 & 76,54 & 107,27 & 37,39 & 6122,88 & 246,61 & $-37,30$ & 283,90 & 87,02 & 160,33 & 160,37 & 6,47 & 648,73 & 76,29 & 27,79 & 24,67 & 197,61 & 105,10 & 107,78 & 166,35 \\
\hline Pelophylax perezi & 30TVL56 & 100,00 & 98,65 & 105,45 & \begin{tabular}{|l|l|}
36,47 \\
\end{tabular} & 6247,34 & 265,84 & $-18,73$ & 284,57 & 108,90 & 182,44 & 182,74 & 24,61 & 536,54 & 62,27 & 20,27 & 26,21 & 162,15 & 83,91 & 91,55 & 138,26 \\
\hline Pelophylax perezi & 30TVL57 & 100,00 & 104,72 & 105,03 & \begin{tabular}{|c|}
36,17 \\
\end{tabular} & \begin{tabular}{ll|}
6252,04 \\
\end{tabular} & 271,03 & \begin{tabular}{|l|l|}
$-13,48$ \\
\end{tabular} & 284,51 & 114,02 & 188,23 & 188,65 & 29,89 & 507,95 & 58,64 & 18,72 & 26,38 & 152,99 & 79,18 & 86,79 & 131,05 \\
\hline Pelophylax perezi & 30TVL58 & 100,00 & 109,69 & 104,92 & 36,27 & 6237,29 & 274,93 & $-8,82$ & 283,75 & 114,42 & 192,60 & 193,04 & 34,23 & 486,60 & 55,97 & 17,97 & 26,23 & 146,29 & 76,12 & 83,23 & 125,49 \\
\hline Pelophylax perezi & 30TVL59 & 100,00 & 108,00 & 105,03 & 36,61 & 6185,94 & 273,14 & $-10,25$ & 283,39 & 124,27 & 190,18 & 190,51 & 33,01 & 493,92 & 57,00 & 18,96 & 25,70 & 148,62 & 78,66 & 86,02 & 127,11 \\
\hline Pelophylax perezi & $\begin{array}{l}\text { 30TVL60 } \\
\end{array}$ & 100,00 & 126,06 & 104,05 & 35,02 & 6558,47 & 295,12 & 4,32 & 290,81 & 83,61 & 213,47 & 213,51 & 46,63 & 447,94 & 57,04 & 11,99 & 33,66 & 152,69 & 58,60 & 58,63 & 124,06 \\
\hline Pelophylax perezi & 30TVL61 & 100,00 & 121,44 & 103,71 & 35,33 & 6520,14 & 289,47 & 0,86 & 288,61 & 79,56 & 208,07 & 208,63 & 42,72 & 457,78 & 56,02 & 13,16 & 31,80 & 151,47 & 63,16 & 63,89 & 124,21 \\
\hline Pelophylax perezi & 30TVL62 & 100,00 & 122,19 & 103,14 & 35,32 & 6491,62 & 288,90 & 1,52 & 287,38 & 80,64 & 208,18 & 208,88 & 43,69 & 450,45 & 54,49 & 13,15 & 31,25 & 147,72 & 63,30 & 64,48 & 120,74 \\
\hline Pelophylax perezi & 30TVL63 & 100,00 & 103,22 & 105,44 & 36,24 & 6361,51 & 272,07 & $-14,94$ & 287,01 & 70,18 & 188,55 & 189,08 & 28,16 & 522,84 & 60,45 & 18,56 & 27,81 & 161,01 & 79,09 & 84,01 & 136,24 \\
\hline Pelophylax perezi & 30TVL64 & 100,00 & 94,16 & 106,62 & 36,72 & 6278,11 & 263,56 & $-23,05$ & 286,62 & 85,77 & 178,82 & 179,12 & 20,69 & 560,23 & 65,27 & 21,59 & 26,17 & 169,19 & 87,76 & 93,92 & 144,27 \\
\hline Pelophylax perezi & 30TVL65 & 100,00 & 82,45 & 107,44 & 37,18 & 6178,77 & 252,63 & $-32,95$ & 285,58 & 94,10 & 166,53 & 166,60 & 10,95 & 619,44 & 72,69 & 26,20 & 24,73 & 188,03 & 100,53 & 105,39 & 158,82 \\
\hline Pelophylax perezi & 30TVL66 & 100,00 & 76,30 & 107,84 & 37,44 & 6119,81 & 246,56 & $-38,21$ & 284,77 & 90,68 & 159,88 & 159,89 & 5,98 & 651,92 & 76,56 & 28,84 & 23,88 & 198,39 & 107,84 & 110,04 & 166,99 \\
\hline Pelophylax perezi & 30TVL67 & 100,00 & 100,57 & 106,06 & 36,81 & 6237,13 & 268,01 & $-17,44$ & 285,45 & 118,41 & 184,05 & 184,31 & 26,33 & 527,83 & 61,34 & 20,66 & 25,47 & 159,01 & 84,49 & 91,42 & 135,66 \\
\hline Pelophylax perezi & 30TVL68 & 100,00 & 108,25 & 105,39 & 36,51 & 6236,98 & 274,38 & $-10,43$ & 284,81 & 125,95 & 191,41 & 191,62 & 33,21 & 493,10 & 56,96 & 18,96 & 25,61 & 147,88 & 78,89 & 85,53 & 126,82 \\
\hline Pelophylax perezi & 30TVL69 & 100,00 & 106,43 & 105,84 & 36,87 & 6183,36 & 272,43 & $-11,99$ & 284,42 & 125,00 & 188,59 & 188,91 & 31,81 & 501,68 & 58,22 & 19,90 & 25,01 & 150,88 & 81,42 & 88,42 & 129,08 \\
\hline Pelophylax perezi & 30TVL70 & 100,00 & 124,57 & 103,99 & 35,16 & 6556,40 & 292,94 & 3,20 & 289,73 & 82,36 & 212,23 & 212,23 & 45,64 & 442,06 & 55,17 & 12,34 & 32,79 & 148,33 & 59,95 & 59,96 & 118,65 \\
\hline Pelophylax perezi & 30TVL71 & 100,00 & 120,88 & 103,79 & 35,43 & 6518,66 & 288,58 & 0,21 & 288,37 & 79,19 & 207,66 & 208,00 & 42,49 & 451,60 & 54,44 & 13,41 & 31,27 & 147,68 & 64,06 & 64,58 & 119,43 \\
\hline Pelophylax perezi & 30TVL72 & 100,00 & 117,74 & 104,08 & 35,80 & 6482,68 & 285,14 & $-2,35$ & 287,49 & 76,32 & 203,73 & 204,45 & 39,86 & 460,90 & 53,92 & 14,48 & 29,91 & 147,44 & 67,16 & 68,99 & 120,82 \\
\hline Pelophylax perezi & 30TVL73 & 100,00 & 112,34 & 104,94 & 36,00 & 6424,94 & 280,08 & $-7,36$ & 287,45 & 72,50 & 197,80 & 198,45 & 35,42 & 480,68 & 55,1 & 16,20 & 28,44 & 149,45 & 72,21 & 75,72 & 125,06 \\
\hline Pelophylax perezi & 30TVL74 & 100,00 & 103,10 & 106,20 & 36,32 & 6343,56 & 271,86 & $-15,71$ & 287,56 & 76,53 & 188,08 & 188,45 & 27,75 & 519,66 & 60,06 & 19,41 & 26,66 & 157,63 & 81,13 & 86,61 & 133,97 \\
\hline Pelophylax perezi & 30TVL75 & 100,00 & 83,23 & 108,20 & \begin{tabular}{|l|l|}
37,13 \\
\end{tabular} & $\begin{array}{ll}6200,53 \\
\end{array}$ & 254,08 & $-33,06$ & 287,14 & 97,75 & 167,60 & 167,63 & 11,31 & 616,34 & 72,44 & 26,55 & 24,32 & 186,92 & \begin{tabular}{|l|l|}
101,18 \\
\end{tabular} & 105,16 & 157,75 \\
\hline Pelophylax perezi & 30TVL76 & 100,00 & 84,50 & 108,12 & \begin{tabular}{l|l|}
37,05 \\
\end{tabular} & 6186,52 & 254,92 & $-32,07$ & 286,99 & 100,32 & 168,44 & 168,50 & 12,55 & 608,11 & 71,52 & 26,34 & 23,99 & 184,73 & 100,57 & 106,50 & 155,64 \\
\hline Pelophylax perezi & 30TVL77 & 100,00 & 97,54 & 107,18 & 36,97 & 6228,79 & 266,13 & $-20,66$ & 286,78 & 115,05 & 181,13 & 181,36 & 23,63 & 543,17 & 63,46 & 22,25 & 24,68 & 163,89 & 88,89 & 95,62 & 139,32 \\
\hline Pelophylax perezi & 30TVL78 & 100,00 & 104,81 & 106,58 & 36,97 & 6231,13 & 272,08 & $-13,99$ & 286,08 & 123,26 & 187,92 & 188,19 & 30,10 & 509,49 & 59,28 & 20,53 & 24,84 & 153,19 & 83,48 & 89,84 & 130,68 \\
\hline Pelophylax perezi & \begin{tabular}{|l|l|} 
30TVL79 \\
\end{tabular} & 100,00 & 109,26 & 106,14 & 37,00 & 6203,81 & 275,37 & \begin{tabular}{|c|}
$-9,81$ \\
\end{tabular} & \begin{tabular}{|l|l|}
285,18 \\
\end{tabular} & 128,27 & 191,55 & \begin{tabular}{|l|}
191,93 \\
\end{tabular} & 34,18 & \begin{tabular}{|l|l|}
491,62 \\
\end{tabular} & 57,06 & 19,99 & $\begin{array}{l}24,75 \\
24,75\end{array}$ & $\begin{array}{l}147,52 \\
14,5\end{array}$ & $\begin{array}{l}51,13 \\
81,13\end{array}$ & $\begin{array}{l}8,21 \\
87,21\end{array}$ & 126,18 \\
\hline Pelophylax perezi & 30TVL80 & 100,00 & 128,46 & 102,32 & 35,07 & 6577,84 & 294,21 & 6,89 & 287,32 & 86,39 & 216,18 & 216,18 & 49,14 & \begin{tabular}{|l|l|}
414,96 \\
\end{tabular} & 51,50 & 11,70 & 32,79 & 138,37 & 57,21 & 57,21 & 106,89 \\
\hline Pelophylax perezi & 30TVL81 & 100,00 & 125,82 & 102,84 & 35,13 & 6542,43 & 291,63 & 4,37 & 287,25 & 84,01 & 213,03 & 213,07 & 46,97 & 423,35 & 51,04 & 12,59 & 31,28 & 138,47 & 60,82 & 60,87 & 108,85 \\
\hline Pelophylax perezi & 30TVL82 & 100,00 & 121,66 & 103,83 & 35,64 & 6497,10 & 288,13 & 0,42 & 287,70 & 80,32 & 207,91 & 208,36 & 43,33 & 438,88 & 51,11 & 13,93 & 29,88 & 140,13 & 65,12 & 66,08 & 112,81 \\
\hline Pelophylax perezi & 30TVL83 & 100,00 & 113,14 & 105,61 & 36,07 & 6430,05 & 281,18 & $-7,22$ & 288,41 & 73,34 & 198,67 & 199,30 & 36,00 & 473,59 & 54,49 & 16,53 & 27,82 & 145,58 & 72,73 & 76,01 & 121,50 \\
\hline Pelophylax perezi & \begin{tabular}{|l|l|} 
30TVL87 \\
\end{tabular} & 100,00 & 94,49 & 108,47 & 37,00 & 6223,54 & $\begin{array}{l}261,10 \\
264,29\end{array}$ & $\mid-24,13$ & \begin{tabular}{|l|}
288,42 \\
\end{tabular} & \begin{tabular}{|l|}
111,81 \\
\end{tabular} & 178,15 & 178,29 & 20,81 & 559,91 & $\begin{array}{l}4,45,81 \\
65\end{array}$ & $\begin{array}{l}24,12 \\
24,12\end{array}$ & $\begin{array}{ll}23,88 \\
23,88\end{array}$ & $\begin{array}{l}169,43 \\
140\end{array}$ & 93,76 & 100,73 & 143,13 \\
\hline Pelophylax perezi & 30TVL88 & 100,00 & 102,05 & 107,89 & 37,00 & 6222,84 & 270,60 & $-17,08$ & 287,69 & 120,28 & 185,22 & 185,51 & 27,69 & 523,70 & 61,33 & 22,14 & 24,10 & 157,90 & 87,73 & 94,40 & 133,97 \\
\hline Pelophylax perezi & 30TVL89 & 100,00 & 110,14 & 107,13 & 37,00 & 6215,73 & 276,77 & $-9,44$ & 286,21 & 129,18 & 192,51 & 192,81 & 34,86 & 489,47 & 57,12 & 20,56 & 24,16 & 146,90 & 82,44 & 87,78 & 125,10 \\
\hline Pelophylax perezi & 30TVL91 & 100,00 & 121,90 & 104,96 & 35,73 & 6522,61 & 289,31 & $-0,26$ & 289,56 & 80,44 & 208,64 & 208,92 & 43,39 & 436,13 & 50,64 & 14,20 & 29,76 & 137,75 & 65,45 & 66,21 & 110,47 \\
\hline Pelophylax perezi & \begin{tabular}{l|} 
30TVL92 \\
\end{tabular} & 100,00 & 120,83 & 105,11 & 35,93 & 6492,10 & 287,99 & $-1,00$ & 288,99 & 79,70 & 206,94 & 207,49 & 42,66 & 438,51 & 50,65 & 14,73 & 28,94 & 136,86 & 67,03 & 68,37 & 110,90 \\
\hline Pelophylax perezi & 30TVL93 & 100,00 & $\begin{array}{l}12,03 \\
115,93\end{array}$ & 106,16 & 36,04 & | 64543,86 & 283,94 & $-5,4,4$ & \begin{tabular}{|l|}
$289,42,49$ \\
\end{tabular} & 76,12 & $\mid 201,56$ & \begin{tabular}{|l|}
202,12 \\
\end{tabular} & $\begin{array}{ll}42,300 \\
38,45\end{array}$ & | & $\begin{array}{l}50,303 \\
53,33\end{array}$ & $\mid$\begin{tabular}{l|}
$4,3,36$ \\
16,
\end{tabular} & $\mid \begin{array}{l}\mid 2,344 \\
27,60\end{array}$ & $\begin{array}{l}139,58 \\
1390\end{array}$ & $\begin{array}{l}1,1,74 \\
71,\end{array}$ & $\begin{array}{l}0 ., 31 \\
74,50\end{array}$ & 115,90 \\
\hline Pelophylax perezi & 30TVL94 & 100,00 & 109,13 & 107,41 & 36,51 & 6384,33 & 278,25 & $-11,94$ & 290,19 & 94,15 & 194,22 & 194,69 & 32,82 & 488,23 & 57,34 & 18,77 & 26,21 & 146,03 & 78,52 & 83,07 & 123,73 \\
\hline Pelophylax perezi & 30TVL96 & 100,00 & 91,51 & 109,60 & \begin{tabular}{|l|l|}
37,08 \\
\end{tabular} & 6245,60 & 262,68 & $-27,70$ & 290,38 & 108,68 & 175,71 & 175,85 & 17,98 & 575,53 & 68,11 & 25,49 & 23,55 & 174,62 & 97,43 & $\begin{array}{lll}103,34 \\
\end{array}$ & 146,49 \\
\hline Pelophylax perezi & 30TVL97 & 100,00 & 95,54 & 109,50 & 37,04 & 6239,01 & 266,14 & $-24,09$ & 290,22 & 113,26 & 179,30 & 179,44 & 21,46 & 556,16 & 65,73 & 24,58 & 23,43 & 168,52 & 94,61 & 101,49 & 141,73 \\
\hline Pelophylax perezi & $\begin{array}{l}\text { 30TVL99 } \\
\end{array}$ & 100,00 & 112,22 & 108,10 & 37,00 & 6224,92 & 279,54 & $-8,33$ & 287,87 & 131,68 & 194,76 & 194,99 & 36,66 & 480,92 & 56,55 & 20,60 & 23,92 & 144,70 & 82,34 & 87,35 & 122,43 \\
\hline Pelophylax perezi & 30TVM02 & 100,00 & 113,42 & 108,19 & $37, \mathrm{C}$ & 5965,23 & 277,90 & $-8,74$ & 286,64 & 122,93 & $\mid 191,99$ & $\begin{array}{l}192,78 \\
\end{array}$ & 40,17 & 466,20 & 53,70 & 17, & 27,33 & 142,52 & 69,50 & 81,74 & 119,02 \\
\hline Pelophylax perezi & 30TVM03 & 100,00 & 110,89 & 108,29 & 37,03 & 5904,28 & 275,08 & $-11,31$ & 286,40 & 126,52 & 188,70 & 189,47 & 38,50 & 480,84 & 55,23 & 18,92 & 26,74 & 146,64 & 72,73 & 85,93 & 122,20 \\
\hline Pelophylax perezi & 30TVM04 & 100,00 & 111,20 & 107,91 & 37,24 & 5838,10 & 274,25 & $-10,61$ & 284,86 & 106,29 & 188,14 & 188,75 & 39,63 & 486,59 & 55,43 & 19,80 & 26,33 & 147,98 & 74,44 & 87,65 & 123,25 \\
\hline Pelophylax perezi & 30TVM05 & 100,00 & 112,95 & 107,09 & 37, & 5760,54 & 274,08 & $-8,37$ & 282,45 & 90,29 & 188,68 & 189,24 & 42,01 & 491,35 & 55,07 & 20,6 & 25,91 & 50,16 & 76,06 & 88,95 & 124,25 \\
\hline Pelophylax perezi & 30TVM07 & 100,00 & 109,41 & 104,96 & 37 & 5617,43 & 266,83 & $\begin{array}{l}-9,09 \\
-9,51 \\
\end{array}$ & 275,92 & $\begin{array}{l}81,92 \\
81,92\end{array}$ & $\begin{array}{l}183,450 \\
\end{array}$ & $\begin{array}{l}183,60 \\
\end{array}$ & $\begin{array}{l}40,16 \\
40,16\end{array}$ & 534,38 & 59 & 24, & 24,48 & 72 & 86,46 & $\begin{array}{l}0,09 \\
96,09 \\
\end{array}$ & 135,46 \\
\hline Pelophylax perezi & 30TVM08 & 100,00 & 111,80 & 102,96 & $37, \varepsilon$ & 5518,87 & 265,60 & $-4,60$ & 270,20 & 85,04 & 184,38 & 184,43 & 43,60 & 547,60 & 61,40 & 25,5 & 23,94 & 170,85 & 90,28 & 97,61 & 139,69 \\
\hline Pelophylax perezi & 30TVM09 & 100,00 & 111,43 & 101,12 & 37,86 & 5430,86 & 262,16 & $-2,76$ & 264,92 & 85,14 & 182,99 & 183,01 & 44,32 & 572,90 & 64,84 & 26,95 & 23,45 & 180,18 & 96,46 & 100,11 & 147,05 \\
\hline Pelophylax perezi & 30TVM10 & 100,00 & 116,10 & 106,11 & 36,93 & 6097,96 & 280,07 & $-4,93$ & 285,01 & 107,70 & 196,38 & 197,21 & 41,09 & 455,39 & 52,32 & 15,94 & 27,82 & 139,40 & 67,54 & 77,48 & 117,18 \\
\hline Pelophylax perezi & 30TVM11 & 100,00 & 114,51 & 106,49 & 37,00 & 6042,88 & 278,37 & $-6,55$ & 284,92 & 115,84 & 194,09 & 194,96 & 40,25 & 462,86 & 53,24 & 16,96 & 27,29 & 17 & 69,51 & 80,18 & 118,63 \\
\hline Pelophylax perezi & 30TVM1 & 100,00 & 11 & 106,63 & 37,00 & $\begin{array}{l}5004,1,48 \\
5981\end{array}$ & 276,42 & $\begin{array}{l}-2,50, \\
-8,06\end{array}$ & \begin{tabular}{|l|}
284,42 \\
284
\end{tabular} & \begin{tabular}{|l|}
123,04 \\
123
\end{tabular} & \begin{tabular}{|l|}
191,60 \\
191,00
\end{tabular} & $\begin{array}{l}192,30 \\
192,36\end{array}$ & $\begin{array}{l}40,35 \\
39,31\end{array}$ & $\begin{array}{l}402,00 \\
472,45\end{array}$ & $\begin{array}{l}35,2 \\
54,2\end{array}$ & $\begin{array}{ll}10,4 \\
18,4\end{array}$ & $\begin{array}{ll}26,84 \\
26,4\end{array}$ & $\begin{array}{l}143,71 \\
143\end{array}$ & \begin{tabular}{|l|l|}
71,90 \\
\end{tabular} & $\begin{array}{l}0,10 \\
83,22\end{array}$ & $\begin{array}{l}110,05 \\
120,59\end{array}$ \\
\hline Pelophylax perezi & 30TVM13 & 100,00 & 109,38 & 106,68 & 37,00 & 5922,03 & 272,75 & $-10,96$ & 283,71 & 126,07 & 187,56 & 188,06 & 36,77 & 489,73 & 56,10 & 19,60 & 25,91 & 148,47 & 75,88 & 87,71 & 124,53 \\
\hline Pelophylax perezi & 30TVM14 & 100,00 & 109,34 & 106,34 & 37,00 & 5863,51 & 271,63 & $-10,27$ & 281,90 & 118,32 & 186,67 & 187,15 & 37,31 & 497,57 & 56,39 & 20,64 & 25,53 & 150,18 & 78,12 & 90,05 & 126,21 \\
\hline Pelophylax perezi & 30TVM15 & 100,00 & 111,19 & 105,43 & 37,01 & 5789,24 & 271,59 & $-7,88$ & 279,47 & 82,72 & 187,42 & 187,72 & 39,77 & 500,25 & 55,85 & 21,35 & 25,09 & 151,78 & 79,31 & 90,31 & 126,99 \\
\hline Pelophylax perezi & 30TVM16 & 100,00 & 111,97 & 104,21 & 37,0 & 5715,59 & 270,18 & $-6,01$ & 276,18 & 82,35 & 186,99 & 187,33 & 41,24 & 511,24 & 56,15 & 22,66 & 24,54 & 155,95 & 82,46 & 92,47 & 125 \\
\hline Pelophylax perezi & 30TVM17 & 100,00 & 110,73 & 103,01 & 37,13 & 5638,93 & 266,86 & $-5,55$ & 272,42 & 81,73 & $\begin{array}{l}184,87 \\
\end{array}$ & 185,04 & 40,97 & 532,14 & 58,37 & 24,53 & 23,95 & 163,16 & 87,60 & 94,81 & 135,47 \\
\hline Pelophylax perezi & 30TVM18 & 100,00 & 105,62 & 102,01 & 37,37 & 5570,86 & 260,36 & $-8,60$ & 268,97 & 76,86 & 179,18 & 179,18 & 36,95 & 569,97 & 62,86 & 27,33 & 23,06 & 174,90 & 96,02 & 99,30 & 145,76 \\
\hline Pelophylax perezi & 30TVM19 & 100,00 & 106,62 & 100,06 & 37,50 & 5472,88 & 257,88 & $-5,60$ & 263,48 & 78,68 & 178,90 & 178,90 & 39,00 & 591,22 & 65,97 & 28,41 & 22,67 & 183,39 & 101,23 & 103,29 & 152,37 \\
\hline Pelophylax perezi & 30 TVM20 & 100,00 & 112,65 & 105,21 & 36,49 & 6104,55 & 276,58 & $-7,16$ & 283,7 & 117,09 & 193,35 & 193, & 37, & 470,57 & 54,04 & 17,01 & 27 & 143 & 71 & 81,12 & 120,62 \\
\hline Pelophylax perezi & 30TVM21 & 100,00 & 117,80 & 105,10 & 36,95 & 6058,18 & 280,57 & $-2,33$ & 282,90 & 86,66 & 197,29 & 198,23 & 43,08 & 454,72 & 51,80 & 16,72 & 26,99 & 138,47 & 69,05 & 78,04 & 116,95 \\
\hline
\end{tabular}




\begin{tabular}{|c|c|c|c|c|c|c|c|c|c|c|c|c|c|c|c|c|c|c|c|c|c|}
\hline TAXON & UTM & $\mathrm{km} 2$ & B101 & B102 & $\mathrm{BIO3}$ & BIO4 & B105 & B106 & B107 & B108 & 8109 & B1010 & BIO11 & BIO12 & 81013 & BIO14 & BIO15 & B1016 & B1017 & B1018 & B1019 \\
\hline Pelophylax perezi & 30TVM22 & 100,00 & 113,55 & 105,43 & 37,00 & 6006,30 & 276,36 & $-6,03$ & 282,39 & 118,28 & 192,68 & 193,21 & 39,70 & 472,53 & 53,98 & 18,31 & 26,17 & 142,92 & 73,27 & 83,16 & 120,81 \\
\hline Pelophylax perezi & 30 TVM23 & 100,00 & 109,67 & 105,44 & 37,00 & 5941,56 & 272,32 & $-9,19$ & 281,50 & 125,40 & 188,09 & 188,45 & 36,70 & 491,21 & 56,07 & 20,01 & 25,35 & 148,21 & 77,60 & 87,96 & 125,23 \\
\hline Pelophylax perezi & 30TVM24 & 100,00 & 109,50 & 104,90 & 37,00 & 5880,93 & 271,14 & $-8,71$ & 279,85 & 106,82 & 187,10 & 187,48 & 37,17 & 498,61 & 56,35 & 20,91 & 25,01 & 149,86 & 79,75 & 89,26 & 126,97 \\
\hline Pelophylax perezi & 30 TVM25 & 100,00 & 111,49 & 103,89 & 37,00 & 5813,87 & 271,12 & $-5,72$ & 276,84 & 79,86 & 187,97 & 188,22 & 39,69 & 501,24 & 55,78 & 21,67 & 24,59 & 151,04 & 81,29 & 90,25 & 127,60 \\
\hline Pelophylax perezi & 30TVM26 & 100,00 & 111,23 & 102,81 & 37,00 & 5753,47 & 269,03 & $-4,78$ & 273,81 & 79,89 & 186,86 & 186,97 & 39,92 & 514,61 & 56,32 & 23,10 & 23,89 & 155,56 & 84,85 & 92,01 & 131,14 \\
\hline Pelophylax perezi & 30TVM27 & 100,00 & 109,36 & 101,58 & 37,00 & 5678,57 & 265,35 & $-5,01$ & 270,37 & 78,58 & 183,95 & 184,03 & 38,87 & 536,70 & 58,13 & 25,04 & 23,22 & 162,80 & 90,19 & 95,39 & 137,09 \\
\hline Pelophylax perezi & 30TVM28 & 100,00 & 106,77 & 100,34 & 37,02 & 5602,76 & 260,64 & $-5,78$ & 266,42 & 76,42 & 180,51 & 180,51 & 37,33 & 565,93 & 61,75 & 27,25 & 22,64 & 172,47 & 96,81 & 98,44 & 145,12 \\
\hline Pelophylax perezi & 30 TVM 29 & 100,00 & 103,68 & 98,99 & 37,13 & 5518,38 & 255,18 & $-6,58$ & 261,75 & 74,01 & \begin{tabular}{|l|l|}
176,60 \\
\end{tabular} & \begin{tabular}{|l|l|}
176,60 \\
\end{tabular} & 35,58 & 601,44 & 66,36 & 29,42 & 22,04 & 184,45 & $\begin{array}{r}104,62 \\
\end{array}$ & 105,03 & 155,32 \\
\hline Pelophylax perezi & 30TVM30 & 100,00 & 113,54 & 104,84 & 36,68 & 6124,35 & 277,16 & $-5,93$ & 283,09 & 117,41 & 194,40 & 195,11 & 38,66 & 470,29 & 53,89 & 17,29 & 26,70 & 142,25 & 72,34 & 80,95 & 121,05 \\
\hline Pelophylax perezi & 30TVM31 & 100,00 & 116,31 & 104,60 & \begin{tabular}{|l|}
36,68 \\
\end{tabular} & 6072,02 & 278,74 & $-3,36$ & 282,10 & 103,63 & 196,28 & 196,77 & 41,52 & 463,01 & 52,81 & 17,39 & 26,34 & 140,08 & 71,91 & 80,16 & 118,98 \\
\hline Pelophylax perezi & 30TVM32 & 100,00 & 112,25 & 104,83 & 36,97 & 6015,64 & 274,71 & $-6,50$ & 281,21 & 123,59 & 191,55 & 191,91 & 38,29 & 479,94 & 54,83 & 19,08 & 25,51 & 144,56 & 76,05 & 84,79 & 123,00 \\
\hline Pelophylax perezi & 30TVM33 & 100,00 & 108,27 & 104,77 & 37,00 & 5964,49 & 270,72 & $-9,20$ & 279,92 & 126,45 & 187,12 & 187,39 & 35,21 & 498,45 & 56,83 & 20,76 & 24,88 & 149,79 & 80,56 & 89,25 & 127,45 \\
\hline Pelophylax perezi & 30TVM34 & 100,00 & 106,97 & 104,04 & 37,00 & 5908,60 & 268,39 & $-9,57$ & \begin{tabular}{l|l}
277,97 \\
\end{tabular} & 121,96 & \begin{tabular}{l|l}
185,07 \\
\end{tabular} & 185,15 & 34,46 & 511,04 & 57,86 & 22,09 & 24,09 & 152,90 & 83,91 & 91,86 & 130,41 \\
\hline Pelophylax perezi & 30 TVM 35 & 100,00 & 109,45 & 103,08 & 37,00 & 5851,53 & 269,04 & $-6,22$ & 275,25 & 91,42 & 186,56 & 186,61 & 37,19 & 509,54 & 56,90 & 22,61 & 23,77 & 151,84 & 84,68 & 91,23 & 130,31 \\
\hline Pelophylax perezi & 30TVM36 & 100,00 & 107,53 & 102,06 & 37,00 & 5790,03 & 265,81 & $-6,63$ & 272,44 & 79,54 & 183,78 & 183,81 & 35,90 & 526,94 & 58,12 & 24,18 & 23,20 & 157,04 & 88,99 & 92,82 & 134,78 \\
\hline Pelophylax perezi & 30TVM37 & 100,00 & 106,62 & 100,78 & 37,00 & 5733,36 & 263,24 & $-6,06$ & 269,30 & 74,05 & 182,03 & 182,05 & 35,59 & 543,52 & 58,96 & 25,78 & 22,52 & 162,43 & 93,38 & 95,74 & 139,28 \\
\hline Pelophylax perezi & 30TVM38 & 100,00 & 106,07 & 99,22 & 37,00 & 5654,97 & 260,06 & $-4,72$ & 264,78 & 73,92 & 180,35 & 180,35 & 35,83 & 565,09 & 60,68 & 27,50 & 22,06 & 170,20 & 98,48 & 99,15 & 145,37 \\
\hline Pelophylax perezi & 30TVM39 & 100,00 & 102,91 & 97,88 & 37,01 & 5555,62 & 254,18 & $-5,56$ & 259,75 & 71,68 & 176,22 & 176,22 & 34,31 & 602,44 & 65,96 & 29,75 & 21,75 & 183,21 & 106,31 & 106,31 & 156,24 \\
\hline Pelophylax perezi & 30 TVM 40 & 100,00 & 113,46 & 104,42 & 36,52 & 6135,33 & 276,98 & $-5,46$ & 282,45 & 122,49 & 194,55 & 195,09 & 38,56 & 472,12 & 54,16 & 17,76 & 26,23 & 142,26 & 74,12 & 81,77 & 121,43 \\
\hline Pelophylax perezi & 30TVM 41 & 100,00 & 115,39 & 104,04 & 36,71 & 6081,07 & 277,89 & $-3,05$ & 280,94 & 108,31 & 195,63 & 195,91 & 40,63 & 467,45 & 53,33 & 18,07 & 25,81 & 140,75 & 74,19 & 81,43 & 120,23 \\
\hline Pelophylax perezi & 30TVM42 & 100,00 & 111,55 & 104,21 & 36,99 & $\begin{array}{ll}6041,66 \\
\end{array}$ & 274,06 & $-6,11$ & 280,17 & \begin{tabular}{|l|l|}
129,77 \\
\end{tabular} & \begin{tabular}{|l|l|}
191,33 \\
\end{tabular} & 191,65 & 37,41 & 484,68 & 55,41 & 19,70 & 24,98 & 145,36 & 78,42 & 84,94 & 124,35 \\
\hline Pelophylax perezi & 30TVM43 & 100,00 & 107,22 & 104,07 & 37,00 & 5987,94 & 269,58 & $\begin{array}{l}-1,39 \\
-9,39 \\
\end{array}$ & 278,97 & 125,28 & 186,45 & 186,49 & 33,98 & 506,27 & 57,85 & 21,60 & 24,22 & 151,88 & 83,48 & 90,24 & 129,68 \\
\hline Pelophylax perezi & 30TVM44 & 100,00 & 105,16 & 103,69 & 37,00 & 5929,56 & 266,49 & $-10,45$ & 276,94 & 122,79 & \begin{tabular}{|l|}
183,57 \\
\end{tabular} & 183,60 & 32,48 & 520,90 & 59,21 & 23,12 & 23,55 & 155,71 & 87,36 & 93,38 & 133,58 \\
\hline Pelophylax perezi & 30TVM 45 & 100,00 & 106,31 & 102,81 & 37,00 & 5873,44 & 266,03 & $-8,04$ & 274,06 & 121,05 & 183,90 & 183,92 & 34,19 & 523,97 & 58,84 & 23,95 & 23,05 & 155,33 & 89,15 & 92,81 & 134,59 \\
\hline Pelophylax perezi & 30TVM46 & 100,00 & 102,56 & 102,01 & 37,00 & 5811,44 & 261,32 & $-10,13$ & 271,45 & 111,71 & 179,48 & 179,48 & 31,14 & 548,59 & 61,10 & 26,01 & 22,41 & 161,84 & 94,85 & 95,70 & 141,36 \\
\hline Pelophylax perezi & 30TVM47 & 100,00 & 103,58 & 100,47 & 37,00 & 5754,95 & 260,05 & $-7,40$ & 267,45 & 78,16 & 179,56 & 179,56 & 32,73 & 555,10 & 60,95 & 27,10 & 22,00 & 163,67 & 97,40 & 97,87 & 143,66 \\
\hline Pelophylax perezi & 30TVM48 & 100,00 & 101,72 & 99,07 & 37,07 & 5679,72 & 255,82 & $-7,16$ & 262,98 & 68,78 & $\begin{array}{l}176,82 \\
\end{array}$ & 176,82 & 31,73 & 578,09 & 62,43 & 28,77 & 21,59 & 171,22 & \begin{tabular}{|c|}
102,78 \\
\end{tabular} & $\mid \begin{array}{r}102,78 \\
\end{array}$ & 150,41 \\
\hline Pelophylax perezi & 30TVM49 & 100,00 & 102,13 & 97,24 & 37,12 & 5571,20 & 252,62 & $-4,45$ & 257,07 & 69,98 & 175,98 & 175,98 & 33,61 & 602,61 & 65,54 & 29,99 & 21,43 & 181,30 & 108,10 & 108,10 & 158,06 \\
\hline Pelophylax perezi & 30TVM50 & 100,00 & 110,55 & 104,77 & 36,84 & 6143,94 & 274,70 & $-7,78$ & 282,48 & 122,81 & 191,94 & 192,25 & 35,78 & 485,23 & 55,82 & 19,06 & 25,37 & 145,75 & 78,05 & 85,01 & 124,84 \\
\hline Pelophylax perezi & 30TVM51 & 100,00 & 113,26 & 104,34 & 36,74 & 6101,44 & 276,36 & $-4,91$ & 281,27 & 126,94 & 193,83 & 194,16 & 38,61 & 476,93 & 54,66 & 19,11 & 25,11 & 142,94 & 77,42 & 84,06 & 122,55 \\
\hline Pelophylax perezi & 30TVM52 & 100,00 & 110,15 & 104,31 & 37,00 & 6051,09 & 272,95 & $-7,05$ & 280,00 & 128,69 & 190,22 & 190,32 & 36,14 & 492,55 & 56,49 & 20,68 & 24,27 & 147,56 & 81,44 & 87,01 & 126,53 \\
\hline Pelophylax perezi & 30TVM53 & 100,00 & 104,78 & 104,49 & 37,00 & 5998,73 & 267,37 & $\mid-11,24$ & 278,61 & $\begin{array}{l}122,68 \\
\end{array}$ & 184,23 & 184,25 & $\begin{array}{ll}30,146 \\
31,62\end{array}$ & |519,89 & 59,55 & 22,90 & 23,56 & $\begin{array}{l}155,87 \\
151,0\end{array}$ & $\begin{array}{l}1,4,64 \\
87,63\end{array}$ & $\begin{array}{l}1,1,27 \\
93\end{array}$ & 133,73 \\
\hline Pelophylax perezi & 30TVM54 & 100,00 & 99,64 & 104,28 & 37,01 & 5928,96 & 261,78 & $-14,93$ & 276,71 & 116,67 & \begin{tabular}{ll|}
178,42 \\
\end{tabular} & 178,42 & 27,65 & 550,25 & 62,66 & 25,36 & 22,82 & 164,55 & 94,37 & 96,50 & $\begin{array}{ll}141,87 \\
\end{array}$ \\
\hline Pelophylax perezi & 30TVM55 & 100,00 & 101,93 & 103,01 & 37,03 & 5877,10 & 262,16 & $-11,48$ & 273,65 & 118,18 & $\begin{array}{ll}179,87 \\
\end{array}$ & 179,87 & 30,22 & 547,68 & 61,75 & 25,84 & 22,42 & 162,52 & 95,08 & 96,40 & 141,54 \\
\hline Pelophylax perezi & 30TVM56 & 100,00 & 97,36 & 102,37 & 37,11 & 5809,75 & 256,47 & $-14,40$ & 270,87 & 113,70 & 174,64 & 174,64 & 26,77 & 579,32 & 64,67 & 28,43 & 21,82 & 170,90 & 102,09 & 102,18 & 150,45 \\
\hline Pelophylax perezi & 30TVM57 & 100,00 & 98,61 & 100,84 & 37,11 & 5748,41 & 255,27 & $-11,40$ & 266,66 & 106,82 & 175,03 & 175,03 & 28,49 & 584,84 & 64,45 & 29,29 & 21,51 & 171,20 & 104,24 & 104,24 & 152,75 \\
\hline Pelophylax perezi & 30TVM58 & 100,00 & $\begin{array}{l}0,0,01 \\
98,86\end{array}$ & $\begin{array}{r}0,04 \\
99,24\end{array}$ & 37,44 & \begin{tabular}{|l}
5607,41 \\
5667
\end{tabular} & 252,48 & $\begin{array}{l}-1,40 \\
-9,10\end{array}$ & $\begin{array}{l}261,58 \\
260\end{array}$ & $\begin{aligned} 0,02,68 \\
69,68\end{aligned}$ & 174,25 & $\begin{array}{l}174,25 \\
174\end{array}$ & $\begin{array}{l}20,45 \\
29,75 \\
\end{array}$ & \begin{tabular}{|l|l|}
600,95 \\
60,95
\end{tabular} & $\begin{array}{l}4,45 \\
65,14\end{array}$ & $\begin{array}{l}30,32 \\
30,32\end{array}$ & $\frac{21,19}{21,19}$ & $\begin{array}{l}11,206 \\
176,48\end{array}$ & $\begin{array}{l}108,41 \\
\end{array}$ & \begin{tabular}{|l|}
108,41 \\
\end{tabular} & 158,28 \\
\hline Pelophylax perezi & 30TVM59 & 100,00 & 99,00 & 97,41 & 37,52 & 5574,17 & 249,40 & $-6,82$ & 256,22 & 66,52 & 173,22 & 173,22 & 31,22 & 624,74 & 66,83 & 31,49 & 21,03 & 185,39 & 113,75 & 113,75 & 166,05 \\
\hline Pelophylax perezi & 30TVM60 & 100,00 & 111,15 & 105,20 & 36,93 & 6157,40 & 275,67 & $-7,15$ & 282,81 & 129,52 & 192,69 & 192,96 & 36,12 & 484,53 & 55,92 & 19,53 & 24,88 & 145,21 & 79,38 & 85,17 & 124,46 \\
\hline Pelophylax perezi & 30TVM61 & 100,00 & 110,19 & 105,12 & 37,00 & 6111,20 & 274,16 & $-7,55$ & 281,71 & 128,98 & 191,00 & 191,29 & 35,64 & 491,30 & 56,61 & 20,54 & 24,34 & 147,28 & 81,72 & 86,87 & 126,25 \\
\hline Pelophylax perezi & 30TVM62 & 100, & 108,38 & 105,01 & 37,00 & 6062,17 & 271,86 & $-8,63$ & 280,49 & 126,90 & 188,79 & 188,91 & 34,46 & 502,86 & 57,81 & 21,81 & 23,59 & 150,64 & 84,96 & 91,00 & 129,31 \\
\hline Pelophylax perezi & 30TVM63 & 100,00 & $\begin{array}{l}10,50 \\
101,94\end{array}$ & $\begin{array}{l}105,01 \\
105,06\end{array}$ & 37,04 & \begin{tabular}{|l|l|}
50097,43 \\
599
\end{tabular} & 267,60 & $\begin{array}{r}--13,03 \\
-13,73 \\
\end{array}$ & $\begin{array}{l}278,49 \\
278,99 \\
\end{array}$ & $\begin{array}{l}110,50 \\
119,5\end{array}$ & $\begin{array}{l}18,1,64 \\
181,64\end{array}$ & \begin{tabular}{|l|}
$180,91,66$ \\
181
\end{tabular} & \begin{tabular}{|l|}
29,210 \\
29,21
\end{tabular} & \begin{tabular}{|l|}
537,350 \\
537,35
\end{tabular} & $\begin{array}{l}1,, 01 \\
61,60\end{array}$ & 24,4 & $\begin{array}{l}22,84 \\
22,84\end{array}$ & \begin{tabular}{|l|}
$160,04,06$ \\
\end{tabular} & $\begin{array}{l}4,30 \\
92,35 \\
\end{array}$ & $\begin{array}{l}1,00 \\
96,47 \\
\end{array}$ & $\begin{array}{l}12,51,56 \\
138,56\end{array}$ \\
\hline Pelophylax perezi & 30TVM64 & 100,00 & 95,36 & 104,86 & 37,20 & 5925,16 & 258,21 & $-18,69$ & 276,90 & 111,96 & 174,48 & 174,49 & 24,00 & 577,95 & 65,75 & 27,61 & 22,01 & 172,62 & 101,03 & 102,07 & 149,71 \\
\hline Pelophylax perezi & 30TVM65 & 100,00 & 99,66 & 103,47 & 37,19 & 5877,67 & 260,07 & $-13,36$ & 273,44 & 116,60 & 177,81 & 177,81 & 28,24 & 565,63 & 63,77 & 27,44 & 21,85 & 167,67 & 99,91 & 100,37 & 146,89 \\
\hline Pelophylax perezi & 30TVM66 & 100,00 & 96,82 & 102,54 & 37,5 & 5810,34 & 255,69 & $-14,68$ & 0,37 & 112,97 & 174,30 & 174,30 & 7 & 592,52 & 65,98 & 29 , & 21,25 & 174,32 & 105,92 & 105,92 & 154,79 \\
\hline Pelophylax perezi & 30TVM67 & 100,00 & 85,73 & 102,20 & 37, & $5724, \varepsilon$ & 243,8 & $-23,75$ & 267,55 & 100,12 & 162,63 & 162,63 & $\begin{array}{l}20,325 \\
17,15\end{array}$ & $\begin{array}{l}672,44 \\
672\end{array}$ & 73,45 & 35, & 20,31 & 195,63 & $\begin{array}{l}121,75 \\
12,7\end{array}$ & $\begin{array}{l}121,75 \\
\end{array}$ & 177,26 \\
\hline Pelophylax perezi & 30TVME & 100,00 & 93,86 & 100,04 & 37,83 & 5660,56 & 248,30 & $-14,12$ & 262,42 & 72,58 & 169,56 & 169,56 & 25,44 & 641,77 & 69,19 & $33, \mathrm{C}$ & 20,53 & 186,60 & 117,08 & 117,08 & 170,02 \\
\hline Pelophylax perezi & 30TVM69 & 100,00 & 98,16 & 97,64 & 37,81 & 5565,22 & 248,23 & $-7,76$ & 255,99 & 65,35 & 172,37 & 172,37 & 30,50 & 646,26 & 68,22 & 32,82 & 20,34 & 190,43 & 118,83 & 118,83 & 172,83 \\
\hline Pelophylax perezi & 30TVM70 & 100,00 & 112,55 & 105,87 & 36,98 & 6160,84 & 277,34 & $-6,28$ & 283,62 & 131,70 & 194,07 & 194,32 & 37,54 & 480,44 & 55,58 & 19,82 & 24,49 & 143,77 & 80,06 & 85,36 & 123,15 \\
\hline Pelophylax perezi & 30TVM71 & 100,00 & 108,84 & 105,97 & 37,00 & 6108,36 & 273,64 & $-9,15$ & 282,79 & 127,60 & 189,80 & 190,02 & 34,56 & 499,72 & 57,78 & 21,62 & 23,67 & 81 & 84,85 & 89,94 & 128,34 \\
\hline Pelophylax perezi & 30TVN & 100,00 & 10 & 105,89 & 37,01 & 606 & 270 & $-10,91$ & 281,34 & 124,35 & 186,61 & 186,65 & 32,47 & 516,80 & 59,62 & 23,21 & 23,02 & \begin{tabular}{|l|}
154,97 \\
\end{tabular} & 89,04 & 93,36 & 133,00 \\
\hline Pelophylax perezi & 30TVM73 & 100,00 & 98,56 & 105,98 & 37,12 & 5997,22 & 262,84 & $-17,20$ & 280,04 & 115,77 & 178,54 & 178,56 & 26,25 & 559,55 & 64,18 & 26,39 & 22,13 & 167,59 & 98,07 & 99,80 & 144,61 \\
\hline Pelophylax perezi & 30TVM74 & 100,00 & 100,22 & 105,01 & 37,27 & |5943,49 & 262,73 & $-14,36$ & $\begin{array}{l}277,09 \\
270\end{array}$ & 117,38 & 179,39 & 179,40 & 28,16 & 559,96 & $\begin{array}{l}4,16 \\
63,73 \\
\end{array}$ & 26,99 & 21,78 & $\begin{array}{l}166,78 \\
\end{array}$ & 99,11 & \begin{tabular}{|l|}
100,65 \\
\end{tabular} & 145,18 \\
\hline Pelophylax perezi & 30TVM75 & 100,00 & 100,45 & 103,88 & 37,25 & 5882,88 & 261,01 & $-12,85$ & 273,87 & 117,54 & 178,77 & 178,77 & 28,93 & 569,77 & 64,18 & 28,18 & 21,36 & 168,50 & 102,01 & 102,59 & 148,42 \\
\hline Pelophylax perezi & 30TVM76 & 100,00 & 87,60 & 103,64 & 37,90 & 5792,22 & 247,70 & $-23,53$ & 271,22 & 102,96 & 165,40 & 165,40 & 18,18 & 656,62 & 72,67 & 34,20 & 20,29 & 192,43 & 119,18 & 119,18 & 172 \\
\hline Pelophylax perezi & 30TVM77 & 100,00 & 77,65 & 102,83 & 37,99 & 5712,01 & 236,49 & $-21,63$ & 268,12 & $\begin{array}{r}91,60 \\
91,0\end{array}$ & 154,71 & 154,71 & 9,76 & 735,33 & 79,78 & 39,36 & 19,46 & 213,12 & 134,59 & 134,59 & 195,12 \\
\hline Pelophylax perezi & 30TVM78 & 100,00 & 88,24 & 101,01 & 38,00 & 5655,53 & 243,54 & $-19,99$ & 263,53 & 69,76 & 164,02 & 164,02 & 20,13 & 687,79 & 73,85 & 36,12 & 19,78 & 198,62 & 126,73 & 126,73 & 183,08 \\
\hline Pelophylax perezi & 30TVM79 & 100,00 & 98,67 & 98,00 & 37,93 & 5559,87 & 248,47 & $-7,68$ & 256,15 & 64,45 & 172,70 & 172,72 & 31,04 & 659,48 & 69,32 & 33,73 & 19,95 & 193,11 & 122,43 & 122,43 & 177,13 \\
\hline Pelophylax perezi & 30TVM80 & 100,00 & 110,79 & 107,04 & 37,00 & 6174,34 & 276,78 & $-8,55$ & 285, & 129,90 & 192,57 & 192 & 35, & 489,78 & 57,03 & 21,07 & 23,77 & 146,94 & 83,42 & 88,50 & 125, \\
\hline Pelophylax perezi & 30TVM81 & 100,00 & 107,37 & 107,21 & 37,07 & 6121,69 & 273,23 & $-11,05$ & 284,28 & 125,88 & 188,52 & 188,66 & 33,26 & 509,37 & 59,19 & 22,79 & 23,06 & 152,96 & 88,11 & 93,40 & 130,80 \\
\hline
\end{tabular}




\begin{tabular}{|c|c|c|c|c|c|c|c|c|c|c|c|c|c|c|c|c|c|c|c|c|c|}
\hline TAXON & UTM & $\mathrm{km} 2$ & BIO1 & B102 & $B 103$ & BIO4 & B105 & B106 & B107 & B108 & B109 & B1010 & BIO11 & B1012 & BIO13 & BIO14 & BIO15 & B1016 & B1017 & B1018 & 81019 \\
\hline Pelophylax perezi & 30TVM82 & 100,00 & 101,36 & 107,39 & 37,35 & 6056,29 & 267,30 & $-15,85$ & 283,15 & 119,08 & 182,21 & 182,22 & 28,29 & 543,64 & 62,84 & 25,53 & 22,24 & 163,19 & 95,59 & 99,04 & 140,21 \\
\hline Pelophylax perezi & 30TVM83 & 100,00 & 98,03 & 106,97 & 37,55 & 6000,19 & 263,21 & $-18,06$ & 281,27 & 115,23 & 178,17 & 178,18 & 25,65 & 568,01 & 65,21 & 27,55 & 21,58 & 169,93 & $\begin{array}{l}101,13 \\
\end{array}$ & 104,28 & 147,14 \\
\hline Pelophylax perezi & 30TVM84 & 100,00 & 97,05 & 106,23 & 37,68 & 5944,40 & 260,66 & $-17,95$ & 278,60 & 114,03 & $\begin{array}{l}176,37 \\
\end{array}$ & $\begin{array}{l}176,37 \\
\end{array}$ & 25,10 & \begin{tabular}{|l|l|}
583,63 \\
\end{tabular} & 66,38 & 29,07 & 21,05 & $\begin{array}{l}173,67 \\
\end{array}$ & 105,01 & $\begin{array}{l}107,08 \\
\end{array}$ & 151,81 \\
\hline Pelophylax perezi & 30TVM85 & 100,00 & 87,08 & 105,51 & 37,98 & 5859,40 & 249,67 & $-25,81$ & 275,48 & 102,62 & 165,79 & 165,79 & 16,95 & 654,34 & 73,23 & 34,11 & 20,19 & $\begin{array}{l}193,01 \\
\end{array}$ & 1119,14 & $\begin{array}{ll}119,61 \\
\end{array}$ & 171,68 \\
\hline Pelophylax perezi & 30TVM86 & 100,00 & 88,57 & 104,39 & 38,00 & 5798,97 & 249,07 & $-23,21$ & 272,28 & 103,98 & 166,36 & 166,36 & 18,99 & $659,17 \mid$ & 72,95 & 34,65 & 19,81 & 193,02 & 120,91 & 120,91 & 173,76 \\
\hline Pelophylax perezi & 30TVM87 & 100,00 & 69,26 & 103,39 & 38,00 & 5696,11 & 228,73 & $-39,70$ & 268,43 & 82,56 & 146,46 & 146,46 & 2,19 & 800,97 & 86,39 & 43,73 & 18,76 & 231,33 & 148,06 & 148,06 & 213,46 \\
\hline Pelophylax perezi & 30TVM88 & 100,00 & 90,20 & 101,26 & 37,99 & 5654,98 & 245,08 & $-18,43$ & 263,51 & 76,82 & 165,95 & 165,95 & 22,02 & 690,99 & 74,06 & 36,42 & 19,29 & 199,16 & 128,53 & 128,53 & 184,51 \\
\hline Pelophylax perezi & 30TVM89 & 100,00 & 103,03 & $\begin{array}{ll}97,94 \\
\end{array}$ & $\begin{array}{ll}37,92 \\
\end{array}$ & 5556,56 & 251,82 & $-4,12$ & 255,95 & 65,56 & $\begin{array}{l}176,62 \\
\end{array}$ & $\begin{array}{l}176,79 \\
\end{array}$ & 35,10 & 653,00 & 68,64 & 33,29 & 19,55 & 191,01 & $\begin{array}{l}122,43 \\
\end{array}$ & \begin{tabular}{|l|l|}
122,43 \\
\end{tabular} & 175,85 \\
\hline Pelophylax perezi & 30TVM90 & 100,00 & 109,67 & 108,41 & 37,01 & \begin{tabular}{ll|l}
6175,28 \\
\end{tabular} & 276,93 & $\begin{array}{l}10,38 \\
\end{array}$ & 287,30 & 128,80 & 191,53 & \begin{tabular}{|l|}
191,73 \\
\end{tabular} & 34,72 & \begin{tabular}{ll|l}
497,12 \\
\end{tabular} & 58,27 & 22,23 & 23,19 & 149,60 & 86,38 & 91,22 & 127,03 \\
\hline Pelophylax perezi & 30TVM91 & 100,00 & 105,88 & 108,52 & \begin{tabular}{|l|}
37,18 \\
\end{tabular} & 6119,48 & 273,03 & $-13,45$ & 286,48 & 124,41 & 187,18 & 187,24 & 31,70 & 520,76 & 60,75 & 24,19 & 22,38 & 156,58 & 91,88 & 96,24 & 133,75 \\
\hline Pelophylax perezi & 30TVM92 & 100,00 & 100,07 & 108,72 & 37,73 & 6058,65 & 267,23 & $-17,95$ & 285,18 & 117,93 & 180,93 & 180,94 & 27,00 & 556,12 & 64,39 & 26,95 & 21,52 & 166,86 & 99,45 & 103,55 & 143,63 \\
\hline Pelophylax perezi & 30TVM93 & 100,00 & $\begin{array}{ll}95,84 \\
\end{array}$ & 108,37 & 37,98 & 6002,07 & 262,09 & $-20,98$ & 283,07 & 112,94 & $\begin{array}{l}176,07 \\
\end{array}$ & \begin{tabular}{ll|}
176,09 \\
\end{tabular} & 23,52 & 587,12 & 67,38 & 29,36 & 20,87 & $\begin{array}{l}175,48 \\
\end{array}$ & 106,11 & $\begin{array}{l}108,37 \\
\end{array}$ & 152,44 \\
\hline Pelophylax perezi & 30TVM94 & 100,00 & 93,69 & 107,52 & 37,99 & 5940,38 & 258,53 & $-21,79$ & 280,32 & 110,41 & 173,17 & 173,17 & 22,16 & 609,52 & 69,25 & 31,33 & 20,35 & 181,15 & 111,26 & 112,79 & 159,04 \\
\hline Pelophylax perezi & 30TVM95 & 100,00 & 73,65 & 106,18 & 38,00 & 5824,96 & 237,28 & $-38,38$ & 275,67 & 87,98 & 152,53 & 152,53 & 4,92 & 747,79 & 82,90 & 40,55 & 19,10 & 219,58 & 137,90 & $\begin{array}{l}137,99 \\
\end{array}$ & 197,28 \\
\hline Pelophylax perezi & 30TVM96 & 100,00 & 83,40 & 105,32 & 38,00 & $\begin{array}{ll}5793,34 \\
\end{array}$ & 244,72 & $-28,48$ & 273,21 & 98,52 & 161,39 & 161,39 & 14,36 & \begin{tabular}{ll|l}
701,13 \\
\end{tabular} & 77,27 & 37,58 & 19,15 & 204,79 & $\begin{array}{ll}129,98 \\
\end{array}$ & \begin{tabular}{|l|l|}
129,98 \\
\end{tabular} & 185,41 \\
\hline Pelophylax perezi & 30TVM97 & 100,00 & 71,52 & 103,63 & 38,00 & 5701,55 & 230,87 & $-37,93$ & 268,80 & 85,05 & 148,69 & \begin{tabular}{ll|}
148,69 \\
\end{tabular} & 4,16 & 797,59 & 86,10 & 43,69 & 18,42 & 230,23 & 148,77 & 148,77 & 212,75 \\
\hline Pelophylax perezi & 30TVM98 & 100,00 & 91,12 & 101,98 & 38,00 & 5661,91 & 246,27 & $-18,21$ & 264,47 & 84,41 & 166,85 & 166,85 & 22,79 & \begin{tabular}{ll|l|}
696,98 \\
\end{tabular} & 74,72 & 36,97 & 18,87 & 200,20 & $\begin{array}{l}130,80 \\
\end{array}$ & $\begin{array}{l}130,80 \\
\end{array}$ & 186,20 \\
\hline Pelophylax perezi & 30TVM99 & 100,00 & 102,76 & 98,85 & 37,97 & 5568,33 & 252,12 & $-5,18$ & 257,30 & 60,80 & $\mid 176,65$ & \begin{tabular}{|l|l|}
176,71 \\
\end{tabular} & 34,77 & 662,93 & 69,71 & 34,25 & 19,01 & 192,52 & 125,39 & 125,39 & 178,41 \\
\hline Pelophylax perezi & 30TVNO0 & 100,00 & 108,50 & 99,59 & 37,93 & 5349,25 & 256,73 & $-3,32$ & 260,05 & 82,66 & 179,20 & 179,20 & 42,52 & $\begin{array}{l}609,08 \\
\end{array}$ & 69,48 & 29,05 & 23,06 & 192,55 & 104,69 & 105,56 & 157,47 \\
\hline Pelophylax perezi & 30TVN01 & 100,00 & 105,02 & 97,94 & 38,00 & 5266,53 & 250,59 & $-4,35$ & 254,94 & 79,44 & 174,73 & $\begin{array}{l}174,73 \\
\end{array}$ & 40,23 & 652,32 & 74,87 & 31,68 & 22,53 & 206,91 & 114,49 & $\begin{array}{l}114,60 \\
\end{array}$ & 170,16 \\
\hline Pelophylax perezi & 30TVN02 & 100,00 & $\begin{array}{ll}94,93 \\
\end{array}$ & 97,31 & 38,01 & 5225,65 & 240,01 & $-12,12$ & 252,13 & 69,28 & $\begin{array}{l}164,63 \\
\end{array}$ & $\begin{array}{ll}164,63 \\
\end{array}$ & 31,41 & $\begin{array}{l}724,43 \\
\end{array}$ & 82,86 & 36,32 & 21,84 & 228,54 & $\begin{array}{ll}129,62 \\
\end{array}$ & $\begin{array}{ll}129,62 \\
\end{array}$ & $\begin{array}{l}191,08 \\
1\end{array}$ \\
\hline Pelophylax perezi & 30TVN03 & 100,00 & $\begin{array}{ll}98,08 \\
\end{array}$ & $\begin{array}{ll}94,63 \\
\end{array}$ & \begin{tabular}{|l|l|}
38,07 \\
\end{tabular} & 5091,35 & 238,07 & $-6,49$ & 244,56 & 73,30 & 165,73 & 165,91 & 36,01 & $\begin{array}{l}748,90 \\
\end{array}$ & 86,70 & 37,29 & 21,95 & $\begin{array}{ll}239,08 \\
\end{array}$ & $\begin{array}{l}135,73 \\
\end{array}$ & $\begin{array}{l}135,79 \\
\end{array}$ & 199,06 \\
\hline Pelophylax perezi & 30TVN04 & 100,00 & $\begin{array}{ll}97,56 \\
\end{array}$ & 92,57 & 38,09 & \begin{tabular}{|l|l|l|}
4993,68 \\
\end{tabular} & 233,93 & $-4,75$ & 238,68 & 73,57 & 163,47 & 164,29 & 36,67 & 786,93 & 91,65 & 39,27 & 21,97 & 252,69 & 144,27 & 144,50 & 210,75 \\
\hline Pelophylax perezi & 30TVN05 & 100,00 & 95,42 & 90,73 & 38,30 . & 4910,96 & 228,77 & $-4,67$ & 233,44 & 71,96 & 159,71 & 161,12 & 35,86 & 832,84 & 97,31 & 41,76 & 21,96 & 268,27 & 152,96 & 154,50 & 224,96 \\
\hline Pelophylax perezi & 30TVN06 & 100,00 & 93,48 & 88,85 & 38,40 & 4816,21 & 223,41 & $-4,68$ & 228,10 & 70,61 & 156,37 & 158,01 & 35,10 & 882,73 & 103,43 & 44,41 & 22,11 & 285,17 & 162,07 & 165,37 & 240,34 \\
\hline Pelophylax perezi & 30TVN10 & 100,00 & 106,85 & 98,15 & 37,69 & 5371,47 & 254,56 & $-3,10$ & 257,66 & 79,73 & 177,87 & 177,87 & 40,46 & 618,46 & 69,84 & 29,82 & 22,42 & 193,83 & 107,60 & 107,86 & 160,68 \\
\hline Pelophylax perezi & 30TVN12 & 100,00 & 97,30 & 95,50 & 38,00 & 5209,78 & 240,46 & $-8,07$ & 248,53 & 71,01 & $\begin{array}{l}166,72 \\
\end{array}$ & 166,72 & 33,68 & $\begin{array}{l}720,35 \\
\end{array}$ & 81,96 & 35,95 & 21,62 & 226,56 & 129,66 & $\begin{array}{ll}129,66 \\
\end{array}$ & $\begin{array}{ll}190,89 \\
\end{array}$ \\
\hline Pelophylax perezi & 30TVN13 & 100,00 & 100,03 & 92,71 & \begin{tabular}{ll|}
37,99 \\
\end{tabular} & 5074,66 & 237,86 & $-3,24$ & 241,09 & 74,87 & 167,07 & 167,61 & $\begin{array}{l}37,92 \\
\end{array}$ & 750,81 & 86,35 & 37,08 & 21,81 & 239,05 & 136,11 & $\begin{array}{l}136,80 \\
\end{array}$ & 200,91 \\
\hline Pelophylax perezi & 30TVN15 & 100,00 & 96,76 & 89,05 & 38,07 & 4883,89 & 227,97 & $-2,11$ & 230,09 & 73,03 & 160,45 & 162,12 & 37,23 & 841,59 & 97,63 & 41,88 & 21,90 & 270,43 & 153,84 & 156,64 & 228,98 \\
\hline Pelophylax perezi & 30TVN16 & 100,00 & 99,13 & 86,20 & 38,09 & 4748,31 & 225,22 & 2,60 & 222,62 & 76,54 & 160,81 & 162,70 & 41,35 & 876,76 & \begin{tabular}{|l|l|}
102,58 \\
\end{tabular} & 43,28 & 22,32 & 284,48 & 159,04 & 164,78 & 240,62 \\
\hline Pelophylax perezi & 30TVN17 & 100,00 & 113,51 & 79,24 & 38,01 & 4450,67 & 227,75 & 21,95 & 205,80 & 93,08 & 170,64 & $\begin{array}{l}172,86 \\
\end{array}$ & 58,77 & 894,42 & \begin{tabular}{|l|l|}
107,47 \\
\end{tabular} & 41,87 & 24,48 & 299,30 & 157,15 & $\begin{array}{l}170,29 \\
\end{array}$ & 248,74 \\
\hline Pelophylax perezi & 30TVN19 & 100,00 & 133,52 & 67,70 & \begin{tabular}{l|l|l}
37,55 \\
\end{tabular} & 3946,92 & 229,38 & 51,28 & 178,10 & 116,49 & 183,18 & 186,10 & 84,48 & \begin{tabular}{|l|l|}
947,99 \\
\end{tabular} & 118,90 & 40,98 & 28,14 & 331,66 & 158,69 & 184,71 & 268,72 \\
\hline Pelophylax perezi & 30TVN21 & 100,00 & 97,95 & 96,18 & 37,84 & 5330,46 & 243,94 & $-8,09$ & 252,03 & 69,77 & 168,82 & 168,82 & 32,69 & \begin{tabular}{|l|l|}
684,67 \\
\end{tabular} & 76,71 & 34,11 & 21,41 & 212,27 & 122,51 & 122,51 & 180,58 \\
\hline Pelophylax perezi & 30TVN22 & 100,00 & \begin{tabular}{|c|}
98,18 \\
\end{tabular} & 94,05 & \begin{tabular}{|l|l|}
37,97 \\
\end{tabular} & 5211,92 & 239,98 & $-5,71$ & 245,69 & 71,22 & 167,44 & 167,58 & 34,47 & \begin{tabular}{|l|l|}
722,47 \\
\end{tabular} & 81,64 & 35,99 & 21,27 & 226,16 & 130,84 & 130,90 & 192,53 \\
\hline Pelophylax perezi & 30 TVN23 & 100,00 & 97,04 & 91,99 & 37,98 & 5098,92 & 234,97 & $-4,75$ & 239,73 & 70,94 & 164,45 & 165,11 & 34,86 & 768,87 & 87,30 & 38,34 & 21,30 & 242,35 & 140,32 & 140,99 & 207,25 \\
\hline Pelophylax perezi & 30TVN24 & 100,00 & 101,35 & 88,78 & 37,93 & 4946,85 & 233,22 & 1,82 & 231,41 & 76,64 & 165,72 & \begin{tabular}{ll|}
167,33 \\
\end{tabular} & 40,81 & \begin{tabular}{ll|}
798,72 \\
\end{tabular} & $\begin{array}{l}91,63 \\
\end{array}$ & 39,16 & 21,85 & 255,50 & \begin{tabular}{ll|}
144,76 \\
\end{tabular} & $\begin{array}{ll}147,93 \\
\end{array}$ & 217,80 \\
\hline Pelophylax perezi & 30TVN25 & 100,00 & 99,07 & 87,23 & 38,01 & 4861,28 & 227,97 & 1,48 & 226,50 & 75,07 & 162,11 & 163,98 & 39,72 & 847,18 & 97,49 & 41,77 & 21,85 & 271,79 & 153,74 & 158,29 & 232,81 \\
\hline Pelophylax perezi & 30 TVN26 & 100,00 & 99,52 & 84,82 & $\begin{array}{ll}38,02 \\
\end{array}$ & 4741,43 & 224,38 & 4,32 & 220,06 & 76,76 & 160,99 & 163,08 & 41,78 & $\begin{array}{l}890,45 \\
\end{array}$ & 103,09 & 43,70 & 22,14 & 287,85 & 160,75 & 167,71 & 246,91 \\
\hline Pelophylax perezi & 30TVN30 & 100,00 & 99,40 & 96,63 & 37,33 & 5448,19 & 247,7 & $-7,01$ & 254,75 & 69,27 & 171,72 & $\begin{array}{l}171,72 \\
\end{array}$ & 32,52 & 648,39 & 71,83 & 32,34 & 21,29 & 198,45 & 115,93 & 15,93 & 170,14 \\
\hline Pelophylax perezi & 30TVN31 & 100,00 & 96,78 & 95,23 & 37,79 & 5345,47 & 242,09 & $-7,86$ & 249,95 & 67,83 & 167,90 & 167,90 & 31,47 & 694,26 & 77,24 & 34,87 & 21,03 & 213,68 & 125,51 & 125,51 & 184,37 \\
\hline Pelophylax perezi & 30TVN32 & 100,00 & $\begin{array}{l}98,01 \\
\end{array}$ & 93,01 & 37,90 & 5220,81 & 238,88 & $-4,56$ & 243,45 & 70,10 & 167,05 & $\begin{array}{l}167,62 \\
\end{array}$ & 34,19 & 729,61 & 81,65 & 36,42 & 21,10 & 226,93 & $\begin{array}{ll}132,83 \\
\end{array}$ & \begin{tabular}{|l|l|}
133,19 \\
\end{tabular} & 196,12 \\
\hline Pelophylax perezi & 30TVN33 & 100,00 & 99,88 & 90,41 & 37,83 & 5087,54 & 235,72 & $-0,61$ & 236,32 & 73,30 & 166,10 & 167,68 & 37,62 & 768,08 & 86,51 & 37,99 & 21,23 & 241,69 & 139,82 & 141,61 & 209,01 \\
\hline Pelophylax perezi & 30TVN34 & 100,00 & 102,11 & 87,56 & \begin{tabular}{|l|l|}
37,89 \\
\end{tabular} & $\begin{array}{ll}4943,68 \\
\end{array}$ & 232,54 & 3,78 & 228,76 & 76,89 & 166,15 & 168,01 & 41,55 & 807,40 & \begin{tabular}{|l|l|}
91,67 \\
\end{tabular} & 39,47 & 21,58 & 257,15 & 145,83 & 150,27 & 222,41 \\
\hline Pelophylax perezi & 30TVN35 & 100,00 & 100,09 & 85,70 & 37, & 4839,53 & 227,32 & 3,92 & 223,40 & 75,82 & 162,73 & 164,78 & 41,04 & 860,57 & 98,02 & 42,14 & 21,75 & 275,25 & 155,33 & 161,40 & 239,24 \\
\hline Pelophylax perezi & 30 TVN36 & 100,00 & 98,50 & 83,98 & 37, & 4741,51 & 222,92 & 4,39 & 218,54 & 75,08 & 159,90 & 161,99 & 40,86 & 910,65 & \begin{tabular}{|l|}
104,03 \\
\end{tabular} & 44,72 & 21,92 & 292,47 & 164,27 & 171,98 & 255,13 \\
\hline Pelophylax perezi & $30 \mathrm{TVN}$ & 100,00 & 127,07 & $\begin{array}{ll}66,93 \\
\end{array}$ & \begin{tabular}{|l|}
37,08 \\
\end{tabular} & 3989,85 & 224,19 & 45,96 & 178,23 & 109,46 & 177,38 & 180,34 & 77,79 & 1017,59 & \begin{tabular}{|l|l|}
124,93 \\
\end{tabular} & \begin{tabular}{ll|}
44,16 \\
\end{tabular} & 27,35 & 351,10 & 170,33 & $\begin{array}{l}197,75 \\
\end{array}$ & 296,26 \\
\hline Pelophylax perezi & 30TVN40 & 100,00 & 100,81 & 95,65 & \begin{tabular}{l|l|}
37,49 \\
\end{tabular} & 5453,55 & 247,77 & $-3,97$ & 251,74 & 69,92 & $\begin{array}{l}173,08 \\
\end{array}$ & 173,21 & 33,90 & 645,41 & 70,98 & 32,20 & 21,06 & $\begin{array}{l}196,42 \\
\end{array}$ & $\begin{array}{ll}116,78 \\
\end{array}$ & $\begin{array}{ll}116,78 \\
\end{array}$ & $\begin{array}{ll}171,18 \\
\end{array}$ \\
\hline Pelophylax perezi & 30TVN41 & 100,00 & 97,97 & 94,24 & 37,84 & 5348,75 & 242,03 & $-5,08$ & 247,11 & 68,22 & 168,75 & 169,27 & 32,69 & 695,17 & 76,59 & 34,88 & 20,91 & 212,73 & 126,85 & 126,95 & 186,38 \\
\hline Pelophylax perezi & 30TVN42 & 100,00 & 94,73 & 92,92 & 37,9 & 5248,90 & 235,92 & $-6,76$ & 242,68 & 66,10 & 163,77 & 164,82 & 30,91 & 748,93 & 82,50 & 37,81 & 20,56 & 230,02 & 137,79 & 137,95 & 202,92 \\
\hline Pelophylax perezi & $30 \mathrm{TVI}$ & 100,00 & 94,96 & 90,73 & 37, & 512 & 232,01 & $-4,57$ & 236,57 & 67,53 & 161,78 & 163,49 & 32,63 & 793,42 & 87,77 & 39,94 & 20,51 & 245,95 & 145,83 & 147,30 & 217,37 \\
\hline Pelophylax perezi & 30TVN44 & 100,00 & 99,73 & 87,26 & $\begin{array}{ll}37,82 \\
\end{array}$ & 4960,01 & 230,43 & 2,49 & 227,94 & 73,85 & 164,09 & 165,94 & 39,32 & 829,36 & 92,90 & 40,81 & 21,28 & 261,53 & 150,31 & 155,01 & 230,64 \\
\hline Pelophylax perezi & 30TVN45 & 100,00 & 103,27 & 83,95 & $\begin{array}{ll}37,82 \\
\end{array}$ & 4805,38 & 228,38 & 8,55 & 219,83 & 78,79 & 165,41 & 167,48 & 44,52 & 868,29 & 98,77 & 41,92 & 21,89 & 277,71 & 155,42 & 163,40 & 244,62 \\
\hline Pelophylax perezi & 30TVN46 & 100,00 & 101,68 & 82,19 & 37,7 & 4705,55 & 224,07 & 8,78 & 215,30 & 78,10 & 162,36 & 164 & 44 & $\begin{array}{l}919,65 \\
\end{array}$ & \begin{tabular}{|l|l|}
105,53 \\
\end{tabular} & 44,48 & 22,03 & 47 & 164,43 & 174,03 & 261,18 \\
\hline Pelophylax perezi & $30 \mathrm{TV}$ & 100 & 84,44 & 84 & 37 & & 211,57 & $-8,16$ & & 50,17 & 146,53 & 148,96 & 27,38 & 1012 & 114 & 51,64 & 20 & 319,08 & 18 & $\begin{array}{l}192,27 \\
\end{array}$ & 286,46 \\
\hline Pelophylax perezi & 30TVN48 & 100,00 & 94,57 & 79,63 & \begin{tabular}{|c|}
37,77 \\
\end{tabular} & 4553,22 & 213,35 & 5,26 & 208,09 & 65,35 & 153,28 & 155,92 & 39,71 & \begin{tabular}{|l|}
1037,07 \\
\end{tabular} & 120,07 & 50,90 & 22,20 & 334,28 & 186,41 & 198,12 & 297,73 \\
\hline Pelophylax perezi & 30TVN49 & 100,00 & 121,90 & 67,96 & 36,93 & 4068,85 & 221,70 & 40,18 & \begin{tabular}{ll|}
181,52 \\
\end{tabular} & \begin{tabular}{ll|}
103,62 \\
\end{tabular} & 173,25 & 176,26 & 71,89 & 1048,45 & 128,75 & 46,12 & 26,42 & 356,67 & 176,45 & 202,64 & 309,96 \\
\hline Pelophylax perezi & 30TVN50 & 100,00 & 100,50 & 95,25 & \begin{tabular}{|l|l|}
37,68 \\
\end{tabular} & 5447,36 & 246,48 & $-3,64$ & 250,12 & 69,33 & 172,36 & 172,86 & 33,82 & 656,37 & 70,75 & 32,93 & 20,83 & 197,61 & 120,26 & 120,34 & 176,11 \\
\hline Pelophy & 3 & 100, & 98,95 & 91 & & 2121 & 237,6 & -1, & & 70, & 167 & 16 & 35,30 & 749,14 & & 37,43 & & & $\mid 137,40$ & 139,13 & 20 \\
\hline Pelophylax perezi & 30TVN54 & 100,00 & 106,21 & 84,98 & \begin{tabular}{|l|l|}
37,53 \\
\end{tabular} & 4905,19 & 233,44 & 10,21 & 223,23 & 80,17 & 169,55 & 171,56 & 46,08 & \begin{tabular}{|l|l|}
826,97 \\
\end{tabular} & 93,60 & 39,72 & 21,58 & 261,92 & \begin{tabular}{|l|l|}
148,03 \\
\end{tabular} & 155,24 & 233,76 \\
\hline Pelophylax perezi & 30TVN55 & 100,00 & 113,55 & 80,20 & 37,16 & 4694,17 & 233,01 & 20,75 & 212,25 & 89,81 & 173,80 & 175,99 & 55,64 & 865,90 & 100,81 & 40,08 & 22,87 & 280,37 & 151,47 & 163,42 & 249,80 \\
\hline
\end{tabular}




\begin{tabular}{|c|c|c|c|c|c|c|c|c|c|c|c|c|c|c|c|c|c|c|c|c|c|}
\hline TAXON & UTM & $\mathrm{km} 2$ & B101 & B102 & $\mathrm{BIO3}$ & BIO4 & B105 & B106 & B107 & B108 & B109 & B1010 & BIO11 & BIO12 & B1013 & BIO14 & BIO15 & B1016 & B1017 & B1018 & B1019 \\
\hline Pelophylax perezi & 30TVN56 & 100,00 & 106,14 & 80,16 & 37,35 & 4654,46 & 225,83 & 14,56 & 211,27 & 82,72 & 165,90 & 168,30 & 49,16 & 930,85 & 108,16 & 44,22 & 22,41 & 299,67 & 164,75 & 176,64 & 268,72 \\
\hline Pelophylax perezi & 30TVN57 & 100,00 & 90,49 & 82,57 & 37,85 & 4709,62 & 214,55 & $-0,90$ & 215,45 & 52,83 & 151,43 & 153,93 & 33,92 & 1014,97 & 115,98 & 50,75 & 21,14 & 321,54 & 184,65 & 193,13 & 291,03 \\
\hline Pelophylax perezi & 30TVN60 & 100,00 & 99,87 & 95,39 & 37,82 & 5454,15 & 245,81 & $-4,22$ & 250,03 & 68,44 & 172,01 & 172,54 & 33,22 & 672,87 & 71,24 & 33,95 & 20,19 & 200,78 & 124,47 & 124,56 & 181,88 \\
\hline Pelophylax perezi & 30TVN61 & 100,00 & 109,10 & 91,23 & 37,38 & 5275,72 & 247,20 & 6,92 & 240,28 & 79,42 & 177,51 & 178,99 & 44,13 & 687,76 & 74,70 & 33,49 & 20,67 & 210,78 & 125,36 & 128,02 & 189,41 \\
\hline Pelophylax perezi & 30TVN62 & 100,00 & 111,51 & 88,30 & 37,32 & 5124,11 & 244,29 & 11,61 & 232,68 & 81,37 & 177,68 & 179,32 & 48,27 & 728,47 & 80,75 & 34,84 & 21,01 & 226,71 & 131,29 & 136,11 & 203,84 \\
\hline Pelophylax perezi & 30TVN63 & 100,00 & 107,20 & 87,07 & 37,60 & 5038,53 & 238,05 & 9,28 & 228,77 & 79,07 & 172,23 & 174,21 & 45,30 & 785,92 & 87,87 & 38,01 & 20,95 & 245,04 & 141,95 & 147,61 & 221,72 \\
\hline Pelophylax perezi & 30TVN64 & 100,00 & 110,67 & 83,52 & 37,36 & 4865,24 & 235,67 & 15,42 & 220,24 & 84,28 & 173,25 & 175,36 & 50,84 & 832,07 & 95,12 & 39,33 & 21,70 & 263,67 & 147,92 & 156,78 & 238,93 \\
\hline Pelophylax perezi & 30TVN66 & 100,00 & 105,04 & 80,32 & 37,39 & 4675,92 & 225,36 & 13,67 & 211,68 & 74,50 & 164,97 & 167,42 & 47,88 & 950,00 & $\mid$\begin{tabular}{|l|l|}
110,36 \\
\end{tabular} & 45,36 & 22,03 & 303,34 & 168,65 & 180,39 & 276,88 \\
\hline Pelophylax perezi & 30TVN67 & 100,00 & 101,25 & 79,16 & 37,55 & 4599,45 & 219,84 & 11,59 & 208,25 & 65,66 & 160,21 & 162,83 & 45,37 & 1010,80 & 117,99 & 48,59 & 22,10 & 323,75 & 179,86 & 192,51 & 296,21 \\
\hline Pelophylax perezi & 30TVN68 & 100,00 & 120,69 & 69,95 & 36,74 & 4232,60 & 224,58 & 36,79 & 187,79 & 100,07 & 174,13 & 177,02 & 68,49 & 1042,82 & 128,30 & 45,78 & 25,59 & 347,40 & 175,27 & 198,70 & 317,65 \\
\hline Pelophylax perezi & 30TVN70 & 100,00 & 104,58 & 94,92 & 37,86 & 5438,01 & 248,84 & 0,10 & 248,73 & 73,09 & 175,77 & 176,68 & 37,92 & 669,04 & 70,87 & 33,55 & 19,95 & 199,48 & 124,75 & 125,08 & 182,08 \\
\hline Pelophylax perezi & 30TVN71 & 100,00 & 109,94 & 91,44 & 37,53 & 5283,77 & 247,82 & 7,43 & 240,39 & 79,87 & 178,32 & 179,88 & 44,84 & 695,56 & 75,50 & 33,96 & 20,25 & 211,65 & 127,88 & 130,55 & 192,67 \\
\hline Pelophylax perezi & 30TVN72 & 100,00 & 106,97 & 89,83 & 37,74 & 5181,20 & 242,08 & 6,58 & 235,50 & 73,49 & 174,00 & 175,75 & 43,37 & 749,71 & 82,34 & 36,79 & 20,27 & 229,53 & 137,57 & 141,17 & 209,90 \\
\hline Pelophylax perezi & 30TVN73 & 100,00 & 112,44 & 85,79 & 37,43 & 5006,60 & 241,04 & 14,90 & 226,15 & 83,56 & 176,85 & 178,75 & 50,72 & 786,61 & 88,77 & 37,40 & 21,15 & 245,54 & 141,27 & 148,32 & 225,13 \\
\hline Pelophylax perezi & 30TVN74 & 100,00 & 107,62 & 84,58 & 37,51 & 4912,95 & 234,44 & 12,03 & 222,40 & 74,75 & 170,82 & 172,86 & 47,35 & 851,06 & 96,70 & 40,89 & 21,06 & 266,57 & 153,21 & 160,98 & 245,17 \\
\hline Pelophylax perezi & 30TVN75 & 100,00 & 105,31 & 82,77 & 37,50 & 4807,18 & 229,48 & 11,75 & 217,73 & 67,09 & 167,05 & 169,38 & 46,57 & 910,55 & 104,51 & 43,79 & 21,23 & 286,82 & 163,32 & 172,66 & 264,81 \\
\hline Pelophylax perezi & 30TVN76 & 100,00 & 107,88 & 79,40 & 37,36 & 4649,58 & 226,83 & 17,28 & 209,55 & 67,34 & 167,40 & 169,86 & 51,09 & 964,32 & 112,88 & 45,46 & 22,21 & 308,11 & 170,29 & 183,10 & 285,22 \\
\hline Pelophylax perezi & 30TVN77 & 100,00 & 122,34 & 71,61 & 36,73 & 4342,73 & 229,04 & 36,54 & 192,50 & 98,41 & 177,24 & 179,90 & 68,68 & 1009,67 & 123,94 & 44,06 & 25,19 & 332,97 & 169,58 & 190,88 & 310,96 \\
\hline Pelophylax perezi & 30TVN78 & 100,00 & 120,92 & 69,74 & 36,68 & 4244,12 & 224,77 & 37,20 & 187,57 & 91,57 & 174,43 & 177,29 & 68,58 & 1066,48 & 131,83 & 46,55 & 25,63 & 353,54 & 178,62 & 202,15 & 330,37 \\
\hline Pelophylax perezi & 30TVN82 & 100,00 & 103,17 & 91,27 & 37,89 & 5220,71 & 240,35 & 2,42 & 237,93 & 60,00 & 170,94 & 172,61 & 39,31 & 771,66 & 84,04 & 38,65 & 19,54 & 233,49 & 143,87 & 146,24 & 215,95 \\
\hline Pelophylax perezi & 30TVN83 & 100,00 & 104,94 & 88,13 & 37,73 & 5072,27 & 237,26 & 6,80 & 230,46 & 63,63 & 170,70 & 172,44 & 42,99 & 820,28 & 91,21 & 40,44 & 20,14 & 252,12 & 150,79 & 155,49 & 233,70 \\
\hline Pelophylax perezi & 30TVN84 & 100,00 & 103,96 & 86,15 & 37,85 & 4963,33 & 233,21 & 7,87 & 225,33 & 55,78 & 167,96 & 170,04 & 43,42 & 871,21 & $\begin{array}{l}98,06 \\
98\end{array}$ & 42,76 & 20,30 & 269,96 & 159,22 & 165,50 & 250,88 \\
\hline Pelophylax perezi & 30 TVN85 & 100,00 & 104,85 & 83,38 & 37,74 & 4828,90 & 229,94 & 11,22 & 218,72 & 54,11 & 166,92 & 169,21 & 45,99 & 924,90 & 105,84 & 44,83 & 20,84 & 290,18 & 167,04 & 175,80 & 270,28 \\
\hline Pelophylax perezi & 30 TVN86 & 100,00 & 105,44 & 80,40 & 37,56 & 4686,24 & 225,87 & 14,56 & 211,31 & 57,21 & 165,48 & 167,92 & 48,38 & 987,13 & 114,97 & 47,12 & 21,75 & 313,49 & 175,99 & 187,50 & 293,23 \\
\hline Pelophylax perezi & 30TVN87 & 100,00 & 124,55 & 70,93 & 36,59 & 4335,24 & 230,32 & 39,18 & 191,14 & 88,84 & 179,24 & 181,90 & 70,99 & 1029,46 & 127,20 & 44,41 & 25,55 & 338,75 & 171,69 & 193,69 & 322,91 \\
\hline Pelophylax perezi & 30TVN88 & 100,00 & 126,70 & 67,62 & 36,38 & 4189,88 & 227,43 & 44,06 & 183,37 & 89,67 & 179,27 & 182,15 & 74,93 & 1088,14 & 136,91 & 45,96 & 26,80 & 362,44 & 178,49 & 204,42 & 347,08 \\
\hline Pelophylax perezi & 30TVN90 & 100,00 & 115,81 & $\begin{array}{ll}94,12 \\
\end{array}$ & 37,79 & 5412,15 & 256,61 & \begin{tabular}{|l|}
9,92 \\
940
\end{tabular} & \begin{tabular}{|l|}
246,69 \\
\end{tabular} & 84,13 & 185,79 & \begin{tabular}{|l|}
186,93 \\
\end{tabular} & 48,72 & \begin{tabular}{|l|l|}
646,25 \\
\end{tabular} & \begin{tabular}{|c|}
68,58 \\
68,
\end{tabular} & 31,89 & 19,62 & \begin{tabular}{|l|}
192,76 \\
\end{tabular} & 122,05 & 123,07 & 176,65 \\
\hline Pelophylax perezi & 30TVN91 & 100,00 & 113,53 & 92,15 & 37,94 & 5299,28 & 251,10 & 10,04 & 241,07 & 80,85 & 181,98 & 183,36 & 48,11 & 698,82 & 75,34 & 34,55 & 19,53 & 209,99 & 131,21 & 133,30 & 193,97 \\
\hline Pelophylax perezi & 30 TVN92 & 100,00 & 117,27 & 88,59 & 37,62 & 5141,02 & 249,09 & 16,71 & 232,37 & 86,20 & 183,32 & 184,93 & 53,60 & 738,05 & 81,65 & 35,49 & 20,21 & 225,82 & 135,85 & 140,65 & 209,57 \\
\hline Pelophylax perezi & 30TVN93 & 100,00 & 115,36 & 86,42 & 37,65 & 5019,65 & 244,13 & 17,40 & 226,73 & 80,67 & 179,86 & 181,60 & 53,52 & 797,27 & 89,48 & 38,23 & 20,47 & 246,02 & 145,48 & 151,88 & 229,88 \\
\hline Pelophylax perezi & 30TVN94 & 100,00 & 108,73 & 85,55 & 37,76 & 4938,92 & 236,51 & 12,67 & 223,84 & 62,07 & 172,20 & 174,24 & 48,30 & 872,13 & 98,54 & 42,44 & 20,30 & 270,24 & 159,39 & 166,11 & 253,37 \\
\hline Pelophylax perezi & 30TVN95 & 100,00 & 106,38 & \begin{tabular}{|l|l|}
83,55 \\
83
\end{tabular} & 37,77 & 4828,87 & 231,28 & $\begin{array}{l}12,65 \\
12,\end{array}$ & 218,63 & 56,30 & $\begin{array}{l}168,32 \\
162\end{array}$ & $\begin{array}{l}170,60 \\
\end{array}$ & $\begin{array}{l}40,55 \\
47,55\end{array}$ & \begin{tabular}{|l|l|}
938,21 \\
\end{tabular} & \begin{tabular}{|r|}
107,38 \\
\end{tabular} & $\begin{array}{l}42,4,50 \\
45,50\end{array}$ & 20,76 & 293,76 & \begin{tabular}{|l|l|}
170,03 \\
\end{tabular} & 178,55 & 276,05 \\
\hline Pelophylax perezi & 30TVN96 & 100,00 & 119,40 & 76,09 & 37,08 & 4543,25 & 232,90 & 30,66 & 202,24 & 72,38 & 177,02 & 179,58 & 63,58 & 990,60 & 118,93 & 44,53 & 23,73 & 319,32 & 170,56 & 186,73 & 305,49 \\
\hline Pelophylax perezi & 30TVN97 & 100,00 & 127,89 & 70,10 & 36,50 & 4311,79 & 232,34 & 43,09 & 189,25 & 84,19 & 182,03 & 184,80 & 74,59 & 1051,79 & 130,99 & 44,68 & 26,18 & 346,75 & 173,91 & 196,73 & 336,28 \\
\hline Pelophylax perezi & 30TVN98 & 100,00 & 127,89 & 67,50 & 36,38 & 4192,74 & 228,50 & 45,43 & 183,07 & 84,73 & 180,31 & 183,21 & 76,13 & 1115,08 & 140,70 & 46,87 & 27,06 & 370,99 & 182,25 & 208,23 & 361,25 \\
\hline Pelophylax perezi & $\begin{array}{l}30 \text { TVN99 } \\
\end{array}$ & 92,00 & 132,29 & 63,55 & 35,85 & 4036,25 & 226,96 & 52,44 & 174,52 & 89,47 & 182,50 & 185,60 & 82,34 & 1168,21 & 150,77 & 47,53 & 28,83 & 394,26 & $\begin{array}{ll}186,08 \\
\end{array}$ & 217,14 & 387,18 \\
\hline Pelophylax perezi & 30TVP00 & $\frac{6,200}{64,00}$ & 137,12 & 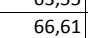 & $\begin{array}{l}3,09 \\
37,79 \\
\end{array}$ & $\begin{array}{l}4050,20 \\
3851,80\end{array}$ & 230,15 & $\begin{array}{ll}55,92 \\
\end{array}$ & 174,23 & \begin{tabular}{|l|}
030,41 \\
120,96 \\
\end{tabular} & $\begin{array}{l}\mid 0<, 30 \\
185,16\end{array}$ & $\begin{array}{l}183,000 \\
188,49\end{array}$ & $\begin{array}{l}82,34 \\
89,16\end{array}$ & \begin{tabular}{|r|}
941,17 \\
9
\end{tabular} & $\mid$ & \begin{tabular}{|l|}
40,62 \\
40,5
\end{tabular} & $\begin{array}{l}28,03 \\
28,75 \\
\end{array}$ & \begin{tabular}{|l|}
331,77 \\
3
\end{tabular} & $\begin{array}{l}157,24 \\
157\end{array}$ & $\frac{21,14}{184,34}$ & $\begin{array}{l}26,10 \\
264,64\end{array}$ \\
\hline Pelophylax perezi & 30TVP10 & 91,00 & 140,29 & 63,68 & 37,35 & 3761,53 & 229,76 & 61,62 & 168,14 & 124,53 & 180,70 & 190,41 & 93,41 & 969,80 & 123,50 & 40,83 & 29,56 & 344,03 & 159,72 & 190,60 & 276,50 \\
\hline Pelophylax perezi & 30TVP11 & 3,00 & 142,42 & 61,75 & 37,17 & 3685,50 & 228,75 & 65,08 & 163,67 & 126,75 & 171,08 & 191,25 & 96,33 & 988,92 & 126,33 & 41,25 & 30,00 & 352,42 & 161,17 & 195,08 & 283,42 \\
\hline Pelophylax perezi & 30TVP20 & 99,00 & 139,47 & 61,90 & 37,03 & 3723,07 & 227,32 & 62,40 & 164,92 & 123,90 & 174,73 & 189,11 & 93,06 & 1010,81 & 127,51 & 42,12 & 29,70 & 358,71 & 165,13 & 198,97 & 291,94 \\
\hline Pelophylax perezi & 30TVP70 & 63,00 & 132,38 & 61,96 & 36,04 & 3914,34 & 223,98 & 54,38 & 169,60 & 109,99 & 181,00 & 184,20 & 83,88 & 1145,87 & 147,06 & 47,15 & 28,51 & 390,81 & 184,07 & 217,65 & 365,75 \\
\hline Pelophylax perezi & 30TWKO4 & 100,00 & 130,37 & 114,95 & 36,94 & 6642,86 & 309,52 & $\begin{array}{ll}1,63 \\
1,63\end{array}$ & 307,89 & \begin{tabular}{|c|}
92,86 \\
90
\end{tabular} & 219,20 & 219,43 & 50,21 & 441,77 & 49,99 & 12,2 & 32,11 & \begin{tabular}{|l|l|}
140,49 \\
140
\end{tabular} & 58,70 & 58,93 & 117,95 \\
\hline Pelophylax perezi & 30TWK05 & 100,00 & 131,79 & 113,23 & 36,63 & 6630,84 & 308,71 & 3,68 & 305,03 & 91,11 & 220,29 & 220,43 & 51,59 & 431,30 & 49,19 & 12,25 & 32,27 & 138,31 & 57,62 & 57,79 & 114,45 \\
\hline Pelophylax perezi & 30TWK06 & 100,00 & 132,45 & 111,60 & 36,29 & 6620,05 & 307,21 & 4,89 & 302,31 & 90,06 & 220,83 & 220,83 & 52,19 & 422,20 & 48,04 & 12,28 & 32,21 & 136,34 & 57,04 & 57,04 & 111,09 \\
\hline Pelophylax perezi & 30TWK13 & 100,00 & 123,29 & 117,98 & 37, & 6629,14 & 305,54 & $-6,08$ & 311,62 & 107,24 & 211,53 & 212,54 & 7 & 474,44 & 4,90 & 13 & 30,69 & 150,29 & 65,49 & 67,36 & 124,68 \\
\hline Pelophylax perezi & 30TWK14 & 100,00 & 120,81 & 116,91 & 37 & 6612,59 & 301,81 & $\begin{array}{l}-7,00 \\
-7,68 \\
\end{array}$ & 309,48 & $\begin{array}{l}104,56 \\
\end{array}$ & 208,88 & 209,86 & 41,75 & 479,51 & 55,6 & 14 & 30,15 & 151,01 & $\begin{array}{l}0,475 \\
67,53 \\
\end{array}$ & 69,73 & $\begin{array}{l}125,27 \\
125,0\end{array}$ \\
\hline Pelophylax perezi & 30TWK & 100,00 & 121,89 & 115,47 & 37,00 & 6600,66 & 300,89 & $-5,96$ & 306,85 & 105,50 & 209,64 & 210,62 & 42,82 & 469,47 & 54,55 & 14,6 & 29,95 & 146,71 & 66,94 & 68,73 & 121,89 \\
\hline Pelophylax perezi & 30TWK16 & 100,00 & 127,79 & 113,26 & 36,87 & 6594,18 & 303,69 & 0,04 & 303,65 & 99,34 & 215,59 & 216,07 & 48,31 & 438,84 & 50,71 & 13,74 & 30,57 & 137,36 & 62,54 & 63,34 & 113,30 \\
\hline Pelophylax perezi & 30TWK24 & 100,00 & 124,19 & 117,79 & 37,38 & 6596,71 & 304,64 & $-5,54$ & 310,18 & 108,39 & 211,75 & 212,77 & 44,76 & 466,35 & 54,82 & 14,50 & 29,86 & 147,90 & 66,71 & 69,05 & 120,30 \\
\hline Pelophylax perezi & 30TWK25 & 100,00 & 125,32 & 116,25 & 37,10 & 6590,00 & 303,86 & $-3,68$ & 307,55 & 110,08 & 212,66 & 213 & 45,93 & 454,83 & 53,64 & 14,42 & 29,77 & 143,11 & 65,92 & 67,82 & 116,49 \\
\hline Pelophylax perezi & \begin{tabular}{|l|}
30 TWK27 \\
\end{tabular} & 100,00 & 12 & 11 & 36 & $\begin{array}{l}0530,00 \\
6562,92\end{array}$ & 302,00 & $\begin{array}{l}-3,00 \\
-0,41 \\
\end{array}$ & 302,41 & \begin{tabular}{|l|}
112,77 \\
127
\end{tabular} & \begin{tabular}{|l|}
214,41 \\
\end{tabular} & \begin{tabular}{|l|}
215,34 \\
215
\end{tabular} & \begin{tabular}{|l|}
48,19 \\
48,
\end{tabular} & \begin{tabular}{|l|}
434,051 \\
431,81
\end{tabular} & $\mid 51,31$ & $\begin{array}{l}4,44 \\
14,39 \\
\end{array}$ & 29,62 & \begin{tabular}{|l|}
133,89 \\
133,8
\end{tabular} & $\begin{array}{l}04,42 \\
64,\end{array}$ & $\begin{array}{ll}65,81 \\
65\end{array}$ & $\begin{array}{l}110,49 \\
108,68\end{array}$ \\
\hline Pelophylax perezi & 30TWK28 & 100,00 & 122,64 & 112,57 & 37,00 & 6538,77 & 296,27 & $-4,50$ & 300,77 & 107,37 & 209,05 & 210,05 & 43,69 & 446,70 & 53,55 & 15,97 & 28,56 & 138,34 & 68,56 & 70,90 & 111,56 \\
\hline Pelophylax perezi & 30TWK29 & 100,00 & 120,61 & 111,60 & 36,97 & 6519,43 & 293,10 & $\begin{array}{l}-4,77 \\
-5,7\end{array}$ & 298,87 & $\begin{array}{l}105,81 \\
\end{array}$ & 206,94 & $\begin{array}{l}207,78 \\
\end{array}$ & 42,03 & 449,01 & 54,25 & 16,81 & 28,10 & 138,53 & 70,50 & 73,21 & 111,14 \\
\hline Pelophylax perezi & 30TWK33 & 100,00 & 116,66 & 120,74 & 38,00 & 6585,14 & 300,33 & $-14,06$ & 314,40 & 100,01 & 204,55 & 205,58 & 38,06 & 505,99 & 60,53 & 16,58 & 29,01 & 163,99 & 74,23 & 78,88 & 129,0 \\
\hline Pelophylax perezi & 30TWK3 & 100,00 & 121,19 & 117,90 & 37,73 & 6561,97 & 300,68 & $-8,71$ & 309,39 & 105,44 & 208,23 & 205 & 42,12 & 474,27 & 57,05 & 15,95 & 28,80 & 151,19 & 71,10 & 74,64 & 115 \\
\hline Pelophylax perezi & \begin{tabular}{|l|}
$30 \mathrm{TWK} 36$ \\
\end{tabular} & $\begin{array}{l}100,00 \\
\end{array}$ & $\begin{array}{l}121,19 \\
119,01\end{array}$ & $\begin{array}{l}111,8,87 \\
1\end{array}$ & $\begin{array}{l}37,150 \\
37,50\end{array}$ & | 6501,1719 & 297,24 & \begin{tabular}{|c|c|}
$-0, / 1$ \\
$-10,25$
\end{tabular} & \begin{tabular}{|l|l|}
307,49 \\
307
\end{tabular} & \begin{tabular}{|l|}
103,19 \\
103,19
\end{tabular} & \begin{tabular}{|l|}
205,88 \\
20,8
\end{tabular} & \begin{tabular}{|l|}
206,86 \\
206
\end{tabular} & $\begin{array}{l}42,12 \\
40,27 \\
\end{array}$ & | 476,96 & $\begin{array}{l}1,703 \\
57,76 \\
\end{array}$ & \begin{tabular}{|l|}
16,77 \\
16,7
\end{tabular} & $\begin{array}{l}2,00 \\
28,38 \\
\end{array}$ & $\begin{array}{l}151,29 \\
151\end{array}$ & $\begin{array}{l}1,10 \\
72,92\end{array}$ & $\begin{array}{l}4,404 \\
76,79\end{array}$ & 1119,53 \\
\hline Pelophylax perezi & 30TWK37 & 100,00 & 123,81 & 114,92 & 37,19 & 6535,77 & 299,05 & $-4,88$ & 303,94 & 108,85 & 210,20 & 211,18 & 44,73 & 448,69 & 54,45 & 15,80 & 28,51 & 140,90 & 69,23 & 72,18 & 111,44 \\
\hline Pelophylax perezi & 30TWK38 & 100,00 & 118,60 & 114,31 & 37,01 & 6511,69 & 293,20 & $-9,39$ & 302,60 & 103,35 & 204,84 & 205,76 & 40,13 & 463,81 & 56,89 & 17,48 & 27,65 & 145,43 & 73,58 & 77,58 & 114,14 \\
\hline Pelophylax perezi & 30TWK43 & 100,00 & 115,33 & 121,93 & 38,00 & 6564,51 & 299,45 & $-16,16$ & 315,60 & 98, & 202, & 204 & 36, & 515,11 & 62,31 & 17,43 & 28 & 168 & 77,36 & 82,94 & 129,92 \\
\hline Pelophylax perezi & $\begin{array}{l}30 \text { TWK } 47 \\
\end{array}$ & 100,00 & 125,16 & 115,75 & 37,51 & 6513,78 & 300,00 & $-4,48$ & 304,48 & 110,39 & 211,02 & 212,13 & 46,05 & 442,48 & 54,79 & 15,90 & 28,29 & 139,99 & 70,01 & 73,56 & 107,91 \\
\hline
\end{tabular}




\begin{tabular}{|c|c|c|c|c|c|c|c|c|c|c|c|c|c|c|c|c|c|c|c|c|c|}
\hline TAXON & UTM & $\mathrm{km} 2$ & B101 & B102 & $\mathrm{BIO3}$ & B104 & B105 & B106 & B107 & B108 & 8109 & BIO10 & BIO11 & BIO12 & B1013 & BIO14 & BIO15 & B1016 & B1017 & B1018 & B1019 \\
\hline Pelophylax perezi & 30TWK53 & 100,00 & 111,27 & 122,96 & 38,14 & 6545,77 & 295,52 & $-20,88$ & 316,40 & 94,02 & 198,63 & 199,73 & 33,01 & 537,06 & 65,77 & 19,21 & 27,92 & 176,51 & 83,23 & 90,26 & 133,53 \\
\hline Pelophylax perezi & 30TWK55 & 100,00 & 117,21 & 120,50 & 38,01 & 6520,51 & 297,60 & $-14,60$ & 312,20 & 101,16 & 203,63 & 204,84 & 38,57 & 496,81 & 61,68 & 18,01 & 27,89 & 161,19 & 78,59 & 84,40 & 122,10 \\
\hline Pelophylax perezi & 30TWK57 & 100,00 & 119,51 & 117,14 & 37,99 & 6488,75 & 295,10 & $-10,90$ & 306,00 & 104,30 & 205,19 & 206,31 & 40,91 & 466,33 & 58,95 & 17,86 & 27,57 & 149,15 & 76,57 & 81,97 & 111,85 \\
\hline Pelophylax perezi & 30TWK58 & 100,00 & 118,81 & 115,73 & 37,71 & 6474,79 & 292,47 & $-11,08$ & 303,55 & 103,83 & 204,13 & 205,10 & 40,08 & 460,90 & 58,77 & 18,36 & 27,27 & 146,40 & 77,21 & 82,94 & 109,38 \\
\hline Pelophylax perezi & 30TWK59 & 100,00 & 105,42 & 115,33 & $\begin{array}{l}37,69 \\
\end{array}$ & $\begin{array}{lll}6438,03 \\
\end{array}$ & 279,56 & $-23,01$ & 302,57 & 91,42 & 190,73 & 191,80 & 28,00 & 513,53 & 65,75 & 22,56 & 25,86 & 162,88 & 89,14 & 97,38 & 121,44 \\
\hline Pelophylax perezi & 30TWK63 & 100,00 & 117,77 & 123,99 & 38,63 & 6517,30 & 301,55 & $-15,71$ & 317,27 & 101,19 & 204,31 & 205,71 & 39,40 & 515,04 & 63,49 & 17,90 & 28,32 & 169,95 & 80,21 & 86,61 & 127,29 \\
\hline Pelophylax perezi & 30TWK64 & 100,00 & 112,60 & 122,68 & 38,29 & 6511,99 & 295,09 & $-20,03$ & 315,11 & 95,84 & $\begin{array}{l}199,12 \\
\end{array}$ & 200,32 & 34,38 & 528,38 & 65,84 & 19,68 & 27,66 & 173,52 & 84,80 & 92,23 & 129,07 \\
\hline Pelophylax perezi & 30TWK66 & 100,00 & 114,23 & 119,39 & 38,00 & 6481,22 & 292,02 & $-17,12$ & 309,14 & 98,42 & 200,04 & 201,21 & 36,14 & 498,53 & $\begin{array}{ll}63,48 \\
\end{array}$ & 19,64 & 27,18 & 161,69 & 83,12 & 90,30 & 118,71 \\
\hline Pelophylax perezi & 30TWK67 & 100,00 & 110,23 & 117,68 & 38,00 & 6460,58 & 286,09 & $-20,18$ & 306,27 & 94,21 & 195,76 & 196,93 & 32,25 & 505,56 & 64,96 & 21,13 & 26,69 & 162,87 & 86,71 & 94,60 & 118,85 \\
\hline Pelophylax perezi & 30TWK68 & 100,00 & 106,73 & 116,36 & \begin{tabular}{|l|l|}
37,98 \\
\end{tabular} & \begin{tabular}{|l|l|l|}
6444,07 \\
\end{tabular} & 281,06 & $-22,78$ & 303,84 & 92,12 & 192,05 & 193,18 & 29,05 & 511,24 & 66,21 & 22,38 & 26,24 & 163,79 & 89,62 & 98,37 & 119,01 \\
\hline Pelophylax perezi & 30TWK69 & 100,00 & 100,23 & 115,12 & \begin{tabular}{|c|}
37,98 \\
\end{tabular} & 6406,54 & 273,40 & $-27,95$ & 301,35 & 108,35 & 185,25 & 186,29 & 23,23 & 534,06 & 69,36 & 24,75 & 25,53 & 171,11 & 95,85 & 105,88 & 123,69 \\
\hline Pelophylax perezi & 30TWK74 & 100,00 & 110,37 & 122,18 & 38,55 & 6485,66 & 291,48 & $-22,01$ & 313,48 & 93,44 & 196,49 & 197,79 & 32,30 & 534,96 & 67,54 & 20,89 & 27,25 & 175,98 & 88,80 & 97,18 & 127,60 \\
\hline Pelophylax perezi & 30TWK75 & 100,00 & 109,20 & 120,60 & 38,14 & 6473,89 & 288,21 & $-22,43$ & 310,64 & 92,58 & 195,14 & 196,34 & 31,22 & 528,06 & 67,51 & 21,41 & 26,89 & 172,83 & 89,73 & 98,27 & 124,22 \\
\hline Pelophylax perezi & 30TWK76 & 100,00 & 105,34 & 118,54 & 38,00 & 6456,16 & 282,14 & $-25,16$ & 307,30 & 88,54 & 191,03 & 192,20 & 27,69 & 532,69 & 68,81 & 22,92 & 26,36 & 173,06 & 93,12 & 102,49 & 123,43 \\
\hline Pelophylax perezi & 30TWK77 & 100,00 & 100,86 & 116,83 & 38,00 & 6434,42 & 275,74 & $-28,48$ & 304,22 & 90,25 & 186,35 & 187,48 & 23,63 & 542,34 & 70,55 & 24,52 & 25,95 & 175,27 & 97,08 & 107,42 & 124,29 \\
\hline Pelophylax perezi & 30TWK78 & 100,00 & 97,08 & 115,41 & 37,98 & 6407,53 & 270,31 & $-31,59$ & 301,90 & 109,17 & 182,16 & 183,24 & 20,19 & 550,90 & 72,06 & 26,03 & 25,54 & 178,22 & 100,62 & 111,84 & 125,32 \\
\hline Pelophylax perezi & 30TWK79 & 100,00 & 93,35 & 114,29 & 37,94 & 6378,58 & 265,36 & $-34,21$ & 299,57 & 112,60 & 178,20 & 179,19 & 16,96 & 562,22 & 73,74 & 27,55 & 25,18 & 182,72 & 104,53 & 116,45 & 127,31 \\
\hline Pelophylax perezi & 30TWK83 & 100,00 & 102,58 & 120,26 & 38,17 & 6476,73 & 282,14 & $-27,89$ & 310,03 & 84,56 & 189,01 & 190,08 & 25,43 & 562,12 & 71,36 & 23,60 & 26,19 & 184,82 & 96,95 & 106,93 & 129,77 \\
\hline Pelophylax perezi & 30TWK84 & 100,00 & 96,47 & 118,36 & 38,01 & 6457,47 & 274,20 & $-32,79$ & 306,99 & 78,13 & 182,81 & 183,78 & 19,61 & 580,26 & 74,21 & 25,90 & 25,51 & 189,63 & 102,94 & 114,16 & 132,22 \\
\hline Pelophylax perezi & 30 TWK85 & 100,00 & 95,13 & 117,38 & 38,00 & 6441,05 & 271,36 & $-33,71$ & 305,07 & 78,52 & \begin{tabular}{|l|l|}
181,13 \\
\end{tabular} & 182,19 & 18,36 & 578,71 & 74,69 & 26,55 & 25,51 & 188,32 & 104,36 & 115,87 & 131,04 \\
\hline Pelophylax perezi & 30TWK86 & 100,00 & 88,77 & 115,56 & 37,99 & 6414,97 & 263,32 & $-38,73$ & 302,05 & 92,32 & 174,60 & 175,45 & 12,55 & 600,71 & 77,7 & 29,01 & 24,95 & 194,99 & 110,73 & 123,49 & 135,10 \\
\hline Pelophylax perezi & 30TWK87 & 100,00 & 91,65 & 114,86 & 37,95 & 6400,00 & 264,45 & $-36,16$ & 300,61 & 106,94 & 176,90 & 177,95 & 15,38 & 579,10 & 75,79 & 28,23 & 25,25 & 188,82 & 107,97 & 120,48 & 129,32 \\
\hline Pelophylax perezi & 30TWK88 & 100,00 & 86,30 & 113,60 & $\begin{array}{l}37,80 \\
\end{array}$ & $\begin{array}{ll}6367,38 \\
\end{array}$ & 257,78 & $-40,42$ & 298,21 & \begin{tabular}{|l|l|}
104,73 \\
\end{tabular} & 171,25 & 172,19 & 10,56 & 599,53 & 78,42 & 30,40 & 24,72 & \begin{tabular}{|l|}
196,11 \\
\end{tabular} & 113,56 & \begin{tabular}{|l|l|}
127,13 \\
\end{tabular} & 133,66 \\
\hline Pelophylax perezi & 30TWK89 & 100,00 & 87,80 & 112,80 & 37,62 & 6350,86 & 257,53 & $-39,03$ & 296,56 & 106,71 & 172,23 & 173,13 & 11,91 & 584,62 & 77,23 & 30,11 & 25,07 & 192,41 & 112,14 & 125,67 & 129,43 \\
\hline Pelophylax perezi & 30TWK93 & 100,00 & 102,88 & 118,10 & \begin{tabular}{|l|l|}
38,03 \\
\end{tabular} & 6449,12 & 279,10 & $-26,42$ & 305,52 & 85,18 & 188,95 & 190,01 & 25,99 & 549,82 & 70,66 & 24,09 & 26,09 & 180,04 & 98,38 & 108,40 & 122,41 \\
\hline Pelophylax perezi & 30TWK94 & 100,00 & 92,23 & 116,03 & 38,00 & 6430,56 & 267,20 & $-35,36$ & 302,56 & 88,19 & 178,35 & 179,33 & 16,06 & 590,88 & 76,23 & 27,84 & 25,12 & 192,64 & 108,68 & 120,74 & 130,77 \\
\hline \begin{tabular}{|l|} 
Pelophylax perezi \\
\end{tabular} & 30TWK95 & 100,00 & 92,36 & 115,23 & 38,00 & 64016,55 & 265,77 & $-35,26$ & \begin{tabular}{|l|}
301,03 \\
\end{tabular} & \begin{tabular}{|l|}
104,81 \\
10,8
\end{tabular} & 178,05 & $\begin{array}{l}179,08 \\
\end{array}$ & 16,05 & 583,27 & 75,98 & 28,08 & 25,35 & $\begin{array}{l}190,72 \\
\end{array}$ & $\begin{array}{l}108,82 \\
\end{array}$ & 121,12 & 128,16 \\
\hline Pelophylax perezi & 30TWK96 & 100,00 & 85,48 & 113,66 & 37,82 & 6392,18 & 257,51 & $-40,91$ & 298,42 & 103,58 & $\begin{array}{l}170,97 \\
\end{array}$ & 171,90 & 9,68 & 610,64 & 79,62 & 30,81 & 24,78 & 200,34 & 116,10 & 129,69 & 133,84 \\
\hline Pelophylax perezi & 30TWK97 & 100,00 & 80,60 & 112,32 & 37,32 & 6361,69 & 251,36 & $-44,86$ & 296,22 & 98,38 & 165,82 & 166,64 & 5,25 & 630,88 & 82,18 & 32,84 & 24,31 & 207,19 & 121,55 & 136,08 & 138,47 \\
\hline Pelophylax perezi & 30TWK98 & 100,00 & 80,94 & 111,58 & 37,14 & 6340,80 & 250,10 & $-44,57$ & 294,66 & 98,89 & 165,63 & 166,52 & 5,51 & 622,34 & 81,77 & 32,99 & 24,56 & 205,50 & 121,34 & 136,15 & 135,74 \\
\hline Pelophylax perezi & 30TWK99 & 100,00 & 85,59 & 111,09 & 37,27 & 6324,33 & 252,81 & $-40,40$ & 293,21 & \begin{tabular}{|l|l|}
104,34 \\
\end{tabular} & 169,66 & 170,64 & 9,83 & 589,39 & 78,67 & 31,47 & 25,33 & 196,45 & 116,27 & 130,66 & 127,00 \\
\hline \begin{tabular}{|l|} 
Pelophylax perezi \\
\end{tabular} & 30TWLO0 & 100,00 & $\begin{array}{l}0,50,08 \\
116,08\end{array}$ & 108,45 & 36,33 & $\begin{array}{l}6509,48 \\
6509\end{array}$ & 287,06 & $\begin{array}{l}-4,40 \\
-7,05 \\
\end{array}$ & $\begin{array}{l}294,12 \\
294\end{array}$ & $\begin{array}{r}04,64 \\
84,66\end{array}$ & 202,66 & $\begin{array}{l}103,28 \\
\end{array}$ & $\begin{array}{ll}0,005 \\
37,98\end{array}$ & \begin{tabular}{|l|}
464,71 \\
\end{tabular} & 54,42 & 16,51 & 28,29 & $\begin{array}{l}142,27 \\
\end{array}$ & 71,14 & $\begin{array}{ll} \\
73,34\end{array}$ & 117,52 \\
\hline Pelophylax perezi & 30TWL01 & 100,00 & 112,37 & 108,54 & $\begin{array}{l}36,55 \\
\end{array}$ & 6474,92 & 283,21 & $-10,34$ & 293,56 & 93,09 & 198,60 & 199,14 & 34,89 & 477,49 & 56,35 & 17,70 & 27,35 & 145,03 & 74,67 & 77,99 & 120,09 \\
\hline Pelophylax perezi & 30TWLO2 & 100,00 & 113,97 & 107,84 & 36,44 & 6456,96 & 283,64 & $-8,43$ & 292,06 & 88,77 & $\begin{array}{ll}199,92 \\
\end{array}$ & 200,45 & 36,67 & 466,53 & 55,17 & 17,42 & 27,31 & 141,64 & 74,02 & 77,20 & 116,93 \\
\hline Pelophylax perezi & 30TWLO3 & 100,00 & 118,13 & 107,04 & 36,16 & 6446,04 & 286,24 & $-4,34$ & 290,58 & 86,60 & 203,59 & 204,21 & 40,31 & 446,77 & 52,88 & 16,51 & 27,15 & 134,88 & 71,42 & 74,17 & 111,64 \\
\hline Pelophylax perezi & 30TWL04 & 100,00 & 111,49 & 108,35 & 36,71 & 6393,51 & 280,81 & $-10,72$ & 291,53 & 108,95 & 196,57 & 196,98 & 34,78 & 476,03 & 56,68 & 18,80 & 25,92 & 142,80 & 77,88 & 82,26 & 119,36 \\
\hline Pelophylax perezi & 30TWL06 & 100,00 & 11,45 & 109,90 & 37,02 & $\frac{6359,11}{6299,10}$ & $\begin{array}{l}20,01 \\
273,06\end{array}$ & $-18,99$ & 292,06 & \begin{tabular}{|l|}
121,29 \\
12,25
\end{tabular} & 186,60 & \begin{tabular}{|l|l|}
186,960 \\
\end{tabular} & $\begin{array}{l}34,13 \\
27,32\end{array}$ & 年 520,55 & $\begin{array}{l}0,000 \\
62,08 \\
\end{array}$ & $\begin{array}{l}20,00 \\
22,55\end{array}$ & 23,99 & $\begin{array}{l}157,77 \\
150,\end{array}$ & $\begin{array}{l}1,100 \\
88,47 \\
\end{array}$ & $\begin{array}{l}0,200 \\
94,78 \\
\end{array}$ & $\begin{array}{l}113,50 \\
131,51\end{array}$ \\
\hline Pelophylax perezi & 30TWL07 & 100,00 & 97,13 & 110,66 & \begin{tabular}{|l|l|}
37,37 \\
\end{tabular} & 6252,88 & 268,36 & $-23,79$ & 292,15 & 115,05 & 180,97 & 181,10 & 22,64 & 549,99 & 65,41 & 24,94 & 23,07 & 167,04 & 95,15 & 102,44 & 139,62 \\
\hline Pelophylax perezi & 30TWL08 & 100,00 & 103,53 & 110,26 & 37,14 & 6239,31 & 273,79 & $-17,74$ & 291,53 & 122,04 & 186,77 & 187,06 & 28,62 & 520,75 & 61,82 & 23,49 & 23,10 & 157,77 & 90,54 & 96,42 & 132,28 \\
\hline Pelophylax perezi & 30TWLO9 & 100,00 & 111,29 & 109,69 & 37,10 & 6223,83 & 279,81 & $-10,20$ & 290,01 & $\begin{array}{ll}130,82 \\
\end{array}$ & 193,85 & 194,13 & 35,80 & 486,75 & 57,70 & 21,77 & 23,37 & 147,02 & 85,05 & 90,21 & 123,55 \\
\hline Pelophylax perezi & 30TWL10 & 100,00 & 111,09 & 110,77 & 36,5 & 6485,27 & 283,86 & $-13,21$ & 297,06 & 94,90 & 197,40 & 198,20 & 33,63 & 486,73 & 58,25 & 18,92 & 27,01 & 149,32 & 76,94 & \begin{tabular}{|l|l|}
80,93 \\
\end{tabular} & 121,82 \\
\hline Pelophylax perezi & 30TWL1 & 100,00 & 114,15 & 109,12 & 36,77 & 6428,10 & 283,77 & $-9,39$ & 293,16 & 102,65 & 199,37 & 200,05 & 36,77 & 463,86 & 55,97 & 18,5 & 26,19 & \begin{tabular}{|l|}
140,01 \\
\end{tabular} & 76,30 & 80,35 & 114,78 \\
\hline Pelophylax perezi & $\begin{array}{l}\text { 30TWL14 } \\
\end{array}$ & 100,00 & 111,38 & 109,54 & 37,00 & 6393,14 & 281,39 & \begin{tabular}{|c|}
$-11,82$ \\
$-1,5$
\end{tabular} & 293,21 & $\begin{array}{l}127,34 \\
\end{array}$ & 196,38 & 196,90 & 34,62 & 475,03 & 57,42 & $\begin{array}{ll}19,64 \\
\end{array}$ & 25,46 & $\begin{array}{l}143,82 \\
140\end{array}$ & 79,57 & 84,34 & 117,86 \\
\hline Pelophylax perezi & 30TWL15 & 100,00 & 106,60 & 110,39 & 37,01 & 6345,94 & 277,34 & $-16,30$ & 293,64 & 126,11 & 191,14 & 191,59 & 30,58 & 498,56 & 60,19 & 21,57 & 24,45 & 151,73 & 85,03 & 90,95 & 124,40 \\
\hline Pelophylax perezi & 30TWL16 & 100,00 & 103,25 & 111,04 & 37,1 & 6304,82 & 274,36 & $-19,40$ & 93,76 & 122,31 & \begin{tabular}{ll|l}
187,32 \\
\end{tabular} & 187,66 & 27,77 & 517,06 & 62,34 & 23, & 23,60 & 157,68 & 89,63 & 96,24 & 129,67 \\
\hline Pelophylax perezi & $30 \mathrm{TWL1}$ & 100,0 & 103,53 & 111,29 & 37 & $\begin{array}{ll}6279,43 \\
6279\end{array}$ & 274,65 & $\begin{array}{l}-19,02 \\
-19,4\end{array}$ & 293,67 & 122,61 & 187,15 & 18 & 28,16 & 519,04 & 62,40 & 23, & 23,10 & 158,25 & \begin{tabular}{|l|l|}
91,01 \\
9
\end{tabular} & $\begin{array}{l}0,474 \\
97,74\end{array}$ & 130,71 \\
\hline Pelophylax perezi & 30TWL & 100,00 & 106,92 & 111,38 & \begin{tabular}{|l|l|}
37,47 \\
\end{tabular} & 6253,36 & 277,41 & $-15,76$ & 293,17 & 126,22 & 190,04 & 190,39 & 31,47 & 505, & 60,63 & 23,32 & 22,98 & 153,90 & 89,39 & 95,45 & 127,78 \\
\hline Pelophylax perezi & 30TWL19 & 100,00 & 110,87 & 111,19 & 37,55 & 6229,64 & 280,75 & $-11,81$ & 292,56 & 130,53 & 193,55 & 193,84 & 35,34 & 490,44 & 58,62 & 22,78 & 22,84 & 148,93 & 87,42 & 93,05 & 124,01 \\
\hline Pelophylax perezi & 30TWL23 & 100,00 & 107,73 & 111,14 & 37,00 & 6395,07 & 279,09 & $-16,64$ & 295,73 & 117,25 & 192,73 & 193,40 & 30,99 & 492,52 & 60,48 & 21,39 & 25,13 & 150,85 & 83,67 & 89,55 & 120,92 \\
\hline Pelophylax perezi & $30 \mathrm{TWL}$ & 100,00 & 107,67 & 111,21 & 37,00 & 6371,25 & 278,73 & $-16,60$ & 295,33 & 127,47 & 192,42 & 192,95 & 31,09 & 491,85 & 60,39 & 21,70 & 24,67 & 150,90 & 84,58 & 90,68 & 121,06 \\
\hline Pelophylax perezi & $30 \mathrm{TWL}$ & 100,00 & 10 & $\begin{array}{l}111,21 \\
111,83\end{array}$ & 37,1 & $\begin{array}{l}051,250 \\
6306,08\end{array}$ & 276,62 & $\begin{array}{l}-18,44 \\
-18,44 \\
\end{array}$ & \begin{tabular}{|l|}
295,06 \\
295
\end{tabular} & 124,83 & $\begin{array}{l}19,29,21 \\
189,21\end{array}$ & \begin{tabular}{|l|l|}
189,83 \\
\end{tabular} & $\begin{array}{l}1,095 \\
29,54\end{array}$ & | & $\begin{array}{l}60,83 \\
61,87 \\
\end{array}$ & 23,41 & $\begin{array}{ll}23,57 \\
23,\end{array}$ & $\begin{array}{l}155,68 \\
150\end{array}$ & $\begin{array}{l}4,300 \\
89,50\end{array}$ & $\begin{array}{l}0,17 \\
96,17\end{array}$ & $\begin{array}{l}121,00 \\
125,79\end{array}$ \\
\hline Pelophylax perezi & 30TWL27 & 100,00 & 103,26 & 112,48 & 37,56 & 6274,36 & 274,86 & $-20,32$ & 295,18 & 122,43 & 186,79 & 187,23 & 27,83 & 520,87 & 63,32 & 24,73 & 22,91 & 159,92 & 93,13 & 100,17 & 130,19 \\
\hline Pelophylax perezi & 30 TWL28 & 100,00 & 104,37 & 112,80 & 37,86 & 6240,78 & 276,01 & $-19,05$ & 295,06 & 123,50 & 187,44 & 187,69 & 29,20 & 519,80 & 62,82 & 25,08 & 22,39 & 159,21 & 93,81 & 100,57 & 130,73 \\
\hline Pelophylax perezi & 30TWL29 & 100,00 & 110,39 & 112,69 & 37,92 & 6226,97 & 281,09 & $-13,42$ & 294,51 & 130,14 & 192,90 & 193,25 & 34,77 & 495,23 & 59,73 & 23,86 & 22,44 & 151,22 & 89,90 & 95,86 & 124,86 \\
\hline Pelophylax perezi & 30TWL30 & 100,00 & 120,48 & 111,99 & 37,01 & 6479,73 & 291,73 & $-6,48$ & 298,21 & 106,04 & 205,97 & 206,87 & 41,95 & 442,85 & 54,92 & 17,53 & 27,35 & 137,01 & 72,47 & 76,33 & 107,34 \\
\hline Pelophylax perezi & 30TWL31 & 100,00 & 109,99 & 112,48 & 37,02 & 6438,92 & 282,18 & $-16,21$ & 298,39 & $\begin{array}{c}5,99 \\
95,4\end{array}$ & 195,36 & 196,18 & 32,47 & 486,30 & 60,61 & 20,92 & 25,80 & 150,60 & 82,16 & 88,14 & 117,84 \\
\hline Pelophylax perezi & 30TWL33 & 100,00 & 103,81 & 112,51 & 37,22 & 6373,87 & 275,82 & $-21,55$ & $\begin{array}{l}297,37 \\
\end{array}$ & 123,36 & 188,46 & 189,08 & 27,23 & 510,20 & 63,66 & 23,53 & 24,61 & 158,45 & 89,10 & 96,39 & 123,95 \\
\hline Pelophylax perezi & 30TWL34 & 100,00 & 103,25 & 112,50 & $\begin{array}{l}37,45 \\
\end{array}$ & 6352,49 & 274,90 & $-21,79$ & 296,68 & 122,84 & 187,75 & 188,19 & 26,94 & 512,13 & 63,82 & 24,03 & 24,14 & 159,32 & 90,44 & 98,01 & 124,74 \\
\hline Pelophylax perezi & 30TWL35 & 100,00 & 101,26 & 112,75 & 37,71 & 6319,27 & 272,95 & $-23,49$ & 296,44 & 120,55 & 185,24 & 185,87 & 25, & 523,95 & 65,03 & 25,26 & 23,49 & 162,96 & 93,88 & 101,78 & 128,29 \\
\hline Pelophylax perezi & $\begin{array}{l}30 \text { TWL36 } \\
\end{array}$ & 100,00 & 100,93 & 113,00 & 37,98 & 6291,45 & 272,63 & $-23,75$ & 296,38 & 120,11 & 184,61 & 185,22 & 25,24 & 528,39 & 65,26 & 25,80 & 23,01 & 164,10 & 95,48 & 103,54 & 130,21 \\
\hline
\end{tabular}




\begin{tabular}{|c|c|c|c|c|c|c|c|c|c|c|c|c|c|c|c|c|c|c|c|c|c|}
\hline TAXON & UTM & $\mathrm{km} 2$ & B101 & B102 & $\mathrm{BIO3}$ & BIO4 & B105 & B106 & B107 & B108 & 8109 & B1010 & BIO11 & BIO12 & B1013 & BIO14 & BIO15 & B1016 & B1017 & 81018 & B1019 \\
\hline Pelophylax perezi & 30TWL37 & 100,00 & 103,16 & 113,23 & 37,99 & 6272,93 & 274,97 & $-21,53$ & 296,50 & 122,53 & 186,64 & 186,98 & 27,49 & 520,99 & 64,03 & 25,62 & 22,73 & 161,25 & 94,88 & 102,47 & 129,11 \\
\hline Pelophylax perezi & 30TWL38 & 100,00 & 107,05 & 113,55 & 38,00 & 6243,97 & 278,66 & $-17,82$ & 296,47 & 126,84 & 189,90 & 190,27 & 31,47 & 506,42 & 62,06 & 24,94 & 22,58 & 156,39 & 92,73 & 99,67 & 126,17 \\
\hline Pelophylax perezi & 30TWL39 & 100,00 & 109,03 & 113,99 & 38,00 & 6221,73 & 280,64 & $-15,73$ & 296,38 & 128,99 & 191,51 & 191,92 & 33,55 & 503,57 & 61,23 & 25,10 & 22,12 & 154,73 & 92,94 & 99,47 & 126,49 \\
\hline Pelophylax perezi & 30TWL40 & 100,00 & 114,67 & 113,48 & 37,26 & 6452,92 & 286,73 & $-13,04$ & 299,77 & 100,75 & 199,92 & 200,86 & 36,63 & 467,13 & 59,14 & 19,67 & 26,48 & 145,99 & 79,27 & 85,05 & 111,52 \\
\hline Pelophylax perezi & 30TWL41 & 100,00 & 106,50 & 113,52 & $\begin{array}{l}37,50 \\
\end{array}$ & 6418,01 & 278,90 & $-20,49$ & 299,39 & \begin{tabular}{|l|l|}
114,28 \\
\end{tabular} & \begin{tabular}{|l|l|}
191,60 \\
\end{tabular} & 192,40 & 29,29 & 499,84 & 63,39 & 22,43 & 25,43 & 156,57 & 86,91 & 94,42 & 119,41 \\
\hline Pelophylax perezi & 30TWL42 & 100,00 & 103,18 & 113,13 & 37,28 & 6382,49 & 275,21 & $-23,22$ & 298,44 & 122,80 & 187,86 & 188,62 & 26,21 & 512,75 & 65,03 & 23,88 & 24,88 & 161,17 & 90,66 & 98,88 & 122,51 \\
\hline Pelophylax perezi & 30TWL45 & 100,00 & 101,42 & 113,01 & 37,96 & 6313,14 & 272,55 & $-24,05$ & 296,60 & \begin{tabular}{|l|l|}
120,94 \\
\end{tabular} & 185,25 & 185,75 & 25,16 & 521,14 & 65,67 & 25,74 & 23,55 & 163,99 & 95,18 & 103,92 & 125,89 \\
\hline Pelophylax perezi & $\begin{array}{l}30 T W L 46 \\
\end{array}$ & 100,00 & 101,78 & 113,18 & 38,00 & 6287,87 & 272,96 & $-23,51$ & 296,47 & 121,38 & 185,08 & 185,94 & 25,77 & 522,12 & 65,52 & 26,11 & 23,19 & 163,97 & 96,14 & 104,76 & 126,84 \\
\hline Pelophylax perezi & 30TWL47 & 100,00 & 103,76 & 113,88 & 38,00 & 6271,11 & 274,91 & $-21,69$ & 296,60 & 123,56 & 186,89 & 187,43 & 27,77 & 516,56 & 64,52 & 26,05 & 22,91 & 161,68 & 95,83 & 104,09 & 126,38 \\
\hline Pelophylax perezi & 30TWL48 & 100,00 & 107,87 & 114,02 & 38,00 & 6247,87 & 279,03 & \begin{tabular}{|l|l|}
$-17,74$ \\
\end{tabular} & 296,77 & 128,00 & 190,51 & 191,08 & 31,85 & 501,45 & 62,41 & 25,29 & 22,61 & 156,52 & 93,48 & 101,12 & 123,39 \\
\hline Pelophylax perezi & 30TWL49 & 100,00 & 106,99 & 114,69 & 38,00 & 6217,22 & 278,67 & $-18,62$ & 297,29 & 126,85 & 189,35 & 189,79 & 31,42 & 514,24 & 63,20 & 26,27 & 22,00 & 159,39 & 96,54 & 104,10 & 128,16 \\
\hline Pelophylax perezi & 30TWL50 & 100,00 & 101,92 & 114,58 & 37,76 & 6412,23 & 275,04 & $-25,82$ & 300,86 & 109,78 & 187,09 & 187,90 & 24,88 & 523,77 & 67,23 & 24,00 & 25,31 & 165,98 & 92,66 & 101,70 & 123,35 \\
\hline Pelophylax perezi & 30TWL51 & 100,00 & 106,28 & 113,61 & 37,56 & 6404,01 & 277,77 & $-21,32$ & 299,08 & 126,63 & 190,97 & 191,94 & 28,86 & 497,92 & 64,29 & 22,93 & 25,53 & 158,24 & 88,77 & 97,15 & 116,70 \\
\hline Pelophylax perezi & 30TWL52 & 100,00 & 104,23 & 113,21 & 37,31 & 6375,36 & 275,06 & $-23,18$ & 298,23 & 124,50 & 188,55 & 189,52 & 27,03 & 504,13 & 65,19 & 23,91 & 25,12 & 160,82 & 91,22 & 100,04 & 118,13 \\
\hline Pelophylax perezi & 30TWL53 & 100,00 & 101,51 & 112,99 & 37,61 & 6349,80 & 271,94 & $-25,38$ & 297,32 & 121,62 & 185,56 & 186,44 & 24,71 & 515,94 & 66,49 & 25,20 & 24,58 & 164,75 & 94,61 & 103,99 & 121,27 \\
\hline Pelophylax perezi & 30TWL54 & 100,00 & 98,00 & 113,00 & $\begin{array}{l}37,85 \\
\end{array}$ & 6319,16 & 268,42 & $-28,34$ & 296,76 & 117,66 & 181,79 & 182,50 & 21,83 & 533,39 & 68,43 & 26,86 & 23,96 & 170,27 & 99,07 & 109,13 & 126,11 \\
\hline Pelophylax perezi & 30TWL55 & 100,00 & 100,28 & 113,00 & 38,00 & 6305,38 & 270,42 & $-25,85$ & 296,27 & 120,17 & 183,82 & 184,44 & 24,16 & 523,34 & 67,03 & 26,47 & 23,74 & 166,91 & 97,78 & 107,47 & 124,24 \\
\hline Pelophylax perezi & 30TWL56 & 100,00 & 109,21 & 112,79 & 37,78 & 6296,60 & 278,20 & $-17,41$ & 295,61 & 129,96 & 192,09 & 192,87 & 32,52 & 481,24 & 61,99 & 23,98 & 24,37 & 153,55 & 89,98 & 98,34 & 114,11 \\
\hline Pelophylax perezi & 30TWL57 & 100,00 & 109,50 & 113,14 & 37,89 & 6275,19 & 278,71 & $-17,05$ & 295,76 & 130,26 & 192,22 & 192,81 & 32,96 & 484,23 & 62,01 & 24,46 & 23,93 & 154,03 & 91,11 & 99,48 & 115,77 \\
\hline Pelophylax perezi & 30TWL58 & 100,00 & 105,42 & 113,92 & 38,00 & 6237,12 & 275,58 & $-21,05$ & 296,62 & 125,66 & 187,77 & 188,27 & 29,52 & 512,34 & 64,56 & 26,47 & 22,81 & 161,72 & 97,19 & 106,07 & 124,56 \\
\hline Pelophylax perezi & 30TWL59 & 100,00 & 101,72 & 114,83 & 38,00 & 6195,27 & 272,78 & $-24,05$ & 296,83 & 121,25 & 183,77 & 184,08 & 26,56 & 541,03 & 67,11 & 28,44 & 21,87 & 169,30 & 103,28 & 112,47 & 133,71 \\
\hline Pelophylax perezi & 30TWL60 & 100,00 & 94,10 & 114,24 & 37,96 & 6381,00 & 266,57 & $-33,26$ & 299,83 & 113,47 & 178,96 & 179,83 & 17,73 & 558,08 & 72,39 & 27,06 & 24,92 & 179,49 & 102,08 & 113,34 & 129,12 \\
\hline Pelophylax perezi & 30TWL61 & 100,00 & 101,79 & 113,57 & 37,77 & 6377,40 & 272,29 & $-25,99$ & 298,28 & 122,08 & 186,20 & 187,18 & 24,97 & 514,26 & 67,48 & 24,75 & 25,52 & 166,23 & \begin{tabular}{|c|}
94,57 \\
\end{tabular} & 104,59 & 118,06 \\
\hline Pelophylax perezi & 30TWL62 & 100,00 & 101,37 & 113,01 & 37,79 & 6352,98 & 271,03 & $-25,93$ & 296,96 & 121,79 & 185,60 & 186,39 & 24,84 & 512,22 & 67,35 & 25,23 & 25,26 & 166,09 & 95,40 & 105,62 & 117,44 \\
\hline Pelophylax perezi & 30TWL63 & 100,00 & 96,81 & 112,75 & 37,77 & 6317,62 & 266,10 & $-29,95$ & 296,05 & 116,80 & 180,55 & 181,35 & 20,76 & 534,33 & 69,84 & 27,17 & 24,62 & 173,16 & 100,73 & 111,84 & 123,35 \\
\hline Pelophylax perezi & 30TWL65 & 100,00 & 99,31 & 112,50 & 37,70 & 6279,44 & 267,61 & $-27,34$ & 294,95 & 119,48 & 182,29 & 182,98 & 23,38 & 523,26 & 68,2 & 27,16 & 24,29 & 169,50 & 99,93 & 110,74 & 121,65 \\
\hline Pelophylax perezi & 30TWL66 & 100,00 & 114,62 & 111,92 & 37,67 & 6300,59 & 281,14 & $-12,89$ & $\begin{array}{l}294,03 \\
\end{array}$ & $\begin{array}{l}136,46 \\
136,4\end{array}$ & $\begin{array}{l}197,15 \\
\end{array}$ & $\begin{array}{l}197,90 \\
\end{array}$ & 37,27 & 450,62 & 59,66 & 22,53 & 25,83 & 146,55 & 85,56 & $\begin{array}{l}10,14 \\
94,23\end{array}$ & 103,89 \\
\hline Pelophylax perezi & 30TWL67 & 100,00 & 115,46 & 112,12 & 37,82 & 6277,88 & 282,14 & $-11,88$ & 294,02 & 137,19 & 197,70 & 198,35 & 38,25 & 450,56 & 59,37 & 22,72 & 25,38 & 146,03 & 85,86 & 94,40 & 104,77 \\
\hline Pelophylax perezi & 30TWL68 & 100,00 & 112,19 & 112,81 & 38,00 & 6249,84 & 279,79 & $-14,71$ & 294,50 & 133,40 & 194,21 & 194,71 & 35,50 & 472,48 & 61,37 & 24,37 & 24,31 & 152,06 & 90,60 & 99,71 & 111,62 \\
\hline Pelophylax perezi & 30TWL69 & 100,00 & 105,75 & 113,71 & 38,00 & 6203,22 & 274,63 & $-20,59$ & 295,21 & 126,26 & 187,52 & 188,01 & 30,14 & 513,90 & 65,31 & 27,15 & 22,89 & 163,44 & 99,22 & 109,04 & 124,14 \\
\hline Pelophylax perezi & 30TWL70 & 100,00 & 91,25 & 113,37 & 37,78 & 6353,50 & 261,86 & $-35,97$ & 297,83 & 110,50 & 175,78 & 176,58 & 15,10 & 567,06 & 74,54 & 28,58 & 25,04 & 185,02 & 106,81 & 119,27 & 128,13 \\
\hline Pelophylax perezi & 30TWL71 & 100,00 & 100,38 & 112,73 & 37,64 & 6345,85 & 268,58 & $-27,65$ & 296,23 & 120,78 & 184,12 & 185,14 & 23,60 & 515,33 & 68,84 & 25,71 & 25,99 & \begin{tabular}{l|l}
169,48 \\
\end{tabular} & \begin{tabular}{|c|}
97,71 \\
97
\end{tabular} & $\begin{array}{l}108,87 \\
\end{array}$ & 115,26 \\
\hline Pelophylax perezi & 30TWL72 & 100,00 & 97,97 & 112,17 & \begin{tabular}{|l|l|l|l}
37,49 \\
\end{tabular} & 6323,04 & 265,56 & $-29,31$ & 294,87 & \begin{tabular}{|l|l|}
118,24 \\
\end{tabular} & 181,43 & 182,42 & 21,56 & 523,62 & 69,92 & 26,82 & 25,62 & 172,54 & 100,47 & 112,13 & 117,24 \\
\hline Pelophylax perezi & 30TWL75 & 100,00 & 98,98 & 111,59 & 37,72 & 6259,97 & 265,10 & $-28,05$ & 293,15 & 119,32 & 181,33 & 182,17 & 22,70 & 519,39 & 69,04 & 27,63 & 25,09 & 170,99 & 101,44 & 1113,35 & 117,90 \\
\hline Pelophylax perezi & 30TWL76 & 100,00 & 112,91 & 111,12 & 37,57 & 6278,00 & 277,68 & $-14,69$ & 292,37 & 134,77 & 195,01 & 195,79 & 35,59 & 452,82 & 61,19 & 23,25 & 26,56 & 149,84 & 87,80 & 97,69 & 102,12 \\
\hline Pelophylax perezi & 30TWL78 & 100,00 & 109,95 & 111,92 & 37,99 & 6229,92 & 275,54 & $-17,08$ & 292,62 & 131,30 & 191,48 & 192,07 & 33,09 & 478,85 & 63,33 & 25,29 & 25,01 & 156,50 & 93,44 & 103,94 & 110,95 \\
\hline Pelophylax perezi & \begin{tabular}{|c|}
30 TWL79 \\
\end{tabular} & 100,00 & 104,45 & 111,52 & 38,00 & 6188,75 & 271,01 & $\begin{array}{l}-1,01,80 \\
-21,80\end{array}$ & \begin{tabular}{|l|}
292,81 \\
\end{tabular} & $\begin{array}{ll}124,98 \\
124,5\end{array}$ & $\begin{array}{l}191,40 \\
185,71\end{array}$ & \begin{tabular}{|l|l|}
186,24 \\
\end{tabular} & $\begin{array}{l}30,05 \\
28,54\end{array}$ & $\begin{array}{l}|r| 0,05 \\
515,73\end{array}$ & $\begin{array}{l}3,35 \\
66,75 \\
\end{array}$ & $\begin{array}{l}27,82 \\
27,82\end{array}$ & 23,01 & \begin{tabular}{|l|l|}
160,43 \\
\end{tabular} & \begin{tabular}{|l|}
$50,44,02$ \\
101
\end{tabular} & $\begin{array}{l}112,18 \\
11,4\end{array}$ & $\begin{array}{l}1122,07 \\
122\end{array}$ \\
\hline Pelophylax perezi & 30TWL80 & 100,00 & 93,70 & 112,16 & 37,43 & 6338,13 & 261,37 & $-33,88$ & 295,25 & 113,39 & \begin{tabular}{|l|l|}
177,54 \\
\end{tabular} & 178,62 & 17,14 & 547,11 & 73,40 & 28,23 & 25,82 & 181,65 & 106,07 & 118,79 & 119,77 \\
\hline Pelophylax perezi & 30TWL81 & 100,00 & 97,90 & 111,48 & 37,50 & 6321,05 & 263,62 & $-29,84$ & 293,47 & 118,21 & 181,09 & 182,18 & 21,06 & 519,85 & 70,65 & 27,08 & 26,58 & $\begin{array}{l}174,08 \\
\end{array}$ & 101,85 & 114,20 & 112,77 \\
\hline Pelophylax perezi & 30TWL82 & 100,00 & 97,99 & 110,86 & 37,4 & 6299,36 & 262,66 & $-29,66$ & 292,32 & 118,45 & 180,81 & 181,82 & 21,38 & 515,71 & 70,29 & 27,27 & 26,64 & 173,13 & 101,89 & 114,38 & 111,89 \\
\hline Pelophylax perezi & 30TWL84 & 100,00 & 94,99 & 110,46 & 37, & 6252,49 & 259,02 & $-32,06$ & 291,09 & 115,23 & 177,24 & 178,15 & 18,86 & 531,21 & 71,79 & 28,95 & 25,79 & $\begin{array}{l}177,66 \\
\end{array}$ & 106,02 & 119,22 & 117,09 \\
\hline Pelophylax perezi & 30TWL85 & 100,00 & 103,23 & 110,33 & 37,60 & 6248,02 & 266,10 & $-24,21$ & 290,31 & 124,35 & 184,99 & 185,88 & 26,57 & \begin{tabular}{|l}
489,99 \\
\end{tabular} & 67,06 & 26,40 & 26,77 & 164,80 & $\begin{array}{l}397,84 \\
9,\end{array}$ & 109,98 & 107,51 \\
\hline Pelophylax perezi & 30TWL86 & 100,00 & 111,77 & 110,10 & 37,39 & 6253,30 & 273,98 & $\begin{array}{l}-16,06 \\
-16,\end{array}$ & 290,04 & 133,62 & 193,20 & 194,05 & 34,47 & 452,72 & 62,41 & 23,91 & 27,49 & 152,45 & 89,84 & 100,90 & 99,51 \\
\hline Pelophylax perezi & 30TWL87 & 100,00 & 118,63 & 109,89 & 37,34 & 6253,85 & 280,35 & $-9,17$ & 289,52 & 141,03 & 199,88 & 200,52 & 40,99 & 427,40 & 59,00 & 22,12 & 27,82 & 143,49 & 83,95 & 94,17 & 94,52 \\
\hline Pelophylax perezi & 30TWL88 & 100,00 & 109,63 & 110,71 & 37,8 & 6213,37 & 272,84 & $-17,42$ & 290,27 & 131,20 & 190,69 & 191,42 & 32,94 & \begin{tabular}{|l|l|}
474,43 \\
\end{tabular} & 64,01 & 25 & 26,03 & 47 & 94,00 & 105,57 & 107,51 \\
\hline Pelophylax perezi & 30TWL89 & 100,00 & 105,14 & 111,17 & 37,6 & 6179,59 & 269,25 & $\frac{-1,4,06}{-21,06}$ & 290,31 & 126,29 & 186,11 & 186,66 & 29,12 & 505,46 & 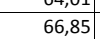 & & 24,67 & 165,75 & \begin{tabular}{|l|}
100,21 \\
\end{tabular} & 112,37 & 116,93 \\
\hline Pelophylax perezi & $30 \mathrm{TWL}$ & 100,00 & 89,55 & 110,45 & 37,31 & 6306,30 & 254,72 & $-37,08$ & 291,80 & 109,03 & $\begin{array}{ll}172,94 \\
\end{array}$ & 173,98 & 13,40 & 560,82 & 76,0 & 30,19 & 26,20 & 188,81 & 112,05 & 126,10 & 119,52 \\
\hline Pelophylax perezi & 30TWL92 & 100,00 & 97,81 & 109,34 & 37,03 & 6271,45 & 259,19 & $-30,01$ & 289,21 & 118,69 & 169,17 & 181,10 & 21,26 & 507,53 & 70,60 & 27,68 & 27,85 & $\begin{array}{l}173,75 \\
\end{array}$ & 103,32 & 116,68 & 106,38 \\
\hline Pelophylax perezi & 30TWL95 & 100,00 & 104,70 & 108,61 & 37,03 & 6229,38 & 264,24 & $-22,89$ & 287,13 & 126,47 & 119,98 & 186,75 & 28,10 & 474,13 & 66,54 & 26,07 & 28,58 & 162,85 & 96,49 & 109,87 & 100,48 \\
\hline Pelophylax perezi & 30TWL96 & 100,00 & 114,84 & 108,49 & 37,00 & 6238,10 & 273,88 & $-13,25$ & 287,14 & 137,29 & 134,40 & 196,50 & 37,36 & 432,44 & 61,23 & 23,08 & 29,47 & 48,54 & 87,15 & 98,77 & 91,95 \\
\hline Pelophylax perezi & \begin{tabular}{|l|}
30 TWL97 \\
\end{tabular} & 100,00 & 118 & 108 & 37,10 & | 6230,0 & 277,77 & $\begin{array}{l}-9,2,18 \\
-9,18\end{array}$ & \begin{tabular}{|l|}
286,95 \\
286
\end{tabular} & $\begin{array}{ll}13,25 \\
141,18\end{array}$ & $\begin{array}{l}192,44 \\
192,4\end{array}$ & $\begin{array}{l}199,92 \\
199,\end{array}$ & $\begin{array}{l}10,81 \\
401\end{array}$ & $\begin{array}{l}452,44 \\
423,72\end{array}$ & $\begin{array}{l}59,67 \\
596\end{array}$ & $\mid 22,31$ & 29,14 & $\begin{array}{l}140,54,52 \\
\end{array}$ & $\mid$\begin{tabular}{l|l|}
84,56 \\
\end{tabular} & $\begin{array}{ll}5,17 \\
95,77\end{array}$ & $\begin{array}{ll}1,51,52 \\
\end{array}$ \\
\hline Pelophylax perezi & 30TWL98 & 100,00 & 113,05 & 109,24 & 37,46 & 6207,38 & 273,55 & $-14,03$ & 287,58 & 135,14 & 193,65 & 194,38 & 36,22 & 453,66 & 62,75 & 24,44 & 27,61 & 153,12 & 90,73 & 102,77 & 100,08 \\
\hline Pelophylax perezi & 30TWL99 & 100,00 & 108,37 & 109,54 & 37,63 & $\begin{array}{l}6177,79 \\
6170\end{array}$ & 269,58 & $-18,17$ & $\begin{array}{l}287,76 \\
\end{array}$ & 129,86 & 188,82 & $\begin{array}{l}189,37 \\
\end{array}$ & 32,00 & 484,29 & 65,71 & 26,49 & 26,22 & $\begin{array}{l}161,51 \\
\end{array}$ & 96,84 & 109,62 & 109,20 \\
\hline Pelophylax perezi & 30TWMO0 & 100,00 & 107,95 & 110,12 & 37,54 & 6176,23 & 276,77 & $-12,99$ & 289,77 & 126,94 & 190,07 & 190,29 & 33,21 & 507,86 & 59,92 & 23,60 & 22,60 & 153,29 & 90,05 & 95,03 & 129,71 \\
\hline Pelophylax perezi & 30TWMO & 100,00 & 104,08 & 110,34 & 37,95 & 6120,19 & 272,82 & $-16,05$ & 288,87 & 122 & 185,46 & 185 & 30,11 & 533,79 & 62,47 & 25,71 & 21,72 & 160,79 & 95,90 & 100,66 & 13 \\
\hline Pelophylax perezi & $\begin{array}{l}\text { 30TWM02 } \\
\end{array}$ & 100,00 & $\begin{array}{r}90,00 \\
97,86\end{array}$ & 1110,42 & 37,99| & 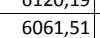 & 266,39 & $\begin{array}{l}-1.0,03 \\
-21,04 \\
\end{array}$ & \begin{tabular}{|l|}
287,40 \\
\end{tabular} & $\begin{array}{l}112,34,60 \\
150\end{array}$ & $\begin{array}{l}178,84 \\
178,84 \\
\end{array}$ & \begin{tabular}{|l|} 
\\
178,89 \\
\end{tabular} & $\begin{array}{l}30,11 \\
24,96\end{array}$ & 573,i,46 & $\begin{array}{l}2,474 \\
66,58 \\
\end{array}$ & $\mid 28,80$ & 20,96 & $\begin{array}{l}172,38 \\
1721\end{array}$ & \begin{tabular}{|l|}
104,40 \\
100
\end{tabular} & $\begin{array}{l}107,16 \\
100\end{array}$ & 148,76 \\
\hline Pelophylax perezi & 30TWMO3 & 100,00 & 93,98 & 109,78 & 38,00 & 6001,04 & 261,56 & $-23,63$ & 285,19 & 110,94 & 174,33 & 174,36 & 21,81 & 605,37 & 69,45 & 31,18 & 20,27 & 180,79 & 110,97 & 113,23 & 157,66 \\
\hline Pelophylax perezi & 30TWM04 & 100,00 & 85,75 & 108,61 & 38,00 & 5923,26 & 251,68 & $-29,78$ & 281,46 & 101,73 & 165,23 & 165,23 & 14,97 & 666,40 & 75,31 & 35,51 & 19,49 & 197,55 & 123,31 & 124,57 & 174,60 \\
\hline Pelophylax perezi & 30TWM05 & 100,00 & 70,14 & 106,53 & 38,00 & 5815,45 & 233,82 & $-42,16$ & 275,98 & 84,29 & 148, & 148 & 1, & 779,62 & 86,31 & 42,85 & 18 & 228,66 & 145,29 & 145,29 & 205,86 \\
\hline Pelophylax perezi & 30TWMO6 & 100,00 & 91,56 & 106,05 & 38,00 & 5817,45 & 252,79 & $\begin{array}{l}-21,79 \\
-21,5\end{array}$ & 274,57 & $\begin{array}{ll}107,69 \\
10\end{array}$ & 169,41 & 169,41 & 21,56 & 661,18 & 73,31 & 35,29 & 19,10 & 193,37 & 124,01 & 124,21 & 174,34 \\
\hline
\end{tabular}




\begin{tabular}{|c|c|c|c|c|c|c|c|c|c|c|c|c|c|c|c|c|c|c|c|c|c|}
\hline TAXON & UTM & $\mathrm{km} 2$ & B101 & B102 & $\mathrm{BIO3}$ & B104 & B105 & B106 & B107 & B108 & B109 & B1010 & BIO11 & BIO12 & B1013 & BIO14 & BIO15 & B1016 & B1017 & B1018 & B1019 \\
\hline Pelophylax perezi & 30TWM08 & 100,00 & 89,97 & 103,04 & 38,06 & 5672,90 & 245,93 & $-20,14$ & 266,06 & 100,88 & 165,91 & 165,91 & 21,54 & 712,04 & 76,42 & 38,20 & 18,40 & 204,14 & 134,80 & 134,80 & 190,31 \\
\hline Pelophylax perezi & 30TWM09 & 100,00 & 110,86 & 98,72 & \begin{tabular}{|l|l|}
37,98 \\
\end{tabular} & 5573,69 & 258,66 & 1,71 & 256,95 & 78,18 & 184,26 & 184,34 & 42,14 & 629,40 & 66,34 & 32,35 & 18,93 & 182,56 & 120,69 & 120,69 & 168,21 \\
\hline Pelophylax perezi & 30TWM10 & 100,00 & 108,22 & 111,68 & 37,99 & 6182,10 & 278,25 & $-14,00$ & 292,25 & 127,44 & 190,30 & 190,62 & 33,28 & 510,07 & 60,55 & 24,45 & 22,13 & 154,48 & 91,96 & 97,78 & 129,99 \\
\hline Pelophylax perezi & 30TWM11 & 100,00 & 103,61 & 112,07 & 38,00 & 6125,34 & 273,87 & $-17,73$ & 291,61 & 122,12 & 185,23 & 185,33 & 29,68 & 541,47 & 63,54 & 26,93 & 21,18 & 163,32 & 98,87 & 104,65 & 139,26 \\
\hline Pelophylax perezi & 30TWM12 & 100,00 & 97,65 & 111,98 & 38,00 & \begin{tabular}{|l|l|}
6063,67 \\
\end{tabular} & 267,47 & $-22,53$ & 290,01 & 115,41 & 178,63 & 178,69 & 24,68 & 582,73 & 67,62 & 30,02 & 20,29 & 174,84 & 107,47 & 111,59 & 151,12 \\
\hline Pelophylax perezi & 30TWM13 & 100,00 & 96,87 & 111,31 & 38,04 & 6017,11 & 265,36 & $-22,23$ & 287,59 & 114,39 & 177,16 & 177,21 & 24,34 & 596,68 & 68,64 & 31,22 & 19,93 & 178,25 & 110,88 & 114,29 & 155,30 \\
\hline Pelophylax perezi & 30TWM14 & 100,00 & 79,04 & 109,12 & 38,02 & 5905,41 & 245,44 & $-36,45$ & 281,89 & 94,44 & 158,69 & 158,69 & 9,01 & 716,27 & 80,58 & 38,98 & 18,83 & 211,92 & 133,97 & 134,53 & 188,09 \\
\hline Pelophylax perezi & 30TWM15 & 100,00 & 68,97 & 107,08 & 38,02 & 5817,98 & 232,96 & $-43,81$ & 276,77 & 83,09 & $\begin{array}{l}147,78 \\
\end{array}$ & $\begin{array}{l}147,78 \\
\end{array}$ & 0,019 & 794,58 & 87,97 & 44,08 & 18,21 & 233,03 & 149,38 & $\begin{array}{l}149,38 \\
\end{array}$ & 209,87 \\
\hline Pelophylax perezi & 30TWM16 & 100,00 & 80,61 & 106,79 & 38,04 & 5796,00 & 242,94 & $-32,60$ & 275,54 & 95,78 & 158,64 & 158,64 & 11,50 & 737,33 & 81,18 & 40,38 & 18,32 & 215,15 & 139,25 & 139,33 & 195,45 \\
\hline Pelophylax perezi & 30TWM17 & 100,00 & 93,83 & 105,35 & 38,08 & 5763,45 & 252,61 & \begin{tabular}{|l|l|}
$-19,24$ \\
\end{tabular} & 271,85 & 110,11 & 170,63 & 170,63 & 24,09 & 674,93 & 74,07 & 36,31 & 18,55 & 196,01 & 128,47 & 128,65 & 178,33 \\
\hline Pelophylax perezi & 30TWM18 & 100,00 & 110,04 & 102,28 & 38,03 & 5706,21 & 262,98 & $-2,26$ & 265,24 & 124,43 & 185,29 & 185,29 & 39,92 & 602,75 & 65,87 & 31,60 & 18,93 & 173,77 & 116,27 & 116,44 & 157,84 \\
\hline Pelophylax perezi & 30TWM19 & 100,00 & 120,28 & 98,44 & \begin{tabular}{|l|l|}
37,98 \\
\end{tabular} & 5591,73 & 266,30 & 9,67 & 256,62 & 88,06 & 193,38 & 193,38 & 50,78 & 581,66 & 62,07 & 29,70 & 19,11 & 168,78 & 113,38 & 113,42 & 152,68 \\
\hline Pelophylax perezi & 30TWM20 & 100,00 & 108,08 & 113,43 & 38,00 & 6181,40 & 279,25 & $-15,51$ & 294,77 & 127,45 & 190,08 & 190,28 & 33,06 & 515,06 & 61,47 & 25,51 & 21,60 & 156,53 & 94,49 & 100,55 & 131,18 \\
\hline Pelophylax perezi & 30TWM21 & 100,00 & 100,66 & 113,99 & 38,01 & 6121,36 & 272,66 & $-21,70$ & 294,36 & 119,20 & 182,35 & 182,44 & 26,96 & 563,46 & 66,20 & 28,99 & 20,58 & 170,03 & 104,49 & 110,10 & 145,54 \\
\hline Pelophylax perezi & 30TWM22 & 100,00 & 96,86 & 113,61 & 38,16 & 6066,54 & 268,07 & $-24,41$ & 292,48 & 114,77 & 177,89 & 177,97 & 24,04 & 594,34 & 68,98 & 31,16 & 19,96 & 178,36 & 111,02 & 115,83 & 154,58 \\
\hline Pelophylax perezi & 30TWM23 & 100,00 & 100,11 & 113,02 & 38,18 & 6033,19 & 269,86 & $-20,79$ & 290,66 & 118,09 & 180,38 & 180,43 & 27,22 & 585,53 & 67,66 & 30,79 & 19,88 & 175,20 & 110,05 & 114,06 & 152,42 \\
\hline Pelophylax perezi & 30TWM24 & 100,00 & 76,56 & 109,64 & 38,18 & 5900,86 & 243,23 & $-39,27$ & 282,50 & 91,92 & 156,19 & 156,19 & 6,65 & 738,56 & 83,14 & 40,72 & 18,55 & 218,56 & 139,47 & 140,34 & 193,94 \\
\hline Pelophylax perezi & 30TWM25 & 100,00 & 68,24 & 107,45 & 38,15 & 5819,86 & 232,22 & $-45,10$ & 277,32 & 82,59 & 147,03 & 147,03 & $-0,29$ & 807,14 & 89,42 & 45,16 & 17,94 & 236,86 & 153,03 & 153,23 & 212,90 \\
\hline Pelophylax perezi & 30TWM26 & 100,00 & 88,12 & 108,23 & 38,21 & 5828,86 & 251,09 & $-27,02$ & 278,11 & 104,26 & 166,05 & 166,05 & 18,05 & 698,10 & 77,51 & 38,12 & 18,28 & 204,48 & 132,99 & 133,36 & $\begin{array}{ll}184,37 \\
\end{array}$ \\
\hline Pelophylax perezi & 30TWM27 & 100,00 & 91,55 & 106,67 & 38,27 & 5774,84 & 251,68 & $-22,38$ & 274,06 & 107,79 & 168,63 & 168,63 & 21,84 & 694,45 & 76,45 & 37,87 & 18,18 & 202,16 & 133,02 & 133,16 & 183,65 \\
\hline Pelophylax perezi & 30TWM28 & 100,00 & 99,88 & 104,49 & 38,32 & 5719,76 & 255,82 & \begin{tabular}{ll|}
$-12,94$ \\
\end{tabular} & 268,76 & 116,42 & 175,71 & 175,71 & 30,24 & 666,60 & 72,70 & 36,00 & 18,18 & 192,58 & 128,78 & 128,95 & 175,86 \\
\hline Pelophylax perezi & 30TWM29 & 100,00 & 120,41 & 100,10 & 38,02 & 5642,81 & 268,08 & 8,30 & 259,78 & 117,56 & 194,07 & 194,07 & 50,30 & 572,70 & 62,49 & 29,95 & 18,94 & 165,38 & 113,07 & 113,23 & 147,71 \\
\hline Pelophylax perezi & 30TWM30 & 100,00 & 104,56 & 115,04 & 38,02 & $\begin{array}{lll}6178,03 \\
\end{array}$ & 277,30 & $-19,92$ & 297,21 & 123,75 & 186,70 & 186,90 & 29,64 & 537,74 & 64,31 & 27,47 & 21,05 & 163,83 & 100,23 & 106,71 & 137,27 \\
\hline Pelophylax perezi & 30TWM31 & 100,00 & 103,45 & 115,62 & 38,23 & 6134,85 & 276,37 & $-20,69$ & 297,06 & 122,47 & 184,84 & 185,21 & 29,02 & 554,93 & 65,48 & 28,72 & 20,44 & 167,84 & 104,20 & 110,61 & 143,26 \\
\hline Pelophylax perezi & 30TWM32 & 100,00 & 100,33 & 115,52 & 38,74 & 6085,66 & 272,95 & $-22,71$ & 295,66 & 118,86 & 181,43 & 181,54 & 26,86 & 582,24 & 67,90 & 30,58 & 19,91 & 175,02 & 110,07 & 115,38 & 151,54 \\
\hline Pelophylax perezi & 30TWM33 & 100,00 & 99,18 & 114,38 & 38,68 & 6035,13 & 269,98 & $-22,77$ & 292,75 & 117,33 & 179,49 & 179,60 & 26,17 & 597,93 & 69,21 & 31,78 & 19,53 & 179,08 & 113,60 & 119,15 & 155,93 \\
\hline \begin{tabular}{|l|} 
Pelophylax perezi \\
\end{tabular} & 30TWM34 & 100,00 & 85,60 & 111,58 & 38,56 & 5936,16 & 253,40 & $-32,75$ & 286,15 & 102,03 & 165,18 & 165,19 & 14,49 & 689,98 & \begin{tabular}{|l|l|}
78,33 \\
\end{tabular} & 37,81 & 18,55 & 204,94 & 131,59 & 133,87 & 180,82 \\
\hline Pelophylax perezi & 30TWM35 & 100,00 & 73,56 & 108,60 & 38,32 & 5840,88 & 238,10 & $-41,36$ & 279,45 & 88,67 & 152,30 & 152,30 & 4,19 & 778,78 & 86,81 & 43,56 & 17,84 & 229,28 & 148,81 & 149,08 & 205,05 \\
\hline Pelophylax perezi & 30TWM36 & 100,00 & 86,13 & 108,96 & 38,61 & 5831,72 & 249,59 & $-29,72$ & 279,31 & 102,28 & 164,16 & 164,16 & 16,16 & 717,70 & 79,76 & 39,59 & 18,01 & 210,42 & 137,64 & 138,29 & 189,70 \\
\hline Pelophylax perezi & 30TWM37 & 100,00 & 96,07 & 107,64 & 38,54 & 5802,31 & 256,53 & $-19,25$ & 275,78 & 113,14 & 173,14 & 173,14 & 25,69 & 672,42 & 74,59 & 36,74 & 18,16 & 196,71 & 129,78 & 130,72 & 176,85 \\
\hline Pelophylax perezi & 30TWM38 & 100,00 & 101,31 & 105,51 & 38,45 & 5753,02 & 257,99 & $-12,79$ & 270,79 & 118,73 & 177,34 & 177,35 & 31,06 & 658,51 & 72,71 & 35,99 & 18,21 & 191,93 & 128,10 & 128,79 & 172,10 \\
\hline \begin{tabular}{|l|} 
Pelophylax perezi \\
\end{tabular} & 30TWM39 & 100,00 & 119,79 & 101,93 & 38,06 & 5702,21 & 269,49 & 6,12 & 263,36 & $\begin{array}{l}138,85 \\
130\end{array}$ & $\begin{array}{l}194,02 \\
194,\end{array}$ & 194,02 & $\begin{array}{ll}1,0,82 \\
8\end{array}$ & \begin{tabular}{|l|l|}
563,84 \\
\end{tabular} & $\begin{array}{l}63,13 \\
63\end{array}$ & 30,29 & \begin{tabular}{|l|l}
19,03 \\
19
\end{tabular} & 164,95 & 112,64 & 113,63 & 142,30 \\
\hline Pelophylax perezi & 30TWM40 & 100,00 & 106,05 & 115,52 & $\begin{array}{l}38,05 \\
\end{array}$ & 6179,69 & 278,45 & $-19,45$ & 297,90 & 125,65 & 187,90 & 188,35 & 30,78 & 530,34 & 64,28 & 27,42 & 21,32 & 162,98 & 100,19 & 107,63 & 134,11 \\
\hline Pelophylax perezi & 30TWM41 & 100,00 & 105,43 & 116,28 & 38,43 & 6140,06 & 278,34 & $-19,78$ & 298,12 & 124,92 & 186,82 & 187,18 & 30,50 & 546,13 & 65,24 & 28,45 & 20,74 & 166,35 & 103,75 & 110,58 & 140,07 \\
\hline Pelophylax perezi & 30TWM42 & 100,00 & 103,64 & 116,72 & 38,95 & 6096,81 & 276,75 & $-20,97$ & 297,71 & 122,70 & 184,62 & 184,78 & 29,42 & 568,59 & 66,79 & 29,94 & 19,90 & 171,65 & 108,52 & 115,21 & 147,62 \\
\hline Pelophylax perezi & 30TWM43 & 100,00 & 101,79 & 115,45 & 38,91 & 6050,05 & 273,08 & $-21,62$ & 294,71 & 120,42 & 182,06 & 182,21 & 28,19 & 586,40 & 68,46 & 31,32 & 19,54 & 176,49 & 112,42 & 119,54 & 152,32 \\
\hline Pelophylax perezi & 30TWM44 & 100,00 & $\begin{array}{l}91,1,01 \\
91\end{array}$ & $\begin{array}{l}111,45 \\
112,88\end{array}$ & 30,71 & $\begin{array}{l}5906,04,44 \\
596\end{array}$ & 259,40 & $\begin{array}{ll}-29,04 \\
-29,18\end{array}$ & \begin{tabular}{|l|}
288,571 \\
\end{tabular} & \begin{tabular}{|l|}
108,27 \\
108,27
\end{tabular} & $\begin{array}{l}\mid 02,060 \\
170,54 \\
\end{array}$ & $\begin{array}{l}\mid 02,21 \\
170,55 \\
\end{array}$ & $\begin{array}{l}\mid 20,15 \\
19,05 \\
\end{array}$ & \begin{tabular}{|l|l|}
662,31 \\
62,31
\end{tabular} & $\begin{array}{l}-70,406 \\
75,82\end{array}$ & $\begin{array}{l}31,2,3 \\
36,30\end{array}$ & $\begin{array}{l}18,65 \\
18,65\end{array}$ & 197,60 & $\begin{array}{l}127,36 \\
127\end{array}$ & $\begin{array}{l}131,80 \\
130\end{array}$ & 173,05 \\
\hline Pelophylax perezi & 30TWM 4 & 100,00 & 82,08 & 110,24 & 38,58 & 5878,70 & 247,42 & $-35,12$ & 282,54 & 98,21 & 160,86 & 160,86 & 11,45 & 731,03 & 82,29 & 40,77 & 17,89 & 216,24 & 140,76 & 141,49 & 191,97 \\
\hline Pelophylax perezi & 30TWM46 & 100,00 & 80,56 & 108,70 & 38,54 & 5819,04 & 243,60 & $-34,96$ & 278,56 & 96,40 & 158,60 & 158,60 & 10,80 & 757,90 & 84,18 & 42,44 & 17,65 & 222,38 & 146,11 & 146,57 & 200,06 \\
\hline Pelophylax perezi & 30TWM47 & 100,00 & 97,51 & 108,40 & 38,58 & 5830,24 & 258,38 & $-19,01$ & 277,40 & 115,15 & 174,78 & 174,78 & 26,59 & 667,01 & 74,69 & 36,66 & 18,24 & 196,31 & 129,31 & 130,20 & 174,48 \\
\hline Pelophylax perezi & 30TWM48 & 100,00 & 105,81 & 106,21 & 38,5 & 5790,45 & 262 & $-9,79$ & 272,38 & 124,10 & 181,99 & 181,99 & 34,73 & $\begin{array}{ll}631,48 \\
\end{array}$ & 70,85 & 34,70 & 18,56 & 185,93 & 123,74 & 124,95 & 162,81 \\
\hline Pelophylax perezi & 30TWM49 & 100,00 & 126,24 & 102,65 & $38, \mathrm{C}$ & 5775,38 & 276,19 & 10,47 & 265,72 & 146,67 & 195,92 & 200,91 & 54,01 & 508,37 & 59,42 & 27,88 & 20,34 & 153,06 & 104,01 & 107,40 & 122,04 \\
\hline Pelophylax perezi & 30TWM50 & 100,00 & 107,07 & 115,01 & 38,01 & 6181,32 & 278,07 & $-18,90$ & 296,97 & 127,18 & 188,72 & 189,23 & 31,86 & 520,60 & 64,27 & 27,27 & 21,79 & 162,18 & 99,62 & 107,97 & 129,36 \\
\hline Pelophylax perezi & 30TWM51 & 100,00 & 106,51 & 115,54 & 38,41 & 6147,29 & 277,73 & $-19,11$ & 296,84 & 126,08 & 187,71 & 187,97 & 31,51 & 535,59 & 65,18 & 28,19 & 21,02 & 165,40 & 102,76 & 110,74 & 134,96 \\
\hline Pelophylax perezi & 30TWM52 & 100,00 & 101,71 & 115,63 & 38,6 & 6093,30 & 273,15 & $-22,72$ & 295,87 & 120,85 & 182,51 & 182,69 & 27,64 & 574,92 & 8,56 & 30,8 & 20,09 & 75,47 & 10,84 & 118,72 & 147,09 \\
\hline Pelophylax perezi & 30TWMS & 100,00 & 99,08 & 114 & 38 & 6046,90 & 269,09 & $-24,29$ & 293,38 & $\begin{array}{l}117,79 \\
\end{array}$ & 179,33 & \begin{tabular}{|l|l|}
179,43 \\
\end{tabular} & 25,55 & \begin{tabular}{|l|l|l|l|l|}
601,88 \\
\end{tabular} & $\begin{array}{l}70,87 \\
7\end{array}$ & 30,60 & 19,51 & 182,47 & $\begin{array}{l}116,30 \\
116,3\end{array}$ & 123,77 & 154,95 \\
\hline Pelophylax perezi & 30TWM! & 100,00 & 84,73 & 111,67 & 38,62 & 5938,56 & 251,56 & $-34,74$ & 286,30 & 101,62 & 164,07 & 164,10 & 13,18 & 701,31 & 80, & 39,10 & 18,36 & 210,06 & 135,73 & 139,05 & 182,08 \\
\hline Pelophylax perezi & 30TWM55 & 100,00 & 88,05 & 110,97 & 38,73 & 5908,63 & 253,33 & $-30,57$ & 283,90 & 105,21 & 166,83 & 166,84 & 16,68 & 696,33 & 79,36 & 38,76 & 18,22 & 207,43 & 134,85 & $\begin{array}{l}136,98 \\
\end{array}$ & 181,61 \\
\hline Pelophylax perezi & 30TWM56 & 100,00 & 92,81 & 109,93 & 38,73 & 5880,87 & 255,93 & $-25,41$ & 281,34 & 110,30 & 170,93 & 170,93 & 21,33 & 683,68 & 77,52 & 37,95 & 18,29 & 202,97 & 132,50 & $\begin{array}{l}134,67 \\
\end{array}$ & 178,30 \\
\hline Pelophylax perezi & 30TWM57 & 100,00 & 98,21 & 108,81 & 38,69 & 5848,62 & 259,01 & $-19,15$ & 278,16 & 116,20 & 175,60 & 179 & 26,84 & 668,28 & 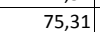 & ton & 18,31 & 56 & 129,69 & 131,56 & 174,25 \\
\hline Pelophylax perezi & $30 T W n$ & 100,00 & $\begin{aligned} 509,21 \\
109,72\end{aligned}$ & 10 & $\frac{00}{38}$ & 583 & 266,50 & \begin{tabular}{|c|c|}
$-1,27$ \\
$-7,27$
\end{tabular} & 27 & $\begin{array}{l}128,72 \\
128,0\end{array}$ & $\begin{array}{l}186,08 \\
186,0\end{array}$ & $\begin{array}{l}186,09 \\
186,0\end{array}$ & $\begin{array}{l}20,04 \\
37,64\end{array}$ & \begin{tabular}{|l|}
$609,73,0$ \\
\end{tabular} & $\mid \begin{array}{l}\mid 2,3,41 \\
69,41\end{array}$ & $\begin{array}{l}30,3,60 \\
33,6\end{array}$ & $\begin{array}{l}18,51 \\
18,94\end{array}$ & 181,50 & $\begin{array}{l}119,68 \\
119,\end{array}$ & $\begin{array}{l}121,36 \\
120\end{array}$ & 155,08 \\
\hline Pelophylax perezi & 30TWM59 & 100,00 & 127,97 & 103,66 & 38,01 & 5820,68 & 278,78 & 10,88 & 267,90 & 148,81 & 191,49 & 203,04 & 54,83 & 495,98 & 59,03 & 27,62 & 20,81 & 152,26 & 101,55 & 105,95 & 115,83 \\
\hline Pelophylax perezi & 30TWM60 & 100,00 & 104,44 & 114,17 & 38,01 & 6169,92 & 273,68 & \begin{tabular}{|l|l|l|}
$-21,68$ \\
-2
\end{tabular} & 295,36 & \begin{tabular}{|l|}
124,74 \\
1240
\end{tabular} & $\begin{array}{l}185,87 \\
\end{array}$ & $\begin{array}{l}186,26 \\
\end{array}$ & 29,28 & 530,32 & $\begin{array}{l}0,51 \\
66,51\end{array}$ & 28,30 & 22,01 & 167,25 & $\begin{array}{l}102,72 \\
\end{array}$ & 112,54 & $\begin{array}{l}129,85 \\
129,82\end{array}$ \\
\hline Pelophylax perezi & 30TWM61 & 100,00 & 104,70 & 114,36 & 38,02 & 6142,12 & 273,87 & $-21,08$ & 294,95 & 124,69 & 185,66 & 186,01 & 29,73 & 540,70 & 66,96 & 28,98 & 21,50 & 169,23 & 104,81 & 114,32 & 133,84 \\
\hline Pelophylax perezi & 30TWN & 100,00 & 99,40 & 114,24 & 38,2 & 6087,27 & 268,43 & $-25,07$ & 293 & 118,60 & 179,88 & 180,16 & 25,34 & 583,53 & 70,72 & 31,80 & 20,43 & 180,39 & 113,42 & 123,01 & 146 \\
\hline Pelophylax perezi & $\begin{array}{l}\text { 30TWM63 } \\
\end{array}$ & $\begin{array}{l}100,00 \\
\end{array}$ & $\begin{array}{l}51,90 \\
91,97\end{array}$ & $\begin{array}{ll}1142,24 \\
112,84\end{array}$ & 年0, 38,32 & $\begin{array}{ll}60018,94 \\
6018\end{array}$ & $\begin{array}{l}250,45 \\
259,63\end{array}$ & $\begin{array}{l}-20,01 \\
-30,03 \\
\end{array}$ & \begin{tabular}{|l|}
289,66 \\
28,6
\end{tabular} & \begin{tabular}{|l|}
110,27 \\
11
\end{tabular} & \begin{tabular}{|l|}
171,93 \\
171,03
\end{tabular} & \begin{tabular}{|l|}
172,04 \\
1704
\end{tabular} & $\begin{array}{l}3,14,11 \\
19,\end{array}$ & \begin{tabular}{|l|l|}
640,81 \\
640,81
\end{tabular} & $70,1 / 2$ & $\begin{array}{l}1,00 \\
35,53\end{array}$ & $\begin{array}{l}2,43 \\
19,41\end{array}$ & $\begin{array}{l}10,55 \\
195,60\end{array}$ & $\begin{array}{l}110,442 \\
124,72 \\
\end{array}$ & $\begin{array}{l}131,51 \\
\end{array}$ & $\begin{array}{l}140,00 \\
163,30\end{array}$ \\
\hline Pelophylax perezi & 30TWM64 & 100,00 & 91,17 & 111,90 & 38,49 & 5971,71 & 257,24 & $-29,86$ & 287,10 & 109,08 & 170,47 & 170,52 & 18,71 & 661,68 & 77,32 & 36,82 & 18,96 & 200,35 & 128,66 & 132,58 & 169,82 \\
\hline Pelophylax perezi & 30TWM65 & 100,00 & 91,99 & 111,00 & 38,69 & 5931,07 & 256,52 & $-27,79$ & 284,32 & 109,95 & 170,67 & 170,70 & 19,94 & 673,25 & 77,72 & 37,49 & 18,67 & 202,23 & 130,87 & 134,42 & 173,94 \\
\hline Pelophylax perezi & 30TWM66 & 100,00 & 97,99 & 110,15 & 38,76 & 5916,93 & 260,65 & $-21,48$ & 282,1 & 116, & 176,20 & 176 & 25 & 653,75 & 75,19 & 36,20 & 18 & 195,80 & 126,85 & 130,21 & 168,89 \\
\hline Pelophylax perezi & 30TWM67 & 100,00 & 105,56 & 108,59 & 38,47 & 5898,47 & 265,38 & $-13,16$ & 278,54 & 124,65 & 183,04 & 183,08 & 32,92 & 625,73 & 71,84 & 34,36 & 19,22 & 187,22 & 121,40 & 124,74 & 160, \\
\hline
\end{tabular}




\begin{tabular}{|c|c|c|c|c|c|c|c|c|c|c|c|c|c|c|c|c|c|c|c|c|c|}
\hline TAXON & UTM & $\mathrm{km} 2$ & B101 & B102 & $\mathrm{BIO3}$ & B104 & B105 & B106 & B107 & B108 & B109 & B1010 & BIO11 & BIO12 & B1013 & BIO14 & BIO15 & B1016 & B1017 & B1018 & B1019 \\
\hline Pelophylax perezi & 30TWM68 & 100,00 & 114,52 & 106,87 & 38,35 & 5868,51 & 270,81 & $-3,59$ & 274,41 & 134,39 & 191,10 & 191,13 & 41,65 & 589,48 & 67,82 & 32,29 & 19,56 & 176,80 & 115,20 & 118,20 & 148,52 \\
\hline Pelophylax perezi & 30TWM69 & 100,00 & 130,87 & 103,68 & 38,11 & 5811,44 & 280,87 & 13,60 & 267,27 & 151,81 & 205,82 & 205,84 & 57,84 & 516,60 & 59,99 & 28,08 & 20,37 & 156,31 & 103,10 & 106,02 & 123,92 \\
\hline Pelophylax perezi & 30TWM70 & 100,00 & 101,95 & 112,74 & 38,00 & 6153,76 & 268,87 & $-23,80$ & 292,68 & 122,02 & 182,86 & 183,36 & 26,70 & 539,21 & 68,60 & 29,42 & 22,51 & 172,22 & 105,79 & 117,20 & 129,60 \\
\hline Pelophylax perezi & 30TWM71 & 100,00 & 101,91 & 112,94 & 38,00 & 6127,89 & 268,84 & $-23,36$ & 292,20 & 121,79 & 182,53 & 182,80 & 26,99 & 551,28 & 69,26 & 30,10 & 22,04 & 174,53 & 107,93 & 118,84 & 134,36 \\
\hline Pelophylax perezi & 30TWM72 & 100,00 & 99,36 & 112,68 & 38,05 & $\begin{array}{ll}6087,58 \\
\end{array}$ & 266,03 & \begin{tabular}{|l|l|}
$-24,67$ \\
\end{tabular} & 290,70 & 119,00 & \begin{tabular}{|l|l|}
179,66 \\
\end{tabular} & 179,81 & 25,04 & 578,93 & 71,36 & 31,90 & 21,09 & 181,13 & 113,30 & 123,71 & 143,23 \\
\hline Pelophylax perezi & 30TWM73 & 100,00 & 98,35 & 112,10 & 38,12 & 6048,86 & 264,16 & $-24,80$ & 288,95 & 117,78 & 178,12 & 178,32 & 24,46 & 600,17 & 72,80 & 33,19 & 20,39 & 185,91 & 117,19 & 126,24 & 150,12 \\
\hline Pelophylax perezi & 30TWM74 & 100,00 & 104,64 & 111,38 & 38,15 & $\begin{array}{ll}6037,67 \\
\end{array}$ & 268,88 & $-18,07$ & 286,95 & 124,35 & 183,90 & 184,07 & 30,39 & 579,31 & 70,04 & 31,70 & 20,70 & 178,88 & 112,50 & 119,76 & 145,13 \\
\hline Pelophylax perezi & 30TWM75 & 100,00 & 105,81 & 110,60 & 38,19 & 6005,52 & 268,75 & $-15,87$ & 284,62 & 125,63 & 184,67 & 184,71 & 31,91 & 589,35 & 70,32 & 32,27 & 20,32 & 180,49 & 114,13 & 120,21 & 148,72 \\
\hline Pelophylax perezi & 30TWM76 & 100,00 & 108,27 & 109,80 & 38,40 & 5979,02 & 269,63 & $-12,52$ & 282,15 & 128,21 & 186,54 & 186,61 & 34,49 & 593,73 & 69,97 & 32,39 & 20,06 & 180,44 & 114,66 & 121,32 & 150,67 \\
\hline Pelophylax perezi & 30TWM77 & 100,00 & 122,10 & 107,81 & 38,04 & 5973,97 & 279,65 & 1,33 & 278,32 & 143,23 & 199,55 & 199,65 & 47,51 & 536,37 & 63,52 & 28,69 & 20,92 & 163,45 & 103,33 & 108,63 & 133,39 \\
\hline Pelophylax perezi & 30TWM78 & 100,00 & 128,49 & 105,82 & 38,03 & 5904,04 & 282,21 & 9,08 & 273,14 & 149,75 & 204,79 & 204,81 & 54,47 & 533,57 & 61,81 & 28,16 & 20,74 & 160,44 & 102,74 & 106,73 & 132,77 \\
\hline Pelophylax perezi & 30TWM79 & 100,00 & 131,83 & 103,92 & 38,15 & 5807,65 & 281,63 & 14,43 & 267,20 & 148,30 & 206,70 & 206,71 & 58,81 & 559,05 & 62,46 & 29,22 & 20,09 & 164,46 & 107,43 & 108,30 & 141,47 \\
\hline Pelophylax perezi & 30TWM80 & 100,00 & 100,41 & 111,41 & 38,00 & 6140,50 & 265,03 & $-24,86$ & 289,89 & 120,77 & 181,07 & 181,43 & 25,11 & 542,10 & 70,08 & 29,99 & 23,26 & 175,30 & 107,45 & 120,22 & 128,10 \\
\hline Pelophylax perezi & 30TWM81 & 100,00 & 95,19 & 111,13 & 38,00 & 6093,47 & 259,76 & $-28,84$ & 288,61 & 114,84 & 175,50 & 175,73 & 20,67 & 584,71 & 73,75 & 32,71 & 21,90 & 186,25 & 115,83 & 127,53 & 140,88 \\
\hline Pelophylax perezi & 30TWM82 & 100,00 & 93,96 & 110,92 & 38,00 & 6058,28 & 258,25 & $-29,35$ & 287,60 & 113,12 & 173,90 & 173,96 & 19,82 & 607,35 & 75,29 & 34,08 & 21,12 & 191,30 & 119,85 & 131,13 & 148,50 \\
\hline Pelophylax perezi & 30TWM83 & 100,00 & 102,29 & 111,08 & 38,01 & 6063,83 & 266,08 & $-21,32$ & 287,40 & 122,23 & 181,75 & 182,01 & 27,54 & 575,06 & 71,24 & 31,73 & 21,45 & 180,48 & 112,34 & 123,17 & 141,63 \\
\hline Pelophylax perezi & 30TWM84 & 100,00 & 112,56 & 110,32 & 38,00 & 6074,30 & 274,85 & $-10,78$ & 285,63 & 133,44 & 191,83 & 191,95 & 37,15 & 536,46 & 66,46 & 28,88 & 22,09 & 167,91 & 103,46 & 111,82 & 132,19 \\
\hline Pelophylax perezi & 30TWM85 & 100,00 & 120,81 & 109,32 & 38,00 & 6070,69 & 281,26 & $-2,30$ & 283,56 & 142,39 & 199,63 & 199,70 & 45,06 & 512,43 & 63,00 & 27,03 & 22,39 & 159,30 & 97,77 & 106,13 & 126,51 \\
\hline Pelophylax perezi & 30TWM86 & 100,00 & 114,20 & 109,04 & 38,09 & 6006,60 & 274,05 & $-7,30$ & 281,35 & 134,91 & 192,58 & 192,63 & 39,61 & 570,80 & 67,81 & 30,55 & 20,97 & 174,04 & 108,84 & 113,47 & $\begin{array}{ll}144,47 \\
\end{array}$ \\
\hline Pelophylax perezi & 30TWM87 & 100,00 & 128,35 & 107,02 & 38,02 & 5975,87 & 284,11 & 7,13 & 276,98 & 149,45 & 205,52 & 205,54 & 53,25 & 532,35 & 62,14 & 27,45 & 21,42 & 160,02 & 100,23 & 104,59 & 134,85 \\
\hline Pelophylax perezi & 30TWM88 & 100,00 & 134,35 & 105,10 & 38,04 & 5889,37 & 286,21 & 14,87 & 271,33 & 132,12 & 210,31 & 210,31 & 60,31 & 546,65 & 61,38 & 27,62 & 21,02 & 160,87 & 102,44 & 104,23 & 141,00 \\
\hline Pelophylax perezi & 30TWM89 & 100,00 & 131,38 & 104,44 & 38,28 & 5824,87 & 281,87 & 13,37 & 268,50 & 108,01 & 206,61 & 206,61 & 58,00 & 599,62 & 65,11 & 30,34 & 20,55 & 175,85 & 111,50 & 111,85 & 158,52 \\
\hline Pelophylax perezi & 30TWM90 & 100,00 & 101,15 & 109,76 & 37,80 & 6132,05 & 263,09 & $-24,37$ & 287,46 & 121,62 & 181,36 & 181,66 & 25,58 & 533,62 & 70,31 & 29,76 & 24,38 & 174,94 & 106,70 & 120,34 & 123,48 \\
\hline Pelophylax perezi & 30TWM91 & 100,00 & 87,84 & 108,99 & 37,95 & 6050,08 & 249,71 & $-35,05$ & 284,76 & 106,85 & 167,60 & 167,79 & 13,94 & 624,44 & 78,82 & 35,82 & 21,71 & 199,61 & 125,27 & 139,48 & 148,70 \\
\hline Pelophylax perezi & 30TWM92 & 100,00 & 72,64 & 106,71 & 37,77 & 5954,64 & 233,16 & $-46,25$ & 279,41 & 89,69 & 152,01 & 152,06 & 0,86 & 739,71 & 89,38 & 43,41 & 19,55 & 230,16 & 148,20 & 155,56 & 180,58 \\
\hline Pelophylax perezi & 30TWM93 & 100,00 & 108,87 & 109,70 & 38,00 & 6087,02 & 270,50 & $-15,03$ & 285,53 & 129,85 & 188,27 & 188,40 & 33,36 & 539,83 & 68,31 & 29,30 & 22,86 & 171,31 & 104,81 & 115,50 & 130,99 \\
\hline \begin{tabular}{|l|} 
Pelophylax perezi \\
\end{tabular} & 30TWM94 & 100,00 & 116,65 & 109,32 & 38,00 & 6088,93 & 277,28 & \begin{tabular}{r|}
$-6,85$ \\
-10
\end{tabular} & 284,12 & 138,12 & $\begin{array}{l}195,80 \\
\end{array}$ & $\begin{array}{l}195,84 \\
\end{array}$ & 40,77 & 518,92 & $\begin{array}{l}0,011 \\
65,08 \\
\end{array}$ & 27,44 & 23,06 & 163,27 & \begin{tabular}{|c|}
99,03 \\
99,03
\end{tabular} & $\begin{array}{l}108,04 \\
\end{array}$ & 127,24 \\
\hline Pelophylax perezi & 30TWM95 & 100,00 & 125,99 & 108,46 & 38,00 & 6076,73 & 284,75 & 2,67 & 282,08 & 148,08 & 204,72 & 204,73 & 49,95 & 501,18 & 61,53 & 25,72 & 22,97 & 154,93 & 94,08 & 100,50 & 124,61 \\
\hline Pelophylax perezi & 30TWM96 & 100,00 & 131,71 & 107,23 & 38,00 & 6028,23 & 288,08 & 9,28 & 278,79 & 153,84 & 209,61 & 209,62 & 55,88 & 508,03 & 60,32 & 25,39 & 22,64 & 153,29 & 94,21 & 97,98 & 128,91 \\
\hline Pelophylax perezi & 30TWM97 & 100,00 & 135,62 & 105,89 & 38,00 & 5954,58 & 289,29 & \begin{tabular}{ll|}
14,64 \\
\end{tabular} & 274,65 & 134,12 & 212,38 & 212,38 & 60,68 & 530,99 & 60,56 & 26,04 & 22,04 & 156,61 & 97,62 & 99,75 & 138,13 \\
\hline Pelophylax perezi & 30TWM98 & 100,00 & 132,69 & 105,57 & 38,03 & 5901,17 & 285,19 & 12,88 & 272,31 & 98,97 & 208,86 & 208,86 & 58,47 & 581,45 & 64,16 & 28,73 & 21,48 & 171,39 & 106,18 & 106,63 & 155,19 \\
\hline Pelophylax perezi & 30TWM99 & 100,00 & 131,07 & 104,91 & 38,25 & 5841,19 & 282,14 & 12,33 & 269,81 & 95,75 & 206,50 & 206,50 & 57,70 & 635,06 & 70,00 & 31,24 & 21,29 & 189,54 & 114,88 & 115,15 & 174,14 \\
\hline Pelophylax perezi & 30TWNO0 & 100,00 & 120,38 & 94,44 & 37,97 & 5419,18 & 260,53 & 13,68 & 246,85 & 88,49 & 190,40 & 191,40 & 53,06 & 629,12 & 66,32 & 31,18 & 19,25 & 187,06 & 120,44 & 121,28 & 170,86 \\
\hline Pelophylax perezi & 30TWN01 & 100,00 & 120,28 & 91,73 & 37,94 & 5288,90 & 256,13 & 16,42 & 239,71 & 88,03 & 188,49 & 189,70 & 54,88 & 677,58 & 72,94 & 33,2 & 19,58 & 203,86 & 128,09 & 130,50 & 187,86 \\
\hline Pelophylax perezi & 30TWNO2 & 100,00 & 122,30 & 88,59 & 37,80 & 5134,56 & 253,13 & 21,27 & 231,85 & 92,57 & 188,13 & 189,59 & 58,65 & 725,80 & 80,04 & 34,78 & 20,01 & 221,58 & 134,57 & 139,36 & 206,13 \\
\hline Pelophylax perezi & 30TWNO3 & 100,00 & 116,25 & 87,55 & 37,88 & 5049,03 & 246,02 & 17,38 & 228,64 & 76,28 & 181,08 & 182,81 & 54,08 & 797,32 & 88,72 & 38,69 & 19,84 & 243,94 & 147,58 & 152,84 & 229,04 \\
\hline Pelophylax perezi & $\begin{array}{l}\text { 30TWN04 } \\
\end{array}$ & 100,00 & 108,15 & $\begin{array}{l}1,35 \\
86,93 \\
\end{array}$ & $\begin{array}{l}37,00 \\
37,99\end{array}$ & $\begin{array}{l}404,032,08 \\
4972,0\end{array}$ & 237,41 & $\begin{array}{l}1,30 \\
11,42 \\
\end{array}$ & $\mid \begin{array}{l}225,94, \\
2259\end{array}$ & $\begin{array}{l}0,0,0 \\
55,08\end{array}$ & \begin{tabular}{|l|}
172,150 \\
172
\end{tabular} & \begin{tabular}{|l|}
174,01 \\
174,14 \\
\end{tabular} & $\begin{array}{l}4,40 \\
47,45\end{array}$ & \begin{tabular}{|l|}
881,71 \\
\end{tabular} & $\begin{array}{ll}0,0,1 / 7 \\
98,74\end{array}$ & $\begin{array}{l}0,05 \\
43,52 \\
\end{array}$ & $\begin{array}{l}19,64 \\
19,67 \\
\end{array}$ & \begin{tabular}{|l|}
273,441 \\
271,4
\end{tabular} & $\begin{array}{l}163,24 \\
163\end{array}$ & \begin{tabular}{|l|}
$168,67,67$ \\
\end{tabular} & 255,44 \\
\hline Pelophylax perezi & 30TWN05 & 100,00 & 111,15 & 83,25 & 37,86 & 4804,25 & 234,88 & $\begin{array}{lll}17,47 \\
\end{array}$ & 217,42 & 60,22 & 172,58 & 174,81 & 52,45 & 940,18 & 107,73 & 45,27 & 20,77 & 294,35 & 170,42 & 179,21 & 278,61 \\
\hline Pelophylax perezi & 30TWN06 & 100,00 & 120,93 & 76,99 & 37,38 & 4558,16 & 235,22 & 31,95 & 203,28 & 72,35 & 178,65 & 181,13 & 65,04 & 998,87 & 119,07 & 45,23 & 23,21 & 320,68 & 173,37 & 188,61 & 308,02 \\
\hline Pelophylax perezi & 30TWN07 & 100,00 & 127,93 & 71,26 & 36,86 & 4332,40 & 233,84 & 43,26 & 190,58 & 82,01 & 182,27 & 185,03 & 74,73 & 1069,85 & 132,35 & 45,96 & 25,77 & 351,14 & 178,23 & 199,87 & 343,06 \\
\hline Pelophylax perezi & 30TWN08 & 100,00 & 130,79 & 67,22 & 36,46 & 4178,09 & 230,99 & 49,14 & 181,86 & 84,61 & 182,80 & 185,90 & 79,44 & 1139,08 & 144,30 & 47,36 & 27,59 & 380,12 & 184,84 & 211,30 & 374,92 \\
\hline Pelophylax perezi & 30TWN09 & 99,00 & 138 & 61,59 & 35,64 & 3978,81 & 229,93 & 59,82 & $\begin{array}{l}170,11 \\
\end{array}$ & 90,52 & 187,26 & 190,50 & 88,95 & 1202,85 & $\begin{array}{l}157,78 \\
\end{array}$ & 47,29 & 30,38 & 411,24 & 187,22 & 220,79 & 410,73 \\
\hline Pelophylax perezi & 30TWN10 & 100,00 & 121,39 & 95,73 & 38,00 & 5462,53 & 262,62 & 13,45 & 249,18 & 88,99 & 192,30 & 192,78 & 53,50 & 617,79 & 64,51 & 31,17 & 18,99 & 181,58 & 120,47 & 120,61 & 165,39 \\
\hline Pelophylax perezi & 30TWN11 & 100,00 & 121,17 & 92,97 & 38,03 & 5325,25 & 258,05 & 16,19 & 241,87 & 87,30 & 189,92 & 190,83 & 55,10 & 671,24 & 71,31 & 33,48 & 19,01 & 200,12 & 129,18 & 130,57 & 183,99 \\
\hline Pelophylax perezi & 30TWN12 & 100,00 & 116,42 & 91,61 & 38,06 & 5218,73 & 251,37 & 13,86 & 237,50 & 78,65 & 183,78 & 185,01 & 51,99 & 741,39 & 80,05 & 37,07 & 18,90 & 22,10 & 43 & 43,53 & 207,29 \\
\hline Pelophylax perezi & 30TWN13 & 100,00 & 117 & 88,77 & 38,00 & 5076,73 & 248,27 & 17,84 & 230,43 & 75,49 & 182,56 & 184,25 & 54,99 & 795,94 & $\begin{array}{l}0,0,64 \\
87,\end{array}$ & 39 & 19,33 & 68 & $\begin{array}{l}149,44 \\
\end{array}$ & $\begin{array}{l}153,49 \\
15,4\end{array}$ & 227,16 \\
\hline Pelophylax perezi & $30 \mathrm{TWN}$ & 100,00 & 114,06 & 86,70 & 38,04 & 4951,83 & 242,09 & 17,31 & 224,79 & 60,66 & 177,48 & 179,45 & 53,44 & 873,38 & 97,76 & 42,79 & 19,69 & 268,69 & 161,95 & 167,58 & 253,84 \\
\hline Pelophylax perezi & 30TWN15 & 100,00 & 110,09 & 85,02 & 38,03 & 4845,20 & 235,85 & 15,60 & 220,25 & 58,25 & 172,10 & 174,23 & 51,07 & 950,45 & 107,55 & 46,56 & 19,95 & 295,50 & 174,82 & 181,79 & 279,59 \\
\hline Pelophylax perezi & 30TWN16 & 100,00 & 98,64 & 85,16 & 38,28 & 4807,67 & 225,03 & 5,69 & 219,33 & 47,92 & 160,34 & 162,73 & 40,71 & 1045,75 & 118,43 & 52,56 & 19,70 & 326,01 & 193,81 & 199,88 & 307,97 \\
\hline Pelophylax perezi & $30 T_{W N 1}$ & 100,00 & 128,64 & 72,98 & 37,36 & 4354,73 & 236,46 & 43,81 & 192,65 & 82,11 & 183,14 & 186,01 & 75,52 & 1079,46 & 131,80 & 47,04 & 24,96 & 18 & 181,94 & 201,95 & 344,04 \\
\hline Pelophylax perezi & $30 \mathrm{TW}$ & 100,00 & $\frac{13}{13}$ & $\begin{array}{l}68,06 \\
68,06\end{array}$ & 36, & $\frac{4}{4}$ & 235 & $\begin{array}{l}3,01 \\
53,62 \\
\end{array}$ & \begin{tabular}{|l|}
181,75 \\
18,5
\end{tabular} & $\begin{array}{l}20,11 \\
89,29 \\
\end{array}$ & \begin{tabular}{|l|}
$186,00,0$ \\
186,
\end{tabular} & \begin{tabular}{|l|}
$189,16,16$ \\
\end{tabular} & 83,60 & \begin{tabular}{|l|l|l|l|}
1148,38 \\
\end{tabular} & \begin{tabular}{|l|}
144,51 \\
1440
\end{tabular} & 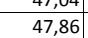 & 27,29 & \begin{tabular}{|l|}
381,57 \\
381
\end{tabular} & \begin{tabular}{|l|}
$186,91,91$ \\
\end{tabular} & \begin{tabular}{|l|}
212,95 \\
21,9
\end{tabular} & 377,88 \\
\hline Pelophylax perezi & 30TWN19 & 100,00 & 136,81 & 64,62 & 36,64 & 4030,81 & 233,08 & 59,18 & 173,91 & 91,57 & 186,35 & 189,85 & 88,01 & 1213,41 & 155,48 & 49,45 & 28,69 & 408,53 & 193,61 & 224,12 & 406,77 \\
\hline Pelophylax perezi & 30TWN20 & 100,00 & 126,10 & 96,62 & 38,00 & 5507,50 & 267,48 & 16,71 & 250,77 & 94,30 & 197,64 & 197,75 & 57,42 & |585,64 & 61,84 & 29,96 & 18,98 & 170,90 & 116,21 & 116,25 & 153,13 \\
\hline Pelophylax perezi & 30TWN21 & 100,00 & 110,79 & 96,77 & 38,36 & 5416,85 & 252,98 & 4,19 & 248,79 & 66,36 & 182,05 & 182,15 & 44,22 & 711,86 & 74,31 & 37,25 & 17,99 & 207,94 & 138,90 & 138,90 & 192,7 \\
\hline Pelophylax perezi & 30TWN22 & 100,00 & 111 & 94,34 & 38,29 & 5288,91 & 250,19 & 7,67 & 242 & 61,67 & 180,75 & 18 & 46,66 & 758,46 & 80,5 & 39,13 & 18,04 & 223,91 & 147,33 & 147,51 & 209 \\
\hline Pelophylax perezi & $\begin{array}{l}30 \text { TWN23 } \\
\end{array}$ & $\begin{array}{l}100,00 \\
\end{array}$ & $111,12,54$ & $\begin{array}{l}4,34 \\
91,62 \\
\end{array}$ & $\begin{array}{l}30,29 \\
38,28\end{array}$ & 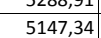 & 246,88 & \begin{tabular}{|c|}
1,33 \\
11,33 \\
\end{tabular} & \begin{tabular}{|l|}
235,56 \\
235,
\end{tabular} & $\begin{array}{l}60,18 \\
60\end{array}$ & \begin{tabular}{|l|}
178,85 \\
170
\end{tabular} & \begin{tabular}{|l|}
180,25 \\
180,25
\end{tabular} & $\begin{array}{l}40,36 \\
49,3\end{array}$ & \begin{tabular}{|l|}
$313,72,72$ \\
\end{tabular} & \begin{tabular}{|c|}
80,030 \\
88,10 \\
\end{tabular} & | & $\begin{array}{l}0,044 \\
18,36\end{array}$ & \begin{tabular}{|l|}
244,33 \\
\end{tabular} & $\begin{array}{l}156,34 \\
156,34\end{array}$ & \begin{tabular}{|l|}
157,56 \\
156
\end{tabular} & $\begin{array}{l}229,17 \\
229,\end{array}$ \\
\hline Pelophylax perezi & 30TWN24 & 100,00 & 119,93 & 86,90 & 38,16 & 4940,64 & 247,10 & 22,81 & 224,29 & 66,12 & 182,88 & 184,78 & 59,15 & 862,41 & 95,99 & 42,06 & 19,59 & 264,73 & 160,61 & 165,94 & 250,16 \\
\hline Pelophylax perezi & 30TWN25 & 100,00 & 117,45 & 84,69 & 38,13 & 4802,05 & 241,38 & 23,20 & 218,18 & 65,44 & 178,44 & 180,66 & 58,75 & 945,48 & 107,01 & 45,75 & 20,05 & 294,32 & 173,45 & 180,86 & 279,21 \\
\hline Pelophylax perezi & 30TWN2 & 100,00 & 113,08 & 82,98 & 38,30 & 4690,10 & 234,81 & 21,53 & 213,2 & 62,92 & 172,6 & 175 & 56, & 1031,02 & 118,07 & 49,92 & 20,60 & 324,36 & $\begin{array}{lll}187,44 \\
\end{array}$ & 196,33 & 308,42 \\
\hline Pelophylax perezi & 30TWN28 & 100,00 & 132,12 & 71,51 & 37,82 & 4217,71 & 237,05 & 50,52 & 186,53 & 86,93 & 184,41 & 187,61 & 81,19 & \begin{tabular}{l|l}
1160,03 \\
1160
\end{tabular} & 142,02 & 0,33 & 25,43 & 381,14 & 194,15 & 216,73 & 372,79 \\
\hline
\end{tabular}




\begin{tabular}{|c|c|c|c|c|c|c|c|c|c|c|c|c|c|c|c|c|c|c|c|c|c|}
\hline TAXON & UTM & $\mathrm{km} 2$ & B101 & B102 & $\mathrm{BIO3}$ & B104 & B105 & B106 & B107 & B108 & B109 & B1010 & BIO11 & BIO12 & B1013 & BIO14 & BIO15 & BIO16 & BIO17 & BIO18 & B1019 \\
\hline Pelophylax perezi & 30TWN29 & 100,00 & 136,55 & 67,88 & 37,67 & 4062,26 & 236,21 & 58,40 & 177,81 & 93,08 & 186,50 & 190,04 & 87,82 & 1216,98 & 151,89 & 51,40 & 26,91 & 405,01 & 199,13 & 226,79 & 398,51 \\
\hline Pelophylax perezi & 30TWN30 & 100,00 & 127,14 & 98,39 & 38,01 & 5580,14 & 270,47 & 15,84 & 254,63 & 115,86 & 199,45 & 199,45 & 57,31 & 562,21 & 61,32 & 29,66 & 19,05 & 162,42 & 113,49 & 113,76 & 142,64 \\
\hline Pelophylax perezi & 30TWN31 & 100,00 & 112,62 & 98,18 & 38,56 & 5463,45 & 255,92 & 4,41 & 251,51 & 69,11 & 184,18 & 184,18 & 45,19 & 698,07 & 73,03 & 37,09 & 17,75 & 201,94 & 137,27 & 137,27 & 186,42 \\
\hline Pelophylax perezi & 30TWN32 & 100,00 & 108,82 & 96,39 & 38,76 & 5341,01 & 249,64 & 3,40 & 246,24 & 51,29 & 179,08 & 179,08 & 43,24 & 775,71 & 81,65 & 40,84 & 17,59 & 227,76 & 150,97 & 150,97 & 212,72 \\
\hline Pelophylax perezi & 30TWN33 & 100,00 & 103,56 & \begin{tabular}{|l|l|}
94,58 \\
\end{tabular} & 38,90 & 5221,61 & 242,10 & 1,07 & \begin{tabular}{|l|l|}
241,03 \\
\end{tabular} & 47,20 & 172,36 & \begin{tabular}{|l|}
172,57 \\
\end{tabular} & 39,87 & 862,93 & 92,57 & \begin{tabular}{|l|l|}
45,23 \\
\end{tabular} & 17,73 & 257,56 & 166,55 & 166,66 & 241,63 \\
\hline Pelophylax perezi & 30TWN34 & 100,00 & 118,90 & 89,15 & 38,76 & 4985,27 & 248,45 & 20,54 & 227,91 & 64,53 & 182,50 & 184,28 & 57,72 & 871,82 & 95,63 & 43,42 & 18,82 & 265,85 & 165,05 & 168,09 & 249,88 \\
\hline Pelophylax perezi & 30TWN35 & 100,00 & 112,87 & 87,58 & 38,92 & 4872,46 & 240,42 & 17,16 & 223,26 & 60,24 & 175,05 & 177,12 & 53,48 & 969,30 & 108,05 & 48,34 & 19,18 & 299,53 & 181,38 & 185,61 & 282,65 \\
\hline Pelophylax perezi & 30TWN36 & 100,00 & 118,93 & 83,30 & 38,89 & 4648,14 & 239,72 & 27,74 & 211,98 & 68,82 & 177,68 & 180,22 & 62,58 & 1040,38 & 118,56 & 50,06 & 20,62 & 327,62 & 188,78 & 197,71 & 311,32 \\
\hline Pelophylax perezi & 30TWN37 & 100,00 & 126,97 & 78,23 & 38,76 & 4416,47 & 240,09 & 40,70 & 199,39 & 79,37 & 182,17 & 185,09 & 73,65 & 1110,02 & 130,25 & 51,03 & 22,59 & 356,79 & 194,15 & 209,22 & 342,71 \\
\hline Pelophylax perezi & 30TWN38 & 100,00 & 125,53 & 76,22 & 38,88 & 4295,56 & 235,67 & \begin{tabular}{ll|}
41,87 \\
\end{tabular} & 193,80 & 79,55 & 178,97 & 182,14 & 73,98 & 1184,68 & 140,08 & 54,29 & 23,10 & 383,79 & 205,43 & 223,01 & 368,89 \\
\hline Pelophylax perezi & 30TWN39 & 100,00 & 130,98 & 72,34 & 38,82 & 4113,23 & 235,15 & 51,13 & 184,02 & 87,08 & 181,70 & 185,18 & 81,85 & 1246,81 & 150,37 & 55,51 & 24,49 & 409,47 & 211,22 & 234,16 & 396,09 \\
\hline Pelophylax perezi & 30TWN40 & 100,00 & 128,64 & 100,21 & 38,06 & 5669,25 & 273,99 & 15,27 & 258,73 & 148,38 & 191,98 & 201,80 & 57,55 & 533,26 & 60,36 & 29,04 & 19,70 & 156,83 & 109,49 & 112,01 & 130,23 \\
\hline Pelophylax perezi & 30TWN41 & 100,00 & 113,05 & 99,65 & 38,75 & 5511,61 & 257,95 & 3,55 & 254,40 & 78,84 & 185,14 & 185,14 & 44,99 & 697,21 & 73,21 & 37,48 & 17,57 & 200,54 & 137,18 & 137,18 & 184,62 \\
\hline Pelophylax perezi & 30TWN42 & 100,00 & 111,66 & 97,48 & \begin{tabular}{|l|l|}
38,97 \\
\end{tabular} & 5372,17 & 253,22 & 4,92 & 248,30 & 55,80 & 182,10 & 182,10 & 45,54 & 765,08 & 79,88 & 40,51 & 17,51 & 223,68 & 149,08 & 149,08 & 207,95 \\
\hline Pelophylax perezi & 30TWN43 & 100,00 & 104,69 & 95,80 & 39,00 & 5253,68 & 244,22 & 1,10 & 243,12 & 47,78 & 173,98 & 173,98 & 40,45 & 867,38 & 92,76 & 45,79 & 17,66 & 258,43 & 167,34 & 167,34 & 241,97 \\
\hline Pelophylax perezi & 30TWN44 & 100,00 & 116,32 & 91,52 & 39,00 & 5041,25 & 248,65 & 16,52 & 232,13 & 61,40 & 180,99 & 182,51 & 54,49 & 893,15 & 97,14 & 45,32 & 18,33 & 271,42 & 170,94 & 171,69 & 254,05 \\
\hline Pelophylax perezi & 30TWN45 & 100,00 & 108,38 & 90,08 & 39,01 & 4932,58 & 239,01 & 11,27 & 227,75 & 55,25 & 171,85 & 173,45 & 48,43 & 998,88 & 110,42 & 50,92 & 18,72 & 307,34 & 189,19 & 190,92 & 289,05 \\
\hline Pelophylax perezi & 30TWN46 & 100,00 & 123,61 & 83,98 & 39,18 & 4612,31 & 243,96 & 32,62 & 211,34 & 73,60 & 181,61 & 184,19 & 67,65 & 1057,52 & 120,02 & 50,76 & 20,66 & 333,64 & 191,58 & 200,33 & 315,99 \\
\hline Pelophylax perezi & 30TWN47 & 100,00 & 127,37 & 80,59 & 39,48 & 4414,46 & 242,24 & 40,45 & 201,79 & 79,66 & 182,45 & 185,32 & 74,13 & \begin{tabular}{|l|}
1134,07 \\
\end{tabular} & 130,68 & 53,16 & 21,75 & 362,79 & 200,85 & $\begin{array}{ll}213,87 \\
\end{array}$ & 344,92 \\
\hline Pelophylax perezi & 30TWN48 & 100,00 & 130,07 & 77,45 & 39,64 & 4246,62 & 240,05 & 46,70 & 193,35 & 84,39 & 182,71 & 185,86 & 79,20 & 1204,46 & 140,81 & 55,47 & 22,78 & 389,75 & 209,58 & 226,82 & 372,07 \\
\hline Pelophylax perezi & 30TWN49 & 83,00 & 135,59 & 73,79 & 39,59 & 4081,88 & 239,93 & 55,56 & 184,37 & 91,69 & 185,64 & 189,10 & 86,91 & 1255,69 & 149,38 & 56,31 & 24,10 & 411,33 & 213,84 & 236,38 & 394,56 \\
\hline Pelophylax perezi & 30TWN50 & 100,00 & 128,81 & 101,63 & 38,17 & 5707,35 & 275,59 & 14,16 & 261,43 & $\begin{array}{r}149,29 \\
\end{array}$ & 178,54 & 202,48 & 57,20 & 531,73 & |60,97 & 29,42 & 19,74 & 159,20 & 108,66 & 111,32 & 127,16 \\
\hline Pelophylax perezi & 30TWN51 & 100,00 & 117,27 & 100,71 & 38,83 & 5560,53 & 262,85 & 6,08 & 256,77 & 96,97 & 189,70 & 189,70 & 48,22 & 677,80 & 71,69 & 36,57 & 17,82 & 194,92 & 133,18 & 133,23 & 177,28 \\
\hline Pelophylax perezi & 30TWN52 & 100,00 & 111,01 & 98,69 & 38,99 & 5410,56 & 253,88 & 3,30 & 250,58 & 54,19 & 181,92 & 181,92 & 44,35 & 784,16 & 81,97 & 41,74 & 17,60 & 229,51 & 151,86 & 151,86 & 213,21 \\
\hline Pelophylax perezi & 30TWN53 & 100,00 & 99,05 & 97,23 & 39,00 & 5289,83 & 240,71 & $-5,51$ & 246,22 & 42,19 & 169,02 & 169,02 & 34,61 & 912,83 & 98,09 & 48,79 & 17,47 & 272,35 & 174,91 & 174,91 & 255,66 \\
\hline Pelophylax perezi & 30TWN54 & 100,00 & 108,16 & 93,91 & 39,01 & 5109,92 & 243,98 & 6,90 & 237,08 & 52,94 & 175,02 & 175,43 & 45,78 & 945,86 & 103,08 & 49,09 & 18,18 & 287,36 & 180,52 & 180,55 & 269,18 \\
\hline Pelophylax perezi & 30TWN55 & 100,00 & 101,96 & 91,96 & 39,17 & 4992,10 & 235,34 & 3,58 & 231,76 & 48,52 & $\mid 167,24$ & 168,02 & 41,50 & $\mid$ & 115,05 & 54,16 & 18,39 & 320,16 & 197,85 & 198,55 & 300,92 \\
\hline Pelophylax perezi & 30TWN57 & 100,00 & 121,94 & 84,15 & 40,03 & 4490,28 & 240,93 & 32,96 & 207,97 & 73,57 & 178,16 & 180,97 & 67,85 & \begin{tabular}{|l|}
1167,68 \\
\end{tabular} & 132,45 & 56,49 & 20,77 & 371,32 & 210,95 & 220,01 & 349,71 \\
\hline Pelophylax perezi & 30TWN58 & 100,00 & 128,13 & 80,12 & 40,23 & 4265,19 & 240,38 & 43,60 & 196,79 & 82,32 & 180,89 & 184,14 & 77,08 & 1240,29 & 142,68 & 58,48 & 21,94 & 399,49 & 218,99 & 233,70 & 377,46 \\
\hline Pelophylax perezi & 30TWN60 & 100,00 & 128,49 & 102,42 & 38,65 & 5712,74 & 275,91 & 13,51 & 262,40 & 148,66 & 202,28 & 202,28 & 56,78 & 570,93 & 63,70 & 30,87 & 19,23 & 168,39 & 113,13 & 114,32 & 141,37 \\
\hline Pelophylax perezi & 30TWN61 & 100,00 & 123,57 & 101,06 & 38,90 & 5586,07 & 268,85 & 11,30 & 257,55 & \begin{tabular}{|l|l|}
97,75 \\
97,
\end{tabular} & 195,97 & 195,97 & 53,90 & 664,02 & 70,13 & 35,35 & 18,29 & 191,84 & 129,09 & 129,09 & 173,33 \\
\hline Pelophylax perezi & 30TWN62 & 100,00 & 116,46 & 99,48 & 39,00 & 5443,10 & 259,68 & 71,40 & 252,25 & $\mid 61,06$ & \begin{tabular}{|l|}
187,44 \\
\end{tabular} & 187,44 & $\begin{array}{ll}49,16 \\
40\end{array}$ & \begin{tabular}{|l|l|}
775,19 \\
\end{tabular} & 81,60 & 40 & $\begin{array}{ll}18,03 \\
\end{array}$ & 228,47 & 148,49 & 148,49 & 211,26 \\
\hline Pelophylax perezi & 30TWN63 & 100,00 & 103,32 & 97,94 & 39,01 & 5316,96 & 245,23 & $-2,27$ & 247,50 & 45,76 & 173,31 & 173,31 & 38,25 & 914,81 & 99,12 & 48,44 & 17,94 & 274,80 & 173,71 & 173,71 & 257,41 \\
\hline Pelophylax perezi & 30TWN64 & 100,00 & 104,07 & 95,58 & 39,10 & 5166,61 & 242,19 & 1,56 & 240,63 & 48,36 & 172,21 & 172,21 & 41,03 & 984,99 & 108,32 & 51,52 & 18,30 & 300,55 & 186,36 & 186,36 & 281,81 \\
\hline Pelophylax perezi & 30TWN65 & 100,00 & 114,75 & 92,10 & 39,59 & 4941,28 & 246,34 & 16,24 & 230,10 & 61,12 & 178,84 & 179,67 & 54,48 & 1037,83 & 115,65 & 52,42 & 19,30 & 323,01 & 194,30 & 195,10 & 302,10 \\
\hline Pelophylax perezi & 30TWN66 & 100,00 & 130,98 & 86,46 & 40,11 & 4575,07 & 251,84 & 39,33 & 212,51 & 81,00 & 188,09 & 190,77 & 75,39 & 1103,43 & 124,59 & 52,88 & 20,87 & 350,55 & 199,35 & 206,77 & 327,82 \\
\hline Pelophylax perezi & \begin{tabular}{|l|} 
30TWN67 \\
\end{tabular} & 100,00 & $\begin{array}{l}13,50,06 \\
123,0\end{array}$ & $\begin{array}{l}80,404 \\
85,63\end{array}$ & 年 40,31 & 44495,82 & 243,12 & $\begin{array}{l}3,35 \\
33,38 \\
\end{array}$ & \begin{tabular}{|l|}
209,73 \\
\end{tabular} & $\begin{array}{l}\mid l, 00 \\
74,62\end{array}$ & \begin{tabular}{|l|}
$179,28,28$ \\
179
\end{tabular} & 182,14 & $\begin{array}{l}\mid 3,399 \\
68,95\end{array}$ & $\begin{array}{l}1109,45 \\
1199,36\end{array}$ & \begin{tabular}{|l|}
135,85 \\
135,
\end{tabular} & 52,00 & 20,85 & 382,33 & 217,09 & 225,01 & 358,30 \\
\hline Pelophylax perezi & 30TWN68 & 100,00 & 128,29 & 82,14 & 40,94 & 4248,49 & 241,72 & 43,40 & 198,32 & 82,67 & 180,87 & 184,08 & 77,57 & 1282,11 & 145,99 & 61,18 & 21,70 & 412,56 & 227,80 & 241,07 & 386,77 \\
\hline Pelophylax perezi & 30TWN69 & 47,00 & 142,35 & 77,38 & \begin{tabular}{|l|l|}
40,97 \\
\end{tabular} & 4040,34 & 247,61 & 61,04 & 186,56 & 98,65 & 191,69 & 195,08 & 93,94 & 1284,21 & 149,00 & 59,06 & 23,20 & 418,49 & 222,79 & 243,99 & 393,32 \\
\hline Pelophylax perezi & 30TWN70 & 100,00 & 128,26 & 103,05 & 38,81 & 5722,17 & 276,35 & 12,53 & 263,82 & 117,08 & 202,17 & 202,17 & 56,39 & 621,40 & 66,86 & \begin{tabular}{|l|l|}
32,47 \\
\end{tabular} & 19,35 & 180,75 & 118,47 & 118,66 & 161,95 \\
\hline Pelophylax perezi & 30TWN71 & 100 & 122,45 & 101,95 & 38,5 & 5618,81 & 269 & 9,36 & 259,82 & 75,45 & 195,46 & 195,46 & 52,41 & 709,88 & 75,1 & 37,01 & 18,93 & 208,65 & 134,01 & 134,01 & 191,71 \\
\hline Pelophylax perezi & 30TWN72 & 100,00 & 120,18 & 100,16 & 39,00 & 5473,56 & 264,10 & \begin{tabular}{|l|l|}
10,08 \\
1,5
\end{tabular} & $\begin{array}{l}254,02 \\
25\end{array}$ & 59,92 & 191,43 & 191,43 & 52,22 & 795,65 & 86,1 & 40,98 & 18,93 & 239,09 & 148,78 & 148,78 & 221,42 \\
\hline Pelophylax perezi & 30TWN73 & 100,00 & 103,41 & 98,80 & 39,01 & 5350,09 & 246,23 & $-3,39$ & 249,61 & 45,57 & 173,73 & 173,73 & 37,87 & 936,65 & 102,89 & 49,35 & 18,41 & 283,47 & 175,99 & 175,99 & 265,79 \\
\hline Pelophylax perezi & 30TWN74 & 100,00 & 100,62 & 96,62 & 39,21 & 5208,45 & 240,12 & $-2,82$ & 242,94 & 44,68 & 169,38 & 169,38 & 37,17 & 1021,25 & 113,47 & 53,57 & 18,56 & 312,86 & 191,86 & 191,86 & 293,94 \\
\hline Pelophylax perezi & 30TWN75 & 100,00 & 108,49 & 94,04 & 39,53 & 5036,57 & 243,08 & 7,88 & 235,20 & 54,16 & 174,61 & 174,66 & 46 & 073,28 & 120,82 & 54,95 & 19,36 & 82 & 200,40 & 00,40 & 313,61 \\
\hline Pelophylax perezi & 30TWN76 & 100,00 & 111 & 90,73 & 39,8 & 4809,98 & 239 & $\begin{array}{r}, 1400 \\
14,90 \\
\end{array}$ & 224,85 & 59,29 & $\begin{array}{l}172,92 \\
\end{array}$ & 17 & 52,67 & 1155,76 & \begin{tabular}{|l|l|}
130,57 \\
\end{tabular} & 58,44 & 19,83 & 363,66 & 213,91 & 216,84 & 340,62 \\
\hline Pelophylax perezi & $30 \mathrm{TWN}$ & 100,00 & 13 & 82,26 & 41,5 & 4169,84 & 247 & 51,34 & 195,95 & 90,94 & 187,18 & 190,48 & 86,04 & 1306,41 & 148,74 & 62,01 & 22,07 & 422,21 & 231,31 & 246,37 & 393,01 \\
\hline Pelophylax perezi & $\begin{array}{l}\text { 30TWN79 } \\
\end{array}$ & 55,00 & 142,54 & 79,19 & 41,49 & 4050,54 & 248,44 & 59,70 & 188,74 & 98,79 & 191,96 & 195,32 & 93,85 & 1318,53 & 152,11 & 61,78 & 22,71 & 428,98 & 231,91 & 252,33 & 399,74 \\
\hline Pelophylax perezi & 30TWN80 & 100,00 & 129,95 & 103,38 & 38,72 & 5737,03 & 278,56 & 13,85 & 264,71 & 94,26 & 204,09 & 204,09 & 57,87 & 659,71 & 71,18 & 33,21 & 20,28 & 196,01 & 121,57 & 121,57 & 179,50 \\
\hline Pelophylax perezi & 30TWN81 & 100,00 & 127,08 & 102,29 & 38,9 & 565 & 274,04 & 12,96 & 9 & 69,60 & 200,10 & 200,10 & 56 & 736,82 & 81,42 & 91 & 20,25 & 85 & 134,50 & 134,50 & 206,27 \\
\hline Pelophylax perezi & 30TWn & 100,00 & 12 & 101,03 & 38 & 552 & 267 & 10,41 & 256,87 & 61,07 & 193,86 & 193,86 & 53,14 & 830,67 & 93,74 & 41,59 & 20,33 & 255,99 & 150,78 & 150,78 & 238,30 \\
\hline Pelophylax perezi & $\begin{array}{l}\text { 30TWN83 } \\
\end{array}$ & 100,00 & 110,64 & 99,59 & 39,01 & 5397,98 & 254,13 & 2,25 & 251,88 & 51,75 & 181,21 & 181,21 & 43,90 & 943,14 & 106,92 & 48,21 & 19,84 & 291,81 & 172,73 & 172,73 & 273,47 \\
\hline Pelophylax perezi & 30TWN84 & 100,00 & 91,57 & $\begin{array}{l}97,49 \\
97\end{array}$ & 39,01 & 5276,41 & 233,10 & \begin{tabular}{|c|c|}
$-2,25$ \\
$-13,28$
\end{tabular} & $\begin{array}{l}246,38 \\
246\end{array}$ & 35,46 & $\begin{array}{l}161,44 \\
161\end{array}$ & $\begin{array}{l}161,44 \\
161\end{array}$ & 27,57 & 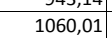 & 118,21 & 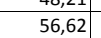 & 18,24 & 323,42 & 199,51 & 199,51 & 305,06 \\
\hline Pelophylax perezi & 30TWN85 & 100,00 & 106,58 & 95,36 & 39,43 & 5114,41 & 243,07 & 4,09 & 238,99 & 51,34 & 173,73 & 173,73 & 43, & 1099,31 & 125,91 & 56,20 & 19,88 & 345,57 & 203,27 & 203,27 & 324,3 \\
\hline Pelophylax perezi & 30TWI & 100,00 & 113 & 92,50 & 39, & 4893 & 244 & 14,93 & 229 & 60,58 & 176 & 17 & 53,68 & 1171,81 & 135 & 58 & 20,63 & 373,55 & 215,77 & 216,84 & 34 \\
\hline Pelophylax perezi & \begin{tabular}{|l|}
30 TWN87 \\
\end{tabular} & $\begin{array}{l}100,00 \\
\end{array}$ & $\begin{array}{l}111,40 \\
114,38\end{array}$ & $\begin{array}{l}2,30,20 \\
90,0\end{array}$ & | & $\begin{array}{l}405,340 \\
4714,87\end{array}$ & 2440,70 & $\begin{array}{l}4,1939 \\
19,19 \\
\end{array}$ & $\begin{array}{l}221,50 \\
221,50\end{array}$ & $\begin{array}{l}\mid c 0,30 \\
63,64 \\
\end{array}$ & 174,15 & $\begin{array}{l}176,25 \\
176\end{array}$ & $\begin{array}{l}57,07 \\
57\end{array}$ & $\mid$\begin{tabular}{|l|l|l|l|}
1253,24 \\
\end{tabular} & 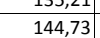 & $\begin{array}{l}30,1 / 2 \\
62,59\end{array}$ & $\begin{array}{l}20,03 \\
20,78\end{array}$ & 401,85 & 230,62 & 231,04 & $\begin{array}{l}345,05 \\
375,75\end{array}$ \\
\hline Pelophylax perezi & 30TWN88 & 100,00 & 129,64 & 84,99 & 41,19 & 4340,68 & 245,11 & 41,00 & 204,11 & 82,85 & 183,45 & 186,52 & 77,15 & 1323,19 & 152,53 & 64,33 & 21,75 & 428,25 & 238,60 & 250,17 & 398,13 \\
\hline Pelophylax perezi & 30TWN89 & 84,00 & 141,98 & 80,34 & 41,12 & $\begin{array}{l}4147,07 \\
\end{array}$ & 249,07 & 56,16 & 192,91 & 97,07 & 192,83 & 196,01 & 91,49 & $\mid 1324,87$ & 154,41 & 63,41 & 22,63 & 431,54 & 237,27 & 257,20 & 400,51 \\
\hline Pelophylax perezi & 30TWN90 & 100,00 & 130,41 & $\begin{array}{ll}103,87 \\
\end{array}$ & 38,51 & 5766,03 & 279,85 & 13,29 & 266,56 & 90,0 & 204 & 204 & 57, & 694 & 78,47 & 33,90 & 21,38 & 210,72 & 124,39 & 124,39 & 195,88 \\
\hline Pelophylax perezi & 30TWN91 & 100,00 & 129,65 & 102,72 & 38,78 & 5672,55 & 277,29 & 14,55 & 262,73 & 67,71 & 202,99 & 202,99 & 58,42 & 767,09 & 88,85 & 37,06 & 21,72 & 238,28 & 135,92 & 35,92 & 222,37 \\
\hline
\end{tabular}




\begin{tabular}{|c|c|c|c|c|c|c|c|c|c|c|c|c|c|c|c|c|c|c|c|c|c|}
\hline TAXON & UTM & $\mathrm{km} 2$ & B101 & B102 & $\mathrm{BIO3}$ & B104 & B105 & B106 & B107 & B108 & B109 & BIO10 & BIO11 & BIO12 & 81013 & BIO14 & BIO15 & BIO16 & BIO17 & B1018 & B1019 \\
\hline Pelophylax perezi & 30TWN92 & 100,00 & 124,90 & 101,77 & 38,94 & 5574,60 & 271,25 & 11,91 & 259,34 & 63,38 & 197,29 & 197,29 & 55,07 & 861,72 & 101,88 & 41,69 & 22,23 & 272,79 & 151,59 & 151,59 & 255,62 \\
\hline Pelophylax perezi & 30TWN93 & 100,00 & 114,54 & 100,49 & 39,01 & 5454,66 & 259,17 & 4,41 & 254,76 & 54,88 & 185,74 & 185,74 & 46,83 & 966,57 & 113,87 & 48,01 & 21,46 & 306,26 & 172,27 & 172,27 & 287,92 \\
\hline Pelophylax perezi & 30TWN94 & 100,00 & 112,33 & 98,54 & 39,03 & 5324,67 & 253,68 & 5,05 & 248,64 & 54,25 & 181,91 & 181,91 & 46,41 & 1044,64 & 123,47 & 52,04 & 21,45 & 333,16 & 187,74 & 187,74 & 313,34 \\
\hline Pelophylax perezi & 30TWN95 & 100,00 & 112,46 & 96,45 & 39,30 & 5169,92 & 249,99 & 7,99 & 242,00 & 56,38 & 180,13 & 180,13 & 48,65 & 1115,28 & 131,91 & 55,58 & 21,42 & 357,89 & 201,88 & 201,88 & 336,12 \\
\hline Pelophylax perezi & 30TWN96 & 100,00 & 104,13 & 94,60 & 39,59 & 5054,56 & 238,99 & 2,51 & 236,48 & 49,88 & \begin{tabular}{|l|}
170,57 \\
\end{tabular} & \begin{tabular}{|l|}
170,57 \\
\end{tabular} & 42,31 & \begin{tabular}{|l|l|}
1187,49 \\
\end{tabular} & \begin{tabular}{|l|l|}
138,57 \\
\end{tabular} & $\begin{array}{ll}60,62 \\
\end{array}$ & 20,39 & 378,00 & 219,52 & 219,52 & 355,21 \\
\hline Pelophylax perezi & 30TWN98 & 100,00 & 120,70 & 87,94 & 40,59 & 4563,81 & 241,46 & 27,30 & 214,15 & 71,55 & 177,77 & 180,49 & 64,91 & 1332,12 & 156,15 & 66,26 & 21,49 & 431,84 & 244,48 & 251,74 & 402,44 \\
\hline Pelophylax perezi & 30TWN99 & 100,00 & 133,51 & 83,01 & $\begin{array}{ll}40,83 \\
\end{array}$ & 4317,29 & 244,87 & 43,87 & 201,01 & 90,02 & 186,91 & 189,84 & 80,53 & 1355,71 & 159,45 & 66,82 & 22,10 & 441,31 & 248,15 & 264,33 & 409,19 \\
\hline Pelophylax perezi & 30TWPOO & 79,00 & 137,74 & 60,59 & 35,91 & 3895,53 & 227,82 & 61,13 & 166,69 & $\begin{array}{ll}93,62 \\
3\end{array}$ & 185,65 & 189,02 & 89,81 & 1245,64 & 163,35 & 49,35 & 30,33 & 425,02 & 194,31 & 229,77 & 424,19 \\
\hline Pelophylax perezi & 30TWP10 & 94,00 & 132,38 & 64,68 & 36,92 & 3975,66 & 228,22 & 55,49 & 172,72 & 89,86 & 181,32 & 184,84 & 84,41 & 1266,20 & 160,96 & 52,91 & 27,98 & 425,57 & 204,62 & 235,59 & 420,02 \\
\hline Pelophylax perezi & 30TWP20 & 75,00 & 136,08 & 66,31 & 37,61 & \begin{tabular}{ll|}
3978,94 \\
\end{tabular} & 233,33 & 59,44 & 173,89 & 93,78 & 184,80 & 188,46 & 88,51 & \begin{tabular}{|l|}
1263,98 \\
\end{tabular} & 158,65 & 53,35 & 27,25 & 422,90 & 205,95 & 236,04 & 415,55 \\
\hline Pelophylax perezi & 30TWP30 & 40,00 & 137,65 & 69,00 & 38,61 & 3995,39 & 236,84 & 60,23 & 176,61 & 94,85 & 186,32 & 190,00 & 89,87 & 1267,71 & 155,84 & 54,73 & 26,05 & 421,16 & 210,02 & 237,97 & 409,79 \\
\hline Pelophylax perezi & 30TWP90 & 28,00 & 138,83 & 80,55 & 40,75 & 4220,05 & 245,72 & 50,41 & 195,31 & 105,70 & 190,86 & 193,91 & 86,75 & 1355,98 & 160,34 & 66,73 & 22,59 & 442,94 & 248,83 & 269,58 & 409,41 \\
\hline Pelophylax perezi & 30TXK03 & 100,00 & 101,39 & 115,46 & 38,00 & 6422,34 & 274,26 & $-26,36$ & 300,62 & 108,73 & 187,13 & 188,25 & 25,08 & 546,18 & 70,89 & 25,10 & 26,10 & 179,06 & 101,39 & 111,61 & 117,34 \\
\hline Pelophylax perezi & 30TXK04 & 100,00 & 91,29 & 113,85 & 37,81 & 6408,16 & 263,32 & $-35,17$ & 298,49 & 109,31 & 177,06 & 177,95 & 15,51 & 588,74 & 76,51 & 28,84 & 25,23 & 193,61 & 111,69 & 123,91 & 126,51 \\
\hline Pelophylax perezi & 30TXK05 & 100,00 & 85,42 & 112,53 & 37,48 & 6386,84 & 256,24 & $-40,19$ & 296,44 & 103,25 & 170,92 & 171,92 & 9,99 & 611,81 & 79,73 & $\begin{array}{l}31,25 \\
\end{array}$ & 24,81 & 201,77 & 117,99 & 131,47 & 131,33 \\
\hline Pelophylax perezi & 30TXK06 & 100,00 & 79,90 & 111,37 & 37,18 & 6361,73 & 249,61 & $-44,79$ & 294,40 & 97,32 & 165,13 & 165,92 & 4,81 & 636,51 & 82,84 & 33,56 & 24,36 & 209,90 & 124,25 & 138,84 & 136,99 \\
\hline Pelophylax perezi & 30TXK07 & 100,00 & 76,83 & 110,40 & \begin{tabular}{|l|l|}
37,03 \\
\end{tabular} & 6336,85 & 245,38 & $-47,18$ & 292,56 & 94,26 & 161,80 & 162,60 & 1,99 & 646,58 & 84,44 & 34,85 & 24,10 & 213,76 & 127,65 & 142,93 & 139,03 \\
\hline Pelophylax perezi & 30TXK08 & 100,00 & 77,03 & 109,66 & \begin{tabular}{|l|l|}
37,08 \\
\end{tabular} & 6312,45 & 243,99 & $-46,97$ & 290,96 & 94,68 & 161,59 & 162,30 & 2,12 & 639,09 & 84,13 & 35,02 & 24,46 & 212,45 & 127,62 & 143,21 & 136,57 \\
\hline Pelophylax perezi & 30TXK09 & 100,00 & 79,59 & 109,00 & 37,00 & 6294,38 & 244,64 & $-44,95$ & 289,60 & 97,81 & 162,42 & 164,38 & 4,53 & 617,75 & 82,36 & 34,29 & 25,07 & 206,99 & 124,88 & 140,40 & $\begin{array}{ll}130,87 \\
\end{array}$ \\
\hline Pelophylax perezi & 30TXK14 & 100,00 & 94,15 & 111,73 & 37,50 & 6385,23 & 262,70 & $-31,40$ & 294,10 & 112,38 & 179,48 & 180,45 & 18,54 & 565,25 & 74,42 & 28,39 & 25,88 & 188,35 & 110,60 & 122,19 & 117,06 \\
\hline Pelophylax perezi & 30TXK15 & 100,00 & 82,18 & 110,27 & 37,05 & 6359,69 & 250,24 & $-41,86$ & 292,10 & 99,40 & 166,42 & 168,26 & 7,14 & 624,09 & 81,44 & 33,05 & 24,62 & 207,10 & 123,55 & 137,40 & 131,11 \\
\hline Pelophylax perezi & 30TXK16 & 100,00 & 80,38 & 109,45 & 37,00 & 6342,31 & 247,30 & $-43,47$ & 290,77 & 97,85 & 161,94 & 166,18 & 5,42 & 626,66 & 82,40 & 33,88 & 24,82 & 208,97 & 125,47 & 140,04 & 131,01 \\
\hline Pelophylax perezi & 30TXK17 & 100,00 & 81,07 & 108,66 & 37,00 & 6320,35 & 246,23 & $-42,92$ & 289,15 & 98,94 & 129,53 & 166,37 & 6,01 & 614,81 & 81,79 & 33,82 & 25,33 & 206,54 & 124,02 & 139,62 & 127,34 \\
\hline Pelophylax perezi & 30TXK18 & 100,00 & 75,69 & 107,67 & 37,00 & 6288,67 & 239,92 & $-47,22$ & 287,14 & 93,29 & 120,62 & 160,59 & 1,25 & 642,11 & 84,96 & 36,08 & 24,72 & 215,03 & 130,37 & 147,04 & 134,20 \\
\hline Pelophylax perezi & 30TXK19 & 100,00 & 83,36 & 107,15 & 37,00 & 6276,76 & 244,69 & $-41,06$ & 285,75 & 102,17 & 44,08 & 167,57 & 8,08 & 586,94 & 80,05 & 33,30 & 26,64 & 200,45 & 118,56 & 137,53 & 119,29 \\
\hline Pelophylax perezi & 30TXK23 & 100,00 & 100,11 & 110,21 & 37,39 & 6373,31 & 266,38 & $-24,35$ & 290,73 & 118,26 & 146,67 & 186,21 & 24,56 & 535,75 & 70,58 & 26,75 & 26,57 & 179,48 & 105,99 & 116,16 & 107,35 \\
\hline Pelophylax perezi & 30TXK24 & 100,00 & 93,48 & 109,31 & 37,07 & 6365,55 & 259,06 & $-30,55$ & 289,61 & 111,53 & $\begin{array}{r}40,95 \\
86,95\end{array}$ & 179,53 & 18,15 & 561,96 & 74,46 & 29,25 & 26,24 & 188,91 & 111,88 & 124,59 & 112,80 \\
\hline Pelophylax perezi & 30TXK25 & 100,00 & 87,44 & 108,39 & 37,00 & 6344,98 & 252,18 & $-36,29$ & 288,47 & 105,20 & 63,33 & 173,14 & 12,24 & 588,16 & 78,06 & 31,61 & 25,82 & 197,97 & 118,21 & 132,53 & 118,65 \\
\hline Pelophylax perezi & 30TXK26 & 100,00 & 87,08 & 107,41 & 37,00 & 6329,36 & 250,13 & $-36,45$ & 286,58 & 105,25 & 49,88 & 172,45 & 11,81 & 580,73 & 78,10 & \begin{tabular}{l|l}
31,95 \\
\end{tabular} & 26,41 & 197,09 & 115,44 & 133,34 & 115,90 \\
\hline Pelophylax perezi & 30TXK27 & 100,00 & 90,92 & 106,46 & 36,99 & 6310,71 & 251,44 & $-33,16$ & 284,60 & 109,82 & 15,49 & 175,78 & 15,49 & 549,27 & 75,58 & 30,67 & 27,89 & 189,27 & 106,92 & 128,99 & 106,92 \\
\hline Pelophylax perezi & 30TXK28 & 100,00 & 84,80 & 105,77 & 36,99 & 6281,25 & 244,63 & $-38,76$ & 283,39 & 103,45 & 18,02 & 169,19 & 9,79 & 578,01 & 79,11 & 32,97 & 27,26 & 198,66 & 113,88 & 137,05 & 113,97 \\
\hline Pelophylax perezi & 30TXK29 & 100,00 & 85,15 & 105,01 & 36,99 & 6255,66 & 243,10 & $-38,75$ & \begin{tabular}{|l|l|}
281,85 \\
\end{tabular} & $\begin{array}{l}104,12 \\
100\end{array}$ & $\begin{array}{l}0,0<2 \\
9,82 \\
\end{array}$ & 168,88 & 9,82 & |569,58 & 78,84 & 32,90 & 27,86 & 197,32 & 111,00 & 137,19 & 111,47 \\
\hline Pelophylax perezi & 30TXK33 & 100,00 & 99,45 & 107,62 & 37,00 & 6345,18 & 262,45 & $-23,41$ & 285,86 & 117,12 & 40,71 & 185,07 & 24,05 & 535,92 & 70,68 & 27,60 & 26,84 & 180,35 & 104,38 & 118,53 & 104,49 \\
\hline Pelophylax perezi & 30TXK34 & 100,00 & 96,54 & 106,77 & 37,00 & 6341,71 & 258,65 & $-26,12$ & 284,78 & 114,40 & 23,29 & 182,16 & 21,10 & 541,29 & 72,33 & 28,84 & 27,11 & 183,53 & 104,59 & 122,41 & 104,60 \\
\hline Pelophylax perezi & 30TXK35 & 100,00 & 91,11 & 105,96 & 37,00 & 6329,52 & 252,52 & $-31,06$ & 283,59 & 109,05 & 34,57 & 176,71 & 16,12 & 562,28 & 75,46 & 30,82 & 26,95 & 191,22 & 109,01 & 129,35 & 109,10 \\
\hline Pelophylax perezi & $\begin{array}{l}30 T \times K 36 \\
\end{array}$ & 100,00 & 89,36 & 105,15 & 36,96 & 6310,23 & 249,32 & $-33,01$ & 282,33 & 107,46 & 14,43 & 174,49 & 14,43 & 562,61 & 76,48 & 31,49 & 27,46 & 192,96 & 108,06 & 132,04 & 108,06 \\
\hline Pelophylax perezi & 30TXK37 & 100,00 & 96,51 & 103,75 & 36,84 & 6301,96 & 252,85 & $\frac{-26,35}{-26}$ & 279,20 & 115,90 & 21,12 & 181,14 & 21,12 & 510,25 & 71,81 & 27,73 & 30,17 & 179,23 & 93,54 & 123,62 & 93,54 \\
\hline Pelophylax perezi & 30TXK39 & 100,00 & 96,64 & 102,03 & 36,50 & 6237,25 & 248,21 & $-27,50$ & 275,72 & 117,08 & 20,75 & 179,66 & 20,75 & 493,07 & 71,48 & 25,97 & 32,38 & 177,07 & 88,36 & 124,17 & 88,36 \\
\hline Pelophylax perezi & 30TXK43 & 100,00 & 118,27 & 104,35 & 37,00 & 6282,53 & 274,74 & $-3,33$ & 278,07 & 136,69 & 43,12 & 202,61 & 43,12 & 444,88 & 59,51 & 22,17 & 29,90 & 150,68 & 80,74 & 97,98 & 80,74 \\
\hline Pelophylax perezi & 30TXK44 & 100,00 & 115,99 & 103,29 & 36,95 & $\begin{array}{ll}6304,84 \\
\end{array}$ & 271,75 & $-5,23$ & 276,98 & 134,93 & 40,46 & 200,65 & 40,46 & 442,88 & 60,61 & 22,91 & 30,87 & 152,32 & 78,36 & 100,94 & 78,36 \\
\hline Pelophylax perezi & 30TXK45 & 100,00 & 100,83 & 103,15 & 36,7 & 6318,85 & 257,94 & $-20,10$ & 278,04 & 119,41 & 25,62 & 186,08 & 25,62 & 503,32 & 69,24 & 27, & 29,50 & 174,30 & 91,03 & 118,84 & 91,03 \\
\hline Pelophylax perezi & 30TXK46 & 100,00 & 100,39 & 102,03 & 36, & 6310,30 & 255,61 & $-20,58$ & 276,19 & 119,41 & 25,17 & 185,30 & 25,17 & $\begin{array}{l}494,29 \\
\end{array}$ & 69,28 & 26,0 & 30,70 & 173,50 & 87,49 & 119,83 & 87,49 \\
\hline Pelophylax perezi & 30TXK47 & 100,00 & 105,58 & 100,56 & 36,06 & 6302,53 & 257,69 & $-15,92$ & 273,61 & 125,56 & 29,86 & 189,98 & 29,86 & 456,05 & 66,08 & 22,62 & 33,51 & 163,82 & 76,81 & 114,08 & 76,81 \\
\hline Pelophylax perezi & 30TXK48 & 100,00 & 106,64 & 99,68 & 36,05 & 6268,44 & 255,85 & $-15,66$ & 271,51 & 127,33 & 30,49 & 190,24 & 30,49 & 442,42 & 65,35 & 21,40 & 35,04 & 161,32 & 73,19 & 113,16 & 73,19 \\
\hline Pelophylax perezi & 30TXK49 & 100,00 & 105,09 & 99,04 & 36,05 & 6222,95 & 251,72 & $-18,01$ & 269,73 & 126,24 & 29,09 & 187,64 & 29,09 & 443,49 & 66,29 & 21, & 35,94 & 163,25 & 73,09 & 115,32 & 73,09 \\
\hline Pelophylax perezi & \begin{tabular}{|l|l|}
$30 T \times K 53$ \\
\end{tabular} & 100,00 & 104,61 & 102,85 & 36,5 & 6278,89 & 261,26 & \begin{tabular}{|c|c|}
$-14,89$ \\
-14
\end{tabular} & 276,15 & 122,03 & 30,58 & 189,31 & 30,58 & 509,56 & 67,23 & 26, & 28,05 & 171,62 & 93,89 & 114,91 & 93,89 \\
\hline Pelophylax perezi & 30TXK54 & 100,00 & 110,14 & 101,39 & 36,45 & 6285,68 & 264,95 & $-9,05$ & 274,00 & 128,37 & 35,58 & 194,76 & 35,58 & 469,38 & 63,75 & 24,5 & 30,30 & 161,03 & 82,34 & 108,75 & 82,34 \\
\hline Pelophylax perezi & 30TXK55 & 100,00 & 113,78 & 99,76 & 36,03 & 6306,82 & 267,17 & $-5,13$ & 272,30 & 132,75 & 38,54 & 198,56 & 38,54 & 438,72 & 61,46 & 21,63 & 32,73 & 153,64 & 73,11 & 104,93 & 73,11 \\
\hline Pelophylax perezi & 30TXK56 & 100,00 & 112,06 & 98,56 & 35,93 & 6318,25 & 264,44 & $-6,62$ & 271,06 & 131,48 & 36,42 & 196,96 & 36,42 & 432,95 & 62,20 & 20,58 & 34,39 & 154,45 & 69,78 & 107,29 & 69,78 \\
\hline Pelophylax perezi & 30TXK59 & 100,00 & 94,94 & 98,25 & 36,00 & 6198,18 & 243,00 & $-25,97$ & 268,97 & 114,45 & 20,13 & 177,62 & 20,13 & 503,23 & 72,60 & 25,45 & 32,69 & 55 & 86,46 & 128,89 & 86,46 \\
\hline Pelophylax perezi & 30ТХК & 100,00 & & 102,00 & 36, & 6236,43 & 241,01 & $-35,06$ & 276,07 & 年 & 38,77 & 167,37 & 10,31 & 644,46 & 81,18 & 35,28 & 24,06 & 210,51 & 127,79 & 140,53 & 127,99 \\
\hline Pelophylax perezi & $\begin{array}{l}30 T \times K 64 \\
\end{array}$ & 100,00 & 87,24 & 100,95 & 36,13 & 6239,38 & 243,50 & $-30,71$ & 274,21 & 103,31 & 23,44 & 171,63 & 14,31 & 605,14 & 78,26 & 33,42 & 25,65 & 201,08 & 116,08 & 137,66 & 116,18 \\
\hline Pelophylax perezi & 30TXK65 & 100,00 & $\begin{array}{l}0,24 \\
101,19\end{array}$ & 98,94 & 36,00 & 6251,87 & 254,13 & $-16,56$ & 270,68 & $\begin{array}{l}118,92 \\
102\end{array}$ & 27,25 & $\begin{array}{l}185,38 \\
\end{array}$ & 27,25 & 510,44 & 69,27 & 26,68 & 29,66 & 174,93 & 89,85 & 121,25 & 89,85 \\
\hline Pelophylax perezi & 30 TXK66 & 100,00 & 108,23 & 97,32 & 35,94 & 6269,53 & 259,48 & $-9,12$ & 268,61 & 126,95 & 33,81 & 192,60 & 33,81 & 458,11 & 64,67 & 22,13 & 33,10 & 161,26 & 74,98 & 112,78 & 74,98 \\
\hline Pelophylax perezi & 30TXK67 & 100,00 & 104 & 96,94 & 35,79 & 6246,24 & 254,15 & $-13,47$ & 267 & 123,62 & 30,08 & 188,43 & 30,08 & 469,72 & 66,91 & 22,78 & 33,33 & 166,56 & 77,30 & 117,66 & 77,30 \\
\hline Pelophylax perezi & $\begin{array}{l}\text { 30TXK68 } \\
\text { 30TKN }\end{array}$ & $\begin{array}{l}100,00 \\
\end{array}$ & 102,25 & $\begin{array}{l}0,344 \\
96,64\end{array}$ & 35,91 & $\begin{array}{l}024,2,44 \\
6212,39\end{array}$ & 249,82 & $\begin{array}{l}-1 ., 4,41 \\
-16,64 \\
\end{array}$ & \begin{tabular}{|l|}
266,47 \\
260
\end{tabular} & $\begin{array}{l}121,72< \\
120\end{array}$ & $\begin{array}{l}30,00 \\
27,74 \\
\end{array}$ & $\begin{array}{l}180,434 \\
185,44 \\
\end{array}$ & $\begin{array}{l}30,00 \\
27,74 \\
\end{array}$ & \begin{tabular}{|l|}
$405,1 / 20$ \\
474,20
\end{tabular} & $\begin{array}{l}60,31 \\
68,32\end{array}$ & 22,89 & $\begin{array}{l}35,35 \\
33,66\end{array}$ & $\begin{array}{l}100,50 \\
169,64\end{array}$ & 78,10 & $\begin{array}{l}11,00 \\
120,54\end{array}$ & 78,10 \\
\hline Pelophylax perezi & 30TXK69 & 100,00 & 100,38 & 96,35 & 35,97 & 6177,58 & 245,97 & $-19,36$ & 265,34 & 120,29 & 25,86 & 182,75 & 25,86 & 478,58 & 69,53 & 23,12 & 34,12 & 172,34 & 79,11 & 123,21 & 79,11 \\
\hline Pelophylax perezi & 30TXK73 & 100,00 & 90,47 & 99,95 & 36,11 & 619230 & 245,25 & -2630 & 271.55 & 106.12 & 20,42 & 174,21 & 18.38 & 604.95 & 76,52 & 32.69 & 2501 & 197.56 & 116.88 & 134,35 & 116,88 \\
\hline Pelophylax perezi & 30TXK74 & 100,00 & 91,00 & 99,13 & 36,01 & 6192,24 & 244,61 & $-25,81$ & 270,42 & $107, \mathrm{C}$ & 18,6 & 174 & 18, & 590,92 & 76,16 & 32,35 & 25 & 195,32 & 111,82 & 134,20 & 111,82 \\
\hline Pelophylax perezi & 30TXK75 & 100,00 & 103,40 & 97,31 & 35,99 & 6193,90 & 254,00 & $\begin{array}{l}-2,13,27 \\
-127\end{array}$ & 267,27 & 120,72 & 30,15 & 186,71 & 30,15 & 508,76 & 68,34 & 26,39 & 29,45 & 172,57 & 89,17 & 119,69 & $\begin{array}{l}4+1,0 \\
89,17\end{array}$ \\
\hline
\end{tabular}




\begin{tabular}{|c|c|c|c|c|c|c|c|c|c|c|c|c|c|c|c|c|c|c|c|c|c|}
\hline TAXON & UTM & $\mathrm{km} 2$ & B101 & B102 & $\mathrm{BIO3}$ & B104 & B105 & B106 & B107 & B108 & B109 & B1010 & BIO11 & BIO12 & B1013 & BIO14 & BIO15 & BIO16 & BIO17 & BIO18 & B1019 \\
\hline Pelophylax perezi & 30TXK76 & 100,00 & 96,20 & 97,25 & 35,99 & 6186,08 & 246,59 & $-20,73$ & 267,32 & 113,50 & 23,07 & 179,41 & 23,07 & 539,14 & 72,73 & 28,49 & 28,82 & 183,65 & 95,95 & 128,89 & 95,95 \\
\hline Pelophylax perezi & 30TXK77 & 100,00 & 88,03 & 97,19 & 36,00 & 6165,48 & 238,27 & $-29,22$ & 267,50 & 105,11 & 15,14 & 170,92 & 15,14 & 579,55 & 77,91 & 31,66 & 27,76 & 197,02 & 105,96 & 139,66 & 105,96 \\
\hline Pelophylax perezi & 30TXK78 & 100,00 & 86,79 & 96,62 & 35,98 & 6147,74 & 235,81 & $-30,66$ & 266,47 & 104,22 & 13,87 & 169,33 & 13,87 & 581,24 & 78,81 & 31,64 & 28,28 & 198,74 & 105,94 & 141,88 & 105,94 \\
\hline Pelophylax perezi & 30TXK79 & 100,00 & 90,39 & 96,06 & \begin{tabular}{l|l}
35,95 \\
\end{tabular} & 6131,76 & 237,29 & $-27,62$ & 264,91 & 108,73 & 17,29 & 172,42 & 17,29 & 551,11 & 76,38 & 28,97 & 30,00 & 191,40 & 97,79 & 137,19 & 97,79 \\
\hline Pelophylax perezi & 30TXK83 & 100,00 & 106,31 & 97,56 & 36,03 & 6113,81 & 256,51 & $-9,25$ & 265,75 & 122,37 & 34,74 & 188,70 & 34,74 & 529,97 & 67,17 & \begin{tabular}{|l|l|}
27,57 \\
\end{tabular} & 27,21 & 171,99 & 98,04 & \begin{tabular}{|l|l|}
116,27 \\
\end{tabular} & 98,04 \\
\hline Pelophylax perezi & 30TXK84 & 100,00 & 112,75 & 96,24 & 36,00 & 6107,56 & 261,01 & $-2,94$ & 263,95 & 129,66 & 40,69 & 194,68 & 40,69 & 489,16 & 63,42 & 25,33 & 29,25 & 160,66 & 86,92 & 109,36 & 86,92 \\
\hline Pelophylax perezi & 30TXK85 & 100,00 & 113,47 & 95,37 & 35,96 & 6117,38 & 260,95 & $-1,89$ & 262,84 & 130,88 & 41,07 & 195,58 & 41,07 & 474,12 & 63,06 & 23,84 & 30,62 & 158,27 & 81,69 & 108,52 & 81,69 \\
\hline Pelophylax perezi & $\begin{array}{l}30 T \times K 86 \\
\end{array}$ & 100,00 & 102,09 & 95,56 & 35,84 & 6136,09 & 250,16 & $-13,75$ & 263,91 & 119,14 & 29,49 & 184,51 & 29,49 & 519,94 & 69,72 & 26,87 & 29,38 & 175,49 & 91,25 & 122,76 & 91,25 \\
\hline Pelophylax perezi & 30TXK87 & 100,00 & 86,28 & 96,04 & 35,94 & 6125,23 & 235,37 & $-29,68$ & 265,04 & 102,63 & 14,27 & 168,73 & 14,27 & 603,92 & 79,63 & 33,52 & 26,50 & 202,00 & 112,33 & 142,80 & 112,33 \\
\hline Pelophylax perezi & 30TXK88 & 100,00 & 86,99 & 95,60 & 35,78 & $\begin{array}{lll}6107,93 \\
\end{array}$ & 234,77 & $-29,32$ & 264,09 & 103,80 & 14,83 & 168,97 & 14,83 & 591,79 & 79,21 & 32,33 & 27,40 & 199,92 & 108,56 & 142,45 & 108,56 \\
\hline Pelophylax perezi & 30TXK89 & 100,00 & 89,89 & 95,19 & 35,86 & 6094,73 & 236,24 & $-26,91$ & 263,15 & 107,44 & 17,72 & 171,58 & 17,72 & 566,46 & 77,28 & 30,17 & 28,85 & 193,84 & 101,71 & 138,72 & 101,71 \\
\hline Pelophylax perezi & 30TXK93 & 100,00 & 115,89 & 95,69 & 36,00 & 6010,63 & 262,18 & 1,05 & 261,12 & 130,54 & 45,08 & 196,67 & 45,08 & 502,89 & 62,32 & 24,72 & 28,11 & 159,14 & 93,18 & 108,58 & 93,18 \\
\hline Pelophylax perezi & 30TXK94 & 100,00 & 119,28 & 94,74 & 36,00 & 6011,05 & 264,14 & 4,03 & 260,11 & 134,87 & 48,01 & 199,74 & 48,01 & 479,71 & 60,69 & 23,89 & 29,46 & 153,64 & 86,55 & 104,66 & 86,55 \\
\hline Pelophylax perezi & 30TXK95 & 100,00 & 108,05 & 94,79 & 35,99 & 6058,85 & 254,35 & $-6,84$ & 261,19 & 124,64 & 36,56 & 189,29 & 36,56 & 518,90 & 67,10 & 27,16 & 28,55 & 169,40 & 93,58 & 116,73 & 93,58 \\
\hline Pelophylax perezi & 30TXK96 & 100,00 & 87,55 & 95,38 & 35,88 & 6087,28 & 236,15 & $-27,25$ & 263,40 & 103,18 & 16,42 & 169,58 & 16,42 & 620,63 & 79,56 & 34,40 & 25,38 & 202,81 & 117,91 & 141,56 & 117,91 \\
\hline Pelophylax perezi & 30TXK97 & 100,00 & 76,32 & 95,25 & 35,61 & 6078,79 & 225,79 & $-38,10$ & 263,89 & 91,31 & 5,56 & 158,37 & 5,56 & 684,15 & 86,82 & 39,06 & 23,75 & 222,42 & 133,91 & 155,19 & 133,91 \\
\hline Pelophylax perezi & $\begin{array}{l}30 T \times K 98 \\
\end{array}$ & 100,00 & 82,76 & 94,76 & 35,80 & 6063,78 & 230,25 & $-32,22$ & 262,47 & 98,75 & 11,65 & 164,31 & 11,65 & 634,63 & 82,64 & 35,73 & 25,51 & 209,67 & 120,22 & 148,25 & 120,22 \\
\hline Pelophylax perezi & 30TXK99 & 100,00 & 87,85 & 94,31 & 35,77 & 6050,55 & 233,66 & $-27,96$ & 261,61 & $\begin{array}{r}104,72 \\
\end{array}$ & 16,28 & 168,97 & 16,28 & 596,15 & 79,43 & 32,70 & 27,18 & 199,91 & 109,85 & 142,78 & 109,85 \\
\hline Pelophylax perezi & 30TXL00 & 100,00 & 87,40 & 108,49 & 37,00 & 6279,95 & 249,65 & $-38,55$ & 288,19 & 106,84 & 120,01 & 171,49 & 11,81 & 564,10 & 77,31 & 31,40 & 26,81 & 192,40 & $\begin{array}{ll}115,47 \\
\end{array}$ & 130,72 & 116,72 \\
\hline Pelophylax perezi & 30TXL03 & 100,00 & 98,95 & 106,91 & 37,00 & 6224,39 & 255,57 & $-28,46$ & 284,03 & 120,35 & 32,00 & 181,13 & 22,49 & 490,08 & 69,96 & 27,81 & 29,75 & 171,77 & 97,98 & 1117,53 & 98,94 \\
\hline Pelophylax perezi & 30TXL06 & 100,00 & 114,08 & 106,94 & 37,01 & 6214,52 & 270,16 & $-13,74$ & 283,90 & 136,69 & 47,45 & 195,19 & 36,60 & 429,45 & 62,00 & 23,40 & 30,77 & 150,01 & 84,97 & 100,88 & 88,75 \\
\hline Pelophylax perezi & 30TXL08 & 100,00 & 119,31 & 107,56 & 37,04 & 6208,37 & 276,96 & $-7,71$ & 284,68 & 141,99 & 146,18 & 200,12 & 41,69 & 421,86 & 60,06 & 22,40 & 29,85 & 144,91 & 84,45 & $\begin{array}{r}96,62 \\
\end{array}$ & 90,46 \\
\hline Pelophylax perezi & 30TXLO9 & 100,00 & 104,34 & 107,92 & 37,44 & 6146,02 & 263,21 & $-21,23$ & 284,44 & 125,70 & 180,56 & 184,90 & 28,30 & 500,73 & 68,44 & 28,05 & 26,75 & 168,42 & 101,68 & \begin{tabular}{|c|}
115,77 \\
\end{tabular} & 111,09 \\
\hline Pelophylax perezi & 30TXL11 & 100,00 & 91,93 & 105,71 & 37,00 & 6228,03 & 248,16 & $-34,27$ & 282,43 & 112,37 & 15,75 & 174,65 & 15,75 & 523,98 & 74,38 & 30,10 & 29,51 & 184,00 & 102,93 & 127,41 & 102,93 \\
\hline Pelophylax perezi & 30TXL12 & 100,00 & 95,85 & 105,01 & 37,00 & 6202,83 & 249,54 & $-31,10$ & 280,64 & 117,09 & 26,91 & 177,72 & 19,57 & 497,81 & 71,90 & 28,04 & 30,91 & 176,99 & 96,26 & 122,93 & 96,50 \\
\hline Pelophylax perezi & 30TXL13 & 100,00 & 98,47 & 104,71 & 37,00 & 6186,85 & 251,01 & $-28,75$ & 279,77 & 120,31 & 31,71 & 179,94 & 22,29 & 482,34 & 70,19 & 26,68 & 31,63 & 172,32 & 92,00 & 119,73 & 93,40 \\
\hline Pelophylax perezi & 30TXL14 & 100,00 & $\begin{array}{l}99,84 \\
99,84\end{array}$ & 104,72 & 37,00 & 6169,05 & 252,13 & $-27,52$ & 279,65 & \begin{tabular}{|l|l|}
121,90 \\
\end{tabular} & 33,18 & 180,88 & 23,67 & $\mid 477,12$ & 69,48 & 26,47 & 31,68 & 170,33 & 90,88 & 118,34 & $\begin{array}{l}3,40 \\
93,38\end{array}$ \\
\hline Pelophylax perezi & 30TXL15 & 100,00 & 101,91 & 104,92 & 37,00 & 6164,67 & 254,79 & $-25,08$ & 279,87 & 123,88 & 35,51 & 182,76 & 25,54 & 472,58 & 68,59 & 26,54 & 31,25 & 167,73 & 90,85 & 116,22 & 94,02 \\
\hline Pelophylax perezi & 30TXL17 & 100,00 & 121,68 & 105,77 & 37,00 & 6202,64 & 276,23 & $-5,73$ & 281,96 & 144,75 & 55,25 & 202,24 & 43,94 & 401,23 & 58,88 & 21,34 & 32,08 & 141,06 & 78,01 & 93,91 & 82,10 \\
\hline Pelophylax perezi & 30TXL18 & 100,00 & 120,30 & 106,30 & 37,00 & 6192,00 & 275,99 & $-6,49$ & 282,48 & 143,19 & 64,53 & 200,77 & 42,88 & 415,63 & 60,05 & 22,16 & 30,99 & 144,16 & 82,69 & 96,31 & 87,34 \\
\hline Pelophylax perezi & 30TXL19 & 100,00 & 114,54 & 106,66 & 37,01 & 6165,47 & 271,34 & $-11,31$ & 282,65 & 136,73 & 157,51 & 194,75 & 37,77 & 451,84 & 63,56 & 24,54 & 28,89 & 154,08 & 90,97 & $\mid 104,31$ & 97,97 \\
\hline Pelophylax perezi & 30TXL20 & 100,00 & 90,82 & 103,97 & 36,94 & 6227,62 & \begin{tabular}{|l|}
245,18 \\
\end{tabular} & $\begin{array}{l}-1,34,25 \\
-34,5\end{array}$ & \begin{tabular}{|l|l|}
279,44 \\
\end{tabular} & \begin{tabular}{|l|l|}
110,87 \\
\end{tabular} & 年15,03 & 173,66 & 15,03 & 527,99 & $\begin{array}{l}5,08 \\
75,08\end{array}$ & 29,67 & 30,20 & 186,55 & 100,45 & $\begin{array}{l}130,35 \\
130,35\end{array}$ & 100,45 \\
\hline Pelophylax perezi & 30TXL21 & 100,00 & 97,52 & 102,87 & \begin{tabular}{|l|l|}
36,87 \\
\end{tabular} & 6191,58 & 247,66 & $-28,73$ & 276,39 & 119,02 & 26,43 & 179,32 & 21,33 & 482,29 & 70,89 & 25,56 & 33,13 & 174,63 & 88,47 & 122,35 & 88,61 \\
\hline Pelophylax perezi & 30TXL22 & 100,00 & 99,03 & 102,34 & 36,82 & 6166,32 & 247,45 & $-27,74$ & 275,19 & 121,14 & 32,12 & 180,13 & 22,89 & 470,05 & 69,89 & 24,30 & 33,92 & 171,59 & 84,86 & $\mid 120,63$ & 85,96 \\
\hline Pelophylax perezi & 30TXL23 & 100,00 & 101,91 & 102,08 & 36,85 & 6139,68 & 248,97 & $-25,49$ & 274,47 & 124,33 & 35,14 & 182,20 & 25,52 & 455,18 & 68,36 & 23,12 & 34,76 & 167,11 & 80,94 & 117,21 & 83,37 \\
\hline Pelophylax perezi & 30TXL24 & 100,00 & 96,83 & 102,61 & 36,90 & 6129,49 & 245,92 & $-29,65$ & 275,58 & 118,51 & 30,43 & 177,20 & 20,92 & 487,09 & 71,41 & 26,08 & 32,53 & 175,48 & 90,18 & 123,84 & 92,75 \\
\hline Pelophylax perezi & $\begin{array}{l}30 T X L 25 \\
3042\end{array}$ & 100,00 & $\begin{aligned} 508,26 \\
108,26\end{aligned}$ & 102,91 & 36,90 & $\begin{array}{l}012,49,97 \\
6139,97\end{array}$ & \begin{tabular}{|l|}
257,01 \\
257
\end{tabular} & $\begin{array}{l}-29,05 \\
-19,15 \\
\end{array}$ & \begin{tabular}{|l|}
276,16 \\
276
\end{tabular} & \begin{tabular}{|l|}
131,01 \\
131,1
\end{tabular} & $\begin{array}{l}0,45 \\
41,78 \\
\end{array}$ & 188,19 & $\begin{array}{ll}30,625 \\
31,62\end{array}$ & \begin{tabular}{|l|l|}
436,55 \\
46,5
\end{tabular} & $\begin{array}{l}1,1,41 \\
65,32\end{array}$ & $\begin{array}{l}20,00 \\
22,83\end{array}$ & $\begin{array}{l}20,53 \\
34,09\end{array}$ & 158,52 & $\begin{array}{ll}79,22 \\
79,20\end{array}$ & $\begin{array}{l}109,849 \\
109,89\end{array}$ & 82,84 \\
\hline Pelophylax perezi & 30TXL26 & 100,00 & 110,44 & 103,49 & 37,00 & 6142,37 & 260,58 & $-16,69$ & 277,27 & 133,28 & 44,19 & 190,35 & 33,72 & 432,69 & 64,38 & 23,15 & 33,33 & 155,67 & 80,09 & $\mid 107,27$ & 83,98 \\
\hline Pelophylax perezi & 30TXL28 & 100,00 & 115,43 & 104,94 & 37,00 & 6159,67 & 269,21 & $-10,72$ & 279,93 & 138,01 & 53,04 & 195,47 & 38,42 & 432,49 & 62,91 & 23,68 & 31,19 & 151,27 & 84,84 & $\mid 102,32$ & 89,23 \\
\hline Pelophylax perezi & 30TXL29 & 100,00 & 129,03 & 105,79 & 37,00 & 6199,42 & 284,79 & 2,71 & 282,08 & 152,03 & 186,86 & 209,20 & 51,42 & 390,97 & 56,82 & 19,76 & 31,35 & 134,55 & 76,47 & 87,68 & 83,30 \\
\hline Pelophylax perezi & 30TXL30 & 100,00 & 102,60 & 100,66 & 36,42 & 6193,90 & 249,52 & $-22,81$ & 272,34 & 124,19 & 28,63 & 184,34 & 26,32 & 452,95 & 67,82 & 22,46 & 35,47 & 166,78 & 77,95 & \begin{tabular}{|l|l|}
117,45 \\
\end{tabular} & 77,98 \\
\hline Pelophylax perezi & 30TXL31 & 100,00 & 104,71 & 99,65 & 36,29 & 6145,01 & 248,19 & $-21,79$ & 269,98 & 127,27 & 37,75 & 185,23 & 28,40 & 435,22 & 66,48 & 20,53 & 37,38 & 162,89 & 72,70 & 115,31 & 73,72 \\
\hline Pelophylax perezi & 30TXL32 & 100,00 & 102,32 & 99,48 & 36,27 & 6111,27 & 244,66 & $-24,75$ & 269,41 & 124,86 & 35,49 & 182,03 & 26,05 & 444,99 & 67,97 & 20,99 & 37,29 & 166,56 & 74,21 & 118,63 & 76,57 \\
\hline Pelophylax perezi & 30TXL33 & 100,00 & 100,56 & 99,81 & 36,35 & 6097,72 & 243,69 & $-26,50$ & 270,19 & 122,92 & 33,88 & 180,03 & 24,34 & 455,56 & 69,13 & 21,99 & 36,32 & 169,37 & 77,45 & 120,71 & 80,36 \\
\hline Pelophylax perezi & 30TXL34 & 100,00 & 106,06 & 100,24 & 36,46 & 6100,01 & 249,72 & $-21,32$ & 271,04 & 128,83 & 39,46 & 185,23 & 29,41 & 435,01 & 6,35 & $21, \mathrm{C}$ & 36,42 & 47 & 74,15 & 113,91 & 77,61 \\
\hline Pelophylax perezi & 30TXL35 & 100,00 & 106,74 & 100,94 & 36,40 & 6099,30 & 252,09 & $-20,23$ & 272,32 & $\begin{array}{l}129,56 \\
\end{array}$ & $\begin{array}{l}0,47 \\
40,4\end{array}$ & 185,94 & 30,32 & $\begin{array}{l}436,62 \\
4362\end{array}$ & $\begin{array}{l}66,18 \\
66,\end{array}$ & $\frac{11,}{21,}$ & 35,22 & 59 & 76,35 & 1112,66 & 79,99 \\
\hline Pelophylax perezi & 30TXL36 & 100,00 & 104,84 & 101,67 & 36,72 & 6102,20 & 252,37 & $-21,44$ & 273,81 & 127,21 & 38,86 & 184,29 & 28,90 & 452,16 & 67,47 & 23,57 & 33,69 & 163,90 & 81,97 & 114,75 & 85,73 \\
\hline Pelophylax perezi & 30TXL37 & 100,00 & 105,99 & 102,56 & 36,94 & 6105,02 & 255,62 & $-19,62$ & 275,24 & 128,20 & 40,07 & 185,40 & 29,86 & 458,17 & 67,36 & 24,91 & 32,15 & 163,42 & 86,02 & 113,66 & 89,81 \\
\hline Pelophylax perezi & 30TXL38 & 100,00 & 120,41 & 103,92 & 36,99 & 6164,83 & 273,13 & $-5,36$ & 278,49 & 143,30 & 61,56 & 200,29 & 43,22 & 408,98 & 60,53 & 21,74 & 32,45 & 144,27 & 78,78 & 96,83 & 82,54 \\
\hline Pelophylax perezi & 30TXL39 & 100,00 & 136,03 & 105,08 & 37,00 & 6222,39 & 291,81 & 9,97 & 281,83 & 159,19 & 209,55 & 216,24 & 57,93 & 367,27 & 54,08 & 17,66 & 32,27 & 126,19 & 70,79 & 76,56 & 77,73 \\
\hline Pelophylax perezi & $30 T x$ & 100,00 & $\frac{130}{97}$ & $\begin{array}{r}98,00 \\
98,44\end{array}$ & 36,00 & $\begin{array}{l}022,3,33 \\
6130,43\end{array}$ & \begin{tabular}{|l|}
241,32 \\
\end{tabular} & $\begin{array}{l}-27,00 \\
-27\end{array}$ & \begin{tabular}{|l|}
261,3032 \\
\end{tabular} & \begin{tabular}{|l|}
118,89 \\
11,8
\end{tabular} & $\begin{array}{l}200,51 \\
27,51 \\
\end{array}$ & \begin{tabular}{|l|}
178,22 \\
\end{tabular} & $\begin{array}{l}1,135 \\
21,91 \\
\end{array}$ & \begin{tabular}{|l|}
474,47 \\
\end{tabular} & $\begin{array}{l}4,00 \\
70,94\end{array}$ & $\begin{array}{l}23,00 \\
23,18\end{array}$ & 35,55 & 175,01 & 80,73 & \begin{tabular}{|l|}
125,40 \\
\end{tabular} & 81,19 \\
\hline Pelophylax perezi & 30TXL42 & 100,00 & 103,06 & 97,26 & 36,00 & 6075,59 & 241,99 & $-23,24$ & 265,22 & 125,75 & 36,52 & 182,22 & 27,15 & 437,31 & 67,55 & 19,54 & 38,94 & 165,59 & 69,53 & 118,96 & 72,10 \\
\hline Pelophylax perezi & 30TXL43 & 100,00 & 103,52 & 97,70 & 36,03 & 6064,31 & 242,87 & $-22,97$ & 265,83 & 126,45 & 37,18 & 182,36 & 27,64 & 437,57 & 67,50 & 19,82 & 38,29 & 165,04 & 70,36 & $\mid 118,27$ & 73,68 \\
\hline Pelophylax perezi & 30TXL44 & 100,00 & 99,57 & 98,60 & 36,16 & 6063,16 & 241,76 & $-26,03$ & 267,80 & 121,83 & 33,31 & 178,59 & 23,97 & 462,21 & 69,90 & 22,22 & 35,83 & 171,22 & 78,36 & 122,62 & 81,31 \\
\hline Pelophylax perezi & $30 \mathrm{TXL}$ & 100,00 & 103,29 & 99,36 & 36,30 & 6071,57 & 246,90 & $-22,48$ & 269,38 & 125,80 & 37,30 & 18 & 27,53 & 450,06 & 68,11 & 22,12 & 35,47 & 165,82 & 77,56 & 117,56 & 86 \\
\hline Pelophylax perezi & \begin{tabular}{|l|l|}
$30 T X L 46$ \\
\end{tabular} & $\begin{array}{l}100,00 \\
\end{array}$ & 104,25 & $\begin{array}{l}100,33 \\
100,33\end{array}$ & $\begin{array}{l}30,00 \\
36,49\end{array}$ & | & \begin{tabular}{|l|}
250,34 \\
250
\end{tabular} & $\begin{array}{l}-20,40 \\
-20,88\end{array}$ & \begin{tabular}{|l|}
271,23 \\
273
\end{tabular} & $\begin{array}{l}126,82 \\
126,8\end{array}$ & $\begin{array}{l}1,104 \\
38,64 \\
\end{array}$ & $\begin{array}{l}10<, 3<2 \\
183,60 \\
\end{array}$ & $\begin{array}{ll}28,84 \\
284\end{array}$ & \begin{tabular}{|l|}
453,360 \\
453
\end{tabular} & $\begin{array}{l}0,11 \\
67,87 \\
\end{array}$ & 23,22 & $\begin{array}{l}30,41 \\
34,01\end{array}$ & $\begin{array}{l}103,02 \\
164,77\end{array}$ & 80,94 & $\begin{array}{l}115,80 \\
115,86\end{array}$ & $\begin{array}{l}8,02,10 \\
84,1\end{array}$ \\
\hline Pelophylax perezi & 30TXL47 & 100,00 & 116,78 & 101,93 & 36,55 & 6133,06 & 266,13 & $-8,87$ & 275,00 & 139,59 & 50,88 & 196,18 & 39,97 & 411,07 & 61,86 & 21,71 & 33,82 & 147,95 & 75,54 & 100,74 & 78,41 \\
\hline Pelophylax perezi & 30TXL48 & 100,00 & 12890 & 103,59 & 36,79 & 619903 & 282.39 & 295 & 279.44 & 152,21 & 70,41 & 20908 & 51.19 & 377.04 & 56.57 & 19,28 & 33,41 & 13300 & 72.59 & 86,71 & 7503 \\
\hline Pelophylax perezi & 30TXL49 & 100,00 & 134,22 & 104,51 & 36,86 & 6213,16 & 289,64 & 8,64 & 281,01 & 157 & 190,27 & 214,42 & 56, & 369,45 & 54,97 & 17,99 & 32 & 127,99 & 71,71 & 80,29 & 76,72 \\
\hline Pelophylax perezi & $30 T X L 50$ & 100,00 & 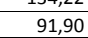 & 98,01 & 36,01 & 6162,41 & 238,94 & $-29,51$ & 268,45 & 111,65 & 17,40 & $\begin{array}{l}173,98 \\
\end{array}$ & \begin{tabular}{|l|l}
17,40 \\
\end{tabular} & 515,99 & 74,51 & 26,49 & 32,53 & 185,27 & 89,94 & $\begin{array}{l}132,2,90 \\
130\end{array}$ & 89,94 \\
\hline
\end{tabular}




\begin{tabular}{|c|c|c|c|c|c|c|c|c|c|c|c|c|c|c|c|c|c|c|c|c|c|}
\hline TAXON & UTM & $\mathrm{km} 2$ & B101 & B102 & $\mathrm{BIO3}$ & BIO4 & B105 & B106 & B107 & B108 & B109 & BIO10 & BIO11 & BIO12 & B1013 & BIO14 & BIO15 & B1016 & B1017 & 81018 & B1019 \\
\hline Pelophylax perezi & 30TXL51 & 100,00 & 87,73 & 98,07 & 36,00 & 6124,77 & 234,65 & $-33,71$ & 268,35 & 107,34 & 13,52 & 169,11 & 13,46 & 539,12 & 77,24 & 28,50 & 31,44 & 192,34 & 96,55 & 138,61 & 96,55 \\
\hline Pelophylax perezi & 30TXL52 & 100,00 & 95,48 & 97,20 & 36,00 & 6089,01 & 238,10 & $-27,74$ & 265,83 & 116,36 & 26,76 & 175,60 & 20,49 & 487,24 & 72,39 & 23,87 & 34,90 & 178,61 & 83,15 & 128,89 & 83,55 \\
\hline Pelophylax perezi & 30TXL53 & 100,00 & 93,34 & 97,36 & 36,00 & 6066,05 & 236,19 & $-29,89$ & 266,08 & 114,21 & 26,24 & 173,12 & 18,58 & 500,72 & 73,83 & 25,11 & 34,01 & 182,28 & 87,26 & 131,60 & 88,09 \\
\hline Pelophylax perezi & 30TXL54 & 100,00 & 90,49 & 97,91 & 36,00 & 6048,23 & 234,72 & $-32,40$ & 267,12 & 111,02 & 24,29 & 169,99 & 16,06 & 520,93 & 75,81 & 27,03 & 32,34 & 187,29 & 93,71 & 135,29 & 94,70 \\
\hline Pelophylax perezi & 30TXL55 & 100,00 & 99,63 & 98,26 & 36,01 & \begin{tabular}{|l|l|}
6049,87 \\
\end{tabular} & 242,98 & $-24,70$ & 267,68 & \begin{tabular}{|l|l|}
121,47 \\
\end{tabular} & 33,74 & 178,65 & 24,53 & 472,58 & 70,42 & 23,61 & 34,13 & 172,20 & 82,48 & 122,96 & 84,61 \\
\hline Pelophylax perezi & 30TXL56 & 100,00 & 108,24 & 99,50 & 36,17 & 6072,37 & 253,65 & $-16,47$ & 270,12 & 130,62 & 42,57 & 187,26 & 32,59 & 438,60 & 65,96 & 22,22 & 34,36 & 159,44 & 77,44 & 111,43 & 79,67 \\
\hline Pelophylax perezi & \begin{tabular}{|l|} 
30TXL57 \\
\end{tabular} & 100,00 & 117,97 & 101,20 & 36,25 & 6124,89 & 266,89 & $-7,00$ & 273,89 & 140,69 & 52,13 & 197,44 & 41,42 & 406,46 & 61,17 & 21,35 & 33,91 & 146,15 & 74,08 & 99,27 & 76,03 \\
\hline Pelophylax perezi & 30TXL58 & 100,00 & 125,99 & 102,66 & 36,40 & 6175,87 & 278,60 & 0,77 & 277,83 & 148,96 & 59,97 & 205,95 & 48,72 & 385,32 & 57,71 & 20,13 & 33,09 & 136,36 & 73,18 & 90,01 & 74,85 \\
\hline Pelophylax perezi & 30TXL60 & 100,00 & 94,83 & 96,48 & 36,00 & 6139,80 & 239,94 & $-25,42$ & 265,35 & 114,68 & 20,78 & 176,50 & 20,78 & 505,03 & 73,01 & 25,25 & 33,01 & 181,19 & 86,05 & 130,33 & 86,05 \\
\hline Pelophylax perezi & 30TXL61 & 100,00 & 90,23 & 96,60 & 35,99 & 6104,58 & 235,41 & $-30,41$ & 265,82 & 109,78 & 16,47 & 171,37 & 16,47 & 529,44 & 75,96 & 27,37 & 31,93 & 188,81 & 92,93 & 136,23 & 92,93 \\
\hline Pelophylax perezi & 30TXL62 & 100,00 & 93,88 & 96,39 & 36,00 & 6076,15 & 237,07 & $-27,70$ & 264,77 & 114,11 & 21,47 & 174,17 & 19,72 & 505,76 & 73,78 & 25,51 & 33,43 & 182,48 & 87,48 & 131,67 & 87,48 \\
\hline Pelophylax perezi & 30TXL63 & 100,00 & 90,23 & 96,66 & 36,00 & 6052,86 & 234,09 & $-31,12$ & 265,21 & 110,10 & 19,00 & 170,15 & 16,26 & 527,51 & 76,18 & 27,39 & 31,97 & 188,53 & 94,05 & 136,34 & 94,05 \\
\hline Pelophylax perezi & 30TXL64 & 100,00 & 97,19 & 96,94 & 36,00 & 6042,81 & 240,17 & $-25,19$ & 265,35 & 118,09 & 31,02 & 176,54 & 22,75 & 489,91 & 72,06 & 24,70 & 33,49 & 176,98 & 85,80 & 126,94 & 86,37 \\
\hline Pelophylax perezi & 30TXL65 & 100,00 & 107,50 & 97,78 & 36,00 & 6055,16 & 250,82 & $-16,10$ & 266,92 & 129,47 & 41,66 & 186,47 & 32,33 & 441,42 & 66,32 & 21,81 & 34,95 & 160,91 & 75,92 & 113,19 & 77,19 \\
\hline Pelophylax perezi & 30TXL66 & 100,00 & 112,34 & 99,02 & \begin{tabular}{|l|l|}
36,03 \\
\end{tabular} & 6072,31 & 258,01 & $-11,55$ & 269,56 & 134,55 & 46,83 & 191,31 & 36,57 & 426,14 & 63,97 & 21,66 & 34,21 & 154,11 & 75,15 & 106,67 & 76,26 \\
\hline Pelophylax perezi & 30TXL67 & 100,00 & 117,43 & 100,42 & 36,10 & 6102,58 & 265,95 & $-6,52$ & 272,46 & 139,90 & 51,90 & 196,82 & 41,34 & 411,37 & 61,44 & 21,69 & 33,30 & 147,14 & 74,86 & 99,97 & 75,70 \\
\hline Pelophylax perezi & $\begin{array}{l}30 T X L 68 \\
\end{array}$ & 100,00 & 123,29 & 101,80 & 36,25 & 6140,66 & 274,94 & $-0,96$ & 275,90 & $\begin{array}{l}145,87 \\
\end{array}$ & 57,65 & 203,00 & 46,66 & 396,42 & 58,78 & 21,01 & 32,39 & 139,89 & 74,69 & 93,15 & 75,25 \\
\hline Pelophylax perezi & 30TXL70 & 100,00 & 91,62 & 95,82 & 35,95 & 6104,33 & 237,03 & $-26,92$ & 263,95 & 110,41 & 18,39 & 173,10 & 18,39 & 535,96 & 75,51 & 27,64 & 30,93 & 188,29 & 93,76 & 135,37 & 93,76 \\
\hline Pelophylax perezi & 30TXL71 & 100,00 & 88,97 & 95,70 & 35,92 & 6076,17 & 234,03 & $-29,79$ & 263,82 & 107,70 & 15,86 & 169,95 & 15,86 & 549,70 & 77,34 & 28,97 & 30,47 & 192,75 & 97,80 & 139,05 & 97,80 \\
\hline Pelophylax perezi & $30 \mathrm{TXL72}$ & 100,00 & 101.13 & 95,36 & 35,98 & 6059,70 & 243,06 & $-19,58$ & 262,65 & 121,64 & 27,75 & $\mid 181,10$ & 27,18 & 478,34 & 70,08 & 23,47 & 34,08 & $\mid 172,16$ & 80,84 & $\mid 123,14$ & 80,84 \\
\hline Pelophylax perezi & 30TXL73 & 100,00 & 99,16 & 95,91 & 35,99 & 6045,63 & 241,52 & $-22,07$ & 263,58 & 119,70 & 27,72 & 178,85 & 25,26 & 487,42 & 71,25 & 24,47 & 33,50 & 174,96 & 83,98 & 125,23 & 83,98 \\
\hline Pelophylax perezi & 30TXL74 & 100,00 & 109,47 & 96,76 & 36,00 & 6044,27 & 252,24 & $-13,11$ & 265,36 & 131,08 & 42,85 & 188,66 & 34,88 & 439,68 & 65,54 & 21,57 & 34,89 & 158,99 & 74,79 & 111,64 & 74,89 \\
\hline Pelophylax perezi & 30TXL75 & 100,00 & 114,92 & 97,98 & 36,00 & $\begin{array}{ll}6066,83 \\
\end{array}$ & 259,62 & $-8,03$ & 267,65 & \begin{tabular}{|l|}
136,97 \\
\end{tabular} & 48,13 & \begin{tabular}{|l|l|}
194,08 \\
\end{tabular} & 39,80 & 419,59 & $\begin{array}{ll}62,66 \\
\end{array}$ & 20,99 & 34,60 & 151,11 & 72,50 & 104,34 & 72,64 \\
\hline Pelophylax perezi & 30TXL76 & 100,00 & 120,30 & 99,40 & 36,04 & 6087,55 & 267,63 & $-3,09$ & 270,72 & 142,67 & 52,88 & 199,61 & 44,59 & 403,03 & 60,00 & 20,77 & 33,93 & 143,90 & 71,35 & 97,52 & 71,46 \\
\hline Pelophylax perezi & 30TXL77 & 100,00 & 120,89 & 100,23 & 36,03 & 6099,63 & 270,27 & $-2,44$ & 272,71 & 143,32 & 52,76 & 200,37 & 45,11 & 404,11 & 59,66 & 21,35 & 32,80 & 143,03 & 73,46 & 96,21 & 73,56 \\
\hline Pelophylax perezi & \begin{tabular}{|l|}
$30 T X L 78$ \\
\end{tabular} & 100,00 & 123,44 & 101,37 & 36,06 & 6119,33 & 275,03 & $-0,11$ & 275,14 & 145,86 & 52,43 & 203,01 & 47,20 & 399,68 & 58,42 & 21,03 & 31,61 & 139,80 & 74,66 & 93,08 & 74,68 \\
\hline Pelophylax perezi & $\begin{array}{l}\text { 30TXL79 } \\
\end{array}$ & 100,00 & 127,20 & 102,48 & 36,18 & 6146,71 & 281,60 & $\begin{array}{l}-1,14 \\
3,56 \\
\end{array}$ & 278,04 & \begin{tabular}{|l|}
149,99 \\
\end{tabular} & 54,67 & 207,17 & 50,63 & \begin{tabular}{|l|l|}
391,98 \\
\end{tabular} & $\begin{array}{l}0,446 \\
56,46\end{array}$ & 20,06 & $\begin{array}{l}1,0 \\
30,52\end{array}$ & 135,25 & 75,40 & 88,81 & 75,40 \\
\hline Pelophylax perezi & 30TXL80 & 100,00 & 92,12 & 94,93 & 35,88 & 6074,91 & 237,01 & $-25,42$ & 262,43 & 110,20 & 19,59 & 173,29 & 19,59 & 548,33 & 75,97 & 28,70 & 29,87 & 189,62 & 97,12 & 135,95 & 97,12 \\
\hline Pelophylax perezi & 30TXL81 & 100,00 & 90,67 & 94,95 & 35,90 & 6049,47 & 235,18 & $-27,06$ & 262,24 & 109,03 & 18,25 & 171,36 & 18,25 & 555,37 & 77,05 & 29,46 & 29,80 & 191,96 & 99,52 & 138,05 & 99,52 \\
\hline Pelophylax perezi & 30TXL82 & 100,00 & 105,61 & 95,06 & 36,00 & 6036,24 & 247,85 & $-14,08$ & 261,93 & 125,84 & 32,08 & 185,38 & 32,08 & 471,49 & 68,23 & 23,19 & 33,44 & 167,17 & 79,96 & 118,27 & 79,96 \\
\hline Pelophylax perezi & 30TXL83 & 100,00 & 109,49 & 95,77 & 35,97 & 6035,23 & 252,01 & $-11,32$ & 263,33 & 130,29 & 36,04 & 188,90 & 35,78 & 452,96 & 66,15 & 22,27 & 33,96 & 161,12 & 76,89 & 112,97 & 76,89 \\
\hline Pelophylax perezi & 30TXL84 & 100,00 & 115,72 & 96,93 & 36,00 & $\mid 6040,90$ & 259,44 & \begin{tabular}{|c|c|}
1,35 \\
$-6,17$ \\
\end{tabular} & $\begin{array}{l}265,62 \\
265\end{array}$ & $\begin{array}{l}137,23 \\
137\end{array}$ & $\begin{array}{l}0,0416 \\
43,16\end{array}$ & \begin{tabular}{|l|l|}
194,89 \\
\end{tabular} & $\begin{array}{ll}41,48 \\
410\end{array}$ & $\mid 427,11$ & $\begin{array}{l}0,110 \\
62,83 \\
\end{array}$ & 21,12 & $\begin{array}{l}34,23 \\
340\end{array}$ & $\begin{array}{l}151,85 \\
15\end{array}$ & 72,94 & $\begin{array}{l}104,76 \\
\end{array}$ & 72,94 \\
\hline Pelophylax perezi & 30TXL85 & 100,00 & 116,66 & 97,82 & 36,00 & 6051,52 & 261,97 & $-5,50$ & 267,48 & 138,31 & 43,75 & 195,76 & 42,05 & 424,05 & 62,31 & 21,52 & 33,57 & 150,21 & 73,66 & 102,92 & 73,66 \\
\hline Pelophylax perezi & 30TXL86 & 100,00 & 126,49 & 99,79 & 36,01 & 6088,22 & 275,16 & 2,99 & 272,17 & 148,82 & 52,40 & 205,93 & 51,04 & 391,26 & 57,25 & 20,01 & 33,19 & 137,14 & 69,25 & 91,28 & 69,25 \\
\hline Pelophylax perezi & 30TXL87 & 100,00 & 132,95 & 101,34 & 36,00 & 6120,77 & 284,55 & 8,68 & 275,87 & 155,74 & 56,94 & 212,68 & 56,86 & 373,65 & 53,97 & 18,64 & 32,14 & 129,19 & 67,90 & 84,27 & 67,90 \\
\hline Pelophylax perezi & 30TXL88 & 100,00 & 134,58 & 102,23 & 36,03 & 6145,04 & 288,41 & 10,24 & 278,17 & 157,57 & 58,01 & 214,51 & 58,01 & 370,96 & 52,88 & 18,25 & 31,04 & 127,03 & 68,71 & 82,26 & 68,71 \\
\hline Pelophylax perezi & $\begin{array}{l}\text { 30TXL89 } \\
\end{array}$ & 100,00 & $\begin{array}{l}134,50 \\
136,03\end{array}$ & 103,14 & 30,15 & $\mid 6159,41$ & $\begin{array}{l}200,41 \\
291,93\end{array}$ & $\begin{array}{l}0,4 \\
11,69 \\
\end{array}$ & $\begin{array}{l}280,112 \\
280,24\end{array}$ & 159,19 & \begin{tabular}{|l|l|}
59,18 \\
5
\end{tabular} & \begin{tabular}{|l|}
216,21 \\
216,1
\end{tabular} & \begin{tabular}{|l|l|}
59,18 \\
5
\end{tabular} & \begin{tabular}{|l|l|}
370,19 \\
\end{tabular} & $\begin{array}{l}32,00 \\
51,84\end{array}$ & \begin{tabular}{l|}
18,06 \\
18,06
\end{tabular} & $\begin{array}{l}1,404 \\
29,77 \\
\end{array}$ & $\begin{array}{ll}125,34 \\
\end{array}$ & $\begin{array}{l}\mid 70,1 / 01 \\
70,01\end{array}$ & $\begin{array}{l}0,200 \\
80,77 \\
\end{array}$ & $\begin{array}{l}0,1 \\
70,01\end{array}$ \\
\hline Pelophylax perezi & 30TXL90 & 100,00 & 93,26 & 94,10 & 35,88 & 6037,54 & 237,51 & $-23,38$ & 260,88 & 110,95 & 21,41 & 173,85 & 21,41 & 560,38 & 76,22 & 29,78 & 28,83 & 190,28 & 100,83 & 135,84 & 100,83 \\
\hline Pelophylax perezi & 30TXL91 & 100,00 & 92,79 & 94,06 & 35,91 & 6024,18 & 236,62 & $-24,29$ & 260,91 & 110,82 & 20,82 & 173,14 & 20,82 & 558,18 & 76,49 & 29,75 & 29,18 & 190,50 & 100,44 & $\mid 136,29$ & 100,44 \\
\hline Pelophylax perezi & 30TXL92 & 100,00 & 108,34 & 94,90 & 35,97 & 6013,94 & 250,88 & $-10,67$ & 261,55 & 128,18 & 35,46 & 187,89 & 35,46 & 475,73 & 67,67 & 23,81 & 32,43 & 165,47 & 81,84 & 115,82 & 81,84 \\
\hline Pelophylax perezi & \begin{tabular}{|l|l|}
$30 T X L 93$ \\
\end{tabular} & 100,00 & 119,24 & 96,28 & 35,99 & 6024,23 & 262,65 & $-1,61$ & 264,25 & 140,10 & 45,57 & 198,47 & 45,57 & 430,39 & 61,95 & 21,19 & 33,56 & 149,75 & 73,45 & 102,24 & 73,45 \\
\hline Pelophylax perezi & 30TXL94 & 100,00 & 121,76 & 97,31 & 36,00 & 6022,52 & 266,54 & 0,07 & 266,46 & \begin{tabular}{|l|l|}
143,10 \\
\end{tabular} & 48,05 & 200,89 & 48,05 & $\begin{array}{l}420,08 \\
400\end{array}$ & 60,5 & 21,03 & 33,48 & \begin{tabular}{|l|l|}
146,01 \\
\end{tabular} & 72,48 & $\begin{array}{ll}98,88 \\
98,8\end{array}$ & 72,48 \\
\hline Pelophylax perezi & 30TXL95 & 100,00 & 119,29 & 97,91 & 36,00 & 6025,98 & 265,34 & $-2,58$ & 267,92 & 140,63 & 45,32 & 198,40 & 45,32 & 428,44 & 61,70 & 21,84 & 32,63 & 148,84 & 75,02 & 101,15 & 75,02 \\
\hline Pelophylax perezi & 30TXL96 & 100,00 & 134,56 & 100,49 & 36,02 & 6076,06 & 284,31 & 10,75 & 273,56 & 157,00 & 59,40 & 213,91 & 59,40 & 377,88 & 53,95 & 18,37 & 32,59 & 129,18 & 67,32 & 84,10 & 67,32 \\
\hline Pelophylax perezi & 30TXL97 & 100,00 & 139,50 & 101,88 & 36,10 & 6104,79 & 291,85 & 15,07 & 276,78 & 162,47 & 63,90 & 219,12 & 63,90 & 364,50 & 51,29 & 19 & 31,80 & 123,17 & 66,23 & 79,08 & 66,23 \\
\hline Pelophylax perezi & 30TXL98 & 100,00 & 142,43 & 102,88 & 36,18 & 6118,22 & 296,5 & 17,65 & 278,88 & 165,50 & 66,35 & 222,14 & 66,35 & 358,47 & 49, & 16 & 30,96 & 119,94 & $\begin{array}{l}0,35 \\
66,09 \\
\end{array}$ & 76,27 & $\begin{array}{l}0,2,09 \\
66,0\end{array}$ \\
\hline Pelophylax perezi & 30TXL99 & 100,00 & 143,05 & 103,63 & 36,55 & 6128,25 & 298,72 & 18,23 & 280,49 & 166,48 & 66,65 & 222,90 & 66,65 & 358,56 & 48,94 & 16,63 & 29,89 & 118,88 & 66,91 & 75,70 & 66,91 \\
\hline Pelophylax perezi & 30TXMO0 & 100,00 & 108,51 & 108,36 & 37,66 & 6146,17 & 267,97 & $-16,90$ & 284,86 & 130,14 & 188,45 & 188,81 & 32,33 & 491,57 & 66,69 & 27,04 & 26,42 & 163,83 & 98,31 & 111,92 & 111,05 \\
\hline Pelophylax perezi & 30TXM01 & 100,00 & 95,38 & 108,00 & 37,85 & 6071,08 & 255,01 & $-28,10$ & 283,11 & 115,35 & 174,92 & 175,13 & 20,77 & 577,34 & 74,88 & 32,82 & 23,46 & 187,54 & 116,08 & 129,63 & 134,59 \\
\hline Pelophylax perezi & 30TXM02 & 100,00 & 100,94 & 108,08 & 37,93 & 6066,93 & 260,75 & $-22,31$ & 283,06 & 121,12 & 180,29 & 180,39 & 26,02 & 566,20 & 72,63 & 31,53 & 23,29 & 181,91 & 112,00 & 124,01 & 134,25 \\
\hline Pelophylax perezi & $30 \mathrm{TXMC}$ & 100,00 & 119,16 & $\begin{array}{l}10,00 \\
108,53\end{array}$ & 37,97 & $\mid 6123,89$ & 278,95 & \begin{tabular}{|c|c|}
$-2,5,19$ \\
-5,
\end{tabular} & \begin{tabular}{|l|}
284,140 \\
\end{tabular} & $\begin{array}{l}14,112 \\
140,97 \\
\end{array}$ & \begin{tabular}{|l|}
$198,70,0$ \\
\end{tabular} & \begin{tabular}{|l|l|}
198,78 \\
198,7
\end{tabular} & $\begin{array}{l}0,0<4 \\
42,79\end{array}$ & \begin{tabular}{|l|}
$490,20,67$ \\
\end{tabular} & $\begin{array}{l}2,305 \\
63,53 \\
\end{array}$ & $\begin{array}{l}31,35 \\
25,64\end{array}$ & $\mid$\begin{tabular}{|l|l|}
24,61 \\
\end{tabular} & \begin{tabular}{|l|}
157,00 \\
15,0
\end{tabular} & 93,63 & $\begin{array}{l}102,45 \\
10,4\end{array}$ & $\begin{array}{l}13,4,25 \\
117,71\end{array}$ \\
\hline Pelophylax perezi & 30TXM04 & 100,00 & 128,32 & 108,00 & 37,95 & 6113,23 & 286,81 & 4,12 & 282,69 & 150,56 & 207,32 & 207,38 & 51,53 & 475,79 & 60,21 & 23,86 & 24,52 & 149,16 & 88,55 & 94,31 & 116,81 \\
\hline Pelophylax perezi & 30TXM05 & 100,00 & 133,34 & 107,29 & 37,99 & 6057,35 & 290,14 & \begin{tabular}{|l|l|}
10,14 \\
\end{tabular} & 279,99 & 155,39 & 211,64 & 211,64 & 57,25 & 485,86 & 59,23 & 23,80 & 23,70 & 148,22 & 89,40 & 92,39 & 122,30 \\
\hline Pelophylax perezi & 30TXM06 & 100,00 & 134,37 & 106,67 & 37,99 & 6021,66 & 289,83 & 12,23 & 277,60 & 155,06 & 212,27 & 212,27 & 58,71 & 513,80 & 60,26 & 25,03 & 22,90 & 152,93 & 93,81 & 95,71 & 132,79 \\
\hline Pelophylax perezi & 30TXM07 & 100,00 & 136,85 & 105,91 & 38,00 & 5960,25 & 290,10 & 15,45 & 274,65 & 102,64 & 213,73 & 213 & 61,61 & 545,48 & 61,27 & 26,12 & 22,41 & 161 & 98,66 & 98,93 & 144,92 \\
\hline Pelophylax perezi & $\begin{array}{l}\text { 30TXM08 } \\
30 \text {. }\end{array}$ & 100,00 & $\begin{array}{l}130,05 \\
134,51\end{array}$ & 105,33 & 38,00 & 59006,84 & 286,66 & $\begin{array}{l}1,45 \\
14,23 \\
\end{array}$ & $\begin{array}{l}27,, 40 \\
272,43\end{array}$ & $\begin{array}{r}02,04 \\
98,32 \\
\end{array}$ & \begin{tabular}{|l|}
$210,73,5$ \\
21
\end{tabular} & \begin{tabular}{|l|}
210,73 \\
210
\end{tabular} & $\begin{array}{l}1,01 \\
60,05 \\
\end{array}$ & \begin{tabular}{|l|}
595,402 \\
595,02
\end{tabular} & $\begin{array}{l}1,27 \\
66,05\end{array}$ & 28,54 & $\begin{array}{l}22,00 \\
22,0\end{array}$ & $\begin{array}{l}178,07 \\
178\end{array}$ & \begin{tabular}{r|}
0,000 \\
106,76 \\
\end{tabular} & \begin{tabular}{|r|r|}
106,98 \\
10,98
\end{tabular} & $\begin{array}{l}144,52 \\
162,32\end{array}$ \\
\hline Pelophylax perezi & 30TXM09 & 100,00 & 131,31 & 105,03 & 38,08 & 5861,17 & 282,84 & 12,12 & 270,72 & 94,86 & 207,03 & 207,03 & 57,59 & 657,07 & 74,70 & 31,62 & 21,99 & 198,86 & 116,63 & 116,63 & 184,39 \\
\hline Pelophylax perezi & 30TXM11 & 100,00 & 108,93 & 107,27 & 37,33 & 6114,24 & 266,96 & $-15,77$ & 282,72 & 130,41 & 188,38 & 188,64 & 33,11 & 500,37 & 67,56 & 27,44 & 26,07 & 165,91 & 99,46 & 112,92 & 113,78 \\
\hline Pelophylax perezi & 30TXM12 & 100,00 & 117,64 & 107,61 & 37,63 & 6132,64 & 276,22 & $-6,61$ & 282,8 & 139,49 & 197, & 197 & 41 & 477,46 & 63,91 & 25,09 & 26,04 & 156 & 92,14 & 101,36 & 111,16 \\
\hline Pelophylax perezi & $30 \mathrm{TXM} 13$ & 100,00 & 121,44 & 107,69 & 37,73 & 6119,63 & 279,95 & $\begin{array}{l}-2,63 \\
-2,63 \\
\end{array}$ & 282,58 & 143,28 & 200,77 & 200,86 & 44,90 & 481,73 & 63,05 & 24,77 & 25,32 & 154,56 & 91,31 & 100,01 & 115,08 \\
\hline
\end{tabular}




\begin{tabular}{|c|c|c|c|c|c|c|c|c|c|c|c|c|c|c|c|c|c|c|c|c|c|}
\hline TAXON & UTM & $\mathrm{km} 2$ & B101 & B102 & $\mathrm{BIO3}$ & B104 & B105 & B106 & B107 & B108 & B109 & B1010 & BIO11 & BIO12 & B1013 & BIO14 & BIO15 & BIO16 & BIO17 & BIO18 & B1019 \\
\hline Pelophylax perezi & 30TXM14 & 100,00 & 132,42 & 107,17 & 37,69 & 6099,90 & 289,75 & 8,56 & 281,19 & 154,72 & 211,33 & 211,37 & 55,81 & 466,15 & 59,06 & 22,67 & 24,96 & 145,23 & 85,77 & 88,68 & 114,99 \\
\hline Pelophylax perezi & 30TXM15 & 100,00 & 137,34 & 106,54 & 37,96 & 6040,20 & 292,78 & 14,55 & 278,22 & 159,61 & 215,33 & 215,33 & 61,35 & 480,36 & 58,18 & 22,85 & 24,02 & 145,01 & 87,32 & 89,54 & 122,01 \\
\hline Pelophylax perezi & 30TXM16 & 100,00 & 136,42 & 106,17 & 38,00 & 6012,49 & 291,15 & 14,39 & 276,76 & 134,60 & 213,97 & 213,97 & 60,58 & 516,44 & 60,18 & 24,55 & 23,20 & 152,87 & 93,38 & 95,00 & 134,77 \\
\hline Pelophylax perezi & 30TXM17 & 100,00 & 132,53 & 106,19 & 38,00 & 5976,67 & 286,65 & 11,06 & 275,59 & 102,39 & 209,63 & 209,63 & 57,17 & 567,05 & 63,84 & 27,16 & 22,45 & 167,42 & 101,85 & 102,41 & 152,02 \\
\hline Pelophylax perezi & 30TXM18 & 100,00 & 130,54 & 105,84 & 38,00 & 5931,66 & 283,74 & 9,80 & 273,94 & 94,21 & 207,13 & 207,13 & 55,90 & 618,58 & 69,70 & \begin{tabular}{|l|l|}
29,63 \\
\end{tabular} & 22,02 & 185,17 & 110,02 & 110,09 & 170,60 \\
\hline Pelophylax perezi & 30TXM19 & 100,00 & 130,52 & 105,12 & 38,01 & 5871,83 & 282,08 & 10,50 & 271,58 & 94,28 & 206,24 & 206,24 & 56,29 & 673,35 & 77,95 & 31,95 & 22,21 & 205,12 & 118,55 & 118,55 & 191,28 \\
\hline Pelophylax perezi & 30TXM20 & 100,00 & 120,56 & 106,08 & 37,00 & 6164,38 & 276,99 & $-4,47$ & 281,46 & 143,08 & 196,55 & 200,55 & 43,73 & 431,75 & 61,31 & 22,69 & 29,33 & 146,86 & 85,24 & 97,42 & 94,21 \\
\hline Pelophylax perezi & $30 \mathrm{TXM} 21$ & 100,00 & 120,15 & 106,34 & 37,10 & 6151,16 & 277,36 & $-4,48$ & 281,84 & 142,54 & \begin{tabular}{|l|l|}
199,81 \\
\end{tabular} & \begin{tabular}{|l|l|}
199,93 \\
\end{tabular} & 43,44 & 447,68 & 62,19 & 23,31 & 28,18 & 149,69 & 87,07 & 97,29 & 100,56 \\
\hline Pelophylax perezi & 30TXM23 & 100,00 & 133,82 & 106,67 & $\begin{array}{l}37,25 \\
\end{array}$ & 6133,99 & 291,05 & 9,61 & 281,44 & 156,30 & 213,06 & 213,06 & 56,85 & 437,57 & 57,78 & \begin{tabular}{|l|l|}
20,95 \\
\end{tabular} & 26,66 & 139,33 & 80,58 & 82,35 & 104,92 \\
\hline Pelophylax perezi & 30TXM24 & 100,00 & 138,28 & 106,28 & \begin{tabular}{|l|l|}
37,48 \\
\end{tabular} & $\begin{array}{ll}6087,83 \\
\end{array}$ & 294,44 & 15,01 & 279,43 & 160,78 & 216,96 & 216,96 & 61,71 & 449,59 & 56,90 & 21,03 & 25,46 & 138,72 & 81,65 & 82,90 & 111,29 \\
\hline Pelophylax perezi & 30TXM25 & 100,00 & 135,71 & 106,21 & 37,74 & 6045,86 & 291,28 & 12,96 & 278,32 & 157,97 & 213,74 & 213,74 & 59,53 & 487,17 & 59,36 & 23,02 & 24,15 & 147,02 & 88,34 & 90,45 & 123,83 \\
\hline Pelophylax perezi & 30TXM26 & 100,00 & 132,34 & 106,18 & $\begin{array}{l}37,95 \\
\end{array}$ & 6011,91 & 287,35 & 10,14 & 277,21 & 140,20 & 209,87 & 209,87 & 56,56 & 530,36 & 62,22 & 25,35 & 23,09 & 157,15 & 95,82 & 99,69 & 138,38 \\
\hline Pelophylax perezi & 30TXM27 & 100,00 & 133,69 & 105,99 & 38,00 & 5966,34 & 287,39 & 12,47 & 274,92 & 96,91 & 210,66 & 210,66 & 58,58 & 564,81 & 63,52 & 26,71 & 22,52 & 167,48 & 101,29 & 102,42 & 151,60 \\
\hline Pelophylax perezi & 30TXM28 & 100,00 & 127,85 & 105,90 & 38,00 & 5923,58 & 280,96 & 7,13 & 273,82 & 91,65 & 204,24 & 204,24 & 53,19 & 630,60 & 71,13 & 30,23 & 21,98 & 188,22 & 112,42 & 112,42 & 173,84 \\
\hline Pelophylax perezi & 30TXM29 & 100,00 & 126,49 & 105,21 & 38,02 & 5856,42 & 278,16 & 6,71 & 271,46 & 87,33 & 202,15 & 202,15 & 52,67 & 689,63 & 79,75 & \begin{tabular}{|l|l|}
32,97 \\
\end{tabular} & 21,94 & 209,18 & 122,07 & 122,07 & 195,51 \\
\hline Pelophylax perezi & 30TXM30 & 100,00 & 133,31 & 105,50 & 37,00 & 6201,89 & 289,74 & 7,93 & 281,81 & 156,36 & 213,27 & 213,35 & 55,65 & 385,79 & 55,91 & 18,82 & 31,03 & 130,92 & 73,59 & 82,72 & 84,01 \\
\hline Pelophylax perezi & 30TXM31 & 100,00 & 132,74 & 105,97 & 37,00 & 6185,86 & 289,84 & 7,61 & 282,22 & 155,36 & 212,79 & 212,79 & 55,28 & 399,55 & 56,88 & 19,28 & 30,17 & 133,56 & 75,02 & 76,72 & 89,52 \\
\hline Pelophylax perezi & 30TXM32 & 100,00 & 134,91 & 106,01 & 37,00 & 6158,24 & 292,16 & 10,49 & 281,66 & 157,51 & 214,41 & 214,42 & 57,63 & 410,03 & 56,70 & 19,42 & 28,87 & 133,87 & 75,70 & 79,25 & 94,99 \\
\hline Pelophylax perezi & 30TXM33 & 100,00 & 138,50 & 106,01 & 37,01 & 6139,19 & 295,47 & 14,89 & 280,58 & 161,23 & 217,79 & 217,79 & 61,48 & 421,05 & 55,96 & $\begin{array}{ll}19,55 \\
\end{array}$ & 27,19 & 133,53 & 76,64 & 78,88 & 100,73 \\
\hline Pelophylax perezi & 30TXM34 & 100,00 & 139,01 & 106,00 & 37,13 & 6091.52 & 295,14 & 16,02 & 279,12 & $\mid 161,30$ & 217,59 & 217,59 & 62,35 & 445,40 & 56,66 & 20,54 & 25,57 & 137,27 & 80,77 & 82.81 & 109,71 \\
\hline Pelophylax perezi & 30TXM35 & 100,00 & 127,31 & 106,02 & 37,54 & 6041,35 & 283,19 & 4,91 & 278,28 & 149,26 & 205,41 & 205,41 & 51,55 & 509,78 & 62,90 & 24,80 & 23,64 & 155,61 & 93,61 & 96,50 & 127,89 \\
\hline Pelophylax perezi & 30TXM36 & 100,00 & 129,18 & 106,00 & 37,92 & 6005,93 & 284,30 & 7,06 & 277,23 & 147,96 & 206,79 & 206,79 & 53,67 & 535,59 & 63,38 & 25,68 & 22,83 & 158,98 & 97,45 & 99,31 & 138,33 \\
\hline Pelophylax perezi & 30TXM37 & 100,00 & 129,39 & 105,94 & 38,00 & 5959,24 & 283,29 & 8,04 & 275,24 & 95,12 & 206,40 & 206,40 & 54,34 & 575,10 & 65,06 & 27,44 & 22,10 & 168,96 & 103,88 & 104,77 & 153,17 \\
\hline Pelophylax perezi & 30TXM38 & 100,00 & 127,53 & 105,31 & 38,00 & 5906,47 & 279,88 & 6,84 & 273,04 & 91,61 & 203,72 & 203,72 & 52,95 & 626,84 & 70,12 & 29,96 & 21,65 & 186,67 & 112,73 & 113,19 & 171,50 \\
\hline Pelophylax perezi & 30TXM39 & 100,00 & 124,96 & 104,99 & 38,09 & 5850,36 & 275,92 & 5,17 & 270,75 & 89,49 & 200,52 & 200,52 & 51,20 & 687,19 & 78,48 & 32,94 & 21,50 & 207,19 & 123,07 & 123,44 & 192,83 \\
\hline Pelophylax perezi & 30TXM40 & 100,00 & 136,26 & 105,00 & 36,99 & 6209,37 & 292,96 & 11,42 & 281,54 & 159,41 & 216,57 & 216,58 & 58,69 & 372,54 & 54,78 & 17,63 & 32,07 & 126,86 & 70,29 & 75,02 & 80,25 \\
\hline Pelophylax perezi & $30 \mathrm{TXM} 41$ & 100,00 & 138,05 & 105,43 & 37,00 & 6186,51 & 295,37 & 13,80 & \begin{tabular}{|l|}
281,57 \\
\end{tabular} & \begin{tabular}{|l|}
160,80 \\
\end{tabular} & 218,13 & 218,13 & 60,69 & 379,92 & 54,90 & 17,58 & 31,18 & 126,83 & 69,95 & 70,45 & $\begin{array}{ll}84,77 \\
84\end{array}$ \\
\hline Pelophylax perezi & 30TXM42 & 100,00 & 139,63 & 105,96 & 37,00 & 6174,59 & 297,19 & 15,96 & 281,24 & 162,39 & 219,56 & 219,56 & 62,39 & 391,62 & 54,69 & 17,77 & 29,69 & 127,56 & 71,12 & 71,12 & 90,34 \\
\hline Pelophylax perezi & 30TXM43 & 100,00 & 141,55 & 105,98 & 37,04 & 6134,37 & 298,47 & 18,29 & 280,18 & 164,34 & 220,72 & 220,72 & 64,52 & 407,81 & 54,45 & 18,40 & 27,56 & 129,07 & 73,85 & 73,85 & 96,77 \\
\hline Pelophylax perezi & 30TXM44 & 100,00 & 138,46 & 105,95 & 37,08 & 6090,79 & 294,70 & 15,47 & 279,23 & 160,71 & 217,24 & 217,24 & 61,92 & 439,31 & 56,51 & 20,22 & 25,72 & 136,14 & 79,98 & 80,42 & 106,61 \\
\hline Pelophylax perezi & 30TXM45 & 100,00 & 134,59 & 105,80 & 37,72 & 6029,52 & 290,12 & 12,27 & 277,86 & 156,46 & 212,67 & 212,67 & 58,95 & 477,71 & 59,03 & 22,36 & 24,01 & 144,83 & 87,31 & 89,01 & 118,78 \\
\hline Pelophylax perezi & 30TXM46 & 100,00 & 132,77 & 105,54 & 37,91 & 5971,76 & 287,08 & $\begin{array}{l}10,98 \\
10,98\end{array}$ & 276,10 & $\begin{array}{l}50,400 \\
154,50\end{array}$ & \begin{tabular}{|l|}
209,96 \\
\end{tabular} & \begin{tabular}{|l|}
209,96 \\
\end{tabular} & 57,60 & 516,95 & $\begin{array}{l}51,24 \\
61,\end{array}$ & 24,34 & $\frac{24,0}{22,70}$ & 152,71 & 94,45 & $\begin{array}{l}94,96 \\
94,\end{array}$ & $\begin{array}{l}132,09 \\
132,0\end{array}$ \\
\hline Pelophylax perezi & 30TXM47 & 100,00 & 127,01 & 105,15 & 38,00 & 5924,83 & 280,12 & 5,91 & 274,20 & 114,17 & 203,30 & 203,30 & 52,28 & 574,10 & 65,48 & 27,61 & 21,59 & 167,26 & 105,23 & 107,09 & 150,34 \\
\hline Pelophylax perezi & 30TXM48 & 100,00 & 120,32 & 104,88 & 38,03 & 5861,92 & 272,18 & 0,66 & 271,51 & 84,90 & 196,10 & 196,10 & 46,53 & 641,09 & 70,74 & 31,44 & 20,65 & 187,44 & 117,89 & 119,70 & 171,65 \\
\hline Pelophylax perezi & 30TXM49 & 100,00 & 111,52 & 104,06 & 38,12 & 5778,43 & 261,90 & $-6,27$ & 268,17 & 76,92 & 186,52 & 186,52 & 39,16 & 720,40 & 78,95 & 36,34 & 19,71 & 210,17 & 133,69 & 136,21 & 195,68 \\
\hline Pelophylax perezi & 30TXM50 & 100,00 & 127,07 & 103,95 & 36,92 & 6172,05 & 282,81 & 2,99 & 279,82 & 149,81 & \begin{tabular}{l|l|l}
172,08 \\
\end{tabular} & 207,02 & 50,14 & 398,22 & 58,16 & 20,01 & 30,77 & 136,78 & 78,05 & 88,28 & 82,88 \\
\hline Pelophylax perezi & 30TXM51 & 100,00 & 139,49 & 105,15 & 30 & $\frac{61 / 207,42}{6207}$ & 290,01 & \begin{tabular}{|l|l|}
16,05 \\
16,
\end{tabular} & $\begin{array}{l}\mid 7,0< \\
281,74 \\
\end{array}$ & \begin{tabular}{|l|}
$145,2,24$ \\
162
\end{tabular} & 220,04 & \begin{tabular}{|l|}
220,05 \\
205
\end{tabular} & $\begin{array}{ll}0,14 \\
62,15\end{array}$ & \begin{tabular}{|l|l|}
$370,2<4$ \\
370,43
\end{tabular} & $\begin{array}{l}30,10 \\
54,14\end{array}$ & $\begin{array}{l}2,01 \\
16,79\end{array}$ & $\begin{array}{ll}0,176 \\
31,68\end{array}$ & 124,02 & $\begin{array}{ll}10,07 \\
67,68\end{array}$ & $\begin{array}{l}0,200 \\
68,56\end{array}$ & $\begin{array}{l}0,01,76 \\
81,76\end{array}$ \\
\hline Pelophylax perezi & 30TXM52 & 100,00 & 143,09 & 105,50 & 37,00 & 6185,55 & 301,45 & 19,96 & 281,49 & 165,82 & 223,27 & 223,27 & 65,90 & 376,27 & 52,77 & 16,77 & 29,73 & 122,47 & 68,11 & 69,04 & 85,61 \\
\hline Pelophylax perezi & 30TXM53 & 100,00 & 132,01 & 105,19 & 37,00 & 6110,04 & 289,16 & 9,31 & 279,85 & 154,31 & 211,09 & 211,12 & 55,67 & 426,69 & 57,63 & 20,29 & 26,89 & 137,25 & 79,52 & 81,85 & 98,06 \\
\hline Pelophylax perezi & 30TXM54 & 100,00 & 131,54 & 105,22 & 37,02 & 6068,09 & 288,00 & 9,05 & 278,95 & 153,54 & 210,17 & 210,17 & 55,69 & 450,30 & 58,54 & 21,42 & 25,18 & 141,39 & 83,80 & 86,24 & 106,26 \\
\hline Pelophylax perezi & 30TXM55 & 100,00 & 130,65 & 105,09 & 37,3 & 6008,16 & 285,82 & 8,62 & 277,20 & 152,32 & 208,28 & 208,36 & 55,40 & 481,03 & 59,8 & 22,92 & 23,46 & 146,85 & 89,62 & 92,53 & 116,77 \\
\hline Pelophylax perezi & 30TXM56 & 100,00 & 131,77 & 105,01 & 37,9 & 5949,14 & 285,46 & 10,50 & 274,96 & 153,61 & 208,60 & 208,63 & 57,17 & 509,43 & 60,64 & 24,06 & 22,18 & 151,01 & 94,66 & 98,75 & 127,41 \\
\hline Pelophylax perezi & 30TXM57 & 100,00 & 124,80 & 104,84 & 38,00 & 5881,56 & 277,18 & 4,57 & 272,62 & 137,31 & 200,75 & 200,76 & 50,84 & 569,34 & 65,41 & 27,60 & 20,89 & 165,63 & 106,48 & 109,27 & 145,84 \\
\hline Pelophylax perezi & 30TXM58 & 100,00 & 113,90 & 103,95 & 38,00 & 5797,35 & 264,50 & $-4,35$ & 268,85 & 116,61 & 188,90 & 188,90 & 41,18 & 649,11 & 72,57 & 32,71 & 19,63 & 186,95 & 122,80 & 126,16 & 168,81 \\
\hline Pelophylax perezi & 30TXM59 & 100,00 & 103,55 & 102,68 & 38,04 & 5708,48 & 252,07 & $-12,97$ & 265,04 & 93,71 & 177,73 & 177,74 & 32,32 & 734,06 & 79,99 & 38,29 & 18,39 & 09,68 & 140,80 & 144,08 & 193,00 \\
\hline Pelophylax perezi & $30 T X M 6$ & 100,00 & 144,69 & 105,21 & 36,3 & 6277,05 & 304,91 & 20,39 & 284,52 & \begin{tabular}{|c|}
168,15 \\
16,15
\end{tabular} & 225,68 & 225,84 & 66,31 & 354,86 & 50,22 & 16,05 & 29,86 & 118,18 & $\begin{array}{r}45,06 \\
65,66 \\
\end{array}$ & $\begin{array}{l}740,81 \\
70,0\end{array}$ & 75,79 \\
\hline Pelophylax perezi & 30TXME & 100,00 & 140,27 & 105,20 & 36,92 & 6196,80 & 299,27 & 16,77 & 282,50 & 163,26 & 220,23 & 220,33 & 62,77 & 378,15 & 52, & 17,40 & 27,95 & 123,81 & 70,57 & 75,92 & 82,54 \\
\hline Pelophylax perezi & 30TXM64 & 100,00 & 119,33 & 104,01 & 37,06 & 5984,79 & 273,83 & $-1,61$ & 275,44 & 140,75 & 196,83 & 196,96 & 44,60 & 484,83 & 62,92 & 24,45 & 23,75 & 153,50 & 94,64 & 102,13 & 110,14 \\
\hline Pelophylax perezi & 30TXM65 & 100,00 & 121,25 & 104,19 & 37,42 & 5940,58 & 275,03 & 0,62 & 274,40 & 142,57 & 198,01 & 198,11 & 46,95 & 503,56 & 63,01 & 25,09 & 22,43 & 155,19 & 97,32 & 103,62 & 118,05 \\
\hline Pelophylax perezi & 30TXM & 100,00 & 128,08 & 104,69 & 37,91 & 5906,69 & 281,10 & 7,36 & 273,74 & 149,54 & 204,25 & 20 & 53,87 & 508,92 & 60,97 & 24,51 & 21,57 & 79 & 97,01 & 100,58 & 123,64 \\
\hline Pelophylax perezi & $30 \mathrm{TXN}$ & 100,00 & 118 & 103,90 & 38,00 & 5817,41 & 270,15 & $\begin{array}{l}0,01 \\
0,01\end{array}$ & 270,13 & \begin{tabular}{|l|}
139,65 \\
139,65
\end{tabular} & \begin{tabular}{|l|}
204,25 \\
194,19 \\
\end{tabular} & \begin{tabular}{|l|}
204,23 \\
194,25 \\
\end{tabular} & $\begin{array}{l}3,0 \\
46,15 \\
\end{array}$ & \begin{tabular}{|l|}
572,81 \\
572
\end{tabular} & $\begin{array}{l}60,77 \\
66,77\end{array}$ & 28,48 & \begin{tabular}{|l|l|}
20,11 \\
\end{tabular} & 168,26 & 11,010 & 114,96 & 142,04 \\
\hline Pelophylax perezi & 30TXM68 & 100,00 & 109,32 & 102,91 & 38,01 & 5729,41 & 258,29 & $-7,86$ & 266,14 & 129,00 & 183,44 & 183,52 & 37,62 & 649,78 & 73,60 & 33,38 & 18,82 & 188,19 & 126,30 & 131,44 & 164,01 \\
\hline Pelophylax perezi & $30 \mathrm{TXM} 69$ & 100,00 & 96,15 & 101,10 & 38,05 & 5631,87 & 242,63 & \begin{tabular}{|c|}
$-18,79$ \\
$-18,79$
\end{tabular} & 261,42 & 113,00 & $\begin{array}{l}169,56 \\
\end{array}$ & $\begin{array}{l}169,58 \\
\end{array}$ & 26,19 & 753,18 & 83,07 & 40,55 & $\begin{array}{l}17,42 \\
17,\end{array}$ & 215,76 & 148,84 & 152,24 & 192,26 \\
\hline Pelophylax perezi & 30TXM70 & 100,00 & 139,91 & 104,45 & 36,05 & 6233,91 & 299,11 & 15,36 & 283,75 & 163,46 & 148,13 & 220,96 & 62,00 & 362,75 & 50,22 & 17,38 & 28,79 & 122,03 & 71,01 & 77,63 & 71,93 \\
\hline Pelophylax perezi & $30 T X N$ & 100,00 & 146,76 & 105,24 & 36,17 & 6257,39 & 307,56 & 21,90 & 285,66 & 170,51 & 227,09 & 22 & 68,17 & 356,92 & 46,94 & 16,56 & 26,97 & 116,55 & 69,08 & 73,65 & 72 \\
\hline Pelophylax perezi & $\begin{array}{l}30 \mathrm{TXM72} \\
3\end{array}$ & $\begin{array}{l}100,00 \\
\end{array}$ & $\begin{array}{l}140,10 \\
139,49\end{array}$ & $\begin{array}{l}105,24 \\
105,01\end{array}$ & $\begin{array}{l}30,17 \mid \\
36,78\end{array}$ & $\begin{array}{l}\mid 623,172,47 \\
6172\end{array}$ & 298,75 & $\begin{array}{l}1,50 \\
15,87 \\
\end{array}$ & \begin{tabular}{|l|}
282,870 \\
282
\end{tabular} & \begin{tabular}{|l|l|}
162,73 \\
\end{tabular} & \begin{tabular}{|l|}
218,90 \\
\end{tabular} & $\begin{array}{l}219,44 \\
219 \\
\end{array}$ & $\begin{array}{l}\mid c 0,11 \\
62,19 \\
\end{array}$ & \begin{tabular}{|l|}
380,41 \\
380,41
\end{tabular} & $\begin{array}{l}0,34 \\
50,38 \\
\end{array}$ & $\begin{array}{l}\mid l 0,00 \\
17,99\end{array}$ & \begin{tabular}{|l|l|}
26,22 \\
26,
\end{tabular} & 1123,59 & $\begin{array}{l}3,00 \\
73,79\end{array}$ & 79,24 & 79,60 \\
\hline Pelophylax perezi & 30TXM74 & 100,00 & 123,39 & 103,77 & 37,03 & 5963,16 & 277,90 & 2,33 & 275,57 & 145,01 & 200,31 & 200,54 & 48,69 & 461,11 & 59,48 & 22,87 & 23,54 & 145,45 & 91,31 & 97,31 & 101,83 \\
\hline Pelophylax perezi & 30TXM75 & 100,00 & 122.42 & 103,73 & 37,22 & 5894.58 & 275,50 & 208 & 273,42 & 143.58 & 198.42 & 198,74 & 48,47 & 487.62 & 61,03 & 24,21 & 22.26 & 150,28 & 96.39 & 101.83 & 110,87 \\
\hline Pelophylax perezi & $30 \mathrm{TXN}$ & 100,00 & 124,55 & 103,96 & 37,89 & 5840,31 & 276,45 & 4,49 & 271,9 & 145,76 & 199 & $200, \mathrm{C}$ & 51, & 504,72 & 61,06 & 24,69 & 21,14 & 151,66 & 99,13 & 103,45 & 118,15 \\
\hline Pelophylax perezi & $30 \mathrm{TXM} 77$ & 100,00 & 114,39 & 102,89 & 38,00 & 5741,08 & 263,99 & $\begin{array}{l}-3,34 \\
-3,44 \\
\end{array}$ & 267,33 & 134,57 & 188,62 & 188,75 & 42,53 & 574,25 & 67,66 & 29,05 & 19,62 & 169,91 & 113,86 & 118,68 & 137,66 \\
\hline
\end{tabular}




\begin{tabular}{|c|c|c|c|c|c|c|c|c|c|c|c|c|c|c|c|c|c|c|c|c|c|}
\hline TAXON & UTM & $\mathrm{km2}$ & BIO1 & BIO2 & $\mathrm{BIO3}$ & B104 & B105 & B106 & B107 & B108 & B109 & BIO10 & BIO11 & B1012 & BIO13 & BIO14 & BIO15 & BIO16 & BIO17 & BIO18 & \begin{tabular}{|l|l|} 
BIO \\
\end{tabular} \\
\hline Pelophylax perezi & 30TXM78 & 100,00 & 105,11 & 101,80 & 38,00 & 5660,68 & 252,52 & $-11,02$ & 263,54 & 124,45 & 178,48 & 178,66 & 34,44 & 651,86 & 74,57 & 34,13 & 18,21 & 189,92 & 130,24 & 135,19 & 159,73 \\
\hline Pelophylax perezi & 30TXM79 & 100,00 & 94,27 & 100,14 & 38,01 & 5578,12 & 239,18 & $-20,06$ & 259,24 & \begin{tabular}{ll|}
112,36 \\
\end{tabular} & $\begin{array}{l}166,83 \\
1\end{array}$ & $\begin{array}{l}166,86 \\
\end{array}$ & 24,87 & 748,31 & 83,20 & \begin{tabular}{ll|}
40,77 \\
\end{tabular} & \begin{tabular}{l|l|}
16,95 \\
1
\end{tabular} & 215,23 & \begin{tabular}{l|l|}
151,02 \\
\end{tabular} & \begin{tabular}{ll|}
156,15 \\
\end{tabular} & 186,56 \\
\hline Pelophylax perezi & 30TXM80 & 100,00 & 145,28 & $\begin{array}{ll}104,63 \\
\end{array}$ & 36,21 & 6190,31 & 303,61 & 20,15 & 283,46 & $\begin{array}{ll}168,93 \\
\end{array}$ & \begin{tabular}{ll|}
79,03 \\
\end{tabular} & 225,67 & 67,72 & 355,22 & 47,42 & 16,52 & 28,16 & \begin{tabular}{ll|}
116,99 \\
\end{tabular} & $\begin{array}{l}69,07 \\
6\end{array}$ & 74,27 & 69,08 \\
\hline Pelophylax perezi & 30TXM81 & 100,00 & 144,28 & 104,85 & 36,36 & 6169,93 & 303,16 & 19,72 & 283,44 & \begin{tabular}{|l|l|l|l}
167,74 \\
\end{tabular} & \begin{tabular}{ll|l}
140,13 \\
\end{tabular} & 224,41 & 66,73 & 363,76 & 47,59 & \begin{tabular}{l|l|l|}
16,95 \\
\end{tabular} & 26,93 & \begin{tabular}{l|l|}
118,23 \\
\end{tabular} & 71,85 & 75,41 & 72,28 \\
\hline Pelophylax perezi & 30TXM82 & 100,00 & 139,35 & 104,73 & 36,89 & 6112,10 & 297,35 & $15,57 \mid$ & 281,78 & $162,46 \mid$ & $174,81 \mid$ & 218,70 & 62,77 | & 381,90 & 49,74 & 18,05 & 25,86 - & 122,92 & 76,19 & 79,36 & 77,58 \\
\hline Pelophylax perezi & 30TXM83 & 100,00 & 136,28 & 104,68 & 37,00 & 6036,82 & 292,76 & 13,48 & 279,28 & 159,10 & 210,90 & 214,44 & \begin{tabular}{|c|}
60,58 \\
\end{tabular} & 400,59 & 51,58 & $\begin{array}{ll}19,03 \\
\end{array}$ & 24,70 & \begin{tabular}{l|l|}
126,96 \\
\end{tabular} & 80,25 & 82,88 & 83,63 \\
\hline Pelophylax perezi & 30TXM84 & 100,00 & 133,34 & 104,30 & 37,08 & 5953,49 & 288,14 & 11,68 & 276,45 & \begin{tabular}{ll|}
155,49 \\
\end{tabular} & 209,82 & 210,30 & 58,63 & 422,34 & 53,57 & 20,11 & 23,76 & 131,74 & 84,71 & 86,98 & 90,53 \\
\hline Pelophylax perezi & 30TXM86 & 100,00 & 124,99 & \begin{tabular}{|l|l|}
103,48 \\
\end{tabular} & 37,99 & 5784,12 & 275,87 & 5,21 & 270,66 & \begin{tabular}{|l|l|}
146,09 \\
\end{tabular} & \begin{tabular}{|l|l|}
199,47 \\
\end{tabular} & \begin{tabular}{ll|}
199,92 \\
\end{tabular} & 52,24 & \begin{tabular}{ll|}
488,99 \\
\end{tabular} & $\begin{array}{l}59,35 \\
\end{array}$ & 23,81 & 21,27 & \begin{tabular}{|l|l|}
147,01 \\
\end{tabular} & \begin{tabular}{l|l|}
98,59 \\
\end{tabular} & $\begin{array}{ll}100,42 \\
\end{array}$ & 110,74 \\
\hline Pelophylax perezi & 30TXM87 & 100,00 & 118,97 & \begin{tabular}{ll|}
102,86 \\
\end{tabular} & 38,00 & 5709,54 & 267,58 & 0,43 & 267,16 & \begin{tabular}{|l|l|}
139,37 \\
\end{tabular} & $\begin{array}{l}192,36 \\
1\end{array}$ & \begin{tabular}{|l|l|}
192,87 \\
\end{tabular} & 47,08 & 538,87 & 63,79 & 26,86 & 19,88 & \begin{tabular}{ll|}
159,26 \\
\end{tabular} & \begin{tabular}{l|l|l|}
109,08 \\
\end{tabular} & \begin{tabular}{l|l|}
111,22 \\
\end{tabular} & 125,26 \\
\hline Pelophylax perezi & 30TXM88 & 100,00 & 112,24 & 102,10 & 38,10 & 5625,63 & 258,76 & $-4,53$ & 263,29 & 132,04 & $184,71 \mid$ & 185,06 & 41,42 & 601,19 _ & 69,05 & 30,72 & 18,49 & 174,65 & 122,07 & 124,87 & 143,51] \\
\hline Pelophylax perezi & 30TXM89 & 100,00 & 102,23 & 100,74 & 38,23 & 5560,33 & 246,57 & $-12,78$ & 259,35 & 120,78 & \begin{tabular}{|l|l|}
174,27 \\
\end{tabular} & \begin{tabular}{|l|l|}
174,50 \\
\end{tabular} & 32,76 & 687,58 & 76,95 & 36,54 & \begin{tabular}{|l|l|}
17,18 \\
\end{tabular} & \begin{tabular}{|l|l|l|}
197,48 \\
\end{tabular} & 140,41 & $\begin{array}{ll}144,25 \\
\end{array}$ & 167,70 \\
\hline Pelophylax perezi & \begin{tabular}{|l|l|}
$30 T X M 90$ \\
\end{tabular} & 100,00 & 145,91 & 104,34 & 36,84 & 6119,99 & 302,47 & 21,05 & \begin{tabular}{|l|l|}
281,42 \\
\end{tabular} & \begin{tabular}{|l|l|}
169,23 \\
\end{tabular} & 69,32 & 225,45 & 69,32 & \begin{tabular}{l|l|}
356,85 \\
\end{tabular} & 47,36 & \begin{tabular}{|l|l|}
16,40 \\
\end{tabular} & 28,47 & \begin{tabular}{|l|l|}
116,04 \\
\end{tabular} & \begin{tabular}{|l|l|}
68,17 \\
\end{tabular} & \begin{tabular}{|l|l|l|}
73,87 \\
\end{tabular} & 68,17 \\
\hline Pelophylax perezi & 30TXM91 & 100,00 & 135,30 & \begin{tabular}{l|l|}
103,86 \\
\end{tabular} & 36,84 & 6068,55 & 291,42 & \begin{tabular}{|l|l|}
11,64 \\
\end{tabular} & 279,78 & 158,16 & \begin{tabular}{|l|l}
59,43 \\
\end{tabular} & 214,25 & 59,43 & 383,24 & 51,33 & \begin{tabular}{l|l|}
18,35 \\
\end{tabular} & 27,52 & 125,38 & 73,84 & 81,24 & 73,84 \\
\hline Pelophylax perezi & 30TXM92 & 100,00 & 129,35 & 103,44 & 36,99 & 5994,92 & 284,30 & \begin{tabular}{ll|}
6,92 \\
\end{tabular} & 277,38 & \begin{tabular}{ll|}
151,60 \\
\end{tabular} & 54,36 & 207,39 & 54,36 & 404,14 & 53,86 & \begin{tabular}{|l|l|l|}
19,69 \\
\end{tabular} & 26,35 & 131,16 & 79,34 & \begin{tabular}{l|l|l|}
86,07 \\
\end{tabular} & 79,34 \\
\hline Pelophylax perezi & 30TXM93 & 100,00 & 129,09 & 103,53 & 37,00 & 5941,32 & 283,25 & 7,50 & 275,75 & $\begin{array}{ll}151,18 \\
\end{array}$ & 76,57 & 206,39 & 54,61 & 412,78 & 53,98 & \begin{tabular}{l|l|}
19,98 \\
\end{tabular} & 25, & \begin{tabular}{ll|l}
131,66 \\
\end{tabular} & 82,86 & 86,85 & 82,89 \\
\hline Pelophylax perezi & 30TXM94 & 100,00 & 125,42 & \begin{tabular}{ll|}
103,15 \\
\end{tabular} & 37,16 & 5845,85 & 277,79 & 5,00 & 272,79 & \begin{tabular}{ll|}
146,96 \\
\end{tabular} & 109,87 & 201,35 & 52,13 & 434,80 & 56,04 & 21,21 & 24,10 & \begin{tabular}{|l|}
136,59 \\
\end{tabular} & \begin{tabular}{l|l}
88,95 \\
\end{tabular} & 91,20 & 89,39 \\
\hline Pelophylax perezi & 30TXM95 & 100,00 & 126,16 & \begin{tabular}{ll|}
103,24 \\
\end{tabular} & 37,72 & 5788,91 & 277,59 & 6,25 & 271,34 & \begin{tabular}{|l|l|}
147,70 \\
\end{tabular} & 190,51 & 201,40 & 53,52 & 449,38 & 56,37 & 21,78 & 22,87 & \begin{tabular}{|l|l|}
138,07 \\
\end{tabular} & 92,75 & 93,08 & 95,25 \\
\hline Pelophylax perezi & $\begin{array}{l}30 T X M 96 \\
\end{array}$ & 100,00 & 121,81 & 102,79 & \begin{tabular}{|l|}
37,98 \\
\end{tabular} & 5713,07 & 271,06 & 2,91 & 268,15 & 142,77 & \begin{tabular}{|l|l|}
195,99 \\
\end{tabular} & \begin{tabular}{|l|l|}
196,03 \\
\end{tabular} & \begin{tabular}{l|l|}
50,15 \\
\end{tabular} & 483,54 & 59,36 & 23,76 & 21,50 & \begin{tabular}{|l|l|}
146,06 \\
\end{tabular} & \begin{tabular}{|l|}
100,17 \\
\end{tabular} & 100,21 & 105,26 \\
\hline Pelophylax perezi & \begin{tabular}{|l|} 
30TXM97 \\
\end{tabular} & 100,00 & 117,48 & 102,31 & 38,00 & 5642,31 & 264,80 & $-0,18$ & \begin{tabular}{|l|l|}
264,98 \\
\end{tabular} & \begin{tabular}{ll|}
137,80 \\
\end{tabular} & $\begin{array}{l}190,56 \\
1\end{array}$ & $\begin{array}{l}190,68 \\
\end{array}$ & 46,59 & 525,89 & \begin{tabular}{l|l}
62,85 \\
\end{tabular} & 26,32 & \begin{tabular}{ll|}
20,06 \\
\end{tabular} & \begin{tabular}{ll|}
156,01 \\
\end{tabular} & \begin{tabular}{l|l}
109,05 \\
\end{tabular} & 109,31 & 117,90 \\
\hline Pelophylax perezi & $\begin{array}{l}30 T X M 98 \\
\end{array}$ & 100,00 & 103,57 & 100,42 & \begin{tabular}{|l|l|}
37,97 \\
\end{tabular} & 5556,27 & 248,27 & $-11,52$ & \begin{tabular}{|l|l|}
259,79 \\
\end{tabular} & 122,65 & \begin{tabular}{l|l|l|}
175,53 \\
\end{tabular} & $\begin{array}{l}175,85 \\
\end{array}$ & 34,1 & 625,63 & 72,82 & $33,-$ & 18, & 183,7 & $\begin{array}{l}131,05 \\
\end{array}$ & \begin{tabular}{ll|}
133,33 \\
\end{tabular} & 144,31 \\
\hline Pelophylax perezi & $\begin{array}{l}\text { 30TXM99 } \\
\end{array}$ & 100,00 & 94,60 & 99,09 & 38,08 & 5505,17 & 237,16 & $-18,87$ & 256,03 & 112,80 & \begin{tabular}{|l|l|}
166,07 \\
\end{tabular} & 166,36 & 26,08 & \begin{tabular}{|l|l|}
718,17 \\
\end{tabular} & 81,02 & 39,44 & \begin{tabular}{ll|}
16,76 \\
\end{tabular} & 208,06 & 150,51 & 154,57 & 170,46 \\
\hline Pelophylax perezi & $\begin{array}{l}30 T X N 00 \\
\end{array}$ & 100,00 & 127,58 & 104,76 & 38,30 & 5801,83 & 278,61 & 9,32 & 269,29 & 70,78 & 202,65 & 202,65 & 54,66 & \begin{tabular}{|l|l|}
733,37 \\
\end{tabular} & 85,78 & \begin{tabular}{l|l|}
35,25 \\
\end{tabular} & 22,26 & $\begin{array}{l}226,05 \\
2\end{array}$ & \begin{tabular}{|l|l|}
128,43 \\
\end{tabular} & \begin{tabular}{|l|l|}
128,43 \\
\end{tabular} & 212,22 \\
\hline Pelophylax perezi & 30TXN01 & 100,00 & 122,08 & \begin{tabular}{ll|}
104,38 \\
\end{tabular} & \begin{tabular}{l|l|}
38,45 \\
\end{tabular} & 5749,16 & 272,88 & 5,07 & 267,82 & 58,33 & \begin{tabular}{|l|l|}
196,59 \\
\end{tabular} & \begin{tabular}{|l|l|}
196,59 \\
\end{tabular} & 49,94 & 823,10 & $\begin{array}{l}98,48 \\
\end{array}$ & \begin{tabular}{|l|}
39,67 \\
\end{tabular} & 22,73 & 259,36 & $\begin{array}{ll}142,68 \\
\end{array}$ & \begin{tabular}{|l|l|}
142,68 \\
\end{tabular} & 244,35 \\
\hline Pelophylax perezi & 30TXN02 & 100,00 & 118,55 & 103,34 & 38,71 & 5664,61 & 267,93 & 3,58 & 264,35 & 56,29 & \begin{tabular}{|l|l|}
192,16 \\
\end{tabular} & $\begin{array}{l}192,16 \\
\end{array}$ & $\begin{array}{l}47,55 \\
\end{array}$ & 908,59 & 110,43 & 43,78 & 23,08 & 291,15 & 156,75 & $\begin{array}{l}156,75 \\
\end{array}$ & 274,93 \\
\hline Pelophylax perezi & 30TXN03 & 100,00 & 117,28 & 101,84 & \begin{tabular}{|l|}
38,87 \\
\end{tabular} & 5563,04 & 264,31 & 4,46 & 259,85 & 56,19 & \begin{tabular}{|l|l|}
189,71 \\
\end{tabular} & 189,71 & \begin{tabular}{ll|l}
47,87 \\
\end{tabular} & 987,76 & 121,64 & 47,40 & 23,5 & 321,10 & \begin{tabular}{l|l|}
170,42 \\
\end{tabular} & \begin{tabular}{l|l}
170,42 \\
\end{tabular} & 303,38 \\
\hline Pelophylax perezi & $\begin{array}{l}30 \mathrm{~T} \times \mathrm{N} 04 \\
\end{array}$ & 100,00 & 120,11 & 99,69 & 38,96 & 5424,70 & 263,16 & 9,95 & 253,21 & 60,57 & 190,76 & 190,76 & 52,43 & 1054,55 & 130,95 & 50,27 & 23,93 & 346,91 & \begin{tabular}{|l|}
182,97 \\
\end{tabular} & 182,97 & 327,25 \\
\hline Pelophylax perezi & 30TXN05 & 100,00 & 110,26 & \begin{tabular}{ll|}
97,76 \\
\end{tabular} & \begin{tabular}{|l|l|}
39,07 \\
\end{tabular} & 5256,90 & 249,72 & 3,59 & 246,12 & 53,32 & $\begin{array}{l}179,04 \\
1\end{array}$ & $\begin{array}{l}179,04 \\
\end{array}$ & 45,21 & 1130,85 & \begin{tabular}{l|l}
136,25 \\
\end{tabular} & 56,18 & 21,96 & 365,42 & 203,32 & 203,32 & 344,20 \\
\hline Pelophylax perezi & 30TXN06 & 100,00 & 106,18 & \begin{tabular}{l|l}
95,55 \\
\end{tabular} & 39,43 & 5116,10 & 241,79 & 2,54 & 239,25 & 50,97 & \begin{tabular}{|l|l|}
173,27 \\
\end{tabular} & \begin{tabular}{|l|l|}
173,27 \\
\end{tabular} & 43,10 & 1195,82 & 142,30 & 60,52 & 21,15 & 384,30 & 219,61 & 219,61 & 361,55 \\
\hline Pelophylax perezi & 30TXN07 & 100,00 & 120,29 & 91,28 & 39,95 & 4846,52 & 246,87 & 20,70 & 226,18 & 68,22 & \begin{tabular}{|l|l|}
181,79 \\
\end{tabular} & 183,66 & 60,27 & 1249,93 & 149,77 & 62,11 & 21,78 & 406,52 & 230,56 & 234,53 & 379,90 \\
\hline Pelophylax perezi & 30TXN08 & 100,00 & 127,35 & 87,62 & 40,13 & 4626,20 & 246,63 & 31,30 & 215,33 & 79,84 & $\begin{array}{l}185,25 \\
\end{array}$ & 187,69 & 69,99 & 1304,00 & 156,08 & 64,90 & 21,99 & 425,17 & 241,37 & 251,01 & 395,35 \\
\hline Pelophylax perezi & 30TXN09 & 67,00 & 131,10 & \begin{tabular}{l|l|}
84,45 \\
\end{tabular} & 40,21 & 4476,51 & 244,47 & 37,44 & 207,04 & $\begin{array}{l}90,90 \\
\end{array}$ & \begin{tabular}{ll|}
186,80 \\
\end{tabular} & \begin{tabular}{|l|l|}
189,40 \\
\end{tabular} & 75,49 & 1344,08 & 160,62 & 67,51 & 22,10 & 438,57 & 250,79 & 265,82 & 405,86 \\
\hline Pelophylax perezi & 30TXN10 & 100,00 & 123,99 & 105,02 & 38,19 & 5829,79 & 275,63 & 5,13 & 270,50 & 65,01 & \begin{tabular}{|l|l|}
199,39 \\
\end{tabular} & 199,39 & 50,54 & 757,65 & 89,75 & 36,32 & 22,51 & 234,27 & 132,08 & 132,08 & 221,01 \\
\hline Pelophylax perezi & 30TXN11 & 100,00 & 112,57 & 104,39 & 38,63 & 5739,69 & 263,64 & $-3,90$ & 267,55 & 49,56 & \begin{tabular}{|l|l|}
187,27 \\
\end{tabular} & 187,27 & \begin{tabular}{ll|}
40,99 \\
\end{tabular} & 859,66 & 101,79 & 42,53 & 21,75 & 267,27 & \begin{tabular}{ll|}
151,36 \\
\end{tabular} & \begin{tabular}{ll|}
151,36 \\
\end{tabular} & 252,99 \\
\hline Pelophylax perezi & 30TXN12 & 100,00 & 104,16 & 102,64 & \begin{tabular}{|l|l|}
38,87 \\
\end{tabular} & 5612,40 & 252,62 & $-9,53$ & 262,15 & 43,29 & \begin{tabular}{|l|l|}
177,51 \\
\end{tabular} & 177,51 & 34,44 & 941,64 & 110,28 & 47,8 & 20,74 & 291,98 & 169,21 & 169,21 & 276,37 \\
\hline Pelophylax perezi & 30TXN13 & 100,00 & 118,26 & 102,80 & 38,63 & 5631,79 & 266,64 & 3,42 & 263,22 & 56,39 & \begin{tabular}{|l|l|}
191,36 \\
\end{tabular} & 191,36 & 47,70 & 996,28 & 125,80 & \begin{tabular}{l|l}
47,05 \\
\end{tabular} & 24,63 & 327,85 & \begin{tabular}{|l|l|}
169,48 \\
\end{tabular} & \begin{tabular}{|l|l|}
169,48 \\
\end{tabular} & 310,93 \\
\hline Pelophylax perezi & 30TXN14 & 100,00 & 114,75 & 100,62 & 38,90 & 5484,35 & 259,12 & 3,13 & 255,99 & \begin{tabular}{|l|l|}
54,69 \\
\end{tabular} & \begin{tabular}{|l|l|}
186,16 \\
\end{tabular} & 186,16 & 46,05 & 1064,60 & 132,53 & 51,37 & 23,62 & 348,62 & \begin{tabular}{ll|}
185,86 \\
\end{tabular} & \begin{tabular}{ll|}
185,86 \\
\end{tabular} & 329,79 \\
\hline Pelophylax perezi & 30TXN15 & 100,00 & 107,71 & 98,34 & 39,02 & 5316,13 & 247,88 & $-0,46$ & 248,34 & \begin{tabular}{|l|l|}
50,04 \\
\end{tabular} & \begin{tabular}{|l|l|}
177,17 \\
\end{tabular} & 177,17 & 41,58 & 1130,84 & 136,92 & 56,58 & 21,81 & \begin{tabular}{|l|l}
364,65 \\
\end{tabular} & 204,42 & 204,42 & 344,08 \\
\hline Pelophylax perezi & 30TXN16 & 100,00 & 94,84 & 95,87 & 39,18 & 5175,51 & 231,62 & $-9,67$ & 241,29 & 39,67 & \begin{tabular}{|l|l|}
162,94 \\
\end{tabular} & \begin{tabular}{l|l|}
162,95 \\
\end{tabular} & 31,2 & 1194,21 & \begin{tabular}{l|l|}
139,45 \\
\end{tabular} & 62,56 & $\begin{array}{l}19,60 \\
\end{array}$ & \begin{tabular}{|l|l|}
376,12 \\
\end{tabular} & 224,05 & 224,05 & 354,54 \\
\hline Pelophylax perezi & 30TXN17 & 100,00 & 121,06 & 92,23 & 39,79 & 938,64 & 24 & 18,70 & 229,73 & 67,68 & 183,71 & 185, & 59,33 & 1233,22 & 149,93 & 61,3 & 22,1 & 402,1 & 228,79 & 233,11 & 376,19 \\
\hline Pelophylax perezi & 30TXN18 & 100,00 & 117,03 & 90,82 & 39,96 & 4835,37 & 241,98 & 16,72 & 225,26 & 65,70 & 178,11 & 180,21 & 56,93 & 1297,17 & \begin{tabular}{|l|l|}
156,49 \\
\end{tabular} & 65,5 & 21,61 & \begin{tabular}{|l|l|}
421,85 \\
\end{tabular} & 243,14 & 248,53 & 394,30 \\
\hline Pelophylax perezi & 30TXN19 & 26,00 & 12 & 85,70 & \begin{tabular}{|l|}
39,96 \\
\end{tabular} & 4614,73 & 244,82 & 32,49 & 212,33 & \begin{tabular}{|l|l|}
96,22 \\
\end{tabular} & \begin{tabular}{|l|l|}
187,60 \\
\end{tabular} & \begin{tabular}{|l|l|}
189,94 \\
\end{tabular} & 71,90 & \begin{tabular}{|l|l|}
1314,87 \\
\end{tabular} & 159,18 & \begin{tabular}{|c|}
66,88 \\
\end{tabular} & 22,29 & \begin{tabular}{|l|l|}
431,17 \\
\end{tabular} & \begin{tabular}{|l|}
249,34 \\
\end{tabular} & 264,29 & 396,94 \\
\hline Pelophylax perezi & 30 TXN20 & 100,00 & 116,12 & \begin{tabular}{|l|l|}
104,93 \\
\end{tabular} & \begin{tabular}{l|l|}
38,45 \\
\end{tabular} & \begin{tabular}{|l|l}
5801,88 \\
\end{tabular} & 267,64 & $-1,72$ & 269,35 & 55,99 & 191,37 & 191,37 & 43,40 & 782,81 & 91,30 & \begin{tabular}{l|l|}
38,45 \\
\end{tabular} & 21,42 & 238,41 & 138,98 & 138,98 & 225,49 \\
\hline Pelophylax perezi & 30TXN21 & 100,00 & 110,77 & \begin{tabular}{|l|}
103,97 \\
\end{tabular} & 38,69 & 5720,06 & 260,75 & $-5,38$ & 266,14 & 48,12 & \begin{tabular}{|l|l|}
185,19 \\
\end{tabular} & \begin{tabular}{|l|l|}
185,19 \\
\end{tabular} & 39,23 & 858,42 & 100,73 & 42,72 & 21,16 & 264,27 & 153,29 & 153,29 & 250,21 \\
\hline Pelophylax perezi & 30TXN22 & 100,00 & 37 & 102,39 & 38,82 & 608,17 & 251,24 & $-10,44$ & 261,68 & 42,50 & $\begin{array}{ll}176,68 \\
\end{array}$ & 176, & 33,5 & \begin{tabular}{|l|l|}
936,79 \\
\end{tabular} & 109,38 & 47,68 & 20,3 & 288,82 & \begin{tabular}{|l|l|}
169,79 \\
\end{tabular} & \begin{tabular}{|l|l|}
169,79 \\
\end{tabular} & 273,40 \\
\hline Pelophylax perezi & \begin{tabular}{|l|l|l|}
$30 T \times N 23$ \\
\end{tabular} & 100,00 & 11 & 102,05 & 38,93 & 5571,81 & 257,65 & $-2,50$ & 260,15 & 50,36 & 183,84 & 183,84 & 41,6 & 988,25 & 120,37 & 48,46 & 22,30 & 315,84 & 175,14 & 175,14 & 299,01 \\
\hline Pelophylax perezi & 30TXN24 & 100,00 & 105,82 & \begin{tabular}{l|l|}
100,25 \\
\end{tabular} & 38,97 & 5446,53 & 249,11 & $-5,28$ & 254,39 & 46,7 & \begin{tabular}{|l|l|}
176,99 \\
\end{tabular} & \begin{tabular}{ll|}
176,99 \\
\end{tabular} & 37,91 & 1056,73 & \begin{tabular}{|l|l|}
127,07 \\
\end{tabular} & 53,08 & 21,29 & 336,13 & \begin{tabular}{|l|l|}
191,33 \\
\end{tabular} & 191,33 & 317,75 \\
\hline Pelophylax perezi & 30 TXN25 & 100,00 & 100,82 & 98,30 & 39,01 & 5322,00 & 240,78 & $-7,48$ & 248,25 & 43,32 & $\begin{array}{l}170,44 \\
1\end{array}$ & $\begin{array}{l}170,44 \\
\end{array}$ & \begin{tabular}{|l|l|}
34,87 \\
\end{tabular} & 1122,83 & 133,32 & 57,64 & \begin{tabular}{|l|l|}
20,37 \\
\end{tabular} & \begin{tabular}{|l|l|}
355,39 \\
\end{tabular} & 207,64 & 207,64 & 335,49 \\
\hline Pelophylax perezi & 30TXN27 & 72,00 & 109,27 & 94,73 & 39,63 & 5078,57 & 241,06 & 4,33 & 236,72 & 54,34 & 174,58 & 175,53 & 45,96 & 1221,24 & 147,16 & 62,18 & 21,02 & 393,30 & 230,13 & 231,38 & 369,47 \\
\hline Pelophylax perezi & 30TXN30 & 100,00 & 115,90 & \begin{tabular}{ll|}
104,45 \\
\end{tabular} & 38,38 & 5773,08 & 266,18 & $-2,04$ & 268,22 & 67,10 & 190,80 & 190,80 & 43,46 & 772,37 & 88,94 & 38,00 & 20,84 & 232,83 & \begin{tabular}{|l|}
139,04 \\
\end{tabular} & \begin{tabular}{|l|}
139,04 \\
\end{tabular} & 219,86 \\
\hline Pelophylax perezi & 30TXN31 & 100,00 & 120 & 103,87 & 38,52 & 5721,66 & 268,99 & 2,92 & 266,06 & 65, & 194,55 & 194,55 & 48,45 & 814,16 & 96,60 & 39,15 & 21,72 & 252,33 & 145,09 & 145,09 & 238,28 \\
\hline Pelophylax perezi & 30TXN32 & 100,00 & 113,49 & \begin{tabular}{l|l|}
102,85 \\
\end{tabular} & 38,92 & 5636,46 & 260,48 & $-2,03$ & 262,51 & \begin{tabular}{|l|l|}
51,78 \\
\end{tabular} & \begin{tabular}{|l|l|}
186,71 \\
\end{tabular} & 186,71 & $\begin{array}{l}2,65 \\
\end{array}$ & 896,38 & 106,61 & 44,13 & 21,28 & 279,60 & \begin{tabular}{|l|l|l}
161,46 \\
\end{tabular} & \begin{tabular}{ll|}
161,46 \\
\end{tabular} & 264,25 \\
\hline Pelophylax perezi & 30TXN33 & 100,00 & 113,11 & 101,81 & 38,94 & 5557,36 & 257,84 & $-1,08$ & 258,92 & 52,09 & \begin{tabular}{|l|l|}
185,17 \\
\end{tabular} & \begin{tabular}{|l|l|}
185,17 \\
\end{tabular} & 43,17 & 960,76 & 115,81 & 47,24 & 21,58 & \begin{tabular}{|l|l|}
303,97 \\
\end{tabular} & \begin{tabular}{|l|l|}
173,33 \\
\end{tabular} & $\begin{array}{l}173,33 \\
\end{array}$ & 287,33 \\
\hline Pelophylax perezi & 30TXN34 & 100,00 & 102,45 & 99,88 & 39,00 & 5425,73 & 244,40 & $-8,52$ & 252,92 & \begin{tabular}{|l|l|}
43,64 \\
\end{tabular} & 173,20 & 173,20 & 34,78 & 1043,23 & 122,97 & 53,41 & 20,09 & 326,28 & 193,20 & 193,20 & 308,08 \\
\hline Pelophylax perezi & $30 \mathrm{TXN}$ & 100,00 & 91, & 97,76 & 38, & 5311 & & $-16,3$ & 247 & & 161 & 161 & & 1113 & 128,04 & 59 , & 10 & 343,19 & 211,70 & 211,70 & 323 \\
\hline Pelophylax perezi & 30TXN36 & 81,00 & 90,19 & 96,37 & 39,05 & 5227,71 & 226,97 & $-16,30$ & 243,27 & 34,44 & \begin{tabular}{|l|l|}
158,80 \\
\end{tabular} & 158,81 & 25,69 & 1166,10 & 134,19 & 62,39 & \begin{tabular}{|l|l|}
18,37 \\
\end{tabular} & 360,71 & 223,80 & 223,80 & 340,07 \\
\hline Pelophylax perezi & $30 \mathrm{TXN40}$ & 100,00 & 108,21 & 103,44 & \begin{tabular}{|l|}
38,47 \\
\end{tabular} & 5707,76 & 256,78 & $-8,56$ & 265,34 & $\begin{array}{ll}71,64 \\
\end{array}$ & \begin{tabular}{ll|}
182,34 \\
\end{tabular} & 182,34 & 36,77 & 781,12 & 86,62 & 39,74 & 19,31 & 229,63 & \begin{tabular}{|l|}
145,28 \\
\end{tabular} & \begin{tabular}{|l|l|l|}
146,48 \\
\end{tabular} & 215,80 \\
\hline Pelophylax perezi & 30TXN41 & 100,00 & 119,31 & \begin{tabular}{|l|l|}
103,47 \\
\end{tabular} & 38,94 & 5672,28 & 266,17 & \begin{tabular}{|l|}
1,97 \\
\end{tabular} & 264,20 & \begin{tabular}{l|l|l}
81,03 \\
\end{tabular} & \begin{tabular}{|l|l|}
192,59 \\
\end{tabular} & \begin{tabular}{|l|l|}
192,59 \\
\end{tabular} & 47,78 & 796,64 & 92,31 & 38,74 & \begin{tabular}{l|l|}
20,62 \\
\end{tabular} & 243,00 & \begin{tabular}{|l|l|}
145,39 \\
\end{tabular} & \begin{tabular}{|l|l|}
145,78 \\
\end{tabular} & 228,46 \\
\hline Pelophyl: & $30 \mathrm{TXN}$ & & & \begin{tabular}{|l|l|}
101,97 \\
\end{tabular} & 38 & & & $-6,84$ & & 48, & 180, & 180 & 37, & 892, & 102,53 & 45, & & & 165,82 & 165,88 & \\
\hline Pelophylax perezi & $30 \mathrm{TXN} 43$ & 100,00 & 105,35 & 101,11 & 39,00 & 5500,27 [ & 248,6 & $-7,84$ & 256,50 & $45,35[$ & 176,90 & 176,90 & 36,38 & \begin{tabular}{|l|}
954,67 \\
\end{tabular} & 110,75 & 48,62 & 19,55 & $293,38 \mid$ & \begin{tabular}{|l|l|}
178,09 \\
\end{tabular} & 178,09 & 276 \\
\hline Pelophylax perezi & 30TXN44 & 100,00 & 88,07 & 98,23 & 38,93 & 5375,46 & 228,34 & $-21,44$ & 249,78 & 30,71 & 158,55 & 158,55 & 21,58 & 1053,74 & 117,87 & 56,95 & 17,45 & 316,51 & 203,15 & 203,15 & 298,49 \\
\hline
\end{tabular}




\begin{tabular}{|c|c|c|c|c|c|c|c|c|c|c|c|c|c|c|c|c|c|c|c|c|c|}
\hline TAXON & UTM & $\mathrm{km} 2$ & B101 & B102 & $\mathrm{BIO3}$ & B104 & B105 & B106 & B107 & B108 & B109 & B1010 & BIO11 & BIO12 & 81013 & BIO14 & BIO15 & BIO16 & BIO17 & B1018 & B1019 \\
\hline Pelophylax perezi & 30TXN45 & 100,00 & 85,92 & 97,14 & 38,97 & 5304,76 & 224,21 & $-21,97$ & 246,18 & 29,51 & 155,51 & 155,51 & 20,47 & 1105,56 & 123,97 & 60,19 & 17,23 & 333,86 & 214,72 & 214,72 & 314,68 \\
\hline Pelophylax perezi & 30 TXN50 & 100,00 & 104,72 & 102,40 & 38,53 & 5650,83 & 251,56 & $-11,08$ & 262,63 & 76,05 & 178,11 & 178,11 & 34,09 & 777,70 & 84,18 & 40,27 & 18,30 & 225,41 & 148,41 & 150,99 & 209,58 \\
\hline Pelophylax perezi & 30 TXN51 & 100,00 & 108,88 & 102,45 & 38,88 & 5601,82 & 254,21 & $-6,87$ & 261,08 & 73,79 & 181,44 & 181,44 & 38,63 & 810,39 & 89,62 & 41,22 & 18,58 & 239,75 & 153,41 & 154,05 & 224,22 \\
\hline Pelophylax perezi & 30 TXN52 & 100,00 & 94,12 & 100,09 & 38,71 & 5497,32 & 237,15 & $-18,39$ & 255,54 & 40,05 & 165,93 & 165,93 & 25,84 & 916,59 & 99,80 & \begin{tabular}{|l|l|l|}
49,03 \\
\end{tabular} & 17,30 & 267,96 & 177,47 & 177,65 & 251,91 \\
\hline Pelophylax perezi & 30TXN53 & 100,00 & 99,49 & 100,32 & 38,99 & 5455,79 & 241,25 & \begin{tabular}{|l|l|}
$-12,97$ \\
\end{tabular} & 254,22 & 40,27 & 170,50 & 170,50 & 31,29 & 945,43 & \begin{tabular}{|c|}
105,78 \\
\end{tabular} & \begin{tabular}{|l|l|}
49,59 \\
\end{tabular} & 17,88 & 282,90 & 181,64 & 181,64 & 266,11 \\
\hline Pelophylax perezi & 30TXN54 & 100,00 & 91,52 & 98,72 & 38,99 & 5372,49 & 231,15 & $-18,93$ & 250,08 & 33,87 & 161,74 & 161,74 & 24,79 & 1018,51 & 113,14 & 54,83 & 17,13 & 304,08 & 198,37 & 198,37 & 286,13 \\
\hline Pelophylax perezi & 30TXN55 & 100,00 & 83,60 & 96,82 & 38,95 & 5296,25 & 221,06 & $-24,57$ & 245,62 & 27,39 & 153,08 & 153,08 & 18,14 & $\begin{array}{ll}1091,06 \\
\end{array}$ & 120,27 & \begin{tabular}{|c|}
60,17 \\
\end{tabular} & 16,46 & 324,97 & 215,11 & 215,11 & 305,78 \\
\hline Pelophylax perezi & 30TXN60 & 100,00 & 96,16 & 100,88 & 38,29 & 5581,02 & 241,26 & $-18,22$ & 259,48 & 85,60 & 168,81 & 168,82 & 26,77 & 795,91 & 85,27 & 42,70 & 17,05 & 226,86 & 156,68 & 159,86 & 207,69 \\
\hline Pelophylax perezi & 30 TXN61 & 100,00 & 103,46 & 101,43 & 38,79 & 5547,82 & 247,30 & $-11,17$ & 258,47 & 72,57 & 175,39 & 175,41 & 34,01 & 809,72 & 86,63 & 42,30 & 17,41 & 234,79 & 157,77 & 159,76 & 217,41 \\
\hline Pelophylax perezi & 30TXN62 & 100,00 & 102,55 & 100,90 & 38,94 & 5489,47 & 244,74 & $-11,35$ & 256,10 & 66,79 & 173,81 & 173,82 & 33,73 & 857,75 & 92,71 & 44,94 & 17,23 & 250,88 & 167,34 & 168,63 & 233,86 \\
\hline Pelophylax perezi & 30 TXN63 & 100,00 & 94,94 & 99,57 & 38,95 & 5416,45 & 235,38 & $-17,14$ & 252,52 & 42,68 & 165,40 & 165,40 & 27,29 & 934,84 & 101,29 & 50,20 & 16,66 & 273,25 & 183,96 & 184,22 & 256,22 \\
\hline Pelophylax perezi & 30TXN64 & 100,00 & 83,53 & 97,27 & 38,80 & 5341,30 & 221,56 & $-25,87$ & 247,43 & 26,82 & 153,35 & 153,35 & 17,30 & 1027,09 & 110,20 & 57,12 & 15,75 & 298,96 & 204,99 & 205,07 & 280,60 \\
\hline Pelophylax perezi & 30TXN70 & 100,00 & $\begin{array}{l}93,34 \\
93,\end{array}$ & 99,94 & 38,19 & 5532,25 & 236,91 & $-20,37$ & 257,28 & \begin{tabular}{|l|}
102,67 \\
1027
\end{tabular} & $\begin{array}{l}165,38 \\
\end{array}$ & \begin{tabular}{|l|l|}
165,39 \\
\end{tabular} & 24,60 & 791,18 & 85,56 & 43,09 & 16,42 & 224,03 & 159,32 & 163,03 & 201,26 \\
\hline Pelophylax perezi & 30TXN71 & 100,00 & 106,47 & 101,52 & 38,92 & 5516,39 & 249,32 & $-8,36$ & 257,68 & 73,80 & 177,73 & 177,85 & 37,28 & 768,70 & 80,66 & 40,01 & 16,93 & 221,67 & 152,48 & 155,23 & 201,94 \\
\hline Pelophylax perezi & 30 TXN72 & 100,00 & 99,76 & 100,32 & 38,92 & 5452,55 & 240,74 & $-13,67$ & 254,42 & 68,84 & 170,46 & 170,51 & 31,48 & 845,69 & 88,74 & 45,10 & 16,26 & 243,56 & 168,79 & 170,71 & 224,78 \\
\hline Pelophylax perezi & 30TXN73 & 100,00 & 85,05 & 97,78 & 38,79 & 5374,32 & 223,78 & $-25,52$ & 249,30 & 41,20 & 155,22 & 155,22 & 18,37 & 957,36 & 99,77 & 53,41 & 15,22 & 272,27 & 193,53 & 194,56 & 254,34 \\
\hline Pelophylax perezi & $30 \mathrm{TXN} 80$ & 100,00 & 95,74 & 99,77 & 38,26 & 5501,36 & 238,35 & $-18,12$ & 256,46 & 111,46 & 167,05 & 167,16 & 27,15 & 759,75 & 82,89 & 41,34 & 16,27 & 215,49 & 155,52 & 160,27 & 188,89 \\
\hline Pelophylax perezi & 30TXN81 & 100,00 & 100,32 & 100,29 & 38,84 & 5463,93 & 241,77 & $-13,60$ & 255,36 & 77,98 & 171,12 & 171,20 & 31,85 & 777,44 & 82,15 & 41,64 & 16,02 & 220,54 & 158,28 & 161,55 & 198,11 \\
\hline Pelophylax perezi & 30 TXN82 & 100,00 & 89,62 & 98,52 & 38,72 & 5404,83 & 229,01 & $-22,31$ & 251,32 & 68,85 & 159,91 & 159,98 & 22,28 & 875,33 & 91,00 & 48,59 & 15,18 & 246,25 & 179,37 & 182,28 & 225,52 \\
\hline Pelophylax perezi & 30TXN83 & 100,00 & 75,68 & 95,40 & 38,34 & 5342,54 & 212,55 & $-33,13$ & 245,68 & 55,34 & $\mid 145,72$ & $\mid 145,72$ & 9,74 & 993,85 & 102,26 & 57,44 & 14,39 & 278,46 & 205,26 & 206,54 & 257,59 \\
\hline Pelophylax perezi & 30 TXN90 & 100,00 & 93,84 & 99,07 & 38,37 & 5463,30 & 235,24 & $-19,39$ & 254,62 & 111,83 & 164,67 & 164,93 & 25,66 & 755,96 & 83,18 & 41,68 & 15,97 & 215,56 & 158,02 & 162,15 & 183,27 \\
\hline Pelophylax perezi & 30 TXN91 & 100,00 & 94,57 & 99,19 & 38,74 & 5424,62 & 234,78 & $-18,37$ & 253,15 & 100,32 & 164,88 & 165,09 & 26,64 & 790,45 & 84,67 & 43,56 & 15,38 & 222,04 & 164,76 & 169,02 & 195,90 \\
\hline Pelophylax perezi & 30 TXN92 & 100,00 & 80,76 & 96,43 & 38,33 & 5376,12 & 218,68 & $-29,57$ & 248,24 & 91,78 & 150,89 & 150,93 & 14,14 & 911,97 & 95,94 & \begin{tabular}{|l|l|}
52,47 \\
\end{tabular} & 14,39 & 254,73 & 190,97 & \begin{tabular}{ll|l}
194,87 \\
\end{tabular} & 229,06 \\
\hline Pelophylax perezi & 30TYK03 & 100,00 & 121,97 & 93,96 & 36,01 & 5896,13 & 264,49 & 7,97 & 256,52 & 131,42 & 70,05 & 201,18 & 52,27 & 500,34 & 61,01 & 23,30 & 28,63 & 161,39 & 94,81 & 108,03 & 95,10 \\
\hline Pelophylax perezi & 30TYK04 & 100,00 & 123,28 & 93,37 & 36,00 & 5899,78 & 264,98 & 9,00 & 255,98 & 132,69 & 57,10 & 202,31 & 53,42 & 485,57 & 60,07 & 22,98 & 29,46 & 156,54 & 90,19 & 105,87 & 90,23 \\
\hline Pelophylax perezi & 30TYK05 & 100,00 & 100,61 & 94,21 & 35,98 & 6014,84 & 246,59 & $-13,39$ & 259,98 & 116,11 & 30,21 & 181,51 & 30,21 & 575,43 & 72,34 & 30,21 & 26,24 & 183,80 & 108,59 & 126,76 & 108,59 \\
\hline \begin{tabular}{|l|} 
Pelophylax perezi \\
\end{tabular} & $\begin{array}{l}\text { 30TYKO6 } \\
\end{array}$ & 100,00 & 82,51 & 94,53 & 35,76 & 6042,75 & 230,55 & \begin{tabular}{|l|l|}
$-31,23$ \\
\end{tabular} & \begin{tabular}{|l|l|}
261,78 \\
\end{tabular} & 梠, & $\begin{array}{ll}12,21 \\
121\end{array}$ & $\begin{array}{l}164,17 \\
1641\end{array}$ & $\begin{array}{ll}12,21 \\
121\end{array}$ & 668,16 & 83,47 & 36,83 & 23,72 & 213,93 & 130,97 & 147,32 & 130,97 \\
\hline Pelophylax perezi & 30TYK07 & 100,00 & 68,33 & 94,32 & 35,40 & 6042,30 & 217,98 & $-44,36$ & 262,34 & 82,14 & $-1,25$ & 150,22 & $-1,25$ & 753,29 & 92,79 & 42,78 & 21,72 & 239,41 & 152,74 & 163,50 & 152,74 \\
\hline Pelophylax perezi & 30TYK08 & 100,00 & 75,69 & 93,84 & 35,46 & 6025,71 & 223,34 & $-37,81$ & 261,16 & 90,59 & 5,51 & 156,97 & 5,51 & 697,84 & 87,99 & 39,66 & 23,44 & 224,99 & 137,49 & 155,86 & 137,49 \\
\hline Pelophylax perezi & 30TYKO9 & 100,00 & 86,99 & 93,51 & 35,51 & 6011,49 & 232,11 & $-27,88$ & 259,99 & 103,30 & 16,13 & 167,61 & 16,13 & 620,20 & 80,92 & 34,51 & 26,07 & 204,10 & 116,77 & 143,94 & 116,77 \\
\hline Pelophylax perezi & 30TYK13 & 100,00 & 133,52 & 91,90 & 36,12 & 5720,51 & 270,72 & 20,66 & 250,06 & 141,93 & 190,10 & 210,40 & 65,70 & 480,60 & 60,84 & 20,39 & 30,59 & 163,49 & 89,91 & 102,94 & 94,05 \\
\hline \begin{tabular}{|l|} 
Pelophylax perezi \\
\end{tabular} & $\begin{array}{l}\text { 30TYK14 } \\
\end{array}$ & 100,00 & 123,12 & 92,46 & 36,00 & 5828,78 & 263,21 & $\begin{array}{l}, 0,57 \\
9,\end{array}$ & 253,64 & \begin{tabular}{|l|l|}
131,23 \\
\end{tabular} & (74,62 & 201,51 & 54,37 & 506,39 & $\begin{array}{l}60,04 \\
61,50\end{array}$ & 23,19 & 28,91 & 164,30 & $\begin{array}{l}96,57 \\
96,\end{array}$ & 110,36 & $\begin{array}{l}4,0,83 \\
96,8\end{array}$ \\
\hline Pelophylax perezi & 30TYK15 & 100,00 & 107,86 & 92,99 & 35,94 & 5930,00 & 251,03 & $-5,59$ & 256,62 & 121,00 & 39,34 & 187,61 & 38,37 & 561,84 & 69,31 & 27,93 & 26,82 & 177,01 & 107,34 & 122,82 & 107,34 \\
\hline Pelophylax perezi & 30TYK16 & 100,00 & 89,12 & 93,38 & 35,75 & 5989,60 & 234,93 & $-23,77$ & 258,70 & 103,82 & 19,38 & 169,94 & 19,38 & 647,59 & 80,16 & 34,49 & 24,11 & 204,66 & 126,70 & 141,65 & 126,70 \\
\hline Pelophylax perezi & 30TYK17 & 100,00 & 79,80 & 93,19 & 35,45 & 5998,27 & 226,32 & $-32,95$ & 259,27 & 94,19 & 10,12 & 160,93 & 10,12 & 696,13 & 86,12 & 38,19 & 23,01 & 220,55 & 138,31 & 152,19 & 138,31 \\
\hline Pelophylax perezi & 30TYK18 & 100,00 & 82,81 & 92,92 & 35,28 & 5984,08 & 228,21 & $-30,54$ & 258,75 & 97,72 & 12,92 & 163,42 & 12,92 & 670,47 & 84,31 & 37,02 & 23,94 & 214,57 & 131,01 & 148,71 & 131,01 \\
\hline Pelophylax perezi & $\begin{array}{l}\text { 30TYK19 } \\
\text { 30 }\end{array}$ & 100,00 & $\begin{array}{l}0,01,04 \\
84,0\end{array}$ & $\begin{array}{ll}2,32,84 \\
92,\end{array}$ & 35,36 & $\begin{array}{ll}5907,400 \\
597,25\end{array}$ & 228,81 & $\begin{array}{l}-39,34 \\
-29,69\end{array}$ & 258,50 & $\begin{array}{ll}11,1 / 50 \\
99,5\end{array}$ & $\begin{array}{l}2,3,15 \\
14,15\end{array}$ & $\begin{array}{l}103,44,42 \\
164\end{array}$ & $\begin{array}{l}2,3,15 \\
14,15\end{array}$ & \begin{tabular}{|l|}
658,21 \\
\end{tabular} & $\begin{array}{l}\quad 84,51 \\
83,72\end{array}$ & 36,58 & 24,62 & 212,06 & 127,53 & $148,1,67$ & 127,53 \\
\hline Pelophylax perezi & 30TYK23 & 100,00 & 144,56 & 89,52 & 36,22 & 5531,22 & 276,12 & 33,26 & 242,86 & 153,56 & 217,08 & 218,90 & 78,57 & 466,90 & 64,05 & 17,85 & 33,37 & 167,93 & 80,47 & 98,66 & 94,84 \\
\hline Pelophylax perezi & 30TYK24 & 100,00 & 128,92 & 91,07 & 36,01 & 5715,12 & 265,81 & 16,21 & 249,60 & 137,03 & 174,89 & 205,76 & 61,53 & 508,72 & 62,90 & 21,82 & 29,73 & 170,49 & 96,40 & 109,53 & 100,30 \\
\hline Pelophylax perezi & 30TYK25 & 100,00 & 107,68 & 92,12 & 35,88 & 5869,38 & 249,48 & $-5,07$ & 254,55 & 118,68 & 48,43 & 186,86 & 39,12 & 584,87 & 70,64 & 28,20 & 26,23 & 183,42 & 114,63 & 126,74 & 114,80 \\
\hline Pelophylax perezi & 30 TYK26 & 100,00 & 100,24 & 92,26 & 35,75 & 5912,12 & 243,11 & $-12,43$ & 255,55 & 114,83 & 31,38 & 179,99 & 31,38 & 609,25 & 74,69 & 30,53 & 25,43 & 189,27 & 118,88 & 132,87 & 118,88 \\
\hline Pelophylax perezi & 30TYK27 & 100,00 & 94,48 & 92,16 & 35,46 & 5924,91 & 237,75 & $-18,30$ & 256,05 & \begin{tabular}{|l|}
108,97 \\
\end{tabular} & 25,47 & 174,32 & 25,47 & 632,28 & 78,20 & 32,69 & 24,78 & 198,42 & 123,46 & 138,70 & 123,46 \\
\hline Pelophylax perezi & 30TYK28 & 100,00 & 91,93 & 92,03 & 35,40 & 5929,76 & 235,15 & $-21,11$ & 256,26 & 107,05 & 22,75 & 171,87 & 22,75 & 639,74 & 79,87 & 33,69 & 24,73 & 202,01 & 124,61 & 141,07 & 124,61 \\
\hline Pelophylax perezi & 30TYK29 & 100,00 & 106,46 & 92,37 & 35,61 & 5904,93 & 247,78 & $-7,97$ & 255,75 & 123,05 & 37,10 & 185,51 & 37,10 & 561,23 & 72,01 & 28,34 & 27,61 & 178,99 & 105,47 & 124,78 & 105,47 \\
\hline Pelophylax perezi & 30TYK33 & 100,00 & 157,83 & 86,51 & 36,28 & 5315,71 & 282,90 & 48,26 & 234,65 & 167,63 & 226,74 & 229,22 & 93,87 & 445,78 & 66,2 & 15,1 & 37,56 & 70,38 & 69,38 & 93,29 & 93,96 \\
\hline Pelophylax perezi & 30TYK34 & 100,00 & 142,37 & 88,91 & 36, & 5524,07 & 273,7 & $\begin{array}{l}0,20 \\
30,99 \\
\end{array}$ & 242,71 & 150,77 & 214,97 & 216,80 & 76,91 & $\begin{array}{l}486,08 \\
486,0\end{array}$ & 65, & 18 & 32,92 & 173,11 & 84,74 & 103,44 & $\begin{array}{l}99,05 \\
99\end{array}$ \\
\hline Pelophylax perezi & 30 TYK & 100,00 & 13 & 90,27 & 35,99 & 5665,03 & 265,95 & 18,15 & 247,80 & 138,52 & 179,23 & 206,97 & 64,04 & 516,23 & 64,66 & 21,4 & 30,31 & 174,27 & 96,55 & 111,27 & 102,75 \\
\hline Pelophylax perezi & $\begin{array}{l}30 \text { TYK36 } \\
\end{array}$ & 100,00 & 120,48 & 90,97 & 35,82 & 5759,56 & 258,38 & $\begin{array}{ll}7,41 \\
7,41\end{array}$ & 250,97 & 128,45 & 105,86 & 197,99 & 52,83 & 546,76 & 66,65 & 24,28 & 28,53 & 176,65 & 105,75 & 118,76 & 107,49 \\
\hline Pelophylax perezi & 30TYK37 & 100,00 & 114,97 & 91,26 & 35,73 & 5801,89 & 254,09 & 1,70 & 252,38 & 124,68 & 54,33 & 193,03 & 46,97 & 560,99 & 68,52 & 25,89 & 27,74 & 177,86 & 109,10 & 122,68 & 109,30 \\
\hline Pelophylax perezi & 30TYK38 & 100,00 & 105,05 & 91,56 & 35,64 & 5850,46 & 245,73 & $-7,82$ & 253,55 & 119,73 & 36,66 & 183,72 & 36,64 & 594,96 & 73,63 & 28,94 & 26,24 & 184,55 & 115,64 & 129,85 & 115,64 \\
\hline Pelophylax perezi & $30 \mathrm{TYK}$ & 100,00 & 11 & 92 & 35 & 5842,47 & 253 & $-0,98$ & 254,55 & 125,77 & 46,14 & 191,87 & 44,99 & 552,52 & 69,58 & 26,05 & 28,10 & 173,67 & 105,55 & 120,14 & 105,55 \\
\hline Pelophylax perezi & 30TYK43 & 100,00 & 160,71 & 85,01 & 36,01 & 5244,10 & 283,73 & 51,85 & 231,88 & 170,75 & 228,53 & 231,13 & 97,66 & 453,06 & 67,77 & 14,71 & 38,72 & 175,56 & 68,20 & 94,68 & 97,40 \\
\hline Pelophylax perezi & 30TYK44 & 100,00 & 154,11 & 86,016 & 36,03 & 5356,39 & 280,45 & $\begin{array}{l}1,03 \\
43,74 \\
\end{array}$ & 236,70 & 162,89 & \begin{tabular}{|l|}
224,01 \\
\end{tabular} & 226,19 & 90,39 & 469,68 & 67,13 & 16,07 & 36,26 & 175,98 & 75,34 & 99,29 & $\begin{array}{l}9,40 \\
98,57\end{array}$ \\
\hline Pelophylax perezi & 30TYK45 & 100,00 & 150,55 & 87,93 & 36,01 & 5431,52 & 279,02 & 38,95 & 240,07 & 158,45 & 221,68 & 223,55 & 86,16 & 475,36 & 66,03 & 16,77 & 35,12 & 174,40 & 79,41 & 101,47 & 97,80 \\
\hline Pelophylax perezi & 30TYK46 & 100,00 & 135,10 & 89,75 & 35,99 & 5606,18 & 268,66 & 22,27 & 246,39 & 142,36 & 206,40 & 210 & 69,29 & 518,79 & 65,81 & 20,37 & 31,31 & 177,99 & 94,90 & 111,56 & 104 \\
\hline Pelophylax perezi & $\begin{array}{l}\text { 30TYK47 } \\
\end{array}$ & $\begin{array}{l}100,00 \\
\end{array}$ & $\begin{array}{l}13,10 \\
121,71\end{array}$ & $\begin{array}{l}50,79 \\
90,79\end{array}$ & $\begin{array}{l}35,97 \\
35,97\end{array}$ & $\begin{array}{l}500,100 \\
5728,22\end{array}$ & $\begin{array}{l}250,00 \\
258,75\end{array}$ & $\begin{array}{r}2<, 21 \\
8,35 \\
\end{array}$ & \begin{tabular}{|l|}
250,40 \\
250
\end{tabular} & \begin{tabular}{|l|}
128,71 \\
128,7
\end{tabular} & \begin{tabular}{|l|}
200,40 \\
137,52 \\
\end{tabular} & \begin{tabular}{|l|l|}
198,86 \\
190
\end{tabular} & $\begin{array}{l}5,26 \\
54,79 \\
\end{array}$ & \begin{tabular}{|l|l|}
557,17 \\
\end{tabular} & $\begin{array}{l}03,01 \\
67,35\end{array}$ & 23,85 & $\begin{array}{l}1,1,51 \\
28,58\end{array}$ & 180,73 & 108,31 & 120,55 & $\begin{array}{l}104,05 \\
110,92\end{array}$ \\
\hline Pelophylax perezi & 30TYK48 & 100,00 & 108,78 & 91,05 & 35,78 & 5802,24 & 248,13 & $-3,89$ & 252,02 & 117,16 & 45,72 & 186,98 & 41,16 & 602,38 & 72,99 & 27,83 & 26,31 & 186,16 & 119,52 & 130,85 & 119,58 \\
\hline Pelophylax perezi & 30TYK49 & 100,00 & 112,81 & 91,67 & 35,87 & 5799,99 & 252,14 & $-1,10$ & 253,24 & 120,85 & 46,74 & 190,63 & 44,90 & 578,67 & 71,28 & 26,39 & 27,33 & 179,76 & 113,38 & 125,70 & 113,40 \\
\hline Pelophylax perezi & 30TYK53 & 60,00 & 165,35 & 83,90 & 36,00 & 5208,10 & 286,17 & 56,26 & 229,9 & 175, & 232,55 & 235,01 & 102,42 & 451,74 & 68,84 & 13,92 & 40,39 & 178,36 & 65,44 & 94,38 & 98,85 \\
\hline Pelophylax perezi & 30TYK54 & 60,00 & 153,71 & 86,33 & 36,02 & 5332,60 & 279,54 & 43,44 & 236,10 & 162,32 & 223,34 & 225,66 & 90,49 & 486,86 & 69,44 & 16,11 & 36,36 & 182,61 & 77,08 & 102,47 & 103,82 \\
\hline
\end{tabular}




\begin{tabular}{|c|c|c|c|c|c|c|c|c|c|c|c|c|c|c|c|c|c|c|c|c|c|}
\hline TAXON & UTM & $\mathrm{km2}$ & B101 & B1O2 & $\mathrm{BIO3}$ & $\mathrm{B104}$ & B105 & B106 & B107 & B108 & B109 & 81010 & B1011 & BIO12 & BIO13 & 81014 & B1015 & B1O16 & B1017 & BIO18 & BIO19 \\
\hline Pelophylax perezi & 30TYK55 & 50,00 & 149,13 & 87,66 & 36,01 & 5415,34 & 277,37 & 37,77 & 239,60 & 156,94 & 220,15 & 222,02 & 85,26 & 496,01 & 68,51 & 17,13 & 34,70 & 181,50 & 82,24 & 105,34 & 103,52 \\
\hline Pelophylax perezi & 30TYK56 & 50,00 & 133,06 & 89,56 & 36,00 & 5592,62 & 266,60 & 20,53 & 246,06 & 140,27 & 207,21 & 208,53 & 67,82 & 542,10 & 68,31 & 20,82 & 30,75 & 185,34 & 98,26 & 115,60 & 111,13 \\
\hline Pelophylax perezi & 30TYK57 & 50,00 & 132,20 & 90,22 & 35,99 & 5624,92 & 266,61 & 18,71 & 247,89 & 138,72 & 204,88 & 208,01 & 66,71 & 539,14 & 66,88 & 21,00 & 30,62 & 182,24 & 99,75 & 115,82 & 109,14 \\
\hline Pelophylax perezi & 30TYK58 & 40,00 & 119,33 & 90,92 & 35,93 & 5731,61 & 256,69 & 5,82 & 250,87 & 125,82 & 149,34 & 196,54 & 52,54 & 578,41 & 69,30 & 24,59 & 28,00 & 185,54 & 113,25 & 124,67 & 116,23 \\
\hline Pelophylax perezi & 30TYK59 & 40,00 & 112,86 & 91,12 & 35,82 & 5774,23 & 251,69 & $-0,48$ & 252,17 & 119,95 & 59,28 & 190,71 & 45,66 & 595,51 & 72,06 & 26,45 & 26,98 & 185,86 & 118,42 & 128,97 & 118,77 \\
\hline Pelophylax perezi & 30TYL00 & 100,00 & 100,68 & 93,65 & 35,72 & 5991,09 & 243,55 & $-15,63$ & 259,18 & 118,49 & 29,31 & 180,54 & 29,31 & 540,35 & 72,88 & 28,51 & 29,16 & 180,99 & 97,22 & 127,50 & 97,22 \\
\hline Pelophylax perezi & 30TYL01 & 100,00 & 95,05 & 93,76 & 35,76 & 5986,23 & 238,47 & $-21,30$ & 259,77 & 112,71 & 23,67 & 174,78 & 23,67 & 564,13 & 76,12 & 30,37 & 28,37 & 189,44 & \begin{tabular}{|l|l|}
102,78 \\
\end{tabular} & 134,63 & 102,78 \\
\hline Pelophylax perezi & 30TYL02 & 100,00 & 108,92 & 94,52 & 36,00 & 5980,92 & 251,53 & \begin{tabular}{|l|}
$2,9,03$ \\
\end{tabular} & 260,56 & 128,27 & 36,94 & 188,23 & 36,94 & 492,30 & 68,41 & 25,25 & 31,07 & 167,44 & 86,54 & 116,54 & 86,54 \\
\hline Pelophylax perezi & 30TYL03 & 100,00 & 120,38 & 96,21 & 36,00 & 5988,00 & 264,03 & 0,13 & 263,90 & 140,84 & 47,60 & 199,38 & 47,60 & 442,49 & 62,33 & 22,27 & 32,47 & 150,72 & 77,01 & 102,17 & 77,01 \\
\hline Pelophylax perezi & 30TYL04 & 100,00 & 128,06 & 97,86 & 36,00 & 6000,80 & 273,61 & 6,32 & 267,29 & 149,40 & 54,93 & 206,99 & 54,88 & 414,35 & 58,48 & 20,44 & 32,87 & 140,48 & 72,46 & 93,32 & 72,46 \\
\hline Pelophylax perezi & 30TYL05 & 100,00 & 135,72 & 99,61 & 36,04 & 6025,13 & 283,62 & 12,59 & 271,03 & 157,66 & 61,97 & 214,66 & 61,74 & 388,46 & 54,65 & 18,39 & 32,93 & 130,68 & 68,50 & 85,03 & 68,50 \\
\hline Pelophylax perezi & 30TYL06 & 100,00 & 142,20 & 101,20 & 36,22 & 6042,49 & 292,40 & 18,20 & 274,20 & 164,69 & 68,48 & 221,25 & 67,81 & 368,36 & 51,33 & 16,74 & 32,70 & 122,58 & 65,86 & 78,34 & 65,86 \\
\hline Pelophylax perezi & 30TYL07 & 100,00 & $\begin{array}{l}144,08 \\
144,08\end{array}$ & 102,25 & 36,37 & 6057,12 & 296,00 & $\begin{array}{ll}19,68 \\
19,68\end{array}$ & 276,32 & $\begin{array}{l}167,03 \\
\end{array}$ & $\begin{array}{ll}69,18 \\
69,10\end{array}$ & 223,23 & $\begin{array}{l}69,18 \\
69,1\end{array}$ & 362,62 & $\begin{array}{l}1,00 \\
50,07\end{array}$ & 16,34 & 31,95 & 120,05 & $\begin{array}{l}55,58 \\
658\end{array}$ & 76,32 & $\begin{array}{l}05,58 \\
65,\end{array}$ \\
\hline Pelophylax perezi & 30TYL08 & 100,00 & 147,00 & 103,29 & 36,75 & 6075,08 & 300,51 & 22,25 & 278,27 & 170,25 & 71,66 & 226,18 & 71,66 & 355,77 & 48,37 & 15,92 & 31,24 & 116,53 & 65,40 & 73,91 & 65,40 \\
\hline Pelophylax perezi & 30TYL09 & 100,00 & 148,51 & 104,01 & 36,99 & 6077,60 & 303,15 & 23,56 & 279,59 & 171,91 & 72,67 & 227,53 & 72,67 & 353,00 & 47,32 & 15,67 & 30,28 & 114,69 & 65,39 & 72,80 & 65,39 \\
\hline Pelophylax perezi & 30TYL10 & 100,00 & 102,54 & 93,13 & 35,82 & 5950,25 & 244,84 & $-13,08$ & 257,92 & 120,08 & 32,05 & 181,99 & 32,05 & 552,67 & 72,99 & 29,41 & 28,32 & 181,29 & 101,44 & 126,59 & 101,44 \\
\hline Pelophylax perezi & 30TYL11 & 100,00 & 106,53 & 93,56 & 35,70 & 5941,94 & 248,77 & $-10,01$ & 258,77 & 124,49 & 35,74 & 185,55 & 35,74 & 528,69 & 70,90 & 27,69 & 29,27 & 174,84 & 95,94 & 121,62 & 95,94 \\
\hline Pelophylax perezi & 30TYL12 & 100,00 & 114,35 & 94,74 & 35,98 & 5948,82 & 256,97 & $-3,66$ & 260,62 & 133,53 & 42,95 & 193,27 & 42,95 & 488,99 & 66,71 & 25,01 & 30,69 & 162,80 & 87,40 & 111,36 & 87,40 \\
\hline Pelophylax perezi & 30TYL13 & 100,00 & 120,96 & 96,19 & 36,00 & 5955,15 & 264,72 & 1,18 & 263,54 & 140,97 & 49,06 & 199,65 & 49,06 & 458,44 & 63,28 & 22,79 & 31,53 & 153,08 & 81,40 & 103,08 & 81,40 \\
\hline Pelophylax perezi & 30TYL14 & 100,00 & 127,50 & 97,79 & 36,00 & 5971,89 & 273,09 & 6,11 & 266,98 & 148,28 & 55,17 & 206,20 & 55,06 & 431,76 & 59,89 & 20,81 & 32,13 & 143,95 & 76,56 & 95,36 & 76,56 \\
\hline Pelophylax perezi & 30TYL15 & 100,00 & 137,35 & 99,78 & 36,18 & 5990,26 & 285,10 & 14,33 & 270,77 & 159,05 & 65,33 & 215,87 & 64,22 & 398,05 & $55, \mathrm{C}$ & 18,12 & 32,69 & 131,48 & 70,89 & 84,97 & 70,89 \\
\hline Pelophylax perezi & 30TYL16 & 100,00 & 146,32 & 101,65 & 36,68 & 6010,72 & 296,19 & 22,16 & 274,02 & 168,23 & 78,09 & 224,96 & 72,52 & 370,77 & 50,68 & $\begin{array}{ll}16,07 \\
\end{array}$ & 32,89 & 120,83 & 66,73 & 76,48 & 66,73 \\
\hline Pelophylax perezi & 30TYL17 & 100,00 & 148,10 & 102,69 & 36,80 & $\begin{array}{ll}6032,76 \\
\end{array}$ & 299,68 & 23,34 & 276,34 & 168,94 & 75,64 & 226,92 & 73,75 & 363,62 & 49,38 & 15,61 & 32,39 & 118,29 & 65,78 & 74,51 & 65,78 \\
\hline Pelophylax perezi & 30TYL18 & 100,00 & 147,57 & 103,69 & 37,00 & 6050,88 & 300,35 & 22,33 & 278,02 & 170,80 & 73,70 & 226,38 & 72,64 & 362,82 & 48,91 & 15,84 & 31,35 & 117,70 & 66,06 & 74,69 & 66,06 \\
\hline Pelophylax perezi & 30TYL19 & 100,00 & 143,86 & 104,00 & 37,00 & 6048,36 & 297,79 & 19,04 & 278,75 & 167,22 & 68,66 & 222,69 & 68,66 & 369,18 & 49,70 & 16,53 & 30,38 & 120,01 & 67,52 & 76,78 & 67,52 \\
\hline Pelophylax perezi & 30TYL20 & 100,00 & 110,80 & 92,95 & 35,91 & 5895,90 & 251,75 & $-4,60$ & 256,35 & 128,26 & 40,93 & 189,42 & 40,93 & 535,13 & 69,78 & 26,77 & 28,71 & 172,13 & 99,11 & 118,94 & 99,11 \\
\hline Pelophylax perezi & 30TYL21 & 100,00 & 123,69 & 94,50 & 36,00 & 5880,54 & 264,86 & 5,84 & 259,02 & $\begin{array}{l}140,88 \\
140\end{array}$ & 55,55 & 201,77 & 53,63 & 480,97 & $\begin{array}{l}3,68 \\
63,68\end{array}$ & 22,64 & 30,88 & 154,82 & $\begin{array}{l}\mid 37,78 \\
87,\end{array}$ & $\begin{array}{l}104,53 \\
\end{array}$ & 87,79 \\
\hline Pelophylax perezi & 30TYL22 & 100,00 & 121,20 & 95,16 & 36,00 & 5905,73 & 263,52 & 2,64 & 260,88 & 139,69 & 51,91 & 199,39 & 50,53 & 484,13 & 64,79 & 23,21 & 30,65 & $\begin{array}{l}157,38 \\
\end{array}$ & 88,16 & 105,77 & 88,17 \\
\hline Pelophylax perezi & 30TYL23 & 100,00 & 129,53 & 96,95 & 36,01 & 5917,39 & 273,45 & 9,05 & 264,40 & 149,44 & 60,86 & 207,72 & 58,37 & 449,66 & 60,72 & 20,57 & 31,81 & 146,05 & 81,33 & 96,20 & 81,34 \\
\hline Pelophylax perezi & 30TYL24 & 100,00 & 134,76 & 98,59 & 36,18 & 5938,88 & 280,62 & 12,99 & 267,63 & 155,68 & 67,53 & 213,03 & 63,11 & 427,03 & 57,93 & 19,04 & 32,34 & 138,71 & 77,01 & 90,07 & 77,03 \\
\hline Pelophylax perezi & 30TYL25 & 100,00 & 142,00 & 100,52 & 36,74 & 5961,88 & 289,83 & 18,81 & 271,02 & 161,28 & 75,85 & 220,33 & 69,60 & 400,61 & 54,32 & 17,21 & 32,90 & 129,56 & 72,24 & 82,60 & 72,25 \\
\hline Pelophylax perezi & 30TYL26 & 100,00 & 147,16 & 102,06 & 36,92 & 5984,36 & 296,05 & $\begin{array}{l}22,70 \\
22,70 \\
\end{array}$ & \begin{tabular}{|l|l|}
$274,18<$ \\
\end{tabular} & $\begin{array}{l}160,48 \\
160\end{array}$ & $\begin{array}{l}0,000 \\
82,08\end{array}$ & \begin{tabular}{|l|}
225,53 \\
\end{tabular} & 73,97 & \begin{tabular}{|l|l|}
381,64 \\
384
\end{tabular} & 51,51 & $\begin{array}{l}\mid 1,212 \\
16,00\end{array}$ & 33,10 & $\begin{array}{l}123,42 \\
\end{array}$ & 68,83 & 77,54 & 68,86 \\
\hline Pelophylax perezi & 30TYL27 & 100,00 & 150,22 & 103,28 & 37,00 & 6004,46 & 301,46 & 25,15 & 276,31 & 159,53 & 83,54 & 228,75 & 76,40 & 369,90 & 49,51 & 15,42 & 32,65 & 119,92 & 67,10 & 74,68 & 67,15 \\
\hline Pelophylax perezi & 30TYL29 & 100,00 & 138,55 & 103,86 & 36,99 & 6033,03 & 292,02 & 13,74 & 278,28 & 161,56 & 63,97 & 217,26 & 63,97 & 391,10 & 52,82 & 17,75 & 30,19 & 127,30 & 70,85 & 82,48 & 70,85 \\
\hline Pelophylax perezi & 30TYL30 & 100,00 & 118,61 & 93,06 & 35,99 & 5838,37 & 258,66 & 2,61 & 256,04 & 131,25 & 51,76 & 196,54 & 49,72 & 527,06 & 67,34 & 24,41 & 29,16 & 166,63 & 99,49 & 115,73 & 99,57 \\
\hline Pelophylax perezi & 30TYL31 & 100,00 & 122,49 & 94,09 & 36,00 & 5848,88 & 263,37 & 5,04 & 258,33 & 136,73 & 55,75 & 200,25 & 53,10 & 507,43 & 65,71 & 23,12 & 29,93 & 161,32 & 94,97 & 109,91 & 95,10 \\
\hline Pelophylax perezi & 30TYL32 & 100,00 & $\begin{array}{l}12,43,59 \\
133,59\end{array}$ & \begin{tabular}{|l|l|}
96,09 \\
96,0
\end{tabular} & 36,10 & $\begin{array}{l}584,0.00 \\
5848,65\end{array}$ & 275,59 & \begin{tabular}{|c|}
13,99 \\
13,
\end{tabular} & \begin{tabular}{|l|}
261,60 \\
260
\end{tabular} & \begin{tabular}{|l|l|}
140,98 \\
140
\end{tabular} & \begin{tabular}{|c|}
59,86 \\
69,8
\end{tabular} & 210,97 & $\begin{array}{ll}3,030 \\
63,95\end{array}$ & \begin{tabular}{|l|}
464,46 \\
\end{tabular} & $\begin{array}{l}30,1 / 79 \\
60\end{array}$ & $\begin{array}{l}\mid 3,12 \\
19,82\end{array}$ & $\begin{array}{ll}31,84 \\
31,\end{array}$ & \begin{tabular}{|l|}
149,59 \\
149
\end{tabular} & 84,77 & \begin{tabular}{|l|}
97,49 \\
97,4
\end{tabular} & 86,31 \\
\hline Pelophylax perezi & \begin{tabular}{|l|}
30 TYL33 \\
\end{tabular} & 100,00 & 136,96 & 97,60 & 36,23 & 5872,92 & 280,81 & 16,10 & 264,72 & 144,41 & 73,30 & 214,55 & 66,74 & 447,91 & 59,08 & 18,85 & 32,32 & 144,72 & 82,19 & 92,25 & 82,85 \\
\hline Pelophylax perezi & 30TYL34 & 100,00 & 142,34 & 99,50 & 36,76 & 5901,58 & 288,19 & 19,92 & 268,27 & 146,99 & 78,78 & 220,24 & 71,52 & 423,89 & 56,32 & 17,36 & 32,97 & 137,90 & 76,94 & 85,89 & 77,94 \\
\hline Pelophylax perezi & 30TYL35 & 100,00 & 143,02 & 100,82 & 36,70 & 5940,71 & 290,94 & 19,49 & 271,45 & 150,37 & 78,90 & 221,16 & 71,21 & 414,94 & 55,39 & 17,11 & 32,87 & 134,25 & 75,32 & 83,91 & 75,83 \\
\hline Pelophylax perezi & 30TYL36 & 100,0 & 149,20 & 102,61 & 36,94 & 5967,16 & 298,83 & 24,44 & 274,39 & 153,92 & 85,32 & 227,44 & 76,60 & 390,97 & 52,10 & 15,74 & 33,37 & 128,10 & 70,41 & 78,03 & 71,10 \\
\hline Pelophylax perezi & 30TYL39 & 100,00 & 138,03 & 104,51 & 37,00 & 6031,40 & 291,85 & 12,97 & 278,88 & 161,19 & 63,64 & 216,90 & 63,64 & 403,20 & 54,17 & 18,13 & 30,51 & 130,85 & 72,66 & 85,02 & 72,66 \\
\hline Pelophylax perezi & 30TYL40 & 100,00 & 109,39 & 91,87 & 35,70 & 5823,57 & 249,52 & $-4,65$ & 254,17 & 122,61 & 42,23 & 187,43 & 41,16 & 589,35 & 73,23 & 27,54 & 26,94 & 182,63 & 115,19 & 128,43 & 115,21 \\
\hline Pelophylax perezi & 30TYL41 & 100,00 & 119,24 & 93,51 & 35,97 & 5819,53 & 259,90 & 2,94 & 256,97 & 129,11 & 54,79 & 196,99 & 50,72 & 543,12 & 68,61 & 24,24 & 28,79 & 170,06 & 104,42 & 117,63 & 104,67 \\
\hline Pelophylax perezi & 30TYL42 & 100,00 & 123,8 & 94,93 & 36,01 & 5838,01 & 265,70 & 5,77 & 259,93 & 134,76 & 59,92 & 201,50 & 54,81 & 520,60 & 66,62 & 22,74 & 29,64 & 163,75 & 99,13 & 111,31 & 99,43 \\
\hline Pelophylax perezi & 30TYL43 & 100,00 & 133 & $\begin{array}{l}4,27 \\
97,27\end{array}$ & 36,27 & 5854,53 & 276,90 & 12,92 & 263,97 & 138,21 & 69,69 & 210,85 & $\begin{array}{l}4,, 3174 \\
63\end{array}$ & 481,13 & 62,31 & 19,97 & 31,23 & 154,15 & 89,95 & \begin{tabular}{|l|l|}
99,95 \\
99
\end{tabular} & $\begin{array}{l}0,45 \\
90,99\end{array}$ \\
\hline Pelophylax perezi & 30TYL44 & 100,00 & 140 & 99,42 & 36,68 & 5888,21 & 286,16 & 18,08 & 268,09 & $\begin{array}{ll}143,57 \\
\end{array}$ & 76,69 & 218,13 & 70,13 & 450,49 & 58,86 & 18,0 & 32,39 & 146,43 & 82,97 & 90,82 & 84,47 \\
\hline Pelophylax perezi & 30TYL45 & 100,00 & 145,58 & 101,43 & 36,95 & 5916,80 & 293,39 & 21,75 & 271,64 & 149,00 & 81,82 & 223,47 & 74,58 & 426,60 & 56,07 & 16,75 & 33,06 & 139,95 & 77,66 & 84,61 & 79,26 \\
\hline Pelophylax perezi & 30TYL46 & 100,00 & 150,73 & 103,24 & 37,00 & 5957,93 & 300,52 & 25,43 & 275,08 & 153,39 & 86,88 & 228,96 & 78,75 & 402,34 & 52,94 & 15,59 & 33,55 & 133,19 & 72,40 & 78,88 & 74,04 \\
\hline Pelophylax perezi & 30TYL47 & 100,00 & 152,55 & 104,68 & 37,01 & 6001,37 & 304,22 & 26,26 & 277,96 & 155,34 & 88,44 & 231,15 & 79,55 & 388,64 & 51,21 & 15,34 & 33,43 & 128,15 & 69,58 & 76,82 & 70,90 \\
\hline Pelophylax perezi & $30 \mathrm{TYL}$ & 100,00 & 140 & $\begin{array}{l}104,68 \\
104\end{array}$ & 37,00 & 6037 & 294,13 & \begin{tabular}{|l|l|}
14,99 \\
14
\end{tabular} & 279,14 & $\begin{array}{l}162,67 \\
162\end{array}$ & $\frac{00,44}{69,21}$ & \begin{tabular}{|l|}
219,93 \\
21,9
\end{tabular} & $\begin{array}{l}6,5,72 \\
66,7\end{array}$ & \begin{tabular}{|l|}
4140,0460 \\
\end{tabular} & $\begin{array}{l}\mid 1,11 \\
55,17\end{array}$ & $\mid \begin{array}{l}\mid 1,34,81 \\
17,8\end{array}$ & $\begin{array}{l}30,45 \\
30,88\end{array}$ & \begin{tabular}{|l|}
133,07 \\
13,0
\end{tabular} & | 75,60 & $\begin{array}{ll}0,020 \\
85,93\end{array}$ & 75,63 \\
\hline Pelophylax perezi & 30TYL49 & 100,00 & 140,20 & 105,57 & 37,00 & 6070,70 & 294,88 & 13,76 & 281,12 & 163,77 & 65,31 & 219,48 & 65,24 & 410,00 & 54,51 & 18,01 & 30,40 & 131,90 & 74,35 & 86,05 & 74,35 \\
\hline Pelophylax perezi & 30TYL50 & 39,00 & $\begin{array}{l}14,26 \\
110,93\end{array}$ & 91,70 & 35,70 & 5798,36 & 250,68 & $-2,77$ & 253,45 & 120,29 & 45,79 & $\mid 188,80$ & 43,29 & 598,38 & $\begin{array}{l}43,23 \\
73,2\end{array}$ & $\begin{array}{l}27,07 \\
2,0\end{array}$ & 26,75 & $\begin{array}{l}184,88 \\
\end{array}$ & $\mid$ & \begin{tabular}{|l|l|}
130,05 \\
\end{tabular} & 118,63 \\
\hline Pelophylax perezi & 30TYL51 & 30,00 & 120,18 & 93,35 & 36,00 & 5791,27 & 260,47 & 4,02 & 256,45 & 127,02 & 56,69 & 197,64 & 52,31 & 556,07 & 69,22 & 23,95 & 28,58 & 174,89 & 108,18 & 121,33 & 108,84 \\
\hline Pelophylax perezi & 30TYL52 & 30,00 & 121,22 & 94,47 & 36,00 & 5820,82 & 262,96 & 3,98 & 258,98 & 129,71 & 57,87 & 198,87 & 52,73 & 545,18 & 68,73 & 23,58 & 28,91 & 170,31 & 105,38 & 117,31 & 105,91 \\
\hline Pelophylax perezi & $\begin{array}{l}\text { 30TYL53 } \\
\text { 301 }\end{array}$ & 28,00 & $\begin{array}{ll}121,22 \\
128,54\end{array}$ & $\begin{array}{l}4,4+54 \\
96,54 \\
\end{array}$ & $\begin{array}{l}30,0 \\
36,07\end{array}$ & 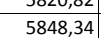 & $\begin{array}{l}20,50 \\
271,93\end{array}$ & $\begin{array}{l}3,50 \\
9,02 \\
\end{array}$ & \begin{tabular}{|l|}
262,90 \\
262
\end{tabular} & \begin{tabular}{|l|}
132,63 \\
\end{tabular} & $\begin{array}{l}\mid r, 00 \\
65,00 \\
\end{array}$ & $\begin{array}{l}150,06,22 \\
\end{array}$ & \begin{tabular}{|l|l|}
59,39 \\
5
\end{tabular} & \begin{tabular}{|l|}
511,17 \\
511,
\end{tabular} & $\begin{array}{l}0,1 / 3 \\
65,32 \\
\end{array}$ & $\begin{array}{l}\mid 21,34 \\
21,3\end{array}$ & $\begin{array}{l}20,11 \\
30,10\end{array}$ & \begin{tabular}{|l|l|}
161,73 \\
\end{tabular} & \begin{tabular}{|}
97,24 \\
97,30
\end{tabular} & \begin{tabular}{|l|}
106,76 \\
10,7
\end{tabular} & $\begin{array}{r}90,34 \\
98,34\end{array}$ \\
\hline Pelophylax perezi & 30TYL54 & 20,00 & 136,03 & 98,91 & 36,57 & 5875,89 & 281,49 & \begin{tabular}{ll|}
14,34 \\
\end{tabular} & 267,14 & 139,37 & 72,29 & 213,83 & 66,17 & 478,94 & 61,80 & 19,17 & 31,37 & 153,89 & 89,77 & 98,31 & 91,17 \\
\hline Pelophylax perezi & 30TYL55 & 20,00 & 147,33 & 101,73 & 37,00 & 5906,85 & 295,18 & 23,21 & 271,97 & 149,97 & 83,45 & 225,12 & 76,67 & 432,97 & 56,36 & 16,42 & 33,30 & 143,39 & 78,88 & 85,85 & 81,06 \\
\hline Pelophylax perezi & 30TYL56 & 17,00 & 151,76 & 103,48 & 37,00 & 5963,08 & 301,56 & 26,04 & 275,5 & 154,04 & 87,64 & 229 & 79 & 409,40 & 53,44 & 15,52 & 33,96 & 136,36 & 73,64 & 79,40 & 75,88 \\
\hline Pelophylax perezi & 30TYMO0 & 100,00 & 141,79 & 104,03 & 37,00 & 6057,24 & 297,07 & 17,57 & 279,50 & 165,20 & 66,37 & 220,77 & 66,37 & 368,12 & 49,32 & 16,90 & 28,98 & 119,94 & 68,82 & 76,91 & 68,82 \\
\hline
\end{tabular}




\begin{tabular}{|c|c|c|c|c|c|c|c|c|c|c|c|c|c|c|c|c|c|c|c|c|c|}
\hline TAXON & UTM & $\mathrm{km} 2$ & BIO1 & B1O2 & $\mathrm{BIO3}$ & B104 & B105 & B106 & B107 & B108 & B109 & B1010 & BIO11 & B1012 & BIO13 & B1014 & BIO15 & B1016 & B1017 & B1018 & B1019 \\
\hline Pelophylax perezi & 30TYM01 & 100,00 & 133,27 & 103,61 & 37,00 & 6003,54 & 287,89 & 10,21 & 277,68 & 155,81 & 58,41 & 211,50 & 58,41 & 390,14 & 52,38 & 18,70 & 27,95 & 127,22 & 73,48 & 83,02 & 73,48 \\
\hline Pelophylax perezi & 30TYM02 & 100,00 & 119,04 & 101,79 & 37,00 & 5880,27 & 270,87 & $-1,21$ & 272,07 & 140,31 & 45,86 & 195,83 & 45,86 & 436,98 & 58,78 & 22,03 & 26,51 & 142,13 & 83,77 & 95,42 & 83,77 \\
\hline Pelophylax perezi & 30TYM03 & 100,00 & 121,30 & 102,29 & 37,03 & 5829,62 & 272,96 & $\frac{1,40}{1,40}$ & 271,56 & 142,63 & 48,45 & 197,35 & 48,45 & 432,10 & 57,20 & 21,41 & 25,71 & 138,24 & 84,15 & 92,54 & 84,15 \\
\hline Pelophylax perezi & 30TYM04 & 100,00 & 125,48 & 102,83 & 37,26 & 5798,20 & 276,78 & 5,29 & 271,49 & 147,01 & 52,65 & 200,93 & 52,65 & 428,08 & 55,41 & 20,74 & 24,85 & 134,31 & 85,16 & 89,79 & 85,16 \\
\hline Pelophylax perezi & 30TYM06 & 100,00 & 119,42 & 102,02 & 38,00 & 5640,66 & 267,08 & 1,31 & 265,77 & 139,94 & 140,33 & 192,75 & 48,47 & \begin{tabular}{|l|l|}
474,58 \\
\end{tabular} & 59,00 & 23,38 & 22,34 & 143,95 & 98,43 & $\begin{array}{l}99,03 \\
\end{array}$ & 99,21 \\
\hline Pelophylax perezi & 30TYM08 & 100,00 & 88,36 & 97,26 & 37,60 & 5508,18 & 230,50 & $-24,23$ & 254,73 & 105,88 & 160,23 & 160,39 & 20,16 & 720,99 & 83,39 & 40,79 & 17,43 & 213,13 & 154,64 & 158,41 & 164,13 \\
\hline Pelophylax perezi & 30TYMO9 & 100,00 & 93,51 & 98,46 & 38,09 & 5475,67 & 235,12 & $-19,66$ & 254,78 & 111,59 & 164,52 & 164,91 & 25,38 & 714,28 & 81,03 & 39,71 & 16,65 & 207,72 & 152,62 & 155,93 & 165,51 \\
\hline Pelophylax perezi & 30TYM10 & 100,00 & 138,18 & 103,97 & 37,00 & 6015,59 & 292,35 & 14,01 & 278,34 & 161,16 & 63,17 & 216,51 & 63,17 & 382,09 & 51,42 & 17,67 & 29,34 & 124,46 & 70,11 & 80,60 & 70,11 \\
\hline Pelophylax perezi & 30TYM11 & 100,00 & 125,77 & 102,62 & 37,00 & 5933,21 & 278,42 & 3,96 & 274,46 & 147,69 & 51,95 & 203,28 & 51,95 & 418,11 & 56,35 & 20,45 & 27,92 & 136,35 & 77,60 & 90,70 & 77,60 \\
\hline Pelophylax perezi & 30TYM12 & 100,00 & 123,51 & 102,56 & 37,00 & 5870,74 & 275,46 & 2,51 & 272,95 & 145,18 & 50,33 & 200,17 & 50,33 & 424,21 & 56,76 & 20,91 & 27,06 & 137,15 & 79,59 & 91,71 & 79,59 \\
\hline Pelophylax perezi & 30TYM13 & 100,00 & 128,50 & 103,47 & 37,09 & 5851,02 & 280,64 & 7,01 & 273,63 & 150,32 & 55,15 & 204,77 & 55,15 & 410,73 & 53,94 & 19,79 & 26,40 & $\begin{array}{l}130,45 \\
\end{array}$ & 78,10 & 86,84 & 78,10 \\
\hline Pelophylax perezi & 30TYM14 & 100,00 & 130,28 & 103,85 & 37,67 & 5801,79 & 281,78 & 9,05 & 272,73 & 152,18 & 57,36 & 205,72 & 57,36 & 414,41 & 53,27 & 19,90 & 25,41 & 129,40 & 80,60 & 86,65 & 80,60 \\
\hline \begin{tabular}{|l|l} 
Pelophylax perezi \\
\end{tabular} & 30TYM15 & 100,00 & 125,70 & 102,99 & \begin{tabular}{|l|l|}
37,97 \\
\end{tabular} & 5700,40 & 274,90 & 5,97 & 268,92 & 147,01 & 53,81 & 199,82 & 53,81 & 433,63 & 55,17 & 20,96 & 24,46 & 133,81 & 85,59 & 90,75 & 85,59 \\
\hline Pelophylax perezi & 30 TYM16 & 100,00 & 120,28 & 102,10 & 38,00 & 5599,41 & 267,16 & 2,13 & 265,03 & 140,79 & 50,66 & 193,06 & 49,74 & 460,89 & 57,81 & 22,69 & 23,24 & 140,17 & 92,80 & 96,65 & 92,80 \\
\hline Pelophylax perezi & 30TYM17 & 100,00 & 109,20 & 100,33 & 37,99 & 5503,85 & 253,56 & $-6,10$ & 259,65 & 128,66 & 49,70 & 180,85 & 40,14 & 533,35 & 65,20 & 27,54 & 20,99 & 160,23 & 111,46 & 114,45 & 111,49 \\
\hline Pelophylax perezi & 30TYM18 & 100,00 & 84,91 & 96,38 & 37,59 & 5494,60 & 226,17 & $-27,16$ & 253,33 & 102,28 & 141,59 & 156,87 & 17,03 & 744,17 & 86,03 & 42,78 & 17,13 & 220,64 & 161,93 & \begin{tabular}{|l|l|}
167,48 \\
\end{tabular} & 166,72 \\
\hline Pelophylax perezi & 30TYM19 & 100,00 & 88,36 & 97,19 & 37,89 & 5459,20 & 228,76 & $-23,99$ & 252,76 & 105,96 & 159,32 & 159,69 & 20,57 & 748,71 & 84,95 & 42,66 & 16,45 & 218,88 & 162,66 & 166,63 & 170,54 \\
\hline Pelophylax perezi & 30 TYM20 & 100,00 & 132,64 & 103,69 & 37,00 & 5998,09 & 286,11 & 8,73 & 277,38 & 155,39 & 58,21 & 210,96 & 58,21 & 405,59 & 54,66 & 19,10 & 29,19 & 132,05 & 73,81 & 86,84 & 73,81 \\
\hline Pelophylax perezi & 30TYM21 & 100,00 & 123,33 & 102,64 & 37,00 & 5920,71 & 275,51 & 1,51 & 274,00 & 145,27 & 49,79 & 200,74 & 49,79 & 433,55 & 58,24 & 21,28 & 27,84 & 141,01 & 79,66 & $\begin{array}{l}44,68 \\
\end{array}$ & 79,66 \\
\hline Pelophylax perezi & 30 TYM22 & 100,00 & 132,19 & 104,33 & \begin{tabular}{|l|l|}
37,03 \\
\end{tabular} & 5924,70 & 285,49 & 8,90 & 276,59 & 154,73 & 57,99 & 209,31 & 57,99 & 405,34 & 53,59 & 19,24 & 27,73 & 129,82 & 75,04 & 86,23 & 75,04 \\
\hline Pelophylax perezi & 30TYM23 & 100,00 & 133,82 & 104,75 & 37,54 & 5886,82 & 286,82 & 10,93 & 275,89 & 156,65 & 59,92 & 210,54 & 59,92 & 404,49 & 52,69 & 19,04 & 27,00 & \begin{tabular}{|l|l|}
127,86 \\
\end{tabular} & 75,98 & 85,29 & 75,98 \\
\hline Pelophylax perezi & 30TYM24 & 100,00 & 128,66 & 103,96 & 37,82 & 5790,78 & 279,75 & 7,34 & 272,41 & 150,75 & 55,90 & 204,04 & 55,90 & 422,33 & 54,45 & 20,46 & 25,78 & 132,25 & 80,26 & 89,67 & 80,26 \\
\hline Pelophylax perezi & 30 TYM 25 & 100,00 & 120,68 & 102,38 & 37,99 & 5658,50 & 268,98 & 1,79 & 267,19 & 141,72 & 49,54 & 194,45 & 49,54 & 446,03 & 57,28 & 22,05 & 24,90 & \begin{tabular}{|l|l|}
138,37 \\
\end{tabular} & 85,43 & $\begin{array}{l}95,15 \\
\end{array}$ & 85,43 \\
\hline Pelophylax perezi & 30TYM26 & 100,00 & 114,57 & 101,09 & 38,00 & 5542,32 & 260,48 & $-1,73$ & 262,21 & 134,72 & 45,07 & 186,83 & 45,07 & 477,26 & 60,33 & 24,09 & 23,59 & 146,04 & 93,28 & 102,42 & 93,28 \\
\hline Pelophylax perezi & 30TYM27 & 100,00 & 104,51 & 99,64 & 37,96 & 5510,83 & 248,36 & $-10,49$ & 258,85 & 123,77 & 35,49 & 176,45 & 35,49 & 568,04 & 69,02 & 30,34 & 20,63 & 171,32 & 117,18 & 125,31 & 117,18 \\
\hline Pelophylax perezi & 30TYM28 & 100,00 & 80,47 & 94,96 & 37,23 & 5496,64 & 220,75 & $-30,73$ & 251,48 & 97,38 & 95,71 & 152,59 & 12,68 & 787,18 & 90,38 & 46,20 & 16,86 & 233,47 & 172,16 & 178,97 & 174,81 \\
\hline Pelophylax perezi & 30TYM29 & 100,00 & 84,97 & 96,22 & 37,69 & 5469,22 & 224,84 & $-26,98$ & 251,82 & 102,39 & 136,47 & 156,46 & 17,19 & 778,39 & 88,14 & 45,28 & 16,32 & 228,35 & 171,44 & 176,99 & 174,64 \\
\hline Pelophylax perezi & 30TYM30 & 100,00 & 133,48 & 104,51 & 37,00 & 6012,76 & 287,51 & 8,84 & \begin{tabular}{|l|}
278,67 \\
\end{tabular} & 156,45 & 58,93 & 211,93 & 58,93 & 413,99 & 55,36 & 19,37 & 29,03 & 134,10 & 75,30 & 88,75 & 75,30 \\
\hline Pelophylax perezi & 30TYM31 & 100,00 & 131,14 & 104,62 & 37,01 & 5981,44 & 285,08 & 6,98 & 278,10 & 154,00 & 56,63 & 209,23 & 56,63 & 419,51 & 55,75 & 20,03 & 28,22 & 135,46 & 76,51 & 90,58 & 76,51 \\
\hline Pelophylax perezi & 30TYM32 & 100,00 & 138,19 & 106,05 & \begin{tabular}{|l|l|}
37,27 \\
\end{tabular} & 5988,27 & 292,56 & 12,96 & 279,60 & 161,64 & 63,01 & 216,03 & 63,01 & 401,36 & 52,40 & 18,84 & 27,82 & 127,94 & 73,90 & 85,51 & 73,90 \\
\hline Pelophylax perezi & 30TYM33 & 100,00 & 134,14 & 105,67 & 37,61 & 5933,01 & 287,56 & 10,00 & 277,56 & 157,45 & 59,48 & 211,13 & 59,48 & 414,51 & 53,65 & 19,94 & 26,74 & 131,27 & 76,99 & 89,01 & 76,99 \\
\hline Pelophylax perezi & 30TYM34 & 100,00 & 128,81 & 104,79 & 37,88 & 5843,16 & 280,60 & $\begin{array}{l}6,17 \\
\end{array}$ & 274,43 & 151,32 & 55,13 & 204,69 & 55,13 & 434,10 & 55,61 & 21,29 & 25,61 & 136,36 & 81,52 & 93,95 & 81,52 \\
\hline Pelophylax perezi & 30TYM35 & 100,00 & 122,90 & 103,67 & 38,00 & 5744,74 & 272,47 & 2,21 & 270,26 & 144,74 & 50,46 & 197,59 & 50,46 & 459,48 & 58,16 & 23,14 & 24,39 & 142,73 & 87,64 & 100,19 & 87,64 \\
\hline Pelophylax perezi & 30 TYM36 & 100,00 & 117,96 & 102,65 & 38,00 & 5659,01 & 265,40 & $-0,73$ & 266,13 & 139,13 & 46,61 & 191,60 & 46,61 & 491,00 & 61,11 & 25,30 & 23,07 & 150,59 & 95,69 & 107,73 & 95,69 \\
\hline Pelophylax perezi & 30TYM37 & 100,00 & 108,87 & 100,92 & 37,97 & 5575,51 & 253,72 & $-7,55$ & 261,27 & 129,00 & 38,75 & 181,38 & 38,75 & 561,21 & 67,92 & 30,15 & 20,78 & 169,79 & 113,60 & 125,45 & 113,60 \\
\hline Pelophylax perezi & 30TYM38 & 100,00 & 78,61 & 94,14 & 36,99 & 5512,26 & 218,56 & $-32,14$ & 250,70 & 95,54 & 56,50 & 151,07 & 10,81 & 816,36 & 93,06 & 48,68 & 16,69 & 242,03 & 177,78 & 186,64 & 179,85 \\
\hline Pelophylax perezi & 30TYM39 & 100,00 & 80,08 & 94,72 & 37,34 & 5482,13 & 219,26 & $-30,90$ & 250,15 & 97,07 & 71,04 & 151,82 & 12,33 & 831,24 & 93,34 & 49,55 & 15,96 & 244,17 & 184,12 & 192,69 & 185,37 \\
\hline Pelophylax perezi & 30TYM40 & 100,00 & 136,72 & 105,85 & 37,00 & 6067,91 & 291,72 & 10,47 & 281,24 & 160,29 & 61,42 & 215,83 & 61,42 & 417,88 & 55,32 & 19,29 & 29,26 & 134,71 & 75,83 & 89,36 & 75,83 \\
\hline Pelophylax perezi & 30TYM41 & 100,00 & 131,22 & 105,50 & \begin{tabular}{|l|l|}
37,03 \\
\end{tabular} & 6030,67 & 285,99 & 5,97 & 280,02 & 154,45 & 56,06 & 209,79 & 56,06 & 434,76 & 57,22 & 20,85 & 28,03 & 140,08 & 79,26 & 94,80 & 79,26 \\
\hline Pelophylax perezi & 30 TYM43 & 90,00 & 130,45 & 105,99 & 37,41 & 5970,19 & 284,57 & 5,68 & 278,89 & 153,76 & 55,27 & 207,92 & 55,27 & 439,32 & 56,62 & 21,78 & 26,46 & 139,74 & 81,06 & 96,76 & 81,06 \\
\hline Pelophylax perezi & 30TYM44 & 90,00 & 125,50 & 104,97 & 37,73 & 5892,04 & 278,01 & 2,38 & 275,64 & 148,18 & 51,16 & 202,16 & 51,16 & 461,30 & 58,73 & 23,45 & 25,10 & 145,44 & 86,27 & 102,47 & 86,27 \\
\hline Pelophylax perezi & 30 TYM 45 & 84,00 & 123,86 & 104,74 & \begin{tabular}{|l|l|}
37,98 \\
\end{tabular} & 5828,88 & 274,78 & 1,53 & 273,25 & 146,26 & 50,07 & 199,42 & 50,07 & 477,57 & 59,82 & 24,62 & 23,96 & 148,90 & 90,79 & 106,57 & 90,79 \\
\hline Pelophylax perezi & 30 TYM 46 & 80,00 & 116,98 & 103,20 & 38,00 & 5734,44 & 265,45 & $-2,60$ & 268,05 & 138,54 & 44,49 & 191,44 & 44,49 & 520,43 & 63,95 & 27,64 & 22,29 & 160,19 & 101,33 & 117,36 & 101,33 \\
\hline Pelophylax perezi & 30TYM47 & 80,00 & 103,99 & 100,19 & 37,82 & 5630,26 & 248,97 & $-12,48$ & 261,45 & 123,89 & 33,43 & 177,30 & 33,43 & 621,35 & 73,81 & 34,77 & 19,80 & 188,02 & 126,75 & 43,15 & 126,75 \\
\hline Pelophylax perezi & 30TYM48 & 72,00 & 85,12 & 95,56 & 37,28 & 5544,62 & 225,99 & $-27,19$ & 253,18 & 102,81 & 19,26 & 157,72 & 16,49 & 784,91 & 89,55 & 46,55 & 17,06 & 233,23 & 169,40 & 183,31 & 169,44 \\
\hline Pelophylax perezi & $30 \mathrm{TYM}$ & 70,00 & 81 & 94,76 & 37,22 & 5508,15 & 220,63 & $-30,19$ & 250,82 & \begin{tabular}{|l|l|}
98,42 \\
98,
\end{tabular} & 23,08 & 153,32 & \begin{tabular}{|l|}
13,07 \\
13,0
\end{tabular} & \begin{tabular}{|c|}
838,58 \\
\end{tabular} & $\begin{array}{l}93,89 \\
93,9\end{array}$ & $\begin{array}{l}40,40 \\
50,40\end{array}$ & 15,92 & 246,55 & $\begin{array}{l}184,52 \\
\end{array}$ & \begin{tabular}{|l|}
197,08 \\
197
\end{tabular} & 184,86 \\
\hline Pelophylax perezi & 30TYNOO & 100,00 & 89,01 & 97,77 & 38,10 & 5436,31 & 229,17 & $-23,37$ & 252,54 & 106,64 & 159,62 & 159,92 & 21,38 & 777,07 & 85,95 & 43,85 & 15,60 & 223,04 & 165,59 & 170,13 & 184,36 \\
\hline Pelophylax perezi & 30TYN01 & 100,00 & 87,26 & 97,46 & 38,44 & 5402,29 & 226,07 & $-24,44$ & 250,51 & 104,60 & 157,51 & 157,71 & 20,01 & 824,62 & 89,14 & 46,93 & 14,90 & 233,53 & 175,42 & $\mid 179,88$ & 199,54 \\
\hline Pelophylax perezi & 30TYN02 & 100,00 & 68,75 & 93,02 & 37,67 & 5353,69 & 204,51 & $-39,25$ & 243,76 & 84,01 & 139,07 & 139,08 & 2,90 & 982,46 & \begin{tabular}{|l|}
104,07 \\
\end{tabular} & 58,76 & 13,90 & 276,88 & 209,18 & 212,16 & 242,29 \\
\hline Pelophylax perezi & 30 TYN1 & 100,00 & 9 & 98,44 & 38,4 & 5430,73 & 233,61 & $-19,36$ & 25 & 111,80 & 163,89 & 164,45 & 25,85 & 740,29 & 82,48 & 41,61 & 15,92 & 213,22 & 160,45 & 164,06 & 171,17 \\
\hline Pelophylax perezi & 30TYN11 & 100,00 & 88,63 & 97,46 & \begin{tabular}{|l|l|}
38,54 \\
\end{tabular} & 5397,75 & 226,94 & $-23,45$ & 250,39 & 106,24 & 158,62 & 158,93 & 21,25 & 810,72 & 88,09 & 46,50 & 14,91 & 230,73 & 175,15 & \begin{tabular}{|l|l|}
179,47 \\
\end{tabular} & 192,09 \\
\hline Pelophylax perezi & 30TYN12 & 100,00 & 59,95 & 90,18 & 37,03 & 5337,92 & 193,96 & $-46,36$ & 240,32 & 74,31 & $\begin{array}{l}130,37 \\
\end{array}$ & 130,42 & $-5,22$ & 1041,24 & 110,51 & 63,90 & 13,66 & 294,87 & 224,28 & 227,15 & 253,79 \\
\hline Pelophylax perezi & 30TYN13 & 100,00 & 47,94 & 86,82 & 36,42 & 5292,12 & 179,49 & $-55,73$ & 235,22 & 60,84 & 118,25 & 118,25 & $-16,06$ & 1150,14 & 120,31 & 72,13 & 13,03 & 323,51 & 247,41 & 248,28 & 284,42 \\
\hline Pelophylax perezi & $30 \mathrm{TYN} 1$ & 42,00 & 31,99 & 81,89 & 35,16 & 5231,31 & 160,33 & $-69,29$ & 229 & 42,90 & 102,19 & 102 & $-30,23$ & 1279,76 & 132,24 & 81,80 & 12,62 & & 11 & 274,11 & 321,20 \\
\hline Pelophylax perezi & 30 TYN20 & 100,00 & 79,04 & 94,91 & 37,70 & 5429,96 & 217,15 & $-31,43$ & 248,58 & 95,84 & 149,84 & 150,06 & 11,87 & 852,74 & 94,30 & 50,61 & 15,16 & 247,23 & 187,08 & 193,73 & 196,25 \\
\hline Pelophylax perezi & 30TYN23 & 100,00 & 31,49 & 80,98 & 34,68 & 5249,75 & 159,70 & $-70,20$ & 229,90 & 42,31 & 101,95 & 101,95 & $-30,77$ & 1263,16 & 131,94 & 81,12 & 12,65 & 355,52 & 272,37 & 273,15 & 312,09 \\
\hline Pelophylax perezi & 30TYN40 & 70,00 & 89,56 & 96,93 & 37,94 & 5489,93 & 228,94 & $-23,40$ & 252,34 & $\begin{array}{r}107,73 \\
\end{array}$ & 44,83 & 161,25 & 21,02 & 802,61 & 88,80 & 47,57 & 15,63 & 233,72 & 177,42 & 186,76 & 178,20 \\
\hline Pelophylax perezi & 31SBC48 & & & & & & & & & & & & & & & & & & & & \\
\hline Pelophylax perezi & 31 & 100,00 & 174,19 & 10 & 39, & 5282,85 & 308,67 & 56 & 252,07 & 152,84 & 241,82 & 244,76 & 10 & 57 & 87,54 & 7,64 & 35 & 250 & 51 & 88,73 & 176 \\
\hline Pelophylax perezi & 31SBC59 & 73,00 & 178,30 & 99,98 & 39,52 & 5248,02 & 311,31 & 60,82 & 250,49 & 157,60 & $\begin{array}{l}245,06 \\
\end{array}$ & 248,11 & 113,73 & 578,22 & 91,41 & 6,83 & 54,31 & 258,70 & 48,95 & 88,32 & 182,77 \\
\hline
\end{tabular}




\begin{tabular}{|c|c|c|c|c|c|c|c|c|c|c|c|c|c|c|c|c|c|c|c|c|c|}
\hline TAXON & UTM & $\mathrm{km2}$ & BIO1 & $\mathrm{B1O2}$ & $\mathrm{BIO3}$ & B104 & B105 & B106 & B107 & B108 & B109 & BIO10 & BIO11 & $\overline{B 1012}$ & BIO13 & BI014 & BIO15 & BIO16 & BIO17 & BIO18 & BlO19 \\
\hline Pelophylax perezi & 31SBD40 & 51,00 & 180,61 & 101,19 & 39,92 & 5239,28 & 313,91 & 62,61 & 251,30 & 159,51 & 247,30 & 250,34 & 115,92 & 572,82 & 90,86 & 7,14 & 54,59 & 256,71 & 48,90 & 88,87 & 180,37 \\
\hline Pelophylax perezi & 31SBE42 & 6,00 & 171,25 & 83,00 & 36,00 & 5146,13 & 289,75 & 62,75 & 227,00 & $\begin{array}{ll}181,88 \\
\end{array}$ & 237,38 & 240,13 & $\begin{array}{l}108,75 \\
\end{array}$ & 440,88 & 69,88 & \begin{tabular}{ll|}
12,38 \\
\end{tabular} & 42,88 & $\begin{array}{l}179,25 \\
1\end{array}$ & 60,13 & 91,38 & 98,25 \\
\hline Pelophylax perezi & 31TBE43 & 42,00 & 168,69 & 83,80 & 36,00 & 5191,27 & 288,73 & 59,20 & 229,53 & $\begin{array}{ll}178,49 \\
\end{array}$ & \begin{tabular}{|l|l|}
235,78 \\
\end{tabular} & 238,10 & 105,92 & 450,08 & 69,67 & 13,00 & 41,61 & \begin{tabular}{|l|l|}
180,04 \\
\end{tabular} & 63,59 & 94,02 & 98,96 \\
\hline Pelophylax perezi & 31TBE44 & 53,00 & 153,70 & 86,17 & 36,00 & 5322,66 & 279,40 & 43,45 & 235,94 & \begin{tabular}{ll|l}
162,33 \\
\end{tabular} & 223,42 & 225,59 & 90,90 & 497,59 & 71,08 & \begin{tabular}{ll|l}
16,06 \\
\end{tabular} & 36,24 & \begin{tabular}{|l|l|}
186,84 \\
\end{tabular} & 77,97 & 104,35 & 107,06 \\
\hline Pelophylax perezi & 31TBE45 & 57,00 & 153,66 & 87,05 & 36,01 & 5360,26 & 280,27 & 42,42 & 237,85 & \begin{tabular}{|l|l|}
161,39 \\
\end{tabular} & 223,80 & 225,93 & 90,54 & \begin{tabular}{ll|}
493,76 \\
\end{tabular} & $\begin{array}{ll}69,85 \\
\end{array}$ & \begin{tabular}{l|l|l|}
16,15 \\
\end{tabular} & 36,06 & \begin{tabular}{ll|}
184,06 \\
\end{tabular} & 79,28 & 104,61 & 104,30 \\
\hline Pelophylax perezi & 31TBE46 & 50,00 & 137,70 & 89,03 & 36,00 & 5531,17 & 269,65 & 25,35 & 244,30 & 144,77 & 210,79 & 212,35 & 73,30 & 538,71 & 69,70 & \begin{tabular}{|l|l|l|}
19,68 \\
\end{tabular} & 31,86 & 187,75 & \begin{tabular}{|c|}
94,87 \\
\end{tabular} & 114,51 & 111,69 \\
\hline Pelophylax perezi & 31TBE47 & 42,00 & 139,21 & 89,90 & 36,00 & 5553,37 & 271,91 & 25,73 & 246,19 & \begin{tabular}{ll|}
145,64 \\
\end{tabular} & 212,67 & 214,06 & 74,59 & 527,90 & 68,06 & 19,19 & 32,11 & 183,50 & 93,84 & 112,96 & 108,14 \\
\hline Pelophylax perezi & 31TBE48 & 47,00 & 131,15 & 90,93 & 36,00 & 5643,69 & 266,31 & 17,18 & 249,13 & \begin{tabular}{|l|l|}
137,00 \\
\end{tabular} & 203,74 & 207,20 & 65,56 & \begin{tabular}{|l|l|}
547,07 \\
\end{tabular} & 67,10 & 21,13 & 30,26 & \begin{tabular}{|l|l|}
183,33 \\
\end{tabular} & \begin{tabular}{|l|l|}
101,84 \\
\end{tabular} & \begin{tabular}{|l|l|}
117,48 \\
\end{tabular} & 110,67 \\
\hline Pelophylax perezi & 31TBE49 & 40,00 & 119,56 & \begin{tabular}{l|l}
91,25 \\
\end{tabular} & 35,92 & 5731,29 & 257,22 & \begin{tabular}{l|l|}
5,59 \\
\end{tabular} & \begin{tabular}{|l|l|}
251,63 \\
\end{tabular} & 125,81 & $\begin{array}{l}145,69 \\
14\end{array}$ & $\begin{array}{l}196,73 \\
\end{array}$ & 52,88 & 581,34 & 69,86 & \begin{tabular}{l|l|l}
24,46 \\
\end{tabular} & 28,17 & $\begin{array}{l}185,85 \\
\end{array}$ & \begin{tabular}{|l|l|}
113,97 \\
\end{tabular} & \begin{tabular}{ll|}
125,36 \\
\end{tabular} & 116,83 \\
\hline Pelophylax perezi & 31TBE53 & & & & & & & & & & & & & & & & & & & & \\
\hline Pelophylax perezi & 31TBE54 & 80,00 & 164,95 & 85,25 & 36,02 & 5226,37 & 287,26 & 54,61 & 232,65 & 173,45 & 233,00 & 235,31 & 103,00 & 473,82 & 71,71 & \begin{tabular}{ll|}
13,63 \\
\end{tabular} & 39,91 & 185,67 & \begin{tabular}{ll|}
69,66 \\
\end{tabular} & 99,72 & 103,14 \\
\hline Pelophylax perezi & 31TBE55 & 100,00 & 159,40 & 86,61 & \begin{tabular}{|l|}
36,07 \\
\end{tabular} & 5294,17 & 284,20 & 48,04 & 236,16 & \begin{tabular}{ll|}
166,89 \\
\end{tabular} & 228,64 & 230,73 & $\begin{array}{l}97,16 \\
\end{array}$ & 490,98 & 71,74 & \begin{tabular}{ll|}
14,86 \\
\end{tabular} & 37,91 & 187,11 & $\begin{array}{ll}75,92 \\
\end{array}$ & \begin{tabular}{l|l|}
104,02 \\
\end{tabular} & 105,02 \\
\hline Pelophylax perezi & 31TBE56 & 100,00 & 156,79 & \begin{tabular}{|l|l|}
87,97 \\
\end{tabular} & 36,03 & 5351,15 & 283,47 & \begin{tabular}{l|l}
4,35 \\
\end{tabular} & 239,12 & \begin{tabular}{|l|l|}
163,37 \\
\end{tabular} & \begin{tabular}{|l|l|}
227,06 \\
\end{tabular} & 229,03 & $\begin{array}{l}94,37 \\
\end{array}$ & 497,19 & 71,13 & 15,40 & 36,96 & \begin{tabular}{ll|}
186,29 \\
\end{tabular} & \begin{tabular}{l|l}
79,45 \\
\end{tabular} & $\begin{array}{l}106,00 \\
\end{array}$ & 104,69 \\
\hline Pelophylax perezi & 31TBE57 & 101,00 & 148,53 & 89,51 & \begin{tabular}{l|l}
36,15 \\
\end{tabular} & 5459,30 & 278,64 & 35,10 & 243,54 & 154,31 & 220,57 & 222,26 & 85,36 & 518,57 & 70,43 & 17,10 & 34,52 & \begin{tabular}{l|l}
186,85 \\
\end{tabular} & 87,53 & \begin{tabular}{l|l|}
110,64 \\
\end{tabular} & 107,71 \\
\hline Pelophylax perezi & 31TBE58 & 99,00 & 141,84 & 90,77 & \begin{tabular}{l|l}
36,05 \\
\end{tabular} & 5544,79 & 274,69 & 27,44 & 247,26 & 146,97 & 215,31 & 216,60 & 77,80 & 533,31 & 69,25 & 18,57 & 32,74 & \begin{tabular}{|l|l|}
186,03 \\
\end{tabular} & 94,08 & \begin{tabular}{l|l}
114,15 \\
\end{tabular} & 109,37 \\
\hline Pelophylax perezi & 31TBE59 & 100,00 & 126,75 & 91,35 & 36,00 & 5672,10 & 263,16 & 12,45 & 250,71 & 132,39 & \begin{tabular}{|l|l|}
198,51 \\
\end{tabular} & 203,30 & 61,11 & 573,99 & 69,69 & 22,45 & 29,45 & 188,32 & \begin{tabular}{|l|l|}
108,58 \\
\end{tabular} & \begin{tabular}{|l|l|}
122,88 \\
\end{tabular} & 117,01 \\
\hline Pelophylax perezi & 31TBE64 & & & & & & & & & & & & & & & & & & & & \\
\hline Pelophylax perezi & 31TBE65 & 61,00 & 169,18 & 86,34 & 36,36 & 5208,07 & 291,59 & 57,66 & 233,93 & 176,24 & 237,21 & 239,49 & 108,25 & 475,79 & 73,49 & $\mid 12,71$ & 41,21 & $\mid 188,24$ & 69,84 & 101,51 & 102,36 \\
\hline Pelophylax perezi & 31TBE66 & 101,00 & 159,37 & 87,61 & 36,12 & 5304,93 & 285,12 & $\begin{array}{ll}47,15 \\
\end{array}$ & 237,97 & 165,57 & 229,12 & 231,24 & 98,10 & 510,59 & 74,43 & \begin{tabular}{ll|}
14,72 \\
\end{tabular} & 37,96 & \begin{tabular}{|l|l|}
193,39 \\
\end{tabular} & \begin{tabular}{ll|}
79,62 \\
\end{tabular} & 108,70 & 108,96 \\
\hline Pelophylax perezi & 31TBE67 & 99,00 & 151,74 & 89,09 & 36,22 & 5395,38 & 280,51 & 38,61 & 241,91 & 157,12 & 223,05 & 224,85 & 89,94 & 532,20 & 74,02 & 16,31 & 35,6 & 194,55 & 87,19 & 113,19 & 112,28 \\
\hline Pelophylax perezi & \begin{tabular}{|l|l|} 
31TBE68 \\
\end{tabular} & 100,00 & 152,41 & 90,56 & 36,46 & 5433,54 & 282,66 & 37,89 & 244,77 & 156,81 & 224,30 & 225,90 & 90,42 & 528,33 & 73,07 & 16,16 & 35,71 & 191,94 & 87,81 & 112,87 & 110,21 \\
\hline Pelophylax perezi & 31TBE69 & 101,00 & 148,92 & 92,00 & 36,53 & 5502,09 & 281,72 & 33,28 & 248,44 & \begin{tabular}{|l|l|}
152,69 \\
\end{tabular} & 221,81 & 223,33 & $\begin{array}{l}86,35 \\
\end{array}$ & 535,42 & 71,96 & \begin{tabular}{|l|l|l|}
16,89 \\
\end{tabular} & 34,60 & \begin{tabular}{|l|l}
190,29 \\
\end{tabular} & \begin{tabular}{l|l}
91,55 \\
\end{tabular} & \begin{tabular}{|l|l|}
114,38 \\
\end{tabular} & 110,82 \\
\hline Pelophylax perezi & 31TBE76 & 47,00 & 160,62 & 87,60 & 36,32 & 5279,43 & 285,97 & 48,37 & 237,60 & \begin{tabular}{ll|}
166,48 \\
\end{tabular} & \begin{tabular}{|l|l|}
230,10 \\
\end{tabular} & 232,30 & 100,23 & 522,03 & 76,90 & \begin{tabular}{|l|l|l|}
14,48 \\
\end{tabular} & \begin{tabular}{|l|l|}
38,40 \\
\end{tabular} & \begin{tabular}{|l|l|}
198,53 \\
\end{tabular} & 80,72 & 111,20 & 112,05 \\
\hline Pelophylax perezi & 31TBE77 & 99,00 & 164,72 & 88,66 & 36,73 & 5260,90 & 290,13 & 51,68 & 238,45 & 169,45 & 234,01 & 236,08 & $\begin{array}{l}105,05 \\
\end{array}$ & 515,23 & 77,21 & 13,70 & 39,55 & \begin{tabular}{ll|l}
197,66 \\
\end{tabular} & \begin{tabular}{|c|}
79,70 \\
\end{tabular} & \begin{tabular}{|l|l|l|l}
111,03 \\
\end{tabular} & 108,34 \\
\hline Pelophylax perezi & 31TBE78 & 100,00 & 163,46 & \begin{tabular}{|l|l|}
90,35 \\
\end{tabular} & 37,00 & 5309,51 & 290,76 & 49,03 & 241,74 & 166,95 & 233,61 & 235,45 & \begin{tabular}{|l|l|}
103,63 \\
\end{tabular} & 521,50 & \begin{tabular}{|l|l|}
76,95 \\
\end{tabular} & 14,0 & 38,9 & 197,60 & 82,61 & 112,80 & 104,24 \\
\hline Pelophylax perezi & 31TBE79 & 100,00 & 159,32 & 91,91 & 37,00 & 5386,39 & 289,44 & 43,72 & 245,72 & \begin{tabular}{|l|l|}
161,93 \\
\end{tabular} & 230,71 & 232,32 & \begin{tabular}{|l|}
99,03 \\
\end{tabular} & 534,70 & 76,57 & 14,82 & 37,58 & \begin{tabular}{|l|l|}
197,79 \\
\end{tabular} & 87,08 & 115,16 & 105,46 \\
\hline Pelophylax perezi & 31TBE87 & 15,00 & 170,22 & 89,00 & 37,00 & 5213,22 & 294,56 & 57,11 & 237,44 & 174,44 & 239,00 & 241,00 & \begin{tabular}{|l|l|}
111,67 \\
\end{tabular} & 509,44 & 79,00 & \begin{tabular}{l|l|}
12,89 \\
\end{tabular} & \begin{tabular}{l|l}
41,22 \\
\end{tabular} & \begin{tabular}{|l|l|}
199,00 \\
\end{tabular} & 77,56 & 111,11 & 96,56 \\
\hline Pelophylax perezi & 31TBE88 & 74,00 & 168,71 & 89,88 & 37,00 & 5244,22 & 294,39 & 54,71 & 239,69 & 172,01 & 237,96 & 240,06 & 109,76 & 520,70 & 79,70 & \begin{tabular}{|l|l|}
13,07 \\
\end{tabular} & \begin{tabular}{|l|l|l|}
41,03 \\
\end{tabular} & 201,58 & 80,84 & \begin{tabular}{|l|}
114,04 \\
\end{tabular} & 97,06 \\
\hline Pelophylax perezi & 31TBE89 & 100,00 & 162,13 & 91,20 & 36,93 & 5325,69 & 290,57 & $\begin{array}{ll}47,15 \\
\end{array}$ & 243,42 & \begin{tabular}{|l|l|}
164,59 \\
\end{tabular} & 232,68 & 234,53 & 102,40 & $\begin{array}{l}547,65 \\
\end{array}$ & 80,27 & \begin{tabular}{|l|l|}
14,27 \\
\end{tabular} & 38,82 & 205,27 & \begin{tabular}{|l|l|}
87,58 \\
\end{tabular} & 118,50 & 103,46 \\
\hline Pelophylax perezi & 31TBE99 & 42,00 & 163,34 & 90,17 & 36,85 & 5294,15 & 290,62 & 49,19 & 241,43 & \begin{tabular}{|l|l|l|}
166,13 \\
\end{tabular} & 233,26 & 235,49 & 103,72 & 555,15 & 82,38 & \begin{tabular}{ll|}
14,23 \\
\end{tabular} & 39,66 & 209,34 & \begin{tabular}{|l|l|}
88,68 \\
\end{tabular} & 121,32 & 104,89 \\
\hline Pelophylax perezi & 31TBF40 & 33,00 & 108,69 & 91,31 & 35,60 & 5789,89 & 248,31 & $-4,47$ & 252,78 & 118,67 & 43,71 & 186,73 & 41,31 & 616,76 & 74,91 & 27,93 & 26,22 & 189,78 & 123,22 & 133,71 & 123,42 \\
\hline Pelophylax perezi & 31TBF41 & 36,00 & 122,72 & 93,48 & 36,00 & 5776,44 & 262,82 & 6,48 & 256,34 & 128,44 & \begin{tabular}{|l|l|}
59,78 \\
\end{tabular} & 200,06 & 55,10 & 555,26 & 68,62 & 23,24 & 28,84 & 176,24 & 108,32 & 120,42 & 109,58 \\
\hline Pelophylax perezi & $31 \mathrm{TBF} 42$ & 30,00 & 127,23 & 95,09 & \begin{tabular}{l|l}
36,05 \\
\end{tabular} & 5800,27 & 268,70 & $\begin{array}{l}9,07 \\
\end{array}$ & 259,64 & 132,14 & \begin{tabular}{l|l|l}
64,05 \\
\end{tabular} & 204,61 & 58,98 & \begin{tabular}{l|l|}
530,95 \\
\end{tabular} & $\begin{array}{l}66,55 \\
\end{array}$ & 21,86 & 29,73 & $\begin{array}{ll}169,23 \\
\end{array}$ & \begin{tabular}{|l|}
102,09 \\
\end{tabular} & $\begin{array}{l}114,75 \\
\end{array}$ & 103,52 \\
\hline Pelophylax perezi & 31TBF43 & 23,00 & 130,70 & 96,81 & 36,14 & 5835,59 & 274,08 & 10,97 & 263,11 & 134,95 & \begin{tabular}{|c|}
67,38 \\
\end{tabular} & 208,35 & 61,97 & 511,16 & 64,92 & 20,78 & 30,35 & 163,16 & 97,27 & 106,70 & 98,78 \\
\hline Pelophylax perezi & 31TBF46 & 13,00 & 152,82 & 103,73 & 37,00 & 5955,64 & 302,64 & 26,95 & 275,68 & 154,95 & 88,86 & 230,91 & 81,09 & 408,23 & 53,32 & 15,23 & 34,00 & 136,55 & 73,09 & $\begin{array}{l}78,95 \\
\end{array}$ & 75,59 \\
\hline Pelophylax perezi & 31TBF50 & 100,00 & 111,46 & 91,01 & 35,60 & 5761,27 & 250,48 & $-1,84$ & 252,32 & 119,02 & 112,78 & 189,19 & 44,59 & 622,24 & 74,61 & 27,16 & 26,54 & 193,39 & \begin{tabular}{|l|l|}
124,08 \\
\end{tabular} & 133,86 & 126,29 \\
\hline Pelophylax perezi & 31 TBF51 & 100,00 & 112,71 & 92,11 & 35,72 & 5780,48 & 252,82 & $-1,59$ & 254,41 & 120,27 & 57,08 & 190,44 & 45,43 & 610,58 & 74,07 & 26,67 & 26,86 & 188,91 & 122,06 & 131,81 & 122,89 \\
\hline Pelophylax perezi & 31 TBF52 & 100,00 & 128,46 & 95,00 & 36,10 & 5780,01 & 269,75 & 10,60 & 259,16 & 132,84 & 94,40 & 205,69 & 60,5 & 543,51 & 67,21 & 21,61 & 29,82 & \begin{tabular}{|l|l|}
174,41 \\
\end{tabular} & \begin{tabular}{|l|l|}
105,04 \\
\end{tabular} & 117,11 & 107,66 \\
\hline Pelophylax perezi & 31TBF53 & 100,00 & 136,58 & \begin{tabular}{|c|}
97,57 \\
\end{tabular} & 36,49 & 5812,02 & 280,01 & 16,22 & 263,80 & \begin{tabular}{|l|l|}
139,80 \\
\end{tabular} & \begin{tabular}{|l|l|}
80,42 \\
\end{tabular} & 213,90 & 68,4 & 507,23 & \begin{tabular}{ll|l}
63,65 \\
\end{tabular} & 19,2 & 31,3 & \begin{tabular}{|l|l|}
165,47 \\
\end{tabular} & 96,33 & \begin{tabular}{|l|l|}
106,67 \\
\end{tabular} & 99,39 \\
\hline Pelophylax perezi & $31 \mathrm{TBF} 54$ & 99,00 & 140,39 & 99,64 & 36,83 & 5861,34 & 286,07 & 18,20 & 267,87 & 143,16 & \begin{tabular}{l|l|}
76,75 \\
\end{tabular} & 218,07 & 71,29 & \begin{tabular}{|l|l|}
482,97 \\
\end{tabular} & 61,42 & 18,17 & 31,96 & 157,98 & 90,49 & 97,66 & 93,44 \\
\hline Pelophylax perezi & 31TBF55 & 99,00 & 145,02 & 101,81 & 36,98 & 5914,32 & 293,11 & 20,89 & \begin{tabular}{|l|}
272,22 \\
\end{tabular} & \begin{tabular}{|l|l|}
147,36 \\
\end{tabular} & 81,11 & 223,09 & 74,75 & \begin{tabular}{|l|l|}
454,87 \\
\end{tabular} & 58,50 & 17,02 & 32,76 & \begin{tabular}{|l|l|}
149,69 \\
\end{tabular} & 83,71 & 90,81 & 86,57 \\
\hline Pelophylax perezi & 31 TBF56 & 101,00 & 149,25 & 103,79 & 37,00 & 5968,08 & 299,46 & 23,32 & 276,13 & 151,39 & 85,09 & 227,61 & 77,52 & 427,93 & 55,50 & 16,12 & 33,29 & 141,42 & \begin{tabular}{|l|l|}
77,47 \\
\end{tabular} & \begin{tabular}{|l|}
83,25 \\
\end{tabular} & 80,08 \\
\hline Pelophylax perezi & 31TBF59 & 100,00 & 143,56 & 107,13 & 37,00 & 6127,80 & 299,68 & 15,58 & 284,10 & 167,14 & 74,32 & 223,41 & $\begin{array}{ll}67,83 \\
\end{array}$ & 414,24 & $\begin{array}{l}54,45 \\
\end{array}$ & \begin{tabular}{l|l|}
17,95 \\
\end{tabular} & 30,49 & 132,41 & \begin{tabular}{|l|}
75,43 \\
\end{tabular} & 86,64 & 75,47 \\
\hline Pelophylax perezi & 31 TBF60 & 100,00 & 131,81 & 92,23 & \begin{tabular}{|l|}
36,17 \\
\end{tabular} & 5648,64 & 268,52 & \begin{tabular}{ll|l}
16,45 \\
\end{tabular} & 252,08 & \begin{tabular}{ll|}
136,55 \\
\end{tabular} & 206,01 & 207,95 & \begin{tabular}{ll|}
66,86 \\
\end{tabular} & 576,26 & \begin{tabular}{|l|}
70,87 \\
\end{tabular} & 21,04 & 30,52 & \begin{tabular}{|l|l|}
191,29 \\
\end{tabular} & \begin{tabular}{|l|}
106,43 \\
\end{tabular} & \begin{tabular}{|l|}
122,69 \\
\end{tabular} & 118,72 \\
\hline Pelophylax perezi & 31TBF61 & 99,00 & 109,30 & 90 & 35,52 & 5755,61 & 248,77 & $-3,78$ & 252,55 & \begin{tabular}{ll|}
116,48 \\
\end{tabular} & \begin{tabular}{|l|l|}
146,49 \\
\end{tabular} & \begin{tabular}{|l|l|}
186,98 \\
\end{tabular} & 42,61 & \begin{tabular}{|l|l|}
648,49 \\
\end{tabular} & 76,95 & 28,02 & 25,89 & 199,39 & 130,34 & 138,81 & 133,36 \\
\hline Pelophylax perezi & 31TBF62 & 101,00 & & 94,24 & 36,04 & 5757,05 & 267,19 & 9,53 & 257,66 & 130,90 & $\begin{array}{ll}188,52 \\
\end{array}$ & 203,58 & 59,5 & 576,00 & 69,50 & 22,39 & 29,10 & 184,31 & 111,21 & 123,23 & 116,88 \\
\hline Pelophylax perezi & 31TBF63 & 100,00 & 136,87 & \begin{tabular}{ll|}
97,23 \\
\end{tabular} & 36,51 & 5786,36 & 279,66 & 16,86 & 262,80 & $\begin{array}{ll}139,95 \\
\end{array}$ & $\begin{array}{l}196,36 \\
19\end{array}$ & 214,02 & 69,52 & 531,63 & 65,19 & \begin{tabular}{l|l|l|}
19,19 \\
\end{tabular} & 31,10 & \begin{tabular}{ll|}
174,12 \\
\end{tabular} & $\begin{array}{l}100,18 \\
\end{array}$ & \begin{tabular}{|l|l|}
113,19 \\
\end{tabular} & 106,70 \\
\hline Pelophylax perezi & 31TBF64 & 100,00 & 142,25 & 99,74 & 36,88 & 5840,12 & 287,64 & 19,92 & 267,72 & \begin{tabular}{|l|l|}
144,62 \\
\end{tabular} & 139,80 & 219,75 & 73,86 & 500,73 & 62,41 & 17,86 & 32,10 & 165,21 & 93,88 & 102,80 & 99,04 \\
\hline Pelophylax perezi & 31TBF65 & 100,00 & 148,14 & 102,33 & 36,99 & 5906,11 & 296,24 & 23,44 & 272,80 & 150,01 & 86,07 & 226,12 & 78,34 & 464,28 & 58,74 & \begin{tabular}{|l|l|}
16,47 \\
\end{tabular} & 33, & $\begin{array}{ll}154,86 \\
\end{array}$ & 85,46 & 93,14 & 89,80 \\
\hline Pelophylax perezi & 31TBF66 & 100,00 & 151,15 & 104,38 & 37,00 & 5977,35 & 301,79 & 24,80 & 276,99 & 153,03 & 86,90 & 229,76 & 79,66 & 436,73 & 55,95 & 15,89 & 33,54 & 145,56 & 78,73 & 85,18 & 82,56 \\
\hline Pelophylax perezi & 31 TBF70 & 100,00 & 150,82 & \begin{tabular}{|l|}
93,17 \\
\end{tabular} & 36,79 & 5497,04 & 284,54 & 34,28 & 250,26 & 153,43 & 223,81 & 225,19 & 89,03 & 552,58 & 74,84 & 16,49 & \begin{tabular}{|l|}
35,08 \\
\end{tabular} & \begin{tabular}{|l|l|}
196,49 \\
\end{tabular} & \begin{tabular}{|l|l|}
93,63 \\
\end{tabular} & \begin{tabular}{|l|l|}
117,83 \\
\end{tabular} & 111,35 \\
\hline Pelophylax perezi & 31TBF71 & 101,00 & 132,77 & 92,82 & 36,20 & 5636,99 & 270,10 & 17,10 & 252,99 & \begin{tabular}{ll|}
136,79 \\
\end{tabular} & \begin{tabular}{|l|l|}
207,72 \\
\end{tabular} & 208,94 & \begin{tabular}{l|l|}
68,45 \\
\end{tabular} & 596,72 & 74,31 & 21,14 & 30,76 & \begin{tabular}{|l|l|}
197,60 \\
\end{tabular} & \begin{tabular}{|l|l|}
109,47 \\
\end{tabular} & \begin{tabular}{ll|}
126,59 \\
\end{tabular} & 123,37 \\
\hline Pelophylax perezi & 31TBF72 & 100,00 & 120,88 & 92,66 & 35,83 & 5726,96 & 260,58 & 5,80 & 254,78 & \begin{tabular}{|l|l|}
126,04 \\
\end{tabular} & \begin{tabular}{|l|l|}
194,37 \\
\end{tabular} & 197,99 & 54,8 & $\begin{array}{l}625,55 \\
\end{array}$ & 75,00 & 24,65 & 27,98 & \begin{tabular}{|l|l|}
197,57 \\
\end{tabular} & \begin{tabular}{|l|l|}
121,08 \\
\end{tabular} & \begin{tabular}{|l|l|}
132,97 \\
\end{tabular} & 129,80 \\
\hline Pelophylax perezi & & & & 96,45 & 36 , & 576 & 278 & $16, \mathrm{~s}$ & 261, & & 212,64 & 213 & 69 & 559,53 & 67,84 & 19, & 30 & 183,26 & \begin{tabular}{|l|}
103,73 \\
\end{tabular} & \begin{tabular}{|l|l|}
118,88 \\
\end{tabular} & 114,94 \\
\hline Pelophylax perezi & 31TBF74 & 101,00 & 142,97 & 99,32 & 36,83 & 5817,97 & 287,63 & 21,03 & 266,60 & 145,31 & \begin{tabular}{|l|l|}
218,19 \\
\end{tabular} & 220,40 & 75,26 & 523,57 & 64,41 & 17,75 & 32,12 & \begin{tabular}{ll|}
173,46 \\
\end{tabular} & \begin{tabular}{|l|}
96,28 \\
\end{tabular} & \begin{tabular}{l|l|}
109,95 \\
\end{tabular} & 106,11 \\
\hline Pelophylax perezi & \begin{tabular}{|l|}
31 TBF75 \\
\end{tabular} & 100,00 & 144,56 & \begin{tabular}{|l|l|}
101,47 \\
\end{tabular} & 36,99 & 5904,87 & 292,23 & 20,69 & 271,54 & 146,80 & 152,31 & 222,69 & 75,06 & \begin{tabular}{|l|l|}
498,08 \\
\end{tabular} & 61,53 & 17,34 & \begin{tabular}{|l|l|}
32,07 \\
\end{tabular} & 163,84 & $\begin{array}{l}2,94 \\
\end{array}$ & \begin{tabular}{|l|l|}
101,99 \\
\end{tabular} & 99,09 \\
\hline Pelophylax perezi & 31TBF76 & 100,00 & 151,21 & 104,35 & $\begin{array}{l}37,05 \\
\end{array}$ & 5991,01 & 301,78 & 24,64 & 277,14 & 153,10 & 86,74 & 229,97 & 79,66 & 451,58 & 57,12 & \begin{tabular}{|l|l|}
15,97 \\
\end{tabular} & 33,44 & 150,71 & 81,91 & 88,18 & 86,67 \\
\hline Pelophyla & 31TBF & 101,00 & & 106,04 & 37,03 & 6095 & & 20,8 & 281,6 & 153 & 83,70 & 228,66 & 74,99 & 442,50 & 56,48 & 16,8 & & 143 & 80,6 & 87,99 & \\
\hline Pelophylax perezi & 31TBF78 & 100,00 & 149,66 & 107,88 & 37,05 & 6187,94 & 306,0 & 20,03 & 286,01 & 159,88 & 84,01 & 230,28 & 73,63 & 426,00 & 54,68 & 17,25 & 31,73 & 136,93 & 76,38 & 86,84 & 78, \\
\hline Pelophylax perezi & 31TBF79 & 100,00 & 147,25 & 109,20 & 37,12 & 6269,06 & 305,94 & 16,52 & 289,42 & \begin{tabular}{|l|l|}
167,96 \\
\end{tabular} & 80,10 & 228,66 & 69,30 & 425,51 & 54,70 & 18,52 & 30,45 & 135,98 & 76,58 & 90,17 & 77,48 \\
\hline
\end{tabular}




\begin{tabular}{|c|c|c|c|c|c|c|c|c|c|c|c|c|c|c|c|c|c|c|c|c|c|}
\hline TAXON & UTM & $\mathrm{km} 2$ & B101 & B102 & $\mathrm{BIO3}$ & B104 & B105 & B106 & B107 & B108 & B109 & B1010 & BIO11 & BIO12 & 81013 & BIO14 & BIO15 & B1016 & B1017 & B1018 & B1019 \\
\hline Pelophylax perezi & 31TBF80 & 99,00 & 161,91 & 93,13 & 37,04 & 5377,75 & 292,75 & 45,29 & 247,46 & 163,14 & 233,20 & 234,91 & 101,67 & 550,62 & 80,09 & 14,42 & 38,54 & 204,72 & 89,35 & 119,45 & 103,11 \\
\hline Pelophylax perezi & 31TBF82 & 100,00 & 162,39 & 97,16 & 37,52 & 5505,06 & 298,44 & 42,41 & 256,03 & 161,91 & 235,44 & 236,63 & 100,91 & 534,86 & 76,70 & 14,34 & 38,35 & 196,78 & 88,67 & 116,74 & 100,34 \\
\hline Pelophylax perezi & 31TBF84 & 99,00 & 147,68 & 98,95 & \begin{tabular}{l|l}
36,85 \\
\end{tabular} & 5772,38 & 290,93 & 25,93 & 265,00 & 149,58 & 223,98 & 224,66 & 80,99 & 533,00 & 66,84 & 16,69 & 33,26 & 180,07 & 94,50 & 113,37 & 110,08 \\
\hline Pelophylax perezi & 31TBF85 & 101,00 & 142,05 & 100,12 & 36,88 & 5881,26 & 288,46 & 19,33 & 269,13 & 144,82 & 217,74 & 220,00 & 72,75 & 531,10 & 64,24 & 18,12 & 31,31 & 172,97 & 98,56 & 109,81 & 108,51 \\
\hline Pelophylax perezi & $\begin{array}{l}\text { 31TBF86 } \\
\end{array}$ & 100,00 & 148,39 & 103,03 & 36,97 & 5982,27 & 297,99 & 22,86 & 275,14 & 150,98 & 118,25 & 227,11 & 76,95 & 480,05 & 59,84 & 16,85 & 32,73 & 158,42 & 88,56 & 96,58 & $\begin{array}{l}94,17 \\
9\end{array}$ \\
\hline Pelophylax perezi & 31TBF87 & 99,00 & 146,56 & 105,28 & 37,01 & 6113,84 & 299,91 & 19,08 & 280,83 & 150,82 & 81,16 & 226,53 & 72,37 & 467,65 & 58,68 & 17,79 & 31,46 & 149,93 & 86,02 & 94,01 & 89,59 \\
\hline Pelophylax perezi & 31TBF88 & 100,00 & 147,34 & 108,04 & 37,01 & \begin{tabular}{ll|}
6253,64 \\
\end{tabular} & 304,80 & 17,25 & 287,55 & 165,05 & 81,18 & 228,70 & 70,27 & 447,09 & 56,39 & 18,29 & 30,66 & 140,92 & 81,15 & 92,29 & 83,36 \\
\hline Pelophylax perezi & $\begin{array}{l}\text { 31TBF89 } \\
\end{array}$ & 100,00 & 153,62 & 110,83 & 37,14 & 6365,95 & 313,92 & 20,69 & 293,23 & 175,86 & 86,64 & 235,78 & 73,82 & 410,63 & 52,12 & 17,70 & 31,02 & 130,95 & 72,10 & 87,34 & 73,76 \\
\hline Pelophylax perezi & 31TBF90 & 101,00 & 166,11 & 91,45 & \begin{tabular}{l|l|}
36,95 \\
\end{tabular} & 5296,97 & 294,19 & 50,89 & 243,29 & 167,91 & 236,18 & 238,11 & 106,50 & 549,27 & 82,41 & 13,79 & 40,63 & 208,34 & 88,54 & 121,87 & 101,14 \\
\hline Pelophylax perezi & 31TBF91 & 99,00 & 167,58 & 93,52 & 37,26 & 5338,64 & 297,71 & 50,72 & 246,99 & 168,19 & 238,26 & 240,07 & 107,74 & 544,71 & 82,29 & 13,61 & 40,87 & 207,22 & 88,10 & 121,40 & 98,81 \\
\hline Pelophylax perezi & 31TBF92 & 100,00 & 154,42 & 94,27 & 36,87 & 5503,33 & 289,07 & 36,95 & 252,12 & 156,01 & 227,38 & 228,80 & 92,66 & 574,65 & 78,97 & 15,66 & 36,24 & 204,95 & 95,11 & 121,81 & 114,87 \\
\hline Pelophylax perezi & 31TBF93 & 100,00 & 149,18 & 95,28 & 36,69 & 5614,96 & 286,96 & 30,72 & 256,24 & 151,58 & 223,56 & 224,74 & 85,42 & 572,98 & 74,83 & 16,53 & 34,38 & 197,79 & 97,31 & 120,03 & 120,59 \\
\hline Pelophylax perezi & 31TBF94 & 101,00 & 158,05 & 98,10 & 36,99 & 5668,52 & 297,90 & 36,88 & 261,03 & 159,60 & 232,83 & 233,79 & 93,17 & 517,33 & 70,50 & 14,62 & 36,83 & 184,75 & 87,80 & 112,56 & 105,25 \\
\hline Pelophylax perezi & 31TBF95 & 99,00 & 154,05 & 99,80 & \begin{tabular}{|l|}
36,98 \\
\end{tabular} & 5812,87 & 297,87 & 31,06 & 266,81 & 156,35 & 221,29 & 231,13 & 85,82 & 504,44 & 64,91 & 15,38 & 34,84 & 173,88 & 88,90 & 109,29 & 102,07 \\
\hline Pelophylax perezi & 31TBF96 & 100,00 & 157,82 & 102,20 & 36,99 & 5922,54 & 304,71 & 32,44 & 272,26 & 160,45 & 108,67 & 235,67 & 87,02 & 455,63 & 59,54 & 14,90 & 35,59 & 158,33 & 80,41 & 99,20 & 87,44 \\
\hline Pelophylax perezi & 31TBF98 & 100,00 & 143,68 & 106,40 & 36,92 & 6260,13 & 300,11 & 14,77 & 285,34 & 167,25 & 77,50 & 225,03 & 66,34 & 481,50 & 59,19 & 19,92 & 29,32 & 150,18 & 89,43 & 100,59 & 91,37 \\
\hline Pelophylax perezi & 31TBF99 & 101,00 & 150,74 & 110,81 & 37,00 & 6448,52 & 312,39 & 17,50 & 294,89 & 177,01 & 83,19 & 233,87 & 69,58 & 432,38 & 54,02 & 19,18 & 30,09 & 138,39 & 76,89 & 94,13 & 78,06 \\
\hline Pelophylax perezi & 31TBG50 & 100,00 & 138,21 & 107,12 & 37,02 & 6135,75 & 294,91 & 10,60 & 284,31 & 162,38 & 61,97 & 218,17 & 61,97 & 426,69 & 55,93 & 19,60 & 29,18 & 137,31 & 77,42 & 91,84 & 77,42 \\
\hline Pelophylax perezi & 31TBG51 & 98,00 & 140,50 & 108,08 & \begin{tabular}{|l|}
37,28 \\
\end{tabular} & 6144,25 & 297,68 & 12,34 & 285,34 & 165,08 & 63,47 & 220,31 & 63,47 & 417,50 & 54,31 & 19,66 & 28,53 & 134,04 & 75,74 & 90,68 & 75,74 \\
\hline Pelophylax perezi & 31TBG52 & 95,00 & 141,99 & 108,70 & 37,72 & 6133,63 & 299,03 & 13,57 & 285,46 & 166,84 & 64,64 & 221,47 & 64,64 & 414,42 & 53,30 & 19,85 & 27,84 & $\mid 132,34$ & 75,50 & 90,61 & 75,50 \\
\hline Pelophylax perezi & 31TBG53 & 91,00 & 136,99 & 108,07 & 37,84 & 6081,00 & 293,13 & 9,83 & 283,30 & 161,46 & 59,98 & 215,63 & 59,98 & 433,43 & 55,19 & 21,52 & 26,36 & 137,94 & 79,68 & 96,34 & 79,68 \\
\hline Pelophylax perezi & 31TBG54 & 87,00 & 133,04 & 107,32 & 37,95 & 6022,70 & 287,83 & 7,08 & 280,74 & 157,12 & 56,73 & 211,02 & 56,73 & 454,14 & 57,03 & 23,13 & 24,92 & 143,35 & 84,73 & \begin{tabular}{|r|r|}
102,08 \\
\end{tabular} & 84,73 \\
\hline Pelophylax perezi & 31TBG55 & 86,00 & 127,18 & 106,08 & \begin{tabular}{|l|l|}
37,98 \\
\end{tabular} & 5933,46 & 279,91 & 3,01 & 276,91 & 150,51 & 51,90 & 203,97 & 51,90 & 485,35 & 60,05 & 25,45 & 23,61 & 151,65 & 92,06 & 110,19 & 92,06 \\
\hline Pelophylax perezi & 31TBG56 & 80,00 & 120,64 & 104,51 & 38,00 & 5838,88 & 270,81 & $-1,19$ & 271,99 & 143,02 & 46,67 & 196,34 & 46,67 & 528,42 & 64,16 & 28,48 & 21,99 & 162,98 & 102,72 & 121,12 & 102,72 \\
\hline Pelophylax perezi & 31TBG57 & 75,00 & 106,03 & 100,90 & 37,82 & 5693,90 & 251,97 & $-11,65$ & 263,62 & 126,45 & 34,42 & 180,16 & 34,42 & 632,45 & 74,49 & 35,77 & 19,60 & 191,70 & 128,20 & 147,83 & 128,20 \\
\hline Pelophylax perezi & 31TBG58 & 76,00 & 96,40 & 98,54 & 37,72 & 5611,27 & 239,51 & $-18,77$ & 258,28 & 115,70 & 26,42 & 169,68 & 26,35 & 720,35 & 82,51 & 42,04 & 17,76 & 215,03 & 151,38 & 169,83 & 151,38 \\
\hline Pelophylax perezi & 31TBG61 & 99,00 & 145,58 & 109,98 & 37,30 & 6252,72 & 304,86 & 14,82 & \begin{tabular}{|l|}
290,04 \\
\end{tabular} & 171,28 & $\frac{20,4,7}{67,70}$ & 226,38 & 66,72 & 412,88 & $\begin{array}{l}\mid 2,3,18 \\
53,18\end{array}$ & $\begin{array}{l}42,4,44 \\
19,4\end{array}$ & 28,93 & 132,63 & \begin{tabular}{|l|}
74,38 \\
74
\end{tabular} & $\begin{array}{l}90,48 \\
90\end{array}$ & 74,38 \\
\hline Pelophylax perezi & 31TBG62 & 101,00 & 141,25 & 109,92 & 37,57 & 6229,27 & 300,44 & 11,38 & 289,06 & 166,70 & 62,44 & 221,72 & 62,44 & 428,83 & 54,71 & 21,03 & 27,52 & 137,81 & 77,77 & 95,93 & 77,77 \\
\hline Pelophylax perezi & 31TBG63 & 100,00 & 138,13 & 109,30 & 37,45 & 6190,12 & 296,38 & 9,06 & 287,32 & 163,46 & 59,56 & 218,05 & 59,56 & 444,79 & 56,09 & 22,57 & 26,18 & 142,27 & 81,40 & 101,05 & 81,40 \\
\hline Pelophylax perezi & 31TBG64 & 100,00 & 135,08 & 108,65 & 37,80 & 6121,91 & 291,72 & 7,18 & 284,54 & 160,03 & 57,18 & 214,06 & 57,18 & 464,06 & 57,65 & 24,18 & 24,68 & 147,08 & 86,22 & 106,54 & 86,22 \\
\hline Pelophylax perezi & 31TBG65 & 100,00 & 130,61 & 107,52 & 37,99 & 6041,61 & 285,10 & 4,24 & 280,85 & 154,81 & 53,60 & 208,61 & 53,60 & 492,92 & 60,26 & 26,36 & 23,34 & 154,58 & 93,23 & 114,26 & 93,23 \\
\hline Pelophylax perezi & \begin{tabular}{|l|} 
31TBG67 \\
\end{tabular} & 100,00 & 109,30 & 101,90 & 37,84 & 5779,44 & 256,70 & 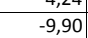 & \begin{tabular}{|l|}
266,60 \\
\end{tabular} & \begin{tabular}{|l|}
130,53 \\
13,51
\end{tabular} & $\begin{array}{ll}30,40 \\
36,43\end{array}$ & \begin{tabular}{|l|l|}
184,31 \\
\end{tabular} & $\begin{array}{ll}30,40 \\
36,43\end{array}$ & 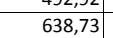 & 74,57 & $\begin{array}{ll}30,58 \\
36,5\end{array}$ & 19,52 & \begin{tabular}{|l|}
194,10 \\
\end{tabular} & \begin{tabular}{r|}
128,38 \\
128
\end{tabular} & $\begin{array}{l}151,61 \\
151\end{array}$ & $\begin{array}{l}2,28,38 \\
128\end{array}$ \\
\hline Pelophylax perezi & 31TBG69 & 100,00 & 108,25 & 101,56 & 38,18 & 5675,63 & 252,42 & $-9,89$ & 262,31 & 129,11 & 36,32 & 181,76 & 36,32 & 690,46 & 77,56 & 40,20 & 17,42 & 204,72 & 144,83 & 163,83 & 144,83 \\
\hline Pelophylax perezi & 31TBG70 & 100,00 & 148,52 & 110,90 & 37,29 & 6343,37 & 309,34 & 16,40 & 292,94 & 174,56 & 79,91 & 230,50 & 68,86 & 414,38 & 53,14 & 18,95 & 29,71 & 133,12 & 74,25 & 90,12 & 74,59 \\
\hline Pelophylax perezi & 31TBG71 & 101,00 & 146,82 & 111,65 & 37,33 & 6372,64 & 308,62 & 14,27 & 294,35 & 173,31 & 68,89 & 228,91 & 66,20 & 418,57 & 53,43 & 20,12 & 28,69 & 135,38 & 74,95 & 93,61 & 74,95 \\
\hline Pelophylax perezi & 31TBG72 & 100,00 & 143,47 & 111,49 & 37,47 & 6354,17 & 305,05 & 11,49 & 293,57 & 169,96 & 62,66 & 225,24 & 62,66 & 433,38 & 54,80 & 21,79 & 27,33 & 140,09 & 78,13 & 99,07 & 78,13 \\
\hline Pelophylax perezi & 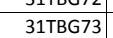 & $\begin{array}{l}100,00 \\
100\end{array}$ & $\begin{array}{l}14,47,63 \\
137,63\end{array}$ & $\begin{array}{l}11,45 \\
110,31\end{array}$ & 37,51 & 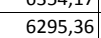 & 297,62 & \begin{tabular}{|l|l|}
7,471 \\
7
\end{tabular} & \begin{tabular}{|l|}
290,45 \\
\end{tabular} & \begin{tabular}{|l|l|}
163,50 \\
\end{tabular} & $\begin{array}{l}\mid l, 100 \\
57,49\end{array}$ & 218,65 & $\begin{array}{l}5,, 49 \\
57,4\end{array}$ & | & $\begin{array}{l}54,700 \\
57,74\end{array}$ & $\mid 24,19$ & 25,66 & $\begin{array}{l}148,73 \\
148,\end{array}$ & $\begin{array}{l}0,15 \\
84,22\end{array}$ & \begin{tabular}{|l|}
107,82 \\
107
\end{tabular} & 84,22 \\
\hline Pelophylax perezi & 31TBG74 & 99,00 & 130,29 & 108,41 & 37,46 & 6184,54 & 287,63 & 2,37 & 285,26 & 155,17 & 51,54 & 210,03 & 51,54 & 504,80 & 62,03 & 27,39 & 24,00 & 160,76 & 93,78 & 119,62 & 93,78 \\
\hline Pelophylax perezi & 31TBG75 & 101,00 & 119,74 & 105,02 & 37,42 & 6025,83 & 272,88 & $-4,03$ & 276,91 & 142,89 & 43,39 & 197,82 & 43,39 & 577,21 & 69,13 & 32,48 & 21.95 & 180,38 & 110,56 & 138,61 & 110,56 \\
\hline Pelophylax perezi & 31TBG76 & 100,00 & 114,29 & 103,19 & 37,55 & 5925,61 & 264,62 & $-7,12$ & 271,74 & 136,52 & 39,39 & 191,15 & 39,39 & 626,68 & 73,45 & 36,04 & 20,47 & 192,91 & 123,16 & 151,35 & 123,16 \\
\hline Pelophylax perezi & $\begin{array}{l}\text { 31TBG78 } \\
\end{array}$ & 99,00 & 102,97 & 99,91 & 37,5 & 5746,41 & 248,14 & $-14,53$ & 262,66 & 123,41 & 30,65 & 177,66 & 30,65 & 739,11 & 83,06 & 44,05 & 17,83 & 221,14 & 152,64 & 179,85 & 152,64 \\
\hline Pelophylax perezi & 31TBG80 & 101,00 & 149,01 & 112,34 & $37, \mathrm{C}$ & 6464,87 & 312,28 & 14,98 & 297,29 & 175,95 & 77,63 & 232,22 & 67,21 & 420,91 & 53,57 & 19,66 & 29,46 & 136,49 & 74,87 & 93,65 & 75,19 \\
\hline Pelophylax perezi & 31TBG81 & 99,00 & 144,13 & 112,80 & 37,06 & 6500,57 & 308,62 & 10,08 & 298,54 & 171,27 & 61,88 & 227,81 & 61,49 & 438,79 & 55,56 & 21,46 & 27,92 & 143,53 & 78,34 & 101,32 & 78,34 \\
\hline Pelophylax perezi & 31TBG82 & 100,00 & 143,98 & 112,66 & 37,23 & 6478,19 & 307,79 & 10,23 & 297,56 & 171,12 & 61,10 & 227,17 & 61,10 & 443,75 & 55,64 & 22,25 & 27,01 & 144,72 & 79,36 & 104,20 & 79,36 \\
\hline Pelophylax perezi & 31TBG83 & 101,00 & $\begin{array}{ll}137,87 \\
\end{array}$ & 111,04 & 37,1 & 6392,31 & 299,49 & 6,20 & 293,29 & 164,28 & 56,06 & 219,93 & 56,06 & 478,18 & 9,13 & 24,94 & 25,45 & 154,74 & 86,73 & 114,39 & 86,73 \\
\hline Pelophylax perezi & 31TBG84 & 100,00 & 122,59 & 105,93 & 37, & 6166,65 & 278,31 & 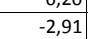 & 281,22 & $\begin{array}{l}146,39 \\
\end{array}$ & 40,40 & 202,31 & 40,41 & 573,46 & 68, & & 22,78 & 181,56 & \begin{tabular}{|l|}
107,77 \\
\end{tabular} & \begin{tabular}{|l|l|}
139,78 \\
\end{tabular} & $\begin{array}{l}107,77 \\
5\end{array}$ \\
\hline Pelophylax perezi & 31TBG85 & 100,00 & 111,18 & 102,07 & 36,97 & 5990,59 & 262,31 & $-9,83$ & 272,14 & 133,19 & 35,87 & 189,03 & 35,87 & 659,40 & 77,26 & 38,34 & 20,88 & 204,44 & 127,95 & 162,20 & 127,95 \\
\hline Pelophylax perezi & 31TBG86 & 100,00 & 110,03 & 101,59 & 37,15 & 5939,24 & 259,66 & \begin{tabular}{|l|l|}
$-10,32$ \\
-10
\end{tabular} & 269,97 & 131,77 & 35,29 & 187,18 & 35,29 & 685,07 & 78,90 & 40,42 & 19,91 & 210,17 & 134,88 & 169,29 & 134,88 \\
\hline Pelophylax perezi & 31TBG87 & 99,00 & 113,15 & 102,51 & 37,53 & 5923,75 & 262,38 & $-7,80$ & 270,18 & 135,37 & 38,20 & 189,80 & 38,20 & 682,45 & 77,66 & 40,58 & 19,25 & 207,88 & 135,63 & 168,85 & 135,63 \\
\hline Pelophylax perezi & 31TBG88 & 100,00 & 102,18 & 99,13 & 37,23 & 5787,06 & 247,31 & $-15,22$ & 262,53 & 122,68 & 29,38 & 177,36 & 29,38 & 781,35 & 86,61 & 47,50 & 17,60 & 233,39 & 161,03 & 193,46 & 161,03 \\
\hline Pelophylax perezi & $\begin{array}{l}\text { 31TBG89 } \\
\end{array}$ & 100,00 & 93 & $\begin{array}{l}95,15 \\
96,45\end{array}$ & 37, & 5683,73 & 235,14 & $\begin{array}{l}-1 ., 21,42 \\
-21,4\end{array}$ & \begin{tabular}{|l|}
256,56 \\
25,
\end{tabular} & $\begin{array}{l}112,220 \\
112,\end{array}$ & $\mid$\begin{tabular}{|l|l|}
$\mid 22,11$ \\
\end{tabular} & 167,15 & 22,11 & $\begin{array}{l}101,30 \\
865,35\end{array}$ & $\begin{array}{l}90,01 \\
94,12\end{array}$ & 53,61 & $\begin{array}{l}1,00 \\
16,39 \\
\end{array}$ & \begin{tabular}{|l|}
254,89 \\
25,8
\end{tabular} & $\begin{array}{l}183,38 \\
183\end{array}$ & $\begin{array}{l}130,40 \\
214,32 \\
\end{array}$ & $\begin{array}{l}101,03 \\
183,38\end{array}$ \\
\hline Pelophylax perezi & 31TBG90 & 99,00 & 152,19 & 113,57 & 37,03 & 6585,30 & 317,65 & 16,56 & 301,09 & \begin{tabular}{|l|l|}
180,08 \\
\end{tabular} & 81,88 & 236,65 & 68,37 & 417,11 & 52,39 & 19,15 & 29,75 & 136,25 & 73,12 & $\begin{array}{l}94,92 \\
\end{array}$ & 73,43 \\
\hline Pelophylax perezi & 31TBG91 & \begin{tabular}{|r|}
101,00 \\
\end{tabular} & 144,86 & 113,76 & 37,00 & 6625,11 & 311,56 & $\begin{array}{ll}9,41 \\
9,51\end{array}$ & 302,15 & 172,86 & $\begin{array}{l}60,33 \\
60.3\end{array}$ & 229,84 & $\begin{array}{ll}60,12 \\
60\end{array}$ & |446,86 & 55,95 & 21,45 & 27,79 & $\begin{array}{l}147,41 \\
\end{array}$ & 79,17 & \begin{tabular}{|l|}
105,92 \\
14,2
\end{tabular} & 79,17 \\
\hline Pelophylax perezi & 31TBG92 & 100,00 & 139,36 & 111,81 & 37,00 & 6528,72 & 303,58 & 6,01 & 297,56 & 166,46 & 55,81 & 223,18 & 55,81 & 478,64 & 59,25 & 23,92 & 26,29 & 156,68 & 85,75 & 115,53 & 85,75 \\
\hline Pelophylax perezi & 31TBG93 & 100,00 & 136,47 & 110,40 & 37,0 & 6439,03 & 298,34 & 4,88 & 293,46 & 162,86 & 54,04 & 215 & 54,04 & 502,64 & 61,38 & 25,94 & 25 & 163,00 & 90,83 & 123,09 & 90, \\
\hline Pelophylax perezi & 31TBG94 & 99,00 & 121,13 & 104,69 & 36,97 & 6185,15 & 276,28 & $-3,73$ & 280,01 & 144,80 & 42,76 & 201,11 & 42,76 & 607,27 & 72,09 & 33,76 & 22,46 & 191,85 & \begin{tabular}{|l|}
114,17 \\
\end{tabular} & 150,78 & 114,17 \\
\hline Pelophylax perezi & 31TBG95 & 99,00 & 113,48 & 101,89 & 36,97 & 6044,06 & 264,99 & $-7,99$ & 272,99 & 135,80 & 37,40 & 191,90 & 37,40 & 673,76 & 78,15 & 38,98 & 20,87 & 209,29 & 129,69 & 168,83 & 129,69 \\
\hline Pelophyla & 31TBG96 & 101,00 & 109,28 & 100,57 & 36,94 & 5963.55 & 258.51 & $-10,71$ & 269,22 & 130.88 & 34,30 & 186,76 & 34,30 & 722.32 & 82,19 & 42.91 & 19,70 & 221,37 & 141.81 & 182.01 & 141,81 \\
\hline Pelophylax perezi & 31TBG97 & 100,00 & 103,86 & 98,78 & 36,81 & 5869,61 & 250,57 & $-14,05$ & 264,62 & 124,61 & 30,24 & 180,16 & 30, & 781,89 & 87,18 & 47,51 & 18 & 236 & 157,26 & 197,22 & 157,26 \\
\hline Pelophylax perezi & 31TBG98 & 101,00 & $\begin{array}{l}96,95 \\
96,9\end{array}$ & 96,72 & 36,77 & 5779,75 & 240,88 & $-18,66$ & 259,55 & 116,62 & 24,69 & 172,27 & 24,69 & 852,84 & 93,25 & 52,82 & 17,31 & 253,77 & 176,14 & 214,29 & 176,14 \\
\hline
\end{tabular}




\begin{tabular}{|c|c|c|c|c|c|c|c|c|c|c|c|c|c|c|c|c|c|c|c|c|c|}
\hline TAXON & UTM & $\mathrm{km} 2$ & B101 & B102 & $\mathrm{BIO3}$ & BIO4 & B105 & B106 & B107 & B108 & B109 & BIO10 & BIO11 & BIO12 & B1013 & BIO14 & BIO15 & BIO16 & BIO17 & BIO18 & B1019 \\
\hline Pelophylax perezi & 31TBG99 & 100,00 & 73,07 & 89,39 & 35,77 & 5592,92 & 210,77 & $-35,62$ & 246,39 & 89,20 & 14,77 & 146,88 & 4,74 & 1012,41 & 109,31 & 64,83 & 15,46 & 295,92 & 219,04 & 243,85 & 220,05 \\
\hline Pelophylax perezi & 31TBH50 & 62,00 & 91,60 & 97,31 & 37,83 & 5526,61 & 231,46 & $-22,06$ & 253,51 & 110,18 & 36,34 & 163,54 & 22,51 & 803,95 & 88,68 & 48,01 & 15,84 & 234,57 & 176,23 & 188,76 & 176,83 \\
\hline Pelophylax perezi & 31TBH61 & 101,00 & 86,55 & 95,72 & 37,64 & \begin{tabular}{|l|}
5505,15 \\
\end{tabular} & 224,68 & $-25,87$ & 250,55 & 104,58 & 39,33 & 158,31 & 17,86 & 884,59 & 95,35 & 54,24 & 14,83 & 255,72 & 196,21 & 209,57 & 197,68 \\
\hline Pelophylax perezi & 31TBH81 & 100,00 & 45,16 & 81,45 & 34,30 & 5396,87 & 175,81 & $-57,61$ & 233,42 & 57,61 & 57,27 & 117,18 & $-19,32$ & 1187,21 & 126,34 & 77,62 & 13,40 & 340,32 & 265,22 & 269,45 & 274,49 \\
\hline Pelophylax perezi & $\begin{array}{l}\text { 31TCE09 } \\
\end{array}$ & 18,00 & 170,48 & 88,16 & 36,96 & 5178,08 & 294,16 & 57,96 & 236,20 & 173,92 & 238,76 & 241,12 & 112,00 & 538,20 & 84,48 & 13,00 & 42,76 & 210,76 & 83,68 & 120,60 & 97,88 \\
\hline Pelophylax perezi & 31TCF00 & 91,00 & 170,15 & 88,95 & 36,96 & 5216,73 & 294,89 & 56,82 & 238,07 & 173,18 & 239,02 & 241,14 & 111,33 & 542,26 & 85,01 & 13,00 & 42,55 & 211,58 & 85,65 & 122,43 & 97,56 \\
\hline Pelophylax perezi & 31TCF01 & 91,00 & 169,24 & 90,59 & 37,01 & 5270,78 & 295,88 & 54,37 & 241,51 & 171,44 & 238,53 & 240,62 & 109,85 & 544,22 & 84,76 & 13,71 & 42,07 & 211,19 & 87,53 & 123,63 & 97,33 \\
\hline Pelophylax perezi & 31TCF02 & 96,00 & 159,45 & 91,76 & 36,80 & 5411,50 & 290,13 & 43,73 & 246,40 & 161,96 & 230,93 & 232,68 & $\begin{array}{l}98,68 \\
98\end{array}$ & 572,99 & 83,03 & 14,95 & 38,52 & 211,12 & 92,86 & 123,94 & 113,35 \\
\hline Pelophylax perezi & 31TCF03 & 100,00 & 155,72 & 93,07 & 36,66 & 5515,29 & 289,47 & 38,63 & 250,84 & 158,56 & 228,46 & 230,07 & 93,19 & 575,78 & 79,59 & 15,14 & 36,69 & 205,50 & 93,77 & 121,01 & 123,05 \\
\hline Pelophylax perezi & 31TCF04 & 100,00 & 154,40 & 94,64 & 36,57 & 5617,50 & 291,10 & 35,83 & 255,28 & 157,61 & 228,30 & 229,60 & 89,45 & 554,93 & 74,48 & 15,61 & 35,81 & 194,72 & 93,81 & 118,16 & 116,40 \\
\hline Pelophylax perezi & 31TCF05 & 100,00 & 159,51 & 96,97 & 36,84 & 5707,16 & 298,92 & 38,62 & 260,29 & 162,82 & 205,02 & 235,38 & 92,45 & 502,93 & 68,89 & 14,89 & 36,64 & 179,87 & 87,99 & 112,60 & 99,25 \\
\hline Pelophylax perezi & 31TCF06 & 100,00 & 146,94 & 98,80 & 36,36 & 5915,29 & 292,01 & 24,43 & 267,58 & 151,15 & 177,38 & 224,94 & 75,96 & 530,69 & 64,09 & 17,86 & 31,50 & 173,85 & 99,04 & 112,21 & 107,57 \\
\hline Pelophylax perezi & \begin{tabular}{|l|}
$31 T C F 07$ \\
\end{tabular} & 101,00 & 142,31 & 100,70 & 36,31 & 6051,46 & 291,38 & $\begin{array}{ll}18,27 \\
\end{array}$ & 273,10 & 147,80 & 78,59 & 221,51 & 68,61 & 528,52 & 62,41 & 19,92 & 29,48 & 166,29 & 101,07 & 111,62 & 104,64 \\
\hline Pelophylax perezi & 31TCF08 & 100,00 & 138,00 & 102,41 & 36,24 & 6171,55 & 290,48 & 12,48 & 278,00 & 159,87 & 72,58 & 218,37 & 61,91 & 530,82 & 63,45 & 22,11 & 27,82 & 163,49 & 101,44 & 113,67 & 102,71 \\
\hline Pelophylax perezi & 31TCF09 & 100,00 & 146,17 & 107,88 & 36,88 & 6403,92 & 305,28 & 15,33 & 289,95 & 171,55 & 78,90 & 228,72 & 65,59 & 471,30 & 57,43 & \begin{tabular}{|l|l|}
21,07 \\
\end{tabular} & 28,69 & 149,71 & 85,98 & 103,90 & 86,57 \\
\hline Pelophylax perezi & 31TCF10 & 64,00 & 169,45 & 86,30 & 36,35 & 5173,92 & 292,05 & 58,19 & 233,86 & 174,08 & 237,55 & 239,82 & 111,01 & 549,32 & 87,30 & 13,34 & 42,91 & 216,00 & 86,18 & 124,69 & 98,97 \\
\hline Pelophylax perezi & 31TCF11 & 34,00 & 169,20 & 87,21 & 36,55 & 5197,79 & 292,89 & 57,21 & 235,68 & 173,32 & 237,71 & 239,98 & 110,73 & 549,23 & 87,16 & 14,00 & 42,80 & 215,45 & 87,46 & 125,54 & 98,16 \\
\hline Pelophylax perezi & 31TCF12 & 25,00 & 165,97 & 89,63 & 36,91 & 5319,41 & 292,97 & 51,66 & 241,31 & 169,56 & 235,78 & 237,78 & 105,91 & 552,69 & 86,22 & 14,84 & 41,78 & 213,66 & 90,25 & 126,19 & 107,44 \\
\hline Pelophylax perezi & 31TCF13 & 95,00 & 155,01 & 89,43 & 36,08 & 5443,29 & 285,01 & 40,86 & 244,15 & 159,62 & 226,56 & 228,42 & 92,51 & 584,05 & 82,37 & \begin{tabular}{|l|}
16,18 \\
\end{tabular} & 37,03 & 210,66 & 97,51 & 126,43 & 121,91 \\
\hline Pelophylax perezi & 31TCF14 & 99,00 & 141,43 & 90,34 & 35,86 & 5617,71 & 276,12 & 26,61 & 249,51 & $\mid 147,04$ & 215,30 & $\mid 216,78$ & 75,68 & 614,80 & 76,57 & 18,80 | & 31,62 & 204,52 & 107,99 & 128,10 & 133,09 \\
\hline Pelophylax perezi & 31TCF15 & 101,00 & 145,84 & 92,56 & 35,91 & 5691,94 & 282,92 & 28,81 & 254,11 & 151,16 & 220,48 & 221,73 & 78,41 & 579,26 & 72,72 & 18,21 & 32,13 & 193,91 & 104,29 & 123,97 & 121,18 \\
\hline Pelophylax perezi & 31TCF16 & 100,00 & 144,25 & 94,60 & 35,96 & 5815,44 & 284,88 & 25,33 & 259,55 & 149,85 & 199,48 & 221,21 & 74,36 & 562,22 & 68,15 & 19,17 & 30,79 & 183,79 & 106,39 & 122,69 & 114,40 \\
\hline Pelophylax perezi & 31TCF17 & 99,00 & 125,28 & 93,84 & 35,53 & 5901,09 & 268,66 & 7,94 & 260,72 & 133,01 & 61,14 & 203,30 & 54,08 & 630,37 & 72,59 & 26,30 & 25,89 & $\begin{array}{ll}190,87 \\
\end{array}$ & 126,36 & 138,57 & 127,53 \\
\hline Pelophylax perezi & 31TCF18 & 101,00 & 134,27 & 98,05 & 35,95 & 6053,09 & 282,00 & 12,50 & 269,50 & 150,27 & 69,86 & 213,36 & 59,84 & 569,94 & 66,61 & 23,90 & 26,82 & 173,44 & 110,70 & 125,38 & 111,34 \\
\hline Pelophylax perezi & 31TCF19 & 100,00 & 141,51 & 102,39 & 36,10 & 6233,94 & 294,30 & 15,42 & 278,88 & 164,79 & 74,35 & 222,12 & 63,49 & 517,98 & 61,49 & 22,94 & 27,60 & 161,22 & 96,77 & 114,76 & 96,87 \\
\hline Pelophylax perezi & 31TCF21 & & & & & & & & & & & & & & & & & & & & \\
\hline Pelophylax perezi & 31TCF24 & 91,00 & 156,86 & 86,37 & 35,72 & 5403,86 & 284,08 & 44,77 & 239,31 & 163,53 & 189,87 & 229,39 & 93,31 & 568,38 & 81,03 & 16,61 & 36,80 & 206,02 & 99,29 & 128,08 & 113,84 \\
\hline Pelophylax perezi & 31TCF25 & 99,00 & 145,13 & 87,91 & 35,27 & 5575,42 & 277,06 & 31,92 & 245,14 & 152,12 & 204,07 & 219,64 & 78,86 & 593,26 & 75,52 & 19,18 & 31,89 & 200,03 & 108,90 & 130,00 & 122,54 \\
\hline Pelophylax perezi & 31TCF 26 & 101,00 & 134,25 & 89,96 & 35,21 & 5736,76 & 271,14 & 19,53 & 251,61 & 141,36 & 186,22 & 210,50 & 65,48 & 618,71 & 72,03 & 22,63 & 28,15 & 196,75 & 120,61 & 135,04 & 127,73 \\
\hline Pelophylax perezi & 31TCF 27 & 100,00 & 120,60 & 89,93 & 35,00 & 5805,41 & 260,19 & 6,82 & 253,36 & 128,42 & 57,11 & 197,84 & 50,98 & 670,91 & 76,09 & 28,75 & 24,87 & 202,60 & 135,85 & 149,16 & 136,49 \\
\hline Pelophylax perezi & 31TCF28 & 100,00 & 129,82 & 93,38 & 35,30 & 5923,63 & 272,63 & 12,25 & 260,38 & 138,93 & 64,02 & 207,74 & 57,47 & 610,76 & 70,25 & 26,00 & 25,96 & 184,97 & 120,04 & 137,98 & 120,13 \\
\hline Pelophylax perezi & 31TCF29 & 100,00 & 139,84 & $\begin{array}{l}0,300 \\
97,39\end{array}$ & 35,82 & 6073,80 & 286,59 & $\begin{array}{l}1,25 \\
17,96 \\
\end{array}$ & 268,64 & \begin{tabular}{|l|l|}
158,81 \\
\end{tabular} & $\begin{array}{l}41,07 \\
71,0\end{array}$ & 218,75 & $\begin{array}{ll}64,14 \\
64,\end{array}$ & 546,20 & 63,61 & 23,82 & 27,30 & 167,30 & 102,78 & 125,16 & 102,78 \\
\hline Pelophylax perezi & 31TCF34 & 34,00 & 163,41 & 81,22 & 34,85 & 5237,07 & 284,63 & 55,20 & 229,44 & 172,05 & 105,51 & 233,73 & 101,17 & 547,44 & 82,49 & 16,22 & 38,78 & 205,51 & 95,22 & 130,27 & 104,29 \\
\hline Pelophylax perezi & 31 TCF 35 & 101,00 & 157,66 & 81,96 & 34,79 & 5332,40 & 281,05 & 48,75 & 232,30 & 166,51 & 109,39 & 228,96 & 93,82 & 557,55 & 78,55 & 17,36 & 35,67 & 201,06 & 100,08 & 130,69 & 109,36 \\
\hline Pelophylax perezi & 31TCF36 & 100,00 & 136,20 & 85,52 & 34,78 & 5605,32 & 267,82 & 25,11 & 242,71 & 144,68 & 167,76 & 210,99 & 68,99 & 624,55 & 74,92 & 22,99 & 28,69 & 202,11 & 121,90 & 139,31 & 128,05 \\
\hline Pelophylax perezi & 31TCF37 & 100,00 & 114,28 & 86,34 & 34,47 & 5723,86 & 250,82 & 4,11 & 246,72 & 122,64 & 48,59 & 190,80 & 46,14 & 718,90 & 80,58 & 32,16 & 23,49 & 215,68 & 146,96 & 160,95 & 147,02 \\
\hline Pelophylax perezi & 31TCF38 & $\begin{array}{l}101,00 \\
100\end{array}$ & $\begin{array}{l}114,20 \\
130,78\end{array}$ & $\begin{array}{l}80,345 \\
89,58\end{array}$ & 34,95 & $\begin{array}{l}5816,48 \\
58120\end{array}$ & 269,14 & \begin{tabular}{|l|l|}
16,21 \\
16
\end{tabular} & $\begin{array}{l}\mid 240,7 / 2 \\
252,92\end{array}$ & \begin{tabular}{|l|}
$138,87,87$ \\
\end{tabular} & \begin{tabular}{|c|}
40,350 \\
64,10
\end{tabular} & 207,49 & $\begin{array}{l}40,14 \\
59,81\end{array}$ & \begin{tabular}{|l|l|l|l|l|}
621,44 \\
\end{tabular} & $\begin{array}{l}\mid c 0,00 \\
70,68\end{array}$ & 26,14 & 26,05 & $\begin{array}{l}191,00 \\
190,56\end{array}$ & $\begin{array}{l}140,50 \\
122,19\end{array}$ & 141,97 & 122,21 \\
\hline Pelophylax perezi & 31TCF44 & 18,00 & 163,59 & 75,71 & 34,00 & 5096,00 & 279,18 & 59,82 & 219,35 & 174,12 & 114,35 & 232,00 & 102,65 & 550,18 & 80,12 & 16,59 & 37,71 & 204,47 & 96,35 & 132,65 & 111,82 \\
\hline Pelophylax perezi & 31TCF45 & 98,00 & 160,62 & 75,79 & 33,81 & 5147,51 & 277,23 & 56,59 & 220,64 & 171,42 & 103,96 & 229,48 & 98,64 & 553,08 & 77,58 & \begin{tabular}{|l|l|}
17,17 \\
\end{tabular} & 36,42 & 201,01 & 97,92 & 132,79 & 113,60 \\
\hline Pelophylax perezi & 31TCF46 & 100,00 & 150,92 & 79,54 & 34,11 & 5368,23 & 273,71 & 43,88 & 229,83 & 161,10 & 122,53 & 222,42 & 85,92 & 572,10 & 73,85 & 19,23 & 32,18 & 196,31 & 106,64 & 133,27 & 117,32 \\
\hline Pelophylax perezi & $\begin{array}{l}\text { 31TCF47 } \\
\end{array}$ & 101,00 & 136,05 & 83,50 & 34,21 & 5592,67 & 266,19 & 26,45 & 239,74 & 145,30 & 76,56 & 210,39 & 68,47 & 621,99 & 73,21 & 24,19 & 27,66 & 199,13 & 122,82 & 141,92 & 125,13 \\
\hline Pelophylax perezi & 31TCF48 & 99,00 & 138,87 & 85,79 & 34,62 & 5687,07 & 271,31 & 26,77 & 244,55 & 147,92 & 74,29 & 213,86 & 69,20 & 591,98 & 69,2 & 23,47 & 27,73 & 188,44 & 115,02 & 136,76 & 115,27 \\
\hline Pelophylax perezi & 31TCF55 & 69,00 & 160,04 & 71,70 & 33,01 & 5056,42 & 272,84 & 59,35 & 213,49 & 172,27 & 199,78 & 227,65 & 99,01 & 559,29 & 75,85 & 17,51 & 35,78 & 200,36 & 98,77 & 133,98 & 122,29 \\
\hline Pelophylax perezi & 31TCF56 & 101,00 & 155,31 & 74,55 & 33,22 & 5207,45 & 272,43 & 52,23 & 220,20 & 166,81 & 167,68 & 224,65 & 92,09 & 566,00 & 74,36 & 19,01 & 32,80 & 197,41 & 104,13 & 134,60 & 119,22 \\
\hline Pelophylax perezi & 31TCF57 & 99,00 & 147,41 & 78,90 & 33,88 & 5423,19 & 270,97 & 40,84 & 230,14 & 157,99 & 100,81 & 219,44 & 81,40 & 581,84 & 72,51 & 21,21 & 29,63 & 63 & 112,55 & 136,12 & 117,33 \\
\hline Pelophylax perezi & 31TCF58 & 101,00 & $\begin{array}{l}134,09 \\
134,09\end{array}$ & 82,51 & 34,01 & 5616,82 & 264,21 & $\begin{array}{l}40,04 \\
25,09 \\
\end{array}$ & 239,12 & \begin{tabular}{|l|l|}
143,74 \\
\end{tabular} & \begin{tabular}{|c|}
67,24 \\
67
\end{tabular} & 208,60 & $\begin{array}{ll}65,96 \\
65\end{array}$ & $\begin{array}{l}633,71 \\
633,4\end{array}$ & 72, & 26,48 & 26,18 & 199,10 & 124,34 & 147,58 & 124,36 \\
\hline Pelophylax perezi & 31TCF65 & 46,00 & 162,50 & 71,04 & 33,00 & 5050,68 & 274,52 & 62,36 & 212,16 & 175,04 & 227,02 & 230,05 & 101,48 & 558,36 & 77,79 & 18,38 & 34,71 & 201,48 & 99,46 & 134,50 & 120,18 \\
\hline Pelophylax perezi & $\begin{array}{l}\text { 31TCF66 } \\
\end{array}$ & 100,00 & 154,23 & 73,09 & 33,01 & 5191,91 & 270,40 & 52,41 & 217,99 & 165,97 & 220,92 & 223,55 & $\begin{array}{l}91,57 \\
91,5 \\
\end{array}$ & 583,63 & 76,96 & 20,63 & 31,16 & 202,41 & 108,47 & 138,47 & 122,70 \\
\hline Pelophylax perezi & 31TCF67 & 101,00 & 145,25 & 76,66 & 33,25 & 5386,18 & 267,13 & 40,66 & 226,47 & 156,07 & 176,01 & 217,00 & 80,06 & 608,72 & 75,16 & 23,26 & 28,20 & 201,90 & 119,23 & 142,62 & 123,55 \\
\hline Pelophylax perezi & 31TCF68 & 99,00 & 131,15 & 79,81 & 33,66 & 5559,16 & 259,21 & 24,77 & 234,45 & 141,26 & 64,97 & 205,27 & 64,24 & 666,55 & 75,62 & 29,08 & 25,12 & 208,11 & 131,83 & 156,38 & 131,86 \\
\hline Pelophylax perezi & $\begin{array}{l}\text { 31TCF69 } \\
\end{array}$ & $\begin{array}{l}501,00 \\
101\end{array}$ & 126,00 & 81,38 & 33,80 & 5630,80 & 256,21 & 18,44 & \begin{tabular}{|l|}
238,525 \\
\end{tabular} & $\begin{array}{l}411,20,73 \\
135\end{array}$ & 58,01 & \begin{tabular}{|l|}
200,83 \\
\end{tabular} & 58,01 & \begin{tabular}{|l|l|}
$688,63,63$ \\
\end{tabular} & $\begin{array}{l}7,024 \\
77,25\end{array}$ & 32,79 & 23,99 & 208,25 & 132,74 & 164,76 & $\begin{array}{l}13,00 \\
132,74\end{array}$ \\
\hline Pelophylax perezi & 31TCF75 & & & & & & & & & & & & & & & & & & & & \\
\hline Pelophylax perezi & 31TCF76 & 100,00 & 158,41 & 71,91 & 32,99 & 5151,24 & 272,81 & 57,54 & 215,27 & 170,21 & 224,63 & 227,14 & 96,04 & 582,02 & 79,99 & 21,60 & 31,08 & 204,76 & 108,70 & 139,79 & 120,42 \\
\hline Pelophylax perezi & 31TCF77 & 101,00 & 145,54 & 74,80 & 33,01 & 5344,03 & 265,69 & 42,47 & (2) & 156,52 & 193,43 & 216,74 & 81,12 & 627,43 & 78,06 & 25,09 & 27,47 & 208,00 & 123,24 & 148,06 & 127,46 \\
\hline Pelophylax perezi & 31TCF78 & 101,00 & 130 & 77,56 & 33 & 5504,74 & 256,71 & 26,05 & 230,66 & 14 & 72, & 20 & 64,67 & 687,65 & 77,72 & 30 & 24,46 & 214,64 & 136,78 & 162,16 & 136,81 \\
\hline Pelophylax perezi & $\begin{array}{l}\text { 31TCF79 } \\
\end{array}$ & $\begin{array}{l}100,00 \\
100\end{array}$ & $\begin{array}{l}13,54,91 \\
128,91\end{array}$ & 78,91 & $\begin{array}{l}33,05 \\
33,06\end{array}$ & $\mid 5569,67$ & 257,32 & $\begin{array}{l}2,300 \\
23,18 \\
\end{array}$ & \begin{tabular}{|l|}
234,140 \\
\end{tabular} & \begin{tabular}{|l|}
138,99 \\
138,9 \\
\end{tabular} & $\begin{array}{l}2,324 \\
61,92\end{array}$ & \begin{tabular}{|l|}
203,094 \\
\end{tabular} & $\begin{array}{ll}61,92 \\
61,9\end{array}$ & $\mid \begin{array}{l}\mid c 01,05 \\
687,95 \\
\end{array}$ & 76,92 & 32,81 & $\begin{array}{l}24,40 \\
24,03\end{array}$ & 214,040 & $\begin{array}{l}130,10 \\
132,79\end{array}$ & $\begin{array}{l}102,10 \\
165,84\end{array}$ & $\begin{array}{l}150,01 \\
132,79\end{array}$ \\
\hline Pelophylax perezi & 31TCF86 & 91,00 & 159,65 & 71,41 & 32,97 & 5147,19 & 273,63 & 59,16 & 214,47 & 171,28 & 226,06 & 228,23 & 97,46 & 592,90 & 83,01 & 22,78 & 30,74 & 209,33 & 111,23 & 142,36 & 121,67 \\
\hline Pelophylax perezi & 31TCF87 & 99,00 & 154,53 & 72,64 & 32,94 & 5250,76 & 271,23 & 52,83 & 218,40 & 165,66 & 222,41 & 224,40 & 90,97 & 606,20 & 80,03 & 24,43 & 28,57 & 207,34 & 117,39 & 145,62 & 122,55 \\
\hline Pelophylax perezi & 31TCF88 & 101,00 & 146,61 & 74,55 & 32,95 & 5379,89 & 267,30 & 43,24 & 224,06 & 157, & 124,6 & 218, & 81 & 630,24 & 76,94 & 26,90 & 26 & 206,60 & 124,75 & 151,34 & 125,14 \\
\hline Pelophylax perezi & 31TCF89 & 101,00 & 139,33 & 76,38 & 32,97 & 5485,22 & 263,93 & 34,78 & 229,15 & 149,73 & 72,92 & 212,16 & 72,92 & 652,83 & 74,95 & 30,19 & 25,02 & 205,62 & 126,21 & 158,68 & 126,21 \\
\hline
\end{tabular}




\begin{tabular}{|c|c|c|c|c|c|c|c|c|c|c|c|c|c|c|c|c|c|c|c|c|c|}
\hline TAXON & UTM & $\mathrm{km} 2$ & B101 & B102 & $\mathrm{BIO3}$ & BIO4 & B105 & B106 & B107 & B108 & B109 & B1010 & BIO11 & BIO12 & B1013 & BIO14 & BIO15 & B1016 & B1017 & B1018 & B1019 \\
\hline Pelophylax perezi & 31TCF96 & 63,00 & 162,17 & 71,02 & 32,93 & 5135,33 & 275,55 & 61,89 & 213,65 & 173,63 & 228,45 & 230,55 & 100,06 & 597,04 & 85,61 & 22,81 & 31,43 & 213,67 & 111,73 & 143,07 & 122,33 \\
\hline Pelophylax perezi & 31TCF97 & 101,00 & 155,44 & 71,73 & 32,62 & 5239,23 & 271,63 & 54,42 & 217,21 & 166,41 & 223,38 & 225,25 & 92,23 & 620,28 & 82,75 & 25,01 & 28,58 & 213,10 & 119,15 & 148,12 & 126,26 \\
\hline Pelophylax perezi & 31TCF98 & 100,00 & 154,06 & 72,97 & 32,69 & 5317,90 & 272,40 & 51,77 & 220,63 & 164,93 & 143,72 & 224,68 & 89,57 & 613,12 & 78,77 & 26,30 & 27,63 & 206,61 & 120,71 & 149,15 & 121,59 \\
\hline Pelophylax perezi & 31TCF99 & 100,00 & 150,56 & 74,29 & 32,61 & 5400,68 & 271,62 & 46,79 & 224,84 & 161,05 & 84,77 & 222,03 & 84,77 & 616,26 & 74,95 & 28,32 & 26,30 & 201,81 & 118,82 & 152,44 & 118,82 \\
\hline Pelophylax perezi & 31TCG00 & 101,00 & 150,62 & 112,15 & 37,00 & 6602,27 & 315,20 & 15,70 & 299,50 & 178,15 & 76,80 & 235,19 & 66,23 & 437,61 & 53,96 & 20,16 & 29,04 & 142,76 & 77,21 & 101,21 & 77,22 \\
\hline Pelophylax perezi & 31TCG01 & 100,00 & 149,52 & 113,44 & 37,00 & 6668,43 & 315,83 & 13,52 & 302,31 & 177,81 & 64,06 & 234,61 & 63,75 & 440,78 & 54,38 & 20,69 & 28,24 & 145,22 & 77,05 & 105,55 & 77,05 \\
\hline Pelophylax perezi & 31TCG02 & 100,00 & 144,62 & 111,92 & 37,00 & 6591,15 & 309,00 & 10,43 & 298,57 & 172,21 & 59,82 & 228,81 & 59,82 & 468,92 & 57,40 & 22,88 & 26,82 & 153,72 & 82,70 & 114,68 & 82,70 \\
\hline Pelophylax perezi & 31TCG03 & 100,00 & 131,63 & 107,10 & 36,88 & 6366,07 & 290,37 & 2,88 & 287,50 & 156,82 & 50,46 & \begin{tabular}{|l|}
213,46 \\
\end{tabular} & 50,46 & 551,20 & 66,24 & 28,90 & 24,44 & 177,22 & 100,41 & 137,19 & 100,41 \\
\hline Pelophylax perezi & 31TCG04 & 101,00 & 118,09 & 101,98 & 36,44 & 6139,49 & 270,86 & $-4,66$ & 275,52 & 140,83 & 40,75 & 197,62 & 40,75 & 651,87 & 76,27 & 36,52 & 22,10 & 204,62 & 122,90 & 164,46 & 122,90 \\
\hline Pelophylax perezi & 31TCG05 & 101,00 & 113,19 & 100,43 & 36,55 & 6053,24 & 263,76 & $-7,62$ & 271,38 & 135,18 & 37,09 & 191,81 & 37,09 & 700,20 & 80,56 & 40,33 & 20,96 & 217,23 & 134,33 & 177,91 & 134,33 \\
\hline Pelophylax perezi & 31TCG06 & 100,00 & 107,47 & 98,54 & 36,54 & 5951,47 & 255,26 & $-11,17$ & 266,43 & 128,46 & 32,85 & 184,80 & 32,85 & 762,64 & 85,91 & 45,06 & 19,62 & 233,25 & 149,42 & 195,38 & 149,42 \\
\hline Pelophylax perezi & 31TCG07 & 100,00 & 103,31 & 97,44 & 36,60 & 5881,46 & 249,24 & $-13,82$ & 263,06 & 123,67 & 29,62 & 179,82 & 29,62 & 817,20 & 90,26 & 49,11 & 18,59 & 246,64 & 163,32 & 209,92 & 163,32 \\
\hline Pelophylax perezi & 31TCG08 & 100,00 & 89,64 & 93,30 & 36,13 & 5736,36 & 231,35 & $-23,12$ & 254,47 & 107,97 & 18,78 & 164,74 & 18,69 & 926,25 & 100,54 & 57,79 & 17,01 & 274,68 & 192,09 & 233,37 & 192,09 \\
\hline Pelophylax perezi & 31TCG09 & 100,00 & 71,88 & 87,96 & 35,48 & 5589,51 & 208,91 & $-35,51$ & 244,42 & 87,62 & 5,34 & 145,74 & 3,81 & 1035,52 & 111,78 & 67,04 & 15,48 & 303,12 & 223,27 & 250,01 & 223,32 \\
\hline Pelophylax perezi & 31TCG10 & 100,00 & 148,09 & 106,57 & 36,55 & 6410,78 & 305,75 & 17,94 & 287,81 & 173,48 & 74,81 & 230,39 & 66,60 & 474,01 & 56,88 & 22,27 & 28,30 & 150,99 & 84,91 & 108,93 & 84,92 \\
\hline Pelophylax perezi & 31TCG11 & 100,00 & 148,88 & 108,25 & 36,80 & 6481,73 & 308,54 & 17,17 & 291,36 & 175,20 & 66,22 & 231,77 & 65,83 & 466,93 & 56,24 & 22,36 & 27,81 & 150,37 & 82,35 & 110,83 & 82,35 \\
\hline Pelophylax perezi & 31TCG12 & 101,00 & 145,60 & 108,07 & 36,81 & 6466,74 & 305,13 & 14,48 & 290,65 & 171,97 & 62,63 & 228,31 & 62,63 & 485,26 & 58,42 & 23,85 & 26,74 & 156,84 & 85,61 & 118,50 & 85,61 \\
\hline Pelophylax perezi & 31TCG13 & 100,00 & 134,26 & 104,94 & 36,54 & 6324,92 & 290,34 & 6,70 & 283,64 & 158,86 & 53,53 & 215,44 & 53,53 & 557,00 & 66,26 & 29,01 & 24,74 & 178,38 & 100,51 & 139,94 & 100,51 \\
\hline Pelophylax perezi & 31TCG14 & 100,00 & 119,22 & 100,30 & 36,13 & 6123,16 & 270,38 & $-2,44$ & 272,82 & 141,63 & 42,18 & 198,48 & 42,18 & 663,98 & 77,33 & 36,82 & 22,38 & 208,67 & 123,72 & 170,29 & 123,72 \\
\hline Pelophylax perezi & 31TCG15 & 99,00 & 101,89 & 95,01 & 35,75 & 5921,92 & 247,70 & $-13,87$ & 261.58 & $\mid 121.46$ & 28,49 & 179,32 & 28,49 & 793,30 & 90,01 & 46,81 & $\begin{array}{ll}19,97 \\
\end{array}$ & 242,68 & 155,53 & 200,06 & 155,53 \\
\hline Pelophylax perezi & 31TCG16 & 101,00 & 105,52 & 96,40 & 36,16 & 5926,78 & 251,74 & $-11,38$ & 263,12 & 125,83 & 31,49 & 182,73 & 31,49 & 796,46 & 89,31 & 46,46 & 19,72 & 243,61 & 154,88 & 207,47 & 154,88 \\
\hline Pelophylax perezi & 31TCG17 & 100,00 & 101,83 & 95,57 & 36,21 & 5870,22 & 246,60 & $-13,95$ & 260,55 & 121,63 & 28,55 & 178,34 & 28,55 & 844,18 & 93,05 & 50,19 & 18,67 & 255,17 & $\begin{array}{l}167,57 \\
\end{array}$ & 219,47 & 167,57 \\
\hline Pelophylax perezi & 31TCG18 & 101,00 & 95,11 & 93,72 & 36,10 & 5789,82 & 237,62 & \begin{tabular}{|c|}
$-18,57$ \\
\end{tabular} & 256,19 & 114,02 & 23,29 & 170,75 & 23,17 & 912,47 & 98,85 & 55,75 & 17,54 & 271,84 & 186,17 & 234,07 & 186,17 \\
\hline Pelophylax perezi & 31TCG19 & 100,00 & 85,20 & 91,00 & 35,91 & 5684,82 & 224,70 & $-25,41$ & 250,11 & 102,57 & 15,24 & 159,72 & 15,13 & 991,70 & 106,40 & 62,57 & 16,37 & 292,01 & 207,85 & 250,60 & 207,85 \\
\hline Pelophylax perezi & 31 TCG20 & 101,00 & 145,21 & 100,43 & 36,00 & 6199,97 & 295,43 & 20,32 & 275,11 & 168,27 & 69,22 & 225,00 & 66,96 & 511,01 & 60,05 & 23,69 & 27,66 & 159,21 & 92,71 & 117,26 & 92,71 \\
\hline Pelophylax perezi & 31TCG21 & 99,00 & 146,83 & 102,35 & 36,07 & 6271,19 & 299,19 & 20,17 & 279,02 & 170,87 & 66,94 & 227,23 & 66,94 & 499,75 & 59,08 & 24,52 & 27,28 & 157,64 & 89,08 & 117,97 & 89,08 \\
\hline Pelophylax perezi & 31TCG22 & 100,00 & $\begin{array}{l}144,19 \\
144,19\end{array}$ & 102,99 & 36,11 & 6293,54 & 297,54 & 17,28 & 280,26 & 168,62 & 60,831 & 224,93 & 63,81 & 513,65 & $\begin{array}{l}30,86 \\
60\end{array}$ & $\begin{array}{l}24,78 \\
25,78\end{array}$ & 26,49 & 163,31 & $\begin{array}{l}30,99 \\
90\end{array}$ & 125,23 & $\begin{array}{l}09,00 \\
90,99\end{array}$ \\
\hline Pelophylax perezi & 31TCG23 & 100,00 & 137,21 & 102,12 & 36,16 & 6250,79 & 289,87 & 11,62 & 278,25 & 161,13 & 57,51 & 217,54 & 57,51 & 557,68 & 65,90 & 28,83 & 25,16 & 177,63 & 99,39 & 140,63 & 99,39 \\
\hline Pelophylax perezi & 31TCG24 & 100,00 & 119,50 & 97,78 & 35,88 & 6070,98 & 268,10 & $-0,65$ & 268,75 & 140,95 & 43,20 & 198,17 & 43,20 & 679,44 & 78,79 & 37,49 & 22,68 & 212,84 & 125,75 & 175,27 & 125,75 \\
\hline Pelophylax perezi & 31 TCG25 & 101,00 & 113,46 & 96,40 & 35,79 & 6002,89 & 260,44 & $-4,72$ & 265,17 & 134,30 & 38,32 & 191,44 & 38,32 & 731,19 & 83,64 & 41,37 & 21,60 & 226,89 & 137,85 & 190,11 & 137,85 \\
\hline Pelophylax perezi & 31 TCG26 & 100,00 & 121,80 & 99,03 & 36,10 & 6058,95 & 270,30 & 0,71 & 269,59 & 144,06 & 44,99 & 200,04 & 44,99 & 689,62 & 78,65 & 38,37 & 21,92 & 215,45 & 127,89 & 183,79 & 127,89 \\
\hline Pelophylax perezi & 31TCG27 & 100,00 & 110,40 & 96,15 & 36,03 & 5934,42 & 255,86 & $-6,71$ & \begin{tabular}{|l|}
262,77 \\
\end{tabular} & $\begin{array}{l}131,10 \\
131\end{array}$ & $\begin{array}{ll}35,86 \\
35,8\end{array}$ & \begin{tabular}{|l|}
187,36 \\
\end{tabular} & $\begin{array}{ll}35,86 \\
35,8\end{array}$ & \begin{tabular}{|l|}
790,05 \\
\end{tabular} & $\begin{array}{ll}0,000 \\
88,08\end{array}$ & $\begin{array}{ll}45,32 \\
\end{array}$ & 20,25 & 242,42 & $\begin{array}{ll}151,64 \\
\end{array}$ & 211,22 & 151,64 \\
\hline Pelophylax perezi & 31TCG28 & 99,00 & 85,87 & 89,44 & 35,39 & 5711,95 & 225,33 & $-23,97$ & 249,30 & 102,84 & 15,88 & 160,93 & 15,79 & 965,62 & 105,61 & 59,56 & 17,35 & 287,94 & 197,62 & 245,02 & 197,62 \\
\hline Pelophylax perezi & 31TCG29 & 101,00 & 72,96 & 86,12 & 34,95 & 5607,02 & 209,42 & $-33,45$ & 242,88 & 88,30 & 7,88 & 147,16 & 4,98 & 1052,25 & 113,75 & 67,49 & 15,78 & 309,17 & 223,17 & 259,37 & 223,46 \\
\hline Pelophylax perezi & 31 TCG30 & 100,00 & 141,64 & 94,83 & 35,43 & 6015,75 & 285,34 & 21,63 & 263,71 & 163,24 & 66,24 & 219,57 & 66,24 & 547,84 & 63,60 & 25,13 & 26,98 & 167,79 & 100,53 & 130,45 & 100,53 \\
\hline Pelophylax perezi & 31TCG31 & 101,00 & 144,05 & 96,82 & 35,74 & 6086,38 & 289,93 & 21,95 & 267,99 & 166,11 & 67,02 & 222,39 & 67,02 & 533,50 & 62,27 & 26,14 & 26,87 & 165,44 & 95,64 & 127,96 & 95,64 \\
\hline Pelophylax perezi & 31TCG32 & 101,00 & 141,61 & 97,91 & 35,83 & 6125,97 & 289,15 & 18,98 & 270,17 & 164,15 & 63,93 & 220,38 & 63,93 & 545,92 & 64,05 & 27,97 & 26,24 & 171,31 & 96,95 & 133,79 & 96,95 \\
\hline Pelophylax perezi & 31TCG33 & 100,00 & 136,32 & 97,96 & 35,89 & 6125,76 & 284,35 & $\begin{array}{ll}14,07 \\
\end{array}$ & 270,28 & 158,88 & 58,65 & 215,15 & 58,65 & 578,41 & 67,94 & 30,14 & 25,21 & 182,78 & 102,51 & 146,70 & 102,51 \\
\hline Pelophylax perezi & 31TCG34 & 100,00 & 126,66 & 96,48 & 35,73 & 6057,52 & 273,47 & 6,68 & 266,79 & 148,22 & 50,25 & 204,90 & 50,25 & 646,01 & 75,22 & 34,60 & 23,94 & 203,36 & 116,24 & 168,70 & 116,24 \\
\hline Pelophylax perezi & 31TCG35 & 100,00 & 102,56 & 91,07 & 35,19 & 5855,30 & 244,94 & $-10,29$ & 255,23 & 120,90 & 30,50 & 179,28 & 30,50 & 813,86 & 92,62 & 46,27 & 20,91 & 250,31 & 154,85 & 211,10 & 154,85 \\
\hline Pelophylax perezi & 31TCG36 & 100,00 & 117,81 & 95,62 & 35,85 & 5979,94 & 263,39 & \begin{tabular}{r|r|}
$-0,18$ \\
\end{tabular} & 263,56 & 138,88 & 42,61 & 195,41 & 42,61 & 723,82 & 82,78 & 39,32 & 22,59 & 226,92 & $\begin{array}{l}131,99 \\
130\end{array}$ & 198,32 & 131,99 \\
\hline Pelophylax perezi & 31TCG37 & 101,00 & 105,48 & 92,90 & 35,55 & 5864,52 & 248,53 & $-8,86$ & 257,39 & 124,87 & 32,59 & 181,90 & 32,59 & 822,30 & 92,24 & 46,80 & 20,57 & 252,73 & \begin{tabular}{|l|l|}
156,84 \\
\end{tabular} & 221,14 & 156,84 \\
\hline Pelophylax perezi & 31TCG38 & 101,00 & 100,74 & 92,05 & 35,65 & 5808,73 & 242,40 & $-12,33$ & 254,73 & 119,60 & 28,60 & $\begin{array}{l}176,52 \\
\end{array}$ & 28,60 & 875,04 & 97,42 & 50,57 & 19,64 & 266,84 & $\begin{array}{l} \\
169,90 \\
\end{array}$ & 237,59 & 169,90 \\
\hline Pelophylax perezi & 31TCG39 & 100,00 & 72,43 & 84,84 & 34,63 & 5608,18 & 208,53 & $-33,39$ & 241,93 & 87,47 & 13,71 & 146,77 & 4,76 & 1056,72 & 114,67 & 66,88 & 16,13 & 310,90 & 222,37 & 261,89 & 223,34 \\
\hline Pelophylax perezi & 31TCG40 & 100,00 & 134,28 & 89,61 & 34,87 & 5866,07 & 273,02 & 19,04 & 253,98 & 153,05 & 61,62 & 210,99 & 61,62 & 604,61 & 69,64 & 28,48 & 25,80 & 182,92 & 33 & 45,81 & 112,33 \\
\hline Pelophylax perezi & 31TCG41 & 100,00 & 139, & $\begin{array}{l}91,10 \\
91,73\end{array}$ & 35,06 & 5936,46 & 279,99 & 21,87 & 258,12 & $\begin{array}{l}159,79 \\
\end{array}$ & $\begin{array}{l}64,88 \\
64\end{array}$ & 216,22 & $\begin{array}{l}1,0<2 \\
64,88\end{array}$ & 575,31 & $\begin{array}{l}66,70 \\
66\end{array}$ & 28 & 26,16 & 176,43 & 103,80 & \begin{tabular}{|l|l|}
140,88 \\
\end{tabular} & 103,80 \\
\hline Pelophylax perezi & 31TCG42 & 99,00 & 138,89 & 93,20 & 35,08 & 5983,99 & 281,33 & 20,20 & 261,13 & 159,89 & 63,45 & 216,18 & 63,45 & 577,85 & 67,41 & 30,0 & 25,98 & 179,55 & 102,43 & 144,34 & 102,43 \\
\hline Pelophylax perezi & 31TCG43 & $\begin{array}{r}101,00 \\
100\end{array}$ & 134,01 & 93,72 & 35,06 & \begin{tabular}{|l|}
6002,69 \\
\end{tabular} & 277,59 & 15,22 & 262,37 & 155,12 & 58,41 & 211,45 & 58,41 & 607,39 & $\begin{array}{ll}71,19 \\
\end{array}$ & 31,74 & 25,31 & 190,79 & 106,90 & 155,82 & 106,90 \\
\hline Pelophylax perezi & 31TCG44 & 100,00 & 131,50 & 94,24 & 35,22 & 6007,63 & 275,71 & 12,66 & 263,05 & 152,78 & 55,70 & 209,05 & 55,70 & 626,31 & 73,35 & 32,62 & 25,01 & 197,87 & 109,67 & 165,11 & 109,67 \\
\hline Pelophylax perezi & 31TCG45 & 101,00 & 114,29 & 91,50 & 35,01 & 5901,49 & 256,68 & $-0,45$ & 257,13 & 133,68 & 40,92 & 191,16 & 40,92 & 741,55 & 85,76 & 39,78 & 23,26 & 232,24 & 15 & 198,86 & 134,15 \\
\hline Pelophylax perezi & 31TCG46 & 100,00 & $\begin{array}{r}14,25 \\
97,35\end{array}$ & 88,30 & 34,8 & 5776,11 & 237,24 & $\begin{array}{l}-0,40 \\
-12,70\end{array}$ & $\mid$\begin{tabular}{|l|}
249,94 \\
2415
\end{tabular} & $\begin{array}{l}\mid 53,00 \\
114,72 \\
\end{array}$ & $\begin{array}{l}40,754 \\
26,74\end{array}$ & 173,27 & $\begin{array}{l}40,754 \\
26,74\end{array}$ & \begin{tabular}{|l|}
$421,303,40$ \\
\end{tabular} & $\begin{array}{l}\mid 03,10 \\
97,85 \\
\end{array}$ & $\begin{array}{l}5,07 \\
49,07\end{array}$ & 20,200 & 264,79 & $\begin{array}{l}164,38 \\
164,3\end{array}$ & \begin{tabular}{|l|}
227,180 \\
22,0
\end{tabular} & $\begin{array}{l}154,15 \\
164,38\end{array}$ \\
\hline Pelophylax perezi & 31TCG47 & 100,00 & 73,25 & 83,05 & 34,10 & 5610,93 & 209,02 & $-30,90$ & 239,92 & 87,44 & 7,54 & 148,02 & 6,28 & 1023,62 & 112,84 & 64,09 & 16,84 & 302,60 & 211,83 & 249,96 & 211,91 \\
\hline Pelophylax perezi & 31TCG49 & 101,00 & 83,04 & 86,28 & 34,86 & |5660,96 & 220,30 & $-24,22$ & 244,53 & $\begin{array}{l}09,18 \\
99,4\end{array}$ & 16,94 & $\begin{array}{l}157,79 \\
150\end{array}$ & $\begin{array}{ll}0,260 \\
14,22\end{array}$ & \begin{tabular}{|c|}
986,01 \\
986,0
\end{tabular} & $\begin{array}{l}108,81 \\
108,\end{array}$ & $\begin{array}{l}60,63 \\
60\end{array}$ & 17,82 & 294,88 & 200,65 & 253,99 & 200,96 \\
\hline Pelophylax perezi & 31TCG50 & 100,00 & 125,20 & 85,47 & 34,08 & 5757,16 & 260,77 & 14,22 & 246,55 & 141,68 & 54,95 & 201,17 & 54,95 & 672,70 & 77,02 & 33,49 & 24,15 & 201,27 & 126,60 & 163,08 & 126,60 \\
\hline Pelophylax perezi & 31TCG52 & 101,00 & 133,87 & 88,88 & 34,67 & 5867,08 & 272,45 & 19,13 & 253,33 & 153,15 & 60,71 & 210,23 & 60,71 & 621,01 & 72,45 & 32,35 & 25,55 & 191,85 & 109,86 & 157,58 & 105 \\
\hline Pelophylax perezi & 31TCG53 & 100,00 & 133,98 & 90,15 & 34,92 & 5900,41 & 273,85 & 18,03 & 255,82 & 153,91 & 60,08 & 210,46 & 60,08 & 622,11 & 72,87 & 31,93 & 25,73 & 194,46 & 108,20 & 161,22 & 108,20 \\
\hline Pelophylax perezi & 31TCG54 & 100,00 & 128,47 & 90,52 & 34,94 & 5904,12 & 269,06 & 12,75 & 256,31 & 148,32 & 54,50 & 204,86 & 54,50 & 656,86 & 77,26 & 33,38 & 25,45 & 207,43 & 113,50 & 175,72 & 113,50 \\
\hline Pelophylax perezi & 31TCG55 & 100,00 & 122,96 & 90,48 & 34,96 & 5889,88 & 263,85 & 7,80 & 256,05 & 142,53 & 49,29 & 199,42 & 49,29 & 693,17 & 81,14 & 35,47 & 25,08 & 219,27 & 120,52 & 189,14 & 120,52 \\
\hline Pelophylax perezi & 31TCG56 & 100,00 & 101,21 & 87,01 & 34,60 & 5759,90 & 239,94 & $-8,37$ & 248, & 118, & 30,82 & 177,04 & 30 & 836,70 & 95,76 & 46,51 & 21,94 & 258,07 & 156,10 & 221,74 & 156 \\
\hline Pelophylax perezi & 31TCG57 & 101,00 & $\begin{aligned} 93,94 \\
93\end{aligned}$ & 86,16 & 34,51 & 5718,43 & 231,94 & $-14,21$ & 246,15 & 110,49 & \begin{tabular}{|l|l}
24,77 \\
\end{tabular} & 169,36 & $\begin{array}{l}24,36 \\
24,33\end{array}$ & 890,55 & 100,86 & 51,10 & 20,70 & 272,21 & 170,57 & 235,88 & 170, \\
\hline
\end{tabular}




\begin{tabular}{|c|c|c|c|c|c|c|c|c|c|c|c|c|c|c|c|c|c|c|c|c|c|}
\hline TAXON & UTM & $\mathrm{km} 2$ & B101 & B102 & $\mathrm{BIO3}$ & B104 & B105 & B106 & B107 & B108 & B109 & B1010 & BIO11 & BIO12 & B1013 & BIO14 & BIO15 & BIO16 & B1017 & B1018 & B1019 \\
\hline Pelophylax perezi & 31TCG58 & 100,00 & 71,26 & 81,66 & 33,93 & 5572,92 & 205,77 & $-31,38$ & 237,16 & 85,01 & 9,53 & 145,67 & 4,98 & 1045,71 & 115,06 & 66,29 & 16,50 & 308,16 & 217,42 & 256,14 & 217,73 \\
\hline Pelophylax perezi & 31TCG59 & 101,00 & 53,42 & 77,91 & 33,18 & 5480,81 & 185,19 & $-46,43$ & 231,62 & 65,12 & 6,63 & 127,25 & $-10,71$ & 1162,71 & 125,42 & 76,56 & 14,33 & 334,58 & 253,12 & 273,89 & 255,58 \\
\hline Pelophylax perezi & 31TCG60 & 101,00 & 123,97 & 82,54 & 33,89 & 5682,52 & 256,82 & 15,55 & 241,28 & 151,45 & 55,06 & 199,25 & 55,06 & 695,57 & 79,27 & 35,38 & 23,78 & 206,99 & 130,82 & 170,18 & 130,82 \\
\hline Pelophylax perezi & 31TCG61 & 99,00 & 125,74 & 83,80 & \begin{tabular}{|l|l|}
33,97 \\
\end{tabular} & 5727,71 & 259,95 & 15,87 & 244,08 & 143,41 & 55,75 & 201,19 & 55,75 & 683,17 & 78,92 & 35,98 & 24,29 & 206,36 & 124,60 & 171,33 & 124,60 \\
\hline Pelophylax perezi & 31TCG62 & 100,00 & 128,55 & 85,27 & 34,02 & 5765,80 & 263,99 & \begin{tabular}{|l|l|}
17,17 \\
\end{tabular} & 246,82 & 146,21 & 57,46 & 204,06 & 57,46 & 667,49 & 77,95 & 34,40 & 25,03 & 205,20 & 118,07 & $\begin{array}{ll}171,74 \\
\end{array}$ & 118,07 \\
\hline Pelophylax perezi & 31TCG63 & 100,00 & 128,65 & 86,51 & 34,10 & 5808,17 & 265,45 & 16,13 & 249,32 & 147,04 & 56,57 & 204,41 & 56,57 & 667,53 & 78,55 & 33,57 & 25,63 & 208,33 & 115,35 & 175,76 & 115,35 \\
\hline Pelophylax perezi & 31TCG64 & 101,00 & 120,85 & 86,78 & 34,10 & 5815,49 & 258,77 & 8,88 & 249,89 & 139,11 & 48,99 & 196,76 & 48,99 & 712,98 & 84,27 & 35,55 & 25,45 & 224,98 & 122,59 & 192,38 & 122,59 \\
\hline Pelophylax perezi & 31TCG65 & 101,00 & 121,13 & 87,71 & 34,33 & 5831,24 & 259,73 & 8,37 & 251,36 & 139,89 & 48,66 & 197,02 & 48,66 & 711,34 & 84,13 & 35,08 & 25,96 & 226,18 & 120,89 & 196,85 & 120,89 \\
\hline Pelophylax perezi & 31TCG66 & 100,00 & 100,32 & 85,03 & 34,11 & 5725,60 & 237,58 & $-7,64$ & 245,22 & 116,90 & 30,95 & 175,84 & 30,66 & 843,93 & 97,14 & 46,30 & 22,37 & 260,39 & 155,95 & 225,38 & 155,97 \\
\hline Pelophylax perezi & 31TCG67 & 100,00 & 99,70 & 85,67 & 34,39 & 5726,07 & 237,23 & $-8,64$ & 245,87 & 116,54 & 30,30 & 175,10 & 29,84 & 851,07 & 97,52 & 47,29 & 22,18 & 262,35 & 158,57 & 229,13 & 158,57 \\
\hline Pelophylax perezi & 31TCG68 & 100,00 & 102,52 & 86,83 & 34,61 & 5742,15 & 240,55 & $-6,99$ & 247,55 & 120,07 & 35,21 & 177,77 & 31,88 & 835,53 & 96,50 & 45,65 & 22,99 & 260,03 & 153,37 & 233,65 & 153,48 \\
\hline Pelophylax perezi & 31TCG69 & 100,00 & 81,66 & 83,19 & 34,16 & 5613,66 & 217,09 & $-22,99$ & 240,08 & 96,70 & 20,97 & 156,14 & 14,08 & 984,49 & 109,60 & 59,94 & 18,40 & 294,83 & 197,92 & 252,69 & 198,74 \\
\hline Pelophylax perezi & 31TCG70 & 100,00 & 134,73 & 80,03 & 33,31 & 5606,56 & 263,71 & 27,21 & 236,49 & 179,06 & 66,32 & 208,80 & 66,32 & 653,16 & 74,56 & 32,30 & 24,83 & 199,86 & 121,51 & 162,07 & 121,51 \\
\hline Pelophylax perezi & 31TCG71 & 101,00 & 127,45 & 81,27 & 33,46 & 5665,09 & 259,12 & 19,54 & 239,58 & 161,52 & 58,44 & 202,31 & 58,44 & 687,89 & 79,31 & 35,96 & 24,35 & 207,74 & 124,61 & 174,50 & 124,61 \\
\hline Pelophylax perezi & 31TCG72 & 101,00 & 126,24 & 82,42 & 33,64 & 5699,56 & 259,27 & 17,33 & 241,95 & 142,78 & 56,45 & 201,25 & 56,45 & 694,37 & 81,27 & 35,29 & 24,88 & 212,50 & 122,24 & 180,40 & 122,24 \\
\hline Pelophylax perezi & 31TCG73 & 100,00 & 121,63 & 83,25 & 33,79 & 5723,55 & 256,15 & 12,41 & 243,74 & 138,51 & 51,61 & 196,92 & 51,61 & 720,62 & 85,22 & 35,85 & 25,23 & 224,42 & 124,60 & 191,02 & 124,60 \\
\hline Pelophylax perezi & 31TCG74 & 100,00 & 116,23 & 83,76 & 33,94 & 5734,19 & 251,71 & 7,01 & 244,69 & 133,10 & 46,16 & 191,64 & 46,16 & 752,23 & 89,30 & 37,21 & 25,30 & 236,62 & 129,29 & 203,23 & 129,29 \\
\hline Pelophylax perezi & 31TCG75 & 100,00 & 113,46 & 84,33 & 33,99 & 5744,27 & 249,75 & 4,17 & 245,58 & 130,70 & 43,18 & 188,87 & 43,18 & 767,56 & 90,93 & 38,16 & 25,40 & 242,60 & 131,87 & 211,41 & 131,87 \\
\hline Pelophylax perezi & 31TCG76 & 101,00 & 82,16 & 80,14 & 33,41 & 5598,00 & 216,28 & $-20,41$ & 236,68 & 95,78 & 19,20 & 157,11 & 15,95 & 964,72 & 108,32 & 56,96 & 19,15 & 286,27 & 192,24 & 241,99 & 192,74 \\
\hline Pelophylax perezi & 31TCG77 & 100,00 & 69,87 & 78,66 & 33,21 & 5544,47 & 203,01 & $-30,74$ & 233,75 & 82,42 & 22,81 & 144,45 & 4,99 & 1048,60 & 115,51 & \begin{tabular}{|l|l|}
64,47 \\
\end{tabular} & 17,03 & 305,64 & 217,30 & 255,84 & 219,13 \\
\hline Pelophylax perezi & 31TCG78 & 101,00 & 85,85 & 82,15 & $\begin{array}{l}33,85 \\
\end{array}$ & 5619,35 & 220,94 & \begin{tabular}{|l|l|}
$-18,18$ \\
\end{tabular} & 239,12 & 100,67 & 23,43 & 160,50 & 18,55 & 949,62 & 106,95 & 56,21 & 19,49 & 285,60 & 186,85 & 246,24 & 187,27 \\
\hline Pelophylax perezi & $\begin{array}{l}\text { 31TCG79 } \\
\end{array}$ & 93,00 & 84,65 & 82,50 & 33,99 & 5614,10 & 219,73 & $-19,88$ & 239,61 & 99,70 & 26,61 & 159,09 & 17,16 & 961,84 & 107,81 & 57,50 & 19,35 & 288,82 & $\begin{array}{l}191,07 \\
\end{array}$ & 250,67 & 192,28 \\
\hline Pelophylax perezi & 31TCG80 & 100,00 & 142,39 & 77,58 & 33,01 & 5522,76 & 268,04 & 36,43 & 231,61 & 182,38 & 74,93 & 215,34 & 74,93 & 629,71 & 73,18 & \begin{tabular}{|l|}
30,88 \\
\end{tabular} & 25,36 & 197,39 & 117,18 & 157,80 & 117,18 \\
\hline Pelophylax perezi & 31TCG81 & 100,00 & 127,46 & 79,08 & 33,01 & 5607,84 & 257,22 & 21,31 & 235,91 & 169,23 & 59,53 & 201,81 & 59,53 & 699,47 & 80,66 & 36,45 & 24,19 & 211,40 & 126,42 & 179,08 & 126,42 \\
\hline Pelophylax perezi & 31TCG82 & 100,00 & 125,96 & 80,09 & 33,02 & 5639,63 & 257,04 & 18,88 & 238,16 & 152,77 & 57,31 & 200,52 & 57,31 & 705,59 & 82,69 & 35,65 & 24,78 & 215,71 & 123,66 & 185,27 & 123,66 \\
\hline Pelophylax perezi & 31TCG83 & 101,00 & 126,54 & 81,20 & \begin{tabular}{|l|l|}
33,17 \\
\end{tabular} & 5680,40 & 258,87 & 18,34 & 240,54 & 143,76 & 57,05 & 201,30 & 57,05 & 704,03 & 83,77 & 34,09 & 25,99 & 219,07 & 119,07 & 189,24 & 119,07 \\
\hline Pelophylax perezi & 31TCG84 & 101,00 & 127,57 & 82,38 & 33,35 & 5708,55 & 260,98 & 18,27 & 242,71 & $\begin{array}{ll}144,95 \\
\end{array}$ & 57,26 & 202,28 & 57,26 & 702,92 & 84,28 & 32,92 & 27,02 & 222,55 & 115,79 & 193,19 & 115,79 \\
\hline Pelophylax perezi & 31TCG85 & 99,00 & 114,33 & 82,40 & 33,63 & 5699,13 & 248,77 & 6,58 & 242,19 & 130,87 & 44,84 & 189,38 & 44,84 & 773,50 & 92,16 & 37,98 & 25,73 & 243,95 & 131,94 & 212,51 & 131,94 \\
\hline Pelophylax perezi & 31TCG86 & 101,00 & 95,66 & 80,92 & 33,60 & 5627,15 & 229,94 & $-8,22$ & 238,16 & 110,43 & 29,12 & 170,56 & 28,44 & 882,62 & 101,85 & 48,92 & 21,74 & 269,03 & 164,82 & 231,88 & 164,88 \\
\hline Pelophylax perezi & 31TCG87 & 99,00 & 67,24 & 77,10 & 32,93 & 5503,48 & 199,44 & $-31,32$ & 230,76 & 78,97 & 13,91 & 141,54 & 3,51 & 1068,36 & 117,04 & 67,59 & 16,05 & 307,45 & 224,74 & 256,98 & 226,27 \\
\hline Pelophylax perezi & 31TCG90 & 101,00 & 136,36 & 75,89 & 32,62 & 5509,64 & 261,97 & 32,01 & 229,96 & \begin{tabular}{|l|l|}
171,63 \\
\end{tabular} & 69,87 & 209,50 & 69,87 & \begin{tabular}{|c|}
671,94 \\
\end{tabular} & 76,56 & 34,14 & 24,21 & 207,62 & 126,49 & 167,94 & 126,49 \\
\hline Pelophylax perezi & 31TCG91 & 100,00 & 140,15 & 77,09 & 32,88 & 5541,55 & 266,71 & $\begin{array}{ll}34,44 \\
34\end{array}$ & 232,27 & \begin{tabular}{|l|l|}
189,30 \\
\end{tabular} & 72,56 & 213,35 & 72,56 & \begin{tabular}{|l|l|}
643,38 \\
\end{tabular} & 74,75 & 33,67 & 25,04 & 200,76 & \begin{tabular}{|l|l|}
115,29 \\
\end{tabular} & 166,79 & 115,29 \\
\hline Pelophylax perezi & 31TCG92 & 100,00 & 140,33 & 78,33 & 32,96 & 5590,75 & 268,39 & 33,30 & 235,10 & 186,10 & 71,64 & 213,80 & 71,64 & 636,67 & 74,62 & 32,24 & 25,90 & 199,55 & 109,06 & 170,61 & 109,06 \\
\hline Pelophylax perezi & 31TCG93 & 101,00 & 136,70 & 79,54 & 32,99 & 5642,96 & 266,60 & 28,65 & 237,95 & 174,71 & 67,27 & 210,65 & 67,27 & 652,16 & 77,27 & 31,63 & 26,70 & 203,39 & 107,92 & 178,76 & 107,92 \\
\hline Pelophylax perezi & 31TCG94 & 100,00 & 127,57 & 80,26 & 33,00 & 5672,18 & 259,42 & 19,64 & 239,77 & 145,23 & 57,99 & 202,01 & 57,99 & 702,18 & 84,92 & 32,64 & 27,54 & 221,86 & 113,81 & 196,36 & 113,81 \\
\hline Pelophylax perezi & 31TCG95 & 101,00 & 111,81 & 80,22 & 33,02 & 5654,02 & 244,94 & 6,04 & 238,90 & 127,50 & 43,42 & 186,65 & 43,42 & 788,95 & 94,18 & 39,23 & 25,53 & 246,95 & 135,20 & 217,09 & 135,20 \\
\hline Pelophylax perezi & 31TCG96 & 101,00 & 83,33 & 77,80 & 32,93 & 5542,42 & 215,76 & $-16,57$ & 232,33 & 95,44 & 20,50 & 157,85 & 18,52 & 965,67 & 108,47 & 57,35 & 18,90 & 283,52 & 192,36 & 241,41 & 193,01 \\
\hline Pelophylax perezi & 31TCG97 & 100,00 & 71,85 & 76,80 & 32,78 & 5500,74 & 203,82 & $-26,53$ & 230,35 & 81,58 & 21,96 & 146,11 & 8,09 & 1042,29 & 114,65 & 64,51 & 16,80 & 300,67 & 216,33 & 253,16 & 218,34 \\
\hline Pelophylax perezi & 31TCG98 & 101,00 & 64,66 & 76,27 & 32,77 & 5478,46 & 196,19 & $-33,27$ & 229,46 & 73,71 & 26,64 & 138,66 & 1,43 & 1092,72 & 118,86 & 68,90 & 15,71 & 312,52 & 231,01 & 261,60 & 235,04 \\
\hline Pelophylax perezi & 31TCG99 & 99,00 & 73,05 & 78,05 & 33,1 & 5513,07 & 205,46 & $-26,95$ & 232,41 & 85,52 & 20,57 & 146,93 & 8,37 & 1043,01 & 114,88 & 64,81 & 16,92 & 303,95 & 215,59 & 557,31 & 218,58 \\
\hline Pelophylax perezi & 31TCHOO & 100,00 & 68,79 & 87,23 & 35, & 5555,01 & 204,79 & $-37,87$ & 242,66 & 84,29 & 9,62 & 142,24 & 1,25 & 1069,98 & 114,43 & 69,85 & 14,91 & 311,25 & 233,39 & 257,94 & 234,06 \\
\hline Pelophylax perezi & $31 \mathrm{TCH} 02$ & 95,00 & 16,76 & 72,03 & 31,69 & 5314,50 & 142,11 & $-81,48$ & 223,59 & 25,51 & 72,44 & 88,96 & $-44,56$ & 1402,13 & 146,60 & 93,5 & 12,24 & 394,75 & 310,47 & 310,92 & 335,91 \\
\hline Pelophylax perezi & 31TCH10 & 101,00 & 70,82 & 86,96 & 35,20 & 5577,10 & 206,95 & $-36,13$ & 243,08 & 86,42 & 10,36 & \begin{tabular}{|l|l|}
144,48 \\
\end{tabular} & 2,97 & 1077,72 & 114,90 & 70,09 & 15,04 & 313,38 & 233,40 & 262,96 & 234,27 \\
\hline Pelophylax perezi & 31TCH11 & 99,00 & 40,14 & 78,04 & 33,24 & 5413,46 & 169,87 & $-60,88$ & 230,75 & 51,68 & 42,97 & 112,88 & $-23,66$ & 1250,71 & 132,46 & 83,15 & 13,13 & 357,02 & 278,78 & 286,50 & 287,67 \\
\hline Pelophylax perezi & $31 \mathrm{TCH} 14$ & & & & & & & & & & & & & & & & & & & & \\
\hline Pelophylax perezi & $31 \mathrm{TCH} 21$ & 100,00 & 28,59 & 74,34 & 32,22 & 5380,76 & 156,52 & $-70,36$ & 226,89 & 38,52 & 49,77 & 101 & $-33,76$ & 1327,84 & 139,92 & 88,51 & 12,64 & 375,89 & 294,86 & 300,09 & 310,24 \\
\hline Pelophylax perezi & $31 \mathrm{TCH} 23$ & 101,00 & 39,35 & 77,48 & 33, & 5379,69 & 168,15 & $-61,19$ & 229,34 & 50,94 & 43,30 & 111,59 & $-24,16$ & 1278,98 & 134,37 & 86,22 & 12,74 & 363,34 & 286,52 & 294,29 & 297,12 \\
\hline Pelophylax perezi & 31TCH30 & 101,00 & 34,97 & 75,26 & 32,50 & 5415,06 & 164,19 & $-64,10$ & 228,29 & 45,33 & 41,12 & 108,31 & $-27,73$ & 1280,86 & 135,90 & 84,92 & 13,07 & 364,04 & 284,49 & 292,27 & 294,25 \\
\hline Pelophylax perezi & $31 \mathrm{TCH} 41$ & 100,00 & 63,26 & 81,99 & 34,13 & 5523,37 & 196,65 & $-40,04$ & 236,68 & 77,13 & 9,88 & 136,79 & $-2,89$ & 1124,23 & 120,96 & 73,64 & 14,88 & 327,29 & 242,00 & 272,27 & 244,91 \\
\hline Pelophylax perezi & $31 \mathrm{TCH} 42$ & 100,00 & 53,73 & 80,04 & 33,75 & 5467,77 & 185,45 & $-48,06$ & 233,50 & 66,64 & 18,61 & 126,77 & $-11,23$ & 1190,48 & 126,61 & 79,35 & 13,87 & 42,55 & 60,50 & 83,88 & 266,82 \\
\hline Pelophylax perezi & 31TCH52 & 99,00 & $\begin{array}{l}38,21 \\
38,21\end{array}$ & $\begin{array}{l}0,044 \\
75,38\end{array}$ & $\begin{array}{l}30, \\
32,\end{array}$ & 5400,44 & $\frac{10,45}{167,34}$ & $\begin{array}{l}-4,00,59 \\
-60,59\end{array}$ & \begin{tabular}{|l|}
227,93 \\
22,0
\end{tabular} & $\mid \begin{array}{l}\mid 40,949 \\
481\end{array}$ & $\begin{array}{l}\mid 0,01 \\
33,73\end{array}$ & 111 & - $-24,56$ & \begin{tabular}{|l|l|}
1280,87 \\
\end{tabular} & \begin{tabular}{|l|}
135,31 \\
1351
\end{tabular} & 85,82 & $\begin{array}{ll}12,01 \\
12,83\end{array}$ & 362,94 & \begin{tabular}{|l|}
284,53 \\
\end{tabular} & $\begin{array}{l}20,00 \\
296,30\end{array}$ & $\begin{array}{l}200,02,04 \\
295\end{array}$ \\
\hline Pelophylax perezi & $31 \mathrm{TCH} 80$ & 17,00 & 26,86 & 71,15 & 31,32 & 5368,95 & 154,94 & $-68,27$ & 223,21 & 34,06 & 68,62 & 100,29 & $-33,26$ & 1345,76 & 140,51 & 87,68 & 12,45 & 371,94 & 296,81 & 302,25 & 316,72 \\
\hline Pelophylax perezi & 31TDF06 & 37,00 & 157,68 & 70,70 & $|32.57|$ & 5176,48 & 272,55 & 58,09 & 214,45 & 168,68 & 224,93 & 226,84 & 95,61 & 632,00 & \begin{tabular}{|c|}
88,07 \\
\end{tabular} & 24,34 & 30,05 & 222,25 & 117,84 & 148,61 & 131,50 \\
\hline Pelophylax perezi & 31TDF07 & 100,00 & 148,43 & 71,25 & 32,08 & 5291,64 & 266,58 & 48,21 & 218,37 & 159,33 & 217,47 & 219,19 & 85,31 & 668,64 & 85,49 & 27,15 & 27,00 & 223,53 & 127,41 & 155,86 & 139,43 \\
\hline Pelophylax perezi & 31TDF08 & 101,00 & 149,24 & 72,06 & $32, \mathrm{C}$ & 5339,18 & 268,69 & 47,90 & 220,79 & 159,90 & 173,09 & $22 C$ & 85,04 & 650,99 & 81,38 & 28,46 & 26,38 & 215,60 & 128,65 & 156,33 & 131 \\
\hline Pelophylax perezi & $\begin{array}{l}\text { J1TRO09 } \\
\text { 31TDF }\end{array}$ & $\begin{array}{l}100,00 \\
100\end{array}$ & $\begin{array}{l}14,24 \\
157,57 \\
\end{array}$ & $\begin{array}{ll}73,07 \\
\end{array}$ & 32,23 & $\begin{array}{ll}53537,40 \\
533,48\end{array}$ & $\begin{array}{l}20,05 \\
276,76\end{array}$ & 54,45 & $\mid \begin{array}{l}\mid 222,32 \\
222,\end{array}$ & \begin{tabular}{|l|l|}
168,05 \\
16,0
\end{tabular} & $\begin{array}{l}3,54 \\
93,54 \\
\end{array}$ & 228,09 & $\begin{array}{l}50,34 \\
92,38 \\
\end{array}$ & \begin{tabular}{|l|l|}
597,40 \\
\end{tabular} & $\begin{array}{l}1,00 \\
76,89 \\
\end{array}$ & $\begin{array}{l}20,40 \\
27,83\end{array}$ & $\begin{array}{l}27,80 \\
27,82\end{array}$ & 201,00 & \begin{tabular}{|l|}
114,380 \\
114
\end{tabular} & 150,33 & $\begin{array}{l}13,10 \\
114,39\end{array}$ \\
\hline Pelophylax perezi & 31TDF16 & & & & & & & & & & & & & & & & & & & & \\
\hline Pelophylax perezi & 31TDF17 & 101,00 & 160,92 & 70,50 & 32,28 & 5174,62 & 276,34 & 61,01 & 15,33 & 171,39 & 221,88 & 229,63 & 98,42 & 629,25 & 90,08 & 24,99 & 31,01 & 224,52 & 120,14 & 150,01 & 129,05 \\
\hline Pelophylax perezi & 31TDF18 & 99,00 & 160,91 & 71,10 & 32,0 & 5239,75 & 277,92 & 59,79 & 218,13 & 171,2 & 130,82 & 230, & 97, & 609,35 & 84,18 & 26,58 & & 213,79 & 118,71 & 150,19 & 120,98 \\
\hline Pelophylax perezi & 31TDF19 & 101,00 & 158,29 & 71,93 & 31,99 & 5322,04 & 277,37 & 55,97 & 221,40 & 169,71 & 96,54 & 228,56 & 93,61 & 602,55 & 78,29 & 29,03 & 27,86 & 204,69 & 115,31 & 153,16 & 115,54 \\
\hline
\end{tabular}




\begin{tabular}{|c|c|c|c|c|c|c|c|c|c|c|c|c|c|c|c|c|c|c|c|c|c|}
\hline TAXON & UTM & $\mathrm{km} 2$ & BIO1 & BIO2 & $\mathrm{BIO3}$ & B104 & BIO5 & B106 & B107 & B108 & B109 & BIO10 & BIO11 & B1012 & 81013 & BIO14 & BIO15 & B1016 & B1017 & B1018 & B1019 \\
\hline Pelophylax perezi & 31TDF26 & & & & & & & & & & & & & & & & & & & & \\
\hline Pelophylax perezi & 31TDF27 & 85,00 & 166,22 & 70,16 & 32,17 & 5089,19 & 280,30 & 66,64 & 213,66 & 176,56 & 218,22 & 233,41 & 104,49 & 618,62 & 94,89 & 23,92 & 33,86 & 229,10 & 117,70 & 148,27 & 125,51 \\
\hline Pelophylax perezi & 31TDF28 & 101,00 & 158,99 & 70,16 & 31,69 & 5227,88 & 276,22 & 58,85 & 217,37 & 169,24 & 158,51 & 228,43 & 95,97 & 626,99 & 86,51 & 27,97 & 28,92 & 218,95 & $\begin{array}{l}124,19 \\
\end{array}$ & $\begin{array}{ll}154,23 \\
\end{array}$ & 126,40 \\
\hline Pelophylax perezi & \begin{tabular}{|l|l|}
31 TDF29 \\
\end{tabular} & 101,00 & 159,89 & 70,96 & 31,86 & 5280,03 & 278,34 & 58,46 & 219,88 & 175,16 & 99,82 & 229,64 & 95,80 & \begin{tabular}{|l|l|}
601,07 \\
\end{tabular} & 80,09 & 29,35 & 28,43 & 206,58 & 115,70 & $\begin{array}{l}153,82 \\
\end{array}$ & 116,03 \\
\hline Pelophylax perezi & 31TDF37 & & & & & & & & & & & & & & & & & & & & \\
\hline Pelophylax perezi & 31TDF38 & 52,00 & 163,90 & 70,18 & 32,17 & 5079,68 & 278,78 & 64,25 & 214,53 & 174,00 & 199,54 & 230,92 & 102,04 & $\begin{array}{l}607,25 \\
\end{array}$ & 90,54 & 25,82 & 32,14 & 220,47 & 117,99 & $\begin{array}{ll}149,53 \\
\end{array}$ & 122,51 \\
\hline Pelophylax perezi & 31TDF39 & 99,00 & 159,05 & 70,45 & 31,72 & 5221,53 & 276,62 & 58,24 & 218,38 & 169,22 & 122,48 & 227,97 & 95,63 & 625,82 & 85,89 & 29,41 & 28,45 & 215,99 & 124,66 & 157,10 & 125,50 \\
\hline Pelophylax perezi & 31TDF49 & 74,00 & 155,34 & 69,84 & 31,34 & 5248,01 & 273,44 & 54,54 & 218,91 & $\begin{array}{l}166,02 \\
\end{array}$ & 191,46 & 224,66 & 91,70 & $\begin{array}{ll}669,03 \\
\end{array}$ & 91,23 & 31,05 & 27,32 & 226,69 & 133,39 & 164,11 & 139,00 \\
\hline Pelophylax perezi & 31TDF59 & 14,00 & 161,65 & $\begin{array}{ll}69,94 \\
\end{array}$ & 31,41 & 5210,88 & 278,76 & $\begin{array}{ll}60,24 \\
\end{array}$ & 218,53 & $\begin{array}{l}171,76 \\
\end{array}$ & 216,00 & 230,12 & 98,29 & $\begin{array}{l}649,65 \\
\end{array}$ & 96,41 & 27,29 & 30,94 & 228,76 & $\begin{array}{l}121,53 \\
\end{array}$ & \begin{tabular}{|l|l|}
155,41 \\
\end{tabular} & 138,59 \\
\hline Pelophylax perezi & 31TDG00 & 100,00 & 147,12 & 74,17 & 32,10 & 5444,61 & 269,96 & 43,25 & 226,71 & 187,89 & 81,00 & 219,13 & 81,00 & 632,84 & 75,08 & 32,57 & 25,41 & 202,78 & 118,11 & 161,49 & 118,11 \\
\hline Pelophylax perezi & 31TDG01 & 101,00 & 148,37 & 75,39 & 32,31 & 5488,51 & 272,64 & 43,17 & 229,47 & 196,91 & 81,18 & 220,65 & 81,18 & \begin{tabular}{ll|}
613,92 \\
\end{tabular} & 72,77 & 32,55 & 25,69 & $\begin{array}{l}197,42 \\
\end{array}$ & 109,00 & 162,21 & 109,00 \\
\hline Pelophylax perezi & 31TDG02 & 101,00 & 146,68 & 76,64 & 32,45 & 5543,49 & 272,71 & 40,25 & 232,46 & 195,43 & 78,39 & 219,41 & 78,39 & 612,12 & 72,23 & 31,38 & 26,17 & 196,17 & 103,62 & 166,15 & 103,62 \\
\hline Pelophylax perezi & 31TDG03 & 100,00 & 138,99 & 77,70 & 32,62 & 5595,96 & 267,33 & 32,06 & 235,27 & 185,64 & 70,21 & 212,47 & 70,21 & \begin{tabular}{|l|l|}
646,98 \\
\end{tabular} & 76,68 & 31,46 & 26,92 & 203,51 & 105,68 & 179,85 & 105,68 \\
\hline Pelophylax perezi & 31TDG04 & 100,00 & 133,54 & 78,74 & 32,86 & 5641,89 & 263,69 & 26,12 & 237,57 & 158,12 & 64,30 & 207,59 & 64,30 & $\begin{array}{l}674,76 \\
\end{array}$ & 81,50 & \begin{tabular}{|l|l|}
31,44 \\
\end{tabular} & 27,99 & 212,37 & 107,54 & $\begin{array}{ll}190,92 \\
\end{array}$ & 107,54 \\
\hline Pelophylax perezi & 31TDG05 & 100,00 & 127,55 & 79,61 & 32,97 & 5659,60 & 259,13 & 19,95 & 239,18 & 144,45 & 58,10 & 201,78 & 58,10 & \begin{tabular}{|l|l|}
706,09 \\
\end{tabular} & 86,06 & 32,36 & 28,71 & 225,31 & 111,86 & 203,49 & 111,86 \\
\hline Pelophylax perezi & 31TDG06 & 100,00 & 106,21 & 79,00 & 32,99 & 5609,13 & 238,65 & 2,26 & 236,39 & 121,23 & 39,69 & $\begin{array}{l}180,73 \\
\end{array}$ & 38,92 & 829,94 & 97,73 & 43,36 & 24,43 & $\begin{array}{ll}255,93 \\
\end{array}$ & $\begin{array}{ll}147,61 \\
\end{array}$ & 225,40 & 147,75 \\
\hline Pelophylax perezi & 31TDG07 & 101,00 & 97,75 & 79,20 & 33,01 & 5585,81 & 230,65 & $-4,96$ & 235,61 & 112,18 & 32,50 & 172,05 & 31,12 & 884,39 & $\begin{array}{l}102,25 \\
\end{array}$ & 48,81 & 21,83 & 268,99 & 165,19 & 234,06 & 165,33 \\
\hline Pelophylax perezi & 31TDG09 & 101,00 & 88,07 & 79,57 & 33,42 & 5552,21 & 221,40 & $\mid-13,35$ & 234,75 & 102,11 & 28,74 & $\mid 162,03$ & 22,14 & 952,05 & \begin{tabular}{|l|l|}
107,28 \\
\end{tabular} & 56,50 & 18,73 & 284,35 & 188,33 & 243,10 & 189,54 \\
\hline Pelophylax perezi & 31TDG10 & 100,00 & 143,65 & 72,82 & 31,99 & 5436,23 & 266,45 & 41,19 & 225,27 & 191,40 & 78,13 & 215,81 & 78,13 & 661,58 & 76,92 & 35,13 & 24,44 & 210,32 & 124,08 & 170,04 & 124,08 \\
\hline Pelophylax perezi & 31TDG11 & 100,00 & 130,92 & 73,96 & 32,00 & 5506,36 & 256,72 & 28,36 & 228,36 & 1779,89 & 64,96 & 204,11 & 64,96 & 711,82 & 81,20 & 37,69 & 23,64 & 220,30 & 129,34 & 187,13 & 129,34 \\
\hline Pelophylax perezi & 31TDG12 & 101,00 & 138,82 & 74,97 & 31,99 & 5534,36 & 264,97 & 34,06 & 230,90 & 187,60 & 71,46 & 211,89 & 71,46 & 664,54 & 77,32 & 33,73 & 25,52 & 209,84 & 113,45 & $\begin{array}{ll}180,96 \\
\end{array}$ & 113,45 \\
\hline Pelophylax perezi & 31TDG13 & 100,00 & 137,51 & 76,02 & 32,01 & 5576,41 & 265,12 & 31,67 & 233,45 & 186,14 & 69,31 & 210,99 & 69,31 & 668,60 & 79,16 & 32,45 & 26,82 & 210,84 & 109,50 & $\begin{array}{ll}187,69 \\
\end{array}$ & 109,50 \\
\hline Pelophylax perezi & 31TDG14 & 101,00 & 129,63 & 76,99 & 32,13 & 5603,61 & 258,87 & 23,76 & 235,10 & \begin{tabular}{|l|l|}
155,03 \\
\end{tabular} & $\mid 61,35$ & 203,38 & 61,35 & 702,44 & 85,59 & 32,35 & 28,71 & 221,47 & \begin{tabular}{|l|l|}
111,01 \\
\end{tabular} & 202,88 & 111,01 \\
\hline Pelophylax perezi & 31TDG15 & 101,00 & 123,04 & 77,90 & 32,41 & 5614,28 & 253,69 & 17,34 & 236,35 & 138,98 & 54,84 & 197,03 & 54,84 & 734,72 & 89,87 & 33,72 & 28,82 & 233,69 & 116,68 & 213,33 & 116,68 \\
\hline Pelophylax perezi & 31TDG16 & 100,00 & 109,61 & 78,14 & 32,94 & 5594,27 & 241,39 & 5,90 & 235,49 & 124,73 & 42,68 & 183,93 & 42,52 & 816,30 & 97,07 & 41,02 & 25,05 & 253,79 & 141,82 & 225,21 & 141,82 \\
\hline Pelophylax perezi & 31TDG17 & 100,00 & 92,30 & 77,43 & 32,98 & 5530,63 & 224,15 & $-7,93$ & 232,07 & 105,48 & 30,03 & 166,30 & 27,32 & \begin{tabular}{|l|l|}
927,47 \\
\end{tabular} & 105,12 & 53,59 & 19,78 & 274,98 & 180,58 & 237,38 & 181,09 \\
\hline Pelophylax perezi & 31TDG18 & 98,00 & 62,33 & 74,21 & 32,38 & 5421,81 & 192,68 & $-33,11$ & 225,79 & 60,52 & 21,32 & 135,92 & 0,71 & 1113,96 & $\begin{array}{l}119,15 \\
\end{array}$ & 70,54 & 14,95 & 312,34 & 240,85 & 260,57 & 245,94 \\
\hline Pelophylax perezi & 31TDG19 & 44,00 & 74,09 & 76,62 & 32,84 & 5468,72 & 205,63 & $-23,84$ & 229,47 & 82,36 & 21,98 & \begin{tabular}{ll|}
147,66 \\
\end{tabular} & 10,64 & $\begin{array}{l}1044,01 \\
\end{array}$ & 113,79 & 65,48 & 16,03 & 299,40 & 218,83 & 252,53 & 222,53 \\
\hline Pelophylax perezi & 31TDG20 & 100,00 & 152,94 & 71,68 & 31,71 & 5379,99 & 273,79 & 50,50 & 223,29 & 200,40 & 87,61 & 223,95 & 87,61 & $\begin{array}{l}634,60 \\
\end{array}$ & 77,02 & 33,88 & 25,47 & 208,06 & 1119,64 & \begin{tabular}{|l|l|}
165,13 \\
\end{tabular} & 119,64 \\
\hline Pelophylax perezi & 31TDG21 & 101,00 & 134,01 & 72,64 & 31,69 & 5474,85 & 258,67 & 31,96 & 226,71 & 182,80 & 68,49 & 206,92 & 68,49 & 718,32 & 81,31 & 38,66 & 23,28 & 224,13 & 132,51 & \begin{tabular}{|l|l|}
188,93 \\
\end{tabular} & 132,51 \\
\hline Pelophylax perezi & 31TDG22 & 99,00 & 125,49 & 73,69 & 31,92 & 5511,67 & 252,13 & 23,39 & 228,73 & $\begin{array}{l}174,44 \\
\end{array}$ & 59,73 & \begin{tabular}{|l|l|}
198,87 \\
\end{tabular} & 59,73 & \begin{tabular}{ll|l}
746,68 \\
\end{tabular} & 87,10 & 38,10 & 23,96 & 229,79 & $\begin{array}{l}133,40 \\
\end{array}$ & 201,19 & 133,40 \\
\hline Pelophylax perezi & 31TDG23 & 101,00 & 120,63 & 74,58 & 32,00 & 5523,95 & 248,55 & 18,30 & 230,24 & 167,35 & 54,73 & 194,10 & 54,73 & 769,68 & 90,82 & 38,58 & 24,64 & 234,97 & 134,90 & 209,82 & 134,90 \\
\hline Pelophylax perezi & 31TDG24 & 100,00 & 126,73 & 75,58 & 32,00 & 5574,07 & 255,26 & 22,19 & 233,07 & 149,77 & 59,32 & 200,34 & 59,32 & 739,43 & 89,01 & 34,71 & 27,42 & 230,37 & 121,26 & 210,88 & 121,26 \\
\hline Pelophylax perezi & 31TDG25 & 100,00 & 120,53 & 76,48 & 32,00 & 5584,37 & 250,26 & 15,99 & 234,26 & 135,76 & 53,10 & 194,30 & 53,10 & $\begin{array}{l}770,56 \\
\end{array}$ & $92, \varepsilon$ & 36,19 & 27,23 & 241,75 & $\begin{array}{l}127,33 \\
\end{array}$ & 219,72 & 127,33 \\
\hline Pelophylax perezi & 31TDG26 & 101,00 & 110,29 & 77,01 & 32,33 & 5569,27 & 241,08 & 7,03 & 234,05 & 124,80 & 43,82 & 184,24 & \begin{tabular}{|l|l|}
43,67 \\
\end{tabular} & 832,47 & 97,84 & 42,19 & 24,08 & 256,10 & 147,86 & 225,80 & 147,86 \\
\hline Pelophylax perezi & 31TDG27 & 101,00 & 99,41 & 77,17 & 32,82 & $\begin{array}{l}5332,74 \\
\end{array}$ & 230,85 & $-1,67$ & 232,51 & 113,10 & 36,06 & 173,24 & 34,05 & $\begin{array}{l}897,92 \\
\end{array}$ & 102,41 & $\begin{array}{ll}49,96 \\
\end{array}$ & 20,58 & 268,64 & $\begin{array}{ll}171,64 \\
\end{array}$ & $\begin{array}{ll}232,58 \\
\end{array}$ & 171,86 \\
\hline Pelophylax perezi & 31TDG28 & 100,00 & 71,10 & 74,64 & 32,52 & 5429,70 & 201,55 & $-24,87$ & 226,41 & 71,42 & 28,10 & 144,59 & 9,08 & 1066,16 & \begin{tabular}{|l|l|}
114,64 \\
\end{tabular} & 66,61 & 15,65 & 301,19 & 226,87 & 252,25 & 231,73 \\
\hline Pelophylax perezi & 31TDG29 & 24,00 & 35,25 & 70,26 & 31,27 & 5344,72 & 163,50 & $-57,55$ & 221,05 & 15,77 & 73,62 & 108,52 & $-23,64$ & 1292,58 & 133,03 & 81,08 & 13,01 & 360,84 & 282,65 & 286,08 & 305,85 \\
\hline Pelophylax perezi & 31TDG30 & 100,00 & 157,83 & 71,01 & 31,53 & 5300,33 & 277,10 & 55,68 & 221,42 & 197,57 & 96,21 & 227,47 & 93,06 & 632,38 & 82,25 & 31,86 & 26,59 & 212,42 & 124,07 & 60,28 & 124,09 \\
\hline Pelophylax perezi & 31TDG31 & 101,00 & 144,71 & 71,51 & 31,09 & 5430,91 & 267,32 & 42,09 & 225,23 & 192,77 & 78,92 & 216,44 & 78,92 & \begin{tabular}{|l|l|}
701,68 \\
\end{tabular} & 81,71 & 38,45 & 23,28 & 223,49 & 133,61 & 182,06 & 133,61 \\
\hline Pelophylax perezi & 31TDG32 & 101,00 & 126,55 & 72,56 & 31,49 & 5485,82 & 252,29 & 24,87 & 227,42 & 175,21 & 61,18 & $\begin{array}{l}199,62 \\
\end{array}$ & 61,18 & $\begin{array}{l}777,76 \\
\end{array}$ & 87,68 & 41,15 & 22,50 & 238,41 & \begin{tabular}{|l|l|}
144,73 \\
\end{tabular} & \begin{tabular}{|l|l|}
204,14 \\
\end{tabular} & 144,73 \\
\hline Pelophylax perezi & 31TDG33 & 100,00 & \begin{tabular}{ll|}
127,01 \\
\end{tabular} & 73,42 & 31,53 & 5519,44 & 253,66 & 24,32 & 229,34 & 175,75 & \begin{tabular}{ll|}
60,87 \\
\end{tabular} & 200,29 & 60,87 & $\begin{array}{l}774,75 \\
\end{array}$ & 89,25 & $\begin{array}{ll}39,24 \\
\end{array}$ & 23,82 & 237,88 & \begin{tabular}{ll|}
138,84 \\
\end{tabular} & $\begin{array}{l}209,39 \\
\end{array}$ & 138,84 \\
\hline Pelophylax perezi & 31TDG34 & 101,00 & 129,94 & 74,44 & 31,72 & 5552,03 & 257,43 & 25,65 & 231,78 & 165,59 & 62,72 & 203,31 & 62,72 & 768,28 & 89,48 & 36,97 & 25,35 & 236,62 & 132,24 & 212,86 & 132,24 \\
\hline Pelophylax perezi & 31TDG35 & 100,00 & 124,92 & 75,47 & 31,97 & 5577,89 & 253,79 & 20,32 & 233,47 & 140,55 & 57,43 & 198,57 & 57,43 & 794,52 & 92,92 & 37,77 & 25,36 & 245,58 & $\begin{array}{lll}137,07 \\
\end{array}$ & 188,86 & 137,07 \\
\hline Pelophylax perezi & 31TDG36 & 100,00 & 114,79 & 76,19 & 32, & 5563,09 & 244,76 & 11,45 & 23 & 130,09 & 48,35 & 188,44 & 48,04 & 837,99 & 96,9 & 42,20 & 23,51 & 256,19 & 151,28 & 225,56 & 151,35 \\
\hline Pelophylax perezi & 31TDG37 & 101,00 & 107,25 & 76,76 & 32,33 & 5546,01 & 238,00 & 4,78 & 233,22 & 121,53 & 42,10 & 180,97 & 41,12 & 876,42 & 99,70 & 46,81 & 21,35 & 263,89 & 165,67 & 227,95 & 165,95 \\
\hline Pelophylax perezi & 31TDG38 & 101,00 & 73,34 & 74,25 & 32,47 & 5414,20 & 203,41 & $-22,12$ & 225,52 & 68,72 & 37,31 & $\begin{array}{l}146,73 \\
\end{array}$ & \begin{tabular}{ll|}
11,69 \\
\end{tabular} & 1057,84 & $\begin{array}{l}112,89 \\
\end{array}$ & $\begin{array}{ll}64,87 \\
\end{array}$ & 15,93 & $\begin{array}{l}300,44 \\
\end{array}$ & 226,13 & 248,49 & 231,54 \\
\hline Pelophylax perezi & 31TDG39 & 75,00 & 30,22 & 69,10 & 30,97 & 5326,44 & 157,92 & $-61,66$ & 219,58 & 7,90 & 87,34 & 103,49 & $-27,81$ & 1327,69 & 135,14 & 82,08 & 13,05 & 73,45 & 287,85 & 89,66 & 317,77 \\
\hline Pelophylax perezi & 31TDG40 & 101,00 & 153,92 & 70,08 & 31,02 & 5322,70 & 273,35 & 51,94 & 221,41 & 184,27 & 153,09 & 224,08 & 89,16 & 686,11 & 89,72 & 33,67 & 25,24 & 226,52 & 139,44 & 169,65 & 141,06 \\
\hline Pelophylax perezi & 31TDG41 & 100,00 & 143,57 & 70,61 & 31,01 & 5418,05 & 265,73 & 41,25 & 224,47 & 191,17 & 83,61 & 215,19 & 78,09 & 744,65 & 88,99 & 40,05 & 22,43 & 234,86 & 148,77 & 186,25 & 148,81 \\
\hline Pelophylax perezi & 31TDG42 & 100,00 & 113,04 & 71,73 & 31,59 & 5434,21 & 238,94 & 14,74 & 224,20 & 152,19 & 57,00 & $\begin{array}{l}186,19 \\
\end{array}$ & 49,79 & $\begin{array}{l}869,95 \\
\end{array}$ & 97,70 & 48,67 & 20,16 & 260,21 & 174,95 & 213,02 & 175,78 \\
\hline Pelophylax perezi & 31TDG43 & 101,00 & 120,79 & 72,53 & 31,36 & 5480,88 & 247,16 & 19,81 & 227,36 & 168,24 & 56,24 & 193,96 & 55,80 & 841,38 & 93,61 & 44,30 & 21,43 & 251,91 & 161,19 & 215,44 & 161,25 \\
\hline Pelophylax perezi & 31TDG44 & 101,00 & 130,89 & 73,43 & 31, & 5539,31 & 257,59 & 26,91 & 230,68 & 168,05 & 63, & 204 & 63 & 819 & 91, & 40,15 & 22 & 246,08 & \begin{tabular}{|l|l|}
151,03 \\
\end{tabular} & 214,89 & 151,03 \\
\hline Pelophylax perezi & $31 \mathrm{TD}$ & 100,00 & 123,43 & 74,48 & 31, & 5541,19 & 251 & $\begin{array}{ll}19,82 \\
\end{array}$ & 23 & 138,59 & 56,68 & $\begin{array}{l}196,77 \\
\end{array}$ & 56,65 & 844 & 94,5 & 41,38 & 22,77 & 254,73 & $\begin{array}{l}155,64 \\
\end{array}$ & 222,07 & 155,64 \\
\hline Pelophylax perezi & 31TDG46 & 101,00 & 98,81 & 74,53 & 32,16 & 5461,29 & 227,98 & 0,29 & 227,69 & 123,23 & 38,16 & 172,11 & 35,25 & $\begin{array}{l}935,05 \\
\end{array}$ & 102,41 & 54,20 & 18,70 & 269,63 & $\begin{array}{l}188,71 \\
\end{array}$ & 229,59 & 189,68 \\
\hline Pelophylax perezi & 31TDG47 & 100,00 & 107,07 & 76,01 & 32,18 & 5516,90 & 237,20 & 5,42 & 231,79 & 122,12 & 43,70 & $\begin{array}{l}180,49 \\
\end{array}$ & 41,55 & $\begin{array}{l}899,99 \\
\end{array}$ & 99,75 & \begin{tabular}{|l|l}
49,27 \\
\end{tabular} & 19,80 & 265,71 & $\begin{array}{l}176,79 \\
\end{array}$ & \begin{tabular}{|l|l|}
226,44 \\
\end{tabular} & 177,02 \\
\hline Pelophylax perezi & 31TDG48 & 99,00 & 90,22 & 75,53 & 32,75 & 5453,60 & 220,57 & $-7,82$ & 228,39 & 99,62 & 32,26 & 163,59 & 26,84 & $\begin{array}{l}975,65 \\
\end{array}$ & 105,37 & 59,03 & 17,02 & 278,09 & 203,11 & 234,79 & 205,54 \\
\hline Pelophylax pet & 31TDG49 & 61,00 & 55,44 & 71, & & 47,45 & 184 & $\mid-37,63$ & 222, & 36,75 & 62 & 12 & -4 & 1168 & 120,65 & 72,21 & & 32 & 255,93 & 262,42 & 276 \\
\hline Pelophylax perezi & 31TDG50 & 100,00 & 149,07 & 69,41 & 30,93 & 5340,44 & 268,83 & 47,51 & 221,32 & 172,34 & 184,93 & 219,62 & 84,45 & \begin{tabular}{|l|l|}
739,98 \\
\end{tabular} & 97,36 & 35,59 & 24,90 & 240,67 & 149,22 & \begin{tabular}{|l|l|}
177,14 \\
\end{tabular} & 156,74 \\
\hline Pelophylax perezi & 31TDG51 & 100,00 & 150,52 & 69,89 & 30,82 & 5412,19 & 271,39 & 47,10 & 224,29 & 175,65 & 190,74 & 221,70 & 84,58 & 751,99 & 97,13 & 37,05 & 23,69 & 241,22 & 152,85 & $\begin{array}{l}178,44 \\
\end{array}$ & 159,64 \\
\hline
\end{tabular}




\begin{tabular}{|c|c|c|c|c|c|c|c|c|c|c|c|c|c|c|c|c|c|c|c|c|c|}
\hline TAXON & UTM & $\mathrm{km2}$ & BIO1 & B102 & $\mathrm{BIO3}$ & BIO4 & B105 & B106 & B107 & B108 & B109 & BIO10 & BIO11 & BIO12 & BIO13 & BIO14 & BIO15 & BIO16 & BIO17 & BIO18 & BlO19 \\
\hline Pelophylax perezi & 31TDG52 & 100,00 & 121,05 & 70,84 & 31,14 & 5416,66 & 245,56 & 21,77 & 223,79 & 158,67 & 73,56 & 193,60 & 57,38 & 871,94 & 101,31 & 48,10 & 20,27 & 261,90 & 179,63 & 207,94 & 181,17 \\
\hline Pelophylax perezi & 31TDG53 & 101,00 & 120,29 & 71,75 & 31,31 & 5454,72 & 245,94 & 19,90 & 226,03 & 168,79 & 56,34 & 193,21 & 55,81 & 879,46 & 97,58 & 47,86 & 20,11 & 259,23 & \begin{tabular}{|l|l|}
176,63 \\
\end{tabular} & 214,88 & 176,63 \\
\hline Pelophylax perezi & 31TDG54 & 100,00 & 125,16 & 72,61 & 31,28 & 5493,16 & 251,46 & 22,80 & 228,67 & \begin{tabular}{l|l|l|}
159,72 \\
\end{tabular} & 59,79 & \begin{tabular}{|l|l|}
198,10 \\
\end{tabular} & 59,49 & 882,49 & 96,36 & 45,17 & 20,85 & 259,02 & \begin{tabular}{ll|}
173,86 \\
\end{tabular} & 217,20 & 173,90 \\
\hline Pelophylax perezi & 31TDG55 & 101,00 & 112,93 & 73,61 & 31,78 & 5470,40 & 240,58 & 12,28 & 228,29 & \begin{tabular}{|l|l|}
146,27 \\
\end{tabular} & 49,85 & \begin{tabular}{|l|l|}
185,97 \\
\end{tabular} & 48,41 & \begin{tabular}{l|l|}
911,09 \\
\end{tabular} & 98,75 & 49,15 & 19,85 & 264,80 & $\begin{array}{l}182,35 \\
\end{array}$ & 222,98 & 182,41 \\
\hline Pelophylax perezi & 31TDG56 & 101,00 & 126,48 & 74,94 & 31,73 & 5552,87 & $254,68 \mid$ & 21,49 & $233,19 \mid$ & 143,13 & 59,32 & $199,65[$ & 59,17 & 878,35 | & 94,59 & 43,36 & 21,32 & 261,01 & $171,38 \mid$ & 218,56 & 171,39 \\
\hline Pelophylax perezi & 31TDG57 & 100,00 & 129,29 & 76,38 & 31,96 & 5582,05 & 258,48 & 22,78 & 235,70 & 147,30 & \begin{tabular}{|l|l|}
61,07 \\
\end{tabular} & 202,62 & \begin{tabular}{|l|l|}
61,07 \\
\end{tabular} & $\begin{array}{l}845,98 \\
\end{array}$ & 92,13 & 42,93 & 20,88 & 250,54 & 166,34 & 210,12 & 166,34 \\
\hline Pelophylax perezi & 31TDG58 & 94,00 & 108,42 & 76,50 & 32,40 & 5508,44 & 238,70 & 6,27 & 232,44 & 122,51 & 45,63 & 181,73 & 42,94 & \begin{tabular}{l|l|}
909,93 \\
\end{tabular} & 97,99 & 51,44 & 18,50 & 263,54 & 186,08 & 220,40 & 187,06 \\
\hline Pelophylax perezi & 31TDG59 & 18,00 & 90,81 & 75,95 & \begin{tabular}{l|l|}
32,85 \\
\end{tabular} & 5439,71 & 221,28 & $-7,67$ & 228,96 & $\begin{array}{l}94,19 \\
\end{array}$ & 36,19 & \begin{tabular}{l|l|}
163,85 \\
\end{tabular} & 27,56 & \begin{tabular}{l|l}
980,58 \\
\end{tabular} & 103,82 & 59,57 & 16,30 & \begin{tabular}{|l|l}
277,15 \\
\end{tabular} & \begin{tabular}{|l|}
209,02 \\
\end{tabular} & 230,66 & 212,69 \\
\hline Pelophylax perezi & 31TDG60 & 61,00 & 154,39 & 69,16 & \begin{tabular}{l|l|}
30,85 \\
\end{tabular} & 5341,51 & 273,27 & 51,57 & 221,70 & \begin{tabular}{ll|l}
165,06 \\
\end{tabular} & \begin{tabular}{|l|l|}
219,98 \\
\end{tabular} & 224,61 & 89,12 & 727,44 & 103,91 & 31,62 & 28,39 & 244,78 & \begin{tabular}{|l|l|}
137,27 \\
\end{tabular} & $\begin{array}{l}168,24 \\
\end{array}$ & 159,08 \\
\hline Pelophylax perezi & 31TDG61 & 101,00 & 146,85 & 69,27 & 30,42 & 5401,26 & 267,46 & 44,08 & 223,38 & 169,79 & 194,63 & 218,05 & 81,26 & 781,72 & 103,63 & 37,41 & 24,57 & 249,46 & 157,06 & 180,94 & 168,79 \\
\hline Pelophylax perezi & 31TDG62 & 101,00 & 149,18 & 69,89 & 30,11 & 5469,89 & 270,71 & \begin{tabular}{|l|l|}
44,27 \\
\end{tabular} & 226,44 & 175,51 & \begin{tabular}{ll|}
190,11 \\
\end{tabular} & 220,84 & \begin{tabular}{l|l}
82,05 \\
\end{tabular} & 782,31 & \begin{tabular}{|l|l|}
103,47 \\
\end{tabular} & 38,13 & 24,38 & 247,74 & \begin{tabular}{|l|l|}
157,19 \\
\end{tabular} & \begin{tabular}{ll|}
178,56 \\
\end{tabular} & 168,20 \\
\hline Pelophylax perezi & 31TDG63 & 100,00 & 134,37 & 70,82 & 30,71 & 5472,86 & 258,25 & 31,14 & 227,11 & \begin{tabular}{|l|l|}
182,29 \\
\end{tabular} & 82,49 & 206,82 & \begin{tabular}{ll|}
68,42 \\
\end{tabular} & 864,54 & 102,08 & 45,97 & 21,14 & 257,04 & \begin{tabular}{|l|l|}
178,28 \\
\end{tabular} & 202,84 & 178,94 \\
\hline Pelophylax perezi & 31TDG64 & 100,00 & 133,71 & 71,88 & 30,84 & 5515,80 & 258,82 & 29,58 & 229,23 & \begin{tabular}{ll|}
177,28 \\
\end{tabular} & 81,89 & 206,53 & \begin{tabular}{ll|}
66,99 \\
\end{tabular} & \begin{tabular}{l|l}
870,25 \\
\end{tabular} & 101,28 & 45,16 & 21,27 & 255,94 & \begin{tabular}{|l|l|}
178,43 \\
\end{tabular} & 203,14 & 178,73 \\
\hline Pelophylax perezi & $\begin{array}{l}\text { 31TDG65 } \\
\end{array}$ & 100,00 & 134,61 & 73,08 & 31,10 & 5543,73 & 260,82 & 29,16 & 231,66 & \begin{tabular}{ll|}
171,21 \\
\end{tabular} & \begin{tabular}{l|l|l}
67,05 \\
\end{tabular} & \begin{tabular}{|l|l|}
207,58 \\
\end{tabular} & \begin{tabular}{l|l|l}
67,05 \\
\end{tabular} & 869,24 & 99,53 & 44,63 & 21,17 & 253,62 & \begin{tabular}{|l|l|}
177,00 \\
\end{tabular} & 205,04 & 177,00 \\
\hline Pelophylax perezi & 31TDG66 & 101,00 & 128,84 & 74,49 & 31,64 & 5531,15 & 256,26 & 23,76 & 232,50 & \begin{tabular}{|l|l|}
153,06 \\
\end{tabular} & $\begin{array}{ll}61,83 \\
\end{array}$ & 201,77 & 61,83 & 877,56 & $\begin{array}{l}97,45 \\
\end{array}$ & 45,15 & 20,8 & 255,27 & \begin{tabular}{ll|}
177,86 \\
\end{tabular} & 209,00 & 177,86 \\
\hline Pelophylax perezi & 31TDG67 & 100,00 & 137,40 & 76,11 & 31,80 & 5580,44 & 265,66 & 29,24 & 236,41 & 175,68 & 68,76 & \begin{tabular}{l|l|}
210,45 \\
\end{tabular} & 68,73 & 808,42 & 94,24 & 42,97 & 21,05 & 236,38 & 165,84 & 188,53 & 165,85 \\
\hline Pelophylax perezi & 31TDG68 & 86,00 & 114,42 & 76,43 & 32,34 & 5500,76 & 243,88 & 11,05 & 232,83 & \begin{tabular}{ll|}
134,60 \\
\end{tabular} & 51,47 & \begin{tabular}{|l|l|}
187,37 \\
\end{tabular} & 48,63 & $\begin{array}{l}893,25 \\
\end{array}$ & 96,76 & 50,69 & 18,58 & 255,03 & \begin{tabular}{|l|}
186,61 \\
\end{tabular} & 211,05 & 187,34 \\
\hline Pelophylax perezi & 31TDG71 & 99,00 & 156,87 & 69,51 & 30,60 & 5364,56 & 275,70 & 52,56 & 223,14 & 167,35 & 224,72 & 227,13 & \begin{tabular}{ll|}
90,86 \\
\end{tabular} & 711,45 & 107,54 & 29,23 & 30,94 & 243,24 & \begin{tabular}{ll|}
129,62 \\
\end{tabular} & \begin{tabular}{l|l|}
160,29 \\
\end{tabular} & 156,59 \\
\hline Pelophylax perezi & 31TDG72 & 101,00 & 154,90 & 69,47 & 30,09 & 5459,06 & 275,20 & 48,78 & 226,42 & 165,21 & \begin{tabular}{|l|l|}
225,52 \\
\end{tabular} & 226,12 & $\begin{array}{l}87,35 \\
\end{array}$ & 736,21 & 108,20 & 31,73 & 28,88 & 244,81 & 137,61 & \begin{tabular}{l|l}
161,82 \\
\end{tabular} & 162,07 \\
\hline Pelophylax perezi & 31TDG73 & 100,00 & 151,59 & 69,54 & 29,97 & 5553,31 & 273,66 & 44,30 & 229,36 & \begin{tabular}{ll|}
165,46 \\
\end{tabular} & 222,68 & 223,75 & 82,6 & 769,42 & 108,47 & 35,29 & 26,44 & 246,62 & \begin{tabular}{|l|l|}
149,64 \\
\end{tabular} & $\begin{array}{l}161,79 \\
\end{array}$ & 168,62 \\
\hline Pelophylax perezi & 31TDG74 & 101,00 & 148,67 & 70,75 & 30,06 & 5587,62 & 272,30 & 40,82 & 231,48 & 177,15 & \begin{tabular}{|l|l|}
209,99 \\
\end{tabular} & 221,44 & 79,36 & \begin{tabular}{|l|l|}
785,67 \\
\end{tabular} & \begin{tabular}{ll|l}
106,68 \\
\end{tabular} & 38,35 & 24,72 & 244,16 & \begin{tabular}{|l|l|}
159,67 \\
\end{tabular} & 167,53 & 169,21 \\
\hline Pelophylax perezi & 31TDG75 & 101,00 & 138,71 & 72,55 & 30,92 & 5523,73 & 263,75 & 32,51 & 231,24 & \begin{tabular}{ll|}
182,50 \\
\end{tabular} & \begin{tabular}{l|l|}
104,51 \\
1
\end{tabular} & 211,21 & 71,13 & \begin{tabular}{l|l|}
832,95 \\
\end{tabular} & $\begin{array}{l}103,27 \\
\end{array}$ & 43,47 & 22,28 & 247,40 & \begin{tabular}{|l|l|}
173,37 \\
\end{tabular} & \begin{tabular}{ll|l}
186,58 \\
\end{tabular} & 174,80 \\
\hline Pelophylax perezi & 31TDG76 & 100,00 & 143,13 & 74,41 & 31,20 & 5552,16 & 269,17 & 35,16 & 234,01 & \begin{tabular}{ll|}
185,68 \\
\end{tabular} & 111,35 & \begin{tabular}{|l|l|}
215,67 \\
\end{tabular} & 74,65 & \begin{tabular}{|l|l|}
784,79 \\
\end{tabular} & 99,79 & 41,08 & 22,69 & 235,03 & $\begin{array}{ll}163,83 \\
\end{array}$ & \begin{tabular}{ll|l}
173,85 \\
\end{tabular} & 164,27 \\
\hline Pelophylax perezi & 31TDG77 & 100,00 & 138,85 & 75,89 & 31,95 & 5538,66 & 266,13 & 30,97 & 235,15 & \begin{tabular}{|l|l|}
177,79 \\
\end{tabular} & $\begin{array}{l}103,96 \\
\end{array}$ & 211,36 & 70,83 & 782,67 & 97,23 & 41,56 & 21,97 & 231,89 & 164,30 & \begin{tabular}{ll|}
174,28 \\
\end{tabular} & 164,77 \\
\hline Pelophylax perezi & $\begin{array}{l}\text { 31TDG78 } \\
\end{array}$ & 93,00 & 127,93 & 77,01 & 32,06 & 5514,09 & 256,73 & 21,64 & 235,10 & \begin{tabular}{ll|}
166,72 \\
\end{tabular} & 73,70 & 200,46 & \begin{tabular}{l|l|l}
60,95 \\
\end{tabular} & 827,53 & 96,41 & 45,54 & 20,13 & 238,31 & $\begin{array}{ll}175,62 \\
\end{array}$ & \begin{tabular}{ll|}
187,78 \\
\end{tabular} & 175,90 \\
\hline Pelophylax perezi & 31TDG79 & 46,00 & 113,70 & 77,44 & 32,85 & 5476,17 & 243,58 & 10,14 & 233,44 & 142,50 & 62,03 & 186,30 & 48,28 & \begin{tabular}{|l|l|}
879,16 \\
\end{tabular} & 98,03 & 50,52 & 18,20 & 248,55 & \begin{tabular}{|l|l|}
189,73 \\
\end{tabular} & 200,52 & 191,48 \\
\hline Pelophylax perezi & 31TDG81 & 58,00 & 156,33 & 69,67 & 30,77 & 5324,65 & 274,68 & 52,23 & 222,45 & 166,76 & 221,85 & 226,11 & 91,01 & \begin{tabular}{ll|}
700,06 \\
\end{tabular} & 108,38 & 27,85 & 32,13 & 241,39 & 125,74 & 155,80 & 153,82 \\
\hline Pelophylax perezi & 31TDG82 & 99,00 & 151,01 & 69,29 & 30,32 & 5396,79 & 270,51 & 46,31 & 224,20 & 161,54 & \begin{tabular}{ll|l}
221,06 \\
\end{tabular} & 221,71 & 84,91 & \begin{tabular}{|l|l|}
744,17 \\
\end{tabular} & 109,39 & 31,64 & 28,92 & 246,43 & 139,20 & $\begin{array}{l}164,30 \\
\end{array}$ & 163,79 \\
\hline Pelophylax perezi & 31TDG83 & 101,00 & 152,89 & 69,74 & 30,10 & 5483,13 & 273,79 & 46,21 & 227,58 & \begin{tabular}{|l|}
163,03 \\
\end{tabular} & 223,94 & 224,33 & 85,14 & 738,58 & 109,55 & 31,46 & 29,01 & 243,75 & 137,25 & \begin{tabular}{|l|}
159,43 \\
\end{tabular} & 163,03 \\
\hline Pelophylax perezi & 31TDG84 & 101,00 & 151,60 & 71,06 & 30,56 & 5502,87 & 273,56 & 44,03 & 229,53 & 161,75 & 222,87 & 223,26 & 83,40 & \begin{tabular}{ll|}
745,99 \\
\end{tabular} & \begin{tabular}{ll|}
107,99 \\
\end{tabular} & 33,42 & 27,63 & 240,70 & \begin{tabular}{ll|}
143,15 \\
\end{tabular} & \begin{tabular}{|l|l|}
156,73 \\
\end{tabular} & 162,27 \\
\hline Pelophylax perezi & 31TDG85 & 101,00 & $\begin{array}{ll}151,47 \\
\end{array}$ & 73,02 & 31,16 & 5489,76 & 274,51 & 43,28 & 231,23 & \begin{tabular}{|l|l|}
163,92 \\
\end{tabular} & \begin{tabular}{|l|l|}
222,63 \\
\end{tabular} & 222,94 & 83,53 & 727,58 & 104,06 & 33,71 & 26,96 & 232,38 & 143,45 & 154,74 & 155,45 \\
\hline Pelophylax perezi & 31TDG86 & 100,00 & 150,17 & 74,92 & 31,76 & 5484,51 & 274,44 & \begin{tabular}{|l|l|}
41,47 \\
\end{tabular} & 232,96 & 160,93 & 221,32 & 221,62 & \begin{tabular}{l|l|}
82,25 \\
\end{tabular} & \begin{tabular}{|l|l|}
708,14 \\
\end{tabular} & 99,79 & 33,60 & 26,14 & 224,22 & \begin{tabular}{|l|l|}
142,91 \\
\end{tabular} & 150,56 & 149,80 \\
\hline Pelophylax perezi & 31TDG87 & 101,00 & 149,24 & 76,75 & 32,16 & 5487,27 & 274,86 & 39,84 & 235,02 & 160,05 & 216,56 & 220,80 & 81,28 & \begin{tabular}{ll|l}
689,46 \\
\end{tabular} & 96,19 & 32,82 & 25,71 & $\begin{array}{l}217,65 \\
\end{array}$ & \begin{tabular}{l|l|l|l|}
140,02 \\
\end{tabular} & \begin{tabular}{l|l|}
146,09 \\
\end{tabular} & 146,16 \\
\hline Pelophylax perezi & & 100,00 & 145,31 & 78,30 & $\begin{array}{l}32,55 \\
\end{array}$ & 5499,28 & 272,62 & 35,72 & 236,90 & 157,99 & 205,09 & 217,05 & 77,44 & 700,65 & 94,38 & 33,65 & 24,44 & 217,15 & 142,92 & 147,29 & 151,21 \\
\hline Pelophylax perezi & 31TDG89 & 82,00 & 138,88 & 79,63 & 32,99 & 5506,15 & 267,94 & 29,75 & 238,19 & 152,98 & 186,80 & 211,01 & 71,29 & \begin{tabular}{ll|l}
724,75 \\
\end{tabular} & 93,55 & 35,45 & 22,99 & 219,97 & 148,58 & 152,88 & 159,90 \\
\hline Pelophylax perezi & 31TDG91 & & & & & & & & & & & & & & & & & & & & \\
\hline Pelophylax perezi & 31TDG92 & 90,00 & 150,89 & 70,44 & 31,30 & 5265,40 & 268,98 & 47,70 & 221,29 & \begin{tabular}{ll|}
161,82 \\
\end{tabular} & 218,54 & 220,26 & 86,91 & 712,95 & \begin{tabular}{l|l|}
106,85 \\
\end{tabular} & 28,68 & 30,50 & 240,38 & 130,56 & \begin{tabular}{ll|l}
156,86 \\
\end{tabular} & 156,52 \\
\hline Pelophylax perezi & 31TDG93 & 101,00 & 149,48 & 71,06 & 31,22 & 5302,24 & 268,45 & 45,39 & 223,06 & \begin{tabular}{|l|l|}
160,19 \\
\end{tabular} & 218,27 & 219,19 & & 722,41 & \begin{tabular}{|l|l|}
106,15 \\
\end{tabular} & 30,10 & 29,09 & 238,99 & 135,13 & $\begin{array}{l}158,25 \\
\end{array}$ & 157,90 \\
\hline Pelophylax perezi & 31TDG94 & 101,00 & 148,97 & 72,30 & 31,6 & 5318,50 & 269,01 & 43,99 & \begin{tabular}{|l|l|}
225,02 \\
\end{tabular} & \begin{tabular}{|l|l|}
159,60 \\
\end{tabular} & 218,08 & 218 & 8 & 721,56 & 104,28 & 31,3 & 28,05 & 234,82 & \begin{tabular}{|l|l|}
138,13 \\
\end{tabular} & \begin{tabular}{|l|l|}
157,69 \\
\end{tabular} & 156,27 \\
\hline Pelophylax perezi & \begin{tabular}{|l|l|}
31 TDG95 \\
\end{tabular} & 100,00 & 155,34 & 74,30 & 32,15 & 5331,84 & 276,12 & 48,17 & 227,95 & 165,50 & 224,38 & 224,95 & 89,64 & 666,18 & 100,65 & 28,02 & 29,82 & \begin{tabular}{|l|l|}
222,45 \\
\end{tabular} & 124,31 & 143,50 & 143,07 \\
\hline Pelophylax perezi & 31TDG96 & 101,00 & 154,32 & 76,03 & 32,57 & 5354,37 & 276,69 & 46,32 & 230,38 & 164,47 & \begin{tabular}{|l|l|}
223,78 \\
\end{tabular} & 224,28 & 88,29 & $\begin{array}{ll}645,72 \\
\end{array}$ & 96,88 & 27,87 & 29,30 & 214,89 & \begin{tabular}{ll|}
123,38 \\
\end{tabular} & 138,33 & 136,76 \\
\hline Pelophylax perezi & 31TDG97 & 101,00 & 154,91 & 77,94 & 32,98 & 5376,61 & 278,77 & 45,78 & 232,99 & 164,75 & 224,66 & 225,07 & 88,52 & $\begin{array}{ll}620,55 \\
\end{array}$ & $\begin{array}{l}93,45 \\
\end{array}$ & 26,50 & 29,39 & 207,71 & \begin{tabular}{|l|l|}
118,15 \\
\end{tabular} & \begin{tabular}{|l|l|}
129,83 \\
\end{tabular} & 131,77 \\
\hline Pelophylax perezi & 31TDG98 & 101,00 & 154,16 & 79,68 & 33,31 & 5404,67 & 279,85 & 43,98 & 235,87 & 163,77 & 224,38 & 224,69 & 87,42 & \begin{tabular}{|l|l|}
614,88 \\
\end{tabular} & 91,59 & 25,70 & 28,95 & 205,24 & \begin{tabular}{|l|l|}
114,78 \\
\end{tabular} & \begin{tabular}{l|l|}
123,02 \\
\end{tabular} & 133,82 \\
\hline Pelophylax perezi & 31TDG99 & 101,00 & 14 & 80,52 & 33,4 & 443,28 & 272,35 & 34,86 & 237,48 & 151,97 & \begin{tabular}{|l|l|}
215,52 \\
\end{tabular} & 215,81 & 77,70 & \begin{tabular}{|c|}
669,90 \\
\end{tabular} & \begin{tabular}{|l|l|}
92,67 \\
\end{tabular} & 29,6 & 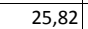 & 213,72 & 128,84 & \begin{tabular}{|l|l|}
135,24 \\
\end{tabular} & 149,82 \\
\hline Pelophylax perezi & 31TDH80 & 1,00 & 14 & 82,12 & 33,46 & 5540,21 & 27 & 32,40 & 242,14 & \begin{tabular}{|l|l|}
151,89 \\
\end{tabular} & 212 , & 216,18 & $\begin{array}{l}75,45 \\
\end{array}$ & 677,58 & 90,55 & 30,60 & 24,48 & 211,47 & 130,48 & 131,98 & 154,59 \\
\hline Pelophylax perezi & 31TDH90 & 17,00 & 130,04 & 80,65 & 33,43 & 5452,04 & 259,87 & 22,49 & 237,38 & 119,93 & 201,55 & 201,87 & 63,90 & 750,58 & 95,23 & 35,71 & 22,82 & \begin{tabular}{|l|}
229,15 \\
\end{tabular} & 150,32 & 154,35 & 172,62 \\
\hline Pelophylax perezi & 31TEG02 & 28,00 & 159,86 & 72,57 & 32,57 & 5126,33 & 275,57 & 56,43 & 219,14 & $\begin{array}{ll}170,95 \\
\end{array}$ & 218,33 & 227,33 & \begin{tabular}{l|l|}
97,29 \\
\end{tabular} & \begin{tabular}{ll|l}
631,48 \\
\end{tabular} & 102,14 & 21,71 & 35,33 & \begin{tabular}{|l|l|}
225,67 \\
\end{tabular} & $\begin{array}{l}106,76 \\
\end{array}$ & \begin{tabular}{ll|l}
137,62 \\
\end{tabular} & 139,43 \\
\hline Pelophylax perezi & 31TEG03 & 93,00 & 153,07 & 72,72 & 32,65 & 5129,58 & 269,70 & 50,30 & 219,40 & 164,14 & 219,05 & 220,85 & 91,19 & 659,64 & 100,74 & 24,89 & 31,94 & 226,71 & 118,30 & $\begin{array}{ll}144,85 \\
\end{array}$ & 143,42 \\
\hline Pelophylax perezi & 31TEG04 & 100,00 & 156,39 & 74,26 & 33,10 & 5126,21 & 273,53 & 52,28 & 221,25 & \begin{tabular}{|l|l|}
167,27 \\
\end{tabular} & 222,84 & 223,95 & 94,16 & \begin{tabular}{|l|l|}
632,72 \\
\end{tabular} & 98,18 & 23,59 & 32,44 & 219,16 & 112,16 & \begin{tabular}{|l|l|}
137,79 \\
\end{tabular} & 137,12 \\
\hline Pelophylax perezi & 31TEG05 & 101,00 & 159 & 76,01 & 33,36 & 5156,94 & 277,61 & 53,28 & 224,33 & 169,69 & 225,81 & 226,69 & 95,95 & 606,38 & 95,44 & 22,60 & 32,90 & 211,53 & 107,01 & 130,96 & 130,71 \\
\hline Pelophylax perezi & 31TEG06 & 97,00 & 158,23 & 77,35 & 33,63 & 5215,84 & 278,52 & 51,12 & 227,39 & 168,48 & \begin{tabular}{|l|l|}
225,83 \\
\end{tabular} & 226,54 & \begin{tabular}{|c|}
94,18 \\
\end{tabular} & \begin{tabular}{|l|l|}
597,79 \\
\end{tabular} & 93,37 & 22,87 & 32,11 & 207,20 & \begin{tabular}{|l|}
107,21 \\
\end{tabular} & \begin{tabular}{|l|}
128,67 \\
\end{tabular} & 128,37 \\
\hline Pelophylax perezi & 31TEG07 & 99,00 & 158,76 & 79,15 & 33,82 & 5266,93 & 280,93 & \begin{tabular}{l|l}
50,05 \\
\end{tabular} & 230,89 & 168,66 & 227,07 & 227,46 & \begin{tabular}{|c|}
93,87 \\
\end{tabular} & $\begin{array}{l}582,46 \\
\end{array}$ & 91,29 & 22,05 & 32,32 & 202,72 & \begin{tabular}{|l|l|}
103,44 \\
\end{tabular} & 119,33 & 126,14 \\
\hline Pelophylax perezi & 31TEG08 & 101,00 & 156,38 & 80,48 & 33,99 & 5305,64 & 280,52 & 46,90 & 233,62 & 166,31 & \begin{tabular}{|l|}
225,23 \\
\end{tabular} & 225,66 & 90,90 & 587,55 & 90,4 & 22,33 & 31,40 & 202,46 & 103,81 & \begin{tabular}{|l|l|}
119,66 \\
\end{tabular} & 129,73 \\
\hline Pelophylax perezi & 31TEG09 & 90,00 & 14 & 80, & 33 & 530 & & 35, & & & & & /8, & \begin{tabular}{|c|c|}
656,66 \\
\end{tabular} & 92,80 & & & 213 & 121,92 & \begin{tabular}{|l|}
133,07 \\
\end{tabular} & 148 \\
\hline Pelophylax perezi & 31TEG13 & 37,00 & 159,26 & 74,63 & 33,92 & 4974,95 & 273,68 & 56,92 & \begin{tabular}{|l|l|}
216,76 \\
\end{tabular} & 170,61 & 210,58 & 225,08 & 99,42 & \begin{tabular}{|l|l|}
587,89 \\
\end{tabular} & 94,26 & 19,53 & 35,63 & 211,92 & 100,21 & 130,21 & 126,39 \\
\hline Pelophylax perezi & 31TEG14 & 82,00 & 158,10 & 75,46 & 34,12 & 4968,86 & 273,17 & 55,60 & 217,57 & 169,46 & 218,00 & 223,94 & \begin{tabular}{l|l|}
98,45 \\
\end{tabular} & 581,97 & $\begin{array}{l}92,08 \\
\end{array}$ & 19,95 & 34,63 & 207,98 & \begin{tabular}{|l|}
101,27 \\
\end{tabular} & \begin{tabular}{|l|l|}
129,57 \\
\end{tabular} & 123,84 \\
\hline Pelophylax perezi & 31TEG15 & 64,00 & 158,06 & 76,80 & 34,23 & 5037,93 & 274,93 & 53,78 & 221,16 & 169,04 & 223,27 & \begin{tabular}{|l|l|}
224,47 \\
\end{tabular} & 97,10 & 582,48 & 91,69 & 20,63 & 33,81 & 206,16 & \begin{tabular}{|l|l|}
102,02 \\
\end{tabular} & \begin{tabular}{l|l|}
127,89 \\
\end{tabular} & 124,51 \\
\hline Pelophy & 31 TFG $\mathrm{C}$ & 17,00 & & & 34 & $207>$ & & 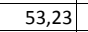 & & 169, & & 225 & 96,69 & 576 & 91, & 20 & & & 100,58 & $\begin{array}{l}125,35 \\
\end{array}$ & 123,88 \\
\hline Pelophylax perezi & 31TEG17 & 27,00 & 152,47 & 79,42 & 34,11 & 5163,5 & 274,11 & 45,63 & 228,47 & 162,74 & 219,58 & 220,32 & 89,89 & \begin{tabular}{|l|l|}
597,79 \\
\end{tabular} & 91,05 & 21,89 & 31,53 & 206,53 & 105,05 & 127,42 & 132,21 \\
\hline Pelophylax perezi & 31TEG18 & 92,00 & 150,02 & 80,18 & 34,19 & 5227,00 & 273,39 & 42,56 & 230,83 & 160,23 & 218,03 & 218,70 & 86,39 & \begin{tabular}{|l|l|}
614,06 \\
\end{tabular} & 91,62 & 23,13 & 30,37 & 208,97 & 108,82 & 128,38 & 137,49 \\
\hline
\end{tabular}




\begin{tabular}{|c|c|c|c|c|c|c|c|c|c|c|c|c|c|c|c|c|c|c|c|c|c|}
\hline TAXON & UTM & $\mathrm{km} 2$ & BIO1 & BIO2 & $B 103$ & BIO4 & B105 & B106 & B107 & 8108 & 8109 & B1010 & BIO11 & B1012 & BIO13 & B1014 & BIO15 & B1016 & B1017 & B1018 & 81019 \\
\hline Pelophylax perezi & 31TEG19 & 30,00 & 151,89 & 82,00 & 34,39 & 5309,02 & 277,59 & 42,27 & 235,32 & 161,70 & 220,98 & 221,36 & 86,77 & 602,16 & 90,39 & 22,30 & 30,66 & 205,52 & 104,05 & 120,39 & 137,52 \\
\hline Pelophylax perezi & 31TEG27 & & & & & & & & & & & & & & & & & & & & \\
\hline Pelophylax perezi & 31TEG28 & 31,00 & 152,98 & 80,93 & 34,83 & 5170,83 & 275,50 & $\begin{array}{ll}45,63 \\
\end{array}$ & \begin{tabular}{|l|l|}
229,88 \\
\end{tabular} & \begin{tabular}{|l|l|}
163,23 \\
\end{tabular} & 220,27 & 220,98 & 90,05 & 588,20 & 90,30 & 20,48 & 32,55 & 205,35 & $\begin{array}{ll}99,82 \\
\end{array}$ & 120,45 & 132,93 \\
\hline Pelophylax perezi & 31TEHOO & 8,00 & 143,60 & 82,49 & 34,11 & 5406,03 & 272,29 & 33,72 & 238,57 & $\begin{array}{ll}147,51 \\
\end{array}$ & 214,13 & 214,46 & 77,38 & 656,68 & 91,94 & 26,81 & 27,44 & 213,72 & 119,09 & \begin{tabular}{ll|}
127,74 \\
\end{tabular} & 152,85 \\
\hline Pleurodeles walt| & 29SMC69 & 100,00 & 147,96 & 70,09 & 41,09 & 3488,38 & 238,79 & 70,50 & 168,29 & 111,22 & 189,22 & 193,04 & 102,87 & $\begin{array}{l}825,55 \\
\end{array}$ & \begin{tabular}{|l|l|}
127,97 \\
\end{tabular} & 5,09 & 64,31 & 370,27 & 36,55 & 38,54 & 344,46 \\
\hline Pleurodeles walt| & 29SMC77 & 7,00 & 165,36 & 77,64 & 41,14 & 3779,50 & 268,86 & 83,14 & 185,71 & 125,50 & 210,64 & 215,21 & 118,00 & 717,43 & 1110,43 & 4,00 & 64,07 & 323,64 & 30,07 & 32,79 & 306,79 \\
\hline 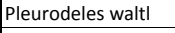 & 29SMC78 & 84,00 & 158,27 & 75,36 & 41,23 & 3702,77 & 257,79 & 77,44 & 180,35 & 119,08 & 202,40 & 206,80 & 111,26 & \begin{tabular}{ll|}
771,92 \\
\end{tabular} & 120,92 & 4,01 & 64,95 & 348,70 & 31,93 & 34,07 & 328,03 \\
\hline Pleurodeles walt| & 29SMC79 & 100,00 & 150,21 & 73,67 & 40,95 & 3685,18 & 248,04 & 70,05 & $\begin{array}{l}177,99 \\
\end{array}$ & 111,34 & $\begin{array}{l}194,26 \\
\end{array}$ & $\begin{array}{l}198,41 \\
\end{array}$ & 103,30 & 825,94 & $\begin{array}{l}128,66 \\
\end{array}$ & 4,51 & 64,91 & 371,05 & 34,95 & 36,68 & 348,66 \\
\hline Pleurodeles walt| & 29SMC87 & 85,00 & 166,33 & 80,39 & 41,04 & 3928,81 & 275,72 & \begin{tabular}{|l|l}
82,47 \\
\end{tabular} & \begin{tabular}{|l|l|}
193,25 \\
\end{tabular} & $\begin{array}{l}125,15 \\
\end{array}$ & 213,91 & 218,71 & $\begin{array}{l}117,74 \\
\end{array}$ & $\begin{array}{l}709,73 \\
\end{array}$ & $\begin{array}{l}108,26 \\
\end{array}$ & 3,85 & 63,78 & $\begin{array}{ll}318,88 \\
\end{array}$ & 29,62 & 32,39 & 304,79 \\
\hline Pleurodeles walt| & 29SMC98 & 24,00 & 170,45 & 81,76 & 40,95 & 4050,98 & 283,33 & 84,93 & 198,40 & 127,79 & 219,81 & 224,26 & 120,24 & \begin{tabular}{|l|l|}
675,07 \\
\end{tabular} & \begin{tabular}{|l|l|}
101,98 \\
\end{tabular} & 3,05 & 63,52 & 301,95 & 27,12 & 30,50 & 290,71 \\
\hline Pleurodeles walt| & 29SMD60 & 71,00 & 150,13 & 67,85 & 41,05 & 3399,25 & 237,06 & 73,70 & 163,36 & 114,29 & \begin{tabular}{|l|l}
190,23 \\
\end{tabular} & 193,60 & 105,75 & $\begin{array}{l}791,66 \\
\end{array}$ & 123,77 & 4,56 & 64,30 & 356,92 & 33,85 & 36,46 & 330,30 \\
\hline Pleurodeles walt| & 29SMD62 & 49,00 & 153,55 & 62,03 & 41,17 & 3118,04 & 230,41 & 81,46 & 148,96 & 120,92 & 189,85 & 192,73 & 112,63 & 711,70 & 116,22 & 4,00 & 63,09 & 320,32 & 30,14 & 34,77 & 294,68 \\
\hline Pleurodeles walt| & 29SMD70 & 101,00 & 148,41 & 71,26 & 40,70 & 3610,41 & 242,95 & 69,60 & 173,35 & 110,39 & $\begin{array}{l}191,61 \\
\end{array}$ & 195,28 & 102,18 & 819,75 & 125,51 & 4,69 & 64,12 & 366,94 & 35,28 & 37,52 & 344,42 \\
\hline Pleurodeles walt| & 29SMD72 & 101,00 & 154,26 & 65,05 & 40,89 & 3286,66 & 237,07 & 79,81 & 157,26 & 119,81 & $\begin{array}{ll}193,07 \\
\end{array}$ & $\begin{array}{l}196,04 \\
\end{array}$ & 111,54 & 718,24 & \begin{tabular}{|l|l|}
115,57 \\
\end{tabular} & 4,02 & 63,12 & 322,51 & 30,11 & 34,39 & 299,55 \\
\hline Pleurodeles walt| & 29SMD75 & 89,00 & 151,32 & 57,80 & 41,23 & 2903,17 & 220,92 & 82,61 & 138,31 & \begin{tabular}{|l|l|}
121,57 \\
\end{tabular} & \begin{tabular}{|l|l|}
185,03 \\
\end{tabular} & \begin{tabular}{ll|}
187,33 \\
\end{tabular} & 113,25 & 677,61 & \begin{tabular}{|l|l|}
113,71 \\
\end{tabular} & 3,95 & 62,35 & 300,55 & 29,35 & 35,85 & 277,62 \\
\hline Pleurodeles walt| & 29SMD85 & 99,00 & 153,92 & 63,22 & 41,25 & 3141,44 & 232,59 & 81,14 & 151,45 & 121,16 & $\begin{array}{ll}190,92 \\
\end{array}$ & 193,39 & 113,04 & 693,97 & 113,00 & 4,06 & 61,81 & 305,79 & 30,54 & 36,53 & 286,46 \\
\hline Pleurodeles walt| & 29SMD86 & 79,00 & 154,64 & 62,85 & 41,60 & 3081,51 & 231,56 & 82,21 & 149,35 & 122,49 & 190,84 & \begin{tabular}{|l|}
193,19 \\
\end{tabular} & 114,37 & \begin{tabular}{|c|}
691,11 \\
\end{tabular} & $\begin{array}{l}112,46 \\
\end{array}$ & 4,04 & 61,43 & 302,84 & 30,71 & 37,30 & 284,19 \\
\hline Pleurodeles walt| & 29SMD93 & 101,00 & 152,29 & 71,58 & 40,51 & 3628,03 & 248,35 & 73,27 & 175,08 & 114,35 & 196,21 & 199,45 & 106,42 & 760,12 & \begin{tabular}{|l|l|}
116,88 \\
\end{tabular} & 4,63 & 61,56 & 333,05 & 34,29 & 38,16 & 318,27 \\
\hline Pleurodeles walt| & 29SMD98 & 58,00 & 154,47 & 68,99 & 42,01 & 3275,73 & 239,79 & 77,49 & 162,30 & 119,74 & \begin{tabular}{|l|l|}
193,37 \\
\end{tabular} & 195,76 & 111,73 & 752,49 & \begin{tabular}{|l|l|}
116,18 \\
\end{tabular} & 5,30 & 59,35 & 321,62 & 37,58 & 44,10 & 307,90 \\
\hline Pleurodeles walt| & 29SMD99 & 35,00 & 152,45 & 70,03 & 42,11 & 3291,15 & 238,72 & 74,76 & 163,96 & 117,54 & \begin{tabular}{ll|l}
191,64 \\
\end{tabular} & 194,07 & 109,53 & 788,54 & 119,77 & 6,00 & 58,43 & 334,07 & 41,22 & 47,77 & 321,45 \\
\hline Pleurodeles walt| & 29SNB12 & 83,00 & 163,34 & 86,34 & 44,66 & 3628,14 & 271,70 & 80,42 & 191,27 & 128,07 & 207,95 & 212,23 & 119,51 & 516,43 & 83,19 & 1,00 & 68,47 & 241,95 & 18,35 & 19,41 & 231,30 \\
\hline Pleurodeles walt| & 29SNB13 & 51,00 & 165,90 & 86,91 & 44,25 & 3706,64 & 276,06 & 81,89 & 194,17 & 129,33 & 211,51 & 215,80 & 121,01 & 513,94 & 82,24 & 1,00 & 68,10 & 240,26 & 18,46 & 19,60 & 229,58 \\
\hline Pleurodeles walt| & 29SNB16 & 24,00 & 167,33 & 88,92 & 43,73 & 3885,90 & 282,76 & 81,06 & 201,69 & 128,55 & 215,29 & 219,73 & 120,39 & 539,57 & 83,76 & 1,00 & 66,53 & 248,24 & 20,00 & 21,00 & 238,41 \\
\hline Pleurodeles walt| & 29SNB17 & 20,00 & 167,92 & 89,56 & 43,36 & 3939,44 & 285,08 & 81,17 & 203,92 & 128,25 & 216,47 & 221,03 & 120,08 & 549,53 & 84,28 & 1,56 & 65,78 & 250,86 & 21,03 & 22,08 & 241,44 \\
\hline Pleurodeles walt| & 29SNB19 & 31,00 & 168,49 & 90,07 & 43,00 & 4041,32 & 288,02 & 80,83 & 207,20 & 127,34 & 218,22 & 222,93 & 119,46 & 569,29 & 86,15 & 2,00 & 64,95 & 257,37 & 22,49 & 23,78 & 248,22 \\
\hline Pleurodeles walt| & 29 SNB21 & 101,00 & 166,71 & 86,81 & 43,34 & 3809,92 & 278,55 & 80,58 & $\begin{array}{l}197,97 \\
\end{array}$ & 129,16 & 214,36 & 218,16 & 120,69 & 498,75 & 80,82 & 0,90 & 69,59 & 237,30 & 16,71 & 17,97 & 225,62 \\
\hline Pleurodeles walt| & 29SNB24 & 100,00 & 162,44 & 89,79 & 43,41 & 3953,88 & 280,03 & 75,26 & 204,76 & 123,45 & 211,84 & 216,11 & 115,18 & 546,36 & 85,42 & 1,08 & 67,06 & 252,79 & 20,07 & 20,88 & 242,88 \\
\hline Pleurodeles walt| & 29SNB25 & 100,00 & 164,72 & 90,25 & 43,24 & 3981,16 & 283,08 & 77,15 & 205,94 & 125,25 & 214,24 & 218,62 & 116,82 & 543,22 & 84,29 & 1,00 & 66,73 & 250,47 & 20,04 & 20,94 & 240,79 \\
\hline Pleurodeles walt| & 29SNB27 & 101,00 & 164,85 & 91,51 & 43,02 & 4077,94 & 286,17 & 76,15 & 210,02 & 124,01 & 215,44 & 219,99 & 115,74 & 565,10 & 86,24 & 1,72 & 65,40 & 256,79 & 22,20 & 22,99 & 248,03 \\
\hline Pleurodeles walt| & 29SNB28 & 101,00 & 163,45 & 91,99 & 42,92 & 4134,08 & 286,67 & 74,44 & 212,23 & 121,86 & 214,92 & 219,54 & 113,86 & 584,01 & 88,30 & 2,00 & 64,69 & 263,26 & 23,58 & 24,30 & 255,08 \\
\hline Pleurodeles walt| & 295 NB29 & 101,00 & 164,16 & 92,20 & 42,84 & 4175,37 & 288,44 & 74,92 & 213,52 & 122,01 & 216,06 & 220,71 & 113,97 & 590,88 & 88,76 & 2,00 & 64,15 & 265,09 & 24,11 & 24,86 & 257,27 \\
\hline Pleurodeles walt| & 29SNB31 & 100,00 & 169,93 & 88,04 & 42,32 & 3993,05 & 285,92 & 80,82 & 205,09 & 130,58 & 220,37 & 224,08 & 121,95 & 491,29 & 79,47 & 0,87 & 69,85 & 235,53 & 15,71 & 17,27 & 223,19 \\
\hline Pleurodeles walt| & 29SNB32 & 100,00 & 157,21 & $\begin{array}{l}90,43 \\
\end{array}$ & 42,89 & 4051,06 & 276,71 & 68,08 & 208,63 & 117,62 & 208,32 & 212,39 & 109,04 & \begin{tabular}{|l|l|}
568,47 \\
\end{tabular} & 89,90 & 1,46 & 67,30 & 263,84 & 21,14 & 22,08 & 253,54 \\
\hline Pleurodeles walt| & 29SNB37 & 100,00 & 164,94 & 93,73 & 42,83 & 4219,59 & 290,82 & 74,07 & 216,75 & 122,57 & 217,72 & 222,23 & 1114,44 & 561,68 & 85,97 & 1,82 & 65,17 & 254,92 & 22,07 & 22,89 & 246,65 \\
\hline Pleurodeles walt| & 29 SNB39 & 100,00 & 165,48 & 94,48 & 42,38 & 4301,43 & 293,85 & 74,15 & 219,70 & 122,07 & 219,27 & 223,98 & 114,02 & 576,49 & 86,88 & 2,00 & 64,22 & 258,47 & 23,19 & 24,02 & 251,19 \\
\hline Pleurodeles walt| & $295 N B 40$ & 40,00 & 169,94 & 88,87 & 42,02 & 4031,70 & 286,43 & 79,40 & 207,02 & 130,30 & 221,06 & 224,83 & 121,79 & 494,32 & 81,45 & 1,00 & 69,98 & 238,64 & 15,89 & 17,36 & 225,43 \\
\hline Pleurodeles walt| & 29SNB41 & 101,00 & 170,42 & 89,54 & 42,32 & 4071,24 & 288,31 & 79,58 & 208,73 & 130,01 & 221,89 & 225,72 & 121,66 & 494,19 & 80,91 & 1,00 & 69,76 & 237,45 & 15,99 & 17,53 & 224,66 \\
\hline Pleurodeles waltt & 29SNB42 & 101,00 & 163,34 & 91,49 & 42,31 & 4153,20 & 284,97 & 71,88 & 213,09 & 122,27 & 215,89 & 219,81 & $\mid 113,77$ & 536,63 & 86,44 & $\mid 1,15$ & 68,24 & 252,48 & 18,58 & 19,76 & 241,22 \\
\hline Pleurodeles walt| & 29SNB47 & 100,00 & 163,18 & 96,28 & 42,48 & 4369,40 & 293,99 & 70,04 & 223,95 & 119,40 & 218,06 & 222,73 & 111,14 & 569,30 & 87,22 & 2,00 & 64,67 & 257,01 & 22,82 & 23,42 & 249,30 \\
\hline Pleurodeles walt| & $295 N B 48$ & 101,00 & 167,66 & 96,33 & 42,62 & 4369,44 & 298,26 & 74,38 & 223,87 & 123,46 & 222,40 & 226,92 & 115,25 & 551,81 & 83,96 & 2,00 & 64,54 & 248,81 & 21,95 & 22,84 & 241,24 \\
\hline Pleurodeles walt| & 29SNB52 & 101,00 & 164,37 & \begin{tabular}{|c|}
92,97 \\
\end{tabular} & 42,21 & 4241,13 & 288,17 & 71,28 & 216,89 & 122,52 & 218,10 & 222,13 & 113,81 & 533,03 & 86,93 & 1,00 & 68,19 & 251,74 & 17,99 & 19,46 & 240,04 \\
\hline Pleurodeles walt| & 29SNB57 & 101,00 & 165,13 & 98,47 & 42,25 & 4481,33 & 299,41 & 69,77 & 229,64 & 119,95 & 221,66 & 226,18 & 111,69 & 554,76 & 85,12 & 1,99 & 64,53 & 250,30 & 21,91 & 22,56 & 242,74 \\
\hline Pleurodeles walt| & 29SNB58 & 100,00 & 167,38 & 98,91 & 42,36 & 4491,59 & 302,26 & 72,00 & 230,26 & 121,99 & 223,90 & 228,48 & 113,80 & 548,53 & 83,37 & 2,00 & 64,49 & 246,13 & 21,50 & 22,24 & 239,15 \\
\hline Pleurodeles walt| & 29SNB59 & 100,00 & 168,86 & 99,21 & 42,32 & 4520,42 & 304,48 & 73,29 & 231,19 & 122,86 & \begin{tabular}{|l|l|}
225,62 \\
\end{tabular} & 230,19 & 114,75 & 547,27 & 82,53 & 2,00 & 63,86 & 244,05 & 22,02 & 22,64 & 237,48 \\
\hline Pleurodeles walt| & 29SNB63 & 101,00 & 160,97 & 95,93 & 42 & 4400,78 & 290,09 & 65,53 & 224,56 & 117,48 & 216,88 & 221,05 & 108,72 & 558,03 & 89,99 & 1,27 & 66,82 & 259,41 & 19,80 & 21,14 & 248,62 \\
\hline Pleurodeles walt| & 29SNB65 & 100,00 & 162,17 & $\begin{array}{ll}98,47 \\
\end{array}$ & 42,03 & 4511,04 & 296,07 & 65,55 & 230,53 & 117,11 & 219,31 & 223,70 & 108,42 & $\begin{array}{l}559,05 \\
\end{array}$ & 87,77 & 1,70 & 65,36 & 255,09 & 20,98 & 22,00 & 246,12 \\
\hline Pleurodeles walt| & 29SNB66 & 101,00 & 162,98 & 99,69 & 42,06 & 4555,55 & 299,11 & 66,03 & 233,08 & 117,41 & 220,63 & 225,06 & 108,82 & 559,86 & 86,75 & 1,99 & 64,56 & 253,15 & 21,71 & 22,47 & 245,11 \\
\hline Pleurodeles walt| & 29SNB67 & 100,00 & 165,05 & 100,68 & 42,10 & 4589,97 & 302,86 & 67,74 & 235,12 & \begin{tabular}{|l|l|}
118,94 \\
\end{tabular} & 223,03 & 227,53 & 110,40 & 553,32 & 84,75 & 2,00 & 64,32 & 248,44 & 21,63 & 22,47 & 241,14 \\
\hline Pleurodeles walt| & 29SNB68 & 101,00 & 164,04 & 101,89 & 42,18 & 4647,18 & 304,28 & 66,41 & 237,87 & 117,29 & 222,77 & 227,32 & 108,81 & 564,32 & 85,29 & 2,00 & 63,15 & 250,55 & 23,05 & 23,58 & 244,48 \\
\hline Pleurodeles walt| & $295 N B 69$ & 101,00 & 167,56 & 102,06 & 42,17 & 4654,46 & 307,85 & 69,73 & 238,13 & 120,29 & 226,15 & 230,81 & 111,92 & 549,62 & 82,76 & 2,00 & 63,20 & 243,19 & 22,15 & 23,03 & 237,45 \\
\hline Pleurodeles walt| & 29SNB72 & 101,00 & 158,56 & 95,96 & 42,03 & 4413,77 & 287,27 & 62,45 & 224,82 & 114,93 & 214,69 & 218,96 & 106,39 & $\begin{array}{l}571,05 \\
\end{array}$ & 92,86 & 1,49 & 66,85 & 265,98 & 20,14 & 21,88 & 254,31 \\
\hline Pleurodeles walt| & 29SNB73 & 101,00 & 155,11 & 97,55 & 42,01 & 4511,24 & 287,61 & 58,42 & 229,19 & 110,50 & 212,56 & 216,92 & $\mid$\begin{tabular}{|l|l|}
102,06 \\
\end{tabular} & 594,00 & \begin{tabular}{|c|c|}
94,58 \\
\end{tabular} & 1,85 & 65,52 & 272,01 & 22,33 & 23,79 & 261,73 \\
\hline Pleurodeles walt| & 29SNB75 & 101,00 & 159,78 & 100,28 & 42,00 & 4621,93 & 297,04 & 61,54 & 235,50 & 113,35 & 218,43 & 222,83 & 105,05 & $\begin{array}{l}572,95 \\
\end{array}$ & 89, & 2,00 & 64,65 & 259,20 & 22,04 & 23,10 & 250,47 \\
\hline Pleurodeles walt| & 29 SNB76 & 100,00 & 161 & 101, & 42 & 4676,71 & 301,01 & 62, & 238,69 & 114 & $22 \mathrm{C}$ & 22 & 105 & 567,53 & 8, & 2,0 & 63,97 & 254,77 & 22,03 & 23,01 & 247 \\
\hline Pleurodeles walt| & 29SNB77 & 101,00 & 162,11 & 103,12 & 42,01 & 4726,24 & 304,26 & 62,65 & 241,60 & $\begin{array}{l}114,45 \\
\end{array}$ & 221,96 & 226,48 & 106,06 & 566,85 & 86,19 & 2,00 & 63,50 & 252,11 & 22,82 & 23,23 & 245,35 \\
\hline Pleurodeles walt| & 29SNB78 & 100,00 & 163,24 & 104,39 & 42,08 & 4765,14 & 307,41 & 63,36 & 244,05 & 115,13 & 223,53 & 228,26 & 106,63 & 564,42 & 85,12 & 2,00 & 63,00 & 248,94 & 23,12 & 23,48 & 243,17 \\
\hline Pleurodeles walt| & 29SNB79 & 100,00 & 166,09 & 105,06 & 42,25 & 4779,42 & 311,19 & 66,12 & 245,07 & 117,61 & 226,48 & 231,18 & 109,12 & 553,21 & 83,07 & 2,00 & 62,53 & 242,47 & 22,90 & 23,34 & 237,38 \\
\hline Pleuroc & 29SNB80 & 97,00 & 169,36 & 92 & $427>7$ & 92,89 & 288,39 & 74,36 & 214,03 & 28,18 & 222,39 & 226 & & 515,13 & 88,79 & 1,00 & 69,74 & 249,99 & 15,82 & 18,36 & 23 \\
\hline Pleurodeles walt| & $295 N B 81$ & 101,00 & 162,83 & 94,57 & 42,07 & 4366,06 & 287,94 & 66,33 & 221,61 & 119,65 & 218,25 & 222,48 & 111,04 & 548,10 & 91,22 & 1,09 & 67,97 & 259,42 & 18,07 & 20,46 & 245,71 \\
\hline Pleurodeles waltl & 29 SNB82 & 101,00 & 157,12 & 96,63 & 41,94 & 4496,11 & 287,34 & 59,58 & 227,76 & 112,64 & 214,29 & 218,59 & 103,89 & 581,80 & 93,91 & 1,63 & 66,26 & 269,03 & 20,85 & 22,90 & 257,09 \\
\hline
\end{tabular}




\begin{tabular}{|c|c|c|c|c|c|c|c|c|c|c|c|c|c|c|c|c|c|c|c|c|c|}
\hline TAXON & UTM & $\mathrm{km} 2$ & BIO1 & BIO2 & $B 103$ & BIO4 & B105 & B106 & B107 & 8108 & 8109 & B1010 & BIO11 & B1012 & BIO13 & BIO14 & BIO15 & B1016 & B1017 & B1018 & 81019 \\
\hline Pleurodeles walt| & 29SNB83 & 99,00 & 153,72 & 98,40 & 41,99 & 4596,25 & 288,04 & 55,56 & 232,47 & 108,30 & 212,29 & 216,57 & 99,42 & 603,65 & 95,34 & 2,03 & 64,86 & 274,47 & 22,96 & 24,69 & 264,03 \\
\hline Pleurodeles walt| & 29SNB84 & 101,00 & 156,82 & 99,72 & 41,99 & 4649,05 & 293,62 & 58,02 & 235,60 & 110,58 & 215,99 & 220,47 & $\begin{array}{l}101,90 \\
\end{array}$ & 587,33 & 91,97 & 2,00 & 64,52 & 265,77 & 22,60 & 24,20 & 255,97 \\
\hline Pleurodeles walt| & 29SNB85 & 101,00 & 160,15 & 101,33 & 42,00 & 4701,10 & 299,33 & $\begin{array}{ll}60,68 \\
\end{array}$ & \begin{tabular}{|l|l|}
238,64 \\
\end{tabular} & $\begin{array}{l}113,07 \\
\end{array}$ & \begin{tabular}{|l|l|}
219,98 \\
\end{tabular} & 224,36 & $\begin{array}{l}104,50 \\
\end{array}$ & $\begin{array}{l}569,56 \\
\end{array}$ & 88,36 & 2,00 & 64,34 & 256,54 & 21,87 & 23,07 & 247,50 \\
\hline Pleurodeles walt| & 29SNB86 & 100,00 & 162,07 & $\begin{array}{l}103,04 \\
\end{array}$ & 42,00 & 4757,32 & 303,96 & 61,80 & 242,16 & 114,11 & 222,48 & 226,92 & \begin{tabular}{ll|}
105,67 \\
\end{tabular} & 561,37 & 85,89 & 2,00 & 63,65 & 250,74 & 22,00 & 23,10 & 242,69 \\
\hline Pleurodeles walt| & 29SNB87 & 101,00 & 164,19 & 104,66 & 42,02 & \begin{tabular}{|l|l|}
4802,14 \\
\end{tabular} & 308,43 & 63,30 & 245,14 & 115,60 & 225,09 & 229,45 & 107,14 & 552,20 & 83,83 & 2,00 & 63,11 & 244,63 & 22,16 & 23,00 & 237,50 \\
\hline Pleurodeles walt| & 29SNB88 & 101,00 & 164,83 & 106,41 & 42,05 & \begin{tabular}{ll|}
4854,87 \\
\end{tabular} & 311,95 & 63,26 & 248,70 & 115,54 & 226,35 & 230,92 & 107,07 & 551,99 & 83,25 & 2,00 & 62,32 & 242,05 & 22,81 & 23,29 & 236,15 \\
\hline 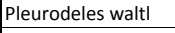 & 29SNB89 & 100,00 & 165,90 & 107,83 & 42,29 & 4898,78 & 315,21 & 63,79 & 251,42 & 115,99 & 227,84 & 232,60 & $\begin{array}{l}107,52 \\
\end{array}$ & 549,89 & 82,33 & 2,00 & 61,86 & 238,70 & 23,05 & 23,82 & 233,98 \\
\hline Pleurodeles walt| & 29SNB94 & 100,00 & 159,33 & $\begin{array}{ll}99,98 \\
\end{array}$ & 41,80 & 4709,88 & 296,68 & 59,39 & 237,29 & 112,16 & 219,24 & 223,63 & $\begin{array}{l}103,63 \\
\end{array}$ & 571,80 & 89,02 & 2,00 & 64,30 & 258,27 & 21,49 & 23,73 & 247,61 \\
\hline Pleurodeles walt| & 29SNB95 & 100,00 & 162,10 & 101,68 & 41,85 & $\begin{array}{lll}4764,64 \\
\end{array}$ & 301,97 & 61,28 & 240,69 & 114,21 & 222,62 & 226,94 & 105,44 & 557,84 & 85,81 & 2,00 & 63,79 & 250,25 & 21,36 & 23,25 & 240,45 \\
\hline Pleurodeles walt| & 295NB96 & 101,00 & 163,94 & 103,58 & 42,00 & 4820,32 & 306,60 & 62,39 & 244,21 & 115,39 & 225,06 & 229,47 & 106,53 & 548,79 & 83,65 & 2,00 & 63,29 & 244,15 & 21,60 & 23,07 & 235,36 \\
\hline Pleurodeles walt| & 29SNB97 & 100,00 & 164,92 & 105,55 & 42,00 & 4874,85 & 310,72 & 62,35 & 248,37 & \begin{tabular}{|l|l|}
115,44 \\
\end{tabular} & 226,73 & 231,23 & 106,64 & 545,94 & 82,66 & 2,00 & 62,55 & 240,46 & 21,97 & 23,29 & 232,84 \\
\hline Pleurodeles walt| & 29SNB98 & 100,00 & 166,44 & 107,51 & 42,05 & 4933,26 & 315,14 & 63,07 & 252,06 & 116,25 & 228,91 & 233,37 & 107,37 & 539,69 & 81,21 & 2,00 & 61,85 & 235,36 & 22,26 & 23,41 & 228,93 \\
\hline Pleurodeles walt| & 29SNB99 & 101,00 & 165,62 & 110,00 & 42,07 & 5015,02 & 318,32 & 61,18 & 257,14 & 114,36 & 229,15 & 233,73 & 105,83 & 547,67 & 81,68 & 2,00 & 61,23 & 235,78 & 23,44 & 23,94 & 231,03 \\
\hline Pleurodeles walt| & 29SNC07 & 101,00 & 169,51 & $\begin{array}{ll}84,83 \\
\end{array}$ & 40,99 & 4161,27 & 287,38 & 82,44 & 204,94 & $\begin{array}{l}125,92 \\
\end{array}$ & 220,59 & 225,31 & \begin{tabular}{ll|}
118,66 \\
\end{tabular} & 667,01 & 99,49 & 3,01 & 63,32 & 296,84 & 27,18 & \begin{tabular}{|l|l|}
30,14 \\
\end{tabular} & 287,32 \\
\hline Pleurodeles walt| & 29SNC08 & 88,00 & 170,53 & 83,66 & 40,89 & 4135,33 & 286,57 & 83,89 & 202,68 & 127,01 & 221,21 & 225,76 & \begin{tabular}{ll|}
119,78 \\
\end{tabular} & $\begin{array}{l}664,00 \\
\end{array}$ & 99,33 & 3,00 & 63,24 & 295,24 & 26,97 & 30,01 & 285,61 \\
\hline Pleurodeles walt| & 29 SNC10 & 71,00 & 168,25 & 89,65 & 42,91 & \begin{tabular}{|l|}
4045,68 \\
\end{tabular} & 287,78 & 80,78 & 207,00 & 127,19 & 218,07 & 222,81 & 119,20 & 583,03 & 87,85 & 2,00 & 64,57 & 262,35 & 23,98 & 24,99 & 253,35 \\
\hline Pleurodeles walt| & 29SNC17 & 101,00 & 170,53 & 86,68 & 41,03 & \begin{tabular}{|l|}
4232,24 \\
\end{tabular} & 291,12 & 82,37 & 208,75 & $\begin{array}{l}126,37 \\
\end{array}$ & $\begin{array}{ll}222,68 \\
\end{array}$ & 227,27 & 118,88 & \begin{tabular}{ll|l}
648,25 \\
\end{tabular} & 95,83 & 3,00 & 62,78 & 286,50 & 27,00 & 29,86 & 278,50 \\
\hline Pleurodeles walt| & 29SNC18 & 101,00 & 170,36 & 85,57 & 40,95 & \begin{tabular}{ll|}
4216,61 \\
\end{tabular} & 289,75 & 82,38 & 207,36 & 126,20 & 222,34 & 226,68 & 118,63 & 654,34 & 96,99 & 3,00 & 62,89 & 288,89 & 27,13 & 30,05 & 280,95 \\
\hline Pleurodeles walt| & 29SNC19 & 100,00 & 169,45 & 84,33 & 40,73 & 4178,78 & 286,88 & 81,82 & 205,06 & 125,35 & 220,79 & 225,15 & \begin{tabular}{ll|}
117,87 \\
\end{tabular} & $\begin{array}{l}663,76 \\
\end{array}$ & 98,49 & 3,00 & 62,52 & 292,10 & 27,61 & 30,92 & 284,15 \\
\hline Pleurodeles walt| & 29SNC21 & 101,00 & 164,38 & 92,12 & 42,16 & 4247,06 & 290,22 & 74,66 & 215,56 & 121,27 & 217,10 & 221,97 & 113,42 & \begin{tabular}{ll|}
612,68 \\
\end{tabular} & 91, & 2,49 & 63,49 & 272,22 & 25,95 & 26,81 & 265,08 \\
\hline Pleurodeles walt| & 29 SNC22 & 99,00 & 166,10 & 91,82 & 42,02 & 4275,52 & 292,11 & 76,33 & 215,78 & 122,47 & 219,16 & 224,04 & 114,58 & 614,17 & 91,45 & 2,67 & 63,12 & 272,23 & 26,19 & 27,32 & 265,21 \\
\hline Pleurodeles walt| & 29SNC23 & 101,00 & 168,86 & 91,32 & 42,00 & \begin{tabular}{ll|}
4281,82 \\
\end{tabular} & 294,32 & 78,88 & \begin{tabular}{|l|l|}
215,44 \\
\end{tabular} & $\begin{array}{l}124,77 \\
\end{array}$ & 221,79 & 226,66 & $\begin{array}{l}116,93 \\
\end{array}$ & 608,71 & $\begin{array}{l}90,47 \\
\end{array}$ & 2,99 & 63,12 & 269,53 & 25,78 & 27,64 & 262,48 \\
\hline Pleurodeles walt| & 29SNC24 & 100,00 & 170,19 & 90,79 & 41,82 & 4295,90 & 295,24 & 80,06 & 215,18 & 125,66 & 223,30 & 228,07 & 1117,87 & \begin{tabular}{|c|}
612,17 \\
\end{tabular} & 90,74 & 2,98 & 62,43 & \begin{tabular}{|l|l|}
270,48 \\
\end{tabular} & 26,14 & 27,79 & 263,54 \\
\hline Pleurodeles walt| & 29SNC25 & 72,00 & 171,37 & 90,26 & 41,50 & 4305,01 & 296,38 & 81,59 & 214,79 & \begin{tabular}{|l|l|}
126,64 \\
\end{tabular} & 224,69 & 229,51 & 119,16 & 611,59 & $\begin{array}{l}90,23 \\
\end{array}$ & 3,00 & 62,83 & 269,90 & 25,77 & 27,76 & 263,10 \\
\hline Pleurodeles walt| & 29SNC26 & 88,00 & 170,97 & 89,48 & 41,11 & 4314,14 & 295,55 & 81,21 & 214,34 & 126,11 & 224,43 & 229,03 & 118,54 & \begin{tabular}{|c|}
625,67 \\
\end{tabular} & 92,01 & 3,00 & 62,56 & 275,11 & 26,84 & 29,01 & 268,52 \\
\hline Pleurodeles walt| & $295 N C 27$ & 101,00 & 170,20 & 88,60 & 40,99 & 4323,06 & 294,15 & 80,47 & 213,68 & 125,06 & 223,61 & 228,18 & 117,38 & 639,31 & 94,12 & 3,00 & 62,43 & 280,42 & 27,36 & 29,82 & 274,05 \\
\hline Pleurodeles walt| & 29SNC28 & 101,00 & 169,01 & 87,66 & 40,97 & 4313,12 & 291,96 & 79,80 & 212,16 & 123,92 & 222,42 & 226,85 & 116,38 & 654,50 & 96,47 & 3,00 & 62,12 & 286,12 & 28,15 & 30,59 & 279,97 \\
\hline Pleurodeles walt| & 29SNC30 & 100,00 & 164,80 & 94,76 & 42,16 & 4339,40 & 294,27 & 73,09 & 221,18 & 120,82 & 218,96 & 223,73 & 112,79 & $\begin{array}{l}591,55 \\
\end{array}$ & 88,55 & 2,06 & 63,69 & 263,40 & 24,27 & 24,90 & 256,82 \\
\hline Pleurodeles walt| & 29SNC31 & 101,00 & 161,27 & 94,95 & 42,00 & 4402,58 & 292,56 & 69,61 & 222,95 & $\mid 116,77$ & 216,36 & 221,20 & 108,72 & 624,36 & 92,71 & 2,89 & 62,71 & 274,96 & 27,25 & 27,68 & 269,36 \\
\hline Pleurodeles walt| & 29SNC32 & 101,00 & 164,58 & 94,37 & 41,92 & 4412,68 & 295,47 & 72,80 & 222,67 & 119,62 & 219,70 & 224,62 & 111,69 & \begin{tabular}{|c|}
614,58 \\
\end{tabular} & 90,98 & 2,73 & 62,64 & 270,49 & 26,43 & 27,17 & 264,92 \\
\hline Pleurodeles walt| & 29SNC33 & 100,00 & 167,77 & 93,79 & 41,93 & \begin{tabular}{|l|l|}
4408,51 \\
\end{tabular} & 297,79 & 76,01 & 221,78 & 122,43 & 222,68 & 227,53 & 114,64 & $\begin{array}{l}605,45 \\
\end{array}$ & 89,46 & 2,95 & 62,79 & 266,27 & 25,92 & 26,94 & 260,68 \\
\hline Pleurodeles walt| & 29SNC34 & 101,00 & 169,72 & 93,09 & 41,86 & $\begin{array}{l}4404,57 \\
\end{array}$ & 299,00 & 78,24 & 220,76 & 124,28 & 224,49 & 229,21 & 116,51 & 603,04 & 88,72 & 2,98 & 62,63 & 264,73 & 25,86 & 26,98 & 259,18 \\
\hline Pleurodeles walt| & 29SNC35 & 101,00 & 171,03 & 92,25 & 41,48 & 4404,83 & 299,52 & 79,46 & 220,05 & 125,40 & 225,77 & 230,49 & 1117,50 & 604,24 & 88,76 & 3,00 & 62,41 & 264,68 & 25,77 & 27,49 & 259,25 \\
\hline Pleurodeles walt| & 29SNC38 & 100,00 & 167,84 & 89,72 & 40,97 & 4423,35 & 294,69 & 76,97 & 217,72 & 121,60 & 222,86 & 227,25 & 113,91 & \begin{tabular}{|c|}
653,12 \\
\end{tabular} & 95,80 & 3,45 & 61,27 & 282,41 & 29,44 & 31,45 & 277,99 \\
\hline Pleurodeles walt| & 29SNC39 & 100,00 & 168,15 & 88,67 & 40,81 & 4385,91 & 293,38 & 77,73 & 215,65 & 122,21 & 222,70 & 227,00 & 114,55 & 657,82 & 96,56 & 3,71 & 61,08 & 283,95 & 29,97 & 32,20 & 279,29 \\
\hline Pleurodeles walt| & 29SNC40 & 101,00 & 167,25 & 97,05 & 42,15 & 4438,80 & 300,13 & 73,75 & 226,38 & 122,15 & 222,81 & 227,46 & 114,11 & 570,75 & 85,50 & 2,00 & 63,50 & 253,58 & 23,46 & 24,21 & 247,48 \\
\hline Pleurodeles walt| & 29SNC41 & 101,00 & 166,46 & 97,10 & 42,00 & \begin{tabular}{|l|l|}
4485,43 \\
\end{tabular} & 300,43 & 72,71 & 227,71 & 120,71 & 222,62 & 227,24 & 112,62 & 584,59 & 86,96 & 2,10 & 63,03 & 257,83 & 24,48 & 25,09 & 252,44 \\
\hline Pleurodeles walt| & 29SNC42 & 99,00 & 168,70 & 96,55 & 42,00 & \begin{tabular}{ll|l}
4483,66 \\
\end{tabular} & 302,16 & 75,09 & 227,07 & \begin{tabular}{ll|l}
122,67 \\
\end{tabular} & 224,64 & 229,38 & 114,78 & 580,33 & 85,94 & 2,06 & 62,96 & 255,20 & 24,26 & 25,13 & 250,04 \\
\hline Pleurodeles walt| & 29SNC44 & 101,00 & 169,99 & 95,22 & 41,79 & 4509,82 & 302,72 & 76,65 & 226,07 & 123,49 & 226,24 & 231,00 & 115,48 & 591,50 & 86,6 & 2,87 & 61,89 & 257,60 & 25,84 & 27,04 & 253,18 \\
\hline Pleurodeles walt| & 29 SNC45 & 101,00 & 169,94 & 94,46 & 41,41 & 4514,58 & 302,27 & 76,89 & 225,38 & 123,17 & 226,18 & 230,97 & 115,35 & 601,31 & 87,88 & 3,00 & 61,71 & 260,69 & 26,58 & 27,74 & 256,66 \\
\hline Pleurodeles walt| & 29SNC47 & 100,00 & 167,73 & 92,62 & 40,97 & 4524,31 & 299,07 & 75,36 & 223,71 & \begin{tabular}{|l|l|}
120,67 \\
\end{tabular} & 224,19 & 228,77 & 112,91 & $\begin{array}{l}635,36 \\
\end{array}$ & $\begin{array}{l}92,66 \\
\end{array}$ & 3,44 & 60,82 & 272,81 & 29,39 & $\begin{array}{ll}30,81 \\
\end{array}$ & 269,64 \\
\hline Pleurodeles walt| & 29SNC48 & 101,00 & 167,37 & $\begin{array}{ll}91,63 \\
\end{array}$ & 40,88 & \begin{tabular}{|l|l|}
4518,73 \\
\end{tabular} & 297,60 & 75,26 & 222,34 & 120,13 & 223,69 & 228,17 & 112,45 & 647,64 & 94,44 & 3,90 & 60,49 & 277,18 & \begin{tabular}{|c|c|}
30,66 \\
\end{tabular} & 32,10 & 274,15 \\
\hline Pleurodeles walt| & 29SNC50 & 101,00 & 169,36 & 99,40 & 42,16 & 4546,86 & 305,86 & 73,78 & 232,08 & 122,96 & 226,42 & 231,14 & 114,82 & 551,54 & 82,71 & 2,00 & 63,51 & 244,19 & 22,46 & 23,32 & 238,44 \\
\hline Pleurodeles walt| & 29SNC52 & 101,00 & $\begin{array}{lll}169,67 \\
\end{array}$ & 98,88 & 42,01 & \begin{tabular}{|l|l|}
4587,13 \\
\end{tabular} & 306,68 & 74,25 & 232,43 & 122,60 & 227,16 & 231,83 & 114,48 & 566,97 & 83,56 & 2,08 & 62,27 & 247,49 & 24,29 & 24,99 & 243,05 \\
\hline Pleurodeles walt| & 29 SNC53 & 100,00 & 170,04 & 98,17 & 4 & 4596,44 & 306,70 & 74,80 & 231,89 & 122,87 & 227,55 & 232,26 & 114,58 & 573,44 & 83,86 & 2,58 & 61,79 & 248,75 & 25,34 & 26,21 & 244,83 \\
\hline Pleurodeles walt| & 29SNC54 & 101,00 & 168,58 & 97,49 & 41,65 & \begin{tabular}{|l|}
4619,20 \\
\end{tabular} & 305,30 & 73,76 & 231,54 & \begin{tabular}{|l|l|}
121,07 \\
\end{tabular} & 226,41 & 231,19 & 113,01 & 590,22 & 85,94 & 2,99 & 61,12 & 254,27 & 26,74 & 27,45 & 251,14 \\
\hline Pleurodeles walt| & 29 SNC55 & 100,00 & 168,90 & 96,51 & 41,20 & 4621,95 & 304,91 & 74,40 & 230,51 & 121,21 & 226,82 & 231,37 & $\begin{array}{ll}113,07 \\
\end{array}$ & 597,31 & 86,69 & 3,00 & 60,85 & 256,22 & 27,24 & 28,15 & 253,45 \\
\hline Pleurodeles walt| & 29SNC56 & 101,00 & $\begin{array}{ll}164,47 \\
\end{array}$ & 95,36 & 40,94 & 4653,64 & 300,76 & 70,51 & 230,25 & 116,51 & 222,78 & 227,54 & 108,55 & 636,12 & 92,18 & 3,69 & 60,01 & 270,33 & 30,59 & 31,18 & 268,80 \\
\hline Pleurodeles walt| & 29SNC60 & 100,00 & 168,91 & 102,19 & 42,14 & 4666,86 & 309,80 & 71,14 & 238,66 & \begin{tabular}{ll|}
121,42 \\
\end{tabular} & 227,67 & 232,32 & 113,08 & 548,16 & 81,95 & 2,00 & 62,98 & 240,78 & 22,67 & 23,01 & 235,76 \\
\hline Pleurodeles walt| & $29 \mathrm{SNC}$ & 100,00 & 169,39 & 102,09 & 42, & 468 & 310,75 & 71,73 & 239,02 & 121,44 & 228,44 & 233,05 & 113,19 & 552,32 & 81,83 & 2,00 & 62,34 & 240,81 & 23,25 & 23,92 & 236,45 \\
\hline Pleurodeles walt| & 29SNC62 & 101,00 & 169,70 & 101,47 & 42,00 & 4702,51 & 310,90 & 72,32 & 238,58 & 121,60 & 228,84 & 233,60 & 113,19 & 557,38 & 81,73 & 2,03 & 61,72 & 241,28 & 24,33 & 24,76 & 237,62 \\
\hline Pleurodeles walt| & 295NC64 & 100,00 & $\mid 167,67$ & 99,66 & 41,58 & 4728,05 & 308,14 & 71,10 & 237,04 & $\mid 118,99$ & 227,06 & 231,73 & $\mid$\begin{tabular}{|l|l|}
110,79 \\
\end{tabular} & 586,38 & 84,68 & 2,98 & 60,50 & 249,87 & 27,36 & 27,77 & 247,77 \\
\hline Pleurodeles walt| & 29SNC65 & 101,00 & 165,21 & 98,42 & 41,09 & 4744,75 & 305,35 & 69,42 & 235,94 & 116,34 & 224,94 & 229,67 & 108,29 & 609,86 & 87,75 & 3,01 & 60,04 & 257,88 & 29,32 & 29,53 & 256,77 \\
\hline Pleurodeles walt| & $29 \mathrm{SNCE}$ & 100,00 & 163,32 & 96,95 & 40, & 4748 & 302,52 & 68,20 & 234 & 113,71 & 223 & 227 & 106,26 & 633,58 & 90,95 & 3,66 & 59,27 & 266,10 & 31,68 & 31,91 & 265 \\
\hline Pleurodeles walt| & 29SNC67 & 101,00 & 160,92 & 95,55 & 40,51 & 4762,73 & 299,50 & 66,41 & 233,08 & 108,31 & 221,06 & 225,57 & 103,85 & 660,70 & 94,83 & 4,00 & 58,89 & 276,39 & 33,88 & 33,97 & 276,32 \\
\hline Pleurodeles walt| & 29SNC68 & 101,00 & 163,25 & 94,70 & 40,31 & \begin{tabular}{|l|}
4730,67 \\
\end{tabular} & 300,30 & 68,96 & 231,34 & 111,72 & 222,91 & 227,37 & 106,33 & 657,62 & 94,41 & 4,00 & 58,85 & 274,96 & 33,71 & 34,14 & 274,80 \\
\hline Pleurodeles walt| & 29SNC69 & 100,00 & 165,62 & 94,16 & 40,24 & \begin{tabular}{|l|l|}
4717,41 \\
\end{tabular} & 301,63 & 71,25 & 230,38 & 115,59 & 224,87 & 229,36 & 108,58 & 652,73 & 93,69 & 4,00 & 58,75 & 272,66 & 33,34 & 34,18 & 272,37 \\
\hline Pleuroc & 29SNC70 & 101,00 & 166,79 & 105,49 & 4209 & 2 & 312,99 & 66,70 & 9 & 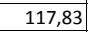 & 227 & & & 554,83 & 82,57 & 2,00 & 6 & 241 & 23,42 & 23,73 & 236,96 \\
\hline Pleurodeles walt| & 29SNC75 & 100,00 & 164,53 & 100,09 & 41,03 & $4838,18]$ & 307,66 & 67,28 & 240,38 & 114,29 & 226,21 & 230, & 106,54 & $\begin{array}{l}604,28 \\
\end{array}$ & 86,00 & 3,00 & 59,13 & 252,46 & 30,18 & 30,18 & 252,28 \\
\hline Pleurodeles walt| & 29SNC76 & 101,00 & 160,29 & 98,06 & 40,77 & 4851,99 & 302,55 & 64,27 & 238,27 & 104,42 & 223,43 & 226,39 & 102,36 & 641,73 & 91,18 & 3,81 & 58,25 & 266,81 & 33,29 & 33,29 & 266,81 \\
\hline
\end{tabular}




\begin{tabular}{|c|c|c|c|c|c|c|c|c|c|c|c|c|c|c|c|c|c|c|c|c|c|}
\hline TAXON & UTM & $\mathrm{km} 2$ & BI01 & BIO2 & $B 103$ & BIO4 & B105 & B106 & B107 & B108 & B109 & B1010 & BIO11 & B1012 & BIO13 & B1014 & BIO15 & B1016 & B1017 & B1018 & B1019 \\
\hline Pleurodeles walt| & 29SNC77 & 101,00 & 158,54 & 96,49 & 40,18 & 4855,58 & 299,73 & 63,38 & 236,35 & 100,76 & 222,23 & 224,66 & 100,60 & 666,05 & 94,64 & 4,08 & 57,82 & 276,19 & 35,39 & 35,39 & 276,19 \\
\hline Pleurodeles walt| & 29SNC79 & 101,00 & 163,50 & 95,29 & 40,00 & 4822,36 & 302,59 & 68,15 & 234,43 & 106,34 & 224,34 & 228,70 & 105,38 & 659,75 & 93,87 & 4,00 & 57,83 & 273,29 & 35,38 & 35,75 & 273,29 \\
\hline Pleurodeles walt| & 29SNC80 & 101,00 & 165,24 & 108,90 & 42,22 & 4951,82 & 316,80 & 62,73 & 254,06 & $\begin{array}{l}114,69 \\
\end{array}$ & 227,97 & 232,64 & \begin{tabular}{|l|}
106,17 \\
\end{tabular} & 558,11 & 82,71 & 2,06 & 61,14 & 239,67 & 24,29 & 24,41 & 236,34 \\
\hline Pleurodeles walt| & 29SNC81 & 101,00 & 165,59 & 108,62 & 42,09 & 4964,21 & 317,28 & 63,29 & 253,99 & 114,89 & 228,42 & 233,08 & \begin{tabular}{|l|}
106,27 \\
\end{tabular} & 561,88 & 82,25 & 2,18 & 60,46 & 239,21 & 25,24 & 25,36 & 236,65 \\
\hline Pleurodeles walt| & 29SNC82 & 99,00 & 167,03 & 107,19 & 42,01 & 4950,75 & 317,14 & 65,50 & 251,64 & 116,11 & 229,61 & 234,29 & 107,79 & 559,42 & 80,96 & 2,64 & 60,02 & 236,69 & 26,40 & 26,50 & 234,41 \\
\hline Pleurodeles walt| & 29SNC84 & 101,00 & 163,50 & 103,66 & 41,22 & \begin{tabular}{ll|}
4958,27 \\
\end{tabular} & 311,40 & 63,87 & 247,52 & 112,01 & 227,62 & 230,76 & 104,36 & 593,24 & 83,70 & 3,01 & 58,59 & 246,40 & 29,81 & 29,81 & 246,24 \\
\hline 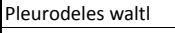 & 29SNC85 & 100,00 & 163,64 & 101,55 & 41,01 & 4935,13 & 309,45 & 65,10 & 244,36 & 108,31 & 227,21 & 230,59 & $\begin{array}{l}104,60 \\
\end{array}$ & 598,99 & 84,16 & 3,00 & 58,12 & 247,69 & 30,76 & 30,76 & 247,69 \\
\hline Pleurodeles walt| & 29SNC86 & 100,00 & 161,19 & 99,26 & 40,70 & 4930,57 & 305,38 & 63,90 & 241,49 & 102,56 & 226,06 & 228,18 & 102,29 & 624,39 & 87,51 & 3,77 & 57,59 & 257,09 & 33,38 & 33,38 & 257,09 \\
\hline Pleurodeles walt| & 29SNC87 & 100,00 & 157,48 & 97,19 & 40,03 & $\begin{array}{l}4938,52 \\
\end{array}$ & 300,59 & \begin{tabular}{|l|l|}
61,44 \\
\end{tabular} & 239,15 & \begin{tabular}{ll|l}
98,67 \\
\end{tabular} & 223,75 & 224,75 & \begin{tabular}{ll|l}
98,67 \\
\end{tabular} & $\begin{array}{l}661,51 \\
\end{array}$ & 92,89 & 4,07 & 57,07 & 271,88 & 36,14 & 36,14 & 271,88 \\
\hline Pleurodeles walt| & 295NC89 & 100,00 & 163,08 & 96,52 & 40,01 & 4922,84 & 304,76 & 66,54 & 238,22 & 104,04 & 225,79 & 229,75 & 103,99 & 654,01 & 92,12 & 4,03 & 57,18 & 268,90 & 36,06 & 36,14 & 268,90 \\
\hline Pleurodeles walt| & 29SNC90 & 100,00 & 163,67 & 112,38 & 42,31 & 5089,53 & 320,41 & 58,57 & 261,84 & 111,71 & 228,54 & 232,88 & 103,12 & 562,60 & 82,93 & 2,10 & 60,35 & 238,93 & 25,01 & 25,10 & 235,98 \\
\hline Pleurodeles walt| & 29SNC91 & 100,00 & 164,76 & 111,73 & 42,12 & 5095,89 & 321,09 & 60,14 & 260,95 & 112,42 & 229,47 & 233,99 & 103,97 & 560,86 & 81,73 & 2,19 & 59,75 & 236,43 & 26,09 & 26,09 & 234,05 \\
\hline Pleurodeles walt| & 29SNC92 & 101,00 & 165,37 & 109,80 & 42,00 & 5080,16 & 319,78 & 61,63 & 258,15 & 113,12 & 230,16 & 234,41 & 104,70 & 562,89 & 80,75 & 2,80 & 59,01 & 235,45 & 27,29 & 27,30 & 233,49 \\
\hline Pleurodeles walt| & 29SNC93 & 100,00 & 163,36 & 107,68 & 41,78 & 5076,10 & 316,32 & \begin{tabular}{ll|}
60,82 \\
\end{tabular} & 255,49 & 1111,17 & 228,91 & 232,37 & 102,78 & 580,06 & 81,76 & 3,00 & 58,43 & 240,55 & 28,79 & 28,79 & 239,58 \\
\hline Pleurodeles walt| & 29SNC94 & 100,00 & 161,65 & 105,11 & 41,13 & 5062,79 & 312,44 & $\begin{array}{ll}60,52 \\
\end{array}$ & 251,92 & 107,12 & 228,18 & 230,52 & 101,29 & $\begin{array}{l}597,04 \\
\end{array}$ & 83,3 & 3,19 & 57,84 & 245,71 & 30,75 & 30,75 & 245,55 \\
\hline Pleurodeles walt| & 29SNC95 & 101,00 & 162,26 & 102,82 & 40,99 & \begin{tabular}{|l|}
5036,47 \\
\end{tabular} & 310,58 & 62,31 & 248,27 & 103,86 & 228,90 & 230,65 & 102,00 & 598,80 & 83,23 & 3,07 & 57,54 & 245,44 & 31,23 & 31,23 & 245,44 \\
\hline Pleurodeles walt| & 29SNC96 & 100,00 & 161,72 & 100,41 & 40,40 & \begin{tabular}{|l|l|}
5014,36 \\
\end{tabular} & 307,90 & 63,07 & 244,83 & 101,64 & 227,53 & 229,77 & 101,64 & $\begin{array}{l}610,86 \\
\end{array}$ & 84,42 & 3,90 & 56,55 & 248,98 & 33,86 & 33,86 & 248,98 \\
\hline Pleurodeles walt| & 29SNC97 & 101,00 & 160,32 & 98,67 & 40,00 & 5013,92 & 305,33 & 62,47 & 242,87 & 100,35 & 227,13 & 228,47 & 100,35 & \begin{tabular}{|c|}
630,48 \\
\end{tabular} & 87,14 & 4,00 & 56,21 & 256,55 & 35,39 & 35,39 & 256,55 \\
\hline Pleurodeles walt| & 29SNC99 & 100,00 & 162,60 & 97,82 & 39,99 & 5028,22 & 307,13 & \begin{tabular}{|c|}
64,41 \\
\end{tabular} & 242,72 & 102,16 & 226,96 & 230,84 & 102,16 & 649,82 & 90,50 & 4,00 & 56,37 & 264,99 & 36,64 & 36,65 & 264,99 \\
\hline Pleurodeles walt| & 29SND05 & 101,00 & 155,97 & 73,29 & 40,97 & 3622,09 & 252,84 & 75,74 & 177,10 & 117,80 & 199,97 & 202,88 & 109,98 & \begin{tabular}{|l|l|}
738,07 \\
\end{tabular} & 113, & 4,51 & 60,61 & 319,44 & 34,41 & 39,11 & 307,22 \\
\hline Pleurodeles walt| & $295 N D 06$ & 101,00 & 149,04 & 73,22 & 40,77 & 3633,73 & 246,47 & 68,94 & $\begin{array}{l}177,54 \\
\end{array}$ & 111,00 & $\begin{array}{l}193,27 \\
\end{array}$ & 196,21 & $\begin{array}{l}103,07 \\
\end{array}$ & 806,23 & 121,74 & 5,64 & 59,51 & 345,03 & 40,37 & 44,62 & 333,78 \\
\hline Pleurodeles walt| & 29SND08 & 101,00 & 154,16 & 73,18 & 41,81 & $\begin{array}{l}3476,62 \\
\end{array}$ & 247,18 & 74,14 & 173,04 & $\begin{array}{l}117,32 \\
\end{array}$ & $\begin{array}{l}195,93 \\
\end{array}$ & $\begin{array}{l}198,56 \\
\end{array}$ & $\begin{array}{l}109,29 \\
\end{array}$ & $\begin{array}{l}778,49 \\
\end{array}$ & 1117,54 & 5,62 & 58,76 & 330,55 & 39,95 & 45,65 & 319,44 \\
\hline Pleurodeles walt| & 29SND09 & 101,00 & 152,42 & 73,80 & 42,05 & 3457,76 & 245,39 & 72,05 & 173,34 & 115,68 & 193,97 & 196,45 & 107,71 & 810,14 & 120,76 & 6,13 & 57,97 & 341,25 & 43,40 & \begin{tabular}{|l|l|l|}
49,26 \\
\end{tabular} & 330,91 \\
\hline Pleurodeles walt| & 29SND11 & 101,00 & 168,36 & 81,61 & 40,94 & \begin{tabular}{ll|l|}
4048,53 \\
\end{tabular} & 280,49 & 82,40 & 198,09 & 125,47 & 217,97 & 221,82 & 118,03 & 666,83 & 99,99 & 3,01 & 62,14 & 292,33 & 28,04 & 31,66 & 283,46 \\
\hline Pleurodeles walt| & 29SND12 & 101,00 & 166,69 & 80,13 & 40,82 & 3974,29 & 276,01 & 81,52 & 194,50 & 124,59 & 215,32 & 218,92 & 117,01 & 675,43 & 101,7 & 3,45 & 61,80 & 295,13 & 29,08 & 32,92 & 285,80 \\
\hline Pleurodeles walt| & 29 SND15 & 100,00 & 159,96 & 77,63 & 40,96 & 3799,61 & 263,78 & 76,55 & 187,23 & 119,64 & 206,39 & 209,51 & 112,04 & 727,13 & 109,49 & 4,44 & 60,20 & 312,69 & 34,41 & 38,76 & 303,14 \\
\hline Pleurodeles walt| & 29SND16 & 100,00 & 153,84 & 77,45 & 40,77 & 3808,84 & 257,99 & 70,53 & $\begin{array}{l}187,46 \\
\end{array}$ & 113,59 & 200,48 & 203,54 & 105,87 & \begin{tabular}{ll|}
788,12 \\
\end{tabular} & $\begin{array}{l}117,47 \\
\end{array}$ & 5,51 & 59,16 & 335,49 & 39,89 & 43,88 & 326,82 \\
\hline Pleurodeles walt| & 29SND17 & 101,00 & $\begin{array}{ll}140,89 \\
\end{array}$ & 77,42 & 40,20 & \begin{tabular}{|l|l|}
3896,44 \\
\end{tabular} & 247,82 & 57,69 & \begin{tabular}{ll|}
190,13 \\
\end{tabular} & 100,32 & 189,19 & $\begin{array}{l}192,27 \\
\end{array}$ & 92,55 & $\begin{array}{l}923,35 \\
\end{array}$ & \begin{tabular}{|l|l|}
136,53 \\
\end{tabular} & 7,84 & 57,81 & 387,36 & 51,57 & 54,11 & 380,57 \\
\hline Pleurodeles walt| & 29SND18 & 100,00 & 150,32 & 77,86 & 41,17 & 3751,52 & 253,42 & 66,79 & 186,64 & 110,63 & 196,26 & 199,05 & 102,79 & 842,71 & 124,44 & 6,59 & 57,92 & 354,03 & 45,62 & 49,85 & 346,48 \\
\hline Pleurodeles walt| & 29SND22 & 100,00 & 167,60 & 83,33 & 40,74 & 4124,58 & 282,55 & 80,19 & 202,35 & 123,82 & 218,37 & 222,03 & 116,25 & 674,42 & 99,93 & 3,95 & 61,12 & 291,85 & 30,32 & 33,83 & 284,68 \\
\hline Pleurodeles walt| & 29SND26 & 101,00 & 159,71 & 81,56 & 41,01 & 3964,80 & 269,88 & 73,31 & 196,58 & 117,48 & 208,47 & 211,54 & 109,77 & 756,41 & $\begin{array}{l}111,66 \\
\end{array}$ & 5,06 & 58,96 & 320,51 & 38,33 & 42,25 & 313,91 \\
\hline Pleurodeles walt| & 29SND27 & 101,00 & 147,54 & 81,31 & 40,44 & 4037,86 & 260,08 & 61,37 & 198,71 & 105,03 & 197,73 & 200,82 & 97,41 & 880,62 & 129,94 & 7,08 & 57,73 & 368,51 & 48,65 & 51,27 & 363,81 \\
\hline Pleurodeles walt| & 29SND28 & 101,00 & 144,18 & 81,60 & 40,51 & 4038,77 & 257,03 & 57,77 & 199,26 & 101,73 & 194,40 & 197,49 & 93,99 & \begin{tabular}{|l|l|}
927,78 \\
\end{tabular} & 136,62 & 7,98 & 57,12 & 385,76 & 53,21 & 55,56 & 381,90 \\
\hline Pleurodeles walt| & 29SND31 & 100,00 & \begin{tabular}{ll|l}
167,67 \\
\end{tabular} & 86,84 & 40,60 & 4312,47 & 289,58 & 78,11 & 211,47 & 122,13 & 221,16 & 225,22 & 114,66 & 672,53 & 98,92 & 3,92 & 60,59 & 289,03 & 31,02 & 33,73 & 284,16 \\
\hline Pleurodeles walt| & 29SND34 & 100,00 & 166,83 & 85,17 & 40,92 & \begin{tabular}{|l|l|}
4174,14 \\
\end{tabular} & 283,97 & 77,71 & 206,26 & 122,48 & 218,47 & 221,85 & 114,71 & 695,73 & 102,21 & 4,03 & 59,65 & 296,03 & 33,76 & 37,29 & 290,63 \\
\hline Pleurodeles walt| & 29SND35 & 101,00 & 166,06 & 85,14 & 40,97 & 4148,63 & 282,49 & 76,77 & 205,72 & 121,66 & 217,32 & 220,53 & 113,93 & 709,63 & 104,27 & 4,45 & 59,05 & 300,66 & 35,14 & 38,83 & 295,42 \\
\hline Pleurodeles walt| & 29SND36 & 101,00 & 163,01 & 85,30 & 40,99 & 4139,85 & 279,47 & 73,62 & 205,86 & 118,69 & 214,20 & 217,29 & 110,95 & 745,59 & \begin{tabular}{|l|l|}
109,38 \\
\end{tabular} & 5,01 & 58,52 & 313,82 & 38,47 & 41,99 & 309,20 \\
\hline Pleurodeles walt| & 29SND38 & 101,00 & 154,11 & 86,06 & 40,92 & $4160,23 \mid$ & 272,22 & 64,23 & 207,99 & 109,68 & 205,85 & 208,84 & 101,98 & 852,33 & 124,75 & 6,88 & 57,12 & 353,53 & 48,20 & 50,95 & 350,97 \\
\hline Pleurodeles walt| & 29SND40 & 100,00 & 168,20 & 89,94 & 40,42 & \begin{tabular}{|l|l|}
4473,58 \\
\end{tabular} & 295,80 & 76,41 & 219,39 & 121,14 & 223,95 & 228,03 & 113,50 & 657,81 & $\begin{array}{ll}96,03 \\
\end{array}$ & 4,00 & 60,04 & $280,67 \mid$ & 31,31 & 33,32 & 277,32 \\
\hline Pleurodeles walt| & $295 N D 41$ & 101,00 & 168,65 & 89,19 & 40,51 & 4432,78 & 294,78 & 77,14 & 217,64 & 121,91 & 223,91 & 227,95 & 114,21 & 662,52 & 96,85 & 4,00 & 60,02 & 282,14 & 31,64 & 34,01 & 278,72 \\
\hline Pleurodeles walt| & 29SND45 & 101,00 & 165,76 & 88,03 & 40,78 & 4321,19 & 288,15 & 74,32 & 213,82 & 119,42 & 219,42 & 222,85 & \begin{tabular}{|l|l|}
111,97 \\
\end{tabular} & 723,74 & $\begin{array}{l}105,79 \\
\end{array}$ & 4,87 & 58,48 & 304,00 & 37,37 & 40,32 & 300,70 \\
\hline Pleurodeles walt| & 29SND46 & 101,00 & 166,58 & 88,53 & 40,98 & 4293,35 & 288,52 & 74,46 & 214,05 & 120,34 & 219,92 & 223,14 & 112,81 & 727,41 & 106,05 & 5,03 & 58,10 & 304,27 & 38,17 & \begin{tabular}{|l|l|}
41,38 \\
\end{tabular} & 301,09 \\
\hline Pleurodeles walt| & 29SND54 & 100,00 & 163,62 & 90,20 & 40,02 & 4533,12 & 292,51 & 70,56 & 221,95 & 115,70 & 220,47 & 224,08 & 107,92 & 735,01 & \begin{tabular}{|l|l|}
107,10 \\
\end{tabular} & 5,02 & 58,32 & 306,96 & 38,58 & 40,59 & 305,63 \\
\hline Pleurodeles walt| & 29SND56 & 100,00 & 164,14 & 90,99 & 40,28 & 4499,20 & 292,42 & 70,03 & 222,39 & 115,91 & 220,46 & 223,79 & 108,37 & 758,66 & 1110,26 & 5,55 & 57,46 & 314,56 & 41,55 & 43,99 & 313,51 \\
\hline Pleurodeles walt| & $\begin{array}{l}\text { 29SND57 } \\
\end{array}$ & 101,00 & 163,58 & 91,65 & 40, & 4487,99 & 292,20 & 68,96 & 223,24 & $\begin{array}{l}114,77 \\
\end{array}$ & 219,93 & 223,01 & 107,82 & 778,36 & 112,98 & 5,93 & 57,09 & 321,51 & 43,46 & 45,93 & 320,79 \\
\hline Pleurodeles walt| & 29SND61 & 100,00 & 168,42 & 93,18 & 40,17 & $\begin{array}{l}4677,65 \\
\end{array}$ & 302,26 & 73,77 & 228,49 & 119,18 & 227,10 & 231,18 & \begin{tabular}{ll|}
111,43 \\
\end{tabular} & 659,02 & 94,8 & 4,00 & 58,62 & 275,31 & 33,64 & 35,16 & 274,36 \\
\hline Pleurodeles walt| & 29SND66 & 101,00 & 165,61 & 93,09 & 40,11 & 4654,14 & 298,53 & 69,45 & 229,09 & 114,68 & 224,13 & 227,40 & 108,00 & 751,99 & 108,81 & 5,59 & 57,07 & 310,31 & 41,83 & 44,10 & 310,05 \\
\hline Pleurodeles walt| & 29SND67 & 100,00 & 162,12 & 93,45 & 40,02 & 4683,37 & 296,33 & 65,63 & 230,70 & 106,61 & 221,41 & 224,52 & 104,51 & 799,38 & 115,80 & 6,27 & 56,69 & 329,00 & 45,86 & 47,63 & 328,94 \\
\hline Pleurodeles walt| & 29SND71 & 100,00 & 168,11 & 94,80 & 40,01 & 4798,65 & 305,51 & 71,85 & 233,66 & 116,48 & 228,52 & 232,59 & 109,66 & 657,29 & 93,77 & 4,01 & 57,93 & 271,99 & 34,92 & 36,13 & 271,84 \\
\hline Pleurodeles walt| & 29 SND74 & 101,00 & 163,90 & 93,73 & 39,83 & 4823,81 & 301,46 & 67,69 & 233,77 & 106,79 & 225,15 & 228,75 & 105,49 & 737,46 & 106,23 & 5,32 & 57,22 & 304,37 & 41,04 & 42,31 & 304,37 \\
\hline Pleurodeles walt| & 29SND76 & 101,00 & 166,34 & 94,80 & 39,87 & 4805,36 & 303,58 & 68,38 & 235,21 & 111,06 & 227,19 & 230,44 & 107,33 & 748,79 & 107,79 & 5,66 & 56,58 & 307,78 & 42,49 & 44,37 & 307,73 \\
\hline Pleurodeles walt| & 29SND80 & 101,00 & 166,63 & 96,48 & 40,00 & 4914,35 & 307,64 & 69,17 & 238,47 & $\mid 107,97$ & 228,70 & 232,91 & $\mid$\begin{tabular}{|l|l|}
107,09 \\
\end{tabular} & $\mid 646,56$ & $\mid 91,14$ & 4,00 & 57,21 & 265,65 & 35,67 & $\mid 36,13$ & 265,65 \\
\hline Pleurodeles walt| & 29SND81 & 101,00 & 168,40 & 96,43 & 40,00 & \begin{tabular}{|l|l|}
4914,53 \\
\end{tabular} & 308,99 & 70,55 & 238,44 & 113,75 & 230,43 & 234, & 108,68 & 649,91 & 91,89 & 4,05 & 57,22 & 267,05 & 35,42 & 36,48 & 267,05 \\
\hline Pleurodeles walt| & 29SND82 & 100,0 & 166 & 95,78 & 39,86 & 皮 & 307,14 & 68,68 & 238,46 & 107,86 & 22 & 232,66 & 106 & 683,16 & 97 & 4,9 & 56,91 & 280,67 & 38,24 & 39,23 & 280,67 \\
\hline Pleurodeles walt| & 29SND85 & 99,00 & 163,36 & 95,07 & 39,14 & 4975,53 & 304,82 & 65,19 & 239,63 & 103,05 & 226,75 & 230,31 & 103,01 & 759,23 & 109,09 & 5,89 & 56,40 & 311,86 & 43,72 & 44,89 & 311,86 \\
\hline Pleurodeles walt| & 29SND86 & 100,00 & 164,90 & 95,70 & 39,27 & 4975,12 & 306,28 & 65,64 & 240,64 & 105,07 & 228,30 & 231,51 & 104,17 & 762,81 & 109,64 & 5,84 & 56,31 & 312,88 & 43,97 & 45,47 & 312,88 \\
\hline Pleurodeles walt| & 29SND90 & 100,00 & 165,34 & 97,75 & 39,97 & 5033,34 & 309,49 & 66,49 & 243,01 & 104,96 & 229,23 & 233,44 & 104,66 & 649,04 & 90,68 & 4,01 & 56,50 & 264,87 & 36,60 & 36,92 & 264,87 \\
\hline Pleuroc & 29SND92 & 100,0 & 167,01 & 97,38 & 39, & 2 & 311 & 67,58 & 5 & $=1$ & & & 10 & 672,80 & $\begin{array}{l}94,69 \\
\end{array}$ & 91 & 56,41 & 274,65 & $3 \varepsilon$ & 39,36 & 27 \\
\hline Pleurodeles walt| & 29SND93 & 100,00 & 166,58 & 97,03 & 39,23 & $5067,16[$ & 310,69 & 67,06 & 243,63 & 107,18 & 231,19 & 234,9 & 105, & 693,44 & $98,05 \mid$ & 5,00 & 56,36 & 283,46 & 39,40 & $40,47 \mid$ & 283,46 \\
\hline Pleurodeles walt| & 29SND94 & 100,00 & 164,63 & 96,36 & 39,00 & 5094,30 & 309,10 & 65,31 & 243,79 & 103,10 & 229,80 & 233,27 & 103,05 & 729,34 & 103,74 & 5,38 & 56,13 & 298,24 & 42,26 & 43,34 & 298,24 \\
\hline
\end{tabular}




\begin{tabular}{|c|c|c|c|c|c|c|c|c|c|c|c|c|c|c|c|c|c|c|c|c|c|}
\hline TAXON & UTM & $\mathrm{km} 2$ & B101 & B102 & $\mathrm{BIO3}$ & BIO4 & B105 & B106 & B107 & B108 & B109 & B1010 & BIO11 & BIO12 & B1013 & BIO14 & BIO15 & BIO16 & BIO17 & B1018 & B1019 \\
\hline Pleurodeles walt| & 29SND96 & 101,00 & 161,90 & 95,79 & 38,71 & 5140,64 & 307,12 & 61,99 & 245,13 & 99,61 & 227,89 & 231,10 & 99,61 & 788,45 & 113,31 & 6,03 & 55,97 & 322,89 & 46,10 & 47,06 & 322,89 \\
\hline Pleurodeles walt| & 29SND97 & 100,00 & 163,64 & 96,61 & 38,69 & 5152,31 & 309,19 & 62,41 & 246,78 & 101,27 & 229,80 & 232,76 & 100,99 & 789,01 & 113,33 & 6,22 & 55,85 & 322,31 & 46,76 & 48,03 & 322,31 \\
\hline Pleurodeles walt| & 29SPBO0 & 100,00 & 168,65 & 91,91 & 41,97 & 4323,17 & 288,65 & 71,93 & 216,72 & 125,49 & 223,02 & 227,16 & 116,65 & 520,02 & 86,18 & 1,01 & 68,52 & 247,88 & 15,63 & 19,26 & 231,80 \\
\hline Pleurodeles walt| & 29SPB01 & 101,00 & 162,03 & 94,36 & 41,61 & \begin{tabular}{|l|l|}
4497,07 \\
\end{tabular} & 288,29 & 63,89 & 224,40 & 117,19 & 218,91 & 223,10 & 108,31 & 555,68 & 89,50 & 1,30 & 66,64 & 258,63 & \begin{tabular}{ll|}
18,44 \\
\end{tabular} & 21,93 & 244,09 \\
\hline Pleurodeles walt| & 29SPB03 & 101,00 & 158,06 & 98,16 & 41,13 & \begin{tabular}{|l|l|}
4706,17 \\
\end{tabular} & 292,82 & 57,77 & 235,05 & 110,68 & 217,75 & 221,95 & 101,91 & 579,27 & 90,05 & 1,99 & \begin{tabular}{|l|l|}
64,43 \\
\end{tabular} & 262,06 & 21,21 & 24,19 & 249,89 \\
\hline Pleurodeles walt| & 29SPB04 & 101,00 & 162,26 & 99,50 & 41,29 & 4747,51 & 299,03 & 61,25 & 237,78 & 114,29 & 222,41 & 226,65 & 105,52 & 555,11 & 85,60 & 1,98 & 64,07 & 250,12 & 20,58 & 23,46 & 238,41 \\
\hline Pleurodeles walt| & 29SPB05 & 100,00 & 163,97 & 101,37 & 41,34 & 4816,27 & 303,75 & 62,08 & 241,66 & 115,01 & 224,98 & 229,16 & 106,18 & 546,64 & 83,50 & 2,00 & 63,37 & 244,04 & 20,84 & 23,48 & 233,34 \\
\hline Pleurodeles waltl & 29SPBO6 & 101,00 & 166,78 & 103,09 & 41,77 & 4864,45 & 308,96 & 64,24 & 244,73 & 117,18 & 228,35 & 232,62 & 108,45 & 531,27 & 80,81 & 1,99 & 62,92 & 235,55 & 20,77 & 23,04 & 225,63 \\
\hline Pleurodeles walt| & 29SPB07 & 101,00 & 166,32 & 105,44 & \begin{tabular}{|l|l|}
41,88 \\
\end{tabular} & 4943,26 & 312,49 & 62,73 & 249,76 & 115,83 & 229,00 & 233,25 & 107,03 & 535,87 & 80,73 & 2,00 & 62,05 & 234,58 & 21,63 & 23,64 & 226,01 \\
\hline Pleurodeles walt| & 29SPB08 & 100,00 & 167,55 & 107,56 & \begin{tabular}{|l|l|}
41,97 \\
\end{tabular} & 5003,47 & 316,84 & 62,99 & 253,84 & 116,34 & 230,95 & 235,25 & 107,44 & 530,96 & 79,44 & 2,00 & 61,50 & 230,09 & 21,97 & 23,82 & 222,77 \\
\hline Pleurodeles walt| & 29SPB09 & 100,00 & 166,65 & 110,11 & 42,02 & 5078,42 & 319,97 & 61,01 & 258,96 & 114,61 & 231,07 & 235,43 & 105,78 & 538,22 & 79,76 & 2,00 & 60,83 & 230,49 & 23,08 & 24,19 & 224,76 \\
\hline Pleurodeles walt| & 29SPB10 & 83,00 & 172,73 & 90,49 & 41,49 & 4345,16 & 291,22 & 75,65 & 215,57 & 128,91 & 227,13 & 231,16 & 120,17 & 499,02 & 81,41 & 1,00 & 68,00 & 236,81 & \begin{tabular}{|l|}
14,28 \\
\end{tabular} & 18,78 & 220,00 \\
\hline Pleurodeles walt| & 29SPB11 & 99,00 & 168,63 & 92,33 & 41,09 & 4481,92 & 291,86 & 70,19 & 221,67 & 123,23 & 224,88 & 228,95 & 114,35 & 520,10 & 83,18 & 1,01 & 66,93 & 242,62 & 16,15 & 20,50 & 226,66 \\
\hline Pleurodeles walt| & 29SPB13 & 100,00 & 163,67 & 96,69 & \begin{tabular}{|l|l|}
40,97 \\
\end{tabular} & 4727,12 & 296,40 & 62,81 & 233,59 & 115,68 & 223,35 & 227,42 & 106,75 & 545,74 & 84,32 & 1,70 & 64,48 & 246,99 & 19,23 & 23,10 & 233,35 \\
\hline Pleurodeles walt| & 29SPB14 & 100,00 & 164,15 & 98,47 & 40,99 & 4808,23 & 300,24 & 62,28 & 237,96 & 114,95 & 224,83 & 228,98 & 106,16 & 543,03 & 83,13 & 1,86 & 63,62 & 243,27 & 19,80 & 23,49 & 230,58 \\
\hline Pleurodeles waltt & 29SPB15 & 101,00 & 166,02 & 100,20 & 41,00 & 4869,35 & 304,94 & 63,33 & 241,61 & 115,96 & 227,46 & 231,61 & 107,26 & 532,74 & 81,03 & 1,93 & 63,12 & 236,72 & 20,00 & 23,43 & 224,84 \\
\hline Pleurodeles walt| & 29SPB16 & 100,00 & 169,62 & 101,78 & 41,12 & 4908,01 & 310,38 & 66,19 & 244,19 & 118,84 & 231,52 & 235,58 & 110,12 & 514,27 & 77,93 & 1,73 & 62,67 & 227,15 & 19,65 & 22,79 & 215,99 \\
\hline Pleurodeles walt| & 29SPB17 & 100,00 & 168,05 & 104,46 & 41,20 & 5005,48 & 313,51 & 63,50 & 250,01 & 116,38 & 231,39 & 235,43 & 107,52 & 524,31 & 78,49 & 1,98 & 61,72 & 228,42 & 21,01 & 23,75 & 218,70 \\
\hline Pleurodeles walt| & 29SPB18 & 101,00 & 168,43 & 106,74 & \begin{tabular}{|l|l|l}
41,49 \\
\end{tabular} & 5064,67 & 317,17 & 62,97 & 254,19 & 116,14 & 232,58 & 236,60 & 107,19 & 524,31 & 77,78 & 2,00 & 60,91 & 225,94 & 21,78 & 23,97 & 217,52 \\
\hline Pleurodeles walt| & 29SPB19 & 100,00 & 168,67 & 108,60 & 41,74 & 5121,81 & 320,40 & 62,43 & 257,97 & 115,63 & 233,61 & 237,66 & 106,71 & 525,02 & 77,21 & 2,00 & 60,35 & 223,97 & 22,44 & 24,26 & 216,79 \\
\hline Pleurodeles walt| & 29SPB22 & 100,00 & 166,31 & 93,15 & 40,33 & 4667,96 & 293,92 & 66,12 & 227,81 & 118,69 & 224,99 & 228,93 & 109,63 & 531,05 & 82,6 & 1,25 & 65,03 & 241,44 & 17,40 & 22,36 & 225,77 \\
\hline Pleurodeles waltt & 29SPB24 & 100,00 & 165,69 & 97,05 & 40,46 & 4849,47 & 300,64 & 63,40 & 237,24 & 115,70 & 226,89 & 230,83 & 107,08 & 533,69 & 81,11 & 1,86 & 63,31 & 237,35 & 19,21 & 23,72 & 223,55 \\
\hline Pleurodeles walt| & 29SPB25 & 100,00 & 169,33 & 98,40 & 40,57 & \begin{tabular}{|l|l|}
4894,24 \\
\end{tabular} & 306,29 & 66,31 & 239,97 & 118,59 & 231,09 & 234,90 & 110,06 & 513,84 & 77,78 & 1,62 & 62,78 & 227,38 & $\begin{array}{l}18,76 \\
\end{array}$ & 23,11 & 214,10 \\
\hline Pleurodeles waltt & 29SPB26 & 101,00 & 169,08 & 100,77 & 40,72 & 4972,45 & 309,87 & 64,94 & 244,93 & 117,62 & 231,85 & 235,79 & 108,74 & 516,25 & 77,31 & 1,88 & 61,94 & 225,79 & 19,77 & 23,69 & 213,66 \\
\hline Pleurodeles walt| & 29SPB27 & 100,00 & 167,14 & 103,45 & 40,86 & 5076,86 & 312,47 & 61,61 & 250,86 & 114,53 & 231,33 & 235,27 & 105,58 & 528,04 & 78,16 & 2,00 & 61,08 & 228,12 & 21,14 & 24,51 & 217,42 \\
\hline Pleurodeles walt| & 29SPB28 & 100,00 & 167,52 & 105,62 & 40,98 & 5143,11 & 316,07 & 60,92 & 255,16 & 113,99 & 232,69 & 236,56 & 105,07 & 527,53 & 77, & 2,00 & 60,50 & 225,69 & 21,84 & 24,69 & 216,24 \\
\hline \begin{tabular}{|l|l|} 
Pleurodeles waltl \\
\end{tabular} & 29SPB29 & 101,00 & 167,13 & 107,53 & 41,02 & 5203,95 & 318,63 & 59,81 & 258,82 & 112,92 & 233,18 & 237,07 & 103,92 & 531,36 & 77,24 & 2,00 & 59,86 & 225,10 & \begin{tabular}{|l|l|}
22,59 \\
\end{tabular} & 25,19 & 216,82 \\
\hline Pleurodeles walt| & 29SPB31 & 58,00 & 174,81 & 88,67 & 40,00 & 4559,20 & 295,23 & 75,87 & 219,36 & 127,54 & 231,51 & 235,26 & 118,59 & 486,49 & 76,64 & 1,00 & 65,94 & 222,86 & 14,03 & 19,99 & 205,03 \\
\hline Pleurodeles walt| & 29SPB32 & 101,00 & 173,23 & 90,13 & 39,87 & 4653,86 & 296,81 & 73,27 & 223,54 & 124,94 & 231,23 & 234,90 & 115,92 & 493,39 & 76,86 & 1,00 & 65,25 & 224,21 & 14,76 & 20,66 & 206,99 \\
\hline Pleurodeles waltt & 29SPB33 & 100,00 & 172,24 & 92,08 & 39,85 & 4756,22 & 299,82 & 71,13 & 228,69 & 122,83 & 231,68 & 235,45 & 113,82 & 497,26 & 76,39 & 1,00 & 64,32 & 223,32 & 15,71 & 21,49 & 206,86 \\
\hline Pleurodeles walt| & 29SPB34 & 101,00 & 170,86 & 94,32 & 39,90 & 4859,98 & 302,54 & 68,46 & 234,07 & 120,14 & 231,78 & 235,50 & 111,38 & 504,14 & 76,40 & 1,15 & 63,32 & 223,70 & \begin{tabular}{|l|l|}
16,99 \\
\end{tabular} & 22,58 & 208,22 \\
\hline \begin{tabular}{|l|} 
Pleurodeles waltl \\
\end{tabular} & $295 \mathrm{SB} 35$ & 101,00 & 169,60 & 96,90 & 39,96 & 4957,53 & 305,73 & (65,96 & \begin{tabular}{|l|}
239,77 \\
\end{tabular} & \begin{tabular}{|l|}
117,77 \\
\end{tabular} & 231,96 & \begin{tabular}{|l|l|}
235,63 \\
\end{tabular} & \begin{tabular}{|l|}
109,06 \\
100
\end{tabular} & 511,72 & 76,62 & $\frac{1,10}{1,60}$ & $\begin{array}{l}52,32 \\
62,\end{array}$ & 224,38 & 18,45 & 23,57 & 210,04 \\
\hline Pleurodeles walt| & 29SPB36 & 99,00 & 171,07 & 98,97 & 40,02 & 5027,06 & 310,27 & 66,23 & 244,03 & 118,48 & 234,36 & 238,01 & 109,54 & 504,43 & 74,85 & 1,80 & 61,47 & 219,22 & 19,03 & 23,80 & 205,73 \\
\hline Pleurodeles walt| & 29SPB37 & 101,00 & 168,89 & 101,83 & 40,13 & 5123,45 & 312,79 & 62,74 & 250,05 & 115,32 & 233,65 & 237,34 & 106,44 & 517,24 & 75,86 & 2,00 & 60,68 & 222,11 & 20,43 & 24,79 & 209,98 \\
\hline Pleurodeles walt| & 29SPB38 & 100,00 & 165,74 & 104,48 & 40,26 & 5217,51 & 314,11 & 58,52 & 255,59 & 111,43 & 231,94 & 235,57 & 102,43 & 536,33 & 77,76 & 2,00 & 60,14 & 227,63 & 22,05 & 25,60 & 217,14 \\
\hline Pleurodeles walt| & 29SPB39 & 100,00 & 165,47 & 106,32 & 40,48 & 5275,48 & 316,66 & 57,26 & 259,40 & 110,34 & 232,63 & 236,23 & 101,60 & 539,62 & 77,46 & 2,16 & 59,39 & 226,96 & 23,19 & 26,27 & 217,56 \\
\hline \begin{tabular}{|l|} 
Pleurodeles waltl \\
\end{tabular} & 29SPB41 & 45,00 & $\begin{array}{l}10,45,94 \\
175,94\end{array}$ & 86,56 & $\begin{array}{l}40,40 \\
39,08\end{array}$ & 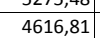 & $\begin{array}{l}291,00 \\
295,17\end{array}$ & $\begin{array}{l}1,20 \\
76,89 \\
\end{array}$ & \begin{tabular}{|l|}
218,28 \\
\end{tabular} & \begin{tabular}{|l|}
127,66 \\
12,0
\end{tabular} & \begin{tabular}{|l|}
233,08 \\
233
\end{tabular} & \begin{tabular}{|l|}
236,77 \\
\end{tabular} & 118,75 & \begin{tabular}{|l|l|}
478,98 \\
478,98
\end{tabular} & $\begin{array}{l}71,406 \\
74,89\end{array}$ & $\frac{1,10}{1,00}$ & $\begin{array}{l}3,0306 \\
66,06\end{array}$ & 217,60 & \begin{tabular}{|l|l}
$2,19,19$ \\
13,1
\end{tabular} & $\begin{array}{l}20,219 \\
20,19\end{array}$ & $\begin{array}{l}191,090 \\
199,08\end{array}$ \\
\hline Pleurodeles walt| & 29SPB42 & 100,00 & 174,39 & 87,81 & 39,07 & 4705,30 & 296,40 & 74,27 & 222,13 & 125,04 & 232,76 & 236,31 & 116,11 & 486,66 & 74,96 & 1,00 & 65,00 & 218,79 & 14,07 & 21,01 & 200,46 \\
\hline Pleurodeles walt| & 29SPB43 & 100,00 & 171,07 & 90,36 & 39,05 & 4835,05 & 298,26 & 69,46 & 228,80 & 120,41 & 231,39 & 234,94 & 111,54 & 503,00 & 76,14 & 1,00 & 63,58 & 223,05 & $15,97 \mid$ & 22,78 & 205,61 \\
\hline Pleurodeles walt| & 29SPB44 & 100,00 & 168,94 & 93,08 & 39,08 & 4953,04 & 301,00 & 65,92 & 235,08 & 116,97 & 230,92 & 234,64 & 108,21 & 514,36 & 76,65 & 1,65 & 62,62 & 225,14 & 17,70 & 24,14 & 208,76 \\
\hline Pleurodeles walt| & $295 P B 46$ & 101,00 & 170,38 & 97,69 & 39,49 & 5097,67 & 309,21 & 64,66 & 244,55 & 116,60 & 234,40 & 237,99 & 107,66 & 508,40 & 74,47 & 2,00 & 61,12 & 218,77 & 19,17 & 24,74 & 204,27 \\
\hline \begin{tabular}{|l|} 
Pleurodeles walt| \\
\end{tabular} & 29SPB47 & 100,00 & 168,88 & 100,49 & 39,82 & 5191,89 & 311,99 & 61,96 & 250,03 & 114,28 & 234,42 & 237,89 & 105,12 & 517,01 & $75, \mathrm{C}$ & 2,00 & 60,66 & 220,39 & 20,28 & 25,11 & 207,22 \\
\hline Pleurodeles walt| & 29SPB48 & 100,00 & 167,76 & 102,78 & 39,96 & 5275,35 & 314,51 & 59,57 & 254,94 & 112,04 & 234,53 & 238,02 & 103,20 & 523,92 & 75,31 & 2,00 & 59,87 & 221,33 & 21,22 & 25,76 & 209,24 \\
\hline Pleurodeles walt| & 29SPB49 & 100,00 & 166,50 & 105,08 & 40,00 & 5340,31 & 316,69 & 57,41 & 259,28 & 110,07 & 234,41 & 237,71 & 101,40 & 532,89 & 75,91 & 2,06 & 59,35 & 223,19 & 22,59 & 26,21 & 212,30 \\
\hline Pleurodeles walt| & 29SPB51 & & & & & & & & & & & & & & & & & & & & \\
\hline \begin{tabular}{|l|} 
Pleurodeles walt| \\
\end{tabular} & 29SPB52 & 100,00 & 175,19 & 85,50 & 38,19 & 4763,32 & 295,72 & 74,92 & 220,80 & 124,69 & 233,97 & 237,43 & 115,81 & 482,36 & 73,92 & 1,00 & 64,48 & 214,43 & 13,55 & 21,57 & 194,99 \\
\hline Pleurodeles walt| & 29SPB53 & 101,00 & 172,90 & 87,90 & 38,16 & 4887 & 298,20 & 71,02 & 227,18 & 121,10 & 233,55 & 236,92 & 112,13 & 493,46 & 74,73 & 1,01 & 63,42 & 216,54 & 15,33 & 23,12 & 197,79 \\
\hline Pleurodeles walt| & 29SPB54 & 101,00 & 170,45 & 90,94 & 38,30 & 5007,82 & 300,94 & 66,97 & 233,97 & 117,41 & 232,94 & 236,36 & 108,48 & 506,42 & 75,65 & 1,51 & 62,28 & 219,73 & 17,00 & 24,36 & 202,13 \\
\hline Pleurodeles waltl & 29SPB55 & 99,00 & 166,69 & 94,61 & 38,71 & 5134,48 & 303,20 & 61,36 & 241,84 & 112,48 & 231,25 & 234,60 & 103,59 & 528,04 & 77,56 & 2,00 & 61,28 & 226,42 & 19,01 & 25,85 & 210,22 \\
\hline Pleurodeles waltl & 29SPB56 & 100,00 & 168,05 & 96,89 & 38,95 & 5204,47 & 307,65 & 61,30 & 246,35 & 112,94 & 233,58 & 236,92 & 103,94 & 520,95 & 76,11 & 2,00 & 60,74 & 221,98 & 19,40 & 25,68 & 206,68 \\
\hline \begin{tabular}{|l|} 
Pleurodeles waltl \\
\end{tabular} & $\begin{array}{l}\text { 29PDP557 } \\
\text { 29SP }\end{array}$ & 100,00 & $\frac{100}{168}$ & 99 & 39 & 5265,48 & 311 & $\begin{array}{l}1,00 \\
60,62\end{array}$ & \begin{tabular}{|l|}
250,73 \\
250
\end{tabular} & \begin{tabular}{|l|}
112,74 \\
\end{tabular} & \begin{tabular}{|l|}
235,06 \\
2350
\end{tabular} & \begin{tabular}{|l|}
238,25 \\
238,25
\end{tabular} & \begin{tabular}{|l|}
103,76 \\
103,5
\end{tabular} & $\mid 519,26$ & $\begin{array}{l}\mid 0,11 \\
75,34\end{array}$ & 2,00 & $\begin{array}{l}0,1 / 09 \\
60,09\end{array}$ & 219,62 & $\begin{array}{l}13,40 \\
20,12\end{array}$ & 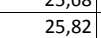 & $\begin{array}{l}205,28 \\
205,28\end{array}$ \\
\hline Pleurodeles walt| & 29SPB58 & 101,00 & 165,17 & 102,30 & 39,26 & 5365,91 & 312,87 & 56,02 & 256,85 & 108,46 & 233,42 & 236,58 & 99,60 & 539,10 & 77,02 & 2,18 & 59,31 & 225,79 & 22,22 & 27,10 & 212,91 \\
\hline Pleurodeles walt| & 29SPB59 & 100,00 & 166,71 & 104,28 & 39,71 & 5416,16 & 316,71 & 56,52 & 260,20 & 109,16 & 235,61 & 238,69 & 100,55 & 531,41 & 75,54 & 2,18 & 58,79 & 221,23 & 22,63 & 27,04 & 209,20 \\
\hline Pleurodeles waltl & 29SPB62 & 100,00 & 176,32 & 82,94 & 37,30 & 4827,46 & 295,47 & 75,96 & 219,51 & 124,72 & 235,65 & 238,97 & 115,88 & 476,06 & 73,79 & 1,00 & 64,06 & 209,23 & 13,14 & 22,10 & 188,61 \\
\hline Pleurodeles waltl & $29 \mathrm{SPB} 63$ & 100,00 & 173,50 & 85,69 & 37,2 & 4955,21 & 29 & 71,32 & 226,33 & 120,63 & 234,78 & 23 & 11. & 490,51 & 75,08 & 1,01 & 62,88 & 213,02 & 14,88 & 23,59 & 19 \\
\hline Pleurodeles walt| & 29SPB64 & 100,00 & 171,35 & 89,14 & 37,69 & 5074,96 & 300,92 & 67,29 & 233,63 & $\begin{array}{l}117,19 \\
\end{array}$ & 234,48 & 237,69 & 108,34 & 502,45 & 75,84 & 1,52 & 62,03 & 215,97 & 16,64 & 24,62 & 197,18 \\
\hline Pleurodeles waltt & 29SPB65 & 101,00 & 170,61 & 92,24 & 37,94 & 5171,80 & 304,69 & 64,81 & 239,88 & 115,30 & 235,21 & 238,42 & 106,43 & 507,57 & 75,85 & 1,94 & 61,13 & 216,36 & 17,85 & 25,54 & 198,55 \\
\hline Pleurodeles walt| & 29SPB66 & 100,00 & 167,46 & 96,09 & 38,26 & 5281,79 & 307,19 & 59,68 & 247,51 & 111,22 & 233,90 & 237,04 & 102,17 & 526,75 & 77,38 & 2,00 & 60,41 & 222,67 & \begin{tabular}{|l|l|}
19,45 \\
\end{tabular} & 26,22 & 206,49 \\
\hline |Pleurodeles walt| & 29SPB67 & 101,00 & 167,34 & 98,94 & 38,73 & 5365,73 & 310,99 & 58,12 & 252,8 & \begin{tabular}{l|l|}
110,08 \\
\end{tabular} & 235,12 & 238,06 & 101, & 527,78 & 76,87 & 2,00 & 59,80 & 221,55 & 20,25 & 26,49 & 206,39 \\
\hline Pleurodeles walt & 29SPB68 & 99,00 & 161,51 & 102,50 & 38,98 & 5475,86 & 310,95 & 50,86 & 260,09 & 103,49 & 231,21 & 234,26 & 94,64 & 565,09 & 80,49 & 2,59 & 58,77 & 234,47 & $24,24,03$ & 29,36 & 221,11 \\
\hline
\end{tabular}




\begin{tabular}{|c|c|c|c|c|c|c|c|c|c|c|c|c|c|c|c|c|c|c|c|c|c|}
\hline TAXON & UTM & $\mathrm{km} 2$ & B101 & B102 & $\mathrm{BIO3}$ & 8104 & B105 & B106 & B107 & B108 & B109 & B1010 & BIO11 & BIO12 & B1013 & BIO14 & BIO15 & B1016 & B1017 & BIO18 & B1019 \\
\hline Pleurodeles walt| & 29SPB69 & 101,00 & 160,85 & 104,80 & 39,03 & 5543,35 & 313,78 & 49,17 & 264,61 & 102,18 & 231,74 & 234,69 & 93,30 & 569,54 & 80,36 & 2,99 & 57,97 & 234,49 & 25,62 & 30,24 & 222,24 \\
\hline Pleurodeles walt| & 29SPB71 & 11,00 & 178,00 & 79,38 & 36,38 & 4854,08 & 293,31 & 77,85 & 215,46 & 125,85 & 236,69 & 240,08 & 116,31 & 471,38 & 74,15 & 1,00 & 64,08 & 205,62 & 12,00 & 22,00 & 183,46 \\
\hline Pleurodeles walt| & 29SPB72 & 100,00 & 177,28 & 80,30 & 36,32 & 4889,62 & 294,83 & 76,74 & 218,10 & 124,96 & 237,14 & 240,23 & 115,76 & 471,86 & 74,05 & 1,00 & 63,85 & 205,10 & 12,65 & 22,54 & 183,14 \\
\hline Pleurodeles walt| & 29SPB73 & 101,00 & 176,50 & 82,76 & 36,45 & 5001,32 & 298,23 & 74,25 & 223,98 & 123,65 & 237,87 & 240,98 & 113,67 & 476,04 & 74,01 & 1,00 & 63,01 & 204,82 & 13,89 & 23,71 & 183,47 \\
\hline Pleurodeles walt| & 29SPB74 & 100,00 & 174,51 & 86,77 & 36,99 & 5116,97 & 301,96 & 70,11 & 231,86 & 119,42 & 237,91 & 240,89 & 1110,45 & 487,26 & 74,79 & 1,03 & 62,14 & 208,15 & 15,20 & 24,17 & 187,95 \\
\hline Pleurodeles walt| & 29SPB75 & 100,00 & 173,17 & 90,78 & 37,35 & 5223,84 & 306,17 & 66,62 & 239,55 & 116,95 & 238,22 & 241,18 & 108,03 & 497,01 & 75,20 & 1,71 & 61,08 & 210,63 & 16,92 & 25,31 & 191,71 \\
\hline Pleurodeles walt| & 29SPB76 & 101,00 & 172,13 & 94,68 & 37,97 & 5322,15 & 310,30 & 63,59 & 246,72 & 115,01 & 238,91 & 241,79 & 105,99 & 504,11 & 75,30 & 1,99 & 60,38 & 212,14 & 18,20 & 25,85 & 194,57 \\
\hline Pleurodeles waltl & 29SPB77 & 100,00 & 169,75 & 98,39 & 38,18 & 5425,29 & 313,11 & 59,47 & 253,64 & 111,36 & 238,29 & 241,06 & 102,64 & 517,79 & 76,19 & 2,01 & 59,74 & 216,32 & $\begin{array}{ll}19,64 \\
\end{array}$ & 26,46 & 200,12 \\
\hline Pleurodeles walt| & 29SPB81 & 49,00 & 177,89 & 79,56 & 36,00 & 4901,23 & 294,59 & 76,90 & 217,69 & 136,93 & 238,02 & 241,00 & 116,18 & 476,69 & 75,25 & 1,00 & 63,82 & 206,57 & 12,51 & 22,87 & 183,93 \\
\hline Pleurodeles walt| & 29SPB82 & 101,00 & 177,98 & 79,33 & 35,82 & 4964,47 & 295,56 & 76,60 & 218,96 & 144,32 & 238,62 & 241,52 & 115,22 & 472,48 & 74,62 & 1,00 & 63,57 & 203,23 & 12,62 & 23,47 & 180,27 \\
\hline Pleurodeles walt| & 29SPB83 & 99,00 & 177,82 & 81,79 & 35,97 & 5067,99 & 299,41 & 74,67 & 224,73 & 146,24 & 239,98 & 242,83 & 113,78 & 473,24 & 74,27 & 1,00 & 62,87 & 202,07 & 13,64 & 23,87 & 179,64 \\
\hline Pleurodeles walt| & 29SPB84 & 101,00 & 174,38 & 87,23 & 36,64 & 5210,35 & 303,54 & 68,52 & 235,02 & 120,05 & 239,13 & 241,89 & 109,09 & 493,86 & 76,00 & 1,26 & 61,76 & 209,21 & 15,46 & 24,91 & 188,50 \\
\hline \begin{tabular}{|l|l|} 
Pleurodeles waltl \\
\end{tabular} & 29SPB85 & 100,00 & 172,92 & $\begin{array}{l}91,72 \\
91,72\end{array}$ & 37,08 & 5321,27 & 307,98 & $\mid 64,69$ & $\mid 243,29$ & 115,49 & $\begin{array}{l}239,49 \\
230\end{array}$ & \begin{tabular}{|l|}
242,16 \\
\end{tabular} & 106,45 & 504,88 & 76,49 & $\begin{array}{ll}, 202 \\
1,83\end{array}$ & 61,00 & 212,53 & $\begin{array}{l}17,19 \\
17,\end{array}$ & 25,68 & 193,27 \\
\hline Pleurodeles walt| & 29SPB86 & 100,00 & 169,77 & 96,12 & 37,83 & 5442,40 & 311,10 & 59,32 & 251,78 & 111,16 & 238,45 & 241,03 & 102,23 & 523,43 & 77,89 & 2,00 & 60,25 & 218,73 & 18,97 & 26,66 & 201,01 \\
\hline Pleurodeles walt| & 29SPB87 & 100,00 & 168,34 & 99,61 & 38,00 & 5531,28 & 314,37 & 56,26 & 258,11 & 108,81 & 238,52 & 241,06 & 99,98 & 531,65 & 78,12 & 2,02 & 59,57 & 220,72 & 20,46 & 27,36 & 204,23 \\
\hline Pleurodeles waltt & 29SPB88 & 100,00 & 162,84 & 103,31 & 38,20 & 5644,99 & 314,91 & 48,97 & 265,94 & 102,43 & 235,01 & 237,46 & 93,42 & 564,64 & 81,17 & 2,69 & 58,47 & 232,19 & 23,76 & 29,72 & 217,38 \\
\hline Pleurodeles walt| & 29SPB89 & 100,00 & 153,82 & 106,46 & 38,23 & 5757,84 & 312,54 & 38,85 & 273,69 & 92,73 & 228,07 & 230,59 & 83,71 & 620,39 & 86,93 & 3,43 & 57,47 & 252,59 & 28,53 & 33,33 & 239,85 \\
\hline Pleurodeles walt| & 29SPB90 & & & & & & & & & & & & & & & & & & & & \\
\hline Pleurodeles walt| & 29SPB91 & 91,00 & 176,63 & 82,44 & 36,29 & 4991,09 & 297,27 & 73,43 & 223,85 & 129,05 & 238,21 & 241,18 & 113,96 & 495,43 & 77,43 & 1,00 & 63,73 & 213,67 & 13,84 & 23,77 & $\begin{array}{ll}191,63 \\
\end{array}$ \\
\hline Pleurodeles walt| & 29SPB92 & 101,00 & 176,34 & 83,35 & 36,08 & 5092,33 & 299,59 & 72,02 & 227,57 & 134,69 & 239,17 & 242,06 & 112,29 & 493,55 & 77,15 & 1,00 & 63,20 & 211,19 & 14,05 & 24,00 & 189,05 \\
\hline Pleurodeles walt| & 29SPB93 & 100,00 & 178,35 & 85,09 & 36,17 & 5167,99 & 304,21 & 72,76 & 231,45 & 147,42 & 242,25 & 244,99 & 113,29 & 482,24 & 75,46 & 1,00 & 62,70 & 205,42 & 14,09 & 24,00 & 183,32 \\
\hline Pleurodeles waltt & 29SPB94 & 101,00 & 174,68 & 89,65 & 36,78 & 5315,18 & 307,38 & 66,53 & 240,84 & 122,55 & 241,05 & 243,73 & 108,15 & 502,46 & 77,16 & 1,28 & 61,65 & 212,05 & 15,74 & 24,94 & 191,58 \\
\hline Pleurodeles walt| & 29SPB95 & 99,00 & 169,82 & 94,92 & 37,18 & 5462,90 & 310,08 & 58,89 & 251,19 & 110,79 & 238,72 & 241,25 & 101,85 & 531,43 & 79,77 & 2,00 & 60,74 & 222,38 & 18,52 & 26,68 & 203,61 \\
\hline Pleurodeles waltt & 29SPB96 & 100,00 & 169,28 & 98,16 & 37,82 & 5549,99 & 313,89 & 56,72 & 257,17 & 109,34 & 239,57 & 242,12 & 100,46 & 534,59 & 79,41 & 2,00 & 60,10 & 222,36 & 19,56 & 27,16 & 204,72 \\
\hline Pleurodeles walt| & 29SPB97 & 100,00 & 170,11 & 100,77 & 38,00 & 5609,81 & 317,98 & 56,11 & 261,87 & 109,56 & 241,47 & 243,77 & 100,57 & 529,92 & 78,18 & 2,00 & 59,68 & 219,39 & 20,10 & 27,11 & 202,56 \\
\hline Pleurodeles walt| & 29SPB98 & 100,00 & 164,84 & 104,28 & 38,01 & 5721,95 & 318,91 & 49,21 & 269,70 & 103,34 & 238,19 & 240,41 & 94,44 & 558,94 & 80,74 & 2,51 & 58,66 & 229,30 & 23,06 & 29,22 & 214,00 \\
\hline \begin{tabular}{|l|l|} 
Pleurodeles waltl \\
\end{tabular} & 29SPB99 & 100,00 & 152,23 & 107,69 & 38,00 & 5848,46 & 313,92 & $\begin{array}{l}45,72 \\
35,78 \\
\end{array}$ & 278,14 & \begin{tabular}{|l|}
90,23 \\
90,3
\end{tabular} & \begin{tabular}{|l|}
227,96 \\
\end{tabular} & \begin{tabular}{|l|}
230,29 \\
\end{tabular} & 81,17 & $\mid 635,97$ & 88,77 & 3,60 & 57,37 & 257,79 & 29,35 & 34,22 & 245,06 \\
\hline Pleurodeles walt| & 29SPCO0 & 101,00 & 165,29 & 112,18 & 42,05 & 5145,05 & 322,05 & 59,05 & 263,01 & 112,51 & 230,68 & 235,07 & 103,90 & 548,84 & 80,47 & 2,00 & 59,99 & 232,29 & 24,28 & 25,03 & 228,07 \\
\hline Pleurodeles walt| & 29SPC03 & 101,00 & 160,69 & 108,62 & 41,23 & 5185,48 & 316,10 & 56,55 & 259,55 & 107,39 & 227,90 & 231,14 & 98,85 & 592,32 & 82,64 & 3,04 & 57,66 & 243,29 & 30,44 & 30,45 & 242,18 \\
\hline Pleurodeles waltt & 29SPC04 & 100,00 & 161,82 & 106,48 & 41,04 & 5164,14 & 314,94 & 58,80 & 256,14 & 108,27 & 229,01 & 231,91 & 100,14 & 589,98 & 81,44 & 3,02 & 57,23 & 241,04 & 30,93 & 30,93 & 240,44 \\
\hline Pleurodeles walt| & 29SPC06 & 100,00 & 163,16 & 102,61 & 40,53 & 5122,15 & 312,29 & 62,04 & 250,25 & 105,59 & 229,36 & 232,55 & 101,71 & 596,58 & 81,61 & 3,75 & 56,34 & 241,45 & 33,24 & 33,24 & 241,42 \\
\hline \begin{tabular}{|l|} 
Pleurodeles waltl \\
\end{tabular} & 29SPC08 & 100,00 & 160,69 & 99,94 & 39,98 & 5139,34 & 308,49 & $\begin{array}{l}60,77 \\
60,4\end{array}$ & 247,72 & \begin{tabular}{|c|}
99,37 \\
99
\end{tabular} & 228,08 & \begin{tabular}{|l|}
230,42 \\
\end{tabular} & | & \begin{tabular}{|l|l|}
640,14 \\
\end{tabular} & $\begin{array}{l}1,01 \\
87,99 \\
\end{array}$ & 4,12 & 55,88 & \begin{tabular}{|l|}
258,78 \\
\end{tabular} & $\begin{array}{l}\mid 3,44 \\
36,81 \\
\end{array}$ & $\begin{array}{l}3,24 \\
36,81\end{array}$ & 258,78 \\
\hline Pleurodeles walt| & 29SPC09 & 100,00 & 162,42 & 99,67 & 39,97 & 5141,97 & 309,99 & 62,39 & 247,60 & 101,25 & 228,39 & 232,14 & 100,70 & 646,09 & 89,10 & 4,17 & 55,93 & 261,45 & 37,30 & 37,32 & 261,45 \\
\hline Pleurodeles waltl & 29SPC10 & 101,00 & 168,64 & 109,86 & 41,74 & 5166,21 & 322,54 & 61,98 & 260,56 & 115,16 & 234,22 & 238,31 & 106,22 & 527,47 & 76,84 & 2,00 & 59,79 & 222,91 & 23,19 & 24,74 & 216,76 \\
\hline Pleurodeles walt| & 29SPC11 & 101,00 & 167,94 & 110,49 & 41,60 & 5210,14 & 323,28 & 61,00 & 262,28 & 113,82 & 234,09 & 238,19 & 105,04 & 534,53 & 76,94 & 2,02 & 59,23 & 223,80 & 24,49 & 25,59 & 218,77 \\
\hline Pleurodeles walt| & 29SPC12 & 99,00 & 167,73 & 109,94 & 41,19 & 5225,10 & 323,02 & 60,97 & 262,05 & 113,38 & 234,04 & 238,20 & 104,57 & 540,49 & 76,70 & 2,27 & 58,39 & 224,17 & 26,18 & 27,20 & 219,97 \\
\hline \begin{tabular}{|l|} 
Pleurodeles waltl \\
\end{tabular} & $295 P C 13$ & $\begin{array}{l}501,00 \\
101\end{array}$ & 160,51 & 109,02 & $\frac{41,10}{41,00}$ & 5282,23 & 317,10 & $\begin{array}{l}54,79 \\
5\end{array}$ & \begin{tabular}{|l|}
262,31 \\
262
\end{tabular} & \begin{tabular}{|l|}
105,93 \\
105
\end{tabular} & $\begin{array}{l}258,044 \\
228,42\end{array}$ & \begin{tabular}{|l|}
232,21 \\
\end{tabular} & \begin{tabular}{|c|}
07,33 \\
97,33
\end{tabular} & $\mid$\begin{tabular}{|l|}
589,14 \\
589
\end{tabular} & 81,72 & $\frac{2,21}{3,00}$ & $\begin{array}{ll}0 ., 35 \\
57,24\end{array}$ & $\mid$\begin{tabular}{|l|}
240,98 \\
240
\end{tabular} & \begin{tabular}{|l|l|}
30,63 \\
303
\end{tabular} & 30,77 & 238,69 \\
\hline Pleurodeles walt| & 29SPC14 & 101,00 & 162,18 & 107,55 & 40,99 & 5257,45 & 316,92 & 57,16 & 259,76 & 107,77 & 229,61 & 233,36 & 99,09 & 584,99 & 80,21 & 3,18 & 56,79 & 237,86 & 31,36 & 31,48 & 236,03 \\
\hline Pleurodeles walt| & 29SPC17 & 99,00 & 163,81 & 103,55 & 40,05 & 5233,55 & 314,91 & 60,52 & 254,39 & 108,59 & 230,76 & 234,53 & 100,84 & 601,24 & 81,32 & 4,00 & 55,57 & 241,35 & 34.91 & 34,91 & 240,92 \\
\hline Pleurodeles waltl & 29SPC18 & 101,00 & 160,60 & 102,15 & 39,90 & 5255,88 & 311,74 & 58,30 & 253,45 & 102,59 & 228,97 & 231,89 & 97,68 & 638,67 & 86,96 & 4,34 & 55,44 & 256,29 & 37,43 & 37,43 & 256,26 \\
\hline Pleurodeles walt| & 29SPC19 & 101,00 & 161,79 & 101,60 & 39,82 & 5264,89 & 312, & 59,40 & 253,21 & 104,32 & 229,51 & 233 & 98,68 & 646,77 & 88,31 & 4,5 & 55,33 & 259,77 & 38,18 & 38,21 & 259,71 \\
\hline Pleurodeles walt| & $295 P C 20$ & 100,00 & 167,25 & 108,79 & 41,00 & 5254,52 & 320,84 & 59,51 & 261,33 & 112,50 & 233,96 & 237,92 & \begin{tabular}{r|r|}
103,49 \\
\end{tabular} & 532,54 & 76,72 & 2,0 & 59,38 & 223,71 & 23,36 & 25,51 & 216,45 \\
\hline Pleurodeles walt| & $295 P C 21$ & 100,00 & 168,08 & 109,25 & 41,01 & 5274,95 & 322,74 & 60,09 & 262,65 & 113,04 & 235,19 & 238,98 & $\begin{array}{ll}104,03 \\
\end{array}$ & 530,51 & 75,64 & 2,06 & 58,64 & 220,93 & 24,62 & 26,39 & 214,45 \\
\hline Pleurodeles walt| & $295 P C 22$ & 101,00 & 168,42 & 109,29 & 40,99 & 5297,34 & 323,47 & 60,32 & 263,15 & 113,02 & 235,75 & 239,61 & 104,16 & 533,19 & 75,13 & 2,37 & 58,07 & 220,33 & 25,82 & 27,36 & 214,65 \\
\hline Pleurodeles walt| & 29SPC23 & 100,00 & 165,26 & 109,13 & 40,97 & 5331,75 & 321,37 & 57,58 & 263,80 & 109,62 & 233,19 & 237,03 & 100,88 & 556,98 & 77,25 & 3,00 & 57,18 & 227,79 & 28,54 & 29,44 & 223,46 \\
\hline \begin{tabular}{|l|} 
Pleurodeles walt| \\
\end{tabular} & 29SPC24 & 100,00 & 165,85 & 108,43 & 40 & 5334,76 & 321 & 58,32 & 263,18 & $\begin{array}{l}109,86 \\
\end{array}$ & 233,76 & 237,63 & $\begin{array}{l}101,18 \\
1018\end{array}$ & 558,27 & 76,57 & 3,00 & 56,60 & 226,87 & 29,57 & 30,35 & 223,10 \\
\hline Pleurodeles walt| & 29SPC25 & 101,00 & 165,01 & 107,59 & 40,39 & 5344,68 & 320,41 & 58,02 & 262,39 & 109,00 & 233,26 & 236,94 & 100,45 & 569,88 & 77,21 & 3,12 & 55,98 & 230,09 & 31,34 & 31,72 & 227,01 \\
\hline Pleurodeles waltl & 29SPC27 & 101,00 & 163,06 & 105,66 & 40,00 & 5364,20 & 317,54 & 57,23 & 260,31 & 106,79 & 231,86 & 235,42 & 98,44 & 602,02 & 80,68 & 4,00 & 55,12 & 240,99 & 35,23 & 35,36 & 239,16 \\
\hline Pleurodeles waltt & 29SPC28 & 100,00 & 159,59 & 104,11 & 39,72 & 5380,03 & 313,91 & 54,76 & 259,15 & 102,98 & 229,49 & 232,40 & 95,14 & 642,65 & 86,77 & 4,51 & 54,97 & 256,99 & 38,20 & 38,24 & 255,93 \\
\hline Pleurodeles waltl & $29 S P C 29$ & 100,00 & 158,40 & 102,98 & 39,39 & 5393,15 & 312,64 & 54,31 & 258,34 & 102,07 & 228,38 & 231,60 & 94,01 & 668,10 & 90,58 & 5,07 & 54,64 & 267,01 & 40,43 & 40,47 & 266,42 \\
\hline \begin{tabular}{|l|} 
Pleurodeles waltl \\
\end{tabular} & $295 \mathrm{PC} 30$ & $\begin{array}{l}101,00 \\
100\end{array}$ & 130,40 & 107,70 & 40 & $\mid$ & 31,04 & \begin{tabular}{|l|l|}
57,17 \\
57
\end{tabular} & \begin{tabular}{|l|}
262,144 \\
\end{tabular} & \begin{tabular}{|l|}
110,25 \\
11,25
\end{tabular} & \begin{tabular}{|l|}
233,87 \\
23,8
\end{tabular} & 237,53 & \begin{tabular}{|l|}
101,40 \\
101,0
\end{tabular} & $\begin{array}{l}538,07 \\
\end{array}$ & $\begin{array}{l}70,50 \\
76,59\end{array}$ & 2,32 & 58,84 & \begin{tabular}{|l|}
224,42 \\
22,1
\end{tabular} & $\begin{array}{l}0,43 \\
24,33 \\
\end{array}$ & $\begin{array}{l}27,07 \\
27,07\end{array}$ & $\begin{array}{l}200,45 \\
215,93\end{array}$ \\
\hline Pleurodeles walt| & 29SPC31 & 100,00 & 166,25 & 108,74 & 40,75 & 5373,15 & 321,21 & 56,92 & 264,29 & 109,87 & 234,71 & 238,28 & 101,01 & 540,34 & 75,98 & 2,89 & 57,64 & 223,15 & 26,13 & 28,48 & 215,62 \\
\hline Pleurodeles walt| & 29SPC32 & 100,00 & 168,44 & 108,99 & 40,68 & 5377,66 & 323,78 & 58,78 & 265,00 & 111,72 & 236,88 & 240,46 & 103,10 & 530,80 & 74,13 & 2,80 & 57,45 & 218,09 & 26,20 & 28,24 & 211,01 \\
\hline Pleurodeles waltl & 29SPC33 & 100,00 & 168,65 & 109,01 & 40,48 & 5392,90 & 324,63 & 58,97 & 265,66 & 111,64 & 237,36 & 240,86 & 103,12 & 533,38 & 73,80 & 2,99 & 56,89 & 217,75 & 27,26 & 28,95 & 211,42 \\
\hline Pleurodeles waltl & $29 S P C 35$ & 100,00 & 167,02 & 108,80 & 40, & 5433,43 & 323,99 & 57,58 & 266,41 & 109,55 & 236,34 & 239 & 101,03 & 553,34 & 75,23 & 3,16 & 55,95 & 223,18 & 30,26 & 31,26 & 218,25 \\
\hline \begin{tabular}{|l|} 
Pleurodeles waltl \\
\end{tabular} & 295PC36 & $\begin{array}{l}101,00 \\
100\end{array}$ & $\begin{array}{l}10,04 \\
164,36\end{array}$ & $\begin{array}{l}10,00 \\
108,31\end{array}$ & 40,12 & 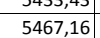 & $\begin{array}{l}321,97 \\
321,97\end{array}$ & $\begin{array}{l}1,30 \\
55,28 \\
\end{array}$ & \begin{tabular}{|l|}
$260,41+69$ \\
\end{tabular} & \begin{tabular}{|l|}
106,72 \\
10,70
\end{tabular} & \begin{tabular}{|l|}
234,434 \\
\end{tabular} & \begin{tabular}{|l|l|}
237,79 \\
\end{tabular} & \begin{tabular}{|l|l|}
98,15 \\
90
\end{tabular} & $\mid \begin{array}{l}\mid 530,34,6 \\
577,66\end{array}$ & $\begin{array}{l}\mid 7,25 \\
77,96\end{array}$ & $\begin{array}{ll}3,100 \\
3,98\end{array}$ & $\begin{array}{ll}55,18 \\
5,50\end{array}$ & \begin{tabular}{|l|}
231,45 \\
23,4
\end{tabular} & $\begin{array}{l}3,13 \\
33,13 \\
\end{array}$ & $\begin{array}{l}1,20 \\
33,78 \\
\end{array}$ & $\begin{array}{l}210,25 \\
227,34\end{array}$ \\
\hline Pleurodeles walt| & 29SPC37 & 100,00 & 165,27 & 107,92 & 40,00 & 5472,45 & 322,58 & 56,23 & 266,34 & 107,39 & 235,64 & 238,79 & 98,97 & 581,16 & 78,36 & 4,00 & 54,85 & 232,22 & 34,01 & 34,58 & 228,44 \\
\hline Pleurodeles waltt & 29SPC38 & 100,00 & 162.29 & 106.91 & 3989 & 5492.93 & 319,66 & 54.09 & 265.57 & 104,35 & 233,02 & 236,21 & 95.88 & 614.36 & 82,31 & 4,41 & 54.57 & 244.89 & 36.96 & 37.18 & 241.92 \\
\hline |Pleurodeles walt| & 29SPC39 & 101,00 & 158,32 & 105,42 & 39,32 & 5511,46 & 315,80 & 51,43 & 264,3 & 100,70 & 229,7 & 232, & 92, & 658,86 & 88,45 & 5,04 & 54,28 & 262,54 & 40,31 & 40,40 & 260,37 \\
\hline Pleurodeles waltl & $29 S P C 40$ & 101,00 & 164,01 & 106,92 & 40,01 & 5409,63 & 317,65 & 54,14 & 263,51 & 107,14 & 233,05 & 236,42 & 98,43 & 550,22 & 77,29 & 2,92 & 57,95 & 227,62 & 25,75 & 28,88 & 218,07 \\
\hline
\end{tabular}




\begin{tabular}{|c|c|c|c|c|c|c|c|c|c|c|c|c|c|c|c|c|c|c|c|c|c|}
\hline TAXON & UTM & $\mathrm{km} 2$ & B101 & B102 & $\mathrm{BIO3}$ & 8104 & B105 & B106 & B107 & B108 & B109 & BIO10 & BIO11 & BIO12 & B1013 & BIO14 & BIO15 & B1016 & B1017 & B1018 & B1019 \\
\hline Pleurodeles walt| & 29SPC41 & 100,00 & 166,05 & 108,00 & 40,01 & 5437,09 & 321,08 & 55,40 & 265,69 & 108,56 & 235,40 & 238,69 & 99,84 & 540,63 & 75,50 & 3,00 & 57,42 & 222,30 & 26,20 & 29,02 & 213,41 \\
\hline Pleurodeles walt| & 29SPC43 & 101,00 & 167,88 & 109,24 & 40,02 & 5501,38 & 325,44 & 56,36 & 269,08 & 109,36 & 238,23 & 241,34 & 100,77 & 533,92 & 73,76 & 3,00 & 56,68 & 217,10 & 27,27 & 29,37 & 209,34 \\
\hline Pleurodeles walt| & 29SPC44 & 100,00 & 168,91 & 109,81 & 40,04 & 5516,29 & 327,01 & 57,07 & 269,94 & 110,10 & 239,67 & 242,44 & 101,43 & 531,63 & 73,28 & 3,00 & 56,19 & 215,10 & 27,82 & 29,73 & 207,85 \\
\hline Pleurodeles walt| & 29SPC45 & 100,00 & 168,72 & 109,90 & 40,02 & 5520,70 & 327,46 & 56,84 & 270,62 & 109,73 & 239,59 & 242,28 & 101,23 & 536,43 & 73,75 & 3,02 & 55,77 & 215,92 & 28,96 & 30,40 & 209,14 \\
\hline Pleurodeles walt| & $29 S P C 46$ & 100,00 & 168,21 & 110,05 & 40,00 & 5541,22 & 327,67 & 56,19 & 271,48 & 108,93 & 239,34 & 242,04 & 100,49 & 546,01 & 74,72 & 3,51 & 55,06 & 218,49 & 31,15 & 32,31 & 212,21 \\
\hline Pleurodeles walt| & 29SPC47 & 101,00 & 167,52 & 110,02 & 40,00 & 5572,71 & 327,53 & 55,35 & 272,18 & 107,90 & 239,20 & 241,86 & 99,60 & 557,72 & 76,07 & 3,98 & 54,43 & 222,23 & 32,93 & 33,83 & 216,36 \\
\hline Pleurodeles walt| & 29SPC50 & 100,00 & 165,21 & 106,32 & 39,84 & 5479,81 & 318,78 & 54,19 & 264,59 & 107,29 & 235,18 & 238,30 & 98,45 & 542,76 & 76,27 & 2,73 & 57,73 & 223,62 & 25,01 & 28,78 & 212,74 \\
\hline Pleurodeles waltl & 29SPC51 & 101,00 & 167,10 & 107,59 & 39,88 & 5507,90 & 322,31 & 55,03 & 267,28 & 108,55 & 237,41 & 240,46 & 99,80 & 533,46 & 74,70 & 3,00 & 57,20 & 218,51 & 25,75 & 29,11 & 208,22 \\
\hline Pleurodeles walt| & 29SPC52 & 100,00 & 168,43 & 108,65 & 39,99 & 5543,99 & 325,30 & 55,72 & 269,58 & 109,37 & 239,34 & 242,17 & 100,59 & 526,22 & 73,52 & 3,00 & 56,66 & 214,39 & 26,14 & 29,12 & 204,65 \\
\hline Pleurodeles walt| & 29SPC53 & 100,00 & 166,86 & 109,71 & 39,99 & 5586,67 & 325,93 & 53,65 & 272,28 & 107,14 & 238,44 & 241,20 & 98,53 & 537,68 & 74,58 & 3,00 & 56,35 & 217,67 & 27,47 & 29,91 & 208,80 \\
\hline Pleurodeles walt| & 29SPC54 & 100,00 & 167,86 & 110,35 & 40,00 & 5602,91 & 327,94 & 54,27 & 273,67 & 107,78 & 239,81 & 242,30 & 99,23 & 534,37 & 73,98 & 3,03 & 55,77 & 215,26 & 28,15 & 30,24 & 206,77 \\
\hline Pleurodeles walt| & 29SPC55 & 101,00 & 166,82 & 111,02 & 39,95 & 5639,14 & 328,46 & 52,88 & 275,58 & 106,43 & 239,38 & 241,86 & 97,84 & 543,21 & 74,81 & 3,39 & 54,97 & 217,40 & 30,10 & 31,80 & 209,48 \\
\hline Pleurodeles walt| & 29SPC57 & 100,00 & 168,13 & 111,79 & 39,96 & 5684,87 & 331,09 & 53,09 & 278,00 & 106,93 & 241,54 & 243,71 & 98,65 & 543,91 & 74,76 & 3,99 & 53,94 & 215,79 & 32,57 & 33,71 & 208,22 \\
\hline Pleurodeles walt| & 29SPC58 & 100,00 & 168,60 & 112,24 & 39,97 & 5700,35 & 332,14 & 53,08 & 279,07 & 107,03 & 242,20 & 244,23 & 98,73 & 546,20 & 75,06 & 4,00 & 53,57 & 216,33 & 33,25 & 34,09 & 208,90 \\
\hline Pleurodeles walt| & 29SPC59 & 100,00 & 167,52 & 112,36 & 39,84 & 5728,25 & 331,77 & 51,96 & 279,81 & 105,68 & 241,69 & 243,64 & 97,36 & 562,54 & 76,98 & 4,17 & 53,42 & 222,29 & 35,05 & 35,62 & 215,23 \\
\hline Pleurodeles waltt & 29SPC60 & 100,00 & 163,18 & 106,26 & 39,15 & 5569,55 & 317,99 & 50,66 & 267,33 & 104,12 & 234,43 & 237,22 & 95,19 & 556,04 & 78,26 & 2,98 & 57,41 & 227,75 & 25,89 & 29,93 & 216,04 \\
\hline Pleurodeles walt| & 29SPC61 & 100,00 & 162,79 & 107,89 & 39,17 & 5622,32 & 320,55 & 49,19 & 271,36 & 103,19 & 234,95 & 237,86 & 94,22 & 558,30 & 78,06 & 3,08 & 56,97 & 227,34 & 26,79 & 30,50 & 216,45 \\
\hline Pleurodeles walt| & 29SPC62 & 100,00 & 167,16 & 108,97 & 39,37 & 5633,15 & 325,76 & 52,92 & 272,84 & 107,02 & 239,42 & 241,86 & 98,14 & 532,84 & 74,71 & 3,00 & 56,49 & 216,13 & 26,27 & 29,60 & 205,40 \\
\hline Pleurodeles walt| & 29SPC63 & 101,00 & 165,10 & 110,21 & 39,51 & 5678,03 & 326,27 & 50,42 & 275,85 & 104,51 & 238,20 & 240,63 & 95,64 & 545,39 & 75,90 & 3,00 & 56,10 & 219,89 & 27,74 & 30,49 & 209,94 \\
\hline Pleurodeles walt| & 29SPC64 & 101,00 & 165,09 & 111,09 & 39,43 & 5713,22 & 327,85 & 49,66 & 278,20 & 104,05 & 238,78 & 241,18 & 95,33 & 546,52 & 75,67 & 3,30 & 55,16 & 218,88 & 29,32 & 31,59 & 209,42 \\
\hline Pleurodeles walt| & 29SPC65 & 99,00 & 164,63 & 111,94 & 39,49 & 5746,92 & 328,91 & 48,54 & 280,37 & 103,08 & 238,90 & 241,08 & 94,49 & 551,15 & 75,98 & 3,9 & 54,29 & 219,39 & 31,55 & 33,24 & 210,27 \\
\hline Pleurodeles walt| & 295PC66 & 101,00 & 163,96 & 112,50 & 39,32 & 5777,11 & 329,45 & 47,39 & 282,05 & 102,15 & 238,82 & 240,75 & 93,51 & 556,83 & 76,53 & 4,01 & 54,10 & 220,64 & 32,59 & 34,07 & 211,91 \\
\hline Pleurodeles walt| & 29SPC67 & 100,00 & 163,22 & 112,86 & 39,25 & 5799,65 & 329,68 & 46,44 & 283,24 & 101,10 & 238,40 & 240,30 & 92,42 & 565,42 & 77,51 & 4,10 & 53,61 & 223,34 & 34,08 & 35,10 & 214,86 \\
\hline Pleurodeles waltt & 29SPC68 & 101,00 & 165,88 & 113,77 & 39,39 & 5827,84 & 333,01 & 48,04 & 284,97 & 102,98 & 241,62 & 243,26 & 94,45 & 550,29 & 75,81 & 4,00 & 53,27 & 216,66 & 33,90 & 34,73 & 207,97 \\
\hline Pleurodeles walt| & 29SPC69 & 100,00 & 168,82 & 114,62 & 39,47 & 5851,69 & 336,48 & 49,70 & 286,78 & 105,11 & 244,84 & 246,10 & 96,77 & 535,56 & 74,10 & 4,00 & 52,84 & 210,37 & 33,94 & 34,49 & 201,39 \\
\hline Pleurodeles walt| & 29SPC70 & 100,00 & 161,09 & 106,73 & 38,95 & 5675,07 & 318,19 & 46,80 & 271,38 & 100,66 & 233,89 & 236,54 & 91,70 & 571,07 & 80,41 & 3,15 & 57,24 & 232,70 & 26,59 & 31,03 & 220,35 \\
\hline \begin{tabular}{|l|l|} 
Pleurodeles waltl \\
\end{tabular} & $295 P C 71$ & 101,00 & 158,40 & 108,44 & 38,92 & 5732,58 & 318,87 & 43,40 & 275,47 & $\begin{array}{l}07,48 \\
97\end{array}$ & $\begin{array}{l}232,29 \\
232\end{array}$ & 234,86 & 88,52 & 587,30 & \begin{tabular}{l|l|}
81,78 \\
\end{tabular} & 3,33 & 56,56 & 237,71 & 28,70 & 32,39 & 226,39 \\
\hline Pleurodeles walt| & $29 S P C 72$ & 100,00 & 165,22 & 109,58 & 39,03 & 5735,12 & 326,20 & 49,42 & 276,78 & 103,68 & 239,04 & 241,32 & 95,01 & 543,63 & 76,32 & 3,01 & 56,35 & 219,52 & 26,65 & 30,28 & 208,00 \\
\hline Pleurodeles walt| & 29SPC73 & 100,00 & 164,62 & 110,88 & 39,01 & 5774,34 & 327,87 & 47,88 & 279,99 & 102,55 & 239,21 & 241,35 & 94,00 & 546,35 & 76,21 & 3,05 & 55,68 & 219,18 & 27,99 & 31,12 & 208,24 \\
\hline Pleurodeles waltt & 29SPC74 & 100,00 & 162,33 & 111,87 & 39,01 & 5819,58 & 327,60 & 45,12 & 282,49 & 99,79 & 237,63 & 239,69 & 91,24 & 560,86 & 77,53 & 3,71 & 54,81 & 223,50 & 30,66 & 33,10 & 213,25 \\
\hline Pleurodeles walt| & 29SPC75 & 100,00 & 160,62 & 112,54 & 38,99 & 5859,96 & 327,79 & 43,08 & 284,70 & 97,82 & 236,75 & 238,66 & 89,31 & 570,99 & 78,47 & 4,01 & 54,31 & 226,36 & 32,31 & 34,26 & 216,50 \\
\hline \begin{tabular}{|l|} 
Pleurodeles waltl \\
\end{tabular} & 29SPC79 & 99,00 & 166,67 & 115,78 & 39,06 & 5948,78 & 337,34 & $\begin{array}{l}45,00 \\
45,49 \\
\end{array}$ & 291,85 & \begin{tabular}{|c|}
101,73 \\
101
\end{tabular} & 244,35 & 245,09 & $\begin{array}{l}53,47 \\
93,\end{array}$ & 531,21 & 73,60 & 4,00 & 52,15 & 207,08 & 34,50 & $\begin{array}{l}35,24 \\
35,24\end{array}$ & 196,76 \\
\hline Pleurodeles walt| & 29SPC80 & 101,00 & 154,66 & 107,93 & 38,41 & 5795,37 & 315,84 & 39,03 & 276,81 & 93,23 & 229,63 & 232,06 & 84,21 & 614,21 & 85,61 & 3,64 & 56,86 & 248,62 & 29,24 & 33,59 & 236,45 \\
\hline Pleurodeles walt| & 29SPC81 & 99,00 & 159,18 & 109,25 & 38,81 & 5818,30 & 321,64 & 42,67 & 278,97 & 97,08 & 234,43 & 236,60 & 88,26 & 583,86 & 81,56 & 3,29 & 56,41 & 235,44 & 28,32 & 32,34 & 223,32 \\
\hline Pleurodeles walt| & $29 S P C 82$ & 101,00 & 160,19 & 110,52 & 38,84 & 5854,69 & 324,58 & 42,86 & 281,71 & 97,50 & 235,97 & 238,01 & 88,63 & 575,40 & 80,09 & 3,43 & 55,90 & 230,86 & 28,88 & 32,50 & 219,15 \\
\hline Pleurodeles walt| & 29SPC83 & 100,00 & 162,91 & 111,65 & 38,96 & 5873,63 & 328,54 & 44,51 & 284,04 & 99,78 & 238,88 & 240,86 & 91,00 & 557,23 & 77,57 & 3,32 & 55,43 & 222,59 & 28,81 & 32,01 & 210,99 \\
\hline \begin{tabular}{|l|} 
Pleurodeles waltl \\
\end{tabular} & $295 P C 85$ & 100,00 & 154,08 & $\begin{array}{l}11,05 \\
112,77\end{array}$ & $\begin{array}{l}38,50 \\
38,61\end{array}$ & S968,82 & 324,12 & $\begin{array}{l}44,10 \\
35,77 \\
\end{array}$ & $\mid \begin{array}{l}\mid 04,04 \\
288,36\end{array}$ & $\begin{array}{ll}50,35 \\
90,3\end{array}$ & \begin{tabular}{|l|}
231,940 \\
231
\end{tabular} & \begin{tabular}{|l|}
233,88 \\
233
\end{tabular} & 81,75 & $\mid \begin{array}{l}\mid \\
611,60\end{array}$ & 83,11 & $\begin{array}{l}3,256 \\
4,36\end{array}$ & $\begin{array}{l}53,43 \\
53,93\end{array}$ & $\mid \begin{array}{l}\mid 24,21,21 \\
241\end{array}$ & $\begin{array}{l}\mid 0,01 \\
34,97\end{array}$ & $\begin{array}{l}2,101 \\
36,92\end{array}$ & 231,16 \\
\hline Pleurodeles walt| & 29SPC86 & 100,00 & 156,27 & 113,57 & 38,80 & 5976,05 & 326,95 & 37,27 & 289,67 & 92,08 & 234,28 & 235,96 & 83,77 & 595,57 & 81,03 & 4,27 & 53,38 & 233,99 & 35,05 & 36,73 & 223,79 \\
\hline Pleurodeles walt| & 29SPC87 & 101,00 & 159,43 & 114,49 & 38,96 & 6000,35 & 331,08 & 39,33 & 291,75 & 94,80 & 237,95 & 239,14 & 86,38 & 570,55 & 78,01 & 4,14 & 52,95 & 223,31 & 34,51 & 36,02 & 212,68 \\
\hline Pleurodeles walt| & 29SPC88 & 100,00 & 163,88 & 115,66 & 39,00 & 5993,57 & 335,55 & 42,50 & 293,05 & 98,77 & 242,25 & 243,16 & 90,53 & 537,45 & 74,13 & 4,00 & 52,71 & 209,84 & 33,10 & 34,49 & 198,71 \\
\hline Pleurodeles walt| & 29SPC90 & 100,00 & 155,39 & 109,04 & 38,17 & 5882,69 & 318,88 & 38,08 & 280,80 & 92,63 & 231,65 & 233,82 & 83,79 & 613,37 & 85,57 & 3,45 & 56,86 & 247,51 & 28,96 & 33,52 & 234,93 \\
\hline Pleurodeles walt| & 29SPC91 & 101,00 & 158,57 & 110,27 & 38,30 & 5915,33 & 323,67 & 40,32 & 283,35 & $\begin{array}{ll}2,27 \\
55,27\end{array}$ & 235,23 & 237,27 & 86,32 & 589,82 & 82,32 & 3,3 & 56,42 & 237,01 & 28,48 & 32,65 & 224,46 \\
\hline Pleurodeles walt| & 29SPC92 & 99,00 & 153,35 & 111,44 & 38,22 & 5977,65 & 321,58 & 34,63 & 286,95 & 89,59 & 231,15 & 233,13 & 80,78 & 621,02 & 85,31 & 3,99 & 55,51 & 247,66 & 31,83 & 35,31 & 236,26 \\
\hline Pleurodeles walt| & 29SPC93 & 101,00 & 159,94 & 112,53 & 38,63 & 5969,28 & 328,46 & 40,33 & 288,14 & 95,84 & 237,50 & 239,16 & 87,01 & 576,55 & 79,75 & 3,52 & 55,27 & 229,36 & 29,91 & 33,20 & 217,51 \\
\hline Pleurodeles walt| & 29SPC94 & 99,00 & 158,64 & 113,32 & 38,53 & 6010,83 & 329,04 & 38,53 & 290,51 & 93,99 & 236,90 & 238,53 & 85,32 & 581,60 & 79,89 & 3,7 & 54,58 & 230,01 & 31,40 & 34,26 & 218,55 \\
\hline \begin{tabular}{|l|} 
Pleurodeles walt| \\
\end{tabular} & 29SPC95 & 101,00 & 153,03 & 113,44 & 38,21 & \begin{tabular}{|l}
6051,86 \\
\end{tabular} & 325,26 & 33,25 & 292,01 & 88,29 & 232,23 & 233,77 & $\begin{array}{l}59,68 \\
79,\end{array}$ & $\begin{array}{l}615,80 \\
\end{array}$ & 83,41 & 4, & 53,75 & 241,99 & 35,09 & 37,22 & 231,30 \\
\hline Pleurodeles walt| & 29SPC96 & 100,00 & 150,56 & 113,48 & 38,09 & 6081,97 & 323,90 & 31,03 & 292,87 & 85,66 & 230,35 & 231,96 & 77,15 & 631,10 & 84,78 & 4,83 & 53,20 & 246,78 & 37,25 & 38,97 & 236,59 \\
\hline Pleurodeles waltl & 29SPC99 & 100,00 & 165,35 & 116,18 & 38,94 & 6062,52 & 338,82 & 42,56 & 296,26 & 99,26 & 244,25 & 245,25 & 90,75 & 516,90 & 71,06 & 4,00 & 51,87 & 200,16 & 32,14 & 34,00 & 187,97 \\
\hline Pleurodeles waltt & $29 S P D 00$ & 101,00 & 164,58 & 99,37 & 39,79 & 5146,66 & 311,81 & 64,14 & 247,67 & 103,56 & 230,05 & 234,15 & 102,51 & 650,04 & 89,94 & 4,54 & 55,90 & 263,25 & 37,71 & 38,10 & 263,25 \\
\hline Pleurodeles waltl & 29SPD01 & 101,00 & 164,77 & 98,75 & 39,30 & 5155,83 & 311,99 & 64,27 & 247,72 & 104,12 & 230,51 & 234,52 & 102,75 & 667,05 & 92,81 & 5,00 & 55,91 & 270,59 & 38,92 & 39,36 & 270,59 \\
\hline \begin{tabular}{|l|} 
Pleurodeles waltl \\
\end{tabular} & $\begin{array}{l}\text { 29SPDDO3 } \\
\text { 29SP }\end{array}$ & 101,00 & 167,25 & 90,155 & $\begin{array}{l}35, \\
39,\end{array}$ & \begin{tabular}{|l}
5191,93 \\
5198
\end{tabular} & 314,55 & $\begin{array}{l}64,82 \\
65,88 \\
\end{array}$ & \begin{tabular}{|l|l|}
248,68 \\
\end{tabular} & \begin{tabular}{|l|}
109,20 \\
109,2
\end{tabular} & \begin{tabular}{|l|}
233,68 \\
2301
\end{tabular} & \begin{tabular}{|l|}
237,16 \\
237
\end{tabular} & $\begin{array}{l}104,42 \\
104\end{array}$ & $\mid \begin{array}{ll}682,99 \\
\end{array}$ & $\begin{array}{l}\mid c, 01 \\
95,73\end{array}$ & 5,00 & 55,90 & $\mid 277,45$ & 年0,92 & $\begin{array}{l}30,56 \\
40,\end{array}$ & 277,45 \\
\hline Pleurodeles walt| & 29SPD04 & 101,00 & 167,18 & 98,12 & 39,00 & 5207,99 & 314,58 & 65,51 & 249,07 & 108,01 & 233,88 & 237,27 & 104,14 & 701,80 & 98,94 & 5,02 & 55,98 & 285,48 & 40,41 & 41,68 & 285,48 \\
\hline \begin{tabular}{|l|l|} 
Pleurodeles waltl \\
\end{tabular} & 29SPD05 & 100,00 & 164,19 & 97,09 & 38,45 & 5241,36 & 311,97 & $\begin{array}{l}53,09 \\
63,\end{array}$ & 248,88 & \begin{tabular}{|l|l|}
101,06 \\
\end{tabular} & $\begin{array}{l}231,63 \\
230\end{array}$ & 234,92 & 100,91 & 747,79 & \begin{tabular}{|c|}
106,27 \\
\end{tabular} & 5,92 & 55,64 & $\begin{array}{l}200,40 \\
304,62\end{array}$ & $\begin{array}{l}40,41+26 \\
44,26\end{array}$ & $\begin{array}{l}45,40 \\
45,40\end{array}$ & 304,62 \\
\hline Pleurodeles waltl & 29SPD06 & 101,00 & 162,42 & 96,54 & 38,07 & 5278,41 & 310,58 & 61,03 & 249,54 & 98,67 & 230,34 & 233,67 & 98,67 & 781,05 & 111,75 & 6,01 & 55,70 & 318,61 & 46,15 & 47,22 & 318,61 \\
\hline Pleurodeles waltl & 29SPD07 & 100,00 & 163,07 & 96,93 & 38,15 & 5303,94 & 311,69 & 60,67 & 251,02 & 99,04 & 231,54 & 23 & 98,93 & 789,75 & 113,19 & 6,18 & 55,53 & 321,77 & 47,18 & 48,37 & 32 \\
\hline \begin{tabular}{|l|} 
Pleurodeles waltl \\
\end{tabular} & $\begin{array}{l}\text { 25PSDO } \\
\text { 29SPD09 }\end{array}$ & $\begin{array}{l}101,00 \\
100\end{array}$ & $\begin{array}{l}10,01,29 \\
161\end{array}$ & $\begin{array}{l}0,35 \\
97,32\end{array}$ & $\begin{array}{l}30,10 \\
37,86 \\
\end{array}$ & \begin{tabular}{|l}
5371,64 \\
5371,68
\end{tabular} & 3111,23 & \begin{tabular}{|l|l|}
57,29 \\
\end{tabular} & \begin{tabular}{|l|}
253,94 \\
254
\end{tabular} & $\begin{array}{l}3,04 \\
96,06 \\
\end{array}$ & \begin{tabular}{|l|}
230,99 \\
230
\end{tabular} & \begin{tabular}{|l|}
233,26 \\
23,26
\end{tabular} & \begin{tabular}{|l|l}
96,06 \\
96,0
\end{tabular} & \begin{tabular}{|l|}
833,96 \\
83,9
\end{tabular} & \begin{tabular}{|l|}
120,30 \\
120
\end{tabular} & $\begin{array}{l}0,10 \\
6,85 \\
\end{array}$ & $\begin{array}{l}55,16 \\
55,16\end{array}$ & |339,27 & | & $\begin{array}{l}40,313 \\
51,89 \\
\end{array}$ & 339,27 \\
\hline Pleurodeles walt| & $29 S P D 10$ & 100,00 & 161,34 & 100,52 & 39,30 & 5273,02 & 312,03 & 59,57 & 252,46 & 102,42 & 228,95 & 232,85 & 98,11 & 669,64 & 92,03 & 4,97 & 55,26 & 269,45 & 39,96 & 40,06 & 269,45 \\
\hline Pleurodeles walt| & 29SPD11 & 101,00 & 164,59 & 100,59 & 39,14 & 5276,51 & 314,93 & 62,16 & 252,77 & 107,17 & 232,23 & 235,88 & 101,03 & 662,80 & 91,24 & 5,00 & 55,36 & 266,99 & 39,18 & 39,92 & 266,87 \\
\hline |Pleurodeles walt| & 29SPD12 & 100,00 & 166,36 & 100,31 & 39,03 & 5282,65 & 316,66 & 63,7 & 252,89 & 110,21 & 234,10 & 237, & 102,66 & 666,77 & 92,14 & 5,00 & 55,42 & 268,94 & 39,34 & 40,14 & 268 \\
\hline \begin{tabular}{|l|} 
Pleurodeles waltl \\
\end{tabular} & 29SPD13 & 100,00 & 165,32 & $\begin{array}{l}99,37 \\
99\end{array}$ & 38,84 & 5312,71 & 15,68 & 63,01 & 252,67 & 107,43 & 233,46 & 237,16 & 101,29 & 694,89 & 96,87 & 5,21 & 55,44 & 280,93 & 41,01 & 42,06 & 280,87 \\
\hline
\end{tabular}




\begin{tabular}{|c|c|c|c|c|c|c|c|c|c|c|c|c|c|c|c|c|c|c|c|c|c|}
\hline TAXON & UTM & $\mathrm{km} 2$ & BIO1 & B102 & $B 103$ & 8104 & B105 & B106 & B107 & B108 & B109 & B1010 & BIO11 & BIO12 & BIO13 & B1014 & BIO15 & B1016 & B1017 & B1018 & 81019 \\
\hline Pleurodeles walt| & 29SPD16 & 100,00 & 161,78 & 96,94 & 37,96 & 5407,71 & 312,48 & 59,44 & 253,04 & 96,84 & 231,64 & 234,87 & 96,84 & 780,17 & 111,29 & 6,00 & 55,41 & 317,28 & 46,43 & 47,58 & 317,28 \\
\hline Pleurodeles walt| & 29SPD17 & 100,00 & 162,40 & 97,18 & 37,83 & 5441,73 & 313,80 & 59,03 & 254,77 & 97,30 & 232,95 & 235,84 & \begin{tabular}{ll|}
96,87 \\
\end{tabular} & 787,81 & 112,55 & 6,00 & 55,10 & 319,82 & 47,48 & 48,64 & 319,82 \\
\hline Pleurodeles walt| & 29SPD18 & 100,00 & 165,73 & \begin{tabular}{ll|}
98,61 \\
\end{tabular} & 37,78 & 5466,37 & 317,80 & 60,42 & 257,38 & 102,76 & 236,73 & 238,93 & 99,37 & 766,83 & $\begin{array}{l}109,26 \\
\end{array}$ & 6,00 & 55,04 & 310,27 & 46,09 & 47,75 & 310,24 \\
\hline Pleurodeles walt| & 29SPD19 & 100,00 & 163,73 & 98,30 & 37,49 & 5511,66 & 316,45 & 57,86 & 258,59 & 99,38 & 235,47 & 237,44 & 96,75 & \begin{tabular}{|l|l|}
798,04 \\
\end{tabular} & $\begin{array}{l}114,38 \\
\end{array}$ & 6,44 & 54,99 & 322,98 & 48,53 & \begin{tabular}{|l|l|}
49,92 \\
\end{tabular} & 322,95 \\
\hline Pleurodeles walt| & 29SPD20 & 100,00 & 159,85 & 102,48 & \begin{tabular}{|l|l|}
39,07 \\
\end{tabular} & 5401,49 & 313,94 & 55,83 & 258,10 & 103,21 & 229,40 & 233,08 & 95,22 & 674,09 & 91,73 & 5,03 & 54,81 & 269,90 & 40,77 & 40,90 & 269,22 \\
\hline Pleurodeles walt| & 29SPD21 & 100,00 & 164,55 & 102,79 & 39,06 & 5396,16 & 318,34 & 59,78 & 258,56 & 107,75 & 233,89 & 237,44 & 99,64 & 654,05 & 88,96 & 5,00 & 54,91 & 262,27 & 39,32 & 39,95 & 261,14 \\
\hline 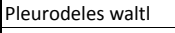 & 29SPD22 & 100,00 & 166,06 & 102,14 & 39,02 & 5404,88 & 319,60 & 61,34 & 258,25 & 109,06 & 235,63 & 238,95 & 100,95 & $\begin{array}{l}661,05 \\
\end{array}$ & 90,44 & 5,06 & 54,90 & 265,60 & 39,65 & 40,57 & 264,47 \\
\hline Pleurodeles walt| & 29SPD23 & 101,00 & 162,56 & \begin{tabular}{ll|}
99,87 \\
\end{tabular} & 38,44 & 5420,56 & 315,60 & 59,50 & 256,09 & 105,28 & 232,51 & 236,07 & 97,74 & 712,61 & 98,85 & 5,84 & 54,81 & 286,88 & 43,34 & $\begin{array}{l}4,26 \\
\end{array}$ & 286,62 \\
\hline Pleurodeles walt| & 29SPD24 & 100,00 & 163,64 & 99,38 & 38,08 & $\begin{array}{l}5448,06 \\
\end{array}$ & 316,78 & \begin{tabular}{|l|l}
60,27 \\
\end{tabular} & 256,51 & 106,05 & 234,11 & 237,44 & 98,42 & $\begin{array}{l}720,95 \\
\end{array}$ & $\begin{array}{l}100,47 \\
\end{array}$ & 5,90 & 54,74 & 290,40 & 43,93 & 45,10 & 290,08 \\
\hline Pleurodeles walt| & 29SPD25 & 101,00 & 160,69 & 97,33 & 37,76 & 5474,17 & 313,32 & 58,49 & 254,84 & 98,78 & 231,64 & 235,06 & 95,46 & 766,08 & 108,18 & 6,11 & 55,04 & 309,96 & 46,21 & 47,49 & 309,96 \\
\hline Pleurodeles walt| & 29SPD26 & 101,00 & 160,01 & 96,71 & 37,40 & 5512,44 & 312,78 & 57,41 & 255,37 & 95,55 & 231,52 & 234,88 & 94,22 & 787,61 & 111,94 & 6,14 & 55,06 & 319,04 & 47,62 & 48,89 & 319,04 \\
\hline Pleurodeles walt| & 29SPD27 & 100,00 & 161,47 & 97,40 & 37,06 & \begin{tabular}{|l|}
5567,78 \\
\end{tabular} & 315,33 & 57,12 & 258,21 & 98,03 & 233,97 & 236,64 & 94,68 & 784,94 & \begin{tabular}{|l|l|}
111,68 \\
\end{tabular} & 6,06 & 54,87 & 317,36 & 47,71 & 48,92 & 317,33 \\
\hline Pleurodeles walt| & 29SPD28 & 101,00 & 163,53 & 98,34 & 37,12 & 5619,06 & 318,43 & 57,26 & 261,16 & 101,12 & 236,92 & 238,95 & 95,64 & 774,94 & 110,22 & 5,99 & 54,79 & 312,52 & 47,14 & 48,58 & 312,37 \\
\hline Pleurodeles walt| & 29SPD29 & 101,00 & 165,74 & 99,41 & 37,31 & 5638,23 & 320,90 & 57,92 & 262,98 & 103,96 & 239,38 & 240,89 & 97,06 & 762,84 & $\begin{array}{l}108,38 \\
\end{array}$ & 5,99 & 54,66 & 306,90 & 46,46 & 48,16 & 306,55 \\
\hline Pleurodeles walt| & 29SPD30 & 100,00 & 161,50 & 105,37 & \begin{tabular}{l|l}
39,15 \\
\end{tabular} & 5515,50 & 318,91 & 54,19 & 264,71 & $\begin{array}{l}103,47 \\
\end{array}$ & 232,66 & 236,00 & 95,16 & \begin{tabular}{|l|l|}
649,40 \\
\end{tabular} & 87,17 & 5,00 & 54,22 & 259,03 & 39,70 & 40,00 & 256,64 \\
\hline Pleurodeles walt| & 29SPD31 & 101,00 & 164,08 & 105,16 & 39,06 & 5516,52 & 321,40 & 56,66 & 264,73 & 105,84 & 235,25 & 238,34 & 97,68 & 647,09 & 86,94 & 5,00 & 54,20 & 258,42 & 39,55 & 40,13 & 255,93 \\
\hline Pleurodeles walt| & 29SPD34 & 101,00 & 160,24 & $\begin{array}{ll}99,30 \\
\end{array}$ & 37,85 & 5550,93 & $\begin{array}{l}315,39 \\
\end{array}$ & 56,72 & \begin{tabular}{ll|}
258,67 \\
\end{tabular} & 102,24 & 232,29 & 235,74 & 94,27 & \begin{tabular}{ll|l}
740,95 \\
\end{tabular} & \begin{tabular}{|l|l|}
103,04 \\
\end{tabular} & 6,14 & 54,40 & 298,01 & 45,47 & 46,65 & 297,21 \\
\hline Pleurodeles walt| & 29SPD35 & 100,00 & 150,96 & 93,90 & 36,71 & 5549,48 & 303,30 & 51,48 & 251,82 & 87,76 & 223,30 & 227,27 & 86,22 & 847,69 & 120,82 & 7,24 & 54,84 & 343,56 & 52,06 & 53,06 & 343,56 \\
\hline Pleurodeles walt| & 29SPD36 & 101,00 & 153,98 & 94,90 & 36,77 & 5604,19 & 307,60 & 52,43 & 255,18 & 91,66 & 227,18 & 230,49 & 87,92 & 831,12 & 118,49 & 6,95 & 54,64 & 336,25 & 51,13 & \begin{tabular}{|l|l|}
52,08 \\
\end{tabular} & 336,14 \\
\hline Pleurodeles walt| & 29SPD37 & 100,00 & 162,36 & 98,66 & \begin{tabular}{l|l|l}
37,05 \\
\end{tabular} & 5674,95 & 318,45 & 56,13 & 262,32 & 101,76 & 236,42 & 238,79 & 94,20 & $\begin{array}{l}758,86 \\
\end{array}$ & $106, \mathrm{~s}$ & 5,99 & 54,36 & 305,26 & $\begin{array}{l}46,45 \\
\end{array}$ & 47,80 & 304,45 \\
\hline Pleurodeles walt| & 29SPD38 & 101,00 & 162,82 & 98,87 & 36,98 & 5732,46 & 319,80 & 55,39 & 264,41 & $\begin{array}{l}101,39 \\
\end{array}$ & 237,89 & 239,77 & 93,75 & 761,73 & $\begin{array}{l}107,66 \\
\end{array}$ & 5,93 & 54,35 & \begin{tabular}{|l|l|}
305,98 \\
\end{tabular} & 46,83 & 48,18 & 305,15 \\
\hline Pleurodeles walt| & 29SPD39 & 101,00 & 163,06 & 99,01 & 36,69 & \begin{tabular}{|l|l|}
5777,13 \\
\end{tabular} & 320,64 & 54,43 & 266,21 & 100,55 & 238,81 & 240,35 & 93,17 & 767,51 & 108,81 & 5,99 & 54,15 & 307,94 & 47,38 & 48,78 & 307,06 \\
\hline Pleurodeles walt| & 29SPD40 & 100,00 & 160,85 & 107,88 & 39,32 & 5634,39 & 321,61 & 50,65 & 270,96 & 101,18 & 233,86 & 236,68 & 93,03 & \begin{tabular}{|l|l|}
641,53 \\
\end{tabular} & 85,81 & 5,19 & 53,71 & 254,70 & 40,13 & 40,43 & 250,73 \\
\hline Pleurodeles walt| & 29SPD41 & 100,00 & 162,43 & 107,64 & 39,01 & 5644,46 & 323,51 & 52,29 & 271,22 & 102,49 & 235,74 & 238,27 & 94,25 & 645,10 & 86,31 & 5,02 & 53,74 & 256,50 & 40,14 & 40,61 & 252,58 \\
\hline Pleurodeles walt| & 29SPD42 & 100,00 & 164,73 & 107,12 & 39,01 & 5646,44 & 325,62 & 54,64 & 270,98 & 104,53 & 238,01 & 240,52 & 96,53 & 643,72 & 86,33 & 5,01 & 53,71 & 256,23 & 39,98 & 40,80 & 252,39 \\
\hline Pleurodeles walt| & \begin{tabular}{|l|}
$29 S P D 43$ \\
\end{tabular} & 99,00 & 163,16 & 104,89 & 38,67 & 5647,58 & 323,13 & 54,71 & 268,42 & 103,38 & 236,58 & 239,30 & 95,26 & \begin{tabular}{|c|}
675,98 \\
\end{tabular} & 91,26 & 5,35 & 53,69 & 269,65 & 42,25 & 43,30 & 266,46 \\
\hline Pleurodeles walt| & 29SPD44 & 101,00 & 155,18 & 99,28 & \begin{tabular}{|l|l|}
37,57 \\
\end{tabular} & 5640,11 & 312,16 & 51,31 & 260,85 & 96,60 & 228,72 & 232,15 & 88,58 & \begin{tabular}{|l|l|}
767,07 \\
\end{tabular} & $\begin{array}{l}106,42 \\
\end{array}$ & 6,42 & 54,01 & $\begin{array}{l}307,69 \\
\end{array}$ & 47,74 & 48,74 & 306,19 \\
\hline Pleurodeles walt| & 29SPD45 & 99,00 & 145,56 & \begin{tabular}{ll|}
94,44 \\
\end{tabular} & 36,50 & 5659,10 & 300,09 & 44,74 & 255,35 & 86,12 & 220,27 & 223,39 & 79,69 & 866,89 & 122,89 & 7,64 & 54,20 & \begin{tabular}{|l|l|}
348,96 \\
\end{tabular} & 54,20 & 54,73 & 348,51 \\
\hline Pleurodeles walt| & 29SPD46 & 100,00 & 156,64 & 97,92 & 36,98 & 5715,55 & 313,60 & 51,85 & 261,75 & 96,79 & 231,46 & 234,36 & 88,84 & 779,71 & 109,38 & 6,38 & 54,05 & 313,09 & 48,41 & 49,55 & 311,72 \\
\hline Pleurodeles walt| & 29SPD47 & 100,00 & 161,78 & 99,90 & 37,00 & 5777,09 & 320,23 & 53,95 & 266,28 & 100,13 & 237,49 & 239,55 & 92,44 & 738,82 & 103,05 & 5,96 & 53,79 & 295,82 & 45,84 & 47,24 & 293,69 \\
\hline Pleurodeles walt| & 29SPD48 & 100,00 & 163,51 & 100,30 & 37,01 & 5812,85 & 322,29 & 54,38 & 267,91 & 100,95 & 239,86 & 241,48 & 93,31 & 729,76 & 101,92 & 5,83 & 53,78 & 291,85 & 45,22 & 46,76 & 289,49 \\
\hline Pleurodeles walt| & 29SPD50 & 101,00 & 161,35 & 110,94 & 39,34 & 5753,36 & 325,81 & 47,58 & 278,22 & 99,84 & 236,19 & 238,25 & 91,60 & 621,37 & 83,68 & 5,08 & 53,01 & 245,32 & 39,71 & 39,97 & 239,52 \\
\hline Pleurodeles walt| & 29SPD52 & 101,00 & 166,26 & 111,13 & \begin{tabular}{l|l|}
39,15 \\
\end{tabular} & 5767,16 & 331,38 & 51,92 & 279,45 & 104,00 & 241,34 & 243,14 & 96,06 & 610,44 & 82,21 & 4,99 & 52,86 & 241,30 & 38,96 & 39,79 & 235,35 \\
\hline Pleurodeles walt| & 29SPD53 & 101,00 & 162,51 & 107,88 & 38,71 & 5768,06 & 326,25 & 50,88 & 275,37 & 100,99 & 237,82 & 239,95 & 92,98 & 656,75 & 87,85 & 5,19 & 52,99 & 260,40 & 41,79 & $\begin{array}{ll}42,66 \\
\end{array}$ & 255,47 \\
\hline Pleurodeles walt| & 29SPD54 & 100,00 & 159,58 & 104,37 & 37,96 & 5772,25 & 321,21 & 50,21 & 271,00 & 98,48 & 235,00 & 237,44 & 90,46 & 698,68 & $\begin{array}{l}94,38 \\
\end{array}$ & 5,69 & 53,15 & 277,95 & 44,20 & 45,22 & 273,87 \\
\hline Pleurodeles walt| & 29SPD55 & 101,00 & 155,24 & 100,88 & 37,30 & 5793,53 & 315,14 & 48,08 & 267,07 & 94,52 & 231,21 & 233,80 & 86,40 & 749,56 & 103,06 & 6,22 & 53,30 & 298,95 & 47,35 & 48,26 & 295,74 \\
\hline Pleurodeles walt| & 29SPD56 & 101,00 & 157,86 & 100,85 & 37,00 & 5829,21 & 317,95 & 49,67 & 268,29 & 96,27 & 234,37 & 236,51 & 88,25 & 735,80 & $\begin{array}{l}101,26 \\
\end{array}$ & 6,06 & 53,23 & 293,24 & 46,52 & 47,58 & 289,84 \\
\hline Pleurodeles walt| & 29SPD57 & 100,00 & 158,85 & 100,45 & 36,94 & 5864,96 & 318,85 & 50,03 & 268,81 & 96,40 & 235,90 & 237,80 & 88,58 & \begin{tabular}{|l|l|}
735,08 \\
\end{tabular} & 101,59 & 6,03 & 53,27 & 292,83 & 46,55 & 47,62 & 289,41 \\
\hline Pleurodeles walt| & 29SPD58 & 101,00 & 160,07 & 100,45 & 36,76 & 5897,48 & 320,11 & 50,25 & 269,86 & 96,85 & 237,75 & 239,16 & 89,13 & \begin{tabular}{|l|l|}
729,97 \\
\end{tabular} & 101,25 & 5,89 & 53,19 & 290,69 & \begin{tabular}{|l|l|}
45,96 \\
\end{tabular} & \begin{tabular}{|l|l|}
47,07 \\
\end{tabular} & 287,24 \\
\hline Pleurodeles walt| & 295 SPD59 & 101,00 & 163,90 & 101,51 & 36,84 & 5918,49 & 324,06 & 52,29 & 271,77 & 99,59 & 241,73 & 242,68 & 92,03 & 700,88 & \begin{tabular}{|l|}
96,96 \\
\end{tabular} & 5,47 & 53,10 & 278,58 & 43,96 & 45,45 & 274,74 \\
\hline Pleurodeles walt| & 29SPD60 & 100,00 & 168,81 & 115,08 & 39,66 & $\begin{array}{l}5867,40 \\
\end{array}$ & 337,01 & 49,50 & 287,52 & 104,80 & 245,21 & 246,19 & 96,54 & $\begin{array}{l}544,56 \\
\end{array}$ & 75,00 & 4,03 & 52,36 & 213,40 & 35,45 & 35,99 & 204,68 \\
\hline Pleurodeles walt| & 29SPD61 & 100,00 & 167,71 & 115,31 & 39,86 & 5882,00 & 336,11 & 48,61 & 287,49 & 103,42 & 244,34 & 245,41 & 95,43 & 563,84 & 77,06 & 4,32 & 52,19 & 220,94 & 36,92 & 37,50 & 212,62 \\
\hline Pleurodeles walt| & 29SPD62 & 100,00 & 165,88 & 114,38 & $\begin{array}{l}39,38 \\
\end{array}$ & 5882,08 & 334,61 & 48,07 & 286,54 & 101,80 & 242,73 & 243,80 & 93,97 & 590,70 & 79,85 & 4,86 & 52,16 & 231,85 & 38,45 & 39,20 & 224,20 \\
\hline Pleurodeles walt| & 29SPD63 & 99,00 & 165,28 & 111,71 & 39,01 & 5881,51 & 332,24 & 49,14 & 283,10 & 101,48 & 242,15 & 243,45 & 93,61 & 608,40 & 81,64 & 4,91 & 52,16 & 239,24 & 39,44 & 40,35 & 232,05 \\
\hline Pleurodeles walt| & 29SPD66 & 100,00 & 155,77 & 102,29 & 36,99 & \begin{tabular}{|l|}
5927,89 \\
\end{tabular} & 318,2 & 45,51 & 272,75 & 92,83 & 233,73 & 235,56 & 84,82 & 719,31 & 97,68 & 5,96 & 52,67 & 284,73 & 46,32 & 47,04 & 279,75 \\
\hline Pleurodeles walt| & 29SPD67 & 100,00 & 160,17 & 102,90 & 37,00 & 5953,39 & 322,70 & 48,59 & 274,10 & 96,39 & 238,64 & 239,99 & 88,50 & $\begin{array}{ll}689,63 \\
\end{array}$ & 93,5 & 5,52 & 52,62 & 272,83 & 43,92 & 45,00 & 267,58 \\
\hline Pleurodeles walt| & 29SPD68 & 100,00 & 162,31 & 102,78 & 37,01 & 5974,32 & 324,56 & 49,86 & 274,70 & 97,69 & 240,99 & 242,01 & $\mid 89,96$ & $\mid$\begin{tabular}{|c|}
677,68 \\
\end{tabular} & $\mid 92,17$ & $\begin{array}{ll}543 \\
\end{array}$ & 52,48 & 267,94 & \begin{tabular}{|c|c|}
43,03 \\
\end{tabular} & \begin{tabular}{|l|l|}
44,25 & \\
\end{tabular} & 262,65 \\
\hline Pleurodeles walt| & 29SPD69 & 99,00 & 163,36 & 102,63 & \begin{tabular}{|l|l}
36,88 \\
\end{tabular} & 5985,69 & 325,23 & 50,46 & 274,77 & 98,32 & 242,23 & 242,91 & 90,58 & 672,44 & 91,76 & 5,20 & 52,53 & 265,70 & 42,64 & 44,03 & 260,42 \\
\hline Pleurodeles walt| & 29SPD70 & 101,00 & 168,47 & 116,41 & 39,00 & 5985,76 & 339,92 & 46,32 & 293,60 & 102,76 & 246,63 & 247,24 & 94,58 & 521,55 & 72,42 & 4,00 & 51,71 & 202,79 & 34,94 & 35,31 & 192,28 \\
\hline Pleurodeles walt| & 29SPD71 & 100,00 & 168,40 & 116,38 & 39,05 & 5976,06 & 339,55 & 46,77 & 292,79 & 102,82 & 246,31 & 247,10 & 94,75 & 533,62 & 73,51 & 4,00 & 51,58 & 207,55 & 35,67 & 36,27 & 197,40 \\
\hline Pleurodeles walt| & 29SPD72 & 101,00 & 167,95 & 115,53 & \begin{tabular}{ll|}
39,09 \\
\end{tabular} & 5969,52 & 338,12 & 47,37 & 290,75 & 102,45 & 245,99 & 246,49 & 94,50 & 549,09 & 74,84 & 4,03 & 51,63 & 214,01 & 36,08 & 36,81 & 204,42 \\
\hline Pleurodeles walt| & 29SPD73 & 100,00 & 164,64 & 112,88 & $\begin{array}{l}38,83 \\
\end{array}$ & 5980,29 & 333,86 & 46,27 & 287,60 & 99,49 & 242,99 & 243,82 & 91,55 & 586,46 & 78,71 & 4,75 & 51,56 & 228,94 & 38,45 & 39,36 & 220,19 \\
\hline Pleurodeles walt| & 29SPD74 & 101,00 & 160,95 & 109,50 & 38,06 & 5989,27 & 328,78 & 45,17 & 283,62 & 96,34 & 239,74 & 240,83 & 88,44 & 626,49 & 83,05 & 5,03 & 51,66 & 245,22 & 40,97 & 41,77 & 237,36 \\
\hline Pleurodeles walt| & 29SPD75 & 100 & 160 & 107 & 37,7 & 6004,66 & 327 , & 45,64 & 281. & 95,76 & 239 & $24 c$ & 87,78 & 640,06 & 84,48 & 5,02 & 51,79 & 250,86 & 41,51 & 42,46 & 24 \\
\hline Pleurodeles walt| & $295 P D 76$ & 101,00 & 158,10 & 105,10 & 37,02 & 6021,02 & 323,91 & 44,77 & 279,14 & 93,63 & 237,60 & 238,68 & 85,63 & 665,40 & 88,27 & 5,44 & 51,81 & 261,00 & 43,29 & 44,05 & 254,05 \\
\hline Pleurodeles walt| & 29SPD77 & 100,00 & 163,55 & 105,60 & 37,01 & 6029,43 & 328,94 & 49,05 & 279,88 & 98,36 & 243,08 & 243,80 & 90,37 & 630,06 & 83,43 & $\begin{array}{l}, 999 \\
\end{array}$ & 51,70 & 246,92 & 40,79 & 42,02 & 239,72 \\
\hline Pleurodeles walt| & 29SPD78 & 101,00 & 163,18 & 104,46 & \begin{tabular}{|l|}
36,98 \\
\end{tabular} & 6042,43 & 327,73 & 48,82 & 278,91 & 97,58 & 242,86 & 243,48 & 89,67 & $\begin{array}{l}638,86 \\
\end{array}$ & 85,31 & 4,99 & 51,72 & 250,58 & 41,22 & 42,48 & 243,70 \\
\hline Pleuroc & 29SPD79 & 100,0 & 164, & 103,93 & 36,99 & 46,74 & 338 & 49,56 & 278,56 & 98,21 & 24 & & 90 & \begin{tabular}{|c|}
634,59 \\
\end{tabular} & 85,11 & 4,96 & & 248,84 & 40,90 & 42,10 & 242,06 \\
\hline Pleurodeles walt| & 29SPD80 & 100,00 & 166,48 & 116,63 & 39,00 & 6016,54 & 338,82 & 43,80 & 295,03 & 101,63 & 244,73 & 245, & 92,25 & 515,78 & 71,39| & 4,00 & 51,66 & 200,01 & 33,50 & 34,65 & 188,28 \\
\hline Pleurodeles walt| & 29SPD82 & 100,00 & 167,14 & 115,38 & 38,95 & 6039,30 & 339,05 & 45,73 & 293,31 & 101,06 & 246,31 & 246,66 & 93,00 & 532,86 & 72,48 & 4,00 & 51,25 & 206,41 & 35,04 & 35,95 & 195,55 \\
\hline
\end{tabular}




\begin{tabular}{|c|c|c|c|c|c|c|c|c|c|c|c|c|c|c|c|c|c|c|c|c|c|}
\hline TAXON & UTM & $\mathrm{km} 2$ & BIO1 & B102 & $B 103$ & BIO4 & B105 & B106 & B107 & B108 & B109 & B1010 & BIO11 & BIO12 & B1013 & B1014 & BIO15 & B1016 & B1017 & B1018 & B1019 \\
\hline Pleurodeles walt| & 29SPD83 & 100,00 & 164,86 & 113,41 & 38,41 & 6057,41 & 336,19 & 44,88 & 291,31 & 98,84 & 244,34 & 244,99 & 90,78 & 559,73 & 75,01 & 4,28 & 51,20 & 216,95 & 36,56 & 37,66 & 206,87 \\
\hline Pleurodeles walt| & 29SPD86 & 100,00 & 160,82 & 107,20 & 37,01 & 6100,64 & 329,33 & 44,68 & 284,66 & 94,91 & 241,38 & 242,02 & 86,92 & 614,69 & 80,48 & 4,97 & 51,01 & 238,84 & 40,42 & 41,25 & 230,18 \\
\hline Pleurodeles walt| & 29SPD87 & 100,00 & 162,66 & 106,46 & 37,01 & 6105,22 & $\begin{array}{l}330,23 \\
\end{array}$ & 46,67 & 283,56 & 96,46 & 243,22 & 243,79 & 88,46 & $\begin{array}{l}606,97 \\
6\end{array}$ & 79,40 & 4,95 & 50,99 & 235,81 & 40,01 & 41,02 & 227,34 \\
\hline Pleurodeles walt| & 29SPD89 & 100,00 & 160,42 & 104,07 & 36,61 & 6124,59 & 326,65 & 45,32 & 281,34 & 93,82 & 241,47 & 241,73 & 86,14 & $\begin{array}{l}627,26 \\
\end{array}$ & 83,17 & 5,00 & 51,11 & 244,16 & 41,07 & 41,74 & 236,20 \\
\hline Pleurodeles walt| & 29SPD93 & 100,00 & 163,21 & 113,01 & \begin{tabular}{|l|}
37,98 \\
\end{tabular} & 6135,61 & 336,21 & 42,49 & 293,72 & 96,36 & 243,83 & 244,27 & 88,26 & 551,54 & 73,30 & 4,07 & 51,00 & 212,45 & 35,73 & 36,68 & 201,47 \\
\hline Pleurodeles walt| & 29SPD95 & 100,00 & 161,11 & 109,48 & 37,20 & 6168,92 & 332,58 & 42,74 & 289,84 & 94,19 & 242,64 & 242,97 & 86,19 & 580,94 & 75,82 & 4,72 & 50,47 & 223,68 & 38,61 & 39,40 & 213,55 \\
\hline 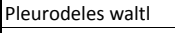 & 29SPD96 & 101,00 & 160,82 & 107,91 & 36,97 & 6178,85 & 331,39 & 43,34 & 288,05 & 93,88 & 242,63 & 242,93 & 85,88 & 586,53 & 76,25 & 4,64 & 50,48 & 226,01 & 38,76 & 39,28 & 216,13 \\
\hline Pleurodeles walt| & 29SPD99 & 100,00 & 158,30 & 104,49 & 36,06 & 6195,90 & 326,29 & \begin{tabular}{ll|}
42,27 \\
\end{tabular} & 284,01 & 90,98 & 240,64 & 240,69 & 83,27 & $\begin{array}{l}610,56 \\
\end{array}$ & 79,83 & 5,00 & 50,47 & 235,55 & 40,64 & 40,75 & 226,44 \\
\hline Pleurodeles walt| & 29SPE10 & 100,00 & 159,18 & 97,18 & \begin{tabular}{ll|l}
36,95 \\
\end{tabular} & 5576,36 & 312,60 & 53,12 & 259,48 & 91,49 & 232,06 & 233,77 & 91,49 & $\begin{array}{l}854,46 \\
\end{array}$ & 123,62 & 6,97 & 54,95 & $\begin{array}{l}346,49 \\
\end{array}$ & 52,60 & 53,47 & 346,49 \\
\hline Pleurodeles walt| & 29SPE12 & 100,00 & 151,78 & 95,52 & 36,56 _ & 5580,80 & 303,98 & 46,12 & 257,86 & 84,14 & 225,44 & 226,36 & 84,14 & 943,37 & 138,41 & 8,12 & 55,08 & 383,08 & 58,69 & 59,05 & 383,08 \\
\hline Pleurodeles walt| & 29SPE20 & 100,00 & 159,02 & 97,11 & \begin{tabular}{|l|l}
36,27 \\
\end{tabular} & 5736,83 & 315,15 & 51,62 & 263,53 & 91,49 & 234,44 & 235,76 & 89,70 & $\begin{array}{l}838,95 \\
\end{array}$ & 120,98 & 6,83 & 54,74 & 338,78 & 51,89 & 52,70 & 338,73 \\
\hline Pleurodeles walt| & 29SPE21 & 100,00 & 157,59 & 97,04 & 36,15 & 5765,61 & 313,94 & 49,60 & 264,34 & 88,08 & 233,56 & 234,55 & 87,85 & 858,44 & 124,23 & 7,02 & 54,74 & 346,39 & 53,52 & 54,15 & 346,39 \\
\hline Pleurodeles walt| & 29SPE22 & 100,00 & 153,76 & \begin{tabular}{|l|l}
96,17 \\
\end{tabular} & 36,13 & 5741,76 & 308,91 & 46,21 & 262,70 & 84,23 & 229,40 & 230,39 & 84,23 & 900,23 & 131,32 & 7,73 & 54,81 & 363,70 & 56,48 & 56,78 & 363,70 \\
\hline Pleurodeles walt| & 29SPE30 & 100,00 & 165,01 & $\begin{array}{ll}99,91 \\
\end{array}$ & \begin{tabular}{l|l|l|}
36,85 \\
\end{tabular} & 5785,91 & 322,58 & 55,11 & 267,47 & 101,66 & 240,95 & 241,99 & $\begin{array}{l}94,62 \\
\end{array}$ & \begin{tabular}{|l|l|}
754,97 \\
\end{tabular} & $\begin{array}{l}106,97 \\
\end{array}$ & 6,00 & 54,14 & 302,59 & 46,47 & 48,13 & 301,33 \\
\hline Pleurodeles walt| & 29SPE31 & 101,00 & 157,49 & $\begin{array}{ll}97,29 \\
\end{array}$ & 36,01 & 5870,90 & 315,45 & 48,45 & 267,00 & 91,57 & 234,94 & 235,83 & 86,60 & 833,36 & 120,00 & 6,90 & 54,25 & \begin{tabular}{|l|l|}
334,68 \\
\end{tabular} & 52,14 & 52,80 & 334,45 \\
\hline Pleurodeles walt| & 29SPE32 & 100,00 & 155,12 & 96,91 & 36,01 & 5844,35 & 312,09 & 46,21 & 265,88 & 88,22 & 232,29 & 232,95 & 84,38 & 856,54 & 123,96 & 7,15 & 54,26 & 343,94 & 53,86 & 54,35 & 343,80 \\
\hline Pleurodeles walt| & 29SPE40 & 101,00 & 164,31 & 100,45 & 36,85 & 5868,35 & 323,23 & 53,36 & 269,86 & 100,41 & 241,48 & 242,36 & 92,96 & 733,33 & \begin{tabular}{|l|l|}
103,07 \\
\end{tabular} & 5,98 & 53,64 & 292,77 & 45,60 & 47,25 & 290,38 \\
\hline Pleurodeles walt| & 29SPE41 & 100,00 & 163,53 & 100,25 & 36,75 & 5876,42 & 322,10 & 52,19 & 269,90 & 99,20 & 240,77 & 241,49 & 91,83 & 744,16 & 105,12 & 6,05 & 53,53 & 296,93 & 46,41 & 48,04 & 294,75 \\
\hline Pleurodeles walt| & 29SPE42 & 99,00 & 156,54 & $\begin{array}{ll}97,94 \\
\end{array}$ & 36,04 & 5903,14 & 314,45 & 46,30 & 268,15 & 92,15 & 234,38 & 234,94 & 84,72 & 808,24 & 115,72 & 6,78 & 53,88 & 322,90 & 50,98 & 51,71 & 321,60 \\
\hline Pleurodeles walt| & 29SPE51 & 101,00 & 162,83 & 100,88 & 36,68 & 5941,95 & 322,45 & 50,59 & 271,86 & 97,88 & 241,23 & 241,63 & 90,42 & \begin{tabular}{|l|l|}
716,97 \\
\end{tabular} & 100,21 & 5,86 & 53,12 & 284,78 & 45,20 & \begin{tabular}{|l|l}
46,64 \\
\end{tabular} & 281,24 \\
\hline Pleurodeles walt| & $\begin{array}{l}\text { 29SPE52 } \\
\end{array}$ & 101,00 & 157,55 & 99,13 & 36,10 & 5958,68 & 316,43 & 46,10 & 270,33 & 92,54 & 236,26 & 236,52 & 84,95 & 761,84 & \begin{tabular}{|l|l|}
107,67 \\
\end{tabular} & 6,19 & 53,17 & 302,85 & 48,50 & 49,19 & 300,00 \\
\hline Pleurodeles walt| & 29SPE61 & 99,00 & 159,52 & 100,65 & 36,13 & $\begin{array}{ll}6011,88 \\
\end{array}$ & 320,19 & \begin{tabular}{|l|l|}
46,94 \\
\end{tabular} & 273,24 & 94,04 & 238,99 & 239,26 & 86,33 & \begin{tabular}{ll|l}
709,88 \\
\end{tabular} & 98,39 & 5,94 & 52,45 & 280,56 & 45,79 & 46,52 & 275,97 \\
\hline Pleurodeles walt| & \begin{tabular}{l|l|} 
29SPE62 \\
\end{tabular} & 100,00 & 155,44 & 99,42 & 36,04 & 6016,15 & 315,34 & 43,59 & 271,75 & 90,01 & 235,19 & 235,31 & 82,29 & \begin{tabular}{|l|l|}
739,68 \\
\end{tabular} & 103,40 & 6,29 & 52,52 & 292,50 & 48,01 & 48,30 & 288,25 \\
\hline Pleurodeles walt| & 29SPE70 & 101,00 & 160,68 & 102,50 & 36,39 & 6061,68 & 323,93 & 46,84 & 277,09 & 94,72 & 240,89 & 241,08 & 86,94 & 661,91 & 89,78 & 5,25 & 51,91 & 259,85 & 42,67 & 43,48 & 253,48 \\
\hline Pleurodeles walt| & 29SPE71 & 100,00 & 159,82 & 101,92 & 36,35 & 6065,58 & 322,31 & 45,97 & 276,34 & 93,66 & 240,05 & 240,17 & 85,82 & $\begin{array}{l}670,65 \\
\end{array}$ & 91,49 & 5,45 & 51,84 & 263,29 & 43,56 & 44,06 & 257,20 \\
\hline Pleurodeles walt| & 29SPE72 & 101,00 & 157,64 & 101,21 & 36,08 & 6065,15 & 319,49 & 44,06 & 275,43 & 91,42 & 237,94 & 238,00 & 83,62 & 684,95 & 93,96 & 5,83 & 51,77 & 268,81 & 45,03 & 45,28 & 262,93 \\
\hline Pleurodeles walt| & $\begin{array}{l}\text { 29SPE82 } \\
\end{array}$ & 100,00 & 156,19 & 101,95 & 36,03 & 6125,07 & 319,99 & 41,74 & 278,25 & 89,41 & 237,48 & 237,48 & 81,48 & $\begin{array}{l}657,45 \\
\end{array}$ & 88,73 & 5,76 & 50,90 & 256,01 & \begin{tabular}{ll|}
44,06 \\
\end{tabular} & 44,06 & 248,87 \\
\hline Pleurodeles walt| & 29SQA19 & 10,00 & 178,00 & 87,00 & 37,00 & \begin{tabular}{|l|l|}
4992,64 \\
\end{tabular} & 302,64 & 72,00 & 230,64 & 136,73 & 240,55 & 243,45 & 115,64 & 523,27 & 80,91 & 1,00 & 64,91 & 227,91 & 14,00 & 22,00 & 207,55 \\
\hline Pleurodeles walt| & 295QA26 & & & & & & & & & & & & & & & & & & & & \\
\hline Pleurodeles walt| & 295QA29 & 85,00 & 178,83 & 87,79 & 37,13 & 5027,68 & 304,23 & 72,22 & 232,02 & 143,22 & 241,99 & 245,02 & 116,11 & 528,25 & 81,26 & 1,00 & 64,74 & 230,03 & 14,15 & 22,00 & 210,30 \\
\hline Pleurodeles walt| & 29SQA35 & 24,00 & 177,69 & 83,83 & \begin{tabular}{|l|}
38,69 \\
\end{tabular} & 4534,21 & 291,17 & 77,52 & 213,66 & 155,45 & 234,41 & 238,17 & 122,10 & 557,24 & 92,62 & 0,00 & 67,28 & 248,90 & $\begin{array}{ll}12,69 \\
\end{array}$ & 20,00 & 230,62 \\
\hline Pleurodeles walt| & 29SQA36 & 95,00 & $\begin{array}{lll}177,07 \\
\end{array}$ & 84,66 & 38,31 & 4649,30 & 293,27 & 75,19 & 218,08 & 153,02 & 235,24 & 238,90 & 119,87 & 554,28 & 90,71 & 0,00 & 66,75 & 246,68 & 13,00 & 20,40 & 228,02 \\
\hline Pleurodeles walt| & 29SQA37 & 70,00 & 177,22 & 84,36 & \begin{tabular}{l|l|l}
37,45 & \\
\end{tabular} & 4807,11 & 296,27 & 74,12 & 222,15 & 152,46 & 237,56 & 241,03 & 117,86 & 551,16 & 87,79 & 0,53 & 65,83 & 242,48 & 13,59 & 21,43 & 223,57 \\
\hline Pleurodeles walt| & 29SQA38 & 99,00 & 178,11 & 85,82 & $\begin{array}{l}37,06 \\
\end{array}$ & $\begin{array}{lll}4961,88 \\
\end{array}$ & 301,15 & 73,00 & 228,15 & 152,06 & 240,71 & 243,84 & 116,70 & 544,02 & 84,41 & 1,00 & 65,20 & \begin{tabular}{|l|l|}
236,98 \\
\end{tabular} & 14,46 & 22,00 & 217,83 \\
\hline Pleurodeles walt| & 295QA39 & 100,00 & 178,93 & 88,43 & 37,01 & 5120,94 & 306,79 & 71,23 & 235,55 & 143,96 & 243,43 & 246,48 & 115,26 & 540,45 & 82,58 & 1,00 & 64,61 & 233,88 & 14,96 & 22,00 & 214,68 \\
\hline Pleurodeles walt| & 29SQA43 & 19,00 & 179,33 & 70,04 & 35,96 & 4462,26 & 279,67 & 86,48 & 193,19 & 158,41 & 234,30 & 238,67 & 123,78 & 609,26 & 105,11 & 0,93 & 68,96 & 264,70 & 11,96 & 22,00 & 248,44 \\
\hline Pleurodeles walt| & 29SQA44 & 26,00 & 179,26 & 71,10 & 35,90 & 4487,74 & 281,03 & 85,62 & \begin{tabular}{|l|}
195,41 \\
\end{tabular} & 157,85 & 234,28 & 238,97 & 123,28 & $\begin{array}{l}601,95 \\
\end{array}$ & 100,23 & 0,38 & 68,10 & 258,90 & 11,90 & 21,03 & 243,23 \\
\hline Pleurodeles walt| & 29SQA45 & 69,00 & 176,93 & 76,35 & 36,36 & 4649,63 & 286,27 & 79,15 & 207,12 & 153,94 & 234,81 & 238,93 & 119,44 & 587,01 & 95,92 & 0,38 & 66,81 & 255,15 & 13,02 & 21,31 & 237,94 \\
\hline Pleurodeles walt| & 29SQA46 & 101,00 & 175,51 & 79,22 & 36,27 & 4778,15 & 290,15 & 74,90 & 215,25 & 151,44 & 235,35 & 239,28 & 116,57 & 579,61 & 92,91 & 0,65 & 66,18 & 252,08 & 13,88 & 21,77 & 234,53 \\
\hline Pleurodeles walt| & 29SQA47 & 99,00 & 176,25 & 80,88 & 35,97 & 4931,20 & 295,24 & 73,49 & 221,75 & 150,49 & 238,23 & 241,92 & 115,29 & 568,75 & 88,95 & 0,97 & 65,60 & 246,05 & 14,79 & 21,97 & 227,88 \\
\hline Pleurodeles walt| & 29SQA48 & 99,00 & $\begin{array}{l}177,43 \\
\end{array}$ & 83,96 & 36,08 & 5077,41 & 301,60 & 72,08 & 229,52 & 148,23 & 241,44 & 244,77 & $\begin{array}{l}114,47 \\
\end{array}$ & 561,33 & 86,13 & 1,00 & 65,01 & 241,91 & \begin{tabular}{l|l|l}
15,03 \\
\end{tabular} & 22,02 & 223,48 \\
\hline Pleurodeles walt| & 29SQA52 & & & & & & & & & & & & & & & & & & & & \\
\hline Pleurodeles walt| & 29SQA53 & 100,00 & 177,64 & 70,43 & $\begin{array}{l}35,65 \\
\end{array}$ & 4493,07 & 279,11 & 84,29 & 194,82 & 143,26 & 232,93 & 237,52 & 121,50 & 635,77 & 110,43 & 1,00 & 69,06 & 277,45 & 13,16 & 23,23 & 262,34 \\
\hline Pleurodeles walt| & 29SQA54 & 93,00 & 177,06 & 70,42 & 34,9 & 4627,92 & 281,23 & 82,24 & 198,99 & 149,73 & 234,27 & 238,95 & 119,38 & 623,61 & 105,06 & 1,00 & 68,15 & 269,05 & 13,48 & 23,19 & 253,37 \\
\hline Pleurodeles walt| & 29SQA55 & 100,00 & 176,14 & 71,50 & 34, & 4748,96 & 283,85 & 79,40 & 204,45 & 150,89 & 235,24 & 239,52 & 117,14 & 611,03 & 99,24 & 1,00 & 67,15 & 261,72 & 14,25 & 22,82 & 245,79 \\
\hline Pleurodeles walt| & 29SQA56 & 100,00 & $\begin{array}{l}173,87 \\
\end{array}$ & 72,93 & 33,94 & 4924,18 & 286,72 & 74,69 & 212,03 & 144,30 & 235,60 & 239,56 & 112,85 & \begin{tabular}{ll|}
606,72 \\
\end{tabular} & 95,02 & 1,00 & 65,93 & 257,52 & 15,55 & 23,43 & 241,52 \\
\hline Pleurodeles walt| & 29SQA57 & 100,00 & 174,19 & 75,94 & 34,00 & \begin{tabular}{|l|l|}
5074,94 \\
\end{tabular} & 292,53 & 72,25 & 220,28 & $\begin{array}{l}137,56 \\
\end{array}$ & 238,01 & 241,78 & $\begin{array}{l}111,32 \\
\end{array}$ & $\begin{array}{l}594,55 \\
\end{array}$ & 90,93 & 1,00 & 65,47 & 252,01 & 16,14 & 23,23 & 235,14 \\
\hline Pleurodeles walt| & 29SQA58 & 101,00 & 175,78 & 81,62 & 34,94 & 5197,06 & 300,87 & 70,73 & 230,14 & 126,74 & 241,48 & 244,90 & 111,45 & 585,37 & 88,62 & 1,00 & 65,05 & 248,94 & 16,59 & 22,96 & 231,55 \\
\hline Pleurodeles walt| & 29SQA59 & 100,00 & 177,81 & 88,22 & 36,01 & 5325,35 & 310,44 & 68,98 & 241,46 & 121,73 & 245,46 & 248,52 & 111,84 & 576,63 & 86,75 & 1,00 & 64,58 & 246,06 & 16,63 & 22,69 & 228,34 \\
\hline Pleurodeles walt| & 295QA60 & & & & & & & & & & & & & & & & & & & & \\
\hline \begin{tabular}{|l|l|} 
Pleurodeles walt1 \\
\end{tabular} & 29SQA62 & 96,00 & 173,91 & 72,69 & 36,69 & 4381,85 & 276,29 & 80,88 & 195,42 & 128,33 & 228,08 & 232,35 & 119,18 & \begin{tabular}{ll|}
703,15 \\
\end{tabular} & 122,12 & 1,00 & 70,45 & 313,64 & 14,39 & 23,54 & 299,47 \\
\hline Pleurodeles walt| & 29SQA63 & 91,00 & 174,26 & 71,55 & 35,73 & 4530,08 & 278,14 & 80,13 & 198,02 & 127,05 & 230,42 & 234,79 & 117,85 & 680,79 & 116,33 & 1,00 & 69,49 & 299,66 & 14,39 & 23,80 & 284,77 \\
\hline Pleurodeles walt| & 29SQA64 & 82,00 & 173,11 & 71,60 & 34,77 & 4697,90 & 280,25 & 77,27 & 202,98 & 123,76 & 231,64 & 235,93 & 114,68 & 667,31 & 111,07 & 1,00 & 68,47 & 289,70 & 14,79 & 24,00 & 274,71 \\
\hline Pleurodeles walt| & $2950 A 6$ & 87,00 & 173 & 71, & 33, & $4 \mathrm{c}-\mathrm{r}$ & 282 & 76,20 & 206,74 & 125 & 233,76 & & 11 & 646 & 104 & 1,00 & 67,41 & 276,87 & 15,43 & 23,97 & 261 \\
\hline Pleurodeles walt| & 295QA66 & 81,00 & 172,10 & 71,69 & 33,18 & 5004,39 & 285,84 & 72,94 & 212,90 & 120,75 & 234,93 & 238,95 & 110,16 & 634,60 & 98,66 & 1,00 & 66,61 & 268,96 & 16,27 & 24,00 & 253,05 \\
\hline Pleurodeles walt| & 29SQA67 & 74,00 & 172,12 & 74,46 & 33,22 & 5156,09 & 291,14 & 70,57 & 220,57 & 1117,32 & 237,22 & 241,03 & 108,40 & 622,43 & 94,41 & 1,00 & 65,77 & 262,61 & 17,00 & 23,99 & 245,97 \\
\hline Pleurodeles walt| & 29SQA68 & 77,00 & 174,05 & 82,09 & \begin{tabular}{|l|l|}
34,77 \\
\end{tabular} & 5281,10 & 301,26 & 68,74 & 232,53 & 117,69 & 241,00 & 244,45 & 108,83 & $\begin{array}{l}609,35 \\
\end{array}$ & 92,02 & 1,00 & 65,39 & 258,86 & 17,01 & 23,36 & 241,70 \\
\hline Pleuroc & 29SQA69 & 71,00 & 177,33 & 89, & 36,24 & 866,12 & 312,16 & 68,35 & $\sqrt{12}+2>$ & 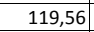 & 45,90 & 248 & 111 & 592,09 & 89,20 & 1,00 & 65,02 & 252,94 & 17,00 & 23,00 & 235,42 \\
\hline Pleurodeles walt| & 29SQB00 & 46,00 & 176,74 & 85,34 & 37,00 & 5008,82 & 299,92 & 71,94 & 227,98 & 123,20 & 239,08 & 242,08 & 114,04 & 511,26 & 79,38 & 1,00 & 64,36 & 221,58 & 14,00 & 23,00 & 200,42 \\
\hline Pleurodeles walt| & 29SQB01 & 100,00 & 177,03 & 85,80 & 36,91 & 5086,65 & 301,93 & 71,36 & 230,57 & 128,89 & 240,26 & 243,19 & 113,39 & 505,93 & 78,73 & 1,00 & 63,83 & 218,10 & 14,01 & 23,13 & 196,75 \\
\hline
\end{tabular}




\begin{tabular}{|c|c|c|c|c|c|c|c|c|c|c|c|c|c|c|c|c|c|c|c|c|c|}
\hline TAXON & UTM & $\mathrm{km} 2$ & B101 & B102 & $\mathrm{BIO3}$ & 8104 & B105 & B106 & B107 & B108 & B109 & B1010 & BIO11 & BIO12 & B1013 & BIO14 & BIO15 & B1016 & B1017 & BIO18 & B1019 \\
\hline Pleurodeles walt| & 29SQB02 & 100,00 & 175,71 & 87,83 & 36,78 & 5211,77 & 304,69 & 68,22 & 236,47 & 121,68 & 240,67 & 243,42 & 110,32 & 511,72 & 79,20 & 1,00 & 63,09 & 218,53 & 14,72 & 23,99 & 197,38 \\
\hline Pleurodeles walt| & 29SQB03 & 100,00 & 176,62 & 90,04 & 36,92 & 5313,06 & 309,19 & 67,62 & 241,57 & 130,20 & 243,06 & 245,67 & 110,08 & 505,56 & 78,12 & 1,00 & 62,66 & 214,59 & 15,01 & 23,97 & 193,80 \\
\hline Pleurodeles walt| & 29SQB04 & 100,00 & 175,53 & 93,32 & 37,02 & 5425,44 & 312,93 & 64,53 & 248,41 & 120,14 & 243,71 & 246,19 & 107,63 & 511,63 & 78,33 & 1,29 & 61,96 & 215,68 & 16,04 & 24,62 & 195,76 \\
\hline Pleurodeles walt| & 29SQB05 & 101,00 & 169,79 & 97,85 & 37,29 & 5573,42 & 314,27 & 56,43 & 257,84 & 109,60 & 240,50 & 242,85 & 100,61 & 543,49 & 81,20 & 2,00 & 60,59 & 226,67 & 19,23 & 27,11 & 208,41 \\
\hline Pleurodeles walt| & 29SQB06 & 101,00 & 165,53 & 101,65 & 37,97 & 5683,37 & 315,98 & 50,49 & 265,49 & 104,53 & 238,24 & 240,44 & 95,45 & 566,49 & 83,17 & 2,01 & 59,96 & 234,53 & 21,17 & 28,32 & 217,67 \\
\hline Pleurodeles walt| & 29SQB07 & 100,00 & 164,82 & 104,21 & 38,00 & 5762,46 & 319,25 & 48,34 & 270,91 & 102,79 & 238,75 & 240,87 & 93,82 & 569,38 & 82,77 & 2,29 & 59,36 & 234,26 & 22,28 & 28,82 & 218,29 \\
\hline Pleurodeles walt| & 29SQB08 & 100,00 & 163,17 & 106,56 & 38,00 & 5835,67 & 321,68 & 45,53 & 276,15 & 100,43 & 238,34 & 240,40 & 91,52 & 576,80 & 82,82 & 2,68 & 58,52 & 235,69 & 23,96 & 29,93 & 220,70 \\
\hline Pleurodeles waltl & 29SQB09 & 101,00 & 149,98 & 109,34 & 38,00 & 5955,40 & 315,23 & 31,79 & 283,43 & 86,71 & 227,37 & 229,53 & 77,75 & 655,52 & $\begin{array}{l}2,060 \\
90,98 \\
\end{array}$ & 3,83 & 57,21 & 264,65 & 30,41 & 35,23 & 252,11 \\
\hline Pleurodeles walt| & 29SQB10 & 96,00 & 177,80 & 87,58 & 37,01 & 5066,93 & 303,78 & 71,44 & 232,34 & 130,63 & 241,16 & 244,08 & 114,66 & 518,74 & 80,20 & 1,00 & 64,27 & 224,79 & 14,00 & 22,93 & 204,25 \\
\hline Pleurodeles walt| & 29SQB11 & 100,00 & 178,60 & 89,13 & 37,01 & 5175,99 & 307,72 & 70,57 & 237,15 & 130,95 & 243,40 & 246,23 & 113,90 & 513,12 & 79,52 & 1,00 & 63,83 & 220,93 & 14,38 & 23,00 & 200,28 \\
\hline Pleurodeles walt| & 29SQB12 & 99,00 & 177,09 & 91,82 & 37,01 & 5318,58 & 311,16 & 67,03 & 244,13 & 119,89 & 244,00 & 246,56 & 110,55 & 519,52 & 80,10 & 1,00 & 63,16 & 221,75 & 15,04 & 23,39 & 201,42 \\
\hline Pleurodeles walt| & 29SQB13 & 101,00 & 175,23 & 94,79 & 37,05 & 5452,54 & 314,19 & 62,94 & 251,25 & 116,11 & 244,04 & 246,46 & 107,10 & 528,76 & 80,87 & 1,01 & 62,52 & 224,05 & 15,94 & 24,02 & 204,34 \\
\hline Pleurodeles walt| & 29SQB14 & 100,00 & 177,04 & 97,18 & 37,40 & 5528,40 & 319,21 & 63,27 & 255,94 & 117,12 & 247,02 & 249,25 & 108,02 & 518,64 & 79,16 & 1,11 & 62,08 & 218,60 & 16,14 & 24,15 & 199,43 \\
\hline Pleurodeles walt| & 29SQB15 & 100,00 & 171,39 & 101,11 & 37,85 & 5671,57 & 320,33 & 55,58 & 264,75 & 110,05 & 243,75 & 245,90 & 101,01 & 548,55 & 81,87 & 1,99 & 60,71 & 228,67 & 19,41 & 26,72 & 210,85 \\
\hline Pleurodeles walt| & 29SQB16 & 99,00 & 168,83 & 104,02 & 38,00 & 5771,93 & 322,70 & 51,44 & 271,26 & 106,39 & 242,73 & 244,82 & 97,38 & 560,74 & 82,61 & 2,01 & 60,17 & 232,12 & 20,69 & 27,51 & 215,31 \\
\hline Pleurodeles waltt & 29SQB17 & 101,00 & 163,36 & 107,06 & 38,00 & 5877,79 & 322,84 & 44,57 & 278,27 & 99,97 & 239,10 & 241,08 & 90,98 & 589,06 & 85,03 & 2,50 & 59,22 & 241,64 & 23,35 & 29,53 & 226,20 \\
\hline Pleurodeles walt| & 29SQB19 & 99,00 & 151,81 & 111,03 & 38,00 & 6028,69 & 319,92 & 31,80 & 288,13 & 87,58 & 230,39 & 232,23 & 78,65 & 649,94 & 90,32 & 3,61 & 57,35 & 262,00 & 29,59 & 34,50 & 249,20 \\
\hline Pleurodeles walt| & 29SQB20 & 100,00 & 179,04 & 89,73 & 37,08 & 5151,40 & 308,35 & 70,87 & 237,48 & \begin{tabular}{r|r|}
134,68 \\
\end{tabular} & 243,99 & 246,81 & 114,96 & 524,89 & 80,86 & 1,00 & 64,52 & 227,17 & 14,90 & 22,01 & 207,32 \\
\hline Pleurodeles walt| & 29SQB21 & 101,00 & 179,80 & 92,42 & 37,20 & 5285,69 & 313,51 & 69,27 & 244,24 & 131,97 & 246,44 & 249,12 & 113,76 & 522,48 & 80,46 & 1,00 & 63,68 & 224,48 & 15,00 & 22,31 & 204,82 \\
\hline Pleurodeles walt| & 29SQB22 & 100,00 & 178,30 & 95,58 & 37,40 & 5428,78 & 317,33 & 65,47 & 251,87 & 119,33 & 247,04 & 249,51 & 110,55 & 529,87 & 81,28 & 1,00 & 63,28 & 226,09 & 15,47 & 22,99 & 206,78 \\
\hline Pleurodeles walt| & 29SQB23 & 100,00 & 175,58 & 99,15 & 37,64 & 5576,75 & 320,65 & 60,34 & 260,32 & 115,05 & 246,60 & 248,85 & 106,15 & 544,32 & 82, & 1,00 & 62,51 & 230,34 & 16,86 & 24,24 & 211,68 \\
\hline Pleurodeles waltt & 29SQB24 & 100,00 & 175,60 & 101,94 & 37,95 & 5673,27 & 325,06 & 58,67 & 266,40 & 114,06 & 248,11 & 250,25 & 104,99 & 543,60 & 81,97 & 1,36 & 61,76 & 228,44 & 18,02 & 24,99 & 210,41 \\
\hline Pleurodeles walt| & 29SQB25 & 99,00 & 170,63 & 105,14 & 37,99 & 5800,16 & 325,97 & 51,97 & 274,00 & 107,85 & 245,09 & 247,13 & 98,82 & 567,97 & 84,15 & 1,98 & 60,84 & 236,44 & 20,20 & 26,87 & 219,51 \\
\hline Pleurodeles waltt & 29SQB26 & 101,00 & 165,03 & 108,10 & 38,00 & 5908,15 & 325,85 & 45,03 & 280,81 & 101,40 & 241,28 & 243,17 & 92,26 & 594,59 & 86,44 & 2,06 & 60,03 & 245,36 & 22,21 & 28,46 & 229,72 \\
\hline Pleurodeles walt| & 29SQB27 & 100,00 & 162,82 & 109,90 & 38,00 & 5980,37 & 327,18 & 41,83 & 285,35 & 98,45 & 240,34 & 242,12 & 89,41 & 602,57 & 86,51 & 2,57 & 59,20 & 246,70 & 24,01 & 29,90 & 231,84 \\
\hline Pleurodeles walt| & 29SQB31 & 100,00 & 180,39 & 95,44 & 37,43 & 5399,35 & 319,24 & 67,63 & 251,61 & 121,85 & 248,92 & 251,55 & 113,18 & 535,35 & 82,11 & 1,00 & 63,83 & 229,68 & 15,20 & 22,00 & 210,79 \\
\hline \begin{tabular}{|l|l|} 
Pleurodeles waltl \\
\end{tabular} & $29 \mathrm{SQB3} 32$ & 100,00 & 179,88 & 99,43 & 37,81 & 5541,95 & 324,76 & 64,30 & 260,46 & $\begin{array}{l}119,66 \\
11,0\end{array}$ & $\begin{array}{l}250,41 \\
\end{array}$ & 252,84 & 110,82 & 540,01 & $\begin{array}{l}\mid 2,211 \\
82,50\end{array}$ & $\begin{array}{l}1,00 \\
1,00\end{array}$ & 63,43 & 230,37 & $\begin{array}{l}16,01 \\
16,0\end{array}$ & 22,43 & 212,05 \\
\hline Pleurodeles walt| & 29SQB33 & 100,00 & 178,05 & 103,27 & 37,99 & 5681,46 & 329,20 & 60,05 & 269,14 & 116,39 & 250,78 & 252,92 & 107,42 & 549,83 & 83,33 & 1,00 & 62,64 & 232,79 & 17,50 & 23,88 & 215,05 \\
\hline Pleurodeles walt| & 29SQB34 & 100,00 & 179,52 & 106,17 & 38,01 & 5772,33 & 334,80 & 59,57 & 275,24 & 116,62 & 253,47 & 255,43 & 107,67 & 542,43 & 81,89 & 1,01 & 62,08 & 228,52 & 18,01 & 23,92 & 211,26 \\
\hline Pleurodeles waltt & 29SQB35 & 101,00 & 175,74 & 109,07 & 38,05 & 5890,17 & 336,24 & 54,13 & 282,11 & 111,61 & 251,58 & 253,33 & 102,63 & 558,45 & 83,11 & 1,74 & 61,18 & 233,21 & 19,53 & 25,44 & 216,83 \\
\hline Pleurodeles walt| & $29 \mathrm{SQB} 36$ & 100,00 & 170,21 & 111,26 & 38,03 & 5991,56 & 335,15 & 47,61 & 287,54 & 105,24 & 247,70 & 249,40 & 96,23 & 581,49 & 85,01 & 2,00 & 60,50 & 240,69 & 21,21 & 26,95 & 225,24 \\
\hline \begin{tabular}{|l|} 
Pleurodeles waltl \\
\end{tabular} & 29SQB37 & 100,00 & 165,23 & 112,90 & 38,01 & 6067,55 & 333,76 & $\begin{array}{ll}42,02 \\
42\end{array}$ & \begin{tabular}{|l|}
291,74 \\
\end{tabular} & \begin{tabular}{|l|}
99,63 \\
99,4
\end{tabular} & 243,99 & \begin{tabular}{|l|}
245,63 \\
\end{tabular} & $\begin{array}{l}0,25 \\
90,71 \\
\end{array}$ & \begin{tabular}{|l|l|}
602,17 \\
\end{tabular} & $\begin{array}{l}3,, 41 \\
86,41\end{array}$ & 2,31 & 59,48 & 246,70 & $\frac{1,121}{23,48}$ & 28,98 & 232,27 \\
\hline Pleurodeles walt| & 29SQB38 & 101,00 & 165,25 & 114,19 & 38,03 & 6120,83 & 336,06 & 41,25 & 294,81 & 99,12 & 244,91 & 246,42 & 90,10 & 596,49 & 84,86 & 2,55 & 58,82 & 242,79 & 24,17 & 29,42 & 228,80 \\
\hline Pleurodeles waltl & 29SQB39 & 100,00 & 163,07 & 115,24 & 38,00 & 6172,04 & 336,21 & 38,54 & 297,66 & 96,41 & 243,54 & 244,97 & 87,38 & 601,53 & 84,57 & 2,78 & 58,19 & 242,94 & 25,49 & 30,41 & 229,54 \\
\hline Pleurodeles walt| & 29SQB45 & 99,00 & 179,99 & 113,45 & 38,61 & 5980,75 & 346,22 & 55,51 & 290,71 & 114,92 & 257,41 & 259,01 & 105,74 & 555,42 & 82,92 & 1,41 & 61,79 & 232,99 & 18,81 & 24,00 & 217,38 \\
\hline Pleurodeles walt| & 29SQB47 & 101,00 & 169,77 & 116,00 & 38,36 & 6146,51 & 342,23 & 44,27 & 297,96 & 103,11 & 249,79 & 251,23 & 94,08 & 591,41 & 85,13 & 2,04 & 59,97 & 242,96 & 22,34 & 27,42 & 228,87 \\
\hline \begin{tabular}{|l|} 
Pleurodeles waltl \\
\end{tabular} & 29SQB448 & 99,00 & 165,34 & 1116,84 & $\frac{30,50}{38,20}$ & $\begin{array}{l}\mid 6140,13 \\
6207,25\end{array}$ & $34,2,24$ & $\begin{array}{ll}4,4,51 \\
39,51\end{array}$ & 300,73 & \begin{tabular}{|c|}
08,16 \\
98,16
\end{tabular} & \begin{tabular}{|l|}
$246,41,4$ \\
\end{tabular} & $\mid 247,64$ & $\begin{array}{l}4,30 \\
89,31\end{array}$ & \begin{tabular}{|l|l|}
606,48 \\
306
\end{tabular} & $\begin{array}{l}x_{3,15} \\
85,72\end{array}$ & 2,53 & 58,92 & 24,50 & $\frac{24,34}{24,30}$ & $\begin{array}{l}29,42 \\
29,31\end{array}$ & $\begin{array}{l}22,0,016 \\
233,16\end{array}$ \\
\hline Pleurodeles walt| & 29SQB49 & 99,00 & 160,27 & 117,41 & 38,07 & 6265,76 & 337,49 & 34,39 & 303,10 & 92,76 & 242,46 & 243,63 & 83,80 & 624,67 & 86,79 & 3,01 & 58,13 & 251,52 & 26,41 & 31,25 & 238,92 \\
\hline Pleurodeles walt| & 29SQB50 & 101,00 & 179,57 & 95,10 & 37,05 & 5466,56 & 320,40 & 67,05 & 253,35 & 120,67 & 249,35 & 252,07 & 111,92 & 570,72 & 86,26 & 1,00 & 64,35 & 243,91 & 16,70 & 22,70 & 226,31 \\
\hline Pleurodeles waltl & 29SQB51 & 100,00 & 181,28 & 101,57 & 37,78 & 5616,31 & 330,24 & 64,46 & 265,78 & 120,27 & 253,19 & 255,54 & 111,54 & 566,30 & $85, \mathrm{c}$ & 1,00 & 64,08 & 242,13 & 16,97 & 22,72 & 224,97 \\
\hline Pleurodeles walt| & 29SQB52 & 100,00 & 182,30 & 107,75 & 38,14 & 5772,57 & 339,60 & 61,60 & 278,00 & 119,54 & 256,69 & 258,72 & 110,67 & 565,41 & 85, & 1,00 & 63,65 & 241,42 & 17,54 & 22,50 & 224,85 \\
\hline 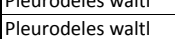 & 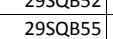 & 100,00 & $\begin{array}{l}18,52,80 \\
182,8\end{array}$ & $\begin{array}{l}101,13 \\
117,92\end{array}$ & $\begin{array}{l}30,14 \\
38,98\end{array}$ & \begin{tabular}{|l|l|}
6077,18 \\
\end{tabular} & 35,00 & $\begin{array}{l}5,, 47 \\
55,\end{array}$ & \begin{tabular}{|l|}
299,360 \\
\end{tabular} & \begin{tabular}{|l|}
116,50 \\
11,5
\end{tabular} & \begin{tabular}{|l|}
260,09 \\
261,79 \\
\end{tabular} & \begin{tabular}{|l|}
$263,1 / 1$ \\
263,16
\end{tabular} & \begin{tabular}{|l|}
107,47 \\
\end{tabular} & \begin{tabular}{|l|}
5539,71 \\
551
\end{tabular} & $\begin{array}{l}3, \\
83,\end{array}$ & $\begin{array}{l}, 1,13 \\
1,13\end{array}$ & $\begin{array}{l}3,203 \\
62,24 \\
\end{array}$ & $\begin{array}{l}241,4 \mathrm{~L} \\
235,80\end{array}$ & $\begin{array}{l}1,34 \\
18,43 \\
\end{array}$ & $\begin{array}{l}23,01 \\
23,0\end{array}$ & $\begin{array}{l}224,83 \\
221,17\end{array}$ \\
\hline Pleurodeles walt| & $29 \mathrm{SQB56}$ & 100,00 & 176,11 & 118,63 & 38,93 & 6163,05 & 350,68 & 48,61 & 302,07 & 109,00 & 256,31 & 257,66 & 100,02 & 582,65 & 85,06 & 1,97 & 61,03 & 242,14 & 20,77 & 25,32 & 228,14 \\
\hline Pleurodeles walt| & 29SQB58 & 100,00 & 164,45 & 119,16 & 38,45 & 6288,16 & 342,96 & 37,21 & 305,74 & 96,54 & 246,97 & 248,00 & 87,55 & 621,15 & 87,10 & 2,57 & 59,09 & 252,23 & 24,62 & 29,52 & 239,62 \\
\hline Pleurodeles walt| & 29SQB59 & 100,00 & 161,72 & 119,53 & 38,08 & 6337,03 & 341,97 & 34,20 & 307,77 & 93,37 & 244,95 & 245,92 & 84,36 & 626,22 & 86,57 & 2,97 & 58,34 & 51,97 & 25,99 & 30,74 & 239,89 \\
\hline \begin{tabular}{|l|} 
Pleurodeles walt| \\
\end{tabular} & 29SQB60 & 65,00 & 179,53 & 96,98 & 37,24 & 5525,91 & 323,05 & $\begin{array}{ll}66,35 \\
66\end{array}$ & 256,70 & \begin{tabular}{|l|l|}
119,86 \\
\end{tabular} & 250,19 & \begin{tabular}{|l|l|}
252,96 \\
\end{tabular} & \begin{tabular}{|l|}
111,27 \\
\end{tabular} & |583,09 & 88,29 & 1,00 & 60,75 & 249,96 & 17,00 & 22,73 & 232,56 \\
\hline Pleurodeles walt| & $295 Q B$ & 62,00 & 182,98 & 110,49 & 38,71 & 5832,79 & 343,73 & 61,26 & 282,48 & 119,58 & 258,21 & 260,28 & 110,66 & 575,13 & 87,33 & 1,00 & 63,97 & 246,17 & 17,90 & 22,00 & 229,97 \\
\hline Pleurodeles walt| & 29SQB63 & 57,00 & 184,32 & 116,90 & 39,00 & 5995,94 & 353,94 & 58,03 & 295,91 & 119,06 & 262,14 & 263,82 & 110,10 & 574,31 & 86,98 & 1,00 & 63,84 & 245,33 & 18,05 & 22,11 & 230,18 \\
\hline Pleurodeles waltt & 29SQB67 & 43,00 & 170,53 & 120,97 & 38,97 & 6280,84 & 349,67 & 42,23 & 307,44 & 102,34 & 252,81 & 253,81 & 93,31 & 608,03 & 86,59 & 2,00 & 60,22 & 249,81 & 22,67 & 27,20 & 236,97 \\
\hline Pleurodeles waltl & $295 Q C 00$ & 100,00 & 152,57 & 110,61 & 38,01 & 5987,54 & 319,70 & 33,50 & 286,20 & 88,75 & 230,46 & 232,42 & 79,85 & 634,96 & $88, \mathrm{C}$ & 3,70 & 56,71 & 255,20 & 30,10 & 34,59 & 242,76 \\
\hline \begin{tabular}{|l|} 
Pleurodeles waltl \\
\end{tabular} & $29 \mathrm{SQC01}$ & $\begin{array}{l}100,00 \\
100\end{array}$ & 150 & $\frac{111}{111}$ & $\begin{array}{l}30, \\
38,\end{array}$ & \begin{tabular}{|c|}
6030,24 \\
600,54
\end{tabular} & 320,13 & $\begin{array}{l}30,31 \\
31,31 \\
\end{array}$ & \begin{tabular}{|l|}
288,80 \\
28,8
\end{tabular} & $\begin{array}{l}\mid 00,15 \\
86,57 \\
\end{array}$ & \begin{tabular}{|l|}
229,460 \\
\end{tabular} & \begin{tabular}{|l|}
231,34 \\
231
\end{tabular} & $\begin{array}{l}77,703 \\
77,71\end{array}$ & \begin{tabular}{|l|l|}
643,26 \\
\end{tabular} & $\begin{array}{l}0,0<2 \\
88,33\end{array}$ & $\frac{3,0}{4,06}$ & $50,1 / 03$ & 256,93 & $\begin{array}{ll}0,10 \\
31,92\end{array}$ & $\begin{array}{l}34,355 \\
3,85\end{array}$ & 245,11 \\
\hline Pleurodeles walt| & $29 \mathrm{SQC02}$ & 101,00 & 150,90 & 112,55 & 38,00 & 6064,71 & 322,05 & 30,95 & 291,10 & 86,38 & 230,08 & 231,97 & 77,51 & 638,97 & 87,25 & 4,11 & 55,41 & 253,83 & 32,80 & 36,32 & 242,32 \\
\hline Pleurodeles walt| & $2950 C 04$ & 100,00 & 162,19 & 114,61 & 38,27 & 6086,43 & 334,44 & 40,11 & 294,33 & 96,37 & 241,55 & 242,96 & 87,75 & 558,28 & 76,98 & 3,34 & 54,69 & 220,37 & 29,30 & 32.56 & 208,18 \\
\hline Pleurodeles waltl & $2950 C 06$ & 100,00 & 151,43 & 114,50 & 38,00 & 6152,60 & 326,90 & 30,33 & 296,57 & 85,56 & 232,32 & 233,59 & 77,10 & 619,90 & 83,06 & 4,68 & 53,24 & 241,60 & 36,05 & 38,10 & 230,70 \\
\hline Pleurodeles waltl & $295 Q C 10$ & 101,00 & 157,87 & 112,11 & 38,00 & 6052,92 & 326,94 & 36,77 & 290,16 & 92,90 & 236,66 & 238,34 & 84,15 & 608,89 & 85,03 & 3,2 & 57,12 & 244,71 & 27,85 & 32,59 & 231,5 \\
\hline Pleurodeles walt| & $29 S 0 C 11$ & 100,00 & 148,36 & 113,07 & 38,00 & 6121,03 & 320,93 & 27,46 & 293,47 & 83,27 & 228,53 & 230,22 & 74,29 & 662,73 & $\begin{array}{ll}90,34 \\
\end{array}$ & 4,26 & 56,03 & 263,69 & 32,92 & 36,88 & 252,11 \\
\hline Pleurodeles waltt & $29 S Q C 12$ & 100,00 & 150,30 & 113,83 & 38,00 & 6146,70 & 324,17 & 28,77 & 295,39 & 84,84 & 230,91 & 232,48 & 75,97 & 644,97 & 87,74 & 4,05 & 55,47 & 255,49 & 32,72 & 36,30 & 243,86 \\
\hline Pleurodeles walt| & $29 \mathrm{SQC13}$ & 100,00 & 157,54 & 114,97 & 38,01 & 6161,86 & 331,80 & 34,74 & 297,06 & 91,12 & 238,20 & 239,41 & 82,41 & 594,93 & 81,35 & 3,71 & 55,09 & 234,82 & 30,46 & 33,99 & 222,73 \\
\hline |Pleurodeles walt| & $29 \mathrm{SQC14}$ & 101,00 & 159,23 & 115,59 & 38,01 & 6171,35 & 334,37 & 35,95 & 298,41 & 92,41 & 239,95 & 241, & 83, & 579,12 & 79,00 & 3,69 & 54,64 & 227,61 & 30,38 & 33,67 & 215,52 \\
\hline \begin{tabular}{|l|} 
Pleurodeles waltl \\
\end{tabular} & $29 \mathrm{SQC16}$ & 100,00 & 158,39 & 116,15 & 38,01 & 6218,94 & 335,43 & 34,82 & 300,61 & 91,30 & 240,07 & 241,02 & 82,66 & 573,53 & 77,26 & 4,05 & 53,32 & 222,97 & 32,25 & 34,93 & 211,15 \\
\hline
\end{tabular}




\begin{tabular}{|c|c|c|c|c|c|c|c|c|c|c|c|c|c|c|c|c|c|c|c|c|c|}
\hline TAXON & UTM & $\mathrm{km} 2$ & BIO1 & B102 & $B 103$ & BIO4 & B105 & B106 & B107 & B108 & B109 & B1010 & BIO11 & B1012 & BIO13 & B1014 & BIO15 & B1016 & B1017 & B1018 & B1019 \\
\hline Pleurodeles walt| & $2950<20$ & 100,00 & 158,69 & 114,03 & 38,00 & 6141,20 & 330,86 & 35,80 & 295,06 & 92,59 & 238,82 & 240,27 & 83,67 & 610,75 & 84,96 & 3,20 & 57,20 & 244,88 & 27,67 & 32,37 & 231,93 \\
\hline Pleurodeles walt| & 29SQC21 & 100,00 & 145,29 & 114,35 & 38,00 & 6208,92 & 321,02 & 23,04 & 297,98 & 79,29 & 227,01 & 228,47 & 70,48 & $\begin{array}{l}684,79 \\
\end{array}$ & 92,50 & 4,51 & 55,84 & 271,28 & 34,24 & 38,10 & 260,10 \\
\hline Pleurodeles walt| & $29 S Q C 23$ & 101,00 & 156,44 & 116,22 & 38,00 & $\begin{array}{l}6236,16 \\
\end{array}$ & 333,51 & 32,47 & $\begin{array}{l}301,04 \\
\end{array}$ & 89,36 & 238,35 & 239,41 & 80,62 & 605,30 & 82,13 & 3,85 & 55,16 & 238,15 & 30,84 & 34,48 & 226,19 \\
\hline Pleurodeles walt| & $295 Q C 24$ & 99,00 & 155,97 & 116,59 & 38,00 & 6269,81 & 334,19 & 31,82 & 302,37 & 88,53 & 238,37 & 239,35 & 79,85 & 601,12 & 80,98 & 3,94 & 54,55 & 235,10 & 31,61 & 34,93 & 223,33 \\
\hline Pleurodeles walt| & 29SQC25 & 100,00 & 154,87 & 116,72 & 38,00 & 6296,31 & 333,94 & 30,57 & 303,37 & 86,94 & 237,62 & 238,51 & 78,50 & \begin{tabular}{|c|}
601,18 \\
\end{tabular} & 80,36 & 4,00 & 53,84 & 233,81 & 32,68 & 35,64 & 222,19 \\
\hline Pleurodeles walt| & 29SQC26 & 100,00 & 157,30 & 117,01 & 38,00 & \begin{tabular}{ll|}
6306,67 \\
\end{tabular} & 336,74 & 32,57 & 304,17 & 89,24 & 240,27 & 241,01 & 80,60 & 579,70 & 77,33 & 4,01 & 53,38 & 224,33 & 32,31 & 35,03 & 212,53 \\
\hline 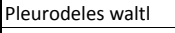 & 29SQC27 & 100,00 & 160,26 & 117,09 & 38,00 & 6298,64 & 339,64 & 35,21 & $\begin{array}{l}304,44 \\
\end{array}$ & 92,04 & 243,19 & 243,81 & 83,50 & 555,99 & 74,05 & 4,00 & 52,60 & 214,13 & 31,88 & 34,19 & 202,09 \\
\hline Pleurodeles walt| & 29SQC28 & 101,00 & 162,42 & 117,04 & 38,00 & 6296,73 & 341,58 & 37,15 & 304,44 & 93,96 & 245,39 & 245,72 & 85,55 & 537,24 & 71,40 & 3,97 & 52,31 & 206,15 & 31,56 & 33,13 & 193,92 \\
\hline Pleurodeles walt| & 29SQC29 & 99,00 & 163,70 & $\begin{array}{ll}116,98 \\
\end{array}$ & \begin{tabular}{ll|}
37,99 \\
\end{tabular} & 6310,48 & 342,96 & $\begin{array}{ll}38,34 \\
\end{array}$ & 304,62 & 94,99 & 247,14 & 247,18 & 86,50 & 523,24 & 69,29 & 3,71 & 51,97 & 200,01 & 30,94 & 31,56 & 187,75 \\
\hline Pleurodeles walt| & 2950 C 30 & 100,00 & 153,54 & 115,83 & 38,00 & 6238,75 & 329,83 & 29,25 & 300,58 & 86,61 & 235,49 & 236,64 & 77,72 & 646,89 & 88,68 & 3,60 & 56,96 & 258,16 & 29,81 & 34,28 & 246,06 \\
\hline Pleurodeles walt| & 29SQC31 & 101,00 & 143,35 & 115,71 & \begin{tabular}{|l|l|l|}
37,99 \\
\end{tabular} & \begin{tabular}{|l|l|}
6285,63 \\
\end{tabular} & 321,80 & 20,01 & 301,79 & 76,51 & 226,30 & 227,65 & 67,74 & 700,80 & 93,93 & 4,65 & 55,87 & 276,69 & 34,98 & 38,88 & 265,89 \\
\hline Pleurodeles walt| & 29SQC32 & 100,00 & 150,07 & $\begin{array}{ll}116,82 \\
\end{array}$ & 38,00 & 6311,19 & 329,47 & 25,56 & 303,92 & 82,63 & 233,28 & 234,30 & 73,90 & 652,92 & 87,76 & 4,06 & 55,58 & 257,04 & 32,41 & 36,21 & 245,72 \\
\hline Pleurodeles walt| & 29SQC37 & 100,00 & 160,43 & 1117,97 & 38,00 & 6361,74 & 341,86 & 34,42 & 307,44 & 91,44 & 244,49 & 244,74 & 82,93 & 555,56 & 73,23 & 3,90 & 52,90 & 213,13 & 31,30 & 33,37 & 201,28 \\
\hline Pleurodeles walt| & 29SQC40 & 101,00 & 158,58 & 118,01 & 38,01 & 6304,75 & 337,41 & 32,34 & 305,07 & \begin{tabular}{ll|}
90,67 \\
\end{tabular} & 241,28 & 242,38 & 81,72 & \begin{tabular}{ll|}
626,43 \\
\end{tabular} & 86,06 & 3,03 & 57,45 & 250,37 & 27,34 & 32,01 & 238,25 \\
\hline Pleurodeles walt| & 29SQC45 & 101,00 & 155,37 & \begin{tabular}{ll|}
118,87 \\
\end{tabular} & 38,00 & 6435,91 & 338,99 & 28,40 & 310,59 & 85,98 & 240,62 & 240,92 & 77,21 & 600,77 & 79,28 & 3,96 & 54,09 & 231,94 & 31,57 & 34,04 & 220,74 \\
\hline Pleurodeles walt| & 29SQC46 & 100,00 & 159,70 & 119,06 & 37,99 & 6443,91 & 343,06 & 32,26 & 310,81 & 89,84 & 244,80 & 244,96 & 81,12 & 569,21 & 75,04 & 3,69 & 53,64 & 218,71 & 30,47 & 32,42 & 207,26 \\
\hline Pleurodeles walt| & 29SQC47 & 99,00 & 162,97 & $\begin{array}{ll}118,88 \\
\end{array}$ & 37,99 & 6437,15 & 345,94 & 35,39 & 310,55 & \begin{tabular}{ll|}
92,87 \\
\end{tabular} & 248,00 & 248,04 & 84,26 & 542,14 & 71,52 & 3,23 & 53,43 & 207,59 & 29,09 & 30,04 & 195,96 \\
\hline Pleurodeles walt| & 29SQC49 & 99,00 & 163,25 & 117,95 & 37,60 & 6448,65 & 346,10 & 36,12 & 309,98 & 92,98 & 248,56 & 248,66 & 84,46 & 523,97 & 68,46 & 3,31 & 52,23 & \begin{tabular}{ll|}
198,42 \\
\end{tabular} & 29,73 & 30,41 & 186,63 \\
\hline Pleurodeles walt| & 29SQC53 & 100,00 & 152,34 & 119,87 & 38,00 & 6469,16 & 337,34 & 24,95 & 312,39 & 82,86 & 237,97 & 238,62 & 74,10 & 638,24 & 84,75 & 3,94 & 55,30 & 248,30 & 31,58 & 35,35 & 237,69 \\
\hline Pleurodeles walt| & 29SQC55 & 100,00 & 158,21 & 120,08 & 38,00 & 6492,21 & 343,57 & 29,89 & 313,68 & 87,86 & 244,27 & 244,42 & 79,23 & 588,23 & 77,8 & 3,70 & 54,34 & 226,40 & 30,18 & 32,39 & 215,47 \\
\hline Pleurodeles walt| & $295 \mathrm{SQC56}$ & 99,00 & 160,23 & 120,02 & 37,93 & 6499,58 & 345,58 & 31,79 & 313,79 & 89,49 & 246,42 & 246,50 & 81,13 & 566,80 & 74,75 & 3,33 & 53,84 & 216,93 & 29,53 & 31,24 & 205,91 \\
\hline Pleurodeles walt| & 29SQC57 & 101,00 & 157,18 & 119,37 & 37,73 & 6509,74 & 342,79 & 29,19 & 313,61 & 86,55 & 243,60 & \begin{tabular}{|l|l|}
243,67 \\
\end{tabular} & 77,96 & 573,23 & 74,97 & 3,87 & 53,01 & 217,74 & 31,36 & 32,25 & 206,81 \\
\hline Pleurodeles walt| & 29SQC58 & 100,00 & 160,35 & 119,09 & $\begin{array}{l}37,65 \\
\end{array}$ & 6510,78 & 345,55 & 32,21 & 313,33 & 89,57 & 246,70 & 246,74 & 81,06 & 547,69 & 71,51 & 3,60 & 52,61 & 207,06 & 30,33 & 30,64 & 195,84 \\
\hline Pleurodeles walt| & 29SQC63 & 22,00 & 148,95 & 120,27 & \begin{tabular}{|l|l|}
37,98 \\
\end{tabular} & 6508,00 & 335,43 & 21,27 & 314,16 & 79,09 & 235,43 & 235,86 & 70,36 & 658,91 & 87,20 & 4,20 & 55,09 & 255,39 & 32,91 & 35,98 & 245,32 \\
\hline Pleurodeles walt| & 29SQD00 & 99,00 & 167,55 & 116,21 & 38,22 & 6138,98 & 342,32 & 43,67 & 298,65 & 100,11 & 247,71 & 248,38 & 91,98 & \begin{tabular}{|l|l|}
499,93 \\
\end{tabular} & 67,99 & 3,50 & 51,91 & $\begin{array}{l}192,61 \\
\end{array}$ & 30,54 & 32,59 & 180,11 \\
\hline Pleurodeles walt| & $295 Q D 07$ & 100,00 & 160,93 & 107,44 & 36,60 & 6257,25 & 332,73 & 42,59 & 290,13 & 93,20 & 243,99 & 244,13 & 85,12 & 562,46 & 72,17 & 4,35 & 49,91 & 214,50 & 37,65 & 37,91 & 203,80 \\
\hline Pleurodeles walt| & 29SQD13 & 101,00 & 161,91 & 112,93 & \begin{tabular}{|l|l|}
37,27 \\
\end{tabular} & 6289,60 & 338,44 & 39,80 & 298,64 & 93,62 & 245,15 & 245,26 & 85,32 & \begin{tabular}{|l|l|}
532,07 \\
\end{tabular} & 69,11 & 4,03 & 50,50 & 201,98 & 34,28 & 34,72 & 190,05 \\
\hline Pleurodeles walt| & 29SQD14 & 100,00 & 158,51 & 110,98 & $\begin{array}{l}36,95 \\
\end{array}$ & 6316,54 & 334,69 & 37,68 & 297,01 & 90,14 & 242,30 & 242,41 & 81,98 & 553,40 & 70,99 & 4,25 & 50,08 & 209,54 & 36,45 & 36,77 & $\begin{array}{ll}197,87 \\
\end{array}$ \\
\hline Pleurodeles walt| & 29SQD15 & 100,00 & 160,22 & 109,91 & 36,91 & 6318,99 & 335,55 & 39,81 & 295,74 & 91,89 & 244,16 & 244,19 & 83,61 & 543,83 & 69,39 & 4,14 & 49,90 & 205,40 & 36,18 & 36,36 & 193,78 \\
\hline Pleurodeles walt| & 29SQD16 & 100,00 & 161,86 & 108,93 & \begin{tabular}{l|l|l}
36,45 \\
\end{tabular} & \begin{tabular}{|l|l|}
6324,93 \\
\end{tabular} & 336,34 & 41,80 & 294,54 & 93,24 & 245,83 & 245,83 & 85,13 & 533,57 & 67,87 & 4,00 & 49,69 & 201,38 & 35,67 & 35,70 & 189,67 \\
\hline Pleurodeles walt| & 29SQD17 & 100,00 & 159,88 & 107,54 & 36,00 & 6335,02 & 333,55 & 40,64 & 292,92 & 91,31 & 244,13 & 244,13 & 83,15 & 544,58 & 68,94 & 4,05 & 49,74 & 205,57 & 36,49 & 36,51 & 194,10 \\
\hline Pleurodeles walt| & 29SQD18 & 100,00 & 158,95 & 106,70 & 36,00 & 6328,08 & 331,75 & 40,47 & 291,28 & 90,38 & 243,22 & 243,22 & 82,34 & 550,14 & 69,56 & 4,51 & 49,38 & 207,69 & 37,51 & 37,51 & $\begin{array}{l}196,47 \\
\end{array}$ \\
\hline Pleurodeles walt| & 29SQD20 & 99,00 & 165,92 & 116,54 & 37,99 & 6306,84 & 344,73 & 40,70 & 304,03 & 97,01 & 249,04 & 249,12 & 88,66 & 506,59 & 66,95 & 3,20 & 51,86 & 193,22 & 29,84 & 30,62 & 180,89 \\
\hline Pleurodeles walt| & 29SQD21 & 101,00 & 167,54 & 115,88 & \begin{tabular}{|l|l|}
37,93 \\
\end{tabular} & \begin{tabular}{|l|l|}
6306,67 \\
\end{tabular} & 345,66 & 42,66 & 302,99 & 98,62 & 250,56 & 250,69 & 90,15 & $\begin{array}{l}493,85 \\
\end{array}$ & 65,03 & 3,03 & 51,52 & \begin{tabular}{|l|l|}
187,80 \\
\end{tabular} & 29,46 & 30,62 & 175,35 \\
\hline Pleurodeles walt| & 29SQD22 & 99,00 & 166,10 & 114,86 & 37,35 & 6329,11 & 344,38 & 41,63 & 302,75 & 96,99 & 249,73 & 249,83 & 88,67 & 500,07 & 65,06 & 3,38 & 50,77 & \begin{tabular}{|l|l|}
189,08 \\
\end{tabular} & 31,18 & 31,49 & 176,83 \\
\hline Pleurodeles walt| & 29SQD23 & 100,00 & 162,78 & 113,37 & 37,00 & 6357,80 & 341,02 & 39,52 & 301,50 & $\begin{array}{l}93,64 \\
\end{array}$ & 247,12 & 247,14 & 85,36 & 515,75 & 66,36 & 4,00 & 50,40 & 194,20 & 32,93 & 33,12 & 182,06 \\
\hline Pleurodeles walt| & 29SQD26 & 101,00 & 159,38 & 108,83 & \begin{tabular}{l|l|l}
36,05 \\
\end{tabular} & 6397,50 & 335,77 & 38,95 & 296,82 & 90,23 & 244,69 & 244,69 & 82,14 & 526,93 & 67,03 & 4,02 & 49,63 & 196,72 & 35,47 & 35,47 & 184,62 \\
\hline Pleurodeles walt| & 29SQD27 & 100,00 & 160,06 & 107,97 & 36,00 & 6397,26 & 335,49 & 39,85 & 295,64 & 90,75 & 245,32 & 245,32 & 82,60 & 521,58 & 66,06 & 4,07 & 49,38 & 194,52 & 35,48 & 35,48 & 182,45 \\
\hline Pleurodeles walt| & 29SQD28 & 101,00 & 162,73 & 108,12 & 36,03 & \begin{tabular}{|c|c|}
6376,15 \\
\end{tabular} & 337,02 & 42,26 & 294,77 & 93,22 & 247,57 & 247,57 & 85,14 & 506,04 & 63,53 & 4,00 & 48,92 & \begin{tabular}{|l|l|}
188,88 \\
\end{tabular} & \begin{tabular}{|l|l|}
34,67 \\
\end{tabular} & 34,67 & 177,03 \\
\hline Pleurodeles walt| & 29SQD30 & 101,00 & 167,20 & 117,05 & 37,79 & 6373,42 & 347,58 & 40,89 & 306,69 & 97,52 & 251,52 & 251,52 & 89,12 & 497,56 & 65,18 & 3,01 & 51,95 & 188,77 & 28,71 & 28,83 & 176,56 \\
\hline Pleurodeles walt| & 29SQD31 & 100,00 & 165,92 & 116,10 & 37,53 & 6383,78 & 346,06 & 40,36 & 305,70 & 96,25 & 250,19 & 250,23 & 87,68 & $\begin{array}{l}499,24 \\
\end{array}$ & $\begin{array}{l}64,97 \\
\end{array}$ & 3,08 & 51,30 & 188,50 & 29,97 & 30,39 & 176,32 \\
\hline Pleurodeles walt| & 29SQD32 & 99,00 & 163,79 & 115,06 & $\begin{array}{l}37,05 \\
\end{array}$ & \begin{tabular}{|l|l|}
6406,58 \\
\end{tabular} & 344,01 & 38,80 & 305,22 & $\begin{array}{l}94,02 \\
\end{array}$ & 248,83 & 248,84 & 85,67 & 506,41 & 65,30 & 3,67 & 50,66 & \begin{tabular}{|l|l|}
190,02 \\
\end{tabular} & 31,50 & 31,52 & 177,81 \\
\hline Pleurodeles walt| & 29SQD33 & 100,00 & 159,75 & 113,57 & 36,93 & $\begin{array}{ll}6431,24 \\
\end{array}$ & 339,81 & 35,92 & 303,89 & 90,02 & 245,19 & 245,19 & 81,60 & 523,70 & 66,91 & 4,03 & 50,19 & 195,72 & 33,60 & 33,66 & 183,56 \\
\hline Pleurodeles walt| & 29SQD35 & 99,00 & $\begin{array}{lll}158,47 \\
\end{array}$ & 110,82 & 36,14 & 6450,33 & 337,36 & 36,26 & 301,10 & 88,72 & 244,43 & 244,43 & 80,42 & 519,96 & 66,67 & 4,00 & 49,57 & 192,81 & 34,79 & 34,79 & 180,51 \\
\hline Pleurodeles walt| & $295 Q D 36$ & 100,00 & 158,56 & $\begin{array}{l}109,69 \\
\end{array}$ & 36,00 & 6453,55 & 336,64 & 37,03 & 299,60 & 88,73 & 244,68 & 244,68 & 80,45 & 515,19 & 66,62 & 4,06 & 49,25 & $\begin{array}{l}190,48 \\
\end{array}$ & 34,98 & 34,98 & 178,10 \\
\hline Pleurodeles walt| & $295 Q D 4$ & 100,00 & 167,71 & $\begin{array}{l}117,67 \\
\end{array}$ & 37,59 & \begin{tabular}{|l|l|}
6440,08 \\
\end{tabular} & 349,40 & 40,25 & 309,15 & 97,20 & 252,73 & 252,73 & 88,58 & $\begin{array}{l}494,36 \\
\end{array}$ & 64,55 & 3,00 & 52,06 & 186,50 & 28,03 & 28,13 & 174,54 \\
\hline Pleurodeles walt| & 29SQD41 & 100,00 & 167,40 & 116,77 & 37,13 & 6444,88 & 349,11 & 40,70 & 308,41 & 96,92 & 252,81 & 252,81 & 88,49 & 488,53 & 63,47 & 3,01 & 51,48 & $\begin{array}{l}183,45 \\
\end{array}$ & 28,49 & 28,51 & 171,45 \\
\hline Pleurodeles walt| & 29SQD42 & 101,00 & 163,45 & 115,65 & 37,00 & 6467,77 & 345,24 & 37,56 & 307,68 & 92,97 & 249,25 & 249,25 & 84,56 & 501,69 & 64,52 & 3,59 & 50,63 & 187,05 & 30,86 & 30,86 & 175,00 \\
\hline Pleurodeles walt| & 29SQD43 & 101,00 & 161,52 & 114,56 & 37,00 & 6485,11 & 343,00 & 36,40 & 306,60 & 90,96 & 247,73 & 247,73 & 82,47 & 504,86 & 64,52 & 3,99 & 50,27 & 187,34 & 32,06 & 32,06 & 175,22 \\
\hline Pleurodeles walt| & $295 \mathrm{SD} 46$ & 101,00 & 158,61 & 111,09 & 36,02 & 6493,81 & 338,07 & 35,56 & 302,51 & 88,12 & 245,17 & 245,17 & 79,77 & 501,75 & 64,84 & 4,00 & 48,76 & 184,06 & 34,20 & 34,20 & 171,66 \\
\hline Pleurodeles walt| & 29SQD47 & 100,00 & 160,86 & 110,70 & \begin{tabular}{|l|l|}
36,07 \\
\end{tabular} & \begin{tabular}{|l|}
6477,91 \\
\end{tabular} & 339,36 & 37,98 & 301,38 & 90,34 & 247,32 & 247,32 & 82,02 & $\begin{array}{l}484,05 \\
\end{array}$ & 62,15 & 4,00 & 48,47 & 177,12 & 33,49 & 33,49 & 164,73 \\
\hline Pleurodeles walt| & 29SQD49 & 101,00 & 157,11 & 109,50 & 36,00 & 6458,45 & 334,03 & 35,16 & 298,87 & 86,68 & 243,30 & 243,30 & 78,69 & \begin{tabular}{|l|l|}
490,88 \\
\end{tabular} & 61,05 & 4,54 & 47,59 & 179,34 & 35,49 & 35,49 & 166,93 \\
\hline |Pleurodeles walt| & 29SQD53 & 97,00 & 165,47 & 115,63 & 37,00 & 6512,83 & 347,79 & 38,87 & 308,92 & 94,19 & 252,03 & 252,03 & 85,84 & 479,56 & 61,44 & 3,16 & 50 & 176,96 & 29,56 & 29,56 & 165,02 \\
\hline Pleurodeles walt| & $295 Q D 5$ & 90,0 & 156,13 & 113,97 & 36,5 & 6540, & 338,76 & 31,17 & 307,59 & 85,11 & 243,50 & 243,50 & 76,94 & 517,89 & 66,59 & $4,2,>>$ & 49,36 & 189,84 & 34,20 & 34,20 & 177 \\
\hline Pleurodeles walt| & 29SQD55 & 82,00 & 156,69 & 113,12 & 36,23 & 6542,17 & 338,71 & 32,22 & 306,49 & 85,59 & 244,25 & 244,25 & 77,52 & 505,80 & 65,25 & 4,08 & 48,90 & 184,66 & 34,11 & 34,11 & 172,52 \\
\hline Pleurodeles walt| & 29SQD56 & 87,00 & 157,94 & 112,30 & 36,01 & $\begin{array}{l}6536,19 \\
\end{array}$ & 338,98 & 33,71 & 305,27 & 86,92 & 245,25 & 245,25 & 78,64 & 492,20 & 63,35 & 4,02 & 48,53 & $\begin{array}{l}179,17 \\
\end{array}$ & 33,79 & 33,79 & 166,85 \\
\hline Pleurodeles walt| & 29SQD57 & 80,00 & 160,28 & 111,88 & 36,03 & 6511,11 & 340,08 & 36,26 & 303,83 & 89,31 & 247,30 & 247,30 & 81,00 & 474,24 & 60,62 & 4,00 & 48,02 & 172,21 & 33,12 & 33,12 & 159,87 \\
\hline Pleuroc & 29SQD59 & 77,00 & 158,03 & 110,91 & 36,04 & 6482,15 & 336,26 & 34,92 & 301,34 & 0 & 244,79 & 244 & 79,16 & $\mid \begin{array}{ll}471,49 \\
\end{array}$ & 58,59 & 33 & 47 & 17 & 34,29 & 34,29 & 15 \\
\hline Pleurodeles walt| & 29SQE00 & 101,00 & 161,64 & 105,82 & 36,28 & \begin{tabular}{ll|l|}
6236,36 \\
\end{tabular} & 330,84 & 43,91 & 286,93 & 93,55 & 244,43 & 244,4 & 85,63 & 559,13 & 71,91 & 4,11 & 49,55 & 213,51 & 37,99 & 37,99 & 203,48 \\
\hline Pleurodeles walt| & 29SQE10 & 100,00 & 161,27 & 106,66 & 36,20 & 6291,10 & 332,27 & 42,40 & 289,87 & 92,50 & 244,82 & 244,82 & 84,49 & 533,24 & 67,80 & 4,52 & 48,95 & 201,42 & 36,81 & 36,81 & 190,60 \\
\hline
\end{tabular}




\begin{tabular}{|c|c|c|c|c|c|c|c|c|c|c|c|c|c|c|c|c|c|c|c|c|c|}
\hline TAXON & UTM & $\mathrm{km} 2$ & BIO1 & B102 & BIO3 & BIO4 & B105 & B106 & BI07 & B108 & B109 & 81010 & B1011 & B1012 & B1013 & BIO14 & BIO15 & BIO16 & B1017 & B1018 & B1019 \\
\hline Pleurodeles waltt & 29SQE12 & 101,00 & 159,51 & 106,20 & 36,38 & 6265,51 & 328,80 & 40,89 & 287,91 & 90,55 & 242,56 & 242,56 & 82,76 & 537,63 & 68,69 & 4,94 & 48,43 & 203,31 & 37,95 & 37,95 & 192,75 \\
\hline Pleurodeles waltt & 29SQE41 & 101,00 & 154,90 & 109,12 & 36,13 & 6419,67 & 330,21 & 33,53 & 296,68 & 84,60 & 240,72 & 240,72 & 76,87 & 489,60 & 60,49 & 4,99 & 46,49 & $\begin{array}{l}178,67 \\
\end{array}$ & 36,92 & 36,92 & 166,26 \\
\hline Pleurodeles walt| & 295QE50 & 70,00 & 159,94 & 110,91 & 36,59 & 6450,74 & 336,84 & 36,84 & 300,00 & 89,39 & 246,15 & 246,15 & 81,11 & $\mid 456,27$ & 56,13 & \begin{tabular}{|l|l|}
4,02 \\
\end{tabular} & 46,66 & $\mid 165,05$ & 33,50 & 33,50 & 152,85 \\
\hline \begin{tabular}{|l|l|l|} 
Pleurodeles walt \\
\end{tabular} & 29SQE51 & 63,00 & 158,98 & 110,69 & 36,68 & 6427,51 & 334,89 & 36,06 & 298,83 & 88,21 & 244,68 & 244,68 & 80,34 & 454,36 & 55,83 & 4,50 & 46,13 & 164,21 & 34,23 & 34,23 & 151,88 \\
\hline Pleurodeles waltt & 29SQE52 & 66,00 & 155,05 & 110,34 & 36,55 & 6425,27 & 330,51 & 32,56 & 297,95 & 84,20 & 240,69 & 240,69 & 76,57 & 463,73 & 57,01 & 5,01 & 45,64 & 167,40 & 36,06 & 36,06 & 154,87 \\
\hline Pleurodeles walt| & 29TNE13 & 97,00 & 154,79 & 80,80 & 43,68 & 3528,08 & 252,14 & 69,20 & 182,95 & 116,15 & 196,97 & $\begin{array}{l}199,18 \\
\end{array}$ & 108,20 & $\begin{array}{l}885,08 \\
\end{array}$ & 126,62 & 8,21 & 54,91 & 362,20 & 53,86 & 60,55 & 356,00 \\
\hline Pleurodeles waltt & 29TNE14 & 94,00 & 153,37 & 80,69 & 43,99 & 3489,40 & 249,04 & 67,60 & $\begin{array}{l}181,44 \\
\end{array}$ & \begin{tabular}{ll|}
114,96 \\
\end{tabular} & 194,89 & $\begin{array}{l}196,96 \\
\end{array}$ & 106,94 & \begin{tabular}{|l|l|}
915,43 \\
\end{tabular} & \begin{tabular}{|l|l|}
130,14 \\
\end{tabular} & 8,93 & 54,31 & 372,73 & 57,22 & 64,43 & 366,66 \\
\hline Pleurodeles walt| & 29TNE15 & 95,00 & 152,10 & 79,87 & 44,23 & 3433,91 & 244,94 & \begin{tabular}{ll|}
66,57 \\
\end{tabular} & 178,37 & 114,04 & 192,57 & 194,69 & 106,07 & 940,82 & 132,95 & 9,80 & 53,87 & 381,66 & 60,01 & 67,97 & 375,23 \\
\hline Pleurodeles walt| & 29TNE17 & 40,00 & 151,00 & 77,70 & 44,97 & 3321,38 & 237,20 & 65,97 & 171,23 & 113,99 & 189,58 & \begin{tabular}{|l|l|}
191,34 \\
\end{tabular} & 105,62 & \begin{tabular}{|l|l|}
973,01 \\
\end{tabular} & 136,21 & 10,34 & 53,00 & \begin{tabular}{|l|}
393,07 \\
\end{tabular} & 63,24 & 72,89 & 385,45 \\
\hline Pleurodeles walt| & 29TNE25 & 101,00 & 153,77 & 85,81 & 44,09 & 3656,36 & 256,26 & 64,15 & 192,11 & 113,23 & 197,53 & $\begin{array}{l}199,63 \\
\end{array}$ & 105,25 & \begin{tabular}{|c|}
947,18 \\
\end{tabular} & 133,35 & 9,75 & 53,42 & 382,17 & 61,32 & 68,27 & 378,15 \\
\hline Pleurodeles walt| & 29TNE26 & 100,00 & 152,32 & 84,16 & 44,45 & 3581,52 & 250,69 & 63,32 & 187,37 & 112,44 & 194,77 & 196,81 & 104,39 & $\begin{array}{l}969,56 \\
\end{array}$ & 136,02 & 10,03 & 53,09 & 390,74 & 63,01 & 70,94 & 385,71 \\
\hline Pleurodeles waltt & 29TNE27 & 100,00 & 150,94 & 81,77 & 44,72 & 3491,93 & 244,10 & $\begin{array}{ll}63,03 \\
\end{array}$ & 181,07 & 111,95 & 191,99 & 193,90 & 103,76 & 988,28 & 138,04 & 10,85 & 52,79 & 397,95 & 65,18 & 74,10 & 391,49 \\
\hline Pleurodeles walt| & 29TNE28 & 101,00 & 149,73 & 78,91 & 45,04 & 3384,36 & 236,65 & 63,11 & 173,54 & \begin{tabular}{ll|}
111,73 \\
\end{tabular} & 189,05 & $\begin{array}{l}190,76 \\
\end{array}$ & \begin{tabular}{|l|l|}
103,37 \\
\end{tabular} & 1002,72 & \begin{tabular}{|l|l|}
139,53 \\
\end{tabular} & 11,00 & 52,55 & 403,88 & 66,14 & 76,54 & 395,56 \\
\hline Pleurodeles walt| & 29TNE29 & 91,00 & 148,62 & 76,34 & 45,23 & 3286,96 & 230,02 & 63,25 & 166,77 & $\begin{array}{l}111,66 \\
\end{array}$ & $\begin{array}{l}186,35 \\
\end{array}$ & \begin{tabular}{|l|l|}
187,93 \\
\end{tabular} & $\begin{array}{l}103,07 \\
\end{array}$ & $\begin{array}{l}1017,60 \\
\end{array}$ & 140,94 & 11,13 & 52,35 & 410,05 & 67,19 & 78,96 & 399,81 \\
\hline Pleurodeles waltt & 29TNE35 & 101,00 & 155,88 & 92,45 & 44,00 & 3919,27 & 269,56 & 61,58 & 207,99 & 112,19 & 203,42 & 205,66 & 104,51 & 950,94 & 133,34 & 9,92 & 53,16 & 381,31 & 62,81 & 68,60 & 379,90 \\
\hline Pleurodeles walt| & 29TNE37 & 100,00 & 151,92 & 88,12 & 44,21 & 3760,17 & 256,36 & 59,47 & 196,88 & 109,94 & 196,99 & 198,97 & 101,90 & 999,56 & 139,38 & 11,00 & 52,72 & 400,87 & 66,69 & 74,56 & 396,25 \\
\hline Pleurodeles waltt & 29TNE43 & 100,00 & 152,01 & 96,88 & 42,29 & 4334,80 & 280,95 & 54,54 & 226,42 & 97,23 & 206,12 & 208,63 & 97,14 & 988,34 & 140,82 & 10,21 & 53,90 & 399,77 & 65,27 & 67,43 & 399,77 \\
\hline Pleurodeles walt| & 29TNE45 & 101,00 & 159,50 & 98,46 & 43,90 & 4164,52 & 283,32 & \begin{tabular}{ll|}
60,82 \\
\end{tabular} & 222,49 & 108,75 & 210,58 & 212,78 & 105,32 & $\begin{array}{l}936,35 \\
\end{array}$ & 130,70 & 9,70 & 52,90 & 374,25 & 62,54 & 67,44 & 374,14 \\
\hline Pleurodeles walt| & 29TNF20 & 39,00 & 148,11 & 75,99 & 45,39 & 3278,87 & 228,40 & 62,72 & 165,68 & 111,24 & $\begin{array}{l}185,74 \\
\end{array}$ & 187,30 & 102,70 & $\begin{array}{l}1033,57 \\
\end{array}$ & 142,44 & \begin{tabular}{ll|}
11,91 \\
\end{tabular} & 52,02 & 416,51 & $\begin{array}{l}68,59 \\
\end{array}$ & 81,88 & 404,38 \\
\hline 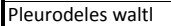 & 29TNF21 & 42,00 & $\begin{array}{lll}147,88 \\
\end{array}$ & 78,33 & 45,13 & \begin{tabular}{|l|l|l|}
3371,42 \\
\end{tabular} & 232,38 & 61,15 & \begin{tabular}{|l|l|}
171,23 \\
\end{tabular} & \begin{tabular}{|l|l|}
110,42 \\
\end{tabular} & \begin{tabular}{|l|l|}
187,18 \\
\end{tabular} & \begin{tabular}{|l|l|}
188,83 \\
\end{tabular} & 101,85 & $\mid 1056,40$ & $\mid$ & \begin{tabular}{|c|c|}
12,05 \\
\end{tabular} & 52,00 & 425,88 & \begin{tabular}{|c|c|c|}
70,18 \\
\end{tabular} & 84,85 & 411,62 \\
\hline Pleurodeles waltt & 29TNF25 & 28,00 & 144,51 & 85,81 & 44,94 & 3674,23 & 243,21 & 54,34 & 188,87 & 104,47 & 189,36 & 191,38 & 97,09 & 1183,21 & 162,30 & 14,83 & 51,15 & 472,75 & 81,40 & 99,72 & 460,91 \\
\hline Pleurodeles waltt & 29TNF26 & 68,00 & 143,71 & 84,72 & 45,01 & 3658,17 & 241,52 & 55,50 & 186,02 & 99,99 & 188,56 & 190,46 & 97,07 & 1215,52 & 165,55 & 15,08 & 51,03 & 482,21 & 83,56 & 100,72 & 480,78 \\
\hline \begin{tabular}{|l|l|l|} 
Pleodeles walt \\
\end{tabular} & 29TNF27 & 83,00 & 143,39 & 83,67 & 44,84 & 3665,84 & 241,48 & 56,50 & 184,98 & 98,16 & 188,60 & 190,35 & 96,94 & 1229,74 & 168,04 & 15,06 & 51,32 & 488,82 & 83,48 & 101,82 & 488,58 \\
\hline Pleurodeles waltt & 29TNF33 & 100,00 & 143,08 & 86,64 & 44,26 & 3769,42 & 244,08 & 50,32 & 193,75 & 101,57 & 188,84 & 190,75 & 93,44 & $\begin{array}{l}1153,38 \\
\end{array}$ & 156,89 & 14,21 & 51,96 & 467,44 & 78,42 & 95,49 & 444,94 \\
\hline Pleurodeles waltt & 29TPE23 & 100,00 & 136,93 & 89,41 & 34,98 & 5655,55 & 286,47 & 34,08 & 252,39 & 69,31 & 212,77 & 212,88 & 69,31 & 1072,25 & $\begin{array}{l}160,25 \\
\end{array}$ & 9,60 & 55,52 & 436,33 & 65,86 & 65,86 & 436,33 \\
\hline Pleurodeles walt| & 29TPE24 & 100,00 & 142,68 & 92,77 & 35,65 & 5654,12 & 293,58 & 37,45 & 256,12 & 74,19 & 217,73 & 218,05 & 74,19 & 1014,30 & $\begin{array}{l}150,67 \\
\end{array}$ & 8,95 & 55,21 & 411,38 & 63,29 & 63,31 & 411,38 \\
\hline Pleurodeles waltt & 29TPE33 & 101,00 & 151,94 & 96,18 & 35,97 & 5812,66 & 307,44 & 43,36 & 264,08 & 84,32 & 228,71 & 229,21 & 81,34 & \begin{tabular}{|l|l|}
887,47 \\
\end{tabular} & 129,32 & 7,58 & 54,42 & 356,64 & 56,06 & 56,28 & 356,61 \\
\hline Pleurodeles walt| & 29TPE34 & 100,00 & 144,07 & 93,37 & 35,58 & 5763,97 & 297,00 & 37,53 & 259,47 & 74,25 & 220,63 & 220,80 & 74,25 & \begin{tabular}{|c|}
963,29 \\
\end{tabular} & \begin{tabular}{|l|l|}
142,08 \\
\end{tabular} & 8,48 & 54,82 & 388,56 & 60,65 & 60,78 & 388,56 \\
\hline Pleurodeles walt| & 29TPE35 & 100,00 & 142,56 & 93,42 & 35,63 & 5737,22 & 294,59 & 35,97 & 258,62 & 72,78 & 218,54 & 218,67 & 72,78 & \begin{tabular}{|c|}
976,71 \\
\end{tabular} & \begin{tabular}{ll|}
144,52 \\
\end{tabular} & 8,80 & 54,84 & 394,12 & \begin{tabular}{ll|}
61,76 \\
\end{tabular} & 61,99 & 394,12 \\
\hline Pleurodeles walt| & 29TPE43 & 101,00 & 153,35 & 97,14 & 35,97 & 5887,56 & 310,18 & 43,60 & 266,59 & 89,12 & 231,20 & 231,48 & 81,69 & 837,38 & 120,72 & 7,00 & 53,85 & 334,35 & 53,38 & 53,65 & 333,63 \\
\hline Pleurodeles walt| & 29TPE44 & 100,00 & 149,48 & 96,03 & 35,86 & 5860,33 & 304,97 & 40,37 & 264,60 & 84,59 & 226,95 & 227,18 & 78,09 & 871,44 & \begin{tabular}{ll|}
126,58 \\
\end{tabular} & 7,52 & 54,06 & 348,36 & 55,63 & 55,78 & 347,93 \\
\hline Pleurodeles waltl & \begin{tabular}{|l|} 
29TPE45 \\
\end{tabular} & 101,00 & 142,38 & 93,54 & 35,41 & 5824,43 & 295,68 & 34,92 & 260,76 & 74,84 & 219,54 & 219,65 & 71,49 & 934,96 & 137,33 & 8,42 & 54,35 & $\begin{array}{l}374,92 \\
\end{array}$ & 59,48 & 59,90 & 374,91 \\
\hline Pleurodeles walt| & 29TPE46 & 99,00 & 140,79 & 93,71 & 35,62 & $\begin{array}{l}5799,87 \\
\end{array}$ & 293,41 & 33,34 & 260,08 & 71,02 & 217,52 & 217,64 & 70,04 & $\begin{array}{l}944,75 \\
\end{array}$ & \begin{tabular}{|l|l|}
139,10 \\
\end{tabular} & 8,62 & 54,33 & $\begin{array}{l}378,87 \\
\end{array}$ & 60,64 & 61,32 & 378,87 \\
\hline Pleurodeles walt| & $\begin{array}{l}\text { 29TPE48 } \\
\end{array}$ & 99,00 & 117,54 & 82,71 & 33,32 & 5674,60 & 261,50 & 16,91 & 244,60 & 48,96 & 192,78 & 193,24 & 48,96 & 1155,77 & 173,94 & 11,18 & 55,15 & 468,54 & 73,04 & 77,68 & 468,54 \\
\hline Pleurodeles walt| & \begin{tabular}{|l|} 
29TPE49 \\
\end{tabular} & 101,00 & 125,55 & 88,94 & 34,86 & 5693,66 & 273,09 & 21,39 & 251,70 & 56,06 & 200,71 & 201,07 & 56,06 & 1071,79 & 160,32 & 10,53 & 54,81 & 432,91 & 69,15 & 71,71 & 432,91 \\
\hline Pleurodeles walt| & 29TPE53 & 100,00 & 151,91 & 97,36 & 35,85 & 5953,50 & 309,70 & 41,55 & 268,15 & 87,23 & 230,81 & 231,01 & 79,58 & 808,77 & 115,52 & 6,97 & 53,33 & 321,81 & 52,04 & 52,23 & 319,62 \\
\hline Pleurodeles walt| & 29TPE54 & 100,00 & 147,75 & 95,98 & 35,62 & 5933,51 & 304,19 & 38,06 & 266,13 & 83,16 & 226,32 & 226,50 & 75,69 & 844,05 & 121,51 & 7,38 & 53,61 & 335,96 & 54,66 & 54,79 & 334,47 \\
\hline Pleurodeles walt| & 29TPE55 & 100,00 & 139,99 & 93,16 & 35,09 & 5892,53 & 294,01 & 32,20 & 261,81 & 76,16 & 218,11 & 218,19 & 68,40 & 909,11 & 132,39 & 8,41 & 53,90 & $\begin{array}{l}362,66 \\
\end{array}$ & 58,54 & 59,38 & 361,92 \\
\hline Pleurodeles walt| & 29TPE56 & 101,00 & 128,25 & 88,22 & 34,20 & $\begin{array}{l}5835,14 \\
\end{array}$ & 278,60 & 23,79 & 254,82 & 62,95 & 205,80 & 206,08 & 57,84 & 1007,41 & \begin{tabular}{|l|l|}
148,40 \\
\end{tabular} & 9,62 & 54,15 & $\begin{array}{l}403,27 \\
\end{array}$ & 64,49 & 67,35 & 403,21 \\
\hline Pleurodeles walt| & 29TPE58 & 101,00 & 120,47 & 85,76 & 33,81 & 5774,86 & 268,03 & 17,55 & 250,48 & 51,08 & 196,97 & 197,58 & 50,51. & 1064,41 & 157,89 & 10,49 & 54,30 & 427,55 & 68,80 & 72,51 & 427,5 \\
\hline Pleurodeles walt| & \begin{tabular}{|l|} 
29TPE59 \\
\end{tabular} & 100,00 & 119,76 & 86,90 & 34,11 & 5766,20 & 267,68 & 16,35 & 251,34 & 49,78 & 196,01 & 196,68 & 49,78 & 1061,22 & 157,39 & 10,70 & 54,14 & 426,26 & 69,47 & 72,85 & 426,26 \\
\hline Pleurodeles walt| & 29TPE63 & 100,00 & 147,31 & 96,56 & 35,56 & 6005,60 & 305,46 & 37,25 & 268,21 & 82,40 & 227,14 & 227,18 & 74,60 & \begin{tabular}{|l|l|}
805,58 \\
\end{tabular} & 114,23 & 7,23 & 52,82 & 319,18 & 52,55 & 52,87 & 315,84 \\
\hline Pleurodeles walt| & 29TPE64 & 101,00 & 148,18 & 97,18 & 35,78 & \begin{tabular}{|l|l|}
5989,67 \\
\end{tabular} & 305,84 & 37,38 & 268,45 & 82,93 & 227,58 & 227,62 & 75,21 & \begin{tabular}{|l|l|}
797,19 \\
\end{tabular} & 113,21 & 7,17 & 52,86 & 315,68 & 52,29 & 52,49 & 312,48 \\
\hline Pleurodeles walt| & 29TPE65 & 100,00 & 129,91 & 90,14 & 34,26 & 5929,70 & 283,01 & 23,91 & 259,10 & 66,46 & 208,92 & 209,16 & 58,67 & 944,84 & 136,77 & 9,21 & 53,25 & $\begin{array}{l}375,78 \\
\end{array}$ & 61,54 & 63,95 & 373,87 \\
\hline Pleurodeles walt| & 29TPE67 & 101,00 & 125,29 & 89,10 & 34,18 & 5888,96 & 276,66 & 19,84 & 256,83 & 61,99 & 203,34 & 203,90 & 54 & \begin{tabular}{|l|l|}
971,07 \\
\end{tabular} & 141,31 & 9, & 53,26 & 386,21 & 64,13 & 66,99 & 385,15 \\
\hline Pleurodeles walt| & \begin{tabular}{|l|} 
29TPE68 \\
\end{tabular} & 99,00 & 124,21 & 89,65 & 34,41 & 5871,67 & 275,38 & 18,51 & 256,87 & 60,36 & 201,86 & 202,53 & 53,08 & \begin{tabular}{|l|l|}
971,17 \\
\end{tabular} & 141,44 & 9,89 & 53,21 & 12 & 64,70 & 67,43 & 385,41 \\
\hline Pleurodeles walt| & 29TPE69 & 101,00 & 123,25 & 90,59 & 34,72 & 5856,27 & 274,74 & 17,18 & 257,56 & 58,81 & 200,55 & 201,39 & 52,01 & \begin{tabular}{|c|}
969,08 \\
\end{tabular} & \begin{tabular}{|l|l|}
141,09 \\
\end{tabular} & 10,03 & 53,06 & 385,06 & 65,36 & 67,80 & 384,65 \\
\hline Pleurodeles walt| & 29TPE73 & 100,00 & 150,30 & 98,84 & 35,77 & $\begin{array}{ll}6062,09 \\
\end{array}$ & 310,71 & $\begin{array}{ll}38,27 \\
\end{array}$ & 272,44 & 84,43 & 230,77 & 230,80 & 76,58 & $\begin{array}{l}739,65 \\
\end{array}$ & $\begin{array}{l}102,88 \\
\end{array}$ & 6,62 & 51,89 & 290,90 & $\begin{array}{ll}49,06 \\
\end{array}$ & 49,23 & 285,78 \\
\hline Pleurodeles walt| & 29TPE77 & 100,00 & 122,37 & 90,04 & 34,30 & 5945,46 & 275,26 & 16,19 & 259,07 & 58,62 & 201,30 & 201,94 & 50,77 & 938,22 & 134,22 & 9,98 & 52,23 & 370,92 & 63,72 & 66,87 & 367,88 \\
\hline Pleurodeles walt| & 29TPE78 & 101,00 & 123,45 & 91,55 & 34,80 & 5941,90 & 276,94 & 16,45 & 60,49 & 59,43 & 202,15 & 202,87 & 51,50 & 917,39 & \begin{tabular}{|l|l|}
131,03 \\
\end{tabular} & 9,84 & 52,04 & 22 & 63,19 & 65,75 & 359,37 \\
\hline Pleurodeles walt| & 29TPE79 & 99,00 & 124,77 & 93,29 & $35, \mathrm{C}$ & 5934,79 & 279,08 & 16,71 & 262,37 & 60,47 & 203,18 & 204,08 & 52 & 896,75 & 127,89 & 9,7 & 51,82 & 353,66 & \begin{tabular}{|c|}
62,66 \\
\end{tabular} & 64,50 & 351,17 \\
\hline Pleurodeles walt| & 29TPE85 & 101,00 & 126,42 & 93,40 & 34,64 & 6044,36 & 283,86 & 18,13 & 265,73 & 61,90 & 207,17 & 207,49 & 54,01 & 867,71 & $\begin{array}{l}120,90 \\
\end{array}$ & 9,38 & 51,16 & 339,84 & 60,08 & 62,81 & 334,06 \\
\hline Pleurodeles walt| & 29TPE87 & 100,00 & 124,01 & 93,18 & 34,67 & $\begin{array}{ll}6018,82 \\
\end{array}$ & 280,22 & 15,67 & 264,55 & 59,25 & 203,85 & 204,61 & 51,39 & 866,80 & \begin{tabular}{|l|l|}
121,19 \\
\end{tabular} & 9,70 & 50,97 & 339,73 & \begin{tabular}{ll|l|}
60,96 \\
\end{tabular} & 63,50 & 334,53 \\
\hline |Pleurodeles walt| & 29TPE89 & 101,00 & 124,13 & 95,26 & 35,25 & 5995,30 & 280,81 & 14,85 & 265,97 & 59,14 & 203,39 & 204,31 & 51,43 & 843,46 & 117,63 & 9,60 & 50,67 & 330,28 & 60,83 & 62,57 & 325,4 \\
\hline Pleurodeles walt| & 29TPF50 & 100,00 & 126,65 & 92,55 & 35,46 & 5783,08 & 277,61 & 19,91 & 257,70 & 55,85 & 202,85 & 203 & 55, & 993,74 & 146,73 & 10,17 & 53,88 & 398,03 & 66,35 & 67,84 & 398 \\
\hline Pleurodeles walt| & 29TPF51 & 101,00 & 131,64 & 96,88 & 36,43 & 5782,81 & 284,82 & 22,60 & 262,23 & 60,43 & 208,01 & 208,14 & 60,43 & 944,00 & 138,90 & 9,93 & 53,56 & 377,33 & 64,01 & 64,23 & 377,33 \\
\hline Pleurodeles walt| & 29TPF53 & 100,00 & 141,10 & 103,66 & 38,12 & 5763,83 & 296,81 & 28,05 & 268,76 & 69,62 & 216,60 & 216,60 & 69,12 & \begin{tabular}{|l|l|}
850,97 \\
\end{tabular} & 123,81 & 9,14 & 52,78 & 337,87 & 57,88 & 57,88 & 337,83 \\
\hline Pleurodeles walt| & 29TPF57 & 101,00 & 134,38 & 105,98 & 38,67 & 5715,32 & 291,15 & 20,48 & 270,66 & 63,93 & 209,56 & 209,56 & 63,28 & 863,64 & 124,24 & 11,01 & 51,61 & 343,18 & 62,44 & 62,44 & 343,14 \\
\hline Pleurodeles walt| & 29TPF58 & 99,00 & 136,87 & 107,07 & 38,82 & 5702,16 & 293,58 & 22,00 & 271,58 & 65,83 & 211,69 & 211, & 65, & \begin{tabular}{l|l|}
829,85 \\
\end{tabular} & 117,91 & 11,02 & 50 & 327,95 & 60,81 & 60,81 & 327,95 \\
\hline Pleurodeles walt| & 29TPF59 & 101,00 & 140,06 & 107,68 & 39,02 & 5679,65 & 296,10 & 24,35 & 271,75 & 70,61 & 214,39 & 214,39 & 68,77 & 794,76 & 111,26 & 10,91 & 50,28 & 312,01 & 58,91 & 58,91 & 312, \\
\hline
\end{tabular}




\begin{tabular}{|c|c|c|c|c|c|c|c|c|c|c|c|c|c|c|c|c|c|c|c|c|c|}
\hline TAXON & UTM & $\mathrm{km} 2$ & B101 & B102 & $\mathrm{BIO3}$ & B104 & B105 & B106 & B107 & B108 & B109 & BIO10 & B1011 & BIO12 & B1013 & BIO14 & BIO15 & B1016 & B1017 & BIO18 & 81019 \\
\hline Pleurodeles walt| & 29TPF61 & 100,00 & 132,16 & 97,93 & 36,39 & 5855,03 & 287,09 & 21,78 & 265,31 & 64,63 & 209,47 & 209,65 & 59,93 & 881,01 & $\begin{array}{r}127,52 \\
\end{array}$ & 9,52 & 52,48 & 348,64 & 61,25 & 61,44 & 348,50 \\
\hline Pleurodeles walt| & 29TPF63 & 101,00 & 134,25 & 101,94 & \begin{tabular}{|l|l|}
37,38 \\
\end{tabular} & 5835,98 & 290,96 & 21,88 & 269,08 & 63,60 & 211,38 & 211,38 & 61,97 & 844,73 & 121,62 & 9,68 & 52,03 & 333,64 & 59,71 & 59,71 & 333,62 \\
\hline Pleurodeles walt| & 29TPF66 & 100,00 & 138,95 & 106,55 & 38,53 & 5783,69 & 296,75 & 23,90 & 272,85 & 68,93 & 214,97 & 214,97 & 66,74 & 780,99 & 110,72 & 9,66 & 50,94 & 307,18 & 56,57 & 56,57 & 306,92 \\
\hline Pleurodeles walt| & 29TPF67 & 100,00 & 138,89 & 107,36 & 38,83 & 5764,51 & 296,72 & 23,36 & 273,36 & 69,09 & 214,57 & 214,57 & 66,78 & 768,30 & 108,26 & 9,93 & 50,41 & 301,58 & 56,62 & 56,62 & 301,41 \\
\hline Pleurodeles walt| & 29TPF68 & 101,00 & 125,92 & 105,07 & 38,24 & 5746,97 & 283,86 & 12,69 & 271,17 & 55,71 & 201,92 & 201,94 & 54,87 & 847,90 & 119,58 & $\begin{array}{l}11,95 \\
\end{array}$ & 50,01 & 334,57 & 65,86 & 65,90 & 334,55 \\
\hline Pleurodeles walt| & 29TPF70 & 101,00 & 126,52 & 95,46 & 35,48 & 5924,88 & 281,66 & 17,39 & 264,27 & 61,88 & 204,75 & 205,50 & 54,21 & 874,26 & 124,50 & 9,71 & 51,57 & 344,34 & 61,95 & 63,13 & 342,25 \\
\hline Pleurodeles walt| & 29TPF71 & 100,00 & 127,17 & 97,36 & \begin{tabular}{|l|}
36,08 \\
\end{tabular} & 5919,39 & 283,19 & 17,05 & 266,14 & 62,28 & 205,32 & 205,96 & 54,80 & 856,38 & 121,62 & 9,80 & 51,38 & 336,79 & 61,71 & 62,35 & 334,93 \\
\hline Pleurodeles waltl & 29TPF72 & 100,00 & 127,59 & 99,08 & 36,53 & 5904,58 & 284,36 & 16,52 & 267,84 & 62,55 & 205,84 & 205,97 & 55,05 & 843,94 & 119,73 & 9,89 & 51,16 & 331,56 & $\begin{array}{ll}61,64 \\
\end{array}$ & 61,79 & 330,15 \\
\hline Pleurodeles walt| & 29TPF73 & 100,00 & 133,46 & 102,44 & \begin{tabular}{|l|l|}
37,27 \\
\end{tabular} & 5891,66 & 291,47 & 20,37 & 271,10 & 67,96 & 211,44 & 211,44 & 60,61 & 792,11 & 111,81 & 9,37 & 50,82 & 310,49 & 57,83 & 57,83 & 309,20 \\
\hline Pleurodeles walt| & 29TPF80 & 100,00 & 124,54 & 96,64 & 35,69 & 5984,11 & 281,57 & 14,38 & 267,19 & 59,31 & 203,48 & 204,49 & 51,68 & 829,57 & 115,42 & 9,69 & 50,31 & 324,36 & 60,92 & 62,19 & 319,90 \\
\hline Pleurodeles walt| & 29TPF81 & 100,00 & 126,60 & 98,86 & 36,16 & 5977,64 & 284,65 & 15,28 & 269,37 & 60,96 & 205,60 & 206,19 & 53,50 & 801,99 & 111,22 & 9,53 & 50,05 & 313,21 & 59,84 & 60,40 & 308,99 \\
\hline Pleurodeles walt| & 29TPF82 & 100,00 & 131,03 & 101,63 & 36,88 & 5965,24 & 290,16 & 18,01 & 272,15 & 64,99 & 210,07 & 210,10 & 57,57 & 761,25 & 105,14 & 9,16 & 49,85 & 296,71 & 57,24 & 57,26 & 292,83 \\
\hline Pleurodeles walt| & 29TPF83 & 101,00 & 129,88 & 102,77 & 37,09 & 5951,56 & 289,35 & 16,37 & 272,99 & 63,97 & 208,81 & 208,81 & 56,52 & 756,55 & 104,25 & 9,48 & 49,50 & 294,66 & 57,70 & 57,70 & 291,10 \\
\hline Pleurodeles walt| & \begin{tabular}{|l|} 
29TPF85 \\
\end{tabular} & 101,00 & 133,76 & 105,84 & 37,90 & 5913,94 & 294,04 & 18,42 & 275,63 & 67,60 & 211,91 & 211,91 & 60,34 & 713,10 & 97,54 & 9,38 & 48,85 & 277,16 & 55,33 & 55,33 & 274,08 \\
\hline Pleurodeles walt| & 29TPF86 & 100,00 & 126,57 & 105,56 & \begin{tabular}{l|l|}
37,85 \\
\end{tabular} & 5900,58 & 287,13 & 11,93 & 275,19 & 60,90 & 204,84 & 204,84 & 53,61 & 744,61 & 101,80 & 10,30 & 48,49 & 289,46 & 59,65 & 59,65 & 287,21 \\
\hline Pleurodeles waltt & 29TPF88 & 101,00 & 131,27 & 108,01 & 38,51 & 5851,74 & 291,97 & 14,96 & 277,01 & 65,44 & 208,61 & 208,61 & 58,38 & 695,99 & 94,18 & 10,34 & 47,79 & 270,13 & 56,85 & 56,85 & 268,09 \\
\hline Pleurodeles walt| & 29TPF89 & 100,00 & 127,67 & 108,27 & 38,52 & 5831,94 & 288,98 & 11,46 & 277,52 & 62,03 & 204,89 & 204,89 & 55,23 & 706,50 & 95,57 & 11,02 & 47,46 & 274,56 & 59,14 & 59,14 & 273,30 \\
\hline Pleurodeles walt| & 29TPF92 & 100,00 & 125,21 & 101,71 & 36,70 & 6019,31 & 285,83 & 12,23 & 273,60 & 58,92 & 205,25 & 205,49 & 51,56 & 742,40 & 99,73 & 9,73 & 48,30 & 287,10 & 58,92 & 59,10 & 280,79 \\
\hline Pleurodeles walt| & 29TPF93 & 100,00 & 125,30 & 103,03 & 37,01 & 6001,13 & 286,26 & 11,60 & 274,66 & 59,07 & 205,17 & 205,17 & 51,65 & 728,21 & 97,39 & 9,94 & 47,86 & 281,22 & 58,88 & 58,88 & 275,19 \\
\hline Pleurodeles walt| & $\begin{array}{l}\text { 29TPF95 } \\
\end{array}$ & 100,00 & 123,98 & 105,18 & 37,72 & 5972,06 & 285,81 & 9,47 & 276,34 & 57,90 & 203,57 & 203,57 & 50,66 & 712,27 & 94,80 & 9,98 & 47,46 & 274,87 & 58,80 & 58,80 & 269,70 \\
\hline Pleurodeles walt| & 29TPF96 & 100,00 & 125,79 & 106,55 & 38,02 & 5947,17 & 287,79 & 10,27 & 277,52 & 59,50 & 204,76 & 204,76 & 52,34 & 691,95 & 91,70 & 10,15 & 47,00 & 266,69 & 57,95 & 57,95 & 261,99 \\
\hline Pleurodeles waltt & 29TPF97 & 101,00 & 119,67 & 106,41 & 37,99 & 5930,73 & 282,07 & 4,67 & 277,39 & 53,80 & 198,61 & 198,61 & 46,65 & 718,31 & 95,14 & 11,02 & 46,70 & 276,97 & 61,95 & 61,95 & 272,98 \\
\hline Pleurodeles walt| & 29TPF98 & 100,00 & 120,57 & 107,46 & \begin{tabular}{ll|}
38,12 \\
\end{tabular} & 5908,98 & 283,11 & 5,07 & 278,03 & 54,57 & 199,09 & 199,09 & 47,67 & 701,41 & 92,47 & \begin{tabular}{|l|}
11,18 \\
\end{tabular} & 46,30 & 270,26 & 61,39 & 61,39 & 266,71 \\
\hline Pleurodeles waltt & 29TPG40 & 100,00 & 139,68 & 107,25 & 39,28 & 5619,81 & 294,02 & 24,54 & 269,48 & 69,90 & 213,18 & 213,18 & 69,41 & 839,87 & 116,78 & 11,78 & 50,19 & 329,39 & 62,42 & 62,42 & 329,39 \\
\hline Pleurodeles walt| & 29TPG41 & 100,00 & 132,24 & 105,64 & 38,95 & 5603,97 & 286,01 & 18,46 & 267,55 & 63,01 & 205,82 & 205,82 & 62,58 & 880,38 & 121,57 & 13,71 & 49,58 & 345,71 & 68,32 & 68,32 & 345,69 \\
\hline Pleurodeles walt| & 29TPG94 & 101,00 & 110,64 & 108,34 & 38,65 & 5772,11 & 272,62 & $-4,27$ & 276,90 & 45,99 & 187,51 & 187,51 & 39,68 & 726,49 & 96,60 & 16,51 & 43,40 & 277,94 & 73,92 & 73,92 & 274,29 \\
\hline \begin{tabular}{|l|l|} 
Pleurodeles waltl \\
\end{tabular} & 29TQE03 & 101,00 & 157,84 & 104,90 & 36,25 & 6197,98 & 324,68 & 40,68 & 284,00 & 89,63 & 240,05 & 240,05 & 81,88 & \begin{tabular}{|l|l|}
573,08 \\
\end{tabular} & 74,32 & $\begin{array}{r}5,06 \\
5,06\end{array}$ & $\begin{array}{l}49,40 \\
49,47\end{array}$ & 219,34 & 39,70 & 39,70 & 209,86 \\
\hline Pleurodeles walt| & 29TQE04 & 100,00 & 154,81 & 104,37 & 36,24 & 6192,69 & 321,03 & 38,01 & 283,02 & 86,55 & 237,01 & 237,01 & 78,85 & 586,07 & 76,24 & 5,54 & 48,99 & 224,24 & 41,44 & 41,44 & 214,93 \\
\hline Pleurodeles walt| & 29TQE07 & 100,00 & 123,62 & 98,16 & 35,33 & 6135,20 & 285,67 & 12,02 & 273,65 & 57,43 & 204,98 & 205,92 & 49,78 & 759,97 & 100,67 & 9,58 & 48,27 & 291,79 & 57,97 & 59,88 & 282,52 \\
\hline Pleurodeles waltt & 29TQE08 & 99,00 & 125,47 & 99,36 & 35,85 & 6122,78 & 287,60 & 13,15 & 274,45 & 58,98 & 206,49 & 207,47 & 51,45 & 736,57 & 97,22 & 9,29 & 48,01 & 282,68 & 56,92 & 58,27 & 273,55 \\
\hline Pleurodeles walt| & 29TQEO9 & 100,00 & 131,30 & 101,86 & 36,17 & 6116,52 & 294,27 & 17,42 & 276,85 & 64,19 & 212,74 & 212,94 & 56,78 & 685,57 & 89,87 & 8,81 & 47,62 & 262,67 & 54,02 & 54,22 & 253,71 \\
\hline \begin{tabular}{|l|} 
Pleurodeles waltl \\
\end{tabular} & 29TQE17 & 100,00 & 116,90 & 99,27 & 35,58 & 6162,49 & 280,77 & $\begin{array}{r}5,20 \\
5,20\end{array}$ & 270,5 & 50,61 & \begin{tabular}{|l|}
198,90 \\
\end{tabular} & \begin{tabular}{|l|}
199,93 \\
\end{tabular} & 43,24 & 757,81 & $\begin{array}{l}3,016 \\
97,69\end{array}$ & $\begin{array}{r}0,01 \\
10,55\end{array}$ & 46,63 & \begin{tabular}{|l|}
287,30 \\
\end{tabular} & $\begin{array}{ll}60,86 \\
60,\end{array}$ & $\begin{array}{ll}4,2,32 \\
3,32\end{array}$ & 276,08 \\
\hline Pleurodeles walt| & 29TQE18 & 101,00 & 125,54 & 101,80 & 36,00 & 6169,60 & 290,29 & 11,75 & 278,54 & 58,30 & 207,24 & 208,30 & 51,04 & 686,06 & 88,32 & 9,12 & 46,56 & 260,12 & 55,46 & 56,49 & 249,12 \\
\hline Pleurodeles walt| & 29TQE19 & 100,00 & 127,25 & 103,00 & 36,19 & 6162,70 & 292,13 & 12,80 & 279,33 & 59,83 & 209,15 & 209,75 & 52,47 & 661,92 & 85,14 & 9,13 & 46,17 & 250,62 & 54,62 & 55,15 & 239,65 \\
\hline Pleurodeles walt| & 29TQE26 & 101,00 & 136,78 & 104,80 & 36,17 & 6252,37 & 305,10 & 20,15 & 284,95 & 68,32 & 220,21 & 220,43 & 60,87 & 600,82 & 76,44 & 7,80 & 46,06 & 224,75 & 48,41 & 48,75 & 212,96 \\
\hline Pleurodeles walt| & 29TQE28 & 100,00 & 119,46 & 102,97 & 36,06 & 6199,91 & 286,09 & 5,50 & 280,59 & 52,27 & 201,76 & 202,81 & 44,99 & 678,62 & 86,57 & 10,04 & 44,90 & 253,79 & 57,87 & 59,40 & 240,81 \\
\hline Pleurodeles walt| & 29TQE36 & 101,00 & 141,63 & 107,36 & 36,79 & 6292,12 & 312,02 & 22,93 & 289,09 & 72,36 & 225,59 & 225,64 & 65,01 & 539,11 & 67,97 & 7,11 & 44,88 & 198,78 & 44,67 & 44,72 & 186,33 \\
\hline Pleurodeles walt| & 29TQE38 & 100,00 & 110,46 & 103,62 & 36,32 & 6198,67 & 278,44 & $-3,04$ & 281,49 & 43,78 & 193,30 & 194,22 & 36,73 & 697,16 & 88,05 & 11,78 & 43,03 & 256,34 & 63,16 & 65,78 & 241,57 \\
\hline Pleurodeles walt| & 29TQE39 & 101,00 & 109,91 & 104,34 & 36,66 & 6188,14 & 277,81 & \begin{tabular}{|c|}
$-3,78$ \\
\end{tabular} & 281,59 & 43,16 & 192,28 & 193,47 & 36,11 & 681,21 & 86,15 & 11,77 & 42,58 & 250,19 & 63,12 & 65,34 & 234,95 \\
\hline Pleurodeles walt| & 29TQE44 & 100,00 & 152,58 & 109,43 & 36,98 & 6344,64 & 325,43 & 31,54 & 293,89 & 82,55 & 237,27 & 237,27 & 74,89 & 477,37 & 59,45 & 5,67 & 45,00 & 173,76 & 38,39 & 38,39 & 161,35 \\
\hline Pleurodeles walt| & 29TQE45 & 100,00 & 151,61 & 109,59 & 37,00 & 6324,97 & 323,68 & 30,62 & 293,06 & 81,56 & 235,82 & 235,82 & 74,03 & 473,99 & 59,14 & 5,99 & 44,33 & 172,29 & 39,09 & 39,09 & 159,80 \\
\hline \begin{tabular}{|l|} 
Pleurodeles walt| \\
\end{tabular} & 29TQE46 & 100,00 & 146,14 & 109,54 & 36,5 & 6308,07 & 317,85 & $\begin{array}{l}0,67 \\
25,67\end{array}$ & 292,17 & 76,37 & 230,16 & 230,17 & 69,01 & 487,99 & 61,03 & 6,55 & 43,85 & 177,18 & 41,57 & 41,57 & 164,23 \\
\hline Pleurodeles walt| & 29TQE48 & 99,00 & 117,99 & 107,09 & 36,82 & 6247,59 & 288,57 & 1,73 & 286,85 & 50,00 & 201,22 & 202,15 & 43,11 & 606,94 & 75,98 & 10,64 & 41,83 & 219,55 & 57,39 & 58,73 & 204,08 \\
\hline Pleurodeles walt| & 29TQE49 & 100,00 & 111,13 & 106,74 & 36,98 & 6218,89 & 281,23 & $-3,86$ & 285,09 & 43,78 & 193,70 & 195,11 & 36,90 & 629,64 & 78,99 & 11,61 & 41,15 & 227,45 & 61,36 & 63,11 & 210,94 \\
\hline Pleurodeles walt| & 29TQE53 & 60,00 & 149,80 & 109,92 & 36,70 & 6408,64 & 324,57 & 27,94 & 296,63 & 79,16 & 235,42 & 235,42 & 71,58 & 480,32 & 59,08 & 5,85 & 44,56 & 173,02 & 39,20 & 39,20 & 160,24 \\
\hline Pleurodeles waltl & 29TQE54 & 53,00 & 143,79 & 109,60 & 36,76 & 6381,46 & 318,09 & 22,92 & 295,17 & 73,69 & 229,20 & 229,32 & 66,36 & 499,15 & 61,49 & 6,79 & 43,84 & 179,41 & 42,44 & 42,54 & 166,18 \\
\hline Pleurodeles walt| & 29TQE55 & 57,00 & 150,76 & 110,57 & 37,00 & 6358,67 & 323,98 & 28,98 & 295,00 & 80,15 & 235,62 & 235,62 & 72,85 & 458,15 & 56,78 & 6,03 & 43,63 & 164,68 & 39,14 & 39,14 & 151,80 \\
\hline Pleurodeles waltl & 29TQE56 & 50,00 & 137,16 & 109,69 & 36,99 & 6325,01 & 310,13 & 17,17 & 292,96 & 67,55 & 221,57 & 221,77 & 60,39 & 507,69 & 62,88 & 7,87 & 42,52 & 181,96 & 45,81 & 46,01 & 168,04 \\
\hline Pleurodeles waltt & 29TQF06 & 100,00 & 125,29 & 107,78 & 38,01 & 6002,93 & 288,91 & 8,85 & 280,05 & 58,28 & 204,97 & 204,97 & 51,21 & 640,23 & 82,02 & 9,97 & 45,41 & 244,05 & 56,19 & 56,19 & 236,84 \\
\hline Pleurodeles waltl & 29TQF07 & 100,00 & 124,47 & 108,48 & 38,15 & 5975,92 & 288,21 & 7,85 & 280,36 & 57,62 & 203,80 & 203,80 & 50 & 634,57 & 81,31 & 10,33 & 45,02 & 67 & 56,70 & 56,70 & 235,01 \\
\hline \begin{tabular}{|l|} 
Pleurodeles waltl \\
\end{tabular} & 29TQF08 & 100,00 & $\frac{124}{119}$ & $\begin{array}{l}10,40 \\
108,56\end{array}$ & 38 & 5959,95 & 280,21 & $\begin{array}{l}3,05 \\
3,05 \\
\end{array}$ & \begin{tabular}{|l|}
280,260 \\
\end{tabular} & $\begin{array}{ll}1,2,92 \\
2,92\end{array}$ & \begin{tabular}{|l|}
198,65 \\
1906
\end{tabular} & \begin{tabular}{|l|}
198,65 \\
1980
\end{tabular} & $\begin{array}{l}30,05 \\
45,99\end{array}$ & \begin{tabular}{|l|l|}
654,23 \\
64,
\end{tabular} & $\begin{array}{l}\mid 1,11 \\
84,20 \\
\end{array}$ & 11,16 & $\begin{array}{ll}43,66 \\
44,66\end{array}$ & \begin{tabular}{|l|}
249,16 \\
249
\end{tabular} & $\begin{array}{ll}60,21 \\
60\end{array}$ & $\begin{array}{ll}60,21 \\
60\end{array}$ & 243,12 \\
\hline Pleurodeles walt| & 29TQF11 & 100,00 & 123,25 & 104,14 & 36,98 & 6128,57 & 287,91 & 8,57 & 279,33 & 55,96 & 204,75 & 205,19 & 48,69 & 659,94 & 84,82 & 9,63 & 45,38 & 249,59 & 56,55 & 56,89 & 238,38 \\
\hline Pleurodeles walt| & 29TQF15 & 101,00 & 120,75 & 107,73 & $37,95 \mid$ & 6071,48 & 286,05 & 4.44 & 281,61 & 53,44 & 201,50 & 201,50 & 46,21 & 621.94 & 79,17 & 10,14 & 43,99 & 234,15 & 57,15 & 57,15 & 223,71 \\
\hline Pleurodeles waltl & 29TQF16 & 100,00 & 119,86 & 108,46 & 38,00 & 6049,59 & 285,22 & 3,36 & 281,85 & 52,53 & 200,33 & 200,33 & 45,51 & 616,45 & 78,70 & 10,64 & 43,43 & 231,63 & 58,12 & 58,12 & 221,61 \\
\hline Pleurodeles waltl & 29TQF17 & 99,00 & 126,84 & 110,00 & 38,23 & 6022,16 & 292,13 & 8,85 & 283,28 & 59,28 & 206,62 & 206,62 & 52 & 571,63 & 73,31 & 9,92 & 43,27 & 214,56 & 53,54 & 53,54 & 20 \\
\hline \begin{tabular}{|l|} 
Pleurodeles waltl \\
\end{tabular} & 29TQF18 & \begin{tabular}{|c|}
100,00 \\
100
\end{tabular} & $\begin{array}{l}12,04,60 \\
122,60\end{array}$ & 110,21 & 38,40 & 6002,109 & 287,87 & $\begin{array}{l}0,07 \\
4,76\end{array}$ & \begin{tabular}{|l|}
283,11 \\
283,11
\end{tabular} & $\begin{array}{l}\mid c 5,0 \\
55,36\end{array}$ & \begin{tabular}{|l|}
$202,28<$ \\
\end{tabular} & \begin{tabular}{|l|}
$202,28<$ \\
\end{tabular} & $\begin{array}{l}32,5,1 \\
48,48\end{array}$ & $\begin{array}{l}/ 1,05 \\
585,02 \\
\end{array}$ & $\begin{array}{l}\mid 75,15 \\
75,58\end{array}$ & \begin{tabular}{r|}
, 52 \\
10,69
\end{tabular} & $\begin{array}{l}43,21 \\
43,04\end{array}$ & \begin{tabular}{|l|}
219,49 \\
2190
\end{tabular} & \begin{tabular}{|l|l|}
56,23 \\
56
\end{tabular} & $\begin{array}{l}50,34 \\
56,23\end{array}$ & $\begin{array}{l}20,00 \\
210,90\end{array}$ \\
\hline Pleurodeles walt| & 29TQF19 & 100,00 & 118,95 & 110,37 & 38,70 & 5982,06 & 284,32 & 1,44 & 282,88 & 52,01 & 198,36 & 198,36 & 45,22 & 596,50 & 77,51 & 11,53 & 42,49 & 223,55 & 59,05 & 59,05 & 215,39 \\
\hline Pleurodeles walt| & 29TQF20 & 100,00 & 122,60 & 105,19 & 36,93 & 6179,35 & 289,29 & 7,16 & 282,13 & 54,98 & 204,59 & 205,36 & 47,62 & 629,76 & 80,45 & 9,78 & 44,21 & 235,08 & 55,74 & 56,30 & 221,92 \\
\hline Pleurodeles walt| & 29TQF24 & 101,00 & 119,11 & 108,31 & 37,93 & 6126,72 & 286,04 & 2,39 & 283,64 & 51,25 & 200,62 & 200, & 44 & 592,82 & 75,47 & 10,10 & 42,64 & 220,00 & 56,88 & 56,90 & 206 \\
\hline \begin{tabular}{|l|} 
Pleurodeles waltl \\
\end{tabular} & 29TQF25 & 100,00 & 118,78 & 109,07 & 38,00 & 6103,65 & 285,76 & 1,81 & 283,94 & 51,01 & 200,04 & 200,04 & 44,07 & 582,67 & 74,56 & 10,54 & 42,24 & 215,88 & 56,95 & 56,95 & 202,80 \\
\hline
\end{tabular}




\begin{tabular}{|c|c|c|c|c|c|c|c|c|c|c|c|c|c|c|c|c|c|c|c|c|c|}
\hline TAXON & UTM & $\mathrm{km} 2$ & B101 & B102 & $\mathrm{BIO3}$ & B104 & B105 & B106 & B107 & B108 & B109 & BIO10 & B1011 & BIO12 & B1013 & BIO14 & BIO15 & BIO16 & B1017 & B1018 & B1019 \\
\hline Pleurodeles walt| & 29TQF26 & 100,00 & 119,46 & 109,95 & 38,00 & 6093,24 & 286,79 & 1,91 & 284,88 & 51,71 & 200,57 & 200,57 & 44,79 & 566,95 & 72,83 & 10,62 & 41,69 & 209,51 & 56,51 & 56,51 & 196,92 \\
\hline Pleurodeles walt| & 29TQF27 & 101,00 & 120,53 & 110,64 & 38,04 & $\begin{array}{l}6077,37 \\
\end{array}$ & 287,51 & 2,25 & 285,26 & 52,64 & 201,23 & 201,23 & 45,72 & 554,07 & 71,52 & 10,61 & 41,49 & 204,46 & 55,79 & 55,79 & 192,65 \\
\hline Pleurodeles walt| & 29TQF28 & 100,00 & 120,82 & 111,21 & 38,30 & 6056,09 & 287,94 & 2,60 & 285,34 & 53,22 & 201,28 & 201,28 & 46,19 & 543,86 & 70,42 & 10,86 & 41,16 & 200,26 & 55,77 & 55,77 & 188,94 \\
\hline Pleurodeles walt| & 29TQF29 & 100,00 & 120,33 & 111,61 & 38,78 & 6032,92 & 287,25 & 1,88 & 285,36 & 52,66 & 200,29 & 200,29 & 45,80 & 541,55 & 70,40 & \begin{tabular}{l|l}
11,25 \\
\end{tabular} & 40,85 & 199,19 & 56,50 & 56,50 & 188,40 \\
\hline Pleurodeles walt| & 29TQF30 & 100,00 & 119,31 & 106,94 & 37,00 & \begin{tabular}{|l|l|}
6208,17 \\
\end{tabular} & 287,95 & 3,01 & 284,94 & 51,33 & 201,75 & 202,61 & 44,15 & 603,73 & 76,57 & 10,06 & 42,51 & 221,76 & 56,64 & 57,28 & 206,68 \\
\hline Pleurodeles walt| & 29TQF35 & 100,00 & 118,97 & 110,87 & 38,08 & 6142,17 & 287,85 & 0,92 & 286,92 & 50,75 & 200,85 & 200,85 & 43,79 & 533,91 & 68,62 & 10,49 & 40,59 & 194,06 & 55,55 & 55,55 & 178,62 \\
\hline Pleurodeles walt| & 29TQF36 & 100,00 & 120,24 & 111,54 & 38,22 & 6129,71 & 289,00 & 1,76 & 287,24 & 52,16 & 201,72 & 201,72 & 45,03 & 517,40 & 66,80 & 10,28 & 40,33 & 187,67 & 54,43 & 54,43 & 172,97 \\
\hline Pleurodeles waltl & 29TQF37 & 100,00 & 118,55 & 111,76 & 38,46 & 6114,85 & 287,34 & 0,26 & 287,08 & 51,81 & 199,80 & 199,80 & 43,42 & 515,96 & $\begin{array}{l}66,72 \\
660\end{array}$ & 10,98 & 39,88 & 186,47 & 55,52 & 55,52 & 172,01 \\
\hline Pleurodeles walt| & 29TQF39 & 101,00 & 117,53 & 112,34 & \begin{tabular}{l|l|}
38,95 \\
\end{tabular} & 6073,13 & 286,20 & $-0,80$ & 287,00 & 54,47 & 198,29 & 198,29 & 42,66 & 509,77 & 66,10 & 11,77 & 38,87 & 183,34 & 57,22 & 57,22 & 169,97 \\
\hline Pleurodeles walt| & 29TQF40 & 100,00 & 116,70 & 108,66 & \begin{tabular}{|l|l|}
37,23 \\
\end{tabular} & 6227,32 & 287,15 & $-0,06$ & 287,21 & 48,54 & 199,46 & 200,47 & 41,83 & 578,11 & 72,63 & 10,60 & 40,89 & 208,46 & 57,44 & 58,19 & 191,94 \\
\hline Pleurodeles walt| & 29TQF41 & 100,00 & 120,12 & 110,06 & 37,78 & 6225,63 & 290,81 & 2,18 & 288,63 & 51,64 & 203,41 & 203,55 & 44,62 & 543,12 & 68,39 & 10,07 & 40,68 & 195,64 & 55,10 & 55,19 & 178,90 \\
\hline Pleurodeles walt| & 29TQF42 & 100,00 & 121,21 & 111,03 & 38,00 & 6213,43 & 291,77 & 2,71 & 289,06 & 53,20 & 204,21 & 204,21 & 45,50 & 522,19 & 66,12 & 10,00 & 40,31 & \begin{tabular}{|l|l|}
187,54 \\
\end{tabular} & 54,20 & 54,20 & 170,50 \\
\hline Pleurodeles walt| & 29TOF44 & 99,00 & 118,41 & 112,01 & 38,09 & 6184,50 & 288,97 & 0,23 & 288,74 & 65,45 & 200,91 & 200,91 & 42,97 & 506,69 & 65,08 & 10,55 & 39,66 & 181,50 & 54,95 & 54,95 & 163,34 \\
\hline Pleurodeles walt| & 29TQF45 & 99,00 & 120,27 & 112,72 & 38,18 & 6173,60 & 290,70 & 1,01 & 289,68 & 74,07 & 202,34 & 202,34 & 44,59 & 485,16 & 62,58 & 10,14 & 39,43 & $\begin{array}{ll}173,62 \\
\end{array}$ & 53,39 & 53,39 & 155,40 \\
\hline Pleurodeles walt| & 29TQF46 & 101,00 & 118,96 & 112,92 & 38,60 & 6153,76 & 289,35 & 0,24 & 289,11 & 76,52 & 200,76 & 200,76 & 43,42 & 481,04 & 62,11 & \begin{tabular}{|l|l|}
10,63 \\
\end{tabular} & 38,93 & \begin{tabular}{|l|l|}
171,84 \\
\end{tabular} & 54,16 & 54,16 & 153,67 \\
\hline Pleurodeles waltt & 29TQF47 & 100,00 & 116,77 & 112,93 & 38,80 & 6141,71 & 287,25 & $-1,44$ & 288,68 & 76,17 & 198,53 & 198,53 & 41,46 & 481,72 & 62,16 & 11,00 & 38,46 & 171,64 & 55,31 & 55,31 & 153,66 \\
\hline Pleurodeles walt| & 29TQF48 & 100,00 & 116,89 & 113,23 & 38,97 & 6130,25 & 286,98 & $-1,75$ & 288,73 & 76,96 & 198,25 & 198,25 & 41,58 & 475,93 & 61,37 & 11,24 & 37,99 & 169,20 & 55,66 & 55,66 & 151,72 \\
\hline Pleurodeles walt| & 29TQF49 & 100,00 & 119,58 & 113,50 & 38,97 & 6115,42 & 289,29 & 0,01 & 289,29 & 80,05 & 200,47 & 200,48 & 43,96 & 459,76 & 59,24 & 11,05 & 37,64 & 163,38 & 54,36 & 54,37 & 146,34 \\
\hline Pleurodeles walt| & 29TQF50 & 33,00 & 117,20 & 110,11 & \begin{tabular}{|l|l|}
37,63 \\
\end{tabular} & 6238,59 & 288,82 & $-0,27$ & 289,09 & 48,91 & 200,27 & 201,05 & 42,04 & 550,61 & 68,77 & 10,71 & 39,96 & \begin{tabular}{|l|l|}
195,89 \\
\end{tabular} & 56,96 & 57,45 & 178,63 \\
\hline Pleurodeles walt| & 29TQF54 & 26,00 & 118,31 & 113,03 & 38,26 & 6183,91 & 289,74 & $-0,34$ & 290,09 & 78,54 & 200,80 & 200,80 & 42,91 & 483,09 & 62,06 & $\begin{array}{l}10,69 \\
\end{array}$ & 39,00 & \begin{tabular}{|l|l|}
172,43 \\
\end{tabular} & 54,46 & 54,46 & 151,34 \\
\hline Pleurodeles walt| & 29TQF59 & 4,00 & 119,55 & 114,00 & 39,00 & 6127,82 & 289,64 & $-0,36$ & 290,00 & 80,00 & 200,64 & 200,64 & 43,91 & 438,91 & 56,27 & 10,73 & 36,91 & \begin{tabular}{|l|l|}
155,64 \\
\end{tabular} & 53,36 & 53,36 & 136,09 \\
\hline Pleurodeles walt| & 29TQG01 & 101,00 & 120,16 & 110,37 & 39,00 & 5890,61 & 283,96 & 2,77 & 281,19 & 54,07 & $\begin{array}{l}198,46 \\
\end{array}$ & $\begin{array}{l}198,46 \\
\end{array}$ & 47,29 & $\begin{array}{l}630,02 \\
\end{array}$ & 82,67 & 12,21 & 43,76 & 239,57 & 60,81 & 60,81 & 235,47 \\
\hline Pleurodeles walt| & 29TQG02 & 100,00 & 118,31 & 110,55 & 39,00 & 5867,35 & 282,03 & 1,14 & 280,89 & 52,36 & 196,31 & 196,31 & 45,68 & 636,56 & 84,01 & \begin{tabular}{|l|}
13,14 \\
\end{tabular} & 43,33 & 241,71 & \begin{tabular}{ll|}
63,07 \\
\end{tabular} & \begin{tabular}{|c|}
63,07 \\
\end{tabular} & 237,84 \\
\hline Pleurodeles waltt & 29TQG04 & 99,00 & 107,72 & 109,04 & 38,75 & 5831,01 & 270,54 & $-7,80$ & 278,34 & 42,36 & 185,45 & 185,45 & 36,15 & 697,38 & 92,22 & 17,25 & 41,55 & 262,69 & 75,26 & 75,26 & 255,74 \\
\hline Pleurodeles walt| & 29TQG10 & 101,00 & 116,77 & 110,67 & 39,00 & 5974,82 & 282,16 & $-0,12$ & 282,28 & 50,13 & 196,21 & 196,21 & 43,23 & 602,56 & 78,66 & 12,23 & 42,09 & 225,51 & 61,11 & 61,11 & 217,74 \\
\hline Pleurodeles walt| & 29TQG30 & 99,00 & 118,24 & 112,71 & 38,98 & 6054,24 & 286,54 & $-0,55$ & 287,09 & 58,13 & 198,47 & 198,47 & 43,35 & 504,83 & 65,56 & 12,00 & 38,70 & \begin{tabular}{|l|l|}
181,38 \\
\end{tabular} & 57,28 & 57,28 & 168,57 \\
\hline \begin{tabular}{|l|l|} 
Pleurodeles waltl \\
\end{tabular} & 29TQG31 & 99,00 & 114,43 & 112,67 & 39,00 & 6039,45 & 282,86 & $\begin{array}{l}-4,10 \\
-4,10\end{array}$ & 286,95 & 56,56 & $\begin{array}{l}194,63 \\
\end{array}$ & $\begin{array}{l}194,63 \\
\end{array}$ & 39,85 & 523,31 & $\begin{array}{l}68,00 \\
68\end{array}$ & 13,26 & 38,07 & $\begin{array}{l}\mid 187,86 \\
\end{array}$ & $\begin{array}{l}61,196 \\
619\end{array}$ & 61,19 & 174,80 \\
\hline Pleurodeles walt| & 29TQG43 & 91,00 & 109,68 & 113,67 & 39,00 & 6041,99 & 279,31 & $-9,32$ & 288,63 & 71,14 & 189,93 & 189,93 & 34,99 & 522,63 & 67,10 & 15,60 & 35,67 & 186,39 & 68,06 & 68,06 & 167,33 \\
\hline Pleurodeles walt| & 29TQG45 & 86,00 & 116,09 & 114,02 & 39,00 & 5989,02 & 284,02 & $-4,08$ & 288,09 & 78,02 & 195,22 & 195,22 & 41,51 & 506,24 & 64,85 & 15,65 & 35,28 & 182,75 & 67,67 & 67,67 & 160,55 \\
\hline Pleurodeles waltt & 30STE49 & & & & & & & & & & & & & & & & & & & & \\
\hline Pleurodeles walt| & $\begin{array}{l}\text { 30STE59 } \\
\end{array}$ & & & & & & & & & & & & & & & & & & & & \\
\hline Pleurodeles walt| & 30STE69 & 90,00 & 166,92 & 83,47 & 39,98 & 4208,93 & 277,68 & 71,14 & 206,55 & 123,23 & 220,05 & 223,59 & 115,12 & 848,89 & 146,18 & 0,58 & 76,41 & 404,67 & 13,56 & 22,34 & 401,74 \\
\hline Pleurodeles walt| & \begin{tabular}{|l|} 
30STE79 \\
\end{tabular} & 80,00 & 165,85 & 86,17 & 40,60 & 4236,28 & 280,03 & 69,61 & 210,41 & 121,75 & 219,52 & 223,38 & 114,45 & \begin{tabular}{|l|}
815,53 \\
\end{tabular} & \begin{tabular}{|l|}
141,61 \\
\end{tabular} & 0,99 & 76,60 & \begin{tabular}{|l|l|}
396,23 \\
\end{tabular} & 13,03 & 22,71 & 390,32 \\
\hline Pleurodeles walt| & 30STF32 & 90,00 & 172,06 & 73,73 & 36,93 & 4378,73 & 275,79 & 78,71 & 197,08 & 126,41 & 226,50 & 230,49 & 117,51 & 741,70 & 127,34 & 1,00 & 71,14 & \begin{tabular}{|l|l|}
333,93 \\
\end{tabular} & 15,08 & 23,50 & 320,08 \\
\hline Pleurodeles walt| & 30STF33 & 90,00 & 171,30 & 73,63 & 35,99 & 4544,89 & 278,05 & 76,28 & 201,77 & 123,77 & 228,06 & 232,17 & 114,86 & 724,33 & 122,30 & 1,00 & 70,20 & 322,57 & 15,14 & 23,99 & 307,85 \\
\hline Pleurodeles walt| & 30STF34 & 90,00 & 171,41 & 73,47 & 35,17 & 4698,44 & 280,66 & 74,99 & 205,66 & 122,05 & 230,19 & 234,29 & 113,12 & 700,70 & 115,90 & 1,00 & 69,12 & 308,26 & 15,67 & 24,01 & 292,74 \\
\hline Pleurodeles walt| & 30STF35 & 81,00 & 172,92 & 73,12 & 34,53 & 4830,34 & 284,27 & 75,48 & 208,79 & 121,93 & 233,49 & 237,52 & 113,13 & 668,82 & 108,03 & 1,00 & 68,07 & 290,48 & 15,98 & 23,88 & 274,22 \\
\hline Pleurodeles walt| & 30STF36 & 80,00 & 171,69 & 75,24 & 34,32 & 5009,00 & 288,16 & 71,81 & 216,35 & 118,67 & 234,80 & 238,68 & 109,86 & 657,79 & 103,48 & 1,00 & 67,23 & 283,17 & 16,55 & 23,91 & 266,49 \\
\hline Pleurodeles walt| & 30STF38 & 72,00 & 171,74 & 86,27 & 35,82 & 5325,61 & 303,23 & 65,21 & 238,02 & 114,89 & 239,46 & 242,79 & 106,25 & 637,94 & 97,45 & 1,00 & 65,84 & 273,76 & 17,25 & 23,73 & 256,61 \\
\hline Pleurodeles walt| & 30STF40 & 79,00 & 170,05 & 77,24 & 38,86 & 4149,76 & 273,55 & 77,47 & 196,08 & 127,19 & 221,86 & 225,45 & 118,45 & 822,55 & 142,23 & 0,24 & 73,99 & 380,45 & 15,04 & 22,30 & 370,92 \\
\hline Pleurodeles walt| & 30STF41 & 100,00 & 172,72 & 74,78 & 38,3 & 4162,68 & 273,71 & 80,79 & 192,92 & 129,06 & 224,63 & 228,16 & 120,80 & 787,68 & 135,86 & 0,0 & 73,02 & 361,95 & 15,05 & 22,06 & 349,54 \\
\hline Pleurodeles walt| & 30STF42 & 100,00 & 172,28 & 74,59 & 37,4 & 4314,16 & 275,88 & 79,09 & 196,79 & 127,13 & 226,17 & 229,93 & 118,57 & 768,15 & $\begin{array}{l}131,09 \\
\end{array}$ & 0,67 & 71,80 & 349,92 & 15,67 & 22,89 & 335,87 \\
\hline Pleurodeles walt| & $\begin{array}{l}\text { 30STF43 } \\
\end{array}$ & 100,00 & 171,37 & 75,07 & 36,61 & 4494,42 & 278,71 & 76,42 & 202,28 & 124,26 & 227,63 & 231,55 & 115,70 & 748,11 & 125,94 & 1,00 & 70,66 & 337,59 & 15,96 & 23,63 & 322,29 \\
\hline Pleurodeles walt| & 30STF44 & 100,00 & 170,27 & 76,41 & 36,06 & 4680,85 & 282,25 & 73,23 & 209,02 & 121,12 & 229,12 & 233,04 & 112,49 & 729,53 & 120,67 & 1,00 & 69,77 & 326,03 & 16,01 & 24,01 & 309,93 \\
\hline Pleurodeles walt| & 30STF45 & 100,00 & 169,68 & 78,14 & 35,66 & 4861,25 & 286,50 & 70,68 & 215,82 & 118,62 & 231,10 & 234, & 109,92 & 708,52 & 114,95 & 1,00 & 68,80 & 13,47 & 16,20 & 24,13 & 296,85 \\
\hline \begin{tabular}{|l|} 
Pleurodeles walt| \\
\end{tabular} & 30STF48 & 100,00 & 171,85 & 89,53 & 36,60 & 5327,55 & 306,51 & 64,98 & 241,53 & $\begin{array}{l}114,9929 \\
110\end{array}$ & 239,74 & 242,99 & $\begin{array}{l}106,50 \\
\end{array}$ & \begin{tabular}{|l|l|}
650,58 \\
\end{tabular} & \begin{tabular}{|l|l|}
100,83 \\
\end{tabular} & 1,00 & $\begin{array}{l}0 ., 06,49 \\
6\end{array}$ & \begin{tabular}{|l|l|l|l|}
282,57 \\
\end{tabular} & $\begin{array}{ll}17,13 \\
17,13\end{array}$ & 23,46 & 264,93 \\
\hline Pleurodeles walt| & 30STF49 & 100,00 & 174,80 & 95,45 & 37,42 & 5455,12 & 316,42 & 64,72 & 251,70 & 116,19 & 244,53 & 247,50 & 107,91 & 627,88 & 96,63 & 1,00 & 65,80 & 272,34 & 17,22 & 22,89 & 254,65 \\
\hline Pleurodeles waltl & 30STF50 & 100,00 & 168,95 & 78,27 & 39,21 & 4103,92 & 272,40 & 75,62 & 196,79 & 126,26 & 220,38 & 223,74 & 117,77 & 855,68 & 146,48 & 0,21 & 74,96 & 398,75 & 15,01 & 22,30 & 392,21 \\
\hline Pleurodeles waltt & 30STF51 & 100,00 & 167,76 & 78,74 & 38,64 & 4257,40 & 274,60 & 73,17 & 201,43 & 123,72 & 221,33 & 224,81 & 114,96 & 835,94 & 142,24 & 0,58 & 73,81 & 388,02 & 15,32 & 23,08 & 378,19 \\
\hline Pleurodeles waltl & 30STF52 & 100,00 & 169,60 & 77,73 & 38,01 & 4336,43 & 276,87 & 74,98 & 201,89 & 124,45 & 224,16 & 227,73 & 116,00 & 802,55 & 136 & 0,89 & 72,62 & 371,01 & 15,89 & 23,25 & 357,32 \\
\hline \begin{tabular}{|l|} 
Pleurodeles waltl \\
\end{tabular} & \begin{tabular}{|l} 
30STF53 \\
30ST
\end{tabular} & 100,00 & 171 & 77,64 & 37,41 & $\begin{array}{l}4350,45 \\
4455,91\end{array}$ & 280,34 & $\begin{array}{l}75,76 \\
75,76\end{array}$ & \begin{tabular}{|l|}
204,58 \\
205
\end{tabular} & \begin{tabular}{|l|}
124,463 \\
\end{tabular} & \begin{tabular}{|l|}
227,16 \\
227
\end{tabular} & \begin{tabular}{|l|}
230,82 \\
\end{tabular} & \begin{tabular}{|l|}
116,13 \\
113
\end{tabular} & 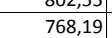 & \begin{tabular}{|l|}
$129,70,0$ \\
129
\end{tabular} & $\begin{array}{l}, 09 \\
1,00\end{array}$ & 71,54 & 353,12 & $\begin{array}{l}1,000 \\
16,00\end{array}$ & 23,21 & 336,74 \\
\hline Pleurodeles walt| & 30STF54 & 100,00 & 167,50 & 81,14 & 37,10 & 4709,99 & 284,60 & 68,95 & 215,66 & 118,41 & 227,11 & 230,79 & 109,68 & 760,61 & 125,99 & 1,00 & 70,60 & 346,04 & 16,13 & 24,07 & 329,51 \\
\hline Pleurodeles walt| & 30STF55 & 100,00 & 165,22 & 84,72 & $\begin{array}{l}37,05 \\
\end{array}$ & 4918,91 & 289,35 & 63,82 & 225,53 & 113,95 & 227,76 & 231,43 & 105,18 & 749,39 & 121,80 & 1,00 & 69,44 & $|337,26|$ & $\mid 17,08$ & 24,59 & 320,86 \\
\hline Pleurodeles waltl & 30STF58 & 100,00 & 171,08 & 94,41 & 37,79 & 5328,45 & 310,34 & 63,45 & 246,89 & 114,27 & 239,19 & 242,22 & 106,05 & 667,79 & 105,33 & 1,00 & 66,99 & 294,63 & 17,19 & 23,25 & 276,42 \\
\hline Pleurodeles waltl & 30STF59 & 100,00 & 173,72 & 99,87 & 38,37 & 5464,44 & 319,76 & 63,21 & 256,55 & 115 & 243,65 & 246 & 10 & 643,67 & 100,88 & 1,00 & 66,33 & 282,79 & 17,21 & 22,81 & 26 \\
\hline \begin{tabular}{|l|} 
Pleurodeles waltl \\
\end{tabular} & 30STF60 & $\begin{array}{l}100,00 \\
\end{array}$ & 163,12 & $\begin{array}{ll}5,08 \\
85,08\end{array}$ & 年0, & $\begin{array}{l}340,4,44 \\
4376,18\end{array}$ & 278,43 & $\begin{array}{l}3,212 \\
65,18 \\
\end{array}$ & \begin{tabular}{|l|}
213,25 \\
2130
\end{tabular} & \begin{tabular}{|l|}
$118,40<$ \\
110
\end{tabular} & \begin{tabular}{|l|}
218,60 \\
2100
\end{tabular} & \begin{tabular}{|l|}
222,23 \\
223
\end{tabular} & $\begin{array}{l}109,53 \\
10,12\end{array}$ & \begin{tabular}{|l|l|}
853,79 \\
\end{tabular} & \begin{tabular}{|c|}
144,88 \\
140
\end{tabular} & $\begin{array}{l}, 00 \\
0,93\end{array}$ & $\begin{array}{l}0,35 \\
75,37\end{array}$ & $\begin{array}{l}02,15 \\
403,55\end{array}$ & $\begin{array}{l}1,142 \\
14,45 \\
\end{array}$ & $\begin{array}{l}2,01 \\
23,76\end{array}$ & $\begin{array}{l}204,05 \\
398,62\end{array}$ \\
\hline Pleurodeles walt| & $\begin{array}{l}\text { 30STF61 } \\
\end{array}$ & 100,00 & 164,61 & 83,27 & 39,14 & 4365,90 & 278,12 & 67,86 & 210,26 & 120,64 & 219,93 & 223,56 & 111,16 & 840,99 & 143,07 & 1,00 & 74,27 & \begin{tabular}{|l|l|}
396,99 \\
\end{tabular} & 15,20 & 23,82 & 386,95 \\
\hline Pleurodeles walt| & 30STF62 & 100,00 & 165,14 & 82,93 & 38,78 & 4449,51 & 279,79 & 68,02 & 211,77 & 119,86 & 221,57 & 225,24 & 110,77 & 820,39 & 138,76 & 1,00 & 73,24 & 384,86 & 15,59 & 23,91 & 371,59 \\
\hline Pleurodeles walt| & 30STF63 & 100,00 & 164,08 & 84,68 & 38,34 & 4621,54 & 283,21 & 65,09 & 218,12 & 116,82 & 222,88 & 226 , & 107, & 800,63 & 133,64 & 1,01 & 71,88 & 371,84 & 16,41 & 24,50 & 356,97 \\
\hline Pleurodeles waltl & 30STF64 & 100,00 & 153,75 & 92,74 & 38,40 & 5017,22 & 287,09 & 48,51 & 238,58 & 102,94 & 218,40 & 221,77 & 93,13 & 819,93 & 131,07 & 1,40 & 70,22 & 371,48 & 18,62 & 27,59 & 360,28 \\
\hline
\end{tabular}




\begin{tabular}{|c|c|c|c|c|c|c|c|c|c|c|c|c|c|c|c|c|c|c|c|c|c|}
\hline TAXON & UTM & $\mathrm{km2}$ & BIO1 & B102 & $\mathrm{BIO3}$ & B104 & B105 & B106 & B107 & B108 & B109 & BIO10 & BIO11 & B1012 & BIO13 & BIO14 & BIO15 & BIO16 & BIO17 & BIO18 & BIO19 \\
\hline Pleurodeles walt! & 30STF65 & 100,00 & 165,30 & 87,84 & 37,91 & 4897,96 & 291,96 & 63,35 & 228,62 & 114,42 & 227,81 & 231,30 & 105,79 & 754,59 & 123,63 & 1,03 & 69,99 & 344,99 & 16,89 & 24,36 & 327,48 \\
\hline Pleurodeles walt| & 30STF66 & 100,00 & 165,34 & 90,67 & 37,88 & 5056,80 & 297,25 & 61,18 & 236,06 & 112,45 & \begin{tabular}{|l|l|}
230,04 \\
\end{tabular} & 233,33 & \begin{tabular}{l|l|l|l|l|}
103,99 \\
\end{tabular} & 737,02 & 119,37 & 1,00 & 69,04 & 333,87 & 17,22 & 24,32 & 315,92 \\
\hline Pleurodeles walt| & 30STF68 & 100,00 & $\begin{array}{l}171,47 \\
\end{array}$ & 97,29 & 38,64 & 5297,85 & 312,87 & 63,87 & 249,01 & \begin{tabular}{l|l|l|l|}
115,13 \\
\end{tabular} & 239,32 & 242,31 & $\begin{array}{l}107,15 \\
\end{array}$ & \begin{tabular}{ll|}
674,89 \\
\end{tabular} & 108,22 & 1,00 & 67,69 & 302,13 & 17,01 & 23,00 & 283,13 \\
\hline Pleurodeles walt| & 30STF69 & 100,00 & 172,93 & 102,83 & 39,14 & 5452,05 & 321,68 & 62,42 & 259,26 & 114,55 & 242,83 & 245,58 & \begin{tabular}{l|l|}
106,81 \\
\end{tabular} & 654,38 & \begin{tabular}{|l|l|}
104,17 \\
\end{tabular} & 1,00 & 67,05 & 291,10 & \begin{tabular}{l|l|l|l|}
16,96 \\
\end{tabular} & 22,61 & 272,50 \\
\hline Pleurodeles walt| & 30STF70 & 100,00 & 170,76 & 82,27 & 40,56 & 4070,03 & \begin{tabular}{|l|l|}
278,45 \\
\end{tabular} & 77,89 & 200,57 & 129,87 & 222,10 & 225,97 & 121,34 & 806,82 & 143,07 & 1,00 & \begin{tabular}{|l|l|l|}
76,03 \\
\end{tabular} & 396,34 & 13,86 & 22,01 & 381,87 \\
\hline Pleurodeles walt| & 30STF71 & 100,00 & 168,40 & 83,23 & 40,00 & 4224,27 & 279,62 & 73,68 & 205,94 & 126,16 & 221,77 & 225,72 & \begin{tabular}{|l|l|}
117,17 \\
\end{tabular} & 808,52 & 141,14 & 1,00 & 75,01 & 393,01 & 14,41 & 22,69 & 376,83 \\
\hline Pleurodeles walt| & 30STF72 & 100,00 & 166,30 & 84,93 & 39,37 & 4410,77 & 282,35 & 69,29 & 213,06 & \begin{tabular}{ll|}
121,98 \\
\end{tabular} & 222,38 & 226,13 & \begin{tabular}{l|l|}
112,89 \\
\end{tabular} & 800,83 & 137,35 & 1,00 & 73,74 & \begin{tabular}{|l|}
383,87 \\
\end{tabular} & 15,21 & 23,45 & 367,23 \\
\hline Pleurodeles walt| & 30STF73 & 100,00 & 163,52 & 87,45 & 39,04 & 4622,44 & 285,46 & 63,84 & \begin{tabular}{|l|l|}
221,63 \\
\end{tabular} & \begin{tabular}{|l|l|}
116,84 \\
\end{tabular} & 222,47 & 226,19 & \begin{tabular}{ll|}
107,54 \\
\end{tabular} & \begin{tabular}{|l|l|}
793,29 \\
\end{tabular} & 133,20 & 1,00 & 72,50 & \begin{tabular}{|l|l|}
374,14 \\
\end{tabular} & \begin{tabular}{|l|l|}
15,97 \\
\end{tabular} & 24,37 & 357,96 \\
\hline Pleurodeles walt| & 30STF74 & 100,00 & 158,09 & 92,03 & \begin{tabular}{ll|}
38,87 \\
\end{tabular} & 4898,94 & 288,79 & 54,41 & 234,38 & $\begin{array}{ll}108,48 \\
\end{array}$ & 221,05 & 224,46 & \begin{tabular}{|c|}
98,97 \\
\end{tabular} & 797,05 & 129,72 & 1,23 & 70,83 & \begin{tabular}{|l|l|}
367,79 \\
\end{tabular} & \begin{tabular}{l|l|l|}
17,65 \\
\end{tabular} & 26,06 & 353,45 \\
\hline Pleurodeles walt1 & 30STF75 & 100,00 & 157,73 & 94,24 & $38,77 \mid$ & 5045,92 & 292,93 & 52,28 & 240,65 & 106,20 & 222,78 & $226,04[$ & 96,92 & 784,05 & 126,18 & 1,29 & 69,82 & 358,35 & 18,22 & 26,35 & 343,30 \\
\hline Pleurodeles walt| & 30STF76 & 100,00 & 162,57 & 94,47 & 38,71 & 5093,79 & 298,56 & 57,03 & 241,52 & \begin{tabular}{ll|}
109,78 \\
\end{tabular} & \begin{tabular}{|l|l|}
228,15 \\
\end{tabular} & 231,24 & \begin{tabular}{|l|l|}
101,07 \\
\end{tabular} & 750,01 & 121,26 & 1,13 & \begin{tabular}{l|l}
69,25 \\
\end{tabular} & 342,29 & \begin{tabular}{l|l|l|l|}
17,83 \\
\end{tabular} & 25,01 & 324,72 \\
\hline Pleurodeles walt| & 30STF77 & 100,00 & 158,26 & 99,27 & 38,87 & 5321,01 & 302,43 & \begin{tabular}{|l|l|}
49,17 \\
\end{tabular} & 253,27 & \begin{tabular}{|l|l|}
103,04 \\
\end{tabular} & \begin{tabular}{|l|l|}
227,22 \\
\end{tabular} & \begin{tabular}{|l|}
230,04 \\
\end{tabular} & 94,22 & 756,27 & 119,35 & 1,35 & 67,90 & 339,33 & 19,30 & 26,55 & 323,32 \\
\hline Pleurodeles walt| & 30STF80 & 43,00 & 175,91 & 82,28 & 41,56 & 3927,69 & 281,94 & 86,09 & \begin{tabular}{|l|l|}
195,84 \\
\end{tabular} & \begin{tabular}{ll|}
137,66 \\
\end{tabular} & 225,39 & 229,80 & \begin{tabular}{ll|}
129,36 \\
\end{tabular} & 749,14 & 138,61 & 1,00 & \begin{tabular}{ll|}
76,92 \\
\end{tabular} & 382,69 & \begin{tabular}{l|l}
3,02 \\
\end{tabular} & 20,77 & 358,81 \\
\hline Pleurodeles walt| & 30STF81 & 100,00 & 173,15 & 83,09 & \begin{tabular}{l|l|l|l|l|}
40,87 & \\
\end{tabular} & 4074,54 & 282,17 & 81,16 & 201,01 & \begin{tabular}{l|l|}
133,03 \\
\end{tabular} & 224,64 & 228,83 & \begin{tabular}{l|l}
124,45 \\
\end{tabular} & 760,43 & 137,52 & 1,00 & \begin{tabular}{ll|}
75,86 \\
\end{tabular} & 382,20 & \begin{tabular}{l|l}
13,55 \\
\end{tabular} & 21,39 & 358,96 \\
\hline Pleurodeles walt| & 30STF82 & 100,00 & 173,59 & 83,40 & 40,32 & 4196,64 & 284,72 & 80,30 & \begin{tabular}{|l|l|}
204,42 \\
\end{tabular} & \begin{tabular}{|l|l|}
131,67 \\
\end{tabular} & $\begin{array}{l}226,76 \\
\end{array}$ & 230,81 & \begin{tabular}{l|l|}
123,30 \\
\end{tabular} & 749,50 & 133,75 & 1,00 & 74,7 & 371,99 & 14,12 & 21,54 & 348,06 \\
\hline Pleurodeles walt| & 30STF84 & 100,00 & 159,27 & 93,11 & 39,21 & 4853,83 & 290,15 & 55,91 & 234,24 & 110,40 & 221,77 & 225,12 & 100,94 & 779,16 & 127,61 & 1,32 & 71,04 & 363,68 & 17,39 & 25,77 & 347,73 \\
\hline Pleurodeles walt| & 30STF85 & 100,00 & 147,33 & 100,24 & 39,00 & 5242,53 & 291,33 & \begin{tabular}{|l|l|}
37,85 \\
\end{tabular} & 253,47 & \begin{tabular}{l|l}
94,49 \\
\end{tabular} & \begin{tabular}{|l|l|}
215,79 \\
\end{tabular} & 218,57 & \begin{tabular}{ll|}
84,58 \\
\end{tabular} & 816,53 & \begin{tabular}{ll|}
126,63 \\
\end{tabular} & 2,14 & \begin{tabular}{|c|}
68,67 \\
\end{tabular} & \begin{tabular}{|l|l|}
367,17 \\
\end{tabular} & 21,33 & 30,02 & 356,10 \\
\hline Pleurodeles walt| & 30STF86 & 100,00 & 139,97 & 104,57 & 39,00 & 5481,88 & 291,96 & 26,83 & 265,13 & $\begin{array}{l}84,45 \\
\end{array}$ & 212,01 & 214,44 & 74,54 & 840,73 & 126,14 & 2,85 & 66,86 & 369,18 & 24,63 & 33,24 & 359,97 \\
\hline Pleurodeles walt| & 30STF87 & 100,00 & 144,08 & 105,08 & 39,00 & 5527,88 & 297,17 & 30,56 & 266,61 & 87,53 & 216,61 & \begin{tabular}{|l|l|}
219,03 \\
\end{tabular} & 77,99 & 815,38 & 123,04 & 2,60 & 66,53 & 358,10 & 23,87 & \begin{tabular}{|l|l|}
31,97 \\
\end{tabular} & 346,90 \\
\hline Pleurodeles walt| & 30STF88 & 100,00 & 159,18 & 103,34 & 39,01 & 5441,13 & 308,69 & 47,81 & 260,88 & \begin{tabular}{|l|l|}
102,47 \\
\end{tabular} & 229,94 & 232,45 & 93,7 & 739,03 & 116,06 & 1,46 & 67,2 & 330,99 & 19,64 & 26,47 & 314,51 \\
\hline Pleurodeles walt| & 30STF91 & 39,00 & 176,17 & 83,33 & 41,17 & 4017,94 & 284,50 & 85,06 & 199,44 & 137,06 & 226,75 & 231,21 & 128,54 & \begin{tabular}{|l|}
719,27 \\
\end{tabular} & 131,94 & 1,00 & \begin{tabular}{ll|}
76,06 \\
\end{tabular} & 365,92 & 13,00 & 20,62 & 341,06 \\
\hline Pleurodeles walt| & 30STF92 & 93,00 & 174,60 & 84,83 & 40,84 & 4174,83 & 286,67 & 81,19 & 205,48 & 133,55 & 227,43 & 231,57 & \begin{tabular}{ll|}
124,91 \\
\end{tabular} & \begin{tabular}{ll|}
713,66 \\
\end{tabular} & 128,04 & 1,00 & 74,88 & 357,33 & $\begin{array}{l}13,87 \\
1\end{array}$ & 21,17 & 333,13 \\
\hline Pleurodeles walt| & 30STF96 & 100,00 & 140,76 & 105,24 & 39,02 & 5472,22 & 292,95 & 27,36 & 265,59 & 85,59 & 212,85 & 215,11 & 75,54 & 823,41 & 123,36 & 2,90 & \begin{tabular}{|c|}
66,79 \\
\end{tabular} & $\begin{array}{l}362,83 \\
\end{array}$ & 24,15 & 32,79 & 353,24 \\
\hline Pleurodeles walt| & 30STG34 & 56,00 & 185,45 & 121,81 & 39,35 & 6122,18 & 361,35 & 56,06 & 305,29 & \begin{tabular}{ll|}
118,62 \\
\end{tabular} & 264,96 & 266,55 & 109,75 & 574,53 & 86,42 & 1,00 & 63,36 & 244,78 & 18,00 & 22,00 & 230,79 \\
\hline Pleurodeles walt| & 30STG39 & 40,00 & 170,22 & 122,02 & 38,84 & 6377,82 & 352,44 & 40,78 & 311,65 & \begin{tabular}{ll|}
100,87 \\
\end{tabular} & 253,89 & 254,67 & 91,93 & 593,58 & 82,44 & 2,22 & 59,2 & \begin{tabular}{l|l|}
239,95 \\
\end{tabular} & 22,91 & 27,60 & 228,11 \\
\hline Pleurodeles waltt & 30STG40 & 100,00 & 178,80 & 101,57 & 38,31 & 5567,91 & 327,09 & 65,27 & 261,82 & 118,66 & 250,12 & 252,82 & \begin{tabular}{|l|}
110,41 \\
\end{tabular} & 603,77 & 92,50 & 1,00 & 65,52 & 261,87 & 17,00 & 22,04 & 244,38 \\
\hline Pleurodeles walt| & 30STG41 & 100,00 & 180,59 & 108,40 & \begin{tabular}{|l|l|}
39,07 \\
\end{tabular} & 5727,80 & 336,93 & \begin{tabular}{ll|}
62,84 \\
\end{tabular} & \begin{tabular}{|l|l|}
274,09 \\
\end{tabular} & 118,44 & 254,23 & 256,61 & \begin{tabular}{l|l|}
110,24 \\
\end{tabular} & \begin{tabular}{|l|l|}
594,63 \\
\end{tabular} & 90,80 & 1,00 & \begin{tabular}{l|l}
64,95 \\
\end{tabular} & 257,31 & \begin{tabular}{l|l|}
17,29 \\
\end{tabular} & 22,00 & 240,40 \\
\hline Pleurodeles walt| & 30STG44 & 100,00 & 183,53 & 121,81 & 39,90 & 6117,17 & \begin{tabular}{ll|l}
358,86 \\
\end{tabular} & 55,53 & 303,33 & 116,78 & 263,25 & \begin{tabular}{|l|l|}
264,59 \\
\end{tabular} & 108,12 & \begin{tabular}{|l|l|}
581,99 \\
\end{tabular} & 87,18 & 1,00 & \begin{tabular}{ll|}
63,46 \\
\end{tabular} & 248,29 & 18,00 & 22,00 & 234,10 \\
\hline Pleurodeles walt| & 30STG48 & 100,00 & 174,66 & 123,03 & 39,00 & 6355,98 & 356,75 & 44,67 & 312,08 & \begin{tabular}{|l|l|}
105,38 \\
\end{tabular} & \begin{tabular}{|l|l|}
258,06 \\
\end{tabular} & 258,77 & \begin{tabular}{|l|}
96,49 \\
\end{tabular} & 588,01 & 82,80 & 2,04 & 60,20 & 240,29 & 21,39 & 25,70 & 228,30 \\
\hline Pleurodeles walt| & 30STG49 & 100,00 & 165,69 & 122,71 & 38,70 & 6434,94 & 349,90 & 35,92 & \begin{tabular}{|l|}
313,99 \\
\end{tabular} & \begin{tabular}{|c|}
95,88 \\
\end{tabular} & 250,41 & 251,07 & \begin{tabular}{|l|l|l|}
87,03 \\
\end{tabular} & 620,24 & 85,77 & 2,65 & 58,86 & 249,59 & 24,31 & 29,03 & 238,44 \\
\hline Pleurodeles walt| & 30STG50 & 100,00 & \begin{tabular}{ll|}
177,03 \\
\end{tabular} & 105,44 & 39,14 & 5583,52 & 329,56 & 63,59 & 265,97 & \begin{tabular}{ll|}
116,68 \\
\end{tabular} & \begin{tabular}{|l|l|}
248,59 \\
\end{tabular} & 251,21 & \begin{tabular}{|l|l|}
108,93 \\
\end{tabular} & \begin{tabular}{|l|l|}
618,46 \\
\end{tabular} & 96,50 & 1,00 & 66,22 & 271,26 & 16,58 & 21,61 & 253,39 \\
\hline Pleurodeles walt| & 30STG51 & 100,00 & 178,28 & 111,45 & 39,81 & 5734,61 & 338,11 & 61,29 & 276,82 & 116,05 & 252,01 & 254,32 & \begin{tabular}{ll|}
108,26 \\
\end{tabular} & 608,31 & 94,08 & 1,00 & $\begin{array}{ll}65,75 \\
\end{array}$ & 265,59 & 16,77 & 21,31 & 248,46 \\
\hline Pleurodeles walt| & 30STG52 & 100,00 & 179,52 & 116,21 & 40,00 & 5879,30 & 345,52 & 58,86 & 286,67 & \begin{tabular}{ll|}
115,59 \\
\end{tabular} & \begin{tabular}{|l|l|}
255,52 \\
\end{tabular} & 257,48 & \begin{tabular}{|l|l|}
107,74 \\
\end{tabular} & \begin{tabular}{ll|}
601,59 \\
\end{tabular} & 91,87 & 1,00 & 64,81 & 260,75 & 17,60 & 21,60 & 244,58 \\
\hline Pleurodeles walt| & 30STG55 & 100,00 & 181,37 & 123,03 & \begin{tabular}{|l|}
39,98 \\
\end{tabular} & 6195,43 & 358,79 & 53,10 & 305,69 & 113,67 & 262,20 & 263,24 & \begin{tabular}{l|l|}
105,06 \\
\end{tabular} & 586,47 & 86,35 & 1,00 & \begin{tabular}{|l|l|}
63,07 \\
\end{tabular} & 248,40 & 18,00 & 22,19 & 234,90 \\
\hline Pleurodeles walt| & 30STG59 & 100,00 & 162,75 & 123,58 & 38,49 & 6489,78 & 349,12 & 32,60 & 316,52 & 92,60 & 248,53 & 249,06 & 83,68 & 639,22 & 88,46 & 2,57 & 58,97 & 255,99 & 24,94 & 29,09 & 245,75 \\
\hline Pleurodeles walt| & 30STG60 & 100,00 & 174,76 & 108,79 & 39,92 & 5594,85 & 330,94 & 61,34 & 269,60 & 114,40 & \begin{tabular}{|l|l|}
246,56 \\
\end{tabular} & 249,06 & \begin{tabular}{|l|l|}
106,93 \\
\end{tabular} & 634,01 & 100,54 & 1,00 & 66,62 & 280,69 & 16,59 & 21,63 & 262,52 \\
\hline Pleurodeles walt| & 30STG61 & 100,00 & 176,62 & 114,36 & 40,43 & 5730,71 & 339,71 & 60,30 & 279,41 & 114,43 & \begin{tabular}{|l|l|}
250,25 \\
\end{tabular} & 252,50 & \begin{tabular}{|l|l|}
107,10 \\
\end{tabular} & 615,43 & 97,20 & 1,00 & 66,46 & 271,11 & 16,10 & 21,01 & 253,67 \\
\hline Pleurodeles walt| & 30STG62 & 100,00 & 178,73 & 117,33 & 40,37 & 5855,19 & 345,65 & 59,25 & 286,41 & 117,71 & 254,33 & 256,22 & \begin{tabular}{|l|l}
107,43 \\
\end{tabular} & 603,73 & 94,25 & 1,00 & 65,71 & 263,97 & 16,18 & 21,00 & 247,31 \\
\hline Pleurodeles walt| & 30STG64 & 100,00 & 178,90 & 121,65 & 40,04 & 6099,63 & 352,74 & 53,57 & 299,16 & \begin{tabular}{ll|}
112,38 \\
\end{tabular} & 258,36 & 259,70 & 104, & 603, & 90,72 & 1,00 & 63,8 & 257,81 & 8,23 & 22,30 & 243,60 \\
\hline Pleurodeles walt| & 30STG65 & 100,00 & 178,83 & 122,93 & 40,00 & 6199,52 & 355,76 & 51,74 & 304,01 & 111,36 & 259,92 & 260,95 & 102,95 & 600,30 & 88,96 & 1,00 & 63,12 & 253,72 & 18,10 & 22,79 & 240,55 \\
\hline Pleurodeles walt| & 30STG67 & 100,00 & 175,46 & 124,19 & 39,23 & 6358,80 & 357,91 & 45,78 & 312,14 & \begin{tabular}{|l|l|}
106,27 \\
\end{tabular} & \begin{tabular}{|l|l|}
259,13 \\
\end{tabular} & 259,64 & \begin{tabular}{|l|l|}
97,48 \\
\end{tabular} & \begin{tabular}{ll|}
605,06 \\
\end{tabular} & 87,20 & 1,63 & \begin{tabular}{l|l|l}
61,45 \\
\end{tabular} & \begin{tabular}{|l|l|}
249,46 \\
\end{tabular} & 19,86 & 24,03 & 238,20 \\
\hline Pleurodeles walt| & 30STG68 & 100,00 & 168,27 & 124,46 & 38,92 & 6463,01 & 353,97 & 37,80 & 316,17 & 98,27 & 253,63 & 253,86 & 89,14 & 629,00 & 88,82 & 2,00 & 60,12 & 254,86 & 22,39 & 25,94 & 244,62 \\
\hline Pleurodeles walt| & 30STG69 & 100,00 & 158,30 & 123,72 & 38,13 & 6543,04 & 346,16 & 27,98 & 318,18 & 87,73 & \begin{tabular}{|l|l|}
245,06 \\
\end{tabular} & 245,34 & \begin{tabular}{ll|}
78,92 \\
\end{tabular} & 664,30 & 91,73 & 2,86 & 58,72 & 264,30 & 26,15 & 28,46 & 255,15 \\
\hline Pleurodeles walt| & 30STG72 & 100,00 & 177,07 & 116,95 & 40,28 & 847,54 & 343,72 & 58,04 & 285,68 & $\begin{array}{ll}113,66 \\
\end{array}$ & 252,76 & 254,48 & $\begin{array}{ll}106,05 \\
\end{array}$ & 615,68 & 96,88 & 1,00 & \begin{tabular}{l|l}
65,85 \\
\end{tabular} & 269,98 & 6,13 & 21,12 & 253,51 \\
\hline Pleurodeles waltt & \begin{tabular}{|l|l|}
30 STG73 \\
\end{tabular} & 100,00 & 17 & 11 & 40,22 & 5955,20 & 348,24 & 57,16 & 291,08 & 114,01 & 256,09 & 257,47 & 106,22 & 607,86 & 94,16 & 1,00 & 65,12 & 263,69 & 16,46 & 21,33 & 248,35 \\
\hline Pleurodeles walt & 30STG79 & 100,00 & 158,45 & 124,13 & 38,25 & 6569,95 & 347,11 & 27,77 & 319,34 & $\begin{array}{l}87,62 \\
\end{array}$ & 245,74 & 245,8 & 78,6 & 668,05 & 92,56 & 2,95 & 58,80 & 264,92 & 25,84 & 27,06 & 256,60 \\
\hline Pleurodeles walt| & 30STG81 & 100,00 & 170,50 & 112,65 & \begin{tabular}{|l|l}
39,99 \\
\end{tabular} & 5754,78 & 332,39 & 53,71 & \begin{tabular}{|l|l|}
278,68 \\
\end{tabular} & $\begin{array}{ll}108,88 \\
\end{array}$ & 245,23 & 247,12 & \begin{tabular}{l|l|l|}
100,98 \\
\end{tabular} & 660,95 & 103,85 & 1,00 & 65,99 & 291,38 & \begin{tabular}{|l|l|}
17,70 \\
\end{tabular} & 23,10 & 274,78 \\
\hline Pleurodeles walt| & 30STG82 & 100,00 & 174,71 & 115,52 & 40,01 & 5849,26 & 340,04 & 55,75 & 284,29 & 111,67 & 250,75 & 252,36 & 103,77 & 635,29 & 99,57 & 1,00 & 65,56 & 278,16 & 17,04 & 22,36 & 262,19 \\
\hline Pleurodeles walt| & 30STG84 & 100,00 & 178,47 & 119,55 & 40,00 & 6065,93 & 349,58 & 54,61 & 294,97 & \begin{tabular}{|l|l|}
112,69 \\
\end{tabular} & 257,68 & 258,66 & \begin{tabular}{ll|}
104,36 \\
\end{tabular} & 613,71 & 93,91 & 1,00 & 64,34 & 262,69 & 17,10 & 22,24 & 249,12 \\
\hline Pleurodeles walt| & 30STG85 & 100,00 & 176,23 & 121 & 39,94 & 6199,54 & 351,67 & 50,30 & 301,37 & 108,99 & 257,54 & 258,30 & 100,60 & 621,77 & 93,35 & 1,00 & 63,29 & 261,99 & 18,00 & 22,97 & 249,97 \\
\hline Pleurodeles walt & 30STG90 & 100,00 & 162,42 & 109,08 & 39,31 & 5685,62 & \begin{tabular}{|l|}
320,47 \\
\end{tabular} & \begin{tabular}{l|l|}
46,95 \\
\end{tabular} & 273,52 & 102,55 & 236,79 & \begin{tabular}{|l|}
238,63 \\
\end{tabular} & 94,09 & $\begin{array}{l}706,63 \\
\end{array}$ & \begin{tabular}{|l|l|}
109,79 \\
\end{tabular} & 1,59 & 66,01 & 312,36 & 19,64 & 25,89 & 296,33 \\
\hline Pleurodeles walt| & 30STG91 & 100,00 & 168,78 & 111,41 & 39,80 & 5755,98 & 329,38 & 51,78 & 277,60 & 107,57 & 243,88 & 245,63 & 99,31 & 672,11 & 105,18 & 1,06 & \begin{tabular}{l|l}
65,85 \\
\end{tabular} & \begin{tabular}{|l|l|}
296,47 \\
\end{tabular} & 18,01 & 23,59 & 280,25 \\
\hline Pleurodeles walt| & 30STG92 & 100,00 & 174,72 & 113,71 & 40,00 & 5824,79 & 337,78 & 55,98 & 281,80 & 112,22 & 250,71 & 252,10 & \begin{tabular}{|l|l|}
104,10 \\
\end{tabular} & $\begin{array}{ll}641,05 \\
\end{array}$ & 100,45 & 1,00 & \begin{tabular}{|c|}
65,68 \\
\end{tabular} & 280,99 & 17,00 & 22,49 & 265,39 \\
\hline Pleurodeles wa & 30ST & 100 & 177, & 116 & 39,5 & 594 & 34 & 55, & 287,44 & 112 & 254 & 255 & 104 & 626 & 97,35 & 1,00 & $64, \varepsilon$ & $2 / 1,58$ & 17,00 & 22,10 & 257 \\
\hline Pleurodeles walt| & 30STG94 & 100,00 & 176,66 & 118,32 & 39,97 & 6085,06 & 346,92 & 52,97 & 293,95 & 110,77 & 256,33 & 257,19 & 102,30 & 627,23 & 95,79 & 1,00 & \begin{tabular}{ll|}
64,06 \\
\end{tabular} & 267,52 & \begin{tabular}{|l|}
17,09 \\
\end{tabular} & 22,91 & 254,72 \\
\hline Pleurodeles walt| & 30STG95 & 100,00 & 176,31 & 120,07 & 39,50 & 6208,13 & 350,58 & 50,28 & 300,31 & \begin{tabular}{ll|}
108,66 \\
\end{tabular} & 257,86 & 258,30 & \begin{tabular}{|l|}
100,41 \\
\end{tabular} & 626,41 & 94,29 & 1,00 & 63,29 & 263,46 & \begin{tabular}{|l|l|l|}
17,53 \\
\end{tabular} & 22,63 & 252,09 \\
\hline Pleurodeles walt| & 30STG97 & 100,00 & 180,20 & 122,08 & 39,01 & 6349,77 & 359,43 & 50,93 & 308,51 & \begin{tabular}{|l|l|l|}
111,03 \\
\end{tabular} & \begin{tabular}{|l|l|}
263,92 \\
\end{tabular} & \begin{tabular}{|l|}
264,04 \\
\end{tabular} & $\begin{array}{ll}101,95 \\
\end{array}$ & 600,20 & 88,64 & 1,05 & \begin{tabular}{|l|l|}
62,49 \\
\end{tabular} & 246,44 & 17,11 & 19,23 & 237,14 \\
\hline Pleuroc & 30STH40 & 100,00 & 16 & 122,37 & 38,23 & 6479, & & 31, & 315, & 90, & 246, & 246 & & 633,1 & 86,42 & $t$ & 58,00 & 251 & & 23 & 24 \\
\hline Pleurodeles walt & 30STH42 & 100,00 & 151,34 & 121,54 & 37,99 & 6546,3 & 339, & 22,35 & 316,71 & 81,06 & 238,43 & 238,74 & 72,14 & 658,05 & 87,87 & 3,93 & 55,88 & 256,05 & 31,06 & 34,19 & 246 \\
\hline Pleurodeles walt| & 30STH43 & 100,00 & 152,44 & 121,60 & 38,00 & 6564,90 & 340,64 & 23,11 & 317,53 & 81,97 & 239,73 & 240,03 & 72,92 & 641,43 & 85,26 & 4,01 & 55,44 & 247,99 & 30,97 & 34,01 & 238,21 \\
\hline
\end{tabular}




\begin{tabular}{|c|c|c|c|c|c|c|c|c|c|c|c|c|c|c|c|c|c|c|c|c|c|}
\hline TAXON & UTM & $\mathrm{km} 2$ & BIO1 & B102 & BIO3 & BIO4 & B105 & B106 & BI07 & B108 & B109 & 81010 & B1011 & BIO12 & B1013 & BIO14 & BIO15 & BIO16 & B1017 & B1018 & B1019 \\
\hline Pleurodeles waltt & 30STH44 & 100,00 & 153,94 & 121,57 & 38,00 & 6575,79 & 342,36 & 24,53 & 317,83 & 83,12 & 241,33 & 241,64 & 74,22 & 622,99 & 82,48 & 4,00 & 54,88 & 239,42 & 30,72 & 33,11 & 229,57 \\
\hline Pleurodeles waltt & 30STH45 & 100,00 & 156,29 & 121,34 & 37,90 & 6582,55 & 344,70 & 26,89 & 317,80 & 85,22 & 243,84 & 243,96 & 76,47 & 599,57 & 79,15 & 3,77 & 54,35 & 229,14 & 30,18 & 31,53 & 219,06 \\
\hline Pleurodeles waltt & 30STH47 & 100,00 & 155,30 & 120,33 & 37,30 & 6604,54 & 343,48 & 26,08 & 317,40 & 83,89 & 243,26 & 243,27 & 75,19 & 581,81 & 75,87 & 4,00 & 53,02 & 219,34 & 31,45 & 31,55 & 209,07 \\
\hline \begin{tabular}{|l|l|l|} 
Pleurodeles walt \\
\end{tabular} & 30STH49 & 100,00 & 161,22 & 119,45 & \begin{tabular}{|l|l|}
37,07 \\
\end{tabular} & \begin{tabular}{|l|l|}
6578,13 \\
\end{tabular} & 347,86 & 32,22 & 315,64 & 89,57 & 248,72 & 248,72 & 80,99 & 532,09 & \begin{tabular}{ll|}
69,07 \\
\end{tabular} & 3,46 & 52,21 & 198,78 & 29,68 & 29,68 & 187,99 \\
\hline Pleurodeles waltt & 30STH50 & 100,00 & 154,55 & 122,76 & 38,00 & 6541,03 & 342,21 & 24,70 & 317,51 & 84,12 & 241,26 & 241,71 & 75,17 & $\begin{array}{l}667,25 \\
\end{array}$ & $\begin{array}{l}90,76 \\
\end{array}$ & 3,32 & 57,67 & 263,34 & 28,34 & 32,51 & 253,95 \\
\hline Pleurodeles walt| & 30STH51 & 100,00 & 153,72 & 122,75 & 38,00 & 6576,28 & 342,43 & 23,63 & 318,80 & 82,89 & 241,05 & 241,33 & 74,09 & 661,33 & 89,25 & 3,54 & 56,83 & 258,68 & 29,39 & 32,99 & 249,47 \\
\hline Pleurodeles waltt & 30STH53 & 100,00 & 154,90 & 122,75 & 38,00 & 6617,85 & 344,73 & 24,51 & 320,22 & 83,45 & 243,01 & 243,06 & 74,60 & $\begin{array}{l}631,86 \\
\end{array}$ & 84,23 & 3,78 & 55,64 & 243,45 & 29,58 & 30,37 & 234,31 \\
\hline Pleurodeles waltt & 30STH54 & 100,00 & 154,50 & 122,49 & $\begin{array}{l}37,96 \\
\end{array}$ & 6634,03 & 344,70 & 23,91 & 320,79 & 82,82 & 243,02 & 243,02 & 74,04 & 621,54 & 82,39 & 4,00 & 55,00 & 237,79 & 30,11 & 30,11 & 228,58 \\
\hline Pleurodeles walt| & 30STH55 & 100,00 & 155,17 & 122,07 & 37,85 & 6633,65 & 344,99 & 24,61 & 320,37 & 83,29 & 243,63 & 243,64 & 74,65 & $\begin{array}{l}606,76 \\
\end{array}$ & 79,93 & 3,98 & 54,26 & 230,53 & 30,33 & 30,50 & 221,18 \\
\hline Pleurodeles walt| & 30STH59 & 100,00 & 158,08 & 120,01 & 37,01 & 6644,11 & 346,61 & 28,50 & 318,10 & 85,85 & 246,69 & 246,69 & 77,37 & 543,94 & 70,90 & 3,76 & 51,89 & 201,49 & 30,76 & 30,76 & 191,24 \\
\hline Pleurodeles walt| & 30STH60 & 100,00 & 154,76 & 123,63 & 38,00 & 6584,50 & 343,96 & 24,34 & 319,62 & 83,79 & 242,28 & 242,47 & 74,96 & 669,32 & 91,24 & 3,44 & 57,66 & 263,09 & 28,16 & 29,76 & 254,51 \\
\hline Pleurodeles waltt & 30STH61 & 100,00 & 152,05 & 123,47 & 38,00 & 6622,53 & 342,36 & 21,54 & 320,82 & 80,86 & 240,30 & 240,46 & 72,04 & $\begin{array}{l}670,25 \\
\end{array}$ & 90,40 & 3,68 & 56,78 & 260,80 & 29,55 & 31,25 & 252,50 \\
\hline Pleurodeles walt| & 30STH62 & 100,00 & 157,57 & $\begin{array}{ll}123,87 \\
\end{array}$ & 38,00 & 6630,11 & 347,98 & 26,14 & 321,84 & 85,75 & 245,83 & 245,90 & 76,93 & \begin{tabular}{|c|}
634,27 \\
\end{tabular} & 85,54 & 3,25 & 56,54 & 245,70 & 27,79 & 28,80 & 237,15 \\
\hline Pleurodeles walt| & 30STH63 & 100,00 & 157,68 & 123,72 & 38,00 & 6652,56 & 348,56 & 26,31 & 322,26 & 85,60 & 246,30 & 246,33 & 76,89 & 621,23 & 83,23 & 3,33 & 56,03 & 238,75 & \begin{tabular}{ll|}
28,07 \\
\end{tabular} & 28,60 & 230,16 \\
\hline Pleurodeles walt| & 30STH64 & 100,00 & 154,32 & 123,17 & 37,97 & 6682,70 & 345,85 & 23,28 & 322,57 & 82,10 & 243,38 & 243,40 & 73,25 & 623,00 & $\mid 82,64$ & 4,00 & 54,93 & 236,89 & $\mid 30,16$ & 30,75 & 228,46 \\
\hline Pleurodeles walt| & 30STH66 & 100,00 & 152,23 & 122,15 & 37,22 & 6697,95 & 343,97 & 21,39 & 322,58 & 79,81 . & 241,83 & 241,83 & 71,41 . & 607,75 & 80,32 & 4,09 & 53,43 & 227,41 & 31,95 & 31,95 & 218,64 \\
\hline Pleurodeles waltt & 30STH69 & 100,00 & 160,45 & 120,86 & 37,00 & 6684,73 & 350,04 & 29,56 & 320,48 & 87,46 & 249,60 & 249,60 & 79,00 & 529,86 & 69,74 & 3,37 & 52,25 & $\begin{array}{l}195,47 \\
\end{array}$ & 28,90 & 28,90 & 185,73 \\
\hline Pleurodeles waltt & 30STH70 & 100,00 & 151,81 & 123,86 & 38,00 & 6621,13 & 342,24 & 21,17 & 321,08 & 80,58 & 240,03 & 240,17 & 71,88 & 685,67 & 93,23 & 3,73 & 57,39 & 267,92 & 29,08 & 30,53 & 260,25 \\
\hline Pleurodeles walt| & 30STH72 & 100,00 & 161,12 & 124,65 & 38,00 & 6671,75 & 352,56 & 28,79 & 323,77 & 88,78 & 249,95 & 249,95 & 79,81 & 621,28 & 84,23 & 3,12 & 57,01 & 239,88 & 26,17 & 26,17 & 232,06 \\
\hline 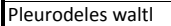 & 30STH73 & 100,00 & 157,96 & \begin{tabular}{ll|l}
124,19 \\
\end{tabular} & 38,00 & 6695,41 & 350,16 & 25,70 & 324,46 & 85,29 & 247,26 & 247,26 & \begin{tabular}{|c|c|}
76,62 \\
\end{tabular} & \begin{tabular}{|l|l|}
621,96 \\
\end{tabular} & $\mid 83,71$ & 3,38 & 55,96 & $\mid 237,66$ & \begin{tabular}{|l|l|}
27,83 & \\
\end{tabular} & \begin{tabular}{|l|l|l|l|}
27,83 & \\
\end{tabular} & 229,96 \\
\hline Pleurodeles waltt & 30STH75 & 100,00 & 155,29 & 123,65 & 37,63 & 6738,76 & 348,04 & 23,29 & 324,75 & 82,23 & 245,27 & 245,27 & 73,59 & 606,42 & 81,36 & 4,00 & 54,31 & 227,60 & 29,78 & 29,78 & 219,78 \\
\hline Pleurodeles waltt & 30STH76 & 100,00 & 152,99 & 122,95 & \begin{tabular}{|l|l|}
37,08 \\
\end{tabular} & 6744,62 & 346,10 & 21,23 & 324,86 & 80,04 & 243,23 & 243,23 & 71,27 & 602,77 & 80,62 & 4,09 & 53,45 & 224,19 & 31,37 & 31,37 & 216,19 \\
\hline \begin{tabular}{|l|l|l|} 
Pleodeles walt \\
\end{tabular} & 30STH79 & 100,00 & 161,64 & 121,60 & 37,05 & 6709,72 & 352,14 & 29,99 & 322,15 & 88,46 & 251,24 & 251,24 & 79,87 & 522,23 & 69,38 & 3,30 & 52,32 & 191,36 & 28,09 & 28,09 & 182,27 \\
\hline Pleurodeles waltt & 30STH80 & 100,00 & 159,47 & 124,72 & 38,00 & 6639,36 & 350,07 & 27,82 & 322,25 & 87,76 & 247,96 & 247,97 & 78,89 & 656,20 & 90,41 & 3,03 & 58,29 & 256,68 & 25,59 & 25,70 & 249,59 \\
\hline Pleurodeles waltt & 30STH82 & 100,00 & 160,47 & 124,88 & 37,99 & 6717,64 & 353,05 & 27,63 & 325,43 & 87,61 & 250,08 & 250,08 & 78,63 & 626,84 & 85,41 & 3,14 & 57,05 & 240,49 & 26,13 & 26,13 & 233,82 \\
\hline Pleurodeles walt| & 30STH86 & 100,00 & 156,58 & 123,79 & \begin{tabular}{|l|l|}
37,37 \\
\end{tabular} & 6782,16 & 350,26 & 23,82 & 326,44 & 82,86 & 247,33 & 247,33 & 74,38 & 585,63 & 79,31 & 3,89 & 53,74 & 216,73 & 29,32 & 29,32 & 209,48 \\
\hline Pleurodeles waltt & 30STH87 & 100,00 & 153,78 & 123,07 & 37,00 & 6781,37 & 347,53 & 21,35 & 326,18 & 80,12 & 244,73 & 244,73 & 71,63 & 582,79 & 78,53 & 4,11 & 52,72 & 213,69 & 31,03 & 31,03 & 206,22 \\
\hline Pleurodeles walt| & 30STH89 & 100,00 & 160,79 & 122,07 & 37,01 & 6751,70 & 352,34 & 28,51 & 323,83 & 87,16 & 251,17 & 251,17 & 78,56 & \begin{tabular}{|l|l|}
523,03 \\
\end{tabular} & 69,94 & 3,46 & 52,02 & 189,93 & 28,30 & 28,30 & 181,55 \\
\hline Pleurodeles walt| & 30STH93 & 100,00 & 152,65 & 124,72 & \begin{tabular}{|l|l|}
37,68 \\
\end{tabular} & 6786,90 & 347,49 & 19,87 & 327,63 & 79,39 & 243,60 & 243,60 & 70,57 & $\begin{array}{l}645,78 \\
\end{array}$ & 88,98 & 3,84 & 55,60 & 242,73 & 29,33 & 29,33 & 237,29 \\
\hline Pleurodeles walt| & 30STH94 & 100,00 & 155,75 & 124,84 & \begin{tabular}{|l|}
37,59 \\
\end{tabular} & 6791,60 & 350,71 & 22,55 & 328,16 & 82,34 & 246,94 & 246,94 & 73,25 & \begin{tabular}{|l|l|}
617,97 \\
\end{tabular} & 85,14 & 3,79 & 55,09 & 230,59 & 28,66 & 28,66 & 224,83 \\
\hline Pleurodeles walt| & 30STH98 & 100,00 & 154,08 & 123,05 & 37,01 & 6809,59 & 348,09 & 21,13 & 326,96 & 79,90 & 245,35 & 245,35 & 71,55 & 563,20 & 76,05 & 4,14 & 51,94 & 203,41 & 31,01 & 31,01 & 196,29 \\
\hline Pleurodeles waltl & 30STH99 & 100,00 & 157,95 & 122,70 & 37,00 & 6791,74 & 350,87 & 24,91 & 325,97 & 83,74 & 248,87 & 248,87 & 75,27 & 532,52 & 71,53 & 3,95 & 51,32 & 191,25 & 29,83 & 29,83 & 183,63 \\
\hline Pleurodeles walt| & 30STJ47 & 80,00 & 158,34 & 112,88 & 36,33 & 6544,45 & 339,35 & 33,48 & 305,87 & 86,83 & 245,83 & 245,83 & 78,67 & $\begin{array}{l}472,85 \\
\end{array}$ & 60,15 & 4,06 & 47,72 & 1770,54 & 33,28 & 33,28 & 158,29 \\
\hline Pleurodeles walt| & 30STJ48 & 80,00 & 157,30 & 112,20 & 36,16 & $\begin{array}{ll}6532,43 \\
\end{array}$ & 337,47 & 32,83 & 304,64 & 85,80 & 244,71 & 244,71 & 77,88 & 470,31 & 59,10 & 4,17 & 47,10 & 169,25 & 33,86 & 33,86 & 156,80 \\
\hline Pleurodeles walt| & 30STJ49 & 71,00 & 156,13 & 111,76 & 36,26 & 6505,03 & 335,34 & 32,39 & 302,95 & 85,06 & 243,28 & 243,28 & 77,19 & 468,44 & 57,95 & 4,65 & 46,47 & 168,19 & 34,86 & 34,86 & 155,72 \\
\hline Pleurodeles walt| & 30STIS0 & 100,00 & 163,18 & 119,64 & 37,01 & 6621,01 & 350,36 & 33,55 & 316,80 & 90,76 & 251,32 & 251,32 & 82,37 & 509,18 & 66,27 & 3,17 & 51,72 & 188,16 & 28,62 & 28,62 & 177,60 \\
\hline Pleurodeles walt| & 30STIS1 & 100,00 & 166,13 & 118,88 & 37,00 & 6600,50 & 352,20 & 36,54 & 315,66 & 93,81 & 254,05 & 254,05 & 85,33 & 485,22 & 62,98 & 3,01 & 51,23 & 178,56 & 28,03 & 28,03 & 167,71 \\
\hline Pleurodeles walt| & 30STI57 & 100,00 & 153,24 & 113,56 & 36,34 & 6576,88 & 335,72 & 27,88 & 307,84 & 81,56 & 241,36 & 241,36 & 73,40 & \begin{tabular}{|l|l|}
485,68 \\
\end{tabular} & 61,27 & 4,99 & 46,87 & 173,18 & 35,75 & 35,75 & 160,91 \\
\hline Pleurodeles walt| & 30STI59 & 100,00 & 153,68 & 112,63 & 36,43 & $\begin{array}{ll}6536,26 \\
\end{array}$ & 333,96 & 28,91 & 305,05 & 82,08 & 241,23 & 241,23 & 74,07 & $\begin{array}{l}466,74 \\
\end{array}$ & 57,20 & 4,98 & 45,69 & 165,74 & 35,83 & 35,83 & 153,15 \\
\hline Pleurodeles walt| & 30STJ60 & 100,00 & 162,60 & 120,19 & 37,01 & $\begin{array}{ll}6670,16 \\
\end{array}$ & 351,09 & $\begin{array}{ll}32,07 \\
\end{array}$ & 319,02 & 89,56 & 251,53 & 251,53 & 81,13 & \begin{tabular}{|l|l|}
507,73 \\
\end{tabular} & 66,73 & 3,06 & 51,73 & 186,28 & 28,21 & 28,21 & 176,27 \\
\hline Pleurodeles walt| & 30STJ61 & 100,00 & 165,51 & 119,52 & 37,00 & 6647,77 & 352,82 & 35,38 & 317,43 & 92,67 & 254,06 & 254,06 & 84,17 & $\begin{array}{l}483,15 \\
\end{array}$ & 63,18 & 3,00 & 51,24 & 176,44 & 27,62 & 27,62 & 166,13 \\
\hline Pleurodeles walt| & 30STJ63 & 100,00 & 165,26 & 117,98 & 37,00 & 6625,51 & 350,97 & 35,78 & 315,19 & 92,52 & 253,61 & 253,61 & 84,17 & \begin{tabular}{ll|}
462,88 \\
\end{tabular} & 60,12 & 3,09 & 49,94 & 167,34 & 28,19 & 28,19 & 156,48 \\
\hline Pleurodeles walt| & 30STJ64 & 100,00 & 162,51 & 117,17 & 37,00 & 6632,60 & 347,78 & 33,68 & 314,10 & 89,64 & 251,03 & 251,03 & 81,49 & $\begin{array}{l}464,40 \\
\end{array}$ & 59,96 & 3,73 & 48,80 & 166,62 & 29,91 & 29,91 & 155,51 \\
\hline Pleurodeles walt| & 30STJ65 & 100,00 & 155,29 & 116,12 & 36,70 & 6632,08 & 340,62 & 27,62 & 313,01 & 83,03 & 244,19 & 244,19 & 74,88 & 484,69 & 61,93 & 4,40 & 47,61 & $\begin{array}{l}172,52 \\
\end{array}$ & 33,67 & 33,67 & 161,03 \\
\hline Pleurodeles walt| & 30STJ67 & 100,00 & 146,09 & 114,28 & 36,10 & \begin{tabular}{|c|c|c|}
6615,83 \\
\end{tabular} & 330,29 & 20,18 & 310,11 & 74,11 & 235,11 & 235,11 & 66, & 505,77 & 62,89 & 5,5 & 45,92 & 178,34 & $3 \varepsilon$ & 38,77 & 165,94 \\
\hline Pleurodeles walt| & 30STJ69 & 100,00 & 148,10 & 113,43 & 36,43 & 6562,40 & 329,99 & 22,97 & 307,02 & 76,38 & 236,27 & 236,27 & 68,73 & 475,96 & 57,61 & 5,61 & 44,69 & 166,87 & 38,15 & 38,15 & 154,07 \\
\hline Pleurodeles walt| & 30STJ70 & 100,00 & 162,94 & 120,93 & 37,00 & 6711,61 & 352,53 & \begin{tabular}{|l|}
31,34 \\
\end{tabular} & 321,19 & 89,45 & 252,49 & 252,49 & 80,99 & 503,63 & 66,61 & 3,16 & 51,62 & \begin{tabular}{ll|}
183,48 \\
\end{tabular} & 27,84 & 27,84 & 174,04 \\
\hline Pleurodeles walt| & 30STJ72 & 100,00 & 164,69 & 119,43 & 37,00 & 6680,79 & 352,41 & $\begin{array}{ll}33,97 \\
\end{array}$ & $\begin{array}{l}318,44 \\
\end{array}$ & 91,25 & 253,77 & 253,77 & 82,93 & $\begin{array}{l}471,15 \\
4\end{array}$ & 61,59 & 3,05 & 50,33 & 169,71 & 27,75 & 27,75 & 159,65 \\
\hline Pleurodeles walt| & 30STJ74 & 100,00 & 162,17 & 117,93 & 37,00 & 6665,46 & 348,56 & 32,45 & 316,11 & 89,02 & 251,31 & 251,31 & 80,81 & \begin{tabular}{|l|l|}
458,88 \\
\end{tabular} & 59,24 & 3,78 & 48,81 & 163,27 & 29,70 & 29,70 & 152,46 \\
\hline Pleurodeles walt| & 30STJ75 & 100,00 & 156,64 & 117,10 & 36,93 & 6659,80 & 342,72 & 27,78 & 14,95 & 83,69 & 245,82 & 245,82 & 75 & \begin{tabular}{|l|l|}
470,78 \\
\end{tabular} & 60,01 & 4,24 & 47,59 & 20 & 32,63 & 32,63 & 154,99 \\
\hline Pleurodeles waltl & 30STJ76 & 100,00 & 140,27 & 115,77 & 36,36 & 6661,01 & 326,81 & 13,58 & 313 & 68,12 & 230,10 & 230,10 & 60,34 & 531,60 & 65,98 & 6,2 & 45,55 & 185,83 & 41,36 & 41,36 & 173,77 \\
\hline Pleurodeles walt| & 30STJ77 & 100,00 & 147,64 & 115,50 & 36,43 & 6635,54 & 332,56 & 20,52 & 312,04 & 75,32 & 236,87 & 236,87 & 67,48 & \begin{tabular}{|l|l|}
485,83 \\
\end{tabular} & 60,11 & 5,42 & 45,44 & $\begin{array}{l}169,46 \\
\end{array}$ & 37,52 & 37,52 & 157,28 \\
\hline Pleurodeles walt| & 30STJ78 & 100,00 & 149,32 & 115,03 & \begin{tabular}{|l|l|}
36,47 \\
\end{tabular} & $\begin{array}{ll}6607,44 \\
\end{array}$ & 332,96 & 22,44 & 310,52 & 77,11 & 238,01 & 238,01 & 69,21 & $\begin{array}{l}468,16 \\
\end{array}$ & $\begin{array}{l}57,26 \\
\end{array}$ & 5,28 & 44,98 & 162,83 & 36,89 & 36,89 & 150,40 \\
\hline Pleurodeles walt| & 30STI80 & 100,00 & 162,30 & 121,46 & 37,00 & 6739,35 & 352,98 & 30,08 & 322,90 & 88,63 & 252,38 & 252,38 & 79,85 & 502,74 & 66,85 & 3,20 & 51,45 & \begin{tabular}{ll|}
181,68 \\
\end{tabular} & 27,79 & 27,79 & 172,88 \\
\hline Pleurodeles walt| & 30STI81 & 100,00 & 163,48 & 120,86 & 37,00 & 6732,77 & 353,18 & 31,55 & 321,62 & 89,64 & 253,32 & 253,32 & 81 & \begin{tabular}{|l|l|}
484,17 \\
\end{tabular} & 63,95 & 3,17 & 50,84 & 173,96 & 27,62 & 27,62 & 164,79 \\
\hline Pleurodeles walt| & 30STI82 & 100,00 & 159,71 & 120,06 & 37,00 & 6722,78 & 349,14 & 28,61 & 320,54 & 86,01 & 249,70 & 249,70 & 77,87 & 486,66 & 63,75 & 3,78 & 49,62 & 173,27 & 29,86 & 29,86 & 163,70 \\
\hline Pleurodeles walt| & 30STI83 & 100,00 & 164,26 & 119,30 & 37,00 & 6693,97 & 351,82 & 33,32 & 318,50 & 91,13 & 253,90 & 253,90 & 82,54 & $\begin{array}{l}454,95 \\
\end{array}$ & 59,16 & 3,09 & 49,66 & 161,80 & 27,59 & 27,59 & 151,82 \\
\hline Pleurodeles walt| & 30STI85 & 100,00 & 156,96 & 117,95 & 36,97 & 6694,57 & 344,17 & 27,14 & 317,03 & 83,64 & 246,83 & 246,83 & 75,42 & $\begin{array}{l}460,36 \\
\end{array}$ & 58,52 & 4,14 & 47,29 & 161,05 & 31,85 & 31,85 & 150,23 \\
\hline Pleurodeles walt| & 30STI86 & 100,00 & 140,42 & 116,69 & 36,62 & 6683,16 & 327,95 & 12,71 & 315,23 & 67,77 & 230,58 & 230,5 & 60, & $\begin{array}{l}519,05 \\
\end{array}$ & 64,15 & 6,31 & 44,92 & 179,38 & \begin{tabular}{|l|l|}
41,07 \\
\end{tabular} & \begin{tabular}{|l|l|}
41,07 \\
\end{tabular} & 167,52 \\
\hline Pleurodeles walt| & 30STI88 & 100,00 & 139,32 & 115,41 & 36,44 & 6633,73 & 324,53 & 12,55 & 311,98 & 67,20 & 228,75 & 228,76 & 59,59 & 498,80 & 59,71 & 6,71 & 43,49 & 170,82 & 42,19 & 42,20 & 158,4 \\
\hline
\end{tabular}




\begin{tabular}{|c|c|c|c|c|c|c|c|c|c|c|c|c|c|c|c|c|c|c|c|c|c|}
\hline TAXON & UTM & $\mathrm{km} 2$ & B101 & B102 & $\mathrm{BIO3}$ & B104 & B105 & B106 & B107 & B108 & B109 & B1010 & BIO11 & BIO12 & B1013 & BIO14 & BIO15 & B1016 & B1017 & BIO18 & B1019 \\
\hline Pleurodeles walt| & 30STJ91 | & 100,00 & 160,67 & 121,29 & 37,00 & 6770,12 & 351,61 & 28,18 & 323,43 & 86,43 & 251,34 & 251,34 & 78,01 & 491,08 & 64,97 & 3,69 & 50,11 & 174,53 & 29,03 & 29,03 & 165,92 \\
\hline Pleurodeles walt| & 30STJ92 & 100,00 & 162,71 & 120,71 & 37,00 & 6751,35 & 352,47 & 30,39 & 322,09 & 91,52 & 253,05 & 253,05 & 80,01 & 468,96 & 61,53 & 3,40 & 49,86 & 165,95 & 28,06 & 28,06 & 156,97 \\
\hline Pleurodeles walt| & 30STJ93 & 100,00 & 161,94 & 119,95 & 37,00 & 6733,40 & 350,90 & 30,21 & 320,68 & 92,86 & 252,06 & 252,06 & 79,61 & 459,79 & 59,58 & 3,71 & 48,80 & 161,48 & 29,06 & 29,06 & 152,00 \\
\hline Pleurodeles walt| & 30STJ95 & 100,00 & 151,63 & 118,54 & 36,72 & 6729,74 & 340,22 & 21,33 & 318,89 & 78,04 & 242,05 & 242,05 & 69,90 & 472,72 & 59,57 & 4,74 & 46,27 & 163,10 & 34,22 & 34,22 & 152,54 \\
\hline Pleurodeles walt| & 30STJ96 & 100,00 & 141,01 & 117,50 & 36,58 & \begin{tabular}{|l|l|l|}
6708,53 \\
\end{tabular} & 329,46 & 12,15 & 317,31 & 68,05 & 231,51 & 231,51 & 60,23 & 505,65 & 62,12 & 6,26 & 44,46 & 172,77 & 40,59 & 40,59 & 161,21 \\
\hline Pleurodeles walt| & 30STJ99 & 100,00 & 144,12 & 116,00 & 36,92 & 6639,23 & 328,68 & 16,24 & 312,44 & 81,03 & 233,58 & 233,58 & 63,90 & 453,93 & 53,31 & 6,28 & 42,61 & 153,03 & 39,44 & 39,44 & 140,27 \\
\hline Pleurodeles walt| & 30STK40 & 70,00 & 157,68 & 111,55 & 36,40 & 6477,31 & 335,56 & 33,93 & 301,63 & 86,53 & 244,31 & 244,31 & 78,84 & 455,27 & 55,76 & 4,71 & 46,00 & 163,25 & 34,57 & 34,57 & 150,81 \\
\hline Pleurodeles waltl & 30STK41 & 70,00 & 160,83 & 111,62 & 36,88 & 6438,31 & 337,22 & 37,00 & 300,22 & 89,67 & 246,68 & 246,68 & 81,92 & 435,49 & 53,34 & 4,25 & 45,75 & 156,26 & 32,98 & 32,98 & 143,93 \\
\hline Pleurodeles walt| & 30STK42 & 61,00 & 159,72 & 111,47 & 37,00 & 6405,93 & 335,10 & 36,22 & 298,88 & 88,79 & 244,95 & 244,95 & 80,91 & 433,38 & 53,14 & 4,72 & 45,05 & 155,24 & 33,98 & 33,98 & 142,80 \\
\hline Pleurodeles walt| & 30STK51 & 100,00 & 161,28 & 112,52 & \begin{tabular}{|l|l|}
36,93 \\
\end{tabular} & 6469,97 & 338,53 & 36,40 & 302,13 & 89,56 & 247,40 & 247,40 & 81,93 & 420,85 & 51,29 & 4,13 & 45,34 & 149,64 & 32,44 & 32,44 & 137,23 \\
\hline Pleurodeles walt| & 30STK62 & 100,00 & 161,23 & 113,17 & 37,00 & 6446,28 & 338,29 & 35,91 & 302,38 & 90,04 & 247,23 & 247,23 & 82,02 & 399,55 & 48,23 & 4,74 & 43,82 & 139,96 & 32,74 & 32,74 & 127,59 \\
\hline Pleurodeles walt| & 30STK71 & 100,00 & 159,49 & 114,03 & 37,00 & 6506,11 & 338,62 & 32,78 & 305,84 & 94,35 & 246,32 & 246,32 & 79,77 & 400,66 & 47,97 & 4,71 & 43,70 & 138,88 & 32,83 & 32,83 & 126,42 \\
\hline Pleurodeles walt| & 30STK72 & 100,00 & 160,40 & 114,00 & 37,00 & 6459,10 & 338,21 & 34,19 & 304,02 & 108,40 & 246,64 & 246,64 & 81,15 & 388,79 & 46,46 & 5,00 & 43,09 & 134,24 & 32,95 & 32,95 & 121,76 \\
\hline Pleurodeles walt| & 30STK81 & 100,00 & 157,36 & 114,90 & 37,00 & 6538,47 & 337,27 & 30,14 & 307,14 & 109,29 & 244,77 & 244,77 & 77,19 & 397,06 & 46,97 & 5,00 & 43,09 & 135,98 & 33,42 & 33,42 & 123,21 \\
\hline Pleurodeles walt| & 30STK82 & 100,00 & 159,99 & 114,49 & 37,00 & 6497,45 & 338,29 & 33,01 & 305,28 & 118,40 & 246,75 & 246,75 & 80,04 & 379,04 & 44,91 & 5,00 & 42,66 & 130,14 & 32,23 & 32,23 & 117,00 \\
\hline Pleurodeles waltt & 30STK91 & 100,00 & 158,53 & 115,07 & 37,00 & 6558,74 & 338,88 & 30,31 & 308,57 & 116,44 & 246,30 & 246,30 & 78,05 & 382,92 & 44,90 & 5,00 & 42,83 & 130,80 & 32,58 & 32,58 & 117,11 \\
\hline Pleurodeles walt| & 30STK92 & 100,00 & 158,97 & 115,00 & 37,00 & 6517,41 & 337,92 & 31,26 & 306,66 & 116,95 & 246,07 & 246,07 & 78,94 & 372,09 & 43,72 & 5,00 & 42,38 & 127,20 & 32,20 & 32,20 & 113,03 \\
\hline Pleurodeles walt| & 30SUF03 & 82,00 & 169,39 & 89,49 & \begin{tabular}{|l|l|}
40,47 \\
\end{tabular} & 4467,10 & 290,21 & 71,31 & 218,90 & 125,21 & 226,56 & 230,21 & 116,17 & 700,22 & 120,39 & 1,22 & 73,03 & 341,09 & 15,43 & 22,72 & 320,33 \\
\hline Pleurodeles walt| & 30SUF06 & 100,00 & 141,85 & 105,55 & 39,09 & 5464,68 & 294,05 & 28,43 & 265,62 & 86,67 & 213,94 & 216,01 & 76,81 & 802,06 & 120,23 & 3,02 & 66,62 & 354,21 & 24,06 & 32,49 & 343,76 \\
\hline Pleurodeles walt| & 30SUF13 & 41,00 & 177,76 & 86,60 & $\begin{array}{l}40,55 \\
\end{array}$ & 4321,56 & 293,13 & 81,98 & 211,15 & 135,25 & 232,73 & 236,49 & 126,22 & 639,44 & 112,78 & 1,00 & 73,62 & 317,35 & 14,11 & 20,27 & 294,35 \\
\hline Pleurodeles walt| & 30SUF16 & 100,00 & 129,29 & 109,97 & 39,02 & 5681,03 & 290,17 & 12,23 & 277,94 & 71,73 & 205,11 & 206,59 & 61,96 & 839,94 & 121, & 4,4 & 64,32 & 360,19 & 29,42 & 38,14 & 352,82 \\
\hline Pleurodeles walt| & 30SUF24 & 94,00 & 168,45 & 92,06 & 40,05 & 4652,58 & 293,99 & 66,92 & 227,07 & 122,51 & 228,58 & 231,67 & $\begin{array}{r}13,12 \\
113\end{array}$ & 654,52 & 109,13 & 1,48 & 71,20 & 313,71 & 16,63 & 23,23 & 294,45 \\
\hline Pleurodeles walt| & 30 SUF 25 & 100,00 & 151,94 & 100,82 & 39,72 & 5156,42 & 294,15 & 42,55 & 251,60 & 100,47 & 219,74 & 221,94 & $\begin{array}{l}90,62 \\
\end{array}$ & 720,34 & 111,42 & 2,52 & 67,90 & 328,08 & 20,82 & 28,60 & 314,10 \\
\hline Pleurodeles waltt & 30SUF38 & 100,00 & 161,50 & 101,88 & 38,99 & 5404,44 & 307,68 & 49,02 & 258,66 & 105,83 & 232,80 & 234,28 & 96,89 & 671,02 & 103,93 & 2,26 & 66,48 & 303,10 & 20,13 & 26,24 & 286,15 \\
\hline Pleurodeles walt| & 30SUF39 & 100,00 & 163,16 & 103,55 & 38,99 & 5526,19 & 312,55 & 49,03 & 263,52 & 105,89 & 236,23 & 237,36 & 97,02 & 666,41 & 102,47 & 2,11 & 65,86 & 298,11 & 20,08 & 26,09 & 281,61 \\
\hline Pleurodeles walt| & 30SUF48 & 100,00 & 164,32 & 99,91 & 38,79 & 5356,79 & 307,45 & 52,37 & 255,08 & 109,16 & 235,01 & 236,27 & 100,19 & 643,47 & 100,51 & 2,44 & 66,35 & 291,23 & 20,14 & 25,76 & 273,91 \\
\hline \begin{tabular}{|l|l|} 
Pleurodeles waltl \\
\end{tabular} & 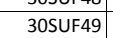 & 100,00 & 161,69 & 103,47 & 38,72 & 5564,11 & 311,51 & 46,74 & \begin{tabular}{|l|l|}
264,78 \\
\end{tabular} & 103,90 & \begin{tabular}{|l|}
235,49 \\
\end{tabular} & 236,38 & 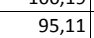 & \begin{tabular}{|l|l|}
651,43 \\
\end{tabular} & \begin{tabular}{|c|}
99,29 \\
9
\end{tabular} & $2,2,53$ & 65,11 & 289,43 & 20,62 & 26,60 & 273,68 \\
\hline Pleurodeles walt| & 30SUF59 & 100,00 & 151,96 & 107,04 & 38,38 & 5743,58 & 309,15 & 34,31 & 274,84 & 92,37 & 228,85 & 229,23 & 83,52 & 661,30 & 97,48 & 3,74 & 62,77 & 285,63 & 23,96 & 28,66 & 272,52 \\
\hline Pleurodeles walt| & 30SUF65 & 71,00 & 178,18 & 86,28 & 38,39 & 4686,09 & 296,79 & 75,63 & 221,16 & 131,94 & 239,13 & 241,45 & 122,25 & 553,97 & 93,95 & 1,93 & 69,95 & 265,73 & 17,57 & 21,24 & 245,09 \\
\hline Pleurodeles waltt & 30SUF66 & 100,00 & 181,38 & 85,40 & 38,01 & 4749,54 & 299,71 & 78,08 & 221,63 & 134,01 & 243,11 & 245,35 & 124,52 & 550,63 & 94,13 & 1,94 & 69,57 & 263,32 & $\begin{array}{ll}17,94 \\
\end{array}$ & 21,02 & 241,76 \\
\hline Pleurodeles walt| & 30SUF69 & 100,00 & 148,18 & 108,52 & 38,10 & 5824,46 & 308,79 & 29,03 & 279,76 & $\mid 87,60$ & 226,42 & 226,51 & 78,91 & 649,50 & 94,31 & 4,30 & 61,40 & 276,40 & 25,32 & 26,83 & 264,26 \\
\hline \begin{tabular}{|l|} 
Pleurodeles waltl \\
\end{tabular} & \begin{tabular}{|l|}
30 SUF76 \\
\end{tabular} & 60,00 & $\begin{array}{l}148,10 \\
178,71\end{array}$ & 86,90 & 37,95 & 4863,15 & 300,02 & $\begin{array}{l}3,37 \\
73,3\end{array}$ & 226,66 & $\begin{array}{l}129,82 \\
120\end{array}$ & \begin{tabular}{|l|}
242,24 \\
242
\end{tabular} & \begin{tabular}{|l|}
244,01 \\
\end{tabular} & $\mid$ & 525,85 & $\begin{array}{l}\mid 8,91 \\
87,91\end{array}$ & 2, & $\begin{array}{ll}1,140 \\
67,84\end{array}$ & 246,26 & $\begin{array}{l}3,54 \\
17,54 \\
\end{array}$ & 21,09 & 227,32 \\
\hline Pleurodeles walt| & 30SUF77 & 100,00 & 159,55 & 100,20 & 38,38 & 5393,29 & 303,62 & 46,13 & 257,50 & 104,07 & 231,38 & 231,93 & 95,20 & 575,35 & 88,88 & 3,26 & 63,66 & 255,70 & 21,20 & 24,50 & 240,32 \\
\hline Pleurodeles walt| & 30SUF79 & 100,00 & 146,45 & 109,68 & 38,06 & 5890,52 & 309,60 & 26,14 & 283,45 & 84,89 & 225,82 & 225,82 & 76,33 & 629,21 & 90,48 & 4,67 & 60,19 & 264,72 & 26,09 & 26,35 & 253,12 \\
\hline Pleurodeles walt| & 30SUF89 & 100,00 & 138,18 & 113,21 & 38,01 & 6037,40 & 308,46 & 15,46 & 293,00 & 75,24 & 219,99 & 219,99 & 66,65 & 639,85 & 88,60 & 5,89 & 57,88 & 261,41 & 29,57 & 29,63 & 252,07 \\
\hline Pleurodeles walt| & $\begin{array}{l}\text { 30SUF98 } \\
\end{array}$ & 100,00 & 164,71 & 100,24 & 38,00 & 5490,06 & 309,73 & 49,53 & 260,20 & 107,06 & 238,20 & 238,29 & 98,92 & 499,38 & 77,35 & 3,34 & 61,90 & 218,94 & 19,81 & 20,69 & 203,59 \\
\hline \begin{tabular}{|l|} 
Pleurodeles waltl \\
\end{tabular} & \begin{tabular}{|l}
30 SUF99 \\
30
\end{tabular} & 100,00 & $\begin{array}{l}104, / 28 \\
131,28\end{array}$ & $\begin{array}{l}10,24 \\
115,92\end{array}$ & 38,00 & $\begin{array}{ll}3450,00 \\
6159,14\end{array}$ & 307,14 & \begin{tabular}{|c|}
6,72 \\
6,72
\end{tabular} & 300,42 & \begin{tabular}{|l|}
67,43 \\
67
\end{tabular} & \begin{tabular}{|l|}
214,93 \\
214
\end{tabular} & \begin{tabular}{|l|}
214,93 \\
\end{tabular} & $\begin{array}{ll}50,525 \\
58,55\end{array}$ & | 651,95 & 87,41 & $\begin{array}{l}3,44 \\
7,08\end{array}$ & 55,91 & \begin{tabular}{|l|}
259,09 \\
\end{tabular} & $\begin{array}{l}1,101 \\
33,13 \\
\end{array}$ & 33,13 & 251,82 \\
\hline Pleurodeles walt| & 30SUG00 & 100,00 & 161,31 & 108,74 & 39,13 & 5694,42 & 318,83 & 45,36 & 273,47 & 101,53 & 236,13 & 237,63 & 92,80 & 707,84 & 109,19 & 1,94 & 65,68 & 312,33 & 20,30 & 26,57 & 296,84 \\
\hline Pleurodeles walt| & 30SUG03 & 100,00 & 175,87 & 114,48 & 39,79 & 5932,09 & 340,65 & 54,95 & 285,69 & 112,20 & 253,78 & 254,65 & 103,90 & 635,93 & 98,28 & 1,00 & 64,87 & 274,76 & 17,00 & 22,97 & 260,99 \\
\hline Pleurodeles walt| & 30SUG04 & 100,00 & 174,68 & 117,00 & 39,43 & 6094,71 & 344,37 & 51,05 & 293,32 & 109,03 & 254,87 & 255,42 & 100,49 & 639,99 & 97,29 & 1,29 & 64,03 & 271,75 & 17,62 & 22,87 & 259,88 \\
\hline Pleurodeles walt| & 30SUG05 & 100,00 & 174,83 & 118,95 & 39,03 & 6223,51 & 349,01 & 49,08 & 299,93 & 107,51 & 256,89 & 257,21 & 98,96 & 636,42 & 95,56 & 1,5 & 63,53 & 266,32 & 17,58 & 22,12 & 255,99 \\
\hline \begin{tabular}{|l|} 
Pleurodeles walt| \\
\end{tabular} & 30 SUG06 & 100,00 & 177,07 & 120,20 & 39,00 & 6308,46 & 354,11 & 49,54 & 304,57 & 108,70 & 260,46 & 260,56 & 100,03 & 624,19 & 92,89 & 1,40 & 62,82 & 257,88 & 17,40 & 18,85 & 248,75 \\
\hline Pleurodeles walt| & 30SUG07 & 100,00 & 178,95 & 121,29 & 38,99 & 6379,80 & 358,43 & 49,71 & 308,72 & 109,61 & 263,26 & 263,31 & 100,66 & 612,95 & 90,28 & 1,50 & 62,29 & 249,83 & 17,50 & 18,83 & 241,77 \\
\hline Pleurodeles walt| & 30SUG08 & 100,00 & 179,07 & 122,27 & 38,65 & 6465,53 & 361,50 & 48,51 & 312,99 & 108,69 & 264,57 & 264,59 & 99,60 & 606,15 & 88,31 & 1,66 & 61,55 & 243,76 & 17,82 & 18,13 & 236,68 \\
\hline Pleurodeles walt| & 30SUG10 & 100,00 & 159,24 & 108,45 & 39,01 & 5718,69 & 316,7 & 42,82 & 273,95 & 99,60 & 234,76 & 235,98 & 90,61 & 707,58 & 107,98 & 2, & 65,19 & 11,06 & 20,88 & 27,25 & 296,25 \\
\hline \begin{tabular}{|l|} 
Pleurodeles walt| \\
\end{tabular} & 30SUG13 & 100,00 & 174,70 & 113,11 & 39,04 & 5956,19 & 338,5 & $\begin{array}{ll}53,39 \\
53,4\end{array}$ & 285,14 & \begin{tabular}{|l|}
110,82 \\
11
\end{tabular} & 253,09 & $\begin{array}{ll}253,78 \\
\end{array}$ & \begin{tabular}{r|r|}
102,18 \\
\end{tabular} & 640,77 & \begin{tabular}{|l|}
98,39 \\
91,3
\end{tabular} & 1, & 64,44 & 275,81 & $\begin{array}{l}2,00 \\
17,38\end{array}$ & 23,21 & 262,82 \\
\hline Pleurodeles walt| & 30 SUG15 & 100,00 & 176,83 & 117,18 & \begin{tabular}{|c|}
38,98 \\
\end{tabular} & 6195,92 & 349,00 & 51,24 & 297,76 & 109,89 & 258,59 & 258,86 & 101,00 & 631,30 & 94,82 & 1,59 & 63,29 & 263,54 & 17,38 & 20,48 & 253,87 \\
\hline Pleurodeles waltl & 30SUG16 & 100,00 & 177,14 & 119,05 & 38,87 & 6319,29 & 353,65 & 49,57 & 304,07 & 108,73 & 260,71 & 260,80 & 99,67 & 628,85 & 93,36 & 1,74 & 62,61 & 258,14 & 17,54 & 19,01 & 250,19 \\
\hline Pleurodeles waltt & 30SUG17 & 100,00 & 176,59 & 120,83 & 38,41 & 6426,45 & 357,16 & 46,85 & 310,31 & 106,78 & 261,70 & 261,72 & 97,71 & 630,39 & 92,22 & 2,00 & 62,09 & 254,40 & 18,00 & 18,23 & 248,02 \\
\hline Pleurodeles waltl & 30SUG19 & 100,00 & 170,83 & 123,41 & 38,00 & 6637,60 & 358,88 & 38,45 & 320,44 & 98,80 & 259,16 & 259,16 & 89,47 & 637,10 & 91,01 & 2,26 & 60,45 & 249,29 & 20,32 & 20,32 & 245,07 \\
\hline \begin{tabular}{|l|} 
Pleurodeles waltl \\
\end{tabular} & 30SUG24 & 100,00 & $\begin{array}{l}17,03 \\
175,65\end{array}$ & $\begin{array}{l}12,41 \\
113,80\end{array}$ & 38,80 & $\begin{array}{l}603090,45 \\
6090\end{array}$ & 342 & 50,23 & \begin{tabular}{|l|}
290,52 \\
290
\end{tabular} & \begin{tabular}{|c|}
50,000 \\
109,98 \\
\end{tabular} & $\mid$ & $\mid 256,36$ & \begin{tabular}{|l|}
03,4174 \\
101,49
\end{tabular} & \begin{tabular}{|l|l|}
634,57 \\
\end{tabular} & \begin{tabular}{|l|l|}
1,101 \\
95,71
\end{tabular} & $2,2,00$ & $\begin{array}{l}0,45 \\
63,62\end{array}$ & \begin{tabular}{|l|}
267,67 \\
267
\end{tabular} & $\begin{array}{l}\mid 20,325 \\
17,95 \\
\end{array}$ & 21,50 & $\begin{array}{l}24,07,17 \\
257\end{array}$ \\
\hline Pleurodeles walt| & 30SUG25 & 100,00 & 177,11 & 115,70 & \begin{tabular}{|l|l|}
38,47 \\
\end{tabular} & 6197,34 & 348,18 & 51,59 & 296,60 & 110,24 & 259,11 & 259,20 & 101,24 & 629,42 & 94,16 & 1,99 & 63,18 & 261,45 & 17,47 & 18,83 & 252,76 \\
\hline Pleurodeles walt| & 30 SUG26 & 100,00 & 174,32 & 118,30 & $38,05 \mid$ & 6364,71 & 351,55 & 46,19 & 305,35 & 105,34 & 258,78 & 258,78 & 96,44 & $|641,77|$ & 94,36 & 2,00 & 62.40 & 261,26 & 18,11 & 18,20 & 254,61 \\
\hline Pleurodeles waltl & 30SUG27 & 100,00 & 176,12 & 119,83 & 38,00 & 6461,01 & 356,74 & 46,04 & 310,70 & 106,12 & 261,92 & 261,92 & 96,58 & 635,43 & 92,68 & 2,00 & 62,12 & 254,70 & 17,76 & 17,76 & 249,60 \\
\hline Pleurodeles waltl & 30 SUG29 & 100,00 & 171,23 & 122,66 & 37,88 & 6667,74 & 359,38 & 38,34 & 321,03 & 100,62 & 260,12 & 260 & 89,40 & 638,74 & 92,99 & 2,38 & 60,78 & 248,38 & 19,95 & 19,95 & 244 \\
\hline \begin{tabular}{|l|} 
Pleurodeles waltl \\
\end{tabular} & $\begin{array}{l}0500230 \\
30 \text { S } 30\end{array}$ & $\begin{array}{l}100,00 \\
\end{array}$ & $\begin{array}{l}1 / 1,25 \\
161,39\end{array}$ & $\begin{array}{l}12,00 \\
106,38\end{array}$ & $\begin{array}{l}3,00 \\
38,92\end{array}$ & 5693,89 & $\begin{array}{l}33,50 \\
316,09\end{array}$ & \begin{tabular}{|l|l|}
44,78 \\
44,7
\end{tabular} & \begin{tabular}{|l|}
271,31 \\
271
\end{tabular} & \begin{tabular}{|l|}
101,95 \\
105
\end{tabular} & $\begin{array}{l}236,83 \\
236\end{array}$ & \begin{tabular}{|l|}
237,75 \\
2312
\end{tabular} & $\begin{array}{l}3,40 \\
93,14 \\
\end{array}$ & \begin{tabular}{|l|}
$670,7,11$ \\
674
\end{tabular} & \begin{tabular}{|c|} 
\\
101,81 \\
\end{tabular} & $2,2,51$ & $\begin{array}{l}0,100 \\
64,53\end{array}$ & \begin{tabular}{|l|}
295,99 \\
295,9
\end{tabular} & \begin{tabular}{|l|l|}
21,35 \\
2,35
\end{tabular} & $\begin{array}{l}11,50 \\
27,45\end{array}$ & $\begin{array}{l}244,50 \\
281,19\end{array}$ \\
\hline Pleurodeles waltt & 30SUG39 & 100,00 & 172,72 & 121,66 & 37,46 & 6673,92 & 360,28 & 39,74 & 320,55 & 103,10 & 261,75 & 261,75 & 90,77 & 634,97 & 94,36 & 2,40 & 60,84 & 247,91 & 19,40 & 19,40 & 242,96 \\
\hline Pleurodeles walt| & 30SUG40 & 100,00 & 164,62 & 104,62 & 38,48 & 5666,15 & 316,75 & 48,21 & 268,55 & 105,23 & 239,72 & 240,42 & 96,60 & 643,79 & 97,35 & 2,44 & 64,83 & 283,87 & 20,00 & 25,60 & 268,63 \\
\hline |Pleurodeles walt| & 30SUG41 & 100,00 & 163,92 & 107,10 & 38,08 & 5819,24 & 321,13 & 45,30 & 275,83 & 102,48 & 241,36 & 241, & 94,0 & 648,59 & 96,53 & 2,91 & 63,63 & 280,68 & 21,20 & 25,07 & 267,16 \\
\hline Pleurodeles waltl & 30SUG48 & 100,00 & 176,47 & 118,81 & 37,23 & 6575,07 & 359,06 & 45,15 & 313,91 & 107,69 & 264,08 & 264,08 & 95,61 & 620,24 & 91,78 & 2,03 & 61,67 & 243,40 & 17,58 & 17,58 & 239,99 \\
\hline
\end{tabular}




\begin{tabular}{|c|c|c|c|c|c|c|c|c|c|c|c|c|c|c|c|c|c|c|c|c|c|}
\hline TAXON & UTM & $\mathrm{km} 2$ & BIO1 & B102 & $B 103$ & BIO4 & B105 & B106 & B107 & B108 & B109 & B1010 & BIO11 & B1012 & BIO13 & B1014 & BIO15 & B1016 & B1017 & B1018 & B1019 \\
\hline Pleurodeles walt| & 30SUG49 & 100,00 & 177,84 & 119,92 & 37,05 & 6641,07 & 362,81 & 45,38 & 317,43 & 108,48 & 266,49 & 266,49 & 96,15 & 608,36 & 91,39 & 2,03 & 61,38 & 238,32 & 17,34 & 17,34 & 233,03 \\
\hline Pleurodeles walt| & 30SUG50 & 100,00 & 164,66 & 103,90 & 38,05 & 5680,63 & 316,29 & 47,89 & 268,40 & $\begin{array}{l}105,03 \\
\end{array}$ & 240,25 & 240,61 & 96,56 & $\begin{array}{l}622,40 \\
\end{array}$ & 93,90 & 2,99 & 63,95 & 273,02 & 20,50 & 25,05 & 257,99 \\
\hline Pleurodeles walt| & 30SUG54 & 100,00 & 169,43 & 111,11 & 37,68 & 6182,19 & $\begin{array}{l}337,53 \\
\end{array}$ & 45,85 & 291,68 & 103,08 & 251,95 & 251,95 & 94,54 & 619,52 & 89,40 & 2,85 & 61,66 & 255,64 & 20,03 & $\begin{array}{ll}20,03 \\
\end{array}$ & 247,58 \\
\hline Pleurodeles walt| & 30SUG55 & 100,00 & 170,56 & $\begin{array}{l}112,87 \\
\end{array}$ & 37,33 & 6300,87 & \begin{tabular}{ll|}
342,64 \\
\end{tabular} & 45,02 & 297,62 & 102,83 & 254,71 & 254,71 & 94,03 & 619,35 & 88,62 & 2,86 & 61,12 & 251,06 & 20,03 & $\begin{array}{ll}20,03 \\
\end{array}$ & 245,03 \\
\hline Pleurodeles walt| & 30SUG59 & 100,00 & 177,31 & 118,25 & 37,00 & 6620,24 & 360,45 & 45,90 & 314,55 & 108,36 & 265,77 & 265,77 & 96,05 & 591,19 & 87,92 & 2,13 & 60,54 & 230,87 & 17,76 & 17,76 & 225,69 \\
\hline Pleurodeles walt| & 30SUG60 & 100,00 & 161,05 & 105,06 & 38,00 & 5764,34 & 315,83 & 43,04 & 272,78 & 100,34 & 238,06 & 238,18 & 91,94 & 607,87 & 90,73 & 3,27 & 62,49 & 263,13 & 21,77 & 23,36 & 249,10 \\
\hline 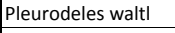 & 30SUG70 & 100,00 & 153,02 & 108,60 & 38,00 & 5919,84 & 315,12 & 32,55 & 282,56 & $\begin{array}{l}90,59 \\
\end{array}$ & 232,64 & 232,64 & 82,25 & 606,43 & 88,06 & 4,36 & 60,45 & 256,18 & 24,30 & 24,34 & 243,79 \\
\hline Pleurodeles walt| & 30SUG71 & 100,00 & 151,62 & 110,58 & 37,88 & 6072,57 & 318,97 & 29,47 & 289,50 & 87,29 & 233,57 & 233,57 & 79,09 & $\begin{array}{l}616,86 \\
\end{array}$ & 87,21 & 4,57 & 59,53 & 255,86 & 25,25 & 25,25 & 245,22 \\
\hline Pleurodeles walt| & 30SUG75 & 100,00 & 155,82 & 114,23 & 37,00 & $\begin{array}{ll}6483,09 \\
\end{array}$ & 334,95 & 29,28 & $\begin{array}{l}305,67 \\
\end{array}$ & 86,84 & 243,34 & 243,34 & 78,06 & $\begin{array}{l}628,75 \\
\end{array}$ & 85,66 & 4,59 & 57,93 & 245,89 & 25,79 & 25,79 & 242,22 \\
\hline Pleurodeles walt| & 30SUG80 & 100,00 & 145,86 & 111,84 & 38,00 & 6057,58 & 314,52 & 23,17 & 291,35 & 81,99 & 227,83 & 227,83 & 73,82 & 607,50 & 85,53 & 5,29 & 58,42 & 250,28 & 26,89 & 26,89 & 239,62 \\
\hline Pleurodeles walt| & 30SUG81 & 100,00 & 153,52 & 110,27 & 37,74 & $\begin{array}{l}6081,48 \\
\end{array}$ & 320,52 & 31,07 & 289,45 & 88,59 & 235,66 & 235,66 & 80,89 & 579,69 & 82,66 & 4,74 & 58,76 & 239,96 & 24,57 & 24,57 & 228,61 \\
\hline Pleurodeles walt| & 30SUG82 & 100,00 & 160,03 & 108,95 & 37,09 & 6113,47 & 325,95 & 37,62 & 288,34 & 94,39 & 242,38 & 242,38 & 86,69 & 565,50 & 80,03 & 4,05 & 59,18 & 233,26 & 22,71 & 22,71 & 222,88 \\
\hline Pleurodeles walt| & 30SUG84 & 100,00 & 153,59 & 113,48 & 36,98 & 6436,52 & 331,44 & 27,62 & 303,83 & 84,82 & 240,74 & 240,74 & 76,60 & 607,21 & 80,98 & 4,97 & 57,11 & 237,89 & 26,17 & 26,17 & 233,38 \\
\hline Pleurodeles walt| & 30SUG90 & 100,00 & 124,09 & $\begin{array}{l}117,99 \\
\end{array}$ & 37,99 & 6306,11 & 305,62 & $-1,53$ & 307,15 & 58,80 & 210,03 & 210,03 & 49,98 & 696,79 & 91,66 & 8,28 & 54,52 & 269,74 & 38,04 & \begin{tabular}{|l|l}
38,04 \\
\end{tabular} & 264,54 \\
\hline Pleurodeles walt| & 30SUG91 & 100,00 & 154,26 & 110,16 & 37,51 & 6085,34 & 321,24 & 31,49 & 289,75 & 89,03 & 236,53 & 236,53 & 81,49 & $\begin{array}{l}549,58 \\
\end{array}$ & 78,58 & 4,79 & 58,01 & 226,02 & 24,42 & 24,42 & 214,44 \\
\hline Pleurodeles walt| & 30SUG92 & 100,00 & 153,51 & 111,81 & 37,11 & 6234,93 & 325,26 & 29,25 & 296,01 & 86,55 & 237,92 & 237,92 & 78,91 & 561,34 & 77,69 & 5,05 & 57,17 & 226,44 & 25,16 & 25,16 & 217,01 \\
\hline Pleurodeles walt| & 30SUG95 & 100,00 & 163,41 & 111,16 & 36,22 & 6471,75 & 339,35 & 37,74 & 301,61 & \begin{tabular}{ll|}
94,24 \\
\end{tabular} & 250,87 & 250,87 & 85,63 & 561,54 & 75,06 & 4,38 & 57,20 & 217,22 & 23,01 & 23,01 & 214,71 \\
\hline Pleurodeles walt| & 30SUG96 & 100,00 & 169,14 & 110,37 & 36,00 & \begin{tabular}{ll|l|}
6498,94 \\
\end{tabular} & 344,60 & 43,37 & 301,23 & 102,06 & 256,68 & 256,68 & 90,79 & 550,85 & 76,01 & 3,79 & 57,74 & 213,36 & 21,20 & 21,20 & 210,45 \\
\hline Pleurodeles walt| & 30SUHO3 & 100,00 & 156,72 & 124,97 & 37,22 & 6812,88 & 351,83 & 22,94 & 328,90 & 84,97 & 248,16 & 248,16 & 73,96 & 629,18 & 88,10 & 3,43 & 56,14 & 235,71 & 27,18 & 27,18 & 231,01 \\
\hline Pleurodeles walt| & 30SUHO4 & 100,00 & 152,84 & 124,93 & \begin{tabular}{l|l|l}
37,05 \\
\end{tabular} & 6831,90 & 348,81 & 19,41 & 329,40 & 81,84 & 244,76 & 244,76 & 70,04 & 628,36 & 87,41 & 3,97 & 54,82 & 232,80 & 29,55 & 29,55 & 227,64 \\
\hline Pleurodeles walt| & 30SUHO5 & 100,00 & 154,29 & 124,77 & 37,14 & 6832,25 & 350,07 & 20,79 & 329,28 & 83,11 & 246,08 & 246,08 & 71,36 & 606,60 & 84,11 & 4,00 & 54,17 & 222,77 & 29,59 & 29,59 & 217,47 \\
\hline Pleurodeles walt| & 30SUH07 & 100,00 & 159,41 & 124,00 & 37,00 & \begin{tabular}{|l|l|}
6836,97 \\
\end{tabular} & \begin{tabular}{ll|}
353,94 \\
\end{tabular} & 25,40 & 328,54 & 85,75 & 251,04 & 251,04 & 76,13 & $\begin{array}{l}553,36 \\
\end{array}$ & 76,10 & 3,42 & 53,17 & 200,52 & 27,60 & 27,60 & 194,65 \\
\hline Pleurodeles walt| & 30SUH08 & 100,00 & 156,61 & 123,59 & 37,00 & \begin{tabular}{|l|l|}
6837,61 \\
\end{tabular} & 350,97 & 22,84 & 328,13 & 81,95 & 248,43 & 248,43 & 73,45 & 549,13 & 74,76 & 3,80 & 52,03 & \begin{tabular}{|l|l|}
197,04 \\
\end{tabular} & 29,49 & 29,49 & 190,72 \\
\hline Pleurodeles walt| & 30SUHO9 & 100,00 & 156,29 & 123,05 & 37,00 & 6827,99 & 350,39 & 22,76 & 327,62 & 81,72 & 247,94 & 247,94 & 73,39 & 533,95 & 72,05 & 4,00 & 51,27 & 190,05 & 30,05 & 30,05 & 183,17 \\
\hline Pleurodeles walt| & 30SUH11 & 100,00 & 153,44 & 124,32 & 37,41 & 6790,20 & 347,48 & 20,28 & 327,20 & 82,93 & 244,46 & 244,46 & 71,11 & 668,52 & 94,50 & 3,88 & 56,90 & 253,99 & 27,99 & 27,99 & 249,24 \\
\hline Pleurodeles walt| & 30SUH12 & 100,00 & 152,39 & 124,68 & 37,23 & 6821,05 & 347,75 & 19,14 & 328,61 & 81,93 & 243,99 & 243,99 & 69,83 & 657,64 & 92,90 & 3,98 & 56,20 & 247,94 & 28,79 & 28,79 & 242,44 \\
\hline Pleurodeles walt| & 30SUH13 & 100,00 & 154,20 & 124,93 & 37,09 & 6841,54 & 350,06 & 20,50 & 329,56 & 83,68 & 246,18 & 246,18 & 71,38 & 636,21 & 89,85 & 3,75 & 55,83 & 238,13 & 28,24 & 28,24 & 232,44 \\
\hline Pleurodeles walt| & 30SUH14 & 100,00 & 150,81 & 124,97 & \begin{tabular}{|l|}
37,02 \\
\end{tabular} & 6860,81 & 347,49 & 17,34 & 330,15 & 80,42 & 243,28 & 243,28 & 67,93 & \begin{tabular}{|l|l|}
632,93 \\
\end{tabular} & 88,78 & 4,17 & 54,50 & 234,54 & 30,24 & 30,24 & 228,31 \\
\hline Pleurodeles walt| & 30SUH15 & 100,00 & 154,26 & 124,99 & 37,00 & 6858,90 & 350,54 & 20,44 & 330,10 & 83,81 & 246,70 & 246,70 & 71,17 & 603,60 & 84,48 & 4,00 & 54,14 & 221,67 & 29,30 & 29,30 & 215,70 \\
\hline Pleurodeles walt| & 30SUH17 & 100,00 & 159,76 & 124,03 & 37,00 & 6852,95 & 354,63 & 25,22 & 329,41 & 88,66 & 251,68 & 251,68 & 76,34 & 548,21 & 75,84 & 3,42 & 53,12 & 197,20 & 27,31 & 27,31 & $\begin{array}{ll}191,87 \\
\end{array}$ \\
\hline Pleurodeles walt| & 30SUH18 & 100,00 & 160,50 & 123,94 & 37,00 & 6853,55 & 354,88 & 26,04 & 328,84 & 87,45 & 252,51 & 252,51 & 76,96 & 528,38 & 72,45 & 3,32 & 52,48 & 188,55 & 27,29 & 27,29 & 183,01 \\
\hline Pleurodeles walt| & 30SUH19 & 100,00 & 156,72 & 123,25 & 37,00 & \begin{tabular}{ll|}
6850,13 \\
\end{tabular} & 351,13 & 22,66 & 328,47 & 82,51 & 248,74 & 248,74 & 73,43 & 527,22 & 71,32 & 3,82 & 51,09 & 186,22 & 29,49 & 29,49 & 180,06 \\
\hline Pleurodeles walt| & $30 \mathrm{SUH} 20$ & 100,00 & 164,69 & 123,62 & \begin{tabular}{l|l|}
37,62 \\
\end{tabular} & 6753,70 & 356,12 & 31,21 & 324,91 & 94,63 & 255,00 & 255,00 & 82,13 & 645,91 & 93,62 & 2,86 & 59,03 & 248,81 & 22,74 & 22,74 & 244,30 \\
\hline Pleurodeles walt| & 30SUH21 & 100,00 & 155,18 & 124,01 & \begin{tabular}{|l|l|}
37,13 \\
\end{tabular} & \begin{tabular}{|l|l|}
6815,08 \\
\end{tabular} & 349,27 & 21,83 & 327,44 & 84,73 & 246,69 & 246,69 & 72,49 & 660,60 & 94,63 & 3,78 & 57,17 & 251,76 & 27,13 & 27,13 & 245,69 \\
\hline Pleurodeles walt| & 30SUH22 & 100,00 & 157,27 & 124,38 & \begin{tabular}{|l|}
37,08 \\
\end{tabular} & 6836,77 & 352,36 & 23,58 & 328,78 & 86,77 & 249,13 & 249,13 & 74,42 & 638,21 & 91,70 & 3,51 & 56,67 & 241,62 & 26,43 & 26,43 & 235,18 \\
\hline Pleurodeles walt| & 30SUH23 & 100,00 & 149,64 & \begin{tabular}{|l|l|}
124,64 \\
\end{tabular} & 37,01 & 6867,08 & 346,31 & 16,29 & 330,03 & 79,18 & 242,11 & 242,11 & 66,75 & 647,95 & 91,83 & 4,34 & 54,98 & 242,28 & 30,37 & 30,37 & 235,08 \\
\hline Pleurodeles walt| & 30SUH24 & 100,00 & 152,59 & 124,99 & 37,00 & \begin{tabular}{|l|l|}
6879,76 \\
\end{tabular} & 349,49 & 18,78 & 330,70 & 82,04 & 245,28 & 245,28 & 69,63 & \begin{tabular}{|l|l|}
621,17 \\
\end{tabular} & 88,01 & 4,03 & 54,46 & 230,47 & 29,16 & 29,16 & 223,26 \\
\hline Pleurodeles walt| & 30SUH28 & 100,00 & 159,77 & 124,01 & 37,00 & \begin{tabular}{ll|l|}
6870,03 \\
\end{tabular} & 354,71 & 25,01 & 329,70 & 88,82 & 252,06 & 252,06 & 76,10 & 525,57 & 72,21 & 3,41 & 52,07 & 186,35 & 27,45 & 27,45 & 180,92 \\
\hline Pleurodeles walt| & 30SUH29 & 100,00 & 159,68 & 123,59 & 37,00 & 6866,72 & 354,01 & 24,97 & 329,04 & 89,87 & 251,91 & 251,91 & 76,03 & $\begin{array}{l}509,45 \\
\end{array}$ & 69,12 & 3,47 & 51,26 & 178,71 & 27,92 & 27,92 & 173,23 \\
\hline Pleurodeles walt| & 30SUH31 & 100,00 & 159,11 & 123,50 & $\begin{array}{l}37,05 \\
\end{array}$ & 6820,64 & 352,68 & 25,53 & 327,15 & 88,65 & 250,72 & 250,72 & 76,22 & 643,77 & $\begin{array}{ll}93,65 \\
\end{array}$ & 3,54 & 57,47 & 246,45 & 25,46 & 25,46 & 239,30 \\
\hline Pleurodeles walt| & 30SUH32 & 100,00 & 156,88 & 123,97 & 37,00 & 6859,15 & 351,87 & 22,99 & 328,88 & 86,10 & 249,13 & 249,13 & 73,61 & $\begin{array}{l}635,38 \\
\end{array}$ & 92,01 & 3,77 & 56,51 & 240,96 & 26,70 & 26,70 & 233,23 \\
\hline Pleurodeles walt| & 30SUH33 & 100,00 & 155,03 & 124,15 & 37,00 & 6882,36 & 351,03 & 20,96 & 330,08 & 84,19 & 247,63 & 247,63 & 71,67 & 625,04 & 89,89 & 3,97 & 55,43 & 234,58 & 27,97 & 27,97 & 226,59 \\
\hline Pleurodeles walt| & 30SUH35 & 100,00 & 153,47 & 124,96 & 37,00 & 6914,82 & 350,41 & 18,82 & 331,59 & 82,61 & 246,64 & 246,64 & 69,85 & 595,47 & 84,36 & 4,00 & 53,71 & 218,63 & 29,03 & 29,03 & 210,82 \\
\hline Pleurodeles walt| & 30SUH36 & 100,00 & 156,80 & 124,81 & 37,00 & \begin{tabular}{|l|l|}
6903,97 \\
\end{tabular} & 353,21 & 21,85 & 331,37 & 86,01 & 249,63 & 249,63 & 72,98 & 566,97 & 79,78 & 3,86 & 53,20 & 205,78 & 28,44 & 28,44 & 198,61 \\
\hline Pleurodeles walt| & 30SUH37 & 100,00 & 158,19 & 124,25 & 37,00 & 6893,18 & 353,98 & 23,16 & 330,82 & 87,52 & 250,85 & 250,85 & 74,40 & 543,75 & 75,72 & 3,51 & 52,56 & 194,90 & 27,77 & 27,77 & 188,42 \\
\hline Pleurodeles walt| & 30SUH38 & 100,00 & 160,64 & 124,02 & 37,00 & $\begin{array}{l}6885,64 \\
\end{array}$ & 355,60 & 25,47 & 330,13 & 89,97 & 253,13 & 253,13 & 76,72 & 517,02 & 71,21 & 3,28 & 52,03 & 182,91 & 26,94 & 26,94 & 177,24 \\
\hline Pleurodeles walt| & 30SUH39 & 100,00 & 155,94 & 124,00 & 37,00 & 6899,70 & 351,46 & 21,01 & 330,45 & 85,36 & 248,87 & 248,87 & 72,04 & 516,53 & 69,93 & 3,90 & 50,60 & $\begin{array}{l}179,69 \\
\end{array}$ & 29,56 & 29,56 & 174,11 \\
\hline Pleurodeles walt| & $30 \mathrm{SUH} 40$ & 100,00 & 166,59 & 121,69 & 37,01 & 6766,19 & 356,73 & 33,38 & 323,35 & 96,41 & 257,32 & 257,32 & 83,97 & $\begin{array}{l}627,45 \\
\end{array}$ & 92,90 & 3,00 & 58,99 & 243,12 & 22,05 & 22,05 & 235,93 \\
\hline Pleurodeles walt| & $30 \mathrm{SUH} 41$ & 100,00 & 163,68 & 122,52 & 37,00 & 6815,77 & 355,97 & 29,91 & 326,06 & 93,17 & 255,18 & 255,18 & 80,68 & \begin{tabular}{|l|l|}
621,48 \\
\end{tabular} & 91,61 & 3,31 & 57,85 & 238,69 & 23,62 & 23,62 & 230,69 \\
\hline Pleurodeles walt| & $30 \mathrm{SUH} 4$ & 100,00 & 159,93 & 123,20 & 37,00 & 6866,91 & 354,13 & 25,70 & 328,43 & 88,95 & 252,18 & 252,18 & 76,42 & 618,63 & 90,50 & 3,56 & 56,64 & 235,22 & 25,44 & 25,44 & 226,66 \\
\hline Pleurodeles walt| & 30SUH44 & 100,00 & 151,10 & 124,14 & 37,00 & 6935,14 & 348,41 & 16,70 & 331,71 & 79,95 & 244,71 & 244,71 & 67,39 & 613,34 & 87,64 & 4,10 & 53,95 & 227,34 & 29,66 & 29,66 & 218,34 \\
\hline Pleurodeles walt| & 30SUH47 & 100,00 & 156,62 & 124,50 & 37,00 & 6912,72 & 352,90 & 21,42 & 331,48 & 85,87 & 249,65 & 249,65 & 72,71 & 541,91 & 75,45 & 3,73 & 52,08 & \begin{tabular}{|l|l|}
193,57 \\
\end{tabular} & 28,44 & 28,44 & 186,43 \\
\hline |Pleurodeles walt| & 30SUH49 & 100,00 & 156,20 & 124,03 & 37,00 & 6904,72 & 351,85 & 21,02 & 330,83 & 85,84 & 249,25 & 249,25 & 72, & 508,38 & 68,64 & 3,86 & 50,16 & 176,05 & 29,40 & 29,40 & 170,30 \\
\hline Pleurodeles walt| & 30SUH54 & 100, & 150,88 & 123,99 & 37,00 & 6938,76 & 347 & 16,38 & 331,58 & 79,54 & 244,46 & 244,46 & 67,07 & 605,83 & 86,74 & $4,4,4$ & 53,43 & 224,08 & 30,25 & 30,25 & 214 \\
\hline Pleurodeles walt| & 30SUH56 & 100,00 & 156,92 & 124,19 & 37,00 & 6927,64 & 353,20 & 21,55 & 331,65 & 85,88 & 250,18 & 250,18 & 72,80 & 550,41 & 77,53 & 3,89 & 52,44 & 198,71 & 28,34 & 28,34 & 190,68 \\
\hline Pleurodeles walt| & 30SUH57 & 100,00 & 151,04 & $\begin{array}{ll}124,89 \\
\end{array}$ & 37,00 & 6933,85 & 348,32 & 15,91 & 332,42 & 80,23 & 244,52 & 244,52 & 67,21 & 552,66 & 76,26 & 4,34 & 50,95 & 195,91 & 31,15 & 31,15 & 188,14 \\
\hline Pleurodeles walt| & 30SUH58 & 100,00 & 155,92 & 124,62 & 37,00 & \begin{tabular}{ll|}
6916,51 \\
\end{tabular} & 352,13 & 20,50 & 331,63 & 87,59 & 249,11 & 249,11 & 72,13 & 518,13 & 70,77 & 3,93 & 50,58 & 181,39 & 29,22 & 29,22 & 174,72 \\
\hline Pleuroc & $30 \mathrm{SUH}$ & 100,00 & 153, & 123,98 & \begin{tabular}{|l|l|}
37,00 \\
\end{tabular} & 6938,73 & 350,60 & 19,02 & 31,58 & 82,97 & 24 & 24 & 69, & 568,39 & 80,88 & 03 & 52,71 & 207,44 & 29,00 & 29,00 & 19 \\
\hline Pleurodeles walt| & 30SUH66 & 100,00 & 147,75 & 124,62 & 37,00 & 6951,08 & 345,61 & 13,05 & 332,56 & 78,56 & 241,74 & 241,74 & 64,00 & 573,10 & 79,68 & 4,80 & 50,88 & 204,96 & 32,71 & 32,71 & 195,86 \\
\hline Pleurodeles walt| & 30SUH71 & 100,00 & 173,71 & 117,85 & 36,75 & 6743,01 & 359,66 & 42,01 & 317,65 & 103,97 & 264,08 & 264,08 & 91,19 & 550,19 & 81,64 & 2,86 & 57,58 & 211,40 & 20,33 & 20,33 & 203,06 \\
\hline
\end{tabular}




\begin{tabular}{|c|c|c|c|c|c|c|c|c|c|c|c|c|c|c|c|c|c|c|c|c|c|}
\hline TAXON & UTM & $\mathrm{km} 2$ & B101 & B102 & $\mathrm{BIO3}$ & 8104 & B105 & B106 & B107 & B108 & B109 & B1010 & B1011 & BIO12 & B1013 & BIO14 & BIO15 & B1016 & B1017 & BIO18 & B1019 \\
\hline Pleurodeles walt| & 30SUH74 & 100,00 & 151,78 & 123,02 & 37,00 & 6941,81 & 348,19 & 17,94 & 330,25 & 80,72 & 245,66 & 245,66 & 68,25 & 582,21 & 83,49 & 4,44 & 52,59 & 214,36 & 30,20 & 30,20 & 203,55 \\
\hline Pleurodeles walt| & 30 SUH75 & 100,00 & 148,38 & 123,98 & 37,00 & 6945,49 & 345,76 & 14,17 & 331,59 & 81,12 & 242,28 & 242,28 & 64,94 & 577,95 & 81,45 & 4,75 & 51,44 & 209,36 & 32,20 & 32,20 & 198,97 \\
\hline Pleurodeles walt| & 30SUH76 & 100,00 & 141,94 & 124,88 & 37,00 & 6962,21 & 340,69 & 7,44 & 333,25 & 90,01 & 236,19 & 236,19 & 58,53 & 583,66 & 80,33 & 5,47 & 49,59 & 208,01 & 35,86 & 35,86 & 197,16 \\
\hline Pleurodeles walt| & 30SUH77 & 100,00 & 147,90 & 125,00 & 37,00 & 6946,68 & 345,71 & 12,77 & 332,94 & 101,20 & 241,78 & 241,78 & 64,02 & 543,49 & 74,16 & 4,66 & 49,51 & 192,43 & 32,81 & 32,81 & 181,97 \\
\hline Pleurodeles walt| & 30SUH78 & 100,00 & 147,51 & 125,44 & 37,00 & \begin{tabular}{|l|l|}
6943,53 \\
\end{tabular} & 345,35 & 11,86 & 333,49 & 101,89 & 241,28 & 241,28 & 63,78 & 527,11 & 70,51 & 4,52 & 48,64 & 184,42 & 33,20 & 33,20 & 174,00 \\
\hline Pleurodeles walt| & 30SUH79 & 100,00 & 146,89 & 125,74 & 37,00 & 6936,43 & 344,63 & 10,99 & 333,64 & 126,48 & 240,77 & 240,77 & 63,22 & 511,78 & 67,01 & 4,52 & 47,64 & 178,23 & 33,67 & 33,67 & 166,41 \\
\hline Pleurodeles walt| & 30SUH82 & 100,00 & 158,93 & 119,88 & 36,38 & 6896,57 & 351,39 & 26,70 & 324,69 & 88,28 & 252,11 & 252,11 & 75,77 & 578,24 & 85,17 & 4,16 & 54,55 & 218,97 & 26,85 & 26,85 & 207,22 \\
\hline Pleurodeles waltl & 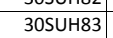 & 100,00 & 150,42 & 121,94 & 36,52 & 6952,54 & 346,31 & 17,11 & 329,19 & 79,19 & 244,50 & 244,50 & 66,77 & 593,26 & 85,86 & 4,98 & 52,75 & 220,49 & 31,11 & 31,11 & 208,25 \\
\hline Pleurodeles walt| & 30SUH84 & 100,00 & 154,04 & 122,48 & 36,91 & 6943,70 & 349,56 & 20,06 & 329,49 & 83,92 & 247,77 & 247,77 & 70,27 & 563,59 & 80,97 & 4,26 & 52,42 & 207,25 & 29,19 & 29,19 & 196,12 \\
\hline Pleurodeles walt| & 30SUH85 & 100,00 & 141,49 & 124,08 & 37,00 & 6965,81 & 339,93 & 7,69 & 332,24 & 91,04 & 235,90 & 235,90 & 58,33 & 591,33 & 82,19 & 5,76 & 49,85 & 213,17 & 36,21 & 36,21 & 200,69 \\
\hline Pleurodeles walt| & 30SUH86 & 100,00 & 145,59 & 124,74 & 37,00 & 6964,43 & 343,72 & 10,73 & 332,99 & 98,61 & 239,85 & 239,85 & 61,92 & 559,53 & 77,06 & 5,04 & 49,66 & 200,49 & 33,95 & 33,95 & 188,22 \\
\hline Pleurodeles walt| & 30SUH87 & 100,00 & 146,01 & 125,26 & 37,00 & 6949,86 & 344,13 & 10,88 & 333,25 & 99,38 & 240,03 & 240,03 & 62,22 & 539,66 & 72,92 & 4,84 & 48,75 & 191,20 & 33,88 & 33,88 & 179,09 \\
\hline Pleurodeles walt| & 30SUH88 & 100,00 & 144,92 & 125,94 & 37,00 & 6940,05 & 343,28 & $\begin{array}{l}, 27 \\
9,2\end{array}$ & 334,01 & 107,70 & 238,79 & 238,79 & 61,38 & 525,05 & 69,43 & 4,77 & 47,69 & 184,06 & 34,63 & 34,63 & 171,40 \\
\hline Pleurodeles walt| & 30SUH92 & 100,00 & 163,76 & 118,20 & $\begin{array}{l}36,05 \\
\end{array}$ & 6865,54 & 353,73 & 32,17 & 321,56 & 93,18 & 256,31 & 256,31 & 80,76 & 550,32 & 81,49 & 3,78 & 54,71 & 208,74 & 24,99 & 24,99 & 196,92 \\
\hline Pleurodeles walt| & 30SUH93 & 100,00 & 157,60 & 120,31 & 36,39 & 6920,18 & 350,89 & 25,01 & 325,88 & 91,03 & 251,12 & 251,12 & 74,21 & 557,10 & 81,35 & 4,24 & 53,21 & 207,95 & 27,88 & 27,88 & 195,62 \\
\hline Pleurodeles waltt & 30SUH97 & 100,00 & 146,86 & 125,39 & 37,00 & 6938,87 & 344,56 & 11,62 & 332,94 & 100,52 & 240,75 & 240,75 & 63,27 & 525,40 & 70,56 & 4,64 & 48,40 & 186,60 & 33,58 & 33,58 & 173,00 \\
\hline Pleurodeles walt| & 30SUH98 & 100,00 & 147,00 & 125,99 & 37,00 & 6930,67 & 344,96 & 11,24 & 333,72 & 118,62 & 240,77 & 240,77 & 63,63 & 505,15 & 66,19 & 4,32 & 47,51 & 177,79 & 33,52 & 33,52 & 163,80 \\
\hline Pleurodeles walt| & 30SUH99 & 100,00 & 146,58 & 126,61 & 37,44 & 6909,73 & 344,29 & 10,52 & 333,77 & 129,35 & 239,97 & 239,97 & 63,37 & 489,23 & 62,42 & 4,24 & 46,61 & 171,92 & 33,88 & 33,88 & 156,11 \\
\hline Pleurodeles walt| & 30SUJO0 & 100,00 & 159,71 & $\begin{array}{lll}122,47 \\
\end{array}$ & 37,00 & 6806,31 & 352,25 & 26,32 & 325,93 & 85,56 & 250,84 & 250,84 & 76,86 & 505,27 & 67,58 & 3,79 & 50,66 & 178,87 & 29,16 & 29,16 & 171,45 \\
\hline Pleurodeles walt| & 30SUJ01 & 100,00 & 160,82 & 121,92 & 37,00 & 6783,25 & 352,34 & 27,82 & 324,52 & 89,92 & 251,71 & 251,71 & 78,15 & 485,01 & 64,20 & 3,49 & 50,32 & 170,88 & 28,56 & 28,56 & 162,91 \\
\hline Pleurodeles walt| & 30SUJ02 & 100,00 & 159,36 & 121,10 & 37,00 & 6790,35 & 350,59 & 26,64 & 323,95 & 89,07 & 250,54 & 250,54 & 76,72 & 476,07 & 62,2 & 3,9 & 49,00 & 166,33 & 29,72 & 29,72 & 157,84 \\
\hline Pleurodeles walt| & $\begin{array}{l}30 \mathrm{suJ03} \\
\end{array}$ & 100,00 & 158,62 & 120,52 & 37,00 & 6769,54 & 348,91 & 26,27 & 322,64 & 99,67 & 249,47 & 249,47 & 76,11 & 465,44 & 60,16 & 3,94 & 48,21 & 161,70 & 30,25 & 30,25 & 152,66 \\
\hline Pleurodeles walt| & 30SUJ07 & 100,00 & 135,85 & 117,40 & \begin{tabular}{|l|l|}
36,73 \\
\end{tabular} & 6696,52 & 323,94 & 7,25 & 316,69 & 68,95 & 226,28 & 226,28 & 55,45 & 503,10 & 60,02 & 7,08 & 42,81 & 168,60 & 43,59 & 43,59 & 156,38 \\
\hline Pleurodeles waltt & 30SUJ08 & 100,00 & 137,04 & 116,82 & 36,70 & 6673,35 & 323,89 & 8,81 & 315,09 & 77,53 & 227,21 & 227,23 & 56,81 & 486,26 & 57,10 & 7,11 & 42,11 & 162,30 & 43,28 & 43,30 & 149,61 \\
\hline Pleurodeles walt| & 30SUJ10 & 100,00 & 160,25 & 122,95 & 37,00 & 6834,18 & 353,38 & 26,25 & 327,13 & 88,09 & 251,96 & 251,96 & 76,84 & 497,58 & 66,73 & 3,46 & 50,66 & 174,90 & 28,12 & 28,12 & 168,17 \\
\hline Pleurodeles walt| & 30SUJ11 & 100,00 & 157,28 & 122,27 & 37,00 & 6821,56 & 350,13 & 23,83 & 326,31 & 87,09 & 248,91 & 248,91 & 74,36 & 493,68 & 65,2 & 4,00 & 49,40 & 171,72 & 30,24 & 30,24 & 164,36 \\
\hline \begin{tabular}{|l|l|} 
Pleurodeles waltl \\
\end{tabular} & 30SUJ12 & 100,00 & 158,19 & 121,74 & 37,00 & 6812,73 & 350,10 & 25,05 & \begin{tabular}{|l|l|}
325,05 \\
\end{tabular} & \begin{tabular}{|c|}
103,86 \\
\end{tabular} & \begin{tabular}{|l|}
249,71 \\
\end{tabular} & \begin{tabular}{|l|}
249,71 \\
\end{tabular} & 75,26 & 474,85 & $\begin{array}{l}0,106 \\
61,96 \\
\end{array}$ & 3,89 & 48,81 & $\begin{array}{l}164,18 \\
164\end{array}$ & 29,88 & $\begin{array}{l}29,48 \\
29,88\end{array}$ & 156,28 \\
\hline Pleurodeles walt| & 30SUJ13 & 100,00 & 156,64 & 121,00 & 37,00 & 6801,50 & 347,80 & 23,78 & 324,02 & 105,67 & 248,01 & 248,01 & 73,92 & 465,89 & 59,87 & 4,12 & 47,67 & 160,01 & 31,00 & 31,00 & 151,35 \\
\hline Pleurodeles walt| & 30SUJ14 & 100,00 & 158,51 & 120,24 & 37,00 & 6776,48 & 348,22 & 25,77 & 322,45 & 113,71 & 249,50 & 249,50 & 75,81 & 446,28 & 56,61 & 4,03 & 47,15 & 153,15 & 30,48 & 30,48 & 143,51 \\
\hline Pleurodeles waltt & 30SUJ15 & 100,00 & 156,77 & 119,64 & 36,98 & 6758,22 & 345,78 & 24,61 & 321,17 & 114,42 & 247,55 & 247,55 & 74,36 & 439,26 & 54,84 & 4,23 & 46,27 & 149,96 & 31,43 & 31,43 & 139,35 \\
\hline Pleurodeles walt| & 30SUJ16 & 100,00 & 150,71 & 118,95 & 36,93 & 6750,22 & 339,48 & 19,53 & 319,95 & 112,31 & 241,65 & 241,65 & 68,87 & 447,62 & 54,79 & 4,97 & 44,69 & 150,97 & 34,73 & 34,73 & 139,90 \\
\hline \begin{tabular}{|l|} 
Pleurodeles waltl \\
\end{tabular} & \begin{tabular}{|l|}
30 SUI18 \\
\end{tabular} & 100,00 & 139,00 & 117,31 & 36,77 & 6694,77 & 326,16 & \begin{tabular}{|c|c|}
9,66 \\
9,50
\end{tabular} & 316,50 & \begin{tabular}{|l|l|l|l|l|l|}
112,17 \\
\end{tabular} & $\begin{array}{l}229,44 \\
22\end{array}$ & \begin{tabular}{|l|}
229,45 \\
\end{tabular} & 58,38 & \begin{tabular}{|l|l|}
467,38 \\
467
\end{tabular} & 54,50 & $\begin{array}{l}4,719 \\
6,79 \\
\end{array}$ & $\begin{array}{l}44,, 90 \\
41,90\end{array}$ & \begin{tabular}{|l|l|}
155,04 \\
\end{tabular} & $44,1,88$ & $\begin{array}{l}44,1,89 \\
4\end{array}$ & 141,82 \\
\hline Pleurodeles walt| & 30SUJ19 & 100,00 & 148,04 & 116,97 & \begin{tabular}{|l|l|}
36,97 \\
\end{tabular} & 6669,21 & 333,37 & 18,23 & 315,14 & 109,39 & 237,87 & 237,87 & 67,00 & 421,03 & 48,61 & 5,94 & 41,92 & 140,41 & 37,41 & 37,41 & 126,60 \\
\hline Pleurodeles walt| & 30 SUJ21 & 100,00 & 150,90 & 122,81 & 37,00 & 6860,03 & 345,34 & 17,14 & 328,20 & 83,00 & 243,38 & 243,38 & 67,96 & 511,42 & 67,13 & 4,54 & 48,50 & 175,59 & 32,87 & 32.87 & 168,88 \\
\hline Pleurodeles walt| & 30 SUJ 22 & 100,00 & 154,62 & 122,09 & 37,00 & 6835,34 & 347,53 & 20,91 & 326,62 & 106,33 & 246,51 & 246,51 & 71,58 & 481,43 & 62,50 & 4,12 & 48,03 & 164,49 & 31,29 & 31,29 & 157,19 \\
\hline Pleurodeles walt| & \begin{tabular}{|l|l|}
$30 \mathrm{SUJU} 23$ \\
\end{tabular} & 100,00 & 154,21 & 121,51 & 37,00 & 6828,54 & 346,38 & 21,01 & 325,37 & 117,96 & 246,11 & 246,11 & 71,29 & 468,02 & 59,81 & 4,23 & 47,12 & 159,10 & 31,90 & 31,90 & 150,66 \\
\hline \begin{tabular}{|l|} 
Pleurodeles waltl \\
\end{tabular} & 305UJ26 & 100,00 & $\begin{array}{l}13,21 \\
152,32\end{array}$ & $\begin{array}{l}121,21 \\
119,27\end{array}$ & 36,81 & 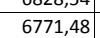 & $\begin{array}{l}340,30 \\
341,38 \\
\end{array}$ & $\begin{array}{l}1,00 \\
20,07 \\
\end{array}$ & \begin{tabular}{|l|}
$321,31,3$ \\
\end{tabular} & \begin{tabular}{|l|}
122,77 \\
\end{tabular} & $\begin{array}{l}\mid 240,11 \\
243,51\end{array}$ & \begin{tabular}{|l|}
243,511 \\
2431
\end{tabular} & $\begin{array}{l}71,29 \\
70,08\end{array}$ & 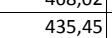 & \begin{tabular}{|c|}
3,201 \\
52,76
\end{tabular} & $\begin{array}{l}4,250 \\
4,90\end{array}$ & $\begin{array}{l}41,12 \\
44,36\end{array}$ & \begin{tabular}{|l|}
146,68 \\
14,0
\end{tabular} & $\begin{array}{l}1,10 \\
34,10\end{array}$ & $\begin{array}{l}1,190 \\
34,10\end{array}$ & $\begin{array}{l}130,00 \\
134,77\end{array}$ \\
\hline Pleurodeles walt| & 30SUJ27 & 100,00 & 144,30 & 118,69 & 36,73 & 6749,11 & 333,08 & 13,26 & 319,82 & 127,03 & 235,39 & 235,39 & 62,75 & 450,37 & 53,29 & 5,94 & 42,70 & 150,73 & 38,40 & 38,40 & 136,93 \\
\hline Pleurodeles walt| & 30SUJ28 & 100,00 & 144,97 & 117,94 & 36,74 & 6718,73 & 332,18 & 14,32 & 317,86 & 127,65 & 235,58 & 235,58 & 63,70 & 436,21 & 50,57 & 6,14 & 41,94 & 145,34 & 38.68 & 38,68 & 130,82 \\
\hline Pleurodeles walt| & 30SUJ29 & 100,00 & 145,47 & 117,08 & 36,76 & 6683,31 & 331,32 & 15,28 & 316,03 & 122,78 & 235,70 & 235,70 & 64,65 & 422,31 & 48,16 & 6,32 & 41,13 & 140,39 & 38,88 & 38,88 & 124,91 \\
\hline Pleurodeles walt| & 30suJ31 & 100,00 & 150,96 & 123,14 & 37,00 & 6882,02 & 345,94 & 16,56 & 329,38 & 115,15 & 243,83 & 243,83 & 67,74 & 502,99 & 65,85 & 4,3 & 48,20 & 171,38 & 32,64 & 32,64 & 164,81 \\
\hline Pleurodeles walt| & 30SUJ32 & 100,00 & 151,82 & 122,74 & 37,00 & 6864,87 & 345,74 & 17,56 & 328,18 & 132,25 & \begin{tabular}{|l|}
244,360 \\
\end{tabular} & 244,36 & 68,72 & \begin{tabular}{|l|l|}
484,56 \\
\end{tabular} & | & 4,3 & 47,40 & $\begin{array}{l}164,73 \\
\end{array}$ & 32,69 & 32,69 & 156,66 \\
\hline Pleurodeles walt| & 30SUJ36 & 100,00 & 152,20 & 119,78 & 36,92 & 6784,40 & 341,57 & 19,43 & 322,15 & 134,07 & 243,51 & 243,51 & 69,69 & 428,59 & 51,38 & 4,99 & 43,87 & 144,37 & 34,22 & 34,22 & 131,29 \\
\hline Pleurodeles walt| & 30SUJ37 & 100,00 & 144,70 & 119,00 & 36,75 & 6775,17 & 333,91 & 12,81 & 321,10 & 128,67 & 236,24 & 236,24 & 62,83 & 441,99 & 51,74 & 5,98 & 42,35 & 148,48 & 38,34 & 38,34 & 132,89 \\
\hline Pleurodeles walt| & 30SUJ39 & 100,00 & 138,86 & 117,22 & 36,46 & 6705,00 & 325,71 & 8,61 & 317,10 & 122,84 & 229,62 & 229,62 & 58 & 437,96 & 50 & 7,14 & 40,21 & 146,02 & 42,50 & 42,50 & 127,45 \\
\hline \begin{tabular}{|l|} 
Pleurodeles walt| \\
\end{tabular} & 30 SUs40 & 100,00 & 152,11 & 124,00 & 37,00 & 6903,59 & 347,91 & $0,17,13$ & 330,78 & $\begin{array}{l}115,87 \\
115\end{array}$ & \begin{tabular}{|l|}
245,17 \\
\end{tabular} & \begin{tabular}{|l|}
245,17 \\
\end{tabular} & 68,48 & 506,47 & 67,03 & 4,2 & $\begin{array}{l}48,74 \\
48,74 \\
\end{array}$ & $\begin{array}{l}173,36< \\
173\end{array}$ & 31,73 & 31,73 & 166,86 \\
\hline Pleurodeles walt| & 30SUJ41 & 100,00 & 150,18 & 123,80 & 37,00 & 6888,35 & 345,62 & 15,44 & 330,18 & 133,39 & 243,10 & 243,10 & 66,82 & 497,24 & 64,62 & 4,46 & 47,59 & 170,07 & 32,98 & 32,98 & 161,42 \\
\hline Pleurodeles waltl & 30 SUJ42 & 100,00 & 146,07 & 123,11 & 37,00 & 6891,55 & 341,34 & 11,74 & 329,60 & 129,14 & 239,19 & 239,19 & 62,95 & 497,35 & 63,27 & 5,08 & 46,15 & 169,92 & 35,59 & 35,59 & 158,83 \\
\hline Pleurodeles waltt & 30SUJ43 & 100,00 & 145,44 & 122,64 & 37,00 & 6874,67 & 339,72 & 11,30 & 328,42 & 128,48 & 238,21 & 238,21 & 62,43 & 485,61 & 60,68 & 5,23 & 45,29 & 165,68 & 36,31 & 36,31 & 152,99 \\
\hline Pleurodeles waltl & 30 SUJ46 & 100,00 & 149,38 & 120,01 & 36,91 & 6803,76 & 339,39 & 16,32 & 323,06 & 133,49 & 241,15 & 241,15 & 66,78 & 431,73 & 51,15 & 5,34 & 43,24 & 146,16 & 35,74 & 35,74 & 130,47 \\
\hline \begin{tabular}{|l|} 
Pleurodeles waltl \\
\end{tabular} & \begin{tabular}{|l|}
$305 U J 47$ \\
3050
\end{tabular} & 100,00 & $\frac{149}{139}$ & 119,04 & $\begin{array}{l}30, \\
36,\end{array}$ & \begin{tabular}{|l}
6777,43 \\
\end{tabular} & 328,92 & $\frac{10,32}{7,78}$ & \begin{tabular}{|l|}
221,14 \\
321
\end{tabular} & \begin{tabular}{|l|}
122,71 \\
122,
\end{tabular} & \begin{tabular}{|l|}
231,06 \\
231
\end{tabular} & \begin{tabular}{|l|}
231,06 \\
231
\end{tabular} & $\begin{array}{l}\mid c 0,10 \\
57,63\end{array}$ & $\mid$\begin{tabular}{|l|}
456,81 \\
451
\end{tabular} & $\mid 52,81$ & $\begin{array}{l}0,344 \\
6,85\end{array}$ & $\begin{array}{l}43,24 \\
41,34\end{array}$ & \begin{tabular}{|l|}
$153,92,0$ \\
153
\end{tabular} & $\begin{array}{l}31,97 \\
41,97\end{array}$ & $\begin{array}{l}5,1,97 \\
41,97\end{array}$ & 135,41 \\
\hline Pleurodeles walt| & 30SUJ50 & 100,00 & 148,90 & 124,47 & 37,00 & 6917,34 & 345,44 & 13,79 & 331,64 & 128,63 & 242,25 & 242,25 & 65,34 & 509,58 & 66,83 & 4,47 & 47,94 & 175,40 & 33,10 & 33,10 & 166,39 \\
\hline Pleurodeles walt| & 30SUJ51 & 100,00 & 150,69 & 124,01 & $37,00 \mid$ & 6903,21 & 346,19 & 15,61 & 330,58 & 133,95 & 243,75 & 243,75 & $67,07 \mid$ & 486,99 & 62,77 & 4,30 & 47,21 & $\mid 167,55$ & 32.59 & 32.59 & 156,91 \\
\hline Pleurodeles waltl & 30SUJ52 & 100,00 & 147,69 & 123,67 & 37,00 & 6888,11 & 342,84 & 12,90 & 329,94 & 130,79 & 240,73 & 240,73 & 64,54 & 482,92 & 60,95 & 4,93 & 45,89 & 165,87 & 34,88 & 34,88 & 153,01 \\
\hline Pleurodeles waltl & 30SUJ53 & 100,00 & 149,64 & 122,92 & 37,00 & 6866,68 & 343,38 & 14,90 & 328,48 & 133,16 & 242, & 242 & 66,54 & 462,56 & 57,40 & 4,74 & 45,35 & 158,46 & 34,27 & 34,27 & 144 \\
\hline Pleurodeles walt| & 30 SUJ54 & 100,00 & 147,92 & 122,07 & 37,00 & 6864,75 & 340,99 & 13,44 & 327,55 & 131,67 & 240,57 & 240,57 & 64,81 & 455,88 & 55,47 & 5,07 & 44,39 & 155,87 & 35,52 & 35,52 & 140,57 \\
\hline Pleurodeles walt| & 30 SUJ55 & 100,00 & 146,73 & 121,31 & 37,00 & 6863,51 & 338,99 & 12,70 & 326,29 & 130,64 & 239,38 & 239,38 & 63,78 & 446,39 & 53,20 & 5,31 & 43,38 & 152,17 & 36,42 & 36,42 & 135,53 \\
\hline Pleurodeles walt| & 30SUJ56 & 100,00 & 144,03 & 120,42 & 36,71 & 6835,28 & 335,41 & 10,61 & 324,80 & 127,69 & 236,51 & 236,51 & 61,60 & 443,45 & 51,75 & 5,95 & 42,22 & 150,82 & 38,71 & 38,71 & 132,20 \\
\hline |Pleurodeles walt| & 30SUJ57 & 100,00 & 132,87 & 119,36 & 36,71 & 6787,24 & 323,47 & 1,64 & 321,84 & 115,81 & 224 & 224 & 51, & 473,97 & 54,74 & 7,79 & 40,19 & 160,11 & 46,02 & 46,03 & 138,46 \\
\hline Pleurodeles waltl & $30 \mathrm{SUJ} 58$ & 100,00 & 131,10 & 118,38 & 36,48 & 6761,15 & 320,51 & 0,67 & 319,85 & 114,06 & 222,93 & 222,93 & 50,26 & 467,69 & 54,66 & 8,25 & 39,29 & 157,42 & 47,50 & 47,50 & 134,38 \\
\hline
\end{tabular}




\begin{tabular}{|c|c|c|c|c|c|c|c|c|c|c|c|c|c|c|c|c|c|c|c|c|c|}
\hline TAXON & UTM & $\mathrm{km} 2$ & B101 & B102 & $\mathrm{BIO3}$ & BIO4 & B105 & B106 & B107 & B108 & B109 & B1010 & BIO11 & BIO12 & B1013 & BIO14 & BIO15 & BIO16 & B1017 & BIO18 & B1019 \\
\hline Pleurodeles walt| & 30SUJ59 & 100,00 & 139,33 & 117,47 & 36,02 & 6758,71 & 326,81 & 7,85 & 318,96 & 123,33 & 230,97 & 230,97 & 57,93 & 426,18 & 49,96 & 7,13 & 39,41 & 142,91 & 42,85 & 42,85 & 121,35 \\
\hline Pleurodeles walt| & 30SUJ60 & 100,00 & 144,95 & 125,02 & 37,00 & 6931,42 & 342,47 & 9,61 & 332,86 & 127,68 & 238,68 & 238,68 & 61,42 & 513,86 & 66,62 & 4,90 & 47,07 & \begin{tabular}{|l|l|}
177,92 \\
\end{tabular} & 35,18 & 35,18 & 165,95 \\
\hline Pleurodeles walt| & 30SUJ61 & 100,00 & 147,49 & 124,72 & 37,00 & 6918,40 & 343,85 & 11,91 & 331,94 & 130,79 & 240,96 & 240,96 & 63,70 & 489,01 & 62,27 & 4,62 & 46,51 & 169,13 & 34,19 & 34,19 & 155,95 \\
\hline Pleurodeles walt| & 30 SUJ62 & 100,00 & 149,63 & 123,97 & 37,00 & 6899,46 & 344,74 & 14,23 & 330,51 & 133,09 & 242,72 & 242,72 & 66,02 & 467,27 & 58,39 & 4,57 & 45,74 & \begin{tabular}{|l|l|}
161,13 \\
\end{tabular} & 33,77 & 33,77 & 147,07 \\
\hline Pleurodeles walt| & $30 \mathrm{SUJ} 63$ & 100,00 & 145,25 & 123,52 & 37,00 & 6890,92 & 340,28 & 10,49 & 329,79 & 128,27 & 238,45 & 238,45 & 62,09 & 469,25 & 57,34 & 5,25 & 44,38 & \begin{tabular}{|l|l|}
161,49 \\
\end{tabular} & 36,57 & 36,57 & 145,12 \\
\hline Pleurodeles walt| & 30SUJ64 & 100,00 & 145,08 & 122,74 & 37,00 & 6870,34 & 338,94 & 10,49 & 328,45 & 128,49 & 238,01 & 238,01 & 62,12 & 457,61 & 54,77 & 5,32 & 43,57 & \begin{tabular}{|l|l|}
157,08 \\
\end{tabular} & 37,04 & 37,04 & 139,56 \\
\hline Pleurodeles walt| & 30SUJ65 & 100,00 & 141,45 & 121,91 & 36,99 & 6863,46 & 334,63 & 7,48 & 327,16 & 124,84 & 234,37 & 234,37 & 58,69 & 459,14 & 53,75 & 5,96 & 42,35 & 157,07 & 39,61 & 39,61 & 137,65 \\
\hline Pleurodeles waltl & \begin{tabular}{|l|}
$305 U J 66$ \\
\end{tabular} & 100,00 & 138,87 & 120,82 & 36,84 & 6853,41 & 330,98 & 5,46 & 325,52 & 122,02 & 231,64 & 231,64 & 56,39 & 456,53 & 52,59 & 6,61 & 41,24 & 155,54 & 41,78 & 41,78 & 134,68 \\
\hline Pleurodeles walt| & 30SUJ67 & 100,00 & 133,27 & 119,57 & $\begin{array}{l}36,55 \\
\end{array}$ & 6810,94 & 324,28 & 1,23 & 323,05 & 116,30 & 225,70 & 225,72 & 51,75 & 467,28 & 54,22 & 7,76 & 39,82 & \begin{tabular}{|c|}
158,18 \\
\end{tabular} & 45,99 & 46,01 & 135,44 \\
\hline Pleurodeles walt| & 30SUJ68 & 100,00 & 127,92 & 118,44 & 36,46 & 6771,95 & 317,75 & $-2,49$ & 320,25 & 110,53 & 220,03 & 220,03 & 47,24 & 475,21 & 56,03 & 8,85 & 38,49 & 160,12 & 49,94 & 49,94 & 135,27 \\
\hline Pleurodeles walt| & 30SUJ70 & 100,00 & 149,86 & 125,35 & 37,00 & 6926,91 & 346,50 & 13,57 & 332,92 & 133,03 & 243,32 & 243,32 & 66,07 & 485,27 & 62,41 & 4,04 & 47,35 & 168,93 & 32,20 & 32,20 & 156,07 \\
\hline Pleurodeles walt| & 30SUJ71 & 100,00 & 150,08 & 125,08 & 37,00 & 6909,14 & 346,05 & 13,92 & 332,12 & 133,77 & 243,34 & 243,34 & 66,37 & 469,68 & 59,18 & 4,21 & 46,36 & 163,15 & 32,79 & 32,79 & 148,78 \\
\hline Pleurodeles walt| & 30SUJ72 & 100,00 & 144,93 & 124,86 & 37,00 & 6910,35 & 341,01 & 9,19 & 331,82 & 128,45 & 238,29 & 238,29 & 61,42 & 474,52 & 58,32 & 4,97 & 44,83 & 164,41 & 36,07 & 36,07 & 147,54 \\
\hline Pleurodeles walt| & 30SUJ73 & 100,00 & 140,36 & 124,17 & 37,00 & 6901,19 & 336,28 & 5,26 & 331,02 & 123,41 & 233,78 & 233,78 & 57,29 & 478,84 & 57,47 & 5,66 & 43,40 & \begin{tabular}{|l|l|}
165,37 \\
\end{tabular} & 39,18 & 39,18 & 146,33 \\
\hline Pleurodeles walt| & 30SUJ74 & 100,00 & 143,51 & 123,26 & 37,00 & 6884,85 & 337,84 & 8,47 & 329,36 & 126,77 & 236,64 & 236,64 & 60,49 & 455,14 & 53,60 & 5,38 & 42,92 & 156,66 & 37,91 & 37,91 & 137,36 \\
\hline Pleurodeles waltt & 30SUJ75 & 100,00 & 140,25 & 122,33 & 37,00 & 6876,04 & 333,81 & 5,96 & 327,85 & 123,67 & 233,36 & 233,36 & 57,40 & 456,66 & 52,75 & 6,19 & 41,78 & 156,56 & 40,66 & 40,66 & 135,52 \\
\hline Pleurodeles walt| & 30SUJ76 & 100,00 & 131,62 & 121,11 & 36,99 & 6845,36 & 324,71 & $-0,64$ & 325,36 & 114,22 & 224,64 & 224,64 & 49,95 & 478,72 & 55,45 & 7,72 & 40,05 & 163,20 & 46,50 & 46,50 & 139,57 \\
\hline Pleurodeles walt| & 30SUJ78 & 100,00 & 129,47 & 118,53 & 36,27 & 6797,85 & 319,50 & $-1,77$ & 321,27 & 112,44 & 221,84 & 221,86 & 48,38 & 467,19 & 55,19 & 8,76 & 38,21 & 157,42 & 49,51 & 49,52 & 132,25 \\
\hline Pleurodeles walt| & 30SUJ79 & 100,00 & 140,64 & 117,26 & 36,00 & 6813,01 & 328,23 & 8,23 & 319,99 & 124,71 & 232,97 & 232,97 & 58,34 & 417,31 & 49,25 & 7,44 & 38,68 & \begin{tabular}{|l|l|}
139,88 \\
\end{tabular} & 43,10 & 43,10 & 117,30 \\
\hline Pleurodeles walt| & 30SUJ80 & 100,00 & 146,51 & 126,21 & $\begin{array}{l}37,15 \\
\end{array}$ & 6912,49 & 343,98 & 10,46 & 333,52 & 129,46 & 240,11 & 240,11 & 63,38 & 484,96 & 61,28 & 4,30 & 46,40 & \begin{tabular}{|l|l|}
169,49 \\
\end{tabular} & 34,09 & 34,09 & 153,91 \\
\hline Pleurodeles walt| & 30SUJ81 & 100,00 & 146,86 & 125,88 & 37,04 & 6901,70 & 343,59 & 10,77 & 332,83 & 130,04 & 240,18 & 240,18 & 63,61 & 470,88 & 58,3 & 4,47 & 45,48 & 164,25 & 34,40 & 34,40 & 147,42 \\
\hline Pleurodeles waltt & 30SUJ82 & 100,00 & 142,16 & 125,58 & 37,00 & 6902,37 & 338,97 & 6,55 & 332,42 & 125,21 & 235,64 & 235,64 & 59,16 & 475,08 & 57,40 & 5,16 & 44,01 & 165,12 & 37,56 & 37,56 & 146,14 \\
\hline Pleurodeles walt| & 30SUJ84 & 100,00 & 147,10 & 123,58 & 37,00 & \begin{tabular}{ll|l|}
6891,58 \\
\end{tabular} & 341,06 & 11,29 & 329,77 & 130,97 & 240,20 & 240,20 & 63,63 & 435,05 & 50,60 & 5,04 & 43,12 & $\begin{array}{ll}150,06 \\
\end{array}$ & 36,03 & 36,03 & 130,50 \\
\hline Pleurodeles waltt & 30SUJ85 & 100,00 & 139,86 & 122,68 & 37,00 & 6883,90 & 333,48 & 5,15 & 328,33 & 123,22 & 233,10 & 233,10 & 57,01 & 452,03 & 52,22 & 6,18 & 41,36 & 154,99 & 41,14 & 41,14 & 133,15 \\
\hline Pleurodeles walt| & 30SUJ86 & 100,00 & 139,18 & 121,51 & 37,00 & 6872,99 & 331,72 & 5,03 & 326,69 & 122,69 & 232,32 & 232,32 & 56,42 & 445,18 & 51,66 & 6,55 & 40,38 & $\begin{array}{ll}151,85 \\
\end{array}$ & 42,23 & 42,23 & 129,33 \\
\hline Pleurodeles walt| & 30SUJ87 & 100,00 & 128,53 & 120,22 & 36,90 & 6825,34 & 320,44 & $-3,11$ & 323,55 & 111,06 & 221,42 & 221,42 & 47,25 & 476,95 & 56, & 8,54 & 38,63 & 161,68 & 49,58 & 49,58 & 136,07 \\
\hline \begin{tabular}{|l|l|} 
Pleurodeles waltl \\
\end{tabular} & 30SUנ88 & 100,00 & 137,01 & 118,73 & 36,06 & 6843,51 & 326,82 & $\begin{array}{l}3,14 \\
3,88 \\
\end{array}$ & 322,94 & 120,65 & $\begin{array}{l}229,86 \\
228\end{array}$ & 229,86 & 54,64 & 436,48 & 51,38 & $\begin{array}{l}7,64 \\
7,67\end{array}$ & 38,58 & $\begin{array}{l}147,06 \\
\end{array}$ & \begin{tabular}{|l|l|}
45,13 \\
\end{tabular} & 45,13 & 123,42 \\
\hline Pleurodeles walt| & 30SUJ89 & 100,00 & 141,21 & 117,18 & 36,00 & 6841,64 & 328,87 & 8,27 & 320,60 & 125,26 & 233,80 & 233,80 & 58,44 & 415,03 & 48,84 & 7,40 & 38,23 & 138,75 & 43,40 & 43,40 & 116,36 \\
\hline Pleurodeles walt| & 30SUJ90 & 100,00 & 147,43 & 126,93 & 37,81 & 6900,37 & 344,48 & 11,01 & 333,48 & 130,56 & 240,56 & 240,56 & 64,01 & 470,35 & 58,48 & 4,19 & 45,79 & 164,89 & 33,69 & 33,69 & 147,89 \\
\hline Pleurodeles waltt & 30SUJ91 & 100,00 & 147,66 & 126,60 & 37,53 & 6892,61 & 344,21 & 11,08 & 333,13 & 131,09 & 240,71 & 240,71 & 64,23 & 455,62 & 55,28 & 4,29 & 45,06 & 159,29 & 33,96 & 33,96 & 141,21 \\
\hline Pleurodeles walt| & 30SUJ92 & 100,00 & 146,89 & 126,23 & 37,28 & 6888,05 & 342,90 & 10,26 & 332,64 & 130,50 & 239,83 & 239,83 & 63,38 & 447,19 & 53,12 & 4,36 & 44,15 & 155,79 & 34,83 & 34,83 & 136,70 \\
\hline \begin{tabular}{|l|} 
Pleurodeles waltl \\
\end{tabular} & 30SUJ94 & 100,00 & $\begin{array}{l}144,67 \\
144,67\end{array}$ & 124,35 & 37,00 & $\begin{array}{ll}68081,74 \\
6810\end{array}$ & 339,03 & \begin{tabular}{|l|l|}
0,86 \\
8,8
\end{tabular} & \begin{tabular}{|l|}
330,17 \\
3
\end{tabular} & 128,28 & \begin{tabular}{|l|}
237,71 \\
231
\end{tabular} & \begin{tabular}{|l|}
237,71 \\
231
\end{tabular} & $\begin{array}{ll}61,62 \\
61,6\end{array}$ & \begin{tabular}{|l|l|}
436,28 \\
\end{tabular} & $\begin{array}{l}50,80 \\
50\end{array}$ & 5,20 & 42,51 & 150,51 & $\begin{array}{l}4,00 \\
37,62\end{array}$ & $\begin{array}{l}37,05 \\
37,62\end{array}$ & 129,38 \\
\hline Pleurodeles walt| & 30SUJ95 & 100,00 & 136,17 & 123,12 & 37,00 & 6876,93 & 330,38 & 1,78 & 328,60 & 119,18 & 229,47 & 229,47 & 53,59 & 460,05 & 53,51 & 6,70 & 40,60 & 157,81 & 43,56 & 43,56 & 134,31 \\
\hline Pleurodeles walt| & 30SUJ96 & 100,00 & 140,58 & 121,71 & 36,98 & 6881,84 & 332,97 & 5,60 & 327,37 & 124,21 & 233,66 & 233,66 & 57,52 & 435,73 & 50,77 & 6,36 & 40,32 & 148,64 & 41,68 & 41,68 & 125,90 \\
\hline Pleurodeles walt| & 30SUJ97 & 100,00 & 132,15 & 120,44 & 36,84 & 6851,92 & 324,03 & $-0,53$ & 324,56 & 115,20 & 225,31 & 225,31 & 50,23 & 460,33 & 54,11 & 8,08 & 38,49 & 155,84 & 47,81 & 47,81 & 130,91 \\
\hline Pleurodeles walt| & 30SUJ98 & 100,00 & 131,73 & 118,86 & 36,18 & 6842,66 & 322,13 & $-0,47$ & 322,60 & 114,83 & 224,72 & 224,73 & 49,97 & 454,45 & 53,69 & 8,53 & 37,87 & 152,77 & 48,75 & 48,75 & 127,88 \\
\hline Pleurodeles walt| & 30SUKO0 & 100,00 & 154,22 & 116,00 & 36,98 & 6606,87 & 336,84 & 25,18 & 311,66 & 111,86 & 242,90 & 242,90 & 73,32 & 397,89 & 46,22 & 5,18 & 42,40 & 134,44 & 34,42 & 34,42 & 120,55 \\
\hline Pleurodeles walt| & 30SUK01 & 100,00 & 154,70 & 115,56 & 37,00 & 6570,73 & 335,95 & 26,02 & 309,94 & 112,48 & 242,89 & 242,89 & 74,18 & 386,27 & 44,60 & 5,27 & 41,76 & \begin{tabular}{|l|l|}
130,38 \\
\end{tabular} & 34,47 & 34,47 & 115,88 \\
\hline Pleurodeles walt| & 30SUK02 & 100,00 & 157,32 & 115,00 & 37,00 & 6535,01 & 336,74 & 28,77 & 307,97 & 115,01 & 244,70 & 244,70 & 76,95 & 368,51 & 42,81 & 5,00 & 41,51 & 125,01 & 33,47 & 33,47 & 109,88 \\
\hline Pleurodeles waltl & 30SUK10 & 100,00 & 155,03 & 116,19 & 36,88 & 6631,04 & 337,90 & 25,12 & 312,77 & 112,80 & 243,99 & 243,99 & 73,90 & 387,96 & 44,67 & 5,10 & 41,97 & 130,74 & 33,97 & 33,97 & 116,10 \\
\hline Pleurodeles walt| & $\begin{array}{l}30 \text { SUK11 } \\
\end{array}$ & 100,00 & 154,99 & 115,95 & 37,00 & 6596,19 & 336,55 & 25,81 & 310,74 & 112,56 & 243,61 & 243,61 & 74,08 & 378,55 & 43,34 & 5,32 & 41,05 & 127,47 & 34,37 & 34,37 & 111,92 \\
\hline Pleurodeles walt| & 30SUK12 & 100,00 & 155,81 & 115,07 & 37,00 & 6556,55 & 335,75 & 26,94 & 308,82 & 113,23 & \begin{tabular}{|l|}
243,57 \\
\end{tabular} & \begin{tabular}{|l|}
243,57 \\
\end{tabular} & 75,22 & 366,27 & 42,02 & 5,35 & $\begin{array}{l}1,0,46 \\
4\end{array}$ & 123,19 & 34,38 & 34,38 & 107,31 \\
\hline Pleurodeles walt| & 30 SUK20 & 100,00 & 152,34 & 116,41 & 36,72 & 6656,78 & 335,88 & 21,83 & 314,05 & 112,85 & 241,70 & 241,70 & 71,10 & 389,60 & 44,33 & 5,61 & 41,33 & 130,12 & 35,49 & 35,49 & 114,67 \\
\hline Pleurodeles walt| & 30 SUK21 & 100,00 & 154,40 & 115,95 & 36,93 & 6627,13 & 336,39 & 24,47 & 311,92 & 111,71 & 243,48 & 243,48 & 73,37 & 373,45 & 42,32 & 5,56 & 40,64 & \begin{tabular}{|l|l|}
125,13 \\
\end{tabular} & 34,54 & 34,54 & 109,02 \\
\hline Pleurodeles walt| & 30 SUK22 & 100,00 & 153,51 & 115,03 & 36,75 & 6590,10 & 334,04 & 24,14 & 309,90 & 110,88 & 241,71 & 241,71 & 72,60 & 366,62 & 41,8 & 6,00 & 40,20 & \begin{tabular}{|l|l|}
122,49 \\
\end{tabular} & 35,40 & 35,40 & 105,70 \\
\hline \begin{tabular}{|l|} 
Pleurodeles walt| \\
\end{tabular} & 305UK30 & 100,00 & 150,69 & 116,42 & 36,44 & 6677,44 & 334,5 & \begin{tabular}{|l|l|}
19,78 \\
\end{tabular} & 314,74 & $\begin{array}{l}120,12 \\
120\end{array}$ & 240,44 & 240,44 & 69,27 & 389,56 & $\begin{array}{l}44,33 \\
44,5\end{array}$ & 5,99 & $\begin{array}{l}0,20 \\
40,58 \\
\end{array}$ & $\begin{array}{l}129,62 \\
129,62\end{array}$ & 36,67 & 36,67 & 113,05 \\
\hline Pleurodeles walt| & 30 SUK31 & 100,00 & 154,50 & 115,69 & 36,49 & 6643,90 & 336,36 & 23,79 & 312,57 & 113,64 & 243,60 & 243,60 & 73,10 & 368,84 & 41,88 & 5,61 & 40,27 & 123,02 & 35,06 & 35,06 & 106,35 \\
\hline Pleurodeles waltl & 30SUK32 & 100,00 & 151,96 & 115,00 & 36,26 & 6621,24 & 332,95 & 22,09 & 310,85 & 111,36 & 240,81 & 240,81 & 70,95 & 366,31 & 42,20 & 6,19 & 39,38 & 121,68 & 36,48 & 36,48 & 104,07 \\
\hline Pleurodeles waltt & 30SUK41 & 100,00 & 148,86 & 115,56 & 36,17 & 6671,69 & 331,60 & 18,05 & 313,56 & 126,31 & 238,56 & 238,56 & 67,48 & 380,72 & 44,31 & 6,51 & 39,38 & 125,79 & 38,29 & 38,29 & 107,69 \\
\hline Pleurodeles waltl & 30SUK51 & 100,00 & 149,50 & 115,26 & 36,00 & 6702,48 & 332,43 & 18,28 & 314,14 & 128,10 & 239,76 & 239,76 & 67,73 & 376,64 & 43,95 & 6,52 & 38,94 & 124,28 & 38,22 & 38,22 & 105,82 \\
\hline \begin{tabular}{|l|} 
Pleurodeles waltl \\
\end{tabular} & 30SUK71 & 100,00 & $\begin{array}{l}14,51,97 \\
151\end{array}$ & $\begin{array}{l}111,20 \\
114,35\end{array}$ & 36,00 & 6764,18 & 334, & $\begin{array}{l}19,20 \\
19,86 \\
\end{array}$ & \begin{tabular}{|l|}
314,90 \\
314
\end{tabular} & $\begin{array}{l}123,22 \\
123,2\end{array}$ & 243,01 & \begin{tabular}{|l|}
243,01 \\
\end{tabular} & \begin{tabular}{|l|l|}
69,30 \\
\end{tabular} & \begin{tabular}{|l|}
369,58 \\
369
\end{tabular} & $\begin{array}{l}42,83 \\
42,84 \\
\end{array}$ & $\frac{6,52}{6,41}$ & \begin{tabular}{|l|l|}
38,61 \\
\end{tabular} & $\begin{array}{l}\mid 2,4,20 \\
121,71\end{array}$ & $\begin{array}{l}30,2< \\
37,82\end{array}$ & $\frac{30,24}{37,82}$ & $\begin{array}{l}103,02 \\
103,32\end{array}$ \\
\hline Pleurodeles walt| & 30SVF08 & 100,00 & 133,56 & 113,95 & 38,03 & 6023,94 & 304,68 & 10,38 & 294,30 & 71,01 & 215,36 & 215,38 & 62,47 & 616,68 & 84,16 & 7,03 & 55,93 & 246,27 & 32,40 & 32,95 & 237,63 \\
\hline Pleurodeles walt| & 30SVF09 & 100,00 & 136,99 & 115,65 & 38,00 & 6143,62 & 311,83 & 11,90 & 299,92 & 72,73 & 220,46 & 220,46 & 64,20 & 596,54 & 80,01 & 6.42 & 55,62 & 238,08 & 29,95 & 29,95 & 229,69 \\
\hline Pleurodeles waltl & 30SVF19 & 100,00 & 139,25 & 116,15 & 38,00 & 6168,30 & 314,74 & 13,34 & 301,40 & 74,45 & 223,03 & 223,03 & 65,97 & 561,14 & 75,10 & 6,36 & 54,89 & 222,64 & 28,74 & 28,74 & 214,12 \\
\hline Pleurodeles waltl & 30SVF39 & 100,00 & 131,54 & 119,18 & 38,00 & 6302,90 & 313,32 & 3,82 & 309,50 & 66,47 & 217,44 & 217,44 & 57,15 & 576,55 & 75,14 & 7,64 & 52,13 & 217,65 & 33,15 & 33,15 & 213 \\
\hline Pleurodeles walt| & 30SVG00 & 100,00 & 140,34 & 115,24 & 37,99 & 6202,73 & 315,66 & \begin{tabular}{|l|l|}
15,01 \\
1
\end{tabular} & 300,65 & 74,86 & 224,61 & 224,61 & 66,69 & 582,23 & 79,01 & 6,38 & 55,46 & 231,74 & 29,46 & 29,46 & 222,61 \\
\hline Pleurodeles waltt & 30SVG01 & 100,00 & 158,93 & 109,21 & 37,43 & 6048,53 & 323,79 & 36,26 & 287,53 & 93,18 & 240,85 & 240,85 & 86,47 & 493,41 & 72,84 & 4,53 & 57,51 & 204,53 & 22,43 & 22,43 & 190,89 \\
\hline Pleurodeles walt| & 30SVG10 & 100,00 & 146,56 & 114,97 & 37,99 & 6181,29 & 320,53 & 20,79 & 299,74 & 80,53 & 230,58 & 230,58 & 72,92 & 519,77 & 71,88 & 5,83 & 55,21 & 208,73 & 26,13 & 26,13 & 197,66 \\
\hline |Pleurodeles walt| & 30SVG12 & 100,00 & 149,03 & 114,67 & 37,13 & 6337,57 & 325,89 & 22,51 & 303,38 & 80,62 & 235,18 & 235, & 73, & 525,07 & 72,16 & 5,99 & 54 & 205,95 & 27,16 & 27,16 & 196,40 \\
\hline Pleurodeles waltl & 30SVG13 & 100,00 & 138,03 & 118,49 & 37,01 & 6573,18 & 324,53 & 9,28 & 315,26 & 68,87 & 227,57 & 227,57 & 60,05 & 604,05 & 78,08 & 7,40 & 53,03 & 225,93 & 32,95 & 32,95 & 222,81 \\
\hline
\end{tabular}




\begin{tabular}{|c|c|c|c|c|c|c|c|c|c|c|c|c|c|c|c|c|c|c|c|c|c|}
\hline TAXON & UTM & $\mathrm{km} 2$ & BIO1 & B102 & $B 103$ & BIO4 & B105 & B106 & B107 & B108 & B109 & B1010 & BIO11 & B1012 & B1013 & B1014 & BIO15 & B1016 & B1017 & B1018 & B1019 \\
\hline Pleurodeles walt| & 30SVG14 & 100,00 & 143,62 & 117,40 & 36,89 & 6630,32 & 330,15 & 14,90 & 315,25 & 75,28 & 233,90 & 233,90 & 64,83 & 589,65 & 77,39 & 6,85 & 53,37 & 220,12 & 31,00 & 31,00 & 217,41 \\
\hline Pleurodeles walt| & 30SVG17 & 100,00 & 157,83 & 112,85 & 35,48 & $\begin{array}{lll}6784,96 \\
\end{array}$ & 343,38 & 30,41 & 312,97 & 88,40 & 249,78 & 249,78 & 76,82 & \begin{tabular}{ll|}
581,42 \\
\end{tabular} & 85,36 & 5,54 & 55,32 & 226,36 & 27,17 & 27,17 & 214,31 \\
\hline Pleurodeles walt| & 30SVG22 & 100,00 & 153,52 & $\begin{array}{l}114,99 \\
\end{array}$ & 37,21 & 6338,62 & 330,23 & 26,31 & 303,92 & 84,42 & 239,78 & 239,78 & 77,80 & 473,18 & 65,41 & 5,45 & 54,03 & 185,84 & 24,53 & 24,53 & 175,09 \\
\hline Pleurodeles walt| & 30SVG23 & 100,00 & 143,48 & 118,29 & 37,00 & 6569,32 & 329,22 & 14,20 & 315,02 & 73,80 & 232,93 & 232,93 & 65,32 & 558,01 & 71,92 & 6,87 & 52,63 & 208,01 & 30,10 & 30,10 & 204,63 \\
\hline Pleurodeles walt| & 30SVG24 & 100,00 & 144,54 & 117,80 & $\begin{array}{l}36,96 \\
\end{array}$ & $\begin{array}{l}6647,62 \\
\end{array}$ & \begin{tabular}{|l|}
331,67 \\
\end{tabular} & 15,37 & 316,30 & 75,56 & 235,03 & 235,03 & 65,56 & 568,15 & 74,36 & 6,89 & 52,60 & 210,27 & 30,69 & 30,69 & 207,29 \\
\hline Pleurodeles walt| & 30SVG26 & 100,00 & 138,11 & 118,47 & $\begin{array}{l}36,35 \\
\end{array}$ & \begin{tabular}{|l|l|}
6793,43 \\
\end{tabular} & 329,70 & 8,59 & 321,11 & 69,51 & 230,62 & 230,62 & 57,78 & 620,03 & 85,90 & 8,01 & 51,60 & 230,96 & 36,29 & 36,29 & 221,40 \\
\hline 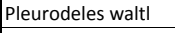 & 30SVG27 & 100,00 & 149,35 & 114,96 & 35,68 & 6835,44 & 338,37 & 21,04 & 317,34 & 80,48 & 242,35 & 242,35 & 68,20 & 594,90 & 86,50 & 6,71 & 53,41 & 227,54 & 31,52 & 31,52 & 214,63 \\
\hline Pleurodeles walt| & 30SVG28 & 100,00 & 167,47 & 109,58 & 35,04 & 6784,30 & 349,56 & 41,31 & 308,25 & 97,45 & 259,05 & 259,05 & 86,04 & 545,37 & 83,71 & 4,61 & 56,18 & 215,71 & 23,85 & 23,85 & 200,56 \\
\hline Pleurodeles walt| & 30SVG32 & 100,00 & 155,35 & 116,17 & \begin{tabular}{ll|}
37,27 \\
\end{tabular} & $\begin{array}{l}6367,30 \\
\end{array}$ & 333,48 & \begin{tabular}{|l|l}
27,03 \\
\end{tabular} & 306,45 & 86,06 & 241,90 & 241,90 & 79,03 & 449,20 & 60,94 & 5,31 & 53,20 & \begin{tabular}{|l|l|}
174,40 \\
\end{tabular} & 23,25 & 23,25 & 164,69 \\
\hline Pleurodeles walt| & 30SVG33 & 100,00 & 145,52 & 118,63 & 37,00 & 6567,88 & 331,36 & 15,78 & 315,57 & 76,20 & 235,00 & 235,00 & 67,37 & 530,49 & 68,97 & 6,75 & 52,08 & 196,18 & 29,18 & 29,18 & 192,47 \\
\hline Pleurodeles walt| & 30SVG41 & 100,00 & 153,30 & 119,43 & 37,94 & \begin{tabular}{|l|l|}
6373,83 \\
\end{tabular} & 334,49 & 23,04 & 311,45 & 85,31 & 239,83 & 239,83 & 76,87 & 453,80 & 62,06 & 5,21 & 53,01 & \begin{tabular}{|l|l|}
173,27 \\
\end{tabular} & 22,75 & 22,75 & 166,64 \\
\hline Pleurodeles walt| & 30SVG42 & 100,00 & 148,23 & 119,59 & 37,30 & \begin{tabular}{ll|l|}
6503,29 \\
\end{tabular} & 333,06 & 17,69 & 315,37 & 79,29 & 236,58 & 236,58 & 70,59 & \begin{tabular}{|l|l|}
494,17 \\
\end{tabular} & 65,33 & 6,06 & 52,03 & 182,97 & 26,45 & 26,45 & 179,08 \\
\hline Pleurodeles walt| & 30SVG43 & 100,00 & 147,47 & 119,11 & 37,00 & 6579,18 & 333,78 & 17,30 & 316,48 & 78,58 & 237,05 & 237,05 & 69,25 & 511,75 & 66,96 & 6,32 & 51,82 & 186,44 & 27,85 & 27,85 & 184,32 \\
\hline Pleurodeles walt| & 30SVG46 & 100,00 & 143,98 & 1117,51 & 36,36 & 6768,92 & 333,58 & 14,49 & 319,08 & 91,27 & 236,06 & 236,06 & 63,70 & $\begin{array}{l}566,46 \\
\end{array}$ & 78,63 & 7,38 & 50,98 & 209,87 & 33,53 & 33,53 & 199,33 \\
\hline Pleurodeles walt| & 30SVG47 & 100,00 & 147,62 & 116,10 & 35,98 & 6802,55 & 336,55 & \begin{tabular}{|l|l|}
18,67 \\
\end{tabular} & 317,88 & 93,94 & 239,99 & 239,99 & $\begin{array}{ll}66,83 \\
\end{array}$ & 562,77 & 80,08 & 6,99 & 51,40 & 211,26 & 32,76 & 32,76 & 197,56 \\
\hline Pleurodeles walt| & 30SVG48 & 100,00 & 160,46 & 112,17 & 35,26 & 6796,60 & 345,24 & 32,91 & 312,34 & 105,88 & 252,39 & 252,39 & 79,30 & 527,44 & 78,75 & 5,40 & 53,53 & 202,94 & 26,89 & 26,89 & 187,64 \\
\hline Pleurodeles walt| & 30SVG49 & 100,00 & 171,87 & 109,65 & 35,37 & 6671,28 & 350,31 & 45,36 & 304,95 & 114,53 & 261,52 & 261,52 & 91,38 & $\begin{array}{l}475,47 \\
\end{array}$ & 70,42 & 3,79 & 54,19 & \begin{tabular}{ll|}
181,92 \\
\end{tabular} & 21,97 & 21,97 & 169,90 \\
\hline Pleurodeles walt| & 30SVG57 & 100,00 & 119,51 & 121,43 & \begin{tabular}{|l|l|}
36,87 \\
\end{tabular} & 6806,40 & 314,62 & $-10,48$ & 325,10 & 69,97 & 212,57 & 212,58 & 40,06 & 653,93 & 86,56 & 11,92 & 45,99 & 235,78 & 51,76 & 51,94 & 217,53 \\
\hline Pleurodeles walt| & 30SVG58 & 100,00 & 148,94 & 115,90 & 36,12 & 6782,17 & 336,74 & 19,89 & 316,85 & 100,73 & 240,96 & 240,96 & 68,35 & $\begin{array}{l}539,85 \\
\end{array}$ & 76,30 & 6,80 & 50,24 & 201,74 & 32,99 & 32,99 & 185,82 \\
\hline Pleurodeles walt| & 30SVG61 & 100,00 & 112,41 & 121,28 & $\begin{array}{l}37,86 \\
\end{array}$ & 6532,90 & 301,90 & $-16,22$ & 318,13 & 62,72 & 201,56 & 201,79 & 36,41 & 659,49 & $82, \varepsilon$ & 12,84 & 46,09 & 233,59 & 52,19 & 55,75 & 224,71 \\
\hline Pleurodeles walt| & 30SVG97 & 100,00 & 154,25 & 113,49 & 36,99 & 6438,83 & 330,70 & 26,98 & 303,72 & 107,68 & 240,95 & 241,14 & 77,26 & $\begin{array}{l}434,65 \\
\end{array}$ & 55,14 & 5,55 & 46,94 & 154,05 & 29,32 & 33,38 & 142,86 \\
\hline Pleurodeles walt| & 30SVG98 & 100,00 & 138,54 & \begin{tabular}{ll|}
117,48 \\
\end{tabular} & 37,01 & 6605,31 & 323,07 & 9,57 & 313,50 & 90,52 & 227,97 & 228,16 & 60,40 & \begin{tabular}{|l|l|}
507,78 \\
\end{tabular} & 64,38 & 8,58 & 44,35 & 179,71 & 41,02 & 43,36 & 161,53 \\
\hline Pleurodeles walt| & 30SVG99 & 100,00 & 148,60 & 115,92 & 37,00 & 6562,74 & 329,82 & 20,00 & 309,82 & 101,51 & 237,17 & 237,29 & 70,40 & 463,21 & 59,05 & 6,64 & 45,31 & \begin{tabular}{|l|l|}
164,47 \\
\end{tabular} & 34,75 & 36,81 & 148,06 \\
\hline Pleurodeles walt| & 30SVH04 & 100,00 & 152,67 & 121,54 & 36,70 & 6943,12 & 347,59 & 19,47 & 328,12 & 105,63 & 246,53 & 246,53 & 69,13 & 547,43 & 78,34 & 4,60 & 51,14 & 202,35 & 30,55 & 30,55 & 187,44 \\
\hline Pleurodeles walt| & 30SVH06 & 100,00 & 152,24 & 123,95 & 37,00 & 6927,25 & 348,01 & 17,46 & 330,55 & 105,68 & 245,73 & 245,73 & $\begin{array}{l}68,59 \\
\end{array}$ & 511,84 & 70,05 & 4,21 & 49,41 & 184,61 & 30,80 & 30,80 & 170,22 \\
\hline Pleurodeles walt| & 30SVH07 & 100,00 & 145,28 & 125,58 & 37,04 & 6933,85 & 342,96 & 10,19 & 332,77 & 98,85 & 239,11 & 239,11 & 61,93 & 519,53 & 68,96 & 4,83 & 47,56 & 184,41 & 34,67 & 34,67 & 169,24 \\
\hline Pleurodeles walt| & 30SVH08 & 100,00 & 146,68 & 126,35 & 37,34 & 6917,47 & 344,27 & 10,82 & 333,44 & 123,90 & 240,12 & 240,12 & 63,49 & $\begin{array}{l}495,58 \\
\end{array}$ & 64,12 & 4,31 & 46,88 & \begin{tabular}{|l|l|}
175,07 \\
\end{tabular} & 33,86 & 33,86 & 159,05 \\
\hline Pleurodeles walt| & 30SVHO9 & 100,00 & 146,35 & 127,13 & \begin{tabular}{|c|}
37,87 \\
\end{tabular} & 6903,11 & 343,78 & $\begin{array}{ll}9,97 \\
\end{array}$ & 333,81 & 129,14 & 239,60 & 239,60 & 63,14 & 478,40 & 60,09 & 4,12 & 46,07 & 168,82 & 33,85 & 33,85 & 151,16 \\
\hline Pleurodeles walt| & 30SVH14 & 100,00 & 157,62 & 120,27 & 36,56 & 6901,44 & 350,06 & 24,96 & 325,10 & 110,93 & 250,79 & 250,79 & 74,49 & 518,31 & 74,11 & 4,22 & 51,24 & \begin{tabular}{|l|l|}
192,18 \\
\end{tabular} & 28,63 & 28,63 & 176,88 \\
\hline Pleurodeles walt| & 30SVH15 & 100,00 & 155,79 & 121,83 & 36,99 & 6898,91 & 349,23 & 22,23 & 327,01 & 109,29 & 248,88 & 248,88 & 72,53 & 506,77 & 70,68 & 4,16 & 50,15 & 185,38 & 29,49 & 29,49 & 170,10 \\
\hline Pleurodeles walt| & 30SVH16 & 100,00 & 151,04 & 123,69 & 37,00 & $\begin{array}{ll}6916,59 \\
\end{array}$ & 346,40 & 16,60 & 329,79 & 104,47 & 244,47 & 244,47 & 67,67 & 505,62 & 68,55 & 4,41 & 48,62 & 182,34 & 31,85 & 31,85 & 166,40 \\
\hline Pleurodeles walt| & 30SVH17 & 100,00 & 147,46 & 125,23 & 37,01 & 6913,02 & 344,08 & 12,32 & 331,76 & 104,38 & 240,95 & 240,95 & 64,36 & 499,75 & 65,82 & 4,52 & 47,34 & 177,79 & 33,55 & 33,55 & 161,52 \\
\hline Pleurodeles walt| & 30SVH18 & 100,00 & 141,26 & 126,56 & 37,49 & 6920,60 & 339,46 & 5,81 & 333,64 & 122,40 & 234,95 & 234,95 & 58,32 & 507,36 & 64,76 & 5,18 & 45,75 & $\begin{array}{l}179,45 \\
\end{array}$ & 37,25 & 37,25 & 160,72 \\
\hline Pleurodeles walt| & 30SVH19 & 100,00 & 143,09 & 127,54 & $\begin{array}{l}37,95 \\
\end{array}$ & \begin{tabular}{|l|l|}
6904,06 \\
\end{tabular} & 340,91 & 6,75 & 334,16 & \begin{tabular}{ll|}
125,67 \\
\end{tabular} & 236,47 & 236,47 & 60,09 & $\begin{array}{l}480,86 \\
\end{array}$ & 59,54 & 4,61 & 45,19 & \begin{tabular}{|l|l|}
169,93 \\
\end{tabular} & 35,97 & 35,97 & 150,17 \\
\hline Pleurodeles walt| & 30 SVH25 & 100,00 & 145,86 & 122,79 & \begin{tabular}{|l|l|}
36,97 \\
\end{tabular} & 6929,03 & 341,56 & 12,40 & 329,17 & 98,79 & 239,69 & 239,69 & 62,92 & 532,36 & 72,99 & 5,53 & 48,12 & 193,73 & 35,29 & 35,29 & 175,10 \\
\hline Pleurodeles walt| & 30 SVH26 & 100,00 & 149,29 & 123,54 & 37,00 & 6905,60 & 344,42 & 15,08 & 329,34 & 102,72 & 242,76 & 242,76 & 66,32 & 502,27 & 67,41 & 4,82 & 47,70 & 180,86 & 33,34 & 33,34 & 163,47 \\
\hline Pleurodeles walt| & 30SVH27 & 100,00 & 148,80 & 124,78 & \begin{tabular}{|l|}
37,01 \\
\end{tabular} & \begin{tabular}{|l|l|}
6891,23 \\
\end{tabular} & 344,31 & 13,92 & 330,39 & 109,97 & 241,93 & 241,93 & 65,91 & $\begin{array}{l}485,85 \\
\end{array}$ & 63,41 & 4,50 & 46,86 & 172,89 & 33,36 & 33,36 & 155,74 \\
\hline Pleurodeles walt| & $30 \mathrm{SVH} 29$ & 100,00 & 145,92 & 127,20 & \begin{tabular}{|l|l|}
37,97 \\
\end{tabular} & 6871,08 & 342,44 & 9,62 & 332,82 & 128,69 & 238,79 & 238,79 & 63,22 & 461,63 & 56,56 & 4,32 & 44,88 & 163,25 & 34,75 & 34,75 & 143,18 \\
\hline Pleurodeles walt| & 30SVH31 & 100,00 & 174,42 & 111,81 & \begin{tabular}{|l|l|}
35,97 \\
\end{tabular} & 6694,98 & 354,4 & 46,19 & 308,23 & 120,97 & 264,31 & 264,31 & 93,27 & \begin{tabular}{|l|l|}
464,98 \\
\end{tabular} & 68,30 & 3,05 & 54,04 & $\begin{array}{l}176,06 \\
\end{array}$ & 21,03 & 21,03 & 164,68 \\
\hline Pleurodeles walt| & 30 SVH 35 & 100,00 & 140,37 & 123,03 & 37,00 & 6930,83 & 336,74 & 7,07 & \begin{tabular}{|l|}
329,67 \\
\end{tabular} & 92,90 & 234,50 & 234,50 & 57,87 & 542,59 & 73,30 & 6,44 & 46,68 & 196,41 & 38,99 & 38,99 & 175,76 \\
\hline Pleurodeles walt| & 30SVH36 & 100,00 & 147,72 & 123,40 & 37,00 & 6898,34 & 342,58 & 13,64 & 328,94 & 101,11 & 241,08 & 241,08 & \begin{tabular}{ll|}
64,94 \\
\end{tabular} & $\begin{array}{l}497,93 \\
\end{array}$ & 66,21 & 5,07 & 46,86 & $\begin{array}{l}178,98 \\
\end{array}$ & 34,49 & 34,49 & 160,34 \\
\hline Pleurodeles walt| & 30SVH38 & 100,00 & 148,85 & 125,41 & \begin{tabular}{|l|l|}
37,41 \\
\end{tabular} & \begin{tabular}{|l|l|}
6858,53 \\
\end{tabular} & 343,64 & 13,66 & 329,98 & 131,73 & 241,52 & 241,52 & 66,19 & 460,18 & 57,72 & 4,16 & 45,48 & \begin{tabular}{|c|}
163,18 \\
\end{tabular} & $\begin{array}{l}33,46 \\
\end{array}$ & \begin{tabular}{|l|l|l|}
33,46 \\
\end{tabular} & 143,98 \\
\hline Pleurodeles walt| & 30SVH39 & 100,00 & 146,88 & 126,43 & \begin{tabular}{|l|l|}
37,87 \\
\end{tabular} & 6853,03 & 342,19 & 10,88 & 331,31 & 129,72 & 239,51 & 239,51 & 64,41 & 452,64 & 55,16 & 4,27 & 44,49 & 159,99 & 34,66 & 34,66 & 139,43 \\
\hline Pleurodeles walt| & $30 \mathrm{SVH} 40$ & 100,00 & 174,85 & 110,15 & 35,93 & 6627,02 & 352,0 & 47,89 & 304,14 & 122,42 & 263,74 & 263,74 & 94,66 & 450,93 & 65,43 & 3,17 & 53,62 & 170,19 & 20,72 & 20,72 & 159,75 \\
\hline Pleurodeles walt| & 30 SVH41 & 100,00 & 172,06 & 112,09 & 36,00 & 6687,70 & 352,28 & 43,94 & 308,34 & 125,90 & 261,96 & 261,96 & 91,14 & 458,41 & 66,63 & 3,46 & 52,76 & $\begin{array}{l}173,03 \\
\end{array}$ & 22,34 & 22,34 & 160,08 \\
\hline Pleurodeles walt| & 30SVH42 & 100,00 & 168,91 & 114,17 & 36,00 & $\begin{array}{l}6738,83 \\
\end{array}$ & 351,87 & 39,52 & 312,34 & 122,59 & 259,43 & 259,43 & 87,43 & $\begin{array}{l}461,65 \\
\end{array}$ & 66,40 & 3,64 & 51,84 & \begin{tabular}{ll|}
173,28 \\
\end{tabular} & 24,00 & 24,00 & 158,57 \\
\hline Pleurodeles walt| & 30SVH43 & 100,00 & 163,33 & \begin{tabular}{|l|l|}
116,73 \\
\end{tabular} & $\begin{array}{l}36,05 \\
\end{array}$ & $\begin{array}{l}6798,84 \\
\end{array}$ & \begin{tabular}{|l|}
349,91 \\
\end{tabular} & 32,62 & 317,29 & 116,79 & 254,96 & 254,96 & $\mid 81,34$ & $\mid \begin{array}{l}471,24 \\
\end{array}$ & 66,79 & \begin{tabular}{|c|c|}
4,03 \\
\end{tabular} & 50,53 & \begin{tabular}{|c|c|}
175,58 \\
\end{tabular} & 26,70 & 26,70 & 158,96 \\
\hline Pleurodeles walt| & $30 \mathrm{SVH} 44$ & 100,00 & 148,33 & 120,66 & 36,76 & 6890,83 & 341,28 & 15,92 & 325,37 & 100,84 & 241,58 & 241,58 & 65,94 & 515,72 & 70,99 & 5,67 & 47,88 & 189,17 & 34,67 & 34,67 & 168,88 \\
\hline Pleurodeles walt| & 30 SVH45 & 100,00 & 135,75 & 123,29 & 37,00 & 6915,99 & 332,29 & 3,01 & 329,29 & 87,90 & 229,84 & 229,84 & 53,68 & 550,14 & 72,97 & 7,40 & 45,32 & \begin{tabular}{|l|l|}
197,48 \\
\end{tabular} & 42,56 & 42,56 & 175,34 \\
\hline Pleurodeles walt| & $30 \mathrm{SVH} 46$ & 100,00 & 146,07 & 123,18 & 37,00 & 6878,33 & 340,31 & 12,33 & 327,98 & 99,86 & 239,18 & 239,18 & 63,76 & 494,85 & 65,02 & 5,43 & 45,99 & 177,10 & 36,01 & 36,01 & 157,28 \\
\hline Pleurodeles walt| & 30SVH47 & 100,00 & 145,99 & 124,14 & 37,00 & 6870,11 & 340,45 & 11,56 & 328,90 & 119,88 & 238,96 & 238,96 & 63,64 & 480,10 & 61,46 & 5,12 & 45,32 & \begin{tabular}{ll|}
170,58 \\
\end{tabular} & 36,08 & 36,08 & 150,46 \\
\hline Pleurodeles walt| & $30 \mathrm{SVH} 48$ & 100,00 & 146,49 & 124,96 & 37,16 & 6857,76 & 340,81 & 11,58 & 329,23 & 128,84 & 239,18 & 239,18 & 63,97 & 464,11 & 57,69 & 5,01 & 44,44 & 164,26 & 35,99 & 35,99 & 143,41 \\
\hline |Pleurodeles walt| & 30SVH49 & 100,00 & 147,50 & 125,45 & 37,46 & 6835,61 & 341,49 & 11,92 & 329,56 & 130,52 & 239,71 & 239,71 & 65,16 & 447,70 & 54,3 & 4,81 & 43,65 & 157,62 & 35,58 & 35,58 & 136,44 \\
\hline Pleurodeles walt| & $30 \mathrm{SVH}$ & 100 & 164 & 112,77 & 36, & 6714 & 346 & 36, & 310 & 117 & 255 & 25 & 84,05 & 475,58 & $68,54 \mid$ & $4,4,4$ & 51,68 & 179,36 & 25,53 & 25,53 & 16 \\
\hline Pleurodeles walt| & 30SVH52 & 100,00 & 170,28 & 113,68 & \begin{tabular}{l|l|l}
36,05 \\
\end{tabular} & $\begin{array}{ll}6664,14 \\
\end{array}$ & 350,71 & 41,16 & 309,55 & 124,24 & 259,68 & 259,68 & 89,45 & 436,84 & 61,14 & 3,31 & 50,87 & 161,84 & 23,39 & 23,39 & 148,33 \\
\hline Pleurodeles walt| & 30SVH53 & 100,00 & 163,20 & 116,49 & 36,24 & 6752,17 & 348,31 & 32,62 & 315,69 & 116,77 & 254,13 & 254,13 & 81,79 & 455,50 & 63,27 & 4,01 & 49,48 & 168,26 & 26,90 & 26,90 & 151,61 \\
\hline Pleurodeles walt| & 30SVH54 & 100,00 & 152,54 & 119,68 & 36,80 & 6830,84 & 342,73 & 20,42 & 322,31 & 105,50 & 244,79 & 244,79 & 70,64 & 485,61 & 65,96 & 5,25 & 47,56 & 177,26 & 32,77 & 32,77 & 157,69 \\
\hline Pleuroc & 30SVH56 & 100,00 & 144 & 122,97 & 37,00 & 864,75 & 3383 & 11,25 & 327,10 & 104 & 237,83 & 237 & & 490,56 & 63,53 & 5,96 & 45,01 & 174,62 & 37,62 & 37,62 & 153,92 \\
\hline Pleurodeles walt| & 30SVH57 & 100,00 & 146,16 & 123,48 & 37,01 & 6850,53 & 339,36 & 11,95 & 327,41 & 127,02 & 238,77 & 238,77 & 63, & 471,66 & 59,66 & 5,38 & 44,42 & 167,22 & 36,88 & 36,88 & 146,25 \\
\hline Pleurodeles walt| & 30SVH58 & 100,00 & 146,40 & 124,25 & 37,12 & 6837,86 & 339,53 & 11,86 & 327,67 & 128,63 & 238,77 & 238,77 & 64,06 & 458,37 & 56,50 & 5,18 & 43,79 & 162,01 & 36,71 & 36,71 & 140,19 \\
\hline
\end{tabular}




\begin{tabular}{|c|c|c|c|c|c|c|c|c|c|c|c|c|c|c|c|c|c|c|c|c|c|}
\hline TAXON & UTM & $\mathrm{km} 2$ & BIO1 & BIO2 & $B 103$ & BIO4 & B105 & B106 & B107 & B108 & B109 & B1010 & BIO11 & BIO12 & BIO13 & B1014 & BIO15 & B1016 & B1017 & B1018 & B1019 \\
\hline Pleurodeles walt| & 30SVH59 & 100,00 & 144,79 & 124,84 & 37,39 & 6825,02 & 338,13 & 9,79 & 328,35 & 127,27 & 236,96 & 236,96 & 62,84 & 454,60 & 55,18 & 5,40 & 42,85 & 160,04 & 38,25 & 38,25 & 136,98 \\
\hline Pleurodeles walt| & 30SVH64 & 100,00 & 154,19 & 119,16 & 36,95 & 6780,69 & 342,24 & 22,47 & $\begin{array}{l}319,76 \\
\end{array}$ & 107,34 & 245,70 & 245,70 & 72,69 & $\begin{array}{l}464,67 \\
4\end{array}$ & 61,84 & 5,05 & 46,69 & \begin{tabular}{|l|l|}
168,01 \\
\end{tabular} & 32,31 & 32,31 & 148,91 \\
\hline Pleurodeles walt| & 30SVH65 & 100,00 & 145,01 & $\begin{array}{l}121,56 \\
\end{array}$ & 37,00 & 6830,51 & 336,83 & 12,36 & $\begin{array}{l}324,47 \\
\end{array}$ & 98,63 & 237,55 & 237,55 & 63,40 & 490,13 & 63,78 & 6,22 & 44,91 & $\begin{array}{l}175,06 \\
\end{array}$ & 37,89 & 37,89 & 153,67 \\
\hline Pleurodeles walt| & 30SVH66 & 100,00 & 143,03 & 122,68 & 37,00 & 6836,81 & 335,70 & 9,75 & 325,95 & 116,32 & 235,58 & 235,58 & 61,51 & 486,52 & 62,02 & 6,23 & 43,92 & $\begin{array}{l}172,68 \\
\end{array}$ & 39,25 & 39,25 & 150,32 \\
\hline Pleurodeles walt| & 30SVH67 & 100,00 & 145,63 & 123,05 & \begin{tabular}{ll|}
37,01 \\
\end{tabular} & 6821,12 & 337,65 & 11,86 & 325,78 & 127,34 & 237,73 & 237,73 & 63,69 & $\begin{array}{l}465,95 \\
\end{array}$ & 58,14 & 5,86 & 43,54 & 164,86 & 38,03 & 38,03 & 142,61 \\
\hline Pleurodeles walt| & 30SVH68 & 100,00 & 146,17 & 123,70 & 37,50 & \begin{tabular}{|l|l|}
6794,27 \\
\end{tabular} & 337,87 & 12,07 & 325,80 & 128,36 & 237,97 & 237,97 & 64,38 & 453,73 & 55,54 & 5,52 & 42,99 & 159,97 & 37,86 & 37,86 & 137,20 \\
\hline 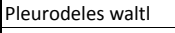 & 30SVH74 & 100,00 & 156,35 & 118,46 & 37,00 & 6713,76 & 341,89 & 24,83 & 317,06 & 109,79 & 246,80 & 246,80 & 75,59 & 442,10 & 57,42 & 4,87 & 45,98 & 158,07 & 31,52 & 31,52 & 139,85 \\
\hline Pleurodeles walt| & 30SVH75 & 100,00 & 148,09 & 120,87 & 37,00 & 6772,70 & 337,37 & 15,63 & 321,74 & 110,62 & 239,64 & 239,64 & 66,96 & \begin{tabular}{|l|l|}
466,38 \\
\end{tabular} & 59,56 & 5,92 & 44,41 & 165,41 & 36,67 & 36,67 & 144,59 \\
\hline Pleurodeles walt| & 30SVH76 & 100,00 & 142,16 & 122,42 & 37,00 & \begin{tabular}{ll|l|}
6812,50 \\
\end{tabular} & 333,83 & 9,07 & 324,76 & 123,00 & 234,41 & 234,41 & 60,91 & $\begin{array}{l}480,67 \\
\end{array}$ & 60,20 & 6,83 & 42,80 & \begin{tabular}{|l|l|}
170,17 \\
\end{tabular} & \begin{tabular}{ll|}
40,83 \\
\end{tabular} & \begin{tabular}{ll|}
40,83 \\
\end{tabular} & 146,37 \\
\hline Pleurodeles walt| & 30SVH87 & 100,00 & 139,49 & 123,06 & 37,12 & 6786,70 & 330,69 & 6,01 & 324,68 & 120,62 & 231,38 & 231,38 & 58,45 & 474,48 & 58,55 & 7,18 & 41,23 & 167,08 & 43,86 & 43,86 & 140,26 \\
\hline Pleurodeles walt| & 30SVH90 & 100,00 & 157,60 & 114,58 & 37,00 & 6514,66 & 335,62 & 29,21 & 306,41 & 111,28 & 245,21 & 245,31 & 79,36 & 423,56 & 53,86 & 5,10 & 46,10 & 150,25 & 29,61 & 31,51 & 135,57 \\
\hline Pleurodeles walt| & 30SVH94 & 100,00 & 149,32 & 119,44 & 37,01 & 6665,62 & 334,43 & 17,92 & 316,51 & 125,98 & 239,23 & 239,23 & 69,49 & \begin{tabular}{ll|}
442,82 \\
\end{tabular} & 55,28 & 6,04 & 43,18 & $\begin{array}{l}155,66 \\
\end{array}$ & 36,73 & 36,77 & 134,33 \\
\hline Pleurodeles walt| & 30SVH98 & 100,00 & 139,86 & 122,99 & 37,83 & $6736,23 \mid$ & 329,23 & 6,42 & 322,81 & 121,03 & 230,88 & 230,88 & 59,26 & 458,89 & 56,75 & 7,38 & 39,95 & 160,64 & 45,17 & 45,17 & 132,16 \\
\hline Pleurodeles walt & 30SVJo0 & 100,00 & 148,87 & $\mid 127,44$ & 38,00 & $\mid 6881,30$ & 345,65 & 11,99 & 333,65 & $\mid \begin{array}{l}132,29 \\
\end{array}$ & 241,78 & 241,78 & 65,87 & 452,13 & 55,12 & 4,00 & 45,43 & \begin{tabular}{|c|c|}
158,93 \\
\end{tabular} & 32,90 & $\mid 32,90$ & $\begin{array}{ll}140,79 \\
\end{array}$ \\
\hline Pleurodeles walt| & 30SVJ01 & 100,00 & 145,96 & 127,77 & $\begin{array}{l}37,97 \\
\end{array}$ & $\begin{array}{ll}6873,92 \\
\end{array}$ & 342,90 & 8,98 & 333,92 & 129,55 & 238,77 & 238,77 & 63,01 & $\begin{array}{l}448,95 \\
\end{array}$ & 53,61 & 4,16 & 44,37 & \begin{tabular}{|l|l|}
157,40 \\
\end{tabular} & 34,68 & 34,68 & 137,48 \\
\hline Pleurodeles walt| & 30 SVJO2 & 100,00 & 143,81 & 127,26 & 38,00 & 6880,20 & 340,49 & 7,06 & 333,44 & 127,11 & 236,74 & 236,74 & 60,84 & 446,77 & 53,00 & 4,54 & 43,43 & 156,01 & 36,44 & 36,44 & 134,77 \\
\hline Pleurodeles walt| & 30SVJ03 & 100,00 & 142,10 & 126,30 & $\begin{array}{l}37,46 \\
\end{array}$ & \begin{tabular}{|l|l|}
6881,69 \\
\end{tabular} & 338,09 & 5,64 & 332,45 & 125,62 & 235,12 & 235,12 & 59,01 & \begin{tabular}{|l|l|}
445,49 \\
\end{tabular} & 52,57 & 5,19 & 42,22 & $\begin{array}{l}154,66 \\
\end{array}$ & 38,37 & 38,37 & 132,61 \\
\hline Pleurodeles walt| & 30SVJ06 & 100,00 & 129,19 & 121,97 & 37,00 & 6851,31 & 322,54 & $-3,91$ & 326,45 & 111,79 & 222,27 & 222,27 & 47,47 & 477,10 & 55,90 & 8,28 & 38,71 & 162,20 & 49,38 & 49,38 & 136,52 \\
\hline Pleurodeles walt| & 30SVJ07 & 100,00 & 131,62 & 120,57 & 36,83 & 6862,95 & 323,58 & $-1,03$ & 324,61 & 114,59 & 224,92 & 224,92 & 49,54 & \begin{tabular}{|l|l|}
460,03 \\
\end{tabular} & 54,08 & 8,21 & 38,10 & 155,29 & 48,46 & $\begin{array}{l}48,46 \\
\end{array}$ & 130,47 \\
\hline Pleurodeles walt| & 30SVJ08 & 100,00 & 128,99 & 118,95 & 36,32 & 6836,28 & 319, & $-2,78$ & 322,32 & 111,71 & 221,98 & 222,00 & 47,55 & 465,26 & 54, & 9,07 & 37,28 & 155,83 & 51,08 & 51,10 & 130,69 \\
\hline Pleurodeles walt| & 30svJo9 & 100,00 & 139,00 & 117,17 & 36,00 & 6873,60 & 327,36 & 5,94 & \begin{tabular}{|l|l|}
321,43 \\
\end{tabular} & 123,10 & 232,25 & 232,25 & 56,13 & 423,66 & 49,44 & 8,03 & 37,47 & 140,40 & 45,81 & 45,81 & 118,53 \\
\hline Pleurodeles walt| & 30SVJ10 & 100,00 & 148,49 & 128,22 & 38,00 & 6857,95 & 344,86 & 11,30 & 333,56 & 132,17 & 240,94 & 240,94 & 65,41 & 442,34 & 53,40 & 4,00 & 44,74 & 155,84 & 33,31 & 33,31 & 136,15 \\
\hline Pleurodeles walt| & 30SVJ11 & 100,00 & 147,16 & 128,77 & 38,00 & \begin{tabular}{ll|l|}
6852,44 \\
\end{tabular} & 343,75 & 9,46 & 334,29 & 131,07 & 239,31 & 239,31 & 64,03 & \begin{tabular}{|l|l|}
431,67 \\
\end{tabular} & 52,12 & 4,00 & 44,03 & 151,79 & 33,87 & 33,87 & 130,75 \\
\hline Pleurodeles walt| & 30SVJ13 & 100,00 & 143,91 & 126,68 & 37,89 & 6858,15 & 339,39 & 7,36 & 332,03 & 127,80 & 236,59 & 236,59 & 61,18 & 430,37 & 51,26 & 4,76 & 42,04 & 149,31 & 37,37 & 37,37 & 127,06 \\
\hline Pleurodeles walt| & 30SVJ14 & 100,00 & 138,22 & 125,37 & 37,23 & \begin{tabular}{ll|}
6874,87 \\
\end{tabular} & 333,56 & 2,55 & 331,01 & 121,61 & 231,30 & 231,30 & 55,50 & \begin{tabular}{|l|l|}
448,08 \\
\end{tabular} & 52,82 & 5,88 & 40,84 & 154,54 & 41,71 & 41,71 & 130,77 \\
\hline Pleurodeles walt| & 30 SVJI15 & 100,00 & 133,32 & 123,81 & 37,00 & 6870,43 & 327,87 & $-0,78$ & 328,66 & 116,26 & 226,57 & 226,57 & 51,09 & 461,95 & 54,07 & 7,10 & 39,51 & \begin{tabular}{|l|l|}
158,08 \\
\end{tabular} & 45,73 & 45,73 & 133,26 \\
\hline Pleurodeles walt| & 30SVJ16 & 100,00 & 125,61 & 122,16 & 37,00 & 6838,57 & 319,31 & $-6,62$ & 325,93 & $\begin{array}{l}107,87 \\
\end{array}$ & 218,67 & 218,67 & 44,38 & 488,71 & 57,26 & 8,93 & 37,88 & $\begin{array}{l}165,76 \\
\end{array}$ & 52,09 & 52,09 & 139,21 \\
\hline Pleurodeles walt| & 30SVJ17 & 100,00 & \begin{tabular}{ll|l}
131,07 \\
\end{tabular} & 120,62 & 36,84 & 6857,65 & 322,85 & $-1,81$ & 324,66 & 114,03 & 224,17 & 224,17 & 49,04 & 461,86 & 54,09 & 8,49 & 37,81 & 155,32 & 49,35 & 49,35 & 130,82 \\
\hline Pleurodeles walt| & 30SVJ18 & 100,00 & 131,14 & 119,15 & 36,31 & 6845,13 & 321,53 & $-1,08$ & 322,61 & 114,18 & 224,04 & 224,04 & 49,31 & 457,24 & 53,43 & 8,76 & 37,21 & 152,28 & 50,13 & 50,13 & 128,56 \\
\hline Pleurodeles walt| & 30 SVJ20 & 100,00 & 147,62 & 128,19 & 38,00 & 6846,08 & 343,72 & 10,63 & 333,09 & 131,12 & 239,85 & 239,85 & 64,75 & 437,74 & 53,16 & 4,03 & 44,23 & 154,48 & 33,94 & 33,94 & 133,55 \\
\hline Pleurodeles walt| & $30 \mathrm{SVJ} 23$ & 100,00 & 145,52 & 126,56 & \begin{tabular}{|l|l|l|}
37,99 \\
\end{tabular} & 6840,83 & 340,04 & 8,74 & 331,30 & 129,61 & 237,74 & 237,74 & 62,74 & 420,08 & 50,24 & 4,60 & 42,20 & 145,53 & 36,85 & 36,85 & 123,39 \\
\hline Pleurodeles walt| & $30 \mathrm{SVJ} 25$ & 100,00 & 134,07 & 123,99 & 37,01 & 6863,34 & 328,14 & $-0,46$ & 328,60 & 117,11 & 227,11 & 227,11 & 51,84 & 456,90 & 53,47 & 7,08 & 39,26 & 155,95 & 45,73 & 45,73 & 131,37 \\
\hline Pleurodeles walt| & 30 SVJ26 & 100,00 & 131,86 & 122,48 & 37,00 & 6854,60 & 324,92 & $-1,52$ & 326,44 & 114,67 & 224,86 & 224,86 & 49,79 & 461,87 & 53,92 & 7,87 & 38,37 & 156,21 & 48,18 & 48,18 & 131,69 \\
\hline Pleurodeles walt| & 30SVJ28 & 100,00 & 135,25 & 119,14 & 36,33 & 6859,47 & 325,16 & 2,30 & 322,87 & 118,86 & 228,19 & 228,19 & 52,80 & \begin{tabular}{|l|l|}
442,13 \\
\end{tabular} & 51,11 & 8,18 & 37,29 & 146,24 & 47,59 & 47,59 & 124,93 \\
\hline Pleurodeles walt| & 30 SVJ30 & 100,00 & 146,76 & 127,10 & 37,99 & 6842,75 & 342,09 & 10,56 & 331,53 & 130,08 & 239,26 & 239,26 & 64,42 & 438,42 & 53,29 & 4,09 & 43,92 & 154,52 & 34,53 & 34,53 & 133,05 \\
\hline Pleurodeles walt| & 30 SVJ32 & 100,00 & 147,26 & 126,73 & 38,00 & 6819,47 & 341,26 & 10,77 & 330,49 & 131,51 & 239,21 & 239,21 & 64,75 & 418,02 & 50,40 & 4,12 & 42,60 & 145,18 & 35,91 & 35,91 & 123,62 \\
\hline Pleurodeles walt| & 30SVJ33 & 100,00 & 146,07 & 125,88 & $\begin{array}{l}37,83 \\
\end{array}$ & 6835,78 & 339,76 & 9,77 & 329,99 & 130,11 & 238,23 & 238,23 & 63,47 & 417,42 & 49,97 & 4,87 & 41,82 & \begin{tabular}{|l|l|}
144,18 \\
\end{tabular} & 37,16 & 37,16 & 122,00 \\
\hline Pleurodeles walt| & 30 SVJ34 & 100,00 & 136 & 125,01 & 37,16 & 6853,50 & 330,64 & 1,10 & 329,54 & 119,39 & 229,01 & 229,01 & 53,96 & 451,78 & 53,40 & 6,54 & 39,76 & 154,97 & 44,15 & 44,15 & 130,48 \\
\hline Pleurodeles walt| & 30SVJ42 & 100,00 & \begin{tabular}{ll|l}
147,07 \\
\end{tabular} & 125,73 & 37,80 & 6824,05 & 340,22 & \begin{tabular}{|l|l|}
11,03 \\
\end{tabular} & 329,18 & 130,93 & 239,08 & 239,08 & 64,71 & 419,65 & 50,4 & 4,93 & 41,76 & \begin{tabular}{|l|l|}
145,29 \\
\end{tabular} & 36,93 & 36,93 & 123,44 \\
\hline Pleurodeles walt| & 30 SVJ 43 & 100,00 & 146,62 & 125,01 & $\begin{array}{l}37,45 \\
\end{array}$ & 6823,15 & 339,09 & 10,59 & 328,50 & \begin{tabular}{|l|}
130,47 \\
\end{tabular} & 238,72 & 238,72 & 64,20 & 415,36 & 49,60 & 5,00 & 41,53 & 142,82 & 37,42 & 37,42 & 121,07 \\
\hline Pleurodeles walt| & 30SVJ44 & 100,00 & \begin{tabular}{ll|l|}
134,94 \\
\end{tabular} & 124,47 & \begin{tabular}{|l|}
37,18 \\
\end{tabular} & \begin{tabular}{|l|l|}
6837,59 \\
\end{tabular} & 328,72 & 0,39 & 328,33 & 117,92 & 227,52 & 227,52 & 52,91 & 457,44 & 53,83 & 7,13 & 39,26 & 156,41 & \begin{tabular}{|l|l|}
46,03 \\
\end{tabular} & $\begin{array}{ll}46,03 \\
\end{array}$ & 131,50 \\
\hline Pleurodeles walt| & 30 SVJ45 & 100,00 & 128,65 & 123,56 & 37,03 & 6835,67 & 322,47 & $-4,44$ & 326,91 & 111,14 & 221,50 & 221,50 & 47,35 & 478,31 & 55,59 & 8,50 & 37,84 & 162,32 & 50,98 & 50,98 & 136,15 \\
\hline Pleurodeles walt| & 30SVJ46 & 100,00 & 138,17 & 122,27 & 37,00 & \begin{tabular}{ll|l|}
6842,14 \\
\end{tabular} & 329,49 & 3,76 & 325,73 & 121,55 & 230,58 & 230,58 & 55,69 & 437,42 & 50,53 & 7,14 & 38,40 & 146,42 & 45,07 & 45,07 & 124,66 \\
\hline Pleurodeles walt| & $30 S V J 53$ & 100,00 & 146,14 & 124,31 & 37,3 & 6814,92 & 337,58 & 10,36 & 327,22 & 130,06 & 238,08 & 238,08 & 63,67 & 416,54 & 49,82 & 5,19 & 41,49 & 143,32 & 38,29 & 38,29 & 120,92 \\
\hline Pleurodeles walt| & 30 SVJJ54 & 100,00 & 144,27 & 123,68 & 37, & 6812,25 & 335,56 & 8,92 & 326,64 & 128,22 & 236,22 & 236,22 & 61,91 & 420,01 & 49,45 & 5,94 & 39,88 & 142,70 & 40,63 & 40,63 & 121,01 \\
\hline Pleurodeles walt| & $30 \mathrm{SV}, \mathrm{J}$ & 100,00 & 138 & 123,14 & 37,03 & 6822,71 & 330,55 & 4,48 & 326,07 & 122,39 & 231,19 & 231,19 & 56,86 & \begin{tabular}{|l|l|}
436,58 \\
\end{tabular} & 50,83 & 7,02 & 38,73 & $\begin{array}{l}147,13 \\
\end{array}$ & 44,65 & 44,65 & 124,51 \\
\hline Pleurodeles walt| & 30 SVJ60 & 100,00 & 146,60 & 124,06 & \begin{tabular}{|l|l|}
37,64 \\
\end{tabular} & $\begin{array}{l}6791,43 \\
\end{array}$ & 337,84 & 11,36 & 326,48 & 129,55 & 237,93 & 237,93 & $\mid 64,54$ & $\mid 433,45$ & \begin{tabular}{|l|l|}
52,76 \\
\end{tabular} & \begin{tabular}{|c|c|}
5,24 \\
\end{tabular} & 41,85 & \begin{tabular}{|l|l|}
151,32 \\
\end{tabular} & $\mid 37,87$ & $\mid 37,87$ & 128,27 \\
\hline Pleurodeles walt| & 30SVJ61 & 100,00 & 146,27 & 124,13 & \begin{tabular}{|l|l|}
37,63 \\
\end{tabular} & 6800,42 & 337,58 & 11,04 & 326,54 & 129,70 & 237,86 & 237,86 & 64,06 & 426,94 & 51,61 & 5,36 & 41,60 & 148,29 & 38,40 & 38,40 & 125,17 \\
\hline Pleurodeles walt| & 30SVJ65 & 100,00 & 142,53 & 122,46 & 37,01 & 6797,50 & 332,62 & 8,01 & 324,61 & 126,37 & 234,29 & 234,29 & 60,49 & 422,73 & 49,10 & 6,82 & 38,56 & \begin{tabular}{ll|}
141,88 \\
\end{tabular} & 43,16 & 43,16 & 120,14 \\
\hline Pleurodeles walt| & $30 \mathrm{SVJG}$ & 100,00 & 139,38 & 119,45 & 36,99 & 6792,24 & 326,91 & 6,43 & 320,48 & 121,76 & 230,94 & 230,94 & 57,30 & 429,52 & 48,12 & 8,10 & 36,96 & 139,14 & 46,72 & 46,72 & 121,38 \\
\hline Pleurodeles walt| & 30SVJ70 & 100,00 & 145,14 & 123,99 & \begin{tabular}{|l|l}
37,99 \\
\end{tabular} & 6779,11 & 335,90 & 10,46 & 325,44 & 127,62 & 236,54 & 236,54 & 63,40 & 436,02 & 53,00 & 6,00 & 40,94 & 151,82 & 40,34 & 40,34 & 127,27 \\
\hline Pleurodeles walt| & $30 S V J 76$ & 100,00 & 143,29 & 121,29 & $\begin{array}{l}37,03 \\
\end{array}$ & 6768,62 & 331,36 & 9,25 & 322,12 & 127,52 & 234,38 & 234,38 & 61,47 & \begin{tabular}{|l|l|}
416,98 \\
\end{tabular} & 47,55 & 7,05 & 37,74 & 137,95 & 44,09 & 44,09 & 117,32 \\
\hline Pleurodeles walt| & 30SVJ77 & 100,00 & 142,13 & 120,53 & 37,00 & 6778,90 & 329,51 & 8,49 & 321,02 & 126,27 & 233,47 & 233,47 & 60,07 & 419,88 & 47,05 & 7,60 & 36,94 & \begin{tabular}{|l|}
137,13 \\
\end{tabular} & 45,58 & 45,58 & 117,90 \\
\hline Pleurodeles walt| & 30SVJ78 & 100 & 141 & 119, & 37,00 & $6 / 69$ & 327 & 7,95 & 319 & 121,23 & 232 & 232 & 58,94 & 422,44 & $4 i$ & 8,00 & 36,31 & 136,81 & 46,45 & 46,45 & 118 \\
\hline Pleurodeles walt| & $30 \mathrm{SVJ} 86$ & 100,00 & 140,81 & 121,76 & 37,16 & 6746,40 & 328,68 & 6,90 & 321,79 & 124,73 & 231,79 & 231,79 & 59,32 & 425,55 & 48,34 & 7,76 & 37,00 & 140,92 & 46,98 & 46,98 & 118,40 \\
\hline Pleurodeles walt| & 30SVJ97 & 100,00 & 140,27 & 120,99 & 37,04 & 6723,97 & 326,42 & 6,76 & 319,66 & 124,05 & 230,68 & 230,68 & 58,99 & 424,32 & 48,05 & 8,25 & 35,79 & 139,12 & 49,18 & 49,18 & 116,06 \\
\hline Pleurodeles walt| & 30SVK10 & 100,00 & 139,54 & 115,28 & 35,74 & $\begin{array}{ll}6879,58 \\
\end{array}$ & 326,16 & 7,09 & 319,07 & 121,73 & 232,81 & 232,81 & 56,51 & 420,94 & 48,24 & 8,56 & 36,62 & 136,80 & 46,77 & 46,77 & 117,76 \\
\hline Pleurod & 30SVK42 & 100,00 & & 112 & 35,34 & 6798,35 & 325,5 & 13,30 & 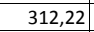 & 99,84 & & & 60,75 & 416,79 & 48,69 & 8,62 & 00 & 140,71 & 44,87 & 44,87 & 121 \\
\hline Pleurodeles walt| & 30SVK50 & 100,00 & 141,80 & 116,19 & 36,00 & 6809,98 & 326,92 & 9,91 & $317,01]$ & 98,08 & 233,49 & 233,49 & 59,15 & 420,79 & 47,14 & 8,24 & 36,94 & 138,66 & 45,49 & 45,49 & 120,36 \\
\hline Pleurodeles walt| & 30SWG08 & 100,00 & 114,83 & 120,64 & 37,04 & 6665,08 & 304,94 & $-14,35$ & 319,29 & 66,73 & 205,73 & 205,99 & 37,30 & 607,25 & 75,59 & 14,07 & 39,93 & 210,27 & 61,06 & 63,95 & 184,67 \\
\hline
\end{tabular}




\begin{tabular}{|c|c|c|c|c|c|c|c|c|c|c|c|c|c|c|c|c|c|c|c|c|c|}
\hline TAXON & UTM & $\mathrm{km} 2$ & B101 & B102 & $\mathrm{BIO3}$ & BIO4 & B105 & B106 & B107 & B108 & 8109 & BIO10 & B1011 & BIO12 & B1013 & BIO14 & BIO15 & B1016 & B1017 & B1018 & B1019 \\
\hline Pleurodeles walt| & 30SWHO6 & 100,00 & 138,07 & 121,96 & 37,75 & 6697,72 & 326,27 & 5,68 & 320,59 & 118,73 & 228,64 & 228,64 & 58,33 & 468,66 & 58,71 & 8,10 & 39,86 & 164,30 & 46,44 & 46,44 & 135,13 \\
\hline Pleurodeles walt| & 30SWH17 & 100,00 & 134,64 & 122,57 & 38,00 & 6673,81 & 322,48 & 2,36 & 320,11 & 115,32 & 224,87 & 224,87 & 55,14 & 470,69 & 59,10 & 9,06 & 38,14 & 164,29 & 51,01 & 51,01 & 131,44 \\
\hline Pleurodeles walt| & 30SWH25 & 100,00 & 140,51 & 120,64 & 38,00 & 6580,19 & 324,05 & 8,96 & 315,09 & 121,21 & 229,27 & 229,33 & 61,99 & 444,95 & 56,81 & 7,98 & 39,07 & 154,85 & 46,07 & 46,40 & 125,01 \\
\hline Pleurodeles walt| & 30SWH27 & 100,00 & 136,53 & 122,09 & 38,00 & 6621,28 & 322,34 & 4,31 & 318,03 & 117,43 & 226,03 & 226,05 & 57,70 & 455,02 & 57,62 & 8,86 & 37,61 & 158,18 & 50,57 & 50,66 & 124,84 \\
\hline Pleurodeles walt| & 30SWH35 & 100,00 & 135,10 & 120,94 & 38,00 & 6562,45 & 318,66 & 3,99 & 314,68 & \begin{tabular}{ll|}
115,32 \\
\end{tabular} & 223,75 & 223,83 & 57,18 & \begin{tabular}{|l|l|}
461,17 \\
\end{tabular} & 59,19 & 9,41 & 37,62 & 159,92 & 51,44 & 51,82 & 126,39 \\
\hline Pleurodeles walt| & $30 \mathrm{SWH} 42$ & 100,00 & 117,07 & 120,59 & 37,97 & 6569,31 & 302,61 & $-12,38$ & 314,99 & 94,95 & 206,40 & 206,77 & 40,55 & 550,65 & 70,50 & 14,42 & 35,34 & 189,73 & 66,72 & 67,18 & 150,78 \\
\hline Pleurodeles walt| & 30SWH43 & 100,00 & 126,58 & 120,40 & 37,99 & 6533,06 & 309,88 & $-3,61$ & 313,49 & 105,78 & 215,07 & 215,37 & 49,71 & 500,56 & 64,43 & 11,81 & 36,40 & 172,66 & 58,66 & 59,34 & 136,50 \\
\hline Pleurodeles waltl & 30SWH96 & 100,00 & 146,16 & 119,44 & 39,02 & 6231,48 & 316,62 & 15,25 & 301,38 & 127,58 & 229,58 & 229,75 & 71,24 & 384,08 & 51,70 & $\begin{array}{r}8,15 \\
8,15\end{array}$ & 37,09 & 128,34 & 49,41 & 50,04 & 91,68 \\
\hline Pleurodeles walt| & 30SWH98 & 100,00 & 135,22 & 120,12 & 39,00 & 6329,12 & 309,50 & 4,43 & 305,07 & 115,99 & 220,40 & 220,40 & 59,50 & 422,79 & 56,25 & 10,82 & 34,58 & 141,73 & 57,86 & 59,99 & 97,90 \\
\hline Pleurodeles walt| & 30SWJ05 & 100,00 & 142,80 & 122,00 & 38,00 & 6677,09 & 328,46 & 9,07 & 319,39 & 126,64 & 232,84 & 232,84 & 62,06 & 415,44 & 47,76 & 7,96 & 36,63 & 138,89 & 47,73 & 47,73 & 112,81 \\
\hline Pleurodeles walt| & 30SWJ06 & 100,00 & 141,19 & 121,88 & \begin{tabular}{|c|}
37,88 \\
\end{tabular} & 6682,22 & 326,79 & 7,55 & 319,24 & 125,00 & 231,17 & 231,17 & 60,55 & 419,66 & 47,80 & 8,17 & 35,69 & 139,11 & 49,30 & 49,30 & 113,53 \\
\hline Pleurodeles walt| & 30SWJ08 & 100,00 & 133,21 & 121,27 & 37,46 & 6701,46 & 319,56 & 0,62 & 318,94 & 116,76 & 222,77 & 223,32 & 52,53 & 448,05 & 51,19 & 10,24 & 34,10 & 146,48 & 55,55 & 56,17 & 120,73 \\
\hline Pleurodeles walt| & 30SWJ10 & 100,00 & 133,74 & 123,38 & 38,00 & 6685,27 & 322,20 & 0,64 & 321,56 & 115,28 & 223,74 & 224,19 & 53,98 & 461,31 & 56,75 & 9,04 & 36,79 & 159,66 & 52,44 & 53,18 & 125,69 \\
\hline Pleurodeles walt| & 30SWJ16 & 100,00 & 140,12 & 122,00 & 38,00 & 6666,75 & 325,28 & 6,48 & 318,80 & 123,81 & 229,56 & 229,85 & 59,51 & 421,10 & 48,23 & 8,81 & 34,97 & 139,57 & 51,18 & 51,48 & 112,48 \\
\hline Pleurodeles walt| & 30SWJ19 & 100,00 & 130,61 & 121,07 & \begin{tabular}{|l|l|}
37,97 \\
\end{tabular} & 6666,29 & 315,92 & $-1,29$ & 317,21 & 114,14 & 219,31 & 220,34 & 50,49 & 456,24 & 52,56 & 11,38 & 32,73 & 148,64 & 58,92 & 60,44 & $\begin{array}{ll}121,03 \\
\end{array}$ \\
\hline Pleurodeles waltt & 30 SWJ30 & 100,00 & 128,96 & 123,06 & 38,00 & 6630,43 & 315,81 & $-3,09$ & 318,89 & 110,17 & 218,38 & 218,71 & 49,96 & 471,51 & 58,39 & 10,96 & 34,82 & 162,29 & 57,77 & 60,31 & 123,33 \\
\hline Pleurodeles walt| & 30 SWJ41 & 100,00 & 126,03 & 123,10 & 38,06 & 6601,84 & 312,03 & $-5,62$ & 317,64 & 106,86 & 214,97 & 215,51 & 47,59 & 477,60 & 58,75 & 11,99 & 33,60 & 163,49 & 61,18 & 65,34 & 121,45 \\
\hline Pleurodeles walt| & 30 SWJ44 & 100,00 & 138,99 & 122,42 & 38,15 & 6559,40 & 321,36 & 5,65 & 315,71 & $\begin{array}{l}122,05 \\
\end{array}$ & 226,37 & 227,07 & 59,77 & 418,64 & 49,25 & 9,55 & 34,06 & 140,64 & 53,42 & 56,30 & 105,57 \\
\hline Pleurodeles walt| & 30 SWJ48 & 100,00 & 128,28 & 123,04 & 38,01 & 6587,38 & 312,77 & $-4,47$ & 317,24 & 111,47 & 216,01 & 216,95 & 49,06 & $\begin{array}{l}465,45 \\
\end{array}$ & 55,03 & 12,82 & 31,04 & 154,44 & 64,16 & 68,21 & $\begin{array}{ll}117,49 \\
\end{array}$ \\
\hline Pleurodeles walt| & 30SWJ51 & 100,00 & 128,77 & 122,86 & 38,44 & 6557,40 & 312,57 & $-2,92$ & 315,49 & $\begin{array}{ll}109,92 \\
\end{array}$ & 216,97 & 217,32 & 50,64 & 460,01 & 57,16 & 11,66 & 33,52 & 156,84 & 59,95 & 64,64 & 114,24 \\
\hline Pleurodeles walt| & 30SWJ52 & 100,00 & 133,79 & 122,73 & 38,44 & 6540,52 & 316,21 & 1,21 & 315,00 & 115,63 & 221,32 & 221,88 & 55,37 & 436,92 & 53,67 & 10,58 & 33,69 & 148,18 & 56,80 & 61,01 & 107,97 \\
\hline Pleurodeles waltt & 30SWJ53 & 100,00 & 137,74 & 122,27 & 38,23 & 6521,12 & 319,09 & 4,77 & 314,32 & 120,05 & 224,80 & 225,45 & 59,29 & 419,71 & 50,70 & 10,01 & 33,95 & 141,49 & 54,44 & 58,21 & 103,51 \\
\hline Pleurodeles walt| & 30 SWJ55 & 100,00 & 137,90 & 122,05 & 38,07 & \begin{tabular}{ll|}
6523,64 \\
\end{tabular} & 319,00 & 4,82 & 314,18 & 120,70 & 224,86 & 225,56 & 59,19 & 420,32 & 49,08 & 10,09 & 32,81 & 140,42 & 55,85 & 59,46 & 103,44 \\
\hline Pleurodeles waltt & 30 SWJ58 & 100,00 & 128,65 & 123,07 & 38,53 & 6547,10 & 311,84 & $-3,84$ & 315,68 & 111,64 & 215,87 & 216,81 & 49,99 & 462,92 & 55,10 & 13,25 & 30,64 & 153,75 & 65,49 & 70,16 & 114,59 \\
\hline Pleurodeles walt| & 30SWJ71 & 100,00 & 140,99 & 121,03 & 38,99 & 6405,53 & 317,45 & 9,01 & 308,44 & 123,35 & 226,69 & 227,11 & 64,01 & 396,14 & 51,00 & 9,06 & 35,01 & 133,14 & 52,21 & 56,97 & 93,13 \\
\hline Pleurodeles walt| & 30 SWJ81 & 100,00 & 142,26 & 120,26 & 39,00 & 6345,87 & 316,32 & 10,66 & 305,66 & 143,41 & 227,08 & 227,17 & 65,83 & 387,37 & 50,60 & 9,09 & 35,01 & 130,10 & 52,23 & 56,99 & 88,11 \\
\hline \begin{tabular}{|l|l|} 
Pleurodeles waltl \\
\end{tabular} & |30SWJ86 & 100,00 & 132,90 & 120,76 & 38,90 & 6422,17 & 309,56 & $\begin{array}{ll}0,13 \\
1,13\end{array}$ & 308,43 & \begin{tabular}{|l|}
115,24 \\
\end{tabular} & 218,52 & 219,16 & 55,49 & \begin{tabular}{|l|l|}
432,76 \\
\end{tabular} & 51,64 & 12,85 & 30,55 & 142,90 & 64,56 & \begin{tabular}{|l|l|}
70,03 \\
\end{tabular} & $\begin{array}{l}99,13 \\
99,1\end{array}$ \\
\hline Pleurodeles walt| & 30SWJ95 & 100,00 & 135,80 & 119,48 & 38,99 & 6356,69 & 309,21 & 4,95 & 304,25 & 125,53 & 220,64 & 221,02 & 59,32 & 416,92 & 49,31 & 12,31 & 31,38 & 136,82 & 62,93 & 68,19 & 92,83 \\
\hline Pleurodeles walt| & 30SWJ96 & 100,00 & 132,25 & 119,58 & 38,97 & 6377,11 & 306,53 & 1,43 & 305,10 & 114,64 & 217,40 & 217,82 & 55,66 & 432,70 & 51,70 & 13,42 & 30,30 & 141,95 & 66,74 & 72,16 & 96,69 \\
\hline Pleurodeles waltt & 30SWJ98 & 100,00 & 124,07 & 119,64 & 38,88 & 6412,39 & 299,97 & $-6,04$ & 306,01 & 106,33 & 209,64 & 210,42 & 47,23 & 468,76 & 57,28 & 16,19 & 28,50 & 154,03 & 75,62 & 82,00 & 105,15 \\
\hline Pleurodeles walt| & 30SWK10 & 100,00 & 127,28 & 120,63 & 37,75 & 6666,16 & 312,45 & $-3,96$ & 316,41 & 110,82 & 215,99 & 217,12 & 47,25 & 467,55 & 54,01 & 12,32 & 32,02 & 151,45 & 61,53 & 63,37 & 123,73 \\
\hline \begin{tabular}{|l|} 
Pleurodeles waltl \\
\end{tabular} & 30 SWK20 & 100,00 & 126,54 & 121,49 & 38,00 & 6633,87 & 311,50 & $-5,05$ & $\begin{array}{l}316,56 \\
31,5\end{array}$ & $\begin{array}{l}109,80 \\
100\end{array}$ & \begin{tabular}{|l|}
214,84 \\
\end{tabular} & \begin{tabular}{|l|l|l|l|l|}
215,95 \\
\end{tabular} & 46,97 & 4771,02 & $\begin{array}{l}4,019 \\
54,95\end{array}$ & $\begin{array}{ll}12,91 \\
12,1\end{array}$ & 31,29 & $\begin{array}{l}153,46 \\
15,45\end{array}$ & $\begin{array}{l}1,33 \\
63,61 \\
\end{array}$ & $\begin{array}{l}6,24 \\
66,24\end{array}$ & 122,91 \\
\hline Pleurodeles walt| & 30SWK41 & 100,00 & 122,46 & 122,80 & 38,01 & 6583,14 & 306,92 & $-10,08$ & 317,00 & 105,83 & 209,96 & 211,16 & 43,49 & 490,88 & 58,69 & 15,08 & 29,70 & 161,28 & 70,79 & 75,39 & 124,37 \\
\hline Pleurodeles walt| & 30SWK81 & 100,00 & 110,82 & 121,81 & 38,53 & 6483,51 & 291,80 & $-20,39$ & 312,19 & 92,95 & 197,45 & 198,55 & 33,73 & 534,36 & 66,63 & 20,43 & 27,09 & $\mid 176,77$ & 88,24 & 96,72 & 124,56 \\
\hline Pleurodeles walt| & 30SWK82 & 100,00 & 110,53 & 121,79 & 38,60 & 6481,56 & 291,16 & $-21,05$ & 312,21 & 92,89 & 196,90 & 198,10 & 33,16 & 535,29 & 67,24 & 20,84 & 27,04 & 176,77 & 89,48 & 98,00 & 124,87 \\
\hline Pleurodeles walt| & 30SWK92 & 100,00 & 111,82 & 119,45 & 38,27 & 6446,76 & 288,67 & $-18,55$ & 307,22 & 94,28 & 197,75 & 198,81 & 34,66 & 517,63 & 65,91 & 20,95 & 26,86 & 170,08 & 89,76 & 98,07 & 116,28 \\
\hline \begin{tabular}{|l|} 
Pleurodeles waltl \\
\end{tabular} & 30SXG19 & 100,00 & 137,75 & 1115,23 & 30,07 & $\begin{array}{l}64459,27 \\
6059\end{array}$ & 302,45 & 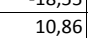 & $\begin{array}{l}51,26 \\
291,59 \\
\end{array}$ & \begin{tabular}{r|r}
313,20 \\
113,05
\end{tabular} & 218,54 & $\begin{array}{l}50,01 \\
219,89\end{array}$ & $\begin{array}{l}34,00 \\
65,82\end{array}$ & $\begin{array}{l}11,05 \\
438,75\end{array}$ & $\begin{array}{l}\mid c 5,11 \\
56,95 \\
\end{array}$ & \begin{tabular}{|l|}
10,43 \\
10,4
\end{tabular} & $\begin{array}{l}20,00 \\
36,39\end{array}$ & $\begin{array}{l}144,390 \\
140\end{array}$ & $\begin{array}{l}52,17 \\
52,37\end{array}$ & 57,23 & $\begin{array}{l}1110,20 \\
113,23\end{array}$ \\
\hline Pleurodeles walt| & $30 S \times G 29$ & 100,00 & 135,25 & 115,02 & 39,09 & 6045,20 & 299,51 & 8,79 & 290,73 & 110,42 & 215,94 & 217,42 & 63,70 & 455,83 & 58,89 & 11,65 & 35,79 & 149,59 & 56,40 & 61,37 & 116,24 \\
\hline Pleurodeles walt| & 30 XG59 & 100,00 & 166,25 & 116,63 & 40,82 & 5702,91 & 318,91 & 36,84 & 282,08 & 136,12 & 241,15 & 242,01 & 96,73 & 338,28 & 50,04 & 4,80 & 44,89 & 122.95 & 30,47 & 43,63 & 87,60 \\
\hline Pleurodeles walt| & $305 \times G 69$ & 100,00 & 167,66 & 116,15 & 41,02 & 5638,52 & 318,49 & 38,72 & 279,77 & 138,34 & 241,47 & 242,52 & 98,66 & 335,36 & 51,44 & 4,60 & 45,19 & 124,75 & 29,79 & 43,90 & 86,18 \\
\hline Pleurodeles walt| & $\begin{array}{l}30 S \times G 76 \\
\end{array}$ & 86,00 & 179,86 & 106,64 & 40,80 & 5252,99 & 317,07 & 57,88 & 259,19 & 153,89 & 247,61 & 249,56 & $\begin{array}{r}115,17 \\
\end{array}$ & 300,50 & 49,40 & 3,09 & 50,35 & 123,67 & 21,62 & 35,51 & 84,13 \\
\hline Pleurodeles walt| & $30 \mathrm{~S} \times \mathrm{HO7}$ & 100,00 & 141,71 & 119,43 & 39,01 & 6233,71 & 312,12 & 11,10 & 301,02 & $\begin{array}{l}122,98 \\
12,0\end{array}$ & 225,34 & 225,46 & | 67,07 & 399,46 & 53,55 & $\begin{array}{ll}, 48 \\
9,48\end{array}$ & 36,12 & 132,63 & 54,67 & 55,28 & 92,22 \\
\hline Pleurodeles walt| & $30 \mathrm{~S} \times \mathrm{H} 16$ & 100,00 & 152,29 & 118,96 & 39,83 & 6094,09 & 317,48 & 21,61 & 295,87 & 133,01 & 233,35 & 233,83 & 78,57 & 364,18 & 48,71 & 7,35 & 38,26 & 119,19 & 46,01 & 48,81 & 84,80 \\
\hline Pleurodeles walt| & $30 \mathrm{SXH} 23$ & 100,00 & 166,99 & 118,20 & 40,32 & 5891,20 & 325,24 & 36,20 & 289,04 & 134,37 & 244,73 & 245,19 & 95,04 & 320,00 & 46,28 & 4,33 & 43,28 & 110,82 & 31,59 & 40,88 & 78,78 \\
\hline Pleurodeles walt| & $30 \mathrm{~S} \times \mathrm{H} 45$ & 100,00 & 153,31 & 117,88 & 40,10 & 5951,01 & 313,1 & 23,56 & 289,58 & \begin{tabular}{ll|}
127,44 \\
\end{tabular} & 232,03 & 232,93 & 81,24 & 378,31 & 52,56 & 7,68 & 38,99 & 126,14 & 46,28 & 54,47 & 87,53 \\
\hline \begin{tabular}{|l|} 
Pleurodeles walt| \\
\end{tabular} & \begin{tabular}{|l|}
$305 \times H 58$ \\
\end{tabular} & 100,00 & 142,56 & 115,13 & 39,85 & 5982,00 & $\begin{array}{l}301, \\
301,\end{array}$ & 15,49 & \begin{tabular}{|l|}
286,25 \\
\end{tabular} & 152,41 & 222,02 & 222,81 & $\mid 70,77$ & |428,47 & 56,95 & 11,25 & 34,88 & 140,04 & 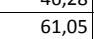 & 67,12 & $\begin{array}{l}95,49 \\
95\end{array}$ \\
\hline Pleurodeles walt| & $30 \mathrm{~S} \times \mathrm{H} 60$ & 100,00 & 179,11 & 119,22 & 41,82 & 5622,63 & 329 & 47,06 & 282,67 & 149,38 & 252,55 & 252,93 & 109,56 & 298,01 & 48,85 & 2,73 & 49,87 & $\begin{array}{l}114,67 \\
\end{array}$ & 22,28 & 37,67 & 76,57 \\
\hline Pleurodeles waltl & $30 \mathrm{~S} \times \mathrm{H} 68$ & 100,00 & 142,02 & 113,82 & 39,87 & 5933,72 & 298,99 & 16,03 & 282,95 & 152,27 & 220,73 & 221,85 & 70,98 & 441,90 & 59,60 & 11,88 & 34,58 & 146,62 & 62,88 & 70,57 & 98,86 \\
\hline Pleurodeles waltt & $30 \mathrm{~S} \times \mathrm{H} 69$ & 100,00 & 134,60 & 112,94 & 39,23 & 5987,64 & 292,94 & 9,47 & 283,47 & 144,47 & 214,34 & 215,40 & 63,29 & 472,17 & 60,75 & 14,14 & 32,32 & 152,42 & 71,63 & 77,29 & 104,75 \\
\hline Pleurodeles waltl & $30 \mathrm{~S} \times \mathrm{H} 71$ & 100,00 & 178,63 & 116,88 & 41,76 & 5550,24 & 326,59 & 48,83 & 277,76 & 150,00 & 250,95 & 251,82 & 110,09 & 298,88 & 51,72 & 3,32 & 49,93 & 117,47 & 24,25 & 41,11 & 73,47 \\
\hline Pleurodeles walt| & 30 SXH89 & 100,00 & 148 & 110,09 & 39,95 & 5750,68 & 298 & 25,22 & 272,85 & 159,33 & 223,96 & 225,60 & 79,03 & 446,46 & 64,77 & 11,42 & 36,43 & 157,67 & 60,70 & 73,58 & 101,23 \\
\hline Pleurodeles walt| & $30 \mathrm{SXH98}$ & 100,00 & 144,32 & 109,36 & 39,72 & 5737,64 & 294,20 & 22,01 & 272,20 & 155,50 & 219,91 & 221,75 & 75,75 & 475,68 & 67,75 & 12,47 & 35,70 & 166,80 & 64,63 & 78,26 & 110,11 \\
\hline \begin{tabular}{|l|l|} 
Pleurodeles waltl \\
\end{tabular} & 30SXH99 & 100,00 & 142,93 & 108,45 & 39,56 & 5746,21 & 292,33 & 21,17 & 271,16 & |154,30 & 218,71 & 220,58 & 74,29 & 482,94 & 68,26 & 13,15 & 34,97 & $\begin{array}{l}168,86 \\
\end{array}$ & $\begin{array}{ll}4,10 \\
67,18\end{array}$ & 80,69 & 111,19 \\
\hline Pleurodeles waltl & 30 SXJ05 & 100,00 & 135,89 & 118,03 & 38,99 & 6306,92 & 306,59 & 6,05 & 300,54 & 151,47 & 220,08 & 220,45 & 59,92 & 416,04 & 49,10 & 12,66 & 31,06 & 136,36 & 64,78 & 69,44 & 90,5 \\
\hline Pleurodeles waltl & $305 \times J 06$ & 100,00 & 133,36 & 117,95 & 38,93 & 6326,24 & 304,54 & 3,48 & 301,06 & 135,99 & 217,79 & 21 & 57 & 426,34 & 50,85 & 13,57 & 30,26 & 138,99 & 67,72 & 72,43 & 92,9 \\
\hline \begin{tabular}{|l|} 
Pleurodeles waltl \\
\end{tabular} & $305 \times 137$ & $\begin{array}{l}100,00 \\
\end{array}$ & 129,43 & 1112,05 & 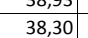 & 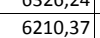 & 2901,93 & $\begin{array}{c}3,40 \\
4,19\end{array}$ & $\begin{array}{l}287,74 \\
2\end{array}$ & \begin{tabular}{|l|l|}
146,47 \\
145
\end{tabular} & $\begin{array}{l}21,2,47 \\
212,4\end{array}$ & $\begin{array}{l}210,260 \\
212,64 \\
\end{array}$ & 55,10 & $\begin{array}{l}420,54 \\
445,05\end{array}$ & $\begin{array}{l}0,00 \\
52,90\end{array}$ & $\begin{array}{l}\mid 0,375 \\
16,54 \\
\end{array}$ & $\begin{array}{l}0,28,95 \\
28,\end{array}$ & \begin{tabular}{|l|l|}
142,84 \\
1428
\end{tabular} & $\begin{array}{l}1,1,29 \\
79,4\end{array}$ & $\begin{array}{l}2,45 \\
80,87 \\
\end{array}$ & 91,56 \\
\hline Pleurodeles waltt & $30 \mathrm{SXJ39}$ & 100,00 & 119,33 & 110,82 & 38,00 & 6279,90 & 283,03 & $-4,71$ & 287,74 & 136,68 & 203,39 & 203,80 & 44,63 & 475,85 & 58,88 & 20,06 & 27,44 & 155,07 & 89,13 & 93,15 & 96,12 \\
\hline Pleurodeles waltt & $305 \times 146$ & 100,00 & 140,77 & 109,92 & 38.90 & 6050,06 & 297.10 & 16,81 & 280,29 & 150,23 & 221.32 & 221,66 & $67.97 \mid$ & 413,15 & 52.03 & 13,81 & 31.29 & 132.51 & 70,02 & 72,27 & 85,21 \\
\hline |Pleurodeles walt| & $30 \mathrm{~S} \times \mathrm{J4}$ & 100,00 & 126,77 & 109,15 & 38,01 & 6183,54 & 286,05 & 3,4 & 282,60 & 143,61 & 209 , & 209,62 & 52, & 454,79 & 54,45 & 18,17 & 28,26 & 145,25 & 84,73 & 85,71 & 91,40 \\
\hline Pleurodeles waltl & $305 \times 149$ & 100,00 & 122,53 & 108,38 & 37,99 & 6213,33 & 282,04 & $-0,13$ & 282,17 & 139,53 & 202,60 & 205,97 & 48,61 & 465,00 & 56,91 & 19,70 & 27,76 & 150,18 & 89,13 & 90,91 & 92,11 \\
\hline
\end{tabular}




\begin{tabular}{|c|c|c|c|c|c|c|c|c|c|c|c|c|c|c|c|c|c|c|c|c|c|}
\hline$\overline{\text { TAXON }}$ & UTM & $\mathrm{km} 2$ & BIO1 & B102 & $B 103$ & BIO4 & B105 & B106 & B107 & B108 & B109 & B1010 & BIO11 & B1012 & BIO13 & B1014 & BIO15 & B1016 & B1017 & B1018 & B1019 \\
\hline Pleurodeles walt| & 30SXJ51 & 100,00 & 133,18 & 112,97 & 39,00 & 6048,94 & 293,03 & 8,12 & 284,91 & 139,41 & 213,86 & 214,76 & 61,01 & 463,61 & 57,82 & 14,67 & 31,29 & 146,88 & 74,18 & 77,11 & 100,44 \\
\hline Pleurodeles walt| & $305 \times 552$ & 100,00 & 129,60 & 112,21 & 38,96 & 6071,79 & 289,74 & 5,25 & 284,49 & 131,89 & 210,86 & 211,45 & 57,43 & $\begin{array}{l}478,03 \\
\end{array}$ & 58,38 & 16,09 & 30,25 & $\begin{array}{l}151,48 \\
\end{array}$ & 78,93 & 81,26 & 102,80 \\
\hline Pleurodeles walt| & $305 \times 556$ & 100,00 & 142,36 & 107,81 & 38,90 & 5975,50 & 294,88 & 20,05 & 274,84 & 151,12 & 221,59 & 222,31 & 70,39 & 417,13 & 54,42 & 13,94 & 31,68 & $\begin{array}{ll}137,42 \\
\end{array}$ & 69,68 & 74,75 & 86,15 \\
\hline Pleurodeles walt| & $305 \times 557$ & 100,00 & 135,43 & 107,41 & 38,28 & $\begin{array}{ll}6046,96 \\
\end{array}$ & 289,62 & 13,45 & 276,17 & 144,99 & 215,97 & 216,39 & 62,89 & 435,39 & 53,66 & $\begin{array}{ll}15,97 \\
\end{array}$ & 29,95 & 139,20 & 77,11 & 80,02 & 88,35 \\
\hline Pleurodeles walt| & 305XJ61 & 100,00 & 137,99 & 111,40 & 39,21 & 5952,97 & 293,82 & 13,92 & 279,90 & 147,24 & 217,15 & 218,16 & 66,81 & $\begin{array}{l}456,65 \\
\end{array}$ & 59,88 & 13,80 & 32,50 & 149,99 & 70,42 & 76,63 & 99,55 \\
\hline Pleurodeles walt| & $305 \times 162$ & 100,00 & 140,55 & 110,31 & $\begin{array}{l}39,25 \\
\end{array}$ & 5927,19 & 294,52 & 17,05 & 277,47 & 150,31 & 219,21 & 220,26 & 69,46 & 446,74 & 59,58 & 13,52 & 32,87 & 148,61 & 69,04 & 75,92 & 96,71 \\
\hline 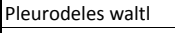 & $305 \times 167$ & 100,00 & 134,58 & 105,47 & 38,08 & 5986,80 & 286,09 & 14,12 & 271,97 & 143,41 & 214,29 & 214,93 & 63,03 & 449,14 & 56,28 & 16,73 & 29,75 & 145,65 & 79,29 & 84,23 & 91,38 \\
\hline Pleurodeles walt| & $305 \times 168$ & 100,00 & 122,35 & 105,18 & 37,93 & 6098,75 & 276,92 & 2,28 & 274,63 & 136,46 & 203,99 & 204,38 & 50,08 & 487,44 & 57,57 & 20,50 & 27,48 & \begin{tabular}{|l|l|}
153,17 \\
\end{tabular} & $\begin{array}{l}92,86 \\
\end{array}$ & 94,41 & 97,42 \\
\hline Pleurodeles walt| & $305 \times 173$ & 100,00 & 134,74 & 107,78 & 38,92 & $\begin{array}{l}5912,92 \\
\end{array}$ & 287,08 & 13,31 & 273,78 & 144,68 & 213,34 & 214,45 & 64,27 & $\begin{array}{l}479,66 \\
4\end{array}$ & 62,49 & 15,88 & 30,90 & $\begin{array}{l}158,43 \\
\end{array}$ & 77,23 & 84,66 & 103,68 \\
\hline Pleurodeles walt| & $305 \times 180$ & 100,00 & 144,00 & 109,08 & 39,48 & 5785,34 & 294,12 & 21,79 & 272,33 & 154,88 & 220,38 & 221,94 & 74,64 & 463,92 & 65,44 & 12,84 & 34,78 & 161,16 & 66,09 & 78,03 & 104,46 \\
\hline Pleurodeles walt| & 305XJ81 & 100,00 & 139,38 & 108,16 & \begin{tabular}{ll|}
39,12 \\
\end{tabular} & 5823,71 & 290,00 & 17,87 & 272,13 & 150,14 & 216,53 & 217,97 & 69,86 & 480,55 & 65,73 & 14,34 & 32,98 & 164,05 & 71,62 & 82,44 & 107,25 \\
\hline Pleurodeles walt| & $305 \times 182$ & 100,00 & 142,61 & 106,86 & 39,12 & 5781,11 & 291,03 & 22,04 & 268,99 & 153,31 & 219,00 & 220,57 & 73,45 & 468,84 & 65,57 & 13,90 & 33,69 & 162,69 & 69,65 & 81,45 & 104,05 \\
\hline Pleurodeles walt| & $305 \times 190$ & 100,00 & 153,25 & 107,17 & 39,81 & 5630,23 & 298,25 & 32,30 & 265,95 & 164,95 & 227,01 & 228,96 & 85,40 & $\begin{array}{l}449,15 \\
\end{array}$ & 68,17 & 11,03 & 38,19 & 164,83 & 58,95 & 75,35 & 103,51 \\
\hline Pleurodeles walt| & $305 \times 191$ & 100,00 & 154,65 & 105,88 & 39,80 & 5600,81 & 298,09 & \begin{tabular}{|l|l}
34,84 \\
\end{tabular} & 263,25 & 166,33 & 227,97 & 230,00 & 87,14 & \begin{tabular}{|l|l|}
446,79 \\
\end{tabular} & 68,62 & \begin{tabular}{ll|}
11,06 \\
\end{tabular} & 38,44 & 165,52 & 58,81 & 75,95 & 102,75 \\
\hline Pleurodeles walt| & $305 \times 992$ & 100,00 & 157,11 & 104,43 & \begin{tabular}{|l|l|}
39,78 \\
\end{tabular} & 5563,59 & 298,29 & \begin{tabular}{|l|l}
38,17 \\
\end{tabular} & 260,11 & 168,70 & 229,72 & 231,88 & 89,87 & \begin{tabular}{ll|}
440,43 \\
\end{tabular} & \begin{tabular}{ll|}
69,03 \\
\end{tabular} & $\begin{array}{ll}10,91 \\
\end{array}$ & 39,15 & $\begin{array}{l}165,36 \\
\end{array}$ & $\begin{array}{l}57,65 \\
\end{array}$ & 75,60 & 101,15 \\
\hline Pleurodeles walt| & 30SXJ99 & 100,00 & 156,57 & 94,70 & 38,02 & 5501,31 & 289,38 & 43,62 & 245,76 & 166,92 & 228,32 & 230,32 & 90,09 & 420,21 & 65,46 & 13,67 & 37,23 & 158,42 & 63,57 & 81,59 & 88,81 \\
\hline Pleurodeles walt| & 30SXK02 & 100,00 & 112,02 & 116,72 & 38,00 & $\begin{array}{l}6418,30 \\
\end{array}$ & 285,11 & $-16,89$ & 302,01 & 102,91 & 197,50 & $\begin{array}{l}198,48 \\
\end{array}$ & 35,11 & 505,36 & 65,11 & 21,51 & 26,86 & 165,13 & 91,23 & 99,35 & 109,06 \\
\hline Pleurodeles walt| & $30 \mathrm{SXK40}$ & 100,00 & 116,01 & 107,73 & \begin{tabular}{|l|l|}
37,78 \\
\end{tabular} & 6252,44 & 276,27 & $-6,16$ & 282,43 & 133,03 & 123,01 & 200,16 & 41,92 & \begin{tabular}{|l|l|}
485,12 \\
\end{tabular} & 60,79 & 22,01 & 27,28 & \begin{tabular}{|l|l|}
158,67 \\
\end{tabular} & 94,35 & 98,94 & 95,01 \\
\hline Pleurodeles walt| & 30SXK50 & 100,00 & 127,65 & 104,81 & 37,71 & 6135,18 & 281,71 & 6,70 & 275,01 & 142,82 & \begin{tabular}{|c|}
92,14 \\
\end{tabular} & 209,82 & 54,41 & \begin{tabular}{|l|l|}
442,77 \\
\end{tabular} & 54,53 & 19,12 & 28,90 & \begin{tabular}{ll|}
142,62 \\
\end{tabular} & 84,56 & 87,90 & 84,95 \\
\hline Pleurodeles walt| & 30SXK51 & 100,00 & 121,03 & 104,12 & 37,22 & 6191,15 & 276,05 & 0,70 & 275,35 & 137,93 & 48,32 & 204,10 & 47,33 & $\begin{array}{l}458,95 \\
\end{array}$ & 57,95 & 21,34 & 28,56 & \begin{tabular}{ll|}
149,92 \\
\end{tabular} & 86,45 & 95,23 & 86,45 \\
\hline Pleurodeles walt| & 30 XXK80 & 100,00 & 133,40 & 98,33 & 37,20 & 5881,55 & 277,88 & 17,42 & 260,45 & 142,60 & 180,96 & 212,31 & 63,21 & 457,53 & 58,17 & 18,99 & 29,97 & 152,34 & 84,32 & 93,37 & 89,68 \\
\hline Pleurodeles walt| & 30SXK90 & 100,00 & 137,15 & $\begin{array}{ll}96,17 \\
\end{array}$ & 37,23 & 5766,21 & 277,84 & 22,66 & 255,19 & $\begin{array}{l}146,16 \\
\end{array}$ & 210,50 & 214,60 & 68,34 & \begin{tabular}{ll|l}
461,90 \\
\end{tabular} & 60,83 & 18,45 & 30,90 & 158,33 & 82,55 & 94,14 & 92,39 \\
\hline Pleurodeles walt| & 30SXK91 & 100,00 & 118,16 & 97,05 & 36,70 & 5962,03 & 264,77 & 3,03 & 261,74 & 128,88 & 86,00 & 198,45 & 47,94 & \begin{tabular}{|l|l|}
516,47 \\
\end{tabular} & 61,85 & 23,82 & 27,32 & \begin{tabular}{|l|l|}
164,19 \\
\end{tabular} & 99,90 & $\begin{array}{l}108,37 \\
\end{array}$ & 100,35 \\
\hline Pleurodeles walt| & 30SXK92 & 100,00 & 118,22 & 96,24 & 36,31 & 5976,35 & 264,32 & 3,29 & 261,02 & 129,84 & 58,95 & 198,64 & 47,90 & 505,18 & 61,45 & 23,95 & 27,82 & 160,42 & 95,62 & 107,63 & 95,73 \\
\hline Pleurodeles walt| & 30SYHO9 & 100,00 & 148,30 & 106,84 & 39,64 & \begin{tabular}{|l|}
5640,08 \\
\end{tabular} & 294,15 & 27,77 & 266,38 & 160,23 & 222,30 & 224,45 & 80,64 & \begin{tabular}{|l|l|}
481,97 \\
\end{tabular} & 70,89 & 12,15 & 37,05 & \begin{tabular}{|l|l|}
174,40 \\
\end{tabular} & 63,64 & 80,44 & 113,50 \\
\hline Pleurodeles walt| & 30SYH18 & 100,00 & 135,72 & 105,93 & 39,01 & 5715,70 & 284,32 & 16,26 & 268,07 & 135,22 & 211,13 & 213,36 & 68,11 & 545,95 & 74,34 & 15,54 & 33,65 & 189,00 & 76,09 & 91,16 & 130,99 \\
\hline Pleurodeles walt| & 30SYJ00 & 100,00 & 155,61 & 105,66 & 39,80 & 5555,91 & 298,20 & 35,92 & 262,28 & $\begin{array}{l}167,72 \\
\end{array}$ & 228,19 & 230,44 & 88,69 & \begin{tabular}{ll|}
460,32 \\
\end{tabular} & 71,19 & $\begin{array}{l}10,76 \\
\end{array}$ & 39,49 & $\begin{array}{l}172,56 \\
\end{array}$ & 58,32 & 77,35 & 108,73 \\
\hline Pleurodeles walt| & 30SYJ01 & 100,00 & 165,16 & 103,69 & \begin{tabular}{|l|}
39,98 \\
\end{tabular} & 5425,32 & 302,72 & 46,92 & 255,79 & 177,70 & 235,58 & 238,01 & 99,28 & 435,34 & 72,06 & 9,13 & 43,17 & \begin{tabular}{ll|}
170,82 \\
\end{tabular} & 51,37 & 73,43 & 104,19 \\
\hline Pleurodeles walt| & 30SYJ08 & 100,00 & \begin{tabular}{ll|}
167,01 \\
\end{tabular} & 92,15 & 38,61 & \begin{tabular}{|l|}
5261,87 \\
\end{tabular} & 292,83 & 56,86 & 235,97 & \begin{tabular}{ll|}
178,53 \\
\end{tabular} & 234,81 & 237,69 & 103,18 & 421,74 & 73,28 & 11,57 & 42,99 & 169,44 & 55,16 & \begin{tabular}{|l|}
78,88 \\
\end{tabular} & 94,67 \\
\hline Pleurodeles walt| & 30SYJO9 & 100,00 & 160,41 & 92,08 & 37,99 & 5362,79 & 288,70 & 49,75 & 238,95 & 171,34 & 230,00 & 232,42 & 95,51 & 428,82 & 69,92 & 13,27 & 39,42 & 166,71 & 61,35 & 82,93 & 93,31 \\
\hline Pleurodeles walt| & 30SYJ23 & 100,00 & 173,90 & 97,01 & 39,91 & 5186,52 & 301,71 & 60,73 & 240,98 & 187,31 & 240,30 & 243,48 & 110,50 & \begin{tabular}{|l|l|}
460,88 \\
\end{tabular} & 80,59 & 8,63 & 48,03 & 190,34 & 49,35 & 79,16 & 118,22 \\
\hline Pleurodeles walt| & $30 \mathrm{SYJ} 29$ & 100,00 & 160,16 & 88,68 & 37,70 & 5226,04 & 284,34 & 52,04 & 232,30 & 171,93 & 227,54 & 230,65 & 97,17 & 462,29 & 75,74 & 13,71 & 40,62 & 182,64 & 63,83 & $\begin{array}{ll}90,03 \\
\end{array}$ & 104,77 \\
\hline Pleurodeles walt| & 30SYJ41 & 92,00 & 178,72 & 99,65 & \begin{tabular}{|l|}
39,99 \\
\end{tabular} & 5194,28 & 309,11 & 62,64 & 246,47 & 156,51 & 244,90 & 248,08 & 114,94 & 503,61 & 82,83 & 7,26 & 51,03 & 216,47 & 47,22 & 82,13 & 143,56 \\
\hline Pleurodeles walt| & 30SYKO0 & 100,00 & 139,41 & 94,26 & \begin{tabular}{|l|l|}
37,13 \\
\end{tabular} & 5666,42 & 277,01 & 26,49 & 250,53 & 148,94 & 214,20 & 215,70 & 71,98 & 472,11 & 64,15 & 18,16 & 31,70 & $\begin{array}{l}165,66 \\
\end{array}$ & 81,42 & 95,94 & 96,76 \\
\hline Pleurodeles walt| & 30SYK10 & 100,00 & 143,46 & 92,15 & 37,02 & 5547,72 & 277,29 & 31,91 & 245,38 & 153,64 & 216,17 & 218,25 & 77,29 & 479,42 & 67,76 & 17,51 & 33,16 & 173,14 & 78,71 & 96,77 & 101,15 \\
\hline Pleurodeles walt| & 30SYK21 & 100,00 & 145,32 & 89,86 & 36,76 & 5470,59 & 276,20 & 34,98 & 241,22 & 155,35 & 216,84 & 219,06 & 80,06 & $\begin{array}{l}483,17 \\
\end{array}$ & 68,68 & 17,47 & 33,96 & 176,54 & 78,74 & 98,83 & 102,43 \\
\hline Pleurodeles walt| & 30SYK22 & 100,00 & 141,91 & 89,99 & \begin{tabular}{|l|}
36,38 \\
\end{tabular} & 5542,24 & 274,33 & 30,88 & 243,45 & 151,30 & 214,58 & 216,54 & 75,93 & 483,39 & 66,07 & 18,39 & 32,69 & 172,99 & 82,58 & 100,81 & 99,84 \\
\hline Pleurodeles walt| & 30SYK32 & 100,00 & 160,29 & 85,89 & 36,64 & 5244,68 & 283,74 & 51,95 & 231,79 & 170,88 & 227,87 & 230,75 & 97,07 & 446,44 & 68,37 & 14,57 & 38,74 & 173,66 & 66,49 & 91,97 & 96,40 \\
\hline Pleurodeles walt| & 30SYK51 & 6,00 & 172,20 & 83,00 & 36,90 & 5063,60 & 290,00 & 65,90 & 224,10 & 184,20 & 236,90 & 240,90 & 111,00 & 436,90 & 70,60 & 12,00 & 43,40 & 179,00 & 57,90 & 89,00 & 99,20 \\
\hline Pleurodeles walt| & 30SYK52 & 57,00 & 171,46 & 82,73 & 36,02 & 5099,43 & 289,46 & 63,70 & 225,76 & 182,67 & 236,61 & 239,70 & 109,33 & 435,60 & 69,07 & 12,52 & 42,66 & 177,43 & 58,92 & 89,85 & 97,71 \\
\hline Pleurodeles walt| & 30TTK43 & 60,00 & 149,16 & 110,74 & 36,88 & $\begin{array}{l}6409,49 \\
\end{array}$ & \begin{tabular}{|l|l|}
324,89 \\
\end{tabular} & $\begin{array}{ll}26,98 \\
\end{array}$ & 297,91 & 78,57 & 234,93 & 234,93 & 71,07 & \begin{tabular}{|l|l|}
468,07 \\
\end{tabular} & 57,26 & 5,87 & 44,11 & $\begin{array}{l}167,16 \\
\end{array}$ & 38,90 & 38,90 & 154,18 \\
\hline Pleurodeles walt| & 30TTK44 & 60,00 & 132,45 & 109,16 & 36,60 & 6377,70 & 307,43 & 12,65 & 294,78 & 62,97 & 217,85 & 218,38 & 55,81 & 543,52 & 66,52 & 8,45 & 42,58 & 193,49 & 48,58 & \begin{tabular}{|c|c|}
49,33 \\
\end{tabular} & 179,36 \\
\hline Pleurodeles walt| & 30TTK59 & 100,00 & 118,74 & 111,53 & \begin{tabular}{|l|l|}
37,89 \\
\end{tabular} & 6264,91 & 292,03 & 0,06 & 291,97 & 50,05 & 202,19 & 203,01 & 43,41 & 522,27 & 64,35 & 10,65 & 38,81 & 182,02 & 55,69 & 56,28 & 164,96 \\
\hline Pleurodeles walt| & 30TTK65 & 100,00 & 113,49 & 109,94 & 36,7 & 6341,39 & 289,57 & $-5,24$ & 294,81 & 45,07 & 198,60 & 199,43 & 38,40 & 586, & 70,42 & 12,04 & 39,20 & 201,93 & 59,78 & 61,71 & 185,52 \\
\hline Pleurodeles walt| & 30TTK66 & 100,00 & 79,21 & 106,14 & 36,4 & 6224,39 & 253,47 & $-34,09$ & 287,56 & 14,25 & $\begin{array}{ll}163,83 \\
\end{array}$ & 164,57 & 7,95 & 803,94 & 95,97 & 19,66 & 37,45 & 276,18 & 86,49 & 92,45 & 257,79 \\
\hline Pleurodeles walt| & 30TTK & 100,00 & 109,14 & 110,24 & \begin{tabular}{|l|l|}
37,07 \\
\end{tabular} & $\begin{array}{l}6281,82 \\
\end{array}$ & 283,90 & $-8,71$ & 292,61 & 41,20 & $\begin{array}{l}192,97 \\
\end{array}$ & 194,39 & 34,75 & 578,5 & 69,88 & $\begin{array}{ll}12,63 \\
\end{array}$ & 37,97 & \begin{tabular}{|l|l|}
198,20 \\
\end{tabular} & 62,04 & 64,14 & 180,73 \\
\hline Pleurodeles walt| & 30TTK68 & 100,00 & 121,72 & 112,60 & $\begin{array}{l}37,88 \\
\end{array}$ & 6290,36 & 296,40 & 1,58 & 294,82 & 52,69 & 205,55 & 206,38 & $\mid 46,00$ & $\mid$\begin{tabular}{|l|l|}
494,14 \\
\end{tabular} & 59,95 | & \begin{tabular}{|c|c|}
10,43 \\
\end{tabular} & 38,06 & $\mid$\begin{tabular}{|l|l|}
168,79 \\
\end{tabular} & \begin{tabular}{|l|l|l}
53,79 \\
\end{tabular} & \begin{tabular}{l|l|l|}
54,29 \\
\end{tabular} & 152,38 \\
\hline Pleurodeles walt| & 30TTK69 & 100,00 & 116,55 & 112,76 & 38,00 & 6255,50 & 290,74 & $-2,36$ & 293,10 & 54,45 & 199,44 & 200,97 & 41,45 & 504,86 & 61,34 & 11,15 & 37,32 & 171,90 & 56,85 & 57,70 & 154,59 \\
\hline Pleurodeles walt| & 30TTK74 & 100,00 & 134,76 & 112,76 & 36,99 & 6418,78 & 312,39 & 11,83 & 300,57 & 68,51 & 220,79 & 221,21 & 57,26 & 470,09 & 55,91 & 8,45 & 40,06 & 159,85 & 46,18 & 46,69 & 145,14 \\
\hline Pleurodeles walt| & 30 30TK 7 & 100,00 & 81,44 & 107,65 & 36,44 & 6263,92 & 257,81 & $-33,16$ & 290,97 & $\begin{array}{ll}16,03 \\
\end{array}$ & 166,67 & $\begin{array}{l}167,38 \\
\end{array}$ & 9,72 & 767,13 & 90,58 & 19,21 & 36,84 & 259,87 & 83,75 & 88,86 & 241,18 \\
\hline Pleurodeles walt| & 30TTK78 & 100,00 & 114,63 & 112,80 & 37,91 & 6271,61 & 289,86 & $-4,61$ & 294,47 & 55,68 & 197,59 & 199,56 & 39,69 & 504,84 & 60,39 & 11,68 & 36,46 & 168,65 & 57,96 & 59,24 & 151,39 \\
\hline Pleurodeles walt| & 30TTK79 & 100,00 & 116,93 & 113,89 & $\begin{array}{l}38,05 \\
\end{array}$ & 6247,73 & 291,87 & $-2,66$ & 294,53 & 73,70 & 199,32 & 201,36 & 41,94 & 479,76 & 57,49 & 11,22 & 36,02 & 159,91 & 56,53 & 57,49 & 142,51 \\
\hline Pleurodeles walt| & 30TTK84 & 100,00 & 134,41 & 113,27 & 37,00 & 6425,82 & 312,65 & 10,59 & 302,07 & 81,47 & 220,52 & 220,95 & 56,82 & 456,62 & 53,71 & 8,67 & 39,33 & 153,00 & 46,50 & 47,06 & 137,83 \\
\hline Pleurodeles walt| & $30 \pi T$ & 100 & 158 & 11 & $37, \mathrm{C}$ & 647 & 336,17 & 31,10 & 305,07 & 116,45 & 244 & 24 & 78,48 & 365 & 43,12 & 5, & 41,74 & 124 & 32,99 & 32,99 & 110,07 \\
\hline Pleurodeles walt| & 30TTK94 & 100,00 & 150,38 & 114,48 & 37,00 & 6451,97 & 328,03 & 24,12 & 303,91 & 108,28 & 236,77 & 236,78 & 71,27 & 381,23 & 44,71 & 6,37 & 39,86 & 128,30 & 37,38 & 37,38 & 113,13 \\
\hline Pleurodeles walt| & 30TTK95 & 100,00 & 94,42 & 110,80 & 36,89 & 6314,75 & 272,60 & $-23,77$ & 296,37 & 36,90 & 179,93 & 180,69 & 21,05 & 643,16 & 74,43 & 17,05 & 35,56 & 210,75 & 74,63 & 78,42 & $\begin{array}{ll}191,89 \\
\end{array}$ \\
\hline Pleurodeles walt| & 30TTL42 & 30,00 & 120,48 & 112,93 & \begin{tabular}{l|l|l}
38,05 \\
\end{tabular} & 6232,91 & 292,73 & 1,11 & 291,61 & 77,20 & 203,64 & 203,64 & 44,57 & 490,30 & 62,09 & 10,07 & 39,20 & 173,45 & 53,66 & 53,66 & 154,52 \\
\hline Pleuroc & $30 T T$ & 20,00 & & 113, & 38, & 206,59 & 291, & 0,07 & 010 & 79,59 & 202,28 & 20 & 43,86 & 458,03 & 59,00 & 10,34 & 38,24 & 163,90 & 53,28 & 53,28 & 14 \\
\hline Pleurodeles walt| & 30TTL50 & 100,00 & 114,93 & 111,65 & 37,99 & 6240,78 & 287,90 & $-2,85$ & 290,75 & 47,54 & 197,78 & 199,05 & 40,02 & 528,6 & 65,29 & 11,17 & 38,41 & \begin{tabular}{|l|l|}
183,98 \\
\end{tabular} & 57,94 & 58,66 & 166,05 \\
\hline Pleurodeles walt| & 30TTL51 & 100,00 & 114,77 & 112,50 & 38,08 & 6230,42 & 287,68 & $-3,20$ & 290,88 & 64,41 & 197,93 & 198,57 & 39,84 & 514,20 & 63,74 & 11,21 & 38,14 & 179,09 & 57,85 & 58,21 & 160,08 \\
\hline
\end{tabular}




\begin{tabular}{|c|c|c|c|c|c|c|c|c|c|c|c|c|c|c|c|c|c|c|c|c|c|}
\hline TAXON & UTM & $\mathrm{km} 2$ & BIO1 & BIO2 & $B 103$ & BIO4 & B105 & B106 & B107 & B108 & 8109 & B1010 & BIO11 & B1012 & BIO13 & BIO14 & BIO15 & B1016 & B1017 & B1018 & B1019 \\
\hline Pleurodeles walt| & 30TTL52 & 100,00 & 118,54 & 113,86 & 38,51 & 6232,96 & 291,42 & $-0,62$ & 292,05 & 78,26 & 201,92 & 201,92 & 42,90 & 480,01 & 60,34 & 10,69 & 38,36 & 168,97 & 54,94 & 54,94 & 147,61 \\
\hline Pleurodeles walt| & 30TTL53 & 100,00 & 120,34 & 114,70 & 38,82 & 6227,93 & 293,23 & 0,35 & 292,88 & \begin{tabular}{l|l}
80,03 \\
\end{tabular} & 203,45 & 203,45 & 44,47 & $\begin{array}{l}455,95 \\
\end{array}$ & 58,28 & $\begin{array}{l}10,16 \\
\end{array}$ & 38,74 & $\begin{array}{l}162,47 \\
\end{array}$ & 52,75 & 52,75 & 138,49 \\
\hline Pleurodeles walt| & 30TTL54 & 100,00 & 119,97 & 114,95 & 38,97 & 6214,41 & \begin{tabular}{|l|l|}
292,67 \\
\end{tabular} & 0,09 & 292,57 & 79,86 & 202,86 & 202,86 & 44,03 & 445,01 & 57,31 & 10,31 & 38,63 & 159,45 & 52,65 & 52,65 & 133,95 \\
\hline Pleurodeles walt| & 30TTL55 & 100,00 & 119,49 & 114,99 & 39,00 & \begin{tabular}{ll|l}
6194,68 \\
\end{tabular} & 291,90 & $-0,15$ & 292,05 & 79,42 & 202,05 & 202,05 & 43,64 & \begin{tabular}{ll|l}
438,15 \\
\end{tabular} & 56,37 & 10,58 & 38,23 & 156,80 & 52,87 & 52,87 & 131,30 \\
\hline Pleurodeles walt| & 30TTL56 & 100,00 & 115,04 & 114,44 & 39,00 & 6165,01 & 287,15 & $-3,84$ & 290,99 & 75,32 & 197,15 & 197,26 & 39,83 & 452,74 & 57,87 & \begin{tabular}{ll|}
11,27 \\
\end{tabular} & 37,59 & 161,16 & 55,84 & 55,92 & $\begin{array}{ll}135,98 \\
\end{array}$ \\
\hline Pleurodeles walt| & 30TTL57 & 100,00 & 115,39 & 114,42 & 39,00 & 6158,74 & 287,28 & $-3,76$ & \begin{tabular}{|l|}
291,04 \\
\end{tabular} & 75,66 & \begin{tabular}{|l|l|}
197,18 \\
\end{tabular} & 197,42 & 40,06 & 444,03 & 56,61 & \begin{tabular}{ll|}
11,27 \\
\end{tabular} & 37,08 & \begin{tabular}{|l|l|}
157,38 \\
\end{tabular} & 55,33 & 55,47 & 133,44 \\
\hline 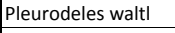 & 30TTL58 & 100,00 & 118,25 & 114,45 & 39,00 & 6157,61 & 289,66 & $-1,44$ & 291,09 & 78,51 & 199,50 & $\begin{array}{l}199,90 \\
\end{array}$ & 42,43 & $\begin{array}{l}426,35 \\
\end{array}$ & 54,25 & 10,94 & 36,63 & 150,60 & 53,39 & 53,63 & 128,16 \\
\hline Pleurodeles walt| & 30TTL59 & 100,00 & 120,08 & 114,38 & 38,99 & 6142,13 & 290,93 & $-0,17$ & 291,10 & 80,44 & 200,75 & 201,21 & \begin{tabular}{ll|}
44,09 \\
\end{tabular} & 416,59 & 52,89 & \begin{tabular}{ll|}
10,56 \\
\end{tabular} & 36,11 & 146,84 & 52,66 & $\begin{array}{l}52,95 \\
\end{array}$ & 125,25 \\
\hline Pleurodeles walt| & 30TTL60 & 100,00 & 114,36 & 113,21 & 38,01 & 6233,21 & 288,24 & $-4,33$ & \begin{tabular}{|l|l|}
292,57 \\
\end{tabular} & \begin{tabular}{|l|l|}
69,27 \\
\end{tabular} & 197,00 & $\begin{array}{l}198,49 \\
\end{array}$ & 39,50 & \begin{tabular}{ll|}
502,62 \\
\end{tabular} & 61,29 & $\begin{array}{l}11,47 \\
\end{array}$ & 36,97 & \begin{tabular}{|l|l|}
171,10 \\
\end{tabular} & 58,14 & 58,96 & 152,82 \\
\hline Pleurodeles walt| & 30TTL61 & 100,00 & 113,50 & 113,97 & 38,46 & \begin{tabular}{|l|l|}
6218,07 \\
\end{tabular} & 287,22 & $-5,21$ & 292,44 & 72,68 & 196,09 & 197,31 & 38,71 & 492,07 & 60,22 & 11,71 & 36,64 & 168,50 & 58,69 & 59,31 & 148,05 \\
\hline Pleurodeles walt| & 30TTL62 & 100,00 & 116,47 & 115,31 & \begin{tabular}{l|l|l}
38,95 \\
\end{tabular} & \begin{tabular}{|l|l|}
6219,87 \\
\end{tabular} & 290,42 & $-2,82$ & \begin{tabular}{|l|}
293,24 \\
\end{tabular} & 76,27 & $\begin{array}{ll}199,71 \\
\end{array}$ & 199,86 & 41,25 & 462,77 & 57,19 & 11,12 & 37,00 & 160,84 & 56,27 & 56,35 & 137,50 \\
\hline Pleurodeles walt| & 30TTL63 & 100,00 & 119,51 & 116,51 & 39,01 & \begin{tabular}{ll|l|}
6228,66 \\
\end{tabular} & \begin{tabular}{|l|l|}
293,60 \\
\end{tabular} & $-0,62$ & 294,22 & 79,06 & 202,72 & 202,72 & \begin{tabular}{|l|l|}
43,67 \\
\end{tabular} & \begin{tabular}{|l|l|}
431,98 \\
\end{tabular} & 54,71 & 10,97 & 37,70 & \begin{tabular}{ll|}
153,08 \\
\end{tabular} & 53,65 & 53,65 & 125,65 \\
\hline Pleurodeles walt| & 30TTL64 & 100,00 & 120,29 & 116,82 & \begin{tabular}{l|l|}
39,05 \\
\end{tabular} & 6221,36 & 294,10 & $-0,18$ & \begin{tabular}{|l|l|}
294,27 \\
\end{tabular} & 80,06 & 203,19 & 203,19 & 44,14 & 413,41 & 52,97 & \begin{tabular}{ll|}
10,68 \\
\end{tabular} & 38,41 & 148,23 & 52,13 & 52,13 & 118,31 \\
\hline Pleurodeles walt| & 30TTL66 & 100,00 & 114,36 & 115,74 & 39,00 & 6172,04 & 287,32 & $-5,11$ & 292,43 & 74,34 & \begin{tabular}{|l|l|}
196,24 \\
\end{tabular} & $\begin{array}{ll}196,68 \\
\end{array}$ & 39,04 & 426,80 & 53,56 & 11,65 & 36,71 & 150,57 & 56,11 & 56,36 & 122,45 \\
\hline Pleurodeles walt| & 30TTL67 & 100,00 & 115,36 & 115,55 & 39,00 & $\begin{array}{ll}6155,89 \\
\end{array}$ & 287,85 & $-4,08$ & \begin{tabular}{|l|l|}
291,93 \\
\end{tabular} & 75,61 & \begin{tabular}{|l|l|}
196,41 \\
\end{tabular} & $\begin{array}{l}197,42 \\
\end{array}$ & \begin{tabular}{ll|}
40,03 \\
\end{tabular} & $\begin{array}{l}417,49 \\
\end{array}$ & 52,16 & $\begin{array}{l}11,57 \\
\end{array}$ & 36,18 & $\begin{array}{l}146,45 \\
\end{array}$ & 55,03 & 55,53 & 119,99 \\
\hline Pleurodeles walt| & \begin{tabular}{|l|l|}
$30 T T L 68$ \\
\end{tabular} & 100,00 & 119,86 & 115,30 & 39,00 & 6157,26 & 291,68 & $-0,43$ & 292,11 & 80,01 & 199,99 & 201,51 & 43,94 & \begin{tabular}{|l|l|}
390,48 \\
\end{tabular} & 48,65 & 10,34 & 35,71 & 136,31 & 51,33 & 52,09 & 111,71 \\
\hline Pleurodeles walt| & 30TTL69 & 100,00 & 122,06 & 115,03 & 39,00 & 6155,46 & 293,29 & 0,89 & 292,40 & 82,50 & 201,72 & 203,25 & 45,71 & \begin{tabular}{|l|l|}
378,28 \\
\end{tabular} & 47,02 & $\begin{array}{l}9,83 \\
\end{array}$ & 35,32 & \begin{tabular}{|l|l|}
131,58 \\
\end{tabular} & 49,88 & 50,85 & 107,96 \\
\hline Pleurodeles walt| & 30TTL70 & 100,00 & 118,69 & 114,98 & \begin{tabular}{|l|l|}
38,57 \\
\end{tabular} & 6219,90 & 293,06 & $-1,30$ & 294,36 & 78,33 & 201,28 & 202,53 & 43,78 & 458,78 & 55,16 & 11,02 & 35,67 & 153,44 & 55,54 & 56,09 & 135,18 \\
\hline Pleurodeles walt| & 30TTL71 & 100,00 & 115,19 & 115,41 & 38,99 & 6196,44 & 289,38 & $-4,39$ & 293,77 & 74,78 & 196,90 & $\begin{array}{l}198,69 \\
\end{array}$ & 40,55 & 461,69 & 55,62 & \begin{tabular}{ll|}
11,56 \\
\end{tabular} & 35,19 & $\begin{array}{l}154,96 \\
\end{array}$ & 57,72 & 58,52 & 134,75 \\
\hline Pleurodeles walt| & 30TTL73 & 100,00 & 120,48 & 118,22 & 39,59 & 6217,77 & 295,16 & $-0,53$ & 295,68 & 79,94 & 203,51 & 203,67 & 44,79 & 414,32 & 50,8 & 10,99 & 35,68 & 142,51 & 53,90 & 53,97 & 118,64 \\
\hline Pleurodeles walt| & 30TTL74 & 100,00 & 119,74 & 118,07 & 39,74 & 6189,04 & 293,94 & $-1,06$ & 295,01 & 79,43 & 202,52 & 202,54 & 44,36 & \begin{tabular}{|l|l|}
397,47 \\
\end{tabular} & 49,66 & 10,92 & 36,87 & 139,32 & 53,40 & 53,40 & 109,99 \\
\hline Pleurodeles walt| & 30TTL75 & 100,00 & 118,36 & 117,62 & 39,62 & 6170,04 & 292,09 & $-1,89$ & \begin{tabular}{|l|l|}
293,97 \\
\end{tabular} & 78,08 & 200,76 & 200,92 & 43,20 & $\begin{array}{l}394,29 \\
\end{array}$ & 49,00 & 11,00 & 36,49 & \begin{tabular}{ll|}
137,82 \\
\end{tabular} & 53,90 & 53,96 & 108,48 \\
\hline Pleurodeles walt| & 30TTL77 & 100,00 & 115,30 & 116,42 & \begin{tabular}{l|l|l|}
39,02 \\
\end{tabular} & 6142,99 & 288,43 & $-4,77$ & 293,20 & 75,46 & 195,38 & 197,22 & 40,21 & 399,37 & 48,49 & 11,80 & 34,90 & 137,61 & 55,20 & 56,19 & 110,71 \\
\hline Pleurodeles walt| & 30TTL78 & 100,00 & 119,71 & 116,10 & 39,00 & 6150,08 & 292,16 & $-0,90$ & 293,06 & 79,96 & $\begin{array}{ll}199,21 \\
\end{array}$ & 201,27 & 43,98 & 375,74 & 45,45 & 10,79 & 34,65 & 129,17 & 51,47 & 52,77 & 103,77 \\
\hline Pleurodeles walt| & 30TTL79 & 100,00 & 123,62 & 115,62 & 39,00 & 6148,60 & 295,08 & 1,99 & 293,09 & 84,09 & 202,65 & 204,89 & 47,22 & 358,17 & 43,27 & $\begin{array}{l}9,79 \\
\end{array}$ & 34,54 & 122,99 & 49,01 & 50,37 & 98,48 \\
\hline Pleurodeles walt| & 30TTL81 & 100,00 & 119,77 & 116,53 & 39,00 & 6165,85 & 293,85 & $-0,93$ & \begin{tabular}{|l|l|}
294,78 \\
\end{tabular} & 79,18 & 200,16 & 202,99 & 45,29 & 424,89 & 50,31 & 11,05 & 33,65 & 138,73 & 55,23 & 56,31 & 120,59 \\
\hline Pleurodeles walt| & 30TTL82 & 100,00 & 1117,57 & 117,17 & 39,34 & 6116,41 & 290,95 & $-2,46$ & 293,41 & 77,21 & $\begin{array}{ll}197,13 \\
\end{array}$ & 200,08 & 43,72 & 421,53 & 50,03 & 11,24 & 33,00 & $\begin{array}{l}137,38 \\
\end{array}$ & 56,54 & 57,75 & 118,50 \\
\hline Pleurodeles walt| & 30TTL83 & 100,00 & 120,42 & 118,34 & 40,00 & \begin{tabular}{|l|l|}
6087,64 \\
\end{tabular} & 293,26 & $-0,31$ & \begin{tabular}{|l|l|}
293,57 \\
\end{tabular} & 79,91 & 199,28 & 202,43 & 46,64 & 400,26 & 47,40 & 11,00 & 32,46 & 130,21 & 54,99 & 56,17 & 111,81 \\
\hline Pleurodeles walt| & 30TTL84 & 100,00 & 118,22 & 118,05 & 40,00 & 6094,94 & 291,11 & $-2,11$ & 293,22 & 77,77 & \begin{tabular}{|l|l|}
197,44 \\
\end{tabular} & 200,09 & 44,13 & \begin{tabular}{|l|l|}
395,58 \\
\end{tabular} & 47,83 & 11,05 & 33,18 & 130,74 & 55,48 & 56,54 & 108,39 \\
\hline Pleurodeles walt| & 30TTL86 & 100,00 & 114,99 & 117,17 & 39,21 & 6118,82 & 288,09 & $-5,01$ & 293,10 & 74,80 & 194,29 & 196,82 & 40,29 & 395,85 & 48,46 & 11,95 & 33,60 & 132,92 & 56,56 & 57,97 & 107,10 \\
\hline Pleurodeles walt| & 30TTL91 & 100,00 & 117,60 & 116,18 & 39,00 & 6136,11 & 291,29 & $-2,71$ & 294,00 & 77,22 & \begin{tabular}{|l|l|}
197,47 \\
\end{tabular} & 200,64 & 43,65 & $\begin{array}{l}418,35 \\
\end{array}$ & 50,18 & 11,39 & 32,73 & 133,71 & 56,42 & 58,07 & 115,02 \\
\hline Pleurodeles walt| & 30TTL92 & 100,00 & 119,23 & 117,02 & 39,26 & 6087,00 & 291,85 & $-1,21$ & \begin{tabular}{|l|l|}
293,05 \\
\end{tabular} & 78,44 & 197,85 & 201,35 & 45,51 & 402,74 & 48,03 & 11,02 & 31,95 & 127,79 & 55,75 & 57,51 & 110,08 \\
\hline Pleurodeles walt| & 30TTL94 & 100,00 & 117,14 & 117,62 & 39,89 & 6042,23 & 289,38 & $-2,95$ & 292,33 & 76,99 & $\begin{array}{l}195,08 \\
\end{array}$ & $\begin{array}{l}198,61 \\
\end{array}$ & 43,79 & 392,83 & 47,39 & 11,57 & 31,49 & 125,51 & 56,71 & 58,87 & 105,48 \\
\hline Pleurodeles walt| & 30TTM51 & 100,00 & 118,76 & 114,38 & 39,00 & 6098,89 & 289,06 & $-1,49$ & \begin{tabular}{l|l|}
290,55 \\
\end{tabular} & 79,56 & \begin{tabular}{|l|l|}
199,21 \\
\end{tabular} & 199,38 & 42,84 & 432,61 & 54,87 & \begin{tabular}{|l|l|}
11,70 \\
\end{tabular} & 35,37 & 152,99 & 56,31 & 56,41 & 131,65 \\
\hline Pleurodeles walt| & 30TTM56 & 80,00 & 115,43 & 114,79 & 39,02 & 5976,23 & 283,90 & $-4,84$ & \begin{tabular}{|l|l|}
288,73 \\
\end{tabular} & 77,50 & 194,25 & 194,25 & 40,71 & 500,38 & 63,39 & 16,95 & 34,12 & 181,13 & 71,15 & 71,15 & 153,10 \\
\hline Pleurodeles walt| & 30TTM61 & 100,00 & 120,34 & 115,00 & 39,00 & 6111,14 & 291,01 & $-0,41$ & 291,42 & 80,98 & 200,24 & 200,94 & 44,43 & 400,67 & 49,91 & 11,19 & 34,43 & 140,49 & 54,41 & 54,76 & 116,63 \\
\hline Pleurodeles walt| & 30TTM62 & 100,00 & 120,20 & 115,04 & 39,00 & 6087,90 & 290,52 & $-0,55$ & 291,06 & 81,15 & 200,17 & 200,39 & 44,52 & 413,72 & 51,54 & 12,11 & 34,03 & 145,85 & 57,31 & 57,43 & 121,43 \\
\hline Pleurodeles walt| & 30TTM63 & 100,00 & 119,25 & 115,18 & 39,00 & 6062,60 & \begin{tabular}{|l|}
289,37 \\
\end{tabular} & $-1,77$ & 291,14 & 80,81 & $\begin{array}{ll}199,31 \\
\end{array}$ & 199,31 & 43,73 & 429,64 & 53,58 & 13,31 & 33,78 & 152,42 & 60,47 & 60,47 & 126,97 \\
\hline Pleurodeles walt| & 30TTM70 & 100,00 & 123,60 & 115,39 & 39,00 & 6134,25 & 294,63 & 1,73 & 292,90 & 84,40 & 202,34 & 204,45 & 47,04 & \begin{tabular}{|l|l|}
363,72 \\
\end{tabular} & 44,02 & $\begin{array}{l}10,25 \\
\end{array}$ & 33,86 & \begin{tabular}{|l|}
125,23 \\
\end{tabular} & 50,36 & 51,65 & 100,75 \\
\hline Pleurodeles walt| & 30TTM72 & 100,00 & 121,22 & 115,76 & 39,00 & 6085,42 & 292,07 & $-0,26$ & 292,33 & 82,42 & 200,30 & 201,51 & 45,26 & 396,00 & 48,23 & 12,26 & 33,17 & 138,25 & 56,89 & 57,44 & 112,25 \\
\hline Pleurodeles walt| & 30TTM73 & 100,00 & \begin{tabular}{|l|l|}
119,93 \\
\end{tabular} & 115,98 & 39,00 & \begin{tabular}{|l|l|}
6054,20 \\
\end{tabular} & \begin{tabular}{|l|}
290,56 \\
\end{tabular} & $-1,70$ & 292,26 & 81,61 & \begin{tabular}{|l|l|}
199,49 \\
\end{tabular} & 199,75 & 44,16 & \begin{tabular}{|l|l|}
413,48 \\
\end{tabular} & 50,49 & 13,51 & 32,68 & $\begin{array}{l}145,36 \\
\end{array}$ & 60,75 & \begin{tabular}{ll|}
60,88 \\
\end{tabular} & 118,08 \\
\hline Pleurodeles walt| & 30TTM83 & 100,00 & 121,46 & 116,04 & 39,00 & 6028,39 & 292,09 & $-0,39$ & 292,48 & 84,00 & 199,86 & 200,99 & 46,17 & 400,38 & 48,43 & 13,59 & 31,92 & 139,41 & 60,23 & 60,83 & 111,39 \\
\hline Pleurodeles walt| & 30TTM85 & 100,00 & 119,63 & 116,05 & $\begin{array}{l}39,03 \\
\end{array}$ & 5984,16 & 289,65 & $-1,88$ & 291,53 & 82,89 & 198,59 & 198,59 & 44,51 & 431,66 & 53,50 & 15,91 & 31,95 & 152,64 & 67,61 & 67,61 & 120,59 \\
\hline Pleurodeles walt| & 30TTM86 & 100,00 & 118,72 & 116,01 & 39,16 & 5951,78 & 288,12 & $-2,99$ & 291,11 & 82,34 & \begin{tabular}{|l|l|}
197,08 \\
\end{tabular} & 197,08 & 43,80 & \begin{tabular}{|l|l|}
448,88 \\
\end{tabular} & 56,30 & 17,25 & 31,89 & \begin{tabular}{|l|l|}
159,88 \\
\end{tabular} & 71,49 & 71,49 & 125,12 \\
\hline Pleurodeles walt| & 30TTM87 & 100,00 & 117,81 & 116,00 & 39,49 & 5920,41 & 286,75 & $-3,75$ & 290,50 & 81,81 & 195,85 & 195,85 & 43,28 & 466,17 & 59,07 & 18,60 & 31,97 & $\begin{array}{l}167,09 \\
\end{array}$ & 75,59 & 75,59 & 129,48 \\
\hline Pleurodeles walt| & 30TTM & 100,00 & 115,22 & 115,85 & \begin{tabular}{|l|l|}
39,87 \\
\end{tabular} & 5866,60 & 283,20 & $-6,04$ & 289,24 & 79,92 & \begin{tabular}{|l|l|}
192,64 \\
\end{tabular} & $\begin{array}{l}192,64 \\
\end{array}$ & 41,29 & $\begin{array}{l}504,66 \\
\end{array}$ & 65,2 & 21,97 & 32,22 & 183,22 & 85,25 & 85,25 & 138,31 \\
\hline Pleurodeles walt| & 30тTM93 & 100,00 & $\begin{array}{ll}121,63 \\
\end{array}$ & 116,31 & 39,02 & 6017,12 & 292,34 & $-0,49$ & 292,83 & 84,57 & 199,03 & 201,21 & 46,42 & 398,03 & 48,02 & 14,06 & 31,29 & \begin{tabular}{|l|l|}
136,86 \\
\end{tabular} & 60,54 & 62,02 & 108,93 \\
\hline Pleurodeles walt| & 30TTM94 & 100,00 & 120,15 & 116,45 & 39,17 & 5991,92 & 290,56 & $-1,88$ & 292,45 & 83,73 & 197,40 & 199,33 & 45,15 & 415,08 & 50,59 & 15,35 & 31,10 & 143,84 & 64,70 & 65,83 & 113,69 \\
\hline Pleurodeles walt| & 30TTM96 & 100,00 & 117,91 & 116,07 & 39,13 & 5937,17 & 287,51 & $-4,03$ & \begin{tabular}{|l|l|}
291,53 \\
\end{tabular} & 82,30 & 196,05 & 196,30 & 43,35 & 448,11 & 55,80 & 17,87 & 31,11 & 157,64 & 73,34 & 73,50 & 122,49 \\
\hline Pleurodeles walt| & 30TTM: & 100,00 & 115,85 & 116,00 & 39,31 & 5914,77 & 285,15 & $-5,94$ & 291,08 & 80,58 & 193,93 & 193,93 & 41,69 & 469,21 & 58,95 & 19,56 & 30,93 & 166,19 & 78,40 & 78,40 & 127,92 \\
\hline Pleurodeles walt| & 30TTM98 & 100,00 & 115,31 & 115,94 & \begin{tabular}{l|l|}
39,65 \\
\end{tabular} & \begin{tabular}{|l|}
5873,47 \\
\end{tabular} & 283,65 & $-6,28$ & \begin{tabular}{|l|l|}
289,93 \\
\end{tabular} & 80,58 & 192,79 & 192,79 & 41,40 & 486,16 & 61,73 & 21,00 & 31,12 & 173,32 & 82,64 & 82,64 & 131,60 \\
\hline Pleurodeles walt| & 30TTN70 & 100,00 & 111,83 & 115,86 & \begin{tabular}{|l|l|}
39,87 \\
\end{tabular} & 5876,95 & 279,96 & $-8,85$ & 288,81 & 76,08 & 189,31 & 189,31 & 37,82 & 541,07 & 70,76 & 23,03 & 32,95 & 198,52 & 90,65 & 90,65 & 151,22 \\
\hline Pleurodeles walt| & 30TTN71 & 100,00 & 108,29 & 115,51 & \begin{tabular}{|c|}
39,98 \\
\end{tabular} & 5833,44 & 275,83 & $-11,51$ & 287,33 & 72,84 & 185,29 & 185,29 & 35,15 & 574,51 & 75,41 & 23,60 & 32,70 & 210,81 & 98,28 & 98,28 & 159,69 \\
\hline Pleurodeles walt| & $30 \pi T$ & 100 & 113 & 115 & 39, & 584 & 281 & $-7,17$ & $28 \varepsilon$ & 78,73 & 190,70 & $19 \mathrm{C}$ & 39, & 525,78 & 68,5 & 22 & 32,40 & 191,86 & 90,45 & 90,45 & 143 \\
\hline Pleurodeles walt| & 30TTN90 & 100,00 & 115,60 & 114,52 & 39,93 & 5754,04 & 280,47 & $-4,69$ & 285,16 & 82,10 & 191,30 & 191,30 & 42,93 & 521,09 & 67,51 & 23,59 & 31,24 & 187,63 & 91,22 & 91,22 & 139,00 \\
\hline Pleurodeles walt| & 30TUK03 & 100,00 & 156,90 & 114,99 & 37,00 & 6503,86 & 335,39 & 28,88 & 306,51 & 114,68 & 243,94 & 243,94 & 76,89 & 361,34 & 42,13 & 5,25 & 40,71 & 122,40 & 33,81 & 33,81 & 106,76 \\
\hline Pleurodeles walt| & 30TUK04 & 100,00 & 152,48 & 114,92 & 37,00 & \begin{tabular}{|l|l|}
6473,37 \\
\end{tabular} & 330,21 & 25,06 & \begin{tabular}{|l|l}
305,15 \\
\end{tabular} & 110,58 & 239,14 & 239,14 & 72,90 & 365,59 & 42,55 & 6,31 & 39,21 & $\begin{array}{l}122,56 \\
\end{array}$ & 36,52 & 36,52 & 106,51 \\
\hline Pleuroc & 30TUK08 & 100,00 & 105 & 113 & 37,8 & 234,50 & 282,07 & $-14,19$ & 96, & & 188 & 19 & 32,37 & 495,59 & 60,24 & 14,20 & & 157,74 & 64,29 & 66,78 & 13 \\
\hline Pleurodeles walt| & 30TUK13 & 100,00 & 153,80 & 115,00 & 37,00 & 6529,68 & 332,82 & 25,31 & 307,51 & 111,49 & 241,18 & 241,18 & 73,63 & 362,19 & 41,65 & 5,97 & 39,65 & 121,37 & 35,44 & 35,44 & 104,84 \\
\hline Pleurodeles walt| & 30TUK14 & 100,00 & 151,35 & 114,68 & 37,00 & 6499,67 & 329,40 & 23,35 & 306,06 & 109,40 & 238,49 & 238,49 & 71,49 & 361,03 & 41,78 & 6,41 & 38,95 & 120,26 & 36,98 & 36,98 & 103,24 \\
\hline
\end{tabular}




\begin{tabular}{|c|c|c|c|c|c|c|c|c|c|c|c|c|c|c|c|c|c|c|c|c|c|}
\hline TAXON & UTM & km2 & BIO1 & $\mathrm{BIO2}$ & BIO3 & BIO4 & B105 & B106 & B107 & B108 & B109 & B1010 & BIO11 & BIO12 & BIO13 & B1014 & BIO15 & BIO16 & B1017 & BIO18 & \begin{tabular}{|l|} 
BIO19 \\
147,18
\end{tabular} \\
\hline Pleurodeles walt| & 30TUK15 & 100,00 & 107,17 & 112,56 & 37,00 & 6357,38 & 286,19 & $-14,32$ & 300,52 & $71,97 \mid$ & 192,81 & 193,76 & 32,42 & 526,62 & 62,91 & 14,19 & 34,84 & 168,06 & 64,68 & 66,84 & 147,18 \\
\hline Pleurodeles walt| & 30TUK23 & 100,00 & 151,83 & 114,95 & 37,00 & 6558,41 & 331,25 & 23,05 & 308,19 & 109,52 & \begin{tabular}{|l|l|}
239,88 \\
\end{tabular} & 239,88 & $\begin{array}{ll}71,45 \\
\end{array}$ & 361,57 & 41,58 & 6,19 & 39,18 & \begin{tabular}{|l|}
120,32 \\
\end{tabular} & 36,54 & 36,54 & 102,94 \\
\hline Pleurodeles walt| & 30TUK24 & 100,00 & 148,45 & 114,23 & 37,00 & 6501,82 & 326,70 & 20,22 & \begin{tabular}{|l|l|}
306,48 \\
\end{tabular} & 106,40 & 235,77 & 235,77 & 68,69 & 362,49 & 42,40 & 6,90 & 38,08 & 119,71 & 38,77 & 38,77 & 101,54 \\
\hline Pleurodeles walt| & 30TUK25 & 100,00 & 135,47 & 113,90 & 37,00 & 6441,15 & 313,42 & 9,08 & 304,35 & \begin{tabular}{|l|l|}
104,99 \\
\end{tabular} & 222,13 & 222,33 & 57,18 & 389,31 & 47,34 & 8,90 & 36,26 & 126,13 & 46,22 & 46,31 & 105,63 \\
\hline Pleurodeles walt| & 30TUK29 & 100,00 & 97,39 & 111,69 & \begin{tabular}{l|l}
37,25 \\
\end{tabular} & 6172,59 & 272,32 & $-22,07$ & 294,39 & 77,13 & \begin{tabular}{l|l|}
179,98 \\
\end{tabular} & \begin{tabular}{|l|l|}
181,63 \\
\end{tabular} & 24,99 & 497,97 & \begin{tabular}{ll|l}
64,06 \\
\end{tabular} & 16,68 & 32,32 & \begin{tabular}{|l|l|}
155,57 \\
\end{tabular} & $\begin{array}{ll}71,03 \\
\end{array}$ & 74,46 & 127,42 \\
\hline Pleurodeles walt| & 30TUK39 & 100,00 & 104,10 & 111,62 & 37,10 & 6184,29 & 278,08 & $-17,14$ & \begin{tabular}{|l|}
295,22 \\
\end{tabular} & \begin{tabular}{|l|l|}
97,69 \\
\end{tabular} & \begin{tabular}{|l|l|}
186,34 \\
\end{tabular} & 188,11 & 30,71 & 449,96 & 60,10 & 15,34 & 32,89 & \begin{tabular}{|l|l|}
142,87 \\
\end{tabular} & \begin{tabular}{ll|l}
66,47 \\
\end{tabular} & \begin{tabular}{l|l}
69,05 \\
\end{tabular} & 109,53 \\
\hline Pleurodeles walt1 & 30тUK43 & 100,00 & 145,94 & 114,02 & $36,11]$ & 6601,61 & 326,07 & 16,37 & 309,70 & 117,03 & 234,62 & 234,62 & 65,32 & 370,04 & 44,08 & 7,20 & 37,97 & 121,24 & 40,37 & 40,37 & 101,62 \\
\hline Pleurodeles walt| & 30TUK45 & 100,00 & 146,31 & 112,88 & 36,51 & 6512,57 & 323,18 & 17,87 & 305,31 & 107,34 & 233,69 & 233,69 & 66,26 & 353,29 & 42,51 & 7,55 & 37,12 & \begin{tabular}{|l|}
115,64 \\
\end{tabular} & 40,71 & 40,71 & 94,95 \\
\hline Pleurodeles walt| & 30TUK49 & 100,00 & 106,49 & 110,67 & 37,00 & 6192,96 & 279,53 & $-15,58$ & 295,10 & 120,31 & \begin{tabular}{l|l|l|}
188,72 \\
\end{tabular} & \begin{tabular}{|l|l|l|}
190,49 \\
\end{tabular} & 32,85 & 428,51 & 58,98 & 14,66 & 33,71 & \begin{tabular}{|l|l|}
138,90 \\
\end{tabular} & \begin{tabular}{l|l}
64,95 \\
\end{tabular} & 67,18 & 100,21 \\
\hline Pleurodeles walt| & 30TUK53 & 100,00 & 150,74 & 113,37 & 36,00 & 6632,21 & 330,08 & 20,54 & 309,54 & 109,54 & 239,77 & 239,77 & 69,22 & 357,35 & 42,01 & 6,85 & 38,16 & $\begin{array}{ll}117,52 \\
\end{array}$ & 38,30 & 38,30 & 98,42 \\
\hline Pleurodeles walt| & 30TUK54 & 100,00 & 131,14 & 112,60 & 36,09 & 6545,57 & 310,48 & 3,62 & 306,87 & \begin{tabular}{l|l|}
113,72 \\
\end{tabular} & 219,40 & 219,58 & \begin{tabular}{l|l|l|}
52,15 \\
\end{tabular} & 401,54 & 50,23 & 9,73 & 35,69 & \begin{tabular}{|l|l|}
130,93 \\
\end{tabular} & 49,81 & \begin{tabular}{ll|}
49,99 \\
\end{tabular} & 104,96 \\
\hline Pleurodeles walt| & 30TUK55 & 100,00 & 140,85 & 112,00 & 36,01 & 6541,56 & 318,01 & 12,68 & \begin{tabular}{|l|}
305,33 \\
\end{tabular} & \begin{tabular}{|l|l|}
110,79 \\
\end{tabular} & 228,88 & 228,88 & \begin{tabular}{ll|}
60,92 \\
\end{tabular} & 365,31 & 44,80 & 8,45 & 35,97 & 118,38 & 44,29 & 44,29 & 96,25 \\
\hline Pleurodeles walt| & 30TUK64 & 100,00 & 143,47 & 111,86 & 36,00 & 6613,83 & 321,64 & 14,24 & 307,40 & 113,18 & 232,51 & 232,51 & 62,66 & 368,43 & 44,41 & 8,08 & 36,43 & \begin{tabular}{|l|}
120,08 \\
\end{tabular} & 43,36 & 43,36 & 98,32 \\
\hline Pleurodeles walt| & 30TUK65 & 100,00 & 132,66 & 111,17 & 36,00 & 6534,47 & 309,78 & 5,08 & 304,70 & \begin{tabular}{l|l|}
113,12 \\
\end{tabular} & 220,75 & \begin{tabular}{|l|l}
220,75 \\
\end{tabular} & \begin{tabular}{l|l|}
53,25 \\
\end{tabular} & 387,33 & 48,71 & 9,88 & 35,14 & \begin{tabular}{|l|l|}
125,27 \\
\end{tabular} & 49,91 & 49,91 & 99,34 \\
\hline Pleurodeles walt| & 30TUK66 & 100,00 & $\begin{array}{ll}113,97 \\
\end{array}$ & 110,31 & 36,34 & 6387,97 & 290,11 & $-9,62$ & 299,73 & 93,62 & 200,12 & 200,66 & 38,09 & 443,80 & 57,94 & 13,48 & 33,95 & \begin{tabular}{|l|l|}
143,79 \\
\end{tabular} & 62,19 & 63,67 & 109,62 \\
\hline Pleurodeles walt| & 30TUK74 & 100,00 & 148,29 & 111,08 & 35,77 & 6661,16 & 326,08 & 18,42 & \begin{tabular}{|l|l|}
307,66 \\
\end{tabular} & 106,53 & 237,77 & 237,77 & 66,49 & 360,88 & 42,33 & 7,73 & 36,76 & 118,60 & 41,34 & 41,34 & 97,94 \\
\hline Pleurodeles walt| & 30TUK75 & 100,00 & 136,04 & 110,17 & 35,75 & 6585,37 & 312,70 & 8,06 & 304,64 & \begin{tabular}{ll|}
107,44 \\
\end{tabular} & 224,68 & 224,68 & 55,91 & 383,44 & 47,1 & 9,64 & 35,07 & \begin{tabular}{|l|l|}
123,98 \\
\end{tabular} & 48,72 & 48,72 & 99,62 \\
\hline Pleurodeles waltt & 30TUK76 & 100,00 & 126,44 & 109,29 & 35,91 & 6486,12 & 301,51 & 0,41 & 301,10 & 104,01 & 213,75 & 214,03 & 48,02 & 399,10 & 51,13 & 11,25 & 34,41 & \begin{tabular}{|l|l|}
128,63 \\
\end{tabular} & 54,68 & 54,91 & 99,41 \\
\hline Pleurodeles walt| & 30TUK77 & 100,00 & 128,57 & 108,45 & \begin{tabular}{|l|l|}
35,97 \\
\end{tabular} & 6458,48 & 301,79 & 2,79 & 299,00 & 98,53 & 215,16 & 215,53 & 50,03 & 387,77 & 49,53 & 11,21 & 34,19 & \begin{tabular}{l|l}
124,92 \\
\end{tabular} & \begin{tabular}{l|l}
53,75 \\
\end{tabular} & \begin{tabular}{l|l}
54,05 \\
\end{tabular} & 96,10 \\
\hline Pleurodeles walt| & 30TUK85 & 100,00 & 145,18 & 109,17 & 35,10 & 6648,13 & 321,11 & 16,44 & 304,68 & 102,51 & 234,40 & 234,40 & 63,61 & 368,66 & 42,96 & 8,57 & 35,71 & \begin{tabular}{|l|l|}
121,13 \\
\end{tabular} & 43,99 & 43,99 & 99,45 \\
\hline Pleurodeles walt| & 30TUK86 & 100,00 & 133,66 & 108,22 & 35,36 & 6561,83 & 308,14 & 6,79 & 301,35 & 98,74 & 221,89 & 222,00 & 53,67 & \begin{tabular}{l|l}
390,65 \\
\end{tabular} & 47,58 & 10,50 & 34,35 & \begin{tabular}{l|l|}
125,95 \\
\end{tabular} & 51,28 & 51,34 & \begin{tabular}{|l|l|}
101,24 \\
\end{tabular} \\
\hline Pleurodeles walt| & 30TUK87 & 100,00 & 133,51 & 107,34 & 35,38 & 6530,87 & 306,06 & 7,06 & 299,00 & 93,52 & 220,89 & 221,09 & 53,58 & 385,86 & 47,13 & 10,80 & 34,08 & 124,41 & 51,68 & 51,78 & 99,15 \\
\hline Pleurodeles walt| & 30TUK88 & 100,00 & 120,92 & 106,42 & 35,70 & 6408,92 & 291,84 & $-2,97$ & 294,81 & 109,49 & 205,88 & 207,34 & 43,50 & 407,06 & 52,75 & 12,92 & 33,55 & 130,32 & 59,09 & 60,40 & 98,12 \\
\hline Pleurodeles walt| & 30TUK89 & 100,00 & 98,05 & 106,76 & 36,38 & 6211,20 & 268,70 & $-21,19$ & 289,90 & 113,77 & 181,84 & \begin{tabular}{ll|}
182,58 \\
\end{tabular} & 25,62 & $\begin{array}{ll}478,86 \\
\end{array}$ & 64,70 & 17,80 & 32,27 & $\begin{array}{l}155,90 \\
\end{array}$ & \begin{tabular}{|l|l|}
74,58 \\
\end{tabular} & 78,62 & 110,54 \\
\hline Pleurodeles walt| & 30TUK96 & 100,00 & 142,41 & 107,19 & 35,01 & 6629,52 & 316,24 & \begin{tabular}{ll|}
14,88 \\
\end{tabular} & 301,36 & \begin{tabular}{ll|}
100,00 \\
\end{tabular} & 231,30 & 231,30 & 60,84 & 380,83 & 44,26 & 9,53 & 35,10 & 125,81 & 46,72 & 46,72 & 103,71 \\
\hline Pleurodeles walt| & 30TUK97 & 100,00 & 130,01 & 106,23 & \begin{tabular}{|l|}
35,08 \\
\end{tabular} & 6535,23 & 302,11 & 4,72 & 297,39 & 91,01 & 217,24 & 217,90 & 50,46 & 406,46 & 48,70 & 11,65 & 33,54 & 131,35 & 54,53 & 54,97 & 105,93 \\
\hline Pleurodeles walt| & 30TUK98 & 100,00 & 117,08 & 105,55 & 35,46 & 6424,03 & 287,68 & $-5,43$ & 293,11 & 92,36 & 202,24 & 203,76 & 39,80 & 433,53 & 54,70 & 14,08 & 32,57 & 137,60 & 62,24 & 64,39 & 106,93 \\
\hline Pleurodeles walt| & 30TUK99 & 100,00 & 96,32 & 106,41 & 36,45 & 6227,65 & 266,97 & $-21,79$ & 288,76 & \begin{tabular}{ll|}
105,56 \\
\end{tabular} & \begin{tabular}{|l|l|}
180,69 \\
\end{tabular} & \begin{tabular}{ll|}
181,32 \\
\end{tabular} & 24,05 & 503,34 & 65,66 & 18,77 & 31,15 & 161,06 & 76,80 & 81,29 & 120,12 \\
\hline Pleurodeles walt| & 30TUL01 & 100,00 & 116,99 & 115,61 & 38,79 & 6125,72 & 290,26 & $-4,01$ & 294,27 & 76,75 & \begin{tabular}{ll|}
196,66 \\
\end{tabular} & \begin{tabular}{|l|}
199,79 \\
\end{tabular} & 43,19 & 409,76 & 50,29 & 11,94 & 32,06 & 129,01 & 57,22 & 59,14 & 109,13 \\
\hline Pleurodeles walt| & 30TUL04 & 100,00 & 118,51 & 116,89 & 39,44 & 6066,89 & 290,54 & $-2,02$ & 292,56 & 78,15 & \begin{tabular}{ll|}
196,72 \\
\end{tabular} & 200,28 & 44,73 & 384,11 & 46,77 & 11,48 & 31,17 & \begin{tabular}{|l|l|}
120,88 \\
\end{tabular} & 56,10 & 58,44 & 101,31 \\
\hline Pleurodeles walt| & 30TUL05 & 100,00 & 119,92 & 117,01 & 39,21 & 6073,97 & 292,05 & $-0,88$ & \begin{tabular}{|l|}
292,92 \\
\end{tabular} & 79,81 & 198,15 & 201,49 & \begin{tabular}{ll|l}
45,87 \\
\end{tabular} & 374,10 & 45,4 & 11, & 31,60 & \begin{tabular}{|l|l|}
119,13 \\
\end{tabular} & 54,34 & 56,68 & 98,92 \\
\hline Pleurodeles walt & 30TULOO & 100,00 & 124,48 & 117,00 & 39,01 & 6110,66 & 296,34 & 1,98 & 294,37 & 85,50 & 202,91 & 205,33 & 48,39 & 362,45 & 42,43 & 11,87 & 31,51 & 119,34 & 53,11 & 55,39 & 96,87 \\
\hline Pleurodeles walt| & 30TUL12 & 100,00 & 115,75 & 115,13 & 38,71 & 6120,06 & 288,45 & $-5,24$ & \begin{tabular}{|l|l|}
293,69 \\
\end{tabular} & 85,69 & \begin{tabular}{l|l|l|}
195,33 \\
\end{tabular} & \begin{tabular}{l|l}
198,45 \\
\end{tabular} & 41,82 & 399,52 & 50,12 & 12,22 & 31,84 & \begin{tabular}{|l|l|}
124,37 \\
\end{tabular} & \begin{tabular}{|l|l|}
57,94 \\
\end{tabular} & 60,50 & 103,02 \\
\hline Pleurodeles walt| & 30TUL14 & 100,00 & 119,47 & 116,01 & 39,00 & 6096,91 & 291,40 & $-1,53$ & 292,94 & \begin{tabular}{|c|}
79,08 \\
\end{tabular} & \begin{tabular}{|l|l|}
198,12 \\
\end{tabular} & 201,34 & \begin{tabular}{|l|l}
44,98 \\
\end{tabular} & 379,21 & 46,62 & 11,81 & 30,89 & 118,57 & 56,08 & \begin{tabular}{|l|l}
58,75 \\
\end{tabular} & 98,30 \\
\hline Pleurodeles walt| & 30TUL15 & 100,00 & 120,68 & 116,36 & 39,02 & 6096,79 & 292,68 & $-0,61$ & 293,29 & 80,60 & \begin{tabular}{|l|l|}
199,20 \\
\end{tabular} & 202,54 & $\begin{array}{l}46,05 \\
\end{array}$ & 373,62 & 45,62 & 11,35 & 31,03 & 117,61 & 54,56 & 57,46 & 97,78 \\
\hline Pleurodeles walt| & 30TUL18 & 100,00 & 123,31 & 116,90 & 39,00 & 6114,50 & 295,28 & 1,28 & 293,99 & 83,96 & 201,97 & 204,40 & 47,29 & 368,44 & 43,48 & 11,85 & 31,01 & 118,60 & 53,89 & 56,66 & 98,44 \\
\hline Pleurodeles walt| & 30TUL23 & 100,00 & 116,90 & 114,53 & 38,55 & 6121,92 & 288,76 & $-4,31$ & 293,07 & 129,16 & 196,38 & 199,30 & 42,62 & 388,19 & 49,19 & 12,16 & 31,45 & 120,77 & 57,43 & 60,30 & 98,07 \\
\hline Pleurodeles walt| & 30TUL24 & 100,00 & 119,42 & 114,94 & 38,87 & 6127,27 & 291,15 & $-1,90$ & 293,05 & 93,05 & \begin{tabular}{|l|l|}
198,64 \\
\end{tabular} & 201,77 & 44,47 & 379,32 & \begin{tabular}{l|l}
47,25 \\
\end{tabular} & 12,00 & 31,03 & \begin{tabular}{|l|}
118,09 \\
\end{tabular} & 56,54 & 59,31 & 97,02 \\
\hline Pleurodeles walt| & 30TUL27 & 100,00 & 121,95 & 116,01 & 39,00 & 6121,77 & 293,83 & 0,06 & 293,77 & 82,36 & 200,81 & \begin{tabular}{|l|}
203,47 \\
\end{tabular} & 46,22 & 375,81 & 45,01 & 12,00 & 30,34 & \begin{tabular}{|l|l|}
118,29 \\
\end{tabular} & 55,65 & \begin{tabular}{|l|l}
58,75 \\
\end{tabular} & 99,25 \\
\hline Pleurodeles walt| & 30TUL30 & 100,00 & 95,80 & 111,23 & 37,54 & 6133,05 & 269,38 & $-23,46$ & 292,84 & 103,81 & \begin{tabular}{|l|l|}
177,94 \\
\end{tabular} & \begin{tabular}{|l|l|}
179,37 \\
\end{tabular} & 23,76 & 485,58 & \begin{tabular}{ll|l}
64,25 \\
\end{tabular} & 17,28 & 32,02 & 153,65 & 72,46 & 76,43 & 119,35 \\
\hline Pleurodeles walt| & 30TUL34 & 100,00 & 120,33 & 113,72 & 38,06 & 6157,84 & 291,43 & $-1,59$ & 293,02 & 122,55 & \begin{tabular}{|l|l|}
200,13 \\
\end{tabular} & 202,90 & 44,89 & 377,64 & 47,43 & 12,01 & 31,18 & 117,38 & 56,37 & 59,41 & 95,32 \\
\hline Pleurodeles walt| & 30TUL40 & 100,00 & 98,29 & 110,34 & 37,06 & 6137,15 & 271,00 & $-21,99$ & 292,99 & 115,20 & \begin{tabular}{|l|l|l|l|}
180,48 \\
\end{tabular} & $\begin{array}{ll}181,82 \\
\end{array}$ & 26,00 & \begin{tabular}{ll|}
459,96 \\
\end{tabular} & 62,84 & 16,79 & 32,74 & \begin{tabular}{ll|}
148,90 \\
\end{tabular} & \begin{tabular}{l|l}
70,95 \\
\end{tabular} & 74,44 & 108,01 \\
\hline Pleurodeles waltt & 30TUL42 & 100,00 & 117,11 & 111,48 & 37,70 & 6190,93 & 287,91 & $-5,11$ & 293,03 & 137,87 & \begin{tabular}{|l|l|}
198,17 \\
\end{tabular} & 200,36 & 42,06 & 385,70 & 50,87 & 13,01 & 32,17 & \begin{tabular}{|l|l|}
123,17 \\
\end{tabular} & 59,00 & 61,30 & 92,32 \\
\hline Pleurodeles walt| & 30TUL50 & 100,00 & 106,06 & 109,31 & 36,96 & 6168,92 & 277,19 & $-15,90$ & 293,08 & 124,70 & \begin{tabular}{l|l|}
188,09 \\
\end{tabular} & \begin{tabular}{|l|l|}
189,54 \\
\end{tabular} & 32,53 & 414,73 & 58,77 & 15,01 & 34,32 & \begin{tabular}{ll|}
137,72 \\
\end{tabular} & 65,86 & 68,31 & 92,25 \\
\hline Pleurodeles walt| & 30TUL57 & 100,00 & 123,07 & 112,78 & 38,02 & 6181,97 & 293,06 & 0,34 & 292,72 & 84,41 & \begin{tabular}{|l|l|}
203,18 \\
\end{tabular} & 205,50 & 46, & 391,90 & 46,43 & $12, \mathrm{C}$ & 30,66 & 121,94 & 56,41 & 61, & 103,59 \\
\hline Pleurodeles walt| & 30TUL66 & 100,00 & 121,00 & 110,45 & 37,55 & 6210,75 & 289,58 & $-0,94$ & 290,52 & 122,36 & \begin{tabular}{|l|l|}
201,98 \\
\end{tabular} & 204,01 & 44, & 398,79 & 48,28 & 12,53 & 30,18 & 123,56 & 58,21 & 63,56 & 102,40 \\
\hline Pleurodeles walt| & 30TUL70 & 100,00 & 95,84 & \begin{tabular}{ll|}
107,16 \\
\end{tabular} & 36,46 & 6136,64 & 265,89 & $-23,49$ & 289,38 & \begin{tabular}{|l|l|}
112,59 \\
\end{tabular} & \begin{tabular}{|l|l|}
178,64 \\
\end{tabular} & \begin{tabular}{|l|l|}
179,37 \\
\end{tabular} & 24,13 & 465,38 & 65,18 & 17,91 & 33,21 & \begin{tabular}{|l|l|}
154,68 \\
\end{tabular} & 75,01 & 79,26 & 103,41 \\
\hline Pleurodeles walt & 30TUL71 & 100,00 & 106,17 & 106,36 & 36,08 & 6191,89 & 274,05 & $-15,29$ & 289,34 & 124,98 & 188,57 & 189,81 & 32,22 & 418,26 & 58,89 & 15,86 & 34,05 & 140,14 & \begin{tabular}{|l|l|}
67,73 \\
\end{tabular} & 71,37 & 91,20 \\
\hline Pleurodeles walt| & \begin{tabular}{|l|l|} 
30TUL79 \\
\end{tabular} & 100,00 & 116,90 & 111,40 & 37,96 & 6113,09 & 285,53 & \begin{tabular}{l|l}
$-5,35$ \\
\end{tabular} & 290,88 & \begin{tabular}{|l|}
86,07 \\
\end{tabular} & \begin{tabular}{|l|l|}
196,91 \\
\end{tabular} & $\begin{array}{ll}198,48 \\
\end{array}$ & 41,60 & 432,60 & 50,56 & 14,06 & 29,12 & \begin{tabular}{|l|l|}
133,23 \\
\end{tabular} & 61,81 & 70,69 & 114,12 \\
\hline Pleurodeles walt| & 30TUL80 & 100,00 & 92,66 & 106,66 & 36,56 & 50,71 & 62,51 & $-25,10$ & 287,61 & 107,84 & 176,05 & 176,55 & 21,48 & $\begin{array}{l}499,76 \\
\end{array}$ & $\begin{array}{l}67,25 \\
\end{array}$ & 19,42 & 31,58 & \begin{tabular}{ll|}
162,96 \\
\end{tabular} & \begin{tabular}{|l|}
78,63 \\
\end{tabular} & 83,80 & 115,60 \\
\hline Pleurodeles walt & 30TUL81 & 100,00 & 105,88 & 10 & 35,99 & 6242,37 & 27 & $-14,65$ & 287,52 & 124,39 & 189,19 & 190,15 & 31,43 & 440,81 & 59,41 & 16,20 & 32,55 & 144,80 & 69,11 & 73,87 & 100,32 \\
\hline Pleurodeles walt| & 30TUL89 & 100,00 & 115,78 & 109,77 & 37,20 & 6117,25 & 282,95 & $-6,84$ & 289,78 & 126,76 & \begin{tabular}{|l|l|}
196,10 \\
\end{tabular} & \begin{tabular}{|l|l|}
197,42 \\
\end{tabular} & 40,47 & 440,64 & 51,64 & 14,72 & 28,99 & \begin{tabular}{|l|}
135,42 \\
\end{tabular} & \begin{tabular}{l|l}
63,55 \\
\end{tabular} & 73,62 & 114,46 \\
\hline Pleurodeles walt| & 30TUL90 & 100,00 & 88,55 & 106,60 & 36,78 & 6147,86 & 258,66 & $-27,33$ & \begin{tabular}{l|l|}
285,99 \\
\end{tabular} & \begin{tabular}{l|l}
96,43 \\
\end{tabular} & \begin{tabular}{l|l|}
172,41 \\
\end{tabular} & \begin{tabular}{|l|l|}
172,71 \\
\end{tabular} & 18,22 & \begin{tabular}{|l|l|}
541,27 \\
\end{tabular} & \begin{tabular}{ll|}
69,75 \\
\end{tabular} & 20,88 & 30,08 & \begin{tabular}{ll|}
172,62 \\
\end{tabular} & 83,43 & 88,12 & 130,46 \\
\hline Pleurodeles walt| & 30TUL91 & 100,00 & 103,04 & 104,20 & 36,11 & 6268,38 & 269,75 & $-15,97$ & 285,72 & \begin{tabular}{|l|}
120,93 \\
\end{tabular} & \begin{tabular}{|l|l|}
187,10 \\
\end{tabular} & \begin{tabular}{|l|l|}
187,99 \\
\end{tabular} & 28,96 & 474,41 & 61,07 & 16,82 & 31,16 & 152,40 & 72,34 & 78,09 & 112,79 \\
\hline Pleurodeles walt| & 30TUM00 & 100,00 & 121,52 & 117,00 & 39,00 & 6099,22 & 293,63 & $-0,48$ & 294,12 & 82,95 & \begin{tabular}{|l|l|}
199,86 \\
\end{tabular} & 202,31 & 45,59 & 376,10 & 44,12 & 12,70 & 31,45 & 124,40 & 55,38 & 58,17 & 101,02 \\
\hline Pleurodeles walt| & 30TUM02 & 100,00 & 121,08 & 117,00 & 39,00 & 6043,71 & 292,43 & $-0,94$ & 293,37 & 83,58 & 198,70 & 200,97 & 45,49 & 392,60 & 46,74 & 14,08 & 30,80 & 132,01 & 59,13 & 61,87 & 106,46 \\
\hline Pleurodeles walt| & \begin{tabular}{|l|l|} 
30TUM06 \\
\end{tabular} & 100,00 & 118,18 & 115,99 & 39,44 & 5893,34 & 287,03 & $-3,74$ & 290,76 & 83,73 & $\begin{array}{l}194,35 \\
\end{array}$ & 196,05 & 44,21 & 448,20 & 55,47 & 18,38 & 30,23 & \begin{tabular}{|l|l|}
155,69 \\
\end{tabular} & 73,56 & 74,99 & 120,66 \\
\hline Pleurodeles walt| & 30TUM07 & 100,00 & 115,87 & 115,88 & 39,41 & 5863,27 & 284,32 & $-6,15$ & 290,46 & 81,90 & \begin{tabular}{l|l|l|}
192,13 \\
\end{tabular} & \begin{tabular}{|l|l|}
193,39 \\
\end{tabular} & 42,38 & \begin{tabular}{ll|}
469,99 \\
\end{tabular} & 58,59 & 20,04 & 30,04 & $\begin{array}{ll}164,18 \\
\end{array}$ & \begin{tabular}{ll|}
79,36 \\
\end{tabular} & 80,14 & 125,95 \\
\hline Pleurodeles walt| & \begin{tabular}{|l|l|} 
30TUM08 \\
\end{tabular} & 100,00 & 112,89 & 115,63 & 39,50 & 5831,26 & 280,83 & $-8,69$ & 289,52 & 79,33 & \begin{tabular}{|l|l|}
189,69 \\
\end{tabular} & \begin{tabular}{l|l}
190,05 \\
\end{tabular} & 39,80 & 495,76 & 62,20 & 21,96 & 30,09 & \begin{tabular}{l|l|}
174,06 \\
\end{tabular} & 85,81 & 86,02 & 132,63 \\
\hline Pleurodeles walt| & 30TUM09 & 100,00 & 113,76 & 114,72 & 39,50 & 5767,30 & 279,73 & \begin{tabular}{|c|}
$-7,10$ \\
\end{tabular} & 286,83 & 80,94 & \begin{tabular}{|l|l|} 
\\
\end{tabular} & \begin{tabular}{|l|l|} 
\\
\end{tabular} & 41,24 & 510,43 & \begin{tabular}{|c|}
64,72 \\
\end{tabular} & 23,28 & 30,11 & 180,32 & \begin{tabular}{|l|}
89,68 \\
\end{tabular} & \begin{tabular}{|l|l|}
89,68 \\
\end{tabular} & 135, \\
\hline
\end{tabular}




\begin{tabular}{|c|c|c|c|c|c|c|c|c|c|c|c|c|c|c|c|c|c|c|c|c|c|}
\hline$\overline{\text { TAXON }}$ & UTM & $\mathrm{km} 2$ & BIO1 & BIO2 & $B 103$ & BIO4 & B105 & B106 & B107 & B108 & B109 & B1010 & BIO11 & B1012 & BIO13 & B1014 & BIO15 & B1016 & B1017 & B1018 & B1019 \\
\hline Pleurodeles walt| & 30TUM11 & 100,00 & 118,37 & 117,00 & 39,00 & 6073,24 & 290,72 & $-3,53$ & 294,26 & 80,71 & 196,67 & 199,01 & 42,72 & 399,96 & 47,04 & 14,32 & 30,24 & 131,10 & 59,76 & 63,84 & 108,02 \\
\hline Pleurodeles walt| & 30TUM16 & 100,00 & 118,70 & 115,79 & 39,37 & 5856,60 & 286,73 & $-3,77$ & 290,50 & 85,25 & 194,20 & 196,06 & 45,19 & 449,58 & 55,12 & 18,70 & 29,39 & 153,91 & 73,29 & 76,26 & 119,81 \\
\hline Pleurodeles walt| & 30TUM17 & 100,00 & 117,29 & 115,08 & 39,24 & 5806,82 & 284,13 & $-4,69$ & 288,82 & 84,79 & \begin{tabular}{|l|}
192,30 \\
\end{tabular} & $\begin{array}{l}194,02 \\
\end{array}$ & 44,52 & $\begin{array}{l}469,07 \\
4\end{array}$ & 58,02 & 20,24 & 29,21 & \begin{tabular}{ll|}
161,68 \\
\end{tabular} & 78,54 & 80,92 & 124,26 \\
\hline Pleurodeles walt| & 30TUM18 & 100,00 & 114,87 & 114,51 & 39,26 & 5750,62 & 280,61 & $-6,58$ & 287,19 & 83,02 & $\begin{array}{l}189,36 \\
\end{array}$ & $\begin{array}{l}190,87 \\
\end{array}$ & 42,83 & 493,50 & 61,48 & 22,02 & 29,04 & 170,85 & 84,79 & 86,58 & 130,20 \\
\hline Pleurodeles walt| & 30TUM19 & 100,00 & 112,08 & 113,84 & \begin{tabular}{l|l|}
39,45 \\
\end{tabular} & 5711,47 & 276,81 & $-8,39$ & 285,20 & 80,59 & 186,43 & 187,57 & 40,66 & 521,27 & 65,33 & 24,05 & 28,83 & 181,12 & 91,78 & 92,82 & 137,14 \\
\hline Pleurodeles walt| & 30TUM22 & 100,00 & 116,34 & 117,00 & 39,00 & 6033,32 & 288,63 & $-5,76$ & 294,39 & 80,11 & 194,44 & 196,61 & 41,35 & 421,60 & 49,58 & 15,54 & 29,37 & 136,94 & 63,37 & 68,72 & 114,20 \\
\hline 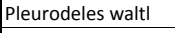 & 30TUM23 & 100,00 & 120,17 & 116,92 & 39,15 & 5964,66 & 290,75 & $-2,26$ & 293,01 & 85,50 & 197,48 & 199,12 & 45,63 & 417,02 & 49,59 & 15,83 & 29,43 & 137,30 & 63,17 & 68,10 & 112,54 \\
\hline Pleurodeles walt| & 30TUM24 & 100,00 & 118,63 & 116,41 & \begin{tabular}{l|l}
39,05 \\
\end{tabular} & 5919,12 & 288,54 & $-4,22$ & 292,76 & $\begin{array}{ll}84,93 \\
\end{array}$ & $\begin{array}{l}195,36 \\
\end{array}$ & $\begin{array}{l}197,06 \\
\end{array}$ & 44,65 & \begin{tabular}{|l|l|}
431,28 \\
\end{tabular} & 51,55 & 17,28 & 29,09 & \begin{tabular}{|l|l|}
143,01 \\
\end{tabular} & 66,56 & 71,83 & 115,78 \\
\hline Pleurodeles walt| & 30TUM26 & 100,00 & 117,05 & 115,38 & $\begin{array}{ll}39,03 \\
\end{array}$ & 5819,70 & 284,64 & $-5,93$ & \begin{tabular}{|l|l|}
290,57 \\
\end{tabular} & 85,09 & 192,47 & 194,16 & 44,41 & $\begin{array}{l}459,45 \\
\end{array}$ & 55,68 & 19,51 & 28,57 & $\begin{array}{l}154,73 \\
\end{array}$ & 74,14 & 79,14 & 121,54 \\
\hline Pleurodeles walt| & 30TUM27 & 100,00 & 117,38 & 114,55 & 39,09 & $\begin{array}{l}5749,96 \\
\end{array}$ & 282,96 & $-4,90$ & \begin{tabular}{|l|l|}
287,87 \\
\end{tabular} & 86,52 & \begin{tabular}{ll|}
191,98 \\
\end{tabular} & 193,45 & 45,56 & \begin{tabular}{|l|l|}
473,03 \\
\end{tabular} & 57,88 & 20,51 & 28,42 & 160,59 & 78,11 & 82,48 & 124,39 \\
\hline Pleurodeles walt| & 30TUM28 & 100,00 & 116,00 & 113,62 & 39,21 & 5688,18 & 279,92 & $-5,54$ & 285,46 & 85,75 & 189,75 & 191,17 & 44,94 & \begin{tabular}{ll|l}
494,83 \\
\end{tabular} & 61,05 & 22,19 & 28,15 & 169,00 & 83,81 & 87,49 & 129,43 \\
\hline Pleurodeles walt| & 30TUM29 & 100,00 & 112,78 & 112,65 & 39,19 & 5631,06 & $275,25 \mid$ & $-7,28$ & 282,52 & 83,09 & 185,99 & $\begin{array}{l}187,28 \\
\end{array}$ & 42,63 & 525,30 & 65,14 & 24,28 & 27,92 & $\begin{array}{l}179,86 \\
\end{array}$ & 91,29 & $\begin{array}{l}94,23 \\
\end{array}$ & 137,08 \\
\hline Pleurodeles walt| & 30TUM34 & 100,00 & 120,10 & 116,06 & 39,00 & 5897,92 & 289,35 & $-3,58$ & 292,93 & 87,40 & $\begin{array}{l}196,63 \\
\end{array}$ & 198,19 & 46,40 & 432,74 & 51,34 & 17,12 & 28,79 & 141,74 & 65,51 & 72,43 & 115,91 \\
\hline Pleurodeles walt| & 30TUM36 & 100,00 & 117,71 & 114,89 & 39,00 & 5767,21 & 284,04 & $-5,85$ & 289,89 & 87,57 & $\begin{array}{l}192,61 \\
\end{array}$ & 194,06 & 45,82 & \begin{tabular}{ll|}
462,38 \\
\end{tabular} & 55,49 & 19,68 & 28,04 & 153,60 & 73,11 & 80,41 & 121,46 \\
\hline Pleurodeles walt| & 30TUM38 & 100,00 & 114,84 & 112,86 & 39,01 & $\begin{array}{l}5647,56 \\
\end{array}$ & \begin{tabular}{|l|}
277,71 \\
\end{tabular} & $-6,86$ & 284,57 & 86,00 & 188,38 & 189,59 & \begin{tabular}{ll|}
44,63 \\
\end{tabular} & 503,23 & 61,25 & 22,71 & 27,38 & $\begin{array}{l}169,15 \\
\end{array}$ & 83,95 & 89,87 & 130,77 \\
\hline Pleurodeles walt| & 30TUM40 & 100,00 & 122,15 & 115,78 & 39,00 & 6114,58 & 293,78 & 0,52 & 293,26 & 78,23 & 201,19 & 203,18 & 45,84 & 410,07 & 47,65 & 13,35 & 29,65 & 129,07 & 58,92 & 63,97 & 113,83 \\
\hline Pleurodeles walt| & 30TUM41 & 100,00 & 116,48 & 116,22 & 39,00 & $\begin{array}{l}6077,18 \\
\end{array}$ & \begin{tabular}{|l|}
289,07 \\
\end{tabular} & $-5,09$ & 294,16 & 77,72 & $\begin{array}{l}195,67 \\
\end{array}$ & $\begin{array}{l}197,33 \\
\end{array}$ & 41,18 & 432,19 & 50,04 & 14,91 & 29,02 & 135,79 & 62,79 & 69,55 & 119,23 \\
\hline Pleurodeles walt| & 30TUM43 & 100,00 & 115,33 & 116,54 & 39,00 & 5937,94 & 286,39 & $-7,99$ & 294,38 & 82,39 & 192,84 & 194,41 & 41,83 & 445,14 & 51,89 & 16,70 & 28,48 & 142,24 & 65,52 & 74,47 & 119,81 \\
\hline Pleurodeles walt| & 30TUM44 & 100,00 & 119,96 & 115,96 & 39,00 & 5873,55 & 288,56 & $-4,79$ & 293,35 & 88,68 & 196,36 & 197,90 & 46,86 & \begin{tabular}{|l|l|}
437,99 \\
\end{tabular} & 51,36 & 17,04 & 28,47 & $\begin{array}{l}141,45 \\
\end{array}$ & 64,96 & 74,22 & 116,53 \\
\hline Pleurodeles walt| & 30TUM45 & 100,00 & 119,78 & 115,23 & 39,00 & 5786,69 & 286,76 & $-4,92$ & 291,69 & $\begin{array}{ll}90,38 \\
\end{array}$ & 195,00 & 196,53 & \begin{tabular}{ll|}
47,87 \\
\end{tabular} & 447,41 & 52,79 & 18,40 & 28,20 & 145,73 & 67,55 & 77,10 & 117,74 \\
\hline Pleurodeles walt| & 30TUM49 & 100,00 & 109,31 & 110,90 & 39,00 & 5549,84 & 269,61 & $-10,74$ & 280,35 & 82,26 & 181,95 & $\begin{array}{l}182,82 \\
\end{array}$ & 40,77 & 548,23 & 65,97 & 25,72 & 26,17 & 181,77 & 92,73 & 100,16 & 141,59 \\
\hline Pleurodeles walt| & 30TUM50 & 100,00 & 124,34 & 114,90 & 38,89 & 6106,90 & 295,01 & 2,06 & 292,94 & \begin{tabular}{|l|l}
62,07 \\
\end{tabular} & 203,37 & 205,14 & 47,94 & $\begin{array}{l}412,16 \\
\end{array}$ & 47,90 & 13,03 & 29,88 & \begin{tabular}{|l|l|}
130,10 \\
\end{tabular} & 58,24 & 63,54 & 115,23 \\
\hline Pleurodeles walt| & 30TUM51 & 100,00 & 122,95 & 115,51 & \begin{tabular}{|l|}
38,98 \\
\end{tabular} & 6066,38 & 293,71 & 0,46 & $\begin{array}{l}293,25 \\
\end{array}$ & 63,90 & 201,60 & 203,15 & 46,92 & $\begin{array}{l}423,85 \\
\end{array}$ & 49,38 & 13,88 & 29,50 & 134,49 & 59,79 & 66,21 & 119,16 \\
\hline Pleurodeles walt| & 30TUM55 & 100,00 & 120,99 & 114,95 & \begin{tabular}{|l|}
38,98 \\
\end{tabular} & 5756,24 & 287,11 & $-5,64$ & 292,75 & 93,99 & 195,90 & 197,43 & 49,67 & 446,02 & 51,90 & 18,06 & 28,31 & 143,43 & 65,46 & 77,75 & 115,77 \\
\hline Pleurodeles walt| & 30TUM56 & 100,00 & 119,70 & 113,90 & 38,97 & 5683,32 & 283,72 & $-5,96$ & 289,69 & 93,62 & 193,73 & 194,98 & 49,34 & 462,42 & 54,10 & 19,69 & 27,77 & 149,64 & 69,88 & 82,09 & 118,81 \\
\hline Pleurodeles walt| & 30TUM57 & 100,00 & 115,86 & 112,71 & 39,00 & 5627,80 & 278,45 & $-8,25$ & 286,70 & 90,00 & 189,36 & 190,38 & 46,43 & 490,84 & 57,69 & 21,75 & 26,95 & 159,46 & 76,90 & 88,51 & 125,72 \\
\hline Pleurodeles walt| & 30TUM58 & 100,00 & 112,95 & 111,22 & 38,98 & 5561,76 & 273,43 & $-9,44$ & \begin{tabular}{|l|l|}
282,87 \\
\end{tabular} & 87,28 & 185,75 & $\begin{array}{l}186,54 \\
\end{array}$ & 44,39 & 520,03 & 61,52 & 23,71 & 26,27 & 169,80 & 84,27 & 94,75 & 133,20 \\
\hline Pleurodeles walt| & 30TUM59 & 100,00 & 110,88 & 109,56 & 39,00 & 5495,01 & 268,95 & $-9,26$ & 278,22 & 85,30 & 182,86 & 183,40 & 43,01 & 548,82 & 65,37 & 25,64 & 25,81 & 180,01 & 91,50 & \begin{tabular}{|l|l|}
100,58 \\
\end{tabular} & 140,82 \\
\hline Pleurodeles walt| & 30TUM60 & 100,00 & 122,48 & \begin{tabular}{|l|l|}
113,60 \\
\end{tabular} & $\begin{array}{l}38,15 \\
\end{array}$ & \begin{tabular}{|l|l|}
6089,17 \\
\end{tabular} & \begin{tabular}{|l|}
292,07 \\
\end{tabular} & $-0,49$ & 292,56 & 86,07 & 201,70 & 203,24 & 46,55 & 419,17 & 48,36 & 13,43 & 29,68 & 131,25 & 58,86 & 66,41 & 114,57 \\
\hline Pleurodeles walt| & 30TUM61 & 100,00 & 120,32 & 114,40 & \begin{tabular}{|l|l|}
38,47 \\
\end{tabular} & 6036,22 & 290,06 & $-3,31$ & 293,37 & 85,23 & 198,96 & 200,41 & 45,18 & 431,13 & 49,61 & 14,44 & 29,26 & 134,87 & 60,73 & 69,65 & 117,55 \\
\hline Pleurodeles walt| & 30TUM64 & 100,00 & 116,19 & 115,26 & 38,27 & 5815,91 & 283,91 & $-11,75$ & 295,66 & 89,12 & 192,21 & 193,42 & 44,57 & 454,02 & 52,14 & 17,58 & 28,65 & 142,29 & 64,78 & 80,12 & 117,01 \\
\hline Pleurodeles walt| & 30TUM66 & 100,00 & 118,44 & 113,53 & \begin{tabular}{|l|}
38,58 \\
\end{tabular} & 5661,01 & 282,08 & $-8,95$ & \begin{tabular}{|l|l|}
291,03 \\
\end{tabular} & 94,38 & 192,27 & 193,35 & 48,90 & 467,21 & 53,63 & 19,92 & 27,83 & 148,82 & 69,35 & 84,41 & 118,20 \\
\hline Pleurodeles walt| & 30TUM72 & 100,00 & 118,17 & 113,46 & 38,02 & 5946,90 & 286,29 & $-7,18$ & \begin{tabular}{|l|l|}
293,47 \\
\end{tabular} & 94,90 & 195,99 & 197,31 & 44,71 & 440,20 & 50,73 & 15,58 & 28,85 & 136,36 & 62,00 & 74,74 & 115,50 \\
\hline Pleurodeles walt| & 30TUM73 & 100,00 & 120,60 & 113,79 & 38,01 & 5866,47 & 287,42 & $-6,64$ & \begin{tabular}{|l|l|}
294,06 \\
\end{tabular} & 99,05 & 197,23 & 198,49 & 48,18 & \begin{tabular}{|l|l|}
436,93 \\
\end{tabular} & 50,23 & 15,99 & 28,97 & \begin{tabular}{|l|}
136,12 \\
\end{tabular} & 61,21 & 75,53 & 113,04 \\
\hline Pleurodeles walt| & 30TUM92 & 100,00 & 115,57 & 109,85 & 37,54 & 5949,25 & 280,94 & $-8,21$ & \begin{tabular}{|l|l|}
289,15 \\
\end{tabular} & 118,36 & 193,69 & 194,72 & 42,41 & 455,61 & 52,67 & 16,73 & 28,10 & 139,89 & 66,34 & 79,40 & 116,79 \\
\hline Pleurodeles walt| & 30TUNOO & 100,00 & 113,28 & 113,74 & \begin{tabular}{|c|}
39,77 \\
\end{tabular} & 5700,10 & 277,23 & $-6,27$ & 283,50 & 81,03 & 188,47 & 188,47 & 41,84 & 531,77 & 67,99 & 24,85 & 30,01 & 188,38 & 94,56 & 94,56 & 140,40 \\
\hline Pleurodeles walt| & 30TUN01 & 100,00 & 111,04 & 112,70 & \begin{tabular}{|l|}
39,98 \\
\end{tabular} & 5628,60 & 272,93 & $-7,22$ & 280,16 & 79,47 & 185,17 & 185,17 & 40,30 & 563,92 & 72,45 & 26,71 & 29,77 & 199,85 & 101,55 & 101,55 & 148,49 \\
\hline Pleurodeles walt| & 30TUN10 & 100,00 & 110,00 & 112,82 & \begin{tabular}{l|l|}
39,55 \\
\end{tabular} & 5650,92 & 272,87 & $-9,21$ & 282,08 & 78,96 & 184,15 & 184,58 & 39,22 & 549,77 & 69,22 & 26,07 & 28,63 & \begin{tabular}{|l|l|}
191,38 \\
\end{tabular} & 98,66 & $\begin{array}{ll}99,03 \\
\end{array}$ & 144,40 \\
\hline Pleurodeles walt| & 30TUN11 & 100,00 & 109,07 & 111,48 & 39,88 & 5567,29 & 269,32 & $-8,31$ & 277,63 & 78,70 & 182,48 & 182,55 & 39,53 & 576,87 & 73,10 & 27,93 & 28,45 & 201,05 & $\begin{array}{l}104,75 \\
\end{array}$ & 104,80 & 151,04 \\
\hline Pleurodeles walt| & 30TUN50 & 100,00 & 108,18 & 107,94 & 39,00 & 5427,27 & 264,00 & $-9,95$ & 273,95 & 82,67 & 179,40 & \begin{tabular}{ll|}
179,86 \\
\end{tabular} & 41,34 & 581,56 & 69,70 & 27,79 & 25,18 & 191,44 & 99,60 & 107,21 & 149,70 \\
\hline Pleurodeles walt| & 30TVK04 & 100,00 & 141,82 & 108,82 & 35,00 & 6739,72 & 319,73 & 12,91 & \begin{tabular}{ll|}
306,82 \\
\end{tabular} & $\begin{array}{ll}98,61 \\
\end{array}$ & 232,45 & 232,45 & 59,53 & $\begin{array}{l}400,06 \\
4\end{array}$ & 45,23 & 9,46 & 35,27 & \begin{tabular}{|l|l|}
131,47 \\
\end{tabular} & 47,25 & 47,25 & 111,22 \\
\hline Pleurodeles walt| & 30TVK06 & 100,00 & 142,47 & 106,21 & 35,00 & 6653,52 & 315,94 & 15,49 & \begin{tabular}{|l|l|}
300,45 \\
\end{tabular} & 99,92 & 231,60 & 231,60 & 60,65 & \begin{tabular}{|l|l|}
393,55 \\
\end{tabular} & 45,92 & 9,78 & 35,14 & 131,53 & 47,31 & 47,31 & 110,19 \\
\hline Pleurodeles walt| & 30TVK07 & 100,00 & 138,22 & 105,19 & 35,00 & 6599,22 & 309,76 & 12,52 & 297,24 & 95,99 & 226,14 & 226,46 & 57,02 & 400,96 & 47,07 & 10,68 & 34,48 & 133,24 & 50,14 & 50,30 & 110,73 \\
\hline Pleurodeles walt| & 30TVK08 & 100,00 & 124,39 & 104,41 & 35,06 & $\begin{array}{l}6501,56 \\
\end{array}$ & 294,21 & 1,24 & \begin{tabular}{|l|}
292,97 \\
\end{tabular} & 83,41 & 209,89 & 211,86 & 45,44 & 432,64 & 51,12 & 13,14 & 32,69 & 139,51 & 58,66 & 60,32 & 113,69 \\
\hline Pleurodeles walt| & $\begin{array}{l}\text { 30TVKO99 } \\
\end{array}$ & 100,00 & 113,60 & 104,19 & 35,3 & 6407,64 & 282,44 & $-7,01$ & 289,45 & 85,27 & 198,75 & 200,05 & 36,88 & 464,05 & 56,18 & 15,15 & 31,66 & \begin{tabular}{|l|l|}
147,87 \\
\end{tabular} & 65,86 & 69,08 & 118,12 \\
\hline Pleurodeles walt| & $30 \mathrm{TVK}$ & 100,00 & 138,91 & 104,25 & \begin{tabular}{ll|}
34,96 \\
\end{tabular} & $\begin{array}{l}6616,96 \\
\end{array}$ & 310,09 & 13,86 & 296,23 & $\begin{array}{l}96,55 \\
\end{array}$ & 227,31 & 227,31 & 57,37 & 414,99 & 49,71 & 10,90 & 35,08 & 140,19 & 50,32 & 50,32 & 118,99 \\
\hline Pleurodeles walt| & $\begin{array}{l}\text { 30TVK18 } \\
\end{array}$ & 100,00 & 131,85 & 103,41 & 34,97 & 6562,13 & 301,39 & 8,21 & 293,18 & 90,01 & 218,54 & 219,79 & 51,45 & 430,06 & 51,12 & 11,99 & 33,87 & 143,24 & 54,72 & 55,46 & 120,27 \\
\hline Pleurodeles walt| & 30TVK19 & 100,00 & 122,10 & 103,03 & 35,01 & 6504,33 & 290,27 & 0,24 & 290,03 & 80,60 & 207,63 & 209,40 & 43,13 & 452,22 & 52,58 & 13,31 & 32,24 & 146,66 & 60,58 & 63,19 & 121,45 \\
\hline Pleurodeles walt| & 30 TVK26 & 100,00 & 138,25 & 104,76 & 34,99 & 6657,59 & 311,19 & 13,42 & 297,77 & 95,62 & 227,21 & 227,21 & 56,31 & 433,86 & 52,36 & 10,97 & 35,88 & 147,81 & 50,58 & 50,58 & 128,45 \\
\hline Pleurodeles walt| & $30 \mathrm{TVI}$ & 100,00 & 135,36 & 103,56 & \begin{tabular}{|l|l|}
34,97 \\
\end{tabular} & 6603,25 & 306,28 & 11,89 & 294,39 & 93,05 & 223,48 & 223,52 & 54,19 & 441,59 & 53,65 & 11,71 & 35,26 & 150,21 & 52,99 & 53,01 & 130,36 \\
\hline Pleurodeles walt| & 30TVK28 & 100,00 & 134,52 & 102,71 & \begin{tabular}{|l|l|}
34,77 \\
\end{tabular} & 6590,42 & 303,93 & 11,24 & \begin{tabular}{|l|l|}
292,69 \\
\end{tabular} & 92,35 & 222,28 & 222,54 & 53,49 & \begin{tabular}{ll|}
438,63 \\
\end{tabular} & 53,81 & 11,70 & 34,89 & 149,35 & 53,68 & 53,80 & 127,92 \\
\hline Pleurodeles walt| & 30TVK29 & 100,00 & 123,83 & 102,72 & 35,00 & 6522,81 & 292,25 & 2,43 & 289,82 & 82,35 & 209,81 & 211,40 & 44,65 & \begin{tabular}{|l|l|}
461,17 \\
\end{tabular} & 55,11 & 13,13 & 33,00 & 152,18 & 60,21 & 62,15 & 128,16 \\
\hline Pleurodeles walt| & 30TVK35 & 100,00 & 140,79 & 106,29 & \begin{tabular}{|l|l|}
34,87 \\
\end{tabular} & \begin{tabular}{|l|l|}
6709,03 \\
\end{tabular} & 316,27 & 14,32 & \begin{tabular}{|l|l|}
301,95 \\
\end{tabular} & $\begin{array}{ll}97,58 \\
\end{array}$ & 230,45 & 230,45 & 58,30 & 432 & 53 & 10,14 & 37,05 & \begin{tabular}{|l|l|}
149,43 \\
\end{tabular} & 48,10 & 48,10 & 129,22 \\
\hline Pleurodeles walt| & 307 & 100 & 139 & 104 & 34 & 6663, & 312 & 14,4 & 297,90 & 96,29 & 22 & & 57,02 & 441 & 54, & 10 & 37,02 & 153,39 & 49,58 & 49,58 & 133,44 \\
\hline Pleurodeles walt| & 30TVK37 & 100,00 & 138,10 & 102,94 & 34,50 & 6626,82 & 309,23 & 14,46 & \begin{tabular}{|l|l|}
294,77 \\
\end{tabular} & 95,56 & 226,59 & 226,59 & 56,19 & 444,80 & 56,12 & 11,12 & 36,95 & 155,32 & 50,47 & 50,47 & 134,92 \\
\hline Pleurodeles walt| & 30TVK38 & 100,00 & 136,31 & 102,21 & 34,23 & $\begin{array}{l}6602,03 \\
\end{array}$ & 306,29 & 13,06 & 293,23 & 93,77 & 224,52 & 224,52 & 54,94 & 443,90 & 56,36 & 11,18 & 36,47 & 154,53 & 51,94 & 51,94 & 132,50 \\
\hline Pleurodeles walt| & 30TVK39 & 100,00 & 132,33 & 102,09 & $\begin{array}{l}34,58 \\
\end{array}$ & 6564,50 & 301,02 & 9,65 & \begin{tabular}{|l|l|}
291,37 \\
\end{tabular} & 90,28 & 219,68 & 220,00 & 51,72 & 447,13 & 56,23 & 11,54 & 35,06 & 153,56 & 55,03 & 55,22 & 130,17 \\
\hline Pleuroc & $30 \mathrm{TV}$ & 100, & 146 & 110,28 & 35,0 & 84,14 & 326,59 & 17,10 & 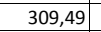 & 103,19 & 237,63 & 237 & 63 & 408,17 & 49,26 & & 37,78 & 14 & 42,91 & 42,91 & 12 \\
\hline Pleurodeles walt| & 30TVK45 & 100,00 & 141,73 & 106,88 & 34,73 & 6731,84 & 318,44 & 14,64 & \begin{tabular}{|l|l|}
303,80 \\
\end{tabular} & $\begin{array}{ll}98,28 \\
\end{array}$ & 231,64 & 231,64 & 58,98 & 432,94 & 54,79 & 9,89 & 37,89 & \begin{tabular}{|l|l|}
151,93 \\
\end{tabular} & 46,67 & 46,67 & 130,14 \\
\hline Pleurodeles walt| & 30TVK47 & 100,00 & $\begin{array}{lll}137,47 \\
\end{array}$ & 103,58 & \begin{tabular}{|l|l|}
34,19 \\
\end{tabular} & \begin{tabular}{|l|l|}
6659,03 \\
\end{tabular} & 310,34 & 12,61 & 297,73 & 94,24 & 226,32 & 226,32 & 55,21 & 449,72 & 58,83 & 10,81 & 38,01 & 159,53 & 49,71 & 49,71 & 136,32 \\
\hline
\end{tabular}




\begin{tabular}{|c|c|c|c|c|c|c|c|c|c|c|c|c|c|c|c|c|c|c|c|c|c|}
\hline TAXON & UTM & $\mathrm{km} 2$ & B101 & BIO2 & BIO3 & B104 & BIO5 & B106 & B107 & B108 & 8109 & B1010 & BIO11 & B1012 & BIO13 & B1014 & BIO15 & B1016 & B1017 & B1018 & B1019 \\
\hline Pleurodeles walt| & 30TVK48 & 100,00 & 135,62 & 103,27 & 34,38 & 6631,22 & 307,45 & 11,59 & 295,86 & 92,62 & 224,08 & 224,08 & 53,97 & 449,55 & 59,09 & 10,81 & 37,42 & 159,03 & 51,06 & 51,06 & 134,80 \\
\hline Pleurodeles walt1 & 30TVK49 & 100,00 & 134,81 & 102,96 & 34,73 & 6603,20 & 305,15 & 11,37 & 293,78 & 92,12 & 222,82 & 222,82 & 53,66 & 442,82 & 58,10 & 10,74 & 36,60 & 155,84 & 52,14 & 52,14 & 130,55 \\
\hline Pleurodeles walt| & $\begin{array}{l}\text { 30TVK53 } \\
\end{array}$ & 100,00 & 144,53 & 111,16 & 35,28 & 6768,78 & 324,73 & 14,94 & 309,79 & 100,76 & 235,02 & 235,02 & 61,71 & 415,71 & 50,65 & 8,66 & 37,63 & $\begin{array}{l}143,47 \\
\end{array}$ & 44,26 & 44,26 & 121,99 \\
\hline Pleurodeles walt| & 30TVK54 & 100,00 & 143,67 & 109,71 & 35,11 & 6755,05 & 322,69 & 15,08 & 307,61 & 99,94 & 233,95 & 233,95 & 60,92 & 420,95 & 52,77 & 9,08 & 37,83 & 147,14 & 44,87 & 44,87 & 124,71 \\
\hline Pleurodeles walt| & 30TVK55 & 100,00 & 141,85 & 108,40 & 34,99 & 6738,40 & 319,77 & 14,16 & 305,61 & 98,29 & 231,79 & 231,79 & 59,30 & 429,84 & 55,43 & 9,63 & 38,22 & 152,05 & 45,89 & 45,89 & 128,52 \\
\hline Pleurodeles walt| & 30TVK56 & 100,00 & 142,59 & 107,10 & 34,73 & 6737,97 & 319,71 & 15,12 & 304,59 & 99,05 & 232,33 & 232,33 & 59,72 & 429,50 & 57,37 & 9,44 & 39,30 & 154,57 & 44,76 & 44,76 & 129,99 \\
\hline Pleurodeles walt| & 30TVK57 & 100,00 & 140,80 & 106,21 & 34,44 & 6736,18 & 317,72 & 13,90 & 303,82 & 97,37 & 230,36 & 230,36 & 58,05 & \begin{tabular}{|l|l|}
437,08 \\
\end{tabular} & 60,00 & 9,60 & 39,76 & 158,71 & 45,75 & 45,75 & 132,97 \\
\hline Pleurodeles walt| & 30TVK59 & 100,00 & 135,08 & 104,62 & 34,94 & 6619,79 & 306,93 & 11,33 & 295,60 & 92,02 & 223,11 & 223,11 & 54,05 & 437,96 & 58,92 & 10,32 & 37,44 & 156,24 & 50,69 & 50,69 & 128,61 \\
\hline Pleurodeles walt| & 30TVK63 & 100,00 & 141,18 & 112,37 & 36,00 & 6743,88 & 321,63 & 11,90 & 309,73 & 97,42 & 231,27 & 231,27 & 58,88 & 423,68 & 51,31 & 9,18 & 36,88 & 144,92 & 46,64 & 46,64 & 122,68 \\
\hline Pleurodeles walt| & 30TVK65 & 100,00 & 136,33 & 110,13 & 35,57 & 6706,47 & 314,83 & 9,29 & 305,54 & 92,67 & 225,97 & 225,97 & 54,79 & 441,00 & 56,15 & 10,42 & 37,09 & 154,02 & 49,42 & 49,42 & 129,26 \\
\hline Pleurodeles walt| & 30TVK69 & 100,00 & 130,82 & \begin{tabular}{ll|}
105,62 \\
\end{tabular} & 35,28 & 6593,60 & 302,23 & 8,04 & 294,19 & 87,81 & \begin{tabular}{|l|l|}
218,64 \\
\end{tabular} & 218,64 & 50,92 & 440,21 & 58,48 & 10,84 & 36,21 & 155,32 & 53,21 & 53,21 & 125,62 \\
\hline Pleurodeles walt| & 30TVK76 & 100,00 & 127,98 & 110,16 & 36,00 & 6648,33 & 304,79 & 2,62 & 302,17 & 84,65 & 216,96 & 216,96 & 47,77 & 456,99 & 56,81 & 12,23 & 34,59 & 155,52 & 55,91 & 55,91 & 129,05 \\
\hline 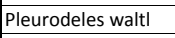 & 30TVK79 & 100,00 & 130,23 & 104,81 & 35,19 & 6592,21 & 299,79 & 7,80 & 291,99 & 87,36 & 218,03 & 218,03 & 50,57 & 428,29 & 55,77 & 10,97 & 34,90 & 148,50 & 54,04 & 54,04 & 117,38 \\
\hline Pleurodeles walt| & 30TVK87 & 100,00 & 125,00 & 109,19 & 36,00 & 6611,96 & 299,33 & 1,01 & 298,32 & 82,09 & 213,40 & 213,40 & 45,56 & 453,26 & 54,74 & 12,95 & 32,86 & 150,36 & 59,67 & 59,67 & 123,08 \\
\hline Pleurodeles walt| & 30TVK88 & 100,00 & 121,64 & 107,84 & \begin{tabular}{l|l|l}
35,95 \\
\end{tabular} & 6583,24 & 294,27 & $-0,88$ & 295,15 & 79,05 & 209,83 & 209,84 & 42,75 & 458,95 & 54,87 & 13,65 & 32,03 & 150,42 & 62,90 & 62,91 & 122,69 \\
\hline Pleurodeles walt| & 30TVL00 & 100,00 & 103,47 & 104,36 & 35,96 & 6315,89 & 271,61 & $-14,89$ & 286,50 & 97,34 & 188,25 & 189,18 & 29,18 & 495,14 & 61,23 & 17,16 & 30,66 & 156,36 & 73,01 & 77,93 & 122,97 \\
\hline Pleurodeles walt| & $\begin{array}{l}\text { 30TVL02 } \\
\end{array}$ & 100,00 & 104,18 & 102,76 & 35,80 & 6328,72 & 269,13 & $-14,21$ & 283,34 & 120,89 & $\begin{array}{ll}188,74 \\
\end{array}$ & 189,91 & 29,02 & $\begin{array}{l}496,09 \\
\end{array}$ & 60,40 & 16,33 & 30,06 & 155,61 & 73,06 & 80,28 & 123,40 \\
\hline Pleurodeles walt| & 30TVL10 & 100,00 & 112,46 & 102,96 & 35,38 & 6427,44 & 279,75 & $-7,11$ & 286,86 & 80,22 & 197,93 & 199,25 & 35,60 & 478,21 & 56,21 & 15,01 & 30,94 & 150,99 & 67,21 & 71,88 & 123,97 \\
\hline Pleurodeles walt| & 30TVL11 & 100,00 & 77,29 & 106,95 & 37,36 & 6068,16 & 247,71 & $-34,23$ & 281,95 & 70,78 & 161,14 & 161,28 & 9,66 & 626,03 & 76,40 & 24,97 & 27,68 & 194,81 & 96,49 & 99,25 & 157,99 \\
\hline Pleurodeles walt| & 30TVL12 & 100,00 & 82,73 & 105,64 & 37,01 & 6128,99 & 251,27 & $-30,42$ & 281,69 & 86,58 & 166,66 & 167,03 & 13,17 & \begin{tabular}{|c|}
603,08 \\
\end{tabular} & 72,94 & 23,32 & 27,85 & 187,35 & 92,53 & 97,16 & 152,35 \\
\hline Pleurodeles walt| & 30TVL14 & 100,00 & 107,35 & 102,19 & 35,99 & 6359,05 & 271,21 & $-11,09$ & 282,30 & 116,53 & 192,19 & 193,14 & 31,24 & 496,32 & 57,82 & 15,51 & 29,34 & 152,82 & 71,83 & 80,63 & 127,33 \\
\hline Pleurodeles walt| & 30TVL15 & 100,00 & 111,79 & 102,60 & 36,00 & 6345,76 & 275,35 & \begin{tabular}{|c|}
$-7,64$ \\
\end{tabular} & 282,99 & $\begin{array}{l}91,05 \\
9\end{array}$ & 195,92 & 197,13 & 35,17 & 478,00 & 55,14 & $\begin{array}{l}14,66 \\
14,6\end{array}$ & 29,35 & \begin{tabular}{|l|l|}
147,29 \\
\end{tabular} & 68,66 & 77,28 & 123,44 \\
\hline Pleurodeles walt| & 30TVL20 & 100,00 & 116,65 & 102,55 & 35,13 & 6465,02 & 284,01 & $-3,38$ & 287,39 & 75,82 & 202,20 & 203,73 & 38,82 & \begin{tabular}{|l|l|}
477,18 \\
\end{tabular} & 55,71 & 14,20 & 31,40 & 153,59 & \begin{tabular}{ll|}
64,93 \\
\end{tabular} & 68,63 & 128,32 \\
\hline Pleurodeles waltt & 30TVL22 & 100,00 & 89,15 & 105,22 & 36,69 & 6195,81 & 257,50 & $-25,31$ & 282,81 & 82,82 & 173,58 & 173,95 & 18,03 & 575,22 & 68,69 & 21,29 & 27,97 & 177,58 & 86,99 & 92,20 & 146,47 \\
\hline Pleurodeles walt| & 30TVL24 & 100,00 & 93,79 & 104,32 & 36,48 & 6221,50 & 260,20 & $-21,89$ & 282,09 & 103,11 & 177,89 & 178,38 & 21,18 & 554,28 & 65,42 & 19,96 & 27,84 & 170,44 & 83,91 & 90,92 & 141,50 \\
\hline Pleurodeles walt| & 30 TVL25 & 100,00 & 108,37 & 102,99 & 35,99 & 6326,98 & 272,63 & $-10,23$ & 282,85 & $\begin{array}{l}93,76 \\
\end{array}$ & 192,45 & 193,55 & 32,51 & 493,86 & 56,84 & 15,78 & 28,86 & 151,52 & 71,94 & 80,44 & 127,86 \\
\hline Pleurodeles walt| & 30TVL27 & 100,00 & \begin{tabular}{ll|}
112,87 \\
\end{tabular} & 103,91 & 36,01 & 6262,71 & 276,90 & $-6,79$ & 283,69 & 86,03 & 195,63 & 196,50 & 36,60 & 471,66 & 54,16 & 15,43 & 28,28 & 144,47 & 69,39 & 77,94 & 122,11 \\
\hline Pleurodeles walt| & 30TVL30 & 100,00 & 119,57 & 102,73 & \begin{tabular}{|l|l|}
35,07 \\
\end{tabular} & 6498,95 & 287,51 & $-0,85$ & 288,36 & 77,69 & 205,32 & 206,90 & 41,19 & 476,05 & 56,83 & 13,65 & 32,14 & 156,14 & 63,41 & 66,05 & 131,37 \\
\hline Pleurodeles walt| & 30TVL31 & 100,00 & 112,12 & 103,04 & 35,52 & 6428,78 & 279,39 & $-6,72$ & 286,11 & 73,78 & 197,50 & 198,75 & 35,20 & 496,87 & 58,38 & 15,25 & 30,58 & 158,92 & $\mid 69,08$ & 73,27 & 133,32 \\
\hline Pleurodeles waltt & 30TVL32 & 100,00 & 89,33 & $\begin{array}{ll}105,67 \\
\end{array}$ & 36,72 & 6214,66 & 258,42 & $-25,45$ & 283,86 & 76,32 & \begin{tabular}{ll|}
173,92 \\
\end{tabular} & 174,25 & 17,79 & 578,12 & 68,50 & 21,47 & 27,60 & 177,52 & 87,52 & 92,90 & 148,19 \\
\hline Pleurodeles walt| & \begin{tabular}{l|l|}
$30 T V L 35$ \\
\end{tabular} & 100,00 & 104,34 & 103,59 & 36,00 & 6301,34 & 269,84 & $-13,51$ & 283,36 & 89,26 & 188,49 & 189,34 & 29,28 & 510,81 & 58,92 & 17,23 & 28,11 & 155,47 & 75,87 & 84,21 & 132,27 \\
\hline Pleurodeles walt| & 30TVL40 & 100,00 & 127,79 & 102,91 & 35,01 & 6550,89 & 296,39 & 5,74 & 290,64 & 85,55 & 214,56 & 215,24 & 47,88 & 454,56 & 57,17 & 12,01 & 34,19 & 154,78 & 57,89 & 58,64 & 129,23 \\
\hline Pleurodeles walt| & 30TVL41 & 100,00 & 120,84 & 102,69 & \begin{tabular}{|l|}
35,08 \\
\end{tabular} & 6501,78 & 288,23 & 0,27 & 287,97 & 79,02 & 206,51 & 207,87 & 42,13 & 468,87 & 56,71 & 13,27 & 31,97 & 154,61 & 63,08 & 65,25 & 129,18 \\
\hline Pleurodeles walt| & 30TVL42 & 100,00 & 106,04 & 103,99 & \begin{tabular}{|l|}
36,08 \\
\end{tabular} & 6376,62 & 273,74 & $-11,87$ & 285,61 & 69,50 & 191,23 & 192,10 & 30,35 & 516,25 & 60,00 & 16,95 & 29,25 & 161,85 & 74,57 & 79,67 & 136,35 \\
\hline Pleurodeles walt| & 30TVL43 & 100,00 & 109,23 & 103,29 & 36,00 & 6385,04 & 275,66 & $-9,20$ & 284,86 & 68,98 & 194,21 & 195,12 & 32,98 & 499,32 & 56,90 & 15,97 & 29,15 & 155,92 & 72,09 & 77,84 & 131,74 \\
\hline Pleurodeles walt| & $\begin{array}{l}\text { 30TVL46 } \\
\end{array}$ & 100,00 & 108,25 & 103,93 & 36,01 & 6293,78 & 273,65 & $-10,18$ & 283,83 & 72,81 & 192,06 & 192,79 & 32,78 & 494,32 & 56,55 & 16,91 & 27,56 & 150,54 & 74,33 & 81,69 & 128,35 \\
\hline Pleurodeles walt| & 30TVL47 & 100,00 & 110,21 & 104,01 & 36,01 & 6266,56 & 275,21 & $\begin{array}{l}-8,54 \\
\end{array}$ & 283,75 & 80,04 & 193,46 & 194,19 & 34,55 & 485,09 & 55,48 & 16,84 & 27,36 & 147,43 & 73,57 & 80,99 & 125,80 \\
\hline Pleurodeles walt| & 30TVL50 & 100,00 & 133,14 & 103,39 & 35,00 & 6579,67 & 302,35 & 10,41 & 291,94 & 90,44 & 220,66 & 220,69 & 52,75 & 434,01 & 57,10 & 10,67 & 35,80 & 152,12 & 53,20 & 53,21 & 124,29 \\
\hline Pleurodeles walt| & 30TVL51 & 100,00 & 128,43 & 102,74 & 35,00 & 6538,75 & 296,04 & 6,70 & 289,35 & 86,38 & 215,28 & 215,54 & 48,77 & 440,69 & 55,86 & 11,65 & 33,64 & 149,99 & 57,75 & 58,04 & 122,79 \\
\hline Pleurodeles walt| & \begin{tabular}{|l|}
$30 T V L 52$ \\
\end{tabular} & 100,00 & 119,14 & 103,05 & 35,49 & 6471,71 & 286,06 & $-0,94$ & 286,99 & 77,81 & 204,90 & 205,77 & 40,94 & 466,92 & 55,77 & 13,73 & 31,05 & 151,94 & 65,03 & 67,44 & 126,10 \\
\hline Pleurodeles walt| & \begin{tabular}{|l|l|} 
30TVL53 \\
\end{tabular} & 100,00 & 109,88 & 103,92 & 36,06 & 6394,79 & 277,01 & $-8,73$ & 285,74 & 72,46 & 195,03 & 195,80 & 33,52 & 497,35 & 57,41 & 16,26 & 28,98 & 155,85 & 72,63 & 77,34 & 131,28 \\
\hline Pleurodeles walt| & 30TVL54 & 100,00 & 97,28 & 105,44 & 36,44 & 6285,75 & 265,47 & $-19,77$ & 285,24 & 84,53 & \begin{tabular}{|l|l|}
181,84 \\
\end{tabular} & 182,24 & 23,39 & 546,22 & 63,27 & 20,09 & 26,97 & 166,33 & 83,72 & 89,91 & 141,45 \\
\hline Pleurodeles walt| & 30TVL55 & 100,00 & 76,54 & 107,27 & 37,39 & 6122,88 & 246,61 & $-37,30$ & 283,90 & 87,02 & 160,33 & 160,37 & 6,47 & 648,73 & 76,29 & 27,79 & 24,67 & 197,61 & 105,10 & 107,78 & 166,35 \\
\hline Pleurodeles walt| & 30TVL57 & 100,00 & 104,72 & 105,03 & 36,1 & 6252,04 & 271,03 & $-13,48$ & 284,51 & 114,02 & 188,23 & 188,65 & 29,89 & 507,95 & 58,64 & 18,72 & 26,38 & 152,99 & 79,18 & 86,79 & 131,05 \\
\hline Pleurodeles walt| & 30TVL61 & 100,00 & 121,44 & 103,71 & 35,3 & 6520,14 & 289,47 & 0,86 & 288,61 & 79,56 & 208,07 & 208,63 & 42,72 & 457,78 & 56,02 & 13,16 & 31,80 & 151,47 & 63,16 & 63,89 & 124,21 \\
\hline \begin{tabular}{|l|} 
Pleurodeles walt| \\
\end{tabular} & 30TVL62 & 100,00 & 122,19 & 103,14 & 35 & 6491,62 & \begin{tabular}{|l|}
288,90 \\
\end{tabular} & $\begin{array}{ll}, 52 \\
1,52\end{array}$ & $\begin{array}{l}287,38 \\
2870\end{array}$ & 80,64 & 208,18 & 208,88 & 43,69 & 450,45 & 54,49 & 13,15 & 31,25 & $\begin{array}{l}147,72 \\
147,7\end{array}$ & 63,30 & $\begin{array}{l}0,303 \\
64,48 \\
\end{array}$ & 120,74 \\
\hline Pleurodeles walt| & 30TVL67 & 100,00 & 100,57 & 106,06 & 36,81 & 6237,13 & 268,01 & $-17,44$ & 285,45 & 118,41 & 184,05 & 184,31 & 26,33 & 527,83 & 61,34 & 20,66 & 25,47 & 159,01 & 84,49 & 91,42 & 135,66 \\
\hline Pleurodeles waltl & 30TVL68 & 100,00 & 108,25 & 105,39 & 36,51 & 6236,98 & 274,38 & $-10,43$ & 284,81 & 125,95 & 191,41 & \begin{tabular}{|l|l|}
191,62 \\
\end{tabular} & 33,21 & 493,10 & 56,96 & 18,96 & 25,61 & $\mid 147.88$ & 78,89 & 85,53 & 126,82 \\
\hline Pleurodeles waltl & 30TVL71 & 100,00 & 120,88 & 103,79 & 35,43 & 6518,66 & 288,58 & 0,21 & 288,37 & 79,19 & 207,66 & 208,00 & 42,49 & 451,60 & 54,44 & 13,41 & 27 & 147,68 & 64,06 & 64,58 & 119,43 \\
\hline Pleurodeles walt| & \begin{tabular}{l|} 
30TVL72 \\
\end{tabular} & 100,00 & 117 & 104,08 & 35 & 6482,68 & 285,14 & $-2,35$ & 287,49 & 76,32 & 203,73 & & 39,86 & 460,90 & 53,92 & 14, & 29,91 & 147,44 & 67,16 & 68,99 & 120,82 \\
\hline Pleurodeles walt| & 30TVL73 & 100,00 & 112,34 & 104,94 & 36,00 & 6424,94 & 280,08 & $-7,36$ & 287,45 & 72,50 & 197,80 & 198,45 & 35,42 & 480,68 & 55,10 & 16,20 & 28,44 & 149,45 & 72,21 & 75,72 & 125,06 \\
\hline Pleurodeles walt| & \begin{tabular}{|l|}
$30 T V L 78$ \\
\end{tabular} & 100,00 & 104,81 & 106,58 & 36,97 & 6231,13 & 272,08 & $-13,99$ & 286,08 & 123,26 & 187,92 & 188,19 & 30,10 & 509,49 & 59,28 & 20,53 & 24,84 & 153,19 & 83,48 & 89,84 & 130,68 \\
\hline Pleurodeles walt| & 30TVL80 & 100,00 & 128,46 & 102,32 & \begin{tabular}{|l|l|}
35,07 \\
\end{tabular} & $\begin{array}{lll}6577,84 \\
\end{array}$ & 294,21 & 6,89 & 287,32 & 86,39 & 216,18 & 216,18 & 49,14 & 414,96 & 51,50 & 11,70 & 32,79 & 138,37 & 57,21 & 57,21 & $\begin{array}{ll}106,89 \\
\end{array}$ \\
\hline Pleurodeles walt| & 30TVL81 & 100,00 & 125,82 & 102,84 & 35,1 & 6542,43 & 291,63 & 4,37 & 287,25 & 84,01 & 213,03 & 21 & 46,97 & 423,35 & 51,04 & 12,59 & 31,28 & 47 & 60,82 & 60,87 & 108 \\
\hline Pleurodeles waltl & 30TVL82 & 100,00 & 121,66 & 103,83 & 35,64 & 6497,10 & 288,13 & 0,42 & 287,70 & 80,32 & 207,91 & 208,36 & 43,33 & 438,88 & 51,11 & 13,93 & 29,88 & 140,13 & 65,12 & 66,08 & 112,81 \\
\hline Pleurodeles walt| & 30TVL83 & 100,00 & 113,14 & 105,61 & \begin{tabular}{|l|l|}
36,07 \\
\end{tabular} & 6430,05 & 281,18 & $-7,22$ & 288,41 & 73,34 & 198,67 & 199,30 & 36,00 & 473,59 & 54,49 & 16,53 & 27,82 & \begin{tabular}{|l|l|}
145,58 \\
\end{tabular} & 72,73 & 76,01 & 121,50 \\
\hline Pleurodeles walt| & 30TVM15 & 100,00 & 111,19 & 105,43 & 37,01 & 5789,24 & 271,59 & $-7,88$ & 279,47 & 82,72 & 187,42 & 187,72 & 39,77 & 500,25 & 55,85 & 21,35 & 25,09 & 151,78 & 79,31 & 90,31 & 126,99 \\
\hline Pleurodeles walt| & 30TVM17 & 100,00 & 110,73 & 103,01 & 37,13 & 5638,93 & 266,86 & $-5,55$ & 272,42 & 81,73 & $\begin{array}{lll}184,87 \\
\end{array}$ & 185,04 & 40,97 & 532,14 & 58,37 & 24,53 & 23,95 & 163,16 & 87,60 & 94,81 & 135,47 \\
\hline Pleurodeles wa & 30TVM24 & 100,00 & 109,50 & 104 & 37,0 & 5880,93 & 271,14 & $-8,7$ & 279, & 106,8 & 187,10 & & 37 & 498,61 & 56,35 & 20,91 & 25,01 & 149,80 & 79,75 & 89,26 & 12 \\
\hline Pleurodeles walt & $30 \mathrm{TVM} 25$ & 100,00 & $\begin{array}{l}111,49 \\
\end{array}$ & \begin{tabular}{|l|l}
103,89 \\
\end{tabular} & 37,00 & 5813,87 & 271,12 & $-5,72$ & \begin{tabular}{|l|}
276,84 \\
\end{tabular} & $\begin{array}{l}79,86 \\
\end{array}$ & 187,97 & 188,22 & 39,69 & 501,24 & 55,78 & 21,67 & 24,59 & 151,04 & 81,29 & 90,25 & 127,60 \\
\hline
\end{tabular}




\begin{tabular}{|c|c|c|c|c|c|c|c|c|c|c|c|c|c|c|c|c|c|c|c|c|c|}
\hline TAXON & UTM & $\mathrm{km} 2$ & B101 & B102 & $\mathrm{BIO3}$ & B104 & B105 & B106 & B107 & B108 & B109 & B1010 & BIO11 & BIO12 & B1013 & BIO14 & BIO15 & B1016 & B1017 & BIO18 & B1019 \\
\hline Pleurodeles walt| & 30TVM26 & 100,00 & 111,23 & 102,81 & 37,00 & 5753,47 & 269,03 & $-4,78$ & 273,81 & 79,89 & 186,86 & 186,97 & 39,92 & 514,61 & 56,32 & 23,10 & 23,89 & 155,56 & 84,85 & 92,01 & 131,14 \\
\hline Pleurodeles walt| & 30TVM31 & 100,00 & 116,31 & 104,60 & \begin{tabular}{|l|}
36,68 \\
\end{tabular} & 6072,02 & 278,74 & $-3,36$ & 282,10 & 103,63 & 196,28 & 196,77 & 41,52 & 463,01 & 52,81 & 17,39 & 26,34 & 140,08 & 71,91 & 80,16 & 118,98 \\
\hline Pleurodeles walt| & 30TVM35 & 100,00 & 109,45 & 103,08 & 37,00 & 5851,53 & 269,04 & $-6,22$ & 275,25 & 91,42 & 186,56 & 186,61 & 37,19 & 509,54 & 56,90 & 22,61 & 23,77 & 151,84 & 84,68 & 91,23 & 130,31 \\
\hline Pleurodeles walt| & 30TVM36 & 100,00 & 107,53 & 102,06 & 37,00 & 5790,03 & 265,81 & $-6,63$ & 272,44 & 79,54 & 183,78 & 183,81 & 35,90 & 526,94 & 58,12 & 24,18 & 23,20 & 157,04 & 88,99 & 92,82 & 134,78 \\
\hline Pleurodeles walt| & 30TVM40 & 100,00 & 113,46 & 104,42 & 36,52 & $\begin{array}{lll}6135,33 \\
\end{array}$ & 276,98 & $-5,46$ & 282,45 & 122,49 & 194,55 & 195,09 & 38,56 & 472,12 & 54,16 & 17,76 & 26,23 & 142,26 & 74,12 & 81,77 & 121,43 \\
\hline Pleurodeles walt| & 30TVM41 & 100,00 & 115,39 & 104,04 & 36,71 & 6081,07 & 277,89 & $-3,05$ & 280,94 & 108,31 & 195,63 & 195,91 & 40,63 & 467,45 & 53,33 & 18,07 & 25,81 & 140,75 & 74,19 & 81,43 & 120,23 \\
\hline Pleurodeles walt| & 30TVM43 & 100,00 & 107,22 & 104,07 & 37,00 & 5987,94 & 269,58 & $-9,39$ & 278,97 & 125,28 & 186,45 & 186,49 & 33,98 & 506,27 & 57,85 & 21,60 & 24,22 & 151,88 & 83,48 & 90,24 & 129,68 \\
\hline Pleurodeles waltl & 30TVM51 & 100,00 & 113,26 & 104,34 & 36,74 & 6101,44 & 276,36 & $-4,91$ & 281,27 & 126,94 & $\begin{array}{l}193,83 \\
\end{array}$ & \begin{tabular}{|l|l|}
194,16 \\
\end{tabular} & 38,61 & 476,93 & 54,66 & 19,11 & 25,11 & 142,94 & 77,42 & 84,06 & 122,55 \\
\hline Pleurodeles walt| & 30TWK36 & 100,00 & 119,01 & 116,87 & 37,50 & 6546,19 & 297,24 & $-10,25$ & 307,49 & 103,19 & 205,88 & 206,86 & 40,27 & 476,96 & 57,76 & 16,77 & 28,38 & 151,29 & 72,92 & 76,79 & 119,53 \\
\hline Pleurodeles walt| & 30TWK68 & 100,00 & 106,73 & 116,36 & \begin{tabular}{|l|l|}
37,98 \\
\end{tabular} & \begin{tabular}{|l|l|l|}
6444,07 \\
\end{tabular} & 281,06 & $-22,78$ & 303,84 & 92,12 & 192,05 & 193,18 & 29,05 & 511,24 & 66,21 & 22,38 & 26,24 & 163,79 & 89,62 & 98,37 & 119,01 \\
\hline Pleurodeles walt| & 30TWK83 & 100,00 & 102,58 & 120,26 & 38,17 & 6476,73 & 282,14 & $-27,89$ & 310,03 & 84,56 & 189,01 & 190,08 & 25,43 & 562,12 & 71,36 & 23,60 & 26,19 & 184,82 & 96,95 & 106,93 & 129,77 \\
\hline Pleurodeles walt| & 30TWL11 & 100,00 & 111,94 & 110,05 & 36,88 & 6467,81 & 283,48 & $-12,04$ & 295,51 & 95,51 & 197,93 & 198,69 & 34,63 & 478,39 & 57,52 & 18,76 & 26,85 & 146,10 & 76,74 & 80,79 & 118,94 \\
\hline Pleurodeles walt| & 30TWL14 & 100,00 & 111,38 & 109,54 & 37,00 & 6393,14 & 281,39 & $-11,82$ & 293,21 & 127,34 & 196,38 & 196,90 & 34,62 & 475,03 & 57,42 & 19,64 & 25,46 & 143,82 & 79,57 & 84,34 & 117,86 \\
\hline Pleurodeles walt| & 30TWL17 & 100,00 & 103,53 & 111,29 & \begin{tabular}{|l|l|}
37,17 \\
\end{tabular} & 6279,43 & 274,65 & $-19,02$ & 293,67 & 122,61 & 187,15 & 187,58 & 28,16 & 519,04 & 62,40 & 23,79 & 23,10 & 158,25 & 91,01 & 97,74 & 130,71 \\
\hline Pleurodeles walt| & 30 TWL23 & 100,00 & 107,73 & 111,14 & 37,00 & 6395,07 & 279,09 & $-16,64$ & 295,73 & 117,25 & 192,73 & 193,40 & 30,99 & 492,52 & 60,48 & 21,39 & 25,13 & 150,85 & 83,67 & 89,55 & 120,92 \\
\hline Pleurodeles waltt & 30TWL24 & 100,00 & 107,67 & 111,21 & 37,00 & 6371,25 & 278,73 & $-16,60$ & 295,33 & 127,47 & 192,42 & 192,95 & 31,09 & 491,85 & 60,39 & 21,70 & 24,67 & 150,90 & 84,58 & 90,68 & 121,06 \\
\hline Pleurodeles walt| & 30 TWL26 & 100,00 & 105,36 & 111,83 & 37,18 & 6306,08 & 276,62 & $-18,44$ & 295,06 & 124,83 & 189,21 & 189,83 & 29,54 & 506,69 & 61,87 & 23,41 & 23,57 & 155,68 & 89,50 & 96,17 & 125,79 \\
\hline Pleurodeles walt| & 30TWL27 & 100,00 & 103,26 & 112,48 & 37,56 & 6274,36 & 274,86 & $-20,32$ & 295,18 & 122,43 & 186,79 & 187,23 & 27,83 & 520,87 & 63,32 & 24,73 & 22,91 & 159,92 & 93,13 & 100,17 & 130,19 \\
\hline Pleurodeles walt| & 30TWL33 & 100,00 & 103,81 & 112,51 & 37,22 & \begin{tabular}{|l|l|}
6373,87 \\
\end{tabular} & 275,82 & $-21,55$ & 297,37 & 123,36 & 188,46 & 189,08 & 27,23 & 510,20 & 63,66 & 23,53 & 24,61 & 158,45 & 89,10 & 96,39 & 123,95 \\
\hline Pleurodeles walt| & 30TWL34 & 100,00 & 103,25 & 112,50 & $\begin{array}{l}37,45 \\
\end{array}$ & 6352,49 & 274,90 & $-21,79$ & 296,68 & 122,84 & 187,75 & 188,19 & 26,94 & 512,13 & 63,82 & 24,03 & 24,14 & 159,32 & 90,44 & 98,01 & 124,74 \\
\hline Pleurodeles walt| & 30TWL35 & 100,00 & 101,26 & 112,75 & 37,71 & 6319,27 & 272,95 & $-23,49$ & 296,44 & 120,55 & 185,24 & 185,87 & 25,27 & 523,95 & 65,03 & 25,26 & 23,49 & 162,96 & 93,88 & 101,78 & 128,29 \\
\hline Pleurodeles waltt & 30TWL36 & 100,00 & 100,93 & 113,00 & 37,98 & 6291,45 & 272,63 & $-23,75$ & 296,38 & 120,11 & 184,61 & 185,22 & 25,24 & 528,39 & 65,26 & 25,80 & 23,01 & 164,10 & 95,48 & 103,54 & 130,21 \\
\hline Pleurodeles walt| & 30TWL41 & 100,00 & 106,50 & 113,52 & 37,50 & 6418,01 & 278,90 & $-20,49$ & 299,39 & 114,28 & 191,60 & 192,40 & 29,29 & 499,84 & 63,39 & 22,43 & 25,43 & 156,57 & 86,91 & 94,42 & 119,41 \\
\hline Pleurodeles waltt & 30TWL50 & 100,00 & 101,92 & 114,58 & 37,76 & 6412,23 & 275,04 & $-25,82$ & 300,86 & 109,78 & 187,09 & 187,90 & 24,88 & 523,77 & 67,23 & 24,00 & 25,31 & 165,98 & 92,66 & 101,70 & 123,35 \\
\hline Pleurodeles walt| & 30TYK33 & 100,00 & 157,83 & 86,51 & 36,28 & 5315,71 & 282,90 & 48,26 & 234,65 & 167,63 & 226,74 & 229,22 & 93,87 & 445,78 & 66,24 & 15,17 & 37,56 & 170,38 & 69,38 & 93,29 & 93,96 \\
\hline Pleurodeles walt| & 30TYK34 & 100,00 & 142,37 & 88,91 & 36,01 & 5524,07 & 273,70 & 30,99 & 242,71 & 150,77 & 214,97 & 216,80 & 76,91 & 486,08 & 65,09 & 18,55 & 32,92 & 173,11 & 84,74 & 103,44 & 99,05 \\
\hline \begin{tabular}{|l|l|} 
Pleurodeles waltl \\
\end{tabular} & 30TYK35 & 100,00 & 130,75 & $\begin{array}{l}90,27 \\
90,27\end{array}$ & 35,99 & 5665,03 & 265,95 & 18,15 & $\mid 247,80$ & 138,52 & 179,23 & 206,97 & 64,04 & 516,23 & $\begin{array}{l}64,66 \\
640\end{array}$ & 21,47 & 30,31 & \begin{tabular}{|l|l|}
174,27 \\
\end{tabular} & $\begin{array}{l}\mid 94,4,55 \\
96,5\end{array}$ & 111,27 & 102,75 \\
\hline Pleurodeles walt| & 30TYK43 & 100,00 & 160,71 & 85,01 & 36,01 & 5244,10 & 283,73 & 51,85 & 231,88 & 170,75 & 228,53 & 231,13 & 97,66 & 453,06 & 67,77 & 14,71 & 38,72 & 175,56 & 68,20 & 94,68 & 97,40 \\
\hline Pleurodeles walt| & 30TYK45 & 100,00 & 150,55 & 87,93 & 36,01 & 5431,52 & 279,02 & 38,95 & 240,07 & 158,45 & 221,68 & 223,55 & 86,16 & 475,36 & 66,03 & 16,77 & 35,12 & 174,40 & 79,41 & 101,47 & 97,80 \\
\hline Pleurodeles waltt & 30TYK46 & 100,00 & 135,10 & 89,75 & 35,99 & 5606,18 & 268,66 & 22,27 & 246,39 & 142,36 & 206,40 & 210,55 & 69,29 & 518,79 & 65,81 & 20,37 & 31,31 & 177,99 & 94,90 & 111,56 & 104,65 \\
\hline Pleurodeles walt| & 30TYK47 & 100,00 & 121,71 & 90,79 & 35,97 & 5728,22 & 258,75 & 8,35 & 250,40 & 128,71 & 137,52 & 198,86 & 54,79 & 557,17 & 67,35 & 23,85 & 28,58 & 180,73 & 108,31 & 120,55 & 110,92 \\
\hline \begin{tabular}{|l|} 
Pleurodeles waltl \\
\end{tabular} & $\begin{array}{l}\text { 30TYK48 } \\
\end{array}$ & 100,00 & 108,78 & 91,05 & 35,78 & 5802,24 & 248,13 & $\begin{array}{c}-3,50 \\
-3,89 \\
\end{array}$ & 252,02 & \begin{tabular}{|l|}
$117,16,16$ \\
\end{tabular} & \begin{tabular}{|l|}
45,72 \\
4
\end{tabular} & $\begin{array}{l}186,980 \\
\end{array}$ & 44,16 & |602,38 & 72,,99 & 27,83 & 26,31 & $\begin{array}{l}186,16 \\
\end{array}$ & \begin{tabular}{|l|l|}
119,52 \\
\end{tabular} & 130,85 & 119,58 \\
\hline Pleurodeles walt| & 30TYK49 & 100,00 & 112,81 & 91,67 & \begin{tabular}{|l|l|}
35,87 \\
\end{tabular} & 5799,99 & 252,14 & $-1,10$ & 253,24 & 120,85 & 46,74 & 190,63 & 44,90 & 578,67 & 71,28 & 26,39 & 27,33 & 179,76 & 113,38 & 125,70 & 113,40 \\
\hline Pleurodeles waltl & $\begin{array}{l}30 \text { TYK54 } \\
\end{array}$ & 60,00 & 153,71 & 86,33 & 36,02 & 5332,60 & 279,54 & 43,44 & 236,10 & 162,32 & 223,34 & 225,66 & 90,49 & 486,86 & 69,44 & 16,11 & 36,36 & 182,61 & 77,08 & 102,47 & 103,82 \\
\hline Pleurodeles walt| & 30TYK55 & 50,00 & 149,13 & 87,66 & 36,01 & 5415,34 & 277,37 & 37,77 & 239,60 & 156,94 & 220,15 & 222,02 & 85,26 & 496,01 & 68,51 & 17,13 & 34,70 & 181,50 & 82,24 & 105,34 & 103,52 \\
\hline Pleurodeles walt| & $\begin{array}{l}30 \text { TYK56 } \\
\end{array}$ & 50,00 & 133,06 & 89,56 & 36,00 & 5592,62 & 266,60 & 20,53 & 246,06 & 140,27 & 207,21 & 208,53 & 67,82 & 542,10 & 68,31 & 20,82 & 30,75 & 185,34 & 98,26 & 115,60 & 111,13 \\
\hline Pleurodeles walt| & 30TYK57 & 50,00 & 132,20 & 90,22 & 35,99 & 5624,92 & 266,61 & 18,71 & 247,89 & 138,72 & 204,88 & 208,01 & 66,71 & 539,14 & $\begin{array}{ll}66,88 \\
\end{array}$ & 21,00 & 30,62 & 182,24 & 99,75 & 115,82 & 109,14 \\
\hline Pleurodeles walt| & 30TYK58 & 40,00 & 119,33 & 90,92 & 35,93 & 5731,61 & 256,69 & 5,82 & 250,87 & 125,82 & 149,34 & 196,54 & 52,54 & 578,41 & 69,30 & 24,59 & 28,00 & 185,54 & 113,25 & 124,67 & 116,23 \\
\hline Pleurodeles walt| & 30TYK59 & 40,00 & 112,86 & 91,12 & 35,82 & 5774,23 & 251,69 & $-0,48$ & 252,17 & 119,95 & 59,28 & 190,71 & 45,66 & 595,51 & 72,06 & 26,45 & 26,98 & 185,86 & 118,42 & 128,97 & 118,77 \\
\hline Pleurodeles walt| & 30TYL30 & 100,00 & 118,61 & 93,06 & 35,99 & 5838,37 & 258,66 & 2,61 & 256,04 & 131,25 & 51,76 & 196,54 & 49,72 & 527,06 & 67,34 & 24,41 & 29,16 & 166,63 & 99,49 & 115,73 & 99,57 \\
\hline \begin{tabular}{|l|l|} 
Pleurodeles waltI \\
\end{tabular} & 30TYL40 & 100,00 & 109,39 & 91,87 & 35,70 & 5823,57 & 249,52 & $-4,65$ & 254,17 & 122,61 & 42,23 & 187,43 & 41,16 & 589,35 & 73, & 27,54 & 26,94 & 182,63 & 115,19 & 128,43 & 115,21 \\
\hline \begin{tabular}{|l|} 
Pleurodeles walt| \\
\end{tabular} & 30TYL50 & 39,00 & 110,93 & 91,70 & 35,70 & 5798,36 & 250,68 & $-2,77$ & 253,45 & 120,29 & 45,79 & 188,80 & 43,29 & 598,38 & 73, & 27,07 & 26,75 & 184,88 & 118,50 & 130,05 & 118,63 \\
\hline Pleurodeles walt| & 30TYL51 & 30,00 & 120,18 & 93,35 & 36,00 & 5791,27 & 260,47 & 4,02 & 256,45 & 127,02 & 56,69 & 197,64 & 52,31 & 556,07 & 69,22 & 23,95 & 28,58 & 174,89 & 108,18 & 121,33 & 108,84 \\
\hline Pleurodeles walt| & 31TBE44 & 53,00 & 153,70 & 86,17 & 36,00 & 5322,66 & 279,40 & 43,45 & 235,94 & 162,33 & 223,42 & 225,59 & 90,90 & 497,59 & 71,08 & 16,06 & 36,24 & 186,84 & 77,97 & 104,35 & 107,06 \\
\hline Pleurodeles walt| & 31TBE45 & 57,00 & 153,66 & 87,05 & 36,01 & 5360,26 & 280,27 & 42,42 & 237,85 & 161,39 & 223,80 & 225,93 & 90,54 & 493,76 & 69,85 & 16,15 & 36,06 & 184,06 & 79,28 & 104,61 & 104,30 \\
\hline \begin{tabular}{|l|} 
Pleurodeles walt| \\
\end{tabular} & 31TBE46 & 50,00 & 137,70 & 89,03 & 36,00 & 5531,17 & 269,65 & $\begin{array}{l}25,35 \\
25,35\end{array}$ & 244,30 & $\begin{array}{l}144,77 \\
\end{array}$ & $\begin{array}{l}210,79 \\
210\end{array}$ & 212,35 & 73,30 & 538,71 & $\begin{array}{l}69,70 \\
69,0\end{array}$ & \begin{tabular}{l|l}
19,68 \\
\end{tabular} & 31,86 & 187,75 & $\begin{array}{l}3,26 \\
94,87 \\
\end{array}$ & 114,51 & 111,69 \\
\hline Pleurodeles walt| & 31TBE 4 & 42,00 & 139 & 89,90 & 36,00 & 5553,37 & 271,91 & 25,73 & 246,19 & 145,64 & 212,67 & 214,06 & 74,59 & 527,90 & 68,06 & 19,19 & 32,11 & 183,50 & 93,84 & 112,96 & 108,14 \\
\hline Pleurodeles walt| & 31TBE48 & 47,00 & 131,15 & 90,93 & 36,00 & 5643,69 & 266,31 & 17,18 & 249,13 & 137,00 & 203,74 & 207,20 & 65,56 & 547,07 & 67,10 & 21,13 & 30,26 & 183,33 & $\begin{array}{r}101,84 \\
104\end{array}$ & 117,48 & 110,67 \\
\hline Pleurodeles waltt & 31TBE49 & 40,00 & 119,56 & 91,25 & 35,92 & 5731,29 & 257,22 & 5,59 & 251,63 & 125,81 & 145,69 & 196,73 & 52,88 & 581,34 & 69,86 & 24,46 & 28,17 & 185,85 & 113,97 & 125,36 & 116,83 \\
\hline Pleurodeles waltl & 31TBE54 & 80,00 & 164,95 & 85,25 & 36,02 & 5226,37 & 287,26 & 54,61 & 232,65 & 173,45 & 233,00 & 235,31 & 103,00 & 473,82 & 71,71 & 13,63 & 39,91 & 185,67 & 69,66 & 99,72 & 103,14 \\
\hline \begin{tabular}{|l|} 
Pleurodeles waltl \\
\end{tabular} & $31 \mathrm{TBE}$ & $\begin{array}{l}0,00,00 \\
100,0\end{array}$ & 159,40 & $\begin{array}{l}0,25 \\
86,61\end{array}$ & $\begin{array}{l}30,02 \\
36,07\end{array}$ & 5294,17 & $\begin{array}{l}20,20 \\
284,20\end{array}$ & \begin{tabular}{|l|l|}
48,04 \\
48
\end{tabular} & \begin{tabular}{|l|}
236,16 \\
23,1
\end{tabular} & \begin{tabular}{|l|}
166,89 \\
16,8
\end{tabular} & \begin{tabular}{|l|}
228,64 \\
220
\end{tabular} & \begin{tabular}{|l|}
230,73 \\
230,1
\end{tabular} & $\begin{array}{l}0,00 \\
97,16\end{array}$ & \begin{tabular}{|l|l|}
490,98 \\
490,
\end{tabular} & $\begin{array}{l}11,11 \\
71,74\end{array}$ & $\begin{array}{l}\mid 3,03 \\
14,86 \\
\end{array}$ & 37,91 & \begin{tabular}{|l|}
187,11 \\
187,1
\end{tabular} & $\begin{array}{l}3,00 \\
75,92\end{array}$ & 104,02 & 105,02 \\
\hline Pleurodeles walt| & 31TBE56 & 100,00 & 156,79 & 87,97 & 36,03 & 5351,15 & 283,47 & 44,35 & 239,12 & 163,37 & 227,06 & 229,03 & 94,37 & 497,19 & 71,13 & 15,40 & 36,96 & 186,29 & 79,45 & 106,00 & 104,69 \\
\hline \begin{tabular}{|l|l|} 
Pleurodeles waltl \\
\end{tabular} & 31TBE57 & 101,00 & 148,53 & 89,51 & 36,15 & 5459,30 & 278,64 & 35,10 & $\mid 243,54$ & 154,31 & 220,57 & 222,26 & 85,36 & 518,57 & 70,43 & 17,10 & 34,52 & 186,85 & 87,53 & 110,64 & 107,71 \\
\hline Pleurodeles waltl & 31TBE58 & 99,00 & 141,84 & 90,77 & 36,05 & 5544,79 & 274,69 & 27,44 & 247,26 & 146,97 & 215,31 & 216,60 & 77,80 & 533,31 & 69,25 & 18,57 & 32,74 & 186,03 & 94,08 & 114,15 & 109,37 \\
\hline Pleurodeles waltl & 31TBE & 100,00 & 126,75 & 91,35 & 36,00 & 5672,10 & 263,16 & 12,45 & 250,71 & 132,39 & 198 & 203 & 61,11 & 573,99 & 69,69 & 22,45 & 29,45 & 188,32 & 108,58 & 122,88 & 117 \\
\hline \begin{tabular}{|l|} 
Pleurodeles waltl \\
\end{tabular} & 31TBE65 & 61,00 & $\begin{array}{l}120,18 \\
169,18\end{array}$ & $\begin{array}{l}1,35 \\
86,34\end{array}$ & 30,36 & 5208,07 & $\begin{array}{l}200,10 \\
291,59\end{array}$ & $\begin{array}{l}2,45 \\
57,66\end{array}$ & \begin{tabular}{|l|}
233,93 \\
23,1
\end{tabular} & \begin{tabular}{|c|} 
\\
176,24 \\
\end{tabular} & \begin{tabular}{|l|}
237,21 \\
237
\end{tabular} & \begin{tabular}{|l|}
239,49 \\
239
\end{tabular} & \begin{tabular}{|l|}
108,25 \\
108
\end{tabular} & \begin{tabular}{|l|l|}
475,79 \\
\end{tabular} & $\begin{array}{l}3,03 \\
73,49 \\
\end{array}$ & \begin{tabular}{|l|}
12,713 \\
12
\end{tabular} & $\begin{array}{l}42,21 \\
41,21\end{array}$ & \begin{tabular}{|l|}
$180,32,24$ \\
188
\end{tabular} & \begin{tabular}{|l|l|}
69,80 \\
69,8
\end{tabular} & $\begin{array}{l}12,00 \\
101,51\end{array}$ & 102,36 \\
\hline Pleurodeles waltt & 31TBE66 & 101,00 & 159,37 & 87,61 & 36,12 & 5304,93 & 285,12 & 47,15 & 237,97 & 165,57 & 229,12 & 231,24 & 98,10 & 510,59 & 74,43 & 14,72 & 37,96 & 193,39 & 79,62 & 108,70 & 108,96 \\
\hline Pleurodeles walt| & \begin{tabular}{|l|} 
31TBE67 \\
\end{tabular} & 99,00 & 151,74 & 89,09 & 36,22 & 5395,38 & 280,51 & 38,61 & 241,91 & 157,12 & 223,05 & 224,85 & 89,94 & 532,20 & 74,02 & 16,31 & 35,63 & 194,55 & 87,19 & 113,19 & 112,28 \\
\hline |Pleurodeles walt| & 31TBE69 & 101,00 & 148,92 & 92,00 & 36,53 & 5502,09 & 281,72 & 33,28 & 248,44 & 152,69 & $221, \varepsilon$ & 223,33 & 86, & 535,42 & 71,96 & 16,89 & 34,60 & 190,29 & 91 & 114,38 & 11 \\
\hline Pleurodeles waltl & 31TBE76 & 47,00 & 160,62 & 87,60 & 36,32 & 5279,43 & 285,97 & 48,37 & 237,60 & 166,48 & 230,10 & 232,30 & 100,23 & 522,03 & 76,90 & 14,48 & 38,40 & 198,53 & 80,72 & 111,20 & 112,05 \\
\hline
\end{tabular}




\begin{tabular}{|c|c|c|c|c|c|c|c|c|c|c|c|c|c|c|c|c|c|c|c|c|c|}
\hline TAXON & UTM & $\mathrm{km} 2$ & BIO1 & BIO2 & $B 103$ & BIO4 & B105 & B106 & B107 & B108 & 8109 & B1010 & BIO11 & B1012 & BIO13 & BIO14 & BIO15 & B1016 & B1017 & B1018 & 81019 \\
\hline Pleurodeles walt| & 31TBE77 & 99,00 & 164,72 & 88,66 & 36,73 & 5260,90 & 290,13 & 51,68 & 238,45 & 169,45 & 234,01 & 236,08 & 105,05 & 515,23 & 77,21 & 13,70 & 39,55 & 197,66 & 79,70 & 111,03 & 108,34 \\
\hline Pleurodeles walt| & 31TBE78 & 100,00 & 163,46 & 90,35 & 37,00 & 5309,51 & 290,76 & 49,03 & 241,74 & 166,95 & 233,61 & 235,45 & $\begin{array}{l}103,63 \\
\end{array}$ & 521,50 & 76,95 & \begin{tabular}{l|l|l}
14,03 \\
\end{tabular} & 38,96 & \begin{tabular}{|l|l|}
197,60 \\
\end{tabular} & 82,61 & $\begin{array}{ll}112,80 \\
\end{array}$ & 104,24 \\
\hline Pleurodeles walt| & 31TBE89 & 100,00 & 162,13 & 91,20 & 36,93 & 5325,69 & 290,57 & 47,15 & 243,42 & $\begin{array}{l}164,59 \\
\end{array}$ & $\begin{array}{ll}232,68 \\
\end{array}$ & 234,53 & \begin{tabular}{|l|}
102,40 \\
\end{tabular} & 547,65 & 80,27 & 14,27 & 38,82 & 205,27 & 87,58 & $\begin{array}{l}118,50 \\
\end{array}$ & 103,46 \\
\hline Pleurodeles walt| & 31TBE99 & 42,00 & 163,34 & 90,17 & 36,85 & 5294,15 & 290,62 & 49,19 & 241,43 & 166,13 & 233,26 & 235,49 & $\begin{array}{l}103,72 \\
\end{array}$ & 555,15 & 82,38 & 14,23 & 39,66 & 209,34 & 88,68 & 121,32 & 104,89 \\
\hline Pleurodeles walt| & 31TBF60 & 100,00 & 131,81 & 92,23 & $36,17 \mid$ & $5648,64[$ & 268,52 & 16,45 & 252,08 & 136,55 & 206,01 & 207,95 & 66,86 & 576,26 & 70,87 & 21,04 & 30,52 & 191,29 & 106,43 & 122,69 & 118,72 \\
\hline Pleurodeles walt| & 31TBF61 & 99,00 & 109,30 & 90,92 & 35,52 & 5755,61 & 248,77 & $-3,78$ & 252,55 & 116,48 & $\begin{array}{ll}146,49 \\
\end{array}$ & 186,98 & 42,61 & 648,49 & 76,95 & 28,02 & 25,89 & 199,39 & 130,34 & 138,81 & 133,36 \\
\hline 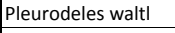 & 31TBF70 & 100,00 & 150,82 & 93,17 & 36,79 & 5497,04 & 284,54 & 34,28 & 250,26 & 153,43 & 223,81 & 225,19 & 89,03 & 552,58 & 74,84 & 16,49 & 35,08 & $\begin{array}{l}196,49 \\
\end{array}$ & 93,63 & 117,83 & 111,35 \\
\hline Pleurodeles walt| & 31TBF71 & 101,00 & 132,77 & 92,82 & 36,20 & 5636,99 & 270,10 & 17,10 & 252,99 & 136,79 & 207,72 & 208,94 & 68,45 & 596,72 & 74,31 & 21,14 & 30,76 & \begin{tabular}{|l|l|}
197,60 \\
\end{tabular} & 109,47 & 126,59 & 123,37 \\
\hline Pleurodeles walt| & 31TBF81 & 100,00 & 164,48 & 95,48 & 37,50 & 5414,10 & 297,55 & 46,15 & 251,40 & 164,37 & 236,30 & 237,81 & \begin{tabular}{|l|l|}
103,97 \\
\end{tabular} & 542,19 & 79,46 & \begin{tabular}{ll|}
14,17 \\
\end{tabular} & 39,14 & 202,26 & 88,71 & 118,75 & 100,01 \\
\hline Pleurodeles walt| & 31TBF83 & 101,00 & 154,13 & 97,79 & \begin{tabular}{ll|}
37,09 \\
\end{tabular} & 5636,11 & \begin{tabular}{|l|l|}
293,67 \\
\end{tabular} & 33,58 & 260,09 & \begin{tabular}{|l|l|}
155,13 \\
\end{tabular} & 228,81 & 229,75 & 90,46 & 533,66 & 71,59 & \begin{tabular}{ll|}
15,66 \\
\end{tabular} & 35,76 & \begin{tabular}{|c|}
188,14 \\
\end{tabular} & 91,76 & \begin{tabular}{ll|l|}
115,07 \\
\end{tabular} & $\begin{array}{ll}106,59 \\
\end{array}$ \\
\hline Pleurodeles walt| & 31TBF84 & 99,00 & 147,68 & 98,95 & \begin{tabular}{l|l|l}
36,85 \\
\end{tabular} & 5772,38 & $290,93 \mid$ & 25,93 & 265,00 & 149,58 & 223,98 & 224,66 & 80,99 & 533,00 & 66,84 & 16,69 & 33,26 & 180,07 & 94,50 & 113,37 & 110,08 \\
\hline Pleurodeles walt| & 31TBF90 & 101,00 & 166,11 & 91,45 & 36,95 & $\begin{array}{l}5296,97 \\
\end{array}$ & 294,19 & 50,89 & 243,29 & 167,91 & 236,18 & 238,11 & 106,50 & \begin{tabular}{|l|l|}
549,27 \\
\end{tabular} & 82,41 & 13,79 & 40,63 & 208,34 & 88,54 & $\begin{array}{l}121,87 \\
\end{array}$ & 101,14 \\
\hline Pleurodeles walt| & 31TBF92 & 100,00 & 154,42 & 94,27 & \begin{tabular}{|l|l|l|}
36,87 \\
\end{tabular} & 5503,33 & \begin{tabular}{|l|}
289,07 \\
\end{tabular} & 36,95 & 252,12 & 156,01 & 227,38 & 228,80 & \begin{tabular}{ll|}
92,66 \\
\end{tabular} & $\begin{array}{l}574,65 \\
\end{array}$ & 78,97 & \begin{tabular}{ll|}
15,66 \\
\end{tabular} & 36,24 & 204,95 & 95,11 & 121,81 & 114,87 \\
\hline Pleurodeles walt| & 31TBF93 & 100,00 & 149,18 & 95,28 & 36,69 & 5614,96 & 286,96 & 30,72 & 256,24 & 151,58 & 223,56 & 224,74 & 85,42 & \begin{tabular}{|l|l|}
572,98 \\
\end{tabular} & 74,83 & 16,53 & 34,38 & \begin{tabular}{|l|l|}
197,79 \\
\end{tabular} & 97,31 & $\begin{array}{ll}120,03 \\
\end{array}$ & 120,59 \\
\hline Pleurodeles walt| & 31TBF94 & 101,00 & 158,05 & 98,10 & 36,99 & $\begin{array}{l}5668,52 \\
\end{array}$ & 297,90 & 36,88 & 261,03 & 159,60 & 232,83 & 233,79 & 93,17 & 517,33 & 70,50 & \begin{tabular}{l|l|}
14,62 \\
\end{tabular} & 36,83 & $\begin{array}{l}184,75 \\
\end{array}$ & 87,80 & $\begin{array}{ll}112,56 \\
\end{array}$ & 105,25 \\
\hline Pleurodeles walt| & 31TCF02 & 96,00 & 159,45 & 91,76 & 36,80 & $\begin{array}{l}5411,50 \\
\end{array}$ & 290,13 & 43,73 & 246,40 & 161,96 & 230,93 & 232,68 & 98,68 & 572,99 & 83,03 & 14,95 & 38,52 & 211,12 & 92,86 & 123,94 & 113,35 \\
\hline Pleurodeles walt| & 31TCF03 & 100,00 & 155,72 & 93,07 & 36,66 & \begin{tabular}{|l|}
5515,29 \\
\end{tabular} & 289,47 & $\begin{array}{ll}38,63 \\
\end{array}$ & \begin{tabular}{|l|l|}
250,84 \\
\end{tabular} & 158,56 & 228,46 & \begin{tabular}{|l|}
230,07 \\
\end{tabular} & \begin{tabular}{|c|}
93,19 \\
\end{tabular} & 575,78 & 79,59 & 15,14 & 36,69 & 205,50 & 93,77 & 121,01 & 123,05 \\
\hline Pleurodeles walt| & 31TCF04 & 100,00 & 154,40 & $\begin{array}{ll}94,64 \\
\end{array}$ & \begin{tabular}{|c|}
36,57 \\
\end{tabular} & 5617,50 & 291,10 & 35,83 & 255,28 & 157,61 & 228,30 & 229,60 & 89,45 & 554,93 & 74,48 & 15,61 & 35,81 & 194,72 & 93,81 & 118,16 & 116,40 \\
\hline Pleurodeles walt| & 31TCF12 & 25,00 & 165,97 & 89,63 & 36,91 & 5319,41 & 292,97 & 51,66 & 241,31 & 169,56 & 235,78 & 237,78 & 105,91 & 552,69 & 86,22 & 14,84 & 41,78 & 213,66 & $\begin{array}{ll}90,25 \\
\end{array}$ & 126,19 & 107,44 \\
\hline Pleurodeles walt| & 31TCF13 & 95,00 & 155,01 & 89,43 & 36,08 & 5443,29 & 285,01 & $\begin{array}{l}40,86 \\
\end{array}$ & 244,15 & $\begin{array}{ll}159,62 \\
\end{array}$ & 226,56 & 228,42 & 92,51 & $\begin{array}{l}584,05 \\
\end{array}$ & 82,37 & 16,18 & 37,03 & 210,66 & 97,51 & \begin{tabular}{|l|l|}
126,43 \\
\end{tabular} & 121,91 \\
\hline Pleurodeles walt| & 31TCF14 & 99,00 & 141,43 & 90,34 & 35,86 & \begin{tabular}{|l|}
5617,71 \\
\end{tabular} & 276,12 & 26,61 & 249,51 & \begin{tabular}{|l|l|}
147,04 \\
\end{tabular} & 215,30 & 216,78 & 75,68 & 614,80 & 76,57 & 18,80 & 31,62 & 204,52 & 107,99 & 128,10 & 133,09 \\
\hline Rana dalmatina & 30TVN77 & 100,00 & 122,34 & 71,61 & 36,73 & 4342,73 & 229,04 & 36,54 & $\begin{array}{l}192,50 \\
\end{array}$ & $\begin{array}{ll}98,41 \\
\end{array}$ & \begin{tabular}{|l|l|}
177,24 \\
\end{tabular} & $\begin{array}{l}179,90 \\
\end{array}$ & 68,68 & 1009,67 & 123,94 & $\begin{array}{l}44,06 \\
\end{array}$ & 25,19 & \begin{tabular}{|l|l|}
332,97 \\
\end{tabular} & $\begin{array}{ll}169,58 \\
\end{array}$ & $\begin{array}{ll}190,88 \\
\end{array}$ & 310,96 \\
\hline Rana dalmatina & 30TVN78 & 100,00 & 120,92 & 69,74 & 36,68 & 4244,12 & 224,77 & 37,20 & 187,57 & 91,57 & \begin{tabular}{|l|l|l}
174,43 \\
\end{tabular} & 177,29 & 68,58 & 1066,48 & 131,83 & 46,55 & 25,63 & 353,54 & 178,62 & 202,15 & 330,37 \\
\hline Rana dalmatina & 30TVN84 & 100,00 & 103,96 & 86,15 & \begin{tabular}{l|l|l}
37,85 \\
\end{tabular} & 4963,33 & 233,21 & 7,87 & 225,33 & 55,78 & 167,96 & 170,04 & 43,42 & 871,21 & $\begin{array}{l}98,06 \\
\end{array}$ & 42,76 & 20,30 & 269,96 & 159,22 & 165,50 & 250,88 \\
\hline Rana dalmatina & 30TVN95 & 100,00 & 106,38 & 83,55 & 37,77 & \begin{tabular}{ll|}
4828,87 \\
\end{tabular} & 231,28 & 12,65 & 218,63 & 56,30 & 168,32 & 170,60 & 47,55 & 938,21 & \begin{tabular}{|l|l|}
107,38 \\
\end{tabular} & 45,50 & 20,76 & 293,76 & 170,03 & 178,55 & 276,05 \\
\hline Rana dalmatina & 30TVN96 & 100,00 & 119,40 & 76,09 & \begin{tabular}{|l|l|}
37,08 \\
\end{tabular} & 4543,25 & 232,90 & 30,66 & 202,24 & 72,38 & 177,02 & 179,58 & 63,58 & 990,60 & 118,93 & 44,53 & 23,73 & 319,32 & 170,56 & 186,73 & 305,49 \\
\hline Rana dalmatina & 30TWN05 & 100,00 & 111,15 & 83,25 & $\begin{array}{l}37,86 \\
\end{array}$ & 4804,25 & 234,88 & 17,47 & 217,42 & 60,22 & 172,58 & 174,81 & 52,45 & $\begin{array}{l}940,18 \\
\end{array}$ & \begin{tabular}{|l|l|}
107,73 \\
\end{tabular} & 45,27 & 20,77 & 294,35 & 170,42 & \begin{tabular}{|l|l|}
179,21 \\
\end{tabular} & 278,61 \\
\hline Rana dalmatina & 30TWN06 & 100,00 & 120,93 & 76,99 & \begin{tabular}{|l|l|}
37,38 \\
\end{tabular} & 4558,16 & 235,22 & 31,95 & 203,28 & 72,35 & $\begin{array}{ll}178,65 \\
\end{array}$ & 181,13 & 65,04 & 998,87 & 119,07 & 45,23 & 23,21 & 320,68 & 173,37 & 188,61 & 308,02 \\
\hline Rana dalmatina & 30TWN15 & 100,00 & 110,09 & 85,02 & 38,03 & 4845,20 & 235,85 & 15,60 & 220,25 & 58,25 & 172,10 & 174,23 & 51,07 & $\begin{array}{l}950,45 \\
\end{array}$ & 107,55 & 46,56 & 19,95 & 295,50 & 174,82 & 181,79 & 279,59 \\
\hline Rana dalmatina & 30TWN16 & 100,00 & $\begin{array}{l}98,64 \\
\end{array}$ & 85,16 & \begin{tabular}{|l|}
38,28 \\
\end{tabular} & \begin{tabular}{|l|l|}
4807,67 \\
\end{tabular} & 225,03 & 5,69 & 219,33 & 47,92 & 160,34 & 162,73 & 40,71 & 1045,75 & 118,43 & 52,56 & 19,70 & 326,01 & 193,81 & 199,88 & 307,97 \\
\hline Rana dalmatina & 30TWN21 & 100,00 & 110,79 & 96,77 & 38,36 & 5416,85 & 252,98 & 4,19 & 248,79 & 66,36 & 182,05 & 182,15 & 44,22 & 711,86 & 74,31 & 37,25 & 17,99 & 207,94 & 138,90 & 138,90 & 192,77 \\
\hline Rana dalmatina & 30TWN22 & 100,00 & 111,72 & 94,34 & 38,29 & 5288,91 & 250,19 & 7,67 & 242,52 & 61,67 & 180,75 & 181,31 & 46,66 & 758,46 & 80,55 & 39,13 & 18,04 & 223,91 & 147,33 & 147,51 & 209,39 \\
\hline Rana dalmatina & 30TWN24 & 100,00 & 119,93 & 86,90 & 38,16 & \begin{tabular}{ll|l}
4940,64 \\
\end{tabular} & 247,10 & 22,81 & 224,29 & 66,12 & 182,88 & 184,78 & 59,15 & 862,41 & 95,99 & \begin{tabular}{ll|}
42,06 \\
\end{tabular} & 19,59 & 264,73 & 160,61 & 165,94 & 250,16 \\
\hline Rana dalmatina & 30TWN25 & 100,00 & 117,45 & 84,69 & 38,13 & 4802,05 & 241,38 & 23,20 & 218,18 & 65,44 & 178,44 & 180,66 & 58,75 & 9445,48 & 107,01 & 45,75 & 20,05 & 294,32 & 173,45 & $\begin{array}{ll}180,86 \\
\end{array}$ & 279,21 \\
\hline Rana dalmatina & 30TWN26 & 100,00 & 113,08 & 82,98 & 38,30 & 4690,10 & 234,81 & 21,53 & 213,27 & 62,92 & 172,61 & 175,10 & 56,11 & $\begin{array}{l}1031,02 \\
\end{array}$ & 118,07 & 49,92 & 20,60 & 324,36 & 187,44 & 196,33 & 308,42 \\
\hline Rana dalmatina & 30TWN32 & 100,00 & 108,82 & 96,39 & 38,76 & 5341,01 & 249,64 & 3,40 & \begin{tabular}{|l|l|}
246,24 \\
\end{tabular} & 51,29 & \begin{tabular}{|l|l|}
179,08 \\
\end{tabular} & \begin{tabular}{ll|}
179,08 \\
\end{tabular} & 43,24 & 775,71 & 81,65 & 40,84 & 17,59 & 227,76 & $\begin{array}{l}150,97 \\
\end{array}$ & $\begin{array}{l}150,97 \\
\end{array}$ & 212,72 \\
\hline Rana dalmatina & 30TWN33 & 100,00 & 103,56 & 94,58 & 38,90 & 5221,61 & 242,10 & 1,07 & 241,03 & 47,20 & 172,36 & 172,57 & 39,87 & 862,93 & 92,57 & 45,23 & 17,73 & 257,56 & 166,55 & 166,66 & 241,63 \\
\hline Rana dalmatina & 30TWN34 & 100,00 & 118,90 & 89,15 & 38,76 & 4985,27 & 248,45 & 20,54 & 227,91 & 64,53 & 182,50 & 184,28 & 57,72 & 871,82 & 95,63 & 43,42 & 18,82 & 265,85 & 165,05 & 168,09 & 249,88 \\
\hline Rana dalmatina & 30TWN35 & 100,00 & 112,87 & 87,58 & 38,92 & 4872,46 & 240,42 & 17,16 & 223,26 & \begin{tabular}{|c|}
60,24 \\
\end{tabular} & 175,05 & 177,12 & 53,48 & 969,30 & $\begin{array}{l}108,05 \\
\end{array}$ & 48,34 & 19,18 & 299,53 & 181,38 & 185,61 & 282,65 \\
\hline Rana dalmatina & 30TWN36 & 100,00 & 118,93 & 83,30 & 38,89 & 4648,14 & 239,72 & 27,74 & 211,98 & 68,82 & 177,68 & 180,22 & 62,58 & $\begin{array}{l}1040,38 \\
\end{array}$ & 118,56 & 50,06 & 20,62 & 327,62 & 188,78 & 197,71 & 311,32 \\
\hline Rana dalmatina & 30TWN42 & 100,00 & 111,66 & 97,48 & \begin{tabular}{|l|l|}
38,97 \\
\end{tabular} & 5372,17 & 253,22 & 4,92 & 248,30 & 55,80 & 182,10 & 182,10 & 45,54 & \begin{tabular}{|l|l|}
765,08 \\
\end{tabular} & 79,88 & 40,51 & 17,51 & 223,68 & \begin{tabular}{|l|l|}
149,08 \\
\end{tabular} & \begin{tabular}{|l|l|}
149,08 \\
\end{tabular} & 207,95 \\
\hline Rana dalmatina & 30TWN43 & 100,00 & 104,69 & 95,80 & 39,00 & \begin{tabular}{|l|l|}
5253,68 \\
\end{tabular} & 244,22 & 1,10 & 243,12 & 47,78 & \begin{tabular}{|l|l|}
173,98 \\
\end{tabular} & 173,98 & 40,45 & \begin{tabular}{|c|}
867,38 \\
\end{tabular} & $\begin{array}{l}92,76 \\
\end{array}$ & 45,79 & 17,66 & 258,43 & 167,34 & $\mid 167,34$ & 241,97 \\
\hline Rana dalmatina & 30TWN44 & 100,00 & 116,32 & 91,52 & 39,00 & 5041,25 & 248,65 & 16,52 & 232,13 & 61,40 & 180,99 & 182,51 & 54,49 & $\begin{array}{l}893,15 \\
\end{array}$ & 97,14 & 45,32 & 18,33 & 271,42 & 170,94 & 171,69 & 254,05 \\
\hline Rana dalmatina & 30TWN52 & 100,00 & 111,01 & 98,69 & 38,99 & 5410,56 & 253, & 3,30 & 250,58 & 54,19 & 181,92 & 181,92 & 44,35 & 784,16 & 81,97 & 41,74 & 17,60 & 229,51 & 151,86 & $\begin{array}{lll}151,86 \\
\end{array}$ & 213,21 \\
\hline \begin{tabular}{|l} 
Rana dalmatina \\
\end{tabular} & $\begin{array}{l}30 \text { TWN64 } \\
\end{array}$ & 100,00 & 104,07 & 95,58 & 39,1 & 5166,61 & 242,19 & 1,56 & 240,63 & 48,36 & 172,21 & 172,21 & 41,03 & $\begin{array}{l}984,99 \\
\end{array}$ & \begin{tabular}{|l|l|}
108,32 \\
\end{tabular} & 51,52 & 18,30 & 300,55 & 186,36 & 186,36 & 281,81 \\
\hline Rana dalmatina & $30 \mathrm{TWN}$ & 100,00 & 114,75 & 92,10 & 39,59 & \begin{tabular}{|l|l|}
4941,28 \\
\end{tabular} & 246,34 & 16,24 & 230,10 & 61,12 & $\begin{array}{ll}178,84 \\
\end{array}$ & $\begin{array}{l}179,67 \\
\end{array}$ & 54,48 & 1037,83 & $\begin{array}{l}115,65 \\
\end{array}$ & 52,42 & 19,30 & 323,01 & 194,30 & $\begin{array}{l}195,10 \\
\end{array}$ & 302,10 \\
\hline Rana dalmatina & 30TWN73 & 100,00 & 103,41 & 98,80 & 39,01 & \begin{tabular}{|l|}
5350,09 \\
\end{tabular} & 246,23 & $-3,39$ & \begin{tabular}{|l|l|}
249,61 \\
\end{tabular} & 45,57 & $\begin{array}{l}173,73 \\
\end{array}$ & $\begin{array}{l}173,73 \\
\end{array}$ & 37,87 & $\begin{array}{l}936,65 \\
\end{array}$ & $\begin{array}{l}102,89 \\
\end{array}$ & 49,35 & 18,41 & 283,47 & $\begin{array}{l}175,99 \\
\end{array}$ & $\begin{array}{l}175,99 \\
\end{array}$ & 265,79 \\
\hline Rana dalmatina & 30TWN75 & 100,00 & 108,49 & 94,04 & 39,53 & 5036,57 & 243,08 & 7,88 & 235,20 & 54,16 & \begin{tabular}{ll|}
174,61 \\
\end{tabular} & 174,66 & 46,97 & $\begin{array}{l}1073,28 \\
\end{array}$ & 120,82 & 54,95 & 19,36 & 334,82 & 200,40 & 200,40 & 313,61 \\
\hline Rana dalmatina & 30TWN82 & 100,00 & 122,08 & 101,03 & 38,99 & 5523,64 & 267,28 & 10,41 & 256,87 & 61,07 & 193,86 & 193,86 & 53,14 & 830,67 & 93,74 & 41,59 & 20,33 & 255,99 & 150,78 & 150,78 & 238,30 \\
\hline Rana dalmatina & 30 TWN & 100,00 & 106,58 & 95,36 & 39,43 & 5114,41 & 243,07 & 4,09 & 238,99 & 51,34 & 173,73 & 173,73 & 43,91 & 1099,31 & 125,91 & 56,20 & 19,88 & 345,57 & 203,27 & 203,27 & 324,35 \\
\hline Rana dalmatina & 30TWN95 & 100,00 & 112,46 & 96,45 & 39,30 & 5169,92 & 249,99 & 7,99 & 242,00 & 56,38 & 180,13 & 180,13 & 48,65 & \begin{tabular}{|l|}
1115,28 \\
\end{tabular} & 131,91 & 55,58 & 21,42 & 357,89 & 201,88 & 201,88 & 336,12 \\
\hline Rana dalmatina & 30TWP20 & 75,00 & 136,08 & 66,31 & 37,61 & 3978,94 & 233,33 & 59,44 & 173,89 & 93,78 & 184,80 & 188,46 & 88,51 & $\begin{array}{l}1263,98 \\
\end{array}$ & 158,65 & 53,35 & 27,25 & 422,90 & 205,95 & 236,04 & 415,55 \\
\hline Rana dalmatina & 30TXN04 & 100,00 & 120,11 & 99,69 & 38,96 & 5424,70 & 263,16 & 9,95 & 253,21 & 60,57 & 190,76 & 190,76 & 52 & 1054,55 & $\begin{array}{l}130,95 \\
\end{array}$ & 50,27 & 23 & 346,91 & 182,97 & 182,97 & 327,25 \\
\hline Rana dalmatina & $30 T \times 1$ & 100, & 110 & 97,76 & $39, \mathrm{C}$ & 525 & 249 & 3,59 & 24 & 35, & \begin{tabular}{|l|l|}
179,04 \\
\end{tabular} & 179,04 & 45 & 1130 & 136 & 56,18 & 21,96 & 365 & 203,32 & 203,32 & 344 \\
\hline Rana dalmatina & 30TXN06 & 100,00 & 106,18 & 95,55 & 39,43 & 5116,10 & 241,79 & 2,54 & 239,25 & 50,97 & 173,27 & 173,27 & 43,10 & 1195,82 & 142,30 & 60,52 & 21,15 & 384,30 & 219,61 & 219,61 & 361,55 \\
\hline Rana dalmatina & 30TXN15 & 100,00 & 107,71 & $\begin{array}{ll}98,34 \\
\end{array}$ & 39,02 & \begin{tabular}{|l}
5316,13 \\
\end{tabular} & 247,88 & $-0,46$ & \begin{tabular}{|l|l|}
248,34 \\
\end{tabular} & \begin{tabular}{|l|l|}
50,04 \\
\end{tabular} & $\begin{array}{ll}177,17 \\
\end{array}$ & $\begin{array}{l}177,17 \\
\end{array}$ & 41,58 & \begin{tabular}{|l|}
1130,84 \\
\end{tabular} & \begin{tabular}{ll|}
136,92 \\
\end{tabular} & 56,58 & 21,81 & $\begin{array}{l}364,65 \\
\end{array}$ & 204,42 & \begin{tabular}{|l|l|}
204,42 \\
\end{tabular} & 344,08 \\
\hline Rana iberica & 29SMD98 & 58,00 & 154,47 & 68,99 & 42,01 & 3275,73 & 239,79 & 77,49 & 162,30 & 119,74 & \begin{tabular}{|l|l|}
193,37 \\
\end{tabular} & 195,76 & 111,73 & 752,49 & \begin{tabular}{|l|l|}
116,18 \\
\end{tabular} & 5,30 & 59,35 & 321,62 & 37,58 & 44,10 & 307,90 \\
\hline Rana ibe & $295 \mathrm{ML}$ & 35,00 & 15 & 70,03 & 42 & 3291, & 23 & 74,76 & 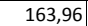 & 4 & 191,64 & 194 & & 788,54 & 119 & 6,00 & 58 & 33. & 41,22 & 47,77 & 32 \\
\hline Rana iberica & 29SND09 & 101,00 & 152,42 & 73,80 & \begin{tabular}{l|l}
42,05 \\
\end{tabular} & 3457,76 & 245,39 & 72,05 & 173,34 & 115,68 & \begin{tabular}{|l|l|}
193,97 \\
\end{tabular} & 196,45 & 107,71 & 810,14 & 120,76 & 6,13 & 57,97 & 341,2 & 43,40 & 49,26 & 330,91 \\
\hline Rana iberica & 29SND29 & 99,00 & 151,13 & 82,99 & \begin{tabular}{|l|l|}
41,45 \\
\end{tabular} & 3942,27 & 261,95 & 63,73 & 198,22 & 109,08 & 199,74 & 202,52 & 101,35 & 876,15 & 128,23 & 7,39 & 56,91 & 363,50 & 50,06 & 53,62 & 359,24 \\
\hline
\end{tabular}




\begin{tabular}{|c|c|c|c|c|c|c|c|c|c|c|c|c|c|c|c|c|c|c|c|c|c|}
\hline TAXON & UTM & $\mathrm{km} 2$ & BIO1 & BIO2 & BIO3 & B104 & 8105 & B106 & B107 & B108 & 8109 & B1010 & BIO11 & BIO12 & BIO13 & B1014 & B1O15 & B1016 & B1017 & B1018 & B1019 \\
\hline Rana iberica & 29SND39 & 101,00 & 153,96 & 87,16 & 41,14 & 4137,05 & 272,16 & 63,43 & 208,73 & 109,60 & 205,40 & 208,28 & 102,00 & 870,46 & 126,93 & 7,33 & 56,63 & 359,14 & 50,47 & 53,44 & 357,18 \\
\hline Rana iberica & $295 N D 46$ & 101,00 & 166,58 & 88,53 & 40,98 & 4293,35 & 288,52 & 74,46 & 214,05 & 120,34 & 219,92 & 223,14 & 112,81 & 727,41 & \begin{tabular}{|l|l|}
106,05 \\
\end{tabular} & 5,03 & 58,10 & \begin{tabular}{|l|}
304,27 \\
\end{tabular} & 38,17 & 41,38 & 301,09 \\
\hline Rana iberica & 29SND59 & 101,00 & 155,63 & 92,85 & \begin{tabular}{|l|l|}
40,48 \\
\end{tabular} & 4542,00 & 286,69 & 60,08 & 226,61 & 100,20 & 212,94 & 215,92 & 99,49 & 886,67 & 128,71 & 7,65 & 56,03 & 363,69 & 53,16 & 54,72 & 363,69 \\
\hline Rana iberica & 29SND66 & 101,00 & 165,61 & 93,09 & 40,11 & 4654,14 & 298,53 & 69,45 & 229,09 & 114,68 & 224,13 & 227,40 & 108,00 & 751,99 & 108,81 & 5,59 & 57,07 & 310,31 & 41,83 & 44,10 & 310,05 \\
\hline Rana iberica & 29SND67 & 100,00 & 162,12 & 93,45 & \begin{tabular}{|l|l|}
40,02 \\
\end{tabular} & 4683,37 & 296,33 & 65,63 & 230,70 & \begin{tabular}{|l|l|}
106,61 \\
\end{tabular} & 221,41 & 224,52 & 104,51 & \begin{tabular}{|l|l|}
799,38 \\
\end{tabular} & \begin{tabular}{|l|l|}
115,80 \\
\end{tabular} & 6,27 & 56,69 & 329,00 & 45,86 & 47,63 & 328,94 \\
\hline Rana iberica & 29SND68 & 101,00 & 159,67 & 93,99 & 40,01 & 4703,47 & 294,69 & 62,56 & \begin{tabular}{|l|l|}
232,14 \\
\end{tabular} & \begin{tabular}{|l|l|}
102,14 \\
\end{tabular} & 219,35 & 222,32 & 101,68 & 838,90 & 121,61 & 6,79 & 56,21 & 344,67 & 49,30 & 50,85 & 344,67 \\
\hline Rana iberica & 29SND69 & 100,00 & 156,26 & 94,39 & 39,99 & 4724,42 & 292,26 & 58,78 & 233,49 & 98,11 & 216,29 & 219,20 & 98,11 & 888,65 & 129,02 & 7,71 & 55,92 & 364,47 & 53,76 & 54,91 & 364,47 \\
\hline Rana iberica & 29SND77 & 101,00 & 163,16 & 94,90 & \begin{tabular}{|l|}
39,62 \\
\end{tabular} & 4845,10 & 301,51 & 64,80 & 236,71 & 105,01 & \begin{tabular}{|l|l|}
224,73 \\
\end{tabular} & 227,83 & 103,70 & \begin{tabular}{|l|}
794,91 \\
\end{tabular} & 114,82 & 6,29 & 56,23 & \begin{tabular}{|l|}
326,38 \\
\end{tabular} & 46,21 & 47,79 & 326,38 \\
\hline Rana iberica & 29SND78 & 100,00 & 156,18 & 94,27 & 39,20 & 4899,09 & 295,88 & 58,04 & 237,84 & 96,54 & 218,78 & 221,83 & 96,54 & 877,66 & 127,63 & 7,38 & 56,02 & 360,54 & 52,64 & 53,34 & 360,54 \\
\hline Rana iberica & 29SND79 & 101,00 & 153,58 & 94,51 & 39,06 & 4917,92 & 293,90 & 55,02 & 238,88 & 93,68 & 216,89 & 219,49 & 93,68 & \begin{tabular}{|c|}
919,63 \\
\end{tabular} & \begin{tabular}{|c|}
133,97 \\
\end{tabular} & 8,12 & 55,83 & 377,20 & 56,25 & 56,71 & 377,20 \\
\hline Rana iberica & 29SND88 & 99,00 & 154,56 & 94,24 & 38,52 & 5066,11 & 297,74 & 55,48 & 242,26 & 93,30 & 220,01 & 222,74 & 93,30 & 894,16 & 130,22 & 7,64 & 55,91 & 366,97 & 54,09 & 54,49 & 366,97 \\
\hline Rana iberica & $29 \mathrm{SND} 89$ & 101,00 & 153,44 & 94,66 & 38,42 & 5085,55 & 297,12 & 53,67 & 243,45 & 91,82 & 219,37 & 221,80 & 91,82 & 921,40 & \begin{tabular}{|l|l|}
134,45 \\
\end{tabular} & 8,01 & 55,71 & 377,72 & 56,39 & 56,68 & 377,72 \\
\hline Rana iberica & 29SNE00 & 96,00 & 154,65 & 74,30 & 42,69 & 3403,58 & 245,97 & 73,88 & $\begin{array}{r}172,10 \\
\end{array}$ & 118,09 & \begin{tabular}{|l|l|}
195,25 \\
\end{tabular} & \begin{tabular}{|l|}
197,60 \\
\end{tabular} & 110,13 & \begin{tabular}{|l|l|}
807,95 \\
\end{tabular} & \begin{tabular}{|l|}
119,72 \\
\end{tabular} & 6,29 & 57,39 & \begin{tabular}{|l|}
338,62 \\
\end{tabular} & 44,00 & 50,49 & 328,45 \\
\hline Rana iberica & 29SNE12 & 101,00 & 154,19 & 80,64 & 43,08 & 3581,21 & 253,36 & 68,70 & 184,66 & 115,14 & 197,19 & 199,53 & 107,27 & 874,10 & 125,94 & 7,94 & 55,56 & 359,32 & 52,16 & 58,23 & 353,13 \\
\hline Rana iberica & 29SNE30 & 100,00 & 151,17 & 88,04 & 41,29 & 4146,76 & 270,31 & 60,08 & 210,23 & 106,59 & 202,74 & 205,56 & 99,05 & \begin{tabular}{|l|}
915,09 \\
\end{tabular} & \begin{tabular}{|l|}
132,98 \\
\end{tabular} & 8,19 & 55,99 & 375,21 & 54,94 & 57,61 & 374,22 \\
\hline Rana iberica & 29SNE31 & 101,00 & 153,26 & 89,56 & \begin{tabular}{|l|l|}
41,83 \\
\end{tabular} & 4109,05 & 272,14 & 61,12 & \begin{tabular}{|l|l|}
211,03 \\
\end{tabular} & 107,35 & 204,18 & 206,82 & 101,14 & \begin{tabular}{|l|}
913,92 \\
\end{tabular} & 131,86 & 8,50 & 55,35 & 373,01 & 56,08 & 59,22 & 372,06 \\
\hline Rana iberica & 29SNE41 & 101,00 & 152,76 & 93,14 & 41,49 & 4345,88 & 279,68 & 57,65 & 222,03 & \begin{tabular}{l|l|}
98,66 \\
\end{tabular} & 207,16 & \begin{tabular}{|l|}
209,86 \\
\end{tabular} & $\begin{array}{l}98,28 \\
\end{array}$ & \begin{tabular}{|l|l|}
939,08 \\
\end{tabular} & \begin{tabular}{|l|}
135,46 \\
\end{tabular} & 8,86 & 55,12 & 382,81 & 58,79 & $\begin{array}{l}60,79 \\
\end{array}$ & 382,81 \\
\hline Rana iberica & 29SNE42 & 100,00 & 150,50 & 94,55 & 41,80 & 4357,86 & 278,69 & 54,41 & 224,29 & 95,73 & 205,08 & 207,75 & 95,73 & \begin{tabular}{|l|l|}
981,85 \\
\end{tabular} & \begin{tabular}{|l|l|}
141,10 \\
\end{tabular} & 9,75 & 54,39 & \begin{tabular}{|l|}
398,97 \\
\end{tabular} & 63,27 & 65,08 & 398,97 \\
\hline Rana iberica & 29SNE50 & 101,00 & 152,49 & \begin{tabular}{|l|l|}
93,64 \\
\end{tabular} & \begin{tabular}{ll|}
40,52 \\
\end{tabular} & 4559,42 & 284,73 & 56,28 & 228,45 & 96,01 & 210,15 & 213,00 & 96,01 & \begin{tabular}{|l|l|}
936,03 \\
\end{tabular} & 135,86 & 8,58 & 55,59 & 383,17 & 57,83 & 59,04 & 383,17 \\
\hline Rana iberica & 29SNE51 & 101,00 & 150,79 & 94,81 & 40,71 & 4567,43 & 283,90 & 53,75 & 230,15 & 94,13 & 208,58 & 211,30 & 94,13 & \begin{tabular}{|l|l|}
971,58 \\
\end{tabular} & 140,67 & 9,29 & 54,97 & 396,61 & 61,51 & 62,51 & 396,61 \\
\hline Rana iberica & 29SNE52 & 100,00 & 145,71 & 94,36 & 40,55 & 4572,50 & 278,62 & 48,77 & 229,86 & 89,08 & 204,36 & 206,28 & 89,08 & 1042,81 & 151,36 & 10,45 & 54,69 & 424,94 & 67,24 & 68,03 & 424,94 \\
\hline Rana iberica & 29SNE60 & 100,00 & 156,03 & 95,70 & 40,18 & 4727,17 & 292,76 & 57,48 & 235,28 & 97,60 & \begin{tabular}{|l|}
216,06 \\
\end{tabular} & 218,82 & 97,60 & \begin{tabular}{|}
909,29 \\
\end{tabular} & \begin{tabular}{|l|l|}
131,69 \\
\end{tabular} & 8,14 & 55,40 & 371,90 & 56,08 & 57,23 & 371,90 \\
\hline Rana iberica & 29SNE61 & 100,00 & 151,40 & 95,90 & \begin{tabular}{l|l|}
40,15 \\
\end{tabular} & 4750,56 & 289,01 & 52,56 & 236,45 & 92,84 & 211,99 & 214,58 & 92,84 & 973,54 & \begin{tabular}{|l|}
141,32 \\
\end{tabular} & 9,16 & 55,04 & \begin{tabular}{|l|}
397,64 \\
\end{tabular} & 61,64 & 62,21 & 397,64 \\
\hline Rana iberica & 29SNE62 & 100,00 & $\begin{array}{l}141,47 \\
\end{array}$ & 93,16 & \begin{tabular}{|l|}
39,39 \\
\end{tabular} & 4773,60 & 277,94 & 44,03 & 233,92 & 83,16 & 204,14 & 205,27 & 83,16 & 1091,31 & 160,04 & 10,87 & 54,99 & 445,90 & 69,95 & 70,01 & 445,90 \\
\hline Rana iberica & 29SNE70 & 101,00 & 154,33 & 95,89 & 39,32 & 4917,30 & 295,29 & 54,54 & 240,75 & $\begin{array}{l}94,07 \\
\end{array}$ & 217,36 & 219,94 & 94,07 & 929,76 & 135,19 & 8,27 & 55,35 & 380,43 & 57,70 & 58,26 & 380,43 \\
\hline Rana iberica & 29SNE71 & 100,00 & 147,42 & 94,63 & \begin{tabular}{|c|}
38,97 \\
\end{tabular} & 4938,86 & 288,14 & 48,14 & 240,01 & 87,19 & 211,97 & 213,50 & 87,19 & 1016,43 & 148,84 & 9,58 & 55,22 & 415,88 & 63,99 & 64,14 & 415,88 \\
\hline Rana iberica & 29SNE72 & 101,00 & 147,01 & 95,68 & 39,19 & 4934,79 & 287,99 & 46,80 & 241,19 & 86,58 & 211,29 & 212,84 & 86,58 & 1037,05 & 151,67 & 10,03 & 55,00 & 423,37 & 66,27 & 66,45 & 423,37 \\
\hline Rana iberica & 29SNE80 & 101,00 & 147,36 & 93,38 & 38,00 & 5105,65 & 290,68 & 48,02 & 242,66 & 85,73 & 214,97 & 216,08 & 85,73 & \begin{tabular}{|l|l|}
999,48 \\
\end{tabular} & 146,99 & 9,09 & 55,62 & 409,81 & 61,75 & 61,78 & 409,81 \\
\hline Rana iberica & 29SNE81 & 100,00 & 139,59 & 91,18 & 37,40 & 5112,34 & 281,58 & 41,21 & 240,36 & 78,28 & 208,20 & 208,53 & 78,28 & 1095,12 & 162,51 & $\begin{array}{r}10,33 \\
\end{array}$ & 55,64 & \begin{tabular}{|c|}
449,06 \\
\end{tabular} & 67,73 & 67,73 & 449,06 \\
\hline Rana iberica & 29SNE82 & 101,00 & 142,45 & 93,26 & \begin{tabular}{|l|l|}
37,95 \\
\end{tabular} & 5101,60 & 285,13 & 42,50 & \begin{tabular}{|l|l|}
242,63 \\
\end{tabular} & 80,70 & 210,18 & 210,85 & 80,70 & 1080,88 & 159,84 & 10,28 & 55,32 & 442,08 & 67,84 & $\begin{array}{ll}67,92 \\
\end{array}$ & 442,08 \\
\hline Rana iberica & 29SNE90 & 100,00 & 144,25 & 91,88 & 37,01 & 5263,55 & 289,66 & 44,62 & 245,03 & 81,28 & 214,68 & 215,34 & 81,28 & 1026,81 & 151,79 & 9,32 & 55,69 & 420,93 & 63,00 & 63,03 & 420,93 \\
\hline Rana iberica & 29SNE91 & 100,00 & 133,40 & 88,25 & \begin{tabular}{|l|l|}
36,15 \\
\end{tabular} & 5252,89 & 276,32 & $\begin{array}{l}35,82 \\
\end{array}$ & 240,49 & 71,19 & 204,67 & 204,67 & 71,19 & 1151,78 & 172,48 & 10,85 & 55,87 & 472,69 & 70,36 & 70,36 & 472,69 \\
\hline Rana iberica & 29SNE92 & 100,00 & 141,13 & 92,11 & \begin{tabular}{|l|l|}
37,01 \\
\end{tabular} & 5261,34 & 286,09 & 40,61 & 245,48 & 77,82 & 211,52 & 211,83 & 77,82 & 1085,70 & 161,39 & 10,10 & 55,59 & \begin{tabular}{|l|l|}
444,37 \\
\end{tabular} & 67,32 & 67,38 & 444,37 \\
\hline Rana iberica & 29SPC77 & 99,00 & 161,64 & 113,86 & 39,01 & 5906,86 & 330,81 & 43,08 & 287,73 & 97,98 & 238,62 & 240,14 & 89,56 & 564,18 & 77,44 & 4,05 & 53,31 & 221,79 & 34,09 & 35,34 & 212,05 \\
\hline Rana iberica & 29SPD26 & 101,00 & 160,01 & 96,71 & 37,40 & 5512,44 & 312,78 & 57,41 & 255,37 & 95,55 & 231,52 & 234,88 & 94,22 & \begin{tabular}{|l|l|}
787,61 \\
\end{tabular} & 111,94 & 6,14 & 55,06 & 319,04 & 47,62 & 48,89 & 319,04 \\
\hline Rana iberica & $295 P D 34$ & 101,00 & 160,24 & 99,30 & 37,85 & 5550,93 & 315,39 & 56,72 & 258,67 & \begin{tabular}{|l|l|}
102,24 \\
\end{tabular} & 232,29 & \begin{tabular}{|l|}
235,74 \\
\end{tabular} & 94,27 & 740,95 & \begin{tabular}{|l|l|}
103,04 \\
\end{tabular} & 6,14 & 54,40 & 298,01 & 45,47 & 46,65 & 297,21 \\
\hline Rana iberica & 29SPD35 & 100,00 & 150,96 & 93,90 & 36,71 & 5549,48 & 303,30 & 51,48 & 251,82 & 87,76 & 223,30 & 227,27 & 86,22 & \begin{tabular}{|l|l|}
847,69 \\
\end{tabular} & 120,82 & 7,24 & 54,84 & 343,56 & 52,06 & 53,06 & 343,56 \\
\hline Rana iberica & 29SPD36 & 101,00 & 153,98 & 94,90 & \begin{tabular}{|l|l|}
36,77 \\
\end{tabular} & 5604,19 & 307,60 & 52,43 & 255,18 & 91,66 & 227,18 & 230,49 & 87,92 & 831,12 & 118,49 & 6,95 & 54,64 & 336,25 & 51,13 & 52,08 & 336,14 \\
\hline Rana iberica & 29SPD38 & 101,00 & 162,82 & 98,87 & 36,98 & 5732,46 & 319,80 & 55,39 & 264,41 & 101,39 & 237,89 & 239,77 & 93,75 & 761,73 & 107,66 & 5,93 & 54,35 & 305,98 & 46,83 & 48,18 & 305,15 \\
\hline Rana iberica & $29 S P D 43$ & 99,00 & 163,16 & 104,89 & 38,67 & 5647,58 & 323,13 & 54,71 & 268,42 & 103,38 & 236,58 & 239,30 & 95,26 & \begin{tabular}{|l|l|}
675,98 \\
\end{tabular} & 91,26 & 5,35 & 53,69 & 269,65 & 42,25 & 43,30 & 266,46 \\
\hline Rana iberica & $29 S P D 44$ & 101,00 & 155,18 & 99,28 & 37,57 & 5640,11 & 312,16 & 51,31 & 260,85 & 96,60 & 228,72 & 232,15 & 88,58 & 767,07 & \begin{tabular}{|r|}
106,42 \\
\end{tabular} & 6,42 & 54,01 & 307,69 & 47,74 & \begin{tabular}{|l|l|}
48,74 \\
\end{tabular} & 306,19 \\
\hline Rana iberica & 29SPD45 & 99,00 & 145,56 & 94,44 & 36,50 & 5659,10 & 300,09 & 44,74 & 255,35 & 86,12 & 220,27 & 223,39 & 79,69 & 866,89 & 122,89 & 7,64 & 54,20 & 348,96 & 54,20 & 54,73 & 348,51 \\
\hline Rana iberica & 29SPD46 & 100,00 & 156,64 & 97,92 & \begin{tabular}{|l|}
36,98 \\
\end{tabular} & 5715,55 & 313,60 & 51,85 & 261,75 & \begin{tabular}{|l|l|}
96,79 \\
\end{tabular} & 231,46 & 234,36 & 88,84 & 779,71 & $\mid$\begin{tabular}{|c|}
109,38 \\
\end{tabular} & 6,38 & 54,05 & |313,09 & 48,41 & 49,55 & 311,72 \\
\hline Rana iberica & 29SPD53 & 101,00 & 162,51 & 107,88 & 38,71 & 5768,06 & 326,25 & 50,88 & 275,37 & 100,99 & 237,82 & 239,95 & 92,98 & 656,75 & \begin{tabular}{|l|}
87,85 \\
\end{tabular} & 5,19 & 52,99 & 260,40 & 41,79 & 42,66 & 255,47 \\
\hline Rana iberica & 29SPD54 & 100,00 & 159,58 & 104,37 & 37,96 & 5772,25 & 321,21 & 50,21 & 271,00 & 98,48 & 235,00 & 237,44 & 90,46 & \begin{tabular}{|c|}
698,68 \\
\end{tabular} & \begin{tabular}{|l|}
94,38 \\
\end{tabular} & 5,69 & 53,15 & 277,95 & 44,20 & 45,22 & 273,87 \\
\hline Rana iberica & $29 S P D 55$ & 101,00 & 155,24 & $\begin{array}{l}100,88 \\
\end{array}$ & 37,30 & 5793,53 & 315,14 & 48,08 & 267,07 & 94,52 & 231,21 & 233,80 & 86,40 & 749,56 & \begin{tabular}{|r|}
103,06 \\
\end{tabular} & 6,22 & 53,30 & 298,95 & 47,35 & 48,26 & 295,74 \\
\hline Rana iberica & 29SPD56 & 101,00 & 157,86 & 100,85 & 37,00 & 5829,21 & 317,95 & 49,67 & 268,29 & 96,27 & $\begin{array}{r}234,37 \\
\end{array}$ & 236,51 & 88,25 & 735,80 & 101,26 & 6,06 & 53,23 & 293,24 & 46,52 & 47,58 & 289,84 \\
\hline Rana iberica & 29SPD62 & 100,00 & 165,88 & 1114,38 & \begin{tabular}{|l|l|}
39,38 \\
\end{tabular} & 5882.08 & 334,61 & 48,07 & 286,54 & $\mid 101,80$ & 242,73 & 243,80 & 93,97 & 590,70 & 79,85 & 4,86 & 52.16 & $231.85 \mid$ & 38.45 & 39,20 & 224,20 \\
\hline Rana iberica & 29SPD63 & 99,00 & 165,28 & 111,71 & 39,01 & 5881,51 & 332,24 & 49,14 & 283,10 & 101,48 & 242,15 & 243,45 & 93,61 & 608,40 & 81,64 & 4,91 & 52,16 & 239,24 & 39,44 & 40,35 & 232,05 \\
\hline Rana iberica & 29SPEOO & 100,00 & 156 , & 96, & 37,36 & 5412 & 306,87 & 52,65 & 254,22 & 91,06 & \begin{tabular}{|l|}
227,34 \\
\end{tabular} & 22 & 91,06 & 892,60 & 129,81 & 7,50 & 55,12 & \begin{tabular}{|c|}
363,46 \\
\end{tabular} & 55,07 & 55,67 & 363,46 \\
\hline Rana iberica & 29SPE01 & 101,00 & 148,83 & 94,02 & 36,76 & 5429,34 & 298,03 & 45,95 & \begin{tabular}{|l|}
252,07 \\
\end{tabular} & 83,36 & 220,92 & 221,77 & 83,36 & 983,23 & \begin{tabular}{|l|}
144,85 \\
\end{tabular} & 8,69 & 55,36 & 401,42 & 60,77 & 60,98 & 401,42 \\
\hline Rana iberica & 29SPE02 & 101,00 & 138,63 & 90,45 & 36,04 & 5409,04 & 285,24 & \begin{tabular}{|l|l|}
37,94 \\
\end{tabular} & 247,30 & 73,95 & 211,46 & 211,53 & 73,95 & 1097,44 & 163,97 & 10,08 & 55,76 & 449,22 & 67,41 & 67,41 & 449,22 \\
\hline Rana iberica & 29SPE11 & 101,00 & 157,91 & 97,35 & \begin{tabular}{|l|l|}
36,95 \\
\end{tabular} & 5583,85 & 311,32 & 51,39 & 259,93 & 90,01 & \begin{tabular}{|l|l|}
231,04 \\
\end{tabular} & 232,51 & 90,01 & 875,06 & 127,01 & 7,26 & 54,90 & 354,47 & 54,36 & 55,11 & 354,47 \\
\hline \begin{tabular}{|l} 
Rana iberi \\
\end{tabular} & 29SPE12 & 100,00 & 151,78 & 95,52 & 36,56 & 5580,80 & 303,98 & 46,12 & 257,86 & 84,14 & \begin{tabular}{|l|l|}
225,44 \\
\end{tabular} & 226,36 & 84,14 & \begin{tabular}{|c|}
943,37 \\
\end{tabular} & 138,41 & 8,12 & 55,08 & \begin{tabular}{|l|l|}
383,08 \\
\end{tabular} & 58,69 & 59,05 & 383,08 \\
\hline Rana iberica & $29 \mathrm{SQD} 44$ & 100,00 & 153,60 & \begin{tabular}{|c|}
112,60 \\
\end{tabular} & 36,38 & 6501,45 & 334,92 & \begin{tabular}{|l|l|}
30,10 \\
\end{tabular} & 304,82 & 83,36 & 240,45 & 240,45 & 75,10 & 541,58 & 69,07 & 4,51 & 49,49 & \begin{tabular}{|l|}
199,98 \\
\end{tabular} & 36,22 & 36,23 & 187,85 \\
\hline Rana iberica & 29SQD58 & 72,00 & 159,68 & 111,35 & \begin{tabular}{|l|}
36,05 \\
\end{tabular} & 6490,86 & 338,59 & 36,23 & 302,36 & 89,04 & 246,51 & 246,51 & 80,72 & $\begin{array}{l}470,35 \\
\end{array}$ & 59,39 & 4,00 & 47,57 & 170,54 & 33,51 & 33,51 & 158,14 \\
\hline Rana iberica & 29SQE11 & 101,00 & 157,74 & 105,92 & \begin{tabular}{|l|l|}
36,02 \\
\end{tabular} & 6286,97 & \begin{tabular}{|l|}
328,03 \\
\end{tabular} & 39,43 & 288,61 & 89,15 & 241,37 & 241,37 & 81,21 & $|550,67|$ & 70,10 & 5,05 & 48,66 & 208,12 & 38,66 & 38,66 & 197,41 \\
\hline Rana iberica & 29TM & & & & & & & & & & & & & & & & & & & & \\
\hline Rana iberica & 29TMH85 & 76,00 & 139,86 & 60 & 38 & 3227,67 & 58 & 70,50 & \begin{tabular}{|l|l|}
154,08 \\
\end{tabular} & \begin{tabular}{|l|l|}
109,07 \\
\end{tabular} & 17 & 182,91 & 99,89 & 1 & 1 & 27,14 & 42,50 & 40 & 1. & \begin{tabular}{ll|}
140,82 \\
\end{tabular} & 344, \\
\hline Rana iberica & 29TMH 86 & \begin{tabular}{|l|l|l}
101,00 \\
\end{tabular} & 140,88 & 60,43 & 39,01 & 3189,41 & 224,79 & 71,89 & 152,90 & 110,68 & 179,94 & $\begin{array}{l}183,48 \\
\end{array}$ & \begin{tabular}{|c|}
101,52 \\
\end{tabular} & 1001,25 & \begin{tabular}{|l|}
143,27 \\
\end{tabular} & 27,08 & 41,99 & \begin{tabular}{|l}
395,29 \\
\end{tabular} & 115,62 & 140,68 & 334,91 \\
\hline
\end{tabular}




\begin{tabular}{|c|c|c|c|c|c|c|c|c|c|c|c|c|c|c|c|c|c|c|c|c|c|}
\hline TAXON & $\overline{\text { UTM }}$ & km2 & BIO1 & B102 & BIO3 & B104 & B105 & B106 & B107 & B108 & B109 & BIO10 & BIO11 & B1012 & BIO13 & BIO14 & BIO15 & BIO16 & BIO17 & BIO18 & BlO19 \\
\hline Rana iberica & 29TMH87 & 60,00 & 143,94 & 60,09 & 39,43 & 3139,24 & 225,93 & 75,29 & 150,63 & 114,11 & 182,18 & 185,88 & 104,93 & 980,60 & 139,88 & 26,78 & 41,41 & 385,48 & 113,95 & 139,40 & 326,89 \\
\hline Rana iberica & 29TMH93 & 45,00 & 142,97 & 60,38 & 38,58 & 3303,65 & 228,01 & 73,36 & 154,65 & 110,67 & 183,91 & 186,81 & 101,71 & 1081,97 & 153,14 & 26,94 & 44,01 & \begin{tabular}{|l|}
431,12 \\
\end{tabular} & \begin{tabular}{|l|}
113,87 \\
\end{tabular} & \begin{tabular}{|l|}
138,10 \\
\end{tabular} & 376,59 \\
\hline Rana iberica & 29TMH94 & 96,00 & \begin{tabular}{|l|l|}
134,43 \\
\end{tabular} & 62,32 & 38,30 & 3383,03 & 224,15 & \begin{tabular}{ll|}
63,56 \\
\end{tabular} & \begin{tabular}{l|l|}
160,59 \\
\end{tabular} & \begin{tabular}{ll|}
101,66 \\
\end{tabular} & \begin{tabular}{|l|l|}
176,79 \\
\end{tabular} & \begin{tabular}{l|l|}
179,88 \\
\end{tabular} & \begin{tabular}{|l|l}
92,99 \\
\end{tabular} & 1163,86 & \begin{tabular}{ll|}
165,96 \\
\end{tabular} & 30,57 & 43,29 & \begin{tabular}{|l|}
460,44 \\
\end{tabular} & \begin{tabular}{|l|l|}
125,92 \\
\end{tabular} & \begin{tabular}{|l|}
149,26 \\
\end{tabular} & 407,56 \\
\hline Rana iberica & 29TMH95 & 101,00 & 132,06 & 62,84 & 38,29 & 3379,81 & 222,68 & 60,82 & \begin{tabular}{|l|l|}
161,87 \\
\end{tabular} & $\begin{array}{l}99,50 \\
\end{array}$ & \begin{tabular}{|l|l|}
174,35 \\
\end{tabular} & \begin{tabular}{l|l|}
177,58 \\
1
\end{tabular} & 90,84 & \begin{tabular}{|l|l|}
1161,49 \\
\end{tabular} & $\begin{array}{ll}163,83 \\
\end{array}$ & 31,54 & 42,44 & \begin{tabular}{|l|l|}
457,27 \\
\end{tabular} & \begin{tabular}{|l|l|}
129,28 \\
\end{tabular} & \begin{tabular}{|l|l|}
152,73 \\
\end{tabular} & 403,12 \\
\hline Rana iberica & 29тMH96 & 101,00 & $132,67 \mid$ & 62,76 & 38,41 & 3336,99 & 222,47 & 61,55 | & 160,92 & 100,76 & $174,14 \mid$ & 177,72 & 91,95 & 1134,29 & 158,51 & 31,50 & 41,88 & $444,68 \mid$ & 129,01 & $152,87 \mid$ & 389,79 \\
\hline Rana iberica & 29TMH97 & 100,00 & $138,07 \mid$ & 61,86 & 38,93 & 3246,93 & 224,66 & 67,91 & 156,75 & 107,19 & $\mid$\begin{tabular}{|l|l|}
178,13 \\
\end{tabular} & \begin{tabular}{|l|l|}
181,82 \\
\end{tabular} & 98,28 & 1062,28 & \begin{tabular}{|l|l|}
147,82 \\
\end{tabular} & 29,67 & 41,14 & 415,54 & $\mid 122,71$ & \begin{tabular}{|l|l|}
147,29 \\
\end{tabular} & 360,00 \\
\hline Rana iberica & 29TMH98 & 28,00 & 142,80 & 61,16 & 39,53 & 3177,18 & 226,53 & 73,42 & 153,11 & \begin{tabular}{|l|}
112,60 \\
\end{tabular} & \begin{tabular}{|l|}
181,80 \\
\end{tabular} & \begin{tabular}{l|l|}
185,62 \\
\end{tabular} & \begin{tabular}{|l|l|}
103,67 \\
\end{tabular} & 1013,53 & 141,49 & 28,18 & 41,00 & \begin{tabular}{|l|}
395,73 \\
\end{tabular} & \begin{tabular}{|l|}
117,49 \\
\end{tabular} & \begin{tabular}{|l|}
142,60 \\
\end{tabular} & 341,07 \\
\hline Rana iberica & 29TNE26 & 100,00 & 152,32 & 84,16 & 44,45 & 3581,52 & 250,69 & 63,32 & 187,37 & 112,44 & \begin{tabular}{|l|l|}
194,77 \\
\end{tabular} & 196,81 & \begin{tabular}{|l|l|}
104,39 \\
\end{tabular} & 969,56 & 136,02 & \begin{tabular}{|l|}
10,03 \\
\end{tabular} & 53,09 & \begin{tabular}{|l|}
390,74 \\
\end{tabular} & 63,01 & 70,94 & 385,71 \\
\hline Rana iberica & 29TNE27 & 100,00 & 150,94 & 81,77 & 44,72 & 3491,93 & 244,10 & \begin{tabular}{l|l}
63,03 \\
\end{tabular} & \begin{tabular}{|l|l|}
181,07 \\
\end{tabular} & \begin{tabular}{ll|}
111,95 \\
\end{tabular} & \begin{tabular}{|l|l|}
191,99 \\
\end{tabular} & \begin{tabular}{|l|l|}
193,90 \\
\end{tabular} & \begin{tabular}{|l|l|}
103,76 \\
\end{tabular} & \begin{tabular}{|l|}
988,28 \\
\end{tabular} & 138,04 & \begin{tabular}{l|l|}
10,85 \\
\end{tabular} & \begin{tabular}{|l|l|}
52,79 \\
\end{tabular} & \begin{tabular}{l|l|}
397,95 \\
\end{tabular} & 65,18 & \begin{tabular}{|l|l|}
74,10 \\
\end{tabular} & 391,49 \\
\hline Rana iberica & 29TNE37 & 100,00 & 151,92 & 88,12 & 44,21 & 3760,17 & 256,36 & 59,47 & \begin{tabular}{|l|l|}
196,88 \\
\end{tabular} & \begin{tabular}{|l|l|}
109,94 \\
\end{tabular} & \begin{tabular}{|l|l|}
196,99 \\
\end{tabular} & \begin{tabular}{|l|}
198,97 \\
\end{tabular} & \begin{tabular}{|l|l|}
101,90 \\
\end{tabular} & 999,56 & \begin{tabular}{|l|}
139,38 \\
\end{tabular} & 11,00 & 52,72 & 400,87 & 66,69 & 74,56 & 396,25 \\
\hline Rana iberica & 29TNE39 & 101,00 & 149,99 & 83,28 & 44,75 & 3590,40 & 244,10 & 59,58 & \begin{tabular}{|l|l|l|}
184,53 \\
\end{tabular} & \begin{tabular}{l|l|}
109,52 \\
\end{tabular} & $\begin{array}{l}192,36 \\
\end{array}$ & \begin{tabular}{|l|l|}
194,02 \\
\end{tabular} & \begin{tabular}{|l|l|}
101,25 \\
\end{tabular} & 1023,95 & 141,72 & \begin{tabular}{|l|}
11,49 \\
\end{tabular} & 52,18 & \begin{tabular}{|l|l|}
411,92 \\
\end{tabular} & 68,18 & \begin{tabular}{|l|}
79,27 \\
\end{tabular} & 402,06 \\
\hline Rana iberica & 29TNE43 & 100,00 & \begin{tabular}{|l|}
152,01 \\
\end{tabular} & 96,88 & 42,29 & 4334,80 & 280,95 & 54,54 & \begin{tabular}{l|l|}
226,42 \\
\end{tabular} & \begin{tabular}{l|l}
97,23 \\
\end{tabular} & \begin{tabular}{|l|}
206,12 \\
\end{tabular} & \begin{tabular}{|l|}
208,63 \\
\end{tabular} & 97,14 & \begin{tabular}{|l|l|}
988,34 \\
\end{tabular} & 140,82 & 10,21 & 53,90 & \begin{tabular}{|l|}
399,77 \\
\end{tabular} & \begin{tabular}{|l|}
65,27 \\
\end{tabular} & \begin{tabular}{ll|}
67,43 \\
\end{tabular} & 399,77 \\
\hline Rana iberica & 29TNE44 & 101,00 & 157,36 & 99,73 & 43,31 & 4271,78 & 286,11 & 58,28 & 227,83 & 102,93 & \begin{tabular}{|l|l|}
210,29 \\
\end{tabular} & 212,65 & 102,55 & 952,53 & 133,76 & 10,00 & 53,12 & 382,72 & 63,82 & 67,21 & 382,71 \\
\hline Rana iberica & 29TNE45 & 101,00 & 159,50 & 98,46 & 43,90 & 4164,52 & 283,32 & 60,82 & 222,49 & 108,75 & 210,58 & 212,78 & 105,32 & 936,35 & 130,70 & 9,70 & 52,90 & 374,25 & 62,54 & 67,44 & 374,14 \\
\hline Rana iberica & 29TNE47 & 101,00 & 154,50 & 94,07 & 43,94 & 4033,16 & 269,87 & $57,67 \mid$ & $212,19 \mid$ & 109,24 & 203,70 & 205,62 & 101,39 & 992,43 & 138,39 & 10,73 & 52,51 & 396,70 & 66,59 & 73,58 & 393,77 \\
\hline Rana iberica & 29TNE48 & 101,00 & 153,62 & 91,44 & 44,01 & 3947,35 & 263,56 & 57,81 & 205,75 & \begin{tabular}{|l|l|}
109,17 \\
\end{tabular} & \begin{tabular}{|l|}
201,37 \\
\end{tabular} & \begin{tabular}{|l|}
203,17 \\
\end{tabular} & \begin{tabular}{|l|l|}
101,12 \\
\end{tabular} & 1001,46 & \begin{tabular}{|l|}
139,26 \\
\end{tabular} & \begin{tabular}{l|l|}
10,96 \\
\end{tabular} & 52,41 & \begin{tabular}{l|l|}
401,25 \\
\end{tabular} & $\begin{array}{ll}66,83 \\
\end{array}$ & $\begin{array}{ll}75,53 \\
\end{array}$ & 395,36 \\
\hline Rana iberica & 29TNE49 & 100,00 & 151,63 & 89,81 & 43,97 & 3905,53 & 258,44 & 56,55 & 201,90 & \begin{tabular}{|l|}
107,68 \\
\end{tabular} & \begin{tabular}{|l|l|}
198,79 \\
\end{tabular} & 200,54 & 99,55 & 1025,40 & \begin{tabular}{|l|l|}
142,39 \\
\end{tabular} & \begin{tabular}{|l|l|}
11,30 \\
\end{tabular} & 52,40 & \begin{tabular}{|l|}
412,01 \\
\end{tabular} & 68,11 & \begin{tabular}{ll|}
78,33 \\
\end{tabular} & 403,22 \\
\hline Rana iberica & 29TNE53 & 101,00 & 151,81 & 98,81 & 41,57 & 4545,58 & 286,84 & 52,19 & 234,65 & $\begin{array}{l}4,84 \\
\end{array}$ & 209,36 & \begin{tabular}{|l|l|}
211,64 \\
\end{tabular} & \begin{tabular}{|l|l|}
94,84 \\
\end{tabular} & 1002,83 & 143,49 & 10,28 & 53,94 & 406,24 & \begin{tabular}{l|l|}
66,25 \\
\end{tabular} & \begin{tabular}{ll|}
67,75 \\
\end{tabular} & 406,24 \\
\hline Rana iberica & 29TNE54 & 101,00 & 156,27 & 102,18 & 42,50 & 4514,23 & 292,22 & $54,61 \mid$ & $237,61 \mid$ & 99,02 & 212,75 & 215,25 & 99,02 & 975,79 & 137,69 & 10,19 & 53,13 & $392,97 \mid$ & $65,87 \mid$ & $68,08 \mid$ & 392,97 \\
\hline Rana iberica & 29TNE55 & 99,00 & 150,55 & 100,13 & 42,22 & 4497,70 & 284,29 & 49,83 & 234,45 & $93,64 \mid$ & 207,01 & 209,27 & 93,64 & 1043,22 & 148,06 & 11,27 & 53,1 & $419,77 \mid$ & 70,97 & 73,17 & 419,77 \\
\hline Rana iberica & 29TNE56 & 101,00 & 150,10 & 99,40 & 42,36 & 4444,24 & 281,01 & 49,47 & 231,54 & 93,55 & 205,67 & 207,82 & 93,41 & 1053,40 & 149,12 & 11,49 & 52,88 & 422,23 & 71,75 & 75,15 & 422,23 \\
\hline Rana iberica & 29TNE57 & 101,00 & 148,69 & 97,64 & 42,53 & 4378,99 & 275,62 & 48,79 & 226,84 & 97,88 & 203,34 & 205,27 & 92,45 & 1070,57 & 151,49 & 11,72 & 52,86 & 428,03 & 72,49 & 77,32 & 427,56 \\
\hline Rana iberica & 29TNE58 & 100,00 & 146,09 & 95,18 & 42,45 & 4321,16 & 268,92 & 47,29 & 221,63 & \begin{tabular}{l|l}
98,02 \\
\end{tabular} & \begin{tabular}{ll|l}
199,92 \\
\end{tabular} & 201,72 & 90,42 & 1099,79 & 155,99 & 12,10 & 52,83 & $\begin{array}{ll}440,82 \\
\end{array}$ & 74,02 & 80,08 & 438,16 \\
\hline Rana iberica & 29TNE59 & 101,00 & 145,60 & 94,24 & 42,64 & 4275,39 & 265,54 & 47,09 & 218,45 & $98,05 \mid$ & 198,66 & 200,38 & 90,22 & 1107,62 & 156,50 & 12,31 & 52,68 & 444,74 & 74,34 & 82,05 & 439,23 \\
\hline Rana iberica & 29TNE63 & 101,00 & 130,56 & 89,14 & 38,42 & 4769,88 & 264,01 & 35,22 & 228,79 & 72,92 & 194,23 & 194,62 & 72,92 & 1221,84 & 181,18 & \begin{tabular}{ll|}
12,82 \\
\end{tabular} & 55,21 & 499,16 & 78,16 & 78,31 & 499,16 \\
\hline Rana iberica & 29TNE64 & 100,00 & 155,81 & 101,81 & 41,50 & 4683,46 & 294,72 & 53,07 & 241,64 & 96,83 & 215,14 & 217,20 & 96,83 & 978,93 & 139,33 & 9,92 & 53,46 & 394,96 & 65,10 & 67,15 & 394,96 \\
\hline Rana iberica & 29TNE65 & 101,00 & 154,92 & 102,10 & 41,75 & 4672,85 & 292,96 & 51,79 & 241,18 & 95,81 & 213,88 & 216,01 & 95,81 & 997,15 & 141,65 & 10,31 & 53,17 & \begin{tabular}{|l|l|}
401,08 \\
\end{tabular} & 66,87 & 69,43 & 401,08 \\
\hline Rana iberica & 29TNE66 & 100,00 & 156,09 & 101,84 & 42,18 & 4606,32 & 291,36 & 52,82 & 238,53 & 97,33 & 213,92 & 215,92 & 97,29 & 989,81 & 139,97 & 10,23 & \begin{tabular}{|l|l|}
52,97 \\
\end{tabular} & 396,23 & 66,28 & 70,18 & 396,23 \\
\hline Rana iberica & 29TNE67 & 100,00 & 151,69 & $99,91$. & 42,00 & 4573,47 & 284,14 & 49,24 & 234,90 & $97,01 \mid$ & 209,18 & $210,97 \mid$ & 93,25 , & 1039,96 & 147,79 & 10,93 & 53,01 & 415,86 & 69,58 . & 74,15 . & 415,82 \\
\hline Rana iberica & 29TNE68 & 101,00 & 134,72 & 93,55 & 40,41 & 4632,53 & 264,80 & 36,08 & 228,72 & 80,31 & \begin{tabular}{|l|l|}
194,14 \\
1
\end{tabular} & $\begin{array}{l}195,64 \\
194\end{array}$ & 76,89 & 1229,75 & 179,29 & 13,54 & $\begin{array}{l}53,76 \\
\end{array}$ & \begin{tabular}{l|l|}
495,74 \\
\end{tabular} & 82,40 & 85,19 & 495,61 \\
\hline Rana iberica & 29TNE69 & 101,00 & 128,02 & 91,01 & 39,86 & 4638,69 & 256,21 & 30,75 & 225,47 & 73,66 & \begin{tabular}{|l|l|}
187,77 \\
\end{tabular} & \begin{tabular}{ll|}
189,16 \\
\end{tabular} & 70,46 & 1311,34 & 192,53 & 14,74 & 54,03 & \begin{tabular}{l|l|}
529,92 \\
\end{tabular} & 88,13 & 90,71 & 529,25 \\
\hline Rana iberica & 29TNE73 & 100,00 & 130,48 & 89,04 & 37,71 & 4935,42 & 267,29 & 34,12 & 233,17 & 71,19 & \begin{tabular}{|l|l|}
196,84 \\
\end{tabular} & $\begin{array}{ll}196,95 \\
\end{array}$ & 71,19 & 1223,43 & 182,48 & 12,47 & 55,44 & $\begin{array}{ll}500,58 \\
\end{array}$ & 77,23 & 77,23 & 500,58 \\
\hline Rana iberica & 29TNE74 & 100,00 & 144,66 & 96,62 & 39,51 & 4909,73 & 284,97 & 43,52 & 241,46 & 84,22 & \begin{tabular}{|l|l|}
208,62 \\
\end{tabular} & 209,88 & 84,22 & 1088,21 & 159,07 & \begin{tabular}{ll|}
10,86 \\
\end{tabular} & 54,50 & 442,33 & $\begin{array}{ll}70,82 \\
\end{array}$ & 71,38 & 442,33 \\
\hline Rana iberica & 29TNE75 & 101,00 & 154,08 & 101,29 & 40,82 & 4855,81 & 295,17 & 49,96 & 245,21 & 93,12 & 215,94 & 217,84 & 93,12 & \begin{tabular}{|l|}
998,76 \\
\end{tabular} & 143,36 & 9,90 & 53,72 & 402,78 & 65,75 & 68,01 & 402,78 \\
\hline Rana iberica & 29TNE76 & 101,00 & 154,06 & 101,53 & 41,08 & 4813,66 & 293,38 & \begin{tabular}{l|l}
49,62 \\
\end{tabular} & 243,76 & 93,18 & 215,14 & \begin{tabular}{|l|l|}
216,88 \\
\end{tabular} & 93,18 & 1005,56 & \begin{tabular}{|l|l|}
143,97 \\
\end{tabular} & 9,99 & \begin{tabular}{|l|l|}
53,47 \\
\end{tabular} & \begin{tabular}{ll|}
404,01 \\
\end{tabular} & 66,34 & 69,56 & 404,01 \\
\hline Rana iberica & 29TNE77 & 100,00 & 151,71 & 100,66 & 41,18 & 4778,52 & 288,89 & 47,59 & 241,30 & \begin{tabular}{ll|}
91,92 \\
\end{tabular} & \begin{tabular}{|l|l|}
212,30 \\
\end{tabular} & 213,84 & $\begin{array}{ll}91,08 \\
\end{array}$ & \begin{tabular}{ll|}
1035,22 \\
\end{tabular} & \begin{tabular}{l|l|}
148,55 \\
\end{tabular} & 10,42 & 53,45 & \begin{tabular}{|l|l|}
415,23 \\
\end{tabular} & \begin{tabular}{|c|}
68,17 \\
\end{tabular} & 72,12 & 415,23 \\
\hline Rana iberica & 29TNE78 & 100,00 & 148,15 & 99,57 & 41,25 & 4758,31 & 283,45 & 44,56 & 238,88 & 92,48 & 208,55 & 209,97 & 87,76 & 1076,81 & 155,12 & $\begin{array}{ll}11,07 \\
\end{array}$ & 53,44 & \begin{tabular}{ll|l}
431,68 \\
\end{tabular} & 70,90 & 75,54 & 431,42 \\
\hline Rana iberica & 29TNE79 & 101,00 & $134,17 \mid$ & 94,47 & 39,91 & 4800,60 & 267,62 & 33,70 & 233,92 & $76,77 \mid$ & $196,11 \mid$ & 197,26 & 74,3 & $1237,77 \mid$ & 181,96 & 13,3 & 54,13 & 499,57 & $81,97 \mid$ & $84,94[$ & 499,52 \\
\hline Rana iberica & 29TNE83 & 100,00 & 136,83 & 91,53 & 37,62 & 5092,52 & 278,06 & 37,73 & 240,33 & $75,38 \mid$ & 204,90 & 205,18 & 75,38 & 1153,36 & 171,78 & 11,27 & 55,46 & 471,89 & 2,49 & 72,49 & 471,89 \\
\hline Rana iberica & 29TNE84 & 101,00 & 133,66 & 90,79 & 37,47 & 5087,30 & 273,82 & 34,71 & 239,11 & 72,27 & 201,61 & 201,88 & 72,27 & 1197,70 & 179,06 & 11,86 & 55,43 & 489,74 & 75,49 & 75,49 & 489,74 \\
\hline Rana iberica & 29TNE85 & 100,00 & 147,50 & 97,92 & 39,26 & 5042,36 & 289,99 & 44,08 & 245,90 & 85,04 & 212,90 & 214,17 & 85,04 & \begin{tabular}{ll|l}
1059,06 \\
\end{tabular} & 155,04 & 10,29 & 54,5 & 429,45 & 68,30 & 69,66 & 429,45 \\
\hline Rana iberica & 29TNE86 & 100,00 & 150,11 & 99,94 & 39,99 & 5010,48 & 292,48 & 45,38 & 247,10 & 87,50 & 214,40 & 215,94 & 87,50 & 1037,19 & 150,83 & $\begin{array}{ll}10,03 \\
\end{array}$ & 54,1 & 418,79 & 67,60 & 69,74 & 418,79 \\
\hline Rana iberica & 29TNE87 & 101,00 & 151,38 & 100,69 & 40,36 & 4969,05 & 292,32 & 46,06 & 246,27 & 88,92 & $214,94 \mid$ & $216,39 \mid$ & 88,82 & 1027,25 & 148,92 & 9,93 & 53,91 & 413,26 & $66,69 \mid$ & $\begin{array}{l}0,08 \\
\end{array}$ & 413,26 \\
\hline Rana iberica & 29TNE88 & 101,00 & 149,07 & 100,28 & 40,46 & 4943,27 & 288,54 & 43,95 & 244,59 & 88,11 & 212,25 & 213,54 & 86,67 & 1056,45 & 153,52 & 10,50 & 53,85 & \begin{tabular}{|l|l|}
424,47 \\
\end{tabular} & 68,67 & 72,72 & 424,47 \\
\hline Rana iberica & 29TNE89 & 99,00 & 143,28 & 98,96 & 40,16 & 4954,20 & 281,94 & 38,90 & 243,03 & 81,35 & 206,81 & \begin{tabular}{ll|}
207,99 \\
\end{tabular} & 80,99 & 1124,35 & 164,80 & 11,31 & \begin{tabular}{|l|l|}
54,06 \\
\end{tabular} & 452,74 & 73,25 & 77,10 & 452,74 \\
\hline Rana iberica & 29TNE93 & 101,00 & 140,56 & 92,62 & 37,11 & 5261,71 & 285,37 & 39,35 & 246,03 & 77,01 & \begin{tabular}{|l|l|}
210,76 \\
\end{tabular} & 211,08 & 77,01 & 1102,34 & 164,09 & 10,29 & 55,49 & 450,73 & 68,82 & 68,84 & 450,73 \\
\hline Rana iberica & 29TNE94 & 100,00 & 125,53 & 86,11 & 35,79 & 5217,44 & 265,27 & 28,23 & 237,05 & 63,45 & \begin{tabular}{ll|l}
195,88 \\
\end{tabular} & \begin{tabular}{l|l|l|l|l|}
195,88 \\
\end{tabular} & 63,4 & 1276,51 & 193,59 & 12,38 & 56,13 & 523,51 & 78,29 & 78,29 & 523,51 \\
\hline Rana iberica & 29TNE95 & 101,00 & 127,45 & 87,81 & 36,31 & 5197,31 & 267,32 & 28,99 & 238,32 & 65,12 . & $196,99 \mid$ & $197,21 \mid$ & 65 & 1266,14 & 191,66 & 12,29 & 55,95 & 518,23 & 8,40 & 78,48 & 518,23 \\
\hline Rana iberica & 29TNE96 & 100,00 & 144,25 & 96,90 & 38,48 & 5194,21 & 288,55 & \begin{tabular}{l|l|}
39,98 \\
\end{tabular} & 248,56 & \begin{tabular}{|l|}
80,12 \\
\end{tabular} & 211,84 & \begin{tabular}{|l|l|}
212,90 \\
\end{tabular} & \begin{tabular}{|l|}
80,12 \\
\end{tabular} & \begin{tabular}{|l|}
1084,89 \\
\end{tabular} & \begin{tabular}{|l|l|}
160,45 \\
\end{tabular} & \begin{tabular}{|l|}
10,32 \\
\end{tabular} & 54,88 & \begin{tabular}{l|l|}
440,40 \\
\end{tabular} & \begin{tabular}{|l|l|}
69,82 \\
\end{tabular} & \begin{tabular}{|l|}
70,58 \\
\end{tabular} & 440,40 \\
\hline Rana iberica & 29TNE97 & 100,00 & 147,75 & 99,20 & 39,25 & 5155,38 & 291,58 & 42,09 & 249,49 & \begin{tabular}{|l|l}
83,40 \\
\end{tabular} & \begin{tabular}{|l|l|}
214,19 \\
\end{tabular} & 215,39 & \begin{tabular}{|l|l|}
83,40 \\
\end{tabular} & \begin{tabular}{l|l|}
1050,55 \\
\end{tabular} & 154,38 & \begin{tabular}{|l|l|}
9,97 \\
\end{tabular} & \begin{tabular}{|l|}
54,49 \\
\end{tabular} & \begin{tabular}{l|l}
424,55 \\
\end{tabular} & \begin{tabular}{|l|l|}
67,60 \\
\end{tabular} & \begin{tabular}{|l|}
69,74 \\
\end{tabular} & 424,55 \\
\hline Rana iberica & 29TNE98 & 100,00 & $\begin{array}{l}146,38 \\
\end{array}$ & \begin{tabular}{|l|}
99,49 \\
\end{tabular} & 39,50 & 5130,69 & 289,32 & 40,54 & 248,78 & 82,20 & 212,43 & 213,62 & 82,20 & 1069,29 & \begin{tabular}{l|l|}
157,42 \\
\end{tabular} & 10,31 & \begin{tabular}{|l|l|}
54,43 \\
\end{tabular} & $\begin{array}{l}431,66 \\
\end{array}$ & \begin{tabular}{ll|}
68,89 \\
\end{tabular} & $\begin{array}{ll}71,63 \\
\end{array}$ & 431,66 \\
\hline Ran iberica & 29TNE99 & 101,00 & 143,90 & 99,38 & 39,62 & 5127,85 & 286,19 & $38,18 \mid$ & $248,01 \mid$ & $79,91 \mid$ & 210,06 & 211,01 & 79,7 & 1097,89 & 162,19 & 10,71 & 54,52 & 443,23 & $70,70 \mid$ & 73,80 & 443,23 \\
\hline Rana iberica & 29TNF27 & 83,00 & 143,39 & 83,67 & 44,84 & 3665,84 & 241,48 & 56,50 & 184,98 & $98,16 \mid$ & 188,60 & 190,35 & $96, \mathbf{9 6}$ & 1229,74 & 168,04 & 15,0 & 51,3 & 488, & 83,48 & 101,82 & 488,58 \\
\hline Rana iberica & 29TN & 101,00 & 148 & 83,26 & 44 & 359 & 241 & \begin{tabular}{|l|}
57,46 \\
\end{tabular} & & \begin{tabular}{|l|}
107,87 \\
\end{tabular} & \begin{tabular}{|l|l|}
190,73 \\
\end{tabular} & \begin{tabular}{|l|}
192,50 \\
\end{tabular} & 99,4 & 1065,36 & \begin{tabular}{l|l|}
146,05 \\
\end{tabular} & 12,24 & 52,00 & \begin{tabular}{|l|l|}
429,98 \\
\end{tabular} & \begin{tabular}{|l|l}
71,06 \\
\end{tabular} & 85,21 & 414,46 \\
\hline Rana iberica & 29TNF32 & 101,00 & 145,57 & 84,92 & 44,51 & 3682,73 & 242,81 & 53,91 & 188,90 & $104,71 \mid$ & $189,77 \mid$ & 191,53 & 96,39 & 1108,58 & 151,23 & 13,26 & $51,97 \mid$ & 448,35 & $74,67 \mid$ & 90,24 & 429,45 \\
\hline Rana iberica & 29TNF33 & 100,00 & 143,08 & 86,64 & 44,26 & 3769,42 & 244,08 & 50,32 & \begin{tabular}{l|l|}
193,75 \\
\end{tabular} & \begin{tabular}{|l|l|}
101,57 \\
\end{tabular} & \begin{tabular}{|l|l|}
188,84 \\
\end{tabular} & \begin{tabular}{|l|}
190,75 \\
\end{tabular} & \begin{tabular}{|l|}
93,44 \\
\end{tabular} & 1153,38 & \begin{tabular}{ll|}
156,89 \\
\end{tabular} & 14,21 & \begin{tabular}{l|l|}
51,96 \\
\end{tabular} & \begin{tabular}{ll|}
467,44 \\
\end{tabular} & \begin{tabular}{ll|}
78,42 \\
\end{tabular} & \begin{tabular}{|l|}
95,49 \\
\end{tabular} & 444,94 \\
\hline Rana iberica & 29TNF34 & 101,00 & 142,93 & 88,24 & 44,24 & 832,79 & 246,60 & 49,26 & 197,34 & 100,95 & 189,74 & 191,72 & $92,80 \mid$ & $\mid 169,53$ & 160,71 & 14,84 & 51,92 & 475,06 & 9,95 & 99,15 & 447,97 \\
\hline Rana ibe & & & & & & & & 50,08 & 19 & 10 & 9 & 193 & & P] & 162 & 15,0 & 51, & 476,56 & & \begin{tabular}{|l|l|}
100,90 \\
\end{tabular} & 450,62 \\
\hline Rana iberica & 29TNF37 & 101,00 & 143,27 & 87,78 & 44,23 & 3880,42 & 248,43 & 52,12 & 196,31 & 100,95 & \begin{tabular}{|l|l|}
191,39 \\
\end{tabular} & \begin{tabular}{|l|l|}
193,10 \\
\end{tabular} & \begin{tabular}{|l|}
93,98 \\
\end{tabular} & \begin{tabular}{|l|}
1219,17 \\
\end{tabular} & 165,45 & 15,05 & \begin{tabular}{|l|}
51,07 \\
\end{tabular} & \begin{tabular}{|l|l|}
485,64 \\
\end{tabular} & 82,94 & \begin{tabular}{|l|l|}
101,87 \\
\end{tabular} & 478,73 \\
\hline Rana iberica & 29TNF38 & 101,00 & 142,52 & 86,87 & 43,81 & 3905,18 & 248,58 & 52,35 & \begin{tabular}{|l|l|}
196,23 \\
\end{tabular} & 99,41 & 191,21 & \begin{tabular}{|l|l|}
192,75 \\
\end{tabular} & \begin{tabular}{|l|}
93,25 \\
\end{tabular} & 1241,90 & 168,32 & 15,31 & 51,18 & \begin{tabular}{|l|l|}
493,36 \\
\end{tabular} & 84,21 & \begin{tabular}{|l|l|}
103,44 \\
\end{tabular} & 490,86 \\
\hline
\end{tabular}




\begin{tabular}{|c|c|c|c|c|c|c|c|c|c|c|c|c|c|c|c|c|c|c|c|c|c|}
\hline TAXON & UTM & km2 & B101 & B102 & B1O3 & B104 & B105 & B106 & B107 & B108 & B109 & BIO10 & BIO11 & BIO12 & B1013 & BIO14 & B1O15 & BIO16 & BIO17 & BIO18 & B1019 \\
\hline Rana iberica & 29TNF39 & 100,00 & 142,67 & 85,68 & 43,22 & 3921,25 & 249,19 & 53,49 & 195,69 & 97,62 & 191,73 & 193,13 & 93,16 & 1252,93 & 169,96 & 15,41 & 51,40 & 497,59 & 84,71 & 104,50 & 496,90 \\
\hline Rana iberica & 29TNF40 & 100,00 & $\begin{array}{l}147,44 \\
\end{array}$ & 89,30 & \begin{tabular}{|l|l|}
43,83 \\
\end{tabular} & 3923,90 & 254,03 & 52,39 & 201,63 & 103,46 & $\begin{array}{l}195,05 \\
\end{array}$ & $\begin{array}{l}196,67 \\
\end{array}$ & 95,31 & 1079,18 & 149,73 & 12,26 & 52,06 & 434,59 & 72,22 & 83,50 & 423,05 \\
\hline Rana iberica & 29TNF41 & 101,00 & 142,38 & 89,36 & 43,37 & 3991,40 & 250,94 & 47,24 & 203,70 & 98,11 & 191,25 & $\begin{array}{l}193,01 \\
\end{array}$ & 90,04 & 1145,99 & 159,30 & 13,48 & 52,06 & 462,52 & 77,32 & 89,31 & 448,96 \\
\hline Rana iberica & 29TNF42 & 100,00 & 139,86 & 89,98 & 43,29 & 4039,26 & 249,99 & 44,34 & 205,65 & 95,41 & 189,66 & 191,42 & 87,24 & 1184,27 & 164,08 & 14,18 & 52,01 & 478,82 & 80,25 & 93,42 & 462,77 \\
\hline Rana iberica & 29TNF43 & 100,00 & 139,21 & \begin{tabular}{|c|}
90,71 \\
\end{tabular} & 43,30 & 4069,14 & 250,59 & 43,39 & 207,20 & 94,59 & 189,62 & \begin{tabular}{|l|}
191,44 \\
\end{tabular} & 86,51 & 1202,18 & 165,41 & 14,71 & 52,01 & 486,77 & 81,77 & 96,65 & 467,70 \\
\hline Rana iberica & 29TNF44 & 101,00 & 145,19 & 91,73 & 43,95 & 4024,80 & 255,19 & 48,47 & 206,73 & 100,89 & 194,71 & 196,60 & 92,76 & 1143,15 & 155,45 & 13,92 & 51,95 & 463,79 & 77,06 & 95,12 & 439,23 \\
\hline Rana iberica & 29TNF45 & 100,00 & 143,60 & 92,24 & 43,84 & 4070,49 & 255,27 & 46,97 & 208,31 & 98,94 & 194,03 & 195,90 & 91,10 & \begin{tabular}{|l|l|}
1174,73 \\
\end{tabular} & 159,85 & 14,55 & 51,68 & 475,51 & 79,77 & 98,42 & 452,40 \\
\hline Rana iberica & 29TNF46 & 101,00 & 139,99 & 92,04 & 43,58 & 4124,76 & 253,26 & 44,26 & 208,99 & 94,91 & \begin{tabular}{|l|}
191,59 \\
\end{tabular} & \begin{tabular}{|l|}
193,29 \\
\end{tabular} & 87,44 & 1229,65 & 167,21 & 15,41 & 51,34 & 495,06 & 84,11 & 101,93 & 478,38 \\
\hline Rana iberica & 29TNF47 & 100,00 & 139,14 & 91,24 & \begin{tabular}{|l|l|}
43,32 \\
\end{tabular} & 4147,14 & 252,84 & 44,35 & 208,48 & 93,89 & 191,25 & 192,76 & 86,61 & 1253,11 & 169,91 & 15,81 & 51,14 & 501,37 & 86,32 & 103,48 & 491,26 \\
\hline Rana iberica & 29TNF48 & 100,00 & 142,13 & 90,79 & \begin{tabular}{|l|l|}
43,15 \\
\end{tabular} & 4135,87 & 255,81 & \begin{tabular}{|l|l|}
47,93 \\
\end{tabular} & 207,87 & 96,82 & $\begin{array}{l}194,12 \\
\end{array}$ & $\begin{array}{l}195,50 \\
\end{array}$ & 89,72 & 1230,59 & 165,88 & 15,35 & 51,02 & 490,29 & 84,29 & 102,44 & 483,04 \\
\hline Rana iberica & 29TNF49 & 101,00 & 139,80 & 89,86 & 42,66 & 4175,54 & 254,55 & 46,33 & 208,22 & 94,19 & 192,55 & 193,76 & 87,19 & 1270,24 & 171,95 & 16,30 & 51,01 & 504,73 & 88,23 & 105,84 & 500,86 \\
\hline Rana iberica & 29TNF50 & 101,00 & 139,58 & 92,61 & \begin{tabular}{|l|l|}
42,17 \\
\end{tabular} & 4304,23 & 258,99 & 41,99 & 217,01 & 92,04 & 193,36 & 195,11 & 84,30 & 1181,11 & 167,89 & 13,43 & 52,76 & 475,58 & 79,54 & 87,48 & 468,92 \\
\hline Rana iberica & 29TNF51 & 101,00 & 130,68 & 90,91 & \begin{tabular}{|l|l|}
41,39 \\
\end{tabular} & 4383,84 & 251,56 & 34,36 & 217,20 & 83,11 & $\begin{array}{l}186,06 \\
\end{array}$ & $\begin{array}{l}187,79 \\
\end{array}$ & 75,27 & 1291,53 & 185,22 & 15,29 & 52,99 & 520,41 & 88,04 & 94,96 & 515,26 \\
\hline Rana iberica & 29TNF52 & 100,00 & 128,82 & 90,79 & 41,34 & 4388,35 & 249,56 & 32,56 & 217,00 & 80,65 & \begin{tabular}{|l|}
184,49 \\
\end{tabular} & 186,10 & 73,51 & 1319,05 & 188,56 & 15,87 & 52,82 & 531,86 & 90,28 & 98,23 & 525,29 \\
\hline Rana iberica & 29TNF53 & 101,00 & 139,12 & 93,95 & $\begin{array}{l}42,65 \\
\end{array}$ & 4304,01 & 258,06 & 40,55 & 217,52 & 91,75 & 192,97 & $\begin{array}{l}194,65 \\
\end{array}$ & 83,83 & 1206,82 & 168,46 & 14,26 & 52,14 & 487,19 & 81,32 & 94,06 & 473,32 \\
\hline Rana iberica & 29TNF54 & 101,00 & 143,24 & 94,76 & 43,14 & 4278,36 & 261,19 & 44,06 & 217,13 & 96,03 & 196,62 & 198,24 & 88,15 & 1165,91 & 160,49 & 13,81 & 51,97 & 470,68 & 78,26 & 93,43 & 453,65 \\
\hline Rana iberica & 29TNF55 & 100,00 & 140,87 & 95,08 & 42,94 & 4326,04 & 260,24 & 41,73 & 218,51 & 93,30 & 195,21 & 196,68 & 85,53 & 1202,49 & 165,11 & 14,53 & 51,85 & 484,56 & 81,28 & 96,84 & 468,84 \\
\hline Rana iberica & 29TNF56 & 101,00 & 139,94 & 95,13 & 42,95 & 4354,26 & 260,13 & 41,13 & 219,00 & 92,16 & $\begin{array}{l}194,79 \\
\end{array}$ & $\begin{array}{l}196,27 \\
\end{array}$ & 84,56 & 1221,82 & 166,99 & 14,97 & 51,64 & 490,56 & 83,17 & 98,86 & $\begin{array}{l}477,69 \\
\end{array}$ \\
\hline Rana iberica & 29TNF57 & 101,00 & 136,33 & 94,43 & 42,54 & 4395,62 & 257,89 & 38,43 & 219,46 & 88,25 & $\begin{array}{l}192,09 \\
\end{array}$ & \begin{tabular}{|l|}
193,38 \\
\end{tabular} & 80,76 & 1271,83 & 173,49 & 15,97 & 51,45 & 508,53 & 87,85 & 102,68 & 500,28 \\
\hline Rana iberica & 29TNF59 & 101,00 & 139,94 & 93,48 & 42,13 & 4393,00 & 261,73 & 42,64 & 219,10 & 91,63 & 195,73 & 196,85 & 84,56 & 1243,58 & 167,10 & 16,12 & 50,99 & 493,44 & 87,40 & 103,38 & 487,78 \\
\hline Rana iberica & 29TNF60 & 100,00 & 135,03 & 94,39 & \begin{tabular}{|l|l|}
41,03 \\
\end{tabular} & 4585,71 & 262,88 & 35,58 & 227,30 & 84,44 & 193,27 & 194,86 & 77,17 & 1237,64 & 179,24 & 13,79 & 53,37 & 498,24 & 82,88 & 88,33 & 495,79 \\
\hline Rana iberica & 29TNF61 & 100,00 & 135,59 & 94,12 & 41,30 & 4545,64 & 261,58 & 36,27 & 225,31 & 84,47 & 193,36 & $\begin{array}{l}194,77 \\
\end{array}$ & 78,12 & 1233,48 & 177,66 & 13,94 & 53,23 & 497,11 & 82,71 & 89,56 & 492,25 \\
\hline Rana iberica & 29TNF62 & 101,00 & 119,24 & 89,37 & $\begin{array}{l}39,56 \\
\end{array}$ & 4648,32 & 246,04 & 23,36 & 222,68 & 65,19 & 179,50 & 180,74 & 62,13 & 1421,55 & 207,84 & 17,24 & 53,69 & 573,99 & 97,86 & 101,46 & 572,57 \\
\hline Rana iberica & 29TNF63 & 100,00 & 137,18 & 96,37 & 41,92 & 4552,30 & 263,63 & 36,45 & 227,18 & 87,09 & $\begin{array}{l}194,87 \\
\end{array}$ & $\begin{array}{l}196,22 \\
\end{array}$ & 79,29 & 1227,80 & 174,69 & 14,04 & 52,72 & 494,00 & 82,05 & 92,22 & 486,62 \\
\hline Rana iberica & 29TNFG4 & 100,00 & 139,87 & 96,89 & 42,25 & 4533,38 & 265,28 & 38,81 & 226,47 & 89,13 & 197,19 & 198,52 & 82,13 & 1200,42 & 169,04 & 13,86 & 52,38 & 482,70 & 80,33 & 92,20 & 473,27 \\
\hline Rana iberica & 29TNF65 & 101,00 & 141,16 & 97,96 & 42,54 & 4548,34 & 267,19 & 39,49 & 227,70 & 90,78 & 198,67 & 199,98 & 83,18 & 1191,76 & 166,29 & 13,82 & 52,13 & 478,12 & 79,78 & 93,05 & 468,42 \\
\hline Rana iberica & 29TNF66 & 100,00 & 140,95 & 98,10 & 42,56 & 4 & 267,53 & \begin{tabular}{|l|}
39,38 \\
39
\end{tabular} & 228,15 & 90,49 & \begin{tabular}{|l|}
198,65 \\
\end{tabular} & \begin{tabular}{|l|}
199,92 \\
\end{tabular} & $\mid$ & 1198,66 & 165,92 & $\begin{array}{l}14,16 \\
14,16\end{array}$ & 51,88 & 479,50 & 80,88 & $\begin{array}{l}94,69 \\
9\end{array}$ & 470,84 \\
\hline Rana iberica & 29TNF67 & 100,00 & 139,03 & 97,85 & \begin{tabular}{|l|l|}
42,15 \\
\end{tabular} & 4589,24 & 266,73 & 37,67 & 229,06 & 88,29 & 197,36 & $\begin{array}{l}198,49 \\
\end{array}$ & 80,91 & 1225,60 & 168,33 & 14,86 & 51,72 & 488,61 & 83,77 & 97,47 & 482,14 \\
\hline Rana iberica & 29TNF68 & 101,00 & 137,90 & 97,23 & \begin{tabular}{|l|l|}
41,97 \\
\end{tabular} & 4606,79 & 266,17 & 37,05 & 229,12 & 87,12 & \begin{tabular}{|l|}
196,63 \\
\end{tabular} & $\begin{array}{l}197,66 \\
\end{array}$ & 79,77 & 1240,93 & 168,44 & 15,51 & 51,33 & 492,91 & 86,19 & \begin{tabular}{|l|l|}
99,84 \\
\end{tabular} & 488,19 \\
\hline Rana iberica & 29TNF69 & 100,00 & 135,31 & 96,15 & 41,53 & 4630,85 & 264,13 & 35,32 & 228,80 & 83,85 & 194,67 & 195,62 & 77,28 & 1267,98 & 170,11 & 16,66 & 50,99 & 502,08 & 90,32 & 103,32 & 498,82 \\
\hline Rana iberica & 29TNF70 & 100,00 & 131,12 & 93,82 & 39,84 & 4794,23 & 263,60 & 31,18 & 232,42 & 74,29 & 193,10 & 194,21 & 71,49 & 1276,03 & 187,97 & 13,92 & 54,17 & 515,51 & 84,71 & 88,05 & 514,91 \\
\hline Rana iberica & 29TNF71 & 101,00 & 138,55 & \begin{tabular}{|l|l|}
97,23 \\
9
\end{tabular} & 41,04 & 4748,50 & 270,65 & \begin{tabular}{|l|}
36,33 \\
3
\end{tabular} & \begin{tabular}{|l|}
$234,32,3$ \\
\end{tabular} & \begin{tabular}{|l|l|}
84,96 \\
\end{tabular} & \begin{tabular}{|l|}
199,28 \\
\end{tabular} & \begin{tabular}{|l|}
200,42 \\
\end{tabular} & 78,59 & $\begin{array}{l}11195,33 \\
\end{array}$ & \begin{tabular}{|l|}
173,64 \\
\end{tabular} & $\mid$ & 53,50 & 480,83 & $\begin{array}{l}48,99 \\
78,9\end{array}$ & $\begin{array}{l}85,21 \\
85,\end{array}$ & 478,45 \\
\hline Rana iberica & 29TNF72 & 100,00 & 124,75 & 93,12 & \begin{tabular}{|l|l|}
39,79 \\
\end{tabular} & 4811,33 & 256,79 & 25,56 & 231,23 & 67,57 & 187,14 & 188,20 & 65,25 & 1354,86 & 199,64 & 15,47 & 54,07 & 547,42 & 91,22 & 94,88 & 546,90 \\
\hline Rana iberica & 29TNF73 & 100,00 & 125,97 & 94,19 & 40,16 & 4798,34 & 257,82 & 26,19 & 231,62 & 69,94 & 188,03 & $\begin{array}{l}189,07 \\
\end{array}$ & 66,37 & 1340,38 & 195,83 & 15,66 & 53,65 & 540,51 & 90,73 & 95,98 & 538,99 \\
\hline Rana iberica & 29TNF74 & 101,00 & 128,99 & 95,57 & 40,63 & 4783,60 & 260,61 & 28,37 & 232,24 & 72,85 & 190,58 & $\begin{array}{l}191,63 \\
\end{array}$ & 69,36 & 1309,76 & 189,73 & 15,35 & 53,31 & 527,26 & 88,82 & 95,55 & 524,72 \\
\hline Rana iberica & 29TNF75 & 100,00 & 137,44 & 99,71 & 41,73 & 4775,34 & 270,14 & 34,08 & 236,05 & 82,59 & 198,39 & 199,50 & 77,09 & 1223,22 & 174,59 & 13,90 & 52,80 & 489,74 & 81,78 & 91,80 & 486,31 \\
\hline 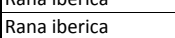 & 29TNF76 & 101,00 & 141,79 & 100,39 & 年 41,196 & 4748,21 & 274,06 & \begin{tabular}{|l|l|}
37,90 \\
37,
\end{tabular} & \begin{tabular}{|l|}
236,17 \\
\end{tabular} & 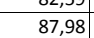 & \begin{tabular}{|l|}
202,21 \\
\end{tabular} & \begin{tabular}{|l|}
203,32 \\
\end{tabular} & 81,53 & \begin{tabular}{|l|l|l|l|l|}
1172,75 \\
\end{tabular} & \begin{tabular}{|l|}
164,56 \\
146
\end{tabular} & $\mid$ & \begin{tabular}{|l|l|}
52,24 \\
\end{tabular} & $\begin{array}{l}40,14 \\
467,99\end{array}$ & $\begin{array}{l}1,1,10 \\
78,52\end{array}$ & $\begin{array}{l}1,00 \\
90,37\end{array}$ & $\begin{array}{l}400,31 \\
462,94\end{array}$ \\
\hline Rana iberica & 29TNF77 & 100,00 & 139,96 & 100,63 & 41,82 & 4786,69 & 273,79 & 35,96 & 237,83 & 85,58 & 201,14 & 201,93 & 79,40 & 1195,50 & 166,38 & 14,04 & 52,04 & 475,06 & 81,10 & 92,96 & 472,06 \\
\hline Rana iberica & 29TNF78 & 101,00 & 126,95 & 97,32 & 40,78 & 4844,60 & 261,42 & 25,75 & 235,68 & 68,04 & 189,60 & $\begin{array}{l}190,52 \\
\end{array}$ & 66,83 & 1333,31 & 185,94 & 17,30 & 52,04 & 531,44 & 94,53 & 103,38 & 531,32 \\
\hline Rana iberica & 29TNF79 & 101,00 & 124,43 & 95,81 & 40,47 & 4841,80 & 258,19 & 24,30 & 233,89 & 65,58 & 187,19 & 188,09 & 64,62 & 1349,39 & 185,11 & 18,55 & 51,51 & 536,28 & 98,47 & 107,09 & 536,16 \\
\hline Rana iberica & 29TNF80 & 101,00 & 137,26 & 97,59 & 39,5 & 4966,71 & 275,12 & 33,90 & 241,22 & 75,65 & 201,18 & 202,29 & 75,13 & 1195,95 & 176,73 & 12,38 & 54,37 & 482,82 & 78,28 & 81,81 & 482,81 \\
\hline Rana iberica & 29TNF81 & 101,00 & 138,58 & $\begin{array}{l}98,97 \\
\end{array}$ & 40,41 & 4957,04 & 276,29 & \begin{tabular}{|l|l|}
34,33 \\
\end{tabular} & \begin{tabular}{|l|}
241,95 \\
2425
\end{tabular} & 78,33 & 202,15 & 203,23 & 76,25 & 1184,88 & $\begin{array}{l}174,47 \\
\end{array}$ & 12,24 & 54,20 & 477,17 & 77,25 & 82,20 & 477,00 \\
\hline Rana iberica & 29TNF82 & 100,00 & 133,58 & 98,23 & 40,21 & 4971,25 & 271,19 & 30,14 & 241,06 & 73,00 & \begin{tabular}{|l|}
197,70 \\
\end{tabular} & $\begin{array}{l}198,66 \\
\end{array}$ & 71,47 & 1244,51 & 184,08 & 13,26 & 54,36 & 502,42 & 81,71 & 86,36 & 502,12 \\
\hline Rana iberica & 29TNF83 & 101,00 & 109,14 & 87,77 & 37,62 & 4975,93 & 242,62 & 12,70 & 229,92 & 49,47 & 175,17 & 175,58 & 49,22 & 1493,52 & 222,19 & 18,53 & 54,42 & 606,03 & 102,49 & 103,59 & 606,01 \\
\hline Rana iberica & 29TNF84 & 101,00 & 118,90 & 93,61 & 39,1 & 4982,55 & 254,88 & 19,09 & 235,79 & 58,28 & 184,21 & 184,84 & 57,85 & \begin{tabular}{|l|l|}
1397,56 \\
\end{tabular} & 206,45 & 16,64 & 54,06 & 565,62 & 95,33 & 98,47 & 565,51 \\
\hline Rana iberica & 29TNF85 & 100,00 & 136,01 & \begin{tabular}{|c|c|}
101,39 \\
\end{tabular} & $\begin{array}{l}41, \\
41,\end{array}$ & 4 & 274,28 & 30,99 & 243,29 & 75,89 & \begin{tabular}{|l|l|l|l|}
199,76 \\
\end{tabular} & \begin{tabular}{|l|}
200,67 \\
\end{tabular} & 73,51 & 1222,05 & \begin{tabular}{|l|}
177,54 \\
\end{tabular} & $\begin{array}{l}13,546 \\
13\end{array}$ & $\begin{array}{l}4,30 \\
53,63\end{array}$ & 490,02 & 81,16 & 89,01 & 489,57 \\
\hline Rana iberica & 29TNF86 & 101,00 & 125,67 & 98,43 & 40,38 & 4998,73 & 264,11 & 23,07 & 241,04 & 64,83 & 190,54 & \begin{tabular}{|l|}
191,36 \\
\end{tabular} & 63,74 & 1325,58 & 192,39 & $15, \mathrm{c}$ & 53,57 & 533,46 & 91,11 & 96,93 & 533,22 \\
\hline Rana iberica & 29TNF87 & 101,00 & 135,01 & \begin{tabular}{|l|}
101,65 \\
\end{tabular} & 41,07 & 4987,46 & 274,44 & 29,83 & 244,61 & 74,73 & 199,17 & $\begin{array}{l}199,92 \\
\end{array}$ & 72.50 & 1223,35 & 174,13 & 14,38 & 52.84 & 488,05 & 83,36 & 92.32 & 487,44 \\
\hline Rana iberica & 29TNF88 & 99,00 & 141,71 & 103,14 & 41,42 & 4974,24 & 281,45 & 35,06 & 246,39 & 83,10 & 205,58 & 206,22 & 78,92 & 1144,18 & 158,88 & 13,41 & 52,08 & 452,19 & 78,01 & 89,11 & 451,23 \\
\hline Rana iberica & 29TNF89 & 101,00 & 138,03 & 102,06 & 40,5 & 4999,15 & 277,95 & 31,91 & 246,04 & 78,21 & 202,41 & 202,92 & 75,17 & 1176,14 & 161,05 & 14,66 & 51,68 & 463,52 & 82,57 & 92,81 & 463,14 \\
\hline Rana iberica & 29TNF90 & $\begin{array}{l}100,00 \\
100\end{array}$ & $\begin{array}{l}130,05 \\
135,74\end{array}$ & $\begin{array}{r}01,00 \\
97,24\end{array}$ & 39 & $\begin{array}{l}459,140 \\
5140,79\end{array}$ & 277,09 & \begin{tabular}{|l|l|l|}
31,58 \\
3
\end{tabular} & \begin{tabular}{|l|}
245,5145 \\
245
\end{tabular} & 71,87 & 202,41 & 203,33 & 71,87 & 1192,29 & 178,24 & 11,99 & 54,96 & 483,60 & 77,32 & 79,46 & 483,60 \\
\hline Rana iberica & 29TNF91 & 100,00 & 132,75 & 97,32 & 39,23 & 5137,78 & 273,84 & 28,79 & 245,06 & 68,99 & 199,50 & 200,32 & 68,99 & 1228,40 & \begin{tabular}{|l|}
184,01 \\
\end{tabular} & 12,60 & 55,01 & 498,40 & 79,94 & 82,35 & 498,40 \\
\hline Rana iberica & 29TNF92 & 101.00 & 126,83 & 96,14 & 39,03 & 5143,95 & 267,40 & 23,92 & 243,48 & 63,31 & $\mid$\begin{tabular}{|c|}
193,92 \\
\end{tabular} & \begin{tabular}{|l|}
194,57 \\
\end{tabular} & 63,31 & 1295,64 & 194,83 & $\mid 13,75$ & 55,18 & 526,94 & 85,17 & 87,05 & 526,94 \\
\hline Rana iberica & 29TNF93 & 100,00 & 112,22 & 89,85 & 37,50 & 5123,48 & 249,76 & 13,62 & 236,13 & 50,27 & 180,26 & 180,45 & 50,27 & 1440,64 & 216,60 & 16,93 & 55,02 & 587,21 & 97,41 & 97,51 & 587,21 \\
\hline Rana iberica & 29TNF94 & 100,00 & 117,18 & 94,18 & 38,6 & 5143,77 & 257,13 & 16,22 & 240,91 & 54,41 & 184,94 & 185 & 54,41 & 1388,86 & 207,75 & 16,25 & 54,85 & 564,88 & 94,28 & 95,58 & 56 \\
\hline $\begin{array}{l}\mid l a l d \\
\text { Rana iberica }\end{array}$ & 29TNF95 & \begin{tabular}{|l|}
101,00 \\
\end{tabular} & $\begin{array}{l}11,1,10 \\
138,40\end{array}$ & $\begin{array}{r}30,10 \\
103,35\end{array}$ & $\begin{array}{l}30,03 \\
40,82\end{array}$ & 5122,49 & 281,31 & $\begin{array}{l}0,2< \\
31,16\end{array}$ & $\mid$ & 75,40 & 204,41 & 205,04 & 74,01 & 1168,52 & 171,57 & 12,46 & 54,07 & 469,70 & 76,62 & 82,85 & 469,33 \\
\hline Rana iberica & 29TNF96 & 100,00 & 122,41 & \begin{tabular}{|l|l|}
99,04 \\
\end{tabular} & 39,60 & 5160,22 & 265,41 & 18,77 & $\mid 246,64$ & 58,88 & \begin{tabular}{|l|}
189,82 \\
\end{tabular} & \begin{tabular}{|c|}
190,40 \\
\end{tabular} & 58,88 & $\mid 1327,04$ & \begin{tabular}{|c|}
195,32 \\
\end{tabular} & $\mid$\begin{tabular}{|l|l|}
16,05 \\
\end{tabular} & 54,19 & 536,19 & 91,36 & 95,12 & 536,19 \\
\hline Rana iberica & 29TNF97 & 100,00 & 115,88 & 95,90 & 39,03 & 5136,17 & 257,03 & 14,56 & 242,47 & 53,35 & 183,44 & 183,91 & 53,35 & 1372,61 & 199,44 & 17,95 & 53,49 & 553,49 & 98,06 & 101,01 & 553,49 \\
\hline Rana iberica & 29TNF98 & 101,00 & 121,02 & 98,41 & 39,61 & 5139,73 & 263,22 & 17,96 & 245,26 & 57,91 & 188,29 & 188 & 57,91 & \begin{tabular}{|l|l|}
1316,53 \\
\end{tabular} & 188,74 & 17,26 & 53,01 & 528,34 & 94,25 & 98,83 & 528,34 \\
\hline Rana iberica & 29TNF99 & 100,00 & 135,05 & \begin{tabular}{|l|}
103,43 \\
\end{tabular} & 40,67 & 5161,06 & 279,51 & 27,52 & 251,99 & 71,37 & 201,96 & 202,26 & 70,61 & 1168,49 & 163,49 & 14,49 & 52,32 & 463,38 & 81,88 & 88,21 & 463,32 \\
\hline
\end{tabular}




\begin{tabular}{|c|c|c|c|c|c|c|c|c|c|c|c|c|c|c|c|c|c|c|c|c|c|}
\hline TAXON & UTM & $\mathrm{km2}$ & B101 & B1O2 & $\mathrm{BIO3}$ & B104 & B105 & B106 & B107 & B108 & B109 & 81010 & B1011 & BIO12 & BIO13 & BIO14 & B1015 & BIO16 & BIO17 & BIO18 & B1019 \\
\hline Rana iberica & 29TNG11 & 68,00 & 142,97 & 75,17 & 42,97 & 3566,09 & 236,70 & 63,82 & 172,88 & 98,36 & 187,37 & 188,68 & 98,36 & 1288,24 & 180,59 & 15,17 & 52,45 & 518,55 & 83,56 & 108,22 & 518,55 \\
\hline Rana iberica & 29TNG12 & 87,00 & 137,29 & 73,96 & $\begin{array}{l}42,06 \\
\end{array}$ & 3627,14 & 232,43 & 58,62 & 173,81 & 92,83 & 182,87 & 184,29 & 92,14 & 1378,35 & 191,82 & \begin{tabular}{|l|l|}
19,18 \\
\end{tabular} & 51,61 & 553,01 & 96,64 & 118,57 & 552,97 \\
\hline Rana iberica & 29TNG13 & 86,00 & 140,49 & 72,13 & 41,64 & 3603,62 & 234,13 & 62,90 & 171,23 & 100,04 & $\begin{array}{l}185,70 \\
\end{array}$ & $\begin{array}{l}187,01 \\
\end{array}$ & 95,30 & 1358,91 & $\begin{array}{l}189,08 \\
\end{array}$ & 19,68 & 51,07 & 544,43 & 96,92 & 119,11 & 541,84 \\
\hline Rana iberica & 29TNG14 & 99,00 & 141,35 & 69,97 & 41,01 & 3592,14 & 233,55 & 65,01 & 168,54 & 103,58 & 186,44 & \begin{tabular}{|l|}
187,73 \\
\end{tabular} & 96,16 & 1368,59 & 193,12 & 21,54 & 50,70 & 549,61 & 101,51 & 122,99 & 542,04 \\
\hline Rana iberica & 29TNG15 & 101,00 & 132,16 & 69,72 & \begin{tabular}{|l|l|}
40,14 \\
\end{tabular} & 3685,33 & 227,32 & 55,75 & 171,56 & 93,81 & 178,93 & 180,33 & 86,39 & 1509,91 & 227,25 & 27,33 & 50,50 & 609,48 & 119,62 & 138,03 & 604,19 \\
\hline Rana iberica & 29TNG16 & 63,00 & 144,91 & 65,38 & 39,81 & 3554,55 & 233,48 & 71,05 & 162,43 & 107,66 & 189,68 & 190,80 & 99,84 & 1361,27 & 195,80 & 24,69 & 49,54 & 549,03 & 108,17 & 128,84 & 528,42 \\
\hline Rana iberica & 29TNG17 & 33,00 & 149,14 & 62,22 & \begin{tabular}{|l|l|}
38,97 \\
\end{tabular} & 3510,00 & 234,61 & 76,97 & 157,64 & 112,28 & 193,11 & 194,33 & 104,31 & 1294,33 & 179,89 & \begin{tabular}{|l|}
25,03 \\
\end{tabular} & 48,31 & 519,61 & 107,44 & 128,50 & 486,56 \\
\hline Rana iberica & 29TNG18 & 45,00 & 144,43 & 61,74 & 38,37 & 3541,20 & 231,42 & 73,05 & \begin{tabular}{|l|}
158,37 \\
\end{tabular} & 107,44 & \begin{tabular}{|l|l}
189,24 \\
\end{tabular} & \begin{tabular}{|l|}
190,36 \\
\end{tabular} & \begin{tabular}{|c|}
99,57 \\
\end{tabular} & $\begin{array}{l}1364,63 \\
\end{array}$ & 199,30 & 28,12 & 48,48 & 549,64 & 116,34 & 136,83 & 520,34 \\
\hline Rana iberica & 29TNG19 & 57,00 & 145,12 & 59,99 & \begin{tabular}{|l|l|}
37,97 \\
\end{tabular} & 3519,84 & 230,93 & 75,11 & 155,82 & 108,43 & 189,61 & 191,00 & 100,84 & $\mid 1316,97$ & 192,33 & 28,91 & 47,32 & 528,09 & 117,50 & 139,10 & 493,80 \\
\hline Rana iberica & 29TNG20 & 101,00 & 138,63 & 80,62 & 42,90 & 3774,84 & 239,93 & 54,36 & $\begin{array}{l}185,56 \\
\end{array}$ & 91,40 & $\begin{array}{l}185,97 \\
\end{array}$ & $\begin{array}{l}187,32 \\
\end{array}$ & 91,40 & 1326,01 & 182,29 & 16,74 & 51,84 & 531,55 & 89,82 & 110,74 & 531,55 \\
\hline Rana iberica & 29TNG21 & 100,00 & 140,46 & 79,05 & 42,58 & 3766,11 & 241,19 & 57,32 & 183,88 & 93,37 & 187,78 & 188,95 & 93,37 & 1319,70 & 182,44 & 16,80 & 51,79 & 528,80 & 89,38 & 111,32 & 528,80 \\
\hline Rana iberica & 29TNG22 & 101,00 & 137,87 & 77,71 & 41,84 & 3802,67 & 239,14 & 55,51 & 183,63 & 92,15 & 185,93 & 187,09 & 90,40 & 1364,18 & 189,74 & 19,11 & 51,39 & 545,54 & 96,55 & 117,25 & 545,41 \\
\hline Rana iberica & 29TNG23 & 100,00 & 133,12 & 76,64 & \begin{tabular}{|l|l|}
41,04 \\
\end{tabular} & 3855,64 & 235,53 & 51,17 & 184,36 & 88,49 & 182,12 & 183,32 & 85,21 & 1450,79 & 209,92 & 22,81 & 50,88 & 581,76 & 108,37 & 126,68 & 581,25 \\
\hline Rana iberica & 29TNG24 & 99,00 & 142,72 & 73,68 & $\begin{array}{ll}40,92 \\
\end{array}$ & 3762,67 & 240,82 & 62,56 & 178,27 & 101,27 & $\begin{array}{l}190,16 \\
\end{array}$ & 191,21 & 95,21 & 1360,54 & 195,29 & 21,41 & 50,56 & 545,50 & 101,24 & 121,49 & 538,65 \\
\hline Rana iberica & 29TNG25 & 101,00 & 142,44 & 71,61 & 40,21 & 3755,29 & 239,25 & 63,49 & 175,77 & $\begin{array}{l}101,68 \\
\end{array}$ & 189,94 & $\begin{array}{l}190,94 \\
\end{array}$ & 95,01 & 1394,60 & 206,60 & 23,94 & 50,39 & 561,40 & 107,55 & 126,99 & 552,19 \\
\hline Rana iberica & 29TNG26 & 100,00 & 137,42 & 70,38 & 39,69 & 3792,18 & 234,78 & 59,26 & 175,52 & 95,03 & 185,76 & 186,73 & 89,89 & 1494,19 & 233,27 & 28,30 & 50,67 & 605,16 & 120,03 & 137,69 & 598,49 \\
\hline Rana iberica & 29TNG27 & 80,00 & 142,23 & 66,90 & 39,02 & 3729,91 & 235,55 & 66,17 & 169,38 & 100,94 & 189,67 & 190,59 & 95,20 & 1456,53 & 226,75 & 28,89 & 50,29 & 590,88 & 119,23 & 137,56 & 576,63 \\
\hline Rana iberica & 29TNG28 & 86,00 & 139,17 & 65,44 & 38,37 & 3735,36 & 232,63 & 64,36 & 168,28 & 99,83 & \begin{tabular}{|l|}
186,87 \\
\end{tabular} & 187,97 & 92,44 & 1463,59 & 227,46 & 31,15 & 49,23 & 589,78 & 125,44 & 144,09 & 572,35 \\
\hline Rana iberica & 29TNG29 & 72,00 & 142,90 & 62,57 & 37,89 & 3707,49 & 233,27 & 70,12 & 163,15 & 103,57 & 190,24 & 191,12 & 96,35 & \begin{tabular}{|l|l|}
1394,43 \\
\end{tabular} & 212,13 & 30,94 & 48,26 & 558,48 & 122,62 & 142,96 & 533,75 \\
\hline Rana iberica & 29TNG30 & 100,00 & 142,44 & 84,53 & 42,87 & 3938,87 & 249,38 & 54,16 & 195,22 & 95,44 & 191,86 & 193,10 & 92,81 & 1270,66 & 172,69 & 15,94 & 51,41 & 505,15 & 86,42 & 106,61 & 504,88 \\
\hline Rana iberica & 29TNG31 & 101,00 & 138,13 & 83,65 & 42,12 & 3997,59 & 246,81 & 50,50 & 196,31 & 90,32 & 188,70 & 189,82 & 88,05 & 1338,81 & 185,48 & \begin{tabular}{|l|l|}
18,15 \\
\end{tabular} & 51,15 & 533,35 & 94,35 & 113,34 & 533,25 \\
\hline Rana iberica & 29TNG32 & 101,00 & 142,57 & 82,02 & 41,84 & 3972,07 & 249,88 & 55,81 & \begin{tabular}{|l|}
194,06 \\
\end{tabular} & $\begin{array}{l}0,75 \\
98,75\end{array}$ & \begin{tabular}{|l|l|}
192,74 \\
\end{tabular} & \begin{tabular}{|l|}
193,71 \\
\end{tabular} & 92,50 & \begin{tabular}{|c|}
1300,19 \\
\end{tabular} & $\begin{array}{l}180,92 \\
\end{array}$ & 17,88 & 51,01 & 516,76 & 92,01 & 111,91 & 515,34 \\
\hline Rana iberica & 29TNG33 & 100,00 & 128,02 & 80,92 & \begin{tabular}{|l|l|}
40,79 \\
\end{tabular} & 4087,55 & 238,12 & 41,92 & 196,20 & 79,68 & \begin{tabular}{|l|}
180,45 \\
\end{tabular} & \begin{tabular}{|c|}
181,48 \\
\end{tabular} & 77,39 & 1483,19 & 217,87 & \begin{tabular}{|l|l|}
24,47 \\
\end{tabular} & 50,58 & 592,61 & 114,75 & 129,94 & 592,45 \\
\hline Rana iberica & 29TNG34 & 100,00 & 130,47 & 79,59 & 40,55 & 4068,19 & 239,44 & 45,08 & 194,36 & 84,61 & 182,58 & 183,56 & 79,95 & 1482,56 & 223,25 & 25,55 & 50,53 & 593,07 & 116,73 & 132,15 & 591,82 \\
\hline Rana iberica & 29TNG35 & 100,00 & 145,15 & 76,03 & 40,07 & 3941,12 & 248,67 & 61,79 & 186,88 & 101,87 & 195,09 & 195,83 & 95,17 & 1342,05 & 200,47 & 22,86 & 50,10 & 537,04 & 104,42 & 122,88 & 526,61 \\
\hline Rana iberica & 29TNG36 & 101,00 & 144,76 & 73,61 & 39,76 & 3928,62 & 246,38 & 62,98 & 183,40 & 101,35 & 194,70 & 195,47 & 95,00 & 1380,58 & 213,07 & 25,50 & 50,08 & 554,99 & 110,69 & 128,51 & 543,54 \\
\hline Rana iberica & 29TNG37 & 100,00 & 139,44 & $\mid 72,37$ & 39,17 & 3952,22 & 241,01 & |58,61 & \begin{tabular}{|l|}
182,39 \\
\end{tabular} & \begin{tabular}{|}
95,37 \\
96
\end{tabular} & 190,05 & $\begin{array}{l}190,83 \\
\end{array}$ & 89,86 & 1472,17 & 236,44 & 29,55 & 50,39 & 593,97 & 122,06 & 138,70 & 586,24 \\
\hline Rana iberica & 29TNG38 & 88,00 & 139,79 & 70,11 & 38,73 & 3935,64 & 239,20 & 60,43 & 178,77 & 97,45 & 190,29 & \begin{tabular}{|l|}
191,03 \\
\end{tabular} & 90,49 & 1461,61 & 233,79 & \begin{tabular}{|l|l|}
31,05 \\
\end{tabular} & 49,66 & 586,56 & 124,93 & 141,71 & 575,20 \\
\hline Rana iberica & 29TNG39 & 101,00 & 136,77 & 68,86 & 38,12 & 3933,53 & 236,40 & 58,27 & \begin{tabular}{|l|}
178,13 \\
\end{tabular} & 94,66 & 187,42 & 188,34 & 87,94 & 1478,41 & 235,28 & \begin{tabular}{|l|}
33,27 \\
\end{tabular} & 48,80 & 590,26 & 130,99 & 148,84 & 576,22 \\
\hline Rana iberica & 29 TNG 40 & 101,00 & 145,85 & 88,48 & 42,53 & 4128,39 & 258,94 & 53,25 & 205,69 & 100,52 & 197,76 & 198,85 & 93,45 & 1208,74 & 163,53 & 15,25 & 50,98 & 478,58 & 83,25 & 102,33 & 474,61 \\
\hline Rana iberica & 29TNG41 & 100,00 & 138,67 & 87,77 & 41,79 & 4212,47 & 254,27 & 46,55 & 207,72 & 92,38 & 192,13 & 193,18 & 85,67 & 1304,64 & 181,44 & 18,13 & 50,77 & 517,18 & 94,26 & 111,32 & 514,42 \\
\hline Rana iberica & 29TNG42 & 100,00 & 137,73 & 86,50 & 4 & 42229,46 & 253,40 & \begin{tabular}{|l|}
46,41 \\
46,5
\end{tabular} & \begin{tabular}{|l|}
206,99 \\
\end{tabular} & \begin{tabular}{|l|}
90,97 \\
\end{tabular} & \begin{tabular}{|l|}
191,60 \\
\end{tabular} & \begin{tabular}{|l|}
192,52 \\
\end{tabular} & \begin{tabular}{|l|}
84,68 \\
\end{tabular} & \begin{tabular}{|l|l|}
1324,39 \\
\end{tabular} & \begin{tabular}{|l|}
187,27 \\
\end{tabular} & 19,51 & 50,38 & 524,80 & $\begin{array}{l}4,2,47 \\
8,4\end{array}$ & 114,94 & 521,03 \\
\hline Rana iberica & 29TNG43 & 101,00 & 137,51 & 85,64 & \begin{tabular}{|l|l|}
40,89 \\
\end{tabular} & 4235,56 & 253,34 & 46,66 & 206,68 & 91,15 & 191,53 & 192,29 & 84,30 & 1342,99 & 195,19 & 21,10 & 50,03 & 532,19 & 103,16 & 118,92 & 527,01 \\
\hline Rana iberica & 29TNG44 & 100,00 & 130,60 & 84,27 & 40,42 & 4270,75 & 246,88 & 40,75 & 206,14 & 84,49 & 185,44 & $\begin{array}{l}186,28 \\
\end{array}$ & 77,45 & 1431,34 & 214,47 & 24,88 & 49,83 & 567,90 & 115,32 & 129,11 & 563,75 \\
\hline Rana iberica & 29TNG45 & 101,00 & 142,30 & 82,14 & 40,13 & 4197,28 & 255,32 & 53,36 & 201,96 & 96,35 & 195,81 & 196,38 & 89,24 & 1323,49 & 199,84 & 23,13 & 49,47 & 524,75 & 106,82 & 122,21 & 513,46 \\
\hline Rana iberica & 29TNG46 & 101,00 & 143,29 & 80,28 & 39,91 & 4175,75 & 254,49 & 55,52 & 198,96 & 97,62 & 196,56 & 197,13 & 90,47 & 1332,85 & 205,65 & 24,82 & 49,20 & 528,98 & 110,47 & 125,52 & 515,79 \\
\hline 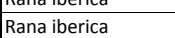 & 29TNG47 & 101,00 & $\begin{array}{l}14,20,40 \\
140,40\end{array}$ & 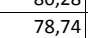 & 39,58 & $\begin{array}{l}4177,19 \\
4179,19\end{array}$ & 250,40 & |53,58 & \begin{tabular}{|l|}
196,820 \\
\end{tabular} & $\begin{array}{l}1,, 0<4 \\
94,83\end{array}$ & \begin{tabular}{|l|}
193,98 \\
\end{tabular} & \begin{tabular}{|l|}
194,52 \\
\end{tabular} & $\begin{array}{l}0,476 \\
87,86\end{array}$ & \begin{tabular}{|l|}
$133,01,06$ \\
1391,0
\end{tabular} & \begin{tabular}{|l|}
221,47 \\
\end{tabular} & $27,27,84$ & $\begin{array}{l}44,20 \\
49,40\end{array}$ & $\begin{array}{l}52,50,23 \\
553,23\end{array}$ & 118,47 & 132,59 & 542,12 \\
\hline Rana iberica & 29TNG48 & 100,00 & 128,16 & 78,41 & 39,08 & 4198,61 & 239,79 & 41,84 & $\begin{array}{l}197,95 \\
\end{array}$ & 83,04 & 182,58 & 183,64 & 76,66 & \begin{tabular}{|l|}
1502,07 \\
\end{tabular} & 239,28 & 32,79 & 48,85 & 595,05 & 133,86 & $\begin{array}{l}147,87 \\
\end{array}$ & 587,57 \\
\hline Rana iberica & 29TNG49 & 101,00 & 125,64 & 77,56 & 38,85 & 4165,73 & 237,61 & \begin{tabular}{|l|l|}
39,97 \\
\end{tabular} & $\begin{array}{l}197,64 \\
\end{array}$ & 81,13 & 179,86 & 181,09 & 75,07 & 1508,88 & 237,59 & 34,66 & 47,92 & 594,55 & 138,65 & 153,11 & 584,39 \\
\hline Rana iberica & 29TNG50 & 101,00 & 140,38 & 92,44 & 41,82 & 4400,09 & 262,18 & 43,75 & 218,44 & 91,96 & 196,36 & 197,28 & 84,86 & 1243,80 & 168,81 & 16,54 & 50,69 & 492,03 & 88,82 & 104,69 & 487,03 \\
\hline Rana iberica & 29TNG51 & 100,00 & 138,16 & 91,40 & 41, & 4425,39 & 260,50 & 42,19 & 218,31 & 89,59 & 194,64 & 195,49 & 82,54 & 1274,66 & 176,06 & 17 & 50,29 & 503,34 & 93,86 & 109,01 & 498,60 \\
\hline $\begin{array}{l}\text { Tadd Iterde } \\
\text { Rana iberica }\end{array}$ & 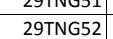 & 100,00 & $\begin{array}{l}130,10 \\
130,71\end{array}$ & $\begin{array}{l}1,40 \\
89,65\end{array}$ & $\begin{array}{l}41,41 \\
40,70\end{array}$ & $\begin{array}{l}4425,395 \\
4468,95\end{array}$ & $200,53,57$ & \begin{tabular}{|l|l|}
35,99 \\
35,99
\end{tabular} & \begin{tabular}{|l|}
217,51 \\
217,57
\end{tabular} & \begin{tabular}{|c|} 
\\
81,64 \\
81,64
\end{tabular} & \begin{tabular}{|l|}
188,204 \\
188,
\end{tabular} & \begin{tabular}{|l|}
188,95 \\
188,95
\end{tabular} & $\begin{array}{l}20,54 \\
75,02\end{array}$ & $\begin{array}{l}12 / 7,00 \\
1357,70\end{array}$ & \begin{tabular}{|l|l|l|l}
191,48 \\
\end{tabular} & $\begin{array}{l}21,98 \\
21,14\end{array}$ & $\begin{array}{l}0,29 \\
49,95\end{array}$ & 5355,88 & $\begin{array}{r}9,80 \\
104,88 \\
\end{array}$ & 1117,86 & $\begin{array}{l}495,00 \\
532,10\end{array}$ \\
\hline Rana iberica & 29TNG53 & 101,00 & 131,96 & 89,04 & 40,50 & 4465,45 & 254,88 & $\begin{array}{l}37,47 \\
\end{array}$ & 217,42 & 83,37 & 189,44 & \begin{tabular}{|l|}
190,19 \\
\end{tabular} & 76,41 & 1345,19 & 193,52 & 21,98 & 49,53 & 529,65 & 106,91 & 119,50 & 523,62 \\
\hline Rana iberica & 29TNG54 & 10100 & 107.50 & 82.47 & 38.62 & 446510 & 228,68 & 18.35 & 210.33 & 60.80 & 166.06 & 167.06 & 54.06 & 1555,27 & 221.33 & 30.16 & 48.53 & 611.15 & 134,21 & 142,65 & 60870 \\
\hline Rana iberica & 29TNG55 & 100,00 & 132,57 & 86,93 & 39,88 & 4446,63 & 254,36 & 39,24 & 215,13 & 84,11 & $\begin{array}{l}189,82 \\
\end{array}$ & $\begin{array}{l}190,56 \\
\end{array}$ & 77,19 & 1347,31 & 201,06 & 24,8 & 48,65 & 28,58 & 114,33 & 126,30 & 517,21 \\
\hline Rana iberica & 29TNG56 & 101,00 & 134,95 & 86,64 & 39,84 & 4443,65 & 256, & 41,37 & 214,96 & 86,19 & \begin{tabular}{|l|}
192,04 \\
\end{tabular} & $\begin{array}{l}192,69 \\
\end{array}$ & 79,37 & 1329,41 & 202,14 & 25,7 & 48,28 & 520,27 & 115,85 & 126,77 & 506,14 \\
\hline Rana iberica & 29TNG57 & 100,00 & 121,78 & 83,80 & 39,37 & 4411,63 & 241,26 & 30,73 & 210,53 & 74,30 & 179,22 & 180,18 & 67,99 & 1462,85 & 223,46 & 30,9 & 47,97 & 573,14 & 131,38 & 142,73 & 565,07 \\
\hline Rana iberica & 29TNG58 & 99,00 & 113,23 & 81,48 & 38,81 & 4356,27 & 232,03 & 24,34 & 207,69 & 66,96 & $\begin{array}{l}170,34 \\
\end{array}$ & \begin{tabular}{|l|l|l|l|l}
171,53 \\
\end{tabular} & 61,18 & 1517,29 & 227,58 & 34,32 & 47,03 & 591,85 & 141,42 & 152,52 & 583,34 \\
\hline Rana iberica & 29TNG59 & 100,00 & 113,55 & 80,92 & 38,72 & 4310,81 & 231,79 & 25,08 & 206,71 & 67,71 & 170,02 & 171,45 & 62,24 & 1509,61 & 226,36 & 35,67 & 46,38 & 586,61 & 144,05 & 155,97 & 575,97 \\
\hline Rana iberica & 29TNG61 & 101,00 & 129,52 & 92,96 & 40,52 & 4652,63 & 257,84 & 31,49 & 226,34 & 76,71 & 189,55 & 190,32 & 71,80 & 1320,79 & 179,13 & 19,68 & 50,09 & 520,45 & 100,31 & 111,37 & 517,43 \\
\hline Rana iberica & \begin{tabular}{|l|l}
$29 T N G 62$ \\
\end{tabular} & \begin{tabular}{|l|}
101,00 \\
100
\end{tabular} & $\begin{array}{l}12,32 \\
115,32\end{array}$ & \begin{tabular}{|c|}
32,90 \\
87,95
\end{tabular} & $\begin{array}{l}40,22 \\
39,30\end{array}$ & $\begin{array}{l}402,005 \\
4647,57\end{array}$ & 241 & $\begin{array}{l}\frac{31,49}{21,15} \\
\end{array}$ & $\mid$\begin{tabular}{|l|}
$220,70,7$ \\
\end{tabular} & 62,37 & $\begin{array}{l}176,03 \\
\end{array}$ & 176,82 & 58,84 & 1450,71 & 198,80 & 24,52 & 49,68 & 571,37 & 116,97 & 125,53 & 570,44 \\
\hline Rana iberica & 29TNG63 & 100,00 & 123,83 & 90,23 & 39,73 & 4660,90 & 251,54 & 27,50 & 224,04 & 72,50 & 184,36 & 185,01 & 66,47 & 1369,05 & 192,82 & 23,31 & 49,05 & 536,57 & 111,71 & 121,10 & 531,94 \\
\hline Rana iberica & 29TNG64 & 101.00 & 110,77 & 85,49 & $38,75 \mid$ & 4618.93 & 235,92 & 18,21 & 217,71 & 61,90 & \begin{tabular}{|l|l|}
171,38 \\
\end{tabular} & $\mid 172,25$ & 55,21 & 1481,37 & 208,95 & 28,14 & 48,52 & 579,94 & 126,96 & 135,08 & 577,66 \\
\hline Rana iberica & 29TNG65 & 100,00 & 104,96 & 83,10 & 38,21 & 4573,78 & 228,97 & 14,35 & 214,62 & 57,06 & 165,27 & 166,23 & 50,52 & 1523,45 & 215,64 & 31,05 & 47,71 & 594,87 & 135,51 & 143,03 & 591,62 \\
\hline Rana iberica & 29TNG66 & 100,00 & 132,97 & $90, \mathrm{C}$ & 39,7 & 4650,79 & 259,97 & 35,22 & 224,75 & 81,72 & 193,13 & 193,56 & 75,17 & 1269,36 & 188,81 & 24,75 & 47,50 & 491,39 & 112,81 & 122,05 & 47 \\
\hline Rana iberica & 29TNG67 & $\begin{array}{l}101,00 \\
\end{array}$ & 131,55 & 88,09 & 39,38 & 4616,44 & 255,96 & 34,71 & 221,25 & 80,76 & $\begin{array}{l}191,40 \\
\end{array}$ & $\begin{array}{l}191,92 \\
\end{array}$ & 74,53 & 1285,02 & \begin{tabular}{|l|}
193,17 \\
\end{tabular} & 26,55 & 47,19 & 496,80 & 116,35 & 126,10 & 482,80 \\
\hline Rana iberica & 29TNG68 & 101,00 & 125,16 & 85,59 & 38,95 & 4545,41 & 247,24 & 30,58 & 216,66 & 75,50 & \begin{tabular}{|l|}
184,41 \\
\end{tabular} & 185,20 & 69,87 & 1345,60 & 201,85 & 29,79 & 46,67 & 519,66 & 125,28 & 137,12 & 507,16 \\
\hline Rana iberica & 29TNG70 & 100,00 & 125,96 & 95,39 & 40,34 & 4836,55 & 259,46 & 25,65 & 233,80 & 69,04 & 188,61 & 189,35 & 66,06 & 1323,33 & $\begin{array}{l}177,65 \\
\end{array}$ & $\mid 18,87$ & 50,92 & 523,00 & 98,51 & 107,73 & 522,32 \\
\hline Rana iberica & 29TNG71 & 101,00 & 123,47 & 93,49 & 39,85 & 4824,53 & 255,95 & 24,26 & 231,69 & 67,47 & 186 & 186 & 64 & 1335,23 & 178,47 & 20,38 & 50 & 525,75 & 102,88 & 111,40 & 524 \\
\hline Rana iberica & 29TNG72 & 100,00 & 97,65 & 83,12 & 37,48 & 4745,83 & 225,53 & 6,75 & 218,78 & 42,20 & 160,59 & 161,38 & 41,58 & 1545,54 & 206,22 & 28,51 & 49,13 & 607,76 & 130,75 & 134,74 & 607,72 \\
\hline
\end{tabular}




\begin{tabular}{|c|c|c|c|c|c|c|c|c|c|c|c|c|c|c|c|c|c|c|c|c|c|}
\hline TAXON & UTM & km2 & B101 & B102 & B1O3 & B104 & B105 & B106 & B107 & B108 & B109 & B1010 & BIO11 & BIO12 & B1013 & BIO14 & B1O15 & B1016 & $\begin{array}{l}1017 \\
10\end{array}$ & B1018 & B1019 \\
\hline Rana iberica & 29TNG73 & 100,00 & 115,12 & 89,06 & 38,83 & 4792,36 & 245,33 & 18,81 & 226,53 & 61,56 & 177,89 & 178,53 & 57,06 & 1389,96 & 190,55 & 24,75 & 48,83 & 543,13 & $\begin{array}{r}116,06 \\
\end{array}$ & $\begin{array}{r}122,88 \\
\end{array}$ & 540,40 \\
\hline Rana iberica & 29TNG74 & 100,00 & 118,22 & 89,85 & 39,04 & 4792,53 & 248,44 & 20,96 & 227,47 & 66,63 & $\begin{array}{l}181,05 \\
\end{array}$ & $\begin{array}{l}181,57 \\
\end{array}$ & 60,02 & 1355,98 & 189,64 & 24,99 & 48,16 & \begin{tabular}{|l|}
527,67 \\
\end{tabular} & 115,35 & 123,03 & 523,51 \\
\hline Rana iberica & 29TNG75 & 100,00 & 95,31 & 81,82 & 37,30 & 4670,94 & 221,61 & 5,29 & 216,32 & 47,01 & 157,29 & 158,27 & 40,48 & 1539,21 & 211,15 & 32,58 & 47,17 & 598,54 & 140,23 & 145,68 & 596,07 \\
\hline Rana iberica & 29TNG76 & 101,00 & 119,59 & 88,52 & 38,71 & 4750,27 & 247,99 & 22,54 & 225,45 & 68,06 & 181,81 & 182,36 & 61,94 & 1331,79 & \begin{tabular}{|c|}
191,78 \\
\end{tabular} & 27,01 & 47,14 & 514,88 & 119,36 & 127,88 & 506,72 \\
\hline Rana iberica & 29TNG77 & 101,00 & 133,18 & 91,21 & 39,10 & 4819,46 & 261,81 & 31,66 & 230,15 & 79,49 & 195,82 & $\begin{array}{l}196,10 \\
\end{array}$ & 73,70 & 1193,18 & 176,81 & 24,51 & 46,56 & 456,50 & 108,58 & 116,42 & 442,62 \\
\hline Rana iberica & 29TNG78 & 100,00 & 139,06 & 89,04 & 38,86 & 4789,06 & 264,12 & 37,72 & 226,40 & 85,44 & 201,18 & 201,45 & 79,82 & 1126,93 & 167,65 & 24,12 & 45,96 & 428,39 & $\begin{array}{l}104,06 \\
\end{array}$ & 112,19 & 412,40 \\
\hline Rana iberica & 29TNG79 & 101,00 & 133,19 & 87,50 & 39,00 & 4661,57 & 256,21 & 34,45 & 221,75 & 81,21 & 193,93 & 194,44 & 76,28 & \begin{tabular}{|l|l|}
1197,87 \\
\end{tabular} & 178,93 & 27,37 & 45,64 & 455,84 & 113,58 & 125,92 & 441,24 \\
\hline Rana iberica & 29TNG80 & 101,00 & 112,87 & 91,32 & 38,75 & 4947,97 & 247,61 & 15,16 & 232,45 & 53,01 & \begin{tabular}{|l|}
177,90 \\
\end{tabular} & \begin{tabular}{|l|}
178,60 \\
\end{tabular} & 53,01 & 1400,14 & \begin{tabular}{|l|l|}
192,11 \\
\end{tabular} & 21,42 & 51,11 & 556,51 & \begin{tabular}{|l|}
107,68 \\
\end{tabular} & 112,99 & 556,51 \\
\hline Rana iberica & 29TNG81 & 99,00 & 115,24 & 91,50 & \begin{tabular}{|l|}
38,82 \\
\end{tabular} & 4947,70 & 249,65 & 16,98 & 232,68 & 55,94 & 180,29 & 180,76 & 55,18 & 1364,75 & 183,45 & 21,60 & 50,37 & 539,13 & 106,90 & 111,89 & 538,88 \\
\hline Rana iberica & 29TNG82 & 101,00 & 108,29 & 87,72 & 38,01 & 4896,41 & 240,41 & 12,73 & $\begin{array}{l}227,68 \\
\end{array}$ & 49,93 & $\begin{array}{l}172,98 \\
\end{array}$ & \begin{tabular}{|l|}
173,49 \\
\end{tabular} & 49,60 & 1410,36 & 187,29 & 24,39 & 49,53 & 554,55 & 115,56 & 120,32 & 554,48 \\
\hline Rana iberica & 29TNG83 & 100,00 & 95,35 & 82,54 & 36,89 & 4825,88 & 224,96 & 4,18 & 220,77 & 39,97 & 159,66 & 160,33 & 38,78 & 1502,75 & 199,67 & 29,19 & 48,38 & 587,88 & 130,81 & $\begin{array}{l}134,52 \\
\end{array}$ & 587,87 \\
\hline Rana iberica & 29TNG84 & 101,00 & 115,06 & 89,61 & 38,44 & 4900,82 & 247,18 & \begin{tabular}{|l|}
17,13 \\
\end{tabular} & 230,05 & 62,29 & 179,62 & 180,01 & 55,89 & 1330,30 & 182,38 & 24,65 & 48,11 & 516,80 & 113,30 & 119,51 & 514,85 \\
\hline Rana iberica & 29TNG85 & 101,00 & 110,38 & 87,58 & 38,09 & 4847,86 & 241,14 & \begin{tabular}{|l|l|}
14,13 \\
\end{tabular} & 227,01 & 58,55 & $\begin{array}{l}174,38 \\
\end{array}$ & \begin{tabular}{|l|}
174,95 \\
\end{tabular} & 52,32 & 1362,59 & 188,53 & 27,05 & 47,48 & 528,30 & 120,16 & 126,83 & 525,43 \\
\hline Rana iberica & 29TNG86 & 100,00 & 118,55 & 89,98 & 38,52 & 4887,39 & 249,84 & 19,15 & 230,69 & 65,38 & 182,86 & 183,30 & 59,50 & 1277,69 & 180,86 & 25,94 & 46,84 & 491,94 & 114,51 & 120,97 & 485,73 \\
\hline Rana iberica & \begin{tabular}{|l|} 
29TNG87 \\
\end{tabular} & 100,00 & 131,52 & 92,63 & 38,90 & 4978,81 & 263,13 & 27,19 & 235,94 & 75,96 & 196,55 & 196,79 & 70,46 & 1135,81 & 164,80 & 23,53 & 46,00 & 431,70 & 103,51 & 109,38 & 420,30 \\
\hline Rana iberica & 29TNG88 & 100,00 & 134,92 & 90,86 & 38,50 & 4962,84 & 263,78 & 30,42 & 233,36 & 79,33 & \begin{tabular}{|l|}
199,65 \\
\end{tabular} & 199,84 & 74,12 & \begin{tabular}{|c|}
1091,09 \\
\end{tabular} & 159,33 & 23,65 & 45,35 & 411,98 & 101,28 & 106,87 & 399,33 \\
\hline Rana iberica & 29TNG90 & 100,00 & 120,45 & 96,51 & 39,18 & 5118,80 & 260,85 & 17,93 & 242,93 & 57,81 & 187,52 & 187,92 & 57,81 & 1287,23 & 177,84 & 18,68 & 51,39 & 510,95 & 96,68 & 101,54 & 510,95 \\
\hline Rana iberica & 29TNG91 & 101,00 & 106,49 & 88,55 & \begin{tabular}{|l|l|}
37,63 \\
\end{tabular} & 5026,95 & 242,03 & 9,90 & 232,12 & 46,30 & 173,06 & 173,50 & 46,30 & 1386,53 & 188,86 & 23,03 & 50,32 & 548,86 & \begin{tabular}{|l|}
111,20 \\
\end{tabular} & 114,51 & 548,86 \\
\hline Rana iberica & 29TNG92 & 101,00 & 104,70 & 86,50 & \begin{tabular}{|l|}
37,29 \\
\end{tabular} & 4987,78 & 238,55 & $\begin{array}{l}9,44 \\
\end{array}$ & 229,12 & 45,29 & 170,90 & 171,31 & 45,29 & 1385,85 & 185,38 & 24,36 & 49,44 & 545,62 & 114,51 & 117,69 & 545,62 \\
\hline Rana iberica & 29TNG93 & 100,00 & 96,32 & 83,47 & 36,63 & 4929,91 & 228,39 & 3,62 & 224,77 & 39,17 & 162,07 & 162,53 & 38,30 & 1441,20 & 190,75 & 27,84 & 48,34 & 563,31 & 125,34 & 128,21 & 563,31 \\
\hline Rana iberica & 29TNG94 & 100,00 & 104,76 & 86,30 & 37,24 & 4947,62 & 237,78 & 9,36 & 228,42 & 50,88 & 170,56 & 170,87 & 45,91 & 1358,63 & 181,85 & 26,28 & 47,98 & 528,21 & 118,26 & 122,51 & 528,04 \\
\hline Rana iberica & 29TNG95 & 100,00 & 116,87 & 91,33 & 38,28 & 5019,76 & 251,70 & $\begin{array}{ll}16,05 \\
\end{array}$ & 235,64 & $60,32,32$ & \begin{tabular}{|l|}
183,07 \\
\end{tabular} & \begin{tabular}{|l|}
183,34 \\
\end{tabular} & 56,20 & $\begin{array}{l}1241,58 \\
\end{array}$ & $\begin{array}{l}170,18 \\
\end{array}$ & 24,06 & 47,21 & \begin{tabular}{|l|}
478,95 \\
\end{tabular} & $\begin{array}{l}108,44 \\
\end{array}$ & \begin{tabular}{|l|}
112,27 \\
\end{tabular} & 475,71 \\
\hline Rana iberica & 29TNG96 & 100,00 & 116,26 & 90,73 & \begin{tabular}{|l|}
38,15 \\
\end{tabular} & 4979,74 & 250,19 & 15,81 & 234,38 & 62,01 & 181,98 & 182,26 & 56,26 & 1238,14 & 172,01 & 25,34 & 46,58 & 475,99 & 111,39 & 116,99 & 471,15 \\
\hline Rana iberica & 29TNG97 & 101,00 & 128,47 & 93,28 & \begin{tabular}{|l|}
38,48 \\
\end{tabular} & 5077,27 & 262,36 & 22,92 & 239,45 & 71,72 & 194,96 & \begin{tabular}{|l|}
195,08 \\
\end{tabular} & 66,47 & 1102,83 & 156,57 & 22,98 & 45,68 & 418,49 & 100,50 & 103,93 & 409,70 \\
\hline Rana iberica & 29TNG98 & 101,00 & 137,22 & 92,45 & \begin{tabular}{|c|}
37,87 \\
\end{tabular} & 5162,84 & 269,37 & 28,60 & 240,77 & 79,01 & 204,71 & 204,75 & 73,95 & 989,93 & 142,03 & 21,46 & 44,79 & 370,10 & 91,71 & 93,81 & 359,00 \\
\hline Rana iberica & 29TNHOO & 16,00 & 147,29 & 59,00 & 38,48 & 3400,52 & 230,67 & 78,95 & 151,71 & 112,29 & 190,24 & \begin{tabular}{|l|}
191,67 \\
\end{tabular} & 104,38 & 1225,90 & 174,48 & 26,95 & 46,81 & 491,57 & 111,81 & 134,71 & 450,57 \\
\hline Rana iberica & 29TNH01 & 40,00 & 144,58 & 59,91 & \begin{tabular}{|l|l|l|}
38,18 \\
\end{tabular} & 3389,01 & 229,52 & 75,00 & $\begin{array}{l}154,52 \\
\end{array}$ & 110,27 & \begin{tabular}{|l|}
186,96 \\
\end{tabular} & $\begin{array}{l}189,12 \\
\end{array}$ & \begin{tabular}{|l|l}
101,96 \\
\end{tabular} & 1190,85 & \begin{tabular}{|l|}
170,30 \\
\end{tabular} & 27,81 & 45,66 & \begin{tabular}{|l|}
475,97 \\
\end{tabular} & \begin{tabular}{|l|l|l|l|l|}
115,04 \\
\end{tabular} & \begin{tabular}{|l|}
138,49 \\
\end{tabular} & 430,70 \\
\hline Rana iberica & 29TNH02 & 97,00 & 132,26 & 63,14 & \begin{tabular}{|l|}
37,98 \\
\end{tabular} & 3521,94 & 224,76 & 60,48 & 164,28 & 97,19 & \begin{tabular}{|l|}
177,01 \\
\end{tabular} & 179,36 & 89,11 & 1311,65 & \begin{tabular}{|l|}
191,91 \\
\end{tabular} & 32,75 & 44,97 & 520,73 & 131,71 & 153,40 & 479,06 \\
\hline Rana iberica & 29TNH03 & 72,00 & 140,28 & 62,04 & \begin{tabular}{|l|l|}
38,15 \\
\end{tabular} & 3441,65 & 229,47 & 68,97 & 160,50 & 106,00 & 183,51 & 186,10 & 97,60 & 1187,87 & 170,53 & 29,84 & 44,38 & 470,94 & 121,46 & 144,58 & 424,12 \\
\hline Rana iberica & 29TNHO4 & 98,00 & 137,01 & 63,14 & 38,09 & 3452,36 & 228,38 & 64,98 & 163,40 & 103,02 & 180,45 & 183,28 & 94,56 & 1187,81 & 169,67 & 31,04 & 43,51 & 468,51 & 125,83 & 148,93 & 420,04 \\
\hline Rana iberica & 29TNH06 & 101,00 & 130,82 & 64,73 & 38,44 & 3443,75 & 224,58 & 58,12 & 166,45 & 97,50 & 174,06 & 177,48 & 89,05 & 1201,01 & 168,81 & 33,56 & 41,93 & 468,53 & 134,43 & 157,51 & 418,84 \\
\hline Rana iberica & 29TNH07 & 101,00 & 135,56 & \begin{tabular}{|l|l|}
63,77 \\
\end{tabular} & 38,94 & 3340,52 & 225,72 & $\mid$\begin{tabular}{|c|c|}
63,71 \\
\end{tabular} & \begin{tabular}{|l|}
162,01 \\
\end{tabular} & \begin{tabular}{|c|}
103,33 \\
\end{tabular} & $\begin{array}{l}176,99 \\
\end{array}$ & $\begin{array}{l}180,78,40 \\
\end{array}$ & \begin{tabular}{|l|l|}
94,75 \\
9
\end{tabular} & $\begin{array}{l}1124,75 \\
1124\end{array}$ & \begin{tabular}{|l|}
155,33 \\
\end{tabular} & $\mid$ & 41,14 & \begin{tabular}{|l|l|}
437,83 \\
\end{tabular} & \begin{tabular}{|l|}
$128,10,10$ \\
\end{tabular} & \begin{tabular}{|l|}
152,02 \\
\end{tabular} & 386,81 \\
\hline Rana iberica & 29TNH08 & 81,00 & 139,86 & 62,83 & \begin{tabular}{|l|l|}
39,45 \\
\end{tabular} & 3245,91 & 226,50 & 68,94 & 157,55 & 108,65 & 179,71 & 183,68 & 99,93 & 1066,54 & 146,17 & 30,11 & 40,82 & 414,13 & 122,84 & 147,26 & 363,35 \\
\hline Rana iberica & 29TNHO9 & 36,00 & 140,84 & 62,53 & 39,81 & 3197,92 & 225,89 & $\begin{array}{l}70,47 \\
\end{array}$ & 155,42 & 110,27 & 179,88 & $\begin{array}{l}184,00 \\
\end{array}$ & 101,47 & 1046,33 & 142,86 & 29,83 & 40,06 & 404,94 & 121,86 & 146,55 & 354,73 \\
\hline Rana iberica & 29TNH10 & 61,00 & 146,39 & 60,06 & 37,91 & 3519,36 & 232,27 & 76,11 & 156,16 & 109,72 & 190,75 & 192,23 & 101,94 & 1275,06 & 185,37 & 28,73 & 46,99 & 509,45 & 116,28 & 138,47 & 472,93 \\
\hline Rana iberica & 29TNH11 & 40,00 & 146,34 & 60,45 & 37,82 & 3518,47 & 233,20 & 75,68 & 157,53 & 109,97 & 190,80 & 192,50 & 102,30 & 1241,93 & 180,28 & 28,89 & 46,24 & 494,43 & 116,57 & 139,20 & 455,66 \\
\hline 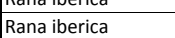 & $\frac{29 \mathrm{TNH} 12}{2}$ & $\begin{array}{l}0,00 \\
80,00\end{array}$ & $\begin{array}{l}14,53,85 \\
143,85\end{array}$ & $\begin{array}{l}00,45 \\
61,84\end{array}$ & 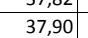 & $\begin{array}{l}351,44^{\prime} \\
3527,18\end{array}$ & 233,33 & \begin{tabular}{|l|}
72,06 \\
72
\end{tabular} & \begin{tabular}{|l|}
161,27 \\
\end{tabular} & \begin{tabular}{|l|}
107,84 \\
\end{tabular} & \begin{tabular}{|l|l|l}
188,46 \\
\end{tabular} & \begin{tabular}{|l|}
190,54 \\
\end{tabular} & \begin{tabular}{|c|}
$102,30,85$ \\
\end{tabular} & \begin{tabular}{|l|l|l|l|}
1225,40 \\
\end{tabular} & \begin{tabular}{|l|}
$177,80,20$ \\
170
\end{tabular} & $\begin{array}{l}\mid 20,805 \\
29,87\end{array}$ & $\begin{array}{l}4,24 \\
45,22\end{array}$ & \begin{tabular}{|}
$\mid 484,45$ \\
485,94 \\
\end{tabular} & \begin{tabular}{|l|l|}
119,86 \\
\end{tabular} & \begin{tabular}{|l|}
142,71 \\
140
\end{tabular} & $\begin{array}{l}453,00 \\
444,59\end{array}$ \\
\hline Rana iberica & 29TNH13 & 101,00 & 134,28 & 65,16 & \begin{tabular}{|l|l|}
37,83 \\
\end{tabular} & 3618,45 & 230,51 & 60,17 & 170,34 & 97,99 & 180,32 & 182,90 & 90,05 & \begin{tabular}{|c|}
1306,88 \\
\end{tabular} & 191,55 & 33,69 & 44,61 & 514,94 & 132,93 & \begin{tabular}{|l|}
154,63 \\
\end{tabular} & 475,23 \\
\hline Rana iberica & 29TNH14 & 100,00 & 133,17 & 66,01 & $|37,97|$ & 3607,29 & 230,45 & 58,59 & $\mid 171,85$ & $\mid 97,29$ & $|178,97|$ & $\mid 181,81$ & 89,22 & 1284,45 & $\mid 186,08$ & 34,10 & 43,76 & 503,35 & \begin{tabular}{|l|l|}
134,48 \\
\end{tabular} & 156,51 & 461,63 \\
\hline Rana iberica & 29TNH15 & 101,00 & 131,49 & 66,60 & 38,05 & 3585,35 & 229,44 & 56,70 & 172,74 & 96,06 & 176,92 & 180,04 & 88,01 & 1269,31 & 181,60 & 34,69 & 42,87 & 494,86 & 136,62 & 158,82 & 451,55 \\
\hline Rana iberica & 29TNH16 & 100,00 & 129,53 & 66,99 & 38,23 & 3553,02 & 227,55 & 54,86 & 172,69 & 94,82 & 174,47 & 177,92 & 86,69 & 1258,25 & 177,72 & 35,39 & 41,99 & 487,99 & $\begin{array}{l}139,03 \\
\end{array}$ & 161,37 & 443,71 \\
\hline Rana iberica & 29TNH18 & 99,00 & 138,18 & 64,56 & 39,53 & 3317,71 & 227,61 & 66,00 & $\begin{array}{l}161,61 \\
\end{array}$ & \begin{tabular}{|c|}
106,04 \\
\end{tabular} & 179,15 & \begin{tabular}{|l|}
183,05 \\
\end{tabular} & $\begin{array}{l}97,47 \\
\end{array}$ & \begin{tabular}{|l|}
1106,27 \\
\end{tabular} & $\begin{array}{l}150,80 \\
\end{array}$ & 31,46 & 40,66 & \begin{tabular}{|l|}
427,34 \\
\end{tabular} & \begin{tabular}{|l|}
126,22 \\
\end{tabular} & \begin{tabular}{|l|}
150,06 \\
\end{tabular} & 380,75 \\
\hline Rana iberica & 29TNH19 & 64,00 & 140,89 & $\begin{array}{l}63,56 \\
\end{array}$ & 39,93 & 3223,95 & 227,11 & 69,77 & \begin{tabular}{|l|l|}
157,34 \\
\end{tabular} & 109,84 & $\begin{array}{l}180,43 \\
\end{array}$ & 184,43 & \begin{tabular}{|l|}
101,17 \\
\end{tabular} & 1059,58 & $\begin{array}{l}143,29 \\
\end{array}$ & 30,28 & 40,01 & \begin{tabular}{|l|}
408,67 \\
\end{tabular} & $\begin{array}{l}122,48 \\
\end{array}$ & 146,75 & 361,63 \\
\hline Rana iberica & 29TNH20 & 100,00 & 140,04 & 63,04 & 37,60 & 3718,64 & 232,42 & \begin{tabular}{ll|}
66,87 \\
\end{tabular} & 165,55 & 101,01 & 187,74 & 188,88 & 93,81 & 1395,50 & 212,46 & 32,47 & 47,52 & 556,28 & 127,28 & \begin{tabular}{|l|}
147,77 \\
\end{tabular} & 529,68 \\
\hline Rana iberica & 29TNH21 & 101,00 & 143,07 & 62,99 & 37,73 & 3680,33 & 234,96 & 69,79 & 165,16 & 104,60 & 190,07 & 191,50 & 97,21 & 1313,98 & 195,41 & 31,39 & 46,36 & 20,52 & 123,46 & 145,06 & 488,04 \\
\hline Rana iberica & 29TNH22 & 98,00 & 142,56 & \begin{tabular}{|l|}
64,37 \\
\end{tabular} & 37,8 & 3673,06 & 236,45 & $\begin{array}{l}68,27 \\
\end{array}$ & \begin{tabular}{|l|l|l|l}
168,18 \\
\end{tabular} & \begin{tabular}{|l|}
104,48 \\
\end{tabular} & \begin{tabular}{|l|l}
189,39 \\
\end{tabular} & \begin{tabular}{|l|}
191,20 \\
\end{tabular} & 97,00 & 1282,23 & \begin{tabular}{|l|}
189,18 \\
\end{tabular} & 31,60 & 45,59 & 505,62 & $\begin{array}{l}124,06 \\
\end{array}$ & \begin{tabular}{|l|}
145,95 \\
\end{tabular} & 4770,89 \\
\hline Rana iberica & $29 \mathrm{TNH} 23$ & 100,00 & 140,69 & 65,81 & 37,91 & 3675,02 & 236,85 & 65,44 & $\begin{array}{l}171,42 \\
\end{array}$ & 102,96 & 187,49 & \begin{tabular}{|l|}
189,76 \\
\end{tabular} & 95,38 & 1268,02 & 185,23 & 32,2 & 44,81 & \begin{tabular}{|l|}
497,28 \\
\end{tabular} & 126,63 & 148,60 & 460,75 \\
\hline Rana iberica & 29TNH24 & 101,00 & 139,46 & 66,85 & 38,14 & 3657,53 & 237,04 & 63,64 & 173,40 & 102,32 & 185,96 & 188,60 & 94,54 & 1247,55 & 180,10 & 32,75 & 43,93 & $\begin{array}{l}486,78 \\
\end{array}$ & 128,33 & 150,59 & 448,39 \\
\hline Rana iberica & 29TNH 25 & 101,00 & 134,22 & 68,49 & 38,02 & 3679,17 & 235,07 & 57,13 & 177,94 & 97,31 & 180,95 & 184,04 & 89,61 & 1277,87 & 182,81 & 34,92 & 42,98 & 495,32 & 135,80 & 157,76 & 456,50 \\
\hline Rana iberica & 29TNH 26 & 101,00 & 129,38 & 69,40 & 38,11 & 3658,94 & 231,39 & 52,28 & 179,10 & 93,09 & 175,81 & 179,24 & 85,42 & 1295,09 & 183,16 & 36,61 & 42,07 & 499,18 & 72 & 163,38 & 459,85 \\
\hline Rana iberica & 29TNH27 & $\begin{array}{l}100,00 \\
100\end{array}$ & 129 & $\begin{array}{l}03,40 \\
68,83\end{array}$ & $\begin{array}{l}30, \\
38,\end{array}$ & $\begin{array}{l}3050,54 \\
3574,89\end{array}$ & $\begin{array}{l}228, \\
228,\end{array}$ & $\begin{array}{l}32,20 \\
53,35\end{array}$ & $\begin{array}{l}175,45 \\
170\end{array}$ & 94,07 & 174,25 & 178,02 & 86,21 & 1259,95 & 175,62 & 36,27 & 41,11 & $\begin{array}{l}484,03 \\
\end{array}$ & $\begin{array}{l}140,94 \\
\end{array}$ & $\begin{array}{l}162,85 \\
\end{array}$ & 443,55 \\
\hline Rana iberica & 29TNH28 & 101,00 & 138,15 & 66,22 & 39,76 & 3371,93 & 229,55 & 64,80 & $\begin{array}{l}164,75 \\
\end{array}$ & 105,12 & 179,97 & \begin{tabular}{|l|}
183,87 \\
\end{tabular} & 96,86 & 1124,24 & 152,92 & 32,00 & 40,55 & 432,17 & 126,98 & 150,29 & 389,89 \\
\hline Rana iberica & 29TNH29 & 39,00 & 138,94 & 65,60 & 40,11 & 3300,89 & 227.96 & 66,33 & $|161,63|$ & \begin{tabular}{|c|}
106,78 \\
\end{tabular} & $\mid 179,56$ & \begin{tabular}{|c|}
183,64 \\
\end{tabular} & 98,28 & 1096,42 & $\mid 147,44$ & $\mid 31.46$ & 39,97 & 420,50 & $\mid 125,51$ & 149,00 & 378,18 \\
\hline Rana iberica & 29TNH30 & 101,00 & 136,38 & 68,31 & 37,86 & 3916,51 & 236,40 & 58,16 & 178,24 & 94,75 & 186,93 & 188,06 & 88,14 & 1444,96 & 225,06 & 34,07 & 47,76 & 572,47 & 132,50 & 151,25 & 553,08 \\
\hline Rana iberica & 29TNH31 & 100,00 & 135,63 & 69,05 & 37,66 & 3905,13 & 237,49 & 56,52 & 180,97 & 94,42 & 186,07 & 187,56 & 87,79 & 1419,43 & 217,60 & 34,79 & 46,73 & 558,64 & 134,36 & 153,66 & 535 \\
\hline Rana iberica & $29 \mathrm{TNH} 32$ & 101,00 & 133,93 & 70,52 & 37,54 & 3913,20 & 238,69 & 53,32 & 185,36 & 93,06 & $\begin{array}{l}184,50 \\
\end{array}$ & $\begin{array}{l}186,35 \\
\end{array}$ & 86,34 & 1407,16 & 212,47 & 35,74 & 45,82 & 550,13 & $\begin{array}{l}137,36 \\
\end{array}$ & $\begin{array}{l}157,02 \\
\end{array}$ & 524,18 \\
\hline Rana iberica & 29TNH33 & 101,00 & 140,89 & 68,88 & 37,78 & 3814,67 & 241,68 & 61,72 & 179,97 & \begin{tabular}{|l|}
101,09 \\
\end{tabular} & $\begin{array}{l}189,69 \\
\end{array}$ & 191,86 & 94,03 & 1286,69 & 188,93 & 32,96 & 44,87 & 500,80 & 127,77 & 149,09 & 469,14 \\
\hline Rana iberica & 29TNH34 & 100,00 & 137,98 & 70,61 & \begin{tabular}{|l|l|}
37,67 \\
\end{tabular} & 3829,36 & 242,21 & 57,25 & 184,96 & 98,68 & 186,96 & 189,58 & 91,35 & 1297,37 & 188,15 & 34,52 & 43,99 & 501,72 & 132,89 & 154,22 & 468,82 \\
\hline Rana iberica & 29TNH35 & 101,00 & 132,84 & 72,28 & 37,68 & 3838,58 & 240,40 & 50,95 & 189, & 94,15 & 182,04 & 185 & 86 & 1326,75 & 190,10 & 36,64 & $4=$ & 509,81 & 140,19 & 161,30 & 476 \\
\hline Rana iberica & 29TNH36 & 101,00 & 129,84 & 72,27 & 38,05 & 3774,65 & 236,38 & $\begin{array}{l}49,07 \\
\end{array}$ & 187,31 & 92,04 & 178,03 & 181,37 & 84,62 & 1317,82 & 186,12 & 37,45 & 42,10 & 504,27 & 143,19 & 164,27 & 469, \\
\hline
\end{tabular}




\begin{tabular}{|c|c|c|c|c|c|c|c|c|c|c|c|c|c|c|c|c|c|c|c|c|c|}
\hline TAXON & UTM & km2 & B101 & B102 & B1O3 & B104 & B105 & BIOG & B107 & B108 & B109 & B1010 & BIO11 & BIO12 & B1013 & BIO14 & B1O15 & BIO16 & BIO17 & BIO18 & B1019 \\
\hline Rana iberica & 29TNH37| & 101,00 & 127,82 & 71,68 & 38,69 & 3685,61 & 231,99 & 48,85 & 183,14 & 91,12 & 174,58 & 178,31 & 83,80 & 1296,43 & $\begin{array}{r}180,66 \\
\end{array}$ & 37,63 & 41,15 & 494,57 & 144,29 & 165,38 & 458,65 \\
\hline Rana iberica & 29TNH38 & 100,00 & 130,25 & 69,90 & \begin{tabular}{|l|l|}
39,58 \\
\end{tabular} & 3529,25 & 228,82 & 54,21 & 174,62 & 95,40 & $\begin{array}{l}174,66 \\
\end{array}$ & 178,55 & 87,84 & 1225,75 & 167,86 & 35,84 & 40,29 & 467,01 & 138,82 & 160,53 & 429,77 \\
\hline Rana iberica & 29TNH39 & 66,00 & 137,72 & 67,21 & 40,50 & 3335,65 & 228,27 & $\begin{array}{l}64,37 \\
\end{array}$ & 163,90 & 104,80 & 178,85 & $\begin{array}{l}182,93 \\
\end{array}$ & 96,84 & 1111,28 & 148,76 & 32,07 & 39,82 & 423,65 & 126,76 & 149,62 & 385,50 \\
\hline Rana iberica & 29TNH40 & 101,00 & 124,43 & 76,64 & 38,40 & 4126,21 & 236,23 & 39,22 & \begin{tabular}{|l|}
197,01 \\
\end{tabular} & 80,58 & 178,19 & $\begin{array}{l}179,63 \\
\end{array}$ & 74,68 & 1499,32 & 232,05 & 36,10 & 47,05 & 587,15 & 141,93 & 157,16 & 573,21 \\
\hline Rana iberica & 29TNH41 & 99,00 & 124,50 & 76,53 & \begin{tabular}{|l|}
38,28 \\
\end{tabular} & 4087,47 & 236,72 & 39,20 & 197,52 & 81,28 & 177,72 & \begin{tabular}{|l|}
179,47 \\
\end{tabular} & 75,52 & 1486,55 & 227,30 & 37,16 & 46,14 & 578,92 & 144,31 & 160,36 & 561,84 \\
\hline Rana iberica & $29 \mathrm{TNH} 42$ & 100,00 & 132,13 & 74,96 & 37,98 & 4042,12 & 242,29 & 47,15 & 195,13 & 89,34 & 184,54 & 186,42 & 83,32 & 1407,67 & 212,28 & 35,99 & 45,57 & 545,52 & 138,23 & 156,49 & 523,46 \\
\hline Rana iberica & $29 \mathrm{TNH} 43$ & 101,00 & 140,12 & 72,87 & 37,98 & 3953,22 & 246,17 & 56,53 & 189,64 & 98,34 & 190,91 & 193,06 & 91,84 & \begin{tabular}{|l|l|}
1293,19 \\
\end{tabular} & 190,16 & 33,42 & 44,74 & 499,02 & 128,68 & 149,06 & 471,50 \\
\hline Rana iberica & 29TNH44 & 99,00 & 134,34 & 75,62 & 37,50 & 4016,51 & 247,01 & 47,82 & $\begin{array}{l}199,18 \\
\end{array}$ & 92,76 & \begin{tabular}{|l|}
186,25 \\
\end{tabular} & \begin{tabular}{|l|}
188,81 \\
\end{tabular} & 86,23 & 1354,82 & \begin{tabular}{|l|l|}
196,79 \\
\end{tabular} & 36,70 & 43,95 & 518,70 & 139,25 & 159,31 & 490,94 \\
\hline Rana iberica & 29TNH45 & 100,00 & 133,85 & 75,41 & 37,71 & 3948,35 & 245,54 & 48,08 & \begin{tabular}{|l|}
197,45 \\
\end{tabular} & 93,39 & 184,49 & 187,60 & 86,62 & 1327,24 & 189,42 & 36,86 & 42,92 & 505,97 & 139,84 & 160,39 & 476,27 \\
\hline Rana iberica & 29TNH46 & 100,00 & 133,61 & 74,17 & \begin{tabular}{|l|l|}
38,49 \\
\end{tabular} & 3807,22 & 241,03 & 50,75 & 190,27 & 94,78 & 182,11 & $\begin{array}{l}185,54 \\
\end{array}$ & 87,87 & 1277,88 & 179,38 & 36,11 & 41,96 & 486,11 & 137,91 & 158,76 & 454,57 \\
\hline Rana iberica & 29TNH47 & 101,00 & 129,79 & 73,67 & 39,01 & 3726,10 & 235,43 & 48,83 & 186,61 & 92,02 & 177,26 & 180,80 & 85,29 & 1276,81 & 177,09 & 37,02 & 41,03 & 484,24 & 141,41 & 162,11 & 451,80 \\
\hline Rana iberica & $29 \mathrm{TNH} 48$ & 99,00 & 130,64 & 71,90 & 39,94 & 3580,81 & 231,16 & 52,91 & 178,25 & 94,65 & 175,87 & 179,58 & 87,62 & 1222,47 & 166,76 & \begin{tabular}{|c|}
35,87 \\
\end{tabular} & 40,09 & 463,07 & 138,08 & 159,15 & 429,36 \\
\hline Rana iberica & 29TNH49 & 99,00 & 138,44 & 68,49 & 41,26 & 3334,69 & 228,73 & 64,79 & 163,94 & 105,25 & 179,57 & 183,74 & 97,48 & 1091,49 & 144,73 & 31,59 & 39,26 & 413,86 & 124,45 & 146,72 & 379,25 \\
\hline Rana iberica & 29TNH50 & 101,00 & 115,81 & 80,39 & \begin{tabular}{|l|}
38,78 \\
\end{tabular} & 4246,05 & 232,99 & 27,72 & 205,27 & 70,53 & 171,45 & 172,95 & 65,34 & 1493,95 & 224,52 & \begin{tabular}{|l|}
36,57 \\
\end{tabular} & 45,84 & 578,78 & 145,19 & 158,22 & 565,92 \\
\hline Rana iberica & 29TNH51 & 100,00 & 117,26 & 79,99 & 38,79 & 4189,91 & 233,81 & 29,61 & 204,20 & 72,66 & 172,18 & 173,85 & 67,67 & $\begin{array}{l}1479,02 \\
\end{array}$ & 221,39 & \begin{tabular}{|l|l|}
37,47 \\
\end{tabular} & 45,33 & 570,71 & 146,62 & 160,59 & 555,60 \\
\hline Rana iberica & 29TNH52 & 101,00 & 121,80 & 79,71 & 38,86 & 4121,18 & 237,20 & \begin{tabular}{|l|l|}
34,24 \\
\end{tabular} & 202,96 & 77,75 & 175,64 & 177,56 & 73,05 & 1442,01 & 214,66 & 37,59 & 44,81 & 553,96 & 145,11 & 160,61 & 535,85 \\
\hline Rana iberica & 29TNH53 & 101,00 & 136,65 & 77,41 & 38,54 & 4049,65 & 247,69 & 49,24 & 198,45 & 93,11 & 188,96 & 191,10 & 87,81 & 1301,01 & 191,18 & \begin{tabular}{|c|}
34,07 \\
\end{tabular} & 44,30 & 497,36 & 130,92 & \begin{tabular}{|l|}
149,73 \\
\end{tabular} & 473,88 \\
\hline Rana iberica & 29TNH54 & 100,00 & 137,07 & 77,10 & 38,52 & 3993,02 & 247,76 & 50,07 & 197,69 & 94,62 & 188,50 & $\begin{array}{l}191,06 \\
\end{array}$ & 89,04 & \begin{tabular}{|l|}
1279,09 \\
\end{tabular} & 184,57 & 34,47 & 43,47 & 486,83 & 131,67 & 151,22 & $\begin{array}{l}461,07 \\
\end{array}$ \\
\hline Rana iberica & 29TNH55 & 101,00 & 132,55 & 77,84 & 38,55 & 3952,98 & 244,93 & 45,58 & 199,35 & 91,08 & 183,42 & 186,37 & 85,47 & 1311,62 & \begin{tabular}{|l|}
186,78 \\
\end{tabular} & 36,64 & 42,66 & 496,98 & 138,85 & 158,30 & 470,35 \\
\hline Rana iberica & 29TNH56 & 101,00 & 131,83 & 76,71 & $38,90 \mid$ & 3858.57 & 241,48 & 46,94 & $\mid 194.54$ & $\mid 91,76$ & \begin{tabular}{|c|}
181,28 \\
\end{tabular} & $\mid 184,54$ & 85,86 & $|1281,64|$ & $|179,77|$ & 36,54 & 41,76 & 484,46 & 138,73 & 158,58 & 456,12 \\
\hline Rana iberica & 29TNH57 & 100,00 & 129,49 & 75,79 & \begin{tabular}{|l|l|}
39,47 \\
\end{tabular} & 3760,92 & 236,42 & 46,84 & 189,58 & 90,69 & 177,58 & 181,00 & 84,70 & 1264,25 & 174,91 & \begin{tabular}{|l|}
36,84 \\
\end{tabular} & 40,79 & 476,82 & 140,23 & \begin{tabular}{|l|l|}
160,14 \\
\end{tabular} & 447,24 \\
\hline Rana iberica & 29TNH58 & 101,00 & 136,43 & 72,36 & 40,72 & 3553,90 & 234,25 & 58,55 & 175,70 & \begin{tabular}{|r|}
100,03 \\
\end{tabular} & $\begin{array}{l}181,02 \\
\end{array}$ & $\begin{array}{l}184,78 \\
\end{array}$ & 93,25 & 1141,24 & \begin{tabular}{|l|l|}
154,04 \\
\end{tabular} & 33,02 & 39,87 & 430,70 & 128,01 & $\begin{array}{l}149,16 \\
\end{array}$ & 399,31 \\
\hline Rana iberica & 29TNH59 & 98,00 & 140,77 & 69,91 & \begin{tabular}{|l|l|}
41,80 \\
\end{tabular} & 3381,91 & 231,80 & \begin{tabular}{|l|l|}
66,23 \\
\end{tabular} & 165,56 & 106,31 & \begin{tabular}{|l|}
182,51 \\
\end{tabular} & \begin{tabular}{|l|}
186,54 \\
\end{tabular} & \begin{tabular}{|l|}
99,09 \\
\end{tabular} & 1058,70 & 139,63 & \begin{tabular}{|l|l|}
30,57 \\
\end{tabular} & 39,04 & 399,41 & 120,42 & 142,28 & $\begin{array}{l}367,09 \\
\end{array}$ \\
\hline Rana iberica & 29TNH60 & 100,00 & 118,94 & 83,20 & 38,98 & 4353,18 & 238,48 & 27,84 & 210,64 & 71,76 & 175,90 & 177,36 & 67,11 & 1409,20 & 210,16 & 34,42 & 45,45 & 541,88 & 137,56 & 150,38 & 528,85 \\
\hline Rana iberica & 29TNH61 & 101,00 & 119,95 & 82,67 & 39,13 & 4262,34 & 238,07 & 29,73 & 208,34 & 73,64 & 175,70 & 177,29 & 69,46 & 1400,04 & 207,77 & 35,43 & 44,95 & 536,38 & 139,36 & 153,01 & 521,48 \\
\hline Rana iberica & 29TNH62 & 101,00 & 126,70 & 82,14 & 39,66 & 4142,87 & 242,07 & 37,06 & 205,01 & 81,27 & 180,62 & 182,46 & 77,59 & 1348,88 & 199,73 & \begin{tabular}{|l|l|}
34,98 \\
\end{tabular} & 44,38 & 514,25 & 135,83 & 151,36 & 496,63 \\
\hline Rana iberica & 29TNH63 & 100,00 & 127,69 & 81,29 & 39,80 & 4046,96 & 241,44 & 39,35 & \begin{tabular}{|l|}
202,09 \\
\end{tabular} & 83,45 & \begin{tabular}{|l|l}
180,25 \\
\end{tabular} & \begin{tabular}{|l|}
182,44 \\
\end{tabular} & 79,89 & $\begin{array}{l}1331,80 \\
133,8\end{array}$ & \begin{tabular}{|l|l|}
194,42 \\
\end{tabular} & 35,67 & 43,65 & 505,65 & 137,02 & $\begin{array}{l}153,53 \\
\end{array}$ & 4885,67 \\
\hline Rana iberica & 29TNH66 & 101,00 & 129,58 & 78,71 & \begin{tabular}{|c|}
39,87 \\
\end{tabular} & 3857,86 & 239,18 & 44,01 & 195,17 & 88,47 & 179,21 & 182,21 & 83,81 & 1260,61 & 176,24 & \begin{tabular}{l|l|}
36,25 \\
\end{tabular} & 41,21 & 474,02 & 137,71 & 156,45 & 447,92 \\
\hline Rana iberica & 29TNH67 & 100,00 & 126,03 & 77,79 & 40,01 & 3800,28 & 234,24 & 42,32 & 191,92 & 86,01 & 174,86 & \begin{tabular}{|l|}
178,03 \\
\end{tabular} & 81,18 & 1264,47 & 174,59 & \begin{tabular}{|l|}
37,33 \\
\end{tabular} & 40,38 & 474,41 & 141,64 & 160,31 & 446,85 \\
\hline Rana iberica & 29TNH68 & 101,00 & 134,85 & 74,68 & 40,77 & 3631,25 & 235,43 & 54,60 & 180,83 & 96,81 & 180,73 & 184,20 & 90,95 & 1139,74 & 153,76 & 33,40 & 39,51 & 427,46 & 128,78 & \begin{tabular}{|l|}
149,04 \\
\end{tabular} & 397,92 \\
\hline Rana iberica & 29TNH69 & 95,00 & 138,76 & 72,50 & 41,54 & 3500,36 & 233,97 & 61,39 & 172,57 & 102,55 & 182,52 & 186,15 & 95,99 & 1070,00 & 141,51 & \begin{tabular}{|l|l|}
31,45 \\
\end{tabular} & 38,83 & 401,11 & 122,61 & 143,65 & 370,04 \\
\hline Rana iberica & 29TNH70 & 101,00 & 121,99 & 85,74 & 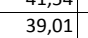 & 4488,05 & 244,15 & \begin{tabular}{|l|l|}
27,49 \\
\end{tabular} & 216,65 & \begin{tabular}{|l|}
72,54 \\
\end{tabular} & \begin{tabular}{|l|}
180,79 \\
\end{tabular} & \begin{tabular}{|l|}
181,86 \\
\end{tabular} & \begin{tabular}{|l|l|}
68,41 \\
\end{tabular} & 1311,15 & \begin{tabular}{|l|}
193,43 \\
\end{tabular} & 31,86 & $\begin{array}{l}44,90 \\
44,\end{array}$ & 500,27 & 128,43 & \begin{tabular}{|l|}
141,1700 \\
\end{tabular} & 487,17 \\
\hline Rana iberica & 29TNH71 & 99,00 & 118,16 & 84,62 & 39,24 & 4357,75 & 238,68 & 26,08 & 212,61 & 70,47 & 175,35 & 176,65 & 66,72 & $\mid 1346,03$ & \begin{tabular}{|l|}
196,75 \\
\end{tabular} & \begin{tabular}{|l|}
34,18 \\
\end{tabular} & 44,25 & 512,73 & 135,22 & 148,12 & 498,57 \\
\hline Rana iberica & 29TNH72 & 100,00 & 120,88 & 84,11 & 39,92 & 4229,67 & 238,74 & 30,06 & 208,68 & 74,28 & $\begin{array}{l}176,17 \\
\end{array}$ & $\begin{array}{l}177,82 \\
\end{array}$ & 71,15 & 1325,34 & 192,94 & 34,76 & 43,67 & 502,72 & 135,75 & 149,76 & 486,41 \\
\hline Rana iberica & 29TNH73 & 101,00 & 126,68 & 83,29 & 40,45 & 4067,70 & 240,51 & 37,36 & 203,15 & 81,38 & 179,54 & 181,47 & 78,91 & 1275,06 & 184,29 & 34,28 & 43,04 & 481,31 & 132,43 & 148,01 & 462,41 \\
\hline Rana iberica & 29TNH74 & 99,00 & 132,39 & 81,96 & 40,60 & 3987,50 & 243,52 & 43,78 & 199,74 & 88,08 & 184,03 & 186,11 & 85,16 & 1213,25 & 173,05 & 33,25 & 42,24 & 455,95 & 127,77 & \begin{tabular}{|l|}
145,03 \\
\end{tabular} & 434,40 \\
\hline 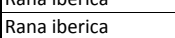 & 29TNH75 & $\begin{array}{l}500,00 \\
100\end{array}$ & 126,05 & $\begin{array}{l}1,154 \\
81,54\end{array}$ & 400,60 & 3942,56 & 237,71 & \begin{tabular}{|l|l|}
38,92 \\
38
\end{tabular} & \begin{tabular}{|l|}
$198,78,7$ \\
\end{tabular} & $\begin{array}{l}80,00 \\
82,92\end{array}$ & \begin{tabular}{|l|}
$177,11,11$ \\
\end{tabular} & \begin{tabular}{|l|}
179,571 \\
179
\end{tabular} & 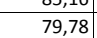 & $\begin{array}{l}121,257,87 \\
125,8\end{array}$ & \begin{tabular}{|l|}
177,32 \\
\end{tabular} & 35,75 & $\begin{array}{l}42,24 \\
41,48\end{array}$ & $\begin{array}{l}45,50 \\
472,00\end{array}$ & 136,39 & \begin{tabular}{|l|}
153,28 \\
153
\end{tabular} & $\begin{array}{l}4549,40 \\
449,29\end{array}$ \\
\hline Rana iberica & 29TNH76 & 100,00 & 123,45 & 80,75 & 40,48 & 3913,96 & 234,63 & 37,28 & \begin{tabular}{|l|}
197,35 \\
\end{tabular} & 81,06 & 174,02 & 176,74 & 77,42 & \begin{tabular}{|l|}
1263,07 \\
\end{tabular} & 175,84 & 36,85 & 40,71 & 472,81 & 140,15 & 157,23 & 448,44 \\
\hline Rana iberica & 29TNH77 & 100,00 & 122,67 & 79,66 & 40,36 & 3855,55 & 232,35 & 37,61 & $\begin{array}{l}194,73 \\
\end{array}$ & 81,38 & 172,28 & 175,29 & 77,27 & 1252,18 & 172,13 & 37,44 & 39,90 & 467,53 & 142,08 & 159,52 & 441,33 \\
\hline Rana iberica & 29TNH78 & 100,00 & 125,41 & 78,00 & 40,75 & 3774,11 & 231,87 & 42,35 & 189,52 & 85,45 & 173,73 & 176,95 & 80,70 & 1203,79 & 163,01 & 36,49 & 39,10 & 448,58 & 138,77 & 157,20 & 420,48 \\
\hline Rana iberica & 29TNH80 & 101,00 & 121,66 & 87,60 & 38,94 & 4624,64 & 246,68 & 24,51 & 222,16 & 70,44 & 182,41 & 183,22 & 66,42 & 1237,66 & $\begin{array}{l}179,48 \\
\end{array}$ & 30,18 & 44,30 & 469,27 & 122,14 & 134,09 & 456,60 \\
\hline $\begin{array}{l}\text { Tadd Iterde } \\
\text { Rana iberica }\end{array}$ & $\begin{array}{l}29 \text { TNNH81 } \\
\end{array}$ & $\frac{101,00}{101,00}$ & $\begin{array}{l}1<1,00 \\
109,95\end{array}$ & $\begin{array}{l}80,100 \\
85,46\end{array}$ & 38, 38,86 & $\begin{array}{l}4024,654 \\
448,49\end{array}$ & $\begin{array}{l}24,08 \\
233,90\end{array}$ & \begin{tabular}{|l|}
$4,31,90$ \\
16,
\end{tabular} & \begin{tabular}{|l|}
216,99 \\
2109
\end{tabular} & \begin{tabular}{|l|}
61,13 \\
613
\end{tabular} & \begin{tabular}{|l|}
$162,41,09$ \\
169
\end{tabular} & $\begin{array}{l}1703,24 \\
170,32\end{array}$ & \begin{tabular}{|l|l|}
50,44 \\
57,19
\end{tabular} & $\begin{array}{l}123,00 \\
1342,06\end{array}$ & \begin{tabular}{|l|l|l|l|}
191,49 \\
\end{tabular} & $\begin{array}{l}30,18 \\
34,69\end{array}$ & $\begin{array}{l}43,51 \\
431\end{array}$ & $\begin{array}{l}409,27 \\
509,67\end{array}$ & $\begin{array}{l}12,14 \\
137,52\end{array}$ & \begin{tabular}{|l|}
148,89 \\
1483
\end{tabular} & $\begin{array}{l}450,00 \\
496,35\end{array}$ \\
\hline Rana iberica & 29TNH82 & 100,00 & 116,25 & 85,54 & 39,56 & 4367,94 & 237,33 & 23,49 & 213,84 & 68,15 & 173,50 & \begin{tabular}{|l|}
175,03 \\
\end{tabular} & 64,72 & \begin{tabular}{|c|}
1291,08 \\
\end{tabular} & 184,62 & 34,22 & 42,98 & 487,78 & 134,11 & $\begin{array}{l}147,04 \\
\end{array}$ & 472,19 \\
\hline Rana iberica & 29TNH84 & 100,00 & 127,03 & 83,97 & 40,5 & 4104,26 & 241,13 & 36,61 & 204,52 & 81,13 & 180,29 & 182,31 & 78,65 & 1198,23 & 169,39 & 33,26 & 41,66 & 448,57 & 128,19 & 144,12 & 428,34 \\
\hline Rana iberica & 29TNH85 & 101,00 & 121,53 & 83,23 & 40,44 & 4063,13 & 235,80 & 32,57 & 203,23 & 76,88 & 174,31 & 176 & 73,91 & 1235,25 & 172,50 & 35,55 & 40,89 & 61,64 & 135,93 & \begin{tabular}{|l|l|}
151,63 \\
\end{tabular} & 439,92 \\
\hline Rana iberica & 29TNH86 & 101,00 & 115,94 & 82,36 & 40,29 & 4041,46 & 230,32 & 28,34 & 201,98 & 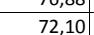 & \begin{tabular}{|c|}
168,44 \\
\end{tabular} & \begin{tabular}{|l|}
170,87 \\
\end{tabular} & | & \begin{tabular}{|l|}
1270,44 \\
120
\end{tabular} & \begin{tabular}{|l|l|}
175,37 \\
\end{tabular} & 37,83 & $\begin{array}{l}0,09 \\
39,99\end{array}$ & $\begin{array}{l}40,104 \\
473,87\end{array}$ & 143,78 & 159,12 & 450,46 \\
\hline Rana iberica & 29TNHE & 100,00 & 120,24 & 81,21 & 40,53 & 3948,06 & 231,67 & 33,64 & 198,03 & 77,44 & \begin{tabular}{|l|}
171,24 \\
\end{tabular} & 173,84 & 73,78 & 1223,72 & 167,01 & 37,04 & 39,34 & 454,95 & 140,50 & 157,10 & 429,47 \\
\hline Rana iberica & 29TNH88 & 101,00 & 120,39 & $\begin{array}{l}79,96 \\
\end{array}$ & 40,75 & 3879,56 & 229,84 & 35,39 & $\begin{array}{l}194,45 \\
\end{array}$ & 78,82 & $\begin{array}{l}170,37 \\
\end{array}$ & $\begin{array}{l}173,09 \\
\end{array}$ & 74,51 & 1209,88 & \begin{tabular}{|l|l|}
163,08 \\
\end{tabular} & 37,42 & 38,62 & 448,59 & 141,75 & 158,84 & 421,24 \\
\hline Rana iberica & 29TNH89 & 100,00 & 118,54 & 78,92 & 40,75 & 3828,43 & 226,61 & 34,99 & 191,62 & 77,91 & 167,77 & 170,85 & 73,56 & 1211,67 & 161,56 & 38,36 & 37,93 & 448,19 & 144,90 & 162,40 & 419,19 \\
\hline Rana iberica & 29TNH90 & 100,00 & 122,24 & 89,38 & 38,96 & 4753,56 & 249,93 & 22,45 & 227,48 & 69,16 & 184,61 & 185,24 & 65,15 & 1166,68 & 166,79 & 28,45 & 43,87 & 40,45 & 115,60 & 126,20 & 428,22 \\
\hline Rana iberica & 29TNH91 & $\begin{array}{l}101,00 \\
101,00\end{array}$ & $\begin{array}{l}12,2,24 \\
118,31\end{array}$ & $\frac{05}{88}$ & 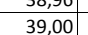 & $\begin{array}{l}46516,30 \\
4616,37\end{array}$ & 244,04 & $\begin{array}{l}\mid 2,, 27 \\
21,27\end{array}$ & \begin{tabular}{|l|}
222,770 \\
20
\end{tabular} & 67,07 & $\mid 178,96$ & 179,91 & 63,44 & 1205,83 & 171,39 & 30,83 & 43,10 & 454,83 & 123,06 & 135,26 & 441,25 \\
\hline Rana iberica & 29TNH93 & 100,00 & 120,09 & 86,50 & 39,86 & 4380,79 & 240,84 & 26,01 & 214,82 & 71,35 & \begin{tabular}{|l|}
177,34 \\
\end{tabular} & 178,84 & 68,32 & 1192,53 & 167,75 & 32,62 & 41,76 & 446,68 & 127,21 & 141,04 & 429,09 \\
\hline Rana iberica & 29TNH94 & 101,00 & 120,48 & 85,68 & 40,00 & 4286,38 & 239,28 & 27,86 & 211,42 & 72,89 & $\mid 176,37$ & \begin{tabular}{|l|l|}
178,07 \\
\end{tabular} & 69,93 & 1187,30 & 165,77 & 33,41 & 41.03 & 443,28 & 129,30 & $|143,69|$ & 423,85 \\
\hline Rana iberica & 29TNH95 & 101,00 & 120,38 & 84,72 & 40,10 & 4199,03 & 237,33 & 29,28 & 208,05 & 73,99 & 175,04 & 176,95 & 70,86 & 1186,55 & 164,11 & 34,36 & 40,28 & 441,78 & 132,04 & $\begin{array}{l}146,98 \\
\end{array}$ & 420,39 \\
\hline Rana iberica & 29TNH97 & 100,00 & 122,66 & 82,42 & 40,76 & 4034,11 & 235,08 & 34,51 & 200,57 & 78,55 & 174,71 & 177,24 & 74,77 & 1155,42 & 156,30 & 35,05 & 38,88 & 427,68 & 133,61 & 150,03 & 402 \\
\hline $\begin{array}{l}\mid l a l d \\
\text { Rana iberica }\end{array}$ & $29 \mathrm{TNH}$ & \begin{tabular}{|l|}
101,00 \\
\end{tabular} & $\begin{array}{l}12,21,00 \\
121,27\end{array}$ & $\begin{array}{l}2,42 \\
81,36\end{array}$ & $\begin{array}{l}40,10 \\
40,79\end{array}$ & \begin{tabular}{|l|l|} 
\\
$3959,49,32$
\end{tabular} & 232,09 & \begin{tabular}{|l|l|}
34,47 \\
34,47
\end{tabular} & \begin{tabular}{|l|}
$190,61 / 1$ \\
\end{tabular} & 78,34 & 172,28 & 174,98 & 74,29 & 1159,91 & 155,18 & 36,09 & 38,11 & 428,21 & 137,12 & 153,85 & 401,04 \\
\hline Rana iberica & 29TNJ60 & 66,00 & 138,42 & 71,58 & 41,92 & 3427,75 & 231,34 & 62,74 & 168,59 & 103,12 & $\begin{array}{l}181,05 \\
\end{array}$ & 184,86 & 96,42 & 1051,61 & 137,08 & \begin{tabular}{|l|l|}
31,55 \\
\end{tabular} & 38,09 & 393,14 & 123,14 & $\begin{array}{l}144,39 \\
\end{array}$ & 360,99 \\
\hline Rana iberica & 29TNJ61 & 82,00 & 138,78 & 70,46 & 42,23 & 3350,75 & 229,34 & 64,74 & 164,60 & 104,63 & 180,27 & 184,22 & 97,70 & \begin{tabular}{|l|}
1035,07 \\
\end{tabular} & 133,93 & \begin{tabular}{|l|l|l}
31,48 \\
\end{tabular} & 37,61 & 386,40 & 123,21 & 144,96 & 352,94 \\
\hline Rana iberica & 29TNJ62 & 77,00 & 138,50 & 69,71 & 42,42 & 3311,98 & 227,83 & 65,35 & 162,48 & 104,89 & 179,31 & 183, & 97,82 & 1028,44 & 132,74 & 31,91 & 37,02 & 383,10 & 124,55 & 146,55 & 348,41 \\
\hline Rana iberica & 29TNJ70 & 100,00 & 127,38 & 75,21 & 41,21 & 3607,29 & 228,03 & 47,99 & 180,04 & 89,86 & 172,98 & 176,58 & 84,18 & 1147,25 & 151,21 & 35,90 & 37,79 & 425,82 & 137,08 & 156,62 & 394,60 \\
\hline
\end{tabular}




\begin{tabular}{|c|c|c|c|c|c|c|c|c|c|c|c|c|c|c|c|c|c|c|c|c|c|}
\hline TAXON & UTM & km2 & B101 & B102 & B1O3 & B104 & B105 & B106 & B107 & B108 & B109 & BIO10 & BIO11 & BIO12 & B1013 & BIO14 & BIO15 & B1016 & BIO17 & B1018 & B1019 \\
\hline Rana iberica & 29TNJ71 & 101,00 & 129,37 & 73,82 & 41,56 & 3531,06 & 227,00 & 51,70 & $\begin{array}{r}175,30 \\
\end{array}$ & 92,88 & $\begin{array}{r}173,72 \\
\end{array}$ & 177,51 & 86,87 & 1112,83 & 144,77 & 35,26 & 37,04 & 412,33 & $\begin{array}{r}135,00 \\
\end{array}$ & $\begin{array}{r}155,22 \\
\end{array}$ & 379,66 \\
\hline Rana iberica & 29TNJ72 & 101,00 & 133,10 & 72,15 & \begin{tabular}{|l|l|}
42,08 \\
\end{tabular} & 3432,01 & 226,92 & 57,35 & 169,57 & 97,92 & 175,90 & 179,71 & 91,45 & 1067,50 & 137,07 & 34,02 & 36,65 & 394,97 & 131,15 & 152,16 & 360,88 \\
\hline Rana iberica & 29TNJ73 & 59,00 & 136,04 & 70,98 & 42,29 & 3368,61 & 227,33 & $\begin{array}{l}61,57 \\
\end{array}$ & 165,76 & 101,66 & 177,81 & 181,81 & 95,03 & 1033,72 & 133,07 & 33,30 & 36,18 & 381,82 & 128,65 & 150,28 & 346,35 \\
\hline Rana iberica & 29TNJ80 & 100,00 & 122,17 & 77,45 & \begin{tabular}{|l|}
40,97 \\
\end{tabular} & 3732,97 & 226,80 & 40,28 & 186,52 & 82,75 & 169,73 & \begin{tabular}{|l|}
173,01 \\
\end{tabular} & 77,78 & 1168,66 & 153,90 & \begin{tabular}{l|l|}
37,45 \\
\end{tabular} & 37,24 & 431,41 & \begin{tabular}{|l|l|}
141,75 \\
\end{tabular} & 160,10 & 400,68 \\
\hline Rana iberica & 29TNJ81 & 100,00 & 123,92 & 76,14 & \begin{tabular}{l|l|}
41,25 \\
\end{tabular} & 3653,63 & 225,79 & 43,65 & 182,14 & 85,62 & 170,26 & \begin{tabular}{|l|}
173,78 \\
\end{tabular} & 80,28 & 1142,11 & 148,61 & 37,10 & 36,76 & 420,70 & 140,61 & 159,65 & 388,46 \\
\hline Rana iberica & 29TNJ82 & 100,00 & 130,16 & 74,18 & 41,87 & 3535,37 & 227,38 & 52,20 & \begin{tabular}{|l|l|}
175,18 \\
\end{tabular} & 93,44 & 174,59 & 178,24 & 87,60 & 1077,42 & 138,13 & 35,11 & 36,12 & 396,33 & \begin{tabular}{|l|}
134,04 \\
\end{tabular} & 154,27 & 362,51 \\
\hline Rana iberica & 29TNJ83 & 101,00 & 130,18 & 72,98 & \begin{tabular}{|l|l|}
41,98 \\
\end{tabular} & 3479,40 & 225,55 & 53,48 & \begin{tabular}{|l|l|}
172,07 \\
\end{tabular} & 94,38 & 173,69 & 177,47 & 88,12 & 1072,64 & 137,44 & 35,55 & 35,79 & 393,85 & \begin{tabular}{|l|l|}
135,68 \\
\end{tabular} & 156,29 & 358,51 \\
\hline Rana iberica & 29TNJ84 & 31,00 & 128,75 & 72,62 & 42,07 & 3463,58 & 223,64 & 52,51 & 171,13 & 93,16 & 172,00 & 175,75 & 86,98 & 1079,11 & \begin{tabular}{|l|}
138,18 \\
\end{tabular} & 36,49 & 35,25 & \begin{tabular}{|l|}
395,05 \\
\end{tabular} & 138,64 & 159,35 & 358,69 \\
\hline Rana iberica & 29TNJ90 & 101,00 & 120,50 & 79,13 & \begin{tabular}{|l|l|}
40,94 \\
\end{tabular} & 3826,89 & 227,57 & 36,78 & 190,79 & 79,70 & 169,58 & 172,59 & 75,19 & 1151,81 & 150,82 & \begin{tabular}{|l|l|}
37,43 \\
\end{tabular} & 36,92 & 423,15 & 141,40 & 158,99 & 392,64 \\
\hline Rana iberica & 29TNJ91 & 101,00 & 119,44 & 78,01 & $\begin{array}{l}41,06 \\
\end{array}$ & 3765,45 & 224,70 & 37,15 & 187,55 & 79,81 & 167,50 & \begin{tabular}{|l|}
170,67 \\
\end{tabular} & 74,70 & 1154,74 & 149,70 & 38,31 & 36,17 & 423,15 & 144,50 & 162,42 & 391,05 \\
\hline Rana iberica & 29TNJ92 & 99,00 & 122,03 & 76,58 & 41,33 & 3678,40 & 224,31 & 41,38 & 182,93 & 83,46 & 168,71 & 172,09 & 78,17 & 1126,56 & 144,34 & 37,91 & 35,67 & 411,83 & 143,04 & 161,75 & 378,12 \\
\hline Rana iberica & 29TNJ93 & 92,00 & 133,74 & 73,98 & \begin{tabular}{|l|l|}
41,97 \\
\end{tabular} & 3525,79 & 229,64 & 55,54 & 174,11 & 96,84 & 177,87 & 181,48 & 91,05 & 1025,37 & 131,62 & 34,11 & 35,33 & 374,76 & 130,39 & 150,86 & 339,41 \\
\hline Rana iberica & 29TPE03 & 99,00 & 143,31 & 93,20 & 36,73 & 5412,20 & 291,02 & 40,40 & 250,62 & 77,86 & 215,25 & 215,73 & 77,86 & 1056,32 & 156,96 & |9,67 & 55,29 & 430,96 & $\begin{array}{l}65,84 \\
\end{array}$ & 65,92 & 430,96 \\
\hline Rana iberica & 29TPE04 & 101,00 & 133,29 & 89,19 & 35,94 & 5376,00 & 277,60 & 32,75 & 244,84 & 68,79 & 205,28 & 205,44 & 68,79 & 1173,62 & 176,92 & \begin{tabular}{l|l|}
10,95 \\
\end{tabular} & 55,84 & 480,06 & 72,32 & 72,34 & 480,06 \\
\hline Rana iberica & 29TPE05 & 101,00 & 126,58 & 86,64 & 35,51 & 5336,17 & 268,16 & 27,58 & 240,57 & 62,81 & 198,19 & 198,24 & 62,81 & 1256,14 & 190,94 & \begin{tabular}{l|l|}
11,95 \\
\end{tabular} & 56,14 & 514,50 & 76,92 & 76,93 & 514,50 \\
\hline Rana iberica & 29TPE06 & 100,00 & 135,12 & 91,66 & 36,74 & 5328,00 & 278,88 & 32,86 & 246,03 & 70,31 & 205,51 & 205,99 & 70,31 & 1164,94 & 175,36 & 11,03 & 55,58 & 475,27 & 73,03 & 73,29 & 475,27 \\
\hline Rana iberica & 29TPE07 & 101,00 & 141,90 & 96,20 & 37,94 & 5321,55 & 287,46 & 36,82 & 250,64 & 76,22 & 211,36 & 212,15 & 76,22 & 1091,34 & 162,71 & 10,26 & 55,15 & 443,22 & 69,66 & 70,37 & 443,22 \\
\hline Rana iberica & 29TPE08 & 100,00 & 144,63 & 98,44 & 38,54 & 5297,72 & 290,27 & 38,25 & 252,02 & 78,79 & 213,46 & 214,23 & 78,79 & 1062,03 & 157,71 & 9,92 & 54,88 & 429,93 & \begin{tabular}{|l|}
67,87 \\
\end{tabular} & 69,61 & 429,93 \\
\hline Rana iberica & 29TPE09 & 100,00 & 139,40 & 97,45 & 38,44 & 5293,84 & 284,18 & 33,86 & 250,32 & 73,69 & 208,42 & 209,06 & 73,69 & 1121,11 & 167,79 & 10,81 & 55,10 & 454,88 & 72,02 & 73,49 & 454,88 \\
\hline Rana iberica & 29TPE13 & 101,00 & 138,06 & 90,21 & $|35,47|$ & 5541,54 & 286,28 & 35,83 & 250,45 & 71,63 & 212,30 & 212.50 & \begin{tabular}{|l|}
71,63 \\
\end{tabular} & 1089,64 & $\mid 163,14$ & 9,87 & 55,65 & $\mid 444,77$ & 66,97 & 66,98 & 444,77 \\
\hline Rana iberica & 29TPE14 & 101,00 & 143,73 & 93,64 & 36,32 & 5535,10 & 293,33 & 39,08 & 254,25 & 76,45 & 217,15 & 217,53 & 76,45 & 1033,99 & 153,73 & 9,37 & 55,26 & 420,45 & 64,75 & 64,79 & 420,45 \\
\hline Rana iberica & 29TPE15 & 99,00 & 129,26 & 87,30 & 35,12 & 5467,14 & 273,53 & 28,66 & \begin{tabular}{|l|}
244,87 \\
\end{tabular} & 63,75 & 202,52 & 202,53 & 63,75 & $\begin{array}{l}1199,32 \\
\end{array}$ & 181,90 & 11,09 & 55,96 & 490,30 & 73,40 & 73,40 & 490,30 \\
\hline Rana iberica & 29TPE16 & 100,00 & 89,37 & 73,79 & \begin{tabular}{|l|}
32,38 \\
\end{tabular} & 5308,01 & 222,81 & $-1,45$ & 224,25 & 29,35 & 162,23 & 162,23 & 29,35 & 1627,76 & 249,32 & 17,25 & 56,10 & 663,37 & 100,90 & 100,90 & 663,37 \\
\hline Rana iberica & 29TPE17 & 100,00 & 105,52 & 77,94 & 33,30 & 5333,84 & 240,87 & 11,12 & 229,75 & 43,46 & 177,77 & \begin{tabular}{|l|}
177,83 \\
\end{tabular} & 43,46 & 1488,39 & 230,10 & 14,23 & 56,81 & 610,46 & 89,59 & 89,68 & 610,46 \\
\hline Rana iberica & 29TPE18 & 101,00 & 138,06 & 94,81 & 37,17 & 5436,40 & 284,38 & 32,78 & 251,60 & 71,02 & 209,38 & 209,73 & 71,02 & 1101,46 & 165,42 & 10,36 & 55,31 & 447,47 & 70,05 & 70,65 & 447,47 \\
\hline Rana iberica & 29TPE19 & 101,00 & 138,73 & 96,68 & 37,72 & 5420,53 & 285,38 & 32,53 & 252,85 & 71,60 & 209,64 & 209,95 & 71,60 & 1094,17 & 164,30 & 10,36 & 55,31 & 444,18 & 69,92 & 70,79 & 444,18 \\
\hline Rana iberica & 29TPE23 & 100,00 & 136,93 & 89,41 & 34,98 & 5655,55 & 286,47 & \begin{tabular}{|l|l|}
34,08 \\
\end{tabular} & \begin{tabular}{|l|}
252,39 \\
\end{tabular} & 69,31 & \begin{tabular}{|l|}
212,77 \\
\end{tabular} & \begin{tabular}{|l|}
212,88 \\
\end{tabular} & 69,31 & 1072,25 & \begin{tabular}{|l|l|}
160,25 \\
\end{tabular} & 9,60 & $\begin{array}{l}5,52 \\
55,52\end{array}$ & \begin{tabular}{|l|}
436,33 \\
\end{tabular} & \begin{tabular}{|l|}
65,86 \\
\end{tabular} & 65,86 & 4336,33 \\
\hline Rana iberica & 29TPE24 & 100,00 & 142,68 & 92,77 & \begin{tabular}{|l|l|}
35,65 \\
\end{tabular} & 5654,12 & 293,58 & 37,45 & 256,12 & 74,19 & 217,73 & 218,05 & 74,19 & 1014,30 & 150,67 & 8,95 & 55,21 & 411,38 & $\begin{array}{l}63,29 \\
\end{array}$ & 63,31 & 411,38 \\
\hline Rana iberica & 29TPE25 & 101,00 & 137,34 & 90,80 & 35,35 & 5606,22 & 285,74 & 33,34 & 252,40 & 69,51 & 211,78 & 212,03 & 69,51 & 1075,73 & 161,29 & 9,71 & 55,46 & 437,30 & 66,83 & 66,87 & 437,30 \\
\hline Rana iberica & 29TPE26 & 101,00 & 103,49 & 76,74 & 32,49 & 5450,47 & 240,55 & 9,06 & 231,49 & 40,44 & 177,45 & 177,47 & 40,44 & 1460,65 & 224,47 & 13,97 & 56,51 & 598,38 & 87,92 & 88,13 & 598,38 \\
\hline Rana iberica & 29TPE27 & 100,00 & 106,99 & 77,23 & \begin{tabular}{|c|}
32,68 \\
\end{tabular} & 5450,44 & 243,96 & 11,69 & 232,27 & 43,10 & 180,52 & 180,54 & 43,10 & 1421,80 & 219,17 & 13,32 & 56,76 & 583,80 & 85,34 & 86,46 & 583,80 \\
\hline Rana iberica & 29TPE28 & 100,00 & 115,82 & 82,63 & 34,00 & 5409,44 & 255,98 & $\begin{array}{l}1,1,15 \\
17,0\end{array}$ & 238,83 & 50,50 & \begin{tabular}{|l|}
188,84 \\
\end{tabular} & \begin{tabular}{|l|}
188,97 \\
\end{tabular} & 50,50 & $\begin{array}{l}14211,44 \\
131,4\end{array}$ & 200,81 & 12,45 & \begin{tabular}{|l|l|}
56,23 \\
\end{tabular} & \begin{tabular}{|l|}
537,03 \\
\end{tabular} & \begin{tabular}{|l|}
80,49 \\
\end{tabular} & $\begin{array}{l}0,404 \\
82,35\end{array}$ & 537,03 \\
\hline Rana iberica & 29TPE29 & 101,00 & 140,71 & 97,32 & \begin{tabular}{|l|l|}
37,40 \\
\end{tabular} & 5537,38 & 289,73 & 33,15 & 256,58 & 72,15 & 213,23 & 213,42 & 72,15 & 1031,62 & 154,36 & $\begin{array}{l}9,59 \\
\end{array}$ & 55,08 & 417,47 & 65,82 & 66,46 & $\begin{array}{l}417,47 \\
\end{array}$ \\
\hline Rana iberica & 29TPE33 & 101,00 & 151,94 & 96,18 & \begin{tabular}{|l|l|}
35,97 \\
\end{tabular} & 5812,66 & 307,44 & 43,36 & 264,08 & 84,32 & 228,71 & 229,21 & 81,34 & 887,47 & 129,32 & 7,58 & 54,42 & 356,64 & 56,06 & 56,28 & 356,61 \\
\hline Rana iberica & 29TPE34 & 100,00 & 144,07 & 93,37 & 35,58 & 5763,97 & 297,00 & 37,53 & 259,47 & 74,25 & 220,63 & 220,80 & 74,25 & 963,29 & $\begin{array}{l}142,08 \\
\end{array}$ & 8,48 & 54,82 & 388,56 & 60,65 & 60,78 & 388,56 \\
\hline Rana iberica & 29TPE36 & 101,00 & 139,74 & 92,73 & 35,61 & 5699,14 & 290,19 & 33,56 & $\begin{array}{ll}256,64 \\
\end{array}$ & 70,23 & 215,06 & 215,18 & 70,23 & 1004,28 & 149,39 & 9,13 & 54,98 & 405,67 & 63,55 & 64,08 & 405,67 \\
\hline 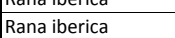 & 29TPE37 & \begin{tabular}{|l|l}
100,00 \\
\end{tabular} & 126,44 & 86,62 & | & 5632,12 & 272,12 & \begin{tabular}{|l|}
24,14 \\
24
\end{tabular} & \begin{tabular}{|l|}
247,948 \\
\end{tabular} & $\mid$\begin{tabular}{l|}
58,40 \\
\end{tabular} & \begin{tabular}{|l|}
201,32 \\
\end{tabular} & \begin{tabular}{|l|}
201,39 \\
\end{tabular} & 58,40 & |1136,45 & \begin{tabular}{|l|}
171,51 \\
171,51
\end{tabular} & $\mid$ & $\begin{array}{l}4,450 \\
55,48\end{array}$ & \begin{tabular}{|l|}
461,98 \\
461
\end{tabular} & \begin{tabular}{|l|}
70,30 \\
70,81
\end{tabular} & $\begin{array}{l}73,010 \\
73,01\end{array}$ & $\begin{array}{l}400,01,98 \\
461,9\end{array}$ \\
\hline Rana iberica & 29TPE38 & 101,00 & 108,42 & 77,78 & 32,55 & 5536,88 & 247,27 & 11,75 & 235,51 & 42,64 & 182,53 & 182,68 & 42,64 & 1323,69 & 202,22 & 12,65 & 56,09 & 541,51 & 81,32 & 87,37 & 541,51 \\
\hline Rana iberica & 29TPE39 & 99,00 & 129,36 & 90,95 & 35,62 & 5612,20 & 276,53 & 24,79 & 251,73 & 60,76 & 203,41 & 203,57 & 60,76 & 1096,85 & 165,15 & 10,54 & 55,27 & 444,89 & 69,91 & 71,83 & 444,89 \\
\hline Rana iberica & 29TPE45 & 101,00 & 142,38 & 93,54 & 35,41 & 5824,43 & 295,68 & 34,92 & 260,76 & 74,84 & 219,54 & 219,65 & 71,49 & 934,96 & 137,33 & 8,42 & 54,35 & 374,92 & \begin{tabular}{|l|l|}
59,48 \\
\end{tabular} & 59,90 & 374,91 \\
\hline Rana iberica & 29TPE46 & 99,00 & 140,79 & 93,71 & 35,62 & 5799,87 & 293,41 & 33,34 & 260,08 & 71,02 & 217,52 & 217,64 & 70,04 & 944,75 & 139,10 & 8,62 & 54,33 & 378,87 & 60,64 & 61,32 & 378,87 \\
\hline Rana iberica & 29TPE48 & $\begin{array}{l}99,00 \\
\end{array}$ & 117,54 & 82,71 & 33,32 & 5674,60 & 261,50 & \begin{tabular}{|l|}
16,91 \\
1
\end{tabular} & 244,60 & 48,96 & \begin{tabular}{|l|}
192,78 \\
\end{tabular} & \begin{tabular}{|l|}
193,24 \\
\end{tabular} & 48,96 & 1155,77 & \begin{tabular}{|l|}
173,94 \\
\end{tabular} & $\mid$ & 55,15 & \begin{tabular}{|l|l|}
468,54 \\
\end{tabular} & 73,04 & $\begin{array}{l}77,68 \\
77\end{array}$ & 468,54 \\
\hline Rana iberica & 29TPE49 & 101,00 & 125,55 & 88,94 & 34,86 & 5693,66 & 273,09 & 21,39 & 251,70 & 56,06 & 200,71 & 201,07 & 56,06 & 1071,79 & 160,32 & 10,53 & 54,81 & 432,91 & 69,15 & 71,71 & 432,91 \\
\hline Rana iberica & 29TPE54 & 100,00 & 147,75 & 95,98 & 35,62 & 5933,51 & 304,19 & 38,06 & 266,13 & 83,16 & 226,32 & 226,50 & 75,69 & 844,05 & 121,51 & 7,38 & 53,61 & 335,96 & 54,66 & 54,79 & 334,47 \\
\hline Rana iberica & 29TPE55 & 100,00 & 139,99 & 93,16 & 35,09 & 5892,53 & 294,01 & 32,20 & 261,81 & 76,16 & 218,11 & 218,19 & 68,40 & 909,11 & 132,39 & 8,41 & 53,90 & 62,66 & 58,54 & 59,38 & 361,92 \\
\hline Rana iberica & 29TPE56 & 101,00 & 128,25 & 88,22 & 34,20 & 5835,14 & 278,60 & 23,79 & 254,82 & 62,95 & \begin{tabular}{|l|}
205,80 \\
210,1
\end{tabular} & \begin{tabular}{|l|}
206,08 \\
20,10
\end{tabular} & 50,84 & $\mid$\begin{tabular}{|c|}
$\mid 1007,41$ \\
\end{tabular} & \begin{tabular}{|l|l|}
148,40 \\
\end{tabular} & $\begin{array}{l}, 41,62 \\
9,62\end{array}$ & 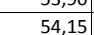 & \begin{tabular}{|l|}
403,27 \\
403
\end{tabular} & 60,44 & 年, & $\begin{array}{l}403,21 \\
403\end{array}$ \\
\hline Rana iberica & 29TPE57 & 100,00 & 122,18 & 85,75 & 33,73 & 5797,09 & 270,24 & 19,26 & 250,98 & 53,93 & 199,19 & \begin{tabular}{|l|}
199,57 \\
\end{tabular} & 52,20 & 1057,68 & 156,75 & 10,24 & 54,34 & 424,65 & 67,76 & 71,56 & 424,64 \\
\hline Rana iberica & 29TPE58 & 101,00 & 120,47 & 85,76 & 33,81 & 5774,86 & 268,03 & 17,55 & 250,48 & 51,08 & 196,97 & $\begin{array}{l}197,58 \\
\end{array}$ & 50,51 & 1064,41 & 157,89 & 10,49 & 54,30 & 427,55 & 68,80 & 72,51 & 427,55 \\
\hline Rana iberica & 29TPE64 & 101,00 & 148,18 & 97,18 & 35,78 & 5989,67 & 305,84 & 37,38 & 268,45 & 82,93 & 227,58 & 227,62 & 75,21 & 797,19 & 113,21 & 7,17 & 52,86 & 315,68 & 52,29 & 52,49 & 312,48 \\
\hline Rana iberica & 29TPE65 & 100,00 & 129,91 & 90,14 & 34,26 & 5929,70 & 283,01 & 23,91 & 259,10 & 66,46 & 208,92 & 209,16 & 58,67 & 944,84 & 136,77 & 9,21 & 53,25 & 375,78 & 61,54 & 63,95 & 373,87 \\
\hline $\begin{array}{l}|l| l \\
\text { Rana iberica }\end{array}$ & 29TPEG6 & \begin{tabular}{|l|l}
100,00 \\
\end{tabular} & 12 & $\begin{array}{l}0,149 \\
86,97\end{array}$ & 33, & 5881,62 & 270,01 & \begin{tabular}{|l|l|}
17,83 \\
1
\end{tabular} & \begin{tabular}{|l|}
254,43 \\
\end{tabular} & $\mid \begin{array}{l}59,20 \\
5\end{array}$ & \begin{tabular}{|l|}
200,18 \\
\end{tabular} & \begin{tabular}{|l|}
200,57 \\
\end{tabular} & \begin{tabular}{|l|}
51,21 \\
5
\end{tabular} & $\begin{array}{r}44,404 \\
1009,52\end{array}$ & $\mid$ & \begin{tabular}{|r|}
$, 20,10$ \\
10,10
\end{tabular} & \begin{tabular}{|l|}
53,46 \\
53
\end{tabular} & $\mid$ & \begin{tabular}{|l|}
05,34 \\
65,82
\end{tabular} & \begin{tabular}{|l|l|}
69,68 \\
6,50
\end{tabular} & $\begin{array}{l}300,97 \\
4\end{array}$ \\
\hline Rana iberica & 29TPEG7 & 101,00 & 125,29 & 89,10 & 34,18 & 5888,96 & 276,66 & 19,84 & 256,83 & 61,99 & 203,34 & 203,90 & 54,13 & \begin{tabular}{|}
971,07 \\
\end{tabular} & 141,31 & 9,83 & 53,26 & \begin{tabular}{|l|}
386,21 \\
\end{tabular} & \begin{tabular}{|l|}
64,13 \\
\end{tabular} & 66,99 & 385,15 \\
\hline Rana iberica & 29TPE75 & 99,00 & 135,54 & 94,15 & $\begin{array}{l}34,92 \\
\end{array}$ & 6008,58 & 292,03 & 26,54 & 265,49 & 70,70 & 215,39 & 215,63 & 62,83 & 847,52 & 119,95 & \begin{tabular}{|l|l|}
8,43 \\
\end{tabular} & 52,10 & 334,35 & \begin{tabular}{|l|}
56,87 \\
\end{tabular} & 58,58 & 330,22 \\
\hline Rana iberica & 29TPE76 & 101,00 & 116,20 & 87,38 & 33,60 & 5936,45 & 267,97 & 12,02 & 255,95 & 53,37 & 195,55 & 196,01 & 45,46 & 998,94 & 143,22 & 10,53 & 52,42 & 395,43 & 67,06 & 71,63 & 392,2 \\
\hline Rana iberica & 29TPE85 & 101,00 & 126,42 & 93,40 & 34,64 & 6044,36 & 283,86 & 18,13 & 265,73 & 61,90 & 207,17 & 207,49 & 54,01 & 867,71 & 120,90 & 9,38 & 51,16 & 339,84 & 60,08 & 62,81 & 33 \\
\hline $\begin{array}{l}\mid l a l d \\
\text { Rana iberica }\end{array}$ & 29TPE86 & $\begin{array}{l}100,00 \\
100\end{array}$ & $\begin{array}{l}120,42 \\
117,60\end{array}$ & $\begin{array}{l}90,40 \\
90,52\end{array}$ & $\begin{array}{l}34,04 \\
34,02\end{array}$ & \begin{tabular}{|l|l|l|l|l|}
6008,49 \\
\end{tabular} & $\begin{array}{l}20,00 \\
272,64\end{array}$ & $\begin{array}{l}1,1,27 \\
11,27\end{array}$ & \begin{tabular}{|l|}
261,36 \\
\end{tabular} & 53,76 & $\begin{array}{l}197,92 \\
\end{array}$ & 198,45 & 45,95 & 928,26 & 130,25 & 10,32 & 51,22 & 364,31 & $\begin{array}{l}64,53 \\
\end{array}$ & |68,45 & 358,97 \\
\hline Rana iberica & 29TPE95 & 100,00 & 133,71 & 97,47 & 35,24 & 6122,54 & 294,97 & 22,26 & 272,71 & 67,52 & 215,21 & 215,54 & 59,77 & 762,82 & 103,58 & 8,34 & 49,95 & 295,84 & 54,36 & 55,87 & 288,21 \\
\hline Rana iberica & 29TPE96 & 100,00 & 121,66 & 94,40 & 34,79 & 6085,22 & 280,54 & 12,66 & 267,88 & 56,49 & 202,72 & 203,40 & 48,71 & 839,86 & 114,81 & 9,92 & 49,81 & 326,27 & 60,70 & 63,49 & 318,88 \\
\hline Rana iberica & 29TPF00 & 101,00 & 139,06 & 98,71 & 38,88 & 5279,84 & 283,75 & 32,90 & 250,85 & 73,23 & 207,69 & 208,2 & 73, & 1127,70 & 168,86 & 10,94 & 55 & 457,17 & 72,42 & 74,61 & 457, \\
\hline Rana iberica & 29TPF01 & 100,00 & 128,78 & 95,58 & 38,14 & 5282,38 & 272,01 & 24,88 & 247,14 & 63,64 & 197,92 & 198,34 & 63,64 & 1241,40 & 187,92 & 12,69 & 55,62 & 505,95 & 80,76 & 81,46 & 505,95 \\
\hline
\end{tabular}




\begin{tabular}{|c|c|c|c|c|c|c|c|c|c|c|c|c|c|c|c|c|c|c|c|c|c|}
\hline TAXON & UTM & $\mathrm{km2}$ & B101 & B102 & $\mathrm{BIO3}$ & B104 & B105 & B106 & B107 & B108 & B109 & 81010 & B1011 & BIO12 & BIO13 & 81014 & BIO15 & B1O16 & B1017 & BIO18 & B1019 \\
\hline Rana iberica & 29TPF02 & 100,00 & 120,33 & 92,91 & 37,62 & 5265,34 & 262,17 & 18,53 & 243,64 & 55,99 & 189,91 & 190,07 & 55,99 & $\begin{array}{r}1328,52 \\
\end{array}$ & 201,64 & 14,36 & 55,81 & 542,65 & 87,32 & 87,58 & 542,65 \\
\hline Rana iberica & 29TPF03 & 101,00 & 113,74 & 90,97 & 37,23 & 5258,84 & 254,54 & 13,44 & 241,10 & 50,04 & $\begin{array}{l}183,61 \\
\end{array}$ & $\begin{array}{l}183,69 \\
\end{array}$ & 50,04 & 1387,50 & 209,98 & 15,89 & 55,33 & 566,60 & 92,49 & 92,91 & 566,60 \\
\hline Rana iberica & 29TPF04 & 100,00 & 128,77 & 101,16 & 39,55 & 5306,69 & 275,19 & 22,47 & 252,72 & 62,85 & \begin{tabular}{|l|}
197,94 \\
\end{tabular} & 198,38 & 62,85 & 1242,10 & 187,23 & 13,26 & 55,32 & 505,25 & 81,75 & 84,25 & 505,25 \\
\hline Rana iberica & 29TPF05 & 100,00 & 142,96 & 106,65 & 40,84 & 5279,31 & 290,93 & 32,77 & 258,16 & 78,24 & 210,95 & 211,44 & 76,34 & 1091,92 & 161,79 & 10,97 & 54,62 & 439,34 & 70,24 & 76,22 & 439,25 \\
\hline Rana iberica & 29TPF06 & 100,00 & 141,31 & 108,38 & 40,93 & 5312,79 & 291,76 & 30,46 & 261,30 & 79,60 & 209,92 & 210,29 & 74,38 & \begin{tabular}{|l|l|}
1113,87 \\
\end{tabular} & 165,33 & 11,38 & 54,92 & 449,72 & 71,98 & 77,73 & 448,75 \\
\hline Rana iberica & 29TPF07 & 101,00 & 129,25 & 104,96 & 40,17 & 5320,59 & 279,02 & 21,27 & 257,75 & 69,15 & 198,58 & 198,93 & 63,25 & 1223,92 & 181,16 & 14,12 & 54,73 & 496,20 & 82,95 & 87,13 & 494,77 \\
\hline Rana iberica & 29TPF08 & 100,00 & 108,66 & 93,52 & 38,00 & 5223,34 & 250,90 & 8,30 & 242,61 & 45,75 & 178,02 & 178,18 & 45,68 & 1370,44 & \begin{tabular}{|l|}
197,65 \\
\end{tabular} & 19,63 & 52,80 & 551,13 & 101,85 & 103,26 & 551,12 \\
\hline Rana iberica & 29TPF09 & 100,00 & 111,77 & 94,08 & 38,18 & 5213,47 & 253,83 & \begin{tabular}{|c|}
10,63 \\
\end{tabular} & 243,20 & 48,68 & 180,74 & 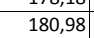 & 48,68 & 1325,43 & 188,43 & 19,36 & 52,06 & 530,87 & $\begin{array}{l}99,87 \\
\end{array}$ & 101,47 & 530,87 \\
\hline Rana iberica & 29TPF10 & 100,00 & 136,14 & 97,26 & 37,92 & 5414,49 & 282,79 & 29,94 & 252,85 & 69,04 & 207,02 & 207,27 & 69,04 & 1121,47 & 169,00 & 10,83 & 55,29 & 455,61 & 72,08 & 72,82 & 455,61 \\
\hline Rana iberica & 29TPF11 & 100,00 & 128,63 & 95,37 & 37,60 & 5404,76 & 274,24 & 23,95 & 250,29 & 62,05 & \begin{tabular}{|l|}
199,63 \\
\end{tabular} & $\begin{array}{l}199,88 \\
\end{array}$ & 62,05 & 1200,90 & 182,25 & 12,14 & 55,80 & 489,67 & \begin{tabular}{ll|}
77,94 \\
\end{tabular} & 78,26 & 489,67 \\
\hline Rana iberica & 29TPF12 & 100,00 & 118,88 & 91,96 & 36,84 & 5385,78 & 262,58 & 16,65 & 245,93 & 53,27 & 190,27 & 190,32 & 53,27 & 1295,22 & 197,19 & 13,90 & 55,95 & 529,52 & 84,37 & 85,12 & 529,52 \\
\hline Rana iberica & 29TPF13 & 101,00 & 121,03 & 95,23 & 37,65 & 5397,58 & 266,55 & 17,10 & 249,45 & 54,91 & 192,27 & 192,40 & 54,91 & 1270,64 & 192,82 & 13,83 & 55,64 & 518,67 & 83,82 & 84,37 & 518,67 \\
\hline Rana iberica & 29TPF14 & 100,00 & 124,50 & 99,18 & 38,54 & 5414,99 & 272,28 & 18,51 & 253,77 & 57,77 & 195,61 & $\begin{array}{l}195,77 \\
\end{array}$ & 57,77 & 1234,38 & 186,67 & 13,56 & 55,38 & 502,96 & 82,15 & 83,12 & 502,96 \\
\hline Rana iberica & 29TPF15 & 100,00 & 140,38 & 106,18 & 40,16 & 5405,68 & 290,95 & 29,63 & 261,32 & 73,99 & 210,42 & 210,69 & 72,49 & 1074,86 & 160,31 & 10,99 & 54,83 & 433,77 & 69,73 & 73,32 & 433,71 \\
\hline Rana iberica & 29TPF16 & 101,00 & 133,02 & 106,93 & 40,08 & 5451,47 & 286,04 & 22,66 & 263,38 & 70,80 & 203,93 & 204,22 & 65,01 & 1150,71 & 172,83 & 12,42 & 55,22 & 467,60 & 76,12 & 78,60 & 466,91 \\
\hline Rana iberica & 29TPF17 & 99,00 & 124,80 & 103,41 & 39,44 & 5430,11 & 275,66 & 16,91 & 258,75 & 60,08 & 195,94 & 196,20 & 57,73 & 1205,82 & $\begin{array}{l}179,03 \\
\end{array}$ & 14,42 & 54,47 & 488,74 & 83,17 & 84,79 & 488,54 \\
\hline Rana iberica & 29TPF18 & 101,00 & 116,77 & 98,81 & 38,68 & 5375,05 & 264,19 & 11,86 & 252,33 & 51,10 & 187,58 & 187,81 & 51,10 & 1252,20 & 182,52 & 16,84 & 53,27 & 505,01 & 90,84 & 91,97 & 505,01 \\
\hline Rana iberica & 29TPF19 & 101,00 & 113,80 & 96,73 & 38,31 & 5336,32 & 259,53 & 10,18 & 249,36 & 48,93 & $\begin{array}{l}184,38 \\
\end{array}$ & $\begin{array}{l}184,52 \\
\end{array}$ & 48,93 & 1255,75 & $\begin{array}{l}179,85 \\
\end{array}$ & 18,12 & 52,30 & $\begin{array}{l}503,68 \\
\end{array}$ & 94,08 & 94,80 & 503,68 \\
\hline Rana iberica & 29TPF20 & 100,00 & 131,99 & 94,76 & 36,96 & 5520,84 & 279,47 & 26,29 & 253,18 & 63,93 & 204,61 & 204,73 & 63,93 & 1119,52 & 169,25 & 10,95 & 55,43 & 455,27 & 72,09 & 72,60 & 455,27 \\
\hline Rana iberica & 29TPF21 & 101,00 & 126,21 & 93,56 & 36,68 & $\mid 5513,60$ & 272,97 & 21,53 & 251.44 & 58,52 & \begin{tabular}{|c|}
198,83 \\
\end{tabular} & \begin{tabular}{|c|}
198,97 \\
\end{tabular} & 58,52 & $\mid 1172,13$ & $\mid 177,94$ & $\mid 11,92$ & 55,70 & 477,64 & 75,95 & 76,74 & 477,64 \\
\hline Rana iberica & 29TPF22 & 100,00 & 123,09 & 94,03 & 36,88 & 5506,71 & 269,90 & 18,45 & 251,45 & 55,53 & 195,71 & 195,79 & 55,53 & 1199,46 & 182,05 & 12,6 & 55,60 & 488,99 & 78,61 & 79,60 & 488,99 \\
\hline Rana iberica & 29TPF23 & 100,00 & 126,79 & 98,25 & 37,87 & 5516,59 & 275,90 & 19,95 & 255,94 & 58,64 & \begin{tabular}{|l|l}
199,26 \\
\end{tabular} & \begin{tabular}{|l|}
199,34 \\
\end{tabular} & 58,64 & 1160,35 & $\begin{array}{l}175,66 \\
\end{array}$ & 12,24 & 55,32 & 472,38 & 76,56 & 77,15 & 472,38 \\
\hline Rana iberica & 29TPF24 & 101,00 & 126,75 & 100,17 & 38,32 & 5518,90 & 277,01 & 19,14 & 257,87 & 58,60 & 199,25 & $\begin{array}{l}199,32 \\
\end{array}$ & 58,60 & 1155,55 & 174,45 & 12,59 & 55,08 & 469,91 & 77,07 & 77,46 & 469,91 \\
\hline Rana iberica & 29TPF28 & 101,00 & 124,70 & 103,28 & 39,13 & 5499,98 & 276,56 & 15,72 & 260,84 & 56,85 & \begin{tabular}{|l|}
197,01 \\
\end{tabular} & \begin{tabular}{|l|}
197,03 \\
\end{tabular} & 56,85 & 1124,99 & 164,65 & 14,44 & 53,30 & 453,16 & 80,03 & 80,49 & 453,16 \\
\hline Rana iberica & 29TPF29 & 100,00 & 119,33 & 100,64 & 38,58 & 5460,93 & 269,38 & 12,14 & 257,24 & 52,55 & 191,46 & 191,47 & 52,55 & 1147,42 & 165,13 & 16,19 & 52,33 & 460,08 & 85,13 & 85,52 & 460,08 \\
\hline Rana iberica & 29TPF30 & 101,00 & 138,54 & 97,73 & 37,13 & 5630,05 & 289,25 & 30,10 & 259,15 & 68,92 & 212,42 & 212,50 & 68,92 & 1001,01 & 149,52 & 9,60 & 54,78 & 403,99 & 64,84 & 65,10 & 403,99 \\
\hline Rana iberica & 29TPF31 & 100,00 & 122,01 & $\begin{array}{l}1,1,03 \\
\end{array}$ & 35,81 & 5592,34 & 269,00 & $\begin{array}{l}17,97 \\
17\end{array}$ & 251,03 & 53,63 & \begin{tabular}{|l|}
195,80 \\
\end{tabular} & \begin{tabular}{|l|}
196,16 \\
\end{tabular} & 53,63 & 1153,91 & \begin{tabular}{|l|}
174,51 \\
1745
\end{tabular} & 11,85 & 55,18 & \begin{tabular}{|l|l}
469,29 \\
\end{tabular} & $\begin{array}{l}75,12 \\
\end{array}$ & 77, & 469,29 \\
\hline Rana iberica & 29TPF32 & 101,00 & 118,52 & 91,48 & 35,98 & 5579,90 & 265,56 & 14,68 & 250,89 & 50,49 & \begin{tabular}{|l|}
192,24 \\
\end{tabular} & \begin{tabular}{|l|}
192,61 \\
\end{tabular} & 50,49 & 1181,51 & 178,55 & 12,66 & 55,06 & 480,60 & 78,06 & 80,25 & 480,60 \\
\hline Rana iberica & 29TPF33 & 101,00 & 117,67 & 93,44 & 36,47 & 5576,81 & 265,92 & 13,04 & 252,89 & 49,59 & 191,29 & 191,61 & 49,59 & 1180,34 & 177,86 & 13,10 & 54,92 & 479,81 & 79,46 & 81,04 & 479,81 \\
\hline Rana iberica & 29TPF34 & 100,00 & 123,76 & 98,46 & 37,58 & 5598,62 & 274,87 & 16,29 & 258,58 & 54,90 & 197,58 & $\begin{array}{l}197,69 \\
\end{array}$ & 54,90 & 1117,24 & 167,71 & 12,54 & 54,69 & 453,09 & 75,71 & 76,31 & 453,09 \\
\hline Rana iberica & 29TPF36 & 100,00 & 136,08 & 105,63 & 39,20 & 5593,92 & 290,39 & 23,96 & 266,43 & 66,31 & 209,21 & 209,21 & 66,31 & 987,88 & 145,90 & 11,16 & 53,79 & 397,09 & 67,05 & 67,16 & 397,09 \\
\hline Rana iberica & 29TPF 38 & 99,00 & 135,86 & 107,09 & $\begin{array}{l}39,20 \\
39,57\end{array}$ & 5593,05 & 290,65 & 22,66 & \begin{tabular}{|l|}
267,99 \\
\end{tabular} & $\begin{array}{l}0,0,02 \\
66,\end{array}$ & $\mid$ & \begin{tabular}{|l|}
208,89 \\
\end{tabular} & $\begin{array}{l}0,011 \\
66,02\end{array}$ & \begin{tabular}{|l|l|l|l|l|}
963,54 \\
\end{tabular} & \begin{tabular}{|l|}
139,80 \\
\end{tabular} & $\begin{array}{l}1,108 \\
11,88\end{array}$ & 52,75 & \begin{tabular}{|l|}
385,04 \\
\end{tabular} & $\begin{array}{l}67,49 \\
67\end{array}$ & $\begin{array}{l}67,52 \\
\end{array}$ & 385,04 \\
\hline Rana iberica & 29TPF39 & 101,00 & 128,98 & 104,90 & 39,08 & 5570,40 & 282,66 & 17,49 & 265,18 & 60,08 & 202,29 & 202,29 & 60,08 & 1002,01 & 143,85 & 13,58 & 51,97 & 400,05 & 73,12 & 73,12 & 400,05 \\
\hline Rana iberica & 29TPF41 & 100,00 & 130,09 & 95,51 & 36,44 & 5704,54 & 281,07 & 22,43 & 258,64 & 59,81 & 205,16 & 205,40 & 59,81 & 1019,40 & 152,10 & 10,51 & 54,47 & 410,99 & 67,65 & 68,26 & 410,99 \\
\hline Rana iberica & 29TPF42 & 101,00 & 129,46 & 97,21 & 36,92 & 5693,92 & 281,22 & 21,12 & 260,10 & 59,25 & 204,42 & 204,60 & 59,25 & 1019,33 & 152,01 & 10,78 & 54,30 & 410,91 & 68,29 & 68,78 & 410,91 \\
\hline Rana iberica & 29TPF43 & 100,00 & 128,47 & 98,78 & 37,29 & 5690,11 & 281,10 & 19,51 & 261,59 & 58,25 & 203,40 & 203,53 & 58,25 & 1018,61 & \begin{tabular}{|l|l|}
151,77 \\
\end{tabular} & 11,11 & 54,11 & 410,75 & 69,20 & 69,37 & 410,75 \\
\hline 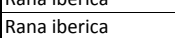 & $\begin{array}{l}29 T P F 47 \\
\end{array}$ & 99,00 & $\begin{array}{l}120,41 \\
132,70\end{array}$ & $\begin{array}{r}50,10 \\
105,43\end{array}$ & $\begin{array}{l}38,2 \\
38,83\end{array}$ & $\begin{array}{l}5005,11 \\
5659,92\end{array}$ & 288,25 & $\frac{10,0}{20,00}$ & \begin{tabular}{|l|l|l|l|l|}
268,25 \\
\end{tabular} & $\begin{array}{l}62,32 \\
62,32\end{array}$ & $\mid$\begin{tabular}{|l|}
207,06 \\
\end{tabular} & \begin{tabular}{|l|}
207,06 \\
\end{tabular} & $\begin{array}{ll}62,32 \\
62,32\end{array}$ & \begin{tabular}{|c|}
938,61 \\
9
\end{tabular} & 136,65 & $\begin{array}{l}1,11,66 \\
11,0\end{array}$ & \begin{tabular}{|c|}
4,411 \\
52,49
\end{tabular} & \begin{tabular}{|}
$\mid 40,15$ \\
375,35 \\
\end{tabular} & $\begin{array}{l}3,20 \\
66,55\end{array}$ & $\begin{array}{l}6,51,55 \\
6\end{array}$ & 375,35 \\
\hline Rana iberica & 29TPF49 & 100,00 & 137,42 & 106,91 & 39,23 & 5629,61 & 292,32 & 23,10 & 269,23 & 67,23 & 211,12 & 211,12 & 66,99 & 873,61 & 123,63 & 11,76 & 51,03 & 345,28 & $\begin{array}{l}63,87 \\
\end{array}$ & $\begin{array}{l}63,87 \\
\end{array}$ & 345,28 \\
\hline Rana iberica & 29TPF57 & 101,00 & 134,38 & 105,98 & 38,67 & 5715,32 & 291,15 & 20,48 & 270,66 & 63,93 & 209,56 & 209,56 & 63,28 & 863,64 & $\mid 124,24$ & 11,01 & 51,61 & $\mid 343,18$ & 62.44 & 62.44 & 343,14 \\
\hline Rana iberica & 29TPF61 & 100,00 & 132,16 & 97,93 & 36,39 & 5855,03 & 287,09 & 21,78 & 265,31 & 64,63 & 209,47 & 209,65 & 59,93 & 881,01 & 127,52 & 9,52 & 52,48 & 348,64 & 61,25 & 61,44 & 348,50 \\
\hline Rana iberica & 29TPF68 & 101,00 & 125,92 & 105,07 & 38,24 & 5746,97 & 283,86 & 12,69 & 271,17 & 55,71 & 201,92 & 201,94 & 54,87 & 847,90 & 119,58 & 11,95 & 50,01 & 334,57 & 65,86 & 65,90 & 334,55 \\
\hline Rana iberica & 29TPF78 & 100,00 & 129,88 & 107,05 & 38,40 & 5809,03 & 289,73 & 14,60 & 275,14 & 62,27 & 206,69 & 206,69 & 57,73 & 759,94 & 105,55 & 10,85 & \begin{tabular}{|l|l|}
49,07 \\
\end{tabular} & 297,53 & \begin{tabular}{|l|l|}
59,92 \\
\end{tabular} & 59,92 & 297,20 \\
\hline Rana iberica & 29TPF79 & 100,00 & 123,01 & 106,30 & 38,32 & 5778,23 & 282,90 & 8,87 & 274,03 & 54,38 & 199,62 & $\begin{array}{l}199,64 \\
\end{array}$ & 51,64 & 793,80 & 109,92 & 12,11 & 48,60 & 311,30 & 65,06 & 65,08 & 311,22 \\
\hline Rana iberica & 29TPF86 & 100,00 & 126,57 & 105,56 & 37,85 & 5900,58 & 287,13 & 11,93 & 275,19 & 60,90 & 204,84 & 204,84 & 53,61 & 744,61 & 101,80 & 10,30 & 48,49 & 289,46 & 59,65 & 59,65 & 287,21 \\
\hline Rana iberica & 29TPF89 & 100,00 & 127,67 & 108,27 & 38,52 & 5831,94 & 288,98 & 11,46 & 277,52 & 62,03 & 204,89 & 204,89 & 55,23 & 706,50 & 95,57 & 11,02 & 47,46 & 274,56 & 59,14 & 59,14 & 273,30 \\
\hline Rana iberica & 29TPG00 & 101,00 & 128,55 & 101,51 & 39,68 & 5268,55 & 274,20 & 21,32 & $\mid 252,88$ & \begin{tabular}{|l|}
63,34 \\
\end{tabular} & \begin{tabular}{|l|}
197,31 \\
\end{tabular} & \begin{tabular}{|l|}
197,49 \\
\end{tabular} & $\mid 63,30$ & 1164,34 & \begin{tabular}{|c|}
161,88 \\
\end{tabular} & $\begin{array}{l}1,0<2 \\
15,93\end{array}$ & 51,68 & \begin{tabular}{|l|l|}
461,28 \\
\end{tabular} & $\begin{array}{l}5,31,32 \\
\end{array}$ & 88,02 & 461,28 \\
\hline Rana iberica & 29TPG01 & 100,00 & 11. & 92,42 & 37,99 & 5168,72 & 251,69 & 11,49 & 240,20 & 49,41 & 180,21 & \begin{tabular}{|l|}
180,35 \\
\end{tabular} & 49,41 & 1289,31 & 176,79 & 20,7 & 50,47 & 510,67 & \begin{tabular}{|l|}
101,87 \\
\end{tabular} & 103,85 & 510,67 \\
\hline Rana iberica & 29TPG02 & 100,00 & 106,85 & 88,80 & 37,21 & 5111,32 & 244,26 & 9,02 & 235,24 & 45,71 & 174,80 & \begin{tabular}{|l|}
174,99 \\
\end{tabular} & 45,71 & 1310,86 & 176,48 & 22,83 & 49,52 & 516,13 & 107,83 & 110,31 & 516,13 \\
\hline Rana iberica & 29TPG03 & 101,00 & 100,34 & 86,02 & 36,70 & 5053,09 & 235,86 & 4,79 & 231,07 & 40,97 & 167,75 & 168,01 & 40,55 & 1349,43 & 178,69 & 25,66 & 48,45 & 527,55 & 116,37 & 118,48 & 527,53 \\
\hline Rana iberica & 29TPG04 & 100,00 & 105,08 & 88,21 & 37,23 & 5064,05 & 241,28 & 7,38 & 233,90 & 49,16 & 172,41 & 172,65 & 44,73 & 1295,86 & 171,56 & 25,20 & 47,82 & 502,97 & 113,33 & 115,43 & 502,81 \\
\hline $\begin{array}{l}|l| l \\
\text { Rana iberica }\end{array}$ & 29TPG05 & 101,00 & $\begin{array}{l}10,00 \\
119,89\end{array}$ & $\begin{array}{l}0,2,21 \\
93,96\end{array}$ & $\frac{13,25}{38,26}$ & \begin{tabular}{|c|}
5150,06 \\
\end{tabular} & $\begin{array}{l}24,20 \\
258,22\end{array}$ & \begin{tabular}{|r|}
15,84 \\
15,
\end{tabular} & \begin{tabular}{|l|l|}
242,38 \\
\end{tabular} & $\begin{array}{l}43,14 \\
63,14\end{array}$ & \begin{tabular}{|c|}
187,92 \\
187
\end{tabular} & \begin{tabular}{|l|}
188,01 \\
\end{tabular} & \begin{tabular}{|l|}
57,21 \\
57,21
\end{tabular} & $\begin{array}{l}129,00 \\
1153,20\end{array}$ & \begin{tabular}{|l|l|l|l|l|l|}
156,06 \\
\end{tabular} & $\mid 22,16$ & \begin{tabular}{|l|l|}
47,08 \\
47
\end{tabular} & \begin{tabular}{|l|}
443,66 \\
\end{tabular} & \begin{tabular}{|l|}
100,34 \\
\end{tabular} & 101,71 & $\begin{array}{l}40,01 \\
440,77\end{array}$ \\
\hline Rana iberica & 29TPG07 & 100,00 & 123,10 & 93,56 & 38,15 & 5116,46 & 259,22 & 18,05 & 241,17 & 66,16 & 190,42 & $\begin{array}{l}190,56 \\
\end{array}$ & 60,93 & 1099,61 & 152,97 & 23,37 & 45,42 & 418,36 & 101,12 & 104,45 & 411,31 \\
\hline Rana iberica & \begin{tabular}{|l|} 
29TPG08 \\
\end{tabular} & 101.00 & 122,86 & 92.65 & 38.09 & 5064,76 & 257,47 & 18,36 & 239,11 & 66,42 & $|189,60|$ & \begin{tabular}{|l|}
189,72 \\
\end{tabular} & $\mid 61.56$ & 1094,30 & $\mid 153,24$ & 24,48 & 44,66 & 414,44 & $\mid 103,56$ & 107,31 & 405,74 \\
\hline Rana iberica & 29TPG09 & 99,00 & 123,31 & 91,60 & 38,18 & 4991,49 & 255,79 & 19,62 & 236,17 & 67,51 & 188,94 & 189,15 & 63,01 & 1087,23 & 152,76 & 25,49 & 43,95 & 410,21 & $\begin{array}{l}105,63 \\
\end{array}$ & 112,58 & 399,86 \\
\hline Rana iberica & 29TPG10 & 100,00 & 126,91 & 102,29 & 39,40 & 5384,67 & 275,27 & 18,51 & 256,76 & 60,43 & 197,61 & 197,66 & 60,43 & 1124,66 & 158,03 & 15,63 & 51,73 & 446,89 & 82,92 & 83,49 & 44 \\
\hline $\begin{array}{l}\mid l a l d \\
\text { Rana iberica }\end{array}$ & 29TPG11 & \begin{tabular}{|l|}
100,00 \\
\end{tabular} & $\begin{array}{l}120,51 \\
130,59\end{array}$ & $\begin{array}{l}10,25 \\
102,55\end{array}$ & $\begin{array}{l}35,40 \\
39,37\end{array}$ & 5301, & 278,26 & $\begin{array}{l}\mid 10,11 \\
21,08\end{array}$ & \begin{tabular}{|l|}
$257,18,18$ \\
250
\end{tabular} & 63,94 & 201,00 & 201,04 & 63,94 & 1069,72 & 146,26 & 15,45 & 50,64 & $\begin{array}{l}420,48 \\
\end{array}$ & 80,50 & 80,87 & 420,48 \\
\hline Rana iberica & 29TPG12 & 100,00 & 115,84 & 95,37 & 38,04 & 5283,63 & 259,08 & 11,91 & 247,16 & 51,65 & $\begin{array}{l}185,68 \\
\end{array}$ & $\begin{array}{l}185,71 \\
\end{array}$ & 51,65 & $\mid 1176,26$ & 158,86 & 19,73 & 49,55 & 462,11 & 95,00 & 95,45 & 462,11 \\
\hline Rana iberica & 29TPG13 & 101.00 & 114,59 & 94,29 & 3788 & 5258.16 & 256,75 & 1116 & 245.59 & 51.08 & 184,25 & 184,28 & 50,83 & 1171.31 & 155,10 & 20,77 & 48.71 & 457,27 & 97.45 & 9795 & 457,27 \\
\hline Rana iberica & 29TPG14 & 101,00 & 113,99 & 93,88 & 37,92 & 5231,74 & 255,38 & 10,69 & 244,69 & 55,23 & $\begin{array}{l}183,38 \\
\end{array}$ & 183,44 & 50,77 & 1159,41 & 152,44 & 21,83 & 47 & 449,20 & 99,54 & 100,49 & 449,09 \\
\hline Rana iberica & 29TPG15 & 99,00 & 117,40 & 94,81 & 38,05 & 5235,88 & 258,51 & 12,64 & 245,87 & 59,84 & 186,75 & 186,77 & 53,92 & 1115,37 & 149,09 & 21,82 & 46,89 & 429,50 & 97,90 & 99,06 & 427 \\
\hline
\end{tabular}




\begin{tabular}{|c|c|c|c|c|c|c|c|c|c|c|c|c|c|c|c|c|c|c|c|c|c|}
\hline TAXON & UTM & km2 & BIO1 & B102 & BIO3 & B104 & B105 & B106 & B107 & B108 & B109 & BIO10 & BIO11 & B1012 & BIO13 & BIO14 & BIO15 & BIO16 & BIO17 & BIO18 & BlO19 \\
\hline Rana iberica & 29TPG17 & 99,00 & 118,91 & 94,17 & 38,01 & 5173,19 & 257,53 & 13,69 & 243,84 & 61,46 & 187,16 & 187,19 & 56,20 & 1081,36 & 147,99 & 23,39 & 45,11 & 412,32 & 100,59 & 101,89 & 406,09 \\
\hline Rana iberica & 29TPG19 & 100,00 & 120,84 & 92,62 & 38,10 & 5065,62 & 255,79 & 16,38 & 239,41 & 64,25 & 187,53 & 187,64 & 59,66 & \begin{tabular}{l|l|}
1054,15 \\
\end{tabular} & \begin{tabular}{ll|}
145,66 \\
\end{tabular} & 24,97 & 43,47 & 397,87 & \begin{tabular}{|l|}
103,63 \\
\end{tabular} & \begin{tabular}{l|l|}
107,49 \\
\end{tabular} & 387,71 \\
\hline Rana iberica & 29TPG20 & 100,00 & 116,55 & 98,57 & 38,25 & 5422,90 & 264,90 & \begin{tabular}{|l|}
10,39 \\
\end{tabular} & 254,51 & \begin{tabular}{l|l}
50,42 \\
\end{tabular} & \begin{tabular}{|l|}
188,25 \\
\end{tabular} & \begin{tabular}{|l|}
188,27 \\
\end{tabular} & 50,42 & \begin{tabular}{|l|l|}
1146,33 \\
\end{tabular} & 161,59 & \begin{tabular}{|l|}
17,49 \\
\end{tabular} & 51,15 & \begin{tabular}{|l|l|}
456,30 \\
\end{tabular} & 88,32 & 88,41 & 456,30 \\
\hline Rana iberica & 29TPG21 & 101,00 & 126,25 & 102,04 & 38,88 & 5451,82 & 275,59 & 16,75 & \begin{tabular}{|l|}
258,84 \\
\end{tabular} & \begin{tabular}{|l|}
59,06 \\
\end{tabular} & $\begin{array}{l}197,96 \\
\end{array}$ & \begin{tabular}{|l|l|}
197,96 \\
\end{tabular} & \begin{tabular}{|l|l|}
59,06 \\
\end{tabular} & \begin{tabular}{ll|}
1047,46 \\
\end{tabular} & \begin{tabular}{ll|}
144,56 \\
\end{tabular} & \begin{tabular}{|l|}
15,91 \\
\end{tabular} & 50,38 & 412,99 & \begin{tabular}{|l|}
80,47 \\
\end{tabular} & \begin{tabular}{|l|}
80,47 \\
\end{tabular} & 412,99 \\
\hline Rana iberica & 29TPG23 & 100,00 & 128,44 & 100,89 & 38,75 & 5426,73 & 275,36 & 18,16 & $257,20 \mid$ & $64,68 \mid$ & 199,68 & $199,68 \mid$ & 61,42 & 993,49 & 130,73 & 16,78 & $48,38 \mid$ & 385,02 & 80,62 & 80,62 & 384,57 \\
\hline Rana iberica & 29TPG24 & 100,00 & \begin{tabular}{|l|}
128,78 \\
\end{tabular} & 100,20 & 38,64 & 5413,35 & 274,57 & \begin{tabular}{|l|l|}
18,36 \\
\end{tabular} & 256,21 & 68,08 & $|199,94|$ & \begin{tabular}{|l|l|}
199,94 \\
\end{tabular} & 62,10 & \begin{tabular}{|l|l|}
972,87 \\
\end{tabular} & 127,05 & \begin{tabular}{|l|l|}
17,39 \\
\end{tabular} & 47,39 & 374,59 & 81,45 & 81,45 & 372,83 \\
\hline Rana iberica & 29TPG25 & 100,00 & 120,04 & 97,11 & 38,12 & 5336,47 & 263,87 & 12,51 & 251,36 & 60,75 & \begin{tabular}{|l|}
190,56 \\
\end{tabular} & 190,56 & 54,99 & 1034,95 & 137,25 & 20,39 & 46,61 & 398,36 & 91,23 & 91,43 & 395,74 \\
\hline Rana iberica & 29TPG26 & 101,00 & 105,01 & 92,90 & 37,58 & 5216,32 & 246,69 & 2,59 & \begin{tabular}{|l|}
244,09 \\
\end{tabular} & $\begin{array}{l}48,25 \\
\end{array}$ & \begin{tabular}{|l|l|}
174,52 \\
\end{tabular} & \begin{tabular}{|l|l|}
174,57 \\
\end{tabular} & 42,60 & \begin{tabular}{l|l|}
1153,25 \\
\end{tabular} & \begin{tabular}{l|l|}
153,62 \\
\end{tabular} & 25,51 & \begin{tabular}{|l|}
45,44 \\
\end{tabular} & \begin{tabular}{|l|l|}
443,06 \\
\end{tabular} & \begin{tabular}{|l|l|}
108,79 \\
\end{tabular} & \begin{tabular}{|l|l|}
109,53 \\
\end{tabular} & 438,97 \\
\hline Rana iberica & 29TPG27 & 100,00 & 92,11 & 89,78 & \begin{tabular}{|l|}
37,22 \\
\end{tabular} & 5108,96 & 231,86 & $-6,13$ & 237,99 & 37,64 & \begin{tabular}{|l|}
160,60 \\
\end{tabular} & 160,72 & \begin{tabular}{|l|}
31,96 \\
\end{tabular} & 1256,74 & 167,10 & 30,40 & 44,18 & 481,01 & \begin{tabular}{|l|l|}
125,38 \\
\end{tabular} & \begin{tabular}{|l|l|}
126,75 \\
125,
\end{tabular} & 474,89 \\
\hline Rana iberica & 29 TPG28 & 101,00 & 102,96 & \begin{tabular}{|l|}
91,96 \\
\end{tabular} & 37,86 & 5109,11 & 242,32 & \begin{tabular}{l|l|}
1,67 \\
\end{tabular} & 240,65 & \begin{tabular}{|l|l|}
47,18 \\
\end{tabular} & \begin{tabular}{|l|}
170,96 \\
\end{tabular} & \begin{tabular}{|l|l|}
171,02 \\
\end{tabular} & \begin{tabular}{|l|l|}
42,07 \\
\end{tabular} & 1159,66 & 156,59 & 27,99 & 43,84 & 442,53 & 115,48 & 117,44 & 435,04 \\
\hline Rana iberica & 29TPG29 & 101,00 & 122,35 & 94,68 & 38,28 & 5148,38 & 259,82 & \begin{tabular}{|l|l|}
16,03 \\
\end{tabular} & 243,79 & $\begin{array}{ll}64,46 \\
\end{array}$ & 190,05 & \begin{tabular}{|l|}
190,13 \\
\end{tabular} & 59,80 & \begin{tabular}{|l|l|}
988,89 \\
\end{tabular} & 135,44 & 23,41 & 43,19 & 373,42 & \begin{tabular}{|l|}
97,58 \\
\end{tabular} & \begin{tabular}{|l|l|}
99,85 \\
\end{tabular} & 363,03 \\
\hline Rana iberica & 29TPG30 & 101,00 & 129,20 & 104,36 & 38,86 & 5549,78 & 281,83 & \begin{tabular}{|l|}
17,57 \\
\end{tabular} & \begin{tabular}{ll|}
264,26 \\
\end{tabular} & \begin{tabular}{ll|}
60,49 \\
\end{tabular} & \begin{tabular}{|l|}
202,10 \\
\end{tabular} & 202,10 & \begin{tabular}{l|l|}
60,49 \\
\end{tabular} & 983,61 & 138,69 & \begin{tabular}{|l|}
14,19 \\
\end{tabular} & \begin{tabular}{|l|l|}
51,07 \\
\end{tabular} & \begin{tabular}{|l|}
390,06 \\
\end{tabular} & \begin{tabular}{|l|}
73,76 \\
\end{tabular} & \begin{tabular}{ll|}
73,76 \\
\end{tabular} & 390,06 \\
\hline Rana iberica & 29TPG31 & 99,00 & 119,83 & 101,17 & 38,41 & 5507,86 & 270,92 & 10,81 & \begin{tabular}{|l|}
260,12 \\
\end{tabular} & 52,25 & \begin{tabular}{|l|l|}
192,70 \\
\end{tabular} & \begin{tabular}{|l|}
192,70 \\
\end{tabular} & \begin{tabular}{l|l}
52,25 \\
\end{tabular} & \begin{tabular}{|l|l|}
1040,03 \\
\end{tabular} & \begin{tabular}{|l|l|}
144,93 \\
\end{tabular} & \begin{tabular}{l|l|}
16,75 \\
\end{tabular} & \begin{tabular}{|l|}
50,13 \\
\end{tabular} & \begin{tabular}{|l|l|}
412,02 \\
\end{tabular} & \begin{tabular}{|l|}
81,99 \\
\end{tabular} & \begin{tabular}{|l|}
81,99 \\
\end{tabular} & 412,02 \\
\hline Rana iberica & 29TPG32 & 100,00 & 121,65 & 101,25 & 38,42 & 5496,12 & 272,07 & \begin{tabular}{|l|}
11,98 \\
\end{tabular} & \begin{tabular}{|l|}
260,09 \\
\end{tabular} & \begin{tabular}{|l|}
54,58 \\
\end{tabular} & \begin{tabular}{|l|l|}
194,31 \\
\end{tabular} & 194,31 & \begin{tabular}{l|l|}
54,26 \\
\end{tabular} & \begin{tabular}{l|l|}
1006,25 \\
\end{tabular} & \begin{tabular}{|l|}
137,16 \\
\end{tabular} & \begin{tabular}{l|l|}
16,95 \\
\end{tabular} & \begin{tabular}{l|l}
49,15 \\
\end{tabular} & 395,01 & 81,34 & 81,34 & 395,01 \\
\hline Rana iberica & $29 \mathrm{TPG} 33$ & 100,00 & 121,95 & 100,70 & 38,33 & 5475,42 & 271,29 & 12,10 & \begin{tabular}{|l|}
259,19 \\
\end{tabular} & \begin{tabular}{|l|l}
57,53 \\
\end{tabular} & \begin{tabular}{|l|l|}
194,34 \\
\end{tabular} & \begin{tabular}{|l|}
194,34 \\
\end{tabular} & 54,80 & \begin{tabular}{|l|l|}
986,87 \\
\end{tabular} & 131,60 & \begin{tabular}{|l|l|}
17,61 \\
\end{tabular} & 48, & 384,05 & 82,26 & 82,26 & 383,95 \\
\hline Rana iberica & 29TPG34 & 101,00 & 119,10 & 99,36 & \begin{tabular}{|l|}
38,15 \\
\end{tabular} & 5438,35 & 267,03 & \begin{tabular}{|l|}
10,11 \\
\end{tabular} & \begin{tabular}{|l|}
256,92 \\
\end{tabular} & \begin{tabular}{|l|l}
58,52 \\
\end{tabular} & \begin{tabular}{|l|l|}
191,03 \\
\end{tabular} & \begin{tabular}{|l|l|}
191,03 \\
\end{tabular} & \begin{tabular}{ll|}
52,56 \\
\end{tabular} & \begin{tabular}{|l|}
996,47 \\
\end{tabular} & \begin{tabular}{ll|}
130,92 \\
\end{tabular} & \begin{tabular}{|l|}
19,09 \\
\end{tabular} & 47,19 & \begin{tabular}{|l|}
385,91 \\
\end{tabular} & 86,18 & 86,18 & 385,02 \\
\hline Rana iberica & 29TPG35 & 101,00 & 108,30 & 95,95 & 37,66 & 5353,04 & 254,26 & 3,04 & \begin{tabular}{l|l}
251,22 \\
\end{tabular} & $\begin{array}{ll}49,68 \\
\end{array}$ & \begin{tabular}{l|l|}
179,55 \\
\end{tabular} & \begin{tabular}{l|l|}
179,55 \\
\end{tabular} & 43,77 & \begin{tabular}{|l|l|}
1075,13 \\
\end{tabular} & 141,59 & 22,76 & \begin{tabular}{|l|l|}
46,07 \\
\end{tabular} & \begin{tabular}{|l|l|}
415,19 \\
\end{tabular} & $\begin{array}{ll}98,62 \\
\end{array}$ & \begin{tabular}{|l|}
98,63 \\
\end{tabular} & 412,73 \\
\hline Rana iberica & 29TPG36 & 100,00 & 92,35 & 91,85 & 37,15 & 5240,03 & 236,01 & $-7,92$ & \begin{tabular}{|l|}
243,93 \\
\end{tabular} & 36,12 & \begin{tabular}{l|l|}
162,64 \\
\end{tabular} & \begin{tabular}{l|l|}
162,65 \\
\end{tabular} & \begin{tabular}{|l|}
30,37 \\
\end{tabular} & 1200,71 & 158,05 & 28,37 & 44,62 & $\begin{array}{l}461,06 \\
\end{array}$ & \begin{tabular}{|l|}
118,24 \\
\end{tabular} & \begin{tabular}{|l|}
118,42 \\
\end{tabular} & 456,30 \\
\hline Rana iberica & 29TPG37| & 100,00 & 81,18 & 89,85 & $36,97 \mid$ & 5161,60 & 223,24 & $-16,66$ & 239,90 & $26,61 \mid$ & 150,66 & 150,77 & 20,92 & 1289,79 & 168,92 & 33,27 & 43,10 & 490,73 & 134,79 & 135,32 & 482,99 \\
\hline Rana iberica & 29TPG38 & 100,00 & 96,75 & 92,85 & 37,72 & 5178,34 & 238,76 & $-4,64$ & 243,39 & $40,47 \mid$ & 165,90 & 165,96 & 35,20 & 1152,50 & 153,75 & 28,99 & 43,10 & 438,96 & 118,41 & 119,17 & 430,55 \\
\hline Rana iberica & 29TPG39 & 100,00 & 108,37 & 94,59 & 38,08 & 5172,07 & 249,16 & 4,24 & 244,93 & 51,08 & 177,02 & 177,05 & 46,20 & \begin{tabular}{|l|l|}
1052,37 \\
\end{tabular} & \begin{tabular}{ll|}
142,06 \\
\end{tabular} & 26,34 & 42,75 & 399,35 & \begin{tabular}{|l|}
107,88 \\
\end{tabular} & 108,52 & 389,15 \\
\hline Rana iberica & 29TPG40 & 100,00 & 139,68 & 107,25 & 39,28 & 5619,81 & 294,02 & 24,54 & 269,48 & \begin{tabular}{|l|l|}
69,90 \\
\end{tabular} & 213,18 & 213,18 & 69,41 & \begin{tabular}{|c|}
839,87 \\
\end{tabular} & \begin{tabular}{|l|}
116,78 \\
\end{tabular} & $\begin{array}{l}11,78 \\
\end{array}$ & \begin{tabular}{|l|}
50,19 \\
\end{tabular} & 329,39 & 62,42 & 62,42 & 329,39 \\
\hline Rana iberica & 29TPG41 & 100,00 & \begin{tabular}{|l|}
132,24 \\
\end{tabular} & $\begin{array}{l}105,64 \\
\end{array}$ & 38,95 & 5603,97 & 286,01 & 18,46 & 267,55 & 63,01 & \begin{tabular}{|l|}
205,82 \\
\end{tabular} & \begin{tabular}{|l|}
205,82 \\
\end{tabular} & \begin{tabular}{l|l|}
62,58 \\
\end{tabular} & 880,38 & \begin{tabular}{|l|l|}
121,57 \\
\end{tabular} & 13,71 & 49,58 & \begin{tabular}{|l|}
345,71 \\
\end{tabular} & 68,32 & 68,32 & 345,69 \\
\hline Rana iberica & 29TPG42 & 101,00 & 119,50 & 102,14 & 38,32 & 5551,84 & 272,26 & $\begin{array}{l}8,95 \\
\end{array}$ & \begin{tabular}{|l|}
263,32 \\
\end{tabular} & 51,70 & \begin{tabular}{|l|l|}
193,03 \\
\end{tabular} & \begin{tabular}{|l|l|}
193,03 \\
\end{tabular} & 51,39 & 962,54 & 131,89 & 16,71 & 48,75 & 378,48 & 79,34 & 79,34 & 378,47 \\
\hline Rana iberica & 29TPG43 & 100,00 & 117,15 & 101,03 & 38,13 & 5522,05 & 268,85 & \begin{tabular}{|l|}
7,27 \\
\end{tabular} & 261,57 & 52,89 & \begin{tabular}{|l|l|}
190,41 \\
\end{tabular} & \begin{tabular}{|l|}
190,41 \\
\end{tabular} & 49,60 & 966,51 & 130,02 & \begin{tabular}{|l|l|}
18,09 \\
\end{tabular} & 47,76 & \begin{tabular}{|l|l|}
377,38 \\
\end{tabular} & 82,60 & 82,60 & 377,30 \\
\hline Rana iberica & 29TPG44 & 100,00 & 113,68 & 99,82 & 38,01 & 5485,88 & 264,16 & 4,66 & 259,50 & 52,80 & 186,67 & \begin{tabular}{|l|}
186,67 \\
\end{tabular} & 46,81 & \begin{tabular}{|l|l|}
981,93 \\
\end{tabular} & 129,95 & $\begin{array}{ll}19,66 \\
\end{array}$ & 46,90 & 381,73 & 87,10 & 87,10 & 380,84 \\
\hline Rana iberica & 29TPG45 & 100,00 & 107,96 & 98,08 & 37,90 & 5433,80 & 257,05 & 0,99 & 256,05 & \begin{tabular}{|l|}
48,08 \\
\end{tabular} & \begin{tabular}{|l|l|}
180,37 \\
\end{tabular} & \begin{tabular}{|l|}
180,37 \\
\end{tabular} & 42,27 & 1017,73 & \begin{tabular}{|l|}
134,12 \\
\end{tabular} & 22,02 & 45,82 & \begin{tabular}{|l|}
393,97 \\
\end{tabular} & \begin{tabular}{l|}
4,42 \\
\end{tabular} & 94,42 & 391,34 \\
\hline Rana iberica & 29TPG46 & 100,00 & 98,28 & 95,56 & \begin{tabular}{|l|}
37,58 \\
\end{tabular} & 5354,62 & 245,40 & $-5,79$ & 251,19 & 39,99 & \begin{tabular}{|l|l|}
169,93 \\
\end{tabular} & \begin{tabular}{|l|l|}
169,93 \\
\end{tabular} & \begin{tabular}{|l|}
34,21 \\
\end{tabular} & 1090,34 & 143,81 & 25,79 & 44,43 & \begin{tabular}{|l|l|}
418,90 \\
\end{tabular} & \begin{tabular}{|l|l|}
107,37 \\
\end{tabular} & \begin{tabular}{|l|}
107,37 \\
\end{tabular} & 413,87 \\
\hline Rana iberica & 29TPG47 & 101,00 & 87,27 & 93,12 & 37,28 & 5272,05 & 232,57 & $-13,80$ & \begin{tabular}{|l|}
246,38 \\
\end{tabular} & \begin{tabular}{|l|l}
30,69 \\
\end{tabular} & \begin{tabular}{|l|l|}
158,08 \\
\end{tabular} & \begin{tabular}{|l|l|}
158,12 \\
\end{tabular} & \begin{tabular}{|l|}
25,08 \\
\end{tabular} & 1178,80 & \begin{tabular}{l|l|}
154,82 \\
\end{tabular} & \begin{tabular}{l|l|}
30,25 \\
\end{tabular} & 43,01 & \begin{tabular}{|l|l|}
449,01 \\
\end{tabular} & \begin{tabular}{|l|}
123,01 \\
\end{tabular} & \begin{tabular}{|l|}
123,16 \\
1
\end{tabular} & 441,24 \\
\hline Rana iberica & 29TPG48 & 100,00 & $\begin{array}{l}108,67 \\
\end{array}$ & 96,86 & \begin{tabular}{|l|}
37,97 \\
\end{tabular} & 5314,99 & 253,42 & 2,25 & \begin{tabular}{|l|}
251,18 \\
\end{tabular} & $\begin{array}{ll}49,64 \\
\end{array}$ & \begin{tabular}{|l|l|}
179,27 \\
1
\end{tabular} & \begin{tabular}{|l|l|}
179,29 \\
\end{tabular} & \begin{tabular}{|l|}
44,47 \\
\end{tabular} & $\begin{array}{l}997,65 \\
9\end{array}$ & \begin{tabular}{|l|l|}
133,38 \\
\end{tabular} & \begin{tabular}{|l|}
24,48 \\
\end{tabular} & \begin{tabular}{|l|l|}
42,97 \\
\end{tabular} & \begin{tabular}{|l|}
380,02 \\
\end{tabular} & \begin{tabular}{|l|}
101,32 \\
\end{tabular} & \begin{tabular}{|l|l|}
101,38 \\
\end{tabular} & 371,02 \\
\hline Rana iberica & 29TPG49 & 101,00 & $\begin{array}{l}118,67 \\
\end{array}$ & 97,49 & 38,41 & 5283,64 & 261,09 & 10,54 & 250,55 & 58,99 & \begin{tabular}{|l|}
188,28 \\
\end{tabular} & \begin{tabular}{|l|}
188,28 \\
\end{tabular} & 54,20 & 919,91 & 123,69 & 22,59 & 42,35 & \begin{tabular}{|l|l|}
348,53 \\
\end{tabular} & \begin{tabular}{|l|}
93,97 \\
\end{tabular} & \begin{tabular}{|l|}
93,97 \\
\end{tabular} & 337,24 \\
\hline Rana iberica & 29TPG50 & 100,00 & 137,60 & 107,47 & 39,01 & 5663,99 & 293,42 & 22,08 & 271,34 & 69,40 & 211,95 & 211,95 & 66,82 & 797,61 & 110,60 & \begin{tabular}{ll|l}
11,75 \\
\end{tabular} & 49,53 & 312,43 & 60,95 & 60,95 & 312,37 \\
\hline Rana iberica & 29TPG52 & 99,00 & 126,28 & 105,19 & 38,73 & 5629,65 & 281,48 & 12,63 & 268,85 & 59,49 & 200,62 & 200,62 & 56,60 & 851,88 & 116,31 & 14,6 & 48,20 & 333,63 & \begin{tabular}{|l|}
70,27 \\
\end{tabular} & \begin{tabular}{l|l|}
70,27 \\
\end{tabular} & 333,50 \\
\hline Rana iberica & 29TPG53 & 101,00 & 118,10 & 103,22 & 38,19 & 5593,68 & 272,73 & 6,29 & 266,44 & $54,78 \mid$ & 192,35 & 192,35 & 49, & 897,29 & 121,15 & \begin{tabular}{|l|l|}
16,78 \\
\end{tabular} & 47,4 & 350,83 & $77,64 \mid$ & $77,64 \mid$ & 350,43 \\
\hline Rana iberica & 29TPG54 & 100,00 & 112,14 & 101,49 & \begin{tabular}{ll|}
37,99 \\
\end{tabular} & 5549,06 & 265,44 & 2,10 & 263,34 & 50,57 & 186,01 & 186,01 & 44,43 & $\begin{array}{l}933,69 \\
\end{array}$ & 123,73 & \begin{tabular}{ll|}
19,01 \\
\end{tabular} & 46,45 & 363,30 & 84,68 & 84,68 & 361,72 \\
\hline Rana iberica & 29TPG55 & 101,00 & 101,87 & 98,62 & 37,70 & 5478,45 & 253,21 & $-4,90$ & \begin{tabular}{|l|l|}
258,12 \\
\end{tabular} & 41,72 & \begin{tabular}{|l|l|}
175,11 \\
1
\end{tabular} & \begin{tabular}{|l|l|}
175,11 \\
\end{tabular} & 35,82 & 1007,10 & 132,54 & 22,70 & \begin{tabular}{l|l}
45,05 \\
\end{tabular} & 389,16 & 96,94 & 96,94 & 385,59 \\
\hline Rana iberica & 29TPG57 & 100,00 & 107,87 & 99,36 & 38,03 & 5437,69 & 257,09 & $-0,42$ & 257,51 & 47,28 & 180,21 & 180,21 & \begin{tabular}{ll|l}
41,88 \\
\end{tabular} & 949,49 & 126,52 & 22,96 & 43,53 & \begin{tabular}{ll|}
363,96 \\
\end{tabular} & 95,28 & 95,28 & 356,65 \\
\hline Rana iberica & 29TPG58 & 99,00 & 113,24 & 99,55 & 38,22 & 5409,77 & 260,71 & 4,08 & 256,63 & 52,44 & $184,97 \mid$ & $184,97 \mid$ & 47,3 & 906,05 & 121,16 & 22,1 & 42, & 345,63 & 92,32 & 92,32 & 336,18 \\
\hline Rana iberica & 29TPG60 & 100,00 & 123,07 & 105,87 & 38,38 & 5712,51 & 281,58 & 9,35 & 272,23 & $52,57 \mid$ & 198,73 & 198,73 & 52,53 & 838,83 & 117,23 & 13,04 & 49,09 & 331,15 & 67,94 & 67,94 & 331,15 \\
\hline Rana iberica & 29TPG61 & 101,00 & 124,66 & 106,28 & 38,58 & 5691,35 & 282,65 & 10,37 & 272,28 & 56,10 & 199,97 & 199,97 & 54,20 & 816,66 & 112,80 & 13,43 & 48,38 & \begin{tabular}{|l|l|}
321,04 \\
\end{tabular} & 67,43 & \begin{tabular}{ll|}
67,43 \\
\end{tabular} & 320,98 \\
\hline Rana iberica & 29TPG62 & 101,00 & 117,17 & 104,76 & 38,23 & 5659,64 & 274,68 & 4,41 & \begin{tabular}{|l|l|}
270,26 \\
\end{tabular} & 52,34 & \begin{tabular}{|l|l|}
192,27 \\
\end{tabular} & \begin{tabular}{|l|l|}
192,27 \\
\end{tabular} & \begin{tabular}{ll|l}
47,48 \\
\end{tabular} & 857,09 & \begin{tabular}{ll|}
117,25 \\
\end{tabular} & \begin{tabular}{l|l|}
15,25 \\
\end{tabular} & 47,61 & \begin{tabular}{|c|}
336,34 \\
\end{tabular} & 74,11 & 74,11 & 336,18 \\
\hline Rana iberica & 29TPG63 & 100,00 & 112,97 & 103,74 & \begin{tabular}{l|l|}
38,15 \\
\end{tabular} & 5628,42 & 269,69 & 1,35 & 268,34 & $\begin{array}{ll}50,38 \\
\end{array}$ & \begin{tabular}{ll|l}
187,93 \\
\end{tabular} & 187,93 & 44 & $\begin{array}{l}878,27 \\
\end{array}$ & $\begin{array}{ll}118,15 \\
\end{array}$ & 16,94 & \begin{tabular}{ll|}
46,75 \\
\end{tabular} & 343,20 & 79,00 & 79,00 & 342,17 \\
\hline Rana iberica & 29TPG64 & 100,00 & 104,22 & 101,47 & 37,91 & 5587,04 & 259,60 & $-4,87$ & $264,47 \mid$ & $42,66 \mid$ & $178,99 \mid$ & 178,99 & 36,56 & 935,40 & 123,39 & 19,90 & 45,50 & 363,13 & 88,84 & 88,84 & 360,58 \\
\hline Rana iberica & 29TPG65 & 100,00 & 91,21 & 98,25 & \begin{tabular}{l|l|}
37,45 \\
\end{tabular} & 5510,92 & 244,11 & $-14,60$ & 258,71 & 31,40 & 165,31 & 165,32 & 25,41 & 1036,29 & 135,29 & 25,12 & 43,62 & \begin{tabular}{|l|l|}
396,79 \\
\end{tabular} & \begin{tabular}{l|l|}
105,96 \\
\end{tabular} & \begin{tabular}{|l|}
106,01 \\
\end{tabular} & 391,05 \\
\hline Rana iberica & 29TPG66 & 100,00 & 85,32 & 97,01 & 37,38 & 5459,42 & 236,65 & $-19,18$ & 255,84 & 26, & 158,82 & 158,85 & 20,53 & 1082,19 & \begin{tabular}{|l|}
140,94 \\
\end{tabular} & 28,45 & 42,32 & 410,84 & 115,68 & \begin{tabular}{|l|}
115,73 \\
\end{tabular} & 402,63 \\
\hline Rana iberica & 29TPG67 & 101,00 & 90,62 & 98,13 & 37,76 & 5449,74 & 241,65 & $-15,01$ & 256,66 & 31,18 & \begin{tabular}{|l|}
163,81 \\
\end{tabular} & 163,81 & 25,53 & 1033,16 & 135,57 & 27,56 & 41,95 & 391,99 & 111,28 & 111,28 & 382,79 \\
\hline Rana iberica & 29TPG68 & 101,00 & 95,38 & 98,77 & \begin{tabular}{|l|}
37,99 \\
\end{tabular} & 5429,41 & 245,36 & $-11,17$ & \begin{tabular}{|l|}
256,53 \\
\end{tabular} & 35, & \begin{tabular}{|l|l|}
168,01 \\
\end{tabular} & 168,01 & 30,2 & \begin{tabular}{|l|l|}
994,16 \\
\end{tabular} & \begin{tabular}{|l|}
131,08 \\
\end{tabular} & \begin{tabular}{|l|l|}
26,93 \\
\end{tabular} & \begin{tabular}{|l|l|}
41,40 \\
\end{tabular} & \begin{tabular}{|l|}
376,34 \\
\end{tabular} & \begin{tabular}{l|l|}
108,56 \\
\end{tabular} & \begin{tabular}{l|l|}
108,56 \\
\end{tabular} & 365,59 \\
\hline Rana iberica & 29TPG69 & 100,00 & 109,58 & 99,72 & 38,42 & 5401,83 & 256,87 & 0,74 & 256,13 & $48,89 \mid$ & 181,12 & 181,12 & 43,70 & 891,67 & 118,02 & 23,64 & 41 & 33 & $96,95[$ & 96,95 & 323,83 \\
\hline Rana iberica & 29TPG70 & 101,00 & 120,49 & \begin{tabular}{|l|}
106,61 \\
\end{tabular} & 38,23 & 5758,56 & 281,01 & 6,19 & 274,81 & \begin{tabular}{l|l}
50,93 \\
\end{tabular} & \begin{tabular}{ll|}
197,05 \\
\end{tabular} & \begin{tabular}{|l|l|}
197,05 \\
\end{tabular} & 49,40 & \begin{tabular}{|l|l|}
797,41 \\
\end{tabular} & \begin{tabular}{|l|}
110,24 \\
\end{tabular} & \begin{tabular}{|l|}
12,70 \\
\end{tabular} & 48,25 & \begin{tabular}{|l|}
313,45 \\
\end{tabular} & 66,84 & 66,84 & 313,45 \\
\hline Rana iberica & 29TPG71 & 99,00 & 106,29 & \begin{tabular}{|l|l|}
103,38 \\
\end{tabular} & \begin{tabular}{|l|}
37,79 \\
\end{tabular} & 5709,64 & 265,63 & $-4,35$ & \begin{tabular}{|l|}
269,98 \\
\end{tabular} & \begin{tabular}{|l|l|l|l|}
41,02 &
\end{tabular} & \begin{tabular}{|l|l|}
182,72 \\
\end{tabular} & \begin{tabular}{|l|l|}
182,73 \\
\end{tabular} & \begin{tabular}{l|l|}
36,85 \\
\end{tabular} & 887,24 & \begin{tabular}{|l|}
120,34 \\
\end{tabular} & \begin{tabular}{|l|}
15,88 \\
\end{tabular} & \begin{tabular}{|l|l|l|l}
47,03 & \\
\end{tabular} & \begin{tabular}{|l|}
346,53 \\
\end{tabular} & \begin{tabular}{|l|}
79,77 \\
\end{tabular} & \begin{tabular}{|l|}
79,77 \\
\end{tabular} & 346,12 \\
\hline Rana iberica & 29TPG72 & 100,00 & $\begin{array}{l}104,66 \\
\end{array}$ & \begin{tabular}{|l|l|}
103,39 \\
\end{tabular} & \begin{tabular}{|l|}
37,88 \\
\end{tabular} & 5685,59 & 263,66 & $-5,85$ & 269,52 & 42,04 & \begin{tabular}{|l|l|}
180,79 \\
\end{tabular} & \begin{tabular}{ll|}
180,80 \\
\end{tabular} & 35,52 & 889,11 & \begin{tabular}{|l|}
119,21 \\
\end{tabular} & \begin{tabular}{l|l|}
17,01 \\
\end{tabular} & \begin{tabular}{ll|}
46,29 \\
\end{tabular} & 346,30 & 82,30 & 82,30 & 345,29 \\
\hline Rana iberica & 29TPG73 & 100,00 & 111,26 & 105,36 & 38,08 & 5681,64 & 270,72 & $-1,27$ & 271,99 & $48,18 \mid$ & $187,11 \mid$ & 187,11 & 41,70 & 830,16 & 111,22 & 16,29 & $46,11 \mid$ & $324,27 \mid$ & 76,84 & 76,84 & 322,77 \\
\hline Rana iberica & 29TPG74 & 100,00 & 102,89 & 103,19 & 37,94 & 5639,26 & 260,53 & $-7,56$ & 268,10 & 40,61 & 178,40 & 178,40 & 34,42 & 888,01 & 117,14 & 19,9 & 44 & 343,11 & 87,15 & 87,15 & $339,61]$ \\
\hline Rana iberica & 29TPG75 & 101,00 & 85,19 & 98,99 & 37 & 5559 & 239 & $-21,08$ & \begin{tabular}{|l|}
260,82 \\
\end{tabular} & \begin{tabular}{|l|}
25,02 \\
\end{tabular} & \begin{tabular}{|l|l|}
159,90 \\
\end{tabular} & \begin{tabular}{|l|}
160,06 \\
\end{tabular} & \begin{tabular}{|l|}
18,98 \\
\end{tabular} & \begin{tabular}{|l|l|}
1030,75 \\
\end{tabular} & \begin{tabular}{|l|}
133,59 \\
\end{tabular} & 26,48 & 42,2 & \begin{tabular}{|l|}
390,72 \\
\end{tabular} & \begin{tabular}{|l|}
110,32 \\
\end{tabular} & \begin{tabular}{|l|l|}
110,63 \\
\end{tabular} & 382,84 \\
\hline Rana iberica & 29TPG76 & 100,00 & 69,20 & 95,75 & 37,03 & 5474,24 & 221,21 & $-33,69$ & 254,90 & $11,21 \mid$ & \begin{tabular}{|l|}
143,07 \\
\end{tabular} & \begin{tabular}{|l|}
143,32 \\
\end{tabular} & 5,10 & \begin{tabular}{|l|l|}
1166,78 \\
\end{tabular} & 148,91 & 33,61 & \begin{tabular}{|l|l|}
40,03 \\
\end{tabular} & \begin{tabular}{|l|l|}
435,09 \\
\end{tabular} & \begin{tabular}{|l|}
133,11 \\
\end{tabular} & \begin{tabular}{|l|l|}
134,16 \\
\end{tabular} & 423,21 \\
\hline Rana iberica & 29TPG77 & 100,00 & \begin{tabular}{ll|}
72,02 \\
\end{tabular} & 96,50 & 37,33 & 5454,39 & 223,74 & $-31,34$ & \begin{tabular}{|l|}
255,08 \\
\end{tabular} & \begin{tabular}{l|l|}
13,92 \\
\end{tabular} & \begin{tabular}{|l|l|}
145,64 \\
\end{tabular} & 145,74 & 7,94 & 1141,30 & 146,33 & 33,84 & 39,61 & 424,73 & \begin{tabular}{|l|}
132,61 \\
1
\end{tabular} & \begin{tabular}{|l|l|}
133,18 \\
\end{tabular} & 411,98 \\
\hline Rana iberica & 29TPG78 & 99,00 & 84,24 & 98,73 & 37,94 & 5461,01 & 235,92 & $-21,51$ & 257,42 & $24,81 \mid$ & 157,54 & 157,55 & 19,16 & 1035,81 & 134,64 & 30,25 & 39,76 & 387,35 & $119,61 \mid$ & 119,70 & 374,39 \\
\hline Rana ibe & $29 \mathrm{TPG}$ & 10 & & & & & & 3,55 & $26 \quad 26$ & 52, & 187, & 187, & 47 & 79 & \begin{tabular}{|l|l|}
105,84 \\
\end{tabular} & 21, & & & 87 & 87,53 & 288,56 \\
\hline Rana iberica & 29TPG80 & 100,00 & 121,05 & 107,95 & 38,31 & 5805,80 & $283, C$ & 5,75 & 277,30 & \begin{tabular}{|l|}
55,69 \\
\end{tabular} & \begin{tabular}{|l|}
198,22 \\
\end{tabular} & 198,22 & 49,43 & 736,72 & 99,75 & \begin{tabular}{|l|l|}
12,07 \\
\end{tabular} & 47,20 & 287,01 & \begin{tabular}{ll|}
63,76 \\
\end{tabular} & 63,76 & 286,57 \\
\hline Rana iberica & 29TPG81 & 100,00 & 112,63 & 106,89 & \begin{tabular}{|l|}
38,07 \\
\end{tabular} & 5769,69 & 274,83 & $-0,95$ & 275,78 & \begin{tabular}{|l|l|}
47,70 \\
\end{tabular} & \begin{tabular}{|l|l|}
189,63 \\
\end{tabular} & \begin{tabular}{|l|l|}
189,63 \\
\end{tabular} & \begin{tabular}{|l|l}
41,79 \\
\end{tabular} & 781,52 & 105,21 & 13,80 & 46,54 & \begin{tabular}{|l|l|}
304,45 \\
\end{tabular} & \begin{tabular}{|l|l|}
70,73 \\
\end{tabular} & \begin{tabular}{|l|}
70,73 \\
\end{tabular} & 304,31 \\
\hline
\end{tabular}




\begin{tabular}{|c|c|c|c|c|c|c|c|c|c|c|c|c|c|c|c|c|c|c|c|c|c|}
\hline TAXON & UTM & $\mathrm{km2}$ & B101 & B102 & $\mathrm{BIO3}$ & B104 & B105 & B106 & 8107 & B108 & B109 & 81010 & B1011 & BIO12 & BIO13 & BIO14 & BIO15 & BIO16 & BIO17 & BIO18 & B1019 \\
\hline Rana iberica & 29TPG82 & 101,00 & 115,92 & 108,05 & 38,48 & 5741,87 & 278,21 & 1,19 & 277,01 & 49,20 & 192,39 & 192,39 & 45,23 & 751,50 & 101,08 & 13,75 & 46,42 & 293,71 & 68,50 & 68,50 & 293,50 \\
\hline Rana iberica & 29TPG83 & 100,00 & 114,34 & 107,76 & \begin{tabular}{|l|l|}
38,57 \\
\end{tabular} & 5717,94 & 275,96 & $-0,14$ & 276,10 & 49,76 & $\begin{array}{l}190,63 \\
\end{array}$ & 190,63 & 43,99 & 756,43 & 100,89 & 14,92 & 45,71 & 294,30 & 71,12 & 71,12 & 293,56 \\
\hline Rana iberica & 29TPG84 & 100,00 & 101,08 & 104,58 & 38,04 & 5694,84 & 260,62 & $-10,39$ & 271,01 & 38,15 & $\begin{array}{l}177,42 \\
\end{array}$ & $\begin{array}{l}177,42 \\
\end{array}$ & 31,99 & 848,62 & 111,77 & 19,55 & 43,67 & 325,23 & 86,52 & 86,52 & 320,86 \\
\hline Rana iberica & 29TPG85 & 99,00 & 90,22 & 102,10 & 37,74 & 5649,05 & 247,58 & $-18,81$ & 266,39 & 28,47 & 166,10 & 166,16 & 22,38 & 931,97 & 121,43 & 24,22 & 41,70 & 352,40 & 101,25 & 101,38 & 344,17 \\
\hline Rana iberica & 29TPG86 & 101,00 & 80,34 & 100,06 & \begin{tabular}{|l|}
37,57 \\
\end{tabular} & 5586,05 & 235,83 & \begin{tabular}{|l|}
$-26,54$ \\
\end{tabular} & 262,37 & 19,98 & 155,48 & $\begin{array}{l}155,64 \\
\end{array}$ & 13,90 & 1015,72 & 130,94 & 29,10 & 40,06 & 379,28 & 116,18 & 116,72 & 367,84 \\
\hline Rana iberica & 29TPG87 & 100,00 & 60,76 & 96,29 & 37,14 & 5479,39 & 213,40 & $-41,90$ & 255,30 & 3,18 & 134,78 & 135,09 & $-3,08$ & 1192,08 & 150,36 & 37,89 & 37,67 & 436,76 & 145,06 & 146,84 & 421,17 \\
\hline Rana iberica & 29TPG88 & 101,00 & 75,96 & 99,19 & 37,83 & 5498,03 & 229,16 & $-29,65$ & 258,81 & 16,66 & 149,91 & 149,95 & 10,69 & \begin{tabular}{|l|l|}
1056,83 \\
\end{tabular} & 135,57 & 32,94 & 38,18 & 389,90 & 128,19 & 128,45 & 374,70 \\
\hline Rana iberica & 29TPG89 & 100,00 & 93,45 & \begin{tabular}{|r|r|r|}
101,35 \\
\end{tabular} & 38,41 & 5516,40 & 245,72 & \begin{tabular}{|l|} 
\\
$-15,37$ \\
\end{tabular} & \begin{tabular}{|l|}
261,10 \\
\end{tabular} & 32,30 & \begin{tabular}{|l}
167,04 \\
\end{tabular} & $\begin{array}{l}167,05 \\
\end{array}$ & 26,82 & \begin{tabular}{|}
919,95 \\
\end{tabular} & 119,41 & 27,68 & 38,68 & 341,52 & 110,07 & 110,10 & 325,83 \\
\hline Rana iberica & 29TPG93 & 100,00 & 114,11 & 109,10 & \begin{tabular}{|l|}
38,82 \\
\end{tabular} & 5783,44 & 276,86 & $-1,48$ & 278,34 & 48,78 & 191,09 & 191,09 & 42,76 & 707,57 & 93,88 & 14,70 & 44,40 & 271,75 & 69,24 & 69,24 & 270,03 \\
\hline Rana iberica & 29TPG94 & 101,00 & 110,64 & 108,34 & 38,65 & 5772,11 & 272,62 & $-4,27$ & 276,90 & 45,99 & \begin{tabular}{|l|}
187,51 \\
\end{tabular} & \begin{tabular}{|l|}
187,51 \\
\end{tabular} & 39,68 & 726,49 & 96,60 & 16,51 & 43,40 & 277,94 & 73,92 & 73,92 & 274,29 \\
\hline Rana iberica & 29TPG95 & 101,00 & 102,24 & 106,49 & 38,29 & 5749,81 & 262,78 & $-11,04$ & 273,82 & 38,15 & 179,12 & 179,12 & 32,12 & 781,86 & 103,44 & 20,04 & 41,76 & 296,35 & 84,39 & 84,39 & 288,95 \\
\hline Rana iberica & 29TPG96 & 100,00 & 97,20 & 105,45 & 38,22 & 5715,20 & 256,35 & $-15,01$ & 271,35 & 33,71 & 173,68 & 173,68 & 27,75 & 820,67 & 107,87 & 22,87 & 40,53 & 308,33 & 92,64 & 92,64 & 298,22 \\
\hline Rana iberica & 29TPG97 & 100,00 & 73,90 & 100,69 & \begin{tabular}{|l|l|}
37,78 \\
\end{tabular} & 5591,12 & 229,81 & $-32,99$ & 262,80 & 13,84 & 149,23 & 149,36 & 7,62 & 1021,92 & 130,38 & 32,26 & 37,71 & 374,88 & 125,27 & 125,90 & 359,55 \\
\hline Rana iberica & 29TPG98 & 100,00 & 85,79 & 102,94 & 38,30 & 5606,91 & 241,86 & $\begin{array}{l}-23,44 \\
\end{array}$ & 265,30 & 24,33 & 161,06 & 161,06 & 18,38 & 920,26 & 118,99 & 28,64 & 37,98 & 339,37 & 112,59 & 112,59 & 324,04 \\
\hline Rana iberica & 29TPG99 & 100,00 & 92,81 & 103,41 & 38,64 & 5591,63 & 247,49 & $-17,53$ & 265,03 & 30,74 & 167,42 & 167,42 & 24,99 & 875,06 & 113,22 & 27,37 & 37,78 & 322,53 & 108,10 & 108,16 & 305,90 \\
\hline Rana iberica & 29TPHOO & 101,00 & 125,61 & 90,94 & 38,56 & 4901,53 & 255,80 & 22,76 & 233,04 & 70,59 & 189,97 & 190,31 & 66,55 & 1067,43 & 150,45 & 25,92 & 43,21 & 400,80 & 106,02 & 114,20 & 388,56 \\
\hline Rana iberica & 29TPHO1 & 100,00 & 124,98 & 90,02 & 38,96 & 4776,79 & 252,75 & $\begin{array}{l}24,07 \\
\end{array}$ & 228,67 & 71,31 & 187,58 & 188,19 & 67,60 & 1077,54 & 151,59 & 27,30 & 42,65 & 403,69 & 109,82 & 122,46 & 389,66 \\
\hline Rana iberica & 29TPH03 & 101,00 & 122,39 & 88,14 & 39,68 & 4526,51 & 245,68 & 25,57 & 220,12 & 71,62 & 181,60 & $\begin{array}{l}182,66 \\
\end{array}$ & 68,41 & 1110,45 & 154,52 & 30,34 & 41,20 & 414,15 & 119,09 & 132,83 & 396,58 \\
\hline Rana iberica & 29TPH04 & 99,00 & 121,42 & 87,18 & 39,96 & 4424,42 & 242,69 & 26,47 & 216,22 & 72,14 & 179,22 & 180,64 & 68,82 & 1120,45 & 154,66 & 31,63 & 40,43 & 416,81 & 123,06 & 137,21 & 397,36 \\
\hline Rana iberica & 29TPH06 & 100,00 & 122,37 & 85,04 & 40,24 & 4221,63 & 238,92 & 30,56 & 208,36 & 75,70 & $\mid 177,15$ & 178,95 & 72.04 & 1114,61 & 150,96 & 33,28 & 38.97 & 412,09 & 127,86 & 143,18 & 388,61 \\
\hline Rana iberica & 29TPH07 & 100,00 & 123,13 & 83,78 & 40,52 & 4121,32 & 237,34 & 33,13 & 204,21 & 77,79 & 176,53 & 178,70 & 74,12 & 1106,65 & 148,29 & 33,80 & 38,24 & 408,04 & 129,36 & 145,35 & 382,48 \\
\hline Rana iberica & 29TPH08 & 100,00 & 124,56 & 82,49 & 40,96 & 4047,40 & 236,24 & 36,13 & 200,11 & 80,26 & 176,78 & 179,07 & 76,20 & 1090,69 & 144,51 & 34,03 & 37,66 & 400,97 & 129,85 & 146,52 & 373,57 \\
\hline Rana iberica & 29TPH09 & 100,00 & 122,75 & 81,56 & \begin{tabular}{|l|l|}
40,98 \\
\end{tabular} & 3966,66 & 232,91 & 35,86 & \begin{tabular}{|l|l|}
197,05 \\
\end{tabular} & 79,73 & \begin{tabular}{|l|}
173,76 \\
\end{tabular} & \begin{tabular}{|l|}
176,37 \\
\end{tabular} & 75,50 & 1103,86 & \begin{tabular}{|l|}
144,75 \\
\end{tabular} & 35,37 & 36,96 & 404,69 & 134,34 & 151,17 & \begin{tabular}{|l|l|}
375,61 \\
\end{tabular} \\
\hline Rana iberica & 29TPH10 & 101,00 & 132,16 & 92,85 & 38,48 & 5032,68 & 264,12 & 25,98 & 238,14 & 75,15 & 197,94 & $\begin{array}{l}198,04 \\
\end{array}$ & 70,82 & 953,14 & 132,65 & 22,92 & 42,71 & 355,93 & 94,51 & 98,62 & 343,08 \\
\hline Rana iberica & 29TPH11 & 101,00 & 125,62 & 91,67 & 38,90 & 4884,10 & 255,94 & 22,64 & 233,31 & 70,55 & 189,69 & 190,05 & 66,56 & 1016,77 & 141,15 & 25,85 & 42,03 & 380,19 & 104,54 & 113,04 & 366,03 \\
\hline Rana iberica & 29TPH12 & 100,00 & 118,21 & 90,44 & 39,02 & 4755,97 & 247,19 & 18,30 & 228,90 & 65,00 & 180,68 & 181,38 & 61,27 & 1085,40 & 149,81 & 29,07 & 41,33 & 405,99 & 115,62 & 127,23 & 390,25 \\
\hline Rana iberica & 29TPH14 & 100,00 & 127,77 & 88,45 & 39,92 & 4530,25 & 250,04 & 30,10 & \begin{tabular}{|l|}
219,94 \\
\end{tabular} & 76,72 & \begin{tabular}{|l|}
186,71 \\
\end{tabular} & \begin{tabular}{|l|l|l|l|l|l}
187,88 \\
\end{tabular} & 73,19 & 1014,92 & \begin{tabular}{|l|}
138,48 \\
\end{tabular} & 28,44 & \begin{tabular}{|l|l|}
39,90 \\
\end{tabular} & 375,81 & 111,82 & 126,42 & 355,63 \\
\hline Rana iberica & 29TPH16 & 101,00 & 125,04 & 86,30 & \begin{tabular}{|l|l|}
40,07 \\
\end{tabular} & 4330,92 & 243,26 & 31,13 & 212,13 & 76,77 & 181,15 & 182,83 & 73,01 & 1042,90 & 139,56 & 31,21 & 38,41 & 383,96 & 120,74 & 136,01 & 359,84 \\
\hline Rana iberica & 29TPH18 & 101,00 & 125,68 & 83,80 & \begin{tabular}{|l|l|}
40,68 \\
\end{tabular} & 4123,85 & 238,95 & \begin{tabular}{|l|}
35,24 \\
\end{tabular} & 203,71 & 80,25 & 178,80 & 180,96 & 76,07 & 1044,09 & 136,94 & 32,81 & $\begin{array}{l}37,04 \\
\end{array}$ & 382,20 & 125,76 & 142,04 & 354,40 \\
\hline Rana iberica & 29TPH 20 & 100,00 & 128,59 & 94,28 & 38,67 & 5087,38 & 263,24 & 21,88 & 241,35 & 70,80 & 195,16 & 195,28 & 66,58 & 936,27 & 128,52 & 22,83 & 42,26 & 350,85 & 94,21 & 97,52 & 337,98 \\
\hline Rana iberica & 29TPH21 & 100,00 & 131,78 & 93,25 & 38,97 & 4996,08 & 263,61 & 26,14 & 237,47 & 75,01 & 196,99 & 197,21 & 70,90 & 914,56 & 125,36 & 22,94 & 41,58 & 340,74 & 94,05 & 100,10 & 325,66 \\
\hline Rana iberica & 29TPH27 & 100,00 & 123,01 & $\begin{array}{l}86,66 \\
86,\end{array}$ & 40,23 & 4337,90 & 241,68 & \begin{tabular}{|l|}
29,27 \\
\end{tabular} & \begin{tabular}{|l|}
212,41 \\
\end{tabular} & $\begin{array}{l}5,81 \\
74,82\end{array}$ & 179,25 & \begin{tabular}{|l|}
180,94 \\
\end{tabular} & 70,80 & 1019,81 & \begin{tabular}{|l|}
133,69 \\
\end{tabular} & 31,80 & \begin{tabular}{|l|}
37,10 \\
37
\end{tabular} & 373,07 & 122,70 & 137,63 & 346,56 \\
\hline Rana iberica & 29TPH30 & 100,00 & 125,13 & 95,64 & 38,73 & 5150,07 & 262,55 & 17,90 & 244,65 & 66,68 & 192,63 & 192,70 & 62,20 & 918,66 & 124,73 & 22,65 & 41,96 & 345,25 & 93,92 & 95,44 & 332,19 \\
\hline Rana iberica & 29TPH31 & 101,00 & 119,04 & 94,44 & 38,82 & 5059,74 & 255,30 & \begin{tabular}{ll|}
14,04 \\
\end{tabular} & 241,25 & 62,01 & 185,63 & 185,73 & 57,79 & 967,60 & 131,02 & 25,32 & 41,14 & 362,64 & 102,89 & 105,66 & 347,87 \\
\hline Rana iberica & 29TPH32 & 101,00 & 111,82 & 93,24 & 38,93 & 4954,82 & 246,85 & 9,55 & 237,30 & 56,42 & 177,15 & 177,45 & 52,28 & 1029,96 & 138,71 & 28,51 & 40,24 & 384,92 & 113,70 & 120,04 & 368,31 \\
\hline Rana iberica & 29TPH33 & 100,00 & 118,60 & 92,65 & 39,09 & 4857,10 & 250,24 & \begin{tabular}{r|}
16,57 \\
\end{tabular} & 233,68 & 63,89 & 182,29 & 182,76 & 59,89 & 983,53 & 132,01 & 27,70 & 39,46 & 365,39 & 110,18 & 120,45 & 346,38 \\
\hline 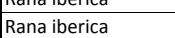 & \begin{tabular}{|l|l|} 
29TPH35 \\
\end{tabular} & 101,00 & $\begin{array}{l}1118,00 \\
118,79\end{array}$ & \begin{tabular}{|l|}
90,60 \\
90,0
\end{tabular} & 39, & $\begin{array}{l}405,1,16 \\
4643,16\end{array}$ & 245,49 & $\begin{array}{l}0,13 \\
20,12\end{array}$ & \begin{tabular}{|l|}
225,38 \\
225
\end{tabular} & $\begin{array}{l}60,00 \\
66,82\end{array}$ & \begin{tabular}{|l|}
$179,40,20$ \\
179
\end{tabular} & \begin{tabular}{|l|}
$180,40,0$ \\
\end{tabular} & \begin{tabular}{|l|l|}
62,86 \\
60
\end{tabular} & \begin{tabular}{|l|}
996,47 \\
996,
\end{tabular} & \begin{tabular}{|l|}
131,71 \\
131,71
\end{tabular} & 30,01 & $\begin{array}{l}3,404 \\
37,94\end{array}$ & 366,67 & $\begin{array}{l}111,10 \\
117,26\end{array}$ & 130,42 & $\begin{array}{l}340,50 \\
343,40\end{array}$ \\
\hline Rana iberica & 29TPH40 & 100,00 & 122,17 & 96,97 & 38,64 & 5220,98 & 262,21 & 14,28 & 247,94 & 62,99 & 190,75 & 190,76 & 58,29 & 893,50 & 120,14 & 22,50 & 41,55 & 336,45 & 93,20 & 93,37 & 322,83 \\
\hline Rana iberica & 29TPH41 & 101,00 & 110,45 & 95,49 & 38,66 & 5128,06 & 250,03 & 5,65 & 244,38 & 52,96 & 178,23 & 178,27 & 48,54 & 986,46 & 132,08 & 26,80 & 40,55 & 370,31 & 108,08 & 108,69 & 355,08 \\
\hline Rana iberica & 29TPH42 & 99,00 & 98,73 & 93,70 & 38,60 & 5033,63 & 237,43 & $-2,60$ & 240,03 & 43,30 & 165,53 & 165,70 & 38,78 & 1084,12 & 143,75 & 31,77 & 39,41 & 404,36 & 124,83 & 128,62 & 386,95 \\
\hline Rana iberica & 29TPH43 & 101,00 & 100,48 & 93,27 & 38,8 & 4951,50 & 237,13 & $-0,22$ & 237,35 & 45,75 & 166,10 & 166,39 & 41,46 & 1075,10 & 142,03 & 32,36 & 38,51 & 398,95 & 126,43 & 132,82 & 379,34 \\
\hline Rana iberica & 29TPH44 & 99,00 & 109,30 & 93,09 & 39,19 & 4862,07 & 242,56 & 8,30 & $\begin{array}{l}234,26 \\
\end{array}$ & 54,97 & \begin{tabular}{|l|}
173,19 \\
\end{tabular} & \begin{tabular}{|l|}
173,70 \\
\end{tabular} & 50,86 & 1015,57 & \begin{tabular}{|l|}
133,86 \\
\end{tabular} & 30,74 & \begin{tabular}{|l|l|}
37,96 \\
\end{tabular} & 375,15 & 120,36 & 129,85 & 353,36 \\
\hline Rana iberica & 29TPH47 & 100,00 & 113,76 & 89,87 & 40,07 & 4540,38 & 238,84 & 17,10 & 221,75 & 63,41 & 172,88 & 174,14 & 59,13 & 1012,02 & 129,93 & 33,27 & 35,72 & 367,70 & 127,70 & 140,68 & 339,47 \\
\hline Rana iberica & 29TPH48 & 101,00 & 117,97 & 88,31 & 40,36 & 4404,92 & 239,19 & 23,24 & 215,96 & 69,26 & 175,12 & \begin{tabular}{ll|}
176,65 \\
\end{tabular} & 64,93 & 993,69 & 127,02 & 33,38 & 34,98 & 359,06 & 127,50 & 141,46 & 328,68 \\
\hline Rana iberica & 29TPH49 & 100,00 & 124,12 & 86,46 & 40,94 & 4260,85 & 240,72 & 31,49 & 209,23 & 77,22 & 179,05 & 180,94 & 72,71 & 962,06 & 123,51 & 32,72 & 34,54 & 45,94 & 124,92 & 139,97 & 313,62 \\
\hline Rana iberica & 29TPH51 & 100,00 & 92,45 & $\begin{array}{l}95,33 \\
55\end{array}$ & 38,24 & 5173,82 & 235,67 & \begin{tabular}{|c|}
$-10,10$ \\
$-10,10$
\end{tabular} & \begin{tabular}{|l|}
245,76 \\
\end{tabular} & 35,76 & 161,46 & \begin{tabular}{|l|}
161,51 \\
\end{tabular} & 30,84 & 1078,35 & \begin{tabular}{|l|l|l|l|l|l|l|}
141,86 \\
\end{tabular} & 31,88 & $\begin{array}{l}39,27 \\
39,27\end{array}$ & 4402,52 & 125,19 & 125,91 & 386,28 \\
\hline Rana iberica & 29TPH52 & 100,00 & 95,85 & 95,19 & 38,70 & 5107,97 & 237,01 & $-6,60$ & 243,60 & 39,57 & 163,73 & 163,78 & 34,81 & 1057,17 & 138,92 & 31,84 & 38,58 & 392,95 & 124,87 & 126,52 & 374,61 \\
\hline Rana iberica & 29TPH53 & 101,00 & 99,11 & 94,86 & 38,92 & 5036,83 & 238,21 & $-2,88$ & 241,09 & 43,45 & 165,90 & 166,06 & 38,90 & 1036,66 & 135,77 & 31.81 & 37,92 & 383,61 & 124,47 & 128,23 & 363,08 \\
\hline Rana iberica & 29TPH54 & 100,00 & 115,34 & 94,76 & 39,46 & 4935,88 & 249,56 & \begin{tabular}{|l|l|}
12,04 \\
\end{tabular} & 237,52 & 59,65 & 179,89 & 180,24 & 55,34 & 926,28 & 120,82 & 27,95 & 37,42 & 341,19 & 110,92 & 118,09 & 318,13 \\
\hline Rana iberica & 29TPH55 & 101,00 & 115,59 & 93,60 & 39,80 & 4824,02 & 247,23 & $\begin{array}{l}14,03 \\
\end{array}$ & 233,20 & 61,30 & 178,62 & 179,20 & 57,08 & 937,10 & 121,15 & 29,23 & 36,63 & 342,96 & 114,97 & 125,70 & 317,72 \\
\hline Rana iberica & 29TPH56 & $\frac{10,00}{100,00}$ & 113 & $\begin{array}{l}30,00 \\
92,57\end{array}$ & $\begin{array}{l}35, \\
39,\end{array}$ & $\begin{array}{l}40 \angle 4,02 \\
4721,95\end{array}$ & $\begin{array}{l}24,25 \\
242,36\end{array}$ & $\begin{array}{l}4,20 \\
12,91 \\
\end{array}$ & \begin{tabular}{|l|}
229,45 \\
229
\end{tabular} & 59,88 & 174,30 & 175,10 & 55,56 & 969,45 & 124,37 & 31,62 & 35,72 & 352,59 & 122,46 & 134,51 & 325,18 \\
\hline Rana iberica & 29TPH57 & 101,00 & 108,53 & 91,48 & 39,99 & 4634,93 & 236,83 & 10,77 & 226,06 & 57,27 & 169,01 & 170,10 & 52,83 & 1012,28 & 129,34 & 34,45 & 34,89 & 366,04 & 131,43 & 143,40 & 336,67 \\
\hline Rana iberica & 29TPH58 & 99,00 & 111,89 & 90,21 & 40,17 & 4511,60 & 236,79 & 15,61 & 221.18 & $\mid 62,19$ & \begin{tabular}{|l|l|}
170,64 \\
\end{tabular} & \begin{tabular}{|l|l|}
171,93 \\
\end{tabular} & 57,57 & 1001.05 & 128,05 & 34,69 & 34,26 & 360,09 & 131,93 & 144,69 & 328,66 \\
\hline Rana iberica & 29TPH59 & 100,00 & 108,28 & 89,15 & 40,38 & 4433,10 & 231,60 & 13,83 & 217,77 & 59,79 & 165,92 & 167,44 & 55,18 & 1039,47 & 132,73 & 37,32 & 33,51 & 371,99 & 140,32 & 153,04 & 338,82 \\
\hline Rana iberica & 29TPH60 & 101,00 & 104,75 & 99,05 & 38,4 & 5352,43 & 251,30 & $-2,77$ & 254,06 & 44,83 & 175,79 & 175,79 & 39,85 & 926,98 & 122,54 & 25,86 & 40,07 & 348,48 & 104,41 & 104,43 & 333,57 \\
\hline $\begin{array}{l}\mid l a l d \\
\text { Rana iberica }\end{array}$ & 29TPH61 & \begin{tabular}{|l|}
101,00 \\
\end{tabular} & $\begin{array}{l}90,15 \\
98,60\end{array}$ & $\begin{array}{l}35,03 \\
97,92\end{array}$ & | & $\begin{array}{l}5271,45 \\
5271,68\end{array}$ & 243,83 & $\begin{array}{l}-2,11 \\
-6,88\end{array}$ & $\begin{array}{l}250,72 \\
250,72\end{array}$ & 40,01 & 168,65 & 168,65 & 35,12 & 979,21 & 128,64 & 28,89 & 38,95 & 365,30 & 114,69 & 114,77 & 348,13 \\
\hline Rana iberica & 29TPH62 & 100,00 & 100,06 & \begin{tabular}{|l|l|}
97,43 \\
\end{tabular} & 38,86 & 5205,83 & 243,35 & $-4,92$ & 248,28 & $\mid 41,99$ & \begin{tabular}{|c|}
169,03 \\
\end{tabular} & \begin{tabular}{|c|}
169,06 \\
\end{tabular} & 37,23 & \begin{tabular}{|c|}
973,89 \\
\end{tabular} & $\mid 127,40$ & 29,47 & 38,08 & 361,44 & 116,54 & 116,88 & 342,10 \\
\hline Rana iberica & 29TPH63 & 100,00 & 96,65 & 96,45 & 38,91 & 5119,07 & 238,28 & $-6,57$ & 244,86 & 39,94 & 164,49 & 164,55 & 35,18 & 1010,04 & 131,23 & 31,90 & 37,11 & 372,28 & 124,46 & 125,75 & 350,78 \\
\hline Rana iberica & 29TPH64 & 100,00 & 101,18 & 95,94 & 39,1 & 5028,11 & 240,07 & $-1,63$ & 241,70 & 45,30 & 167 & 167 & 40 & 986,45 & 127,35 & 31,77 & 36 & 361,41 & 123,68 & 127,55 & 337,53 \\
\hline Rana iberica & 29TPH67 & 100,00 & 111,40 & 92,64 & 40,16 & 4672,44 & 240,37 & 12,48 & 227,89 & 59,48 & 172,27 & 173,21 & 54,89 & 959,28 & 123,40 & 33,20 & 34,14 & 344,70 & 127,14 & 138,91 & 313,97 \\
\hline
\end{tabular}




\begin{tabular}{|c|c|c|c|c|c|c|c|c|c|c|c|c|c|c|c|c|c|c|c|c|c|}
\hline TAXON & UTM & $\mathrm{km} 2$ & BI01 & BIO2 & BIO3 & BIO4 & B105 & B106 & B107 & B108 & B109 & B1010 & BIO11 & B1012 & BIO13 & BIO14 & B1015 & B1016 & B1017 & 81018 & 81019 \\
\hline Rana iberica & 29TPH68 & 100,00 & 112,91 & 91,50 & 40,35 & 4561,33 & 239,10 & 15,52 & 223,58 & 62,99 & $\begin{array}{r}172,22 \\
\end{array}$ & $\begin{array}{r}173,42 \\
\end{array}$ & 57,89 & 963,04 & 124,25 & 34,13 & 33,53 & 344,15 & 129,85 & $\begin{array}{r}142,22 \\
\end{array}$ & 311,33 \\
\hline Rana iberica & 29TPH69 & 101,00 & 111,30 & 90,22 & 40,59 & 4455,73 & 235,18 & $\begin{array}{l}15,77 \\
\end{array}$ & 219,40 & 62,47 & 169,08 & $\begin{array}{l}170,64 \\
\end{array}$ & $\begin{array}{l}57,66 \\
\end{array}$ & \begin{tabular}{|c|}
990,84 \\
\end{tabular} & \begin{tabular}{|l|}
127,71 \\
\end{tabular} & \begin{tabular}{l|l|}
36,23 \\
\end{tabular} & 32,91 & \begin{tabular}{|l|}
352,08 \\
\end{tabular} & \begin{tabular}{|l|l|}
136,38 \\
\end{tabular} & \begin{tabular}{|l|l|}
148,98 \\
\end{tabular} & 317,42 \\
\hline Rana iberica & 29TPH70 & 99,00 & \begin{tabular}{|l|l|}
120,04 \\
\end{tabular} & 101,98 & \begin{tabular}{l|l|}
38,92 \\
\end{tabular} & \begin{tabular}{|l|l|l|}
5464,69 \\
\end{tabular} & 267,27 & 7,93 & 259,34 & 57,30 & \begin{tabular}{|l|}
191,79 \\
\end{tabular} & \begin{tabular}{|l|}
191,79 \\
\end{tabular} & \begin{tabular}{|l|}
52,47 \\
\end{tabular} & \begin{tabular}{|l|}
768,84 \\
\end{tabular} & \begin{tabular}{|l|l|}
101,73 \\
\end{tabular} & \begin{tabular}{|l|}
20,23 \\
\end{tabular} & 40,17 & \begin{tabular}{|l|}
290,06 \\
\end{tabular} & $\begin{array}{l}85,34 \\
\end{array}$ & \begin{tabular}{|l|l|}
85,34 \\
\end{tabular} & 274,12 \\
\hline Rana iberica & 29TPH71 & 100,00 & \begin{tabular}{|l|l|}
113,94 \\
\end{tabular} & \begin{tabular}{ll|}
100,82 \\
\end{tabular} & \begin{tabular}{|l|}
38,97 \\
\end{tabular} & 5392,16 & 260,03 & 3,76 & 256,27 & \begin{tabular}{|l|}
52,37 \\
\end{tabular} & 184,91 & 184,91 & \begin{tabular}{ll|}
47,68 \\
\end{tabular} & \begin{tabular}{|l|}
816,87 \\
\end{tabular} & \begin{tabular}{|l|l|}
107,39 \\
\end{tabular} & 22,93 & 39,03 & \begin{tabular}{|l|}
305,75 \\
\end{tabular} & $\begin{array}{l}94,65 \\
\end{array}$ & $\begin{array}{l}94,65 \\
\end{array}$ & 287,50 \\
\hline Rana iberica & 29TPH72 & 100,00 & 106,85 & 99,74 & 38,99 & 5300,89 & 251,67 & $-0,98 \mid$ & 252,65 & 46,96 & 176,72 & 176,72 & 42,12 & $876,57 \mid$ & 114,23 & 26,39 & 37,74 & 324,95 & 106,04 & 106,04 & 304,42 \\
\hline Rana iberica & 29TPH73 & 101,00 & 86,82 & $\begin{array}{l}97,28 \\
\end{array}$ & \begin{tabular}{|l|}
38,88 \\
\end{tabular} & 5179,44 & 231,19 & $-16,28$ & 247,47 & 30,10 & 155,82 & 155,92 & 25,01 & 1044,37 & \begin{tabular}{|l|}
133,86 \\
\end{tabular} & 35,11 & 35,84 & \begin{tabular}{|l|}
381,04 \\
\end{tabular} & 134,58 & 135,46 & 358,23 \\
\hline Rana iberica & 29TPH74 & 100,00 & 79,80 & 95,67 & 38,76 & 5085,43 & 222,37 & $-21,16$ & 243,53 & 24,80 & \begin{tabular}{|l|}
147,66 \\
\end{tabular} & \begin{tabular}{|l|}
147,86 \\
\end{tabular} & \begin{tabular}{|l|l|}
19,67 \\
\end{tabular} & 1114,89 & \begin{tabular}{|l|l|}
141,35 \\
\end{tabular} & 39,34 & 34,79 & \begin{tabular}{|l|l|}
402,99 \\
\end{tabular} & 148,23 & $\begin{array}{l}150,17 \\
\end{array}$ & 377,98 \\
\hline Rana iberica & 29TPH75 & 101,00 & $\begin{array}{ll}94,02 \\
\end{array}$ & 96,11 & \begin{tabular}{l|l|}
39,45 \\
\end{tabular} & \begin{tabular}{|l|l|}
4995,44 \\
\end{tabular} & 233,21 & \begin{tabular}{|l|l|} 
& $-7,67$ \\
\end{tabular} & 240,88 & 39,08 & $\begin{array}{l}160,11 \\
\end{array}$ & $\begin{array}{l}160,38 \\
\end{array}$ & \begin{tabular}{|l|l|}
34,17 \\
\end{tabular} & 1015,93 & \begin{tabular}{|l|}
129,58 \\
\end{tabular} & 35,50 & 34,52 & \begin{tabular}{|l|l|}
366,79 \\
\end{tabular} & \begin{tabular}{|l|}
135,23 \\
\end{tabular} & \begin{tabular}{|l|l|}
139,76 \\
\end{tabular} & 339,58 \\
\hline Rana iberica & 29TPH78 & 100,00 & $\begin{array}{l}114,42 \\
\end{array}$ & \begin{tabular}{|l|l|}
92,48 \\
\end{tabular} & \begin{tabular}{l|l|}
40,65 \\
4
\end{tabular} & \begin{tabular}{|l|l|}
4583,52 \\
\end{tabular} & 241,15 & $\begin{array}{l}16,33 \\
\end{array}$ & 224,81 & $\begin{array}{l}67,71 \\
\end{array}$ & \begin{tabular}{|l|}
173,87 \\
\end{tabular} & \begin{tabular}{|l|}
175,05 \\
\end{tabular} & \begin{tabular}{|l|l|}
58,89 \\
\end{tabular} & \begin{tabular}{|l|l|}
927,82 \\
9
\end{tabular} & $\begin{array}{l}120,75 \\
\end{array}$ & 33,81 & 32,65 & \begin{tabular}{|l|}
328,82 \\
\end{tabular} & \begin{tabular}{|l|}
128,45 \\
\end{tabular} & \begin{tabular}{|l|}
140,50 \\
\end{tabular} & 294,39 \\
\hline Rana iberica & 29TPH81 & 99,00 & \begin{tabular}{|l|l|}
126,87 \\
\end{tabular} & \begin{tabular}{|l|l|}
102,37 \\
\end{tabular} & 39,00 & 5448,44 & 272,65 & \begin{tabular}{|l|l|}
13,83 \\
\end{tabular} & 258,82 & 63,77 & \begin{tabular}{|l|}
197,98 \\
\end{tabular} & \begin{tabular}{|l|l|}
197,98 \\
\end{tabular} & 59,01 & \begin{tabular}{|l|l|}
694,68 \\
\end{tabular} & \begin{tabular}{l|l|}
91,52 \\
\end{tabular} & \begin{tabular}{|l|}
18,59 \\
\end{tabular} & 38,74 & 259,96 & 80,41 & 80,41 & 239,84 \\
\hline Rana iberica & 29TPH82 & 99,00 & 115,22 & 101,69 & \begin{tabular}{|l|}
39,04 \\
\end{tabular} & 5381,48 & 260,87 & 4,64 & 256,23 & 53,53 & 185,86 & 185,86 & 48,75 & 776,09 & \begin{tabular}{|l|}
101,55 \\
\end{tabular} & 22,88 & 37,42 & 287,61 & 94,74 & \begin{tabular}{|l|l|}
94,74 \\
\end{tabular} & 265,39 \\
\hline Rana iberica & 29TPH83 & 101,00 & 103,10 & 100,38 & 39,18 & 5272,73 & 248,04 & $-4,25$ & 252,29 & \begin{tabular}{|l|}
43,77 \\
\end{tabular} & \begin{tabular}{|l|}
172,58 \\
\end{tabular} & \begin{tabular}{|l|}
172,58 \\
\end{tabular} & 38,79 & 876,14 & \begin{tabular}{|l|l|}
113,19 \\
\end{tabular} & 28,54 & 35,80 & \begin{tabular}{|l|l|}
320,06 \\
\end{tabular} & \begin{tabular}{|l|}
112,79 \\
\end{tabular} & \begin{tabular}{|l|}
112,79 \\
\end{tabular} & 295,79 \\
\hline Rana iberica & 29TPH84 & 99,00 & 84,45 & \begin{tabular}{|l|l|}
98,01 \\
\end{tabular} & 39,11 & 5161,57 & 228,83 & $-18,65$ & 247,48 & 28,14 & 153,10 & 153,23 & 22,80 & 1035,10 & \begin{tabular}{|l|l|}
131,26 \\
\end{tabular} & 37,17 & 34,15 & \begin{tabular}{|l|l|}
372,30 \\
\end{tabular} & 140,47 & 142,00 & 346,19 \\
\hline Rana iberica & 29TPH85 & 100,00 & 86,49 & \begin{tabular}{|l|l|}
97,08 \\
\end{tabular} & \begin{tabular}{|l|}
39,39 \\
\end{tabular} & 5063,74 & 228,23 & $-15,52$ & 243,75 & 31,32 & $\begin{array}{l}153,68 \\
\end{array}$ & \begin{tabular}{|l|}
153,93 \\
\end{tabular} & 26,09 & 1038,17 & \begin{tabular}{|l|}
131,85 \\
\end{tabular} & 38,02 & 33,43 & \begin{tabular}{|l|l|}
371,23 \\
\end{tabular} & 143,15 & $\begin{array}{l}146,55 \\
\end{array}$ & 342,91 \\
\hline Rana iberica & 29TPH86 & 100,00 & \begin{tabular}{|l|l|}
92,14 \\
\end{tabular} & \begin{tabular}{|l|l|}
96,67 \\
9
\end{tabular} & \begin{tabular}{|l|}
39,75 \\
\end{tabular} & \begin{tabular}{|l|l|}
4962,72 \\
\end{tabular} & 231,10 & $-9,28$ & 240,38 & 37,85 & $\begin{array}{l}157,69 \\
\end{array}$ & \begin{tabular}{|l|}
158,06 \\
\end{tabular} & \begin{tabular}{|l|}
32,74 \\
\end{tabular} & 1009,01 & \begin{tabular}{|l|}
128,96 \\
\end{tabular} & 37,55 & 32,85 & 359,18 & 141,06 & 147,50 & 328,58 \\
\hline Rana iberica & 29TPH90 & 100,00 & \begin{tabular}{|l|l|}
99,73 \\
\end{tabular} & 103,64 & \begin{tabular}{|l|}
38,78 \\
\end{tabular} & 5565,35 & 252,92 & $-11,42$ & 264,33 & $\begin{array}{l}37,12 \\
\end{array}$ & \begin{tabular}{|l|}
173,61 \\
\end{tabular} & \begin{tabular}{|l|}
173,61 \\
\end{tabular} & 31,75 & 828,61 & \begin{tabular}{|l|l|}
107,49 \\
\end{tabular} & 25,79 & 37,44 & \begin{tabular}{|l|}
305,64 \\
\end{tabular} & 103,15 & 103,15 & 287,18 \\
\hline Rana iberica & 29TPH91 & 100,00 & 123,96 & 104,01 & 39,00 & 5549,99 & \begin{tabular}{|l|}
273,22 \\
\end{tabular} & 9,52 & \begin{tabular}{|l|}
263,70 \\
\end{tabular} & 59,34 & \begin{tabular}{|l|}
196,45 \\
\end{tabular} & \begin{tabular}{|l|}
196,45 \\
\end{tabular} & 54,78 & $\begin{array}{l}671,06 \\
\end{array}$ & 89,20 & 18,55 & 38,11 & \begin{tabular}{|l|}
250,52 \\
\end{tabular} & 80,57 & 80,57 & 229,55 \\
\hline Rana iberica & 29TPH93 & 101,00 & 107,31 & $\begin{array}{l}102,32 \\
\end{array}$ & \begin{tabular}{|l|}
39,65 \\
\end{tabular} & 5336,26 & 253,68 & $-1,99$ & 255,66 & 46,81 & 177,48 & 177,48 & 41,85 & 807,54 & \begin{tabular}{|l|}
105,61 \\
\end{tabular} & 26,68 & 35,10 & 293,24 & 106,52 & 106,52 & 267,56 \\
\hline Rana iberica & 29TPH94 & 100,00 & 95,70 & 100,75 & 39,73 & 5221,88 & 241,01 & $\begin{array}{l}-10,36 \\
\end{array}$ & 251,37 & \begin{tabular}{|l|}
37,77 \\
\end{tabular} & 164,72 & 164,75 & $\begin{array}{l}32,52 \\
\end{array}$ & \begin{tabular}{|c|}
909,10 \\
\end{tabular} & \begin{tabular}{|l|l|}
117,19 \\
\end{tabular} & 32,61 & 33,67 & 325,71 & 125,11 & $\begin{array}{l}125,58 \\
\end{array}$ & 298,14 \\
\hline Rana iberica & 29TPH95 & 101,00 & 82,12 & \begin{tabular}{|l|l|}
98,49 \\
\end{tabular} & 39,41 & 5119,52 & 226,07 & $-20,73$ & 246,80 & 26,62 & 150,14 & 150,32 & 21,01 & 1033,23 & \begin{tabular}{|l|}
130,99 \\
\end{tabular} & 39,47 & 32,41 & \begin{tabular}{|l|}
366,08 \\
\end{tabular} & 147,11 & \begin{tabular}{|l|l|}
149,18 \\
\end{tabular} & 336,68 \\
\hline Rana iberica & 29TPH96 & 100,00 & \begin{tabular}{|l|l|}
95,13 \\
\end{tabular} & 98,32 & 40,01 & \begin{tabular}{|l|l|}
4996,45 \\
\end{tabular} & 234,96 & \begin{tabular}{|l|l|} 
& $-7,69$ \\
\end{tabular} & 242,65 & 43,34 & 160,89 & 161,15 & 34,80 & 956,82 & \begin{tabular}{|l|l|}
123,38 \\
\end{tabular} & 36,55 & 32,03 & \begin{tabular}{|l|}
337,68 \\
\end{tabular} & 137,32 & 142,85 & 305,49 \\
\hline Rana iberica & 29TPJ00 & 100,00 & 117,21 & 80,76 & \begin{tabular}{|l|}
40,90 \\
\end{tabular} & 3933,58 & 227,10 & $\begin{array}{l}1,59 \\
\end{array}$ & \begin{tabular}{|l|}
195,51 \\
\end{tabular} & 75,04 & $\begin{array}{l}167,82 \\
\end{array}$ & $\begin{array}{l}170,58 \\
\end{array}$ & 70,49 & $\begin{array}{l}1145,39 \\
\end{array}$ & \begin{tabular}{|l|}
148,93 \\
\end{tabular} & \begin{tabular}{|l|l|}
37,93 \\
\end{tabular} & 36,25 & \begin{tabular}{|l|l|}
418,76 \\
\end{tabular} & \begin{tabular}{|l|}
142,92 \\
\end{tabular} & \begin{tabular}{|l|l|}
159,58 \\
\end{tabular} & 388,07 \\
\hline Rana iberica & 29ТРJ01 & \begin{tabular}{|l|}
101,00 \\
\end{tabular} & 112,48 & 79,91 & \begin{tabular}{|l|l|}
40,93 \\
\end{tabular} & 3893,99 & 221,85 & 28,54 & \begin{tabular}{|l|}
193,32 \\
\end{tabular} & $\mid 71,38$ & \begin{tabular}{|l|}
162,61 \\
\end{tabular} & \begin{tabular}{|l|l|}
165,58 \\
\end{tabular} & \begin{tabular}{|c|}
66,65 \\
\end{tabular} & 1180,63 & $|152,27|$ & \begin{tabular}{|l|l|}
40,25 \\
\end{tabular} & 35,61 & \begin{tabular}{|l|l|}
430,41 \\
\end{tabular} & \begin{tabular}{|l|}
150,73 \\
\end{tabular} & \begin{tabular}{|l|}
167,32 \\
\end{tabular} & $\begin{array}{l}398,02 \\
\end{array}$ \\
\hline Rana iberica & 29ТРJ02 & 101,00 & 123,80 & 77,64 & 41,36 & 3730,50 & 226,94 & 41,71 & 185,24 & 84,33 & $\mid 171,23$ & 174,39 & 79,08 & 1089,72 & 138,96 & 36,99 & 35,12 & 396,56 & 139,64 & 158,09 & 362,56 \\
\hline Rana iberica & 29TPJ03 & 101,00 & $\begin{array}{l}127,49 \\
\end{array}$ & 76,06 & \begin{tabular}{l|l|}
41,66 \\
\end{tabular} & 3640,31 & 227,42 & 47,19 & 180,23 & 89,29 & 173,45 & 176,91 & 83,71 & 1057,71 & \begin{tabular}{|l|}
135,04 \\
\end{tabular} & 36,25 & 34,85 & \begin{tabular}{|l|l|}
384,15 \\
\end{tabular} & 137,13 & 156,45 & 348,63 \\
\hline Rana iberica & 29TPJ10 & 101,00 & 112,25 & 82,44 & \begin{tabular}{|l|}
40,65 \\
\end{tabular} & 4047,22 & 225,37 & 25,05 & 200,32 & 68,87 & 164,45 & 167,13 & 64,32 & 1150,58 & 148,39 & 39,02 & 35,57 & 418,62 & $\begin{array}{l}146,55 \\
\end{array}$ & 162,06 & $\begin{array}{l}387,48 \\
\end{array}$ \\
\hline Rana iberica & 29TPJ11 & 99,00 & 107,59 & 81,49 & \begin{tabular}{|l|l|}
40,67 \\
\end{tabular} & 4002,55 & 220,11 & 21,82 & \begin{tabular}{|l|}
198,28 \\
\end{tabular} & 65,15 & 159,35 & 162,08 & $\begin{array}{l}60,56 \\
\end{array}$ & 1187,50 & \begin{tabular}{|l|l|}
151,90 \\
\end{tabular} & $\begin{array}{l}41,50 \\
\end{array}$ & 34,98 & 430,71 & $\begin{array}{l}154,62 \\
\end{array}$ & 170,05 & 397,96 \\
\hline Rana iberica & 29TPJ12 & 100,00 & 123,46 & 78,92 & \begin{tabular}{|l|}
41,39 \\
\end{tabular} & $\begin{array}{l}3807,52 \\
\end{array}$ & 228,45 & \begin{tabular}{|l|}
39,93 \\
\end{tabular} & $\begin{array}{l}188,52 \\
\end{array}$ & 82,91 & \begin{tabular}{|l|}
171,92 \\
\end{tabular} & \begin{tabular}{|l|}
174,97 \\
\end{tabular} & 77,90 & 1067,06 & \begin{tabular}{|l|}
135,81 \\
\end{tabular} & \begin{tabular}{|l|}
36,83 \\
\end{tabular} & 34,70 & \begin{tabular}{|l|l|}
386,28 \\
\end{tabular} & $\begin{array}{l}138,65 \\
\end{array}$ & 156,57 & 351,79 \\
\hline |Rana iberica & 29TPJ13 & 90,00 & 132,24 & 76,74 & 41,84 & 3674,46 & 232,24 & 50,79 & 181,45 & 93,37 & 178,62 & 181,91 & 87,82 & 1000,76 & 128,78 & 34,41 & 34,42 & 361,84 & 130,66 & 149,97 & 325,86 \\
\hline Rana iberica & 29TPJ20 & 101,00 & 115,98 & 83,44 & \begin{tabular}{|l|l|}
40,87 \\
\end{tabular} & 4089,90 & 229,64 & 27,49 & 202,15 & 71,75 & 168,76 & 171,14 & 67,24 & 1089,15 & 138,99 & 37,26 & 35,04 & 394,35 & 140,28 & 155,81 & 362,46 \\
\hline Rana iberica & 29TPJ21 & 100,00 & 120,79 & 81,71 & \begin{tabular}{|l|l|}
41,15 \\
\end{tabular} & \begin{tabular}{|l|}
3971,63 \\
\end{tabular} & 230,49 & \begin{tabular}{|l|l|}
34,14 \\
\end{tabular} & 196,35 & 77,94 & \begin{tabular}{|l|}
171,70 \\
\end{tabular} & \begin{tabular}{|l|}
174,29 \\
\end{tabular} & 73,26 & 1057,61 & \begin{tabular}{|l|}
134,68 \\
\end{tabular} & \begin{tabular}{|l|}
36,63 \\
\end{tabular} & 34,61 & \begin{tabular}{|l|l|}
381,88 \\
\end{tabular} & 137,79 & 154,38 & 348,21 \\
\hline Rana iberica & 29TPJ22 & 101,00 & 128,39 & 79,59 & \begin{tabular}{|l|}
41,46 \\
\end{tabular} & 3830,80 & 233,22 & 43,66 & 189,56 & 87,41 & 177,09 & 180,01 & 82,31 & 1008,09 & 129,29 & 35,01 & 34,31 & 363,16 & 132,31 & 150,16 & 327,92 \\
\hline Rana iberica & 29TPJ23 & 94,00 & 133,06 & 77,66 & 41,91 & $\begin{array}{l}3722,46 \\
\end{array}$ & 234,09 & 50,41 & 183,68 & 93,41 & 180,09 & 183,18 & 88,03 & \begin{tabular}{|c|}
977,56 \\
\end{tabular} & \begin{tabular}{|l|l|}
126,37 \\
\end{tabular} & 34,11 & 33,99 & \begin{tabular}{|l|l|}
351,59 \\
\end{tabular} & 129,36 & 148,23 & 314,92 \\
\hline Rana iberica & 29TPJ30 & 100,00 & 121,04 & 84,16 & \begin{tabular}{l|l|}
40,86 \\
\end{tabular} & 4126,23 & 234,68 & 31,21 & 203,47 & 76,08 & \begin{tabular}{|l|}
174,03 \\
\end{tabular} & 176,41 & 71,45 & 1022,14 & \begin{tabular}{|l|}
130,45 \\
\end{tabular} & 35,14 & 34,61 & \begin{tabular}{|l|l|}
368,39 \\
\end{tabular} & \begin{tabular}{|l|}
133,01 \\
\end{tabular} & $\begin{array}{l}148,65 \\
\end{array}$ & 335,45 \\
\hline Rana iberica & 29TPJ31 & 100,00 & 135,22 & 81,16 & \begin{tabular}{|l|}
41,29 \\
\end{tabular} & 3932,80 & 241,41 & 47,83 & $\begin{array}{l}193,58 \\
\end{array}$ & 92,40 & 185,17 & 187,79 & 87,18 & \begin{tabular}{|l|l|}
929,59 \\
\end{tabular} & 120,41 & 31,68 & 34,24 & 333,90 & 121,13 & 138,70 & 299,17 \\
\hline Rana iberica & 29TPJ32 & 91,00 & 136,61 & $\begin{array}{l}79,53 \\
\end{array}$ & \begin{tabular}{|l|}
41,78 \\
\end{tabular} & 3831,15 & 239,88 & \begin{tabular}{|l|}
51,33 \\
\end{tabular} & 188,55 & 95,22 & 185,06 & \begin{tabular}{|l|}
187,84 \\
\end{tabular} & 89,85 & \begin{tabular}{|l|l|}
927,72 \\
\end{tabular} & \begin{tabular}{|l|l|}
120,65 \\
1
\end{tabular} & 32,12 & 33,99 & \begin{tabular}{|l|l|}
332,50 \\
\end{tabular} & \begin{tabular}{|l|}
122,39 \\
\end{tabular} & \begin{tabular}{|l|l|}
140,73 \\
\end{tabular} & 296,34 \\
\hline Rana iberica & 29TPJ40 & 101,00 & 128,17 & 84,57 & \begin{tabular}{|l|l|}
41,07 \\
\end{tabular} & \begin{tabular}{|l|l|}
4134,92 \\
\end{tabular} & 240,82 & \begin{tabular}{|l|}
37,28 \\
\end{tabular} & 203,54 & 82,84 & \begin{tabular}{|l|}
181,01 \\
\end{tabular} & \begin{tabular}{|l|}
183,25 \\
\end{tabular} & 77,93 & \begin{tabular}{|l|l|}
945,88 \\
\end{tabular} & \begin{tabular}{|l|}
122,14 \\
\end{tabular} & 32,70 & 34,02 & \begin{tabular}{|l|l|}
338,76 \\
\end{tabular} & \begin{tabular}{|l|}
124,47 \\
\end{tabular} & 140,34 & 304,66 \\
\hline Rana iberica & 29TPJ41 & 100,00 & 129,11 & 83,08 & \begin{tabular}{|l|}
41,29 \\
\end{tabular} & 4026,54 & 238,90 & 40,38 & $\begin{array}{l}198,52 \\
\end{array}$ & 85,34 & 180,45 & 182,99 & 80,33 & \begin{tabular}{|c|}
948,94 \\
\end{tabular} & 122,89 & 33,48 & 33,49 & 338,62 & 126,88 & 143,42 & 302,84 \\
\hline Rana iberica & 29TPJ42 & 53,00 & $\begin{array}{ll}137,48 \\
\end{array}$ & 80,69 & 41,72 & 3889,44 & 242,19 & 50,71 & 191,48 & 96,05 & 186,59 & 189,31 & 89,93 & \begin{tabular}{|l|l|}
902,47 \\
\end{tabular} & \begin{tabular}{|l|}
118,12 \\
\end{tabular} & \begin{tabular}{|l|}
31,63 \\
\end{tabular} & 33,45 & \begin{tabular}{|l|}
321,57 \\
\end{tabular} & 120,77 & $\begin{array}{l}138,51 \\
\end{array}$ & 284,69 \\
\hline Rana iberica & 29TPJ50 & 100,00 & 121,44 & 86,51 & 40,99 & 4230,20 & 237,81 & 29,27 & 208,54 & 75,28 & \begin{tabular}{|l|l|}
175,91 \\
\end{tabular} & \begin{tabular}{|l|}
177,87 \\
\end{tabular} & 70,33 & 965,29 & \begin{tabular}{|l|l|l|}
124,76 \\
\end{tabular} & 34,64 & 33,15 & \begin{tabular}{|l|}
343,49 \\
\end{tabular} & 130,84 & $\begin{array}{l}145,53 \\
\end{array}$ & 308,23 \\
\hline Rana iberica & 29TPJ61 & 101,00 & \begin{tabular}{|l|}
128,73 \\
\end{tabular} & 85,00 & \begin{tabular}{|l|l|}
41,49 \\
\end{tabular} & 4095,14 & 240,69 & 38,16 & 202,54 & 93,10 & 180,98 & \begin{tabular}{|l|}
183,27 \\
\end{tabular} & \begin{tabular}{ll|}
79,05 \\
\end{tabular} & \begin{tabular}{|l|l|}
912,44 \\
\end{tabular} & \begin{tabular}{|l|}
119,82 \\
\end{tabular} & 33,86 & 32,17 & \begin{tabular}{|l|l|}
321,09 \\
\end{tabular} & \begin{tabular}{|l|}
127,55 \\
\end{tabular} & \begin{tabular}{|l|l|}
142,96 \\
\end{tabular} & 282,41 \\
\hline Rana iberica & 29TPJ71 & 100,00 & $\begin{array}{l}120,92 \\
\end{array}$ & 87,16 & \begin{tabular}{|l|l|}
41,43 \\
\end{tabular} & 4487,18 & 236,81 & 29,09 & \begin{tabular}{|l|}
207,72 \\
\end{tabular} & 87,25 & $\begin{array}{l}174,57 \\
\end{array}$ & \begin{tabular}{|l|l|}
176,78 \\
\end{tabular} & 70,42 & \begin{tabular}{|l|l|}
941,81 \\
\end{tabular} & \begin{tabular}{|l|}
123,60 \\
\end{tabular} & 36,55 & 31,16 & \begin{tabular}{|l|l|}
328,99 \\
\end{tabular} & $\begin{array}{l}136,06 \\
\end{array}$ & \begin{tabular}{|l|l|}
150,07 \\
\end{tabular} & 288,43 \\
\hline Rana iberica & 29TPJ81 & 101,00 & 126,36 & 87,08 & \begin{tabular}{|l|l|}
41,82 \\
\end{tabular} & \begin{tabular}{|l|l|}
4144,52 \\
\end{tabular} & 240,59 & 34,49 & 206,10 & 102,20 & 179,16 & 181,45 & 75,99 & \begin{tabular}{|l|l|}
896,35 \\
\end{tabular} & \begin{tabular}{|l|l|}
118,96 \\
\end{tabular} & 35,47 & 30,70 & 311,92 & 132,18 & 146,10 & 267,74 \\
\hline Rana iberica & 29TPJ91 & 99,00 & 119,93 & 88,97 & 41,8 & \begin{tabular}{|l|l|}
4195,91 \\
\end{tabular} & 237,16 & 27,14 & 210,02 & 96,71 & 173,61 & 175,77 & 69,22 & \begin{tabular}{|l|}
921,04 \\
\end{tabular} & \begin{tabular}{|l|l|}
122,25 \\
\end{tabular} & 38,30 & 29,70 & \begin{tabular}{|l|l|}
317,98 \\
\end{tabular} & 140,67 & 153,30 & 270,80 \\
\hline Rana iberica & 29TQE05 & 101,00 & 138,92 & 100,86 & 35,66 & 6179,17 & 303,34 & 24,93 & 278,40 & 71,73 & 221,24 & 221,47 & 63,98 & \begin{tabular}{|c|}
681,18 \\
\end{tabular} & 89,82 & 7,55 & 48,70 & 261,17 & 50,10 & 50,85 & 251,98 \\
\hline Rana iberica & 29TQE06 & 100,00 & 119,30 & 96,47 & \begin{tabular}{|l|}
34,97 \\
\end{tabular} & 6132,22 & 280,84 & 9,10 & 271,74 & 53,72 & 201,13 & \begin{tabular}{|l|}
201,82 \\
\end{tabular} & 46,16 & \begin{tabular}{|l|}
805,73 \\
\end{tabular} & \begin{tabular}{|l|}
107,34 \\
\end{tabular} & \begin{tabular}{|l|l|}
10,19 \\
\end{tabular} & 48,41 & \begin{tabular}{|l|l|}
309,67 \\
\end{tabular} & $\begin{array}{l}60,69 \\
\end{array}$ & \begin{tabular}{|l|l|}
63,48 \\
\end{tabular} & 300,38 \\
\hline Rana iberica & 29TQE07 & 100,00 & \begin{tabular}{|l|l|}
123,62 \\
\end{tabular} & \begin{tabular}{|c|}
98,16 \\
\end{tabular} & |35,33 & 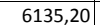 & 285,67 & \begin{tabular}{l|l}
12,02 \\
\end{tabular} & 273,65 & \begin{tabular}{|l|l|l|}
57,43 \\
\end{tabular} & \begin{tabular}{|l|l|}
204,98 \\
\end{tabular} & 205,92 & \begin{tabular}{|l|l|}
49,78 \\
\end{tabular} & $|759,97|$ & $|100,67|$ & \begin{tabular}{|l|l|}
9,58 \\
\end{tabular} & \begin{tabular}{ll|}
48,27 \\
\end{tabular} & \begin{tabular}{|l|l|}
291,79 \\
\end{tabular} & \begin{tabular}{|l|l|}
57,97 \\
\end{tabular} & \begin{tabular}{|l|l|}
59,88 \\
\end{tabular} & 282,52 \\
\hline Rana iberica & 29TQE08 & 99,00 & 125,47 & 99,36 & 35,8 & 6122,78 & 287,60 & 13,15 & 274,45 & 58,98 & 206,49 & 207,47 & 51,45 & 736,57 & 97,22 & 9,29 & 48,01 & 282,68 & 56,92 & 58,27 & 273,55 \\
\hline Rana iberica & 29TQE16 & 100,00 & 126,83 & 100,71 & 35,60 & \begin{tabular}{|c|}
6194,17 \\
\end{tabular} & 292,02 & 13,50 & 278,52 & 59,89 & 209,38 & 209,97 & 52,39 & 705,71 & 90,99 & 9,18 & 47,08 & 267,62 & 55,30 & 56,81 & 256,77 \\
\hline Rana iberica & 29TQE17 & 100,00 & 116,90 & 99,27 & 35,5 & 6162,49 & 280,77 & 5,20 & 275,57 & 50,61 & $\begin{array}{l}198,90 \\
\end{array}$ & $\begin{array}{l}199,93 \\
\end{array}$ & 43,24 & 757,81 & 97,69 & 10,55 & 46,63 & 287,30 & 60,86 & 63,32 & 276,08 \\
\hline Rana iberica & 29TQE18 & 101,00 & \begin{tabular}{|l|}
125,54 \\
\end{tabular} & \begin{tabular}{|l|}
101,80 \\
\end{tabular} & 36,00 & 6169,60 & 290,29 & 11,75 & 278,54 & 58,30 & 207,24 & 208,30 & 51,04 & \begin{tabular}{ll|}
686,06 \\
\end{tabular} & 88,32 & 9,12 & 46,56 & 260,12 & 55,46 & 56,49 & 249,12 \\
\hline Rana iberica & 29TQE27 & 100,00 & 115,21 & 101,46 & \begin{tabular}{|l|}
35,89 \\
\end{tabular} & 6193,50 & 281,50 & 2,46 & 279,03 & 48,61 & 197,91 & 198,74 & 41,40 & \begin{tabular}{|l|}
724,32 \\
\end{tabular} & \begin{tabular}{|l|}
92,23 \\
\end{tabular} & 10,95 & 45,11 & 270,80 & 61,14 & 63,60 & 257,91 \\
\hline Rana iberica & 29TQE28 & 100,00 & 119,46 & \begin{tabular}{|l|l|}
102,97 \\
\end{tabular} & \begin{tabular}{|l|}
36,06 \\
\end{tabular} & 199,91 & 286,09 & 5,50 & 280,59 & 52,27 & 201,76 & 202,81 & \begin{tabular}{|l|l|}
44,99 \\
\end{tabular} & \begin{tabular}{|l|l|}
678,62 \\
\end{tabular} & \begin{tabular}{|l|}
86,57 \\
\end{tabular} & \begin{tabular}{|l|}
10,04 \\
\end{tabular} & 44 & 253,79 & 57,87 & 59,40 & 240,81 \\
\hline Rana iberica & 29TQE38 & 100,00 & 110,46 & 103,62 & 36, & 6 & 278,44 & $-3,04$ & 281,49 & 43,78 & 193,30 & 194 & 36,73 & 697,16 & 88,05 & 11,78 & 43,03 & 256,34 & 63,16 & 65,78 & 241,57 \\
\hline Rana iberica & 29TQE39 & 101,00 & 109,91 & 104,34 & 36,66 & 6188,14 & 277,81 & $-3,78$ & 281,59 & 43,16 & 192,28 & \begin{tabular}{|l|}
193,47 \\
\end{tabular} & 36,11 & 681,21 & 86,15 & 11,77 & 42,58 & 250,19 & 63,12 & 65,34 & 234,95 \\
\hline Rana iberica & 29TQE47 & 101,00 & $\begin{array}{l}140,64 \\
\end{array}$ & 109,38 & \begin{tabular}{|l|}
37,03 \\
\end{tabular} & $\begin{array}{l}6294,98 \\
\end{array}$ & \begin{tabular}{|l|}
312,04 \\
\end{tabular} & \begin{tabular}{|l|l|}
20,83 \\
\end{tabular} & 291,21 & 71,06 & \begin{tabular}{|l|}
224,69 \\
\end{tabular} & 224,75 & 63,78 & $\begin{array}{l}502,05 \\
5\end{array}$ & $\begin{array}{l}62,86 \\
\end{array}$ & 7,40 & 43,31 & \begin{tabular}{|l|l|}
182,16 \\
\end{tabular} & \begin{tabular}{|l|l|}
44,17 \\
\end{tabular} & $\begin{array}{l}44,21 \\
\end{array}$ & 168,79 \\
\hline Rana iberica & 29TQE48 & 99,00 & 117,99 & 107,09 & \begin{tabular}{l|l|}
36,82 \\
\end{tabular} & \begin{tabular}{|l|l|}
6247,59 \\
\end{tabular} & 288,57 & 1,73 & 286,85 & 50,00 & 201,22 & 202,15 & 43,11 & 606,94 & 75,98 & 10,64 & 41,83 & 219,55 & 57,39 & 58,73 & 204,08 \\
\hline Rana ibe & 29TQE49 & 100,00 & 11 & 106,74 & 36, & 39 & 281 & $-3,86$ & 85,09 & \begin{tabular}{|l|l|}
43,78 \\
\end{tabular} & \begin{tabular}{|l|}
193,70 \\
\end{tabular} & 19 & 36 & \begin{tabular}{|l|l|}
629,64 \\
\end{tabular} & 78,99 & \begin{tabular}{|l|l|}
11,61 \\
\end{tabular} & 41 & 227,45 & 61,36 & 63,11 & 21 \\
\hline Rana iberica & 29TQE56 & 50,00 & 137,16 & 109,69 & \begin{tabular}{|l|l|}
36,99 \\
\end{tabular} & \begin{tabular}{|c|}
6325,01 \\
\end{tabular} & 310,13 & 17,17 & 292,96 & 67,55 & 221,57 & 221,77 & 60,39 & \begin{tabular}{|l|l|}
507,69 \\
\end{tabular} & \begin{tabular}{|l|l|}
62,88 \\
\end{tabular} & 7,87 & 42,52 & \begin{tabular}{|l|l|}
181,96 \\
\end{tabular} & 45,81 & 46,01 & $\begin{array}{l}168,04 \\
\end{array}$ \\
\hline Rana iberica & 29TQE57 & 42,00 & 139,19 & 110,38 & \begin{tabular}{|l|l|}
37,06 \\
\end{tabular} & 6308,52 & 311,71 & 18,79 & 292,92 & 69,40 & 223,40 & 223,47 & 62,26 & \begin{tabular}{|l|l|}
486,51 \\
\end{tabular} & 60,44 & 7,65 & 42,35 & 174,30 & 44,42 & 44,45 & $\begin{array}{l}160,43 \\
\end{array}$ \\
\hline
\end{tabular}




\begin{tabular}{|c|c|c|c|c|c|c|c|c|c|c|c|c|c|c|c|c|c|c|c|c|c|}
\hline TAXON & UTM & km2 & B101 & B102 & B1O3 & B104 & B105 & B106 & B107 & B108 & B109 & BIO10 & B1011 & BIO12 & 81013 & BIO14 & B1O15 & BIO16 & BIO17 & BIO18 & B1019 \\
\hline Rana iberica & 29TQE58 & 47,00 & 134,90 & 110,69 & 37,23 & 6298,43 & 307,31 & 14,87 & 292,44 & 65,49 & 219,16 & 219,25 & 58,23 & 493,18 & 61,34 & 8,28 & 41,59 & 176,15 & 46,67 & 46,74 & 161,74 \\
\hline Rana iberica & 29TQE59 & 40,00 & 109,11 & 107,80 & $\begin{array}{l}37,02 \\
\end{array}$ & 6220,82 & 280,18 & $-6,55$ & 286,74 & 41,68 & $\begin{array}{l}191,77 \\
\end{array}$ & 193,17 & 35,12 & 618,22 & 76,86 & \begin{tabular}{|l|l|}
12,17 \\
\end{tabular} & 39,94 & 220,18 & 62,66 & 64,60 & 203,06 \\
\hline Rana iberica & 29TQF30 & 100,00 & 119,31 & 106,94 & 37,00 & 6208,17 & 287,95 & 3,01 & 284,94 & 51,33 & 201,75 & 202,61 & 44,15 & 603,73 & 76,57 & 10,06 & 42,51 & 221,76 & 56,64 & 57,28 & 206,68 \\
\hline Rana iberica & 29TQF40 & 100,00 & 116,70 & 108,66 & \begin{tabular}{|l|}
37,23 \\
\end{tabular} & 6227,32 & 287,15 & $-0,06$ & 287,21 & 48,54 & 199,46 & 200,47 & 41,83 & 578,11 & $72,63 \mid$ & 10,60 & 40,89 & 208,46 & 57,44 & 58,19 & \begin{tabular}{|l|l|}
191,94 \\
\end{tabular} \\
\hline Rana iberica & 29TQF48 & 100,00 & 116,89 & 113,23 & \begin{tabular}{|l|}
38,97 \\
\end{tabular} & 6130,25 & 286,98 & $-1,75$ & 288,73 & 76,96 & 198,25 & 198,25 & 41,58 & 475,93 & 61,37 & 11,24 & 37,99 & 169,20 & 55,66 & 55,66 & 151,72 \\
\hline Rana iberica & 29TQG01 & 101,00 & 120,16 & 110,37 & 39,00 & 5890,61 & 283,96 & 2,77 & 281,19 & 54,07 & 198,46 & \begin{tabular}{|l|}
198,46 \\
\end{tabular} & 47,29 & 630,02 & 82,67 & 12,21 & 43,76 & 239,57 & 60,81 & 60,81 & 235,47 \\
\hline Rana iberica & 29TQG03 & 100,00 & 114,88 & 110,19 & \begin{tabular}{|l|l|}
38,98 \\
\end{tabular} & 5844,04 & 278,26 & $-1,66$ & 279,92 & 49,20 & 192,60 & 192,60 & 42,71 & 654,32 & $86,67 \mid$ & \begin{tabular}{|l|l|}
14,58 \\
\end{tabular} & 42,81 & 247,97 & 66,98 & 66,98 & 243,35 \\
\hline Rana iberica & 29TQG04 & 99,00 & 107,72 & 109,04 & 38,75 & 5831,01 & 270,54 & \begin{tabular}{|c|}
$-7,80$ \\
\end{tabular} & 278,34 & 42,36 & \begin{tabular}{|l|}
185,45 \\
\end{tabular} & \begin{tabular}{|l|}
185,45 \\
\end{tabular} & 36,15 & \begin{tabular}{|l|l|}
697,38 \\
\end{tabular} & 92,22 & 17,25 & 41,55 & 262,69 & 75,26 & 75,26 & 255,74 \\
\hline Rana iberica & 29TQG05 & 99,00 & 104,21 & 108,35 & 38,61 & 5812,30 & 266,16 & $-10,78$ & 276,93 & 39,18 & 181,82 & 181,82 & 33,12 & 720,31 & 95,06 & 19,42 & 40,52 & 270,01 & 80,76 & 80,76 & 260,84 \\
\hline Rana iberica & 29TQG06 & 101,00 & 97,59 & 107,19 & 38,63 & 5777,70 & 258,37 & \begin{tabular}{|c|}
$-16,03$ \\
\end{tabular} & 274,40 & 33,35 & $\begin{array}{l}174,90 \\
\end{array}$ & $\begin{array}{l}174,90 \\
\end{array}$ & 27,26 & 770,14 & 100,90 & 22,35 & 39,27 & 286,20 & 90,40 & 90,40 & 274,29 \\
\hline Rana iberica & 29TQG07 & 100,00 & 75,27 & 102,87 & 38,12 & 5659,24 & 233,23 & $-33,33$ & 266,56 & 14,21 & 151,42 & 151,61 & 7,86 & 961,33 & 122,26 & 31,36 & 36,71 & 349,51 & 121,47 & 122,08 & 332,88 \\
\hline Rana iberica & 29TQG08 & 101,00 & 91,65 & 105,70 & 38,72 & 5689,42 & 249,91 & $-20,20$ & 270,11 & 28,60 & 167,69 & 167,69 & 22,55 & 827,64 & \begin{tabular}{|l|}
107,08 \\
\end{tabular} & 26,22 & 37,28 & 303,34 & 103,64 & 103,64 & 287,04 \\
\hline Rana iberica & 29TQG13 & 101,00 & 111,71 & 110,86 & 39,00 & 5909,07 & 276,33 & $-5,18$ & 281,51 & 45,45 & 190,29 & 190,29 & 38,81 & 625,53 & 82,37 & 15,30 & 40,67 & 232,93 & 68,39 & 68,39 & 224,64 \\
\hline Rana iberica & 29TQG14 & 100,00 & 106,12 & 110,05 & \begin{tabular}{|l|l|}
38,93 \\
\end{tabular} & 5890,84 & 270,36 & \begin{tabular}{|l|l|}
$-10,14$ \\
\end{tabular} & 280,50 & 40,21 & \begin{tabular}{|l|}
184,73 \\
\end{tabular} & \begin{tabular}{|l|}
184,73 \\
\end{tabular} & 33,77 & 662,20 & 87,05 & \begin{tabular}{|l|l|}
17,70 \\
\end{tabular} & 39,73 & 245,46 & 75,48 & 75,48 & 235,49 \\
\hline Rana iberica & 29TQG16 & 100,00 & 100,74 & 109,21 & \begin{tabular}{|l|l|}
38,89 \\
\end{tabular} & 5841,69 & 263,66 & \begin{tabular}{|l|l|}
$-14,63$ \\
\end{tabular} & 278,29 & 35,43 & 178,66 & 178,66 & 29,22 & 704,69 & 92,02 & 21,13 & 38,13 & 258,67 & 85,76 & 85,76 & 245,22 \\
\hline Rana iberica & 29TQG17 & 99,00 & 86,69 & 106,75 & 38,59 & 5763,06 & 247,73 & $-25,75$ & 273,49 & 23,37 & 163,90 & 163,98 & 16,91 & 819,81 & 105,11 & 26,84 & 36,33 & 296,73 & 105,56 & 105,69 & 279,85 \\
\hline Rana iberica & 29TQG18 & 100,00 & 80,36 & 105,43 & 38,57 & 5693,88 & 239,67 & $-30,51$ & 270,17 & 18,24 & 156,74 & 156,79 & 11,85 & 880,15 & 111,79 & 30,29 & 35,26 & 316,01 & 117,00 & 117,16 & 297,01 \\
\hline Rana iberica & 29TQG19 & 100,00 & 79,56 & 105,02 & 38,69 & 5646,93 & 237,74 & $-30,67$ & 268,41 & 19,16 & 155,26 & 155,32 & 11,68 & 896,95 & 113,42 & 31,78 & 34,56 & 320,53 & 121,64 & 121,95 & 299,87 \\
\hline Rana iberica & 29TQG24 & 99,00 & 106,53 & 111,31 & 38,98 & 5942,33 & 272,67 & $-10,62$ & 283,29 & 40,28 & 185,74 & 185,74 & 33,40 & 617,64 & $\begin{array}{l}80,63 \\
\end{array}$ & \begin{tabular}{|l|l|}
17,53 \\
\end{tabular} & 38,15 & 224,86 & 74,17 & 74,17 & 212,30 \\
\hline Rana iberica & 29TQG25 & 101,00 & 110,34 & 111,69 & 39,00 & 5924,36 & 275,84 & $-7,58$ & 283,42 & 47,51 & 189,06 & 189,06 & 36,88 & 598,86 & 78,31 & \begin{tabular}{|l|l|}
17,36 \\
\end{tabular} & 37,81 & 217,92 & 72,90 & 72,90 & 204,71 \\
\hline Rana iberica & 29TQG26 & 100,00 & 107,80 & 111,40 & 39,00 & 5903,09 & 272,74 & $-9,90$ & 282,63 & 53,23 & 186,34 & 186,34 & 34,78 & 619,73 & 80,76 & \begin{tabular}{|l|l|l|}
18,88 \\
\end{tabular} & 37,12 & 224,81 & 77,87 & 77,87 & 209,72 \\
\hline Rana iberica & 29TQG28 & 99,00 & 90,53 & 108,82 & 38,88 & 5790,17 & 253,27 & \begin{tabular}{|c|}
$-23,63$ \\
\end{tabular} & 276,91 & 40,68 & $\begin{array}{l}167,92 \\
\end{array}$ & \begin{tabular}{|l|}
167,93 \\
\end{tabular} & 20,00 & 757,65 & 96,61 & 26,40 & 34,76 & 270,71 & 103,29 & 103,30 & 250,27 \\
\hline Rana iberica & 29TQG34 & 100,00 & 109,08 & 112,74 & \begin{tabular}{|l|l|}
38,97 \\
\end{tabular} & 5982,61 & 276,92 & $-9,39$ & 286,31 & 65,83 & 188,59 & 188,59 & 35,17 & \begin{tabular}{|l|l|}
564,89 \\
\end{tabular} & 73,18 & \begin{tabular}{|l|l|}
16,72 \\
\end{tabular} & 36,65 & 202,73 & 71,26 & 71,26 & 187,20 \\
\hline Rana iberica & 29TQG35 & 100,00 & 113,57 & 113,09 & 39,00 & 5964,48 & 280,43 & $-5,71$ & 286,14 & 74,89 & $\begin{array}{l}192,48 \\
\end{array}$ & $\begin{array}{l}192,48 \\
\end{array}$ & 39,41 & 547,40 & 70,94 & $\begin{array}{ll}16,45 \\
\end{array}$ & 36,42 & 197,66 & 69,83 & 69,83 & 180,30 \\
\hline Rana iberica & 29TQG43 & 91,00 & 109,68 & $\begin{array}{l}113,67 \\
\end{array}$ & 39,00 & 6041,99 & 279,31 & $-9,32$ & 288,63 & 71,14 & 189,93 & 189,93 & 34,99 & 522,63 & 67,10 & 15,60 & 35,67 & 186,39 & 68,06 & 68,06 & 167,33 \\
\hline Rana iberica & 29TQG45 & 86,00 & 116,09 & 114,02 & 39,00 & 5989,02 & 284,02 & $-4,08$ & 288,09 & 78,02 & 195,22 & 195,22 & 41,51 & 506,24 & 64,85 & 15,65 & 35,28 & 182,75 & 67,67 & $\begin{array}{l}67,67 \\
\end{array}$ & 160,55 \\
\hline Rana iberica & 29TQG46 & 80,00 & 114,57 & 113,95 & 39,00 & 5963,28 & 282,04 & $\begin{array}{l}-5,0,28 \\
-5,2\end{array}$ & \begin{tabular}{|l}
287,32 \\
\end{tabular} & 76,54 & \begin{tabular}{|l|}
193,27 \\
\end{tabular} & \begin{tabular}{|l|}
193,27 \\
\end{tabular} & $\begin{array}{l}41,1,03 \\
40,03\end{array}$ & 523,95 & 66,95 & 17,08 & $\begin{array}{l}3,20 \\
34,98\end{array}$ & 189,85 & 71,64 & 71,64 & 165,34 \\
\hline Rana iberica & 29TQH06 & 100,00 & 75,75 & 98,36 & $\begin{array}{l}39,55 \\
\end{array}$ & 5077,99 & 219,51 & $-26,07$ & 245,58 & 25,65 & 143,30 & 143,55 & 15,40 & \begin{tabular}{|c|}
1068,91 \\
\end{tabular} & 134,83 & \begin{tabular}{|l|l|}
43,64 \\
\end{tabular} & 30,77 & 372,93 & 159,67 & 162,90 & 340,47 \\
\hline Rana iberica & 29TQH16 & 100,00 & 66,93 & 98,64 & 39,36 & 5134,50 & 212,62 & $\begin{array}{l}-34,94 \\
\end{array}$ & 247,56 & 17,86 & 135,50 & \begin{tabular}{|l|}
135,73 \\
\end{tabular} & 6,21 & 1106,53 & 138,03 & $\begin{array}{l}47,02 \\
\end{array}$ & 29,70 & 382,01 & 170,17 & $\begin{array}{l}172,03 \\
\end{array}$ & 349,10 \\
\hline Rana iberica & $29 \mathrm{TQH} 24$ & 99,00 & 66,71 & 101,63 & 39,24 & 5330,72 & 217,60 & $-38,48$ & 256,08 & 21,64 & 138,11 & 138,12 & 3,36 & 1040,19 & 129,59 & 43,94 & 30,02 & 359,10 & 159,94 & 160,02 & 327,76 \\
\hline Rana iberica & $29 \mathrm{TQH} 34$ & 100,00 & 80,43 & 105,04 & 39,82 & 5386,52 & 233,25 & $-27,99$ & 261,24 & 48,34 & 152,13 & 152,13 & 15,37 & 900,06 & 114,37 & 38,95 & 29,75 & 313,48 & 142,37 & 142,37 & 275,13 \\
\hline Rana iberica & 29TQH37 & 99,00 & $\begin{array}{l}0,46,09 \\
7\end{array}$ & \begin{tabular}{|l|l|}
100,54 \\
\end{tabular} & 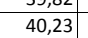 & 5063,42 & 220,15 & $\begin{array}{l}-26,83 \\
-2,\end{array}$ & \begin{tabular}{|l|}
246,98 \\
\end{tabular} & $\begin{array}{l}40,04,0 \\
43,00\end{array}$ & \begin{tabular}{|l|}
143,21 \\
\end{tabular} & \begin{tabular}{|l|}
143,59 \\
\end{tabular} & 15,63 & $\begin{array}{r}1014,50 \\
\end{array}$ & 128,25 & | 40,39 & 27,91 & 346,75 & 165,85 & 169,67 & 304,04 \\
\hline Rana iberica & $29 \mathrm{TQH} 42$ & 61,00 & 100,85 & 110,74 & 40,00 & 5628,50 & 260,72 & $-14,08$ & 274,80 & 66,18 & 175,30 & 175,30 & 31,25 & 690,90 & \begin{tabular}{|l|}
90,27 \\
\end{tabular} & 29,02 & 31,64 & 248,73 & 109,09 & 109,09 & 206,38 \\
\hline Rana iberica & 29TQH44 & 55,00 & 85,53 & 106,75 & 39,96 & 5416,52 & 239,67 & $\begin{array}{l}-24,34 \\
\end{array}$ & 264,01 & 53,52 & 157,49 & 157,49 & 19,69 & 842,54 & 107,92 & 37,39 & 29,48 & 295,18 & 136,52 & 136,52 & 251,94 \\
\hline Rana iberica & 29TQJ01 & 101,00 & 126,22 & 88,44 & 42,23 & 4110,48 & 240,86 & 34,05 & 206,81 & 104,11 & 178,50 & 180,95 & 76,45 & 878,86 & \begin{tabular}{|c|}
118,09 \\
\end{tabular} & 37,42 & 29,36 & 302,72 & 137,04 & 149,67 & 250,74 \\
\hline Rana iberica & 29TQJ11 & 99,00 & 116,27 & 91,42 & 42,38 & 4195,11 & 235,68 & 22,75 & 212,93 & 93,97 & 169,88 & 172,19 & 65,80 & 923,49 & 123,35 & 41,56 & 28,29 & 315,14 & 149,59 & 160,54 & 260,00 \\
\hline 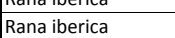 & 29TQJ12 & $\begin{array}{l}3,000 \\
67,00\end{array}$ & 128,44 & $\begin{array}{l}1,424 \\
86,26\end{array}$ & 年 42,70 & $\begin{array}{l}4159,11 \\
3958,19\end{array}$ & 238,60 & $\begin{array}{l}2,13 \\
38,66\end{array}$ & \begin{tabular}{|l|}
199,98 \\
\end{tabular} & \begin{tabular}{|c|}
108,11 \\
\end{tabular} & \begin{tabular}{|l|}
178,40 \\
170
\end{tabular} & \begin{tabular}{|l|}
181,22 \\
1210
\end{tabular} & $\begin{array}{l}30,50 \\
80,56\end{array}$ & \begin{tabular}{|l|}
$82,43,15$ \\
884
\end{tabular} & 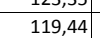 & 年 39,41 & \begin{tabular}{|l|}
28,25 \\
28,78
\end{tabular} & 302,11 & $\begin{array}{l}14,53 \\
142,53\end{array}$ & 155,16 & 244,59 \\
\hline Rana iberica & 29TQJ21 & 99,00 & 125,99 & 89,26 & 42,98 & 4019,27 & 239,73 & 34,48 & 205,25 & 105,42 & 176,76 & 179,55 & 77,59 & 879,09 & 119,14 & 40,58 & 28,35 & 298,48 & 145,41 & 156,50 & 237,74 \\
\hline Rana iberica & 29TQJ22 & 90,00 & 130,15 & 85,35 & \begin{tabular}{|l|l|}
42,88 \\
\end{tabular} & 3889,16 & 238,31 & 41,39 & 196,92 & 110,84 & 179,08 & 182,20 & 83,20 & 877,27 & 119,15 & 40,31 & 28,57 & 298,33 & 144,64 & 156,96 & 237,01 \\
\hline Rana iberica & 30STJ87 & 100,00 & 139,50 & 116,00 & 36,29 & 6660,10 & 326,07 & 12,18 & 313,89 & 67,07 & 229,44 & 229,44 & 59,43 & 510,14 & 62,04 & 6,55 & 44,22 & 175,34 & 41,84 & 41,84 & 162,97 \\
\hline Rana iberica & 30STJ88 & 100,00 & 139,32 & 115,41 & 36,44 & 6633,73 & 324,53 & 12,55 & 311,98 & 67,20 & 228,75 & 228,76 & 59,59 & 498,80 & 59,71 & 6,71 & 43,49 & 170,82 & 42,19 & 42,20 & 158,02 \\
\hline Rana iberica & 30STJ89 & 100,00 & 147,49 & \begin{tabular}{|l|}
115,24 \\
\end{tabular} & 36,63 & 6605,04 & 331,02 & 20,20 & $\begin{array}{l}110,82 \\
\end{array}$ & 75,09 & 236,35 & 236,35 & 67,44 & 452,42 & 53,79 & 5,80 & 43,54 & 154,66 & 37,88 & 37,88 & 141,99 \\
\hline Rana iberica & 30STJ96 & 100,00 & 141,01 & 117,50 & 36,58 & 6708,53 & 329,46 & 12,15 & 317,31 & 68,05 & 231,51 & 231,51 & 60,23 & 505,65 & 62,12 & 6,26 & 44,46 & 172,77 & 40,59 & 40,59 & 161,21 \\
\hline Rana iberica & 30STJ97 & 100,00 & 127,72 & 116,23 & 36,51 & 6662,72 & 315,44 & 1,45 & 313,99 & 55,93 & 218,06 & 218,12 & 48,59 & 552,82 & 65,80 & 8,28 & 42,71 & 187,37 & 48,65 & 48,73 & 174,55 \\
\hline Rana iberica & 30STJ98 & 100,00 & 132,35 & 115,84 & 36,44 & 6643,61 & 318,84 & 5,84 & 313,00 & 60,65 & 222,37 & 222,40 & 53,04 & 517,27 & 60,93 & 7,73 & 42,39 & 174,55 & 46,10 & 46,14 & 161,46 \\
\hline Rana iberica & 30sujo6 & 100,00 & 149,68 & $\begin{array}{l}118,42 \\
118,42\end{array}$ & 36,74 & 6729,45 & 337,97 & \begin{tabular}{|l|}
19,17 \\
19
\end{tabular} & \begin{tabular}{|l|}
318,81 \\
\end{tabular} & $\begin{array}{l}0,0,45 \\
90\end{array}$ & 240,28 & 240,28 & 68,12 & $\mid$ & 56,62 & 5,14 & 44,90 & 155,97 & 35,53 & 35,53 & 145,01 \\
\hline Rana iberica & 30SUJ07 & 100,00 & 135,85 & 117,40 & 36,73 & 6696,52 & 323,94 & 7,25 & 316,69 & 68,95 & 226,28 & 226,28 & 55,45 & 503,10 & 60,02 & 7,08 & 42,81 & 168,60 & 43,59 & 43,59 & 156,38 \\
\hline Rana iberica & 30SUJ08 & 100,00 & 137,04 & 116,82 & 36,70 & 6673,35 & 323,89 & 8,81 & 315,09 & 77,53 & $\begin{array}{l}227,21 \\
\end{array}$ & $\begin{array}{l}227,23 \\
\end{array}$ & 56,81 & 486,26 & 57,10 & 7,11 & 42,11 & 162,30 & 43,28 & 43,30 & 149,61 \\
\hline Rana iberica & 30TTK44 & 60,00 & 132,45 & 109,16 & 36,60 & 6377,70 & 307,43 & \begin{tabular}{r|}
12,65 \\
\end{tabular} & 294,78 & 62,97 & 217,85 & 218,38 & 55,81 & 543,52 & 66,52 & 8,45 & 42,58 & 193,49 & 48,58 & 49,33 & 179,36 \\
\hline Rana iberica & 30TTK45 & 50,00 & 131,76 & 109,35 & 36,72 & 6352,00 & 305,94 & 12,08 & 293,86 & 62,33 & 216,75 & 217,14 & 55 & 538,41 & 66,14 & 8,77 & 42,37 & 191,61 & 49,05 & 49,87 & 177,23 \\
\hline Rana iberica & $\begin{array}{l}50 T T K 49 \\
\end{array}$ & $\begin{array}{l}0,00 \\
40,00\end{array}$ & $\begin{array}{l}131,10 \\
115,98\end{array}$ & \begin{tabular}{|l|}
109,66 \\
109,6
\end{tabular} & 30,29 & $\frac{053,200}{6252,05}$ & 288, & \begin{tabular}{|c|}
$-1,390$ \\
$-1,39$
\end{tabular} & \begin{tabular}{|l|}
289,640 \\
289
\end{tabular} & 47,76 & 199,29 & 200,29 & 41,29 & 562,68 & 69,73 & 11,05 & 39,69 & 198,97 & 57,68 & 58,81 & 182,14 \\
\hline Rana iberica & 30TTK55 & 100,00 & 108,84 & 107,86 & \begin{tabular}{|l|l|}
36,47 \\
\end{tabular} & 6312,55 & 283,49 & $-7,86$ & 291,36 & 41,26 & \begin{tabular}{|l|}
193,66 \\
\end{tabular} & \begin{tabular}{|l|}
194,57 \\
\end{tabular} & 34,53 & 643,86 & 78,32 & \begin{tabular}{|l|l|}
12,68 \\
\end{tabular} & 40,28 & 226,02 & 62,99 & 65,62 & 209,65 \\
\hline Rana iberica & 30TTK56 & 100,00 & 125,09 & 110,34 & 36,99 & 6336,47 & 299,69 & 5,54 & 294,16 & 55,85 & 209,65 & 210,40 & 48,89 & 532,56 & 65,03 & \begin{tabular}{|l|}
9,79 \\
\end{tabular} & 40,50 & 186,53 & 52,18 & 52,97 & $\begin{array}{l}171,06 \\
\end{array}$ \\
\hline Rana iberica & 30TTK57 & 100,00 & 125,48 & 111,03 & 37,08 & 6317,04 & 299,69 & 5,65 & 294,04 & 56,32 & 209,99 & 210,54 & 49,34 & 515,12 & 63,05 & 9,67 & 39,93 & 180,10 & 51,77 & 52,14 & 164,56 \\
\hline Rana iberica & 30TTK58 & 100,00 & 125,15 & 111,64 & 37,57 & 6296,49 & 298,85 & 5,27 & 293,58 & 56,00 & 209,26 & 209,81 & 49,13 & 503,89 & 61,86 & 9,69 & 39,55 & 175,86 & 51,83 & 52,15 & 155 \\
\hline Rana iberica & 30TTK59 & 100,00 & 118,74 & 111,53 & 37,89 & 6264,91 & 292,03 & 0,06 & 291,97 & 50,05 & 202,19 & 203,01 & 43,41 & 522,27 & 64,35 & 10,65 & 38,81 & 182,02 & 55,69 & 56,28 & 164,96 \\
\hline Rana iberica & 30TाK63 & 100,00 & 151,82 & 112,81 & 37,00 & 6440,76 & 328,96 & 27,44 & \begin{tabular}{|l|}
301,52 \\
\end{tabular} & \begin{tabular}{|l|l|}
80,68 \\
\end{tabular} & $\mid 238,04$ & 238,04 & $\mid 73,12$ & \begin{tabular}{|l|l|}
425,74 \\
\end{tabular} & 51,26 & \begin{tabular}{|l|l|}
5,77 \\
\end{tabular} & 42,79 & 148,26 & 36,99 & 36,99 & 135,22 \\
\hline Rana iberica & 30TTK64 & 100,00 & 125,55 & 110,94 & 36,79 & 6392,01 & 302,50 & 4,83 & \begin{tabular}{|l|}
297,67 \\
\end{tabular} & 56,05 & 211,25 & 211,87 & 49,11 & 535.59 & 64,29 & 9,79 & 40,50 & 185,12 & 51.99 & 53,12 & 169,90 \\
\hline Rana iberica & 30TTK65 & 100,00 & 113,49 & 109,94 & 36,78 & 6341,39 & 289,57 & $-5,24$ & 294,81 & 45,07 & 198,60 & 199, & 38, & 586,38 & 70,42 & 12,04 & 39,20 & 201,93 & 59,78 & 61,71 & 185,52 \\
\hline Rana iberica & 30TTK66 & 100,00 & 79,21 & 106,14 & 36,41 & 6224,39 & 253,47 & $-34,09$ & 287,56 & 14,25 & 163,83 & 164,57 & 7,95 & 803,94 & 95,97 & 19,66 & 37,45 & 276,18 & 86,49 & 92,45 & 257,79 \\
\hline
\end{tabular}




\begin{tabular}{|c|c|c|c|c|c|c|c|c|c|c|c|c|c|c|c|c|c|c|c|c|c|}
\hline TAXON & UTM & km2 & B101 & B102 & B1O3 & B104 & B105 & B106 & B107 & B108 & B109 & BIO10 & BIO11 & BIO12 & 81013 & BIO14 & B1O15 & BIO16 & BIO17 & B1018 & B1019 \\
\hline Rana iberica & 30TTK67| & 100,00 & 109,14 & 110,24 & 37,07 & 6281,82 & 283,90 & $-8,71$ & 292,61 & 41,20 & 192,97 & 194,39 & 34,75 & 578,51 & 69,88 & 12,63 & 37,97 & 198,20 & 62,04 & 64,14 & 180,73 \\
\hline Rana iberica & 30TTK69 & 100,00 & 116,55 & 112,76 & 38,00 & 6255,50 & 290,74 & $-2,36$ & 293,10 & 54,45 & 199,44 & 200,97 & 41,45 & 504,86 & 61,34 & 11,15 & 37,32 & 171,90 & 56,85 & 57,70 & 154,59 \\
\hline Rana iberica & 30TTK74 & 100,00 & 134,76 & 112,76 & 36,99 & 6418,78 & 312,39 & 11,83 & 300,57 & 68,51 & 220,79 & 221,21 & 57,26 & 470,09 & 55,91 & 8,45 & 40,06 & 159,85 & \begin{tabular}{|l|}
46,18 \\
\end{tabular} & 46,69 & 145,14 \\
\hline Rana iberica & 30TTK75 & 100,00 & 81,44 & 107,65 & 36,44 & 6263,92 & 257,81 & $-33,16$ & 290,97 & 16,03 & \begin{tabular}{|l|}
166,67 \\
\end{tabular} & 167,38 & 9,72 & 767,13 & 90,58 & 19,21 & 36,84 & 259,87 & 83,75 & 88,86 & 241,18 \\
\hline Rana iberica & 30TTK76 & 100,00 & 91,53 & 108,77 & \begin{tabular}{|l|l|}
36,79 \\
\end{tabular} & \begin{tabular}{|c|c|}
6260,14 \\
\end{tabular} & 267,27 & $-24,49$ & 291,75 & 25,18 & 175,92 & $\begin{array}{l}177,06 \\
\end{array}$ & 18,91 & 680,86 & 80,72 & 16,69 & 36,68 & 229,91 & 75,34 & 79,58 & 211,18 \\
\hline Rana iberica & 30TTK77 & 100,00 & 97,20 & 109,86 & \begin{tabular}{|l|l|}
37,13 \\
\end{tabular} & 6246,57 & 272,49 & $-19,59$ & 292,07 & 30,34 & 180,93 & 182,39 & 24,13 & 626,00 & 74,51 & 15,30 & 36,35 & 210,42 & \begin{tabular}{|l|}
70,67 \\
\end{tabular} & 74,09 & 191,65 \\
\hline Rana iberica & 30TTK84 & 100,00 & 134,41 & 113,27 & 37,00 & 6425,82 & 312,65 & 10,59 & 302,07 & 81,47 & 220,52 & 220,95 & 56,82 & 456,62 & 53,71 & 8,67 & 39,33 & 153,00 & 46,50 & 47,06 & $\begin{array}{l}137,83 \\
\end{array}$ \\
\hline Rana iberica & 30TाK85 & 100,00 & 78,37 & 108,42 & 36,60 & $\begin{array}{l}6264,29 \\
\end{array}$ & 255,69 & \begin{tabular}{|c|}
$-36,63$ \\
\end{tabular} & 292,32 & 13,03 & 163,74 & \begin{tabular}{|l|}
164,41 \\
\end{tabular} & \begin{tabular}{|c|}
6,90 \\
\end{tabular} & \begin{tabular}{|l|l|l|l|}
760,19 \\
\end{tabular} & 88,73 & 20,16 & 35,67 & 253,42 & \begin{tabular}{|l|}
86,09 \\
\end{tabular} & 91,79 & 233,99 \\
\hline Rana iberica & 30тTK86 & 100,00 & 104,01 & 111,33 & \begin{tabular}{|l|}
37,03 \\
\end{tabular} & 6298,99 & 281,10 & $-14,76$ & 295,86 & 38,62 & 188,25 & 189,81 & 30,01 & 569,76 & 66,99 & 14,01 & 36,09 & 188,25 & 65,19 & 67,68 & 169,77 \\
\hline Rana iberica & 30TTK87 & 100,00 & 112,29 & 112,73 & \begin{tabular}{|l|l|}
37,60 \\
\end{tabular} & 6295,44 & 288,80 & \begin{tabular}{|l|}
$-7,63$ \\
\end{tabular} & 296,43 & 62,51 & $\begin{array}{l}195,94 \\
\end{array}$ & \begin{tabular}{|l|}
197,81 \\
\end{tabular} & 37,44 & 507,78 & 59,81 & 12,44 & 35,86 & 166,60 & 59,43 & 61,05 & 148,84 \\
\hline Rana iberica & 30TTK88 & 100,00 & 115,08 & 113,70 & \begin{tabular}{|l|l|}
37,98 \\
\end{tabular} & 6268,39 & 290,92 & $-5,17$ & 296,09 & 72,80 & 197,78 & 200,01 & 40,13 & 480,61 & 56,77 & 11,78 & 35,36 & 157,37 & 57,66 & 58,97 & 139,60 \\
\hline Rana iberica & 30TTK89 & 100,00 & 114,12 & 114,19 & 38,01 & 6219,95 & 289,16 & $-5,91$ & 295,07 & 73,80 & 195,95 & 198,39 & 39,77 & 472,86 & 55,95 & 11,97 & 34,69 & 154,65 & 58,43 & 59,90 & 136,11 \\
\hline Rana iberica & 30TTK94 & 100,00 & 150,38 & $\begin{array}{l}114,48 \\
\end{array}$ & 37,00 & 6451,97 & 328,03 & 24,12 & 303,91 & \begin{tabular}{|l|}
108,28 \\
\end{tabular} & 236,77 & 236,78 & 71,27 & 381,23 & 44,71 & 6,37 & 39,86 & 128,30 & \begin{tabular}{|l|}
37,38 \\
\end{tabular} & 37,38 & $\begin{array}{l}113,13 \\
\end{array}$ \\
\hline Rana iberica & 30TTK95 & 100,00 & 94,42 & 110,80 & \begin{tabular}{|l|l|}
36,89 \\
\end{tabular} & 6314,75 & 272,60 & $-23,77$ & 296,37 & 36,90 & 179,93 & 180,69 & 21,05 & 643,16 & 74,43 & 17,05 & 35,56 & 210,75 & $\begin{array}{l}44,63 \\
\end{array}$ & 78,42 & \begin{tabular}{|l|l|}
191,89 \\
\end{tabular} \\
\hline Rana iberica & 30тTK96 & 100,00 & 91,54 & 110,67 & 37,01 & 6268,13 & 268,93 & $-26,01$ & 294,93 & 33,22 & 176,05 & 177,31 & 18,89 & 629,13 & 73,17 & 17,20 & 34,74 & 204,69 & $\begin{array}{l}75,06 \\
\end{array}$ & 79,02 & 184,84 \\
\hline Rana iberica & 30TTN53 & 58,00 & 93,44 & 109,66 & 39,99 & 5543,63 & 251,73 & $-19,50$ & 271,23 & 60,25 & 166,97 & 166,97 & 25,44 & 749,48 & 97,07 & 33,26 & 30,23 & 266,40 & 122,49 & 122,49 & 220,42 \\
\hline Rana iberica & 30TTN54 & 50,00 & 85,92 & 107,32 & 39,96 & 5432,77 & 240,95 & $-24,42$ & 265,37 & 54,00 & 157,99 & 157,99 & 19,85 & 827,83 & 105,94 & 37,45 & 29,26 & 289,86 & 136,27 & 136,33 & 244,65 \\
\hline Rana iberica & 30TTN58 & 40,00 & 101,37 & 100,83 & \begin{tabular}{|c|}
41,87 \\
\end{tabular} & 4746,45 & 237,37 & $-0,77$ & 238,13 & 75,35 & 163,05 & 164,07 & 43,82 & 878,58 & 115,75 & 42,27 & 27,45 & 300,85 & 150,50 & $\begin{array}{l}157,87 \\
\end{array}$ & 243,32 \\
\hline Rana iberica & 30TTN62 & 100,00 & 104,34 & 112,87 & 40,00 & 5683,40 & 266,90 & $-12,56$ & 279,46 & 69,82 & 179,35 & 179,35 & 33,50 & 640,29 & $\begin{array}{l}84,06 \\
\end{array}$ & 28,65 & 31,66 & 232,06 & \begin{tabular}{|l|l|}
106,62 \\
\end{tabular} & 106,62 & \begin{tabular}{|l|l|}
182,98 \\
\end{tabular} \\
\hline Rana iberica & 30TTN63 & 100,00 & 97,88 & 110,95 & 40,00 & 5567,66 & 257,41 & $-16,42$ & 273,84 & 64,54 & 171,46 & 171,46 & 28,97 & 704,86 & 91,85 & 32,32 & 30,37 & 252,02 & \begin{tabular}{|l|l|}
118,46 \\
\end{tabular} & 118,46 & 202,02 \\
\hline Rana iberica & 30TTN64 & 100,00 & 88,79 & 108,26 & 40,01 & 5445,67 & 244,62 & $-22,48$ & 267,11 & 56,85 & 160,94 & 160,94 & 22,20 & 795,50 & 102,14 & 37,00 & 28,97 & 279,16 & \begin{tabular}{|l|l|}
134,13 \\
\end{tabular} & 134,13 & 230,18 \\
\hline Rana iberica & 30TTN74 & 100,00 & 83,51 & 107,91 & 39,82 & 5452,56 & 240,04 & $-27,45$ & 267,49 & 52,10 & \begin{tabular}{|l|}
155,92 \\
\end{tabular} & $\begin{array}{l}155,92 \\
\end{array}$ & 17,04 & 818,40 & \begin{tabular}{|l|l|l|l|l|}
103,75 \\
\end{tabular} & 39,17 & 28,25 & 284,09 & \begin{tabular}{|l|}
140,87 \\
\end{tabular} & \begin{tabular}{|l|l}
140,88 \\
\end{tabular} & 234,68 \\
\hline Rana iberica & 30TTP60 & 100,00 & 129,66 & 89,93 & \begin{tabular}{|l|l|}
43,73 \\
\end{tabular} & 3918,14 & 241,79 & 38,42 & 203,37 & 111,05 & 178,84 & 181,95 & 82,53 & 850,03 & \begin{tabular}{|l|}
116,32 \\
\end{tabular} & 42,40 & 28,38 & 284,03 & \begin{tabular}{|l|}
149,06 \\
\end{tabular} & 158,09 & 214,18 \\
\hline Rana iberica & 30TUK04 & 100,00 & 152,48 & 114,92 & 37,00 & 6473,37 & 330,21 & 25,06 & 305,15 & 110,58 & 239,14 & 239,14 & 72,90 & 365,59 & 42,55 & 6,31 & 39,21 & 122,56 & 36,52 & 36,52 & 106,51 \\
\hline Rana iberica & 30TUK05 & 100,00 & 91,60 & 111,19 & 36,98 & 6312,57 & 270,40 & $-26,92$ & 297,31 & 37,66 & 177,25 & 178,03 & 18,63 & 640,32 & 74,19 & 17,84 & 34,65 & 206,66 & \begin{tabular}{|l|}
76,97 \\
\end{tabular} & 80,68 & 186,89 \\
\hline Rana iberica & 30TUK06 & 100,00 & 80,47 & 110,13 & \begin{tabular}{|l|l|}
36,98 \\
\end{tabular} & 6240,22 & 258,27 & $-35,89$ & 294,16 & 23,13 & 165,30 & 166,20 & 9,04 & 683,23 & 79,23 & 20,24 & 33,51 & 219,28 & 84,51 & 89,35 & 198,20 \\
\hline Rana iberica & 30TUK07 & 100,00 & $\begin{array}{l}0,46,67 \\
\end{array}$ & 109,66 & 37,02 & 6199,42 & 253,59 & \begin{tabular}{|c|}
$-38,70$ \\
-30
\end{tabular} & 292,29 & 15,36 & \begin{tabular}{|l|}
161,19 \\
\end{tabular} & 161,95 & \begin{tabular}{|l|}
5,096 \\
\end{tabular} & \begin{tabular}{|l|l|}
693,74 \\
\end{tabular} & 80,34 & 21,14 & 32,93 & 222,01 & \begin{tabular}{|l|}
87,41 \\
\end{tabular} & \begin{tabular}{|l|}
93,44 \\
\end{tabular} & 200,16 \\
\hline Rana iberica & 30TUK08 & 100,00 & 105,93 & 113,03 & \begin{tabular}{|l|}
37,83 \\
\end{tabular} & 6234,50 & 282,07 & $-14,19$ & 296,26 & 64,14 & 188,86 & 190,86 & 32,37 & 495,59 & 60,24 & 14,20 & 33,61 & 157,74 & $\begin{array}{l}64,29 \\
\end{array}$ & 66,78 & 136,18 \\
\hline Rana iberica & 30TUK14 & 100,00 & 151,35 & 114,68 & 37,00 & 6499,67 & 329,40 & 23,35 & 306,06 & 109,40 & 238,49 & 238,49 & 71,49 & 361,03 & 41,78 & 6,41 & 38,95 & 120,26 & \begin{tabular}{|l|l|}
36,98 \\
\end{tabular} & 36,98 & 103,24 \\
\hline Rana iberica & 30TUK15 & 100,00 & 107,17 & 112,56 & 37,00 & 6357,38 & 286,19 & $-14,32$ & 300,52 & 71,97 & 192,81 & 193,76 & 32,42 & 526,62 & 62,91 & 14,19 & 34,84 & 168,06 & 64,68 & 66,84 & 147,18 \\
\hline Rana iberica & 30TUK16 & 100,00 & 82,40 & 110,78 & 37,00 & 6241,99 & 260,71 & $-34,80$ & 295,51 & 35,77 & 167,32 & 168,13 & 10,85 & 646,15 & 76,49 & 19,65 & 32,89 & 203,86 & $\begin{array}{l}82,49 \\
\end{array}$ & 87,53 & 181,66 \\
\hline Rana iberica & 30TUK17 & 100,00 & $\begin{array}{l}2,49,97 \\
79,\end{array}$ & 110,37 & 37,01 & $\mid \begin{array}{l}6204,22 \\
6204\end{array}$ & 257,10 & \begin{tabular}{|c|}
$-36,50$ \\
-36
\end{tabular} & \begin{tabular}{|l|}
293,60 \\
\end{tabular} & 31,32 & \begin{tabular}{|l|}
164,45 \\
\end{tabular} & \begin{tabular}{|l|}
165,12 \\
\end{tabular} & \begin{tabular}{|c|}
9,03 \\
9
\end{tabular} & \begin{tabular}{|l|l|}
648,18 \\
\end{tabular} & 77,16 & $\mid$ & $\begin{array}{l}2,0,38 \\
32,38\end{array}$ & 203,69 & \begin{tabular}{|l|}
84,44 \\
\end{tabular} & \begin{tabular}{|l|}
89,93 \\
\end{tabular} & $\begin{array}{l}181,01 \\
181,01\end{array}$ \\
\hline Rana iberica & 30TUK18 & 100,00 & 85,68 & 110,95 & \begin{tabular}{|l|l|}
37,17 \\
\end{tabular} & \begin{tabular}{|c|}
6184,79 \\
\end{tabular} & 261,81 & \begin{tabular}{|l|l|}
$-31,63$ \\
\end{tabular} & 293,44 & 40,94 & 169,28 & 170,44 & 14,40 & 600,66 & 72,73 & 19,18 & 32,23 & 188,44 & \begin{tabular}{|l|l|}
80,13 \\
\end{tabular} & 85,09 & \begin{tabular}{|l|l|}
164,78 \\
\end{tabular} \\
\hline Rana iberica & 30TUK19 & 100,00 & 92,96 & 111,70 & \begin{tabular}{|l|l|}
37,53 \\
\end{tabular} & 6162,45 & 268,20 & $-25,55$ & 293,75 & 55,26 & $\begin{array}{l}175,56 \\
\end{array}$ & 177,18 & 21,10 & 536,76 & 66,86 & 17,20 & 32,19 & 168,07 & 73,77 & 77,81 & 143,09 \\
\hline Rana iberica & 30 TUK24 & 100,00 & 148,45 & 114,23 & 37,00 & 6501,82 & 326,70 & 20,22 & 306,48 & 106,40 & 235,77 & 235,77 & 68,69 & 362,49 & 42,40 & 6,90 & 38,08 & 119,71 & 38,77 & 38,77 & 101,54 \\
\hline Rana iberica & 30TUK25 & 100,00 & 135,47 & 113,90 & 37,00 & 6441,15 & 313,42 & 9,08 & 304,35 & 104,99 & 222,13 & 222,33 & 57,18 & 389,31 & 47,34 & 8,90 & 36,26 & 126,13 & 46,22 & 46,31 & 105,63 \\
\hline 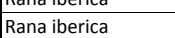 & \begin{tabular}{|l|}
30 TUK 26 \\
\end{tabular} & 100,00 & $\begin{array}{r}30,41, \\
94,91\end{array}$ & 111,50 & 37,00 & $\mid \begin{array}{l}6274,71,75 \\
627\end{array}$ & $\begin{array}{l}27,42,94 \\
272,94\end{array}$ & \begin{tabular}{|c|}
$-24,70$ \\
$-24,5$
\end{tabular} & \begin{tabular}{|l|}
297,69 \\
297,69
\end{tabular} & \begin{tabular}{|}
04,75 \\
72,72
\end{tabular} & \begin{tabular}{|l|}
179,80 \\
19,85
\end{tabular} & \begin{tabular}{|l|l|l|l|l|}
180,69 \\
\end{tabular} & $\begin{array}{l}1,100 \\
21,95\end{array}$ & $\mid$ & 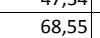 & \begin{tabular}{|c|}
$0,0,80$ \\
16,0
\end{tabular} & $\begin{array}{l}30,20 \\
3,22\end{array}$ & 175,91 & \begin{tabular}{|l|}
43,24 \\
73,17
\end{tabular} & \begin{tabular}{|l|l|}
76,114 \\
76,48
\end{tabular} & $\begin{array}{l}149,03 \\
149,86\end{array}$ \\
\hline Rana iberica & 30TUK27 & 100,00 & 89,82 & 111,24 & 37,00 & 6224,85 & 266,71 & $-28,78$ & 295,48 & 70,00 & 173,92 & 174,90 & 17,89 & 566,20 & 70,59 & 18,04 & 32,43 & 178,04 & 76,65 & 80,72 & 150,68 \\
\hline Rana iberica & 30TUK28 & 100,00 & 80,02 & 110,48 & 37,01 & 6176,16 & 256,19 & $-36,62$ & 292,81 & 47,95 & 163,94 & 164,79 & 9,42 & 625,94 & 76,25 & 21,04 & 31,64 & 195,47 & 85 & 91,35 & 169,35 \\
\hline Rana iberica & 30TUK29 & 100,00 & 97,39 & 111,69 & 37,25 & 6172,59 & 272,32 & $-22,07$ & 294,39 & 77,13 & 179,98 & \begin{tabular}{|l|}
181,63 \\
\end{tabular} & 24,99 & 497,97 & 64,06 & 16,68 & 32,32 & 155,57 & \begin{tabular}{|l|l|}
71,03 \\
\end{tabular} & 74,46 & 127,42 \\
\hline Rana iberica & 30 TUK35 & 100,00 & 129,37 & 113,05 & 36,90 & 6435,29 & 307,23 & 3,53 & 303,71 & 102,52 & 215,81 & 216,31 & 51,82 & 408,73 & 50,69 & 10,20 & 35,68 & 132,82 & 50,62 & 51,16 & 108,39 \\
\hline Rana iberica & 30TUK36 & 100,00 & 90,23 & 111,35 & 37,00 & $\mid 6263,98$ & 268,25 & $-29,08$ & 297,34 & 71,25 & 175,15 & 175,99 & $\begin{array}{l}1,0605 \\
18,05\end{array}$ & 568,18 & 71,19 & 17,99 & 32,66 & 180,80 & \begin{tabular}{|l|}
77,02 \\
\end{tabular} & 80,79 & 149,91 \\
\hline Rana iberica & 30TUK37 & 100,00 & 95,44 & 111,44 & 37,00 & 6240,27 & 272,10 & $-24,57$ & 296,67 & 77,51 & 179,49 & 180,74 & 22,86 & 520,51 & 67,05 & 16,80 & 32,78 & 165,76 & 72,71 & 76,01 & 133,20 \\
\hline Rana iberica & 30TUK38 & 100,00 & 85,05 & 110,75 & 37,00 & 6175,64 & 261,01 & $-32,71$ & 293,72 & 65,94 & 168,71 & 169,68 & 13,97 & 576,70 & 72,81 & 19,77 & 31,65 & 181,17 & 81,46 & 86,51 & 149,94 \\
\hline Rana iberica & 30TUK39 & 100,00 & 104,10 & 111,62 & 37,10 & 6184,29 & 278,08 & \begin{tabular}{|l|l|}
$-17,14$ \\
\end{tabular} & 295,22 & 97,69 & 186,34 & 188,11 & 30,71 & 449,96 & 60,10 & 15,34 & 32,89 & 142,87 & \begin{tabular}{|l|l|}
66,47 \\
\end{tabular} & 69,05 & 109,53 \\
\hline Rana iberica & 30TUK46 & 100,00 & 100,93 & 111,37 & 36,83 & \begin{tabular}{|l|}
6305,77 \\
6
\end{tabular} & 278,33 & \begin{tabular}{|l|l|}
$-20,28$ \\
-12
\end{tabular} & \begin{tabular}{|l|}
298,61 \\
\end{tabular} & 82,70 & \begin{tabular}{|l|}
$186,21,21$ \\
\end{tabular} & \begin{tabular}{|l|l|}
186,97 \\
\end{tabular} & $\mid \begin{array}{l}27,26 \\
27\end{array}$ & |508,86 & 65,08 & $\begin{array}{l}15,94,92 \\
\end{array}$ & 33,13 & 163,43 & $\begin{array}{l}70,41 \\
70,14 \\
\end{array}$ & $\begin{array}{l}72,82 \\
7\end{array}$ & 130,45 \\
\hline Rana iberica & 30 TUK48 & 100,00 & 88,76 & 110,42 & 37,00 & 6176,06 & 264,24 & $-29,81$ & 294,05 & 71,09 & 172,36 & 173,36 & 17,44 & 539,78 & 70,30 & 18,85 & 31,91 & 171,63 & 78,73 & 83,12 & $\begin{array}{l}134,92 \\
\end{array}$ \\
\hline Rana iberica & 30 TUK56 & 100,00 & 118,29 & 111,17 & 36,41 & 6398,64 & 294,72 & \begin{tabular}{|l|}
$-5,92$ \\
\end{tabular} & 300,64 & 92,11 & 204,53 & 204,95 & 41,94 & 438,19 & 55,93 & 12,85 & 34,18 & 141,45 & 59,34 & $\begin{array}{l}60,68 \\
\end{array}$ & 111,31 \\
\hline Rana iberica & 30TUK57 & 100,00 & 117,59 & 110,53 & 36,51 & 6344,52 & 292,32 & $-6,49$ & 298,81 & 102,44 & 202,68 & 203,47 & 41,46 & 410,25 & 54,77 & 12,60 & 34,25 & 132,62 & 58,94 & 59,81 & 98,93 \\
\hline Rana iberica & 30TUK66 & 100,00 & 113,97 & 110,31 & 36,34 & 6387,97 & 290,11 & $-9,62$ & 299,73 & 93,62 & 200,12 & 200,66 & 38,09 & 443,80 & 57,94 & 13,48 & 33,95 & 143,79 & 62,19 & 63,67 & 109,62 \\
\hline Rana iberica & 30TUKE & $\frac{10,00}{100,00}$ & 11 & $\begin{array}{l}110,51 \\
109,57\end{array}$ & 30,24 & 6353,57 & 289,42 & $\begin{array}{l}-8,02 \\
-8,52\end{array}$ & \begin{tabular}{|l|}
297,9415 \\
\end{tabular} & 99,45 & 200,54 & 201,23 & 39,29 & 424,64 & 56,42 & 13,34 & 33,94 & 137,14 & 61,37 & 62,58 & 102,34 \\
\hline Rana iberica & 30TUK76 & 100,00 & 126,44 & 109,29 & 35,91 & 6486,12 & 301,51 & 0,41 & 301,10 & \begin{tabular}{|l|}
104,01 \\
\end{tabular} & 213,75 & 214,03 & 48,02 & 399,10 & 51,13 & 11,25 & 34,41 & 128,63 & 54,68 & 54,91 & 99,41 \\
\hline Rana iberica & 30TUK77 & 100,00 & 128,57 & 108,45 & \begin{tabular}{|l|l|}
35,97 \\
\end{tabular} & 6458,48 & 301,79 & 2,79 & 299,00 & 98,53 & 215,16 & 215,53 & 50,03 & 387,77 & 49,53 & 11,21 & 34,19 & 124,92 & 53,75 & 54,05 & 96,10 \\
\hline Rana iberica & 30TUK89 & 100,00 & 98,05 & 106,76 & 36,38 & 6211,20 & 268,70 & $-21,19$ & 289,90 & 113,77 & 181,84 & 182,58 & 25,62 & 478,86 & 64,70 & 17,80 & 32,27 & 155,90 & 74,58 & 78,62 & 110,54 \\
\hline Rana iberica & 30TUK99 & 100,00 & 96,32 & 106,41 & 36,45 & 6227,65 & 266,97 & $-21,79$ & 288,76 & 105,56 & 180,69 & 181,32 & 24,05 & 503,34 & 65,66 & 18,77 & 31,15 & 161,06 & 76,80 & 81,29 & 120,12 \\
\hline $\begin{array}{l}\mid l a l d \\
\text { Rana iberica }\end{array}$ & 30TUL90 & \begin{tabular}{|l|}
100,00 \\
\end{tabular} & $\begin{array}{l}0.02,55 \\
8,55\end{array}$ & $\begin{array}{l}10,41 \\
106,60\end{array}$ & $\mid$ & 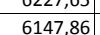 & 258,66 & $\begin{array}{l}-27,33 \\
-27,33\end{array}$ & \begin{tabular}{|l|}
$280,96,19$ \\
285
\end{tabular} & \begin{tabular}{|c|}
96,43 \\
\end{tabular} & \begin{tabular}{|l|}
172,41 \\
\end{tabular} & \begin{tabular}{|l|}
172,71 \\
\end{tabular} & 18,22 & 541,27 & 69,75 & 20,88 & 30,08 & 172,62 & 83,43 & 88,12 & 130,46 \\
\hline Rana iberica & 30TUL91 & 100,00 & 103,04 & 104,20 & 36,11 & 6268,38 & 269,75 & $|-15,97|$ & 285,72 & \begin{tabular}{|c|}
120,93 \\
\end{tabular} & $\mid$\begin{tabular}{|c|}
187,10 \\
\end{tabular} & $\mid$\begin{tabular}{|c|}
187,99 \\
\end{tabular} & 28,96 & 4774,41 & \begin{tabular}{|l|l|}
61,07 \\
\end{tabular} & \begin{tabular}{|l|l|}
16,82 \\
\end{tabular} & 31,16 & 152,40 & 72,34 & $\mid 78,09$ & $\begin{array}{l}112,79 \\
\end{array}$ \\
\hline Rana iberica & 30TUN06 & 100,00 & 67,79 & 102,16 & 39,56 & 5215,84 & 217.31 & -37.60 & 254.91 & 40,02 & 137.45 & \begin{tabular}{|l|}
137,62 \\
\end{tabular} & 5,61 & 963.07 & $\mid 117,60$ & 49,21 & 24,66 & 320,48 & 173.26 & 173,77 & 271.29 \\
\hline Rana iberica & 30TUN22 & 100,00 & 103,05 & 108,81 & 39,66 & 5432,62 & 259,46 & $\begin{array}{l}-12,24 \\
\end{array}$ & 271,70 & 74,61 & 174,47 & 174 & 35,75 & 634,62 & 79,38 & 31,56 & 26,73 & 217,08 & 116,31 & 116,92 & 166,18 \\
\hline Rana iberica & 30TUN27 & 100,00 & 75,72 & 99,31 & 39,73 & 5038,60 & 219,20 & $-27,67$ & 246,87 & 50,11 & 142,64 & 143,19 & 15,47 & 937,74 & 114,70 & 48,99 & 23,88 & 310,48 & 172,98 & 174,52 & 257,13 \\
\hline
\end{tabular}




\begin{tabular}{|c|c|c|c|c|c|c|c|c|c|c|c|c|c|c|c|c|c|c|c|c|c|}
\hline TAXON & UTM & km2 & B101 & B102 & B1O3 & B104 & B105 & B106 & B107 & B108 & B109 & BIO10 & BIO11 & BIO12 & B1013 & BIO14 & B1O15 & BIO16 & BIO17 & B1018 & B1019 \\
\hline Rana iberica & 30TUN39 & 100,00 & 107,75 & 88,69 & 40,18 & 4470,70 & 229,18 & 11,69 & 217,48 & 87,06 & 165,69 & 167,45 & 53,23 & 867,20 & 111,23 & 44,20 & 25,51 & 293,17 & 158,73 & 167,19 & 228,33 \\
\hline Rana iberica & 30TUN56 & 100,00 & 54,14 & 97,61 & \begin{tabular}{|l|l|}
38,77 \\
\end{tabular} & 5154,62 & 200,68 & $-47,84$ & 248,52 & 24,53 & 124,04 & 124,04 & $-6,25$ & 1057,32 & 122,17 & 56,16 & 21,65 & 335,88 & 192,65 & 192,66 & 294,61 \\
\hline Rana iberica & 30 UN 65 & 100,00 & 69,90 & 98,53 & 38,94 & 5144,39 & 215,94 & $-34,28$ & 250,22 & 43,91 & 139,24 & 139,24 & 8,80 & 926,83 & 108,09 & 48,77 & 21,90 & 296,21 & 169,89 & 169,89 & 252,41 \\
\hline Rana iberica & 30TUN68 & 100,00 & 96,86 & 88,38 & 39,26 & 4626,31 & 222,21 & 0,02 & 222,19 & 75,25 & 157,31 & 158,81 & 40,88 & 912,28 & 112,01 & \begin{tabular}{l|l}
46,25 \\
\end{tabular} & 23,97 & 302,74 & 166,82 & 173,13 & 246,33 \\
\hline Rana iberica & 30TUP00 & 100,00 & 126,74 & 83,46 & \begin{tabular}{|l|l|}
41,44 \\
\end{tabular} & 4057,12 & 235,08 & \begin{tabular}{|l|l|}
36,23 \\
\end{tabular} & 198,85 & 108,39 & 178,43 & 181,14 & 77,34 & 829,34 & 111,57 & 41,76 & 27,54 & 281,62 & 149,04 & 159,96 & 210,49 \\
\hline Rana iberica & 30TUP10 & 100,00 & 128,41 & 81,58 & 40,93 & 4066,27 & 235,21 & 38,27 & 196,94 & 110,11 & 180,23 & 182,88 & 78,61 & 820,87 & 109,97 & 40,75 & 27,43 & 280,47 & 146,78 & 158,76 & 210,20 \\
\hline Rana iberica & 30TUP20 & 100,00 & 134,88 & 77,88 & 40,29 & 3995,93 & 237,12 & 46,48 & 190,63 & 117,35 & 185,62 & 188,38 & 85,65 & 802,19 & 107,72 & 38,63 & 27,90 & 276,54 & 141,34 & 155,20 & 206,81 \\
\hline Rana iberica & $\begin{array}{l}\text { 30TVKO9 } \\
\end{array}$ & 100,00 & 113,60 & 104,19 & 35,39 & 6407,64 & 282,44 & \begin{tabular}{|c|}
$-7,01$ \\
\end{tabular} & 289,45 & 85,27 & $\begin{array}{l}198,75 \\
\end{array}$ & 200,05 & 36,88 & 464,05 & \begin{tabular}{|}
56,18 \\
\end{tabular} & 15,15 & 31,66 & 147,87 & 65,86 & 69,08 & 118,12 \\
\hline Rana iberica & 30TVL00 & 100,00 & 103,47 & 104,36 & 35,96 & 6315,89 & 271,61 & $-14,89$ & 286,50 & 97,34 & 188,25 & 189,18 & 29,18 & 495,14 & 61,23 & 17,16 & 30,66 & 156,36 & 73,01 & 77,93 & 122,97 \\
\hline Rana iberica & 30TVL01 & 100,00 & 80,62 & 106,71 & \begin{tabular}{|l|l|}
37,19 \\
\end{tabular} & 6073,35 & 250,45 & $-32,06$ & 282,52 & 83,05 & 164,19 & 164,30 & 12,32 & 595,66 & 74,22 & 23,49 & 28,36 & 187,09 & 91,97 & 95,44 & 147,75 \\
\hline Rana iberica & 30TVL11 & 100,00 & 77,29 & 106,95 & 37,36 & 6068,16 & 247,71 & $-34,23$ & 281,95 & 70,78 & 161,14 & 161,28 & 9,66 & 626,03 & 76,40 & 24,97 & 27,68 & 194,81 & 96,49 & 99,25 & 157,99 \\
\hline Rana iberica & 30TVL12 & 100,00 & 82,73 & 105,64 & 37,01 & 6128,99 & 251,27 & $-30,42$ & 281,69 & 86,58 & 166,66 & \begin{tabular}{|l|}
167,03 \\
\end{tabular} & 13,17 & 603,08 & 72,94 & 23,32 & 27,85 & 187,35 & 92,53 & 97,16 & 152,35 \\
\hline Rana iberica & 30TVL21 & 100,00 & 84,19 & 106,10 & 36,89 & 6169,99 & 254,29 & $-29,16$ & 283,45 & 61,23 & \begin{tabular}{|l|}
168,71 \\
\end{tabular} & 169,10 & 14,22 & 607,58 & 72,58 & 23,35 & 27,95 & 188,62 & 92,03 & 95,29 & 156,05 \\
\hline Rana iberica & 30TVL22 & 100,00 & 89,15 & 105,22 & 36,69 & 6195,81 & 257,50 & $-25,31$ & 282,81 & 82,82 & 173,58 & 173,95 & 18,03 & 575,22 & 68,69 & \begin{tabular}{|l|}
21,29 \\
\end{tabular} & 27,97 & 177,58 & 86,99 & 92,20 & $\begin{array}{l}146,47 \\
\end{array}$ \\
\hline Rana iberica & 30TVL23 & 100,00 & 72,79 & 106,73 & 37,51 & 6045,02 & 242,56 & $-38,25$ & 280,81 & 68,29 & 156,35 & 156,48 & 5,44 & 658,42 & 78,70 & 27,16 & 26,32 & 202,81 & 103,42 & 105,63 & 167,97 \\
\hline Rana iberica & 30TVL31 & 100,00 & 112,12 & 103,04 & 35,52 & 6428,78 & 279,39 & $-6,72$ & 286,11 & 73,78 & 197,50 & 198,75 & 35,20 & 496,87 & 58,38 & 15,25 & 30,58 & 158,92 & 69,08 & 73,27 & 133,32 \\
\hline Rana iberica & 30TVL32 & 100,00 & 89,33 & 105,67 & 36,72 & 6214,66 & 258,42 & $-25,45$ & 283,86 & 76,32 & 173,92 & 174,25 & 17,79 & 578,12 & 68,50 & 21,47 & 27,60 & 177,52 & 87,52 & 92,90 & 148,19 \\
\hline Rana iberica & 30TVL33 & 100,00 & 93,59 & 104,76 & 36,51 & 6246,76 & 261,29 & $-22,01$ & 283,30 & 79,89 & \begin{tabular}{|l|}
178,09 \\
\end{tabular} & 178,63 & 20,99 & 562,40 & 65,76 & 20,43 & 27,73 & 172,92 & 84,79 & 90,65 & $\begin{array}{l}145,03 \\
\end{array}$ \\
\hline Rana iberica & 30TVL34 & 100,00 & 86,44 & 105,55 & 36,82 & 6168,71 & 254,56 & $\begin{array}{l}-27,94 \\
\end{array}$ & 282,50 & 96,85 & 170,42 & 170,66 & 15,35 & 591,88 & 69,86 & 22,81 & 26,76 & 181,19 & 91,63 & 97,38 & $\begin{array}{l}151,49 \\
\end{array}$ \\
\hline Rana iberica & 30TVN67 & 100,00 & 101,25 & 79,16 & 37,55 & 4599,45 & 219,84 & 11,59 & 208,25 & 65,66 & 160,21 & 162,83 & 45,37 & 1010,80 & 117,99 & \begin{tabular}{|l|l|}
48,59 \\
\end{tabular} & 22,10 & 323,75 & 179,86 & 192,51 & 296,21 \\
\hline Rana iberica & 30TVN77 & 100,00 & 122,34 & 71,61 & 36,73 & 4342,73 & 229,04 & 36,54 & 192,50 & 98,41 & 177,24 & 179,90 & 68,68 & 1009,67 & 123,94 & 44,06 & 25,19 & 332,97 & 169,58 & 190,88 & 310,96 \\
\hline Rana iberica & 30TVN78 & 100,00 & 120,92 & 69,74 & 36,68 & 4244,12 & 224,77 & 37,20 & 187,57 & $\begin{array}{l}01,57 \\
91\end{array}$ & \begin{tabular}{|l|}
174,43 \\
\end{tabular} & $\begin{array}{l}177,29 \\
\end{array}$ & 60,58 & 1006,48 & \begin{tabular}{|l|}
131,83 \\
\end{tabular} & 46,55 & 25,63 & 353,54 & 178,62 & 202,15 & 330,37 \\
\hline Rana iberica & 30TVN98 & 100,00 & 127,89 & 67,50 & \begin{tabular}{|l|}
36,38 \\
\end{tabular} & 4192,74 & 228,50 & 45,43 & \begin{tabular}{|l|}
183,07 \\
\end{tabular} & 84,73 & 180,31 & 183,21 & 76,13 & 1115,08 & 140,70 & \begin{tabular}{|l|l|}
46,87 \\
\end{tabular} & 27,06 & 370,99 & 182,25 & 208,23 & 361,25 \\
\hline Rana iberica & 30TWN06 & 100,00 & 120,93 & 76,99 & 37,38 & 4558,16 & 235,22 & 31,95 & 203,28 & 72,35 & 178,65 & 181,13 & 65,04 & 998,87 & 119,07 & 45,23 & 23,21 & 320,68 & 173,37 & 188,61 & 308,02 \\
\hline \begin{tabular}{|l|l|} 
Rana iberica \\
\end{tabular} & 30TWN15 & 100,00 & 110,09 & 85,02 & 38.03 & 4845,20 & 235.85 & 15,60 & 220,25 & 58.25 & 172,10 & 174,23 & 51,07 & 950.45 & 107.55 & 46.56 & 19,95 & 295,50 & 174.82 & 181,79 & 279.59 \\
\hline Rana iberica & 30TWN16 & 100,00 & 98,64 & 85,16 & 38,28 & 4807,67 & 225,03 & 5,69 & 219,33 & 47,92 & 160,34 & 162,73 & 40,71 & 1045,75 & 118,43 & 52,56 & 19,70 & 326,01 & 193,81 & 199,88 & 307,97 \\
\hline Rana iberica & 30TWN17 & 100,00 & 128,64 & $\frac{10,10}{72,98}$ & 37,36 & 4354,73 & 236,46 & \begin{tabular}{|l|}
43,81 \\
\end{tabular} & \begin{tabular}{|l|}
192,65 \\
\end{tabular} & 82,11 & \begin{tabular}{|l|}
183,14 \\
\end{tabular} & \begin{tabular}{|l|}
186,01 \\
\end{tabular} & 45,52 & 1079,46 & \begin{tabular}{|l|}
131,80 \\
\end{tabular} & 47,04 & 24,96 & 352,18 & 181,94 & 201,95 & 344,04 \\
\hline Rana iberica & 30 TWN25 & 100,00 & 117,45 & 84,69 & \begin{tabular}{|l|l|}
38,13 \\
\end{tabular} & 4802,05 & 241,38 & 23,20 & 218,18 & 65,44 & 178,44 & 180,66 & 58,75 & 945,48 & \begin{tabular}{|l|}
107,01 \\
\end{tabular} & \begin{tabular}{|l|}
45,75 \\
\end{tabular} & 20,05 & 294,32 & 173,45 & 180,86 & 279,21 \\
\hline Rana iberica & 30TWN27 & 100,00 & 120,50 & 77,90 & \begin{tabular}{|l|}
38,17 \\
\end{tabular} & 4471,05 & 234,66 & 33,45 & 201,21 & 72,74 & \begin{tabular}{|l|}
176,71 \\
\end{tabular} & \begin{tabular}{ll|}
179,56 \\
\end{tabular} & 66,37 & 1097,43 & 129,37 & 50,81 & 22,51 & 352,25 & 192,55 & 207,20 & 338,87 \\
\hline Rana iberica & 30TWN29 & 100,00 & 136,55 & 67,88 & 37,67 & 4062,26 & 236,21 & 58,40 & 177,81 & 93,08 & 186,50 & 190,04 & 87,82 & \begin{tabular}{|l|}
1216,98 \\
\end{tabular} & 151,89 & 51,40 & 26,91 & 405,01 & 199,13 & 226,79 & 398,51 \\
\hline Rana iberica & 30TWN38 & 100,00 & 125,53 & 76,22 & 38,88 & 4295,56 & 235,67 & 41,87 & 193,80 & 79,55 & 178,97 & 182,14 & 73,98 & \begin{tabular}{|l|}
1184,68 \\
\end{tabular} & 140,08 & 54,29 & 23,10 & 383,79 & 205,43 & 223,01 & 368,89 \\
\hline Rana iberica & 30TWN65 & 100,00 & 114,75 & 92,10 & 39,59| & 4941,28 & 246,34 & $\begin{array}{l}1,160 \\
16,24 \\
\end{array}$ & 230,10 & 61,12 & 178,84 & \begin{tabular}{|l|}
179,67 \\
\end{tabular} & 54,48 & $\begin{array}{l}1037,83 \\
\end{array}$ & \begin{tabular}{|l|l|}
115,65 \\
\end{tabular} & 52,42 & 19,30 & 323,01 & 194,30 & 195,10 & 302,10 \\
\hline Rana iberica & 30TWP10 & 94,00 & 132,38 & 64,68 & 36,92 & 3975,66 & 228,22 & 55,49 & 172,72 & 89,86 & 181,32 & 184,84 & 84,41 & 1266,20 & 160,96 & 52,91 & 27,98 & 425,57 & 204,62 & 235,59 & 420,02 \\
\hline Rana iberica & 30TWP20 & 75,00 & 136,08 & 66,31 & 37,61 & 3978,94 & 233,33 & 59,44 & 173,89 & 93,78 & 184,80 & 188,46 & 88,51 & \begin{tabular}{|l|}
1263,98 \\
\end{tabular} & 158,65 & 53,35 & 27,25 & 422,90 & 205,95 & 236,04 & 415,55 \\
\hline Rana pyrenaica & 30 TXN26 & 89,00 & 93,17 & 96,25 & 39,11 & 5206,27 & 230,03 & $-12,54$ & 242,57 & 37,57 & 161,61 & 161,63 & 28,95 & 1181,31 & 137,49 & 62,37 & 19,12 & 369,64 & 223,78 & 223,78 & 348,52 \\
\hline Rana pyrenaica & 30 TXN55 & 100,00 & 83,60 & 96,82 & 38,95 & 5296,25 & 221,06 & $-24,57$ & 245,62 & 27,39 & 153,08 & 153,08 & 18,14 & 1091,06 & 120,27 & 60,17 & 16,46 & 324,97 & 215,11 & 215,11 & 305,78 \\
\hline Rana pyrenaica & 30 TXN56 & 37,00 & 79,52 & 95,46 & 38,96 & 5231,69 & 215,01 & $-27,01$ & 242,02 & 24,21 & 148,19 & 148,19 & 14,99 & 1149,13 & 126,64 & 64,19 & 16,15 & 343,11 & 228,41 & 228,41 & 322,84 \\
\hline Rana pyrenaica & 30 TXN65 & 92,00 & 75,72 & 95,36 & 38,75 & \begin{tabular}{|l|l|}
5277,87 \\
\end{tabular} & 211,78 & $-31,52$ & 243,30 & 20,16 & 145,08 & 145,08 & 10,64 & 1101,25 & 117,80 & 62,58 & 15,22 & 320,67 & 221,68 & 221,68 & 301,24 \\
\hline Rana pyrenaica & 30TXN66 & 6,00 & 87,25 & 96,60 & 39,35 & 5232,89 & 221,79 & $-20,99$ & 242,79 & 31,36 & 155,43 & 155,50 & 22,10 & \begin{tabular}{|l|}
1101,02 \\
\end{tabular} & 121,46 & 60,74 & 16,26 & 328,58 & 220,57 & 220,71 & 308,65 \\
\hline Rana pyrenaica & 30TXN74 & 100,00 & 67,09 & 93,69 & 38,16 & 5304,14 & 202,82 & $-39,59$ & 242,41 & 15,92 & 136,99 & 136,99 & 2,03 & 1089,61 & 112,52 & 63,81 & 14,30 & 307,78 & 223,36 & 223,49 & 288,38 \\
\hline Rana pyrenaica & 30 TXN75 & 83,00 & 65,57 & 93,03 & 38,28 & 5259,30 & 199,91 & $-40,09$ & 240,00 & 10,91 & 134,93 & 134,93 & 1,10 & 1131,74 & 117,47 & 66,48 & 14,20 & 322,24 & 232,28 & 232,28 & 302,19 \\
\hline Rana pyrenaica & 30TXN84 & 100,00 & 50,41 & 89,26 & 37,13 & 5272,72 & 183,66 & $-53,41$ & 237,07 & 35,53 & 120,55 & 120,55 & $-13,35$ & 1171,25 & 119,66 & 71,51 & 13,39 & 325,22 & 244,61 & 244,93 & 302,94 \\
\hline Rana pyrenaica & 30 TXN85 & 53,00 & 42,17 & 86,92 & 36,71 & 5231,16 & 173,46 & $-60,17$ & 233,62 & 9,99 & 112,02 & 112,02 & $-20,73$ & \begin{tabular}{|l|}
1248,27 \\
\end{tabular} & 126,53 & 77,25 & 13,13 & 346,39 & 261,15 & 261,15 & 324,94 \\
\hline Rana pyrenaica & 30TXN93 & 100,00 & 48,20 & 88,18 & 36,68 & 5295,76 & 181,29 & $-55,86$ & 237,16 & 58,64 & 118,67 & 118,67 & $-15,74$ & 1150,99 & 119,68 & 71,05 & 13,38 & 322,05 & 242,88 & 243,18 & 291,27 \\
\hline Rana pyrenaica & 30TYM31 & 100,00 & 131,14 & 104,62 & 37,01 & 5981,44 & 285,08 & 6,98 & 278,10 & 154,00 & 56,63 & 209,23 & 56,63 & 419,51 & 55,75 & 20,03 & 28,22 & 135,46 & 76,51 & 90,58 & 76,51 \\
\hline Rana pyrenaica & 30TYNO2 & 100,00 & 68,75 & 93,02 & 37,67 & 5353,69 & 204,51 & $-39,25$ & 243,76 & $\begin{array}{l}44,01 \\
84\end{array}$ & 139,07 & 139,08 & 2,90 & \begin{tabular}{|l|l|}
982,46 \\
98,
\end{tabular} & \begin{tabular}{|l|}
104,07 \\
\end{tabular} & 58,76 & 13,90 & 276,40 & 209,18 & 212,16 & 242,29 \\
\hline Rana pyrenaica & 30TYN03 & 99,00 & 36,88 & 84,36 & 35,64 & 5266,47 & 167,53 & $-65,62$ & 233,15 & 48,42 & 107,42 & 107,42 & $-25,95$ & 1224,93 & 127,53 & 77,30 & 13,04 & 343,70 & 260,60 & 260,76 & 307,40 \\
\hline Rana pyrenaica & 30TYN12 & 100,00 & 59,95 & 90,18 & 37,03 & 5337,92 & 193,96 & $-46,36$ & 240,32 & 74,31 & 130,37 & 130,42 & $-5,22$ & 1041,24 & 110,51 & 63,90 & 13,66 & 294,87 & 224,28 & 227,15 & 253,79 \\
\hline Rana pyrenaica & 30TYN13 & 100,00 & 47,94 & 86,82 & 36,42 & 5292,12 & 179,49 & $-55,73$ & 235,22 & 60,84 & 118,25 & 118,25 & $-16,06$ & 1150,14 & 120,31 & 72,13 & 13,03 & 323,51 & 247,41 & 248,28 & 284,42 \\
\hline Rana pyrenaica & 30TYN22 & 100,00 & 50,84 & 86,83 & 36,1 & 5324,42 & 183,01 & $-53,86$ & 236,86 & 64,18 & 121,53 & 121,54 & $-13,60$ & \begin{tabular}{|l|}
1107,97 \\
\end{tabular} & 117,49 & 69,53 & 13,33 & 314,53 & 240,49 & 242,34 & 268,20 \\
\hline Rana pyrenaica & $\begin{array}{l}\text { 30TYN23 } \\
\text { ThN }\end{array}$ & 100,00 & 31 & $\begin{array}{l}0,035 \\
80,98\end{array}$ & 34,6 & $\begin{array}{l}524,49,75 \\
5245\end{array}$ & \begin{tabular}{|l|}
$159,70,0$ \\
159,
\end{tabular} & $\begin{array}{l}-5,00 \\
-70,20\end{array}$ & \begin{tabular}{|l|}
$229,90,9$ \\
\end{tabular} & $\mid \begin{array}{l}\mid c 4,10 \\
42,31\end{array}$ & 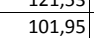 & \begin{tabular}{|l|}
101,95 \\
101,95
\end{tabular} & $\begin{array}{l}-10,00 \\
-30,77 \\
\end{array}$ & |1263,16 & \begin{tabular}{|l|}
131,94 \\
131,94
\end{tabular} & 8 & $\begin{array}{l}12,35 \\
12,65\end{array}$ & 355,52 & $\begin{array}{l}24,45 \\
272,37\end{array}$ & 273,15 & $\begin{array}{l}20,20 \\
312,09\end{array}$ \\
\hline Rana pyrenaica & 30TYN30 & 100,00 & 73,98 & 93,03 & 37,18 & 5439,41 & 211,19 & $-35,42$ & 246,60 & 90,23 & 120,12 & 145,42 & 7,01 & 902,70 & $\begin{array}{l}99,28 \\
\end{array}$ & 54,75 & 14,94 & 262,06 & 199,63 & 205,61 & 206,37 \\
\hline Rana pyrenaica & 30TYN31 & 100,00 & 70,22 & 92,07 & 37,21 & 5403,92 & 205,96 & $-38,19$ & 244,15 & 85,95 & 140,27 & 141,19 & 3,76 & 955,42 & 103,40 & 58,53 & 14,31 & 274,77 & 210,92 & 216,40 & 222,30 \\
\hline Rana pyrenaica & 30TYN32 & 100,00 & 53,61 & 87,07 & 36,17 & 5340,93 & \begin{tabular}{|c|c|}
185,78 \\
\end{tabular} & $\mid-51,45$ & 237,22 & 67,34 & 124,30 & 124,31 & $\mid-11,23$ & $\begin{array}{ll}1094,52 \\
\end{array}$ & 116,32 & 69,00 & 13,39 & 311,69 & 239,92 & 243,42 & 261,42 \\
\hline Rana pyrenaica & 30TYN33 & 73,00 & 24,93 & 78,12 & 33,5 & 5242,21 & 151,45 & $-75,58$ & 227,03 & 34,83 & 95,59 & 95,59 & $-36,74$ & 1312,23 & 137,11 & 85,36 & 12,44 & 369,86 & 284,55 & 284,55 & 32 \\
\hline Rana pyrenaica & 30TYN41 & 60,00 & 68,64 & 91,25 & 36,95 & 5417,10 & 204,09 & $-39,29$ & 243,38 & 84,25 & $\mid$ & 139,81 & 2,00 & \begin{tabular}{|l|l|}
977,54 \\
\end{tabular} & $\begin{array}{l}105,69 \\
\end{array}$ & 60,61 & 14,23 & 281,73 & 217,47 & 223,80 & 225,39 \\
\hline Rana pyrenaica & 30TYN42 & 60,00 & 32,27 & 79,78 & 34,22 & 5289,33 & 160,47 & $-69,20$ & 229,68 & 43,05 & 103,33 & 103,33 & $-30,38$ & 1247,89 & 131,84 & 80,87 & 12,80 & 354,47 & 272,80 & 273,09 & 300,99 \\
\hline Rana pyrenaica & 30TYN43 & 7,00 & 32,10 & 79,82 & 34,30 & 5264,38 & 159,53 & $-69,34$ & 228,88 & 42,99 & 102,71 & 102,71 & $-30,40$ & 1270,33 & 132,88 & 82,49 & 12,58 & 358,52 & 277,48 & 278,31 & 309,23 \\
\hline Rana pyrenaica & 31TBH51 & 66,00 & 72,18 & 91,90 & 37,08 & 5440,33 & 208,14 & $-36,69$ & 244,83 & 88,29 & 81, & 143 & 5, & 963,17 & 103,96 & 59,76 & 14,44 & 277,84 & 214,91 & 223,19 & 220 \\
\hline Rana pyrenaica & 31TBH52 & 61,00 & 26,09 & 77,48 & 33,53 & 5281,27 & 152,94 & $-74,49$ & 227,43 & 36,03 & 97,28 & 97,28 & $-36,08$ & 1296,34 & 136,53 & 84,57 & 12,68 & 367,71 & 283,47 & 283,64 & 313,16 \\
\hline
\end{tabular}




\begin{tabular}{|c|c|c|c|c|c|c|c|c|c|c|c|c|c|c|c|c|c|c|c|c|c|}
\hline TAXON & UTM & $\mathrm{km} 2$ & BIO1 & B102 & $B 103$ & BIO4 & B105 & B106 & B107 & B108 & B109 & B1010 & BIO11 & BIO12 & BIO13 & B1014 & BIO15 & B1016 & B1017 & B1018 & 81019 \\
\hline Rana pyrenaica & 31TBH61 & 101,00 & 86,55 & 95,72 & 37,64 & 5505,15 & 224,68 & $-25,87$ & 250,55 & 104,58 & 39,33 & 158,31 & 17,86 & 884,59 & 95,35 & 54,24 & 14,83 & 255,72 & 196,21 & 209,57 & 197,68 \\
\hline Rana pyrenaica & 31ТВH62 & 100,00 & 46,28 & 83,24 & 35,06 & 5349,68 & 176,70 & $-57,15$ & 233,85 & 58,97 & 105,13 & 117,52 & $-18,02$ & 1169,48 & 123,92 & 75,53 & 13,20 & 333,57 & 259,65 & 262,50 & 275,92 \\
\hline Rana pyrenaica & 31TBH71 & 99,00 & 55,15 & 85,39 & 35,34 & 5420,49 & 187,79 & $-50,20$ & 237,99 & 69,03 & 58,75 & 127,11 & $-10,36$ & 1111,69 & 118,50 & 71,49 & 13,75 & 319,11 & 247,34 & 254,56 & 256,27 \\
\hline Rana temporaria & 29TNG59 & 100,00 & 113,55 & 80,92 & 38,72 & 4310,81 & 231,79 & 25,08 & 206,71 & 67,71 & 170,02 & $\begin{array}{l}171,45 \\
\end{array}$ & 62,24 & 1509,61 & 226,36 & 35,67 & 46,38 & 586,61 & 144,05 & $\begin{array}{l}155,97 \\
\end{array}$ & 575,97 \\
\hline Rana temporaria & 29TNH05 & 99,00 & 130,21 & 64,82 & 38,15 [ & 3496,92 & 225,11 & 57,22 & 167,89 & 96,18 & 174,38 & 177,55 & 87,89 & 1236,42 & $176,17 \mid$ & 33,76 & 42,70 & 484,35 & 135,19 & 157,82 & 436,14 \\
\hline Rana temporaria & 29TNH06 & 101,00 & 130,82 & 64,73 & 38,44 & 3443,75 & 224,58 & 58,12 & 166,45 & 97,50 & \begin{tabular}{ll|}
174,06 \\
\end{tabular} & \begin{tabular}{|l|l|}
177,48 \\
\end{tabular} & 89,05 & 1201,01 & 168,81 & 33,56 & 41,93 & \begin{tabular}{|l|l|}
468,53 \\
\end{tabular} & 134,43 & 157,51 & 418,84 \\
\hline Rana temporaria & 29TNH07 & 101,00 & 135,56 & 63,77 & 38,93 & 3340,52 & 225,72 & 63,71 & 162,01 & 103,33 & 176,99 & 180,78 & 94,75 & 1124,75 & 155,33 & 31,65 & 41,14 & 437,83 & 128,10 & 152,02 & 386,81 \\
\hline Rana temporaria & 29TNH15 & 101,00 & 131,49 & 66,60 & \begin{tabular}{l|l|}
38,05 \\
\end{tabular} & 3585,35 & 229,44 & 56,70 & 172,74 & 96,06 & 176,92 & 180,04 & 88,01 & 1269,31 & 181,60 & 34,69 & 42,87 & 494,86 & 136,62 & 158,82 & 451,55 \\
\hline Rana temporaria & 29TNH16 & 100,00 & 129,53 & 66,99 & 38,23 & 3553,02 & 227,55 & 54,86 & $\begin{array}{l}172,69 \\
\end{array}$ & 94,82 & $\begin{array}{l}174,47 \\
\end{array}$ & \begin{tabular}{ll|l}
177,92 \\
\end{tabular} & 86,69 & 1258,25 & $\begin{array}{l}177,72 \\
\end{array}$ & 35,39 & 41,99 & 487,99 & \begin{tabular}{l|l|}
139,03 \\
\end{tabular} & \begin{tabular}{|l|l|}
161,37 \\
\end{tabular} & 443,71 \\
\hline Rana temporaria & $29 \mathrm{TNH} 24$ & 101,00 & 139,46 & 66,85 & 38,14 & \begin{tabular}{|l|l|}
3657,53 \\
\end{tabular} & 237,04 & $\begin{array}{ll}63,64 \\
\end{array}$ & 173,40 & 102,32 & \begin{tabular}{ll|}
185,96 \\
\end{tabular} & \begin{tabular}{|l|l|}
188,60 \\
\end{tabular} & 94,54 & 1247,55 & \begin{tabular}{|l|l|}
180,10 \\
\end{tabular} & 32,75 & 43,93 & 486,78 & 128,33 & 150,59 & 448,39 \\
\hline Rana temporaria & 29TNH25 & 101,00 & 134,22 & 68,49 & 38,02 & 3679,17 & \begin{tabular}{|l|}
235,07 \\
\end{tabular} & 57,13 & 177,94 & 97,31 & 180,95 & \begin{tabular}{|l|l|}
184,04 \\
\end{tabular} & 89,61 & \begin{tabular}{|l|l|}
1277,87 \\
\end{tabular} & 182,81 & 34,92 & 42,98 & 495,32 & $\begin{array}{l}135,80 \\
\end{array}$ & 157,76 & 456,50 \\
\hline Rana temporaria & $29 \mathrm{TNH} 26$ & 101,00 & 129,38 & 69,40 & 38,11 & 3658,94 & 231,39 & 52,28 & 179,10 & 93,09 & 175,81 & \begin{tabular}{|l|l|}
179,24 \\
\end{tabular} & 85,42 & 1295,09 & $\begin{array}{l}183,16 \\
\end{array}$ & 36,61 & 42,07 & 499,18 & 141,72 & $\begin{array}{ll}163,38 \\
\end{array}$ & 459,85 \\
\hline Rana temporaria & 29TNH27 & 100,00 & 129,17 & 68,83 & 38,77 & 3574,89 & 228,79 & 53,35 & 175,45 & 94,07 & 174,25 & 178,02 & 86,21 & 1259,95 & 175,62 & 36,27 & 41,11 & 484,03 & 140,94 & 162,85 & 443,55 \\
\hline Rana temporaria & 29TNH28 & 101,00 & 138,15 & 66,22 & 39,76 & 3371,93 & 229,55 & 64,80 & 164,75 & 105,12 & 179,97 & $\mid 183,87$ & 96,86 & 1124,24 & 152,92 & 32,00 & 40,55 & 432,17 & 126,98 & 150,29 & 389,89 \\
\hline Rana temporaria & $29 \mathrm{TNH} 29$ & 39,00 & 138,94 & 65,60 & 40,11 & 3300,89 & 227,96 & 66,33 & 161,63 & 106,78 & \begin{tabular}{ll|}
179,56 \\
\end{tabular} & \begin{tabular}{|l|l|}
183,64 \\
\end{tabular} & 98,28 & 1096,42 & 147,44 & 31,46 & 39,97 & 420,50 & 125,51 & 149,00 & 378,18 \\
\hline Rana temporaria & 29TNH33 & 101,00 & 140,89 & 68,88 & 37,78 & $\begin{array}{l}3814,67 \\
\end{array}$ & 241,68 & 61,72 & $\begin{array}{l}179,97 \\
\end{array}$ & 101,09 & $\begin{array}{l}189,69 \\
\end{array}$ & $\begin{array}{l}191,86 \\
1\end{array}$ & 94,03 & $\begin{array}{l}1286,69 \\
\end{array}$ & \begin{tabular}{ll|l|}
188,93 \\
\end{tabular} & 32,96 & 44,87 & 500,80 & 127,77 & $\begin{array}{l}149,09 \\
\end{array}$ & 469,14 \\
\hline Rana temporaria & 29TNH34 & 100,00 & 137,98 & 70,61 & \begin{tabular}{|l|l|}
37,67 \\
\end{tabular} & 3829,36 & 242,21 & 57,25 & $\begin{array}{l}184,96 \\
\end{array}$ & 98,68 & 186,96 & \begin{tabular}{ll|l}
189,58 \\
\end{tabular} & 91,35 & \begin{tabular}{|l|}
1297,37 \\
\end{tabular} & $\begin{array}{l}188,15 \\
\end{array}$ & 34,52 & 43,99 & 501,72 & 132,89 & $\begin{array}{ll}154,22 \\
\end{array}$ & 468,82 \\
\hline Rana temporaria & 29TNH35 & 101,00 & 132,84 & 72,28 & \begin{tabular}{ll|l}
37,68 &
\end{tabular} & 3838,58 & 240,40 & 50,95 & 189,45 & 94,15 & 182,04 & $\mid 185,10$ & 86,75 & $\mid 1326,75$ & $\mid$\begin{tabular}{|l|l|}
190,10 \\
\end{tabular} & $\mid 36,64$ & 43,10 & 509,81 & $\mid$\begin{tabular}{|l|l|}
140,19 \\
\end{tabular} & 161,30 & \begin{tabular}{ll|l}
476,37 \\
\end{tabular} \\
\hline Rana temporaria & 29TNH37 & 101,00 & 127,82 & 71,68 & 38,69 ] & $3685,61 \mid$ & 231,99 & 48,85 & 183,14 & 91,12 & 174,58 & 178,31 & 83,80 & 1296,43 & 180,66 & 37,63 & 41,15 & $494,57]$ & 144,29 & 165,38 & 458,65 \\
\hline Rana temporaria & 29TNH38 & 100,00 & 130,25 & 69,90 & 39,58 & 3529,25 & 228,82 & 54,21 & $\begin{array}{l}174,62 \\
\end{array}$ & 95,40 & 174,66 & $\begin{array}{l}178,55 \\
\end{array}$ & 87,84 & $\begin{array}{l}1225,75 \\
\end{array}$ & $\begin{array}{l}167,86 \\
\end{array}$ & 35,84 & 40,29 & 467,01 & 138,82 & 160,53 & 429,77 \\
\hline Rana temporaria & $29 \mathrm{TNH} 43$ & 101,00 & 140,12 & 72,87 & 37,98 & 3953,22 & 246,17 & 56,53 & 189,64 & 98,34 & 190,91 & 193,06 & 91,84 & $\begin{array}{l}1293,19 \\
\end{array}$ & 190,16 & 33,42 & 44,74 & \begin{tabular}{ll|l}
499,02 \\
\end{tabular} & \begin{tabular}{ll|}
128,68 \\
\end{tabular} & 499,06 & 471,50 \\
\hline Rana temporaria & 29TNH45 & 100,00 & 133,85 & 75,41 & 37,71 & 3948,35 & 245,54 & $\begin{array}{ll}48,08 \\
\end{array}$ & 197,45 & 93,39 & $\begin{array}{l}184,49 \\
\end{array}$ & \begin{tabular}{|l|l|}
187,60 \\
\end{tabular} & 86,62 & \begin{tabular}{|l|}
1327,24 \\
\end{tabular} & \begin{tabular}{l|l|}
189,42 \\
\end{tabular} & 36,86 & 42,92 & 505,97 & 139,84 & 160,39 & 476,27 \\
\hline Rana temporaria & $29 \mathrm{TNH} 46$ & 100,00 & 133,61 & 74,17 & 38,49 & 3807,22 & \begin{tabular}{|l|l|}
241,03 \\
\end{tabular} & 50,75 & $\begin{array}{l}190,27 \\
\end{array}$ & 94,78 & 182,11 & 185,54 & 87,87 & \begin{tabular}{|l|l|}
1277,88 \\
\end{tabular} & $\begin{array}{l}179,38 \\
\end{array}$ & 36,11 & 41,96 & 486,11 & 137,91 & $\begin{array}{l}158,76 \\
\end{array}$ & 454,57 \\
\hline Rana temporaria & 29TNH47 & 101,00 & 129,79 & 73,67 & 39,01 & 3726,10 & 235,43 & $\begin{array}{ll}48,83 \\
\end{array}$ & 186,61 & 92,02 & 177,26 & \begin{tabular}{|l|l|}
180,80 \\
\end{tabular} & 85,29 & 1276,81 & 177,09 & 37,02 & 41,03 & 484,24 & 141,41 & 162,11 & 451,80 \\
\hline Rana temporaria & 29TNH48 & \begin{tabular}{|l|l|}
99,00 \\
\end{tabular} & 130,64 & 71,90 & 39,94 & 3580,81 & 231,16 & 52,91 & 178,25 & 94,65 & $\mid 175,87$ & $\mid 179,58$ & 87,62 & $\mid 1222,47$ & 166,76 & 35,87 & 40,09 & $\mid 463,07$ & $\mid$\begin{tabular}{|c|}
138,08 \\
\end{tabular} & 159,15 & 429,36 \\
\hline Rana temporaria & $29 \mathrm{TNH} 49$ & 99,00 & 138,44 & 68,49 & 41,26 & 3334,69 & 228,73 & 64,79 & 163,94 & 105,25 & 179,57 & 183,74 & 97,48 & $\begin{array}{l}1091,49 \\
\end{array}$ & 144,73 & 31,59 & 39,26 & 413,86 & 124,45 & 146,72 & 379,25 \\
\hline Rana temporaria & $29 \mathrm{TNH} 50$ & 101,00 & 115,81 & 80,39 & 38,78 & 4246,05 & 232,99 & 27,72 & 205,27 & 70,53 & 171,45 & 172,95 & 65,34 & \begin{tabular}{|l|}
1493,95 \\
\end{tabular} & 224,52 & 36,57 & 45,84 & 578,78 & 145,19 & 158,22 & 565,92 \\
\hline Rana temporaria & 29TNH52 & 101,00 & 121,80 & 79,71 & 38,86 & 4121,18 & 237,20 & 34,24 & 202,96 & 77,75 & 175,64 & $\begin{array}{l}177,56 \\
\end{array}$ & 73,05 & 1442,01 & 214,66 & 37,59 & 44,81 & 553,96 & 145,11 & 160,61 & 535,85 \\
\hline Rana temporaria & 29TNH55 & 101,00 & 132,55 & 77,84 & 38,55 ] & 3952,98 & 244,93 & 45,58 & 199,35 & 91,08 & 183,42 & 186,37 & 85,47 & 1311,62 & 186,78 & 36,64 & 42,66 & 496,98 & 138,85 & 158,30 & 470,35 \\
\hline Rana temporaria & 29TNH56 & 101,00 & 131,83 & 76,71 & 38,90 & 3858,57 & 241,48 & \begin{tabular}{|l|l|}
46,94 \\
\end{tabular} & 194,54 & 91,76 & 181,28 & \begin{tabular}{|l|l|}
184,54 \\
\end{tabular} & 85,86 & $\begin{array}{l}1281,64 \\
\end{array}$ & \begin{tabular}{|l|l|}
179,77 \\
\end{tabular} & 36,54 & 41,76 & $\begin{array}{l}484,46 \\
\end{array}$ & \begin{tabular}{|l|l|}
138,73 \\
\end{tabular} & $\begin{array}{ll}158,58 \\
\end{array}$ & 456,12 \\
\hline Rana temporaria & 29TNH57 & 100,00 & 129,49 & 75,79 & 39,47 & 3760,92 & 236,42 & 46,84 & 189,58 & 90,69 & 177,58 & \begin{tabular}{|l|l|}
181,00 \\
\end{tabular} & 84,70 & 1264,25 & \begin{tabular}{|l|l|}
174,91 \\
\end{tabular} & 36,84 & 40,79 & \begin{tabular}{ll|}
476,82 \\
\end{tabular} & $\begin{array}{ll}140,23 \\
\end{array}$ & $\begin{array}{ll}160,14 \\
\end{array}$ & 447,24 \\
\hline Rana temporaria & 29TNH58 & 101,00 & 136,43 & 72,36 & \begin{tabular}{|l|l|}
40,72 \\
\end{tabular} & 3553,90 & 234,25 & 58,55 & 175,70 & 100,03 & 181,02 & \begin{tabular}{|l|l|}
184,78 \\
\end{tabular} & 93,25 & $\mid 1141,24$ & $\mid$\begin{tabular}{|l|l|}
154,04 \\
\end{tabular} & 33,02 & 39,87 & \begin{tabular}{|l|l|}
430,70 \\
\end{tabular} & $\mid 128,01$ & \begin{tabular}{|l|l|}
149,16 \\
\end{tabular} & 399,31 \\
\hline Rana temporaria & 29TNH59 & 98,00 & 140,77 & 69,91 & 41,80 & 3381,91 & 231,80 & 66,23 & 165,56 & 106,31 & 182,51 & 186,54 & \begin{tabular}{ll|}
99,09 \\
\end{tabular} & 1058,70 & \begin{tabular}{|l|l|}
139,63 \\
\end{tabular} & 30,57 & 39,04 & 399,41 & 120,42 & 142,28 & 367,09 \\
\hline Rana temporaria & 29TNH62 & 101,00 & 126,70 & 82,14 & 39,66 & 4142,87 & 242,07 & 37,06 & 205,01 & 81,27 & 180,62 & 182,46 & 77,59 & 1348,88 & 199,73 & 34,98 & 44,38 & 514,25 & 135,83 & 151,36 & 496,63 \\
\hline Rana temporaria & $29 \mathrm{TNH} 63$ & 100,00 & 127,69 & 81,29 & 39,80 & \begin{tabular}{ll|l|}
4046,96 \\
\end{tabular} & 241,44 & 39,35 & 202,09 & 83,45 & 180,25 & \begin{tabular}{|l|l|}
182,44 \\
\end{tabular} & 79,89 & \begin{tabular}{|l|}
1331,88 \\
\end{tabular} & $\begin{array}{l}194,42 \\
\end{array}$ & $\begin{array}{l}35,67 \\
\end{array}$ & 43,65 & 505,65 & \begin{tabular}{|l|l|}
137,02 \\
\end{tabular} & 153,53 & 485,67 \\
\hline Rana temporaria & 29TNH66 & 101,00 & 129,58 & 78,71 & \begin{tabular}{ll|}
39,87 \\
\end{tabular} & 3857,86 & 239,18 & 44,01 & 195,17 & 88,47 & 179,21 & 182,21 & 83,81 & 1260,61 & 176,24 & 36,25 & 41,21 & \begin{tabular}{ll|l}
474,02 \\
\end{tabular} & 137,71 & $\begin{array}{l}156,45 \\
\end{array}$ & 447,92 \\
\hline Rana temporaria & 29TNH67 & 100,00 & 126,03 & 77,79 & 40,01 & 3800,28 & 234,24 & 42,32 & 191,92 & 86,01 & $\begin{array}{l}174,86 \\
\end{array}$ & $\begin{array}{l}178,03 \\
\end{array}$ & 81,18 & \begin{tabular}{|l|l|}
1264,47 \\
\end{tabular} & 174,59 & 37,33 & 40,38 & 474,41 & \begin{tabular}{ll|}
141,64 \\
\end{tabular} & $\begin{array}{l}160,31 \\
\end{array}$ & 446,85 \\
\hline Rana temporaria & 29TNH68 & 101,00 & 134,85 & 74,68 & \begin{tabular}{|l|l|}
40,77 \\
\end{tabular} & 3631,25 & 235,43 & 54,60 & 180,83 & 96,81 & 180,73 & 184,20 & 90,95 & 1139,74 & $\begin{array}{l}153,76 \\
\end{array}$ & 33,4 & 39,51 & 27,46 & 28,78 & 49,04 & 397,92 \\
\hline Rana temporaria & 29TNH69 & 95,00 & 138,76 & 72,50 & 41,54 & 3500,36 & 233,97 & 61,39 & $\mid 172,57$ & 102,55 & 182,52 & 186,15 & 95,99 & 1070,00 & 141,51 & 31,45 & 38,83 & 401,11 & 122,61 & 143,65 & 370,04 \\
\hline Rana temporaria & 29TNH72 & 100,00 & 120,88 & 84,11 & 39,92 & \begin{tabular}{|l|l|}
4229,67 \\
\end{tabular} & 238,74 & 30,06 & 208,68 & 74,28 & 176,17 & 177,82 & 71,15 & 1325,34 & 192,94 & 34,76 & 43,67 & 502,72 & 135,75 & 149,76 & 486,41 \\
\hline Rana temporaria & 29TNH73 & 101,00 & 126,68 & 83,29 & \begin{tabular}{l|l|l}
40,45 \\
\end{tabular} & 4067,70 & 240,51 & 37,36 & 203,15 & 81,38 & 179,54 & $\begin{array}{l}181,47 \\
\end{array}$ & 78,91 & $\begin{array}{l}1275,06 \\
\end{array}$ & \begin{tabular}{|l|l|}
184,29 \\
\end{tabular} & 34,28 & 43,04 & 481,31 & \begin{tabular}{|l|l|}
132,43 \\
\end{tabular} & 148,01 & 462,41 \\
\hline Rana temporaria & 29TNH77 & 100,00 & 122,67 & 79,66 & \begin{tabular}{ll|l}
40,36 \\
\end{tabular} & 3855,55 & 232,35 & $\begin{array}{ll}37,61 \\
\end{array}$ & 194,73 & 81,38 & 172,28 & $\begin{array}{l}175,29 \\
\end{array}$ & 77,27 & 1252,18 & $\begin{array}{l}172,13 \\
\end{array}$ & 37,44 & 39,90 & 467,53 & \begin{tabular}{ll|}
142,08 \\
\end{tabular} & $\begin{array}{ll}159,52 \\
\end{array}$ & 441,33 \\
\hline Rana temporaria & 29TNH78 & 100,00 & 125,41 & 78,00 & 40,75 & $3774,11 \mid$ & 231,87 & 42,35 & 189,52 & 85,45 & 173,73 & 176,95 & 80,70 & 1203,79 & $163,01]$ & 36,49 & 39,10 & 448,58 & 138,77 & 157,20 & 420,48 \\
\hline Rana temporaria & 29TNH79 & 101,00 & 127,95 & 76,35 & \begin{tabular}{ll|}
40,99 \\
\end{tabular} & 3677,10 & 230,73 & 46,82 & 183,90 & 89,37 & $\begin{array}{l}174,66 \\
\end{array}$ & $\begin{array}{l}178,06 \\
\end{array}$ & 84,01 & $\begin{array}{l}1160,08 \\
\end{array}$ & 154,75 & \begin{tabular}{ll|}
35,67 \\
\end{tabular} & 38,39 & 431,51 & 135,97 & $\begin{array}{l}155,20 \\
\end{array}$ & 401,73 \\
\hline Rana temporaria & 29TNH84 & 100,00 & 127,03 & 83,97 & 40,5 & 4104,26 & 241 & 36,61 & 204,52 & 81,13 & 180,29 & 182,31 & 78,65 & 1198,23 & 169,39 & 33,26 & 41,66 & 448,57 & 128,19 & 144,12 & 428,34 \\
\hline Rana temporaria & 29TNH85 & 101,00 & 121,53 & 83,23 & 40,44 & 4063,13 & 235,80 & 32,57 & 203,23 & 76,88 & 174,31 & 176,45 & 73,91 & 1235,25 & 172,50 & 35,55 & 40,89 & 461,64 & 135,93 & 151,63 & 439,92 \\
\hline Rana temporaria & 29TNH86 & 101,00 & 115,94 & 82,36 & \begin{tabular}{l|l|}
40,29 \\
\end{tabular} & $\begin{array}{l}4041,46 \\
\end{array}$ & $\begin{array}{l}230,32 \\
\end{array}$ & 28,34 & 201,98 & 72,10 & 168,44 & $\begin{array}{l}170,87 \\
\end{array}$ & 68,70 & $\begin{array}{l}1270,44 \\
\end{array}$ & $\begin{array}{l}175,37 \\
\end{array}$ & 37,83 & 39,99 & $\begin{array}{l}473,87 \\
\end{array}$ & \begin{tabular}{|l|l|}
143,78 \\
\end{tabular} & $\begin{array}{ll}159,12 \\
\end{array}$ & 450,46 \\
\hline Rana temporaria & 29TNH87 & 100,00 & 120,24 & 81,21 & 40,53 & 3948,06 & 231,67 & 33,64 & 198,03 & 77,44 & 171,24 & 173,84 & 73,78 & 1223,72 & 167,01 & 37,04 & 39,34 & 454,95 & 0,50 & 157,10 & 429,47 \\
\hline Rana temporaria & 29TNH88 & 101,00 & 120,39 & 79,96 & 40,75 & 3879,56 & 229,84 & 35,39 & 194,45 & 78,82 & 170,37 & \begin{tabular}{ll|}
173,09 \\
\end{tabular} & 74,51 & $\begin{array}{l}1209,88 \\
\end{array}$ & \begin{tabular}{ll|}
163,08 \\
\end{tabular} & 37,42 & 38,62 & 448,59 & 141,75 & $\begin{array}{ll}158,84 \\
\end{array}$ & 421,24 \\
\hline Rana temporaria & $29 \mathrm{TNH}$ & 100,00 & 118,54 & 78,92 & $\begin{array}{l}40,75 \\
\end{array}$ & \begin{tabular}{|l|l|}
3828,43 \\
\end{tabular} & 226,61 & 34,99 & $\begin{array}{l}191,62 \\
\end{array}$ & 77,91 & 167,77 & $\begin{array}{l}170,85 \\
\end{array}$ & 73,56 & 1211,67 & $\begin{array}{l}161,56 \\
\end{array}$ & 38,36 & 37,93 & 448,19 & \begin{tabular}{|l|l|}
144,90 \\
\end{tabular} & 162,40 & 419,19 \\
\hline Rana temporaria & 29TNH90 & 100,00 & 122,24 & $\begin{array}{ll}89,38 \\
\end{array}$ & \begin{tabular}{l|l|}
38,96 \\
\end{tabular} & $\begin{array}{l}4753,56 \\
\end{array}$ & 249,93 & 22,45 & 227,48 & 69,16 & 184,61 & \begin{tabular}{|l|l|}
185,24 \\
\end{tabular} & 65,15 & 1166,68 & 166,79 & 28,45 & 43,87 & 440,45 & 115,60 & $\begin{array}{l}126,20 \\
\end{array}$ & 428,22 \\
\hline Rana temporaria & 29TNH91 & 101,00 & 118,31 & 88,03 & 39,00 & 4616,37 & 244,04 & 21,27 & 222,77 & 67,07 & 178,96 & 179,91 & 63,44 & 1205,83 & 171,39 & 30,83 & 43,10 & 454,83 & 123,06 & 135,26 & 441, \\
\hline Rana temporaria & 29TNH92 & 101,00 & 117,40 & 87,18 & 39,25 & 4506,35 & 240,98 & 22,00 & 。 & 67,39 & 176,50 & 17 & 64,03 & 1213,36 & 171,45 & 32,25 & 4 & 456 & 99 & ,71 & 44 \\
\hline Rana temporaria & $29 \mathrm{TNH}$ & 101,00 & 120,38 & 84 & 40, & 4 & 237 & 29,28 & 208,05 & 73,99 & 175,04 & $\begin{array}{l}176,95 \\
\end{array}$ & 70,86 & $\begin{array}{l}1186,55 \\
\end{array}$ & 16 & 34,36 & 40,28 & \begin{tabular}{|l|l|}
441,78 \\
\end{tabular} & 132,04 & 146,98 & 420 \\
\hline Rana temporaria & 29TNH96 & 101,00 & 121,63 & 83,64 & 40,42 & 4105,72 & 236,21 & 32,01 & 204,20 & 76,47 & \begin{tabular}{ll|}
174,88 \\
\end{tabular} & \begin{tabular}{|l|l|}
177,02 \\
\end{tabular} & 73,10 & $\begin{array}{l}1172,85 \\
\end{array}$ & 160,54 & 34,80 & 39,63 & 435,42 & 133,02 & 148,72 & 411,98 \\
\hline Rana temporaria & 29TNH97 & 100,00 & 122,66 & 82,42 & \begin{tabular}{ll|}
40,76 \\
\end{tabular} & 4034,11 & 235,08 & $\begin{array}{ll}34,51 \\
\end{array}$ & 200,57 & 78,55 & 174,71 & \begin{tabular}{|l|l|}
177,24 \\
\end{tabular} & 74,77 & 1155,42 & $\begin{array}{l}156,30 \\
\end{array}$ & 35,05 & 38,88 & 27,68 & \begin{tabular}{|l|l|}
133,61 \\
\end{tabular} & 50,03 & 402,29 \\
\hline Rana temporaria & 29TNH98 & 101,00 & 121,27 & 81,36 & 40,79 & 3959,32 & 232,09 & 34,47 & 197,61 & 78,34 & 172,28 & 174,98 & 74,29 & 1159,91 & 155,18 & 36,09 & 38,11 & 428,21 & 137,12 & 153,85 & 401,04 \\
\hline Ranat & & 100,00 & & & $40, \mathrm{~s}$ & & & 36,08 & 94, & 79,50 & 17 & & 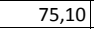 & J & 15 & 36 & & 42 & 138,80 & 156,01 & 395 \\
\hline Rana temporaria & $29 \mathrm{TNJ} 4$ & 18,00 & 140,90 & 67,00 & 41,90 & 3225,38 & 226,97 & 68,62 & 158,34 & 109,17 & 180,34 & \begin{tabular}{ll|}
184,66 \\
\end{tabular} & 101,00 & $\begin{array}{l}1040,24 \\
\end{array}$ & $\begin{array}{l}135,86 \\
\end{array}$ & 30,03 & 39,00 & 394,31 & 119,52 & 142,10 & 359,5 \\
\hline Rana temporaria & 29TNJ60 & 66,00 & 138,42 & 71,58 & 41,92 & 3427,75 & 231,34 & 62,74 & 168,59 & 103,12 & 181,05 & 184,86 & 96,42 & 1051,61 & \begin{tabular}{|l|l|}
137,08 \\
\end{tabular} & 31,55 & 38,09 & 393,14 & 123,14 & 144,39 & 360,99 \\
\hline
\end{tabular}




\begin{tabular}{|c|c|c|c|c|c|c|c|c|c|c|c|c|c|c|c|c|c|c|c|c|c|}
\hline TAXON & UTM & $\mathrm{km2}$ & BIO1 & B102 & BIO3 & B104 & B105 & B106 & B107 & B108 & B109 & BIO10 & BIO11 & B1012 & BIO13 & BIO14 & BIO15 & BIO16 & BIO17 & BIO18 & BI019 \\
\hline Rana temporaria & 29TNJ61 & 82,00 & 138,78 & 70,46 & 42,23 & 3350,75 & 229,34 & 64,74 & 164,60 & 104,63 & 180,27 & 184,22 & 97,70 & 1035,07 & 133,93 & 31,48 & 37,61 & 386,40 & 123,21 & 144,96 & 352,94 \\
\hline Rana temporaria & 29TNJ62 & 77,00 & 138,50 & 69,71 & 42,42 & 3311,98 & 227,83 & 65,35 & 162,48 & 104,89 & 179,31 & 183,41 & 97,82 & 1028,44 & 132,74 & 31,91 & 37,02 & 383,10 & 124,55 & 146,55 & 348,41 \\
\hline Rana temporaria & 29TNJ70 & 100,00 & $\begin{array}{l}127,38 \\
\end{array}$ & 75,21 & 41,21 & 3607,29 & 228,03 & 47,99 & \begin{tabular}{|l|l|}
180,04 \\
\end{tabular} & 89,86 & \begin{tabular}{ll|l}
172,98 \\
\end{tabular} & \begin{tabular}{ll|l}
176,58 \\
\end{tabular} & 84,18 & 1147,25 & 151,21 & 35,90 & 37,79 & \begin{tabular}{l|l}
425,82 \\
\end{tabular} & \begin{tabular}{ll|}
137,08 \\
\end{tabular} & \begin{tabular}{ll|}
156,62 \\
\end{tabular} & 394,60 \\
\hline Rana temporaria & 29TNJ72 & 101,00 & 133,10 & 72,15 & 42,08 & 3432,01 & 226,92 & 57,35 & \begin{tabular}{ll|}
169,57 \\
\end{tabular} & 97,92 & \begin{tabular}{ll|l}
175,90 \\
17
\end{tabular} & \begin{tabular}{|l|l|}
179,71 \\
\end{tabular} & 91,45 & 1067,50 & \begin{tabular}{|l|l|}
137,07 \\
\end{tabular} & 34,02 & 36,65 & 394,97 & \begin{tabular}{|l|l|}
131,15 \\
\end{tabular} & \begin{tabular}{ll|}
152,16 \\
\end{tabular} & 360,88 \\
\hline Rana temporaria & 29TNJ80 & 100,00 & 122,17 & 77,45 & 40,97 & 3732,97 & 226,80 & $40,28 \mid$ & 186,52 & $82,75 \mid$ & 169,73 & $173,01 \mid$ & 77,78 & 1168,66 & 153,90 & 37,45 & 37,24 & $431,41 \mid$ & $141,75 \mid$ & 160,10 & 400,68 \\
\hline Rana temporaria & 29TNJ81 & 100,00 & 123,92 & 76,14 & 41,25 & 3653,63 & 225,79 & 43,65 & \begin{tabular}{|l|l|}
182,14 \\
\end{tabular} & 85,62 & $\begin{array}{ll}170,26 \\
\end{array}$ & \begin{tabular}{ll|l}
173,78 \\
\end{tabular} & 80,28 & 1142,11 & 148,61 & 37,10 & 36,76 & \begin{tabular}{|l|l}
420,70 \\
\end{tabular} & \begin{tabular}{|l|}
140,61 \\
\end{tabular} & \begin{tabular}{l|l|}
159,65 \\
\end{tabular} & 388,46 \\
\hline Rana temporaria & 29TNJ82 & 100,00 & 130,16 & 74,18 & 41,87 & 3535,37 & 227,38 & 52,20 & 175,18 & 93,44 & 174,59 & 178,24 & 87,60 & 1077,42 & 138,13 & 35,11 & 36,12 & 396,33 & \begin{tabular}{|l|}
134,04 \\
\end{tabular} & 154,27 & 362,51 \\
\hline Rana temporaria & 29TNJ83 & 101,00 & 130,18 & 72,98 & 41,98 & 3479,40 & 225,55 & 53,48 & \begin{tabular}{|l|l|}
172,07 \\
\end{tabular} & 94,38 & $\begin{array}{l}173,69 \\
\end{array}$ & \begin{tabular}{|l|l|}
177,47 \\
\end{tabular} & 88,12 & 1072,64 & 137,44 & 35,55 & 35,79 & \begin{tabular}{l|l|}
393,85 \\
\end{tabular} & $\begin{array}{ll}135,68 \\
\end{array}$ & \begin{tabular}{l|l|}
156,29 \\
\end{tabular} & 358,51 \\
\hline Rana temporaria & 29TNJ84 & 31,00 & 128,75 & 72,62 & 42,07 & 3463,58 & 223,64 & 52,51 & \begin{tabular}{l|l}
171,13 \\
\end{tabular} & 93,16 & \begin{tabular}{ll|l}
172,00 \\
\end{tabular} & \begin{tabular}{l|l|l|}
175,75 \\
\end{tabular} & 86,98 & 1079,11 & 138,18 & 36,49 & 35,25 & \begin{tabular}{l|l|}
395,05 \\
\end{tabular} & $\begin{array}{l}138,64 \\
\end{array}$ & \begin{tabular}{l|l|}
159,35 \\
\end{tabular} & 358,69 \\
\hline Rana temporaria & 29TNJ90 & 101,00 & 120,50 & 79,13 & 40,94 & 3826,89 & 227,57 & 36,78 & 190,79 & 79,70 & 169,58 & $172,59 \mid$ & 75,19 & 1151,81 & 150,82 & 37,43 & 36,92 & 423,15 & 141,40 & 158,99 & 392,64 \\
\hline Rana temporaria & 29TNJ91 & 101,00 & 119,44 & 78,01 & 41,06 & 3765,45 & 224,70 & 37,15 & 187,55 & 79,81 & \begin{tabular}{ll|l}
167,50 \\
\end{tabular} & \begin{tabular}{|l|l|}
170,67 \\
1
\end{tabular} & 74,70 & 1154,74 & 149,70 & 38,31 & 36,17 & 423,15 & \begin{tabular}{ll|l}
144,50 \\
\end{tabular} & \begin{tabular}{ll|}
162,42 \\
\end{tabular} & 391,05 \\
\hline Rana temporaria & 29TNJ92 & 99,00 & 122,03 & 76,58 & 41,33 & 3678,40 & 224,31 & 41,38 & \begin{tabular}{l|l|}
182,93 \\
\end{tabular} & 83,46 & 168,71 & \begin{tabular}{ll|l}
172,09 \\
\end{tabular} & 78,17 & 1126,56 & 144,34 & 37,91 & 35,67 & \begin{tabular}{ll|}
411,83 \\
\end{tabular} & \begin{tabular}{|l|l|}
143,04 \\
\end{tabular} & $\begin{array}{l}161,75 \\
\end{array}$ & 378,12 \\
\hline Rana temporaria & 29TNJ93 & 92,00 & 133,74 & 73,98 & 41,97 & 3525,79 & 229,64 & 55,54 & 174,11 & 96,84 & \begin{tabular}{|l|l|}
177,87 \\
\end{tabular} & \begin{tabular}{ll|l}
181,48 \\
\end{tabular} & 91,05 & 1025,37 & 131,62 & 34,11 & 35,33 & \begin{tabular}{|l|}
374,76 \\
\end{tabular} & 130,39 & 150,86 & 339,41 \\
\hline Rana temporaria & 29TPG37 & 100,00 & 81,18 & 89,85 & 36,97 & 5161,60 & 223,24 & $-16,66$ & 239,90 & $26,61 \mid$ & 150,66 & $150,77 \mid$ & 20,92 & 1289,79 & 168,92 & 33,27 & 43,10 & 490,73 & 134,79 & 135,32 & 482,999 \\
\hline Rana temporaria & 29TPG47 & 101,00 & 87,27 & 93,12 & 37,28 & 5272,05 & 232,57 & - $-13,80 \mid$ & 246,38 & 30,69 ] & 158,08 & 158,12 & 25,08 & 1178,80 & 154,82 & 30,25 & $43,01[$ & 449,01 & $123,01 \mid$ & 123,16 & 441,24 \\
\hline Rana temporaria & 29TPG79 & 101,00 & 115,29 & 102,23 & 38,71 & 5504,49 & 264,82 & 3,55 & 261,28 & 52,63 & $\begin{array}{ll}187,88 \\
\end{array}$ & \begin{tabular}{|l|l|}
187,88 \\
\end{tabular} & 47,61 & 798,91 & 105,84 & 21,01 & 40,71 & \begin{tabular}{|l|l|}
302,25 \\
\end{tabular} & \begin{tabular}{|l|l|}
87,53 \\
\end{tabular} & 87,53 & 288,56 \\
\hline Rana temporaria & 29TPH05 & 100,00 & 120,25 & 86,16 & 40,00 & 4330,66 & 239,66 & 26,82 & 212,84 & 72,25 | & \begin{tabular}{|l|l|}
176,64 \\
\end{tabular} & \begin{tabular}{|l|l|}
178,33 \\
\end{tabular} & \begin{tabular}{ll|}
68,88 \\
\end{tabular} & \begin{tabular}{ll|}
1130,62 \\
\end{tabular} & 154,64 & 32,99 & 39,74 & \begin{tabular}{|l|l|}
419,44 \\
\end{tabular} & \begin{tabular}{|l|l|}
127,24 \\
\end{tabular} & $\begin{array}{l}141,76 \\
\end{array}$ & 397,95 \\
\hline Rana temporaria & 29TPH07 & 100,00 & 123,13 & 83,78 & 40,52 & 4121,32 & 237,34 & 33,13 & 204,21 & 77,79 & \begin{tabular}{ll|l}
176,53 \\
\end{tabular} & \begin{tabular}{|l|l|}
178,70 \\
\end{tabular} & 74,12 & 1106,65 & 148,29 & 33,80 & 38,24 & \begin{tabular}{ll|l}
408,04 \\
\end{tabular} & \begin{tabular}{ll|}
129,36 \\
\end{tabular} & $\begin{array}{l}145,35 \\
\end{array}$ & 382,48 \\
\hline Rana temporaria & 29ТPH08 & 100,00 & 124,56 & 82,49 & 40,96 & 4047,40 & 236,24 & 36,13 & 200,11 & 80,26 _ & 176,78 & $179,07 \mid$ & 76,20 & 1090,69 & $144,51 \mid$ & 34,03 & 37,66 & $400,97 \mid$ & 129,85 & 146,52 & 373,57 \\
\hline Rana temporaria & 29TPHO9| & 100,00 & 122,75 & 81,56 & 40,98 & 3966,66 & 232,91 & 35,86 & 197,05 & 79,73 & 173,76 & $\mid 176,37$ & 75,50 & 1103,8 & 144,75 & 35,37 & 36,96 & 404,69 & 134,34 & 151,17 & 375,61 \\
\hline Rana temporaria & 29TPH16 & 101,00 & 125,04 & 86,30 & 40,07 & 4330,92 & 243,26 & 31,13 & 212,13 & 76,77 & 181,15 & 182,83 & 73,01 & 1042,90 & 139,56 & 31,21 & 38,41 & 383,96 & 120,74 & 136,01 & 359,84 \\
\hline Rana temporaria & 29TPH17 & 100,00 & 126,18 & 84,96 & 40,36 & 4216,44 & 241,65 & 34,25 & 207,40 & 79,44 & $\begin{array}{l}180,65 \\
1\end{array}$ & \begin{tabular}{l|l|}
182,65 \\
\end{tabular} & 75,51 & 1038,06 & $\begin{array}{l}137,45 \\
\end{array}$ & 31,90 & 37,78 & \begin{tabular}{|l|l|}
381,03 \\
\end{tabular} & \begin{tabular}{ll|}
122,60 \\
\end{tabular} & $\begin{array}{l}138,47 \\
13\end{array}$ & 354,94 \\
\hline Rana temporaria & 29TPH18 & 101,00 & $\begin{array}{ll}125,68 \\
\end{array}$ & 83,80 & 40,68 & 4123,85 & 238,95 & 35,24 & 203,71 & 80,25 & \begin{tabular}{ll|}
178,80 \\
\end{tabular} & \begin{tabular}{ll|}
180,96 \\
\end{tabular} & \begin{tabular}{|l|l|}
76,07 \\
\end{tabular} & 1044,09 & 136,94 & 32,81 & 37,04 & 382,20 & \begin{tabular}{ll|}
125,76 \\
\end{tabular} & \begin{tabular}{|l|l|}
142,04 \\
\end{tabular} & 354,40 \\
\hline Rana temporaria & 29TPH25 & 100,00 & 126,69 & 88,78 & 40,00 & 4525,55 & 249,07 & 29,25 & 219,82 & $75,85[$ & 185,51 & 186,73 & 72,08 & 981,64 & 131,10 & 28,68 & 38,5 & $361,47 \mid$ & 112,42 & 126,98 & 338,67 \\
\hline Rana temporaria & 29TPH26 & 100,00 & 121,66 & 87,84 & 40,00 & 4444,56 & 243,07 & 26,02 & 217,05 & 71,93 & 179,43 & \begin{tabular}{|l|l|}
180,73 \\
\end{tabular} & 68,04 & 1026,71 & 136,01 & 31,28 & 37,83 & 377,12 & 121,13 & 135,50 & 352,61 \\
\hline Rana temporaria & 29TPH27 & 100,00 & 123,01 & 86,66 & 40,23 & 4337,90 & 241,68 & 29,27 & 212,41 & 74,82 & 179,25 & 180,94 & 70,80 & 1019,81 & 133,69 & 31,80 & 37,10 & 373,07 & 122,70 & \begin{tabular}{|l|l|}
137,63 \\
\end{tabular} & 346,56 \\
\hline Rana temporaria & 29TPH29 & 100,00 & 120,52 & 84,35 & 40,81 & 4153,65 & 235,10 & 30,25 & 204,85 & 75,22 & \begin{tabular}{ll|}
774,12 \\
\end{tabular} & 176,39 & 70,75 & 1050,29 & 135,08 & 34,75 & 35,81 & 381,62 & 131,94 & 147,61 & 351,42 \\
\hline Rana temporaria & 29TPH37 & 101,00 & 115,11 & 88,43 & 40,03 & 4458,08 & 237,97] & 19,80 & 218,17 & 65,63 & 173,12 & 174,59 & $61,61 \mid$ & 1040,39 & 135,09 & 33,49 & $36,41 \mid$ & 379,57 & 128,52 & 142,10 & 352,46 \\
\hline Rana temporaria & 29TPH39 & 100,00 & 120,33 & 85,68 & 40,81 & 4224,79 & 236,71 & 28,66 & 208,05 & $73,78 \mid$ & 174,85 . & 176,75 & 69,58 & 1018,56 & 129,79 & 34,2 & $35, \mathrm{C} \quad \mathrm{r}$ & 368,25 & 130,32 & 145,46 & 337,16 \\
\hline Rana temporaria & 29TPH48 & 101,00 & 117,97 & 88,31 & 40,36 & 4404,92 & 239,19 & 23,24 & \begin{tabular}{|l|l|}
215,96 \\
\end{tabular} & $\begin{array}{ll}69,26 \\
\end{array}$ & $\begin{array}{l}175,12 \\
12\end{array}$ & $\begin{array}{l}176,65 \\
1\end{array}$ & \begin{tabular}{ll|}
64,93 \\
\end{tabular} & $\begin{array}{l}993,69 \\
9\end{array}$ & 127,02 & 33,38 & 34,98 & $\begin{array}{l}359,06 \\
3\end{array}$ & $\begin{array}{l}127,50 \\
\end{array}$ & $\begin{array}{l}141,46 \\
\end{array}$ & 328,68 \\
\hline Rana temporaria & 29TPH49 & 100,00 & 124,12 & 86,46 & 40,94 & 4260,85 & 240,72 & 31,49 & \begin{tabular}{|l|}
209,23 \\
\end{tabular} & 77,22 & 179,05 & 180,94 & 72,71 & 962,06 & 123,51 & 32,72 & 34,54 & \begin{tabular}{|l|}
345,94 \\
\end{tabular} & \begin{tabular}{|l|l|}
124,92 \\
\end{tabular} & \begin{tabular}{|l|}
139,97 \\
\end{tabular} & 313,62 \\
\hline Rana temporaria & 29TPH52 & 100,00 & 95,85 & 95,19 & 38,70 & 5107,97 & 237,01 & $-6,60$ & 243,60 & 39,57 & $\begin{array}{ll}163,73 \\
\end{array}$ & \begin{tabular}{ll|l}
163,78 \\
\end{tabular} & 34,81 & 1057,17 & 138,92 & 31,84 & 38,58 & 392,95 & $\begin{array}{l}124,87 \\
\end{array}$ & \begin{tabular}{ll|}
126,52 \\
\end{tabular} & 374,61 \\
\hline Rana temporaria & 29TPH53 & 101,00 & $99,11$. & 94,86 & 38,92 & 5036,83 & $238,21]$ & $-2,88$ & 241,09 & $43,45[$ & 165,90 & 166,06 & 38,90 [ & 1036,66 & 135,77 & $31, \varepsilon \quad r \quad>$ & 37,9 & $383,61 \mid$ & $124,47 \mid$ & 128,23 & 363,08 \\
\hline Rana temporaria & 29TPH55 & 101,00 & 115,59 & 93,60 & 39,80 & 4824,02 & 247,23 & 14,03 & 233,20 & 61,30 | & 178,62 & 179,20 & 57,0 & 937,10 & 121,15 & 29,23 & 36,63 & 342,96 & 114,97 & 125,70 & 317,72 \\
\hline Rana temporaria & $29 \mathrm{TPH} 56$ & 100,00 & 112,59 & 92,57 & 39,92 & 4721,95 & 242,36 & 12,91 & 229,45 & 59,88 & 174,30 & 175,10 & 55,56 & $\begin{array}{l}969,45 \\
\end{array}$ & 124,37 & 31,62 & 35,72 & \begin{tabular}{|l|l|}
352,59 \\
\end{tabular} & 122,46 & 134,51 & 325,18 \\
\hline Rana temporaria & 29TPH57 & 101,00 & 108,53 & 91,48 & 39,99 & 4634,93 & 236,83 & 10,77 & 226,06 & 57,27 & 169,01 & 170,10 & 52,83 & 1012,28 & 129,34 & 34,45 & 34,89 | & 366,04 & 131,43 & 143,40 & 336,67 \\
\hline Rana temporaria & 29TPH58 & 99,00 & 111,89 & 90,21 & 40,17 & 4511,60 & 236,79 & 15,61 & 221,18 & 62,19 & \begin{tabular}{ll|}
170,64 \\
1
\end{tabular} & $\begin{array}{ll}171,93 \\
\end{array}$ & 57,57 & 1001,05 & 128,05 & 34,69 & 34,26 & 360,09 & \begin{tabular}{|l|l|}
131,93 \\
\end{tabular} & $\begin{array}{l}144,69 \\
\end{array}$ & 328,66 \\
\hline Rana temporaria & 29TPH62 & 100,00 & 100,06 & 97,43 & 38,86 & 5205,83 & 243,35 & $-4,92$ & 248,28 & 41,99 & 169,03 & 169,06 & 37,2 & 973,89 & 127,40 & 29,47 & 38,0 & 361,44 & 116,54 & 116,88 & 342,10 \\
\hline Rana temporaria & 29TPH63 & 100,00 & 96,65 & 96,45 & 38,91 & 5119,07 & 238,28 & $-6,57$ & 244,86 & $39,94 \mid$ & 164,49 & 164,55 & 35,18 & 1010,04 & 131,23 & 31,90 & 37,11 & 372,28 & 124,46 & 125,75 & 350,78 \\
\hline Rana temporaria & 29TPH64 & 100,00 & 101,18 & 95,94 & 39,16 & 5028,11 & 240,07 & $-1,63$ & 241,70 & 45,30 & 167,53 & 167,73 & 40,68 & 986,45 & 127,35 & 31,77 & 36,41 & 361,41 & \begin{tabular}{|l|}
123,68 \\
\end{tabular} & \begin{tabular}{|l|l}
127,55 \\
\end{tabular} & 337,53 \\
\hline Rana temporaria & 29TPH68 & 100,00 & 112,91 & 91,50 & 40,35 & 4561,33 & 239,10 & 15,52 & 223,58 & 62,99 & \begin{tabular}{ll|}
172,22 \\
\end{tabular} & \begin{tabular}{ll|}
173,42 \\
\end{tabular} & 57,89 & 963,04 & 124,25 & 34,13 & 33,53 & $\begin{array}{l}344,15 \\
\end{array}$ & 129,85 & 142,22 & 311,33 \\
\hline Rana temporaria & 29TPH71 & 100,00 & 113,94 & 100,82 & 38,97 & 5392,16 & 260,03 & \begin{tabular}{l|l|}
3,76 \\
\end{tabular} & 256,27 & 52,37 & \begin{tabular}{|l|l|}
184,91 \\
\end{tabular} & \begin{tabular}{l|l|}
184,91 \\
\end{tabular} & 47, & \begin{tabular}{|l|l|}
816,87 \\
\end{tabular} & 107,39 & 22,93 & 39,03 & $\begin{array}{l}305,75 \\
\end{array}$ & $\begin{array}{l}94,65 \\
9\end{array}$ & \begin{tabular}{l|l}
94,65 \\
\end{tabular} & 287,50 \\
\hline Rana temporaria & 29TPH73 & 101,00 & 86,82 & 97,28 & 38,88 & 5179,44 & 231,19 & $-16,28$ & $247,47 \mid$ & 30,10 & 155,82 & 155,92 & $25,01 \mid$ & 1044,37 & 133,86 & 35,11 . & 35,84 & 81,04 & 134,58 & 135,46 & 358,23 \\
\hline Rana temporaria & 29TPH74 & 100,00 & 79,80 & 95,67 & 38,76 & 5085,43 & 222,37 & $-21,16$ & 243,53 & 24,80 & \begin{tabular}{|l|l|l}
147,66 \\
\end{tabular} & \begin{tabular}{|l|l|}
147,86 &
\end{tabular} & 19,67 & 1114,89 & 141,35 & 39,34 & 34,79 & \begin{tabular}{|l|l|}
402,99 \\
\end{tabular} & $\mid 148,23$ & $\mid 150,17$ & 377,98 \\
\hline Rana temporaria & 29TPH75 & 101,00 & 94,02 & 96,11 & 39,45 & 4995,44 & 233,21 & $-7,67$ & 240,88 & 39,08 & 160,11 & 160,38 & 34,17 & 1015,93 & 129,58 & 35,50 & 34,52 & 366,79 & 135,23 & \begin{tabular}{|l|l|}
139,76 \\
\end{tabular} & 339,58 \\
\hline Rana temporaria & 29TPH78 & 100,00 & 114,42 & 92,48 & 40,65 & 4583,52 & 241,15 & 16,33 & 224,81 & 67,71 & 173,87 & 175,05 & 58, & 927,82 & 120,75 & 33, & 32, & 328,82 & 128,45 & 140,50 & 294,39 \\
\hline Rana temporaria & 29TPH84 & 99,00 & 84,45 & 98,01 & 39,11 & 57] & 33 & $-18,65 \mid$ & 247,48 & 28, & 153 & 153,23 & 22 & 1035,10 & 131,26 & 37,17 & 34,15 [ & 372,30 & 140,47 & 142,00 & 346,19 \\
\hline Rana temporaria & 29TPH85 & 100,00 & 86,49 & 97,08 & 39,39 & 5063,74 & 8,23 & $-15,52$ & 243,75 & 31 & 153,68 & 153,93 & 26,0 & 1038,17 & 131,85 & 38,4 & $33,4,2>1$ & 371,23 & 143,15 & 146,55 & 342,91 \\
\hline Rana temporaria & 29TPH86 & 100,00 & 92,14 & 96,67 & 39,75 & 4962,72 & 231,10 & $-9,28$ & 240,38 & 37,85 & \begin{tabular}{|l|l|}
157,69 \\
\end{tabular} & \begin{tabular}{|l|l|}
158,06 \\
\end{tabular} & 32,74 & 1009,01 & 128,96 & 37,55 & 32,85 & 359,18 & \begin{tabular}{|l|l|}
141,06 \\
\end{tabular} & \begin{tabular}{|l|l|}
147,50 \\
\end{tabular} & 328,58 \\
\hline Rana temporaria & 29TPH94 & 100,00 & 95,70 & 100,75 & 39,73 & 5221,88 & & $-10,36$ & 251,37 & 37,77 & \begin{tabular}{ll|}
164,72 \\
\end{tabular} & $\begin{array}{l}164,75 \\
\end{array}$ & 32,52 & 909,10 & 117,19 & 32,61 & 33,67 & 325,71 & 125,11 & 125,58 & 298,14 \\
\hline Rana temporaria & 29TPH95 & 101,00 & 82,12 & 98,49 & 39,41 & 5119,52 & 226,07 & $-20,73$ & 246,80 & 26,62 & \begin{tabular}{|l|l|}
150,14 \\
\end{tabular} & 150,32 & 21,01 & 1033,23 & 130,99 & 39,47 & 32,41 & 366,08 & 147,11 & \begin{tabular}{ll|}
149,18 \\
\end{tabular} & 336,68 \\
\hline Rana temporaria & 29TPH96 & 100,00 & 95,13 & 98,32 & 40,01 & 4996,45 & 234,96] & $-7,69 \mid$ & 242,65 | & $43,34[$ & 160,89 | & 161,15 | & 34,8 & 956,82 & 123,38 & 36,5 & $32, \mathrm{C} \quad \mathrm{q}$ & $337,68 \mid$ & 137,32 & 142,85 - & 305,49 \\
\hline Rana temporaria & 29TPJ00 & 100,00 & 117,21 & 80,76 & 40,90 & 3933,5 & 227, & 31,59 & 195, & $75,04[$ & 167,82 & 170,58 & 70, & 1145,39 & 148,93 & 37 & 36 & 418, & 142,92 & 159,58 & \\
\hline Rana temporaria & 29TPJ01 & 101 & 112,48 & & 40, & 389 & 221 & 28,54 & & & \begin{tabular}{ll|}
162,61 \\
\end{tabular} & \begin{tabular}{ll|}
165,58 \\
\end{tabular} & 66 & 118 & 152,27 & 40,2 & 35,61 & \begin{tabular}{|l|l|}
430,41 \\
\end{tabular} & \begin{tabular}{|l|l|}
150,73 \\
\end{tabular} & \begin{tabular}{|l|l|l|l|}
167,32 \\
\end{tabular} & 398, \\
\hline Rana temporaria & 29TPJ03 & 101,00 & 127,49 & 76,06 & 41,66 & 3640,31 & 227,42 & 47,19 & 180,23 & 89,29 & 173,45 & 176,91 & 83,71 & 1057,71 & 135,04 & 36,25 & 34,85 & 384,15 & 137,13 & 156,45 & 348,63 \\
\hline Rana temporaria & 29TPJ10 & 101,00 & 112,25 & 82,44 & 40,65 & 4047,22 & 225,37 & \begin{tabular}{|l|l|}
25,05 \\
\end{tabular} & \begin{tabular}{|l|}
200,32 \\
\end{tabular} & \begin{tabular}{ll|}
68,87 \\
\end{tabular} & 164,45 & \begin{tabular}{ll|l}
167,13 \\
\end{tabular} & 64,32 & 1150,58 & 148,39 & 8,02 & 35,57 & 18,62 & 146,55 & \begin{tabular}{ll|}
162,06 \\
\end{tabular} & 387,48 \\
\hline Rana temporaria & 29TPJ11 & 99,00 ب & 107,59 & 81,49 & 40,67 & 4002,55 & 220,11 & 21,82 & 198,28 & 65,15 | & 159,35 & 162,08 & 60,56 & 1.87,50 & 151,90 & 41,50 & 34,98 , & $430,71 \mid$ & 154,62 & 170,05 & 397,96 \\
\hline Rana te & & & & & 40,87 & & & 27 & & & & 171,14 & 67,24 & & & 37,26 & 35,04 & & 14 & 155,81 & \\
\hline Rana temporaria & 29TPJ21 & 100,00 & 120,79 & 81,71 & 41,15 & 3971, & 230,49 & 34,14 & 196,35 & 77,94 & \begin{tabular}{|l|l|}
171,70 \\
\end{tabular} & 174,29 & 73,26 & 1057,61 & 134,68 & 36,63 & 34,61 & 381,88 & \begin{tabular}{|l|l|}
137,79 \\
\end{tabular} & 154,38 & 348,21 \\
\hline Rana temporaria & 29TPJ22 & 101,00 & 128,39 & 79,59 & 41,46 & 3830,80 & 233,22 & 43,66 & 189,56 & $87,41 \mid$ & 177,09 & 180,01 & 82,31 & 1008,09 & 129,29 & 35,01 & 34,31 & 363,16 & 132,31 & 150,16 & 327,92 \\
\hline
\end{tabular}




\begin{tabular}{|c|c|c|c|c|c|c|c|c|c|c|c|c|c|c|c|c|c|c|c|c|c|}
\hline TAXON & UTM & $\mathrm{km2}$ & BIO1 & B1O2 & $\mathrm{BIO3}$ & B104 & B105 & B106 & 8107 & B108 & B109 & 81010 & B1011 & BIO12 & B1013 & 81014 & B1015 & B1016 & B1017 & B1018 & B1019 \\
\hline Rana temporaria & 29ТРנ33 & & & & & & & & & & & & & & & & & & & & \\
\hline Rana temporaria & 29TPJ42 & 53,00 & 137,48 & 80,69 & 41,72 & 3889,44 & 242,19 & 50,71 & 191,48 & 96,05 & 186,59 & 189,31 & 89,93 & 902,47 & 118,12 & 31,63 & 33,45 & 321,57 & 120,77 & 138,51 & 284,69 \\
\hline Rana temporaria & 29TPJ60 & 100,00 & 108,41 & 88,88 & 40,73 & 4367,70 & 230,35 & 15,04 & 215,32 & 61,15 & 165,12 & 166,80 & 56,09 & \begin{tabular}{r|}
1025,98 \\
\end{tabular} & 132,00 & 38,71 & 32,21 & 362,76 & 144,13 & \begin{tabular}{|l|l|}
156,86 \\
\end{tabular} & 326,34 \\
\hline Rana temporaria & 29TPJ61 & 101,00 & 128,73 & 85,00 & 41,49 & 4095,14 & 240,69 & 38,16 & 202,54 & 93,10 & 180,98 & 183,27 & 79,05 & 912,44 & 119,82 & 33,86 & 32,17 & 321,09 & 127,55 & 142,96 & 282,41 \\
\hline Rana temporaria & 29TPJ71 & 100,00 & 120,92 & 87,16 & 41,43 & \begin{tabular}{|l|l|}
4187,18 \\
\end{tabular} & 236,81 & 29,09 & 207,72 & 87,25 & 174,57 & 176,78 & 70,42 & 941,81 & 123,60 & 36,55 & 31,16 & 328,99 & 136,06 & 150,07 & 288,43 \\
\hline Rana temporaria & 29TPJ81 & 101,00 & 126,36 & 87,08 & 41,82 & 4144,52 & 240,59 & 34,49 & 206,10 & 102,20 & 179,16 & 181,45 & 75,99 & 896,35 & 118,96 & 35,47 & 30,70 & 311,92 & 132,18 & 146,10 & 267,74 \\
\hline Rana temporaria & 29TPJ91 & 99,00 & 119,93 & 88,97 & 41,88 & 4195,91 & 237,16 & 27,14 & 210,02 & 96,71 & 173,61 & 175,77 & 69,22 & 921,04 & 122,25 & 38,30 & 29,70 & 317,98 & 140,67 & 153,30 & 270,80 \\
\hline Rana temporaria & 29TPJ92 & 60,00 & 135,50 & 84,06 & 42,06 & 3954,26 & 243,15 & 46,30 & $\begin{array}{l}196,86 \\
\end{array}$ & 114,32 & 185,50 & 188,13 & 87,30 & 853,51 & \begin{tabular}{|l|l|}
114,98 \\
\end{tabular} & 34,70 & 30,12 & 296,43 & 128,88 & 143,72 & 246,58 \\
\hline Rana temporaria & 29TQH05 & 100,00 & 74,91 & 99,24 & 39,39 & 5169,66 & 220,93 & $-28,05$ & 248,98 & 21,71 & 143,89 & 143,99 & 13,48 & 1055,92 & 132,96 & 42,27 & 31,32 & 370,01 & 155,47 & 156,53 & 339,66 \\
\hline Rana temporaria & 29TQH06 & 100,00 & 75,75 & 98,36 & 39,55 & 5077,99 & 219,51 & $-26,07$ & 245,58 & 25,65 & 143,30 & 143,55 & 15,40 & 1068,91 & 134,83 & 43,64 & 30,77 & 372,93 & 159,67 & 162,90 & 340,47 \\
\hline Rana temporaria & 29TQH15 & 101,00 & 81,08 & 101,33 & 39,73 & 5205,83 & 228,01 & $-23,78$ & 251,80 & 40,02 & 150,30 & 150,34 & 18,68 & 976,59 & 124,20 & 40,07 & 30,67 & 340,54 & 147,50 & 148,47 & 307,29 \\
\hline Rana temporaria & 29TQH16 & 100,00 & 66,93 & 98,64 & 39,36 & 5134,50 & 212,62 & $-34,94$ & 247,56 & 17,86 & 135,50 & 135,73 & 6,21 & \begin{tabular}{|l|}
1106,53 \\
\end{tabular} & 138,03 & 47,02 & 29,70 & 382,01 & 170,17 & 172,03 & 349,10 \\
\hline Rana temporaria & 29TQH18 & 100,00 & 95,92 & 98,41 & 40,99 & 4799,57 & 232,27 & $-4,90$ & 237,17 & 66,99 & 158,66 & 159,54 & 38,11 & 950,54 & 123,74 & 41,10 & 29,04 & 328,33 & 149,54 & 157,77 & 284,51 \\
\hline Rana temporaria & $29 \mathrm{TQH} 26$ & 100,00 & 67,82 & 99,91 & 39,58 & 5166,21 & 214,59 & $-35,04$ & 249,64 & 28,79 & 136,77 & 136,99 & 6,55 & 1070,76 & 133,82 & 46,89 & 28,95 & 367,11 & 168,84 & 170,41 & 332,03 \\
\hline Rana temporaria & 29TQH27 & 100,00 & 82,73 & 100,29 & 40,40 & 5017,34 & 225,37 & $-20,01$ & 245,38 & 50,25 & 149,06 & 149,50 & 22,69 & 987,79 & 126,24 & 43,63 & 28,73 & 340,24 & 157,60 & 162,62 & 298,65 \\
\hline Rana temporaria & 29 TQH35 & 100,00 & 65,89 & 101,62 & 39,46 & 5274,92 & 215,64 & $-38,68$ & 254,32 & 26,89 & 136,50 & 136,58 & 3,29 & 1041,54 & 129,55 & 46,18 & 28,59 & 356,23 & 166,27 & 166,70 & 320,59 \\
\hline Rana temporaria & 29TQH36 & 100,00 & 63,68 & 100,41 & 39,56 & 5201,10 & 211,47 & $-39,53$ & 251,01 & 22,61 & 133,22 & 133,42 & 2,10 & 1080,66 & 134,02 & 48,65 & 28,20 & 368,40 & 174,22 & 175,09 & 331,37 \\
\hline Rana temporaria & 29TQH37 & 99,00 & 76,09 & 100,54 & 40,23 & 5063,42 & 220,15 & $-26,83$ & 246,98 & 43,00 & 143,21 & 143,59 & 15,63 & 1014,50 & 128,25 & 46,39 & 27,91 & 346,75 & 165,85 & 169,67 & 304,04 \\
\hline Rana temporaria & 29TQH46 & 43,00 & 79,65 & 103,34 & 40,08 & 5209,52 & 227,79 & $-26,32$ & 254,12 & 49,01 & 148,73 & 148,81 & 16,87 & 936,81 & 119,09 & 43,05 & 28,14 & 323,01 & 154,69 & 155,94 & 278,01 \\
\hline Rana temporaria & 29TQH47 & 44,00 & 75,53 & 101,29 & 40,28 & 5101,29 & 220,78 & $-28,04$ & 248,82 & 46,44 & 143,26 & 143,49 & 14,57 & 995,96 & 125,88 & 46,40 & 27,50 & 340,32 & 165,71 & 169,18 & 295,24 \\
\hline Rana temporaria & 29тQH49 & 36,00 & 119,17 & 96,75 & 43,23 & 4295,38 & 243,54 & 22,00 & 221,54 & 96,79 & 173,94 & 176,08 & 67,15 & 850,54 & 115,13 & 41,21 & 27,98 & 287,88 & 146,23 & 154,65 & 224,27 \\
\hline Rana temporaria & 29TQJ00 & 100,00 & 113,08 & 92,84 & 41,78 & 4381,67 & 236,87 & 17,31 & 219,56 & 88,49 & 169,52 & 171,28 & 60,21 & 922,77 & 122,26 & 39,35 & 29,15 & 317,84 & 143,82 & 154,93 & 269,66 \\
\hline Rana temporaria & 29TQJ10 & 101,00 & 112,08 & 94,18 & 42,09 & \begin{tabular}{ll|l|}
4375,64 \\
\end{tabular} & 236,76 & 15,77 & 220,99 & 88,00 & 168,30 & 170,18 & 59,21 & 918,37 & 122,16 & 40,88 & 28,38 & 314,46 & 147,79 & 157,97 & 261,87 \\
\hline Rana temporaria & 29TQJ11 & 99,00 & 116,27 & 91,42 & 42,38 & 4195,11 & 235,68 & 22,75 & 212,93 & 93,97 & 169,88 & 172,19 & 65,80 & \begin{tabular}{|l|l|}
923,49 \\
\end{tabular} & 123,35 & 41,56 & 28,29 & 315,14 & 149,59 & 160,54 & 260,00 \\
\hline Rana temporaria & 29TQJ12 & 67,00 & 128,44 & 86,26 & 42,76 & 3958,19 & 238,64 & 38,66 & 199,98 & 108,11 & 178,40 & 181,22 & 80,56 & 884,15 & 119,44 & 39,41 & 28,78 & 302,11 & 142,53 & 155,16 & 244,59 \\
\hline Rana temporaria & 29TQJ22 & 90,00 & 130,15 & 85,35 & 42,88 & 3889,16 & 238,31 & 41,39 & 196,92 & 110,84 & 179,08 & 182,20 & 83,20 & 877,27 & 119,15 & 40,31 & 28,57 & 298,33 & 144,64 & 156,96 & 237,01 \\
\hline Rana temporaria & 30STG47 & 100,00 & 175,54 & $\begin{array}{l}122,95 \\
122\end{array}$ & 39,06 & 6315,07 & $\begin{array}{l}356,46 \\
35,4\end{array}$ & $\begin{array}{ll}45,87 \\
4,5\end{array}$ & 310,59 & $\begin{array}{l}106,04 \\
106,78\end{array}$ & 258,24 & 259,07 & $\begin{array}{l}3,202 \\
97,82\end{array}$ & 593,90 & 84 & \begin{tabular}{|l}
$\mid$ \\
1,76 \\
\end{tabular} & 60,90 & 245,11 & $\begin{array}{r}20,94 \\
20\end{array}$ & 25,34 & 232,64 \\
\hline Rana temporaria & 30 XSG39 & 100,00 & 159,56 & 115,53 & 40,17 & 5803,77 & 315,15 & 31,25 & 283,89 & 128,48 & 236,18 & 237,14 & 89,25 & 351,11 & 48,74 & 5,53 & 42,01 & 122,20 & 34,09 & 44,18 & 91,23 \\
\hline Rana temporaria & 30TTN53 & 58,00 & 93,44 & 109,66 & 39,99 & 5543,63 & 251,73 & $-19,50$ & 271,23 & 60,25 & 166,97 & 166,97 & 25,44 & 749,48 & 97,07 & 33,26 & 30,23 & 266,40 & 122,49 & 122,49 & 220,42 \\
\hline Rana temporaria & 30TTN54 & 50,00 & 85,92 & 107,32 & 39,96 & 5432,77 & 240,95 & $-24,42$ & 265,37 & 54,00 & 157,99 & 157,99 & 19,85 & 827,83 & 105,94 & 37,45 & 29,26 & 289,86 & 136,27 & 136,33 & 244,65 \\
\hline Rana temporaria & 30TTN57 & 40,00 & 80,32 & 101,50 & 40,59 & 5044,29 & 224,09 & $-23,27$ & 247,36 & 48,70 & 147,08 & 147,50 & 19,76 & 969,47 & 123,17 & 45,82 & 27,36 & 330,80 & 163,18 & 167,47 & 282,82 \\
\hline Rana temporaria & 30TTN63 & 100,00 & $\begin{array}{ll}90,32 \\
97,88\end{array}$ & $\begin{array}{l}110,95 \\
11,0\end{array}$ & 40,00 & 5567,66 & 257,41 & $\begin{array}{l}-2,16,42 \\
-16,4\end{array}$ & \begin{tabular}{|l|}
273,84 \\
\end{tabular} & $\begin{array}{ll}64,54 \\
64,\end{array}$ & $\begin{array}{l}171,46 \\
171\end{array}$ & 171,46 & 28,97 & 704,86 & \begin{tabular}{|l|l|}
91,85 \\
9
\end{tabular} & $\begin{array}{l}3,320 \\
32,32\end{array}$ & 30,37 & $\begin{array}{l}50,000 \\
252,02\end{array}$ & $\begin{array}{l}118,46 \\
\end{array}$ & 118,46 & 202,02 \\
\hline Rana temporaria & 30TTN64 & 100,00 & 88,79 & 108,26 & 40,01 & 5445,67 & 244,62 & $-22,48$ & 267,11 & 56,85 & 160,94 & 160,94 & 22,20 & 795,50 & 102,14 & 37,00 & 28,97 & 279,16 & 134,13 & 134,13 & 230,18 \\
\hline Rana temporaria & 30TTN66 & 100,00 & 75,87 & 102,94 & 40,22 & 5193,28 & 223,88 & $-29,61$ & 253,49 & 46,30 & 144,83 & 144,96 & 13,51 & 955,68 & 120,26 & 45,30 & 27,28 & 325,99 & $\mid 161,73$ & 162,86 & 279,55 \\
\hline Rana temporaria & 30TTN76 & 100,00 & 78,15 & 103,75 & 40,21 & 5204,15 & 227,04 & $-28,09$ & 255,13 & 49,18 & 147,27 & 147,36 & 15,44 & 919,81 & 115,94 & 44,84 & 26,84 & 313,84 & 159,43 & 160,50 & 263,60 \\
\hline Rana temporaria & 30TTN84 & 100,00 & 93,04 & 109,27 & 40,02 & 5449,02 & 249,85 & $-19,49$ & 269,34 & 62,02 & 165,11 & 165,11 & 25,95 & 741,51 & 95,24 & 36,19 & 28,41 & 259,91 & 131,66 & 131,66 & 204,84 \\
\hline $\begin{array}{l}\text { Rana temporaria } \\
\text { and }\end{array}$ & 30TTN85 & 100,00 & $\begin{array}{l}3,04 \\
81,85\end{array}$ & $\begin{array}{l}106,21 \\
10,2\end{array}$ & 39,96 & 53333,53 & \begin{tabular}{|l|}
235,12 \\
23,1
\end{tabular} & $\begin{array}{l}-1,27,29 \\
-27,29\end{array}$ & $\begin{array}{l}262,41 \\
262\end{array}$ & $\begin{array}{ll}52,04 \\
52\end{array}$ & $\begin{array}{l}10,14 \\
152,64\end{array}$ & \begin{tabular}{|l|}
152,66 \\
152,1
\end{tabular} & $\begin{array}{l}3,05 \\
17,04\end{array}$ & $\begin{array}{l}41,51 \\
846,14\end{array}$ & $\mid$\begin{tabular}{|c|}
5,24 \\
106,77
\end{tabular} & \begin{tabular}{|c|c|}
40,86 \\
41,86
\end{tabular} & $\begin{array}{l}27,41 \\
27,03\end{array}$ & \begin{tabular}{|l|}
290,70 \\
\end{tabular} & $\begin{array}{l}149,41 \\
140\end{array}$ & $\begin{array}{l}149,46 \\
140\end{array}$ & 230,04 \\
\hline Rana temporaria & 30TTN86 & 100,00 & 67,17 & 102,66 & 39,65 & 5239,59 & 217,27 & $-38,20$ & 255,47 & 38,17 & 137,15 & 137,28 & 4,70 & 982,46 & 121,12 & 48,64 & 25,75 & 330,25 & 171,88 & 172,24 & 283,22 \\
\hline Rana temporaria & 30TTN94 & 100,00 & 93,59 & 108,77 & 40,01 & 5418,02 & 249,74 & $-18,79$ & 268,53 & 63,35 & 165,26 & 165,26 & 26,95 & 733,11 & 93,67 & 36,51 & 27.87 & 255,42 & 132.52 & 132.52 & 199,38 \\
\hline Rana temporaria & 30TTN95 & 100,00 & 76,79 & 105,17 & 39,78 & 5315,46 & 229,65 & $-31,55$ & 261,19 & 47,66 & \begin{tabular}{ll|}
147,52 \\
\end{tabular} & 147,55 & 12,59 & 876,14 & 108,91 & 44,02 & 26,10 & 296,94 & 156,47 & 156,71 & 245,86 \\
\hline Rana temporaria & 30TTN96 & 100,00 & 67,08 & 102,48 & 39,64 & 5231,01 & 217,01 & $-38,30$ & 255,30 & 38,78 & 136,90 & 137,01 & 4,63 & \begin{tabular}{|c|}
974,58 \\
\end{tabular} & 119,49 & 49,01 & 25,20 & 325,77 & 172,95 & 173,32 & 277,70 \\
\hline Rana temporaria & 30TाP60 & 100,00 & 129,66 & 89,93 & 43,73 & 3918,14 & 241,79 & 38,42 & 203,37 & $\begin{array}{ll}111,05 \\
111\end{array}$ & \begin{tabular}{|l|l|}
178,84 \\
\end{tabular} & 181,95 & 82,53 & 850,03 & 116,32 & 42,40 & 28,38 & 284,03 & 149,06 & 158,09 & 214,18 \\
\hline Rana temporaria & 30TUN05 & 100,00 & 80,94 & 105,08 & 39,84 & 5291,33 & 233,09 & $-27,70$ & 260,79 & 52,43 & 151,28 & 151,33 & 16,81 & 841,23 & 104,65 & 42,91 & 25,69 & 284,91 & 152,84 & 153,09 & 231,68 \\
\hline Rana temporaria & 30TUN06 & 10000 & 67.79 & 102.16 & 3956 & 5215.84 & 217.31 & -37.60 & 254.91 & 40.02 & 137.45 & 137.62 & 561 & $963.07 \mid$ & 11760 & 49,21 & 24.66 & 320.48 & 173.26 & 173,77 & 27129 \\
\hline Rana temporaria & 30TUN07 & 100,00 & 74,75 & 100,90 & 39,99 & 5084,37 & 219,96 & $-29,25$ & 249,21 & 48,05 & 142,29 & 142,70 & 13,83 & 947,55 & 117,25 & 48,74 & 24,89 & 316,92 & \begin{tabular}{|l|l|}
171,84 \\
\end{tabular} & 174,25 & 263,42 \\
\hline Rana temporaria & 30TUN15 & 100,00 & 85,63 & 104,51 & 39,87 & 5240,96 & 236,08 & $-23,11$ & 259,20 & 58,00 & $\begin{array}{l}145,09 \\
155,09\end{array}$ & 155,18 & 21,91 & 811,94 & \begin{tabular}{|l|l|}
101,07 \\
\end{tabular} & 41,83 & 25,48 & 274,37 & $\begin{array}{l}141,24,27 \\
\end{array}$ & $\begin{array}{l}149,98 \\
\end{array}$ & 219,77 \\
\hline Rana temporaria & 30TUN16 & 100,00 & 78,12 & 102,39 & 39,84 & 5167,15 & 226,15 & $-28,03$ & 254,18 & 51,17 & 146,75 & 147,05 & 15,97 & 888,69 & 109,61 & 45,98 & 24,75 & 297,35 & 162,91 & 163,98 & 243,87 \\
\hline Rana temporaria & 30TUN17 & 100,00 & 79,01 & 100,01 & 39,96 & 5033,41 & 222,44 & $-24,72$ & 247,16 & 53,18 & 145,73 & 146,35 & 18,47 & 921,48 & \begin{tabular}{|l|l|l}
114,09 \\
\end{tabular} & 47,83 & 24,58 & 307,72 & 168,94 & $\begin{array}{l}171,41 \\
\end{array}$ & 252,54 \\
\hline Rana temporaria & 30TUN18 & 100,00 & 89,65 & 97,48 & 40,52 & 4836,49 & 226,22 & $-11,92$ & 238,14 & 65,36 & 153,17 & 154,21 & 31,25 & 898,12 & 113,38 & 46,80 & 24,96 & 301,86 & 165,37 & 170,20 & 241,54 \\
\hline Rana temporaria & 30TUN24 & 100,00 & 90,07 & 105,16 & 39,77 & 5281,60 & 241,81 & $-20,16$ & 261,97 & 62,69 & 160,11 & 160,14 & 25,69 & 760,14 & 94,15 & 38,96 & 25,36 & 25 & 140,39 & 140,77 & 203,05 \\
\hline Rana temporaria & 30TUN26 & 100,00 & 73,81 & $\begin{array}{l}101,07 \\
\end{array}$ & 39,60 & 5150 & 221,03 & $\frac{2,12}{-31,47}$ & 252,51 & $\begin{array}{ll}47,44 \\
\end{array}$ & $\begin{array}{l}142,43 \\
\end{array}$ & 142,67 & 12,10 & 917,93 & $\mid$ & 47,71 & 23,88 & 303,48 & 168,51 & 169,33 & 252,25 \\
\hline Rana temporaria & 30 TUN27 & 100,00 & 75,72 & 99,31 & 39,73 & 5038,60 & 219,20 & $-27,67$ & 246,87 & 50,11 & 142,64 & 143,19 & 15,47 & 937,74 & 114,70 & 48,99 & 23,88 & 310,48 & 172,98 & $\begin{array}{l}174,52 \\
\end{array}$ & 257,13 \\
\hline Rana temporaria & 30TUN29 & 100,00 & 120,79 & 86,30 & 40,72 & 4299,01 & 236,04 & 26,43 & 209,61 & 101,17 & 176,11 & 178,13 & 68,15 & 816,80 & 107,64 & 40,96 & 26,72 & 278,91 & 147,87 & 158,09 & 210,73 \\
\hline Rana temporaria & 30TUN35 & 100,00 & 83,84 & 102,02 & 39,59 & 5166,43 & 231,60 & $-23,32$ & 254,91 & 57,79 & 152,46 & 152,70 & 21,45 & 828,77 & 101,18 & 42,98 & 24,12 & 275,09 & 153,42 & 153,77 & 222,86 \\
\hline Rana temporaria & 30TUN36 & 100,00 & 81,83 & 100,10 & 39,74 & 5077,09 & 226,35 & $-23,31$ & 249,66 & 56,39 & 149,19 & 149,59 & 20,72 & 872,92 & 106,65 & 45,55 & 23,93 & 289,19 & 161,93 & 162,79 & 235 \\
\hline Rana temporaria & \begin{tabular}{|l|}
$30 T$ TUN37 \\
\end{tabular} & $\begin{array}{l}100,00 \\
100\end{array}$ & $\begin{array}{l}01,00 \\
79,28\end{array}$ & $\begin{array}{r}10,10 \\
97,90\end{array}$ & 39,70 & 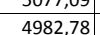 & \begin{tabular}{|l|}
220,31 \\
220,31
\end{tabular} & $\begin{array}{l}-23,51 \\
-23,47 \\
\end{array}$ & \begin{tabular}{|l|}
243,78 \\
243
\end{tabular} & 54,46 & 145,36 & 145,99 & 19,53 & 923,41 & 112,72 & 48,30 & 23,67 & 304,85 & 171,00 & 172,65 & 251,05 \\
\hline Rana temporaria & 30TUN38 & 100,00 & 77,77 & 95,54 & 39,75 & 4880,97 & 215,01 & $-22,60$ & 237,61 & 52,92 & 142,35 & 143,25 & 19,38 & 971,99 & 118,52 & 50,96 & 23,61 & 319,81 & 179,35 & 182,11 & 265,67 \\
\hline Rana temporaria & 30TUN39 & 100,00 & 107,75 & 88,69 & 40,18 & 4470,70 & 229,18 & 11,69 & 217,48 & 87,06 & 165,69 & 167,45 & 53,23 & 867,20 & 111,23 & 44,20 & 25,51 & 293,17 & 158,73 & 167,19 & 228,33 \\
\hline Rana temporaria & 30TUN45 & 100,00 & 76,39 & 100,89 & 39,15 & 5173,28 & 224,06 & $-29,82$ & 253,88 & 50,36 & 145,58 & 145 & 14 & 876,55 & 104,95 & 45,73 & 23,18 & 286,34 & 161,28 & 161,54 & 237,51 \\
\hline Rana temporaria & 30TUN46 & 100,00 & 72,65 & 99,05 & 39,24 & 5099,93 & 217,71 & $-31,28$ & 248,99 & 47,16 & 140,96 & 141,15 & 11,77 & 929,34 & 111,11 & 48,75 & 22,86 & 302,76 & 171,73 & 171,79 & 253,64 \\
\hline
\end{tabular}




\begin{tabular}{|c|c|c|c|c|c|c|c|c|c|c|c|c|c|c|c|c|c|c|c|c|c|}
\hline TAXON & UTM & $\mathrm{km} 2$ & BIO1 & BIO2 & $B 103$ & BIO4 & B105 & B106 & 8107 & B108 & B109 & B1010 & BIO11 & B1012 & BIO13 & B1014 & BIO15 & B1016 & B1017 & B1018 & 81019 \\
\hline Rana temporaria & 30TUN47 & 100,00 & 66,54 & 97,04 & 39,20 & 5034,80 & 209,15 & $-35,25$ & 244,41 & 40,70 & 134,10 & 134,40 & 6,82 & 1002,78 & 119,17 & 52,86 & 22,54 & 324,81 & 184,95 & 185,50 & 276,72 \\
\hline Rana temporaria & 30TUN48 & 100,00 & 67,51 & 94,53 & 39,34 & 4919,88 & 205,76 & $-31,83$ & 237,59 & 39,98 & 133,37 & 134,05 & 9,35 & 1040,16 & 123,97 & 54,86 & 22,76 & 337,29 & 191,38 & 193,21 & 288,05 \\
\hline Rana temporaria & 30TUN49 & 100,00 & 100,95 & 88,36 & 39,92 & 4525,81 & 223,92 & 5,10 & 218,82 & 80,02 & 159,82 & 161,59 & 46,13 & 905,04 & $\begin{array}{l}113,95 \\
\end{array}$ & 46,21 & 24,80 & 303,52 & 165,79 & $\begin{array}{l}173,43 \\
\end{array}$ & 241,78 \\
\hline Rana temporaria & 30TUN54 & 100,00 & 75,20 & 101,38 & 39,01 & 5232,19 & 224,77 & $-31,92$ & 256,68 & 49,17 & 145,45 & 145,45 & 12,64 & 858,34 & $\begin{array}{l}101,26 \\
\end{array}$ & 44,68 & 22,65 & 277,25 & $\begin{array}{l}156,33 \\
\end{array}$ & $\begin{array}{l}156,65 \\
\end{array}$ & 231,81 \\
\hline Rana temporaria & 30TUN55 & 100,00 & 67,09 & $99,61$. & 38,96 & 5184,02 & 214,98 & $-37,53$ & 252,51 & 40,85 & 137,07 & 137,07 & 5,56 & 938,72 & 109,96 & 49,34 & 22,30 & 301,20 & 171,41 & 171,43 & 256,99 \\
\hline Rana temporaria & 30TUN56 & 100,00 & 54,14 & 97,61 & 38,77 & 5154,62 & 200,68 & $-47,84$ & 248,52 & 24,53 & 124,04 & 124,04 & $-6,25$ & 1057,32 & 122,17 & 56,16 & 21,65 & 335,88 & 192,65 & 192,66 & 294,61 \\
\hline Rana temporaria & 30TUN57 & 100,00 & 76,96 & 95,17 & 39,27 & $\begin{array}{l}4934,79 \\
\end{array}$ & 215,46 & $-24,06$ & 239,52 & 52,90 & 142,68 & 143,37 & 18,05 & 952,74 & 114,06 & 49,92 & 22,76 & 310,09 & 176,30 & 177,79 & 259,61 \\
\hline Rana temporaria & 30TUN58 & 100,00 & 64,12 & 93,81 & \begin{tabular}{l|l|}
39,15 \\
\end{tabular} & 4927,86 & 202,28 & $-34,64$ & 236,92 & 36,02 & 130,13 & 130,90 & 6,13 & 1062,61 & 125,24 & 56,25 & 22,12 & 342,21 & \begin{tabular}{|l|l|}
195,97 \\
\end{tabular} & $\begin{array}{l}197,36 \\
\end{array}$ & 294,85 \\
\hline Rana temporaria & 30TUN65 & 100,00 & 69,90 & 98,53 & 38,94 & $\begin{array}{l}5144,39 \\
\end{array}$ & 215,94 & $-34,28$ & 250,22 & 43,91 & 139,24 & 139,24 & 8,80 & $\begin{array}{l}926,83 \\
\end{array}$ & $\begin{array}{l}108,09 \\
\end{array}$ & \begin{tabular}{ll|}
48,77 \\
\end{tabular} & 21,90 & 296,21 & $\begin{array}{l}169,89 \\
\end{array}$ & $\begin{array}{ll}169,89 \\
\end{array}$ & 252,41 \\
\hline Rana temporaria & 30TUN66 & 100,00 & $\begin{array}{ll}64,93 \\
\end{array}$ & 96,69 & 38,92 & 5085,61 & 208,57 & $-37,11$ & 245,68 & 39,03 & 133,55 & 133,73 & 4,92 & $\begin{array}{l}990,62 \\
\end{array}$ & \begin{tabular}{|l|l|}
115,28 \\
\end{tabular} & 52,41 & 21,68 & 315,93 & 182,13 & 182,35 & 272,32 \\
\hline Rana temporaria & 30TUN68 & 100,00 & 96,86 & 88,38 & 39,26 & 4626,31 & 222,21 & 0,02 & 222,19 & 75,25 & 157,31 & $\begin{array}{l}158,81 \\
\end{array}$ & 40,88 & $\begin{array}{l}912,28 \\
\end{array}$ & 112,01 & 46,25 & 23,97 & 302,74 & 166,82 & $\begin{array}{l}173,13 \\
\end{array}$ & 246,33 \\
\hline Rana temporaria & 30TUN69 & 100,00 & 117,26 & 81,33 & 39,36 & 4297,31 & 229,34 & 25,31 & 204,04 & 98,33 & $\begin{array}{l}172,43 \\
\end{array}$ & $\begin{array}{l}174,63 \\
\end{array}$ & 64,57 & \begin{tabular}{|l|l|}
870,67 \\
\end{tabular} & \begin{tabular}{|l|l|}
110,78 \\
\end{tabular} & 42,19 & 25,82 & 296,73 & 155,49 & $\begin{array}{ll}167,92 \\
\end{array}$ & 233,20 \\
\hline Rana temporaria & 30TUN74 & 100,00 & 89,82 & 98,09 & 38,98 & 5102,09 & 233,30 & $-16,41$ & 249,71 & 65,46 & $\mid 157,94$ & $\mid 157,94$ & 28,13 & 792,77 & 93,82 & 40,51 & 22,65 & 256,46 & $\mid 144,87$ & 144,87 & 210,52 \\
\hline Rana temporaria & 30TUN75 & 100,00 & 83,51 & 96,70 & 38,99 ] & 5049,08 & 225,18 & $-20,38$ & 245,56 & 59,29 & 151,16 & 151,18 & 22,95 & 856,41 & 101,02 & 44,38 & 22,20 & 276,21 & 158,04 & 158,04 & 229,83 \\
\hline Rana temporaria & 30TUN76 & 100,00 & 80,56 & 94,80 & 38,99 & \begin{tabular}{l|l|}
4971,70 \\
\end{tabular} & \begin{tabular}{|l|}
219,32 \\
\end{tabular} & $-21,07$ & 240,39 & 56,74 & 147,03 & \begin{tabular}{ll|}
147,40 \\
\end{tabular} & 21,09 & $\begin{array}{l}907,74 \\
\end{array}$ & 107,14 & 47,28 & 22,14 & 292,77 & 168,25 & 168,85 & 245,53 \\
\hline Rana temporaria & 30TUN77 & 100,00 & 100,68 & 89,17 & 39,02 & 4685,74 & 227,64 & 2,26 & 225,38 & 79,21 & 161,77 & 163,30 & 43,65 & 862,21 & 105,34 & 43,26 & 23,71 & 285,81 & $\begin{array}{l}157,89 \\
\end{array}$ & 163,00 & 231,25 \\
\hline Rana temporaria & 30TUN79 & 100,00 & 123,58 & 78,04 & 39,04 & 4201,48 & 231,11 & 33,69 & 197,42 & 105,42 & 177,32 & $\begin{array}{l}179,72 \\
\end{array}$ & 71,90 & \begin{tabular}{l|l|}
867,25 \\
\end{tabular} & $\begin{array}{l}110,66 \\
\end{array}$ & 40,79 & 26,48 & 298,05 & 152,39 & $\begin{array}{l}167,59 \\
\end{array}$ & 234,12 \\
\hline Rana temporaria & 30TUN84 & 100,00 & \begin{tabular}{|c|c|}
95,87 \\
\end{tabular} & \begin{tabular}{|c|c|}
95,97 \\
\end{tabular} & \begin{tabular}{|c|c|}
38,78 \\
\end{tabular} & 5037,41 & 235,94 & $-9,26$ & 245,21 & 72,10 & \begin{tabular}{|l|l}
163,01 \\
\end{tabular} & \begin{tabular}{|l|l|}
163,01 \\
\end{tabular} & 34,63 & 773,53 & 91,48 & 38,99 & 22,55 & 250,52 & $\mid 141,46$ & $\mid 141,46$ & 205,00 \\
\hline Rana temporaria & 30TUN85 & 100,00 & 75,40 & 95,93 & 38,82 & 5077,38 & 217,77 & $-27,32$ & 245,09 & 50,12 & 143,84 & 143,85 & 14,98 & 908,83 & 105,03 & 47,62 & 21,45 & 288,47 & 167,41 & 167,41 & 246,18 \\
\hline Rana temporaria & 30TUN86 & 100,00 & 66,77 & 94,64 & 38,78 & 5038,34 & 207,94 & $-33,90$ & 241,84 & 40,28 & 134,84 & 135,01 & 7,35 & 990,20 & 113,64 & 52,54 & 21,05 & 312,65 & 183,28 & 183,33 & 271,50 \\
\hline Rana temporaria & 30TUN87 & 100,00 & 88,78 & 89,96 & 38,97 & 4779,18 & 219,30 & $-9,24$ & 228,53 & 66,52 & 151,61 & \begin{tabular}{ll|}
153,06 \\
\end{tabular} & 31,26 & $\begin{array}{l}919,68 \\
\end{array}$ & $\begin{array}{l}109,43 \\
\end{array}$ & 47,08 & 22,49 & 299,16 & 169,77 & \begin{tabular}{|l|l|}
173,11 \\
\end{tabular} & 249,70 \\
\hline Rana temporaria & 30TUN88 & 100,00 & 112,28 & 82,25 & 38,92 & 4422,59 & 227,97 & 18,89 & 209,08 & 92,69 & 169,27 & 171,39 & $\begin{array}{ll}58,07 \\
\end{array}$ & $\begin{array}{l}878,46 \\
\end{array}$ & $\begin{array}{l}108,95 \\
\end{array}$ & 42,39 & 24,85 & 296,31 & $\begin{array}{ll}157,07 \\
\end{array}$ & $\begin{array}{ll}168,16 \\
\end{array}$ & 237,92 \\
\hline Rana temporaria & 30TUN89 & 100,00 & 127,09 & 75,33 & 38,78 & 4128,39 & 231,24 & 38,99 & 192,25 & 109,28 & $\begin{array}{l}179,62 \\
\end{array}$ & 182,10 & 76,02 & 878,53 & $\begin{array}{l}111,87 \\
\end{array}$ & 40,39 & 26,85 & \begin{tabular}{ll|}
303,48 \\
\end{tabular} & $\begin{array}{ll}152,44 \\
\end{array}$ & $\begin{array}{l}170,10 \\
\end{array}$ & 239,38 \\
\hline Rana temporaria & 30TUN95 & 100,00 & 78,28 & 94,44 & \begin{tabular}{|c|}
38,47 \\
\end{tabular} & 5046,53 & 218,68 & $-23,58$ & 242,26 & 53,54 & 146,15 & 146,33 & 18,04 & $\begin{array}{l}901,17 \\
9\end{array}$ & $\begin{array}{l}103,65 \\
\end{array}$ & 46,95 & 21,24 & 285,22 & 166,28 & $\begin{array}{ll}166,34 \\
\end{array}$ & 244,29 \\
\hline Rana temporaria & 30TUN96 & 100,00 & 78,44 & 92,35 & 38,73 & 4948,25 & 215,06 & $-21,10$ & 236,15 & 54,41 & 144,41 & 145,20 & 19,49 & $\begin{array}{l}937,75 \\
\end{array}$ & \begin{tabular}{|l|l|}
108,48 \\
\end{tabular} & 48,88 & 21,28 & 298,43 & 173,79 & 174,56 & 255,77 \\
\hline Rana temporaria & 30TUN97 & 100,00 & 96,77 & 86,74 & 38,76 & 4674,80 & 222,08 & 0,53 & 221,54 & 75,08 & 157,79 & 159,46 & 40,07 & 905,34 & 108,19 & 45,29 & 22,97 & 296,79 & 165,17 & 171,07 & 246,67 \\
\hline Rana temporaria & 30TUN98 & 100,00 & 117,02 & 79,04 & 38,54 & 4334,54 & 228,44 & 25,87 & 202,56 & 97,81 & 172,57 & $\begin{array}{l}174,82 \\
\end{array}$ & 63,65 & 887,01 & $\begin{array}{l}109,93 \\
\end{array}$ & 41,75 & 25,30 & \begin{tabular}{|l|l|}
300,98 \\
\end{tabular} & 156,30 & 170,18 & 242,66 \\
\hline Rana temporaria & 30TUN99 & 100,00 & 129,86 & 72,59 & 38,23 & 4062,29 & 231,07 & 43,82 & 187,25 & 112,45 & 181,34 & 183,99 & 79,52 & 896,31 & $\begin{array}{l}113,76 \\
\end{array}$ & 40,26 & 27,29 & 311,29 & 153,49 & $\begin{array}{l}173,86 \\
\end{array}$ & 247,30 \\
\hline Rana temporaria & 30TUP00 & 100,00 & 126,74 & 83,46 & 41,44 & 4057,12 & 235,08 & 36,23 & 198,85 & 108,39 & 178,43 & $\begin{array}{l}181,14 \\
\end{array}$ & 77,34 & 829,34 & \begin{tabular}{|l|l|}
111,57 \\
\end{tabular} & 41,76 & 27,54 & 281,62 & 149,04 & 159,96 & 210,49 \\
\hline Rana temporaria & 30TUP01 & 98,00 & 132,84 & 77,05 & \begin{tabular}{l|l|l}
40,95 \\
\end{tabular} & 3870,73 & 232,49 & $\begin{array}{ll}46,63 \\
\end{array}$ & $\begin{array}{l}185,86 \\
\end{array}$ & 115,81 & 181,85 & $\begin{array}{l}184,96 \\
\end{array}$ & 85,62 & 834,29 & 112,99 & 41,12 & 27,93 & 284,33 & $\begin{array}{ll}147,81 \\
\end{array}$ & $\begin{array}{ll}160,77 \\
\end{array}$ & 212,72 \\
\hline Rana temporaria & 30TUP02 & 40,00 & 136,08 & 73,30 & \begin{tabular}{ll|l}
40,65 \\
\end{tabular} & 3764,03 & 230,71 & 52,45 & 178,26 & 119,80 & \begin{tabular}{ll|}
183,68 \\
\end{tabular} & $\begin{array}{l}186,80 \\
\end{array}$ & 90,21 & 839,39 & \begin{tabular}{|l|l|}
114,00 \\
\end{tabular} & 40,95 & 28,24 & 286,77 & $\begin{array}{ll}147,48 \\
\end{array}$ & 161,79 & 215,03 \\
\hline Rana temporaria & 30TUP10 & 100,00 & 128,41 & 81,58 & \begin{tabular}{|l|l|}
0,93 \\
\end{tabular} & 4066,27 & 235,21 & 38,27 & 196,94 & 1110,11 & 180,23 & $\mid 182,88$ & 78,61 & 820,87 & $\mid 109,97$ & $\mid 40,75$ & 27,43 & 280,47 & $\mid 146,78$ & 158,76 & 210,20 \\
\hline Rana temporaria & 30TUP11 & 96,00 & 128,99 & 78,27 & \begin{tabular}{l|l|l}
40,69 & \\
\end{tabular} & 3961,70 & 231,50 & 41,54 & 189,96 & 111,36 & 179,31 & 182,19 & 80,64 & 846,18 & 113,34 & 41,76 & 27,45 & 289,11 & 150,50 & 163,76 & 218,27 \\
\hline Rana temporaria & 30TUP12 & 20,00 & 136,32 & 73,40 & 40,36 & 3793,60 & 231,56 & 52,20 & 179,36 & 120,20 & 184,20 & 187,40 & 90,04 & 836,8 & 113,28 & 40,60 & 28,04 & 287,08 & $\mid 147,12$ & 161,92 & 215,56 \\
\hline Rana temporaria & 30TUP20 & 100,00 & 134,88 & 77,88 & \begin{tabular}{l|l|}
40,29 \\
\end{tabular} & 3995,93 & 237,12 & 46,48 & 190,63 & 117,35 & \begin{tabular}{ll|}
185,62 \\
\end{tabular} & 188,38 & 85,65 & 802,19 & \begin{tabular}{|l|l|}
107,72 \\
\end{tabular} & 38,63 & 27,90 & 276,54 & 141,34 & 155,20 & 206,81 \\
\hline Rana temporaria & 30TUP21 & 65,00 & 132,62 & 76,72 & 40,33 & 3942,74 & 233,28 & $\begin{array}{ll}45,64 \\
\end{array}$ & $\begin{array}{l}187,64 \\
\end{array}$ & 1115,31 & 182,62 & 185,54 & 84,31 & 833,38 & 111,64 & 40,50 & 27,68 & 286,53 & $\begin{array}{l}147,33 \\
\end{array}$ & $\begin{array}{ll}161,81 \\
\end{array}$ & 215,78 \\
\hline Rana temporaria & 30TUP30 & 100,00 & 126,56 & 80,18 & 40,24 & 4107,21 & 233,28 & 36,55 & \begin{tabular}{|l|l|}
196,73 \\
\end{tabular} & 108,50 & $\mid 178,94$ & $\mid \begin{array}{l}181,48 \\
\end{array}$ & 76,06 & 836,94 & $\mid 110,50$ & \begin{tabular}{|l|l|l|}
40,98 \\
\end{tabular} & 27,01 & 287,16 & $\mid \begin{array}{l}149,31 \\
\end{array}$ & $\mid 162,56$ & 217,93 \\
\hline Rana temporaria & 30TUP41 & 33,00 & 138,78 & 73,41 & 39,85 & 3899,74 & 235,78 & 53,22 & 182,57 & 122,20 & 187,98 & 190,93 & 90,63 & 823,13 & 109,76 & 38,24 & 28,22 & 286,70 & 142,54 & 160,09 & 217,26 \\
\hline Rana temporaria & 30TUP90 & 55,00 & 139,28 & 68,17 & 38,04 & 3876,10 & 233,27 & 56,65 & 176,62 & 123,02 & 187,99 & 190,92 & 91,08 & 899,96 & 116,01 & 39,06 & 28,81 & 317,35 & 150,91 & 175,76 & 250,17 \\
\hline Rana temporaria & 30TVN06 & 100,00 & 93,48 & 88,85 & 38,40 & 4816,21 & 223,41 & $-4,68$ & 228,10 & 70,61 & 156,37 & 158,01 & 35,10 & 882,73 & $\begin{array}{l}103,43 \\
\end{array}$ & 44,41 & 22,11 & 285,17 & 162,07 & $\begin{array}{l}165,37 \\
\end{array}$ & 240,34 \\
\hline Rana temporaria & 30TVN07 & 100,00 & 100,52 & 84,68 & \begin{tabular}{l|l|}
38,35 \\
\end{tabular} & 4629,05 & 223,08 & 5,55 & 217,53 & 79,01 & 160,53 & 162,49 & 44,18 & $\begin{array}{l}903,90 \\
\end{array}$ & \begin{tabular}{|l|l|}
107,70 \\
\end{tabular} & 44,50 & 22,99 & 296,89 & 163,57 & 171,12 & 247,80 \\
\hline Rana temporaria & 30TVN15 & 100,00 & 96,76 & 89,05 & $\begin{array}{l}38,07 \\
\end{array}$ & \begin{tabular}{ll|l|}
4883,89 \\
\end{tabular} & 227,97 & $-2,11$ & 230,09 & 73,03 & 160,45 & 162,12 & 37,23 & 841,59 & $\begin{array}{l}97,63 \\
\end{array}$ & 41,88 & 21,90 & 270,43 & $\begin{array}{ll}153,84 \\
\end{array}$ & $\begin{array}{ll}156,64 \\
\end{array}$ & 228,98 \\
\hline Rana temporaria & 30TVN17 & 100,00 & 113,51 & 79,24 & 38,01 & 4450,67 & 227,75 & 21,95 & 205,80 & 93,08 & $\begin{array}{l}170,64 \\
\end{array}$ & $\begin{array}{l}172,86 \\
\end{array}$ & 58,77 & 894,42 & \begin{tabular}{|l|l|}
107,47 \\
\end{tabular} & \begin{tabular}{ll|}
41,87 \\
\end{tabular} & 24,48 & 299,30 & 157,15 & $\begin{array}{l}170,29 \\
\end{array}$ & 248,74 \\
\hline Rana temporaria & 30TVN18 & 100,00 & 123,42 & 73,44 & 37,91 & 4194,33 & 228,38 & 36,56 & \begin{tabular}{|l|l|}
191,82 \\
\end{tabular} & 104,73 & 176,70 & 1799,34 & 71,52 & 922,62 & \begin{tabular}{|l|l|}
113,21 \\
\end{tabular} & $\mid 41,53$ & 26,22 & 315,78 & 158,21 & 177,78 & 259,29 \\
\hline Rana temporaria & 30TVN24 & 100,00 & 101,35 & 88,78 & 37, & 4946,85 & 233 & 1,82 & 231,41 & 76,64 & 165,72 & 167,33 & 40,81 & 798,72 & 91,63 & 39,16 & 21,85 & 255,50 & 144,76 & 147,93 & 217,80 \\
\hline Rana temporaria & 30TVN25 & 100,00 & 99,07 & 87,23 & 38,01 & 4861,28 & 227,97 & 1,48 & 226,50 & 75,07 & 162,11 & 163,98 & 39,72 & 847,18 & 97,49 & 41,77 & 21,85 & 271,79 & 153,74 & 158,29 & 232,81 \\
\hline Rana temporaria & 30 TVN26 & 100,00 & $\begin{array}{ll}99,52 \\
\end{array}$ & 84,82 & 38,02 & 4741,43 & 224,38 & 4,32 & 220,06 & 76,76 & 160,99 & \begin{tabular}{ll|}
163,08 \\
\end{tabular} & 41,78 & $\begin{array}{l}890,45 \\
\end{array}$ & $\begin{array}{l}103,09 \\
\end{array}$ & 43,70 & 22,14 & 287,85 & 160,75 & 167,71 & 246,91 \\
\hline Rana temporaria & 30TVN35 & 100,00 & 100,09 & 85,70 & 37,99 ] & 4839,53 & 227,32 & 3,92 & 223,40 & 75,82 & 162,73 & 164,78 & 41,04 & 860,57 & 98,02 & 42,14 & 21,75 & 75,25 & 155,33 & 161,40 & 239,24 \\
\hline Rana temporaria & 30TVN36 & 100,00 & 98,50 & 83,98 & 37,94 & $\begin{array}{l}4741,51 \\
\end{array}$ & 222,92 & 4,39 & 218,54 & 75,08 & 159,90 & 161,99 & 40,86 & $\begin{array}{l}910,65 \\
\end{array}$ & \begin{tabular}{|l|l|}
104,03 \\
\end{tabular} & 44,72 & 21,92 & 292,47 & 164,27 & 171,98 & 255,13 \\
\hline Rana temporaria & $30 \mathrm{TVN}$ & 100,00 & 106,25 & 78,95 & 37,64 & \begin{tabular}{ll|l|}
4519,87 \\
\end{tabular} & 222,60 & 15,81 & 206,80 & 83,86 & 164,41 & 166,69 & 51,04 & $\begin{array}{l}948,49 \\
\end{array}$ & 110,55 & 45,01 & 23,36 & 311,21 & 167,55 & $\begin{array}{ll}180,65 \\
\end{array}$ & 269,49 \\
\hline Rana temporaria & 30TVN46 & 100,00 & 101,68 & 82,19 & 37,70 & 4705,55 & 224,07 & 8,78 & 215,30 & 78,10 & 162,36 & 164,63 & 44,20 & $\begin{array}{l}919,65 \\
\end{array}$ & 105,53 & 44,48 & 22,03 & 295,47 & 164,43 & 174,03 & 261,18 \\
\hline Rana temporaria & 30TVN47 & 100,00 & 84,44 & 84,65 & 37,98 & 4773,45 & 211,57 & $-8,16$ & 219,73 & 50,17 & 146,53 & 148,96 & 27,38 & 1012,71 & 114,26 & 51,64 & 20,71 & 319,08 & 186,35 & 192,27 & 286,46 \\
\hline Rana temporaria & 30TVN48 & 100,00 & 94,57 & 79,63 & 37,7 - & 4553,22 & 213,35 & 5,26 & 208,09 & 65,35 & 153,28 & 155,92 & 39,71 & 1037,07 & 120,07 & 50,90 & 22,20 & 334,28 & 41 & 198,12 & 297 \\
\hline Rana temporaria & $30 \mathrm{TV}$ & 100 & 90 & 82 & 37 & 62 & 214 & $-0,90$ & 215,45 & 52,83 & 151,43 & 15 & 33,92 & \begin{tabular}{|l|}
1014,97 \\
\end{tabular} & \begin{tabular}{|l|l|}
115,98 \\
\end{tabular} & 50 & 21,14 & 321,54 & 18 & \begin{tabular}{|l|l|}
193,13 \\
\end{tabular} & 291 \\
\hline Rana temporaria & 30TVN58 & 100,00 & 108,37 & 74,56 & $\begin{array}{l}37,25 \\
\end{array}$ & \begin{tabular}{|l|l|}
4385,44 \\
\end{tabular} & 219,45 & 21,93 & 197,52 & 82,71 & 164,34 & \begin{tabular}{|l|l|}
167,09 \\
\end{tabular} & 54,88 & $\begin{array}{l}1034,62 \\
\end{array}$ & \begin{tabular}{|l|l|}
123,48 \\
\end{tabular} & \begin{tabular}{ll|}
48,07 \\
\end{tabular} & 23,87 & 339,52 & 179,88 & \begin{tabular}{|l|l|}
197,78 \\
\end{tabular} & 305,10 \\
\hline Rana temporaria & 30TVN67 & 100,00 & 101,25 & 79,16 & \begin{tabular}{l|l|}
37,55 \\
\end{tabular} & 4599,45 & 219,84 & 11,59 & 208,25 & 65,66 & 160,21 & 162,83 & 45,37 & 1010,80 & \begin{tabular}{|l|l|}
117,99 \\
\end{tabular} & 48,59 & 22,10 & 23,75 & 79,86 & $\begin{array}{ll}192,51 \\
\end{array}$ & 296,21 \\
\hline Rana temporaria & 30TVN68 & 100,00 & 120,69 & 69,95 & 36,74 & 4232,60 & 224,58 & 36,79 & 187,79 & 100,07 & 174,13 & 177,02 & 68,49 & 1042,82 & 128,30 & 45,78 & 25,59 & 347,40 & 175,27 & 198,70 & 317,65 \\
\hline Ranat & & 100 & & & 37 & 12,95 & & 12,03 & $\mid 22,40$ & 74,75 & 17 & 17 & 47 & 851 & 96 & 40,89 & & 266,57 & 153,21 & 160,98 & 24 \\
\hline Rana temporaria & $30 \mathrm{TVN} 7$ & 100,00 & 122,34 & 71,61 & 36,7 & 4342,73 & 229,04 & 36,54 & 192,50 & 98,41 & 177,24 & 179,90 & 68,68 & 1009,67 & 123,94 & 44,06 & 25,19 & 332,97 & 169,58 & $\begin{array}{ll}190,88 \\
\end{array}$ & 310,96 \\
\hline Rana temporaria & 30TVN78 & 100,00 & 120,92 & 69,74 & 36,68 & 4244,12 & 224,77 & 37,20 & 187,57 & 91,57 & 174,43 & $\begin{array}{l}177,29 \\
\end{array}$ & 68,58 & 1066,48 & 131,83 & 46,55 & 25,63 & 353,54 & 178,62 & 202,15 & 330,37 \\
\hline
\end{tabular}




\begin{tabular}{|c|c|c|c|c|c|c|c|c|c|c|c|c|c|c|c|c|c|c|c|c|c|}
\hline TAXON & UTM & $\mathrm{km2}$ & BIO1 & $\begin{array}{l}\mathrm{BIO2} \\
\end{array}$ & $\mathrm{BIO3}$ & B104 & B105 & B106 & B107 & B108 & B109 & BIO10 & BIO11 & $\overline{B 1012}$ & BIO13 & BIO14 & BIO15 & BIO16 & BIO17 & BIO18 & BIO19 \\
\hline Rana temporaria & 30TVN79 & 100,00 & 123,75 & 66,45 & 36,40 & 4096,70 & 222,63 & 42,77 & 179,86 & 95,72 & 175,16 & 178,28 & 73,33 & 1118,18 & 140,30 & 47,95 & 26,70 & 374,65 & 184,63 & 212,21 & 350,73 \\
\hline Rana temporaria & 30TVN84 & 100,00 & 103,96 & 86,15 & 37,85 & 4963,33 & 233,21 & 7,87 & 225,33 & 55,78 & 167,96 & 170,04 & 43,42 & 871,21 & 98,06 & 42,76 & 20,30 & 269,96 & 159,22 & 165,50 & 250,88 \\
\hline Rana temporaria & 30TVN85 & 100,00 & 104,85 & 83,38 & 37,74 & 4828,90 & 229,94 & 11,22 & 218,72 & 54,11 & $\begin{array}{ll}166,92 \\
\end{array}$ & 169,21 & 45,99 & 924,90 & 105,84 & 44,83 & 20,84 & 290,18 & \begin{tabular}{ll|}
167,04 \\
\end{tabular} & \begin{tabular}{ll|}
175,80 \\
\end{tabular} & 270,28 \\
\hline Rana temporaria & 30TVN87 & 100,00 & 124,55 & 70,93 & 36,59 & 4335,24 & 230,32 & 39,18 & \begin{tabular}{|l|l|}
191,14 \\
\end{tabular} & 88,84 & $\begin{array}{l}179,24 \\
19\end{array}$ & 181,90 & \begin{tabular}{ll|}
70,99 \\
\end{tabular} & 1029,46 & 127,20 & 44,41 & 25,55 & 338,75 & $\begin{array}{l}171,69 \\
\end{array}$ & $\begin{array}{l}193,69 \\
\end{array}$ & 322,91 \\
\hline Rana temporaria & 30TVN88 & 100,00 & 126,70 & 67,62 & 36,38 . & 4189,88 & 227,43 & $44,06[$ & $183,37 \mid$ & $89,67 \mid$ & $179,27 \mid$ & $182,15[$ & 74,93 & 1088,14 & $136,91 \mid$ & 45,96 & 26,80 . & $362,44 \mid$ & 178,49 & 204,42 & 347,08 \\
\hline Rana temporaria & 30TVN93 & 100,00 & $\begin{array}{ll}115,36 \\
\end{array}$ & 86,42 & 37,65 & 5019,65 & 244,13 & \begin{tabular}{|l|l|}
17,40 \\
\end{tabular} & 226,73 & 80,67 & $\begin{array}{ll}179,86 \\
\end{array}$ & 181,60 & 53,52 & \begin{tabular}{|l|l|}
797,27 \\
\end{tabular} & 89,48 & 38,23 & 20,47 & \begin{tabular}{|l|l|}
246,02 \\
\end{tabular} & \begin{tabular}{|l|l|}
145,48 \\
\end{tabular} & \begin{tabular}{ll|}
151,88 \\
\end{tabular} & 229,88 \\
\hline Rana temporaria & 30TVN94 & 100,00 & 108,73 & 85,55 & 37,76 & 4938,92 & 236,51 & 12,67 & 223,84 & 62,07 & 172,20 & 174,24 & 48,30 & 872,13 & 98,54 & 42,44 & 20,30 & 270,24 & \begin{tabular}{|l|l|}
159,39 \\
\end{tabular} & \begin{tabular}{|l|}
166,11 \\
\end{tabular} & 253,37 \\
\hline Rana temporaria & 30TVN95 & 100,00 & 106,38 & 83,55 & 37,77 & 4828,87 & 231,28 & 12,65 & \begin{tabular}{|l|l|}
218,63 \\
\end{tabular} & 56,30 & \begin{tabular}{l|l|}
168,32 \\
\end{tabular} & 170,60 & $\begin{array}{l}47,55 \\
\end{array}$ & 938,21 & 107,38 & 45,50 & 20,76 & 293,76 & \begin{tabular}{|l|l}
170,03 \\
\end{tabular} & $\begin{array}{l}178,55 \\
\end{array}$ & 276,05 \\
\hline Rana temporaria & 30TVN96 & 100,00 & 119,40 & 76,09 & 37,08 & 4543,25 & 232,90 & 30,66 & 202,24 & 72,38 & \begin{tabular}{ll|l}
177,02 \\
1
\end{tabular} & \begin{tabular}{ll|}
179,58 \\
\end{tabular} & 63,58 & 990,60 & 118,93 & 44,53 & 23,73 & 319,32 & $\begin{array}{l}170,56 \\
\end{array}$ & $\begin{array}{ll}186,73 \\
\end{array}$ & 305,49 \\
\hline Rana temporaria & 30TVN97 & 100,00 & 127,89 & 70,10 & 36,50 & 4311,79 & 232,34 & 43,09 & 189,25 & 84,19 & 182,03 & 184,80 & 74,59 & 1051,79 & 130,99 & 44,68 & 26,18 & 346,75 & 173,91 & 196,73 & 336,28 \\
\hline Rana temporaria & 30TVN98 & 100,00 & 127,89 & 67,50 & 36,38 & 4192,74 & 228,50 & 45,43 & \begin{tabular}{|l|l|}
183,07 \\
\end{tabular} & 84,73 & 180,31 & 183,21 & 76,13 & 1115,08 & 140,70 & 46,87 & 27,06 & 370,99 & \begin{tabular}{l|l|}
182,25 \\
\end{tabular} & \begin{tabular}{|l|}
208,23 \\
\end{tabular} & 361,25 \\
\hline Rana temporaria & 30TVN99 & 92,00 & 132,29 & 63,55 & 35,85 & 4036,25 & 226,96 & 52,44 & \begin{tabular}{ll|l}
174,52 \\
\end{tabular} & 89,47 & \begin{tabular}{l|l|}
182,50 \\
\end{tabular} & 185,60 & 82,34 & 1168,21 & 150,77 & 47,53 & 28,83 & 394,26 & \begin{tabular}{ll|}
186,08 \\
\end{tabular} & 217,14 & 387,18 \\
\hline Rana temporaria & 30TVPOO & 64,00 & 137,12 & 66,61 & 37,79 & 3851,80 & 230,15 & 55,92 & 174,23 & 120,96 & $\begin{array}{l}85,16 \\
18,\end{array}$ & 188,49 & 89,16 & 941,17 & 120,19 & 40,62 & 28,75 & 331,77 & 157,24 & 184,34 & 264,64 \\
\hline Rana temporaria & 30TWN02 & 100,00 & 122,30 & 88,59 & 37,80 & 5134,56 & 253,13 & $21,27 \mid$ & 231,85 & $92,57 \mid$ & 188,13 & 189,59 & 58,65 . & 725,80 & 80,04 & $34,78 \mid$ & $20,01 \mid$ & 221,58 & 134,57 & 139,36 & 206,13 \\
\hline Rana temporaria & 30TWN03 & 100,00 & 116,25 & 87,55 & 37,88 . & 5049,03 & 246,02 & 17,38 . & $228,64 \mid$ & 76,28 . & 181,08 & 182,81 & 54,0 & 797,32 & 88,72 & 38,69 & 19,84 & 243,94 & 147,58 & 152,84 & 229,04 \\
\hline Rana temporaria & 30TWN04 & 100,00 & 108,15 & 86,93 & \begin{tabular}{ll|}
37,99 \\
\end{tabular} & 4972,08 & 237,41 & 11,42 & 225,99 & \begin{tabular}{|l|l|}
55,08 \\
\end{tabular} & \begin{tabular}{|l|l|}
172,15 \\
\end{tabular} & \begin{tabular}{|l|l|}
174,14 \\
\end{tabular} & $\begin{array}{l}47,45 \\
\end{array}$ & 881,71 & 98,74 & 43,52 & \begin{tabular}{|l|l|}
19,67 \\
\end{tabular} & 271,41 & \begin{tabular}{|l|}
163,24 \\
\end{tabular} & $\begin{array}{l}168,67 \\
1\end{array}$ & 255,44 \\
\hline Rana temporaria & 30TWN05 & 100,00 & 111,15 & 83,25 & 37,86 & 4804,25 & 234,88 & \begin{tabular}{|l|l|}
17,47 \\
\end{tabular} & 217,42 & 60,22 & \begin{tabular}{ll|l}
172,58 \\
\end{tabular} & \begin{tabular}{|l|}
174,81 \\
\end{tabular} & 52,45 & 940,18 & 107,73 & 45,27 & 20,77 & 294,35 & \begin{tabular}{l|l|l|}
170,42 \\
\end{tabular} & $\begin{array}{l}179,21 \\
\end{array}$ & 278,61 \\
\hline Rana temporaria & 30TWN06 & 100,00 & 120,93 & 76,99 & 37,38 & 4558,16 & 235,22 & 31,95 & 203,28 & 72,35 & $\begin{array}{l}178,65 \\
\end{array}$ & 181,13 & 65,04 & $\begin{array}{l}998,87 \\
\end{array}$ & \begin{tabular}{|l|l|}
119,07 \\
\end{tabular} & 45,23 & 23,21 & \begin{tabular}{|l|l|}
320,68 \\
\end{tabular} & \begin{tabular}{|l|l|}
173,37 \\
\end{tabular} & \begin{tabular}{|l|}
188,61 \\
\end{tabular} & 308,02 \\
\hline Rana temporaria & 30TWN07 & 100,00 & 127,93 & 71,26 & 36,86 & 4332,40 & 233,84 & 43,26 & 190,58 & $82,01 \mid$ & $182,27 \mid$ & 185,03 & 74,73 & 1069,85 & 132,35 & 45,96 & $25,77 \mid$ & 351,14 & 178,23 & $199,87 \mid$ & 343,06 \\
\hline Rana temporaria & 30TWN08 & 100,00 & 130,79 & 67,22 & 36,46 & 4178,09 & 230,99 & 49,14 & 181,86 & $84,61 \mid$ & 182,80 & 185,90 & 79,44 & 1139,08 & 144,30 & 47,36 & 27,59 & 380,12 & 184,84 & 211,30 & 374,92 \\
\hline Rana temporaria & 30TWN09 & 99,00 & 138,12 & 61,59 & 35,64 & 3978,81 & 229,93 & 59,82 & 170,11 & 90,52 & 187,26 & 190,50 & 88,95 & 1202,85 & 157,78 & 47,29 & 30,38 & 411,24 & 187,22 & 220,79 & 410,73 \\
\hline Rana temporaria & 30TWN11 & 100,00 & 121,17 & 92,97 & 38,03 & 5325,25 & 258,05 & 16,19 & 241,87 & 87,30 & \begin{tabular}{l|l|}
189,92 \\
\end{tabular} & $\begin{array}{ll}190,83 \\
\end{array}$ & 55,10 & 671,24 & 71,31 & 33,48 & \begin{tabular}{ll|}
19,01 \\
\end{tabular} & 200,12 & \begin{tabular}{|l|l|}
129,18 \\
\end{tabular} & \begin{tabular}{|l|l|}
130,57 \\
\end{tabular} & 183,99 \\
\hline Rana temporaria & 30TWN12 & 100,00 & $\begin{array}{l}116,42 \\
\end{array}$ & 91,61 & 38,06 & 5218,73 & 251,37 & 13,86 & 237,50 & 78,65 & $\begin{array}{l}183,78 \\
\end{array}$ & 185,01 & 51,99 & 741,39 & 80,05 & \begin{tabular}{|l|l|}
37,07 \\
\end{tabular} & 18,90 & 222,10 & \begin{tabular}{ll|}
141,43 \\
\end{tabular} & \begin{tabular}{|l|l|}
143,53 \\
\end{tabular} & 207,29 \\
\hline Rana temporaria & 30TWN13 & 100,00 & 117,52 & 88,77 & 38,00 & 5076,73 & 248,27] & $17,84[$ & 230,43 & 75,49 & 182,56 & 184,25 & 54,99] & 795,94 [ & 87,64 & 39,16 _ & 19,33 & 241,68 & 149,44 & 153,49 & 227,16 \\
\hline Rana temporaria & 30TWN14 & 100,00 & 114,06 & 86,70 & 38,04 & 4951,83 & 242,09 & 17,31 & 224,79 & 60,66 & \begin{tabular}{ll|l}
177,48 \\
\end{tabular} & 179,45 & 53,44 & 873,38 & 97,76 & 42,79 & \begin{tabular}{ll|}
19,69 \\
\end{tabular} & 268,69 & 161,95 & 167,58 & 253,84 \\
\hline Rana temporaria & 30TWN15 & 100,00 & 110,09 & 85,02 & 38,03 & 4845,20 & 235,85 & 15,60 & 220,25 & 58,25 & 172,10 & 174,23 & 51,07 & \begin{tabular}{|l|l|}
950,45 \\
\end{tabular} & 107,55 & 46,56 & \begin{tabular}{l|l|l|}
19,95 \\
\end{tabular} & 295,50 & \begin{tabular}{|l|}
174,82 \\
\end{tabular} & \begin{tabular}{|l|l|}
181,79 \\
\end{tabular} & 279,59 \\
\hline Rana temporaria & 30TWN16 & 100,00 & 98,64 & 85,16 & 38,28 & 4807,67 & 225,03 & 5,69 & 219,33 & 47,92 & 160,34 & 162,73 & 40,71 & 1045,75 & 118,43 & 52,56 & 19,70 & 326,01 & 193,81 & \begin{tabular}{ll|}
199,88 \\
\end{tabular} & 307,97 \\
\hline Rana temporaria & 30TWN17 & 100,00 & 128,64 & 72,98 & 37,36 & 4354,73 & 236,46 & 43,81 & $\begin{array}{l}192,65 \\
\end{array}$ & 82,11 & \begin{tabular}{|l|l|}
183,14 \\
\end{tabular} & 186,01 & 75,52 & 1079,46 & 131,80 & 47,04 & 24,96 & 352,18 & \begin{tabular}{|l|l|}
181,94 \\
\end{tabular} & \begin{tabular}{l|l|}
201,95 \\
\end{tabular} & 344,04 \\
\hline Rana temporaria & 30TWN18 & 100,00 & 134,32 & 68,06 & 36,94 [ & 4171,27 & 235,38 & 53,62 & 181,75 & $89,29 \mid$ & 186,00 & 189,16 & 83,60 & 1148,38 | & $144,51 \mid$ & 47,86 & 27,29 , & $381,57 \mid$ & 186,91 & 212,95 & 377,88 \\
\hline Rana temporaria & 30TWN19 & 100,00 & 136,81 & 64,62 & 36,64 & 4030,81 & 233,08 & 59,18 & \begin{tabular}{ll|}
173,91 \\
\end{tabular} & 91,57 & $\begin{array}{l}186,35 \\
\end{array}$ & $\begin{array}{l}189,85 \\
\end{array}$ & 88,01 & 1213,41 & 155,48 & \begin{tabular}{l|l|}
49,45 \\
\end{tabular} & 28,69 & \begin{tabular}{ll|}
408,53 \\
\end{tabular} & \begin{tabular}{|l|l|}
193,61 \\
\end{tabular} & 224,12 & 406,77 \\
\hline Rana temporaria & 30TWN20 & 100,00 & 126,10 & 96,62 & 38,00 & 5507,50 & 267,48 & 16,71 & 250,77 & 94,30 & \begin{tabular}{|l|l|}
197,64 \\
\end{tabular} & 197,75 & 57,42 & 585,64 & 61,84 & 29,96 & 18,98 & \begin{tabular}{ll|l}
170,90 \\
\end{tabular} & \begin{tabular}{ll|}
116,21 \\
\end{tabular} & \begin{tabular}{l|l}
116,25 \\
\end{tabular} & 153,13 \\
\hline Rana temporaria & 30TWN22 & 100,00 & 111,72 & 94,34 & 38,29 & 5288,91 & 250,19 & $\begin{array}{ll}7,67 \\
\end{array}$ & 242,52 & 61,67 & 180,75 & 181,31 & 46,66 & 758,46 & 80,55 & 39,13 & 18,04 & 223,91 & 147,33 & \begin{tabular}{|l|}
147,51 \\
\end{tabular} & 209,39 \\
\hline Rana temporaria & 30TWN23 & 100,00 & 112,54 & 91,62 & 38,28 & 5147,34 & 246,88 & 11,33 & 235,56 & 60,18 & 178,85 & 180,25 & 49,36 & 813,72 & 88,10 & 41,3 & 18,3 & 244,33 & 156,34 & \begin{tabular}{ll|}
157,56 \\
\end{tabular} & 229,17 \\
\hline Rana temporaria & 30TWN24 & 100,00 & 119,93 & 86,90 & 38,16 & 4940,64 & 247,10 & 22,81 & 224,29 & 66,12 & 182,88 & 184,78 & 59,15 & 862,41 & 95,99 & \begin{tabular}{|l|l}
42,06 \\
\end{tabular} & 19,59 & 264,73 & 160,61 & 165,94 & 250,16 \\
\hline Rana temporaria & 30TWN25 & 100,00 & 117,45 & 84,69 & 38,13 & 4802,05 & 241,38 & 23,20 & 218,18 & 65,44 & \begin{tabular}{ll|}
178,44 \\
\end{tabular} & \begin{tabular}{ll|}
180,66 \\
\end{tabular} & $\begin{array}{l}58,75 \\
\end{array}$ & 945,48 & 107,01 & 45,75 & 20,05 & 294,32 & 173,45 & $\begin{array}{l}180,86 \\
\end{array}$ & 279,21 \\
\hline Rana temporaria & 30TWN26 & 100,00 & 113,08 & 82,98 & 38,30 & 4690,10 & 234,81 & 21,53 & 213,27 & 62,92 & $172,61 \mid$ & 175,10 & 56,11 & 1031,02 & 118,07 & 49,92 & 20,60 & 324,36 & $187,44[$ & 196,33 & 308,42 \\
\hline Rana temporaria & 30TWN27 & 100,00 & 120,50 & 77,90 & 38,17 & 4471,05 & 234,66 & 33,45 & 201,21 & 72,74 & 176,71 & \begin{tabular}{ll|l}
179,56 \\
\end{tabular} & 66,37 & 1097,43 & 129,37 & 50,81 & 22,51 & 352,25 & \begin{tabular}{l|l|}
192,55 \\
\end{tabular} & \begin{tabular}{|l|l|}
207,20 \\
\end{tabular} & 338,87 \\
\hline Rana temporaria & 30TWN28 & 100,00 & 132,12 & 71,51 & 37,82 & 4217,71 & 237,05 & 50,52 & 186,53 & 86,93 & $184,41 \mid$ & $187,61 \mid$ & 81,1 & 1160,03 & 142,02 & 50,3 & $25,4<>>$ & 381,14 & 194,15 & 216,73 & 372,79 \\
\hline Rana temporaria & 30TWN29 & 100,00 & 136,55 & 67,88 & 37,67 & 4062,26 & 236,21 _ & 58,40 & 177,81 & 93,08 & 186,50 & 190,04 & 87,82 & 1216,98 & 151,89 & 51,40 & 26,91 & 405,01 & 199,13 & 226,79 & $398,51]$ \\
\hline Rana temporaria & 30TWN30 & 100,00 & 127,14 & 98,39 & 38,01 & 5580,14 & 270,47 & 15,84 & 254,63 & 115,86 & 199,45 & 199,45 & 57,31 & 562,21 & 61,32 & 29,66 & \begin{tabular}{l|l|}
19,05 \\
\end{tabular} & \begin{tabular}{|l|}
162,42 \\
\end{tabular} & \begin{tabular}{|l|l|}
113,49 \\
\end{tabular} & \begin{tabular}{|l|l|}
113,76 \\
\end{tabular} & 142,64 \\
\hline Rana temporaria & 30TWN31 & 100,00 & 112,62 & 98,18 & 38,56 & 5463,45 & 255,92 & 4,41 & 251,51 & 69,11 & $\begin{array}{l}184,18 \\
\end{array}$ & 184,18 & 45, & $\begin{array}{ll}698,07 \\
\end{array}$ & 73,03 & \begin{tabular}{|l|l|}
37,09 \\
\end{tabular} & \begin{tabular}{l|l}
17,75 \\
\end{tabular} & \begin{tabular}{|l|l|}
201,94 \\
\end{tabular} & \begin{tabular}{|l|l|}
137,27 \\
\end{tabular} & \begin{tabular}{|l|l|}
137,27 \\
\end{tabular} & 186,42 \\
\hline Rana temporaria & 30TWN32 & 100,00 & 108,82 & 96,39 & 38,76 & 5341,01 & 249,64 & 3,40 & 246,24 & 51, & $\begin{array}{l}179,08 \\
19\end{array}$ & $\begin{array}{l}179,08 \\
\end{array}$ & 43, & 775,71 & 81,65 & 40,84 & \begin{tabular}{l|l|}
17,59 \\
\end{tabular} & 227,76 & \begin{tabular}{|l|l|}
150,97 \\
1
\end{tabular} & \begin{tabular}{|l|l|}
150,97 \\
1
\end{tabular} & 212,72 \\
\hline Rana temporaria & 30TWN33 & 100,00 & 103,56 & 94,58 & 38,90 & $5221,61$. & 242,10 & 1,07 & 241,03 & 47,20 & 172,36 & 172,57 & $39,87 \mid$ & 862,93 & $92,57 \mid$ & 45,23 & 17,73 & 257,56 & 166,55 & 166,66 & 241,63 \\
\hline Rana temporaria & 30TWN34 & 100,00 & 118,90 & 89,15 & 38,76 & 4985,27 & 45 & 20,54 & 227,91 & $64,53 \mid$ & 182,50 & 184,28 & 57,72 & 871,82 & 95,63 & \begin{tabular}{|l|l|l|}
43,42 \\
\end{tabular} & 18,82 & 265,85 & $\mid 165,05$ & \begin{tabular}{|l|l|}
168,09 \\
\end{tabular} & 249,88 \\
\hline Rana temporaria & 30TWN35 & 100,00 & 112,87 & 87,58 & 38,92 & 4872,46 & 240,42 & 17,16 & 223,26 & 60,24 & \begin{tabular}{|l|l|}
175,05 \\
\end{tabular} & 177,12 & 53,48 & 969,30 & 108,05 & 48,34 & 19,18 & 299,53 & 181,38 & 185,61 & 282,65 \\
\hline Rana temporaria & 30TWN36 & 100,00 & 118,93 & 83,30 & 38,89 & 4648,14 & 2 & 27,74 & 211, & 68,82 & 177,68 & 180,22 & 62, & 1040,38 & 118,56 & 50, & 20,62 & 327,62 & \begin{tabular}{|l|l|l|}
188,78 \\
\end{tabular} & 197,71 & 311,32 \\
\hline Rana temporaria & 30TWN37 & 100 & 126,97 & 78,23 & 38, & .116,47| & 9 & 40, & 199 & 79, & $182,17 \mid$ & 185,09 & 73 & 111 & 5] & 51,0 & 22,59 & 356,79 & 194,15 & 209,22 & 342,71 \\
\hline Rana temporaria & 30TWN38 & 100,00 & 125,53 & 76,22 & 38,88 & 295,56 & 35,67 & 41,87 & 193,80 & 79,55 & 178,97 & 182,14 & 73, & 1184,68 & 140,08 & 54,2 & 3,10 . & 383,79 & 205,43 & 223,01 & 368,89 \\
\hline Rana temporaria & 30TWN39 & 100,00 & 130,98 & 72,34 & 38,82 & 113,23 & 235,15 & 51,13 & \begin{tabular}{|l|l|}
184,02 \\
\end{tabular} & \begin{tabular}{|l|l|}
87,08 \\
\end{tabular} & \begin{tabular}{|l|l|}
181,70 \\
\end{tabular} & 185,18 & \begin{tabular}{l|l|}
81,85 \\
\end{tabular} & 1246,81 & \begin{tabular}{|l|l|}
150,37 \\
\end{tabular} & 55,51 & 24,49 & \begin{tabular}{|l|l|}
409,47 \\
\end{tabular} & 211,22 & \begin{tabular}{|l|}
234,16 \\
\end{tabular} & 396,09 \\
\hline Rana temporaria & 30TWN40 & 100,00 & 128,64 & $100,21$. & 38,06 & 5669,25 & 273,99 & 15,27 & 258,73 & 148,38 . & 191,98 | & 201,80 & 57,55 & 533,26 & 60,36 & 29,04 & 19,70 . & \begin{tabular}{l|l}
156,83 \\
\end{tabular} & \begin{tabular}{|l|l|}
109,49 \\
\end{tabular} & \begin{tabular}{|l|}
112,01 \\
\end{tabular} & 130,23 \\
\hline Rana temporaria & 30TWN41 & 100,00 & 113,05 & $\begin{array}{ll}99,65 \\
\end{array}$ & 38,75 & 11,61 & 257,95 & 3,55 & 254,40 & 78, & \begin{tabular}{|l|l|}
185,14 \\
\end{tabular} & 185,14 & 44,99 & 697,21 & 73,21 & 37,48 & 57 & 200,54 & \begin{tabular}{ll|l}
137,18 \\
\end{tabular} & \begin{tabular}{ll|}
137,18 \\
\end{tabular} & 184,62 \\
\hline Rana temporaria & 30TWN42 & 100,00 & 111,66 & 97,48 & $38,97 \mid$ & 372,17 & 253,22 & 4,92 & 248,30 & 55,8 & \begin{tabular}{|l|l|}
182,10 \\
\end{tabular} & 182,10 & 45,5 & 765,08 & 79,88 & 40,5 & 17,51 & 223,68 & \begin{tabular}{|l|l|}
149,08 \\
\end{tabular} & \begin{tabular}{|l|l|}
149,08 \\
\end{tabular} & 207,95 \\
\hline Rana temporaria & 30TWN43 & 100,00 & 104,69 & 95,80 & 39,00 & 253,6 & 244 & 1,10 & 243,12 & 47,7 & 173,98 & 173,98 & 40 & 867,38 & 92,76 & 45, & 17,6 & 258,43 & 167,34 & 167,34 & \\
\hline Rana temporaria & $30 \mathrm{TW}$ & 100 & 116 & & 39 & 504 & & 16,52 & & 61, & 180 & 182 & 54 & $\begin{array}{l}893,15 \\
\end{array}$ & 97,14 & 45 & \begin{tabular}{|l|l|}
18,33 \\
\end{tabular} & 271,42 & 170 & \begin{tabular}{|l|l|}
171,69 \\
\end{tabular} & 254, \\
\hline Rana temporaria & 30TWN45 & 100,00 & 108,38 & 90,08 & 39,01 & 4932,58 & 239,01 & 11,27 & 227,75 & 55,25 & 171,85 & 173,45 & 48,43 & 998,88 & 110,42 & 50,92 & 18,72 & 307,34 & 189,19 & 190,92 & 289,05 \\
\hline Rana temporaria & 30TWN46 & 100,00 & 123,61 & 83,98 & 39,18 & 4612,31 & 243,96 & 32,62 & 211,34 & 73,60 & 181,61 & 184,19 & \begin{tabular}{l|l|}
67,65 \\
\end{tabular} & $\begin{array}{l}1057,52 \\
\end{array}$ & 20,02 & $\begin{array}{l}0,76 \\
\end{array}$ & 0,66 & 333,64 & \begin{tabular}{ll|l}
191,58 \\
\end{tabular} & 200,33 & 315,99 \\
\hline Rana temporaria & 30TWN47 & 100,00 & $127,37 \mid$ & 80,59 & 39,48 & 44144,46 & 242,24 & 40,45 & 201,79 & $79,66[$ & 182,45 & 185,32 & 74,13 & .134,07| & 130,68 & 53,16 & 21,75 & 362,79 & 200,85 | & $213,87 \mid$ & 344,92 \\
\hline Rana te & & & & & & & & 46,70 & & & & 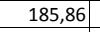 & 79,20 & of & 140 & 55,47 & 22,78 & 389,75 & 209,58 & 226,82 & 372,07 \\
\hline Rana temporaria & 30TWN49 & 83,00 & 135,59 & 73,79 & 39,59 & 4081,88 & 239, & 55,56 & 184,3 & \begin{tabular}{|l|l|}
91,69 \\
\end{tabular} & 185,64 & 189,10 & 86,91 & 1255,69 & 149,38 & 56,31 & 24,10 & 411,33 & 213,84 & 236,38 & 394,56 \\
\hline Rana temporaria & 30TWN52 & 100,00 & 111,01 & 98,69 & 38,99 & 5410,56 & 253,88 & 3,30 & 250,58 & 54,19 | & 181,92 & 181,92 & 44,35 & 784,16 & 81,97 & 41,74 & 17,60 & 229,51 & 151,86 & 151,86 & 213,21 \\
\hline
\end{tabular}




\begin{tabular}{|c|c|c|c|c|c|c|c|c|c|c|c|c|c|c|c|c|c|c|c|c|c|}
\hline TAXON & UTM & $\mathrm{km} 2$ & B101 & B102 & $\mathrm{BIO3}$ & B104 & B105 & B106 & B107 & B108 & B109 & BIO10 & B1011 & BIO12 & B1013 & BIO14 & BIO15 & BIO16 & BIO17 & BIO18 & B1019 \\
\hline Rana temporaria & 30TWN53 & 100,00 & 99,05 & 97,23 & 39,00 & 5289,83 & 240,71 & $-5,51$ & 246,22 & 42,19 & 169,02 & 169,02 & 34,61 & 912,83 & 98,09 & 48,79 & 17,47 & 272,35 & 174,91 & 174,91 & 255,66 \\
\hline Rana temporaria & 30TWN54 & 100,00 & 108,16 & 93,91 & 39,01 & 5109,92 & 243,98 & 6,90 & 237,08 & 52,94 & 175,02 & 175,43 & 45,78 & 945,86 & 103,08 & $\begin{array}{l}49,09 \\
\end{array}$ & 18,18 & 287,36 & 180,52 & 180,55 & 269,18 \\
\hline Rana temporaria & 30TWN55 & 100,00 & 101,96 & 91,96 & 39,17 & 4992,10 & 235,34 & 3,58 & 231,76 & 48,52 & 167,24 & 168,02 & 41,50 & 1042,61 & 115,05 & 54,16 & 18,39 & 320,16 & 197,85 & 198,55 & 300,92 \\
\hline Rana temporaria & 30TWN56 & 100,00 & 121,30 & 86,70 & 39,73 & 4667,95 & 244,58 & 28,76 & 215,83 & 70,68 & 180,08 & 182,54 & 64,62 & 1082,56 & 121,58 & 52,97 & 20,11 & 340,60 & 198,55 & 204,39 & 320,05 \\
\hline Rana temporaria & \begin{tabular}{|l|} 
30TWN57 \\
\end{tabular} & 100,00 & 121,94 & 84,15 & 40,03 & $\begin{array}{ll}4490,28 \\
\end{array}$ & 240,93 & 32,96 & 207,97 & 73,57 & 178,16 & 180,97 & 67,85 & 1167,68 & 132,45 & 56,49 & 20,77 & 371,32 & 210,95 & 220,01 & 349,71 \\
\hline Rana temporaria & 30TWN58 & 100,00 & 128,13 & 80,12 & 40,23 & 4265,19 & 240,38 & 43,60 & 196,79 & 82,32 & 180,89 & 184,14 & 77,08 & 1240,29 & 142,68 & 58,48 & 21,94 & 399,49 & 218,99 & 233,70 & 377,46 \\
\hline Rana temporaria & 30TWN63 & 100,00 & 103,32 & 97,94 & 39,01 & 5316,96 & 245,23 & $-2,27$ & 247,50 & 45,76 & 173,31 & 173,31 & 38,25 & 914,81 & 99,12 & 48,44 & 17,94 & 274,80 & 173,71 & 173,71 & 257,41 \\
\hline Rana temporaria & 30TWN64 & 100,00 & 104,07 & 95,58 & 39,10 & 5166,61 & 242,19 & 1,56 & 240,63 & 48,36 & 172,21 & 172,21 & 41,03 & 984,99 & 108,32 & 51,52 & 18,30 & 300,55 & 186,36 & 186,36 & 281,81 \\
\hline Rana temporaria & 30TWN65 & 100,00 & 114,75 & 92,10 & 39,59 & 4941,28 & 246,34 & 16,24 & 230,10 & 61,12 & 178,84 & 179,67 & 54,48 & 1037,83 & 115,65 & 52,42 & 19,30 & 323,01 & 194,30 & 195,10 & 302,10 \\
\hline Rana temporaria & 30TWN66 & 100,00 & 130,98 & 86,46 & 40,11 & $\begin{array}{ll}4575,07 \\
\end{array}$ & 251,84 & 39,33 & 212,51 & 81,00 & 188,09 & 190,77 & 75,39 & 1103,43 & 124,59 & 52,88 & 20,87 & 350,55 & 199,35 & 206,77 & 327,82 \\
\hline Rana temporaria & 30TWN67 & 100,00 & 123,06 & 85,63 & 40,39 & 4495,82 & 243,12 & 33,38 & 209,73 & 74,62 & 179,28 & 182,14 & 68,95 & 1199,36 & 135,85 & 58,32 & 20,85 & 382,33 & 217,09 & 225,01 & 358,30 \\
\hline Rana temporaria & 30TWN68 & 100,00 & 128,29 & 82,14 & 40,94 & 4248,49 & 241,72 & 43,40 & 198,32 & 82,67 & 180,87 & 184,08 & 77,57 & 1282,11 & 145,99 & 61,18 & 21,70 & 412,56 & 227,80 & 241,07 & 386,77 \\
\hline Rana temporaria & 30TWN69 & 47,00 & 142,35 & 77,38 & \begin{tabular}{|l|l|}
40,97 \\
\end{tabular} & 4040,34 & 247,61 & 61,04 & 186,56 & 98,65 & 191,69 & 195,08 & 93,94 & 1284,21 & 149,00 & 59,06 & 23,20 & 418,49 & 222,79 & 243,99 & 393,32 \\
\hline Rana temporaria & 30TWN73 & 100,00 & 103,41 & 98,80 & 39,01 & 5350,09 & 246,23 & $-3,39$ & 249,61 & 45,57 & 173,73 & 173,73 & 37,87 & 936,65 & 102,89 & 49,35 & 18,41 & 283,47 & 175,99 & 175,99 & 265,79 \\
\hline Rana temporaria & 30TWN74 & 100,00 & 100,62 & 96,62 & 39,21 & 5208,45 & 240,12 & $-2,82$ & 242,94 & 44,68 & 169,38 & 169,38 & 37,17 & 1021,25 & 113,47 & 53,57 & 18,56 & 312,86 & 191,86 & 191,86 & 293,94 \\
\hline Rana temporaria & 30TWN75 & 100,00 & 108,49 & 94,04 & 39,53 & 5036,57 & 243,08 & 7,88 & 235,20 & 54,16 & 174,61 & 174,66 & 46,97 & 1073,28 & 120,82 & 54,95 & 19,36 & 334,82 & 200,40 & 200,40 & 313,61 \\
\hline Rana temporaria & 30TWN76 & 100,00 & 111,01 & 90,73 & 39,88 & 4809,98 & 239,75 & 14,90 & 224,85 & 59,29 & 172,92 & 174,38 & 52,67 & 1155,76 & 130,57 & 58,44 & 19,83 & 363,66 & 213,91 & 216,84 & 340,62 \\
\hline Rana temporaria & 30TWN77 & 100,00 & 129,54 & 85,98 & 40,78 & 4449,01 & 248,19 & 39,74 & 208,45 & 81,29 & 184,82 & 187,75 & 75,75 & 1224,90 & 139,65 & 59,02 & 21,43 & 393,34 & 220,21 & 229,16 & 366,76 \\
\hline Rana temporaria & 30TWN78 & 100,00 & 136,02 & 82,26 & 41,51 & \begin{tabular}{ll|l}
4169,84 \\
\end{tabular} & 247,28 & 51,34 & 195,95 & 90,94 & 187,18 & 190,48 & 86,04 & $\mid 1306,41$ & 148,74 & 62,01 & 22,07 & 422,21 & 231,31 & 246,37 & 393,01 \\
\hline Rana temporaria & 30TWN79 & 55,00 & 142,54 & 79,19 & 41,49 & 4050,54 & 248,44 & 59,70 & 188,74 & 98,79 & 191,96 & 195,32 & 93,85 & 1318,53 & 152,11 & \begin{tabular}{|c|}
61,78 \\
\end{tabular} & 22,71 & 428,98 & 231,91 & 252,33 & 399,74 \\
\hline Rana temporaria & 30TWN84 & 100,00 & 91,57 & 97,49 & 39,01 & 5276,41 & 233,10 & $-13,28$ & 246,38 & 35,46 & 161,44 & 161,44 & 27,57 & 1060,01 & 118,21 & 56,62 & 18,24 & 323,42 & 199,51 & 199,51 & 305,06 \\
\hline Rana temporaria & 30TWN85 & 100,00 & 106,58 & 95,36 & 39,43 & 5114,41 & 243,07 & $\begin{array}{r}4,09 \\
4,09\end{array}$ & 238,99 & 51,34 & 173,73 & 173,73 & 43,91 & 1099,31 & 125,91 & 56,20 & 19,88 & 345,57 & 203,27 & 203,27 & 324,35 \\
\hline Rana temporaria & 30TWN86 & 100,00 & 113,46 & 92,50 & 39,91 & 4893,48 & 244,21 & 14,93 & 229,28 & 60,58 & 176,77 & 177,71 & 53,68 & 1171,81 & 135,21 & 58,72 & 20,63 & 373,55 & 215,77 & 216,84 & 349,65 \\
\hline Rana temporaria & 30TWN87 & 100,00 & 114,38 & 90,20 & 40,28 & 4714,87 & 240,70 & 19,19 & 221,50 & 63,64 & 174,15 & 176,25 & 57,07 & 1253,24 & 144,73 & 62,59 & 20,78 & 401,85 & 230,62 & 233,34 & 375,75 \\
\hline Rana temporaria & 30TWN88 & 100,00 & 129,64 & 84,99 & 41,19 & 4340,68 & 245,11 & 41,00 & 204,11 & 82,85 & 183,45 & 186,52 & 77,15 & 1323,19 & 152,53 & 64,33 & 21,75 & 428,25 & 238,60 & 250,17 & 398,13 \\
\hline Rana temporaria & 30TWN89 & 84,00 & 141,98 & 80,34 & 41,12 & $\begin{array}{l}4147,07 \\
\end{array}$ & 249,07 & 56,16 & 192,91 & 97,07 & 192,83 & 196,01 & 91,49 & 1324,87 & 154,41 & 63,41 & 22,63 & 431,54 & 237,27 & 257,20 & 400,51 \\
\hline Rana temporaria & 30TWN94 & 100,00 & 112,33 & 98,54 & 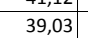 & 5324,67 & 253,68 & $\begin{array}{r}50,05 \\
5,05 \\
\end{array}$ & 248,64 & 54,25 & 181,91 & 181,91 & 46,41 & 1044,64 & \begin{tabular}{|l|}
123,47 \\
134,4
\end{tabular} & 52,04 & 21,45 & 333,16 & 187,74 & $\begin{array}{l}187,74 \\
\end{array}$ & 313,34 \\
\hline Rana temporaria & 30TWN95 & 100,00 & 112,46 & 96,45 & 39,30 & 5169,92 & 249,99 & 7,99 & 242,00 & 56,38 & 180,13 & 180,13 & 48,65 & 1115,28 & 131,91 & 55,58 & 21,42 & 357,89 & 201,88 & 201,88 & 336,12 \\
\hline Rana temporaria & 30TWN96 & 100,00 & 104,13 & 94,60 & 39,59 & 5054,56 & 238,99 & 2,51 & 236,48 & 49,88 & 170,57 & 170,57 & 42,31 & \begin{tabular}{|l|}
1187,49 \\
\end{tabular} & 138,57 & 60,62 & 20,39 & 378,00 & 219,52 & 219,52 & 355,21 \\
\hline Rana temporaria & 30TWN97 & 100,00 & 110,60 & 91,78 & 40,00 & 4839,21 & 239,44 & 12,53 & 226,92 & 58,56 & 172,80 & 174,20 & 51,36 & 1259,47 & 147,50 & 63,49 & 20,90 & 404,84 & 233,16 & 234,64 & 379,23 \\
\hline Rana temporaria & 30TWN98 & 100,00 & 120,70 & 87,94 & 40,59 & 4563,81 & 241,46 & 27,30 & 214,15 & 71,55 & 177,77 & 180,49 & 64,91 & 1332,12 & 156,15 & 66,26 & 21,49 & 431,84 & 244,48 & 251,74 & 402,44 \\
\hline Rana temporaria & \begin{tabular}{|l|} 
30TWN99 \\
\end{tabular} & 100,00 & 133,51 & 83,01 & 40,83 & $\begin{array}{l}430,010 \\
4317,29\end{array}$ & 244,87 & $\begin{array}{ll}4,87 \\
43,\end{array}$ & 201,01 & $\begin{array}{ll}1,0,02 \\
002\end{array}$ & 186,91 & $\begin{array}{l}189,84 \\
\end{array}$ & 80,53 & $\mid$ & 159,45 & 66,82 & 22,10 & $\begin{array}{l}451,04 \\
441,31\end{array}$ & 248,15 & 264,33 & 40,49 \\
\hline Rana temporaria & 30TWP00 & 79,00 & 137,74 & 60,59 & 35,91 & 3895,53 & 227,82 & 61,13 & 166,69 & 93,62 & 185,65 & 189,02 & 89,81 & 1245,64 & 163,35 & 49,35 & 30,33 & 425,02 & 194,31 & 229,77 & 424,19 \\
\hline Rana temporaria & 30TWP10 & 94,00 & 132,38 & 64,68 & 36,92 & 3975,66 & 228,22 & 55,49 & 172,72 & 89,86 & 181,32 & 184,84 & 84,41 & 1266,20 & 160,96 & 52,91 & 27,98 & 425,57 & 204,62 & 235,59 & 420,02 \\
\hline Rana temporaria & 30TWP30 & 40,00 & 137,65 & 69,00 & 38,61 & 3995,39 & 236,84 & 60,23 & 176,61 & 94,85 & 186,32 & 190,00 & 89,87 & 1267,71 & 155,84 & 54,73 & 26,05 & 421,16 & 210,02 & 237,97 & 409,79 \\
\hline Rana temporaria & 30TWP90 & 28,00 & 138,83 & 80,55 & 40,75 & 4220,05 & 245,72 & 50,41 & 195,31 & 105,70 & 190,86 & 193,91 & 86,75 & 1355,98 & 160,34 & 66,73 & 22,59 & 442,94 & 248,83 & 269,58 & 409,41 \\
\hline $\begin{array}{l}\text { Rana temporaria } \\
\text { and }\end{array}$ & 30TXNO3 & $\begin{array}{l}20,000 \\
100,00\end{array}$ & $\begin{array}{l}13,030 \\
117,28\end{array}$ & $\begin{array}{ll}0.0,30 \\
101,84\end{array}$ & 38,87 & 年 52263,04 & 264,12 & \begin{tabular}{r|}
0,446 \\
4,46
\end{tabular} & $\mid$ & \begin{tabular}{|c|c|}
56,19 \\
56
\end{tabular} & $\begin{array}{l}189,71 \\
189,0\end{array}$ & \begin{tabular}{|l|}
189,71 \\
198,1
\end{tabular} & $\begin{array}{l}\mid l 0,115 \\
47,87\end{array}$ & \begin{tabular}{|l|}
353,70 \\
987,76
\end{tabular} & \begin{tabular}{|l|}
121,64 \\
121,54
\end{tabular} & 47,40 & $\begin{array}{l}23,53 \\
23,51\end{array}$ & 321,10 & $\begin{array}{l}24,03 \\
170,42\end{array}$ & $\begin{array}{l}203,00 \\
170,42 \\
\end{array}$ & $\begin{array}{l}305,41 \\
303,38\end{array}$ \\
\hline Rana temporaria & 30TXNO4 & 100,00 & 120,11 & 99,69 & 38,96 & 5424,70 & 263,16 & 9,95 & 253,21 & 60,57 & 190,76 & 190,76 & 52,43 & 1054,55 & 130,95 & 50,27 & 23,93 & 346,91 & 182,97 & 182,97 & 327,25 \\
\hline Rana temporaria & 30TXN05 & 100,00 & 110,26 & 97,76 & \begin{tabular}{|l|l|}
39,07 \\
\end{tabular} & 5256,90 & 249,72 & 3,59 & 246,12 & 53,32 & 179,04 & 179,04 & 45,21 & 1130,85 & 136,25 & 56,18 & 21,96 & 365,42 & 203,32 & 203,32 & 344,20 \\
\hline Rana temporaria & 30TXN06 & 100,00 & 106,18 & 95,55 & 39,43 & 5116,10 & 241,79 & 2,54 & 239,25 & 50,97 & 173,27 & 173,27 & 43,10 & 1195,82 & 142,30 & 60,52 & 21,15 & 384,30 & 219,61 & 219,61 & 361,55 \\
\hline Rana temporaria & 30 TXN07 & 100,00 & 120,29 & 91,28 & 39,5 & 4846,52 & 246,87 & 20,70 & 226,18 & 68,22 & 181,79 & 183,66 & 60,27 & 1249,93 & 149,77 & 62,11 & 21,78 & 406,52 & 230,56 & 234,53 & 379,90 \\
\hline Rana temporaria & 30TXN08 & 100,00 & 127,35 & 87,62 & 40,13 & 4626,20 & 246,63 & 31,30 & 215,33 & 79,84 & 185,25 & $\begin{array}{l}187,69 \\
\end{array}$ & 69,99 & 1304,00 & 156,08 & 64,90 & 21,99 & 425,17 & 241,37 & 251,01 & 395,35 \\
\hline Rana temporaria & 30 TXN09 & 67,00 & 131,10 & 84,45 & 40,21 & 4476,51 & 244,47 & 37,44 & 207,04 & 90,90 & 186,80 & 189,40 & 75,49 & \begin{tabular}{|l|}
1344,08 \\
\end{tabular} & 160,62 & 67,51 & 22,10 & 438,57 & 250,79 & 265,82 & 405,86 \\
\hline Rana temporaria & 30TXN15 & 100,00 & 107,71 & 98,34 & 39,02 & 5316,13 & 247,88 & $-0,46$ & 248,34 & 50,04 & 177,17 & 177,17 & 41,58 & 1130,84 & 136,92 & 56,58 & 21,81 & 364,65 & 204,42 & 204,42 & 344,08 \\
\hline Rana temporaria & 30 TXN16 & 100,00 & 94,84 & 95,87 & 39,18 & 5175,51 & 231,62 & $-9,67$ & 241,29 & 39,67 & 162,94 & 162,95 & 31, & 1194,21 & 139,45 & 62,5 & 19,60 & 12 & 24,05 & 224,05 & 354,54 \\
\hline Rana temporaria & 30TXN17 & 100,00 & 121,06 & 92,23 & 39,79 & 4938,64 & 248,4 & 18,70 & 229,73 & 67,68 & $\mid \begin{array}{l}\mid 182,731 \\
\end{array}$ & 185,35 & 59,33 & 1233,22 & \begin{tabular}{|l|l|}
149,93 \\
\end{tabular} & 61, & 22,18 & 402,18 & 228,79 & 233,11 & 376,19 \\
\hline Rana temporaria & $30 \mathrm{TXN}$ & 100,00 & 117,03 & 90,82 & 39,96 & 4835,37 & 241 & 16,72 & 225,26 & 65,70 & 178,11 & 180,21 & 56,93 & \begin{tabular}{|l|}
1297,17 \\
\end{tabular} & 156,49 & 65,5 & 21,61 & 421,85 & 243,14 & 248,53 & 394,30 \\
\hline Rana temporaria & $\begin{array}{l}\text { 30TXN19 } \\
\end{array}$ & 26,00 & 129,97 & 85,70 & 39,96 & 4614,73 & 244,82 & 32,49 & 212,33 & 96,22 & 187,60 & 189,94 & 71,90 & 1314,87 & 159,18 & 66,88 & 22,29 & 431,17 & 249,34 & 264,29 & 396,94 \\
\hline Rana temporaria & $30 \mathrm{TXN} 23$ & 100,00 & 111,31 & 102,05 & 38,93 & 5571,81 & 257,65 & $-2,50$ & 260,15 & 50,36 & 183,84 & 183,84 & 41,60 & 988,25 & 120,37 & 48,46 & 22,30 & 315,84 & 175,14 & 175,14 & 299,01 \\
\hline Rana temporaria & 30 TXN25 & 100,00 & 100,82 & 98,30 & 39,01 & 5322,00 & 240,78 & $-7,48$ & 248,25 & 43,32 & 170,44 & 170,44 & 34,87 & \begin{tabular}{|l|}
1122,83 \\
\end{tabular} & 133,32 & 57,64 & 20,37 & 39 & 207,64 & 207,64 & 335,49 \\
\hline $\begin{array}{l}\text { Rana temporaria } \\
\text { and }\end{array}$ & \begin{tabular}{|l|}
$30 T X N 26$ \\
\end{tabular} & 89,00 & $\begin{array}{l}93,02 \\
93,17\end{array}$ & $\begin{array}{l}30,00 \\
96,25 \\
\end{array}$ & 39 & 5206,27 & $\begin{array}{l}240,10 \\
230,03\end{array}$ & \begin{tabular}{|l|l|}
$-12,40$ \\
$-12,54$
\end{tabular} & \begin{tabular}{|l|}
242,57 \\
245
\end{tabular} & 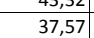 & \begin{tabular}{|l|}
161,61 \\
101
\end{tabular} & $\begin{array}{l}161,63 \\
161,4\end{array}$ & 28, 28,95 & \begin{tabular}{|l|l|l|l|}
1181,31 \\
\end{tabular} & \begin{tabular}{|l|l|}
137,49 \\
137
\end{tabular} & $\mid 62,37$ & $\begin{array}{l}19,12 \\
2,51\end{array}$ & 369,64 & 223,78 & \begin{tabular}{|l|}
223,78 \\
\end{tabular} & 348,45 \\
\hline Rana temporaria & 30TXN27 & 72,00 & 109,27 & 94,73 & 39,63 & 5078,57 & 241,06 & 4,33 & 236,72 & 54,34 & 174,58 & 175,53 & 45,96 & 1221,24 & 147,16 & 62,18 & 21,02 & 393,30 & 230,13 & 231,38 & 369,47 \\
\hline Rana temporaria & 30TXN28 & 100,00 & 112,90 & 92,41 & \begin{tabular}{|l|l|}
39,88 \\
\end{tabular} & 4942,30 & 239,95 & 9,99 & 229,95 & 59,69 & $\mid$\begin{tabular}{|l|}
175,67 \\
\end{tabular} & 177,35 & 51.08 & 1269,48 & $\mid 153,18$ & $\mid 64,76$ & 21,08 & 410,29 & 240,76 & 245,22 & 384,35 \\
\hline Rana temporaria & 30 TXN32 & 100,00 & 113,49 & 102,85 & 38,92 & 5636,46 & 260,48 & $-2,03$ & 262,51 & 51,78 & 186,71 & 186,71 & 42,65 & 896,38 & 106,61 & 44,13 & 21,28 & 279,60 & 161,46 & 161,46 & 264,25 \\
\hline Rana temporaria & 30 TXN33 & 100,00 & 113,11 & 101,81 & 38,94 & 5557,36 & 257,84 & $-1,08$ & 258,92 & 52,09 & 185 & 185 & 43 & 960,76 & 115,81 & 47,24 & 21,58 & 303,97 & 173,33 & 173,33 & 28 \\
\hline Rana temporaria & 30 XN35 & 100,00 & 91,78 & $\begin{array}{ll}97,76 \\
\end{array}$ & 38,99 & 5311,18 & 231,03 & $-16,31$ & 247,34 & 35,01 & 161,50 & 161,50 & 26,25 & 1113,44 & 128,04 & 59,14 & 18,53 & 343,19 & 211,70 & 211,70 & 323,82 \\
\hline Rana temporaria & 30 TXN36 & 81,00 & 90,19 & 96,37 & 39,05 & 5227,71 & 226,97 & $-16,30$ & 243,27 & 34,44 & 158,80 & 158,81 & 25,69 & 1166,10 & 134,19 & 62,39 & 18,37 & 360,71 & 223,80 & 223,80 & 340,07 \\
\hline Rana temporaria & 30TXN37 & & & & & & & & & & & & & & & & & & & & \\
\hline Rana temporaria & 30TXN41 & 100,00 & 11 & 47 & 38,94 & 72,28 & 17 & 1,97 & 0 & \begin{tabular}{|l|l|}
81,03 \\
\end{tabular} & 9 & 192,59 & 47 & 796,64 & 92,31 & 38,74 & 62 & 00 & 145,39 & 145,78 & 228,46 \\
\hline Rana temporaria & 30 TXN44 & 100,00 & 88,07 & 98,23 & 38,93 & 5375,46 & 228,34 & $-21,44$ & 249,78 & 30,71 & 158,55 & 158,55 & 21,58 & 1053,74 & 117,87 & 56,95 & 17,45 & 316,51 & 203,15 & 203,15 & 298,49 \\
\hline
\end{tabular}




\begin{tabular}{|c|c|c|c|c|c|c|c|c|c|c|c|c|c|c|c|c|c|c|c|c|c|}
\hline TAXON & UTM & $\mathrm{km2}$ & BIO1 & $\begin{array}{l}\mathrm{BIO2} \\
\end{array}$ & $\mathrm{BIO3}$ & BIO4 & B105 & B106 & B107 & B108 & B109 & BIO10 & BIO11 & B1012 & BIO13 & BIO14 & BIO15 & BIO16 & BIO17 & BIO18 & BlO19 \\
\hline Rana temporaria & 30TXN45 & 100,00 & 85,92 & 97,14 & 38,97 & 5304,76 & 224,21 & $-21,97$ & 246,18 & 29,51 & 155,51 & 155,51 & 20,47 & $\begin{array}{r}1105,56 \\
\end{array}$ & 123,97 & 60,19 & 17,23 & 333,86 & 214,72 & 214,72 & 314,68 \\
\hline Rana temporaria & 30TXN46 & 75,00 & 86,27 & 96,27 & 39,05 & 5234,26 & 222,50 & $-20,60$ & 243,10 & 30,64 & 154,88 & 154,91 & 21,63 & 1150,02 & 129,98 & 62,58 & 17,33 & 350,31 & 224,32 & 224,35 & 329,99 \\
\hline Rana temporaria & 30TXN54 & 100,00 & 91,52 & 98,72 & 38,99 & 5372,49 & 231,15 & $-18,93$ & 250,08 & 33,87 & \begin{tabular}{|l|l|}
161,74 \\
\end{tabular} & \begin{tabular}{ll|}
161,74 \\
\end{tabular} & 24,79 & 1018,51 & \begin{tabular}{|l|l|}
113,14 \\
\end{tabular} & 54,83 & 17,13 & 304,08 & $\begin{array}{l}198,37 \\
\end{array}$ & $\begin{array}{l}198,37 \\
\end{array}$ & 286,13 \\
\hline Rana temporaria & 30TXN55 & 100,00 & 83,60 & 96,82 & 38,95 & 5296,25 & 221,06 & $-24,57$ & 245,62 & 27,39 & \begin{tabular}{ll|l}
153,08 \\
\end{tabular} & \begin{tabular}{ll|}
153,08 \\
\end{tabular} & 18,14 & \begin{tabular}{ll|l}
1091,06 \\
\end{tabular} & \begin{tabular}{|l|l|}
120,27 \\
\end{tabular} & 60,17 & \begin{tabular}{ll|l}
16,46 \\
\end{tabular} & \begin{tabular}{|l|l|}
324,97 \\
\end{tabular} & 215,11 & 215,11 & 305,78 \\
\hline Rana temporaria & 30TXN56 & 37,00 & 79,52 & 95,46 & 38,96 & 5231,69 & 215,01 & $-27,01]$ & 242,02 & $24,21 \mid$ & 148,19 & 148,19 & 14,99 & 1149,13 & $126,64[$ & 64,19 & 16,15 | & $343,11 \mid$ & $228,41 \mid$ & 228,41 & 322,84 \\
\hline Rana temporaria & 30TXN63 & 100,00 & 94,94 & 99,57 & 38,95 & 5416,45 & 235,38 & $-17,14$ & 252,52 & 42,68 & \begin{tabular}{|l|l|l|}
165,40 \\
\end{tabular} & 165,40 & 27,29 & 934,84 & 101,29 & 50,20 & \begin{tabular}{ll|l}
16,66 \\
\end{tabular} & 273,25 & \begin{tabular}{ll|}
183,96 \\
\end{tabular} & \begin{tabular}{ll|}
184,22 \\
\end{tabular} & 256,22 \\
\hline Rana temporaria & 30TXN64 & 100,00 & 83,53 & 97,27 & 38,80 & 5341,30 & 221,56 & $-25,87$ & 247,43 & 26,82 & 153,35 & 153,35 & 17,30 & 1027,09 & 110,20 & 57,12 & 15,75 & 298,96 & 204,99 & 205,07 & 280,60 \\
\hline Rana temporaria & 30TXN65 & 92,00 & 75,72 & 95,36 & 38,75 & 5277,87 & 211,78 & $-31,52$ & 243,30 & 20,16 & \begin{tabular}{|l|l|l|}
145,08 \\
\end{tabular} & \begin{tabular}{|l|l|}
145,08 \\
\end{tabular} & 10,64 & 1101,25 & 117,80 & 62,58 & 15,22 & \begin{tabular}{|l|l|}
320,67 \\
\end{tabular} & 221,68 & 221,68 & 301,24 \\
\hline Rana temporaria & 30TXN66 & 6,00 & 87,25 & 96,60 & 39,35 & 5232,89 & 221,79 & $-20,99$ & 242,79 & 31,36 & \begin{tabular}{l|l|l|l|}
155,43 \\
\end{tabular} & $\begin{array}{l}155,50 \\
\end{array}$ & 22,10 & \begin{tabular}{l|l|l|l|}
1101,02 \\
\end{tabular} & 121,46 & 60,74 & \begin{tabular}{ll|}
16,26 \\
\end{tabular} & \begin{tabular}{|l|l|}
328,58 \\
\end{tabular} & 220,57 & 220,71 & 308,65 \\
\hline Rana temporaria & 30TXN74 & 100,00 & 67,09 & 93,69 & 38,16 & 5304,14 & 202,82 & $-39,59$, & $242,41 \mid$ & 15,92 & $136,99 \mid$ & 136,99 & 2,03 & 1089,61 & 112,52 & $63,81$. & 14,30 & 307,78 & 223,36 & 223,49 & 288,38 \\
\hline Rana temporaria & 30TXN75 & 83,00 & 65,57 & 93,03 & 38,28 & 5259,30 & 199,91 & $-40,09$ & 240,00 & 10,91 & $\begin{array}{ll}134,93 \\
\end{array}$ & \begin{tabular}{ll|}
134,93 \\
\end{tabular} & 1,10 & 1131,74 & \begin{tabular}{|l|l|}
117,47 \\
\end{tabular} & 66,48 & 14,20 & 322,24 & 232,28 & 232,28 & 302,19 \\
\hline Rana temporaria & 30TXN83 & 100,00 & 75,68 & 95,40 & 38,34 & 5342,54 & 212,55 & $-33,13$ & 245,68 & 55,34 & \begin{tabular}{l|l}
445,72 \\
\end{tabular} & 145,72 & 9,74 & $\begin{array}{l}993,85 \\
\end{array}$ & 102,26 & 57,44 & 14,39 & 278,46 & 205,26 & 206,54 & 257,59 \\
\hline Rana temporaria & 30TXN84 & 100,00 & 50,41 & 89,26 & 37,13 & 5272,72 & 183,66 & $-53,41$ & 237,07 & 35,53 . & 120,55 & 120,55 & $-13,35$ & 1171,25 | & 119,66 & 71,51 & 13,39 & 325,22 & 244,61 & 244,93 & 302,94 \\
\hline Rana temporaria & 30TXN85 & 53,00 & 42,17 & 86,92 & 36,71 & 5231,16 & 173,46 & $-60,17 \mid$ & 233,62 & 9,99 & 112,02 & 112,02 & $-20,73$ & 1248,27 & 126,53 & 77,25 & 13,13 & 346,39 & 261,15 & 261,15 & 324,94 \\
\hline Rana temporaria & 30TXN90 & 100,00 & 93,84 & 99,07 & 38,37 & 5463,30 & 235,24 & $-19,39$ ] & 254,62 & 111,83 & $164,67 \mid$ & 164,93 & 25,66 & 755,96 & 83,18 & 41,6 & 15,97 & 215,56 & 158,02 & 162,15 & 183,27 \\
\hline Rana temporaria & 30TXN93 & 100,00 & 48,20 & 88,18 & 36,68 & 5295,76 & 181,29 & $-55,86$ & 237,16 & $\begin{array}{l}58,64 \\
\end{array}$ & \begin{tabular}{|l|l|}
118,67 \\
1
\end{tabular} & $\begin{array}{l}118,67 \\
1\end{array}$ & $-15,74$ & 1150,99 & 119,68 & 71,05 & 13,38 & \begin{tabular}{l|l|}
322,05 \\
\end{tabular} & 242,88 & 243,18 & 291,27 \\
\hline Rana temporaria & 30TXN94 & 50,00 & 49,03 & 88,31 & 36,92 & 5266,55 & 181,26 & $-54,64$ & 235,91 & 53,19 & \begin{tabular}{|l|l|}
119,07 \\
\end{tabular} & $\begin{array}{l}119,07 \\
\end{array}$ & $-14,66$ & 1173,98 & 120,41 & 72,41 & 13,14 & 326,20 & 247,68 & \begin{tabular}{|l|l|}
248,08 \\
\end{tabular} & 300,06 \\
\hline Rana temporaria & 30TYNOO & 100,00 & 89,01 & 97,77 & 38,10 & 5436,31 & 229,17 & $-23,37$ & 252,54 & \begin{tabular}{ll|}
106,64 \\
\end{tabular} & $\begin{array}{ll}159,62 \\
\end{array}$ & 159,92 & 21,38 & \begin{tabular}{|l|l|}
777,07 \\
7
\end{tabular} & 85,95 & 43,85 & 15,60 & 223,04 & $\begin{array}{l}165,59 \\
\end{array}$ & $\begin{array}{l}170,13 \\
\end{array}$ & 184,36 \\
\hline Rana temporaria & 30TYN01 & 100,00 & 87,26 & 97,46 & 38,44 & 5402,29 & 226,07 & $-24,44$ & 250,51 & 104,60 & 157,51 & $157,71 \mid$ & $20,01 \mid$ & 824,62 & 89,14 & 46,93 & 14,90 | & 233,53 & 175,42 & 179,88 & 199,54 \\
\hline Rana temporaria & 30TYN02 & 100,00 & 68,75 & 93,02 & 37,67 & 5353,69 & 204,51 & $-39,25$ & 243,76 & $84,01 \mid$ & $139,07 \mid$ & 139,08 & 2,90 & 982,46 & 104,07 & 58,76 & 13,90 & 276,88 & 209,18 & 212,16 & 242,29 \\
\hline Rana temporaria & 30TYN03 & 99,00 & 36,88 & 84,36 & 35,64 & 5266,47 & 167,53 & $-65,62$ & 233,15 & 48,42 & 107,42 & 107,42 & $-25,95$ & 1224,93 & 127,53 & 77,30 & 13,04 & 343,70 & 260,60 & 260,76 & 307,40 \\
\hline Rana temporaria & 30TYN04 & 24,00 & 37,92 & 84,46 & 35,90 & 5244,13 & 168,00 & $-64,05$ & 232,05 & 49,61 & 108,08 & 108,08 & $-24,88$ & 1240,59 & 127,92 & 78,29 & $12,91 \mid$ & 345,81 & 264,09 & 264,09 & 313,63 \\
\hline Rana temporaria & 30TYN12 & 100,00 & 59,95 & 90,18 & 37,03 & 5337,92 & 193,96 & $-46,36$ & 240,32 & 74,31 & \begin{tabular}{|l|l|}
130,37 \\
\end{tabular} & 130,42 & $-5,22$ & 1041,24 & 110,51 & 63,90 & \begin{tabular}{ll|}
13,66 \\
\end{tabular} & \begin{tabular}{|l|l|}
294,87 \\
\end{tabular} & 224,28 & 227,15 & 253,79 \\
\hline Rana temporaria & 30TYN13 & 100,00 & 47,94 & 86,82 & 36,42 & 5292,12 & 179,49 & $-55,73$ & 235,22 & $60,84[$ & 118,25 & 118,25 & $-16,06$ & 1150,14 & $120,31 \mid$ & 72,13 & 13,03 & $323,51 \mid$ & $247,41 \mid$ & 248,28 & 284,42 \\
\hline Rana temporaria & 30TYN14 & 42,00 & 31,99 & 81,89 & 35,16 & 5231,31 & 160,33 & $-69,29$ & 229,62 & 42,90 & 102,19 & 102,19 & $-30,23$ & 1279,76 & 132,24 & 81,80 & 12,62 & 357,57 & 274,11 & 274,11 & 321,20 \\
\hline Rana temporaria & 30TYN21 & 100,00 & 66,17 & 91,41 & 37,11 & 5384,10 & 201,54 & $-41,29$ & 242,83 & 81,39 & \begin{tabular}{|l|l|}
137,00 \\
\end{tabular} & 137,03 & 0,17 & 975,38 & 105,45 & 59,65 & 14,11 & 279,86 & 212,92 & 216,61 & 230,55 \\
\hline Rana temporaria & 30TYN22 & 100,00 & 50,84 & 86,83 & 36,13 & 5324,42 & 183,01 & $-53,86$ & 236,86 & 64,18 & \begin{tabular}{l|l|l|}
121,53 \\
\end{tabular} & \begin{tabular}{|l|l|}
121,54 \\
\end{tabular} & $-13,60$ & \begin{tabular}{|l|l|}
1107,97 \\
\end{tabular} & 117,49 & 69,53 & 13,33 & 314,53 & 240,49 & 242,34 & 268,20 \\
\hline Rana temporaria & 30TYN23 & 100,00 & 31,49 & 80,98 & 34,68 & 5249,75 & 159,70 & $-70,20$ & 229,90 & 42,31 & $\begin{array}{ll}101,95 \\
\end{array}$ & 101,95 & $-30,77$ & 1263,16 & 131,94 & 81,12 & 12,65 & 355,52 & 272,37 & 273,15 & 312,09 \\
\hline Rana temporaria & 30TYN24 & 45,00 & 12,23 & $75,01$. & 33,06 & 5179,52 & 136,49 & $-86,88 \mid$ & $223,37 \mid$ & 20,55 [ & 82,48 _ ا & 82,48 & $-47,96$ & 1414,76 & $146,01]$ & 92,52 & 12,06 & 395,43 & 303,44 & 303,44 & 355,09 \\
\hline Rana temporaria & 30TYN32 & 100,00 & 53,61 & 87,07 & \begin{tabular}{|l|}
36,17 \\
\end{tabular} & 5340,93 & 185,78 & $-51,45$ & 237,22 & 67,34 & \begin{tabular}{ll|}
124,30 \\
\end{tabular} & 124,31 & $-11,23$ & $\begin{array}{l}094,52 \\
\end{array}$ & 116,32 & 69,00 & 13,39 & $\begin{array}{l}311,69 \\
\end{array}$ & \begin{tabular}{|l|l|}
239,92 \\
\end{tabular} & 243,42 & 261,42 \\
\hline Rana temporaria & 30TYN33 & 73,00 & 24,93 & 78,12 & 33,91 & 5242,21 & 151,45 & \begin{tabular}{|l|l|}
$-75,58$ \\
\end{tabular} & \begin{tabular}{|l|l|}
227,03 \\
\end{tabular} & 34,83 & \begin{tabular}{l|l|}
95,59 \\
\end{tabular} & 95,59 & $-36,74$ & 1312,23 & 137,11 & 85,36 & 12,44 & 369,86 & 284,55 & 284,55 & 322,51 \\
\hline Rana temporaria & 30TYN34 & 5,00 & 19,10 & 76,05 & 33,38 & 5195,92 & 143,63 & $-80,59$ & 224,21 & 28,24 & 89,30 & 89,30 & $-41,75$ & 1371,27 & 141,84 & 89,65 & 12,14 & 383,84 & 296,44 & 296,44 & 340,91 \\
\hline Rana temporaria & 30TYN41 & 60,00 & 68,64 & 91,25 & 36,95 & 5417,10 & 204,09 & $-39,29$ & 243,38 & $84,25[$ & 128,36 & $139,81 \mid$ & 2,00 & $977,54[$ & 105,69 & 60,61 & 14, & 281,73 & 217,47 & 223,80 & 225,39 \\
\hline Rana temporaria & 30TYN42 & 60,00 & 32,27 & 79,78 & 34,22 & 5289,33 & 160,47 & $-69,20$ & 229,68 & 43,05 | & 103,33 & 103,33 & $-30,38$ & 1247,89 & 131,84 & 80,87 & 12, & 354 & 272,80 & 273,09 & 300,99 \\
\hline Rana temporaria & 31TBG80 & 101,00 & 149,01 & 112,34 & 37,09 & 6464,87 & 312,28 & \begin{tabular}{ll|}
14,98 \\
\end{tabular} & \begin{tabular}{|l|l|}
297,29 \\
\end{tabular} & \begin{tabular}{ll|}
175,95 \\
\end{tabular} & $\begin{array}{ll}77,63 \\
\end{array}$ & 232,22 & 67,21 & 420,91 & 53,57 & 19,66 & 29,46 & \begin{tabular}{|l|l|}
136,49 \\
\end{tabular} & \begin{tabular}{|l|l|}
74,87 \\
\end{tabular} & \begin{tabular}{l|l}
93,65 \\
\end{tabular} & 75,19 \\
\hline Rana temporaria & 31TBH51 & 66,00 & 72,18 & 91,90 & 37,08 & 5440,33 & 208,14 & $-36,69$ & 244,83 & 88,29 & 81,93 & \begin{tabular}{|l|l|}
143,57 \\
\end{tabular} & 5,17 & 963,17 & $\begin{array}{l}103,96 \\
\end{array}$ & 59,76 & \begin{tabular}{|l|}
14,44 \\
\end{tabular} & \begin{tabular}{|l|l|}
277,84 \\
\end{tabular} & \begin{tabular}{|l|}
214,91 \\
\end{tabular} & 223,19 & 220,08 \\
\hline Rana temporaria & 31TBH52 & 61,00 & 26,09 & 77,48 & 33,53 & 5281,27 & 152,94 & \begin{tabular}{|l|l|l}
$-74,49$ \\
\end{tabular} & 227,43 & 36,03 & 97,28 & 97,28 & $-36,08$ & 1296,34 & 136,53 & 84,57 & 12,68 & 367,71 & \begin{tabular}{|l|l|}
283,47 \\
\end{tabular} & 283,64 & 313,16 \\
\hline Rana temporaria & 31TBH62 & 100,00 & 46,28 & 83,24 & 35,06 & 5349,68 & 176,70 & $-57,15$ & 233,85 & $58,97 \mid$ & 105,13 & 117,52 & $-18,0$ & 11169,48 & 123,92 & 75,53 & 13, & 333, & 259,65 & 262,50 & 275,92 \\
\hline Rana temporaria & 31TBH63 & 36,00 & 21,95 & 75,16 & 32,93 & 5248,28 & 146,94 & $-77,73$ & 224,67 & $31,48 \mid$ & 92,89 [ & 92,89 [ & $-39,50$ & 1345,64 & 140,64 & 88,57 & 12,28 & 379,52 & 294,93 & 294,93 & 327,05 \\
\hline Rana temporaria & 31TBH72 & 96,00 & 38,68 & 80,03 & 34,10 & 5337,34 & 167,37 & $-63,47$ & 230,84 & 50,35 & 85,49 & 110,15 & $-24,84$ & 1231,11 & 129,94 & 80,44 & 12,89 & 350,21 & 273,33 & 276,04 & 291,12 \\
\hline Rana temporaria & 31TBH82 & 99,00 & 23,05 & 74,61 & 32,54 & 5307,09 & 149,13 & $-76,48$ & 225,61 & 32,80 & 82,46 & 94,82 & $-38,87$ & 1343,39 & 141,01 & 88,87 & \begin{tabular}{|l|l|}
12,47 \\
\end{tabular} & 380,00 & \begin{tabular}{|l|l|}
296,94 \\
\end{tabular} & 297,26 & 321,47 \\
\hline Rana temporaria & 31TBH90 & 100,00 & 67,45 & 87,70 & \begin{tabular}{l|l|}
35,65 \\
\end{tabular} & 5529,86 & 203,16 & $-39,40$ & 242,56 & 82,86 & \begin{tabular}{ll|}
11,64 \\
\end{tabular} & 140,52 & $0, \mathrm{c}$ & 1058,72 & \begin{tabular}{l|l|l|}
113,45 \\
\end{tabular} & 68,57 & \begin{tabular}{|l|l|}
14,69 \\
\end{tabular} & \begin{tabular}{|l|l|}
307,44 \\
\end{tabular} & 233,12 & \begin{tabular}{l|l|}
251,45 \\
\end{tabular} & 233,86 \\
\hline Rana temporaria & 31тВН91| & 100,00 & 57,69 & 84,80 . & 35,00 & 5466,00 & 190,84 & $-47,45 \mid$ & 238,29 & 71,85 & $34,21 \mid$ & 130,24 & $-8,32$ & 1130,54 & 119,98 & 73,84 & 13,92 & 325,03 & 251,39 & $264,91 \mid$ & 256,33 \\
\hline Rana temporaria & 31TBH92 & 100,00 & 27,92 & 75,45 & 32,68 & 5333,73 & 154,78 & $-72,13$ & 226,91 & 38,21 & 69,40 & 99,83 . & $-34,58$ & 1322,21 & $\mid 138,87$ & 87,78 & 12,61 & 374,57 & 293,48 & 295,91 & 313,36 \\
\hline Rana temporaria & 31TCG09 & 100,00 & 71,88 & 87,96 & 35,48 & 5589,51 & 208,91 & $-35,51$ & 244,42 & 87,62 & 5,34 & 145,74 & 3,81 & 1035,52 & 111,78 & 67,04 & 15,48 & 303,12 & 223,27 & 250,01 & 223,32 \\
\hline Rana temporaria & 31TCG10 & 100,00 & 148,09 & 106,57 & 36,55 & 6410,78 & 305,75 & \begin{tabular}{ll|}
17,94 \\
\end{tabular} & 287,81 & 173,48 & 74,81 & 230,39 & 66,60 & 474,01 & 56,88 & 22,27 & 28,30 & 150,99 & 84,91 & \begin{tabular}{|l|}
108,93 \\
\end{tabular} & 84,92 \\
\hline Rana temporaria & 31TCG38 & 101,00 & 100,74 & 92,05 & \begin{tabular}{l|l|}
35,65 \\
\end{tabular} & 5808,73 & 242,40 & $-12,33$ & 254,73 & \begin{tabular}{ll|}
119,60 \\
\end{tabular} & 28,60 & 176,52 & 28,6 & 875,04 & $\begin{array}{ll}97,42 \\
\end{array}$ & 50,57 & 19,64 & 266,84 & $\begin{array}{l}169,90 \\
\end{array}$ & $\begin{array}{l}237,59 \\
\end{array}$ & 169,90 \\
\hline Rana temporaria & 31 TCG39 & 100,00 & 72,43 & 84,84 & 34,63 & 508,18 & 208 & $-33,39$, & 241 & $87,47 \mid$ & $13,71 \mid$ & 146,77 & 4,76 & 1056,72 & 114,67 & 66,88 & 16,13 & 310,90 & 222,37 & 261,89 & 223,34 \\
\hline Rana temporaria & \begin{tabular}{|l|l}
31 TCG59 \\
\end{tabular} & 101,00 & 53,42 & 77,91 & 33,18 & 5480,81 & 9 & $-46,43$ & 231,62 & \begin{tabular}{|l|l|}
65,12 \\
\end{tabular} & 6,63 & \begin{tabular}{|l|l|}
127,25 \\
\end{tabular} & $-10,71$ & 1162,71 & \begin{tabular}{l|l|}
125,42 \\
\end{tabular} & 76,56 & 14,33 & 334,58 & 253,12 & \begin{tabular}{|l|l|}
273,89 \\
\end{tabular} & 255,58 \\
\hline Rana temporaria & 31TCG78 & 101,00 & 85,85 & 82,15 & 33,85 . & 5619,35 & 220,94 & \begin{tabular}{|c|}
$-18,18$ \\
\end{tabular} & 239,12 & \begin{tabular}{|l|}
100,67 \\
\end{tabular} & 23,43 & 160,50 & $\begin{array}{l}18,55 \\
\end{array}$ & 949,62 & \begin{tabular}{l|l|}
106,95 \\
\end{tabular} & 56,21 & \begin{tabular}{|l|}
19,49 \\
\end{tabular} & 285,60 & \begin{tabular}{l|l|}
186,85 \\
\end{tabular} & \begin{tabular}{|l|}
246,24 \\
\end{tabular} & 187,27 \\
\hline Rana temporaria & 31TCG79 & 93,00 & 84,65 & 82,50 & 33,99 & 614,10 & 73 & $\begin{array}{ll}-19,88 \\
\end{array}$ & 239,61 & 99,70 & 26,61 & 159,09 & 17,16 & 961,84 & 107,81 & 57,50 & 19,35 & 288,82 & \begin{tabular}{|l|l|}
191,07 \\
\end{tabular} & 250,67 & 192,28 \\
\hline Rana temporaria & 31TCG87 & 99,00 & 67,24 & 77,10 & 32,93 & 5503,48 & 199,44 & $-31,32$ & 230,76 & $78,97 \mid$ & $13,91 \mid$ & 141,54 & 3,5 & 1068,36 & 117,04 & 67,59 & 16,05 [ & $307,45 \mid$ & 224,74 & 256,98 & 226,27 \\
\hline Rana temporaria & 31TCG88 & 100,00 & 63,33 & 76,98 & 32,89 & 5497,30 & 195 & $-35,57$ & 230,86 & $73,6,-29$ & 28, & 137, & $-0,4$ & 1098,8 & 119,62 & 68,98 & 15, & 316 & 231,11 & 263,61 & 235,88 \\
\hline Rana temporaria & $31 \mathrm{TCC}$ & 99,00 & & & 33 & 5506,40 & & $-33,72$ & & 78, & 20,48 & \begin{tabular}{|l|l|}
140,17 \\
\end{tabular} & 1,86 & 1083,69 & 118,31 & 67,99 & \begin{tabular}{l|l}
16,35 \\
\end{tabular} & \begin{tabular}{|l|l|}
313,94 \\
\end{tabular} & 227,60 & 264,52 & 231,28 \\
\hline Rana temporaria & 31TCG96 & 101,00 & 83,33 & 77,80 & 32,93 & 5542,42 & 215,76 & $-16,57$ & 232,33 & $\begin{array}{l}95,44 \\
\end{array}$ & 20,50 & \begin{tabular}{l|l}
157,85 \\
\end{tabular} & 18,52 & 965,67 & \begin{tabular}{|l|l|}
108,47 \\
\end{tabular} & 57,35 & 18,90 & 283,52 & \begin{tabular}{ll|}
192,36 \\
\end{tabular} & 241,41 & 193,01 \\
\hline Rana temporaria & 31TCG97 & 100,00 & 71,85 & 76,80 & 32,78 & 5500,74 & 203,82 & $-26,53$ & 230,35 & 81,58 & 21,96 & 146,11 & 8,09 & 1042,29 & 114,65 & 4,51 & 6,80 & 300,67 & 216,33 & 253,16 & 218,34 \\
\hline Rana temporaria & 31TCG98 & 101,00 & 64,66 & 76,27 . & $32,77 \mid$ & 5478,46 & 196,19 & $-33,27$ & 229,46 & $73,71 \mid$ & 26,64 & 138,66 & 1,43 & 1092,72 & 118,86 & 68,90 & $15,71 \mid$ & 312,52 & $231,01 \mid$ & 261,60 & 235,04 \\
\hline Rana te & & & & & & 5 & & $-26,95$ & & 85 & 20,57 & 146,93 & 8 & & & & 16 , & & 215,59 & 25 & 218,58 \\
\hline Rana temporaria & 31TCH01 & 100,00 & 24,67 & 73,95 & 32,18 & 5343,58 & 151,48 & $-74,40$ & 225,88 & 34,28 & 76,49 & 97,0 & \begin{tabular}{|c|}
$-37,29$ \\
\end{tabular} & 1335,78 & 140,91 & 88,65 & \begin{tabular}{ll|}
12,56 \\
\end{tabular} & 378,69 & 297,24 & 298,31 & 314,84 \\
\hline Rana temporaria & 31ТCHO2 & 95,00 & 16,76 & 72,03 & 31,69 & 5314,50 & 142,11 & $-81,48$ & 223,59 & 25,51 & \begin{tabular}{|l|l|}
72,44 \\
\end{tabular} & 88,96 & $-44,56$ & 1402,13 & 146,60 & $\begin{array}{l}93,52 \\
\end{array}$ & 12,24 & 394,75 & 310,47 & 310,92 & 335,91 \\
\hline
\end{tabular}




\begin{tabular}{|c|c|c|c|c|c|c|c|c|c|c|c|c|c|c|c|c|c|c|c|c|c|}
\hline TAXON & UTM & $\mathrm{km2}$ & BIO1 & $\begin{array}{l}\mathrm{BIO2} \\
\end{array}$ & $\mathrm{BIO3}$ & B104 & B105 & B106 & B107 & B108 & B109 & BIO10 & BIO11 & BIO12 & BIO13 & BIO14 & BIO15 & BIO16 & BIO17 & BIO18 & BlO19 \\
\hline Rana temporaria & $31 \mathrm{TCH} 03$ & 12,00 & 56,29 & 83,90 & 34,95 & 5433,32 & 187,96 & $-48,19$ & 236,15 & 70,27 & 32,02 & 128,30 & $-9,55$ & 1176,73 & 123,28 & 78,25 & 13,22 & 336,01 & 262,95 & 275,64 & 270,55 \\
\hline Rana temporaria & 31TCH10 & 101,00 & 70,82 & 86,96 & 35,20 & 5577,10 & 206,95 & $-36,13$ & 243,08 & 86,42 & 10,36 & 144,48 & 2,97 & 1077,72 & 114,90 & 70,09 & 15,04 & 313,38 & 233,40 & 262,96 & 234,27 \\
\hline Rana temporaria & 31TCH11 & 99,00 & 40,14 & 78,04 & 33,24 & 5413,46 & 169,87 & $-60,88$ & 230,75 & 51,68 & 42,97 & 112,88 & $-23,66$ & 1250,71 & \begin{tabular}{ll|}
132,46 \\
\end{tabular} & 83,15 & 13,13 & 357,02 & 278,78 & 286,50 & 287,67 \\
\hline Rana temporaria & 31TCH12 & 99,00 & 35,17 & 76,66 & 32,96 & 5377,96 & 163,51 & $-65,17$ & 228,68 & 46,14 & 49,97 & 107,55 & $-28,01$ & 1292,35 & 136,01 & 86,41 & 12,75 & \begin{tabular}{|l|l|}
367,07 \\
\end{tabular} & 288,25 & \begin{tabular}{|l|}
293,91 \\
\end{tabular} & 301,36 \\
\hline Rana temporaria & 31TCH13 & & & & & & & & & & & & & & & & & & & & \\
\hline Rana temporaria & 31TCH14 & & & & & & & & & & & & & & & & & & & & \\
\hline Rana temporaria & $31 \mathrm{TCH} 20$ & 99,00 & 29,54 & 74,46 & 32,24 & 5393,53 & 158,03 & $-69,34$ & 227,37 & 39,43 & 54,78 & 102,71 & $-32,76$ & \begin{tabular}{|l|}
1309,39 \\
\end{tabular} & 138,61 & 86,76 & 12,76 & 371,32 & 291,52 & 295,71 & 303,96 \\
\hline Rana temporaria & $31 \mathrm{TCH} 21$ & 100,00 & 28,59 & 74,34 & 32,22 & 5380,76 & 156,52 & $-70,36$ & 226,89 & 38,52 & 49,77 & 101,43 & $-33,76$ & 1327,84 & 139,92 & 88,51 & 12,64 & 375,89 & 294,86 & 300,09 & 310,24 \\
\hline Rana temporaria & $31 \mathrm{TCH} 22$ & 100,00 & 36,77 & 76,64 & 32,94 & 5390,09 & 165,55 & $-63,34$ & 228,89 & 47,95 & 40,53 & 109,38 & $-26,45$ & 1286,02 & 135,51 & 86,24 & \begin{tabular}{|l|l|}
12,79 \\
\end{tabular} & \begin{tabular}{|l|l|}
365,47 \\
\end{tabular} & \begin{tabular}{|l|l|}
286,99 \\
\end{tabular} & \begin{tabular}{|l|l|}
294,17 \\
\end{tabular} & 298,24 \\
\hline Rana temporaria & $31 \mathrm{TCH} 23$ & 101,00 & 39,35 & 77,48 & 33,21 & 5379,69 & 168,15 & $-61,19$ - & 229,34 & $50,94[$ & 43,30 & 111,59 & $-24,16$ & 1278,98 & 134,37 & 86,22 & 12,74 & 363,34 & 286,52 & 294,29 & 297,12 \\
\hline Rana temporaria & 31TCH24 & & & & & & & & & & & & & & & & & & & & \\
\hline Rana temporaria & $31 \mathrm{TCH} 30$ & 101,00 & 34,97 & 75,26 & 32,50 & 5415,06 & 164,19 & $\begin{array}{l}-64,10 \\
\end{array}$ & 228,29 & 45,33 & 41,12 & 108,31 & $-27,73$ & 1280,86 & 135,90 & 84,92 & \begin{tabular}{|l|l|}
13,07 \\
\end{tabular} & 364,04 & 284,49 & \begin{tabular}{|l|}
292,27 \\
\end{tabular} & 294,25 \\
\hline Rana temporaria & 31TCH31 & 101,00 & 16,34 & 70,81 & 31,23 & 5342,24 & 142,52 & $-80,45$ & 222,97 & 24,73 & 73,74 & 89,29 & $-44,29$ & 1407,13 & \begin{tabular}{|l|}
147,27 \\
\end{tabular} & 93,70 & 12,09 & 394,26 & 312,75 & 313,65 & 334,46 \\
\hline Rana temporaria & 31TCH32 & 100,00 & 30,59 & 74,37 & 32,30 & 5365,39 & 158,33 & $-67,99$ & 226,33 & $40,75 \mid$ & 55,22 & 103,22 & $-31,65$. & 1322,80 & 139,29 & 88,89 & $12,41 \mid$ & 374,10 & 296,83 & 300,48 & 308,79 \\
\hline Rana temporaria & 31ТCH33 & 94,00 & 28,42 & 73,96 & 32,25 & 5346,24 & 155,51 . & - $-70,03$ & 225,54 & 38,52 & 56,33 & 100,74 & $-33,62$ & 1344,27 & 140,94 & 90,78 & 12,1 & 379,09 & 302,24 & 304,95 & 316,39 \\
\hline Rana temporaria & 31TCH34 & 2,00 & 66,65 & 85,02 & 34,99 & 5504,73 & 200,11 & $-38,88$ & 238,99 & 81,76 & 24,92 & $\begin{array}{l}139,35 \\
19\end{array}$ & $-0,33$ & 1134,10 & 119,36 & 76,22 & 13,78 & 327,18 & 248,53 & \begin{tabular}{|l|l|}
278,37 \\
\end{tabular} & 255,48 \\
\hline Rana temporaria & 31TCH40 & 99,00 & 67,52 & 82,72 & 34,24 & 5557,99 & 201,88 & $-36,39$ & 238,27 & 81,69 & 12,90 & \begin{tabular}{ll|}
141,48 \\
\end{tabular} & 0,85 & 1089,40 & \begin{tabular}{ll|}
118,08 \\
\end{tabular} & 70,05 & 15,66 & 319,18 & 231,33 & 268,49 & 233,07 \\
\hline Rana temporaria & 31TCH41 & 100,00 & 63,26 & 81,99 & 34,13 & 5523,37 & 196,65 & $-40,04$ & 236,68 & 77,13 & 9,88 & $\begin{array}{l}136,79 \\
\end{array}$ & $-2,89$ & 1124,23 & 120,96 & 73,64 & 14,88 & \begin{tabular}{|l|l|}
327,29 \\
\end{tabular} & 242,00 & \begin{tabular}{|l|}
272,27 \\
\end{tabular} & 244,91 \\
\hline Rana temporaria & $31 \mathrm{TCH} 42$ & 100,00 & 53,73 & 80,04 & 33,75 & 5467,77 & 185,45 & $-48,06[$ & 233,50 & $66,64[$ & $18,61 \mid$ & 126,77 & $-11,23$ & 1190,48 & 126,61 & 79,35 & $13,87 \mid$ & 342,55 & 260,50 & 283,88 & 266,82 \\
\hline Rana temporaria & 31TCH43 & 60,00 & 43,68 & 77,61 & 33,20 & 5405,50 & 173,36 & $-5,52$ & 229,88 & 55,53 . & 26,16 & 116,18 & $-20,01$ & 1253,39 & 132,37 & 84,77 & 12,95 & 357,19 & 279,18 & 291,92 & 287,73 \\
\hline Rana temporaria & 31TCH50 & 100,00 & 71,39 & 82,70 & 34,26 & 5567,46 & 205,94 & $-32,33$ & 238,27 & 85,79 & 11,74 & 145,40 & 4,63 & 1063,64 & 116,05 & 67,96 & 16,14 & 313,12 & 222,89 & 264,81 & 224,47 \\
\hline Rana temporaria & 31TCH51 & 101,00 & 67,54 & 82,16 & 34,13 & 5539,02 & 201,42 & $-35,78$ & 237,21 & 81,70 & 15,01 & \begin{tabular}{|l|l|l|}
141,19 \\
\end{tabular} & 1,18 & 1094,70 & 118,56 & 70,96 & \begin{tabular}{|l|l|}
15,47 \\
\end{tabular} & \begin{tabular}{|l|l|}
320,44 \\
\end{tabular} & 232,44 & \begin{tabular}{|l|l}
270,99 \\
\end{tabular} & 235,29 \\
\hline Rana temporaria & 31TCH52 & 99,00 & 38,21 & 75,38 & 32,56 & 5400,44 & 167,34 & $-60,59$ & \begin{tabular}{|l|l|}
227,93 \\
\end{tabular} & 48,91 & 33,73 & 111,10 & $-24,56$ & \begin{tabular}{|l|l|}
1280,87 \\
\end{tabular} & 135,31 & 85,82 & 12,83 & 362,94 & 284,53 & \begin{tabular}{|l|l|}
296,30 \\
\end{tabular} & 295,04 \\
\hline Rana temporaria & 31TCH60 & 100,00 & 43,75 & 75,39 & 32,54 & 5429,16 & 173,81 & $-54,41]$ & 228,22 & 54,28 . & 15,13 & 117,26 & $-18,95$ [ & 1231,44 & 131,27 & 81,77 & $13,31 \mid$ & $349,41 \mid$ & $271,67 \mid$ & 285,63 & 278,23 \\
\hline Rana temporaria & 31TCH61 & 101,00 & 43,72 & 75,90 & 32,65 & 5428,46 & 173,92 & $-55,01$ & 228,93 & 54,61 & 25,73 & \begin{tabular}{|l|}
117,07 \\
\end{tabular} & $-19,20$ & 1239,91 & 131,77 & 82,07 & 13,39 & 352,25 & 272,38 & 289,12 & 281,41 \\
\hline Rana temporaria & 31TCH62 & 86,00 & 25,43 & 72,18 & 31,67 & 5356,26 & 153,02 & \begin{tabular}{|l|}
$-71,17$ \\
\end{tabular} & 224,19 & 34,47 & 52,42 & 98,35 & $-35,47$ & 1362,91 & 142,62 & 91,10 & 12,01 & 380,74 & 303,49 & 308,27 & 321,17 \\
\hline Rana temporaria & 31TCH70 & 25,00 & 63,07 & 78,72 & 33,28 & 5501,75 & 195,50 & $-37,42$ & 232,93 & 75,62 & 13,79 & 136,87 & $-1,66$ & 1110,05 & 120,56 & 71,60 & 15,38 & 321,86 & 235,70 & 269,98 & 239,61 \\
\hline Rana temporaria & 31TCH71 & 16,00 & 42,06 & 74,86 & 32,44 & 5413,72 & 171,80 & $-55,63$ & 227,43 & 52,47 & 31,98 & 115,36 & $-20,23$ & \begin{tabular}{|l|}
1250,03 \\
\end{tabular} & 132,67 & 82,76 & 13,23 & 353,38 & 273,94 & 289,90 & 285,08 \\
\hline Rana temporaria & 31TCH72 & 2,00 & 31,13 & 72,90 & 31,93 & 5365,65 & 159,33 & $-65,51$. & $224,84 \mid$ & $40,46 \mid$ & 47,63 & 104,04 & $-30,04[$ & 1324,96 & 139,04 & 88,49 & 12,2 & 370,43 & 295,28 & 301,96 & 309,85 \\
\hline Rana temporaria & $\begin{array}{l}31 \mathrm{TCH} 80 \\
\end{array}$ & 17,00 & 26,86 & 71,15 & 31,32 & 5368,95 & 154,94 & $-68,27$ & 223,21 & 34,06 & 68,62 & \begin{tabular}{|l|l|}
100,29 \\
\end{tabular} & $-33,26$ & $\begin{array}{l}1345,76 \\
\end{array}$ & 140,51 & 87,68 & \begin{tabular}{l|l|}
12,45 \\
\end{tabular} & $\begin{array}{l}371,94 \\
3\end{array}$ & 296,81 & \begin{tabular}{l|l}
302,25 \\
\end{tabular} & 316,72 \\
\hline Rana temporaria & 31TCH90 & 57,00 & 22,38 & 69,87 & 31,00 & 5348,90 & $\begin{array}{l}149,96 \\
\end{array}$ & -71,69 & 221,65 & 20,28 & 76,64 & 95,73 & $-36,89$ & $\begin{array}{l}1376,73 \\
\end{array}$ & 142,64 & 89,22 & 12,14 & \begin{tabular}{|l|l|}
377,34 \\
\end{tabular} & \begin{tabular}{|l|}
303,91 \\
\end{tabular} & 305,72 & 327,94 \\
\hline Rana temporaria & 31TDG03 & 100,00 & 138,99 & 77,70 & 32,62 & 5595,96 & 267,33 & 32,06 & 235,27 & \begin{tabular}{|l|l|}
185,64 \\
\end{tabular} & 70,21 & 212,47 & 70,21 & \begin{tabular}{ll|l}
646,98 \\
\end{tabular} & \begin{tabular}{ll|}
76,68 \\
\end{tabular} & 31,46 & 26,92 & 203,51 & \begin{tabular}{ll|}
105,68 \\
\end{tabular} & $\begin{array}{l}179,85 \\
\end{array}$ & 105,68 \\
\hline Rana temporaria & 31TDG06 & 100,00 & 106,21 & 79,00 & 32,99] & 5609,13 & 238,65 & 2,26 & 236,39 & 121,23 & 39,69 & 180,73 & 38,92 . & $829,94[$ & 97,73 & 43,36 & 24,4 & 255,93 & $147,61 \mid$ & 225,40 & 147,75 \\
\hline Rana temporaria & 31TDG07 & 101,00 & 97,75 & 79,20 & 33,01 & 5585,81 & 230,65 & $-4,96$ & 235,61 & 112,18 & 32,50 & 172,05 & 31,12 & $884,39 \mid$ & 102,25 & 48,81 & 21,83 & 268,99 & 165,19 & 234,06 & 165,33 \\
\hline Rana temporaria & \begin{tabular}{|l|}
$31 T D G 08$ \\
\end{tabular} & 101,00 & 67,80 & 75,83 & \begin{tabular}{l|l|}
32,65 \\
\end{tabular} & 5466,88 & 199,08 & $-29,52$ & 228,60 & 74,25 & 25,33 & 141,74 & \begin{tabular}{l|l}
4,84 \\
\end{tabular} & $\begin{array}{l}1075,86 \\
\end{array}$ & 116,99 & 67,49 & \begin{tabular}{ll|}
15,94 \\
\end{tabular} & \begin{tabular}{|l|l|}
307,24 \\
\end{tabular} & 226,72 & \begin{tabular}{|l|}
258,04 \\
\end{tabular} & 230,88 \\
\hline Rana temporaria & \begin{tabular}{|l|l|}
31 TDG09 \\
\end{tabular} & 101,00 & 88,07 & 79,57 & 33,42 & 5552,21 & 221,40 & $-13,35$ & 234,75 & 102,11 & 28,74 & 162,03 & 22,14 & 952,05 & $\begin{array}{l}107,28 \\
\end{array}$ & 56,50 & 18,73 & \begin{tabular}{|l|l|}
284,35 \\
\end{tabular} & \begin{tabular}{|l|}
188,33 \\
\end{tabular} & 243,10 & 189,54 \\
\hline Rana temporaria & $\begin{array}{l}31 \text { TDG16 } \\
\end{array}$ & 100,00 & 109,61 & 78,14 & 32,94 & 5594,27 & 241,39 & 5,90 & 235,49 & \begin{tabular}{ll|}
124,73 \\
\end{tabular} & 42,68 & 183,93 & 42,52 & 816,30 & $\begin{array}{l}97,07 \\
\end{array}$ & 41,02 & 25,05 & \begin{tabular}{|l|l|}
253,79 \\
\end{tabular} & \begin{tabular}{l|l}
141,82 \\
\end{tabular} & 225,21 & 141,82 \\
\hline Rana temporaria & 31TDG17 & 100,00 & 92,30 & 77,43 & $32,9=>0$ & 5530,63 & 224,15 & $-7,93$ & 232,07 & 105,48 & 30,03 & 166,30 & 27,32 & $927,47 \mid$ & 105,12 & 53,59 & 19,78 & 274,98 & 180,58 & 237,38 & 181,09 \\
\hline Rana temporaria & 31TDG18 & 98,00 & 62,33 & 74,21 & 32,38 & 5421,81 & 192,68 & $-33,11$ & 225,79 & 60,52 & 21,32 & 135,92 & 0,71 & 1113,96 & 119,15 & 70,54 & 14,95 & 312,34 & 240,85 & 260,57 & 245,94 \\
\hline Rana temporaria & \begin{tabular}{|l|l|}
31 TDG19 \\
\end{tabular} & 44,00 & 74,09 & 76,62 & 32,84 & 5468,72 & 205,63 & $-23,84$ & 229,47 & 82,36 & 21,98 & 147,66 & 10,64 & \begin{tabular}{|l|}
1044,01 \\
\end{tabular} & 113,79 & 65,48 & 16,03 & 299,40 & 218,83 & 252,53 & 222,53 \\
\hline Rana temporaria & $\begin{array}{l}31 \text { TDG20 } \\
\end{array}$ & 100,00 & 152,94 & 71,68 & 31,71 & 5379,99 & 273,79 & 50,50 & 223,29 & 200,40 & 87,61 & 223,95 & 87,61 & $\begin{array}{l}634,60 \\
\end{array}$ & 77,02 & 33,88 & \begin{tabular}{|l|l|}
25,47 \\
\end{tabular} & \begin{tabular}{ll|}
208,06 \\
\end{tabular} & \begin{tabular}{ll|}
119,64 \\
\end{tabular} & \begin{tabular}{ll|}
165,13 \\
\end{tabular} & 119,64 \\
\hline Rana temporaria & $\begin{array}{l}31 \text { TDG26 } \\
\end{array}$ & 101,00 & 110,29 & 77,01 & 32,33 & 5569,27 & 241,08 & \begin{tabular}{l|l}
7,03 \\
\end{tabular} & 234,05 & 124,80 & 43,82 & 184,24 & 43,67 & 832,47 & 97,84 & 42,19 & 24,08 & 256,10 & $\begin{array}{l}147,86 \\
\end{array}$ & 225,80 & 147,86 \\
\hline Rana temporaria & 31TDG27 & 101,00 & 99,41 & 77,17 . & 32,82 & 5532,74 & 230,85 & $-1,67 \mid$ & $232,51 \mid$ & 113,10 & 36,06 & 173,24 & 34,05 - & 897,92 & $102,41 \mid$ & 49,96 & 20,58 _ & 268,64 & 171,64 & 232,58 & 171,86 \\
\hline Rana temporaria & \begin{tabular}{|l|}
31 TDG28 \\
\end{tabular} & 100,00 & 71,10 & 74,64 & 32,52 & 5429,70 & 201,55 & $-24,87$ & 226,41 & 71,42 & 28,10 & $\begin{array}{l}144,59 \\
\end{array}$ & 9,08 & 1066,16 & 114,64 & 66,61 & 15,65 & 301,19 & \begin{tabular}{|l|l|}
226,87 \\
\end{tabular} & 252,25 & 231,73 \\
\hline Rana temporaria & \begin{tabular}{|l|l|}
$31 T D G 29$ \\
\end{tabular} & 24,00 & 35,25 & 70,26 & 31,27 & 5344,72 & 163,50 & $-57,55$ & 221,05 & 15,77 & 73,62 & 108,52 & $-23,64$ & \begin{tabular}{|l|}
1292,58 \\
\end{tabular} & 133,03 & 81,08 & 13,01 & 360,84 & 282,65 & 286,08 & 305,85 \\
\hline Rana temporaria & 31TDG30 & 100,00 & 157,83 & 71,01 & 31,53 & 5300,33 & 277,10 & 55,68 & 221,42 & 197, & 96,21 & 227,47 & 93,06 & 632,38 & 82,25 & 31,86 & 26,59 & 212,42 & \begin{tabular}{|l|l|}
124,07 \\
\end{tabular} & 160,28 & 124,09 \\
\hline Rana temporaria & 31TDG34 & 101,00 & 129,94 & 74,44 & 31,7 & 5552,03 & 257,43 & $25,65 \mid$ & 231,78 & 165 & 62, & $203,31 \mid$ & 62, & 768,28 & $89,48[$ & 36,97 & 25,35 & 236,62 & 132,24 & 212,86 & 132,24 \\
\hline Rana temporaria & 31TDG35 & 100,00 & 124,92 & 75,47 & 31,97 ] & 5577,89 & Y & 20,32 & 233,47 & 140,55 & 57 & 198,5 & 57. & 794,52 & 92,92 & 37,77 & 25,3 & 245,58 & 137,07 & 218,86 & 137,07 \\
\hline Rana temporaria & \begin{tabular}{|l|l|}
31 TDG36 \\
\end{tabular} & 100,00 & 114,79 & 76,19 & 32,08 & 5563,09 & 4,76 & \begin{tabular}{|l|l}
11,45 \\
\end{tabular} & 233,31 & \begin{tabular}{|l|l|}
130,09 \\
\end{tabular} & 48,35 & \begin{tabular}{|l|l|}
188,44 \\
\end{tabular} & 48,04 & \begin{tabular}{|l|l|}
837,99 \\
\end{tabular} & 96,99 & 42,20 & 23,51 & 256,19 & \begin{tabular}{|l|l|}
151,28 \\
\end{tabular} & 225,56 & 151,35 \\
\hline Rana temporaria & 31TDG37 & 101,00 & 107,25 & 76,76 & 32,33 & 5546,01 & 238 & 4,78 & 233,22 & \begin{tabular}{|l|l|}
121,53 \\
\end{tabular} & 42,10 & \begin{tabular}{|l|}
180,97 \\
\end{tabular} & 41,12 & 876,42 & 99,70 & 46,81 & 21,35 & 263,89 & \begin{tabular}{|l|l|}
165,67 \\
\end{tabular} & \begin{tabular}{|l|l|}
227,95 \\
\end{tabular} & 165,95 \\
\hline Rana temporaria & 31TDG38 & 101,00 & 73,34 & 74,25 & $\begin{array}{l}32,47 \\
\end{array}$ & 5414,20 & 203,41 & $-22,12$ & 225,52 & \begin{tabular}{ll|}
68,72 \\
\end{tabular} & 37,31 & \begin{tabular}{ll|}
146,73 \\
\end{tabular} & \begin{tabular}{ll|}
11,69 \\
\end{tabular} & 1057,84 & 112,89 & 64,87 & \begin{tabular}{ll|}
15,93 \\
\end{tabular} & 300,44 & 226,13 & 248,49 & 231,54 \\
\hline Rana temporaria & 31TDG39 & 75,00 & 30,22 & 69,10 & 30,97 & 5326,44 & 157,92 & $-61,66$ - & 219,58 & 7,90 & $87,34[$ & 103,49 & $-27,81 \mid$ & \begin{tabular}{|l|l|}
1327,69 \\
\end{tabular} & 135,14 & 82,08 & 13,05 | & 73,45 & 287,85 & 289,66 & 317,77 \\
\hline Rana temporaria & 31TDG42 & 100,00 & 113,04 & 71,73 & 31,59 & 434,21 & 238, & 14,74 & 224,20 & 152,19 & 57,00 & 186,19 & 49,79 & 869,95 & 97,70 & 48, & 20, & 26 & 174,95 & 213,02 & 179 \\
\hline Rana temporaria & 31TDC & 101,00 & 12 & 72,53 & 31 & 548 & & 19 & 227,36 & \begin{tabular}{|l|l|}
168,24 \\
\end{tabular} & 56,24 & & 55,80 & \begin{tabular}{|l|l|}
841,38 \\
\end{tabular} & 93,61 & 44,30 & 21,43 & 251,91 & \begin{tabular}{|l|l}
161,19 \\
\end{tabular} & 215,44 & 161,25 \\
\hline Rana temporaria & 31TDG44 & 101,00 & 130,89 & 73,43 & 31,21 & 5539,31 & 257,59 & 26,91 & 230,68 & 168,05 & 63,87 & 204,03 & 63,87 . & 819,11 & 91,15 & 40,15 & 22,82 & 246,08 & 151,03 & 214,89 & 151,03 \\
\hline Rana temporaria & 31TDG45 & 100,00 & 123,43 & 74,48 & 31,81 & 5541,19 & 251,55 & \begin{tabular}{l|l|l|}
19,82 \\
\end{tabular} & 231,73 & \begin{tabular}{ll|l}
138,59 \\
\end{tabular} & 56,68 & \begin{tabular}{|l|l|}
196,77 \\
\end{tabular} & 56,65 & 44,31 & $\begin{array}{l}94,95 \\
\end{array}$ & 41,38 & 22,77 & 254,73 & $\begin{array}{l}155,64 \\
1\end{array}$ & \begin{tabular}{|l|l|}
222,07 \\
\end{tabular} & 155,64 \\
\hline Rana temporaria & 31TDG46 & 101,00 & $98,81$. & 74,53 & 32,16 & 5461,29 & 227, & 0,29 & $227,69 \mid$ & 123,23 & 38,16 [ & $172,11 \mid$ & 35,25 | & $935,05 \mid$ & 102,41 & 54,20 & 18,70 & 269,63 & $188,71 \mid$ & 229,59 & 189,68 \\
\hline Rana te & & 100,00 & 107 & & & & & 5,42 & 9 & 122 & & 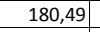 & 41,55 & \begin{tabular}{l|l|l|l|l|}
899,99 \\
\end{tabular} & 99,75 & & 19,80 & & $\begin{array}{l}176,79 \\
\end{array}$ & 226,44 & 177,02 \\
\hline Rana temporaria & \begin{tabular}{|l|}
$31 T D G 48$ \\
\end{tabular} & 99,00 & 90,22 & 75,53 & 32,75 & 5453,60 & 220,57 & $-7,82$ & 228,39 & \begin{tabular}{l|l}
99,62 \\
\end{tabular} & 32,26 & 163,59 & 26,84 & 975,65 & \begin{tabular}{|l|l|}
105,37 \\
\end{tabular} & 59,03 & 17,02 & 278,09 & 203,11 & 234,79 & 205,54 \\
\hline Rana temporaria & 31TDG49 & 61,00 & 55,44 & 71,98 & 31,95 & 5347,45 & 184,37 & $-37,63$ & 222,00 & 36,75 | & 62,02 & 128,52 & $-4,12$ & 1168,61 & 120,65 & 72,21 & 14,13 & 328,65 & 255,93 & 262,42 & 270,85 \\
\hline
\end{tabular}




\begin{tabular}{|c|c|c|c|c|c|c|c|c|c|c|c|c|c|c|c|c|c|c|c|c|c|}
\hline TAXON & UTM & $\mathrm{km} 2$ & B101 & B102 & $\mathrm{BIO3}$ & B104 & B105 & B106 & B107 & B108 & B109 & B1010 & BIO11 & BIO12 & B1013 & BIO14 & B1015 & BIO16 & BIO17 & B1018 & B1019 \\
\hline Rana temporaria & 31TDG51 & 100,00 & 150,52 & 69,89 & 30,82 & 5412,19 & 271,39 & 47,10 & 224,29 & 175,65 & 190,74 & 221,70 & 84,58 & 751,99 & 97,13 & 37,05 & 23,69 & 241,22 & 152,85 & 178,44 & 159,64 \\
\hline Rana temporaria & 31TDG52 & 100,00 & 121,05 & 70,84 & 31,14 & 5416,66 & 245,56 & 21,77 & 223,79 & 158,67 & 73,56 & 193,60 & 57,38 & 871,94 & 101,31 & 48,10 & 20,27 & 261,90 & 179,63 & 207,94 & 181,17 \\
\hline Rana temporaria & 31TDG53 & 101,00 & 120,29 & 71,75 & 31,31 & 5454,72 & 245,94 & 19,90 & 226,03 & 168,79 & 56,34 & 193,21 & 55,81 & 879,46 & 97,58 & 47,86 & 20,11 & 259,23 & 176,63 & 214,88 & 176,63 \\
\hline Rana temporaria & 31TDG54 & 100,00 & 125,16 & 72,61 & 31,28 & 5493,16 & 251,46 & 22,80 & 228,67 & 159,72 & 59,79 & 198,10 & 59,49 & 882,49 & 96,36 & 45,17 & 20,85 & 259,02 & 173,86 & 217,20 & 173,90 \\
\hline Rana temporaria & 31TDG55 & 101,00 & 112,93 & 73,61 & 31,78 & 5470,40 & 240,58 & 12,28 & 228,29 & 146,27 & 49,85 & 185,97 & 48,41 & 911,09 & 98,75 & 49,15 & 19,85 & 264,80 & 182,35 & 222,98 & 182,41 \\
\hline Rana temporaria & 31TDG56 & 101,00 & 126,48 & 74,94 & 31,73 & $\begin{array}{ll}5552,87 \\
\end{array}$ & 254,68 & 21,49 & 233,19 & 143,13 & 59,32 & 199,65 & 59,17 & 878,35 & 94,59 & 43,36 & 21,32 & 261,01 & 171,38 & 218,56 & 171,39 \\
\hline Rana temporaria & 31TDG57 & 100,00 & 129,29 & 76,38 & 31,96 & 5582,05 & 258,48 & 22,78 & 235,70 & 147,30 & 61,07 & 202,62 & 61,07 & 845,98 & 92,13 & 42,93 & 20,88 & 250,54 & 166,34 & 210,12 & 166,34 \\
\hline Rana temporaria & 31TDG58 & 94,00 & 108,42 & 76,50 & 32,40 & 5508,44 & 238,70 & 6,27 & 232,44 & 122,51 & 45,63 & 181,73 & 42,94 & \begin{tabular}{|l|l|}
909,93 \\
\end{tabular} & 97,99 & 51,44 & 18,50 & 263,54 & 186,08 & 220,40 & 187,06 \\
\hline Rana temporaria & 31TDG59 & 18,00 & 90,81 & 75,95 & 32,85 & 5439,71 & 221,28 & $-7,67$ & 228,96 & 94,19 & 36,19 & 163,85 & 27,56 & 980,58 & 103,82 & 59,57 & 16,30 & 277,15 & 209,02 & 230,66 & 212,69 \\
\hline Rana temporaria & 31TDG62 & 101,00 & 149,18 & 69,89 & 30,11 & 5469,89 & 270,71 & 44,27 & 226,44 & 175,51 & 190,11 & 220,84 & 82,05 & 782,31 & 103,47 & 38,13 & 24,38 & 247,74 & 157,19 & 178,56 & 168,20 \\
\hline Rana temporaria & 31TDG63 & 100,00 & 134,37 & 70,82 & 30,71 & 5472,86 & 258,25 & 31,14 & 227,11 & 182,29 & 82,49 & 206,82 & 68,42 & 864,54 & 102,08 & 45,97 & 21,14 & 257,04 & 178,28 & 202,84 & 178,94 \\
\hline Rana temporaria & 31TDG64 & 100,00 & 133,71 & 71,88 & 30,84 & 5515,80 & 258,82 & 29,58 & 229,23 & 177,28 & 81,89 & 206,53 & 66,99 & 870,25 & 101,28 & 45,16 & 21,27 & 255,94 & 178,43 & 203,14 & 178,73 \\
\hline Rana temporaria & 31TDG68 & 86,00 & 114,42 & 76,43 & 32,34 & 5500,76 & 243,88 & 11,05 & 232,83 & 134,60 & 51,47 & 187,37 & 48,63 & 893,25 & 96,76 & 50,69 & 18,58 & 255,03 & 186,61 & 211,05 & 187,34 \\
\hline Rana temporaria & 31TDG77 & 100,00 & 138,85 & 75,89 & 31,95 & 5538,66 & 266,13 & 30,97 & 235,15 & 177,79 & 103,96 & 211,36 & 70,83 & 782,67 & 97,23 & 41,56 & 21,97 & 231,89 & 164,30 & 174,28 & 164,77 \\
\hline Rana temporaria & 31TDG78 & 93,00 & 127,93 & 77,01 & 32,06 & 5514,09 & 256,73 & 21,64 & 235,10 & 166,72 & 73,70 & 200,46 & 60,95 & 827,53 & 96,41 & 45,54 & 20,13 & 238,31 & 175,62 & 187,78 & 175,90 \\
\hline Rana temporaria & 31TDG79 & 46,00 & 113,70 & 77,44 & 32,85 & 5476,17 & 243,58 & 10,14 & 233,44 & 142,50 & 62,03 & 186,30 & 48,28 & 879,16 & 98,03 & 50,52 & 18,20 & 248,55 & 189,73 & 200,52 & 191,48 \\
\hline Rana temporaria & 31TDG89 & 82,00 & 138,88 & 79,63 & 32,99 & 5506,15 & 267,94 & 29,75 & 238,19 & 152,98 & 186,80 & 211,01 & 71,29 & 724,75 & 93,55 & 35,45 & 22,99 & 219,97 & 148,58 & 152,88 & 159,90 \\
\hline Rana temporaria & 31TDG99 & 101,00 & 144,56 & 80,52 & 33,46 & 5443,28 & 272,35 & 34,86 & 237,48 & 151,97 & 215,52 & 215,81 & 77,70 & 669,90 & 92,67 & 29,61 & 25,82 & 213,72 & 128,84 & 135,24 & 149,82 \\
\hline Rana temporaria & 31TDHOO & 28,00 & 50,10 & 74,04 & 32,22 & 5406,83 & 179,99 & $-45,96$ & 225,95 & 54,34 & 38,71 & 123,44 & $-11,53$ & 1195,66 & 126,85 & 77,40 & 13,68 & 334,47 & 260,85 & 277,01 & 270,95 \\
\hline Rana temporaria & 31TDH10 & 1,00 & 66,35 & 76,06 & 32,71 & 5443,68 & 197,47 & $-31,08$ & 228,54 & 73,65 & 28,11 & 139,74 & 3,46 & \begin{tabular}{ll|}
1094,46 \\
\end{tabular} & 117,96 & 69,86 & 14,97 & 310,84 & 233,85 & 260,63 & 239,64 \\
\hline Rana temporaria & 31TDH80 & 1,00 & 143,90 & 82,12 & 33,46 & 5540,21 & 274,54 & 32,40 & 242,14 & 151,89 & 212,72 & 216,18 & 75,45 & 677,58 & 90,55 & 30,60 & 24,48 & 211,47 & 130,48 & 131,98 & 154,59 \\
\hline Rana temporaria & 31TDH90 & 17,00 & 130,04 & 80,65 & 33,43 & 5452,04 & 259,87 & 22,49 & 237,38 & 119,93 & 201,55 & 201,87 & 63,90 & 750,58 & 95,23 & 35,71 & 22,82 & 229,15 & 150,32 & 154,35 & 172,62 \\
\hline Rana temporaria & 31TEG09 & 90,00 & 144,42 & 80,68 & 33,90 & 5361,71 & 271,10 & 35,65 & 235,45 & 153,62 & 214,34 & 214,71 & 78,84 & 656,66 & 92,80 & 27,31 & 27,12 & 213,79 & 121,92 & 133,07 & 148,59 \\
\hline Rana temporaria & 31TEHOO & 8,00 & 143,60 & 82,49 & 34,11 & 5406,03 & 272,29 & 33,72 & 238,57 & 147,51 & 214,13 & 214,46 & 77,38 & 656,68 & 91,94 & 26,81 & 27,44 & 213,72 & 119,09 & 127,74 & 152,85 \\
\hline Salamandra salamandra & 29SMC69 & 100,00 & 147,96 & 70,09 & 41,09 & 3488,38 & 238,79 & 70,50 & 168,29 & 111,22 & 189,22 & 193,04 & 102,87 & 825,55 & 127,97 & 5,09 & 64,31 & 370,27 & 36,55 & 38,54 & 344,46 \\
\hline Salamandra salam & 29SMC78 & 84,00 & 158,27 & 75,36 & 41,23 & 3702,77 & 257,79 & 77,44 & 180,35 & 119,08 & 202,40 & 206,80 & 111,26 & 771,92 & 120,92 & 4,01 & 64,95 & 348,70 & 31,93 & 34,07 & 328,03 \\
\hline Salamandra salamandra & $295 M C 79$ & 100,00 & 150,21 & 73,67 & $\frac{4,25}{40,95}$ & 3685,18 & 248,04 & 70,05 & 177,99 & 111,34 & $\begin{array}{ll}204,404 \\
194,26\end{array}$ & $\begin{array}{l}2198,41 \\
\end{array}$ & $\begin{array}{l}103,30 \\
\end{array}$ & 825,94 & \begin{tabular}{|l|l|l|l|l|l|}
128,66 \\
\end{tabular} & 4,51 & 64,91 & 371,05 & 34,95 & 36,68 & 348,66 \\
\hline Salamandra salamandra & $295 M C 85$ & 48,00 & 162,61 & 81,58 & 41,70 & 3901,56 & 272,91 & 79,16 & 193,75 & 122,18 & 209,94 & 214,84 & 114,66 & 712,75 & 108,22 & 3,94 & 63,17 & 318,22 & 31,22 & 33,31 & 304,73 \\
\hline Salamandra salamandra & $295 M C 86$ & 60,00 & 166,21 & 81,36 & 41,33 & 3924,44 & 276,58 & 82,44 & 194,15 & 125,29 & 213,76 & 218,67 & 117,97 & 698,01 & 106,28 & 3,82 & 63,62 & 313,06 & 29,58 & 32,19 & 299,45 \\
\hline Salamandra salamandra & 29SMC87 & 85,00 & 166,33 & 80,39 & 41,04 & 3928,81 & 275,72 & 82,47 & 193,25 & 125,15 & 213,91 & 218,71 & 117,74 & 709,73 & 108,26 & 3,85 & 63,78 & 318,88 & 29,62 & 32,39 & 304,79 \\
\hline Salamandra salamandra & 29SMC88 & 76,00 & 164,78 & 79,29 & 40,77 & 3947,81 & 273,54 & 81,14 & 192,41 & 123,28 & 212,72 & 217,34 & 115,89 & 731,80 & 111,36 & 3,84 & 63,98 & 328,19 & 30,27 & 32,97 & 314,90 \\
\hline Salamandra salamandra & $295 \mathrm{SC} 89$ & 101,00 & 162,23 & 77,29 & 40,59 & $\begin{array}{ll}384,101 \\
3890,32\end{array}$ & 267,64 & $\frac{1,14}{79,42}$ & $\begin{array}{l}188,21 \\
\end{array}$ & $\begin{array}{ll}121,02 \\
\end{array}$ & 209,27 & 213,48 & $\begin{array}{l}113,54 \\
1130\end{array}$ & 744,37 & \begin{tabular}{|l|l|}
113,05 \\
13
\end{tabular} & $\begin{array}{l}3,04 \\
3,82 \\
-1\end{array}$ & $\begin{array}{l}5,03 \\
64,03\end{array}$ & 333,09 & 30,62 & 33,27 & 318,85 \\
\hline Salamandra salamandra & 29SMC95 & 57,00 & 161,90 & 83,83 & 41,27 & 4053,90 & 277,25 & 76,73 & 200,52 & 120,01 & 211,56 & 216,45 & 112,46 & 712,24 & 107,07 & 3,97 & 62,97 & 316,56 & 31,18 & 33,15 & 305,23 \\
\hline Salamandra salamandra & 29SMC96 & 101,00 & 166,61 & 83,55 & 41,10 & 4057,78 & 281,52 & 81,08 & 200,44 & 124,31 & 216,16 & 221,07 & 116,95 & 689,66 & 104,09 & 3,57 & 63,35 & 308,21 & 28,87 & 31,62 & 296,61 \\
\hline Salamandra salamandra & 29SMD60 & 71,00 & 150,13 & 67,85 & 41,05 & 3399,25 & 237,06 & 73,70 & 163,36 & 114,29 & 190,23 & 193,60 & 105,75 & 791,66 & 123,77 & 4,56 & 64,30 & 356,92 & 33,85 & 36,46 & 330,30 \\
\hline Salamandra salamandra & 29SMD61 & 56,00 & 151,29 & 65,25 & 41,09 & 3287,54 & 233,99 & 76,85 & 157,14 & 116,75 & 189,82 & 193,05 & 108,30 & 756,94 & 120,51 & 4,18 & 63,64 & 340,78 & 32,10 & 35,60 & 314,88 \\
\hline Salamandra salamandra & 29SMD70 & $\begin{array}{l}0,0,00 \\
101,00\end{array}$ & 148,41 & $\mid \frac{\mid, 25}{71,26}$ & 44,03 & $\begin{array}{l}320,734 \\
3610,41\end{array}$ & 242,95 & $\begin{array}{ll}0,090 \\
69,60\end{array}$ & \begin{tabular}{|l|l|l|l|l|}
173,35 \\
\end{tabular} & \begin{tabular}{|l|l|l|l|l|}
110,39 \\
\end{tabular} & \begin{tabular}{|l|}
$193,0<61$ \\
191,6
\end{tabular} & $\begin{array}{l}195,28 \\
195,28\end{array}$ & \begin{tabular}{|l|l}
102,18 \\
102
\end{tabular} & $\mid$\begin{tabular}{|l|}
819,75 \\
\end{tabular} & $\mid$\begin{tabular}{|l|}
$\mid 25,5,51$ \\
1251
\end{tabular} & $\begin{array}{l}4,10 \\
4,69\end{array}$ & $\begin{array}{l}64,12 \\
64,12\end{array}$ & $\begin{array}{l}34,10 \\
366,94\end{array}$ & $\frac{2,14}{35,28}$ & $\begin{array}{l}37,00 \\
3,52\end{array}$ & $\begin{array}{l}314,00 \\
344,42 \\
\end{array}$ \\
\hline Salamandra salamandra & 29SMD71 & 100,00 & 150,71 & 68,40 & 40,60 & 3472,66 & 240,14 & 73,81 & 166,34 & 114,08 & 192,05 & 195,36 & 105,94 & 776,94 & 121,19 & 4,36 & 63,53 & 348,12 & 33,01 & 36,16 & 325,55 \\
\hline Salamandra salamandra & 29SMD72 & 101,00 & 154,26 & 65,05 & 40,89 & 3286,66 & 237,07 & 79,81 & 157,26 & 119,81 & 193,07 & 196,04 & 111,54 & 718,24 & 115,57 & 4,02 & 63,12 & 322.51 & 30,11 & 34,39 & 299,55 \\
\hline Salamandra salamandra & 29SMD73 & 101,00 & 153,51 & 62,06 & 41,03 & 3133,32 & 231,06 & 81,41 & 149,66 & 120,85 & 190,32 & 193,01 & 112,66 & 696,19 & 114,21 & 4,00 & 62,63 & 11,64 & 29,42 & 34,60 & 288,44 \\
\hline Salamandra salamandra & $295 M D 74$ & 88,00 & 151,73 & 59, & $\frac{6}{6}$ & 3010,96 & 224,95 & 81,51 & 143,43 & 120,61 & 186,91 & 189,33 & 112,29 & 688,41 & \begin{tabular}{|l|l|}
114,38 \\
\end{tabular} & 3,95 & 62,44 & 306,73 & 29,59 & 35,33 & 283,54 \\
\hline Salamandra salamandra & 29SMD75 & 89,00 & 151,32 & 57,80 & & 2903,17 & 220,92 & 82,61 & 138,31 & 121,57 & 185,03 & 187,33 & 113,25 & 677,61 & 113,71 & 3,95 & 62,35 & 300,55 & 29,35 & 35,85 & 277,62 \\
\hline Salamandra salamandra & 29SMD80 & 101,00 & 155,19 & 74,75 & 40,26 & 3803,25 & 256,91 & 73,98 & 182,93 & 115,18 & 201,22 & 205,14 & 107,34 & 778,76 & 117,50 & 4,20 & 63,64 & 346,89 & 32,86 & 35,49 & 330,61 \\
\hline Salamandra salamandra & 29SMD81 & 101,00 & 150,37 & 72,32 & 40,14 & 3700,78 & 248,21 & 70,74 & 177,47 & 111,64 & 195,10 & 198,73 & 103,66 & 795,14 & 120,81 & 4,60 & 62,82 & 352,42 & 34,73 & 37,59 & 335,04 \\
\hline Salamandra salamandra & 29SMD83 & 100,00 & 153,13 & 66,84 & 40,67 & 3384,17 & 239,89 & 77,50 & 162,39 & 117,72 & 193,62 & 196 & 109,72 & 725,88 & 15,35 & 4, & 62,31 & 22,08 & 31,21 & 35,70 & 303,04 \\
\hline Salamandra salamandra & 29SMD84 & 101,00 & 154,34 & 6 & 4 & 3237,16 & 236,09 & 80,47 & 155,62 & 12 & $\begin{array}{l}192,73 \\
192\end{array}$ & 19 & 112,40 & $\begin{array}{l}260,000 \\
698,05 \\
\end{array}$ & \begin{tabular}{|l|l|}
113,05 \\
11,00
\end{tabular} & & $\begin{array}{l}2,1,10 \\
62,10\end{array}$ & $\begin{array}{ll}32,090 \\
309,29\end{array}$ & $\begin{array}{l}1,21 \\
30,02\end{array}$ & $\begin{array}{l}5,10 \\
35,43 \\
\end{array}$ & 280,73 \\
\hline Salamandra salamandra & $29 \mathrm{SMD}$ & 99,00 & 15 & 63 & 41 & 3141,44 & 232,59 & 81,14 & 151,45 & 121,16 & 190,92 & 193,39 & 113,04 & 693,97 & 113,00 & 4,6 & 61,81 & 305,79 & 30,54 & 36,53 & 286,46 \\
\hline Salamandra salamandra & 29SMD86 & 79,00 & 154,64 & 62,85 & 41,60 & 3081,51 & 231,56 & 82,21 & 149,35 & 122,49 & 190,84 & 193,19 & 114,37 & 691,11 & 112,46 & 4,04 & 61,43 & 302,84 & 30,71 & 37,30 & 284,19 \\
\hline Salamandra salamandra & 29SMD87 & 17,00 & 155,55 & 63,89 & 41,92 & 3097,29 & 233,29 & 82,21 & 151,08 & 123,13 & 191,87 & 194,16 & 114,97 & 698,42 & 112,39 & 4,13 & 60,89 & 303,76 & 32,03 & 38,92 & 286,34 \\
\hline Salamandra salaman & 29SMD90 & 83,00 & 162,53 & 7751409 & 40,45 & 3918,62 & 268,93 & 79,41 & 189 & 121,24 & 210,21 & 21 & 113,53 & 723,44 & 109,03 & 3,60 & 63,15 & 321,26 & 30,05 & 33,21 & 308,79 \\
\hline Salamandra salamandra & $29 S M D$ & $\begin{array}{l}0,0,00 \\
101,00\end{array}$ & $\frac{15}{15}$ & 73 & $\frac{40}{40}-3 x-3$ & 3718,49 & 250,45 & \begin{tabular}{|c|}
76,15 \\
76,1
\end{tabular} & \begin{tabular}{|l|}
179,30 \\
179,3
\end{tabular} & \begin{tabular}{|l|l|l|l|l|}
117,38 \\
\end{tabular} & \begin{tabular}{|l|}
201,57 \\
201
\end{tabular} & \begin{tabular}{|l|}
204,95 \\
\end{tabular} & \begin{tabular}{|l|}
109,56 \\
13,5
\end{tabular} & $\mid$\begin{tabular}{|l|}
738,14 \\
\end{tabular} & \begin{tabular}{|l|}
113,18 \\
13,18
\end{tabular} & $\begin{array}{l}, 00 \\
4,07\end{array}$ & $\begin{array}{l}3,1129 \\
62,29\end{array}$ & 325,77 & 31,79 & $\begin{array}{l}35,24 \\
35,54\end{array}$ & 311,36 \\
\hline Salamandra salamandra & 29SMD93 & 101,00 & 152,29 & 71,58 & 40,51 & 3628,03 & 248,35 & 73,27 & 175,08 & 114,35 & 196,21 & 199,45 & 106,42 & 760,12 & 116,88 & 4,63 & 61,56 & 333,05 & 34,29 & 38,16 & 318,27 \\
\hline Salamandra salamandra & 29SMD94 & 100,00 & 154,66 & 69,63 & 40,84 & 3484,84 & 245,83 & 77,01 & 168,82 & $\begin{array}{l}118,17 \\
\end{array}$ & $\begin{array}{l}196,54 \\
196\end{array}$ & $\begin{array}{l}199,51 \\
\end{array}$ & $\begin{array}{l}110,10 \\
\end{array}$ & 725,66 & $\begin{array}{l}113,71 \\
113\end{array}$ & 4,11 & $\begin{array}{l}1,57 \\
61,57 \\
\end{array}$ & 318,32 & 32,08 & 36,79 & 302,73 \\
\hline Salamandra salamandra & 29SMD95 & 101,00 & 154,16 & 68,46 & 41,02 & 3399,61 & 242,54 & 77,46 & 165,08 & 118,55 & 194,88 & 197,66 & 110,52 & 724,99 & 114,07 & > & (61) & 316,49 & 32,79 & 38,09 & 300,91 \\
\hline Salamandra salaman & $29 S M D$ & 92,00 & 15 & 67 & 41, & 3283,66 & 238,79 & 77,36 & 161,43 & 119,03 & 192,74 & 19 & 11 & 740,74 & 115,77 & 4,83 & 60,01 & 319,21 & 35,65 & 41,78 & 304 \\
\hline Salamandra salamandra & 29SNB12 & 83,00 & $\begin{array}{l}13,03 \\
163,34\end{array}$ & \begin{tabular}{|c|}
86,34 \\
8
\end{tabular} & $\begin{array}{l}44,044 \\
44,66\end{array}$ & $\begin{array}{l}320,300 \\
3628,14\end{array}$ & 272,70 & $\begin{array}{l}1,00,42 \\
80\end{array}$ & \begin{tabular}{|l|}
191,27 \\
191
\end{tabular} & \begin{tabular}{|l|}
128,07 \\
120
\end{tabular} & \begin{tabular}{|l|}
$192,4,4$ \\
207,95
\end{tabular} & \begin{tabular}{|l|l|}
212,23 \\
\end{tabular} & $\begin{array}{l}11,, 515 \\
119\end{array}$ & \begin{tabular}{|l|l|l|l|l|}
516,43 \\
\end{tabular} & \begin{tabular}{|c|c|}
83,19 \\
83,19
\end{tabular} & $\begin{array}{l}, 03 \\
1,00 \\
\end{array}$ & $\begin{array}{l}60,47 \\
68,4\end{array}$ & $\frac{21,21}{241,95}$ & $\begin{array}{l}5,03 \\
18,35 \\
\end{array}$ & $\begin{array}{l}41,10 \\
19,41\end{array}$ & 231,30 \\
\hline Salamandra salamandra & 29SNB13 & 51,00 & 165,90 & 86,91 & 44,25 & 3706,64 & 276,06 & 81,89 & 194,17 & 129,33 & 211,51 & 215,80 & 121,01 & 513,94 & 82,24 & 1,00 & 68,10 & 240,26 & 18,46 & 19,60 & 229,58 \\
\hline Salamandr & 29SNB14 & 19,00 & 166,42 & 87,92 & 44,00 & 3803,89 & 279,44 & 81,19 & 198,25 & 128,75 & 213,33 & 217,72 & 120,36 & 522,64 & 82,56 & 1,00 & 67,69 & 243,06 & 18,89 & 19,89 & 232,81 \\
\hline Salamar & 29SNB16 & 24,00 & 167,33 & 88,92 & 43,7 & 3885,90 & 282,76 & 81,0 & 201,69 & 128, & 215,29 & 219 & 120 & 539,57 & 83,76 & 1,00 & 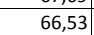 & 248,24 & 20,00 & 21,00 & 238,41 \\
\hline Salamandra salamandra & 29 SNB21 & 101,00 & 166,71 & 86,81 & 43,34 & 3809,92 & 88,55 & 80,58 & 197,97 & 129,16 & 214,36 & 218,16 & 120,69 & 498,75 & 80,82 & 0,90 & 69,59 & 237,30 & 16,71 & 17,97 & 225,62 \\
\hline
\end{tabular}




\begin{tabular}{|c|c|c|c|c|c|c|c|c|c|c|c|c|c|c|c|c|c|c|c|c|c|}
\hline TAXON & UTM & $\mathrm{km} 2$ & B101 & $\mathrm{B1O2}$ & $\mathrm{BIO3}$ & 8104 & B105 & B106 & B107 & B108 & B109 & BIO10 & B1011 & BIO12 & B1013 & B1014 & B1015 & B1016 & BIO17 & B1018 & B1019 \\
\hline Salamandra salamandra & 29SNB22 & 101,00 & 159,48 & 88,59 & 43,57 & 3863,33 & 274,21 & 73,06 & 201,15 & 121,65 & 207,70 & 211,89 & 113,22 & 545,39 & 86,20 & 1,08 & 67,90 & 254,36 & 19,78 & 20,69 & 243,97 \\
\hline Salamandra salamandra & $295 N B 23$ & 101,00 & 160,57 & 89,23 & 43,49 & 3904,89 & 276,69 & 73,70 & 202,99 & 122,19 & 209,27 & 213,56 & 113,87 & 548,35 & 86,14 & 1,15 & 67,36 & 254,48 & 20,17 & 21,04 & 244,38 \\
\hline Salamandra salamandra & $295 N B 24$ & 100,00 & 162,44 & 89,79 & 43,41 & 3953,88 & 280,03 & 75,26 & 204,76 & 123,45 & 211,84 & 216,11 & $\mid 115,18$ & 546,36 & 85,42 & $\begin{array}{l}1,1,08 \\
1,08\end{array}$ & 67,06 & 252,79 & 20,07 & 20,88 & 242,88 \\
\hline Salamandra salamandra & 29SNB25 & 100,00 & 164,72 & 90,25 & 43,24 & 3981,16 & 283,08 & 77,15 & 205,94 & 125,25 & 214,24 & 218,62 & 116,82 & 543,22 & 84,29 & 1,00 & 66,73 & 250,47 & 20,04 & 20,94 & 240,79 \\
\hline Salamandra salamandra & 29SNB26 & 101,00 & 167,37 & 90,54 & 43,07 & 4006,83 & 286,40 & 79,38 & 207,03 & 127,37 & 217,05 & 221,60 & 119,02 & 539,28 & 83,16 & 1,06 & 66,34 & 247,82 & 20,04 & 21,07 & 238,29 \\
\hline Salamandra salamandra & 29 SNB27 & 101,00 & 164,85 & 91,51 & 43,02 & 4077,94 & 286,17 & 76,15 & 210,02 & 124,01 & 215,44 & 219,99 & 115,74 & 565,10 & 86,24 & 1,72 & 65,40 & 256,79 & 22,20 & 22,99 & 248,03 \\
\hline Salamandra salamandra & 29 SNB28 & 101,00 & 163,45 & 91,99 & 42,92 & 4134,08 & 286,67 & 74,44 & 212,23 & 121,86 & 214,92 & 219,54 & 113,86 & 584,01 & 88,30 & 2,00 & 64,69 & 263,26 & 23,58 & 24,30 & 255,08 \\
\hline Salamandra salamandra & $295 N B 29$ & $\begin{array}{l}101,00 \\
\end{array}$ & $\begin{array}{l}164,16 \\
164,\end{array}$ & 92,20 & $\frac{42,824}{42,84}$ & 4175,37 & 288,44 & 74,92 & 213,52 & 122,01 & 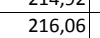 & 220,71 & \begin{tabular}{|l|}
113,97 \\
13
\end{tabular} & \begin{tabular}{|l|l|l|}
590,88 \\
\end{tabular} & $\begin{array}{ll}80,70 \\
88,76\end{array}$ & 2,00 & \begin{tabular}{|c|c|}
64,15 \\
\end{tabular} & 265,09 & 24,11 & 24,86 & 257,27 \\
\hline Salamandra salamandra & 29SNB31 & 100,00 & 169,93 & 88,04 & 42,32 & 3993,05 & 285,92 & 80,82 & 205,09 & \begin{tabular}{|c|}
130,58 \\
\end{tabular} & 220,37 & 224,08 & 121,95 & 491,29 & 79,47 & 0,87 & 69,85 & 235,53 & 15,71 & 17,27 & 223,19 \\
\hline Salamandra salamandra & 29SNB32 & 100,00 & 157,21 & 90,43 & 42,89 & 4051,06 & 276,71 & 68,08 & 208,63 & 117,62 & 208,32 & 212,39 & 109,04 & 568,47 & 89,90 & 1,46 & 67,30 & 263,84 & 21,14 & 22,08 & 253,54 \\
\hline Salamandra salamandra & 29 SNB33 & 101,00 & 153,17 & 91,73 & 42,96 & 4104,42 & 275,13 & 63,85 & 211,28 & 113,12 & 205,01 & 209,21 & 104,51 & 597,67 & 93,49 & 1,78 & 66,16 & 273,78 & 23,43 & 24,04 & 264,44 \\
\hline Salamandra salamandra & 29 SNB34 & 100,00 & 160,98 & 91,92 & 42,89 & 4116,92 & 283,24 & 71,08 & 212,15 & 120,35 & 212,75 & 217,05 & 111,80 & 557,87 & 87,50 & 1,29 & 66,59 & 257,51 & 20,82 & 21,67 & 247,82 \\
\hline Salamandra salamandra & 29 SNB36 & 101,00 & 165,93 & 92,97 & 42,95 & 4165,94 & 289,95 & 75,37 & 214,58 & 124,09 & 217,99 & 222,40 & 115,90 & 546,52 & 84,50 & 1,23 & 66,02 & 250,43 & 20,62 & 21,50 & 241,41 \\
\hline Salamandra salamandra & 29SNB37 & 100,00 & 164,94 & 93,73 & 42,83 & 4219,59 & 290,82 & 74,07 & \begin{tabular}{|l|l|}
216,75 \\
\end{tabular} & 122,57 & 217,72 & 222,23 & 114,44 & 561,68 & 85,97 & 1,82 & 65,17 & 254,92 & 22,07 & 22,89 & 246,65 \\
\hline Salamandra salamandra & 29SNB38 & 101,00 & 165,56 & 94,17 & 42,70 & 4258,45 & 292,73 & 74,44 & 218,29 & 122,77 & 218,79 & 223,35 & 114,49 & 567,57 & 86,11 & 2,00 & 64,57 & 256,00 & 22,76 & 23,43 & 248,21 \\
\hline Salamandra salamandra & 29SNB39 & 100,00 & 165,48 & 94,48 & 42,38 & 4301,43 & 293,85 & 74,15 & 219,70 & 122,07 & 219,27 & 223,98 & 114,02 & 576,49 & 86,88 & 2,00 & 64,22 & 258,47 & 23,19 & 24,02 & 251,19 \\
\hline Salamandra salamandra & 29 SNB41 & 101,00 & 170,42 & 89,54 & 42,32 & 4071,24 & 288,31 & 79,58 & 208,73 & 130,01 & 221,89 & 225,72 & 121,66 & 494,19 & 80,91 & 1,00 & 69,76 & 237,45 & 15,99 & 17,53 & 224,66 \\
\hline Salamandra salamandra & $295 N B 42$ & 101,00 & 163,34 & 91,49 & 42,31 & 4153,20 & 284,97 & 71,88 & 213,09 & 122,27 & 215,89 & 219,81 & 113,77 & 536,63 & 86,44 & 1,15 & 68,24 & 252,48 & 18,58 & 19,76 & 241,22 \\
\hline Salamandra salamandra & 29SNB43 & 100,00 & 158,19 & 93,15 & 42,49 & 4219,30 & 282,90 & 66,29 & 216,61 & 116,56 & 211,49 & 215,67 & 108,04 & 570,05 & 90,55 & 1,33 & 66,86 & 263,84 & 21,04 & 21,89 & 253,89 \\
\hline Salamandra salamandra & 29SNB44 & 101,00 & 165,33 & 93,32 & 42,45 & 4231,12 & 290,31 & 73,10 & 217,20 & 123,17 & 218,62 & 222,87 & 114,75 & 534,47 & 84,80 & 1,00 & 67,20 & 248,69 & 18,80 & 19,94 & 238,53 \\
\hline Salamandra salamandra & 29SNB45 & 101,00 & 165,68 & 94,29 & 42,55 & 4266,08 & 292,32 & 73,3 & 218,98 & 122,99 & 219,44 & 223,80 & 114,73 & 538,78 & 84,63 & 1,02 & 66,67 & 248,75 & 19,45 & 20,42 & 239,24 \\
\hline Salamandra salamandra & $295 N B 46$ & 100,00 & $\begin{array}{l}\mid 01,06 \\
161,56\end{array}$ & 95,68 & 42,42 & 4340,36 & 291,18 & 68,73 & 222,45 & 118,32 & 216,23 & 220,75 & 109,95 & 570,36 & 88,19 & 1,79 & 60,12 & 258,97 & 22,44 & 23,13 & 250,85 \\
\hline Salamandra salamandra & 29 SNB47 & 100,00 & 163,18 & 96,28 & 42,48 & 4369,40 & 293,99 & 70,04 & 223,95 & 119,40 & 218,06 & 222,73 & 111,14 & 569,30 & 87,22 & 2,00 & 64,67 & 257,01 & 22,82 & 23,42 & 249,30 \\
\hline Salamandra salamandra & 29 SNB49 & 101,00 & 168,13 & 96,77 & 42,39 & 4402,72 & 299,73 & 74,62 & 225,11 & 123,45 & 223,21 & 227,86 & 115,34 & 557,31 & 84,01 & 2,00 & 64,01 & 249,32 & 22,72 & 23,49 & 242,42 \\
\hline Salamandra salamandra & 29 SNB52 & 101,00 & 164,37 & 92,97 & 42,21 & 4241,13 & 288,17 & \begin{tabular}{|c|}
71,28 \\
\end{tabular} & 216,89 & 122,52 & 218,10 & 222,13 & 113,81 & 533,03 & 86,93 & 1,00 & 68,19 & 251,74 & 17,99 & 19,46 & 240,04 \\
\hline Salamandra salamandra & $295 N B 53$ & 100,00 & 164,55 & 94,13 & 42,08 & 4297,53 & 290,68 & 70,92 & 219,76 & 121,89 & 218,86 & 223,08 & 113,30 & 535,86 & 86,47 & 1,00 & 67,62 & 251,14 & 18,31 & 19,68 & 240,12 \\
\hline Salamandra salamandra & 29SNB54 & 101,00 & $\begin{array}{l}\mid 04,53 \\
161,55\end{array}$ & 94,59 & $\begin{array}{ll}42,30 \\
42,24\end{array}$ & 4 & $\mid \begin{array}{l}\mid 290,00 \\
290,54\end{array}$ & 67,43 & 223,11 & $\begin{array}{l}\mid 12,05 \\
118,29\end{array}$ & $\begin{array}{ll}21,00,73 \\
216,73\end{array}$ & 220,94 & \begin{tabular}{|l|}
109,71 \\
109
\end{tabular} & $\begin{array}{l}55,00 \\
557,76\end{array}$ & $\begin{array}{l}\mid 80,417 \\
88,57\end{array}$ & 1,26 & \begin{tabular}{|c|c|c|}
66,41 \\
\end{tabular} & $\mid 257,43$ & $\begin{array}{l}\mid 0,31 \\
20,39\end{array}$ & $\begin{array}{l}21,00 \\
21,41\end{array}$ & 247,12 \\
\hline Salamandra salamandra & $295 N B 55$ & 100,00 & 162,91 & 96,57 & 42,24 & 4398,71 & 293,67 & 68,26 & 225,41 & 118,99 & 218,50 & 222,80 & 110,58 & 555,57 & 87,30 & 1,36 & 65,95 & 254,66 & 20,70 & 21,57 & 245,62 \\
\hline Salamandra salamandra & 29 SNB56 & 101,00 & $\mid 159,93$ & 97,96 & $\begin{array}{ll}42,07 \\
42,07\end{array}$ & 4473,81 & 293,72 & 64,86 & 228,86 & 115,26 & 216,56 & 221,03 & $\begin{array}{ll}106,94 \\
\end{array}$ & 579,15 & 89,53 & 2,00 & $\mid 64,59$ & 261,53 & 23,14 & 23,72 & 253,80 \\
\hline Salamandra salamandra & 29 SNB59 & 100,00 & 168,86 & 99,21 & 42,32 & 4520,42 & 304,48 & 73,29 & 231,19 & 122,86 & 225,62 & 230,19 & 114,75 & 547,27 & 82,53 & 2,00 & 63,86 & 244,05 & 22,02 & 22,64 & 237,48 \\
\hline Salamandra salamandra & $295 N B 62$ & 100,00 & 164,87 & 94,21 & 42,18 & 4299,61 & 290,15 & 70,25 & 219,91 & 122,35 & 219,43 & 223,56 & 113,72 & 533,42 & 87,70 & 1,01 & 68,11 & 252,20 & 17,90 & 19,49 & 240,04 \\
\hline Salamandra salamandra & $295 \mathrm{NB63}$ & 101,00 & $\begin{array}{l}\mid 0,40,97 \\
160,97 \\
\end{array}$ & 95,93 & $\begin{array}{l}42,10 \\
42,07 \\
\end{array}$ & $\begin{array}{ll}4240,00,78 \\
4400\end{array}$ & $\begin{array}{l}290,09 \\
290,09 \\
\end{array}$ & 60,25 & \begin{tabular}{|l|}
124,51 \\
224,56
\end{tabular} & 117,48 & 216,88 & 221,05 & 108,72 & 558,03 & 89,99 & 1,27 & 66,82 & 259,41 & 19,80 & 21,14 & 248,62 \\
\hline Salamandra salamandra & $295 N B 64$ & 100,00 & 158,55 & 97,46 & 42,01 & 4485,71 & 291,07 & 62,47 & 228,60 & 114,12 & 215,45 & 219,80 & 105,29 & 576,21 & 91,25 & 1,79 & 65,55 & 263,75 & 21,95 & 23,02 & 254,29 \\
\hline Salamandra salamandra & 29SNB65 & 100,00 & 162,17 & 98,47 & 42,03 & 4511,04 & 296,07 & 65,55 & 230,53 & 117,11 & 219,31 & 223,70 & 108,42 & 559,05 & 87,77 & 1,7 & 65,36 & 255,09 & 20,98 & 22,00 & 246,12 \\
\hline Salamandra salamandra & 29 SNB66 & 101,00 & 162,98 & 99,69 & 42,0 & 4555,55 & 299,11 & 66 , & 233,08 & 117,41 & 220,63 & 225,06 & 108,82 & 559,86 & 86,75 & 1,9 & 64,56 & 253,15 & 21,71 & 22,47 & 245,11 \\
\hline Salamandra salamandra & 29 SNB71 & 100,00 & 165,37 & 93,75 & 42,25 & 4281,43 & 288,74 & 70,12 & 218,62 & \begin{tabular}{|l|l|l|}
123,08 \\
\end{tabular} & 219,68 & 223,82 & 114,36 & 532,25 & 89,16 & 1,00 & 68,54 & 253,83 & 17,50 & 19,48 & 240,31 \\
\hline Salamandra salamandra & 29 SNB72 & 101,00 & 158,56 & 95,96 & 42,03 & 4413,77 & 287,27 & \begin{tabular}{l|l}
62,45 \\
\end{tabular} & 224,82 & 114,93 & 214,69 & 218,96 & 106,39 & 571,05 & 92,86 & 1,49 & 66,85 & 265,98 & 20,14 & 21,88 & 254,31 \\
\hline Salamandra salamandra & $295 N B 73$ & 101,00 & 155,11 & 97,55 & 42,01 & 4511,24 & 287,61 & 58,42 & 229,19 & 110,50 & 212,56 & 216,92 & 102,06 & 594,00 & 94,58 & 1,85 & 65,52 & 272,01 & 22,33 & 23,79 & 261,73 \\
\hline Salamandra salamandra & 29 SNB74 & 100,00 & 155,46 & 98,99 & 42,00 & 4582,57 & 290,88 & 57,98 & 232,90 & 109,87 & 213,81 & 218,20 & 101,36 & 595,08 & 93,54 & 2,00 & 64,75 & 269,91 & 23,20 & 24,36 & 260,62 \\
\hline Salamandra salamandra & 29 SNB75 & 101,00 & 9,78 & 100,28 & 42,0 & 621,93 & 297,04 & 61,54 & 235,50 & 113,35 & 218,43 & 222,83 & 105,05 & 572,95 & 89,41 & 2,00 & 64,65 & 259,20 & 22,04 & 23,10 & 250,47 \\
\hline Salamandra salamandra & 29 SNB81 & 101,00 & 162,83 & $\begin{array}{l}94,57 \\
94,6 \\
\end{array}$ & 42,07 & 4366,06 & 287,94 & 66,33 & 221,61 & 119,65 & 218,25 & 222,48 & 111,04 & 548,10 & $\begin{array}{l}31,22 \\
91,1\end{array}$ & 1,09 & $\mid \begin{array}{ll}67,97 \\
\end{array}$ & 259,42 & 18,07 & 20,46 & 245,71 \\
\hline Salamandra salamandra & $29 \mathrm{SNB} 82$ & 101,00 & 15 & 96,63 & 41,94 & 4496,11 & 287,34 & 59,58 & 227,76 & 112,64 & 214,29 & 218,59 & 103,89 & 581,80 & 93,91 & 1,63 & 66,26 & 269,03 & 20,85 & 22,90 & 257,09 \\
\hline Salamandra salamandra & 295NB83 & 99,00 & 153,72 & 98,40 & 41,99 & 4596,25 & 288,04 & 55,56 & 232,47 & 108,30 & 212,29 & 216,57 & $\begin{array}{l}99,42 \\
\end{array}$ & 603,65 & 95,34 & 2,03 & 64,86 & 274,47 & 22,96 & 24,69 & 264,03 \\
\hline Salamandra salamandra & 29 SNB84 & 101,00 & 82 & 99,72 & $41, \mathrm{c}$ & 4649,05 & 293,62 & 58 & 235,60 & 110,58 & 215,99 & 220,47 & 101,90 & 587,33 & 91,97 & 2,00 & 64,52 & 265,77 & 22,60 & 24,20 & 255,97 \\
\hline Salamandra salamandra & 29SNB91 & 101,00 & 158,51 & 95,20 & 41,5 & 4472,75 & 285,95 & 60,85 & 225,10 & 114,12 & 215,32 & 219,49 & 105,46 & 573,59 & 93,32 & 1,59 & 66,76 & 267,24 & 19,59 & 22,46 & 253,81 \\
\hline Salamandra salamandra & 295NB92 & 100,00 & \begin{tabular}{|l|}
150,90 \\
150,90
\end{tabular} & $\begin{array}{ll}90,20 \\
97,38\end{array}$ & 41,3 & 4624,20 & $\begin{array}{l}\mid 203,93 \\
284,06\end{array}$ & $\begin{array}{l}0,03 \\
52,19\end{array}$ & 231,87 & \begin{tabular}{|l|l|l|l|l|}
105,03 \\
\end{tabular} & \begin{tabular}{|l|l|l|l|}
209,76 \\
\end{tabular} & \begin{tabular}{|l|}
213,97 \\
2139
\end{tabular} & 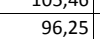 & $\begin{array}{ll}620,53 \\
620,53\end{array}$ & $\begin{array}{l}30,32 \\
97,73 \\
\end{array}$ & $\begin{array}{l}1,979 \\
1,99\end{array}$ & $\begin{array}{ll}64,87 \\
64,8\end{array}$ & $\mid 281,73$ & 23,16 & 25,60 & $\begin{array}{l}23,01 \\
270,38 \\
\end{array}$ \\
\hline Salamandra salamandra & 295NB93 & 101,00 & 154,65 & 98,68 & 41,62 & 4663,30 & 289,92 & 55,33 & 234,59 & \begin{tabular}{|l|l|}
108,13 \\
\end{tabular} & 214,02 & 218,37 & 99,52 & 599,00 & 93,82 & 2,02 & 64,50 & 271,15 & 22,54 & 24,85 & 260,13 \\
\hline Salamandra salamandra & $295 N B 94$ & 100,00 & 159,33 & 99,98 & 41,80 & 4709,88 & 296,68 & 59,39 & 237,29 & 112,16 & 219,24 & 223,63 & 103,63 & 571,80 & 89,02 & 2,00 & 64,30 & 258,27 & 21,49 & 23,73 & 247,61 \\
\hline Salamandra salamandra & $29 \mathrm{SNCO5}$ & 13,00 & 170,3 & 85,90 & 41,70 & 4110,10 & 287,80 & 83 & 204,30 & 127 & 220,80 & 225,50 & 120,40 & 644,60 & 96,70 & 3,1 & 63,80 & 287,90 & 26,40 & 29,30 & 277,70 \\
\hline Salamandra salamandra & 29 SNC06 & 92,00 & 166 & 85 & 41, & & 285 & 79 & 205,97 & 122 & 217 & 222,47 & 115,64 & 681 & 101,62 & 3, & 63,05 & 302,61 & 28,84 & 31,25 & 293,11 \\
\hline Salamandra salamandra & $295 N C 07$ & 101,00 & 169,51 & 84,83 & 40,99 & 4161,27 & 287,38 & 82,44 & 204,94 & 125,92 & 220,59 & 225,31 & 118,66 & 667,01 & $\begin{array}{l}290,49 \\
99,4\end{array}$ & 3,01 & 63,32 & 296,84 & 27,18 & 30,14 & 287,32 \\
\hline Salamandra salamandra & $295 \mathrm{SCO}$ & 44,00 & 169,96 & 82,41 & 40,92 & 4094,55 & 283,96 & 83,82 & 200,14 & 126,75 & 220,06 & 224,33 & 119,35 & 666,27 & 99,81 & 3,00 & 63,11 & 295,30 & 27,00 & 30,45 & 285,77 \\
\hline Salamandra salamandra & $29 \mathrm{SNC} 18$ & 101,00 & 170,36 & 85,57 & 40,95 & 4216,61 & 289,75 & 82,38 & 207,36 & 126,20 & 222,34 & 226,68 & 118,63 & 654,34 & 96,99 & 3,00 & 62,89 & 288,89 & 27,13 & 30,05 & 280,95 \\
\hline Salamandra salamand & 29SNC19 & 100,00 & 169,45 & & 40,73 & 70 & 20 & $81, \varepsilon$ & 205,06 & 125,35 & 2007 & 225,15 & 117,87 & 663,76 & 98,49 & . & 62,52 & 292,10 & 27,61 & 30,92 & 284,15 \\
\hline Salamandra salamandra & $295 N C 20$ & & & & $4 L_{i}$ & $4 \angle Z 4$ & & 13,92 & 214,99 & 120,64 & 215,90 & $2 \angle 0$, & $\mid$ & 606,74 & 90,73 & 2,30 & $\mid 63,70$ & 270,56 & 25,52 & 26,30 & 263 \\
\hline Salamandra salamandra & $295 N C 21$ & 101,00 & \begin{tabular}{|l|}
164,38 \\
04,5
\end{tabular} & 92,12 & 42,16 & 4247,06 & 290,22 & 74,66 & 215,56 & 121,27 & 217,10 & 221,97 & 113,42 & 612,68 & 91,38 & 2,49 & 63,49 & 272,22 & 25,95 & 26,81 & 265,08 \\
\hline Salamandra salamandra & $295 N C 22$ & 99,00 & 166,10 & 91,82 & 42,02 & 4275,52 & 292,11 & 76,33 & 215,78 & 122,47 & 219,16 & 224,04 & \begin{tabular}{|l|l|}
114,58 \\
\end{tabular} & 614,17 & 91,45 & 2,67 & 63,12 & 272,23 & 26,19 & 27,32 & 265,21 \\
\hline Salamandra salamandra & $29 \mathrm{SNC} 23$ & 101,00 & 168,86 & 91,32 & 42,00 & 4281,82 & 294,32 & 78,88 & 215,44 & 124,77 & 221,79 & 226,66 & 116,93 & 608,71 & 90,47 & 2,99 & 63,12 & 269,53 & 25,78 & 27,64 & 262 \\
\hline Salam & 29 SNC27 & 101,00 & 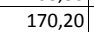 & & 40,5 & 232 & & 80, & 213 & 125, & 223,61 & 228 & 117 & & & 3,00 & 62,43 & 280 & 27,36 & 29,82 & 27 \\
\hline Salamandra salamandra & $295 \mathrm{NC} 28$ & 101,00 & 169,01 & 8 & $\begin{array}{l}40,95 \\
40,97\end{array}$ & 4313,12 & \begin{tabular}{|l|l|l|}
291,96 \\
\end{tabular} & 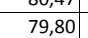 & $\begin{array}{l}212,0 \\
212,16\end{array}$ & 123,92 & $\frac{22,01}{222,42}$ & 226,85 & \begin{tabular}{|l|}
116,38 \\
\end{tabular} & 6 & \begin{tabular}{|l|l|}
96,47 \\
96
\end{tabular} & 3,00 & $\begin{array}{l}62,13 \\
62,12\end{array}$ & $\begin{array}{l}280,42 \\
286,12\end{array}$ & 28,15 & $\mid$ & 279,97 \\
\hline
\end{tabular}




\begin{tabular}{|c|c|c|c|c|c|c|c|c|c|c|c|c|c|c|c|c|c|c|c|c|c|}
\hline TAXON & UTM & $\mathrm{km} 2$ & B101 & $\mathrm{B1O2}$ & $\mathrm{BIO3}$ & 8104 & B105 & B106 & B107 & B108 & B109 & BIO10 & BIO11 & BIO12 & B1013 & B1014 & 81015 & B1016 & BIO17 & B1018 & BIO19 \\
\hline Salamandra salamandra & 29SNC30 & 100,00 & 164,80 & 94,76 & 42,16 & 4339,40 & 294,27 & 73,09 & 221,18 & 120,82 & 218,96 & 223,73 & 112,79 & 591,55 & 88,55 & 2,06 & 63,69 & 263,40 & 24,27 & 24,90 & 256,82 \\
\hline Salamandra salamandra & $295 N C 31$ & 101,00 & 161,27 & 94,95 & 42,00 & 4402,58 & 292,56 & 69,61 & 222,95 & 116,77 & 216,36 & 221,20 & 108,72 & 624,36 & 92,71 & 2,89 & 62,71 & 274,96 & 27,25 & 27,68 & 269,36 \\
\hline Salamandra salamandra & $295 N C 32$ & 101,00 & \begin{tabular}{|l|l|l|l|l|l|}
164,58 \\
\end{tabular} & 94,37 & 41,92 & 4412,68 & 295,47 & 72,80 & 222,67 & 119,62 & 219,70 & 224,62 & 111,69 & 614,58 & $\begin{array}{ll}90,98 \\
0,1\end{array}$ & 2,73 & 62,64 & 270,49 & 26,43 & 27,17 & 264,92 \\
\hline Salamandra salamandra & 29 SNC35 & 101,00 & 171,03 & 92,25 & 41,48 & 4404,83 & 299,52 & 79,46 & 220,05 & 125,40 & 225,77 & 230,49 & 117,50 & 604,24 & 88,76 & 3,00 & 62,41 & 264,68 & 25,77 & 27,49 & 259,25 \\
\hline Salamandra salamandra & 29SNC37 & 101,00 & 169,03 & 90,66 & 40,99 & 4427,78 & 296,69 & 77,94 & 218,75 & 122,70 & 224,05 & 228,61 & \begin{tabular}{|l|}
115,18 \\
\end{tabular} & \begin{tabular}{|c|c|}
636,97 \\
\end{tabular} & 93,47 & 3,05 & 61,64 & 276,64 & 28,14 & 30,01 & 271,91 \\
\hline Salamandra salamandra & 29 SNC38 & 100,00 & 167,84 & 89,72 & 40,97 & 4423,35 & 294,69 & 76,97 & 217,72 & 121,60 & 222,86 & 227,25 & 113,91 & 653,12 & 95,80 & 3,45 & 61,27 & 282,41 & 29,44 & 31,45 & 277,99 \\
\hline Salamandra salamandra & 29 SNC39 & 100,00 & 168,15 & 88,67 & 40,81 & 4385,91 & 293,38 & 77,73 & 215,65 & 122,21 & 222,70 & 227,00 & 114,55 & 657,82 & 96,56 & 3,71 & 61,08 & 283,95 & 29,97 & 32,20 & 279,29 \\
\hline Salamandra salamandra & $295 N C 40$ & 101,00 & 167,25 & 97,05 & 42,15 & 4438,80 & 300,13 & 73,75 & 226,38 & \begin{tabular}{|l|l|}
122,15 \\
\end{tabular} & 222,81 & 227,46 & 114,11 & \begin{tabular}{|l|l|}
570,75 \\
\end{tabular} & 85,50 & 2,00 & 63,50 & 253,58 & 23,46 & 24,21 & 247,48 \\
\hline Salamandra salamandra & 29SNC41 & 101,00 & 166,46 & 97,10 & 42,00 & 4485,43 & 300,43 & 72,71 & 227,71 & 120,71 & 222,62 & 227,24 & 112,62 & 584,59 & 86,96 & 2,10 & 63,03 & 257,83 & 24,48 & 25,09 & 252,44 \\
\hline Salamandra salamandra & 29 SNC45 & 101,00 & 169,94 & 94,46 & 41,41 & 4514,58 & 302,27 & 76,89 & 225,38 & \begin{tabular}{|l|l|}
123,17 \\
\end{tabular} & 226,18 & 230,97 & 115,35 & 601,31 & 87,88 & 3,00 & 61,71 & 260,69 & 26,58 & 27,74 & 256,66 \\
\hline Salamandra salamandra & 29 SNC46 & 100,00 & 168,48 & 93,61 & 41,02 & 4534,77 & 300,59 & 75,62 & 224,97 & 121,42 & 225,07 & 229,66 & 113,51 & 619,70 & 90,45 & 3,03 & 61,34 & 267,23 & 27,81 & 29,05 & 263,86 \\
\hline Salamandra salamandra & $295 N C 47$ & 100,00 & 167,73 & 92,62 & 40,97 & 4524,31 & 299,07 & 75,36 & 223,71 & 120,67 & 224,19 & 228,77 & 112,91 & 635,36 & 92,66 & 3,44 & 60,82 & 272,81 & 29,39 & 30,81 & 269,64 \\
\hline Salamandra salamandra & $295 N C 48$ & 101,00 & 167,37 & 91,63 & 40,88 & 4518,73 & 297,60 & 75,26 & 222,34 & 120,13 & 223,69 & 228,17 & $\begin{array}{l}112,45 \\
\end{array}$ & 647,64 & 94,44 & 3,90 & 60,49 & 277,18 & 30,66 & 32,10 & 274,15 \\
\hline Salamandra salamandra & 29SNC49 & 101,00 & 167,49 & 90,72 & 40,48 & 4504,72 & 296,56 & 75,55 & 221,01 & 120,28 & 223,71 & 227,97 & 112,67 & 655,11 & 95,53 & 3,96 & 60,30 & 279,75 & 31,13 & 32,90 & 276,80 \\
\hline Salamandra salamandra & 29 SNC50 & 101,00 & 169,36 & 99,40 & 42,16 & 4546,86 & 305,86 & 73,78 & 232,08 & 122,96 & 226,42 & 231,14 & 114,82 & 551,54 & 82,71 & 2,00 & 63,51 & 244,19 & 22,46 & 23,32 & 238,44 \\
\hline Salamandra salamandra & 29SNC51 & 101,00 & 169,44 & 99,28 & 42,04 & 4569,18 & 306,46 & 73,87 & 232,59 & 122,67 & 226,81 & 231,38 & 114,65 & 560,00 & 83,21 & 2,00 & 62,58 & 245,94 & 23,75 & 24,40 & 240,90 \\
\hline Salamandra salamandra & 29 SNC52 & 101,00 & 169,67 & 98,88 & 42,01 & 4587,13 & 306,68 & 74,25 & 232,43 & 122,60 & 227,16 & 231,83 & 114,48 & 566,97 & 83,56 & 2,08 & 62,27 & 247,49 & 24,29 & 24,99 & 243,05 \\
\hline Salamandra salamandra & 29 SNC56 & 101,00 & 164,47 & 95,36 & 40,94 & 4653,64 & 300,76 & 70,51 & 230,25 & 116,51 & 222,78 & 227,54 & 108,55 & 636,12 & 92,18 & 3,69 & 60,01 & 270,33 & 30,59 & 31,18 & 268,80 \\
\hline Salamandra salamandra & 29 SNC57 & 100,00 & 163,63 & 94,28 & 40,87 & 4652,67 & 298,97 & 70,09 & 228,88 & 115,47 & 221,89 & 226,65 & 107,55 & 653,05 & 94,55 & 4,00 & 59,70 & 276,30 & 32,10 & 32,64 & 275,18 \\
\hline Salamandra salamandra & 29 SNC58 & 101,00 & 166,18 & 93,38 & 40,73 & 4621,51 & 299,98 & 72,89 & 227,09 & 118,19 & 224,19 & 228,68 & 110,35 & 646,13 & 93,50 & 4,00 & 59,70 & 273,34 & 31,76 & 32,74 & 271,86 \\
\hline Salamandra salamandra & 29SNC59 & 101,00 & 166,11 & 92,51 & 40,31 & 4606,06 & 298,89 & 73,02 & 225,86 & 118,06 & 223,91 & 228,27 & 110,24 & 657,11 & 95,19 & 4,00 & 59, & 277,46 & 32,31 & 33,59 & 275,99 \\
\hline Salamandra salamandra & $295 \mathrm{NC63}$ & 100,00 & \begin{tabular}{|l|l|l|l|}
169,43 \\
\end{tabular} & 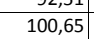 & $\begin{array}{l}40,1,97 \\
41\end{array}$ & 4709,57 & 310,18 & 72,45 & 237,73 & 120,91 & 228,61 & 233,21 & 1112,84 & $\mid \begin{array}{l}\mid 567,75 \\
\end{array}$ & 82,31 & 2,86 & 60,67 & 243,66 & 26,02 & 26,75 & 240,76 \\
\hline Salamandra salamandra & 29 SNC64 & 100,00 & 167,67 & 99,66 & 41,58 & 4728,05 & 308,14 & 71,10 & 237,04 & \begin{tabular}{|c|}
118,99 \\
\end{tabular} & 227,06 & 231,73 & 110,79 & 586,38 & 84,68 & 2,98 & 60,50 & 249,87 & 27,36 & 27,77 & 247,77 \\
\hline Salamandra salamandra & 29 SNC65 & 101,00 & 165,21 & 98,42 & 41,09 & 4744,75 & 305,35 & 69,42 & 235,94 & 116,34 & 224,94 & 229,67 & 108,29 & 609,86 & 87,75 & 3,01 & 60,04 & 257,88 & 29,32 & 29,53 & 256,77 \\
\hline Salamandra salamandra & 29 SNC66 & 100,00 & 163,32 & 96,95 & 40,96 & 4748,38 & 302,52 & 68,20 & 234,32 & 113,71 & 223,07 & 227,75 & 106,26 & 633,58 & 90,95 & 3,66 & 59,27 & 266,10 & 31,68 & 31,91 & 265,71 \\
\hline Salamandra salamandra & $295 \mathrm{SNC67}$ & 101,00 & 160,92 & 95,55 & 40,51 & 4762,73 & 299,50 & 66,41 & 233,08 & 108,31 & 221,06 & 225,57 & 103,85 & 660,70 & 94,83 & 4,00 & 58,89 & 276,39 & 33,88 & 33,97 & 276,32 \\
\hline Salamandra salamandra & $295 \mathrm{NC} 68$ & 101,00 & $\begin{array}{l}\mid 0,92,25 \\
163,25\end{array}$ & $\begin{array}{l}30,70 \\
94,70\end{array}$ & $\begin{array}{ll}40,31 \\
40,31\end{array}$ & 4730,67 & $\mid 300,30$ & 68,4196 & $\begin{array}{l}23,00 \\
231,34\end{array}$ & $\begin{array}{l}110,31,72 \\
11,72\end{array}$ & 222,91 & 227,37 & \begin{tabular}{|l|l|l|l|l|l|l|}
106,33 \\
\end{tabular} & 657,62 & $\begin{array}{l}34,03 \\
94,41 \\
\end{array}$ & 4,400 & S8,85 & 274,96 & 33,71 & 34,14 & 274,80 \\
\hline Salamandra salamandra & 29 SNC73 & 101,00 & 167,30 & 103,29 & 41,94 & 4840,16 & 312,68 & 68,40 & 244,28 & 117,58 & 228,25 & 233,07 & 109,32 & 571,18 & 81,99 & 3,00 & 59,96 & 242,07 & 27,26 & 27,38 & 240,14 \\
\hline Salamandra salamandra & $295 N C 74$ & 101,00 & $\begin{array}{l}164,58 \\
\end{array}$ & 101,83 & 41,31 & 4855,15 & 309,36 & 66,51 & 242,84 & 114,73 & 226,27 & 230,53 & 106,55 & 594,93 & $\begin{array}{l}84,98 \\
84,\end{array}$ & 3,00 & 59,55 & 250,03 & 28,86 & 28,86 & 249,31 \\
\hline Salamandra salamandra & $29 S N C 75$ & 100,00 & 164,53 & 100,09 & 41,03 & 4838,18 & 307,66 & 67,28 & 240,38 & 114,29 & 226,21 & 230,19 & 106,54 & 604,28 & 86,00 & 3,00 & 59,13 & 252,46 & 30,18 & 30,18 & 252,28 \\
\hline Salamandra salamandra & $295 N C 76$ & 101,00 & 160,29 & $\begin{array}{l}98,06 \\
98,0\end{array}$ & 40,77 & 4851,99 & 302,55 & 64,27 & 238,27 & 104,42 & 223,43 & 226,39 & 102,36 & 641,73 & 91,18 & 3,81 & 58,25 & 266,81 & 33,29 & 33,29 & 266,81 \\
\hline Salamandra salamandra & 295NC77 & 101,00 & \begin{tabular}{|l|l|}
158,54 \\
158
\end{tabular} & $\begin{array}{l}30,00 \\
96,49\end{array}$ & $\begin{array}{ll}40,17 \\
40,18\end{array}$ & 40355,58 & \begin{tabular}{|l|l|}
290,73 \\
299,73
\end{tabular} & |ct, 63 & 236,35 & \begin{tabular}{l|l|l|l|l|}
100,76 \\
\end{tabular} & 222,23 & 224,66 & $\begin{array}{l}\mid 0,300 \\
100,60\end{array}$ & $\begin{array}{l}04,15 \\
666,05\end{array}$ & $\begin{array}{l}1,10 \\
94,64 \\
\end{array}$ & $\begin{array}{l}0,01 \\
4,08\end{array}$ & 57,82 & \begin{tabular}{|l|}
20,01 \\
276,19
\end{tabular} & 35,39 & 35,39 & 270,019 \\
\hline Salamandra salamandra & $295 N C 78$ & 99,00 & 160,21 & 95,62 & 40,11 & 4836,39 & 300,15 & 65,21 & 234,94 & 102,41 & 222,25 & 225,85 & 102,35 & 669,04 & 95,14 & 4,02 & 57,86 & 277,31 & 35,75 & 35,75 & 277,31 \\
\hline Salamandra salamandra & 29 SNC79 & 101,00 & 163,50 & 95,29 & 40,00 & 4822,36 & 302,59 & 68,15 & 234,43 & 106,34 & 224,34 & 228,70 & 105,38 & 659,75 & 93,87 & 4,00 & $57, \varepsilon$ & 273,29 & 35,38 & 35,75 & 273,29 \\
\hline Salamandra salamandra & $295 N C 83$ & 101,00 & 165,01 & 105,72 & 41,8 & 4963,12 & 314,42 & 64, & 250,23 & 113 & 228,62 & 232,37 & 105,65 & 577,32 & 82,20 & 3,0 & 59, & 241,88 & 28,08 & 28,08 & 240,77 \\
\hline Salamandra salamandra & $295 N C 86$ & 100,00 & 161,19 & 99,26 & 40,70 & 4930,57 & 305,38 & 63,90 & 241,49 & 102,56 & 226,06 & 228,18 & 102,29 & 624,39 & 87,51 & 3,77 & 57,59 & 257,09 & 33,38 & 33,38 & 257,09 \\
\hline Salamandra salamandra & 29 SNC87 & 100,00 & 157,48 & 97,19 & 40,03 & 4938,52 & 300,59 & 61,44 & 239,15 & 98,67 & 223,75 & 224,75 & 98,67 & 661,51 & 92,89 & 4,07 & 57,07 & 271,88 & 36,14 & 36,14 & 271,88 \\
\hline Salamandra salamandra & $295 \mathrm{SC} 88$ & 101,00 & 158,80 & 96,51 & 39,99 & 4931,32 & 301,25 & 62,78 & 238,47 & 100,02 & 224,18 & 225,94 & 100,02 & 667,61 & 93,90 & 4,19 & 56,95 & 274,30 & 36,84 & 36,84 & 274,30 \\
\hline Salamandra salamandra & $295 N C 89$ & 100,00 & 163,08 & 96,52 & 40,01 & 4922,84 & 304,76 & 66,54 & 238,22 & 104,04 & 225,79 & 229,75 & 103,99 & 654,01 & 92,12 & 4,03 & 57,18 & 268,90 & 36,06 & 36,14 & 268,90 \\
\hline Salamandra salamandra & 29 SNC92 & 101,00 & 165,37 & 109,80 & 42,00 & 080,16 & 319,78 & 1,63 & 258,15 & 113,12 & 230,16 & 234,41 & 104,70 & 562,89 & 80,75 & 2,80 & 59,01 & 235,45 & 27,29 & 27,30 & 233,49 \\
\hline Salamandra salamandra & $295 \mathrm{NC93}$ & 100,00 & 36 & 7,68 & 41,78 & 5076,10 & 2 & 60,82 & 255,49 & $\mid 111,17$ & 228,91 & 232,37 & 102,78 & 580,06 & 81,76 & 3,00 & 58,43 & 240,55 & 28,79 & 28,79 & 239,58 \\
\hline Salamandra salamandra & 295 NC94 & 10 & 16 & & 41,13 & 506 & 312 & 60,52 & 251,92 & 107 & 228,18 & 230,52 & 101,29 & 597,04 & 83,31 & $3,19 \mid$ & 57,84 & 245,71 & 30,75 & 30,75 & 245,55 \\
\hline Salamandra salamandra & $295 N C 95$ & 101,00 & 16 & $\begin{array}{l}\mid 102,82 \\
102\end{array}$ & 40,99 & 5036,47 & 310,58 & 62,31 & 248,27 & 103,86 & 228,90 & 230,65 & 102,00 & 598,80 & 83,23 & 3,07 & 57,54 & 245,44 & 31,23 & 31,23 & 245,44 \\
\hline Salamandra salamandra & 29 SNC96 & 100,00 & 161,72 & 100,41 & 40,40 & 5014,36 & 307,90 & 63,07 & 244 & 101,64 & 227,53 & 229,77 & 101,64 & 610,86 & 84,42 & 3,90 & 56,55 & 248,98 & 33,86 & 33,86 & 248,98 \\
\hline Salamandra salamandra & 29 SNC97 & 101,00 & 160,32 & $\begin{array}{l}\mid 98,67 \\
98,6\end{array}$ & $40, \mathrm{C}$ & 013,92 & 305,33 & 62,47 & 242,87 & 100,35 & 227,13 & 228,47 & 100,35 & 630,48 & 87,14 & 4,00 & 56,21 & 256,55 & 35,39 & 35,39 & 256,55 \\
\hline Salamandra salamandra & $295 N C 98$ & $\begin{array}{l}101,00 \\
100\end{array}$ & 160 & | & 40, & 5019,94 & 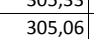 & $\begin{array}{ll}0,42,60 \\
62\end{array}$ & $\begin{array}{l}242,0 \\
242,46\end{array}$ & $\begin{array}{l}100,33 \\
100\end{array}$ & 226,64 & $\begin{array}{l}228,4,62 \\
228,62\end{array}$ & \begin{tabular}{|l|l|}
100,33 \\
100
\end{tabular} & $\begin{array}{l}650,40,31 \\
646\end{array}$ & \begin{tabular}{|l|l|l|l|}
89,76 \\
\end{tabular} & 4,001 & 56,42 & | 263,36 & 年, 36,37 & 年, 36,37 & 263,36 \\
\hline Salamandra salamandra & $295 \mathrm{SNC99}$ & 100,00 & 162,60 & 97,82 & 39,99 & 5028,22 & 307,13 & 64,41 & 242,72 & 102,16 & 226,96 & 230,84 & 102,16 & 649,82 & 90,50 & 4,00 & 56,37 & 264,99 & 36,64 & 36,65 & 264,99 \\
\hline Salamandra salamandra & 29SND01 & 100,00 & 167,07 & 78,62 & 40,80 & 3916,19 & 274,05 & 83,15 & 190,90 & \begin{tabular}{|c|}
125,68 \\
\end{tabular} & 214,87 & 218,61 & 118,06 & 673,62 & 102,52 & 3,04 & 62,79 & 298,01 & 27,32 & 31,21 & 286,83 \\
\hline Salamandra salamandra & 29 SND02 & 101,00 & 164,16 & 76,6 & $40, \varepsilon$ & 3826,01 & 267,79 & 81 & 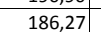 & , & $2 \pi$ & 214 & 116,05 & 686,86 & 105,02 & 3,2 & 62,0 & 302,33 & 29,19 & 33,27 & 290,53 \\
\hline Salamandra salamandra & 29SND03 & 101,00 & 160 & 75, & 40 & & 26 & 78 & 182 & 120 & 206 & 209,56 & 113 & 707 & 108 & 3,99 & 61 & 30 & 31,18 & 35,44 & 297,42 \\
\hline \begin{tabular}{|l} 
Salamandra salamandrandra \\
Sala
\end{tabular} & 29SND04 & $\begin{array}{l}100,00 \\
100\end{array}$ & \begin{tabular}{|l|}
$159,03,03$ \\
159
\end{tabular} & $\begin{array}{l}\mid 73,24 \\
74,02\end{array}$ & $\begin{array}{ll}40,1 / 2 \\
40,93\end{array}$ & 3672,60 & \begin{tabular}{|l|}
251,315 \\
257,33
\end{tabular} & 78,10 & $\begin{array}{l}18,94 \\
179,23\end{array}$ & $\begin{array}{l}120,80 \\
120,14\end{array}$ & $\mid 200,25$ & $\begin{array}{l}200,30 \\
206,64\end{array}$ & \begin{tabular}{|c|}
112,16 \\
112,38
\end{tabular} & $\mid 713,86$ & \begin{tabular}{|l|}
109,256 \\
109,86
\end{tabular} & 3,02 & $\begin{array}{l}01,30 \\
61,19\end{array}$ & |30,53 & 31, & 36,53 & 298,42 \\
\hline Salamandra salamandra & $29 S N D 05$ & 101,00 & 155,97 & 73,29 & 40,97 & 3622,09 & 252,84 & 75,74 & 177,10 & 117,80 & 199,97 & 202,88 & 109,98 & 738,07 & 113,12 & 4,51 & 60,61 & 319,44 & 34,41 & 39,11 & 307,22 \\
\hline Salamandra salamandra & 29SND06 & 101,00 & 149,04 & 73,22 & 40,77 & 3633,73 & 246,47 & 68,94 & 177,54 & 111,00 & 193,27 & 196,21 & 103,07 & 806,23 & 121,74 & 5,64 & 59,51 & 345,03 & 40,37 & 44,62 & 333,78 \\
\hline Salaman & 29SND07 & 100,00 & 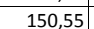 & 72 & 41,12 & 250 & 4 & 70, & 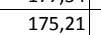 & 1,1, & , & 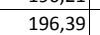 & 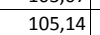 & 801,6 & & 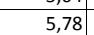 & $59, \mathrm{C}$ & 341,15 & | & 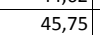 & 329,98 \\
\hline Salamandra salamandra & $29 \mathrm{SND} 08$ & & 13 & & $4 I_{i}$ & $34 / 6$, & & 74,14 & $1 / 3,04$ & $11 /, 32$ & $195,93]$ & 198,56 & 109,29 & $\frac{778,}{778,}$ & 117, & , & 58, & 330,55 & 39,95 & 45,65 & 319,44 \\
\hline Salamandra salamandra & 29 SND09 & 101,00 & 152,42 & 73,80 & 42,05 & 3457,76 & 245,39 & \begin{tabular}{l|l|}
72,05 \\
\end{tabular} & 173,34 & 115,68 & 193,97 & 196,45 & 107,71 & 810,14 & 120,76 & 6,13 & 57,97 & 341,25 & 43,40 & 49,26 & 330,91 \\
\hline Salamandra salamandra & $29 S N D 12$ & 101,00 & 166,69 & 80,13 & 40,82 & 3974,29 & 276,01 & 81,52 & 194,50 & 124,59 & 215,32 & 218,92 & 117,01 & 675,43 & 101,78 & 3,45 & 61,80 & 295,13 & 29,08 & 32,92 & 285,80 \\
\hline Salamandra salamandra & 29 SND13 & 100,00 & 162,92 & 79,09 & 40,77 & 3927,40 & 270,65 & 78,49 & 192,16 & 121,42 & 211,05 & 214,49 & 113,77 & 702,38 & 105,55 & 4,00 & 61,02 & 304,83 & 31,85 & 35,66 & 295,47 \\
\hline Salam & 29SND15 & 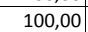 & & 77 & & 50 & 263, & 76, & 187,23 & 19,64 & 206 & 209 & 112,04 & 727 & 109 & 4,44 & 60,2 & & & 38,76 & 303 \\
\hline Salamandra salamandra & $29 S N D 16$ & 100,00 & $\mid 153,84$ & 77,45 & 40,77 & 3808,84 & 257,99 & 70,53 & $\begin{array}{l}\mid 01,25 \\
187,46 \\
\end{array}$ & 113,59 & 200,48 & 203,54 & $\mid 105,87$ & 788,12 & 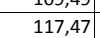 & 5,51 & 59,16 & 335,49 & $\begin{array}{l}34,41 \\
39,89 \\
\end{array}$ & 43,88 & 326,82 \\
\hline
\end{tabular}




\begin{tabular}{|c|c|c|c|c|c|c|c|c|c|c|c|c|c|c|c|c|c|c|c|c|c|}
\hline TAXON & UTM & $\mathrm{km} 2$ & BIO1 & B102 & $\mathrm{BIO3}$ & 8104 & B105 & B106 & B107 & B108 & B109 & BIO10 & BIO11 & BIO12 & B1013 & B1014 & 81015 & B1016 & BIO17 & B1018 & 81019 \\
\hline Salamandra salamandra & 29SND17 & 101,00 & 140,89 & 77,42 & 40,20 & 3896,44 & 247,82 & 57,69 & 190,13 & 100,32 & 189,19 & 192,27 & 92,55 & 923,35 & 136,53 & 7,84 & 57,81 & 387,36 & 51,57 & 54,11 & 380,57 \\
\hline Salamandra salamandra & 29SND18 & 100,00 & 150,32 & 77,86 & 41,17 & 3751,52 & 253,42 & 66,79 & 186,64 & \begin{tabular}{|l|l|}
110,63 \\
\end{tabular} & 196,26 & 199,05 & 102,79 & 842,71 & 124,44 & 6,59 & 57,92 & 354,03 & 45,62 & 49,85 & 346,48 \\
\hline Salamandra salamandra & $29 \mathrm{SND} 19$ & 100,00 & 155,32 & 78,63 & 41,99 & 3664,69 & 256,27 & 71,28 & 184,99 & $\begin{array}{l}116,06 \\
116,0\end{array}$ & 199,79 & 202,38 & 108,15 & 810,80 & 119,14 & 6,25 & 57,62 & 339,55 & 44,17 & 49,25 & 331,81 \\
\hline Salamandra salamandra & 29SND20 & 100,00 & 168,46 & 85,41 & 40,66 & 4240,96 & 287,78 & 79,95 & 207,83 & 123,80 & 220,89 & 224,97 & 116,20 & 665,77 & 98,32 & 3,52 & 61,55 & 289,62 & 29,26 & 32,28 & 283,13 \\
\hline Salamandra salamandra & 29SND24 & 100,00 & 164,81 & 81,94 & 40,97 & 4020,68 & 276,34 & 78,16 & \begin{tabular}{|c|}
198,18 \\
\end{tabular} & \begin{tabular}{|l|}
122,04 \\
\end{tabular} & 214,24 & 217,55 & 114,29 & 700,91 & 103,93 & 4,00 & 60,20 & 300,66 & 33,15 & 36,90 & 293,36 \\
\hline Salamandra salamandra & $295 N D 25$ & 101,00 & 161,26 & 81,61 & 40,91 & 3997,80 & 272,25 & 74,87 & 197,38 & 118,84 & 210,46 & 213,58 & 111,06 & 735,20 & 108,67 & 4,79 & 59,47 & 313,26 & 36,15 & 39,89 & 306,39 \\
\hline Salamandra salamandra & 29SND26 & 101,00 & 159,71 & 81,56 & 41,01 & 3964,80 & 269,88 & 73,31 & 196,58 & 117,48 & 208,47 & 211,54 & 109,77 & 756,41 & 111,66 & 5,06 & 58,96 & 320,51 & 38,33 & 42,25 & 313,91 \\
\hline Salamandra salamandra & $295 N D 27$ & 101,00 & 147,54 & 81,31 & 40,44 & 4037,86 & 260,08 & 61,37 & 198,71 & 105,03 & 197,73 & 200,82 & 97,41 & 880,62 & 129,94 & 7,08 & 57,73 & 368,51 & 48,65 & 51,27 & 363,81 \\
\hline Salamandra salamandra & 29SND28 & 101,00 & 144,18 & 81,60 & 40,51 & 4038,77 & 257,03 & 57,77 & 199,26 & \begin{tabular}{|l|l}
101,73 \\
\end{tabular} & 194,40 & \begin{tabular}{|l|l|l}
197,49 \\
\end{tabular} & 93,99 & \begin{tabular}{|c|}
927,78 \\
\end{tabular} & 136,62 & 7,98 & 57,12 & 385,76 & 53,21 & 55,56 & 381,90 \\
\hline Salamandra salamandra & 29 SND29 & 99,00 & 151,13 & 82,99 & 41,45 & 3942,27 & 261,95 & 63,73 & 198,22 & \begin{tabular}{|l|}
109,08 \\
\end{tabular} & 199,74 & 202,52 & 101,35 & \begin{tabular}{|c|}
876,15 \\
\end{tabular} & 128,23 & 7,39 & 56,91 & 363,50 & 50,06 & 53,62 & 359,24 \\
\hline Salamandra salamandra & 29SND31 & 100,00 & 167,67 & 86,84 & 40,60 & 4312,47 & 289,58 & 78,11 & 211,47 & 122,13 & 221,16 & 225,22 & 114,66 & 672,53 & 98,92 & 3,92 & 60,59 & 289,03 & 31,02 & 33,73 & 284,16 \\
\hline Salamandra salamandra & $29 \mathrm{SND} 36$ & 101,00 & 163,01 & 85,30 & 40,99 & 4139,85 & 279,47 & 73,62 & 205,86 & 118,69 & 214,20 & 217,29 & 110,95 & 745,59 & \begin{tabular}{|r|r|}
109,38 \\
\end{tabular} & 5,01 & 58,52 & 313,82 & 38,47 & 41,99 & 309,20 \\
\hline Salamandra salamandra & 29 SND37 & 100,00 & 157,30 & 85,38 & 40,79 & 4154,40 & 274,52 & 67,86 & 206,66 & 112,97 & 208,89 & 211,94 & 105,38 & 810,35 & 118,84 & 6,19 & 57,83 & 338,33 & 44,14 & 47,12 & 334,79 \\
\hline Salamandra salamandra & 29SND38 & 101,00 & 154,11 & 86,06 & 40,92 & 4160,23 & 272,22 & 64,23 & 207,99 & 109,68 & 205,85 & 208,84 & \begin{tabular}{|l|l|}
101,98 \\
\end{tabular} & 852,33 & 124,75 & 6,88 & 57,12 & 353,53 & 48,20 & 50,95 & 350,97 \\
\hline Salamandra salamandra & 29SND39 & 101,00 & 153,96 & 87,16 & 41,14 & 4137,05 & 272,16 & 63,43 & 208,73 & 109,60 & 205,40 & 208,28 & 102,00 & 870,46 & 126,93 & 7,33 & 56,63 & 359,14 & 50,47 & 53,44 & 357,18 \\
\hline Salamandra salamandra & 29SND41 & 101,00 & 168,65 & 89,19 & 40,51 & 4432,78 & 294,78 & 77,14 & 217,64 & 121,91 & 223,91 & 227,95 & 114,21 & 662,52 & 96,85 & 4,00 & 60,02 & 282,14 & 31,64 & 34,01 & 278,72 \\
\hline Salamandra salamandra & $295 N D 43$ & 101,00 & 165,55 & 88,08 & 40,38 & 4386,48 & 289,87 & 74,40 & 215,47 & 119,04 & 220,25 & 223,94 & $\frac{114,31}{111,32}$ & 704,16 & 103,05 & 4,47 & 59,20 & 297,69 & 35,20 & 37,73 & 294,37 \\
\hline Salamandra salamandra & 29SND45 & 101,00 & 165,76 & 88,03 & 40,78 & 4321,19 & 288,15 & 74,32 & 213,82 & 119,42 & 219,42 & 222,85 & 111,97 & 723,74 & 105,79 & 4,87 & 58,48 & 304,00 & 37,37 & 40,32 & 300,70 \\
\hline Salamandra salamandra & 29SND46 & 101,00 & 166,58 & 88,53 & 40,98 & 4293,35 & 288,52 & 74,46 & \begin{tabular}{|l|l|}
214,05 \\
\end{tabular} & 120,34 & 219,92 & 223,14 & 112,81 & 727,41 & 106,05 & 5,03 & 58,10 & 304,27 & 38,17 & 41,38 & 301,09 \\
\hline Salamandra salamandra & 29SND47 & 101,00 & 163,11 & 89,05 & 40,96 & 4309,41 & 285,90 & 70,68 & 215,21 & 116,77 & 216,77 & 219,84 & 109,16 & 770,68 & 112,25 & 5,77 & 57,55 & 320,32 & 42,06 & 45,06 & 318,06 \\
\hline Salamandra salamandra & 29SND48 & 100,00 & 160,19 & 89,82 & 41,00 & 4310,84 & 283,68 & 67,29 & 216,38 & 113,66 & 213,89 & 216,89 & 106,16 & 813,88 & 118,38 & 6,42 & 56,90 & 336,12 & 46,13 & 48,98 & 334,85 \\
\hline Salamandra salamandra & $29 \mathrm{SND} 50$ & 101,00 & 167,79 & $\begin{array}{ll}51,83 \\
91,83\end{array}$ & 40,21 & 4577,92 & $\begin{array}{l}2909,08 \\
299\end{array}$ & 74,61 & 224,47 & 119,69 & 225,07 & 229,25 & 111,94 & 656,23 & $\begin{array}{r}+10,0 \\
95,12 \\
\end{array}$ & $4,4,00$ & 59,42 & 277,02 & 32,25 & 33,94 & 275,19 \\
\hline Salamandra salamandra & 29SND54 & 100,00 & 163,62 & 90,20 & 40,02 & 4533,12 & 292,51 & 70,56 & 221,95 & 115,70 & 220,47 & 224,08 & 107,92 & 735,01 & 107,10 & 5,02 & 58,32 & 306,96 & 38,58 & 40,59 & 305,63 \\
\hline Salamandra salamandra & $29 \mathrm{SND} 55$ & 100,00 & 162,59 & 90,29 & 40,09 & 4516,73 & 291,27 & 69,36 & 221,91 & 114,68 & 219,35 & 222,82 & 107,06 & 757,73 & 110,34 & 5,54 & 57,69 & 315,09 & 41,03 & 43,10 & 314,16 \\
\hline Salamandra salamandra & $295 N D 59$ & 101,00 & 155,63 & 92,85 & 40,48 & 4542,00 & 286,69 & 60,08 & 226,61 & 100,20 & 212,94 & 215,92 & 99,49 & 886,67 & 128,71 & 7,65 & 56,03 & 363,69 & 53,16 & 54,72 & 363,69 \\
\hline Salamandra salamandra & $295 N D 60$ & 100,00 & 167,56 & 93,60 & 40,16 & 4693,55 & 302,33 & 73,11 & 229,22 & 118,44 & 226,51 & 230,75 & 110,51 & 652,08 & 93,74 & 4,00 & 58,75 & 272,51 & 33,19 & 34,41 & 271,85 \\
\hline Salamandra salamandra & $295 N D 61$ & 100,00 & $\begin{array}{ll}10,50 \\
168,42\end{array}$ & $\begin{array}{ll}93,18 \\
93,18\end{array}$ & $\begin{array}{l}40,10 \\
40,17\end{array}$ & 40577,65 & \begin{tabular}{|c|}
302,26 \\
302,26
\end{tabular} & 73,77 & 228,49 & $\begin{array}{l}\mid 119,44 \\
119,18\end{array}$ & 227,10 & 231,18 & 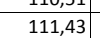 & $\begin{array}{l}\mid 65,00 \\
659,02\end{array}$ & \begin{tabular}{|c|c|}
94,87 \\
4
\end{tabular} & 4,400 & 58,62 & 275,31 & 33,64 & 34,16 & 27,03 \\
\hline Salamandra salamandra & 29SND64 & 100,00 & 163,53 & 92,14 & 39,99 & 4671,31 & 296,93 & 68,86 & 228,06 & 112,76 & 222,46 & 226,16 & 106,44 & 739,71 & 107,19 & 5,24 & 57,64 & 306,74 & 40,06 & 41,67 & 306,59 \\
\hline Salamandra salamandra & $295 N D 65$ & 101,00 & 162,54 & 92,21 & 39,99 & 4676,03 & 296,03 & 67,40 & 228,53 & 110,27 & 221,56 & 225,14 & 105,29 & 763,63 & 110,71 & 5,94 & 57,23 & 315,68 & 42,68 & 44,36 & 315,62 \\
\hline Salamandra salamandra & $295 N D 66$ & 101,00 & 165,61 & 93,09 & 40,11 & 4654,14 & 298,53 & 69,45 & 229,09 & 114,68 & 224,13 & 227,40 & 108,00 & 751,99 & 108,81 & 5,59 & 57,07 & 310,31 & 41,83 & 44,10 & 310,05 \\
\hline Salamandra salamandra & $295 N D 67$ & 100,00 & 162,12 & 93,45 & 40,02 & 4683,37 & 296,33 & 65,63 & 230,70 & 106,61 & 221,41 & 224,52 & 104,51 & 799,38 & 115,80 & 6,27 & 56,69 & 329,00 & 45,86 & 47,63 & 328,94 \\
\hline \begin{tabular}{|l} 
Salamandra salamandra \\
\end{tabular} & $295 N D 68$ & 101,00 & $\frac{10,112}{159,67}$ & $\begin{array}{c}30,45 \\
93,99\end{array}$ & $\begin{array}{ll}40,0<2 \\
40,01\end{array}$ & $\begin{array}{l}4003,31 \\
4703,47\end{array}$ & \begin{tabular}{|l|l|}
290,35 \\
294,69
\end{tabular} & $\begin{array}{l}0,035 \\
62,56\end{array}$ & 232,14 & $\begin{array}{l}02,014 \\
102,14\end{array}$ & $\begin{array}{l}2219,41 \\
2195\end{array}$ & 2222,32 & $\begin{array}{l}101,68 \\
101,68\end{array}$ & \begin{tabular}{|l|l|}
838,90 \\
\end{tabular} & $\begin{array}{l}\mid 1,0,0 \\
121,61 \\
\end{array}$ & $0 ., 79$ & \begin{tabular}{|c|c|}
56,21 \\
\end{tabular} & \begin{tabular}{|l|}
344,67 \\
344,67
\end{tabular} & 493,30 & - 41,030 & 344,67 \\
\hline Salamandra salamandra & 29SND70 & 101,00 & 166,85 & 95,14 & 40,07 & 4804,47 & 305,03 & 70,95 & 234,08 & 113,76 & 227,38 & 231,65 & 108,60 & 651,19 & 92,75 & 4,00 & 57,94 & 269,61 & 34,63 & 35,48 & 269,59 \\
\hline Salamandra salamandra & 29SND71 & 100,00 & 168,11 & 94,80 & 40,01 & 4798,65 & 305,51 & 71,85 & 233,66 & 116,48 & 228,52 & 232,59 & 109,66 & 657,29 & 93,77 & 4,01 & 57,93 & 271,99 & 34,92 & 36,13 & 271,84 \\
\hline Salamandra salamandra & $295 N D 72$ & 101,00 & 167,56 & 94,45 & 40,0 & 4800,62 & 304,86 & 71,40 & 233,45 & 115, & 228,11 & 232,07 & 109,13 & 676,64 & 96,79 & 4,45 & 57,64 & 279,63 & 36,56 & 37,84 & 279,55 \\
\hline Salamandra salamandra & $295 N D 74$ & 101,00 & 163,90 &, 73 & 39,83 & 4823,81 & 301,46 & 67,69 & 233,77 & 106,79 & 225,15 & 228,75 & 105,49 & 737,46 & 106,23 & 5,32 & 57,22 & 304,37 & 41,04 & 42,31 & 304,37 \\
\hline Salamandra salamandra & 29SND75 & 100,00 & 164,11 & 93,99 & 39,71 & 4828,13 & 301,70 & 67,27 & 234,44 & 106,90 & 225,40 & 228,76 & 105,26 & 751,74 & 108,35 & 5,77 & 56,91 & 309,75 & 42,51 & 43,99 & 309,75 \\
\hline Salamandra salamandra & $295 N D 76$ & 101,00 & 166,34 & 94,80 & 39,87 & 4805,36 & 303,58 & \begin{tabular}{|c|c|}
68,38 \\
\end{tabular} & 235,21 & 111,06 & 227,19 & 230,44 & 107,33 & 748,79 & 107,79 & 5,66 & 56,58 & 307,78 & 42,49 & 44,37 & 307,73 \\
\hline Salamandra salamandra & 29SND78 & 100,00 & 156,18 & 94,27 & 39,20 & 4899,09 & 295,88 & 58,04 & 237,84 & 96,54 & 218,78 & 221,83 & 96,54 & 877,66 & 127,63 & 7,38 & 56,02 & 360,54 & 52,64 & 53,34 & 360,54 \\
\hline Salamandra salamandra & 29SND79 & 101,00 & 3,58 & 94,51 & 39,0 & 917,92 & 293,90 & 55,02 & 238,88 & \begin{tabular}{|c|}
93,68 \\
\end{tabular} & 216,89 & 219,49 & 93,68 & 919,63 & 133,97 & 8,1 & 55,83 & 377,20 & 56,25 & 56,71 & 377,20 \\
\hline Salamandra salamandra & $295 N D 80$ & 101,00 & 16 & $\begin{array}{l}94,11 \\
96,48\end{array}$ & 40 & 4914,35 & 30 & 69,17 & 238,47 & $\mid$ & 228,70 & 232,91 & \begin{tabular}{|c|}
107,09 \\
\end{tabular} & 646,56 & \begin{tabular}{|c|}
91,14 \\
91,
\end{tabular} & 4,00 & 57,21 & 265,65 & 35,67 & 36,13 & 265,65 \\
\hline Salamandra salamandra & 29SND81 & 10 & 16 & 96,43 & 40 & 491 & 308,99 & $\begin{array}{l}70,55 \\
\end{array}$ & 238,44 & 113 & 230,43 & 234,46 & 108,68 & 649,91 & 91,89 & 4,05 & 57,22 & 267,05 & 35,42 & 36,48 & 267,05 \\
\hline Salamandra salamandra & $295 N D 82$ & 100,00 & 166,25 & $\begin{array}{ll}95,78 \\
55,7\end{array}$ & 39,86 & 4933,50 & 30 & 68,68 & 238,46 & 107,86 & 228,73 & 232,66 & 106,37 & $\mid 683,16$ & 97,01 & 4,95 & 56,91 & 280,67 & 38,24 & 39,23 & 280,67 \\
\hline Salamandra salamandra & 29SND84 & 101,00 & 166,20 & 95,57 & 39,56 & 4949,48 & 307,08 & 67,8 & 239,22 & 107,46 & 229,05 & 232,68 & 105,90 & 717,25 & 102,55 & 5,08 & 56,79 & 294,66 & 40,21 & 41,54 & 294,66 \\
\hline Salamandra salamandra & 29SND86 & 100,00 & 164,90 & 0 & 39,27 & 4975,12 & 306,28 & 65,64 & 240,64 & 105,07 & 228,30 & 231,51 & 104,17 & 762,81 & 109,64 & 5,84 & 56,31 & 312,88 & 43,97 & 45,47 & 312,88 \\
\hline Salamandra salamandra & $295 N D 87$ & $\begin{array}{l}101,00 \\
100\end{array}$ & $\begin{array}{ll}163,28 \\
\end{array}$ & 95 & 39,23 & 5002,83 & $\begin{array}{l}300,20 \\
305,49\end{array}$ & $\begin{array}{l}0,04 \\
63,42\end{array}$ & $\begin{array}{l}24,04 \\
242,07\end{array}$ & $\begin{array}{l}102,54 \\
104\end{array}$ & $\begin{array}{l}227,30 \\
227,23\end{array}$ & 230,24 & $\begin{array}{l}\mid 02,16 \\
102,16\end{array}$ & $\begin{array}{l}790,01 \\
794,42\end{array}$ & $\begin{array}{l}114,52 \\
114,52\end{array}$ & 6, 604 & $\begin{array}{l}50,011 \\
56,04 \\
\end{array}$ & $\begin{array}{l}31,00 \\
325,44\end{array}$ & 46,72 & $\begin{array}{l}43,4,10 \\
48,10\end{array}$ & 325,44 \\
\hline Salamandra salamandra & $295 N D 88$ & 99,00 & 154,56 & 94,24 & 38,52 & 5066,11 & 297,74 & 55,48 & 242,26 & 93,30 & 220,01 & 222,74 & 93,30 & 894,16 & 130,22 & 7,64 & 55,91 & 366,97 & 54,09 & 54,49 & 366,97 \\
\hline Salamandra salamandra & 29SND89 & 101,00 & 153,44 & 94,66 & 38,42 & 5085,55 & 297,12 & 53,67 & 243,45 & 91,82 & 219,37 & 221,80 & 91,82 & 921,40 & 134,45 & 8,01 & 55,71 & 377,72 & 56,39 & 56,68 & 377,72 \\
\hline Salamandra salamandra & $295 N D 90$ & 100,00 & 165,34 & 97,75 & 39,97 & 5033,34 & ו & 66, & 2.10 & \begin{tabular}{|c|}
104,96 \\
\end{tabular} & 229 & 233,44 & 104,66 & 649,04 & 90,68 & 4,6 & 56 & 264,87 & 36,60 & 36,92 & 264,87 \\
\hline Salamandra salamandra & 29SND91 & 100,00 & & 97, & 39, & 5042 & 30 & & 24 & 105 & 229 & 233 & 104 & 666 & 93,51 & 4,7 & 56 & 272,06 & & 38,47 & 272,06 \\
\hline 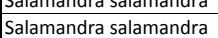 & $295 N D 92$ & $\begin{array}{l}100,00 \\
100\end{array}$ & \begin{tabular}{|l|}
163,322 \\
167,01
\end{tabular} & $\begin{array}{l}1,14 \\
97,38 \\
\end{array}$ & $\begin{array}{l}3,1 / 4 \\
39,53\end{array}$ & $\begin{array}{l}504,201 \\
5042,72\end{array}$ & $\begin{array}{l}|c| 09 \\
311,14\end{array}$ & $\begin{array}{ll}00,10 \\
67,58\end{array}$ & 2424,925 & $\begin{array}{l}0,51 \\
108,42 \\
\end{array}$ & $\begin{array}{l}22,01,32 \\
231\end{array}$ & 235,16 & \begin{tabular}{|l|l|l|l|}
105,97 \\
\end{tabular} & $\begin{array}{l}600,33 \\
672,80\end{array}$ & $\begin{array}{l}93,51 \\
94,69\end{array}$ & $\begin{array}{l}4,1 / 1 \\
4,91\end{array}$ & $\begin{array}{c}30,11 \\
56,41 \\
\end{array}$ & $\begin{array}{l}27,00 \\
274,65\end{array}$ & $\begin{array}{l}30,0< \\
38,37\end{array}$ & 30,47! & 2774,65 \\
\hline Salamandra salamandra & $29 \mathrm{SND} 93$ & 100,00 & 166,58 & 97,03 & 39,23 & 5067,16 & 310,69 & 67,06 & 243,63 & \begin{tabular}{|c|}
107,18 \\
\end{tabular} & 231,19 & 234,92 & 105,31 & 693,44 & 98,05 & 5,00 & 56,36 & 283,46 & 39,40 & 40,47 & 283,46 \\
\hline Salamandra salamandra & 29SND94 & 100,00 & 164,63 & 96,36 & 39,00 & 5094,30 & 309,10 & 65,31 & 243,79 & 103,10 & 229,80 & 233,27 & 103,05 & 729,34 & 103,74 & 5,38 & 56,13 & 298,24 & 42,26 & 43,34 & 298,24 \\
\hline Salamandra salamand & $29 \mathrm{SND} 95$ & 101,00 & , & & 38,97 & 5107,33 & | & 64,56 & 244,41 & 102,61 & 229,69 & 233,08 & 102,46 & 749,64 & 1 & 5,86 & 56,03 & 306,62 & & 44,92 & 306,62 \\
\hline Salamandra salamandra & $29 \mathrm{SND}$ & & & & 38,71 & 5140, & & 61,99 & 245,13 & 99,61 & 227,89 & 231,10 & 99 & 788, & 1 & 0, & 50,97 & 322,89 & 46,10 & 47,06 & 322, \\
\hline Salamandra salamandra & 29SND97 & 100,00 & 163,64 & 96,61 & 38,69 & 5152,31 & 309,19 & 62,41 & 246,78 & 101,27 & 229,80 & 232,76 & 100,99 & 789,01 & 113,33 & 6,22 & 55,85 & 322,31 & 46,76 & 48,03 & 322,31 \\
\hline Salamandra salamandra & $295 N D 98$ & 101,00 & 159,65 & $\begin{array}{l}96,07 \\
9,1\end{array}$ & 38,20 & 5204,60 & 306,12 & 58,25 & 247,87 & 96,60 & 226,80 & 229,56 & 96,60 & 842,70 & 121,84 & 6,97 & 55,70 & 344,44 & 50,83 & 51,66 & 344,44 \\
\hline Salamandra salamandra & 29SND99 & 100,00 & 157,27 & 95,94 & 38,03 & 5233,99 & 304,20 & 55,38 & 248,82 & 93,83 & 224,97 & 227,49 & 93,83 & 880,99 & 127,97 & 7,45 & 55,45 & 360,06 & 53,78 & 54,41 & 360,06 \\
\hline Salan & 29SNE01 & 71,00 & & & 43, & 3391 & & 73, & 172 & 118,78 & 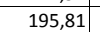 & 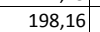 & 110,9 & 820 & 12 & 6, & 56,68 & & 29 & 53,10 & 331 \\
\hline Salamandra salamandra & $29 \mathrm{NNE} 10$ & 101,00 & 155,98 & 79,34 & 42,57 & 3622,00 & 256,06 & 71,49 & \begin{tabular}{l|l}
184,58 \\
\end{tabular} & $\begin{array}{l}\mid 116,108 \\
116,98\end{array}$ & $\begin{array}{l}199,01 \\
\end{array}$ & 202,30 & 109,14 & 821,60 & $\begin{array}{l}119,97 \\
\end{array}$ & 6 & $\begin{array}{l}0,009 \\
56,95\end{array}$ & $\begin{array}{l}34,1,42 \\
341,94\end{array}$ & 45,90 & 51,55 & 334,68 \\
\hline
\end{tabular}




\begin{tabular}{|c|c|c|c|c|c|c|c|c|c|c|c|c|c|c|c|c|c|c|c|c|c|}
\hline TAXON & UTM & $\mathrm{km} 2$ & B101 & $\mathrm{B1O2}$ & $\mathrm{BIO3}$ & 8104 & B105 & B106 & B107 & B108 & B109 & 81010 & B1011 & BIO12 & B1013 & B1014 & 81015 & B1016 & BIO17 & B1018 & 81019 \\
\hline Salamandra salamandra & 29SNE11 & 101,00 & 155,21 & 80,06 & 42,88 & 3601,97 & 254,96 & 70,29 & 184,66 & 116,16 & 198,65 & 201,09 & 108,34 & $845,97 \mid$ & 122,64 & 7,29 & 56,16 & 349,90 & 48,92 & 54,74 & 343,15 \\
\hline Salamandra salamandra & 29SNE12 & 101,00 & 154,19 & 80,64 & 43,08 & 3581,21 & 253,36 & 68,70 & 184,66 & 115,14 & \begin{tabular}{|l|}
197,19 \\
\end{tabular} & 199,53 & 107,27 & 874,10 & 125,94 & 7,94 & 55,56 & 359,32 & 52,16 & 58,23 & 353,13 \\
\hline Salamandra salamandra & 29SNE20 & 101,00 & 152,52 & 84,09 & 41,92 & 3904,09 & 262,92 & 64,42 & 198,50 & 110,37 & 200,48 & 203,16 & 102,82 & 879,72 & 128,01 & 7,63 & 56,25 & 363,10 & 51,42 & 55,46 & 359,14 \\
\hline Salamandra salamandra & 29SNE21 & 100,00 & 154,41 & 85,30 & 42,49 & 3858,25 & 264,11 & 65,67 & 198,45 & 112,57 & 201,62 & 204,18 & 104,94 & 879,25 & 127,02 & 7,92 & 55,83 & 361,05 & 52,38 & 56,89 & 357,44 \\
\hline Salamandra salamandra & 29SNE22 & 101,00 & 156,45 & 86,16 & 43,06 & 3801,99 & 264,73 & 66,96 & 197,77 & 114,81 & 202,60 & 205,01 & 107,05 & 877,24 & 125,73 & 8,03 & 55,11 & 358,35 & 53,36 & 58,58 & 354,81 \\
\hline Salamandra salamandra & 29SNE30 & 100,00 & 151,17 & 88,04 & 41,29 & 4146,76 & 270,31 & 60,08 & 210,23 & 106,59 & 202,74 & 205,56 & 99,05 & 915,09 & 132,98 & 8,19 & 55,99 & 375,21 & 54,94 & 57,61 & 374,22 \\
\hline Salamandra salamandra & 29SNE31 & 101,00 & 153,26 & 89,56 & 41,83 & 4109,05 & 272,14 & 61,12 & 211,03 & 107,35 & 204,18 & 206,82 & 101,14 & 913,92 & 131,86 & 8,50 & 55,35 & 373,01 & 56,08 & 59,22 & 372,06 \\
\hline Salamandra salamandra & 29SNE32 & 100,00 & $\begin{array}{l}\mid 5,203,67 \\
153\end{array}$ & $\begin{array}{l}\mid c 0,88 \\
90,8\end{array}$ & $\begin{array}{ll}42,35 \\
42,44\end{array}$ & 4083,90 & 272,45 & $\begin{array}{ll}\mid c 1,72 \\
60,72\end{array}$ & 211,73 & $\begin{array}{l}0,56 \\
106,56\end{array}$ & 204,07 & 206,71 & 101,62 & $\mid \begin{array}{l}\mid 929,17 \\
929\end{array}$ & 133,19 & 8,90 & $\mid 54,84$ & 377,49 & 58,40 & $\begin{array}{ll}61,262 \\
61,82\end{array}$ & 376,70 \\
\hline Salamandra salamandra & 29SNE40 & 101,00 & 155,32 & 91,90 & 41,29 & 4330,14 & 280,92 & 61,01 & 219,91 & \begin{tabular}{|l|l|}
104,81 \\
\end{tabular} & \begin{tabular}{|l|}
209,47 \\
\end{tabular} & 212,15 & 100,99 & 894,76 & 129,51 & 7,94 & 55,79 & 365,99 & 54,14 & 56,49 & 365,92 \\
\hline Salamandra salamandra & 29SNE41 & 101,00 & 152,76 & 93,14 & 41,49 & 4345,88 & 279,68 & 57,65 & 222,03 & $\begin{array}{l}98,66 \\
\end{array}$ & 207,16 & 209,86 & 98,28 & 939,08 & 135,46 & 8,86 & 55,12 & 382,81 & 58,79 & 60,79 & 382,81 \\
\hline Salamandra salamandra & 29SNE42 & 100,00 & 150,50 & 94,55 & 41,80 & 4357,86 & 278,69 & 54,41 & 224,29 & 95,73 & 205,08 & 207,75 & 95,73 & 981,85 & 141,10 & 9,75 & 54,39 & 398,97 & 63,27 & 65,08 & 398,97 \\
\hline Salamandra salamandra & 29SNE50 & 101,00 & 152,49 & 93,64 & 40,52 & 4559,42 & 284,73 & 56,28 & 228,45 & 96,01 & 210,15 & 213,00 & 96,01 & 936,03 & 135,86 & 8,58 & 55,59 & 383,17 & 57,83 & 59,04 & 383,17 \\
\hline Salamandra salamandra & 29SNE51 & 101,00 & 150,79 & 94,81 & 40,71 & 4567,43 & 283,90 & 53,75 & \begin{tabular}{|l|l}
230,15 \\
\end{tabular} & 94,13 & 208,58 & 211,30 & 94,13 & $\begin{array}{l}971,58 \\
\end{array}$ & 140,67 & 9,29 & 54,97 & 396,61 & 61,51 & 62,51 & 396,61 \\
\hline Salamandra salamandra & 29SNE52 & 100,00 & 145,71 & 94,36 & 40,55 & 4572,50 & 278,62 & 48,77 & 229,86 & 89,08 & 204,36 & 206,28 & 89,08 & 1042,81 & 151,36 & 10,45 & 54,69 & 424,94 & 67,24 & 68,03 & 424,94 \\
\hline Salamandra salamandra & 29SNE60 & 100,00 & 156,03 & 95,70 & 40,18 & 4727,17 & 292,76 & 57,48 & 235,28 & \begin{tabular}{|c|}
97,60 \\
\end{tabular} & 216,06 & 218,82 & 97,60 & 909,29 & 131,69 & 8,14 & 55,40 & 371,90 & 56,08 & 57,23 & 371,90 \\
\hline Salamandra salamandra & 29SNE61 & 100,00 & 151,40 & 95,90 & 40,15 & 4750,56 & 289,01 & 52,56 & 236,45 & 92,84 & 211,99 & 214,58 & 92,84 & 973,54 & 141,32 & 9,16 & 55,04 & 397,64 & 61,64 & 62,21 & 397,64 \\
\hline Salamandra salamandra & 29SNE62 & 100,00 & 141,47 & 93,16 & 39,39 & 4773,60 & 277,94 & 44,03 & 233,92 & 83,16 & 204,14 & 205,27 & 83,16 & 1091,31 & 160,04 & 10,87 & 54,99 & 445,90 & 69,95 & 70,01 & 445,90 \\
\hline Salamandra salamandra & 29SNE70 & 101,00 & 154,33 & 95,89 & 39,32 & 4917,30 & 295,29 & 54,54 & 240,75 & \begin{tabular}{|c|}
94,07 \\
\end{tabular} & 217,36 & 219,94 & 94,07 & 929,76 & 135,19 & 8,27 & 55,35 & 380,43 & 57,70 & 58,26 & 380,43 \\
\hline Salamandra salamandra & 29SNE71 & 100,00 & 147,42 & 94,63 & 38,97 & 4938,86 & 288,14 & 48,14 & 240,01 & 87,19 & 211,97 & 213,50 & 87,19 & 1016,43 & 148,84 & 9,58 & 55,22 & 415,88 & 63,99 & 64,14 & 415,88 \\
\hline Salamandra salamandra & 29SNE72 & 101,00 & 147,01 & 95,68 & 39,19 & 4934,79 & 287,99 & 46,80 & 241,19 & 86,58 & 211,29 & 212,84 & 86,58 & 1037,05 & 151,67 & 10,03 & 55,00 & 423,37 & 66,27 & 66,45 & 423,37 \\
\hline Salamandra salamandra & 29SNE80 & 101,00 & 147,36 & 93,38 & 38,00 & 5105,65 & 290,68 & 48,02 & 242,66 & 85,73 & 214,97 & 216,08 & 85,73 & 999,48 & 146,99 & 9,09 & 55,62 & 409,81 & 61,75 & 61,78 & 409,81 \\
\hline Salamandra salamandra & 29SNE81 & 100,00 & 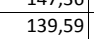 & 91,18 & 37,40 & 5112,34 & 281,58 & 41,21 & 240,36 & 78,28 & 208,20 & 208,53 & $\begin{array}{l}78,28 \\
78,28\end{array}$ & $\begin{array}{r}1095,12 \\
10\end{array}$ & 162,51 & \begin{tabular}{|c|c|}
0,303 \\
10,3
\end{tabular} & $\begin{array}{l}55,64 \\
554\end{array}$ & $\begin{array}{l}449,01 \\
4496 \\
\end{array}$ & 67,73 & 67,73 & 449,06 \\
\hline Salamandra salamandra & 29SNE82 & 101,00 & 142,45 & 93,26 & 37,95 & 5101,60 & 285,13 & 42,50 & 242,63 & 80,70 & 210,18 & 210,85 & 80,70 & \begin{tabular}{|l|}
1080,88 \\
\end{tabular} & 159,84 & 10,28 & 55,32 & 442,08 & 67,84 & 67,92 & 442,08 \\
\hline Salamandra salamandra & 29SNE90 & 100,00 & 144,25 & 91,88 & 37,01 & 5263,55 & 289,66 & 44,62 & 245,03 & 81,28 & 214,68 & 215,34 & 81,28 & 1026,81 & 151,79 & 9,32 & 55,69 & 420,93 & 63,00 & 63,03 & 420,93 \\
\hline Salamandra salamandra & 29SNE91 & 100,00 & 133,40 & 88,25 & 36,15 & 5252,89 & 276,32 & 35,82 & 240,49 & 71,19 & 204,67 & 204,67 & 71,19 & \begin{tabular}{|l|}
1151,78 \\
\end{tabular} & 172,48 & \begin{tabular}{c|c}
10,85 \\
\end{tabular} & 55,87 & 472,69 & 70,36 & 70,36 & 472,69 \\
\hline Salamandra salamandra & 29SNE92 & 100,00 & 141,13 & 92,11 & 37,01 & 5261,34 & 286,09 & 40,61 & 245,48 & 77,82 & 211,52 & 211,83 & 77,82 & 1085,70 & 161,39 & 10,10 & 55,59 & 444,37 & 67,32 & 67,38 & 444,37 \\
\hline Salamandra salamandra & 29SPBO1 & 101,00 & \begin{tabular}{|l|l|l|l|l|}
162,03 \\
\end{tabular} & $\begin{array}{ll}32,11 \\
94,36\end{array}$ & $\frac{31,61}{41,61}$ & 4497,07 & $\begin{array}{l}200,09 \\
288,29\end{array}$ & 63,81 & 224,40 & \begin{tabular}{r|r|}
117,19 \\
119
\end{tabular} & 218,91 & $\frac{21,03}{223,10}$ & 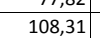 & \begin{tabular}{|l|l|}
555,68 \\
50
\end{tabular} & \begin{tabular}{|c|}
01,59 \\
89,50
\end{tabular} & 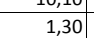 & 66,64 & |258,63 & $\begin{array}{l}\mid l 1,34 \\
18,44 \\
\end{array}$ & 21,93 & 244,09 \\
\hline Salamandra salamandra & $295 P B 02$ & 100,00 & 156,21 & 96,72 & 41,06 & 4645,49 & 288,15 & 56,77 & 231,38 & 109,81 & 215,06 & 219,32 & 100,94 & 589,35 & 92,50 & 1,92 & 64,92 & 268,40 & 21,17 & 24,40 & 255,58 \\
\hline Salamandra salamandra & $295 \mathrm{SBO3}$ & 101,00 & $\mid 158,06$ & 98,16 & 41,13 & 4706,17 & 292,82 & 57,77 & 235,05 & \begin{tabular}{|l|l|l|l|l|}
110,68 \\
\end{tabular} & 217,75 & 221,95 & 101,91 & 579,27 & 90,05 & 1,99 & $\begin{array}{ll}64,43 \\
64,\end{array}$ & 262,06 & 21,21 & 24,19 & 249,89 \\
\hline Salamandra salamandra & $295 P B 04$ & 101,00 & 162,26 & 99,50 & 41,2 & 4747,51 & 299,03 & 61,25 & 237,78 & 114,29 & 222,41 & 226,65 & 105,52 & 555,11 & 85,60 & 1, & 64,07 & 250,12 & 20,58 & 23,46 & 238,41 \\
\hline Salamandra salamandra & $295 \mathrm{SB} 07$ & 101,00 & 166,32 & 105,44 & 41,88 & 4943,26 & 312,49 & 62,73 & 249,76 & 115,83 & 229,00 & 233,25 & 107,03 & 535,87 & 80,73 & 2,00 & 62,05 & 234,58 & 21,63 & 23,64 & 226,01 \\
\hline Salamandra salamandra & 29SPB11 & 99,00 & \begin{tabular}{|l|l|l|l|l|l|}
168,63 \\
\end{tabular} & 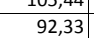 & $\begin{array}{l}41,00 \\
41,09 \\
\end{array}$ & 4438,200 & \begin{tabular}{|l|}
291,45 \\
291,86
\end{tabular} & $\begin{array}{l}0,13 \\
70,19\end{array}$ & $\begin{array}{l}24,167 \\
221,67\end{array}$ & \begin{tabular}{|l|l|l|l|l|}
123,23 \\
\end{tabular} & 224,88 & 228,95 & $\begin{array}{l}\mid 0,03 \\
114,35 \\
\end{array}$ & \begin{tabular}{|l|l|}
520,10 \\
520
\end{tabular} & $\begin{array}{l}\mid c 0,11 \\
83,18 \\
\end{array}$ & $\frac{2,001}{1,01}$ & $\mid \begin{array}{ll}62,030 \\
66,93\end{array}$ & \begin{tabular}{|l|}
243,30 \\
242,62
\end{tabular} & $\begin{array}{l}\mid 1,035 \\
16,15\end{array}$ & 20,50 & 226,66 \\
\hline Salamandra salamandra & $29 S P B 12$ & 101,00 & 159,55 & 95,59 & 40,93 & 4684,63 & 290,54 & 59,33 & 231,21 & 112,27 & 218,81 & 222,92 & 103,22 & 570,01 & 88,50 & 1,90 & 64,84 & 258,87 & 19,90 & 23,92 & 244,94 \\
\hline Salamandra salamandra & 29SPB15 & 101,00 & 166,02 & 100,20 & 41,0 & 4869,35 & 304,94 & 63,33 & 241,61 & 115,96 & 227,46 & 231,61 & 107,26 & 532,74 & 81,03 & $1, \mathrm{~s}$ & 63,12 & 236,72 & 20,00 & 23,43 & 224,84 \\
\hline Salamandra salamandra & $295 P B 16$ & 100,00 & 169,62 & 101,78 & 41,1 & 4908,01 & 310,38 & 66, & 244,19 & 118,84 & 231,52 & 235,58 & 110,12 & 514,27 & 77,93 & 1,7 & 62, & 227,15 & 19,65 & 22,79 & 215,99 \\
\hline Salamandra salamandra & 29SPB17 & 100,00 & 168,05 & 104,46 & 41,20 & 5005,48 & 313,51 & 63,50 & 250,01 & 116,38 & 231,39 & 235,43 & 107,52 & 524,31 & 78,49 & 1,98 & 61,72 & 228,42 & 21,01 & 23,75 & 218,70 \\
\hline Salamandra salamandra & 29SPB18 & 101,00 & 168,43 & 106,74 & 41,49 & 5064,67 & 317,17 & 62,97 & 254,19 & 116,14 & 232,58 & 236,60 & 107,19 & 524,31 & 77,78 & 2,00 & 60,91 & 225,94 & 21,78 & 23,97 & 217,52 \\
\hline Salamandra salamandra & $295 P B 21$ & 97,00 & 172,04 & 90,53 & 40,61 & 4512,68 & 293,65 & 73,35 & 220,30 & 125,89 & 228,34 & 232,29 & 116,95 & 501,29 & 79,80 & 1,00 & 66,59 & 232,37 & 14,78 & 20,05 & 215,44 \\
\hline Salamandra salamandra & $295 P B 22$ & 100,00 & 166,31 & 93,15 & 40,33 & 4667,96 & 293,92 & 66,12 & 227,81 & 118,69 & 224,99 & 228,93 & 109,63 & 531,05 & 82,62 & 1,25 & 65,03 & 241,44 & 17,40 & 22,36 & 225,77 \\
\hline Salamandra salamandra & 29SPB25 & 100,00 & 16 & 98,40 & 40,57 & 4894,24 & A & & 239,97 & 118,59 & 231,09 & 234,90 & 110,06 & 513,84 & 77,78 & 1,62 & 62,78 & 227,38 & 18,76 & 23,11 & 214,10 \\
\hline Salamandra salamandra & $295 P B 26$ & 101,00 & 8 & 100,77 & 40,72 & 4972,45 & 309,87 & 64,94 & 244,93 & $\begin{array}{l}117,62 \\
117,62\end{array}$ & 231,85 & 235,79 & 108,74 & 516,25 & 77,31 & $\begin{array}{l}1,0<4 \\
1,88\end{array}$ & 61,94 & 225,79 & 19,77 & 23,69 & 213,66 \\
\hline Salamandra salamandra & $295 P B 27$ & 100,00 & 16 & 45 & 40 & 5076,86 & 312,47 & 61 & 250,86 & 114,53 & 231,33 & 235,27 & 105,58 & 528,04 & 78,16 & 2,1 & 61,08 & 228,12 & 21,14 & 24,51 & 217,42 \\
\hline Salamandra salamandra & $295 P B 28$ & 100,00 & 167,52 & 105,62 & 40,98 & 5143,11 & 316,07 & 60,92 & 255,16 & $\begin{array}{l}113,99 \\
113,5\end{array}$ & 232,69 & 236,56 & 105,07 & 527,53 & 77,44 & 2,00 & 60 & 225,69 & 21,84 & 24,69 & 216,24 \\
\hline Salamandra salamandra & $295 P B 29$ & 101,00 & 13 & 107,53 & 41,02 & 5203,95 & 318,63 & 59 & 258 & 112,92 & 233,18 & 237,07 & 103,92 & 531,36 & 77,24 & 2,00 & 59,86 & 225,10 & 22,59 & 25,19 & 216,82 \\
\hline Salamandra salamandra & $295 P B 32$ & 101,00 & 17 & 90,13 & 39,87 & 4653,86 & 296,81 & 73,27 & 223,54 & 124,94 & 231,23 & 234,90 & 115,92 & 493,39 & 76,86 & 1,00 & 65,25 & 224,21 & 14,76 & 20,66 & 206,99 \\
\hline Salamandra salamandra & 29SPBS3 & 100,00 & 17 & $\begin{array}{l}90,13 \\
92,08\end{array}$ & $\begin{array}{l}35,01 \\
39,85 \\
\end{array}$ & 47035,22 & $\begin{array}{l}290,01 \\
299,82\end{array}$ & 71,13 & 228,69 & $\mid \begin{array}{l}\mid 2,42,83 \\
1228\end{array}$ & \begin{tabular}{|l|}
$\mid 3,1,25$ \\
231,68
\end{tabular} & 235,45 & $\begin{array}{ll}113,82 \\
113\end{array}$ & $\begin{array}{l}497,39 \\
497,26\end{array}$ & $\begin{array}{l}70,000 \\
76,39\end{array}$ & $\begin{array}{l}1,000 \\
1,00\end{array}$ & $\begin{array}{ll}64,32 \\
64,\end{array}$ & $\begin{array}{l}222,41 \\
223,32\end{array}$ & $\begin{array}{l}14,71 \\
151\end{array}$ & $\begin{array}{l}21,40 \\
21,49\end{array}$ & 206,86 \\
\hline Salamandra salamandra & $295 P B 34$ & 101,00 & 170,86 & 94,32 & 39,90 & 4859,98 & 302,54 & 68,46 & 234,07 & 120,14 & 231,78 & 235,50 & 111,38 & 504,14 & 76,40 & 1,15 & 63,32 & 223,70 & 16,99 & 22,58 & 208,22 \\
\hline Salamandra salamandra & 29SPB35 & 101,00 & 16 & 96,90 & 39,96 & 4957,53 & 305,73 & 65,96 & 239,77 & 117,77 & 231,96 & 235,63 & 109,06 & 511,72 & 76,62 & 1,60 & 62,32 & 224,38 & 18,45 & 23,57 & 210,04 \\
\hline Salamandra salamandra & $295 P B 36$ & 99,00 & 17 & 98,97 & 40 & 5027,06 & 31 & 66 & 244,03 & 118,48 & 234,36 & 238 & 109,54 & 504 & 74,85 & 1, & 61, & 219,22 & 19,03 & 23,80 & 205,73 \\
\hline Salamandra salamandra & $29 \mathrm{SPB}=$ & 101,00 & & 10 & 40 & 5 & & & & 32 & 233 & 237 & 106,44 & 51 & 75,86 & 2, & 60, & 222,11 & 20, & 24,79 & 209,98 \\
\hline Salamandra salamandra & $295 P B 38$ & 100,00 & 165,74 & 104,48 & 40,26 & 5217,51 & 314,11 & 58,52 & 255,59 & 111,43 & 231,94 & 235,57 & $\begin{array}{ll}102,43 \\
\end{array}$ & 536,33 & 77,76 & 2,00 & 60,14 & 227,63 & 22,05 & 25,60 & 217,14 \\
\hline Salamandra salamandra & $295 P B 39$ & 100,00 & 165,47 & 106,32 & 40,48 & 5275,48 & 316,66 & 57,26 & 259,40 & 110,34 & 232,63 & 236,23 & 101,60 & 539,62 & 77,46 & 2,16 & 59,39 & 226,96 & 23,19 & 26,27 & 217,56 \\
\hline Salamandra salamandra & $295 P B 42$ & 100,00 & 174,39 & 87,81 & 39,07 & 4705,30 & 296,40 & 74,27 & 222,13 & 125,04 & 232,76 & 236,31 & 116,11 & 486,66 & 74,96 & 1,00 & 65,00 & 218,79 & 14,07 & 21,01 & 200,46 \\
\hline Salamandra salamandra & $295 P B 43$ & 100,00 & & & 39,05 & 4835,05 & & 69,46 & 228,80 & 120,41 & 231,39 & 234,94 & 111,54 & 503,00 & 76,14 & 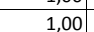 & 63,5 & 223,05 & 15,97 & 22,78 & 205,61 \\
\hline Salamandra salamandra & $295 P B 44$ & & & & 39 & 4953,0 & & 65,92 & 235,08 & $116,9 /$ & 230,92 & 234,64 & 108,21 & 514, & 76,65 & & 62 & 225,14 & 17,70 & 24,14 & 208 \\
\hline Salamandra salamandra & $295 P B 45$ & 101,00 & 167,17 & 95,93 & 39,15 & 5057,97 & 303,87 & 62,46 & 241,41 & 114,03 & 230,75 & 234,29 & 105,23 & 524,81 & 77,31 & 1,95 & 61,65 & 227,20 & 19,13 & 25,01 & 212,03 \\
\hline Salamandra salamandra & $295 P B 46$ & 101,00 & 170,38 & 97,69 & 39,49 & 5097,67 & 309,21 & 64,66 & 244,55 & 116,60 & 234,40 & 237,99 & 107,66 & 508,40 & 74,47 & 2,00 & 61,12 & 218,77 & 19,17 & 24,74 & 204,27 \\
\hline Salamandra salamandra & 29SPB47 & 100,00 & 168,88 & 100,49 & 39,82 & 5191,89 & 310 & 61,96 & 250,03 & 114,28 & 234,42 & 237,89 & 105,12 & 517,01 & 75,01 & 2,00 & 60,66 & 220,39 & 20,28 & 25,11 & 207,22 \\
\hline Salam & $29 S P B$ & 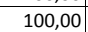 & & & & 275 , & & & 254,94 & 12,04 & 234 & 238,02 & 103 & 52 & 75 & 2, & 59 & & 21,22 & 76 & \\
\hline Salamandra salamandra & $295 P B 49$ & 100,00 & 166,50 & 105,08 & 40,00 & 5340,31 & 316,69 & 57,41 & 259,28 & $\mid \begin{array}{l}\mid 11,0,07 \\
110,\end{array}$ & 234,41 & 237,71 & 101,40 & 532,89 & 75,91 & 2,06 & 59,35 & 223,19 & 22,59 & 26,21 & $20,212,30$ \\
\hline
\end{tabular}




\begin{tabular}{|c|c|c|c|c|c|c|c|c|c|c|c|c|c|c|c|c|c|c|c|c|c|}
\hline TAXON & UTM & $\mathrm{km} 2$ & B101 & $\mathrm{B1O2}$ & $\mathrm{BIO3}$ & 8104 & B105 & B106 & B107 & B108 & B109 & 81010 & BIO11 & BIO12 & B1013 & B1014 & 81015 & BIO16 & BIO17 & B1018 & B1019 \\
\hline Salamandra salamandra & 29SPB52 & 100,00 & 175,19 & 85,50 & 38,19 & 4763,32 & 295,72 & 74,92 & 220,80 & 124,69 & 233,97 & 237,43 & 115,81 & 482,36 & 73,92 & 1,00 & 64,48 & 214,43 & 13,55 & 21,57 & 194,99 \\
\hline Salamandra salamandra & $295 P B 53$ & 101,00 & 172,90 & 87,90 & 38,16 & 4887,35 & 298,20 & 71,02 & 227,18 & 121,10 & 233,55 & 236,92 & 112,13 & 493,46 & 74,73 & 1,01 & 63,42 & 216,54 & 15,33 & 23,12 & 197,79 \\
\hline Salamandra salamandra & $295 \mathrm{SBS5}$ & 99,00 & 166,69 & $\begin{array}{l}94,61 \\
94\end{array}$ & 38,71 & 5134,48 & 303,20 & 61,36 & 241,84 & 112,48 & 231,25 & 234,60 & $\mid 103,59$ & 528,04 & 77,56 & 2,00 & \begin{tabular}{|c|c|}
61,28 \\
61,28
\end{tabular} & 226,42 & 19,01 & 25,85 & 210,22 \\
\hline Salamandra salamandra & $295 P B 56$ & 100,00 & 168,05 & 96,89 & 38,95 & 5204,47 & 307,65 & 61,30 & 246,35 & 112,94 & 233,58 & 236,92 & 103,94 & 520,95 & 76,11 & 2,00 & 60,74 & 221,98 & 19,40 & 25,68 & 206,68 \\
\hline Salamandra salamandra & $295 P B 57$ & 100,00 & 168,52 & 99,30 & 39,05 & 5265,48 & 311,35 & 60,62 & 250,73 & 112,74 & 235,06 & 238,25 & 103,76 & 519,26 & 75,34 & 2,00 & 60,09 & 219,62 & 20,12 & 25,82 & 205,28 \\
\hline Salamandra salamandra & $295 P B 58$ & 101,00 & 165,17 & 102,30 & 39,26 & 5365,91 & 312,87 & 56,02 & 256,85 & 108,46 & 233,42 & 236,58 & 99,60 & 539,10 & 77,02 & 2,18 & 59,31 & 225,79 & 22,22 & 27,10 & 212,91 \\
\hline Salamandra salamandra & $295 P B 63$ & 100,00 & 173,50 & 85,69 & 37,29 & 4955,21 & 297,65 & 71,32 & 226,33 & 120,63 & 234,78 & 237,93 & 111,59 & 490,51 & 75,08 & 1,01 & 62,88 & 213,02 & 14,88 & 23,59 & 193,09 \\
\hline Salamandra salamandra & $295 P B 64$ & 100,00 & 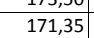 & $\begin{array}{l}89,14 \\
89,14\end{array}$ & 37,69 & 5074,96 & 300,92 & 67,29 & 233,63 & $\begin{array}{l}117,19 \\
119\end{array}$ & 234,48 & 237,69 & \begin{tabular}{|l|l|}
108,34 \\
11,
\end{tabular} & | & 75,84 & $\begin{array}{l}1,525 \\
1,52\end{array}$ & $\begin{array}{l}62,00 \\
62,03 \\
\end{array}$ & $\mid 215,97$ & $\begin{array}{l}14,00 \\
16,64\end{array}$ & 24,62 & $\begin{array}{l}197,18 \\
\end{array}$ \\
\hline Salamandra salamandra & 29SPB68 & 99,00 & 161,51 & 102,50 & 38,98 & 5475,86 & 310,95 & 50,86 & 260,09 & \begin{tabular}{|c|}
103,49 \\
\end{tabular} & 231,21 & 234,26 & 94,64 & 565,09 & 80,49 & 2,59 & 58,77 & 234,47 & 24,03 & 29,36 & 221,11 \\
\hline Salamandra salamandra & 29SPB69 & 101,00 & 160,85 & 104,80 & 39,03 & 5543,35 & 313,78 & 49,17 & 264,61 & 102,18 & 231,74 & 234,69 & 93,30 & 569,54 & 80,36 & 2,99 & 57,97 & 234,49 & 25,62 & 30,24 & 222,24 \\
\hline Salamandra salamandra & $295 P B 73$ & 101,00 & 176,50 & 82,76 & 36,45 & 5001,32 & 298,23 & 74,25 & 223,98 & 123,65 & 237,87 & 240,98 & 113,67 & 476,04 & 74,01 & 1,00 & 63,01 & 204,82 & 13,89 & 23,71 & 183,47 \\
\hline Salamandra salamandra & $295 P B 74$ & 100,00 & 174,51 & 86,77 & 36,99 & 5116,97 & 301,96 & 70,11 & 231,86 & 119,42 & 237,91 & 240,89 & 110,45 & 487,26 & 74,79 & 1,03 & 62,14 & 208,15 & 15,20 & 24,17 & 187,95 \\
\hline Salamandra salamandra & $295 \mathrm{SP} 76$ & 101,00 & 172,13 & 94,68 & 37,97 & 5322,15 & 310,30 & 63,59 & 246,72 & 115,01 & 238,91 & 241,79 & 105,99 & 504,11 & 75,30 & 1,99 & 60,38 & 212,14 & 18,20 & 25,85 & 194,57 \\
\hline Salamandra salamandra & 29SPB77 & 100,00 & 169,75 & 98,39 & 38,18 & 5425,29 & 313,11 & 59,47 & 253,64 & 111,36 & 238,29 & 241,06 & 102,64 & 517,79 & 76,19 & 2,01 & 59,74 & 216,32 & 19,64 & 26,46 & 200,12 \\
\hline Salamandra salamandra & 29SPB78 & 101,00 & 163,20 & 102,44 & 38,68 & 5548,81 & 313,16 & 51,22 & 261,94 & \begin{tabular}{|l|}
104,07 \\
\end{tabular} & 233,97 & 236,76 & 95,18 & 557,05 & 79,98 & 2,45 & 58,67 & 230,14 & 23,44 & 29,16 & 215,80 \\
\hline Salamandra salamandra & 29SPB79 & 100,00 & 158,60 & 105,26 & 38,94 & 5641,23 & 313,68 & 45,54 & 268,14 & 98,76 & 231,00 & 233,69 & 89,80 & 585,79 & 82,62 & 3,10 & 57,73 & 239,91 & 26,44 & 31,26 & 227,16 \\
\hline Salamandra salamandra & $295 P B 82$ & 101,00 & 177,98 & 79,33 & 35,82 & 4964,47 & 295,56 & 76,60 & 218,96 & 144,32 & 238,62 & 241,52 & $\begin{array}{r}15,22 \\
\end{array}$ & 472,48 & 74,62 & 1,00 & 63,57 & 203,23 & 12,62 & 23,47 & 180,27 \\
\hline Salamandra salamandra & $295 P B 83$ & 99,00 & 177,82 & 81,79 & 35,97 & 5067,99 & 299,41 & 74,67 & 224,73 & 146,24 & 239,98 & 242,83 & 113,78 & 473,24 & 74,27 & 1,00 & 62,87 & 202,07 & 13,64 & 23,87 & 179,64 \\
\hline Salamandra salamandra & $295 P B 85$ & 100,00 & 172,92 & 91,72 & 37,08 & 5321,27 & 307,98 & 64,69 & 243,29 & 115,49 & 239,49 & 242,16 & 106,45 & 504,88 & 76,49 & 1,83 & 61,00 & 212,53 & 17,19 & 25,68 & 193,27 \\
\hline Salamandra salamandra & 29SPB86 & 100,00 & 169,77 & 96,12 & 37,83 & 5442,40 & 311,10 & 59,32 & 251,78 & 111,16 & 238,45 & 241,03 & 102,23 & 523,43 & 77,89 & 2,00 & 60,25 & 218,73 & 18,97 & 26,66 & 201,01 \\
\hline Salamandra salamandra & $295 P B 87$ & 100,00 & 168,34 & 99,61 & 38,00 & 5531,28 & 314,37 & 56,26 & 258,11 & 108,81 & 238,52 & 241,06 & 99,98 & 531,65 & 78,12 & 2,02 & 59,57 & 220,72 & 20,46 & 27,36 & 204,23 \\
\hline Salamandra salamandra & 295PB88 & 100,00 & \begin{tabular}{|l|l|}
162,84 \\
\end{tabular} & $\mid \begin{array}{r}103,31 \\
103\end{array}$ & 38,20 & 5644,99 & 314,91 & 48,97 & 265,94 & $\begin{array}{l}02,43 \\
1024\end{array}$ & 235,01 & 237,46 & 93,42 & 564,64 & 81,17 & 2,69 & 58,47 & 232,19 & 23,76 & 29,72 & 217,38 \\
\hline Salamandra salamandra & $295 P B 89$ & 100,00 & 153,82 & 106,46 & 38,23 & 5757,84 & 312,54 & 38,85 & 273,69 & 92,73 & 228,07 & 230,59 & 83,71 & 620,39 & 86,93 & 3,43 & 57,47 & 252,59 & 28,53 & 33,33 & 239,85 \\
\hline Salamandra salamandra & $295 P B 93$ & 100,00 & 178,35 & 85,09 & 36,17 & 5167,99 & 304,21 & 72,76 & 231,45 & 147,42 & 242,25 & 244,99 & 113,29 & 482,24 & 75,46 & 1,00 & 62,70 & 205,42 & 14,09 & 24,00 & 183,32 \\
\hline Salamandra salamandra & $295 P B 95$ & 99,00 & 169,82 & 94,92 & 37,18 & 5462,90 & 310,08 & 58,89 & 251,19 & 110,79 & 238,72 & 241,25 & 101,85 & 531,43 & 79,77 & 2,00 & 60,74 & 222,38 & 18,52 & 26,68 & 203,61 \\
\hline Salamandra salamandra & $295 P B 96$ & 100,00 & 169,28 & 98,16 & 37,82 & 5549,99 & 313,89 & 56,72 & 257,17 & 109,34 & 239,57 & 242,12 & 100,46 & 534,59 & 79,41 & 2,00 & 60,10 & 222,36 & 19,56 & 27,16 & 204,72 \\
\hline Salamandra salamandra & 295PB97 & 100,00 & $\mid \begin{array}{l}\mid 0,20 \\
170,11\end{array}$ & $\mid$ & 38,00 & 5609,81 & | & 56,11 & 261,87 & 109,56 & 241,47 & 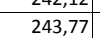 & \begin{tabular}{|l|}
100,57 \\
\end{tabular} & 529,92 & $\mid 78,18$ & 2,00 & $\begin{array}{l}\mid c 0,10,6 \\
59,68\end{array}$ & 21219,39 & 20,10 & 27,11 & 202,56 \\
\hline Salamandra salamandra & 29SPB98 & 100,00 & 164,84 & 104,28 & 38,01 & 5721,95 & 318,91 & 49,21 & 269,70 & 103,34 & 238,19 & 240,41 & 94,44 & 558,94 & 80,74 & 2,51 & 58,66 & 229,30 & 23,06 & 29,22 & 214,00 \\
\hline Salamandra salamandra & $295 P B 99$ & 100,00 & $\mid 152,23$ & $\mid 107,69$ & 38,00 & 5848,46 & 313,92 & 35,78 & 278,14 & 90,23 & 227,96 & 230,29 & 81,17 & 635,97 & 88,77 & 3,60 & 57,37 & 257,79 & 29,35 & 34,22 & 245,06 \\
\hline Salamandra salamandra & $295 \mathrm{SPC}$ & 101,00 & 166,33 & 110,50 & 41,87 & 5160,53 & 322,00 & 60,85 & 261,15 & 112,99 & 231,84 & 236,18 & 104,34 & 552,50 & 78,82 & 2,5 & 58,68 & 229,86 & 26,91 & 27,28 & 227,05 \\
\hline Salamandra salamandra & $295 \mathrm{PCO3}$ & 101,00 & 160,69 & 108,62 & 41,23 & 5185,48 & 316,10 & 56,55 & 259,55 & 107,39 & 227,90 & 231,14 & 98,85 & 592,32 & 82,64 & 3,04 & 57,66 & 243,29 & 30,44 & 30,45 & 242,18 \\
\hline Salamandra salamandra & $295 \mathrm{PCO}$ & $\begin{array}{l}100,00 \\
100\end{array}$ & $\begin{array}{l}161,82 \\
161,82\end{array}$ & \begin{tabular}{|l|l|l|l|l|l|}
106,48 \\
\end{tabular} & 41,04 & $\begin{array}{l}510,460 \\
5164,14\end{array}$ & $\begin{array}{l}|c|, 10 \\
314,94 \\
\end{array}$ & 58,80 & 25 & $\begin{array}{l}108,27 \\
108\end{array}$ & 229,01 & $\mid 231,91$ & \begin{tabular}{|c|} 
\\
$100,14,0$ \\
\end{tabular} & $\begin{array}{l}59,32 \\
589,98\end{array}$ & $\begin{array}{l}02,04 \\
81,44 \\
\end{array}$ & 3,02 & $\begin{array}{l}37,00 \\
57,23\end{array}$ & $\begin{array}{l}24,25 \\
241,04\end{array}$ & 30,93 & $\begin{array}{l}30,45 \\
30,93 \\
\end{array}$ & 240,44 \\
\hline Salamandra salamandra & $295 \mathrm{SC06}$ & 100,00 & 163,16 & 102,61 & 40,53 & 5122,15 & 312,29 & 62,04 & 250,25 & 105,59 & 229,36 & 232,55 & 101,71 & 596,58 & 81,61 & 3,75 & 56,34 & 241,45 & 33,24 & 33,24 & 241,42 \\
\hline Salamandra salamandra & 29SPC07 & 101,00 & 162,37 & 101,10 & 40,03 & 5119,50 & 310,44 & 61,96 & 248,48 & 101,92 & 229,31 & 231,74 & 100,87 & 613,08 & 83,86 & 4,00 & 55,95 & 247,58 & 35,10 & 35,10 & 247,58 \\
\hline Salamandra salamandra & $295 \mathrm{SCO}$ & 100,00 & 160,69 & 99,94 & 39,98 & 5139,34 & 308,49 & 60,77 & 247,72 & 99,37 & 228,08 & 230,42 & 99,08 & 640,14 & 87,99 & 4,12 & 55,88 & 258,78 & 36,81 & 36,81 & 258,78 \\
\hline Salamandra salamandra & $295 \mathrm{SPCO}$ & 100,00 & 162,42 & 99,67 & 39,97 & 5141,97 & 309,99 & 62,39 & 247,60 & 101,25 & 228,39 & 232,14 & 100,70 & 646,09 & 89,10 & 4,17 & 55,93 & 261,45 & 37,30 & 37,32 & 261,45 \\
\hline Salamandra salamandra & 29SPC12 & 99,00 & 167,73 & 109,94 & 41,19 & 5225,10 & 323,02 & 60,97 & 262,05 & 113,38 & 234,04 & 238,20 & 104,57 & 540,49 & 76,70 & 2,27 & 58,39 & 224,17 & 26,18 & 27,20 & 219,97 \\
\hline Salamandra salamandra & $295 \mathrm{SC} 13$ & 101,00 & 160,51 & 109,02 & 41,00 & 5282,23 & 317,10 & 54,79 & 262,31 & 105,93 & 228,42 & 232,21 & 97,33 & 589,14 & 81,72 & 3,00 & 57,24 & 240,98 & 30,63 & 30,77 & 238,69 \\
\hline Salamandra salamandra & 29SPC14 & 101,00 & 162,18 & 107,55 & 40,99 & 5257,45 & 316,92 & 57 & 259,76 & 107,77 & 229,61 & 233,36 & 99,09 & 584,99 & 80,21 & 3,18 & 56,79 & 237,86 & 31,36 & 31,48 & 236,03 \\
\hline Salamandra salamandra & $295 \mathrm{SC17}$ & 99,00 & 163,81 & 103,55 & 40,05 & 33,55 & 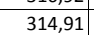 & 60,52 & 254,39 & 108,59 & 230,76 & 234,53 & 100,84 & 601,24 & t & 4,00 & 55,57 & 241,35 & 34,91 & 34,91 & 240,92 \\
\hline Salamandra salamandra & $295 \mathrm{SC} 18$ & \begin{tabular}{|r|r|}
101,00 \\
\end{tabular} & 60 & 15 & 39,90 & 5255,88 & 4 & 58 & 253,45 & 102,59 & 228,97 & 231,89 & \begin{tabular}{|l|}
97,68 \\
9
\end{tabular} & $\mid 638,67$ & $\mid 86,96$ & 4,34 & 55,44 & 256,29 & 37,43 & 37,43 & 256,26 \\
\hline Salamandra salamandra & $295 \mathrm{SP} 22$ & 10 & 16 & 10 & 40,99 & 5297,34 & 32 & 60 & 263,15 & 11 & 235,75 & 239,61 & 104,16 & 533,19 & 75,13 & 2,37 & 58,07 & 220,33 & 25,82 & 27,36 & 214,65 \\
\hline Salamandra salamandra & $295 \mathrm{PC23}$ & 100,00 & 16 & $\frac{10}{10}$ & 40,97 & 53 & $\frac{52}{32}$ & $\begin{array}{l}57,58 \\
57\end{array}$ & 263,80 & $\begin{array}{ll}109,62 \\
\end{array}$ & 233,19 & 237,03 & 100,88 & 556,98 & 77,25 & 3,00 & 57,18 & 227,79 & 28,54 & 29,44 & 223,46 \\
\hline Salamandra salamandra & $295 P C 24$ & 100,00 & 165,85 & 108,43 & 40,86 & 5334,76 & 32 & 58 & 263,18 & 109,86 & 233,76 & 237,63 & 101,18 & 558,27 & 76,57 & 3,6 & 56,60 & 226,87 & 29,57 & 30,35 & 223,10 \\
\hline Salamandra salamandra & $295 P C 25$ & 101,00 & 165,01 & 107,59 & 40,3 & 344,68 & 320,41 & 58,02 & 262,39 & 109,00 & 233,26 & 236,94 & 100,45 & 569,88 & 77,21 & 3,12 & 55,98 & 230,09 & 31,34 & 31,72 & 227,01 \\
\hline Salamandra salamandra & $295 \mathrm{PC26}$ & 100,00 & \begin{tabular}{|l|}
163,0138 \\
163
\end{tabular} & \begin{tabular}{|l|}
106,58 \\
106
\end{tabular} & 40,6 & 5357,52 & 318 & 50,02 & $\begin{array}{l}262,39 \\
261,42\end{array}$ & $\begin{array}{l}107,29 \\
107\end{array}$ & $\begin{array}{l}23,20 \\
231,94\end{array}$ & \begin{tabular}{|l|l|}
$235,54,68$ \\
235
\end{tabular} & \begin{tabular}{|c|}
90,456 \\
98,68
\end{tabular} & $\begin{array}{l}580,00 \\
588,79\end{array}$ & 78,97 & $3, \frac{3,2}{3,99}$ & 55,43 & 236,50 & 33,58 & 33,74 & 234,22 \\
\hline Salamandra salamandra & $295 \mathrm{PC27}$ & 101,00 & 163,06 & 105,66 & 40,00 & 5364,20 & 317,54 & 57,23 & 260,31 & 106,79 & 231,86 & 235,42 & 98,44 & 602,02 & 80,68 & 4,00 & 55,12 & 240,99 & 35,23 & 35,36 & 239,16 \\
\hline Salamandra salamandra & $295 \mathrm{SC28}$ & 100,00 & 159,59 & 104,11 & 39,72 & 5380,03 & 313,91 & 54,76 & 259,15 & 102,98 & 229,49 & 232,40 & 95,14 & 642,65 & 86,77 & 4,51 & 54,97 & 256,99 & 38,20 & 38,24 & 255,93 \\
\hline Salamandra salamandra & $295 P C 29$ & 100,00 & 158,40 & 102,98 & 39,39 & 5393,15 & 312,64 & 54 & 258 & 102,07 & 228,38 & 231,60 & 94 & 668,10 & 90,58 & 5, & 54,6 & 267,01 & 40,43 & 40,47 & 266,42 \\
\hline Salamandra salamandra & $295 P C 30$ & 101,00 & 16 & & 40 & & & & 262 & & 233 & 237 & 101,40 & 538 & 76,59 & 2, & 58 & 224,42 & 24 & 27,07 & 215,93 \\
\hline Salamandra salamandra & $295 P C 31$ & 100,00 & 166,25 & 108,74 & 40,75 & 5373,15 & 321,21 & 56,92 & 264,29 & 109,87 & 234,71 & 238,28 & 101,01 & 540,34 & 75,98 & 2,89 & 57,64 & 223,15 & 26,13 & 28,48 & 215,62 \\
\hline Salamandra salamandra & $295 P C 32$ & 100,00 & 168,44 & 108,99 & 40,68 & 5377,66 & 323,78 & 58,78 & 265,00 & 111,72 & 236,88 & 240,46 & 103,10 & 530,80 & 74,13 & 2,80 & 57,45 & 218,09 & 26,20 & 28,24 & 211,01 \\
\hline Salamandra salamandra & $295 P C 36$ & 101,00 & 164,36 & 108,31 & 40,00 & 5467,16 & 321,97 & 55,28 & 266,69 & 106,72 & 234,42 & 237,79 & 98,15 & 577,66 & 77,96 & 3,98 & 55,18 & 231,45 & 33,13 & 33,78 & 227,34 \\
\hline Salamandra salamandra & $295 P C 37$ & 100,00 & 年 & 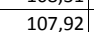 & 40,00 & 5472,45 & th & 年 & 266,34 & 107,39 & 235,64 & 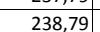 & 98,97 & 581,16 & 78,36 & 年 & 54, & 232,22 & 34,01 & 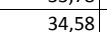 & 228,44 \\
\hline Salamandra salamandra & $295 \mathrm{SC} 38$ & & & & 39, & 3492 & & 34 & $265,57 \mid$ & 104, & 233,02 & 236,21 & 95,88 & 614 & 82,31 & $4,4 \Psi_{1}$ & 54, & 244,89 & 36,96 & 37,18 & 241, \\
\hline Salamandra salamandra & $295 P C 39$ & 101,00 & 158,32 & 105,42 & 39,32 & 5511,46 & 315,80 & 51,43 & 264,37 & 100,70 & 229,73 & 232,91 & 92,33 & 658,86 & 88,45 & 5,04 & 54,28 & 262,54 & 40,31 & 40,40 & 260,37 \\
\hline Salamandra salamandra & $295 P C 40$ & 101,00 & $\mid 164,01$ & 106,92 & 40,01 & 5409,63 & 317,65 & 54,14 & 263,51 & 107,14 & 233,05 & 236,42 & 98,43 & 550,22 & 77,29 & 2,92 & 57,95 & 227,62 & 25,75 & 28,88 & 218,07 \\
\hline Salamandra salamandra & $295 P C 44$ & 100,00 & 168,91 & 109,81 & 40,04 & 516,29 & 27,01 & 57,07 & 269,94 & 110,10 & 239,67 & 242,44 & 101,43 & 531,63 & 73,28 & 3,00 & 56,19 & 215,10 & 27,82 & 29,73 & 207,85 \\
\hline Salamar & $295 \mathrm{SC4}$ & 1000 & & & 40, & 5520 & & 56, & 270,62 & 109, & 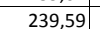 & 242 & 101, & 536 & 73 & 3, & 55, & 215,92 & 28,96 & 30,40 & \\
\hline Salamandra salamandra & $295 \mathrm{SC4}$ & 100,00 & $\begin{array}{ll}168,21 \\
\end{array}$ & 110,05 & 40,00 & 5541,22 & $\mid 327,67$ & 56,04 & 271,48 & $\begin{array}{ll}108,93 \\
\end{array}$ & 239,34 & $\mid \begin{array}{l}\mid 42,20 \\
242,04\end{array}$ & \begin{tabular}{|l|l|l|l|}
100,49 \\
\end{tabular} & 546,01 & 74,72 & 3,51 & 55,06 & 218,49 & $\begin{array}{l}\mid 0,0,15 \\
31,15\end{array}$ & 32,31 & 212,21 \\
\hline
\end{tabular}




\begin{tabular}{|c|c|c|c|c|c|c|c|c|c|c|c|c|c|c|c|c|c|c|c|c|c|}
\hline TAXON & UTM & $\mathrm{km} 2$ & BIO1 & $\mathrm{B1O2}$ & $\mathrm{BIO3}$ & 8104 & B105 & B106 & B107 & B108 & B109 & BIO10 & BIO11 & BIO12 & B1013 & B1014 & 81015 & B1016 & B1017 & B1018 & B1019 \\
\hline Salamandra salamandra & 29SPC47| & 101,00 & 167,52 & 110,02 & 40,00 & 5572,71 & 327,53 & 55,35 & 272,18 & 107,90 & 239,20 & 241,86 & 99,60 & 557,72 & 76,07 & 3,98 & 54,43 & 222,23 & 32,93 & 33,83 & 216,36 \\
\hline Salamandra salamandra & $295 P C 48$ & 100,00 & 166,22 & 109,81 & 39,98 & 5599,39 & 326,71 & 54,12 & 272,59 & 106,36 & 238,41 & 241,00 & 98,04 & 575,10 & 78,17 & 4,08 & 54,29 & 228,73 & 34,55 & 35,15 & 223,27 \\
\hline Salamandra salamandra & $295 P C 49$ & 101,00 & 165,01 & \begin{tabular}{|l|l|}
109,48 \\
\end{tabular} & 39,91 & 5613,73 & 325,70 & 53,33 & 272,37 & 105,11 & 237,55 & 240,08 & 96,82 & 595,18 & 80,41 & 4,58 & 53,77 & 236,19 & 36,72 & 37,23 & 231,34 \\
\hline Salamandra salamandra & 29SPC51 & 101,00 & 167,10 & 107,59 & 39,88 & 5507,90 & 322,31 & 55,03 & 267,28 & \begin{tabular}{|c|c|}
108,55 \\
\end{tabular} & 237,41 & 240,46 & 99,80 & 533,46 & 74,70 & 3,00 & 57,20 & 218,51 & 25,75 & 29,11 & 208,22 \\
\hline Salamandra salamandra & $295 P C 52$ & 100,00 & 168,43 & 108,65 & 39,99 & 5543,99 & 325,30 & 55,72 & 269,58 & \begin{tabular}{|c|}
109,37 \\
\end{tabular} & 239,34 & 242,17 & 100,59 & 526,22 & 73,52 & 3,00 & 56,66 & 214,39 & 26,14 & 29,12 & 204,65 \\
\hline Salamandra salamandra & $295 \mathrm{SP} 57$ & 100,00 & 168,13 & 111,79 & 39,96 & 5684,87 & 331,09 & 53,09 & 278,00 & 106,93 & 241,54 & 243,71 & 98,65 & 543,91 & 74,76 & 3,99 & 53,94 & 215,79 & 32,57 & 33,71 & 208,22 \\
\hline Salamandra salamandra & $295 P C 58$ & 100,00 & 168,60 & 112,24 & 39,97 & 5700,35 & 332,14 & 53,08 & 279,07 & 107,03 & 242,20 & 244,23 & 98,73 & 546,20 & 75,06 & 4,00 & 53,57 & 216,33 & 33,25 & 34,09 & 208,90 \\
\hline Salamandra salamandra & $295 \mathrm{SC59}$ & 100,00 & 167,52 & \begin{tabular}{|l|l|l|l|l|}
112,36 \\
\end{tabular} & 39,84 & 5728,25 & $\mid 331,77$ & 51,96 & 279,81 & 105,68 & 241,69 & 243,64 & 97,36 & 562,54 & 76,98 & 4,47 & 53,42 & 222,29 & 35,05 & 35,62 & 215,23 \\
\hline Salamandra salamandra & $295 \mathrm{SP60}$ & 100,00 & 163,18 & 106,26 & 39,15 & 5569,55 & 317,99 & 50,66 & 267,33 & \begin{tabular}{|l|l|}
104,12 \\
\end{tabular} & 234,43 & 237,22 & 95,19 & 556,04 & 78,26 & 2,98 & 57,41 & 227,75 & 25,89 & 29,93 & 216,04 \\
\hline Salamandra salamandra & 295PC67 & 100,00 & 163,22 & 112,86 & 39,25 & 5799,65 & 329,68 & 46,44 & 283,24 & 101,10 & 238,40 & 240,30 & 92,42 & 565,42 & 77,51 & 4,10 & 53,61 & 223,34 & 34,08 & 35,10 & 214,86 \\
\hline Salamandra salamandra & $295 P C 69$ & 100,00 & 168,82 & 114,62 & 39,47 & 5851,69 & 336,48 & 49,70 & 286,78 & 105,11 & 244,84 & 246,10 & 96,77 & 535,56 & 74,10 & 4,00 & 52,84 & 210,37 & 33,94 & 34,49 & 201,39 \\
\hline Salamandra salamandra & $295 P C 70$ & 100,00 & 161,09 & 106,73 & 38,95 & 5675,07 & 318,19 & 46,80 & 271,38 & 100,66 & 233,89 & 236,54 & 91,70 & 571,07 & 80,41 & 3,15 & 57,24 & 232,70 & 26,59 & 31,03 & 220,35 \\
\hline Salamandra salamandra & 29SPC71 & 101,00 & 158,40 & 108,44 & 38,92 & 5732,58 & 318,87 & 43,40 & 275,47 & $\begin{array}{l}97,48 \\
\end{array}$ & 232,29 & 234,86 & 88,52 & 587,30 & 81,78 & 3,33 & 56,56 & 237,71 & 28,70 & 32,39 & 226,39 \\
\hline Salamandra salamandra & $295 P C 72$ & 100,00 & 165,22 & 109,58 & 39,03 & 5735,12 & 326,20 & 49,42 & 276,78 & 103,68 & 239,04 & 241,32 & 95,01 & 543,63 & 76,32 & 3,01 & 56,35 & 219,52 & 26,65 & 30,28 & 208,00 \\
\hline Salamandra salamandra & $295 \mathrm{SP} 74$ & 100,00 & 162,33 & 111,87 & 39,01 & 5819,58 & 327,60 & 45,12 & 282,49 & \begin{tabular}{|c|}
99,79 \\
\end{tabular} & 237,63 & 239,69 & 91,24 & 560,86 & 77,53 & 3,71 & 54,81 & 223,50 & 30,66 & 33,10 & 213,25 \\
\hline Salamandra salamandra & $295 \mathrm{SP} 80$ & 101,00 & 154,66 & 107,93 & 38,41 & 5795,37 & 315,84 & 39,03 & 276,81 & \begin{tabular}{|c|}
93,23 \\
\end{tabular} & 229,63 & 232,06 & 84,21 & 614,21 & 85,61 & 3,64 & 56,86 & 248,62 & 29,24 & 33,59 & 236,45 \\
\hline Salamandra salamandra & $295 P C 81$ & 99,00 & 159,18 & 109,25 & 38,81 & 5818,30 & 321,64 & 42,67 & 278,97 & 97,08 & 234,43 & 236,60 & 88,26 & 583,86 & 81,56 & 3,29 & 56,41 & 235,44 & 28,32 & 32,34 & 223,32 \\
\hline Salamandra salamandra & $295 P C 82$ & 101,00 & 160,19 & 110,52 & 38,84 & 5854,69 & 324,58 & 42,86 & 281,71 & 97,50 & 235,97 & 238,01 & 88,63 & 575,40 & 80,09 & 3,43 & 55,90 & 230,86 & 28,88 & 32,50 & 219,15 \\
\hline Salamandra salamandra & $295 P C 83$ & 100,00 & 162,91 & 111,65 & 38,96 & 5873,63 & 328,54 & 44,51 & 284,04 & \begin{tabular}{|c|}
99,78 \\
\end{tabular} & 238,88 & 240,86 & 91,00 & 557,23 & 77,57 & 3,32 & 55,43 & 222,59 & 28,81 & 32,01 & 210,99 \\
\hline Salamandra salamandra & $295 P C 85$ & 100,00 & 154,08 & 112,77 & 38,61 & 5968,82 & 324,12 & 35,77 & 288,36 & $\begin{array}{l}90,35 \\
\end{array}$ & 231,94 & 233,88 & 81,75 & 611,60 & 83,11 & 4,36 & 53,93 & 241,21 & 34,97 & 36,92 & 231,16 \\
\hline Salamandra salamandra & $295 \mathrm{SP} 86$ & 100,00 & 156,27 & 113,57 & 38,80 & 5976,05 & 326,95 & 37,27 & \begin{tabular}{|l|}
289,67 \\
\end{tabular} & \begin{tabular}{|c|}
92,08 \\
\end{tabular} & 234,28 & 235,96 & 83,77 & 595,57 & 81,03 & 4,27 & 53,38 & 233,99 & 35,05 & 36,73 & 223,79 \\
\hline Salamandra salamandra & $295 \mathrm{SC90}$ & 100,00 & $\mid 155,39$ & 109,04 & 38,17 & 5882,69 & 318,88 & 38,08 & 280,80 & 92,63 & 231,65 & 233,82 & 83,79 & 613,37 & 85,57 & 3,45 & 56,86 & 247,51 & 28,96 & 33,52 & 234,93 \\
\hline Salamandra salamandra & 29SPC91 & 101,00 & 158,57 & 110,27 & 38,30 & 5915,33 & 323,67 & 40,32 & 283,35 & 95,27 & 235,23 & 237,27 & 86,32 & 589,82 & 82,32 & 3,35 & 56,42 & 237,01 & 28,48 & 32,65 & 224,46 \\
\hline Salamandra salamandra & $295 \mathrm{SC92}$ & 99,00 & 153,35 & 111,44 & 38,22 & 5977,65 & 321,58 & 34,63 & 286,95 & 89,59 & 231,15 & 233,13 & 80,78 & 621,02 & 85,31 & 3,99 & 55,51 & 247,66 & 31,83 & 35,31 & 236,26 \\
\hline Salamandra salamandra & $295 P C 94$ & 99,00 & 158,64 & 113,32 & 38,53 & 6010,83 & 329,04 & 38,53 & 290,51 & 93,99 & 236,90 & 238,53 & 85,32 & 581,60 & 79,89 & 3,74 & 54,58 & 230,01 & 31,40 & 34,26 & 218,55 \\
\hline Salamandra salamandra & $295 \mathrm{PC95}$ & 101,00 & 153,03 & 113,44 & 38,21 & 6051,86 & 325,26 & 33,25 & 292,01 & 88,29 & 232,23 & 233,77 & 79,68 & 615,80 & 83,41 & 4,51 & 53,75 & 241,99 & 35,09 & 37,22 & 231,30 \\
\hline Salamandra salamandra & $295 \mathrm{PC96}$ & 100,00 & $\mid \begin{array}{l}\mid 350,03 \\
150,56\end{array}$ & \begin{tabular}{|l|l|l|l|l|}
113,48 \\
\end{tabular} & $\begin{array}{ll}30,24 \\
38,09\end{array}$ & $\begin{array}{l}6081,900 \\
6081,97\end{array}$ & $\mid \frac{32,23,90}{323,90}$ & 31,03 & $\begin{array}{l}29,01 \\
292,87\end{array}$ & 每o, 85,66 & 230,35 & 231,96 & 77,15 & \begin{tabular}{|l|l|l|}
631,10 \\
631
\end{tabular} & $\begin{array}{l}\mid l 3,41 \\
84,78\end{array}$ & $\begin{array}{l}4,51 \\
4,83\end{array}$ & 53,20 & $\begin{array}{l}24,59 \\
246,78\end{array}$ & 37,25 & 38,97 & 236,59 \\
\hline Salamandra salamandra & 29SPC97 & 100,00 & 160,76 & 115,31 & 38,64 & 6068,26 & 333,90 & 38,94 & 294,96 & 95,06 & 240,01 & 241,08 & 86,54 & 555,76 & 76,01 & 4,06 & 53,00 & 216,93 & 32,91 & 34,71 & 205,42 \\
\hline Salamandra salamandra & $29 S P D 00$ & 101,00 & 164,58 & 99,37 & 39,79 & 5146,66 & 311,81 & 64,14 & 247,67 & 103,56 & 230,05 & 234,15 & 102,51 & 650,04 & 89,94 & 4,54 & 55,90 & 263,25 & 37,71 & 38,10 & 263,25 \\
\hline Salamandra salamandra & $29 S P D 01$ & 101,00 & 164,77 & 98,75 & 39,3 & 5155,83 & 311,99 & 64,27 & 247,72 & 104,12 & 230,51 & 234,52 & 102,75 & 667,05 & 92,81 & 5,00 & 55,91 & 270,59 & 38,92 & 39,36 & 270,59 \\
\hline Salamandra salamandra & $295 \mathrm{PDO2}$ & 100,00 & 167,21 & 98,91 & 39,28 & 5169,43 & 314,35 & 66,14 & 248,21 & 109,00 & 233,19 & 236,94 & 104,65 & 665,74 & 92,82 & 4,97 & 55,84 & 270,11 & 38,65 & 39,55 & 270,11 \\
\hline Salamandra salamandra & 29SPD03 & 101,00 & 167,25 & 98,55 & 39,03 & 5191,98 & 314,55 & 65,88 & 248,68 & 109,20 & 233,68 & 237,16 & 104,42 & 682,99 & 95,73 & 5,00 & 55,90 & 277,45 & 39,46 & 40,56 & 277,45 \\
\hline Salamandra salamandra & 29SPD05 & 100,00 & 164,19 & 97,09 & 38,45 & 5241,36 & 311,97 & 63,09 & 248,88 & 101,06 & 231,63 & 234,92 & 100,91 & 747,79 & 106,27 & 5,92 & 55,64 & 304,62 & 44,26 & 45,40 & 304,62 \\
\hline Salamandra salamandra & 29SPD06 & 101,00 & 162,42 & 96,54 & 38,07 & 5278,41 & 310,58 & 61,03 & 249,54 & \begin{tabular}{|c|}
98,67 \\
\end{tabular} & 230,34 & 233,67 & 98,67 & 781,05 & 111,75 & 6,01 & 55,70 & 318,61 & 46,15 & 47,22 & 318,61 \\
\hline Salamandra salamandra & $29 S P D 07$ & 100,00 & 163,07 & 96,93 & 38,15 & 5303,94 & 311,69 & 60, & 251,02 & 99, & 231,54 & 234,37 & 98,93 & 789,75 & 113,19 & 6,1 & 55, & 321,77 & 47,18 & 48,37 & 321,77 \\
\hline Salamandra salamandra & 29SPD08 & 101,00 & 164,65 & 97,86 & 38,19 & 5326,48 & 313,87 & 60,86 & 253,01 & 100,50 & 233,51 & 235,92 & 99,80 & 788,15 & 112,94 & 6,20 & 55,25 & 320,35 & 47,34 & 48,77 & 320,35 \\
\hline Salamandra salamandra & 29SPD09 & 101,00 & 161,29 & 97,32 & 37,86 & 5371,68 & 311,23 & 57,29 & 253,94 & 96,06 & 230,99 & 233,26 & 96,06 & 833,96 & 120,30 & 6,85 & 55,16 & 339,27 & 50,81 & 51,89 & 339,27 \\
\hline Salamandra salamandra & 29SPD10 & 100,00 & 161,34 & 100,52 & 39,30 & 5273,02 & 312,03 & 59,57 & 252,46 & 102,42 & 228,95 & 232,85 & 98,11 & 669,64 & 92,03 & 4,97 & 55,26 & 269,45 & 39,96 & 40,06 & 269,45 \\
\hline Salamandra salamandra & 29SPD11 & 101,00 & 164,59 & 100,59 & 39,14 & 5276,51 & 314,93 & 62,16 & 252,77 & 107,17 & 232,23 & 235,88 & \begin{tabular}{|l|l|l|l|}
101,03 \\
\end{tabular} & 662,80 & 91,24 & 5,00 & 55,36 & 266,99 & 39,18 & 39,92 & 266,87 \\
\hline Salamandra salamandra & 29SPD12 & 100,00 & 166,36 & 100,31 & $39, \mathrm{C}$ & 82,65 & + & 77 & 252,89 & 110,21 & 234,10 & 237,65 & 102,66 & 666,77 & 92,14 & 5,00 & 55,42 & 268,94 & 39,34 & 40,14 & 268,71 \\
\hline Salamandra salamandra & $29 S P D 13$ & 100,00 & 32 & \begin{tabular}{|l|l|}
99,37 \\
\end{tabular} & $38, \varepsilon$ & 5312,71 & 8 & 6 & 252,67 & $\mid 107,43$ & 233,46 & 237,16 & 101,29 & 694,89 & $\begin{array}{ll}96,87 \\
667\end{array}$ & 5,21 & $\begin{array}{l}5,4,44 \\
55\end{array}$ & 280,93 & 41,01 & 42,06 & 280,87 \\
\hline Salamandra salamandra & 29SPD14 & 101,00 & & 98,75 & 38,55 & 5330,92 & 315,60 & & 252,77 & 106,32 & 233,90 & 237,29 & 101,11 & \begin{tabular}{|l|l|}
714,56 \\
\end{tabular} & 100,17 & 5,54 & 55,28 & 289,08 & 42,56 & 43,73 & 289,07 \\
\hline Salamandra salamandra & $29 S P D 15$ & 99,00 & $\mid 162,46$ & 97,29 & 38,02 & 5371,46 & 312,91 & 60,64 & 252,27 & \begin{tabular}{|c|c|}
98,53 \\
\end{tabular} & 231,79 & 235,15 & 97,96 & 757,44 & 107,32 & 5,59 & 55,27 & 307,57 & 45,20 & 46,33 & 307,57 \\
\hline Salamandra salamandra & $29 S P D 16$ & 100,00 & 161,78 & 96,94 & 37,96 & 5407,71 & 312,48 & 59 & 253 & 96 & 231,64 & 234,87 & 96,84 & 780,17 & 111,29 & 6,00 & 55,41 & 317,28 & 46,43 & 47,58 & 317,28 \\
\hline Salamandra salamandra & 29SPD17 & 100,00 & 162,40 & 97,18 & 37,83 & 441,73 & 313,80 & 59,6 & 254,77 & 97,30 & 232,95 & 235,84 & 96,87 & 787,81 & 112,55 & 6,00 & 55,10 & 319,82 & 47,48 & 48,64 & 319,82 \\
\hline Salamandra salamandra & 29SPD18 & 100,00 & $\frac{10}{16}$ & $\begin{array}{l}31,16 \\
98,61\end{array}$ & $\begin{array}{l}37,05 \\
37,78 \\
\end{array}$ & 5466,37 & $\begin{array}{ll}317,00 \\
317,80\end{array}$ & $\begin{array}{l}6,0,42 \\
60,42\end{array}$ & 257,38 & \begin{tabular}{r|r}
102,76 \\
\end{tabular} & \begin{tabular}{|l|l|}
236,73 \\
236,73
\end{tabular} & 238,93 & 年 & 766,01 & \begin{tabular}{|l|l|l|l|l|}
109,26 \\
\end{tabular} & $0,0,0$ & 55 & $\begin{array}{l}31,02 \\
310,27\end{array}$ & $\begin{array}{l}46,409 \\
46,09\end{array}$ & $\begin{array}{l}40,04 \\
47,75\end{array}$ & $\begin{array}{l}31,02 \\
310,24 \\
\end{array}$ \\
\hline Salamandra salamandra & 29SPD20 & 100,00 & 159,85 & \begin{tabular}{|r|r|r|r|r|}
102,48 \\
\end{tabular} & 39,07 & 5401,49 & 313,94 & 55,8 & 258,10 & 103,21 & 229,40 & 233,08 & 95,22 & 674,09 & 91,73 & 5,03 & 54,81 & 269,90 & 40,77 & 40,90 & 269,22 \\
\hline Salamandra salamandra & 29SPD21 & 100,00 & 164,55 & 102,79 & 39,06 & 5396,16 & 318,34 & 59,78 & 258,56 & \begin{tabular}{ll|}
107,75 \\
\end{tabular} & 233,89 & 237,44 & 99,64 & 654,05 & 88,96 & 5,00 & 54,91 & 262,27 & 39,32 & 39,95 & 261,14 \\
\hline Salamandra salamandra & $29 S P D 22$ & 100,00 & 16 & 102,14 & 39,6 & 04,88 & 319,60 & 61, & 258 & 109,06 & 235 & 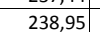 & 100 & 661,05 & 90,44 & 5, & 54, & 265,60 & 39,65 & 40,57 & 264,47 \\
\hline Salamandra salamandra & $29 S P D 24$ & 100,00 & 16 & 99 & 38 & 6 & & & & 106 & 236 & 237 & 98 & 720, & 100,47 & 5,5 & 54 & 290,40 & 43,93 & 45,10 & 290,08 \\
\hline Salamandra salamandra & $29 S P D 25$ & 101,00 & 160,69 & 97,33 & 37,76 & 5474,17 & 313,32 & 58,49 & 254,84 & $\begin{array}{l}98,78 \\
98\end{array}$ & 231,64 & 235,06 & 95,46 & 766,08 & 108,18 & 6,11 & 55,04 & 309,96 & 46,21 & 47,49 & 309,96 \\
\hline Salamandra salamandra & $29 S P D 26$ & 101,00 & 160,01 & 96,71 & 37,40 & 5512,44 & 312,78 & 57,41 & 255,37 & 95,55 & 231,52 & 234,88 & 94,22 & 787,61 & 111,94 & 6,14 & 55,06 & 319,04 & 47,62 & 48,89 & 319,04 \\
\hline Salamandra salamandra & $29 S P D 27$ & 100,00 & 161,47 & 97,40 & 37,06 & 5567,78 & 315,33 & 57,12 & 258,21 & \begin{tabular}{|c|}
98,03 \\
\end{tabular} & 233,97 & 236,64 & \begin{tabular}{|c|}
94,68 \\
\end{tabular} & 784,94 & 111,68 & 6,06 & 54,87 & 317,36 & 47,71 & 48,92 & 317,33 \\
\hline Salamandra salamand & 29SPD28 & 101,00 & & & 37,12 & 619,06 & & 57,26 & 261,16 & 101,12 & 年 & 0,0 & 95,64 & 774,94 & 110,22 & 509 & 54, & 312,52 & 47,14 & 48,58 & 312,37 \\
\hline Salamandra salamandra & $29 S P D 29$ & & & & 37 & 5638,23 & & & 262,98 & 103,96 & 239,38 & 240,89 & $\frac{97,0}{97,0}$ & 762,84 & 108,38 & 5, & 54, & 306,90 & 46,46 & 4 & 306 \\
\hline Salamandra salamandra & $29 \mathrm{SPD} 30$ & 100,00 & 161,50 & 105,37 & 39,15 & 5515,50 & 318,91 & 54,19 & 264,71 & 103,47 & 232,66 & 236,00 & 95,16 & 649,40 & 87,17 & 5,00 & 54,22 & 259,03 & 39,70 & 40,00 & 256,64 \\
\hline Salamandra salamandra & 29SPD31 & 101,00 & 164,08 & 105,16 & 39,06 & 5516,52 & 321,40 & 56,66 & 264,73 & 105,84 & 235,25 & 238,34 & 97,68 & 647,09 & 86,94 & 5,00 & 54,20 & 258,42 & 39,55 & 40,13 & 255,93 \\
\hline Salamandra salamandra & $29 S P D 32$ & 101,00 & 164,90 & 104,14 & 38,99 & 524,03 & 21,94 & 57,97 & 263,97 & 106,51 & 236,26 & 239,30 & 98,44 & 659,01 & 89,18 & 5,07 & 54,34 & 263,67 & 40,15 & 41,02 & 261,4 \\
\hline Salam & $29 S P D 33$ & 1000 & & 101 , & 38,4 & 52315 & & 57, & 261, & 104,52 & 6 & 4 & 96,38 & 699 & 95,88 & 5, & 54 & 280,39 & & $24 \mid$ & 278 \\
\hline Salamandra salamandra & 29SPD34 & 101,00 & $\begin{array}{l}162,24 \\
160,24\end{array}$ & \begin{tabular}{|c|c|}
99,30 \\
9,30
\end{tabular} & 37,85 & 5 & 315,39 & 56,72 & 258,67 & 102,24 & 232,29 & 235,74 & 94,27 & \begin{tabular}{|l|}
740,95 \\
740,4
\end{tabular} & 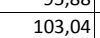 & 6,14 & 54,40 & 298,01 & $\mid$ & $\begin{array}{l}44,24 \\
46,65\end{array}$ & 297,21 \\
\hline
\end{tabular}




\begin{tabular}{|c|c|c|c|c|c|c|c|c|c|c|c|c|c|c|c|c|c|c|c|c|c|}
\hline$\overline{\text { TAXON }}$ & UTM & $\mathrm{km} 2$ & BIO1 & BIO2 & 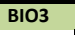 & 8104 & B105 & 8106 & B107 & B108 & B109 & BIO10 & BIO11 & BIO12 & BIO13 & BIO14 & BIO15 & B1016 & $\begin{array}{ll}1017 \\
17\end{array}$ & BIO18 & BIO19 \\
\hline Salamandra salamandra & 29SPD35 & 100,00 & 150,96 & 93,90 & 36,71 & 5549,48 & 303,30 & 51,48 & 251,82 & 87,76 & 223,30 & 227,2 & 86,22 & 847,69 & 120,82 & 7,24 & 54,84 & 343,56 & 52,06 & 53,06 & 343,56 \\
\hline Salamandra salamandra & 29SPD36 & 101,00 & $\begin{array}{ll}153,98 \\
\end{array}$ & 94,90 & 36,77 & 5604,19 & $\begin{array}{l}307,60 \\
\end{array}$ & 52,43 & 255,18 & 91,66 & 227,18 & 230,49 & 87,92 & 831,12 & 118,49 & 6,95 & 54,64 & 336,25 & 51,13 & 52,08 & 336,14 \\
\hline Salamandra salamandra & 29SPD37 & 100,00 & 162,36 & 98,66 & 37,05 & 5674,95 & 318,45 & 56,13 & 262,32 & 101,76 & 236,42 & 238,79 & 94,20 & 758,86 & $\begin{array}{l}106,97 \\
\end{array}$ & 5,99 & 54,36 & 305,26 & 46,45 & 47,80 & 304,45 \\
\hline Salamandra salamandra & 29SPD38 & 101,00 & 162,82 & 98,87 & 36,98 & 5732,46 & 319,80 & 55,39 & 264,41 & 101,39 & 237,89 & 239,77 & 93,75 & 761,73 & 107,66 & 5,93 & 54,35 & 305,98 & 46,83 & 48,18 & 305,15 \\
\hline Salamandra salamandra & 29SPD40 & 100,00 & 160,85 & 107,88 & 39,32 & 5634,39 & 321,61 & 50,65 & 270,96 & 101,18 & 233,86 & 236,68 & \begin{tabular}{ll|}
93,03 \\
\end{tabular} & 641,53 & 85,81 & 5,19 & 53,71 & 254,70 & 40,13 & 40,43 & 250,73 \\
\hline Salamandra salamandra & 29SPD41 & 100,00 & 162,43 & 107,64 & 39,01 & 5644,46 & 323,51 & 52,29 & 271,22 & 102,49 & 235,74 & 238,27 & $\begin{array}{l}94,25 \\
\end{array}$ & 645,10 & 86,31 & 5,02 & 53,74 & 256,50 & 40,14 & 40,61 & 252,58 \\
\hline Salamandra salamandra & 29SPD42 & 100,00 & 164,73 & 107,12 & 39,01 & 5646,44 & 325,62 & 54,64 & 270,98 & 104,53 & 238,01 & 240,52 & 96,53 & 643,72 & 86,33 & 5,01 & 53,71 & 256,23 & 39,98 & 40,80 & 252,39 \\
\hline Salamandra salamandra & 29SPD43 & 99,00 & 163,16 & 104,89 & 38,67 & 5647,58 & 323,13 & 54,71 & 268,42 & 103,38 & 236,58 & 239,30 & 95,26 & 675,98 & 91,26 & 5,35 & 53,69 & 269,65 & \begin{tabular}{ll|}
42,25 \\
\end{tabular} & 43,30 & 266,46 \\
\hline Salamandra salamandra & 29SPD44 & 101,00 & 155,18 & 99,28 & 37,57 & 5640,11 & 312,16 & 51,31 & 260,85 & 96,60 & 228,72 & \begin{tabular}{l|l|}
232,15 \\
\end{tabular} & 88,58 & 767,07 & 106,42 & 6,42 & 54,01 & $\begin{array}{l}307,69 \\
\end{array}$ & 47,74 & 48,74 & 306,19 \\
\hline Salamandra salamandra & 29SPD45 & 99,00 & 145,56 & 94,44 & 36,50 & 5659,10 & 300,09 & 44,74 & 255,35 & 86,12 & 220,27 & 223,39 & 79,69 & 866,89 & 122,89 & 7,64 & 54,20 & 348,96 & 54,20 & 54,73 & 348,51 \\
\hline Salamandra salamandra & 29SPD46 & 100,00 & 156,64 & 97,92 & 36,98 & 5715,55 & 313,60 & 51,85 & 261,75 & 96,79 & 231,46 & 234,36 & 88,84 & 779,71 & 109,38 & 6,38 & 54,05 & 313,09 & 48,41 & 49,55 & 311,72 \\
\hline Salamandra salamandra & 29SPD47 & 100,00 & 161,78 & 99,90 & 37,00 & 5777,09 & 320,23 & 53,95 & 266,28 & 100,13 & 237,49 & 239,55 & 92,44 & 738,82 & 103,05 & 5,96 & 53,79 & 295,82 & 45,84 & 47,24 & 293,69 \\
\hline Salamandra salamandra & 29SPD48 & 100,00 & 163,51 & 100,30 & 37,01 & 5812,85 & 322,29 & 54,38 & 267,91 & 100,95 & 239,86 & 241,48 & 93,31 & 729,76 & 101,92 & 5,83 & 53,78 & 291,85 & 45,22 & 46,76 & 289,49 \\
\hline Salamandra salamandra & 29SPD49 & 99,00 & 164,02 & 100,39 & 36,89 & 5853,23 & 323,01 & 53,88 & 269,13 & 100,56 & 240,91 & 242,15 & 93,07 & 730,46 & 102,34 & 5,78 & 53,71 & 291,92 & 45,35 & 46,81 & 289,43 \\
\hline Salamandra salamandra & 29SPD50 & 101,00 & 161,35 & 110,94 & 39,34 & 5753,36 & 325,81 & 47,58 & 278,22 & 99,84 & 236,19 & 238,25 & 91,60 & 621,37 & 83,68 & 5,08 & 53,01 & 245,32 & 39,71 & 39,97 & 239,52 \\
\hline Salamandra salamandra & 29SPD51 & 100,00 & 164,01 & 111,44 & 39,36 & 5761,51 & 328,97 & 49,73 & 279,23 & 102,11 & 239,04 & 240,87 & 93,99 & 614,70 & 82,82 & 4,99 & 52,89 & 242,76 & 39,40 & 39,88 & 236,78 \\
\hline Salamandra salamandra & 29SPD52 & 101,00 & 166,26 & 111,13 & 39,15 & 5767,16 & 331,38 & 51,92 & 279,45 & 104,00 & 241,34 & 243,14 & $\begin{array}{l}96,06 \\
\end{array}$ & 610,44 & 82,21 & 4,99 & 52,86 & 241,30 & 38,96 & 39,79 & 235,35 \\
\hline Salamandra salamandra & 29SPD53 & 101,00 & 162,51 & 107,88 & 38,71 & 5768,06 & 326,25 & 50,88 & 275,37 & 100,99 & 237,82 & $\begin{array}{l}239,95 \\
\end{array}$ & \begin{tabular}{|c|}
92,98 \\
\end{tabular} & 656,75 & 87,85 & 5,19 & 52,99 & 260,40 & 41,79 & 42,66 & 255,47 \\
\hline Salamandra salamandra & 29SPD54 & 100,00 & 159,58 & 104,37 & 37,96 & 5772,25 & 321,21 & 50,21 & 271,00 & 98,48 & 235,00 & 237,44 & $\begin{array}{l}90,46 \\
\end{array}$ & 698,68 & 94,38 & 5,69 & 53,15 & 277,95 & 44,20 & 45,22 & 273,87 \\
\hline Salamandra salamandra & 29SPD55 & 101,00 & 155,24 & 100,88 & 37,30 & 5793,53 & 315,14 & 48,08 & 267,07 & 94,52 & 231,21 & 233,80 & 86,40 & 749,56 & 103,06 & 6,22 & 53,30 & 298,95 & 47,35 & 48,26 & 295,74 \\
\hline Salamandra salamandra & 29SPD56 & 101,00 & 157,86 & 100,85 & 37,00 & 5829,21 & 317,95 & 49,67 & 268,29 & 96,27 & 234,37 & 236,51 & 88,25 & 735,80 & 101,26 & 6,06 & 53,23 & 293,24 & 46,52 & 47,58 & 289,84 \\
\hline Salamandra salamandra & 29SPD59 & 101,00 & 163,90 & 101,51 & 36,84 & 5918,49 & 324,06 & 52,29 & 271,77 & $\begin{array}{l}99,59 \\
\end{array}$ & 241,73 & 242,68 & \begin{tabular}{|c|}
92,03 \\
\end{tabular} & 700,88 & 96,96 & 5,47 & 53,10 & 278,58 & 43,96 & 45,45 & 274,74 \\
\hline Salamandra salamandra & 29SPD60 & 100,00 & 168,81 & 115,08 & 39,66 & 5867,40 & 337,01 & 49,50 & 287,52 & 104,80 & 245,21 & 246,19 & 96,54 & 544,56 & 75,00 & 4,03 & 52,36 & 213,40 & 35,45 & 35,99 & 204,68 \\
\hline Salamandra salamandra & 29SPD61 & 100,00 & 167,71 & 115,31 & 39,86 & 5882,00 & 336,11 & 48,61 & 287,49 & 103,42 & 244,34 & 245,41 & \begin{tabular}{|c|}
95,43 \\
\end{tabular} & 563,84 & 77,06 & 4,32 & 52,19 & 220,94 & 36,92 & 37,50 & 212,62 \\
\hline Salamandra salamandra & 29SPD62 & 100,00 & 165,88 & 114,38 & 39,3 & 5882,08 & 33 & 48,07 & 286,54 & 101, & 242,73 & 243,80 & 93,97 & 590,70 & 79,85 & 4,86 & 52, & 231,85 & 38,45 & 39,20 & 224,20 \\
\hline Salamandra salamandra & 29SPD63 & 99,00 & 165,28 & 111,71 & 39,01 & 5881,51 & 332,24 & 49,14 & 283,10 & 101,48 & 242,15 & 243,45 & 93,61 & 608,40 & 81,64 & 4,91 & 52,16 & 239,24 & 39,44 & 40,35 & 232,05 \\
\hline Salamandra salamandra & 29SPD65 & 99,00 & 159,07 & 105,07 & 37,66 & 5905,09 & 322,77 & 47,30 & 275,47 & 96,15 & 236,66 & 238,35 & 88,16 & 682,61 & 91,35 & 5,51 & 52,42 & 269,79 & 43,77 & 44,68 & 264,17 \\
\hline Salamandra salamandra & $\begin{array}{ll}29 S P D 67 \\
\end{array}$ & 100,00 & 160,17 & 102,90 & 37,00 & 5953,39 & 322,70 & 48,59 & 274,10 & 96,39 & 238,64 & 239,99 & 88,50 & 689,63 & 93,57 & 5,52 & 52,62 & 272,83 & 43,92 & 45,00 & 267,58 \\
\hline Salamandra salamandra & 29SPD68 & 100,00 & 162,31 & 102,78 & 37,01 & 5974,32 & 324,56 & 49,86 & 274,70 & 97,69 & 240,99 & 242,01 & 89,96 & 677,68 & 92,17 & 5,34 & 52,48 & 267,94 & 43,03 & 44,25 & 262,65 \\
\hline Salamandra salamandra & $29 S P D 72$ & 101,00 & 167,95 & 115,53 & 39,09 & 5969,52 & 338,12 & 47,37 & 290,75 & 102,45 & 245,99 & 246,49 & 94,50 & 549,09 & 74,84 & 4,03 & 51,63 & 214,01 & 36,08 & 36,81 & 204,42 \\
\hline Salamandra salamandra & 29SPD73 & 100,00 & 164,64 & 112,88 & 38,83 & 5980,29 & 333,86 & 46,27 & 287,60 & 99,49 & 242,99 & 243,82 & 91,55 & 586,46 & 78,71 & 4,75 & 51,56 & 228,94 & 38,45 & 39,36 & 220,19 \\
\hline Salamandra salamandra & 29SPD76 & 101,00 & 158,10 & 105,10 & 37,02 & 6021,02 & 323,91 & 44,77 & 279,14 & 93,63 & 237,60 & 238,68 & 85,63 & 665,40 & 88,27 & 5,44 & 51,81 & 261,00 & 43,29 & 44,05 & 254,05 \\
\hline Salamandra salamandra & $295 P D 78$ & 101,00 & 163,18 & 104,46 & 36,98 & 6042,43 & 327,73 & 48,82 & 278,91 & 97,58 & 242,86 & 243,48 & 89,67 & 638,86 & 85,31 & 4,99 & 51,72 & 250,58 & 41,22 & 42,48 & 243,70 \\
\hline Salamandra salamandra & 29SPD79 & 100,00 & 164,08 & 103,93 & 36,99 & 6046,74 & 328,12 & 49,56 & 278,56 & 98,21 & 243,88 & 244,25 & $\begin{array}{l}90,47 \\
\end{array}$ & 634,59 & 85,11 & 4,96 & 51,67 & 248,84 & 40,90 & 42,10 & 242,06 \\
\hline Salamandra salamandra & 29SPD83 & 100,00 & 164,86 & 113,41 & 38,41 & 6057,41 & 336,19 & 44,88 & 291,31 & 98,84 & 244,34 & 244,99 & 90,78 & 559,73 & 75,01 & 4,28 & 51,20 & 216,95 & 36,56 & 37,66 & 206,87 \\
\hline Salamandra salamandra & $29 S P D 85$ & 100,00 & 162,03 & 109,12 & 37,66 & 6085,60 & 331,38 & 44,92 & 286,45 & 96,06 & 242,24 & 242,89 & 88,12 & 600,05 & 79,06 & 4,84 & 51,03 & 233,03 & 39,47 & 40,46 & 223,95 \\
\hline Salamandra salamandra & 29SPD95 & 100,00 & 161,11 & 109,48 & 37,20 & 6168,92 & 332,58 & 42,74 & 289,84 & 94,19 & 242,64 & \begin{tabular}{|l|l|}
242,97 \\
\end{tabular} & 86,19 & 580,94 & 75,82 & 4,72 & 50,47 & 223,68 & 38,61 & 39,40 & 213,55 \\
\hline Salamandra salamandra & 29SPD96 & 101,00 & 160,82 & 107,91 & 36,97 & 6178,85 & 331,39 & 43, & 288,05 & 93,88 & 242,6 & 242,93 & 85,88 & 586,53 & 76,25 & 4,64 & 50,48 & 226,01 & 38,76 & 39,28 & 216,13 \\
\hline Salamandra salamandra & 29SPE00 & 100,00 & 156,61 & 96,31 & 37,36 & 5412,16 & 306 & 52, & 254,22 & 91, & 227,3 & 229,15 & 91 & 892,60 & 129,81 & 7,5 & 55, & 363,46 & 55,07 & 55,67 & 363,46 \\
\hline Salamandra salamandra & 29SPE01 & 101,00 & 14 & 94,02 & 36,76 & 5429,34 & 298,03 & 45,95 & 252,07 & 83,36 & 220,92 & 221,77 & 83,36 & 983,23 & 144,85 & 8,69 & 55,36 & 401,42 & 60,77 & 60,98 & 401,42 \\
\hline Salamandra salamandra & 29SPE02 & 101,00 & 138,63 & 90,45 & 36,04 & 5409,04 & 285,24 & 37,94 & 247,30 & 73,95 & 211,46 & 211,53 & 73,95 & 1097,44 & 163,97 & 10,08 & 55,76 & 449,22 & 67,41 & 67,41 & 449,22 \\
\hline Salamandra salamandra & 29SPE10 & 100,00 & 159,18 & 97,18 & 36,95 & 5576,36 & 312,60 & 53,12 & 259,48 & 91,49 & 232,06 & 233,77 & 91,49 & 854,46 & 123,62 & 6,97 & 54,95 & \begin{tabular}{|l|}
346,49 \\
\end{tabular} & 52,60 & 53,47 & 346,49 \\
\hline Salamandra salamandra & 29SPE11 & 101,00 & 157,91 & 97,35 & 36,95 & 5583,85 & 311,32 & 51, & 259,93 & 90,01 & 231,04 & 232,51 & 90,01 & 875,06 & 127,01 & 7,26 & 54,90 & 354,47 & 54,36 & 55,11 & 354,47 \\
\hline Salamandra salamandra & 29SPE12 & 100,00 & 1,78 & 95,52 & 36,56 & 5580,80 & & 46,12 & 257, & 84,1 & 225,4 & 226,36 & 84,14 & 943,37 & 138,41 & 8,1 & 55,08 & 383,08 & 58,69 & 59,05 & 383,08 \\
\hline Salamandra salamandra & 29SPE20 & 10 & 159,0 & 97 & 36,27 & 5736,83 & 5 & 51 & 263 & 91, & 234,44 & 235,76 & 89,7 & 838,95 & 120,98 & 6,83 & 54,74 & 338,78 & 51,89 & 52,70 & 338,73 \\
\hline Salamandra salamandra & 29SPE21 & 100,00 & 15 & 97,04 & 36,15 & 5765,61 & 313,94 & 49,60 & 264,34 & 88,0 & 233,56 & 234,55 & 87,85 & 858,44 & 124,23 & 7,02 & 54,74 & 346,39 & 53,52 & 54,15 & 346,39 \\
\hline Salamandra salamandra & 295 SE22 & 100,00 & 153,76 & 96,17 & 36,13 & 5741,76 & 308,91 & 46,21 & 262,70 & 84,23 & 229,40 & 230,39 & 84,23 & 900,23 & 131,32 & 7,73 & 54,81 & 363,70 & 56,48 & 56,78 & 363,70 \\
\hline Salamandra salamandra & 29SPE30 & 100,00 & 165,01 & 99,91 & 36,85 & 5785,91 & 322,58 & 55, & 267,47 & 101,66 & 240,95 & 241,99 & 94,62 & 754,97 & 106,97 & 6,00 & 54,14 & 302,59 & 46,47 & 48,13 & 301,33 \\
\hline Salamandra salamandra & 29SPE31 & 101,00 & 157,49 & 97,29 & 36,01 & 5870,90 & 5 & 48 & 267 & 91,57 & 234,94 & 235,83 & 86,60 & 833, & 120,00 & 6,9 & 54, & 334,68 & 52,14 & 52,80 & 334,45 \\
\hline Salamandra salamandra & $29 S P E 32$ & & & & 36,01 & 5844,35 & 31 & 46 & 265 & 88 & 232 & 232,95 & 84, & 856,54 & 123,96 & 7,15 & 54,26 & 343,94 & 53,86 & 54,35 & 343,80 \\
\hline Salamandra salamandra & 29SPE40 & 101,00 & 164,31 & 100,45 & 36,85 & 5868,35 & 323,23 & 53,36 & 269,86 & 100,41 & 241,48 & 242,36 & 92,96 & 733,33 & 103,07 & 5,98 & 53,64 & 292,77 & 45,60 & 47,25 & 290,38 \\
\hline Salamandra salamandra & 29SPE41 & 100,00 & 163,53 & 100,25 & 36,75 & 5876,42 & 322,10 & 52,19 & 269,90 & 99,20 & 240,77 & 241,49 & 91,83 & 744,16 & 105,12 & 6,05 & 53,53 & 296,93 & 46,41 & 48,04 & 294,75 \\
\hline Salamandra salamandra & 29SPE42 & 99,00 & \begin{tabular}{ll|l}
156,54 \\
\end{tabular} & 97,94 & 36,04 & 5903,14 & 314,45 & 46,30 & 268,15 & 92,15 & 234,38 & 234,94 & 84,72 & 808,24 & 115,72 & 6,78 & 53,88 & 322,90 & 50,98 & 51,71 & 321,60 \\
\hline Salamandra salamand & $29 \mathrm{SPE}$ & 100 & & 101 & 36, & 5932 & & & 271 & 99 & & 242 & & 705,68 & & 5, & 53 & 280,54 & 44,12 & 45,66 & \\
\hline Salamandra salamandra & 29SPE51 & 101,00 & 162,83 & 100,88 & 36,68 & 5941,95 & 322,45 & 50,59 & 271,86 & 97,88 & 241,23 & 241,63 & 90,42 & 716,97 & 100,21 & 5,86 & 53,12 & 284,78 & 45,20 & 46,64 & 281,24 \\
\hline Salamandra salamandra & 29SPE52 & 101,00 & 157,55 & 99,13 & 36,10 & 5958,68 & 316,43 & 46,10 & 270,33 & 92,54 & 236,26 & 236,52 & 84,95 & 761,84 & 107,67 & 6,19 & 53,17 & $\begin{array}{l}302,85 \\
\end{array}$ & 48,50 & 49,19 & 300,00 \\
\hline Salamandra salamandra & 29SPE60 & 101,00 & 160,83 & 101,30 & 36,43 & 6005,53 & 322,03 & 48,31 & 273,71 & 95,56 & 240,07 & 240,54 & 87,79 & 697,13 & 96,08 & 5,66 & 52,50 & 275,62 & 44,60 & 45,66 & 270,71 \\
\hline Salaman & 29SPE & 99 & 159,52 & 100,65 & 36,13 & 011, & 320, & 46,94 & 273,24 & 94,04 & 238,99 & 239,26 & 86,33 & 709,88 & 98,39 & 5,94 & 52,45 & 280,56 & 45,79 & 46,52 & 275,97 \\
\hline Salamandra salamand & 29SPEG & 100 & 155 & 99 & 36 & & 510 & & 271,7 & $90,01[$ & 235,19 & 235,31 & 82,2 & 739,68 & $103,4 \mathrm{C}$ & 6,29 & 52,52 & 292,50 & 48,01 & 48,30 & 288 \\
\hline Salamandra salamandra & $295 P E 70$ & 101,00 & 160,68 & 102,50 & 36,39 & 6061,68 & 323,93 & 46,84 & 277,09 & \begin{tabular}{|l|l}
94,72 \\
\end{tabular} & 240,89 & 241,08 & 86,94 & 661,91 & \begin{tabular}{|}
89,78 \\
89
\end{tabular} & 5,25 & 51,91 & 259,85 & $\mid \begin{array}{l}\mid 40,67 \\
42\end{array}$ & 43,48 & 253,48 \\
\hline
\end{tabular}




\begin{tabular}{|c|c|c|c|c|c|c|c|c|c|c|c|c|c|c|c|c|c|c|c|c|c|}
\hline TAXON & UTM & $\mathrm{km} 2$ & BIO1 & $\mathrm{B1O2}$ & $\mathrm{BIO3}$ & 8104 & B105 & B106 & B107 & B108 & B109 & BIO10 & B1011 & BIO12 & B1013 & B1014 & 81015 & B1016 & BIO17 & B1018 & B1019 \\
\hline Salamandra salamandra & 29SPE71 & 100,00 & 159,82 & 101,92 & 36,35 & 6065,58 & 322,31 & 45,97 & 276,34 & 93,66 & 240,05 & 240,17 & 85,82 & 670,65 & 91,49 & 5,45 & 51,84 & 263,29 & 43,56 & 44,06 & 257,20 \\
\hline Salamandra salamandra & $295 P E 72$ & 101,00 & 157,64 & 101,21 & 36,08 & 6065,15 & 319,49 & 44,06 & 275,43 & 91,42 & 237,94 & 238,00 & 83,62 & 684,95 & 93,96 & 5,83 & 51,77 & 268,81 & 45,03 & 45,28 & 262,93 \\
\hline Salamandra salamandra & $295 P E 80$ & 100,00 & 161,60 & \begin{tabular}{|l|l|l|l|l|}
103,86 \\
\end{tabular} & 36,56 & 6119,63 & 326,96 & 46,28 & 280,68 & 94,92 & 242,58 & 242,65 & 87,03 & 621,49 & 82,74 & 5,02 & 51,02 & 241,96 & 40,81 & 44,16 & 234,20 \\
\hline Salamandra salamandra & 29SQA53 & 100,00 & 177,64 & 70,43 & 35,65 & 4493,07 & 279,11 & 84,29 & 194,82 & 143,26 & 232,93 & 237,52 & 121,50 & 635,77 & 110,43 & 1,00 & 69,06 & 277,45 & 13,16 & 23,23 & 262,34 \\
\hline Salamandra salamandra & 29SQA56 & 100,00 & 173,87 & 72,93 & 33,94 & 4924,18 & 286,72 & 74,69 & 212,03 & \begin{tabular}{|l|l|}
144,30 \\
\end{tabular} & 235,60 & 239,56 & 112,85 & 606,72 & 95,02 & 1,00 & 65,93 & 257,52 & 15,55 & 23,43 & 241,52 \\
\hline Salamandra salamandra & 29SQA57 & 100,00 & 174,19 & 75,94 & 34,00 & 5074,94 & 292,53 & 72,25 & 220,28 & 137,56 & 238,01 & 241,78 & 111,32 & 594,55 & 90,93 & 1,00 & 65,47 & 252,01 & 16,14 & 23,23 & 235,14 \\
\hline Salamandra salamandra & 29SQA62 & 96,00 & 173,91 & 72,69 & 36,69 & 4381,85 & 276,29 & 80,88 & 195,42 & 128,33 & 228,08 & 232,35 & 119,18 & 703,15 & 122,12 & 1,00 & 70,45 & 313,64 & 14,39 & 23,54 & 299,47 \\
\hline Salamandra salamandra & 29SQA63 & 91,00 & 174,26 & 71,55 & 35,73 & 4530,08 & 278,14 & 80,13 & 198,02 & 127,05 & 230,42 & 234,79 & 117,85 & 680,79 & 116,33 & 1,00 & 69,49 & 299,66 & 14,39 & 23,80 & 284,77 \\
\hline Salamandra salamandra & 29SQA65 & 87,00 & 173,45 & 71,17 & 33,89 & 4832,19 & 282,94 & 76,20 & 206,74 & 123,52 & 233,76 & 237,93 & 113,34 & 646,16 & 104,12 & 1,00 & 67,41 & 276,87 & 15,43 & 23,97 & 261,60 \\
\hline Salamandra salamandra & 2950B04 & 100,00 & 175,53 & 93,32 & 37,02 & 5425,44 & 312.93 & 64,53 & 248,41 & 120,14 & 243,71 & 246,19 & 107,63 & 511,63 & 78,33 & 1,29 & 61.96 & 215,68 & 16,04 & 24,62 & 195,76 \\
\hline Salamandra salamandra & 29SQB05 & 101,00 & 169,79 & 97,85 & 37,29 & 5573,42 & 314,27 & 56,43 & 257,84 & 109,60 & 240,50 & 242,85 & 100,61 & 543,49 & 81,20 & 2,00 & 60,59 & 226,67 & 19,23 & 27,11 & 208,41 \\
\hline Salamandra salamandra & 29SQB06 & 101,00 & 165,53 & 101,65 & 37,97 & 5683,37 & 315,98 & 50,49 & 265,49 & 104,53 & 238,24 & 240,44 & 95,45 & 566,49 & 83,17 & 2,01 & 59,96 & 234,53 & 21,17 & 28,32 & 217,67 \\
\hline Salamandra salamandra & 29SQB07 & 100,00 & 164,82 & 104,21 & 38,00 & 5762,46 & 319,25 & 48,34 & 270,91 & \begin{tabular}{|l|l|}
102,79 \\
\end{tabular} & 238,75 & 240,87 & 93,82 & 569,38 & 82,77 & 2,29 & 59,36 & 234,26 & 22,28 & 28,82 & 218,29 \\
\hline Salamandra salamandra & 29SQB08 & 100,00 & 163,17 & 106,56 & 38,00 & 5835,67 & 321,68 & 45,53 & 276,15 & 100,43 & 238,34 & 240,40 & 91,52 & 576,80 & 82,82 & 2,68 & 58,52 & 235,69 & 23,96 & 29,93 & 220,70 \\
\hline Salamandra salamandra & 29SQB09 & 101,00 & 149,98 & 109,34 & 38,00 & 5955,40 & 315,23 & 31,79 & 283,43 & 86,71 & 227,37 & 229,53 & 77,75 & 655,52 & 90,98 & 3,83 & 57,21 & 264,65 & 30,41 & 35,23 & 252,11 \\
\hline Salamandra salamandra & 29SQB14 & 100,00 & 177,04 & 97,18 & 37,40 & 5528,40 & 319,21 & 63,27 & 255,94 & 117,12 & 247,02 & 249,25 & 108,02 & 518,64 & 79,16 & 1,11 & 62,08 & 218,60 & 16,14 & 24,15 & 199,43 \\
\hline Salamandra salamandra & 29SQB15 & 100,00 & 171,39 & 101,11 & 37,85 & 5671,57 & 320,33 & 55,58 & 264,75 & \begin{tabular}{|c|c|}
110,05 \\
\end{tabular} & 243,75 & 245,90 & 101,01 & 548,55 & 81,87 & $\begin{array}{l}1,1+1 \\
1,99\end{array}$ & 60,71 & 228,67 & 19,41 & 26,72 & 210,85 \\
\hline Salamandra salamandra & $29 S Q B 16$ & 99,00 & 168,83 & 104,02 & 38,00 & 5771,93 & 322,70 & 51,44 & 271,26 & 106,39 & 242,73 & 244,82 & 97,38 & 560,74 & 82,61 & 2,01 & 60,17 & 232,12 & 20,69 & 27,51 & 215,31 \\
\hline Salamandra salamandra & 29SQB17 & 101,00 & 163,36 & 107,06 & 38,00 & 5877,79 & 322,84 & 44,57 & 278,27 & 99,97 & 239,10 & 241,08 & 90,98 & 589,06 & 85,03 & 2,50 & 59,22 & 241,64 & 23,35 & 29,53 & 226,20 \\
\hline Salamandra salamandra & 29SQB18 & 100,00 & 159,01 & 109,34 & 38,00 & 5957,20 & 322,97 & 39,38 & 283,59 & 95,16 & 236,25 & 238,07 & 86,15 & 610,38 & 86,62 & 2,97 & 58,25 & 248,23 & 25,93 & 31,53 & 233,97 \\
\hline Salamandra salamandra & 29SQB19 & 99,00 & 151,81 & 111,03 & 38,00 & 6028,69 & 319,92 & 31,80 & \begin{tabular}{|l|}
288,13 \\
\end{tabular} & \begin{tabular}{|c|}
87,58 \\
\end{tabular} & 230,39 & 232,23 & 78,65 & 649,94 & 90,32 & 3,61 & 57,35 & 262,00 & 29,59 & 34,50 & 249,20 \\
\hline Salamandra salamandra & 295QB24 & 100,00 & $\begin{array}{l}175,60 \\
17,0\end{array}$ & $\begin{array}{l}101,94 \\
101,\end{array}$ & 37,95 & 5673,27 & 325,06 & 58,67 & 266,40 & \begin{tabular}{r|r}
114,06 \\
\end{tabular} & 248,11 & 250,25 & \begin{tabular}{|c|c|}
104,99 \\
\end{tabular} & 543,60 & 81,97 & $\begin{array}{l}0,0136 \\
1,36\end{array}$ & 61,76 & 228,44 & 18,02 & 24,99 & $24,210,41$ \\
\hline Salamandra salamandra & $295 \mathrm{SQB} 25$ & 99,00 & 170,63 & 105,14 & 37,99 & 5800,16 & 325,97 & 51,97 & 274,00 & \begin{tabular}{ll|}
107,85 \\
\end{tabular} & 245,09 & 247,13 & 98,82 & 567,97 & 84,15 & 1,98 & 60,84 & 236,44 & 20,20 & 26,87 & 219,51 \\
\hline Salamandra salamandra & 295QB26 & 101,00 & 165,03 & 108,10 & 38,00 & 5908,15 & 325,85 & 45,03 & 280,81 & 101,40 & 241,28 & 243,17 & 92,26 & 594,59 & 86,44 & 2,06 & 60,03 & 245,36 & 22,21 & 28,46 & 229,72 \\
\hline Salamandra salamandra & 29SQB27 & 100,00 & 162,82 & 109,90 & 38,00 & 5980,37 & 327,18 & 41,83 & 285,35 & $\begin{array}{l}98,45 \\
\end{array}$ & 240,34 & 242,12 & 89,41 & 602,57 & 86,51 & 2,57 & 59,20 & 246,70 & 24,01 & 29,90 & 231,84 \\
\hline Salamandra salamandra & 295QB28 & 100,00 & 158,95 & 111,69 & 38,00 & 6054,53 & 326,96 & 37,32 & 289,64 & 94,01 & 237,72 & 239,36 & 85,00 & 619,95 & 87,61 & 2,99 & 58,42 & 251,77 & 26,12 & 31,53 & 237,91 \\
\hline Salamandra salamandra & 29SQB28 & 100,00 & 158,47 & $\mid \begin{array}{l}\mid 112,97 \\
112,97\end{array}$ & 38,00 & $\begin{array}{ll}60098,34 \\
6093\end{array}$ & | 328,68 & 36,09 & 292,049 & 92,01 & 237,91 & 239,45 & 83 & $\mid 619,05$ & $\begin{array}{l}\mid l,, 01 \\
86,71\end{array}$ & 3,20 & \begin{tabular}{c|c|c|}
57,68 \\
\end{tabular} & 249,70 & $\begin{array}{l}20,12 \\
27,20\end{array}$ & 32,28 & 236,40 \\
\hline Salamandra salamandra & 29SQBB33 & 100,00 & 178,05 & 103,27 & 37,99 & 5681,46 & 329,20 & 60,05 & 269,14 & 116,39 & 250,78 & 252,92 & 107,42 & \begin{tabular}{|l|l|}
549,83 \\
\end{tabular} & 83,33 & 1,00 & 62,64 & 232,79 & 17,50 & 23,88 & 215,05 \\
\hline Salamandra salamandra & 29SQB344 & 100,00 & 179,52 & $\begin{array}{ll}106,17 \\
\end{array}$ & 38,01 & 5772,33 & 334,80 & 59,57 & 275,24 & 116,62 & 253,47 & 255,43 & $\mid 107,67$ & 542,43 & 81,89 & 1,01 & $\begin{array}{ll}62,08 \\
\end{array}$ & 228,52 & 18,01 & $\begin{array}{l}23,00 \\
23,92\end{array}$ & 211,26 \\
\hline Salamandra salamandra & $29 S Q B 35$ & 101,00 & 175,74 & 109,07 & 38,05 & 5890,17 & 336,24 & 54,13 & 282,11 & 111,61 & 251,58 & 253,33 & 102,63 & 558,45 & 83,11 & 1,74 & 61,18 & 233,21 & 19,53 & 25,44 & 216,83 \\
\hline Salamandra salamandra & $295 Q B 37$ & 100,00 & 165,23 & 112,90 & 38,01 & 6067,55 & 333,76 & 42,02 & 291,74 & 99,63 & 243,99 & 245,63 & 90,71 & 602,17 & 86,41 & 2,31 & 59,48 & 246,70 & 23,48 & 28,98 & 232,27 \\
\hline Salamandra salamandra & $\begin{array}{l}2950 \mathrm{COB} \\
29 \mathrm{QB} 38\end{array}$ & $\begin{array}{l}101,00 \\
100\end{array}$ & $\begin{array}{l}10,250 \\
165,25\end{array}$ & $\begin{array}{l}114,19 \\
114\end{array}$ & $\begin{array}{ll}30,01 \\
38,03 \\
\end{array}$ & 6120,83 & \begin{tabular}{|l|l|}
335,06 \\
336,06
\end{tabular} & $\begin{array}{l}42,02 \\
41,25\end{array}$ & 294,81 & 99,0s & 244,93 & $\begin{array}{l}24,03 \\
246,42\end{array}$ & 90,10 & \begin{tabular}{|l|l|}
596,49 \\
596,49
\end{tabular} & $\begin{array}{l}\mid c 0,41+ \\
84,86 \\
\end{array}$ & $2,2,5$ & $\begin{array}{l}5,40 \\
58,82\end{array}$ & $\begin{array}{l}24,1 \\
242,79\end{array}$ & $\begin{array}{l}\mid 20,40 \\
24,17\end{array}$ & $\begin{array}{l}20,50 \\
29,42\end{array}$ & 228,80 \\
\hline Salamandra salamandra & $295 Q B 39$ & 100,00 & 163,07 & 115,24 & 38,00 & 6172,04 & 336,21 & 38,54 & 297,66 & 96,41 & 243,54 & 244,97 & 87,38 & 601,53 & 84,57 & 2,78 & 58,19 & 242,94 & 25,49 & 30,41 & 229,54 \\
\hline Salamandra salamandra & 29SQB45 & 99,00 & 179,99 & 113,45 & 38,61 & 5980,75 & 346,22 & 55,51 & 290,71 & 114,92 & 257,41 & 259,01 & 105,74 & 555,42 & 82,92 & 1,41 & 61,79 & 232,99 & 18,81 & 24,00 & 217,38 \\
\hline Salamandra salamandra & 29SQB48 & 99,00 & 165,34 & 116,84 & 38,2 & 6207,25 & 340,24 & 39 & 300,73 & 98,16 & 246,41 & 247,64 & 89,31 & 606,48 & 85,72 & 2,53 & 58,92 & 246,50 & 24,30 & 29,31 & 233,16 \\
\hline Salamandra salamandra & 29SQB56 & 100,00 & 176,11 & 118,63 & 38,93 & 6163,05 & 350,68 & 48,61 & 302,07 & 109,00 & 256,31 & 257,66 & 100,02 & 582,65 & 85,06 & 1,97 & 61,03 & 242,14 & 20,77 & 25,32 & 228,14 \\
\hline Salamandra salamandra & 29SQB57 & 100,00 & 171,79 & 119,16 & 38,85 & 6226,66 & 348,23 & 44,11 & 304,11 & 104,11 & 253,04 & 254,23 & 95,11 & 594,15 & 85,23 & 2,00 & 60,20 & 244,31 & 22,15 & 26,90 & 230,84 \\
\hline Salamandra salamandra & $295 Q B 59$ & 100,00 & 161,72 & 119,53 & 38,08 & 6337,03 & 341,97 & 34,20 & 307,77 & $\begin{array}{l}93,37 \\
\end{array}$ & 244,95 & 245,92 & 84,36 & 626,22 & 86,57 & 2,97 & 58,34 & 251,97 & 25,99 & 30,74 & 239,89 \\
\hline Salamandra salamandra & $29 \mathrm{SQB} 63$ & 57,00 & 184,32 & 116,90 & 39,00 & 5995,94 & 353,94 & 58, & 295,91 & 119,06 & 262,14 & 263,82 & 110,10 & 574,31 & 86,98 & 1,00 & 63,84 & 245,33 & 18,05 & 22,11 & 230,18 \\
\hline Salamandra salamandra & 29SQB67 & 43,00 & 0,53 & 0,97 & 38,97 & 80,84 & 9,67 & 42 & 307,44 & 102,34 & 252,81 & 253,81 & 93,31 & 608, & 86,59 & 2,00 & 60,22 & 249,81 & 22,67 & 27,20 & 236,97 \\
\hline Salamandra salamandra & $2950<00$ & $\begin{array}{l}100,00 \\
\end{array}$ & 57 & ,61 & 38,01 & 5987,54 & 319,70 & 33 & 286,20 & 88,75 & 230,46 & 232,42 & 79,85 & 634,96 & 88,02 & 3,70 & 56,71 & 255,20 & 30,10 & 34,59 & 242,76 \\
\hline Salamandra salamandra & $295 Q C 01$ & 100,00 & & 8 & 38 & 6030,24 & 320,13 & & 288 & & 229,46 & 231,34 & 77,71 & 643,26 & 88,33 & 4,06 & 56,03 & 256,93 & 31,92 & 35,85 & 245,11 \\
\hline Salamandra salamandra & $2950 \mathrm{CCO}$ & 101,00 & 150,90 & 11 & 38,00 & 6064,71 & 322,05 & 30 & 291,10 & 86,38 & 230,08 & 231,97 & 77,51 & $\mid 638,97$ & 87,25 & 4,11 & 55,41 & 253,83 & 32,80 & 36,32 & 242,32 \\
\hline Salamandra salamandra & $29 S Q C 04$ & 100,00 & 162,19 & 114,61 & 38,27 & 086,43 & 334,44 & 40, & 294,33 & 96 & 241,55 & 242,96 & 87,75 & 558,28 & 76,98 & 3,34 & 54,69 & 220,37 & 29,30 & 32,56 & 208,18 \\
\hline Salamandra salamandra & $29 S Q C 06$ & 100,00 & 151,43 & 50 & 38,00 & 152,60 & 326,9 & 30,33 & 296,57 & 85,56 & 232,32 & 233,59 & 77,10 & 619,90 & 83,06 & 4,68 & 53,24 & 241,60 & 36,05 & 38,10 & 230,70 \\
\hline Salamandra salamandra & $295 \mathrm{SC} 10$ & $\begin{array}{l}101,00 \\
100\end{array}$ & $\frac{15}{15}$ & $\frac{1}{1}$ & 38,6 & $\begin{array}{ll}612,200 \\
6052,92\end{array}$ & 326,94 & $\begin{array}{l}3,, 73 \\
36,77\end{array}$ & | & $\begin{array}{l}0,300 \\
92,90\end{array}$ & 236,66 & 238,34 & 84,15 & $\begin{array}{ll}608,89 \\
\end{array}$ & $\begin{array}{l}\mid 85,03 \\
85,03 \\
\end{array}$ & $\begin{array}{l}4,200 \\
3,21\end{array}$ & $\begin{array}{l}57,124 \\
57,12\end{array}$ & $\begin{array}{l}24,00 \\
244,71\end{array}$ & 27,85 & 32,59 & 231,55 \\
\hline Salamandra salamandra & $295 \mathrm{SaC11}$ & 100,00 & 148,36 & 113,07 & 38,00 & 6121,03 & 320,93 & 27,46 & 293,47 & 83,2 & 228,53 & 230,22 & 74,29 & \begin{tabular}{|c|}
662,73 \\
\end{tabular} & 90,34 & 4,26 & 56,03 & 263,69 & 32,92 & 36,88 & 252,11 \\
\hline Salamandra salamandra & $29 S Q C 21$ & 100,00 & 145,29 & 114,35 & 38,00 & 6208,92 & 321,02 & 23,04 & 297,98 & 79,29 & 227,01 & 228,47 & 70,48 & 684,79 & 92,50 & 4,51 & 55,84 & 271,28 & 34,24 & 38,10 & 260,10 \\
\hline Salamandra salamandra & $29 S Q C 25$ & 100,00 & 87 &, 72 & 38,00 & 6296,31 & 3,94 & 30, & 303,3 & 86,9 & 237 & 238,51 & 78,50 & 601,18 & 80,36 & 4, & 53,84 & 233,81 & 32,68 & 35,64 & 222,19 \\
\hline Salamandra salamandra & $29 S Q C 31$ & 101,00 & & & 37 & 63 & & & 301 & 76 & 226 & $227>-7$ & 67 & 700 & 93,93 & & 55,87 & 276,69 & 34,98 & 38,88 & 265,89 \\
\hline \begin{tabular}{|l} 
Salamandra salamandrandra \\
Sala
\end{tabular} & $\frac{250<31}{2950 C 32}$ & $\begin{array}{l}100,00 \\
100\end{array}$ & \begin{tabular}{|l|}
$153,0,07$ \\
150
\end{tabular} & \begin{tabular}{|l|}
$113,1,82$ \\
116,8
\end{tabular} & $\begin{array}{ll}38,09 \\
38,00\end{array}$ & $\begin{array}{l}0 \angle 8,003 \\
6311,19\end{array}$ & \begin{tabular}{|l|l|}
329,40 \\
329,47
\end{tabular} & 25,56 & $\begin{array}{l}301,19 \\
303,92\end{array}$ & $\begin{array}{r}80,21 \\
82,63\end{array}$ & $\begin{array}{l}22,33,28 \\
233\end{array}$ & $\begin{array}{l}223,03 \\
234,30\end{array}$ & $\mid \begin{array}{ll}\mid 21,14 \\
73,90\end{array}$ & $\begin{array}{l}60,00 \\
652,92\end{array}$ & \begin{tabular}{|c|}
87,76 \\
70,
\end{tabular} & $\begin{array}{l}4,05 \\
4,06 \\
\end{array}$ & $\begin{array}{c}35,015 \\
55,58\end{array}$ & $\begin{array}{l}25,09 \\
257,04\end{array}$ & 32,41 & $\begin{array}{l}30,00 \\
36,21\end{array}$ & $\begin{array}{l}20,85,69 \\
245,72\end{array}$ \\
\hline Salamandra salamandra & $295 \mathrm{SQC33}$ & 100,00 & 153,02 & 117,28 & 38,00 & 6330,62 & 333,25 & 27,94 & 305,31 & 85,31 & 236,62 & 237,48 & 76,49 & 627,71 & 84,15 & 4,00 & 55,13 & 245,93 & 31,71 & 35,48 & 234,45 \\
\hline Salamandra salamandra & $29 S Q C 39$ & 101,00 & 165,75 & 117,51 & 37,97 & 6367,88 & 346,27 & 39,30 & 306,97 & 96,22 & 249,75 & 249,85 & 87,54 & 511,19 & 67,20 & 3,08 & 52,34 & 194,91 & 28,83 & 30,27 & 182,78 \\
\hline Salamandra salamand & $29 S Q C 41$ & 99,00 & $\theta$ & 117,83 & 38,00 & 53,23 & 331,26 & 24 & 306,44 & 82,53 & 234 & 235 & 73,66 & 662 & 89 & 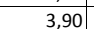 & & 261,88 & & 35,70 & 250,75 \\
\hline Salamandra salamandra & $295 Q C 42$ & 101,00 & & & & 376,73 & & 26,75 & 307,9 & $84,5 /$ & 237,21 & 237,92 & 75,77 & 640,44 & 85,79 & 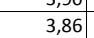 & 55,69 & 251,67 & $31,08 \mid$ & 35,10 & 240,44 \\
\hline Salamandra salamandra & $29 S Q C 49$ & 99,00 & 163,25 & 117,95 & 37,60 & 6448,65 & 346,10 & 36,12 & 309,98 & 92,98 & 248,56 & 248,66 & 84,46 & 523,97 & 68,46 & 3,31 & 52,23 & 198,42 & 29,73 & 30,41 & 186,63 \\
\hline Salamandra salamandra & $295 \mathrm{SaC60}$ & 32,00 & 155,24 & 120,45 & 38,00 & 6427,15 & 339,05 & 27,25 & 311,80 & 86,07 & 240,15 & 240,95 & 77,16 & 654,55 & 88,64 & 3,35 & 57,42 & 259,98 & 28,73 & 33,25 & 249,11 \\
\hline Salamandra salamandra & 29 SQD15 & 100,00 & 160,22 & 109,91 & 36,91 & 318,99 & 335,55 & 39,81 & 295,74 & 91,89 & 244,16 & 244,19 & 83,61 & 543,83 & 69,39 & 4,14 & 49,90 & 205,40 & 36,18 & 36,36 & 193, \\
\hline Salam & 29SQD23 & 100, & & & 37, & 57,80 & & 39 & 301,5 & 93,64 & 247, & t & 85 & 515 & 66 , & 4,0 & 50,40 & 194 & 32,93 & 33,12 & 182 \\
\hline Salamandra salamandra & $29 S Q D 34$ & 100,00 & 158,26 & $\mid 112,18$ & 36,66 & $\begin{array}{ll}643,00 \\
642,42\end{array}$ & $\mid$\begin{tabular}{|l|l|}
337,87 \\
337
\end{tabular} & 35,26 & 302,62 & 88,47 & $\begin{array}{l}24,12 \\
244,05 \\
\end{array}$ & 244,05 & $\begin{array}{l}80,09 \\
80,0\end{array}$ & 526,71 & 60,01 & $\begin{array}{l}4,00 \\
4,03\end{array}$ & $\begin{array}{ll}4,4,66 \\
\end{array}$ & $\begin{array}{ll}195,96 \\
\end{array}$ & 34,72 & $\begin{array}{l}34,72 \\
34,72\end{array}$ & 183,75 \\
\hline
\end{tabular}




\begin{tabular}{|c|c|c|c|c|c|c|c|c|c|c|c|c|c|c|c|c|c|c|c|c|c|}
\hline TAXON & UTM & $\mathrm{km} 2$ & B101 & $\mathrm{B1O2}$ & $\mathrm{BIO3}$ & 8104 & B105 & B106 & B107 & B108 & B109 & BIO10 & B1011 & BIO12 & B1013 & B1014 & 81015 & B1016 & B1017 & B1018 & B1019 \\
\hline Salamandra salamandra & 29SQD44 & 100,00 & 153,60 & 112,60 & 36,38 & 6501,45 & 334,92 & 30,10 & 304,82 & 83,36 & 240,45 & 240,45 & 75,10 & 541,58 & 69,07 & 4,51 & 49,49 & 199,98 & 36,22 & 36,23 & 187,85 \\
\hline Salamandra salamandra & 29SQE41 & 101,00 & 154,90 & 109,12 & 36,13 & 6419,67 & 330,21 & 33,53 & 296,68 & 84,60 & 240,72 & 240,72 & 76,87 & 489,60 & 60,49 & 4,99 & 46,49 & \begin{tabular}{|l|l|}
178,67 \\
\end{tabular} & 36,92 & 36,92 & 166,26 \\
\hline Salamandra salamandra & 29SQE50 & 70,00 & 159,94 & 110,91 & 36,59 & 6450,74 & 336,84 & 36,84 & 300,00 & 89,39 & 246,15 & 246,15 & 81,11 & 456,27 & 56,13 & 4,02 & 46,66 & 165,05 & 33,50 & 33,50 & 152,85 \\
\hline Salamandra salamandra & 29SQE51 & 63,00 & 158,98 & 110,69 & 36,68 & 6427,51 & 334,89 & 36,06 & 298,83 & 88,21 & 244,68 & 244,68 & 80,34 & 454,36 & 55,83 & 4,50 & 46,13 & 164,21 & 34,23 & 34,23 & 151,88 \\
\hline Salamandra salamandra & 29TMH84 & 11,00 & 139,81 & 60,94 & 38,75 & 3273,38 & 225,63 & 70,25 & 155,38 & 108,50 & 180,31 & 183,69 & 99,50 & 1055,56 & 150,25 & 27,56 & 43,06 & 419,00 & 116,56 & 140,94 & 361,06 \\
\hline Salamandra salamandra & 29TMH85 & 76,00 & 139,86 & 60,66 & 38,86 & 3227,67 & 224,58 & 70,50 & 154,08 & 109,07 & 179,49 & 182,91 & 99,89 & 1022,70 & 146,27 & 27,14 & 42,50 & 405,09 & 116,07 & 140,82 & 344,98 \\
\hline Salamandra salamandra & 29TMH86 & 101,00 & 140,88 & 60,43 & 39,01 & 3189,41 & 224,79 & 71,89 & 152,90 & 110,68 & 179,94 & 183,48 & 101,52 & 1001,25 & 143,27 & 27,08 & 41,99 & 395,29 & 115,62 & 140,68 & 334,91 \\
\hline Salamandra salamandra & $29 \mathrm{TMH} 87$ & 60,00 & $\begin{array}{l}\mid 4,06,94 \\
143,94 \\
\end{array}$ & $\begin{array}{l}0,45 \\
60,09 \\
\end{array}$ & 39,43 & 3139,24 & 225,93 & 75,29 & 150,63 & 114,11 & 182,18 & $\begin{array}{l}\mid 00,40 \\
185,88 \\
\end{array}$ & \begin{tabular}{|l|l|l|l|l|}
104,93 \\
\end{tabular} & \begin{tabular}{r|}
980,60 \\
\end{tabular} & \begin{tabular}{|l|l|}
139,88 \\
\end{tabular} & 26,78 & $\begin{array}{ll}41,41 \\
41,4\end{array}$ & \begin{tabular}{|l|l|}
385,48 \\
385
\end{tabular} & \begin{tabular}{|l|l|l|l|l|l|}
113,95 \\
\end{tabular} & $\begin{array}{l}139,40 \\
\end{array}$ & 326,89 \\
\hline Salamandra salamandra & 29TMH92 & 25,00 & 141,23 & 60,49 & 38,14 & 3378,23 & 227,51 & 71,47 & \begin{tabular}{ll|}
156,05 \\
\end{tabular} & \begin{tabular}{|l|l|}
107,72 \\
\end{tabular} & \begin{tabular}{|c|}
183,44 \\
\end{tabular} & 185,91 & 99,12 & 1175,86 & 168,47 & 28,44 & 44,98 & 469,60 & 117,91 & 141,35 & 420,91 \\
\hline Salamandra salamandra & 29TMH93 & 45,00 & 142.97 & 60,38 & 38,58 & 3303,65 & 228,01 & 73,36 & 154,65 & $|110,67|$ & 183,91 & 186,81 & $\mid 101,71$ & $\mid 081.97$ & 153,14 & 26,94 & 44,01 & 431,12 & $\mid 113,87$ & $\mid 138,10$ & 376,59 \\
\hline Salamandra salamandra & 29TMH94 & 96,00 & 134,43 & 62,32 & 38,30 & 3383,03 & 224,15 & 63,56 & 160,59 & 101,66 & 176,79 & 179,88 & 92,99 & 1163,86 & 165,96 & 30,57 & 43,29 & 460,44 & 125,92 & 149,26 & 407,56 \\
\hline Salamandra salamandra & 29TMH95 & 101,00 & 132,06 & 62,84 & 38,29 & 3379,81 & 222,68 & 60,82 & 161,87 & 99,50 & 174,35 & 177,58 & 90,84 & 1161,49 & 163,83 & 31,54 & 42,44 & 457,27 & \begin{tabular}{|l|}
129,28 \\
\end{tabular} & 152,73 & 403,12 \\
\hline Salamandra salamandra & 29TMH98 & 28,00 & 142,80 & 61,16 & 39,53 & 3177,18 & 226,53 & 73,42 & 153,11 & 112,60 & 181,80 & 185,62 & \begin{tabular}{|c|}
103,67 \\
\end{tabular} & 1013,53 & 141,49 & 28,18 & 41,00 & 395,73 & 117,49 & 142,60 & 341,07 \\
\hline Salamandra salamandra & 29TNE13 & 97,00 & 154,79 & 80,80 & 43,68 & 3528,08 & 252,14 & 69,20 & \begin{tabular}{ll|}
182,95 \\
\end{tabular} & \begin{tabular}{|c|}
116,15 \\
\end{tabular} & \begin{tabular}{|l|}
196,97 \\
\end{tabular} & 199,18 & 108,20 & 885,08 & 126,62 & 8,21 & 54,91 & 362,20 & 53,86 & 60,55 & 356,00 \\
\hline Salamandra salamandra & 29TNE14 & 94,00 & 153,37 & 80,69 & 43,99 & 3489,40 & 249,04 & 67,60 & 181,44 & \begin{tabular}{ll|}
114,96 \\
\end{tabular} & \begin{tabular}{|c|}
194,89 \\
\end{tabular} & 196,96 & 106,94 & \begin{tabular}{|c|}
915,43 \\
\end{tabular} & 130,14 & 8,93 & 54,31 & 372,73 & 57,22 & 64,43 & 366,66 \\
\hline Salamandra salamandra & 29TNE15 & 95,00 & 152,10 & 79,87 & 44,23 & 3433,91 & 244,94 & 66,57 & \begin{tabular}{|l|l|}
178,37 \\
\end{tabular} & \begin{tabular}{|l|l|}
114,04 \\
\end{tabular} & \begin{tabular}{|c|}
192,57 \\
\end{tabular} & 194,69 & 106,07 & 940,82 & 132,95 & 9,80 & 53,87 & 381,66 & 60,01 & 67,97 & 375,23 \\
\hline Salamandra salamandra & 29TNE17 & 40,00 & 151,00 & 77,70 & 44,97 & 3321,38 & 237,20 & 65,97 & 171,23 & 113,99 & 189,58 & 191,34 & 105,62 & 973,01 & 136,21 & 10,34 & 53,00 & 393,07 & 63,24 & 72,89 & 385,45 \\
\hline Salamandra salamandra & 29TNE23 & 100,00 & 156,94 & 86,62 & 43,62 & 3755,01 & 263,74 & 67,06 & 196,68 & 115,60 & 202,23 & 204,55 & 107,75 & 889,55 & 126,60 & 8,44 & 54,58 & 361,68 & 55,13 & 60,88 & 358,13 \\
\hline Salamandra salamandra & 29TNE26 & 100,00 & 152,32 & 84,16 & 44,45 & 3581,52 & 250,69 & 63,32 & 187,37 & 112,44 & 194,77 & 196,81 & 104,39 & 969,56 & 136,02 & 10,03 & 53,09 & 390,74 & 63,01 & 70,94 & 385,71 \\
\hline Salamandra salamandra & 29TNE27 & 100,00 & 150,94 & 81,77 & 44,72 & 3491,93 & 244,10 & 63,03 & \begin{tabular}{|l|}
181,07 \\
\end{tabular} & 111,95 & 191,99 & 193,90 & 103,76 & 988,28 & 138,04 & 10,85 & 52,79 & 397,95 & 65,18 & 74,10 & 391,49 \\
\hline Salamandra salamandra & 29TNE28 & 101,00 & 149,73 & 78,91 & 45,04 & 3384,36 & 236,65 & 63,11 & 173,54 & 111,73 & 189,05 & 190,76 & 103,37 & 1002,72 & 139,53 & $11, \mathrm{c}$ & 52,55 & 403,88 & 66,14 & 76,54 & 395,56 \\
\hline Salamandra salamandra & 29TNE33 & 101,00 & 158,16 & 92,64 & 43,21 & 4010,56 & 275,56 & 64,01 & 211,56 & 112,29 & 207,16 & 209,62 & 106,24 & $\begin{array}{r}02,78 \\
9027\end{array}$ & 127,94 & \begin{tabular}{|c|}
8,74 \\
\end{tabular} & 54,15 & $\begin{array}{l}40,00 \\
364,73 \\
\end{array}$ & 57,45 & 61,96 & 363,85 \\
\hline Salamandra salamandra & 29TNE34 & 100,00 & 158,71 & 92,86 & 43,79 & 3959,58 & 274,19 & 64,23 & 209,97 & 114,31 & 206,84 & 209,11 & 106,97 & 911,58 & 128,28 & 9,09 & 53,73 & 366,69 & 58,88 & 64,19 & 365,55 \\
\hline Salamandra salamandra & 29TNE37 & 100,00 & 151,92 & 88,12 & 44,21 & 3760,17 & 256,36 & 59,47 & 196,88 & 109,94 & 196,99 & 198,97 & 101,90 & 999,56 & 139,38 & 11,00 & 52,72 & 400,87 & 66,69 & 74,56 & 396,25 \\
\hline Salamandra salamandra & 29TNE38 & 100,00 & 151,17 & 85,28 & 44,48 & 3655,62 & 249,50 & 59,88 & 189,62 & 110,04 & 194,48 & 196,30 & 101,87 & 1009,27 & 140,22 & 11,01 & 52,38 & 405,38 & 67,20 & 76,61 & 398,25 \\
\hline Salamandra salamandra & 29TNE39 & 101,00 & 149,99 & 83,28 & 44,75 & 3590,40 & 244,10 & 59,58 & \begin{tabular}{|l|l|}
184,53 \\
\end{tabular} & 109,52 & 192,36 & 194,02 & 101,25 & 1023,95 & 141,72 & 11,49 & 52,18 & 411,92 & 68,18 & 79,27 & 402,06 \\
\hline Salamandra salamandra & 29TNE43 & 100,00 & $\mid \begin{array}{l}\mid 152,01 \\
152,\end{array}$ & $\begin{array}{l}\mid c 3,20 \\
96,88\end{array}$ & $\begin{array}{ll}44,2,29 \\
42,29\end{array}$ & 43334,80 & $\mid \begin{array}{l}244,10 \\
280,95\end{array}$ & 54,54 & $\begin{array}{l}204,30 \\
226,42\end{array}$ & \begin{tabular}{|c|}
97,23 \\
97,23
\end{tabular} & 206,12 & 208,63 & \begin{tabular}{|l|}
97,14 \\
97
\end{tabular} & $\mid$ & $\begin{array}{l}\mid 41,1<2 \\
140,82\end{array}$ & $\mid 10,21$ & $\mid \frac{52,10}{53,90}$ & | & 每o, 65,27 & 67,43 & $\begin{array}{l}40,00,77 \\
399,7\end{array}$ \\
\hline Salamandra salamandra & 29TNE45 & 101,00 & 159,50 & 98,46 & 43,90 & 4164,52 & 283,32 & 60,82 & 222,49 & \begin{tabular}{|l|l|}
108,75 \\
\end{tabular} & 210,58 & 212,78 & 105,32 & 936,35 & 130,70 & 9,70 & 52,90 & 374,25 & 62,54 & 67,44 & 374,14 \\
\hline Salamandra salamandra & 29TNE46 & 100,00 & 155,75 & 96,92 & 43,75 & 4129,05 & 276,81 & 57,49 & 219,32 & 107,60 & 206,33 & 208,40 & 101,84 & 981,31 & 136,99 & 10,65 & 52,63 & 391,48 & 66,27 & 71,75 & 391,01 \\
\hline Salamandra salamandra & 29TNE47 & 101,00 & 154,50 & 94,07 & 43,94 & 4033,16 & 269,87 & 57,67 & 212,19 & 109,24 & 203,70 & 205,62 & 101,39 & 992,43 & 138,39 & 10,73 & 52,51 & 396,70 & 66,59 & 73,58 & 393,77 \\
\hline Salamandra salamandra & 29TNE48 & 101,00 & 153,62 & 91,44 & 44,01 & 3947,35 & 263,56 & 57,81 & 205,75 & 109,17 & 201,37 & 203,17 & 101,12 & 1001,46 & 139,26 & 10,96 & 52,41 & 401,25 & 66,83 & 75,53 & 395,36 \\
\hline Salamandra salamandra & 29TNE49 & 100,00 & 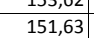 & \begin{tabular}{|c|c|}
19,81 \\
991
\end{tabular} & $\begin{array}{ll}44,01 \\
43,97\end{array}$ & $\begin{array}{ll}394,7505,53 \\
390\end{array}$ & \begin{tabular}{|l|l|}
258,40 \\
258,44
\end{tabular} & 56,55 & 201,90 & $\begin{array}{l}107,68 \\
107\end{array}$ & $\begin{array}{l}|c|, 139 \\
198,79\end{array}$ & 200,54 & \begin{tabular}{r|}
09,12 \\
99,55
\end{tabular} & $\begin{array}{l}1025,40 \\
100\end{array}$ & \begin{tabular}{|l|l|}
142,39 \\
142
\end{tabular} & $\begin{array}{l}0,30 \\
11,30\end{array}$ & \begin{tabular}{|c|c|c|}
52,40 \\
\end{tabular} & $\begin{array}{l}4012,25 \\
412,01\end{array}$ & $\begin{array}{l}60,030 \\
68,11\end{array}$ & 78,33 & 403,22 \\
\hline Salamandra salamandra & 29TNE53 & 101,00 & 151,81 & 98,81 & 41,57 & 4545,58 & 286,84 & 52,19 & 234,65 & 94,84 & 209,36 & 211,64 & 94,84 & 1002,83 & 143,49 & 10,28 & 53,94 & 406,24 & 66,25 & 67,75 & 406,24 \\
\hline Salamandra salamandra & 29TNE54 & 101,00 & 156,27 & 102,18 & 42,50 & 4514,23 & 292,22 & 54,61 & 237,61 & 99,02 & 212,75 & 215,25 & 99,02 & 975,79 & 137,69 & 10, & 53,13 & 392,97 & 65,87 & 68,08 & 392,97 \\
\hline Salamandra salamandra & 29TNE55 & 99,00 & 150,55 & 100,13 & 42,2 & 4497,70 & 284,29 & & 234 & 93,64 & 207,01 & 209,27 & 93,64 & 1043,22 & 148,06 & 11, & 53,18 & 419,77 & 70,97 & 73,17 & 419,77 \\
\hline Salamandra salamandra & 29TNE56 & 101,00 & 150,10 & 99,40 & 42,36 & 4444,24 & 281,01 & 49,47 & 231,54 & 93,55 & 205,67 & 207,82 & 93,41 & 1053,40 & 149,12 & 11,49 & 52,88 & 422,23 & 71,75 & 75,15 & 422,23 \\
\hline Salamandra salamandra & 29TNE57 & 101,00 & 148,69 & 97,64 & 42,53 & 4378,99 & 275,62 & 48,79 & 226,84 & 97,88 & 203,34 & 205,27 & 92,45 & 1070,57 & 151,49 & 11,72 & 52,86 & 428,03 & 72,49 & 77,32 & 427,56 \\
\hline Salamandra salamandra & 29TNE58 & 100,00 & 146,09 & 95,18 & 42,45 & 4321,16 & 268,92 & 47,29 & 221,63 & 98,02 & 199,92 & 201,72 & 90,42 & 1099,79 & 155,99 & 12,10 & 52,83 & 440,82 & 74,02 & 80,08 & 438,16 \\
\hline Salamandra salamandra & 29TNE59 & 101,00 & 145,60 & 94,24 & 42,64 & 4275,39 & 265,54 & 47, & 218,45 & \begin{tabular}{l|l}
98,05 \\
\end{tabular} & 198,66 & 200,38 & 90,22 & 1107,62 & 156,50 & 12,31 & 52,68 & 444,74 & 74,34 & 82,05 & 439,23 \\
\hline Salamandra salamandra & 29TNE63 & 101,00 & 0,56 & 89,14 & 38, & 699,88 & 01 & 35 & 228,79 & 72,92 & 194,23 & 194,62 & 72,92 & 1221,84 & 181,18 & $12, \varepsilon$ & 55,21 & 499,16 & 78,16 & 78,31 & 499,16 \\
\hline Salamandra salamandra & 29TNE64 & $\frac{10}{10}$ & 81 & 101,81 & 41, & 4683,46 & 72 & 53 & 241,64 & 96,83 & 215,14 & 217,20 & 96,83 & $\begin{array}{r}721,049 \\
978,93\end{array}$ & 139,33 & |ct, & 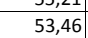 & 394,96 & 65,10 & 67,15 & 394,96 \\
\hline Salamandra salamandra & 29TNE65 & & & & 41 & 4672,85 & 29 & & 241,18 & 95 & 213,88 & 216,01 & 95,81 & \begin{tabular}{|c|}
997,15 \\
\end{tabular} & 141,65 & 10 & & 401,08 & 66,87 & 69,43 & 401,08 \\
\hline Salamandra salamandra & 29TNE66 & 100,00 & $\mid \begin{array}{l}\mid 34,0,09 \\
\end{array}$ & 101,84 & 42,18 & 4606,32 & 291,36 & 52 & 238,53 & 97,013 & 213,92 & 215,92 & $\begin{array}{l}97,29 \\
7,29\end{array}$ & 989,81 & 139,97 & 10,23 & 52,97 & 396,23 & 66,28 & $\begin{array}{l}70,45 \\
70,18 \\
\end{array}$ & 396,23 \\
\hline Salamandra salamandra & 29TNE67 & 100,00 & 151,69 & 99,91 & 42,00 & 47 & 284,14 & 49, & 234 & 97 & 209,18 & 210,97 & 93,25 & 1039,96 & 147,79 & 10,93 & 53,01 & 415,86 & 69,58 & 74,15 & 415,82 \\
\hline Salamandra salamandra & 29TNE68 & 101,00 & 22 & 93,55 & 40,41 & 632,53 & 264,8 & 36, & 228,72 & 80,31 & 194,14 & 195,64 & 76,89 & 1229,75 & 179,29 & 13,54 & 53,76 & 495,74 & 82,40 & 85,19 & 495,61 \\
\hline Salamandra salamandra & $\begin{array}{l}\text { 29TNE69 } \\
\end{array}$ & $\begin{array}{l}101,00 \\
100\end{array}$ & 12 & \begin{tabular}{|c|}
91,01 \\
91,01
\end{tabular} & $\begin{array}{ll}40,41+86 \\
39,86\end{array}$ & 4638,69 & 256,2 & 30,75 & 225,47 & $\begin{array}{l}\mid c 0,51 \\
73,66\end{array}$ & \begin{tabular}{|l|l|l|l|l|}
187,77 \\
\end{tabular} & $\begin{array}{l}189,16 \\
\end{array}$ & $\begin{array}{l}70,03 \\
70,46\end{array}$ & $\mid \begin{array}{l}\mid 123,113 \\
1311,34 \\
\end{array}$ & 192,53 & $\mid \begin{array}{l}30,744 \\
14,74\end{array}$ & 54,03 & $\begin{array}{l}4529,92 \\
5292\end{array}$ & $\begin{array}{l}82,4013 \\
88,13\end{array}$ & $\begin{array}{l}\mid l, 1,3 \\
90,71\end{array}$ & 529,25 \\
\hline Salamandra salamandra & 29TNE73 & 100,00 & 130,48 & 89,04 & 37,71 & 4935,42 & 267,29 & 34,12 & 233,17 & 71,19 & 196,84 & 196,95 & 71,19 & 1223,43 & 182,48 & 12,47 & 55,44 & 500,58 & 77,23 & 77,23 & 500,58 \\
\hline Salamandra salamandra & 29TNE74 & 100,00 & 144,66 & 96,62 & 39,51 & 4909,73 & 284,97 & 43,52 & 241,46 & 84,22 & 208,62 & 209,88 & 84,22 & 1088,21 & 159,07 & 10,86 & 54,50 & 442,33 & 70,82 & 71,38 & 442,33 \\
\hline Salamandra salamandra & 29TNE75 & 101,00 & 08 & 101,29 & 40 & 55,81 & 295 & & 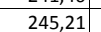 & 93 & 215,94 & 217,84 & & 998, & 143,36 & $\frac{9,}{9,}$ & 53 & 402,78 & 65,75 & 68,01 & 402,78 \\
\hline Salamandra salamandra & 29TNE76 & 10 & 15 & & 41, & 66 & & & & & 215 & 216 & & 100 & & & 53,47 & 404,01 & 66,34 & 69,56 & 404,01 \\
\hline \begin{tabular}{|l} 
Salamandra salamandrandra \\
Sala
\end{tabular} & $\begin{array}{l}\text { 29TNET7 } \\
\text { 29TNE7 }\end{array}$ & $\begin{array}{l}100,00 \\
100\end{array}$ & \begin{tabular}{|l|}
$154,71,71$ \\
\end{tabular} & $\begin{array}{l}100,53 \\
100,66\end{array}$ & $\begin{array}{l}41,06 \\
41,18 \\
\end{array}$ & $\begin{array}{l}481,300 \\
4778,52\end{array}$ & \begin{tabular}{|l|}
293,50 \\
288,89
\end{tabular} & 47,02 & 242,30 & 91, 9 & 212,14 & $\begin{array}{l}213,00 \\
213,84\end{array}$ & $\begin{array}{l}93,10 \\
91,08\end{array}$ & $\begin{array}{l}1035,22 \\
1035\end{array}$ & $\begin{array}{l}\mid 43,97 \\
148,55 \\
\end{array}$ & $\begin{array}{r}9,99 \\
10,42 \\
\end{array}$ & $\begin{array}{l}30,44 \\
53,45 \\
\end{array}$ & $\begin{array}{l}404,01 \\
415,23\end{array}$ & $\begin{array}{l}\mid 60,34 \\
68,17\end{array}$ & $\begin{array}{l}69,30 \\
72,12\end{array}$ & 440,015 \\
\hline Salamandra salamandra & 29TNE78 & 100,00 & 148,15 & 99,57 & 41,25 & 4758,31 & 283,45 & 44,56 & 238,88 & \begin{tabular}{|c|}
92,48 \\
\end{tabular} & 208,55 & 209,97 & 87,76 & $\begin{array}{l}1076,81 \\
\end{array}$ & 155,12 & 11,07 & 53,44 & 431,68 & 70,90 & 75,54 & 431,42 \\
\hline Salamandra salamandra & 29TNE79 & 101,00 & 134,17 & 94,47 & 39,91 & 4800,60 & 267,62 & 33,70 & 233,92 & 76,77 & 196,11 & 197,26 & 74,32 & 1237,77 & 181,96 & 13,33 & 54,13 & 499,57 & 81,97 & 84,94 & 499,52 \\
\hline Salamand & 29TNE83 & $100, \mathrm{C}$ & 136,83 & & 37,62 & 5092,52 & 278,06 & & 正 & 75,38 & 204,90 & 205,18 & 75,38 & 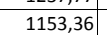 & & & 55,46 & 471,89 & 72,49 & 72,49 & 471,89 \\
\hline Salamandra salamandra & 29TNE84 & & & & 37,47 & & & & 23 & 72, & 201 & 201,88 & 72, & & 179 & & 55,43 & 489,74 & 75,49 & 75,49 & 489,74 \\
\hline Salamandra salamandra & $\begin{array}{l}\text { 29TNE85 } \\
\end{array}$ & 100,00 & 147,50 & 97,92 & 39,26 & 5042,36 & 289,99 & 44,08 & 245,90 & 85,04 & 212,90 & 214,17 & 85,04 & 1059,06 & 155,04 & 10,29 & 54,51 & 429,45 & 68,30 & 69,66 & 429,45 \\
\hline Salamandra salamandra & 29TNE86 & 100,00 & 150,11 & 99,94 & 39,99 & 5010,48 & 292,48 & 45,38 & 247,10 & 87,50 & 214,40 & 215,94 & 87,50 & 1037,19 & 150,83 & 10,03 & 54,12 & 418,79 & 67,60 & 69,74 & 418,79 \\
\hline Salamandra salamandra & 29TNE87 & 101,00 & 151,38 & 100,69 & 40,36 & 4969,05 & 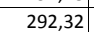 & 46,06 & 246,27 & 88,92 & 214,94 & 216,39 & 88,82 & 027,25 & 148,92 & 9,93 & 53,91 & 413,26 & 66,69 & 70,08 & 413,26 \\
\hline Salan & 29TNE & 99 & & & & 0512 & & & 243, & & $206-2+3$ & 207 & 80 & & & 11, & 54,06 & & 73,25 & 77,10 & \\
\hline Salamandra salamandra & 29TNE94 & 100,00 & $\begin{array}{l}24,25,53 \\
25\end{array}$ & 86,11 & 35,79 & 5217,44 & $\mid 265,27$ & 28,23 & $\begin{array}{l}2437,05 \\
237,05\end{array}$ & | 61,43 & \begin{tabular}{|l|r|}
195,88 \\
\end{tabular} & $\mid$ & 63,45 & $\begin{array}{l}1276,51 \\
127,\end{array}$ & $\begin{array}{ll}193,59 \\
\end{array}$ & $\begin{array}{l}1,31 \\
12,38\end{array}$ & 56,13 & 523,51 & 78,29 & 78,29 & 523,51 \\
\hline
\end{tabular}




\begin{tabular}{|c|c|c|c|c|c|c|c|c|c|c|c|c|c|c|c|c|c|c|c|c|c|}
\hline TAXON & UTM & $\mathrm{km} 2$ & B101 & $\mathrm{B1O2}$ & $\mathrm{B1O3}$ & 8104 & B105 & B106 & B107 & B108 & B109 & 81010 & B1011 & BIO12 & B1013 & B1014 & 81015 & B1016 & BIO17 & B1018 & B1019 \\
\hline Salamandra salamandra & 29TNE95 & 101,00 & 127,45 & 87,81 & 36,31 & 5197,31 & 267,32 & 28,99 & 238,32 & 65,12 & 196,99 & 197,21 & 65,12 & 1266,14 & 191,66 & 12,29 & 55,95 & 518,23 & 78,40 & 78,48 & 518,23 \\
\hline Salamandra salamandra & 29TNE96 & 100,00 & 144,25 & 96,90 & 38,48 & 5194,21 & 288,55 & 39,98 & 248,56 & 80,12 & 211,84 & 212,90 & 80,12 & 1084,89 & 160,45 & 10,32 & 54,88 & 440,40 & 69,82 & 70,58 & 440,40 \\
\hline Salamandra salamandra & 29TNE97 & 100,00 & 147,75 & 99,20 & 39,25 & 5155,38 & 291,58 & 42,09 & 249,49 & 83,40 & 214,19 & 215,39 & 83,40 & 1050,55 & 154,38 & $\begin{array}{l}9,97 \\
9,97\end{array}$ & 54,49 & 424,55 & 67,60 & 69,74 & 424,55 \\
\hline Salamandra salamandra & 29TNE98 & 100,00 & 146,38 & 99,49 & 39,50 & 5130,69 & 289,32 & 40,54 & 248,78 & 82,20 & 212,43 & 213,62 & 82,20 & 1069,29 & 157,42 & 10,31 & 54,43 & 431,66 & 68,89 & 71,63 & 431,66 \\
\hline Salamandra salamandra & 29TNE99 & 101,00 & 143,90 & 99,38 & 39,62 & 5127,85 & 286,19 & 38,18 & 248,01 & 79,91 & 210,06 & 211,01 & 79,71 & \begin{tabular}{|l|}
1097,89 \\
\end{tabular} & 162,19 & 10,71 & 54,52 & 443,23 & 70,70 & 73,80 & 443,23 \\
\hline Salamandra salamandra & 29TNF20 & 39,00 & 148,11 & 75,99 & 45,39 & 3278,87 & 228,40 & 62,72 & 165,68 & 111,24 & 185,74 & 187,30 & 102,70 & \begin{tabular}{|l|}
1033,57 \\
\end{tabular} & 142,44 & 11,91 & 52,02 & 416,51 & 68,59 & 81,88 & 404,38 \\
\hline Salamandra salamandra & 29TNF25 & 28,00 & 144,51 & 85,81 & 44,94 & 3674,23 & 243,21 & 54,34 & 188,87 & 104,47 & 189,36 & 191,38 & 97,09 & 1183,21 & 162,30 & 14,83 & 51,15 & 472,75 & 81,40 & 99,72 & 460,91 \\
\hline Salamandra salamandra & 29TNF26 & 26,00 & $\mid 143,71$ & 84,72 & 45,01 & 3658,17 & $\mid 241,52$ & 55,50 & $\begin{array}{l}\mid 0,06,02 \\
186,02\end{array}$ & \begin{tabular}{|l|l|}
99,99 \\
\end{tabular} & 188,56 & \begin{tabular}{|l|l|}
190,46 \\
\end{tabular} & 97,07 & $\begin{array}{l}1215,52 \\
1215 \\
\end{array}$ & $\begin{array}{l}165,55 \\
165\end{array}$ & $\begin{array}{l}4,000 \\
15,08\end{array}$ & 51,03 & 482,21 & 83,56 & \begin{tabular}{|l|l|}
100,72 \\
\end{tabular} & 480,78 \\
\hline Salamandra salamandra & 29TNF27 & 83,00 & 143,39 & 83,67 & 44,84 & 3665,84 & 241,48 & 56,50 & \begin{tabular}{|l|l|}
184,98 \\
\end{tabular} & \begin{tabular}{|c|}
98,16 \\
\end{tabular} & 188,60 & 190,35 & 96,94 & 1229,74 & 168,04 & 15,06 & 51,32 & 488,82 & 83,48 & 101,82 & 488,58 \\
\hline Salamandra salamandra & 29TNF29 & 100,00 & 143,40 & 81.55 & 43,81 & 3705,16 & 242,68 & 58,44 & 184,24 & 96,74 & 189,45 & 190,99 & 96,74 & 1253,60 & $172.57 \mid$ & 14,95 & 51.94 & 500,80 & 83,10 & 104,21 & 500,80 \\
\hline Salamandra salamandra & 29TNF30 & 97,00 & 149,38 & 82,52 & 44,75 & 3564,68 & 241,69 & 59,15 & 182,54 & 109,24 & 191,41 & 193,03 & 100,90 & 1039,18 & 143,20 & 11,86 & 52,06 & 418,81 & 69,12 & 81,84 & 406,13 \\
\hline Salamandra salamandra & 29TNF31 & 101,00 & 148,07 & 83,26 & 44,69 & 3597,97 & 241,68 & 57,46 & 184,22 & 107,87 & \begin{tabular}{|c|}
190,73 \\
\end{tabular} & 192,50 & 99,47 & 1065,36 & 146,05 & 12,24 & 52,00 & 429,98 & 71,06 & 85,21 & 414,46 \\
\hline Salamandra salamandra & 29TNF33 & 100,00 & 143,08 & 86,64 & 44,26 & 3769,42 & 244,08 & 50,32 & \begin{tabular}{|l|l|}
193,75 \\
\end{tabular} & 101,57 & 188,84 & 190,75 & 93,44 & 1153,38 & 156,89 & 14,21 & 51,96 & 467,44 & 78,42 & 95,49 & 444,94 \\
\hline Salamandra salamandra & 29TNF34 & 101,00 & 142,93 & 88,24 & 44,24 & 3832,79 & 246,60 & 49,26 & 197,34 & $\begin{array}{ll}100,95 \\
\end{array}$ & 189,74 & 191,72 & 92,80 & 1169,53 & 160,71 & 14,84 & 51,92 & 475,06 & 79,95 & 99,15 & 447,97 \\
\hline Salamandra salamandra & 29TNF35 & 101,00 & 143,79 & 89,17 & 44,34 & 3853,99 & 248,86 & 50,08 & \begin{tabular}{|c|}
198,78 \\
\end{tabular} & $\begin{array}{ll}101,82 \\
\end{array}$ & \begin{tabular}{|c|}
191,19 \\
\end{tabular} & 193,23 & 93,92 & 1176,16 & 162,85 & 15,00 & 51,60 & 476,56 & 80,52 & 100,90 & 450,62 \\
\hline Salamandra salamandra & 29TNF36 & 100,00 & 142,72 & 88,75 & 44,37 & 3874,54 & 248,10 & 50,30 & 197,80 & 100,59 & 190,60 & 192,54 & 93,19 & 1208,89 & 165,64 & 15,18 & 51,16 & 484,74 & 82,84 & 101,99 & 470,16 \\
\hline Salamandra salamandra & 29TNF40 & 100,00 & 147,44 & 89,30 & 43,83 & 3923,90 & 254,03 & 52,39 & 201,63 & 103,46 & 195,05 & 196,67 & 95,31 & 1079,18 & 149,73 & 12,26 & 52,06 & 434,59 & 72,22 & 83,50 & 423,05 \\
\hline Salamandra salamandra & 29TNF41 & 101,00 & 142,38 & 89,36 & 43,37 & 3991,40 & 250,94 & 47,24 & 203,70 & 98,11 & 191,25 & 193,01 & 90,04 & 1145,99 & 159,30 & 13,48 & 52,06 & 462,52 & 77,32 & 89,31 & 448,96 \\
\hline Salamandra salamandra & 29TNF43 & 100,00 & 139,21 & 90,71 & 43,30 & 4069,14 & 250,59 & 43,39 & 207,20 & \begin{tabular}{|c|}
94,59 \\
\end{tabular} & 189,62 & 191,44 & 86,51 & 1202,18 & 165,41 & 14,71 & 52,01 & 486,77 & 81,77 & 96,65 & 467,70 \\
\hline Salamandra salamandra & 29TNF45 & 100,00 & 143,60 & 92,24 & 43,84 & 4070,49 & 255,27 & 46,97 & 208,31 & 98,94 & 194,03 & 195,90 & 91,10 & 1174,73 & 159,85 & 14,55 & 51,68 & 475,51 & 79,77 & 98,42 & 452,40 \\
\hline Salamandra salamandra & 29TNF46 & 101,00 & 139,99 & 92,04 & 43,5 & 4124,76 & 253,26 & 44,26 & 208,99 & 94,91 & 191,59 & 193,29 & 87,44 & 1229,65 & 167,21 & 15,41 & 51,34 & \begin{tabular}{|c|}
495,06 \\
\end{tabular} & 84,11 & \begin{tabular}{|l|l|}
101,93 \\
\end{tabular} & 478,38 \\
\hline Salamandra salamandra & 29TNF47 & 100,00 & 139,14 & 91,24 & 43,32 & 4147,14 & 252,84 & 44,35 & 208,48 & 93,89 & 191,25 & 192,76 & 86,61 & 1253,11 & $\mid 169,91$ & $\begin{array}{l}25,41+1 \\
5,81\end{array}$ & 51,14 & 501,37 & $\begin{array}{l}84,1+32 \\
86,\end{array}$ & \begin{tabular}{|l|l|l}
103,48 \\
\end{tabular} & 491,26 \\
\hline Salamandra salamandra & 29TNF48 & 100,00 & 142,13 & 90,79 & 43,15 & 4135,87 & 255,81 & 47,93 & 207,87 & 96,82 & 194,12 & 195,50 & 89,72 & \begin{tabular}{|l|l}
1230,59 \\
\end{tabular} & 165,88 & 15,35 & 51,02 & 490,29 & 84,29 & 102,44 & 483,04 \\
\hline Salamandra salamandra & 29TNF49 & 101,00 & 139,80 & 89,86 & 42,66 & 4175,54 & 254,55 & 46,33 & 208,22 & 94,19 & 192,55 & 193,76 & 87,19 & 1270,24 & 171,95 & 16,30 & 51,01 & 504,73 & 88,23 & 105,84 & 500,86 \\
\hline Salamandra salamandra & 29TNF50 & 101,00 & 139,58 & 92,61 & 42,17 & 4304,23 & 258,99 & 41,99 & 217,01 & 92,04 & 193,36 & 195,11 & 84,30 & 1181,11 & 167,89 & 13,43 & 52,76 & 475,58 & 79,54 & 87,48 & 468,92 \\
\hline Salamandra salamandra & 29TNF51 & 101,00 & 130,68 & 90,91 & 41,39 & 4383,84 & 251,56 & 34,36 & 217,20 & 83,11 & 186,06 & 187,79 & 75,27 & 1291,53 & 185,22 & 15,29 & 52,99 & 520,41 & 88,04 & 94,96 & 515,26 \\
\hline Salamandra salamandra & 29TNF52 & 100,00 & $\begin{array}{l}5,06 \\
128,82\end{array}$ & 90,79 & 41,34 & $\begin{array}{ll}4305,204 \\
4388,35\end{array}$ & $\mid 249,56$ & 32,56 & 217,00 & \begin{tabular}{l|l}
03,11 \\
80,65
\end{tabular} & $\begin{array}{l}10,040 \\
184,49\end{array}$ & $\mid \frac{\mid 0,1,13}{186,10}$ & 73,51 & \begin{tabular}{|l|}
1319,05 \\
1319
\end{tabular} & \begin{tabular}{|l|l|l|l|l|l|}
188,56 \\
\end{tabular} & $\mid 15,87$ & \begin{tabular}{|c|}
52,82 \\
5
\end{tabular} & $\mid \begin{array}{ll}52,41,86 \\
531\end{array}$ & $\begin{array}{l}00,04 \\
90,28\end{array}$ & $\begin{array}{l}34,50 \\
98,23\end{array}$ & 525,29 \\
\hline Salamandra salamandra & 29TNF53 & 101,00 & 139,12 & 93,95 & 42,65 & 4304,01 & 258,06 & 40,55 & 217,52 & $\begin{array}{l}91,75 \\
\end{array}$ & \begin{tabular}{|c|}
192,97 \\
\end{tabular} & 194,65 & 83,83 & 1206,82 & 168,46 & 14,26 & 52,14 & 487,19 & 81,32 & 94,06 & 473,32 \\
\hline Salamandra salamandra & 29TNF55 & 100,00 & $\mid \begin{array}{l}\mid 340,87 \\
140,\end{array}$ & 95,08 & 42,94 & 4326,04 & 260,24 & 41,73 & 218,51 & 93,30 & 195,21 & 196,68 & $\begin{array}{l}85,53 \\
85,53\end{array}$ & $\begin{array}{l}1202,49 \\
120\end{array}$ & 165,11 & 14,53 & 51,85 & 484,56 & $\begin{array}{l}\mid 81,28 \\
81,28\end{array}$ & 96,84 & 468,84 \\
\hline Salamandra salamandra & 29TNF56 & 101,00 & 139,94 & 95,13 & 42,95 & 4354,26 & 260,13 & 41,13 & 219,00 & 92,16 & 194,79 & 196,27 & 84,56 & 1221,82 & 166,99 & 14,97 & 51,64 & 490,56 & 83,17 & 98,86 & 477,69 \\
\hline Salamandra salamandra & 29TNF58 & 100,00 & 142,10 & 94,36 & 42,68 & 4362,30 & 262,89 & 44,19 & 218,70 & 94,05 & 197,22 & 198,42 & 86,75 & 1212,75 & 162,86 & 15,06 & 51,03 & 482,85 & 83,48 & 99,97 & 474,72 \\
\hline Salamandra salamandra & 29TNF60 & 100,00 & $\begin{array}{l}\mid 42,103 \\
135,03 \\
\end{array}$ & 94,39 & 4 & 4585,71 & \begin{tabular}{|l|l|}
202,85 \\
262,88
\end{tabular} & 35,58 & 227,30 & 84,44 & | & \begin{tabular}{|l|}
194,46 \\
19486
\end{tabular} & $\begin{array}{l}00,1 / 1 \\
77,17\end{array}$ & \begin{tabular}{|l|}
1237,64 \\
1237
\end{tabular} & \begin{tabular}{|l|}
$179,24,24$ \\
\end{tabular} & $\begin{array}{l}0,00 \\
13,79 \\
\end{array}$ & \begin{tabular}{|l|l|}
53,37 \\
5
\end{tabular} & $\begin{array}{l}490,03 \\
498,24\end{array}$ & 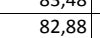 & 88,33 & 495,79 \\
\hline Salamandra salamandra & 29TNF61 & 100,00 & 135,59 & 94,12 & 41,30 & 4545,64 & 261,58 & 36,27 & 225,31 & \begin{tabular}{|l|l}
84,47 \\
\end{tabular} & 193,36 & 194,77 & 78,12 & 1233,48 & 177,66 & 13,94 & 53,23 & 497,11 & 82,71 & 89,56 & 492,25 \\
\hline Salamandra salamandra & 29TNF62 & 101,00 & 119,24 & 89,37 & 39,56 & 4648,32 & 246,04 & 23, & 222,68 & 65,19 & 179,50 & 180,74 & 62,13 & 1421,55 & 207,84 & 17,24 & 53,69 & 573,99 & 97,86 & 101,46 & 572,57 \\
\hline Salamandra salamandra & 29TNF63 & 100,00 & 137,18 & 96,37 & 41, & 4552,30 & 263,63 & 36, & 227,18 & 87,09 & 194,87 & 196,22 & 79,29 & 1227,80 & 174,69 & 14, & 52,72 & 494,00 & 82,05 & 92,22 & 486,62 \\
\hline Salamandra salamandra & 29TNFG6 & 100,00 & 140,95 & 98,10 & 42,56 & 4557,92 & 267,53 & 39,38 & 228,15 & 90,49 & 198,65 & 199,92 & 82,92 & 1198,66 & 165,92 & 14, & 51,88 & 479,50 & 80,88 & 94,69 & 470,84 \\
\hline Salamandra salamandra & \begin{tabular}{|l|} 
29TNF67 \\
\end{tabular} & 100,00 & 139,03 & 97,85 & 42,15 & 4589,24 & 266,73 & 37,67 & 229,06 & 88,29 & 197,36 & 198,49 & 80,91 & 1225,60 & 168,33 & 14,86 & 51,72 & 488,61 & 83,77 & 97,47 & 482,14 \\
\hline Salamandra salamandra & 29TNF69 & 100,00 & 135,31 & 96,15 & 41,53 & 4630,85 & 264,13 & 35,32 & 228,80 & \begin{tabular}{|l|l|}
83,85 \\
\end{tabular} & 194,67 & 195,62 & 77,28 & \begin{tabular}{|l|}
1267,98 \\
\end{tabular} & 170,11 & 16,66 & 50,99 & \begin{tabular}{|c|}
502,08 \\
\end{tabular} & 90,32 & 103,32 & 498,82 \\
\hline Salamandra salamandra & 29TNF70 & 100,00 & 131,12 & 93,82 & 39,84 & 4794,23 & 263,60 & & 232,42 & 74,29 & 193,10 & 194,21 & 71,49 & 1276,03 & 187,97 & 13,6 & 54,17 & 515,51 & 84,71 & 88,05 & 514,91 \\
\hline Salamandra salamandra & 29TNF71 & 101,00 & 55 & 97,23 & 41 & 4748,50 & 0,65 & 36, & 234,32 & 84,96 & 199,28 & 200,42 & 78,59 & 1195,33 & 173,64 & 12, & 53,50 & 480,83 & 8,99 & 85,21 & 478,45 \\
\hline Salamandra salamandra & 29TNF72 & 100,00 & 75 & 93,12 & $\frac{4+1}{39}$ & 4811,33 & 256,79 & 25 & 231,23 & 67, 67 & 187,14 & 188,20 & 65,25 & $\begin{array}{l}1354,86 \\
1350\end{array}$ & $\mid 199,64$ & 15, & 54,07 & 547,42 & 91,22 & $\begin{array}{l}\mid c 0,2 \pm \\
94,88\end{array}$ & 546,90 \\
\hline Salamandra salamandra & 29TNF73 & 10 & & 94,19 & 40 & 4798,34 & 257,82 & 26,19 & 231,62 & 69,94 & 188,03 & 189,07 & 66,37 & 1340,38 & 195,83 & 15,66 & 53,65 & 540,51 & 90,73 & 95,98 & 538,99 \\
\hline Salamandra salamandra & 29TNF74 & 101,00 & 128,99 & 95,57 & 40,63 & 4783,60 & 260,61 & 28, & 232,24 & 72,85 & $\begin{array}{l}190,05 \\
190,58\end{array}$ & 191,63 & 69,36 & $\begin{array}{l}1309,76 \\
130,\end{array}$ & 189,73 & 15,35 & 53,31 & 527,26 & 88,82 & 95,55 & 524,72 \\
\hline Salamandra salamandra & 29TNF77 & 100,00 & 139,96 & 100,63 & 41, & 4786,69 & 79 & 35 & 237 & 85, & 201,14 & 201,93 & 79,40 & 1195,50 & 166,38 & 14,04 & 52,04 & 475,06 & 81,10 & 92,96 & 472,06 \\
\hline Salamandra salamandra & 29TNF79 & 101,00 & 124,43 & 95,81 & 40,4 & 841,80 & 258,19 & 24 & 233,89 & 65,58 & 187,19 & 188,09 & 64,62 & 1349,39 & 185,11 & 18,5 & 51,51 & 536,28 & 98,47 & 107,09 & 536,16 \\
\hline Salamandra salamandra & 29TNF80 & $\begin{array}{l}101,00 \\
100\end{array}$ & 13 & 年, & 39,4l & 44966,71 & $\begin{array}{l}270,13 \\
275,12\end{array}$ & 33,90 & $\begin{array}{l}23,09 \\
241,22\end{array}$ & $\begin{array}{l}0.30 \\
75,65\end{array}$ & \begin{tabular}{|l|l|}
201,18 \\
201,
\end{tabular} & $\begin{array}{l}2002,29 \\
2029\end{array}$ & 75,13 & \begin{tabular}{|l|}
1195,95 \\
1195
\end{tabular} & $\begin{array}{l}\mid 03,11 \\
176,73 \\
\end{array}$ & \begin{tabular}{|l|l|}
12,38 \\
128
\end{tabular} & \begin{tabular}{|l|l|}
54,37 \\
\end{tabular} & $\begin{array}{l}350,20 \\
482,82\end{array}$ & $\begin{array}{ll}78,28 \\
78,28\end{array}$ & \begin{tabular}{|l|l|}
81,81 \\
\end{tabular} & $\begin{array}{ll}530,10 \\
482,81\end{array}$ \\
\hline Salamandra salamandra & 29TNF81 & 101,00 & 13 & 98,97 & 40,41 & 4957,04 & 276,29 & 34, & 241,95 & 78,33 & 202,15 & 203,23 & 76,25 & 1184,88 & 174,47 & 12,24 & 54,20 & 477,17 & 77,25 & 82,20 & 477,00 \\
\hline Salamandra salamandra & 29TNF82 & 100,00 & 133,58 & 98,23 & 40,21 & 4971,25 & 271,19 & 30,1 & 241,06 & 73,00 & 197,70 & 198,66 & 71,47 & 1244,51 & 184,08 & 13, & 54,36 & 502,42 & 81,71 & 86,36 & 502,12 \\
\hline Salamandra salamandra & 29TNF83 & 101,00 & 10 & 年 & 37,62 & 7007 t & 242, & & 229,5 & 49 & 175 & 急 & 49 & 1493 & 222 & 18 & 54 & 606,03 & 102,49 & 103,59 & 606,01 \\
\hline Salamandra salamandra & 29TNF84 & 101,00 & & 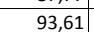 & 39, & & 25 & & 235 & 58 & & 184,84 & 57 & & & 16 & 54,06 & 565,62 & 95,33 & 98,47 & 565,51 \\
\hline Salamandra salamandra & 29TNF86 & 101,00 & 125,67 & 98,43 & 40,38 & 4998,73 & 264,11 & 23,07 & 241,04 & 60,203 & 190,54 & 191,36 & 63,74 & \begin{tabular}{|l|}
1325,58 \\
\end{tabular} & 192,39 & 15,93 & 53,57 & 533,46 & 91,11 & 96,93 & 533,22 \\
\hline Salamandra salamandra & 29TNF87 & 101,00 & 135,01 & 101,65 & 41,07 & 4987,46 & 274,44 & 29,83 & 244,61 & 74,73 & 199,17 & 199,92 & 72,50 & 1223,35 & 174,13 & 14,38 & 52,84 & 488,05 & 83,36 & 92,32 & 487,44 \\
\hline Salamandra salamandra & 29TNF88 & 99,00 & 141,71 & 103,14 & 41,42 & 4974,24 & 281,45 & 35,06 & 246,39 & 83,10 & 205,58 & 206,22 & 78,92 & 1144,18 & 158,88 & 13,41 & 52,08 & 452,19 & 78,01 & 89,11 & 451,23 \\
\hline Salamandra salam & 29TNF90 & 100,00 & 135,74 & & 39,1 & 7 & 40 & 31, & 245,51 & 71,87 & 202,41 & 203,33 & & 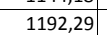 & & 10,1 & 54,96 & 483,60 & & 79,46 & 483,60 \\
\hline Salamandra salamandra & 29TNF91 & & & & & 5137 & & 28,79 & 245, & 68 & 199 & 200,32 & 68, & $122>>2$ & $184>2>>$ & 12, & 55,01 & 498,40 & 79,94 & 82,35 & 498,40 \\
\hline Salamandra salamandra & 29TNF92 & 101,00 & 126,83 & 96,14 & 39,03 & 5143,95 & 267,40 & 23,92 & 243,48 & 63,31 & 193,92 & 194,57 & 63,31 & 1295,64 & 194,83 & 13,75 & 55,18 & 526,94 & 85,17 & 87,05 & 526,94 \\
\hline Salamandra salamandra & 29TNF93 & 100,00 & 112,22 & 89,85 & 37,50 & 5123,48 & 249,76 & 13,62 & 236,13 & 50,27 & 180,26 & 180,45 & 50,27 & 1440,64 & 216,60 & 16,93 & 55,02 & 587,21 & 97,41 & 97,51 & 587,21 \\
\hline Salamandra salamandra & 29TNF94 & 100,00 & 117,18 & 18 & 38,63 & 43,77 & 257,13 & 16,22 & 240,91 & 54,41 & 184,94 & 185,37 & 54,41 & 1388,86 & 207,75 & 16,25 & 54,85 & \begin{tabular}{|l|l|}
564,88 \\
\end{tabular} & 94,28 & 95,58 & 564,88 \\
\hline & 29TNF95 & 101,00 & & & 40 & 5 & & & 250 & 75 & 201 & 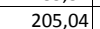 & 74 & & & 12, & 54,07 & & 76,62 & 82,85 & \\
\hline Salamandra salamandra & 29TNF96 & 100,00 & 122,41 & 99,04 & 39,60 & 5160,22 & 265,41 & $\mid 18,77$ & 246,64 & 58,88 & $\begin{array}{ll}189,82 \\
202\end{array}$ & \begin{tabular}{|l|}
190,40 \\
\end{tabular} & 58,88 & $\begin{array}{l}1327,04 \\
1327\end{array}$ & 195,32 & 16,05 & 54,19 & 536,19 & \begin{tabular}{l|l}
91,36 \\
91,36
\end{tabular} & $\begin{array}{l}62,03 \\
95,12\end{array}$ & 536,19 \\
\hline
\end{tabular}




\begin{tabular}{|c|c|c|c|c|c|c|c|c|c|c|c|c|c|c|c|c|c|c|c|c|c|}
\hline TAXON & UTM & $\overline{\mathrm{km} 2}$ & BIO1 & $\mathrm{B1O2}$ & $\mathrm{BIO3}$ & $\begin{array}{ll}B 104 \\
\end{array}$ & B105 & B106 & B107 & B108 & B109 & BIO10 & BIO11 & BIO12 & BIO13 & BIO14 & BIO15 & B1016 & BIO17 & BIO18 & BlO19 \\
\hline Salamandra salamandra & 29TNF97 & 100,00 & 115,88 & 95,90 & 39,03 & 5136,17 & 257,03 & 14,56 & 242,47 & 53,35 & 183,44 & 183,91 & 53,35 & 1372,61 & 199,44 & 17,95 & 53,49 & 553,49 & 98,06 & 101,01 & 553,49 \\
\hline Salamandra salamandra & 29TNF98 & 101,00 & 121,02 & 98,41 & 39,61 & 5139,73 & 263,22 & \begin{tabular}{ll|l}
17,96 \\
\end{tabular} & 245,26 & 57,91 & $\begin{array}{l}188,29 \\
\end{array}$ & $\begin{array}{l}188,76 \\
\end{array}$ & 57,91 & 1316,53 & 188,74 & 17,26 & 53,01 & 528,34 & 94,25 & $\begin{array}{ll}98,83 \\
\end{array}$ & 528,34 \\
\hline Salamandra salamandra & 29TNF99 & 100,00 & 135,05 & 103,43 & 40,67 & 5161,06 & 279,51 & 27,52 & 251,99 & 71,37 & 201,96 & 202,26 & 70,61 & 1168,49 & 163,49 & 14,49 & 52,32 & 463,38 & 81,88 & 88,21 & 463,32 \\
\hline Salamandra salamandra & \begin{tabular}{l|l|} 
29TNG06 \\
\end{tabular} & 3,00 & 146,50 & 63,83 & 40,00 & 3452,67 & 231,67 & 74,33 & 157,33 & 110,50 & \begin{tabular}{l|l|}
189,33 \\
\end{tabular} & \begin{tabular}{|l|l|}
191,17 \\
\end{tabular} & \begin{tabular}{ll|}
102,50 \\
\end{tabular} & 1307,17 & 181,00 & 23,00 & 49,00 & \begin{tabular}{|l|}
525,83 \\
\end{tabular} & \begin{tabular}{|l|l|}
103,17 \\
\end{tabular} & 125,33 & 502,17 \\
\hline Salamandra salamandra & \begin{tabular}{|l|} 
29TNG07 \\
\end{tabular} & & & & & & & & & & & & & & & & & & & & \\
\hline Salamandra salamandra & 29TNG08 & & & & & & & & & & & & & & & & & & & & \\
\hline Salamandra salamandra & 29TNG09 & & & & & & & & & & & & & & & & & & & & \\
\hline Salamandra salamandra & 29TNG11 & 68,00 & 142,97 & 75,17 & 42,97 & 3566,09 & 236,70 & 63,82 & \begin{tabular}{|l|l}
172,88 \\
\end{tabular} & 98,36 & \begin{tabular}{|l|l|}
187,37 \\
\end{tabular} & $\begin{array}{l}188,68 \\
\end{array}$ & 98,36 & 1288,24 & 180,59 & 15,17 & 52,45 & \begin{tabular}{l|l}
518,55 \\
\end{tabular} & 83,56 & \begin{tabular}{ll|}
108,22 \\
\end{tabular} & 518,55 \\
\hline Salamandra salamandra & $\begin{array}{l}\text { 29TNG12 } \\
\end{array}$ & 87,00 & 137,29 & 73,96 & 42,06 & 3627,14 & 232,43 & 58,62 & 173,81 & 92,83 & \begin{tabular}{|l|l|}
182,87 \\
\end{tabular} & $\begin{array}{l}184,29 \\
\end{array}$ & 92,14 & 1378,35 & 191,82 & 19,18 & 51,61 & 553,01 & 96,64 & \begin{tabular}{|c|}
118,57 \\
\end{tabular} & 552,97 \\
\hline Salamandra salamandra & \begin{tabular}{|l|l|} 
29TNG13 \\
\end{tabular} & 86,00 & 140,49 & 72,13 & 41,64 & 3603,62 & 234,13 & 62,90 & 171,23 & 100,04 & \begin{tabular}{|c|}
185,70 \\
\end{tabular} & 187,01 & 95,30 & 1358,91 & 189,08 & 19,68 & 51,07 & 544,43 & 96,92 & 119,11 & 541,84 \\
\hline Salamandra salamandra & 29TNG14 & 99,00 & 141,35 & 69,97 & 41,01 & 3592,14 & 233,55 & 65,01 & 168,54 & 103,58 & 186,44 & 187,73 & 96,16 & 1368,59 & 193,12 & 21,54 & 50,70 & 549,61 & 101,51 & 122,99 & 542,04 \\
\hline Salamandra salamandra & $\begin{array}{l}\text { 29TNG15 } \\
\end{array}$ & 101,00 & 132,16 & 69,72 & 40,14 & 3685,33 & 227,32 & 55,75 & \begin{tabular}{|l|l|}
171,56 \\
\end{tabular} & 93,81 & \begin{tabular}{l|l|l|l|l|l|}
178,93 \\
\end{tabular} & 180,33 & 86,39 & 1509,91 & 227,25 & 27,33 & 50,50 & 609,48 & 119,62 & 138,03 & 604,19 \\
\hline Salamandra salamandra & $\begin{array}{l}\text { 29TNG16 } \\
\end{array}$ & 63,00 & 144,91 & 65,38 & 39,81 & 3554,55 & 233,48 & $\begin{array}{ll}71,05 \\
\end{array}$ & \begin{tabular}{ll|l}
162,43 \\
\end{tabular} & \begin{tabular}{ll|}
107,66 \\
\end{tabular} & \begin{tabular}{l|l|l|}
189,68 \\
\end{tabular} & \begin{tabular}{|c|}
190,80 \\
\end{tabular} & 99,84 & 1361,27 & 195,80 & 24,69 & 49,54 & 549,03 & \begin{tabular}{|c|}
108,17 \\
\end{tabular} & \begin{tabular}{|c|}
128,84 \\
\end{tabular} & 528,42 \\
\hline Salamandra salamandra & $\begin{array}{l}\text { 29TNG17 } \\
\end{array}$ & 33,00 & 149,14 & 62,22 & 38,97 & 3510,00 & 234,61 & 76,97 & \begin{tabular}{|l|l|}
157,64 \\
\end{tabular} & \begin{tabular}{|l|l|}
112,28 \\
\end{tabular} & \begin{tabular}{|c|}
193,11 \\
\end{tabular} & 194,33 & \begin{tabular}{l|l|}
104,31 \\
\end{tabular} & 1294,33 & 179,89 & 25,03 & 48,31 & 519,61 & $\begin{array}{l}107,44 \\
\end{array}$ & $\begin{array}{l}128,50 \\
\end{array}$ & 486,56 \\
\hline Salamandra salamandra & $\begin{array}{l}\text { 29TNG18 } \\
\end{array}$ & 45,00 & 144,43 & 61,74 & 38,37 & 3541,20 & 231,42 & \begin{tabular}{l|l}
73,05 \\
\end{tabular} & 158,37 & \begin{tabular}{|l|l|}
107,44 \\
\end{tabular} & 189,24 & 190,36 & \begin{tabular}{|c|}
99,57 \\
\end{tabular} & 1364,63 & 199,30 & 28,12 & 48,48 & 549,64 & \begin{tabular}{|c|}
116,34 \\
\end{tabular} & \begin{tabular}{|l|l}
136,83 \\
\end{tabular} & 520,34 \\
\hline Salamandra salamandra & 29TNG19 & 57,00 & 145,12 & 59,99 & \begin{tabular}{|c|}
37,97 \\
\end{tabular} & 3519,84 & 230,93 & 75,11 & 155,82 & 108,43 & \begin{tabular}{|l|l|}
189,61 \\
\end{tabular} & 191,00 & 100,84 & $\begin{array}{l}1316,97 \\
\end{array}$ & 192,33 & 28,91 & 47,32 & 528,09 & 117,50 & 139,10 & 493,80 \\
\hline Salamandra salamandra & $\begin{array}{l}\text { 29TNG20 } \\
\end{array}$ & 101,00 & 138,63 & 80,62 & 42,90 & 3774,84 & 239,93 & 54,36 & 185,56 & 91,40 & \begin{tabular}{|c|}
185,97 \\
\end{tabular} & 187,32 & 91,40 & 1326,01 & 182,29 & 16,74 & 51,84 & \begin{tabular}{l|l}
531,55 \\
\end{tabular} & 89,82 & \begin{tabular}{|c|}
110,74 \\
\end{tabular} & 531,55 \\
\hline Salamandra salamandra & 29TNG21 & 100,00 & 140,46 & 79,05 & 42,58 & 3766,11 & 241,19 & 57,32 & 183,88 & 93,37 & 187,78 & 188,95 & 93,37 & 1319,70 & 182,44 & 16,80 & 51,79 & 528,80 & 89,38 & 111,32 & 528,80 \\
\hline Salamandra salamandra & 29TNG22 & 101,00 & 137,87 & 77,71 & 41,84 & 3802,67 & 239,14 & 55,51 & \begin{tabular}{l|l|l}
183,63 \\
\end{tabular} & 92,15 & \begin{tabular}{l|l|l|l|}
185,93 \\
\end{tabular} & 187,09 & 90,40 & 1364,18 & 189,74 & 19,11 & 51,39 & 545,54 & 96,55 & \begin{tabular}{l|l}
117,25 \\
\end{tabular} & 545,41 \\
\hline Salamandra salamandra & 29TNG23 & 100,00 & 133,12 & 76,64 & 41,0 & 3855,64 & 235,53 & 51,17 & \begin{tabular}{|l|l|l}
184,36 \\
\end{tabular} & 88,49 & 182,12 & 183,32 & 85,2 & 1450,79 & 209,92 & 22, & 50,88 & 581,76 & \begin{tabular}{|c|}
108,37 \\
\end{tabular} & \begin{tabular}{|c|}
126,68 \\
\end{tabular} & 581,25 \\
\hline Salamandra salamandra & 29TNG24 & 99,00 & 142,72 & 73,68 & 40,92 & 3762,67 & 240,82 & 62,56 & 178,27 & 101,27 & 190,16 & 191,21 & 95,21 & 1360,54 & 195,29 & 21,41 & 50,56 & 545,50 & 101,24 & 121,49 & 538,65 \\
\hline Salamandra salamandra & $\begin{array}{l}\text { 29TNG25 } \\
\end{array}$ & 101,00 & 142,44 & 71,61 & 40,21 & 3755,29 & 239,25 & 63,49 & 175,77 & 101,68 & \begin{tabular}{|l|l|}
189,94 \\
\end{tabular} & 190,94 & 95,01 & 1394,60 & 206,60 & 23,94 & 50,39 & 561,40 & $\begin{array}{l}107,55 \\
\end{array}$ & \begin{tabular}{|l|}
126,99 \\
\end{tabular} & 552,19 \\
\hline Salamandra salamandra & $\begin{array}{l}29 T N G 26 \\
\end{array}$ & 100,00 & 137,42 & 70,38 & 39,69 & 3792,18 & 234,78 & 59,26 & \begin{tabular}{|c|}
175,52 \\
\end{tabular} & \begin{tabular}{l|l|}
95,03 \\
\end{tabular} & $\begin{array}{l}185,76 \\
\end{array}$ & \begin{tabular}{|l|l|}
186,73 \\
\end{tabular} & 89,89 & 1494,19 & 233,27 & 28,30 & 50,67 & \begin{tabular}{|c|c|}
605,16 \\
\end{tabular} & \begin{tabular}{|l|l|l|}
120,03 \\
\end{tabular} & \begin{tabular}{|c|}
137,69 \\
\end{tabular} & 598,49 \\
\hline Salamandra salamandra & 29TNG27 & 80,00 & 142,23 & 66,90 & 39,02 & 3729,91 & 235,55 & 66,17 & 169,38 & 100,94 & 189,67 & \begin{tabular}{|c|}
190,59 \\
\end{tabular} & 95,20 & 1456,53 & 226,75 & 28,89 & 50,29 & \begin{tabular}{|l|l|}
590,88 \\
\end{tabular} & \begin{tabular}{|l|l|}
119,23 \\
\end{tabular} & \begin{tabular}{ll|}
137,56 \\
\end{tabular} & 576,63 \\
\hline Salamandra salamandra & $\begin{array}{l}\text { 29TNG28 } \\
\end{array}$ & 86,00 & 139,17 & 65,44 & 38,37 & 3735,36 & 232,63 & 64,36 & 168,28 & 99,83 & 186,87 & 187,97 & 92,4 & 1463,59 & 227,46 & 31, & 49, & 589,78 & \begin{tabular}{|c|}
125,44 \\
\end{tabular} & \begin{tabular}{|c|}
144,09 \\
\end{tabular} & 572,35 \\
\hline Salamandra salamandra & \begin{tabular}{|l|} 
29TNG29 \\
\end{tabular} & 72,00 & 142,90 & 62,57 & 37,89 & 3707,49 & 233,27 & 70,12 & 163,15 & 103,57 & 190,24 & 191,12 & 96,35 & 1394,43 & 212,13 & 30,94 & 48,26 & 558,48 & 122,62 & 142,96 & 533,75 \\
\hline Salamandra salamandra & 29TNG31 & 101,00 & 138,13 & 83,65 & 42,12 & 3997,59 & 246,81 & 50,50 & 196,31 & 90,32 & \begin{tabular}{|c|}
188,70 \\
\end{tabular} & 189,82 & 88,05 & 1338,81 & \begin{tabular}{|c|}
185,48 \\
\end{tabular} & 18,15 & 51,15 & 533,35 & $\begin{array}{l}94,35 \\
\end{array}$ & \begin{tabular}{|c|}
113,34 \\
\end{tabular} & 533,25 \\
\hline Salamandra salamandra & \begin{tabular}{|l|l|}
$29 T N G 32$ \\
\end{tabular} & 101,00 & 142,57 & 82,02 & 41,84 & 3972,07 & 249,88 & 55,81 & 194,06 & 98,75 & 192,74 & 193,71 & 92,50 & 1300,19 & 180,92 & 17,88 & 51,01 & 516,76 & 92,01 & 111,91 & 515,34 \\
\hline Salamandra salamandra & 29TNG33 & 100,00 & 128,02 & 80,92 & 40,79 & 4087,55 & 238,12 & 41,92 & 196,20 & 79,68 & $\begin{array}{l}180,45 \\
\end{array}$ & \begin{tabular}{|l|l|}
181,48 \\
\end{tabular} & 77,39 & 1483,19 & 217,87 & 24,47 & 50,58 & 592,61 & \begin{tabular}{ll|l}
114,75 \\
\end{tabular} & 129,94 & 592,45 \\
\hline Salamandra salamandra & 29TNG34 & 100,00 & 130,47 & 79,59 & $\begin{array}{l}40,55 \\
\end{array}$ & 4068,19 & 239,44 & 45,08 & 194,36 & 84,61 & 182,58 & 183,56 & 79,95 & \begin{tabular}{ll|}
1482,56 \\
\end{tabular} & 223,25 & 25,55 & 50,53 & 593,07 & 116,73 & 132,15 & 591,82 \\
\hline Salamandra salamandra & \begin{tabular}{|l|l|} 
29TNG35 \\
\end{tabular} & 100,00 & 145,15 & 76,03 & 40,07 & 3941,12 & 248,67 & 61,79 & 186,88 & 101,87 & 195,09 & 195,83 & 95,17 & 1342,05 & 200,47 & 22,86 & 50,10 & 537,04 & 104,42 & 122,88 & 526,61 \\
\hline Salamandra salamandra & 29TNG36 & 101,00 & 144,76 & 73,61 & 39,76 & 3928,62 & 246,38 & 62,98 & 183,40 & 101,35 & \begin{tabular}{|c|}
194,70 \\
\end{tabular} & \begin{tabular}{|c|}
195,47 \\
\end{tabular} & 95,00 & 1380,58 & 213,07 & 25,50 & 50,08 & 554,99 & \begin{tabular}{|c|}
110,69 \\
\end{tabular} & 128,51 & 543,54 \\
\hline Salamandra salamandra & 29TNG38 & 88,00 & 139,79 & 70,11 & 38,73 & 3935,64 & 239,20 & 60,43 & 178,77 & 97,45 & 190,29 & 191,03 & 90,49 & 1461,61 & 233,79 & 31,05 & 49,66 & 586,56 & \begin{tabular}{|l|l|l|}
124,93 \\
\end{tabular} & 141,71 & 575,20 \\
\hline Salamandra salamandra & 29TNG39 & 101,00 & 136,77 & 68,86 & 38,12 & 3933,53 & 236,40 & 58,27 & 178,13 & 94,66 & \begin{tabular}{|l|l|}
187,42 \\
\end{tabular} & 188,34 & 87,94 & 1478,41 & 235,28 & 33,27 & 48,80 & 590,26 & 130,99 & 148,84 & 576,22 \\
\hline Salamandra salamandra & 29TNG40 & 101,00 & 145,85 & 88,48 & \begin{tabular}{|l|l}
42,53 \\
\end{tabular} & 4128,39 & 258,94 & 53,25 & 205,69 & 100,52 & 197,76 & 198,85 & 93,45 & 1208,74 & 163,53 & 15,25 & 50,98 & 478,58 & \begin{tabular}{r|}
83,25 \\
\end{tabular} & 102,33 & 474,61 \\
\hline Salamandra salamandra & 29TNG41 & 100,00 & 138,67 & 87,77 & 41,79 & 4212,47 & 254,27 & 46,55 & 207,72 & 92,38 & 192,13 & 193,18 & 85,67 & 1304,64 & 181,44 & 18,13 & 50,77 & 517,18 & 94,26 & 111,32 & 514,42 \\
\hline Salamandra salamandra & 29TNG42 & 100,00 & 137,73 & 86,50 & 41,29 & 4229,46 & 253,40 & 46,41 & 206,99 & 90,97 & 191,60 & 192,52 & 84,6 & 1324,39 & 187,27 & 19,51 & 50,38 & 524,80 & \begin{tabular}{|l|l|}
98,47 \\
\end{tabular} & 114,94 & 521,03 \\
\hline Salamandra salamandra & 29TNG43 & 101,00 & 137,51 & 85,64 & 40,89 & 4235,56 & 253,34 & 46,66 & 206,68 & 91,15 & \begin{tabular}{|c|}
191,53 \\
\end{tabular} & 192,29 & 84, & 1342,99 & 195,19 & 21,10 & 50,03 & 532,19 & \begin{tabular}{|c|}
103,16 \\
\end{tabular} & \begin{tabular}{ll|}
118,92 \\
\end{tabular} & 527,01 \\
\hline Salamandra salamandra & 29TNG44 & 100,00 & 130,60 & 84,27 & 40,42 & 4270,75 & 246,88 & 40,75 & 206,1 & 84,49 & \begin{tabular}{|c|}
185,44 \\
\end{tabular} & 186,28 & 77,4 & 1431,34 & 214,47 & 24,8 & 49,8 & 567,90 & \begin{tabular}{|c|}
115,32 \\
\end{tabular} & \begin{tabular}{|l|}
129,11 \\
\end{tabular} & 563,75 \\
\hline Salamandra salamandra & \begin{tabular}{l|l|} 
29TNG45 \\
\end{tabular} & 101,00 & 142,30 & 82,14 & 40,13 & 197,28 & 255,32 & 53,36 & 201,96 & 96,35 & 195,81 & 196, & 89,2 & 1323,49 & 199,84 & 23,1 & 49,47 & 524,75 & 106,82 & 122,21 & 513,46 \\
\hline Salamandra salamandra & 29TNG46 & 101,00 & 14 & 80,28 & 39,91 & 4175,75 & 254,49 & 55,52 & \begin{tabular}{ll|}
198,96 \\
\end{tabular} & \begin{tabular}{|c|}
97,62 \\
\end{tabular} & \begin{tabular}{ll|}
196,56 \\
\end{tabular} & \begin{tabular}{|l|l|}
197,13 \\
\end{tabular} & 90, & 1332,85 & 205,65 & 24,82 & 49,20 & 528,98 & \begin{tabular}{|l|}
110,47 \\
\end{tabular} & $\begin{array}{l}125,52 \\
\end{array}$ & 515,79 \\
\hline Salamandra salamandra & 29TNG48 & 100,00 & & 78,41 & 39,08 & 4198,61 & 239,79 & 41,84 & 197,95 & 83,04 & 182,58 & 183,64 & 76, & $\begin{array}{ll}1502,07 \\
\end{array}$ & 239,28 & 32,79 & 48,85 & \begin{tabular}{|l|l}
595,05 \\
\end{tabular} & 133,86 & \begin{tabular}{|l|l|}
147,87 \\
\end{tabular} & 587,57 \\
\hline Salamandra salamandra & 29TNG49 & 101,00 & 125,64 & 77,56 & \begin{tabular}{l|l}
38,85 \\
\end{tabular} & 4165,73 & 237,61 & \begin{tabular}{|c|}
39,97 \\
\end{tabular} & \begin{tabular}{|c|}
197,64 \\
\end{tabular} & 81,13 & $\begin{array}{l}179,86 \\
\end{array}$ & \begin{tabular}{|l|l|}
181,09 \\
\end{tabular} & \begin{tabular}{|c|}
75,07 \\
\end{tabular} & 1508,88 & 237,59 & 34,66 & 47,92 & $\begin{array}{l}594,55 \\
\end{array}$ & $\begin{array}{l}138,65 \\
\end{array}$ & 153,11 & 584,39 \\
\hline Salamandra salamand & 29TNG50 & 101,00 & 8 & 92,44 & 41,82 & 00,09 & 18 & 43,75 & 218,44 & 91,96 & 196, & 197,28 & 84,8 & 1243,80 & 168,81 & 16,54 & 50,69 & \begin{tabular}{|l|l}
492,03 \\
\end{tabular} & 88,82 & \begin{tabular}{|c|}
104,69 \\
\end{tabular} & 487,03 \\
\hline Salamandra salamandra & 29TNG51 & 10 & $1:$ & 91 & 41, & 442 & 0 & 42 & 218,31 & 89 & 194,64 & 195,49 & 82,5 & 127 & 176,06 & 17,98 & 50,29 & 503,34 & 93,86 & 109,01 & 498,60 \\
\hline Salamandra salamandra & 29TNG52 & 100 & & 89,65 & 40,70 & 4468,95 & & 35,99 & 217 & 81, & 188,2 & \begin{tabular}{l|l|}
188,95 \\
\end{tabular} & 75,0 & 1357,70 & \begin{tabular}{|l|l|}
191,48 \\
\end{tabular} & 21,14 & 49,95 & 535,88 & 104,88 & \begin{tabular}{l|l|}
117,86 \\
\end{tabular} & 532,10 \\
\hline Salamandra salamandra & \begin{tabular}{|l|l|} 
29TNG53 \\
\end{tabular} & 101,00 & 131,96 & 89,04 & 40,50 & 4465,45 & 254,88 & 37,47 & 217,42 & 83,37 & 189,44 & 190,19 & 76,41 & 1345,19 & 193,52 & 21,98 & 49,53 & 529,65 & 106,91 & 119,50 & 523,62 \\
\hline Salamandra salamandra & 29TNG54 & 101,00 & 107,50 & 82,47 & 38,62 & 4465,10 & 228,68 & 18 & 210,33 & 60 & \begin{tabular}{ll|l}
166,06 \\
\end{tabular} & 167,06 & 54,06 & \begin{tabular}{|l|}
1555,27 \\
\end{tabular} & 221,33 & 30,1 & 48,5 & 611,15 & 134,21 & \begin{tabular}{l|l|}
142,65 \\
\end{tabular} & 608,70 \\
\hline Salamandra salamandr & \begin{tabular}{l|l|} 
29TNG55 \\
\end{tabular} & 100,00 & 132,57 & 86,93 & 39,88 & 446,63 & 254 & 39, & 215,13 & 84 & 189,82 & 190,56 & 77, & 1347,31 & 201,06 & 24, & 48,65 & 528,58 & \begin{tabular}{|l|l|}
114,33 \\
\end{tabular} & 126,30 & 517,21 \\
\hline Salamandra salamandra & 29 TNC & 10 & & & 39,84 & 4443,65 & 256,33 & 41, & 214,96 & 86, & 192,04 & 192,69 & 79, & 1329,41 & 202,14 & 25,73 & 48,28 & 520,27 & 115,85 & 126,77 & 506,14 \\
\hline Salamandra salamandra & 29TNG59 & 100,00 & 113,55 & 80,92 & 38,72 & 4310,81 & 231,79 & 25,08 & 206,71 & 67,71 & \begin{tabular}{l|l|}
170,02 \\
\end{tabular} & \begin{tabular}{ll|}
171,45 \\
\end{tabular} & 62,2 & 1509,61 & 226,36 & 35,67 & 46,38 & 586,61 & \begin{tabular}{l|l}
144,05 \\
\end{tabular} & \begin{tabular}{|l|l|}
155,97 \\
\end{tabular} & 575,97 \\
\hline Salamandra sal & 29TNG60 & 100,00 & 134,74 & 95,32 & 41,24 & 4644,93 & 263,68 & 35,02 & 228,66 & 83,36 & \begin{tabular}{|l|l|}
194,34 \\
\end{tabular} & \begin{tabular}{|c|}
195,08 \\
\end{tabular} & 76,56 & 1273,15 & 170,29 & 17,49 & 50,72 & 502,46 & \begin{tabular}{|c|}
92,99 \\
\end{tabular} & 105,74 & 499,23 \\
\hline Salamandra salamandra & 29TNG61 & 101,00 & 129,52 & 92,96 & 40,52 & 4652,63 & 7570 & 31,49 & 226,34 & & \begin{tabular}{ll|}
189,55 \\
\end{tabular} & 190, & 71,8 & 1320,79 & 179,1 & 19,6 & 50,09 & 520,45 & 100,31 & \begin{tabular}{|c|}
111,37 \\
\end{tabular} & 517,43 \\
\hline Salamandra salamand & $29 T N G$ & 101, & & 87, & 39,30 & & & 21, & & & & $1 / 6$ & 58,6 & & 198,80 & & 49,68 & 571 & \begin{tabular}{|l|l|}
116,97 \\
\end{tabular} & 125,53 & 570,44 \\
\hline Salamandra salamandra & \begin{tabular}{l|l|} 
29TNG63 \\
\end{tabular} & 100,00 & 123,83 & 90,23 & 39,73 & 4660,90 & 251,54 & 27,50 & 224,04 & 72,50 & 184,36 & 185,01 & \begin{tabular}{|c|}
66,47 \\
\end{tabular} & 1369,05 & 192,82 & 23,31 & 49,05 & 536,57 & 111,71 & \begin{tabular}{|c|}
121,10 \\
\end{tabular} & 531,94 \\
\hline Salamandra salamandra & 29TNG64 & 101,00 & 110,77 & 85,49 & $\begin{array}{l}38,75 \\
\end{array}$ & 4618,93 & 235,92 & 18,21 & 217,71 & 61,90 & 171,38 & \begin{tabular}{|l|l|}
172,25 \\
\end{tabular} & 55,21 & \begin{tabular}{|l|}
1481,37 \\
\end{tabular} & 208,95 & 28,14 & 48,52 & 579,94 & 126,96 & \begin{tabular}{|l|l|}
135,08 \\
\end{tabular} & 577,66 \\
\hline Salamandra salamandra & $\begin{array}{l}\text { 29TNG65 } \\
\end{array}$ & 100,00 & 104,96 & 83,10 & 38,21 & 4573,78 & 228,97 & \begin{tabular}{l|l}
14,35 \\
\end{tabular} & \begin{tabular}{|l|l|l|}
214,62 \\
\end{tabular} & 57,06 & \begin{tabular}{|c|}
165,27 \\
\end{tabular} & 166,23 & 50,52 & 1523,45 & 215,64 & 31,05 & 47,71 & \begin{tabular}{|l|l|}
594,87 \\
\end{tabular} & 135,51 & \begin{tabular}{|l|l|l|}
143,03 \\
\end{tabular} & 591,62 \\
\hline Salama & 29TNG & & & & & & & & & & & & & & & & 47,50 & & 112 & \begin{tabular}{l|l|}
122,05 \\
\end{tabular} & \\
\hline Salamandra salamandra & 29TNG67 & 101,00 & 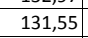 & 88,09 & 39,38 & 4616,4 & 230, & 34,11 & 221,25 & 80,76 & 191,40 & 191,9 & 74,5 & 1280,0 & 193,17 & 26,55 & 47,19 & 496,80 & \begin{tabular}{|c|c|}
116,35 \\
\end{tabular} & 126,10 & 482, \\
\hline Salamandra salamandra & 29TNG68 & 101,00 & 125,16 & 85,59 & 38,95 & 4545,41 & 247,24 & 30,58 & 216,66 & 75,50 & 184,41 & 185,20 & 69,87 & 1345,60 & 201,85 & 29,79 & 46,67 & 519,66 & 125,28 & 137,12 & 507,16 \\
\hline
\end{tabular}




\begin{tabular}{|c|c|c|c|c|c|c|c|c|c|c|c|c|c|c|c|c|c|c|c|c|c|}
\hline TAXON & UTM & $\mathrm{km2}$ & B101 & $\mathrm{B1O2}$ & $\mathrm{BIO3}$ & $\mathrm{B104}$ & B105 & $\mathrm{B106}$ & B107 & B108 & B109 & 81010 & B1011 & B1012 & $\mathrm{BIO13}$ & B1014 & B1015 & 81016 & B1017 & B1018 & B1019 \\
\hline Salamandra salamandra & 29TNG69 & 101,00 & 130,59 & 84,99 & 39,07 & 4480,68 & 250,32 & 36,18 & 214,14 & 81,15 & 188,92 & 189,76 & 75,99 & 1312,73 & 200,11 & 30,08 & 46,38 & 505,62 & 123,59 & 137,23 & 491,56 \\
\hline Salamandra salamandra & 29TNG70 & 100,00 & 125,96 & 95,39 & 40,34 & 4836,55 & 259,46 & 25,65 & 233,80 & \begin{tabular}{|c|}
69,04 \\
\end{tabular} & 188,61 & 189,35 & 66,06 & 1323,33 & 177,65 & 18,87 & 50,92 & 523,00 & 98,51 & 107,73 & 522,32 \\
\hline Salamandra salamandra & 29TNG71 & 101,00 & 123,47 & 93,49 & 39,85 & 4824,53 & 255,95 & 24,26 & 231,69 & \begin{tabular}{|c|c|}
67,47 \\
\end{tabular} & 186,21 & 186,93 & 64,12 & 1335,23 & 178,47 & 20,38 & 50,23 & 525,75 & \begin{tabular}{|c|}
102,88 \\
\end{tabular} & 111,40 & 524,43 \\
\hline Salamandra salamandra & 29TNG72 & 100,00 & 97,65 & 83,12 & 37,48 & 4745,83 & 225,53 & 6,75 & 218,78 & 42,20 & \begin{tabular}{|c|}
160,59 \\
\end{tabular} & 161,38 & 41,58 & 1545,54 & 206,22 & 28,51 & 49,13 & 607,76 & 130,75 & 134,74 & 607,72 \\
\hline Salamandra salamandra & 29TNG73 & 100,00 & 115,12 & 89,06 & 38,83 & 4792,36 & 245,33 & 18,81 & 226,53 & 61,56 & 177,89 & 178,53 & 57,06 & 1389,96 & 190,55 & 24,75 & 48,83 & 543,13 & 116,06 & 122,88 & 540,40 \\
\hline Salamandra salamandra & 29TNG74 & 100,00 & 118,22 & 89,85 & 39,04 & 4792,53 & 248,44 & 20,96 & 227,47 & 66,63 & 181,05 & 181,57 & 60,02 & 1355,98 & 189,64 & 24,99 & 48,16 & 527,67 & 115,35 & 123,03 & 523,51 \\
\hline Salamandra salamandra & 29TNG75 & $\begin{array}{l}100,00 \\
100\end{array}$ & $\begin{array}{cc}110,24 \\
95,31\end{array}$ & $\begin{array}{ll}83,00 \\
81,82\end{array}$ & 37,30 & 4670,93 & $\mid \begin{array}{l}\mid 240,44 \\
221,61\end{array}$ & $\begin{array}{r}2,, 29 \\
5,29\end{array}$ & $\frac{22,41}{216,32}$ & 年, 40,01 & $\begin{array}{l}101,03 \\
157,29\end{array}$ & $\mid$ & $\begin{array}{l}40,0<4 \\
40,48\end{array}$ & $\mid$ & $\mid \frac{109,04}{211,15}$ & $\begin{array}{ll}4,395 \\
32,5\end{array}$ & $\begin{array}{l}40,10 \\
47,17\end{array}$ & $\mid 598,54$ & \begin{tabular}{|l|l|}
140,23 \\
140,
\end{tabular} & \begin{tabular}{|l|}
145,68 \\
145
\end{tabular} & 596,07 \\
\hline Salamandra salamandra & 29TNG76 & 101,00 & 119,59 & 88,52 & 38,71 & 4750,27 & 247,99 & 22,54 & 225,45 & 68,06 & 181,81 & 182,36 & 61,94 & 1331,79 & 191,78 & 27,01 & 47,14 & 514,88 & 119,36 & 127,88 & 506,72 \\
\hline Salamandra salamandra & 29TNG77 & 101,00 & 133,18 & 91,21 & 39,10 & 4819,46 & 261,81 & 31,66 & 230,15 & 79,49 & 195,82 & 196,10 & 73,70 & 1193,18 & 176,81 & 24,51 & 46,56 & 456,50 & 108,58 & 116,42 & 442,62 \\
\hline Salamandra salamandra & 29TNG80 & 101,00 & 112,87 & 91,32 & $\mid 38,75$ & 4947,97 & 247,61 & $\mid 15,16$ & 232,45 & 53,01 & 177,90 & 178,60 & 53,01 & 1400,14 & 192,11 & 21,42 & 51,11 & 556,51 & $\mid 107,68$ & $\mid 112,99$ & 556,51 \\
\hline Salamandra salamandra & 29TNG81 & 99,00 & 115,24 & 91,50 & 38,82 & 4947,70 & 249,65 & 16,98 & 232,68 & 55,94 & 180,29 & 180,76 & 55,18 & 1364,75 & 183,45 & 21,60 & 50,37 & 539,13 & 106,90 & 111,89 & 538,88 \\
\hline Salamandra salamandra & 29TNG82 & 101,00 & 108,29 & 87,72 & 38,01 & 4896,41 & 240,41 & 12,73 & 227,68 & \begin{tabular}{|l|l|}
49,93 \\
\end{tabular} & 172,98 & 173,49 & 49,60 & 1410,36 & 187,29 & 24,39 & 49,53 & 554,55 & 115,56 & 120,32 & 554,48 \\
\hline Salamandra salamandra & 29TNG83 & 100,00 & 95,35 & 82,54 & 36,89 & 4825,88 & 224,96 & 4,18 & 220,77 & 39,97 & 159,66 & 160,33 & 38,78 & 1502,75 & 199,67 & 29,19 & 48,38 & 587,88 & 130,81 & 134,52 & 587,87 \\
\hline Salamandra salamandra & 29TNG84 & 101,00 & 115,06 & 89,61 & 38,44 & 4900,82 & 247,18 & 17,13 & 230,05 & 62,29 & 179,62 & 180,01 & 55,89 & 1330,30 & 182,38 & 24,65 & 48,11 & 516,80 & 113,30 & 119,51 & 514,85 \\
\hline Salamandra salamandra & 29TNG86 & 100,00 & 118,55 & 89,98 & 38,52 & 4887,39 & 249,84 & 19,15 & 230,69 & 65,38 & 182,86 & 183,30 & 59,50 & \begin{tabular}{|l|}
1277,69 \\
\end{tabular} & 180,86 & 25,94 & 46,84 & 491,94 & 114,51 & 120,97 & 485,73 \\
\hline Salamandra salamandra & 29TNG88 & 100,00 & 134,92 & 90,86 & 38,50 & 4962,84 & 263,78 & 30,42 & 233,36 & 79,33 & 199,65 & 199,84 & 74,12 & 1091,09 & 159,33 & 23,65 & 45,35 & 411,98 & \begin{tabular}{|l|l|l|}
101,28 \\
\end{tabular} & 106,87 & 399,33 \\
\hline Salamandra salamandra & 29TNG90 & 100,00 & 120,45 & 96,51 & 39,18 & 5118,80 & 260,85 & 17,93 & 242,93 & 57,81 & 187,52 & 187,92 & 57,81 & 1287,23 & 177,84 & 18,68 & 51,39 & 510,95 & 96,68 & 101,54 & 510,95 \\
\hline Salamandra salamandra & 29TNG91 & 101,00 & 106,49 & 88,55 & 37,63 & 5026,95 & 242,03 & 9,90 & 232,12 & 46,30 & 173,06 & 173,50 & 46,30 & 1386,53 & 188,86 & 23,03 & 50,32 & 548,86 & 111,20 & 114,51 & 548,86 \\
\hline Salamandra salamandra & 29TNG92 & 101,00 & 104,70 & 86,50 & 37,29 & 4987,78 & 238,55 & 9,44 & 229,12 & 45,29 & 170,90 & 171,31 & 45,29 & 1385,85 & 185,38 & 24,36 & 49,44 & 545,62 & 114,51 & 117,69 & 545,62 \\
\hline Salamandra salamandra & 29TNG93 & 100,00 & 96,32 & 83,47 & 36,6 & 4929,91 & 228,39 & 3,62 & 224,77 & 39,17 & 162,07 & 162,53 & 38,30 & 1441,20 & 190,75 & 27,84 & 48,34 & 563,31 & 125,34 & 128,21 & 563,31 \\
\hline Salamandra salamandra & 29TNG94 & 100,00 & 104,76 & 80,30 & 37,24 & 4947,62 & 237,78 & $\begin{array}{l}, 0< \\
9,36\end{array}$ & 228,42 & 50,88 & 170,56 & 170,87 & 45,91 & 1358,63 & 181,85 & 26,28 & 47, 47,98 & 528,21 & $\mid 118,26$ & $\mid 122,51$ & 528,04 \\
\hline Salamandra salamandra & 29TNG96 & 100,00 & 116,26 & 90,73 & 38,15 & 4979,74 & 250,19 & 15,81 & 234,38 & 62,01 & 181,98 & 182,26 & 56,26 & 1238,14 & 172,01 & 25,34 & 46,58 & 475,99 & 111,39 & 116,99 & 471,15 \\
\hline Salamandra salamandra & 29TNG97 & 101,00 & 128,47 & 93,28 & 38,48 & 5077,27 & 262,36 & 22,92 & 239,45 & 71,72 & 194,96 & 195,08 & 66,47 & 1102,83 & 156,57 & 22,98 & 45,68 & 418,49 & 100,50 & 103,93 & 409,70 \\
\hline Salamandra salamandra & 29TNG98 & 101,00 & 137,22 & 92,45 & 37,87 & 5162,84 & 269,37 & 28,60 & 240,77 & 79,01 & 204,71 & 204,75 & 73,95 & 989,93 & 142,03 & 21,46 & 44,79 & 370,10 & 91,71 & 93,81 & 359,00 \\
\hline Salamandra salamandra & 29TNG99 & 101,00 & 13 & 91,03 & 38, & 5016,64 & 264,07 & 28, & 235,55 & $77,8 \varepsilon$ & 199, & 200,11 & 73,2 & 1026,37 & 147,59 & 23 & 44 & 384,14 & 97,82 & 102,91 & 372,22 \\
\hline Salamandra salamandra & 29TNHO0 & 16,00 & $\begin{array}{l}134,29 \\
147,29 \\
\end{array}$ & $\begin{array}{l}51,030 \\
59,00\end{array}$ & $\begin{array}{l}30,14 \\
38,48\end{array}$ & 3400,52 & 230,67 & $\begin{array}{l}20,32 \\
78,95\end{array}$ & $\begin{array}{l}23,30 \\
151,71\end{array}$ & $\begin{array}{r}11,00 \\
112,29\end{array}$ & \begin{tabular}{|l|l|}
190,24 \\
\end{tabular} & $\begin{array}{l}|c|, 1 \\
191,67\end{array}$ & \begin{tabular}{|r|r|r|r|}
104,38 \\
\end{tabular} & $\begin{array}{l}1225,90 \\
120,\end{array}$ & $\begin{array}{l}|c| c \mid, 48 \\
174,48\end{array}$ & 26,265 & 46,81 & $\begin{array}{l}304,14 \\
491,57\end{array}$ & \begin{tabular}{|c|c|}
111,81 \\
111,81
\end{tabular} & $\begin{array}{l}\mid 134,71 \\
134,\end{array}$ & $45,2,57$ \\
\hline Salamandra salamandra & 29TNH01 & 40,00 & 144,58 & 59,91 & 38,18 & 3389,01 & 229,52 & 75,00 & 154,52 & 110,27 & 186,96 & 189,12 & 101,96 & 1190,85 & 170,30 & 27,81 & 45,66 & 475,97 & 115,04 & 138,49 & 430,70 \\
\hline Salamandra salamandra & 29TNHO2 & 97,00 & 132,26 & $\frac{63,14}{63,}$ & 37,98 & 3521,94 & 224,76 & 60,48 & \begin{tabular}{|l|l|l}
164,28 \\
\end{tabular} & \begin{tabular}{|l|l|}
97,19 \\
\end{tabular} & 177,01 & $\mid 179,36$ & 89,11 & $\begin{array}{l}1311,65 \\
131,05\end{array}$ & 191,91 & 32,75 & 44,97 & 520,73 & 131,71 & $\begin{array}{l}153,40 \\
\end{array}$ & 479,06 \\
\hline Salamandra salamandra & 29TNHO3 & 72,00 & 140,28 & 62,04 & 38,15 & 3441,65 & 229,47 & 68,97 & 160,50 & 106,00 & 183,51 & 186,10 & 97,60 & \begin{tabular}{|l|}
1187,87 \\
\end{tabular} & 170,53 & 29,84 & 44,38 & 470,94 & 121,46 & 144,58 & 424,12 \\
\hline Salamandra salamandra & 29TNH05 & 99,00 & 130,21 & 64,82 & 38,1 & 3496,92 & 225,11 & 57,22 & 167,89 & 96,18 & \begin{tabular}{|l|l|l|}
174,38 \\
\end{tabular} & 177,55 & 87,89 & 1236,42 & 176,17 & 33,7 & 42,70 & 484,35 & 135,19 & 157,82 & 436,14 \\
\hline 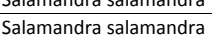 & \begin{tabular}{|l|}
29 TNHOG \\
2
\end{tabular} & $\begin{aligned} 91,01,00 \\
101\end{aligned}$ & $\begin{array}{l}130,21 \\
130,82\end{array}$ & $\begin{array}{ll}64,02 \\
64,73\end{array}$ & 38,44 & $\begin{array}{ll}3494,392 \\
344,75\end{array}$ & $\begin{array}{l}224,11 \\
224,58\end{array}$ & $\begin{array}{l}3,22 \\
58,12\end{array}$ & $\begin{array}{l}\mid 10,09 \\
166,45\end{array}$ & $97,90,50$ & $\begin{array}{l}174,30 \\
174,06\end{array}$ & \begin{tabular}{|l|}
177,43 \\
177,48
\end{tabular} & $\begin{array}{l}81,89 \\
89,05\end{array}$ & $\begin{array}{l}120,44 \\
1201,01 \\
\end{array}$ & \begin{tabular}{|l|l|}
168,81 \\
168,
\end{tabular} & 33,56 & 44,93 & |464,53 & \begin{tabular}{|l|}
134,43 \\
134,43
\end{tabular} & \begin{tabular}{|l|}
157,02 \\
157,51
\end{tabular} & $\begin{array}{ll}450,14 \\
418,84\end{array}$ \\
\hline Salamandra salamandra & 29TNH07 & 101,00 & 135,56 & 63,77 & 38,93 & 3340,52 & 225,72 & 63,71 & 162,01 & 103,33 & 176,99 & 180,78 & 94,75 & 1124,75 & 155,33 & 31,65 & 41,14 & 437,83 & 128,10 & 152,02 & 386,81 \\
\hline Salamandra salamandra & 29TNHO8 & 81,00 & \begin{tabular}{|l|l|}
139,86 \\
130
\end{tabular} & \begin{tabular}{|c|c|}
62,83 \\
\end{tabular} & 39,45 & 3245,91 & $\mid 226,50$ & |cos, 6 & \begin{tabular}{l|l}
10,01 \\
157,55
\end{tabular} & 108,65 & 179,71 & $\mid$\begin{tabular}{|l|l|}
183,68 \\
183
\end{tabular} & 99,93 & $\begin{array}{l}1+4,13 \\
1066,54\end{array}$ & $\mid \begin{array}{l}\mid 14,, 30,17 \\
146\end{array}$ & 30,11 & 40, 40,82 & | 45,03 & \begin{tabular}{|l|l|}
122,84 \\
122
\end{tabular} & 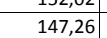 & 360,01 \\
\hline Salamandra salamandra & 29TNHO9 & 36,00 & 140,84 & 62,53 & 39,81 & 3197,92 & 225,89 & 70,47 & 155,42 & 110,27 & 179,88 & 184,00 & 101,47 & 1046,33 & 142,86 & 29,83 & 40,06 & 404,94 & 121,86 & 146,55 & 354,73 \\
\hline Salamandra salamandra & 29TNH10 & 61,00 & $\begin{array}{l}14,0,39 \\
146,39\end{array}$ & $\mid \begin{array}{ll}60,06 \\
60,5\end{array}$ & 37,91 & 3519,36 & 232,27 & 76,11 & 156,16 & 109,72 & 190,75 & 192,23 & 101,94 & $\begin{array}{l}1275,06 \\
120,5\end{array}$ & 185,37 & 28,73 & 46,99 & 509,45 & 116,28 & 138,47 & 472,93 \\
\hline 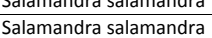 & $\begin{array}{l}29 \mathrm{TNH} 11 \\
2\end{array}$ & $\begin{array}{l}40,00 \\
40,0 \\
\end{array}$ & $14,146,34$ & $\begin{array}{l}60,40 \\
60,45 \\
\end{array}$ & $\begin{array}{l}37,91 \\
37,82\end{array}$ & $\begin{array}{l}3519,300 \\
3518,47\end{array}$ & $\mid \begin{array}{l}\mid 32,27 \\
233,20\end{array}$ & $\frac{\mid 0,11}{75,68}$ & $\begin{array}{l}30,10 \\
157,53\end{array}$ & \begin{tabular}{|l|l|l|l|l|}
109,97 \\
\end{tabular} & $\begin{array}{l}\mid l 90,73 \\
190,80\end{array}$ & $\begin{array}{l}92,23 \\
192,50\end{array}$ & \begin{tabular}{|l|}
102,34 \\
102,3
\end{tabular} & $\begin{array}{l}124,, 90 \\
124,93\end{array}$ & \begin{tabular}{|l|}
$\mid 103,5 \prime$ \\
180,28
\end{tabular} & 280,89 & - $40,99,24$ & \begin{tabular}{|c|}
30,45 \\
494,43
\end{tabular} & \begin{tabular}{|l|}
116,20 \\
116,57
\end{tabular} & \begin{tabular}{|l|}
$139,4,20$ \\
139
\end{tabular} & 4455,66 \\
\hline Salamandra salamandra & 29TNH13 & 101,00 & 134,28 & 65,16 & 37,83 & 3618,45 & 230,51 & 60,17 & 170,34 & 97,99 & 180,32 & 182,90 & 90,05 & 1306,88 & 191,55 & 33,69 & 44,61 & 514,94 & 132,93 & 154,63 & 475,23 \\
\hline Salamandra salamandra & 29TNH14 & 100,00 & & 66,01 & 37,97 & 3607,29 & 230,45 & 58, & 171 & 97,29 & 178,97 & 181,81 & 89,2 & 1284,45 & 186,08 & 34, & 43,76 & \begin{tabular}{|l|l|}
503,35 \\
\end{tabular} & 134,48 & 156,51 & 461,63 \\
\hline Salamandra salamandra & $29 T N H 15$ & 101,00 & 13 & 66,60 & 38,0 & 3585,35 & 229,44 & 56 & 172 & 96, & 176 & 180 & 88 & 1269,31 & 181,60 & 34, & 42, & 494,86 & 136,62 & 158,82 & 451,55 \\
\hline Salamandra salamandra & 29TNH16 & 100,00 & 129,53 & 66 & 38,2 & 553,02 & 227,55 & 54,86 & 172 & 94 & 174 & 177,92 & 86,69 & 1258,25 & 177,72 & 35, & 41,5 & 487,99 & 139,03 & 161,37 & 443,71 \\
\hline Salamandra salamandra & 29TNH19 & 64,00 & 140,89 & 63,56 & 39,93 & 3223,95 & 227,11 & 64,77 & 157,34 & $\begin{array}{r}209,84 \\
109\end{array}$ & 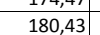 & 184,43 & $\mid \begin{array}{l}0,01,17 \\
101,1\end{array}$ & $\begin{array}{l}12059,58 \\
\end{array}$ & 143,29 & 30,28 & 40, & 408,67 & 122,48 & 146,75 & 361,63 \\
\hline Salamandra salamandra & 29TNH2O & 100,00 & 140,04 & 63,04 & 37,60 & 3718,64 & 232,42 & 66,87 & 165,55 & 101,01 & 187,7 & 188,88 & 93,81 & 1395,50 & 212,46 & 32, & 47,52 & 556,28 & 127,28 & 147,77 & 529,68 \\
\hline Salamandra salamandra & 29TNH22 & 98,00 & 142,56 & 64,37 & 37,83 & 3673,06 & 236,45 & 68,27 & 168,18 & 104,48 & 189,3 & 191,20 & 97,00 & 1282,23 & 189,18 & 31, & 45,59 & 505,62 & 124,06 & 145,95 & 470,89 \\
\hline Salaman & 29TNH23 & 100,00 & 140, & & 37, & a & & & 171 & 102 & 187 & 189,76 & 95,3 & & & 32, & 44 & 497,28 & 126,63 & 148,60 & 460,75 \\
\hline Salamandra salamandra & 29TNH24 & 10 & 13 & 6 & 38 & 365 & 23 & 63,64 & 173 & 102 & 185 & 188,60 & 94 & 1247,55 & 180,10 & 32, & 43 & 486,78 & 128,33 & 150,59 & 448,39 \\
\hline Salamandra salamandra & $29 T N H 25$ & 10 & & 68 & 38 & 3679,17 & 235,07 & 57,13 & 177 & 97,3 & 180,9 & 184,04 & 89,6 & 1277,87 & 182,81 & 34,92 & 42,98 & 495,32 & 135,80 & 157,76 & 456,50 \\
\hline Salamandra salamandra & 29TNH27 & 100,00 & $\begin{array}{l}129,17 \\
129,1 \\
\end{array}$ & $\begin{array}{l}0,4,83 \\
68,83\end{array}$ & 38,77 & 3574,89 & 228,79 & 53,35 & 175,45 & $\begin{array}{l}3,, 1,07 \\
94,\end{array}$ & 174,25 & $\begin{array}{l}104,04 \\
178,02\end{array}$ & 86,21 & $\begin{array}{l}1259,95 \\
125\end{array}$ & $\begin{array}{l}\mid 02,01 \\
175,62\end{array}$ & 36,27 & 41,11 & 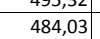 & $\begin{array}{l}350,00 \\
140,94\end{array}$ & 162,85 & 443,50 \\
\hline Salamandra salamandra & $29 \mathrm{TNH} 28$ & 101,00 & 138,15 & 66,22 & 39,76 & 3371,93 & 229,55 & 64,80 & 164,75 & 105,12 & 179,97 & 183,87 & 96,86 & 1124,24 & 152,92 & 32,00 & 40,55 & 432,17 & 126,98 & 150,29 & 389,89 \\
\hline Salamandra salamandra & 29TNH29 & 39,00 & 13 & 6 & 40,1 & 30 & 227 & 66,33 & 16 & 106 & 179,56 & 183 & 98,2 & 10 & 147 & 31, & 39 & 420,50 & 125,51 & 149,00 & 378,18 \\
\hline Salamandra salamandra & $29 \mathrm{TNH}$ & & & & $\frac{40}{37}$ & 391 & & $\frac{00}{58}$ & $17 \varepsilon$ & 94 & 186 & $\frac{183}{188}$ & $\begin{array}{l}90, \\
88,\end{array}$ & & $\mid \begin{array}{l}\mid 42,44 \\
225,06\end{array}$ & 34 & 47 & $\begin{array}{l}\mid 42,50 \\
572,47\end{array}$ & 13 & $\begin{array}{l}4,00 \\
151,25\end{array}$ & $\begin{array}{l}3 / 2,10 \\
553,08\end{array}$ \\
\hline Salamandra salamandra & 29TNH31 & 10 & 135,63 & 69,05 & 37,66 & 3905,13 & 237,49 & 56,52 & 180,97 & 94,42 & 186,07 & 187,56 & 87,79 & 1419,43 & 217,60 & 34,79 & 46,73 & 558,64 & 134,36 & 153,66 & 535,47 \\
\hline Salamandra salamandra & 29TNH32 & $\begin{array}{l}101,00 \\
100\end{array}$ & \begin{tabular}{l|l}
133,93 \\
13,9
\end{tabular} & $\begin{array}{l}70,52 \\
70,5\end{array}$ & 37,54 & $\begin{array}{l}39013,20 \\
3913,20\end{array}$ & \begin{tabular}{|l|}
238,69 \\
23,45
\end{tabular} & 50,324 & $\begin{array}{l}\mid l o, 51 \\
185,36\end{array}$ & \begin{tabular}{|l|}
93,42 \\
93,06
\end{tabular} & $\begin{array}{l}\mid l 0,0 \\
184,50\end{array}$ & 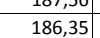 & 86,34 & $\begin{array}{l}140,43 \\
1407,16 \\
\end{array}$ & $\mid \begin{array}{l}\mid 12,0,47 \\
212,4\end{array}$ & 35,74 & 45,82 & $\begin{array}{l}5300,04 \\
550,13\end{array}$ & \begin{tabular}{|l|}
137,36 \\
137,36
\end{tabular} & $\begin{array}{l}153,00 \\
157,02 \\
\end{array}$ & 524,18 \\
\hline Salamandra salamandra & 29TNH33 & 101,00 & 140,89 & 68,88 & 37,78 & 3814,67 & 241,68 & 61,72 & 179,97 & 101,09 & 189,69 & 191,86 & 94,03 & 1286,69 & 188,93 & 32,96 & 44,87 & 500,80 & 127,77 & $\begin{array}{l}149,09 \\
\end{array}$ & 469,14 \\
\hline Salaman & 29TN & & & & 37 & & & & & & & & & & & & 43 & & 132,89 & 154,22 & 46 \\
\hline Salamandra salamandra & 29TNH35 & & & 72, & 37,68 & 3838,58 & $\mid 242,410$ & 50,95 & $\begin{array}{l}104,50 \\
189,45\end{array}$ & $\begin{array}{l}90,00 \\
94,15\end{array}$ & $\begin{array}{l}100,00 \\
182,04\end{array}$ & 185,10 & 86,7 & $\mid$ & $\mid$ & 36,64 & 43,10 & 509,81 & 140,19 & 161,30 & 476,37 \\
\hline Salamandra salamandra & 29TNH36 & 101,00 & 129,84 & 72,27 & 38,05 & 3774,65 & 236,38 & 49,07 & 187,31 & 92,04 & 178,03 & 181,37 & 84,62 & 1317,82 & 186,12 & 37,45 & 42,10 & 504,27 & 143,19 & 164,27 & 469,58 \\
\hline Salamandra salamandra & 29TNH37 & 101,00 & 127,82 & 71,68 & 38,69 & 3685,61 & 231,99 & 48,85 & 183,14 & 91,12 & 174,58 & 178,31 & 83,80 & \begin{tabular}{|l|}
1296,43 \\
\end{tabular} & 180,66 & 37,63 & 41,15 & 494,57 & 144,29 & 165,38 & 458,65 \\
\hline Salaman & $29 \mathrm{TN}$ & & & & 40,50 & 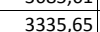 & & & & 104,80 & 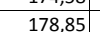 & 182,93 & 96,84 & & 148 & 32,07 & 39,82 & 423 & 126,76 & 149,62 & (50) \\
\hline Salamanc & $29 \mathrm{TNh}$ & 101,0 & 124 & 76, & 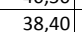 & & & & $197, \mathrm{C}$ & 80,5 & $178,1 \mathrm{C}$ & 179,6 & 74,6 & & 232 & 36 & 47, & 587,15 & 141,93 & 157,16 & \\
\hline 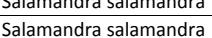 & $\begin{array}{l}29 \mathrm{TNH} 441 \\
2\end{array}$ & $\begin{array}{r}10,090 \\
99,00\end{array}$ & $\frac{124,43}{124,50}$ & $\begin{array}{l}10,04 \\
76,53\end{array}$ & $\begin{array}{l}38,40 \\
38,28\end{array}$ & $\begin{array}{l}412,21 \\
4087,47\end{array}$ & \begin{tabular}{|l|}
230,23 \\
236,72
\end{tabular} & 39,22 & $\begin{array}{l}197,01 \\
197,52 \\
\end{array}$ & $\begin{array}{l}80,58 \\
81,28\end{array}$ & $\begin{array}{l}178,19 \\
177,72\end{array}$ & \begin{tabular}{|l|}
$1 / 19,63$ \\
179,47
\end{tabular} & $\begin{array}{l}74,68 \\
75,52\end{array}$ & $\begin{array}{l}1499,32 \\
148,55 \\
\end{array}$ & $\mid$\begin{tabular}{|l|l}
232,03 \\
227,30
\end{tabular} & $\begin{array}{l}36,10 \\
37,16\end{array}$ & | 41,05 & $\begin{array}{l}58,13 \\
578,92\end{array}$ & \begin{tabular}{|l|}
141,93 \\
144,31
\end{tabular} & $\mid$\begin{tabular}{|l}
$\mid 51 /, 16$ \\
160,36
\end{tabular} & 561,84 \\
\hline
\end{tabular}




\begin{tabular}{|c|c|c|c|c|c|c|c|c|c|c|c|c|c|c|c|c|c|c|c|c|c|}
\hline TAXON & UTM & $\mathrm{km} 2$ & BIO1 & $\mathrm{B1O2}$ & $\mathrm{BIO3}$ & 8104 & B105 & B106 & B107 & B108 & B109 & BIO10 & BIO11 & BIO12 & B1013 & B1014 & 81015 & B1016 & BIO17 & B1018 & Bl019 \\
\hline Salamandra salamandra & 29TNH42 & 100,00 & 132,13 & 74,96 & 37,98 & 4042,12 & 242,29 & 47,15 & 195,13 & 89,34 & 184,54 & 186,42 & 83,32 & 1407,67 & 212,28 & 35,99 & 45,57 & 545,52 & 138,23 & 156,49 & 523,46 \\
\hline Salamandra salamandra & 29TNH43 & 101,00 & 140,12 & 72,87 & 37,98 & 3953,22 & 246,17 & 56,53 & 189,64 & 98,34 & 190,91 & 193,06 & 91,84 & 1293,19 & 190,16 & 33,42 & 44,74 & 499,02 & 128,68 & 149,06 & 471,50 \\
\hline Salamandra salamandra & 29TNH44 & 99,00 & 134,34 & 75,62 & 37,50 & 4016,51 & 247,01 & 47,82 & 199,18 & 92,76 & 186,25 & 188,81 & 86,23 & 1354,82 & 196,79 & 36,70 & 43,95 & 518,70 & 139,25 & 159,31 & 490,94 \\
\hline Salamandra salamandra & 29TNH45 & 100,00 & 133,85 & 75,41 & 37,71 & 3948,35 & 245,54 & 48,08 & 197,45 & 93,39 & 184,49 & 187,60 & 86,62 & 1327,24 & 189,42 & 36,86 & 42,92 & 505,97 & 139,84 & 160,39 & 476,27 \\
\hline Salamandra salamandra & 29TNH47 & 101,00 & 129,79 & 73,67 & 39,01 & 3726,10 & 235,43 & 48,83 & 186,61 & $\begin{array}{l}92,02 \\
\end{array}$ & 177,26 & 180,80 & 85,29 & 1276,81 & 177,09 & 37,02 & 41,03 & 484,24 & 141,41 & 162,11 & 451,80 \\
\hline Salamandra salamandra & 29TNH48 & 99,00 & 130,64 & 71,90 & 39,94 & 3580,81 & 231,16 & 52,91 & 178,25 & 94,65 & 175,87 & 179,58 & 87,62 & 1222,47 & 166,76 & 35,87 & 40,09 & 463,07 & 138,08 & 159,15 & 429,36 \\
\hline Salamandra salamandra & 29TNH49 & 99,00 & 138,44 & 68,49 & 41,26 & 3334,69 & 228,73 & 64,79 & 163,94 & 105,25 & 179,57 & 183,74 & \begin{tabular}{|c|}
97,48 \\
\end{tabular} & 1091,49 & 144,73 & 31,59 & 39,26 & 413,86 & 124,45 & 146,72 & 379,25 \\
\hline Salamandra salamandra & 29TNH50 & 101,00 & 115,81 & $\begin{array}{ll}80,39 \\
80,39\end{array}$ & $\begin{array}{ll}41,26 \\
38,78\end{array}$ & 4246,05 & 232,99 & 27,72 & 205,27 & $\begin{array}{r}, 2 \\
70,53 \\
\end{array}$ & 171,45 & 172,95 & 65,34 & 1493,95 & 224,52 & 36,57 & $\frac{\mid 3,20}{45,84}$ & $\begin{array}{l}415,00 \\
578,78\end{array}$ & \begin{tabular}{|l|l|l|l|l|}
145,19 \\
\end{tabular} & 158,22 & 565,92 \\
\hline Salamandra salamandra & 29TNH51 & 100,00 & 117,26 & 79,99 & 38,79 & 4189,91 & 233,81 & 29,61 & 204,20 & 72,66 & \begin{tabular}{|c|}
172,18 \\
\end{tabular} & 173,85 & \begin{tabular}{|c|}
67,67 \\
\end{tabular} & 1479,02 & 221,39 & 37,47 & 45,33 & 570,71 & 146,62 & 160,59 & 555,60 \\
\hline Salamandra salamandra & 29TNH53 & 101,00 & 136,65 & 77,41 & 38,54 & 4049,65 & 247,69 & 49,24 & 198,45 & 93,11 & 188,96 & 191,10 & 87,81 & 1301,01 & 191,18 & 34,07 & 44,30 & 497,36 & 130,92 & 149,73 & 473,88 \\
\hline Salamandra salamandra & 29TNH55 & 101,00 & 132,55 & 77,84 & 38,55 & 3952,98 & 244,93 & 45,58 & 199,35 & 91,08 & 183,42 & 186,37 & 85,47 & 1311,62 & 186,78 & 36,64 & 42,66 & 496,98 & \begin{tabular}{|l|l|}
138,85 \\
\end{tabular} & 158,30 & 470,35 \\
\hline Salamandra salamandra & 29TNH56 & 101,00 & 131,83 & 76,71 & 38,90 & 3858,57 & 241,48 & 46,94 & 194,54 & 91,76 & 181,28 & 184,54 & 85,86 & 1281,64 & 179,77 & 36,54 & 41,76 & 484,46 & 138,73 & 158,58 & 456,12 \\
\hline Salamandra salamandra & 29TNH57 & 100,00 & 129,49 & 75,79 & 39,47 & 3760,92 & 236,42 & 46,84 & 189,58 & \begin{tabular}{|c|}
90,69 \\
\end{tabular} & 177,58 & 181,00 & 84,70 & 1264,25 & 174,91 & 36,84 & 40,79 & 476,82 & 140,23 & 160,14 & 447,24 \\
\hline Salamandra salamandra & 29TNH58 & 101,00 & 136,43 & 72,36 & 40,72 & 3553,90 & 234,25 & 58,55 & 175,70 & \begin{tabular}{|l|l|}
100,03 \\
\end{tabular} & 181,02 & 184,78 & 93,25 & 1141,24 & 154,04 & 33,02 & 39,87 & 430,70 & 128,01 & 149,16 & 399,31 \\
\hline Salamandra salamandra & 29TNH59 & 98,00 & 140,77 & 69,91 & 41,80 & 3381,91 & 231,80 & 66,23 & \begin{tabular}{ll|}
165,56 \\
\end{tabular} & 106,31 & 182,51 & 186,54 & $\begin{array}{l}99,09 \\
\end{array}$ & 1058,70 & 139,63 & 30,57 & 39,04 & 399,41 & 120,42 & 142,28 & 367,09 \\
\hline Salamandra salamandra & 29TNH60 & 100,00 & 118,94 & 83,20 & 38,98 & 4353,18 & 238,48 & 27,84 & 210,64 & 71,76 & 175,90 & 177,36 & 67,11 & 1409,20 & 210,16 & 34,42 & 45,45 & 541,88 & 137,56 & 150,38 & 528,85 \\
\hline Salamandra salamandra & 29TNH61 & 101,00 & 119,95 & 82,67 & 39,13 & 4262,34 & 238,07 & 29,73 & 208,34 & 73,64 & 175,70 & 177,29 & 69,46 & 1400,04 & 207,77 & 35,43 & 44,95 & 536,38 & 139,36 & 153,01 & 521,48 \\
\hline Salamandra salamandra & 29TNH62 & 101,00 & 126,70 & 82,14 & 39,66 & 4142,87 & 242,07 & 37,06 & 205,01 & 81,27 & 180,62 & 182,46 & 77,59 & 1348,88 & 199,73 & 34,98 & 44,38 & 514,25 & 135,83 & 151,36 & 496,63 \\
\hline Salamandra salamandra & 29TNH63 & 100,00 & 127,69 & 81,29 & 39,80 & 4046,96 & 241,44 & 39,35 & 202,09 & \begin{tabular}{|l|l|}
83,45 & \\
\end{tabular} & 180,25 & 182,44 & 79,89 & 1331,88 & 194,42 & 35,67 & 43,65 & 505,65 & 137,02 & 153,53 & 485,67 \\
\hline Salamandra salamandra & 29TNH64 & 101,00 & 133,27 & 80,09 & 39,73 & 3986,03 & 244,84 & 45,28 & 199,56 & 89,76 & 184,79 & 187,14 & 85,81 & 1267,58 & 182,28 & 34,57 & 42,88 & 479,13 & 132,16 & 150,26 & 456,27 \\
\hline Salamandra salamandra & 29TNH65 & 101,00 & 130,40 & 79,78 & 39,77 & 3917,78 & 241,68 & 43,59 & 198,09 & 88,21 & 181,02 & 183,65 & 84,03 & 1279,46 & 181,47 & 35 , & 42,05 & 482,16 & 136,82 & 155,12 & 457,82 \\
\hline Salamandra salamandra & 29TNH67 & 100,00 & 126,03 & 77,79 & 40,01 & 3800,28 & 234,24 & 42,32 & 191,92 & 86,01 & \begin{tabular}{l|l}
174,86 \\
\end{tabular} & $\begin{array}{l}178,03 \\
\end{array}$ & 8 & 1264,47 & $\begin{array}{l}171,41 \\
174,59 \\
\end{array}$ & 37,33 & $\begin{array}{ll}40,38 \\
40,\end{array}$ & 474,41 & 141,64 & $\mid \begin{array}{l}\mid 160,31 \\
\end{array}$ & 446,85 \\
\hline Salamandra salamandra & 29TNH68 & 101,00 & 134,85 & 74,68 & 40,77 & 3631,25 & 235,43 & 54,60 & 180,83 & 96,81 & 180,73 & 184,20 & 90,95 & 1139,74 & 153,76 & 33,40 & 39,51 & 427,46 & \begin{tabular}{|l|l|}
128,78 \\
\end{tabular} & 149,04 & 397,92 \\
\hline Salamandra salamandra & 29TNH69 & 95,00 & 138,76 & 72,50 & 41,54 & 3500,36 & 233,97 & 61,39 & 172,57 & \begin{tabular}{|r|r|r|r|r|}
102,55 \\
\end{tabular} & 182,52 & 186,15 & 95,99 & 1070,00 & 141,51 & 31,45 & 38,83 & 401,11 & 122,61 & 143,65 & 370,04 \\
\hline Salamandra salamandra & 29TNH70 & 101,00 & 121,99 & 85,74 & 39,01 & 4488,05 & 244,15 & 27,49 & 216,65 & 72,54 & 180,79 & 181,86 & 68,41 & 1311,15 & 193,43 & 31,86 & 44,90 & 500,27 & 128,43 & 141,17 & 487,17 \\
\hline Salamandra salamandra & 29TNH72 & 100,00 & 120,88 & 84,11 & 39,92 & 4229,67 & 238,74 & 30,06 & 208,68 & 74,28 & 176,17 & 177,82 & 71,15 & 1325,34 & 192,94 & 34,76 & 43,67 & 502,72 & 135,75 & 149,76 & 486,41 \\
\hline Salamandra salamandra & 29TNH73 & 101,00 & $\begin{array}{l}12,00 \\
126,68\end{array}$ & $\begin{array}{l}84,29 \\
83,29\end{array}$ & $\begin{array}{ll}30,45 \\
40,45\end{array}$ & 4067,70 & $\mid 240,51$ & 37,36 & 203,15 & $\begin{array}{l}74,20 \\
81,38\end{array}$ & 179,54 & \begin{tabular}{|l|l|l|l|l|}
181,47 \\
\end{tabular} & 78,91 & $\begin{array}{l}1275,06 \\
1274\end{array}$ & $\begin{array}{l}192,54,29 \\
184\end{array}$ & $\begin{array}{l}34,16 \\
34,28\end{array}$ & \begin{tabular}{|l|l|}
43,04 \\
43
\end{tabular} & $\mid 481,31$ & $\begin{array}{l}3,1,43 \\
132,43\end{array}$ & \begin{tabular}{|l|}
148,01 \\
148,0
\end{tabular} & 462,41 \\
\hline Salamandra salamandra & 29TNH74 & 99,00 & 132,39 & 81,96 & 40,60 & 3987,50 & 243,52 & 43,78 & 199,74 & 88,08 & \begin{tabular}{|l|l|}
184,03 \\
\end{tabular} & 186,11 & 85,16 & 1213,25 & 173,05 & 33,25 & 42,24 & 455,95 & 127,77 & 145,03 & 434,40 \\
\hline Salamandra salamandra & 29TNH77 & 100,00 & 122,67 & 79,66 & 40,36 & 3855,55 & 232,35 & 37,61 & 194,73 & 81,38 & 172,28 & 175,29 & 77,27 & 1252,18 & 172,13 & 37,44 & 39,90 & 467,53 & 142,08 & 159,52 & 441,33 \\
\hline Salamandra salamandra & 29TNH78 & 100,00 & 125,41 & 78,00 & 40,75 & 3774,11 & 231,87 & 42,35 & 189,52 & 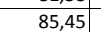 & 173,73 & 176,95 & 80,70 & 1203,79 & 163,01 & 36 & 39,10 & 448,58 & 138,77 & 157,20 & 420,48 \\
\hline Salamandra salamandra & 29TNH79 & 101,00 & 127,95 & 76,35 & 40,99 & 3677,10 & 230,73 & 46,82 & 183,90 & 89,37 & 174,66 & 178,06 & 84,01 & 1160,08 & 154,75 & 35,67 & 38,39 & 431,51 & 135,97 & 155,20 & 401,73 \\
\hline Salamandra salamandra & 29TNH80 & 101,00 & 121,66 & 80,03 & $\begin{array}{l}30,94 \\
38,94\end{array}$ & 4624,64 & \begin{tabular}{|l|l|}
$25,13,68$ \\
2468
\end{tabular} & 24,51 & 222,16 & $\begin{array}{l}0,44 \\
70,01\end{array}$ & 182,41 & 183,22 & $\begin{array}{l}04,01 \\
66,42\end{array}$ & $\begin{array}{l}11237,66 \\
1237\end{array}$ & \begin{tabular}{|l|l|l|l|l|l|}
179,48 \\
\end{tabular} & $\begin{array}{l}30,018 \\
30,18\end{array}$ & \begin{tabular}{|c|c|}
30,30 \\
44,30
\end{tabular} & | & \begin{tabular}{|l|}
122,14 \\
122
\end{tabular} & \begin{tabular}{|l|l|l|l|l|l|}
134,09 \\
\end{tabular} & 456,60 \\
\hline Salamandra salamandra & 29TNH84 & 100,00 & 127,03 & 83,97 & 40,56 & 4104,26 & 241,13 & 36,61 & 204,52 & 81,13 & 180,29 & 182,31 & 78,65 & 1198,23 & 169,39 & 33,26 & 41,66 & 448,57 & 128,19 & 144,12 & 428,34 \\
\hline Salamandra salamandra & 29TNH85 & 101,00 & 121,53 & 83,23 & 40,4 & 4063,13 & 235,80 & 32,57 & 203,23 & 76,8 & 174,31 & 176,45 & 73,91 & 1235,25 & 172,50 & 35, & 40,89 & 461,64 & 135,93 & 151,63 & 439,92 \\
\hline Salamandra salamandra & 29 TNH86 & 101,00 & & 82,36 & 40,2 & 4041,46 & 230,32 & 28 & 201, & 72 & 168,44 & 170,87 & 68,70 & 1270,44 & 175,37 & 37, & 39,99 & 473,87 & 143,78 & 159,12 & 450,46 \\
\hline Salamandra salamandra & 29TNH87 & 100,00 & 120,24 & 81,21 & 40,53 & 3948,06 & 231,67 & 33,64 & 198,03 & 77,44 & 171,24 & 173,84 & 73,78 & 1223,72 & 167,01 & 37,04 & 39,34 & 454,95 & 140,50 & 157,10 & 429,47 \\
\hline Salamandra salamandra & 29TNH88 & 101,00 & 120,39 & 79,96 & 40,75 & 3879,56 & 229,84 & 35,39 & \begin{tabular}{l|l|}
194,45 \\
\end{tabular} & 78,82 & 170,37 & 173,09 & 74,51 & 1209,88 & 163,08 & 37,42 & 38,62 & 448,59 & 141,75 & 158,84 & 421,24 \\
\hline Salamandra salamandra & 29TNH89 & 100,00 & 118,54 & 78,92 & 40,75 & 3828,43 & 226,61 & 34,99 & 191,62 & 77,91 & 167,77 & 170,85 & 73,56 & 1211,67 & 161,56 & 38,36 & 37,93 & 448,19 & 144,90 & 162,40 & 419,19 \\
\hline Salamandra salamandra & 29TNH91 & 101,00 & 11 & 88,03 & $39, \mathrm{C}$ & 4616,37 & 244,04 & 21,27 & 222,77 & 67,07 & 178,96 & 179,91 & 63,44 & 1205,83 & 171,39 & 30,8 & 43,10 & 454,83 & 123,06 & 135,26 & 441,25 \\
\hline salamandra & 29TNH93 & 10 & 09 & 86,50 & 39 & 880,79 & 240,84 & 26,0 & 214,82 & 71 & 177,34 & 178,84 & 68,3 & 1192,53 & 167,75 & 32, & 41, & 446,68 & 127,21 & 141,04 & 429,09 \\
\hline Salamandra salamandra & 29TNH94 & 10 & 48 & 85,68 & 40 & 4286,38 & 23 & 27,86 & 211,42 & 72,89 & 176,37 & 178,07 & $\frac{69,5}{69,9}$ & $\begin{array}{l}1187,30 \\
112,5\end{array}$ & 165,77 & 33, & 41,03 & 443,28 & $\mid 129,30$ & $\mid 143,69$ & 423,85 \\
\hline Salamandra salamandra & 29TNH95 & 16 & & 72 & 40 & $419 !$ & 23 & 29,28 & 208,05 & 73, & 175,04 & 176,95 & 70,86 & 118 & 164,11 & 34 & 40,28 & 441,78 & 132,04 & 146,98 & 420,39 \\
\hline Salamandra salamandra & 29TNH97 & 100,00 & 122,66 & 82,42 & 40, & 4034,11 & 235,08 & 34,51 & 200,57 & 78,55 & 174,71 & 177,24 & 74,77 & 1155,42 & $\frac{104,11}{156,30}$ & 35, & 38,88 & 427,68 & 133,61 & 150,03 & 402,29 \\
\hline Salamandra salamandra & 29TNH98 & 101,00 & 7 & 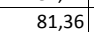 & 40, & 3959,32 & 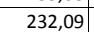 & 34,4 & 197 & 78 & 172,28 & 174,98 & 74,29 & 1159,91 & 155,18 & 36, & 38 & 428,21 & 137,12 & 153,85 & 401,04 \\
\hline Salamandra salamandra & 29TNH99 & 100,00 & & 24 & 40,5 & 3889,75 & 230,11 & $36, \mathrm{C}$ & 194, & 79, & 171,34 & 174,06 & 75,10 & 1152,55 & 152,47 & 36, & 37, & $\begin{array}{l}424,45 \\
\end{array}$ & 138,80 & 156,01 & 395,57 \\
\hline Salamandra salamandra & 29TNJ40 & $\begin{array}{c}18,00 \\
18,00 \\
\end{array}$ & $\frac{14}{14}$ & $\frac{6}{6}$ & $44, \frac{1,5}{41,}$ & 3225,38 & 22 & $\begin{array}{l}30,062 \\
68,62\end{array}$ & $\begin{array}{l}194,03 \\
158,34\end{array}$ & \begin{tabular}{|c|}
109,17 \\
\end{tabular} & \begin{tabular}{|l|l|l|l|l|}
180,34 \\
\end{tabular} & $\begin{array}{l}184,66 \\
184,6\end{array}$ & \begin{tabular}{r|r|r|}
101,00 \\
\end{tabular} & $\begin{array}{l}1040,24 \\
1040\end{array}$ & 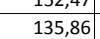 & $\begin{array}{ll}30, \\
30,\end{array}$ & $\begin{array}{ll}39,050 \\
39,00\end{array}$ & $\begin{array}{l}4244,43 \\
394,31\end{array}$ & $\begin{array}{l}1130,00 \\
119,52\end{array}$ & $\begin{array}{l}142,10 \\
142\end{array}$ & 359,59 \\
\hline Salamandra salamandra & 29TNJ50 & 35,00 & 140,32 & 69,33 & 42,05 & 3314,98 & 229,41 & 66,90 & 162,51 & 106,79 & 181,08 & 185,25 & 99,56 & 1041,52 & 135,65 & 30,56 & 38,54 & 392,02 & 120,49 & 142,51 & 359,29 \\
\hline Salamandra salamandra & 29TNJ51 & 48,00 & 137,32 & 69,06 & 42,18 & 3289,25 & 226,38 & 64, & \begin{tabular}{|l|l|}
161,79 \\
\end{tabular} & 104,32 & 177,74 & 182,08 & 96,99 & $\begin{array}{l}1053,97 \\
\end{array}$ & 136,43 & 32,00 & 37,81 & 395,00 & 125,51 & 147,40 & 360,88 \\
\hline Salamandra salamandra & 29TNJ60 & 66,00 & & 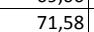 & 41 & 3427, & 231, & 62 , & 168 & 103 & , & 184,86 & 96,42 & 1051, & 137,08 & 31, & 38 & 393,14 & 123,14 & 144,39 & 360,99 \\
\hline Salamandra salamandra & 29TN & 82,00 & & 70, & 42 & & & 64 & & 104 & 180 & 18 & 97 & & 13 & 31 & & 386,40 & 123,21 & 144,96 & 352,94 \\
\hline Salamandra salamandra & 29TNJ62 & 77,00 & 138,50 & 69,71 & 42,42 & 3311,98 & 227,83 & 65,35 & 162,48 & 104,89 & 179,31 & 183,41 & 97,82 & 1028,44 & 132,74 & 31,91 & 37,02 & 383,10 & 124,55 & 146,55 & 348,41 \\
\hline Salamandra salamandra & 29TNJ70 & 100,00 & 127,38 & 75,21 & 41,21 & 3607,29 & 228,03 & 47,99 & 180,04 & 89,86 & \begin{tabular}{|l|l|}
172,98 \\
\end{tabular} & \begin{tabular}{|c|}
176,58 \\
\end{tabular} & 84,18 & 1147,25 & 151,21 & 35,90 & 37,79 & 425,82 & 137,08 & 156,62 & 394,60 \\
\hline Salamandra salamandra & 29TNJ71 & 101,00 & 129,37 & 73,82 & 41,56 & 3531,06 & 227,00 & 51,70 & 175,30 & $\begin{array}{l}92,88 \\
\end{array}$ & 173,72 & 177,51 & 86,87 & 1112,83 & 144,77 & 35,26 & 37,04 & 412,33 & 135,00 & 155,22 & 379,66 \\
\hline Salamandra salamandra & 29TNI80 & 100,00 & & 年 & 40,97 & 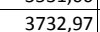 & 250 & 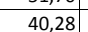 & 1. & 82,7 & & 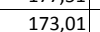 & 77,78 & & 153 & & 37,24 & 431,41 & 141,75 & 160,10 & 400,68 \\
\hline Salamandra salamandra & $29 \mathrm{TN}$ & & & & $4 I_{i}$ & 505 & & & 182,14 & & $1 / 0,26$ & $1 / 3,18$ & 80, & 1142, & 148, & & 36,76 & 420,70 & 140,61 & 159,65 & 388,46 \\
\hline Salamandra salamandra & 29TN82 & 100,00 & 130,16 & 74,18 & 41,87 & 3535,37 & 227,38 & 52,20 & 175,18 & 93,44 & 174,59 & 178,24 & 87,60 & 1077,42 & 138,13 & 35,11 & 36,12 & 396,33 & 134,04 & 154,27 & 362,51 \\
\hline Salamandra salamandra & 29TNI83 & 101,00 & 130,18 & 72,98 & 41,98 & 3479,40 & 225,55 & 53,48 & 172,07 & \begin{tabular}{|c|}
94,38 \\
\end{tabular} & 173,69 & 177,47 & 88,12 & 1072,64 & 137,44 & 35,55 & 35,79 & 393,85 & \begin{tabular}{|c|c|}
135,68 \\
\end{tabular} & 156,29 & 358,51 \\
\hline Salamandra salamandra & 29TNI84 & 31,00 & 128,7 & 72,62 & 42,07 & 463,58 & 223,64 & 525 & 171,13 & 93,16 & 172,00 & 175,75 & 86,98 & 1079,11 & 138,18 & 36,49 & 35,25 & 395,05 & 138,64 & 159,35 & 358,69 \\
\hline & 29TN & 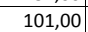 & & & 40 & 3826 & & & 190 & 79 & 169 & 172 & 75,19 & & 15 & 37, & & & & 158,99 & \\
\hline Salamandra salamandra & 29TNJ91 & 101,00 & 119,44 & 78,01 & $\begin{array}{ll}40,04,06 \\
41,1\end{array}$ & 3765,45 & 224,70 & 37,15 & \begin{tabular}{l|l}
187,55 \\
\end{tabular} & 79,81 & 167,50 & 170,67 & 74,70 & $\begin{array}{l}1154,74 \\
11,0\end{array}$ & $\mid$ & 38,31 & \begin{tabular}{|l|l|}
36,17 \\
3
\end{tabular} & 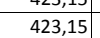 & \begin{tabular}{|l|}
141,40 \\
1440
\end{tabular} & \begin{tabular}{|l|l|}
162,42 \\
\end{tabular} & 391,05 \\
\hline
\end{tabular}




\begin{tabular}{|c|c|c|c|c|c|c|c|c|c|c|c|c|c|c|c|c|c|c|c|c|c|}
\hline TAXON & UTM & $\mathrm{km} 2$ & BIO1 & $\mathrm{B1O2}$ & $\mathrm{BIO3}$ & 8104 & B105 & B106 & B107 & B108 & B109 & 81010 & B1011 & BIO12 & B1013 & B1014 & 81015 & B1016 & BIO17 & B1018 & B1019 \\
\hline Salamandra salamandra & 29TNJ92 & 99,00 & 122,03 & 76,58 & 41,33 & 3678,40 & 224,31 & 41,38 & 182,93 & 83,46 & 168,71 & 172,09 & 78,17 & 1126,56 & 144,34 & 37,91 & 35,67 & 411,83 & 143,04 & 161,75 & 378,12 \\
\hline Salamandra salamandra & 29TNJ93 & 92,00 & 133,74 & 73,98 & 41,97 & 3525,79 & 229,64 & 55,54 & 174,11 & 96,84 & \begin{tabular}{|l|l|}
177,87 \\
\end{tabular} & 181,48 & 91,05 & 1025,37 & 131,62 & 34,11 & 35,33 & 374,76 & 130,39 & 150,86 & 339,41 \\
\hline Salamandra salamandra & 29TNI94 & 26,00 & 139,35 & 72,33 & 42,44 & 3429,44 & 231,53 & 63,05 & \begin{tabular}{|l|l|l|}
168,49 \\
\end{tabular} & $\begin{array}{r}103,72 \\
\end{array}$ & 181,98 & 185,72 & 97,65 & $\begin{array}{r}980,72 \\
\end{array}$ & $\mid 127,09$ & $\begin{array}{l}32,65 \\
32,65\end{array}$ & $\begin{array}{l}35,09 \\
35,\end{array}$ & 358,56 & 125,33 & 146,77 & 322,12 \\
\hline Salamandra salamandra & 29TPE03 & 99,00 & 143,31 & 93,20 & 36,73 & 5412,20 & 291,02 & 40,40 & 250,62 & 77,86 & 215,25 & 215,73 & 77,86 & 1056,32 & 156,96 & 9,67 & 55,29 & 430,96 & 65,84 & 65,92 & 430,96 \\
\hline Salamandra salamandra & 29TPE05 & 101,00 & 126,58 & 86,64 & 35,51 & 5336,17 & 268,16 & 27,58 & 240,57 & 62,81 & \begin{tabular}{|c|}
198,19 \\
\end{tabular} & 198,24 & 62,81 & 1256,14 & 190,94 & 11,95 & 56,14 & 514,50 & 76,92 & 76,93 & 514,50 \\
\hline Salamandra salamandra & 29TPE06 & 100,00 & 135,12 & 91,66 & 36,74 & 5328,00 & 278,88 & 32,86 & 246,03 & 70,31 & 205,51 & 205,99 & 70,31 & 1164,94 & 175,36 & 11,03 & 55,58 & 475,27 & 73,03 & 73,29 & 475,27 \\
\hline Salamandra salamandra & 29TPE07 & 101,00 & 141,90 & 96,20 & 37,94 & 5321,55 & 287,46 & 36,82 & 250,64 & 76,22 & 211,36 & 212,15 & 76,22 & 1091,34 & 162,71 & 10,26 & 55,15 & 443,22 & 69,66 & 70,37 & 443,22 \\
\hline Salamandra salamandra & 29TPE08 & 100,00 & 144,63 & 98,44 & 38,54 & 5297,72 & 290,27 & 38,25 & 252,02 & 78,79 & 213,46 & 214,23 & 78,79 & 1062,03 & 157,71 & 9,92 & 54,88 & 429,93 & 67,87 & 69,61 & 429,93 \\
\hline Salamandra salamandra & 29TPE09 & 100,00 & 139,40 & 97,45 & 38,44 & 5293,84 & 284,18 & 33,86 & 250,32 & 73,69 & 208,42 & 209,06 & 73,69 & 1121,11 & 167,79 & 10,81 & 55,10 & 454,88 & 72,02 & 73,49 & 454,88 \\
\hline Salamandra salamandra & 29TPE13 & 101,00 & 138,06 & 90,21 & 35,47 & 5541,54 & 286,28 & 35,83 & 250,45 & 71,63 & 212,30 & 212,50 & 71,63 & 1089,64 & 163,14 & 9,87 & 55,65 & 444,77 & 66,97 & 66,98 & 444,77 \\
\hline Salamandra salamandra & 29TPE14 & 101,00 & 143,73 & 93,64 & 36,32 & 5535,10 & 293,33 & 39,08 & 254,25 & \begin{tabular}{l|l}
76,45 \\
\end{tabular} & 217,15 & 217,53 & 76,45 & 1033,99 & 153,73 & 9,37 & 55,26 & 420,45 & 64,75 & 64,79 & 420,45 \\
\hline Salamandra salamandra & 29TPE15 & 99,00 & 129,26 & 87,30 & 35,12 & 5467,14 & 273,53 & 28,66 & 244,87 & 63,75 & 202,52 & 202,53 & 63,75 & 1199,32 & 181,90 & 11,09 & 55,96 & 490,30 & 73,40 & 73,40 & 490,30 \\
\hline Salamandra salamandra & 29TPE16 & 100,00 & 89,37 & 73,79 & 32,38 & 5308,01 & 222,81 & $-1,45$ & 224,25 & $\begin{array}{l}29,35 \\
\end{array}$ & 162,23 & 162,23 & 29,35 & 1627,76 & 249,32 & 17,25 & 56,10 & \begin{tabular}{|c|}
663,37 \\
\end{tabular} & 100,90 & 100,90 & 663,37 \\
\hline Salamandra salamandra & 29TPE17 & 100,00 & 105,52 & 77,94 & 33,30 & 5333,84 & 240,87 & 11,12 & 229,75 & 43,46 & 177,77 & 177,83 & 43,46 & 1488,39 & 230,10 & 14,23 & 56,81 & 610,46 & 89,59 & 89,68 & 610,46 \\
\hline Salamandra salamandra & 29TPE18 & 101,00 & 138,06 & 94,81 & 37,17 & 5436,40 & 284,38 & 32,78 & 251,60 & 71,02 & 209,38 & 209,73 & 71,02 & 1101,46 & 165,42 & 10,36 & 55,31 & 447,47 & 70,05 & 70,65 & $\begin{array}{lll}447,47 \\
\end{array}$ \\
\hline Salamandra salamandra & 29TPE19 & 101,00 & 138,73 & 96,68 & 37,72 & 5420,53 & 285,38 & 32,53 & 252,85 & 71,60 & 209,64 & 209,95 & 71,60 & 1094,17 & 164,30 & 10,36 & 55,31 & 444,18 & 69,92 & 70,79 & 444,18 \\
\hline Salamandra salamandra & 29TPE23 & 100,00 & 136,93 & 89,41 & 34,98 & 5655,55 & 286,47 & 34,08 & 252,39 & 69,31 & 212,77 & 212,88 & 69,31 & 1072,25 & 160,25 & 9,60 & 55,52 & 436,33 & 65,86 & 65,86 & 436,33 \\
\hline Salamandra salamandra & 29TPE24 & 100,00 & 142,68 & 92,77 & 35,65 & 5654,12 & 293,58 & 37,45 & 256,12 & 74,19 & 217,73 & 218,05 & 74,19 & 1014,30 & 150,67 & 8,95 & 55,21 & 411,38 & 63,29 & 63,31 & 411,38 \\
\hline Salamandra salamandra & 29TPE25 & 101,00 & 137,34 & 90,80 & 35,35 & 5606,22 & 285,74 & 33,34 & 252,40 & 69,51 & 211,78 & 212,03 & 69,51 & 1075,73 & 161,29 & 9,71 & 55,46 & 437,30 & 66,83 & 66,87 & 437,30 \\
\hline Salamandra salamandra & 29TPE26 & 101,00 & 103,49 & 76,74 & 32,49 & 5450,47 & 240,55 & 9,06 & 231,49 & 40,44 & \begin{tabular}{ll|}
177,45 \\
\end{tabular} & 177,47 & 40,44 & 1460,65 & 224,47 & 13,97 & 56,51 & 598,38 & 87,92 & 88,13 & 598,38 \\
\hline Salamandra salamandra & 29TPE27 & 100,00 & 106,99 & 77,23 & 32,68 & 5450,44 & 243,96 & 11,69 & 232,27 & 43,10 & 180,52 & 180,54 & 43,10 & 1421,80 & 219,17 & 13,32 & 56,76 & 583,80 & 85,34 & 86,46 & 583,80 \\
\hline Salamandra salamandra & 29TPE28 & 100,00 & 115,82 & 82,63 & 34,00 & 5469,42 & 255,98 & 17,15 & 238,83 & 50,50 & 188,84 & $\mid 188,97$ & 50,50 & 1311,44 & 200,81 & 12,45 & 56,23 & 537,03 & 80,49 & 82,35 & 537,03 \\
\hline Salamandra salamandra & 29TPE29 & 101,00 & 140,71 & 97,32 & 37,40 & 5537,38 & 289,73 & 33,15 & 256,58 & 72,15 & 213,23 & 213,42 & 72,15 & 1031,62 & 154,36 & 9,59 & 55,08 & 417,47 & 65,82 & 66,46 & 417,47 \\
\hline Salamandra salamandra & 29TPE33 & 101,00 & 151,94 & 96,18 & 35,97 & 5812,66 & 307,44 & 43,36 & 264,08 & 84,32 & 228,71 & 229,21 & 81,34 & $\begin{array}{l}887,47 \\
\end{array}$ & 129,32 & 7,58 & 54,42 & 356,64 & 56,06 & 56,28 & 356,61 \\
\hline Salamandra salamandra & 29TPE34 & 100,00 & 144,07 & 93,37 & 35,58 & 5763,97 & 297,00 & 37,53 & 259,47 & \begin{tabular}{ll|}
74,25 \\
\end{tabular} & 220,63 & 220,80 & 74,25 & 963,29 & 142,08 & 8,48 & 54,82 & 388,56 & 60,65 & 60,78 & 388,56 \\
\hline Salamandra salamandra & 29TPE36 & 101,00 & 139,74 & 92,73 & 35,61 & 5699,14 & 290,19 & 33,56 & 256,64 & 70,23 & 215,06 & 215,18 & 70,23 & 1004,28 & 149,39 & 9,13 & 54,98 & 405,67 & 63,55 & 64,08 & 405,67 \\
\hline Salamandra salamandra & 29TPE37 & 100,00 & $\mid \begin{array}{l}\mid 5,1,4 \\
126,44\end{array}$ & 86,62 & $\begin{array}{l}30,013 \\
34,39\end{array}$ & 5632,12 & |l, & 24,14 & 247,04 & 58,40 & 201,32 & $\mid \begin{array}{l}\mid 201,39 \\
201,39\end{array}$ & 58,40 & $\begin{array}{l}1136,45 \\
1136\end{array}$ & \begin{tabular}{|l|}
$\mid 47,391$ \\
171,51
\end{tabular} & $\mid \begin{array}{c}3,15 \\
10,64\end{array}$ & $\begin{array}{l}54,48 \\
55,4\end{array}$ & |401,08 & $\mid 70,81$ & $\begin{array}{l}73,01 \\
73,01\end{array}$ & 461,98 \\
\hline Salamandra salamandra & 29TPE38 & 101,00 & 108,42 & 77,78 & 32,55 & 5536,88 & 247,27 & 11,75 & 235,51 & 42,64 & 182,53 & 182,68 & 42,64 & 1323,69 & 202,22 & 12,65 & 56,09 & 541,51 & 81,32 & 87,37 & 541,51 \\
\hline Salamandra salamandra & 29TPE39 & 99,00 & 129,36 & 90,95 & 35,62 & 5612,20 & 276,53 & 24,79 & 251,73 & 60,76 & 203,41 & 203,57 & 60,76 & 1096,85 & 165,15 & 10,54 & 55,27 & 444,89 & 69,91 & 71,83 & 444,89 \\
\hline Salamandra salamandra & 29TPE43 & 101,00 & 153,35 & 97,14 & 35,97 & 5887,56 & 310,18 & 43,60 & 266,59 & 89,12 & 231,20 & 231,48 & 81,69 & 837,38 & 120,72 & 7,00 & 53,85 & 334,35 & 53,38 & 53,65 & 333,63 \\
\hline Salamandra salamandra & 29TPE44 & 100,00 & 149,48 & 96,03 & 35,86 & 5860,33 & 304,97 & 40,37 & 264,60 & 84,59 & 226,95 & 227,18 & 78,09 & 871,44 & 126,58 & 7,52 & 54,06 & 348,36 & 55,63 & 55,78 & 347,93 \\
\hline Salamandra salamandra & 29TPE45 & $\begin{array}{l}101,00 \\
100\end{array}$ & \begin{tabular}{|l|}
142,40 \\
142,38 \\
\end{tabular} & 93,54 & $\begin{array}{l}30,00 \\
35,41 \\
\end{array}$ & $\begin{array}{l}50024,43 \\
5824\end{array}$ & | 204,65 & 34,92 & $\begin{array}{l}204,00 \\
260,76\end{array}$ & $\begin{array}{l}-74,83 \\
74,84\end{array}$ & 219,54 & | $219,65 \mid$ & 71,49 & $\begin{array}{l}\mid r /, 44 \\
934,96\end{array}$ & \begin{tabular}{|l|l|}
137,33 \\
137
\end{tabular} & $\begin{array}{ll}8,242 \\
8,42\end{array}$ & \begin{tabular}{|c|}
54,35 \\
54
\end{tabular} & $\begin{array}{l}340,30 \\
374,92\end{array}$ & $\begin{array}{l}59,03 \\
59,48\end{array}$ & 59,90 & 374,91 \\
\hline Salamandra salamandra & 29TPE46 & 99,00 & 140,79 & 93,71 & 35,62 & 5799,87 & 293,41 & 33,34 & 260,08 & 71,02 & 217,52 & 217,64 & 70,04 & 944,75 & 139,10 & 8,62 & 54,33 & 378,87 & 60,64 & 61,32 & 378,87 \\
\hline Salamandra salamandra & 29TPE47 & 101,00 & 132,53 & 90,33 & 34,91 & 5754,58 & 282,24 & 27,16 & 255,08 & 62,33 & 208,59 & 208,83 & 62,33 & 1017,71 & 151,31 & 9,6 & 54,73 & 409,90 & 64,86 & 66,79 & 409,90 \\
\hline Salamandra salamandra & 29TPE48 & 99,00 & 117,54 & 82,71 & 33,32 & 5674,60 & 261,50 & 16,91 & 244,60 & 48,9 & 192,78 & 193,24 & 48,96 & 1155,77 & 173,94 & 11, & 55,15 & 468,54 & 73,04 & 77,68 & 468,54 \\
\hline Salamandra salamandra & 29TPE49 & 101,00 & 125,55 & 88,94 & 34,86 & 5693,66 & 273,09 & 21,39 & 251,70 & 56,06 & 200,71 & 201,07 & 56,06 & 1071,79 & 160,32 & 10,53 & 54,81 & 432,91 & 69,15 & 71,71 & 432,91 \\
\hline Salamandra salamandra & 29TPE53 & 100,00 & 151,91 & 97,36 & 35,85 & 5953,50 & 309,70 & 41,55 & 268,15 & \begin{tabular}{|c|}
87,23 \\
\end{tabular} & 230,81 & 231,01 & 79,58 & 808,77 & 115,52 & 6,97 & 53,33 & 321,81 & 52,04 & 52,23 & 319,62 \\
\hline Salamandra salamandra & 29TPE54 & 100,00 & 147,75 & 95,98 & 35,62 & 5933,51 & 304,19 & 38,06 & 266,13 & 83,16 & 226,32 & 226,50 & 75,69 & 844,05 & 121,51 & 7,38 & 53,61 & 335,96 & 54,66 & 54,79 & 334,47 \\
\hline Salamandra salamandra & 29TPE55 & 100,00 & 139,99 & 93,16 & 35,09 & 5892,53 & 294,01 & 32,20 & 261,81 & 76,16 & 218,11 & 218,19 & 68,40 & 909,11 & 132,39 & 8,41 & 53,90 & 362,66 & 58,54 & 59,38 & 361,92 \\
\hline Salamandra salamandra & 29TPE56 & 101,00 & 3,25 & 88,22 & 34,2 & 35,14 & 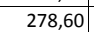 & 23 & 254,82 & 62,95 & 205,80 & 206,08 & 57,84 & 1007,41 & 148,40 & 9,6 & 54,15 & 403,27 & 64,49 & 67,35 & 403,21 \\
\hline Salamandra salamandra & 29TPE57 & $\frac{10}{10}$ & 18 & 85,75 & $\begin{array}{l}33, \\
33,\end{array}$ & 5797,09 & 27 & 19,26 & 250,98 & 53 & 199,19 & 199,57 & 52,20 & $\begin{array}{l}1057,68 \\
108\end{array}$ & 156,75 & 10,2 & 54,34 & 424,65 & 67,76 & 71,56 & 424,64 \\
\hline Salamandra salamandra & 29TPE58 & & 12 & 85,76 & 33, & 5774,86 & 268 & 17,55 & 250,48 & & 196,97 & 197,58 & 50,51 & 1064,41 & 157,89 & 10,49 & 54,30 & \begin{tabular}{|l|}
427,55 \\
\end{tabular} & 68,80 & 72,51 & 427,55 \\
\hline Salamandra salamandra & 29TPE63 & 10 & 147,31 & 96,56 & 35,56 & 6005,60 & 305,46 & 37,25 & 268,21 & 82,40 & 227,14 & 227,18 & 74,60 & \begin{tabular}{|l|}
805,58 \\
805,58
\end{tabular} & 114,23 & 7,23 & 52,82 & 319,18 & 52,55 & 52,87 & 315,84 \\
\hline Salamandra salamandra & 29TPE64 & 10 & 18 & 97,18 & 35,78 & 39,67 & 305,84 & 37 & 268 & 82 & 227,58 & 227,62 & 75,21 & 797,19 & 113,21 & 7,1 & 52,86 & 315,68 & 52,29 & 52,49 & 312,48 \\
\hline Salamandra salamandra & 29TPE65 & 100 & 129,91 & 90,14 & 34,26 & 29,70 & 283,01 & 23,91 & 259,10 & 66,46 & 208,92 & 209,16 & 58,67 & 944,84 & $\mid \begin{array}{l}\mid 136,77 \\
136,1\end{array}$ & 9,21 & 53,25 & 375,78 & 61,54 & 63,95 & 373,87 \\
\hline Salamandra salamandra & 29TPE66 & 10 & 12 & $\begin{array}{ll}0,149 \\
86,97\end{array}$ & 33,7 & 5881,62 & $\begin{array}{l}\mid 023,01 \\
272,26\end{array}$ & 17,83 & 254,43 & $\begin{array}{l}50,40 \\
59,20\end{array}$ & \begin{tabular}{|l|}
200,18 \\
\end{tabular} & $\begin{array}{l}\mid 200,57 \\
200\end{array}$ & $\begin{array}{ll}51,21 \\
51\end{array}$ & $\begin{array}{r}34,, 44 \\
1009,52 \\
\end{array}$ & $\begin{array}{ll}147,16 \\
140,16\end{array}$ & $\begin{array}{r}1,210 \\
10,10\end{array}$ & \begin{tabular}{|c|}
53,46 \\
532
\end{tabular} & $\begin{array}{l}402,21 \\
402,21\end{array}$ & $\begin{array}{ll}61,34,82 \\
65\end{array}$ & $\begin{array}{l}69,68 \\
69,\end{array}$ & $\begin{array}{l}37,0,07 \\
400,97\end{array}$ \\
\hline Salamandra salamandra & 29TPE67 & 101,00 & & 89,10 & 34,18 & 5888,96 & 276,66 & 19,84 & \begin{tabular}{|l|l|}
256,83 \\
\end{tabular} & 61,99 & 203,34 & 203,90 & 54,13 & $\begin{array}{l}971,07 \\
\end{array}$ & 141,31 & 9,83 & 53,26 & 386,21 & 64,13 & 66,99 & 385,15 \\
\hline Salamandra salamandra & 29TPE73 & 100,00 & 30 & 98,84 & 35,77 & 6062,09 & 310,71 & 38,27 & 272,44 & 84,43 & 230,77 & 230,80 & 76,58 & 739,65 & 102,88 & 6,62 & 51,89 & 290,90 & 49,06 & 49,23 & 285,78 \\
\hline Salamandra salamandra & 29TPE76 & 101,00 & & 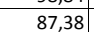 & 33, & 36,45 & 267,97 & 12, & 255 & 53 & 195, & 196,01 & 45,46 & 998,94 & 143 & 10,5 & 52 & 395,43 & 67,06 & 71,63 & 392,21 \\
\hline Salamandra salamandra & 29TPE77 & 10 & & 9 & 34, & 6 & & & 259 & & 201 & 201 & 50 & 938 & & 9, & & & 63,72 & 66,87 & 367,88 \\
\hline Salamandra salamandra & 29TPE85 & 101,00 & 126,42 & 93,40 & 34,64 & 6044,36 & 283,86 & 18,13 & 265,73 & 61,90 & 207,17 & 207,49 & 54,01 & 867,71 & 120,90 & 9,38 & 51,16 & 339,84 & 60,08 & 62,81 & 334,06 \\
\hline Salamandra salamandra & 29TPE86 & 100,00 & 117,60 & 90,52 & 34,02 & 6008,49 & 272,64 & 11,27 & 261,36 & 53,76 & 197,92 & 198,45 & 45,95 & 928,26 & 130,25 & 10,32 & 51,22 & 364,31 & 64,53 & 68,45 & 358,97 \\
\hline Salamandra salamandra & 29TPE87 & 100,00 & 124,01 & 93,18 & 34,67 & 6018,82 & 280,22 & 15,67 & 264,55 & 59,25 & 203,85 & 204,61 & 51,39 & 866,80 & 121,19 & 9,70 & 50,97 & 339,73 & 60,96 & 63,50 & 334,53 \\
\hline Salamandra salamand & 29TPE95 & 100,00 & & & 35,24 & 10 & & & 277 & 67,52 & | & 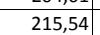 & 59,77 & 762,8 & 1.21 & 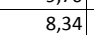 & & 295,84 & 54,36 & 55,87 & 288,21 \\
\hline Salamandra salamandra & 29TP & & & & 34, & 6085 & & & 267 & 56,49 & 202 & 203 & 48,71 & 839 & 114 & & 49,81 & 326,27 & 60,70 & 63,49 & 318,88 \\
\hline Salamandra salamandra & 29TPE97 & 101,00 & 123,33 & 95,54 & 35,03 & 6081,09 & 282,39 & 13,56 & 268,83 & 57,85 & 204,07 & 204,93 & $\begin{array}{ll}40,15 \\
50,15\end{array}$ & 815,68 & 111,21 & \begin{tabular}{|l|l|}
9,77 \\
\end{tabular} & 49,60 & 316,66 & 59,75 & 62,02 & 309,32 \\
\hline Salamandra salamandra & 29TPE99 & 100,00 & 129,38 & 99,10 & 35,98 & 6061,66 & 289,52 & 17,34 & 272,18 & 63,10 & 209,68 & 210,36 & 55,57 & 750,64 & \begin{tabular}{|l|l|l|l|}
101,66 \\
\end{tabular} & 8,98 & 49,19 & 290,90 & 56,43 & 57,15 & 283,99 \\
\hline Salamandra salamandra & 29TPF01 & 100,00 & 128,78 & 95,58 & 38,14 & 5282,38 & 72,01 & 24,88 & 247,14 & 63,64 & 197,92 & 198,34 & 63,64 & 1241,40 & 187,92 & 12,69 & 55,62 & 505,95 & 80,76 & 81,46 & 505,95 \\
\hline Salam & 29TPt & & & & & & & & 241,10 & 50,04 & 183, & 183 & 50,04 & 387 & & 15 , & 55,33 & 56 & 92,49 & 92,91 & \\
\hline Salamandra salamandra & 29TPF04 & 100,00 & $\mid 128,77$ & 101,16 & 39,55 & 5306,69 & 275,19 & 22,47 & 252,72 & $\begin{array}{ll}62,85 \\
62,\end{array}$ & $\begin{array}{l}197,94 \\
197\end{array}$ & \begin{tabular}{|l|l|}
198,38 \\
\end{tabular} & 62,85 & 1242,10 & 187,23 & $\begin{array}{ll}20,003 \\
3,26\end{array}$ & 55,32 & 505,25 & 81,75 & 84,25 & 505,25 \\
\hline
\end{tabular}




\begin{tabular}{|c|c|c|c|c|c|c|c|c|c|c|c|c|c|c|c|c|c|c|c|c|c|}
\hline TAXON & UTM & $\mathrm{km} 2$ & BIO1 & $\mathrm{B1O2}$ & $\mathrm{BIO3}$ & B104 & B105 & B106 & B107 & B108 & B109 & 81010 & B1011 & BIO12 & B1013 & B1014 & 81015 & B1016 & BIO17 & B1018 & 81019 \\
\hline Salamandra salamandra & 29TPF06 & 100,00 & 141,31 & 108,38 & 40,93 & 5312,79 & 291,76 & 30,46 & 261,30 & 79,60 & 209,92 & 210,29 & 74,38 & 1113,87 & 165,33 & 11,38 & 54,92 & 449,72 & 71,98 & 77,73 & 448,75 \\
\hline Salamandra salamandra & 29TPF07 & 101,00 & 129,25 & 104,96 & 40,17 & 5320,59 & 279,02 & 21,27 & 257,75 & 69,15 & 198,58 & 198,93 & 63,25 & 1223,92 & 181,16 & 14,12 & 54,73 & 496,20 & 82,95 & 87,13 & 494,7 \\
\hline Salamandra salamandra & 29TPF08 & 100,00 & 108,66 & $\begin{array}{l}34,52 \\
93,52 \\
\end{array}$ & 38,00 & 5223,34 & 250,90 & $\begin{array}{r}\mid 8,30 \\
8,30\end{array}$ & 242,61 & 45,75 & 178,02 & 178,18 & 45,68 & 1370,44 & 197,65 & 19,63 & 52,80 & 551,13 & 101,85 & $\mid 103,26$ & 551,12 \\
\hline Salamandra salamandra & 29TPF09 & 100,00 & 111,77 & 94,08 & 38,18 & 5213,47 & 253,83 & 10,63 & 243,20 & 48,68 & 180,74 & 180,98 & 48,68 & 1325,43 & 188,43 & 19,36 & 52,06 & 530,87 & 99,87 & 101,47 & 530,87 \\
\hline Salamandra salamandra & 29TPF10 & 100,00 & 136,14 & 97,26 & 37,92 & 5414,49 & 282,79 & 29,94 & 252,85 & 69,04 & 207,02 & 207,27 & 69,04 & 1121,47 & 169,00 & 10,83 & 55,29 & 455,61 & 72,08 & 72,82 & 455,61 \\
\hline Salamandra salamandra & 29TPF11 & 100,00 & 128,63 & 95,37 & 37,60 & 5404,76 & 274,24 & 23,95 & 250,29 & \begin{tabular}{ll|l}
62,05 \\
\end{tabular} & 199,63 & 199,88 & 62,05 & 1200,90 & 182,25 & 12,14 & 55,80 & 489,67 & 77,94 & 78,26 & 489,67 \\
\hline Salamandra salamandra & 29TPF12 & 100,00 & 118,88 & 91,96 & 36,84 & 5385,78 & 262,58 & 16,65 & 245,93 & 53,27 & 190,27 & 190,32 & 53,27 & 1295,22 & 197,19 & 13,90 & 55,95 & 529,52 & 84,37 & 85,12 & 529,52 \\
\hline Salamandra salamandra & 29TPF13 & 101,00 & 121,03 & 95,23 & 37,65 & 5397,58 & 266,55 & 17,10 & 249,45 & 54,91 & 192,27 & 192,40 & 54,91 & 1270,64 & 192,82 & 13,83 & 55,64 & 518,67 & 83,82 & 84,37 & 518,67 \\
\hline Salamandra salamandra & 29TPF15 & 100,00 & 140,38 & 106,18 & 40,16 & 5405,68 & 290,95 & 29,63 & 261,32 & 73,99 & 210,42 & 210,69 & 72,49 & 1074,86 & 160,31 & 10,99 & 54,83 & 433,77 & 69,73 & 73,32 & 433,71 \\
\hline Salamandra salamandra & 29TPF16 & 101,00 & 133,02 & 106,93 & 40,08 & 5451,47 & 286,04 & 22,66 & 263,38 & 70,80 & 203,93 & 204,22 & 65,01 & 1150,71 & 172,83 & 12,42 & 55,22 & 467,60 & 76,12 & 78,60 & 466,91 \\
\hline Salamandra salamandra & 29TPF17 & 99,00 & 124,80 & 103,41 & 39,44 & 5430,11 & 275,66 & 16,91 & 258,75 & 60,08 & 195,94 & 196,20 & 57,73 & 1205,82 & 179,03 & 14,42 & 54,47 & 488,74 & 83,17 & 84,79 & 488,54 \\
\hline Salamandra salamandra & 29TPF18 & 101,00 & 116,77 & 98,81 & 38,68 & 5375,05 & 264,19 & 11,86 & 252,33 & 51,10 & 187,58 & 187,81 & 51,10 & 1252,20 & 182,52 & 16,84 & 53,27 & 505,01 & 90,84 & 91,97 & 505,01 \\
\hline Salamandra salamandra & 29TPF19 & 101,00 & 113,80 & 96,73 & 38,31 & 5336,32 & 259,53 & 10,18 & 249,36 & \begin{tabular}{|l|l}
48,93 \\
\end{tabular} & 184,38 & 184,52 & 48,93 & 1255,75 & 179,85 & 18,12 & 52,30 & 503,68 & 94,08 & 94,80 & 503,68 \\
\hline Salamandra salamandra & 29TPF20 & 100,00 & 131,99 & 94,76 & 36,96 & 5520,84 & 279,47 & 26,29 & 253,18 & 63,93 & 204,61 & 204,73 & 63,93 & 1119,52 & 169,25 & 10,95 & 55,43 & 455,27 & 72,09 & 72,60 & 455,27 \\
\hline Salamandra salamandra & 29TPF21 & 101,00 & 126,21 & 93,56 & 36,68 & 5513,60 & 272,97 & 21,53 & 251,44 & 58,52 & \begin{tabular}{|c|}
198,83 \\
\end{tabular} & 198,97 & 58,52 & 1172,13 & 177,94 & 11,92 & 55,70 & 477,64 & 75,95 & 76,74 & 477,64 \\
\hline Salamandra salamandra & 29TPF22 & 100,00 & 123,09 & 94,03 & 36,88 & 5506,71 & 269,90 & 18,45 & 251,45 & \begin{tabular}{|c|}
55,53 \\
\end{tabular} & 195,71 & 195,79 & 55,53 & 1199,46 & 182,05 & 12,66 & 55,60 & 488,99 & 78,61 & 79,60 & 488,99 \\
\hline Salamandra salamandra & 29TPF23 & 100,00 & 126,79 & 98,25 & 37,87 & 5516,59 & 275,90 & 19,95 & 255,94 & 58,64 & 199,26 & 199,34 & 58,64 & 1160,35 & 175,66 & 12,24 & 55,32 & 472,38 & 76,56 & 77,15 & 472,38 \\
\hline Salamandra salamandra & $29 T$ PF 24 & 101,00 & 126,75 & 100,17 & 38,32 & 5518,90 & 277,01 & 19,14 & 257,87 & 58,60 & \begin{tabular}{|l|l|}
199,25 \\
\end{tabular} & 199,32 & 58,60 & 1155,55 & 174,45 & 12,59 & 55,08 & 469,91 & 77,07 & 77,46 & 469,91 \\
\hline Salamandra salamandra & 29TPF25 & 100,00 & 140,51 & 106,44 & 39,69 & 5513,85 & 293,37 & 28,59 & 264,78 & 71,32 & 212,18 & 212,25 & 71,32 & 1019,19 & 151,94 & 10,54 & 54,60 & 410,81 & 66,63 & 67,38 & 410,81 \\
\hline Salamandra salamandra & 29TPF26 & 100,00 & 140,98 & 107,60 & 39,89 & 5514,54 & 294,66 & 28,42 & 266,25 & 73,20 & 212,58 & 212,65 & 71,78 & 1005,65 & 149,08 & 10,67 & 54,36 & 404,49 & 66,37 & 67,06 & 404,46 \\
\hline Salamandra salamandra & 29TPF27 & 101,00 & 127,74 & 104,65 & 39,2 & 5523,54 & 281,02 & 17,96 & 263,06 & 61,2 & 200,19 & 200,25 & 59,37 & 1117,23 & 165,84 & 13,3 & 54,31 & 451,90 & 77,02 & 77,42 & 451,81 \\
\hline Salamandra salamandra & 29TPF28 & 101,00 & 124,70 & $\begin{array}{l}103,28 \\
\end{array}$ & 39,13 & 5499,98 & 276,56 & 15,72 & 260,84 & 56,85 & 197,01 & 197,03 & 56,85 & 1124,99 & $\begin{array}{l}164,65 \\
164,65\end{array}$ & 14,44 & 53,30 & 453,16 & 80,03 & 80,49 & 453,16 \\
\hline Salamandra salamandra & 29TPF29 & 100,00 & 119,33 & 100,64 & 38,58 & 5460,93 & 269,38 & 12,14 & 257,24 & 52,55 & 191,46 & 191,47 & 52,55 & 1147,42 & 165,13 & 16,19 & 52,33 & 460,08 & 85,13 & 85,52 & 460,08 \\
\hline Salamandra salamandra & 29TPF30 & 101,00 & 138,54 & 97,73 & 37,13 & 5630,05 & 289,25 & 30,10 & 259,15 & 68,92 & 212,42 & 212,50 & 68,92 & 1001,01 & 149,52 & 9,60 & 54,78 & 403,99 & 64,84 & 65,10 & 403,99 \\
\hline Salamandra salamandra & 29TPF32 & 101,00 & 118,52 & 91,48 & 35,98 & 5579,90 & 265,56 & 14,68 & 250,89 & 50,49 & 192,24 & 192,61 & 50,49 & 1181,51 & 178,55 & 12,66 & 55,06 & 480,60 & 78,06 & 80,25 & 480,60 \\
\hline Salamandra salamandra & 29TPF33 & 101,00 & 117,67 & 93,44 & 36,47 & 5576,81 & 265,92 & 13,04 & 252,89 & 49,59 & 191,29 & 191,61 & 49,59 & 1180,34 & 177,86 & 13,10 & 54,92 & 479,81 & 79,46 & 81,04 & 479,81 \\
\hline Salamandra salamandra & 29TPF35 & 101,00 & $\mid 137,94$ & \begin{tabular}{|c|}
305,49 \\
105
\end{tabular} & $\begin{array}{ll}30,49 \\
39,15\end{array}$ & $\begin{array}{l}537,01 \\
5607,72\end{array}$ & $\mid \begin{array}{l}\mid 292,32 \\
292,31\end{array}$ & 25,79 & 26,05 & 67, 67,82 & 211,25 & $\mid 211,27$ & $\begin{array}{l}45,39 \\
67,82\end{array}$ & \begin{tabular}{r|}
982,27 \\
9
\end{tabular} & $\mid \begin{array}{l}\mid 14,000 \\
146,01\end{array}$ & $\begin{array}{l}10,54 \\
10,54\end{array}$ & \begin{tabular}{|c|c|}
4,3418 \\
\end{tabular} & $\begin{array}{l}417,01 \\
395,49\end{array}$ & 65,43 & 61,04, & $\begin{array}{l}4 / 3,01 \\
395,49\end{array}$ \\
\hline Salamandra salamandra & 29TPF36 & 100,00 & 136,08 & 105,63 & 39,20 & 5593,92 & 290,39 & 23,96 & 266,43 & 66,31 & 209,21 & 209,21 & 66,31 & 987,88 & 145,90 & 11,16 & 53,79 & 397,09 & 67,05 & 67,16 & 397,09 \\
\hline Salamandra salamandra & 29TPF37 & 101,00 & $\mid 136,96$ & 106,85 & 39,44 & 5597,15 & 291,74 & 23,96 & 267,78 & 66,93 & 209,96 & 209,98 & 60,93 & $\begin{array}{l}970,00 \\
970,32\end{array}$ & 142,26 & 11,30 & 53,38 & 388,98 & 66,55 & 66,61 & 388,98 \\
\hline Salamandra salamandra & 29TPF38 & 99,00 & 135,86 & 107,09 & 39,57 & 5593,05 & 290,65 & 22,66 & 267,99 & 66,02 & 208,89 & 208,89 & 66,02 & 963,54 & 139,80 & 11, & 52,75 & 385,04 & 67,49 & 67,52 & 385,04 \\
\hline Salamandra salamandra & 29TPF39 & 101,00 & 128,98 & 104,90 & 39,08 & 5570,40 & 282,66 & 17,49 & 265,18 & 60,08 & 202,29 & 202,29 & 60,08 & 1002,01 & 143,85 & 13,58 & 51,97 & 400,05 & 73,12 & 73,12 & 400,05 \\
\hline Salamandra salamandra & 29TPF41 & $\begin{array}{l}100,00 \\
100\end{array}$ & $\begin{array}{l}\mid l 20,50 \\
130,09 \\
\end{array}$ & \begin{tabular}{|c|}
05,51 \\
95,
\end{tabular} & $\begin{array}{l}35,06 \\
36,44 \\
\end{array}$ & 5704,54 & \begin{tabular}{|l|}
202,007 \\
281,07
\end{tabular} & $\begin{array}{l}\frac{1,43}{22,43} \\
\end{array}$ & 258,10 & $\begin{array}{l}50,00 \\
59,81\end{array}$ & 205,16 & $\mid \begin{array}{l}\mid 20<, 43 \\
205,40\end{array}$ & $\begin{array}{l}59,000 \\
59,81\end{array}$ & $\begin{array}{l}1019,40 \\
1019\end{array}$ & \begin{tabular}{|l|}
152,05 \\
152,10
\end{tabular} & $\begin{array}{l}\mid 0,50 \\
10,51\end{array}$ & \begin{tabular}{|l|l|}
54,47 \\
5
\end{tabular} & $\begin{array}{l}40,0309 \\
410,99\end{array}$ & $\begin{array}{l}\mid r, 12 \\
67,65\end{array}$ & $\begin{array}{l}63,12 \\
68,26\end{array}$ & $\begin{array}{ll}400,030 \\
410,99\end{array}$ \\
\hline Salamandra salamandra & 29TPF42 & 101,00 & 129,46 & 97,21 & 36,92 & 5693,92 & 281,22 & 21,12 & 260,10 & \begin{tabular}{|l|l|}
59,25 \\
\end{tabular} & 204,42 & 204,60 & 59,25 & 1019,33 & 152,01 & 10,78 & 54,30 & 410,91 & 68,29 & 68,78 & 410,91 \\
\hline Salamandra salamandra & 29TPF44 & 100,00 & 132,75 & 102,47 & 38,08 & 5697,92 & 287,24 & 21,71 & 265,53 & \begin{tabular}{|c|}
62,03 \\
\end{tabular} & 207,71 & 207,71 & 62,03 & 972,21 & 144,25 & 10,68 & 53,94 & 391,00 & 66,10 & 66,10 & 391,00 \\
\hline Salamandra salamandra & 29TPF45 & 100,00 & & & $38, \varepsilon$ & 5667,42 & 295,95 & 27 & 268,58 & 70,6 & 214,86 & 214,86 & 69,73 & 898,03 & 131,61 & 9,8 & 53,24 & 358,68 & 60,80 & 60,80 & 358,68 \\
\hline Salamandra salamandra & 29TPF46 & 101,00 & 123,35 & 101,60 & 38,00 & 5663,76 & 277,73 & 13,58 & 264,15 & 53,73 & 198,39 & 198,39 & 53,73 & $\begin{array}{r}1028,48 \\
\end{array}$ & 151,52 & 12,73 & 53,08 & 413,96 & 73,53 & 73,53 & 413,96 \\
\hline Salamandra salamandra & 29TPF47 & 99,00 & 132,70 & 105,43 & 38,83 & 5659,92 & 288,25 & 20,00 & 268,25 & 62,32 & 207,06 & 207,06 & 62,32 & 938,61 & 136,65 & 11,66 & 52,49 & 375,35 & 66,55 & 66,55 & 375,35 \\
\hline Salamandra salamandra & 29TPF48 & 101,00 & 140,12 & 107,65 & 39,32 & 5646,39 & 295,76 & 25,48 & 270,27 & 69, & 214,06 & 214,06 & 69,34 & 865,86 & 123,90 & 10,87 & 51,73 & 343,18 & 61,50 & 61,50 & 343,18 \\
\hline Salamandra salamandra & 29TPF49 & 100,00 & 137,42 & 106,91 & 39,23 & 5629,61 & 292,32 & 23,10 & 269,23 & 67, & 211,12 & 211,12 & 66,99 & 873,61 & 123,63 & 11,76 & 51,03 & 345,28 & 63,87 & 63,87 & 345,28 \\
\hline Salamandra salamandra & 29TPF50 & 100,00 & 65 & 92,55 & 35,4 & 783,08 & 277,61 & 19,91 & 257,70 & & 202,85 & 203,38 & 55,85 & 993,74 & 146,73 & 10, & 53,88 & 398,03 & 6,35 & 67,84 & 398,03 \\
\hline Salamandra salamandra & 29TPF52 & 100,00 & 54 & $\mid$ & 37,4 & 5779,03 & 292,46 & 25, & 266,49 & 65, & 213,69 & 213,69 & $\frac{65,00}{65,70}$ & 888,20 & 129,97 & $\frac{16}{9,}$ & 53,19 & 353,77 & 60,27 & 60,27 & 353,77 \\
\hline Salamandra salamandra & 29TPF53 & 10 & & 16 & 38,12 & 5763,83 & 296,81 & 28 & 268,76 & 69, & 216,60 & 216,60 & 69 & 850,97 & 123,81 & 9, & 52,78 & 337,87 & 57,88 & 57,88 & 337,83 \\
\hline Salamandra salamandra & 29TPF54 & 101,00 & $\begin{array}{l}141,68 \\
142,68\end{array}$ & 105,21 & 38,51 & 5744,58 & 298,77 & 28,79 & 269,97 & 72,03 & 217,84 & 217,84 & 70,80 & 832,23 & $\mid \begin{array}{l}\mid 20,63 \\
120,63\end{array}$ & $\begin{array}{l}9,06 \\
9,06 \\
\end{array}$ & 52,52 & 329,99 & 56,84 & 56,84 & 329,90 \\
\hline Salamandra salamandra & 29TPF55 & 100,00 & 143,81 & 25 & 38,74 & 5720,69 & 300,02 & 29, & 270,76 & 74 & 218 & 218,64 & 72,02 & 814,43 & 117,22 & 9,14 & 52,12 & 322,14 & 56,22 & 56,22 & 321,98 \\
\hline Salamandra salamandra & 29TPF56 & 100,00 & 13 & 105,69 & 38,5 & 705,64 & 295,63 & 25,55 & 270,08 & 70,9 & 214,41 & 214,41 & 68,22 & 837,54 & 120,32 & 9,97| & 51,84 & 331,83 & 59,22 & 59,22 & 331,53 \\
\hline Salamandra salamandra & 29TPF57 & $\begin{array}{l}101,00 \\
100\end{array}$ & & \begin{tabular}{|l|}
105,98 \\
105
\end{tabular} & $\begin{array}{l}38, \\
38,\end{array}$ & 5715,32 & $\begin{array}{l}291,15 \\
291,15\end{array}$ & 20,48 & 270,06 & 63,9 & \begin{tabular}{|l|}
209,56 \\
\end{tabular} & 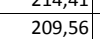 & $\begin{array}{ll}63,28 \\
63,28\end{array}$ & 863,64 & $\mid \begin{array}{l}\mid 24,52 \\
124,24\end{array}$ & $\begin{array}{l}31,01 \\
11,01\end{array}$ & \begin{tabular}{|l|l|}
51,61 \\
\end{tabular} & $\begin{array}{l}35,03 \\
343,18\end{array}$ & $\begin{array}{l}3,2,44 \\
62,4\end{array}$ & $\begin{array}{l}3,2,44 \\
62,4\end{array}$ & 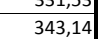 \\
\hline Salamandra salamandra & 29TPF58 & 99,00 & 136,87 & 107,07 & 38,82 & 5702,16 & 293,58 & 22,00 & 271,58 & 65, & 211,69 & 211,69 & 65,64 & 829,85 & 117,91 & 11,02 & 50,93 & 327,95 & 60,81 & 60,81 & 327,95 \\
\hline Salamandra salamandra & 29TPF59 & 101,00 & 140,06 & 107,68 & 39,02 & 5679,65 & 296,10 & 24,35 & 271,75 & 70,61 & 214,39 & 214,39 & 68,77 & 794,76 & 111,26 & 10,91 & 50,28 & 312,01 & 58,91 & 58,91 & 312,01 \\
\hline Salamandra salamandra & 29TPF60 & 100,00 & 95 & 93,99 & 35,55 & 5856,68 & 279, & 18 & 261 & & 204,05 & 204,72 & 55 & 931,01 & 135 & 9,8 & 52,8 & 369,36 & 63,92 & 65,18 & 369,14 \\
\hline Salamandra salamandra & 29TP & 10 & & & 36 , & & 28 & & & & 209 & 205 & & & 12 & & 52,48 & 348,64 & 61,25 & 61,44 & 348,50 \\
\hline \begin{tabular}{|l} 
Salamandra salamandrandra \\
Sala
\end{tabular} & 29TPF62 & $\begin{array}{l}100,00 \\
100\end{array}$ & \begin{tabular}{|l|}
132,104 \\
131,94 \\
\end{tabular} & $\begin{array}{l}1,95 \\
99,50\end{array}$ & $\begin{array}{l}30,35 \\
36,82\end{array}$ & $\begin{array}{l}5854,030 \\
5846,01\end{array}$ & $\begin{array}{l}\mid 28,09 \\
287,62\end{array}$ & 20,89 & $\begin{array}{l}20,51 \\
266,74\end{array}$ & 每4,03 & 2009,20 & \begin{tabular}{|l|}
$209,03,32$ \\
\end{tabular} & S9,935 & $\begin{array}{l}80,01 \\
870,22\end{array}$ & \begin{tabular}{|l|}
125,57 \\
125,5
\end{tabular} & $\begin{array}{l}9,22 \\
9,66\end{array}$ & \begin{tabular}{c|c|}
52,26 \\
52,2
\end{tabular} & $\begin{array}{l}34,04 \\
344,02\end{array}$ & $\mid \begin{array}{ll}\mid c 1,25 \\
61,16\end{array}$ & $\begin{array}{l}01,44 \\
61,35\end{array}$ & $\begin{array}{l}340,50 \\
343,96 \\
\end{array}$ \\
\hline Salamandra salamandra & 29TPF63 & 101,00 & 134,25 & $\begin{array}{r}101,94 \\
\end{array}$ & 37,38 & 5835,98 & 290,96 & 21,88 & 269,08 & 63,60 & 211,38 & 211,38 & 61,97 & 844,73 & 121,62 & 9,68 & 52,03 & 333,64 & 59,71 & 59,71 & 333,62 \\
\hline Salamandra salamandra & 29TPF65 & 101,00 & 133,16 & 104,27 & 37,93 & 5804,01 & 290,69 & 19,73 & 270,97 & 62,06 & 209,68 & 209,68 & 61,14 & 831,42 & 118,91 & 10,13 & 51,36 & 328,13 & 60,39 & 60,39 & 328,13 \\
\hline Salaman & 29TPF & 100,00 & & 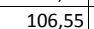 & 38,5 & 783,69 & . & & 272 & 68 & 214,97 & 214 & 66,7 & 780, & & 9,6 & 50,94 & 307,18 & 56,57 & 56,57 & 306,92 \\
\hline Salamandra salamandra & $29 \mathrm{TF}$ & & & & 38 & 704, & & & 273,36 & 69 & $214,5 /$ & 214 & 66,7 & 168, & 108,26 & & 50,41 & 301,58 & 56,62 & 56,62 & 301, \\
\hline Salamandra salamandra & 29TPF68 & 101,00 & 125,92 & 105,07 & 38,24 & 5746,97 & 283,86 & 12,69 & 271,17 & 55,71 & 201,92 & 201,94 & 54,87 & 847,90 & 119,58 & 11,95 & 50,01 & 334,57 & 65,86 & 65,90 & 334,55 \\
\hline Salamandra salamandra & 29TPF69 & 100,00 & 124,72 & 105,60 & 38,38 & 5737,43 & 282,95 & 11,12 & 271,83 & 53,84 & 200,67 & 200,69 & 53,80 & 842,56 & 118,37 & 12,49 & 49,51 & 332,58 & 66,68 & 66,71 & 332,58 \\
\hline Salamandra salamandra & 29TPF70 & 101,00 & 126,52 & 95,46 & 35,48 & 924,88 & 281,66 & 17,39 & 264,27 & 61,88 & 204,75 & 205,50 & 54,21 & 874,26 & 124,50 & 9,71 & 51,57 & 344,34 & 61,95 & 63,13 & 342, \\
\hline Salam & 29TP & . & & & r & 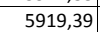 & & 17, & 266,14 & 62, & 205,32 & 205, & 54 & & 121 & 9, & 51,38 & 336 & 61,71 & 62,35 & \\
\hline Salamandra salamandra & $29 T P F 72$ & 100,00 & 127,59 & 99,08 & 36,53 & 5904,58 & |28,13 & 16,52 & 267,84 & \begin{tabular}{ll|l}
62,55 \\
62
\end{tabular} & 205,84 & 205,97 & 55,05 & 843,94 & \begin{tabular}{|l|l|l|l|l|}
119,73 \\
\end{tabular} & 9,89 & 51,16 & 331,56 & $\begin{array}{ll}61,64 \\
61,64\end{array}$ & $\begin{array}{ll}61,79 \\
1,79\end{array}$ & 330,15 \\
\hline
\end{tabular}




\begin{tabular}{|c|c|c|c|c|c|c|c|c|c|c|c|c|c|c|c|c|c|c|c|c|c|}
\hline TAXON & UTM & $\mathrm{km} 2$ & B101 & $\mathrm{B1O2}$ & $\mathrm{BIO3}$ & B104 & $\mathrm{B105}$ & B106 & B107 & B108 & B109 & 81010 & BIO11 & B1012 & $\mathrm{BIO13}$ & B1014 & B1015 & 81016 & B1017 & B1018 & B1019 \\
\hline Salamandra salamandra & 29TPF73 & 100,00 & 133,46 & 102,44 & 37,27 & 5891,66 & 291,47 & 20,37 & 271,10 & 67,96 & 211,44 & 211,44 & 60,61 & 792,11 & 111,81 & 9,37 & 50,82 & 310,49 & 57,83 & 57,83 & 309,20 \\
\hline Salamandra salamandra & 29TPF74 & 101,00 & 141,89 & 105,77 & 38,07 & 5862,92 & 300,65 & 26,54 & 274,11 & 75,85 & 218,98 & 218,98 & 68,70 & 723,89 & 101,04 & 8,58 & 50,33 & 282,67 & 52,56 & 52,56 & 280,76 \\
\hline Salamandra salamandra & 29TPF75 & 99,00 & 134,33 & 105,26 & 37,99 & 5864,59 & 293,29 & 19,66 & 273,63 & 67,46 & 211,71 & 211,71 & 61,42 & 765,39 & 107,37 & 9,63 & 50,20 & 299,43 & 57,12 & 57,12 & 298,61 \\
\hline Salamandra salamandra & 29TPF76 & 101,00 & 133,84 & 105,95 & 38,20 & 5841,09 & 292,79 & 18,91 & 273,88 & 66,99 & 210,85 & 210,86 & 61,26 & 757,77 & 105,79 & 9,82 & 49,82 & 296,32 & 57,40 & 57,40 & 295,41 \\
\hline Salamandra salamandra & 29TPF78 & 100,00 & 129,88 & 107,05 & 38,40 & 5809,03 & 289,73 & 14,60 & 275,14 & 62,27 & 206,69 & 206,69 & 57,73 & 759,94 & 105,55 & \begin{tabular}{|c|c|}
10,85 \\
\end{tabular} & 49,07 & 297,53 & 59,92 & 59,92 & 297,20 \\
\hline Salamandra salamandra & 29TPF79 & 100,00 & 123,01 & 106,30 & 38,32 & 5778,23 & 282,90 & 8,87 & 274,03 & 54,38 & 199,62 & 199,64 & 51,64 & 793,80 & 109,92 & 12,11 & 48,60 & 311,30 & 65,06 & 65,08 & 311,22 \\
\hline Salamandra salamandra & 29TPF81 & 100,00 & 126,60 & 98,86 & 36,16 & 5977,64 & 284,65 & 15,28 & 269,37 & 60,96 & 205,60 & 206,19 & 53,50 & 801,99 & 111,22 & |9,53 & 50,05 & 313,21 & 59,84 & 60,40 & 308,99 \\
\hline Salamandra salamandra & 29TPF82 & 100,00 & 131,03 & 101,63 & 36,88 & 5965,24 & 290,16 & 18,01 & 272,15 & 64,99 & 210,07 & 210,10 & 57,57 & 761,25 & 105,14 & 9,16 & 49,85 & 296,71 & 57,24 & 57,26 & 292,83 \\
\hline Salamandra salamandra & 29TPF83 & 101,00 & 129,88 & 102,77 & 37,09 & 5951,56 & 289,35 & 16,37 & 272,99 & 63,97 & 208,81 & 208,81 & 56,52 & 756,55 & 104,25 & 9,48 & 49,50 & 294,66 & 57,70 & 57,70 & 291,10 \\
\hline Salamandra salamandra & 29TPF84 & 99,00 & 136,85 & 105,53 & 37,81 & 5927,83 & 296,95 & 21,49 & 275,46 & 70,53 & 215,16 & 215,16 & 63,22 & 702,12 & 96,03 & 8,77 & 49,13 & 272,78 & 53,29 & $\mid 53,29$ & 269,14 \\
\hline Salamandra salamandra & 29TPF85 & 101,00 & 133,76 & 105,84 & 37,90 & 5913,94 & 294,04 & 18,42 & 275,63 & 67,60 & 211,91 & 211,91 & 60,34 & 713,10 & 97,54 & 9,38 & 48,85 & 277,16 & 55,33 & 55,33 & 274,08 \\
\hline Salamandra salamandra & 29TPF86 & 100,00 & 126,57 & 105,56 & 37,85 & 5900,58 & 287,13 & 11,93 & 275,19 & 60,90 & 204,84 & 204,84 & 53,61 & 744,61 & 101,80 & 10,30 & 48,49 & 289,46 & 59,65 & 59,65 & 287,21 \\
\hline Salamandra salamandra & 29TPF87 & 99,00 & 128,44 & 106,95 & 38,07 & 5880,29 & 289,34 & 12,93 & 276,42 & 62,64 & 206,21 & 206,21 & 55,45 & 721,95 & 98,36 & 10,32 & 48,11 & 280,52 & 58,36 & 58,36 & 278,59 \\
\hline Salamandra salamandra & 29TPF88 & 101,00 & 131,27 & 108,01 & 38,51 & 5851,74 & 291,97 & 14,96 & 277,01 & 65,44 & 208,61 & 208,61 & 58,38 & 695,99 & 94,18 & 10,34 & 47,79 & 270,13 & 56,85 & 56,85 & 268,09 \\
\hline Salamandra salamandra & 29TPF89 & 100,00 & 127,67 & 108,27 & 38,52 & 5831,94 & 288,98 & 11,46 & 277,52 & 62,03 & 204,89 & 204,89 & 55,23 & 706,50 & 95,57 & 11,02 & 47,46 & 274,56 & 59,14 & 59,14 & 273,30 \\
\hline Salamandra salamandra & 29TPF91 & 101,00 & 127,38 & 101,04 & 36,35 & 6036,27 & 287,82 & 14,43 & 273,39 & 60,91 & 207,49 & 207,84 & 53,55 & 739,90 & 99,64 & 9,21 & 48,60 & 286,37 & 57,43 & 57,71 & 279,78 \\
\hline Salamandra salamandra & 29TPF94 & 100,00 & 127,14 & 104,70 & 37,31 & 5992,22 & 288,67 & 12,45 & 276,22 & 60,62 & 206,74 & 206,74 & 53,35 & 706,35 & 94,23 & 9,63 & 47,70 & 272,59 & 57,28 & 57,28 & 267,10 \\
\hline Salamandra salamandra & 29TPF95 & 100,00 & 123,98 & 105,18 & 37,72 & 5972,06 & 285,81 & 9,47 & 276,34 & 57,90 & 203,57 & 203,57 & 50,66 & 712,27 & 94,80 & 9,98 & 47,46 & 274,87 & 58,80 & 58,80 & 269,70 \\
\hline Salamandra salamandra & 29TPF96 & 100,00 & 125,79 & 106,55 & 38,02 & 5947,17 & 287,79 & 10,27 & 277,52 & 59,50 & 204,76 & 204,76 & 52,34 & 691,95 & 91,70 & 10,15 & 47,00 & 266,69 & 57,95 & 57,95 & 261,99 \\
\hline Salamandra salamandra & 29TPF97 & 101,00 & 119,67 & 106,41 & 37,99 & 5930,73 & 282,07 & 4,67 & 277,39 & 53,80 & 198,61 & 198,61 & 46,65 & 718,31 & 95,14 & $11, \mathrm{C}$ & 46,70 & 276,97 & 61,95 & 61,95 & 272,98 \\
\hline Salamandra salamandra & 29TPF98 & 100,00 & 120,57 & 107,46 & 38,12 & 5908,98 & 283,11 & 5,07 & 278,03 & 54,57 & 199,09 & \begin{tabular}{|c|}
199,09 \\
\end{tabular} & 47,67 & 701,41 & 92,47 & 11,18 & 46,30 & 270,26 & 61,39 & 61,39 & 266,71 \\
\hline Salamandra salamandra & 29TPF99 & 100,00 & 130,68 & 109,56 & 38,84 & 5876,27 & 292,54 & 13,18 & 279,36 & 64,36 & 208,23 & 208,23 & 57,49 & 638,01 & 83,60 & 10,49 & 46,07 & 245,56 & 55,23 & 55,23 & 241,94 \\
\hline Salamandra salamandra & 29TPG00 & 101,00 & 128,55 & 101,51 & 39,68 & 5268,55 & 274,20 & 21,32 & 252,88 & 63,34 & 197,31 & 197,49 & 63,30 & 1164,34 & 161,88 & 15,93 & 51,68 & 461,28 & 85,32 & 88,02 & 461,28 \\
\hline Salamandra salamandra & 29TPG01 & 100,00 & 111,76 & 92,42 & 37,99 & 5168,72 & 251,69 & 11,49 & 240,20 & 49,41 & 180,21 & 180,35 & 49,41 & 1289,31 & 176,79 & 20,77 & 50,47 & 510,67 & 101,87 & \begin{tabular}{|l|l}
103,85 \\
\end{tabular} & 510,67 \\
\hline Salamandra salamandra & 29TPG03 & 101,00 & 100,34 & 86,02 & 36,7 & 5053,09 & 235,86 & 4,7 & 231,07 & 40,97 & 167,75 & 168,01 & 40,55 & 1349,43 & 178,69 & 25, & 48 & 527 & 116,37 & 118,48 & 527,53 \\
\hline Salamandra salamandra & 29TPG04 & 100,00 & $\begin{array}{l}105,08 \\
105\end{array}$ & 80,21 & 37,23 & $\begin{array}{l}5064,05 \\
5064\end{array}$ & 241,28 & $\begin{array}{l}7,19 \\
7,38\end{array}$ & $\mid 233,90$ & 49,16 & $\begin{array}{ll}172,41 \\
\end{array}$ & $\begin{array}{l}170,01 \\
172,65\end{array}$ & 年4 44,73 & $\begin{array}{l}\mid 34,45 \\
1295,86\end{array}$ & 171,56 & $\begin{array}{l}25,200 \\
25,20\end{array}$ & $\begin{array}{ll}40,435 \\
47,82\end{array}$ & | & 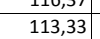 & \begin{tabular}{|l|l|l|l|l}
115,43 \\
\end{tabular} & 502,81 \\
\hline Salamandra salamandra & 29TPG05 & 101,00 & 119,89 & 93,96 & 38,26 & 5155,67 & 258,22 & 15,84 & 242,38 & 63,14 & 187,92 & 188,01 & 57,21 & 1153,20 & 156,06 & 22,16 & 47,08 & 443,66 & 100,34 & 101,71 & 440,77 \\
\hline Salamandra salamandra & 29TPG07 & 100,00 & 123,10 & 93,56 & 38,15 & 5116,46 & 259,22 & 18,05 & $\mid 241,17$ & 66,16 & 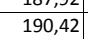 & $\begin{array}{l}190,56 \\
\end{array}$ & $\begin{array}{ll}60,93 \\
60,93\end{array}$ & 1099,61 & 152,97 & 23,37 & $\begin{array}{ll}45,42 \\
452\end{array}$ & $44,0,36$ & 101,12 & 104,45 & 411,31 \\
\hline Salamandra salamandra & 29TPG09 & 99,00 & 123,31 & 91,60 & 38,18 & 4991,49 & 255,79 & 19,62 & 236,17 & 67,51 & 188,94 & 189,15 & 63,01 & 1087,23 & 152,76 & 25,49 & 43,95 & 410,21 & 105,63 & 112,58 & 399,86 \\
\hline Salamandra salamandra & 29TPG10 & 100,00 & 126,91 & 102,29 & 39,40 & 5384,67 & 275,27 & 18,51 & 256,76 & 60,43 & 197,61 & 197,66 & 60,43 & 1124,66 & 158,03 & 15,6 & 51,73 & 446,89 & 82,92 & 83,49 & 446,89 \\
\hline 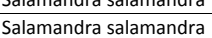 & 29 PTP12 & $\begin{array}{l}100,00 \\
100,00\end{array}$ & $12,15,84$ & $\begin{array}{l}10,259 \\
55,37 \\
\end{array}$ & $\begin{array}{l}35,404 \\
38,04\end{array}$ & $\begin{array}{l}5388,401 \\
5283,63\end{array}$ & 259,08 & 11,91 & $\begin{array}{l}\mid 350,0 \\
247,16\end{array}$ & $\begin{array}{l}\mid c 0,45 \\
51,65\end{array}$ & \begin{tabular}{|l|}
197,01 \\
185,68
\end{tabular} & $\begin{array}{l}\mid 99,00 \\
185,71\end{array}$ & $\begin{array}{l}.00,45 \\
51,65\end{array}$ & $\begin{array}{ll}114,400 \\
1176,26\end{array}$ & \begin{tabular}{|l|l|}
158,03 \\
158,86
\end{tabular} & $\begin{array}{l}10,03 \\
19,73 \\
\end{array}$ & $\begin{array}{ll}1,1 / 5 \\
49,55\end{array}$ & $\begin{array}{l}4402,09 \\
46211\end{array}$ & $\begin{array}{l}82,92 \\
95,00\end{array}$ & $\begin{array}{l}83,49 \\
95,45\end{array}$ & $\begin{array}{l}44,62,11 \\
462\end{array}$ \\
\hline Salamandra salamandra & 29TPG13 & 101,00 & 114,59 & 94,29 & 37,88 & 5258,16 & 256,75 & 11,16 & 245,59 & 51,08 & 184,25 & 184,28 & 50,83 & 1171,31 & 155,10 & 20,77 & 48,71 & 457,27 & $\begin{array}{l}97,45 \\
\end{array}$ & 97,95 & 457,27 \\
\hline Salamandra salamandra & 29 PPG14 & $\begin{array}{l}101,00 \\
100\end{array}$ & \begin{tabular}{|l|l|l|l}
113,99 \\
\end{tabular} & $\begin{array}{ll}4,23 \\
93,88\end{array}$ & $\begin{array}{l}31,00 \\
37,92\end{array}$ & $\begin{array}{ll}5230,100 \\
5231,74\end{array}$ & 255,38 & $\begin{array}{l}1,10 \\
10,69\end{array}$ & \begin{tabular}{|l|}
243,69 \\
244,69
\end{tabular} & $\begin{array}{l}51,23 \\
55,23\end{array}$ & \begin{tabular}{|l|}
184,253 \\
183,38
\end{tabular} & $\begin{array}{l}\mid 104,20 \\
183,44\end{array}$ & $\begin{array}{l}50,03 \\
50,77\end{array}$ & |ll/, & 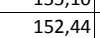 & 21,83 & $\begin{array}{ll}40,173 \\
47,73\end{array}$ & 4449,20 & $\begin{array}{l}31,43 \\
99,54\end{array}$ & $\mid$ & 449,09 \\
\hline Salamandra salamandra & 29 TPG15 & 99,00 & 117,40 & 94,81 & 38,05 & 5235,88 & 258,51 & 12,64 & 245,87 & 59,84 & 186,75 & 186,77 & 53,92 & 1115,37 & 149,09 & $21, \varepsilon$ & 46,89 & 429,50 & 97,90 & 99,06 & 427,21 \\
\hline Salamandra salamandra & 29TPG16 & 101,00 & 115,22 & \begin{tabular}{|c|c|}
93,66 \\
\end{tabular} & 37,91 & 5183,58 & 254,83 & $\mid 11,28$ & 243,54 & 58,25 & 183,88 & 183,96 & 52,68 & 1123,78 & 151,97 & 23,44 & \begin{tabular}{|l|l|}
45,97 \\
40,9
\end{tabular} & 431,18 & 102,31 & $\mid \begin{array}{r}103,57 \\
\end{array}$ & 427,11 \\
\hline 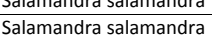 & 29 PTP19 & $\begin{array}{l}100,00 \\
100\end{array}$ & $\begin{array}{ll}112,26 \\
120,84\end{array}$ & $\begin{array}{l}92,62 \\
92,2\end{array}$ & $\begin{array}{l}31,11 \\
38,10\end{array}$ & $\begin{array}{l}5180,305 \\
5062,62\end{array}$ & 255,79 & $\begin{array}{l}\mid 1,26 \\
16,38 \\
\end{array}$ & \begin{tabular}{|l|}
2439,41 \\
239
\end{tabular} & $\mid$\begin{tabular}{c|c|c|}
64,25 \\
64
\end{tabular} & \begin{tabular}{|l|}
183,00 \\
187,53
\end{tabular} & $\begin{array}{l}18,90 \\
187,64\end{array}$ & $\begin{array}{l}32,08 \\
59,66\end{array}$ & $\begin{array}{l}1120,1 / 1 \\
1054,15\end{array}$ & $\mid \begin{array}{l}\mid 51,97 \\
145,66\end{array}$ & $\mid \begin{array}{ll}24,94 \\
24,97\end{array}$ & \begin{tabular}{|l|}
43,47 \\
43,
\end{tabular} & \begin{tabular}{|l|} 
\\
451,10
\end{tabular} & \begin{tabular}{|l|}
$103,51,63$ \\
\end{tabular} & \begin{tabular}{|l|}
107,49 \\
107,49
\end{tabular} & $\begin{array}{l}42,11 \\
387,71\end{array}$ \\
\hline Salamandra salamandra & 29TPG 20 & 100,00 & 116,55 & 98,57 & 38,25 & 5422,90 & 264,90 & 10,39 & 254,51 & 50,42 & 188,25 & 188,27 & 50,42 & 1146,33 & 161,59 & 17,49 & 51,15 & 456,30 & 88,32 & 88,41 & 456,30 \\
\hline Salamandra salamandra & 29TPG21 & 101,00 & 126,25 & 102,04 & 38,88 & 5451,82 & 275,59 & 16 & 258,84 & 59,06 & 197,96 & 197,96 & 59,06 & 1047,46 & 144,56 & 15 & 50,38 & 412,99 & 80,47 & 80,47 & 412,99 \\
\hline Salamandra salamandra & 29 TPG 23 & 100,00 & 128,44 & 100,89 & 38,75 & 5426,73 & 275,36 & 18,1 & 257,20 & 64 & 199 & 199,68 & 61 & 993,49 & 130,73 & 16, & 48,38 & 385,02 & 80,62 & 80,62 & 384,57 \\
\hline Salamandra salamandra & 29TPG24 & 100,00 & 128,78 & 100,20 & 38,64 & 5413,35 & 274 & 18,36 & 256,21 & 68,08 & 199,94 & 199,94 & 62,1 & 972,87 & 127,05 & 17, & 47,39 & 374,59 & 81,45 & 81,45 & 372,83 \\
\hline $\begin{array}{l}\text { Salamandra salamanandra } \\
\text { Salamdra sana }\end{array}$ & 2991924 & $\begin{array}{l}100,00 \\
100,00\end{array}$ & $\begin{array}{l}128,8,0 \\
120,04 \\
\end{array}$ & $\begin{array}{r}10,20 \\
97,11\end{array}$ & $\begin{array}{l}38,644 \\
38,12\end{array}$ & $\begin{array}{l}5413,353 \\
533,47\end{array}$ & \begin{tabular}{|l|}
263,87 \\
267
\end{tabular} & $\frac{18,36}{12,51}$ & $\mid \frac{\mid 250,21}{251,36}$ & $\begin{array}{l}68,08 \\
60,75 \\
\end{array}$ & \begin{tabular}{|l|}
$199,94,56$ \\
\end{tabular} & $\begin{array}{l}199,94 \\
190,56\end{array}$ & 62,10 & $\begin{array}{r}97,, 8 \mid \\
1034,95\end{array}$ & $\mid \begin{array}{l}\mid 217,05 \\
137,25\end{array}$ & \begin{tabular}{|l|}
20,39 \\
\end{tabular} & \begin{tabular}{|l|}
46,69 \\
46,61
\end{tabular} & $\begin{array}{l}3 / 4,59 \\
398,36\end{array}$ & $\begin{array}{l}1,45 \\
91,23 \\
\end{array}$ & $\begin{array}{l}81,45 \\
91,43\end{array}$ & $37,85,74$ \\
\hline Salamandra salamandra & 29TPG26 & 101,00 & 105,01 & 92,90 & 37,58 & 5216,32 & 246,69 & $\begin{array}{r}2,59 \\
2,2 \\
\end{array}$ & 244,09 & 48,25 & 174,52 & 174,57 & 42,60 & 1153,25 & 153,62 & 25,51 & 45,44 & 443,06 & 108,79 & \begin{tabular}{|c|}
109,53 \\
\end{tabular} & 438,97 \\
\hline Salamandra salamandra & 29TPG28 & 101,00 & 102,96 & 91,96 & 37,86 & 5109,11 & 242,32 & 1,67 & 240,65 & 47,18 & 170,96 & 171,02 & 42,07 & 1159,66 & 156,59 & 27,99 & 43,84 & 442,53 & 115,48 & 117,44 & 435,04 \\
\hline Salamandra salamandra & 29TPG29 & 101,00 & a & 94,68 & 38, & 148,38 & 9,82 & 16, & 243,79 & 64,46 & 190,05 & 190,13 & 59,80 & 988,89 & 135,44 & 23,41 & 43,19 & 373,42 & 97,58 & 99,85 & 363,03 \\
\hline Salamandra salamandra & $29 T$ P 30 & 101,00 & 12 & 104,36 & 38 & 5549,78 & 281 & 17 & 264 & 60,49 & 202,10 & 202,10 & 60, & 983,61 & 138,69 & 14 & 51,07 & 390,06 & 73,76 & 73,76 & 390,06 \\
\hline Salamandra salamandra & $29 T$ PG 31 & 99,00 & & $\begin{array}{l}101,17 \\
\end{array}$ & 38,41 & 5507,86 & 270,92 & 10,81 & 260 & 52,25 & 192,70 & 192,70 & 52,2 & 1040,03 & 144,93 & 16,75 & 50,13 & 412,02 & 81,99 & 81,99 & 412,02 \\
\hline Salamandra salamandra & 29TPG 32 & \begin{tabular}{|l|}
100,00 \\
100
\end{tabular} & $\begin{array}{l}121,65 \\
1205\end{array}$ & $\begin{array}{l}101,25 \\
1017\end{array}$ & $\begin{array}{ll}30,414 \\
38,42\end{array}$ & 5496,12 & $\begin{array}{ll}272,07 \\
272\end{array}$ & $\begin{array}{l}10,01 \\
11,98\end{array}$ & $\mid 260,09$ & \begin{tabular}{|l|l|}
54,58 \\
\end{tabular} & 194,31 & 194,31 & 54,26 & 1006,25 & $\mid \begin{array}{l}137,16 \\
137,16\end{array}$ & 16,95 & $\begin{array}{l}30,15 \\
49,15 \\
\end{array}$ & $\begin{array}{l}41,02 \\
395,01\end{array}$ & 81,34 & 81,34 & 395,01 \\
\hline Salamandra salamandra & $29 \mathrm{TPG} 33$ & 100,00 & 121,95 & 100,70 & 38,33 & 5475,42 & 271,29 & 12,10 & 259,19 & 57,53 & 194,34 & 194,34 & 54,80 & 986,87 & 131,60 & 17,61 & 48,16 & 384,05 & 82,26 & 82,26 & 383,95 \\
\hline Salamandra salamandra & 29TPG34 & 101,00 & 119,10 & 99,36 & 38,1 & 5438 & 267 & 10,1 & 256, & 58 & 191 & 191,03 & 52 & 996,47 & 130 & 19 & 47,19 & 385,91 & 86,18 & 86,18 & 385,02 \\
\hline Salamandra salamandra & $29 \mathrm{TPG}$ & & & 91 & 37, & 524 & $\frac{20}{23}$ & $\begin{array}{l}\mid, 1,11 \\
-7,92\end{array}$ & 243 & & $\begin{array}{l}\mid 91,03 \\
162,64 \\
\end{array}$ & $\begin{array}{l}\mid 9,1,03 \\
162,65\end{array}$ & $\frac{52}{30}$ & $\begin{aligned} 990,44^{\prime} & 1200,71\end{aligned}$ & $\begin{array}{l}\mid 50,92 \\
158,05\end{array}$ & 28 & \begin{tabular}{|c|}
44,62 \\
44,62
\end{tabular} & \begin{tabular}{|l|l|}
$30,91,06$ \\
461
\end{tabular} & \begin{tabular}{|c|}
80,10 \\
118,24
\end{tabular} & \begin{tabular}{|l|}
80,10 \\
118,42
\end{tabular} & $\begin{array}{l}38,04 \\
456,30\end{array}$ \\
\hline Salamandra salamandra & 29TPG37 & 100,00 & 81,18 & 89,85 & 36,97 & 5161,60 & 223,24 & $-16,66$ & 239,90 & 26,61 & 150,66 & 150,77 & 20,92 & 1289,79 & 168,92 & 33,27 & 43,10 & 490,73 & 134,79 & 135,32 & 482,99 \\
\hline Salamandra salamandra & 29 TPG 38 & $\begin{array}{l}100,00 \\
\end{array}$ & 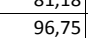 & $\begin{array}{l}30,03 \\
92,85 \\
\end{array}$ & $\begin{array}{ll}37,72 \\
37,1\end{array}$ & 5178,34 & \begin{tabular}{|l|l|}
238,76 \\
\end{tabular} & $\begin{array}{l}-40,00 \\
-4,64\end{array}$ & \begin{tabular}{|l|l|}
243,39 \\
\end{tabular} & $\begin{array}{l}0,014 \\
40,47 \\
\end{array}$ & $\begin{array}{l}150,000 \\
165,90\end{array}$ & $\begin{array}{l}365,96 \\
165\end{array}$ & 35,20 & $\mid \frac{120,150}{1152,50}$ & \begin{tabular}{|l|l|}
153,75 \\
153
\end{tabular} & 28,99 & \begin{tabular}{|l|l|}
43,10 \\
43
\end{tabular} & $\begin{array}{l}45,13 \\
438,96\end{array}$ & $\mid \begin{array}{l}318,41 \\
118,41\end{array}$ & $\begin{array}{l}53,32 \\
119,17 \\
\end{array}$ & $40,430,55$ \\
\hline Salamandra salamandra & $29 T$ P 40 & 100,00 & 139,68 & 107,25 & 39,28 & 5619,81 & 294,02 & 24,54 & 269,48 & 69,90 & 213,18 & 213,18 & 69,41 & 839,87 & 116,78 & 11,78 & 50,19 & 329,39 & $\begin{array}{c}\mid-10,1-1 \\
62,42\end{array}$ & $\frac{2,42}{62,2}$ & 329,39 \\
\hline Salaman & $29 T \mathrm{PC}$ & & & 105,64 & 38 & & 286 & 18,46 & & & 205 & 205 & & 880,38 & & 13 & 49,58 & & 68,32 & 68,32 & \\
\hline Salamandra salamandra & $29 \mathrm{TPG} 42$ & & 119 & $\begin{array}{l}102,14 \\
104\end{array}$ & 38,32 & 5551,84 & 272,26 & \begin{tabular}{|c|c|}
8,405 \\
8,95
\end{tabular} & 263,32 & $\begin{array}{l}\mid 5,701 \\
51,70\end{array}$ & \begin{tabular}{l|l}
05,02 \\
193,03
\end{tabular} & \begin{tabular}{|l|l|l|l|l|}
193,03 \\
\end{tabular} & | & $\begin{array}{l}\mid \\
962,54 \\
962,50\end{array}$ & 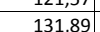 & 16,71 & 48,75 & 378,48 & 79,34 & 79,34 & 378,47 \\
\hline Salamandra salamandra & 29TPG43 & 100,00 & 117,15 & 101,03 & 38,13 & 5522,05 & 268,85 & 7,27 & 261,57 & 52,89 & 190,41 & 190,41 & 49,60 & 966,51 & 130,02 & 18,09 & 47,76 & 377,38 & 82,60 & 82,60 & 377,30 \\
\hline Salamandra salamandra & 29TPG44 & 100,00 & 113,68 & 99,82 & 38,01 & 5485,88 & 264,16 & 4,66 & 259,50 & 52,80 & 186,67 & 186,67 & 46,81 & 981,93 & 129,95 & 19,66 & 46,90 & 381,73 & 87,10 & 87,10 & 380,84 \\
\hline Salamar & 29TPG & 10 & 98 & 95,56 & 37,58 & 354,6 & 245,4 & $-5,79$ & 251,19 & 39,99 & 169,93 & 169,93 & 34,21 & 1090,34 & 143,81 & 25,79 & 44,43 & 418,90 & 107,37 & 107,37 & 413,87 \\
\hline Salamandra salamand & $29 T P G$ & & & & 37,2 & 5272, & 232 & $-13,80$ & 246,3 & & 158,08 & 158,12 & 25,0 & 1178,8 - & 154 & 30,2 & 43,01 & 449,01 & 123,01 & 123,16 & 44 \\
\hline 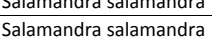 & 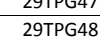 & $\begin{array}{l}10,000 \\
100,00\end{array}$ & \begin{tabular}{|c|c|c|c|}
108,67 \\
\end{tabular} & $\begin{array}{l}93,11 \\
96,86 \\
\end{array}$ & $\begin{array}{l}33,28 \\
37,97 \\
\end{array}$ & $\begin{array}{l}527,200 \\
5314,99\end{array}$ & 253,42 & $\begin{array}{r}-13,80 \\
2,25\end{array}$ & $\begin{array}{l}24 b, 38 \\
251,18 \\
\end{array}$ & \begin{tabular}{|c|}
30,69 \\
49,64
\end{tabular} & \begin{tabular}{|l|}
$178,08,27$ \\
179
\end{tabular} & \begin{tabular}{|c|}
138,12 \\
179,29
\end{tabular} & $\begin{array}{l}25,08 \\
44,47\end{array}$ & $\begin{array}{r}r 18,800 \\
997,65\end{array}$ & \begin{tabular}{|l|}
134,82 \\
133,38
\end{tabular} & $\begin{array}{l}30,25 \\
24,48\end{array}$ & \begin{tabular}{|l|}
42,97 \\
42
\end{tabular} & \begin{tabular}{|l|}
4490,01 \\
3802
\end{tabular} & \begin{tabular}{|l|}
123,01 \\
101,32
\end{tabular} & \begin{tabular}{|l|}
123,16 \\
101,38
\end{tabular} & $\begin{array}{l}44,1,24 \\
371,02\end{array}$ \\
\hline
\end{tabular}




\begin{tabular}{|c|c|c|c|c|c|c|c|c|c|c|c|c|c|c|c|c|c|c|c|c|c|}
\hline TAXON & UTM & $\mathrm{km} 2$ & BIO1 & B102 & $\mathrm{BIO3}$ & B104 & B105 & B106 & B107 & B108 & B109 & 81010 & BIO11 & BIO12 & B1013 & B1014 & 81015 & B1016 & BIO17 & B1018 & Bl019 \\
\hline Salamandra salamandra & 29TPG49 & 101,00 & 118,67 & 97,49 & 38,41 & 5283,64 & 261,09 & 10,54 & 250,55 & 58,99 & 188,28 & 188,28 & 54,20 & 919,91 & 123,69 & 22,59 & 42,35 & 348,53 & 93,97 & 93,97 & 337,24 \\
\hline Salamandra salamandra & 29TPG50 & 100,00 & 137,60 & 107,47 & 39,01 & 5663,99 & 293,42 & 22,08 & 271,34 & 69,40 & 211,95 & 211,95 & 66,82 & 797,61 & 110,60 & 11,75 & 49,53 & 312,43 & 60,95 & 60,95 & 312,37 \\
\hline Salamandra salamandra & 29TPG51 & 100,00 & 135,10 & 106,82 & 38,97 & 5652,70 & 290,36 & 19,93 & 270,43 & 68,85 & 209,35 & 209,35 & 64,65 & 802,20 & 109,94 & 12,67 & 48,85 & 313,40 & 63,25 & 63,25 & 313,23 \\
\hline Salamandra salamandra & 29TPG52 & 99,00 & 126,28 & 105,19 & 38,73 & 5629,65 & 281,48 & 12,63 & 268,85 & 59,49 & 200,62 & 200,62 & 56,60 & 851,88 & 116,31 & 14,69 & 48,20 & 333,63 & 70,27 & 70,27 & 333,50 \\
\hline Salamandra salamandra & 29TPG53 & 101,00 & 118,10 & 103,22 & 38,19 & 5593,68 & 272,73 & $\begin{array}{r}, 29 \\
6,29 \\
\end{array}$ & 266,44 & \begin{tabular}{|l|l|l|}
54,78 \\
\end{tabular} & 192,35 & 192,35 & 49,42 & 897,29 & 121,15 & 16,78 & 47,42 & 350,83 & 77,64 & 77,64 & 350,43 \\
\hline Salamandra salamandra & 29TPG54 & 100,00 & 112,14 & 101,49 & 37,99 & 5549,06 & 265,44 & 2,10 & 263,34 & 50,57 & 186,01 & 186,01 & 44,43 & 933,69 & 123,73 & 19,01 & $\begin{array}{ll}46,45 \\
\end{array}$ & 363,30 & 84,68 & 84,68 & 361,72 \\
\hline Salamandra salamandra & 29TPG55 & 101,00 & 101,87 & 98,62 & 37,70 & 5478,45 & 253,21 & $-4,90$ & 258,12 & 41,72 & 175,11 & 175,11 & 35,82 & 1007,10 & 132,54 & 22,70 & 45,05 & 389,16 & 96,94 & 96,94 & 385,59 \\
\hline Salamandra salamandra & 29TPG58 & 99,00 & 113,24 & $\begin{array}{ll}90,025 \\
99,55\end{array}$ & 38,22 & 5409,77 & $\mid \frac{25,21}{260,71}$ & 4,08 & 256,63 & 52,44 & $\mid$ & $\mid \frac{184,97}{\mid 184,}$ & $\begin{array}{l}40,02 \\
47,33\end{array}$ & 906,05 & $\mid 121,16$ & 22,17 & 42,81 & 345,63 & 92,32 & 92,32 & 336,18 \\
\hline Salamandra salamandra & 29TPG59 & 101,00 & 120,87 & 99,39 & 38,56 & 5362,54 & 265,42 & 10,95 & \begin{tabular}{|l|l|}
254,47 \\
\end{tabular} & \begin{tabular}{|l|l|}
59,95 & \\
\end{tabular} & \begin{tabular}{|c|}
191,56 \\
\end{tabular} & 191,56 & 55,12 & 854,10 & 114,17 & 21,06 & 41,95 & 323,58 & 88,29 & 88,29 & 311,47 \\
\hline Salamandra salamandra & 29TPG60 & 100,00 & \begin{tabular}{ll|l}
123,07 \\
\end{tabular} & \begin{tabular}{|l|l}
105,87 \\
\end{tabular} & 38,38 & 5712,51 & 281,58 & 9,35 & 272,23 & 52,57 & 198,73 & 198,73 & 52,53 & 838,83 & 117,23 & 13,04 & 49,09 & 331,15 & 67,94 & 67,94 & 331,15 \\
\hline Salamandra salamandra & 29TPG61 & 101,00 & 124,66 & 106,28 & 38,58 & 5691,35 & 282,65 & 10,37 & 272,28 & 56,10 & 199,97 & 199,97 & 54,20 & 816,66 & 112,80 & 13,43 & 48,38 & 321,04 & 67,43 & 67,43 & 320,98 \\
\hline Salamandra salamandra & 29TPG62 & 101,00 & 117,17 & 104,76 & 38,23 & 5659,64 & 274,68 & 4,41 & 270,26 & 52,34 & 192,27 & 192,27 & 47,48 & 857,09 & 117,25 & 15,25 & 47,61 & 336,34 & 74,11 & 74,11 & 336,18 \\
\hline Salamandra salamandra & 29TPG63 & 100,00 & 112,97 & 103,74 & 38,15 & 5628,42 & 269,69 & 1,35 & 268,34 & 50,38 & 187,93 & 187,93 & 44,10 & \begin{tabular}{|l|}
878,27 \\
\end{tabular} & 118,15 & 16,94 & 46,75 & 343,20 & 79,00 & 79,00 & 342,17 \\
\hline Salamandra salamandra & 29TPG64 & 100,00 & 104,22 & 101,47 & 37,91 & 5587,04 & 259,60 & $-4,87$ & 264,47 & 42,66 & 178,99 & 178,99 & 36,56 & 935,40 & 123,39 & 19,90 & 45,50 & 363,13 & 88,84 & 88,84 & 360,58 \\
\hline Salamandra salamandra & 29TPG65 & 100,00 & 91,21 & 98,25 & 37,45 & 5510,92 & 244,11 & $-14,60$ & 258,71 & 31,40 & 165,31 & 165,32 & 25,41 & 1036,29 & 135,29 & 25,12 & 43,62 & 396,79 & \begin{tabular}{ll|}
105,96 \\
\end{tabular} & 106,01 & 391,05 \\
\hline Salamandra salamandra & 29TPG67 & 101,00 & 90,62 & 98,13 & 37,76 & 5449,74 & 241,65 & $-15,01$ & 256,66 & 31,18 & 163,81 & 163,81 & 25,53 & 1033,16 & 135,57 & 27,56 & 41,95 & 391,99 & 111,28 & 111,28 & 382,79 \\
\hline Salamandra salamandra & 29TPG68 & 101,00 & 95,38 & 98,77 & 37,99 & 5429,41 & 245,36 & $-11,17$ & 256,53 & 35,56 & 168,01 & 168,01 & 30,21 & 994,16 & 131,08 & 26,93 & 41,40 & 376,34 & 108,56 & 108,56 & 365,59 \\
\hline Salamandra salamandra & 29TPG69 & 100,00 & 109,58 & 99,72 & 38,42 & 5401,83 & 256,87 & 0,74 & 256,13 & 48,89 & 181,12 & 181,12 & 43,70 & 891,67 & 118,02 & 23,64 & 41,01 & 336,82 & 96,95 & 96,95 & 323,83 \\
\hline Salamandra salamandra & 29TPG70 & 101,00 & 120,49 & 106,61 & 38,23 & 5758,56 & 281,01 & 6,19 & 274,81 & 50,93 & 197,05 & 197,05 & 49,40 & 797,41 & 110,24 & 12,70 & 48,25 & 313,45 & 66,84 & 66,84 & 313,45 \\
\hline Salamandra salamandra & 29TPG71 & 99,00 & 106,29 & 103,38 & 37,79 & 5709,64 & 265,63 & $-4,35$ & 269,98 & 41,02 & 182,72 & 182,73 & 36,85 & 887,24 & 120,34 & 15,88 & 47,03 & 346,53 & 79,77 & 79,77 & 346,12 \\
\hline Salamandra salamandra & 29TPG72 & 100,00 & 104,66 & 103,39 & 37,8 & 5685,59 & 263,66 & $-5,85$ & 269,52 & 42,0 & \begin{tabular}{|l|l|}
180,79 \\
\end{tabular} & 180,80 & 35,52 & 889,11 & 119,21 & 17, & 46,29 & 346,30 & 82,30 & 82,30 & 345,29 \\
\hline Salamandra salamandra & 29TPG73 & 100,00 & 111,26 & 105,36 & 38,08 & 5681,64 & 270,72 & $\begin{array}{l}-1,27 \\
-1,27 \\
\end{array}$ & 271,99 & 48,18 & 187,11 & 187,11 & 41,70 & \begin{tabular}{|l|l|l|l|}
830,16 \\
\end{tabular} & $\frac{11,21}{111,22}$ & 16,29 & 46,11 & 324,27 & 76,84 & 76,84 & 322,77 \\
\hline Salamandra salamandra & 29TPG74 & 100,00 & 102,89 & 103,19 & 37,94 & 5639,26 & 260,53 & $-7,56$ & 268,10 & 40,61 & 178,40 & 178,40 & 34,42 & 888,01 & 117,14 & 19,58 & 44,67 & 343,11 & 87,15 & 87,15 & 339,61 \\
\hline Salamandra salamandra & 29TPG76 & 100,00 & 69,20 & 95,75 & 37,03 & 5474,24 & 221,21 & $-33,69$ & 254,90 & 11,21 & 143,07 & 143,32 & 5,10 & \begin{tabular}{|l|}
1166,78 \\
\end{tabular} & 148,91 & 33,61 & 40,03 & 435,09 & 133,11 & 134,16 & 423,21 \\
\hline Salamandra salamandra & 29TPG80 & 100,00 & 121,05 & 107,95 & 38,31 & 5805,80 & 283,05 & 5,75 & 277,30 & 55,69 & 198,22 & 198,22 & 49,43 & 736,72 & 99,75 & 12,07 & 47,20 & 287,01 & 63,76 & 63,76 & 286,57 \\
\hline Salamandra salamandra & 29TPG81 & 100,00 & 112,63 & 106,89 & 38,07 & 5769,69 & 274,83 & $-0,95$ & 275,78 & 47,70 & 189,63 & 189,63 & 41,79 & 781,52 & 105,21 & 13,80 & 46,54 & 304,45 & 70,73 & 70,73 & 304,31 \\
\hline Salamandra salamandra & 29TPG82 & 101,00 & $\begin{array}{ll}11,2,03 \\
115,92\end{array}$ & $\begin{array}{l}10,05,05 \\
108,\end{array}$ & 38,48 & 5741,87 & $\mid \begin{array}{ll}\mid 7,0,03 \\
278,21\end{array}$ & \begin{tabular}{|l|l} 
\\
1,19
\end{tabular} & 277,01 & 49,20 & $\begin{array}{l}\mid 00,03 \\
192,39\end{array}$ & \begin{tabular}{|l|l|}
192,39 \\
192,39
\end{tabular} & 45,23 & 751,50 & \begin{tabular}{|l|}
101,08 \\
101,08
\end{tabular} & $\begin{array}{l}30,00 \\
13,75\end{array}$ & 460,42 & 2903,71 & 68,50 & 68,50 & 293,50 \\
\hline Salamandra salamandra & 29TPG83 & 100,00 & 114,34 & 107,76 & 38,57 & 5717,94 & 275,96 & $-0,14$ & 276,10 & 49,76 & \begin{tabular}{|l|}
190,63 \\
\end{tabular} & 190,63 & 43,99 & 756,43 & 100,89 & 14,92 & 45,71 & 294,30 & 71,12 & 71,12 & 293,56 \\
\hline Salamandra salamandra & 29TPG84 & 100,00 & 101,08 & 104,58 & 38,04 & 5694,84 & 260,62 & \begin{tabular}{|c|c|c|}
$-10,39$ \\
\end{tabular} & 271,01 & 38,15 & 177,42 & 177,42 & 31,99 & 848,62 & 111,77 & 19,55 & 43,67 & 325,23 & 86,52 & 86,52 & 320,86 \\
\hline Salamandra salamandra & 29TPG85 & 99,00 & 90,22 & 102,10 & 37,74 & 5649,05 & 247,58 & $-18,81$ & 266,39 & 28,47 & 166,10 & 166,16 & 22,38 & \begin{tabular}{|c|}
931,97 \\
\end{tabular} & 121,43 & 24, & 41,70 & 352,40 & \begin{tabular}{|c|c|}
101,25 \\
\end{tabular} & 101,38 & 344,17 \\
\hline Salamandra salamandra & 29TPG86 & 101,00 & 80,34 & 100,06 & 37,57 & 5586,05 & 235,83 & $-26,54$ & 262,37 & 19,98 & 155,48 & 155,64 & 13,90 & 1015,72 & 130,94 & 29,10 & 40,06 & 379,28 & 116,18 & 116,72 & 367,84 \\
\hline Salamandra salamandra & $\begin{array}{l}\text { 29TPG87 } \\
\end{array}$ & 100,00 & $\begin{array}{l}60,34 \\
60,76 \\
\end{array}$ & $\begin{array}{c}10,000 \\
96,29 \\
\end{array}$ & $\begin{array}{l}37,174 \\
37,14\end{array}$ & $\begin{array}{l}530,000 \\
5479,39\end{array}$ & \begin{tabular}{|l|l|}
213,40 \\
213,40
\end{tabular} & - & 250,31 & \begin{tabular}{|c|}
3,18 \\
3,18 \\
\end{tabular} & $\begin{array}{l}\mid 35,40 \\
134,78\end{array}$ & \begin{tabular}{|l|}
135,09 \\
135
\end{tabular} & $\mid \begin{array}{l}\mid 3,508 \\
-3,08\end{array}$ & $\begin{array}{l}1192,08 \\
1192,\end{array}$ & $\mid \begin{array}{l}\mid 50,54 \\
150,36\end{array}$ & 37,89 & $\begin{array}{l}470,67 \\
37,67\end{array}$ & $\begin{array}{l}3 / 2,20 \\
436,76\end{array}$ & \begin{tabular}{|l|}
145,06 \\
145
\end{tabular} & \begin{tabular}{|l|l|l|l|l|}
146,84 \\
\end{tabular} & $\begin{array}{ll}301,04 \\
421,17\end{array}$ \\
\hline Salamandra salamandra & 29TPG88 & 101,00 & 75,96 & 99,19 & 37,83 & 5498,03 & 229,16 & $-29,65$ & 258,81 & 16,66 & 149,91 & 149,95 & 10,69 & 1056,83 & 135,57 & 32,94 & 38,18 & 389,90 & 128,19 & 128,45 & 374,70 \\
\hline Salamandra salamandra & 29TPG89 & 100,00 & 93,45 & 101,35 & 38,41 & 5516,40 & 245,72 & $-15,37$ & 261,10 & 32,3 & 167,04 & 167,05 & 26,82 & 919,95 & 119,41 & 27,68 & 38,68 & 341,52 & 110,07 & 110,10 & 325,83 \\
\hline Salamandra salamandra & 29TPG90 & 101,00 & 125,92 & 109,62 & 38,77 & 5856,70 & 288,50 & 8,71 & 279,79 & 60 & 203,44 & 203,44 & 53,2 & 655,17 & 85,95 & 11 & 45, & 252,45 & 58,32 & 58,32 & 249,87 \\
\hline Salamandra salamandra & 29TPG91 & 100,00 & 118,94 & 109,38 & 38,64 & 5827,16 & 282,27 & 2,54 & 279,73 & 53,38 & 196,21 & 196,21 & 46,87 & 687,62 & 90,57 & 12,47 & 45,58 & 265,21 & 63,42 & 63,42 & 264,07 \\
\hline Salamandra salamandra & 29TPG92 & 100,00 & 117,79 & 109,49 & 38,73 & 5801,07 & 281 & 1,55 & 279,58 & 51,24 & 194,91 & 194,91 & 45,98 & \begin{tabular}{|c|c|}
690,75 \\
\end{tabular} & 91,31 & 13,20 & 45,22 & 266,29 & 65,12 & 65,12 & 265,58 \\
\hline Salamandra salamandra & 29TPG93 & 100,00 & 114,11 & 109,10 & 38,82 & 5783,44 & 276,86 & $-1,48$ & 278,34 & & \begin{tabular}{|c|}
191,09 \\
\end{tabular} & 191,09 & 42,76 & 707,57 & 93,88 & 14,70 & 44,40 & 271,75 & 69,24 & 69,24 & 270,03 \\
\hline Salamandra salamandra & 29TPG94 & 101,00 & 110,64 & 108,34 & 38,65 & 5772,11 & 272,62 & $-4,27$ & 276,90 & 45,99 & 187,51 & 187,51 & 39,68 & 726,49 & 96,60 & 16,51 & 43,40 & 277,94 & 73,92 & 73,92 & 274,29 \\
\hline Salamandra salamandra & 29TPG95 & 101,00 & 102,24 & 106,49 & 38,29 & 5749,81 & 78 & $-11,04$ & 273,82 & 38,15 & 179,12 & 179,12 & 32,12 & 781,86 & 103,44 & 20,04 & 41, & 296,35 & 84,39 & 84,39 & 288,95 \\
\hline Salamandra salamandra & 29TPG96 & 100,00 & $\begin{array}{c}10,24 \\
97,20\end{array}$ & 势, & 38,22 & 5715,20 & 25 & -15 & 271,35 & 33 & 173,68 & $\mid 173,68$ & 27,75 & 820,67 & 107,87 & 22,87 & 40, & 308,33 & 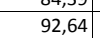 & $\begin{array}{l}94,64 \\
92,64\end{array}$ & 298,22 \\
\hline Salamandra salamandra & 29TPG97 & 10 & & 100,69 & 37,78 & 559 & 229 & -32 & 262,80 & 13, & 149 & 149,36 & 7,62 & 1021,92 & 130,38 & 32,26 & & 374,88 & $\mid 125,27$ & 125,90 & 359,55 \\
\hline Salamandra salamandra & 29TPG98 & 10 & 85,79 & 102,94 & 38,30 & 5606,91 & 241,86 & $-23,44$ & 265,30 & 24,33 & 161,06 & 161,06 & \begin{tabular}{r|r|r|r|r|}
18,38 \\
\end{tabular} & \begin{tabular}{|c|}
920,26 \\
921,2
\end{tabular} & 118,99 & 28,64 & 37,98 & 339,37 & 112,59 & 112,59 & 324,04 \\
\hline Salamandra salamandra & 29TPHOO & 101,00 & 125,61 & 90,94 & 38,56 & 4901,53 & 255,80 & 22, & 233,04 & 70 & 189,97 & 190,31 & 66 & 1067,43 & 150,45 & 25,92 & 43,21 & 400,80 & 106,02 & 114,20 & 388,56 \\
\hline Salamandra salamandra & 29TPH01 & 100,00 & 88 & 90,02 & 38,96 & 4776,79 & 252,75 & 24,07 & 228,67 & 71,31 & 187,58 & 188,19 & 67,6 & 1077,54 & 151,59 & 27,30 & 42,65 & 403,69 & 109,82 & 122,46 & 389,66 \\
\hline Salamandra salamandra & $\begin{array}{l}\text { 29TPH02 } \\
\end{array}$ & $\begin{aligned} 90,00 \\
99,\end{aligned}$ & 12 & $\begin{array}{ll}0,0<12 \\
89,12\end{array}$ & 39, & 4652,13 & 251,70 & 27,49 & 224,21 & $\begin{array}{l}7,21,29 \\
74,29\end{array}$ & \begin{tabular}{|l|l}
187,64 \\
187
\end{tabular} & \begin{tabular}{|l|l|}
188,44 \\
188,4
\end{tabular} & $\frac{10,0}{70,9}$ & $\begin{array}{l}1066,92 \\
106,\end{array}$ & $\begin{array}{l}\mid 1,1,59 \\
149,59 \\
\end{array}$ & 27,96 & $\begin{array}{l}42,03 \\
41,88\end{array}$ & $\begin{array}{l}-40,09 \\
398,26\end{array}$ & $\begin{array}{l}111,13 \\
111,13\end{array}$ & $\begin{array}{l}12,40 \\
125,05 \\
\end{array}$ & 382,20 \\
\hline Salamandra salamandra & 29TPHO3 & 101,00 & & 88,14 & 39,68 & 4526,51 & 245,68 & 25, & 220,12 & 71,6 & 181,60 & 182,66 & 68,41 & 1110,45 & 154,52 & 30,34 & 41,20 & 414,15 & 119,09 & 132,83 & 396,58 \\
\hline Salamandra salamandra & 29TPH05 & 100,00 & 120,25 & 86,16 & 40,00 & 4330,66 & 239,66 & 26,8 & 212,84 & 72,25 & \begin{tabular}{|c|}
176,64 \\
\end{tabular} & 178,33 & 68,88 & 1130,62 & 154,64 & 32,99 & 39,74 & 419,44 & 127,24 & 141,76 & 397,95 \\
\hline Salamandra salamandra & 29TPH07 & 100,00 & 12 & 83,78 & 40,52 & 4121,32 & 237,34 & 33 & 204 & & 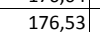 & 178 & & 1106 & 148 & 33, & 38, & 408,04 & 129,36 & 145,35 & 382,48 \\
\hline Salamandra salamandra & 29TPH08 & 10 & & 82 & 40 & & & & 200 & 80 & $1 / 6$ & $17 \mathrm{~s}$ & & & & & & 400,97 & 129,85 & 146,52 & 373,57 \\
\hline Salamandra salamandra & 29TPHO9 & 100,00 & 122,75 & 81,56 & 40,98 & 3966,66 & 232,91 & 35,86 & \begin{tabular}{|l|l|l|l|}
197,05 \\
\end{tabular} & 79,73 & 173,76 & 176,37 & 75,50 & 1103,86 & $\begin{array}{l}444,75 \\
144\end{array}$ & 35,37 & 36,96 & 404,69 & 134,34 & 151,17 & 375,61 \\
\hline Salamandra salamandra & 29TPH13 & 101,00 & 119,95 & 89,56 & 39,25 & 4654,25 & 246,39 & 21,29 & 225,10 & 67,82 & 180,91 & 181,77 & 64,29 & 1074,00 & 147,45 & 29,69 & 40,64 & 400,06 & 116,88 & 129,88 & 382,25 \\
\hline Salamandra salamandra & 29TPH16 & 101,00 & 125,04 & 86,30 & 40,07 & 4330,92 & 243,26 & 31,13 & 212,13 & 76,77 & 181,15 & 182,83 & 73,01 & 1042,90 & 139,56 & 31,21 & 38,41 & 383,96 & 120,74 & 136,01 & 359,84 \\
\hline Salaman & 29TPH17 & 18 & & & 40,36 & 1 & 241,65 & & 207,40 & 79,44 & 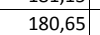 & 100 & 755 & 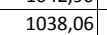 & & 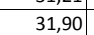 & & 381,03 & 122,60 & 138,47 & 354,94 \\
\hline Salamandra salamandra & 29TPH18 & & & & 40, & & & & 203,7 & 80,25 & 178,80 & 180,96 & 76, & 1044 & 136,94 & 32, & $3 /$ & 382,20 & 125,76 & 142,04 & 354,40 \\
\hline Salamandra salamandra & 29TPH19 & 100,00 & 123,57 & 82,76 & 40,98 & 4058,01 & 235,39 & 34,93 & 200,46 & 79,42 & 175,75 & 178,19 & 74,90 & 1060,94 & 137,80 & 34,36 & 36,39 & 387,31 & 130,66 & 147,15 & 357,73 \\
\hline Salamandra salamandra & 29TPH 25 & 100,00 & 126,69 & 88,78 & 40,00 & 4525,55 & 249,07 & 29,25 & 219,82 & \begin{tabular}{|l|l|}
75,85 \\
\end{tabular} & 185,51 & 186,73 & 72,08 & 981,64 & 131,10 & 28,68 & 38,56 & 361,47 & 112,42 & 126,98 & 338,67 \\
\hline Salamandra salamandra & $29 \mathrm{TPH} 26$ & 100,00 & 121,66 & 87,84 & 40,00 & 4444,56 & 43,07 & 26,02 & 217,05 & 71,93 & 179,43 & 180,73 & 68,04 & 1026,71 & 136,01 & 31,28 & 37,83 & 377,12 & 121,13 & 135,50 & 352,61 \\
\hline Salam & 29TPH29 & 10 & 120 & & 40 & 152 & & 30, & 204 & 75, & 174,12 & & 70,7 & 1050 & & & 35 & & & & \\
\hline Salamandra salamandra & $29 \mathrm{TPH} 35$ & 101,00 & 118,79 & 90,60 & 39,82 & 4643,16 & 245,49 & 20,12 & 225,38 & $\begin{array}{l}6,262 \\
66,82\end{array}$ & 179,40 & 180,40 & 62,86 & \begin{tabular}{|c|}
996,47 \\
906,20
\end{tabular} & $\mid 131,71$ & 30,01 & 年, 37,94 & \begin{tabular}{|l|l|}
366,67 \\
367
\end{tabular} & 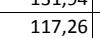 & \begin{tabular}{|l|}
130,42 \\
130
\end{tabular} & 343,40 \\
\hline
\end{tabular}




\begin{tabular}{|c|c|c|c|c|c|c|c|c|c|c|c|c|c|c|c|c|c|c|c|c|c|}
\hline TAXON & UTM & $\mathrm{km2}$ & BIO1 & $\mathrm{BIO2}$ & $\mathrm{BIO3}$ & BIO4 & B105 & 8106 & B107 & B108 & B109 & BIO10 & BIO11 & BIO12 & B1013 & B1014 & B1015 & B1016 & BIO17 & BIO18 & 81019 \\
\hline Salamandra salamandra & 29TPH37 & 101,00 & 115,11 & 88,43 & 40,03 & 4458,08 & 237,97 & 19,80 & 218,17 & 65,63 & 173,12 & 174,59 & 61,61 & 1040,39 & 135,09 & 33,49 & 36,41 & 379,57 & 128,52 & 142,10 & 352,46 \\
\hline Salamandra salamandra & 29TPH38 & 101,00 & 119,86 & 87,02 & 40,46 & 4332,46 & 238,97 & 26,55 & 212,42 & 72,01 & \begin{tabular}{|l|}
176,02 \\
\end{tabular} & 177,71 & 67,77 & 1012,15 & 129,91 & 33,23 & 35,76 & 367,39 & 127,05 & 141,69 & 338,09 \\
\hline Salamandra salamandra & 29TPH40 & 100,00 & 122,17 & 96,97 & 38,64 & 5220,98 & 262,21 & 14,28 & 247,94 & 62,99 & 190,75 & 190,76 & 58,29 & $\begin{array}{r}893,50 \\
\end{array}$ & 120,14 & 22,50 & 41,55 & 336,45 & 93,20 & 93,37 & 322,83 \\
\hline Salamandra salamandra & 29TPH41 & 101,00 & 110,45 & 95,49 & 38,66 & 5128,06 & 250,03 & 5,65 & 244,38 & 52,96 & 178,23 & 178,27 & 48,54 & 986,46 & 132,08 & 26,80 & 40,55 & 370,31 & 108,08 & 108,69 & 355,08 \\
\hline Salamandra salamandra & 29TPH42 & 99,00 & 98,73 & 93,70 & 38,60 & 5033,63 & 237,43 & $-2,60$ & \begin{tabular}{|l|l|l|}
240,03 \\
\end{tabular} & 43,30 & \begin{tabular}{|c|}
165,53 \\
\end{tabular} & 165,70 & \begin{tabular}{|c|}
38,78 \\
\end{tabular} & 1084,12 & 143,75 & 31,77 & 39,41 & 404,36 & 124,83 & 128,62 & 386,95 \\
\hline Salamandra salamandra & 29TPH44 & 99,00 & 109,30 & 93,09 & 39,19 & 4862,07 & 242,56 & 8,30 & 234,26 & 54,97 & 173,19 & 173,70 & 50,86 & \begin{tabular}{|l|}
1015,57 \\
\end{tabular} & 133,86 & 30,74 & 37,96 & 375,15 & 120,36 & 129,85 & 353,36 \\
\hline Salamandra salamandra & 29TPH45 & 100,00 & 111,85 & 92,25 & 39,68 & 4763,05 & 242,47 & 11,89 & 230,58 & 58,62 & 174,21 & 174,95 & 54,51 & 1003,77 & 131,25 & 31,17 & 37,17 & 368,70 & 121,41 & 132,90 & 344,71 \\
\hline Salamandra salamandra & 29TPH46 & 100,00 & 109,87 & 91,19 & 39,78 & 4666,34 & 238,61 & 11,67 & 226,94 & 58,09 & \begin{tabular}{ll|}
170,95 \\
\end{tabular} & 171,92 & 53,92 & 1027,55 & 133,24 & 33,07 & 36,41 & 375,50 & 127,47 & 139,49 & 349,42 \\
\hline Salamandra salamandra & 29TPH47 & 100,00 & 113,76 & 89,87 & 40,07 & 4540,38 & 238,84 & 17,10 & 221,75 & 63,41 & \begin{tabular}{|c|}
172,88 \\
\end{tabular} & 174,14 & 59,13 & 1012,02 & 129,93 & 33,27 & 35,72 & 367,70 & 127,70 & 140,68 & 339,47 \\
\hline Salamandra salamandra & 29TPH48 & 101,00 & 117,97 & 88,31 & 40,36 & 4404,92 & 239,19 & 23,24 & 215,96 & 69,26 & 175,12 & 176,65 & 64,93 & 993,69 & 127,02 & 33,38 & 34,98 & 359,06 & 127,50 & 141,46 & 328,68 \\
\hline Salamandra salamandra & 29TPH49 & 100,00 & 124,12 & 86,46 & 40,94 & 4260,85 & 240,72 & 31,49 & 209,23 & 77,22 & \begin{tabular}{|l|l|}
179,05 \\
\end{tabular} & 180,94 & 72,71 & 962,06 & 123,51 & 32,72 & 34,54 & 345,94 & 124,92 & 139,97 & 313,62 \\
\hline Salamandra salamandra & 29TPH50 & 99,00 & 103,52 & 97,16 & 38,31 & 5267,63 & 247,89 & $-2,19$ & 250,08 & 44,77 & 173,39 & 173,39 & 40,01 & 986,10 & 131,01 & 27,03 & 40,63 & 371,34 & 108,83 & 108,87 & 357,52 \\
\hline Salamandra salamandra & 29TPH51 & 100,00 & 92,45 & 95,33 & 38,24 & 5173,82 & 235,67 & $-10,10$ & 245,76 & 35,76 & \begin{tabular}{|l|l|}
161,46 \\
\end{tabular} & 161,51 & 30,84 & 1078,35 & 141,86 & 31,88 & 39,27 & 402,52 & 125,19 & 125,91 & 386,28 \\
\hline Salamandra salamandra & 29TPH52 & 100,00 & 95,85 & 95,19 & 38,70 & 5107,97 & 237,01 & $-6,60$ & 243,60 & 39,57 & 163,73 & \begin{tabular}{|l|l|}
163,78 \\
\end{tabular} & 34,81 & 1057,17 & 138,92 & 31,84 & 38,58 & 392,95 & 124,87 & 126,52 & 374,61 \\
\hline Salamandra salamandra & 29TPH54 & 100,00 & 115,34 & 94,76 & 39,46 & 4935,88 & 249,56 & 12,04 & 237,52 & \begin{tabular}{l|l|l|}
59,65 \\
\end{tabular} & \begin{tabular}{|c|}
179,89 \\
\end{tabular} & 180,24 & 55,34 & 926,28 & 120,82 & 27,95 & 37,42 & 341,19 & 110,92 & 118,09 & 318,13 \\
\hline Salamandra salamandra & 29TPH55 & 101,00 & 115,59 & 93,60 & 39,8 & 4824,02 & 247,23 & 14,03 & 233,20 & 61,30 & 178,62 & 179,20 & 57,08 & 937,10 & 121,15 & 29,23 & 36,63 & 342,96 & 114,97 & 125,70 & 317,72 \\
\hline Salamandra salamandra & 29TPH56 & 100,00 & 112,59 & 92,57 & 39,92 & 4721,95 & 242,36 & 12,91 & 229,45 & 59,88 & 174,30 & 175,10 & 55,56 & 969,45 & 124,37 & 31,62 & 35,72 & 352,59 & 122,46 & 134,51 & 325,18 \\
\hline Salamandra salamandra & 29TPH57 & 101,00 & 108,53 & 91,48 & 39,99 & 4634,93 & 236,83 & 10,77 & 226,06 & 57,27 & 169,01 & 170,10 & 52,83 & 1012,28 & 129,34 & 34,45 & 34,89 & 366,04 & 131,43 & 143,40 & 336,67 \\
\hline Salamandra salamandra & 29TPH58 & 99,00 & 111,89 & 90,21 & 40,17 & 4511,60 & 236,79 & 15,61 & 221,18 & \begin{tabular}{|c|}
62,19 \\
\end{tabular} & \begin{tabular}{|c|}
170,64 \\
\end{tabular} & 171,93 & 57,57 & 1001,05 & 128,05 & 34,69 & 34,26 & 360,09 & 131,93 & 144,69 & 328,66 \\
\hline Salamandra salamandra & 29TPH60 & 101,00 & 104,75 & 99,05 & 38,49 & 5352,43 & 251,30 & $-2,77$ & 254,06 & \begin{tabular}{|l|l|l|}
44,83 & \\
\end{tabular} & \begin{tabular}{|c|}
175,79 \\
\end{tabular} & 175,79 & 39,85 & 926,98 & 122,54 & 25,86 & 40,07 & 348,48 & 104,41 & 104,43 & 333,57 \\
\hline Salamandra salamandra & 29TPH61 & 101,00 & 98,60 & 97,92 & 38,58 & 5271,68 & 243,83 & $-6,88$ & 250,72 & 40,01 & \begin{tabular}{|l|l|}
168,65 \\
\end{tabular} & 168,65 & 35,12 & 979,21 & 128,64 & 28,89 & 38,95 & 365,30 & 114,69 & 114,77 & 348,13 \\
\hline Salamandra salamandra & 29TPH62 & 100,00 & 100,06 & 97,43 & 38,86 & 5205,83 & 243,35 & $-4,92$ & 248,28 & 41,99 & $\begin{array}{l}169,03 \\
169\end{array}$ & 169,06 & 37,23 & $\mid 973,89$ & 127,40 & 29,47 & 38,08 & 361,44 & 116,54 & 116,88 & 342,10 \\
\hline Salamandra salamandra & 29TPH63 & 100,00 & 96,65 & 96,45 & 38,91 & 5119,07 & 238,28 & $-6,57$ & 244,86 & \begin{tabular}{|c|}
39,94 \\
\end{tabular} & \begin{tabular}{|c|}
164,49 \\
\end{tabular} & 164,55 & 35,18 & 1010,04 & 131,23 & 31,90 & 37,11 & 372,28 & 124,46 & 125,75 & 350,78 \\
\hline Salamandra salamandra & 29TPH64 & 100,00 & 101,18 & 95,94 & 39,16 & 5028,11 & 240,07 & $-1,63$ & 241,70 & 45,30 & 167,53 & 167,73 & 40,68 & $\begin{array}{r}986,45 \\
\end{array}$ & 127,35 & 31,77 & 36,41 & 361,41 & 123,68 & 127,55 & 337,53 \\
\hline Salamandra salamandra & 29TPH68 & 100,00 & 112,91 & 91,50 & 40,35 & 4561,33 & 239,10 & 15,52 & 223,58 & 62,99 & 172,22 & 173,42 & 57,89 & 963,04 & 124,25 & 34, & 33,53 & 344,15 & 129,85 & 142,22 & 311,33 \\
\hline Salamandra salamandra & 29TPH70 & 99,00 & 120,04 & 101,98 & 38,92 & 5464,69 & 267,27 & 7,93 & 259,34 & 57,30 & 191,79 & 191,79 & 52,47 & 768,84 & 101,73 & 20,23 & 40,17 & 290,06 & 85,34 & 85,34 & 274,12 \\
\hline Salamandra salamandra & 29TPH72 & 100,00 & 106,85 & $\begin{array}{ll} & \\
99,74\end{array}$ & 38,99 & 5300,89 & 251,67 & $\begin{array}{ll}-0,98 \\
-0,98\end{array}$ & 252,65 & 46,96 & 176,72 & 176,72 & 42,12 & 876,57 & 114,23 & 26,39 & 37,74 & 324,95 & $\mid$\begin{tabular}{|c|}
106,04 \\
\end{tabular} & $\mid$\begin{tabular}{|c|}
106,04 \\
\end{tabular} & 304,42 \\
\hline Salamandra salamandra & 29TPH73 & 101,00 & 86,82 & 97,28 & 38,88 & 5179,44 & 231,19 & $-16,28$ & 247,47 & 30,10 & 155,82 & 155,92 & 25,01 & 1044,37 & 133,86 & 35,11 & 35,84 & 381,04 & 134,58 & 135,46 & 358,23 \\
\hline Salamandra salamandra & 29TPH74 & 100,00 & 79,80 & 95,67 & 38,76 & 5085,43 & 222,37 & $-21,16$ & 243,53 & 24,80 & \begin{tabular}{|c|}
147,66 \\
\end{tabular} & 147,86 & \begin{tabular}{|l|l|}
19,67 \\
\end{tabular} & 1114,89 & 141,35 & 39,34 & 34,79 & 402,99 & 148,23 & 150,17 & 377,98 \\
\hline Salamandra salamandra & 29TPH75 & 101,00 & 94,02 & 96,11 & 39,45 & 4995,44 & 233,21 & $-7,67$ & 240,88 & 39,08 & 160,11 & 160,38 & 34,17 & 1015,93 & 129,58 & 35,50 & 34,52 & 366,79 & 135,23 & 139,76 & 339,58 \\
\hline Salamandra salamandra & 29TPH78 & 100,00 & 114,42 & 92,48 & 40,65 & 4583,52 & 241,15 & 16,33 & 224,81 & 67,71 & \begin{tabular}{|l|l|}
173,87 \\
\end{tabular} & 175,05 & 58,89 & $\begin{array}{r}927,82 \\
\end{array}$ & 120,75 & 33,81 & 32,65 & 328,82 & 128,45 & 140,50 & 294,39 \\
\hline Salamandra salamandra & 29TPH80 & 101,00 & 115,40 & 103,38 & 38,97 & 5547,08 & 265,72 & 2,60 & 263,12 & 51,78 & 188,51 & 188,51 & 46,90 & 754,35 & 99,32 & 20,75 & 39,45 & 283,55 & 87,01 & 87,01 & 266,77 \\
\hline Salamandra salamandra & 29TPH82 & 99,00 & 115,22 & 101,69 & 39,04 & 5381,48 & 260,87 & 4,64 & 256,23 & 53,53 & 185,86 & 185,86 & 48,75 & 776,09 & 101,55 & 22,88 & 37,42 & 287,61 & 94,74 & 94,74 & 265,39 \\
\hline Salamandra salamandra & 29TPH83 & 101,00 & 103,10 & 100,38 & 39,18 & 5272,73 & 248,04 & $-4,25$ & 252,29 & 43,77 & \begin{tabular}{|c|}
172,58 \\
\end{tabular} & 172,58 & 38,79 & 876,14 & 113,19 & 28,54 & 35,80 & 320,06 & 112,79 & 112,79 & 295,79 \\
\hline Salamandra salamandra & 29TPH84 & 99,00 & 84,45 & 98,01 & 39,11 & 5161,57 & 228,83 & $-18,65$ & 247,48 & 28,14 & 153,10 & 153,23 & 22,80 & 1035,10 & 131,26 & 37,17 & 34,15 & 372,30 & 140,47 & 142,00 & 346,19 \\
\hline Salamandra salamandra & 29TPH85 & 100,00 & 86,49 & 97,08 & 39,39 & 5063,74 & 228,23 & $-15,52$ & 243,75 & 31,32 & 153,68 & 153,93 & 26,09 & 1038,17 & 131,85 & 38,02 & 33,43 & 371,23 & 143,15 & 146,55 & 342,91 \\
\hline Salamandra salamandra & 29TPH86 & 100,00 & 92,14 & 96,67 & 39,75 & 4962,72 & 231,10 & $-9,28$ & 240,38 & 37, & 157,69 & 158,06 & 32,74 & 1009,01 & 128,96 & 37, & 32,85 & 359,18 & 141,06 & 147,50 & 328,58 \\
\hline Salamandra salamandra & 29TPH89 & 101,00 & 101,12 & 93,28 & 40,81 & 4598,28 & 230,46 & 4,05 & 226,41 & 53,60 & 161,11 & 162,30 & 46,03 & $\begin{array}{l}1004,39 \\
\end{array}$ & 129,82 & 39, & 31,03 & 351,25 & 146,93 & 157,47 & 313,99 \\
\hline Salamandra salamandra & 29TPH90 & 100,00 & 99,73 & 103,64 & 38,78 & 5565,35 & 252,92 & $-11,42$ & 264,33 & 37 & 173 & 173,61 & 31,75 & 828,61 & 107,49 & 25, & 37,44 & 305,64 & 103,15 & \begin{tabular}{ll|}
103,15 \\
\end{tabular} & 287,18 \\
\hline Salamandra salamandra & 29TPH91 & 100,00 & 123,96 & 104,01 & $39, \mathrm{C}$ & 5549,99 & 273,22 & 9,52 & 263,70 & 59, & \begin{tabular}{|l|l|}
196,45 \\
\end{tabular} & \begin{tabular}{|l|l|}
196,45 \\
\end{tabular} & 54 & \begin{tabular}{|l|l|}
671,06 \\
\end{tabular} & 89,20 & 18,5 & 38,11 & 250,52 & 80,57 & 80,57 & 229,55 \\
\hline Salamandra salamandra & 29TPH93 & 101,00 & 107,31 & 102,32 & 39,65 & 5336,26 & 253,68 & $\begin{array}{l}-1,99 \\
\end{array}$ & 255,66 & 46,81 & 177,48 & 177,48 & 41,85 & 807,54 & 105,61 & 26,68 & 35,10 & 293,24 & $\mid 106,52$ & $\mid \begin{array}{l}\mid 06,52 \\
106\end{array}$ & 267,56 \\
\hline Salamandra salamandra & 29TPH94 & 100,00 & 95,70 & 100,75 & 39,73 & 5221,88 & 241,01 & $-10,36$ & 251,37 & 37, & 164,72 & 164,75 & 32,52 & 909,10 & 117,19 & 32,61 & 33,67 & 325,71 & 125,11 & \begin{tabular}{|l|l}
125,58 \\
\end{tabular} & 298,14 \\
\hline Salamandra salamandra & 29TPH95 & 101,00 & 82,12 & 98,49 & 39,41 & 5119,52 & 226,07 & $-20,73$ & 246,80 & 26,62 & \begin{tabular}{|c|}
150,14 \\
\end{tabular} & 150,32 & 21,01 & 1033,23 & 130,99 & 39,47 & 32,41 & 366,08 & 147,11 & 149,18 & 336,68 \\
\hline Salamandra salamandra & 29TPH96 & 100,00 & 95,13 & 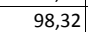 & 40,01 & 996,45 & 4,96 & -7, & 242, & 43, & 160 & 161,15 & 34,80 & 956,82 & 123,38 & 36, & 32, & 337,68 & 137,32 & 142,85 & 305,49 \\
\hline Salamandra salamandra & 29тPJ00 & $1 \mathrm{c}$ & 117,21 & 80,76 & 40 & 3933,58 & 227 & 31, & 195 & 75, & 167 & 170 & 70, & 1145 & 148 & 37, & 36,25 & 418,76 & 142,92 & 159,58 & 388,07 \\
\hline Salamandra salamandra & 29TPJ01 & 101,00 & $\frac{11}{11}$ & 79,91 & 40,93 & 3893,99 & 221,85 & 28,54 & 193 & 71, & 162,61 & 165,58 & 66,6 & $\begin{array}{l}1180,63 \\
1180\end{array}$ & 152,27 & 40,25 & 35,61 & 430,41 & \begin{tabular}{|l|l|l|l|l|}
150,73 \\
\end{tabular} & 167,32 & 398,02 \\
\hline Salamandra salamandra & 29TPJ02 & 101,00 & 123,80 & 77,64 & 41,36 & 3730,50 & 226,94 & 41,71 & 185,24 & 84,33 & \begin{tabular}{|l|l|l|}
171,23 \\
\end{tabular} & 174,39 & 79,08 & 1089,72 & 138,96 & 36,99 & 35,12 & 396,56 & 139,64 & 158,09 & 362,56 \\
\hline Salamandra salamandra & 29тPJ03 & 101,00 & 127,49 & 76,06 & 41,66 & 3640,31 & 227,42 & 47,19 & 180,23 & 89,29 & $\begin{array}{l}173,45 \\
\end{array}$ & 176,91 & 83,71 & 1057,71 & 135,04 & 36,25 & 34,85 & 384,15 & 137,13 & \begin{tabular}{ll|}
156,45 \\
\end{tabular} & 348,63 \\
\hline Salamandra salamandra & 29TPJ10 & 101,00 & 112 & 82,44 & 40,65 & 4047,22 & 225,37 & 25,05 & 200, & 68, & 164 & 167,13 & 64, & 1150 & 148, & 39, & 35 & 418,62 & 146,55 & 162,06 & 387,48 \\
\hline Salamandra salamandra & 29TPJ11 & 99,00 & & & 40,67 & 4002,55 & & & 198,28 & & 159 & 162,08 & 60, & 1187 & & 41 & 34,98 & 430,71 & 154,62 & 170,05 & 397,96 \\
\hline Salamandra salamandra & 29TPJ12 & 100,00 & 123,46 & 78,92 & 41,39 & 3807,52 & 228,45 & 39,93 & $\begin{array}{l}188,52 \\
\end{array}$ & 82,91 & \begin{tabular}{|l|}
171,92 \\
\end{tabular} & 174,97 & 77,90 & $\begin{array}{l}1067,06 \\
\end{array}$ & 135,81 & 36,83 & 34,70 & 386,28 & 138,65 & 156,57 & 351,79 \\
\hline Salamandra salamandra & 29TPJ13 & 90,00 & 132,24 & 76,74 & 41,84 & 3674,46 & 232,24 & 50,79 & \begin{tabular}{|c|}
181,45 \\
\end{tabular} & 93,37 & 178,62 & 181,91 & 87,82 & 1000,76 & 128,78 & 34,41 & 34,42 & 361,84 & 130,66 & 149,97 & 325,86 \\
\hline Salamandra salamandra & 29TPJ14 & 15,00 & 139,48 & 74,95 & 42,25 & 3577,10 & 235,45 & 59,75 & \begin{tabular}{|c|}
175,70 \\
\end{tabular} & 101,97 & 184,30 & 187,65 & 95,88 & 947,25 & 123,18 & 32,45 & 34,15 & 342,13 & 124,05 & \begin{tabular}{|l|l|}
144,27 \\
\end{tabular} & 305,15 \\
\hline Salaman & 29TP & 100,00 & & & 41 , & 71,63 & 230 & 34 & & 77 & $1 / 1$ & $1 / 4$ & & 1057 & & & 34,61 & 38 & 137,79 & 154,38 & 34 \\
\hline Salamandra salamandra & 29TPJ22 & 101,00 & 128,39 & 79,59 & 41,46 & 3830,80 & 233 & 43,66 & 189,56 & 87,41 & 177,09 & 180,01 & 82,3 & 1008,09 & 129,29 & 35,01 & 34,31 & 363,16 & 132,31 & 150,16 & 327,92 \\
\hline Salamandra salamandra & 29TPJ23 & 94,00 & 133,06 & 77,66 & 41,91 & 3722,46 & 234,09 & 50,41 & 183,68 & 93,41 & 180,09 & 183,18 & 88,03 & 977,56 & \begin{tabular}{|l|l|}
126,37 \\
\end{tabular} & 34,11 & 33,99 & 351,59 & \begin{tabular}{|l|l|}
129,36 \\
\end{tabular} & 148,23 & 314,92 \\
\hline Salamandra salamandra & 29TPJ30 & 100,00 & 121,04 & 84,16 & 40,86 & 4126,23 & 234,68 & 31,21 & \begin{tabular}{|l|}
203,47 \\
\end{tabular} & \begin{tabular}{|c|}
76,08 \\
\end{tabular} & \begin{tabular}{|l|l|l|l|}
174,03 \\
\end{tabular} & 176,41 & \begin{tabular}{ll|l}
71,45 \\
\end{tabular} & 1022,14 & 130,45 & 35,14 & 34,61 & 368,39 & 133,01 & 148,65 & 335,45 \\
\hline Salamar & 29TPJ31 & 100,00 & & 81,16 & 41,29 & 2, & 241 & 47,8 & 193,58 & 92,40 & 185 & 187,79 & 87,18 & 929,59 & 120,41 & 31,68 & 34,24 & 333,90 & 121,13 & 138,70 & 299, \\
\hline Salamandra salamandra & 29TPJ32 & 91,00 & 136,61 & 79,53 & 41,78 & 3831,15 & 239,88 & 51,33 & 188,55 & 95,22 & 185,06 & 187,84 & 89,85 & 927,72 & 120,65 & 32,12 & 33,99 & 332,50 & 122,39 & 140,73 & 296,34 \\
\hline Salamandra salamandra & 29TPJ33 & & & & & & & & & 0,02 & & & & & & & & & & & \\
\hline
\end{tabular}




\begin{tabular}{|c|c|c|c|c|c|c|c|c|c|c|c|c|c|c|c|c|c|c|c|c|c|}
\hline TAXON & UTM & $\mathrm{km} 2$ & BIO1 & $\mathrm{BIO2}$ & $\mathrm{BIO3}$ & BIO4 & BIO5 & B106 & B107 & B108 & B109 & BIO10 & BIO11 & BIO12 & BIO13 & B1014 & B1015 & B1016 & B1017 & B1018 & B1019 \\
\hline Salamandra salamandra & 29TPJ40 & 101,00 & 128,17 & 84,57 & 41,07 & 4134,92 & 240,82 & 37,28 & 203,54 & 82,84 & 181,01 & 183,25 & 77,93 & 945,88 & 122,14 & 32,70 & 34,02 & 338,76 & 124,47 & 140,34 & 304,66 \\
\hline Salamandra salamandra & 29TPJ50 & 100,00 & 121,44 & 86,51 & 40,99 & 4230,20 & 237,81 & 29,27 & 208,54 & 75,28 & 175,91 & 177,87 & 70,33 & 965,29 & 124,76 & 34,64 & 33,15 & 343,49 & 130,84 & 145,53 & 308,23 \\
\hline Salamandra salamandra & 29TPJ52 & 41,00 & 139,23 & 81,22 & 41,72 & 3912,25 & 244,14 & 51,68 & $\begin{array}{l}192,46 \\
\end{array}$ & 111,51 & 188,72 & \begin{tabular}{|c|}
191,29 \\
\end{tabular} & 91,29 & 874,91 & 115,40 & 31,32 & 32,94 & 309,83 & 119,20 & 136,62 & 271,68 \\
\hline Salamandra salamandra & 29TPJ60 & 100,00 & 108,41 & 88,88 & 40,73 & 4367,70 & 230,35 & 15,04 & 215,32 & 61,15 & 165,12 & 166,80 & 56,09 & 1025,98 & 132,00 & 38,71 & 32,21 & 362,76 & \begin{tabular}{l|l|l|}
144,13 \\
\end{tabular} & 156,86 & 326,34 \\
\hline Salamandra salamandra & 29TPJ61 & 101,00 & 128,73 & 85,00 & 41,49 & 4095,14 & 240,69 & 38,16 & 202,54 & 93,10 & 180,98 & \begin{tabular}{|c|}
183,27 \\
\end{tabular} & 79,05 & 912,44 & 119,82 & 33,86 & 32,17 & 321,09 & 127,55 & 142,96 & 282,41 \\
\hline Salamandra salamandra & 29TPJ62 & 54,00 & 139,54 & 81,85 & 41,87 & 3920,14 & 244,99 & 51,45 & \begin{tabular}{|c|}
193,54 \\
\end{tabular} & 117,69 & $\begin{array}{l}189,06 \\
\end{array}$ & 191,73 & 91,50 & 858,44 & 114,06 & 31,57 & 32,26 & 302,67 & 119,81 & 136,55 & 261,82 \\
\hline Salamandra salamandra & 29TPJ71 & 100,00 & 120,92 & 87,16 & 41,43 & 4187,18 & 236,81 & 29,09 & 207,72 & 87,25 & 174,57 & 176,78 & 70,42 & 941,81 & 123,60 & 36,55 & 31,16 & 328,99 & 136,06 & 150,07 & 288,43 \\
\hline Salamandra salamandra & 29TPJ81 & 101,00 & 126,36 & 87,08 & 41,82 & 4144,52 & 240,59 & 34,49 & 206,10 & 102,20 & 179,16 & $\begin{array}{l}181,45 \\
\end{array}$ & 75,99 & 896,35 & 118,96 & 35,47 & 30,70 & 311,92 & 132,18 & 146,10 & 267,74 \\
\hline Salamandra salamandra & 29TPJ90 & 100,00 & 114,77 & 91,70 & 41,64 & 4366,20 & 237,38 & 19,38 & 218,00 & 87,72 & 171,05 & \begin{tabular}{|c|}
172,75 \\
\end{tabular} & 62,01 & 927,64 & 122,50 & 38,00 & 30,01 & 321,15 & 140,21 & 151,97 & 276,80 \\
\hline Salamandra salamandra & 29TPJ92 & 60,00 & 135,50 & 84,06 & 42,06 & 3954,26 & 243,15 & 46,30 & 196,86 & 114,32 & 185,50 & 188,13 & 87,30 & 853,51 & 114,98 & 34,70 & 30,12 & 296,43 & \begin{tabular}{|l|l|}
128,88 \\
\end{tabular} & 143,72 & 246,58 \\
\hline Salamandra salamandra & 29TQE04 & 100,00 & 154,81 & 104,37 & 36,24 & 6192,69 & 321,03 & 38,01 & \begin{tabular}{|l|l|}
283,02 \\
\end{tabular} & 86,55 & 237,01 & 237,01 & $\begin{array}{l}78,85 \\
\end{array}$ & 586,07 & 76,24 & 5,54 & 48,99 & 224,24 & 41,44 & 41,44 & 214,93 \\
\hline Salamandra salamandra & 29TQE06 & 100,00 & 119,30 & 96,47 & 34,97 & 6132,22 & 280,84 & 9,10 & 271,74 & 53,72 & 201,13 & 201,82 & 46,16 & 805,73 & 107,34 & 10,19 & 48,41 & 309,67 & 60,69 & 63,48 & 300,38 \\
\hline Salamandra salamandra & 29TQE07 & 100,00 & 123,62 & 98,16 & 35,33 & 6135,20 & 285,67 & 12,02 & 273,65 & 57,43 & 204,98 & 205,92 & \begin{tabular}{|c|}
49,78 \\
\end{tabular} & 759,97 & 100,67 & 9,58 & 48,27 & 291,79 & 57,97 & 59,88 & 282,52 \\
\hline Salamandra salamandra & 29TQE08 & 99,00 & 125,47 & 99,36 & 35,85 & 6122,78 & 287,60 & 13,15 & 274,45 & 58,98 & 206,49 & \begin{tabular}{|l|l|}
207,47 \\
\end{tabular} & $\begin{array}{l}51,45 \\
\end{array}$ & 736,57 & 97,22 & 9,29 & 48,01 & 282,68 & 56,92 & 58,27 & 273,55 \\
\hline Salamandra salamandra & 29TQE09 & 100,00 & 131,30 & 101,86 & 36,17 & 6116,52 & 294,27 & 17,42 & $\begin{array}{l}276,85 \\
\end{array}$ & 64,19 & 212,74 & 212,94 & 56,78 & 685,57 & 89,87 & 8,81 & 47,62 & 262,67 & 54,02 & 54,22 & 253,71 \\
\hline Salamandra salamandra & 29TQE16 & 100,00 & 126,83 & 100,71 & 35,60 & 6194,17 & 292,02 & 13,50 & 278,52 & 59,89 & 209,38 & \begin{tabular}{|l|l|}
209,97 \\
\end{tabular} & 52,39 & 705,71 & 90,99 & 9,18 & 47,08 & 267,62 & 55,30 & 56,81 & 256,77 \\
\hline Salamandra salamandra & 29TQE17 & 100,00 & 116,90 & 99,27 & 35,58 & 6162,49 & 280,77 & 5,20 & 275,57 & 50,61 & 198,90 & $\begin{array}{l}199,93 \\
\end{array}$ & 43,24 & 757,81 & $\begin{array}{l}97,69 \\
\end{array}$ & 10,55 & 46,63 & 287,30 & $\begin{array}{l}60,86 \\
\end{array}$ & 63,32 & 276,08 \\
\hline Salamandra salamandra & 29TQE18 & 101,00 & 125,54 & 101,80 & 36,00 & 6169,60 & 290,29 & 11,75 & 278,54 & 58,30 & 207,24 & 208,30 & 51,04 & 686,06 & 88,32 & 9,12 & 46,56 & 260,12 & 55,46 & 56,49 & 249,12 \\
\hline Salamandra salamandra & 29TQE26 & 101,00 & 136,78 & 104,80 & 36,17 & 6252,37 & 305,10 & 20,15 & \begin{tabular}{l|l|}
284,95 \\
\end{tabular} & 68,32 & 220,21 & 220,43 & 60,87 & 600,82 & 76,44 & 7,80 & 46,06 & 224,75 & 48,41 & 48,75 & 212,96 \\
\hline Salamandra salamandra & 29TQE27 & 100,00 & 115,21 & 101,46 & 35,89 & 6193,50 & 281,50 & 2,46 & 279,03 & 48,61 & 197,91 & 198,74 & 41,40 & 724,32 & 92,23 & 10,95 & 45,11 & 270,80 & 61,14 & 63,60 & 257,91 \\
\hline Salamandra salamandra & 29TQE28 & 100,00 & 119,46 & 102,97 & 36,06 & 6199,91 & 286,09 & 5,50 & 280,59 & 52,27 & 201,76 & 202,81 & 44,99 & 678,62 & 86,57 & 10,04 & 44,90 & 253,79 & 57,87 & 59,40 & 240,81 \\
\hline Salamandra salamandra & 29TQE29 & 100,00 & 116,36 & 103,20 & 36,24 & 6180,34 & 282,62 & 2,50 & 280,12 & 49,27 & 198,36 & $\begin{array}{l}199,41 \\
\end{array}$ & 42,10 & 682,64 & 87,11 & 10,50 & 44,39 & 254,87 & 59,63 & 61,24 & 241,53 \\
\hline Salamandra salamandra & 29TQE38 & 100,00 & 110,46 & 103,62 & 36,3 & \begin{tabular}{|c|c|}
6198,67 \\
\end{tabular} & 278,44 & $-3,04$ & 281,49 & 43,78 & 193,30 & 194,22 & 36,73 & 697,16 & 88,05 & 11, & 43,03 & 256,34 & 63,16 & 65,78 & 241,57 \\
\hline Salamandra salamandra & 29TQE39 & 101,00 & 109,91 & 104,34 & 36,66 & 6188,14 & 277,81 & $-3,78$ & 281,59 & 43,16 & 192,28 & \begin{tabular}{|c|}
193,47 \\
\end{tabular} & 36,11 & 681,21 & 86,15 & 11,77 & 42,58 & 250,19 & 63,12 & 65,34 & 234,95 \\
\hline Salamandra salamandra & 29TQE43 & 100,00 & 153,78 & 109,25 & 36,69 & 6364,03 & 327,23 & 32,72 & 294,51 & 83,69 & 238,77 & 238,77 & 76,06 & \begin{tabular}{|l|l|}
479,93 \\
\end{tabular} & 59,67 & 5,32 & 45,56 & 174,91 & 37,56 & 37,56 & 162,53 \\
\hline Salamandra salamandra & 29TQE47 & 101,00 & 140,64 & 109,38 & 37,03 & 6294,98 & 312,04 & 20,83 & 291,21 & 71,06 & 224,69 & 224,75 & 63,78 & 502,05 & 62,86 & 7,40 & 43,31 & 182,16 & 44,17 & 44,21 & 168,79 \\
\hline Salamandra salamandra & 29TQE48 & 99,00 & 117,99 & 107,09 & 36,82 & 6247,59 & 288,57 & 1,73 & \begin{tabular}{ll|}
286,85 \\
\end{tabular} & 50,00 & 201,22 & 202,15 & 43,11 & 606,94 & 75,98 & 10,64 & 41,83 & 219,55 & 57,39 & 58,73 & 204,08 \\
\hline Salamandra salamandra & 29TQE49 & 100,00 & 111,13 & 106,74 & 36,9 & 6218,89 & 281,23 & $-3,86$ & 285,09 & 43,78 & 193,70 & \begin{tabular}{|c|}
195,11 \\
\end{tabular} & 36,90 & 629,64 & 78,99 & 11, & 41,15 & 227,45 & 61,36 & 63,11 & 210,94 \\
\hline Salamandra salamandra & 29TQE56 & 50,00 & 137,16 & 109,69 & 36,99 & 6325,01 & 310,13 & 17,17 & 292,96 & 67,55 & 221,57 & 221,77 & 60,39 & 507,69 & 62,88 & 7,87 & 42,52 & 181,96 & 45,81 & 46,01 & 168,04 \\
\hline Salamandra salamandra & 29TQE57 & 42,00 & 139,19 & 110,38 & 37,06 & 6308,52 & 311,71 & 18,79 & \begin{tabular}{|l|l|}
292,92 \\
\end{tabular} & 69,40 & 223,40 & \begin{tabular}{|c|}
223,47 \\
\end{tabular} & 62,26 & 486,51 & 60,44 & 7,65 & 42,35 & 174,30 & 44,42 & 44,45 & 160,43 \\
\hline Salamandra salamandra & 29TQE58 & 47,00 & 134,90 & 110,69 & 37,23 & 6298,43 & 307,31 & 14,87 & 292,44 & 65,49 & 219,16 & 219,25 & 58,23 & 493,18 & 61,34 & 8,28 & 41,59 & 176,15 & 46,67 & 46,74 & 161,74 \\
\hline Salamandra salamandra & 29TQE59 & 40,00 & 109,11 & 107,80 & 37,02 & 6220,82 & 280,18 & $-6,55$ & 286,74 & 41,68 & 191,77 & \begin{tabular}{|c|}
193,17 \\
\end{tabular} & 35,12 & 618,22 & 76,86 & 12,17 & 39,94 & 220,18 & 62,66 & 64,60 & 203,06 \\
\hline Salamandra salamandra & 29TQF06 & 100,00 & 125,29 & 107,78 & 38,6 & 6002,93 & 288,91 & 8,8 & 280,0 & 58,28 & 204,97 & \begin{tabular}{|l|}
204,97 \\
\end{tabular} & 51,21 & 640,23 & 82,02 & 9,9 & 45,41 & 244,05 & 56,19 & 56,19 & 236,84 \\
\hline Salamandra salamandra & 29TQF07 & 100,00 & 124,47 & 108,48 & 38,15 & 5975,92 & 288,21 & 7,85 & 280,36 & 57,62 & 203,80 & 203,80 & 50,69 & 634,57 & 81,31 & 10,33 & 45,02 & 241,67 & 56,70 & 56,70 & 235,01 \\
\hline Salamandra salamandra & 29TQF08 & 100,00 & 119,33 & 108,56 & 38,17 & 5959,95 & 283,31 & 3,05 & 280,26 & 52,92 & 198,65 & \begin{tabular}{l|l|}
198,65 & \\
\end{tabular} & 45,99 & 654,23 & 84,20 & \begin{tabular}{|c|}
11,16 \\
\end{tabular} & 44,66 & 249,16 & 60,21 & 60,21 & 243,12 \\
\hline Salamandra salamandra & 29TQF09 & 101,00 & 126,93 & 110,16 & 38,94 & 5930,54 & 290,50 & 9,14 & 281,36 & 60,20 & 205,50 & 205,50 & 53,32 & 605,30 & 78,18 & 10,60 & 44,49 & 230,27 & 55,42 & 55,42 & 224,78 \\
\hline Salamandra salamandra & 29TQF17 & 99,00 & 126,84 & 110,00 & 38,23 & 6022,16 & 292,13 & 8,85 & 283,28 & 59,28 & 206,62 & 206,62 & 52,31 & 571,63 & 73,31 & 9,92 & 43,27 & 214,56 & 53,54 & 53,54 & 205,38 \\
\hline Salamandra salamandra & 29TQF18 & 100,00 & 50 &, 21 & 38,4 & 005,49 & 287,87 & 4,76 & 283,11 & 55,36 & 202,28 & 202,28 & 48,48 & 585,02 & 75,58 & 10,6 & 43,04 & 219,49 & 56,23 & 56,23 & 210,90 \\
\hline Salamandra salamandra & 29TQF19 & 100,00 & 95 &, 37 & 38,7 & 5982,06 & 284,32 & 1,44 & 282,88 & 52,01 & 198,36 & 198,36 & 45,22 & 596,50 & 77,51 & 11, & 42,49 & 223,55 & 59,05 & 59,05 & 215,39 \\
\hline Salamandra salamandra & 29TQF28 & 10 & & & 38, & 605 & 287,94 & 2,6 & 285 & 53,22 & 201,28 & 201,28 & 46 & 543,86 & 70,42 & 10, & 41,16 & 200,26 & 55,77 & 55,77 & 188,94 \\
\hline Salamandra salamandra & 29TQF29 & 100,00 & 120,33 & 111,61 & 38, & 6032,92 & 287,25 & 1,88 & 285,36 & 52,66 & 200,29 & 200,29 & 45,80 & 541,55 & 70,40 & 11, & 40,85 & 199,19 & 56,50 & 56,50 & 188,40 \\
\hline Salamandra salamandra & 29TQF35 & 100,00 & 11 & \begin{tabular}{|l|l|}
110,87 \\
\end{tabular} & $38, \mathrm{C}$ & 6142,17 & 287,85 & 0,92 & 286,92 & 50,75 & 200,85 & 200,85 & 43,79 & 533,91 & 68,62 & 10, & 40,59 & 194,06 & 55,55 & 55,55 & 178,62 \\
\hline Salamandra salamandra & 29TQF36 & 100,00 & 120,24 & 111,54 & 38,22 & 9,71 & 289,00 & 1,76 & 287,24 & 52,16 & 201,72 & 201,72 & 45,03 & 517,40 & 66,80 & 10,28 & 40,33 & 187,67 & 54,43 & 54,43 & 172,97 \\
\hline Salamandra salamandra & 29TQF39 & 101,00 & 11 & 112,34 & 38,95 & 6073,13 & 286,20 & $-0,80$ & 287,00 & 54,47 & 198,29 & 198,29 & 42,66 & 509,77 & 66,10 & 11,77 & 38,87 & 183,34 & 57,22 & 57,22 & 169,97 \\
\hline Salamandra salamandra & 29TQF40 & 100,00 & 116,70 & 108,66 & 37,23 & 6227,32 & 287,15 & $-0,06$ & 287,21 & 48,54 & 199,46 & 200,47 & 41,83 & 578,11 & 72,63 & 10,60 & 40,89 & 208,46 & 57,44 & 58,19 & 191,94 \\
\hline Salamandra salamandra & 29TOF50 & 33,00 & 117,20 & 110,11 & 37,63 & 6238,59 & 288,82 & $-0,27$ & 289,09 & 48,91 & 200,27 & 201,05 & 42,04 & 550,61 & 68,77 & 10,71 & 39,96 & 195,89 & 56,96 & 57,45 & 178,63 \\
\hline Salamandra salamandra & 29TQG00 & 99,00 & 123,09 & 110,27 & 38, & 5918,68 & 286, & 5,4 & 281,47 & 56 , & 201,70 & 201,70 & 49 & 619,22 & 80, & 11, & 44, & 235,64 & 58,29 & 58,29 & 230,85 \\
\hline Salamandra salamandra & 29TQG01 & 101,00 & 12 & & 39 & 589 & & 2, & & & 198,46 & 198,46 & & 630 & 82, & 12 & 43,76 & 239,57 & 60, & 60,81 & 235,47 \\
\hline Salamandra salamandra & 29TQG02 & 100,00 & 118,31 & 111 & $\begin{array}{l}39, \\
39,\end{array}$ & 5867,35 & 282,03 & 1,14 & 280,89 & 52,36 & 196,31 & 196,31 & 45,68 & $\mid 636,56$ & 84,01 & 13,14 & 43,33 & 241,71 & 63,07 & 63,07 & 237,84 \\
\hline Salamandra salamandra & 29TQG03 & 100,00 & 114,88 & 110,19 & 38,98 & 5844,04 & 278,26 & $-1,66$ & 279,92 & 49,20 & 192,60 & 192,60 & 42,71 & 654,32 & 86,67 & 14,58 & 42,81 & 247,97 & 66,98 & 66,98 & 243,35 \\
\hline Salamandra salamandra & 29TQG04 & 99,00 & 107,72 & 109,04 & 38,75 & 5831,01 & 270,54 & $-7,80$ & 278,34 & 42,36 & 185,45 & $\begin{array}{l}185,45 \\
\end{array}$ & 36,15 & 697,38 & 92,22 & 17,25 & 41,55 & 262,69 & 75,26 & 75,26 & 255,74 \\
\hline Salamandra salamand & $29 T Q G$ & 99,00 & 104,21 & $r$ & 38,61 & 5812,30 & 2665 & $-10,78$ & 276, & 39,18 & 181,82 & 181, & 33, & 720,31 & 95,06 & 19, & 40, & 270,01 & 80,76 & 80,76 & 26 \\
\hline Salamandra salamandra & $29 T Q C$ & 101,00 & & & 38 & & & $-16,03$ & 274,40 & 33,35 & 174,90 & 174,90 & 27,2 & 770,14 & 100,90 & $22-25+2$ & 39,27 & 286,20 & 90,40 & 90,40 & 274,29 \\
\hline Salamandra salamandra & 29TQG07 & 100,00 & 75,27 & 102,87 & 38,12 & 5659,24 & 233,23 & $-33,33$ & 266,56 & 14,21 & 151,42 & 151,61 & 7,86 & 961,33 & 122,26 & 31,36 & 36,71 & 349,51 & \begin{tabular}{|c|}
121,47 \\
\end{tabular} & 122,08 & 332,88 \\
\hline Salamandra salamandra & 29TQG10 & 101,00 & 116,77 & 110,67 & 39,00 & 5974,82 & 282,16 & $-0,12$ & 282,28 & 50,13 & 196,21 & 196,21 & 43,23 & 602,56 & 78,66 & \begin{tabular}{|l|l|}
12,23 \\
\end{tabular} & 42,09 & 225,51 & 61,11 & 61,11 & 217,74 \\
\hline Salamandra salamandra & 29TQG11 & 99,00 & 115,18 & 110,82 & 38,98 & 5954,86 & 280,36 & $-1,87$ & 282,23 & 48,68 & 194,38 & 194,38 & 41,81 & 608,24 & 79,75 & 13,07 & 41,70 & 227,39 & 63,06 & 63,06 & 219,83 \\
\hline Salam & $29 T Q$ & 100,00 & & 110 & 38, & 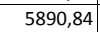 & & $-10,14$ & 280, & & 3 & 184, & & & 87, & 17, & & 24 & 75,48 & 75,48 & \\
\hline Salamandra salamandra & $29 \mathrm{TQ}$ & 10 & & 11 & 38,99 & 5876 & 27 & $-9,53$ & 280,07 & 40,80 & 185,13 & 185,13 & $34,51 \mid$ & 658,88 & 86,64 & 18,55 & 39,18 & 243,62 & 76,94 & 76,94 & 232,45 \\
\hline Salamandra salamandra & 29TQG16 & 100,00 & 100,74 & 109,21 & 38,89 & 5841,69 & 263,66 & \begin{tabular}{|c|}
$-14,63$ \\
\end{tabular} & 278,29 & 35,43 & \begin{tabular}{|c|}
178,66 \\
\end{tabular} & 178,66 & 29,22 & 704,69 & 92,02 & 21,13 & 38,13 & 258,67 & 85,76 & 85,76 & 245,22 \\
\hline Salamandra salamandra & 29TQG17 & 99,00 & 86,69 & 106,75 & 38,59 & 5763,06 & 247,73 & $-25,75$ & 273,49 & 23,37 & 163,90 & 163,98 & 16,91 & 819,81 & 105,11 & 26,84 & 36,33 & 296,73 & 105,56 & 105,69 & 279,85 \\
\hline
\end{tabular}




\begin{tabular}{|c|c|c|c|c|c|c|c|c|c|c|c|c|c|c|c|c|c|c|c|c|c|}
\hline TAXON & UTM & $\mathrm{km} 2$ & B101 & $\mathrm{B1O2}$ & $\mathrm{BIO3}$ & 8104 & B105 & B106 & B107 & B108 & B109 & 81010 & B1011 & BIO12 & B1013 & B1014 & 81015 & BIO16 & BIO17 & B1018 & B1019 \\
\hline Salamandra salamandra & 29TQG20 & 100,00 & 116,37 & 111,62 & 38,94 & 6018,44 & 283,37 & $-1,28$ & 284,65 & 49,07 & 196,27 & 196,27 & 42,19 & 557,49 & 72,66 & 12,32 & 40,29 & 204,73 & 59,88 & 59,88 & 194,08 \\
\hline Salamandra salamandra & 29TQG24 & 99,00 & 106,53 & 111,31 & 38,98 & 5942,33 & 272,67 & $-10,62$ & 283,29 & 40,28 & 185,74 & 185,74 & 33,40 & 617,64 & 80,63 & 17,53 & 38,15 & 224,86 & 74,17 & 74,17 & 212,30 \\
\hline Salamandra salamandra & 29TQG27 & 101,00 & $\begin{array}{l}06,95 \\
96,95\end{array}$ & $\mid \begin{array}{l}111,01 \\
110,\end{array}$ & 38,90 & 5850,44 & 261,05 & $-18,67$ & 279,72 & 45,32 & 175,08 & 175,08 & 25,39 & 700,54 & 90,26 & 23,14 & 35,87 & 251,96 & 92,35 & 92,35 & 234,13 \\
\hline Salamandra salamandra & 29TQG28 & 99,00 & 90,53 & 108,82 & 38,88 & 5790,17 & 253,27 & $-23,63$ & 276,91 & \begin{tabular}{|c|c|}
40,68 \\
\end{tabular} & 167,92 & 167,93 & 20,00 & 757,65 & 96,61 & 26,40 & 34,76 & 270,71 & 103,29 & 103,30 & 250,27 \\
\hline Salamandra salamandra & 29TQG30 & 99,00 & 118,24 & 112,71 & 38,98 & 6054,24 & 286,54 & $-0,55$ & 287,09 & 58,13 & \begin{tabular}{|c|}
198,47 \\
\end{tabular} & \begin{tabular}{|c|}
198,47 \\
\end{tabular} & 43,35 & 504,83 & 65,56 & 12,00 & 38,70 & $\mid 181,38$ & 57,28 & 57,28 & 168,57 \\
\hline Salamandra salamandra & 29TQG32 & 101,00 & 115,15 & 112,95 & 39,00 & 6022,04 & 283,26 & $-3,62$ & 286,87 & \begin{tabular}{r|r|}
62,35 \\
\end{tabular} & 194,93 & 194,93 & 40,52 & 521,67 & 67,79 & 13,77 & 37,72 & 187,15 & 62,19 & 62,19 & 173,83 \\
\hline Salamandra salamandra & 29TQG33 & 100,00 & 109,75 & 112,69 & 38,99 & 6005,46 & 277,86 & $-8,55$ & 286,41 & 60,00 & 189,58 & 189,58 & 35,59 & 555,71 & 72,08 & 15,75 & 37,15 & 199,17 & 68,57 & 68,57 & 184,91 \\
\hline Salamandra salamandra & 29TQG34 & 100,00 & \begin{tabular}{|l|l|}
109,08 \\
\end{tabular} & 112,74 & 38,97 & 5982,61 & 276,92 & - $-9,39$ & 286,31 & 65,83 & 188,59 & \begin{tabular}{|l|l|}
188,59 \\
\end{tabular} & 35,17 & 564,89 & 73,18 & 16,72 & 36,65 & 202,73 & 71,26 & 71,26 & 187,20 \\
\hline Salamandra salamandra & 29TQG35 & 100,00 & 113,57 & 113,09 & 39,00 & 5964,48 & 280,43 & $-5,71$ & 286,14 & 74,89 & \begin{tabular}{|c|}
192,48 \\
\end{tabular} & 192,48 & 39,41 & 547,40 & 70,94 & 16,45 & 36,42 & 197,66 & 69,83 & 69,83 & 180,30 \\
\hline Salamandra salamandra & 29TQG37 & 100,00 & 107,03 & 112,53 & 39,00 & 5911,25 & 273,25 & $-11,47$ & 284,72 & 69,31 & 185,40 & 185,40 & 33,77 & 599,10 & 77,00 & 20,05 & 35,24 & 216,74 & 81,45 & 81,45 & \begin{tabular}{ll|l}
193,97 \\
\end{tabular} \\
\hline Salamandra salamandra & 29TQG40 & 100,00 & 116,85 & 113,49 & 38,97 & 6098,32 & 286,63 & $-2,42$ & 289,05 & \begin{tabular}{|c|}
77,78 \\
\end{tabular} & 197,83 & 197,83 & 41,59 & 470,69 & 60,57 & 11,96 & 37,01 & 167,12 & 57,16 & 57,16 & 149,90 \\
\hline Salamandra salamandra & 29TQG41 & 98,00 & 116,63 & 113,70 & 39,00 & 6077,83 & 286,10 & $-2,87$ & 288,97 & 77,60 & 197,19 & 197,19 & 41,35 & 474,35 & 61,05 & 12,53 & 36,55 & 168,65 & 58,62 & 58,62 & 151,31 \\
\hline Salamandra salamandra & 29TQHOO & 100,00 & 94,55 & 105,13 & 38,92 & 5600,79 & 249,85 & $-16,95$ & 266,81 & 32,10 & \begin{tabular}{ll|}
169,06 \\
\end{tabular} & 169,06 & 26,22 & 825,40 & \begin{tabular}{|l|l|}
106,08 \\
\end{tabular} & 27,42 & 35,97 & 300,08 & \begin{tabular}{|l|l|}
107,77 \\
\end{tabular} & 107,77 & 280,01 \\
\hline Salamandra salamandra & 29TQH05 & 100,00 & 74,91 & 99,24 & 39,39 & 5169,66 & 220,93 & $-28,05$ & 248,98 & 21,71 & 143,89 & 143,99 & 13,48 & 1055,92 & 132,96 & 42,27 & 31,32 & 370,01 & 155,47 & 156,53 & 339,66 \\
\hline Salamandra salamandra & 29TQHO6 & 100,00 & 75,75 & 98,36 & 39,55 & 5077,99 & 219,51 & $-26,07$ & 245,58 & \begin{tabular}{|l|l|l|}
25,65 & \\
\end{tabular} & 143,30 & 143,55 & 15,40 & 1068,91 & 134,83 & 43,64 & 30,77 & 372,93 & \begin{tabular}{|c|}
159,67 \\
\end{tabular} & 162,90 & 340,47 \\
\hline Salamandra salamandra & 29TQH15 & 101,00 & 81,08 & 101,33 & 39,73 & 5205,83 & 228,01 & $-23,78$ & 251,80 & 40,02 & 150,30 & 150,34 & 18,68 & 976,59 & 124,20 & 40,07 & 30,67 & 340,54 & 147,50 & 148,47 & 307,29 \\
\hline Salamandra salamandra & 29TQH17 & 101,00 & 79,56 & 98,86 & 40,06 & 5002,85 & 221,57 & $-22,19$ & 243,76 & 40,09 & 145,80 & 146,25 & 19,84 & 1034,18 & 131,39 & 44,28 & 29,41 & 357,21 & 160,63 & 165,63 & 319,74 \\
\hline Salamandra salamandra & $29 \mathrm{TQH} 21$ & 99,00 & 90,49 & 107,60 & 39,20 & 5617,95 & 248,60 & $-21,87$ & \begin{tabular}{|l|}
270,47 \\
\end{tabular} & 53,99 & 165,27 & 165,27 & 21,89 & 794,80 & 101,78 & 30,23 & 32,91 & 282,67 & \begin{tabular}{|l|l|}
115,17 \\
\end{tabular} & \begin{tabular}{|l|l|}
115,17 \\
\end{tabular} & 254,36 \\
\hline Salamandra salamandra & $29 \mathrm{TQH} 24$ & 99,00 & 66,71 & 101,63 & 39,24 & 5330,72 & 217,60 & $-38,48$ & 256,08 & 21,64 & 138,11 & 138,12 & 3,36 & 1040,19 & 129,59 & 43,94 & 30,02 & 359,10 & 159,94 & 160,02 & 327,76 \\
\hline Salamandra salamandra & 29TQH26 & 100,00 & 67,82 & 99,91 & 39,58 & 5166,21 & 214,59 & $-35,04$ & 249,64 & 28,79 & 136,77 & 136,99 & 6,55 & 1070,76 & 133,82 & 46,89 & 28,95 & 367,11 & 168,84 & 170,41 & 332,03 \\
\hline Salamandra salamandra & $29 \mathrm{TQH} 27$ & 100,00 & 82,73 & 100,29 & 40,4 & 5017,34 & 225,37 & $-20,01$ & 245,38 & 50,25 & 149,06 & 149,50 & 22,69 & 987,79 & 126,24 & 43, & 28,7 & 340,24 & 157,60 & 162,62 & 298,65 \\
\hline Salamandra salamandra & 29TQH37 & 99,00 & 76,09 & 100,54 & 40,23 & 5063,42 & 220,15 & $-26,83$ & 246,98 & 43,00 & 143,21 & 143,59 & 15,63 & 1014,50 & 128,25 & $\begin{array}{l}45,35 \\
46,39 \\
\end{array}$ & 27,91 & 346,75 & 165,85 & 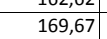 & 304,04 \\
\hline Salamandra salamandra & 29TQH44 & 55,00 & 85,53 & 106,75 & 39,96 & 5416,52 & 239,67 & $-24,34$ & 264,01 & 53,52 & \begin{tabular}{|l|l|}
157,49 \\
\end{tabular} & 157,49 & 19,69 & 842,54 & 107,92 & 37,39 & 29,48 & 295,18 & 136,52 & 136,52 & 251,94 \\
\hline Salamandra salamandra & 29TQH47 & 44,00 & 75,53 & 101,29 & 40,28 & 5101,29 & 220,78 & $-28,04$ & 248,82 & 46,44 & 143,26 & 143,49 & 14,57 & 995,96 & 125,88 & 46,40 & 27,50 & 340,32 & 165,71 & 169,18 & 295,24 \\
\hline Salamandra salamandra & 29TQH49 & 36,00 & 119,17 & 96,75 & 43,23 & 4295,38 & 243,54 & 22,00 & 221,54 & 96,79 & 173,94 & 176,08 & 67,15 & 850,54 & 115,13 & 41,2 & 27,98 & 287,88 & 146,23 & 154,65 & 224,27 \\
\hline Salamandra salamandra & 29TQJ00 & 100,00 & 113,08 & 92,84 & 41,78 & 4381,67 & 236,87 & 17,31 & 219,56 & 88,49 & 169,52 & 171,28 & 60,21 & 922,77 & 122,26 & 39,35 & 29,15 & 317,84 & 143,82 & 154,93 & 269,66 \\
\hline Salamandra salamandra & $29 T Q J 01$ & 101,00 & $\begin{array}{l}\mid 1,0,06 \\
126,22 \\
\end{array}$ & 88,44 & 42,23 & $\begin{array}{l}430,101 \\
4110,48\end{array}$ & $\mid \frac{250,01}{240,86}$ & $\begin{array}{l}3,51,05 \\
34,1\end{array}$ & 206,81 & \begin{tabular}{|l|}
0,43 \\
104,11
\end{tabular} & 178,50 & \begin{tabular}{|l|l|}
180,95 \\
180
\end{tabular} & $\begin{array}{l}00,21 \\
76,45\end{array}$ & 878,86 & $\begin{array}{l}\mid 2<2,009 \\
118,09\end{array}$ & 37,42 & 29,36 & $\begin{array}{l}31,04 \\
302,72\end{array}$ & \begin{tabular}{|l|}
137,02 \\
137,04
\end{tabular} & \begin{tabular}{|l|}
149,67 \\
149
\end{tabular} & 250,74 \\
\hline Salamandra salamandra & $29 T Q, J 02$ & 55,00 & 134,41 & 84,61 & 42,41 & 3939,63 & 242,38 & 45,21 & 197,17 & \begin{tabular}{|l|l|}
113,77 \\
\end{tabular} & 184,19 & 186,89 & 86,64 & 853,56 & 115,54 & 36,12 & 29,65 & 294,62 & 132,68 & 146,74 & 240,90 \\
\hline Salamandra salamandra & 29TQJ11 & 99,00 & 116,27 & 91,42 & 42,38 & 4195,11 & 235,68 & 22,75 & 212,93 & \begin{tabular}{|c|}
93,97 \\
\end{tabular} & \begin{tabular}{|c|}
169,88 \\
\end{tabular} & 172,19 & 65,80 & \begin{tabular}{|c|}
923,49 \\
\end{tabular} & 123,35 & 41, & 28,29 & 315,14 & 149,59 & 160,54 & 260,00 \\
\hline Salamandra salamandra & $29 T Q / 22$ & 90,00 & 130,15 & 85,35 & 42,88 & 3889,16 & 238,31 & 41,39 & 196,92 & 110,84 & 179,08 & 182,20 & 83,20 & 877,27 & 119,15 & 40, & 28,57 & 298,33 & 144,64 & 156,96 & 237,01 \\
\hline Salamandra salamandra & 29TQJ30 & 101,00 & 127,88 & 91,32 & 43,13 & 4054,48 & 243,58 & 34,92 & 208,66 & 107,35 & 179,16 & 181,83 & 78,92 & 847,54 & 115,61 & 40,04 & 28,46 & 286,68 & 142,90 & 152,81 & 223,23 \\
\hline Salamandra salamandra & 29TQJ32 & 74,00 & 134,23 & 83,35 & 43,00 & 3796,84 & 238,70 & 46,89 & 191,82 & 116,10 & 181,84 & 185,14 & 88,38 & 858,30 & 117,33 & 40,27 & 28,58 & 290,85 & 144,00 & 156,31 & 226,00 \\
\hline Salamandra salamandra & 30STE59 & & & & & & & & & & & & & & & & & & & & \\
\hline Salamandra salamandra & 30STE69 & 0 & 166,92 & 83,47 & 39,98 & 08,93 & 277,68 & 71,14 & 206,55 & 123,23 & 220,05 & 223,59 & 115,12 & 848,89 & 146,18 & 0,58 & 41 & 404,67 & 13,56 & 22,34 & 401,74 \\
\hline Salamandra salamandra & 30STE79 & 80,00 & & 86,17 & 40,6 & 4236,28 & 280,03 & 69,61 & 210, & 121 & 219,52 & 223,38 & 114 & 815,53 & 141,61 & 0, & 76,60 & 396,23 & 13,03 & 22,71 & 390,32 \\
\hline Salamandra salamandra & 30STF32 & 90,00 & 172,06 & 1,73 & 36,93 & 4378,73 & 275,79 & 78,71 & \begin{tabular}{|l|l|l|l|l|}
197,08 \\
\end{tabular} & 126,41 & 226,50 & 230,49 & 117,51 & 741,70 & 127,34 & $1, \mathrm{C}$ & 71,14 & 333,93 & 15,08 & 23,50 & 320,08 \\
\hline Salamandra salamandra & 30STF33 & 90,00 & 171,30 & 73,63 & 35,99 & 4544,89 & 278,05 & 76,28 & 201,77 & 123,77 & 228,06 & 232,17 & 114,86 & 724,33 & 122,30 & 1,00 & 70,20 & \begin{tabular}{|c|}
322,57 \\
\end{tabular} & 15,14 & 23,99 & 307,85 \\
\hline Salamandra salamandra & $30 \mathrm{STF} 35$ & 81,00 & 172,92 & 73,12 & 34,53 & 4830,34 & 284,27 & 75,48 & 208,79 & 121,93 & 233,49 & 237,52 & 113,13 & 668,82 & 108,03 & 1,00 & 68,07 & 290,48 & 15,98 & 23,88 & 274,22 \\
\hline Salamandra salamandra & 30STF40 & 79,00 & 170,05 & 77,24 & 38,86 & 4149,76 & 273,55 & 77,47 & 196,08 & 127,19 & 221,86 & 225,45 & 118,45 & \begin{tabular}{|c|}
822,55 \\
\end{tabular} & 142,23 & 0,24 & 73,99 & 380,45 & 15,04 & 22,30 & 370,92 \\
\hline Salamandra salamandra & 30STF43 & 100,00 & 17 & 75,07 & 36,61 & 494,42 & 8,71 & 76 & 202,28 & 124,26 & 227,63 & 231,55 & 115,70 & 748,11 & 125,94 & 1,0 & 70,66 & 337,59 & 15,96 & 23,63 & 322,29 \\
\hline Salamandra salamandra & 30STF45 & 100,00 & 16 & 4 & 35,66 & 4861,25 & 286,50 & 70, & 215,82 & 118,62 & 231,10 & 234,95 & 109,92 & 708,52 & 114,95 & $\frac{1,0}{1,0}$ & 68,80 & 313,47 & 16,20 & 24,13 & 296,85 \\
\hline Salamandra salamandra & 30STF46 & & & & 35,49 & 4987,73 & 29 & 71 & \begin{tabular}{|l|l|}
220,45 \\
\end{tabular} & 119 & 235,35 & 239,11 & 110,95 & 673,38 & 107,45 & 1, & 67,82 & 295,25 & 16,53 & 23,51 & 277,60 \\
\hline Salamandra salamandra & 30STF47 & 100,00 & 171,66 & 83,90 & 35,81 & 5167,62 & 29 & 68,02 & 230,64 & 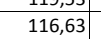 & 237,20 & 240,68 & 108,14 & 662,66 & 103,91 & 1,00 & $\mid 66,96$ & 288,72 & 17,01 & 23,58 & 271,04 \\
\hline Salamandra salamandra & 30STF50 & 100,00 & 168,95 & 78,27 & 39,21 & 4103,92 & 272,40 & 75 & 196,79 & 126,26 & 220,38 & 223,74 & 117,77 & 855,68 & 146,48 & 0,21 & 74,96 & 398,75 & 15,01 & 22,30 & 392,21 \\
\hline Salamandra salamandra & 30STF51 & 100,00 & 16 & 74 & 38,64 & 4257,40 & 274,60 & 73,17 & 201,43 & 123,72 & 221,33 & 224,81 & 114,96 & 835,94 & 142,24 & on & 73,81 & 388,02 & 15,32 & 23,08 & 378,19 \\
\hline Salamandra salamandra & 30STF52 & $\frac{10}{10}$ & $\frac{16}{16}$ & 7 & 38,01 & 4333,43 & 276,87 & 74,98 & $\begin{array}{l}201,45 \\
201,89\end{array}$ & \begin{tabular}{l|l}
124,45 \\
124,45
\end{tabular} & $\begin{array}{l}224,33 \\
224,16\end{array}$ & $\begin{array}{l}222,01 \\
227,73\end{array}$ & $\begin{array}{l}14,0,00 \\
116,1\end{array}$ & 802,55 & $\begin{array}{l}14<, 24 \\
136,23 \\
\end{array}$ & $\begin{array}{l}0,00 \\
0,89 \\
\end{array}$ & $\begin{array}{l}72,61 \\
72,62\end{array}$ & $\begin{array}{l}30,02 \\
371,01\end{array}$ & $\begin{array}{l}\mid l,, 52 \\
15,89 \\
\end{array}$ & 23,25 & 357,32 \\
\hline Salamandra salamandra & 30 STF53 & 100,00 & 171,09 & 77,64 & 37,41 & 4455,91 & 280,34 & 75, & 204,58 & 124,36 & 227,16 & 230,82 & 116,13 & 768,19 & 129,70 & 1,00 & 71,54 & 353,12 & 16,00 & 23,21 & 336,74 \\
\hline Salamandra salamandra & 30STF54 & 100,00 & 167,50 & 81,14 & 37,10 & 4709,99 & 284,60 & 68, & 215,66 & 118 & 227,11 & 230,79 & 109,68 & 760,61 & 125,99 & 1,00 & 70,60 & 346,04 & 16,13 & 24,07 & 329,51 \\
\hline Salamandra salamandra & 30STF60 & 100,00 & 16 & 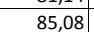 & 39,39 & 4376,18 & 20 & 65 & 213 & 118 & 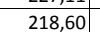 & 222,23 & 109,53 & 853, & 144,88 & 0, & 75 & 403,55 & 14,45 & 23,76 & 398,62 \\
\hline Salamandra salamandra & 30STF61 & 100 & & & 39, & 90 & & 67 & 210, & & 215 & 223,56 & 11 & 840 & 143 & 1,4 & & 396,99 & 15,20 & 23,82 & 386,95 \\
\hline \begin{tabular}{|l} 
Salamandra salamandrandra \\
Sala
\end{tabular} & 30STF62 & $\begin{array}{l}100,00 \\
100\end{array}$ & 16 & $\begin{array}{l}\mid 83,27 \\
82,93\end{array}$ & $\begin{array}{l}35,14 \\
38,78\end{array}$ & $4404,90,51$ & $\begin{array}{l}\mid 70,12 \\
279,79\end{array}$ & $\begin{array}{l}0,00 \\
68,02\end{array}$ & $\begin{array}{l}21,20 \\
211,77\end{array}$ & $\begin{array}{l}12,04 \\
119,86\end{array}$ & 221,57 & $\mid \begin{array}{l}225,50 \\
224,24\end{array}$ & \begin{tabular}{|l|}
$111,10,77$ \\
\end{tabular} & $\begin{array}{l}840,99 \\
820,39\end{array}$ & \begin{tabular}{|l|}
$\mid$ \\
138,76
\end{tabular} & $\frac{1,00}{1,00}$ & $\begin{array}{ll}74,27 \\
73,24\end{array}$ & | 394,996 & $\begin{array}{l}13,20 \\
15,59\end{array}$ & 23,91 & 30,59 \\
\hline Salamandra salamandra & 30STF63 & 100,00 & 164,08 & 84,68 & 38,34 & 4621,54 & 283,21 & 65,09 & 218,12 & 116,82 & 222,88 & 226,50 & 107,74 & 800,63 & 133,64 & 1,01 & 71,88 & 371,84 & 16,41 & 24,50 & 356,97 \\
\hline Salamandra salamandra & 30STF64 & 100,00 & 153,75 & 92,74 & 38,40 & 5017,22 & 287,09 & 48,51 & 238,58 & 102,94 & 218,40 & 221,77 & 93,13 & 819,93 & 131,07 & 1,40 & 70,22 & 371,48 & 18,62 & 27,59 & 360,28 \\
\hline Salamandra salam & 30STF65 & 100,00 & & & 37,91 & 4897,96 & 291,96 & 633 & 年 & I & $w_{1}$ & 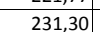 & 105,79 & 754 & 123,63 & -1 & & 344,99 & 16,89 & 24,36 & 327,48 \\
\hline Salamandra salamandra & 30STF66 & & & & & 056 & & & 236, & 112 & 230 & 233 & 103, & 73 & 119 & & 69, & 333,87 & 17,22 & 24,32 & 315 \\
\hline Salamandra salamandra & 30STF70 & 100,00 & 170,76 & 82,27 & 40,56 & 4070,03 & 278,45 & 77,89 & 200,57 & 129,87 & 222,10 & 225,97 & 121,34 & 806,82 & 143,07 & 1,00 & 76,03 & 396,34 & 13,86 & 22,01 & 381,87 \\
\hline Salamandra salamandra & 30STF71 & 100,00 & 168,40 & 83,23 & 40,00 & 4224,27 & 279,62 & 73,68 & 205,94 & 126,16 & 221,77 & 225,72 & 117,17 & 808,52 & 141,14 & 1,00 & 75,01 & 393,01 & 14,41 & 22,69 & 376,83 \\
\hline Salamandra salamandra & 30STF72 & 100,00 & 166,30 & 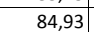 & 39,37 & 4410,77 & 282,35 & 69,29 & 213,06 & 121,98 & 222,38 & 226,13 & 112,89 & 800,83 & 137,35 & 1,00 & 73,74 & 383,87 & 15,21 & 23,45 & 367, \\
\hline Salan & 30STF73 & & & & & 622, & & 63, & 221 & & 20 & 226 & 107, & 793 & 133 & 1, & 72 & & 15,97 & 24,37 & 357 \\
\hline Salamandra salamandra & 30STF74 & 100,00 & 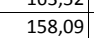 & 92,03 & 38,87 & 4898,94 & 288,79 & $\begin{array}{l}54,04 \\
54,41\end{array}$ & 234,38 & \begin{tabular}{|l|l|l|l|l|}
108,48 \\
\end{tabular} & 2221,05 & 224,46 & \begin{tabular}{|c|}
98,97 \\
98,
\end{tabular} & 797,05 & $\begin{array}{ll}129,72 \\
\end{array}$ & 1,23 & 70,83 & 367,79 & 17,65 & 26,06 & 353,45 \\
\hline
\end{tabular}




\begin{tabular}{|c|c|c|c|c|c|c|c|c|c|c|c|c|c|c|c|c|c|c|c|c|c|}
\hline TAXON & UTM & $\mathrm{km} 2$ & BIO1 & $\mathrm{B1O2}$ & $\mathrm{BIO3}$ & 8104 & B105 & B106 & B107 & B108 & B109 & BIO10 & B1011 & BIO12 & B1013 & BIO14 & 81015 & B1016 & B1017 & B1018 & $B 1019$ \\
\hline Salamandra salamandra & 30STF75 & 100,00 & 157,73 & 94,24 & 38,77 & 5045,92 & 292,93 & 52,28 & 240,65 & 106,20 & 222,78 & 226,04 & 96,92 & 784,05 & 126,18 & 1,29 & 69,82 & 358,35 & 18,22 & 26,35 & 343,30 \\
\hline Salamandra salamandra & 30 STF76 & 100,00 & 162,57 & 94,47 & 38,71 & 5093,79 & 298,56 & 57,03 & 241,52 & \begin{tabular}{|l|l|}
109,78 \\
\end{tabular} & 228,15 & 231,24 & \begin{tabular}{|c|}
101,07 \\
\end{tabular} & 750,01 & 121,26 & 1,13 & 69,25 & 342,29 & 17,83 & 25,01 & 324,72 \\
\hline Salamandra salamandra & 30STF77 & 100,00 & 158,26 & 99,27 & 38,87 & 5321,01 & 302,43 & 49,17 & 253,27 & 103,04 & 227,22 & 230,04 & 94,22 & 756,27 & 119,35 & 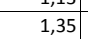 & $\frac{60,720}{67,90}$ & 339,33 & 19,30 & 26,55 & 323,32 \\
\hline Salamandra salamandra & 30STF78 & 100,00 & 164,69 & 100,93 & 38,99 & 5369,97 & 310,85 & 55,05 & 255,80 & 108,20 & 233,97 & 236,78 & 99,91 & 714,16 & 113,74 & 1,04 & 67,65 & 320,81 & 18,01 & 24,51 & 302,89 \\
\hline Salamandra salamandra & 30STF80 & 43,00 & 175,91 & 82,28 & 41,56 & 3927,69 & 281,94 & 86,09 & \begin{tabular}{|c|}
195,84 \\
\end{tabular} & \begin{tabular}{|c|}
137,66 \\
\end{tabular} & 225,39 & 229,80 & 129,36 & 749,14 & 138,61 & 1,00 & 76,92 & 382,69 & 13,02 & 20,77 & 358,81 \\
\hline Salamandra salamandra & 30STF81 & 100,00 & 173,15 & 83,09 & 40,87 & 4074,54 & 282,17 & 81,16 & 201,01 & 133,03 & 224,64 & 228,83 & 124,45 & 760,43 & 137,52 & 1,00 & 75,86 & 382,20 & 13,55 & 21,39 & 358,96 \\
\hline Salamandra salamandra & 30STF82 & 100,00 & 173,59 & 83,40 & 40,32 & 4196,64 & 284,72 & 80,30 & 204,42 & 131,67 & 226,76 & 230,81 & 123,30 & 749,50 & 133,75 & 1,00 & 74,76 & 371,99 & 14,12 & 21,54 & 348,06 \\
\hline Salamandra salamandra & 30STF83 & 100,00 & 173,10 & 84,66 & 39,84 & 4358,86 & 287,95 & 77,71 & 210,25 & 129,07 & 228,36 & 232,25 & 120,63 & 739,53 & 129,64 & 1,00 & 73,58 & \begin{tabular}{|l|l|l|}
361,28 \\
\end{tabular} & \begin{tabular}{l|l}
14,88 & \\
14,8 &
\end{tabular} & 21,88 & 337,73 \\
\hline Salamandra salamandra & 30STF84 & 100,00 & 159,27 & 93,11 & 39,21 & 4853,83 & 290,15 & 55,91 & 234,24 & 110,40 & 221,77 & 225,12 & 100,94 & 779,16 & 127,61 & 1,32 & 71,04 & 363,68 & 17,39 & 25,77 & 347,73 \\
\hline Salamandra salamandra & 30STF85 & 100,00 & 147,33 & 100,24 & 39,00 & 5242,53 & 291,33 & 37,85 & 253,47 & \begin{tabular}{|c|}
94,49 \\
\end{tabular} & 215,79 & 218,57 & 84,58 & 816,53 & 126,63 & 2,14 & 68,67 & 367,17 & 21,33 & 30,02 & 356,10 \\
\hline Salamandra salamandra & 30STF86 & 100,00 & 139,97 & 104,57 & 39,00 & 5481,88 & 291,96 & 26,83 & 265,13 & \begin{tabular}{l|l}
84,45 \\
\end{tabular} & 212,01 & 214,44 & 74,54 & 840,73 & 126,14 & 2,85 & 66,86 & 369,18 & 24,63 & 33,24 & 359,97 \\
\hline Salamandra salamandra & 30STF87 & 100,00 & 144,08 & 105,08 & 39,00 & 5527,88 & 297,17 & 30,56 & 266,61 & 87,53 & 216,61 & 219,03 & 77,99 & 815,38 & 123,04 & 2,60 & 66,53 & 358,10 & 23,87 & 31,97 & 346,90 \\
\hline Salamandra salamandra & 30STF88 & 100,00 & 159,18 & 103,34 & 39,01 & 5441,13 & 308,69 & 47,81 & 260,88 & \begin{tabular}{|l|l|}
102,47 \\
\end{tabular} & 229,94 & 232,45 & 93,75 & 739,03 & 116,06 & 1,46 & 67,26 & 330,99 & 19,64 & 26,47 & 314,51 \\
\hline Salamandra salamandra & 30STF89 & 100,00 & 164,97 & 105,62 & 39,37 & 5509,10 & 317,27 & 52,51 & 264,76 & \begin{tabular}{ll|}
106,85 \\
\end{tabular} & 236,40 & 238,74 & 98,66 & 703,42 & 111,41 & 1,05 & 67,10 & 314,99 & 18,34 & 24,40 & 297,42 \\
\hline Salamandra salamandra & 30STF91 & 39,00 & 176,17 & 83,33 & 41,17 & 4017,94 & 284,50 & 85,06 & \begin{tabular}{|c|}
199,44 \\
\end{tabular} & 137,06 & 226,75 & 231,21 & 128,54 & 719,27 & 131,94 & 1,00 & 76,06 & 365,92 & 13,00 & 20,62 & 341,06 \\
\hline Salamandra salamandra & 30STF92 & 93,00 & 174,60 & 84,83 & 40,84 & 4174,83 & 286,67 & 81,19 & 205,48 & 133,55 & 227,43 & 231,57 & 124,91 & 713,66 & 128,04 & 1,00 & 74,88 & 357,33 & 13,87 & 21,17 & 333,13 \\
\hline Salamandra salamandra & 30STF93 & 100,00 & 166,98 & 89,40 & 40,09 & 4514,49 & 288,77 & 68,36 & 220,41 & 122,21 & 224,76 & 228,44 & 113,05 & 735,55 & 125,81 & 1,13 & 72,92 & 356,18 & 15,45 & 23,38 & 336,01 \\
\hline Salamandra salamandra & 30STF94 & 100,00 & 159,15 & 94,59 & 39,62 & 4860,97 & 291,42 & 55,28 & 236,14 & 110,56 & 221,89 & 225,26 & 100,99 & 759,01 & 124,04 & 1,38 & 70,95 & 355,90 & 17,41 & 25,68 & 339,61 \\
\hline Salamandra salamandra & 30STF95 & 100,00 & 151,72 & 99,36 & 39,19 & 5148,58 & 293,22 & 43,49 & 249,72 & 99,93 & 218,81 & 221,64 & 90,19 & 783,50 & 123,22 & 1,91 & 69,12 & 357,32 & 19,93 & 28,33 & 343,75 \\
\hline Salamandra salamandra & 30STF96 & 100,00 & 140,76 & 105,24 & 39,02 & 5472,22 & 292,95 & 27,36 & 265,59 & 85,59 & 212,85 & 215,11 & 75,54 & 823,41 & 123,36 & 2,90 & 66,79 & 362,83 & 24,15 & 32,79 & 353,24 \\
\hline Salamandra salamandra & 30STF97 & 100,00 & 150,34 & 103,86 & 39,00 & 5436,48 & 300,43 & 38,15 & 262,28 & \begin{tabular}{|c|}
94,78 \\
\end{tabular} & 221,63 & 223,92 & 85,39 & 776,73 & 119,36 & 2,20 & 67,05 & 346,44 & 21,62 & 29,46 & 332,90 \\
\hline Salamandra salamandra & 30STF98 & 100,00 & $\mid 156,77$ & $\begin{array}{l}104,40 \\
\end{array}$ & 39,06 & 5475,32 & 307,66 & 44,50 & 263,16 & 100,01 & 228,30 & 230,60 & 91,14 & 743,66 & 115,82 & 1,85 & $\begin{array}{l}67,04 \\
67\end{array}$ & 332,79 & 20,44 & 27,36 & 317,06 \\
\hline Salamandra salamandra & 30STF99 & 100,00 & 162,62 & 106,09 & 39,23 & 5534,61 & 315,61 & 49,36 & 266,25 & 104,63 & 234,77 & 236,86 & 96,04 & 712,37 & 111,81 & 1,42 & 66,75 & 318,54 & 19,35 & 25,61 & 301,63 \\
\hline Salamandra salamandra & 30STG39 & 40,00 & 170,22 & 122,02 & 38,84 & 6377,82 & 352,44 & 40,78 & 311,65 & 100,87 & 253,89 & 254,67 & 91,93 & 593,58 & 82,44 & 2,22 & 59,20 & 239,95 & 22,91 & 27,60 & 228,11 \\
\hline Salamandra salamandra & 30STG47 & 100,00 & 175,54 & 122,95 & 39,06 & 6315,07 & 356,46 & 45,87 & 310,59 & 106,78 & 258,24 & 259,07 & 97,82 & 593,90 & 84,53 & 1,76 & 60,90 & 245,11 & 20,94 & 25,34 & 232,64 \\
\hline Salamandra salamandra & 30STG48 & 100,00 & 174,66 & 123,03 & 39,00 & 6355,98 & 356,75 & 44,67 & 312,08 & 105,38 & 258,06 & 258,77 & 96,49 & 588,01 & 82,80 & 2,04 & 60,20 & 240,29 & 21,39 & 25,70 & 228,30 \\
\hline Salamandra salamandra & 30STG49 & 100,00 & $\begin{array}{l}174,069 \\
165,69\end{array}$ & $\mid \frac{123,03}{122,71}$ & $\frac{35,00}{38,70}$ & $\begin{array}{ll}6353,90 \\
6434,94\end{array}$ & $\begin{array}{l}\mid c 50,13 \\
349,90\end{array}$ & 35,92 & 313,99 & $\begin{array}{r}05,30 \\
95,88 \\
\end{array}$ & 250,41 & 251,07 & 87,03 & $\begin{array}{l}30,01 \\
620,24\end{array}$ & $\begin{array}{l}02,000 \\
85,77\end{array}$ & 2,64 & $\mid 58,86$ & 242,25 & 24,31 & 29,03 & 238,44 \\
\hline Salamandra salamandra & 30STG57 & 100,00 & 178,89 & 124,02 & 39,27 & 6320,81 & 360,30 & 48,86 & \begin{tabular}{|l|l|}
311,45 \\
\end{tabular} & \begin{tabular}{|l|l|}
110,09 \\
\end{tabular} & 261,71 & 262,37 & 100,99 & 584,72 & 83,77 & 1,46 & 61,38 & 241,95 & 19,40 & 23,80 & 229,87 \\
\hline Salamandra salamandra & 30STG58 & 100,00 & $\mid 168,71$ & \begin{tabular}{|l|l|l|l|l|}
123,92 \\
\end{tabular} & 39,00 & 6427,23 & 353,35 & 38,44 & 314,92 & \begin{tabular}{|l|l}
99,08 \\
\end{tabular} & 253,38 & 254,00 & \begin{tabular}{|l|l}
90,12 \\
\end{tabular} & 621,32 & 87,25 & 2,01 & 59,98 & 252,34 & 22,64 & 27,19 & 241,33 \\
\hline Salamandra salamandra & 30STG59 & 100,00 & 162,75 & 123,58 & 38,49 & 6489,78 & 349,12 & 32,60 & 316,52 & 92,60 & 248,53 & 249,06 & 83,68 & 639,22 & 88,46 & 2,57 & 58,97 & 255,99 & 24,94 & 29,09 & 245,75 \\
\hline Salamandra salamandra & 30STG67 & 100,00 & 175,46 & 124,19 & 39,23 & 6358,80 & 357,91 & 45,78 & 312,14 & 106,27 & 259,13 & 259,64 & 97,48 & 605,06 & 87,20 & 1,63 & 61,45 & 249,46 & 19,86 & 24,03 & 238,20 \\
\hline Salamandra salamandra & 30STG68 & 100,00 & \begin{tabular}{|l|}
168,27 \\
168,27
\end{tabular} & $\mid \begin{array}{l}\mid 2,4,19 \\
124,46\end{array}$ & $\begin{array}{l}35,53 \\
38,92 \\
\end{array}$ & $\begin{array}{l}030,000 \\
6463,01\end{array}$ & | & 37,80 & $\mid$ & \begin{tabular}{|l|}
98,27 \\
98
\end{tabular} & 253,63 & 253,86 & $\begin{array}{l}31,40 \\
89,14\end{array}$ & $\begin{array}{l}600,00 \\
629,00\end{array}$ & $\begin{array}{l}81,20 \\
88,82\end{array}$ & $\frac{1,050}{2,00}$ & $\begin{array}{l}60,13 \\
60,12\end{array}$ & \begin{tabular}{|l|l|}
254,40 \\
254,86
\end{tabular} & 22,39 & 25,93 & 243,202 \\
\hline Salamandra salamandra & 30STG69 & 100,00 & 158,30 & 123,72 & 38,13 & 6543,04 & 346,16 & 27,98 & 318,18 & 87,73 & 245,06 & 245,34 & 78,92 & 664,30 & 91,73 & 2,86 & 58,72 & 264,30 & 26,15 & 28,46 & 255,15 \\
\hline Salamandra salamandra & 30STG79 & 100,00 & 158,45 & 124,13 & 38,25 & 6569,95 & 347,11 & 27,77 & 319,34 & 87,62 & 245,74 & 245,83 & 78,66 & 668,05 & 92,56 & 2,95 & 58,80 & 264,92 & 25,84 & 27,06 & 256,60 \\
\hline Salamandra salamandra & 30STG96 & 100,00 & 177,84 & 121,31 & 39,1 & 6287,33 & 355,09 & 50,04 & 305,05 & \begin{tabular}{|c|c|}
109,46 \\
\end{tabular} & 260,51 & 260,79 & 100,73 & 616,07 & 91,77 & 1,0 & 62,92 & 255,89 & 17,31 & 20,45 & 245,68 \\
\hline Salamandra salamandra & 30STH40 & 100,00 & 160,71 & 122,37 & 38,23 & 6479,99 & 346,34 & 31,07 & 315,27 & 90,63 & 246,38 & 246,83 & 81,72 & 633,15 & 86,42 & 2,97 & 58,00 & 251,74 & 26,43 & 30,23 & 241,17 \\
\hline Salamandra salamandra & 30STH41 & 100,00 & 160,59 & 122,44 & 38,03 & 6501,08 & 346,94 & 30,69 & 316,24 & 90,13 & 246,60 & 246,97 & 81,27 & 623,32 & 84,59 & 3,05 & 57,23 & 245,85 & 26,93 & 30,72 & 235,46 \\
\hline Salamandra salamandra & 30STH42 & 100,00 & 151,34 & 121,54 & 37,99 & 6546,37 & 339,06 & 22,35 & 316,71 & 81,06 & 238,43 & 238,74 & 72,14 & 658,05 & 87,87 & 3,93 & 55,88 & 256,05 & 31,06 & 34,19 & 246,37 \\
\hline Salamandra salamandra & 30STH50 & 100,00 & 154,55 & 122,76 & 38,00 & 6541,03 & 342,21 & 24,70 & 317,51 & 84,12 & 241,26 & 241,71 & 75,17 & 667,25 & 90,76 & 3,32 & 57,67 & 263,34 & 28,34 & 32,51 & 253,95 \\
\hline Salamandra salamandra & 30STH52 & 100,00 & 26 & 2,84 & 38,0 & 6601,11 & 343,57 & 24,05 & 319,52 & 83,09 & 242,07 & 242,18 & 74,22 & 646,74 & 86,74 & 3,6 & 56,34 & 251,10 & 29,43 & 31,63 & 241,95 \\
\hline Salamandra salamandra & 30STH60 & 100,00 & 76 & , 63 & 38,0 & 6584,50 & 34 & 24,34 & 319,62 & 83,79 & 242,28 & 242,47 & 74,96 & 6699,32 & 91,24 & 3,44 & 57,66 & 263,09 & 28,16 & 29,76 & 254,51 \\
\hline Salamandra salamandra & 30STH61 & 100,00 & 15 & & 38 & 6622,53 & 342,36 & 21,54 & 320,82 & 80,86 & 240,30 & 240,46 & 72,04 & \begin{tabular}{|l|l}
670,25 \\
\end{tabular} & 90,40 & 3,68 & 56,78 & 260,80 & 29,55 & 31,25 & 252,50 \\
\hline Salamandra salamandra & 30STH70 & 100,00 & 151,81 & 123,86 & 38,00 & 6621,13 & 342,24 & 21,17 & 321,08 & 80,58 & 240,03 & 240,17 & 71,88 & $\mid 685,67$ & 93,23 & 3,73 & 57,39 & 267,92 & 29,08 & 30,53 & 260,25 \\
\hline Salamandra salamandra & 30STH72 & 100,00 & 12 & 65 & 38,00 & 6671,75 & 352,56 & 28 & 323,77 & 88 & 249,95 & 249,95 & 79,81 & 621,28 & 84,23 & 3,12 & 57,01 & 239,88 & 26,17 & 26,17 & 232,06 \\
\hline Salamandra salamandra & 30STH80 & 100,00 & 159,47 & 124,72 & $38, \mathrm{C}$ & 639,36 & 350,07 & 27,82 & 322,25 & 87,76 & 247,96 & 247,97 & 78,89 & 656,20 & 90,41 & 3,03 & 58,29 & 256,68 & 25,59 & 25,70 & 249,59 \\
\hline Salamandra salamandra & 30STH81 & 100,00 & 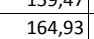 & 97 & $\begin{array}{l}30, \\
38,\end{array}$ & 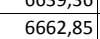 & | & 32,29 & 323,52 & $\begin{array}{l}0,1,05 \\
92,55\end{array}$ & $\begin{array}{l}24,30 \\
253,64\end{array}$ & | 253,64 & $\begin{array}{l}80,03 \\
83,63\end{array}$ & $\mid 622,20$ & $\begin{array}{r}80,71+2 \\
852\end{array}$ & 2,64 & \begin{tabular}{|l|l|}
58,18 \\
\end{tabular} & $\begin{array}{l}23,00 \\
241,91\end{array}$ & 23,87 & 23,87 & 2434,87 \\
\hline Salamandra salamandra & 30STH82 & 100,00 & 160,47 & 124,88 & 37,99 & 6717,64 & 353,05 & 27,63 & \begin{tabular}{|l|l|}
325,43 \\
\end{tabular} & 87,61 & 250,08 & 250,08 & 78,63 & 626,84 & 85,41 & 3,14 & 57,05 & 240,49 & 26,13 & 26,13 & 233,82 \\
\hline Salamandra salamandra & 30STH90 & 100,00 & 165,87 & 124,90 & 38,01 & 6649,20 & 356,02 & 33,41 & 322,61 & $\begin{array}{l}93,65 \\
\end{array}$ & 254,33 & 254,33 & 84,77 & 634,47 & 88,36 & 2,52 & 59,05 & 247,76 & 22,97 & 22,97 & 241,61 \\
\hline Salamandra salamandra & 30STH91 & 100,00 & 51 & 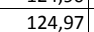 & 37,99 & 6701,95 & 355,13 & 30 & 221 & & 252 & 252,71 & 81 & 631,52 & 87,42 & 2, & 58,05 & 243,73 & 24,30 & 24,30 & 237,81 \\
\hline Salamandra salamandra & 30STH & 100,00 & & & 37, & 763,98 & & 6 & 326 & 81 & & & 72 & 651 & 89,77 & 3,5 & 56,58 & 247,49 & & 28,03 & 241,99 \\
\hline \begin{tabular}{|l} 
Salamandra salamandrandra \\
Sala
\end{tabular} & 30STH93 & $\begin{array}{l}100,00 \\
100\end{array}$ & $\begin{array}{l}354,90 \\
152,65 \\
\end{array}$ & $\begin{array}{l}124,0< \\
124,72 \\
\end{array}$ & $\begin{array}{ll}37,600 \\
37,68\end{array}$ & $\begin{array}{ll}0 / 30,390 \\
6786,90\end{array}$ & | 340,93 & $\begin{array}{l}2,0,87 \\
19,87\end{array}$ & 327,63 & $\begin{array}{l}81,84 \\
79,39\end{array}$ & 24243,60 & 24243,60 & $\begin{array}{l}72,92 \\
70,57\end{array}$ & | $651,2<\mid$ & $\begin{array}{l}89,11 \\
88,98\end{array}$ & 3,84 & $\begin{array}{l}30,30 \\
55,60\end{array}$ & $\begin{array}{l}\mid 24,49 \\
242,73\end{array}$ & 290,33 & 290,33 & 237,29 \\
\hline Salamandra salamandra & 30STH94 & 100,00 & 155,75 & 124,84 & 37,59 & 6791,60 & 350,71 & 22,55 & 328,16 & 82,34 & 246,94 & 246,94 & 73,25 & 617,97 & 85,14 & 3,79 & 55,09 & 230,59 & 28,66 & 28,66 & 224,83 \\
\hline Salamandra salamandra & 30STH97 & 100,00 & 159,33 & 123,80 & 37,09 & 6807,79 & 353,41 & 25,99 & 327,42 & 85,22 & 250,69 & 250,69 & 76,50 & 555,60 & 75,74 & 3,37 & 53,54 & 203,08 & 27,64 & 27,64 & 196,31 \\
\hline Salaman & 30STJ76 & 100,00 & & & 36,3 & 6661,01 & 29 & 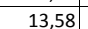 & 313 & & 230,10 & | & 60,34 & 531,60 & & (s) & 45,55 & 185,83 & | & 41,36 & 173,77 \\
\hline Salamandra salamandra & 30STJ77 & & & & 36,4 & 6635,54 & & 20,52 & 312,04 & /5, & 236, & 236, & $\frac{67,4}{67,4}$ & 485,8 & 60,11 & 5,4 & 45,44 & $\begin{array}{l}169,03 \\
169,46\end{array}$ & 37,52 & 37,52 & 157 \\
\hline Salamandra salamandra & 30STJ86 & 100,00 & 140,42 & 116,69 & 36,62 & 6683,16 & 327,95 & 12,71 & 315,23 & 67,77 & 230,58 & 230,58 & 60,09 & 519,05 & 64,15 & 6,31 & 44,92 & 179,38 & 41,07 & 41,07 & 167,52 \\
\hline Salamandra salamandra & 30STJ87 & 100,00 & 139,50 & 116,00 & 36,29 & 6660,10 & 326,07 & 12,18 & 313,89 & 67,07 & 229,44 & 229,44 & 59,43 & 510,14 & 62,04 & 6,55 & 44,22 & 175,34 & 41,84 & 41,84 & 162,97 \\
\hline Salamandra salamandra & 30STJ88 & 100,00 & 139,32 & 115,41 & 36,44 & 633,73 & 324,53 & 12,55 & 311,98 & 67,20 & 228,75 & 228,76 & 59,59 & 498,80 & 59,71 & 6,71 & 43,49 & 170,82 & 42,19 & 42,20 & 158,02 \\
\hline Salam & 30STJE & 100,0 & & & & 050 & & 20, & 310,82 & 75, & 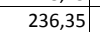 & & 67,44 & 452 & 53 & 5,80 & 43,54 & 15 & 88 & 37,88 & 14 \\
\hline Salamandra salamandra & 30STJ96 & 100,00 & 141,,01 & $\mid 117,50$ & 36,58 & 6708,53 & $\mid 329,46$ & 12,15 & 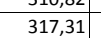 & $\begin{array}{l}6,0,05 \\
68\end{array}$ & 231,51 & 231,51 & $\begin{array}{l}0,40,23 \\
60\end{array}$ & \begin{tabular}{|l|l}
45,45 & \\
505,65
\end{tabular} & $\frac{62,12}{62,12}$ & $\frac{0,260}{6,26}$ & \begin{tabular}{|l|}
44,446 \\
44,
\end{tabular} & $\begin{array}{l}172,77 \\
\end{array}$ & $\begin{array}{l}1,000 \\
40,59\end{array}$ & $\begin{array}{l}1,000 \\
40,59\end{array}$ & 161,21 \\
\hline
\end{tabular}




\begin{tabular}{|c|c|c|c|c|c|c|c|c|c|c|c|c|c|c|c|c|c|c|c|c|c|}
\hline TAXON & UTM & $\mathrm{km} 2$ & BIO1 & $\mathrm{B1O2}$ & $\mathrm{BIO3}$ & B104 & B105 & 8106 & B107 & B108 & B109 & 81010 & BIO11 & BIO12 & $\mathrm{BIO13}$ & B1014 & B1015 & 81016 & B1017 & B1018 & BIO19 \\
\hline Salamandra salamandra & 30STJ97 & 100,00 & 127,72 & 116,23 & 36,51 & 6662,72 & 315,44 & 1,45 & 313,99 & 55,93 & 218,06 & 218,12 & 48,59 & 552,82 & 65,80 & 8,28 & 42,71 & 187,37 & 48,65 & 48,73 & 174,55 \\
\hline Salamandra salamandra & 30STJ98 & 100,00 & 132,35 & 115,84 & 36,44 & 6643,61 & 318,84 & 5,84 & 313,00 & 60,65 & 222,37 & 222,40 & 53,04 & 517,27 & 60,93 & 7,73 & 42,39 & 174,55 & 46,10 & 46,14 & 161,46 \\
\hline Salamandra salamandra & 30STK41 & 70,00 & 160,83 & 111,62 & 36,88 & 6438,31 & 337,22 & 37,00 & 300,22 & 89,67 & 246,68 & 246,68 & 81,92 & 435,49 & 53,34 & 4,25 & 45,75 & 156,26 & 32,98 & 32,98 & 143,93 \\
\hline Salamandra salamandra & 30 SUF03 & 82,00 & 169,39 & 89,49 & 40,47 & 4467,10 & 290,21 & 71,31 & 218,90 & 125,21 & 226,56 & 230,21 & \begin{tabular}{|c|}
116,17 \\
\end{tabular} & 700,22 & 120,39 & 1,22 & 73,03 & 341,09 & 15,43 & 22,72 & 320,33 \\
\hline Salamandra salamandra & 30 SUF04 & 100,00 & 150,08 & 99,70 & 39,78 & 5072,33 & 290,43 & 42,10 & 248,32 & 99,75 & 216,34 & 219,17 & 89,69 & 772,31 & 120,92 & 2,11 & 69,39 & 353,55 & 20,02 & 28,71 & 341,47 \\
\hline Salamandra salamandra & 30SUF05 & 100,00 & 145,33 & 102,83 & 39,29 & 5290,31 & 292,21 & 34,25 & 257,95 & 92,33 & 214,78 & 217,25 & 82,33 & 790,04 & 120,53 & 2,57 & 67,83 & 354,48 & 22,08 & 30,76 & 343,39 \\
\hline Salamandra salamandra & 30 SUF06 & 100,00 & 141,85 & 105,55 & 39,09 & 5464,68 & 294,05 & 28,43 & 265,62 & 86,67 & 213,94 & 216,01 & 76,81 & 802,06 & 120,23 & 3,02 & 66,62 & 354,21 & 24,06 & 32,49 & 343,76 \\
\hline Salamandra salamandra & 30 SUF07 & 100,00 & 148,85 & 104,70 & 39,04 & 5460,91 & 299,82 & 35,93 & 263,89 & 93,13 & 220,67 & 222,81 & 83,66 & 769,43 & 117,27 & 2,48 & 66,68 & 342,70 & 22,23 & 30,04 & 329,43 \\
\hline Salamandra salamandra & 30 SUF09 & 100,00 & 153,81 & 107,61 & 39,00 & 5651,03 & 310,21 & 38,57 & 271,64 & 95,21 & 228,32 & 229,94 & 86,20 & 742,10 & 112,92 & 2,29 & 65,64 & 326,77 & 22,01 & 28,98 & 312,48 \\
\hline Salamandra salamandra & 30 SUF13 & 41,00 & 177,76 & 86,60 & 40,55 & 4321,56 & 293,13 & $\mid 81,98$ | & 211,15 & 135,25 & 232,73 & 236,49 & 126,22 & 639,44 & 112,78 & 1,00 & 73,62 & 317,35 & 14,11 & 20,27 & 294,35 \\
\hline Salamandra salamandra & 30 SUF15 & 100,00 & 137,05 & 106,49 & 39,38 & 5453,24 & 289,99 & 23,00 & 266,99 & 82,54 & 209,28 & 211,17 & 72,27 & 805,45 & 119,46 & 3,47 & 66,20 & 353,64 & 25,29 & 34,08 & 345,22 \\
\hline Salamandra salamandra & 30 SUF 16 & 100,00 & 129,29 & 109,97 & 39,02 & 5681,03 & 290,17 & 12,23 & 277,94 & 71,73 & 205,11 & 206,59 & 61,96 & 839,94 & 121,57 & 4,46 & 64,32 & 360,19 & 29,42 & 38,14 & 352,82 \\
\hline Salamandra salamandra & 30SUF17 & 100,00 & 139,45 & 108,08 & 39,01 & 5631,49 & 296,76 & 23,59 & 273,17 & 82,19 & 214,24 & 215,90 & 72,48 & 790,95 & 116,12 & 3,52 & 64,97 & 344,10 & 25,83 & 33,99 & 333,83 \\
\hline Salamandra salamandra & 30SUF18 & 100,00 & 145,50 & 107,76 & 39,00 & 5650,69 & 302,14 & 29,69 & 272,45 & 87,59 & 220,36 & 221,86 & 78,06 & 764,70 & 113,56 & 3,09 & 65,04 & 334,29 & 24,24 & 31,91 & 322,21 \\
\hline Salamandra salamandra & 30 SUF19 & 100,00 & 153,66 & 107,43 & 39,00 & 5652,85 & 309,79 & 38,03 & 271,76 & 95,08 & 228,48 & 229,80 & 86,25 & 731,08 & 110,58 & 2,50 & 65,31 & 321,66 & 22,23 & 29,17 & 307,50 \\
\hline Salamandra salamandra & 30 SUF 24 & 94,00 & 168,45 & 92,06 & 40,05 & 4652,58 & 293,99 & 66,92 & 227,07 & 122,51 & 228,58 & 231,67 & 113,12 & 654,52 & 109,13 & 1,48 & 71,20 & 313,71 & 16,63 & 23,23 & 294,45 \\
\hline Salamandra salamandra & 30 SUF 25 & 100,00 & 151,94 & 100,82 & 39,72 & 5156,42 & 294,15 & 42,55 & 251,60 & 100,47 & 219,74 & 221,94 & 90,62 & 720,34 & 111,42 & 2,52 & 67,90 & 328,08 & 20,82 & 28,60 & 314,10 \\
\hline Salamandra salamandra & 30 SUF 26 & 100,00 & 139,10 & 106,50 & 39,10 & 5504,40 & 293,23 & 24,74 & 268,49 & 83,18 & 212,23 & 213,84 & 73,82 & 778,80 & 115,34 & 3,84 & 65,27 & 341,04 & 26,48 & 34,36 & 329,79 \\
\hline Salamandra salamandra & 30 SUF 27 & 100,00 & 147,31 & 105,57 & 39,00 & 5509,06 & 299,63 & 33,14 & 266,49 & 91,15 & 220,22 & 221,83 & 81,75 & 740,65 & 110,76 & 3,10 & 65,66 & 327,50 & 23,41 & 30,92 & 314,60 \\
\hline Salamandra salamandra & 30 SUF 29 & 100,00 & 159,16 & 105,45 & 39,00 & 5574,05 & 311,62 & 44 & 267,08 & 101,3 & 232,83 & 234,14 & 92,55 & 696,91 & 106,71 & 2, & 65,71 & 309,96 & 20,84 & 27,23 & 294,31 \\
\hline Salamandra salamandra & 30 SUF 34 & 86,00 & 168,50 & 91,96 & 39,99 & 4679,37 & 294,07 & 66,24 & 227,83 & 122,48 & 229,17 & 232,01 & 113,01 & 630,40 & 103,78 & 1,59 & 70,51 & 301,26 & 16,97 & 23,19 & 282,53 \\
\hline Salamandra salamandra & 30 SUF 35 & 100,00 & 158,75 & 97,82 & 39,57 & 5031,04 & 295,61 & 51,20 & 244,41 & 108,57 & 224,73 & 226,96 & 98,93 & 671,78 & 105,65 & 2,26 & 68,27 & 310,74 & 19,50 & 26,30 & 294,46 \\
\hline Salamandra salamandra & $30 \mathrm{SUF} 36$ & 100,00 & 168,44 & 94,62 & 39,09 & 4960,52 & 300,68 & 62,44 & 238,24 & 118,42 & 233,11 & 235,40 & 109,13 & 645,01 & 104,60 & 1,90 & 69,21 & 303,24 & 18,20 & 23,92 & 283,39 \\
\hline Salamandra salamandra & 30 SUF 37 & 100,00 & 154,78 & 102,31 & 39,00 & 5375,08 & 301,58 & 42,60 & 258,97 & 100,04 & 225,88 & 227,42 & 90,71 & 694,24 & 106,26 & 2,77 & 66,19 & 311,65 & 21,86 & 28,57 & 296,34 \\
\hline Salamandra salamandra & 30 SUF 38 & 100,00 & 161,50 & 101,88 & 38,5 & 5404,44 & 307,68 & 49,02 & 258,66 & 105,8 & 232,80 & 234,28 & 96,89 & 671,02 & 103,93 & 2,2 & 66,48 & 303,10 & 20,13 & 26,24 & 286,15 \\
\hline Salamandra salamandra & 30 SUF 45 & 100,00 & $\begin{array}{ll}10,158,58 \\
168\end{array}$ & $\begin{aligned} 21,00 \\
92,63 \\
\end{aligned}$ & $\begin{array}{ll}30,250 \\
39,20\end{array}$ & 4834,96 & 296,72 & $\begin{array}{l}4,02 \\
63,92\end{array}$ & 232,80 & $\mid \begin{array}{l}\mid 120,05 \\
120,46 \\
\end{array}$ & 231,56 & $\begin{array}{l}23,20 \\
233,94\end{array}$ & 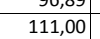 & $\mid \frac{\mid \gamma, 0<}{617,16}$ & \begin{tabular}{|l|l|}
100,64 \\
100
\end{tabular} & 2,04 & $\begin{array}{ll}60,40 \\
69,42\end{array}$ & \begin{tabular}{|l|l|}
291,88 \\
\end{tabular} & |l, 17,94 & 23,56 & 272,80 \\
\hline Salamandra salamandra & 30 SUF55 & 100,00 & 166,07 & 93,57 & 39,03 & 4922,22 & 296,25 & 59,76 & 236,49 & 117,03 & 230,54 & 232,58 & 107,47 & 602,98 & 97,23 & 2,34 & 68,10 & 281,26 & 19,05 & 24,29 & 263,55 \\
\hline Salamandra salamandra & 305 UF56 & 100,00 & 179,54 & 87,59 & 38,50 & 4770,36 & 300,70 & 76,10 & 224,60 & 131,76 & 241,54 & 243,85 & 122,45 & 574,20 & 97,38 & 1,66 & 70,02 & 275,22 & 17,46 & 21,11 & 253,32 \\
\hline Salamandra salamandra & 30 SUF59 & 100,00 & 151,96 & 107,04 & 38,38 & 5743,58 & 309,15 & 34,31 & 274,84 & 92,37 & 228,85 & 229,23 & 83,52 & 661,30 & 97,48 & 3,74 & 62,77 & 285,63 & 23,96 & 28,66 & 272,52 \\
\hline Salamandra salamandra & 30 SUF65 & 71,00 & 178,18 & 86,28 & 38,39 & 4686,09 & 296,79 & 75,63 & 221,16 & 131,94 & 239,13 & 241,45 & 122,25 & 553,97 & 93,95 & 1,93 & 69,95 & 265,73 & 17,57 & 21,24 & 245,09 \\
\hline 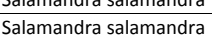 & $\frac{305003}{305 \text { UF79 }}$ & $\frac{1,000}{100,00}$ & $\begin{array}{ll}17,1,16 \\
146,45\end{array}$ & $\begin{array}{l}80,26 \\
109,68\end{array}$ & $\begin{array}{l}30,35 \\
38,06 \\
\end{array}$ & $\begin{array}{l}4080,009 \\
589,52\end{array}$ & 309,60 & $\mid \frac{\mid c, 03}{26,14}$ & $\begin{array}{l}221,10 \\
283,45 \\
\end{array}$ & \begin{tabular}{|c|}
151,94 \\
84,89
\end{tabular} & $\mid$\begin{tabular}{|l|}
225,82 \\
225,5
\end{tabular} & 2225,82 & \begin{tabular}{|l|l|}
12,23 \\
76,33
\end{tabular} & | & $\begin{array}{l}0,48 \\
90,4\end{array}$ & $\begin{array}{l}1,45 \\
4,67\end{array}$ & $\begin{array}{l}65,19 \\
60,19 \\
\end{array}$ & $\begin{array}{l}\mid 20,13 \\
264,72\end{array}$ & 26,09 & $\begin{array}{ll}21,24 \\
26,35\end{array}$ & 2433,12 \\
\hline Salamandra salamandra & 30 SUF89 & 100,00 & 138,18 & 113,21 & 38,01 & 6037,40 & 308,46 & 15,46 & 293,00 & 75,24 & 219,99 & 219,99 & 66,65 & 639,85 & 88,60 & 5,89 & 57,88 & 261,41 & 29,57 & 29,63 & 252,07 \\
\hline Salamandra salamandra & 30 UUF99 & $\begin{array}{l}100,00 \\
\end{array}$ & \begin{tabular}{|l|l|}
131,28 \\
130
\end{tabular} & $\begin{array}{l}113,21 \\
115,92\end{array}$ & $\begin{array}{ll}30,010 \\
38,00\end{array}$ & 6159,14 & 307,14 & $\begin{array}{r}\mid r, 40 \\
6,72 \\
\end{array}$ & 300,42 & $\begin{array}{l}6,24 \\
67,43\end{array}$ & \begin{tabular}{|l|l|}
214,93 \\
\end{tabular} & 214,93 & 58,55 & | & $\begin{array}{ll}80,004 \\
87,41\end{array}$ & $\begin{array}{l}0,05 \\
7,08\end{array}$ & 55,91 & $\begin{array}{l}201,41 \\
259,09\end{array}$ & 33,13 & 33,13 & 251,82 \\
\hline Salamandra salamandra & $305 U G 09$ & 100,00 & 171,41 & 123,90 & 38,02 & 6601,14 & 359,11 & 39,39 & 319,72 & 99,62 & 259,17 & 259,17 & 90,60 & 629,89 & 89,50 & 2,11 & 60,41 & 248,30 & 20,38 & 20,38 & 242,66 \\
\hline Salamandra salamandra & 30 SUG19 & 100,00 & 170,83 & 123,41 & 38,00 & 6637,60 & 358,88 & 38,45 & 320,44 & 98,80 & 259,16 & 259,16 & 89,47 & 637,10 & 91,01 & 2,26 & 60,45 & 249,29 & 20,32 & 20,32 & 245,07 \\
\hline 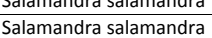 & 3054629 & $\begin{array}{l}100,00 \\
100\end{array}$ & 171,23 & $\begin{array}{l}12,4,41 \\
122,66\end{array}$ & 30,80 & $\begin{array}{l}-603,1,00 \\
6667,74\end{array}$ & 359,38 & 38,45 & \begin{tabular}{|l|l|}
321,03 \\
321
\end{tabular} & \begin{tabular}{|l|}
50,00 \\
100,62
\end{tabular} & \begin{tabular}{|l|}
250,10 \\
260,12
\end{tabular} & $\begin{array}{l}26,10 \\
260,12\end{array}$ & 899,40 & $\begin{array}{l}\mid \\
638,74 \\
638,74\end{array}$ & $\begin{array}{l}|c|, 11 \\
92,99 \\
\end{array}$ & $2,2,38$ & $\begin{array}{l}60,45 \\
60,78 \\
\end{array}$ & $\begin{array}{l}\mid 449,29 \\
248,38\end{array}$ & $\begin{array}{l}20,32 \\
19,95\end{array}$ & $\begin{array}{l}20,32 \\
19,95 \\
\end{array}$ & 244,06 \\
\hline Salamandra salamandra & $305 \mathrm{SU} 39$ & 100,00 & 172,72 & 121,66 & 37,46 & 6673,92 & 360,28 & 39,74 & 320,55 & 103,10 & 261,75 & 261,75 & 90,77 & 634,97 & 94,36 & 2,40 & 60,84 & 247,91 & 19,40 & 19,40 & 242,96 \\
\hline Salamandra salamandra & 30 SUG 49 & 100,00 & 177,84 & 119,92 & 37,05 & 6641,07 & 362,81 & 45,38 & 317,43 & 108,48 & 266,49 & 266,49 & 96,15 & 608,36 & 91,39 & $2, \mathrm{c}$ & 61,38 & 238,32 & 17,34 & 17,34 & 233,03 \\
\hline Salamandra salamandra & $305 \cup 680$ & 100,00 & 145,86 & 111,84 & 38,6 & 6057,58 & 31 & 23, & 291,35 & 81, & 227,83 & 227,83 & 73 & 607,50 & 85,53 & 5,2 & 58, & 250,28 & 26,89 & 26,89 & 239,62 \\
\hline Salamandra salamandra & 30 SUG90 & 100,00 & 124,09 & 117,99 & 37,99 & 6306,11 & 305,62 & $-1,53$ & 307,15 & 58,8 & 210,03 & 210,03 & 49,98 & 696,79 & 91,66 & 8,28 & 54 & 269,74 & 38,04 & 38,04 & 264,54 \\
\hline $\begin{array}{l}\text { Salamandra salamanandra } \\
\text { Salamdra sana }\end{array}$ & $305 U G 91$ & $\begin{array}{l}100,00 \\
100,00\end{array}$ & $\begin{array}{l}154,29 \\
154,26 \\
\end{array}$ & \begin{tabular}{|l|l|l|l|l|}
110,16 \\
\end{tabular} & $\begin{array}{l}37,59 \\
37,51 \\
\end{array}$ & $\begin{array}{ll}6308,11 \\
6085,34\end{array}$ & $30,62,24$ & 31,49 & \begin{tabular}{|l|l|}
289,75 \\
289,5
\end{tabular} & $\begin{array}{l}38,00 \\
89,03\end{array}$ & \begin{tabular}{|l|}
236,53 \\
23,
\end{tabular} & 231,03 & $\begin{array}{l}49,98 \\
81,49\end{array}$ & $\begin{array}{l}690,19 \\
549,58\end{array}$ & $\begin{array}{l}1,060 \\
78,58\end{array}$ & $\begin{array}{l}8,8,79 \\
4,79\end{array}$ & $\begin{array}{l}54,525 \\
58,01 \\
\end{array}$ & $\begin{array}{l}269,74 \\
226,02\end{array}$ & 24,042 & 248,42 & 2064,54 \\
\hline Salamandra salamandra & 30 SUHOO & 100,00 & 165,63 & 124,63 & 38,00 & 6680,67 & 356,48 & 32,82 & 323,66 & 93,24 & 254,76 & 254,76 & 84,18 & 638,97 & 89,64 & 2,68 & 59,13 & 247,83 & 22,80 & 22,80 & 242,89 \\
\hline Salamandra salamandra & 30SUHO1 & 100,00 & 161,68 & 124,97 & 37,98 & 6747,20 & 354,36 & 28,29 & 326,07 & 88,7 & 251,77 & 251,77 & 79,41 & 640,75 & 89,85 & 3,03 & 58,01 & 245,15 & 24,70 & 24,70 & 240,57 \\
\hline Salamandra salamandra & 30SUHO2 & 100,00 & 15 & - & 37,43 & 797,93 & 346,13 & 18,10 & 328,02 & 79,8 & 242,27 & 242,27 & 68,97 & 665,09 & 92,69 & 3,96 & 56,19 & 250,52 & 29,42 & 29,42 & 245,90 \\
\hline Salamandra salamandra & 30SUHO3 & 10 & 15 & 12 & 37, & 681 & 351 & 22,94 & 328,5 & 84,6 & 248,16 & 248,16 & 73,96 & 629,18 & 88,10 & 3,43 & 56,14 & 235,71 & 27,18 & 27,18 & 231,01 \\
\hline Salamandra salamandra & 30 SUHOG & 100,00 & 15 & 12 & 37,01 & 6840,76 & 351,82 & 22,84 & 328,98 & 84 & 248,40 & 248,40 & 73,47 & 581,11 & 80,24 & 3,99 & 53,46 & 211,54 & 29,10 & 29,10 & 206,06 \\
\hline Salamandra salamandra & 30 SUH10 & 100,00 & $\begin{array}{l}160,43 \\
1603\end{array}$ & $\begin{array}{l}124,05 \\
12,15 \\
\end{array}$ & 37,94 & 6743,60 & 352,50 & 27,41 & |325,09 & $\begin{array}{l}84,00 \\
89,12\end{array}$ & $\mid 240,70$ & $\begin{array}{l}240,40 \\
250,70\end{array}$ & $\begin{array}{l}78,41 \\
78,31\end{array}$ & $\mid \frac{601,1}{659,05}$ & $\mid \frac{\mid 0,24}{93,60}$ & 3,05 & $\begin{array}{l}58,405 \\
58,55\end{array}$ & 253,14 & 24,49 & 24,49 & 249,34 \\
\hline Salamandra salamandra & 30SUH11 & 100,00 & 153,44 & 124,32 & 37,41 & 6790,20 & 347,48 & 20,28 & 327,20 & 82,93 & 244,46 & 244,46 & 71,11 & 668,52 & 94,50 & 3,88 & 56,90 & 253,99 & 27,99 & 27,99 & 249,24 \\
\hline Salamandra salamandra & 30 SUH12 & 100,00 & 15 & 4 & 37,23 & 6821,05 & 347 & 19 & 328 & 81,6 & 243,99 & 243,99 & 69,83 & 657,64 & 92,90 & 3, & 56,20 & 247,94 & 28,79 & 28,79 & 242,44 \\
\hline Salamandra salamandra & 30 sosth & 10 & & & 37 & 6841 & $\frac{341}{350}$ & $\frac{19}{20}$ & $\frac{320}{329}$ & $\begin{array}{l}81, \\
83,\end{array}$ & \begin{tabular}{|l|}
$243,9,18$ \\
246
\end{tabular} & $\begin{array}{l}24,99 \\
246,18\end{array}$ & 71 & $\mid$ & $\begin{array}{l}29,85 \\
89,8\end{array}$ & , & $\begin{array}{ll}30,20 \\
55,83\end{array}$ & $\begin{array}{l}24 r, 94 \\
238,13\end{array}$ & 28,24 & 28,24 & 232,44 \\
\hline Salamandra salamandra & 30 SUH14 & 100,00 & 150,81 & 124,97 & 37,02 & 6860,81 & 347,49 & 17,34 & 330,15 & 80,42 & 243,28 & 243,28 & 67,93 & 632,93 & 88,78 & 4,17 . & 54,50 & 234,54 & 30,24 & 30,24 & 228,31 \\
\hline Salamandra salamandra & 30 SUH15 & 100,00 & 154,26 & 124,99 & 37,00 & 6858,90 & 350,54 & 20,44 & 330,10 & 83,81 & 246,70 & 246,70 & 71,17 & 603,60 & 84,48 & 4,00 & 54,14 & 221,67 & 29,30 & 29,30 & 215,70 \\
\hline Salamandra salamandra & 30 SUH16 & 100,00 & 156,14 & 124,60 & 37,00 & 6864,75 & 351,95 & 21,92 & 330,03 & 85,47 & 248,42 & 248,42 & 72,77 & 580,00 & 80,66 & 4,00 & 53,32 & 210,65 & 29,02 & 29,02 & 204,95 \\
\hline Salamandra salamand & $30 \mathrm{sur}$ & & & & 37 & & & 31 & 32 & & 255 & 255 & 82 & 64 & 93,62 & 2, & 59,03 & & 22,74 & 22,74 & \\
\hline 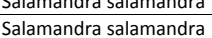 & 3050 & 100 & $\begin{array}{l}154,09 \\
155,18 \\
\end{array}$ & $\begin{array}{l}123,020 \\
124,01 \\
\end{array}$ & $\begin{array}{l}37,02 \\
37,13 \\
\end{array}$ & $\begin{array}{ll}6 / 315,0 \\
6815,08\end{array}$ & 350,12 & $\frac{31,21}{21,83}$ & \begin{tabular}{|l|}
324,91 \\
327,44
\end{tabular} & \begin{tabular}{|c|}
84,73 \\
84,73
\end{tabular} & \begin{tabular}{|l|}
$243,00,69$ \\
\end{tabular} & $\begin{array}{l}23,00 \\
246,69\end{array}$ & $\begin{array}{l}82,13 \\
72,49\end{array}$ & $\begin{array}{l}643,91 \\
660,60\end{array}$ & $\begin{array}{l}33,62 \\
94,63\end{array}$ & $\begin{array}{l}2,86 \\
3,78 \\
\end{array}$ & $\begin{array}{l}39,03 \\
57,17\end{array}$ & $\begin{array}{l}248,81 \\
251,76\end{array}$ & 22,13 & 227,13 & 2445,69 \\
\hline Salamandra salamandra & 30 SUH 22 & 100,00 & 157,27 & 124,38 & 37,08 & 6836,77 & 352,36 & 23,58 & 328,78 & 86,77 & 249,13 & 249,13 & 74,42 & 638,21 & 91,70 & 3,51 & 56,67 & 241,62 & 26,43 & 26,43 & 235,18 \\
\hline Salamandra salamandra & $30 \mathrm{SUH} 23$ & 100,00 & 149,64 & 124,64 & 37,01 & 6867,08 & 346,31 & 16,29 & 330,03 & 79,18 & 242,11 & 242,11 & 66,75 & 647,95 & 91,83 & 4,34 & 54,98 & 242,28 & 30,37 & 30,37 & 235,08 \\
\hline Salamandra salamandra & 30 SUH 25 & 100,00 & 155,16 & , & 37,00 & 6879,92 & 351,62 & 20,82 & 330,80 & 84,49 & 247,76 & 247,76 & 71,97 & 596,25 & 84,09 & 3,99 & 54,09 & 219 & 28,85 & 28,85 & \\
\hline Salamandra salamand & $30 \mathrm{SUH}$ & 100 & 157 & & 37, & 6887 & 353 & 22,5 & 330,86 & $86,4 \xi>>2$ & 249,83 & 249,83 & 73,66 & 571,7 & 80,10 & 3,89 ] & 53,37 & 207,64 & 28,53 & 28,53 & 201 \\
\hline 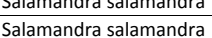 & 30 SUH 28 & $\begin{array}{l}100,00 \\
100,00\end{array}$ & $\begin{array}{l}13,2,77 \\
159,77\end{array}$ & $\begin{array}{l}124,10 \\
124,01\end{array}$ & 37,00 & $\begin{array}{l}6887,2,03 \\
6870,03\end{array}$ & 353,44 & 25,01 & $\begin{array}{l}3300,80 \\
329,70\end{array}$ & \begin{tabular}{|c|}
86,49 \\
88,82
\end{tabular} & \begin{tabular}{|l|}
2452,03 \\
252,06
\end{tabular} & $\begin{array}{l}24,83 \\
252,06\end{array}$ & $\begin{array}{l}73,60 \\
76,10\end{array}$ & $\mid \begin{array}{l}\mid 5 / 1,13 \\
525,57\end{array}$ & $\mid \begin{array}{ll}80,10 \\
72,21\end{array}$ & $\begin{array}{l}3,391 \\
3,41\end{array}$ & $\begin{array}{l}3,32\} \\
52,07 \\
\end{array}$ & \begin{tabular}{|l|}
20,04 \\
186,35
\end{tabular} & $\begin{array}{l}28,53 \\
27,45\end{array}$ & $\begin{array}{l}28,53 \\
27,45 \\
\end{array}$ & $\begin{array}{l}201,17 \\
180,92\end{array}$ \\
\hline
\end{tabular}




\begin{tabular}{|c|c|c|c|c|c|c|c|c|c|c|c|c|c|c|c|c|c|c|c|c|c|}
\hline TAXON & UTM & $\mathrm{km} 2$ & BIO1 & $\mathrm{B1O2}$ & $\mathrm{BIO3}$ & 8104 & B105 & B106 & B107 & B108 & B109 & BIO10 & B1011 & BIO12 & B1013 & B1014 & 81015 & B1016 & BIO17 & B1018 & 81019 \\
\hline Salamandra salamandra & 30SUH30 & 100,00 & 162,30 & 122,87 & 37,04 & 6771,33 & 354,04 & 29,24 & 324,80 & 92,31 & 253,16 & 253,16 & 80,00 & 647,49 & 94,59 & 3,26 & 58,61 & 249,89 & 23,69 & 23,69 & 243,64 \\
\hline Salamandra salamandra & 30 SUH31 & 100,00 & 159,11 & 123,50 & 37,05 & 6820,64 & 352,68 & 25,53 & 327,15 & \begin{tabular}{|c|c|}
88,65 & \\
\end{tabular} & 250,72 & 250,72 & 76,22 & 643,77 & 93,65 & 3,54 & 57,47 & 246,45 & 25,46 & 25,46 & 239,30 \\
\hline Salamandra salamandra & 30SUH32 & 100,00 & $\mid \begin{array}{l}\mid 156,88 \\
156,1\end{array}$ & 123,97 & 37,00 & 6859,15 & 351,87 & 22,99 & 328,88 & 86,10 & 249,13 & 249,13 & 73,61 & 635,38 & 92,01 & 3,77 & 56,51 & 240,95 & 26,70 & 26,70 & 233,23 \\
\hline Salamandra salamandra & 30SUH33 & 100,00 & 155,03 & 124,15 & 37,00 & 6882,36 & 351,03 & 20,96 & 330,08 & 84,19 & 247,63 & 247,63 & \begin{tabular}{|c|}
71,67 \\
\end{tabular} & 625,04 & 89,89 & 3,97 & 55,43 & 234,58 & 27,97 & 27,97 & 226,59 \\
\hline Salamandra salamandra & 30 SUH34 & 100,00 & 152,05 & 124,73 & 37,00 & 6907,64 & 348,98 & 17,85 & 331,13 & 81,11 & 245,16 & 245,16 & 68,66 & \begin{tabular}{|c|c|}
617,62 \\
\end{tabular} & 87,99 & 4,11 & 54,31 & 229,10 & 29,42 & 29,42 & 220,93 \\
\hline Salamandra salamandra & $30 \mathrm{SUH} 36$ & 100,00 & 156,80 & 124,81 & 37,00 & 6903,97 & 353,21 & 21,85 & 331,37 & 86,01 & 249,63 & 249,63 & 72,98 & 566,97 & 79,78 & 3,86 & 53,20 & 205,78 & 28,44 & 28,44 & 198,61 \\
\hline Salamandra salamandra & $30 \mathrm{SUH} 37$ & 100,00 & 158,19 & 124,25 & 37,00 & 6893,18 & 353,98 & 23,16 & 330,82 & 87,52 & 250,85 & 250,85 & 74,40 & 543,75 & 75,72 & 3,51 & 52,56 & 194,90 & 27,77 & 27,77 & 188,42 \\
\hline Salamandra salamandra & 30 SUH38 & 100,00 & \begin{tabular}{|l|l|}
160,64 \\
150,
\end{tabular} & 124,02 & 37,00 & 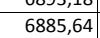 & 355,60 & 25,47 & 330,13 & 89,97 & 253,13 & 253,13 & 76,72 & 517,02 & 71,21 & 3,28 & 52,03 & 182,91 & 26,94 & 26,94 & $\begin{array}{l}170,47,24 \\
\end{array}$ \\
\hline Salamandra salamandra & $30 \mathrm{SUH} 40$ & 100,00 & 166,59 & 121,69 & 37,01 & 6766,19 & 356,73 & 33,38 & 323,35 & 96,41 & 257,32 & 257,32 & \begin{tabular}{|l|l|}
83,97 \\
\end{tabular} & $\begin{array}{l}627,45 \\
\end{array}$ & 92,90 & 3,00 & 58,99 & 243,12 & 22,05 & 22,05 & 235,93 \\
\hline Salamandra salamandra & $30 \mathrm{SUH} 41$ & 100,00 & 163,68 & 122,52 & 37,00 & 6815,77 & 355,97 & 29,91 & 326,06 & \begin{tabular}{|c|}
93,17 \\
\end{tabular} & 255,18 & 255,18 & 80,68 & \begin{tabular}{|c|c|}
621,48 \\
\end{tabular} & 91,61 & 3,31 & 57,85 & 238,69 & 23,62 & 23,62 & 230,69 \\
\hline Salamandra salamandra & $30 \mathrm{SUH} 42$ & 100,00 & 159,93 & 123,20 & 37,00 & 6866,91 & 354,13 & 25,70 & 328,43 & \begin{tabular}{l|l}
8,95 \\
\end{tabular} & 252,18 & 252,18 & 76,42 & 618,63 & 90,50 & 3,56 & 56,64 & 235,22 & 25,44 & 25,44 & 226,66 \\
\hline Salamandra salamandra & $30 \mathrm{SUH} 43$ & 100,00 & 154,47 & 123,89 & 37,00 & 6906,66 & 350,66 & 20,31 & 330,36 & 83,37 & 247,52 & 247,52 & 70,86 & 619,21 & 89,46 & 3,99 & 55,09 & 232,34 & 28,04 & 28,04 & 223,41 \\
\hline Salamandra salamandra & $30 \mathrm{SUH} 44$ & 100,00 & 151,10 & 124,14 & 37,00 & 6935,14 & 348,41 & 16,70 & 331,71 & \begin{tabular}{l|l|}
79,95 \\
\end{tabular} & 244,71 & 244,71 & 67,39 & 613,34 & 87,64 & 4,10 & 53,95 & 227,34 & 29,66 & 29,66 & 218,34 \\
\hline Salamandra salamandra & $30 \mathrm{SUH} 45$ & 100,00 & 153,57 & 124,49 & 37,00 & 6930,52 & 350,69 & 18,71 & 331,98 & 82,64 & 247,05 & 247,05 & 69,74 & 587,65 & 83,48 & 4,00 & 53,46 & 215,42 & 28,93 & 28,93 & 206,93 \\
\hline Salamandra salamandra & $30 \mathrm{SUH} 47$ & 100,00 & 156,62 & 124,50 & 37,00 & 6912,72 & 352,90 & 21,42 & 331,48 & \begin{tabular}{|l|l|}
85,87 \\
\end{tabular} & 249,65 & 249,65 & 72,71 & 541,91 & 75,45 & 3,73 & 52,08 & \begin{tabular}{|c|}
193,57 \\
\end{tabular} & 28,44 & 28,44 & 186,43 \\
\hline Salamandra salamandra & 30 SUH50 & 100,00 & 175,19 & 119,49 & 37,00 & 6695,72 & 361,25 & 42,80 & 318,44 & 105,48 & 264,70 & 264,70 & 93,00 & 587,42 & 87,73 & 2,28 & 59,74 & 228,21 & 18,78 & 18,78 & 221,46 \\
\hline Salamandra salamandra & 30 UHH1 & 100,00 & 167,94 & 121,13 & 37,00 & 6800,02 & 358,36 & 34,78 & 323,58 & \begin{tabular}{|l|l|}
97,66 \\
\end{tabular} & 259,20 & 259,20 & 84,95 & 597,88 & 88,85 & 2,99 & 58,12 & 230,16 & 22,01 & 22,01 & 221,71 \\
\hline Salamandra salamandra & 30 SUH52 & 100,00 & 156,27 & 122,73 & 37,00 & 6888,54 & 350,98 & 22,63 & 328,35 & \begin{tabular}{l|l|}
85,45 \\
\end{tabular} & 249,04 & 249,04 & 72,88 & 619,82 & 90,50 & 3,96 & 55,71 & 235,00 & 27,16 & 27,16 & 225,29 \\
\hline Salamandra salamandra & 30SUH53 & 100,00 & 151,46 & 123,55 & 37,00 & 6923,90 & 347,84 & 17,35 & 330,49 & 80,16 & 244,83 & 244,83 & 67,78 & 620,32 & 89,50 & 4,44 & 54,35 & 232,18 & 29,65 & 29,65 & 222,21 \\
\hline Salamandra salamandra & 30 SUH54 & 100,00 & 150,88 & 123,99 & 37,00 & 6938,76 & 347,95 & 16,38 & 331,58 & 79,54 & 244,46 & 244,46 & 67,07 & 605,83 & 86,74 & 4,39 & 53,43 & 224,08 & 30,25 & 30,25 & 214,33 \\
\hline Salamandra salamandra & 30 SUH56 & 100,00 & 156,92 & 124,19 & 37,00 & 6927,64 & 353,20 & 21,55 & 331,65 & 85,8 & 250,18 & 250,18 & 72,80 & 550,41 & 77,53 & 3,89 & 52,44 & 198,71 & 28,34 & 28,34 & 190,68 \\
\hline Salamandra salamandra & 30SUH57 & 100,00 & \begin{tabular}{|l|l|}
151,04 \\
\end{tabular} & $\begin{array}{l}\mid 124,89 \\
124,89\end{array}$ & 37,00 & 6933,85 & 348,32 & 15,91 & 332,42 & $\begin{array}{l}8,00 \\
80,23 \\
\end{array}$ & 244,52 & 244,52 & 67,21 & 552,66 & 76,26 & 4, 434 & 50,95 & $\mid 195,91$ & 31,15 & 31,15 & 188,14 \\
\hline Salamandra salamandra & 30SUH61 & 100,00 & 168,19 & 119,91 & 36,98 & 6799,46 & 357,62 & 35,53 & 322,10 & 98,02 & 259,55 & 259,55 & 85,31 & 583,79 & 86,68 & 3,14 & 57,68 & 224,48 & 22,09 & 22,09 & 215,60 \\
\hline Salamandra salamandra & $30 \mathrm{SUH} 62$ & 100,00 & 159,36 & 121,62 & 36,99 & 6883,64 & 352,88 & 26,08 & 326,81 & 88,66 & 252,18 & 252,18 & 76,03 & 598,82 & 88,01 & 3,83 & 55,69 & 227,40 & 26,00 & 26,00 & 217,16 \\
\hline Salamandra salamandra & 30 UH 65 & 100,00 & 153,88 & 123,98 & 37,00 & 6938,73 & 350,60 & 19,02 & 331,58 & 82,97 & 247,51 & 247,51 & 69,97 & 568,39 & 80,88 & 4,03 & 52,71 & 207,44 & 29,00 & 29,00 & 198,00 \\
\hline Salamandra salamandra & 30 SUH66 & 100,00 & 147,75 & 124,62 & 37,00 & 6951,08 & 345,61 & 13,05 & 332,56 & 78,56 & 241,74 & 241,74 & 64,00 & 573,10 & 79,68 & 4,80 & 50,88 & 204,96 & 32,71 & 32,71 & 195,86 \\
\hline Salamandra salamandra & 30SUH69 & 100,00 & $\begin{array}{ll}44,1,55 \\
1485\end{array}$ & $\begin{array}{l}\mid 214,02 \\
125,02\end{array}$ & 37,00 & $\begin{array}{ll}6530,100 \\
693,00\end{array}$ & $\mid \begin{array}{l}\mid 34,01 \\
345,94\end{array}$ & $\begin{array}{l}13,03 \\
13,06\end{array}$ & 332,88 & $\begin{array}{r}110,30 \\
116,64\end{array}$ & 242,25 & 242,25 & 64,80 & $\mid 517,39$ & $\begin{array}{l}6,0,56 \\
68,5\end{array}$ & 4,400 & $\begin{array}{l}0,00 \\
48,32\end{array}$ & $\mid 179,27$ & 32,96 & 32,96 & $\begin{array}{l}15,00,88 \\
169 \\
\end{array}$ \\
\hline Salamandra salamandra & $30 \mathrm{SUH70}$ & 100,00 & 177,69 & 116,12 & 36,80 & 6647,14 & 359,74 & 47,10 & 312,63 & \begin{tabular}{|l|}
108,78 \\
\end{tabular} & 266,65 & 266,65 & 96,31 & 544,59 & 80,35 & 2,31 & 58,69 & 210,57 & 18,35 & 18,35 & 204,07 \\
\hline Salamandra salamandra & 30 UHH72 & 100,00 & 164,01 & 120,13 & 36,78 & 6853,19 & 355,20 & 31,22 & 323,98 & 93,39 & 256,33 & 256,33 & 80,81 & 571,80 & 84,39 & 3,52 & 55,76 & 217,34 & 24,27 & 24,27 & 207,05 \\
\hline Salamandra salamandra & 30SUH73 & 100,00 & 150,43 & 122,52 & 36,84 & 6938,53 & 346,58 & 16,95 & 329,64 & 79,37 & 244,26 & 244,26 & 66,90 & 603,05 & 87,12 & 4,85 & 53,18 & 224,50 & 30,80 & 30,80 & 213,05 \\
\hline Salamandra salamandra & 30 SUH74 & 100,00 & 151,78 & 123,02 & 37,00 & 6941,81 & 348,19 & 17,94 & 330,25 & 80,72 & 245,66 & 245,66 & 68,25 & 582,21 & 83,49 & 4,44 & 52,59 & 214,36 & 30,20 & 30,20 & 203,55 \\
\hline Salamandra salamandra & 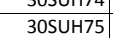 & $\begin{array}{l}100,00 \\
\end{array}$ & \begin{tabular}{|l|l|l|l|}
148,38 \\
\end{tabular} & \begin{tabular}{|l|l|l|l|l|l|}
123,98 \\
\end{tabular} & 37,00 & $\begin{array}{ll}634,1,4 \\
694,49\end{array}$ & $\mid \begin{array}{l}\mid \\
340,13\end{array}$ & $\mid \begin{array}{l}\mid l, 54 \\
14,17\end{array}$ & | & $\begin{array}{l}\frac{80,1 / 2}{81,12} \\
\end{array}$ & $\begin{array}{l}24,00 \\
242,28\end{array}$ & $\begin{array}{l}24,00 \\
242,28\end{array}$ & | 60,25 & | 50,21 & $\begin{array}{l}\mid 03,45 \\
81,45 \\
\end{array}$ & $\begin{array}{l}4,44) \\
4,75\end{array}$ & \begin{tabular}{|c|c|}
51,44 \\
51,5
\end{tabular} & \begin{tabular}{|l|l|}
209,36 \\
\end{tabular} & 32,20 & 32,20 & $\begin{array}{l}03,03 \\
198,97 \\
\end{array}$ \\
\hline Salamandra salamandra & 30 SUH76 & 100,00 & 141,94 & 124,88 & 37,00 & 6962,21 & 340,69 & 7,44 & 333,25 & 90,01 & 236,19 & 236,19 & 58,53 & 583,66 & 80,33 & 5,47 & 49,59 & 208,01 & 35,86 & 35,86 & 197,16 \\
\hline Salamandra salamandra & 30 SUH78 & 100,00 & 147,51 & 125,44 & 37,00 & 6943,53 & 345,35 & 11,86 & 333,49 & 101,89 & 241,28 & 241,28 & 63,78 & 527,11 & 70,51 & 4,52 & 48,64 & 184,42 & 33,20 & 33,20 & 174,00 \\
\hline Salamandra salamandra & $30 \mathrm{SUH} 83$ & 100,00 & 150,42 & 121,94 & 36,52 & 6952,54 & 346,31 & 17,11 & 329 & 79,19 & 244,50 & 244,50 & 66,77 & 593,26 & 85,86 & 4,9 & 52,75 & 220,49 & 31,11 & 31,11 & 208,25 \\
\hline Salamandra salamandra & $30 \mathrm{SUH} 84$ & 100,00 & 154,04 & 122,48 & 36,91 & 6943,70 & 349,56 & 20,06 & 329,49 & 83,92 & 247,77 & 247,77 & 70,27 & 563,59 & 80,97 & 4,26 & 52,42 & 207,25 & 29,19 & 29,19 & 196,12 \\
\hline Salamandra salamandra & 30 UH 85 & 100,00 & 141,49 & 124,08 & 37,00 & 6965,81 & 339,93 & 7,69 & 332,24 & 91,04 & 235,90 & 235,90 & 58,33 & 591,33 & 82,19 & 5,76 & 49,85 & 213,17 & 36,21 & 36,21 & 200,69 \\
\hline Salamandra salamandra & 30 SUH86 & 100,00 & 145,59 & 124,74 & 37,00 & 6964,43 & 343,72 & 10,73 & 332,99 & 98,61 & 239,85 & 239,85 & 61,92 & 559,53 & 77,06 & 5,04 & 49,66 & 200,49 & 33,95 & 33,95 & 188,22 \\
\hline Salamandra salamandra & 30SUH91 & 100,00 & 173,91 & 115,37 & 36,04 & 6737,19 & 357,76 & 43,66 & 314,10 & \begin{tabular}{|c|}
104,35 \\
\end{tabular} & 264,36 & 264,36 & 91,91 & 522,34 & 77,31 & 3,08 & 56,38 & 200,06 & 20,91 & 20,91 & 190,64 \\
\hline Salamandra salamandra & 30SUH94 & 100,00 & 155,04 & 1,73 & 36,89 & 27,27 & 99,65 & 21,51 & 328,14 & 100,29 & 248,67 & 248,67 & 71,53 & 549,85 & 78,94 & 4,31 & 52,02 & 202,57 & 29,14 & 29,14 & 190,15 \\
\hline Salamandra salamandra & 30SUH95 & 100,00 & $\mid 140,41$ & 03 & 37,00 & 6966,58 & 33 & \begin{tabular}{|c|c|}
6,78 \\
6
\end{tabular} & 332,16 & |92,296 & $\begin{array}{l}2435,03 \\
235\end{array}$ & 235,03 & 57,38 & 584,27 & 80,83 & 5,92 & 49,15 & 211,03 & 37,01 & 37,01 & 196,48 \\
\hline Salamandra salamandra & 30SUH97 & 100,00 & 146 & 9 & 37,00 & 6938,87 & 344,56 & 11,62 & 332,94 & 100, & 240,75 & 240,75 & 63,27 & 525,40 & 70,56 & 4,64 & 48,40 & 186,60 & 33,58 & 33,58 & 173,00 \\
\hline Salamandra salamandra & $\begin{array}{l}30 \text { SUJ07 } \\
\end{array}$ & 100,00 & 135,85 & 117,40 & 36,73 & 6696,52 & 323,94 & $\begin{array}{r}7,25 \\
7,25 \\
\end{array}$ & 316,69 & \begin{tabular}{|c|c|}
68,95 \\
\end{tabular} & 226,28 & 226,28 & $\begin{array}{l}55,45 \\
55,17\end{array}$ & 503,10 & 60,02 & 7,08 & 42,81 & 168,60 & 43,59 & 43,59 & 156,38 \\
\hline Salamandra salamandra & $305 \cup J 08$ & 100,00 & 137,04 & 82 & 36,70 & 6673,35 & 323,89 & 8,81 & 315,09 & 77,53 & 227,21 & 227,23 & 56,81 & 486,26 & 57,10 & 7,11 & 42,11 & 162,30 & 43,28 & 43,30 & 149,61 \\
\hline Salamandra salamandra & 30SUJ14 & 100,00 & 158,51 & 120,24 & 37,00 & 776,48 & 348,22 & 25,77 & 322,45 & 113,71 & 249,50 & 249,50 & 75,81 & 446,28 & 56,61 & $\begin{array}{l}4,03 \\
4\end{array}$ & $\begin{array}{ll}47,15 \\
4\end{array}$ & 153,15 & 30,48 & 30,48 & 143,51 \\
\hline Salamandra salamandra & 305 U 154 & 100,00 & \begin{tabular}{|l|l|}
156,77 \\
156,7
\end{tabular} & $\mid \begin{array}{l}\mid 219,24 \\
119,64\end{array}$ & $\begin{array}{l}3,0,98 \\
36,98\end{array}$ & 6758,22 & \begin{tabular}{|l|l|}
340,26 \\
345,78
\end{tabular} & 24,61 & $\begin{array}{l}32,45 \\
321,17\end{array}$ & $\begin{array}{l}1114,42 \\
11,42\end{array}$ & 247,55 & 247,35 & $\begin{array}{l}70,01 \\
74,36 \\
\end{array}$ & $\begin{array}{l}4449,20 \\
439,26\end{array}$ & $\begin{array}{l}50,01 \\
54,84\end{array}$ & $\begin{array}{l}4,253 \\
4,23\end{array}$ & $\begin{array}{l}41,15 \\
46,27 \\
\end{array}$ & $\begin{array}{l}\mid 3,1396 \\
149,96\end{array}$ & $\begin{array}{l}30,40 \\
31,43 \\
\end{array}$ & $\begin{array}{l}30,40 \\
31,43 \\
\end{array}$ & 139,35 \\
\hline Salamandra salamandra & $305 \mathrm{SU} 21$ & 100,00 & 150,90 & 122,81 & 37,00 & 6860,03 & 345,34 & 17,14 & 328,20 & 83,00 & 243,38 & 243,38 & 67,96 & 511,42 & 67,13 & 4,54 & 48,50 & 175,59 & 32,87 & 32,87 & 168,88 \\
\hline Salamandra salamandra & 30 SUJ26 & 100,00 & 152,32 & 119,27 & 36,81 & 6771,48 & 341,38 & 20,07 & 321,31 & 122,77 & 243,51 & 243,51 & 70,08 & 435,45 & 52,76 & 4,90 & 44,36 & 146,68 & 34,10 & 34,10 & 134,77 \\
\hline Salamandra salamandra & $305 \mathrm{~s} 31$ & 100,00 & 150,96 &, 14 & 37,00 & 6882,02 & 345 & 16,56 & 329 & 115 & 243 & 243,83 & 67,74 & 502,9 & 65,85 & 4, & 48,20 & 171,38 & 32,64 & 32,64 & 164,81 \\
\hline Salamandra salamandra & $30 \mathrm{su}$ & 100,00 & 15 & 120 & 37,00 & 05 & & $19, \varepsilon$ & 323, & 133 & 244 & 244 & 70 & 439 & 53,72 & 4,6 & 44,76 & 148,41 & 33,46 & 33,46 & 136,42 \\
\hline Salamandra salamandra & $305 \mathrm{U} 33$ & 100,00 & 131,12 & 117,91 & 36,48 & 6727,14 & 319,99 & 1,57 & 318,42 & 114,04 & 222,45 & 222,45 & 50,72 & 480,95 & 55,18 & 8,10 & 40,09 & $\begin{array}{l}\mid 400,68 \\
160,68\end{array}$ & 46,89 & 46,89 & 141,54 \\
\hline Salamandra salamandra & $30 \mathrm{suJ} 43$ & 100,00 & 145,44 & 122,64 & 37,00 & 6874,67 & 339,72 & 11,30 & 328,42 & 128,48 & 238,21 & 238,21 & 62,43 & 485,61 & 60,68 & 5,23 & 45,29 & 165,68 & 36,31 & 36,31 & 152,99 \\
\hline Salamandra salamandra & $305 \cup J 44$ & 100,00 & 150,27 & 121,69 & 37,00 & 6850,13 & 342,60 & 16,21 & 326,39 & 133,96 & 242,56 & 242,56 & 67,19 & 455,08 & 56,06 & 4,84 & 45,04 & 154,78 & 34,32 & 34,32 & 141,87 \\
\hline Salamandra salamandra & $3050 J 46$ & 100,00 & 年 & 121,0 & 36,91 & 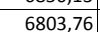 & 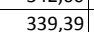 & 16,32 & 323,06 & 133,49 & 241,15 & 241,15 & 66,78 & 431,73 & & 5,34 & 43,24 & 146,16 & 35,74 & 35,74 & 130,47 \\
\hline Salamandra salamandra & 3054347 & 100 & & & 36, & 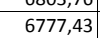 & & \begin{tabular}{|c|}
7,78 \\
7,52
\end{tabular} & 321,14 & 122 & 231,06 & 231,06 & 57, & 456,81 & 52,81 & 6,8 & 41,34 & 153,92 & 41,97 & 41,97 & 135 \\
\hline Salamandra salamandra & $305 \mathrm{UJ} 48$ & 100,00 & 128,70 & 118,21 & 36,60 & 6735,84 & 318,01 & $-0,92$ & 318,93 & 111,44 & 220,25 & 220,25 & 48,31 & 482,80 & 55,92 & 8,52 & 39,42 & 161,99 & 48,59 & 48,59 & 140,19 \\
\hline Salamandra salamandra & $305 \cup u 49$ & 100,00 & 140,21 & 117,42 & 36,08 & 6738,94 & 327,38 & 9,10 & 318,27 & 124,44 & 231,39 & 231,39 & 58,99 & 427,31 & 49,60 & 6,98 & 39,94 & 142,94 & 41,89 & 41,89 & 123,03 \\
\hline Salamandra salamandra & $305 \cup J 50$ & 100,00 & 148,90 & 124,47 & 37,00 & 6917,34 & 345,44 & 13,79 & 331,64 & 128,63 & 242,25 & 242,25 & 65,34 & 509,58 & 66,83 & 4,47 & 47,94 & 175,40 & 33,10 & 33,10 & 166,39 \\
\hline Salaman & $305 \cup J 52$ & 100, & & & 37,0 & 6888, & & 12,5 & 329, & 130 & 240 & 240 & 64 & 482 & & 4, & 45,89 & 165 & 34,88 & 34,88 & 153,01 \\
\hline Salamandra salamandra & 3050357 & 100,00 & \begin{tabular}{|l|l|l|}
132,87 \\
\end{tabular} & \begin{tabular}{|l|l}
119,36 \\
\end{tabular} & 36,71 & 60 & \begin{tabular}{|l|l|l|}
323,47 \\
\end{tabular} & $\mid$ & 321,84 & 115,81 & $\begin{array}{l}24, r 3 \\
224,95\end{array}$ & $\begin{array}{l}24,1 \\
224,97\end{array}$ & 51,61 & $\mid$ & 54,74 & 7,79 & 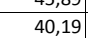 & \begin{tabular}{|l}
160,11 \\
\end{tabular} & $\begin{array}{r}4,00 \\
46,02\end{array}$ & $\begin{array}{r}4,00 \\
46,03\end{array}$ & $\begin{array}{l}138,46 \\
\end{array}$ \\
\hline
\end{tabular}




\begin{tabular}{|c|c|c|c|c|c|c|c|c|c|c|c|c|c|c|c|c|c|c|c|c|c|}
\hline TAXON & UTM & $\mathrm{km} 2$ & BIO1 & $\mathrm{B1O2}$ & $\mathrm{BIO3}$ & 8104 & B105 & B106 & B107 & B108 & B109 & BIO10 & B1011 & BIO12 & B1013 & B1014 & 81015 & B1016 & BIO17 & B1018 & BIO19 \\
\hline Salamandra salamandra & 30SUJ58 & 100,00 & 131,10 & 118,38 & 36,48 & 6761,15 & 320,51 & 0,67 & 319,85 & 114,06 & 222,93 & 222,93 & 50,26 & 467,69 & 54,66 & 8,25 & 39,29 & 157,42 & 47,50 & 47,50 & 134,38 \\
\hline Salamandra salamandra & 3050159 & 100,00 & 139,33 & 117,47 & 36,02 & 6758,71 & 326,81 & 7,85 & 318,96 & 123,33 & 230,97 & 230,97 & 57,93 & 426,18 & 49,96 & 7,13 & 39,41 & 142,91 & 42,85 & 42,85 & 121,35 \\
\hline Salamandra salamandra & 3050362 & 100,00 & $\mid 149,63$ & 123,97 & 37,00 & 6899,46 & 344,74 & 14,23 & 330,51 & $\begin{array}{l}\mid 133,09 \\
\end{array}$ & 242,72 & 242,72 & 66,02 & 467,27 & 58,39 & 4,57 & 45,74t| & 161,13 & 33,77 & 33,77 & 147,07 \\
\hline Salamandra salamandra & 30 SUJ63 & 100,00 & 145,25 & 123,52 & 37,00 & 6890,92 & 340,28 & 10,49 & \begin{tabular}{|c|}
329,79 \\
\end{tabular} & 128,27 & 238,45 & 238,45 & 62,09 & 469,25 & 57,34 & 5,25 & 44,38 & 161,49 & 36,57 & 36,57 & 145,12 \\
\hline Salamandra salamandra & 30 SUJ64 & 100,00 & 145,08 & 122,74 & 37,00 & 6870,34 & 338,94 & 10,49 & $\begin{array}{l}328,45 \\
\end{array}$ & \begin{tabular}{|l|}
128,49 \\
\end{tabular} & 238,01 & 238,01 & 62,12 & 457,61 & 54,77 & 5,32 & 43,57 & 157,08 & 37,04 & 37,04 & 139,56 \\
\hline Salamandra salamandra & 30 SUJ65 & 100,00 & 141,45 & 121,91 & 36,99 & 6863,46 & 334,63 & 7,48 & 327,16 & 124,84 & 234,37 & 234,37 & 58,69 & 459,14 & 53,75 & 5,96 & 42,35 & 157,07 & 39,61 & 39,61 & 137,65 \\
\hline Salamandra salamandra & 305UJ66 & 100,00 & 138,87 & 120,82 & 36,84 & 6853,41 & 330,98 & 5,46 & 325,52 & 122,02 & 231,64 & 231,64 & 56,39 & 456,53 & 52,59 & 6,61 & 41,24 & 155,54 & 41,78 & 41,78 & 134,68 \\
\hline Salamandra salamandra & 30SUJ67 & 100,00 & 133,27 & 119,57 & 36,55 & 6810,94 & 324,28 & 1,23 & 323,05 & 116,30 & 225,70 & 225,72 & 51,75 & 467,28 & 54,22 & 7,76 & 39,82 & 158,18 & 45,99 & 46,01 & 135,44 \\
\hline Salamandra salamandra & 30 SUJ68 & 100,00 & 127,92 & 118,44 & 36,46 & 6771,95 & 317,75 & $-2,49$ & 320,25 & \begin{tabular}{|l|}
110,53 \\
\end{tabular} & 220,03 & 220,03 & 47,24 & 475,21 & 56,03 & 8,85 & 38,49 & 160,12 & 49,94 & 49,94 & 135,27 \\
\hline Salamandra salamandra & $30 \mathrm{SUJ72}$ & 100,00 & 144,93 & 124,86 & 37,00 & 6910,35 & 341,01 & 9,19 & 331,82 & \begin{tabular}{ll|}
128,45 \\
\end{tabular} & 238,29 & 238,29 & 61,42 & 474,52 & 58,32 & 4,97 & 44,83 & 164,41 & 36,07 & 36,07 & 147,54 \\
\hline Salamandra salamandra & $30 \mathrm{suJ73}$ & 100,00 & 140,36 & 124,17 & 37,00 & 6901,19 & 336,28 & 5,26 & 331,02 & 123,41 & 233,78 & 233,78 & 57,29 & 478,84 & 57,47 & 5,66 & 43,40 & 165,37 & 39,18 & 39,18 & 146,33 \\
\hline Salamandra salamandra & $305 \cup J 74$ & 100,00 & 143,51 & 123,26 & 37,00 & 6884,85 & 337,84 & 8,47 & 329,36 & 126,77 & 236,64 & 236,64 & 60,49 & 455,14 & 53,60 & 5,38 & 42,92 & 156,66 & 37,91 & 37,91 & 137,36 \\
\hline Salamandra salamandra & 30 SUJ75 & 100,00 & 140,25 & 122,33 & 37,00 & 6876,04 & 333,81 & 5,96 & $\begin{array}{l}327,85 \\
\end{array}$ & 123,67 & 233,36 & 233,36 & 57,40 & 456,66 & 52,75 & 6,19 & 41,78 & 156,56 & 40,66 & 40,66 & 135,52 \\
\hline Salamandra salamandra & 30 SUJ76 & 100,00 & 131,62 & 121,11 & 36,99 & 6845,36 & 324,71 & $-0,64$ & 325,36 & 114,22 & 224,64 & 224,64 & 49,95 & 478,72 & 55,45 & 7,72 & 40,05 & 163,20 & 46,50 & 46,50 & 139,57 \\
\hline Salamandra salamandra & 30SUJ77 & 100,00 & 129,08 & 119,84 & 36,69 & 6811,62 & 320,59 & $-2,58$ & 323,17 & \begin{tabular}{|c|}
111,64 \\
\end{tabular} & 221,71 & 221,73 & 47,82 & 479,38 & 56,10 & 8,50 & 38,99 & 162,42 & 49,09 & 49,11 & 137,63 \\
\hline Salamandra salamandra & $30 \mathrm{SUJ78}$ & 100,00 & 129,47 & 118,53 & 36,27 & 6797,85 & 319,50 & $-1,77$ & 321,27 & 112,44 & 221,84 & 221,86 & 48,38 & 467,19 & 55,19 & 8,76 & 38,21 & 157,42 & 49,51 & 49,52 & 132,25 \\
\hline Salamandra salamandra & $305 \mathrm{U} 382$ & 100,00 & 142,16 & 125,58 & 37,00 & 6902,37 & 338,97 & 6,55 & 332,42 & 125,21 & 235,64 & 235,64 & 59,16 & 475,08 & 57,40 & 5,16 & 44,01 & 165,12 & 37,56 & 37,56 & 146,14 \\
\hline Salamandra salamandra & $305 U J 85$ & 100,00 & 139,86 & 122,68 & 37,00 & 6883,90 & 333,48 & 5,15 & \begin{tabular}{|c|}
328,33 \\
\end{tabular} & 123,22 & 233,10 & 233,10 & 57,01 & 452,03 & 52,22 & 6,18 & 41,36 & 154,99 & 41,14 & 41,14 & 133,15 \\
\hline Salamandra salamandra & 305UנJ87 & 100,00 & 128,53 & 120,22 & 36,90 & 6825,34 & 320,44 & $-3,11$ & 323,55 & 111,06 & 221,42 & 221,42 & 47,25 & 476,95 & 56,08 & 8,54 & 38,63 & 161,68 & 49,58 & 49,58 & 136,07 \\
\hline Salamandra salamandra & 30SUJ92 & 100,00 & 146,89 & 126,23 & 37,28 & 6888,05 & 342,90 & 10,26 & 332,64 & 130,50 & 239,83 & 239,83 & 63,38 & 447,19 & 53,12 & 4,36 & 44,15 & 155,79 & 34,83 & 34,83 & 136,70 \\
\hline Salamandra salamandra & $30 S U K 40$ & 100,00 & 146,53 & 116,44 & 36,23 & 6706,19 & 331,25 & 15,48 & 315,77 & 129,94 & 236,95 & 236,95 & 65,07 & 397,08 & 46,01 & 6,48 & 39,79 & 131,86 & 39,04 & 39,04 & 113,41 \\
\hline Salamandra salamandra & 30 SVFO99 & 100,00 & $\begin{array}{l}\mid 140,95 \\
136,99 \\
\end{array}$ & 115,65 & 38,00 & 6143,62 & 311,83 & $\begin{array}{l}2,4,0 \\
11,90\end{array}$ & 299,92 & 72,73 & 220,46 & 220,46 & 64,20 & 596,54 & 80,01 & 6,42 & 55,62 & 238,08 & 29,95 & 29,95 & 229,69 \\
\hline Salamandra salamandra & 30 SVG97 & 100,00 & 154,25 & 113,49 & 36,99 & 6438,83 & 330,70 & 26,98 & 303,72 & 107,68 & 240,95 & 241,14 & 77,26 & 434,65 & 55,14 & 5,55 & 46,94 & 154,05 & 29,32 & 33,38 & 142,86 \\
\hline Salamandra salamandra & 30SVG98 & 100,00 & 138,54 & 117,48 & 37,01 & 6605,31 & 323,07 & 9,57 & 313,50 & 90,52 & 227,97 & 228,16 & 60,40 & 507,78 & 64,38 & 8,58 & 44,35 & 179,71 & 41,02 & 43,36 & 161,53 \\
\hline Salamandra salamandra & 30SVG99 & 100,00 & 148,60 & 115,92 & 37,00 & 6562,74 & 329,82 & 20,00 & 309,82 & 101,51 & 237,17 & 237,29 & 70,40 & 463,21 & 59,05 & 6,64 & 45,31 & 164,47 & 34,75 & 36,81 & 148,06 \\
\hline Salamandra salamandra & 30 SVHO1 & 100,00 & 173,25 & 114,34 & 36,00 & 6739,98 & 356,56 & 43,78 & \begin{tabular}{|l|l|}
312,78 \\
\end{tabular} & 103,74 & 263,86 & 263,86 & 91,44 & 511,77 & 75,83 & 3,23 & 55,60 & 195,58 & 21,62 & 21,62 & 185,27 \\
\hline Salamandra salamandra & 30SVHO2 & 100,00 & $\mid \begin{array}{l}\mid 7,25,13 \\
166,13\end{array}$ & $\mid \begin{array}{l}\mid 114,549 \\
116,79\end{array}$ & 36,00 & 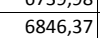 & | 350,40 & 35 & 319,33 & $\begin{array}{r}96,14 \\
96,84\end{array}$ & 258,00 & 258,00 & 83,31 & 530,30 & $\begin{array}{l}70,003 \\
78,73\end{array}$ & 3,62 & 54,44 & $\mid$ & $\begin{array}{l}21,02 \\
24,27\end{array}$ & 24,27 & $\begin{array}{l}\mid 103,26 \\
188,86 \\
\end{array}$ \\
\hline Salamandra salamandra & $30 \mathrm{SVHO4}$ & 100,00 & 152,67 & 121,54 & 36,70 & 6943,12 & 347,59 & 19,47 & 328,12 & \begin{tabular}{|l|l|}
105,63 \\
\end{tabular} & 246,53 & 246,53 & 69,13 & 547,43 & 78,34 & 4,60 & 51,14 & 202,35 & 30,55 & 30,55 & 187,44 \\
\hline Salamandra salamandra & 30SVH05 & 100,00 & $\mid 144,87$ & 123,50 & 37,00 & 6956,21 & 342,06 & $\begin{array}{l}\mid 1,4,07 \\
11,\end{array}$ & 330,99 & $\begin{array}{r}97,66 \\
97\end{array}$ & 239,15 & 239,15 & 61,62 & 557,74 & 77,28 & 5,44 & 49,29 & 202,56 & 34,99 & 34,99 & 186,84 \\
\hline Salamandra salamandra & 30SVHO6 & 100,00 & 152,24 & 123,95 & 37,00 & 6927,25 & 348,01 & 17,46 & 330,55 & 105,68 & 245,73 & 245,73 & 68,59 & 511,84 & 70,05 & 4,21 & 49,41 & 184,61 & 30,80 & 30,80 & 170,22 \\
\hline Salamandra salamandra & 30 SVHO7 & 100,00 & 145,28 & 125,58 & 37,04 & 6933,85 & 342,96 & 10,19 & 332,77 & 98,85 & 239,11 & 239,11 & 61,93 & 519,53 & 68,96 & 4,83 & 47,56 & 184,41 & 34,67 & 34,67 & 169,24 \\
\hline Salamandra salamandra & $\begin{array}{l}\text { SOSVHO8 } \\
30 \mathrm{NHO}\end{array}$ & $\begin{array}{l}100,00 \\
\end{array}$ & \begin{tabular}{|l|}
$\mid$ \\
146,208 \\
\end{tabular} & $\mid \begin{array}{l}\mid 26,30 \\
126,35\end{array}$ & 37,34 & $\begin{array}{l}\mid 6930,03 \\
6917,47\end{array}$ & \begin{tabular}{|l|}
344,27 \\
344,27
\end{tabular} & $\frac{10,13}{10,82}$ & 333,44 & 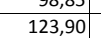 & 240,12 & 2424,12 & $\begin{array}{l}\mid 01,70 \\
63,49\end{array}$ & \begin{tabular}{|c|}
495,58 \\
495
\end{tabular} & $\begin{array}{ll}60,12 \\
64,12\end{array}$ & $4,4,31$ & $\begin{array}{l}4 r, 30 \\
46,88\end{array}$ & \begin{tabular}{|l|}
1704,41 \\
175,07
\end{tabular} & 34,86 & 34,86 & \begin{tabular}{|l|l|}
159,05 \\
159
\end{tabular} \\
\hline Salamandra salamandra & 30SVH11 & 100,00 & 173,27 & 113,34 & 36,00 & 6740,93 & 355,86 & 44,18 & 311,68 & 103,58 & 263,83 & 263,83 & 91,41 & 500,60 & 74,46 & 3,27 & 55,22 & 191,21 & 21,66 & 21,66 & 180,09 \\
\hline Salamandra salamandra & 30SVH12 & 100,00 & 165,95 & 116,11 & 36,00 & 6846,00 & 353,68 & 35,44 & 318,24 & 105,58 & 258,18 & 258,18 & 83,22 & 519,72 & 77,25 & 3,74 & 53,92 & 197,10 & 24,62 & 24,62 & 183,63 \\
\hline Salamandra salamandra & 30SVH13 & 100,00 & & & 36,0 & 6870,86 & 352,93 & 31, & 321,22 & 115,03 & 255,89 & 255,89 & 80,25 & 515,05 & 75,36 & 3,7 & 52,7 & 193,19 & 25,86 & 25,86 & 179,25 \\
\hline Salamandra salamandra & 30SVH14 & 100,00 & 157,62 & 120,27 & 36,56 & 6901,44 & 350,06 & 24,96 & 325,10 & 110,93 & 250,79 & 250,79 & 74,49 & 518,31 & 74,11 & 4,22 & 51,24 & 192,18 & 28,63 & 28,63 & 176,88 \\
\hline Salamandra salamandra & 30 SVH15 & 100,00 & 155,79 & 121,83 & 36,99 & 6898,91 & 349,23 & 22,23 & 327,01 & 109,29 & 248,88 & 248,88 & 72,53 & 506,77 & 70,68 & 4,16 & 50,15 & 185,38 & 29,49 & 29,49 & 170,10 \\
\hline Salamandra salamandra & 30SVH16 & 100,00 & 151,04 & 123,69 & 37,00 & 6916,59 & 346,40 & 16,60 & 329,79 & 104,47 & 244,47 & 244,47 & 67,67 & 505,62 & 68,55 & 4,41 & 48,62 & 182,34 & 31,85 & 31,85 & 166,40 \\
\hline Salamandra salamandra & $30 \mathrm{SVH} 24$ & 100,00 & 155,16 & 120,19 & 36,47 & 6904,58 & 347,68 & 22,64 & 325,04 & 108,23 & 248,43 & 248,43 & 72,14 & 515,62 & 73,10 & 4,60 & 50,27 & 191,16 & 30,13 & 30,13 & 173,88 \\
\hline Salamandra salamandra & $30 \mathrm{SVH} 25$ & 100,00 & 145,86 & 79 & 36,97 & 229,03 & 341,56 & 12,40 & 329,17 & 98,79 & 239,69 & 239,69 & 62,92 & 532,36 & 72,99 & 5,53 & 48,12 & 193,73 & 35,29 & 35,29 & 175,10 \\
\hline Salamandra salamandra & 30 SVH26 & 100,00 & 29 & 54 & 37,00 & 6905,60 & 344,42 & $\begin{array}{l}15,08 \\
15,08\end{array}$ & 329,34 & \begin{tabular}{|c|}
102,72 \\
\end{tabular} & 242,76 & 242,76 & 66,32 & 502,27 & 67,41 & 4,82 & 47,70 & 180,86 & 33,34 & 33,34 & 163,47 \\
\hline Salamandra salamandra & $30 \mathrm{SVH} 33$ & 100,00 & 16 & 11 & 36,00 & 6826,59 & 351,34 & 33,03 & 318,31 & 117,36 & 255,90 & 255,90 & \begin{tabular}{|c|}
81,46 \\
\end{tabular} & 484,88 & 69,84 & 3,89 & 51,35 & 181,73 & 26,11 & 26,11 & 165,59 \\
\hline Salamandra salamandra & 30SVH34 & 100,00 & 153,79 & 120,08 & 36,59 & 6892,22 & 345,85 & 21,45 & 324,40 & 106,64 & 246,91 & 246,91 & $\begin{array}{ll}71,05 \\
71,05 \\
\end{array}$ & $\begin{array}{l}408,60 \\
508,68\end{array}$ & 71,43 & 4,85 & 49,44 & 188,17 & 31,19 & $\begin{array}{l}20,119 \\
31,19 \\
\end{array}$ & 169,55 \\
\hline Salamandra salamandra & $30 \mathrm{SVH} 35$ & 100,00 & 140,37 & 123,03 & 37,00 & 6930,83 & 336,74 & 7,07 & 329,67 & 92,90 & 234,50 & 234,50 & 57,87 & 542,59 & 73,30 & 6,44 & 46,68 & 196,41 & 38,99 & 38,99 & 175,76 \\
\hline Salamandra salamandra & $30 \mathrm{SVH} 36$ & 100,00 & 147,72 & 123,40 & 37,00 & 6898,34 & 342,58 & 13,64 & 328,94 & 101,11 & 241,08 & 241,08 & 64,94 & 497,93 & 66,21 & 5,07 & 46,86 & 178,98 & 34,49 & 34,49 & 160,34 \\
\hline Salamandra salamandra & $30 \mathrm{SVH} 43$ & 100,00 & 33 & $\begin{array}{l}123,40,73 \\
116,1\end{array}$ & 36,05 & 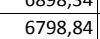 & | & $\begin{array}{l}3,04 \\
32,62\end{array}$ & 317,29 & \begin{tabular}{l|l}
116,79 \\
\end{tabular} & $\begin{array}{l}24,00 \\
254,96\end{array}$ & $\begin{array}{l}24,00 \\
254,96 \\
\end{array}$ & 81,34 & $\begin{array}{l}471,24 \\
471,53\end{array}$ & $\begin{array}{l}\mid c 0,11 \\
66,79 \\
\end{array}$ & $\begin{array}{l}3,0103 \\
4,03\end{array}$ & $\begin{array}{l}40,00 \\
50,53\end{array}$ & $\begin{array}{l}177,30 \\
175,58\end{array}$ & 26,70 & $\begin{array}{l}34,45 \\
26,70\end{array}$ & 158,586 \\
\hline Salamandra salamandra & 30 SVH44 & 100,00 & 148,33 & 120,66 & 36,76 & 6890,83 & 341,28 & 15,92 & 325,37 & 100,84 & 241,58 & 241,58 & 65,94 & 515,72 & 70,99 & 5,67 & 47,88 & 189,17 & 34,67 & 34,67 & 168,88 \\
\hline Salamandra salamandra & 30 SVH45 & 100,00 & 135,75 & 123,29 & 37,00 & 6915,99 & 332,29 & 3,01 & 329,29 & 87,90 & 229,84 & 229,84 & 53,68 & 550,14 & 72,97 & 7,40 & 45,32 & 197,48 & 42,56 & 42,56 & 175,34 \\
\hline Salamandra salamandra & 30 SVH53 & 100,00 & 16 & 1 & 36,2 & 6752,17 & 348,31 & 32, & 315,69 & 116 & 254 & 250 & & 455,50 & 63,27 & 4,6 & 49,4 & 168,26 & 26,90 & 26,90 & 151,61 \\
\hline Salamandra salamandra & 30 SVH54 & 100,00 & 15 & & 36 & 6830 & & 20 & 322 & 105,50 & 244 & 24 & 70 & 485 & 65,96 & 5, & 47 & 177,26 & 32,77 & 32,77 & 157,69 \\
\hline Salamandra salamandra & 30SVH64 & 100,00 & 154,19 & 119,16 & 36,95 & 6780,69 & 342,24 & 22,47 & 319,76 & 107,34 & 245,70 & 245,70 & 72,69 & 464,67 & 61,84 & 5,05 & 46,69 & 168,01 & 32,31 & 32,31 & 148,91 \\
\hline Salamandra salamandra & 30 SVH65 & 100,00 & 145,01 & 121,56 & 37,00 & 6830,51 & 336,83 & 12,36 & 324,47 & 98,63 & 237,55 & 237,55 & 63,40 & 490,13 & 63,78 & 6,22 & 44,91 & 175,06 & 37,89 & 37,89 & 153,67 \\
\hline Salamandra salamandra & 30SVH73 & 100,00 & 158,57 & 117,19 & 36,92 & 6693,90 & 342,66 & 27,94 & 314,72 & \begin{tabular}{|c|}
112,08 \\
\end{tabular} & 248,70 & 248,70 & 78,07 & 440,84 & 58,22 & 4,71 & 46,95 & 159,03 & 29,90 & 29,90 & 141,52 \\
\hline Salamandra salamandra & 30 SVH74 & 100,00 & בוס & & 37,00 & (2), & 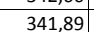 & 24,83 & 317,06 & 109,79 & 246,80 & 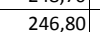 & 75,59 & 442 & 57,42 & 4,87 & 45,5 & 158,07 & 31,52 & 31,52 & 139,85 \\
\hline Salamandra salamandra & $30 \mathrm{SVt}$ & & & 12 & & & & 15,63 & 321,74 & 110,62 & 239,64 & 239,64 & 66,96 & 466,38 & 59,56 & 5, & 44 & 165,41 & 36,67 & 36,67 & 144 \\
\hline Salamandra salamandra & 30SVH76 & 100,00 & $\begin{array}{ll}142,16 \\
\end{array}$ & 122,42 & 37,00 & 6812,50 & 333,83 & 9 & 324,76 & 123,00 & 234,41 & 234,41 & 60,91 & 480,67 & 60,20 & 6,83 & 42,80 & 170,17 & 40,83 & 40,83 & 146,37 \\
\hline Salamandra salamandra & 30 SVH84 & 100,00 & 151,55 & 119,32 & 37,00 & 6704,51 & 337,58 & 19,89 & 317,69 & 108,82 & 241,97 & 241,97 & 71,14 & 447,91 & 56,74 & 5,63 & 44,35 & 158,38 & 34,87 & 34,87 & 138,63 \\
\hline Salamandra salamandra & 30 SVH 85 & 100,00 & 146,29 & 120,92 & 37,01 & 6742,36 & 334,64 & 13,91 & 320,72 & 123,55 & 237,31 & 237,31 & 65,56 & 461,99 & 57,69 & 6,39 & 43,18 & 163,03 & 38,59 & 38,59 & 140,59 \\
\hline Salam & $30 \mathrm{SVH}$ & 100, & & 121, & 37, & 70 & & 11,4 & 3100 & 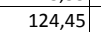 & 234 & & 63,41 & 460 & 57,2 & 6,8 & 41, & 162,34 & 40,95 & 40,95 & 13 \\
\hline Salamandra salamandra & 30SVH97 & 100,00 & \begin{tabular}{|l|}
139,67 \\
\end{tabular} & $\mid \begin{array}{l}\mid 21,02 \\
122,69\end{array}$ & 37,56 & 6736,95 & 329,12 & \begin{tabular}{|c|c|}
6,52 \\
6,52
\end{tabular} & $\mid$ & 120,83 & 230,82 & 230,82 & $\begin{array}{l}\mid \\
59,4,15\end{array}$ & 4065,53 & 57,73 & $\frac{0,000}{7,51}$ & $\mid$ & $\begin{array}{l}163,32 \\
\end{array}$ & \begin{tabular}{|l|l|}
44,75 \\
4
\end{tabular} & \begin{tabular}{|l|l|}
44,75 \\
4
\end{tabular} & $\begin{array}{l}135,38 \\
\end{array}$ \\
\hline
\end{tabular}




\begin{tabular}{|c|c|c|c|c|c|c|c|c|c|c|c|c|c|c|c|c|c|c|c|c|c|}
\hline TAXON & UTM & $\mathrm{km} 2$ & BIO1 & $\mathrm{B1O2}$ & $\mathrm{BIO3}$ & 8104 & B105 & B106 & B107 & B108 & B109 & BIO10 & B1011 & BIO12 & B1013 & B1014 & 81015 & B1016 & BIO17 & B1018 & B1019 \\
\hline Salamandra salamandra & 30svJ06 & 100,00 & 129,19 & 121,97 & 37,00 & 6851,31 & 322,54 & $-3,91$ & 326,45 & 111,79 & 222,27 & 222,27 & 47,47 & 477,10 & 55,90 & 8,28 & 38,71 & 162,20 & 49,38 & 49,38 & 136,52 \\
\hline Salamandra salamandra & $30 \mathrm{SV} J 08$ & 100,00 & 128,99 & 118,95 & 36,32 & 6836,28 & 319,54 & $-2,78$ & 322,32 & 111,71 & 221,98 & 222,00 & 47,55 & 465,26 & 54,82 & 9,07 & 37,28 & 155,83 & 51,08 & 51,10 & 130,69 \\
\hline Salamandra salamandra & 30SWG08 & 100,00 & 114,83 & 120,64 & 37,04 & 6665,08 & 304,94 & $-14,35$ & 319,29 & |66,73 & 205,73 & 205,99 & 37,30 & 607,25 & $\begin{array}{l}74,562 \\
759\end{array}$ & 14,07 & 39,93 & 210,27 & 61,06 & 63,95 & 184,67 \\
\hline Salamandra salamandra & 30SWG09 & 100,00 & 121,09 & 120,41 & 37,09 & 6669,44 & 310,41 & $-8,41$ & 318,82 & 79,84 & 211,79 & 212,10 & 43,19 & 574,48 & 71,75 & 12,40 & 40,50 & 199,80 & 56,02 & 58,31 & 174,50 \\
\hline Salamandra salamandra & 30 SWG24 & 100,00 & \begin{tabular}{|l|l|}
141,87 \\
\end{tabular} & 112,34 & 37,29 & 6229,59 & 312,96 & 16,88 & 296,08 & \begin{tabular}{|c|}
95,09 \\
\end{tabular} & 225,51 & 226,74 & 68,09 & 441,81 & 55,15 & 7,41 & 43,24 & 150,25 & 35,69 & 42,24 & 140,01 \\
\hline Salamandra salamandra & 30SWG28 & 100,00 & 130,69 & 117,71 & 37,32 & 6494,73 & 312,40 & 2,30 & 310,10 & 107,79 & 218,55 & 219,21 & 54,36 & 504,53 & 64,02 & 10,30 & 40,24 & \begin{tabular}{ll|}
173,95 \\
\end{tabular} & 48,59 & 52,84 & 151,06 \\
\hline Salamandra salamandra & 30SWG29 & 100,00 & 110,30 & 120,44 & 37,52 & 6619,50 & 298,79 & $-18,26$ & 317,05 & 87,32 & 200,58 & 201,02 & 33,63 & 610,67 & 77,00 & 16,02 & 37,12 & 210,14 & 68,94 & 70,97 & 177,13 \\
\hline Salamandra salamandra & 30SWG49 & 100,00 & 122,95 & 118,41 & 37,96 & 6475,62 & 304,59 & $-5,06$ & 309,65 & \begin{tabular}{|l|l|}
100,98 \\
\end{tabular} & 210,68 & 211,39 & 47,27 & 526,21 & 67,58 & 12,72 & 37,10 & 180,48 & 58,56 & 61,17 & 149,34 \\
\hline Salamandra salamandra & 30 SWHOO & 100,00 & 135,70 & 118,81 & 37,07 & 6620,45 & 321,12 & 5,99 & 315,12 & $\begin{array}{l}97,55 \\
\end{array}$ & 225,36 & 225,55 & 57,45 & 503,33 & 63,04 & 9,04 & 42,12 & 176,09 & 44,77 & 46,68 & 153,98 \\
\hline Salamandra salamandra & 30SWH01 & 100,00 & 131,25 & 119,80 & 37,08 & 6658,89 & 318,57 & 1,16 & 317,42 & $\begin{array}{ll}100,95 \\
\end{array}$ & 221,56 & 221,69 & 52,66 & 522,87 & 65,45 & 10,09 & 41,08 & 182,81 & 49,46 & 50,68 & 157,44 \\
\hline Salamandra salamandra & 30SWHO2 & 100,00 & 144,42 & 118,63 & 37,09 & 6611,24 & 328,17 & 14,06 & 314,11 & 115,59 & 233,70 & 233,81 & 65,58 & 459,73 & 57,65 & 7,20 & 42,47 & 160,87 & 39,82 & 40,88 & 139,07 \\
\hline Salamandra salamandra & 30SWH06 & 100,00 & 138,07 & 121,96 & 37,75 & 6697,72 & 326,27 & 5,68 & 320,59 & 118,73 & 228,64 & 228,64 & 58,33 & 468,66 & 58,71 & 8,10 & 39,86 & 164,30 & 46,44 & 46,44 & 135,13 \\
\hline Salamandra salamandra & 30 SWH10 & 100,00 & 119,81 & 120,31 & 37,38 & 6638,95 & 308,01 & $-9,60$ & 317,61 & $\begin{array}{ll}94,93 \\
\end{array}$ & 210,08 & 210,42 & 42,17 & 569,87 & 71,55 & 13,20 & 38,99 & 197,38 & 59,80 & 61,74 & 168,19 \\
\hline Salamandra salamandra & 30SWH11 & 100,00 & 134,09 & 119,02 & 37,29 & 6587,66 & 318,37 & 4,40 & 313,97 & \begin{tabular}{|l|l|}
111,43 \\
\end{tabular} & 223,24 & 223,42 & 56,20 & 498,22 & 62,81 & 9,64 & 40,51 & 173,14 & 48,17 & 50,10 & 147,80 \\
\hline Salamandra salamandra & 30SWH12 & 100,00 & 134,78 & 119,67 & 37,38 & 6609,19 & 319,85 & 4,54 & 315,31 & 114,20 & 224,19 & 224,34 & 56,55 & 491,51 & 62,07 & 9,38 & 40,19 & 171,31 & 48,13 & 49,49 & 144,39 \\
\hline Salamandra salamandra & 30SWH14 & 100,00 & 148,97 & 119,01 & 37,71 & 6557,42 & 330,43 & 17,86 & 312,57 & 130,21 & 237,24 & 237,24 & 70,45 & 422,51 & 53,51 & 6,37 & 41,31 & 147,08 & 38,62 & 38,94 & 123,22 \\
\hline Salamandra salamandra & 30 SWH2O & 100,00 & 97,98 & 121,82 & 37,70 & 6678,92 & 289,86 & $-30,73$ & 320,59 & 74,45 & 189,41 & 189,81 & 21,11 & 674,38 & 84,46 & 19,71 & $\begin{array}{l}35,07 \\
31,\end{array}$ & 231,49 & 82,36 & 82,62 & 191,90 \\
\hline Salamandra salamandra & 30 SWH21 & 100,00 & 108,66 & 121,42 & 37,75 & 6662,13 & 298,65 & $-20,64$ & 319,29 & 85,88 & 199,53 & 199,80 & 31,31 & 615,27 & 77,37 & 16,50 & 36,18 & 212,34 & 72,30 & 72,93 & 175,07 \\
\hline Salamandra salamandra & 30 SWH22 & 100,00 & 129,43 & 120,05 & 37,79 & 6589,29 & 314,54 & $-0,47$ & 315,01 & \begin{tabular}{|c|}
108,49 \\
\end{tabular} & 218,69 & 218,97 & 51,83 & 507,32 & 64,45 & 10,86 & 38,66 & 176,13 & 53,73 & 54,77 & 145,49 \\
\hline Salamandra salamandra & 30 SWH23 & 100,00 & 135,81 & 119,95 & 37,88 & 6573,86 & 319,58 & 5,31 & 314,27 & \begin{tabular}{|c|}
115,67 \\
\end{tabular} & 224,68 & 224,79 & 57,81 & 473,78 & 60,36 & 9,25 & 39,12 & 164,77 & 48,83 & 49,47 & 135,25 \\
\hline Salamandra salamandra & 30 SWH24 & 100,00 & 144,52 & 119,50 & 37,97 & 6537,57 & 326,10 & 13,49 & 312,61 & 125,46 & 232,60 & 232,66 & 66,33 & 431,48 & 55,08 & 7,33 & 39,93 & 149,76 & 42,48 & 42,80 & 123,02 \\
\hline Salamandra salamandra & 30 SWH 30 & 100,00 & 102,13 & 120,83 & 37,45 & 6632,01 & 291,64 & $\frac{-26,45}{-26,36}$ & 318,00 & 78,76 & 192,94 & 193,40 & 25,83 & 644,83 & 81,33 & 18,94 & $\begin{array}{l}34,79 \\
34,7 \\
\end{array}$ & 221,03 & 79,58 & 80,12 & 181,02 \\
\hline Salamandra salamandra & 30SWH31 & 100,00 & 108,29 & 121,08 & 37,73 & 6625,97 & 297,12 & $-20,70$ & 317,82 & 85,36 & 198,76 & 199,10 & 31,57 & 606,90 & 76,87 & 16,75 & 35,28 & 209,08 & 73,52 & 73,98 & 169,73 \\
\hline Salamandra salamandra & 30 SWH32 & 100,00 & 114,08 & 121,17 & 37,90 & 6616,64 & 301,82 & $-15,40$ & 317,22 & 91,90 & 204,23 & 204,44 & 36,99 & 573,92 & 72,88 & 15,03 & 35,73 & 198,20 & 68,40 & 68,88 & 159,72 \\
\hline Salamandra salamandra & 30SWH33 & 100,00 & 115,28 & 121,64 & 37,99 & 6624,59 & 303,36 & $-14,60$ & 317,95 & 93,55 & 205,45 & 205,58 & 37,90 & 563,74 & 71,58 & 14,55 & 35,49 & 195,09 & 67,78 & 68,03 & 155,56 \\
\hline Salamandra salamandra & 30 SWH34 & 100,00 & 127,64 & 121,06 & 37,99 & 6585,76 & 312,86 & $-2,88$ & 315,74 & \begin{tabular}{|c|}
107,04 \\
\end{tabular} & 216,92 & 217,02 & 50,06 & 499,64 & 63,86 & 11,34 & 36,86 & 173,19 & 57,30 & 57,69 & 137,60 \\
\hline Salamandra salamandra & 30SWH35 & 100,00 & 135,10 & $\begin{array}{l}\mid 21,06 \\
120,94\end{array}$ & $\frac{38,00}{38,2}$ & $\begin{array}{ll}630,2,10 \\
6562,45\end{array}$ & $\mid \begin{array}{l}\mid c 1,00 \\
318,66\end{array}$ & $\begin{array}{l}-2,00 \\
3,99\end{array}$ & 314,68 & 115,32 & 223,75 & 223,83 & 50,18 & | $45,1,17$ & $\begin{array}{l}03,00 \\
59,19\end{array}$ & $\mid$\begin{tabular}{|c|c|}
9,41 \\
9
\end{tabular} & $\begin{array}{l}30,00 \\
37,62\end{array}$ & \begin{tabular}{|l|l|l|}
159,92 \\
\end{tabular} & 51,44 & 51,82 & 126,39 \\
\hline Salamandra salamandra & 30SWH36 & 100,00 & 126,54 & 122,05 & 38,00 & 6610,75 & 312,94 & $-4,77$ & 317,70 & 106,23 & 216,08 & 216,18 & 48,37 & 497,56 & 63,25 & 11,47 & 36,08 & 172,49 & 58,95 & 59,70 & 134,27 \\
\hline Salamandra salamandra & 30 SWH40 & 100,00 & 111,35 & 119,94 & 37,86 & 6555,71 & 296,98 & $-17,14$ & 314,12 & 88,53 & 200,57 & 201,16 & 35,33 & 587,22 & 74,95 & 16,23 & 35,18 & 201,40 & 71,21 & 72,18 & 163,32 \\
\hline Salamandra salamandra & 30SWH41 & 100,00 & 104,01 & 120,89 & 37,87 & 6607,13 & 292,17 & $-24,69$ & 316,87 & 80,68 & 194,50 & 194,73 & 27,95 & 624,24 & 79,20 & 18,58 & 33,92 & 213,93 & 79,32 & 79,43 & 171,15 \\
\hline Salamandra salamandra & 30 SWH42 & 100,00 & 117,07 & 120,59 & 37,97 & 6569,31 & 302,61 & $-12,38$ & 314,99 & 94,95 & 206,40 & 206,77 & 40,55 & 550,65 & 70,50 & 14,42 & 35,34 & 189,73 & 66,72 & 67,18 & 150,78 \\
\hline Salamandra salamandra & - & 100,00 & 126,58 & $\begin{array}{l}\mid 20,40 \\
120,40\end{array}$ & $\begin{array}{ll}37,99 \\
37,9\end{array}$ & $\begin{array}{ll}6303,13 \\
653,06\end{array}$ & | & \begin{tabular}{|c|c|}
$-32,001$ \\
$-3,61$
\end{tabular} & $\begin{array}{l}314,39 \\
313,49\end{array}$ & \begin{tabular}{|c|}
34,53 \\
105,78
\end{tabular} & 215,07 & 215,37 & | 40,70 & $\begin{array}{l}50,05 \\
500,56\end{array}$ & $\begin{array}{ll}64,43 \\
640\end{array}$ & $\begin{array}{l}4,42 \\
11,81\end{array}$ & \begin{tabular}{|c|c|}
36,40 \\
36,40
\end{tabular} & \begin{tabular}{|l|l|}
172,66 \\
172
\end{tabular} & $\begin{array}{ll}50,66 \\
58,66\end{array}$ & $\mid \begin{array}{l}\mid l, 10 \\
59,34\end{array}$ & $\begin{array}{l}130,10 \\
136,50\end{array}$ \\
\hline Salamandra salamandra & 30 SWH44 & 100,00 & 120,14 & 121,30 & 38,00 & 6578,54 & 305,68 & $-10,05$ & \begin{tabular}{|c|}
315,73 \\
\end{tabular} & 98,81 & 209,57 & 209,66 & 42,99 & 529,28 & 67,71 & 13,53 & 35,21 & 182,61 & 64,91 & 65,25 & 142,30 \\
\hline Salamandra salamandra & 30 SWH45 & 100,00 & 122,26 & 121,51 & 38,00 & 6578,14 & 307,64 & $-8,31$ & \begin{tabular}{|l|l|}
315,95 \\
\end{tabular} & 101,38 & 211,55 & 211,58 & 44,91 & 515,95 & 65,98 & 13,00 & 35,23 & 178,04 & 63,34 & 64,24 & 137,55 \\
\hline Salamandra salamandra & 30 SWH46 & 100,00 & & 122,13 & 38,00 & 6610,28 & 302,89 & -14,96 & 317,85 & 94,21 & 205,38 & 205,49 & 38,10 & 545,61 & 69,02 & 14, & 33,92 & 188,01 & 69,40 & 70,86 & 143,76 \\
\hline Salamandra salamandra & 30 SWH47 & 100,00 & 121,31 & 122,45 & 38,00 & 6603,47 & 307,74 & $-9,66$ & 317,40 & \begin{tabular}{|c|}
100,72 \\
\end{tabular} & 210,66 & 210,88 & 43,54 & 512,44 & 64,99 & 13,08 & 34,31 & 176,73 & 64,28 & 66,55 & 134,06 \\
\hline Salamandra salamandra & 30 SWH48 & 100,00 & 128,17 & 122,68 & 38,01 & 6592,98 & 313,42 & $-3,22$ & 316,64 & 108,55 & 217,20 & 217,39 & 50,02 & 475,49 & 60,40 & 11,24 & 34,95 & 163,85 & 58,73 & 61,09 & 123,44 \\
\hline Salamandra salamandra & 30SWH51 & 100,00 & 10 & 120,33 & 37,85 & 6578,31 & 289,47 & $-25,73$ & 315,19 & 79,39 & 192,83 & 193,01 & 26,90 & 627,86 & 79,82 & 19,57 & 32,97 & 214,10 & 82,39 & 82,44 & 169,05 \\
\hline Salamandra salamandra & 30 SWH53 & 100,00 & 123,01 & 120,28 & 38,00 & 6502,48 & 305,49 & $-6,56$ & 312,05 & 101,84 & 211,27 & 211,45 & 46,66 & 513,34 & 66,25 & 13,13 & 35,28 & 176,21 & 63,08 & 63,49 & 137,18 \\
\hline Salamandra salamandra & 30SWH54 & 100,00 & 1,29 & 31 & 38,04 & 6,47 & 2,01 & 1,13 & 310,89 & 110,88 & 218,81 & 218,99 & 54,62 & 468,32 & 60,97 & 10, & 5,17 & 161,00 & 56,14 & 56,56 & 124,16 \\
\hline Salamandra salamandra & 30 SWH55 & 100,00 & ,66 & $\mid 121,17$ & 38,03 & $\begin{array}{l}040,42,07 \\
6532,\end{array}$ & 2 & $\frac{1,1}{-8,37}$ & 313,69 & 100,71 & 210,34 & 210,44 & 44,6 & 514,17 & 65,99 & 13, & 34,55 & 176,47 & 65,08 & 66,08 & 134,49 \\
\hline Salamandra salamandra & 30 SWH56 & 100,00 & & & 38,00 & 6568,34 & 30 & $-12,63$ & 315,42 & 96,35 & 206,74 & 206,80 & 40,53 & 530,40 & 67,58 & 14, & 33,55 & 182,10 & 68,66 & 70,37 & 137,23 \\
\hline Salamandra salamandra & 30 SWH57 & 100,00 & 114,82 & 122,09 & 38,00 & 6587,10 & 300,95 & $-15,36$ & 316,31 & 93,56 & 204,25 & 204,32 & 37,72 & 539,45 & 68,25 & 15,29 & 32,92 & 185,07 & 70,97 & 73,38 & 138,21 \\
\hline Salamandra salamandra & 30SWH61 & 100,00 & 09 &, 62 & 37,93 & 511,14 & 89 & $-19,90$ & 311 & 85,27 & 197,10 & 197,38 & 32,68 & 592,88 & 75,97 & 18,7 & 33,04 & 201,65 & 78,14 & 78,20 & 157,47 \\
\hline Salamandra salamandra & 30SWH62 & 100,00 & 122,64 & , 54 & 38,00 & 448,83 & 303,26 & $-6,08$ & 309,34 & $\mid$ & 210,08 & 210,48 & 47,03 & 510,83 & 66,39 & 13, & 34,84 & 174,56 & 63,86 & 64,27 & 135,26 \\
\hline Salamandra salamandra & 30SWH63 & 100,00 & $\begin{array}{l}130,84 \\
130,89\end{array}$ & , 64 & $\begin{array}{ll}30,00 \\
38,07\end{array}$ & 6418,81 & 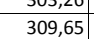 & $\begin{array}{l}-0,00 \\
1,35\end{array}$ & 308,30 & $\begin{array}{l}11,10,42 \\
110\end{array}$ & 217,51 & \begin{tabular}{|l|l|}
217,96 \\
217
\end{tabular} & $\begin{array}{ll}41,039 \\
54,92\end{array}$ & $\begin{array}{l}31,03 \\
467,12\end{array}$ & $\begin{array}{l}\mid 60,23 \\
61,21\end{array}$ & $\begin{array}{l}\mid 1,, 34 \\
11,03\end{array}$ & 35,84 & 159,75 & $\begin{array}{l}25,000 \\
56,89\end{array}$ & 57,26 & $\begin{array}{l}13,22,81 \\
12281\end{array}$ \\
\hline Salamandra salamandra & 30 SWH64 & 100,00 & 143,58 & 119,04 & 38,44 & 6357,51 & 318,63 & 13,18 & \begin{tabular}{|l|l}
305,45 \\
\end{tabular} & 124,52 & 228,84 & 229,14 & 67,52 & 406,88 & 53,85 & 8,03 & 37,66 & 138,73 & 46,86 & 47,79 & 106,31 \\
\hline Salamandra salamandra & 30SWH66 & 100,00 & 125,89 & 121,30 & 38,14 & 6490,78 & 307,56 & $-4,69$ & 312,25 & \begin{tabular}{|c|}
105,67 \\
\end{tabular} & 213,69 & 213,75 & 49,07 & 483,00 & 62,73 & 12,45 & 34,30 & 165,42 & 62,13 & 63,59 & 122,54 \\
\hline Salamandra salamandra & 30SWH67 & 100,00 & 121, & 71 & 38, & 6519,50 & 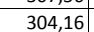 & -9, & 313 & 100 & 209 & 209 & 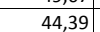 & 503, & 64 & 13, & 33, & 172,13 & 66, & 69,38 & 126,38 \\
\hline Salamandra salamandra & 30 SWH72 & 100 & & & 38 & 6439 & 29 & $-11,6$ & 308 & & 204 & 202 & & 539 & 69, & 15, & 33,44 & 183,02 & 71,05 & 71,07 & 140,00 \\
\hline \begin{tabular}{|l} 
Salamandra salamandrandra \\
Sala
\end{tabular} & | & $\begin{array}{l}100,00 \\
100\end{array}$ & $\begin{array}{l}10,02 \\
122,36 \\
\end{array}$ & \begin{tabular}{|l|}
119,87 \\
119,87
\end{tabular} & $\begin{array}{l}38,00 \\
38,13 \\
\end{array}$ & $\begin{array}{l}045,300 \\
6426,94\end{array}$ & $\mid$\begin{tabular}{|l|}
301,87 \\
301,87
\end{tabular} & \begin{tabular}{|c|}
$-11,03$ \\
$-6,58$
\end{tabular} & $\begin{array}{l}30,01 \\
308,45\end{array}$ & $\begin{array}{r}94,13 \\
101,08 \\
\end{array}$ & $\begin{array}{l}2009,64 \\
209\end{array}$ & \begin{tabular}{|l|l|l|l|l|l|}
209,83 \\
\end{tabular} & $\begin{array}{l}41,45 \\
47,00\end{array}$ & $\begin{array}{l}53,00 \\
505,47\end{array}$ & $\begin{array}{l}09,03 \\
65,92 \\
\end{array}$ & $\begin{array}{l}0,30 \\
13,66\end{array}$ & \begin{tabular}{|c|c|}
34,00 \\
34,0
\end{tabular} & $\begin{array}{l}103,02 \\
171,94\end{array}$ & $\begin{array}{l}\mid 1,05 \\
65,78\end{array}$ & $\begin{array}{l}61,01,79 \\
65,\end{array}$ & $\begin{array}{l}14,09 \\
129,99\end{array}$ \\
\hline Salamandra salamandra & 30 SWH76 & 100,00 & 132,95 & 120,81 & 38,82 & 6408,51 & 311,01 & 2,16 & 308,85 & 113,34 & 219,48 & 219,49 & 56,69 & 444,69 & 58,68 & 10,75 & 35,01 & 151,40 & 57,19 & 58,24 & 110,40 \\
\hline Salamandra salamandra & 30 SWH77 & 100,00 & 123,18 & 121,17 & 38,41 & 6470,92 & 304,12 & $-7,16$ & 311,29 & 102,78 & 210,74 & 210,77 & 46,77 & 489,06 & 63,27 & 13,52 & 33,29 & 166,43 & 65,67 & 68,23 & 120,31 \\
\hline Salamandra salamandra & 30SWH82 & 100,00 & & & 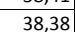 & 0 & 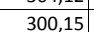 & $-5,17$ & 305,32 & 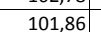 & 209,27 & 209,86 & 48,48 & 502,28 & & 13 & 33,91 & 169,65 & 65,89 & 66,19 & 128,66 \\
\hline Salamandra salamandra & 30 SWH83 & 10 & & & & & & $-1,8$ & 305,43 & 106,50 & 213,11 & 213,46 & 52,27 & 479, & 63,04 & 12,64 & 34,44 & 162,31 & 62,58 & 62,96 & 121 \\
\hline Salamandra salamandra & 30 SWH85 & 100,00 & 148,53 & 118,95 & 39,00 & 6241,77 & 319,29 & 17,79 & 301,50 & 130,34 & 231,99 & 232,27 & 73,44 & 377,51 & 50,75 & 7,36 & 37,82 & 126,92 & 45,61 & 46,44 & 93,48 \\
\hline Salamandra salamandra & 30SWH91 & 100,00 & 141,29 & 117,12 & 38,93 & 6162,53 & 309,87 & 12,71 & 297,16 & 121,52 & 223,81 & 224,52 & 67,92 & 415,86 & 54,98 & 9,03 & 37,18 & 138,75 & 48,73 & 52,23 & 107,13 \\
\hline Salamandra salamandra & 30SWH92 & 100,00 & 137,53 & 17,82 & 38,78 & 220,34 & 08,26 & 8,64 & 299,62 & 117,55 & 220,95 & 221,68 & 63,68 & 433,09 & 57,22 & 10,15 & 36,25 & 144,87 & 53,48 & 55,89 & 109,89 \\
\hline Salan & $30 \mathrm{SWH}$ & 100 & & & 39 & 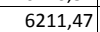 & & 11,96 & 299,92 & 2,12 & 8 & 225 , & 67 & 411 & & 9,0 & 36,84 & 137 & 50,45 & 52,65 & 103,01 \\
\hline Salamandra salamandra & 30SXG29 & 100,00 & 135,25 & \begin{tabular}{|l|l|l|l|}
115,02 \\
\end{tabular} & 39,09 & 6045,20 & 299,51 & \begin{tabular}{|c|c|}
8,79 \\
\end{tabular} & 290,73 & 110,42 & 215,94 & $\frac{22,34,}{217,42}$ & $\mid 63,70$ & $\begin{array}{l}41,25 \\
455,83\end{array}$ & 58,89 & \begin{tabular}{|}
, 000 \\
11,65
\end{tabular} & $\begin{array}{l}0,04 \\
35,79\end{array}$ & \begin{tabular}{|l}
149,59 \\
\end{tabular} & 56,40 & $\begin{array}{l}61,37 \\
61,3\end{array}$ & 116,24 \\
\hline
\end{tabular}




\begin{tabular}{|c|c|c|c|c|c|c|c|c|c|c|c|c|c|c|c|c|c|c|c|c|c|}
\hline TAXON & UTM & $\mathrm{km} 2$ & BIO1 & $\mathrm{B1O2}$ & $\mathrm{BIO3}$ & 8104 & B105 & B106 & B107 & B108 & B109 & BIO10 & BIO11 & BIO12 & B1013 & B1014 & 81015 & B1016 & BIO17 & B1018 & BIO19 \\
\hline Salamandra salamandra & 30тTK44 & 60,00 & 132,45 & 109,16 & 36,60 & 6377,70 & 307,43 & 12,65 & 294,78 & 62,97 & 217,85 & 218,38 & 55,81 & 543,52 & 66,52 & 8,45 & 42,58 & 193,49 & 48,58 & 49,33 & 179,36 \\
\hline Salamandra salamandra & 30TाK45 & 50,00 & 131,76 & 109,35 & 36,72 & 6352,00 & 305,94 & 12,08 & 293,86 & 62,33 & 216,75 & 217,14 & 55,19 & 538,41 & 66,14 & 8,77 & 42,37 & \begin{tabular}{|l|}
191,61 \\
\end{tabular} & 49,05 & 49,87 & 177,23 \\
\hline Salamandra salamandra & 30TTK46 & 50,00 & 135,01 & 110,26 & 36,96 & 6344,70 & 308,87 & 14,62 & 294,25 & 65,34 & 219,75 & 220,12 & 58,21 & 503,96 & 62,09 & 8,23 & 41,86 & 178,99 & 46,81 & 47,03 & 164,68 \\
\hline Salamandra salamandra & 30TTK48 & 40,00 & 134,10 & 111,33 & 37,38 & 6306,80 & 307,13 & 13,61 & 293,52 & \begin{tabular}{|l|l|l|}
64,43 \\
\end{tabular} & 218,56 & 218,64 & 57,33 & 483,51 & 59,92 & 8,43 & 40,90 & 171,39 & 46,87 & 46,92 & 156,69 \\
\hline Salamandra salamandra & 30TтK49 & 40,00 & 115,98 & 109,66 & 37,29 & 6252,05 & 288,25 & $-1,39$ & 289,64 & 47,76 & \begin{tabular}{|c|}
199,29 \\
\end{tabular} & 200,29 & 41,29 & 562,68 & 69,73 & 11,05 & 39,69 & $\mid 198,97$ & 57,68 & 58,81 & 182,14 \\
\hline Salamandra salamandra & 30TTK54 & 100,00 & 126,02 & 109,80 & 36,64 & 6379,98 & 302,00 & 6,26 & 295,74 & 56,83 & 211,49 & 212,14 & 49,72 & 553,85 & 67,17 & 9,55 & 41,46 & 194,51 & 51,85 & 52,86 & 179,58 \\
\hline Salamandra salamandra & 30TTK55 & 100,00 & 108,84 & 107,86 & 36,47 & 6312,55 & 283,49 & $-7,86$ & 291,36 & 41,26 & 193,66 & 194,57 & 34,53 & 643,86 & 78,32 & 12,68 & 40,28 & 226,02 & 62,99 & 65,62 & 209,65 \\
\hline Salamandra salamandra & $30 T \mathrm{~K} 56$ & 100,00 & $\begin{array}{l}125,09 \\
125,09\end{array}$ & $\mid \begin{array}{l}\mid 110,34 \\
110,\end{array}$ & 36,99 & 6336,47 & |los, 299,69 & 5,54 & 294,16 & 55, 55 & 209,65 & 210,40 & $\begin{array}{l}34,359 \\
48,89\end{array}$ & 532,00 & $\begin{array}{ll}65,03 \\
65\end{array}$ & $\mid$ & 40,50 & $\begin{array}{l}\mid 22,02 \\
186,53\end{array}$ & 52,18 & 52,97 & 171,06 \\
\hline Salamandra salamandra & 30TTK57 & 100,00 & 125,48 & 111,03 & 37,08 & 6317,04 & 299,69 & 5,65 & 294,04 & 56,32 & 209,99 & 210,54 & 49,34 & 515,12 & 63,05 & 9,67 & 39,93 & 180,10 & 51,77 & 52,14 & 164,56 \\
\hline Salamandra salamandra & 30TTK58 & 100,00 & 125,15 & 111,64 & 37,57 & 6296,49 & 298,85 & 5,27 & 293,58 & 56,00 & 209,26 & 209,81 & 49,13 & 503,89 & 61,86 & 9,69 & 39,55 & 175,86 & 51,83 & 52,15 & 159,95 \\
\hline Salamandra salamandra & 30TTK59 & 100,00 & 118,74 & 111,53 & 37,89 & 6264,91 & 292,03 & 0,06 & 291,97 & 50,05 & 202,19 & 203,01 & 43,41 & 522,27 & 64,35 & 10,65 & 38,81 & 182,02 & 55,69 & 56,28 & 164,96 \\
\hline Salamandra salamandra & 30TTK64 & 100,00 & 125,55 & 110,94 & 36,79 & 6392,01 & 302,50 & 4,83 & 297,67 & 56,05 & 211,25 & 211,87 & 49,11 & 535,59 & 64,29 & 9,79 & 40,50 & 185,12 & 51,99 & 53,12 & 169,90 \\
\hline Salamandra salamandra & $30 \pi T K 65$ & 100,00 & 113,49 & 109,94 & 36,78 & 6341,39 & 289,57 & $-5,24$ & 294,81 & \begin{tabular}{|l|l}
45,07 \\
\end{tabular} & 198,60 & 199,43 & 38,40 & 586,38 & 70,42 & 12,04 & 39,20 & 201,93 & 59,78 & 61,71 & 185,52 \\
\hline Salamandra salamandra & 30тTK66 & 100,00 & 79,21 & 106,14 & 36,41 & 6224,39 & 253,47 & $-34,09$ & 287,56 & \begin{tabular}{|c|}
14,25 \\
\end{tabular} & 163,83 & 164,57 & 7,95 & 803,94 & 95,97 & 19,66 & 37,45 & 276,18 & 86,49 & 92,45 & 257,79 \\
\hline Salamandra salamandra & 30TTK67 & 100,00 & 109,14 & 110,24 & 37,07 & 6281,82 & 283,90 & $-8,71$ & 292,61 & 41,20 & \begin{tabular}{|c|}
192,97 \\
\end{tabular} & 194,39 & 34,75 & 578,51 & 69,88 & 12,63 & 37,97 & 198,20 & 62,04 & 64,14 & 180,73 \\
\hline Salamandra salamandra & 30TтK68 & 100,00 & 121,72 & 112,60 & 37,88 & 6290,36 & 296,40 & 1,58 & 294,82 & 52,69 & 205,55 & 206,38 & 46,00 & 494,14 & 59,95 & 10,43 & 38,06 & 168,79 & 53,79 & 54,29 & 152,38 \\
\hline Salamandra salamandra & 30TTK69 & 100,00 & 116,55 & 112,76 & 38,00 & 6255,50 & 290,74 & $-2,36$ & 293,10 & 54,45 & 199,44 & 200,97 & 41,45 & 504,86 & 61,34 & 11,15 & 37,32 & 171,90 & 56,85 & 57,70 & 154,59 \\
\hline Salamandra salamandra & 30TाK74 & 100,00 & 134,76 & 112,76 & 36,99 & 6418,78 & 312,39 & 11,83 & 300,57 & 68,51 & 220,79 & 221,21 & 57,26 & 470,09 & 55,91 & 8,45 & 40,06 & 159,85 & 46,18 & 46,69 & 145,14 \\
\hline Salamandra salamandra & 30TTK75 & 100,00 & 81,44 & 107,65 & 36,44 & 6263,92 & 257,81 & $-33,16$ & 290,97 & 16,03 & 166,67 & 167,38 & 9,72 & 767,13 & 90,58 & 19,21 & 36,84 & 259,87 & 83,75 & 88,86 & 241,18 \\
\hline Salamandra salamandra & 30TाK76 & 100,00 & 91,53 & 108,77 & 36,79 & 6260,14 & 267,27 & $-24,49$ & 291,75 & 25,18 & 175,92 & 177,06 & 18,91 & 680,86 & 80,72 & 16,69 & 36,68 & 229,91 & 75,34 & 79,58 & 211,18 \\
\hline Salamandra salamandra & 30TTK77 & 100,00 & 97,20 & 109,86 & 37,13 & 6246,57 & 272,49 & $-19,59$ & 292,07 & 30,3 & 180,93 & 182,39 & 24,13 & 626,00 & 74,51 & 15 , & 36 , & 210,42 & 70,67 & 74,09 & 191,65 \\
\hline Salamandra salamandra & 30TाK78 & 100,00 & 114,63 & 112,80 & 37,91 & 6271,61 & 289,86 & $-4,61$ & 294,47 & 55,68 & 197,59 & 199,56 & 39,69 & 504,84 & 60,39 & 11,68 & 36,46 & $\begin{array}{l}2168,45 \\
1685\end{array}$ & 57,96 & 59,24 & 151,39 \\
\hline Salamandra salamandra & 30TाK79 & 100,00 & 116,93 & 113,89 & 38,05 & 6247,73 & 291,87 & $-2,66$ & 294,53 & 73,70 & 199,32 & 201,36 & 41,94 & 479,76 & 57,49 & 11,22 & 36,02 & 159,91 & 56,53 & 57,49 & 142,51 \\
\hline Salamandra salamandra & 30TाK84 & 100,00 & 134,41 & 113,27 & 37,00 & 6425,82 & 312,65 & 10,59 & 302,07 & 81,47 & 220,52 & 220,95 & 56,82 & 456,62 & 53,71 & 8,67 & 39,33 & 153,00 & 46,50 & 47,06 & 137,83 \\
\hline Salamandra salamandra & $30 T \pi K 85$ & 100,00 & 78,37 & 108,42 & 36,60 & 6264,29 & 255,69 & $-36,63$ & 292,32 & 13,03 & 163,74 & 164,41 & 6,90 & 760,19 & 88,73 & 20,16 & 35,67 & 253,42 & 86,09 & 91,79 & 233,99 \\
\hline Salamandra salamandra & $30 T \pi K 86$ & 100,00 & 104,01 & 111,33 & 37,03 & 6298,99 & 281,10 & $-14,76$ & 295,86 & 38,62 & 188,25 & 189,81 & 30,01 & 569,76 & 66,99 & 14,01 & 36,09 & 188,25 & 65,19 & 67,68 & 169,77 \\
\hline Salamandra salamandra & 30TTK87 & 100,00 & 112,29 & \begin{tabular}{|l|l|l|l|}
112,73 \\
\end{tabular} & $\begin{array}{ll}37,650 \\
37,60\end{array}$ & 6295,44 & $\frac{201,0}{288,80}$ & $\begin{array}{l}-74,6 \\
-7,63\end{array}$ & 296,00 & S2,02 & $\begin{array}{l}190,25 \\
195,94\end{array}$ & $\begin{array}{l}\mid c 0,01 \\
197,81\end{array}$ & 37,44 & 507,78 & $\mid \begin{array}{ll}\mid 59,81 \\
5\end{array}$ & $\begin{array}{l}4,014 \\
2,44\end{array}$ & 35,86 & $\mid \frac{\mid 0,25}{166,60}$ & $\mid \begin{array}{l}\mid c 0,13 \\
59,43\end{array}$ & $\begin{array}{l}61,00 \\
61,05 \\
\end{array}$ & 148,84 \\
\hline Salamandra salamandra & 30TTK88 & 100,00 & 115,08 & 113,70 & 37,98 & 6268,39 & 290,92 & $-5,17$ & 296,09 & 72,80 & \begin{tabular}{|c|}
197,78 \\
\end{tabular} & 200,01 & 40,13 & 480,61 & 56,77 & 11,78 & 35,36 & 157,37 & 57,66 & 58,97 & 139,60 \\
\hline Salamandra salamandra & 30TTK94 & 100,00 & 150,38 & 114,48 & 37,00 & 6451,97 & 328,03 & 24,12 & 303,91 & 108,28 & 236,77 & 236,78 & 71,27 & 381,23 & 44,71 & $\begin{array}{r}6,37 \\
6,37 \\
\end{array}$ & 39,86 & 128,30 & 37,38 & 37,38 & 113,13 \\
\hline Salamandra salamandra & 30TाK95 & 100,00 & 94,42 & 110,80 & 36,89 & 6314,75 & 272,60 & $-23,77$ & 296,37 & 36,90 & 179,93 & 180,69 & 21,05 & 643,16 & 74,43 & 17,05 & 35,56 & 210,75 & 74,63 & 78,42 & 191,89 \\
\hline Salamandra salamandra & 30TाK96 & 100,00 & 91,54 & 110,67 & 37,01 & 6268,13 & 268,93 & $-26,01$ & 294,93 & 33,22 & 176,05 & 177,31 & 18,89 & 629,13 & 73,17 & 17,20 & 34,74 & 204,69 & 75,06 & 79,02 & 184,84 \\
\hline Salamandra salamandra & 30TाK99 & 100,00 & $\begin{aligned} 107,21 \\
107,21\end{aligned}$ & $\mid \begin{array}{l}\mid 113,47 \\
113\end{array}$ & $\begin{array}{ll}31,010 \\
38,00\end{array}$ & $\begin{array}{l}\mid 020,109 \\
6202,06\end{array}$ & \begin{tabular}{|l|l|}
282,46 \\
282,4
\end{tabular} & $\begin{array}{l}-20,01 \\
-12,23\end{array}$ & 294,69 & | $60,2<$ & $\begin{array}{l}189,34 \\
189\end{array}$ & $\begin{array}{l}\mid 11,31 \\
191,49\end{array}$ & $\begin{array}{l}10,05 \\
33,69\end{array}$ & \begin{tabular}{|l|}
488,99 \\
482,5
\end{tabular} & $\mid \begin{array}{l}\mid 5,11 \\
58,71\end{array}$ & $\begin{array}{l}13,45 \\
13,4\end{array}$ & 33,69 & \begin{tabular}{|l|l|l|l}
157,33 \\
\end{tabular} & $\begin{array}{l}63,01 \\
63,01\end{array}$ & $\begin{array}{l}65,0<25 \\
65,25\end{array}$ & $\begin{array}{l}104,04 \\
136,74\end{array}$ \\
\hline Salamandra salamandra & $30 T T \angle 40$ & 39,00 & 117,22 & 110,80 & 37,98 & 6241,55 & 289,36 & $-0,44$ & 289,80 & 48,96 & 200,42 & 201,29 & 42,09 & 537,40 & 66,89 & 10,84 & 39,51 & 189,65 & 56,73 & 57,22 & 172,22 \\
\hline Salamandra salamandra & 30TTL50 & 100,00 & 114,93 & 111,65 & 37,99 & 6240,78 & 287,90 & $-2,85$ & 290,75 & 47,5 & 197,78 & 199,05 & 40,02 & 528,61 & 65,29 & 11, & 38,41 & 183,98 & 57,94 & 58,66 & 166,05 \\
\hline Salamandra salamandra & 30TTL56 & 100,00 & 115,04 & 114,44 & 39,0 & 6165,01 & 287,15 & $-3,8$ & 290,99 & 75,3 & 197,15 & 197,26 & 39,83 & 452,74 & 57,87 & 11, & 37,59 & 161,16 & 55,84 & 55,92 & 135,98 \\
\hline Salamandra salamandra & $30 T T L 57$ & 100,00 & 115,39 & 114,42 & 39,00 & 6158,74 & 287,28 & $-3,76$ & 291,04 & 75,66 & 197,18 & 197,42 & 40,06 & 444,03 & 56,61 & 11,27 & 37,08 & 157,38 & 55,33 & 55,47 & 133,44 \\
\hline Salamandra salamandra & 30TTL60 & 100,00 & 114,36 & 113,21 & 38,01 & 6233,21 & 288,24 & $-4,33$ & 292,57 & 69,27 & 197,00 & 198,49 & 39,50 & 502,62 & 61,29 & 11,47 & 36,97 & 171,10 & 58,14 & 58,96 & 152,82 \\
\hline Salamandra salamandra & 30TTL61 & 100,00 & 113,50 & 113,97 & 38,46 & 6218,07 & 287,22 & $-5,21$ & 292,44 & 72, & 196,09 & 197,31 & 38,71 & 492,07 & 60,22 & 11,71 & 36,64 & 168,50 & 58,69 & 59,31 & 148,05 \\
\hline Salamandra salamandra & 30TTL73 & 100,00 & 120,48 & 118,22 & 39,59 & 6217,77 & 295,16 & $-0,53$ & 295,68 & 79,94 & 203,51 & 203,67 & 44,79 & 414,32 & 50,82 & 10,99 & 35,68 & 142,51 & 53,90 & 53,97 & 118,64 \\
\hline Salamandra salamandra & 30тTL90 & 100,00 & 29 &, 12 & 38,60 & 58,75 & 58 & $-5,88$ & 294,46 & 74,0 & 195,12 & 197,74 & 40,25 & 442,18 & 53, & 12,1 & 33,2 & 141,85 & 58,34 & 60,13 & 122,18 \\
\hline Salamandra salamandra & 30TTM50 & 100,00 & 2 & 5 & $\begin{array}{ll}39, \\
39,\end{array}$ & 19,15 & 3 & $\frac{-1,20}{-1,20}$ & 290,73 & 79,56 & 199,50 & 199,86 & 43,12 & 425,39 & 54,04 & 11, & 35,80 & $\begin{array}{l}41,0,07 \\
150,\end{array}$ & 54,46 & 54,70 & 128,83 \\
\hline Salamandra salamandra & 30TTM53 & 90,00 & & 11 & 39, & 6052,98 & 28 & $-3,53$ & 290,01 & 77 & 196,54 & 196,54 & 41,24 & 461,58 & 58,57 & 13, & 34,71 & \begin{tabular}{|c|}
164,57 \\
\end{tabular} & 62,22 & 62,22 & 141,87 \\
\hline Salamandra salamandra & 30TTM60 & $\begin{array}{r}00,00 \\
100\end{array}$ & 120,34 & 115,00 & 39,00 & 6131,49 & 291,38 & $\begin{array}{l}-0,43 \\
-0,43\end{array}$ & 291,81 & 80,93 & 199,72 & 201,24 & 44,30 & 389,94 & 48,50 & 10 & 34,65 & 135,93 & 52,24 & 53,13 & $14,2,21$ \\
\hline Salamandra salamandra & 30TTM72 & 100,00 & 121,22 & 115,76 & 39,00 & 6085,42 & 07 & $-0,26$ & 292 & 82 & 200,30 & 201,51 & 45,26 & 396,00 & 48,23 & 12, & 33, & 138,25 & 56,89 & 57,44 & 112,25 \\
\hline Salamandra salamandra & 30TTN53 & 58,00 & 93,44 & 109,66 & 39,99 & 543,63 & 251,73 & $-19,50$ & 271,23 & 60,25 & 166,97 & 166,97 & 25,44 & 749,48 & 97,07 & 33, & 30,2 & 266,40 & \begin{tabular}{|c|}
122,49 \\
\end{tabular} & 122,49 & 220,42 \\
\hline Salamandra salamandra & 30TTN54 & 50,00 & 85 & 32 & $\begin{array}{ll}35,96 \\
39,96\end{array}$ & 5432,77 & 240,95 & $\begin{array}{l}-1-3,40 \\
-24,42\end{array}$ & 265,37 & $\mid \begin{array}{l}54,03 \\
54,00\end{array}$ & \begin{tabular}{|l|l|}
157,99 \\
\end{tabular} & \begin{tabular}{|l|l|}
157,99 \\
\end{tabular} & $\begin{array}{l}20,44 \\
19,85\end{array}$ & \begin{tabular}{|l|r|}
827,83 \\
\end{tabular} & $\mid \begin{array}{l}5,05 \\
105,94\end{array}$ & $\begin{array}{l}30, \\
37,\end{array}$ & 29,26 & $\begin{array}{l}280,40 \\
289,86\end{array}$ & $\mid$ & $\begin{array}{l}13,4,33 \\
136,33\end{array}$ & 244,65 \\
\hline Salamandra salamandra & 30TTN56 & 47,00 & 65,31 & 101,61 & 39,72 & 5231,31 & 214,28 & $-38,83$ & 253,11 & 31,13 & 135,35 & 135,42 & 3,28 & 1038,97 & 128,89 & 48, & 27,40 & 352,92 & 172,06 & 172,99 & 312,22 \\
\hline Salamandra salamandra & 30TTN57 & 40,00 & 80,32 & 101,50 & 40,59 & 5044,29 & 224,09 & $-23,27$ & 247,36 & 48,70 & \begin{tabular}{|l|l|}
147,08 \\
\end{tabular} & 147,50 & 19,76 & 969,47 & 123,17 & 45, & 27,36 & 330,80 & 163,18 & 167,47 & 282,82 \\
\hline Salamandra salamandra & 30TTN59 & 34,00 & 107,65 & 97,71 & 42,5 & 4464,14 & 236,69 & 9,2 & 227 & & 165 & 167,02 & 53,90 & 894,86 & 118 & 43, & 27, & 303,14 & 154,69 & 162,37 & 241,67 \\
\hline Salamandra salamandra & 30 TTN & 100,00 & 97, & 110,95 & 40 & 66 & 25 & -16, & 273 & 64 & 171 & 171 & 28 & 704 & \begin{tabular}{|c|c|}
91,85 \\
\end{tabular} & 32 & & 252,02 & 118,46 & 118,46 & 202,02 \\
\hline Salamandra salamandra & 30TTN64 & 100,00 & 88,79 & 108,26 & 40,01 & 5445,67 & 244,62 & $-22,48$ & 267,11 & 56,85 & 160,94 & 160,94 & 22,20 & 795,50 & $\mid 102,14$ & 37,00 & 28,97 & 279,16 & 134,13 & 134,13 & 230,18 \\
\hline Salamandra salamandra & 30TTN65 & 100,00 & 79,02 & 105,37 & 39,96 & 5328,69 & 231,28 & $-29,09$ & 260,37 & 48,33 & 149,91 & 149,92 & 14,66 & 894,13 & 113,10 & 42,03 & 27,92 & 308,30 & 150,90 & 151,08 & 261,42 \\
\hline Salamandra salamandra & 30TTN66 & 100,00 & 75,87 & 102,94 & 40,22 & 5193,28 & 223,88 & $-29,61$ & 253,49 & 46,30 & 144,83 & 144,96 & 13,51 & 955,68 & 120,26 & 45,30 & 27,28 & 325,99 & 161,73 & 162,86 & 279,55 \\
\hline Salaman & 30 TTN & 100,00 & & 102,5 & 41,3 & 4950,98 & . & $-9,5$ & 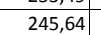 & 67,26 & 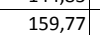 & 1602 & |רונות & 870,41 & & 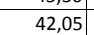 & & 299,19 & | & 154,85 & 243,77 \\
\hline Salamandra salamandra & $30 T$ & & & $\frac{102}{95}$ & $\frac{41}{43}$ & 4250, & & 22,63 & 219,26 & 97, & $1 / 3,16$ & $1 / 5,43$ & 67, & 853, & 115 & 42, & & 287,22 & 149,88 & 157,86 & 220 \\
\hline Salamandra salamandra & 30TTN72 & 100,00 & 101,50 & 113,74 & 39,99 & 5728,56 & 266,30 & $-16,17$ & 282,47 & 67,27 & 177,26 & 177,26 & 30,08 & 637,13 & 83,05 & 28,18 & 31,32 & 230,49 & 109,92 & 109,92 & 178,09 \\
\hline Salamandra salamandra & 30TTN73 & 100,00 & 96,86 & 111,50 & 40,00 & 5591,34 & 257,71 & $-18,05$ & 275,76 & 63,91 & 170,84 & 170,84 & 27,56 & 694,81 & 90,14 & 32,83 & 29,98 & 247,84 & 120,24 & 120,24 & 195,01 \\
\hline Salamandra salamandra & 30TTN75 & 100,00 & 78,74 & 105,74 & 39,91 & 5340,06 & 231,84 & $-29,75$ & 261,59 & 48,48 & 149,70 & 149,71 & 14,15 & 879,32 & 110,85 & 42,46 & 27,29 & 302,26 & 151,78 & 151,81 & 252,92 \\
\hline Salam & $30 T T$ & & & & 40,2 & & 227 & $-28,09$ & 255,13 & 49,18 & 147 & & 15, & 919 & & 44, & 26,8 & & 15 & 160,50 & 263 \\
\hline Salamandra salamandra & 30TTN77 & 100,00 & 98,10 & 102,69 & $\begin{array}{ll}40,21,42 \\
41,4\end{array}$ & 4924,04 & 238,68 & $\begin{array}{l}2,6,54 \\
-6,54\end{array}$ & 245,21 & $\begin{array}{l}4,1,23 \\
771,2\end{array}$ & $\mid \begin{array}{l}\mid 4,2,47 \\
162,47\end{array}$ & 163,09 & 38,12 & \begin{tabular}{|c|}
840,56 \\
\end{tabular} & \begin{tabular}{|l|}
109,74 \\
\end{tabular} & $\begin{array}{ll}44,746 \\
41,76\end{array}$ & 27,21 & $\begin{array}{l}\mid 1,0,04 \\
288,74\end{array}$ & \begin{tabular}{|l}
148,43 \\
\end{tabular} & \begin{tabular}{|l}
153,87 \\
\end{tabular} & 229,47 \\
\hline
\end{tabular}




\begin{tabular}{|c|c|c|c|c|c|c|c|c|c|c|c|c|c|c|c|c|c|c|c|c|c|}
\hline TAXON & UTM & $\mathrm{km} 2$ & BIO1 & $\mathrm{B1O2}$ & $\mathrm{BIO3}$ & 8104 & B105 & B106 & B107 & B108 & B109 & BIO10 & B1011 & BIO12 & B1013 & B1014 & B1015 & B1016 & BIO17 & B1018 & B1019 \\
\hline Salamandra salamandra & 30TTN86 & 100,00 & 67,17 & 102,66 & 39,65 & 5239,59 & 217,27 & $-38,20$ & 255,47 & 38,17 & 137,15 & 137,28 & 4,70 & 982,46 & 121,12 & 48,64 & 25,75 & 330,25 & 171,88 & 172,24 & 283,22 \\
\hline Salamandra salamandra & 30TTN93 & 100,00 & 101,07 & 111,23 & 40,01 & 5538,27 & 260,69 & $-14,21$ & 274,90 & 69,69 & 174,09 & 174,09 & 32,15 & 658,48 & 84,97 & 31,07 & 29,28 & 233,02 & 119,10 & 119,10 & 176,86 \\
\hline Salamandra salamandra & 30TTN94 & 100,00 & 93,59 & 108,77 & 40,01 & 5418,02 & 249,74 & $-18,79$ & 268,53 & \begin{tabular}{c|c|}
63,35 \\
\end{tabular} & 165,26 & 165,26 & 26,95 & 733,11 & 93,67 & 36,51 & 27,87 & 255,42 & 132,52 & 132,52 & 199,38 \\
\hline Salamandra salamandra & 30TTN96 & 100,00 & 67,08 & 102,48 & 39,64 & 5231,01 & 217,01 & $-38,30$ & 255,30 & \begin{tabular}{|c|}
38,78 \\
\end{tabular} & 136,90 & 137,01 & 4,63 & \begin{tabular}{|c|}
974,58 \\
\end{tabular} & 119,49 & 49,01 & 25,20 & 325,77 & 172,95 & 173,32 & 277,70 \\
\hline Salamandra salamandra & 30TTP60 & 100,00 & 129,66 & 89,93 & 43,73 & 3918,14 & 241,79 & 38,42 & 203,37 & 111,05 & 178,84 & 181,95 & 82,53 & 850,03 & 116,32 & 42,40 & 28,38 & 284,03 & 149,06 & 158,09 & 214,18 \\
\hline Salamandra salamandra & 30TTP61 & 100,00 & 129,82 & 86,42 & 43,49 & 3821,66 & 237,68 & \begin{tabular}{|c|}
41,25 \\
\end{tabular} & 196,43 & 112,19 & 177,79 & 181,16 & 84,08 & 870,34 & 118,96 & 43,35 & 28,28 & 290,93 & 152,34 & 162,18 & 220,58 \\
\hline Salamandra salamandra & 30TTP62 & 99,00 & 135,89 & 79,64 & 42,56 & 3713,09 & 235,61 & 50,83 & 184,78 & 118,95 & 182,44 & 185,98 & 91,25 & 853,17 & 117,04 & 41,15 & 28,65 & 288,29 & 146,45 & 158,71 & 219,36 \\
\hline Salamandra salamandra & 30TाP70 & 100,00 & $\begin{array}{l}129,49 \\
12,4\end{array}$ & 87,84 & 443,33 & 3916,04 & $\mid 239,58$ & 39,05 & 200,53 & 111,44 & 178,87 & $\begin{array}{l}181,95 \\
181,95\end{array}$ & 82,37 & 844,56 & $\mid 115,45$ & 42,68 & 28,30 & 282,58 & \begin{tabular}{|l|}
149,95 \\
\end{tabular} & \begin{tabular}{|l|l|l|l|l|}
159,09 \\
\end{tabular} & 211,07 \\
\hline Salamandra salamandra & 30TTP82 & 60,00 & 138,75 & 71,62 & 40,72 & 3679,04 & 230,37 & 56,65 & 173,71 & \begin{tabular}{|l|l|}
122,63 \\
\end{tabular} & \begin{tabular}{ll|}
185,16 \\
\end{tabular} & 188,74 & 94,25 & 829,42 & 113,76 & 40,20 & 28,83 & 282,16 & 143,90 & 157,39 & 211,51 \\
\hline Salamandra salamandra & 30тTP90 & 100,00 & 125,74 & 85,39 & 42,02 & 4035,10 & 235,66 & 34,97 & 200,69 & 107,35 & 177,08 & 179,92 & 76,99 & 839,03 & 113,34 & 42,65 & 27,70 & 283,30 & 151,08 & 161,13 & 211,51 \\
\hline Salamandra salamandra & 30TTP91 & 100,00 & 126,39 & 81,66 & 41,69 & 3926,47 & 231,46 & 38,29 & 193,18 & 108,81 & 176,19 & 179,21 & 78,95 & 863,94 & 116,71 & 43,76 & 27,58 & 291,58 & 154,86 & 165,97 & 219,20 \\
\hline Salamandra salamandra & 30TTP92 & 50,00 & 134,30 & 74,18 & 40,98 & 3749,07 & 229,58 & 50,70 & 178,88 & 117,98 & 181,69 & \begin{tabular}{|l|l|}
184,95 \\
\end{tabular} & 88,89 & 849,13 & 115,64 & 41,84 & 28,09 & 288,26 & 149,61 & 162,86 & 216,03 \\
\hline Salamandra salamandra & 30TUK04 & 100,00 & 152,48 & 114,92 & 37,00 & 6473,37 & 330,21 & 25,06 & \begin{tabular}{|l|l}
305,15 \\
\end{tabular} & 110,58 & 239,14 & 239,14 & 72,90 & 365,59 & 42,55 & 6,31 & 39,21 & 122,56 & 36,52 & 36,52 & 106,51 \\
\hline Salamandra salamandra & 30TUK05 & 100,00 & 91,60 & 111,19 & 36,98 & 6312,57 & 270,40 & $-26,92$ & 297,31 & 37,66 & 177,25 & 178,03 & 18,63 & 640,32 & 74,19 & 17,84 & 34,65 & 206,66 & 76,97 & 80,68 & 186,89 \\
\hline Salamandra salamandra & 30TUK06 & 100,00 & 80,47 & 110,13 & 36,98 & 6240,22 & 258,27 & $-35,89$ & 294,16 & 23,13 & 165,30 & 166,20 & 9,04 & \begin{tabular}{|c|c|}
683,23 \\
\end{tabular} & 79,23 & 20,24 & 33,51 & 219,28 & 84,51 & 89,35 & 198,20 \\
\hline Salamandra salamandra & 30TUK07 & 100,00 & 76,67 & 109,66 & 37,02 & 6199,42 & 253,59 & $-38,70$ & 292,29 & 15,36 & \begin{tabular}{|c|}
161,19 \\
\end{tabular} & 161,95 & 5,96 & 693,74 & 80,34 & 21,1 & 32,93 & 222,01 & 87,41 & 93,44 & 200,16 \\
\hline Salamandra salamandra & 30TUK08 & 100,00 & 105,93 & 113,03 & 37,83 & 6234,50 & 282,07 & $-14,19$ & 296,26 & 64,14 & 188,86 & 190,86 & 32,37 & 495,59 & 60,24 & 14,20 & 33,61 & 157,74 & 64,29 & 66,78 & 136,18 \\
\hline Salamandra salamandra & 30TUK14 & 100,00 & 151,35 & 114,68 & 37,00 & 6499,67 & 329,40 & 23,35 & 306,06 & 109,40 & 238,49 & 238,49 & 71,49 & 361,03 & 41,78 & 6,41 & 38,95 & 120,26 & 36,98 & 36,98 & 103,24 \\
\hline Salamandra salamandra & 30TUK15 & 100,00 & 107,17 & 112,56 & 37,00 & 6357,38 & 286,19 & $-14,32$ & 300,52 & 71,97 & 192,81 & 193,76 & 32,42 & 526,62 & 62,91 & 14,19 & 34,84 & 168,06 & 64,68 & 66,84 & 147,18 \\
\hline Salamandra salamandra & 30TUK16 & 100,00 & 82,40 & 110,78 & 37,00 & 6241,99 & 260,71 & $-34,80$ & 295,51 & 35,77 & 167,32 & 168,13 & 10,85 & 646,15 & 76,49 & 19,65 & 32,89 & 203,86 & 82,49 & 87,53 & 181,66 \\
\hline Salamandra salamandra & 30TUK17 & 100,00 & 79,97 & 110,37 & 37,01 & 6204,22 & 257,10 & $-36,50$ & 293,60 & 31,32 & 164,45 & 165,12 & 9,03 & 648,18 & 77,16 & 20, & 32,38 & 203,69 & 84,44 & 89,93 & 181,01 \\
\hline Salamandra salamandra & 30TUK19 & 100,00 & 92,96 & $\frac{111,70}{111,}$ & 37,53 & 6162,45 & 268,20 & $-25,55$ & 293,75 & 55,26 & 175,56 & 177,18 & 21,10 & \begin{tabular}{|l|l|l|}
536,76 \\
\end{tabular} & 66,86 & 17,20 & 32,19 & 168,07 & $\mid 73,77$ & 77,81 & 143,09 \\
\hline Salamandra salamandra & 30TUK25 & 100,00 & 135,47 & 113,90 & 37,00 & 6441,15 & 313,42 & 9,08 & 304,35 & 104,99 & 222,13 & 222,33 & 57,18 & 389,31 & 47,34 & 8,90 & 36,26 & 126,13 & 46,22 & 46,31 & 105,63 \\
\hline Salamandra salamandra & 30TUK26 & 100,00 & 94,91 & 111,68 & 37,00 & 6277,75 & 272,94 & $-24,75$ & 297,69 & 72,72 & 179,80 & 180,69 & 21,95 & 555,93 & 68,55 & 16,80 & 33,22 & 175,91 & 73,17 & 76,48 & 149,86 \\
\hline Salamandra salamandra & 30TUK27 & 100,00 & 89,82 & 111,24 & 37,00 & 6224,85 & 266,71 & $-28,78$ & 295,48 & 70,00 & 173,92 & 174,90 & 17,89 & 566,20 & 70,59 & 18,04 & 32,43 & 178,04 & 76,65 & 80,72 & 150,68 \\
\hline Salamandra salamandra & $\begin{array}{l}30 T U K 28 \\
\end{array}$ & 100,00 & 80,02 & 110,48 & 37,01 & 6176,16 & 256,19 & $-36,62$ & 292,81 & 47,95 & 163,94 & 164,79 & 9,42 & 625,94 & 76,25 & 21,04 & 31,64 & 195,47 & 85,60 & 91,35 & 169,35 \\
\hline Salamandra salamandra & $\begin{array}{l}30 \text { TUK29 } \\
30\end{array}$ & 100,00 & $\begin{array}{ll}90,0<3 \\
97,39\end{array}$ & $\begin{array}{l}\mid 110,40 \\
111,69\end{array}$ & $\frac{31,101}{37,25}$ & $\begin{array}{ll}017,100 \\
6172,59\end{array}$ & $\mid \begin{array}{l}\mid 27,192 \\
272,32\end{array}$ & $\begin{array}{l}-22,07 \\
-207\end{array}$ & $\begin{array}{l}29,01 \\
294,39\end{array}$ & 77, 73 & $\mid 179,98$ & $\begin{array}{l}\mid 184,63 \\
181,63\end{array}$ & $\begin{array}{r}34,4 c^{2} \\
249\end{array}$ & $\mid 492,, 97$ & $\begin{array}{l}0,20 \\
64,06 \\
\end{array}$ & $\mid \begin{array}{l}\mid 1,044 \\
16,68\end{array}$ & 32,32 & $\mid \begin{array}{l}\mid 755,41 \\
155\end{array}$ & $\begin{array}{l}\mid l 3,00 \\
71,03\end{array}$ & 74,46 & $\begin{array}{l}127,42 \\
127,43\end{array}$ \\
\hline Salamandra salamandra & 30TUK35 & 100,00 & 129,37 & 113,05 & 36,90 & 6435,29 & 307,23 & 3,53 & 303,71 & 102,52 & 215,81 & 216,31 & 51,82 & 408,73 & 50,69 & 10,20 & 35,68 & 132,82 & 50,62 & 51,16 & 108,39 \\
\hline Salamandra salamandra & \begin{tabular}{|l|l|}
$30 T U K 37$ \\
\end{tabular} & 100,00 & 95,44 & 111,44 & 37,00 & 6240,27 & 272,10 & $-24,57$ & 296,67 & 77,51 & $\mid \begin{array}{l}2179,49 \\
\end{array}$ & 180,74 & 22,86 & 520,51 & 67,05 & 16,80 & 32,78 & $\begin{array}{ll}165,76 \\
\end{array}$ & 72,71 & 76,01 & 133,20 \\
\hline Salamandra salamandra & 30TUK46 & 100,00 & 100,93 & 111,37 & 36,83 & 6305,77 & 278,33 & $-20,28$ & 298,61 & 82,70 & 186,21 & 186,97 & 27,26 & 508,86 & 65,08 & 15,92 & 33,13 & 163,43 & 70,14 & 72,82 & 130,45 \\
\hline Salamandra salamandra & $\begin{array}{l}30 \text { TUK48 } \\
\end{array}$ & 100,00 & 88,76 & 110,42 & 37,00 & 6176,06 & 264,24 & $-29,81$ & 294,05 & 71,09 & 172,36 & 173,36 & 17,44 & 539,78 & 70,30 & 18,85 & 31,91 & 171,63 & 78,73 & 83,12 & 134,92 \\
\hline Salamandra salamandra & $\begin{array}{l}\text { SOTUK54 } \\
300\end{array}$ & $\begin{array}{l}100,00 \\
\end{array}$ & $\begin{array}{ll}0,0,10 \\
131,14\end{array}$ & \begin{tabular}{|l|l|l|l|}
112,60 \\
\end{tabular} & $\begin{array}{l}31,00 \\
36,09 \\
\end{array}$ & $\begin{array}{ll}0174,50 \\
6545\end{array}$ & \begin{tabular}{|l|l|}
310,48 \\
\end{tabular} & $\begin{array}{r}-25,01 \\
3,62\end{array}$ & $\begin{array}{l}306,87 \\
306,87\end{array}$ & $\begin{array}{r}\mid r, 03 \\
113,72 \\
\end{array}$ & 219,40 & 219,58 & $\begin{array}{l}\mid r, 44 \\
52,15\end{array}$ & $\begin{array}{l}\mid \\
401,54\end{array}$ & $\begin{array}{ll}0,00,23 \\
\end{array}$ & $\mid$\begin{tabular}{|c|c|}
9,73 \\
9,73
\end{tabular} & 35,69 & \begin{tabular}{|l|l|l|l|l|}
130,93 \\
\end{tabular} & 49,81 & 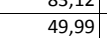 & $\begin{array}{ll}104,56 \\
104,96\end{array}$ \\
\hline Salamandra salamandra & 30TUK56 & 100,00 & 118,29 & 111,17 & 36,41 & 6398,64 & 294,72 & $-5,92$ & 300,64 & 92,11 & 204,53 & 204,95 & 41,94 & 438,19 & 55,93 & 12,85 & 34,18 & 141,45 & 59,34 & 60,68 & 111,31 \\
\hline Salamandra salamandra & 30TUK57 & 100,00 & 117,59 & 110,53 & 36,51 & 6344,52 & 292,32 & $-6,49$ & 298,81 & 102,44 & 202,68 & 203,47 & 41,46 & 410,25 & 54,77 & 12,60 & 34, & 132,62 & 58,94 & 59,81 & 98,93 \\
\hline Salamandra salamandra & 30TUK65 & 100,00 & 13 & 17 & 36,0 & 6534,47 & 309,78 & 5,08 & 304,70 & 113,12 & 220,75 & 220,75 & 53,2 & 387,33 & 48,71 & 9,8 & 35, & 125,27 & 49,91 & 49,91 & 99,34 \\
\hline Salamandra salamandra & 30TUK66 & 100,00 & 113,97 & 110,31 & 36,34 & 6387,97 & 290,11 & $-9,62$ & 299,73 & 93,62 & 200,12 & 200,66 & 38,09 & 443,80 & 57,94 & 13,48 & 33,95 & 143,79 & 62,19 & 63,67 & 109,62 \\
\hline Salamandra salamandra & 30TUK67 & 100,00 & 115,18 & 109,57 & 36,26 & 6353,57 & 289,42 & $-8,52$ & 297,94 & \begin{tabular}{l|l|}
99,45 & \\
\end{tabular} & 200,54 & 201,23 & 39,29 & 424,64 & 56,42 & 13,34 & 33,94 & 137,14 & 61,37 & 62,58 & 102,34 \\
\hline Salamandra salamandra & 30TUK68 & 100,00 & 112,38 & 108,73 & 36,22 & 6287,41 & 284,87 & $-10,69$ & 295,57 & 119,11 & 196,26 & 197,41 & 37,17 & 413,36 & 57,04 & 13,77 & 34,30 & 134,88 & 62,91 & 64,32 & 94,84 \\
\hline Salamandra salamandra & 30TUK69 & 100,00 & 100,89 & 108,38 & 36,53 & 6170,98 & 272,44 & $-20,11$ & 292,55 & 118,39 & 183,75 & 184,77 & 28,19 & 441,47 & 62,70 & 16,10 & 34,16 & 146,82 & 70,40 & 73,12 & 97,69 \\
\hline Salamandra salamandra & 30TUK75 & 100,00 & 136,04 & 17 & 35 & 85,37 & 12,70 & 8,06 & 304,64 & 107,44 & 224,68 & 224,68 & 55,91 & 383,44 & 47,17 & 9,64 & 35,07 & 123,98 & 48,72 & 48,72 & 99,62 \\
\hline Salamandra salamandra & \begin{tabular}{|l|}
$30 T U K 76$ \\
\end{tabular} & 100,00 & 126,44 & 29 & 35,91 & 6486,12 & 51 & 0,41 & 301,10 & 104,01 & 213,75 & $\begin{array}{l}214,03 \\
214,03\end{array}$ & 48,02 & 399,10 & 51,13 & 11,25 & 34,41 & 128,63 & 54,68 & 54,91 & 99,41 \\
\hline Salamandra salamandra & 30TUK77 & 10 & 12 & 10 & 35,97 & 6458,48 & 30 & 2,79 & 299,00 & 98,53 & 215,16 & 215,53 & 50 & 387,77 & 49,53 & 11,21 & 34,19 & 124,92 & 53,75 & 54,05 & 96,10 \\
\hline Salamandra salamandra & 30TUK86 & 100,00 & 133,66 & 108,22 & 35,36 & $\begin{array}{ll}64561,83 \\
6561\end{array}$ & 308,14 & 6,79 & 301,35 & 98,74 & 221,89 & 222,00 & 53,67 & 390,65 & 47,58 & $\begin{array}{l}11,21 \\
0,50\end{array}$ & 34,35 & \begin{tabular}{l|l}
125,95 \\
\end{tabular} & 51,28 & 51,34 & 101,24 \\
\hline Salamandra salamandra & 30TUK88 & 100,00 & 120,92 & 106,42 & 35,70 & 408,92 & 291,84 & $-2,97$ & 294,81 & 109,49 & 205,88 & 207,34 & 43,50 & 407,06 & 52,75 & 12,92 & 33,55 & 130,32 & 59,09 & 60,40 & 98,12 \\
\hline Salamandra salamandra & 30TUK89 & 100,00 & 98,05 & 106,76 & 36,3 & 11,20 & 268,70 & $-21,19$ & 289,90 & 113,77 & 181,84 & 182,58 & 25,62 & 478,86 & 64,70 & $17, \varepsilon$ & 32,27 & 155,90 & 74,58 & 78,62 & 110,54 \\
\hline Salamandra salamandra & $\begin{array}{l}\text { 30TUK98 } \\
30 \text {. }\end{array}$ & 100,00 & 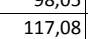 & 55 & 35,4 & $\begin{array}{ll}641,24,03 \\
642,\end{array}$ & 287,68 & $\begin{array}{c}-21,13 \\
-5,43\end{array}$ & 293,11 & 92,36 & $\begin{array}{l}\mid 01,04 \\
202,24\end{array}$ & $\begin{array}{l}\mid 0,30 \\
203,76\end{array}$ & $\begin{array}{l}20,0<2 \\
39,80\end{array}$ & $\begin{array}{l}47,00 \\
433,53\end{array}$ & 54,70 & $\begin{array}{l}14,000 \\
14,08 \\
\end{array}$ & 32,57 & $\begin{array}{l}137,60 \\
137,60\end{array}$ & $\begin{array}{l}62,24 \\
62,2 \\
\end{array}$ & $\begin{array}{l}60,0<39 \\
64,39\end{array}$ & 106,93 \\
\hline Salamandra salamandra & $\begin{array}{l}\text { 30TUK99 } \\
\end{array}$ & 100,00 & 96,32 & 106,41 & 36,45 & 6227,65 & 266,97 & $-21,79$ & 288,76 & $\begin{array}{ll}105,56 \\
\end{array}$ & 180,69 & 181,32 & 24,05 & 503,34 & 65,66 & 18,77 & 31,15 & 161,06 & 76,80 & 81,29 & 120,12 \\
\hline Salamandra salamandra & 30TUL10 & 100,00 & 105,50 & 113,35 & 38,00 & 6158,47 & 279,81 & $-14,82$ & 294,62 & 66,88 & \begin{tabular}{|c|}
186,88 \\
\end{tabular} & 189,25 & 32,29 & 457,60 & 58,11 & 14,33 & 32,32 & 143,10 & 64,54 & 67,35 & 118,90 \\
\hline Salamandra salamandra & 30TUL24 & 100,00 & 119,42 & 年 & 38,87 & 27,27 & 29 & $-1,5$ & 293, & 93,05 & 198,64 & 201,77 & 44 & 379,32 & 47, & 12, & 31, & 118,09 & 56,54 & 59,31 & 97,02 \\
\hline Salamandra salamandra & 30TU & 100,00 & 95,80 & & 37,54 & & & -23, & 292 & 103 & 4 & 7 & & 485,58 & 64, & 17 & & 153,65 & 72,46 & 76,43 & 119,35 \\
\hline \begin{tabular}{|l} 
Salamandra salamandrandra \\
Sala
\end{tabular} & $\begin{array}{l}\text { SOTLSO } \\
30 \text { TUL50 }\end{array}$ & $\begin{array}{l}100,00 \\
100\end{array}$ & $\begin{array}{r}9,06,06 \\
106,0\end{array}$ & \begin{tabular}{|l|}
109,31 \\
109
\end{tabular} & $\begin{array}{ll}30,34 \\
36,96\end{array}$ & $\begin{array}{ll}0130,003 \\
6168,92\end{array}$ & \begin{tabular}{|l|}
279,50 \\
277,19 \\
\end{tabular} & - & 2993,04 & $\begin{array}{l}\mid 10,01 \\
124,70\end{array}$ & $\begin{array}{l}\mid 71,54 \\
188,09\end{array}$ & $\begin{array}{l}\mid 789,54 \\
189,54\end{array}$ & 232,53 & |46,50 & $\begin{array}{l}44,25 \\
58,77 \\
\end{array}$ & $\begin{array}{l}1,200 \\
15,01\end{array}$ & $34,0<2$ & \begin{tabular}{|l|}
33,03 \\
137,72
\end{tabular} & $\begin{array}{l}\mid 2 L, 40 \\
65,86\end{array}$ & $\begin{array}{l}60,45 \\
68,31\end{array}$ & $\begin{array}{r}\mid 11,53 \\
92,25 \\
\end{array}$ \\
\hline Salamandra salamandra & 30TUL90 & 100,00 & 88,55 & 106,60 & 36,78 & 6147,86 & 258,66 & $-27,33$ & 285,99 & 96,43 & 172,41 & 172,71 & 18,22 & 541,27 & 69,75 & 20,88 & 30,08 & 172,62 & 83,43 & 88,12 & 130,46 \\
\hline Salamandra salamandra & 30TUN02 & 100,00 & 106,83 & 111,48 & 40,00 & 5549,11 & 266,75 & $-9,47$ & 276,22 & 76,01 & 180,08 & \begin{tabular}{|c|}
180,08 \\
\end{tabular} & 37,55 & 606,52 & 77,94 & 29,18 & 29,16 & 213,89 & 110,31 & 110,31 & 159,96 \\
\hline Salaman & $30 T U N C$ & 100,00 & 80,94 & 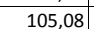 & 39, & , & 233,09 & $-27,70$ & 260,79 & 52,43 & 1512 & 15120 & 16,81 & 841,23 & 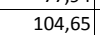 & 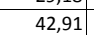 & 25 & 284,91 & 152,84 & 153,09 & 231,68 \\
\hline Salamandra salamandra & 50101 & & & & & & & $-37,60$ & 254,91 & 40,02 & 137,45 & $13 \pi$ & $\frac{1,0}{5,6}$ & $\mid \begin{array}{l}\mid 963,07 \\
963,07\end{array}$ & 117, & 49, & 24 & 320,48 & $\mid 173,26$ & 173,77 & 271 \\
\hline Salamandra salamandra & 30TUN07 & 100,00 & 74,75 & 100,90 & 39,99 & 5084,37 & 219,96 & $-29,25$ & 249,21 & \begin{tabular}{l|l}
40,05 \\
48,
\end{tabular} & 142,29 & 142,70 & 13,83 & 947,55 & 117,25 & 48,74 & 24,89 & 316,92 & 171,84 & 174,25 & 263,42 \\
\hline Salamandra salamandra & $\begin{array}{l}\text { 30TUN08 } \\
\end{array}$ & 100,00 & 104,95 & 97,14 & 41,16 & 4688,53 & 236,60 & 3,67 & 232,94 & 81,42 & 165,94 & 167,09 & 47,70 & 829,06 & 108,07 & 42,92 & 26,34 & 282,16 & 152,16 & 159,10 & 216,77 \\
\hline Salamandra salamandra & 30TUN13 & 100,00 & 98,49 & 108,60 & 39,99 & 114,90 & 54,58 & $-15,25$ & 269,83 & 69,63 & 170,10 & 170,10 & 31,66 & 678,60 & 85,67 & 34,26 & 27,12 & 233,87 & 124,96 & 124,96 & 179,56 \\
\hline Salam & $30 \mathrm{TUN}$ & 10 & & & 39, & 40,96 & 236 & $-23,1$ & 259,20 & 58,00 & 155 & 155 & 21,9 & 811 & 101 & & 25 & & 14 & & \\
\hline Salamandra salamandra & 30TUN16 & 100,00 & $\begin{array}{ll}78,12 \\
8,12\end{array}$ & 102,39 & 39,84 & 5167,15 & 226,15 & $-28,03$ & 254,18 & 51,17 & $\begin{array}{l}43,0,75 \\
146,\end{array}$ & 147,05 & $\mid \frac{\mid 1,1+1}{15,97}$ & $|888,69|$ & 109,61 & \begin{tabular}{|l|l|}
45,90 \\
458
\end{tabular} & $\mid$ & 297,35 & \begin{tabular}{|l}
162,21 \\
162,9
\end{tabular} & $\begin{array}{l}163,98 \\
\end{array}$ & 243,87 \\
\hline
\end{tabular}




\begin{tabular}{|c|c|c|c|c|c|c|c|c|c|c|c|c|c|c|c|c|c|c|c|c|c|}
\hline TAXON & UTM & $\mathrm{km} 2$ & BIO1 & B102 & $\mathrm{BIO3}$ & 8104 & B105 & B106 & B107 & B108 & B109 & 81010 & B1011 & BIO12 & B1013 & B1014 & 81015 & BIO16 & B1017 & B1018 & $\begin{array}{ll}\text { BIO19 } \\
\end{array}$ \\
\hline Salamandra salamandra & 30TUN17 & 100,00 & 79,01 & 100,01 & 39,96 & 5033,41 & 222,44 & $-24,72$ & 247,16 & 53,18 & 145,73 & 146,35 & 18,47 & 921,48 & 114,09 & 47,83 & 24,58 & 307,72 & 168,94 & 171,41 & 252,54 \\
\hline Salamandra salamandra & 30TUN26 & 100,00 & 73,81 & 101,07 & 39,60 & 5150,06 & 221,03 & $-31,47$ & 252,51 & 47,44 & 142,43 & 142,67 & 12,10 & 917,93 & 111,60 & 47,71 & 23,88 & 303,48 & 168,51 & 169,33 & 252,25 \\
\hline Salamandra salamandra & 30TUN27 & 100,00 & 75,72 & 99,31 & 39,73 & 5038,60 & 219,20 & $-27,67$ & 246,87 & 50,11 & 142,64 & 143,19 & 15,47 & 937,74 & 114,70 & 48,99 & 23,88 & 310,48 & \begin{tabular}{|l|l|}
172,98 \\
\end{tabular} & 174,52 & 257,13 \\
\hline Salamandra salamandra & 30TUN28 & 100,00 & 101,45 & 94,45 & 40,44 & 4692,05 & 231,99 & 1,17 & 230,82 & \begin{tabular}{c|c}
78,75 \\
\end{tabular} & 162,61 & 163,93 & 44,35 & 848,18 & 108,39 & 43,83 & 25,41 & 286,60 & 156,44 & 162,58 & 223,46 \\
\hline Salamandra salamandra & 30TUN29 & 100,00 & 120,79 & 86,30 & 40,72 & 4299,01 & 236,04 & 26,43 & 209,61 & \begin{tabular}{|l|l|}
101,17 \\
\end{tabular} & 176,11 & 178,13 & 68,15 & 816,80 & 107,64 & 40,96 & 26,72 & 278,91 & \begin{tabular}{|l|l|}
147,87 \\
\end{tabular} & 158,09 & 210,73 \\
\hline Salamandra salamandra & 30 TUN34 & 100,00 & 88,73 & 103,95 & 39,55 & 5248,49 & 239,22 & $-20,92$ & 260,13 & 62,25 & 158,39 & 158,48 & 24,98 & \begin{tabular}{|l|l|}
770,03 \\
\end{tabular} & 94,34 & 39,53 & 24,52 & 256,87 & 142,16 & 142,87 & 205,21 \\
\hline Salamandra salamandra & 30TUN35 & 100,00 & 83,84 & 102,02 & 39,59 & 5166,43 & 231,60 & $-23,32$ & 254,91 & 57,79 & 152,46 & 152,70 & 21,45 & 828,77 & 101,18 & 42,98 & 24,12 & 275,09 & 153,42 & 153,77 & 222,86 \\
\hline Salamandra salamandra & 30TUN36 & 100,00 & $\begin{array}{l}80,04,83 \\
81,2\end{array}$ & 100,10 & $\begin{array}{ll}39,74 \\
39,7\end{array}$ & 5077,09 & 226,35 & -23,31 & 249,66 & 56,39 & 149,19 & 149,59 & 20,72 & 872,92 & 106,65 & 45,55 & 23,93 & 289,19 & \begin{tabular}{|l|l|l}
161,93 \\
\end{tabular} & $\mid 162,79$ & 235,85 \\
\hline Salamandra salamandra & 30TUN37 & 100,00 & 79,28 & 97,90 & 39,70 & 4982,78 & 220,31 & $-23,47$ & 243,78 & 54,46 & 145,36 & 145,99 & 19,53 & 923,41 & 112,72 & 48,30 & 23,67 & 304,85 & 171,00 & 172,65 & 251,05 \\
\hline Salamandra salamandra & 30TUN38 & 100,00 & 77,77 & 95,54 & 39,75 & 4880,97 & 215,01 & $-22,60$ & 237,61 & 52,92 & 142,35 & 143,25 & 19,38 & 971,99 & 118,52 & 50,96 & 23,61 & 319,81 & 179,35 & 182,11 & 265,67 \\
\hline Salamandra salamandra & 30TUN39 & 100,00 & 107,75 & 88,69 & 40,18 & 4470,70 & 229,18 & 11,69 & 217,48 & 87,06 & 165,69 & 167,45 & 53,23 & 867,20 & 111,23 & 44,20 & 25,51 & 293,17 & 158,73 & 167,19 & 228,33 \\
\hline Salamandra salamandra & 30TUN43 & 100,00 & 93,60 & 104,56 & 39,16 & 5282,69 & 244,86 & $-17,88$ & 262,73 & 67,40 & 163,50 & 163,55 & 29,04 & 719,69 & 87,54 & 36,59 & 24,45 & 238,82 & 131,28 & 133,60 & 189,55 \\
\hline Salamandra salamandra & 30 TUN45 & 100,00 & 76,39 & 100,89 & 39,15 & 5173,28 & 224,06 & $-29,82$ & 253,88 & 50,36 & 145,58 & 145,65 & 14,36 & \begin{tabular}{l|l|}
876,55 \\
\end{tabular} & 104,95 & 45,73 & 23,18 & 286,34 & \begin{tabular}{|l|l}
161,28 \\
\end{tabular} & 161,54 & 237,51 \\
\hline Salamandra salamandra & 30TUN46 & 100,00 & 72,65 & 99,05 & 39,24 & 5099,93 & 217,71 & $-31,28$ & 248,99 & 47,16 & 140,96 & 141,15 & 11,77 & 929,34 & 111,11 & 48,75 & 22,86 & 302,76 & 171,73 & 171,79 & 253,64 \\
\hline Salamandra salamandra & 30TUN47 & 100,00 & 66,54 & 97,04 & 39,20 & 5034,80 & 209,15 & $-35,25$ & 244,41 & 40,70 & 134,10 & 134,40 & 6,82 & 1002,78 & 119,17 & 52,86 & 22,54 & 324,81 & \begin{tabular}{ll|}
184,95 \\
\end{tabular} & 185,50 & 276,72 \\
\hline Salamandra salamandra & 30TUN48 & 100,00 & 67,51 & 94,53 & 39,34 & 4919,88 & 205,76 & $-31,83$ & 237,59 & \begin{tabular}{|c|}
39,98 \\
\end{tabular} & 133,37 & 134,05 & 9,35 & 1040,16 & 123,97 & 54,86 & 22,76 & 337,29 & 191,38 & 193,21 & 288,05 \\
\hline Salamandra salamandra & 30TUN49 & 100,00 & 100,95 & 88,36 & 39,92 & 4525,81 & 223,92 & 5,10 & 218,82 & 80,02 & 159,82 & 161,59 & 46,13 & 905,04 & 113,95 & 46,21 & 24,80 & 303,52 & 165,79 & $\mid 173,43$ & 241,78 \\
\hline Salamandra salamandra & $30 T$ TN54 & 100,00 & 75,20 & 101,38 & 39,01 & 5232,19 & 224,77 & $-31,92$ & 256,68 & 49,17 & \begin{tabular}{|l|l|}
145,45 \\
\end{tabular} & 145,45 & 12,64 & 858,34 & 101,26 & 44,68 & 22,65 & 277,25 & 156,33 & 156,65 & 231,81 \\
\hline Salamandra salamandra & 30TUN55 & 100,00 & 67,09 & 99,61 & 38,96 & 5184,02 & 214,98 & $-37,53$ & 252,51 & 40,85 & 137,07 & 137,07 & 5,56 & 938,72 & 109,96 & 49,34 & 22,30 & 301,20 & 171,41 & 171,43 & 256,99 \\
\hline Salamandra salamandra & 30TUN56 & 100,00 & 54,14 & 97,61 & 38,77 & 5154,62 & 200,68 & $-47,84$ & 248,52 & 24,53 & 124,04 & 124,04 & $-6,25$ & 1057,32 & 122,17 & 56,16 & 21,65 & 335,88 & 192,65 & 192,66 & 294,61 \\
\hline Salamandra salamandra & 30TUN57 & 100,00 & 76,96 & 95,17 & 39,27 & 4934,79 & 215,46 & $-24,06$ & 239,52 & 52,90 & 142,68 & 143,37 & 18,05 & 952,74 & 114,06 & 49, & 22, & 310,09 & 176,30 & 177,79 & 259,61 \\
\hline Salamandra salamandra & 30TUN58 & 100,00 & 64,12 & 93,81 & 39,15 & 4927,86 & 202,28 & $\begin{array}{l}-34,64 \\
-34\end{array}$ & 236,92 & 36,02 & 130,13 & 130,90 & $\begin{array}{r}6,0,13 \\
\end{array}$ & 1062,61 & 125,24 & 56,25 & 22,12 & 342,21 & 195,97 & 197,36 & 294,85 \\
\hline Salamandra salamandra & 30 TUN59 & 100,00 & 114,75 & 83,58 & 39,86 & 4343,91 & 229,66 & 21,50 & 208,16 & 95,38 & 170,75 & 172,82 & 61,66 & $\begin{array}{r}863,78 \\
\end{array}$ & 110,35 & 42,60 & 25,75 & 293,55 & 155,75 & 166,59 & 229,39 \\
\hline Salamandra salamandra & 30TUN65 & 100,00 & 69,90 & 98,53 & 38,94 & 5144,39 & 215,94 & $-34,28$ & 250,22 & 43,91 & 139,24 & 139,24 & 8,80 & 926,83 & 108,09 & 48,77 & 21,90 & 296,21 & 169,89 & 169,89 & 252,41 \\
\hline Salamandra salamandra & 30TUN68 & 100,00 & 96,86 & 88,38 & 39,26 & 4626,31 & 222,21 & 0,02 & 222,19 & \begin{tabular}{c|c|}
75,25 \\
\end{tabular} & 157,31 & 158,81 & 40,88 & 912,28 & 112,01 & 46,25 & 23,97 & 302,74 & 166,82 & 173,13 & 246,33 \\
\hline Salamandra salamandra & 30TUN69 & 100,00 & 117,26 & 81,33 & 39,36 & 4297,31 & 229,34 & 25,31 & 204,04 & 98,33 & \begin{tabular}{|l|l|}
172,43 \\
\end{tabular} & 174,63 & 64,57 & 870,67 & 110,78 & 42,19 & 25,82 & 296,73 & 155,49 & 167,92 & 233,20 \\
\hline Salamandra salamandra & 30TUN75 & 100,00 & $\begin{aligned} & 11,20 \\
& 83,51\end{aligned}$ & $\begin{array}{l}1,30 \\
96,70 \\
\end{array}$ & $\begin{array}{l}35,009 \\
38,99\end{array}$ & $\begin{array}{ll}4254,13,08 \\
504,\end{array}$ & $\mid 225,18$ & 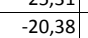 & 245,56 & 50,29 & $\begin{array}{l}\mid 7,431,16 \\
151\end{array}$ & \begin{tabular}{|l|l|l|l|l|}
151,18 \\
\end{tabular} & 22,95 & 856,41 & \begin{tabular}{|l|l|l|l|l|}
101,02 \\
\end{tabular} & $\begin{array}{l}42,13 \\
44,38 \\
\end{array}$ & 22,20 & 276,21 & \begin{tabular}{|l|}
158,04 \\
158,04
\end{tabular} & \begin{tabular}{|l|}
158,04 \\
158,
\end{tabular} & 229,83 \\
\hline Salamandra salamandra & 30TUN76 & 100,00 & 80,56 & 94,80 & 38,99 & 4971,70 & 219,32 & $-21,07$ & 240,39 & 56,74 & 147,03 & 147,40 & 21,09 & 907,74 & 107,14 & 47,28 & 22,14 & 292,77 & 168,25 & 168,85 & 245,53 \\
\hline Salamandra salamandra & 30TUN79 & 100,00 & 123,58 & 78,04 & 39,04 & 4201,48 & 231,11 & 33,69 & $\begin{array}{l}24,30,42 \\
197\end{array}$ & 105,42 & 177,32 & 179,72 & 71,90 & 867,25 & $\mid 110,66$ & 40,79 & 26,48 & 298,05 & 152,39 & 167,59 & 234,12 \\
\hline Salamandra salamandra & 30TUN85 & 100,00 & 75,40 & 95,93 & 38,82 & 5077,38 & 217,77 & $-27,32$ & 245,09 & 50,12 & 143,84 & 143,85 & 14,98 & 908,83 & 105,03 & 47 & 21, & 288,47 & 167,41 & 167,41 & 246,18 \\
\hline Salamandra salamandra & 30TUN86 & 100,00 & 66,77 & 94,64 & 38,78 & 5038,34 & 207,94 & $-33,90$ & 241,84 & 40,28 & 134,84 & 135,01 & 7,35 & 990,20 & 113,64 & 52,54 & 21,05 & 312,65 & $\mid 183,28$ & $\mid 183,33$ & 271,50 \\
\hline Salamandra salamandra & \begin{tabular}{|l|}
30 TUN87 \\
3
\end{tabular} & 100,00 & $\begin{array}{ll}80,717 \\
88,\end{array}$ & $\mid \begin{array}{cc}44,04 \\
89,96\end{array}$ & $\begin{array}{l}30,10 \\
38,97 \\
\end{array}$ & $\begin{array}{ll}300,034 \\
4779,18\end{array}$ & 219,30 & $\begin{array}{c}-9,2,24 \\
-9,24\end{array}$ & 2228,53 & - 40,20 & $\begin{array}{l}\mid 35,04 \\
151,61\end{array}$ & \begin{tabular}{|l|}
153,06 \\
153
\end{tabular} & $\mid \begin{array}{l}31,26 \\
31,26\end{array}$ & $\begin{array}{l}99,20 \\
919,68\end{array}$ & \begin{tabular}{|l|l|l|l|l|}
109,43 \\
\end{tabular} & $\begin{array}{l}32,54 \\
47,08\end{array}$ & 22,49 & \begin{tabular}{|l|l|l|l|l|}
299,16 \\
\end{tabular} & \begin{tabular}{|l|}
169,20 \\
169,77
\end{tabular} & \begin{tabular}{|l|}
173,33 \\
173,11
\end{tabular} & 249,70 \\
\hline Salamandra salamandra & 30TUN88 & 100,00 & 112,28 & 82,25 & 38,92 & 4422,59 & 227,97 & 18,89 & 209,08 & \begin{tabular}{|c|}
92,69 \\
\end{tabular} & 169,27 & 171,39 & 58,07 & 878,46 & 108,95 & 42,39 & 24,85 & 296,31 & 157,07 & 168,16 & 237,92 \\
\hline Salamandra salamandra & 30TUN94 & 100,00 & 97,51 & 94,17 & 38,50 & 5005,21 & 235,48 & $-6,21$ & 241,69 & 73,75 & \begin{tabular}{ll|}
164,15 \\
\end{tabular} & 164,25 & 36,64 & 776,04 & 91,17 & 38,84 & 22,19 & 250,43 & 142,05 & 142,05 & 206,47 \\
\hline Salamandra salamandra & 30TUN95 & 100,00 & 78,28 & 94,44 & 38,47 & 5046,53 & 218,68 & $-23,58$ & 242,26 & 53,5 & 146,15 & 146,33 & 18, & 901,17 & 103,65 & 46, & 21, & 285,22 & 166,28 & 166,34 & 244,29 \\
\hline Salamandra salamandra & 30TUN96 & 100,00 & 78,44 & 92,35 & 38,73 & 4948,25 & 215,06 & $-21,10$ & 236,15 & 54,41 & 144,41 & 145,20 & 19,49 & 937,75 & 108,48 & 48,6 & 21,28 & 298,43 & 173,79 & 174,56 & 255,77 \\
\hline Salamandra salamandra & 30TUN97 & 100,00 & 96,77 & 86,74 & 38,76 & 4674,80 & 222,08 & 0,53 & 221,54 & \begin{tabular}{|l|l|}
75,08 \\
\end{tabular} & 157,79 & 159,46 & 40,0 & 905,34 & 108,19 & 45, & 22,97 & 296,79 & 165,17 & 171,07 & 246,67 \\
\hline Salamandra salamandra & 30TUN98 & 100,00 & 117,02 & 79,04 & 38,54 & 4334,54 & 228,44 & 25,87 & 202,56 & 97,81 & 172,57 & 174,82 & 63,65 & 887,01 & 109,93 & 41, & 25,30 & 300,98 & 156,30 & 170,18 & 242,66 \\
\hline Salamandra salamandra & 30TUN99 & 100,00 & 129,86 & 72,59 & 38,23 & 4062,29 & 231,07 & 43,82 & 187,25 & \begin{tabular}{|l|l|}
112,45 \\
\end{tabular} & 181,34 & 183,99 & 79,52 & 896,31 & 113,76 & 40, & 27,29 & 311,29 & 153,49 & 173,86 & 247,30 \\
\hline Salamandra salamandra & 30TUP01 & 98,00 & 84 & 77,05 & 40,95 & 0,73 & 49 & 46 & 185,86 & 115,81 & 181,85 & 184,96 & 85,62 & 834 & 112,99 & 41, & 27, & 284,33 & 147,81 & 160,77 & 212,72 \\
\hline Salamandra salamandra & 30TUP10 & 100,00 & 41 & 81,58 & 40,93 & 4066,27 & 235,21 & & $\begin{array}{l}196,004 \\
196,94\end{array}$ & $\begin{array}{l}\mid 110,011 \\
110,11\end{array}$ & 180,23 & 182,88 & 78 & 820,87 & 109,97 & 40, & 27,43 & 280,47 & \begin{tabular}{|l|}
146,78 \\
146,
\end{tabular} & 158,76 & 210,20 \\
\hline Salamandra salamandra & 30TUP11 & 96,00 & & 78,27 & 40,69 & 3961,70 & 231 & & 189,96 & 111 & 179,31 & 182,19 & 80 & 846,18 & 113,34 & 41, & 27,45 & 289,11 & 150,50 & 163,76 & 218,27 \\
\hline Salamandra salamandra & 30TUP20 & 100,00 & & 77,88 & 40,29 & 3995,93 & 237,12 & 46,48 & 190,63 & 117,35 & 185,62 & 188,38 & 80,65 & 802,19 & 107,72 & 38, & 27,90 & 276,54 & 141,34 & 155,20 & 206,81 \\
\hline Salamandra salamandra & 30TUP21 & 65,00 & 13 & 76,72 & 40,33 & 42,74 & 28 & 45 & 187, & 115,31 & 182,62 & 185,54 & & 833,38 & 111,64 & 40, & 27,68 & 286,53 & 147,33 & 161,81 & 215,78 \\
\hline Salamandra salamandra & 30TUP40 & 100,00 & 12 & 79,37 & 39, & 26,27 & 32,18 & 35,84 & 196,34 & 107,63 & 178,33 & 180,71 & 74,97 & 848,13 & 111,03 & 41, & 26,89 & 291,40 & 150,82 & 164,76 & 223,18 \\
\hline Salamandra salamandra & $\begin{array}{l}30 \text { TOP50 } \\
30\end{array}$ & 98,00 & & $\begin{array}{l}75,96 \\
79,96\end{array}$ & 39, & 4200,57 & | 228,53 & 29,22 & 199,32 & $\begin{array}{l}100,99 \\
100\end{array}$ & $\begin{array}{l}173,14 \\
173,14\end{array}$ & \begin{tabular}{|l|l|l|l|}
175,58 \\
\end{tabular} & \begin{tabular}{l|l}
67,98 \\
67
\end{tabular} & $\begin{array}{l}840,13 \\
880,12\end{array}$ & $\mid \begin{array}{l}111,03 \\
113,34\end{array}$ & 42,80 & $\begin{array}{l}20,05 \\
26,28\end{array}$ & 300,74 & $\begin{array}{l}\mid 50,02 \\
156,98 \\
\end{array}$ & $\begin{array}{l}104,10 \\
170,55\end{array}$ & 234,89 \\
\hline Salamandra salamandra & 30TUP60 & 75,00 & & 75,75 & 39,19 & 4064,14 & 232,53 & 42,05 & 190,47 & 112,40 & 181,46 & 184,08 & 79,68 & 859,68 & 111,71 & 40, & 27,31 & 297,76 & 149,96 & 167,00 & 230,73 \\
\hline Salamandra salamandra & 30TUP70 & 60,00 & 138,51 & 71,72 & 38,94 & 3944,71 & 235,56 & 53,15 & 182,42 & 121,71 & 188,22 & 190,99 & 89,35 & 851,58 & 111,16 & 38, & 28,35 & 298,79 & 145,09 & 165,69 & 231,25 \\
\hline Salamandra salamandra & 30TUP80 & 52,00 & 14 & 69,54 & 38, & 3892,03 & 235,48 & 57,06 & 178 & 124 & 189, & 192 & 92,19 & 868 & 112 & 37, & 28 & 306,16 & 146,00 & 169,13 & 238,68 \\
\hline Salamandra salamandra & $30 T \mathrm{TL}$ & 55,00 & & & 38 & & & 56 & $1 /$ & 123 & & $19 c$ & & 899 & 116 & 39, & & 31 & 150,91 & 175,76 & 250,17 \\
\hline Salamandra salamandra & 30TVK08 & 100,00 & 124,39 & 104,41 & 35,06 & 6501,56 & 294,21 & 1,24 & 292,97 & \begin{tabular}{|c|}
83,41 \\
\end{tabular} & 209,89 & 211,86 & 45,44 & 432,64 & 51,12 & 13,14 & 32,69 & 139,51 & 58,66 & 60,32 & 113,69 \\
\hline Salamandra salamandra & 30TVKO9 & 100,00 & 113,60 & 104,19 & 35,39 & 6407,64 & 282,44 & $-7,01$ & 289,45 & 85,27 & 198,75 & 200,05 & 36,88 & 464,05 & 56,18 & 15,15 & 31,66 & 147,87 & 65,86 & 69,08 & 118,12 \\
\hline Salamandra salamandra & 30TVLOO & 100,00 & 103,47 & 104,36 & 35,96 & 6315,89 & 271,61 & $-14,89$ & 286,50 & 97,34 & 188,25 & 189,18 & 29,18 & 495,14 & 61,23 & 17,16 & 30,66 & 156,36 & 73,01 & 77,93 & 122,97 \\
\hline Salaman & 30TVL01 & 100,00 & & & & 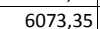 & 250 & $-32,06$ & 20,0 & \begin{tabular}{|l|l|}
83,05 \\
\end{tabular} & 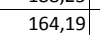 & 164,30 & & 595,66 & & 23, & & 187,09 & 91,97 & 95,44 & 147,75 \\
\hline Salamandra salamandra & $30 \mathrm{TV}$ & & & & 35, & 6328 & & $-14,21$ & 283,34 & \begin{tabular}{|c|}
120,89 \\
12
\end{tabular} & 188,14 & 189; & & 496 & 60,40 & 16 & 30 & 155,61 & 73,06 & 80,28 & 123,40 \\
\hline Salamandra salamandra & 30TVL07 & 100,00 & 116,73 & 105,12 & 36,17 & 6250,86 & 281,10 & $-4,31$ & 285,42 & 94,92 & 199,00 & 200,28 & 40,25 & 447,60 & 51,91 & 14,11 & 29,45 & 137,76 & 64,35 & 73,21 & 115,57 \\
\hline Salamandra salamandra & 30TVL10 & 100,00 & 112,46 & 102,96 & 35,38 & 6427,44 & 279,75 & $-7,11$ & 286,86 & 80,22 & 197,93 & 199,25 & 35,60 & 478,21 & 56,21 & 15,01 & 30,94 & 150,99 & 67,21 & 71,88 & 123,97 \\
\hline Salamandra salamandra & 30TVL11 & 100,00 & 77,29 & 106,95 & 37,36 & 6068,16 & 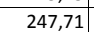 & $-34,23$ & 281,95 & 70,78 & 161,14 & 161,28 & 9,66 & 626,03 & 76,40 & 24,97 & 27,68 & 194,81 & 96,49 & 99,25 & 157 \\
\hline Salan & $30 \mathrm{TVL}$ & 100, & & & & - & & $-30,4$ & 281, & 86,58 & (6) & & 13, & 603 & 72, & 23, & & & 92,53 & 97,16 & 152,35 \\
\hline Salamandra salamandra & 30TVL14 & 100,00 & 107,35 & 102,19 & 35,99 & 6359,05 & 271,21 & $\begin{array}{ll}-11,09 \\
\end{array}$ & 282,30 & \begin{tabular}{|l|l|}
116,53 \\
1150
\end{tabular} & 192,19 & \begin{tabular}{|l|l|}
193,14 \\
\end{tabular} & 31,24 & 496,00 & 57,82 & 15,51 & 29,34 & $\begin{array}{ll}152,82 \\
\end{array}$ & 71,83 & 80,63 & 127,33 \\
\hline
\end{tabular}




\begin{tabular}{|c|c|c|c|c|c|c|c|c|c|c|c|c|c|c|c|c|c|c|c|c|c|}
\hline TAXON & UTM & $\mathrm{km} 2$ & BIO1 & $\mathrm{B1O2}$ & $\mathrm{BIO3}$ & 8104 & B105 & B106 & B107 & B108 & B109 & 81010 & B1011 & BIO12 & B1013 & B1014 & 81015 & B1016 & BIO17 & B1018 & 81019 \\
\hline Salamandra salamandra & 30TVL21 & 100,00 & 84,19 & 106,10 & 36,89 & 6169,99 & 254,29 & $-29,16$ & 283,45 & 61,23 & 168,71 & 169,10 & 14,22 & 607,58 & 72,58 & 23,35 & 27,95 & 188,62 & 92,03 & 95,29 & 156,05 \\
\hline Salamandra salamandra & 30TVL22 & 100,00 & 89,15 & 105,22 & 36,69 & 6195,81 & 257,50 & $-25,31$ & 282,81 & 82,82 & \begin{tabular}{|l|l|}
173,58 \\
\end{tabular} & 173,95 & 18,03 & 575,22 & 68,69 & 21,29 & 27,97 & 177,58 & 86,99 & 92,20 & 146,47 \\
\hline Salamandra salamandra & 30TVL23 & 100,00 & $\begin{array}{l}72,79 \\
72,7\end{array}$ & \begin{tabular}{|l|l|l|l|l|l|}
106,73 \\
\end{tabular} & 37,51 & $\begin{array}{ll}\mid 6045,02 \\
6045\end{array}$ & 242,56 & $-38,25$ & 280,81 & or, 6 & 156,35 & 156,48 & 5,44 & 658,42 & 78,70 & 27,16 & 26,32 & 202,81 & $\mid \begin{array}{l}\mid 103,42 \\
\end{array}$ & $\mid \begin{array}{r}\mid 2,20 \\
105,63 \\
\end{array}$ & $\begin{array}{l}14,47,97 \\
167,9\end{array}$ \\
\hline Salamandra salamandra & 30TVL31 & 100,00 & 112,12 & 103,04 & 35,52 & 6428,78 & 279,39 & $-6,72$ & 286,11 & 73,78 & 197,50 & 198,75 & 35,20 & 496,87 & 58,38 & 15,25 & 30,58 & 158,92 & 69,08 & 73,27 & 133,32 \\
\hline Salamandra salamandra & 30TVL32 & 100,00 & 89,33 & 105,67 & 36,72 & 6214,66 & 258,42 & $-25,45$ & 283,86 & 76,32 & \begin{tabular}{ll|}
173,92 \\
\end{tabular} & 174,25 & 17,79 & 578,12 & 68,50 & 21,47 & 27,60 & 177,52 & 87,52 & 92,90 & 148,19 \\
\hline Salamandra salamandra & 30TVL33 & 100,00 & 93,59 & 104,76 & 36,51 & 6246,76 & 261,29 & $-22,01$ & 283,30 & 79,89 & 178,09 & 178,63 & 20,99 & 562,40 & 65,76 & 20,43 & 27,73 & 172,92 & 84,79 & 90,65 & 145,03 \\
\hline Salamandra salamandra & 30TVL34 & 100,00 & 86,44 & 105,55 & 36,82 & 6168,71 & 254,56 & $-27,94$ & 282,50 & $\begin{array}{l}96,85 \\
\end{array}$ & 170,42 & 170,66 & 15,35 & 591,88 & 69,86 & 22,81 & 26,76 & 181,19 & 91,63 & 97,38 & 151,49 \\
\hline Salamandra salamandra & 30TVL44 & 100,00 & 95,01 & 105,03 & 36,40 & 6252,22 & 262,72 & $-21,24$ & 283,96 & 86,56 & 179,36 & 179,79 & 21,82 & 555,86 & 64,66 & 20,44 & 27,23 & 170,18 & 84,87 & 90,53 & 143,55 \\
\hline Salamandra salamandra & 30TVL54 & 100,00 & 97,28 & 105,44 & 36,44 & 6285,75 & 265,47 & $-19,77$ & 285,24 & \begin{tabular}{|c|}
84,53 \\
\end{tabular} & 181,84 & 182,24 & 23,39 & 546,22 & 63,27 & 20,09 & 26,97 & 166,33 & 83,72 & 89,91 & 141,45 \\
\hline Salamandra salamandra & 30TVL55 & 100,00 & 76,54 & 107,27 & 37,39 & 6122,88 & 246,61 & $-37,30$ & 283,90 & 87,02 & \begin{tabular}{|l|l|}
160,33 \\
\end{tabular} & 160,37 & 6,47 & \begin{tabular}{|c|c|}
648,73 \\
\end{tabular} & 76,29 & 27,79 & 24,67 & 197,61 & 105,10 & 107,78 & 166,35 \\
\hline Salamandra salamandra & 30TVL66 & 100,00 & 76,30 & 107,84 & 37,44 & 6119,81 & 246,56 & $-38,21$ & 284,77 & 90,68 & 159,88 & 159,89 & 5,98 & 651,92 & 76,56 & 28,84 & 23,88 & 198,39 & 107,84 & 110,04 & 166,99 \\
\hline Salamandra salamandra & 30TVL75 & 100,00 & 83,23 & 108,20 & 37,13 & 6200,53 & 254,08 & $-33,06$ & 287,14 & 97,75 & 167,60 & 167,63 & 11,31 & 616,34 & 72,44 & 26,55 & 24,32 & 186,92 & \begin{tabular}{|l|l|}
101,18 \\
\end{tabular} & 105,16 & 157,75 \\
\hline Salamandra salamandra & 30TVL88 & 100,00 & 102,05 & 107,89 & 37,00 & 6222,84 & 270,60 & $-17,08$ & 287,69 & 120,28 & 185,22 & 185,51 & 27,69 & 523,70 & 61,33 & 22,14 & 24,10 & 157,90 & 87,73 & 94,40 & 133,97 \\
\hline Salamandra salamandra & 30TVL89 & 100,00 & 110,14 & 107,13 & 37,00 & 6215,73 & 276,77 & $-9,44$ & 286,21 & 129,18 & 192,51 & 192,81 & 34,86 & 489,47 & 57,12 & 20,56 & 24,16 & 146,90 & 82,44 & 87,78 & 125,10 \\
\hline Salamandra salamandra & 30TVL97 & 100,00 & 95,54 & 109,50 & 37,04 & 6239,01 & 266,14 & $-24,09$ & 290,22 & 113,26 & 179,30 & 179,44 & 21,46 & 556,16 & 65,73 & 24,58 & 23,43 & 168,52 & 94,61 & 101,49 & 141,73 \\
\hline Salamandra salamandra & 30TVM06 & 100,00 & 113,92 & 105,86 & 37,31 & 5681,69 & 272,60 & $-6,31$ & 278,90 & \begin{tabular}{|l|}
86,09 \\
\end{tabular} & 188,46 & 188,94 & 43,75 & 502,32 & 55,56 & 21,98 & 25,36 & 154,82 & 79,12 & 91,04 & 127,23 \\
\hline Salamandra salamandra & 30TVM59 & 100,00 & 99,00 & 97,41 & 37,52 & 5574,17 & 249,40 & $-6,82$ & 256,22 & 66,52 & 173,22 & 173,22 & 31,22 & 624,74 & 66,83 & 31,49 & 21,03 & 185,39 & 113,75 & 113,75 & 166,05 \\
\hline Salamandra salamandra & 30TVM76 & 100,00 & 87,60 & 103,64 & 37,90 & 5792,22 & 247,70 & $-23,53$ & 271,22 & 102,96 & 165,40 & 165,40 & 18,18 & 656,62 & 72,67 & 34,20 & 20,29 & 192,43 & 119,18 & 119,18 & 172,73 \\
\hline Salamandra salamandra & 30TVM77 & 100,00 & 77,65 & 102,83 & 37,99 & 5712,01 & 236,49 & $-31,63$ & 268,12 & 91,60 & 154,71 & 154,71 & 9,76 & 735,33 & 79,78 & 39,36 & 19,46 & 213,12 & 134,59 & 134,59 & 195,12 \\
\hline Salamandra salamandra & 30TVM79 & 100,00 & 98,67 & 98,00 & 37,93 & 5559,87 & 248,47 & $-7,68$ & 256,15 & \begin{tabular}{|c|c|}
64,45 & 1 \\
\end{tabular} & 172,70 & 172,72 & 31,04 & 659,48 & 69,32 & 33,73 & 19,95 & 193,11 & 122,43 & 122,43 & 177,13 \\
\hline Salamandra salamandra & 30TVM83 & 100,00 & 98,03 & 106,97 & 37,55 & 6000,19 & 263,21 & $-18,06$ & 281,27 & \begin{tabular}{|c|}
115,23 \\
\end{tabular} & 178,17 & 178,18 & 25,65 & 568,01 & 65,21 & 27, & 21, & 169,93 & 101,13 & 104,28 & 147,14 \\
\hline Salamandra salamandra & 30 TVM 86 & 100,00 & 88,57 & 104,39 & 38,00 & 5798,97 & 249,07 & $-23,21$ & 272,28 & \begin{tabular}{|l|l|l|l|}
103,98 \\
\end{tabular} & $\begin{array}{l}166,36 \\
\end{array}$ & 166,36 & 18,99 & $\mid 659,17$ & $\begin{array}{l}72,95 \\
72,\end{array}$ & 34,65 & 19,81 & 193,02 & 120,91 & \begin{tabular}{|l|l|l|l|l|}
120,91 \\
\end{tabular} & 173,76 \\
\hline Salamandra salamandra & 30TVM 87 & 100,00 & 69,26 & 103,39 & 38,00 & 5696,11 & 228,73 & $-39,70$ & 268,43 & 82,56 & 146,46 & 146,46 & 2,19 & 800,97 & 86,39 & 43,73 & 18,76 & 231,33 & 148,06 & 148,06 & 213,46 \\
\hline Salamandra salamandra & 30 TVM 88 & 100,00 & 90,20 & 101,26 & 37,99 & 5654,98 & 245,08 & $-18,43$ & 263,51 & 76,82 & 165,95 & 165,95 & 22,02 & 690,99 & 74,06 & 36,42 & 19,29 & 199,16 & 128,53 & 128,53 & 184,51 \\
\hline Salamandra salamandra & 30TVM92 & 100,00 & 100,07 & 108,72 & 37,73 & 6058,65 & 267,23 & $-17,95$ & 285,18 & \begin{tabular}{|l|l|}
117,93 \\
\end{tabular} & 180,93 & 180,94 & 27,00 & 556,12 & 64,39 & 26,95 & 21,52 & 166,86 & 99,45 & 103,55 & 143,63 \\
\hline Salamandra salamandra & 30 TVM93 & 100,00 & 95,84 & 108,37 & 37,98 & 6002,07 & 262,09 & $-20,98$ & 283,07 & 112,94 & 176,07 & 176,09 & 23,52 & 587,12 & 67,38 & 29,36 & 20,87 & 175,48 & 106,11 & 108,37 & 152,44 \\
\hline Salamandra salamandra & 30TVM95 & 100,00 & $\frac{73,04}{73,65}$ & 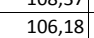 & 38,00 & 5824,96 & $\mid 237,28$ & - & $\begin{array}{l}20,07 \\
275,67\end{array}$ & \begin{tabular}{|r|}
87,98 \\
\end{tabular} & 152,53 & $\mid 152,53$ & $\begin{array}{r}20,32 \\
4,92 \\
\end{array}$ & $\mid 747,79$ & $\begin{array}{l}82,90 \\
82\end{array}$ & $\begin{array}{l}25,005 \\
40,55\end{array}$ & $\mid \begin{array}{l}20,010 \\
9,10\end{array}$ & \begin{tabular}{|l|l|}
219,58 \\
219
\end{tabular} & \begin{tabular}{|l|l|l|l|l|}
137,90 \\
\end{tabular} & \begin{tabular}{|l|l|}
137,99 \\
\end{tabular} & 197,44 \\
\hline Salamandra salamandra & 30TVM97 & 100,00 & 71,52 & 103,63 & 38,00 & 5701,55 & 230,87 & $-37,93$ & 268,80 & $\begin{array}{l}85,05 \\
\end{array}$ & 148,69 & 148,69 & 4,16 & 797,59 & 86,10 & 43,69 & 18,42 & 230,23 & 148,77 & 148,77 & 212,75 \\
\hline Salamandra salamandra & 30TVM98 & 100,00 & 91,12 & 101,98 & 38,00 & 5661,91 & 246,27 & $-18,21$ & 264,47 & 84,41 & $\begin{array}{l}166,85 \\
166,0\end{array}$ & 166,85 & 22,79 & 696,98 & 74,72 & $\begin{array}{l}35,97 \\
36,97\end{array}$ & 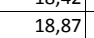 & 200,20 & 130,80 & 130,80 & 186,20 \\
\hline Salamandra salamandra & 30TVM99 & 100,00 & 102,76 & 98,85 & 37,97 & 5568,33 & 252,12 & $-5,18$ & 257,30 & 60,80 & 176,65 & 176,71 & 34,77 & 662,93 & 69,71 & 34,25 & 19,01 & 192,52 & 125,39 & 125,39 & 178,41 \\
\hline Salamandra salamandra & 30TVN05 & 100,00 & 95,42 & 90,73 & 38,30 & 4910,96 & 228,77 & $-4,67$ & 233,44 & 71,96 & 159,71 & 161,12 & 35,86 & 832,84 & 97,31 & 41,76 & 21,96 & 268,27 & 152,96 & 154,50 & 224,96 \\
\hline Salamandra salamandra & 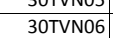 & 100,00 & $\begin{array}{l}0,424 \\
93,48 \\
\end{array}$ & 88,85 & $\begin{array}{l}30,00 \\
38,40\end{array}$ & 48116,21 & 223,41 & $\begin{array}{l}-2,07 \\
-4,68\end{array}$ & 228,10 & $\begin{array}{l}71,70 \\
70,61\end{array}$ & \begin{tabular}{|l|l|}
156,37 \\
\end{tabular} & \begin{tabular}{|l|}
158,01 \\
158,01
\end{tabular} & 35, & $\begin{array}{l}\mid 85,04,73 \\
882,73\end{array}$ & $\mid$\begin{tabular}{|c|c|}
103,43 \\
103
\end{tabular} & $\begin{array}{l}41,16 \\
44,41\end{array}$ & 22,11 & $\mid$\begin{tabular}{|l|l|}
$\mid 285,17$ \\
285
\end{tabular} & 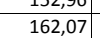 & \begin{tabular}{|l|}
165,37 \\
165
\end{tabular} & 240,34 \\
\hline Salamandra salamandra & 30TVN07 & 100,00 & 100,52 & 84,68 & 38,35 & 4629,05 & 223,08 & 5,55 & 217,53 & 79,01 & 160,53 & 162,49 & 44,18 & 903,90 & 107,70 & 44,50 & 22,99 & 296,89 & 163,57 & 171,12 & 247,80 \\
\hline Salamandra salamandra & 30 TVN08 & 100,00 & 114,79 & 77,93 & 38,15 & 4336,81 & 225,90 & 24,59 & 201,32 & 95,42 & 170,30 & 172,68 & 61,49 & 914,93 & 111,99 & 42,93 & 25,00 & 309,04 & 160,82 & 175,62 & 253,13 \\
\hline Salamandra salamandra & 30 TVNO9 & 100,00 & 129,50 & 70,83 & 37,9 & 4028,56 & 229 & 45,03 & 184 & 112,20 & 180,51 & 183 & 79,67 & 926,02 & 116,51 & 41, & 27, & 321,69 & \begin{tabular}{l|l}
157,55 \\
\end{tabular} & 179,96 & 258,62 \\
\hline Salamandra salamandra & 30TVN12 & 100,00 & 97,30 & 95,50 & 38,00 & 5209,78 & 240,46 & $\begin{array}{l}-8,07 \\
-8,07 \\
\end{array}$ & 248,53 & 71,01 & 166,72 & 166,72 & 33,68 & 720,35 & \begin{tabular}{|c|}
81,96 \\
\end{tabular} & 35,6 & 21,62 & 226,56 & 129,66 & 129,66 & 190,89 \\
\hline Salamandra salamandra & 30TVN15 & 100,00 & 96,76 & 89,05 & 38,07 & 4883,89 & 227,97 & $-2,11$ & 230,09 & \begin{tabular}{|l|l|}
73,03 \\
\end{tabular} & 160,45 & 162,12 & 37,23 & 841,59 & 97,63 & 41,88 & 21,90 & 270,43 & 153,84 & 156,64 & 228,98 \\
\hline Salamandra salamandra & $\begin{array}{l}\text { 30TVN17 } \\
\end{array}$ & 100,00 & 113,51 & 79,24 & 38,01 & 4450,67 & 227,75 & 21,95 & 205,80 & 93,08 & 170,64 & 172,86 & 58,77 & 894,42 & 107,47 & 41,87 & 24,48 & 299,30 & 157,15 & 170,29 & 248,74 \\
\hline Salamandra salamandra & 30TVN18 & 100,00 & 123,42 & 73,44 & 37,91 & 4194,33 & 228,38 & 36,56 & 191,82 & 104,7 & 176,70 & 179,34 & 71,52 & 922,62 & 113,21 & 41,53 & 26,22 & 315,78 & 158,21 & 177,78 & 259,29 \\
\hline Salamandra salamandra & 30 TVN22 & 100,00 & 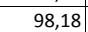 & 94,05 & 37,97 & 211,92 & 239,98 & $-5,71$ & 245,69 & 71 & 167,44 & 167,58 & 34,47 & 722,47 & 81,64 & 35,5 & 21,27 & 226,16 & 130,84 & 130,90 & 192,53 \\
\hline Salamandra salamandra & 30TVN23 & 100,00 & 97,04 & 91,99 & 37,98 & 5098,92 & 23 & $-4,75$ & 239,73 & 70,9 & 164,45 & 165,11 & 34,86 & 768,87 & 87,30 & 38, & 21, & 242,35 & 140,32 & 140,99 & 207,25 \\
\hline Salamandra salamandra & 30 TVN24 & 10 & 101,35 & 88,78 & 37, & 494 & 233,22 & 1,82 & 231,41 & 76 & 165 & 167 & 40,81 & 798,72 & 91,63 & 39 & 21 & 255,50 & 144,76 & 147,93 & 217,80 \\
\hline Salamandra salamandra & 30 TVN25 & 100,00 & $\begin{array}{l}99,07 \\
99,0 \\
\end{array}$ & 87,23 & 38,01 & 4861,28 & 227,97 & $\begin{array}{l}, 02 \\
1,48 \\
\end{array}$ & 226,50 & 75, & 162,11 & 163,98 & $\begin{array}{l}39,72 \\
39,72 \\
\end{array}$ & 847,18 & 97,49 & 41,77 & 21,85 & 271,79 & 153,74 & $\begin{array}{l}458,29 \\
\end{array}$ & 232,81 \\
\hline Salamandra salamandra & 30 TVN26 & 100,00 & 99,52 & 84,82 & 38,02 & 4741,43 & 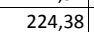 & 4,32 & 220,06 & 76 & 160,99 & 163,08 & 41,78 & 890,45 & 103,09 & 43,70 & 22,14 & 287,85 & 160,75 & 167,71 & 246,91 \\
\hline Salamandra salamandra & 30 TVN27 & 100,00 & 107,99 & 79,62 & 37,86 & 11,05 & 224,35 & \begin{tabular}{ll|}
16,62 \\
\end{tabular} & 207,73 & 86,80 & 166,03 & 168,27 & 52,73 & 923,58 & 108,73 & 43,7 & 23,61 & 305,11 & 163,16 & 175,73 & 259,52 \\
\hline Salamandra salamandra & 30TVN29 & $\begin{aligned} 90,00 \\
99,\end{aligned}$ & $\frac{13}{13}$ & 6 & 37,6 & $\begin{array}{ll}431,007 \\
3907,55\end{array}$ & $\mid \begin{array}{l}227,93 \\
227,97\end{array}$ & $\begin{array}{l}5,02,15 \\
53,15\end{array}$ & $\begin{array}{l}201,13 \\
174,82\end{array}$ & \begin{tabular}{r|r|}
117,08 \\
\end{tabular} & $\begin{array}{l}182,03 \\
182,91\end{array}$ & 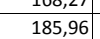 & $\begin{array}{ll}85,29 \\
85,29\end{array}$ & | & $\begin{array}{ll}121,71 \\
121,5\end{array}$ & 41,80 & 28,39 & | & $\begin{array}{l}162,102 \\
162,62\end{array}$ & $\mid 191,11$ & 281,65 \\
\hline Salamandra salamandra & 30TVN32 & 100,00 & 98,01 & 93,01 & 37,90 & 5220,81 & 238,88 & $-4,56$ & \begin{tabular}{|l|l|}
243,45 \\
\end{tabular} & 70,1 & \begin{tabular}{|c|c|}
167,05 \\
\end{tabular} & 167,62 & 34,19 & 729,61 & 81,65 & 36,42 & 21,10 & 226,93 & 132,83 & 133,19 & 196,12 \\
\hline Salamandra salamandra & 30 TVN33 & 100,00 & 99,88 & 90,41 & 37,83 & 5087,54 & 235,72 & $-0,6$ & 236,32 & 73,3 & 166,10 & 167,68 & 37,62 & 768,08 & 86,51 & 37,99 & 21,23 & 241,69 & 139,82 & 141,61 & 209,01 \\
\hline Salamandra salamandra & 30 TVN34 & 100,00 & 102,11 & 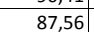 & 37 & 4943,68 & 232,54 & 3, & 228 & 76 & 166 & 168 & 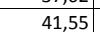 & 807,4 & 91, & 39, & 21, & 257,15 & 145,83 & 150,27 & 222,41 \\
\hline Salamandra salamandra & $30 \mathrm{TVN}$ & 10 & 10 & & 37 & & & 3,4 & 223 & & 162 & 164 & 41, & 860, & 98 & 42 & 21 & 275,25 & 155,33 & 161,40 & 239,24 \\
\hline Salamandra salamandra & 30 TVN36 & 100,00 & 98,50 & 83,98 & 37,94 & 4741,51 & 222,92 & 4,39 & 218,54 & 75,08 & 159,90 & 161,99 & 40,86 & 910,65 & $\begin{array}{r}04,03 \\
104\end{array}$ & 44,72 & 21,92 & 292,47 & 164,27 & 171,98 & 255,13 \\
\hline Salamandra salamandra & $\begin{array}{l}\text { 30TVN37 } \\
\end{array}$ & 100,00 & $\begin{array}{r}106,25 \\
\end{array}$ & 78,95 & 37,64 & 4519,87 & 222,60 & 15,81 & 206,80 & 83,86 & 164,41 & 166,69 & 51,04 & 948,49 & 110,55 & 45,01 & 23,36 & 311,21 & 167,55 & 180,65 & 269,49 \\
\hline Salamandra salamandra & 30 TVN42 & 100,00 & 94,73 & 92,92 & 37,97 & 5248,90 & 235,92 & $-6,76$ & 242,68 & 66,10 & 163,77 & 164,82 & 30,91 & 748,93 & 82,50 & 37,81 & 20,56 & 230,02 & 137,79 & 137,95 & 202,92 \\
\hline Salaman & 30 TVN & 100,00 & & & 37,93 & 126,11 & 4 & $-4,57$ & 236 , & 67,53 & 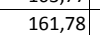 & 163,49 & & 793,4 & 87 & 39,94 & & 245,95 & 145,83 & 147,30 & 217,37 \\
\hline Salamandra salamandra & 30TVN44 & & & & & & & 2,49 & 227,94 & 73,8 & 164,09 & 165,94 & 39, & 829, & 92, & 40, & 21 & 261,53 & 150,31 & 155,01 & 230,64 \\
\hline Salamandra salamandra & 30 TVN46 & 100,00 & 101,68 & 82,19 & 37,70 & 4705,55 & 224,07 & 8,78 & 215,30 & 78,10 & 162,36 & 164,63 & 44,20 & 919,65 & 105,53 & 44,48 & 22,03 & 295,47 & 164,43 & 174,03 & 261,18 \\
\hline Salamandra salamandra & 30TVN47 & 100,00 & 84,44 & 84,65 & 37,98 & 4773,45 & 211,57 & $-8,16$ & 219,73 & 50,17 & 146,53 & 148,96 & 27,38 & 1012,71 & 114,26 & 51,64 & 20,71 & 319,08 & 186,35 & 192,27 & 286,46 \\
\hline Salamandra salamandra & 30 TVN48 & 100,00 & 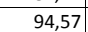 & 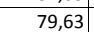 & 37,77 & 4553,22 & 213,35 & 5,26 & 208,09 & 65,35 & 153,28 & 155,92 & 39,71 & 1037,07 & 120,07 & 50,90 & 22,20 & 334,28 & 186,41 & 198,12 & 297, \\
\hline Salan & $30 \mathrm{TVI}$ & 100, & 12 & & 36 & 068 & & 40,18 & 181,52 & 103, & 173 & & 71 & 1048 & 128 & 46, & 26 & & & 64 & \\
\hline Salamandra salamandra & 30 TVN52 & 100,00 & 98,95 & 91,42 & 37,73 & 5221,31 & 237,64 & $\begin{array}{c}4,1,86 \\
-1,86 \\
\end{array}$ & 239,51 & \begin{tabular}{|c|} 
\\
70,07 \\
\end{tabular} & $\begin{array}{ll}167,23 \\
\end{array}$ & $\begin{array}{l}168,60 \\
\end{array}$ & 35,30 & $\begin{array}{l}\mid 740,45 \\
749,14 \\
\end{array}$ & \begin{tabular}{|c|c|}
81,75 \\
81,
\end{tabular} & $\begin{array}{l}40,112 \\
37,43 \\
\end{array}$ & $\begin{array}{l}20,46 \\
20,46 \\
\end{array}$ & $\begin{array}{l}229,92 \\
229\end{array}$ & \begin{tabular}{|l}
137,4 \\
\end{tabular} & \begin{tabular}{|l|l|l|l|}
139,13 \\
\end{tabular} & 205,45 \\
\hline
\end{tabular}




\begin{tabular}{|c|c|c|c|c|c|c|c|c|c|c|c|c|c|c|c|c|c|c|c|c|c|}
\hline TAXON & UTM & $\mathrm{km} 2$ & BIO1 & $\mathrm{B1O2}$ & $\mathrm{BIO3}$ & 8104 & B105 & B106 & B107 & B108 & B109 & 81010 & B1011 & BIO12 & B1013 & B1014 & 81015 & B1016 & BIO17 & B1018 & BIO19 \\
\hline Salamandra salamandra & 30TVN53 & 100,00 & 99,65 & 89,08 & 37,80 & 5092,41 & 234,07 & 0,99 & 233,08 & 71,91 & 165,73 & 167,58 & 37,53 & 792,05 & 87,44 & 39,24 & 20,59 & 245,68 & 144,52 & 147,93 & 219,92 \\
\hline Salamandra salamandra & 30TVN56 & 100,00 & 106,14 & 80,16 & 37,35 & 4654,46 & 225,83 & 14,56 & 211,27 & 82,72 & 165,90 & 168,30 & 49,16 & 930,85 & 108,16 & 44,22 & 22,41 & 299,67 & 164,75 & 176,64 & 268,72 \\
\hline Salamandra salamandra & 30TVN57 & 100,00 & 90,49 & 82,57 & 37,85 & 4709,62 & 214,55 & $\begin{array}{l}-0,90 \\
-1,90\end{array}$ & 215,45 & 52,83 & 151,43 & 153,93 & 33,92 & 1014,97 & 115,98 & 50,75 & $\begin{array}{ll}21,14 \\
214\end{array}$ & 321,54 & 184,65 & 193,13 & 291,03 \\
\hline Salamandra salamandra & 30TVN58 & 100,00 & 108,37 & 74,56 & 37,25 & 4385,44 & 219,45 & 21,93 & 197,52 & 82,71 & 164,34 & 167,09 & 54,88 & 1034,62 & 123,48 & 48,07 & 23,87 & 339,52 & 179,88 & 197,78 & 305,10 \\
\hline Salamandra salamandra & 30TVN59 & 100,00 & 126,02 & 66,15 & 36,59 & 4031,09 & 223,35 & 45,27 & \begin{tabular}{|l|}
178,07 \\
\end{tabular} & \begin{tabular}{|c|}
107,64 \\
\end{tabular} & \begin{tabular}{ll|}
176,66 \\
\end{tabular} & 179,72 & 76,24 & 1066,38 & 132,93 & 45,83 & 27,00 & 363,23 & $\begin{array}{l}176,75 \\
\end{array}$ & 205,10 & 322,81 \\
\hline Salamandra salamandra & 30 TVN62 & 100,00 & 111,51 & 88,30 & 37,32 & 5124,11 & 244,29 & 11,61 & 232,68 & 81,37 & 177,68 & 179,32 & 48,27 & 728,47 & 80,75 & 34,84 & 21,01 & 226,71 & 131,29 & 136,11 & 203,84 \\
\hline Salamandra salamandra & 30 TVN63 & 100,00 & 107,20 & 87,07 & 37,60 & 5038,53 & 238,05 & 9,28 & 228,77 & 79,07 & 172,23 & 174,21 & 45,30 & 785,92 & 87,87 & 38,01 & 20,95 & 245,04 & 141,95 & 147,61 & 221,72 \\
\hline Salamandra salamandra & 30TVN65 & 100,00 & 108,42 & 81,64 & 37,37 & 4761,87 & 230,73 & \begin{tabular}{r|r|r|r|r|}
15,28 \\
\end{tabular} & 215,45 & 82,29 & 169,62 & $\mid \begin{array}{l}\mid 171,90 \\
\end{array}$ & 50,06 & \begin{tabular}{|l|l|}
889,65 \\
\end{tabular} & $\mid \begin{array}{l}\mid 02,73 \\
102,7\end{array}$ & 42,10 & 21,96 & $\begin{array}{l}24,03,26 \\
283\end{array}$ & \begin{tabular}{|l|l|l|l|}
157,77 \\
\end{tabular} & $\mid$ & 257,69 \\
\hline Salamandra salamandra & 30TVN66 & 100,00 & 105,04 & 80,32 & 37,39 & 4675,92 & 225,36 & \begin{tabular}{|l|}
13,67 \\
\end{tabular} & 211,68 & 74,50 & \begin{tabular}{|l|l|}
164,97 \\
\end{tabular} & 167,42 & 47,88 & 950,00 & 110,36 & 45,36 & 22,03 & 303,34 & \begin{tabular}{ll|}
168,65 \\
\end{tabular} & 180,39 & 276,88 \\
\hline Salamandra salamandra & 30 TVN67 & 100,00 & 101,25 & 79,16 & 37,55 & 4599,45 & 219,84 & 11,59 & 208,25 & 65,66 & 160,21 & 162,83 & 45,37 & 1010,80 & 117,99 & 48,59 & 22,10 & 323,75 & 179,86 & 192,51 & 296,21 \\
\hline Salamandra salamandra & 30 TVN68 & 100,00 & 120,69 & 69,95 & 36,74 & 4232,60 & 224,58 & 36,79 & 187,79 & 100,07 & 174,13 & 177,02 & 68,49 & 1042,82 & 128,30 & 45,78 & 25,59 & 347,40 & 175,27 & 198,70 & 317,65 \\
\hline Salamandra salamandra & 30 TVN73 & 100,00 & 112,44 & 85,79 & 37,43 & 5006,60 & 241,04 & 14,90 & 226,15 & 83,56 & 176,85 & 178,75 & 50,72 & 786,61 & 88,77 & 37,40 & 21,15 & 245,54 & 141,27 & 148,32 & 225,13 \\
\hline Salamandra salamandra & 30TVN74 & 100,00 & 107,62 & 84,58 & 37,51 & 4912,95 & 234,44 & 12,03 & 222,40 & $\begin{array}{l}74,75 \\
\end{array}$ & 170,82 & 172,86 & 47,35 & 851,06 & 96,70 & 40,89 & 21,06 & 266,57 & 153,21 & \begin{tabular}{|l|l|}
160,98 \\
\end{tabular} & 245,17 \\
\hline Salamandra salamandra & 30TVN75 & 100,00 & 105,31 & 82,77 & 37,50 & 4807,18 & 229,48 & 11,75 & 217,73 & 67,09 & 167,05 & 169,38 & 46,57 & 910,55 & 104,51 & 43,79 & 21,23 & 286,82 & 163,32 & 172,66 & 264,81 \\
\hline Salamandra salamandra & 30TVN78 & 100,00 & 120,92 & 69,74 & 36,68 & 4244,12 & 224,77 & 37,20 & \begin{tabular}{|c|}
187,57 \\
\end{tabular} & \begin{tabular}{|c|}
91,57 \\
\end{tabular} & \begin{tabular}{|l|l|}
174,43 \\
\end{tabular} & 177,29 & 68,58 & 1066,48 & 131,83 & 46,55 & 25,63 & 353,54 & 178,62 & 202,15 & 330,37 \\
\hline Salamandra salamandra & 30TVN79 & 100,00 & 123,75 & 66,45 & 36,4 & 4096,70 & 222,63 & 42,77 & $\begin{array}{ll}179,86 \\
\end{array}$ & 95,72 & 175,16 & 178,28 & 73,33 & 1118,18 & 140,30 & 47,95 & 26,70 & 374,65 & 184,63 & 212,21 & 350,73 \\
\hline Salamandra salamandra & 30 TVN84 & 100,00 & 103,96 & 86,15 & 37,85 & 4963,33 & 233,21 & 7,87 & 225,33 & 55,78 & 167,96 & 170,04 & 43,42 & 871,21 & \begin{tabular}{|l|}
98,06 \\
\end{tabular} & 42,76 & 20,30 & 269,96 & 159,22 & 165,50 & 250,88 \\
\hline Salamandra salamandra & 30 TVN85 & 100,00 & 104,85 & 83,38 & 37,74 & 4828,90 & 229,94 & 11,22 & 218,72 & 54,11 & 166,92 & 169,21 & 45,99 & 924,90 & 105,84 & 44,83 & 20,84 & 290,18 & 167,04 & 175,80 & 270,28 \\
\hline Salamandra salamandra & 30 TVN89 & 100,00 & 128,19 & 64,79 & 36,19 & 4057,18 & 224,63 & 47,99 & 176,64 & 90,41 & 178,88 & 181,96 & 78,10 & 1143,30 & 145,65 & 47,71 & 27,72 & 384,24 & 185,29 & 214,87 & 368,93 \\
\hline Salamandra salamandra & 30 TVN92 & 100,00 & 117,27 & 88,59 & 37,62 & 5141,02 & 249,09 & 16,71 & 232,37 & 86,20 & 183,32 & 184,93 & 53,60 & 738,05 & 81,65 & 35,49 & 20,21 & 225,82 & 135,85 & 140,65 & 209,57 \\
\hline Salamandra salamandra & 30 TVN94 & 100,00 & 108,73 & 85,55 & 37,76 & 4938,92 & 236,51 & \begin{tabular}{|l|}
12,67 \\
\end{tabular} & 223,84 & 62,07 & 172,20 & 174,24 & 48,30 & 872,13 & 98,54 & 42, & 20,30 & 270,24 & 159,39 & 166,11 & 253,37 \\
\hline Salamandra salamandra & 30 TVN95 & 100,00 & 106,38 & 83,55 & 37,77 & 4828,87 & 231,28 & 12,65 & 218,63 & 56,30 & 168,32 & 170,60 & 47,55 & 938,21 & 107,38 & 45,50 & 20,76 & 293,76 & 170,03 & 178,55 & 276,05 \\
\hline Salamandra salamandra & 30TVN99 & 92,00 & 132,29 & 63,55 & 35,85 & 4036,25 & 226,96 & 52,44 & 174,52 & 89,47 & 182,50 & 185,60 & 82,34 & 1168,21 & 150,77 & 47,53 & 28,83 & 394,26 & 186,08 & 217,14 & 387,18 \\
\hline Salamandra salamandra & 30TVP20 & 99,00 & 139,47 & 61,90 & 37,03 & 3723,07 & 227,32 & 62,40 & 164,92 & 123,90 & 174,73 & 189,11 & 93,06 & 1010,81 & 127,51 & 42,12 & 29,70 & 358,71 & 165,13 & 198,97 & 291,94 \\
\hline Salamandra salamandra & 30TVP31 & 33,00 & 141,27 & 58,56 & 36,50 & 3605,85 & 224,90 & 67,10 & 157,79 & 126,46 & 168,79 & 189,33 & 96,25 & 1070,27 & 135,50 & 43,90 & 30,44 & 381,94 & 170,77 & 211,92 & 313,67 \\
\hline Salamandra salamandra & $\begin{array}{l}\text { 30TVP40 } \\
\end{array}$ & 99,00 & 137,02 & 60,62 & 36,34 & 3756,43 & 224,89 & 60,58 & 164,32 & 120,99 & 179,46 & 187,05 & 90,33 & 1075,99 & 136,42 & 44,40 & 29,36 & 378,07 & 174,43 & 210,23 & 322,33 \\
\hline Salamandra salamandra & 30TVP50 & $\begin{array}{l}500,00 \\
100\end{array}$ & 135,87 & $\begin{array}{ll}60,0<9 \\
60,90\end{array}$ & $\begin{array}{l}30,44 \\
36,17\end{array}$ & $\begin{array}{l}370,45 \\
3806,96\end{array}$ & $\mid \begin{array}{l}\mid 224,63 \\
224,75\end{array}$ & | 50,300 & $\begin{array}{l}104,52 \\
165,78\end{array}$ & 119,22 & \begin{tabular}{|l|l|l|l|}
183,13 \\
\end{tabular} & $\mid \frac{\mid 0,06,0}{186,40}$ & 88,57 & $\mid \frac{1097,40}{1097}$ & \begin{tabular}{|l|l|l|l|l|l|}
139,97 \\
\end{tabular} & 45,10 & 29,04 & $\mid 382,13$ & \begin{tabular}{|l|l|l|l|l}
177,06 \\
\end{tabular} & $\mid 212,35$ & 336,43 \\
\hline Salamandra salamandra & 30TWM04 & 100,00 & 85,75 & 108,61 & 38,00 & 5923,26 & 251,68 & $-29,78$ & 281,46 & \begin{tabular}{|l|l|l|l|}
101,73 \\
\end{tabular} & \begin{tabular}{|l|l|}
165,23 \\
\end{tabular} & 165,23 & 14,97 & 666,40 & 75,31 & 35,51 & 19,49 & \begin{tabular}{|l|l|}
197,55 \\
\end{tabular} & 123,31 & 124,57 & 174,60 \\
\hline Salamandra salamandra & 30TWM05 & 100,00 & $\frac{70,14}{70,14}$ & 106,53 & 38,00 & 5815,45 & 233,82 & $-42,16$ & $\begin{array}{l}27,45,98 \\
275\end{array}$ & $\begin{array}{r}84,29 \\
\end{array}$ & 148,92 & 148,92 & $\mid$ & 779,62 & 86,31 & 42,85 & 18,61 & 228,66 & 145,29 & 145,29 & 205,86 \\
\hline Salamandra salamandra & 30TWM45 & 100,00 & 82,08 & 110,24 & 38,58 & 5878,70 & 247,42 & $-35,12$ & 282,54 & 98,21 & 160,86 & 160,86 & 11,45 & 731,03 & 82,29 & 40, & 17,89 & 216,24 & 140,76 & 141,49 & 191,97 \\
\hline Salamandra salamandra & 30 TWM46 & 100,00 & 80,56 & 108,70 & 38,54 & 5819,04 & 243,60 & $-34,96$ & 278,56 & 96,40 & 158,60 & 158,60 & 10,80 & 757,90 & 84,18 & 42,44 & 17,65 & 222,38 & 146,11 & 146,57 & 200,06 \\
\hline Salamandra salamandra & 30TWM82 & 100,00 & $\begin{array}{l}\mid c 0,30 \\
93,96 \\
\end{array}$ & $\begin{array}{ll}110,92 \\
110,9\end{array}$ & $\begin{array}{l}30,04 \\
38,00\end{array}$ & $\begin{array}{ll}301058,28 \\
6058,\end{array}$ & $\begin{array}{l}243,06 \\
258,25\end{array}$ & - $-29,35$ & $\begin{array}{l}28,30 \\
287,60\end{array}$ & $\begin{array}{r}5,40,12 \\
113,12\end{array}$ & $\begin{array}{l}13,00 \\
173,90\end{array}$ & \begin{tabular}{|l|l|}
173,96 \\
173
\end{tabular} & $\begin{array}{l}0,00 \\
19,82\end{array}$ & $\mid 607,35$ & 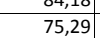 & $\begin{array}{l}42,44 \\
34,08\end{array}$ & $\begin{array}{l}1,, 130 \\
21,12\end{array}$ & \begin{tabular}{|l|l|}
$\mid 22,30$ \\
191,30
\end{tabular} & $\begin{array}{l}\mid+40,11 \\
119,85 \\
\end{array}$ & \begin{tabular}{|l|}
131,13 \\
131
\end{tabular} & 20,00 \\
\hline Salamandra salamandra & 30 TWM83 & 100,00 & 102,29 & 111,08 & 38,01 & 6063,83 & 266,08 & $-21,32$ & 287,40 & 122,23 & 181,75 & 182,01 & 27,54 & 575,06 & 71,24 & 31,73 & 21,45 & 180,48 & 112,34 & 123,17 & 141,63 \\
\hline Salamandra salamandra & 30TWN05 & 100,00 & 111,15 & 83,25 & 37,86 & 4804,25 & 234,88 & 17,4 & 217,42 & 60,22 & 172,58 & 174,81 & 52,4 & 940,18 & 107,73 & 45, & 20,77 & 294,35 & 170,42 & 179,21 & 278,61 \\
\hline Salamandra salamandra & 30TWN06 & 100,00 & 120,93 & 76,99 & 37,38 & 4558,16 & 235,22 & 31, & 203 & 72,35 & 178,65 & 181,13 & 65, & 998,87 & 119,07 & 45, & 23,21 & 320,68 & 173,37 & 188,61 & 308,02 \\
\hline Salamandra salamandra & 30TWN08 & 100,00 & 130,79 & 67,22 & 36,46 & 4178,09 & 230,99 & 49,14 & 181,86 & 84,61 & 182,80 & 185,90 & 79,44 & 1139,08 & 144,30 & 47,36 & 27,59 & 380,12 & 184,84 & 211,30 & 374,92 \\
\hline Salamandra salamandra & 30TWNO9 & 99,00 & 138,12 & 61,59 & 35,64 & 3978,81 & 229,93 & 59,82 & 170,11 & 90,52 & 187,26 & 190,50 & 88,95 & 1202,85 & 157,78 & 47,29 & 30,38 & 411,24 & 187,22 & 220,79 & 410,73 \\
\hline Salamandra salamandra & 30TWN14 & 100,00 & 114,06 & 86,70 & 38,04 & 4951,83 & 242,09 & 17,31 & 224,79 & 60, & 177,48 & 179,45 & 53,44 & 873,38 & 97,76 & 42,79 & 19,69 & 268,69 & 161,95 & 167,58 & 253,84 \\
\hline Salamandra salamandra & 30TWN15 & 100,00 & 110,09 & 85,02 & 38,03 & 4845,20 & 235,85 & 15,60 & 220,25 & 58 & 172,10 & 174,23 & 51,07 & 950,45 & 107,55 & 46, & 19,95 & 295,50 & 174,82 & 181,79 & 279,59 \\
\hline Salamandra salamandra & 30TWN16 & 10 & 98,64 & 85,16 & 38,28 & 807,67 & 4 & 5,69 & 219,33 & 47 & 160,34 & 62,73 & 40,71 & 1045,75 & 118,43 & 52, & 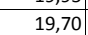 & 326,01 & 193,81 & 199,88 & 307,97 \\
\hline Salamandra salamandra & 30TWN17 & 100,00 & \begin{tabular}{r|r|r|}
128,64 \\
\end{tabular} & 98 & 37,36 & 4354,73 & 23 & 43,81 & 192,65 & $\frac{41}{82}-x-x$ & 183,14 & 186,01 & 75,9 & 1079,46 & $\mid 131,80$ & 47, & 24,96 & 352,18 & 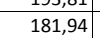 & 201,95 & 344,04 \\
\hline Salamandra salamandra & 30 TWN23 & 10 & & 2 & 38 & 5147,34 & 246,88 & 11,33 & 235,56 & & 178,85 & 180,25 & 49, & 813,72 & 88,10 & 41,36 & 18,36 & 244,33 & 156,34 & 157,56 & 229,17 \\
\hline Salamandra salamandra & 30TWN26 & 100,00 & 113,08 & 82,98 & 38,30 & 4690,10 & 234,81 & 21,53 & 213,27 & 62, & 172,61 & 175,10 & 56,11 & 1031,02 & $\mid \begin{array}{l}0,18,07 \\
118,0\end{array}$ & 49,92 & 20,60 & 324,36 & 187,44 & 196,33 & 308,42 \\
\hline Salamandra salamandra & 30TWN27 & 100,00 & 50 & 77,90 & 38,17 & 71,05 & 7 & 33,45 & 201 & 72 & 176,71 & 179,56 & 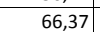 & 1097,43 & 129,37 & $50, \varepsilon$ & 22,51 & 352,25 & 192,55 & 207,20 & 338,87 \\
\hline Salamandra salamandra & 30TWN31 & 100,00 & 52 & 98,18 & 38,56 & 463,45 & 255 & 4,41 & 251,51 & 65 & 184,18 & 184,18 & 45,19 & |698,07 & 73,03 & 37,09 & 17,75 & 201,94 & 137,27 & 137,27 & 186,42 \\
\hline Salamandra salamandra & 30TWN33 & 100,00 & 10 & $\frac{9}{9}$ & $\begin{array}{l}30, \\
38, \\
\end{array}$ & 5221,61 & $\mid \frac{25,92}{242,10}$ & $\begin{array}{l}\mid, 41,07 \\
1,07\end{array}$ & 242,03 & 47 & 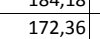 & $\mid$ & $\begin{array}{l}43,15 \\
39,87\end{array}$ & \begin{tabular}{|l|l|}
862,93 \\
\end{tabular} & $\begin{array}{l}\mid 3,05 \\
92,57 \\
\end{array}$ & $\frac{35,}{45,}$ & $\begin{array}{l}1,1,73 \\
17,2\end{array}$ & $\mid 257,56$ & $\begin{array}{l}\mid 31,27 \\
166,55\end{array}$ & $\begin{array}{l}\mid 31,27 \\
166,66\end{array}$ & 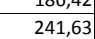 \\
\hline Salamandra salamandra & 30TWN36 & 100,00 & & 83,30 & 38,89 & 4648,14 & 239,72 & 27,74 & 211,98 & 68,82 & 177,68 & 180,22 & 62,58 & 1040,38 & 118,56 & 50,06 & 20,62 & 327,62 & 188,78 & 197,71 & 311,32 \\
\hline Salamandra salamandra & 30TWN37 & 100,00 & 126,97 & 78,23 & 38,76 & 4416,47 & 240,09 & 40,70 & 199,39 & 79,37 & \begin{tabular}{|c|}
182,17 \\
\end{tabular} & 185,09 & 73,65 & 1110,02 & 130,25 & 51, & 22,59 & 356,79 & $\begin{array}{l}194,15 \\
\end{array}$ & 209,22 & 342,71 \\
\hline Salamandra salamandra & 30TWN41 & 100,00 & & 99,65 & 38,75 & 5511,61 & 257,95 & 3,5 & 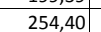 & & 185 & 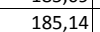 & & 697,21 & 73, & 37 & & 200,54 & 137,18 & 137,18 & 184,62 \\
\hline Salamandra salamandra & 30TWN43 & 10 & & & 39 & & & 1,1 & & & $1 / 3$ & & & 867 & 92,76 & & & 258,43 & 167,34 & 167,34 & 241,97 \\
\hline \begin{tabular}{|l} 
Salamandra salamandrandra \\
Sala
\end{tabular} & - & $\begin{array}{l}100,00 \\
100\end{array}$ & \begin{tabular}{|l|l|}
123,61 \\
\end{tabular} & $\begin{array}{l}30,00 \\
83,98\end{array}$ & $\begin{array}{l}39,00 \\
39,18 \\
\end{array}$ & $\begin{array}{l}32512,31 \\
4612,31\end{array}$ & $\mid \begin{array}{ll}244,22 \\
243,96\end{array}$ & $\begin{array}{r}1,10 \\
32,62\end{array}$ & $\begin{array}{l}24,12 \\
211,34\end{array}$ & 73,180 & $\begin{array}{l}17,90 \\
181,61\end{array}$ & \begin{tabular}{|l|}
184,19 \\
184,19
\end{tabular} & $\begin{array}{l}40,45 \\
67,65 \\
\end{array}$ & \begin{tabular}{l|l}
805,78 \\
1057,52
\end{tabular} & \begin{tabular}{|l|}
52,10 \\
120,02 \\
\end{tabular} & $\begin{array}{l}43,19 \\
50,76\end{array}$ & $\begin{array}{l}20,66 \\
200\end{array}$ & $\begin{array}{l}\mid 23,45 \\
333,64\end{array}$ & \begin{tabular}{|l|}
101,54 \\
191,58
\end{tabular} & $\mid$\begin{tabular}{|l|}
$\mid 010,54$ \\
200,33
\end{tabular} & $\begin{array}{ll}24,915,99 \\
315,99\end{array}$ \\
\hline Salamandra salamandra & 30TWN47 & 100,00 & 127,37 & 80,59 & 39,48 & 4414,46 & 242,24 & 40,45 & 201,79 & 79,66 & \begin{tabular}{|l|l|}
182,45 \\
\end{tabular} & 185,32 & 74,13 & 1134,07 & 130,68 & 53,16 & 21,75 & 362,79 & 200,85 & 213,87 & 344,92 \\
\hline Salamandra salamandra & 30TWN48 & 100,00 & 130,07 & 77,45 & 39,64 & 4246,62 & 240,05 & 46,70 & 193,35 & 84,39 & 182,71 & 185,86 & 79,20 & 1204,46 & 140,81 & 55,47 & 22,78 & 389,75 & 209,58 & 226,82 & 372,07 \\
\hline Salamandra salamandra & 30TWN53 & 100,00 & & not & 39,00 & 20,0 & $2+1,05$ & $-5,51$ & 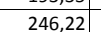 & 42,19 & 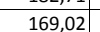 & 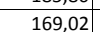 & & 912,8 & & & & 272,35 & & 174,91 & 255,66 \\
\hline Salamandra salamandra & 30TWN54 & & & & 39, & & & 6, & 236 & 52, & $1 / 5$ & $1 / 5$ & 45, & 945,86 & \begin{tabular}{|c|}
103,08 \\
\end{tabular} & & & 287,36 & 180,52 & 180,55 & 269 \\
\hline Salamandra salamandra & 30TWN55 & 100,00 & 101,96 & 91,96 & 39,17 & 4992,10 & 235,34 & 3,58 & 231,76 & 48,52 & 167,24 & 168,02 & 41,50 & 1042,61 & 115,05 & 54,16 & 18,39 & 320,16 & \begin{tabular}{|c|c|}
197,85 \\
\end{tabular} & 198,55 & 300,92 \\
\hline Salamandra salamandra & 30TWN56 & 100,00 & 121,30 & 86,70 & 39,73 & 4667,95 & 244,58 & 28,76 & 215,83 & 70,68 & 180,08 & 182,54 & 64,62 & 1082,56 & 121,58 & 52,97 & 20,11 & 340,60 & 198,55 & 204,39 & 320,05 \\
\hline Salamandra salamandra & 30TWN57 & 100,00 & 121,94 & 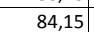 & 40,03 & 4490,28 & 240,93 & 32,96 & 207,97 & 73,57 & 178,16 & 180,97 & 67,85 & 1167,68 & 132,45 & 56,49 & 20,77 & 371,32 & 210,95 & 220,01 & 349,71 \\
\hline Salame & $30 \mathrm{TWI}$ & & & & 40, & & & 43,6 & & & 180,89 & 184 & 77 & 1240 & & 58, & 21,94 & & 218,99 & & \\
\hline Salamandra salamandra & 30TWN64 & 100,00 & 104,07 & 95,58 & $\begin{array}{ll}40,25 \\
39,10\end{array}$ & 5166,61 & 242,19 & $\begin{aligned} 4,00 \\
1,56\end{aligned}$ & 240,63 & 告, 48,36 & 172,21 & 172,21 & 41,03 & \begin{tabular}{|c|} 
\\
984,99 \\
\end{tabular} & $\begin{array}{l}42,, 632 \\
08,32\end{array}$ & $\begin{array}{ll}51,52 \\
51,5\end{array}$ & $\mid 18,30$ & \begin{tabular}{|c|}
300,55 \\
300,45
\end{tabular} & \begin{tabular}{|l|l}
186,36 \\
186
\end{tabular} & $\mid \begin{array}{l}\mid 186,36 \\
\end{array}$ & 281,81 \\
\hline
\end{tabular}




\begin{tabular}{|c|c|c|c|c|c|c|c|c|c|c|c|c|c|c|c|c|c|c|c|c|c|}
\hline TAXON & UTM & $\mathrm{km} 2$ & BIO1 & $\mathrm{BIO2}$ & $\mathrm{BIO3}$ & BIO4 & BIO5 & B106 & B107 & B108 & B109 & BIO10 & BIO11 & BIO12 & BIO13 & B1014 & B1015 & B1016 & BIO17 & B1018 & B1019 \\
\hline Salamandra salamandra & 30TWN65 & 100,00 & 114,75 & 92,10 & 39,59 & 4941,28 & 246,34 & 16,24 & 230,10 & 61,12 & 178,84 & 179,67 & 54,48 & 1037,83 & 115,65 & 52,42 & 19,30 & 323,01 & 194,30 & 195,10 & 302,10 \\
\hline Salamandra salamandra & 30TWN67 & 100,00 & 123,06 & 85,63 & 40,39 & 4495,82 & 243,12 & 33,38 & 209,73 & 74,62 & 179,28 & 182,14 & \begin{tabular}{l|l|l}
68,95 \\
\end{tabular} & 1199,36 & 135,85 & 58,32 & 20,85 & 382,33 & 217,09 & 225,01 & 358,30 \\
\hline Salamandra salamandra & 30TWN68 & 100,00 & 128,29 & 82,14 & 40,94 & 4248,49 & 241,72 & 43,40 & \begin{tabular}{l|l}
198,32 \\
\end{tabular} & 82,67 & 180,87 & $\begin{array}{l}184,08 \\
\end{array}$ & 77,57 & \begin{tabular}{|l|l|}
1282,11 \\
\end{tabular} & 145,99 & 61,18 & 21,70 & 412,56 & 227,80 & 241,07 & 386,77 \\
\hline Salamandra salamandra & 30TWN69 & 47,00 & 142,35 & 77,38 & 40,97 & 4040,34 & 247,61 & 61,04 & $\begin{array}{l}186,56 \\
\end{array}$ & 98,65 & 191,69 & $\begin{array}{l}195,08 \\
\end{array}$ & 93,94 & \begin{tabular}{|l|l|}
1284,21 \\
\end{tabular} & 149,00 & 59,06 & 23,20 & 418,49 & 222,79 & 243,99 & 393,32 \\
\hline Salamandra salamandra & 30TWN73 & 100,00 & 103,41 & 98,80 & 39,01 & 5350,09 & 246,23 & $-3,39$ & 249,61 & 45,57 & 173,73 & \begin{tabular}{|c|}
173,73 \\
\end{tabular} & \begin{tabular}{|l|l|}
37,87 \\
\end{tabular} & 936,65 & 102,89 & 49,35 & 18,41 & 283,47 & 175,99 & 175,99 & 265,79 \\
\hline Salamandra salamandra & 30TWN74 & 100,00 & 100,62 & 96,62 & 39,21 & 5208,45 & 240,12 & $-2,82$ & 242,94 & 44,68 & 169,38 & 169,38 & 37,17 & 1021,25 & $\begin{array}{ll}113,47 \\
\end{array}$ & 53,57 & 18,56 & 312,86 & 191,86 & $\begin{array}{l}191,86 \\
\end{array}$ & 293,94 \\
\hline Salamandra salamandra & 30TWN75 & 100,00 & 108,49 & 94,04 & 39,53 & 5036,57 & 243,08 & 7,88 & 235,20 & 54,16 & 174,61 & 174,66 & \begin{tabular}{|l|l|}
46,97 \\
\end{tabular} & 1073,28 & 120,82 & 54,95 & 19,36 & 334,82 & 200,40 & 200,40 & 313,61 \\
\hline Salamandra salamandra & 30TWN76 & 100,00 & 111,01 & 90,73 & 39,88 & 4809,98 & 239,75 & 14,90 & \begin{tabular}{l|l|}
224,85 \\
\end{tabular} & 59,29 & 172,92 & 174,38 & 52,67 & 1155,76 & 130,57 & 58,44 & 19,83 & 363,66 & 213,91 & 216,84 & 340,62 \\
\hline Salamandra salamandra & 30TWN77 & 100,00 & 129,54 & 85,98 & 40,78 & 4449,01 & 248,19 & 39,74 & 208,45 & 81,29 & 184,82 & 187,75 & 75,75 & 1224,90 & 139,65 & 59,02 & 21,43 & 393,34 & 220,21 & 229,16 & 366,76 \\
\hline Salamandra salamandra & 30TWN78 & 100,00 & 136,02 & 82,26 & 41,51 & 4169,84 & 247,28 & 51,34 & \begin{tabular}{ll|}
195,95 \\
\end{tabular} & 90,94 & 187,18 & 190,48 & 86,04 & 1306,41 & 148,74 & 62,01 & 22,07 & 422,21 & 231,31 & 246,37 & 393,01 \\
\hline Salamandra salamandra & 30TWN83 & 100,00 & 110,64 & 99,59 & 39,01 & 5397,98 & 254,13 & 2,25 & 251,88 & 51,75 & 181,21 & 181,21 & 43,90 & 943,14 & 106,92 & 48,21 & 19,84 & 291,81 & 172,73 & 172,73 & 273,47 \\
\hline Salamandra salamandra & 30TWN84 & 100,00 & 91,57 & 97,49 & 39,01 & 5276,41 & 233,10 & $-13,28$ & 246,38 & 35,46 & 161,44 & 161,44 & 27,57 & 1060,01 & 118,21 & 56,62 & 18,24 & 323,42 & 199,51 & 199,51 & 305,06 \\
\hline Salamandra salamandra & 30TWN85 & 100,00 & 106,58 & 95,36 & 39,43 & 5114,41 & 243,07 & 4,09 & 238,99 & 51,34 & 173,73 & \begin{tabular}{|l|l|}
173,73 \\
\end{tabular} & 43,91 & \begin{tabular}{ll|}
1099,31 \\
\end{tabular} & 125,91 & 56,20 & 19,88 & 345,57 & 203,27 & 203,27 & 324,35 \\
\hline Salamandra salamandra & 30TWN86 & 100,00 & 113,46 & 92,50 & 39,91 & 4893,48 & 244,21 & 14,93 & 229,28 & 60,5 & 176,77 & 177,71 & 53,68 & \begin{tabular}{|c|}
1171,81 \\
\end{tabular} & 135,21 & 58,7 & 20, & 373,55 & 215,77 & 216,84 & 349,65 \\
\hline Salamandra salamandra & 30TWN87 & 100,00 & 114,38 & 90,20 & 40,28 & 4714,87 & 240,70 & 19,19 & 221,50 & 63,64 & 174,15 & \begin{tabular}{|l|l|}
176,25 \\
\end{tabular} & 57,07 & 1253,24 & 144,73 & 62,59 & 20,78 & 401,85 & 230,62 & 233,34 & 375,75 \\
\hline Salamandra salamandra & 30TWN88 & 100,00 & 129,64 & 84,99 & 41,19 & 4340,68 & 245,11 & 41,00 & 204,11 & 82,85 & 183,45 & \begin{tabular}{ll|}
186,52 \\
\end{tabular} & \begin{tabular}{ll|l}
77,15 \\
\end{tabular} & 1323,19 & 152,53 & 64,33 & 21,75 & \begin{tabular}{ll|l}
428,25 \\
\end{tabular} & 238,60 & 250,17 & 398,13 \\
\hline Salamandra salamandra & 30TWN89 & 84,00 & 141,98 & 80,34 & 41,12 & 4147,07 & 249,07 & 56,16 & 192,91 & \begin{tabular}{|c|}
97,07 \\
\end{tabular} & 192,83 & $\begin{array}{l}196,01 \\
\end{array}$ & 91,49 & \begin{tabular}{|c|c|}
1324,87 \\
\end{tabular} & 154,41 & 63,41 & 22,63 & 431,54 & 237,27 & 257,20 & 400,51 \\
\hline Salamandra salamandra & 30TWN95 & 100,00 & 112,46 & 96,45 & 39,30 & 5169,92 & 249,99 & 7,99 & 242,00 & 56,38 & 180,13 & 180,13 & 48,65 & 1115,28 & 131,91. & 55,58 & 21,42 & 357,89 & 201,88 & 201,88 & 336,12 \\
\hline Salamandra salamandra & 30 TWN96 & 100,00 & 104,13 & 94,60 & 39,5 & 5054,56 & 238,99 & 2,51 & 236,48 & 49,8 & 170,57 & \begin{tabular}{|c|}
170,57 \\
\end{tabular} & 42,31 & \begin{tabular}{|c|c|}
1187,49 \\
\end{tabular} & 138,57 & 60,62 & 20,39 & 378,00 & 219,52 & 219,52 & 355,21 \\
\hline Salamandra salamandra & 30TWN97 & 100,00 & 110,60 & 91,78 & 40,00 & 4839,21 & 239,44 & 12,53 & 226,92 & 58,56 & 172,80 & 174,20 & 51,36 & 1259,47 & 147,50 & 63,49 & 20,90 & 404,84 & 233,16 & 234,64 & 379,23 \\
\hline Salamandra salamandra & 30TWN98 & 100,00 & 120,70 & 87,94 & 40,59 & 4563,81 & 241,46 & 27,30 & 214,15 & 71,55 & 177,77 & 180,49 & 64,91 & 1332,12 & 156,15 & 66,26 & 21,49 & 431,84 & 244,48 & 251,74 & 402,44 \\
\hline Salamandra salamandra & 30TWN99 & 100,00 & 133,51 & 83,01 & 40,83 & 4317,29 & 244,87 & 43,87 & 201,01 & 90,02 & 186,91 & \begin{tabular}{l|l|}
189,84 \\
\end{tabular} & 80,53 & \begin{tabular}{|c|}
1355,71 \\
\end{tabular} & 159,45 & \begin{tabular}{ll|}
66,82 \\
\end{tabular} & 22,10 & 441,31 & 248,15 & 264,33 & 409,19 \\
\hline Salamandra salamandra & 30TWP10 & 94,00 & 132,38 & 64,68 & 36,92 & 3975,66 & 228,22 & 55, & \begin{tabular}{|l|}
172,72 \\
\end{tabular} & 89,86 & 181,32 & 184,84 & 84,41 & 1266,20 & 160,96 & 52,91 & 27,98 & 425,57 & 204,62 & 235,59 & 420,02 \\
\hline Salamandra salamandra & 30TXM01 & 100,00 & 95,38 & 108,00 & 37,85 & 6071,08 & 255,01 & $-28,10$ & 283,11 & 115,35 & 174,92 & \begin{tabular}{|c|}
175,13 \\
\end{tabular} & 20,77 & 577,34 & 74,88 & 32,82 & 23,46 & 187,54 & \begin{tabular}{|c|}
116,08 \\
\end{tabular} & 129,63 & 134,59 \\
\hline Salamandra salamandra & $\begin{array}{l}30 \text { TXM15 } \\
\end{array}$ & 100,00 & 137,34 & 106,54 & 37,96 & 6040,20 & 292,78 & 14,55 & 278,22 & 159,61 & 215,33 & 215,33 & \begin{tabular}{ll|l}
61,35 \\
\end{tabular} & 480,36 & 58,18 & 22,85 & 24,02 & 145,01 & 87,32 & 89,54 & 122,01 \\
\hline Salamandra salamandra & 30 TXM23 & 100,00 & 133,82 & 106,67 & 37,25 & 6133,99 & 291,05 & 9,61 & 281,44 & 156,30 & 213,06 & 213,06 & $\begin{array}{l}56,85 \\
\end{array}$ & 437,57 & 57,78 & 20,95 & 26,66 & 139,33 & 80,58 & 82,35 & 104,92 \\
\hline Salamandra salamandra & 30TXM88 & 100,00 & 112,24 & 102,10 & 38,10 & 5625,63 & 258,76 & $-4,53$ & 263,29 & 132,04 & 184,71 & \begin{tabular}{ll|}
185,06 \\
\end{tabular} & \begin{tabular}{l|l}
41,42 \\
\end{tabular} & 601,19 & 69,05 & 30,72 & 18,49 & $\begin{array}{l}174,65 \\
\end{array}$ & 122,07 & 124,87 & 143,51 \\
\hline Salamandra salamandra & 30TXM89 & 100,00 & 102,23 & 100,74 & 38,2 & 5560,33 & 246,57 & $-12,78$ & 259, & 120,7 & 174,27 & 174,50 & 32,76 & 687,58 & 76,95 & 36,54 & 17,18 & \begin{tabular}{|c|c|}
197,48 \\
\end{tabular} & 140,41 & 144,25 & 167,70 \\
\hline Salamandra salamandra & 30TXN06 & 100,00 & 106,18 & 95,55 & 39,43 & 5116,10 & 241,79 & 2,54 & 239,25 & 50,97 & 173,27 & 173,27 & 43,10 & 1195,82 & 142,30 & 60,52 & 21,15 & 384,30 & 219,61 & 219,61 & 361,55 \\
\hline Salamandra salamandra & 30TXN07 & 100,00 & 120,29 & 91,28 & 39,95 & 4846,52 & 246,87 & 20,70 & 226,18 & 68,22 & 181,79 & \begin{tabular}{ll|}
183,66 \\
\end{tabular} & 60,27 & \begin{tabular}{|c|c|}
1249,93 \\
\end{tabular} & 149,77 & 62,11 & 21,78 & 406,52 & 230,56 & 234,53 & 379,90 \\
\hline Salamandra salamandra & 30TXN08 & 100,00 & 127,35 & 87,62 & 40,13 & 4626,20 & 246,63 & 31,30 & 215,33 & 79,84 & 185,25 & 187,69 & 69,99 & 1304,00 & 156,08 & 64,90 & 21,99 & 425,17 & 241,37 & 251,01 & 395,35 \\
\hline Salamandra salamandra & 30TXN09 & 67,00 & 131,10 & 84,45 & 40,21 & 4476,51 & 244,47 & 37,44 & 207,04 & 90,9 & 186,80 & 189,40 & 75,49 & 1344,08 & 160,62 & 67,51 & 22,10 & 438,57 & 250,79 & 265,82 & 405,86 \\
\hline Salamandra salamandra & 30TXN12 & 100,00 & 104,16 & 102,64 & 38,87 & 5612,40 & 252,62 & $-9,5$ & 262, & 43, & 177,51 & 177,51 & 34,44 & 941,64 & 110,28 & 47,85 & 20, & 291,98 & 169,21 & 169,21 & 276,37 \\
\hline Salamandra salamandra & 30TXN14 & 100,00 & 114,75 & 100,62 & 38,90 & 5484,35 & 259,12 & 3,13 & 255,99 & 54,69 & 186,16 & 186,16 & 46,05 & 1064,60 & 132,53 & 51,37 & 23,62 & 348,62 & 185,86 & 185,86 & 329,79 \\
\hline Salamandra salamandra & 30TXN15 & 100,00 & 107,71 & 98,34 & 39,02 & 5316,13 & 247,88 & $-0,46$ & 248,34 & 50,04 & 177,17 & \begin{tabular}{|c|}
177,17 \\
\end{tabular} & \begin{tabular}{|c|}
41,58 \\
\end{tabular} & 1130,84 & 136,92 & 56,58 & 21,81 & 364,65 & 204,42 & 204,42 & 344,08 \\
\hline Salamandra salamandra & 30 TXN16 & 100,00 & 94,84 & 95,87 & 39,18 & 5175,51 & 231,62 & $-9,67$ & 241,29 & 39,67 & 162,94 & \begin{tabular}{|l|l|}
162,95 \\
\end{tabular} & 31,27 & 1194,21 & 139,45 & 62,56 & 19,60 & 376,12 & 224,05 & \begin{tabular}{|l|l|}
224,05 \\
\end{tabular} & 354,54 \\
\hline Salamandra salamandra & 30TXN17 & 100,00 & 121,06 & 92,23 & 39,79 & 4938,64 & 248,44 & 18,70 & 229,73 & 67,68 & 183,71 & $\begin{array}{l}185,35 \\
\end{array}$ & 59,33 & 1233,22 & 149,93 & 61,36 & 22,18 & 402,18 & 228,79 & 233,11 & 376,19 \\
\hline Salamandra salamandra & 30TXN18 & 100,00 & 03 & 90,82 & 39,5 & 5,37 & 8 & 16,7 & 225,26 & 65 & 178,11 & 180,21 & 56,93 & 1297,17 & 156,49 & 65,53 & 21,6 & 421,85 & 243,14 & 248,53 & 394,30 \\
\hline Salamandra salamandra & 30 & 100,00 & 10 & 102,39 & $38, \varepsilon$ & 3,17 & 25 & $-10,44$ & 261,68 & 42,5 & 176,68 & 176,68 & 33,57 & 936,79 & 109,38 & 47,68 & 20,38 & 288,82 & 169,79 & 169,79 & 273,40 \\
\hline Salamandra salamandra & 30 TXN23 & 100,00 & & 102,05 & 38 & & 25 & $-2,50$ & 260,15 & 50, & 183,84 & 183,84 & 41 & 988,25 & 120,37 & 48,46 & 22,30 & 315,84 & 175,14 & 175,14 & 299,01 \\
\hline Salamandra salamandra & 30TXN25 & 100,00 & 100,82 & 98,30 & 39,01 & 5322,00 & 240,78 & $-7,48$ & 248,25 & 43,32 & 170,44 & $\begin{array}{l}170,44 \\
\end{array}$ & 34,87 & 1122,83 & 133,32 & 57,64 & 20,37 & 355,39 & 207,64 & 207,64 & 335,49 \\
\hline Salamandra salamandra & $30 T X N 26$ & 89,00 & 93,17 & 96,25 & 39,11 & 5206,27 & 230,03 & $-12,54$ & 242,57 & 37,57 & 161,61 & \begin{tabular}{|l|l|}
161,63 \\
\end{tabular} & 28,95 & 1181,31 & 137,49 & 62,37 & 1012 & 369,64 & 223,78 & 223,78 & 348,52 \\
\hline Salamandra salamandra & $30 T X N 27$ & 72,00 & 109,27 & 94,73 & 39,63 & 078,57 & 241,06 & 4,3 & 23 & 54,3 & 174,58 & \begin{tabular}{|l|l|}
175,53 \\
\end{tabular} & 45,96 & 1221,24 & 147,16 & 62,18 & 21,02 & 393,30 & 230,13 & 231,38 & 369,47 \\
\hline Salamandra salamandra & 30TXN28 & 100,00 & 112,90 & 92,41 & 39,88 & 4942,30 & 239,95 & 9,99 & 229,95 & 59, & 175,67 & 177,35 & 51,08 & 1269,48 & 153,18 & 64,76 & 21,08 & 410,29 & 240,76 & 245,22 & 384,35 \\
\hline Salamandra salamandra & 30 TXN29 & 28,00 & 124,35 & 88,39 & 39,99 & 4757,15 & 243,02 & 23,58 & 219,44 & 85, & 184,21 & 186,09 & 64,29 & 1294,07 & 157,29 & 66,15 & 21,94 & 422,26 & 247,30 & 260,13 & 391,01 \\
\hline Salamandra salamandra & 30TXN35 & 100,00 & 91,78 & 97,76 & 38,99 & 5311,18 & 231,03 & $-16,31$ & 247,34 & 35,0 & 161,50 & 161,50 & 26,25 & \begin{tabular}{|c|}
1113,44 \\
\end{tabular} & 128,04 & 59,14 & 18,53 & 343,19 & 211,70 & 211,70 & 323,82 \\
\hline Salamandra salamandra & 30TXN36 & 81,00 & 90,19 & 96,37 & 39,05 & 5227,71 & 226,97 & $-16,30$ & 243,27 & 34,44 & 158,80 & \begin{tabular}{|c|}
158,81 \\
\end{tabular} & 25,69 & $\mid 1166,10$ & 134,19 & 62,39 & 18,37 & 360,71 & 223,80 & 223,80 & 340,07 \\
\hline Salamandra salamandra & 30TXN37 & & & & & & & & & & & & & & & & & & & & \\
\hline Salamandra salamandra & 30TXN44 & 100,00 & 88,07 & 98,23 & 38,93 & 5375,46 & 228,34 & $-21,44$ & 249,78 & 30,71 & 158,55 & \begin{tabular}{l|l|}
158,55 \\
\end{tabular} & 21,58 & 1053,74 & 117,87 & 56,95 & 17,45 & 316,51 & 203,15 & 203,15 & 298,49 \\
\hline Salamandra salamandra & 30 TXN46 & 75,00 & 86,27 & 96,27 & 39,05 & 5234,26 & 222,50 & $-20,60$ & 243,10 & 30,64 & 154,88 & 154,91 & 21,63 & 1150,02 & 129,98 & 62,58 & 17,33 & 350,31 & 224,32 & 224,35 & 329,99 \\
\hline Salamandra salamandra & 30TXN47 & & & & & & & & & & & & & & & & & & & & \\
\hline Salamandra salamandra & 30 XNN52 & 0 & 12 & 100,09 & 1 & 2 & 5 & $-18,39$ & 54 & S & 3 & 93 & 25,84 & 916,59 & 99,80 & 49,03 & 30 & 267,96 & 177,47 & 177,65 & 251,91 \\
\hline Salamandra salamandra & $30 \mathrm{TX}$ & & & $\begin{aligned} 96,82 \\
96\end{aligned}$ & & & & -24 & 24 & & & & 18,1 & 1091,06 & 120,27 & 60,17 & 16,46 & 324,97 & 215,11 & 215,11 & 305,78 \\
\hline Salamandra salamandra & 30 TXN56 & 37,00 & 79,52 & 95,46 & 38,96 & 5231,69 & 215,01 & $-27,01$ & 242,02 & 24,21 & 148,19 & 148,19 & 14,99 & 1149,13 & 126,64 & 64,19 & 16,15 & 343,11 & 228,41 & 228,41 & 322,84 \\
\hline Salamandra salamandra & 30TXN63 & 100,00 & 94,94 & 99,57 & 38,95 & 5416,45 & 235,38 & $-17,14$ & 252,52 & 42,68 & 165,40 & 165,40 & 27,29 & 934,84 & 101,29 & 50,20 & 16,66 & 273,25 & \begin{tabular}{ll|}
183,96 \\
\end{tabular} & 184,22 & 256,22 \\
\hline Salamandra salamandra & 30TXN64 & 100,00 & 83,53 & 97,27 & 38,80 & 341,30 & 221,56 & $-25,87$ & 247,43 & 26,82 & 153,35 & 153,35 & 17,30 & 1027,09 & 110,20 & 57,12 & 15,75 & 298,96 & 204,99 & 205,07 & 280,60 \\
\hline Salam & & 92,0 & & & & & & & & & 3 & & & & & & & 320 & & 68 & \\
\hline Salamandra salamandra & 30TXN66 & 6,00 & & & 39,35 & & & -20,99| & 242,79 & 31,36 & 15 & 0 & 22,10 & 02 & 121,46 & 60,74 & 16,26 & 328,58 & 220,57 & 220,71 & 308,65 \\
\hline Salamandra salamandra & 30TXN74 & 100,00 & 67,09 & 93,69 & 38,16 & 5304,14 & 202,82 & $-39,59$ & 242,41 & 15,92 & 136,99 & \begin{tabular}{|c|}
136,99 \\
\end{tabular} & 2,03 & \begin{tabular}{ll|}
1089,61 \\
\end{tabular} & 112,52 & 63,81 & 14,30 & 307,78 & 223,36 & 223,49 & 288,38 \\
\hline Salamandra salamandra & 30TXN75 & 83,00 & 65,57 & 93,03 & 38,28 & 5259,30 & 199,91 & $-40,09$ & 240,00 & 10,91 & 134,93 & 134,93 & 1,10 & 1131,74 & 117,47 & 66,48 & 14,20 & 322,24 & 232,28 & 232,28 & 302,19 \\
\hline
\end{tabular}




\begin{tabular}{|c|c|c|c|c|c|c|c|c|c|c|c|c|c|c|c|c|c|c|c|c|c|}
\hline TAXON & UTM & $\mathrm{km} 2$ & BIO1 & B102 & $\mathrm{BIO3}$ & 8104 & B105 & B106 & B107 & B108 & B109 & BIO10 & B1011 & BIO12 & B1013 & B1014 & 81015 & B1016 & BIO17 & B1018 & B1019 \\
\hline Salamandra salamandra & 30TXN80 & 100,00 & 95,74 & 99,77 & 38,26 & 5501,36 & 238,35 & $-18,12$ & 256,46 & 111,46 & 167,05 & 167,16 & 27,15 & 759,75 & 82,89 & 41,34 & 16,27 & 215,49 & 155,52 & 160,27 & 188,89 \\
\hline Salamandra salamandra & 30 TXN83 & 100,00 & 75,68 & 95,40 & 38,34 & 5342,54 & 212,55 & $-33,13$ & 245,68 & 55,34 & \begin{tabular}{|l|l|}
145,72 \\
\end{tabular} & 145,72 & 9,74 & $\begin{array}{l}993,85 \\
\end{array}$ & 102,26 & 57,44 & 14,39 & 278,46 & 205,26 & 206,54 & 257,59 \\
\hline Salamandra salamandra & 30TXN84 & 100,00 & 50,41 & 89,26 & 37,13 & 5272,72 & 183,66 & $-53,41$ & $\begin{array}{l}237,07 \\
237,07\end{array}$ & 35,53 & 120,55 & 120,55 & $-13,35$ & $\begin{array}{r}\mid 1171,25 \\
1170\end{array}$ & 119,66 & 71,51 & 13,39 & 325,22 & 244,61 & 244,93 & 302,94 \\
\hline Salamandra salamandra & 30 TXN85 & 53,00 & 42,17 & 86,92 & 36,71 & 5231,16 & 173,46 & $-60,17$ & 233,62 & $\begin{array}{l}9,99 \\
\end{array}$ & 112,02 & 112,02 & $-20,73$ & 1248,27 & 126,53 & 77,25 & 13,13 & 346,39 & 261,15 & 261,15 & 324,94 \\
\hline Salamandra salamandra & 30TXN93 & 100,00 & 48,20 & 88,18 & 36,68 & 5295,76 & 181,29 & $-55,86$ & 237,16 & 58,64 & 118,67 & 118,67 & $-15,74$ & 1150,99 & 119,68 & 71,05 & 13,38 & 322,05 & 242,88 & 243,18 & 291,27 \\
\hline Salamandra salamandra & 30 TXN94 & 50,00 & 49,03 & 88,31 & 36,92 & 5266,55 & 181,26 & $-54,64$ & 235,91 & 53,19 & 119,07 & 119,07 & $-14,66$ & \begin{tabular}{|l|}
1173,98 \\
\end{tabular} & 120,41 & 72,41 & 13,14 & 326,20 & 247,68 & 248,08 & 300,06 \\
\hline Salamandra salamandra & 30TYN01 & 100,00 & 87,26 & 97,46 & 38,44 & 5402,29 & 226,07 & $-24,44$ & 250,51 & 104,60 & 157,51 & 157,71 & 20,01 & 824,62 & 89,14 & 46,93 & 14,90 & 233,53 & 175,42 & 179,88 & 199,54 \\
\hline Salamandra salamandra & 30TYNO3 & 99,00 & $\begin{array}{ll}36,88 \\
362\end{array}$ & 84,36 & 35,64 & 5266,47 & 167,53 & $-65,62$ & 233,15 & 48,42 & 107,42 & 107,42 & \begin{tabular}{r|r|r|r|}
$-25,95$ \\
\end{tabular} & \begin{tabular}{r|r|}
1224,93 \\
\end{tabular} & $\mid \begin{array}{l}0,1,43 \\
127,53\end{array}$ & 77,30 & $\begin{array}{l}4,04 \\
13,04 \\
\end{array}$ & $\mid \frac{343,70}{343}$ & 260,60 & 260,76 & 307,40 \\
\hline Salamandra salamandra & 30TYN04 & 24,00 & 37,92 & 84,46 & 35,90 & 5244,13 & 168,00 & $-64,05$ & 232,05 & 49,61 & \begin{tabular}{|l|}
108,08 \\
\end{tabular} & 108,08 & $-24,88$ & 1240,59 & 127,92 & 78,29 & 12,91 & 345,81 & 264,09 & 264,09 & 313,63 \\
\hline Salamandra salamandra & 30TYN13 & 100,00 & 47,94 & 86,82 & 36,42 & 5292,12 & 179,49 & $-55,73$ & 235,22 & \begin{tabular}{|c|}
60,84 \\
\end{tabular} & 118,25 & 118,25 & $-16,06$ & 1150,14 & 120,31 & 72,13 & 13,03 & 323,51 & 247,41 & 248,28 & 284,42 \\
\hline Salamandra salamandra & 30 TYN14 & 42,00 & 31,99 & 81,89 & 35,16 & 5231,31 & 160,33 & $-69,29$ & 229,62 & 42,90 & 102,19 & 102,19 & $-30,23$ & 1279,76 & 132,24 & 81,80 & 12,62 & 357,57 & 274,11 & 274,11 & 321,20 \\
\hline Salamandra salamandra & 30TYN24 & 45,00 & 12,23 & 75,01 & 33,06 & 5179,52 & 136,49 & $-86,88$ & 223,37 & 20,55 & 82,48 & 82,48 & $-47,96$ & 1414,76 & 146,01 & 92,52 & 12,06 & 395,43 & 303,44 & 303,44 & 355,09 \\
\hline Salamandra salamandra & 30 TYN42 & 60,00 & 32,27 & 79,78 & 34,22 & 5289,33 & 160,47 & $-69,20$ & 229,68 & $\begin{array}{l}43,05 \\
\end{array}$ & 103,33 & 103,33 & $-30,38$ & 1247,89 & 131,84 & 80,87 & 12,80 & \begin{tabular}{|l|}
354,47 \\
\end{tabular} & 272,80 & 273,09 & 300,99 \\
\hline Salamandra salamandra & 31твH52 & 61,00 & 26,09 & 77,48 & 33,53 & 5281,27 & 152,94 & $-74,49$ & 227,43 & 36,03 & 97,28 & 97,28 & $-36,08$ & 1296,34 & 136,53 & 84,57 & 12,68 & 367,71 & 283,47 & 283,64 & 313,16 \\
\hline Salamandra salamandra & 31TBH62 & 100,00 & 46,28 & 83,24 & 35,06 & 5349,68 & 176,70 & $-57,15$ & 233,85 & 58,97 & \begin{tabular}{|c|}
105,13 \\
\end{tabular} & 117,52 & $-18,02$ & 1169,48 & 123,92 & 75,53 & 13,20 & 333,57 & 259,65 & 262,50 & 275,92 \\
\hline Salamandra salamandra & 31TBH91 & 100,00 & 57,69 & 84,80 & 35,00 & 5466,00 & 190,84 & $-47,45$ & 238,29 & 71,85 & 34,21 & 130,24 & $-8,32$ & 1130,54 & 119,98 & 73, & 13,92 & 325,03 & 251,39 & 264,91 & 256,33 \\
\hline Salamandra salamandra & 31TBH92 & 100,00 & 27,92 & 75,45 & 32,68 & 5333,73 & 154,78 & $-72,13$ & 226,91 & 38,21 & 69,40 & 99,83 & $-34,58$ & 1322,21 & 138,87 & 87,78 & 12,61 & 374,57 & 293,48 & 295,91 & 313,36 \\
\hline Salamandra salamandra & 31TCF06 & 100,00 & 146,94 & 98,80 & 36,36 & 5915,29 & 292,01 & 24,43 & 267,58 & \begin{tabular}{|l|l|}
151,15 \\
\end{tabular} & 177,38 & 224,94 & 75,96 & 530,69 & 64,09 & 17,86 & 31,50 & 173,85 & 99,04 & 112,21 & 107,57 \\
\hline Salamandra salamandra & 31TCF15 & 101,00 & 145,84 & 92,56 & 35,91 & 5691,94 & 282,92 & 28,81 & 254,11 & 151,16 & 220,48 & 221,73 & 78,41 & 579,26 & 72,72 & 18,21 & 32,13 & 193,91 & 104,29 & 123,97 & 121,18 \\
\hline Salamandra salamandra & 31TCF16 & 100,00 & 144,25 & 94,60 & 35,96 & 5815,44 & 284,88 & 25,33 & 259,55 & 149,85 & 199,48 & 221,21 & 74,36 & 562,22 & 68,15 & 19,17 & 30,79 & 183,79 & 106,39 & 122,69 & 114,40 \\
\hline Salamandra salamandra & 31TCF17 & 99,00 & 125,28 & 93,84 & 35,53 & 5901,09 & 268,66 & 7,94 & 260,72 & 133,01 & 61,14 & 203,30 & 54,08 & \begin{tabular}{|c|c|}
630,37 \\
\end{tabular} & 72,59 & 26,3 & 25,89 & 190,87 & 126,36 & 138,57 & 127,53 \\
\hline Salamandra salamandra & 31 TCF27 & 100,00 & 120,60 & 89,93 & 35,00 & 5805,41 & 260,19 & 6,82 & 253,36 & 128,42 & 57,11 & 197,84 & $\begin{array}{l}50,98 \\
50,\end{array}$ & 670,91 & 76,09 & 28,75 & $\begin{array}{l}24,87 \\
24,8\end{array}$ & 202,60 & 135,85 & 149,16 & 136,49 \\
\hline Salamandra salamandra & 31 TCF29 & 100,00 & 139,84 & 97,39 & 35,82 & 6073,80 & 286,59 & \begin{tabular}{r|r}
17,96 \\
\end{tabular} & 268,64 & 158,81 & 71,07| & 218,75 & 64,14 & 546,20 & 63,61 & 23,82 & 27,30 & 167,30 & 102,78 & 125,16 & 102,78 \\
\hline Salamandra salamandra & 31 TCF36 & 100,00 & 136,20 & 85,52 & 34,78 & 5605,32 & 267,82 & 25,11 & 242,71 & 144,68 & 167,76 & 210,99 & 68,99 & 624,55 & 74,92 & 22,99 & 28,69 & 202,11 & 121,90 & 139,31 & 128,05 \\
\hline Salamandra salamandra & 31 TCF37 & 100,00 & 114,28 & 86,34 & 34,47 & 5723,86 & 250,82 & 4,11 & 246,72 & 122,64 & 48,59 & 190,80 & 46,14 & 718,90 & 80,58 & 32,16 & 23,49 & 215,68 & 146,96 & \begin{tabular}{|c|c|}
160,95 \\
\end{tabular} & 147,02 \\
\hline Salamandra salamandra & 31 TCF 38 & 101,00 & 130,78 & 89,58 & 34,95 & 5816,48 & 269,14 & 16,21 & 252,92 & 138,87 & 64,10 & 207,49 & 59,81 & 621,44 & 70,68 & 26,14 & 26,05 & 190,56 & 122,19 & 141,97 & 122,21 \\
\hline Salamandra salamandra & 31 TCF 46 & 100,00 & $\begin{array}{ll}130,100 \\
150,92\end{array}$ & 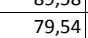 & 34,11 & $\begin{array}{l}5010,40 \\
5368,23\end{array}$ & $\mid 273,71$ & $\begin{array}{l}\mid 0,21 \\
43,88\end{array}$ & 229,83 & $\begin{array}{l}\mid 3,01,10 \\
161,10\end{array}$ & \begin{tabular}{|c|c|}
122,53 \\
\end{tabular} & 222,42 & 85,92 & $\mid \frac{\mid 2,1,44}{572,10}$ & $\begin{array}{l}70,00 \\
73,85\end{array}$ & \begin{tabular}{|l|l|l|l|}
19,23 \\
\end{tabular} & $\begin{array}{l}\mid 0,03 \\
32,18 \\
\end{array}$ & 196,31 & $\mid$ & $\mid \begin{array}{l}\mid 43,, 27 \\
133\end{array}$ & $\begin{array}{l}x_{2,2,21} \\
117,32 \\
\end{array}$ \\
\hline Salamandra salamandra & 31 TCF 47 & 101,00 & 136,05 & 83,50 & 34,21 & 5592,67 & 266,19 & 26,45 & 239,74 & 145,30 & 76,56 & 210,39 & 68,47 & 621,99 & 73,21 & 24,19 & 27,66 & 199,13 & 122,82 & 141,92 & 125,13 \\
\hline Salamandra salamandra & 31 TCF 48 & 99,00 & 138,87 & 85,79 & 34,62 & 5687,07 & 271,31 & 26,77 & 244,55 & $\begin{array}{l}14,37,92 \\
147\end{array}$ & 74,29 & 213,86 & 69,20 & 591,98 & 69,21 & 23,47 & 27,73 & 188,44 & 115,02 & \begin{tabular}{|l|l|l|l|}
136,76 \\
\end{tabular} & 115,27 \\
\hline Salamandra salamandra & 31 TCF 49 & 101,00 & 128,02 & 87,40 & 34,56 & 5785,10 & 264,77 & 15,34 & 249,44 & 140,59 & 57,40 & 204,29 & 57,40 & 644,86 & 73,53 & 29,42 & 25,06 & 194,61 & 124,06 & 151,48 & 124,06 \\
\hline Salamandra salamandra & 31 TCF58 & 101,00 & 134,09 & 82,51 & 34,01 & 5616,82 & 264,21 & 25,09 & 239,12 & 143,74 & 67,24 & 208,60 & 65,96 & 633,71 & 72,56 & 26,48 & 26,18 & 199,10 & 124,34 & 147,58 & 124,36 \\
\hline \begin{tabular}{|l} 
Salamandra salamandra \\
\end{tabular} & 3 & 100,00 & $\begin{array}{l}134,05 \\
125,75\end{array}$ & \begin{tabular}{|l|l|l|}
84,04 \\
\end{tabular} & $\begin{array}{ll}34,01 \\
34,01\end{array}$ & $\begin{array}{l}501099,40 \\
569,\end{array}$ & \begin{tabular}{|l|l|}
259,31 \\
259
\end{tabular} & $\begin{array}{l}2,0,02 \\
16,02\end{array}$ & 243,14 & $\begin{array}{l}14,14 \\
136,53\end{array}$ & $\mid \begin{array}{ll}\mid r, 24 \\
56,71\end{array}$ & 201,32 & $\mid \begin{array}{l}\mid 20,70 \\
56,71\end{array}$ & $\mid$ & $\begin{array}{l}72,0,18 \\
76,1\end{array}$ & $\begin{array}{l}20,40 \\
31,49\end{array}$ & $\begin{array}{l}\mid 20,10 \\
24,39 \\
\end{array}$ & 203,12 & \begin{tabular}{|l|}
129,84 \\
1296
\end{tabular} & \begin{tabular}{|l|}
159,50 \\
159,53
\end{tabular} & $\begin{array}{l}124,30 \\
129,86 \\
\end{array}$ \\
\hline Salamandra salamandra & 31TCF65 & 46,00 & 162,50 & 71,04 & 33,00 & 5050,68 & 274,52 & 62,36 & 212,16 & 175,04 & 227,02 & 230,05 & \begin{tabular}{|l|l|}
101,48 \\
\end{tabular} & 558,36 & 77,79 & 18,38 & 34,71 & 201,48 & 99,46 & 134,50 & 120,18 \\
\hline Salamandra salamandra & 31TCF66 & 100,00 & 154,23 & 73,09 & 33,01 & 5191,91 & 270,40 & 52,41 & 217,99 & 165,97 & 220,92 & 223,55 & 91,57 & 583,63 & 76,96 & 20,6 & 31,16 & 202,41 & 108,47 & 138,47 & 122,70 \\
\hline Salamandra salamandra & 31TCF67 & 101,00 & 145,25 & 76,66 & 33,25 & 5386,18 & 267,13 & 40,66 & 226,47 & 156 & 176,01 & 217,00 & 80,06 & 608,72 & 75,16 & 23, & 28,20 & 201,90 & 119,23 & 142,62 & 123,55 \\
\hline Salamandra salamandra & 31 TCF 68 & 99,00 & 131,15 & 79,81 & 33,66 & 5559,16 & 259,21 & 24,77 & 234,45 & 141,26 & |64,97 & 205,27 & 64,24 & 666,55 & 75,62 & 29,08 & 25,12 & 208,11 & 131,83 & 156,38 & 131,86 \\
\hline Salamandra salamandra & 31TCF69 & 101,00 & 126,00 & 81,38 & 33,80 & 5630,80 & 256,95 & 18,44 & 238,52 & 135,73 & 58,01 & 200,83 & 58,01 & 688,63 & 77,25 & 32,79 & 23,99 & 208,25 & 132,74 & 164,76 & 132,74 \\
\hline Salamandra salamandra & 31 TCF76 & 100,00 & 158,41 & 71,91 & 32,99 & 5151,24 & 272,81 & 57,54 & 215,27 & 170,21 & 224,63 & 227,14 & 96,04 & 582,02 & 79,99 & 21,60 & 31,08 & 204,76 & 108,70 & 139,79 & 120,42 \\
\hline Salamandra salamandra & 31TCF77 & 101,00 & 145,54 & 74,80 & 33,01 & 5344,03 & 265,69 & 42,47 & 223,23 & 156,52 & 193,43 & 216,74 & 81,12 & 627,43 & 78,06 & $25, \mathrm{C}$ & 27,47 & 208,00 & 123,24 & 148,06 & 127,46 \\
\hline Salamandra salamandra & 31TCF78 & 101,00 & 130,54 & 77,56 & 33,0 & 504,74 &, 71 & 26 & 230,66 & 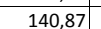 & 72,92 & 04,04 & 64,67 & 687,65 & 77,72 & 30, & 24,46 & 214,64 & 136,78 & 162,16 & 136,81 \\
\hline Salamandra salamandra & 31TCF79 & 100,00 & 128,91 & 78,91 & 33,06 & 5569,67 & 257,32 & 23,18 & 234,14 & $13 \varepsilon$ & 61,92 & 203,09 & 61,92 & 687,95 & 76,92 & 32, & 24,03 & 210,20 & 132,79 & 165,84 & 132,79 \\
\hline Salamandra salamandra & 31 TCF86 & 91,00 & & 71,41 & 32,97 & 5147,19 & 273 & & 214,47 & 177 & \begin{tabular}{|l|l|}
226,06 \\
\end{tabular} & 228,23 & 97,46 & 592,90 & 83,01 & 22,78 & 30,74 & 209,33 & 111,23 & 142,36 & 121,67 \\
\hline Salamandra salamandra & 31TCF87 & 99,00 & & 72,64 & 32,94 & 5250,76 & 271,23 & 52,83 & 218,40 & 165,66 & 222,41 & 224,40 & 90,97 & 606,20 & 80,03 & 24,43 & 28,57 & 207,34 & 117,39 & 145,62 & 122,55 \\
\hline Salamandra salamandra & 31TCF88 & 101,00 & 146,61 & 74,55 & 32,95 & 5379,89 & 26 & 43, & 224,06 & 157,43 & 124,63 & 218,17 & 81,53 & 630,24 & 76,94 & 26, & 26,52 & 206,60 & 124,75 & 151,34 & 125,14 \\
\hline Salamandra salamandra & 31TCF89 & 101,00 & 139,33 & 7 & 32,97 & 5485,22 & 26 & 34,7 & 229,15 & 149 & $\begin{array}{r}72,0 \\
72,92\end{array}$ & 212,16 & 72,92 & 652,83 & 74,95 & 30,7 & 25,02 & 205,62 & 126,21 & 158,68 & 126,21 \\
\hline Salamandra salamandra & 31 TCF96 & $\begin{array}{l}101,00 \\
63,00\end{array}$ & & 7 & 32,93 & 5135,33 & $\frac{20}{27}$ & $\begin{array}{ll}34,109 \\
61,89\end{array}$ & 21213,65 & $\begin{array}{l}\mid l 4,15 \\
173,63\end{array}$ & \begin{tabular}{r|r|r|}
228,45 \\
\end{tabular} & 230,55 & \begin{tabular}{r|r|}
100,06 \\
\end{tabular} & $\begin{array}{l}05,05 \\
597,04\end{array}$ & 85,61 & $\begin{array}{l}30,19 \\
22,81\end{array}$ & 31,43 & \begin{tabular}{|l|}
213,67 \\
213
\end{tabular} & $\begin{array}{l}\mid 111,73 \\
111,73\end{array}$ & \begin{tabular}{|l|l|}
143,07 \\
143
\end{tabular} & $\begin{array}{ll}122,33 \\
122,3\end{array}$ \\
\hline Salamandra salamandra & 31TCF97 & 101,00 & 155,44 & 71,73 & 32,62 & 5239,23 & 271,63 & 54,42 & 217,21 & 166,41 & 223,38 & 225,25 & 92,23 & 620,28 & 82,75 & 25,01 & 28,58 & 213,10 & 119,15 & 148,12 & 126,26 \\
\hline Salamandra salamandra & 31TCF98 & 100,00 & 154,06 & 72,97 & 32,69 & 5317,90 & 272,40 & 51,77 & 220,63 & \begin{tabular}{|l|l}
164,93 \\
\end{tabular} & 143,72 & 224,68 & 89,57 & 613,12 & 78,77 & 26,30 & 27,63 & 206,61 & 120,71 & 149,15 & 121,59 \\
\hline Salamandra salamandra & 31TCF99 & 100,00 & 150,56 & 74,29 & 32, & 5400,68 & 271, & 46, & 224 & 4 & 84 & 222,03 & & 616 & 74,95 & 28, & 26, & 201,81 & 118,82 & 152,44 & 118,82 \\
\hline Salamandra salamandra & $31 \mathrm{TC}$ & 10 & & 100 & 36 & 6053 & & -7, & $2 / 1$ & & & 19 & 37 & & 80,56 & & & & 134,33 & 177,91 & 134 \\
\hline 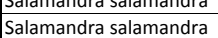 & 31TCG14 & $\begin{array}{l}100,00 \\
100\end{array}$ & \begin{tabular}{|l|}
119,22 \\
119,2
\end{tabular} & $\begin{array}{l}10,45 \\
100,30\end{array}$ & $\begin{array}{l}0,350 \\
36,13 \\
\end{array}$ & $\begin{array}{ll}00323,24 \\
6123,16\end{array}$ & \begin{tabular}{|l|}
270,38 \\
27,0
\end{tabular} & $\begin{array}{l}-1,02 \\
-2,44\end{array}$ & $\begin{array}{l}27,30 \\
272,82\end{array}$ & $\begin{array}{l}\mid 3,1,10 \\
141,63\end{array}$ & $\begin{array}{l}31,09 \\
42,18\end{array}$ & $\begin{array}{l}\mid 9,1,01 \\
198,48\end{array}$ & $\begin{array}{l}31,09 \\
42,18\end{array}$ & $\begin{array}{l}0,20 \\
663,98\end{array}$ & $\begin{array}{l}80,30 \\
77,33 \\
\end{array}$ & $\begin{array}{l}40,53 \\
36,82\end{array}$ & $\begin{array}{l}20,30 \\
22,38\end{array}$ & $\mid$\begin{tabular}{|l|l|}
208,67 \\
208
\end{tabular} & \begin{tabular}{|l|}
134,33 \\
123,72
\end{tabular} & \begin{tabular}{|l|}
170,29 \\
170
\end{tabular} & \begin{tabular}{|l|}
134,33 \\
123,72 \\
\end{tabular} \\
\hline Salamandra salamandra & 31TCG16 & 101,00 & 105,52 & $\begin{array}{c}96,40 \\
96\end{array}$ & 36,16 & 5926,78 & 251,74 & $-11,38$ & 263,12 & 125,83 & 31,49 & 182,73 & 31,49 & 796,46 & 89,31 & 46,46 & 19,72 & 243,61 & 154,88 & 207,47 & 154,88 \\
\hline Salamandra salamandra & $31 \mathrm{TCG} 19$ & 100,00 & 85,20 & 91,00 & 35,91 & 5684,82 & 224,70 & $-25,41$ & 250,11 & 102,57 & 15,24 & 159,72 & 15,13 & 991,70 & 106,40 & 62,57 & 16,37 & 292,01 & 207,85 & 250,60 & 207,85 \\
\hline Salamandra salamand & 31 TCG24 & 100,00 & 119,50 & & 35,88 & 6070,98 & & $-0,6$ & & 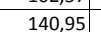 & & & 43,20 & 679,4 & & 37, & 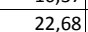 & 212,84 & 125,75 & 175,27 & 125,75 \\
\hline Salaman & & 99, & & & 35 , & 571 & 225 & $-23,97$ & 249 & 10 & 15, & & 15,7 & 965,62 & 105 & 59, & & 287,94 & 197,62 & 245,02 & \\
\hline Salamandra salamandra & 31TCG34 & 100,00 & \begin{tabular}{|l|l|}
126,66 \\
\end{tabular} & $\begin{array}{l}96,48 \\
96,4\end{array}$ & 35,73 & 6057,52 & 273,47 & \begin{tabular}{|c|c|}
6,68 \\
\end{tabular} & 266,79 & 148,22 & 50,25 & 204,90 & 50,25 & 646,01 & 75,22 & 34,60 & 23,94 & 203,36 & 116,24 & 168,70 & 116,24 \\
\hline Salamandra salamandra & 31 TCG35 & 100,00 & 102,56 & 91,07 & 35,19 & 5855,30 & 244,94 & $-10,29$ & 255,23 & 120,90 & 30,50 & 179,28 & 30,50 & \begin{tabular}{|c|}
813,86 \\
\end{tabular} & 92,62 & 46,27 & 20,91 & 250,31 & \begin{tabular}{|l|l|}
154,85 \\
\end{tabular} & 211,10 & 154,85 \\
\hline Salamandra salamandra & 31TCG36 & 100,00 & 117,81 & 95,62 & 35,85 & 5979,94 & 263,39 & $-0,18$ & 263,56 & 138,88 & 42,61 & 195,41 & 42,61 & 723,82 & 82,78 & 39,32 & 22,59 & 226,92 & 131,99 & 198,32 & 131,99 \\
\hline Salan & $31 \mathrm{TCC}$ & 1010 & & & 35,5 & 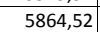 & & $-8,8$ & 257,39 & & 32 & 181, & 32 & & 92 , & 46 & 20 & & 156,84 & 221,14 & \\
\hline Salamandra salamandra & 31TCG38 & 101,00 & 100,74 & 92,05 & 35,65 & 5808,73 & 242,40 & $\begin{array}{l}-0,000 \\
-12,33 \\
\end{array}$ & 254,73 & $\begin{array}{l}\mid l 24,0 \\
119,60\end{array}$ & 28,60 & 176,52 & 28,60 & 875,04 & $\begin{array}{ll}97,42 \\
7,4\end{array}$ & $\begin{array}{l}40,007 \\
50,57\end{array}$ & $\begin{array}{ll}19,64 \\
\end{array}$ & 266,84 & 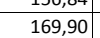 & 237,59 & 169,90 \\
\hline
\end{tabular}




\begin{tabular}{|c|c|c|c|c|c|c|c|c|c|c|c|c|c|c|c|c|c|c|c|c|c|}
\hline TAXON & UTM & $\mathrm{km} 2$ & BIO1 & $\mathrm{B1O2}$ & $\mathrm{BIO3}$ & 8104 & B105 & B106 & B107 & B108 & B109 & BIO10 & BIO11 & BIO12 & B1013 & B1014 & B1015 & B1016 & B1017 & B1018 & B1019 \\
\hline Salamandra salamandra & 31TCG39 & 100,00 & 72,43 & 84,84 & 34,63 & 5608,18 & 208,53 & $-33,39$ & 241,93 & 87,47 & 13,71 & 146,77 & 4,76 & 1056,72 & 114,67 & 66,88 & 16,13 & 310,90 & 222,37 & 261,89 & 223,34 \\
\hline Salamandra salamandra & 31TCG42 & 99,00 & 138,89 & 93,20 & 35,08 & 5983,99 & 281,33 & 20,20 & 261,13 & 159,89 & \begin{tabular}{l|l}
63,45 \\
\end{tabular} & 216,18 & 63,45 & 577,85 & 67,41 & 30,03 & 25,98 & 179,55 & 102,43 & 144,34 & 102,43 \\
\hline Salamandra salamandra & 31TCG45 & 101,00 & $\begin{array}{ll}114,29 \\
114,\end{array}$ & 91,50 & 35,01 & 5901,49 & 256,68 & $-0,45$ & 257,13 & $\mid 133,68$ & 40,92 & 191,16 & 40,92 & 741,55 & 85,76 & 39,78 & 23,26 & 232,24 & 134,15 & 198,86 & 134,15 \\
\hline Salamandra salamandra & 31 TCG46 & 100,00 & 97,35 & 88,30 & 34,84 & 5776,11 & 237,24 & $-12,70$ & 249,94 & 114,72 & 26,74 & 173,27 & 26,74 & 863,40 & 97,85 & 49,07 & 20,60 & 264,79 & 164,38 & 227,18 & 164,38 \\
\hline Salamandra salamandra & 31 TCG49 & 101,00 & 83,04 & 86,28 & 34,86 & 5660,96 & 220,30 & $-24,22$ & 244,53 & 99,18 & 16,94 & 157,79 & 14,22 & 986,01 & 108,81 & 60,63 & 17,82 & 294,88 & 200,65 & 253,99 & 200,96 \\
\hline Salamandra salamandra & 31TCG50 & 100,00 & 125,20 & 85,47 & 34,08 & 5757,16 & 260,77 & 14,22 & 246,55 & 141,68 & 54,95 & 201,17 & \begin{tabular}{r|r|}
54,95 \\
\end{tabular} & 672,70 & 77,02 & 33,49 & 24,15 & 201,27 & 126,60 & 163,08 & 126,60 \\
\hline Salamandra salamandra & 31 TCG54 & 100,00 & 128,47 & 90,52 & 34,94 & 5904,12 & 269,06 & 12,75 & 256,31 & 148,32 & 54,50 & 204,86 & 54,50 & 656,86 & 77,26 & 33,38 & 25,45 & 207,43 & 113,50 & 175,72 & 113,50 \\
\hline Salamandra salamandra & 31TCG55 & 100,00 & 122,96 & 90,48 & 34,96 & 5889,88 & 263,85 & 7,80 & 256,05 & 142,53 & 49,29 & 199,42 & 49,29 & 693,17 & 81,14 & 35,47 & 25,08 & 219,27 & 120,52 & 189,14 & 120,52 \\
\hline Salamandra salamandra & 31 TCG56 & 100,00 & 101,21 & 87,01 & 34,60 & 5759,90 & 239,94 & $-8,37$ & 248,31 & 118,44 & 30,82 & 177,04 & 30,82 & 836,70 & 95,76 & 46,51 & 21,94 & 258,07 & 156,10 & 221,74 & 156,10 \\
\hline Salamandra salamandra & 31 TCG58 & 100,00 & 71,26 & 81,66 & 33,93 & 5572.92 & 205,77 & $-31,38$ & 237,16 & 85,01 & 9,53 & 145,67 & \begin{tabular}{|l|l|l}
4,98 &
\end{tabular} & 1045,71 & 115,06 & 66,29 & 16,50 . & 308,16 & 217.42 & 256,14 & 217,73 \\
\hline Salamandra salamandra & 31TCG59 & 101,00 & 53,42 & 77,91 & 33,18 & 5480,81 & 185,19 & $-46,43$ & 231,62 & 65,12 & 6,63 & 127,25 & $-10,71$ & 1162,71 & 125,42 & 76,56 & 14,33 & 334,58 & 253,12 & 273,89 & 255,58 \\
\hline Salamandra salamandra & 31TCG60 & 101,00 & 123,97 & 82,54 & 33,89 & 5682,52 & 256,82 & 15,55 & 241,28 & 151,45 & 55,06 & 199,25 & 55,06 & 695,57 & 79,27 & 35,38 & 23,78 & 206,99 & 130,82 & 170,18 & 130,82 \\
\hline Salamandra salamandra & 31TCG61 & 99,00 & 125,74 & 83,80 & 33,97 & 5727,71 & 259,95 & 15,87 & 244,08 & 143,41 & 55,75 & 201,19 & 55,75 & 683,17 & 78,92 & 35,98 & 24,29 & 206,36 & 124,60 & 171,33 & 124,60 \\
\hline Salamandra salamandra & 31TCG62 & 100,00 & 128,55 & 85,27 & 34,02 & 5765,80 & 263,99 & 17,17 & 246,82 & 146,21 & 57,46 & 204,06 & 57,46 & 667,49 & 77,95 & 34,40 & 25,03 & 205,20 & 118,07 & 171,74 & 118,07 \\
\hline Salamandra salamandra & 31TCG63 & 100,00 & 128,65 & 86,51 & 34,10 & 5808,17 & 265,45 & 16,13 & 249,32 & 147,04 & 56,57 & 204,41 & 56,57 & 667,53 & 78,55 & 33,57 & 25,63 & 208,33 & $\begin{array}{l}115,35 \\
\end{array}$ & 175,76 & 115,35 \\
\hline Salamandra salamandra & 31 T1CG64 & 101,00 & 120,85 & 86,78 & 34,10 & 5815,49 & 258,77 & 8,88 & 249,89 & 139,11 & 48,99 & 196,76 & 48,99 & 712,98 & 84,27 & 35,55 & 25,45 & 224,98 & 122,59 & 192,38 & 122,59 \\
\hline Salamandra salamandra & 31TCG65 & 101,00 & 121,13 & 87,71 & 34,33 & 5831,24 & 259,73 & 8,37 & 251,36 & 139,89 & 48,66 & 197,02 & 48,66 & 711,34 & 84,13 & 35,08 & 25,96 & 226,18 & 120,89 & 196,85 & 120,89 \\
\hline Salamandra salamandra & 31 TCG66 & 100,00 & 100,32 & 85,03 & 34,11 & 5725,60 & 237,58 & $-7,64$ & 245,22 & 116,90 & 30,95 & 175,84 & 30,66 & 843,93 & 97,14 & 46,30 & 22,37 & 260,39 & 155,95 & 225,38 & 155,97 \\
\hline Salamandra salamandra & 31TCG68 & 100,00 & 102,52 & 86,83 & 34,61 & 5742,15 & 240,55 & $-6,99$ & \begin{tabular}{|l|l}
247,55 \\
\end{tabular} & 120,07 & 35,21 & 177,77 & 31,88 & 835,53 & 96,50 & 45,65 & 22,99 & 260,03 & 153,37 & 233,65 & 153,48 \\
\hline Salamandra salamandra & 31TCG69 & 100,00 & 81,66 & 83,19 & 34,16 & 5613,66 & 217,09 & $-22,99$ & 240,08 & 96,70 & 20,97 & 156,14 & 14,08 & $\begin{array}{l}984,49 \\
\end{array}$ & 109,60 & 59,94 & 18,40 & 294,83 & 197,92 & 252,69 & 198,74 \\
\hline Salamandra salamandra & 31TCG71 & 101,00 & 127,45 & 81,27 & 33,46 & 5665,09 & 259,12 & 19,54 & 239,58 & 161,52 & 58,44 & 202,31 & 58,44 & 687,89 & 79,31 & 35, & 24, & 207,74 & 124,61 & 174,50 & 124,61 \\
\hline Salamandra salamandra & 31TCG72 & 101,00 & 126,24 & 82,42 & 33,64 & 5699,56 & 259,27 & 17,33 & 241,95 & \begin{tabular}{|l|l|l|l|l|}
142,78 \\
\end{tabular} & $\begin{array}{l}56,445 \\
56,45\end{array}$ & 201,25 & $\begin{array}{l}56,445 \\
56,45\end{array}$ & $\begin{array}{l}\mid 694,37 \\
694,37\end{array}$ & 81,27 & 35,29 & 24,88 & 212,50 & 122,24 & 180,40 & 122,24 \\
\hline Salamandra salamandra & 31TCG73 & 100,00 & 121,63 & 83,25 & 33,79 & 5723,55 & 256,15 & 12,41 & 243,74 & 138,51 & 51,61 & 196,92 & 51,61 & 720,62 & 85,22 & 35,85 & 25,23 & 224,42 & 124,60 & 191,02 & 124,60 \\
\hline Salamandra salamandra & 31 TCG74 & 100,00 & 116,23 & 83,76 & 33,94 & 5734,19 & 251,71 & 7,01 & 244,69 & 133,10 & 46,16 & 191,64 & 46,16 & 752,23 & 89,30 & 37,21 & 25,30 & 236,62 & 129,29 & 203,23 & 129,29 \\
\hline Salamandra salamandra & 31TCG75 & 100,00 & 113,46 & 84,33 & 33,99 & 5744,27 & 249,75 & 4,17 & 245,58 & 130,70 & 43,18 & 188,87 & 43,18 & 767,56 & 90,93 & 38,16 & 25,40 & 242,60 & 131,87 & 211,41 & 131,87 \\
\hline Salamandra salamandra & 31TCG76 & 101,00 & 82,16 & 80,14 & 33,41 & 5598,00 & 216,28 & $-20,41$ & 236,68 & 95,78 & 19,20 & 157,11 & 15,95 & 964,72 & 108,32 & 56,96 & 19,15 & 286,27 & 192,24 & 241,99 & 192,74 \\
\hline Salamandra salamandra & 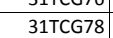 & 101,00 & $\begin{array}{l}\mid 82,10 \\
85,85\end{array}$ & 82,15 & 33,85 & 56519,35 & $\mid \begin{array}{l}\mid 10,20 \\
220,94\end{array}$ & $\begin{array}{l}-20,41 \\
-18,18\end{array}$ & $\begin{array}{l}230,00 \\
239,12\end{array}$ & $\mid$\begin{tabular}{|c|}
100,67 \\
\end{tabular} & 23,43 & | & $\mid \begin{array}{l}18,55 \\
18,5\end{array}$ & 9499,62 & $\begin{array}{l}\mid 0,32, \\
106,95 \\
\end{array}$ & 56,21 & $\mid \frac{19,43}{19,49}$ & 280,270 & \begin{tabular}{|l|l|l|l|}
186,85 \\
\end{tabular} & $\mid \begin{array}{l}\mid 4,1,39 \\
246,24\end{array}$ & $\mid 187,27$ \\
\hline Salamandra salamandra & 31TCG79 & 93,00 & 84,65 & 82,50 & 33,99 & 5614,10 & 219,73 & $-19,88$ & 239,61 & 99,70 & 26,61 & 159,09 & 17,16 & 961,84 & 107,81 & 57,50 & 19,35 & 288,82 & 191,07 & 250,67 & 192,28 \\
\hline Salamandra salamandra & 31TCG80 & 100,00 & 142,39 & 77,58 & 33,01 & 5522,76 & 268,04 & 36,43 & 231,61 & 182,38 & 74,93 & 215,34 & 74,93 & 629,71 & 73,18 & 30,88 & 25,36 & 197,39 & 117,18 & 157,80 & 117,18 \\
\hline Salamandra salamandra & 31TCG81 & 100,00 & 127,46 & 79,08 & 33,01 & 5607,84 & 257,22 & 21,31 & 235,91 & 169,23 & 59,53 & 201,81 & 59,53 & 699,47 & 80,66 & 36 & 24,19 & 211,40 & 126,42 & 179,08 & 126,42 \\
\hline Salamandra salamandra & 31TCG82 & 100,00 & 125,96 & 80,09 & 33,02 & 5639,63 & 257,04 & 18,88 & 238,16 & 152,77 & 57,31 & 200,52 & 57,31 & 705,59 & 82,69 & 35,65 & 24,78 & 215,71 & 123,66 & 185,27 & 123,66 \\
\hline Salamandra salamandra & 31TCG83 & 101,00 & 126,54 & 81,20 & 33,17 & 5680,40 & 258,87 & 18,34 & 240,54 & 143,76 & \begin{tabular}{|l|l}
57,05 \\
\end{tabular} & 201,30 & \begin{tabular}{|c|c|}
57,05 \\
\end{tabular} & 704,03 & 83,77 & 34,09 & 25,99 & 219,07 & 119,07 & 189,24 & 119,07 \\
\hline Salamandra salamandra & 31TCG84 & 101,00 & 127,57 & 82,38 & 33,35 & 5708,55 & 260,98 & 18,27 & 242,71 & 144,95 & 57,26 & 202,28 & 57,26 & 702,92 & 84,28 & 32,92 & 27,02 & 222,55 & 115,79 & 193,19 & 115,79 \\
\hline Salamandra salamandra & 31 TCG85 & 99,00 & 114,33 & 82,40 & 33,63 & 5699,13 & 248,77 & 6,58 & 242,19 & 130,87 & 44,84 & 189,38 & 44,84 & 773,50 & 92,16 & 37,98 & 25,73 & 243,95 & 131,94 & 212,51 & 131,94 \\
\hline Salamandra salamandra & 31TCG86 & 101,00 & 95,66 & 80,92 & 33,6 & 5627,15 & 229,94 & $-8,2$ & 238,16 & 110,43 & 29,12 & 170,56 & 28,44 & 882,62 & 101,85 & 48 & 21,74 & 269,03 & 164,82 & 231,88 & 164,88 \\
\hline Salamandra salamandra & 31TCG87 & 99,00 & 67,24 & 77,10 & 32,93 & 5503,48 & 199,44 & $-31,32$ & 230,76 & 78,97 & 13,91 & 141,54 & 3,51 & $\begin{array}{r}1068,36 \\
\end{array}$ & 117,04 & 67,59 & 16,05 & 307,45 & 224,74 & 256,98 & 226,27 \\
\hline Salamandra salamandra & 31TCG88 & 100,00 & 63,33 & 76,98 & 32,89 & 5497,30 & 195,29 & $-35,57$ & 230,86 & 73,67 & 28,23 & 137,52 & $-0,41$ & \begin{tabular}{|l|}
1098,87 \\
\end{tabular} & 119,62 & 68,98 & 15,87 & 316,04 & 231,11 & 263,61 & 235,88 \\
\hline Salamandra salamandra & 31TCG89 & 99,00 & 66,22 & 77,80 & 33,05 & 5506,40 & 198,47 & $-33,72$ & 232,19 & 78,52 & 20,48 & 140,17 & 1,86 & 1083,69 & 118,31 & 67,99 & 16,35 & 313,94 & 227,60 & 264,52 & 231,28 \\
\hline Salamandra salamandra & 31TCG90 & 101,00 & 136,36 & 75,89 & 32,62 & 5509,64 & 261,97 & 32,01 & 229,96 & 171,63 & 69,87 & 209,50 & 69,87 & 671,94 & 76,56 & 34, & 24,21 & 207,62 & 126,49 & 167,94 & 126,49 \\
\hline Salamandra salamandra & 31TCG91 & 100,00 & 140,15 & 77,09 & 32,88 & 541,55 & 266,71 & 34,44 & 232,27 & 189,30 & 72,5 & 213,35 & 72,56 & 643,38 & 74,75 & 33 & 25,04 & 200,76 & 115,29 & 166,79 & 115,29 \\
\hline Salamandra salamandra & 31TCG92 & 100,00 & 140,33 & 16 & 32,96 & 5590,75 & 268,39 & 33,30 & 235,10 & 186,10 & 71,64 & 213,80 & 71,64 & $\mid 636,67$ & 74,62 & 32, & 25,90 & 199,55 & 109,06 & 170,61 & 109,06 \\
\hline Salamandra salamandra & 31TCG95 & 10 & 111,81 & 80,22 & 33,02 & 5654,02 & 244,94 & 6,04 & 238,90 & 127 & 43, & 186,65 & 43,42 & \begin{tabular}{|l|l|}
788,95 \\
\end{tabular} & 94,18 & 39, & 25,53 & 246,95 & 135,20 & 217,09 & 135,20 \\
\hline Salamandra salamandra & 31TCG96 & 101,00 & $\begin{array}{l}41,01 \\
83,33 \\
\end{array}$ & $\frac{\mid c 0,26}{77,80}$ & 32,93 & 5542,42 & 215,76 & $-16,57$ & 232,33 & $\begin{aligned} 25,44 \\
25\end{aligned}$ & 20, & 157,85 & 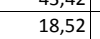 & 965,67 & $\mid \begin{array}{r}108,47 \\
\end{array}$ & 57,35 & 18,90 & 283,52 & 192,36 & 241,41 & 193,01 \\
\hline Salamandra salamandra & 31TCG97 & 100,00 & 71,85 & 76,80 & 32,78 & 5500,74 & 203,82 & $-26,53$ & 230 & 81 & 21 & 146,11 & 8,09 & 1042,29 & 114,65 & 64,5 & 16,80 & 300,67 & 216,33 & 253,16 & 218,34 \\
\hline Salamandra salamandra & 31TCG98 & 101,00 & 64,66 & 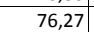 & 32,77 & 5478,46 & 196,19 & $-33,27$ & 229,46 & 73, & 26,6 & 138,66 & 1,43 & 1092,72 & 118,86 & 68,90 & 15,71 & 312,52 & 231,01 & 261,60 & 235,04 \\
\hline Salamandra salamandra & 31TCG99 & $\begin{array}{l}\quad+1,00 \\
99,00\end{array}$ & 73 & 78 & 33,11 & $\begin{array}{l}54713,07 \\
5513,07\end{array}$ & 205,46 & $\begin{array}{l}-26,27 \\
-26,95 \\
-2\end{array}$ & 232,41 & $\begin{array}{l}\mid 3,1,5 \\
85,52\end{array}$ & 20,5 & $\begin{array}{l}346,90 \\
146,93\end{array}$ & \begin{tabular}{|l|}
$, 1,45$ \\
8,37
\end{tabular} & 1043,01 & \begin{tabular}{|l|l|l|l|l}
114,88 \\
\end{tabular} & $\begin{array}{ll}60,301 \\
64,81\end{array}$ & $\begin{array}{l}1,1,1 \\
16,92\end{array}$ & | 301,32 & | $21,1,59$ & 257,31 & 218,58 \\
\hline Salamandra salamandra & 31TCHO2 & 95,00 & 16,76 & 72,03 & 31,69 & 5314,50 & 142,11 & $-81,48$ & 223,59 & 25,51 & 72,44 & 88,96 & \begin{tabular}{|c|c|}
$-44,56$ \\
\end{tabular} & 1402,13 & 146,60 & 93,52 & 12,24 & 394,75 & 310,47 & 310,92 & 335,91 \\
\hline Salamandra salamandra & $31 \mathrm{TCH} 03$ & 12,00 & 56,29 & 83,90 & 34,95 & 5433,32 & 187,96 & $-48,19$ & 236,15 & 70,27 & 32,02 & 128,30 & $-9,55$ & 1176,73 & 123,28 & 78,25 & 13,22 & 336,01 & 262,95 & 275,64 & 270,55 \\
\hline Salamandra salamandra & $31 \mathrm{TCH} 10$ & 101,00 & 70,82 & 86,9 & 35,20 & 5577,1 & 206,5 & -36 & 243 & 86 & 10 & 144,48 & 2,97 & 1077 & 114,90 & 70,6 & 15,04 & 313,38 & 233,40 & 262,96 & 234,27 \\
\hline Salamandra salamandra & 31TCH12 & 99,00 & 35,17 & 76,66 & 32,96 & 5377,96 & 163,51 & $-65,17$ & 228,68 & 46,14 & 49,97 & 107,55 & $-28,01$ & 1292,35 & 136,01 & 86,41 & 12,75 & 367,07 & 288,25 & 293,91 & 301,36 \\
\hline Salamandra salamandra & $31 \mathrm{TCH} 13$ & & & & & & & & & & & & & & & & & & & & \\
\hline Salamandra salamandra & 31TCH14 & & & & & & & & & & & & & & & & & & & & \\
\hline Salamandra salamandra & $31 \mathrm{TCH} 22$ & 100,00 & 36,77 & 76,64 & 32,94 & 5390,09 & 165,55 & $-63,34$ & 228,89 & 47,95 & 40,53 & 109,38 & $-26,45$ & \begin{tabular}{|l|}
1286,02 \\
\end{tabular} & 135,51 & 86,24 & 12,79 & 365,47 & 286,99 & 294,17 & 298,24 \\
\hline Salamandra salamandra & 31TCH23 & 101,00 & 39,35 & 77,48 & 33,21 & 5379,69 & 168,15 & $-61,19$ & 229,34 & 50,94 & 43,30 & 111,59 & $-24,16$ & $\begin{array}{l}1278,98 \\
\end{array}$ & 134,37 & 86,22 & 12,74 & 363,34 & 286,52 & 294,29 & 297 \\
\hline Salamandra salamandra & 31TCH24 & & & & & & & & & & & & & & & & & & & & \\
\hline Salamandra salamandra & $31 \mathrm{TCH} 30$ & 101,00 & 34,97 & 75,26 & 32,50 & 5415,06 & 164,19 & $-64,10$ & 228,29 & 45,33 & 41,12 & 108,31 & $-27,73$ & 1280,86 & 135,90 & 84,92 & 13,07 & 364,04 & 284,49 & 292,27 & 294,25 \\
\hline Salamandra salamandra & $31 \mathrm{TCH} 32$ & 100,00 & 30,59 & 74,37 & 32,30 & 5365,39 & 158,33 & $-67,99$ & 226,33 & 40,75 & 55,22 & 103,22 & $-31,65$ & 1322,80 & 139,29 & 88,89 & 12,41 & 374,10 & 296,83 & 300,48 & 308,79 \\
\hline Salamandra salamandra & $31 \mathrm{TCH} 33$ & 94,00 & & 73,96 & 32,25 & 346,24 & 155 & $-70,03$ & 225,54 & 38,52 & 56,33 & 100,74 & $-33,62$ & 344,27 & 140,94 & 90,78 & 12,19 & 379,09 & 302,24 & 304,95 & 316,39 \\
\hline Salam & 31 TCH & (90) & & & & & & & & & 12 , & & 0, & 1089, & & 70 & & & & 268,49 & 23 \\
\hline Salamandra salamandra & $31 \mathrm{TCH} 41$ & 100,00 & $\frac{\mid r, 326}{63,26}$ & 81,99 & $\begin{array}{l}34,13 \\
34,13 \\
\end{array}$ & 5523,37 & 196,65 & $-40,04$ & 236,68 & $\mid 77,13$ & 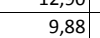 & $\begin{array}{l}141,40 \\
136,79 \\
\end{array}$ & $\frac{\mid, 05}{-2,89}$ & 1124,23 & $\begin{array}{ll}120,96 \\
\end{array}$ & 73,64 & $\begin{array}{l}214,88 \\
\end{array}$ & $\begin{array}{l}327,29 \\
327\end{array}$ & 242,00 & $\mid$ & 244,91 \\
\hline
\end{tabular}




\begin{tabular}{|c|c|c|c|c|c|c|c|c|c|c|c|c|c|c|c|c|c|c|c|c|c|}
\hline TAXON & UTM & $\mathrm{km} 2$ & BIO1 & $\mathrm{B1O2}$ & $\mathrm{BIO3}$ & 8104 & B105 & B106 & B107 & B108 & B109 & 81010 & B1011 & BIO12 & B1013 & B1014 & 81015 & B1016 & BIO17 & B1018 & B1019 \\
\hline Salamandra salamandra & $31 \mathrm{TCH} 42$ & 100,00 & 53,73 & 80,04 & 33,75 & 5467,77 & 185,45 & $-48,06$ & 233,50 & 66,64 & 18,61 & 126,77 & $-11,23$ & 1190,48 & 126,61 & 79,35 & 13,87 & 342,55 & 260,50 & 283,88 & 266,82 \\
\hline Salamandra salamandra & 31TCH50 & 100,00 & 71,39 & 82,70 & 34,26 & 5567,46 & 205,94 & $-32,33$ & 238,27 & 85,79 & 11,74 & 145,40 & 4,63 & 1063,64 & 116,05 & 67,96 & 16,14 & 313,12 & 222,89 & 264,81 & 224,47 \\
\hline Salamandra salamandra & 31TCH51 & 101,00 & 67,54 & 82,16 & 34,13 & 5539,02 & 201,42 & $-35,78$ & 237,21 & 81,70 & 15,01 & 141,19 & $\begin{array}{l}4,18 \\
1,18\end{array}$ & 1094,70 & 118,56 & 70,96 & 15,47 & 320,44 & 232,44 & 270,99 & 235,29 \\
\hline Salamandra salamandra & $31 \mathrm{TCH} 53$ & 13,00 & 58,38 & 80,89 & 33,87 & 5485,23 & 190,67 & $-44,20$ & \begin{tabular}{|l|l|}
234,88 \\
\end{tabular} & 71,88 & 29,31 & 131,43 & $-7,10$ & 1166,48 & 124,06 & 77,42 & 14,06 & 336,38 & 253,41 & 282,39 & 261,69 \\
\hline Salamandra salamandra & $31 \mathrm{TCH} 61$ & 101,00 & 43,72 & 75,90 & 32,65 & 5428,46 & 173,92 & $-55,01$ & 228,93 & 54,61 & 25,73 & 117,07 & $-19,20$ & 1239,91 & 131,77 & 82,07 & 13,39 & 352,25 & 272,38 & 289,12 & 281,41 \\
\hline Salamandra salamandra & $31 \mathrm{TCH} 70$ & 25,00 & 63,07 & 78,72 & 33,28 & 5501,75 & 195,50 & $-37,42$ & 232,93 & 75,62 & 13,79 & 136,87 & $-1,66$ & 1110,05 & 120,56 & 71,60 & 15,38 & 321,86 & 235,70 & 269,98 & 239,61 \\
\hline Salamandra salamandra & $31 \mathrm{TCH} 71$ & 16,00 & 42,06 & 74,86 & 32,44 & 5413,72 & 171,80 & $-55,63$ & 227,43 & 52,47 & 31,98 & 115,36 & $-20,23$ & 1250,03 & 132,67 & 82,76 & 13,23 & 353,38 & 273,94 & 289,90 & 285,08 \\
\hline Salamandra salamandra & 31TCH72 & 2,00 & 31,13 & 72,90 & 31,93 & 5365,65 & 159,33 & $-65,51$ & 224,84 & 40,46 & 47,63 & \begin{tabular}{|l|l|}
104,04 \\
\end{tabular} & - & $\begin{array}{l}1324,96 \\
1320\end{array}$ & 139,04 & 88,49 & $\begin{array}{l}\mid 0,25 \\
12,24 \\
\end{array}$ & 370,43 & 295,28 & 301,96 & 309,85 \\
\hline Salamandra salamandra & $31 \mathrm{TCH} 80$ & 17,00 & 26,86 & 71,15 & 31,32 & 5368,95 & 154,94 & $-68,27$ & 223,21 & 34,06 & 68,62 & 100,29 & $-33,26$ & 1345,76 & 140,51 & 87,68 & 12,45 & 371,94 & 296,81 & 302,25 & 316,72 \\
\hline Salamandra salamandra & $31 \mathrm{TCH} 90$ & 57,00 & 22,38 & 69,87 & 31,00 & 5348,90 & 149,96 & $-71,69$ & 221,65 & 20,28 & 76,64 & 95,73 & $-36,89$ & 1376,73 & 142,64 & 89,22 & 12,14 & 377,34 & 303,91 & 305,72 & 327,94 \\
\hline Salamandra salamandra & 31TDF06 & 37,00 & 157,68 & 70,70 & 32,57 & 5176,48 & 272,55 & 58,09 & 214,45 & 168,68 & 224,93 & 226,84 & 95,61 & 632,00 & 88,07 & 24,34 & 30,05 & 222,25 & 117,84 & 148,61 & 131,50 \\
\hline Salamandra salamandra & 31TDF07 & 100,00 & 148,43 & 71,25 & 32,08 & 5291,64 & 266,58 & 48,21 & 218,37 & 159,33 & 217,47 & 219,19 & 85,31 & 668,64 & 85,49 & 27,15 & 27,00 & 223,53 & 127,41 & 155,86 & 139,43 \\
\hline Salamandra salamandra & 31TDF08 & 101,00 & 149,24 & 72,06 & 32,09 & 5339,18 & 268,69 & 47,90 & 220,79 & 159,90 & 173,09 & 220,30 & 85,04 & 650,99 & 81,38 & 28,46 & 26,38 & 215,60 & \begin{tabular}{|l|l|}
128,65 \\
1
\end{tabular} & 156,33 & 131,18 \\
\hline Salamandra salamandra & 31TDF09 & 100,00 & 157,57 & 73,07 & 32,23 & 5337,48 & 276,76 & 54,45 & 222,32 & \begin{tabular}{|l|l|}
168,05 \\
\end{tabular} & 93,54 & 228,09 & 92,38 & 597,40 & 76,89 & 27,83 & 27,82 & 201,93 & 114,38 & 150,33 & 114,39 \\
\hline Salamandra salamandra & 31TDF16 & & & & & & & & & & & & & & & & & & & & \\
\hline Salamandra salamandra & 31TDF17 & 101,00 & 160,92 & 70,50 & 32,28 & 5174,62 & 276,34 & 61,01 & 215,33 & \begin{tabular}{|l|l|}
171,39 \\
\end{tabular} & 221,88 & 229,63 & 98,42 & 629,25 & 90,08 & 24,99 & 31,01 & 224,52 & 120,14 & 150,01 & 129,05 \\
\hline Salamandra salamandra & 31TDF18 & 99,00 & 160,91 & 71,10 & 32,03 & 5239,75 & 277,92 & 59,79 & 218,13 & 171,23 & 130,82 & 230,38 & 97,46 & 609,35 & 84,18 & 26,58 & 29,69 & 213,79 & 118,71 & 150,19 & 120,98 \\
\hline Salamandra salamandra & 31TDF19 & 101,00 & 158,29 & 71,93 & 31,99 & 5322,04 & 277,37 & 55,97 & 221,40 & 169,71 & 96,54 & 228,56 & 93,61 & $\begin{array}{l}602,55 \\
\end{array}$ & 78,29 & 29,03 & 27,86 & 204,69 & 115,31 & 153,16 & 115,54 \\
\hline Salamandra salamandra & 31TDF27 & 85,00 & 166,22 & 70,16 & 32,17 & 5089,19 & 280,30 & 66,64 & 213,66 & 176,56 & 218,22 & 233,41 & 104,49 & 618,62 & 94,89 & 23,92 & 33,86 & 229,10 & 117,70 & 148,27 & 125,51 \\
\hline Salamandra salamandra & 31TDF28 & 101,00 & 158,99 & 70,16 & 31,69 & 5227,88 & 276,22 & 58,85 & 217,37 & 169,24 & 158,51 & 228,43 & 95,97 & 626,99 & 86,51 & 27,97 & 28,92 & 218,95 & 124,19 & 154,23 & 126,40 \\
\hline Salamandra salamandra & 31 TDF29 & 101,00 & 159,89 & 70,96 & 31,86 & 5280,03 & 278,34 & 58,46 & 219,88 & 175,16 & 99,82 & 229,64 & 95,80 & 601,07 & 80,09 & 29,35 & 28,43 & 206,58 & 115,70 & 153,82 & 116,03 \\
\hline Salamandra salamandra & 31 TDF38 & 52,00 & \begin{tabular}{|l|l|}
163,90 \\
\end{tabular} & 70,18 & 32,17 & 5079,68 & 278,78 & 64,25 & 214,53 & 174,00 & \begin{tabular}{rl|}
199,04 \\
\end{tabular} & 230,92 & \begin{tabular}{|r|r|}
102,04 \\
\end{tabular} & 607,25 & $\begin{array}{l}90,54 \\
90,5\end{array}$ & 25,82 & 32,14 & 220,47 & 117,99 & 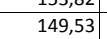 & 122,51 \\
\hline Salamandra salamandra & 31TDF39 & 99,00 & 159,05 & 70,45 & 31,72 & 5221,53 & 276,62 & 58,24 & 218,38 & 169,22 & 122,48 & 227,97 & 95,63 & 625,82 & 85,89 & 29,41 & 28,45 & 215,99 & 124,66 & 157,10 & 125,50 \\
\hline Salamandra salamandra & 31TDF49 & 74,00 & 155,34 & 69,84 & 31,34 & 5248,01 & 273,44 & 54,54 & 218,91 & 166,02 & 191,46 & 224,66 & 91,70 & 669,03 & 91,23 & 31,05 & 27,32 & 226,69 & 133,39 & 164,11 & 139,00 \\
\hline Salamandra salamandra & 31TDF59 & 14,00 & 161,65 & 69,94 & 31,41 & 5210,88 & 278,76 & 60,24 & 218,53 & 171,76 & 216,00 & 230,12 & 98,29 & 649,65 & 96,41 & 27,29 & 30,94 & 228,76 & 121,53 & 155,41 & 138,59 \\
\hline Salamandra salamandra & 31TDG00 & 100,00 & 147,12 & 74,17 & 32,10 & 5444,61 & 269,96 & 43,25 & 226,71 & 187,89 & 81,00 & 219,13 & 81,00 & 632,84 & 75,08 & 32,57 & 25,41 & 202,78 & 118,11 & 161,49 & 118,11 \\
\hline Salamandra salamandra & 31TDG01 & 101,00 & \begin{tabular}{|l|l|}
148,37 \\
\end{tabular} & 75,39 & $\frac{32,14}{32,31}$ & 5488,51 & $\mid \begin{array}{l}\mid 203,904 \\
272,64\end{array}$ & 43,17 & 229,47 & $\begin{array}{l}\mid 01,03 \\
196,91\end{array}$ & 81,18 & $\mid 220,65$ & 81,18 & $\mid 63,04$ & $\begin{array}{l}72,77 \\
72,7\end{array}$ & 32,55 & $\mid \begin{array}{l}25,69 \\
25,6\end{array}$ & $\begin{array}{l}\mid 02,10 \\
197,42\end{array}$ & \begin{tabular}{|l|l|l|l|l|}
109,00 \\
\end{tabular} & $\mid$\begin{tabular}{|l|}
162,21 \\
162,
\end{tabular} & $\begin{array}{l}110,14 \\
109,00\end{array}$ \\
\hline Salamandra salamandra & 31TDG02 & 101,00 & 146,68 & 76,64 & 32,45 & 5543,49 & 272,71 & 40,25 & 232,46 & \begin{tabular}{|l|l|}
195,43 \\
\end{tabular} & 78,39 & 219,41 & 78,39 & 612,12 & 72,23 & 31,38 & 26,17 & 196,17 & 103,62 & 166,15 & 103,62 \\
\hline Salamandra salamandra & 31TDG03 & 100,00 & 138,99 & 77,70 & 32,62 & 5595,96 & 267,33 & 32,06 & 235,27 & 185,64 & 70,21 & 212,47 & 70,21 & 646,98 & 76,68 & 31,46 & 26,92 & 203,51 & $\begin{array}{l}105,68 \\
\end{array}$ & 179,85 & 105,68 \\
\hline Salamandra salamandra & 31TDG04 & 100,00 & 133,54 & 78,74 & 32,86 & 5641,89 & 263,69 & 26,12 & 237,57 & 158,12 & 64,30 & 207,59 & 64,30 & 674,76 & 81,50 & 31, & 27,99 & 212,37 & 107,54 & 190,92 & 107,54 \\
\hline Salamandra salamandra & 31TDG05 & 100,00 & 127,55 & 79,61 & 32,97 & 5659,60 & 259,13 & 19,95 & 239,18 & 144,45 & 58,10 & 201,78 & 58,10 & 706,09 & 86,06 & 32,36 & 28,71 & 225,31 & 111,86 & 203,49 & 111,86 \\
\hline Salamandra salamandra & $\begin{array}{l}\text { 31TDG06 } \\
31 \text { To }\end{array}$ & $\begin{array}{l}100,00 \\
\end{array}$ & \begin{tabular}{|l|l|}
106,21 \\
\end{tabular} & $\mid 79,00$ & $\begin{array}{ll}32,979 \\
32,99\end{array}$ & 50509,13 & | & $\mid \begin{array}{r}\mid c, 26 \\
2,26\end{array}$ & 236,39| & $\begin{array}{l}144,43 \\
121,23\end{array}$ & 30,0 & \begin{tabular}{|l|}
180,73 \\
180,73
\end{tabular} & $\begin{array}{l}30,10 \\
38,92\end{array}$ & \begin{tabular}{|l|l|l|l|}
829,94 \\
\end{tabular} & $\begin{array}{l}00,00 \\
97,73 \\
\end{array}$ & 年 & $\begin{array}{ll}24,1 / 43 \\
243\end{array}$ & $\mid \frac{22,31}{255,93}$ & \begin{tabular}{|l|l|l|l|l|}
147,61 \\
\end{tabular} & $\mid \begin{array}{l}\mid 20,45,40 \\
225\end{array}$ & $\begin{array}{l}11,00 \\
147,75\end{array}$ \\
\hline Salamandra salamandra & 31TDG07 & 101,00 & 97,75 & 79,20 & 33,01 & 5585,81 & 230,65 & $-4,96$ & 235,61 & 112,18 & 32,50 & 172,05 & 31,12 & 884,39 & 102,25 & 48,81 & 21,83 & 268,99 & 165,19 & 234,06 & 165,33 \\
\hline Salamandra salamandra & 31TDG08 & 101,00 & 67,80 & 75,83 & 32,65 & 5466,88 & 199,08 & $-29,52$ & 228,60 & 74,25 & 25, & 141,74 & 4,84 & 1075,86 & 116,99 & 67, & 15,94 & 307,24 & 226,72 & 258,04 & 230,88 \\
\hline Salamandra salamandra & 31TDG09 & 101,00 & 88,07 & 79, & 33,4 & 5552,21 & 221,40 & -13, & 234,75 & 102 & 28,7 & 162,03 & 22,14 & 952,05 & 107,28 & 56 & 18,73 & 284,35 & 188,33 & 243,10 & 189,54 \\
\hline Salamandra salamandra & 31TDG10 & 100,00 & 143,65 & 72,82 & 31,99 & 5436,23 & 266,45 & 41,19 & 225,27 & \begin{tabular}{|c|c|}
191,40 \\
\end{tabular} & 78,13 & 215,81 & 78,13 & 661,58 & $\begin{array}{l}7,202 \\
76,92\end{array}$ & 35,13 & 24,44 & 210,32 & 124,08 & 170,04 & 124,08 \\
\hline Salamandra salamandra & 31TDG11 & 100,00 & 130,92 & 73,96 & 32,00 & 5506,36 & 256,72 & 28,36 & 228,36 & 179,89 & 64,96 & 204,11 & 64,96 & 711,82 & 81,20 & 37,69 & 23,64 & 220,30 & 129,34 & 187,13 & 129,34 \\
\hline Salamandra salamandra & 31 TDG12 & 101,00 & 138,82 & 74,97 & 31,99 & 5534,36 & 264,97 & 34,06 & 230,90 & 187,60 & 71,46 & 211,89 & 71,46 & 664,54 & 77,32 & 33,73 & 25,52 & 209,84 & 113,45 & 180,96 & 113,45 \\
\hline Salamandra salamandra & 31TDG13 & 100,00 & 137,51 & 76,02 & 32,01 & 5576,41 & 265,12 & 31, & 233,45 & 186,14 & 69,31 & 210,99 & 69,31 & 668,60 & 79,16 & 32, & 26,82 & 210,84 & 109,50 & 187,69 & 109,50 \\
\hline Salamandra salamandra & 31TDG14 & 101,00 & 129,63 & 76,99 & 32,13 & 03,61 & (2) & 23, & 235,10 & 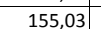 & 61,35 & 203,38 & 61,35 & 702,44 & 85,59 & 32, & 28,71 & 221,47 & 111,01 & 202,88 & 111,01 \\
\hline Salamandra salamandra & 31TDG15 & 101,00 & 123,04 & 90 & 32,41 & 5614,28 & 25 & 17,34 & 236,35 & 138,9 & 54,84 & 197,03 & 54,84 & 734,72 & 89,87 & 33, & $\frac{20,11}{28,82}$ & 233,69 & $\mid$ & 213,33 & 116,68 \\
\hline Salamandra salamandra & $31 \mathrm{TD}$ & 100,00 & 109,61 & 78,14 & 32,94 & 559 & 241 & 5,90 & 235,49 & 124 & 42, & 183,93 & 42,52 & 816,30 & 97,07 & 41,02 & 25,05 & 253,79 & & 225,21 & 141,82 \\
\hline Salamandra salamandra & 31TDG17 & 100,00 & $\begin{array}{r}92,30 \\
92,\end{array}$ & 77,43 & 32,98 & 5530,63 & 224,15 & $\begin{array}{c}-7,93 \\
\end{array}$ & 232,07 & $\begin{array}{l}105,48 \\
105\end{array}$ & 30,03 & 166,30 & 27,32 & 927,47 & $\mid 105,12$ & 53,59 & 19,78 & 274,98 & $\begin{array}{l}\mid 41,02,58 \\
180,\end{array}$ & 237,38 & $\begin{array}{l}141,02,09 \\
181\end{array}$ \\
\hline Salamandra salamandra & 31 TDG18 & 98,00 & 62,33 & 74,21 & 32 & 21,81 & 68 & -33, & 225 & 60,52 & 21 & 135,92 & 0,71 & 1113,96 & 119,15 & 70,5 & 14 & 312,34 & 240,85 & 260,57 & 245,94 \\
\hline Salamandra salamandra & 31TDG19 & 44,00 & 74,09 & 1 & 32,8 & 468,72 & 205,63 & $-23,84$ & 229,47 & 82,36 & 21,98 & 147,66 & 10,64 & 1044,01 & 113,79 & 65, & 16,03 & 299,40 & 218,83 & 252,53 & 222,53 \\
\hline Salamandra salamandra & 31TDG20 & $\begin{array}{l}400,00 \\
\end{array}$ & \begin{tabular}{rl|r|}
152,94 \\
\end{tabular} & 7 & $\begin{array}{l}32, \\
31,\end{array}$ & 5379,99 & $\begin{array}{l}\mid 20,03 \\
273,79\end{array}$ & $\begin{array}{c}-20,04 \\
50,50\end{array}$ & 223,29 & \begin{tabular}{r|r|}
200,40 \\
\end{tabular} & 87,61 & $\begin{array}{l}243,00 \\
223,95 \\
\end{array}$ & 87,61 & 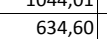 & $\begin{array}{l}77,02 \\
77,3\end{array}$ & $\begin{array}{l}30,40 \\
33,88 \\
\end{array}$ & $\begin{array}{l}20,437 \\
25,47\end{array}$ & $\begin{array}{l}208,06 \\
208,40\end{array}$ & $\begin{array}{l}\mid 110,03 \\
119,64\end{array}$ & $\begin{array}{l}\mid 5,35 \\
165,13\end{array}$ & $\begin{array}{ll}2119,64 \\
119,64\end{array}$ \\
\hline Salamandra salamandra & 31TDG21 & 101,00 & & 72,64 & 31,69 & 5474,85 & 258,67 & 31, & 226,71 & 182, & 68,49 & 206,92 & 68,49 & 718,32 & 81,31 & 38,66 & 23,28 & 224,13 & 132,51 & 188,93 & 132,51 \\
\hline Salamandra salamandra & 31 TDG22 & 99,00 & 12 & 73,69 & 31,92 & 5511,67 & 252,13 & 23, & 228,73 & 174,4 & 59,73 & 198,87 & 59,73 & 746,68 & 87,10 & 38, & 23,96 & 229,79 & 133,40 & 201,19 & 133,40 \\
\hline Salamandra salamandra & 31 TDG23 & 101,00 & 4 & -7 & 32 & 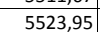 & 248,55 & 18 & 2 & 167, & & 194,10 & 54 & 769,68 & 90, & 38, & 24 & 234,97 & 134,90 & 209,82 & 134,90 \\
\hline Salamandra salamandra & $31 \mathrm{TDC}$ & 16 & & & 32 & & & 22 & & & & 200 & & & 89 & & & 230,37 & 121,26 & 210,88 & 121,26 \\
\hline Salamandra salamandra & 31 TDG25 & 100,00 & 120,53 & 76,48 & 32,00 & 5584,37 & 250,26 & 15,99 & 234,26 & 135,76 & 53,10 & 194,30 & 53,10 & 770,56 & 92,84 & 36,19 & 27,23 & 241,75 & 127,33 & 219,72 & 127,33 \\
\hline Salamandra salamandra & 31 TDG26 & 101,00 & 110,29 & 77,01 & 32,33 & 5569,27 & 241,08 & 7,03 & 234,05 & 124,80 & 43,82 & 184,24 & 43,67 & 832,47 & 97,84 & 42,19 & 24,08 & 256,10 & 147,86 & 225,80 & 147,86 \\
\hline Salamandra salamandra & 31 TDG27 & 101,00 & 99,41 & 77,17 & 32,82 & 5532,74 & 230,85 & $-1,67$ & 232,51 & 113,10 & 36,06 & 173,24 & 34,05 & 897,92 & 102,41 & 49,96 & 20,58 & 268,64 & 171,64 & 232,58 & 171,86 \\
\hline Salamandra salamandra & 31TDG28 & 100,00 & 71,1 & & 32,52 & 年 & & $1 \%$ & 年 & 71, & 28,10 & 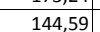 & 9,08 & 1066 & 19 & & 15,65 & 301,19 & 226,87 & 252,25 & 231,73 \\
\hline Salamandra salamandra & 31TDG29 & 24 & & & 31 & & & -57 & $2 \angle 1$, & 15, & 73,62 & 108, & \begin{tabular}{|c|c|}
$-23,64$ \\
\end{tabular} & 1292, & 133, & & 13,01 & 360,84 & 282,65 & 286,08 & 305 \\
\hline Salamandra salamandra & 31 TDG30 & 100,00 & 157,83 & 71,01 & 31,53 & 5300,33 & 277,10 & 55,68 & 221,42 & 197,57 & 96,21 & 227,47 & 93,06 & 632,38 & 82,25 & 31,86 & 26,59 & 212,42 & 124,07 & 160,28 & 124,09 \\
\hline Salamandra salamandra & 31TDG31 & 101,00 & 144,71 & 71,51 & 31,09 & 5430,91 & 267,32 & 42,09 & 225,23 & 192,77 & 78,92 & 216,44 & 78,92 & 701,68 & 81,71 & 38,45 & 23,28 & 223,49 & 133,61 & 182,06 & 133,61 \\
\hline Salamandra salamandra & 31 TDG32 & 101,00 & 126,55 & 72,56 & 31,49 & 85,82 & 252,29 & 24,87 & 227,42 & 175,21 & 61,18 & 199,62 & 61,18 & 777,76 & 87,68 & 41,15 & 22,50 & 238,41 & 144,73 & 204,14 & 144,73 \\
\hline Salam & $31 \mathrm{THC}$ & 100, & & & & & & 24 & 22 & $7 \pi$ & 60 & 200 & 60,87 & & & 39, & & & 13 & 209,39 & 138 \\
\hline Salamandra salamandra & 31 TDG 34 & 101,00 & 129,94 & 74,44 & 31,72 & 5552,03 & 257,43 & 25,65 & 231,78 & 165,59 & 62,72 & 203,31 & $\begin{array}{ll}62,72 \\
62\end{array}$ & 768,28 & $\begin{array}{ll}89,48 \\
89\end{array}$ & 36,97 & 25,35 & 236,62 & \begin{tabular}{|l|l|}
132,24 \\
\end{tabular} & 212,86 & 132,24 \\
\hline
\end{tabular}




\begin{tabular}{|c|c|c|c|c|c|c|c|c|c|c|c|c|c|c|c|c|c|c|c|c|c|}
\hline TAXON & UTM & $\mathrm{km} 2$ & BIO1 & $\mathrm{B1O2}$ & $\mathrm{BIO3}$ & 8104 & B105 & B106 & B107 & B108 & B109 & BIO10 & B1011 & BIO12 & B1013 & B1014 & 81015 & B1016 & BIO17 & B1018 & B1019 \\
\hline Salamandra salamandra & 31TDG35 & 100,00 & 124,92 & 75,47 & 31,97 & 5577,89 & 253,79 & 20,32 & 233,47 & 140,55 & 57,43 & 198,57 & 57,43 & 794,52 & 92,92 & 37,77 & 25,36 & 245,58 & 137,07 & 218,86 & 137,07 \\
\hline Salamandra salamandra & 31 TDG36 & 100,00 & 114,79 & 76,19 & 32,08 & 5563,09 & 244,76 & 11,45 & 233,31 & \begin{tabular}{|l|l|}
130,09 \\
\end{tabular} & 48,35 & 188,44 & 48,04 & 837,99 & 96,99 & 42,20 & 23,51 & 256,19 & 151,28 & 225,56 & 151,35 \\
\hline Salamandra salamandra & 31TDG37 & 101,00 & 107,25 & 76,76 & 32,33 & 5546,01 & 238,00 & \begin{tabular}{|l|}
4,78 \\
4,78
\end{tabular} & 233,22 & $\begin{array}{l}121,53 \\
\end{array}$ & 42,10 & 180,97 & 41,12 & 876,42 & 99,70 & 46,81 & 21,35 & 263,89 & 165,67 & 227,95 & 165,95 \\
\hline Salamandra salamandra & 31TDG38 & 101,00 & 73,34 & 74,25 & 32,47 & 5414,20 & 203,41 & $-22,12$ & 225,52 & 68,72 & 37,31 & 146,73 & 11,69 & 1057,84 & 112,89 & 64,87 & 15,93 & 300,44 & 226,13 & 248,49 & 231,54 \\
\hline Salamandra salamandra & 31TDG39 & 75,00 & 30,22 & 69,10 & 30,97 & 5326,44 & 157,92 & $-61,66$ & 219,58 & 7,90 & 87,34 & 103,49 & $-27,81$ & 1327,69 & 135,14 & 82,08 & 13,05 & 373,45 & 287,85 & 289,66 & 317,77 \\
\hline Salamandra salamandra & 31TDG40 & 101,00 & 153,92 & 70,08 & 31,02 & 5322,70 & 273,35 & 51,94 & 221,41 & 184,27 & 153,09 & 224,08 & 89,16 & 686,11 & 89,72 & 33,67 & 25,24 & 226,52 & 139,44 & 169,65 & 141,06 \\
\hline Salamandra salamandra & 31TDG41 & 100,00 & 143,57 & 70,61 & 31,01 & 5418,05 & 265,73 & 41,25 & 224,47 & 191,17 & 83,61 & 215,19 & 78,09 & 744,65 & 88,99 & 40,05 & 22,43 & 234,86 & 148,77 & 186,25 & 148,81 \\
\hline Salamandra salamandra & 31TDG42 & 100,00 & 113,04 & 71,73 & 31,59 & 5434,21 & 238,94 & 14,74 & 224,20 & 152,19 & | 57,00 & $\begin{array}{l}2186,19 \\
186\end{array}$ & 49,79 & 869,95 & $\begin{array}{l}\mid c 0,70 \\
97,7\end{array}$ & 48,67 & 20,16 & 260,21 & $\begin{array}{l}174,95 \\
\end{array}$ & 213,02 & $\begin{array}{l}140,01 \\
175,78\end{array}$ \\
\hline Salamandra salamandra & 31TDG43 & 101,00 & 120,79 & 72,53 & 31,36 & 5480,88 & 247,16 & 19,81 & 227,36 & 168,24 & 56,24 & 193,96 & 55,80 & 841,38 & 93,61 & 44,30 & 21,43 & 251,91 & \begin{tabular}{|c|}
161,19 \\
\end{tabular} & 215,44 & 161,25 \\
\hline Salamandra salamandra & 31TDG44 & 101,00 & 130,89 & 73,43 & 31,21 & 5539,31 & 257,59 & 26,91 & 230,68 & 168,05 & 63,87 & 204,03 & 63,87 & 819,11 & 91,15 & 40,15 & 22,82 & 246,08 & 151,03 & 214,89 & 151,03 \\
\hline Salamandra salamandra & 31TDG45 & 100,00 & 123,43 & 74,48 & 31,81 & 5541,19 & 251,55 & 19,82 & 231,73 & 138,59 & 56,68 & 196,77 & 56,65 & 844,31 & 94,95 & 41,38 & 22,77 & 254,73 & 155,64 & 222,07 & 155,64 \\
\hline Salamandra salamandra & 31TDG46 & 101,00 & 98,81 & 74,53 & 32,16 & 5461,29 & 227,98 & 0,29 & 227,69 & 123,23 & 38,16 & 172,11 & 35,25 & 935,05 & 102,41 & 54,20 & 18,70 & 269,63 & 188,71 & 229,59 & 189,68 \\
\hline Salamandra salamandra & 31TDG47 & 100,00 & 107,07 & 76,01 & 32,18 & 5516,90 & 237,20 & 5,42 & 231,79 & 122,12 & 43,70 & \begin{tabular}{|l|l|}
180,49 \\
\end{tabular} & 41,55 & \begin{tabular}{|l|}
899,99 \\
\end{tabular} & 99,75 & 49,27 & 19,80 & 265,71 & 176,79 & 226,44 & 177,02 \\
\hline Salamandra salamandra & 31TDG48 & 99,00 & 90,22 & 75,53 & 32,75 & 5453,60 & 220,57 & $-7,82$ & 228,39 & 99,62 & 32,26 & 163,59 & 26,84 & 975,65 & 105,37 & 59,03 & 17,02 & 278,09 & 203,11 & 234,79 & 205,54 \\
\hline Salamandra salamandra & 31TDG49 & 61,00 & 55,44 & 71,98 & 31,95 & 5347,45 & 184,37 & $-37,63$ & 222,00 & \begin{tabular}{|l|l}
36,75 \\
\end{tabular} & 62,02 & 128,52 & $-4,12$ & 1168,61 & 120,65 & 72,21 & 14,13 & 328,65 & 255,93 & 262,42 & 270,85 \\
\hline Salamandra salamandra & 31 TDG50 & 100,00 & 149,07 & 69,41 & 30,93 & 5340,44 & 268,83 & 47,51 & 221,32 & 172,34 & 184,93 & 219,62 & 84,45 & 739,98 & 97,36 & 35,59 & 24,90 & 240,67 & 149,22 & 177,14 & 156,74 \\
\hline Salamandra salamandra & 31TDG51 & 100,00 & 150,52 & 69,89 & 30,82 & 5412,19 & 271,39 & 47,10 & 224,29 & 175,65 & 190,74 & 221,70 & 84,58 & 751,99 & 97,13 & 37,05 & 23,69 & 241,22 & 152,85 & 178,44 & 159,64 \\
\hline Salamandra salamandra & 31TDG52 & 100,00 & 121,05 & 70,84 & 31,14 & 5416,66 & 245,56 & 21,77 & 223,79 & 158,67 & 73,56 & 193,60 & 57,38 & 871,94 & 101,31 & 48,10 & 20,27 & 261,90 & 179,63 & 207,94 & 181,17 \\
\hline Salamandra salamandra & 31TDG53 & 101,00 & 120,29 & 71,75 & 31,31 & 5454,72 & 245,94 & 19,90 & 226,03 & 168,79 & 56,34 & 193,21 & 55,81 & 879,46 & 97,58 & 47,86 & 20,11 & 259,23 & 176,63 & 214,88 & 176,63 \\
\hline Salamandra salamandra & 31 TDG54 & 100,00 & 125,16 & 72,61 & 31,28 & 5493,16 & 251,46 & 22,80 & 228,67 & 159,72 & 59,79 & 198,10 & 59,49 & 882,49 & 96,36 & 45,17 & 20,85 & 259,02 & 173,86 & 217,20 & 173,90 \\
\hline Salamandra salamandra & 31TDG55 & 101,00 & 112,93 & 73,61 & 31,7 & 5470,40 & 240,58 & 12,28 & 228,29 & \begin{tabular}{|l|}
146,27 \\
\end{tabular} & 49,85 & 185,97 & 48,41 & 911,09 & 98,75 & 49 , & 19,85 & 264,80 & 182,35 & 222,98 & 182,41 \\
\hline Salamandra salamandra & 31TDG56 & 101,00 & 126,48 & 74,94 & 31,73 & 5552,87 & $\begin{array}{l}254,68 \\
254\end{array}$ & 21,49 & 233,19 & $\begin{array}{l}143,13 \\
143,13\end{array}$ & 59,32 & 199,65 & $\begin{array}{l}45,17 \\
59,17 \\
\end{array}$ & 878,35 & 94,59 & $\begin{array}{ll}43,13 \\
43,36\end{array}$ & 21,32 & 261,01 & 171,38 & 218,56 & 171,39 \\
\hline Salamandra salamandra & 31TDG57 & 100,00 & 129,29 & 76,38 & 31,96 & 5582,05 & 258,48 & 22,78 & 235,70 & 147,30 & 61,07 & 202,62 & 61,07 & 845,98 & 92,13 & 42,93 & 20,88 & 250,54 & 166,34 & 210,12 & 166,34 \\
\hline Salamandra salamandra & 31TDG58 & 94,00 & 108,42 & 76,50 & 32,40 & 5508,44 & 238,70 & 6,27 & 232,44 & 122,51 & 45,63 & 181,73 & 42,94 & 909,93 & 97,99 & 51,44 & 18,50 & 263,54 & 186,08 & 220,40 & 187,06 \\
\hline Salamandra salamandra & 31TDG59 & 18,00 & 90,81 & 75,95 & 32,85 & 5439,71 & 221,28 & $-7,67$ & 228,96 & 94,19 & 36,19 & 163,85 & 27,56 & 980,58 & 103,82 & 59,57 & 16,30 & 277,15 & 209,02 & 230,66 & 212,69 \\
\hline Salamandra salamandra & 31TDG60 & 61,00 & 154,39 & 69,16 & 30,85 & 5341,51 & 273,27 & 51,57 & 221,70 & \begin{tabular}{|l|l|}
165,06 \\
\end{tabular} & 219,98 & 224,61 & 89,12 & 727,44 & 103,91 & 31,62 & 28,39 & 244,78 & 137,27 & 168,24 & 159,08 \\
\hline Salamandra salamandra & 31TDG61 & $\begin{array}{l}0,101,00 \\
100\end{array}$ & 146,85 & $\begin{array}{l}\mid c 9,27 \\
69,27\end{array}$ & $\begin{array}{l}30,03 \\
30,42\end{array}$ & 5401,26 & $\mid 267,46$ & 44,08 & 223,38 & $\begin{array}{l}\mid 00,00 \\
169,79\end{array}$ & $\begin{array}{l}\mid 194,60 \\
194,63\end{array}$ & 212,01 & $\begin{array}{l}\mid 05,12 \\
81,26 \\
\end{array}$ & 781,72 & \begin{tabular}{|l|l|}
103,63 \\
\end{tabular} & $\begin{array}{l}31,024 \\
37,41\end{array}$ & \begin{tabular}{|l|l|}
24,57 \\
24,5
\end{tabular} & 242,10 & $\mid$ & \begin{tabular}{|l|}
180,2494 \\
\end{tabular} & $\begin{array}{l}15,08,79 \\
168\end{array}$ \\
\hline Salamandra salamandra & 31TDG62 & 101,00 & 149,18 & 69,89 & 30,11 & 5469,89 & 270,71 & 44,27 & 226,44 & 175,51 & 190,11 & 220,84 & 82,05 & 782,31 & 103,47 & 38,13 & 24,38 & 247,74 & 157,19 & 178,56 & 168,20 \\
\hline Salamandra salamandra & 31TDG63 & 100,00 & $\begin{array}{l}134,37 \\
13,10\end{array}$ & 70,82 & 30,71 & 5472,86 & 258,25 & 31,14 & 227,11 & $\mid 182,29$ & $\mid 82,49$ & 206,82 & 68,42 & 864,54 & \begin{tabular}{|l|l|}
102,08 \\
\end{tabular} & 45,97 & 21,14 & 257,04 & 178,28 & 202,84 & 178,94 \\
\hline Salamandra salamandra & 31TDG64 & 100,00 & & 71,88 & 30,84 & 5515,80 & 258,82 & 29,58 & 229,23 & 177,28 & 81,89 & 206,53 & 66,99 & 870,25 & 101,28 & 45,16 & 21,27 & 255,94 & 178,43 & 203,14 & 178,73 \\
\hline Salamandra salamandra & 31TDG65 & 100,00 & 134,61 & 73,08 & 31,10 & 5543,73 & 260,82 & 29,16 & 231,66 & 171,21 & 67,05 & 207,58 & 67,05 & 869,24 & 99,53 & 44,63 & 21,17 & 253,62 & 177,00 & 205,04 & 177,00 \\
\hline \begin{tabular}{|l} 
Salamandra salamandra \\
\end{tabular} & $\begin{array}{l}\text { 31TDG66 } \\
31 \text { The }\end{array}$ & 101,00 & 128,84 & $\begin{array}{l}74,49 \\
74,49\end{array}$ & $\begin{array}{ll}1,10 \\
31,64\end{array}$ & 5531,15 & \begin{tabular}{|l|l|}
256,26 \\
256,26
\end{tabular} & 23,76 & 232,50 & $\begin{array}{l}\mid>1,21 \\
153,06\end{array}$ & $\mid \begin{array}{ll}\mid 61,83 \\
61,83\end{array}$ & \begin{tabular}{|l|l}
201,77 \\
\end{tabular} & $\begin{array}{ll}61,83 \\
1,83\end{array}$ & $\begin{array}{l}\mid 800,24 \\
877,56\end{array}$ & $\begin{array}{l}97,45 \\
97,4\end{array}$ & 445,15 & 20,81 & \begin{tabular}{|l|}
$\mid 255,27$ \\
255
\end{tabular} & $\begin{array}{l}177,86 \\
177\end{array}$ & \begin{tabular}{|l|}
209,00 \\
\end{tabular} & 177,86 \\
\hline Salamandra salamandra & 31TDG67 & 100,00 & 137,40 & 76,11 & 31,80 & 5580,44 & 265,66 & 29,24 & 236,41 & 175,68 & 68,76 & 210,45 & 68,73 & 808,42 & 94,24 & 42,97 & 21,05 & 236,38 & 165,84 & 188,53 & 165,85 \\
\hline Salamandra salamandra & 31TDG68 & 86,00 & 114,42 & 76,43 & 32,34 & 5500,76 & 243,88 & 11,05 & 232,83 & 134,60 & 51,47 & 187,37 & 48,63 & 893,25 & 96,76 & 50,69 & 18,58 & 255,03 & 186,61 & 211,05 & 187,34 \\
\hline Salamandra salamandra & 31TDG70 & & & & & & & & & & & & & & & & & & & & \\
\hline Salamandra salamandra & 31TDG71 & 99,00 & 156,87 & 69,51 & 30,60 & 5364,56 & 275,70 & 52,56 & 223,14 & 167,35 & 224,72 & 227,13 & 90,86 & 711,45 & 107,54 & 29,23 & 30,94 & 243,24 & 129,62 & 160,29 & 156,59 \\
\hline 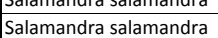 & $\begin{array}{l}\mid \text { S1DG/1 } \\
31 \text { TDG72 }\end{array}$ & $\begin{aligned} 91,01,00 \\
101\end{aligned}$ & $\begin{array}{l}130,81 \\
154,90\end{array}$ & $\begin{array}{l}\mid c 9,31 \\
69,47\end{array}$ & $\begin{array}{l}30,00 \\
30,09\end{array}$ & $\begin{array}{l}5305,400 \\
545,06\end{array}$ & $\mid \begin{array}{ll}275,20 \\
275,2\end{array}$ & $\begin{array}{l}32,50 \\
48,78\end{array}$ & 226,42 & \begin{tabular}{|l|l|l|l|l|}
165,21 \\
\end{tabular} & 225,52 & 226,12 & $\begin{array}{l}90,00 \\
87,35 \\
\end{array}$ & 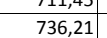 & \begin{tabular}{|l|}
108,20 \\
108,
\end{tabular} & $\begin{array}{l}29,25 \\
31,73\end{array}$ & $\begin{array}{l}30,34 \\
28,88\end{array}$ & $\mid \frac{24,24}{244,81}$ & \begin{tabular}{|l|}
137,02 \\
137,61
\end{tabular} & \begin{tabular}{|l|}
160,29 \\
161,82
\end{tabular} & $\begin{array}{l}130,59 \\
162,07\end{array}$ \\
\hline Salamandra salamandra & $31 \mathrm{TDG73}$ & 100,00 & 15 & 69,54 & 29,97 & 5553,31 & 273,66 & 44 & 229,36 & 165,46 & 222,68 & 223,75 & 82,63 & 769,42 & 108,47 & 35,29 & 26,44 & 246,62 & 149,64 & $\mid 161,79$ & 168,62 \\
\hline Salamandra salamandra & 31 TDG74 & 101,00 & 148,67 & 70,75 & 30,06 & 5587,62 & 272,30 & 40 & 231,48 & 177,15 & 209,99 & 221,44 & 79,36 & 785,67 & 106,68 & 38,3 & 24,72 & 244,16 & 159,67 & 167,53 & 169,21 \\
\hline Salamandra salamandra & 31TDG75 & 101,00 & & $=$ & 30,5 & 23,73 & 75 & 32 & 231,24 & 32,50 & 104,51 & 211,21 & 71,13 & 832,95 & 103,27 & 43, & 2,28 & 247,40 & 173,37 & 186,58 & 174,80 \\
\hline Salamandra salamandra & 31TDG76 & 100,00 & 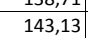 & 14 & 31 & 5552,16 & 26 & 35 & 234,01 & 185,68 & 111,35 & 215,67 & 74,65 & 784,79 & \begin{tabular}{|c|}
99,79 \\
99,2
\end{tabular} & $\begin{array}{l}43, \\
41,\end{array}$ & 22,69 & 235,03 & |163,83 & 173,85 & 164,27 \\
\hline Salamandra salamandra & 31TDG77 & 100,00 & & 75,89 & 31 & 5538,66 & 266,13 & & 23 & 17 & 103 & 211,36 & 70,83 & 782,67 & 97,23 & 41, & & 231,89 & 164,30 & \begin{tabular}{|l|l|}
174,28 \\
\end{tabular} & 164,77 \\
\hline Salamandra salamandra & 31TDG78 & $\begin{array}{r}93,00 \\
93\end{array}$ & & 77,01 & 32,06 & 5514,09 & 256,73 & 21,64 & 235,10 & 166,72 & 73,70 & 200,46 & 60,95 & 827,53 & 96,41 & 45,54 & 20,13 & 238,31 & 175,62 & 187,78 & 175,90 \\
\hline Salamandra salamandra & 31TDG79 & 46,00 & 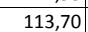 & 77,44 & 32,85 & 76,17 & 243,58 & 10, & 233,44 & 142,50 & 62, & 186,30 & 48,28 & 879,16 & 98,03 & 50,5 & 18,20 & 248,55 & 189,73 & 200,52 & 191,48 \\
\hline Salamandra salamandra & 31TDG81 & 58,00 & 15 & 69,67 & 30,77 & 324,65 & 274,68 & 52 , & 222,45 & 166,76 & 221,85 & 226,11 & 91,01 & 700,06 & 108,38 & 27, & 32,13 & 241,39 & 125,74 & 155,80 & 153,82 \\
\hline Salamandra salamandra & $\begin{array}{l}\text { 31TDG82 } \\
31 \text {. }\end{array}$ & $\begin{array}{ll}0,000 \\
99,00\end{array}$ & 15 & 6 & 30,32 & 5396,79 & $\begin{array}{l}274,00 \\
270,51\end{array}$ & 40,251 & 2224,20 & 161,54 & $\begin{array}{l}221,05 \\
221,06\end{array}$ & 2221,71 & 84,91 & 744,17 & \begin{tabular}{|l|l|}
109,39 \\
109
\end{tabular} & $\begin{array}{ll}21,005 \\
31,64\end{array}$ & $\frac{32,13}{28,92}$ & $\begin{array}{l}24,39 \\
246,43\end{array}$ & 139,20 & $\begin{array}{l}5,00 \\
164,30\end{array}$ & $\begin{array}{ll}353,04 \\
163,79\end{array}$ \\
\hline Salamandra salamandra & 31TDG83 & 101,00 & & 69,74 & 30,10 & 5483,13 & 273,79 & 46,21 & 227,58 & \begin{tabular}{|l|l|}
163,03 \\
\end{tabular} & 223,94 & 224,33 & 85,14 & 738,58 & 109,55 & 31,46 & 29,01 & 243,75 & 137,25 & 159,43 & 163,03 \\
\hline Salamandra salamandra & 31TDG84 & 101,00 & 60 & 71,06 & 30,56 & 5502,87 & 273,5 & 44,03 & 229,53 & \begin{tabular}{ll|}
161,75 \\
\end{tabular} & 222,87 & 223,26 & 83,40 & 745,99 & 107,99 & 33,42 & 27,63 & 240,70 & 143,15 & 156,73 & 162,27 \\
\hline Salamandra salamandra & 31 TDG85 & 101,00 & & -1 & 31 & 89,76 & 274,5 & 43, & (2) & 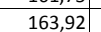 & 222 & 222 & & 727,58 & 104,06 & 33 & 26, & 232,38 & \begin{tabular}{l|l}
143,45 \\
\end{tabular} & 154,74 & 155,45 \\
\hline Salamandra salamandra & 31TDG86 & 10 & & & 31 & & & & 232 & $\frac{1}{3}$ & & 22 & & 708 & 99 & & & 224,22 & 142,91 & 150,56 & 149,80 \\
\hline 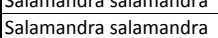 & \begin{tabular}{|l|}
31 TDG87 \\
3
\end{tabular} & $\begin{array}{l}101,00 \\
101\end{array}$ & \begin{tabular}{|l|l|}
149,24 \\
141
\end{tabular} & $\begin{array}{l}74,92 \\
76,75\end{array}$ & $\begin{array}{l}1,1,16 \\
32,16\end{array}$ & $\begin{array}{l}5488,21 \\
548,27\end{array}$ & \begin{tabular}{|l|}
274,86 \\
2748
\end{tabular} & - 41,49 & 235,02 & \begin{tabular}{l|l}
100,93 \\
160,05
\end{tabular} & $2121,32,56$ & 2220,80 & $\begin{array}{l}8<, 25 \\
81,28 \\
\end{array}$ & $\begin{array}{l}\mid 0,14 \\
689,46\end{array}$ & $\begin{array}{l}96,19 \\
96,19\end{array}$ & 32,82 & $\frac{20,14}{25,71}$ & $\begin{array}{l}224,22 \\
217,65\end{array}$ & $\begin{array}{l}44,91 \\
140,02\end{array}$ & $\begin{array}{l}30,50 \\
146,09 \\
\end{array}$ & $\begin{array}{l}14,80 \\
146,16\end{array}$ \\
\hline Salamandra salamandra & 31TDG88 & 100,00 & 145,31 & 78,30 & 32,55 & 5499,28 & 272,62 & 35,72 & 236,90 & 157,99 & 205,09 & 217,05 & 77,44 & 700,65 & 94,38 & 33,65 & 24,44 & 217,15 & 142,92 & 147,29 & 151,21 \\
\hline Salamandra salamandra & 31TDG89 & 82,00 & 138,88 & 79,63 & 32,99 & 5506,15 & 267,94 & 29,75 & 238,19 & 152,98 & 186,80 & 211,01 & 71,29 & 724,75 & 93,55 & 35,45 & 22,99 & 219,97 & 148,58 & 152,88 & 159,90 \\
\hline Salamandra salamand & 31TDG91 & & & & & & & & & & & & & & & & & & & & \\
\hline Salaman & TDG92 & & & 70,44 & 0 & 0 & 268,98 & 47 & 22 & & & & & 71 & 10 & 28 & & & 130,56 & 156,86 & 156 \\
\hline Salamandra salamandra & \begin{tabular}{|l|l|l|l|l|l}
31 DG 93 \\
\end{tabular} & $\begin{array}{r}01,00 \\
100\end{array}$ & 149,48 & 71,06 & 31,22 & 5302,24 & 268,45 & 45,39 & 223,06 & 160,19 & 218,27 & 219,19 & 84,88 & 722,41 & 106,15 & 30,10 & 29,09 & 238,99 & 135,13 & 158,25 & 157,90 \\
\hline Salamandra salamandra & 31TDG94 & 101,00 & 148,97 & 72,30 & 31,68 & 5318,50 & 269,01 & 43,99 & 225,02 & 159,60 & 218,08 & 218,93 & 84,16 & 721,56 & 104,28 & 31,32 & 28,05 & 234,82 & 138,13 & 157,69 & 156,27 \\
\hline Salamandra salamandra & 31TDG95 & 100,00 & 155,34 & & 32,15 & 31,84 & 76,10 & 10 & 227,95 & 165,50 & 224,38 & 224,95 & 89,64 & 666,18 & 100,65 & 28,02 & 29,82 & 222,45 & 124,31 & 143,50 & 143, \\
\hline Salan & 年 & 101,00 & & & & 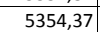 & & & 88 & & 272 & & 88, & & & & & 214,89 & 12 & 138,33 & \\
\hline Salamandra salamandra & 31TDG97 & 101,00 & 154,91 & 77,94 & 32,98 & 5376,61 & 278,77 & 45,78 & 232,99 & \begin{tabular}{l|l|l|l|l|}
164,75 \\
\end{tabular} & 224,66 & 2225,07 & $\begin{array}{ll}88,52 \\
88,5\end{array}$ & $\begin{array}{ll}620,55 \\
620,5\end{array}$ & $\begin{array}{l}93,45 \\
93,45\end{array}$ & 26,50 & 29,39 & 207,71 & $\begin{array}{l}\mid 118,15 \\
115\end{array}$ & \begin{tabular}{|l|l|}
129,83 \\
\end{tabular} & 131,77 \\
\hline
\end{tabular}




\begin{tabular}{|c|c|c|c|c|c|c|c|c|c|c|c|c|c|c|c|c|c|c|c|c|c|}
\hline TAXON & UTM & $\mathrm{km} 2$ & BIO1 & B102 & $\mathrm{BIO3}$ & 8104 & 8105 & B106 & B107 & B108 & B109 & BIO10 & B1011 & BIO12 & B1013 & B1014 & 81015 & B1016 & 81017 & B1018 & 81019 \\
\hline Salamandra salamandra & 31TDG98 & 101,00 & 154,16 & 79,68 & 33,31 & 5404,67 & 279,85 & 43,98 & 235,87 & 163,77 & 224,38 & 224,69 & 87,42 & 614,88 & 91,59 & 25,70 & 28,95 & 205,24 & 114,78 & 123,02 & 133,82 \\
\hline Salamandra salamandra & 31TDG99 & 101,00 & 144,56 & 80,52 & 33,46 & 5443,28 & 272,35 & 34,86 & 237,48 & 151,97 & 215,52 & 215,81 & 77,70 & 669,90 & 92,67 & 29,61 & 25,82 & 213,72 & 128,84 & 135,24 & 149,82 \\
\hline Salamandra salamandra & 31TDHOO & 28,00 & 50,10 & 74,04 & 32,22 & 5406,83 & 179,99 & $-44,96$ & 225,95 & 54,34 & 38,71 & 123,44 & $-11,53$ & $\begin{array}{r}1195,66 \\
10\end{array}$ & 126,85 & 77,40 & 13,68 & 334,47 & 260,85 & 277,01 & 270,95 \\
\hline Salamandra salamandra & 31TDH10 & 1,00 & 66,35 & 76,06 & 32,71 & 5443,68 & 197,47 & $-31,08$ & 228,54 & 73,65 & 28,11 & 139,74 & 3,46 & 1094,46 & 117,96 & 69,86 & 14,97 & 310,84 & 233,85 & 260,63 & 239,64 \\
\hline Salamandra salamandra & 31TDH80 & 1,00 & 143,90 & 82,12 & 33,46 & 5540,21 & 274,54 & 32,40 & 242,14 & \begin{tabular}{|l|l|}
151,89 \\
\end{tabular} & 212,72 & 216,18 & $\begin{array}{l}75,45 \\
\end{array}$ & 677,58 & 90,55 & 30,60 & 24,48 & 211,47 & \begin{tabular}{|c|}
130,48 \\
\end{tabular} & 131,98 & 154,59 \\
\hline Salamandra salamandra & 31TDH90 & 17,00 & 130,04 & 80,65 & 33,43 & 5452,04 & 259,87 & 22,49 & 237,38 & 119,93 & 201,55 & 201,87 & 63,90 & 750,58 & 95,23 & 35,71 & 22,82 & 229,15 & 150,32 & 154,35 & 172,62 \\
\hline Salamandra salamandra & 31TEG02 & 28,00 & 159,86 & 72,57 & 32,57 & 5126,33 & 275,57 & 56,43 & 219,14 & 170,95 & 218,33 & 227,33 & 97,29 & 631,48 & 102,14 & 21,71 & 35,33 & 225,67 & 106,76 & 137,62 & 139,43 \\
\hline Salamandra salamandra & 31TEG03 & 93,00 & 153,07 & 72,72 & 32,65 & 5129,58 & 269,70 & 50,30 & 219,40 & 164,14 & 219,05 & 220,85 & 91,19 & 659,64 & 100,74 & 24,89 & 31,94 & 226,71 & 118,30 & \begin{tabular}{|l|l|l|}
144,85 \\
\end{tabular} & 143,42 \\
\hline Salamandra salamandra & 31TEG04 & 100,00 & 156,39 & 74,26 & 33,10 & 5126,21 & 273,53 & 52,28 & 221,25 & \begin{tabular}{|l|l|}
167,27 \\
\end{tabular} & 222,84 & 223,95 & 94,16 & 632,72 & 98,18 & 23,59 & 32,44 & 219,16 & 112,16 & 137,79 & 137,12 \\
\hline Salamandra salamandra & 31TEG08 & 101,00 & 156,38 & 80,48 & 33,99 & 5305,64 & 280,52 & 46,90 & 233,62 & 166,31 & 225,23 & 225,66 & 90,90 & 587,55 & 90,46 & 22,33 & 31,40 & 202,46 & 103,81 & 119,66 & 129,73 \\
\hline Salamandra salamandra & 31TEG09 & 90,00 & 144,42 & 80,68 & 33,90 & 5361,71 & 271,10 & 35,65 & 235,45 & 153,62 & 214,34 & 214,71 & 78,84 & 656,66 & 92,80 & 27,31 & 27,12 & 213,79 & 121,92 & 133,07 & 148,59 \\
\hline Salamandra salamandra & 31TEG13 & 37,00 & 159,26 & 74,63 & 33,92 & 4974,95 & 273,68 & 56,92 & 216,76 & 170,61 & 210,58 & 225,08 & 99,42 & 587,89 & 94,26 & 19,53 & 35,63 & 211,92 & 100,21 & 130,21 & 126,39 \\
\hline Salamandra salamandra & 31TEG16 & 17,00 & 158,85 & 77,65 & 34,00 & 5097,04 & 277,38 & 53,23 & 224,15 & 169,54 & 224,85 & 225,92 & 96,69 & 576,65 & 91,23 & 20,46 & 33,62 & 204,23 & 100,58 & 125,35 & 123,88 \\
\hline Salamandra salamandra & 31TEG17 & 27,00 & 152,47 & 79,42 & 34,11 & 5163,58 & 274,11 & 45,63 & 228,47 & 162,74 & 219,58 & 220,32 & 89,89 & 597,79 & 91,05 & 21,89 & 31,53 & 206,53 & \begin{tabular}{ll|}
105,05 \\
\end{tabular} & 127,42 & 132,21 \\
\hline Salamandra salamandra & 31TEG18 & 92,00 & 150,02 & 80,18 & 34,19 & 5227,00 & 273,39 & 42,56 & 230,83 & \begin{tabular}{|l|}
160,23 \\
\end{tabular} & \begin{tabular}{|l|}
218,03 \\
\end{tabular} & 218,70 & 86,39 & 614,06 & 91,62 & 23,13 & 30,37 & 208,97 & 108,82 & 128,38 & 137,49 \\
\hline Salamandra salamandra & 31TEG19 & 30,00 & 151,89 & 82,00 & 34,39 & 5309,02 & 277,59 & 42,27 & 235,32 & 161,70 & 220,98 & 221,36 & 86,77 & 602,16 & 90,39 & 22,30 & 30,66 & 205,52 & \begin{tabular}{|l|l|}
104,05 \\
\end{tabular} & 120,39 & 137,52 \\
\hline Salamandra salamandra & 31TEG27 & & & & & & & & & & & & & & & & & & & & \\
\hline Salamandra salamandra & 31TEG28 & 31,00 & 152,98 & 80,93 & 34,83 & 5170,83 & 275,50 & 45,63 & 229,88 & 163,23 & 220,27 & 220,98 & 90,05 & 588,20 & 90,30 & 20,48 & 32,55 & 205,35 & 99,82 & 120,45 & 132,93 \\
\hline Salamandra salamandra & 31TEHOO & 8,00 & 143,60 & 82,49 & 34,11 & 5406,03 & 272,29 & 33,72 & 238,57 & 147,51 & 214,13 & 214,46 & 77,38 & 656,68 & 91,94 & 26,81 & 27,44 & 213,72 & 119,09 & 127,74 & 152,85 \\
\hline Triturus marmoratus & 29SMC69 & 100,00 & 147,96 & 70,09 & 41,09 & 3488,38 & 238,79 & 70,50 & 168,29 & 111,22 & 189,22 & 193,04 & 102,87 & 825,55 & 127,97 & 5,09 & 64,31 & 370,27 & 36,55 & 38,54 & 344,46 \\
\hline Triturus marmoratus & 29SMC77 & 7,00 & 165,36 & 77,64 & 41,14 & 3779,50 & 268,86 & 83,14 & 185,71 & 125,50 & 210,64 & 215,21 & 118,00 & 717,43 & 110,43 & 4,00 & 64,07 & 323,64 & 30,07 & 32,79 & 306,79 \\
\hline Triturus marmoratus & $295 \mathrm{MC} 78$ & 84,00 & 158,27 & 75,36 & 41,23 & 3702,77 & 257,79 & . 77,44 & 180,35 & $\begin{array}{l}119,08 \\
119,0\end{array}$ & 202,40 & 206,80 & 111,26 & 771,92 & $\begin{array}{ll}120,92 \\
120,95\end{array}$ & 4,01 & 64,95 & 348,70 & 31,93 & 34,07 & 328,03 \\
\hline Triturus marmoratus & $29 S M C 79$ & 100,00 & 150,21 & 73,67 & 40,95 & 3685,18 & 248,04 & 70,05 & 177,99 & 111,34 & 194,26 & 198,41 & 103,30 & 825,94 & 128,66 & 4,51 & 64,91 & 371,05 & 34,95 & 36,68 & 348,66 \\
\hline Triturus marmoratus & $295 \mathrm{MC} 87$ & 85,00 & 166,33 & 80,39 & 41,04 & 3928,81 & 275,72 & 82,47 & 193,25 & 125,15 & 213,91 & 218,71 & 117,74 & 709,73 & 108,26 & 3,85 & 63,78 & 318,88 & 29,62 & 32,39 & 304,79 \\
\hline Triturus marmoratus & $29 S M C 88$ & 76,00 & 164,78 & 79,29 & 40,77 & 3947,81 & 273,54 & 81,14 & 192,41 & 123,28 & 212,72 & 217,34 & 115,89 & 731,80 & 111,36 & 3,84 & 63,98 & 328,19 & 30,27 & 32,97 & 314,90 \\
\hline Triturus marmoratus & $295 M D 60$ & 71,00 & 150,13 & 67,85 & 41,05 & 3399,25 & 237,06 & 73,70 & \begin{tabular}{|l|l|}
163,36 \\
\end{tabular} & 114,29 & 190,23 & 193,60 & 105,75 & 791,66 & 123,77 & 4,56 & 64,30 & 356,92 & 33,85 & 36,46 & 330,30 \\
\hline Triturus marmoratus & 29SMD61 & 56,00 & $\begin{array}{ll}130,19 \\
151,29\end{array}$ & $\frac{\mid c r, 00}{65,25}$ & $\begin{array}{l}41,05 \\
41,09\end{array}$ & 3287,54 & 233,99 & 76,85 & $\begin{array}{l}10,30 \\
157,14\end{array}$ & $\begin{array}{l}\mid 114,23 \\
116,75\end{array}$ & 189,82 & 193,05 & $\begin{array}{l}\mid 08,130 \\
108,30\end{array}$ & 756,94 & $\mid 120,51$ & $\begin{array}{l}4,18 \\
4,18\end{array}$ & \begin{tabular}{|c|c|}
63,64 \\
630
\end{tabular} & |350,78| & 32,10 & $\begin{array}{l}30,40 \\
35,60\end{array}$ & 314,88 \\
\hline Triturus marmoratus & 29SMD70 & 101,00 & 148,41 & 71,26 & 40,70 & 3610,41 & 242,95 & 69,60 & 173,35 & 110,39 & 191,61 & 195,28 & \begin{tabular}{|l|l|}
102,18 \\
\end{tabular} & 819,75 & 125,51 & 4,69 & 64,12 & 366,94 & 35,28 & 37,52 & 344,42 \\
\hline Triturus marmoratus & 29SMD71 & 100,00 & 150,71 & 68,40 & 40,60 & 3472,66 & 240,14 & 73,81 & 166,34 & 114,08 & \begin{tabular}{|l|l|}
192,05 \\
\end{tabular} & 195,36 & 105,94 & 776,94 & 121,19 & 4,36 & 63,53 & 348,12 & 33,01 & 36,16 & 325,55 \\
\hline Triturus marmoratus & 29 SMD72 & 101,00 & 154,26 & 65,05 & 40,89 & 3286,66 & 237,07 & 79,81 & 157,26 & 119,81 & 193,07 & 196,04 & 111,54 & 718,24 & 115,57 & 4,02 & 63,12 & 322,51 & 30,11 & 34,39 & 299,55 \\
\hline Triturus marmoratus & $29 \mathrm{SMD} 73$ & 101,00 & 153,51 & 62,06 & 40,03 & 3133,32 & 231,06 & 81,41 & $\begin{array}{l}149,66 \\
149\end{array}$ & \begin{tabular}{|l|l}
120,01 \\
120
\end{tabular} & 190,32 & 193,01 & 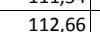 & 696,19 & 114,21 & $\begin{array}{ll}4,00 \\
4,00\end{array}$ & 62,63 & 311,64 & 29,42 & 34,60 & 288,44 \\
\hline Triturus marmoratus & 29SMD74 & 88,00 & $\begin{array}{ll}151,73 \\
151,4\end{array}$ & $\begin{array}{ll}02,000 \\
59,61\end{array}$ & $\begin{array}{l}41,05 \\
41,06\end{array}$ & 3010,96 & 224,95 & $\begin{array}{l}81,41 \\
81,51\end{array}$ & $\begin{array}{l}14,00 \\
143,43\end{array}$ & $\begin{array}{l}|c|, 05 \\
120,61\end{array}$ & $\begin{array}{ll}186,91 \\
186,9\end{array}$ & $\begin{array}{l}189,33 \\
189\end{array}$ & $\begin{array}{l}112,00 \\
112,29\end{array}$ & $\begin{array}{l}\mid 68,19 \\
688,41\end{array}$ & \begin{tabular}{|l|l|l|l|l|}
114,38 \\
\end{tabular} & $\begin{array}{ll}3,00 \\
3,95\end{array}$ & \begin{tabular}{|c|c|}
62,44 \\
62,
\end{tabular} & \begin{tabular}{|l|l|}
306,73 \\
306,73
\end{tabular} & 29,59 & 34,33 & 280,44 \\
\hline Triturus marmoratus & $295 M D 75$ & 89,00 & 151,32 & 57,80 & 41,23 & 2903,17 & 220,92 & 82,61 & 138,31 & 121,57 & \begin{tabular}{|l|l|}
185,03 \\
\end{tabular} & 187,33 & 113,25 & 677,61 & 113,71 & 3,95 & 62,35 & 300,55 & 29,35 & 35,85 & 277,62 \\
\hline Triturus marmoratus & 29SMD80 & 101,00 & 155,19 & 74,75 & 40,26 & 3803,25 & 256,91 & 73,98 & 182,93 & 115,18 & 201,22 & 205,14 & 107,34 & 778,76 & 117,50 & 4,20 & 63,64 & 346,89 & 32,86 & 35,49 & 330,61 \\
\hline Triturus marmoratus & 29SMD81 & 101,00 & 150,37 & 72,32 & 40,1 & 3700,78 & 248,21 & 70,7 & 177,47 & 111,64 & 195,10 & 198,73 & 103,66 & 795,14 & 120,81 & 4,60 & 62,82 & 352,42 & 34,73 & 37,59 & 335,04 \\
\hline Triturus marmoratus & 29 SMD82 & 101,00 & 153,03 & 69,44 & 40,40 & 3534,30 & 244,96 & 75,42 & 169,54 & 116,00 & 195,51 & 198,77 & 108,01 & 749,30 & 116,86 & 4,18 & 62,60 & 333,04 & 32,12 & 35,86 & 314,60 \\
\hline Triturus marmoratus & 29SMD83 & 100,00 & 153,13 & 66,84 & 40,67 & 3384,17 & 239,89 & 77,50 & 162,39 & 117,72 & 193,62 & 196,54 & 109,72 & 725,88 & 115,35 & 4,19 & 62,31 & 322,08 & 31,21 & 35,70 & 303,04 \\
\hline Triturus marmoratus & $295 M D 85$ & 99,00 & 153,92 & 63,22 & 41,25 & 3141,44 & 232,59 & 81,14 & 151,45 & 121,16 & 190,92 & 193,39 & 113,04 & 693,97 & 113,00 & 4,06 & 61,81 & 305,79 & 30,54 & 36,53 & 286,46 \\
\hline Triturus marmoratus & 29SMD90 & 83,00 & 162,53 & 77,54 & 40,45 & 3918,62 & 268,93 & 79,41 & 189,52 & 121,24 & 210,21 & 214,18 & 113,53 & 723,44 & 109,03 & 3,60 & 63,15 & 321,26 & 30,05 & 33,21 & 308,79 \\
\hline Triturus marmoratus & 29SMD92 & 101,00 & 43 & 73,36 & 40,42 & 718,49 & 5,45 & 76,15 & 179,30 & 117,38 & 201,57 & 204,95 & 109,56 & 738,14 & 113,18 & 4,07 & 62,29 & 325,77 & 31,79 & 35,54 & 311,36 \\
\hline Triturus marmoratus & 29SMD93 & 101,00 & 29 & 71,58 & 40,51 & 3628,03 & 248,35 & 73,27 & 175,08 & 114,35 & 196,21 & 199,45 & 106,42 & 760,12 & $\begin{array}{l}\mid 11,16,88 \\
116\end{array}$ & 4,63 & $\mid \frac{\mid, 25}{61,56}$ & 333,05 & 34,29 & 38,16 & 318,27 \\
\hline Triturus marmoratus & 29SMD95 & 10 & 15 & 68,46 & 41,02 & 3399,61 & 242,54 & 77,46 & 165,08 & 11 & \begin{tabular}{|c|}
194,88 \\
\end{tabular} & 197,66 & 110,52 & 724,99 & 114,07 & 4,23 & 61,16 & 316,49 & 32,79 & 38,09 & 300,91 \\
\hline Triturus marmoratus & $295 M D 96$ & 101,00 & 153,52 & 60,99 & 41,25 & 3337,48 & 240,05 & 77,19 & 162,86 & 118,46 & 193,38 & 195,98 & 110,44 & 732,84 & 115,06 & 4,58 & 60,60 & 317,84 & 34,29 & 40,05 & 302,60 \\
\hline Triturus marmoratus & 29SMD97 & 92,00 & 153,65 & 67,96 & 41,64 & 3283,66 & 238,79 & 77,3 & 161,43 & 119,03 & 192,74 & 195,21 & 111,05 & 740,74 & 115,77 & 4,83 & 60,01 & 319,21 & 35,65 & 41,78 & 304,47 \\
\hline Triturus marmoratus & 29SMD98 & 58,00 & 154,47 & 68,99 & 42,01 & 3275,73 & 239,79 & 77,49 & 162,30 & 119,74 & 193,37 & 195,76 & 111,73 & 752,49 & 116,18 & 5,30 & 59,35 & 321,62 & 37,58 & 44,10 & 307,90 \\
\hline Triturus marmoratus & $\begin{array}{l}\text { 29SNB12 } \\
\text { 29510 }\end{array}$ & 83,00 & $\begin{array}{l}154,4 ! \\
163,34 \\
\end{array}$ & \begin{tabular}{|l|l|}
80,34 \\
86,
\end{tabular} & $\begin{array}{ll}42,01 \\
44,66\end{array}$ & 3628,14 & 271,70 & $\begin{array}{l}8,40,42 \\
80\end{array}$ & $\begin{array}{l}191,27 \\
191,2\end{array}$ & $\mid 128,07$ & \begin{tabular}{|l|l}
207,95 \\
\end{tabular} & 212,23 & $\begin{array}{l}1119,51 \\
119,51\end{array}$ & 515,43 & \begin{tabular}{|l|}
$+10,10$ \\
83,19
\end{tabular} & $\frac{3,00}{1,00}$ & 年, & 242,02 & $\begin{array}{l}31,30 \\
18,35 \\
\end{array}$ & $\begin{array}{l}49,41 \\
49,1\end{array}$ & 231,30 \\
\hline Triturus marmoratus & 29SNB13 & 51,00 & 165,90 & 86,91 & 44,25 & 3706,64 & 276,06 & 81,89 & 194,17 & 129,33 & 211,51 & 215,80 & 121,01 & 513,94 & 82,24 & 1,00 & 68,10 & 240,26 & 18,46 & 19,60 & 229,58 \\
\hline Triturus marmoratus & 29 SNB21 & 101,00 & 166,71 & 86,81 & 43,34 & 3809,92 & 278,55 & 80, & \begin{tabular}{|l|l|}
197,97 \\
\end{tabular} & 129,16 & 214,36 & 218,16 & 120,69 & 498,75 & 80,82 & 0,90 & 69,59 & 237,30 & 16,71 & 17,97 & 225,62 \\
\hline Triturus marmoratus & 29 SNB23 & 101,00 & 16 & & 43,4 & 04,8 & 27 & & 202,99 & 122, & 209,27 & 213,56 & 113,87 & 548,35 & 86,14 & 1,1 & 67,36 & 254,48 & 20,17 & 21,04 & 244,38 \\
\hline Triturus marmoratus & 29 SNB28 & 101,00 & $16=$ & 91 & 42 & & 286 & 74 & 212 & 121, & 214 & 219,54 & 113,86 & 58 & 88,30 & 2,00 & 64,69 & 263,26 & 23,58 & 24,30 & 255,08 \\
\hline Triturus marmoratus & 29 SNB32 & 100,00 & 157,21 & \begin{tabular}{|l|l|}
90,43 \\
\end{tabular} & 42,89 & 4051,06 & 276,71 & 68,08 & 208,63 & 117,62 & 208,32 & 212,39 & 109,04 & 568,47 & 89,90 & 1,46 & 67,30 & 263,84 & 21,14 & 22,08 & 253,54 \\
\hline Triturus marmoratus & 295NB33 & 101,00 & 153,17 & 91,73 & 42,96 & 4104,42 & 275,13 & 63,85 & 211,28 & 113,12 & 205,01 & 209,21 & 104,51 & 597,67 & 93,49 & 1,78 & 66,16 & 273,78 & 23,43 & 24,04 & 264,44 \\
\hline Triturus marmoratus & 29 SNB38 & 101,00 & 165,56 & 94,17 & 42,70 & 4258,45 & 292,73 & 74,44 & 218,29 & 122,77 & 218,79 & 223,35 & 114,49 & 567,57 & 86,11 & 2,00 & 64,57 & 256,00 & 22,76 & 23,43 & 248,21 \\
\hline Triturus marmorat & 29SNB41 & 101,00 & D & & 42,32 & 4071,24 & . & 79,5 & 208,73 & 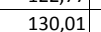 & 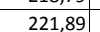 & 225,72 & 121,66 & 494 & 80,91 & 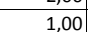 & 69,76 & 237,45 & 15,99 & 17,53 & 224,66 \\
\hline Triturus marmoratus & 29 SNB42 & & & & & & & 71,88 & 213,09 & 124 & 215, & 219 & 113,77 & 536,63 & 86,44 & & 68,24 & 252,48 & 18,58 & 19,76 & 241,22 \\
\hline Triturus marmoratus & \begin{tabular}{|l|}
$295 N B 44$ \\
\end{tabular} & 101,00 & 165,33 & 93,32 & 42,45 & 4231,12 & 290,31 & 73,10 & 217,20 & 123,17 & 218,62 & 222,87 & 114,75 & 534,47 & 84,80 & 1,00 & 67,20 & 248,69 & 18,80 & 19,94 & 238,53 \\
\hline Triturus marmoratus & 29SNB49 & 101,00 & 168,13 & 96,77 & 42,39 & 4402,72 & 299,73 & 74,62 & 225,11 & 123,45 & 223,21 & 227,86 & 115,34 & 557,31 & 84,01 & 2,00 & 64,01 & 249,32 & 22,72 & 23,49 & 242,42 \\
\hline Triturus marmoratus & 29 SNB52 & 101,00 & 164,37 & 92,97 & 42,21 & 4241,13 & 288,17 & \begin{tabular}{|c|}
71,28 \\
\end{tabular} & 216,89 & 122,52 & 218,10 & 222,13 & 113,81 & 533,03 & 86,93 & 1,00 & 68,19 & 251,74 & 17,99 & 19,46 & 240,04 \\
\hline Triturus & 29SNB57 & 101,00 & & & 42, & 481, & 299 & 69, & 229,64 & 119, & 221, & 226 & 111 & 554 & 85 & 1,99 & 64,53 & 250,30 & 21,91 & 22,56 & \\
\hline Triturus marmoratus & 29 SNB58 & 100,00 & 167,38 & \begin{tabular}{ll|}
98,91 \\
98,1
\end{tabular} & $\begin{array}{ll}42,36 \\
42,36\end{array}$ & 4491,59 & 302,26 & 72,00 & 230,26 & 121,99 & 223,90 & 228,48 & 113,80 & 548,53 & \begin{tabular}{|l|l|}
83,37 \\
3,12
\end{tabular} & 2,00 & $\begin{array}{l}44,49 \\
64,1\end{array}$ & 246,13 & 21,50 & 22,24 & 239,15 \\
\hline
\end{tabular}




\begin{tabular}{|c|c|c|c|c|c|c|c|c|c|c|c|c|c|c|c|c|c|c|c|c|c|}
\hline TAXON & UTM & $\mathrm{km} 2$ & B101 & $\mathrm{B1O2}$ & $\mathrm{BIO3}$ & BIO4 & B105 & B106 & B107 & B108 & B109 & B1010 & B1011 & B1012 & B1013 & B1014 & B1015 & B1016 & $\begin{array}{ll}1017 \\
17\end{array}$ & B1018 & B1019 \\
\hline Triturus marmoratus & 29SNB74 & 100,00 & 155,46 & 98,99 & 42,00 & 4582,57 & 290,88 & 57,98 & 232,90 & 109,87 & 213,81 & 218,20 & 101,36 & 595,08 & 93,54 & 2,00 & 64,75 & 269,91 & 23,20 & 24,36 & 260,62 \\
\hline Triturus marmoratus & 29SNB75 & 101,00 & 159,78 & 100,28 & 42,00 & 4621,93 & 297,04 & 61,54 & 235,50 & 113,35 & 218,43 & 222,83 & 105,05 & 572,95 & 89,41 & 2,00 & 64,65 & 259,20 & 22,04 & 23,10 & 250,47 \\
\hline Triturus marmoratus & 29 SNB80 & 97,00 & 169,36 & 92,45 & 42,75 & 4192,89 & 288,39 & 74,36 & 214,03 & 128,18 & 222,39 & 226,50 & 119,50 & 515,13 & 88,79 & 1,00 & 69,74 & 249,99 & 15,82 & 18,36 & 234,58 \\
\hline Triturus marmoratus & 29SNB82 & 101,00 & 157,12 & 96,63 & 41,94 & 4496,11 & 287,34 & 59,58 & 227,76 & 112,64 & 214,29 & 218,59 & 103,89 & 581,80 & 93,91 & 1,63 & 66,26 & 269,03 & 20,85 & 22,90 & 257,09 \\
\hline Triturus marmoratus & 29SNB83 & 99,00 & 153,72 & 98,40 & 41,99 & 4596,25 & 288,04 & 55,56 & 232,47 & 108,30 & 212,29 & 216,57 & 99,42 & 603,65 & 95,34 & 2,03 & 64,86 & 274,47 & 22,96 & 24,69 & 264,03 \\
\hline Triturus marmoratus & 29SNB84 & 101,00 & 156,82 & 99,72 & 41,99 & 4649,05 & 293,62 & 58,02 & 235,60 & 110,58 & 215,99 & 220,47 & 101,90 & 587,33 & 91,97 & 2,00 & 64,52 & 265,77 & 22,60 & 24,20 & 255,97 \\
\hline Triturus marmoratus & 29SNB85 & 101,00 & 160,15 & 101,33 & 42,00 & 4701,10 & 299,33 & 60,68 & 238,64 & \begin{tabular}{|l|l|}
113,07 \\
\end{tabular} & 219,98 & 224,36 & 104,50 & 569,56 & 88,36 & 2,00 & 64,34 & 256,54 & 21,87 & 23,07 & 247,50 \\
\hline Triturus marmoratus & 295NB86 & 100,00 & 162,07 & 103,04 & 42,00 & 4757,32 & 303,96 & 61,80 & 242,16 & 114,11 & 222,48 & 226,92 & 105,67 & 561,37 & 85,89 & 2,00 & 63,65 & 250,74 & 22,00 & 23,10 & 242,69 \\
\hline Triturus marmoratus & 29SNB89 & 100,00 & 165,90 & 107,83 & 42,29 & 4898,78 & 315,21 & 63,79 & 251,42 & 115,99 & 227,84 & 232,60 & 107,52 & 549,89 & 82,33 & 2,00 & 61,86 & 238,70 & 23,05 & 23,82 & 233,98 \\
\hline Triturus marmoratus & 29SNB92 & 100,00 & 150,90 & 97,38 & 41,39 & 4624,20 & 284,06 & 52,19 & 231,87 & 105,03 & 209,76 & 213,97 & 96,25 & 620,53 & 97,73 & 1,99 & 64,87 & 281,73 & 23,16 & 25,60 & 270,38 \\
\hline Triturus marmoratus & 29SNB93 & 101,00 & 154,65 & 98,68 & 41,62 & 4663,30 & 289,92 & 55,33 & 234,59 & 108,13 & 214,02 & 218,37 & 99,52 & 599,00 & 93,82 & 2,02 & 64,50 & 271,15 & 22,54 & 24,85 & 260,13 \\
\hline Triturus marmoratus & 29SNB97 & 100,00 & 164,92 & 105,55 & 42,00 & 4874,85 & 310,72 & 62,35 & 248,37 & 115,44 & 226,73 & 231,23 & 106,64 & 545,94 & 82,66 & 2,00 & 62,55 & 240,46 & 21,97 & 23,29 & 232,84 \\
\hline Triturus marmoratus & 29SNB98 & 100,00 & 166,44 & 107,51 & \begin{tabular}{ll|l}
42,05 \\
\end{tabular} & 4933,26 & 315,14 & 63,07 & 252,06 & 116,25 & 228,91 & 233,37 & 107,37 & 539,69 & 81,21 & 2,00 & 61,85 & 235,36 & 22,26 & 23,41 & 228,93 \\
\hline Triturus marmoratus & 29SNC08 & 88,00 & 170,53 & 83,66 & 40,89 & 4135,33 & 286,57 & 83,89 & 202,68 & 127,01 & 221,21 & 225,76 & 119,78 & 664,00 & 99,33 & 3,00 & 63,24 & 295,24 & 26,97 & 30,01 & 285,61 \\
\hline Triturus marmoratus & 29SNC17 & 101,00 & 170,53 & 86,68 & \begin{tabular}{|l|l|l|}
41,03 \\
\end{tabular} & 4232,24 & 291,12 & 82,37 & 208,75 & 126,37 & 222,68 & 227,27 & 118,88 & $\begin{array}{l}648,25 \\
\end{array}$ & 95,83 & 3,00 & 62,78 & 286,50 & 27,00 & 29,86 & 278,50 \\
\hline Triturus marmoratus & 29 SNC18 & 101,00 & 170,36 & 85,57 & 40,95 & 4216,61 & 289,75 & 82,38 & 207,36 & 126,20 & 222,34 & 226,68 & 118,63 & 654,34 & 96,99 & 3,00 & 62,89 & 288,89 & 27,13 & 30,05 & 280,95 \\
\hline Triturus marmoratus & 29SNC19 & 100,00 & 169,45 & 84,33 & 40,73 & 4178,78 & 286,88 & 81,82 & 205,06 & 125,35 & 220,79 & 225,15 & 117,87 & 663,76 & 98,49 & 3,00 & 62,52 & 292,10 & 27,61 & 30,92 & 284,15 \\
\hline Triturus marmoratus & $295 N C 20$ & 100,00 & 163,43 & 92,33 & 42,46 & 4224,95 & 288,91 & 73,92 & 214,99 & 120,64 & 215,90 & 220,69 & 112,66 & 606,74 & 90,73 & 2,30 & 63,70 & 270,56 & 25,52 & 26,30 & 263,18 \\
\hline Triturus marmoratus & $295 N C 22$ & 99,00 & 166,10 & 91,82 & 42,02 & 4275,52 & 292,11 & 76,33 & 215,78 & 122,47 & 219,16 & 224,04 & 114,58 & 614,17 & 91,45 & 2,67 & 63,12 & 272,23 & 26,19 & 27,32 & 265,21 \\
\hline Triturus marmoratus & 29SNC23 & 101,00 & 168,86 & 91,32 & 42,00 & 4281,82 & 294,32 & 78,88 & 215,44 & 124,77 & 221,79 & 226,66 & 116,93 & 608,71 & 90,47 & 2,99 & 63,12 & 269,53 & 25,78 & 27,64 & 262,48 \\
\hline Triturus marmoratus & 29SNC24 & 100,00 & 170,19 & 90,79 & \begin{tabular}{ll|}
41,82 & \\
\end{tabular} & 4295,90 & 295,24 & 80,06 & 215,18 & 125,66 & 223,30 & 228,07 & 117,87 & \begin{tabular}{|c|}
612,17 \\
\end{tabular} & 90, & 2,9 & 62,43 & 270,48 & 26,14 & 27,79 & 263,54 \\
\hline Triturus marmoratus & 29 SNC25 & 72,00 & 171,37 & 90,26 & 41,50 & 4305,01 & 296,38 & 81,59 & 214,79 & 126,64 & 224,69 & 229,51 & $\mid 119,16$ & 611,59 & 90,23 & 3,00 & 62,83 & 269,90 & 25,77 & 27,76 & 263,10 \\
\hline Triturus marmoratus & 29SNC31 & 101,00 & 161,27 & 94,95 & 42,00 & 4402,58 & 292,56 & 69,61 & 222,95 & 116,77 & 216,36 & 221,20 & 108,72 & 624,36 & 92,71 & 2,89 & 62,71 & 274,96 & 27,25 & 27,68 & 269,36 \\
\hline Triturus marmoratus & 29SNC32 & 101,00 & 164,58 & 94,37 & 41,92 & 4412,68 & 295,47 & 72,80 & 222,67 & 119,62 & 219,70 & 224,62 & 111,69 & 614,58 & 90,98 & 2,73 & 62,64 & 270,49 & 26,43 & 27,17 & 264,92 \\
\hline Triturus marmoratus & $295 N C 34$ & 101,00 & 169,72 & 93,09 & 41,86 & 4404,57 & 299,00 & 78,24 & 220,76 & 124,28 & 224,49 & 229,21 & 116,51 & 603,04 & 88,72 & 2,98 & 62,63 & 264,73 & 25,86 & 26,98 & 259,18 \\
\hline Triturus marmoratus & 29SNC35 & 101,00 & 171,03 & 92,25 & 41,48 & 4404,83 & 299,52 & 79,46 & 220,05 & 125,40 & 225,77 & 230,49 & 117,50 & 604,24 & 88,7 & 3,00 & 62,41 & 264,68 & 25,77 & 27,49 & 259,25 \\
\hline Triturus marmoratus & $295 N C 36$ & 100,00 & 169,00 & 91,56 & $\begin{array}{l}41,40 \\
41,06\end{array}$ & 4431,00 & 297,64 & 77,78 & 219,86 & 122,84 & 224,17 & 228,71 & 115,32 & 627,90 & $\begin{array}{l}90,10 \\
92,08\end{array}$ & 3,00 & $62,1,85$ & 273,39 & 27,58 & 29,37 & 268,51 \\
\hline Triturus marmoratus & 29SNC37 & 101,00 & 169,03 & 90,66 & 40,99 & 4427,78 & 296,69 & 77,94 & 218,75 & 122,70 & 224,05 & 228,61 & 115,18 & 636,97 & 93,47 & 3,05 & 61,64 & 276,64 & 28,14 & 30,01 & 271,91 \\
\hline Triturus marmoratus & 29 SNC41 & 101,00 & 166,46 & 97,10 & 42,00 & 4485,43 & 300,43 & 72,71 & 227,71 & 120,71 & 222,62 & 227,24 & 112,62 & 584,59 & 86,96 & 2,10 & 63,03 & 257,83 & 24,48 & 25,09 & 252,44 \\
\hline Triturus marmoratus & 29 SNC42 & 99,00 & 168,70 & 96,55 & 42,00 & 4483,66 & 302,16 & 75,09 & 227,07 & 122,67 & 224,64 & 229,38 & 114,78 & 580,33 & 85,94 & 2,06 & 62,96 & 255,20 & 24,26 & 25,13 & 250,04 \\
\hline Triturus marmoratus & $295 N C 48$ & 101,00 & 167,37 & 91,63 & 40,88 & 4518,73 & 297,60 & 75,26 & 222,34 & 120,13 & 223,69 & 228,17 & 112,45 & 647,64 & 94,44 & 3,90 & 60,49 & 277,18 & 30,66 & 32,10 & 274,15 \\
\hline Triturus marmoratus & $295 N C 49$ & 101,00 & 167,49 & 90,72 & 40,40 & 4504,72 & 296,56 & 75,55 & 221,01 & 120,28 & 223,71 & 227,97 & \begin{tabular}{|l|}
112,67 \\
112,67
\end{tabular} & 655,11 & $\begin{array}{l}44,5453 \\
\end{array}$ & 3,96 & 60,30 & 279,75 & 31,13 & 32,90 & 276,80 \\
\hline Triturus marmoratus & 29SNC52 & 101,00 & 169,67 & 98,88 & 42,01 & 4587,13 & 306,68 & 74,25 & 232,43 & 122,60 & 227,16 & 231,83 & 114,48 & 566,97 & 83,56 & 2,08 & 62,27 & 247,49 & 24,29 & 24,99 & 243,05 \\
\hline Triturus marmoratus & 29SNC53 & 100,00 & 170,04 & 98,17 & \begin{tabular}{|c|}
41,97 \\
\end{tabular} & 4596,44 & 306,70 & 74,80 & 231,89 & 122,87 & 227,55 & 232,26 & 114,58 & 573,44 & 83,86 & 2,58 & 61,79 & 248,75 & 25,34 & 26,21 & 244,83 \\
\hline Triturus marmoratus & 29 SNC55 & 100,00 & 168,90 & 96,51 & 41,20 & 4621,95 & 304,91 & 74,40 & 230,51 & 121,21 & 226,82 & 231,37 & 113,07 & 597,31 & 86,6 & 3,00 & 60,85 & 256,22 & 27,24 & 28,15 & 253,45 \\
\hline Triturus marmoratus & 29 SNC56 & 101,00 & 164,47 & 95,36 & 40,94 & 4653,64 & 300,76 & 70,51 & 230,25 & 116,51 & 222,78 & 227,54 & 108,55 & 636,12 & 92,18 & 3,69 & 60,01 & 270,33 & 30,59 & 31,18 & 268,80 \\
\hline Triturus marmoratus & $295 N C 63$ & 100,00 & 169,43 & 100,65 & 41,97 & 4709,57 & 310,18 & 72,45 & 237,73 & 120,91 & 228,61 & 233,21 & 112,84 & 567,75 & 82,31 & 2,86 & 60,67 & 243,66 & 26,02 & 26,75 & 240,76 \\
\hline Triturus marmoratus & $295 N C 64$ & 100,00 & 167,67 & 99,66 & 41,58 & 4728,05 & 308,14 & 71,10 & 237,04 & 118,99 & 227,06 & 231,73 & 110,79 & 586,38 & 84,68 & 2,98 & 60,50 & 249,87 & 27,36 & 27,77 & 247,77 \\
\hline Triturus marmoratus & 29SNC65 & 101,00 & 165,21 & 98,42 & 41,09 & 4744,75 & 305,35 & 69,42 & 235,94 & 116,34 & 224,94 & 229,67 & 108,29 & 609,86 & 87,75 & 3,0 & 60,04 & 257,88 & 29,32 & 29,53 & 256,77 \\
\hline Triturus marmoratus & 29SNC66 & 100,00 & 163,32 & 96,95 & 40,96 & 4748,38 & 302,52 & 68,20 & 234,32 & 113,71 & 223,07 & 227,75 & 106,26 & 633,58 & 90,95 & 3,66 & 59,27 & 266,10 & 31,68 & 31,91 & 265,71 \\
\hline Triturus marmoratus & 29 SNC67 & 101,00 & 160,92 & 95,55 & 40,51 & 4762,73 & 299,50 & 66,41 & 233,08 & 108,31 & 221,06 & 225,57 & 103,85 & 660,70 & 94,83 & 4,0 & 58,89 & 276,39 & 33,88 & 33,97 & 276,32 \\
\hline Triturus marmoratus & 29 SNC68 & 101,00 & 163,25 & 94,70 & 40, & 4730,67 & 300,30 & $\begin{array}{ll}68,96 \\
\end{array}$ & 231,34 & 111,72 & 222,91 & 227,37 & 106,33 & 657,62 & 94,41 & 4,00 & 58,85 & 274,96 & 33,71 & 34,14 & 274,80 \\
\hline Triturus marmoratus & $295 N C 69$ & 100,00 & 165,62 & 94,16 & 40,24 & 4717,41 & 301,63 & 71,25 & 230,38 & 115,59 & 224,87 & 229,36 & 108,58 & 652,73 & $\begin{array}{l}93,69 \\
93\end{array}$ & 4,00 & 58,75 & 272,66 & 33,34 & 34,18 & 272,37 \\
\hline Triturus marmoratus & $295 N C 73$ & 101,00 & 167,30 & 103,29 & 41,94 & 4840,16 & 312,68 & 68,40 & 244,28 & 117,58 & 228,25 & 233,07 & 109,32 & 571,18 & 81,99 & 3,00 & 59,96 & 242,07 & 27,26 & 27,38 & 240,14 \\
\hline Triturus marmoratus & $295 N C 74$ & 101,00 & 164,58 & 101,83 & 41,3 & 4855,15 & 309,36 & 66,51 & 242,84 & 114,73 & 226,27 & 230 & 106,55 & 594,93 & 84, & 3,00 & 59,55 & 250,03 & 28,86 & 28,86 & 249,31 \\
\hline Triturus marmoratus & $295 N C 75$ & 100,00 & 164,53 & 100,09 & 41,0 & 4838,18 & 307,66 & $\begin{array}{ll}67,28 \\
\end{array}$ & 240,38 & 114,29 & 226,21 & 230, & 106,54 & \begin{tabular}{|c|c|}
604,28 \\
\end{tabular} & $\begin{array}{l}84,0,0 \\
86,0 \\
\end{array}$ & 3,00 & 59,13 & 252,46 & 30,18 & $\begin{array}{l}30,0,18 \\
30,\end{array}$ & 252,28 \\
\hline Triturus marmoratus & $29 S N C 76$ & 101,00 & 160,29 & 98,06 & 40, & 4851,99 & 302,55 & 64,27 & 238,27 & 104,42 & 223,43 & 226,39 & 102,36 & 641,73 & 91,18 & $3, \varepsilon$ & 58,25 & 266,81 & 33,29 & 33,29 & 266,81 \\
\hline Triturus marmoratus & 29 SNC77 & 101,00 & 158,54 & 96,49 & 40,18 & 4855,58 & 299,73 & 63,38 & 236,35 & 100,76 & 222,23 & 224,66 & 100,60 & 666,05 & 94,64 & 4,08 & 57,82 & 276,19 & 35,39 & 35,39 & 276,19 \\
\hline Triturus marmoratus & 29 SNC81 & 101,00 & 165,59 & 108,62 & 42,09 & 4964,21 & 317,28 & 63,29 & 253,99 & 114,89 & 228,42 & 233,08 & 106,27 & 561,88 & 82,25 & 2,18 & 60,46 & 239,21 & 25,24 & 25,36 & 236,65 \\
\hline Triturus marmoratus & 29 SNC86 & 100,00 & 161,19 & 99,26 & 40,70 & 4930,57 & 305,38 & 63,90 & 241,49 & 102,56 & 226,06 & 228,18 & 102 & 624,39 & 87,51 & 3,77 & 57,59 & 257,09 & 33,38 & 33,38 & 257,09 \\
\hline Triturus marmoratus & $295 \mathrm{NC} 87$ & 100,00 & 157,48 & 9 & $\frac{40}{40}-3 x-3$ & 4938,52 & 300,59 & $\begin{array}{l}61,44 \\
61, \\
\end{array}$ & \begin{tabular}{|l|}
239,15 \\
239
\end{tabular} & \begin{tabular}{|l|l|}
98,67 \\
98,
\end{tabular} & 223,75 & \begin{tabular}{|l|l|}
224,75 \\
240
\end{tabular} & \begin{tabular}{|l|}
98,67 \\
98,67
\end{tabular} & $\begin{array}{l}\mid 224,33 \\
661,51\end{array}$ & $\begin{array}{l}\mid 01,11 \\
92,89 \\
\end{array}$ & $\frac{4,1}{4,0}$ & 57,07 & \begin{tabular}{|l|}
271,88 \\
\end{tabular} & $\begin{array}{l}3,00 \\
36,14 \\
\end{array}$ & $\begin{array}{l}30,0 \\
36,14 \\
\end{array}$ & 271,88 \\
\hline Triturus marmoratus & 29 SNC96 & 100,00 & 161,72 & 100,41 & 40,40 & 5014,36 & 307,90 & 63,07 & 244,83 & 101,64 & 227,53 & 229,77 & 101,64 & 610,86 & 84,42 & 3,90 & 56,55 & 248,98 & 33,86 & 33,86 & 248,98 \\
\hline Triturus marmoratus & 29SNC97 & 101,00 & 160,32 & 98,67 & 40,00 & 5013,92 & 305,33 & 62,47 & 242,87 & 100,35 & 227,13 & 228,47 & 100,35 & \begin{tabular}{|c|}
630,48 \\
\end{tabular} & 87,14 & 4,00 & 56,21 & 256,55 & 35,39 & 35,39 & 256,55 \\
\hline Triturus marmoratus & 29SNC98 & 101,00 & 160,41 & 97,95 & 40,00 & 5019,94 & 305,06 & 62,60 & 242,46 & 100,33 & 226,64 & 228,62 & 100,33 & 646,31 & 89,76 & 4,01 & 56,42 & 263,36 & 36,37 & 36,37 & 263,36 \\
\hline Triturus marmoratus & 29 SND05 & 101,00 & 155,97 & 73,29 & 40,97 & 3622,09 & 252,84 & 75,74 & 177,10 & 117,80 & 199,97 & 202 & 109 & 738,07 & 113,12 & 4,51 & 60,61 & 319,44 & 34,41 & 39,11 & 307 \\
\hline Triturus marmoratus & 29SND06 & $\begin{array}{l}101,00 \\
101\end{array}$ & 149,04 & $\begin{array}{l}73,22 \\
73,22\end{array}$ & $\begin{array}{l}40,91 \\
40,77\end{array}$ & 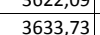 & 24,04 & 68,94 & $\begin{array}{l}171,10 \\
177,54 \\
\end{array}$ & 111,00 & 193,27 & 196,21 & 103,07 & 806,23 & 121,74 & 5,64 & 59,51 & 345,03 & 40,37 & 44,62 & 333,78 \\
\hline Triturus marmoratus & 29SND07 & 100,00 & 150,55 & 72,97 & 41,12 & 3560,35 & 245,85 & 70,64 & 175,21 & 112,96 & 193,75 & 196,39 & 105,14 & 801,02 & 121,01 & 5,78 & 59,06 & 341,15 & 40,96 & 45,75 & 329,98 \\
\hline Triturus & 29SND08 & 101.00 & 154,16 & 73.18 & 41.81 & 3476,62 & 247.18 & 74.14 & 173,04 & 117,32 & 195.93 & 198.56 & 109,29 & 778.49 & 117.5 & 5,62 & 58.76 & 330,55 & 39.95 & 45,65 & 319,44 \\
\hline Triturus ! & 29SND10 & 101,00 & 169,07 & 82,95 & 40,83 & 115,42 & 283,87 & 82,42 & 201,4 & 125,60 & 219,60 & 223,64 & 118 & 664,85 & 99,11 & 3,00 & 62,31 & 292,12 & 27,81 & 31,06 & 283,75 \\
\hline Triturus marmoratus & $29 \mathrm{SND} 11$ & $\begin{array}{l}101,00 \\
\end{array}$ & 168,36 & 81,61 & 40,94 & 4048,53 & 280,49 & 82,40 & 198,09 & 125,47 & 217,97 & 221,82 & \begin{tabular}{|l|l|}
118,03 \\
\end{tabular} & \begin{tabular}{|l|l|}
666,83 \\
\end{tabular} & $\begin{array}{l}99,99 \\
9\end{array}$ & 3,01 & 62,14 & 292,33 & 28,04 & 31,66 & 283,46 \\
\hline
\end{tabular}




\begin{tabular}{|c|c|c|c|c|c|c|c|c|c|c|c|c|c|c|c|c|c|c|c|c|c|}
\hline TAXON & UTM & $\mathrm{km} 2$ & B101 & B102 & $\mathrm{BIO3}$ & BIO4 & B105 & 8106 & B107 & $\mathrm{B108}$ & B109 & 81010 & BIO11 & BIO12 & B1013 & BIO14 & BIO15 & BIO16 & BIO17 & B1018 & B1019 \\
\hline Triturus marmoratus & 29SND12 & 101,00 & 166,69 & 80,13 & 40,82 & 3974,29 & 276,01 & 81,52 & 194,50 & 124,59 & 215,32 & 218,92 & 117,01 & 675,43 & 101,78 & 3,45 & 61,80 & 295,13 & 29,08 & 32,92 & 285,80 \\
\hline Triturus marmoratus & 29SND15 & 100,00 & 159,96 & 77,63 & 40,96 & 3799,61 & 263,78 & 76,55 & 187,23 & 119,64 & 206,39 & 209,51 & 112,04 & 727,13 & 109,49 & 4,44 & 60,20 & 312,69 & 34,41 & 38,76 & 303,14 \\
\hline Triturus marmoratus & 29 SND16 & 100,00 & 153,84 & 77,45 & 40,77 & 3808,84 & 257,99 & 70,53 & 187,46 & 113,59 & 200,48 & 203,54 & 105,87 & 788,12 & 117,47 & 5,51 & 59,16 & 335,49 & 39,89 & 43,88 & 326,82 \\
\hline Triturus marmoratus & 29SND17 & 101,00 & 140,89 & 77,42 & 40,20 & 3896,44 & 247,82 & 57,69 & 190,13 & 100,32 & 189,19 & 192,27 & 92,55 & 923,35 & 136,53 & 7,84 & 57,81 & 387,36 & 51,57 & 54,11 & 380,57 \\
\hline Triturus marmoratus & 29SND18 & 100,00 & 150,32 & 77,86 & 41,17 & 3751,52 & 253,42 & 66,79 & 186,64 & 110,63 & 196,26 & 199,05 & 102,79 & 842,71 & 124,44 & 6,59 & 57,92 & 354,03 & 45,62 & 49,85 & 346,48 \\
\hline Triturus marmoratus & 29SND22 & 100,00 & 167,60 & 83,33 & 40,74 & 4124,58 & 282,55 & 80,19 & 202,35 & 123,82 & 218,37 & 222,03 & 116,25 & 674,42 & 99,93 & 3,95 & 61,12 & 291,85 & 30,32 & 33,83 & 284,68 \\
\hline Triturus marmoratus & 29SND26 & 101,00 & 159,71 & 81,56 & 41,01 & 3964,80 & 269,88 & 73,31 & 196,58 & 117,48 & 208,47 & 211,54 & 109,77 & 756,41 & 111,66 & 5,06 & 58,96 & 320,51 & 38,33 & 42,25 & 313,91 \\
\hline Triturus marmoratus & $29 S N D 27$ & 101,00 & 147,54 & 81,31 & 40,44 & 4037,86 & 260,08 & 61,37 & 198,71 & 105,03 & $\begin{array}{l}197,73 \\
\end{array}$ & 200,82 & 97,41 & 880,62 & 129,94 & 7,08 & 57,73 & 368,51 & 48,65 & 51,27 & 363,81 \\
\hline Triturus marmoratus & 29SND28 & 101,00 & 144,18 & 81,60 & 40,51 & 4038,77 & 257,03 & 57,77 & 199,26 & 101,73 & 194,40 & 197,49 & 93,99 & 927,78 & 136,62 & 7,98 & 57,12 & 385,76 & 53,21 & 55,56 & 381,90 \\
\hline Triturus marmoratus & 29SND29 & 99,00 & 151,13 & 82,99 & 41,45 & 3942,27 & 261,95 & 63,73 & 198,22 & 109,08 & 199,74 & 202,52 & 101,35 & 876,15 & 128,23 & 7,39 & 56,91 & 363,50 & 50,06 & 53,62 & 359,24 \\
\hline Triturus marmoratus & 29SND35 & 101,00 & 166,06 & 85,14 & 40,97 & 4148,63 & 282,49 & 76,77 & 205,72 & 121,66 & 217,32 & 220,53 & 113,93 & 709,63 & 104,27 & 4,45 & 59,05 & 300,66 & 35,14 & 38,83 & 295,42 \\
\hline Triturus marmoratus & 29SND36 & 101,00 & 163,01 & 85,30 & 40,99 & 4139,85 & 279,47 & 73,62 & 205,86 & 118,69 & 214,20 & 217,29 & 110,95 & 745,59 & 109,38 & 5,01 & 58,52 & 313,82 & 38,47 & 41,99 & 309,20 \\
\hline Triturus marmoratus & 29SND37 & 100,00 & 157,30 & 85,38 & 40,79 & 4154,40 & 274,52 & 67,86 & 206,66 & 112,97 & 208,89 & 211,94 & 105,38 & 810,35 & 118,84 & 6,19 & 57,83 & 338,33 & 44,14 & 47,12 & 334,79 \\
\hline Triturus marmoratus & 29SND38 & 101,00 & 154,11 & 86,06 & 40,92 & 4160,23 & 272,22 & 64,23 & 207,99 & 109,68 & 205,85 & 208,84 & 101,98 & 852,33 & 124,75 & 6,88 & 57,12 & 353,53 & 48,20 & 50,95 & 350,97 \\
\hline Triturus marmoratus & 29SND39 & 101,00 & 153,96 & 87,16 & 41,14 & 4137,05 & 272,16 & 63,43 & 208,73 & 109,60 & 205,40 & 208,28 & 102,00 & 870,46 & 126,93 & 7,33 & 56,63 & 359,14 & \begin{tabular}{|l|l|}
50,47 \\
\end{tabular} & 53,44 & 357,18 \\
\hline Triturus marmoratus & 29 SND43 & 101,00 & 165,55 & 88,08 & 40,38 & 4386,48 & 289,87 & 74,40 & 215,47 & 119,04 & 220,25 & 223,94 & 111,32 & 704,16 & 103,05 & 4,47 & 59,20 & 297,69 & 35,20 & 37,73 & 294,37 \\
\hline Triturus marmoratus & 29SND44 & 100,00 & 163,98 & 87,84 & 40,42 & 4365,45 & 287,47 & 72,59 & 214,88 & 117,42 & 218,27 & 221,88 & 109,75 & 727,36 & 106,51 & 4,88 & 58,87 & 306,26 & \begin{tabular}{l|l|}
37,05 \\
\end{tabular} & 39,69 & 303,29 \\
\hline Triturus marmoratus & 29SND45 & 101,00 & 165,76 & 88,03 & 40,78 & 4321,19 & 288,15 & 74,32 & 213,82 & 119,42 & 219,42 & 222,85 & 111,97 & 723,74 & 105,79 & 4,87 & 58,48 & 304,00 & 37,37 & 40,32 & 300,70 \\
\hline Triturus marmoratus & 29SND46 & 101,00 & 166,58 & 88,53 & 40,98 & 4293,35 & 288,52 & 74,46 & 214,05 & 120,34 & 219,92 & 223,14 & 112,81 & 727,41 & 106,05 & 5,03 & 58,10 & 304,27 & 38,17 & 41,38 & 301,09 \\
\hline Triturus marmoratus & 295ND47 & 101,00 & 163,11 & 89,05 & 40,96 & 4309,41 & 285,90 & 70,68 & 215,21 & $\mid 116,77$ & 216,77 & 219,84 & $\mid 109,16$ & 770,68 & 112,25 & 5,77 & 57,55 & 320,32 & 42,06 & 45,06 & 318,06 \\
\hline Triturus marmoratus & 29SND48 & 100,00 & 160,19 & 89,82 & 41,00 & 4310,84 & 283,68 & 67,29 & 216,38 & 113,66 & 213,89 & 216,89 & 106,16 & 813,88 & 118,38 & 6,42 & 56,90 & 336,12 & 46,13 & 48,98 & 334,85 \\
\hline Triturus marmoratus & $29 \mathrm{SND50}$ & 101,00 & 167,79 & 91,83 & 40,21 & 4577,92 & 299,08 & 74,61 & 224,47 & 119,69 & 225,07 & 229,25 & 111,94 & 656,23 & 95,12 & 4,00 & 59,42 & 277,02 & 32,25 & 33,94 & 275,19 \\
\hline Triturus marmoratus & 29SND52 & 101,00 & 165,51 & 90,66 & 40,03 & 4560,99 & 295,47 & 72,48 & 222,99 & 117,32 & 222,66 & 226,66 & 109,70 & 695,99 & 101,16 & 4,66 & 58,88 & 292,10 & 35,66 & 37,49 & 290,59 \\
\hline Triturus marmoratus & 29 SND54 & 100,00 & 163,62 & 90,20 & 40,02 & 4533,12 & 292,51 & 70,56 & 221,95 & 115,70 & 220,47 & 224,08 & 107,92 & 735,01 & 107,10 & 5,02 & 58,32 & 306,96 & 38,58 & 40,59 & 305,63 \\
\hline Triturus marmoratus & 29 SND55 & 100,00 & 162,59 & 90,29 & 40,09 & 4516,73 & 291,27 & 69,36 & 221,91 & 114,68 & 219,35 & 222,82 & 107,06 & 757,73 & 110,34 & 5,54 & 57,69 & 315,09 & 41,03 & 43,10 & 314,16 \\
\hline Triturus marmoratus & 29SND56 & 100,00 & 164,14 & 90,99 & 40,28 & 4499,20 & 292,42 & 70,03 & 222,39 & 115,91 & 220,46 & 223,79 & 108,37 & 758,66 & 110,26 & 5,55 & 57,46 & 314,56 & 41,55 & 43,99 & 313,51 \\
\hline Triturus marmoratus & $29 S N D 57$ & 101,00 & 163,58 & 91,65 & 40,52 & 4487, & 292,20 & 68,96 & 223,24 & \begin{tabular}{|l|l|l}
114,77 \\
\end{tabular} & 219,93 & 223,01 & 107,82 & 778,36 & 112,98 & 5,93 & 57,09 & 321,51 & 43,46 & \begin{tabular}{|l|l|}
45,93 \\
\end{tabular} & 320,79 \\
\hline Triturus marmoratus & 29SND58 & 99,00 & 160,41 & 92,24 & 40,51 & 4511,64 & 290,14 & 65,14 & 224,99 & 108,50 & 217,14 & 220,11 & 104,43 & 823,70 & 119,57 & 6,61 & 56,51 & 338,98 & 47,61 & 49,76 & 338,68 \\
\hline Triturus marmoratus & 29 SND59 & 101,00 & 155,63 & 92,85 & 40,48 & 4542,00 & 286,69 & 60,08 & 226,61 & 100,20 & 212,94 & 215,92 & 99,49 & 886,67 & 128,71 & 7,65 & 56,03 & 363,69 & 53,16 & 54,72 & 363,69 \\
\hline Triturus marmoratus & 29 SND60 & 100,00 & 167,56 & 93,60 & 40,16 & 4693,55 & 302,33 & 73,11 & 229,22 & 118,44 & 226,51 & 230,75 & 110,51 & 652,08 & 93,74 & 4,00 & 58,75 & 272,51 & 33,19 & 34,41 & 271,85 \\
\hline Triturus marmoratus & 29SND61 & 100,00 & 168,42 & 93,18 & 40,17 & 4677,65 & 302,26 & 73,77 & 228,49 & 119,18 & 227,10 & 231,18 & 111,43 & 659,02 & 94,87 & 4,00 & 58,62 & 275,31 & 33,64 & 35,16 & 274,36 \\
\hline Triturus marmoratus & 29SND62 & 100,00 & 166,34 & $\begin{array}{ll}0,106 \\
92,62\end{array}$ & 40,02 & 4682,53 & 300,06 & 71,66 & $\mid 228,40$ & \begin{tabular}{|l|l|l|l|l|}
116,55 \\
\end{tabular} & 225,23 & $\begin{array}{ll}229,08 \\
2210\end{array}$ & $\begin{array}{l}109,13 \\
10,15\end{array}$ & \begin{tabular}{|l|l|l|l|l|}
689,45 \\
\end{tabular} & $\begin{array}{l}4,0,4 \\
99,47 \\
\end{array}$ & $\frac{4,60}{4,62}$ & \begin{tabular}{|c|c|c|}
58,18 \\
\end{tabular} & 287,12 & \begin{tabular}{|l|l|l}
36,23 \\
\end{tabular} & 37,75 & 286,52 \\
\hline Triturus marmoratus & 29SND64 & 100,00 & 163,53 & 92,14 & 39,99 & 4671,31 & 296,93 & 68,86 & 228,06 & 112,76 & 222,46 & 226,16 & 106,44 & 739,71 & 107,19 & 5,24 & 57,64 & 306,74 & 40,06 & 41,67 & 306,59 \\
\hline Triturus marmoratus & 29 SND65 & 101,00 & 162,54 & 92,21 & 39,99 & 4676,03 & 296,03 & 67,49 & 228,53 & 110,27 & 221,56 & 225,14 & 105,29 & 763,63 & 110,71 & 5,94 & 57,23 & 315,68 & 42,68 & 44,36 & 315,62 \\
\hline Triturus marmoratus & 29 SND66 & 101,00 & 165,61 & 93,09 & 40,11 & 4654,14 & 298,53 & 69,45 & 229,09 & 114,68 & 224,13 & 227,40 & 108,00 & 751,99 & 108,81 & 5,59 & 57,07 & 310,31 & 41,83 & 44,10 & 310,05 \\
\hline Triturus marmoratus & 29SND67 & 100,00 & 162,12 & 93,45 & 40,02 & 4683,37 & 296,33 & 65,63 & 230,70 & 106,61 & 221,41 & 224,52 & 104,51 & 799,38 & 115,80 & 6,27 & 56,69 & 329,00 & 45,86 & 47,63 & 328,94 \\
\hline Triturus marmoratus & 29SND68 & 101,00 & $\frac{10,14}{159,67}$ & \begin{tabular}{|c|c|}
93,99 \\
93
\end{tabular} & $\begin{array}{ll}40,01 \\
40\end{array}$ & 4 & 294,69 & $\begin{array}{l}3,0356 \\
62,56\end{array}$ & 232,14 & \begin{tabular}{|l|}
102,14 \\
102
\end{tabular} & \begin{tabular}{|l|l|}
219,35 \\
\end{tabular} & $\begin{array}{l}222,32,32 \\
222\end{array}$ & \begin{tabular}{|l|}
101,68 \\
101,5
\end{tabular} & \begin{tabular}{|c|}
838,90 \\
830
\end{tabular} & \begin{tabular}{|l|}
121,61 \\
121,0
\end{tabular} & $\begin{array}{ll}6,219 \\
6,79\end{array}$ & $\begin{array}{ll}56,21 \\
56\end{array}$ & 344,67 & $\begin{array}{l}49,00 \\
49,30\end{array}$ & $\begin{array}{l}44,035 \\
50,85\end{array}$ & 344,67 \\
\hline Triturus marmoratus & 29SND69 & 100,00 & 156,26 & 94,39 & 39,99 & 4724,42 & 292,26 & 58,78 & 233,49 & 98,11 & 216,29 & 219,20 & 98,11 & 888,65 & 129,02 & 7,71 & 55,92 & 364,47 & 53,76 & 54,91 & 364,47 \\
\hline Triturus marmoratus & 29SND70 & 101,00 & 166,85 & 95,14 & 40,07 & 4804,47 & 305,03 & 70,95 & 234,08 & 113,76 & 227,38 & 231,65 & 108,60 & 651,19 & 92,75 & 4,00 & 57,94 & 269,61 & 34,63 & 35,48 & 269,59 \\
\hline Triturus marmoratus & 29SND71 & 100,00 & 168,11 & 94,80 & 40,01 & 4798,65 & 305,51 & 71,85 & 233,66 & 116,48 & 228,52 & 232,59 & 109,66 & 657,29 & 93,77 & 4,01 & 57,93 & 271,99 & 34,92 & 36,13 & 271,84 \\
\hline Triturus marmoratus & 29 SND75 & 100,00 & 164 & 93, & 39,71 & 4828,13 & 301,70 & 67,27 & 234,44 & 106,90 & 225,40 & 228 & 105,26 & 751,74 & 108,35 & 5,77 & 56,91 & 309,75 & 42,51 & 43,99 & 309,75 \\
\hline Triturus marmoratus & 29 SND76 & 101,00 & 166 & 94,80 & 39,87 & 4805,36 & 303,58 & 68,38 & 235,21 & 111,06 & 227,19 & 230,44 & 107,33 & 748,79 & 107,79 & 5,66 & 56,58 & 307,78 & \begin{tabular}{|l|l|}
42,49 \\
\end{tabular} & 44,37 & 307,73 \\
\hline Triturus marmoratus & 29SND77 & 101,00 & 163,16 & 94,90 & 39,62 & 4845,10 & 301,51 & 64,80 & 236,71 & 105,01 & 224,73 & 227,83 & 103,70 & 794,91 & 114,82 & 6,29 & 56,23 & 326,38 & 46,21 & 47,79 & 326,38 \\
\hline Triturus marmoratus & 29SND78 & 100,00 & 156,18 & 94,27 & 39,20 & 4899,09 & 295,88 & 58,04 & 237,84 & 96,54 & 218,78 & 221,83 & 96,54 & 877,66 & 127,63 & 7,38 & 56,02 & 360,54 & 52,64 & 53,34 & 360,54 \\
\hline Triturus marmoratus & 29SND80 & 101,00 & 166 & 96,48 & 40,00 & 4914,35 & 307,64 & 69,17 & 238,47 & 107,97 & 228,70 & 232 & 107,09 & 646,56 & 91,14 & 4,00 & 57,21 & 265,65 & \begin{tabular}{|c|}
35,67 \\
\end{tabular} & 36,13 & 265,65 \\
\hline Triturus marmoratus & $29 S N D 82$ & 100,00 & 166 & $\begin{array}{ll}05,78 \\
95\end{array}$ & 39,86 & 4933,50 & 307,14 & 68,68 & 238,46 & 107,86 & 228,73 & 232,66 & 106,37 & 683,16 & $\begin{array}{l}97,01 \\
97,01\end{array}$ & 4,95 & 56,91 & 280,67 & 38,24 & 39,23 & 280,67 \\
\hline Triturus marmoratus & 29SND85 & 99,00 & 163 & 95,07 & 39,14 & 497 & 304,82 & 65,19 & 239,63 & 103,05 & 226,75 & 230,31 & 103,01 & 759,23 & \begin{tabular}{|c|}
109,09 \\
\end{tabular} & 5,8 & 56,40 & 311,86 & 43,72 & 44,89 & 311,86 \\
\hline Triturus marmoratus & $29 S N D 86$ & 100,00 & 164,90 & 95,70 & 39,27 & 4975,12 & 306,28 & 65,64 & 240,64 & 105,07 & 228,30 & 231,51 & 104,17 & 762,81 & 109,64 & 5,84 & 56,31 & 312,88 & 43,97 & 45,47 & 312,88 \\
\hline Triturus marmoratus & 29 SND87 & 101,00 & 163,28 & 95,93 & 39,23 & 5002,83 & 305,49 & 63,42 & 242,07 & 102,54 & 227,23 & 230,24 & 102,16 & 794,42 & 114,52 & 6,29 & 56,04 & 325,44 & 46,72 & 48,10 & 325,44 \\
\hline Triturus marmoratus & 29SND88 & 99,00 & 154,56 & 94,24 & 38,52 & 5066,11 & 297,74 & 55,48 & 242,26 & 93,30 & 220,01 & 222,74 & 93,30 & 894,16 & 130,22 & 7,64 & 55,91 & 366,97 & 54,09 & 54,49 & 366,97 \\
\hline Triturus marmoratus & \begin{tabular}{|l|}
$295 N D 89$ \\
2950
\end{tabular} & $\begin{aligned} 301,00 \\
101,0\end{aligned}$ & $\frac{154}{153}$ & 94 & 38,52 & 508 & 297,12 & $\begin{array}{l}30,40 \\
53,67\end{array}$ & $\begin{array}{l}42,206 \\
243,45 \\
\end{array}$ & 91,82 & 219,37 & 221,80 & 91,82 & 921,40 & 134,45 & 8,01 & 55,71 & 377,72 & 56,39 & 56,68 & 377,72 \\
\hline Triturus marmoratus & 29 SND90 & 100,00 & 165,34 & 97,75 & 39,97 & 5033,34 & 309,49 & 66,49 & 243,01 & 104,96 & 229,23 & 233,44 & 104,66 & 649,04 & 90,68 & 4,01 & 56,50 & 264,87 & 36,60 & 36,92 & 264,87 \\
\hline Triturus marmoratus & 29SND91 & 100,00 & 165,52 & 97,41 & 39,74 & 5042,61 & 309,69 & 66,78 & 242,92 & 105,51 & 229,67 & 233,77 & 104,78 & 666,33 & 93,51 & 4,71 & 56,51 & 272,06 & 38,02 & 38,47 & 272,06 \\
\hline Triturus marmoratus & 29 SND95 & 101,00 & 164,40 & 96,29 & 38,97 & 5107,33 & 308,97 & 64,56 & 244,41 & 102,61 & 229,69 & 233,08 & 102,46 & 749,64 & 107,05 & 5,86 & 56,03 & 306,62 & 43,75 & 44,92 & 306,62 \\
\hline Triturus marmoratus & 29 SND96 & 101,00 & 161 & 95,79 & 38,71 & 5140,64 & 307,12 & 61,99 & 245,13 & 99,61 & 227,89 & 23. & 99,61 & 788,45 & 113,31 & 6,03 & 55,97 & 322,89 & 46,10 & 47,06 & 322 \\
\hline Triturus marmoratus & \begin{tabular}{|l|}
$29 S N D 97$ \\
290
\end{tabular} & $\begin{array}{l}100,00 \\
100\end{array}$ & $\begin{array}{l}101,50 \\
163,64\end{array}$ & | & 38,11 & $\begin{array}{l}5145,34 \\
5151\end{array}$ & 309,19 & $\begin{array}{l}1,393 \\
62,41 \\
\end{array}$ & \begin{tabular}{l|}
245,78 \\
246,7
\end{tabular} & \begin{tabular}{|l|}
101,27 \\
\end{tabular} & 229,80 & 232,76 & 100,99 & 789,01 & 113,33 & 6,22 & 55,85 & 322,31 & 46,76 & 48,03 & 322,31 \\
\hline Triturus marmoratus & 29SND98 & 101,00 & 159,65 & 96,07 & 38,20 & 5204,60 & 306,12 & 58,25 & 247,87 & 96,60 & 226,80 & 229,56 & 96,60 & 842,70 & 121,84 & 6,97 & 55,70 & 344,44 & 50,83 & 51,66 & 344,44 \\
\hline Triturus r & 29SND99 & 100,00 & 157.27 & 95.94 & 38.03 & 5233.99 & 304,20 & 55,38 & 248,82 & 93,83 & 224.97 & 227,49 & 93.83 & 880.99 & $\mid 127.97$ & 7.45 & 55,45 & 360,06 & 53,78 & 54,41 & 360,06 \\
\hline Triturus marmoratus & 29SNE00 & 96,00 & 154,65 & 74,30 & 42,69 & 3403,58 & 245,97 & 73,88 & 172,10 & 118,09 & 195,2 & 197 & 110, & 807,95 & 119,72 & 6,29 & 57,39 & 338,62 & 44,00 & 50,49 & 328,45 \\
\hline Triturus marmoratus & 29SNE10 & 101,00 & 155,98 & 79,34 & 42,57 & 3622,00 & 256,06 & 71,49 & 184,58 & 116,98 & 199,76 & 202,30 & 109,14 & 821,60 & 119,97 & 6,60 & 56,95 & 341,94 & 45,99 & 51,55 & 334,68 \\
\hline
\end{tabular}




\begin{tabular}{|c|c|c|c|c|c|c|c|c|c|c|c|c|c|c|c|c|c|c|c|c|c|}
\hline$\overline{\text { TAXON }}$ & UTM & $\mathrm{km} 2$ & BIO1 & B102 & $B 103$ & BIO4 & B105 & B106 & B107 & B108 & $B 109$ & B1010 & BI011 & B1012 & BIO13 & 81014 & B1015 & B1016 & B1017 & B1018 & B1019 \\
\hline Triturus marmoratus & 29SNE11 & 101,00 & 155,21 & 80,06 & 42,88 & 3601,97 & 254,96 & 70,29 & 184,66 & 116,16 & 198,65 & 201,09 & 108,34 & 845,97 & 122,64 & 7,29 & 56,16 & 349,90 & 48,92 & 54,74 & 343,15 \\
\hline Triturus marmoratus & 29SNE20 & 101,00 & 152,52 & 84,09 & 41,92 & 3904,09 & 262,92 & 64,42 & 198,50 & 110,37 & 200,48 & 203,16 & $\begin{array}{l}102,82 \\
\end{array}$ & 879,72 & 128,01 & 7,63 & 56,25 & 363,10 & 51,42 & 55,46 & 359,14 \\
\hline Triturus marmoratus & 29SNE21 & 100,00 & 154,41 & 85,30 & 42,49 & 3858,25 & 264,11 & 65,67 & 198,45 & 112,57 & 201,62 & 204,18 & 104,94 & 879,25 & \begin{tabular}{ll|}
127,02 \\
\end{tabular} & 7,92 & 55,83 & 361,05 & 52,38 & 56,89 & 357,44 \\
\hline Triturus marmoratus & 29SNE22 & 101,00 & 156,45 & 86,16 & 43,06 & 3801,99 & 264,73 & 66,96 & 197,77 & 114,81 & 202,60 & 205,01 & 107,05 & 877,24 & 125,73 & 8,03 & 55,11 & 358,35 & 53,36 & 58,58 & 354,81 \\
\hline Triturus marmoratus & 29SNE30 & 100,00 & 151,17 & 88,04 & 41,29 & 4146,76 & 270,31 . & 60,08 & 210,23 & 106,59 & 202,74 & 205,56 & 99,05 & 915,09 & 132,98 & 8,19 & 55,99 & 375,21 & 54,94 & 57,61 & 374,22 \\
\hline Triturus marmoratus & 29SNE31 & 101,00 & 153,26 & 89,56 & 41,83 & 4109,05 & 272,14 & 61,12 & 211,03 & 107,35 & 204,18 & 206,82 & 101,14 & 913,92 & 131,86 & 8,50 & 55,35 & 373,01 & 56,08 & 59,22 & 372,06 \\
\hline Triturus marmoratus & 29SNE32 & 100,00 & 153,67 & 90,88 & 42,44 & 4083,90 & 272,45 & 60,72 & 211,73 & 106,56 & 204,07 & 206,71 & 101,62 & 929,17 & 133,19 & 8,90 & 54,84 & 377,49 & 58,40 & 61,82 & 376,70 \\
\hline Triturus marmoratus & 29SNE40 & 101,00 & 155,32 & 91,90 & 41,29 & 4330,14 & 280,92 & 61,01 & 219,91 & 104,81 & 209,47 & 212,15 & 100,99 & 894,76 & 129,51 & 7,94 & 55,79 & 365,99 & 54,14 & 56,49 & 365,92 \\
\hline Triturus marmoratus & 29SNE41 & 101,00 & 152,76 & 93,14 & \begin{tabular}{l|l|}
41,49 \\
\end{tabular} & 4345,88 & 279,68 & 57,65 & 222,03 & 98,66 & 207,16 & 209,86 & 98,28 & $\begin{array}{l}939,08 \\
\end{array}$ & $\begin{array}{l}135,46 \\
\end{array}$ & 8,86 & 55,12 & 382,81 & 58,79 & 60,79 & 382,81 \\
\hline Triturus marmoratus & 29SNE42 & 100,00 & 150,50 & 94,55 & 41,80 & 4357,86 & 278,69 & 54,41 & 224,29 & 95,73 & 205,08 & 207,75 & 95,73 & $\begin{array}{l}981,85 \\
\end{array}$ & \begin{tabular}{|c|}
141,10 \\
\end{tabular} & 9,75 & 54,39 & \begin{tabular}{|c|}
398,97 \\
\end{tabular} & 63,27 & \begin{tabular}{|c|c|}
65,08 \\
\end{tabular} & 398,97 \\
\hline Triturus marmoratus & 29SNE50 & 101,00 & 152,49 & 93,64 & \begin{tabular}{l|l}
40,52 \\
\end{tabular} & 4559,42 & 284,73 & 56,28 & 228,45 & 96,01 & 210,15 & 213,00 & 96,01 & \begin{tabular}{|c|}
936,03 \\
\end{tabular} & 135,86 & 8,58 & 55,59 & 383,17 & 57,83 & 59,04 & 383,17 \\
\hline Triturus marmoratus & 29SNE51 & 101,00 & 150,79 & 94,81 & 40,71 & 4567,43 & 283,90 & 53,75 & 230,15 & 94,13 & 208,58 & 211,30 & 94,13 & $\begin{array}{l}971,58 \\
\end{array}$ & \begin{tabular}{|l|l|}
140,67 \\
\end{tabular} & 9,29 & 54,97 & 396,61 & 61,51 & 62,51 & 396,61 \\
\hline Triturus marmoratus & 29SNE52 & 100,00 & 145,71 & 94,36 & \begin{tabular}{l|l}
40,55 \\
\end{tabular} & 4572,50 & 278,62 & 48,77 & 229,86 & 89,08 & 204,36 & 206,28 & 89,08 & 1042,81 & 151,36 & 10,45 & 54,69 & 424,94 & 67,24 & 68,03 & 424,94 \\
\hline Triturus marmoratus & 29SNE60 & 100,00 & 156,03 & 95,70 & 40,18 & 4727,17 & 292,76 & 57,48 & 235,28 & 97,60 & 216,06 & 218,82 & 97,60 & 909,29 & 131,69 & 8,14 & 55,40 & 371,90 & 56,08 & 57,23 & 371,90 \\
\hline Triturus marmoratus & 29SNE61 & 100,00 & 151,40 & 95,90 & \begin{tabular}{l|l|l|}
40,15 & \\
\end{tabular} & $\begin{array}{l}4750,56 \\
\end{array}$ & 289,01 & 52,56 & 236,45 & 92,84 & 211,99 & 214,58 & 92,84 & 973,54 & 141, & \begin{tabular}{l|l}
9,16 \\
\end{tabular} & 55,04 & 397,64 & 61,64 & 62,21 & 397,64 \\
\hline Triturus marmoratus & 29SNE70 & 101,00 & 154,33 & 95,89 & \begin{tabular}{ll|}
39,32 \\
\end{tabular} & 4917,30 & 295,29 & 54,54 & 240,75 & \begin{tabular}{c|}
94,07 \\
\end{tabular} & 217,36 & 219,94 & 94,07 & $\begin{array}{l}929,76 \\
\end{array}$ & 135,19 & 8,27 & 55,35 & \begin{tabular}{|c|}
380,43 \\
\end{tabular} & 57,70 & 58,26 & 380,43 \\
\hline Triturus marmoratus & 29SNE71 & 100,00 & 147,42 & \begin{tabular}{l|l}
94,63 \\
\end{tabular} & 38,97 & 4938,86 & 288,14 & 48,14 & 240,01 & 87,19 & 211,97 & 213,50 & 87,19 & 1016,43 & 148,84 & 9,58 & 55,22 & 415,88 & 63,99 & 64,14 & 415,88 \\
\hline Triturus marmoratus & 29SNE72 & 101,00 & 147,01 & 95,68 & 39,19 & 4934,79 & 287,99 & 46,80 & 241,19 & 86,58 & 211,29 & 212,84 & 86,58 & $\mid 1037,05$ & $|151,67|$ & 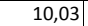 & 55,00 & $\mid 423,37$ & 66,27 & 66,45 & \begin{tabular}{|l|l|l}
423,37 \\
\end{tabular} \\
\hline Triturus marmoratus & 29SNE80 & 101,00 & 147,36 & 93,38 & 38,00 & 5105,65 & 290,68 & 48,02 & 242,66 & 85,73 & 214,97 & 216,08 & 85,73 & \begin{tabular}{|c|}
999,48 \\
\end{tabular} & 146,99 & 9,09 & 55,62 & 409,81 & $\begin{array}{l}61,75 \\
\end{array}$ & \begin{tabular}{|c|}
61,78 \\
\end{tabular} & 409,81 \\
\hline Triturus marmoratus & 29SNE81 & 100,00 & 139,59 & 91,18 & 37,40 & 5112,34 & 281,5 & 41,21 & 240,36 & 78,28 & 208,20 & 208,53 & 78,28 & 1095,12 & 162, & 10,33 & 55,64 & $\begin{array}{l}449,06 \\
\end{array}$ & 67,73 & 67,73 & 449,06 \\
\hline Triturus marmoratus & 29SNE82 & 101,00 & 142,45 & 93,26 & 37,95 & $\begin{array}{l}5101,60 \\
\end{array}$ & 285,13 & 42,50 & 242,63 & 80,70 & 210,18 & 210,85 & 80,70 & 1080,88 & 159,84 & 10,28 & 55,32 & 442,08 & 67,84 & 67,92 & 442,08 \\
\hline Triturus marmoratus & 29SNE90 & 100,00 & 144,25 & 91,88 & 37,01 & 5263,55 & 289,66 & 44,62 & 245,03 & 81,28 & 214,68 & 215,34 & 81,28 & 1026,81 & 151,79 & 9,32 & 55,69 & \begin{tabular}{ll|}
420,93 \\
\end{tabular} & 63,00 & 63,03 & 420,93 \\
\hline Triturus marmoratus & 29SNE91 & 100,00 & 133,40 & 88,25 & 36,15 & 5252,89 & 276,32 & 35,82 & 240,49 & 71,19 & 204,67 & 204,67 & 71,19 & $\begin{array}{l}1151,78 \\
\end{array}$ & \begin{tabular}{|c|}
172,48 \\
\end{tabular} & 10,85 & 55,87 & 472,69 & 70,36 & 70,36 & 472,69 \\
\hline Triturus marmoratus & 29SNE92 & 100,00 & 141,13 & 92,11 & 37,01 & 5261,34 & 286,09 & 40,61 & 245,48 & 77,82 & 211,52 & 211,83 & 77,82 & 1085,70 & 161,39 & 10,10 & 55,59 & 444,37 & 67,32 & 67,38 & 444,37 \\
\hline Triturus marmoratus & 29SPB03 & 101,00 & 158,06 & 98,16 & 41,13 & 4706,17 & 292,82 & 57,77 & 235,05 & 110,68 & 217,75 & 221,95 & 101,91 & 579,27 & 90,0 & 1,99 & 64,43 & 262,06 & 21,21 & 24,19 & 249,89 \\
\hline Triturus marmoratus & 29SPB07 & 101,00 & 166,32 & 105,44 & \begin{tabular}{ll|}
41,88 \\
\end{tabular} & 4943,26 & 312,49 & 62,73 & 249,76 & 115,83 & 229,00 & 233,25 & 107,03 & 535,87 & 80,73 & 2,00 & 62,05 & 234,58 & 21,63 & 23,64 & 226,01 \\
\hline Triturus marmoratus & 29SPB11 & 99,00 & 168,63 & 92,33 & \begin{tabular}{l|l|l}
41,09 \\
\end{tabular} & 4481,92 & 291,86 & 70,19 & 2221,67 & 123,23 & 224,88 & 228,95 & 114,35 & 520,10 & 83,18 & 1,01 & 66,93 & 242,62 & 16,15 & 20,50 & 226,66 \\
\hline Triturus marmoratus & 29SPB13 & 100,00 & 163,67 & $\begin{array}{l}96,69 \\
\end{array}$ & \begin{tabular}{|l|l|}
40,97 & \\
\end{tabular} & 4727,12 & 296,40 & \begin{tabular}{l|l}
62,81 \\
\end{tabular} & 233,59 & 115,68 & 223,35 & 227,42 & 106,75 & 545,74 & 84,32 & 1,70 & 64,48 & 246,99 & 19,23 & 23,10 & 233,35 \\
\hline Triturus marmoratus & 29SPB14 & 100,00 & 164,15 & 98,47 & 40,99 & 4808,23 & 300,24 & 62,28 & 237,96 & 114,95 & 224,83 & 228,98 & 106,16 & 543,03 & 83,13 & 1,86 & 63,62 & 243,27 & 19,80 & 23,49 & 230,58 \\
\hline Triturus marmoratus & 29SPB15 & 101,00 & 166,02 & 100,20 & 41,00 & 4869,35 & 304,94 & 63,33 & 241,61 & 115,96 & 227,46 & 231,61 & 107,26 & 532,74 & 81,03 & 1,93 & 63,12 & 236,72 & 20,00 & 23,43 & 224,84 \\
\hline Triturus marmoratus & 29SPB16 & 100,00 & 169,62 & 101,78 & 41,12 & \begin{tabular}{|c|c|}
4908,01 \\
\end{tabular} & 310,38 & 66,19 & 244,19 & 118,84 & 231,52 & 235,58 & 110,12 & 514,27 & 77,93 & 1,73 & 62,67 & 227,15 & 19,65 & 22,79 & 215,99 \\
\hline Triturus marmoratus & 29SPB21 & 97,00 & 172,04 & 90,53 & 40,61 & 4512,68 & 293,65 & 73,35 & 220,30 & 125,89 & 228,34 & 232,29 & 116,95 & 501,29 & 79,80 & 1,00 & 66,59 & 232,37 & 14,78 & 20,05 & 215,44 \\
\hline Triturus marmoratus & 29SPB23 & 101,00 & 168,25 & 94,56 & 40,32 & 4735,29 & 298,46 & 67,19 & 231,27 & 119,61 & 227,77 & 231,71 & 110,66 & 519,73 & 80,23 & 1,19 & 64,47 & 234,68 & 17,37 & 22,16 & 219,59 \\
\hline Triturus marmoratus & 29SPB24 & 100,00 & 165,69 & 97,05 & $\begin{array}{l}40,46 \\
\end{array}$ & 4849,47 & 300,64 & 63,40 & 237,24 & 115,70 & 226,89 & 230,83 & 107,08 & 533,69 & 81,11 & 1,86 & 63,31 & 237,35 & 19,21 & 23,72 & 223,55 \\
\hline Triturus marmoratus & 29SPB25 & 100,00 & 169,33 & 98,40 & \begin{tabular}{|c|}
40,57 \\
\end{tabular} & 4894,24 & 306,29 & 66,31 & 239,97 & 118,59 & 231,09 & 234,90 & 110,06 & 513,84 & 77,78 & 1,62 & 62,78 & 227,38 & 18,76 & 23,11 & 214,10 \\
\hline Triturus marmoratus & 29SPB26 & 101,00 & 169,08 & 100,77 & 40,72 & 4972,45 & 309,87 & \begin{tabular}{|c|}
64,94 \\
\end{tabular} & 244,93 & 1117,62 & 231,85 & 235,79 & 108,74 & $\begin{array}{l}516,25 \\
\end{array}$ & 77,31 & 1,88 & 61,94 & 225,79 & 19,77 & 23,69 & 213,66 \\
\hline Triturus marmoratus & 29SPB27 & 100,00 & 167,14 & 103,45 & $\begin{array}{l}40,86 \\
\end{array}$ & 5076,86 & 312,47 & 61,61 & 250,86 & 114,53 & 231,33 & 235,27 & 105,58 & 528,04 & 78,16 & 2,00 & 61,08 & 228,12 & 21,14 & 24,51 & 217,42 \\
\hline Triturus marmoratus & 29SPB28 & 100,00 & 167,52 & 105,62 & \begin{tabular}{ll|}
40,98 \\
\end{tabular} & 5143,11 & 316,07 & 60,92 & 255,16 & 113,99 & 232,69 & 236,56 & 105,07 & 527,53 & 77,4 & 2,00 & 60,50 & 225,69 & 21,84 & 24,69 & 216,24 \\
\hline Triturus marmoratus & 29SPB29 & 101,00 & 167,13 & 107,53 & 41,02 & 5203,95 & 318, & 59,81 & 258,82 & 112,92 & 233,18 & 237,07 & 103,92 & 531,36 & 77,2 & 2,00 & 59,86 & 225,10 & 22,59 & 25,19 & 216,82 \\
\hline Triturus marmoratus & $29 S P B 31$ & 58,00 & 174,81 & 88,67 & 40,00 & 4559,20 & 295, & 75,87 & 219,36 & 127,54 & 231,51 & 235,26 & 118,59 & 486,49 & 76,64 & 1,00 & 65,94 & 222,86 & 14,03 & 19,99 & 205,03 \\
\hline Triturus marmoratus & 29SPB33 & 100,00 & 172,24 & \begin{tabular}{l|l}
92,08 \\
\end{tabular} & \begin{tabular}{l|l|l|}
39,85 \\
\end{tabular} & 4756,22 & 299,82 & 71,13 & 228,69 & 122,83 & 231,68 & 235,45 & 113,82 & $\begin{array}{l}497,26 \\
\end{array}$ & 76,39 & 1,00 & 64,32 & 223,32 & 15,71 & 21,49 & 206,86 \\
\hline Triturus marmoratus & 29SPB35 & 101,00 & 169,60 & 96,90 & \begin{tabular}{ll|}
39,96 \\
\end{tabular} & 4957,53 & 305,73 & $\begin{array}{ll}65,96 \\
\end{array}$ & 239,77 & 1117,77 & 231,96 & 235,63 & 109,06 & 511,72 & 76,62 & 1,60 & 62,32 & 224,38 & 18,45 & 23,57 & 210,04 \\
\hline Triturus marmoratus & 29SPB36 & 99,00 & 171,07 & 98,97 & \begin{tabular}{l|l}
40,02 \\
\end{tabular} & 5027,06 & 310,27 & 66,23 & 244,03 & 118,48 & 234,36 & 238,01 & 109,54 & 504,43 & 74,85 & 1,80 & 61,47 & 219,22 & \begin{tabular}{ll|}
19,03 \\
\end{tabular} & 23,80 & 205,73 \\
\hline Triturus marmoratus & 29SPB38 & 100,00 & 165,74 & 104,48 & 40,26 & 5217,51 & 314,11 & 58,52 & 255,59 & 111,43 & 231,94 & 235,57 & 102,43 & 536,33 & 77,76 & 2,00 & 60,14 & 227,63 & 22,05 & 25,60 & 217,14 \\
\hline Triturus marmoratus & 29SPB39 & 100,00 & 165,47 & 106,32 & 40,4 & 5275,48 & 316 & 57,26 & 259,40 & 110,34 & 232,63 & 236,23 & 101,60 & 539,62 & 77,46 & 2,16 & 59,39 & 226,96 & 23,19 & 26,27 & 217,56 \\
\hline Triturus marmoratus & 29SPC00 & 101,00 & 165 & 112,18 & \begin{tabular}{l|l}
42,05 \\
\end{tabular} & 5145,05 & 322,05 & 59,05 & 263,01 & 112,51 & 230,68 & 235,07 & 103,90 & 548,84 & 80, & 2,00 & 59,99 & 232,29 & 24,28 & 25,03 & 228,07 \\
\hline Triturus marmoratus & 29SPC03 & 101,00 & 160,69 & 108,62 & 41,23 & \begin{tabular}{|l|}
5185,48 \\
\end{tabular} & 316,10 & 56,55 & 259,55 & 107,39 & 227,90 & 231,14 & 98,85 & 592,32 & 82,64 & 3,04 & 57,66 & 243,29 & 30,44 & 30,45 & 242,18 \\
\hline Triturus marmoratus & 29SPC04 & 100,00 & 161,82 & 106,48 & 41,04 & 5164,14 & 314,94 & 58,80 & 256,14 & 108,27 & 229,01 & 231,91 & 100,14 & 589,98 & 81,44 & 3,02 & 57,23 & 241,04 & 30,93 & 30,93 & 240,44 \\
\hline Triturus marmoratus & 29SPC06 & 100,00 & 163,16 & 102,61 & $\begin{array}{l}40,53 \\
\end{array}$ & 5122,15 & 312,29 & 62,04 & 250,25 & 105,59 & 229,36 & 232,55 & 101,71 & 596,58 & 81, & 3,75 & 56,34 & 241,45 & 33,24 & 33,24 & 241,42 \\
\hline Triturus marmoratus & $295 P C 07$ & 101,00 & 162,37 & 101,10 & $40, \mathrm{C}$ & 5119,50 & 310, & 61,96 & 248,48 & 101,92 & 229,31 & 231,74 & 100,87 & 613,08 & 83,86 & 4,00 & 55,95 & 247,58 & 35,10 & 35,10 & 247,58 \\
\hline Triturus marmoratus & 29SPC08 & 100,00 & 160,69 & 99,94 & \begin{tabular}{|c|}
39,98 \\
\end{tabular} & 5139,34 & 308,49 & 60,77 & 247,72 & 99,37 & 228,08 & 230,42 & 99,08 & 640,14 & 87,99 & 4,12 & 55,88 & 258,78 & 36,81 & 36,81 & 258,78 \\
\hline Triturus marmoratus & 29SPC13 & 101,00 & 160,51 & 109,02 & 41,00 & 5282,23 & 317,10 & 54,79 & 262,31 & 105,93 & 228,42 & 232,21 & 97,33 & 589,14 & 81,72 & 3,00 & 57,24 & 240,98 & 30,63 & 30,77 & 238,69 \\
\hline Triturus marmoratus & 29SPC15 & 99,00 & 165,51 & 106,22 & \begin{tabular}{|c|}
40,89 \\
\end{tabular} & 5234,90 & 318,45 & 60,80 & 257,65 & 110,85 & 232 & 2 & 102,37 & 570,58 & 77,63 & 3 & 56,58 & 31,28 & 30,94 & 31,19 & 2 \\
\hline Triturus marmoratus & 29SPC18 & 101 & 160 & 102 & 39 & 2 & 311, & 58,30 & 253 & 102,59 & $22 \varepsilon$ & 233 & 97,68 & 638 & 86,9 & 4,3 & 55,44 & 256,29 & 37,43 & 37,43 & 256 \\
\hline Triturus marmoratus & 29SPC23 & 100,00 & 165,26 & 109,13 & \begin{tabular}{|l|l|}
40,97 & \\
\end{tabular} & 5331,75 & 321,37 & 57,58 & 263,80 & 109,62 & 233,19 & 237,03 & 100,88 & 556,98 & 77,25 & 3,00 & 57,18 & 227,79 & 28,54 & 29,44 & 223,46 \\
\hline Triturus marmoratus & 29SPC28 & 100,00 & 159,59 & 104,11 & 39,72 & 5380,03 & 313,91 & 54,76 & 259,15 & 102,98 & 229,49 & 232,40 & \begin{tabular}{l|l|l}
95,14 \\
\end{tabular} & $\begin{array}{l}642,65 \\
\end{array}$ & 86,77 & 4,51 & 54,97 & 256,99 & 38,20 & 38,24 & 255,93 \\
\hline Triturus marmoratus & 29SPC29 & 100,00 & 158,40 & 102,98 & 39,39 & 5393,15 & 312,64 & 54,31 & 258,34 & 102,07 & 228,38 & 231,60 & 94,01 & 668,10 & 90,58 & 5,07 & 54,64 & 267,01 & 40,43 & 40,47 & 266,42 \\
\hline $\mid T_{\mathrm{Tri}}$ & $295 P C 32$ & 100,0 & 168,44 & 108,99 & 40,6 & 5377,66 & 323, & 58, & 55,00 & 11 & 23 & & $\mid 103,10$ & 530,80 & 74 & 2,80 & 57 & 21 & 26,20 & 28,24 & 21 \\
\hline Triturus marmoratus & 29SPC33 & 100,00 & 168,65 & 109,01 & \begin{tabular}{|c|}
40,48 \\
\end{tabular} & 5392,90 & 324,63 & 58,97 & 265,66 & 111,64 & 237,36 & 240,86 & 103,12 & 533,38 & 73,80 & 2,99 & 56,89 & 217,75 & 27,26 & 28,95 & 211,42 \\
\hline Triturus marmoratus & $295 P C 34$ & 101,00 & 167,87 & 109,05 & 40,35 & 5414,99 & 324,48 & 58,33 & 266,15 & 110,67 & 236,92 & 240,31 & 102,11 & 542,35 & 74,31 & 3,00 & 56,41 & 220,05 & 28,47 & 29,80 & 214,46 \\
\hline
\end{tabular}




\begin{tabular}{|c|c|c|c|c|c|c|c|c|c|c|c|c|c|c|c|c|c|c|c|c|c|}
\hline$\overline{\text { TAXON }}$ & UTM & $\mathrm{km} 2$ & BI01 & B102 & $B 103$ & BIO4 & B105 & B106 & B107 & B108 & B109 & B1010 & BIO11 & B1012 & BIO13 & 81014 & B1015 & B1016 & B1017 & B1018 & B1019 \\
\hline Triturus marmoratus & 29SPC35 & 100,00 & 167,02 & 108,80 & 40,12 & 5433,43 & 323,99 & 57,58 & 266,41 & 109,55 & 236,34 & 239,79 & 101,03 & 553,34 & 75,23 & 3,16 & 55,95 & 223,18 & 30,26 & 31,26 & 218,25 \\
\hline Triturus marmoratus & 29SPC37 & 100,00 & 165,27 & 107,92 & 40,00 & 5472,45 & 322,58 & 56,23 & 266,34 & 107,39 & 235,64 & 238,79 & \begin{tabular}{l|l|}
98,97 \\
\end{tabular} & $\begin{array}{l}581,16 \\
\end{array}$ & 78,36 & 4,00 & 54,85 & 232,22 & 34,01 & \begin{tabular}{ll|}
34,58 \\
\end{tabular} & 228,44 \\
\hline Triturus marmoratus & 29SPC43 & 101,00 & 167,88 & 109,24 & 40,02 & 5501,38 & 325,44 & 56,36 & 269,08 & 109,36 & 238,23 & 241,34 & 100,77 & 533,92 & 73,76 & 3,00 & 56,68 & 217,10 & 27,27 & 29,37 & 209,34 \\
\hline Triturus marmoratus & 29SPC44 & 100,00 & 168,91 & 109,81 & 40,04 & 5516,29 & 327,01 & 57,07 & 269,94 & 110,10 & 239,67 & 242,44 & 101,43 & 531,63 & 73,28 & 3,00 & 56,19 & 215,10 & 27,82 & 29,73 & 207,85 \\
\hline Triturus marmoratus & 29SPC45 & 100,00 & 168,72 & 109,90 & 40,02 & 5520,70 & 327,46 & 56,84 & 270,62 & 109,73 & 239,59 & 242,28 & 101,23 & 536,43 & 73,75 & 3,02 & 55,77 & 215,92 & 28,96 & 30,40 & 209,14 \\
\hline Triturus marmoratus & 29SPC48 & 100,00 & 166,22 & 109,81 & 39,98 & 5599,39 & 326,71 & 54,12 & 272,59 & 106,36 & 238,41 & 241,00 & 98,04 & 575,10 & 78,17 & 4,08 & 54,29 & 228,73 & 34,55 & 35,15 & 223,27 \\
\hline Triturus marmoratus & 29SPC49 & 101,00 & 165,01 & 109,48 & 39,91 & 5613,73 & 325,70 & 53,33 & 272,37 & 105,11 & 237,55 & 240,08 & 96,82 & 595,18 & 80,41 & 4,58 & 53,77 & 236,19 & 36,72 & 37,23 & 231,34 \\
\hline Triturus marmoratus & 29SPC51 & 101,00 & 167,10 & 107,59 & 39,88 & 5507,90 & 322,31 & 55,03 & 267,28 & 108,55 & 237,41 & 240,46 & 99,80 & \begin{tabular}{|l|l}
533,46 \\
\end{tabular} & 74,70 & 3,00 & 57,20 & 218,51 & 25,75 & 29,11 & 208,22 \\
\hline Triturus marmoratus & 29SPC52 & 100,00 & 168,43 & 108,65 & 39,99 & 5543,99 & 325,30 & 55,72 & 269,58 & 109,37 & 239,34 & 242,17 & 100,59 & 526,22 & 73,52 & 3,00 & 56,66 & 214,39 & 26,14 & 29,12 & 204,65 \\
\hline Triturus marmoratus & 29SPC53 & 100,00 & 166,86 & 109,71 & 39,99 & 5586,67 & 325,93 & 53,65 & 272,28 & 107,14 & 238,44 & 241,20 & 98,53 & \begin{tabular}{|c|}
537,68 \\
\end{tabular} & 74,58 & 3,00 & 56,35 & 217,67 & 27,47 & 29,91 & 208,80 \\
\hline Triturus marmoratus & 29SPC54 & 100,00 & 167,86 & 110,35 & 40,00 & 5602,91 & 327,94 & 54,27 & 273,67 & 107,78 & 239,81 & 242,30 & 99,23 & 534,37 & 73,98 & 3,03 & 55,77 & 215,26 & 28,15 & 30,24 & 206,77 \\
\hline Triturus marmoratus & 29SPC61 & 100,00 & 162,79 & 107,89 & 39,17 & 5622,32 & 320,55 & 49,19 & 271,36 & 103,19 & 234,95 & 237,86 & 94,22 & 558,30 & 78,06 & 3,08 & 56,97 & 227,34 & 26,79 & 30,50 & 216,45 \\
\hline Triturus marmoratus & 29SPC62 & 100,00 & 167,16 & 108,97 & 39,37 & 5633,15 & 325,76 & 52,92 & 272,84 & 107,02 & 239,42 & 241,86 & 98,14 & 532,84 & 74,71 & 3,00 & 56,49 & 216,13 & 26,27 & 29,60 & 205,40 \\
\hline Triturus marmoratus & 29SPD01 & 101,00 & 164,77 & 98,75 & 39,30 & 5155,83 & 311,99 & \begin{tabular}{|c|}
64,27 \\
\end{tabular} & 247,72 & 104,12 & 230,51 & 234,52 & 102,75 & $\begin{array}{l}667,05 \\
\end{array}$ & 92,81 & 5,00 & 55,91 & 270,59 & 38,92 & 39,36 & 270,59 \\
\hline Triturus marmoratus & 29SPD03 & 101,00 & 167,25 & $\begin{array}{l}98,55 \\
\end{array}$ & 39,03 & 5191,98 & 314,55 & 65,88 & 248,68 & 109,20 & 233,68 & 237,16 & 104,42 & $\begin{array}{l}682,99 \\
\end{array}$ & 95,73 & 5,00 & 55,90 & 277,45 & 39,46 & \begin{tabular}{ll|}
40,56 \\
\end{tabular} & 277,45 \\
\hline Triturus marmoratus & 29SPD05 & 100,00 & 164,19 & 97,09 & 38,45 & 5241,36 & 311,97 & 63,09 & 248,88 & 101,06 & 231,63 & 234,92 & 100,91 & 747,79 & \begin{tabular}{|c|}
106,27 \\
\end{tabular} & 5,92 & 55,64 & 304,62 & 44,26 & 45,40 & 304,62 \\
\hline Triturus marmoratus & 29SPD06 & 101,00 & 162,42 & 96,54 & 38,07 & 5278,41 & 310,58 & 61,03 & 249,54 & \begin{tabular}{l|l|}
98,67 \\
\end{tabular} & 230,34 & 233,67 & \begin{tabular}{l|l}
98,67 \\
\end{tabular} & $\begin{array}{l}781,05 \\
7\end{array}$ & 111,75 & 6,01 & 55,70 & 318,61 & 46,15 & 47,22 & 318,61 \\
\hline Triturus marmoratus & 29SPD07 & 100,00 & 163,07 & 96,93 & 38,15 & 5303,94 & 311,69 & 60,67 & 251,02 & 99,04 & 231,54 & 234,37 & 98,93 & 789,75 & $\mid 113,19$ & 6,18 & 55,53 & $\mid 321,77$ & 47,18 & 48,37 & 321,77 \\
\hline Triturus marmoratus & 29SPD08 & 101,00 & 164,65 & $\begin{array}{l}97,86 \\
\end{array}$ & 38,19 & 5326,48 & 313,87 & 60,86 & 253,01 & 100,50 & 233,51 & 235,92 & 99,80 & $\begin{array}{l}788,15 \\
\end{array}$ & 112,94 & 6,20 & 55,25 & 320,35 & 47,34 & 48,77 & 320,35 \\
\hline Triturus marmoratus & 29SPD09 & 101,00 & 161,29 & 97,32 & 37,86 & 5371,68 & 311,23 & 57,29 & 253,94 & 96,06 & 230,99 & 233,26 & 96,06 & 833,96 & 120, & 6,85 & 55,16 & 339,27 & 50,81 & 51,89 & 339,27 \\
\hline Triturus marmoratus & 29SPD11 & 101,00 & 164,59 & 100,59 & 39,14 & 5276,51 & 314,93 & 62,16 & 252,77 & 107,17 & 232,23 & 235,88 & 101,03 & 662,80 & 91,24 & 5,00 & 55,36 & 266,99 & 39,18 & 39,92 & 266,87 \\
\hline Triturus marmoratus & 29SPD12 & 100,00 & 166,36 & 100,31 & 39,03 & 5282,65 & 316,66 & 63,77 & 252,89 & 110,21 & 234,10 & 237,65 & \begin{tabular}{ll|}
102,66 \\
\end{tabular} & 666,77 & 92,14 & 5,00 & 55,42 & 268,94 & 39,34 & \begin{tabular}{|l|l|}
40,14 \\
\end{tabular} & 268,71 \\
\hline Triturus marmoratus & 29SPD13 & 100,00 & 165,32 & 99,37 & 38,84 & 5312,71 & 315,68 & 63,01 & 252,67 & 107,43 & 233,46 & 237,16 & 101,29 & 694,89 & 96,87 & 5,21 & 55,44 & 280,93 & 41,01 & 42,06 & 280,87 \\
\hline Triturus marmoratus & 29SPD14 & 101,00 & 165,21 & 98,75 & 38,55 & 5330,92 & 315,60 & 62,83 & 252,77 & 106,32 & 233,90 & 237,29 & 101,11 & 714,56 & 100,17 & 5,54 & 55,28 & 289,08 & 42,56 & 43,73 & 289,07 \\
\hline Triturus marmoratus & 29SPD15 & 99,00 & 162,46 & 97,29 & 38,02 & 5371,46 & 312,91 & 60,64 & 252,27 & 98,53 & 231,79 & 235,15 & \begin{tabular}{c|}
97,96 \\
\end{tabular} & 757,44 & 107,32 & 5,99 & 55,27 & 307,57 & 45,20 & 46,33 & 307,57 \\
\hline Triturus marmoratus & 29SPD16 & 100,00 & 161,78 & 96,94 & 37,96 & 5407,71 & 312,48 & 59,44 & 253,04 & 96,84 & 231,64 & 234,87 & 96,84 & 780,17 & 111,29 & 6,00 & 55,41 & 317,28 & 46,43 & 47,58 & 317,28 \\
\hline Triturus marmoratus & 29SPD17 & 100,00 & 162,40 & 97,18 & 37,83 & 5441,73 & 313,80 & \begin{tabular}{|l|l}
59,03 \\
\end{tabular} & 254,77 & 97,30 & 232,95 & 235,84 & \begin{tabular}{l|l|}
96,87 \\
\end{tabular} & 787,81 & $\begin{array}{l}112,55 \\
\end{array}$ & 6,00 & 55,10 & 319,82 & 47,48 & \begin{tabular}{l|l}
48,64 \\
\end{tabular} & 319,82 \\
\hline Triturus marmoratus & 29SPD18 & 100,00 & 165,73 & $\begin{array}{l}98,61 \\
\end{array}$ & 37,78 & 5466,37 & 317,80 & 60,42 & 257,38 & 102,76 & 236,73 & 238,93 & $\begin{array}{l}99,37 \\
\end{array}$ & 766,83 & $\begin{array}{l}109,26 \\
\end{array}$ & 6,00 & 55,04 & 310,27 & 46,09 & 47,75 & 310,24 \\
\hline Triturus marmoratus & 29SPD19 & 100,00 & 163,73 & 98,30 & 37,49 & 5511,66 & 316,45 & 57,86 & 258,59 & 99,38 & 235,47 & 237,44 & 96,75 & 798,04 & 114,38 & 6,44 & 54,99 & 322,98 & 48,53 & 49,92 & 322,95 \\
\hline Triturus marmoratus & 29SPD21 & 100,00 & 164,55 & 102,79 & 39,06 & 5396,16 & 318,34 & 59,78 & 258,56 & 107,75 & 233,89 & 237,44 & 99,64 & 654,05 & 88,96 & 5,00 & 54,91 & 262,27 & 39,32 & 39,95 & 261,14 \\
\hline Triturus marmoratus & 29SPD22 & 100,00 & 166,06 & 102,14 & 39,02 & 5404,88 & 319,60 & 61,34 & 258,25 & $\begin{array}{l}109,06 \\
\end{array}$ & 235,63 & 238,95 & 100,95 & 661,05 & 90,44 & 5,06 & 54,90 & 265,60 & 39,65 & 40,57 & 264,47 \\
\hline Triturus marmoratus & 29SPD25 & 101,00 & 160,69 & 97,33 & 37,76 & 5474,17 & 313,32 & 58,49 & 254,84 & 98,78 & 231,64 & 235,06 & 95,46 & \begin{tabular}{|c|}
766,08 \\
\end{tabular} & 108,18 & 6,11 & 55,04 & 309,96 & 46,21 & 47,49 & 309,96 \\
\hline Triturus marmoratus & 29SPD26 & 101,00 & 160,01 & 96,71 & 37,40 & 5512,44 & 312,78 & 57,41 & 255,37 & 95,55 & 231,52 & 234,88 & 94,22 & 787,61 & 111,94 & 6,14 & 55,06 & 319,04 & 47,62 & 48,89 & 319,04 \\
\hline Triturus marmoratus & 29SPD27 & 100,00 & 161,47 & 97,40 & 37,06 & 5567,78 & 315,33 & 57,12 & 258,21 & 98,03 & 233,97 & 236,64 & 94,68 & 784,94 & 111,6 & 6,06 & 54,87 & 317,36 & 47,71 & \begin{tabular}{ll|}
48,92 \\
\end{tabular} & 317,33 \\
\hline Triturus marmoratus & 29SPD31 & 101,00 & 164,08 & 105,16 & 39,06 & 5516,52 & 321,40 & 56,66 & 264,73 & 105,84 & 235,25 & 238,34 & 97,68 & 647,09 & 86,94 & 5,00 & 54,20 & 258,42 & 39,55 & 40,13 & 255,93 \\
\hline Triturus marmoratus & 29SPD33 & 100,00 & 162,66 & 101,92 & 38,40 & 5533,15 & 318,94 & 57,36 & 261,57 & 104,52 & 234,36 & 237,56 & 96,38 & $\begin{array}{l}699,47 \\
\end{array}$ & 95,88 & 5,75 & 54,18 & 280,39 & 43,21 & \begin{tabular}{l|l}
44,24 \\
\end{tabular} & 278,84 \\
\hline Triturus marmoratus & 29SPD34 & 101,00 & 160,24 & 99,30 & 37,85 & 5550,93 & 315,39 & 56,72 & 258,67 & 102,24 & 232,29 & 235,74 & 94,27 & $\begin{array}{l}740,95 \\
\end{array}$ & 103,04 & 6,14 & 54,40 & 298,01 & 45,47 & 46,65 & 297,21 \\
\hline Triturus marmoratus & 29SPD35 & 100,00 & 150,96 & 93,90 & 36,71 & 5549,48 & 303,30 & 51,48 & 251,82 & 87,76 & 223,30 & 227,27 & 86,22 & 847,69 & 120,82 & 7,24 & 54,84 & 343,56 & 52,06 & 53,06 & 343,56 \\
\hline Triturus marmoratus & 29SPD36 & 101,00 & 153,98 & 94,90 & 36,77 & 5604,19 & 307,60 & 52,43 & 255,18 & 91,66 & 227,18 & 230,49 & 87,92 & 831,12 & 118,49 & 6,95 & 54,64 & 36,25 & 51,13 & 52,08 & 336,14 \\
\hline Triturus marmoratus & 29SPD37 & 100,00 & 162,36 & 98,66 & 37,05 & 5674,95 & 318,45 & 56,13 & 262,32 & 101,76 & 236,42 & 238,79 & 94,20 & 758,86 & 106,97 & 5,99 & 54,36 & 305,26 & 46,45 & 47,80 & 304,45 \\
\hline Triturus marmoratus & 29SPD43 & 99,00 & 163,16 & 104,89 & 38,67 & 5647,58 & 323,13 & 54,71 & 268,42 & 103,38 & 236,58 & 239,30 & 95,26 & $\begin{array}{l}675,98 \\
\end{array}$ & 91,26 & 5,35 & 53,69 & 269,65 & 42,25 & 43,30 & 266,46 \\
\hline Triturus marmoratus & 29SPD44 & 101,00 & 155,18 & 99,28 & 37,57 & 5640,11 & 312,16 & 51,31 & 260,85 & 96,60 & 228,72 & 232,15 & 88,58 & \begin{tabular}{|c|}
767,07 \\
\end{tabular} & $\begin{array}{l}106,42 \\
\end{array}$ & 6,42 & 54,01 & 307,69 & 47,74 & \begin{tabular}{l|l}
48,74 \\
\end{tabular} & 306,19 \\
\hline Triturus marmoratus & 29SPD45 & 99,00 & 145,56 & 94,44 & 36,50 & 5659,10 & 300,09 & 44,74 & 255,35 & 86,12 & 220,27 & 223,39 & 79,69 & 866,89 & 122,89 & 7,64 & 54,20 & 348,96 & 54,20 & 54,73 & 348,51 \\
\hline Triturus marmoratus & 29SPD49 & 99,00 & 164,02 & 100,39 & 36,8 & 5853,23 & 323,01 & 53,88 & 269,13 & 100,56 & 240,91 & 242,15 & 93,07 & 730,46 & 102,34 & 5,78 & 53,71 & 91,92 & 45,35 & 46,81 & 289,43 \\
\hline \begin{tabular}{|l|} 
Triturus marmoratus \\
\end{tabular} & 29SPD52 & 101,00 & 166,26 & 111,13 & 39, & 5767,16 & 331, & 51,92 & 279,45 & 104,00 & 241,34 & 243,14 & 96,06 & 610,44 & 82,21 & 4,99 & 52,86 & 241,30 & 38,96 & 39,79 & 235,35 \\
\hline Triturus marmoratus & 29SPD53 & 101,00 & 162,51 & 107,88 & 38, & 5768,06 & 326,25 & 50,88 & 275,37 & 100,99 & 237,82 & 239,95 & 92,98 & 656,7 & 87, & 5,19 & 52,99 & 260,40 & 41,79 & 42,66 & 255,47 \\
\hline Triturus marmoratus & 29SPD59 & 101,00 & 163,90 & 101,51 & 36,84 & 5918,49 & 324,06 & 52,29 & 271,77 & $\begin{array}{l}99,59 \\
\end{array}$ & 241,73 & 242,68 & 92,03 & \begin{tabular}{ll|}
700,88 \\
\end{tabular} & $\begin{array}{l}96,96 \\
\end{array}$ & 5,47 & 53,10 & 278,58 & 43,96 & 45,45 & 274,74 \\
\hline Triturus marmoratus & 29SPD61 & 100,00 & 167,71 & 115,31 & 39,86 & 5882,00 & 336,11 & 48,61 & 287,49 & 103,42 & 244,34 & 245,41 & 95,43 & 563,84 & 77,06 & 4,32 & 52,19 & 220,94 & 36,92 & 37,50 & 212,62 \\
\hline Triturus marmoratus & 29SPD63 & 99,00 & 165,28 & 111,71 & 39,01 & 5881,51 & 332,24 & 49,14 & 283,10 & 101,48 & 242,15 & 243,45 & 93,61 & 608,40 & 81,64 & 4,91 & 52,16 & 239,24 & 39,44 & 40,35 & 232,05 \\
\hline Triturus marmoratus & 29SPD69 & 99,00 & 163,36 & 102,63 & 36,8 & 5985 & 325,23 & 50,46 & 274,77 & 98,32 & 242,23 & 242,91 & 90,58 & 672,44 & 91,76 & 5,20 & 52,53 & 265,70 & 42,64 & 44,03 & 260,42 \\
\hline Triturus marmoratus & 29SPE00 & 100,00 & 156,61 & 96,31 & 37,36 & 5412,16 & 306,87 & 52,65 & 254,22 & 91,06 & 227,34 & 229,15 & 91,06 & 892,60 & 129,81 & 7,50 & 55,12 & 363,46 & 55,07 & 55,67 & 363,46 \\
\hline Triturus marmoratus & 29SPE02 & 101,00 & 138,63 & 90,45 & 36,04 & 5409,04 & 285,24 & 37,94 & 247,30 & 73,95 & 211,46 & 211,53 & 73,95 & 1097,44 & 163,97 & 10,08 & 55,76 & 449,22 & 67,41 & 67,41 & 449,22 \\
\hline Triturus marmoratus & 29SPE10 & 100,00 & 159,18 & 97,18 & 36,95 & 5576,36 & 312,6 & 53,12 & 259,48 & 91,49 & 232,06 & 23 & 91,49 & 854,46 & \begin{tabular}{l|l|}
123,62 \\
\end{tabular} & 6, & 54 & 346,49 & 52,60 & 53,47 & 346,49 \\
\hline Triturus marmoratus & $29 \mathrm{SP}$ & 101 & 157 & 97, & 36 & 558 & & 51,39 & 259,93 & 90,01 & 231,04 & 23 & 90,01 & 875,06 & 127 & 7,26 & 54,90 & 354,47 & 54,36 & 55,11 & 354,47 \\
\hline Triturus marmoratus & 29SPE12 & 100,00 & 151,78 & 95,52 & 36,56 & 5580,80 & 303,98 & 46,12 & 257,86 & 84,14 & 225,44 & 226,36 & 84,14 & \begin{tabular}{|c|c|}
943,37 \\
\end{tabular} & 138,41 & 8,12 & 55,08 & \begin{tabular}{|l|}
383,08 \\
\end{tabular} & 58,69 & 59,05 & 383,08 \\
\hline Triturus marmoratus & 29SPE21 & 100,00 & 157,59 & \begin{tabular}{l|l}
97,04 \\
\end{tabular} & 36,15 & 5765,61 & 313,94 & 49,60 & 264,34 & 88,08 & 233,56 & 234,55 & 87,85 & 858,44 & \begin{tabular}{l|l|l|}
124,23 \\
\end{tabular} & 7,02 & 54,74 & 346,39 & 53,52 & 54,15 & 346,39 \\
\hline Triturus marmoratus & 29SPE22 & 100,00 & 153,76 & 96,17 & 36,13 & 5741,76 & 308,91 & 46,21 & 262,70 & 84,23 & 229,40 & 230,39 & 84,23 & 900,23 & 131,32 & 7,73 & 54,81 & 363,70 & 56,48 & 56,78 & 363,70 \\
\hline $\mid T_{\mathrm{Tri}}$ & 29SPE30 & 100,00 & 165 & 99,91 & 36,85 & 785,9 & 322. & 55, & 267,47 & $\mid 101,66$ & 240 & & 94 & 75 & 106 & 6,00 & 54,14 & 302,59 & $\mid 46,47$ & 48,13 & 301,33 \\
\hline Triturus marmoratus & 29SPE31 & 101,00 & 157,49 & 97,29 & 36,01 & 5870,90 & 315,45 & 48,45 & 267,00 & 91,57 & 234,94 & 235,83 & 86,60 & 833,36 & 120,00 & 6,90 & 54,25 & \begin{tabular}{|c|}
334,68 \\
\end{tabular} & 52,14 & 52,80 & 334,45 \\
\hline Triturus marmoratus & 29SPE32 & 100,00 & 155,12 & 96,91 & 36,01 & 5844,35 & 312,09 & 46,21 & 265,88 & 88,22 & 232,29 & 232,95 & 84,38 & 856,54 & 123,96 & 7,15 & 54,26 & 343,94 & 53,86 & 54,35 & 343,80 \\
\hline
\end{tabular}




\begin{tabular}{|c|c|c|c|c|c|c|c|c|c|c|c|c|c|c|c|c|c|c|c|c|c|}
\hline TAXON & UTM & $\mathrm{km} 2$ & B101 & $\mathrm{B1O2}$ & $\mathrm{BIO3}$ & B104 & B105 & B106 & B107 & $\mathrm{B108}$ & B109 & 81010 & BIO11 & BIO12 & 81013 & BIO14 & B1015 & B1016 & $\begin{array}{ll}1017 \\
17\end{array}$ & B1018 & B1019 \\
\hline Triturus marmoratus & 29SPE40 & 101,00 & 164,31 & 100,45 & 36,85 & 5868,35 & 323,23 & 53,36 & 269,86 & 100,41 & 241,48 & 242,36 & 92,96 & 733,33 & 103,07 & 5,98 & 53,64 & 292,77 & 45,60 & 47,25 & 290,38 \\
\hline Triturus marmoratus & 29SPE41 & 100,00 & 163,53 & 100,25 & 36,75 & 5876,42 & 322,10 & 52,19 & 269,90 & 99,20 & 240,77 & 241,49 & 91,83 & 744,16 & 105,12 & 6,05 & 53,53 & 296,93 & 46,41 & 48,04 & 294,75 \\
\hline Triturus marmoratus & 29SPE42 & 99,00 & 156,54 & 97,94 & 36,04 & 5903,14 & 314,45 & 46,30 & 268,15 & 92,15 & 234,38 & 234,94 & 84,72 & 808,24 & 115,72 & 6,78 & 53,88 & 322,90 & 50,98 & 51,71 & 321,60 \\
\hline Triturus marmoratus & 29SPE50 & 100,00 & 163,77 & 101,27 & 36,87 & 5932,29 & 323,69 & 51,76 & 271,94 & 99,08 & 241,85 & 242,54 & 91,55 & 705,68 & 98,12 & 5,53 & 53,11 & 280,54 & 44,12 & 45,66 & 276,80 \\
\hline Triturus marmoratus & 29SPE51 & 101,00 & 162,83 & 100,88 & 36,68 & 5941,95 & 322,45 & 50,59 & 271,86 & 97,88 & 241,23 & 241,63 & 90,42 & 716,97 & 100,21 & 5,86 & 53,12 & 284,78 & 45,20 & 46,64 & 281,24 \\
\hline Triturus marmoratus & 29SPE52 & 101,00 & 157,55 & 99,13 & 36,10 & 5958,68 & 316,43 & 46,10 & 270,33 & 92,54 & 236,26 & 236,52 & 84,95 & 761,84 & 107,67 & 6,19 & 53,17 & 302,85 & 48,50 & 49,19 & 300,00 \\
\hline Triturus marmoratus & 29SPE60 & 101,00 & 160,83 & 101,30 & 36,43 & 6005,53 & 322,03 & 48,31 & 273,71 & 95,56 & 240,07 & 240,54 & 87,79 & 697,13 & 96,08 & 5,66 & 52,50 & 275,62 & 44,60 & 45,66 & 270,71 \\
\hline Triturus marmoratus & 29SPE61 & 99,00 & 159,52 & 100,65 & 36,13 & 6011,88 & 320,19 & 46,94 & 273,24 & 94,04 & 238,99 & 239,26 & 86,33 & 709,88 & 98,39 & 5,94 & 52,45 & 280,56 & 45,79 & 46,52 & 275,97 \\
\hline Triturus marmoratus & 29SPE62 & 100,00 & 155,44 & 99,42 & 36,04 & 6016,15 & 315,34 & 43,59 & 271,75 & 90,01 & 235,19 & 235,31 & 82,29 & 739,68 & 103,40 & 6,29 & 52,52 & 292,50 & 48,01 & 48,30 & 288,25 \\
\hline Triturus marmoratus & 29SPE72 & 101,00 & 157,64 & 101,21 & $\mid 36,08$ | & 6065,15 & 319,49 & 44,06 & 275,43 & 91,42 & 237,94 & 238,00 & 83,62 & 684,95 . & 93,96 & 5,83 & 51,77 & 268,81 & 45,03 & 45,28 & 262,93 \\
\hline Triturus marmoratus & 29SQA39 & 100,00 & 178,93 & 88,43 & 37,01 & 5120,94 & 306,79 & 71,23 & 235,55 & 143,96 & 243,43 & 246,48 & 115,26 & 540,45 & 82,58 & 1,00 & 64,61 & 233,88 & 14,96 & 22,00 & 214,68 \\
\hline Triturus marmoratus & 29TMH74 & & & & & & & & & & & & & & & & & & & & \\
\hline Triturus marmoratus & 29TMH76 & 18,00 & 142,36 & 59,45 & 39,14 & 3130,50 & 224,05 & 74,18 & 149,86 & 112,64 & 180,45 & 184,00 & 103,45 & 970,82 & 140,59 & 26,09 & 42,05 & 384,09 & 112,86 & 138,27 & 322,23 \\
\hline Triturus marmoratus & 29TMH85 & 76,00 & 139,86 & 60,66 & 38,86 & 3227,67 & 224,58 & 70,50 & 154,08 & 109,07 & 179,49 & 182,91 & 99,89 & 1022,70 & 146,27 & 27,14 & 42,50 & 405,09 & 116,07 & 140,82 & 344,98 \\
\hline Triturus marmoratus & 29TMH91 & 46,00 & 146,53 & 59,04 & 38,62 & 3311,15 & 229,18 & 78,01 & 151,16 & 113,22 & 187,59 & 189,99 & 104,65 & 1143,04 & 161,42 & 26,24 & 45,56 & 458,00 & 110,67 & 134,49 & 409,85 \\
\hline Triturus marmoratus & 29TMH92 & 25,00 & 141,23 & 60,49 & 38,14 & 3378,23 & 227,51 & 71,47 & 156,05 & 107,72 & 183,44 & 185,91 & 99,12 & 1175,86 & 168,47 & 28,44 & 44,98 & 469,60 & 117,91 & 141,35 & 420,91 \\
\hline Triturus marmoratus & 29TMH98 & 28,00 & 142,80 & 61,16 & 39,53 & 3177,18 & 226,53 & 73,42 & 153,11 & 112,60 & 181,80 & 185,62 & 103,67 & 1013,53 & 141,49 & 28,18 & 41,00 & 395,73 & 117,49 & 142,60 & 341,07 \\
\hline Triturus marmoratus & 29TNE13 & 97,00 & 154,79 & 80,80 & 43,68 & 3528,08 & 252,14 & 69,20 & \begin{tabular}{l|l}
182,95 \\
\end{tabular} & 116,15 & 196,97 & 199,18 & 108,20 & 885,08 & 126,62 & 8,21 & 54,91 & 362,20 & 53,86 & 60,55 & 356,00 \\
\hline Triturus marmoratus & 29TNE14 & 94,00 & 153,37 & 80,69 & 43,99 & 3489,40 & 249,04 & 67,60 & 181,44 & 114,96 & 194,89 & 196,96 & 106,94 & 915,43 & 130,14 & 8,93 & 54,31 & 372,73 & 57,22 & 64,43 & 366,66 \\
\hline Triturus marmoratus & 29TNE15 & 95,00 & 152,10 & 79,87 & 44,23 & 3433,91 & 244,94 & 66,57 & \begin{tabular}{|l|l|}
178,37 \\
\end{tabular} & 114,04 & 192,57 & 194,69 & 106,07 & 940,82 & 132,95 & 9,80 & 53,87 & 381,66 & 60,01 & 67,97 & 375,23 \\
\hline Triturus marmoratus & 29TNE17 & 40,00 & 151,00 & 77,70 & 44,97 & 3321,38 & 237,20 & 65,97 & \begin{tabular}{|l|l|}
171,23 \\
\end{tabular} & 113,99 & 189,58 & 191,34 & 105,62 & 973,01 & 136,21 & 10,3 & 53,00 & 393,07 & 63,24 & 72,89 & 385,45 \\
\hline Triturus marmoratus & 29TNE24 & 101,00 & 157,05 & 86,34 & 43,98 & 3694,57 & 261,43 & 67,16 & 194,27 & \begin{tabular}{|l|l|}
116,16 \\
\end{tabular} & 201,40 & 203,60 & \begin{tabular}{l|l}
108,25 \\
\end{tabular} & $\begin{array}{l}901,97 \\
\end{array}$ & 127,53 & 8 & 53,98 & 365,32 & 57,08 & 63,58 & 361,36 \\
\hline Triturus marmoratus & 29TNE26 & 100,00 & 152,32 & 84,16 & $\begin{array}{l}44,45 \\
\end{array}$ & 3581,52 & 250,69 & 63,32 & \begin{tabular}{|c|}
187,37 \\
\end{tabular} & 112,44 & 194,77 & 196,81 & 104,39 & 969,56 & 136,02 & 10,03 & 53,09 & 390,74 & 63,01 & 70,94 & 385,71 \\
\hline Triturus marmoratus & 29TNE27 & 100,00 & 150,94 & 81,77 & 44,72 & 3491,93 & 244,10 & 63,03 & 181,07 & 111,95 & 191,99 & 193,90 & 103,76 & 988,28 & 138,04 & 10,85 & 52,79 & 397,95 & 65,18 & 74,10 & 391,49 \\
\hline Triturus marmoratus & 29TNE28 & 101,00 & 149,73 & 78,91 & 45,04 & 3384,36 & 236,65 & 63,11 & 173,54 & 111,73 & 189,05 & 190,76 & 103,37 & 1002,72 & 139,53 & 11,00 & 52,55 & 403,88 & 66,14 & 76,54 & 395,56 \\
\hline Triturus marmoratus & 29TNE29 & 91,00 & 148,62 & 76,34 & 45,23 & 3286,96 & 230,02 & 63,25 & 166,77 & 111,66 & 186,35 & 187,93 & 103,07 & 1017,60 & 140,94 & 11,13 & 52,35 & 410,05 & 67,19 & 78,96 & 399,81 \\
\hline Triturus marmoratus & 29TNE33 & 101,00 & 158,16 & 92,64 & 43,21 & 4010,56 & 275,56 & $\begin{array}{l}64,01 \\
64\end{array}$ & 211,56 & 112,29 & 207,16 & 209,62 & 106,24 & 902,78 & $\mid 127,94$ & 8,74 & 54,15 & 364,73 & 57,45 & 61,96 & 363,85 \\
\hline Triturus marmoratus & 29TNE34 & 100,00 & 158,71 & 92,86 & 43,79 & 3959,58 & 274,19 & 64,23 & 209,97 & 114,31 & 206,84 & 209,11 & 106,97 & 911,58 & 128,28 & 9,09 & 53,73 & 366,69 & 58,88 & 64,19 & 365,55 \\
\hline Triturus marmoratus & 29TNE36 & 101,00 & 153,32 & 90,79 & \begin{tabular}{|l|l|}
44,05 \\
\end{tabular} & 3857,75 & 263,38 & 59,66 & 203,71 & 110,21 & 199,93 & 201,99 & 102,41 & 984,04 & 137,65 & 10,85 & 52,91 & 394,26 & 65,75 & 72,21 & 391,82 \\
\hline Triturus marmoratus & 29TNE37 & 100,00 & 151,92 & 88,12 & 44,21 & 3760,17 & 256,36 & 59,47 & 196,88 & 109,94 & 196,99 & 198,97 & 101,90 & 999,56 & 139,38 & 11,00 & 52,72 & 400,87 & 66,69 & 74,56 & 396,25 \\
\hline Triturus marmoratus & 29TNE38 & 100,00 & 151,17 & 85,28 & 44,48 & 3655,62 & 249,50 & 59,88 & 189,62 & 110,04 & 194,48 & 196,30 & 101,87 & 1009,27 & 140,22 & 11,01 & 52,38 & 405,38 & 67,20 & 76,61 & 398,25 \\
\hline Triturus marmoratus & 29TNE43 & 100,00 & 152,01 & $\begin{array}{l}90,200 \\
96,88 \\
\end{array}$ & $\begin{array}{ll}44,40 \\
42,29\end{array}$ & 4334,80 & 280,95 & 54,54 & $\begin{array}{ll}226,42 \\
2\end{array}$ & 97,23 & 206,12 & 208,63 & $\begin{array}{l}97,14 \\
97,14\end{array}$ & 988,34 & \begin{tabular}{l|l}
140,82 \\
140,82
\end{tabular} & 10,21 & 53,90 & \begin{tabular}{|l|l|}
399,77 \\
\end{tabular} & 65,27 & $\begin{array}{ll}6,401 \\
\end{array}$ & 399,77 \\
\hline Triturus marmoratus & 29TNE44 & 101,00 & 157,36 & 99,73 & 43,31 & 4271,78 & 286,11 & 58,28 & 227,83 & 102,93 & 210,29 & 212,65 & 102,55 & 952,53 & 133,76 & 10,00 & 53,12 & 382,72 & 63,82 & 67,21 & 382,71 \\
\hline Triturus marmoratus & 29TNE45 & 101,00 & 159,50 & 98,46 & 43,90 & 4164,52 & 283,32 & 60,82 & 222,49 & 108,75 & 210,58 & 212,78 & 105,32 & 936,35 & 130,70 & 9,70 & 52,90 & 374,25 & 62,54 & 67,44 & 374,14 \\
\hline Triturus marmoratus & 29TNE46 & 100,00 & 155,75 & 96,92 & 43,75 & 4129,05 & 276,81 & 57,49 & 219,32 & 107,60 & 206,33 & 208,40 & 101,84 & 981,31 & 136,99 & 10,65 & 52,63 & 391,48 & 66,27 & 71,75 & 391,01 \\
\hline Triturus marmoratus & 29TNE47 & 101,00 & 154,50 & 94,07 & 43,94 & 4033,16 & 269,87 & 57,67 & 212,19 & 109,24 & 203,70 & 205,62 & 101,39 & 992,43 & 138,39 & 10,73 & 52,51 & 396,70 & 66,59 & 73,58 & 393,77 \\
\hline Triturus marmoratus & 29TNE48 & 101,00 & 153,62 & 91,44 & 44,01 & 3947,35 & 263,56 & 57,81 & 205,75 & 109,17 & 201,37 & 203,17 & 101,12 & 1001,46 & 139,26 & 10,96 & 52,41 & 401,25 & 66,83 & 75,53 & 395,36 \\
\hline Triturus marmoratus & 29TNE49 & 100,00 & 151,63 & 89,81 & 43,97 & 3905,53 & 258,44 & 56,55 & 201,90 & 107,68 & 198,79 & 200,54 & 99,55 & 1025,40 & 142,39 & 11,30 & 52,40 & 412,01 & 68,11 & 78,33 & 403,22 \\
\hline Triturus marmoratus & 29TNE53 & 101,00 & 151,81 & 98,81 & 41,57 & 4545,58 & 286,84 & 52,19 & 234,65 & 94,84 & 209,36 & 211,64 & 94,84 & 1002,83 & 143,49 & 10,28 & 53,94 & 406,24 & 66,25 & 67,75 & 406,24 \\
\hline Triturus marmoratus & 29TNE54 & 101,00 & 156,27 & 102,18 & 42,50 & 4514,23 & 292,22 & 54,61 & 237,61 & 99,02 & 212,75 & 215,25 & 99,02 & 975,79 & 137,69 & 10,19 & 53,13 & 392,97 & 65,87 & 68,08 & 392,97 \\
\hline Triturus marmoratus & 29TNE55 & 99,00 & 150,55 & 100,13 & 42 & 4497,70 & 284,29 & 49,83 & 234,45 & 93,64 & 207,01 & 209,27 & 93,64 & 1043,22 & 148,06 & 11,27 & 53,18 & 419,77 & 70,97 & 73,17 & 419,77 \\
\hline Triturus marmoratus & 29TNE56 & 101,00 & 150,10 & 99,40 & 42, & 4444,24 & 281,01 & $\begin{array}{l}4,0,47 \\
4\end{array}$ & 231,54 & 93,55 & 205,67 & 207,82 & 93,41 & 1053,40 & 149,12 & 11,49 & 52,88 & 422,23 & 71,75 & 75,15 & 422,23 \\
\hline Triturus marmoratus & $\begin{array}{l}\text { 29TNE57 } \\
\end{array}$ & 101,00 & 148,69 & 97,64 & 42,53 & 4378,99 & 275,62 & 48,79 & 226,84 & 97,88 & 203,34 & 205,27 & 92,45 & 1070,57 & \begin{tabular}{|l|l|l|l|}
151,49 \\
\end{tabular} & 11,72 & 52,86 & 428,03 & 72,49 & 77,32 & 427,56 \\
\hline Triturus marmoratus & \begin{tabular}{|l|l|} 
29TNE58 \\
\end{tabular} & 100,00 & 146,09 & 95,18 & $\begin{array}{l}42,45 \\
\end{array}$ & 4321,16 & 268,92 & 47,29 & 221,63 & 98,02 & 199,92 & 201,72 & 90,42 & 1099,79 & 155,99 & 12,10 & 52,83 & 440,82 & 74,02 & 80,08 & 438,16 \\
\hline Triturus marmoratus & 29TNE63 & 101,00 & 130,56 & 89,14 & 38,42 & 4769,88 & 264,0 & 35,22 & 228,79 & 72,92 & 194,23 & 194,62 & 72,92 & 1221,84 & 181,18 & $12, \varepsilon$ & 55,21 & 499,16 & 78,16 & 78,31 & 499,16 \\
\hline Triturus marmoratus & 29TNE65 & 101,00 & 154,92 & 102,10 & 41,7 & 4672 & 292 & 51,79 & 241,18 & $\begin{array}{l}95,81 \\
95,\end{array}$ & \begin{tabular}{|l|l|}
213,88 \\
\end{tabular} & $\begin{array}{l}216,01 \\
216,0\end{array}$ & 95,81 & 梠 & $\begin{array}{l}\mid 0,101,0 \\
141,65\end{array}$ & 10 & 53,17 & \begin{tabular}{|l|}
401,08 \\
40,0
\end{tabular} & $\mid 0,10,87$ & $\begin{array}{ll}0,431 \\
69,43\end{array}$ & 40 \\
\hline Triturus marmoratus & 29TNE66 & 100,00 & 156 & 101,84 & 42, & 4606,32 & 291,36 & 52,82 & 238,53 & 97,33 & 213,92 & 215,92 & 97,29 & 989,81 & 139,97 & 10,2 & 52,97 & 396,23 & 66,28 & 70,18 & 396,23 \\
\hline Triturus marmoratus & 29TNE67 & 100,00 & 151,69 & 99,91 & 42,00 & 4573,47 & 284,14 & 49,24 & 234,90 & 97,01 & 209,18 & 210,97 & 93,25 & \begin{tabular}{|l|}
1039,96 \\
\end{tabular} & 147,79 & 10,93 & 53,01 & 415,86 & 69,58 & 74,15 & 415,82 \\
\hline Triturus marmoratus & 29TNE68 & 101,00 & 134,72 & 93,55 & 40,41 & 4632,53 & 264,80 & 36,08 & 228,72 & 80,31 & 194,14 & 195,64 & 76,89 & 1229,75 & 179,29 & 13,54 & 53,76 & 495,74 & 82,40 & 85,19 & 495,61 \\
\hline Triturus marmoratus & 29TNE69 & 101,00 & 128,02 & 91,01 & 39,8 & 4638,69 & 256,21 & 30,75 & 25,47 & 73,66 & 187,77 & 189,16 & 70,46 & 1311,34 & 192,53 & 14,74 & 54,03 & 529,92 & 88,13 & 90,71 & 529,25 \\
\hline Triturus marmoratus & \begin{tabular}{|l|} 
29TNE73 \\
\end{tabular} & 100,00 & $\frac{120}{130}$ & $\begin{array}{l}1,01 \\
89,04\end{array}$ & 35, & $\frac{4}{4}$ & $\frac{256}{267}$ & $\begin{array}{l}30,1 / 12 \\
34,12\end{array}$ & 23 & 71,19 & 196,84 & 196,95 & 71,19 & 1223,43 & 182,48 & 12,47 & 55,44 & 500,58 & 77,23 & 77,23 & 500,58 \\
\hline Triturus marmoratus & 29TNE74 & 100,00 & 144,66 & 96,62 & 39,51 & 4909,73 & 284,97 & 43,52 & 241,46 & 84,22 & 208,62 & 209,88 & 84,22 & 1088,21 & 159,07 & 10,86 & 54,50 & 442,33 & 70,82 & 71,38 & 442,33 \\
\hline Triturus marmoratus & 29TNE75 & 101,00 & 154,08 & 101,29 & 40,82 & 4855,81 & 295,17 & 49,96 & 245,21 & 93,12 & 215,94 & 217,84 & 93,12 & 998,76 & 143,36 & 9,90 & 53,72 & 402,78 & 65,75 & 68,01 & 402,78 \\
\hline Triturus marmoratus & 29TNE76 & 101,00 & 154,06 & 101,53 & 41,08 & 4813,66 & 293,38 & 49,62 & 243,76 & 93,18 & 215,14 & 216,88 & 93,18 & 1005,56 & 143,97 & 9,99 & 53,47 & 404,01 & 66,34 & 69,56 & 404,01 \\
\hline Triturus marmoratus & 29TNE77 & 100,00 & 151,71 & 100,66 & 41,1 & 4778,52 & 288,89 & 47,59 & 241,30 & 91,92 & 212,30 & 213,84 & 91,08 & 1035,22 & 148,55 & 10,42 & 53,45 & 415,23 & 68,17 & 72,12 & 415 \\
\hline Triturus marmoratus & 29TNE78 & $\begin{array}{l}100,00 \\
100\end{array}$ & 148,15 & $\begin{array}{r}90,00 \\
99,57 \\
\end{array}$ & 年11,25 & 4758,31 & 280,05 & \begin{tabular}{|c|}
44,56 \\
44,5
\end{tabular} & $\begin{array}{ll}238,88 \\
238,\end{array}$ & 92,48 & 208,55 & 209,97 & 87,76 & 1076,81 & 155,12 & 11,07 & 53,44 & 431,68 & 70,90 & 75,54 & 431,42 \\
\hline Triturus marmoratus & 29TNE79 & 101,00 & 134,17 & 94,47 & 39,91 & 4800,60 & 267,62 & 33,70 & 233,92 & 76,77 & 196,11 & 197,26 & 74,32 & 1237,77 & 181,96 & 13,33 & 54,13 & 499,57 & 81,97 & 84,94 & 499,52 \\
\hline Triturus marmoratus & 29TNE83 & 100,00 & 136,83 & 91,53 & 37,62 & 5092,52 & 278,06 & 37,73 & 240,33 & 75,38 & 204,90 & 205,18 & 75,38 & 1153,36 & 171,78 & $\mid 11,27$ & 55,46 & 471,89 & 72,49 & 72,49 & 471,89 \\
\hline Triturus & 29TNE84 & 101,00 & 133,66 & 90,79 & 37,47 & 5087,30 & 273,82 & 34,7 & 239 & 72,2 & 201,61 & 201, & 72, & 1197,70 & 179,06 & 11,86 & 55,43 & 489,74 & 75,49 & 75,49 & 489 \\
\hline Triturus marmoratus & 29TNE85 & 100,00 & 147,50 & 97,92 & 39,26 & 5042,36 & 289,99 & 44,08 & 245,90 & 85,04 & 212,90 & 214,17 & 85,04 & 1059,06 & 155,04 & 10,29 & 54,51 & 429,45 & 68,30 & 69,66 & 429,45 \\
\hline
\end{tabular}




\begin{tabular}{|c|c|c|c|c|c|c|c|c|c|c|c|c|c|c|c|c|c|c|c|c|c|}
\hline$\overline{\text { TAXON }}$ & UTM & $\mathrm{km} 2$ & BI01 & B102 & $B 103$ & BIO4 & B105 & B106 & B107 & B108 & 8109 & B1010 & BIO11 & B1012 & BIO13 & 81014 & B1015 & B1016 & B1017 & B1018 & 81019 \\
\hline Triturus marmoratus & 29TNE86 & 100,00 & 150,11 & 99,94 & 39,99 & 5010,48 & 292,48 & 45,38 & 247,10 & 87,50 & 214,40 & 215,94 & 87,50 & 1037,19 & 150,83 & 10,03 & 54,12 & 418,79 & 67,60 & 69,74 & 418,79 \\
\hline Triturus marmoratus & 29TNE87 & 101,00 & 151,38 & 100,69 & 40,36 & 4969,05 & 292,32 & 46,06 & 246,27 & 88,92 & 214,94 & 216,39 & 88,82 & 1027,25 & 148,92 & 9,93 & 53,91 & $\begin{array}{l}413,26 \\
\end{array}$ & 66,69 & 70,08 & 413,26 \\
\hline Triturus marmoratus & 29TNE88 & 101,00 & 149,07 & 100,28 & 40,46 & 4943,27 & 288,54 & 43,95 & 244,59 & 88,11 & 212,25 & 213,54 & 86,67 & 1056,45 & 153,52 & 10,50 & 53,85 & \begin{tabular}{|l|l|}
424,47 \\
\end{tabular} & 68,67 & 72,72 & 424,47 \\
\hline Triturus marmoratus & 29TNE89 & 99,00 & 143,28 & 98,96 & 40,16 & 4954,20 & 281,94 & 38,90 & 243,03 & 81,35 & 206,81 & 207,99 & 80,99 & 1124,35 & 164,80 & 11,31 & 54,06 & 452,74 & 73,25 & 77,10 & 452,74 \\
\hline Triturus marmoratus & 29TNE96 & 100,00 & 144,25 & 96,90 & 38,48 & $5194,21]$ & 288,55 & 39,98 & 248,56 & 80,12 & 211,84 & 212,90 & 80,12 & 1084,89 & 160,45 & 10,32 & 54,88 & 440,40 & 69,82 & 70,58 & 440,40 \\
\hline Triturus marmoratus & 29TNE97 & 100,00 & 147,75 & 99,20 & 39,25 & 5155,38 & 291,58 & 42,09 & 249,49 & 83,40 & 214,19 & 215,39 & 83,40 & 1050,55 & 154,38 & 9,97 & 54,49 & 424,55 & 67,60 & 69,74 & 424,55 \\
\hline Triturus marmoratus & 29TNE98 & 100,00 & 146,38 & 99,49 & 39,50 & 5130,69 & 289,32 & 40,54 & 248,78 & 82,20 & 212,43 & 213,62 & 82,20 & 1069,29 & 157,42 & 10,31 & 54,43 & 431,66 & 68,89 & 71,63 & 431,66 \\
\hline Triturus marmoratus & 29TNF20 & 39,00 & 148,11 & 75,99 & 45,39 & 3278,87 & 228,40 & 62,72 & \begin{tabular}{|c|}
165,68 \\
\end{tabular} & 111,24 & \begin{tabular}{|l|l|}
185,74 \\
\end{tabular} & 187,30 & 102,70 & 1033,57 & 142,44 & 11,91 & 52,02 & 416,51 & 68,59 & 81,88 & 404,38 \\
\hline Triturus marmoratus & 29TNF21 & 42,00 & 147,88 & 78,33 & 45,13 & 3371,42 & 232,38 & 61,15 & 171,23 & 110,42 & 187,18 & 188,83 & 101,85 & 1056,40 & 144,77 & 12,05 & 52,00 & \begin{tabular}{|c|}
425,88 \\
\end{tabular} & 70,18 & 84,85 & 411,62 \\
\hline Triturus marmoratus & 29TNF25 & 28,00 & 144,51 & 85,81 & 44,94 & \begin{tabular}{|c|}
3674,23 \\
\end{tabular} & 243,21 & 54,34 & \begin{tabular}{|c|}
188,87 \\
\end{tabular} & \begin{tabular}{|l|l|}
104,47 \\
\end{tabular} & 189,36 & 191,38 & 97,09 & 1183,21 & 162,30 & 14,83 & 51,15 & $\begin{array}{l}472,75 \\
\end{array}$ & 81,40 & 99,72 & 460,91 \\
\hline Triturus marmoratus & 29TNF26 & 68,00 & 143,71 & 84,72 & 45,01 & $\begin{array}{l}3658,17 \\
\end{array}$ & 241,52 & 55,50 & \begin{tabular}{l|l|}
186,02 \\
\end{tabular} & 99,99 & 188,56 & 190,46 & 97,07 & 1215,52 & 165,55 & 15,08 & 51,03 & 482,21 & 83,56 & 100,72 & 480,78 \\
\hline Triturus marmoratus & 29TNF27 & 83,00 & 143,39 & 83,67 & 44,84 & 3665,84 & 241,48 & 56,50 & \begin{tabular}{|l|l|}
184,98 \\
\end{tabular} & 98,16 & $\begin{array}{l}188,60 \\
\end{array}$ & 190,35 & 96,94 & 1229,74 & 168,04 & \begin{tabular}{ll|}
15,06 \\
\end{tabular} & 51,32 & 488,82 & 83,48 & 101,82 & 488,58 \\
\hline Triturus marmoratus & 29TNF28 & 101,00 & 142,97 & 82,67 & 44,28 & 3688,89 & 241,72 & 57,07 & $\begin{array}{l}184,65 \\
\end{array}$ & 96,45 & 188,66 & 190,33 & 96,40 & 1246,49 & $\begin{array}{ll}171,06 \\
\end{array}$ & 15,08 & 51,64 & 496,82 & 83,70 & 103,29 & 496,82 \\
\hline Triturus marmoratus & 29TNF29 & 100,00 & 143,40 & 81,55 & 43,81 & 3705,16 & 242,68 & 58,44 & \begin{tabular}{|l|l|}
184,24 \\
\end{tabular} & \begin{tabular}{|c|}
96,74 \\
\end{tabular} & 189,45 & 190,99 & 96,74 & 1253,60 & 172,57 & 14,95 & 51,94 & 500,80 & 83,10 & 104,21 & 500,80 \\
\hline Triturus marmoratus & 29TNF30 & 97,00 & 149,38 & 82,52 & \begin{tabular}{l|l}
44,75 \\
\end{tabular} & 3564,68 & 241,69 & 59,15 & \begin{tabular}{|c|}
182,54 \\
\end{tabular} & 109,24 & \begin{tabular}{|l|l|l|}
191,41 \\
\end{tabular} & \begin{tabular}{|l|l}
193,03 \\
\end{tabular} & 100,90 & 1039,18 & \begin{tabular}{|c|}
143,20 \\
\end{tabular} & \begin{tabular}{c|c|}
11,86 \\
\end{tabular} & 52,06 & 418,81 & \begin{tabular}{l|l|}
69,12 \\
\end{tabular} & 81,84 & 406,13 \\
\hline Triturus marmoratus & 29TNF31 & 101,00 & 148,07 & 83,26 & \begin{tabular}{|c|}
44,69 \\
\end{tabular} & \begin{tabular}{|c|c|}
3597,97 \\
\end{tabular} & 241,68 & 57,46 & \begin{tabular}{ll|}
184,22 \\
\end{tabular} & \begin{tabular}{|l|l|}
107,87 \\
\end{tabular} & \begin{tabular}{|l|l|}
190,73 \\
\end{tabular} & \begin{tabular}{|c|}
192,50 \\
\end{tabular} & $\begin{array}{l}99,47 \\
\end{array}$ & 1065,36 & $\begin{array}{l}146,05 \\
\end{array}$ & 12,24 & 52,00 & \begin{tabular}{|c|}
429,98 \\
\end{tabular} & 71,06 & 85,21 & 414,46 \\
\hline Triturus marmoratus & 29TNF32 & 101,00 & 145,57 & 84,92 & 44,51 & 3682,73 & 242,81 & 53,91 & \begin{tabular}{|c|}
188,90 \\
\end{tabular} & 104,71 & 189,77 & 191,53 & 96,39 & $\begin{array}{l}1108,58 \\
\end{array}$ & 151,23 & 13,26 & 51,97 & 448,35 & 74,67 & 90,24 & 429,45 \\
\hline Triturus marmoratus & 29TNF33 & 100,00 & 143,08 & 86,64 & 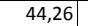 & 3769,42 & 244,08 & 50,32 & $\mid 193,75$ & 101,57 & 188,84 & 190,75 & 93,44 & 1153,38 & 156,89 & $\mid 14,21$ & 51,96 & $\mid 467,44$ & 78,42 & 95,49 & $\begin{array}{l}444,94 \\
\end{array}$ \\
\hline Triturus marmoratus & 29TNF34 & 101,00 & 142,93 & 88,24 & 44,24 & 3832,79 & 246,60 & 49,26 & $197,34[$ & 100,95 & 189,74 & 191,72 & 92,80 & 1169,53 & 160,71 & 14,84 & 51,92 & 475,06 & 79,95 & 99,15 & 447,97 \\
\hline Triturus marmoratus & 29TNF35 & 101,00 & 143,79 & 89,17 & 44,34 & 3853,99 & 248,8 & 50,08 & $\begin{array}{l}198,78 \\
\end{array}$ & 101,82 & 191,19 & 193,23 & 93,92 & 1176,16 & $\begin{array}{l}162,85 \\
\end{array}$ & 15,00 & 51,60 & $\begin{array}{l}476,56 \\
\end{array}$ & 80,52 & 100,90 & 450,62 \\
\hline Triturus marmoratus & 29TNF36 & 100,00 & 142,72 & 88,75 & 44,37 & 3874,54 & 248,10 & 50,30 & \begin{tabular}{|c|}
197,80 \\
\end{tabular} & 100,59 & 190,60 & 192,54 & 93,19 & 1208,89 & 165,64 & 15,18 & 51,16 & 484,74 & 82,84 & 101,99 & 470,16 \\
\hline Triturus marmoratus & 29TNF37 & 101,00 & 143,27 & 87,78 & 44,23 & 3880,42 & 248,43 & 52,12 & 196,31 & 100,95 & 191,39 & $\begin{array}{l}193,10 \\
\end{array}$ & 93,98 & $\begin{array}{l}1219,17 \\
\end{array}$ & $\begin{array}{l}165,45 \\
\end{array}$ & 15,05 & 51,07 & 485,64 & 82,94 & $\begin{array}{l}101,87 \\
\end{array}$ & 478,73 \\
\hline Triturus marmoratus & 29TNF39 & 100,00 & 142,67 & 85,68 & 43,22 & 3921,25 & 249,19 & 53,49 & $\begin{array}{l}195,69 \\
\end{array}$ & 97,62 & 191,73 & 193,13 & 93,16 & 1252,93 & 169,96 & 15,41 & 51,40 & 497,59 & 84,71 & 104,50 & 496,90 \\
\hline Triturus marmoratus & 29TNF40 & 100,00 & 147,44 & 89,30 & 43,83 & 3923,90 & 254,03 & 52,39 & 201,63 & 103,46 & 195,05 & 196,67 & 95,31 & 1079,18 & 149,73 & 12,26 & 52,06 & 434,59 & 72,22 & 83,50 & 423,05 \\
\hline Triturus marmoratus & 29TNF41 & 101,00 & 142,38 & 89,36 & \begin{tabular}{|l|l|}
43,37 & \\
\end{tabular} & \begin{tabular}{|l|}
3991,40 \\
\end{tabular} & 250,94 & 47,24 & 203,70 & 98,11 & 191,25 & 193,01 & 90,04 & 1145,99 & 159,30 & 13,48 & 52,06 & 462,52 & 77,32 & 89,31 & 448,96 \\
\hline Triturus marmoratus & 29TNF43 & 100,00 & 139,21 & 90,71 & 43,30 & 4069,14 & 250,59 & 43,39 & 207,20 & 94,59 & 189,62 & 191,44 & 86,51 & 1202,18 & 165,41 & 14,71 & 52,01 & 486,77 & 81,77 & 96,65 & 467,70 \\
\hline Triturus marmoratus & 29TNF44 & 101,00 & 145,19 & 91,73 & \begin{tabular}{l|l}
43,95 & \\
\end{tabular} & 4024,80 & 255,19 & 48,47 & 206,73 & 100,89 & \begin{tabular}{|l|l|}
194,71 \\
\end{tabular} & 196,60 & 92,76 & 1143,15 & $\begin{array}{l}155,45 \\
\end{array}$ & 13,92 & 51,95 & 463,79 & 77,06 & 95,12 & 439,23 \\
\hline Triturus marmoratus & 29TNF45 & 100,00 & 143,60 & 92,24 & 43,84 & 4070,49 & 255,27 & 46,97 & 208,31 & \begin{tabular}{l|l}
98,94 \\
\end{tabular} & \begin{tabular}{|l|l|l}
194,03 \\
\end{tabular} & 195,90 & 91,10 & 1174,73 & $\begin{array}{l}159,85 \\
\end{array}$ & 14,55 & 51,68 & 475,51 & 79,77 & 98,42 & 452,40 \\
\hline Triturus marmoratus & 29TNF46 & 101,00 & 139,99 & 92,04 & 43,58 & 4124,76 & 253,26 & 44,26 & 208,99 & 94,91 & 191,59 | & 193,29 & 87,44 & 1229,65 & 167,21 & 15,41 & 51,34 & 495,06 & 84,11 & 101,93 & 478,38 \\
\hline Triturus marmoratus & 29TNF47 & 100,00 & 139,14 & 91,24 & 43,32 & 4147,14 & 252,84 & 44,35 & 208,48 & 93,89 & 191,25 & 192,76 & 86,61 & 1253,11 & 169,91 & 15,81 & 51,14 & 501,37 & 86,32 & 103,48 & 491,26 \\
\hline Triturus marmoratus & 29TNF49 & 101,00 & 139,80 & 89,86 & 42,66 & 4175,54 & 254,55 & 46,33 & 208,22 & 94,19 & 192,55 & $\begin{array}{l}193,76 \\
\end{array}$ & 87,19 & 1270,24 & 171,95 & 16,30 & 51,01 & 504,73 & 88,23 & 105,84 & 500,86 \\
\hline Triturus marmoratus & 29TNF50 & 101,00 & 139,58 & 92,61 & \begin{tabular}{|c|}
42,17 \\
\end{tabular} & 4304,23 & 258,99 & 41,99 & 217,01 & 92,04 & 193,36 & 195,11 & 84,30 & 1181,11 & 167,89 & 13,43 & 52,76 & 475,58 & 79,54 & 87,48 & 468,92 \\
\hline Triturus marmoratus & 29TNF51 & 101,00 & 130,68 & 90,91 & 41,39 & 4383,84 & 251,56 & 34,36 & 217,20 & 83,11 & 186,06 & 187,79 & 75,27 & 1291,53 & 185,22 & 15,29 & 52,99 & 520,41 & 88,04 & 94,96 & 515,26 \\
\hline Triturus marmoratus & 29TNF52 & 100,00 & 128,82 & 90,79 & 41,34 & 4388,35 & 249,56 & 32,56 & 217,00 & 80,65 & 184,49 & 186,10 & 73,51 & 1319,05 & $\begin{array}{l}188,56 \\
\end{array}$ & 15,87 & 52,82 & $\begin{array}{l}531,86 \\
\end{array}$ & 90,28 & $\begin{array}{l}98,23 \\
\end{array}$ & 525,29 \\
\hline Triturus marmoratus & 29TNF53 & 101,00 & 139,12 & 93,95 & \begin{tabular}{l|l|l}
42,65 & \\
\end{tabular} & 4304,01 & 258,06 & 40,55 & 217,52 & 91,75 & 192,97 & 194,65 & 83,83 & 1206,82 & 168,46 & 14,26 & 52,14 & 487,19 & 81,32 & 94,06 & 473,32 \\
\hline Triturus marmoratus & 29TNF55 & 100,00 & 140,87 & 95,08 & 42,94 & 4326,04 & 260,24 & 41,73 & 218,51 & 93,30 & 195,21 & \begin{tabular}{ll|}
196,68 \\
\end{tabular} & 85,53 & 1202,49 & 165,11 & 14,53 & 51,85 & $\begin{array}{l}484,56 \\
\end{array}$ & 81,28 & 96,84 & 468,84 \\
\hline Triturus marmoratus & 29TNF56 & 101,00 & 139,94 & 95,13 & \begin{tabular}{l|l}
42,95 \\
\end{tabular} & 4354,26 & 260,13 & 41,13 & 219,00 & 92,16 & 194,79 & 196,27 & 84,56 & 1221,82 & 166,99 & 14,97 & 51,64 & 490,56 & 83,17 & 98,86 & 477,69 \\
\hline Triturus marmoratus & 29TNF57 & 101,00 & 136,33 & 94,43 & 42,54 & 4395,62 & 257,89 & 38,43 & 219,46 & 88,25 & 192,09 & 193,38 & 80,76 & 1271,83 & 173,49 & 15,97 & 51,45 & 508,53 & 87,85 & 102,68 & 500,28 \\
\hline Triturus marmoratus & 29TNF58 & 100,00 & 142, & 94,36 & \begin{tabular}{|l|l}
42,68 \\
\end{tabular} & 4362,30 & 262,89 & 44,19 & 218,70 & 94,05 & 197,22 & 198,42 & 86,75 & 1212,75 & $\begin{array}{l}162,86 \\
\end{array}$ & 15,06 & 51,03 & 82,85 & 83,48 & \begin{tabular}{|c|}
99,97 \\
\end{tabular} & 474,72 \\
\hline Triturus marmoratus & 29TNF59 & 101,00 & \begin{tabular}{ll|}
139,94 \\
\end{tabular} & 93,48 & 42,13 & 4393,00 & 261,73 & 42,64 & 219,10 & 91,63 & 195,73 & 196,85 & 84,56 & 1243,58 & 167,10 & 16,12 & 50,99 & 493,44 & 87,40 & 103,38 & 487,78 \\
\hline Triturus marmoratus & 29TNF60 & 100,00 & 135,03 & 94,39 & $41, \mathrm{C}$ & $\begin{array}{l}4585,71 \\
\end{array}$ & 262,88 & 35,58 & 227,30 & 84,44 & 193,27 & 194,86 & 77,17 & 1237,64 & 179,24 & \begin{tabular}{|c|}
13,79 \\
\end{tabular} & 53,37 & 498,24 & 82,88 & 88,33 & 495,79 \\
\hline Triturus marmoratus & 29TNF61 & 100,00 & 135,59 & 94,12 & 41,30 & $\begin{array}{l}4545,64 \\
\end{array}$ & 261,58 & 36,27 & 225,31 & 84,47 & 193,36 & 194,77 & 78,12 & 1233,48 & 177,66 & 13,94 & 53,23 & 497,11 & 82,71 & 89,56 & 492,25 \\
\hline Triturus marmoratus & 29TNF62 & 101,00 & 119,24 & 89,37 & 39,56 & 4648,32 & 246,04 & 23,36 & 222,68 & 65,19 & 179,50 & 180,74 & 62,13 & 1421,55 & 207,84 & 17,24 & 53,69 & 573,99 & 97,86 & $\begin{array}{ll}101,46 \\
\end{array}$ & 572,57 \\
\hline Triturus marmoratus & 29TNF63 & 100,00 & 137, & 96,37 & 41,92 & 4552,30 & 263,6 & 36,45 & 227,18 & 87,09 & \begin{tabular}{|l|l|}
194,87 \\
\end{tabular} & 196,22 & 79,29 & 1227,80 & 174,69 & 14,04 & 52,72 & 494,00 & 82,05 & 92,22 & 486,62 \\
\hline Triturus marmoratus & 29TNF65 & 101,00 & 141 & 97,96 & 42 & 4548, & 267, & 39,49 & 227,70 & 90,78 & 198,67 & 199,98 & 83,18 & $\begin{array}{l}1191,76 \\
\end{array}$ & 166,29 & 13,82 & 52,13 & 478,12 & 79,78 & 93,05 & 468,42 \\
\hline Triturus marmoratus & 29TNF66 & 100,00 & 140,95 & 98,10 & 42,56 & 4557,92 & 267,53 & 39,38 & \begin{tabular}{|l|l|}
228,15 \\
\end{tabular} & 90,49 & 198,65 & 199,92 & 82,92 & 1198,66 & 165,92 & 14,16 & 51,88 & 479,50 & 80,88 & 94,69 & 470,84 \\
\hline Triturus marmoratus & 29TNF67 & 100,00 & 139,03 & 97,85 & \begin{tabular}{l|l|l|}
42,15 \\
\end{tabular} & 4589,24 & 266,73 & 37,67 & 229,06 & 88,29 & 197,36 & 198,49 & 80,91 & 1225,60 & \begin{tabular}{ll|}
168,33 \\
\end{tabular} & \begin{tabular}{c|c|}
14,86 \\
\end{tabular} & 51,72 & 488,61 & 83,77 & $\begin{array}{l}97,47 \\
\end{array}$ & 482,14 \\
\hline Triturus marmoratus & 29TNF68 & 101,00 & 137,90 & 97,23 & 41, & 4606,79 & 266,17 & 37,05 & 229,12 & 87,12 & 196,63 & 197,66 & 79,77 & 1240,93 & 168,44 & 15,51 & 51,33 & 92,91 . & 86,19 & 99,84 & 488,19 \\
\hline Triturus marmoratus & 29TNF69 & 100,00 & 135,31 & 96,15 & 41,5 & 4630,85 & 264,13 & 35,32 & 228,80 & 83,85 & 194,67 & 195,62 & 77,28 & 1267,98 & 170,11 & 16,66 & 50,99 & 502,08 & 90,32 & 103,32 & 498,82 \\
\hline Triturus marmoratus & 29TNF & 100,00 & 131 & 93,82 & 39, & 4794,23 & 263 & 31,18 & 232,42 & 74,29 & 193,10 & 194,21 & 71,49 & 1276,03 & 187,97 & 13,92 & 54,17 & 515,51 & 84,71 & 88,05 & 514,91 \\
\hline Triturus marmoratus & 29TNF71 & 101,00 & 138,55 & 97,23 & 41,02 & 4748,50 & 270,65 & 36,33 & 234,32 & 84,96 & 199,28 & 200,42 & 78,59 & 1195,33 & 173,64 & 12,91 & 53,50 & 480,83 & 78,99 & 85,21 & 478,45 \\
\hline Triturus marmoratus & 29TNF72 & 100,00 & 124,75 & 93,12 & 39,7 & 4811,33 & 256,79 & 25,56 & 231,23 & 67,57 & 187,14 & 188,20 & 65,25 & 1354,86 & 199,64 & 15,47 & 54,07 & 547,42 & 91,22 & 94,88 & 546,90 \\
\hline Triturus marmoratus & 29TNF73 & 100,00 & 125,97 & 94,19 & 40 & 998,34 & 257,82 & 26,19 & 31,62 & \begin{tabular}{|c|}
69,94 \\
\end{tabular} & 18 & 18 & 66 & $\begin{array}{l}1340,38 \\
\end{array}$ & \begin{tabular}{|c|}
195,83 \\
\end{tabular} & 15,66 & 5 & 540 & $9 \mathrm{c}$ & 95,98 & 53 \\
\hline Triturus marmoratus & $29 \mathrm{TN}$ & 101 & 128 & 95,57 & 40 & & 260 & 28,37 & 232,24 & 72,85 & 190 & 19 & 69,36 & 1309,76 & 189 & $15+3+5$ & 53, & 527,26 & 88 & $\mid 95,55$ | & 524 \\
\hline Triturus marmoratus & 29TNF76 & 101,00 & 141,79 & 100,39 & \begin{tabular}{|c|}
41,96 \\
\end{tabular} & \begin{tabular}{|l|}
4748,21 \\
\end{tabular} & 274,06 & 37,90 & 236,17 & 87,98 & 202,21 & 203,32 & 81,53 & 1172,75 & 164,56 & 13,40 & 52,24 & 467,99 & 78,52 & 90,37 & 462,94 \\
\hline Triturus marmoratus & 29TNF78 & 101,00 & 126,95 & 97,32 & 40,78 & \begin{tabular}{ll|l}
4844,60 \\
\end{tabular} & 261,42 & 25,75 & 235,68 & \begin{tabular}{|c|}
68,04 \\
\end{tabular} & $\begin{array}{ll}189,60 \\
\end{array}$ & $\begin{array}{l}190,52 \\
\end{array}$ & 66,83 & 1333,31 & 185,94 & 17,30 & 52,04 & 531,44 & 94,53 & $\begin{array}{l}103,38 \\
\end{array}$ & 531,32 \\
\hline Triturus marmoratus & 29TNF79 & 101,00 & 124,43 & 95,81 & \begin{tabular}{|l|l}
40,47 \\
\end{tabular} & 4841,80 & 258,19 & 24,30 & 233,89 & 65,58 & 187,19 & 188,09 & 64,62 & 1349,39 & 185,11 & 18,55 & 51,51 & 536,28 & 98,47 & 107,09 & 536,16 \\
\hline$m$ & $29 \mathrm{TN}$ & 101, & & 97,59 & & 66,71 & 275 , & 33,90 & 41, & 75,65 & 8 & 20 & 75 & 1195,95 & & 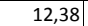 & & 482 & 78,28 & 81 & 48 \\
\hline Triturus marmoratus & 29TNF81 & 101,00 & 138,58 & 98,97 & 40,41 & 4957,04 & 276,29 & 34,33 & 241, & 78,33 & 202,15 & 203,2 & 76,2 & $\begin{array}{l}1184,88 \\
\end{array}$ & 174,4 & 12,24 & 54,20 & 477,17 & 77,25 & 82,20 & 477,00 \\
\hline Triturus marmoratus & 29TNF82 & 100,00 & 133,58 & 98,23 & 40,21 & 4971,25 & 271,19 & 30,14 & 241,06 & 73,00 & 197,70 & \begin{tabular}{ll|}
198,66 \\
\end{tabular} & 71,47 & 1244,51 & \begin{tabular}{|l|l|}
184,08 \\
\end{tabular} & 13,26 & 54,36 & 502,42 & 81,71 & 86,36 & 502,12 \\
\hline
\end{tabular}




\begin{tabular}{|c|c|c|c|c|c|c|c|c|c|c|c|c|c|c|c|c|c|c|c|c|c|}
\hline TAXON & UTM & $\mathrm{km} 2$ & B101 & $\mathrm{B1O2}$ & $\mathrm{BIO3}$ & B104 & B105 & 8106 & B107 & $\mathrm{B108}$ & B109 & B1010 & BIO11 & BIO12 & B1013 & B1014 & B1015 & BIO16 & BIO17 & B1018 & B1019 \\
\hline Triturus marmoratus & 29TNF83 & 101,00 & 109,14 & 87,77 & 37,62 & 4975,93 & 242,62 & 12,70 & 229,92 & 49,47 & 175,17 & 175,58 & 49,22 & 1493,52 & 222,19 & 18,53 & 54,42 & 606,03 & 102,49 & 103,59 & 606,01 \\
\hline Triturus marmoratus & 29TNF84 & 101,00 & 118,90 & 93,61 & 39,19 & 4982,55 & 254,88 & 19,09 & 235,79 & 58,28 & 184,21 & 184,84 & 57,85 & 1397,56 & 206,45 & 16,64 & 54,06 & 565,62 & 95,33 & 98,47 & 565,51 \\
\hline Triturus marmoratus & 29TNF85 & 100,00 & 136,01 & 101,39 & 41,17 & 4965,90 & 274,28 & 30,99 & 243,29 & 75,89 & 199,76 & 200,67 & 73,51 & 1222,05 & 177,54 & 13,56 & 53,63 & 490,55 & 81,16 & 89,01 & 489,57 \\
\hline Triturus marmoratus & 29TNF86 & 101,00 & 125,67 & 98,43 & 40,38 & 4998,73 & 264,11 & 23,07 & 241,04 & 64,83 & 190,54 & 191,36 & 63,74 & 1325,58 & 192,39 & 15,93 & 53,57 & 533,46 & 91,11 & 96,93 & 533,22 \\
\hline Triturus marmoratus & 29TNF87 & 101,00 & 135,01 & 101,65 & \begin{tabular}{|l|l|}
41,07 & \\
\end{tabular} & 4987,46 & 274,44 & 29,83 & 244,61 & 74,73 & 199,17 & 199,92 & 72,50 & 1223,35 & 174,13 & 14,38 & 52,84 & 488,05 & 83,36 & 92,32 & 487,44 \\
\hline Triturus marmoratus & 29TNF88 & 99,00 & 141,71 & 103,14 & 41,42 & 4974,24 & 281,45 & 35,06 & 246,39 & 83,10 & 205,58 & 206,22 & 78,92 & 1144,18 & 158,88 & 13,41 & 52,08 & 452,19 & 78,01 & 89,11 & 451,23 \\
\hline Triturus marmoratus & 29TNF89 & 101,00 & 138,03 & 102,06 & \begin{tabular}{ll|l}
40,95 & \\
\end{tabular} & 4999,15 & 277,95 & 31,91 & 246,04 & 78,21 & 202,41 & 202,92 & 75,17 & 1176,14 & 161,05 & 14,66 & 51,68 & 463,52 & 82,57 & 92,81 & 463,14 \\
\hline Triturus marmoratus & 29TNF90 & 100,00 & 135,74 & 97,24 & 39,11 & 5140,79 & 277,09 & 31,58 & 245,51 & 71,87 & 202,41 & 203,33 & 71,87 & 1192,29 & 178,24 & 11,99 & 54,96 & 483,60 & 77,32 & 79,46 & 483,60 \\
\hline Triturus marmoratus & 29TNF91 & 100,00 & 132,75 & 97,32 & 39,23 & 5137,78 & 273,84 & 28,79 & 245,06 & 68,99 & 199,50 & 200,32 & 68,99 & 1228,40 & 184,01 & 12,60 & 55,01 & 498,40 & 79,94 & 82,35 & 498,40 \\
\hline Triturus marmoratus & 29TNF92 & 101,00 & 126,83 & 96,14 & \begin{tabular}{|c|}
39,03 \\
\end{tabular} & 5143,95 & 267,40 & 23,92 & 243,48 & 63,31 & 193,92 & 194,57 & 63,31 & 1295,64 & 194,83 & 13,75 & 55,18 & 526,94 & 85,17 & 87,05 & 526,94 \\
\hline Triturus marmoratus & 29TNF93 & 100,00 & 112,22 & 89,85 & 37,50 & 5123,48 & 249,76 & 13,62 & 236,13 & 50,27 & 180,26 & 180,45 & 50,27 & 1440,64 & 216,60 & 16,93 & 55,02 & 587,21 & 97,41 & 97,51 & 587,21 \\
\hline Triturus marmoratus & 29TNF95 & 101,00 & 138,40 & 103,35 & 40,82 & 5122,49 & 281,31 & 31,16 & 250,14 & 75,40 & 204,41 & 205,04 & 74,01 & 1168,52 & 171,57 & 12,46 & 54,07 & 469,70 & 76,62 & 82,85 & 469,33 \\
\hline Triturus marmoratus & 29TNF96 & 100,00 & 122,41 & 99,04 & 39,60 & 5160,22 & 265,41 & 18,77 & 246,64 & 58,88 & 189,82 & 190,40 & 58,88 & 1327,04 & 195,32 & 16,05 & 54,19 & 536,19 & 91,36 & 95,12 & 536,19 \\
\hline Triturus marmoratus & 29TNF97 & 100,00 & 115,88 & 95,90 & 39,03 & 5136,17 & 257,03 & 14,56 & 242,47 & 53,35 & 183,44 & 183,91 & 53,35 & 1372,61 & 199,44 & 17,95 & 53,49 & 553,49 & 98,06 & 101,01 & 553,49 \\
\hline Triturus marmoratus & 29TNF98 & 101,00 & 121,02 & 98,41 & 39,61 & 5139,73 & 263,22 & 17,96 & 245,26 & 57,91 & 188,29 & 188,76 & 57,91 & \begin{tabular}{ll|}
1316,53 \\
\end{tabular} & 188,74 & 17,26 & 53,01 & 528,34 & 94,25 & 98,83 & 528,34 \\
\hline Triturus marmoratus & 29TNF99 & 100,00 & 135,05 & 103,43 & 40,67 & 5161,06 & 279,51 & 27,52 & 251,99 & 71,37 & 201,96 & 202,26 & 70,61 & 1168,49 & 163,49 & 14,49 & 52,32 & 463,38 & 81,88 & 88,21 & 463,32 \\
\hline Triturus marmoratus & 29TNG12 & 87,00 & 137,29 & 73,96 & 42,06 & 3627,14 & 232,43 & 58,62 & 173,81 & 92,83 & 182,87 & 184,29 & 92,14 & 1378,35 & 191,82 & 19,18 & 51,61 & 553,01 & 96,64 & 118,57 & 552,97 \\
\hline Triturus marmoratus & 29TNG14 & 99,00 & 141,35 & 69,97 & 41,01 & 3592,14 & 233,55 & 65,01 & 168,54 & 103,58 & 186,44 & 187,73 & 96,16 & 1368,59 & 193,12 & 21,54 & 50,70 & 549,61 & 101,51 & 122,99 & 542,04 \\
\hline Triturus marmoratus & 29TNG15 & 101,00 & 132,16 & 69,72 & 40,14 & 3685,33 & 227,32 & 55,75 & 171,56 & 93,81 & 178,93 & 180,33 & 86,39 & 1509,91 & 227,25 & 27,33 & 50,50 & 609,48 & 119,62 & 138,03 & 604,19 \\
\hline Triturus marmoratus & 29TNG16 & 63,00 & 144,91 & 65,38 & 39,81 & 3554,55 & 233,48 & 71,05 & 162,43 & 107,66 & 189,68 & 190,80 & 99,84 & 1361,27 & 195,80 & 24,69 & 49,54 & 549,03 & 108,17 & 128,84 & 528,42 \\
\hline Triturus marmoratus & 29TNG17 & 33,00 & 149,14 & 62,22 & 38,97 & 3510,00 & 234,61 & 76,97 & 157,64 & 112,28 & 193,11 & 194,33 & 104,31 & 1294,33 & 179,89 & 25,03 & 48,31 & 519,61 & 107,44 & 128,50 & 486,56 \\
\hline Triturus marmoratus & 29TNG18 & 45,00 & 144,43 & 61,74 & 38,37 & 3541,20 & 231,42 & 73,05 & 158,37 & 107,44 & 189,24 & 190,36 & 99,57 & 1364,63 & 199,30 & 28,12 & 48,48 & 549,64 & 116,34 & 136,83 & 520,34 \\
\hline Triturus marmoratus & 29TNG19 & 57,00 & 145,12 & 59,99 & \begin{tabular}{|c|}
37,97 \\
\end{tabular} & 3519,84 & 230,93 & 75,11 & 155,82 & 108,43 & 189,61 & 191,00 & 100,84 & 1316,97 & 192,33 & 28,91 & 47,32 & 528,09 & 117,50 & 139,10 & 493,80 \\
\hline Triturus marmoratus & 29TNG22 & 101,00 & 137,87 & 77,71 & 41,84 & 3802,67 & 239,14 & 55,51 & 183,63 & 92,15 & 185,93 & 187,09 & 90,40 & 1364,18 & 189,74 & 19,11 & 51,39 & 545,54 & 96,55 & 117,25 & 545,41 \\
\hline Triturus marmoratus & 29TNG24 & 99,00 & 142,72 & 73,68 & 40,92 & 3762,67 & 240,82 & 62,56 & 178,27 & 101,27 & 190,16 & 191,21 & 95,21 & 1360,54 & 195,29 & 21,41 & 50,56 & 545,50 & 101,24 & 121,49 & 538,65 \\
\hline Triturus marmoratus & 29TNG25 & 101,00 & 142,44 & 71,61 & 40,21 & 3755,29 & 239,25 & 63,49 & 175,77 & 101,68 & 189,94 & 190,94 & 95,01 & 1394,60 & 206,60 & 23,94 & 50,39 & 561,40 & 107,55 & 126,99 & 552,19 \\
\hline Triturus marmoratus & 29TNG26 & 100,00 & 137,42 & 70,38 & 39,69 & 3792,18 & 234,78 & \begin{tabular}{|c|}
59,26 \\
\end{tabular} & 175,52 & $\begin{array}{l}\mid 1,000 \\
95,03\end{array}$ & \begin{tabular}{|l|l|}
185,76 \\
\end{tabular} & 186,73 & 89,89 & 1494,19 & 233,27 & 28,30 & 50,67 & 605,16 & 120,03 & 137,69 & 598,49 \\
\hline Triturus marmoratus & 29TNG27 & 80,00 & 142,23 & 66,90 & 39,02 & 3729,91 & 235,55 & 66,17 & 169,38 & 100,94 & 189,67 & 190,59 & 95,20 & 1456,53 & 226,75 & 28,89 & 50,29 & 590,88 & 119,23 & 137,56 & 576,63 \\
\hline Triturus marmoratus & 29TNG28 & 86,00 & 139,17 & 65,44 & 38,37 & 3735,36 & 232,63 & 64,36 & 168,28 & 99,83 & 186,87 & 187,97 & 92,44 & 1463,59 & 227,46 & 31,15 & 49,23 & 589,78 & 125,44 & 144,09 & 572,35 \\
\hline Triturus marmoratus & 29TNG29 & 72,00 & 142,90 & 62,57 & 37,89 & 3707,49 & 233,27 & 70,12 & 163,15 & 103,57 & 190,24 & 191,12 & 96,35 & 1394,43 & 212,13 & 30,94 & 48,26 & 558,48 & 122,62 & 142,96 & 533,75 \\
\hline Triturus marmoratus & 29TNG31 & 101,00 & 138,13 & 83,65 & 42,12 & 3997,59 & 246,81 & 50,50 & 196,31 & 90,32 & 188,70 & 189,82 & 88,05 & 1338,81 & 185,48 & 18,15 & 51,15 & 533,35 & 94,35 & 113,34 & 533,25 \\
\hline Triturus marmoratus & 29TNG32 & 101,00 & 142,57 & 82,02 & 年 41,84 & 3972,07 & 249,01 & 55,81 & $\begin{array}{l}194,06 \\
1940\end{array}$ & $\begin{array}{l}0,0,75 \\
98,75\end{array}$ & 192,74 & $\begin{array}{l}193,71 \\
193,71\end{array}$ & $\begin{array}{ll}92,50 \\
92,5\end{array}$ & $\mid \begin{array}{l}\mid 3500,19 \\
130,19\end{array}$ & \begin{tabular}{|l|}
180,92, \\
\end{tabular} & \begin{tabular}{l|l}
17,88 \\
17
\end{tabular} & 51,01 & 516,76 & 92,01 & 111,94 & 515,34 \\
\hline Triturus marmoratus & 29TNG33 & 100,00 & 128,02 & 80,92 & 40,79 & 4087,55 & 238,12 & 41,92 & 196,20 & 79,68 & 180,45 & 181,48 & 77,39 & 1483,19 & 217,87 & 24,47 & 50,58 & 592,61 & 114,75 & 129,94 & 592,45 \\
\hline Triturus marmoratus & 29TNG34 & 100,00 & 130,47 & 79,59 & 40,55 & 4068,19 & 239,44 & 45,08 & 194,36 & 84,61 & 182,58 & 183,56 & 79,95 & 1482,56 & 223,25 & 25,5 & 50,53 & 593,07 & 116,73 & 132,15 & 591,82 \\
\hline Triturus marmoratus & 29TNG35 & 100,00 & 145,15 & 76,03 & 40,07 & 3941,12 & 248,67 & 61,79 & 186,88 & 101,87 & 195,09 & 195,83 & 95,17 & 1342,05 & 200,47 & 22,86 & 50,10 & 537,04 & 104,42 & 122,88 & 526,61 \\
\hline Triturus marmoratus & 29TNG36 & 101,00 & 144,76 & 73,61 & 39,76 & 3928,62 & 246,38 & 62,98 & 183,40 & 101,35 & 194,70 & 195,47 & 95,00 & 1380,58 & 213,07 & 25,50 & 50,08 & 554,99 & 110,69 & 128,51 & 543,54 \\
\hline Triturus marmoratus & 29TNG38 & 88,00 & $\begin{array}{l}149,10 \\
139,79\end{array}$ & 70,11 & 38,73 & $\begin{array}{ll}352,0,04 \\
3935,64\end{array}$ & $\begin{array}{ll}24,50 \\
239,20\end{array}$ & $\begin{array}{l}60,43 \\
60,2 \\
\end{array}$ & \begin{tabular}{|l|l|l|l|l|l|}
178,77 \\
\end{tabular} & \begin{tabular}{|c|}
01,30 \\
97,45 \\
\end{tabular} & 190,29 & $\begin{array}{l}190,41,03 \\
191\end{array}$ & $\begin{array}{l}90,00 \\
90,49\end{array}$ & | $130,01,61$ & \begin{tabular}{|l|l|l|l|l|}
233,79 \\
\end{tabular} & 31,05 & \begin{tabular}{l|l}
40,66 \\
49,6
\end{tabular} & 586,56 & 124,93 & 141,71 & 575,20 \\
\hline Triturus marmoratus & 29TNG39 & 101,00 & 136,77 & 68,86 & 38,12 & 3933,53 & 236,40 & 58,27 & 178,13 & 94,66 & 187,42 & 188,34 & 87,94 & 1478,41 & 235,28 & 33,27 & 48,80 & 590,26 & 130,99 & 148,84 & 576,22 \\
\hline Triturus marmoratus & 29TNG40 & 101,00 & 145,85 & 88,48 & 42,53 & 4128,39 & 258,94 & 53,25 & 205,69 & 100,52 & 197,76 & 198,85 & 93,45 & 1208,74 & $\mid 163,53$ & 15,25 & 50,98 & 478,58 & 83,25 & 102,33 & 474,61 \\
\hline Triturus marmoratus & 29TNG41 & 100,00 & 138,67 & 87,77 & 41,7 & 4212,47 & 254,27 & 46,55 & 207,72 & 92,38 & 192,13 & 193,18 & 85,67 & 1304,64 & 181,44 & 18,13 & 50,77 & 517,18 & 94,26 & 111,32 & 514,42 \\
\hline Triturus marmoratus & 29TNG43 & 101,00 & 137,51 & 85,64 & 40,89 & 4235,56 & 253,34 & 46,66 & 206,68 & 91,15 & 191,53 & 192,29 & 84,30 & 1342,99 & 195,19 & 21,1 & 50,03 & 532,19 & 103,16 & 118,92 & 527,01 \\
\hline Triturus marmoratus & 29TNG44 & 100,00 & 130,60 & 84,27 & 40,42 & 4270,75 & 246,88 & 40,75 & 206,14 & 84,49 & 185,44 & 186,28 & 77,45 & 1431,34 & 214,47 & 24 & 49,83 & 567,90 & 115,32 & 129,11 & 563,75 \\
\hline Triturus marmoratus & 29TNG48 & 100,00 & 128,16 & 78,41 & 39,08 & 4198,61 & 239,79 & 41,84 & 197,95 & 83,04 & 182,58 & 183,64 & 76,66 & 1502,07 & 239,28 & 32,79 & 48,85 & 595,05 & 133,86 & 147,87 & 587,57 \\
\hline Triturus marmoratus & 29TNG49 & 101,00 & 125,64 & 77,56 & 38,85 & 4165,73 & 237,61 & 39,97 & 197,64 & 81,13 & 179,86 & 181,09 & 75,07 & 1508,88 & 237,59 & 34,66 & 47,92 & 594,55 & 138,65 & 153,11 & 584,39 \\
\hline Triturus marmoratus & 29TNG50 & 101,00 & 140,38 & 92,44 & 41, & 4400,09 & 262,18 & 43,75 & 218,44 & 91,96 & 196,36 & 197,28 & 84,86 & 1243,80 & 68,81 & 16, & 50,69 & 22,03 & 88,82 & 04,69 & 487,03 \\
\hline Triturus marmoratus & 29TNG51 & 100,00 & 138 & $\begin{array}{l}91,440 \\
11,40\end{array}$ & $\frac{41,4}{41,4}$ & 4425,39 & 260,50 & 42,19 & 218,31 & 89,59 & 194,64 & 195,49 & 82,54 & $\begin{array}{l}1274,66 \\
127,66\end{array}$ & \begin{tabular}{|l|l|l}
176,06 \\
\end{tabular} & & 50,29 & 503,34 & $\begin{array}{ll}0.0,02 \\
93,86\end{array}$ & 109,01 & 498,60 \\
\hline Triturus marmoratus & 29TNG52 & 100,00 & 13 & 89,65 & 40, & 4468,95 & 253,57 & 35,99 & 217,57 & 81,64 & 188,20 & 188,95 & 75,02 & 1357,70 & 191,48 & 21,14 & 49,95 & 535,88 & 104,88 & 117,86 & 532,10 \\
\hline Triturus marmoratus & 29TNG53 & 101,00 & 131,96 & 89,04 & 40,50 & 4465,45 & 254,88 & 37,47 & 217,42 & 83,37 & 189,44 & 190,19 & 76,41 & 1345,19 & 193,52 & 21,98 & 49,53 & 529,65 & 106,91 & 119,50 & 523,62 \\
\hline Triturus marmoratus & 29TNG54 & 101,00 & 107,50 & 82,47 & 38,62 & 4465,10 & 228,68 & 18,35 & 210,33 & 60,80 & 166,06 & 167,06 & 54,06 & 1555,27 & 221,33 & 30,16 & 48,53 & 611,15 & 134,21 & 142,65 & 608,70 \\
\hline Triturus marmoratus & 29TNG58 & 99,00 & 113,23 & 81,48 & $38, \varepsilon$ & 4356,27 & 232,03 & 24,34 & 207,69 & 66,96 & 170,34 & 171,53 & 61,18 & 1517,29 & 227,58 & 34,32 & 47,03 & 85 & 42 & 152,52 & 583,34 \\
\hline Triturus marmoratus & 29TNG5 & $\begin{array}{l}500,00 \\
100\end{array}$ & $11:$ & $\frac{01}{80}$ & $3 \varepsilon$ & 0,01 & 231,79 & 24,08 & \begin{tabular}{|l|}
206,71 \\
203
\end{tabular} & $\mid \begin{array}{ll}\mid 60,70 \\
671\end{array}$ & $\begin{array}{l}170,02 \\
170\end{array}$ & $\begin{array}{ll}171,45 \\
171\end{array}$ & \begin{tabular}{l|l}
62,24 \\
621
\end{tabular} & 1509,61 & $\mid$\begin{tabular}{|l|l|}
$\mid 226,36$ \\
\end{tabular} & 35, & $\begin{array}{ll}44,35 \\
46,38\end{array}$ & 586,61 & $\begin{array}{l}141,4 \mathrm{~L} \\
144,05\end{array}$ & 155,97 & $\begin{array}{l}503,24 \\
575,97\end{array}$ \\
\hline Triturus marmoratus & 29TNG60 & 100,00 & 134,74 & 95,32 & 41,24 & 4644,93 & 263,68 & 35,02 & 228,66 & 83,36 & 194,34 & 195,08 & 76,56 & 1273,15 & 170,29 & 17,49 & 50,72 & 502,46 & 92,99 & 105,74 & 499,23 \\
\hline Triturus marmoratus & 29TNG61 & 101,00 & 129,52 & 92,96 & 40,52 & 4652,63 & 257,84 & 31,49 & 226,34 & 76,71 & 189,55 & 190,32 & 71,80 & 1320,79 & 179,13 & 19,68 & 50,09 & 520,45 & 100,31 & 111,37 & 517,43 \\
\hline Triturus marmoratus & 29TNG62 & 101,00 & 115,32 & 87,95 & 39,30 & 4647,57 & 241,85 & 21,15 & 220,70 & 62,37 & 176,03 & 176,82 & 58,84 & 1450,71 & 198,80 & 24,52 & 49,68 & 571,37 & 116,97 & 125,53 & 570,44 \\
\hline Triturus marmoratus & 29TNG63 & 100,00 & 123,83 & 90,23 & 39,7 & 4660,90 & 251,54 & 27,50 & 224,04 & 72,50 & 184,36 & 185,01 & 66,47 & 1369,05 & 192,82 & 23,31 & 49,05 & 536,57 & 111,71 & 121,10 & 53 \\
\hline Triturus marmoratus & $\begin{array}{l}29 T N G 64 \\
2904\end{array}$ & $\begin{array}{l}101,00 \\
100\end{array}$ & $\begin{array}{l}12,03 \\
110,77\end{array}$ & $\begin{array}{l}80,25 \\
85,49\end{array}$ & 38,75 & $\begin{array}{ll}400,050 \\
4618,93 \\
\end{array}$ & 235,92 & $\begin{array}{l}1,20 \\
18,21 \\
\end{array}$ & \begin{tabular}{|l|l|}
217,71 \\
\end{tabular} & 61,90 & 171,38 & 172,25 & 55,21 & 1481,37 & 208,95 & 28,14 & 48,52 & 579,94 & 126,96 & 135,08 & 577,66 \\
\hline Triturus marmoratus & 29TNG65 & 100,00 & 104,96 & 83,10 & 38,21 & 4573,78 & 228,97 & 14,35 & 214,62 & 57,06 & 165,27 & 166,23 & 50,52 & 1523,45 & 215,64 & 31,05 & 47,71 & 594,87 & 135,51 & 143,03 & 591,62 \\
\hline Triturus marmoratus & 29TNG66 & 100,00 & 132,97 & 90,07 & 39,70 & 4650,79 & 259,97 & 35,22 & 224,75 & 81,72 & 193,13 & 193,56 & 75,17 & 1269,36 & 188,81 & 24,75 & 47,50 & 491,39 & 112,81 & 122,05 & 476,26 \\
\hline Triturus & 29TNG68 & 101,00 & 125,16 & 85,59 & 38,95 & 45,41 & 247,24 & 30,58 & 216,66 & 75,50 & 184 & 185 & 69 & 1345,60 & 201,85 & 29,79 & 46 & 519,66 & 125,28 & 137,12 & 507 \\
\hline Triturus marmoratus & 29TNG70 & 100,00 & 125,96 & 95,39 & 40,34 & 4836,55 & 259,46 & 25,65 & 233,80 & 69,04 & 188,61 & 189,35 & 66,06 & 1323,33 & 177,65 & 18,87 & 50,92 & 523,00 & 98,51 & 107,73 & 522, \\
\hline
\end{tabular}




\begin{tabular}{|c|c|c|c|c|c|c|c|c|c|c|c|c|c|c|c|c|c|c|c|c|c|}
\hline TAXON & UTM & $\mathrm{km} 2$ & B101 & $\mathrm{B1O2}$ & $\mathrm{BIO3}$ & BIO4 & B105 & 8106 & B107 & $\mathrm{B108}$ & B109 & B1010 & BIO11 & BIO12 & B1013 & B1014 & BIO15 & B1016 & B1017 & B1018 & B1019 \\
\hline Triturus marmoratus & 29TNG71 & 101,00 & 123,47 & 93,49 & 39,85 & 4824,53 & 255,95 & 24,26 & 231,69 & 67,47 & 186,21 & 186,93 & 64,12 & 1335,23 & 178,47 & 20,38 & 50,23 & 525,75 & 102,88 & 111,40 & 524,43 \\
\hline Triturus marmoratus & 29TNG72 & 100,00 & 97,65 & 83,12 & 37,48 & 4745,83 & 225,53 & 6,75 & 218,78 & 42,20 & 160,59 & 161,38 & 41,58 & 1545,54 & 206,22 & 28,51 & 49,13 & 607,76 & 130,75 & 134,74 & 607,72 \\
\hline Triturus marmoratus & 29 TNG73 & 100,00 & 115,12 & 89,06 & 38,83 & 4792,36 & 245,33 & 18,81 & 226,53 & 61,56 & 177,89 & 178,53 & 57,06 & 1389,96 & 190,55 & 24,75 & 48,83 & 543,13 & 116,06 & 122,88 & 540,40 \\
\hline Triturus marmoratus & 29TNG74 & 100,00 & 118,22 & 89,85 & 39,04 & 4792,53 & 248,44 & 20,96 & 227,47 & 66,63 & 181,05 & 181,57 & 60,02 & 1355,98 & 189,64 & 24,99 & 48,16 & 527,67 & 115,35 & 123,03 & 523,51 \\
\hline Triturus marmoratus & 29TNG75 & 100,00 & 95,31 & 81,82 & 37,30 & 4670,94 & 221,61 & 5,29 & 216,32 & 47,01 & 157,29 & 158,27 & 40,48 & 1539,21 & 211,15 & 32,58 & 47,17 & 598,54 & 140,23 & 145,68 & 596,07 \\
\hline Triturus marmoratus & 29TNG76 & 101,00 & 119,59 & 88,52 & 38,71 & 4750,27 & 247,99 & 22,54 & 225,45 & 68,06 & 181,81 & 182,36 & 61,94 & 1331,79 & 191,78 & 27,01 & 47,14 & 514,88 & 119,36 & 127,88 & 506,72 \\
\hline Triturus marmoratus & 29TNG78 & 100,00 & 139,06 & 89,04 & 38,86 & 4789,06 & 264,12 & 37,72 & 226,40 & 85,44 & 201,18 & 201,45 & 79,82 & \begin{tabular}{|l|l|}
1126,93 \\
\end{tabular} & 167,65 & 24,12 & 45,96 & 428,39 & 104,06 & 112,19 & 412,40 \\
\hline Triturus marmoratus & 29TNG81 & 99,00 & 115,24 & 91,50 & 38,82 & 4947,70 & 249,65 & 16,98 & 232,68 & 55,94 & 180,29 & 180,76 & 55,18 & 1364,75 & 183,45 & 21,60 & 50,37 & 539,13 & 106,90 & 111,89 & 538,88 \\
\hline Triturus marmoratus & 29TNG82 & 101,00 & 108,29 & 87,72 & 38,01 & 4896,41 & 240,41 & 12,73 & 227,68 & 49,93 & 172,98 & 173,49 & 49,60 & 1410,36 & 187,29 & 24,39 & 49,53 & 554,55 & 115,56 & 120,32 & 554,48 \\
\hline Triturus marmoratus & 29TNG83 & 100,00 & 95,35 & 82,54 & 36,89 & 4825,88 & 224,96 & 4,18 & 220,77 & 39,97 & 159,66 & 160,33 & 38,78 & 1502,75 & 199,67 & 29,19 & 48,38 & 587,88 & 130,81 & 134,52 & 587,87 \\
\hline Triturus marmoratus & 29TNG84 & 101,00 & 115,06 & 89,61 & 38,44 & 4900,82 & 247,18 & 17,13 & 230,05 & 62,29 & 179,62 & 180,01 & 55,89 & 1330,30 & 182,38 & 24,65 & 48,11 & 516,80 & 113,30 & 119,51 & 514,85 \\
\hline Triturus marmoratus & 29TNG85 & 101,00 & 110,38 & 87,58 & 38,09 & 4847,86 & 241,14 & 14,13 & 227,01 & 58,55 & 174,38 & 174,95 & 52,32 & 1362,59 & 188,53 & 27,05 & 47,48 & 528,30 & 120,16 & 126,83 & 525,43 \\
\hline Triturus marmoratus & 29TNG86 & 100,00 & 118,55 & 89,98 & 38,52 & 4887,39 & 249,84 & 19,15 & 230,69 & 65,38 & 182,86 & 183,30 & 59,50 & 1277,69 & 180,86 & 25,94 & 46,84 & 491,94 & 114,51 & 120,97 & 485,73 \\
\hline Triturus marmoratus & 29TNG87 & 100,00 & 131,52 & 92,63 & 38,90 & 4978,81 & 263,13 & 27,19 & 235,94 & 75,96 & 196,55 & 196,79 & 70,46 & 1135,81 & 164,80 & 23,53 & 46,00 & 431,70 & 103,51 & 109,38 & 420,30 \\
\hline Triturus marmoratus & 29TNG88 & 100,00 & 134,92 & 90,86 & 38,50 & 4962,84 & 263,78 & 30,42 & 233,36 & 79,33 & 199,65 & 199,84 & 74,12 & $\begin{array}{ll}1091,09 \\
\end{array}$ & 159,33 & 23,65 & 45,35 & 411,98 & 101,28 & 106,87 & 399,33 \\
\hline Triturus marmoratus & 29TNG91 & 101,00 & 106,49 & 88,55 & 37,63 & 5026,95 & 242,03 & 9,90 & 232,12 & 46,30 & 173,06 & 173,50 & 46,30 & 1386,53 & 188,86 & 23,03 & 50,32 & 548,86 & 111,20 & 114,51 & 548,86 \\
\hline Triturus marmoratus & 29TNG92 & 101,00 & 104,70 & 86,50 & 37,29 & 4987,78 & 238,55 & 9,44 & 229,12 & 45,29 & 170,90 & 171,31 & 45,29 & 1385,85 & 185,38 & 24,36 & 49,44 & 545,62 & 114,51 & 117,69 & 545,62 \\
\hline Triturus marmoratus & 29TNG93 & 100,00 & 96,32 & 83,47 & 36,63 & 4929,91 & 228,39 & 3,62 & 224,77 & 39,17 & 162,07 & 162,53 & 38,30 & 1441,20 & 190,75 & 27,84 & 48,34 & 563,31 & 125,34 & 128,21 & 563,31 \\
\hline Triturus marmoratus & 29TNG94 & 100,00 & 104,76 & 86,30 & 37,24 & 4947,62 & 237,78 & 9,36 & 228,42 & 50,88 & 170,56 & 170,87 & 45,91 & 1358,63 & 181,85 & 26,28 & 47,98 & 528,21 & 118,26 & 122,51 & 528,04 \\
\hline Triturus marmoratus & 29TNG98 & 101,00 & 137,22 & 92,45 & 37.87 & 5162,84 & 269,37 & 28,60 & 240,77 & 79,01 & 204,71 & 204,75 & 73,95 & 989,93 & 142,03 & 21,46 & 44,79 & 370,10 & 91,71 & 93,81 & 359,00 \\
\hline Triturus marmoratus & 29TNG99 & 101,00 & 134,39 & 91,03 & 38,14 & 5016,64 & 264,07 & 28,52 & 235,55 & 77,88 & 199,94 & 200,11 & 73,24 & 1026,37 & 147,59 & 23,5 & 44,20 & 384,14 & 97,82 & 102,91 & 372,22 \\
\hline Triturus marmoratus & 29TNHOO & 16,00 & 147,29 & 59,00 & 38,48 & 3400,52 & 230,67 & 78,95 & 151,71 & 112,29 & 190,24 & \begin{tabular}{|l|l|l|l|l|}
191,67 \\
\end{tabular} & 104,38 & 1225,90 & $\begin{array}{l}174,48 \\
\end{array}$ & 26,95 & 46,81 & 491,57 & \begin{tabular}{rl|}
111,81 \\
\end{tabular} & 134,71 & 450,57 \\
\hline Triturus marmoratus & 29TNH02 & 97,00 & 132,26 & 63,14 & 37,98 & 3521,94 & 224,76 & 60,48 & 164,28 & 97,19 & 177,01 & 179,36 & 89,11 & 1311,65 & 191,91 & 32,75 & 44,97 & 520,73 & 131,71 & 153,40 & 479,06 \\
\hline Triturus marmoratus & 29TNH03 & 72,00 & 140,28 & 62,04 & 38,15 & 3441,65 & 229,47 & 68,97 & 160,50 & 106,00 & 183,51 & 186,10 & 97,60 & 1187,87 & 170,53 & 29,84 & 44,38 & 470,94 & 121,46 & 144,58 & 424,12 \\
\hline Triturus marmoratus & 29TNH05 & 99,00 & 130,21 & 64,82 & 38,15 & 3496,92 & 225,11 & 57,22 & 167,89 & 96,18 & 174,38 & 177,55 & 87,89 & 1236,42 & 176,17 & 33,76 & 42,70 & 484,35 & 135,19 & 157,82 & 436,14 \\
\hline Triturus marmoratus & 29TNH08 & 81,00 & 139,86 & 62,83 & 39,45 & 3245,91 & 226,50 & 68,94 & 157,55 & 108,65 & 179,71 & 183,68 & 99,93 & 1066,54 & 146,17 & 30,11 & 40,82 & 414,13 & 122,84 & 147,26 & 363,35 \\
\hline Triturus marmoratus & 29TNHO9 & 36,00 & 140,84 & $\begin{array}{ll}62,53 \\
\end{array}$ & 39,81 & $\begin{array}{ll}3197,92 \\
3197\end{array}$ & 225,89 & 70,47 & 155,42 & 110,27 & 179,88 & 184,00 & $\mid$ & 1046,33 & $\mid 142,86$ & \begin{tabular}{l|l}
29,83 \\
29
\end{tabular} & $\begin{array}{ll}40,06 \\
40,\end{array}$ & \begin{tabular}{|l|l|}
404,94 \\
\end{tabular} & \begin{tabular}{|l|l|}
121,86 \\
\end{tabular} & 146,55 & 354,73 \\
\hline Triturus marmoratus & 29TNH10 & 61,00 & 146,39 & 60,06 & 37,91 & 3519,36 & 232,27 & 76,11 & 156,16 & 109,72 & 190,75 & 192,23 & 101,94 & 1275,06 & 185,37 & 28,73 & 46,99 & 509,45 & 116,28 & 138,47 & 472,93 \\
\hline Triturus marmoratus & 29TNH11 & 40,00 & 146,34 & 60,45 & 37,82 & 3518,47 & 233,20 & 75,68 & 157,53 & 109,97 & 190,80 & 192,50 & 102,30 & 1241,93 & 180,28 & 28,89 & 46,24 & 494,43 & 116,57 & 139,20 & 455,66 \\
\hline Triturus marmoratus & 29TNH13 & 101,00 & 134,28 & 65,16 & 37,83 & 3618,45 & 230,51 & 60,17 & 170,34 & 97,99 & 180,32 & 182,90 & 90,05 & 1306,88 & 191,55 & 33,69 & 44,61 & 514,94 & 132,93 & 154,63 & 475,23 \\
\hline Triturus marmoratus & 29TNH14 & 100,00 & 133,17 & 66,01 & 37,97 & 3607,29 & 230,45 & 58,59 & 171,85 & 97,29 & 178,97 & 181,81 & 89,22 & 1284,45 & 186,08 & 34,10 & 43,76 & 503,35 & 134,48 & 156,51 & 461,63 \\
\hline Triturus marmoratus & 29TNH19 & 64,00 & 140,89 & 60,56 & 39,93 & 3223,95 & 227,11 & \begin{tabular}{|c|c|}
69,77 \\
69,
\end{tabular} & 157,34 & \begin{tabular}{|c|}
109,84 \\
\end{tabular} & \begin{tabular}{|l|l|}
180,43 \\
\end{tabular} & \begin{tabular}{|l|l|l}
184,43 \\
\end{tabular} & \begin{tabular}{|l|}
101,17 \\
1017
\end{tabular} & $\begin{array}{l}12059,58 \\
105,58\end{array}$ & \begin{tabular}{|l|l|l|l|l}
143,29 \\
\end{tabular} & 30,28 & 40,01 & \begin{tabular}{|l|l|}
408,67 \\
\end{tabular} & \begin{tabular}{|l|}
122,48 \\
12,4
\end{tabular} & 146,75 & 361,63 \\
\hline Triturus marmoratus & $29 \mathrm{TNH} 20$ & 100,00 & 140,04 & 63,04 & 37,60 & 3718,64 & 232,42 & 66,87 & 165,55 & 101,01 & 187,74 & 188,88 & 93,81 & 1395,50 & 212,46 & 32,47 & 47,52 & 556,28 & 127,28 & 147,77 & 529,68 \\
\hline Triturus marmoratus & 29TNH21 & 101,00 & 143,07 & 62,99 & 37,73 & 3680,33 & 234,96 & 69,79 & 165,16 & 104,60 & 190,07 & 191,50 & 97,21 & 1313,98 & 195,41 & 31 & 46,36 & 520,52 & 123,46 & 145,06 & 488,04 \\
\hline Triturus marmoratus & 29TNH22 & 98,00 & 142,56 & 64,37 & 37,83 & 3673,06 & 236,45 & 68,27 & 168,18 & 104,48 & 189,39 & 191,20 & 97,00 & 1282,23 & 189,18 & 31,60 & 45,59 & 505,62 & 124,06 & 145,95 & 470,89 \\
\hline Triturus marmoratus & 29TNH23 & 100,00 & 140,69 & 65,81 & 37,91 & 3675,02 & 236,85 & 65,44 & 171,42 & 102,96 & 187,49 & 189,76 & 95,38 & 1268,02 & 185,23 & 32,23 & 44,81 & 497,28 & 126,63 & 148,60 & 460,75 \\
\hline Triturus marmoratus & 29TNH24 & 101,00 & $\begin{array}{l}149,03 \\
139,46\end{array}$ & 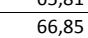 & 38,14 & 3657,53 & 237,04 & $\begin{array}{l}63,64 \\
63,5 \\
\end{array}$ & $\begin{array}{l}11,424 \\
73,40 \\
\end{array}$ & $\begin{array}{l}102,320 \\
102,3\end{array}$ & \begin{tabular}{|l|}
185,96 \\
185,49
\end{tabular} & $\begin{array}{l}188,60 \\
188,0\end{array}$ & $\begin{array}{l}3,300 \\
94,54 \\
\end{array}$ & $\begin{array}{l}120,04 \\
1247,55\end{array}$ & \begin{tabular}{|l|}
180,10 \\
180,10
\end{tabular} & \begin{tabular}{|c|c|c|}
32,75 \\
\end{tabular} & $\begin{array}{l}44,10 \\
43,93 \\
\end{array}$ & \begin{tabular}{|l|}
$\mid 486,78$ \\
486,7
\end{tabular} & \begin{tabular}{|l|l|}
128,33 \\
\end{tabular} & $\begin{array}{l}140,00 \\
150,59\end{array}$ & 448,39 \\
\hline Triturus marmoratus & 29TNH25 & 101,00 & 134,22 & 68,49 & 38,02 & 3679,17 & 235,07 & 57,13 & 177,94 & 97,31 & 180,95 & 184,04 & 89,61 & 1277,87 & 182,81 & 34,92 & 42,98 & 495,32 & 135,80 & 157,76 & 456,50 \\
\hline Triturus marmoratus & 29TNH27 & 100,00 & 129,17 & 68,83 & 38,77 & 3574,89 & 228,79 & 53,35 & 175,45 & 94,07 & 174,25 & 178,02 & 86,21 & 1259,95 & 175,62 & 36,27 & 41,11 & 484,03 & 140,94 & 162,85 & 443,55 \\
\hline Triturus marmoratus & 29TNH28 & 101,00 & 138,15 & 66,22 & 39,76 & 3371,93 & 229,55 & 64,80 & 164,75 & 105,12 & 179,97 & 183,87 & 96,86 & 1124,24 & 152,92 & 32,00 & 40,55 & 432,17 & 126,98 & 150,29 & 389,89 \\
\hline Triturus marmoratus & 29TNH29 & 39,00 & 138,94 & 65,60 & 40,11 & 3300,89 & 227,96 & 66,33 & 161,63 & 106,78 & 179,56 & 183,64 & 98,28 & 1096,42 & 147,44 & 31,46 & 39,97 & 420,50 & 125,51 & 149,00 & 378,18 \\
\hline Triturus marmoratus & 29TNH31 & 100,00 & 135,63 & 69,05 & 37,66 & 3905,13 & 237,49 & 56,52 & 180,97 & 94,42 & 186,07 & 187,56 & 87,79 & 1419,43 & 217,60 & 34,7 & 46,73 & 558,64 & 134,36 & 153,66 & 535,47 \\
\hline Triturus marmoratus & 29TNH33 & 101,00 & 140,89 & 68,88 & 37,78 & 3814,67 & 241,68 & 61,72 & 179,97 & 101,09 & 189,69 & 191,86 & 94,03 & 1286,69 & 188,93 & 32,96 & 44,87 & 500,80 & 127,77 & 149,09 & 469,14 \\
\hline Triturus marmoratus & 29TNH34 & 100,00 & 137,98 & 70,61 & 37,67 & 3829,36 & 242,21 & 57,25 & 184,96 & 98,68 & 186,96 & 189,58 & 91,35 & $\mid 1297,37$ & 188,15 & 34,52 & 43,99 & 501,72 & 132,89 & 154,22 & 468,82 \\
\hline Triturus marmoratus & 29TNH35 & 101,00 & 132,84 & 72,28 & 37, & 3838,58 & 240,40 & 50,95 & 189,45 & 94,15 & 182,04 & 185,10 & 86,75 & 1326,75 & 190,10 & 36,64 & 43,10 & 81 & 40,19 & 61,30 & 476,37 \\
\hline Triturus marmoratus & 29TNH37 & 101,00 & 127,82 & 71,68 & 38 & 3685,61 & 231,99 & 48,85 & 183,14 & $\begin{array}{l}4,11,12 \\
91,\end{array}$ & \begin{tabular}{|l|}
174,58 \\
174,
\end{tabular} & & 83,80 & 1296,43 & 180,66 & 37,63 & 41 & & $\begin{array}{l}444,29 \\
\end{array}$ & 165,38 & 458,65 \\
\hline Triturus marmoratus & $29 \mathrm{TNH}$ & 66,00 & 137,72 & 67,21 & 40,50 & 3335,65 & 228,27 & 64,37 & 163,90 & 104,80 & 178,85 & 182,93 & 96,84 & 1111,28 & 148,76 & 32, & 39,82 & 423,65 & 126,76 & 149,62 & 385,50 \\
\hline Triturus marmoratus & 29 TNH40 & $\begin{aligned} 101,00 \\
\end{aligned}$ & 124,43 & 76,64 & 38,40 & 4126,21 & 236,23 & 39,22 & 197,01 & 80,58 & 178,19 & 179,63 & 74,68 & 1499,32 & 232,05 & 36,10 & 47,05 & 587,15 & 141,93 & 157,16 & 573,21 \\
\hline Triturus marmoratus & 29TNH42 & 100,00 & 132,13 & 74,96 & 37,98 & 4042,12 & 242,29 & 47,15 & 195,13 & 89,34 & 184,54 & 186,42 & 83,32 & 1407,67 & 212,28 & 35,99 & 45,57 & 545,52 & 138,23 & 156,49 & 523,46 \\
\hline Triturus marmoratus & $29 \mathrm{TNH} 43$ & 101,00 & 140,12 & 72,87 & 37,98 & 3953,22 & 246,17 & 56,53 & 189,64 & 98,34 & 190,91 & 193,06 & 91,84 & 1293,19 & 190,16 & 33,42 & 44,74 & 02 & 68 & 149,06 & 471,50 \\
\hline Triturus marmoratus & 29TNH44 & 99,00 & 13 & $\frac{7,201}{75,62}$ & $\frac{37,}{37,}$ & $\frac{5}{4}$ & 2 & $\begin{array}{l}0,30 \\
47,82\end{array}$ & $\begin{array}{l}199,184 \\
199,\end{array}$ & \begin{tabular}{|c|}
92,76 \\
92,76
\end{tabular} & 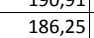 & $\begin{array}{l}188,81 \\
188,0\end{array}$ & $\begin{array}{l}1,24 \\
86,23\end{array}$ & $\begin{array}{l}129,1,19 \\
1354,82\end{array}$ & 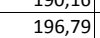 & $\begin{array}{l}30,44 \\
36,70\end{array}$ & \begin{tabular}{|c|c|}
43,95 \\
\end{tabular} & \begin{tabular}{|l|}
$518,70<$ \\
\end{tabular} & \begin{tabular}{|l|}
139,25 \\
1390
\end{tabular} & 159,31 & 490,94 \\
\hline Triturus marmoratus & 29TNH45 & 100,00 & 133,85 & 75,41 & 37,71 & 3948,35 & 245,54 & 48,08 & 197,45 & 93,39 & 184,49 & 187,60 & 86,62 & 1327,24 & 189,42 & 36,86 & 42,92 & 505,97 & 139,84 & 160,39 & 476,27 \\
\hline Triturus marmoratus & 29TNH46 & 100,00 & 133,61 & 74,17 & 38,49 & 3807,22 & 241,03 & 50,75 & 190,27 & 94,78 & 182,11 & 185,54 & 87,87 & 1277,88 & 179,38 & 36,11 & 41,96 & 486,11 & 137.91 & 158,76 & 454,57 \\
\hline Triturus marmoratus & 29TNH47 & 101,00 & 129,79 & 73,67 & 39,01 & 3726,10 & 235,43 & 48,83 & 186,61 & 92,02 & 177,26 & 180,80 & 85,29 & 1276,81 & 177,09 & 37,02 & 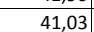 & 484,24 & 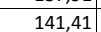 & 162,11 & 451,80 \\
\hline Triturus marmoratus & 29 TNH 48 & 99,00 & 130,64 & 71,90 & 39,94 & 3580,81 & 231,16 & 52,91 & 178,25 & 94,65 & 175,87 & 179 & 87,62 & 1222,47 & 166,76 & 35,87 & 40,09 & 463,07 & 138,08 & 159,15 & 425 \\
\hline Triturus marmoratus & $\begin{array}{l}29 \mathrm{TNH} 49 \\
2\end{array}$ & $\begin{array}{ll}35,00 \\
99,00\end{array}$ & 138,44 & $\begin{array}{l}1,100 \\
68,49\end{array}$ & 41,26 & $\begin{array}{l}350,019 \\
3334,69\end{array}$ & 228,73 & \begin{tabular}{|c|c|c|}
64,79 \\
64
\end{tabular} & $\begin{array}{l}16,25 \\
163,94 \\
\end{array}$ & 105,25 & 179,57 & 183,74 & 97,48 & 1091,49 & 144,73 & 31,59 & 39,26 & 413,86 & 124,45 & 146,72 & 379,25 \\
\hline Triturus marmoratus & 29TNH50 & 101,00 & 115,81 & 80,39 & 38,78 & 4246,05 & 232,99 & 27,72 & 205,27 & 70,53 & 171,45 & 172,95 & 65,34 & 1493,95 & 224,52 & 36,57 & 45,84 & 578,78 & 145,19 & 158,22 & 565,92 \\
\hline Triturus marmoratus & 29TNH53 & 101,00 & 136,65 & 77,41 & 38,54 & 4049,65 & 247,69 & 49,24 & 198,45 & 93,11 & 188,96 & 191,10 & 87,81 & 1301,01 & 191,18 & 34,07 & 44,30 & 497,36 & 130,92 & 49,73 & 473,88 \\
\hline Triturus & 29TNH54 & 100,00 & 137,07 & 77,10 & 38,52 & 3993,02 & 247,76 & 50,07 & 197,69 & 94,62 & 188,50 & 191, & 89 & 1279,09 & 184,57 & 34,47 & & 486 & 131,67 & 151,22 & 461, \\
\hline Triturus marmoratus & 29TNH55 & 101,00 & 132,55 & 77,84 & 38,55 & 952,98 & 244,93 & 45,58 & 199,35 & 91,08 & 183,42 & 186,37 & 85,47 & 1311,62 & 86,78 & 36,64 & 42,66 & 496,98 & 138,85 & 158,30 & 470,35 \\
\hline
\end{tabular}




\begin{tabular}{|c|c|c|c|c|c|c|c|c|c|c|c|c|c|c|c|c|c|c|c|c|c|}
\hline TAXON & UTM & $\mathrm{km} 2$ & B101 & B102 & $\mathrm{BIO3}$ & B104 & B105 & B106 & B107 & $\mathrm{B108}$ & B109 & B1010 & BIO11 & BIO12 & B1013 & B1014 & B1015 & BIO16 & BIO17 & B1018 & B1019 \\
\hline Triturus marmoratus & 29TNH56 & 101,00 & 131,83 & 76,71 & 38,90 & 3858,57 & 241,48 & 46,94 & 194,54 & 91,76 & 181,28 & 184,54 & 85,86 & 1281,64 & 179,77 & 36,54 & 41,76 & 484,46 & 138,73 & 158,58 & 456,12 \\
\hline Triturus marmoratus & 29TNH57 & 100,00 & 129,49 & 75,79 & \begin{tabular}{|l|l|}
39,47 \\
\end{tabular} & 3760,92 & 236,42 & 46,84 & 189,58 & 90,69 & 177,58 & 181,00 & 84,70 & 1264,25 & 174,91 & 36,84 & 40,79 & 476,82 & 140,23 & 160,14 & 447,24 \\
\hline Triturus marmoratus & 29TNH58 & 101,00 & 136,43 & 72,36 & 40,72 & 3553,90 & 234,25 & 58,55 & 175,70 & 100,03 & 181,02 & 184,78 & 93,25 & 1141,24 & 154,04 & 33,02 & 39,87 & 430,70 & 128,01 & 149,16 & 399,31 \\
\hline Triturus marmoratus & 29TNH59 & 98,00 & 140,77 & 69,91 & 41,80 & 3381,91 & 231,80 & 66,23 & 165,56 & 106,31 & 182,51 & 186,54 & 99,09 & 1058,70 & 139,63 & 30,57 & 39,04 & 399,41 & 120,42 & 142,28 & 367,09 \\
\hline Triturus marmoratus & 29TNH60 & 100,00 & 118,94 & 83,20 & 38,98 & 4353,18 & 238,48 & 27,84 & 210,64 & 71,76 & 175,90 & 177,36 & 67,11 & 1409,20 & 210,16 & 34,42 & 45,45 & 541,88 & 137,56 & 150,38 & 528,85 \\
\hline Triturus marmoratus & 29TNH61 & 101,00 & 119,95 & 82,67 & 39,13 & 4262,34 & 238,07 & 29,73 & 208,34 & 73,64 & 175,70 & 177,29 & 69,46 & 1400,04 & 207,77 & 35,43 & 44,95 & 536,38 & 139,36 & 153,01 & 521,48 \\
\hline Triturus marmoratus & 29TNH62 & 101,00 & 126,70 & 82,14 & 39,66 & 4142,87 & 242,07 & 37,06 & 205,01 & 81,27 & 180,62 & 182,46 & 77,59 & 1348,88 & 199,73 & 34,98 & 44,38 & 514,25 & 135,83 & 151,36 & 496,63 \\
\hline Triturus marmoratus & 29TNH63 & 100,00 & 127,69 & 81,29 & 39,80 & 4046,96 & 241,44 & 39,35 & 202,09 & 83,45 & 180,25 & 182,44 & 79,89 & 1331,88 & 194,42 & 35,67 & 43,65 & 505,65 & 137,02 & 153,53 & 485,67 \\
\hline Triturus marmoratus & 29TNH66 & 101,00 & 129,58 & 78,71 & \begin{tabular}{|c|}
39,87 \\
\end{tabular} & 3857,86 & 239,18 & 44,01 & 195,17 & 88,47 & 179,21 & 182,21 & 83,81 & 1260,61 & 176,24 & 36,25 & 41,21 & 474,02 & 137,71 & 156,45 & 447,92 \\
\hline Triturus marmoratus & 29TNH67 & 100,00 & 126,03 & 77,79 & 40,01 & 3800,28 & 234,24 & 42,32 & 191,92 & 86,01 & 174,86 & 178,03 & 81,18 & 1264,47 & 174,59 & 37,33 & 40,38 & 474,41 & 141,64 & 160,31 & 446,85 \\
\hline Triturus marmoratus & 29TNH68 & 101,00 & 134,85 & 74,68 & 40,77 & 3631,25 & 235,43 & 54,60 & 180,83 & 96,81 & 180,73 & 184,20 & 90,95 & 1139,74 & 153,76 & 33,40 & 39,51 & 427,46 & 128,78 & 149,04 & 397,92 \\
\hline Triturus marmoratus & 29TNH69 & 95,00 & 138,76 & 72,50 & 41,54 & 3500,36 & 233,97 & 61,39 & 172,57 & 102,55 & 182,52 & 186,15 & 95,99 & 1070,00 & 141,51 & 31,45 & 38,83 & 401,11 & 122,61 & 143,65 & 370,04 \\
\hline Triturus marmoratus & 29TNH70 & 101,00 & 121,99 & 85,74 & 39,01 & 4488,05 & 244,15 & 27,49 & 216,65 & 72,54 & $\begin{array}{l}180,79 \\
\end{array}$ & 181,86 & 68,41 & 1311,15 & 193,43 & 31,86 & 44,90 & 500,27 & 128,43 & 141,17 & 487,17 \\
\hline Triturus marmoratus & 29TNH72 & 100,00 & 120,88 & 84,11 & 39,92 & 4229,67 & 238,74 & 30,06 & 208,68 & 74,28 & 176,17 & 177,82 & 71,15 & 1325,34 & 192,94 & 34,76 & 43,67 & 502,72 & 135,75 & 149,76 & 486,41 \\
\hline Triturus marmoratus & 29TNH73 & 101,00 & 126,68 & 83,29 & \begin{tabular}{l|l|l}
40,45 & \\
\end{tabular} & 4067,70 & 240,51 & 37,36 & 203,15 & 81,38 & 179,54 & 181,47 & 78,91 & 1275,06 & 184,29 & 34,28 & 43,04 & 481,31 & 132,43 & 148,01 & 462,41 \\
\hline Triturus marmoratus & 29TNH76 & 100,00 & 123,45 & 80,75 & 40,48 & 3913,96 & 234,63 & 37,28 & 197,35 & 81,06 & 174,02 & 176,74 & 77,42 & 1263,07 & 175,84 & 36,85 & 40,71 & 472,81 & 140,15 & 157,23 & 448,44 \\
\hline Triturus marmoratus & 29TNH77 & 100,00 & 122,67 & 79,66 & 40,36 & 3855,55 & 232,35 & 37,61 & 194,73 & 81,38 & 172,28 & 175,29 & 77,27 & 1252,18 & 172,13 & 37,44 & 39,90 & 467,53 & 142,08 & 159,52 & 441,33 \\
\hline Triturus marmoratus & 29TNH78 & 100,00 & 125,41 & 78,00 & 40,75 & 3774,11 & 231,87 & 42,35 & 189,52 & 85,45 & 173,73 & 176,95 & 80,70 & 1203,79 & 163,01 & 36,49 & 39,10 & 448,58 & 138,77 & 157,20 & 420,48 \\
\hline Triturus marmoratus & 29TNH82 & 100,00 & 116,25 & 85,54 & 39,56 & 4367,94 & 237,33 & 23,49 & 213,84 & 68,15 & 173,50 & 175,03 & 64,72 & 1291,08 & 184,62 & 34,22 & 42,98 & 487,78 & 134,11 & 147,04 & 472,19 \\
\hline Triturus marmoratus & 29TNH85 & 101,00 & 121,53 & 83,23 & 40,44 & 4063,13 & 235,80 & 32.57 & 203,23 & 76,88 & 174,31 & 176,45 & 73,91 & 1235,25 & 172,50 & 35,55 & 40,89 & 461,64 & 135,93 & 151,63 & 439,92 \\
\hline Triturus marmoratus & 29TNH88 & 101,00 & 120,39 & 79,96 & 40,75 & 3879,56 & 229,84 & 35,39 & 194,45 & 78,82 & 170,37 & 173,09 & 74,51 & 1209,88 & 163,08 & 37,4 & 38,62 & 48,59 & 141,75 & 158,84 & 421,24 \\
\hline Triturus marmoratus & 29TNH90 & 100,00 & 122,24 & 89,38 & 38,96 & 4753,56 & 249,93 & 22,45 & 227,48 & 69,16 & 184,61 & 185,24 & 65,15 & $\begin{array}{l}1166,68 \\
1160\end{array}$ & 166,79 & 28,45 & 43,87 & 440,45 & 115,60 & 126,20 & 428,22 \\
\hline Triturus marmoratus & 29TNH91 & 101,00 & 118,31 & 88,03 & 39,00 & 4616,37 & 244,04 & 21,27 & 222,77 & 67,07 & 178,96 & 179,91 & 63,44 & 1205,83 & 171,39 & 30,83 & 43,10 & 454,83 & 123,06 & 135,26 & 441,25 \\
\hline Triturus marmoratus & 29TNH92 & 101,00 & 117,40 & 87,18 & 39,25 & 4506,35 & 240,98 & 22,00 & 218,98 & 67,39 & 176,50 & 177,65 & 64,03 & 1213,36 & 171,45 & 32,25 & 42,41 & 456,32 & 126,99 & 139,71 & 440,75 \\
\hline Triturus marmoratus & 29TNH93 & 100,00 & 120,09 & 86,50 & 39,86 & 4380,79 & 240,84 & 26,01 & 214,82 & 71,35 & 177,34 & 178,84 & 68,32 & 1192,53 & 167,75 & 32,62 & 41,76 & 446,68 & 127,21 & 141,04 & 429,09 \\
\hline Triturus marmoratus & 29TNH97 & 100,00 & 122,66 & 82,42 & 40,76 & 4034,11 & 235,08 & 34,51 & 200,57 & 78,55 & 174,71 & 177,24 & 74,77 & 1155,42 & 156,30 & 35,05 & 38,88 & 427,68 & 133,61 & 150,03 & 402,29 \\
\hline Triturus marmoratus & 29TNH98 & 101,00 & 121,27 & \begin{tabular}{|l|l|l|l|}
81,36 \\
\end{tabular} & 40,79 & 3959,32 & 232,09 & 34,47 & $\begin{array}{l}197,61 \\
\end{array}$ & 78,34 & 172,28 & 174,98 & 74,29 & 1159,91 & 155,18 & 36,09 & 38,11 & 428,21 & 137,12 & 153,85 & 401,04 \\
\hline Triturus marmoratus & 29TNJ40 & 18,00 & 140,90 & 67,00 & 41,90 & 3225,38 & 226,97 & 68,62 & 158,34 & 109,17 & 180,34 & 184,66 & 101,00 & 1040,24 & 135,86 & 30,03 & 39,00 & 394,31 & 119,52 & 142,10 & 359,59 \\
\hline Triturus marmoratus & 29TNJ50 & 35,00 & 140,32 & 69,33 & 42,05 & 3314,98 & 229,41 & 66,90 & 162,51 & 106,79 & 181,08 & 185,25 & 99,56 & 1041,52 & 135,65 & 30,56 & 38,54 & 392,02 & 120,49 & 142,51 & 359,29 \\
\hline Triturus marmoratus & 29TNJ51 & 48,00 & 137,32 & 69,06 & 42,18 & 3289,25 & 226,38 & 64,58 & 161,79 & 104,32 & 177,74 & 182,08 & 96,99 & 1053,97 & 136,43 & 32,00 & 37,81 & 395,00 & 125,51 & 147,40 & 360,88 \\
\hline Triturus marmoratus & 29TNJ52 & 12,00 & 139,57 & 68,29 & 42,50 & 3239,32 & 226,61 & 67,61 & 159,00 & 107,07 & 179,29 & 183,57 & 99,82 & 1024,82 & 132,75 & 31,04 & 37,57 & 383,82 & 122,86 & 145,32 & 348,71 \\
\hline Triturus marmoratus & 29TNJ60 & 66,00 & 138,42 & $\begin{array}{ll}71,58 \\
7\end{array}$ & 4L, 41,92 & 3427,75 & 231,34 & $\mid 62,74$ & $\begin{array}{l}168,59 \\
\end{array}$ & $\begin{array}{l}103,12 \\
\end{array}$ & 181,05 & $\begin{array}{ll}184,86 \\
184,\end{array}$ & $\begin{array}{ll}0,062 \\
96,42\end{array}$ & 1051,61 & 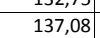 & 31,55 & 38,09 & 393,14 & 123,14 & 144,39 & 3600,99 \\
\hline Triturus marmoratus & 29TNJ61 & 82,00 & 138,78 & 70,46 & 42,23 & 3350,75 & 229,34 & 64,74 & 164,60 & 104,63 & 180,27 & 184,22 & 97,70 & \begin{tabular}{|l|}
1035,07 \\
\end{tabular} & 133,93 & 31,48 & 37,61 & 386,40 & 123,21 & 144,96 & 352,94 \\
\hline Triturus marmoratus & 29TNJ62 & 77,00 & 138,50 & 69,71 & 42,42 & 3311,98 & 227,83 & 65,35 & 162,48 & 104,89 & 179,31 & 183,41 & 97,82 & 1028,44 & 132,74 & 31,91 & 37,02 & 383,10 & 124,55 & 146,55 & 348,41 \\
\hline Triturus marmoratus & 29TNJ70 & 100,00 & 127,38 & 75,21 & 41,21 & 3607,29 & 228,03 & 47,99 & 180,04 & 89,86 & 172,98 & 176,58 & 84,18 & 1147,25 & 151,21 & 35,90 & 37,79 & 425,82 & 137,08 & 156,62 & 394,60 \\
\hline Triturus marmoratus & 29TNJ71 & 101,00 & 129,37 & 73,82 & 41,56 & 3531,06 & 227,00 & 51,70 & 175,30 & 92,88 & 173,72 & 177,51 & 86,87 & 1112,83 & 144,77 & 35,26 & 37,04 & 412,33 & 135,00 & 155,22 & 379,66 \\
\hline Triturus marmoratus & 29TNJ72 & 101,00 & 133,10 & 72,15 & 42,08 & 3432,01 & 226,92 & 57,35 & 169,57 & 97,92 & 175,90 & 179,71 & 91,45 & 1067,50 & 137,07 & 34,02 & 36,65 & 394,97 & 131,15 & 152,16 & 360,88 \\
\hline Triturus marmoratus & 29TNJ80 & 100,00 & 122,17 & 77,45 & 40,97 & 3732,97 & 226,80 & 40,28 & 186,52 & 82,75 & 169,73 & 173,01 & 77,78 & 1168,66 & 153,90 & 37,45 & 37,24 & 431,41 & 141,75 & 160,10 & 400,68 \\
\hline Triturus marmoratus & 29TNJ81 & 100,00 & 123,92 & 76,14 & 41,25 & 3653,63 & 225,79 & 43,65 & 182,14 & 85,62 & 170,26 & 173,78 & 80,28 & 1142,11 & 148,61 & 37,10 & 36,76 & 420,70 & 140,61 & 159,65 & 388,46 \\
\hline Triturus marmoratus & 29TNJ84 & 31,00 & 128,75 & 72,62 & 42,07 & 3463,58 & 223,64 & 52,51 & 171,13 & 93,16 & 172,00 & 175,75 & 86,98 & 1079,11 & 138,18 & 36,49 & 35,25 & 395,05 & 138,64 & 159,35 & 358,69 \\
\hline Triturus marmoratus & 29TNJ91 & 101,00 & 119,44 & 78 & 41,06 & 3765,45 & 224,70 & 37,15 & 187,55 & 79,81 & 167,50 & 170,67 & 74,70 & 1154,74 & 149,70 & 38 & 36,17 & 423,15 & 144,50 & 162,42 & 391,05 \\
\hline Triturus marmoratus & 29TNJ93 & 92,00 & 133,74 & 73,98 & 41,9 & 3525,79 & 229,64 & 55,54 & 174,11 & 96,84 & 177,87 & 181,48 & 91,05 & 1025,37 & 131,62 & 34, & 35,33 & 374,76 & 130,39 & 150,86 & 339,41 \\
\hline Triturus marmoratus & 29TPE03 & 99,00 & 143,31 & 93,20 & 36,73 & 5412,20 & 291,02 & 40,40 & 250,62 & 77,86 & 215,25 & 215,73 & 77,86 & 1056,32 & 156,96 & 9,67 & 55,29 & 430,96 & 65,84 & 65,92 & 430,96 \\
\hline Triturus marmoratus & 29TPE05 & 101,00 & 126,58 & 86,64 & 35,51 & 5336,17 & 268,16 & 27,58 & 240,57 & 62,81 & 198,19 & 198,24 & 62,81 & 1256,14 & 190,94 & 11,95 & 56,14 & 514,50 & 76,92 & 76,93 & 514,50 \\
\hline Triturus marmoratus & 29TPE06 & 100,00 & 135,12 & 9 & 36,7 & 5328,00 & 278,8 & 32,86 & 246,03 & 70,31 & 205,51 & 205,99 & 70,31 & 1164,94 & 175,36 & 11,03 & 55,58 & 75,27 & 73,03 & 73,29 & 475,27 \\
\hline Triturus marmoratus & 29TPE07 & 101,00 & 141,90 & 9 & 37, & 5321,55 & 287,4 & 36,82 & 250,64 & 76,22 & 211,36 & & 76,22 & 1091,34 & 162,71 & $\frac{1,2}{10,2}$ & 55,15 & $\begin{array}{ll}47,2,27 \\
443,22\end{array}$ & 69,66 & 70,37 & 443,22 \\
\hline Triturus marmoratus & 29TPE08 & 100,00 & 144 & 98,44 & 38, & 5297,72 & 290 & 38,25 & 252,02 & 78,79 & 213,46 & 214,23 & 78,79 & 1062,03 & 157,71 & 9,92 & 54,88 & 429,93 & 67,87 & 69,61 & 429,93 \\
\hline Triturus marmoratus & 29TPE09 & 100,00 & 139,40 & 97,45 & 38,44 & 5293,84 & 284,18 & 33,86 & 250,32 & 73,69 & 208,42 & 209,06 & 73,69 & 1121,11 & 167,79 & 10,81 & 55,10 & 454,88 & 72,02 & 73,49 & 454,88 \\
\hline Triturus marmoratus & 29TPE13 & 101,00 & 138,06 & 90,21 & 35,47 & 5541,54 & 286,28 & 35,83 & 250,45 & 71,63 & 212,30 & 212,50 & 71,63 & 1089,64 & 163,14 & 9,87 & 55,65 & 444,77 & 66,97 & 66,98 & 444,77 \\
\hline Triturus marmoratus & 29TPE14 & 101,00 & 143,73 & 93,64 & 36 , & 5535,10 & 293,33 & 39,08 & 254,25 & 76,45 & 217,15 & 217,53 & 76,45 & 1033,99 & 153,73 & 9,37 & 55,26 & 20,45 & 64,75 & 64,79 & 420,45 \\
\hline Triturus marmoratus & 29TPE15 & 99,00 & $\begin{array}{l}1429,26 \\
129,26\end{array}$ & 87 & 35 & S4667,14 & 273 & $\begin{array}{l}3,00 \\
28,66 \\
\end{array}$ & \begin{tabular}{|l|}
244,87 \\
\end{tabular} & $\begin{array}{l}\mid 0,435 \\
63,75 \\
\end{array}$ & $\begin{array}{l}202,52 \\
202\end{array}$ & 202,53 & $\begin{array}{l}0,0,75 \\
63,75\end{array}$ & $\begin{array}{l}1199,32 \\
1199\end{array}$ & 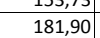 & \begin{tabular}{|c|c|}
11,09 \\
11,0
\end{tabular} & 55,20 & $\begin{array}{l}42,45 \\
490,30\end{array}$ & 73,40 & 73,40 & $\begin{array}{l}42,45 \\
490,30\end{array}$ \\
\hline Triturus marmoratus & 29TPE16 & 100,00 & 89,37 & 73,79 & 32,38 & 5308,01 & 222,81 & $-1,45$ & 224,25 & 29,35 & 162,23 & 162,23 & 29,35 & \begin{tabular}{l|}
1627,76 \\
\end{tabular} & 249,32 & 17,25 & 56,10 & 663,37 & 100,90 & 100,90 & 663,37 \\
\hline Triturus marmoratus & 29TPE17 & 100,00 & 105,52 & 77,94 & 33,30 & 5333,84 & 240,87 & 11,12 & 229,75 & 43,46 & 177,77 & 177,83 & 43,46 & 1488,39 & 230,10 & 14,23 & 56,81 & 610,46 & 89,59 & 89,68 & 610,46 \\
\hline Triturus marmoratus & 29TPE18 & 101,00 & 138,06 & 94,81 & 37,17 & 5436,40 & 284,38 & 32,78 & 251,60 & 71,02 & 209,38 & 209,73 & 71,02 & 1101,46 & 165,42 & 10,36 & 55,31 & 447,47 & 70,05 & 70,65 & 447,47 \\
\hline Triturus marmoratus & 29TPE19 & 101,00 & 138,73 & 96,68 & 37 & 5420,53 & 285,38 & 32,53 & 252,85 & 71,60 & 209,64 & 209,95 & 71,60 & 1094,17 & 164,30 & 10,36 & 55,31 & 444,18 & 69,92 & 70,79 & 444 \\
\hline Triturus marmoratus & 29TPE23 & $\begin{array}{l}100,00 \\
100\end{array}$ & $\begin{array}{l}130,15 \\
136,93\end{array}$ & \begin{tabular}{|c|}
80,00 \\
89,41 \\
\end{tabular} & |lon & $\begin{array}{ll}342,350 \\
5655,55\end{array}$ & $\begin{array}{l}20,50 \\
286,47\end{array}$ & \begin{tabular}{|c|c|}
32,03 \\
34,08
\end{tabular} & \begin{tabular}{|l|}
252,390 \\
252,
\end{tabular} & 69,31 & 212,77 & 212,88 & 69,31 & 1072,25 & 160,25 & 9,60 & 55,52 & 436,33 & 65,86 & 65,86 & 436,33 \\
\hline Triturus marmoratus & 29TPE24 & 100,00 & 142,68 & 92,77 & 35,65 & 5654,12 & 293,58 & 37,45 & 256,12 & 74,19 & 217,73 & 218,05 & 74,19 & 1014,30 & 150,67 & 8,95 & 55,21 & 411,38 & 63,29 & 63,31 & 411,38 \\
\hline Triturus marmoratus & 29TPE25 & 101,00 & 137,34 & 90,80 & 35,35 & 5606,22 & 285,74 & 33,34 & 252,40 & 69,51 & 211,78 & 212,03 & 69,51 & 1075,73 & 161,29 & 9,71 & 55,46 & 437,30 & 66,83 & 66,87 & 437,30 \\
\hline Triturus & 29TPE26 & 101,00 & 103,49 & 76,74 & 32,49 & 5450,47 & 240,55 & 9,06 & 31,49 & 40, & 177 & 177, & 40 & 1460,65 & 224,47 & 13,97 & 56 & 598,38 & 87,92 & 88,13 & 598 \\
\hline Triturus marmoratus & 29TPE27 & 100,00 & 106,99 & 77,23 & 32,68 & 5450,44 & 243,96 & 11,69 & 232,27 & 43,10 & 180,52 & 180,54 & 43,10 & 1421,80 & 219,17 & 13,32 & 56,76 & 83,80 & 85,34 & 86,46 & 583,80 \\
\hline
\end{tabular}




\begin{tabular}{|c|c|c|c|c|c|c|c|c|c|c|c|c|c|c|c|c|c|c|c|c|c|}
\hline TAXON & UTM & $\mathrm{km} 2$ & $\mathrm{BIO1}$ & B1O2 & $\mathrm{BIO3}$ & $\mathrm{B104}$ & $\mathrm{B105}$ & $\mathrm{B106}$ & B107 & B108 & $\mathrm{BIO9}$ & 81010 & B1011 & BIO12 & $\mathrm{B1O13}$ & 81014 & B1015 & B1016 & B1017 & $\mathrm{BIO18}$ & B1019 \\
\hline Triturus marmoratus & 29TPE28 & 100,00 & 115,82 & 82,63 & 34,00 & 5469,42 & 255,98 & 17,15 & 238,83 & 50,50 & 188,84 & 188,97 & 50,50 & 1311,44 & 200,81 & 12,45 & 56,23 & 537,03 & 80,49 & 82,35 & 537,03 \\
\hline Triturus marmoratus & 29TPE29 & 101,00 & 140,71 & 97,32 & 37,40 & 5537,38 & 289,73 & 33,15 & 256,58 & 72,15 & 213,23 & 213,42 & 72,15 & 1031,62 & 154,36 & 9,59 & 55,08 & 417,47 & 65,82 & 66,46 & 417,47 \\
\hline Triturus marmoratus & 29TPE33 & 101,00 & 151,94 & 96,18 & 35,97 & 5812,66 & 307,44 & 43,36 & 264,08 & 84,32 & 228,71 & 229,21 & 81,34 & 887,47 & 129,32 & 7,58 & 54,42 & 356,64 & 56,06 & 56,28 & 356,61 \\
\hline Triturus marmoratus & 29TPE34 & 100,00 & 144,07 & 93,37 & 35,58 & 5763,97 & 297,00 & 37,53 & 259,47 & 74,25 & 220,63 & 220,80 & 74,25 & 963,29 & 142,08 & 8,48 & 54,82 & 388,56 & 60,65 & 60,78 & 388,56 \\
\hline Triturus marmoratus & 29TPE35 & 100,00 & 142,56 & 93,42 & 35,63 & 5737,22 & 294,59 & \begin{tabular}{|c|}
35,97 \\
\end{tabular} & 258,62 & 72,78 & 218,54 & 218,67 & 72,78 & 976,71 & 144,52 & 8,80 & 54,84 & 394,12 & 61,76 & 61,99 & 394,12 \\
\hline Triturus marmoratus & 29TPE36 & 101,00 & 139,74 & 92,73 & 35,61 & 5699,14 & 290,19 & 33,56 & 256,64 & 70,23 & 215,06 & 215,18 & 70,23 & 1004,28 & 149,39 & 9,13 & 54,98 & 405,67 & 63,55 & 64,08 & 405,67 \\
\hline Triturus marmoratus & 29TPE37 & 100,00 & 126,44 & 86,62 & 34,39 & 5632,12 & 272,12 & 24,14 & 247,98 & 58,40 & 201,32 & 201,39 & 58,40 & 1136,45 & 171,51 & 10,64 & 55,48 & 461,98 & 70,81 & 73,01 & 461,98 \\
\hline Triturus marmoratus & 29TPE38 & 101,00 & 108,42 & 77,78 & 32,55 & 5536,88 & 247,27 & 11,75 & 235,51 & 42,64 & 182,53 & 182,68 & 42,64 & 1323,69 & 202,22 & 12,65 & 56,09 & 541,51 & 81,32 & 87,37 & 541,51 \\
\hline Triturus marmoratus & 29TPE39 & 99,00 & 129,36 & 90,95 & 35,62 & 5612,20 & 276,53 & 24,79 & 251,73 & 60,76 & 203,41 & 203,57 & 60,76 & 1096,85 & 165,15 & 10,54 & 55,27 & 444,89 & 69,91 & 71,83 & 444,89 \\
\hline Triturus marmoratus & 29TPE43 & 101,00 & 153,35 & 97,14 & 35,97 & 5887,56 & 310,18 & 43,60 & 266,59 & 89,12 & 231,20 & 231,48 & 81,69 & 837,38 & 120,72 & 7,00 & 53,85 & 334,35 & 53,38 & 53,65 & 333,63 \\
\hline Triturus marmoratus & 29TPE44 & 100,00 & 149,48 & 96,03 & 35,86 & 5860,33 & 304,97 & 40,37 & 264,60 & 84,59 & 226,95 & 227,18 & 78,09 & 871,44 & 126,58 & 7,52 & 54,06 & 348,36 & 55,63 & 55,78 & 347,93 \\
\hline Triturus marmoratus & 29TPE45 & 101,00 & 142,38 & 93,54 & 35,41 & 5824,43 & 295,68 & 34,92 & 260,76 & 74,84 & 219,54 & 219,65 & 71,49 & 934,96 & 137,33 & 8,42 & 54,35 & 374,92 & 59,48 & 59,90 & 374,91 \\
\hline Triturus marmoratus & 29TPE46 & 99,00 & 140,79 & 93,71 & 35,62 & 5799,87 & 293,41 & 33,34 & 260,08 & 71,02 & 217,52 & 217,64 & 70,04 & 944,75 & 139,10 & 8,62 & 54,33 & 378,87 & 60,64 & 61,32 & 378,87 \\
\hline Triturus marmoratus & 29TPE48 & 99,00 & 117,54 & 82,71 & 33,32 & 5674,60 & 261,50 & 16,91 & 244,60 & 48,96 & 192,78 & 193,24 & 48,96 & 1155,77 & 173,94 & 11,18 & 55,15 & 468,54 & 73,04 & 77,68 & 468,54 \\
\hline Triturus marmoratus & 29TPE49 & 101,00 & 125,55 & 88,94 & 34,86 & 5693,66 & 273,09 & 21,39 & 251,70 & 56,06 & 200,71 & 201,07 & 56,06 & \begin{tabular}{|c|c|}
1071,79 \\
\end{tabular} & 160,32 & 10,53 & 54,81 & 432,91 & 69,15 & 71,71 & 432,91 \\
\hline Triturus marmoratus & 29TPE53 & 100,00 & 151,91 & 97,36 & 35,85 & 5953,50 & 309,70 & 41,55 & 268,15 & 87,23 & 230,81 & 231,01 & 79,58 & 808,77 & 115,52 & 6,97 & 53,33 & 321,81 & 52,04 & 52,23 & 319,62 \\
\hline Triturus marmoratus & 29TPE54 & 100,00 & 147,75 & 95,98 & 35,62 & 5933,51 & 304,19 & 38,06 & 266,13 & 83,16 & 226,32 & 226,50 & 75,69 & 844,05 & 121,51 & 7,38 & 53,61 & 335,96 & 54,66 & 54,79 & 334,47 \\
\hline Triturus marmoratus & 29TPE55 & 100,00 & 139,99 & 93,16 & 35,09 & 5892,53 & 294,01 & 32,20 & 261,81 & 76,16 & 218,11 & 218,19 & 68,40 & 909,11 & 132,39 & 8,41 & 53,90 & 362,66 & 58,54 & 59,38 & 361,92 \\
\hline Triturus marmoratus & 29TPE56 & 101,00 & 128,25 & 88,22 & 34,20 & 5835,14 & 278,60 & 23,79 & 254,82 & 62,95 & 205,80 & 206,08 & 57,84 & 1007,41 & 148,40 & 9,62 & 54,15 & 403,27 & 64,49 & 67,35 & 403,21 \\
\hline Triturus marmoratus & 29TPE58 & 101,00 & 120,47 & 85,76 & 33,81 & 5774,86 & 268,03 & 17,55 & 250,48 & 51,08 & 196,97 & 197,58 & 50,51 & 1064,41 & 157,89 & 10,49 & 54,30 & 427,55 & 68,80 & 72,51 & 427,55 \\
\hline Triturus marmoratus & 29TPE59 & 100,00 & 119,76 & 86,90 & 34,11 & 5766,20 & 267,68 & 16,35 & 251,34 & 49,78 & 196,01 & 196,68 & 49,78 & 1061,22 & 157,39 & 10,70 & 54,14 & 426,26 & 69,47 & 72,85 & 426,26 \\
\hline Triturus marmoratus & 29TPE63 & 100,00 & 147,31 & 96,56 & 35,56 & 6005,60 & 305,46 & 37,25 & 268,21 & 82,40 & 227,14 & 227,18 & 74,60 & 805,58 & 114,23 & 7,23 & 52,82 & 319,18 & 52,55 & 52,87 & 315,84 \\
\hline Triturus marmoratus & 29TPE64 & 101,00 & 148,18 & 97,18 & \begin{tabular}{|c|}
35,78 \\
\end{tabular} & 5989,67 & 305,84 & 37,38 & 268,45 & 82,93 & 227,58 & 227,62 & 75,21 & 797,19 & 113,21 & 7,17 & 52,86 & 315,68 & 52,29 & 52,49 & 312,48 \\
\hline Triturus marmoratus & 29TPE65 & 100,00 & 129,91 & 90,14 & 34,26 & 5929,70 & 283,01 & 23,91 & 259,10 & 66,46 & 208,92 & 209,16 & 58,67 & 944,84 & 136,77 & 9,21 & 53,25 & 375,78 & 61,54 & 63,95 & 373,87 \\
\hline Triturus marmoratus & 29TPE66 & 100,00 & 121,79 & 86,97 & 33,72 & 5881,62 & 272,26 & 17,83 & 254,43 & 59,20 & 200,18 & 200,57 & 51,21 & 1009,52 & 147,16 & 10,10 & 53,46 & 402,21 & 65,82 & 69,68 & 400,97 \\
\hline Triturus marmoratus & 29TPE69 & 101,00 & 123,25 & 90,59 & 34,72 & 5856,27 & 274,74 & 17,18 & 257,56 & 58,81 & 200,55 & 201,39 & 52,01 & 969,08 & 141,09 & 10,03 & 53,06 & 385,06 & 65,36 & 67,80 & 384,65 \\
\hline Triturus marmoratus & 29TPE73 & 100,00 & 150,30 & 98,84 & 35,77 & 6062,09 & 310,71 & 38,27 & 272,44 & \begin{tabular}{l|l}
84,43 \\
\end{tabular} & 230,77 & 230,80 & 76,58 & 739,65 & \begin{tabular}{|l|l|}
102,88 \\
\end{tabular} & $\begin{array}{r}0,62 \\
6\end{array}$ & 51,89 & 290,90 & $\begin{array}{l}49,06 \\
490\end{array}$ & 49,23 & 285,78 \\
\hline Triturus marmoratus & 29TPE75 & 99,00 & 135,54 & 94,15 & 34,92 & 6008,58 & 292,03 & 26,54 & 265,49 & 70,70 & 215,39 & 215,63 & 62,83 & 847,52 & 119,95 & 8,43 & 52,10 & 334,35 & 56,87 & 58,58 & 330,22 \\
\hline Triturus marmoratus & 29TPE77 & 100,00 & 122,37 & 90,04 & 34,30 & 5945,46 & 275,26 & 16,19 & 259,07 & 58,62 & 201,30 & 201,94 & 50,77 & 938,22 & 134,22 & 9,98 & 52,23 & 370,92 & 63,72 & 66,87 & 367,88 \\
\hline Triturus marmoratus & 29TPE78 & 101,00 & 123,45 & 91,55 & 34,80 & 5941,90 & 276,94 & 16,45 & 260,49 & 59,43 & 202,15 & 202,87 & 51,50 & 917,39 & 131,03 & 9,84 & 52,04 & 362,22 & 63,19 & 65,75 & 359,37 \\
\hline Triturus marmoratus & 29TPE79 & 99,00 & 124,77 & 93,29 & 35,09 & 5934,79 & 279,08 & 16,71 & 262,37 & 60,47 & 203,18 & 204,08 & 52,60 & 896,75 & 127,89 & 9,73 & 51,82 & 353,66 & 62,66 & 64,50 & 351,17 \\
\hline Triturus marmoratus & 29TPE84 & 101,00 & 146,87 & \begin{tabular}{|l|l|}
99,36 \\
9
\end{tabular} & 35,82 & 6104,88 & 308,40 & 33,98 & 274,42 & 80,31 & $\mid 227,97$ & 228,03 & 72,56 & $\begin{array}{ll}717,78 \\
\end{array}$ & | & 6,86 & 51,03 & \begin{tabular}{|l|l|}
280,18 \\
\end{tabular} & 49,20 & 49,35 & 273,80 \\
\hline Triturus marmoratus & 29TPE85 & 101,00 & 126,42 & 93,40 & 34,64 & 6044,36 & 283,86 & 18,13 & 265,73 & 61,90 & 207,17 & 207,49 & 54,01 & 867,71 & 120,90 & 9,38 & 51,16 & 339,84 & 60,08 & 62,81 & 334,06 \\
\hline Triturus marmoratus & 29TPE86 & 100,00 & 117,60 & 90,52 & 34,02 & 6008,49 & 272,64 & 11,27 & 261,36 & 53,76 & 197,92 & 198,45 & 45,95 & 928,26 & 130,25 & 10,32 & 51,22 & 364,31 & 64,53 & 68,45 & 358,97 \\
\hline Triturus marmoratus & 29TPE87 & 100,00 & 124,01 & 93,18 & 34,67 & 6018,82 & 280,22 & 15,67 & 264,55 & 59,25 & 203,85 & 204,61 & 51,39 & 866,80 & 121,19 & 9,70 & 50,97 & 339,73 & 60,96 & 63,50 & 334,53 \\
\hline Triturus marmoratus & 29TPE89 & 101,00 & 124,13 & 95,26 & 35,25 & 5995,30 & 280,81 & 14,85 & 265,97 & 59,14 & 203,39 & 204,31 & 51,43 & 843,46 & 117,63 & 9,60 & 50,67 & 330,28 & 60,83 & 62,57 & 325,45 \\
\hline Triturus marmoratus & 29TPE95 & 100,00 & 133,71 & $\begin{array}{l}\mid 0,200 \\
97,47 \\
\end{array}$ & 35,24 & $\begin{array}{ll}353,22,54 \\
612,4\end{array}$ & $\begin{array}{l}20,01 \\
294,97\end{array}$ & $\frac{24,03}{22,26}$ & \begin{tabular}{|l|}
272,71 \\
271
\end{tabular} & $\mid \frac{35,44}{67,52}$ & \begin{tabular}{|l|}
215,21 \\
2153
\end{tabular} & \begin{tabular}{|l|l|}
215,54 \\
\end{tabular} & $\begin{array}{l}1,435 \\
59,77\end{array}$ & $\begin{array}{l}4352,40 \\
762,82\end{array}$ & \begin{tabular}{|l|}
103,58 \\
103
\end{tabular} & 8,34 & 40,05 & \begin{tabular}{|l|}
$290,20,84$ \\
295
\end{tabular} & $\begin{array}{l}0,03 \\
54,36 \\
\end{array}$ & $\begin{array}{ll}5,251 \\
5,87\end{array}$ & $\begin{array}{ll}228,45 \\
288,21\end{array}$ \\
\hline Triturus marmoratus & 29TPE96 & 100,00 & 121,66 & 94,40 & 34,79 & 6085,22 & 280,54 & 12,66 & 267,88 & 56,49 & 202,72 & 203,40 & 48,71 & 839,86 & 114,81 & 9,92 & 49,81 & 326,27 & 60,70 & 63,49 & 318,88 \\
\hline Triturus marmoratus & 29TPE97 & 101,00 & 123,33 & 95,54 & \begin{tabular}{|c|}
35,03 \\
\end{tabular} & 6081,09 & 282,39 & 13,56 & 268,83 & 57,85 & 204,07 & 204,93 & 50,15 & 815,68 & 111,21 & 9,77 & 49,60 & 316,66 & 59,75 & 62,02 & 309,32 \\
\hline Triturus marmoratus & 29TPE98 & 100,00 & 128,77 & 98,03 & 35,72 & 6080,10 & 288,79 & 17,22 & 271,56 & 62,50 & 209,12 & 209,95 & 54,96 & 765,26 & 103,76 & 9,16 & 49,35 & 296,62 & 56,86 & 57,99 & 289,48 \\
\hline Triturus marmoratus & 29TPF00 & 101,00 & 139,06 & 98,71 & 38,88 & 5279,84 & 283,75 & 32,90 & 250,85 & 73,23 & 207,69 & 208,26 & 73,23 & 1127,70 & 168,86 & 10,94 & 55,06 & 57,17 & 72,42 & 74,61 & 457,17 \\
\hline Triturus marmoratus & 29TPF06 & 100,00 & 141,31 & 108,38 & 40,9 & 5312,79 & 291,76 & 30,46 & 261,30 & 79,60 & 209,92 & 210,29 & 74,38 & 1113,87 & 165,33 & 11,38 & 54,92 & 449,72 & 71,98 & 77,73 & 448,75 \\
\hline Triturus marmoratus & \begin{tabular}{|l|} 
29TPF07 \\
\end{tabular} & 101,00 & 129,25 & 104,96 & 40,17 & 5320,59 & 279,02 & 21,27 & 257,75 & 69,15 & 198,58 & 198,93 & 63,25 & 1223,92 & 181,16 & 14,12 & 54,73 & 496,20 & 82,95 & 87,13 & 494,77 \\
\hline Triturus marmoratus & \begin{tabular}{|l|} 
29TPF08 \\
\end{tabular} & 100,00 & 108,66 & 93,52 & 38,00 & 5223,34 & 250,90 & 8,30 & 242,61 & 45,75 & 178,02 & 178,18 & 45,68 & 1370,44 & 197,65 & 19,63 & 52,80 & 551,13 & 101,85 & 103,26 & 551,12 \\
\hline Triturus marmoratus & 29TPF09 & 100,00 & 111,77 & 94,08 & 38,18 & 5213,47 & 253,83 & 10,63 & 243,20 & 48,68 & 180,74 & 180,98 & 48,68 & 1325,43 & 188,43 & 19,36 & 52,06 & 30,87 & 99,87 & 101,47 & 530,87 \\
\hline Triturus marmoratus & 29TPF10 & 100,00 & 136,14 & 97,26 & 37,9 & 5414,49 & $\frac{28,0}{282,7}$ & 29,94 & 252,85 & $\begin{array}{l}69,04 \\
69,0 \\
\end{array}$ & 207,02 & 207,27 & $\begin{array}{l}40,040 \\
69,04\end{array}$ & $\begin{array}{l}1321,47 \\
1121,47\end{array}$ & \begin{tabular}{|l|l|}
169,00 \\
\end{tabular} & 10,83 & 55,29 & $\begin{array}{ll}455,61 \\
\end{array}$ & 72,08 & 72,82 & 455,61 \\
\hline Triturus marmoratus & 29TPF11 & 100,00 & 128,63 & 95,37 & 37, & 5404,76 & 274 & 23,95 & 250,29 & 62,05 & 199,63 & 199,88 & 62,05 & 1200,90 & 182,25 & 12,14 & 55,80 & 489,67 & 77,94 & 78,26 & 489,67 \\
\hline Triturus marmoratus & 29TPF12 & 100,00 & 118,88 & 91,96 & 36,84 & 5385,78 & 262,58 & 16,65 & 245,93 & 53,27 & 190,27 & 190,32 & 53,27 & 1295,22 & 197,19 & 13,90 & 55,95 & 529,52 & $|84,37|$ & 85,12 & 529,52 \\
\hline Triturus marmoratus & 29TPF13 & 101,00 & 121,03 & 95,23 & 37,65 & 5397,58 & 266,55 & 17,10 & 249,45 & 54,91 & 192,27 & 192,40 & 54,91 & 1270,64 & 192,82 & 13,83 & 55,64 & 518,67 & 83,82 & 84,37 & 518,67 \\
\hline Triturus marmoratus & 29TPF14 & 100,00 & 124,50 & 99,18 & 38,5 & 5414,99 & 272,28 & 18,51 & 253,77 & 57,77 & 195,61 & 195,77 & 57,77 & 1234,38 & 186,67 & 13,56 & 55,38 & 02,96 & 82,15 & 83,12 & 502,96 \\
\hline Triturus marmoratus & $\begin{array}{l}\text { 29TPF16 } \\
\text { 29TP }\end{array}$ & $\begin{array}{l}10,000 \\
101,00\end{array}$ & 13 & 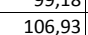 & $\begin{array}{ll}30, \\
40,\end{array}$ & $\begin{array}{l}541,951,47 \\
5451,\end{array}$ & 286, & $\begin{array}{l}\frac{10,31}{22,66} \\
\end{array}$ & 263,38 & 70,80 & 203,93 & 204 & 65,01 & 1150,71 & 172,83 & 12,42 & 55,22 & 467,60 & 76,12 & 78,60 & 466,91 \\
\hline Triturus marmoratus & 29TPF18 & 101,00 & 116,77 & 98,81 & 38,68 & 5375,05 & 264,19 & 11,86 & 252,33 & 51,10 & 187,58 & 187,81 & 51,10 & 1252,20 & 182,52 & 16,84 & 53,27 & 505,01 & 90,84 & 91,97 & 505,01 \\
\hline Triturus marmoratus & 29TPF19 & 101,00 & 113,80 & 96,73 & 38,31 & 5336,32 & 259,53 & 10,18 & 249,36 & 48,93 & 184,38 & 184,52 & 48,93 & 1255,75 & 179,85 & 18,12 & 52,30 & 503,68 & 94,08 & 94,80 & 503,68 \\
\hline Triturus marmoratus & 29TPF20 & 100,00 & 131,99 & 94,76 & 36,96 & 5520,84 & 279,47 & 26,29 & 253,18 & 63,93 & 204,61 & 204,73 & 63,93 & 1119,52 & 169,25 & 10,95 & 55,43 & 455,27 & 72,09 & 72,60 & 455,27 \\
\hline Triturus marmoratus & 29TPF21 & 101,00 & 126,21 & 93,56 & 36, & 5513,60 & 272,97 & 21,53 & 251,44 & 58,52 & 198,83 & 198 & 58,52 & 1172,13 & 177,94 & 11,92 & 55,70 & 477,64 & 75,95 & 76,74 & 477 \\
\hline Triturus marmoratus & $\begin{array}{l}\text { 29TPF22 } \\
\end{array}$ & $\begin{array}{l}100,00 \\
100\end{array}$ & $\begin{array}{l}120,21 \\
123,09\end{array}$ & $\begin{array}{l}5,00 \\
94,03 \\
\end{array}$ & | & 5506,71 & 269,90 & $\begin{array}{l}1,335 \\
18,45 \\
\end{array}$ & $\begin{array}{l}251,44 \\
251,45 \\
\end{array}$ & 55,53 & 195,71 & 195,79 & 55,53 & 1199,46 & 182,05 & 12,66 & 55,60 & 488,99 & 78,61 & 79,60 & 488,99 \\
\hline Triturus marmoratus & 29TPF23 & 100,00 & 126,79 & 98,25 & 37,87 & 5516,59 & 275,90 & 19,95 & 255,94 & 58,64 & 199,26 & 199,34 & 58,64 & 1160,35 & 175,66 & 12,24 & 55,32 & 472,38 & 76,56 & 77,15 & 472,38 \\
\hline Triturus marmoratus & 29TPF24 & 101,00 & 126,75 & 100,17 & 38,32 & 5518,90 & 277,01 & 19,14 & 257,87 & 58,60 & 199,25 & 199,32 & 58,60 & 1155,55 & 174,45 & 12,59 & 55,08 & 469,91 & 77,07 & 77,46 & 469,91 \\
\hline Triturus & 29TPF25 & 100,00 & 140,51 & 106,44 & 39,69 & 5513,85 & 293,37 & 28,59 & 264,78 & 71,32 & 212,18 & 212 & 71, & 1019,19 & 151,94 & 10,54 & 54,60 & 410,81 & 66,63 & 67,38 & 410,81 \\
\hline Triturus marmoratus & 29TPF26 & 100,00 & 140,98 & 107,60 & 39,89 & 5514,54 & 294,66 & 28,42 & 266,25 & 73,20 & 212,58 & 212,65 & 71,78 & 1005,65 & 149,08 & 10,67 & 54,36 & 404,49 & 66,37 & 67,06 & 404 \\
\hline
\end{tabular}




\begin{tabular}{|c|c|c|c|c|c|c|c|c|c|c|c|c|c|c|c|c|c|c|c|c|c|}
\hline TAXON & UTM & $\mathrm{km} 2$ & B101 & $\mathrm{B1O2}$ & $\mathrm{BIO3}$ & BIO4 & B105 & 8106 & B107 & $\mathrm{B108}$ & B109 & 81010 & BIO11 & BIO12 & B1013 & BIO14 & B1015 & BIO16 & B1017 & $\mathrm{BIO18}$ & B1019 \\
\hline Triturus marmoratus & 29TPF27 & 101,00 & 127,74 & 104,65 & 39,24 & 5523,54 & 281,02 & 17,96 & 263,06 & 61,29 & 200,19 & 200,25 & 59,37 & 1117,23 & 165,84 & 13,31 & 54,31 & 451,90 & 77,02 & 77,42 & 451,81 \\
\hline Triturus marmoratus & 29TPF28 & 101,00 & 124,70 & 103,28 & 39,13 & 5499,98 & 276,56 & 15,72 & 260,84 & 56,85 & 197,01 & 197,03 & 56,85 & 1124,99 & 164,65 & 14,44 & 53,30 & 453,16 & 80,03 & 80,49 & 453,16 \\
\hline Triturus marmoratus & 29TPF29 & 100,00 & 119,33 & 100,64 & 38,58 & 5460,93 & 269,38 & 12,14 & 257,24 & 52,55 & 191,46 & 191,47 & 52,55 & 1147,42 & 165,13 & 16,19 & 52,33 & 460,08 & 85,13 & 85,52 & 460,08 \\
\hline Triturus marmoratus & 29TPF30 & 101,00 & 138,54 & 97,73 & 37,13 & 5630,05 & 289,25 & 30,10 & 259,15 & 68,92 & 212,42 & 212,50 & 68,92 & 1001,01 & 149,52 & 9,60 & 54,78 & \begin{tabular}{|l|l}
403,99 \\
\end{tabular} & 64,84 & 65,10 & 403,99 \\
\hline Triturus marmoratus & 29TPF31 & 100,00 & 122,01 & 91,03 & 35,81 & 5592,34 & 269,00 & \begin{tabular}{|c|}
17,97 \\
\end{tabular} & 251,03 & 53,63 & 195,80 & 196,16 & 53,63 & 1153,91 & 174,51 & 11,85 & 55,18 & 469,29 & 75,12 & 77,18 & 469,29 \\
\hline Triturus marmoratus & 29TPF32 & 101,00 & 118,52 & 91,48 & 35,98 & 5579,90 & 265,56 & 14,68 & 250,89 & 50,49 & 192,24 & 192,61 & 50,49 & 1181,51 & 178,55 & 12,66 & 55,06 & 480,60 & 78,06 & 80,25 & 480,60 \\
\hline Triturus marmoratus & 29TPF33 & 101,00 & 117,67 & 93,44 & \begin{tabular}{|c|}
36,47 \\
\end{tabular} & 5576,81 & 265,92 & 13,04 & 252,89 & 49,59 & 191,29 & 191,61 & 49,59 & 1180,34 & 177,86 & 13,10 & 54,92 & 479,81 & 79,46 & 81,04 & 479,81 \\
\hline Triturus marmoratus & 29TPF34 & 100,00 & 123,76 & 98,46 & 37,58 & 5598,62 & 274,87 & 16,29 & 258,58 & 54,90 & $\begin{array}{l}197,58 \\
\end{array}$ & 197,69 & 54,90 & 1117,24 & 167,71 & 12,54 & 54,69 & 453,09 & 75,71 & 76,31 & 453,09 \\
\hline Triturus marmoratus & 29TPF35 & 101,00 & 137,94 & 105,49 & \begin{tabular}{l|l|l|}
39,15 \\
\end{tabular} & 5607,72 & 292,31 & 25,79 & 266,52 & 67,82 & 211,25 & 211,27 & 67,82 & 982,27 & 146,01 & 10,54 & 54,18 & \begin{tabular}{|c|}
395,49 \\
\end{tabular} & 65,43 & 65,51 & 395,49 \\
\hline Triturus marmoratus & 29TPF36 & 100,00 & 136,08 & 105,63 & 39,20 & 5593,92 & 290,39 & 23,96 & 266,43 & 66,31 & 209,21 & 209,21 & 66,31 & 987,88 & 145,90 & 11,16 & 53,79 & 397,09 & 67,05 & 67,16 & 397,09 \\
\hline Triturus marmoratus & 29TPF37 & 101,00 & 136,96 & 106,85 & 39,44 & 5597,15 & 291,74 & 23,96 & 267,78 & 66,93 & 209,96 & 209,98 & 66,93 & 970,32 & 142,26 & 11,30 & 53,38 & \begin{tabular}{|c|}
388,98 \\
\end{tabular} & 66,55 & 66,61 & 388,98 \\
\hline Triturus marmoratus & 29TPF38 & 99,00 & 135,86 & 107,09 & 39,57 & 5593,05 & 290,65 & 22,66 & 267,99 & 66,02 & 208,89 & 208,89 & 66,02 & 963,54 & 139,80 & 11,88 & 52,75 & 385,04 & 67,49 & 67,52 & 385,04 \\
\hline Triturus marmoratus & 29TPF39 & 101,00 & 128,98 & 104,90 & 39,08 & 5570,40 & 282,66 & 17,49 & 265,18 & 60,08 & 202,29 & 202,29 & 60,08 & 1002,01 & 143,85 & 13,58 & 51,97 & \begin{tabular}{|l|l|l|}
400,05 \\
\end{tabular} & 73,12 & 73,12 & 400,05 \\
\hline Triturus marmoratus & 29TPF41 & 100,00 & 130,09 & 95,51 & 36,44 & 5704,54 & 281,07 & 22,43 & 258,64 & 59,81 & 205,16 & 205,40 & 59,81 & 1019,40 & 152,10 & 10,51 & 54,47 & 410,99 & 67,65 & 68,26 & 410,99 \\
\hline Triturus marmoratus & 29TPF42 & 101,00 & 129,46 & 97,21 & 36,92 & 5693,92 & 281,22 & 21,12 & 260,10 & 59,25 & 204,42 & 204,60 & 59,25 & $\begin{array}{ll}1019,33 \\
\end{array}$ & 152,01 & \begin{tabular}{|c|}
10,78 \\
\end{tabular} & 54,30 & 410,91 & 68,29 & 68,78 & 410,91 \\
\hline Triturus marmoratus & 29TPF43 & 100,00 & 128,47 & 98,78 & 37,29 & 5690,11 & 281,10 & 19,51 & 261,59 & 58,25 & 203,40 & 203,53 & 58,25 & 1018,61 & 151,77 & 11,11 & 54,11 & 410,75 & 69,20 & 69,37 & 410,75 \\
\hline Triturus marmoratus & 29TPF44 & 100,00 & 132,75 & 102,47 & \begin{tabular}{|c|}
38,08 \\
\end{tabular} & 5697,92 & 287,24 & 21,71 & 265,53 & 62,03 & 207,71 & 207,71 & 62,03 & 972,21 & 144,25 & 10,68 & 53,94 & 391,00 & 66,10 & 66,10 & 391,00 \\
\hline Triturus marmoratus & 29TPF45 & 100,00 & 140,70 & 105,77 & 38,89 & 5667,42 & 295,95 & 27,37 & 268,58 & 70,06 & 214,86 & 214,86 & 69,73 & 898,03 & 131,61 & 9,86 & 53,24 & 358,68 & 60,80 & 60,80 & 358,68 \\
\hline Triturus marmoratus & 29TPF46 & 101,00 & 123,35 & 101,60 & 38,00 & 5663,76 & 277,73 & 13,58 & 264,15 & 53,73 & 198,39 & 198,39 & 53,73 & 1028,48 & 151,52 & 12,73 & 53,08 & 413,96 & 73,53 & 73,53 & 413,96 \\
\hline Triturus marmoratus & 29TPF47 & 99,00 & 132,70 & 105,43 & 38,83 & 5659,92 & 288,25 & 20,00 & 268,25 & 62,32 & 207.06 & 207.06 & 62,32 & 938,61 & 136,65 & 11,66 & 52.49 & 375,35 & 66,55 & 66,55 & 375,35 \\
\hline Triturus marmoratus & 29TPF48 & 101,00 & 140,12 & 107,65 & 39,32 & 5646,39 & 295,76 & 25,48 & 270,27 & 69,34 & 214,06 & 214,06 & 69,34 & 865,86 & 123,90 & \begin{tabular}{|c|}
10,87 \\
\end{tabular} & 51,73 & 343,18 & 61,50 & 61,50 & 343,18 \\
\hline Triturus marmoratus & 29TPF49 & 100,00 & 137,42 & 106,91 & 39,23 & 5629,61 & 292,32 & 23,10 & 269,23 & 67,23 & 211,12 & 211,12 & 66,99 & 873,61 & 123,63 & 11,76 & 51,03 & 345,28 & 63,87 & 63,87 & 345,28 \\
\hline Triturus marmoratus & 29TPF50 & 100,00 & 126,65 & 92,55 & 35,46 & 5783,08 & 277,61 & 19,91 & 257,70 & 55,85 & 202,85 & 203,38 & 55,85 & 993,74 & 146,73 & 10,17 & 53,88 & \begin{tabular}{|c|}
398,03 \\
\end{tabular} & 66,35 & 67,84 & 398,03 \\
\hline Triturus marmoratus & 29TPF52 & 100,00 & 137,54 & 101,08 & 37,46 & 5779,03 & 292,46 & 25,97 & 266,49 & 65,88 & 213,69 & 213,69 & 65,70 & 888,20 & 129,97 & 9,39 & 53,19 & 353,77 & 60,27 & 60,27 & 353,77 \\
\hline Triturus marmoratus & 29TPF53 & 100,00 & 141,10 & 103,66 & 38,12 & 5763,83 & 296,81 & 28,05 & 268,76 & 69,62 & 216,60 & 216,60 & 69,12 & 850,97 & 123,81 & 9,14 & 52,78 & 337,87 & 57,88 & 57,88 & 337,83 \\
\hline Triturus marmoratus & 29TPF54 & 101,00 & 142,68 & 105,21 & 38,51 & 5744,58 & 298,77 & 28,79 & 269,97 & 72,03 & 217,84 & 217,84 & 70,80 & 832,23 & 120,63 & 9,06 & 52,52 & 329,99 & 56,84 & 56,84 & 329,90 \\
\hline Triturus marmoratus & 29TPF55 & 100,00 & 143,81 & 106,25 & 38,74 & 5720,69 & 300,02 & 29,27 & 270,76 & 74,26 & 218,64 & 218,64 & 72,02 & 814,43 & 117,22 & $\begin{array}{l}, 0,14 \\
\end{array}$ & 52,12 & 322,14 & 56,22 & 56,22 & 321,98 \\
\hline Triturus marmoratus & 29TPF56 & 100,00 & 139,49 & 105,69 & 38,59 & 5705,64 & 295,63 & 25,55 & 270,08 & 70,99 & 214,41 & 214,41 & 68,22 & 837,54 & 120,32 & 9,97 & 51,84 & \begin{tabular}{|l|l|}
331,83 \\
\end{tabular} & 59,22 & 59,22 & 331,53 \\
\hline Triturus marmoratus & 29TPF57 & 101,00 & 134,38 & 105,98 & 38,67 & 5715,32 & 291,15 & 20,48 & 270,66 & 63,93 & 209,56 & 209,56 & 63,28 & 863,64 & 124,24 & 11,01 & 51,61 & 343,18 & 62,44 & 62,44 & 343,14 \\
\hline Triturus marmoratus & 29TPF58 & 99,00 & 136,87 & 107,07 & 38,82 & 5702,16 & 293,58 & 22,00 & 271,58 & 65,83 & 211,69 & 211,69 & 65,64 & 829,85 & 117,91 & 11,02 & 50,93 & 327,95 & 60,81 & 60,81 & 327,95 \\
\hline Triturus marmoratus & 29TPF59 & 101,00 & 140,06 & 107,68 & 39,02 & 5679,65 & 296,10 & 24,35 & 271,75 & 70,61 & 214,39 & 214,39 & 68,77 & 794,76 & 111,26 & 10,91 & 50,28 & 312,01 & 58,91 & 58,91 & 312,01 \\
\hline Triturus marmoratus & 29TPF61 & 100,00 & 132,16 & 97,93 & 36,39 & 5855,03 & 287,09 & $\begin{array}{l}24,73 \\
21,78 \\
\end{array}$ & 265,31 & $\frac{0,01}{64,63}$ & \begin{tabular}{|l|}
209,47 \\
\end{tabular} & 209,65 & 59,93 & 881,01 & $\begin{array}{l}127,52 \\
127\end{array}$ & 9,52 & 52,48 & 348,64 & $\begin{array}{l}0,2125 \\
61,25\end{array}$ & 60,54 & 348,50 \\
\hline Triturus marmoratus & 29TPF62 & 100,00 & 131,94 & 99,50 & 36,82 & 5846,01 & 287,62 & 20,89 & 266,74 & 63,30 & 209,20 & 209,32 & 59,75 & 870,22 & 125,57 & 9,66 & 52,26 & 344,02 & 61,16 & 61,35 & 343,96 \\
\hline Triturus marmoratus & 29TPF63 & 101,00 & 134,25 & 101,94 & 37,38 & 5835,98 & 290,96 & 21,88 & 269,08 & 63,60 & 211,38 & 211,38 & 61,97 & 844,73 & 121,62 & 9,68 & 52,03 & 333,64 & 59,71 & 59,71 & 333,62 \\
\hline Triturus marmoratus & 29TPF64 & 99,00 & 141,58 & 105,17 & 38,20 & 5807,07 & 298,94 & 27,17 & 271,77 & 72,58 & 217,82 & 217,82 & 69,07 & 782,20 & 111,55 & 8,88 & 51,52 & 307,77 & 55,02 & 55,02 & 307,29 \\
\hline Triturus marmoratus & 29TPF65 & 101,00 & 133,16 & 104,27 & 37,93 & 5804,01 & 290,69 & 19,73 & 270,97 & 62,06 & 209,68 & 209,68 & 61,14 & 831,42 & 118,91 & 10,13 & 51,36 & 328,13 & 60,39 & 60,39 & 328,13 \\
\hline Triturus marmoratus & 29TPF66 & 100,00 & $\begin{array}{l}13,10 \\
138,95\end{array}$ & 106,55 & 38,53 & 5783,69 & 296,75 & 23,90 & \begin{tabular}{|l|}
272,85 \\
\end{tabular} & 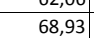 & \begin{tabular}{|l|}
214,97 \\
21
\end{tabular} & \begin{tabular}{|l|}
214,97 \\
210
\end{tabular} & $\begin{array}{l}61,44 \\
66,74\end{array}$ & \begin{tabular}{|l|l|l|l|}
780,99 \\
\end{tabular} & \begin{tabular}{|l|}
110,72 \\
110,72
\end{tabular} & $\mid$ & $\begin{array}{ll}1,150 \\
50,94\end{array}$ & | & $\begin{array}{l}\mid 20,535 \\
56,57\end{array}$ & $\begin{array}{l}0,35 \\
56,57\end{array}$ & 306,92 \\
\hline Triturus marmoratus & $\begin{array}{l}\text { 29TPF67 } \\
\end{array}$ & 100,00 & 138,89 & 107,36 & 38,83 & 5764,51 & 296,72 & 23,36 & 273,36 & 69,09 & 214,57 & 214,57 & 66,78 & 768,30 & 108,26 & 9,93 & 50,41 & \begin{tabular}{|c|}
301,58 \\
\end{tabular} & 56,62 & 56,62 & 301,41 \\
\hline Triturus marmoratus & 29TPF68 & 101,00 & 125,92 & 105,07 & 38,24 & 5746,97 & 283,86 & 12,69 & 271,17 & 55,71 & 201,92 & 201,94 & 54,87 & 847,90 & 119,58 & 11,95 & 50,01 & 334,57 & 65,86 & 65,90 & 334,55 \\
\hline Triturus marmoratus & 29TPF69 & 100,00 & 124,72 & 105,60 & 38,38 & 5737,43 & 282,95 & 11,12 & 271,83 & 53,84 & 200,67 & 200,69 & 53,80 & 842,56 & 118,37 & 12,49 & 49,51 & 332,58 & 66,68 & 66,71 & 332,58 \\
\hline Triturus marmoratus & 29TPF70 & 101,00 & 126,52 & 95,46 & 35,4 & 5924,88 & 281,66 & 17,39 & 264,27 & 61,88 & 204,75 & 205,50 & 54,21 & 874,26 & 124,50 & 9,71 & 51,57 & 344,34 & 61,95 & 63,13 & 342,25 \\
\hline Triturus marmoratus & 29TPF71 & 100,00 & 127,17 & 97,36 & $36, \mathrm{C}$ & 5919,39 & 283,19 & 17,05 & 266,14 & 62,28 & 205,32 & 205,96 & 54,80 & 856,38 & 121,62 & 9,8 & 51,38 & 336,79 & 61,71 & 62,35 & 334,93 \\
\hline Triturus marmoratus & 29TPF72 & 100,00 & 127,59 & 99,08 & 36,53 & $\begin{array}{l}5904,58 \\
\end{array}$ & 284,36 & 16,52 & 267,84 & 62,55 & 205,84 & 205,97 & 55,05 & 843,94 & 119,73 & 9,89 & 51,16 & 331,56 & 61,64 & 61,79 & 330,15 \\
\hline Triturus marmoratus & 29TPF73 & 100,00 & 133,46 & 102,44 & 37,2 & 5891,66 & 291,47 & 20,37 & 271,10 & 67,96 & 211,44 & 211,44 & 60,61 & 792,11 & 111,81 & 9,37 & 50,82 & 310,49 & 57,83 & 57,83 & 309,20 \\
\hline Triturus marmoratus & 29TPF74 & 101,00 & 141 & 105,77 & 38,0 & 5862,92 & 300,65 & 26,54 & 27 & 75,85 & 218,98 & $21 \varepsilon$ & 68,70 & 723,89 & 101,04 & 8,5 & 50,33 & 82,67 & 52,56 & 52,56 & 280,76 \\
\hline Triturus marmoratus & 29TPF75 & 99,00 & 134 & 105,26 & 37,9 & 5864,5 & 293,29 & 19,66 & 27 & $\begin{array}{l}6,400 \\
67,46\end{array}$ & 211,71 & & 61,42 & 765,39 & $\mid \begin{array}{l}\mid 107,37 \\
\end{array}$ & $\begin{array}{ll}0,-1 \\
9,6\end{array}$ & 50,20 & 299,43 & 57,12 & 57,12 & 298,61 \\
\hline Triturus marmoratus & 29TPF76 & 101,00 & 133 & 10 & 38, & 584 & 292,79 & 18,91 & 273,88 & 66,99 & 210,85 & 210,86 & 61,26 & 757,77 & 105,79 & 9,8 & 49,82 & 296,32 & 57,40 & 57,40 & 295,41 \\
\hline Triturus marmoratus & 29TPF77 & 100,00 & 137,67 & 107,68 & 38,62 & 5820,77 & 296,98 & 21,54 & 275,44 & 71,36 & 214,26 & 214,26 & 64,96 & 721,04 & 99 & 9,74 & 49,31 & 281,24 & 54,96 & 54,96 & 280,28 \\
\hline Triturus marmoratus & 29TPF78 & 100,00 & 129,88 & 107,05 & 38,40 & 5809,03 & 289,73 & 14,60 & 275,14 & 62,27 & 206,69 & 206,69 & 57,73 & 759,94 & 105,55 & 10,85 & 49,07 & 297,53 & 59,92 & 59,92 & 297,20 \\
\hline Triturus marmoratus & 29TPF79 & 100,00 & 123,01 & 106,30 & 38,32 & 5778,23 & 282,90 & 8,87 & 274,03 & 54,38 & 199,62 & 199,64 & 51,64 & 793,80 & 109,92 & 12,11 & 48,60 & 311,30 & 65,06 & 65,08 & 311,22 \\
\hline Triturus marmoratus & 29TPF80 & 100,00 & 12 & $\begin{aligned} 90,50 \\
96,64\end{aligned}$ & 35 & 5984,11 & 281,57 & \begin{tabular}{c|c|}
14,38 \\
140
\end{tabular} & \begin{tabular}{|l|}
267,19 \\
\end{tabular} & $\mid$\begin{tabular}{|c|}
49,31 \\
59
\end{tabular} & 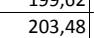 & \begin{tabular}{|l|}
204,49 \\
\end{tabular} & $\begin{array}{ll}1,1,68 \\
51\end{array}$ & \begin{tabular}{|l|l|}
829,57 \\
\end{tabular} & \begin{tabular}{|l|l|l|l|l|l|}
115,42 \\
\end{tabular} & 然, & $\begin{array}{l}40,0,31 \\
50,1\end{array}$ & 324,36 & $\begin{array}{l}0,009 \\
60,92\end{array}$ & $\begin{array}{l}3,000 \\
62,19\end{array}$ & 319,90 \\
\hline Triturus marmoratus & 29TPF81 & 100,00 & 126,60 & 98,86 & 36,16 & 5977,64 & 284,65 & 15,28 & 269,37 & 60,96 & 205,60 & 206,19 & 53,50 & 801,99 & 111,22 & 9,53 & 50,05 & 313,21 & 59,84 & 60,40 & 308,99 \\
\hline Triturus marmoratus & 29TPF82 & 100,00 & 131,03 & 101,63 & 36,88 & 5965,24 & 290,16 & 18,01 & 272,15 & 64,99 & 210,07 & 210,10 & 57,57 & 761,25 & 105,14 & 9,16 & 49,85 & 296,71 & 57,24 & 57,26 & 292,83 \\
\hline Triturus marmoratus & 29TPF83 & 101,00 & 129,88 & 102,77 & 37,09 & 5951,56 & 289,35 & 16,37 & 272,99 & 63,97 & 208,81 & 208,81 & 56,52 & 756,55 & 104,25 & 9,48 & 49,50 & 294,66 & 57,70 & 57,70 & 291,10 \\
\hline Triturus marmoratus & 29TPF84 & 99,00 & 136,85 & 105,53 & 37,8 & 5927,83 & 296,95 & 21,49 & 275,46 & 70,53 & 215,16 & 215 & 63 & 702,12 & 96,03 & 等 & 49,13 & 272,78 & 53,29 & 53,29 & 26 \\
\hline Triturus marmoratus & 29TPF85 & 101,00 & 133,76 & 105,84 & 37,90 & 5913,94 & 294,04 & 18,42 & 275,63 & 67,60 & 211,91 & 211,91 & 60,34 & 713,10 & 97,54 & 9,38 & 48,85 & 277,16 & 55,33 & 55,33 & 274,08 \\
\hline Triturus marmoratus & 29TPF86 & 100,00 & 126,57 & 105,56 & 37,85 & 5900,58 & 287,13 & 11,93 & 275,19 & 60,90 & 204,84 & 204,84 & 53,61 & 744,61 & 101,80 & 10,30 & 48,49 & 289,46 & 59,65 & 59,65 & 287,21 \\
\hline Triturus marmoratus & 29TPF87 & 99,00 & 128,44 & 106,95 & 38,07 & 5880,29 & 289,34 & 12,93 & 276,42 & 62,64 & 206,21 & 206,21 & 55,45 & 721,95 & 98,36 & 10,32 & 48,11 & 280,52 & 58,36 & 58,36 & 278 \\
\hline Triturus & 29TPF88 & 101,00 & 131,27 & 108,01 & 38,51 & 5851,74 & 291,97 & 14,96 & 277 & 65,44 & 208 & 208 & 58 & 695,99 & 94,18 & 10,34 & 4 & 270,13 & 56,85 & 56,85 & 26 \\
\hline Triturus marmoratus & 29TPF89 & 100,00 & 127,67 & 108,27 & 38,52 & 5831,94 & 288,98 & 11,46 & 277,52 & 62,03 & 204,89 & 204,89 & 55,23 & 706,50 & 95,57 & 11,02 & 47,46 & 274,56 & 59,14 & 59,14 & 273,30 \\
\hline
\end{tabular}




\begin{tabular}{|c|c|c|c|c|c|c|c|c|c|c|c|c|c|c|c|c|c|c|c|c|c|}
\hline TAXON & UTM & $\mathrm{km} 2$ & $\mathrm{BIO1}$ & $\mathrm{B1O2}$ & $\mathrm{BIO3}$ & $\mathrm{B104}$ & B105 & $\mathrm{B106}$ & $\mathrm{B107}$ & B108 & B109 & 81010 & B1011 & BIO12 & B1O13 & BIO14 & B1015 & BIO16 & BIO17 & B1018 & B1019 \\
\hline Triturus marmoratus & 29TPF93 & 100,00 & 125,30 & 103,03 & 37,01 & 6001,13 & 286,26 & 11,60 & 274,66 & 59,07 & 205,17 & 205,17 & 51,65 & 728,21 & 97,39 & 9,94 & 47,86 & 281,22 & 58,88 & 58,88 & 275,19 \\
\hline Triturus marmoratus & 29TPF94 & 100,00 & 127,14 & 104,70 & 37,31 & 5992,22 & 288,67 & 12,45 & 276,22 & 60,62 & 206,74 & 206,74 & 53,35 & 706,35 & 94,23 & 9,63 & 47,70 & 272,59 & 57,28 & 57,28 & 267,10 \\
\hline Triturus marmoratus & 29TPF95 & 100,00 & 123,98 & 105,18 & 37,72 & 5972,06 & 285,81 & 9,47 & 276,34 & 57,90 & 203,57 & 203,57 & 50,66 & 712,27 & 94,80 & 9,98 & 47,46 & 274,87 & 58,80 & 58,80 & 269,70 \\
\hline Triturus marmoratus & 29TPF96 & 100,00 & 125,79 & 106,55 & 38,02 & 5947,17 & 287,79 & 10,27 & 277,52 & 59,50 & 204,76 & 204,76 & 52,34 & 691,95 & 91,70 & \begin{tabular}{l|l|l|}
10,15 \\
\end{tabular} & 47,00 & 266,69 & 57,95 & 57,95 & 261,99 \\
\hline Triturus marmoratus & 29TPF97 & 101,00 & 119,67 & 106,41 & 37,99 & 5930,73 & 282,07 & 4,67 & 277,39 & 53,80 & 198,61 & 198,61 & 46,65 & 718,31 & 95,14 & 11,02 & 46,70 & 276,97 & 61,95 & 61,95 & 272,98 \\
\hline Triturus marmoratus & 29TPF98 & 100,00 & 120,57 & 107,46 & 38,12 & 5908,98 & 283,11 & 5,07 & 278,03 & 54,57 & 199,09 & 199,09 & 47,67 & 701,41 & 92,47 & 11,18 & 46,30 & 270,26 & 61,39 & 61,39 & 266,71 \\
\hline Triturus marmoratus & 29TPF99 & 100,00 & 130,68 & 109,56 & 38,84 & 5876,27 & 292,54 & 13,18 & 279,36 & 64,36 & 208,23 & 208,23 & 57,49 & 638,01 & 83,60 & \begin{tabular}{|l|l|}
10,49 \\
\end{tabular} & 46,07 & 245,56 & 55,23 & 55,23 & 241,94 \\
\hline Triturus marmoratus & 29TPG00 & 101,00 & 128,55 & 101,51 & 39,68 & 5268,55 & 274,20 & 21,32 & 252,88 & 63,34 & 197,31 & 197,49 & 63,30 & $\begin{array}{ll}1164,34 \\
1164\end{array}$ & 161,88 & 15,93 & 51,68 & 461,28 & 85,32 & 88,02 & 461,28 \\
\hline Triturus marmoratus & 29TPG01 & 100,00 & 111,76 & 92,42 & 37,99 & 5168,72 & 251,69 & 11,49 & 240,20 & 49,41 & 180,21 & 180,35 & 49,41 & 1289,31 & 176,79 & 20,77 & 50,47 & 510,67 & \begin{tabular}{|l|l|}
101,87 \\
\end{tabular} & 103,85 & 510,67 \\
\hline Triturus marmoratus & 29TPG03 & 101,00 & 100,34 & 86,02 & 36,70 & 5053,09 & 235,86 & 4,79 & 231,07 & 40,97 & 167,75 & 168,01 & 40,55 & 1349,43 & 178,69 & 25,66 & 48,45 & 527,55 & 116,37 & 118,48 & 527,53 \\
\hline Triturus marmoratus & 29TPG04 & 100,00 & 105,08 & 88,21 & 37,23 & 5064,05 & 241,28 & 7,38 & 233,90 & 49,16 & 172,41 & 172,65 & 44,73 & 1295,86 & 171,56 & 25,20 & 47,82 & 502,97 & 113,33 & 115,43 & 502,81 \\
\hline Triturus marmoratus & 29TPG05 & 101,00 & 119,89 & 93,96 & 38,26 & 5155,67 & 258,22 & 15,84 & 242,38 & 63,14 & 187,92 & 188,01 & 57,21 & 1153,20 & 156,06 & 22,16 & 47,08 & 443,66 & 100,34 & 101,71 & 440,77 \\
\hline Triturus marmoratus & 29TPG06 & 101,00 & 120,72 & 93,71 & 38,19 & 5132,34 & 258,02 & 16,47 & 241,55 & 63,99 & 188,26 & 188,35 & 58,39 & 1133,64 & 155,70 & 22,98 & 46,17 & 434,04 & 101,53 & 103,93 & 429,13 \\
\hline Triturus marmoratus & 29TPG07 & 100,00 & 123,10 & 93,56 & 38,15 & 5116,46 & 259,22 & 18,05 & 241,17 & 66,16 & 190,42 & 190,56 & 60,93 & 1099,61 & 152,97 & 23,37 & 45,42 & 418,36 & 101,12 & 104,45 & 411,31 \\
\hline Triturus marmoratus & 29TPG10 & 100,00 & 126,91 & 102,29 & 39,40 & 5384,67 & 275,27 & 18,51 & 256,76 & 60,43 & 197,61 & 197,66 & 60,43 & 1124,66 & 158,03 & 15,63 & 51,73 & 446,89 & 82,92 & 83,49 & 446,89 \\
\hline Triturus marmoratus & 29TPG12 & 100,00 & 115,84 & 95,37 & 38,04 & 5283,63 & 259,08 & 11,91 & 247,16 & 51,65 & 185,68 & 185,71 & 51,65 & 1176,26 & 158,86 & 19,73 & 49,55 & 462,11 & 95,00 & 95,45 & 462,11 \\
\hline Triturus marmoratus & 29TPG13 & 101,00 & 114,59 & 94,29 & 37,88 & 5258,16 & 256,75 & 11,16 & 245,59 & 51,08 & 184,25 & 184,28 & 50,83 & 1171,31 & 155,10 & 20,77 & 48,71 & 457,27 & 97,45 & 97,95 & 457,27 \\
\hline Triturus marmoratus & 29TPG15 & 99,00 & 117,40 & 94,81 & 38,05 & 5235,88 & 258,51 & 12,64 & 245,87 & 59,84 & 186,75 & 186,77 & 53,92 & 1115,37 & 149,09 & 21,82 & 46,89 & 429,50 & 97,90 & 99,06 & 427,21 \\
\hline Triturus marmoratus & 29TPG17 & 99,00 & 118,91 & 94,17 & 38,01 & 5173,19 & 257,53 & 13,69 & 243,84 & 61,46 & 187,16 & 187,19 & 56,20 & 1081,36 & 147,99 & 23,39 & 45,11 & 412,32 & \begin{tabular}{|c|}
100,59 \\
\end{tabular} & 101,89 & 406,09 \\
\hline Triturus marmoratus & 29TPG20 & 100,00 & 116,55 & 98,57 & 38,25 & 5422,90 & 264,90 & 10,39 & 254,51 & 50,42 & 188,25 & 188,27 & 50,42 & 1146,33 & 161,59 & \begin{tabular}{|l|l|l|}
17,49 \\
\end{tabular} & 51,15 & 456,30 & 88,32 & 88,41 & 456,30 \\
\hline Triturus marmoratus & 29TPG22 & 101,00 & 133,16 & 103,27 & 39,01 & 5460,32 & 282,04 & 21,44 & 260,59 & 66,48 & 204,71 & 204,71 & 65,46 & 970,41 & 130,05 & 15,04 & 49,31 & 377,52 & 75,53 & 75,53 & 377,52 \\
\hline Triturus marmoratus & 29TPG23 & 100,00 & 128,44 & 100,89 & 38,75 & 5426,73 & 275,36 & 18,16 & 257,20 & 64,68 & \begin{tabular}{|l|}
199,68 \\
\end{tabular} & 199,68 & 61,42 & $\begin{array}{l}993,49 \\
\end{array}$ & $\begin{array}{l}130,73 \\
\end{array}$ & 16,78 & 48,38 & 385,02 & 80,62 & 80,62 & 384,57 \\
\hline Triturus marmoratus & 29TPG24 & 100,00 & 128,78 & 100,20 & 38,64 & 5413,35 & 274,57 & 18,36 & 256,21 & 68,08 & 199,94 & 199,94 & 62,10 & 972,87 & 127,05 & \begin{tabular}{|c|}
17,39 \\
\end{tabular} & 47,39 & 374,59 & 81,45 & 81,45 & 372,83 \\
\hline Triturus marmoratus & 29TPG28 & 101,00 & 102,96 & 91,96 & 37,86 & 5109,11 & 242,32 & 1,67 & 240,65 & 47,18 & 170,96 & 171,02 & 42,07 & 1159,66 & 156,59 & 27,99 & 43,84 & 442,53 & \begin{tabular}{|c|}
115,48 \\
\end{tabular} & 117,44 & 435,04 \\
\hline Triturus marmoratus & 29TPG30 & 101,00 & 129,20 & 104,36 & 38,86 & 5549,78 & 281,83 & 17,57 & 264,26 & 60,49 & 202,10 & 202,10 & 60,49 & 983,61 & 138,69 & 14,19 & 51,07 & 390,06 & 73,76 & 73,76 & 390,06 \\
\hline Triturus marmoratus & 29TPG32 & 100,00 & 121,65 & 101,25 & 38,42 & 5496,12 & 272,07 & 11,98 & 260,09 & 54,58 & 194,31 & 194,31 & 54,26 & 1006,25 & 137,16 & 16,95 & 49,15 & 395,01 & 81,34 & 81,34 & 395,01 \\
\hline Triturus marmoratus & 29TPG33 & 100,00 & 121,95 & 100,70 & 38,33 & 5475,42 & 271,29 & $\begin{array}{l}12,10 \\
12,10\end{array}$ & 259,19 & 57,53 & \begin{tabular}{|l|l|}
194,34 \\
\end{tabular} & $\begin{array}{l}194,34 \\
194,\end{array}$ & 54,80 & $\begin{array}{l}986,87 \\
9\end{array}$ & 131,60 & 17,61 & 48,16 & 384,05 & 82,26 & $\begin{array}{l}8,264 \\
82,26\end{array}$ & 383,95 \\
\hline Triturus marmoratus & 29TPG34 & 101,00 & 119,10 & 99,36 & 38,15 & 5438,35 & 267,03 & 10,11 & 256,92 & 58,52 & 191,03 & 191,03 & 52,56 & 996,47 & 130,92 & 19,09 & 47,19 & 385,91 & 86,18 & 86,18 & 385,02 \\
\hline Triturus marmoratus & 29TPG37 & 100,00 & 81,18 & 89,85 & 36,97 & 5161,60 & 223,24 & $-16,66$ & 239,90 & 26,61 & 150,66 & 150,77 & 20,92 & 1289,79 & 168,92 & 33,27 & 43,10 & 490,73 & \begin{tabular}{|c|}
134,79 \\
\end{tabular} & 135,32 & 482,99 \\
\hline Triturus marmoratus & 29TPG38 & 100,00 & 96,75 & 92,85 & 37,72 & 5178,34 & 238,76 & $-4,64$ & 243,39 & 40,47 & 165,90 & 165,96 & 35,20 & 1152,50 & 153,75 & 28,99 & 43,10 & 438,96 & 118,41 & 119,17 & 430,55 \\
\hline Triturus marmoratus & 29TPG40 & 100,00 & 139,68 & 107,25 & 39,28 & 5619,81 & 294,02 & 24,54 & 269,48 & 69,90 & 213,18 & 213,18 & 69,41 & 839,87 & 116,78 & 11,78 & 50,19 & 329,39 & 62,42 & 62,42 & 329,39 \\
\hline Triturus marmoratus & 29TPG41 & 100,00 & 132,24 & 105,64 & 38,95 & 5603,97 & 286,01 & \begin{tabular}{|l|l|}
18,46 \\
\end{tabular} & 267,55 & 63,01 & 205,82 & 205,82 & \begin{tabular}{l|l}
62,58 \\
62
\end{tabular} & \begin{tabular}{|l|l|}
880,38 \\
\end{tabular} & \begin{tabular}{|l|l|l|l|l|}
121,57 \\
\end{tabular} & 13,71 & 40,58 & 345,71 & \begin{tabular}{|c|}
68,32 \\
\end{tabular} & $\begin{array}{l}68,32 \\
68,32\end{array}$ & 345,69 \\
\hline Triturus marmoratus & 29TPG42 & 101,00 & 119,50 & 102,14 & 38,32 & 5551,84 & 272,26 & 8,95 & 263,32 & 51,70 & 193,03 & 193,03 & 51,39 & 962,54 & 131,89 & 16,71 & 48,75 & 378,48 & 79,34 & 79,34 & 378,47 \\
\hline Triturus marmoratus & 29TPG43 & 100,00 & 117,15 & 101,03 & 38,13 & 5522,05 & 268,85 & 7,27 & 261,57 & 52,89 & 190,41 & 190,41 & 49,60 & 966,51 & 130,02 & 18,09 & 47,76 & 377,38 & 82,60 & 82,60 & 377,30 \\
\hline Triturus marmoratus & 29TPG47 & 101,00 & 87,27 & 93,12 & 37,28 & 5272,05 & 232,57 & $-13,80$ & 246,38 & 30,69 & 158,08 & 158,12 & 25,08 & 1178,80 & 154,82 & 30,25 & 43,01 & 449,01 & 123,01 & 123,16 & 441,24 \\
\hline Triturus marmoratus & 29TPG48 & 100,00 & 108,67 & 96,86 & 37,97 & 5314,99 & 253,42 & 2,25 & 251,18 & 49,64 & 179,27 & 179,29 & 44,47 & 997,65 & 133,38 & 24,48 & 42,97 & 380,02 & 101,32 & 101,38 & 371,02 \\
\hline Triturus marmoratus & 29TPG49 & 101,00 & 118,67 & 97,49 & 38,41 & 5283,64 & 261,09 & 10,54 & 250,55 & 58,99 & 188,28 & 188,28 & 54,20 & 919,91 & 123,69 & 22,59 & 42,35 & 348,53 & 93,97 & 93,97 & 337,24 \\
\hline Triturus marmoratus & 29TPG50 & 100,00 & 137,60 & 107,47 & 39,01 & 5663,99 & 293,42 & 22,08 & 271,34 & 69,40 & 211,95 & 211,95 & 66,82 & 797,61 & 110,60 & 11,75 & 49,53 & 312,43 & 60,95 & 60,95 & 312,37 \\
\hline Triturus marmoratus & 29TPG51 & 100,00 & 135,10 & 106,82 & 38,97 & 5652,70 & 290,36 & \begin{tabular}{|l|l|}
19,93 \\
\end{tabular} & 270,43 & 68,85 & 209,35 & 209,35 & 64,65 & 802,20 & 109,94 & $|12,67|$ & 48,85 & 313,40 & \begin{tabular}{|c|}
63,25 \\
\end{tabular} & 63,25 & 313,23 \\
\hline Triturus marmoratus & 29TPG52 & 99,00 & 126,28 & 105,19 & 38,73 & 5629,65 & 281,48 & 12,63 & 268,85 & 59,49 & 200,62 & 200,62 & 56,60 & 851,88 & 116,31 & 14,69 & 48,20 & 333,63 & 70,27 & 70,27 & 333,50 \\
\hline Triturus marmoratus & 29TPG53 & 101,00 & 118,10 & 103,22 & 38,19 & 5593,68 & 272,73 & 6,29 & 266,44 & 54,78 & 192,35 & 192,35 & 49,42 & 897,29 & 121,15 & 16,78 & 47,42 & 350,83 & 77,64 & 77,64 & 350,43 \\
\hline Triturus marmoratus & 29TPG54 & 100,00 & 11 & 101,49 & 37,99 & 5549,06 & 265,44 & 2,10 & 263,34 & 50,57 & 186,01 & 186,01 & 44,43 & 933,69 & 123 & 19,0 & 46,45 & 363,30 & 84,68 & 84,68 & 361,72 \\
\hline Triturus marmoratus & 29TPG55 & 101,00 & 101,87 & 98,62 & 37,70 & 5478,45 & 253,21 & $-4,90$ & 258,12 & 41,72 & 175,11 & 175,11 & 35,82 & 1007,10 & 132,54 & 22,70 & 45,05 & 389,16 & 96,94 & 96,94 & 385,59 \\
\hline Triturus marmoratus & 29TPG59 & 101,00 & 120,87 & 99,39 & 38,56 & 5362,54 & 265,42 & 10,95 & 254,47 & 59,95 & 191,56 & 191,56 & 55,12 & 854,10 & 114,17 & 21,06 & 41,95 & 323,58 & 88,29 & 88,29 & 311,47 \\
\hline Triturus marmoratus & 29TPG60 & 100,00 & 123,07 & 105,87 & 38, & 5712,51 & 281,5 & 9,35 & 272,23 & 52,57 & 198,73 & 198,73 & 52,53 & 838,83 & 117,23 & 13,04 & 49,09 & 15 & 67,94 & 67,94 & 331,15 \\
\hline Triturus marmoratus & 29TPG61 & 101,00 & 124,66 & 106,28 & 38, & 5691,35 & 282 & \begin{tabular}{|c|}
10,37 \\
10,
\end{tabular} & 272,28 & 56,10 & \begin{tabular}{|l|l|}
199,97 \\
\end{tabular} & 19 & 54,20 & \begin{tabular}{|l|l|}
816,66 \\
\end{tabular} & $\mid 112,80$ & 13,43 & 48,38 & 321,04 & 67,43 & 67,43 & 320,98 \\
\hline Triturus marmoratus & 29TPG62 & 101,00 & 11 & 104,76 & 38,23 & 5659,64 & 274 & 4,41 & 270,26 & 52,34 & 192,27 & 192,27 & 47,48 & 857,09 & 117,25 & 15,2 & 47,61 & 336,34 & 74,11 & 74,11 & 336,18 \\
\hline Triturus marmoratus & 29TPG63 & 100,00 & 112,97 & 103,74 & 38,15 & 5628,42 & 269,69 & $\frac{1,1+35}{1,35}$ & 268,34 & 50,38 & 187,93 & 187,93 & 44,10 & 878,27 & 118,15 & 16,94 & 46,75 & 343,20 & 79,00 & 79,00 & 342,17 \\
\hline Triturus marmoratus & 29TPG64 & 100,00 & 104,22 & 101,47 & 37,91 & 5587,04 & 259,60 & $-4,87$ & 264,47 & 42,66 & 178,99 & 178,99 & 36,56 & 935,40 & 123,39 & 19,90 & 45,50 & 363,13 & 88,84 & 88,84 & 360,58 \\
\hline Triturus marmoratus & 29TPG65 & 100,00 & 91,21 & 98,25 & 37,45 & 5510,92 & 244,11 & $-14,60$ & 258 & 31,40 & 165,31 & 165,32 & 25,41 & 1036,29 & 135,29 & 25,12 & 43,62 & 79 & 105,96 & 106,01 & 391,05 \\
\hline Triturus marmoratus & \begin{tabular}{|l|}
$29 T P G 67$ \\
\end{tabular} & $\begin{array}{l}10,000 \\
101,00\end{array}$ & & $\begin{array}{l}0,2020 \\
98,13\end{array}$ & 37 & 5449,74 & 241 & $\begin{array}{l}-14,00 \\
-15,01 \\
\end{array}$ & \begin{tabular}{|l|}
$250,1 / 1$ \\
2566
\end{tabular} & 31,18 & 163,81 & 163,81 & 25,53 & 1033,16 & 135, & 27,56 & 41,95 & 391,99 & 111,28 & 111,28 & 382,79 \\
\hline Triturus marmoratus & 29TPG68 & 101,00 & 95,38 & 98,77 & 37,99 & 5429,41 & 245,36 & $-11,17$ & 256,53 & 35,56 & 168,01 & 168,01 & 30,21 & 994,16 & 131,08 & 26,93 & 41,40 & 376,34 & 108,56 & 108,56 & 365,59 \\
\hline Triturus marmoratus & 29TPG69 & 100,00 & 109,58 & 99,72 & 38,42 & 5401,83 & 256,87 & 0,74 & 256,13 & 48,89 & 181,12 & 181,12 & 43,70 & 891,67 & 118,02 & 23,64 & 41,01 & 336,82 & 96,95 & 96,95 & 323,83 \\
\hline Triturus marmoratus & 29TPG70 & 101,00 & 120,49 & 106,61 & 38,23 & 5758,56 & 281,01 & 6,19 & 274,81 & 50,93 & 197,05 & 197,05 & 49,40 & 797,41 & 110,24 & 12,70 & & 313,45 & 66,84 & 66,84 & 313,45 \\
\hline Triturus marmoratus & 29TPG71 & 99,00 & 106,29 & 103,38 & 37 & 5709,64 & 265,63 & $-4,35$ & 269,98 & 41,02 & 182,72 & 18 & 36,85 & 887,24 & 120,34 & 15,88 & 47,03 & 346,53 & 79,77 & 79,77 & 34 \\
\hline Triturus marmoratus & \begin{tabular}{|l|}
$29 T P G 72$ \\
\end{tabular} & \begin{tabular}{|l|}
100,00 \\
100
\end{tabular} & $\begin{array}{l}10,25 \\
104,66\end{array}$ & $\begin{array}{l}10,50 \\
103,39\end{array}$ & 37,88 & 5685,59 & 2003,65 & $\begin{array}{l}-2,505 \\
-5,85 \\
\mid\end{array}$ & $\begin{array}{l}265,50 \\
269,52 \\
\end{array}$ & 42,04 & 180,79 & 180,80 & 35,52 & 889,11 & 119,21 & 17,01 & 46,29 & 346,30 & 82,30 & 82,30 & 345,29 \\
\hline Triturus marmoratus & 29TPG73 & 100,00 & 111,26 & 105,36 & 38,08 & 5681,64 & 270,72 & $-1,27$ & 271,99 & 48,18 & 187,11 & 187,11 & 41,70 & 830,16 & 111,22 & 16,29 & 46,11 & 324,27 & 76,84 & 76,84 & 322,77 \\
\hline Triturus marmoratus & 29TPG74 & 100,00 & 102,89 & 103,19 & 37,94 & 5639,26 & 260,53 & $-7,56$ & 268,10 & 40,61 & 178,40 & 178,40 & 34,42 & 888,01 & 117,14 & 19,58 & 44,67 & 343,11 & \begin{tabular}{|l|l|}
87,15 \\
\end{tabular} & 87,15 & 339,6 \\
\hline Triturus & 29TPG76 & 100,00 & 69,20 & 95,75 & 37,03 & 5474,24 & 221,21 & $-33,69$ & 254,90 & 11,2 & 143, & 143 & 5, & 1166,78 & 148,91 & 33,61 & 40 & 435,09 & 133,11 & 134,16 & 423 \\
\hline Triturus marmoratus & 29TPG77 & 100,00 & 72,02 & 96,50 & 37,33 & 5454,39 & 223,74 & $-31,34$ & 255,08 & 13,92 & 145,64 & 145,74 & 7,94 & 1141,30 & $\begin{array}{l}446,33 \\
140\end{array}$ & 33,84 & 39,61 & 424,73 & 132,61 & 133,18 & 4411,98 \\
\hline
\end{tabular}




\begin{tabular}{|c|c|c|c|c|c|c|c|c|c|c|c|c|c|c|c|c|c|c|c|c|c|}
\hline TAXON & UTM & $\mathrm{km} 2$ & $\mathrm{BIO1}$ & $\mathrm{B1O2}$ & $\mathrm{BIO3}$ & $\mathrm{B104}$ & B105 & $\mathrm{B106}$ & $\mathrm{B107}$ & B108 & $\mathrm{BIO9}$ & 81010 & B1011 & $\mathrm{BIO12}$ & B1O13 & BIO14 & BIO15 & BIO16 & BIO17 & $\mathrm{BIO18}$ & B1019 \\
\hline Triturus marmoratus & 29TPG78 & 99,00 & 84,24 & 98,73 & 37,94 & 5461,01 & 235,92 & $-21,51$ & 257,42 & 24,81 & 157,54 & 157,55 & 19,16 & 1035,81 & 134,64 & 30,25 & 39,76 & 387,35 & 119,61 & 119,70 & 374,39 \\
\hline Triturus marmoratus & 29TPG79 & 101,00 & 115,29 & 102,23 & 38,71 & 5504,49 & 264,82 & 3,55 & 261,28 & 52,63 & 187,88 & 187,88 & 47,61 & 798,91 & 105,84 & 21,01 & 40,71 & 302,25 & 87,53 & 87,53 & 288,56 \\
\hline Triturus marmoratus & 29TPG80 & 100,00 & 121,05 & 107,95 & 38,31 & 5805,80 & 283,05 & 5,75 & 277,30 & 55,69 & 198,22 & 198,22 & 49,43 & 736,72 & 99,75 & 12,07 & 47,20 & 287,01 & 63,76 & 63,76 & 286,57 \\
\hline Triturus marmoratus & 29TPG81 & 100,00 & 112,63 & 106,89 & 38,07 & 5769,69 & 274,83 & $-0,95$ & 275,78 & 47,70 & 189,63 & 189,63 & 41,79 & 781,52 & 105,21 & 13,80 & 46,54 & 304,45 & 70,73 & 70,73 & 304,31 \\
\hline Triturus marmoratus & 29TPG82 & 101,00 & 115,92 & 108,05 & 38,48 & 5741,87 & 278,21 & 1,19 & 277,01 & 49,20 & 192,39 & 192,39 & 45,23 & 751,50 & 101,08 & 13,75 & 46,42 & 293,71 & 68,50 & 68,50 & 293,50 \\
\hline Triturus marmoratus & 29TPG83 & 100,00 & 114,34 & 107,76 & 38,57 & 5717,94 & 275,96 & $-0,14$ & 276,10 & 49,76 & 190,63 & 190,63 & 43,99 & 756,43 & 100,89 & 14,92 & 45,71 & 294,30 & 71,12 & 71,12 & 293,56 \\
\hline Triturus marmoratus & 29TPG84 & 100,00 & 101,08 & 104,58 & 38,04 & 5694,84 & 260,62 & $-10,39$ & 271,01 & 38,15 & 177,42 & 177,42 & 31,99 & 848,62 & 111,77 & 19,55 & 43,67 & 325,23 & 86,52 & 86,52 & 320,86 \\
\hline Triturus marmoratus & 29TPG85 & 99,00 & 90,22 & 102,10 & 37,74 & 5649,05 & 247,58 & $-18,81$ & 266,39 & 28,47 & 166,10 & 166,16 & 22,38 & \begin{tabular}{|l|l|}
931,97 \\
\end{tabular} & 121,43 & 24,22 & 41,70 & 352,40 & 101,25 & 101,38 & 344,17 \\
\hline Triturus marmoratus & 29TPG86 & 101,00 & 80,34 & 100,06 & \begin{tabular}{|c|}
37,57 \\
\end{tabular} & 5586,05 & 235,83 & $-26,54$ & 262,37 & 19,98 & 155,48 & 155,64 & 13,90 & 1015,72 & 130,94 & 29,10 & 40,06 & 379,28 & 116,18 & 116,72 & 367,84 \\
\hline Triturus marmoratus & 29TPG87 & 100,00 & 60,76 & 96,29 & 37,14 & 5479,39 & 213,40 & $-41,90$ & 255,30 & 3,18 & $\begin{array}{l}134,78 \\
\end{array}$ & 135,09 & $-3,08$ & 1192,08 & 150,36 & 37,89 & 37,67 & 436,76 & 145,06 & 146,84 & 421,17 \\
\hline Triturus marmoratus & 29TPG88 & 101,00 & 75,96 & 99,19 & 37,83 & 5498,03 & 229,16 & $-29,65$ & 258,81 & 16,66 & 149,91 & 149,95 & 10,69 & 1056,83 & 135,57 & 32,94 & 38,18 & 389,90 & 128,19 & 128,45 & 374,70 \\
\hline Triturus marmoratus & 29TPG90 & 101,00 & 125,92 & 109,62 & 38,77 & 5856,70 & 288,50 & 8,71 & 279,79 & 60,02 & 203,44 & 203,44 & 53,20 & 655,17 & 85,95 & 11,25 & 45,79 & 252,45 & 58,32 & 58,32 & 249,87 \\
\hline Triturus marmoratus & 29TPG91 & 100,00 & 118,94 & 109,38 & 38,64 & 5827,16 & 282,27 & 2,54 & 279,73 & 53,38 & 196,21 & 196,21 & 46,87 & 687,62 & 90,57 & 12,47 & 45,58 & 265,21 & 63,42 & 63,42 & 264,07 \\
\hline Triturus marmoratus & 29TPG92 & 100,00 & 117,79 & 109,49 & 38,73 & 5801,07 & 281,12 & 1,55 & 279,58 & 51,24 & 194,91 & 194,91 & 45,98 & 690,75 & 91,31 & 13,20 & 45,22 & 266,29 & 65,12 & 65,12 & 265,58 \\
\hline Triturus marmoratus & 29TPG93 & 100,00 & 114,11 & 109,10 & 38,82 & 5783,44 & 276,86 & $-1,48$ & 278,34 & 48,78 & 191,09 & 191,09 & 42,76 & 707,57 & 93,88 & 14,70 & 44,40 & 271,75 & 69,24 & 69,24 & 270,03 \\
\hline Triturus marmoratus & 29TPG94 & 101,00 & 110,64 & 108,34 & 38,65 & 5772,11 & 272,62 & $-4,27$ & 276,90 & 45,99 & 187,51 & 187,51 & 39,68 & 726,49 & 96,60 & 16,51 & 43,40 & 277,94 & 73,92 & 73,92 & 274,29 \\
\hline Triturus marmoratus & 29TPG95 & 101,00 & 102,24 & 106,49 & 38,29 & 5749,81 & 262,78 & $-11,04$ & 273,82 & 38,15 & 179,12 & 179,12 & 32,12 & 781,86 & 103,44 & 20,04 & 41,76 & 296,35 & 84,39 & 84,39 & 288,95 \\
\hline Triturus marmoratus & 29TPG96 & 100,00 & 97,20 & 105,45 & 38,22 & 5715,20 & 256,35 & $-15,01$ & 271,35 & 33,71 & 173,68 & 173,68 & 27,75 & 820,67 & 107,87 & 22,87 & 40,53 & 308,33 & 92,64 & 92,64 & 298,22 \\
\hline Triturus marmoratus & 29TPG97 & 100,00 & 73,90 & 100,69 & 37,78 & 5591,12 & 229,81 & $-32,99$ & 262,80 & 13,84 & 149,23 & 149,36 & 7,62 & 1021,92 & 130,38 & 32,26 & 37,71 & 374,88 & 125,27 & 125,90 & 359,55 \\
\hline Triturus marmoratus & 29TPG98 & 100,00 & 85,79 & 102,94 & 38,30 & 5606,91 & 241,86 & $-23,44$ & 265,30 & 24,33 & 161,06 & 161,06 & 18,38 & 920,26 & 118,99 & 28,64 & 37,98 & 339,37 & 112,59 & 112,59 & 324,04 \\
\hline Triturus marmoratus & 29TPH01 & 100,00 & 124,98 & 90,02 & 38,96 & 4776,79 & 252,75 & 24,07 & 228,67 & 71,31 & 187,58 & 188,19 & 67,60 & 1077,54 & 151,59 & 27,30 & 42,65 & 403,69 & 109,82 & 122,46 & 389,66 \\
\hline Triturus marmoratus & 29TPHO2 & 99,00 & 126,84 & 89,12 & 39,16 & 4652,13 & 251,70 & 27,49 & 224,21 & 74,29 & 187,64 & 188,44 & 70,94 & 1066,92 & 149,59 & 27,96 & 41,88 & 398,26 & 111,13 & 125,05 & 382,20 \\
\hline Triturus marmoratus & 29TPH07 & 100,00 & 123,13 & 83,78 & $\begin{array}{l}40,52 \\
\end{array}$ & 4121,32 & 237,34 & 33,13 & 204,21 & 77,79 & 176,53 & 178,70 & 74,12 & 1106,65 & 148,29 & 33,80 & 38,24 & 408,04 & 129,36 & 145,35 & 382,48 \\
\hline Triturus marmoratus & 29TPH11 & 101,00 & 125,62 & 91,67 & 38,90 & 4884,10 & 255,94 & 22,64 & 233,31 & 70,55 & 189,69 & 190,05 & 66,56 & 1016,77 & 141,15 & 25,85 & 42,03 & 380,19 & 104,54 & 113,04 & 366,03 \\
\hline Triturus marmoratus & 29TPH16 & 101,00 & 125,04 & 86,30 & 40,07 & 4330,92 & 243,26 & 31,13 & 212,13 & 76,77 & 181,15 & 182,83 & 73,01 & 1042,90 & 139,56 & 31,21 & 38,41 & 383,96 & 120,74 & 136,01 & 359,84 \\
\hline Triturus marmoratus & 29TPH18 & 101,00 & 125,68 & 83,80 & 40,68 & 4123,85 & 238,95 & 35,24 & 203,71 & 80,25 & 178,80 & 180,96 & 76,07 & 1044,09 & 136,94 & 32,81 & 37,04 & 382,20 & 125,76 & 142,04 & 354,40 \\
\hline Triturus marmoratus & 29TPH23 & 101,00 & 119,56 & 91,15 & 39,07 & 47762,91 & 248,70 & $\begin{array}{l}19,16 \\
19,16\end{array}$ & 229,53 & 60,02 & 181,97 & 182,57 & 62,19 & 1024,94 & $\mid 139,16$ & 28,49 & 40,09 & 381,25 & 112,89 & 125,25 & 363,04 \\
\hline Triturus marmoratus & 29TPH31 & 101,00 & 119,04 & 94,44 & 38,82 & 5059,74 & 255,30 & 14,04 & 241,25 & 62,01 & 185,63 & 185,73 & 57,79 & 967,60 & 131,02 & 25,32 & 41,14 & 362,64 & 102,89 & 105,66 & 347,87 \\
\hline Triturus marmoratus & 29TPH35 & 101,00 & 118,79 & 90,60 & 39,82 & 4643,16 & 245,49 & 20,12 & 225,38 & 66,82 & 179,40 & 180,40 & 62,86 & 996,47 & 131,71 & 30,01 & 37,94 & 366,67 & 117,26 & 130,42 & 343,40 \\
\hline Triturus marmoratus & 29TPH38 & 101,00 & 119,86 & 87,02 & 40,46 & 4332,46 & 238,97 & 26,55 & 212,42 & 72,01 & 176,02 & 177,71 & 67,77 & 1012,15 & 129,91 & 33,23 & 35,76 & 367,39 & 127,05 & 141,69 & 338,09 \\
\hline Triturus marmoratus & 29TPH44 & 99,00 & 109,30 & 93,09 & 39,19 & 4862,07 & 242,56 & 8,30 & 234,26 & 54,97 & 173,19 & 173,70 & 50,86 & 1015,57 & 133,86 & 30,74 & 37,96 & 375,15 & 120,36 & 129,85 & 353,36 \\
\hline Triturus marmoratus & $29 \mathrm{TPH} 45$ & 100,00 & 111,85 & 92,25 & 39,68 & 4763,05 & 242,47 & \begin{tabular}{|c|c|}
11,89 \\
\end{tabular} & \begin{tabular}{|l|l|}
230,58 \\
\end{tabular} & 58,62 & 174,21 & 174,95 & 54,51 & 1003,77 & $\begin{array}{l}31,25 \\
131,\end{array}$ & 31,17 & 37,17 & 368,70 & 121,41 & 132,90 & 344,71 \\
\hline Triturus marmoratus & 29TPH50 & 99,00 & 103,52 & 97,16 & 38,31 & 5267,63 & 247,89 & $-2,19$ & 250,08 & 44,77 & 173,39 & 173,39 & 40,01 & 986,10 & 131,01 & 27,03 & 40,63 & 371,34 & 108,83 & 108,87 & 357,52 \\
\hline Triturus marmoratus & 29TPH51 & 100,00 & 92,45 & 95,33 & 38,24 & 5173,82 & 235,67 & $-10,10$ & 245,76 & 35,76 & 161,46 & 161,51 & 30,84 & 1078,35 & 141,86 & 31,88 & 39,27 & 402,52 & 125,19 & 125,91 & 386,28 \\
\hline Triturus marmoratus & \begin{tabular}{|l|l|}
$29 T P H 55$ \\
\end{tabular} & 101,00 & 115,59 & 93,60 & 39,80 & 4824,02 & 247,23 & 14,03 & 233,20 & 61,30 & 178,62 & 179,20 & 57,08 & 937,10 & 121,15 & 29,23 & 36,63 & 342,96 & 114,97 & 125,70 & 317,72 \\
\hline Triturus marmoratus & 29TPH56 & 100,00 & 112,59 & 92,57 & 39,92 & 4721,95 & 242,36 & 12,91 & 229,45 & 59,88 & 174,30 & 175,10 & 55,56 & 969,45 & 124,37 & 31,62 & 35,72 & 352,59 & 122,46 & 134,51 & 325,18 \\
\hline Triturus marmoratus & 29TPH58 & 99,00 & 111,89 & 90,21 & 40,17 & 4511,60 & 236,79 & 15,61 & 221,18 & 62,19 & 170,64 & 171,93 & 57,57 & 1001,05 & 128,05 & 34,69 & 34,26 & 360,09 & 131,93 & 144,69 & 328,66 \\
\hline Triturus marmoratus & 29TPH60 & 101,00 & 104,75 & 99,05 & 38,49 & 5352,43 & 251,30 & $-2,77$ & 254,06 & 44,83 & 175,79 & 175,79 & 39,85 & 926,98 & 122,54 & 25,86 & 40,07 & 348,48 & 104,41 & 104,43 & 333,57 \\
\hline Triturus marmoratus & 29TPH62 & 100,00 & 100,06 & 97,43 & 38,86 & 5205,83 & 243,35 & $-4,92$ & 248,28 & 41,99 & 169,03 & 169,06 & 37,23 & 973,89 & 127,40 & 29,47 & 38.08 & 361,44 & 116,54 & 116,88 & 342,10 \\
\hline Triturus marmoratus & 29TPH67 & 100,00 & 111,40 & 92,64 & 40,16 & 4672,44 & 240,37 & 12,48 & 227,89 & 59,48 & 172,27 & 173,21 & 54,89 & 959,28 & 123,40 & 33,20 & 34,14 & 344,70 & 127,14 & 138,91 & 313,97 \\
\hline Triturus marmoratus & 29TPH68 & 100,00 & 112,91 & 91,50 & 40,35 & 4561,33 & 239,10 & 15,52 & 223,58 & 62,99 & 172,22 & 173,42 & 57,89 & 963,04 & 124,25 & 34,13 & 33,53 & 344,15 & 129,85 & 142,22 & 311,33 \\
\hline Triturus marmoratus & 29TPH70 & 99,00 & 120,04 & 101,98 & 38, & 5464,69 & 267,27 & 7,93 & 259,34 & 57,30 & 191,79 & 191,79 & 52,47 & 768,84 & 101,73 & 20, & 40,17 & 290,06 & 85,34 & 85,34 & 274,12 \\
\hline Triturus marmoratus & 29TPH71 & 100,00 & 113,94 & 100,82 & 38,97 & 5392,16 & 260,03 & 3,76 & 256,27 & 52,37 & 184,91 & 184,91 & 47,68 & 816,87 & 107,39 & 22,93 & 39,03 & 305,75 & 94,65 & 94,65 & 287,50 \\
\hline Triturus marmoratus & 29TPH73 & 101,00 & 86,82 & 97,28 & 38,88 & 5179,44 & 231,19 & $-16,28$ & 247,47 & 30,10 & 155,82 & 155,92 & 25,01 & 1044,37 & 133,86 & 35,11 & 35,84 & 381,04 & 134,58 & 135,46 & 358,23 \\
\hline Triturus marmoratus & 29TPH74 & 100,00 & 79,80 & 95,67 & 38,7 & 5085,43 & 222,37 & $-21,16$ & 243,53 & 24,80 & 147,66 & 147,86 & 19,67 & 1114,89 & 141,35 & 39,34 & 34,79 & 402,99 & 48,23 & 150,17 & 377,98 \\
\hline Triturus marmoratus & 29TPH77 & 101,00 & 109,22 & 93,94 & 40,1 & 4735,34 & 240,26 & 9,41 & 230,85 & 57,06 & $\begin{array}{l}\mid 171,00 \\
171,00\end{array}$ & $\begin{array}{l}41,1,77 \\
171\end{array}$ & 51,94 & $\begin{array}{r}943,31 \\
943\end{array}$ & $\begin{array}{l}2121,95 \\
121,\end{array}$ & 33,73 & 33,37 & 336,65 & 128,55 & 139,42 & 304,64 \\
\hline Triturus marmoratus & 29TPH78 & 100,00 & 11 & 92,48 & \begin{tabular}{l|l|l}
40,65 \\
\end{tabular} & 4583,52 & 241,15 & 16,33 & 224,81 & 67,71 & 173,87 & 175,05 & 58,89 & 927,82 & 120,75 & 33, & 32,65 & 328,82 & 128,45 & 140,50 & 294,39 \\
\hline Triturus marmoratus & 29TPH80 & 101,00 & 115,40 & 103,38 & 38,97 & 5547,08 & 265,72 & 2,60 & 263,12 & 51,78 & 188,51 & 188,51 & 46,90 & 754,35 & 99,32 & 20,75 & 39,45 & 283,55 & 87,01 & 87,01 & 266,77 \\
\hline Triturus marmoratus & 29TPH81 & 99,00 & 126,87 & 102,37 & 39,00 & 5448,44 & 272,65 & 13,83 & 258,82 & 63,77 & 197,98 & 197,98 & 59,01 & 694,68 & 91,52 & 18,59 & 38,74 & 259,96 & 80,41 & 80,41 & 239,84 \\
\hline Triturus marmoratus & 29TPH82 & 99,00 & 115,22 & 101,69 & 39,04 & 5381,48 & 260,87 & 4,64 & 256 & 53,53 & 185,86 & 185,86 & 48,75 & 776,09 & 101,55 & 22,88 & 37,42 & 287,61 & 94,74 & 94,74 & 265,39 \\
\hline Triturus marmoratus & $\begin{array}{l}\text { 29TPH } 84 \\
\end{array}$ & $\begin{array}{ll}35,00 \\
99,00\end{array}$ & 84,24 & $\begin{aligned} 0,05 \\
98,01\end{aligned}$ & $\begin{array}{l}35, \\
39,\end{array}$ & $\begin{array}{l}530,140 \\
5161,57\end{array}$ & 228,83 & \begin{tabular}{|c|c|c|}
$-18,65$ \\
\end{tabular} & \begin{tabular}{|l|}
240,435 \\
247,4
\end{tabular} & 28,14 & 153,10 & 153,23 & 22,80 & 1035,10 & 131,26 & 37,17 & 34,15 & 372,30 & 140,47 & 142,00 & 346,19 \\
\hline Triturus marmoratus & 29TPH91 & 100,00 & 123,96 & 104,01 & 39,00 & 5549,99 & 273,22 & 9,52 & 263,70 & 59,34 & 196,45 & 196,45 & 54,78 & 671,06 & 89,20 & 18,55 & 38,11 & 250,52 & 80,57 & 80,57 & 229,55 \\
\hline Triturus marmoratus & 29TPJ11 & 99,00 & 107,59 & 81,49 & \begin{tabular}{|l|l|}
40,67 & \\
\end{tabular} & 4002,55 & 220,11 & 21,82 & 198,28 & 65,15 & 159,35 & 162,08 & 60,56 & 1187,50 & 151,90 & 41,50 & 34,98 & 430,71 & 154,62 & 170,05 & 397,96 \\
\hline Triturus marmoratus & 29TPJ40 & 101,00 & 128,17 & 84,57 & \begin{tabular}{|c|}
41,07 \\
\end{tabular} & 4134,92 & 240,82 & 37,28 & 203,54 & 82,84 & 181,01 & 183,25 & 77,93 & 945,88 & 122,14 & 32,70 & 34,02 & 338,76 & 124,47 & 140,34 & 304,66 \\
\hline Triturus marmoratus & 29TPJ50 & 100,00 & 121,44 & 86,51 & 40,5 & 4230,20 & 237,81 & 29,27 & 208,54 & 75,28 & 175,91 & 177 & 70,33 & 965,29 & 124,76 & 34,64 & 33,15 & 343,49 & 130,84 & 145,53 & $30 \varepsilon$ \\
\hline Triturus marmoratus & $\begin{array}{l}\text { 29TPJ51 } \\
\text { 29T3 }\end{array}$ & $\begin{aligned} 90,000 \\
98,00\end{aligned}$ & $\begin{array}{l}121,44 \\
136,87\end{array}$ & $\begin{array}{l}80,1 \\
82,83 \\
\end{array}$ & | 40,59 & $\begin{array}{ll}420,200 \\
3998,40\end{array}$ & 244,68 & $\begin{array}{l}20,27 \\
47,71 \\
\end{array}$ & \begin{tabular}{|l|l|}
196,96 \\
196
\end{tabular} & 101,82 & 187,53 & 190,06 & 87,89 & 881,10 & 115,75 & 31,25 & 33,10 & 312,48 & 119,11 & 135,91 & 275,45 \\
\hline Triturus marmoratus & 29TPJ52 & 41,00 & 139,23 & 81,22 & 41,72 & 3912,25 & 244,14 & 51,68 & 192,46 & 111,51 & 188,72 & 191,29 & 91,29 & 874,91 & 115,40 & 31,32 & 32,94 & 309,83 & 119,20 & 136,62 & 271,68 \\
\hline Triturus marmoratus & 29TPJ62 & 54,00 & 139,54 & 81,85 & 41,87 & 3920,14 & 244,99 & 51,45 & 193,54 & 117,69 & 189,06 & 191,73 & 91,50 & 858,44 & 114,06 & 31,57 & 32,26 & 302,67 & 119,81 & 136,55 & 261,82 \\
\hline Triturus & 29TPJ70 & 100,00 & 117,75 & 88,93 & 41,1 & 4315,91 & 237,40 & 23,89 & 213,52 & 80,05 & 173,40 & 175 & 65,58 & 946,03 & 123,60 & 36,09 & & 332,03 & 135,04 & 488,20 & 293 \\
\hline Triturus marmoratus & 29TPנ82 & 58,00 & 138,31 & 83,19 & 42,02 & 3938,42 & 244,93 & 49,47 & 195,46 & \begin{tabular}{r|r|}
117,08 \\
\end{tabular} & 188,16 & 190,77 & 90,12 & 844,71 & 113,54 & 33,05 & 30,98 & 295,40 & 123,81 & 139,59 & 248,57 \\
\hline
\end{tabular}




\begin{tabular}{|c|c|c|c|c|c|c|c|c|c|c|c|c|c|c|c|c|c|c|c|c|c|}
\hline TAXON & UTM & $\mathrm{km} 2$ & B101 & $\mathrm{B1O2}$ & $\mathrm{BIO3}$ & B104 & B105 & B106 & B107 & $\mathrm{B108}$ & B109 & B1010 & B1011 & BIO12 & 81013 & BIO14 & B1015 & BIO16 & B1017 & B1018 & B1019 \\
\hline Triturus marmoratus & 29TPJ92 & 60,00 & 135,50 & 84,06 & 42,06 & 3954,26 & 243,15 & 46,30 & 196,86 & 114,32 & 185,50 & 188,13 & 87,30 & 853,51 & 114,98 & 34,70 & 30,12 & 296,43 & 128,88 & 143,72 & 246,58 \\
\hline Triturus marmoratus & 29TQE06 & 100,00 & 119,30 & 96,47 & \begin{tabular}{|l|l|}
34,97 \\
\end{tabular} & 6132,22 & 280,84 & 9,10 & 271,74 & 53,72 & 201,13 & 201,82 & 46,16 & 805,73 & 107,34 & 10,19 & 48,41 & \begin{tabular}{|c|}
309,67 \\
\end{tabular} & 60,69 & 63,48 & 300,38 \\
\hline Triturus marmoratus & 29TQE07 & 100,00 & 123,62 & 98,16 & 35,33 & 6135,20 & 285,67 & 12,02 & 273,65 & 57,43 & 204,98 & 205,92 & 49,78 & 759,97 & 100,67 & 9,58 & 48,27 & 291,79 & 57,97 & 59,88 & 282,52 \\
\hline Triturus marmoratus & 29TQE08 & 99,00 & 125,47 & 99,36 & $\begin{array}{l}35,85 \\
\end{array}$ & 6122,78 & 287,60 & 13,15 & 274,45 & 58,98 & 206,49 & 207,47 & 51,45 & 736,57 & 97,22 & 9,29 & 48,01 & 282,68 & 56,92 & 58,27 & 273,55 \\
\hline Triturus marmoratus & 29TQE09 & 100,00 & 131,30 & 101,86 & 36,17 & 6116,52 & 294,27 & 17,42 & 276,85 & 64,19 & 212,74 & 212,94 & 56,78 & 685,57 & 89,87 & 8,81 & 47,62 & 262,67 & 54,02 & 54,22 & 253,71 \\
\hline Triturus marmoratus & 29TQE17 & 100,00 & 116,90 & 99,27 & 35,58 & 6162,49 & 280,77 & 5,20 & 275,57 & 50,61 & 198,90 & 199,93 & 43,24 & 757,81 & 97,69 & 10,55 & 46,63 & 287,30 & 60,86 & 63,32 & 276,08 \\
\hline Triturus marmoratus & 29TQE18 & 101,00 & 125,54 & 101,80 & 36,00 & 6169,60 & 290,29 & 11,75 & 278,54 & 58,30 & 207,24 & 208,30 & 51,04 & 686,06 & 88,32 & 9,12 & 46,56 & 260,12 & 55,46 & 56,49 & 249,12 \\
\hline Triturus marmoratus & 29TQE19 & 100,00 & 127,25 & 103,00 & 36,19 & 6162,70 & 292,13 & 12,80 & 279,33 & 59,83 & 209,15 & 209,75 & 52,47 & 661,92 & 85,14 & 9,13 & 46,17 & 250,62 & 54,62 & 55,15 & 239,65 \\
\hline Triturus marmoratus & 29TQE28 & 100,00 & 119,46 & 102,97 & 36,06 & 6199,91 & 286,09 & 5,50 & 280,59 & 52,27 & 201,76 & 202,81 & 44,99 & 678,62 & 86,57 & 10,04 & 44,90 & 253,79 & 57,87 & 59,40 & 240,81 \\
\hline Triturus marmoratus & 29TQE38 & 100,00 & 110,46 & 103,62 & 36,32 & \begin{tabular}{|c|c|}
6198,67 \\
\end{tabular} & 278,44 & $-3,04$ & 281,49 & 43,78 & 193,30 & 194,22 & 36,73 & 697,16 & 88,05 & 11,78 & 43,03 & 256,34 & 63,16 & 65,78 & 241,57 \\
\hline Triturus marmoratus & 29TQE39 & 101,00 & 109,91 & 104,34 & 36,66 & 6188,14 & 277,81 & $-3,78$ & 281,59 & 43,16 & 192,28 & 193,47 & 36,11 & 681,21 & 86,15 & 11,77 & 42,58 & 250,19 & 63,12 & 65,34 & 234,95 \\
\hline Triturus marmoratus & 29TQE47 & 101,00 & 140,64 & 109,38 & 37,03 & 6294,98 & 312,04 & 20,83 & 291,21 & 71,06 & 224,69 & 224,75 & 63,78 & 502,05 & 62,86 & 7,40 & 43,31 & 182,16 & 44,17 & 44,21 & 168,79 \\
\hline Triturus marmoratus & 29TQE48 & 99,00 & 117,99 & 107,09 & 36,82 & 6247,59 & 288,57 & 1,73 & 286,85 & 50,00 & 201,22 & 202,15 & 43,11 & 606,94 & 75,98 & 10,64 & 41,83 & 219,55 & 57,39 & 58,73 & 204,08 \\
\hline Triturus marmoratus & 29TQE49 & 100,00 & 111,13 & 106,74 & \begin{tabular}{|c|}
36,98 \\
\end{tabular} & 6218,89 & 281,23 & $-3,86$ & 285,09 & 43,78 & 193,70 & 195,11 & 36,90 & 629,64 & 78,99 & 11,61 & 41,15 & 227,45 & 61,36 & 63,11 & 210,94 \\
\hline Triturus marmoratus & 29TQE57 & 42,00 & 139,19 & 110,38 & 37,06 & 6308,52 & 311,71 & 18,79 & 292,92 & 69,40 & 223,40 & 223,47 & 62,26 & 486,51 & 60,44 & 7,65 & 42,35 & 174,30 & 44,42 & 44,45 & 160,43 \\
\hline Triturus marmoratus & 29TQE58 & 47,00 & 134,90 & 110,69 & 37,23 & 6298,43 & 307,31 & 14,87 & 292,44 & 65,49 & 219,16 & 219,25 & 58,23 & 493,18 & 61,34 & 8,28 & 41,59 & 176,15 & 46,67 & 46,74 & 161,74 \\
\hline Triturus marmoratus & 29TQF05 & 99,00 & 122,03 & 106,32 & 37,58 & 6018,77 & 285,45 & 6,53 & 278,92 & 55,32 & 202,18 & 202,18 & 48,14 & 667,94 & 85,85 & 10,00 & 45,79 & 255,06 & 58,03 & 58,03 & 247,19 \\
\hline Triturus marmoratus & 29TQF07 & 100,00 & 124,47 & 108,48 & 38,15 & 5975,92 & 288,21 & 7,85 & 280,36 & 57,62 & 203,80 & 203,80 & 50,69 & 634,57 & 81,31 & 10,33 & 45,02 & 241,67 & 56,70 & 56,70 & 235,01 \\
\hline Triturus marmoratus & 29TQF08 & 100,00 & 119,33 & 108,56 & 38,17 & 5959,95 & 283,31 & 3,05 & 280,26 & 52,92 & 198,65 & 198,65 & 45,99 & 654,23 & 84,20 & 11,16 & 44,66 & 249,16 & 60,21 & 60,21 & 243,12 \\
\hline Triturus marmoratus & 29TQF09 & 101,00 & 126,93 & 110,16 & 38,94 & 5930,54 & 290,50 & 9,14 & 281,36 & 60,20 & 205,50 & 205,50 & 53,32 & 605,30 & 78,18 & 10,60 & 44,49 & 230,27 & 55,42 & 55,42 & 224,78 \\
\hline Triturus marmoratus & 29TQF11 & 100,00 & 123,25 & 104,14 & 36,98 & \begin{tabular}{ll|l}
6128,57 \\
\end{tabular} & 287,91 & 8,57 & 279,33 & 55,96 & 204,75 & 205,19 & 48,69 & 659,94 & 84,82 & 9,63 & 45,38 & 249,59 & 56,55 & 56,89 & 238,38 \\
\hline Triturus marmoratus & 29TQF12 & 100,00 & 122,99 & 105,13 & 37,00 & 6111,62 & 287,74 & 7,87 & 279,87 & 55,62 & 204,36 & 204,60 & 48,39 & 647,71 & 83,04 & 9,79 & 44,91 & 244,60 & 56,76 & 56,92 & 233,47 \\
\hline Triturus marmoratus & 29TQF14 & 99,00 & 120,89 & 106,77 & \begin{tabular}{|c|}
37,49 \\
\end{tabular} & 6081,66 & 286,01 & 5,07 & 280,95 & 53,65 & 201,93 & 201,93 & 46,56 & 633,33 & 80,74 & 10,00 & 44,27 & 238,69 & 57,48 & 57,48 & 227,90 \\
\hline Triturus marmoratus & 29TQF15 & 101,00 & 120,75 & 107,73 & \begin{tabular}{r|r|}
37,95 \\
\end{tabular} & 6071,48 & 286,05 & 4,44 & 281,61 & 53,44 & 201,50 & 201,50 & 46,21 & 621,94 & 79,17 & 10,14 & 43,99 & 234,15 & 57,15 & 57,15 & 223,71 \\
\hline Triturus marmoratus & 29TQF16 & 100,00 & 119,86 & 108,46 & 38,00 & 6049,59 & 285,22 & 3,36 & 281,85 & 52,53 & 200,33 & 200,33 & 45,51 & 616,45 & 78,70 & 10,64 & 43,43 & 231,63 & 58,12 & 58,12 & 221,61 \\
\hline Triturus marmoratus & 29TQF17 & 99,00 & 126,84 & 110,00 & 38,23 & 6022,16 & 292,13 & 8,85 & 283,28 & 59,28 & 206,62 & 206,62 & 52,31 & 571,63 & 73,31 & 9,92 & 43,27 & 214,56 & 53,54 & 53,54 & 205,38 \\
\hline Triturus marmoratus & 29TQF18 & 100,00 & 122,60 & 110,21 & 38,40 & 6005,49 & 287,87 & $\begin{array}{l}0,01 \\
4,76\end{array}$ & 283,11 & 55,36 & 202,28 & 202,28 & 48,48 & 585,02 & 75,58 & 10,69 & 43,04 & 219,49 & 56,23 & 56,23 & 210,90 \\
\hline Triturus marmoratus & 29TQF19 & 100,00 & 118,95 & 110,37 & 38,70 & 5982,06 & 284,32 & 1,44 & 282,88 & 52,01 & 198,36 & 198,36 & 45,22 & 596,50 & 77,51 & \begin{tabular}{|l|l|l|}
11,53 \\
\end{tabular} & 42,49 & 223,55 & 59,05 & 59,05 & 215,39 \\
\hline Triturus marmoratus & 29TQF21 & 101,00 & 123,91 & 106,41 & 37,00 & 6166,18 & 290,78 & 7,72 & 283,06 & 55,99 & 206,19 & 206,34 & 48,80 & 606,68 & 77,50 & 9,49 & 43,88 & 226,22 & 54,70 & 54,79 & 213,01 \\
\hline Triturus marmoratus & 29TQF22 & 100,00 & 122,91 & 107,17 & 37,21 & 6155,81 & 289,87 & 6,40 & 283,47 & 54,95 & 205,13 & 205,15 & 47,82 & 599,66 & 76,48 & 9,97 & 43,38 & 223,26 & 55,36 & 55,37 & 209,93 \\
\hline Triturus marmoratus & 29TQF24 & 101,00 & 119,11 & 108,31 & \begin{tabular}{|c|}
37,93 \\
\end{tabular} & 6126,72 & 286,04 & 2,39 & 283,64 & 51,25 & 200,62 & 200,65 & 44,23 & 592,82 & 75,47 & 10,10 & 42,64 & 220,00 & 56,88 & 56,90 & 206,55 \\
\hline Triturus marmoratus & 29TQF25 & 100,00 & 118,78 & 109,07 & 38,00 & 6103,65 & 285,76 & $\frac{2,81}{1,81}$ & 283,94 & 51,01 & $\begin{array}{l}200,04 \\
204\end{array}$ & 200,04 & 44,07 & \begin{tabular}{|l|l|}
582,67 \\
\end{tabular} & 74,56 & 10,54 & $\frac{42,24}{42,24}$ & 215,88 & $\begin{array}{l}50,000 \\
56,95\end{array}$ & 56,95 & 202,80 \\
\hline Triturus marmoratus & 29TQF26 & 100,00 & 119,46 & 109,95 & 38,00 & 6093,24 & 286,79 & 1,91 & 284,88 & 51,71 & 200,57 & 200,57 & 44,79 & 566,95 & 72,83 & 10,62 & 41,69 & 209,51 & 56,51 & 56,51 & 196,92 \\
\hline Triturus marmoratus & 29TQF27 & 101,00 & 120,53 & 110,64 & 38,04 & 6077,37 & 287,51 & 2,25 & 285,26 & 52,64 & 201,23 & 201,23 & 45,72 & 554,07 & 71,52 & 10,61 & 41,49 & 204,46 & 55,79 & 55,79 & 192,65 \\
\hline Triturus marmoratus & 29TQF28 & 100,00 & 120,82 & 111,21 & 38,30 & 6056,09 & 287,94 & 2,60 & 285,34 & 53,22 & 201,28 & 201,28 & 46,19 & 543,86 & 70,42 & 10,86 & 41,16 & 200,26 & 55,77 & 55,77 & 188,94 \\
\hline Triturus marmoratus & 29TQF29 & 100,00 & 120,33 & 111,61 & 38,78 & 6032,92 & 287,25 & 1,88 & 285,36 & 52,66 & 200,29 & 200,29 & 45,80 & 541,55 & 70,40 & 11,25 & 40,85 & 199,19 & 56,50 & 56,50 & 188,40 \\
\hline Triturus marmoratus & 29TQF30 & 100,00 & $\begin{array}{ll}119,30 \\
119,31\end{array}$ & $\begin{array}{ll}11,01,94 \\
106,94\end{array}$ & 37,00 & $\begin{array}{ll}6203,52,17 \\
620\end{array}$ & 287,25 & $\begin{array}{l}1,00 \\
3,01 \\
\end{array}$ & \begin{tabular}{|l|}
284,94 \\
284
\end{tabular} & \begin{tabular}{|l|l}
51,33 \\
\end{tabular} & 201,75 & 202,61 & $\begin{array}{l}43,00 \\
44,15 \\
\end{array}$ & \begin{tabular}{|c|c|}
603,73 \\
603,7
\end{tabular} & 70,57 & 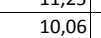 & $\begin{array}{l}40,05 \\
42,51\end{array}$ & 221,76 & $\begin{array}{l}50,0064 \\
56,64\end{array}$ & $\begin{array}{l}30,200 \\
57,28\end{array}$ & $\begin{array}{l}200,40 \\
206,68\end{array}$ \\
\hline Triturus marmoratus & 29TQF34 & 100,00 & 118,35 & 110,22 & 38,01 & 6155,54 & 287,30 & 0,83 & 286,47 & 50,35 & 200,59 & 200,59 & 43,27 & 549,21 & 70,31 & 10,36 & 41,10 & 200,35 & 56,01 & 56,01 & 184,51 \\
\hline Triturus marmoratus & 29TQF35 & 100,00 & 118,97 & 110,87 & \begin{tabular}{|c|}
38,08 \\
\end{tabular} & 6142,17 & 287,85 & 0,92 & 286,92 & 50,75 & 200,85 & 200,85 & 43,79 & 533,91 & 68,62 & 10,49 & 40,59 & 194,06 & 55,55 & 55,55 & 178,62 \\
\hline Triturus marmoratus & 29TQF36 & 100,00 & 120,24 & 111,54 & 38,22 & 6129,71 & 289,00 & 1,76 & 287,24 & 52,16 & 201,72 & 201,72 & 45,03 & 517,40 & 66,80 & 10,28 & 40,33 & 187,67 & 54,43 & 54,43 & 172,97 \\
\hline Triturus marmoratus & 29TQF37 & 100,00 & 118,55 & 111,76 & 38,46 & 6114,85 & 287,34 & 0,26 & 287,08 & 51,81 & 199,80 & 199,80 & 43,42 & 515,96 & 66,72 & 10,98 & 39,88 & 186,47 & 55,52 & 55,52 & 172,01 \\
\hline Triturus marmoratus & 29TQF38 & 100,00 & 117,16 & 112,03 & 38,5 & 6097,53 & 285,87 & $-0,68$ & 286,55 & 50,01 & 198,18 & 198,18 & 42,05 & 517,13 & 66,94 & 11,24 & 39,33 & 186,47 & 57,05 & 57,05 & 172,52 \\
\hline Triturus marmoratus & 29TQF39 & 101,00 & 117,53 & 112,34 & $\begin{array}{l}38,95 \\
\end{array}$ & 6073,13 & 286,20 & $-0,80$ & 287,00 & 54,47 & 198,29 & 198,29 & 42,66 & 509,77 & 66,10 & 11,77 & 38,87 & 183,34 & 57,22 & 57,22 & 169,97 \\
\hline Triturus marmoratus & 29TQF40 & 100,00 & 116,70 & 108,66 & 37,23 & 6227,32 & 287,15 & $-0,06$ & 287,21 & 48,54 & 199,46 & 200,47 & 41,83 & 578,11 & 72,63 & 10,60 & 40,89 & 208,46 & 57,44 & 58,19 & 191,94 \\
\hline Triturus marmoratus & 29TQF44 & 99,00 & 118,41 & 112,01 & 38,0 & 6184,50 & 288,97 & 0,23 & 288,74 & 65,45 & 200,91 & 200,91 & 42,97 & 506,69 & 65,08 & 10,55 & 39,66 & 181,50 & 54,95 & 54,95 & 163,34 \\
\hline Triturus marmoratus & 29TQF45 & 99,00 & 120,27 & 112,72 & $\frac{38,1}{38,1}$ & 6173,60 & 290,70 & $\begin{array}{ll}, 2,01 \\
\end{array}$ & 289,68 & $\begin{array}{l}34,07 \\
\end{array}$ & 202,34 & 202,34 & 44,59 & 485,16 & $\begin{array}{l}62,58 \\
62,\end{array}$ & 10,14 & 39,43 & 173,62 & 53,39 & 53,39 & 155,40 \\
\hline Triturus marmoratus & 29TQF46 & 101,00 & 118,96 & 112,92 & 38,60 & 6153,76 & 289,35 & 0,24 & 289,11 & 76,52 & 200,76 & 200,76 & 43,42 & 481,04 & 62,11 & 10,6 & 38,93 & 171,84 & 54,16 & 54,16 & 153,67 \\
\hline Triturus marmoratus & 29TQF47 & 100,00 & 116,77 & 112,93 & 38,80 & 6141,71 & 287,25 & $\begin{array}{ll}-1,44 \\
-1,44 \\
\end{array}$ & 288,68 & 76,17 & 198,53 & 198,53 & 41,46 & 481,72 & 62,16 & 11,00 & 38,46 & 171,64 & 55,31 & 55,31 & 153,66 \\
\hline Triturus marmoratus & 29TQF48 & 100,00 & 116,89 & 113,23 & 38,97 & 6130,25 & 286,98 & $-1,75$ & 288,73 & 76,96 & 198,25 & 198,25 & 41,58 & 475,93 & 61,37 & 11,24 & 37,99 & 169,20 & 55,66 & 55,66 & 151,72 \\
\hline Triturus marmoratus & 29TQF49 & 100,00 & 119,58 & 113,50 & 38,97 & 6115,42 & 289,29 & 0,01 & 289,29 & 80,05 & 200,47 & 200,48 & 43,96 & 459,76 & 59,24 & 11,05 & 37,64 & 163,38 & 54,36 & 54,37 & 146,34 \\
\hline Triturus marmoratus & 29TQF50 & 33,00 & $\frac{117}{117}$ & $\begin{array}{ll}1110,30 \\
110,11\end{array}$ & 30, & $\frac{011,442}{6238,59}$ & 280,25 & $\begin{array}{c}-0,01 \\
-0,27 \\
\end{array}$ & \begin{tabular}{|l|}
289,09 \\
289
\end{tabular} & \begin{tabular}{|l|l|}
48,91 \\
4
\end{tabular} & \begin{tabular}{|l|}
200,27 \\
\end{tabular} & 201,05 & $\begin{array}{l}43,00 \\
42,04\end{array}$ & 550,61 & $\mid \frac{30,24}{68,77}$ & $\mid 1,0,71$ & 39,96 & $\begin{array}{l}\mid 0103,00 \\
195,89\end{array}$ & \begin{tabular}{|c|}
$4,30,96$ \\
56,
\end{tabular} & 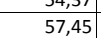 & $\begin{array}{l}140,34 \\
178,63\end{array}$ \\
\hline Triturus marmoratus & 29TQF54 & 26,00 & 118,31 & 113,03 & 38,26 & 6183,91 & 289,74 & $-0,34$ & 290,09 & 78,54 & 200,80 & 200,80 & 42,91 & 483,09 & 62,06 & 10,69 & 39,00 & 172,43 & 54,46 & 54,46 & 151,34 \\
\hline Triturus marmoratus & 29TQF59 & 4,00 & 119,55 & 114,00 & 39,00 & 6127,82 & 289,64 & $-0,36$ & 290,00 & 80,00 & 200,64 & 200,64 & 43,91 & 438,91 & 56,27 & 10,73 & 36,91 & \begin{tabular}{|c|}
155,64 \\
\end{tabular} & 53,36 & 53,36 & 136,09 \\
\hline Triturus marmoratus & 29TQG00 & 99,00 & 123,09 & 110,27 & 38,96 & 5918,68 & 286,88 & 5,41 & 281,47 & 56,58 & 201,70 & 201,70 & 49,72 & 619,22 & 80,70 & 11,43 & 44,19 & 235,64 & 58,29 & 58,29 & 230,85 \\
\hline Triturus marmoratus & 29TQG01 & 101,00 & 120,16 & 110,37 & $39, \mathrm{C}$ & 5890,61 & 283,96 & 2,77 & 281,19 & 54,07 & 198,46 & 198,46 & 47 & 630,02 & 82,67 & 12 & 43,76 & 239,57 & 60,81 & 60,81 & 235 \\
\hline Triturus marmoratus & 29TQG02 & 100,00 & 118,31 & 110,55 & 39,00 & 5867,35 & 282,03 & 1,14 & 280,89 & 52,36 & 196,31 & 196,31 & 45,68 & 636,56 & 84,01 & 13,14 & 43,33 & 241,71 & 63,07 & 63,07 & 237,84 \\
\hline Triturus marmoratus & 29TQG03 & 100,00 & 114,88 & 110,19 & 38,98 & 5844,04 & 278,26 & $-1,66$ & 279,92 & 49,20 & 192,60 & 192,60 & 42,71 & 654,32 & 86,67 & 14,58 & 42,81 & 247,97 & 66,98 & 66,98 & 243,35 \\
\hline Triturus marmoratus & 29TQG04 & 99,00 & 107,72 & 109,04 & 38,75 & 5831,01 & 270,54 & $-7,80$ & 278,34 & 42,36 & 185,45 & 185,45 & 36,15 & 697,38 & 92,22 & 17,25 & 41,55 & 262,69 & 75,26 & 75,26 & 255,74 \\
\hline Triturus marmoratus & 29TQG06 & 101,00 & 97,59 & 107,19 & 38,63 & 5777,70 & 258,37 & $-16,03$ & 274,40 & 33,35 & 174,90 & 174 & 27, & 770,14 & 100,90 & 22,35 & 39,27 & 286,20 & 90,40 & 90,40 & 274,29 \\
\hline Triturus marmoratus & $29 \mathrm{TQG10}$ & 101,00 & 116,77 & 110,67 & 39,00 & 5974,82 & 282,16 & $-0,12$ & 282,28 & 50,13 & 196,21 & 196,21 & 43,23 & 602,56 & 78,66 & 12,23 & 42,09 & 225,51 & 61,11 & 61,11 & 217,74 \\
\hline
\end{tabular}




\begin{tabular}{|c|c|c|c|c|c|c|c|c|c|c|c|c|c|c|c|c|c|c|c|c|c|}
\hline TAXON & UTM & $\mathrm{km} 2$ & B101 & $\mathrm{B1O2}$ & $\mathrm{BIO3}$ & 8104 & B105 & B106 & B107 & $\mathrm{B108}$ & B109 & BIO10 & BIO11 & BIO12 & B1013 & BIO14 & B1015 & BIO16 & B1017 & B1018 & B1019 \\
\hline Triturus marmoratus & 29TQG11 & 99,00 & 115,18 & 110,82 & 38,98 & 5954,86 & 280,36 & $-1,87$ & 282,23 & 48,68 & 194,38 & 194,38 & 41,81 & 608,24 & 79,75 & 13,07 & 41,70 & 227,39 & 63,06 & 63,06 & 219,83 \\
\hline Triturus marmoratus & 29TQG13 & 101,00 & 111,71 & 110,86 & 39,00 & 5909,07 & 276,33 & $-5,18$ & 281,51 & 45,45 & 190,29 & 190,29 & 38,81 & 625,53 & 82,37 & 15,30 & 40,67 & 232,93 & 68,39 & 68,39 & 224,64 \\
\hline Triturus marmoratus & 29 TQG15 & 100,00 & 106,85 & 110,18 & 38,99 & 5876,78 & 270,54 & $-9,53$ & 280,07 & 40,80 & 185,13 & 185,13 & 34,51 & 658,88 & 86,64 & 18,55 & 39,18 & 243,62 & 76,94 & 76,94 & 232,45 \\
\hline Triturus marmoratus & 29TQG16 & 100,00 & 100,74 & 109,21 & 38,89 & 5841,69 & 263,66 & $-14,63$ & 278,29 & 35,43 & 178,66 & 178,66 & 29,22 & 704,69 & 92,02 & 21,13 & 38,13 & 258,67 & 85,76 & 85,76 & 245,22 \\
\hline Triturus marmoratus & 29TQG20 & 100,00 & 116,37 & 111,62 & 38,94 & 6018,44 & 283,37 & $-1,28$ & 284,65 & 49,07 & 196,27 & 196,27 & 42,19 & 557,49 & 72,66 & 12,32 & 40,29 & 204,73 & 59,88 & 59,88 & 194,08 \\
\hline Triturus marmoratus & 29TQG23 & 100,00 & 110,98 & 111,77 & 38,99 & 5962,96 & 277,49 & $-6,65$ & 284,14 & 44,06 & 190,24 & 190,24 & 37,44 & 586,56 & 76,79 & 15,58 & 38,85 & 214,35 & 68,07 & 68,07 & 203,04 \\
\hline Triturus marmoratus & 29TQG24 & 99,00 & 106,53 & 111,31 & \begin{tabular}{|c|}
38,98 \\
\end{tabular} & 5942,33 & 272,67 & $-10,62$ & 283,29 & 40,28 & 185,74 & 185,74 & 33,40 & 617,64 & 80,63 & \begin{tabular}{|l|l|}
17,53 \\
\end{tabular} & 38,15 & 224,86 & 74,17 & 74,17 & 212,30 \\
\hline Triturus marmoratus & 29 TQG27 & 101,00 & 96,95 & 110,01 & 38,90 & 5850,44 & 261,05 & $-18,67$ & 279,72 & 45,32 & 175,08 & 175,08 & 25,39 & 700,54 & 90,26 & 23,14 & 35,87 & 251,96 & 92,35 & 92,35 & 234,13 \\
\hline Triturus marmoratus & 29TQG29 & 100,00 & 96,24 & 109,51 & 39,00 & 5766,36 & 258,20 & $-18,81$ & 277,01 & 57,97 & 172,96 & 172,96 & 25,51 & 722,97 & 92,54 & 25,52 & 34,64 & 259,38 & 99,82 & 99,82 & 236,58 \\
\hline Triturus marmoratus & 29TQG30 & 99,00 & 118,24 & 112,71 & \begin{tabular}{|c|}
38,98 \\
\end{tabular} & 6054,24 & 286,54 & $-0,55$ & 287,09 & 58,13 & 198,47 & 198,47 & 43,35 & 504,83 & 65,56 & 12,00 & 38,70 & 181,38 & 57,28 & 57,28 & 168,57 \\
\hline Triturus marmoratus & 29TQG31 & 99,00 & 114,43 & 112,67 & 39,00 & 6039,45 & 282,86 & $-4,10$ & 286,95 & 56,56 & 194,63 & 194,63 & 39,85 & 523,31 & 68,00 & 13,26 & 38,07 & 187,86 & 61,19 & 61,19 & 174,80 \\
\hline Triturus marmoratus & 29TQG34 & 100,00 & 109,08 & 112,74 & 38,97 & 5982,61 & 276,92 & $-9,39$ & 286,31 & 65,83 & 188,59 & 188,59 & 35,17 & 564,89 & 73,18 & 16,72 & 36,65 & 202,73 & 71,26 & 71,26 & 187,20 \\
\hline Triturus marmoratus & 29TQG37 & 100,00 & 107,03 & 112,53 & 39,00 & 5911,25 & 273,25 & $-11,47$ & 284,72 & 69,31 & 185,40 & 185,40 & 33,77 & 599,10 & 77,00 & \begin{tabular}{|l|l|}
20,05 \\
\end{tabular} & 35,24 & 216,74 & 81,45 & 81,45 & 193,97 \\
\hline Triturus marmoratus & 29TQG40 & 100,00 & 116,85 & 113,49 & \begin{tabular}{|c|}
38,97 \\
\end{tabular} & 6098,32 & 286,63 & $-2,42$ & 289,05 & 77,78 & 197,83 & 197,83 & 41,59 & 470,69 & 60,57 & \begin{tabular}{ll|l}
11,96 \\
\end{tabular} & 37,01 & 167,12 & 57,16 & 57,16 & 149,90 \\
\hline Triturus marmoratus & 29TQG41 & 98,00 & 116,63 & 113,70 & 39,00 & 6077,83 & 286,10 & $-2,87$ & 288,97 & 77,60 & $\mid$\begin{tabular}{|l|l|}
197,19 \\
\end{tabular} & $\mid$\begin{tabular}{|l|l|}
197,19 \\
\end{tabular} & 41,35 | & 474,35 & 61,05 & 12,53 & 36,55 & $\mid 168,65$ | & 58,62 & 58,62 & 151,31 \\
\hline Triturus marmoratus & 29TQG45 & 86,00 & 116,09 & 114,02 & 39,00 & 5989,02 & 284,02 & $-4,08$ & 288,09 & 78,02 & 195,22 & 195,22 & 41,51 & 506,24 & 64,85 & 15,65 & 35,28 & 182,75 & 67,67 & 67,67 & 160,55 \\
\hline Triturus marmoratus & $29 \mathrm{TQG} 46$ & 80,00 & 114,57 & 113,95 & 39,00 & 5963,28 & 282,04 & $-5,28$ & 287,32 & 76,54 & 193,27 & 193,27 & 40,03 & 523,95 & 66,95 & 17,08 & 34,98 & 189,85 & 71,64 & 71,64 & 165,34 \\
\hline Triturus marmoratus & 29TQG47 & 75,00 & 110,56 & 113,81 & 39,00 & 5933,95 & 278,12 & $-8,62$ & 286,74 & 72,76 & 189,15 & 189,15 & 36,70 & 553,25 & 70,70 & 19,14 & 34,52 & 200,81 & 77,97 & 77,97 & 173,41 \\
\hline Triturus marmoratus & 29TQHOO & 100,00 & 94,55 & 105,13 & 38,92 & 5600,79 & 249,85 & $-16,95$ & 266,81 & 32,10 & 169,06 & 169,06 & 26,22 & 825,40 & 106,08 & 27,42 & 35,97 & 300,08 & 107,77 & 107,77 & 280,01 \\
\hline Triturus marmoratus & 29TQH05 & 100,00 & 74,91 & 99,24 & 39,39 & 5169,66 & 220,93 & $-28,05$ & 248,98 & 21,71 & 143,89 & 143,99 & 13,48 & 1055,92 & 132,96 & 42,27 & 31,32 & 370,01 & 155,47 & 156,53 & 339,66 \\
\hline Triturus marmoratus & 29тQH06 & 100,00 & 75,75 & 98,36 & 39,55 & 5077,99 & 219,51 & $-26,07$ & 245,58 & 25,65 & 143,30 & 143,55 & 15 & 1068,91 & 134,83 & 43,64 & 30,77 & 372,93 & 159,67 & 162,90 & 340,47 \\
\hline Triturus marmoratus & 29TQH15 & 101,00 & 81,08 & 101,33 & 39,73 & 5205,83 & 228,01 & $-23,78$ & 251,80 & 40,02 & 150,30 & 150,34 & 18,68 & 976,59 & 124,20 & 40,07 & 30,67 & 340,54 & 147,50 & 148,47 & 307,29 \\
\hline Triturus marmoratus & 29тQH21 & 99,00 & 90,49 & 107,60 & 39,20 & 5617,95 & 248,60 & $-21,87$ & 270,47 & 53,99 & 165,27 & 165,27 & 21,89 & 794,80 & $\mid 101,78$ & 30,23 & 32,91 & \begin{tabular}{|c|}
282,67 \\
\end{tabular} & 115,17 & 115,17 & 254,36 \\
\hline Triturus marmoratus & $29 \mathrm{TQH} 22$ & 101,00 & 97,35 & 107,61 & 39,82 & 5548,37 & 253,24 & $-15,01$ & 268,25 & 62,72 & 170,84 & 170,84 & 29,21 & 763,37 & 99,10 & 29,43 & 32,63 & 272,84 & 112,24 & 112,24 & 240,44 \\
\hline Triturus marmoratus & 29TQH30 & 101,00 & 105,34 & 111,31 & 39,43 & 5755,78 & 267,51 & $-11,20$ & 278,71 & 69,03 & 181,46 & 181,46 & 33,96 & 647,92 & 84,30 & 24,21 & 33,58 & 234,91 & 94,58 & 94,58 & 202,69 \\
\hline Triturus marmoratus & 29TQH35 & 100,00 & 65,89 & 101,62 & 39,46 & 5274,92 & 215,64 & $-38,68$ & 254,32 & 26,89 & 136,50 & 136,58 & 3,29 & 1041,54 & 129,55 & 46,18 & 28,59 & 356,23 & 166,27 & 166,70 & 320,59 \\
\hline Triturus marmoratus & $29 \mathrm{TQH36}$ & 100,00 & 63,68 & 100,41 & 39,56 & 5201,10 & 211,47 & $\begin{array}{ll}-39,53 \\
-39,53\end{array}$ & 251,01 & 22,61 & $\begin{array}{l}133,22 \\
\end{array}$ & 133,42 & $\frac{\mid 2,25}{2,10}$ & $\begin{array}{l}1080,66 \\
106\end{array}$ & 134,02 & 48,65 & 28,20 & 368,40 & 174,22 & 175,09 & 331,37 \\
\hline Triturus marmoratus & 29TQH42 & 61,00 & 100,85 & 110,74 & 40,00 & 5628,50 & 260,72 & $-14,08$ & 274,80 & 66,18 & 175,30 & 175,30 & 31,25 & 690,90 & 90,27 & 29,02 & 31,64 & 248,73 & 109,09 & 109,09 & 206,38 \\
\hline Triturus marmoratus & $29 \mathrm{TQH} 49$ & 36,00 & 119,17 & 96,75 & 43,23 & 4295,38 & 243,54 & 22,00 & 221,54 & 96,79 & 173,94 & 176,08 & 67,15 & 850,54 & 115,13 & 41,21 & 27,98 & 287,88 & 146,23 & 154,65 & 224,27 \\
\hline Triturus marmoratus & 29TQJ11 & 99,00 & 116,27 & 91,42 & 42,38 & 4195,11 & 235,68 & 22,75 & 212,93 & 93,97 & 169,88 & 172,19 & 65,80 & 923,49 & 123,35 & 41,56 & 28,29 & 315,14 & 149,59 & 160,54 & 260,00 \\
\hline Triturus marmoratus & 29TQJ32 & 74,00 & 134,23 & 83,35 & 43,00 & 3796,84 & 238,70 & 46,89 & 191,82 & 116,10 & 181,84 & 185,14 & 88,38 & 858,30 & 117,33 & 40,27 & 28,58 & 290,85 & 144,00 & 156,31 & 226,00 \\
\hline Triturus marmoratus & 30TाK47 & 50,00 & 130,68 & $\begin{array}{l}0,30,36 \\
110,36\end{array}$ & 37,00 & 6328,70 & 304,17 & $\begin{array}{l}0,00 \\
10,70 \\
\end{array}$ & \begin{tabular}{|l|l|l|l|l|l|}
293,48 \\
\end{tabular} & 61,23 & 215,45 & 215,70 & 54,12 & 511,74 & $\mid$\begin{tabular}{c|c|c|}
63,16 \\
63,5
\end{tabular} & $\begin{aligned} 4,21 \\
8,91\end{aligned}$ & 41,23 & 181,62 & $\begin{array}{c}34,40 \\
49,12\end{array}$ & | & 166,80 \\
\hline Triturus marmoratus & 30TTK48 & 40,00 & 134,10 & 111,33 & 37,38 & 6306,80 & 307,13 & 13,61 & 293,52 & 64,43 & 218,56 & 218,64 & 57,33 & 483,51 & 59,92 & 8,43 & 40,90 & \begin{tabular}{|c|}
171,39 \\
\end{tabular} & 46,87 & 46,92 & 156,69 \\
\hline Triturus marmoratus & 30TTK57 & 100,00 & 125,48 & 111,03 & \begin{tabular}{|c|}
37,08 \\
\end{tabular} & 6317,04 & 299,69 & 5,65 & 294,04 & 56,32 & 209,99 & 210,54 & 49,34 & 515,12 & 63,05 & 9,67 & 39,93 & 180,10 & 51,77 & 52,14 & 164,56 \\
\hline Triturus marmoratus & 30TTK58 & 100,00 & 125,15 & 111,64 & 37,57 & 6296,49 & 298,85 & 5,27 & 293,58 & 56,00 & 209,26 & 209,81 & 49,13 & 503,89 & 61,86 & 9,69 & 39,55 & 175,86 & 51,83 & 52,15 & 159,95 \\
\hline Triturus marmoratus & 30TTK59 & 100,00 & 118,74 & 111,53 & 37,89 & 6264,91 & 292,03 & 0,06 & 291,97 & 50,05 & 202,19 & 203,01 & 43,41 & 522,27 & 64,35 & 10,65 & 38,81 & 182,02 & 55,69 & 56,28 & 164,96 \\
\hline Triturus marmoratus & 30TTK66 & 100,00 & 79,21 & 106,14 & 36,41 & 6224,39 & 253,47 & $-34,09$ & 287,56 & 14,25 & 163,83 & 164,57 & 7,95 & 803,94 & 95,97 & 19,66 & 37,45 & 276,18 & 86,49 & 92,45 & 257,79 \\
\hline Triturus marmoratus & 30TTK67 & 100,00 & 109,14 & 110,24 & \begin{tabular}{|c|}
37,07 \\
\end{tabular} & 6281,82 & 283,90 & $-8,71$ & 292,61 & 41,20 & 192,97 & 194,39 & 34,75 & 578,51 & 69,88 & 12,63 & 37,97 & 198,20 & 62,04 & 64,14 & 180,73 \\
\hline Triturus marmoratus & 30TTK68 & 100,00 & 121,72 & 112,60 & \begin{tabular}{|c|}
37,88 \\
\end{tabular} & 6290,36 & 296,40 & 1,58 & 294,82 & 52,69 & 205,55 & 206,38 & 46,00 & 494,14 & 59,95 & 10,43 & 38,06 & 168,79 & 53,79 & 54,29 & 152,38 \\
\hline Triturus marmoratus & 30TTK69 & 100,00 & 116,55 & 112,76 & 38,00 & 6255,50 & 290,74 & $-2,36$ & 293,10 & 54,45 & 199,44 & 200,97 & 41,45 & 504,86 & 61,34 & 11,15 & 37,32 & 171,90 & 56,85 & 57,70 & 154,59 \\
\hline Triturus marmoratus & 30TTK76 & 100,00 & 91,53 & 108,77 & 36,79 & 6260,14 & 267,27 & $-24,49$ & 291,75 & 25,18 & 175,92 & 177,06 & 18,91 & 680,86 & 80,72 & 16,69 & 36,68 & 229,91 & 75,34 & 79,58 & 211,18 \\
\hline Triturus marmoratus & 30TTK77 & 100,00 & 97,20 & 109,86 & 37,13 & 6246,57 & 272,49 & $-19,59$ & 292,07 & 30,34 & 180,93 & 182,39 & 24,13 & 626,00 & 74,51 & 15,30 & 36,35 & 210,42 & 70,67 & 74,09 & 191,65 \\
\hline Triturus marmoratus & 30TTK78 & 100,00 & 114,63 & 112,80 & 37,91 & 6271,61 & 289,86 & $-4,61$ & 294,47 & 55,68 & 197,59 & 199,56 & 39,69 & 504,84 & 60,39 & 11,68 & 36,46 & 168,65 & 57,96 & 59,24 & 151,39 \\
\hline Triturus marmoratus & 30TTK79 & 100,00 & 116,93 & 113,89 & $38, \mathrm{C}$ & 6247,73 & 291,87 & $-2,66$ & 294,53 & 73,70 & 199,32 & 201,36 & 41,94 & 479,76 & 57,49 & 11,22 & 36,02 & 159,91 & 56,53 & 57,49 & 142,51 \\
\hline Triturus marmoratus & 30TTK86 & 100,00 & 104 & 111,33 & 37,03 & 6298,99 & 281,10 & $-14,76$ & 295,86 & 38,62 & 188,25 & 189,81 & 30,01 & 569,76 & 66,99 & 14,01 & 36,09 & \begin{tabular}{ll|}
188,25 \\
\end{tabular} & 65,19 & 67,68 & 169,77 \\
\hline Triturus marmoratus & 30TाK87 & 100,00 & 112 & 112,73 & 37,60 & 6295,44 & $\frac{201,1}{288,8}$ & \begin{tabular}{|c|c|}
4,63 \\
\end{tabular} & 296,43 & $\begin{array}{ll}62,51 \\
\end{array}$ & \begin{tabular}{|l|l|}
195,94 \\
\end{tabular} & \begin{tabular}{|l|l|}
197,81 \\
\end{tabular} & 37,44 & 507,78 & 59,81 & 12,44 & 35,86 & $\begin{array}{l}00,25 \\
166,60 \\
\end{array}$ & \begin{tabular}{|l|l}
59,43 \\
\end{tabular} & 61,05 & 148,84 \\
\hline Triturus marmoratus & 30TTK89 & 100,00 & 11 & 114,19 & 38,01 & 6219,95 & 289,16 & $-5,91$ & 295,07 & 73,80 & 195,95 & 198,39 & 39,77 & 472,86 & 55,95 & \begin{tabular}{|c|}
11,97 \\
\end{tabular} & 34,69 & \begin{tabular}{l|l|l|}
154,65 \\
\end{tabular} & 58,43 & 59,90 & 136,11 \\
\hline Triturus marmoratus & $\begin{array}{l}30 \mathrm{TTK} 96 \\
\end{array}$ & 100,00 & 91,54 & 110,67 & 37,01 & 6268,13 & 268,93 & $-26,01$ & 294,93 & 33,22 & 176,05 & 177,31 & 18,89 & 629,13 & 73,17 & 17,20 & 34,74 & 204,69 & 75,06 & 79,02 & 184,84 \\
\hline Triturus marmoratus & 30TTK98 & 100,00 & 111,33 & 113,54 & 37,94 & 6252,65 & 287,35 & $-8,85$ & 296,19 & 70,37 & 194,08 & 196,31 & 37,04 & 480,69 & 57,37 & 12,67 & 34,32 & 155,03 & 60,19 & 61,95 & 135,37 \\
\hline Triturus marmoratus & 30TTL40 & 39,00 & 117,22 & 110,80 & 37,98 & 6241,55 & 289,36 & $-0,44$ & 289,80 & 48,96 & 200,42 & 201,29 & 42,09 & 537,40 & 66,89 & 10,84 & 39,51 & 189,65 & 56,73 & 57,22 & 172,22 \\
\hline Triturus marmoratus & $30 T T L$ & $\frac{20,00}{20,0}$ & $\frac{11}{115}$ & $\frac{113}{113}$ & 38 & $\mid 6206,59$ & $\begin{array}{l}291, \\
291, \\
\end{array}$ & $\begin{array}{c}-0,44 \\
0,07 \\
\end{array}$ & \begin{tabular}{|l|}
291,41 \\
291
\end{tabular} & $\begin{array}{l}40,505 \\
79,59\end{array}$ & \begin{tabular}{l|l}
202,28 \\
\end{tabular} & \begin{tabular}{|l|}
202,28 \\
\end{tabular} & \begin{tabular}{|c|c|}
43,86 \\
43,86
\end{tabular} & $\begin{array}{l}351,40 \\
458,03\end{array}$ & $\begin{array}{l}0,030 \\
59,00\end{array}$ & $\begin{array}{l}\mid 0,04 \\
10,34\end{array}$ & 38,24 & $\begin{array}{l}\mid 0,03,90 \\
163,90\end{array}$ & $\begin{array}{ll}50,1728 \\
53,28\end{array}$ & 53,28 & 141,10 \\
\hline Triturus marmoratus & 30TTL50 & 100,00 & 114,93 & 111,65 & 37,99 & 6240,78 & 287,90 & $-2,85$ & 290,75 & 47,54 & $\begin{array}{l}197,78 \\
\end{array}$ & 199,05 & 40,02 & 528,61 & 65,29 & \begin{tabular}{|c|}
11,17 \\
\end{tabular} & 38,41 & \begin{tabular}{|c|}
183,98 \\
\end{tabular} & 57,94 & 58,66 & 166,05 \\
\hline Triturus marmoratus & 30TTL51 & 100,00 & 114,77 & 112,50 & 38,08 & 6230,42 & 287,68 & $-3,20$ & 290,88 & 64,41 & 197,93 & 198,57 & 39,84 & 514,20 & 63,74 & 11,21 & 38,14 & 179,09 & 57,85 & 58,21 & 160,08 \\
\hline Triturus marmoratus & 30TTL52 & 100,00 & 118,54 & 113,86 & 38,51 & 6232,96 & 291,42 & $-0,62$ & 292,05 & 78,26 & 201,92 & 201,92 & 42,90 & 480,01 & 60,34 & 10,69 & 38,36 & 168,97 & 54,94 & 54,94 & 147,61 \\
\hline Triturus marmoratus & 30TTL53 & 100,00 & 120,34 & 114,70 & 38,8 & 6227,93 & 293,23 & 0,35 & 292,88 & 80,03 & 203,45 & 203,45 & 44,47 & \begin{tabular}{|c|}
455,95 \\
\end{tabular} & 58,28 & 10,16 & 38,74 & 162,47 & 52,75 & 52,75 & $13 \varepsilon$ \\
\hline Triturus marmoratus & \begin{tabular}{|l|}
$30 T T L 54$ \\
3054
\end{tabular} & $\begin{array}{l}100,00 \\
100\end{array}$ & $\begin{array}{l}12,54 \\
119,97\end{array}$ & $\begin{array}{ll}1144,16 \\
114,95\end{array}$ & 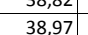 & 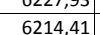 & $\begin{array}{l}293,25 \\
292,67 \\
\end{array}$ & $\begin{array}{l}0,50 \\
0,09 \\
\end{array}$ & \begin{tabular}{|l|}
32,000 \\
292,57 \\
\end{tabular} & 79,86 & 202,86 & 202,86 & 44,03 & 445,01 & 57,31 & 10,31 & 38,63 & 159,45 & 52,65 & 52,65 & 133,95 \\
\hline Triturus marmoratus & 30TTL55 & 100,00 & 119,49 & 114,99 & 39,00 & 6194,68 & 291,90 & $-0,15$ & 292,05 & 79,42 & 202,05 & 202,05 & 43,64 & 438,15 & 56,37 & 10,58 & 38,23 & 156,80 & 52,87 & 52,87 & 131,30 \\
\hline Triturus marmoratus & 30TTL56 & 100,00 & 115,04 & 114,44 & 39,00 & 6165,01 & 287,15 & $-3,84$ & 290,99 & 75,32 & 197,15 & 197,26 & 39,83 & 452,74 & 57,87 & $\mid 11,27$ & 37,59 & 161,16 & 55,84 & 55,92 & 135,98 \\
\hline Triturus r & 30TTL57 & 100,00 & 115,39 & 114,42 & 39,00 & 6158,74 & 287,28 & $-3,76$ & 291,04 & 75,66 & 197,18 & 197, & 40, & 444,03 & 56,61 & 11,27 & 37,08 & 157,38 & 55,33 & 55,47 & 133,44 \\
\hline Triturus marmoratus & 30TTL58 & 100,00 & 118,25 & 114,45 & 39,00 & 6157,61 & 289,66 & $-1,44$ & 291,09 & 78,51 & 199,50 & 199,90 & 42,43 & 426,35 & 54,25 & 10,94 & 36,63 & 150,60 & 53,39 & 53,63 & 128,16 \\
\hline
\end{tabular}




\begin{tabular}{|c|c|c|c|c|c|c|c|c|c|c|c|c|c|c|c|c|c|c|c|c|c|}
\hline TAXON & UTM & $\mathrm{km} 2$ & B101 & $\mathrm{B1O2}$ & $\mathrm{BIO3}$ & BIO4 & B105 & B106 & B107 & $\mathrm{B108}$ & B109 & B1010 & BIO11 & BIO12 & B1013 & BIO14 & B1015 & BIO16 & BIO17 & BIO18 & B1019 \\
\hline Triturus marmoratus & 30TTL59 & 100,00 & 120,08 & 114,38 & 38,99 & 6142,13 & 290,93 & $-0,17$ & 291,10 & 80,44 & 200,75 & 201,21 & 44,09 & 416,59 & 52,89 & 10,56 & 36,11 & 146,84 & 52,66 & 52,95 & 125,25 \\
\hline Triturus marmoratus & 30TTL60 & 100,00 & 114,36 & 113,21 & 38,01 & 6233,21 & 288,24 & $-4,33$ & 292,57 & 69,27 & 197,00 & 198,49 & 39,50 & 502,62 & 61,29 & 11,47 & 36,97 & 171,10 & 58,14 & 58,96 & 152,82 \\
\hline Triturus marmoratus & 30TTL61 & 100,00 & 113,50 & 113,97 & 38,46 & 6218,07 & 287,22 & $-5,21$ & 292,44 & 72,68 & 196,09 & 197,31 & 38,71 & 492,07 & 60,22 & 11,71 & 36,64 & 168,50 & 58,69 & 59,31 & 148,05 \\
\hline Triturus marmoratus & 30TTL62 & 100,00 & 116,47 & 115,31 & 38,95 & 6219,87 & 290,42 & $-2,82$ & 293,24 & 76,27 & 199,71 & 199,86 & 41,25 & 462,77 & 57,19 & 11,12 & 37,00 & 160,84 & 56,27 & 56,35 & 137,50 \\
\hline Triturus marmoratus & 30TTL63 & 100,00 & 119,51 & 116,51 & 39,01 & \begin{tabular}{ll|}
6228,66 \\
\end{tabular} & 293,60 & $-0,62$ & 294,22 & 79,06 & 202,72 & 202,72 & 43,67 & 431,98 & 54,71 & 10,97 & 37,70 & 153,08 & 53,65 & 53,65 & 125,65 \\
\hline Triturus marmoratus & 30TTL64 & 100,00 & 120,29 & 116,82 & 39,05 & 6221,36 & 294,10 & $-0,18$ & 294,27 & 80,06 & 203,19 & 203,19 & 44,14 & 413,41 & 52,97 & 10,68 & 38,41 & 148,23 & 52,13 & 52,13 & 118,31 \\
\hline Triturus marmoratus & 30TTL65 & 100,00 & 118,88 & 116,50 & 39,01 & 6191,56 & 292,08 & $-1,21$ & 293,29 & 78,72 & 201,26 & 201,26 & 43,07 & 410,75 & 52,21 & \begin{tabular}{|c|}
10,97 \\
\end{tabular} & 37,74 & 146,54 & 53,00 & 53,00 & 116,99 \\
\hline Triturus marmoratus & 30TTL66 & 100,00 & 114,36 & 115,74 & 39,00 & 6172,04 & 287,32 & $\begin{array}{l}-5,11 \\
-5,11 \\
\end{array}$ & 292,43 & 74,34 & 196,24 & $\begin{array}{l}2196,68 \\
\end{array}$ & 39,04 & 426,80 & 53,56 & 11,65 & 36,71 & 150,57 & 56,11 & 56,36 & 122,45 \\
\hline Triturus marmoratus & 30TTL67 & 100,00 & 115,36 & 115,55 & 39,00 & 6155,89 & 287,85 & $-4,08$ & 291,93 & 75,61 & 196,41 & 197,42 & 40,03 & 417,49 & 52,16 & 11,57 & 36,18 & 146,45 & 55,03 & 55,53 & 119,99 \\
\hline Triturus marmoratus & 30TTL68 & 100,00 & 119,86 & 115,30 & 39,00 & 6157,26 & 291,68 & $-0,43$ & 292,11 & 80,01 & 199,99 & 201,51 & 43,94 & 390,48 & 48,65 & 10,34 & 35,71 & 136,31 & 51,33 & 52,09 & 111,71 \\
\hline Triturus marmoratus & 30TTL69 & 100,00 & 122,06 & 115,03 & 39,00 & 6155,46 & 293,29 & 0,89 & 292,40 & 82,50 & 201,72 & 203,25 & 45,71 & 378,28 & 47,02 & 9,83 & 35,32 & 131,58 & 49,88 & 50,85 & 107,96 \\
\hline Triturus marmoratus & 30TTL70 & 100,00 & 118,69 & 114,98 & 38,57 & 6219,90 & 293,06 & $-1,30$ & 294,36 & 78,33 & 201,28 & 202,53 & 43,78 & 458,78 & 55,16 & 11,02 & 35,67 & 153,44 & 55,54 & 56,09 & 135,18 \\
\hline Triturus marmoratus & 30TTL71 & 100,00 & 115,19 & 115,41 & 38,99 & 6196,44 & 289,38 & $-4,39$ & 293,77 & 74,78 & 196,90 & 198,69 & 40,55 & 461,69 & 55,62 & \begin{tabular}{|l|l|}
11,56 \\
\end{tabular} & 35,19 & 154,96 & 57,72 & 58,52 & 134,75 \\
\hline Triturus marmoratus & 30TTL73 & 100,00 & 120,48 & 118,22 & 39,59 & 6217,77 & 295,16 & $-0,53$ & 295,68 & 79,94 & 203,51 & 203,67 & 44,79 & 414,32 & 50,82 & 10,99 & 35,68 & 142,51 & 53,90 & 53,97 & 118,64 \\
\hline Triturus marmoratus & 30TTL74 & 100,00 & 119,74 & 118,07 & 39,74 & 6189,04 & 293,94 & $-1,06$ & 295,01 & 79,43 & 202,52 & 202,54 & 44,36 & 397,47 & 49,66 & \begin{tabular}{ll|}
10,92 \\
\end{tabular} & 36,87 & 139,32 & 53,40 & 53,40 & 109,99 \\
\hline Triturus marmoratus & 30TTL75 & 100,00 & 118,36 & 117,62 & 39,62 & 6170,04 & 292,09 & $-1,89$ & 293,97 & 78,08 & 200,76 & 200,92 & 43,20 & 394,29 & 49,00 & 11,00 & 36,49 & 137,82 & 53,90 & 53,96 & 108,48 \\
\hline Triturus marmoratus & 30TTL76 & 100,00 & 115,98 & 116,93 & 39,04 & 6154,60 & 289,42 & $-4,00$ & 293,42 & 75,96 & 197,03 & 198,15 & 40,83 & 399,35 & 49,00 & 11,38 & 35,69 & 138,35 & 54,94 & 55,48 & 110,35 \\
\hline Triturus marmoratus & 30TTL77 & 100,00 & 115,30 & 116,42 & 39,02 & 6142,99 & 288,43 & $-4,77$ & 293,20 & 75,46 & 195,38 & 197,22 & 40,21 & 399,37 & 48,49 & 11,80 & 34,90 & 137,61 & 55,20 & 56,19 & 110,71 \\
\hline Triturus marmoratus & 30TTL78 & 100,00 & 119,71 & 116,10 & 39,00 & 6150,08 & 292,16 & $-0,90$ & 293,06 & 79,96 & 199,21 & 201,27 & 43,98 & 375,74 & 45,45 & 10,79 & 34,65 & 129,17 & 51,47 & 52,77 & 103,77 \\
\hline Triturus marmoratus & 30TTL79 & 100,00 & 123,62 & 115,62 & 39,00 & 6148,60 & 295,08 & 1,99 & 293,09 & 84,09 & 202,65 & 204,89 & 47,22 & 358,17 & 43,27 & 9,79 & 34,54 & 122,99 & 49,01 & 50,37 & 98,48 \\
\hline Triturus marmoratus & 30TTL83 & 100,00 & 120,42 & 118,34 & 40,00 & 6087,64 & 293,26 & $-0,31$ & 293,57 & 79,91 & 199,28 & 202,43 & 46,64 & 400,26 & 47,40 & 11,00 & 32,46 & 130,21 & 54,99 & 56,17 & 111,81 \\
\hline Triturus marmoratus & 30TTL85 & 100,00 & 117,38 & 117,95 & 39,95 & 6110,75 & 290,40 & $-3,05$ & 293,45 & 76,89 & 196,71 & 199,36 & 43,06 & 390,23 & 47,82 & 11,22 & 33,78 & 130,64 & 55,23 & 56,36 & 105,81 \\
\hline Triturus marmoratus & 30TTL87 & 100,00 & 117,45 & 117,01 & 39,01 & 6128,10 & 290,28 & $-3,02$ & 293,30 & 77,47 & 196,72 & 199,04 & 42,31 & 381,31 & 46,22 & 11,59 & 33,62 & 128,43 & 54,19 & 55,82 & 103,11 \\
\hline Triturus marmoratus & 30TTL88 & 100,00 & 120,04 & 116,87 & 39,00 & 6129,04 & 292,54 & $-0,96$ & 293,50 & 80,56 & 199,23 & 201,35 & 44,43 & 369,22 & 44,14 & 11,29 & 33,43 & 124,61 & 52,34 & 54,01 & 99,94 \\
\hline Triturus marmoratus & 30TTL90 & 100,00 & 114,29 & 115,12 & 38,60 & 6168,75 & 288,58 & $-5,88$ & 294,46 & 74,00 & 195,12 & 197,74 & 40,25 & 442,18 & 53,26 & 12,10 & 33,22 & 141,85 & 58,34 & 60,13 & 122,18 \\
\hline Triturus marmoratus & 30TTL94 & 100,00 & 117,14 & 117,62 & 39,89 & 6042,23 & 289,38 & $-2,95$ & 292,33 & 76,99 & 195,08 & 198,61 & 43,79 & 392,83 & 47,39 & \begin{tabular}{|c|}
11,57 \\
\end{tabular} & 31,49 & 125,51 & 56,71 & 58,87 & 105,48 \\
\hline Triturus marmoratus & 30TTL95 & 100,00 & 117,80 & 117,64 & 39,72 & 6069,91 & 290,40 & $\begin{array}{ll}-2,562 \\
-2,62\end{array}$ & 293,02 & 77,74 & $\begin{array}{l}196,23 \\
\end{array}$ & $\begin{array}{l}199,40 \\
\end{array}$ & 44,09 & 383,52 & |46,63 & 11,36 & 32,12 & 124,15 & 55,46 & 57,44 & 102,38 \\
\hline Triturus marmoratus & 30TTL99 & 100,00 & 123,40 & 116,79 & 39,00 & 6113,62 & 295,29 & 1,44 & 293,85 & 84,35 & 202,00 & 204,42 & 47,40 & 361,10 & 42,50 & \begin{tabular}{l|l|l|}
11,65 \\
\end{tabular} & 32,23 & 120,58 & 52,20 & 54,24 & 97,04 \\
\hline Triturus marmoratus & 30TTM50 & 100,00 & 118,92 & 114,25 & 39,00 & 6119,15 & 289,53 & $-1,20$ & 290,73 & 79,56 & 199,50 & 199,86 & 43,12 & 425,39 & 54,04 & 11,10 & 35,80 & 150,07 & 54,46 & 54,70 & 128,83 \\
\hline Triturus marmoratus & 30TTM56 & 80,00 & 115,43 & 114,79 & 39,02 & 5976,23 & 283,90 & $-4,84$ & 288,73 & 77,50 & 194,25 & 194,25 & 40,71 & 500,38 & 63,39 & 16,95 & 34,12 & 181,13 & 71,15 & 71,15 & 153,10 \\
\hline Triturus marmoratus & 30TTM57 & 80,00 & 112,37 & 114,69 & 39,02 & 5954,96 & 280,73 & $-7,69$ & 288,41 & 74,69 & 191,03 & 191,03 & 37,87 & 527,27 & 67,28 & 18,87 & 33,90 & 191,45 & 76,99 & 76,99 & 160,66 \\
\hline Triturus marmoratus & 30TTM59 & 70,00 & 113,74 & 114,05 & 39,83 & 5850,72 & 279,31 & $-5,75$ & \begin{tabular}{|l|l|}
285,06 \\
\end{tabular} & 76,92 & $\begin{array}{l}190,78 \\
\end{array}$ & $\begin{array}{l}190,78 \\
\end{array}$ & 40,39 & 550,41 & $\begin{array}{l}71,79 \\
71,79\end{array}$ & 21,13 & 33,42 & 201,25 & 83,59 & 83,59 & 164,39 \\
\hline Triturus marmoratus & 30TTM60 & 100,00 & 120,34 & 115,00 & 39,00 & 6131,49 & 291,38 & $-0,43$ & 291,81 & 80,93 & 199,72 & 201,24 & 44,30 & 389,94 & 48,50 & \begin{tabular}{|l|l|}
10,63 \\
\end{tabular} & 34,65 & 135,93 & 52,24 & 53,13 & 112,21 \\
\hline Triturus marmoratus & 30TTM62 & 100,00 & 120,20 & 115,04 & 39,00 & 6087,90 & 290,52 & $-0,55$ & 291,06 & 81,15 & 200,17 & 200,39 & 44,52 & 413,72 & 51,54 & 12,11 & 34,03 & 145,85 & 57,31 & 57,43 & 121,43 \\
\hline Triturus marmoratus & 30TTM68 & 100,00 & 115,66 & 115,14 & 39,30 & 5920,82 & 283,44 & $-4,84$ & 288,27 & 78,75 & 193,59 & 193,59 & 41,14 & 510,51 & 65,92 & 19,61 & 33,18 & 186,15 & 78,70 & 78,70 & 149,35 \\
\hline Triturus marmoratus & 30TTM72 & 100,00 & 121,22 & 115,76 & 39,00 & 6085,42 & 292,07 & $-0,26$ & 292,33 & 82,42 & 200,30 & 201,51 & 45,26 & 396,00 & 48,23 & 12,26 & 33,17 & 138,25 & 56,89 & 57,44 & 112,25 \\
\hline Triturus marmoratus & 30TTM75 & 100,00 & 119,06 & 115,99 & 39,01 & 6000,19 & 289,02 & $-2,23$ & 291,25 & 81,85 & 198,19 & 198,19 & 43,90 & 441,94 & 55,03 & 15,57 & 32,62 & 157,67 & 66,79 & 66,79 & 126,77 \\
\hline Triturus marmoratus & 30TTM79 & 100,00 & 114,03 & 115,95 & 39,95 & 5900,76 & 282,31 & $-7,13$ & 289,43 & 77,75 & 191,87 & 191,87 & 39,68 & 517,01 & 67,13 & 21,75 & 32,80 & 188,87 & 84,68 & 84,68 & 145,62 \\
\hline Triturus marmoratus & 30TTM83 & 100,00 & 121,46 & 116,04 & 39,00 & 6028,39 & 292,09 & $-0,39$ & 292,48 & 84,00 & 199,86 & 200,99 & 46,17 & 400,38 & 48,43 & 13,59 & 31,92 & 139,41 & 60,23 & 60,83 & 111,39 \\
\hline Triturus marmoratus & 30TTM85 & 100,00 & 119,63 & 116,05 & 39,03 & 5984,16 & 289,65 & $-1,88$ & 291,53 & 82,89 & 198,59 & 198,59 & 44,51 & 431,66 & 53,50 & 15,91 & 31,95 & 152,64 & 67,61 & 67,61 & 120,59 \\
\hline Triturus marmoratus & 30TTM89 & 100,00 & 115,22 & 115,85 & 39,87 & 5866,60 & 283,20 & $-6,04$ & 289,24 & 79,92 & 192,64 & 192,64 & 41,29 & 504,66 & 65,27 & 21,97 & 32,22 & 183,22 & 85,25 & 85,25 & 138,31 \\
\hline Triturus marmoratus & 30TTM90 & 100,00 & 120,98 & 116,89 & 39,01 & 6105,73 & 292,91 & $-0,06$ & 293,57 & 82,10 & \begin{tabular}{|l|}
199,48 \\
\end{tabular} & 201,74 & 45,03 & 373,56 & 43,81 & 12,30 & 31,86 & 125,32 & 54,53 & 56,83 & 100,95 \\
\hline Triturus marmoratus & 30TTM92 & 100,00 & 120,89 & 116,64 & 39,00 & 6061,87 & 292,44 & $-1,17$ & 293,61 & 83,17 & 198,99 & 201,06 & 45,29 & 389,62 & 46,38 & 13,51 & 31,44 & 132,64 & 58,42 & 60,35 & 106,25 \\
\hline Triturus marmoratus & 30TтM93 & 100,00 & 121,63 & 116,31 & 39,02 & 6017,12 & 292,34 & $-0,49$ & 292,83 & 84,57 & 199,03 & 201,21 & 46,42 & 398,03 & 48,02 & 14,06 & 31,29 & 136,86 & 60,54 & 62,02 & 108,93 \\
\hline Triturus marmoratus & 30TTN53 & 58,00 & 93,44 & 109,66 & 39,99 & 5543,63 & 251,73 & $-19,50$ & 271,23 & 60,25 & 166,97 & 166,97 & 25,44 & 749,48 & 97,07 & 33,26 & 30,23 & 40 & 122,49 & 122,49 & 220,42 \\
\hline Triturus marmoratus & 30TTN54 & 50,00 & & 107,32 & 39,96 & 5432,77 & 240,95 & $-24,42$ & 265,37 & 54,00 & 157,99 & 15 & 19,85 & 827,83 & $\mid \begin{array}{r}\mid r, 05,94 \\
105\end{array}$ & 37,45 & 29,26 & 289,86 & 136,27 & 136,33 & 244,65 \\
\hline Triturus marmoratus & 30TTN59 & 34,00 & 107,65 & 97,71 & 42,53 & 4464,14 & 236,69 & 9,24 & 227,45 & 84,37 & 165,18 & 167,02 & 53,90 & 894,86 & 118,92 & 43,8 & 27,39 & 303,14 & 154,69 & 162,37 & 241,67 \\
\hline Triturus marmoratus & 30TTN60 & 100,00 & 112,30 & 114,63 & 39,92 & 5825,36 & 278,29 & \begin{tabular}{|c|c|c|}
$-7,38$ \\
\end{tabular} & 285,67 & 76,30 & 189,01 & 189,01 & 39,02 & 557,37 & 73,12 & 23,30 & 32,92 & 204,20 & 89,71 & 89,71 & 160,39 \\
\hline Triturus marmoratus & 30TTN61 & 100,00 & 109,29 & 114,10 & 39,99 & 5768,96 & 273,99 & $-9,38$ & 283,37 & 73,76 & 185,24 & 185,24 & 36,90 & 590,31 & 77,69 & 25,53 & 32,54 & 215,87 & 96,86 & 96,86 & 168,97 \\
\hline Triturus marmoratus & 30TTN63 & 100,00 & 97,88 & 110,95 & 40,00 & 5567,66 & 257,41 & $-16,42$ & 273,84 & 64,54 & 171,46 & 171,46 & 28,97 & 704,86 & 91,85 & 32,32 & 30,37 & 02 & 118,46 & 118,46 & 202,02 \\
\hline Triturus marmoratus & 30 TTN & 100,00 & 88 & 108,26 & 40,01 & 5445,67 & 244,62 & $\begin{array}{ll}-1.2,42 \\
-22,48\end{array}$ & \begin{tabular}{|l|}
267,11 \\
\end{tabular} & $\begin{array}{l}56,85 \\
\end{array}$ & \begin{tabular}{|l|l|l|l|}
160,94 \\
\end{tabular} & \begin{tabular}{|l|l|l|l|}
160,94 \\
\end{tabular} & $\frac{20,2,20}{22,0}$ & \begin{tabular}{|l|}
795,50 \\
\end{tabular} & \begin{tabular}{|c|}
102,14 \\
102,14
\end{tabular} & 37,00 & 28,97 & 279,16 & $\begin{array}{l}130,40 \\
134,13\end{array}$ & $\begin{array}{l}130,40 \\
134,13\end{array}$ & 230,18 \\
\hline Triturus marmoratus & 30TTN69 & 100,00 & 119,03 & 95,86 & 43,27 & 4250,99 & 241,90 & 22,63 & 219,26 & 97,51 & 173,16 & 175,43 & 67,69 & 853,09 & 115,27 & 42,55 & 27,79 & 287,22 & 149,88 & 157,86 & 220,65 \\
\hline Triturus marmoratus & 30TTN70 & 100,00 & 111,83 & 115,86 & 39,87 & 5876,95 & 279,96 & $-8,85$ & 288,81 & 76,08 & $\mid 189,31$ & 189,31 & 37,82 & $|541,07|$ & $\mid 70,76$ & 23,03 & 32.95 & 198,52 & 90,65 & 90,65 & 151,22 \\
\hline Triturus marmoratus & 30TTN71 & 100,00 & 108,29 & 115,51 & 39,98 & 5833,44 & 275,83 & $-11,51$ & 287,33 & 72,84 & 185,29 & 185,29 & 35,15 & 574,51 & 75,41 & 23,60 & 32,70 & 210,81 & 98,28 & 98,28 & 159,6 \\
\hline Triturus marmoratus & 30TTN72 & 100,00 & 101,50 & 113,74 & 39,99 & 5728,56 & 266,30 & $-16,17$ & 282,47 & 67,27 & 177,26 & 177 & 30,08 & 637,13 & 83,05 & 28,18 & 31,32 & 230,49 & 109,92 & 109,92 & 17 \\
\hline Triturus marmoratus & 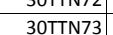 & $\begin{array}{l}100,00 \\
100\end{array}$ & 90,56 & $11,1,50$ & 40,00 & 5591,34 & 257,71 & $\begin{array}{c}-18,17 \\
-18,05 \\
\end{array}$ & $\begin{array}{l}20<, 41 \\
275,76 \\
\end{array}$ & 63,91 & 170,84 & 170,84 & 27,56 & 694,81 & $\begin{array}{l}90,14 \\
90\end{array}$ & 32,83 & 29,98 & 247,84 & 120,24 & 120,24 & 195,01 \\
\hline Triturus marmoratus & 30TTN74 & 100,00 & 83,51 & 107,91 & 39,82 & 5452,56 & 240,04 & $-27,45$ & 267,49 & 52,10 & 155,92 & 155,92 & 17,04 & 818,40 & 103,75 & 39,17 & 28,25 & 284,09 & 140,87 & 140,88 & 234,68 \\
\hline Triturus $\mathrm{m}$ & 30TTN78 & 100,00 & 117,13 & 98,23 & 42,67 & 4460.95 & 244,70 & 17,29 & 227.41 & 94,18 & \begin{tabular}{|l|}
174,32 \\
\end{tabular} & 176,00 & 62,72 & 810,13 & 109.11 & \begin{tabular}{|l|l|}
40,72 \\
\end{tabular} & 27.66 & 275,34 & 144,16 & 151,84 & 209,04 \\
\hline Triturus r & 30TTN81 & 100,00 & 112,09 & 115,44 & 39,99 & 5801,20 & 278,79 & $-8,02$ & 286 & 77,48 & 188 & 188,47 & 38 & 549,74 & 72,17 & 22,12 & 32,53 & 201,18 & 96,41 & 96,41 & 148,43 \\
\hline Triturus marmoratus & 30TTN82 & 100,00 & 108,29 & 114,24 & 40,00 & 5713,11 & 272,77 & \begin{tabular}{|c|c|c|}
$-10,27$ \\
-12
\end{tabular} & 283,04 & 74,53 & 183,56 & 183,56 & 36,55 & 591,44 & 77,61 & 24,31 & 31,73 & 214,95 & 104,96 & $\begin{array}{r}104,96 \\
\end{array}$ & 159,59 \\
\hline
\end{tabular}




\begin{tabular}{|c|c|c|c|c|c|c|c|c|c|c|c|c|c|c|c|c|c|c|c|c|c|}
\hline TAXON & UTM & $\mathrm{km} 2$ & BIO1 & BIO2 & $B 103$ & BIO4 & B105 & B106 & B107 & B108 & $B 109$ & B1010 & BIO11 & B1012 & BIO13 & 81014 & B1015 & B1016 & B1017 & B1018 & B1019 \\
\hline Triturus marmoratus & 30TTN83 & 100,00 & 100,81 & 111,97 & 40,01 & 5578,91 & 261,61 & $-14,78$ & 276,39 & 68,47 & 174,49 & 174,49 & 31,46 & 662,58 & 86,12 & 30,41 & 30,02 & 236,55 & 117,88 & 117,88 & 180,73 \\
\hline Triturus marmoratus & 30TTN90 & 100,00 & 115,60 & 114,52 & 39,93 & 5754,04 & 280,47 & $-4,69$ & 285,16 & 82,10 & 191,30 & 191,30 & 42,93 & 521,09 & 67,51 & 23,59 & 31,24 & 187,63 & 91,22 & 91,22 & 139,00 \\
\hline Triturus marmoratus & 30TTN91 & 100,00 & 112,42 & 114,10 & 39,99 & 5708,68 & 276,63 & $-6,76$ & 283,39 & 79,24 & 187,61 & \begin{tabular}{ll|}
187,61 \\
\end{tabular} & 40,64 & 551,70 & 71,77 & 24,11 & 31,20 & 198,91 & 98,15 & 98,15 & 146,58 \\
\hline Triturus marmoratus & 30TTN92 & 100,00 & 107,67 & $\begin{array}{l}13,09 \\
\end{array}$ & 40,00 & 5642,44 & 270,31 & $-10,03$ & 280,35 & 75,30 & 182,14 & 182,14 & 36,94 & 595,94 & 77,47 & 26,22 & 30,55 & 213,70 & 107,31 & 107,31 & 158,62 \\
\hline Triturus marmoratus & 30TTN93 & 100,00 & 101,07| & 111,23 & $40,01]$ & 5538,27 & 260,69 & $-14,21$ & 274,90 & 69,69 & 174,09 & 174,09 & 32,15 & 658,48 & $84,97 \mid$ & 31,07 & 29,28 & 233,02 & 119,10 & 119,10 & 176,86 \\
\hline Triturus marmoratus & 30TTN94 & 100,00 & 93,59 & $\begin{array}{l}108,77 \\
\end{array}$ & 40,01 & 5418,02 & 249,74 & $-18,79$ & 268,53 & 63,35 & 165,26 & 165,26 & 26,95 & 733,11 & 93,67 & 36,51 & 27,87 & 255,42 & 132,52 & 132,52 & 199,38 \\
\hline Triturus marmoratus & 30TTP60 & 100,00 & 129,66 & 89,93 & 43,73 & 3918,14 & 241,79 & 38,42 & 203,37 & 111,05 & 178,84 & 181,95 & 82,53 & 850,03 & 116,32 & 42,40 & 28,38 & 284,03 & $\begin{array}{l}149,06 \\
\end{array}$ & 158,09 & 214,18 \\
\hline Triturus marmoratus & 30TTP73 & & & & & & & & & & & & & & & & & & & & \\
\hline Triturus marmoratus & 30TTP80 & 100,00 & 126,93 & 86,91 & 42,80 & 3981,43 & 237,32 & 36,17 & 201,14 & 108,64 & 177,37 & 180,30 & 78,91 & 843,78 & \begin{tabular}{|c|}
114,67 \\
\end{tabular} & 42,99 & 27,94 & 283,30 & 151,37 & 160,74 & 211,27 \\
\hline Triturus marmoratus & 30TTP82 & 60,00 & 138,75 & 71,62 & \begin{tabular}{|l|l|}
40,72 & \\
\end{tabular} & \begin{tabular}{|c|}
3679,04 \\
\end{tabular} & 230,37 & 56,65 & 173,71 & 122,63 & 185,16 & 188,74 & 94,25 & 829,42 & \begin{tabular}{|c|}
113,76 \\
\end{tabular} & 40,20 & 28,83 & 282,16 & \begin{tabular}{|c|}
143,90 \\
\end{tabular} & 157,39 & 211,51 \\
\hline Triturus marmoratus & 30TUK08 & 100,00 & 105,93 & 113,03 & 37,83 & 6234,50 & \begin{tabular}{|l|}
282,07 \\
\end{tabular} & $-14,19$ & 296,26 & 64,14 & 188,86 & 190,86 & 32,37 & 495,59 & 60,24 & 14,20 & 33,61 & 157,74 & 64,29 & 66,78 & 136,18 \\
\hline Triturus marmoratus & 30TUK16 & 100,00 & 82,40 & 110,78 & 37,00 & 6241,99 & 260,71 & $-34,80$ & 295,51 & 35,77 & 167,32 & 168,13 & 10,85 & 646,15 & 76,49 & 19,65 & 32,89 & 203,86 & 82,49 & 87,53 & 181,66 \\
\hline Triturus marmoratus & 30TUK17 & 100,00 & 79,97 & 110,37 & 37,01 & 6204,22 & 257,10 & $-36,50$ & 293,60 & 31,32 & 164,45 & 165,12 & 9,03 & 648,18 & 77,16 & 20,45 & 32,38 & 203,69 & 84,44 & 89,93 & 181,01 \\
\hline Triturus marmoratus & 30TUK18 & 100,00 & 85,68 & 110,95 & \begin{tabular}{|c|}
37,17 \\
\end{tabular} & 6184,79 & 261,81 & $-31,63$ & 293,44 & 40,94 & 169,28 & 170,44 & 14,40 & 600,66 & 72,73 & 19,18 & 32,23 & 188,44 & 80,13 & 85,09 & 164,78 \\
\hline Triturus marmoratus & 30TUK27 & 100,00 & 89,82 & 111,24 & 37,00 & 6224,85 & $\begin{array}{l}266,71 \\
\end{array}$ & $-28,78$ & 295,48 & 70,00 & 173,92 & 174,90 & \begin{tabular}{c|c|}
17,89 \\
\end{tabular} & 566,20 & 70,59 & 18,04 & 32,43 & 178,04 & 76,65 & 80,72 & 150,68 \\
\hline Triturus marmoratus & 30TUK28 & 100,00 & 80,02 & 110,48 & 37,01 & \begin{tabular}{|c|c|}
6176,16 \\
\end{tabular} & 256,19 & $-36,62$ & 292,81 & 47,95 & 163,94 & \begin{tabular}{|c|}
164,79 \\
\end{tabular} & 9,42 & 625,94 & 76,25 & 21,04 & 31,64 & \begin{tabular}{|c|}
195,47 \\
\end{tabular} & 85,60 & 91,35 & 169,35 \\
\hline Triturus marmoratus & 30TUK29 & 100,00 & $\begin{array}{l}97,39 \\
\end{array}$ & $\begin{array}{l}111,69 \\
\end{array}$ & 37,25 & 6172,59 & 272,32 & $-22,07$ & 294,39 & 77,13 & 179,98 & \begin{tabular}{ll|}
181,63 \\
\end{tabular} & 24,99 & $\begin{array}{l}497,97 \\
4\end{array}$ & 64,06 & 16,68 & 32,32 & 155,57 & 71,03 & 74,46 & 127,42 \\
\hline Triturus marmoratus & 30TUK39 & 100,00 & 104,10 & 111,62 & 37,10 & 6184,29 & 278,08 & $-17,14$ & 295,22 & 97,69 & $\mid 186,34$ & 188,11 & 30,71 & 449,96 & 60,10 & $\mid 15,34$ & 32,89 & $|142,87|$ & 66,47 & 69,05 & 109,53 \\
\hline Triturus marmoratus & 30TUK49 & 100,00 & 106,49 & 110,67 & 37,00 & $\begin{array}{l}6192,96 \\
\end{array}$ & 279,53 & $-15,58$ & 295,10 & 120,31 & 188,72 & 190,49 & 32,85 & 428,51 & 58,98 & \begin{tabular}{ll|}
14,66 \\
\end{tabular} & 33,71 & 138,90 & 64,95 & 67,18 & 100,21 \\
\hline Triturus marmoratus & 30TUK57 & 100,00 & 117,59 & 110,53 & 36,51 & 6344,52 & 292,32 & $-6,49$ & 298,81 & 102,44 & 202,68 & 203,47 & 41,46 & \begin{tabular}{l|l|}
410,25 \\
\end{tabular} & 54,77 & 12,60 & 34,25 & 132,62 & 58,94 & 59,81 & 98,93 \\
\hline Triturus marmoratus & 30TUK58 & 100,00 & 96,35 & 109,92 & 36,98 & $\begin{array}{l}6196,46 \\
\end{array}$ & 270,65 & $-23,76$ & 294,41 & 85,99 & 179,84 & 180,83 & 24,11 & 484,28 & 65,80 & 16,94 & 32,88 & 156,43 & 73,19 & 76,41 & 114,71 \\
\hline Triturus marmoratus & 30TUK59 & 100,00 & 103,59 & 109,52 & 36,96 & \begin{tabular}{l|l|l|}
6183,07 \\
\end{tabular} & 275,94 & $-17,90$ & 293,85 & 121,31 & 186,10 & $\begin{array}{l}187,49 \\
\end{array}$ & 30,31 & \begin{tabular}{ll|l}
432,48 \\
\end{tabular} & 60,85 & 15,26 & 34,09 & 142,54 & 67,51 & 69,93 & 97,73 \\
\hline Triturus marmoratus & 30TUK69 & 100,00 & 100,89 & 108,38 & 36,53 & 6170,98 & 272,44 & $-20,11$ & 292,55 & 1118,39 & 183,75 & $\mid 184,77$ & 28,19 & $\mid 441,47$ & 62,70 & $\mid 16,10$ & 34,16 & $\mid 146,82$ & 70,40 & 73,12 & 97,69 \\
\hline Triturus marmoratus & 30TUK85 & 100,00 & 145,18 & 109,17 & 35,10 . & 6648,13 & 321,11 & 16,44 & 304,68 & 102,51 & 234,40 & 234,40 & 63,61 & 368,66 & 42,96 & $8,57 \mid$ & 35,71 & 121,13 & 43,99 & 43,99 & 99,45 \\
\hline Triturus marmoratus & 30TUK86 & 100,00 & 133,66 & 108,22 & 35,36 & 6561,83 & 308,14 & 6,79 & 301,35 & 98,74 & 221,89 & 222,00 & \begin{tabular}{|c|}
53,67 \\
\end{tabular} & $\begin{array}{l}390,65 \\
\end{array}$ & 47,58 & 10,50 & 34,35 & 125,95 & 51,28 & 51,34 & 101,24 \\
\hline Triturus marmoratus & 30TUK89 & 100,00 & 98,05 & 106,76 & 36,38 & 6211,20 & 268,70 & $-21,19$ & 289,90 & 113,77 & 181,84 & 182,58 & 25,62 & $\begin{array}{l}478,86 \\
\end{array}$ & 64,70 & 17,80 & 32,27 & 155,90 & 74,58 & 78,62 & 110,54 \\
\hline Triturus marmoratus & 30TULO0 & 100,00 & 110,18 & 114,28 & 38,09 & 6167,10 & 284,62 & $-10,15$ & 294,77 & 70,03 & 191,37 & $\begin{array}{l}193,92 \\
\end{array}$ & 36,64 & 447,81 & 55,41 & 13,05 & 32,65 & $\begin{array}{l}141,66 \\
\end{array}$ & 61,14 & 63,42 & 119,99 \\
\hline Triturus marmoratus & 30TUL04 & 100,00 & 118,51 & 116,89 & 39,44 & 6066,89 & 290,54 & $-2,02$ & 292,56 & 78,15 & 196,72 & 200,28 & 44,73 & 384,11 & 46,77 & 11,48 & 31,17 & 120,88 & 56,10 & 58,44 & 101,31 \\
\hline Triturus marmoratus & 30TUL05 & 100,00 & 119,92 & 117,01 & 39,21 . & 6073,97 & 292,05 & $-0,88$ | & 292,92 & 79,81 & 198,15 & 201,49 & 45,87 & 374,10 & 45,45 & 11,11 & 31,60 & 119,13 & 54,34 & 56,68 & 98,92 \\
\hline Triturus marmoratus & 30TUL06 & 100,00 & 120,28 & 117,02 & 39,16 & 6083,57 & 292,61 & $-0,73$ & 293,34 & 80,51 & 198,68 & 201,75 & 45,65 & 371,36 & 44,96 & 11,37 & 31,54 & 119,15 & 54,14 & 56,68 & 98,24 \\
\hline Triturus marmoratus & 30TULO9 & 100,00 & 124,48 & 117,00 & 39,01 & 6110,66 & 296,34 & 1,98 & 294,37 & 85,50 & 202,91 & 205,33 & 48,39 & 362,45 & 42,43 & \begin{tabular}{ll|}
11,87 \\
\end{tabular} & 31,51 & 119,34 & 53,11 & 55,39 & 96,87 \\
\hline Triturus marmoratus & 30TUL13 & 100,00 & 117,23 & 115,59 & 38,98 & \begin{tabular}{|c|c|}
6106,01 \\
\end{tabular} & 289,51 & $-3,42$ & 292,93 & 83,52 & 196,31 & 199,53 & 43,05 & 389,36 & 48,44 & 12,00 & 31,30 & 121,10 & 57,11 & 59,78 & 100,52 \\
\hline Triturus marmoratus & 30TUL16 & 100,00 & 121,14 & 116,50 & \begin{tabular}{ll|}
39,06 \\
\end{tabular} & 6101,75 & 293,16 & $-0,21$ & 293,38 & 81,37 & 199,89 & 202,88 & 46,11 & 371,73 & 44,97 & 11,71 & 30,99 & 117,60 & 54,68 & 57,42 & 97,91 \\
\hline Triturus marmoratus & 30TUL18 & 100,00 & 123,31 & 116,90 & 39,00 & 6114,50 & $295,2 \varepsilon$ & 1,28 & 293,99 & 83,96 & 201,97 & 204,40 & 47,29 & 368,44 & 43,48 & 11,85 & 31,01 & 118,60 & 53,89 & $\begin{array}{l}56,66 \\
\end{array}$ & 98,44 \\
\hline Triturus marmoratus & 30TUL23 & 100,00 & 116,90 & 114,53 & $\begin{array}{l}38,55 \\
\end{array}$ & 6121,92 & 288,76 & $-4,31$ & 293,07 & 129,16 & 196,38 & 199,30 & 42,62 & 388,19 & 49,19 & 12,16 & 31,45 & 120,77 & 57,43 & 60,30 & 98,07 \\
\hline Triturus marmoratus & 30TUL24 & 100,00 & 119,42 & 114,94 & \begin{tabular}{|c|}
38,87 \\
\end{tabular} & 6127,27 & 291,15 & $-1,90$ & 293,05 & 93,05 & $\begin{array}{l}198,64 \\
\end{array}$ & 201,77 & 44,47 & 379,32 & 47,25 & 12,00 & 31,03 & 118,09 & 56,54 & 59,31 & 97,02 \\
\hline Triturus marmoratus & 30TUL25 & 100,00 & 120,94 & 115,34 & 39,00 & 6132,99 & 292,69 & $-0,53$ & 293,22 & 80,93 & 200,23 & 203,11 & 45,72 & $\begin{array}{l}374,95 \\
\end{array}$ & 46,05 & 11,99 & 30,37 & 117,06 & 55,76 & 58,77 & 97,00 \\
\hline Triturus marmoratus & 30TUL29 & 100,00 & 124,35 & 116,46 & 39,00 & 6110,26 & 295,87 & 1,75 & 294,12 & 85,78 & 202,97 & 205,22 & 47,91 & 377,03 & 44,03 & 12,18 & 30,50 & 120,93 & 54,84 & 58,46 & 101,84 \\
\hline Triturus marmoratus & 30TUL30 & 100,00 & 95,80 & 111,23 & 37,54 & 6133,05 & 269,38 & $-23,46$ & 292,84 & 103,81 & 177,94 & 179,37 & 23,76 & \begin{tabular}{|c|}
485,58 \\
\end{tabular} & $\begin{array}{l}64,25 \\
\end{array}$ & 17,28 & 32,02 & $\begin{array}{l}153,65 \\
\end{array}$ & 72,46 & 76,43 & 119,35 \\
\hline Triturus marmoratus & 30TUL33 & 100,00 & 117,32 & 113,31 & 38,09 & 6159,14 & 288,86 & $-4,16$ & 293,02 & 138,29 & 197,56 & 200,19 & 42,31 & 385,28 & 49,53 & 12,49 & 31,67 & 121,03 & 57,71 & 60,76 & 95,71 \\
\hline Triturus marmoratus & 30TUL38 & 100,00 & 122,01 & 115,66 & 39,00 & 6139,48 & 293,63 & 0,19 & 293,44 & 82,82 & 201,31 & 203,60 & 45,82 & \begin{tabular}{|c|}
386,17 \\
\end{tabular} & 45,38 & 12,31 & 30,30 & \begin{tabular}{ll|l}
121,43 \\
\end{tabular} & 56,31 & 60,28 & 103,48 \\
\hline Triturus marmoratus & 30TUL49 & 100,00 & 123,73 & 115,15 & 39,00 & 6132,16 & 294,86 & 1,85 & 293,01 & 85,12 & 202,97 & 204,89 & 47,32 & 397,40 & $\begin{array}{l}46,06 \\
\end{array}$ & 12,77 & 29,75 & $\begin{array}{l}124,49 \\
\end{array}$ & 57,33 & 61,80 & $\begin{array}{ll}108,98 \\
\end{array}$ \\
\hline Triturus marmoratus & 30TUL50 & 100,00 & 106,06 & 109,31 & 36,96 & 6168,92 & 277,19 & $-15,90$ & 293,08 & 124,70 & 188,09 & 189,54 & 32,53 & 414,73 & 58,77 & 15,01 & 34,32 & 137,72 & 65,86 & 68,31 & 92,25 \\
\hline Triturus marmoratus & 30TUL56 & 100,00 & 122,10 & 112,07 & 38,00 & 6182,96 & 291,5 & $-0,10$ & 291,64 & 108,31 & 202,33 & 204,53 & 45,69 & 388,29 & 47,19 & 12,05 & 30,90 & 120,47 & 56,23 & 61,05 & 100,49 \\
\hline Triturus marmoratus & 30TUL57 & 100,00 & 123,07 & 112,78 & 38,02 & 6181 & 293, & 0,34 & 292,72 & 84,41 & 203,18 & 205,50 & 46,37 & 391,90 & 46,43 & 12,03 & 30,66 & 121,94 & 56,41 & 61,21 & 103,59 \\
\hline Triturus marmoratus & 30TUL58 & 100,00 & 123,85 & 11 & 38,29 & 6158,24 & 294,08 & 1,67 & 292,41 & 85,56 & 203,82 & 205,75 & $\begin{array}{l}47,39 \\
\end{array}$ & $397, \mathrm{C}$ & 46,06 & 12,08 & 30,10 & $\begin{array}{l}123,65 \\
\end{array}$ & 56,97 & 61,73 & 106,99 \\
\hline Triturus marmoratus & 30TUL59 & 100,00 & 124,59 & 114,18 & 38,41 & 6141,55 & $\begin{array}{l}294,91 \\
\end{array}$ & 2,19 & 292,73 & 86,62 & 203,97 & 205,89 & 47,84 & $\begin{array}{l}403,19 \\
\end{array}$ & 46,57 & 12,84 & 29,82 & 125,94 & 57,73 & 62,66 & 110,59 \\
\hline Triturus marmoratus & 30TUL60 & 100,00 & 104,58 & 107,76 & 36,22 & 6148,58 & 274,42 & $-17,22$ & 291,64 & 122,81 & 186,65 & 187,74 & 31,39 & 412,56 & 60,01 & 15,35 & 35,14 & 139,47 & 67,69 & 70,06 & 87 \\
\hline Triturus marmoratus & 30TUL67 & 100,00 & 122,54 & 111,32 & 37,93 & 6189,27 & 291,36 & $-0,03$ & 291,39 & 90,32 & 203,01 & 204,96 & 45,99 & \begin{tabular}{|c|}
399,58 \\
\end{tabular} & 47,35 & 12,35 & 30,15 & 123,99 & 57,42 & 63,21 & 104,70 \\
\hline Triturus marmoratus & $30 \mathrm{TU}$ & 100,00 & 122,60 & 112,92 & 38, & 6127 & 292 & $-0,01$ & 292,04 & 85,78 & 202,30 & 203,99 & 46,31 & 412,80 & 47,56 & 13,17 & 29,66 & 128,49 & 58,56 & 65,24 & 111,82 \\
\hline Triturus marmoratus & 30TUL70 & 100,00 & 95,84 & 107,16 & 36,46 & 6136,64 & 265,89 & $-23,49$ & 289,38 & 112,59 & 178,64 & $\begin{array}{ll}179,37 \\
\end{array}$ & 24,13 & 465,38 & 65,18 & 17,91 & 33,21 & 154,68 & 75,01 & 79,26 & 103,41 \\
\hline Triturus marmoratus & 30TUL71 & 100,00 & 106,17 & 106,36 & 36,08 & 6191,89 & 274,05 & $-15,29$ & 289,34 & 124,98 & 188,57 & 189,81 & 32,22 & 418,26 & 58,89 & 15,86 & 34,05 & 140,14 & 67,73 & 71,37 & 91,20 \\
\hline Triturus marmoratus & 30TUL78 & 100,00 & 120,36 & 110,48 & 37,5 & 59,98 & 288,13 & $-2,19$ & 31 & 96,41 & 200,69 & 202,44 & 44. & 417,91 & 48, & 38 & 29 & 129,16 & 59,82 & 67,49 & $10 \mathrm{~s}$ \\
\hline Triturus marmoratus & $30 T$ & 100,00 & 116 & 111 & 37, & & 285 & $-5,35$ & 290,88 & 86,07 & 196 & 198,48 & 41,60 & 432,60 & 50,5 & 14,06 & 29,12 & 133,23 & 61,81 & 70,69 & 114,12 \\
\hline Triturus marmoratus & 30TUL80 & 100,00 & 92,66 & 106,66 & 36,56 & \begin{tabular}{|c|c|}
6150,71 \\
\end{tabular} & 262,51 & $-25,10$ & 287,61 & 107,84 & 176,05 & 176,55 & 21,48 & 499,76 & 67,25 & 19,42 & 31,58 & 162,96 & 78,63 & 83,80 & 115,60 \\
\hline Triturus marmoratus & 30TUL81 & 100,00 & 105,88 & 104,96 & 35,99 & $\begin{array}{l}6242,37 \\
\end{array}$ & $\begin{array}{l}272,87 \\
\end{array}$ & $-14,65$ & $\begin{array}{ll}287,52 \\
\end{array}$ & 124,39 & 189,19 & 190,15 & 31,43 & 440,81 & 59,41 & 16,20 & 32,55 & 144,80 & 69,11 & 73,87 & 100,32 \\
\hline Triturus marmoratus & 30TUL89 & 100,00 & 115,78 & 109,77 & 37,20 & 6117,25 & 282,95 & $-6,84$ & 289,78 & 126,76 & 196,10 & 197,42 & 40,47 & 440,64 & 51,64 & 14,72 & 28,99 & 135,42 & 63,55 & 73,62 & 114,46 \\
\hline $\mid T_{\mathrm{Tri}}$ & 30TUL90 & 100,00 & & & 36,7 , & ? & $2 x^{2}+2+3$ & $\mid-27,33$ & 85,99 & 96 & 172 & & 18 & 541 & 69 & 20,88 & 30,08 & 17 & 83,43 & 88,12 & 13 \\
\hline Triturus marmoratus & 30TUL92 & 100,00 & 112,51 & 102,63 & 35,62 & 6364,53 & 276,80 & $-8,16$ & 284,96 & 131,29 & 196,61 & 198,26 & 35,66 & 449,85 & 55,77 & 14,37 & 31,18 & \begin{tabular}{|c|}
142,48 \\
\end{tabular} & 66,20 & 72,41 & 109,86 \\
\hline Triturus marmoratus & 30TUL98 & 100,00 & 117,03 & 107,34 & 36,97| & 6183,03 & 282,61 & $-4,76$ & 287,37 & 112,48 & 198,30 & $\begin{array}{l}199,66 \\
\end{array}$ & 41,16 & 440,27 & 51,47 & 14,26 & 29,06 & 135,63 & 63,50 & 72,80 & 113,82 \\
\hline
\end{tabular}




\begin{tabular}{|c|c|c|c|c|c|c|c|c|c|c|c|c|c|c|c|c|c|c|c|c|c|}
\hline TAXON & UTM & $\mathrm{km} 2$ & $\mathrm{BIO1}$ & $\mathrm{B1O2}$ & $\mathrm{BIO3}$ & B104 & B105 & $\mathrm{B106}$ & 8107 & B108 & 8109 & 81010 & B1011 & $\mathrm{BIO12}$ & B1O13 & 81014 & B1015 & B1016 & BIO17 & $\mathrm{BIO18}$ & B1019 \\
\hline Triturus marmoratus & 30тUм00 & 100,00 & 121,52 & 117,00 & 39,00 & 6099,22 & 293,63 & $-0,48$ & 294,12 & 82,95 & 199,86 & 202,31 & 45,59 & 376,10 & 44,12 & 12,70 & 31,45 & 124,40 & 55,38 & 58,17 & 101,02 \\
\hline Triturus marmoratus & 30TUM01 & 100,00 & 119,56 & 117,00 & 39,00 & 6081,99 & 291,62 & $-2,32$ & 293,94 & 81,27 & 197,82 & 200,03 & 43,72 & 390,11 & 46,00 & 13,86 & 30,87 & 129,80 & 58,25 & 61,39 & 105,43 \\
\hline Triturus marmoratus & 30TUM02 & 100,00 & 121,08 & 117,00 & 39,00 & 6043,71 & 292,43 & $-0,94$ & 293,37 & 83,58 & 198,70 & 200,97 & 45,49 & 392,60 & 46,74 & 14,08 & 30,80 & 132,01 & 59,13 & 61,87 & 106,46 \\
\hline Triturus marmoratus & 30TUM06 & 100,00 & 118,18 & 115,99 & 39,44 & 5893,34 & 287,03 & $-3,74$ & 290,76 & 83,73 & 194,35 & 196,05 & 44,21 & 448,20 & 55,47 & 18,38 & 30,23 & 155,69 & 73,56 & 74,99 & 120,66 \\
\hline Triturus marmoratus & 30TUM07 & 100,00 & 115,87 & 115,88 & 39,41 & 5863,27 & 284,32 & $-6,15$ & 290,46 & 81,90 & 192,13 & 193,39 & 42,38 & 469,99 & 58,59 & 20,04 & 30,04 & 164,18 & 79,36 & 80,14 & 125,95 \\
\hline Triturus marmoratus & 30TUM09 & 100,00 & 113,76 & 114,72 & 39,50 & 5767,30 & 279,73 & $-7,10$ & 286,83 & 80,94 & 189,89 & 189,89 & 41,24 & 510,43 & 64,72 & 23,28 & 30,11 & 180,32 & 89,68 & 89,68 & 135,52 \\
\hline Triturus marmoratus & 30TUM11 & 100,00 & 118,37 & 117,00 & 39,00 & 6073,24 & 290,72 & $-3,53$ & 294,26 & 80,71 & \begin{tabular}{|l|l|}
196,67 \\
\end{tabular} & 199,01 & 42,72 & 399,96 & 47,04 & 14,32 & 30,24 & 131,10 & 59,76 & 63,84 & 108,02 \\
\hline Triturus marmoratus & 30TUM15 & 100,00 & 119,22 & 116,09 & 39,10 & 5907,52 & 288,30 & $\begin{array}{c}-3,32 \\
-1,3 \\
\end{array}$ & 291,62 & 85,19 & 195,62 & 197,24 & 45,13 & 434,67 & 52,85 & 17,52 & 29,52 & 147,70 & 69,14 & 72,57 & 116,46 \\
\hline Triturus marmoratus & 30TUM17 & 100,00 & 117,29 & 115,08 & 39,24 & 5806,82 & 284,13 & $-4,69$ & 288,82 & 84,79 & 192,30 & 194,02 & 44,52 & 469,07 & 58,02 & 20,24 & 29,21 & \begin{tabular}{|c|}
161,68 \\
\end{tabular} & 78,54 & 80,92 & 124,26 \\
\hline Triturus marmoratus & 30TUM18 & 100,00 & 114,87 & 114,51 & 39,26 & 5750,62 & 280,61 & $-6,58$ & 287,19 & 83,02 & 189,36 & 190,87 & 42,83 & 493,50 & 61,48 & 22,02 & 29,04 & 170,85 & 84,79 & 86,58 & 130,20 \\
\hline Triturus marmoratus & 30TUM19 & 100,00 & 112,08 & 113,84 & 39,45 & 5711,47 & 276,81 & $-8,39$ & 285,20 & 80,59 & 186,43 & 187,57 & 40,66 & 521,27 & 65,33 & 24,05 & 28,83 & 181,12 & 91,78 & 92,82 & 137,14 \\
\hline Triturus marmoratus & 30TUM20 & 100,00 & 120,71 & 116,99 & 39,00 & 6089,06 & 292,77 & $-1,37$ & 294,14 & 82,76 & 199,27 & 201,29 & 44,73 & 394,51 & 46,10 & 13,34 & 30,16 & 126,82 & 58,12 & 62,25 & 106,86 \\
\hline Triturus marmoratus & 30TUM22 & 100,00 & 116,34 & 117,00 & 39,00 & 6033,32 & 288,63 & $-5,76$ & 294,39 & 80,11 & 194,44 & 196,61 & 41,35 & 421,60 & 49,58 & 15,54 & 29,37 & 136,94 & 63,37 & 68,72 & 114,20 \\
\hline Triturus marmoratus & 30TUM23 & 100,00 & 120,17 & 116,92 & 39,15 & 5964,66 & 290,75 & $-2,26$ & 293,01 & 85,50 & 197,48 & 199,12 & 45,63 & 417,02 & 49,59 & 15,83 & 29,43 & 137,30 & 63,17 & 68,10 & 112,54 \\
\hline Triturus marmoratus & 30TUM27 & 100,00 & 117,38 & 114,55 & 39,09 & 5749,96 & 282,96 & $-4,90$ & 287,87 & 86,52 & 191,98 & 193,45 & 45,56 & 473,03 & 57,88 & 20,51 & 28,42 & 160,59 & 78,11 & 82,48 & 124,39 \\
\hline Triturus marmoratus & 30TUM28 & 100,00 & 116,00 & 113,62 & 39,21 & 5688,18 & 279,92 & $-5,54$ & 285,46 & 85,75 & 189,75 & 191,17 & 44,94 & 494,83 & 61,05 & 22,19 & 28,15 & 169,00 & 83,81 & 87,49 & 129,43 \\
\hline Triturus marmoratus & 30TUM33 & 100,00 & 116,86 & 116,91 & 39,00 & 5964,17 & 287,89 & $-6,16$ & 294,05 & 82,65 & 194,20 & 196,15 & 42,60 & 435,02 & 51,10 & 16,41 & 28,95 & 140,78 & 65,07 & 72,13 & 117,56 \\
\hline Triturus marmoratus & 30TUM34 & 100,00 & 120,10 & 116,06 & 39,00 & 5897,92 & 289,35 & $-3,58$ & 292,93 & 87,40 & 196,63 & 198,19 & 46,40 & 432,74 & 51,34 & 17,12 & 28,79 & 141,74 & 65,51 & 72,43 & 115,91 \\
\hline Triturus marmoratus & 30TUM 35 & 100,00 & 119,29 & 115,69 & 39,01 & 5833,60 & 287,07 & $-4,72$ & 291,80 & 87,83 & 194,83 & 196,56 & 46,54 & 445,27 & 53,14 & 18,44 & 28,56 & 146,99 & 68,80 & 76,01 & 117,87 \\
\hline Triturus marmoratus & 30TUM39 & 100,00 & 112,70 & 111,60 & 39,02 & 5574,34 & 273,58 & $-7,33$ & 280,91 & 84,59 & 185,41 & 186,47 & 43,48 & 530,67 & 64,97 & 24,63 & 27,08 & 179,08 & 90,80 & 95,92 & 137,57 \\
\hline Triturus marmoratus & 30TUM40 & 100,00 & 122,15 & 115,78 & 39,00 & 6114,58 & 293,7 & 0,52 & 293,26 & 78,23 & 201,19 & 203,18 & 45,84 & 410,07 & 47,65 & 13,35 & 29,65 & 129,07 & 58,92 & 63,97 & 113,83 \\
\hline Triturus marmoratus & 30TUM41 & 100,00 & 116,48 & 116,22 & 39,00 & 6077,18 & 289,07 & $-5,09$ & 294,16 & 77,72 & 195,67 & 197,33 & 41,18 & 432,19 & 50,04 & 14,91 & 29,02 & $\begin{array}{l}135,79 \\
\end{array}$ & 62,79 & 69,55 & 119,23 \\
\hline Triturus marmoratus & 30TUM43 & 100,00 & 115,33 & 116,54 & 39,00 & 5937,94 & 286,39 & $-7,99$ & 294,38 & 82,39 & \begin{tabular}{|c|}
192,84 \\
\end{tabular} & 194,41 & 41,83 & 445,14 & 51,89 & 16,70 & 28,48 & 142,24 & 65,52 & 74,47 & 119,81 \\
\hline Triturus marmoratus & 30TUM45 & 100,00 & 119,78 & 115,23 & 39,00 & 5786,69 & 286,76 & $-4,92$ & 291,69 & 90,38 & 195,00 & 196,53 & 47,87 & 447,41 & 52,79 & 18,40 & 28,20 & 145,73 & 67,55 & 77,10 & 117,74 \\
\hline Triturus marmoratus & 30TUM47 & 100,00 & 115,94 & 113,37 & 39,00 & 5664,99 & 279,62 & $-7,53$ & 287,15 & 88,30 & 189,80 & 191,02 & 45,72 & 487,52 & 58,13 & 21,51 & 27,29 & 160,58 & 77,79 & 86,99 & 126,13 \\
\hline Triturus marmoratus & 30TUM50 & 100,00 & 124,34 & 114,90 & 38,89 & 6106,90 & 295,01 & 2,06 & 292,94 & 62,07 & 203,37 & 205,14 & 47,94 & 412,16 & 47,90 & 13,03 & 29,88 & 130,10 & 58,24 & 63,54 & 115,23 \\
\hline Triturus marmoratus & 30TUM51 & 100,00 & 122,95 & 115,51 & 38,98 & 6066,38 & 293,71 & 0,46 & 293,25 & 63,90 & 201,60 & 203,15 & 46,92 & 423,85 & 49,38 & $\begin{array}{l}13,80 \\
13,88\end{array}$ & 29,50 & 134,49 & $\begin{array}{l}0,2,44 \\
59,79\end{array}$ & 66,21 & 119,16 \\
\hline Triturus marmoratus & 30TUM54 & 100,00 & 118,23 & 115,84 & 38,94 & 5842,82 & 286,59 & $-7,87$ & 294,45 & 89,16 & 194,26 & 195,91 & 45,86 & 446,61 & 51,50 & 17,21 & 28,76 & 142,14 & 64,70 & 76,95 & 117,39 \\
\hline Triturus marmoratus & 30TUM55 & 100,00 & 120,99 & 114,95 & 38,98 & 5756,24 & 287,11 & $-5,64$ & 292,75 & 93,99 & 195,90 & 197,43 & 49,67 & 446,02 & 51,90 & 18,06 & 28,31 & 143,43 & 65,46 & 77,75 & 115,77 \\
\hline Triturus marmoratus & 30TUM56 & 100,00 & 119,70 & 113,90 & 38,97 & 5683,32 & 283,72 & $-5,96$ & 289,69 & 93,62 & 193,73 & 194,98 & 49,34 & 462,42 & 54,10 & 19,69 & 27,77 & 149,64 & 69,88 & 82,09 & 118,81 \\
\hline Triturus marmoratus & 30TUM57 & 100,00 & 115,86 & 112,71 & 39,00 & 5627,80 & 278,45 & $-8,25$ & 286,70 & 90,00 & 189,36 & 190,38 & 46,43 & 490,84 & 57,69 & 21,75 & 26,95 & 159,46 & 76,90 & 88,51 & 125,72 \\
\hline Triturus marmoratus & 30TUM60 & 100,00 & 122,48 & 113,60 & 38,15 & 6089,17 & 292,07 & $\begin{array}{ll}-0,20 \\
-0,49 \\
-20\end{array}$ & 292,56 & 80,07 & 201,70 & 203,24 & $\begin{array}{l}40,45 \\
46,55\end{array}$ & \begin{tabular}{|l|l|}
419,17 \\
49,4
\end{tabular} & $\begin{array}{l}1,3,36 \\
\end{array}$ & $\mid 13,43$ & 29,68 & \begin{tabular}{|l|l|}
131,25 \\
\end{tabular} & 58,86 & $\begin{array}{l}6,5,41 \\
66,4\end{array}$ & 114,57 \\
\hline Triturus marmoratus & 30TUM61 & 100,00 & 120,32 & 114,40 & \begin{tabular}{|c|}
38,47 \\
\end{tabular} & 6036,22 & 290,06 & $-3,31$ & 293,37 & 85,23 & 198,96 & 200,41 & 45,18 & 431,13 & 49,61 & 14,44 & 29,26 & 134,87 & 60,73 & 69,65 & 117,55 \\
\hline Triturus marmoratus & 30TUM63 & 100,00 & 119,17 & 115,22 & 38,41 & 5885,32 & 287,68 & $-7,44$ & 295,12 & 89,93 & 195,93 & 197,41 & 46,32 & 439,86 & 50,41 & 16,09 & 29,01 & 138,04 & 62,10 & 75,25 & 115,75 \\
\hline Triturus marmoratus & 30TUM67 & 100,00 & 116,04 & 111,89 & 38,72 & 5599,05 & 277,43 & $-8,96$ & 286,39 & 91,78 & 189,24 & 190,09 & 47,21 & 492,99 & 57,07 & 21,84 & 26,85 & 158,02 & 76,02 & 89,84 & 124,90 \\
\hline Triturus marmoratus & 30TUM69 & 100,00 & 111,43 & 108,16 & 38,76 & 5459,33 & 267,92 & $-8,51$ & 276,42 & 86,93 & 183,06 & 183,58 & 44,34 & 551,94 & 65,01 & 25,76 & 25,35 & $\begin{array}{ll}179,23 \\
\end{array}$ & 91,25 & 101,52 & 140,89 \\
\hline Triturus marmoratus & 30TUM70 & 100,00 & 120,65 & 112,09 & 38,00 & 6069,25 & 288,93 & $-2,75$ & 291,68 & 88,68 & 199,90 & 201,46 & 45,47 & 426,42 & \begin{tabular}{l|l}
49,18 \\
\end{tabular} & 14,18 & 29,31 & 132,47 & 60,36 & 69,57 & 113,54 \\
\hline Triturus marmoratus & 30TUM74 & 100,00 & 121,31 & 113,99 & 38,00 & 5780,65 & 286,95 & $-7,65$ & 294,60 & 103,09 & 196,71 & 197,91 & 50,21 & 438,37 & 50,55 & 16,69 & 29,02 & 136,96 & 61,24 & 77,77 & 111,05 \\
\hline Triturus marmoratus & 30TUM75 & 100,00 & 118,92 & 113,79 & 38,02 & 5711,37 & 283,52 & $-10,29$ & 293,81 & 104,70 & 193,40 & 194,54 & 49,02 & 454,39 & 52,15 & 18,33 & 28.52 & 141.93 & 64.84 & 82.43 & 113,56 \\
\hline Triturus marmoratus & 30TUM76 & 100,00 & 118,33 & 112,23 & 38,03 & 5644,23 & 280,66 & $-9,05$ & 289,70 & 95,17 & 192,05 & 193,00 & 49,30 & 471,03 & 53,46 & 20,07 & 27,54 & 148,38 & 69,53 & 85,92 & 117,91 \\
\hline Triturus marmoratus & 30TUM80 & 100,00 & 118,00 & 110,56 & 37,5 & 6067,71 & 284 & $-5,22$ & 290,20 & 105,01 & 197,54 & 198,71 & 43,04 & 437,78 & 50,6 & 14,66 & 28,99 & 135,09 & 62,41 & 72,84 & 114,67 \\
\hline Triturus marmoratus & 30TUM & 100,00 & 112,43 & 102,95 & 38,00 & 5414,49 & 264 & $\mid-3,80$ & 267,82 & 87,41 & 183,62 & 183,69 & 45,63 & 564,68 & 64,6 & 26,34 & 24,06 & $\begin{array}{l}179,09 \\
\end{array}$ & 93,83 & 101,38 & 144,31 \\
\hline Triturus marmoratus & 30TUN & 100,00 & 113,28 & 113,74 & 39,77 & 5700,10 & 277,23 & $-6,27$ & 283,50 & 81,03 & 188,47 & 188,47 & 41,84 & 531,77 & 67,99 & 24,85 & 30,01 & 188,38 & 94,56 & 94,56 & 140,40 \\
\hline Triturus marmoratus & 30TUN01 & 100,00 & 111,04 & 112,70 & 39,98 & 5628,60 & 272,93 & $-7,22$ & 280,16 & 79,47 & 185,17 & 185,17 & 40,30 & 563,92 & 72,45 & 26,71 & 29,77 & 199,85 & 101,55 & 101,55 & 148,49 \\
\hline Triturus marmoratus & 30TUNO2 & 100,00 & 106,8 & 111,48 & 40,00 & 5549,11 & 266,75 & $-9,47$ & 276,22 & 76,01 & 180,08 & 180,08 & 37,55 & 606,52 & 77,94 & 29,18 & 29,16 & 89 & 110,31 & 110,31 & 159,96 \\
\hline Triturus marmoratus & 30TUN03 & 100,00 & 103, & 109,88 & 40,00 & \begin{tabular}{|l|}
5459,93 \\
\end{tabular} & 260,54 & \begin{tabular}{|c|c|c|}
$-11,11$ \\
-12
\end{tabular} & 271,66 & 73,21 & 175,34 & 175,34 & 35,38 & $\begin{array}{l}600,41 \\
650,4\end{array}$ & 83,54 & 32,09 & 28,48 & 228,09 & 118,83 & 118,83 & 172,09 \\
\hline Triturus marmoratus & 30TUN04 & 100,00 & 96 & 107,92 & 39,99 & 5364,44 & 250,54 & $-16,02$ & 266,56 & 66,93 & 167,02 & 167,02 & 30,00 & 718,23 & 91,48 & 36,42 & 27,36 & 248,75 & 131,44 & 131,44 & 192,26 \\
\hline Triturus marmoratus & 30 TUN06 & 100,00 & 67,79 & 102,16 & 39,56 & 5215,84 & 217,31 & $\frac{-37,60}{-37}$ & 254,91 & 40,02 & 137,45 & 137,62 & 5,61 & 963,07 & 117,60 & 49,21 & 24,66 & 320,48 & 173,26 & 173,77 & 271,29 \\
\hline Triturus marmoratus & 30TUN10 & 100,00 & 110,00 & 112,82 & 39,55 & 5650,92 & 272,87 & $-9,21$ & 282,08 & 78,96 & 184,15 & 184,58 & 39,22 & 549,77 & 69,22 & 26,07 & 28,63 & 191,38 & 98,66 & 99,03 & 144,40 \\
\hline Triturus marmoratus & 30TUN11 & 100,00 & 109,07 & 111,48 & 39,88 & 5567,29 & 269,32 & $-8,31$ & 277,63 & 78,70 & 182,48 & 182,55 & 39 & 576,87 & 73,10 & 27,93 & 28,45 & 05 & 104,75 & 104,80 & 151,04 \\
\hline Triturus marmoratus & $30 \mathrm{TU}$ & 100,00 & 105 & $\begin{array}{l}111,40 \\
110,09\end{array}$ & 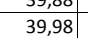 & | & 263 & \begin{tabular}{|c|c|}
$-0,31$ \\
$-10,52$
\end{tabular} & 273,65 & 75,65 & $\begin{array}{ll}10,40 \\
177,55\end{array}$ & \begin{tabular}{|l|l|l|l|l|l|l|}
177,55 \\
\end{tabular} & | 35,93 & \begin{tabular}{|l|l|l|l|l|l|}
619,48 \\
\end{tabular} & 78,58 & $\mid \begin{array}{l}\mid 1,0,70 \\
30\end{array}$ & $\begin{array}{l}27,435 \\
27,93\end{array}$ & $\mid 215,26$ & 113,46 & 113,46 & 162,66 \\
\hline Triturus marmoratus & 30TUN14 & 100,00 & 91,91 & 106,65 & 39,90 & 5329,67 & 245,37 & $-19,25$ & 264,62 & 63,65 & 162,49 & 162,50 & 26,67 & 743,89 & 93,24 & 37,99 & 26,26 & 253,88 & 136,95 & 137,00 & 199,17 \\
\hline Triturus marmoratus & 30TUN16 & 100,00 & 78,12 & 102,39 & 39,84 & 5167,15 & 226,15 & $-28,03$ & 254,18 & 51,17 & 146,75 & 147,05 & 15,97 & 888,69 & 109,61 & 45,98 & 24,75 & 297,35 & 162,91 & 163,98 & 243,87 \\
\hline Triturus marmoratus & 30TUN17 & 100,00 & 79,01 & 100,01 & 39,96 & 5033,41 & 222,44 & $-24,72$ & 247,16 & 53,18 & 145,73 & 146,35 & 18,47 & 921,48 & 114,09 & 47,83 & 24,58 & 307,72 & 168,94 & 171,41 & 252,54 \\
\hline Triturus marmoratus & $30 \mathrm{TUN}$ & 100,00 & 103,05 & 108,81 & 39,66 & 5432,62 & 259,46 & $-12,24$ & 271,70 & 74,61 & 174,47 & 174,79 & 35 & 634,62 & 79,38 & 31,56 & 26,73 & 217,08 & 116,31 & 116,92 & 166 \\
\hline Triturus marmoratus & $\begin{array}{l}30 \text { U UN29 } \\
3\end{array}$ & 100,00 & 120,79 & 80,01 & $\begin{array}{l}3,00,72 \\
40,72\end{array}$ & $\begin{array}{l}3459,020 \\
429,01\end{array}$ & 230,40 & $\begin{array}{c}-1,2,24 \\
26,43 \\
\end{array}$ & 209,61 & \begin{tabular}{|r|}
1401,17 \\
\end{tabular} & $\begin{array}{ll}17,46,11 \\
176,1\end{array}$ & $\begin{array}{ll}178,13 \\
178\end{array}$ & $\begin{array}{ll}30,1 / 1 \\
68,15\end{array}$ & \begin{tabular}{|l|}
8546,80 \\
816
\end{tabular} & \begin{tabular}{|r|} 
\\
107,64 \\
\end{tabular} & \begin{tabular}{|c|}
1,0096 \\
40,96
\end{tabular} & $\begin{array}{l}26,172 \\
26,72\end{array}$ & \begin{tabular}{|l|}
278,91 \\
\end{tabular} & 147,87 & 158,02 & $\begin{array}{l}200,10 \\
210,73\end{array}$ \\
\hline Triturus marmoratus & 30TUN32 & 100,00 & 103,38 & 107,30 & 39,40 & 5369,91 & 257,61 & $-11,11$ & 268,72 & 76,31 & 173,92 & 174,31 & 37,19 & 640,16 & 79,22 & 31,81 & 25,89 & 216,41 & 116,32 & 118,36 & 166,88 \\
\hline Triturus marmoratus & 30TUN43 & 100,00 & 93,60 & 104,56 & 39,16 & 5282,69 & 244,86 & $-17,88$ & 262,73 & 67,40 & 163,50 & 163,55 & 29,04 & 719,69 & 87,54 & 36,59 & 24,45 & 238,82 & 131,28 & 133,60 & 189,55 \\
\hline Triturus r & 30TUN50 & 100,00 & 108,18 & 107,94 & 39,00 & 5427,27 & 264,00 & $-9,95$ & 273,95 & 82,67 & 179,40 & 179 & 41, & 581,56 & 69,70 & 27,79 & 25,18 & 191,44 & 99,60 & 107,21 & $14 \mathrm{~s}$ \\
\hline Triturus marmoratus & 30TUN55 & 100,00 & 67,09 & 99,61 & 38,96 & 5184,02 & 214,98 & $-37,53$ & 252,51 & 40,85 & 137,07 & 137,07 & \begin{tabular}{|c|}
5,56 \\
51,5
\end{tabular} & 938,72 & 109,96 & 49,34 & 22,30 & 301,20 & 171,41 & 171,43 & 256,99 \\
\hline
\end{tabular}




\begin{tabular}{|c|c|c|c|c|c|c|c|c|c|c|c|c|c|c|c|c|c|c|c|c|c|}
\hline TAXON & UTM & $\mathrm{km} 2$ & B101 & $\mathrm{B1O2}$ & $\mathrm{BIO3}$ & B104 & B105 & B106 & B107 & $\mathrm{B108}$ & B109 & BIO10 & BIO11 & BIO12 & B1013 & BIO14 & BIO15 & BIO16 & $\begin{array}{ll}1017 \\
17\end{array}$ & B1018 & B1019 \\
\hline Triturus marmoratus & 30TUN61 & 100,00 & 103,72 & 104,85 & 38,99 & 5328,17 & 255,71 & $-11,23$ & 266,94 & 79,01 & 174,02 & 174,09 & 38,44 & 631,21 & 75,10 & 30,81 & 24,13 & 205,94 & 109,97 & 115,17 & 163,11 \\
\hline Triturus marmoratus & 30TUN66 & 100,00 & 64,93 & 96,69 & 38,92 & 5085,61 & 208,57 & $-37,11$ & 245,68 & 39,03 & 133,55 & 133,73 & 4,92 & 990,62 & 115,28 & 52,41 & 21,68 & 315,93 & 182,13 & 182,35 & 272,32 \\
\hline Triturus marmoratus & 30 TUN68 & 100,00 & 96,86 & 88,38 & 39,26 & 4626,31 & 222,21 & 0,02 & 222,19 & 75,25 & 157,31 & 158,81 & 40,88 & 912,28 & 112,01 & 46,25 & 23,97 & 302,74 & 166,82 & 173,13 & 246,33 \\
\hline Triturus marmoratus & 30TUN71 & 100,00 & 103,74 & 103,20 & 38,69 & 5300,40 & 254,09 & $-10,03$ & 264,13 & 79,26 & 173,72 & 173,73 & 38,92 & 638,52 & 75,21 & 31,10 & 23,84 & 206,53 & 110,94 & 114,36 & 165,02 \\
\hline Triturus marmoratus & 30TUN74 & 100,00 & 89,82 & 98,09 & 38,98 & 5102,09 & 233,30 & $-16,41$ & 249,71 & 65,46 & 157,94 & 157,94 & 28,13 & 792,77 & 93,82 & 40,51 & 22,65 & 256,46 & 144,87 & 144,87 & 210,52 \\
\hline Triturus marmoratus & 30TUN84 & 100,00 & 95,87 & 95,97 & 38,78 & 5037,41 & 235,94 & $-9,26$ & 245,21 & 72,10 & 163,01 & 163,01 & 34,63 & 773,53 & 91,48 & 38,99 & 22,55 & 250,52 & 141,46 & 141,46 & 205,00 \\
\hline Triturus marmoratus & 30TUN90 & 100,00 & 109,22 & 101,28 & 38,00 & 5337,25 & 258,43 & $-4,49$ & 262,92 & 84,31 & 179,54 & 179,57 & 43,42 & 602,44 & 69,40 & 28,63 & 23,47 & 191,90 & 102,63 & 104,81 & 155,11 \\
\hline Triturus marmoratus & 30 TUN93 & 100,00 & 101,05 & 95,72 & 38,19 & 5085,48 & 241,52 & $-4,99$ & 246,51 & 76,96 & 168,68 & 168,68 & 38,88 & 728,04 & 85,35 & 35,99 & 22,53 & 234,67 & 131,51 & 131,51 & 192,18 \\
\hline Triturus marmoratus & 30TUN94 & 100,00 & 97,51 & 94,17 & 38,50 & 5005,21 & 235,48 & $-6,21$ & 241,69 & 73,75 & 164,15 & 164,25 & 36,64 & 776,04 & 91,17 & 38,84 & 22,19 & 250,43 & 142,05 & 142,05 & 206,47 \\
\hline Triturus marmoratus & 30TUN98 & 100,00 & 117,02 & 79,04 & 38,54 & 4334,54 & 228,44 & 25,87 & 202,56 & 97,81 & 172,57 & 174,82 & 63,65 & 887,01 & 109,93 & 41,75 & 25,30 & 300,98 & 156,30 & 170,18 & 242,66 \\
\hline Triturus marmoratus & 30TUPOO & 100,00 & 126,74 & 83,46 & 41,44 & 4057,12 & 235,08 & 36,23 & 198,85 & 108,39 & 178,43 & 181,14 & 77,34 & 829,34 & 111,57 & 41,76 & 27,54 & 281,62 & 149,04 & 159,96 & 210,49 \\
\hline Triturus marmoratus & 30TUP01 & 98,00 & 132,84 & 77,05 & 40,95 & 3870,73 & 232,49 & 46,63 & 185,86 & 115,81 & 181,85 & 184,96 & 85,62 & 834,29 & 112,99 & 41,12 & 27,93 & 284,33 & 147,81 & 160,77 & 212,72 \\
\hline Triturus marmoratus & 30TUP02 & 40,00 & 136,08 & 73,30 & 40,65 & 3764,03 & 230,71 & 52,45 & 178,26 & 119,80 & 183,68 & 186,80 & 90,21 & 839,39 & 114,00 & 40,95 & 28,24 & 286,77 & 147,48 & 161,79 & 215,03 \\
\hline Triturus marmoratus & 30TUP11 & 96,00 & 128,99 & 78,27 & 40,69 & 3961,70 & 231,50 & 41,54 & 189,96 & 111,36 & 179,31 & 182,19 & 80,64 & 846,18 & 113,34 & 41,76 & 27,45 & 289,11 & 150,50 & 163,76 & 218,27 \\
\hline Triturus marmoratus & 30TUP20 & 100,00 & 134,88 & 77,88 & 40,29 & 3995,93 & 237,12 & 46,48 & 190,63 & 117,35 & 185,62 & 188,38 & 85,65 & 802,19 & 107,72 & 38,63 & 27,90 & 276,54 & 141,34 & 155,20 & 206,81 \\
\hline Triturus marmoratus & 30TUP21 & 65,00 & 132,62 & 76,72 & 40,33 & 3942,74 & 233,28 & 45,64 & 187,64 & 115,31 & 182,62 & 185,54 & 84,31 & 833,38 & 111,64 & 40,50 & 27,68 & 286,53 & 147,33 & 161,81 & 215,78 \\
\hline Triturus marmoratus & 30TUP30 & 100,00 & 126,56 & 80,18 & 40,24 & 4107,21 & 233,28 & 36,55 & 196,73 & 108,50 & 178,94 & 181,48 & 76,06 & 836,94 & 110,50 & 40,98 & 27,01 & 287,16 & 149,31 & 162,56 & 217,93 \\
\hline Triturus marmoratus & 30TUP31 & 47,00 & 138,43 & 74,00 & 40,01 & 3894,79 & 235,65 & 52,49 & 183,16 & 121,57 & 187,60 & 190,48 & 90,33 & 816,59 & 109,47 & 38,40 & 28,28 & 283,51 & 141,96 & 158,43 & 213,59 \\
\hline Triturus marmoratus & 30TVK39 & 100,00 & 132,33 & 102,09 & 34,58 & 6564,50 & 301,02 & 9,65 & 291,37 & 90,28 & 219,68 & 220,00 & 51,72 & 447,13 & 56,23 & 11,54 & 35,06 & \begin{tabular}{|c|}
153,56 \\
\end{tabular} & 55,03 & 55,22 & 130,17 \\
\hline Triturus marmoratus & 30TVL02 & 100,00 & 104,18 & 102,76 & 35,80 & 6328,72 & 269,13 & $-14,21$ & 283,34 & 120,89 & 188,74 & 189,91 & 29,02 & 496,09 & 60,40 & 16,33 & 30,06 & 155,61 & 73,06 & 80,28 & 123,40 \\
\hline Triturus marmoratus & 30TVL07 & 100,00 & 116,73 & 105,12 & 36,17 & 6250,86 & 281,10 & $-4,31$ & 285,42 & 94,92 & 199,00 & 200,28 & 40,25 & 447,60 & 51,91 & 14,11 & 29,45 & 137,76 & 64,35 & 73,21 & 115,57 \\
\hline Triturus marmoratus & 30TVL10 & 100,00 & 112,46 & 102,96 & 35,38 & 6427,44 & 279,75 & $-7,11$ & 286,86 & 80,22 & 197,93 & 199,25 & 35,60 & 478,21 & 56,21 & 15,01 & 30,94 & 150,99 & 67,21 & 71,88 & 123,97 \\
\hline Triturus marmoratus & 30TVL12 & 100,00 & 82,73 & 105,64 & 37,01 & 6128,99 & 251,27 & $-30,42$ & 281,69 & 86,58 & 166,66 & 167,03 & 13,17 & 603,08 & 72,94 & 23,32 & 27,85 & $\begin{array}{l}187,35 \\
\end{array}$ & 92,53 & 97,16 & 152,35 \\
\hline Triturus marmoratus & 30TVL14 & 100,00 & 107,35 & 102,19 & 35,99 & 6359,05 & 271,21 & $-11,09$ & 282,30 & 116,53 & 192,19 & 193,14 & 31,24 & 496,32 & 57,82 & 15,51 & 29,34 & 152,82 & 71,83 & 80,63 & 127,33 \\
\hline Triturus marmoratus & 30TVL15 & 100,00 & 111,79 & 102,60 & 36,00 & 6345,76 & 275,35 & $-7,64$ & 282,99 & 91,05 & 195,92 & 197,13 & 35,17 & 478,00 & 55,14 & 14,66 & 29,35 & 147,29 & 68,66 & 77,28 & 123,44 \\
\hline Triturus marmoratus & 30TVL17 & 100,00 & 115,73 & 104,16 & 36,00 & 6265,15 & 279,67 & $-4,48$ & 284,15 & 77,97 & 198,56 & 199,49 & 39,31 & 457,07 & 52,53 & 14,51 & 28,91 & 140,66 & 66,03 & 74,70 & 118,49 \\
\hline Triturus marmoratus & 30TVL19 & 100,00 & 115,14 & 105,68 & 36,66 & 6155,45 & 279,34 & $-5,468$ & 285,02 & 107,13 & 196,25 & $\begin{array}{l}197,19 \\
\end{array}$ & 39,82 & 457,84 & 52,77 & 15,62 & 27,99 & 140,09 & 67,60 & 77,27 & 117,99 \\
\hline Triturus marmoratus & 30TVL22 & 100,00 & 89,15 & 105,22 & 36,69 & 6195,81 & 257,50 & $-25,31$ & 282,81 & 82,82 & 173,58 & 173,95 & 18,03 & 575,22 & 68,69 & 21,29 & 27,97 & \begin{tabular}{|c|c|}
177,58 \\
\end{tabular} & 86,99 & 92,20 & 146,47 \\
\hline Triturus marmoratus & 30TVL23 & 100,00 & 72,79 & 106,73 & 37,51 & 6045,02 & 242,56 & $-38,25$ & 280,81 & 68,29 & 156,35 & 156,48 & 5,44 & 658,42 & 78,70 & 27,16 & 26,32 & 202,81 & 103,42 & 105,63 & 167,97 \\
\hline Triturus marmoratus & 30TVL24 & 100,00 & 93,79 & 104,32 & 36,48 & 6221,50 & 260,20 & $-21,89$ & 282,09 & 103,11 & 177,89 & 178,38 & 21,18 & 554,28 & 65,42 & 19,96 & 27,84 & 170,44 & 83,91 & 90,92 & 141,50 \\
\hline Triturus marmoratus & 30TVL27 & 100,00 & 112,87 & 103,91 & 36,01 & 6262,71 & 276,90 & $-6,79$ & 283,69 & 86,03 & 195,63 & 196,50 & 36,60 & 471,66 & 54,16 & 15,43 & 28,28 & 144,47 & 69,39 & 77,94 & 122,11 \\
\hline Triturus marmoratus & 30TVL32 & 100,00 & 89,33 & 105,67 & 36,72 & 6214,66 & 258,42 & $-25,45$ & 283,86 & $\mid 76,32$ & $\begin{array}{ll}173,92 \\
\end{array}$ & 174,25 & $\begin{array}{l}00,00 \\
17,79 \\
\end{array}$ & 578,12 & $\begin{array}{l}4,10 \\
68,50\end{array}$ & 21,47 & $\begin{array}{l}\mid 20,260 \\
27,60\end{array}$ & 177,52 & $\begin{array}{ll}3,52 \\
37,\end{array}$ & 92,90 & 148,19 \\
\hline Triturus marmoratus & 30TVL34 & 100,00 & 86,44 & 105,55 & 36,82 & 6168,71 & 254,56 & $-27,94$ & 282,50 & 96,85 & 170,42 & 170,66 & 15,35 & 591,88 & 69,86 & 22,81 & 26,76 & \begin{tabular}{|c|}
181,19 \\
\end{tabular} & 91,63 & 97,38 & 151,49 \\
\hline Triturus marmoratus & 30TVL35 & 100,00 & 104,34 & 103,59 & 36,00 & 6301,34 & 269,84 & $-13,51$ & 283,36 & 89,26 & 188,49 & 189,34 & 29,28 & 510,81 & 58,92 & 17,23 & 28,11 & 155,47 & 75,87 & 84,21 & 132,27 \\
\hline Triturus marmoratus & 30TVL42 & 100,00 & 106,04 & 103,99 & 36,08 & 6376,62 & 273,74 & $-11,87$ & 285,61 & 69,50 & 191,23 & 192,10 & 30,35 & 516,25 & 60,00 & 16,95 & 29,25 & 161,85 & 74,57 & 79,67 & 136,35 \\
\hline Triturus marmoratus & 30TVL43 & 100,00 & 109,23 & 103,29 & 36,00 & 6385,04 & 275,66 & $-9,20$ & 284,86 & 68,98 & 194,21 & 195,12 & 32,98 & 499,32 & 56,90 & 15,97 & 29,15 & 155,92 & 72,09 & 77,84 & 131,74 \\
\hline Triturus marmoratus & 30TVL44 & 100,00 & 95,01 & 105,03 & 36,40 & 6252,22 & 262,72 & $-21,24$ & 283,96 & 86,56 & 179,36 & 179,79 & 21,82 & 555,86 & 64,66 & 20,44 & 27,23 & \begin{tabular}{|c|}
170,18 \\
\end{tabular} & 84,87 & 90,53 & 143,55 \\
\hline Triturus marmoratus & 30TVL47 & 100,00 & 110,21 & 104,01 & 36,01 & 6266,56 & 275,21 & $-8,54$ & 283,75 & 80,04 & 193,46 & 194,19 & 34,55 & 485,09 & 55,48 & 16,84 & 27,36 & 147,43 & 73,57 & 80,99 & 125,80 \\
\hline Triturus marmoratus & 30TVL49 & 100,00 & 103,11 & 105,19 & 36,68 & 6153,76 & 268,55 & $-14,83$ & 283,38 & 119,62 & 185,19 & 185,55 & 29,06 & 512,73 & 59,46 & 19,73 & 25,87 & 155,59 & 80,97 & 90,08 & 131,61 \\
\hline Triturus marmoratus & 30TVL52 & 100,00 & 119,14 & 103,05 & 35,4 & 6471,71 & 286,06 & $-0,94$ & 286,99 & 77,81 & 204,90 & 205,77 & 40,94 & 466,92 & 55,77 & 13,73 & 31,05 & 151,94 & 65,03 & 67,44 & 126,10 \\
\hline Triturus marmoratus & 30TVL53 & 100,00 & 109,88 & 103,92 & 36,06 & 6394,79 & 277,01 & $-8,73$ & 285,74 & 72,46 & 195,03 & 195,80 & 33,52 & 497,35 & 57,41 & 16,26 & 28,98 & 155,85 & 72,63 & 77,34 & 131,28 \\
\hline Triturus marmoratus & 30TVL58 & 100,00 & 109,69 & 104,92 & 36,27 & 6237,29 & 274,93 & $-8,82$ & 283,75 & 114,42 & 192,60 & 193,04 & 34,23 & 486,60 & 55,97 & 17,97 & 26,23 & 146,29 & 76,12 & 83,23 & 125,49 \\
\hline Triturus marmoratus & 30TVL59 & 100,00 & 108,00 & 105,03 & 36,61 & 6185,94 & 273,14 & $-10,25$ & 283,39 & 124,27 & 190,18 & 190,51 & 33,01 & 493,92 & 57,00 & 18,96 & 25,70 & 148,62 & 78,66 & 86,02 & 127,11 \\
\hline Triturus marmoratus & 30TVL65 & 100,00 & 82,45 & 107,44 & 37,18 & 6178,77 & 252,63 & $-32,95$ & 285,58 & 94,10 & 166,53 & 166,60 & 10,95 & 619,44 & 72,69 & 26,20 & 24,73 & \begin{tabular}{|l|l|}
188,03 \\
\end{tabular} & 100,53 & 105,39 & 158,82 \\
\hline Triturus marmoratus & 30TVL66 & 100,00 & 76,30 & 107,84 & 37,4 & 6119,81 & 246,56 & $-38,21$ & 284,77 & 90,68 & 159,88 & 159,89 & 5,98 & 651,92 & 76,56 & 28,84 & 23,88 & 98,39 & 107,84 & 110,04 & 166,99 \\
\hline Triturus marmoratus & 30TVL67 & 100,00 & 100,57 & 106,06 & 36,8 & 6237,13 & 268,01 & $-17,44$ & 285,45 & $\begin{array}{r}118,41 \\
110\end{array}$ & $\begin{array}{l}184,05 \\
134,\end{array}$ & 184,31 & 26,33 & 527,83 & 61,34 & 26 & 25,47 & 159,01 & $\begin{array}{r}80,449 \\
84,49 \\
\end{array}$ & 91,42 & 135,66 \\
\hline Triturus marmoratus & 30TVL68 & 100,00 & 108,25 & 105,39 & 36,51 & 6236,98 & 274,38 & $-10,43$ & 284,81 & 125,95 & 191,41 & 191,62 & 33,21 & 493,10 & 56,96 & 18,96 & 25,61 & \begin{tabular}{|c|c|}
147,88 \\
\end{tabular} & 78,89 & 85,53 & 126,82 \\
\hline Triturus marmoratus & 30TVL75 & 100,00 & 83,23 & 108,20 & 37,13 & 6200,53 & 254,08 & $-33,06$ & 287,14 & $\begin{array}{r}97,75 \\
97\end{array}$ & 167,60 & 167,63 & 11,31 & 616,34 & 72,44 & 26,55 & 24,32 & 186,92 & \begin{tabular}{r|r|}
101,18 \\
\end{tabular} & 105,16 & 157,75 \\
\hline Triturus marmoratus & 30 TVL76 & 100,00 & 84,50 & 108,12 & 37,05 & 6186,52 & 254,92 & $-32,07$ & 286,99 & 100,32 & 168,44 & 168,50 & 12,55 & 608,11 & 71,52 & 26,34 & 23,99 & 184,73 & 100,57 & 106,50 & 155,64 \\
\hline Triturus marmoratus & 30TVL77 & 100,00 & 97,54 & 107,18 & 36,9 & 6228,79 & 266,13 & $-20,66$ & 286,78 & 115,05 & 181,13 & 181,36 & 23,63 & 543,17 & 63,46 & 22,25 & 24,68 & 89 & 88,89 & 95,62 & 139,32 \\
\hline Triturus marmoratus & 30TVLE & 100,00 & 88,62 & 108,83 & 37,01 & $\begin{array}{ll}02219,83 \\
621,83\end{array}$ & $\frac{20}{25}$ & $\begin{array}{l}-29,30 \\
-29,34\end{array}$ & $\mid$\begin{tabular}{|l|}
288,71 \\
288
\end{tabular} & \begin{tabular}{|l|}
105,40 \\
150
\end{tabular} & \begin{tabular}{|l|}
172,68 \\
172,15
\end{tabular} & $\begin{array}{l}172,75 \\
172,1\end{array}$ & $\begin{array}{l}\mid 3,05 \\
15,67 \\
\end{array}$ & \begin{tabular}{|l|l|l|l|}
588,72 \\
\end{tabular} & $\begin{array}{l}3,406 \\
69,34 \\
\end{array}$ & $\frac{2,25}{25,68}$ & $\begin{array}{l}4,300 \\
23,87 \\
\end{array}$ & $\begin{array}{l}\mid 03,09 \\
178,59\end{array}$ & $\begin{array}{l}0,030 \\
98,32 \\
\end{array}$ & $\begin{aligned} 5,04 \\
104,12\end{aligned}$ & 150,35 \\
\hline Triturus marmoratus & $\begin{array}{l}0 \text { TVL87 } \\
\end{array}$ & 100,00 & 94,49 & 108,47 & 37,00 & 6223,54 & 264,29 & $-24,13$ & 288,42 & 111,81 & 178,15 & 178,29 & 20,81 & 559,91 & 65,81 & 24,12 & 23,88 & \begin{tabular}{|c|c|}
169,43 \\
\end{tabular} & 93,76 & 100,73 & 143,13 \\
\hline Triturus marmoratus & 30TVL88 & 100,00 & 102,05 & 107,89 & 37,00 & \begin{tabular}{l|l|l|}
6222,84 \\
\end{tabular} & 270,60 & $-17,08$ & 287,69 & 120,28 & 185,22 & 185,51 & 27,69 & 523,70 & 61,33 & 22,14 & 24,10 & 157,90 & 87,73 & 94,40 & 133,97 \\
\hline Triturus marmoratus & 30TVL97 & 100,00 & 95,54 & 109,50 & 37,04 & 6239,01 & 266,14 & $-24,09$ & 290,22 & 113,26 & 179,30 & 179,44 & 21,46 & 556,16 & 65,73 & 24,58 & 23,43 & 168,52 & 94,61 & 101,49 & 141,73 \\
\hline Triturus marmoratus & 30TVL99 & 100,00 & 112,22 & 108,10 & 37,00 & 6224,92 & 279,54 & $-8,33$ & 287 & 131,68 & 194,76 & 194 & 36,66 & 480,92 & 56,55 & 20,60 & 23 & 144,70 & 82,34 & 87,35 & 122 \\
\hline Triturus marmoratus & 30TVM06 & 100,00 & 113,92 & 105,86 & 37,31 & 5681,69 & 272,60 & $-6,31$ & 278,90 & 86,09 & 188,46 & 188,94 & 43,75 & 502,32 & 55,56 & 21,98 & 25,36 & 154,82 & 79,12 & 91,04 & 127,23 \\
\hline Triturus marmoratus & 30TVMO9 & 100,00 & 111,43 & 101,12 & 37,86 & 5430,86 & 262,16 & $-2,76$ & 264,92 & 85,14 & 182,99 & 183,01 & 44,32 & 572,90 & 64,84 & 26,95 & 23,45 & \begin{tabular}{|c|}
180,18 \\
\end{tabular} & 96,46 & 100,11 & 147,05 \\
\hline Triturus marmoratus & 30TVM15 & 100,00 & 111,19 & 105,43 & 37,01 & 5789,24 & 271,59 & $-7,88$ & 279,47 & 82,72 & 187,42 & 187,72 & 39,77 & 500,25 & 55,85 & 21,35 & 25,09 & \begin{tabular}{|c|}
151,78 \\
\end{tabular} & 79,31 & 90,31 & 126,99 \\
\hline Triturus & 30 TVM16 & 100,00 & 111,97 & 104,21 & 37,01 & 5715,59 & 270,18 & $-6,01$ & 276,18 & 82,3 & 186,99 & 187 & 41 & 511,24 & 56,15 & 22,66 & 24,54 & 15 & 82,46 & 92,47 & 129, \\
\hline Triturus marmoratus & 30TVM17 & 100,00 & 110,73 & 103,01 & 37,13 & 5638,93 & 266,86 & $-5,55$ & 272,42 & 81,73 & 184,87 & 185,04 & 40,97 & 532,14 & 58,37 & 24,53 & 23,95 & 163,16 & 87,60 & 94,81 & 135,47 \\
\hline
\end{tabular}




\begin{tabular}{|c|c|c|c|c|c|c|c|c|c|c|c|c|c|c|c|c|c|c|c|c|c|}
\hline TAXON & UTM & $\mathrm{km} 2$ & $\mathrm{BIO1}$ & $\mathrm{B1O2}$ & $\mathrm{BIO3}$ & $\mathrm{B104}$ & B105 & $\mathrm{B106}$ & 8107 & B108 & B109 & 81010 & B1011 & $\mathrm{BIO12}$ & B1O13 & 81014 & B1015 & B1016 & B1017 & $\mathrm{BIO18}$ & B1019 \\
\hline Triturus marmoratus & 30TVM19 & 100,00 & 106,62 & 100,06 & 37,50 & 5472,88 & 257,88 & $-5,60$ & 263,48 & 78,68 & 178,90 & 178,90 & 39,00 & 591,22 & 65,97 & 28,41 & 22,67 & 183,39 & 101,23 & 103,29 & 152,37 \\
\hline Triturus marmoratus & 30 TVM21 & 100,00 & 117,80 & 105,10 & \begin{tabular}{l|l|l}
36,95 \\
\end{tabular} & 6058,18 & 280,57 & $-2,33$ & 282,90 & 86,66 & 197,29 & 198,23 & 43,08 & 454,72 & 51,80 & 16,72 & 26,99 & 138,47 & 69,05 & 78,04 & 116,95 \\
\hline Triturus marmoratus & 30TVM22 & 100,00 & 113,55 & 105,43 & 37,00 & 6006,30 & 276,36 & $-6,03$ & 282,39 & 118,28 & 192,68 & 193,21 & 39,70 & 472,53 & 53,98 & 18,31 & 26,17 & 142,92 & 73,27 & 83,16 & 120,81 \\
\hline Triturus marmoratus & 30 TVM23 & 100,00 & 109,67 & 105,44 & 37,00 & 5941,56 & 272,32 & $-9,19$ & 281,50 & 125,40 & 188,09 & 188,45 & 36,70 & 491,21 & 56,07 & 20,01 & 25,35 & 148,21 & 77,60 & 87,96 & 125,23 \\
\hline Triturus marmoratus & 30TVM24 & 100,00 & 109,50 & 104,90 & 37,00 & 5880,93 & 271,14 & $-8,71$ & 279,85 & 106,82 & 187,10 & 187,48 & 37,17 & 498,61 & 56,35 & 20,91 & 25,01 & 149,86 & 79,75 & 89,26 & 126,97 \\
\hline Triturus marmoratus & 30TVM25 & 100,00 & 111,49 & 103,89 & 37,00 & 5813,87 & 271,12 & $-5,72$ & 276,84 & 79,86 & 187,97 & 188,22 & 39,69 & 501,24 & 55,78 & 21,67 & 24,59 & 151,04 & 81,29 & 90,25 & 127,60 \\
\hline Triturus marmoratus & 30TVM27 & 100,00 & 109,36 & 101,58 & 37,00 & 5678,57 & 265,35 & $-5,01$ & 270,37 & 78,58 & 183,95 & 184,03 & 38,87 & 536,70 & 58,13 & 25,04 & 23,22 & 162,80 & 90,19 & 95,39 & 137,09 \\
\hline Triturus marmoratus & 30 TVM 28 & 100,00 & 106,77 & 100,34 & 37,02 & 5602,76 & 260,64 & $-5,78$ & 266,42 & 76,42 & 180,51 & 180,51 & 37,33 & 565,93 & 61,75 & 27,25 & 22,64 & 172,47 & 96,81 & 98,44 & 145,12 \\
\hline Triturus marmoratus & 30 TVM30 & 100,00 & 113,54 & 104,84 & 36,68 & 6124,35 & 277,16 & $-5,93$ & 283,09 & 117,41 & 194,40 & 195,11 & 38,66 & 470,29 & 53,89 & 17,29 & 26,70 & 142,25 & 72,34 & 80,95 & 121,05 \\
\hline Triturus marmoratus & 30TVM31 & 100,00 & 116,31 & 104,60 & 36,68 & 6072,02 & 278,74 & $-3,36$ & 282,10 & 103,63 & 196,28 & 196,77 & 41,52 & 463,01 & 52,81 & 17,39 & 26,34 & 140,08 & 71,91 & 80,16 & 118,98 \\
\hline Triturus marmoratus & 30TVM32 & 100,00 & 112,25 & 104,83 & 36,97 & 6015,64 & 274,71 & $-6,50$ & 281,21 & 123,59 & 191,55 & 191,91 & 38,29 & 479,94 & 54,83 & 19,08 & 25,51 & 144,56 & 76,05 & 84,79 & 123,00 \\
\hline Triturus marmoratus & 30TVM33 & 100,00 & 108,27 & 104,77 & 37,00 & 5964,49 & 270,72 & $-9,20$ & 279,92 & 126,45 & 187,12 & 187,39 & 35,21 & 498,45 & 56,83 & 20,76 & 24,88 & 149,79 & 80,56 & 89,25 & 127,45 \\
\hline Triturus marmoratus & 30TVM34 & 100,00 & 106,97 & 104,04 & 37,00 & 5908,60 & 268,39 & $-9,57$ & \begin{tabular}{l|l}
277,97 \\
\end{tabular} & 121,96 & 185,07 & 185,15 & 34,46 & 511,04 & 57,86 & 22,09 & 24,09 & 152,90 & 83,91 & 91,86 & 130,41 \\
\hline Triturus marmoratus & 30 TVM 35 & 100,00 & 109,45 & 103,08 & 37,00 & 5851,53 & 269,04 & $-6,22$ & 275,25 & 91,42 & 186,56 & 186,61 & 37,19 & 509,54 & 56,90 & 22,61 & 23,77 & 151,84 & 84,68 & 91,23 & 130,31 \\
\hline Triturus marmoratus & 30TVM36 & 100,00 & 107,53 & 102,06 & 37,00 & 5790,03 & 265,81 & $-6,63$ & 272,44 & 79,54 & 183,78 & 183,81 & 35,90 & 526,94 & 58,12 & 24,18 & 23,20 & 157,04 & 88,99 & 92,82 & 134,78 \\
\hline Triturus marmoratus & 30TVM38 & 100,00 & 106,07 & 99,22 & 37,00 & 5654,97 & 260,06 & $-4,72$ & 264,78 & 73,92 & 180,35 & 180,35 & 35,83 & 565,09 & 60,68 & 27,50 & 22,06 & 170,20 & 98,48 & 99,15 & 145,37 \\
\hline Triturus marmoratus & 30TVM39 & 100,00 & 102,91 & 97,88 & 37,01 & 5555,62 & 254,18 & $-5,56$ & 259,75 & 71,68 & 176,22 & 176,22 & 34,31 & 602,44 & 65,96 & 29,75 & 21,75 & 183,21 & 106,31 & 106,31 & 156,24 \\
\hline Triturus marmoratus & 30 TVM 40 & 100,00 & 113,46 & 104,42 & 36,52 & 6135,33 & 276,98 & $-5,46$ & 282,45 & 122,49 & 194,55 & 195,09 & 38,56 & 472,12 & 54,16 & 17,76 & 26,23 & 142,26 & 74,12 & 81,77 & 121,43 \\
\hline Triturus marmoratus & 30TVM41 & 100,00 & 115,39 & 104,04 & 36,71 & $\begin{array}{ll}6081,07 \\
\end{array}$ & 277,89 & $-3,05$ & 280,94 & 108,31 & 195,63 & 195,91 & 40,63 & 467,45 & 53,33 & 18,07 & 25,81 & 140,75 & 74,19 & 81,43 & 120,23 \\
\hline Triturus marmoratus & 30 TVM 42 & 100,00 & 111,55 & 104,21 & 36,99 & 6041,66 & 274,06 & $-6,11$ & 280,17 & 129,77 & 191,33 & 191,65 & 37,41 & 484,68 & 55,41 & 19,70 & 24,98 & 145,36 & 78,42 & 84,94 & 124,35 \\
\hline Triturus marmoratus & 30 TVM 43 & 100,00 & 107,22 & 104,07 & 37,00 & 5987,94 & 269,58 & $-9,39$ & 278,97 & 125,28 & 186,45 & 186,49 & 33,98 & 506,27 & 57,85 & 21,60 & 24,22 & 151,88 & 83,48 & 90,24 & 129,68 \\
\hline Triturus marmoratus & 30TVM44 & 100,00 & 105,16 & 103,69 & 37,00 & 5929,56 & 266,49 & $-10,45$ & 276,94 & 122,79 & 183,57 & 183,60 & 32,48 & 520,90 & 59,21 & 23,12 & 23,55 & 155,71 & 87,36 & 93,38 & 133,58 \\
\hline Triturus marmoratus & 30 TVM 45 & 100,00 & 106,31 & 102,81 & 37,00 & 5873,44 & 266,03 & $-8,04$ & 274,06 & 121,05 & 183,90 & 183,92 & 34,19 & 523,97 & 58,84 & 23,95 & 23,05 & 155,33 & 89,15 & 92,81 & 134,59 \\
\hline Triturus marmoratus & 30 TVM 46 & 100,00 & 102,56 & 102,01 & 37,00 & 5811,44 & 261,32 & $-10,13$ & 271,45 & 111,71 & 179,48 & 179,48 & 31,14 & 548,59 & 61,10 & 26,01 & 22,41 & 161,84 & 94,85 & 95,70 & 141,36 \\
\hline Triturus marmoratus & 30TVM47 & 100,00 & 103,58 & 100,47 & 37,00 & 5754,95 & 260,05 & $-7,40$ & 267,45 & 78,16 & 179,56 & 179,56 & 32,73 & 555,10 & 60,95 & 27,10 & 22,00 & 163,67 & 97,40 & 97,87 & 143,66 \\
\hline Triturus marmoratus & 30TVM48 & 100,00 & 101,72 & 99,07 & \begin{tabular}{|c|}
37,07 \\
\end{tabular} & 5679,72 & 255,82 & $-7,16$ & 262,98 & 68,78 & 176,82 & 176,82 & 31,73 & 578,09 & 62,43 & 28,77 & 21,59 & 171,22 & 102,78 & 102,78 & 150,41 \\
\hline Triturus marmoratus & 30 TVM 49 & 100,00 & 102,13 & 97,24 & 37,12 & 5571,20 & 252,62 & $-4,45$ & 257,07 & $\begin{array}{ll}69,98 \\
69\end{array}$ & $\begin{array}{l}175,98 \\
175\end{array}$ & $\begin{array}{ll}175,98 \\
\end{array}$ & 33,61 & 602,61 & $\begin{array}{l}2,45,54 \\
654\end{array}$ & 29,99 & 21,43 & $\mid 181,30$ & 108,10 & 108,10 & 158,06 \\
\hline Triturus marmoratus & 30 TVM50 & 100,00 & 110,55 & 104,77 & 36,84 & 6143,94 & 274,70 & $-7,78$ & 282,48 & 122,81 & 191,94 & 192,25 & 35,78 & 485,23 & 55,82 & 19,06 & 25,37 & 145,75 & 78,05 & 85,01 & 124,84 \\
\hline Triturus marmoratus & 30TVM51 & 100,00 & 113,26 & 104,34 & 36,74 & 6101,44 & 276,36 & $-4,91$ & 281,27 & 126,94 & 193,83 & 194,16 & 38,61 & 476,93 & 54,66 & 19,11 & 25,11 & 142,94 & 77,42 & 84,06 & 122,55 \\
\hline Triturus marmoratus & 30TVM52 & 100,00 & 110,15 & 104,31 & 37,00 & 6051,09 & 272,95 & $-7,05$ & 280,00 & 128,69 & 190,22 & 190,32 & 36,14 & 492,55 & 56,49 & 20,68 & 24,27 & 147,56 & 81,44 & 87,01 & 126,53 \\
\hline Triturus marmoratus & 30TVM54 & 100,00 & 99,64 & 104,28 & 37,01 & 5928,96 & 261,78 & $-14,93$ & 276,71 & 116,67 & 178,42 & 178,42 & 27,65 & 550,25 & 62,66 & 25,36 & 22,82 & 164,55 & 94,37 & 96,50 & 141,87 \\
\hline Triturus marmoratus & 30TVM55 & 100,00 & 101,93 & 103,01 & 37,03 & 5877,10 & 262,16 & $\begin{array}{ll}-11,40 \\
-11,48\end{array}$ & 273,65 & \begin{tabular}{|l|l|}
118,18 \\
\end{tabular} & \begin{tabular}{|l|l|l|l|l|l|}
179,87 \\
\end{tabular} & \begin{tabular}{|l|l|l|l|l|}
179,87 \\
\end{tabular} & 30,22 & 547,68 & $\begin{array}{l}02,700 \\
61,75 \\
\end{array}$ & 25,84 & 22,42 & $\begin{array}{ll}162,52 \\
\end{array}$ & $\begin{array}{l}94,08 \\
95,0\end{array}$ & 96,40 & 141,54 \\
\hline Triturus marmoratus & 30TVM56 & 100,00 & 97,36 & 102,37 & 37,11 & 5809,75 & 256,47 & $-14,40$ & 270,87 & 113,70 & 174,64 & 174,64 & 26,77 & 579,32 & 64,67 & 28,43 & 21,82 & 170,90 & 102,09 & 102,18 & 150,45 \\
\hline Triturus marmoratus & 30TVM58 & 100,00 & 98,86 & 99,24 & 37,44 & 5667,41 & 252,48 & $-9,10$ & 261,58 & 69,68 & 174,25 & 174,25 & 29,75 & 600,95 & 65,14 & 30,3 & 21,19 & 176,48 & 108,41 & 108,41 & 158,28 \\
\hline Triturus marmoratus & 30TVM59 & 100,00 & 99,00 & 97,41 & 37,52 & 5574,17 & 249,40 & $-6,82$ & 256,22 & 66,52 & 173,22 & 173,22 & 31,22 & 624,74 & 66,83 & 31,49 & 21,03 & 185,39 & 113,75 & 113,75 & 166,05 \\
\hline Triturus marmoratus & 30TVM60 & 100,00 & 111,15 & 105,20 & 36,93 & 6157,40 & 275,67 & $-7,15$ & 282,81 & 129,52 & 192,69 & 192,96 & 36,12 & 484,53 & 55,92 & 19,53 & 24,88 & 145,21 & 79,38 & 85,17 & 124,46 \\
\hline Triturus marmoratus & 30TVM61 & 100,00 & 110,19 & 105,12 & 37,00 & 6111,20 & 274,16 & $-7,55$ & 281,71 & 128,98 & 191,00 & 191,29 & 35,64 & 491,30 & 56,61 & 20,54 & 24,34 & 147,28 & 81,72 & 86,87 & 126,25 \\
\hline Triturus marmoratus & 30TVME & 100,00 & 101,94 & 105,06 & 37,04 & 5997,43 & 265,26 & $-13,73$ & 278,99 & 119,57 & 181,64 & 181,66 & 29,21 & 537,35 & 61,60 & 24,48 & 22,84 & 161,06 & 92,35 & 96,47 & 138,56 \\
\hline Triturus marmoratus & 30TVM64 & 100,00 & 95,36 & 104,86 & 37,20 & 5925,16 & 258,21 & $-18,69$ & 276,90 & 111,96 & 174,48 & 174,49 & 24,00 & 577,95 & 65,75 & 27,61 & 22,01 & 172,62 & 101,03 & 102,07 & 149,71 \\
\hline Triturus marmoratus & 30TVM65 & 100,00 & 99,66 & 103,47 & 37,19 & 5877,67 & 260,07 & $-13,36$ & 273,44 & 116,60 & 177,81 & 177,81 & 28,24 & 565,63 & 63,77 & 27,44 & 21,85 & 167,67 & 99,91 & 100,37 & 146,89 \\
\hline Triturus marmoratus & 30TVM66 & 100,00 & 96,82 & 102,54 & 37 & 5810,34 & 255,69 & $-14,68$ & 270,37 & 112,97 & 174,30 & 174,30 & 26,32 & 592,52 & 65,98 & 29,71 & 21,25 & 174,32 & 105,92 & 105,92 & 154,79 \\
\hline Triturus marmoratus & 30TVM68 & 100,00 & 93,86 & 100,04 & 37,8 & 5660,56 & 248,30 & $-14,12$ & 262,42 & 72,58 & 169,56 & 169,56 & 25,44 & $\begin{array}{ll}641,77 \\
\end{array}$ & 69, & 33,0 & 20,53 & 186,60 & \begin{tabular}{|l|l|}
117,08 \\
\end{tabular} & 117,08 & 170,02 \\
\hline Triturus marmoratus & 30TVM70 & 100,00 & 112,55 & 105,87 & 36,98 & 6160,84 & 277,34 & $-6,28$ & 283,62 & 131,70 & 194,07 & 194,32 & 37,54 & 480,44 & 55,58 & 19,82 & 24,49 & 143,77 & 80,06 & 85,36 & 123,15 \\
\hline Triturus marmoratus & 30TVM72 & 100,00 & 106,10 & 105,89 & $37, \mathrm{C}$ & 6061,74 & 270,43 & $-10,91$ & 281,34 & 124,35 & 186,61 & 186,65 & 32,47 & 516,80 & 59,62 & 23,21 & 23,02 & 154,97 & 89,04 & 93,36 & 133,00 \\
\hline Triturus marmoratus & 30TVM73 & 100,00 & 98,56 & 105,98 & 37,1 & 5997,22 & 262,84 & $-17,20$ & 280,04 & 115,77 & 178,54 & 178,56 & 26 & 559,55 & 64, & 26,39 & 22,13 & 7,59 & 98,07 & 99,80 & 144,61 \\
\hline Triturus marmoratus & 30TVM74 & 100,00 & 100,22 & 105,01 & 37,2 & 5943,49 & 262,73 & $-14,36$ & 277,09 & 117,38 & 179,39 & 179,40 & 28,16 & 559,96 & $\begin{array}{l}63, \\
63,\end{array}$ & 26,99 & 21,78 & $\begin{array}{l}166,78 \\
\end{array}$ & $\begin{array}{l}90,11 \\
99,1\end{array}$ & 100,65 & 145,18 \\
\hline Triturus marmoratus & 30TVM & 100,00 & 100,45 & 103,88 & 37,2 & 5882,88 & 261,01 & $-12,85$ & $\begin{array}{ll}273,87 \\
\end{array}$ & 117,54 & 178,77 & 178,77 & 28,93 & 569,77 & 64,18 & 28,18 & 21,36 & 168,50 & 102,01 & 102,59 & 148,42 \\
\hline Triturus marmoratus & 30TVM76 & 100,00 & 87,60 & 103,64 & 37,90 & 5792,22 & 247,70 & $-23,53$ & 271,22 & 102,96 & 165,40 & 165,40 & 18,18 & 656,62 & 72,67 & 34,20 & 20,29 & 192,43 & 119,18 & 119,18 & 172,73 \\
\hline Triturus marmoratus & 30TVM77 & 100,00 & 77,65 & 102,83 & 37,99 & 5712,01 & 236,49 & $-31,63$ & 268,12 & 91,60 & 154,71 & 154,71 & 9,76 & 735,33 & 79,78 & 39,36 & 19,46 & 213,12 & 134,59 & 134,59 & 195,12 \\
\hline Triturus marmoratus & 30TVM78 & 100,00 & 88,24 & 101,01 & 38,00 & 5655,53 & 243,54 & $-19,99$ & 3 & 69,76 & 164,02 & 164,02 & 20,13 & 687,79 & 73 & 36,12 & 19,78 & 198,62 & 126,73 & 126,73 & 183,08 \\
\hline Triturus marmoratus & $30 \mathrm{TVM}$ & 100,00 & $\frac{00}{98}$ & 98,00 & 37,93 & $\begin{array}{l}5559,87 \\
5559\end{array}$ & 248,47 & \begin{tabular}{|c|c|}
$-1,68$ \\
$-7,68$
\end{tabular} & \begin{tabular}{|l|l|}
256,15 \\
250
\end{tabular} & $\begin{array}{ll}64,45 \\
64,\end{array}$ & \begin{tabular}{|l|}
$172,70<$ \\
\end{tabular} & $\begin{array}{l}104,0<2 \\
172,72\end{array}$ & $\begin{array}{l}\mid 0,130 \\
31,04\end{array}$ & $\mid \begin{array}{ll}\mid 659,48 \\
651,\end{array}$ & $\begin{array}{l}5,303 \\
69,32 \\
\end{array}$ & $\frac{0,1}{33,7}$ & 19,95 & $\begin{array}{l}190,11 \\
193,1\end{array}$ & \begin{tabular}{|l|l|l|l|l|}
122,43 \\
\end{tabular} & $\begin{array}{l}12,123 \\
122,43\end{array}$ & $\begin{array}{l}103,00 \\
177,13\end{array}$ \\
\hline Triturus marmoratus & 30TVM 80 & 100,00 & 110,79 & 107,04 & 37,00 & 6174,34 & 276,78 & $-8,55$ & 285,32 & 129,90 & 192,57 & 192,73 & 35,75 & 489,78 & 57,03 & 21,07 & 23,77 & 146,94 & 83,42 & 88,50 & 125,37 \\
\hline Triturus marmoratus & 30TVM81 & 100,00 & 107,37 & 107,21 & \begin{tabular}{|c|}
37,07 \\
\end{tabular} & 6121,69 & 273,23 & $-11,05$ & 284,28 & 125,88 & 188,52 & 188,66 & 33,26 & 509,37 & 59,19 & 22,79 & 23,06 & 152,96 & 88,11 & 93,40 & 130,80 \\
\hline Triturus marmoratus & 30TVM82 & 100,00 & 101,36 & 107,39 & 37,35 & 6056,29 & 267,30 & $-15,85$ & 283,15 & 119,08 & 182,21 & 182,22 & 28,29 & 543,64 & 62,84 & 25,53 & 22,24 & 163,19 & 95,59 & 99,04 & 140,21 \\
\hline Triturus marmoratus & $30 \mathrm{TVM}$ & 100,00 & 98,03 & 106,97 & 37,55 & 6000 & 263,21 & $-18,06$ & 28 & 115,23 & 178 & 178 & 25,65 & 568,01 & 65, & 27,55 & 21,58 & 169,93 & 101,13 & 104,28 & 147 \\
\hline Triturus marmoratus & 30TVM84 & 100,00 & 97,05 & 106,23 & 37,68 & 5944,40 & 260,66 & $-17,95$ & 278,60 & 114,03 & 176,37 & 176,37 & 25,10 & 583,63 & 66,38 & 29,07 & 21,05 & 173,67 & 105,01 & 107,08 & 151,81 \\
\hline Triturus marmoratus & 30TVM 85 & 100,00 & 87,08 & 105,51 & 37,98 & 5859,40 & 249,67 & $-25,81$ & 275,48 & 102,62 & 165,79 & 165,79 & 16,95 & 654,34 & 73,23 & 34,11 & 20,19 & 193,01 & 119,14 & 119,61 & 171,68 \\
\hline Triturus marmoratus & 30TVM86 & 100,00 & 88,57 & 104,39 & 38,00 & 5798,97 & 249,07 & $-23,21$ & 272,28 & 103,98 & 166,36 & 166,36 & 18,99 & 659,17 & 72,95 & 34,65 & 19,81 & 193,02 & 120,91 & 120,91 & 173,76 \\
\hline Triturus & 30TVM87 & 100,00 & 69,26 & 103,39 & 38,00 & 5696,11 & 228,73 & $-39,70$ & 268, & 82,56 & 146,46 & 146, & 2, & 800,97 & 86,39 & 43 & 18 & 23 & 148,06 & 48,06 & 213,46 \\
\hline Triturus marmoratus & 30TVM88 & 100,00 & 90,20 & 101,26 & 37,99 & 5654,98 & 245,08 & $-18,43$ & 263,51 & 76,82 & 165,95 & 165,95 & 22,02 & 690,99 & 74,06 & 36,42 & 19,29 & 199,16 & 128,53 & 128,53 & 184 \\
\hline
\end{tabular}




\begin{tabular}{|c|c|c|c|c|c|c|c|c|c|c|c|c|c|c|c|c|c|c|c|c|c|}
\hline TAXON & UTM & $\mathrm{km} 2$ & B101 & $\mathrm{B1O2}$ & $\mathrm{BIO3}$ & B104 & B105 & B106 & B107 & $\mathrm{B108}$ & B109 & B1010 & BIO11 & BIO12 & B1013 & B1014 & B1015 & B1016 & $\begin{array}{ll}1017 \\
17\end{array}$ & B1018 & B1019 \\
\hline Triturus marmoratus & 30TVM89 & 100,00 & 103,03 & 97,94 & 37,92 & 5556,56 & 251,82 & $-4,12$ & 255,95 & 65,56 & 176,62 & 176,79 & 35,10 & 653,00 & 68,64 & 33,29 & 19,55 & 191,01 & 122,43 & 122,43 & 175,85 \\
\hline Triturus marmoratus & 30 TVM90 & 100,00 & 109,67 & 108,41 & 37,01 & 6175,28 & 276,93 & $-10,38$ & 287,30 & 128,80 & 191,53 & 191,73 & 34,72 & 497,12 & 58,27 & 22,23 & 23,19 & 149,60 & 86,38 & 91,22 & 127,03 \\
\hline Triturus marmoratus & 30TVM91 & 100,00 & 105,88 & 108,52 & 37,18 & 6119,48 & 273,03 & $-13,45$ & 286,48 & 124,41 & 187,18 & 187,24 & 31,70 & 520,76 & 60,75 & 24,19 & 22,38 & 156,58 & 91,88 & 96,24 & 133,75 \\
\hline Triturus marmoratus & 30TVM92 & 100,00 & 100,07 & 108,72 & 37,73 & 6058,65 & 267,23 & $-17,95$ & 285,18 & 117,93 & 180,93 & 180,94 & 27,00 & 556,12 & 64,39 & 26,95 & 21,52 & 166,86 & 99,45 & 103,55 & 143,63 \\
\hline Triturus marmoratus & 30TVM93 & 100,00 & 95,84 & 108,37 & 37,98 & 6002,07 & 262,09 & $-20,98$ & 283,07 & 112,94 & 176,07 & 176,09 & 23,52 & 587,12 & 67,38 & 29,36 & 20,87 & 175,48 & 106,11 & 108,37 & 152,44 \\
\hline Triturus marmoratus & 30TVM94 & 100,00 & 93,69 & 107,52 & 37,99 & 5940,38 & 258,53 & $-21,79$ & 280,32 & 110,41 & 173,17 & 173,17 & 22,16 & 609,52 & 69,25 & 31,33 & 20,35 & 181,15 & 111,26 & 112,79 & 159,04 \\
\hline Triturus marmoratus & 30TVM95 & 100,00 & 73,65 & 106,18 & 38,00 & 5824,96 & 237,28 & $-38,38$ & 275,67 & 87,98 & 152,53 & 152,53 & 4,92 & 747,79 & 82,90 & 40,55 & 19,10 & 219,58 & 137,90 & 137,99 & 197,28 \\
\hline Triturus marmoratus & 30TVM96 & 100,00 & 83,40 & 105,32 & 38,00 & 5793,34 & 244,72 & $-28,48$ & 273,21 & 98,52 & 161,39 & 161,39 & 14,36 & 701,13 & 77,27 & 37,58 & 19,15 & 204,79 & 129,98 & 129,98 & 185,41 \\
\hline Triturus marmoratus & 30TVM97 & 100,00 & 71,52 & 103,63 & 38,00 & 5701,55 & 230,87 & $-37,93$ & 268,80 & 85,05 & 148,69 & 148,69 & 4,16 & 797,59 & 86,10 & 43,69 & 18,42 & 230,23 & 148,77 & 148,77 & 212,75 \\
\hline Triturus marmoratus & 30TVM98 & 100,00 & 91,12 & 101,98 & 38,00 & 5661,91 & 246,27 & $-18,21$ & 264,47 & 84,41 & 166,85 & 166,85 & 22,79 & 696,98 & 74,72 & 36,97 & 18,87 & 200,20 & 130,80 & 130,80 & 186,20 \\
\hline Triturus marmoratus & 30TVM99 & 100,00 & 102,76 & 98,85 & 37,97 & 5568,33 & 252,12 & $-5,18$ & 257,30 & 60,80 & 176,65 & 176,71 & 34,77 & 662,93 & 69,71 & 34,25 & 19,01 & 192,52 & 125,39 & 125,39 & 178,41 \\
\hline Triturus marmoratus & 30TVNOO & 100,00 & 108,50 & 99,59 & 37,93 & 5349,25 & 256,73 & $-3,32$ & 260,05 & 82,66 & 179,20 & 179,20 & 42,52 & 609,08 & 69,48 & 29,05 & 23,06 & 192,55 & 104,69 & 105,56 & 157,47 \\
\hline Triturus marmoratus & 30TVN02 & 100,00 & 94,93 & 97,31 & 38,01 & 5225,65 & 240,01 & $-12,12$ & 252,13 & 69,28 & 164,63 & 164,63 & 31,41 & 724,43 & 82,86 & 36,32 & 21,84 & 228,54 & 129,62 & 129,62 & 191,08 \\
\hline Triturus marmoratus & 30TVN03 & 100,00 & 98,08 & 94,63 & 38,07 & 5091,35 & 238,07 & $-6,49$ & 244,56 & 73,30 & 165,73 & 165,91 & 36,01 & 748,90 & 86,70 & 37,29 & 21,95 & 239,08 & 135,73 & 135,79 & 199,06 \\
\hline Triturus marmoratus & 30TVN04 & 100,00 & 97,56 & 92,57 & 38,09 & 4993,68 & 233,93 & $-4,75$ & 238,68 & 73,57 & 163,47 & 164,29 & 36,67 & 786,93 & 91,65 & 39,27 & 21,97 & 252,69 & 144,27 & 144,50 & 210,75 \\
\hline Triturus marmoratus & 30 TVN12 & 100,00 & 97,30 & 95,50 & 38,00 & 5209,78 & 240,46 & $-8,07$ & 248,53 & 71,01 & 166,72 & 166,72 & 33,68 & 720,35 & 81,96 & 35,95 & 21,62 & 226,56 & 129,66 & 129,66 & 190,89 \\
\hline Triturus marmoratus & 30TVN15 & 100,00 & 96,76 & 89,05 & 38,07 & 4883,89 & 227,97 & $-2,11$ & 230,09 & 73,03 & 160,45 & 162,12 & 37,23 & 841,59 & 97,63 & 41,88 & 21,90 & 270,43 & 153,84 & 156,64 & 228,98 \\
\hline Triturus marmoratus & 30TVN16 & 100,00 & 99,13 & 86,20 & 38,09 & 4748,31 & 225,22 & 2,60 & 222,62 & 76,54 & 160,81 & 162,70 & 41,35 & 876,76 & 102,58 & 43,28 & 22,32 & 284,48 & 159,04 & 164,78 & 240,62 \\
\hline Triturus marmoratus & 30TVN18 & 100,00 & 123,42 & 73,44 & 37,91 & 4194,33 & 228,38 & 36,56 & 191,82 & 104,73 & 176,70 & 179,34 & 71,52 & 922,62 & 113,21 & 41,53 & 26,22 & 315,78 & 158,21 & 177,78 & 259,29 \\
\hline Triturus marmoratus & 30TVN19 & 100,00 & 133,52 & 67,70 & 37,55 & 3946,92 & 229,38 & 51,28 & 178,10 & 116,49 & 183,18 & 186,10 & 84,48 & 947,99 & 118,90 & 40,98 & 28,14 & 331,66 & 158,69 & 184,71 & 268,72 \\
\hline Triturus marmoratus & 30TVN22 & 100,00 & 98,18 & 94,05 & 37,97 & 5211,92 & 239,98 & $-5,71$ & 245,69 & 71,22 & 167,44 & 167,58 & 34,47 & 722,47 & 81,6 & 35,99 & 21,27 & 226,16 & 130,84 & 130,90 & 192,53 \\
\hline Triturus marmoratus & 30TVN23 & 100,00 & 97,04 & 91,99 & 37,98 & 5098,92 & 234,97 & $-4,75$ & 239,73 & 70,94 & 164,45 & 165,11 & 34,86 & 768,87 & 87,30 & 38,34 & 21,30 & 242,35 & 140,32 & 140,99 & 207,25 \\
\hline Triturus marmoratus & 30TVN24 & 100,00 & 101,35 & 88,78 & 37,93 & 4946,85 & 233,22 & 1,82 & 231,41 & 76,64 & 165,72 & 167,33 & 40,81 & 798,72 & 91,63 & 39,16 & 21,85 & 255,50 & 144,76 & 147,93 & 217,80 \\
\hline Triturus marmoratus & 30TVN25 & 100,00 & 99,07 & 87,23 & 38,01 & 4861,28 & 227,97 & 1,48 & 226,50 & 75,07 & 162,11 & 163,98 & 39,72 & 847,18 & 97,49 & 41,77 & 21,85 & 271,79 & 153,74 & 158,29 & 232,81 \\
\hline Triturus marmoratus & 30 TVN26 & 100,00 & 99,52 & 84,82 & 38,02 & 4741,43 & 224,38 & 4,32 & 220,06 & 76,76 & 160,99 & 163,08 & 41,78 & 890,45 & 103,09 & 43,70 & 22,14 & 287,85 & 160,75 & 167,71 & 246,91 \\
\hline Triturus marmoratus & 30TVN30 & 100,00 & 99,40 & 96,63 & 37,33 & 5448,19 & 247,74 & $-7,01$ & 254,75 & 69,27 & 171,72 & 171,72 & 32,52 & 648,39 & 71,83 & 32,34 & 21,29 & 198,45 & 115,93 & 115,93 & 170,14 \\
\hline Triturus marmoratus & 30TVN31 & 100,00 & 96,78 & 95,23 & 37,79 & 5345,47 & 242,09 & $-7,86$ & 249,95 & 67,83 & 167,90 & 167,90 & 31,47 & \begin{tabular}{|l|l|}
694,26 \\
\end{tabular} & $\begin{array}{l}1,1,00 \\
77,24\end{array}$ & 34,87 & 21,03 & 213,68 & 125,51 & 125,51 & 184,37 \\
\hline Triturus marmoratus & 30TVN32 & 100,00 & 98,01 & 93,01 & 37,90 & 5220,81 & 238,88 & $-4,56$ & 243,45 & 70,10 & 167,05 & 167,62 & 34,19 & 729,61 & 81,65 & 36,42 & 21,10 & 226,93 & 132,83 & 133,19 & 196,12 \\
\hline Triturus marmoratus & 30TVN33 & 100,00 & 99,88 & 90,41 & 37,83 & 5087,54 & 235,72 & $-0,61$ & 236,32 & 73,30 & 166,10 & 167,68 & 37,62 & 768,08 & 86,51 & 37,99 & 21,23 & 241,69 & 139,82 & 141,61 & 209,01 \\
\hline Triturus marmoratus & 30 TVN34 & 100,00 & 102,11 & 87,56 & 37,89 & 4943,68 & 232,54 & 3,78 & 228,76 & 76,89 & 166,15 & 168,01 & 41,55 & 807,40 & 91,67 & 39,47 & 21,58 & 257,15 & 145,83 & 150,27 & 222,41 \\
\hline Triturus marmoratus & 30TVN35 & 100,00 & 100,09 & 85,70 & 37,99 & 4839,53 & 227,32 & 3,92 & 223,40 & 75,82 & 162,73 & 164,78 & 41,04 & 860,57 & 98,02 & 42,14 & 21,75 & 275,25 & 155,33 & 161,40 & 239,24 \\
\hline Triturus marmoratus & 30TVN36 & 100,00 & 98,50 & 83,98 & 37,94 & 4 & 222,92 & $\begin{array}{ll}, 339 \\
4,4\end{array}$ & 218,54 & $\begin{array}{l}75,08 \\
75,0\end{array}$ & 159,90 & $\begin{array}{ll}161,99 \\
\end{array}$ & $\begin{array}{ll}40,86 \\
40\end{array}$ & 910,65 & \begin{tabular}{|r|r|r|r|r|r|}
104,03 \\
\end{tabular} & $\begin{array}{ll}44,724 \\
44,\end{array}$ & 21,92 & 292,47 & \begin{tabular}{|l|l|l}
164,27 \\
\end{tabular} & $\begin{array}{l}171,98 \\
171\end{array}$ & 255,13 \\
\hline Triturus marmoratus & 30TVN37 & 100,00 & 106,25 & 78,95 & 37,64 & $\begin{array}{lll}4519,87 \\
\end{array}$ & 222,60 & 15,81 & 206,80 & 83,86 & 164,41 & 166,69 & 51,04 & 948,49 & 110,55 & 45,01 & 23,36 & 311,21 & 167,55 & 180,65 & 269,49 \\
\hline Triturus marmoratus & 30TVN41 & 100,00 & 97,97 & 94,24 & 37,84 & 5348,75 & 242,03 & $-5,08$ & 247,11 & 68,22 & 168,75 & 169,27 & 32,69 & 695,17 & 76,59 & 34,88 & 20,91 & 212,73 & 126,85 & 126,95 & 186,38 \\
\hline Triturus marmoratus & 30 TVN42 & 100,00 & 94,73 & 92,92 & 37,97 & 5248,90 & 235,92 & $-6,76$ & 242,68 & 66,10 & 163,77 & 164,82 & 30,91 & 748,93 & 82,50 & 37,81 & 20,56 & 230,02 & 137,79 & 137,95 & 202,92 \\
\hline Triturus marmoratus & 30TVN43 & 100,00 & 94,96 & 90,73 & 37,93 & 5126,11 & 232,01 & $-4,57$ & 236,57 & 67,53 & 161,78 & 163,49 & 32,63 & 793,42 & 87,77 & 39,94 & 20,51 & 245,95 & 145,83 & 147,30 & 217,37 \\
\hline Triturus marmoratus & 30TVN44 & 100,00 & 99,73 & 87,26 & 37,82 & 4960,01 & 230,43 & 2,49 & 227,94 & 73,85 & 164,09 & 165,94 & 39,32 & 829,36 & 92,90 & 40,81 & 21,28 & 261,53 & 150,31 & 155,01 & 230,64 \\
\hline Triturus marmoratus & 30TVN45 & 100,00 & 103,27 & 83,95 & 37,82 & 4805,38 & 228,38 & 8,55 & 219,83 & 78,79 & 165,41 & 167,48 & 44,52 & 868,29 & 98,77 & 41,92 & 21,89 & 277,71 & 155,42 & 163,40 & 244,62 \\
\hline Triturus marmoratus & 30 TVN46 & 100,00 & 101,68 & 82,19 & 37,70 & 4705,55 & 224,07 & 8,78 & 215,30 & 78,10 & 162,36 & 164,63 & 44,20 & 919,65 & 105,53 & 44,48 & 22,03 & 295,47 & 164,43 & 174,03 & 261,18 \\
\hline Triturus marmoratus & 30TVN52 & 100,00 & 98,95 & 91,42 & 37,73 & 5221,31 & 237,64 & $-1,86$ & 239,51 & 70,07 & 167,23 & 168,60 & 35,30 & 749,14 & 81,75 & 37,43 & 20,46 & 229,92 & 137,40 & 139,13 & 205,45 \\
\hline Triturus marmoratus & 30 TVN55 & 100,00 & 113,55 & 80,20 & 37,16 & 4694,17 & 233,01 & 20,75 & 212,25 & 89,81 & 173,80 & 175,99 & 55,64 & 865,90 & 100,81 & 40,08 & 22,87 & 280,37 & 151,47 & 163,42 & 249,80 \\
\hline \begin{tabular}{|l} 
Triturus marmoratus \\
\end{tabular} & \begin{tabular}{|l|}
30 TVN56 \\
3
\end{tabular} & 100,00 & $\begin{array}{l}11,50,14 \\
106,14\end{array}$ & $\begin{array}{ll}0,20 \\
80,16\end{array}$ & $\frac{3,1,10}{37,35}$ & $\begin{array}{ll}4094,117 \\
4654,46\end{array}$ & 225,81 & \begin{tabular}{|l|l|l|}
14,56 \\
\end{tabular} & $\begin{array}{l}211,23 \\
211,27 \\
\end{array}$ & $\begin{array}{l}85,101 \\
82,72 \\
\end{array}$ & $\begin{array}{l}1 / 7,05 \\
165,90\end{array}$ & \begin{tabular}{|l|}
168,30 \\
163
\end{tabular} & \begin{tabular}{|c|}
35,164 \\
49,16
\end{tabular} & $\begin{array}{l}030,90 \\
930,85 \\
\end{array}$ & \begin{tabular}{|l|l|l|l|l|}
108,16 \\
\end{tabular} & $\begin{array}{l}40,26 \\
44,22\end{array}$ & $\begin{array}{ll}2,81 \\
22,41\end{array}$ & \begin{tabular}{|l|}
290,671 \\
299
\end{tabular} & $\begin{array}{l}161,41 \\
164,75 \\
\end{array}$ & \begin{tabular}{|l|l|}
1736,64 \\
\end{tabular} & $\begin{array}{l}24,80 \\
268,72 \\
\end{array}$ \\
\hline Triturus marmoratus & 30TVN57 & 100,00 & 90,49 & 82,57 & 37,85 & 4709,62 & 214,55 & $-0,90$ & 215,45 & 52,83 & 151,43 & 153,93 & 33,92 & 1014,97 & 115,98 & 50,75 & 21,14 & 321,54 & 184,65 & 193,13 & 291,03 \\
\hline Triturus marmoratus & 30TVN61 & 100,00 & 109,10 & 91,23 & 37,38 & 5275,72 & 247,20 & 6,92 & 240,28 & 79,42 & 177,51 & 178,99 & 44,13 & 687,76 & 74,70 & 33,49 & 20,67 & 210,78 & 125,36 & 28,02 & 189,41 \\
\hline Triturus marmoratus & 30TVN62 & 100,00 & 111,51 & 88,30 & 37,3 & 5124,11 & 244,29 & 11,61 & 232,68 & 81,37 & 177,68 & 179,32 & 48,27 & 728,47 & 80,75 & 34,84 & 21,01 & 26,71 & 131,29 & 36,11 & 203,84 \\
\hline Triturus marmoratus & 30TVN63 & 100,00 & 107,20 & 87,07 & 37, & 5038 & 238,05 & $\begin{array}{cc}, 1,02 \\
9,28 \\
\end{array}$ & 228,77 & 79,07 & 172,23 & 174,21 & \begin{tabular}{|l|l|}
45,30 \\
\end{tabular} & $\begin{array}{l}20,49 \\
785,92\end{array}$ & $\begin{array}{l}0,11 \\
87,87 \\
\end{array}$ & 38 & 20,95 & 245,04 & 141,95 & \begin{tabular}{|l|l|}
147,61 \\
\end{tabular} & 221,72 \\
\hline Triturus marmoratus & 30TVN64 & 100,00 & 111 & 83,52 & 37,36 & 4865,24 & 235,67 & 15,42 & 220,24 & 84,28 & 173,25 & 175,36 & 50,84 & 832,07 & 95,1 & 39, & 21,70 & 263,67 & 147,92 & 156,78 & 238,93 \\
\hline Triturus marmoratus & $\begin{array}{l} \\
30 T V N 67 \\
\end{array}$ & 100,00 & 101,25 & 79,16 & 37,55 & 4599,45 & 219,84 & 11,59 & 208,25 & 65,66 & 160,21 & 162,83 & 45,37 & 1010,80 & $\mid$\begin{tabular}{|l|l|}
117,99 \\
\end{tabular} & 48,59 & 22,10 & 323,75 & 179,86 & 192,51 & 296,21 \\
\hline Triturus marmoratus & 30TVN70 & 100,00 & 104,58 & 94,92 & 37,86 & 5438,01 & 248,84 & 0,10 & 248,73 & 73,09 & 175,77 & 176,68 & 37,92 & 669,04 & 70,87 & 33,55 & 19,95 & 199,48 & 124,75 & \begin{tabular}{l|l}
125,08 \\
\end{tabular} & 182,08 \\
\hline Triturus marmoratus & 30TVN71 & 100,00 & 109,94 & 91,44 & 37,53 & 5283,77 & 247,82 & 7,43 & 9 & 79,87 & 178,32 & 179,88 & 44,84 & 695,56 & 75,50 & 33,96 & 20,25 & 65 & 127,88 & 130,55 & 192,67 \\
\hline Triturus marmoratus & 307 & 100,00 & $\frac{10}{10}$ & $\begin{array}{l}1,44 \\
89,83\end{array}$ & 37, & 5 & $\begin{array}{l}24,02 \\
242,08\end{array}$ & $\frac{7,45}{6,58}$ & 235,50 & 73,49 & 174,00 & 175,75 & 43,37 & 749,71 & 82,34 & 36,79 & 20,27 & 229,53 & 137,57 & 141,17 & 209,90 \\
\hline Triturus marmoratus & 30TVN73 & 100,00 & 112,44 & 85,79 & 37,43 & 5006,60 & 241,04 & 14,90 & 226,15 & 83,56 & 176,85 & 178,75 & 50,72 & 786,61 & 88,77 & 37,40 & 21,15 & 245,54 & 141,27 & 148,32 & 225,13 \\
\hline Triturus marmoratus & 30TVN74 & 100,00 & 107,62 & 84,58 & 37,51 & 4912,95 & 234,44 & 12,03 & 222,40 & 74,75 & 170,82 & 172,86 & 47,35 & 851,06 & 96,70 & 40,89 & 21,06 & 266,57 & 153,21 & 160,98 & 245,17 \\
\hline Triturus marmoratus & 30 TVN75 & 100,00 & 105,31 & 82,77 & 37,50 & 4807,18 & 229,48 & 11,75 & 217,73 & 67,09 & 167,05 & 169,38 & 46,57 & 910,55 & 104,51 & 43,79 & 21,23 & 286,82 & 163,32 & 172,66 & 264,81 \\
\hline Triturus marmoratus & 30 TVN76 & 100,00 & 107,88 & 79,40 & 37,36 & 464 & 226,83 & 17,28 & 209,55 & 67,34 & 167,40 & 169,86 & 51,09 & 964,32 & 112,88 & 45,46 & 22,21 & 308,11 & 170,29 & 183,10 & 28 \\
\hline Triturus marmoratus & 30TVN77 & 100,00 & 122,34 & 71,61 & 36,73 & 4342,73 & 229,04 & 36,54 & 192,50 & 98,41 & 177,24 & 179,90 & 68,68 & 1009,67 & 123,94 & 44,06 & 25,19 & 332,97 & 169,58 & 190,88 & 310,96 \\
\hline Triturus marmoratus & 30TVN78 & 100,00 & 120,92 & 69,74 & 36,68 & 4244,12 & 224,77 & 37,20 & 187,57 & 91,57 & 174,43 & 177,29 & 68,58 & 1066,48 & 131,83 & 46,55 & 25,63 & 353,54 & 178,62 & 202,15 & 330,37 \\
\hline Triturus marmoratus & 30TVN82 & 100,00 & 103,17 & 91,27 & 37,89 & 5220,71 & 240,35 & 2,42 & 237,93 & 60,00 & 170,94 & 172,61 & 39,31 & 771,66 & 84,04 & 38,65 & 19,54 & 233,49 & 143,87 & 146,24 & 215,95 \\
\hline Triturus r & 30TVN83 & 100,00 & 104,94 & 88,13 & 37,73 & 5072,27 & 237,26 & 6,80 & 230,46 & 63,63 & 170,70 & 172 & 42 & 820,28 & 91 & 40,44 & 20,14 & 252,12 & 150,79 & 155,49 & 233 \\
\hline Triturus marmoratus & 30 TVN84 & 100,00 & 103,96 & 86,15 & 37,85 & 4963,33 & 233,21 & 7,87 & 225,33 & 55,78 & 167,96 & 170,04 & 43,42 & 871,21 & 98,06 & 42,76 & 20,30 & 269,96 & 159,22 & 65,50 & 250,88 \\
\hline
\end{tabular}




\begin{tabular}{|c|c|c|c|c|c|c|c|c|c|c|c|c|c|c|c|c|c|c|c|c|c|}
\hline TAXON & UTM & $\mathrm{km} 2$ & B101 & B102 & $\mathrm{BIO3}$ & B104 & B105 & B106 & B107 & $\mathrm{B108}$ & B109 & B1010 & BIO11 & BIO12 & B1013 & BIO14 & B1015 & B1016 & BIO17 & B1018 & B1019 \\
\hline Triturus marmoratus & 30TVN85 & 100,00 & 104,85 & 83,38 & 37,74 & 4828,90 & 229,94 & 11,22 & 218,72 & 54,11 & 166,92 & 169,21 & 45,99 & 924,90 & 105,84 & 44,83 & 20,84 & 290,18 & 167,04 & 175,80 & 270,28 \\
\hline Triturus marmoratus & 30 TVN86 & 100,00 & 105,44 & 80,40 & 37,56 & 4686,24 & 225,87 & 14,56 & 211,31 & 57,21 & 165,48 & 167,92 & 48,38 & 987,13 & 114,97 & 47,12 & 21,75 & 313,49 & 175,99 & 187,50 & 293,23 \\
\hline Triturus marmoratus & 30TVN87 & 100,00 & 124,55 & 70,93 & 36,59 & 4335,24 & 230,32 & 39,18 & 191,14 & 88,84 & 179,24 & 181,90 & 70,99 & 1029,46 & 127,20 & 44,41 & 25,55 & 338,75 & 171,69 & 193,69 & 322,91 \\
\hline Triturus marmoratus & 30TVN88 & 100,00 & 126,70 & 67,62 & 36,38 & 4189,88 & 227,43 & 44,06 & 183,37 & 89,67 & 179,27 & 182,15 & 74,93 & 1088,14 & 136,91 & 45,96 & 26,80 & 362,44 & 178,49 & 204,42 & 347,08 \\
\hline Triturus marmoratus & 30TVN91 & 100,00 & 113,53 & 92,15 & 37,94 & 5299,28 & 251,10 & 10,04 & 241,07 & 80,85 & 181,98 & 183,36 & 48,11 & 698,82 & 75,34 & 34,55 & 19,53 & 209,99 & 131,21 & 133,30 & 193,97 \\
\hline Triturus marmoratus & 30TVN92 & 100,00 & 117,27 & 88,59 & 37,62 & 5141,02 & 249,09 & 16,71 & 232,37 & 86,20 & 183,32 & 184,93 & 53,60 & 738,05 & 81,65 & 35,49 & 20,21 & 225,82 & 135,85 & 140,65 & 209,57 \\
\hline Triturus marmoratus & 30TVN93 & 100,00 & 115,36 & 86,42 & 37,65 & 5019,65 & 244,13 & 17,40 & 226,73 & 80,67 & 179,86 & 181,60 & 53,52 & 797,27 & 89,48 & 38,23 & 20,47 & 246,02 & 145,48 & 151,88 & 229,88 \\
\hline Triturus marmoratus & 30TVN94 & 100,00 & 108,73 & 85,55 & 37,76 & 4938,92 & 236,51 & 12,67 & 223,84 & 62,07 & 172,20 & 174,24 & 48,30 & 872,13 & 98,54 & 42,44 & 20,30 & 270,24 & 159,39 & 166,11 & 253,37 \\
\hline Triturus marmoratus & 30 TVN96 & 100,00 & 119,40 & 76,09 & 37,08 & 4543,25 & 232,90 & 30,66 & 202,24 & 72,38 & 177,02 & 179,58 & 63,58 & 990,60 & 118,93 & 44,53 & 23,73 & 319,32 & 170,56 & 186,73 & 305,49 \\
\hline Triturus marmoratus & 30TVN99 & 92,00 & 132,29 & 63,55 & 35,85 & 4036,25 & 226,96 & 52,44 & 174,52 & 89,47 & 182,50 & 185,60 & 82,34 & 1168,21 & 150,77 & 47,53 & 28,83 & 394,26 & 186,08 & 217,14 & 387,18 \\
\hline Triturus marmoratus & 30TVPOO & 64,00 & 137,12 & 66,61 & 37,79 & 3851,80 & 230,15 & 55,92 & 174,23 & 120,96 & 185,16 & 188,49 & 89,16 & 941,17 & 120,19 & 40,62 & 28,75 & 331,77 & 157,24 & 184,34 & 264,64 \\
\hline Triturus marmoratus & 30TVP11 & 3,00 & 142,42 & 61,75 & \begin{tabular}{|c|}
37,17 \\
\end{tabular} & 3685,50 & 228,75 & 65,08 & 163,67 & 126,75 & 171,08 & 191,25 & 96,33 & 988,92 & 126,33 & 41,25 & 30,00 & 352,42 & 161,17 & 195,08 & 283,42 \\
\hline Triturus marmoratus & 30TVP31 & 33,00 & 141,27 & 58,56 & 36,50 & 3605,85 & 224,90 & 67,10 & 157,79 & 126,46 & 168,79 & 189,33 & 96,25 & 1070,27 & 135,50 & 43,90 & 30,44 & 381,94 & 170,77 & 211,92 & 313,67 \\
\hline Triturus marmoratus & 30TVP41 & 44,00 & 138,96 & 58,91 & \begin{tabular}{|l|}
36,27 \\
\end{tabular} & 3675,51 & 223,92 & 64,09 & 159,83 & 123,56 & 171,44 & 187,82 & 93,19 & 1103,65 & 140,79 & 45,16 & 29,78 & 389,87 & 177,44 & 216,39 & 332,03 \\
\hline Triturus marmoratus & 30TVP51 & 62,00 & 139,49 & 58,70 & 36,04 & 3704,47 & 224,75 & 64,47 & 160,28 & 123,59 & 181,65 & 188,60 & 93,16 & 1118,94 & 143,78 & 45,42 & 29,88 & 393,06 & 179,04 & 217,62 & 343,98 \\
\hline Triturus marmoratus & 30TVP61 & 17,00 & 137,40 & 59,60 & 36,00 & 3760,60 & 224,27 & 61,20 & 163,07 & 120,93 & 183,73 & 187,13 & 90,33 & 1137,47 & 146,53 & 46,27 & 29,33 & 395,47 & 181,73 & 219,20 & 356,13 \\
\hline Triturus marmoratus & 30TVP90 & 11,00 & 139,70 & 59,48 & 35,35 & 3886,30 & 228,13 & 62,13 & 166,00 & 100,17 & 187,70 & 190,87 & 91,13 & 1202,09 & 158,83 & 46,74 & 30,87 & 411,13 & 185,74 & 222,04 & 408,35 \\
\hline Triturus marmoratus & 30TWL19 & 100,00 & 110,87 & 111,19 & 37,55 & 6229,64 & 280,75 & $-11,81$ & 292,56 & 130,53 & 193,55 & 193,84 & 35,34 & 490,44 & 58,62 & 22,78 & 22,84 & 148,93 & 87,42 & 93,05 & 124,01 \\
\hline Triturus marmoratus & 30TWL29 & 100,00 & 110,39 & 112,69 & 37,92 & 6226,97 & 281,09 & $-13,42$ & 294,51 & 130,14 & 192,90 & 193,25 & 34,77 & 495,23 & 59,73 & 23,86 & 22,44 & 151,22 & 89,90 & 95,86 & 124,86 \\
\hline Triturus marmoratus & 30TWL38 & 100,00 & 107,05 & 113,55 & 38,00 & 6243,97 & 278,66 & $-17,82$ & 296,47 & 126,84 & 189,90 & 190,27 & 31,47 & 506,42 & 62,06 & 24,94 & 22,58 & 156,39 & 92,73 & 99,67 & 126,17 \\
\hline Triturus marmoratus & 30TWL39 & 100,00 & 109,03 & 113,99 & 38,00 & 6221,73 & 280,64 & $-15,73$ & 296,38 & 128,99 & 191,51 & 191,92 & 33,55 & 503,57 & 61,23 & 25,10 & 22,12 & 154,73 & 92,94 & 99,47 & 126,49 \\
\hline Triturus marmoratus & 30TWL49 & 100,00 & 106,99 & 114,69 & 38,00 & 6217,22 & 278,67 & $-18,62$ & 297,29 & 126,85 & 189,35 & 189,79 & 31,42 & 514,24 & 63,20 & 26,27 & 22,00 & 159,39 & 96,54 & 104,10 & 128,16 \\
\hline Triturus marmoratus & 30TWL89 & 100,00 & 105,14 & \begin{tabular}{|l|l|}
111,17 \\
\end{tabular} & \begin{tabular}{|c|}
37,98 \\
\end{tabular} & 6179,59 & 269,25 & $-21,06$ & 290,31 & 126,29 & 186,11 & \begin{tabular}{|c|}
186,66 \\
\end{tabular} & 29,12 & 505,46 & 66,85 & 27,59 & 24,67 & 165,75 & 100,21 & 112,37 & 116,93 \\
\hline Triturus marmoratus & 30TWL98 & 100,00 & 113,05 & 109,24 & 37,46 & 6207,38 & 273,55 & $-14,03$ & 287,58 & 135,14 & 193,65 & 194,38 & 36,22 & 453,66 & 62,75 & 24,44 & 27,61 & 153,12 & 90,73 & 102,77 & 100,08 \\
\hline Triturus marmoratus & 30TWMO2 & 100,00 & 97,86 & 110,42 & 37,99 & 6061,51 & 266,39 & $-21,04$ & 287,44 & 115,60 & 178,84 & 178,89 & 24,96 & 574,46 & 66,58 & 28,80 & 20,96 & 172,38 & 104,40 & 107,16 & 148,76 \\
\hline Triturus marmoratus & 30TWM03 & 100,00 & 93,98 & 109,78 & 38,00 & 6001,04 & 261,56 & $-23,63$ & 285,19 & 110,94 & 174,33 & 174,36 & 21,81 & 605,37 & 69,45 & 31,18 & 20,27 & 180,79 & 110,97 & 113,23 & 157,66 \\
\hline Triturus marmoratus & 30TWMO4 & 100,00 & 85,75 & 108,61 & 38,00 & 5923,26 & 251,68 & $-29,78$ & 281,46 & $\begin{array}{l}101,73 \\
\end{array}$ & 165,23 & 165,23 & $\begin{array}{l}21,01 \\
14,97\end{array}$ & 666,40 & 75,31 & 35,51 & 19,49 & 197,55 & 123,31 & $\begin{array}{l}124,57 \\
12,5\end{array}$ & 174,60 \\
\hline Triturus marmoratus & 30TWM05 & 100,00 & 70,14 & 106,53 & 38,00 & 5815,45 & 233,82 & $-42,16$ & 275,98 & 84,29 & 148,92 & 148,92 & 1,64 & 779,62 & 86,31 & 42,85 & 18,61 & 228,66 & 145,29 & 145,29 & 205,86 \\
\hline Triturus marmoratus & 30TWMO6 & 100,00 & 91,56 & 106,05 & 38,00 & 5817,45 & 252,79 & $-21,79$ & 274,57 & 107,69 & 169,41 & 169,41 & 21,56 & 661,18 & 73,31 & 35,29 & 19,10 & 193,37 & 124,01 & 124,21 & 174,34 \\
\hline Triturus marmoratus & 30TWM07 & 100,00 & 70,76 & 104,27 & 38,01 & 5708,69 & 230,51 & $-39,31$ & 269,82 & 84,63 & 148,01 & 148,01 & 3,28 & 811,61 & 87,62 & 44,84 & 18,14 & 234,22 & 152,54 & 152,54 & 216,71 \\
\hline Triturus marmoratus & 30TWM08 & 100,00 & 89,97 & 103,04 & 38,06 & 5672,90 & 245,93 & $-20,14$ & 266,06 & 100,88 & 165,91 & 165,91 & 21,54 & 712,04 & 76,42 & 38,20 & 18,40 & 204,14 & 134,80 & 134,80 & 190,31 \\
\hline Triturus marmoratus & 30TWM09 & 100,00 & 110,86 & $\begin{array}{r}98,72 \\
98,72\end{array}$ & 37,98 & 5573,69 & $\mid \begin{array}{l}258,66 \\
258,66\end{array}$ & 1,71 & 256,95 & \begin{tabular}{|l|}
78,18 \\
78,0
\end{tabular} & 184,26 & 184,34 & $\frac{21,34}{42,14}$ & $\mid 129,40$ & $\begin{array}{l}0,4,34 \\
66,34\end{array}$ & 32,35 & 18,40 & 182,56 & 120,69 & $\begin{array}{l}320,69 \\
120\end{array}$ & 168,21 \\
\hline Triturus marmoratus & 30TWM11 & 100,00 & 103,61 & 112,07 & 38,00 & 6125,34 & 273,87 & $-17,73$ & 291,61 & 122,12 & 185,23 & 185,33 & 29,68 & 541,47 & 63,54 & 26,93 & 21,18 & 163,32 & 98,87 & 104,65 & 139,26 \\
\hline Triturus marmoratus & 30TWM12 & 100,00 & 97,65 & 111,98 & 38,00 & 6063,67 & 267,47 & $-22,53$ & 290,01 & 115,41 & 178,63 & 178,69 & 24,68 & 582,73 & 67,62 & 30,02 & 20,29 & 174,84 & 107,47 & 111,59 & 151,12 \\
\hline Triturus marmoratus & 30TWM13 & 100,00 & 96,87 & 111,31 & 38,04 & 6017,11 & 265,36 & $-22,23$ & 287,59 & 114,39 & 177,16 & 177,21 & 24,34 & 596,68 & 68,64 & 31,22 & 19,93 & 178,25 & 110,88 & 114,29 & 155,30 \\
\hline Triturus marmoratus & 30TWM14 & 100,00 & 79,04 & 109,12 & 38,02 & 5905,41 & 245,44 & $-36,45$ & 281,89 & 94,44 & 158,69 & 158,69 & 9,01 & 716,27 & 80,58 & 38,98 & 18,83 & 211,92 & 133,97 & 134,53 & 188,09 \\
\hline Triturus marmoratus & 30TWM15 & 100,00 & $\begin{array}{ll}68,947 \\
68,97\end{array}$ & $\begin{array}{l}107,08 \\
107,2\end{array}$ & $\begin{array}{l}30,02 \\
38,02\end{array}$ & $\begin{array}{l}5301,44 \\
581,98\end{array}$ & $\mid$\begin{tabular}{|l|}
232,96 \\
232,9
\end{tabular} & $\begin{array}{l}-3,4,43 \\
-43,81 \\
\end{array}$ & \begin{tabular}{|l|l|}
271,095 \\
276,77
\end{tabular} & $\begin{array}{r}34,4409 \\
33,0\end{array}$ & \begin{tabular}{|l|l|l|l|l}
147,78 \\
\end{tabular} & \begin{tabular}{|l|l|l}
147,78 \\
\end{tabular} & $\begin{array}{l}3,11 \\
0,49\end{array}$ & \begin{tabular}{|l|}
794,58 \\
\end{tabular} & 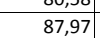 & - 30,08 & $\begin{array}{l}18,21 \\
18,21\end{array}$ & 233,03 & 149,38 & \begin{tabular}{|l|}
149,38 \\
149,
\end{tabular} & $\begin{array}{l}200,097 \\
2098\end{array}$ \\
\hline Triturus marmoratus & 30TWM16 & 100,00 & 80,61 & 106,79 & 38,04 & 5796,00 & 242,94 & $-32,60$ & 275,54 & 95,78 & 158,64 & 158,64 & 11,50 & 737,33 & 81,18 & 40,38 & 18,32 & 215,15 & 139,25 & 139,33 & 195,45 \\
\hline Triturus marmoratus & 30TWM17 & 100,00 & 93,83 & 105,35 & 38,08 & 5763,45 & 252,61 & $-19,24$ & 271,85 & 110,11 & 170,63 & 170,63 & 24,09 & 674,93 & $74,07 \mid$ & 36,31 & 18,55 & 196,01 & 128,47 & 128,65 & 178,33 \\
\hline Triturus marmoratus & 30TWM18 & 100,00 & 110,04 & 102,28 & 38,03 & 5706,21 & 262,98 & $-2,26$ & 265,24 & 124,43 & 185,29 & 185,29 & 39,92 & 602,75 & 65,87 & 31,60 & 18,93 & 173,77 & 116,27 & 116,44 & 157,84 \\
\hline Triturus marmoratus & 30TWM1 & 100,00 & 120,28 & 98,44 & 37,98 & 5591,73 & 266 & 9,67 & 256,62 & 88,06 & 193,38 & 193,38 & 50,78 & 581,66 & 62,07 & 29,70 & 19,11 & 168,78 & 113,38 & 113,42 & 152,68 \\
\hline Triturus marmoratus & $30 \mathrm{TWM}^{2}$ & 100,00 & 108,08 & 113,43 & 38,00 & 6181,40 & 279,25 & $-15,51$ & 294,77 & 127,45 & 190,08 & 190,28 & 33,06 & 515,06 & 61,47 & 25,5 & 21,60 & 156,53 & 94,49 & 100,55 & 131,18 \\
\hline Triturus marmoratus & 30TWM21 & 100,00 & 100,66 & 113,99 & 38,01 & 6121,36 & 272,66 & $-21,70$ & 294,36 & 119,20 & 182,35 & 182,44 & 26,96 & 563,46 & 66,20 & 28,99 & 20,58 & 170,03 & 104,49 & 110,10 & 145,54 \\
\hline Triturus marmoratus & 30TWM22 & 100,00 & 96,86 & 113,61 & 38,16 & 6066,54 & 268,07 & $-24,41$ & 292,48 & 114,77 & 177,89 & 177,97 & 24,04 & 594,34 & 68,98 & 31,16 & 19,96 & 78,36 & 111,02 & 115,83 & 154,58 \\
\hline Triturus marmoratus & 30TWM23 & 100,00 & 100,11 & 113,02 & 38,18 & 6033,19 & 269,86 & $-20,79$ & 0,66 & 118,09 & 180,38 & 180,43 & 27,22 & 585,53 & 67,66 & 30,79 & 19,88 & 55,20 & 05 & 14,06 & 152,42 \\
\hline Triturus marmoratus & 30 TWM24 & 100,00 & 76,56 & 109,64 & $\frac{50}{38}$ & 5900,86 & 243 & $-39,27$ & 282,50 & $\begin{array}{l}31,0,92 \\
91,92\end{array}$ & $\begin{array}{l}156,19 \\
156\end{array}$ & $\frac{15}{15}$ & 6,65 & 738,56 & 83,14 & 40,7 & 18,55 & 218,56 & 139,47 & 140,34 & 193,94 \\
\hline Triturus marmoratus & 30 TWM & 100,00 & 68,24 & 107,45 & $\begin{array}{l}38,15 \\
\end{array}$ & 5819,86 & 232 & $-45,10$ & 277,32 & 82,59 & 147,03 & 147,03 & $-0,29$ & 807,14 & 89,42 & 45,16 & 17,94 & 236,86 & 153,03 & 153,23 & 212,90 \\
\hline Triturus marmoratus & 30 TWM26 & 100,00 & 88,12 & 108,23 & 38,21 & 5828,86 & 251,09 & $-27,02$ & 278,11 & 104,26 & 166,05 & 166,05 & 18,05 & 698,10 & 77,51 & 38,12 & 18,28 & 204,48 & 132,99 & 133,36 & 184,37 \\
\hline Triturus marmoratus & 30TWM27 & 100,00 & 91,55 & 106,67 & 38,27 & 5774,84 & 251,68 & $-22,38$ & 274,06 & 107,79 & 168,63 & 168,63 & 21,84 & 694,45 & 76,45 & 37,87 & 18,18 & 202,16 & 133,02 & 133,16 & 183,65 \\
\hline Triturus marmoratus & 30TWM28 & 100,00 & 99,88 & 104,49 & 38,32 & 5719,76 & 255,82 & $-12,94$ & 68,76 & 116,42 & 175,71 & 17 & 30,24 & 666,60 & 72,70 & 36,00 & 18,18 & 192,58 & 128,78 & 128,95 & 175,86 \\
\hline Triturus marmoratus & $30 T W n$ & 100,00 & $\begin{aligned} 93,00 \\
120,41\end{aligned}$ & $\frac{10}{10}$ & $\frac{50}{38}$ & 5642,81 & 26 & $\frac{\mid-12,43}{8,30}$ & \begin{tabular}{|l|}
259,78 \\
25,10
\end{tabular} & \begin{tabular}{|l|l|l|l|}
117,56 \\
\end{tabular} & \begin{tabular}{|l|l|}
194,07 \\
\end{tabular} & \begin{tabular}{|l|l|l|l|l|}
194,07 \\
\end{tabular} & 50,30 & 572,70 & $\frac{12,10}{62,49}$ & 290,95 & $\begin{array}{l}18,10 \\
18,94\end{array}$ & 165,38 & $\begin{array}{ll}120,10 \\
113,07\end{array}$ & \begin{tabular}{|l|l|l|l|l|l}
113,23 \\
\end{tabular} & $\begin{array}{l}147,00 \\
147,71\end{array}$ \\
\hline Triturus marmoratus & 30TWM30 & 100,00 & 104,56 & 115,04 & 38,02 & 6178,03 & 277,30 & $-19,92$ & 297,21 & 123,75 & 186,70 & 186,90 & 29,64 & 537,74 & 64,31 & 27,47 & 21,05 & 163,83 & 100,23 & 106,71 & 137,27 \\
\hline Triturus marmoratus & 30TWM31 & 100,00 & 103,45 & 115,62 & 38,23 & 6134,85 & 276,37 & $-20,69$ & 297.06 & 122,47 & 184,84 & 185,21 & 29,02 & 554,93 & 65,48 & 28,72 & 20,44 & 167,84 & 104,20 & 110,61 & 143,26 \\
\hline Triturus marmoratus & 30TWM32 & 100,00 & 100,33 & 115,52 & 38,74 & 6085,66 & 272,95 & $-22,71$ & 295,66 & 118,86 & 181,43 & 181,54 & 26,86 & 582,24 & 67,90 & 30,58 & 19,91 & 175,02 & 110,07 & 115,38 & 151,54 \\
\hline Triturus marmoratus & 30TWN & 100,00 & 99,18 & 114,38 & 38,68 & 6035,13 & 269 & $-22,77$ & 292,75 & 117,33 & 179,49 & 17 & 26,17 & 597,93 & 69,21 & 31,78 & 19,53 & 179,08 & 113,60 & 119,15 & 155 \\
\hline Triturus marmoratus & 30TWM34 & 100,00 & 85,60 & 111,58 & 38,56 & 5936,16 & 253,40 & $-32,75$ & 286,15 & 102,03 & 165,18 & 165,19 & 14,49 & 689,98 & 78,33 & 37,81 & 18,55 & 204,94 & 131,59 & 133,87 & 180,82 \\
\hline Triturus marmoratus & 30TWM 35 & 100,00 & 73,56 & 108,60 & 38,32 & 5840,88 & 238,10 & $-41,36$ & 279,45 & 88,67 & 152,30 & 152,30 & 4,19 & 778,78 & 86,81 & 43,56 & 17,84 & 229,28 & 148,81 & 149,08 & 205,05 \\
\hline Triturus marmoratus & 30TWM36 & 100,00 & 86,13 & 108,96 & 38,61 & 5831,72 & 249,59 & $-29,72$ & 279,31 & 102,28 & 164,16 & 164,16 & 16,16 & 717,70 & 79,76 & 39,59 & 18,01 & 210,42 & 137,64 & 138,29 & 189,70 \\
\hline Triturus & 30TWM37 & 100,00 & 96,07 & \begin{tabular}{ll|}
107,64 \\
\end{tabular} & 38,54 & 5802,31 & 256,53 & $-19,2$ & 。 & 113,14 & 173 & 173 & 25 & 672,42 & 74,59 & 36,74 & 18,16 & 196,71 & 129,78 & 130,72 & 176 \\
\hline Triturus marmoratus & 30TWM 38 & 100,00 & 101,31 & 105,51 & 38,45 & 5753,02 & 257,99 & $-12,79$ & 270,79 & 118,73 & 177,34 & 177,35 & 31,06 & 658,51 & 72,71 & 35,99 & 18,21 & 191,93 & 28,10 & $\mid 28,79$ & 172,10 \\
\hline
\end{tabular}




\begin{tabular}{|c|c|c|c|c|c|c|c|c|c|c|c|c|c|c|c|c|c|c|c|c|c|}
\hline TAXON & UTM & $\mathrm{km} 2$ & $\mathrm{BIO1}$ & $\mathrm{B1O2}$ & $\mathrm{BIO3}$ & $\mathrm{B104}$ & B105 & $\mathrm{B106}$ & $\mathrm{B107}$ & B108 & $\mathrm{BIO9}$ & 81010 & B1011 & BIO12 & B1O13 & 81014 & B1015 & B1016 & B1017 & $\mathrm{BIO18}$ & B1019 \\
\hline Triturus marmoratus & зотWM39 & 100,00 & 119,79 & 101,93 & 38,06 & 5702,21 & 269,49 & 6,12 & 263,36 & 138,85 & 194,02 & 194,02 & 48,82 & 563,84 & 63,13 & 30,29 & 19,03 & 164,95 & 112,64 & 113,63 & 142,30 \\
\hline Triturus marmoratus & 30 TWM40 & 100,00 & 106,05 & 115,52 & $\begin{array}{l}38,05 \\
\end{array}$ & 6179,69 & 278,45 & $-19,45$ & 297,90 & 125,65 & 187,90 & 188,35 & 30,78 & 530,34 & 64,28 & 27,42 & 21,32 & 162,98 & 100,19 & 107,63 & 134,11 \\
\hline Triturus marmoratus & 30TWM41 & 100,00 & 105,43 & 116,28 & 38,43 & 6140,06 & 278,34 & $-19,78$ & 298,12 & 124,92 & 186,82 & 187,18 & 30,50 & 546,13 & 65,24 & 28,45 & 20,74 & 166,35 & 103,75 & 110,58 & 140,07 \\
\hline Triturus marmoratus & 30TWM42 & 100,00 & 103,64 & 116,72 & 38,95 & 6096,81 & 276,75 & $-20,97$ & 297,71 & 122,70 & 184,62 & 184,78 & 29,42 & 568,59 & 66,79 & 29,94 & 19,90 & 171,65 & 108,52 & 115,21 & 147,62 \\
\hline Triturus marmoratus & 30TWM43 & 100,00 & 101,79 & 115,45 & 38,91 & 6050,05 & 273,08 & $-21,62$ & 294,71 & 120,42 & 182,06 & 182,21 & 28,19 & 586,40 & 68,46 & 31,32 & 19,54 & 176,49 & 112,42 & 119,54 & 152,32 \\
\hline Triturus marmoratus & 30TWM44 & 100,00 & 91,01 & 112,88 & 38,79 & 5964,44 & 259,40 & $-29,18$ & 288,57 & 108,27 & 170,54 & 170,55 & 19,05 & 662,31 & 75,82 & 36,30 & 18,65 & 197,60 & 127,36 & 131,80 & 173,05 \\
\hline Triturus marmoratus & 30TWM45 & 100,00 & 82,08 & 110,24 & 38,58 & 5878,70 & 247,42 & $-35,12$ & 282,54 & 98,21 & 160,86 & 160,86 & 11,45 & 731,03 & 82,29 & 40,77 & 17,89 & 216,24 & 140,76 & 141,49 & \begin{tabular}{ll|l}
191,97 \\
\end{tabular} \\
\hline Triturus marmoratus & 30TWM46 & 100,00 & 80,56 & 108,70 & 38,54 & 5819,04 & 243,60 & $-34,96$ & 278,56 & $\begin{array}{l}0,40 \\
96,40\end{array}$ & 158,60 & 158,60 & 10,80 & 757,90 & 84,18 & 42,44 & 17,65 & 222,38 & 146,11 & 146,57 & 200,06 \\
\hline Triturus marmoratus & 30TWM47 & 100,00 & 97,51 & 108,40 & 38,58 & 5830,24 & 258,38 & $-19,01$ & 277,40 & 115,15 & $\begin{array}{ll}174,78 \\
\end{array}$ & \begin{tabular}{ll|}
174,78 \\
\end{tabular} & 26,59 & 667,01 & 74,69 & 36,66 & 18,24 & \begin{tabular}{|c|}
196,31 \\
\end{tabular} & 129,31 & 130,20 & 174,48 \\
\hline Triturus marmoratus & 30TWM48 & 100,00 & 105,81 & 106,21 & 38,58 & 5790,45 & 262,59 & $-9,79$ & 272,38 & 124,10 & 181,99 & 181,99 & 34,73 & 631,48 & 70,85 & 34,70 & 18,56 & 185,93 & 123,74 & 124,95 & 162,81 \\
\hline Triturus marmoratus & 30TWM49 & 100,00 & 126,24 & 102,65 & 38,02 & 5775,38 & 276,19 & 10,47 & 265,72 & 146,67 & 195,92 & 200,91 & 54,01 & 508,37 & 59,42 & 27,88 & 20,34 & 153,06 & 104,01 & 107,40 & 122,04 \\
\hline Triturus marmoratus & 30TWM50 & 100,00 & 107,07 & 115,01 & 38,01 & 6181,32 & 278,07 & $-18,90$ & 296,97 & 127,18 & 188,72 & 189,23 & 31,86 & 520,60 & 64,27 & 27,27 & 21,79 & 162,18 & 99,62 & 107,97 & 129,36 \\
\hline Triturus marmoratus & 30TWM51 & 100,00 & 106,51 & 115,54 & 38,41 & 6147,29 & 277,73 & $-19,11$ & 296,84 & \begin{tabular}{|l|l|l|l|l|}
126,08 \\
\end{tabular} & \begin{tabular}{|l|l|}
187,71 \\
\end{tabular} & 187,97 & 31,51 & 535,59 & $\begin{array}{ll}4,2618 \\
\end{array}$ & 28,19 & 21,02 & 165,40 & \begin{tabular}{r|r|}
102,76 \\
\end{tabular} & 110,74 & 134,96 \\
\hline Triturus marmoratus & 30TWM52 & 100,00 & 101,71 & 115,63 & 38,63 & 6093,30 & 273,15 & $-22,72$ & 295,87 & 120,85 & 182,51 & 182,69 & 27,64 & 574,92 & 68,56 & 30,83 & 20,09 & 175,47 & 110,84 & 118,72 & 147,09 \\
\hline Triturus marmoratus & 30TWM53 & 100,00 & 99,08 & 114,75 & 38,75 & 6046,90 & 269,09 & $-24,29$ & 293,38 & 117,79 & 179,33 & 179,43 & 25,55 & 601,88 & 70,87 & 32,60 & 19,51 & 182,47 & 116,30 & 123,77 & 154,95 \\
\hline Triturus marmoratus & 30TWM54 & 100,00 & 84,73 & 111,67 & 38,62 & 5938,56 & 251,56 & $-34,74$ & 286,30 & 101,62 & 164,07 & 164,10 & 13,18 & 701,31 & 80,52 & 39,10 & 18,36 & 210,06 & 135,73 & 139,05 & 182,08 \\
\hline Triturus marmoratus & 30TWM55 & 100,00 & 88,05 & 110,97 & 38,73 & 5908,63 & 253,33 & $-30,57$ & 283,90 & 105,21 & 166,83 & 166,84 & 16,68 & 696,33 & 79,36 & 38,76 & 18,22 & 207,43 & 134,85 & 136,98 & 181,61 \\
\hline Triturus marmoratus & 30TWM57 & 100,00 & 98,21 & 108,81 & 38,69 & 5848,62 & 259,01 & $-19,15$ & 278,16 & 116,20 & 175,60 & 175,60 & 26,84 & 668,28 & 75,31 & 36,92 & 18,31 & 197,56 & 129,69 & 131,56 & 174,25 \\
\hline Triturus marmoratus & 30TWM58 & 100,00 & 109,72 & 106,79 & 38,52 & 5832,45 & 266,50 & \begin{tabular}{|l|l|}
$-7,27$ \\
\end{tabular} & 273,77 & 128,72 & 186,08 & 186,09 & 37,64 & 609,73 & 69,41 & 33,60 & 18,94 & 181,50 & 119,68 & 121,36 & 155,08 \\
\hline Triturus marmoratus & 30TWM59 & 100,00 & 127,97 & 103,66 & 38,01 & 5820,68 & 278,78 & 10,88 & 267,90 & 148,81 & 191,49 & 203,04 & 54,83 & 495,98 & 59,03 & 27,62 & 20,81 & 152,26 & 101,55 & 105,95 & 115,83 \\
\hline Triturus marmoratus & 30TWM63 & 100,00 & 91,97 & 112,84 & 38,32 & 6018,94 & 259,63 & $-30,03$ & 289,66 & 110,27 & 171,93 & 172,04 & 19,11 & 640,81 & $75, \mathbf{9}$ & 35,5 & 19,41 & 195,60 & 124,72 & 131,51 & 163,30 \\
\hline Triturus marmoratus & 30TWM66 & 100,00 & 97,99 & 110,15 & 38,76 & 5916,93 & 260,65 & $\begin{array}{ll}-21,48 \\
-21\end{array}$ & 282,12 & 116,42 & 176,20 & 176,23 & 25,69 & 653,75 & 75,19 & 36,20 & 18,76 & 195,80 & 126,85 & 130,21 & 168,89 \\
\hline Triturus marmoratus & 30TWM67 & 100,00 & 105,56 & 108,59 & \begin{tabular}{|c|}
38,47 \\
\end{tabular} & 5898,47 & 265,38 & $-13,16$ & 278,54 & 124,65 & 183,04 & 183,08 & 32,92 & 625,73 & 71,84 & 34,36 & 19,22 & 187,22 & 121,40 & 124,74 & 160,55 \\
\hline Triturus marmoratus & 30TWM68 & 100,00 & 114,52 & 106,87 & 38,35 & 5868,51 & 270,81 & $-3,59$ & 274,41 & 134,39 & 191,10 & 191,13 & 41,65 & 589,48 & 67,82 & 32,29 & 19,56 & 176,80 & 115,20 & 118,20 & 148,52 \\
\hline Triturus marmoratus & 30TWM69 & 100,00 & 130,87 & 103,68 & 38,11 & 5811,44 & 280,87 & 13,60 & 267,27 & 151,81 & 205,82 & 205,84 & 57,84 & 516,60 & 59,99 & 28,08 & 20,37 & 156,31 & 103,10 & 106,02 & 123,92 \\
\hline Triturus marmoratus & 30TWM73 & 100,00 & 98,35 & 112,10 & 38,12 & 6048,86 & 264,16 & $-24,80$ & 288,95 & 117,78 & 178,12 & 178,32 & 24,46 & 600,17 & 72,80 & 33,19 & 20,39 & 185,91 & 117,19 & 126,24 & 150,12 \\
\hline Triturus marmoratus & 30TWM74 & 100,00 & 104,64 & 111,38 & 38,15 & 6037,67 & 268,88 & $-18,07$ & 286,95 & 124,35 & $\begin{array}{l}183,90 \\
\end{array}$ & $\begin{array}{ll}184,07 \\
\end{array}$ & 30,39 & 579,31 & 70,04 & 31,70 & 20,70 & $\begin{array}{ll}178,88 \\
\end{array}$ & 112,50 & 119,76 & 145,13 \\
\hline Triturus marmoratus & 30TWM75 & 100,00 & 105,81 & 110,60 & 38,19 & 6005,52 & 268,75 & $-15,87$ & 284,62 & 125,63 & 184,67 & 184,71 & 31,91 & 589,35 & 70,32 & 32,27 & 20,32 & 180,49 & 114,13 & 120,21 & 148,72 \\
\hline Triturus marmoratus & 30TWM76 & 100,00 & 108,27 & 109,80 & 38,40 & 5979,02 & 269,63 & $-12,52$ & 282,15 & 128,21 & 186,54 & 186,61 & 34,49 & 593,73 & 69,97 & 32,39 & 20,06 & 180,44 & 114,66 & 121,32 & 150,67 \\
\hline Triturus marmoratus & 30TWM77 & 100,00 & 122,10 & 107,81 & 38,04 & 5973,97 & 279,65 & 1,33 & 278,32 & 143,23 & 199,55 & 199,65 & 47,51 & 536,37 & 63,52 & 28,69 & 20,92 & 163,45 & 103,33 & 108,63 & 133,39 \\
\hline Triturus marmoratus & 30TWM78 & 100,00 & 128,49 & 105,82 & 38,03 & 5904,04 & 282,21 & 9,08 & 273,14 & 149,75 & 204,79 & 204,81 & 54,47 & 533,57 & 61,81 & 28,16 & 20,74 & 160,44 & 102,74 & 106,73 & 132,77 \\
\hline Triturus marmoratus & 30TWM79 & 100,00 & 131,83 & 103,92 & 38,15 & 5807,65 & $280,21,63$ & \begin{tabular}{r|r|}
14,43 \\
14
\end{tabular} & 267,20 & 148,30 & 206,70 & 206,71 & 58,81 & 559,05 & \begin{tabular}{l|l}
62,46 \\
62
\end{tabular} & 29,22 & 20,09 & 164,46 & 107,43 & 108,30 & 141,47 \\
\hline Triturus marmoratus & 30TWM81 & 100,00 & 95,19 & 111,13 & 38,00 & 6093,47 & 259,76 & $-28,84$ & 288,61 & 114,84 & 175,50 & 175,73 & 20,67 & 584,71 & 73,75 & 32,71 & 21,90 & 186,25 & 115,83 & 127,53 & 140,88 \\
\hline Triturus marmoratus & 30TWM82 & 100,00 & 93,96 & 110,92 & 38,00 & 6058,28 & 258,25 & $-29,35$ & 287,60 & 113,12 & 173,90 & 173,96 & 19,82 & 607,35 & 75,29 & 34,08 & 21,12 & 191,30 & 119,85 & 131,13 & 148,50 \\
\hline Triturus marmoratus & 30TWM83 & 100,00 & 102,29 & 111,08 & 38,01 & 6063,83 & 266,08 & $-21,32$ & 287,40 & 122,23 & 181,75 & 182,01 & 27,54 & 575,06 & 71,24 & 31,73 & 21,45 & 180,48 & 112,34 & 123,17 & 141,63 \\
\hline Triturus marmoratus & 30TWM84 & 100,00 & 112,56 & 110,32 & 38,00 & 6074,30 & 274,85 & $-10,78$ & 285,63 & 133,44 & 191,83 & 191,95 & 37,15 & 536,46 & 66,46 & 28,88 & 22,09 & 167,91 & 103,46 & 111,82 & 132,19 \\
\hline Triturus marmoratus & 30TWM85 & 100,00 & 120,81 & 109,32 & 38,00 & 6070,69 & 281,26 & $-2,30$ & 283,56 & 142,39 & 199,63 & 199,70 & 45,06 & 512,43 & 63,00 & 27,03 & 22,39 & 159,30 & 97,77 & 106,13 & 126,51 \\
\hline Triturus marmoratus & $30 \mathrm{TWM}$ & 100,00 & 114,20 & 109,04 & 38,09 & 6006,60 & 274,05 & $-7,30$ & 281,35 & 134,91 & 192,58 & 192,63 & 39,61 & 570,80 & 67,81 & 30,55 & 20,97 & 174,04 & 108,84 & 113,47 & 144,47 \\
\hline Triturus marmoratus & 30TWM87 & 100,00 & 128,35 & 107,02 & 38,02 & $\begin{array}{ll}5975,87 \\
\end{array}$ & 284,11 & 7,13 & 276,98 & 149,45 & 205,52 & 205,54 & 53,25 & 532,35 & 62,14 & 27,45 & 21,42 & 160,02 & 100,23 & 104,59 & 134,85 \\
\hline Triturus marmoratus & 30TWM88 & 100,00 & 134,35 & 105,10 & 38,04 & 5889,37 & 286,21 & \begin{tabular}{ll|}
14,87 \\
\end{tabular} & 271,33 & 132,12 & 210,31 & 210,31 & 60,31 & 546,65 & 61,38 & 27,62 & 21,02 & 160,87 & 102,44 & 104,23 & 141,00 \\
\hline Triturus marmoratus & 30TWM89 & 100,00 & 131,38 & 104,44 & 38,2 & 5824,87 & 281,87 & 13,37 & 268,50 & 108,01 & 206,61 & 206,61 & 58,00 & 599,62 & 65 , & 30,34 & 20,55 & 175,85 & 111,50 & 111,85 & 158,52 \\
\hline Triturus marmoratus & 30TWM92 & 100,00 & 72,64 & 106,71 & 37,7 & 5954,64 & 233,16 & $-46,25$ & 279,41 & \begin{tabular}{|c|c|}
89,69 \\
\end{tabular} & $\mid 152,01$ & $\begin{array}{ll}152,06 \\
\end{array}$ & $\begin{array}{c}0,060 \\
0,86 \\
\end{array}$ & 739,71 & 89,38 & 43 & 19,55 & 230,16 & 148,20 & 155,56 & 180,58 \\
\hline Triturus marmoratus & 30TWM93 & 100,00 & 108,87 & 109,70 & 38,00 & 6087,02 & 270,50 & $-15,03$ & 285,53 & 129,85 & 188,27 & 188,40 & 33,36 & 539,83 & 68,31 & 29,30 & 22,86 & 171,31 & 104,81 & 115,50 & 130,99 \\
\hline Triturus marmoratus & 30TWM94 & 100,00 & 116,65 & 109,32 & 38,00 & 6088,93 & 277,28 & $-6,85$ & 284,12 & 138,12 & 195,80 & 195,84 & 40,77 & 518,92 & 65,08 & 27,44 & 23,06 & 163,27 & 99,03 & 108,04 & 127,24 \\
\hline Triturus marmoratus & 30TWM95 & 100,00 & 125,99 & 108,46 & 38,00 & 6076,73 & 284,75 & 2,67 & 282,08 & 148,08 & 204,72 & 3 & 49,95 & 501,18 & 61,5 & 25, & 22,97 & 93 & 94,08 & 100,50 & 124,61 \\
\hline Triturus marmoratus & 30TWM96 & 100,00 & 131,71 & 107,23 & 38,0 & 6028,23 & 288,08 & 9,28 & 278,79 & $\begin{array}{l}\mid 430,84 \\
153,84 \\
\end{array}$ & 209,61 & 20 & 55,88 & 508,03 & 60, & 25 & 22,64 & 29 & 94,21 & 97,98 & 128,91 \\
\hline Triturus marmoratus & $30 \mathrm{TWN}$ & 100,00 & 13 & 105,89 & 38,00 & 5954,58 & 289,29 & 14,64 & 274,65 & 134,12 & 212,38 & 212,38 & 60,68 & 530,99 & 60,4 & 26,04 & 22,04 & 156,61 & 97,62 & 99,75 & 138,13 \\
\hline Triturus marmoratus & 30TWM98 & 100,00 & 132,69 & 105,57 & 38,03 & 5901,17 & 285,19 & 12,88 & 272,31 & $\begin{array}{ll}98,97 \\
\end{array}$ & 208,86 & 208,86 & 58,47 & 581,45 & 64,16 & 28,73 & 21,48 & 171,39 & $\begin{aligned} 106,18 \\
\end{aligned}$ & 106,63 & 155,19 \\
\hline Triturus marmoratus & 30TWM99 & 100,00 & 131,07 & 104,91 & 38,25 & 5841,19 & 282,14 & 12,33 & 269,81 & 95,75 & 206,50 & 206,50 & 57,70 & 635,06 & 70,00 & 31,24 & 21,29 & 189,54 & 114,88 & 115,15 & 174,14 \\
\hline Triturus marmoratus & 30TWNOO & 100,00 & 120,38 & 94,44 & 37,97 & 5419,18 & 260,53 & 13,68 & 246,85 & 88,49 & 190,40 & 191,40 & 53,06 & 629,12 & 66,32 & 31,18 & 19,25 & 06 & 120,44 & 121,28 & 17 \\
\hline Triturus marmoratus & $30 \mathrm{TWN}$ & 100,00 & $\frac{12}{12}$ & $\begin{array}{l}94,444 \\
91,73\end{array}$ & 37 & 5288,90 & 256,13 & $\begin{array}{l}0,00 \\
16,42 \\
\end{array}$ & \begin{tabular}{|l|}
239,71 \\
239,1
\end{tabular} & \begin{tabular}{l|l}
80,434 \\
88,03
\end{tabular} & $\begin{array}{l}180,49 \\
188,4\end{array}$ & 189,70 & 54,88 & $\mid \begin{array}{l}\mid 203,12 \\
677,58\end{array}$ & $\begin{array}{l}0,322 \\
72,94 \\
\end{array}$ & $\frac{1,1}{33,2}$ & $\begin{array}{l}19,25 \\
19,58\end{array}$ & \begin{tabular}{|l|l|}
203,86 \\
\end{tabular} & $\begin{array}{l}128,09 \\
128\end{array}$ & $\begin{array}{l}121,20 \\
130,50\end{array}$ & 187,86 \\
\hline Triturus marmoratus & 30TWNO2 & 100,00 & 122,30 & 88,59 & 37,80 & 5134,56 & 253,13 & 21,27 & 231,85 & 92,57 & 188,13 & 189,59 & 58,65 & 725,80 & 80,04 & 34,78 & 20,01 & 221,58 & 134,57 & 139,36 & 206,13 \\
\hline Triturus marmoratus & 30TWNO3 & 100,00 & 116,25 & 87,55 & \begin{tabular}{|c|}
37,88 \\
\end{tabular} & 5049,03 & 246,02 & 17,38 & 228,64 & 76,28 & 181,08 & 182,81 & 54,08 & 797,32 & 88,72 & 38,69 & 19,84 & 243,94 & 147,58 & 152,84 & 229,04 \\
\hline Triturus marmoratus & 30TWN05 & 100,00 & 111,15 & 83,25 & 37,86 & 4804,25 & 234,88 & 17,47 & 217,42 & 60,22 & 172,58 & 174,81 & 52,45 & 940,18 & 107,73 & 45,27 & 20,77 & & 170,42 & 179,21 & 278,61 \\
\hline Triturus marmoratus & 30TWN & 100,00 & 120 & 76,99 & 37,3 & 4558,16 & 235,22 & 31,95 & 203,28 & 72,35 & 178,65 & 18 & 65,04 & 998,87 & 119,07 & 45,23 & 23,21 & 320,68 & 173,37 & 188,61 & $30 \varepsilon$ \\
\hline Triturus marmoratus & 30TWN08 & 100,00 & 130,79 & 67,22 & 36,46 & 4178,09 & 230,99 & 49,14 & 181,86 & 84,61 & 182,80 & 185,90 & 79,44 & 1139,08 & 144,30 & 47,36 & 27,59 & 380,12 & 184,84 & 211,30 & 374,92 \\
\hline Triturus marmoratus & 30TWN09 & 99,00 & 138,12 & 61,59 & 35,64 & 3978,81 & 229,93 & 59,82 & 170,11 & 90,52 & 187,26 & 190,50 & 88,95 & 1202,85 & 157,78 & 47,29 & 30,38 & 411,24 & 187,22 & 220,79 & 410,73 \\
\hline Triturus marmoratus & 30TWN10 & 100,00 & 121,39 & 95,73 & 38,00 & 5462,53 & 262,62 & 13,45 & 249,18 & 88,99 & 192,30 & 192,78 & 53,50 & 617,79 & 64,51 & 31,17 & 18,99 & 181,58 & 120,47 & 120,61 & 165,39 \\
\hline Triturus & 30TWN11 & 100,00 & 121,17 & 92,97 & 38,03 & 5325,25 & 258,05 & 16,19 & 241, & 87,30 & 189, & 190 & 55, & 671,24 & 71,31 & 33,48 & 19,01 & 200 & 129,18 & 130,57 & 18 \\
\hline Triturus marmoratus & 30TWN14 & 100,00 & 114,06 & 86,70 & 38,04 & 4951,83 & 242,09 & 17,31 & 224,79 & 60,66 & 177,48 & 179,45 & 53,44 & 873,38 & 97,76 & 42,79 & 19,69 & 68,69 & 61,95 & 67,58 & 253, \\
\hline
\end{tabular}




\begin{tabular}{|c|c|c|c|c|c|c|c|c|c|c|c|c|c|c|c|c|c|c|c|c|c|}
\hline TAXON & UTM & $\mathrm{km} 2$ & B101 & $\mathrm{B1O2}$ & $\mathrm{BIO3}$ & BIO4 & B105 & B106 & B107 & $\mathrm{B108}$ & B109 & B1010 & BIO11 & BIO12 & B1013 & BIO14 & B1015 & BIO16 & BI017 & B1018 & B1019 \\
\hline Triturus marmoratus & 30TWN15 & 100,00 & 110,09 & 85,02 & 38,03 & 4845,20 & 235,85 & 15,60 & 220,25 & 58,25 & 172,10 & 174,23 & 51,07 & 950,45 & 107,55 & 46,56 & 19,95 & 295,50 & 174,82 & 181,79 & 279,59 \\
\hline Triturus marmoratus & 30TWN16 & 100,00 & 98,64 & 85,16 & 38,28 & 4807,67 & 225,03 & 5,69 & 219,33 & 47,92 & 160,34 & 162,73 & 40,71 & 1045,75 & 118,43 & 52,56 & 19,70 & 326,01 & 193,81 & 199,88 & 307,97 \\
\hline Triturus marmoratus & 30TWN19 & 100,00 & 136,81 & 64,62 & 36,64 & 4030,81 & 233,08 & 59,18 & 173,91 & 91,57 & 186,35 & 189,85 & 88,01 & 1213,41 & 155,48 & 49,45 & 28,69 & 408,53 & 193,61 & 224,12 & 406,77 \\
\hline Triturus marmoratus & 30 TWN20 & 100,00 & 126,10 & 96,62 & 38,00 & 5507,50 & 267,48 & 16,71 & 250,77 & 94,30 & 197,64 & 197,75 & 57,42 & 585,64 & 61,84 & 29,96 & 18,98 & 170,90 & 116,21 & 116,25 & 153,13 \\
\hline Triturus marmoratus & 30TWN21 & 100,00 & 110,79 & 96,77 & 38,36 & 5416,85 & 252,98 & 4,19 & 248,79 & 66,36 & 182,05 & 182,15 & 44,22 & 711,86 & 74,31 & 37,25 & 17,99 & 207,94 & 138,90 & 138,90 & 192,77 \\
\hline Triturus marmoratus & 30TWN22 & 100,00 & 111,72 & 94,34 & 38,29 & 5288,91 & 250,19 & 7,67 & 242,52 & 61,67 & 180,75 & 181,31 & 46,66 & 758,46 & 80,55 & 39,13 & 18,04 & 223,91 & 147,33 & 147,51 & 209,39 \\
\hline Triturus marmoratus & 30TWN23 & 100,00 & 112,54 & 91,62 & 38,28 & 5147,34 & 246,88 & 11,33 & 235,56 & 60,18 & 178,85 & 180,25 & 49,36 & 813,72 & 88,10 & 41,36 & 18,36 & 244,33 & 156,34 & 157,56 & 229,17 \\
\hline Triturus marmoratus & 30TWN24 & 100,00 & 119,93 & 86,90 & 38,16 & 4940,64 & 247,10 & 22,81 & 224,29 & 66,12 & 182,88 & 184,78 & 59,15 & 862,41 & 95,99 & 42,06 & 19,59 & 264,73 & 160,61 & 165,94 & 250,16 \\
\hline Triturus marmoratus & 30 TWN25 & 100,00 & 117,45 & 84,69 & 38,13 & 4802,05 & 241,38 & 23,20 & 218,18 & 65,44 & 178,44 & 180,66 & 58,75 & 945,48 & 107,01 & 45,75 & 20,05 & 294,32 & 173,45 & 180,86 & 279,21 \\
\hline Triturus marmoratus & 30TWN26 & 100,00 & 113,08 & 82,98 & 38,30 & 4690,10 & 234,81 & 21,53 & 213,27 & 62,92 & 172,61 & 175,10 & 56,11 & 1031,02 & 118,07 & 49,92 & 20,60 & 324,36 & 187,44 & 196,33 & 308,42 \\
\hline Triturus marmoratus & 30TWN32 & 100,00 & 108,82 & 96,39 & 38,76 & 5341,01 & 249,64 & 3,40 & 246,24 & 51,29 & 179,08 & 179,08 & 43,24 & 775,71 & 81,65 & 40,84 & 17,59 & 227,76 & 150,97 & 150,97 & 212,72 \\
\hline Triturus marmoratus & 30TWN33 & 100,00 & 103,56 & 94,58 & 38,90 & 5221,61 & 242,10 & 1,07 & 241,03 & 47,20 & 172,36 & 172,57 & 39,87 & 862,93 & 92,57 & 45,23 & 17,73 & 257,56 & 166,55 & 166,66 & 241,63 \\
\hline Triturus marmoratus & 30TWN34 & 100,00 & 118,90 & 89,15 & 38,76 & 4985,27 & 248,45 & 20,54 & 227,91 & 64,53 & 182,50 & 184,28 & 57,72 & 871,82 & 95,63 & 43,42 & 18,82 & 265,85 & 165,05 & 168,09 & 249,88 \\
\hline Triturus marmoratus & 30TWN36 & 100,00 & 118,93 & 83,30 & 38,89 & 4648,14 & 239,72 & 27,74 & 211,98 & 68,82 & 177,68 & 180,22 & 62,58 & 1040,38 & 118,56 & 50,06 & 20,62 & 327,62 & 188,78 & 197,71 & 311,32 \\
\hline Triturus marmoratus & 30 TWN40 & 100,00 & 128,64 & 100,21 & 38,06 & 5669,25 & 273,99 & 15,27 & 258,73 & 148,38 & 191,98 & 201,80 & 57,55 & 533,26 & 60,36 & 29,04 & 19,70 & 156,83 & 109,49 & 112,01 & 130,23 \\
\hline Triturus marmoratus & 30TWN41 & 100,00 & 113,05 & 99,65 & 38,75 & 5511,61 & 257,95 & 3,55 & 254,40 & 78,84 & 185,14 & 185,14 & 44,99 & 697,21 & 73,21 & 37,48 & 17,57 & 200,54 & 137,18 & 137,18 & 184,62 \\
\hline Triturus marmoratus & 30TWN42 & 100,00 & 111,66 & 97,48 & 38,97 & 5372,17 & 253,22 & 4,92 & 248,30 & 55,80 & 182,10 & 182,10 & 45,54 & 765,08 & 79,88 & 40,51 & 17,51 & 223,68 & 149,08 & 149,08 & 207,95 \\
\hline Triturus marmoratus & 30TWN43 & 100,00 & 104,69 & 95,80 & 39,00 & 5253,68 & 244,22 & 1,10 & 243,12 & 47,78 & 173,98 & 173,98 & 40,45 & 867,38 & 92,76 & 45,79 & 17,66 & 258,43 & 167,34 & 167,34 & 241,97 \\
\hline Triturus marmoratus & 30TWN44 & 100,00 & 116,32 & 91,52 & 39,00 & 5041,25 & 248,65 & 16,52 & 232,13 & 61,40 & 180,99 & 182,51 & 54,49 & 893,15 & 97,14 & 45,32 & 18,33 & 271,42 & 170,94 & 171,69 & 254,05 \\
\hline Triturus marmoratus & 30TWN45 & 100,00 & 108,38 & 90,08 & 39,01 & 4932,58 & 239,01 & 11,27 & 227,75 & 55,25 & 171,85 & 173,45 & 48,43 & 998,88 & 1110,42 & 50,92 & 18,72 & 307,34 & 189,19 & 190,92 & 289,05 \\
\hline Triturus marmoratus & 30TWN47 & 100,00 & 127,37 & 80,59 & 39,48 & 4414,46 & 242,24 & 40,45 & 201,79 & 79,66 & 182,45 & 185,32 & 74,13 & 1134,07 & 130,68 & 53,16 & 21,75 & 362,79 & 200,85 & 213,87 & 344,92 \\
\hline Triturus marmoratus & 30TWN49 & 83,00 & 135,59 & 73,79 & 39,59 & 4081,88 & 239,93 & 55,56 & 184,37 & 91,69 & 185,64 & 189,10 & 86,91 & 1255,69 & 149,38 & 56,31 & 24,10 & 411,33 & 213,84 & 236,38 & 394,56 \\
\hline Triturus marmoratus & 30TWN50 & 100,00 & 128,81 & 101,63 & 38,17 & 5707,35 & 275,59 & 14,16 & 261,43 & 149,29 & 178,54 & 202,48 & 57,20 & 531,73 & 60,97 & 29,42 & 19,74 & 159,20 & 108,66 & 111,32 & 127,16 \\
\hline Triturus marmoratus & 30TWN51 & 100,00 & 117,27 & 100,71 & 38,83 & 5560,53 & 262,85 & 6,08 & 256,77 & 96,97 & 189,70 & 189,70 & 48,22 & 677,80 & 71,69 & 36,57 & 17,82 & 194,92 & 133,18 & 133,23 & 177,28 \\
\hline Triturus marmoratus & 30TWN52 & 100,00 & 111,01 & 98,69 & 38,99 & 5410,56 & 253,88 & 3,30 & 250,58 & 54,19 & 181,92 & 181,92 & 44,35 & 784,16 & 81,97 & 41,74 & 17,60 & 229,51 & 151,86 & 151,86 & 213,21 \\
\hline Triturus marmoratus & 30TWN53 & 100,00 & 99,05 & 97,23 & 39,00 & 5289,83 & 240,71 & $-5,51$ & 246,22 & 42,19 & 169,02 & 169,02 & 34,61 & 912,83 & 98,09 & 48,79 & 17,47 & 272,35 & 174,91 & 174,91 & 255,66 \\
\hline Triturus marmoratus & 30TWN54 & 100,00 & 108,16 & 93,91 & 39,01 & 5109,92 & 243,98 & 6,90 & \begin{tabular}{|l|l|}
237,08 \\
\end{tabular} & $\mid 52,94$ & 175,02 & 175,43 & $\begin{array}{ll}44,78 \\
45,7\end{array}$ & 945,86 & \begin{tabular}{|c|}
103,08 \\
\end{tabular} & 49,09 & 18,18 & 287,36 & 180,52 & 180,55 & 269,18 \\
\hline Triturus marmoratus & 30TWN56 & 100,00 & 121,30 & 86,70 & 39,73 & 4667,95 & 244,58 & 28,76 & 215,83 & 70,68 & 180,08 & 182,54 & 64,62 & 1082,56 & 121,58 & 52,97 & 20,11 & 340,60 & 198,55 & 204,39 & 320,05 \\
\hline Triturus marmoratus & 30TWN58 & 100,00 & 128,13 & 80,12 & 40,23 & 4265,19 & 240,38 & 43,60 & 196,79 & 82,32 & 180,89 & 184,14 & 77,08 & 1240,29 & 142,68 & 58,48 & 21,94 & 399,49 & 218,99 & 233,70 & 377,46 \\
\hline Triturus marmoratus & 30TWN59 & 44,00 & 139,91 & 75,83 & 40,32 & 4069,49 & 244,87 & 58,97 & 185,90 & 95,91 & 189,63 & 193,12 & 91,12 & 1259,76 & 147,65 & 57,21 & 23,51 & 411,15 & 216,65 & 238,33 & 390,14 \\
\hline Triturus marmoratus & 30TWN60 & 100,00 & 128,49 & 102,42 & 38,65 & 5712,74 & 275,91 & 13,51 & 262,40 & 148,66 & 202,28 & 202,28 & 56,78 & 570,93 & 63,70 & 30,87 & 19,23 & 168,39 & 113,13 & 114,32 & 141,37 \\
\hline Triturus marmoratus & 30TWN61 & 100,00 & 123,57 & 101,06 & 38,90 & 5586,07 & 268,85 & $\begin{array}{ll}11,30 \\
11,0\end{array}$ & 257,55 & \begin{tabular}{r|r|r|r|r|}
97,75 \\
\end{tabular} & \begin{tabular}{|l|l|}
195,97 \\
\end{tabular} & \begin{tabular}{|l|l|}
195,97 \\
\end{tabular} & 53,90 & 664,02 & 70,13 & 35,35 & 18,29 & 191,84 & 129,09 & 129,09 & 1743,33 \\
\hline Triturus marmoratus & 30TWN62 & 100,00 & 116,46 & 99,48 & 39,00 & 5443,10 & 259,68 & 7,43 & 252,25 & 61,06 & 187,44 & 187,44 & 49,16 & 775,19 & 81,60 & 40,88 & 18,03 & 228,47 & 148,49 & 148,49 & 211,26 \\
\hline Triturus marmoratus & 30TWN63 & 100,00 & 103,32 & 97,94 & 39,01 & 5316,96 & 245,23 & $-2,27$ & 247,50 & 45,76 & 173,31 & 173,31 & 38,25 & 914,81 & 99,12 & 48,44 & 17,94 & 274,80 & 173,71 & 173,71 & 257,41 \\
\hline Triturus marmoratus & 30TWN64 & 100,00 & 104,07 & 95,58 & 39,10 & 5166,61 & 242,19 & 1,56 & 240,63 & 48,36 & 172,21 & 172,21 & 41,03 & 984,99 & 108,32 & 51,52 & 18,30 & 300,55 & 186,36 & 186,36 & 281,81 \\
\hline Triturus marmoratus & 30TWN65 & 100,00 & 114,75 & 92,10 & 39,59 & 4941,28 & 246,34 & 16,24 & 230,10 & 61,12 & 178,84 & 179,67 & 54,48 & 1037,83 & 115,65 & 52,42 & 19,30 & 323,01 & 194,30 & 195,10 & 302,10 \\
\hline Triturus marmoratus & 30TWN66 & 100,00 & 130,98 & 86,46 & 40,11 & 4575,07 & 251,84 & 39,33 & 212,51 & 81,00 & 188,09 & 190,77 & 75,39 & 1103,43 & 124,59 & 52,88 & 20,87 & 350,55 & 199,35 & 206,77 & 327,82 \\
\hline Triturus marmoratus & $30 \mathrm{TWNG}$ & 47,00 & 142,35 & 77,38 & 40,97 & 4040,34 & 247,61 & 61,04 & 186,56 & 98,65 & 191,69 & 195,08 & 93,94 & 1284,21 & 149,00 & 59,06 & 23,20 & 418,49 & 222,79 & 243,99 & 393,32 \\
\hline Triturus marmoratus & 30TWN70 & 100,00 & 128,26 & 103,05 & 38,81 & 5722,17 & 276,35 & 12,53 & 263,82 & 117,08 & 202,17 & 202,17 & 56,39 & 621,40 & 66,86 & \begin{tabular}{|c|}
32,47 \\
\end{tabular} & 19,35 & 180,75 & 118,47 & 118,66 & 161,95 \\
\hline Triturus marmoratus & 30TWN72 & 100,00 & 120,18 & 100,16 & 39,00 & 5473,56 & 264,10 & 10,08 & 254,02 & 59,92 & 191,43 & 191,43 & 52,22 & 795,65 & 86,12 & 40,98 & 18,93 & 239,09 & 48,78 & 48,78 & 221,42 \\
\hline Triturus marmoratus & 30TWN73 & 100,00 & 103,41 & 98,80 & 39,01 & 5350,09 & 246,23 & $-3,39$ & 249,61 & 45,57 & 173,73 & 17 & 37,87 & 936,65 & 102,89 & 49,35 & 18,41 & 283,47 & 175,99 & 175,99 & 265,79 \\
\hline Triturus marmoratus & 30TWN74 & 100,00 & 100,62 & 96,62 & 39,21 & 5208,45 & 240,12 & $-2,82$ & 242,94 & 44,68 & 169,38 & 169,38 & 37,17 & 1021,25 & 113,47 & 53, & 18,56 & 312,86 & 191,86 & 191,86 & 293,94 \\
\hline Triturus marmoratus & 30TWN75 & 100,00 & 108,49 & 94,04 & 39,53 & 5036,57 & 243,08 & 7,88 & 235,20 & 54,16 & 174,61 & 174,66 & 46,97 & \begin{tabular}{|l|}
1073,28 \\
\end{tabular} & 120,82 & 54,95 & 19,36 & 334,82 & 200,40 & 200,40 & 313,61 \\
\hline Triturus marmoratus & 30TWN77 & 100,00 & 129,54 & 85,98 & 40,78 & 4449,01 & 248,19 & 39,74 & 208,45 & 81,29 & 184,82 & 187,75 & 75,75 & 1224,90 & 139,65 & 59,02 & 21,43 & 393,34 & 220,21 & 229,16 & 366,76 \\
\hline Triturus marmoratus & 30TWN79 & 55,00 & 142,54 & 79,19 & 41, & 4050,54 & 248,44 & 59,70 & 8,74 & 98,79 & 191,96 & 195,32 & 93,85 & 1318,53 & 152,11 & 78 & 22,71 & 28,98 & 91 & 52,33 & 399,74 \\
\hline Triturus marmoratus & 30TWN81 & 100,00 & 127 & 102,29 & $3 \varepsilon$ & 5634,65 & 274,404 & 12,96 & $\frac{10}{26}$ & 69,60 & 20 & & 56,46 & \begin{tabular}{|l|l|}
736,82 \\
5
\end{tabular} & 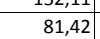 & & 20,25 & 222,85 & 134,50 & 134,50 & 206,27 \\
\hline Triturus marmoratus & $30 \mathrm{TWI}$ & 100,00 & 12 & 101,03 & 38,99 & 5523,64 & 267,28 & 10,41 & 256,87 & 61,07 & 193,86 & 193,86 & 53,14 & 830,67 & 93,74 & 41,5 & 20,33 & 255,99 & 150,78 & 150,78 & 238,30 \\
\hline Triturus marmoratus & 30 TWN83 & 100,00 & 110,64 & 99,59 & 39,01 & 5397,98 & 254,13 & 2,25 & 251,88 & 51,75 & 181,21 & 181,21 & 43,90 & 943,14 & $\begin{array}{r}106,92 \\
\end{array}$ & 48,21 & 19,84 & 291,81 & 172,73 & 172,73 & 273,47 \\
\hline Triturus marmoratus & 30TWN84 & 100,00 & 91,57 & 97,49 & 39,01 & 5276,41 & 233,10 & $-13,28$ & 246,38 & 35,46 & 161,44 & 161,44 & 27,57 & 1060,01 & 118,21 & 56,62 & 18,24 & 323,42 & 199,51 & 199,51 & 305,06 \\
\hline Triturus marmoratus & 30TWN86 & 100,00 & 113,46 & 92,50 & 39,91 & 4893,48 & 244,21 & 14,93 & 229 & 60,58 & 176 & 17 & 53,68 & 1171,81 & 135,21 & 58,72 & 20,63 & 373,55 & 215,77 & 216,84 & 349,65 \\
\hline Triturus marmoratus & $30 \mathrm{TWI}$ & 84,00 & $\frac{1}{14}$ & 80 & $\frac{41,12}{41,12}$ & \begin{tabular}{|}
4147,407 \\
414707
\end{tabular} & 249,07 & 56,16 & $\mid$\begin{tabular}{|l|}
192,91 \\
12,0
\end{tabular} & $\begin{array}{l}\mid c 0,0 \\
97,07 \\
\end{array}$ & 192,83 & \begin{tabular}{|l|}
196,01 \\
\end{tabular} & $\begin{array}{l}0,00 \\
91,49 \\
\end{array}$ & $\mid \begin{array}{l}111,01 \\
1324,87\end{array}$ & \begin{tabular}{|l|l|}
154,41 \\
154,1
\end{tabular} & 63, 63,41 & 22,63 & 431,54 & 237,27 & 257,20 & $\begin{array}{l}34,05 \\
400,51\end{array}$ \\
\hline Triturus marmoratus & 30TWN90 & 100,00 & 130,41 & 103,87 & 38,51 & 5766,03 & 279,85 & 13,29 & 266,56 & 90,01 & 204,94 & 204,94 & 57,74 & 694,81 & 78,47 & 33,90 & 21,38 & 210,72 & 124,39 & 124,39 & 195,88 \\
\hline Triturus marmoratus & 30TWN91 & 100,00 & 129,65 & 102,72 & 38,78 & 5672,55 & 277,29 & 14,55 & 262,73 & 67,71 & 202,99 & 202,99 & 58,42 & 767,09 & 88,85 & 37,06 & 21,72 & 238,28 & 135,92 & 135,92 & 222,37 \\
\hline Triturus marmoratus & 30TWN92 & 100,00 & 124,90 & 101,77 & 38,94 & 5574,60 & 271,25 & 11,91 & 259,34 & 63,38 & 197,29 & 197,29 & 55,07 & 861,72 & 101,88 & 41,69 & 22,23 & 272,79 & 151,59 & 151,59 & 255,62 \\
\hline Triturus marmoratus & $30 \mathrm{TWI}$ & 100,00 & 114,54 & 100,49 & 39,01 & 5454,66 & 259,17 & 4,41 & 254,76 & 54,88 & 185,74 & 185,74 & 46,83 & 966,57 & 113,87 & 48,01 & 21,46 & 306,26 & 172,27 & 172,27 & 28 \\
\hline Triturus marmoratus & 30TWN94 & 100,00 & 112,33 & 98,54 & 39,03 & 5324,67 & 253,68 & 5,05 & 248,64 & 54,25 & 181,91 & 181,91 & 46,41 & 1044,64 & 123,47 & 52,04 & 21,45 & 333,16 & 187,74 & 187,74 & 313,34 \\
\hline Triturus marmoratus & 30TWN95 & 100,00 & 112,46 & 96,45 & 39,30 & 5169,92 & 249,99 & 7,99 & 242,00 & 56,38 & 180,13 & 180,13 & 48,65 & 1115,28 & 131,91 & 55,58 & 21,42 & 357,89 & 201,88 & 201,88 & 336,12 \\
\hline Triturus marmoratus & 30TWN99 & 100,00 & 133,51 & 83,01 & 40,83 & 4317,29 & 244,87 & 43,87 & 201,01 & 90,02 & 186,91 & 189,84 & 80,53 & 1355,71 & 159,45 & 66,82 & 22,10 & 441,31 & 248,15 & 264,33 & 409,19 \\
\hline Triturus & 30TWP10 & 94,00 & 132,3 & 64,68 & 36,92 & 3975,66 & 228,22 & 55,49 & 72,72 & 89,86 & 181 & 184 & 84 & 1266,20 & 160,96 & 52,91 & 27,98 & 425,57 & 204,62 & 235,59 & $420, \mathrm{C}$ \\
\hline Triturus marmoratus & 30 TWP20 & 75,00 & 136,08 & 66,31 & 37,61 & 3978,94 & 33,33 & 59,44 & 173,89 & 93,78 & 184,80 & 188,46 & 88,51 & 1263,98 & 58,65 & 53,35 & 27,25 & 422,90 & 5,95 & 236,04 & 415,55 \\
\hline
\end{tabular}




\begin{tabular}{|c|c|c|c|c|c|c|c|c|c|c|c|c|c|c|c|c|c|c|c|c|c|}
\hline TAXON & UTM & $\mathrm{km} 2$ & B101 & $\mathrm{B1O2}$ & $\mathrm{BIO3}$ & BIO4 & B105 & B106 & B107 & $\mathrm{B108}$ & B109 & 81010 & BIO11 & BIO12 & 81013 & B1014 & B1015 & B1016 & $\begin{array}{ll}1017 \\
17\end{array}$ & B1018 & B1019 \\
\hline Triturus marmoratus & 30TWP90 & 28,00 & 138,83 & 80,55 & 40,75 & 4220,05 & 245,72 & 50,41 & 195,31 & 105,70 & 190,86 & 193,91 & 86,75 & 1355,98 & 160,34 & 66,73 & 22,59 & 442,94 & 248,83 & 269,58 & 409,41 \\
\hline Triturus marmoratus & 30TXL08 & 100,00 & 119,31 & 107,56 & 37,04 & 6208,37 & 276,96 & $-7,71$ & 284,68 & 141,99 & 146,18 & 200,12 & 41,69 & 421,86 & 60,06 & 22,40 & 29,85 & 144,91 & 84,45 & 96,62 & 90,46 \\
\hline Triturus marmoratus & 30TXLO9 & 100,00 & 104,34 & 107,92 & 37,44 & 6146,02 & 263,21 & $-21,23$ & 284,44 & 125,70 & 180,56 & 184,90 & 28,30 & 500,73 & 68,44 & 28,05 & 26,75 & 168,42 & 101,68 & 115,77 & 111,09 \\
\hline Triturus marmoratus & 30TXL18 & 100,00 & 120,30 & 106,30 & 37,00 & 6192,00 & 275,99 & $-6,49$ & 282,48 & 143,19 & 64,53 & 200,77 & 42,88 & 415,63 & 60,05 & 22,16 & 30,99 & 144,16 & 82,69 & 96,31 & 87,34 \\
\hline Triturus marmoratus & 30TXL19 & 100,00 & 114,54 & 106,66 & 37,01 & 6165,47 & 271,34 & $-11,31$ & 282,65 & 136,73 & 157,51 & 194,75 & 37,77 & 451,84 & 63,56 & 24,54 & 28,89 & 154,08 & 90,97 & 104,31 & 97,97 \\
\hline Triturus marmoratus & 30TXL28 & 100,00 & 115,43 & 104,94 & 37,00 & 6159,67 & 269,21 & $-10,72$ & 279,93 & 138,01 & 53,04 & 195,47 & 38,42 & 432,49 & 62,91 & 23,68 & 31,19 & 151,27 & 84,84 & 102,32 & 89,23 \\
\hline Triturus marmoratus & 30TXL39 & 100,00 & 136,03 & 105,08 & 37,00 & 6222,39 & 291,81 & 9,97 & 281,83 & 159,19 & 209,55 & 216,24 & 57,93 & 367,27 & 54,08 & 17,66 & 32,27 & 126,19 & 70,79 & 76,56 & 77,73 \\
\hline Triturus marmoratus & $\begin{array}{l}30 T \times L 59 \\
\end{array}$ & 100,00 & 129,44 & 103,72 & 36,76 & 6194,66 & 284,36 & 4,46 & 279,90 & 152,35 & 86,37 & 209,63 & 51,99 & 381,46 & 56,62 & 19,18 & 32,24 & 132,99 & 74,91 & 86,16 & 76,85 \\
\hline Triturus marmoratus & 30TXM02 & 100,00 & 100,94 & 108,08 & 37,93 & 6066,93 & 260,75 & $-22,31$ & 283,06 & 121,12 & 180,29 & 180,39 & 26,02 & 566,20 & 72,63 & 31,53 & 23,29 & 181,91 & 112,00 & 124,01 & 134,25 \\
\hline Triturus marmoratus & 30TXM03 & 100,00 & 119,16 & 108,53 & 37,97 & 6123,89 & 278,95 & $-5,19$ & 284,14 & 140,97 & 198,70 & 198,78 & 42,79 & 490,67 & 63,53 & 25,64 & 24,61 & 157,00 & 93,63 & 102,45 & 117,71 \\
\hline Triturus marmoratus & 30TXM05 & 100,00 & 133,34 & 107,29 & 37,99 & 6057,35 & 290,14 & 10,14 & 279,99 & 155,39 & 211,64 & 211,64 & 57,25 & 485,86 & 59,23 & 23,80 & 23,70 & 148,22 & 89,40 & 92,39 & 122,30 \\
\hline Triturus marmoratus & 30TXM06 & 100,00 & 134,37 & 106,67 & 37,99 & 6021,66 & 289,83 & 12,23 & 277,60 & 155,06 & 212,27 & 212,27 & 58,71 & 513,80 & 60,26 & 25,03 & 22,90 & 152,93 & 93,81 & 95,71 & 132,79 \\
\hline Triturus marmoratus & 30TXM07 & 100,00 & 136,85 & 105,91 & 38,00 & 5960,25 & 290,10 & 15,45 & 274,65 & 102,64 & 213,73 & 213,73 & 61,61 & 545,48 & 61,27 & 26,12 & 22,41 & 161,47 & 98,66 & 98,93 & 144,92 \\
\hline Triturus marmoratus & 30TXM09 & 100,00 & 131,31 & 105,03 & 38,08 & 5861,17 & 282,84 & 12,12 & 270,72 & 94,86 & 207,03 & 207,03 & 57,59 & 657,07 & 74,70 & 31,62 & 21,99 & 198,86 & 116,63 & 116,63 & 184,39 \\
\hline Triturus marmoratus & 30TXM12 & 100,00 & 117,64 & 107,61 & 37,63 & 6132,64 & 276,22 & $-6,61$ & 282,83 & 139,49 & 197,34 & 197,41 & 41,34 & 477,46 & 63,91 & 25,09 & 26,04 & 156,16 & 92,14 & 101,36 & 111,16 \\
\hline Triturus marmoratus & 30TXM13 & 100,00 & 121,44 & 107,69 & 37,73 & 6119,63 & 279,95 & $-2,63$ & 282,58 & 143,28 & 200,77 & 200,86 & 44,90 & 481,73 & 63,05 & 24,77 & 25,32 & 154,56 & 91,31 & 100,01 & 115,08 \\
\hline Triturus marmoratus & 30TXM15 & 100,00 & 137,34 & 106,54 & 37,96 & 6040,20 & 292,78 & 14,55 & 278,22 & 159,61 & 215,33 & 215,33 & 61,35 & 480,36 & 58,18 & 22,85 & 24,02 & 145,01 & 87,32 & 89,54 & 122,01 \\
\hline Triturus marmoratus & 30TXM16 & 100,00 & 136,42 & 106,17 & 38,00 & 6012,49 & 291,15 & 14,39 & 276,76 & 134,60 & 213,97 & 213,97 & 60,58 & 516,44 & 60,18 & 24,55 & 23,20 & 152,87 & 93,38 & 95,00 & 134,77 \\
\hline Triturus marmoratus & 30TXM17 & 100,00 & 132,53 & 106,19 & 38,00 & 5976,67 & 286,65 & 11,06 & 275,59 & 102,39 & 209,63 & 209,63 & 57,17 & 567,05 & 63,84 & 27,16 & 22,45 & 167,42 & 101,85 & 102,41 & 152,02 \\
\hline Triturus marmoratus & 30TXM18 & 100,00 & 130,54 & 105,84 & 38,00 & 5931,66 & 283,74 & 9,80 & 273,94 & 94,21 & 207,13 & 207,13 & 55,90 & 618,58 & 69,70 & 29,63 & 22,02 & $\mid 185,17$ & 110,02 & $\mid 110,09$ & 170,60 \\
\hline Triturus marmoratus & 30TXM19 & 100,00 & 130,52 & 105,12 & 38,01 & 5871,83 & 282,08 & 10,50 & 271,58 & 94,28 & 206,24 & 206,24 & 56,29 & 673,35 & 77,95 & 31,95 & 22,21 & 205,12 & 118,55 & 118,55 & 191,28 \\
\hline Triturus marmoratus & 30 TXM25 & 100,00 & 135,71 & 106,21 & 37,74 & 6045,86 & 291,28 & 12,96 & 278,32 & 157,97 & 213,74 & 213,74 & 59,53 & 487,17 & 59,36 & 23,02 & 24,15 & 147,02 & 88,34 & \begin{tabular}{|c|}
90,45 \\
\end{tabular} & 123,83 \\
\hline Triturus marmoratus & 30TXM26 & 100,00 & 132,34 & 106,18 & 37,95 & 6011,91 & 287,35 & 10,14 & 277,21 & 140,20 & 209,87 & 209,87 & 56,56 & 530,36 & 62,22 & 25,35 & 23,09 & 157,15 & 95,82 & 99,69 & 138,38 \\
\hline Triturus marmoratus & 30TXM27 & 100,00 & 133,69 & 105,99 & 38,00 & 5966,34 & 287,39 & 12,47 & 274,92 & 96,91 & 210,66 & 210,66 & 58,58 & 564,81 & 63,52 & 26,71 & 22,52 & 167,48 & 101,29 & 102,42 & 151,60 \\
\hline Triturus marmoratus & 30TXM28 & 100,00 & 127,85 & 105,90 & 38,00 & 5923,58 & 280,96 & 7,13 & 273,82 & 91,65 & 204,24 & 204,24 & 53,19 & 630,60 & 71,13 & 30,23 & 21,98 & 188,22 & 112,42 & 112,42 & 173,84 \\
\hline Triturus marmoratus & 30TXM29 & 100,00 & 126,49 & 105,21 & 38,02 & 5856,42 & 278,16 & 6,71 & 271,46 & 87,33 & 202,15 & 202,15 & 52,67 & 689,63 & 79,75 & 32,97 & 21,94 & 209,18 & 122,07 & 122,07 & 195,51 \\
\hline Triturus marmoratus & $30 \mathrm{TXM} 38$ & 100,00 & 127,53 & 105,31 & 38,00 & 5906,47 & 279,88 & $\begin{array}{ll}0,1 / 24 \\
6,84\end{array}$ & 273,04 & 91,61 & 203,72 & 203,72 & 52,95 & $\mid 626,84$ & 70,12 & 29,96 & 21,65 & $\mid \begin{array}{l}\mid 286,67 \\
180\end{array}$ & 112,73 & $\begin{array}{l}113,19 \\
\end{array}$ & 171,50 \\
\hline Triturus marmoratus & 30TXM39 & 100,00 & 124,96 & 104,99 & 38,09 & 5850,36 & 275,92 & 5,17 & 270,75 & 89,49 & 200,52 & 200,52 & 51,20 & 687,19 & 78,48 & 32,94 & 21,50 & 207,19 & 123,07 & 123,44 & 192,83 \\
\hline Triturus marmoratus & 30TXM48 & 100,00 & 120,32 & 104,88 & 38,03 & 5861,92 & 272,18 & 0,66 & 271,51 & 84,90 & 196,10 & 196,10 & 46,53 & 641,09 & 70,74 & 31,44 & 20,65 & 187,44 & 117,89 & 119,70 & 171,65 \\
\hline Triturus marmoratus & 30TXM49 & 100,00 & 111,52 & 104,06 & 38,12 & 5778,43 & 261,90 & $-6,27$ & 268,17 & 76,92 & 186,52 & 186,52 & 39,16 & 720,40 & 78,95 & 36,34 & 19,71 & 210,17 & 133,69 & 136,21 & 195,68 \\
\hline Triturus marmoratus & 30TXM57 & 100,00 & 124,80 & 104,84 & 38,00 & 5881,56 & 277,18 & 4,57 & 272,62 & 137,31 & 200,75 & 200,76 & 50,84 & 569,34 & 65,41 & 27,60 & 20,89 & 165,63 & 106,48 & 109,27 & 145,84 \\
\hline Triturus marmoratus & 30TXM58 & 100,00 & 113,90 & 103,95 & 38,00 & 5797,35 & 264,50 & $\begin{array}{l}-4,35 \\
-4,35 \\
\end{array}$ & 268,85 & 116,61 & 188,90 & 188,90 & $\begin{array}{ll}41,18 \\
418\end{array}$ & \begin{tabular}{ll|}
649,11 \\
\end{tabular} & $\begin{array}{l}20,41+57 \\
72,\end{array}$ & 32,71 & 19,63 & \begin{tabular}{|l|l|}
186,95 \\
\end{tabular} & 122,80 & $\begin{array}{ll}126,16 \\
\end{array}$ & 1468,81 \\
\hline Triturus marmoratus & 30TXM59 & 100,00 & 103,55 & 102,68 & 38,04 & 5708,48 & 252,07 & $-12,97$ & 265,04 & 93,71 & \begin{tabular}{|l|l|}
177,73 \\
\end{tabular} & 177,74 & 32,32 & 734,06 & 79,99 & 38,29 & 18,39 & 209,68 & 140,80 & 144,08 & 193,00 \\
\hline Triturus marmoratus & 30TXM61 & 100,00 & 144,69 & 105,21 & 36,38 & 6277,05 & 304,91 & 20,39 & 284,52 & 168,15 & 225,68 & 225,84 & 66,31 & 354,86 & 50,22 & 16,05 & 29,86 & 118,18 & 65,66 & 70,81 & 75,79 \\
\hline Triturus marmoratus & 30TXM62 & 100,00 & 140,27 & 105,20 & 36,92 & 6196,80 & 299,27 & 16,77 & 282,50 & 163,26 & 220,23 & 220,33 & 62,77 & 378,15 & 52,03 & 17,40 & 27,95 & 123,81 & 70,57 & 75,92 & 82,54 \\
\hline Triturus marmoratus & 30TXM66 & 100,00 & 128,08 & 104,69 & 37,91 & 5906,69 & 281,10 & 7,36 & 273,74 & 149,54 & 204,25 & 204,33 & 53,87 & 508,92 & 60,97 & 24,51 & 21,57 & 151,79 & 97,01 & 100,58 & 123,64 \\
\hline Triturus marmoratus & 30TXM67 & 100,00 & 118,97 & 103,90 & 38,00 & 5817,41 & 270,15 & 0,01 & 270,13 & 139,65 & 194,19 & 194,25 & 46,15 & 572,81 & 66,77 & 28,48 & 20,11 & 168,26 & 110,30 & 114,96 & 141,91 \\
\hline Triturus marmoratus & 30TXM68 & 100,00 & 109,32 & 102,91 & 38,01 & 5729,41 & 258,29 & $-7,86$ & 266,14 & 129,00 & 183,44 & 183,52 & 37,62 & 649,78 & 73,60 & 33,38 & 18,82 & 188,19 & 126,30 & 131,44 & 164,01 \\
\hline Triturus marmoratus & 30TXM69 & 100,00 & 96,15 & 101,10 & 38,05 & 5631,87 & 242,63 & $-18,79$ & 261,42 & 113,00 & 169,56 & 169,58 & 26,19 & 753,18 & 83,07 & 40,55 & 17,42 & 215,76 & 148,84 & 152,24 & 192,26 \\
\hline Triturus marmoratus & 30TXM71 & 100,00 & 146,76 & 105,24 & 36,17 & 6257,39 & 307,56 & 21,90 & 285,66 & 170,51 & 227,09 & 227,87 & 68,17 & 356,92 & 46,94 & 16,56 & 26,97 & 116,55 & 69,08 & 73,65 & 72,93 \\
\hline Triturus marmoratus & 30TXM76 & 100,00 & 124,55 & 103,96 & 37,89 & 5840,31 & 276,45 & 4,49 & 271,96 & 145,76 & 199,77 & 200,03 & 51,17 & 504,72 & 61,06 & 24,69 & 21,14 & 151,66 & 99,13 & 103,45 & 118,15 \\
\hline \begin{tabular}{|l} 
Triturus marmoratus \\
\end{tabular} & 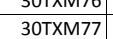 & 100,00 & $\begin{array}{l}12,53 \\
114,39\end{array}$ & $\begin{array}{l}102,90 \\
102,89\end{array}$ & $\frac{3,205}{38,00}$ & \begin{tabular}{|l|}
544,51 \\
5741,08
\end{tabular} & 263,45 & $\begin{array}{r}x^{-3,49} \\
-3,34\end{array}$ & \begin{tabular}{|l|}
267,33 \\
\end{tabular} & $\begin{array}{l}134,57 \\
134,5 \\
\end{array}$ & 198,17 & \begin{tabular}{|l|}
188,75 \\
\end{tabular} & $\begin{array}{l}1,111 \\
42,53\end{array}$ & $\begin{array}{l}04,1<2 \\
574,25\end{array}$ & $\begin{array}{l}61,00 \\
67,66\end{array}$ & \begin{tabular}{|c|}
24,05 \\
29,05
\end{tabular} & $\begin{array}{l}1,14 \\
19,62\end{array}$ & \begin{tabular}{|l|}
169,90 \\
169
\end{tabular} & \begin{tabular}{|l|}
95,15 \\
113,86 \\
\end{tabular} & \begin{tabular}{|l|}
118,68 \\
118,6
\end{tabular} & $\begin{array}{l}118,15 \\
137,66\end{array}$ \\
\hline Triturus marmoratus & 30TXM78 & 100,00 & 105,11 & 101,80 & 38,00 & 5660,68 & 252,52 & $-11,02$ & 263,54 & 124,45 & 178,48 & 178,66 & 34,44 & 651,86 & 74,57 & 34,13 & 18,21 & 189,92 & 130,24 & 135,19 & 159,73 \\
\hline Triturus marmoratus & 30TXM79 & 100,00 & 94,27 & 100,14 & 38,01 & 5578,12 & 239,18 & $-20,06$ & 259,24 & 112,36 & 166,83 & 166,86 & 24,87 & 748,31 & 83,20 & 40,77 & 16,95 & 215,23 & 151,02 & 156,15 & 186,56 \\
\hline Triturus marmoratus & 30TXM80 & 100,00 & 145,28 & 104,63 & 36,21 & 6190,31 & 303,61 & 20,15 & 283,46 & 168,93 & 79,03 & 225,67 & 67,72 & 355,22 & 47,42 & 16,52 & 28,16 & 16,99 & 69,07 & 74,27 & 69,08 \\
\hline Triturus marmoratus & $30 \mathrm{TXM} 87$ & 100,00 & $\begin{array}{l}14,20 \\
118,97\end{array}$ & 102,86 & 38,00 & $\begin{array}{l}5709,54 \\
\end{array}$ & 267,58 & $\begin{array}{c}2,113 \\
0,43 \\
\end{array}$ & 267,16 & $\begin{array}{ll}139,37 \\
\end{array}$ & 192,36 & 192,87 & $\begin{array}{l}47,08 \\
47\end{array}$ & \begin{tabular}{|l|l|}
538,87 \\
38,2
\end{tabular} & $\begin{array}{l}63,79 \\
63,42\end{array}$ & 26,86 & 19,88 & 159,26 & \begin{tabular}{rl|}
109,08 \\
\end{tabular} & 111,22 & $\begin{array}{r}125,26 \\
\end{array}$ \\
\hline Triturus marmoratus & $30 T \times M$ & 100,00 & 112 & 102,10 & 38,10 & 5625,63 & 258,76 & $-4,53$ & 263,29 & 132,04 & 184,71 & 185,06 & 41,42 & 601,19 & 69,0 & 30,72 & 18,49 & 174,65 & 122,07 & 124,87 & 143,51 \\
\hline Triturus marmoratus & 30 TXM89 & 100,00 & 102,23 & 100,74 & 38,23 & 5560,33 & 246,57 & $-12,78$ & 259,35 & 120,78 & 174,27 & 174,50 & 32,76 & 687,58 & 76,95 & 36,54 & 17,18 & 197,48 & 140,41 & 144,25 & 167,70 \\
\hline Triturus marmoratus & 30TXM92 & 100,00 & 129,35 & 103,44 & 36,99 & 5994,92 & 284,30 & 6,92 & 277,38 & 151,60 & 54,36 & 207,39 & 54,36 & 404,14 & 53,86 & 19,69 & 26,35 & 131,16 & 79,34 & 86,07 & 79,34 \\
\hline Triturus marmoratus & $30 T X N$ & 100,00 & 125,42 & 103,15 & 37,16 & 5845,85 & 277,79 & 5,00 & 272,79 & 146,96 & 109,87 & 201,35 & 52,13 & 434,80 & 56,04 & 21,21 & 24,10 & 136,59 & 88,95 & 91,20 & 89,39 \\
\hline Triturus marmoratus & $\frac{30 \mathrm{TX}}{3010}$ & 100,00 & $\frac{12}{12}$ & 104,76 & 38, & \begin{tabular}{|l}
5801,03 \\
5801,83
\end{tabular} & 278,61 & $\begin{array}{l}0,0,32 \\
9,2\end{array}$ & 269,29 & $\begin{array}{l}140,50 \\
70,78\end{array}$ & 202,65 & $\frac{20}{20}$ & |54,66 & $\begin{array}{l}\mid 754,00 \\
733,37 \\
\end{array}$ & $\begin{array}{l}30,04 \\
85,78\end{array}$ & 35, & $\frac{24,10}{22,26}$ & \begin{tabular}{|l|}
226,05 \\
22,0
\end{tabular} & \begin{tabular}{|l|l|}
128,43 \\
128
\end{tabular} & \begin{tabular}{|c|c|}
128,43 \\
120
\end{tabular} & $\begin{array}{l}0,212,22 \\
212\end{array}$ \\
\hline Triturus marmoratus & $30 \mathrm{TXN01}$ & 100,00 & 122,08 & 104,38 & 38,45 & 5749,16 & 272,88 & 5,07 & 267,82 & 58,33 & 196,59 & 196,59 & 49,94 & 823,10 & 98,48 & 39,67 & 22,73 & 259,36 & 142,68 & 142,68 & 244,35 \\
\hline Triturus marmoratus & $30 \mathrm{TXN02}$ & 100,00 & 118,55 & 103,34 & 38,71 & 5664,61 & 267,93 & 3,58 & 264,35 & 56,29 & 192,16 & 192,16 & 47,55 & 908,59 & 110,43 & 43,78 & 23,08 & 291,15 & 156,75 & 156,75 & 274,93 \\
\hline Triturus marmoratus & 30TXN03 & 100,00 & 117,28 & 101,84 & 38,87 & 5563,04 & 264,31 & 4,46 & 259,85 & 56,19 & 189,71 & 189,71 & 47,87 & 987,76 & 121,64 & 47,40 & 23,51 & 321,10 & 170,42 & 170,42 & 303,38 \\
\hline Triturus marmoratus & 30 TXN04 & 100,00 & 120,11 & 99,69 & 38,96 & 5424,70 & 263,16 & 9,95 & 253,21 & 60,57 & 190,76 & 190,76 & 52,43 & 1054,55 & 130,95 & 50,27 & 23,93 & 346,91 & 182,97 & 182,97 & 327 \\
\hline Triturus marmoratus & $\begin{array}{l}30 \text { TXN05 } \\
305\end{array}$ & 100,00 & $\begin{array}{ll}12,11 \\
110,26\end{array}$ & $\begin{array}{l}35,03 \\
97,76\end{array}$ & 39,07 & 5256,90 & $\begin{array}{l}20,10 \\
249,72\end{array}$ & 3,50 & \begin{tabular}{|l|}
246,121 \\
246
\end{tabular} & 53,32 & 179,04 & 179,04 & 45,21 & 1130,85 & 136,25 & 56,18 & 21,96 & 365,42 & 203,32 & 203,32 & 344,20 \\
\hline Triturus marmoratus & $30 T \times N 06$ & 100,00 & 106,18 & 95,55 & 39,43 & 5116,10 & 241,79 & 2,54 & 239,25 & 50,97 & 173,27 & 173,27 & 43,10 & 1195,82 & 142,30 & 60,52 & 21,15 & 384,30 & 219,61 & 219,61 & 361,55 \\
\hline Triturus marmoratus & $30 \mathrm{TXN10}$ & 100,00 & 123,99 & 105,02 & 38,19 & 5829,79 & 275,63 & 5,13 & 270,50 & 65,01 & 199,39 & 199,39 & 50,54 & 757,65 & 89,75 & 36,32 & 22,51 & 234,27 & 32,08 & 132,08 & 221,0 \\
\hline Triturus & 30TXN11 & 100,00 & 112,57 & 104,39 & 38,63 & 5739,69 & 263,64 & $-3,90$ & 267,55 & 49,56 & 187, & 187 & 40, & 859,66 & 101,79 & 42,53 & 21 & 26 & 151,36 & 51,36 & 252 \\
\hline Triturus marmoratus & 30 TXN12 & 100,00 & 104,16 & 102,64 & 38,87 & 5612,40 & 252,62 & $-9,53$ & 262,15 & 43,29 & 177,51 & 177,51 & 34,44 & 941,64 & 110,28 & 47,85 & 20,74 & 291,98 & 169,21 & 169,21 & 276,37 \\
\hline
\end{tabular}




\begin{tabular}{|c|c|c|c|c|c|c|c|c|c|c|c|c|c|c|c|c|c|c|c|c|c|}
\hline TAXON & UTM & $\overline{\mathrm{km} 2}$ & BIO1 & B102 & $\mathrm{BIO3}$ & B104 & B105 & B106 & B107 & B108 & B109 & BIO10 & BIO11 & BIO12 & 81013 & BIO14 & BIO15 & BIO16 & BIO17 & BIO18 & BlO19 \\
\hline Triturus marmoratus & 30TXN13 & 100,00 & 118,26 & 102,80 & 38,63 & 5631,79 & 266,64 & 3,42 & 263,22 & 56,39 & 191,36 & 191,36 & 47,70 & 996,28 & 125,80 & 47,05 & 24,63 & 327,85 & 169,48 & 169,48 & 310,93 \\
\hline Triturus marmoratus & 30TXN14 & 100,00 & 114,75 & 100,62 & 38,90 & 5484,35 & 259,12 & 3,13 & 255,99 & 54,69 & \begin{tabular}{|l|l}
186,16 \\
\end{tabular} & $\begin{array}{l}186,16 \\
\end{array}$ & \begin{tabular}{l|l}
46,05 \\
\end{tabular} & $\begin{array}{l}1064,60 \\
\end{array}$ & 132,53 & 51,37 & 23,62 & 348,62 & $\begin{array}{l}185,86 \\
\end{array}$ & $\begin{array}{l}185,86 \\
\end{array}$ & 329,79 \\
\hline Triturus marmoratus & 30TXN17 & 100,00 & $\begin{array}{ll}121,06 \\
\end{array}$ & 92,23 & 39,79 & 4938,64 & 248,44 & 18,70 & 229,73 & 67,68 & 183,71 & 185,35 & 59,33 & 1233,22 & 149,93 & 61,36 & 22,18 & 402,18 & 228,79 & 233,11 & 376,19 \\
\hline Triturus marmoratus & 30TXN20 & 100,00 & 116,12 & 104,93 & 38,45 & 5801,88 & 267,64 & $-1,72$ & 269,35 & 55,99 & \begin{tabular}{|l|l|}
191,37 \\
\end{tabular} & \begin{tabular}{|c|}
191,37 \\
\end{tabular} & 43,40 & 782,81 & 91,30 & 38,45 & 21,42 & 238,41 & \begin{tabular}{|l|l|l|}
138,98 \\
\end{tabular} & \begin{tabular}{|l|l|}
138,98 \\
\end{tabular} & 225,49 \\
\hline Triturus marmoratus & 30TXN21 & 100,00 & 110,77 & 103,97| & 38,69 & 5720,06 & 260,75 & $-5,38$ & 266,14 . & 48,12 . & 185,19 | & 185,19 & 39,23 & 858,42 & 100,73 & 42,72 & 21,16 [ & $264,27 \mid$ & 153,29 & 153,29 & 250,21 \\
\hline Triturus marmoratus & 30TXN22 & 100,00 & 103,37 & 102,39 & 38,82 & 5608,17 & 251,24 & $-10,44$ & 261,68 & 42,50 & 176,68 & 176,68 & 33,57 & \begin{tabular}{|c|}
936,79 \\
\end{tabular} & 109,38 & 47,68 & 20,38 & 288,82 & 169,79 & 169,79 & 273,40 \\
\hline Triturus marmoratus & 30TXN30 & 100,00 & 115,90 & 104,45 & 38,38 & 5773,08 & 266,18 & $-2,04$ & 268,22 & 67,10 & \begin{tabular}{|c|}
190,80 \\
\end{tabular} & 190,80 & 43,46 & 772,37 & 88,94 & 38,00 & 20,84 & 232,83 & $\begin{array}{l}139,04 \\
\end{array}$ & \begin{tabular}{l|l|}
139,04 \\
\end{tabular} & 219,86 \\
\hline Triturus marmoratus & 30TXN31 & 100,00 & 120,59 & 103,87 & 38,52 & 5721,66 & 268,99 & 2,92 & 266,06 & 65,57 & 194,55 & $\begin{array}{l}194,55 \\
\end{array}$ & \begin{tabular}{l|l}
48,45 \\
\end{tabular} & $\begin{array}{l}814,16 \\
\end{array}$ & 96,60 & 39,15 & 21,72 & 252,33 & \begin{tabular}{ll|}
145,09 \\
\end{tabular} & \begin{tabular}{ll|}
145,09 \\
\end{tabular} & 238,28 \\
\hline Triturus marmoratus & 30TXN32 & 100,00 & 113,49 & 102,85 & 38,92 & 5636,46 & 260,48 & $-2,03$ & 262,51 & 51,78 & 186,71 & 186,71 & \begin{tabular}{l|l|l}
42,65 \\
\end{tabular} & \begin{tabular}{l|l}
896,38 \\
\end{tabular} & 106,61 & 44,13 & 21,28 & 279,60 & $\begin{array}{l}161,46 \\
\end{array}$ & $\begin{array}{l}161,46 \\
\end{array}$ & 264,25 \\
\hline Triturus marmoratus & 30TXN33 & 100,00 & 113,11 & 101,81 & 38,94 & 5557,36 & 257,84 & $-1,08$ & \begin{tabular}{|l|l|}
258,92 \\
\end{tabular} & \begin{tabular}{|l|l|}
52,09 \\
\end{tabular} & 185,17 & \begin{tabular}{|c|}
185,17 \\
\end{tabular} & \begin{tabular}{|c|}
43,17 \\
\end{tabular} & \begin{tabular}{|c|}
960,76 \\
\end{tabular} & 115,81 & 47,24 & 21,58 & 303,97 & 173,33 & 173,33 & 287,33 \\
\hline Triturus marmoratus & 30TXN40 & 100,00 & 108,21 & 103,44 & \begin{tabular}{|l|}
38,47 \\
\end{tabular} & 5707,76 & 256,78 & $-8,56$ & 265,34 & 71,64 & 182,34 & 182,34 & 36,77 & 781,12 & 86,62 & 39,74 & 19,31 & 229,63 & 145,28 & \begin{tabular}{|c|}
146,48 \\
\end{tabular} & 215,80 \\
\hline Triturus marmoratus & 30TXN41 & 100,00 & 119,31 & $\begin{array}{ll}103,47 \\
\end{array}$ & 38,94 & 5672,28 & 266,17 & 1,97 & 264,20 & \begin{tabular}{|l|l|}
81,03 \\
\end{tabular} & \begin{tabular}{|l|l|}
192,59 \\
\end{tabular} & 192,59 & 47,78 & 796,64 & 92,31 & 38,74 & 20,62 & 243,00 & \begin{tabular}{|c|}
145,39 \\
\end{tabular} & 145,78 & 228,46 \\
\hline Triturus marmoratus & 30TXN43 & 100,00 & 105,35 & 101,11 & 39,00 & 5500,27 & 248,66 & $-7,84$ & 256,50 & 45,35 & \begin{tabular}{l|l|l|}
176,90 \\
\end{tabular} & \begin{tabular}{|c|}
176,90 \\
\end{tabular} & 36,38 & $\begin{array}{l}954,67 \\
\end{array}$ & \begin{tabular}{l|l|l}
110,75 \\
\end{tabular} & 48,62 & \begin{tabular}{l|l}
19,55 \\
\end{tabular} & 293,38 & $\begin{array}{l}178,09 \\
\end{array}$ & \begin{tabular}{ll|}
178,09 \\
\end{tabular} & 276,66 \\
\hline Triturus marmoratus & 30 TXN46 & 75,00 & 86,27 & 96,27 & \begin{tabular}{l|l|}
39,05 \\
\end{tabular} & 5234,26 & 222,50 & $-20,60$ & 243,10 & 30,64 & \begin{tabular}{l|l}
154,88 \\
\end{tabular} & 154,91 & 21,63 & 1150,02 & 129,98 & 62,58 & 17,33 & 350,31 & 224,32 & 224,35 & 329,99 \\
\hline Triturus marmoratus & 30TXN50 & 100,00 & 104,72 & 102,40 & 38,53 & 5650,83 & 251,56 & $-11,08$ & 262,63 & 76,05 & 178,11 & 178,11 & 34,09 & \begin{tabular}{|c|}
777,70 \\
\end{tabular} & 84,18 & 40,2 & 18, & 225,41 & 148,41 & \begin{tabular}{l|l|}
150,99 \\
\end{tabular} & 209,58 \\
\hline Triturus marmoratus & 30TXN51 & 100,00 & 108,88 & 102,45 & 38,88 & 5601,82 & 254,21 & $-6,87$ & 261,08 & 73,79 & \begin{tabular}{|l|l|}
181,44 \\
\end{tabular} & 181,44 & 38,63 & \begin{tabular}{|l|}
810,39 \\
\end{tabular} & 89,62 & 41,22 & $\begin{array}{l}18,58 \\
\end{array}$ & 239,75 & 153,41 & \begin{tabular}{l|l}
154,05 \\
\end{tabular} & 224,22 \\
\hline Triturus marmoratus & 30TXN52 & 100,00 & 94,12 & 100,09 & 38,71 & 5497,32 & 237,15 & $-18,39$ & 255,54 & 40,05 & \begin{tabular}{|l|l|}
165,93 \\
\end{tabular} & 165,93 & 25,84 & \begin{tabular}{l|l}
916,59 \\
\end{tabular} & 99,80 & 49,03 & 17,30 & 267,96 & \begin{tabular}{|c|}
177,47 \\
\end{tabular} & $\begin{array}{l}177,65 \\
\end{array}$ & 251,91 \\
\hline Triturus marmoratus & 30TXN53 & 100,00 & 99,49 & 100,32 & 38,99 & 5455,79 & 241,25 & $-12,97$ & 254,22 & 40,27 & $\begin{array}{l}170,50 \\
1\end{array}$ & 170,50 & 31,29 & 945,43 & 105,78 & 49,59 & 17,88 & 282,90 & \begin{tabular}{|c|}
181,64 \\
\end{tabular} & \begin{tabular}{|l|l|}
181,64 \\
\end{tabular} & 266,11 \\
\hline Triturus marmoratus & 30TXN54 & 100,00 & 91,52 & 98,72 & 38,99 & 5372,49 & 231,15 & $-18,93$ & 250,08 & 33,87 & 161,74 & 161,74 & 24,79 & 1018,51 & 113,14 & 54,83 & 17,13 & 304,08 & \begin{tabular}{|c|}
198,37 \\
\end{tabular} & \begin{tabular}{|c|}
198,37 \\
\end{tabular} & 286,13 \\
\hline Triturus marmoratus & 30TXN55 & 100,00 & 83,60 & 96,82 & \begin{tabular}{l|l}
38,95 \\
\end{tabular} & 5296,25 & 221,06 & $-24,57$ & 245,62 & 27,39 & \begin{tabular}{l|l|l|l|}
153,08 \\
\end{tabular} & 153,0 & 18,1 & 1091,06 & 120,27 & 60,1 & 16, & 324,97 & 215,11 & 215,11 & 305,78 \\
\hline Triturus marmoratus & 30TXN56 & 37,00 & 79,52 & 95,46 & \begin{tabular}{ll|}
38,96 \\
\end{tabular} & 5231,69 & 215,01 & $-27,01$ & 242,02 & 24,21 & \begin{tabular}{|l|l|}
148,19 \\
\end{tabular} & 148,19 & 14,99 & 1149,13 & 126,64 & 64,19 & \begin{tabular}{l|l}
16,15 \\
\end{tabular} & 343,11 & 228,41 & 228,41 & 322,84 \\
\hline Triturus marmoratus & 30TXN60 & 100,00 & 96,16 & 100,88 & 38,29 & 5581,02 & 241,26 & $-18,22$ & 259,48 & 85,60 & \begin{tabular}{ll|}
168,81 \\
\end{tabular} & 168,82 & 26,77 & 795,91 & 85,27 & 42,70 & \begin{tabular}{l|l|}
17,05 \\
\end{tabular} & 226,86 & \begin{tabular}{ll|}
156,68 \\
\end{tabular} & $\begin{array}{l}159,86 \\
\end{array}$ & 207,69 \\
\hline Triturus marmoratus & 30TXN63 & 100,00 & 94,94 & 99,57 & 38,95 & 5416,45 & 235,38 & $-17,14$ & 252,52 & 42,68 & \begin{tabular}{|l|l|l|}
165,40 \\
\end{tabular} & 165,40 & 27,29 & \begin{tabular}{|c|}
934,84 \\
\end{tabular} & 101,29 & 50,20 & \begin{tabular}{ll|}
16,66 \\
\end{tabular} & 273,25 & \begin{tabular}{ll|}
183,96 \\
\end{tabular} & 184,22 & 256,22 \\
\hline Triturus marmoratus & 30TXN74 & 100,00 & 67,09 & 93,69 & 38,16 & 5304,14 & 202,82 & $-39,59$ ] & 242,41 & 15,92 & 136,99 | & 136,99 | & 2,03 & 1089,61 & 112,52 & 63,81 . & 14,30 & 307,78 & 223,36 & 223,49 & 288,38 \\
\hline Triturus marmoratus & 30TXN80 & 100,00 & 95,74 & 99,77 & 38,26 & 5501,36 & 238,35 & $-18,12$ & 256,46 & \begin{tabular}{ll|l}
111,46 \\
\end{tabular} & $\begin{array}{l}167,05 \\
\end{array}$ & 167,16 & \begin{tabular}{l|l|l}
27,15 \\
\end{tabular} & 759,75 & 82,89 & 41,34 & 16,2 & 215,49 & 155,52 & \begin{tabular}{|l|}
160,27 \\
\end{tabular} & 188,89 \\
\hline Triturus marmoratus & 30TXN90 & 100,00 & 93,84 & 99,07 & 38,37 & 5463,30 & 235,24 & $-19,39$ & 254,62 & 111,83 & \begin{tabular}{|c|c|}
164,67 \\
\end{tabular} & \begin{tabular}{ll|l}
164,93 \\
\end{tabular} & 25,66 & $\begin{array}{l}755,96 \\
\end{array}$ & 83,18 & 41,68 & \begin{tabular}{|c|}
15,97 \\
\end{tabular} & 215,56 & \begin{tabular}{l|l}
158,02 \\
\end{tabular} & \begin{tabular}{l|l}
162,15 \\
\end{tabular} & 183,27 \\
\hline Triturus marmoratus & 30TXN91 & 100,00 & 94,57 & 99,19 & 38,74 & 5424,62 & 234,78 & $-18,37$ & 253,15 & 100,32 & 164,88 & \begin{tabular}{ll|}
165,09 \\
\end{tabular} & 26,64 & \begin{tabular}{ll|}
790,45 \\
\end{tabular} & 84,67 & 43,56 & 15,38 & 222,04 & \begin{tabular}{ll|}
164,76 \\
\end{tabular} & 169,02 & 195,90 \\
\hline Triturus marmoratus & 30TYLO9 & 100,00 & 148,51 & 104,01 & 36,99 & 6077,60 & $\begin{array}{l}303,15 \\
\end{array}$ & 23,56 & 279,59 & 171,91 & 72,67 & 227,53 & \begin{tabular}{|l|l|}
72,67 \\
\end{tabular} & 353,00 & 47,32 & 15,67 & 30,28 & \begin{tabular}{|c|}
114,69 \\
\end{tabular} & 65,39 & 72,80 & 65,39 \\
\hline Triturus marmoratus & 30TYNO0 & 100,00 & 89,01 . & 97,77 & 38,10 | & 5436,31 & 229,17 & $-23,37 \mid$ & $252,54 \mid$ & $106,64 \mid$ & 159,62 & 159,92 & 21,38 & $777,07 \mid$ & 85,95 . & 43,85 & 15,60 [ & 223,04 & 165,59 & 170,13 & 184,36 \\
\hline Triturus marmoratus & 30TYN01 & 100,00 & 87,26 & 97,46 & 38,44 & 5402,29 & 226,07 & $-24,44$ & 250,51 & 104,60 & 157,51 & 157,71 & 20,01 & \begin{tabular}{|c|}
824,62 \\
\end{tabular} & 89,14 & 46,93 & $\begin{array}{l}14,90 \\
\end{array}$ & 233,53 & \begin{tabular}{|c|}
175,42 \\
\end{tabular} & \begin{tabular}{|c|}
179,88 \\
\end{tabular} & 199,54 \\
\hline Triturus marmoratus & 31TBE79 & 100,00 & 159,32 & 91,91 & 37,00 & 5386,39 & 289,44 & 43,72 & 245,72 & \begin{tabular}{|l|l|l|l|}
161,93 \\
\end{tabular} & 230,71 & 232,32 & $\begin{array}{l}99,03 \\
\end{array}$ & \begin{tabular}{|l|l|}
534,70 \\
\end{tabular} & 76,57 & 14,82 & 37,58 & \begin{tabular}{|c|}
197,79 \\
\end{tabular} & 87,08 & \begin{tabular}{|c|c|}
115,16 \\
\end{tabular} & 105,46 \\
\hline Triturus marmoratus & \begin{tabular}{|l|} 
31TBE89 \\
\end{tabular} & 100,00 & 162,13 & 91,20 & 36,93 & 5325,69 & 290,57 & \begin{tabular}{l|l}
47,15 \\
\end{tabular} & 243,42 & 164,59 & 232,68 & 234,53 & 102,40 & $\begin{array}{l}547,65 \\
\end{array}$ & 80,27 & 14,27 & 38,82 & 205,27 & 87,58 & 118,50 & 103,46 \\
\hline Triturus marmoratus & 31TBE99 & 42,00 & 163,34 & 90,17 & 36,85 & 5294,15 & 290,62 & 49,19 & 241,43 & \begin{tabular}{ll|l}
166,13 \\
\end{tabular} & 233,26 & 235,49 & 103,72 & 555,15 & 82,38 & 14,23 & 39,66 & 209,34 & 88,68 & \begin{tabular}{l|l}
121,32 \\
\end{tabular} & 104,89 \\
\hline Triturus marmoratus & 31 TBF60 & 100,00 & 131,81 & 92,23 & \begin{tabular}{|c|}
36,17 \\
\end{tabular} & 5648,64 & 268,52 & 16,45 & 252,08 & 136,55 & 206,01 & \begin{tabular}{l|l|}
207,95 \\
\end{tabular} & $\begin{array}{l}66,86 \\
\end{array}$ & 576,2 & 70,87 & 21,04 & 30,52 & 191,29 & 106,43 & \begin{tabular}{ll|}
122,69 \\
\end{tabular} & 118,72 \\
\hline Triturus marmoratus & 31TBF61 & 99,00 & 109,30 & 90,92 & 35,52 & 5755,61 & 248,77 & $-3,78$ & 252,55 & \begin{tabular}{|l|l|}
116,48 \\
\end{tabular} & \begin{tabular}{|l|l|}
146,49 \\
\end{tabular} & \begin{tabular}{|l|}
186,98 \\
\end{tabular} & 42,61 & \begin{tabular}{|c|}
648,49 \\
\end{tabular} & 76,95 & 28,02 & 25,89 & \begin{tabular}{|c|}
199,39 \\
\end{tabular} & 130,34 & 138,81 & 133,36 \\
\hline Triturus marmoratus & 31TBF70 & 100,00 & 150,82 & 93,17 & 36,79 & 5497,04 & 284,54 & 34,28 & 250,26 & 153,43 & 223,81 & 225,19 & 89,03 & \begin{tabular}{|l|l}
552,58 \\
\end{tabular} & 74,84 & 16,49 & 35,08 & \begin{tabular}{|c|}
196,49 \\
\end{tabular} & $\begin{array}{l}3,63 \\
\end{array}$ & \begin{tabular}{l|l|l|}
117,83 \\
\end{tabular} & 111,35 \\
\hline Triturus marmoratus & 31TBF71 & 101,00 & 132,77 & 92,82 & 36,20 & 5636,99 & 270,10 & 17,10 & 252,99 & \begin{tabular}{|l|l|l|l|l}
136,79 \\
\end{tabular} & 207,72 & 208,94 & \begin{tabular}{l|l|l}
68,45 \\
\end{tabular} & \begin{tabular}{|l|l}
596,72 \\
\end{tabular} & 74,31 & 21,14 & 30,76 & $\begin{array}{l}197,60 \\
\end{array}$ & $\begin{array}{l}109,47 \\
\end{array}$ & $\begin{array}{l}126,59 \\
1\end{array}$ & 123,37 \\
\hline Triturus marmoratus & 31 TBF72 & 100,00 & 120,88 & 92,66 & 35,83 & 5726,96 & 260,58 & 5,80 & 254,78 & 126,04 & \begin{tabular}{|l|l|}
194,37 \\
\end{tabular} & \begin{tabular}{|c|}
197,99 \\
\end{tabular} & 54,81 & $\begin{array}{l}625,55 \\
\end{array}$ & 75,00 & 24,6 & 27, & \begin{tabular}{|c|}
197,57 \\
\end{tabular} & \begin{tabular}{|l|l|}
121,08 \\
\end{tabular} & \begin{tabular}{|c|}
132,97 \\
\end{tabular} & 129,80 \\
\hline Triturus marmoratus & 31TBF80 & 99,00 & 161,91 & 93,13 & 37,04 & 5377,75 & 292,75 & 45,29 & 247,46 & 163,14 & 233,20 & 234,9 & 101, & 550,62 & 80,09 & 14, & 38,5 & 204,72 & \begin{tabular}{l|l}
89,35 \\
\end{tabular} & \begin{tabular}{l|l}
119,45 \\
\end{tabular} & 103,11 \\
\hline Triturus marmoratus & 31TBF81 & 100,00 & 164,48 & 95,48 & 37,50 & 5414,10 & 297,55 & \begin{tabular}{|l|l}
46,15 \\
\end{tabular} & 251,40 & \begin{tabular}{|l|l|}
164,37 \\
\end{tabular} & 236,30 & 237,81 & \begin{tabular}{|l|l|}
103,97 \\
\end{tabular} & \begin{tabular}{|l|}
542,19 \\
\end{tabular} & 79,46 & 14, & 39,14 & 202,26 & 88,71 & 118,75 & 100,01 \\
\hline Triturus marmoratus & 31 TBF82 & 100,00 & 162,39 & 97,16 & 37,52 & 5505,06 & 298,44 & 42,41 & \begin{tabular}{|l|l|l|}
256,03 \\
\end{tabular} & 161,91 & 235,44 & 236,63 & 100,91 & $\begin{array}{l}534,86 \\
\end{array}$ & 76,70 & 14,34 & \begin{tabular}{ll|}
38,35 \\
\end{tabular} & $\begin{array}{l}196,78 \\
\end{array}$ & 88,67 & \begin{tabular}{|c|}
116,74 \\
\end{tabular} & 100,34 \\
\hline Triturus marmoratus & 31TBF90 & 101,00 & 166,11 & 91,45 & \begin{tabular}{l|l|}
36,95 \\
\end{tabular} & 5296,97 & 294,19 & \begin{tabular}{|l|}
50,89 \\
\end{tabular} & 243,29 & 167,91 & 236,18 & 238,11 & 106,50 & \begin{tabular}{|l|l|}
549,27 \\
\end{tabular} & 82,41 & 13,79 & \begin{tabular}{ll|l}
40,63 \\
\end{tabular} & 208,34 & 88,54 & \begin{tabular}{|l|l|}
121,87 \\
\end{tabular} & 101,14 \\
\hline Triturus marmoratus & 31TBF91 & 99,00 & 167,58 & 93,52 & 37,26 & 5338,64 & 297,71 & 50,72 & 246,99 & 168,19 & 238,26 & 240,07 & 107,74 & 544,71 & 82,29 & 13,61 & \begin{tabular}{|l|l|}
40,87 & \\
\end{tabular} & 207,22 & 88,10 & \begin{tabular}{|c|}
121,40 \\
\end{tabular} & 98,81 \\
\hline Triturus marmoratus & 31TBF92 & 100,00 & 15 & & 36,87 & 503,33 & 289 & 36,95 & 252,12 & $156, \mathrm{C}$ & 227,38 & 228,80 & 92 & 574,65 & 78,97 & 15,6 & t & 204,95 & 95,11 & 121,81 & 114,87 \\
\hline Triturus marmoratus & 31TBF94 & 101,00 & 15 & 98 & 36,99 & 5668,52 & 297. & 36,88 & 261,03 & 159,60 & 232,83 & 233,79 & & 517,33 & 70,50 & 14,62 & 36,4 & $\begin{array}{l}184,75 \\
\end{array}$ & 87,80 & 112,56 & 105,25 \\
\hline Triturus marmoratus & \begin{tabular}{|l|}
31 TCF02 \\
\end{tabular} & 96,00 & 159,45 & 91,76 & 36,80 & 5411,50 & 290,13 & 43,73 & 246,40 & \begin{tabular}{ll|l}
161,96 \\
\end{tabular} & 230, & 232,6 & 98,6 & \begin{tabular}{|l|}
572,99 \\
\end{tabular} & 83,03 & 14,95 & 38,5 & 211,12 & $\begin{array}{l}92,86 \\
\end{array}$ & \begin{tabular}{l|l|}
123,94 \\
\end{tabular} & 113,35 \\
\hline Triturus marmoratus & 31 TCG45 & 101,00 & 114,29 & 91,50 & 35,01 & 5901,49 & 256,68 & $-0,45$ & 257,13 & \begin{tabular}{|l|l|l|l}
133,68 \\
\end{tabular} & \begin{tabular}{l|l}
40,92 \\
\end{tabular} & $\begin{array}{l}191,16 \\
\end{array}$ & 40,92 & \begin{tabular}{ll|}
741,55 \\
\end{tabular} & 85,76 & 39,78 & 23,26 & 232,24 & \begin{tabular}{l|l|l|}
134,15 \\
\end{tabular} & $\begin{array}{l}198,86 \\
\end{array}$ & 134,15 \\
\hline Triturus marmoratus & $31 \mathrm{TCH} 23$ & 101,00 & 39,35 & 77,48 & 33,21 & 5379,69 & 168,15 & $-61,19$ & 229,34 & 50,94 & 43,30 & 111,59 & $-24,16$ & 1278,98 & 134,37 & 86,22 & 12,7 & 363,34 & 286,52 & 294,29 & 297 \\
\hline Triturus marmoratus & 31TDF27 & 85,00 & 166,22 & 70,16 & 32,17 & 5089,19 & 280, & 66,64 & 213,66 & \begin{tabular}{|l|l|}
176,56 \\
\end{tabular} & 218,22 & 233,41 & \begin{tabular}{ll|}
104,49 \\
\end{tabular} & \begin{tabular}{|c|}
618,62 \\
\end{tabular} & 94,89 & 23,9 & 33,86 & 229,10 & 117,70 & \begin{tabular}{|c|}
148,27 \\
\end{tabular} & 125,51 \\
\hline Triturus marmoratus & 31TDF28 & 101,00 & & 70, & 31,69 & 5227,88 & 276,2 & \begin{tabular}{|c|}
58,85 \\
\end{tabular} & 217 & 169,24 & 158,51 & 228,43 & 95,97 & 626,99 & 86,51 & 27,97 & 28,92 & 218,95 & \begin{tabular}{|c|}
124,19 \\
\end{tabular} & 154,23 & 126,40 \\
\hline Triturus marmoratus & 31 TDF29 & 101,00 & 159,89 & 70,96 & 31,86 & 5280,03 & 278,34 & 58,46 & 219,88 & 175,16 & $\begin{array}{l}99,82 \\
\end{array}$ & 229,64 & 95,80 & \begin{tabular}{|l|l|}
601,07 \\
\end{tabular} & 80,09 & 29,35 & 28,43 & 206,58 & \begin{tabular}{|l|l|}
115,70 \\
\end{tabular} & 153,82 & 116,03 \\
\hline Triturus marmoratus & 31TDF39 & 99,00 & 159,05 & 70,45 & 31,72 & 5221,53 & 276,62 & 58,24 & 218,38 & 169,22 & 122,48 & 227,97 & 95,63 & \begin{tabular}{ll|}
625,82 \\
\end{tabular} & 85,89 & 29,41 & 28,45 & 215,99 & \begin{tabular}{ll|}
124,66 \\
\end{tabular} & 157,10 & 125,50 \\
\hline Triturus marmoratus & $\begin{array}{l}\text { 31TDG05 } \\
\end{array}$ & 100,00 & 127,55 & 79,61 & 32,9 & 5659,60 & 259 & \begin{tabular}{|c|}
19,95 \\
\end{tabular} & 239 , & 144,4 & 58,10 & 201,7 & 58 & \begin{tabular}{|c|}
706,09 \\
\end{tabular} & 86,0 & 32, & 28, & 225,31 & 111,86 & 203,49 & 111 \\
\hline Triturus marmoratus & $31 \mathrm{TDG}$ & 100 & 10 & 79 & 32, & 560 & 238 & 2,2 & $236+2+20$ & & 39, & 180 & 38 & 829,94 & 97,73 & 43, & 24, & 255,93 & 147,61 & 225,40 & 147, \\
\hline Triturus marmoratus & \begin{tabular}{|l|}
31 TDG10 \\
\end{tabular} & 100,00 & 143,65 & 72,82 & 31,99 & 5436,23 & 266,45 & 41,19 & 225,27 & 191,40 & 78,13 & 215,81 & 78,13 & $\begin{array}{l}661,58 \\
\end{array}$ & 76,92 & 35,13 & 24,44 & 210,32 & \begin{tabular}{|l|}
124,08 \\
\end{tabular} & \begin{tabular}{|l|}
170,04 \\
\end{tabular} & 124,08 \\
\hline Triturus marmoratus & 31TDG11 & 100,00 & 130,92 & 73,96 & 32,00 & 5506,36 & 256,72 & 28,36 & 228,36 & $\begin{array}{l}179,89 \\
\end{array}$ & \begin{tabular}{ll|l}
64,96 \\
\end{tabular} & 204,11 & \begin{tabular}{ll|}
64,96 \\
\end{tabular} & \begin{tabular}{l|l}
711,82 \\
\end{tabular} & 81,20 & 37,69 & 23,64 & 220,30 & \begin{tabular}{|c|}
129,34 \\
\end{tabular} & \begin{tabular}{|l|l|l|}
187,13 \\
\end{tabular} & 129,34 \\
\hline Triturus marmoratus & $\begin{array}{l}31 \text { TDG12 } \\
\end{array}$ & 101,00 & 138,82 & 74,97 & 31,99 & 5534,36 & 264,97 & 34,06 & 230,90 & 187,60 & 71,46 & 211,89 & 71,46 & 664,54 & 77,32 & 33,73 & 25,52 & 209,84 & $\begin{array}{l}113,45 \\
\end{array}$ & \begin{tabular}{ll|}
180,96 \\
\end{tabular} & 113,45 \\
\hline Triturus r & & & & & 32, & 5 & & 31, & 233 & 18 & 69 & 210, & 69 & 668, & 79 & 32 & & & \begin{tabular}{|c|}
109,50 \\
\end{tabular} & & \\
\hline Triturus marmoratus & 31TDG1 & 100,00 & 109,61 & 78,14 & 32,94 & 5594,27 & 241,39 & $\begin{array}{l}5,90 \\
\end{array}$ & 235,49 & 124,7 & 42,68 & 183,93 & 42,52 & 816,30 & 97,07 & 41,02 & 25,05 & 253,79 & \begin{tabular}{l|l}
141,82 \\
\end{tabular} & 225,21 & 141, \\
\hline Triturus marmoratus & 31TDG20 & 100,00 & 152,94 & 71,68 & 31,71 & 5379,99 & 273,79 & 50,50 & 223,29 & 200,40 & 87,61 & 223,95 & 87,61 & 634,60 & 77,02 & 33,88 & 25,47 & 208,06 & 119,64 & 165,13 & 119,64 \\
\hline
\end{tabular}




\begin{tabular}{|c|c|c|c|c|c|c|c|c|c|c|c|c|c|c|c|c|c|c|c|c|c|}
\hline TAXON & UTM & $\overline{\mathrm{km} 2}$ & BIO1 & $\begin{array}{c}\mathrm{BIO2} \\
\end{array}$ & $\mathrm{BIO3}$ & B104 & B105 & B106 & B107 & B108 & B109 & BIO10 & BIO11 & $\overline{B 1012}$ & BIO13 & BIO14 & BIO15 & B1016 & BIO17 & BIO18 & BlO19 \\
\hline Triturus marmoratus & 31TDG21 & 101,00 & 134,01 & 72,64 & 31,69 & 5474,85 & 258,67 & 31,96 & 226,71 & 182,80 & 68,49 & 206,92 & 68,49 & 718,32 & 81,31 & 38,66 & 23,28 & 224,13 & 132,51 & 188,93 & 132,51 \\
\hline Triturus marmoratus & 31TDG22 & 99,00 & 125,49 & 73,69 & 31,92 & 5511,67 & 252,13 & 23,39 & 228,73 & 174,44 & 59,73 & $\begin{array}{l}198,87 \\
19\end{array}$ & 59,73 & 746,68 & 87,10 & 38,10 & 23,96 & 229,79 & \begin{tabular}{|c|}
133,40 \\
\end{tabular} & 201,19 & 133,40 \\
\hline Triturus marmoratus & 31TDG23 & 101,00 & 120,63 & 74,58 & 32,00 & 5523,95 & 248,55 & 18,30 & 230,24 & 167,35 & 54,73 & 194,10 & 54,73 & 769,68 & 90,82 & 38,58 & 24,64 & 234,97 & \begin{tabular}{|l|l|}
134,90 \\
\end{tabular} & 209,82 & 134,90 \\
\hline Triturus marmoratus & 31TDG24 & 100,00 & 126,73 & 75,58 & 32,00 & 5574,07 & 255,26 & 22,19 & 233,07 & 149,77 & 59,32 & 200,34 & 59,32 & 739,43 & 89,01 & 34,71 & 27,42 & 230,37 & \begin{tabular}{|l|l|}
121,26 \\
\end{tabular} & 210,88 & 121,26 \\
\hline Triturus marmoratus & 31TDG25 & 100,00 & 120,53 & 76,48 & 32,00 . & 5584,37 & 250,26 & 15,99 & 234,26 . & $135,76 \mid$ & 53,10 , & 194,30 & 53,10 . & 770,56 & 92,84 & 36,19 & 27,23 & $241,75 \mid$ & 127,33 & 219,72 & 127,33 \\
\hline Triturus marmoratus & $\begin{array}{l}31 \text { TDG26 } \\
\end{array}$ & 101,00 & 110,29 & 77,01 & 32,33 & 5569,27 & 241,08 & 7,03 & 234,05 & 124,80 & 43,82 & 184,24 & 43,67 & 832,47 & 97,84 & 42,19 & 24,08 & 256,10 & \begin{tabular}{ll|}
147,86 \\
\end{tabular} & 225,80 & 147,86 \\
\hline Triturus marmoratus & \begin{tabular}{|l|l|}
31 TDG30 \\
\end{tabular} & 100,00 & 157,83 & 71,01 & 31,53 & 5300,33 & 277,10 & 55,68 & 221,42 & 197,57 & 96,21 & 227,47 & 93,06 & 632,38 & \begin{tabular}{c|c}
82,25 \\
\end{tabular} & 31,86 & 26,59 & 212,42 & \begin{tabular}{|l|l|}
124,07 \\
\end{tabular} & \begin{tabular}{|c|}
160,28 \\
\end{tabular} & 124,09 \\
\hline Triturus marmoratus & 31TDG31 & 101,00 & 144,71 & 71,51 & 31,09 & 5430,91 & 267,32 & 42,09 & 225,23 & 192,77 & $\begin{array}{ll}78,92 \\
\end{array}$ & 216,44 & 78,92 & 701,68 & 81,71 & 38,45 & 23,28 & 223,49 & 133,61 & \begin{tabular}{ll|}
182,06 \\
\end{tabular} & 133,61 \\
\hline Triturus marmoratus & $\begin{array}{l}31 \text { TDG32 } \\
\end{array}$ & 101,00 & 126,55 & 72,56 & 31,49 & 5485,82 & 252,29 & 24,87 & 227,42 & 175,21 & 61,18 & 199,62 & 61,18 & 777,76 & 87,68 & 41,15 & 22,50 & 238,41 & 144,73 & 204,14 & 144,73 \\
\hline Triturus marmoratus & 31TDG33 & 100,00 & 127,01 & 73,42 & 31,53 & 5519,44 & 253,66 & 24,32 & 229,34 & 175,75 & \begin{tabular}{|c|}
60,87 \\
\end{tabular} & 200,29 & \begin{tabular}{|c|}
60,87 \\
\end{tabular} & $\begin{array}{l}774,75 \\
\end{array}$ & $\begin{array}{l}89,25 \\
\end{array}$ & 39,24 & 23,82 & 237,88 & \begin{tabular}{ll|}
138,84 \\
\end{tabular} & 209,39 & 138,84 \\
\hline Triturus marmoratus & 31TDG34 & 101,00 & 129,94 & 74,44 & 31,72 & 5552,03 & 257,43 & 25,65 & 231,78 & \begin{tabular}{|c|}
165,59 \\
\end{tabular} & \begin{tabular}{|c|}
62,72 \\
\end{tabular} & 203,31 & \begin{tabular}{|c|}
62,72 \\
\end{tabular} & 768,28 & 89,48 & 36,97 & 25,35 & 236,62 & 132,24 & 212,86 & 132,24 \\
\hline Triturus marmoratus & $\begin{array}{l}31 \text { TDG35 } \\
\end{array}$ & 100,00 & 124,92 & 75,47 & 31,97 & 5577,89 & 253,79 & 20,32 & 233,47 & 140,55 & 57,43 & \begin{tabular}{|c|}
198,57 \\
\end{tabular} & 57,43 & 794,52 & 92,92 & 37,77 & 25,36 & 245,58 & \begin{tabular}{|l|l|}
137,07 \\
\end{tabular} & 218,86 & 137,07 \\
\hline Triturus marmoratus & 31TDG40 & 101,00 & 153,92 & 70,08 & 31,02 & 5322,70 & 273,35 & 51,94 & 221,41 & 184,27 & 153,09 & 224,08 & 89,16 & 686,11 & 89,72 & 33,67 & 25,24 & 226,52 & 139,44 & 169,65 & 141,06 \\
\hline Triturus marmoratus & 31TDG41 & 100,00 & 143,57 & 70,61 & 31,01 & 5418,05 & 265,73 & 41,25 & 224,47 & \begin{tabular}{|l|l|}
191,17 \\
\end{tabular} & 83,61 & 215,19 & 78,09 & $\begin{array}{l}744,65 \\
\end{array}$ & 88,99 & 40,05 & 22,43 & 234,86 & \begin{tabular}{|c|}
148,77 \\
\end{tabular} & \begin{tabular}{l|l}
186,25 \\
\end{tabular} & 148,81 \\
\hline Triturus marmoratus & $\begin{array}{l}31 \text { TDG42 } \\
\end{array}$ & 100,00 & 113,04 & 71,73 & 31,59 & 5434,21 & 238,94 & 14,74 & 224,20 & \begin{tabular}{|l|l|l|}
152,19 \\
\end{tabular} & 57,00 & 186,19 & 49,7 & 869,95 & 97,70 & 48,6 & 20,1 & 260,21 & \begin{tabular}{ll|}
174,95 \\
\end{tabular} & 213,02 & 175,78 \\
\hline Triturus marmoratus & $\begin{array}{l}31 \text { TDG43 } \\
\end{array}$ & 101,00 & 120,79 & 72,53 & 31,36 & 5480,88 & 247,16 & 19,81 & 227,36 & 168,24 & 56,24 & $\begin{array}{l}193,96 \\
\end{array}$ & 55,80 & 841,38 & 93,61 & 44,30 & 21,43 & 251,91 & \begin{tabular}{|c|}
161,19 \\
\end{tabular} & 215,44 & 161,25 \\
\hline Triturus marmoratus & \begin{tabular}{|l|l|}
$31 T D G 44$ \\
\end{tabular} & 101,00 & 130,89 & 73,43 & 31,21 & 5539,31 & 257,59 & 26,91 & 230,68 & 168,05 & 63,87 & 204,03 & 63,87 & 819,11 & 91,15 & 40,15 & 22,82 & 246,08 & \begin{tabular}{|l|l|l|}
151,03 \\
\end{tabular} & 214,89 & 151,03 \\
\hline Triturus marmoratus & $\begin{array}{l}31 \text { TDG45 } \\
\end{array}$ & 100,00 & 123,43 & 74,48 & 31,81 & 5541,19 & 251,55 & 19,82 & 231,73 & \begin{tabular}{ll|}
138,59 \\
\end{tabular} & 56,68 & \begin{tabular}{|c|}
196,77 \\
\end{tabular} & 56,65 & 844,31 & 94,95 & 41,38 & 22,77 & 254,73 & \begin{tabular}{|c|}
155,64 \\
\end{tabular} & 222,07 & 155,64 \\
\hline Triturus marmoratus & \begin{tabular}{|l|l|}
$31 T D G 46$ \\
\end{tabular} & 101,00 & 98,81 & 74,53 & 32,16 & 5461,29 & 227,98 & 0,29 & 227,69 & 123,23 & 38,16 & 172,11 & \begin{tabular}{|c|}
35,25 \\
\end{tabular} & $\begin{array}{l}935,05 \\
\end{array}$ & 102,41 & 54,20 & 18,70 & 269,63 & 188,71 & 229,59 & 189,68 \\
\hline Triturus marmoratus & $\begin{array}{l}31 \text { TDG48 } \\
\end{array}$ & 99,00 & 90,22 & 75,53 & \begin{tabular}{l|l}
32,75 \\
\end{tabular} & 5453,60 & 220,57 & $-7,82$ & 228,39 & 99,62 & 32,26 & 163,59 & 26,8 & $\begin{array}{l}975,65 \\
\end{array}$ & 105,37 & 59,03 & $17, \mathrm{C}$ & 278,09 & 203,11 & 234,79 & 205,54 \\
\hline Triturus marmoratus & $\begin{array}{l}\text { 31TDG49 } \\
\end{array}$ & 61,00 & 55,44 & 71,98 & \begin{tabular}{l|l|}
31,95 \\
\end{tabular} & 5347,45 & 184,37 & $-37,63$ & 222,00 & 36,75 & \begin{tabular}{|c|}
62,02 \\
\end{tabular} & 128,52 & $-4,12$ & 1168,61 & 120,65 & 72,21 & \begin{tabular}{|l|l|l|}
14,13 \\
\end{tabular} & 328,65 & 255,93 & 262,42 & 270,85 \\
\hline Triturus marmoratus & $\begin{array}{l}31 \text { TDG50 } \\
3\end{array}$ & 100,00 & 149,07 & 69,41 & 30,93 & 5340,44 & 268,83 & 47,51 & 221,32 & 172,34 & \begin{tabular}{l|l|l|l|l}
184,93 \\
\end{tabular} & 219,62 & 84,45 & \begin{tabular}{ll|l}
739,98 \\
\end{tabular} & 97,36 & 35,59 & 24,90 & 240,67 & \begin{tabular}{ll|}
149,22 \\
\end{tabular} & \begin{tabular}{|l|l|}
177,14 \\
\end{tabular} & 156,74 \\
\hline Triturus marmoratus & 31TDG51 & 100,00 & 150,52 & 69,89 & 30,82 & 5412,19 & 271,39 & 47,10 & 224,29 & 175,65 & \begin{tabular}{|l|l|}
190,74 \\
\end{tabular} & 221,70 & 84,58 & 751,99 & 97,13 & 37,05 & 23,69 & 241,22 & 152,85 & $\begin{array}{l}178,44 \\
\end{array}$ & 159,64 \\
\hline Triturus marmoratus & 31TDG52 & 100,00 & 121,05 & 70,84 & 31,14 & 5416,66 & 245,56 & $21,77 \mid$ & 223,79 & $158,67 \mid$ & 73,56 & 193,60 & 57,38 & $871,94[$ & $101,31 \mid$ & 48,10 & 20,27 & 261,90 & 179,63 & 207,94 & 181,17 \\
\hline Triturus marmoratus & \begin{tabular}{l|l}
31 TDG53 \\
\end{tabular} & 101,00 & 120,29 & 71,75 & 31,31 & 5454,72 & 245,94 & 19,90 & 226,03 & \begin{tabular}{|l|l|}
168,79 \\
\end{tabular} & 56,34 & 193,21 & 55,8 & 879,46 & 97,58 & 47,86 & 20,1 & 259,23 & \begin{tabular}{|l|l|}
176,63 \\
\end{tabular} & 214,88 & 176,63 \\
\hline Triturus marmoratus & \begin{tabular}{|l|}
$31 T D G 54$ \\
\end{tabular} & 100,00 & 125,16 & 72,61 & 31,28 & 5493,16 & 251,46 & 22,80 & 228,67 & 159,72 & 59,79 & \begin{tabular}{|c|}
198,10 \\
\end{tabular} & 59,49 & 882,49 & 96,36 & 45,17 & 20,85 & 259,02 & 173,86 & 217,20 & 173,90 \\
\hline Triturus marmoratus & 31TDG55 & 101,00 & 112,93 & 73,61 & 31,78 & 5470,40 & 240,58 & 12,28 & 228,29 & 146,27 & \begin{tabular}{l|l}
49,85 \\
\end{tabular} & \begin{tabular}{|l|l|}
185,97 \\
\end{tabular} & 48,41 & \begin{tabular}{|l|l|}
911,09 \\
\end{tabular} & \begin{tabular}{c|c|}
98,75 \\
\end{tabular} & 49,15 & \begin{tabular}{l|l}
19,85 \\
\end{tabular} & 264,80 & $\begin{array}{l}182,35 \\
\end{array}$ & 222,98 & 182,41 \\
\hline Triturus marmoratus & $\begin{array}{l}31 \text { TDG56 } \\
\end{array}$ & 101,00 & 126,48 & 74,94 & 31,73 & 5552,87 & 254,68 & 21,49 & 233,19 & 143,13 & 59,32 & $\begin{array}{l}199,65 \\
\end{array}$ & 59,17 & $\begin{array}{l}878,35 \\
\end{array}$ & 94,59 & 43,36 & 21,32 & 261,01 & 171,38 & 218,56 & 171,39 \\
\hline Triturus marmoratus & 31TDG57 & 100,00 & 129,29 & 76,38 & 31,96 & 5582,05 & 258,48 & 22,78 & 235,70 & $147,30 \mid$ & $61,07 \mid$ & 202,62 & $61,07 \mid$ & 845,98 & 92,13 & 42,93 & 20,88 ] & 250,54 & 166,34 & 210,12 & 166,34 \\
\hline Triturus marmoratus & \begin{tabular}{|l|}
$31 T D G 59$ \\
\end{tabular} & 18,00 & 90,81 & 75,95 & \begin{tabular}{l|l}
32,85 \\
\end{tabular} & 5439,71 & 221,28 & $-7,67$ & 228,96 & \begin{tabular}{|c|}
94,19 \\
\end{tabular} & 36,19 & \begin{tabular}{ll|}
163,85 \\
\end{tabular} & 27,56 & \begin{tabular}{|c|}
980,58 \\
\end{tabular} & 103,82 & 59,57 & 16,30 & 277,15 & 209,02 & 230,66 & 212,69 \\
\hline Triturus marmoratus & $\begin{array}{l}\text { 31TDG60 } \\
\end{array}$ & 61,00 & 154,39 & 69,16 & \begin{tabular}{l|l|}
30,85 \\
\end{tabular} & 5341,51 & 273,27 & 51,57 & 221,70 & \begin{tabular}{|l|l|}
165,06 \\
\end{tabular} & 219,98 & 224,61 & 89,12 & 727,44 & 103,91 & 31,62 & 28,39 & 244,78 & \begin{tabular}{|c|}
137,27 \\
\end{tabular} & \begin{tabular}{|c|}
168,24 \\
\end{tabular} & 159,08 \\
\hline Triturus marmoratus & 31TDG61 & 101,00 & 146,85 & 69,27 & 30,42 & 5401,26 & 267,46 & 44,08 & 223,38 & 169,79 & \begin{tabular}{ll|l}
194,63 \\
\end{tabular} & 218,05 & 81,26 & 781,72 & 103,63 & 37,41 & 24,57 & 249,46 & \begin{tabular}{ll|}
157,06 \\
\end{tabular} & $\begin{array}{l}180,94 \\
\end{array}$ & 168,79 \\
\hline Triturus marmoratus & $\begin{array}{l}31 \text { TDG62 } \\
\end{array}$ & 101,00 & 149,18 & 69,89 & 30,11 & 5469,89 & 270,71 & 44,27 & 226,44 & 175,51 & \begin{tabular}{ll|}
190,11 \\
\end{tabular} & 220,84 & \begin{tabular}{l|l}
82,05 \\
\end{tabular} & 782,31 & 103,47 & 38,13 & 24,38 & 247,74 & \begin{tabular}{|c|}
157,19 \\
\end{tabular} & $\begin{array}{l}178,56 \\
\end{array}$ & 168,20 \\
\hline Triturus marmoratus & $\begin{array}{l}31 \text { TDG63 } \\
\end{array}$ & 100,00 & 134,37 & 70,82 & 30,71 & 5472,86 & 258,25 & 31,14 & 227,11 & \begin{tabular}{|l|l|l|l}
182,29 \\
\end{tabular} & 82,49 & 206,82 & 68,42 & 864,5 & 102,08 & 45,97 & 21,14 & 257,04 & 178,28 & 202,84 & 178,94 \\
\hline Triturus marmoratus & \begin{tabular}{|l|}
$31 T D G 64$ \\
\end{tabular} & 100,00 & 133,71 & 71,88 & 30,84 & 5515,80 & 258,82 & 29,58 & 229,23 & 177,28 & \begin{tabular}{|l|}
81,89 \\
\end{tabular} & 206,53 & 66,99 & $\begin{array}{l}870,25 \\
\end{array}$ & 101,28 & 45,16 & 21,27 & 255,94 & \begin{tabular}{|l|l|}
178,43 \\
\end{tabular} & 203,14 & 178,73 \\
\hline Triturus marmoratus & $\begin{array}{l}31 \text { TDG65 } \\
\end{array}$ & 100,00 & 134,61 & 73,08 & 31,10 & 5543,73 & 260,82 & 29,16 & 231,66 & 171,21 & \begin{tabular}{ll|l}
67,05 \\
\end{tabular} & 207,58 & \begin{tabular}{l|l|l}
67,05 \\
\end{tabular} & 869,24 & 99,53 & 44,63 & 21,17 & 253,62 & \begin{tabular}{|l|l|}
177,00 \\
\end{tabular} & 205,04 & 177,00 \\
\hline Triturus marmoratus & $\begin{array}{l}31 \text { TDG66 } \\
\end{array}$ & 101,00 & 128,84 & 74,49 & 31,64 & 5531,15 & 256,26 & 23,76 & 232,50 & 153,06 & \begin{tabular}{|l|l|l|l}
61,83 \\
\end{tabular} & 201,77 & 61,83 & 877,56 & 97,45 & 45,15 & 20,81 & 255,27 & \begin{tabular}{|c|}
177,86 \\
\end{tabular} & 209,00 & 177,86 \\
\hline Triturus marmoratus & \begin{tabular}{|l|} 
31TDG67 \\
\end{tabular} & 100,00 & 137,40 & 76,11 & 31,80 & 5580,44 & 265,66 & 29,24 & 236,41 & 175,68 & 68,76 & 210,45 & 68,73 & 808,42 & 94,24 & 42,97 & 21,05 & 236,38 & \begin{tabular}{|c|}
165,84 \\
\end{tabular} & \begin{tabular}{|l|l}
188,53 \\
\end{tabular} & 165,85 \\
\hline Triturus marmoratus & $\begin{array}{l}31 \text { TDG68 } \\
\end{array}$ & 86,00 & 114,42 & 76, & 32,34 & 5500,76 & 243,88 & 11,05 & 232,83 & \begin{tabular}{ll|}
134,60 \\
\end{tabular} & 51,47 & 187,37 & 48,63 & 893,25 & 96,76 & 50,69 & 18,5 & 255,03 & 186,61 & \begin{tabular}{l|l}
211,05 \\
\end{tabular} & 187,34 \\
\hline Triturus marmoratus & 31TDG71 & 99,00 & 156,87 & 69,51 & 30,60 & 5364,56 & 275,70 & 52,56 & 223,14 & 167,35 & 224,72 & 227,13 & 90,86 & \begin{tabular}{|l|l|}
711,45 \\
\end{tabular} & 107,54 & 29,23 & 30,94 & 243,24 & 129,62 & 160,29 & 156,59 \\
\hline Triturus marmoratus & $\begin{array}{l}\text { 31TDG72 } \\
\end{array}$ & 101,00 & 154 & 69,47 & 30,09 & 5459,06 & 275,20 & 48,78 & 226,42 & 165,21 & 225,52 & 226,12 & 87,3 & 736,21 & 108,20 & 31,73 & 28,88 & 244,81 & 137,61 & \begin{tabular}{l|l}
161,82 \\
\end{tabular} & 162,07 \\
\hline Triturus marmoratus & $\begin{array}{l}\text { 31TDG73 } \\
\end{array}$ & 100,00 & 151,59 & 69,54 & 29,97 & 5553,31 & 273,66 & 44,30 & 229,36 & \begin{tabular}{ll|l}
165,46 \\
\end{tabular} & 222,68 & 223,75 & 82,63 & 769,42 & \begin{tabular}{|c|}
108,47 \\
\end{tabular} & 35,29 & 26,44 & 246,62 & \begin{tabular}{|c|}
149,64 \\
\end{tabular} & \begin{tabular}{|c|}
161,79 \\
\end{tabular} & 168,62 \\
\hline Triturus marmoratus & $\begin{array}{l}31 \text { TDG75 } \\
\end{array}$ & 101,00 & 138,71 & 72,55 & 30,92 & 5523,73 & 263,75 & 32,51 & 231,24 & 182,50 & \begin{tabular}{|c|}
104,51 \\
\end{tabular} & 211,21 & 71,13 & \begin{tabular}{l|l}
832,95 \\
\end{tabular} & 103,27 & 43,47 & 22,28 & 247,40 & \begin{tabular}{|c|}
173,37 \\
\end{tabular} & \begin{tabular}{|c|}
186,58 \\
\end{tabular} & 174,80 \\
\hline Triturus marmoratus & $\begin{array}{l}31 \text { TDG76 } \\
\end{array}$ & 100,00 & 1 & 74 & 31,2 & 552,16 & 7 & 35, & 234,01 & 185,68 & 111,35 & 215,67 & 74,6 & \begin{tabular}{|c|}
784,79 \\
\end{tabular} & 99,79 & 41,08 & 22,6 & 235,03 & 163,83 & $\begin{array}{l}173,85 \\
\end{array}$ & 164,27 \\
\hline \begin{tabular}{|l|l} 
Triturus marmoratus \\
\end{tabular} & 31TDG77 & 100,00 & 13 & 75 & 31 & 5538,66 & 26 & 30,97 & 235,15 & \begin{tabular}{ll|}
177,79 \\
\end{tabular} & 103,96 & 211,36 & 70,8 & 782,67 & 97,23 & 41,56 & 21,97 & 231,89 & 164,30 & 174,28 & 164,77 \\
\hline Triturus marmoratus & \begin{tabular}{|l|l|}
$31 T D G 78$ \\
\end{tabular} & 93,00 & & 77,01 & 32,06 & 5514,09 & 256,73 & 21,64 & 235,10 & 166,72 & 73,70 & 200,46 & 60,9 & 827,53 & 96,41 & 45,54 & 20,13 & 238,31 & $\begin{array}{l}175,62 \\
\end{array}$ & 187,78 & 175,90 \\
\hline Triturus marmoratus & 31TDG81 & 58,00 & 156,33 & 69,67 & 30,77 & 5324,65 & 274,68 & 52,23 & 222,45 & \begin{tabular}{|c|}
166,76 \\
\end{tabular} & 221,85 & 226,11 & 91,01 & \begin{tabular}{ll|}
700,06 \\
\end{tabular} & 108,38 & 27,85 & 32,13 & 241,39 & \begin{tabular}{|c|}
125,74 \\
\end{tabular} & $\begin{array}{l}155,80 \\
\end{array}$ & 153,82 \\
\hline Triturus marmoratus & 31TDG82 & 99,00 & 151,01 & 69,29 & 30,32 & 5396,79 & 270,51 & 46,31 & 224,20 & 161,54 & 221,06 & 221,71 & 84,91 & \begin{tabular}{|l|l|}
744,17 \\
\end{tabular} & 109,39 & 31,64 & 28,92 & 246,43 & 139,20 & 164,30 & 163,79 \\
\hline Triturus marmoratus & \begin{tabular}{|l|}
$31 T D G 83$ \\
\end{tabular} & 101,00 & 152,89 & 69,74 & 30,10 & 5483,13 & 273,79 & 46,21 & 227,58 & \begin{tabular}{|l|l|l|}
163,03 \\
\end{tabular} & 223,94 & 224,33 & 85,1 & 738,58 & $\begin{array}{l}109,55 \\
\end{array}$ & 31,46 & 29,01 & 243,75 & \begin{tabular}{|l|l|}
137,25 \\
\end{tabular} & \begin{tabular}{|l|l|}
159,43 \\
\end{tabular} & 163,03 \\
\hline Triturus marmoratus & 31TDG84 & 101,00 & 151 & 71, & 30,56 & 5502,87 & 273,56 & 44,03 & 229,53 & 161,75 & 222,87 & 223,26 & 83,40 & 745,99 & 107,99 & 33,42 & 27,63 & 240,70 & \begin{tabular}{|c|}
143,15 \\
\end{tabular} & 156,73 & 162,27 \\
\hline Triturus marmoratus & \begin{tabular}{l|l}
31 TDG85 \\
\end{tabular} & 101,00 & 151,47 & 73,02 & 31,16 & 5489,76 & 274,51 & 43,28 & 231,23 & \begin{tabular}{|l|l|}
163,92 \\
\end{tabular} & 222,63 & 222,94 & \begin{tabular}{|c|}
83,53 \\
\end{tabular} & 727,58 & \begin{tabular}{l|l|}
104,06 \\
\end{tabular} & 33,71 & 26,96 & 232,38 & \begin{tabular}{l|l|}
143,45 \\
\end{tabular} & 154,74 & 155,45 \\
\hline Triturus marmoratus & $\begin{array}{l}31 \text { TDG86 } \\
\end{array}$ & 100,00 & 150,17 & 74,92 & 31,76 & 5484,51 & 274,44 & 41,47 & 232,96 & \begin{tabular}{ll|}
160,93 \\
\end{tabular} & 221,32 & 221,62 & 82,25 & 708,14 & 99,79 & 33,60 & 26,14 & 224,22 & 142,91 & 150,56 & 149,80 \\
\hline Triturus marmoratus & \begin{tabular}{|l|} 
31TDG87 \\
\end{tabular} & 101,00 & 149,24 & 76, & 32,16 & 5487,27 & 274,86 & 39,84 & 235,02 & 160,05 & 216,56 & 220, & 81 & 689,46 & 96,19 & 32,82 & 25, & 217,65 & \begin{tabular}{l|l|l}
140,02 \\
\end{tabular} & \begin{tabular}{ll|}
146,09 \\
\end{tabular} & 146,16 \\
\hline Triturus marmorat & 31 & 100,00 & & 78 & 32, & 549 & 27 & 35 & 236, & \begin{tabular}{|l|l|}
157,99 \\
\end{tabular} & 205, & 217 & 77,44 & 700 & 94,38 & 33,65 & 24,44 & 217 & 142,92 & \begin{tabular}{|l|}
147,29 \\
\end{tabular} & 151,21 \\
\hline Triturus marmoratus & \begin{tabular}{|l|}
$31 T D G 89$ \\
\end{tabular} & 82,00 & 138,88 & 79,63 & 32,99 & 5506,15 & 267,94 & 29,75 & 238,19 & 152,98 & \begin{tabular}{|c|}
186,80 \\
\end{tabular} & 211,01 & 71,29 & $\begin{array}{l}724,75 \\
\end{array}$ & 93,55 & 35,45 & 22,99 & 219,97 & \begin{tabular}{|l|l|}
148,58 \\
\end{tabular} & \begin{tabular}{|l|}
152,88 \\
\end{tabular} & 159,90 \\
\hline Triturus marmoratus & 31TDG93 & 101,00 & 149,48 & 71,06 & 31,22 & 5302,24 & 268,45 & 45,39 & 223,06 & \begin{tabular}{|c|}
160,19 \\
\end{tabular} & 218,27 & 219,19 & 84,88 & 722,41 & $\begin{array}{l}106,15 \\
\end{array}$ & 30,10 & 29,09 & 238,99 & 135,13 & \begin{tabular}{l|l}
158,25 \\
1
\end{tabular} & 157,90 \\
\hline Triturus marmoratus & $\begin{array}{l}\text { 31TDG94 } \\
\end{array}$ & 101,00 & 148,97 & 72,30 & 31,68 & 5318,50 & 269,01 & 43,99 & \begin{tabular}{|l|l|}
225,02 \\
\end{tabular} & 159,60 & \begin{tabular}{|l|l|}
218,08 \\
\end{tabular} & 218,93 & 84,16 & $\begin{array}{l}721,56 \\
\end{array}$ & 104,28 & 31,32 & 28,05 & 234,82 & 138,13 & \begin{tabular}{|c|}
157,69 \\
\end{tabular} & 156,27 \\
\hline 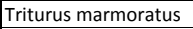 & & 101,00 & & & & & & & 20 & & 22 & 224 & 88, & 645 & 96,88 & 27 & & & 12 & 13 & \\
\hline Triturus marmoratus & 31TDG97 & 101,00 & 154,91 & 77, & 32,98 & 5376, & 278, & 45,78 & 232,99 & \begin{tabular}{|c|}
164,75 \\
\end{tabular} & 224,66 & 225,07 & 88,52 & \begin{tabular}{ll|}
620,55 \\
\end{tabular} & $\begin{array}{l}93,45 \\
\end{array}$ & 26,50 & 29,39 & 207,71 & \begin{tabular}{|c|c|}
118,15 \\
\end{tabular} & \begin{tabular}{|l|l|l|}
129,83 \\
\end{tabular} & 131, \\
\hline Triturus marmoratus & \begin{tabular}{|l|l|}
$31 T D G 98$ \\
\end{tabular} & 101,00 & 154,16 & 79,68 & 33,31 & 5404,67 & 279,85 & 43,98 & 235,87 & 163,77 & 224,38 & 224,69 & 87,42 & 614,88 & 91,59 & 25,70 & 28,95 & 205,24 & 114,78 & 123,02 & 133,82 \\
\hline
\end{tabular}




\begin{tabular}{|c|c|c|c|c|c|c|c|c|c|c|c|c|c|c|c|c|c|c|c|c|c|}
\hline TAXON & UTM & $\mathrm{km} 2$ & BIO1 & B102 & $B 103$ & BIO4 & B105 & B106 & B107 & B108 & B109 & B1010 & BIO11 & B1012 & BIO13 & 81014 & B1015 & B1016 & B1017 & B1018 & B1019 \\
\hline Triturus marmoratus & 31TDG99 & 101,00 & 144,56 & 80,52 & 33,46 & 5443,28 & 272,35 & 34,86 & 237,48 & 151,97 & 215,52 & 215,81 & 77,70 & 669,90 & 92,67 & 29,61 & 25,82 & 213,72 & 128,84 & 135,24 & 149,82 \\
\hline Triturus marmoratus & 31TDH90 & 17,00 & 130,04 & 80,65 & 33,43 & 5452,04 & 259,87 & 22,49 & 237,38 & 119,93 & 201,55 & 201,87 & 63,90 & 750,58 & 95,23 & 35,71 & 22,82 & 229,15 & 150,32 & 154,35 & 172,62 \\
\hline Triturus marmoratus & 31TEG02 & 28,00 & 159,86 & 72,57 & 32,57 & 5126,33 & 275,57 & 56,43 & 219,14 & 170,95 & 218,33 & 227,33 & 97,29 & 631,48 & 102,14 & 21,71 & 35,33 & 225,67 & 106,76 & 137,62 & 139,43 \\
\hline Triturus marmoratus & 31TEG03 & 93,00 & 153,07 & 72,72 & 32,65 & 5129,58 & 269,70 & 50,30 & 219,40 & 164,14 & 219,05 & 220,85 & 91,19 & 659,64 & 100,74 & 24,89 & 31,94 & 226,71 & 118,30 & 144,85 & 143,42 \\
\hline Triturus marmoratus & 31TEG04 & 100,00 & 156,39 & 74,26 & 33,10 | & 5126,21 . & 273,53 & 52,28 & 221,25 & 167,27 & 222,84 & 223,95 & 94,16 & 632,72 & 98,18 & 23,59 & 32,44 & 219,16 & 112,16 & 137,79 & 137,12 \\
\hline Triturus marmoratus & 31TEG05 & 101,00 & 159,00 & 76,01 & 33,36 & 5156,94 & 277,61 & 53,28 & 224,33 & 169,69 & 225,81 & 226,69 & 95,95 & 606,38 & 95,44 & 22,60 & 32,90 & 211,53 & 107,01 & 130,96 & 130,71 \\
\hline Triturus marmoratus & 31TEG07 & 99,00 & 158,76 & 79,15 & 33,82 & 5266,93 & 280,93 & 50,05 & 230,89 & 168,66 & 227,07 & 227,46 & 93,87 & 582,46 & 91,29 & 22,05 & 32,32 & 202,72 & 103,44 & 119,33 & 126,14 \\
\hline Triturus marmoratus & 31TEG08 & 101,00 & 156,38 & 80,48 & 33,99 & 5305,64 & 280,52 & 46,90 & 233,62 & 166,31 & 225,23 & 225,66 & 90,90 & $\begin{array}{l}587,55 \\
\end{array}$ & 90,46 & 22,33 & 31,40 & 202,46 & 103,81 & $\begin{array}{l}119,66 \\
\end{array}$ & 129,73 \\
\hline Triturus marmoratus & 31TEG09 & 90,00 & 144,42 & 80,68 & 33,90 & 5361,71 & 271,10 & 35,65 & 235,45 & 153,62 & 214,34 & 214,71 & 78,84 & $\begin{array}{l}656,66 \\
\end{array}$ & 92,80 & 27,31 & 27,12 & 213,79 & \begin{tabular}{ll|}
121,92 \\
\end{tabular} & \begin{tabular}{|c|}
133,07 \\
\end{tabular} & 148,59 \\
\hline Triturus marmoratus & 31TEG13 & 37,00 & 159,26 & 74,63 & \begin{tabular}{ll|}
33,92 & \\
\end{tabular} & 4974,95 & 273,68 & 56,92 & 216,76 & \begin{tabular}{ll|}
170,61 \\
\end{tabular} & 210,58 & 225,08 & 99,42 & 587,89 & $\begin{array}{l}94,26 \\
\end{array}$ & 19,53 & 35,63 & 211,92 & 100,21 & 130,21 & 126,39 \\
\hline Triturus marmoratus & 31TEG14 & 82,00 & 158,10 & 75,46 & 34,12 & 4968,86 & 273,17 & 55,60 & 217,57 & 169,46 & 218,00 & 223,94 & 98,45 & 581,97 & 92,08 & 19,95 & 34,63 & 207,98 & \begin{tabular}{|c|}
101,27 \\
\end{tabular} & 129,57 & 123,84 \\
\hline Triturus marmoratus & 31TEG15 & 64,00 & 158,06 & 76,80 & 34,23 & 5037,93 & 274,93 & 53,78 & 221,16 & 169,04 & 223,27 & 224,47 & 97,10 & 582,48 & 91,69 & 20,63 & 33,81 & 206,16 & 102,02 & 127,89 & 124,51 \\
\hline Triturus marmoratus & 31TEG16 & 17,00 & 158,85 & 77,65 & 34,00 & 5097,04 & 277,38 & 53,23 & 224,15 & 169,54 & 224,85 & 225,92 & \begin{tabular}{c|c|}
96,69 \\
\end{tabular} & $\begin{array}{l}576,65 \\
\end{array}$ & 91,23 & 20,46 & 33,62 & 204,23 & 100,58 & 125,35 & 123,88 \\
\hline Triturus marmoratus & 31TEG17 & 27,00 & 152,47 & 79,42 & 34,11 & 5163,58 & 274,11 & 45,63 & 228,47 & 162,74 & 219,58 & 220,32 & 89,89 & 597,79 & 91,05 & 21,89 & 31,53 & 206,53 & $\begin{array}{l}105,05 \\
\end{array}$ & 127,42 & 132,21 \\
\hline Triturus marmoratus & 31TEG18 & 92,00 & \begin{tabular}{l|l}
150,02 \\
\end{tabular} & 80,18 & 34,19 & 5227,00 & 273,39 & 42,56 & 230,83 & 160,23 & 218,03 & 218,70 & 86,39 & $\begin{array}{l}614,06 \\
\end{array}$ & $\begin{array}{l}91,62 \\
\end{array}$ & 23,13 & 30,37 & 208,97 & \begin{tabular}{ll|}
108,82 \\
\end{tabular} & 128,38 & 137,49 \\
\hline Triturus marmoratus & 31TEG19 & 30,00 & 151,89 & 82,00 & \begin{tabular}{|c|}
34,39 \\
\end{tabular} & 5309,02 & 277,59 & 42,27 & 235,32 & 161,70 & 220,98 & 221,36 & 86,77 & 602,16 & 90,39 & 22,30 & 30,66 & 205,52 & 104,05 & 120,39 & 137,52 \\
\hline Triturus marmoratus & 31TEG28 & 31,00 & 152,98 & 80,93 & 34,83 & 5170,83 & 275,50 & \begin{tabular}{l|l}
45,63 \\
\end{tabular} & 229,88 & 163,23 & 220,27 & 220,98 & 90,05 & 588,20 & 90,30 & 20,48 & 32,55 & 205,35 & 99,82 & 120,45 & 132,93 \\
\hline Triturus marmoratus & 31TEHOO & 8,00 & 143,60 & 82,49 & 34,11 & 5406,03 & 272,29 & 33,72 & 238,57 & 147,51 & 214,13 & 214,46 & 77,38 & 656,68 & 91,94 & 26,81 & 27,44 & 213,72 & 119,09 & $\mid 127,74$ & 152,85 \\
\hline Triturus pygmaeus & 29SPB32 & 101,00 & 173,23 & 90,13 & \begin{tabular}{|l|}
39,87 \\
\end{tabular} & 4653,86 & 296,81 & 73,27 & 223,54 & 124,94 & 231,23 & 234,90 & 115,92 & 493,39 & 76,86 & 1,00 & 65,25 & 224,21 & 14,76 & 20,66 & 206,99 \\
\hline Triturus pygmaeus & 29SPB34 & 101,00 & 170,86 & 94,32 & 39,90 & 4859,98 & 302,54 & $\begin{array}{l}68,46 \\
\end{array}$ & 234,07 & 120,14 & 231,78 & 235,50 & 111,38 & 504, & 76, & 1,15 & 63,32 & 223,70 & 16,99 & 22,58 & 208,22 \\
\hline Triturus pygmaeus & 29SPB42 & 100,00 & 174,39 & 87,81 & 39,07 & $\begin{array}{l}4705,30 \\
\end{array}$ & 296,40 & 74,27 & 222,13 & 125,04 & 232,76 & 236,31 & 116,11 & 486,66 & 74,96 & 1,00 & 65,00 & 218,79 & 14,07 & 21,01 & 200,46 \\
\hline Triturus pygmaeus & 29SPB43 & 100,00 & 171,07 & 90,36 & \begin{tabular}{l|l|}
39,05 \\
\end{tabular} & 4835,05 & 298,26 & 69,46 & 228,80 & 120,41 & 231,39 & 234,94 & 111,54 & 503,00 & 76,14 & 1,00 & 63,58 & 223,05 & 15,97 & 22,78 & 205,61 \\
\hline $\mid$ & 29SPB44 & 100,00 & 168,94 & 93,08 & 39,08 & 49553,04 & 301,00 & 65,92 & 235,08 & $\mid 116,97$ & 230,92 & 234,64 & $\mid 108,21$ & 514,36 & 76,65 & $\mid 1,65$ & 62,62 & 225,14 & 17,70 & 24,14 & 208,76 \\
\hline Triturus pygmaeus & 29SPB46 & 101,00 & 170,38 & 97,69 & 39,49 & 5097,67 & 309,21 & 64,66 & 244,55 & 116,60 & 234,40 & 237,99 & 107,66 & 508,40 & 74,47 & 2,00 & 61,12 & 218,77 & 19,17 & 24,74 & 204,27 \\
\hline Triturus pygmaeus & 29SPB47 & 100,00 & 168,88 & 100,49 & $\begin{array}{ll}39,82 \\
\end{array}$ & 5191,89 & 311,99 & 61,96 & 250,03 & 114,28 & 234,42 & 237,89 & 105,12 & 517,01 & 75,01 & 2,00 & 60,66 & 220,39 & 20,28 & 25,11 & 207,22 \\
\hline Triturus pygmaeus & 29SPB53 & 101,00 & 172,90 & 87,90 & 38,16 & 4887,35 & 298,20 & 71,02 & 227,18 & 121,10 & 233,55 & 236,92 & 112,13 & $\begin{array}{l}493,46 \\
\end{array}$ & 74,73 & 1,01 & 63,42 & 216,54 & 15,33 & 23,12 & 197,79 \\
\hline Triturus pygmaeus & 29SPB54 & 101,00 & 170,45 & 90,94 & 38,30 & 5007,82 & 300,94 & 66,97 & 233,97 & 1117,41 & 232,94 & 236,36 & 108,48 & 506,42 & 75,65 & 1,51 & 62,28 & 219,73 & 17,00 & 24,36 & 202,13 \\
\hline Triturus pygmaeus & 29SPB56 & 100,00 & 168,05 & $\begin{array}{ll}96,89 \\
\end{array}$ & \begin{tabular}{l|l}
38,95 \\
\end{tabular} & 5204,47 & 307,65 & 61,30 & 246,35 & 112,94 & 233,58 & 236,92 & 103,94 & $\begin{array}{l}520,95 \\
\end{array}$ & 76,11 & 2,00 & 60,74 & 221,98 & 19,40 & 25,68 & 206,68 \\
\hline Triturus pygmaeus & 29SPB58 & 101,00 & 165,17 & 102,30 & 39,26 & 5365,91 . & 312,87 & 56,02 & 256,85 & 108,46 & 233,42 & 236,58 & 99,60 & 539,10 & 77,02 & 2,18 & 59,31 & 225,79 & 22,22 & 27,10 & 212,91 \\
\hline Triturus pygmaeus & 29SPB62 & 100,00 & 176,32 & 82,94 & 37,30 & 4827,46 & 295,47 & 75,96 & 219,51 & 124,72 & 235,65 & 238,97 & 115,88 & 476,06 & 73,79 & 1,00 & 64,06 & 209,23 & 13,14 & 22,10 & 188,61 \\
\hline Triturus pygmaeus & 29SPB63 & 100,00 & 173,50 & 85,69 & 37,29 & 4955,21 & 297,65 & 71,32 & 226,33 & 120,63 & 234,78 & 237,93 & 111,59 & \begin{tabular}{|l|}
490,51 \\
\end{tabular} & 75,08 & 1,01 & 62,88 & 213,02 & 14,88 & 23,59 & 193,09 \\
\hline Triturus pygmaeus & 29SPB65 & 101,00 & 170,61 & 92,24 & 37,94 & 5171,80 & 304,69 & 64,81 & 239,88 & 115,30 & 235,21 & 238,42 & 106,43 & 507,57 & 75,85 & 1,94 & 61,13 & 216,36 & 17,85 & 25,54 & 198,55 \\
\hline Triturus pygmaeus & 29SPB69 & 101,00 & 160,85 & 104,80 & 39,03 & 5543,35 & 313,78 & 49,17 & 264,61 & 102,18 & 231,74 & 234,69 & 93,30 & 569,54 & 80,36 & 2,99 & 57,97 & 234,49 & 25,62 & 30,24 & 222,24 \\
\hline Triturus pygmaeus & 29SPB72 & 100,00 & 177,28 & 80,30 & 36,32 & 4889,62 & 294,83 & 76,74 & 218,10 & 124,96 & 237,14 & 240,23 & 115,76 & $\begin{array}{l}471,86 \\
\end{array}$ & 74,05 & 1,00 & 63,85 & 205,10 & $\begin{array}{l}12,65 \\
\end{array}$ & 22,54 & 183,14 \\
\hline Triturus pygmaeus & 29SPB75 & 100,00 & 173,17 & 90,78 & $\begin{array}{l}37,35 \\
\end{array}$ & 5223,84 & 306,17 & 66,62 & 239,55 & 116,95 & 238,22 & 241,18 & 108,03 & 497,01 & 75,20 & 1,71 & 61,08 & 210,63 & 16,92 & 25,31 & 191,71 \\
\hline Triturus pygmaeus & 29SPB76 & 101,00 & 172,13 & 94,68 & \begin{tabular}{|l|l|}
37,97 \\
\end{tabular} & 5322,15 & 310,30 & 63,59 & 246,72 & 1115,01 & 238,91 & 241,79 & $\begin{array}{l}105,99 \\
\end{array}$ & 504,11 & 75,30 & 1,99 & 60,38 & 212,14 & 18,20 & 25,85 & 194,57 \\
\hline Triturus pygmaeus & \begin{tabular}{|l|} 
29SPB77 \\
\end{tabular} & 100,00 & 169,75 & 98,39 & 38,18 & 5425,29 & 313,11 & 59,47 & 253,64 & 111,36 & 238,29 & 241,06 & 102,64 & 517,79 & 76,19 & 2,01 & 59,74 & 216,32 & 19,64 & 26,46 & 200,12 \\
\hline Triturus pygmaeus & 29SPB79 & 100,00 & 158,60 & 105,26 & 38,94 & 5641,23 & 313,68 & 45,54 & 268,14 & 98,76 & 231,00 & 233,69 & 89,80 & 585,79 & 82,62 & 3,10 & 57,73 & 239,91 & 26,44 & 31,26 & 227,16 \\
\hline Triturus pygmaeus & 29SPB81 & 49,00 & 177,89 & 79,56 & 36,00 & 4901,23 & \begin{tabular}{|l|l|}
294,59 \\
\end{tabular} & 76,90 & 217,69 & 136,93 & 238,02 & 241,00 & 116,18 & 476,69 & 75,25 & 1,00 & 63,82 & 06,57 & 12,51 & 22,87 & 183,93 \\
\hline Triturus pygmaeus & $295 \mathrm{SPB2}$ & 101,00 & 177,98 & 79,33 & 35,82 & 4964,47 & 295,56 & 76,60 & 218,96 & 144,32 & 238,62 & 241,52 & 115,22 & 472,48 & 74,62 & 1,00 & 63,57 & 203,23 & 12,62 & 23,47 & 180,27 \\
\hline Triturus pygmaeus & 29SPB85 & 100,00 & 172,92 & 91,72 & $\begin{array}{l}37,08 \\
\end{array}$ & \begin{tabular}{|l|l|}
5321,27 \\
\end{tabular} & 307,98 & 64,69 & 243,29 & 115,49 & 239,49 & 242,16 & 106,45 & $\begin{array}{l}504,88 \\
\end{array}$ & 76,49 & 1,83 & 61,00 & 212,53 & 17,19 & 25,68 & 193,27 \\
\hline Triturus pygmaeus & 29SPB86 & 100,00 & 169,77 & 96,12 & $\begin{array}{l}37,83 \\
\end{array}$ & 5442,40 & 311,10 & 59,32 & 251,78 & 111,16 & 238,45 & 241,03 & 102,23 & 523,43 & 77,89 & 2,00 & 60,25 & 218,73 & 18,97 & 26,66 & 201,01 \\
\hline Triturus pygmaeus & 29SPB87 & 100,00 & 168,34 & 99,61 & 38,00 & 5531,28 & \begin{tabular}{|l|}
314,37 \\
\end{tabular} & 56,26 & 258,11 & 108,81 & 238,52 & 241,06 & 99,98 & 531,65 & 78,12 & 2,02 & 59,57 & 220,72 & 20,46 & 27,36 & 204,23 \\
\hline Triturus pygmaeus & 29SPB88 & 100,00 & 162,84 & 103,31 & 38,20 & 5644,99 & 314,91 & 48,97 & 265,94 & 102,43 & 235,01 & 237,46 & 93,42 & 564,64 & 81,17 & 2,69 & 58,47 & 232,19 & 23,76 & 29,72 & 217,38 \\
\hline Triturus pygmaeus & 29SPB89 & 100,00 & 153,82 & 106,46 & 38,23 & 5757,84 & 312,54 & 38,85 & 273,69 & 92,73 & 228,07 & 230,59 & 83,71 & 620,39 & 86,93 & 3,43 & 57,47 & 252,59 & 28,53 & 33,33 & 239,85 \\
\hline Triturus pygmaeus & 29SPB90 & & & & & & & & & & & & & & & & & & & & \\
\hline Triturus pygmaeus & 29SPB91 & 91,00 & 176,63 & 82,44 & 36,29 & $\begin{array}{l}4991,09 \\
\end{array}$ & 297,27 & 73,43 & 223,85 & 129,05 & 238,21 & 241,18 & \begin{tabular}{ll|}
113,96 \\
\end{tabular} & $\begin{array}{ll}495,43 \\
\end{array}$ & 77,43 & 1,00 & 63,73 & 213,67 & 13,84 & 23,77 & 191,63 \\
\hline Triturus pygmaeus & 29SPB92 & 101,00 & 176,34 & 83,35 & 36,08 & 5092,33 & 299,59 & 72,02 & 227,57 & 134,69 & 239,17 & 242,06 & 112,29 & 493,55 & 77,1 & 1,00 & 63,20 & 211,19 & 14,05 & 24,00 & $18 \mathrm{c}$ \\
\hline Triturus pygmaeus & 29SPB93 & 100,00 & 178,35 & 85,09 & \begin{tabular}{|c|}
36,17 \\
\end{tabular} & 5167,99 & 304,21 & 72,76 & 231,45 & 147,42 & 242,25 & 244,99 & 113,29 & 482,24 & 75,46 & 1,00 & 62,70 & 205,42 & 14,09 & 24,00 & 183,32 \\
\hline Triturus pygmaeus & 29SPB95 & 99,00 & 169,82 & 94,92 & 37,18 & 5462,90 & 310,08 & 58,89 & 251,19 & 110,79 & 238,72 & 241,25 & 101,85 & 531,43 & 79,77 & 2,00 & 60,74 & 222,38 & 18,52 & 26,68 & 203,61 \\
\hline Triturus pygmaeus & 29SPB99 & 100,00 & 152,23 & 107,69 & 38,00 & 5848,46 & 313,92 & 35,78 & 278,14 & 90,23 & 227,96 & 230,29 & 81,17 & 635,97 & 88,77 & 3,60 & 57,37 & 257,79 & 29,35 & 34,22 & 245,06 \\
\hline Triturus pygmaeus & 29SPC56 & 100,00 & 166,97 & 111,41 & \begin{tabular}{|l|l|}
39,97 \\
\end{tabular} & 5663,56 & 329,39 & 52,77 & 276,63 & 106,25 & 240,07 & 242,45 & 97,86 & 546,35 & 75,01 & 3,92 & 54,31 & 217,49 & 31,92 & 33,19 & 209,91 \\
\hline Triturus pygmaeus & 29SPC57 & 100,00 & 168,13 & 111,79 & 39,5 & 5684,87 & 331,09 & 53,09 & 278,00 & 106,93 & 241,54 & 243,71 & 98,65 & 543,91 & 74 & 3,99 & 53,94 & 215,79 & 32 & 33,71 & 20 \\
\hline Triturus pygmaeus & 295 & 100 & 168 & 112,24 & 39, & 570 & 332,14 & 53,08 & 27 & 107 & 242,20 & & 98,73 & 546 & 75,06 & $4,0 \cup$ & 53,57 & 216,33 & 33,25 & 34,09 & $20 \varepsilon$ \\
\hline Triturus pygmaeus & 29SPC59 & 100,00 & 167,52 & 112,36 & 39,84 & 5728,25 & 331,77 & 51,96 & 279,81 & 105,68 & 241,69 & 243,64 & 97,36 & 562,54 & 76,98 & 4,17 & 53,42 & 222,29 & 35,05 & 35,62 & 215,23 \\
\hline Triturus pygmaeus & 29SPC60 & 100,00 & 163,18 & 106,26 & \begin{tabular}{ll|}
39,15 \\
\end{tabular} & 5569,55 & 317,99 & 50,66 & 267,33 & $\begin{array}{l}104,12 \\
\end{array}$ & 234,43 & 237,22 & 95,19 & 556,04 & 78,26 & 2,98 & 57,41 & 227,75 & 25,89 & 29,93 & 216,04 \\
\hline Triturus pygmaeus & 29SPC66 & 101,00 & 163,96 & 112,50 & 39,32 & 5777,11 & 329,45 & 47,39 & 282,05 & 102,15 & 238,82 & 240,75 & 93,51 & 556,83 & 76,53 & 4,01 & 54,10 & 220,64 & 32,59 & 34,07 & 211,91 \\
\hline Triturus & 295PC67 & 100,0 & 163 & 11 . & 39 & 90 & 329,68 & 46, & 2 & & 0 & 24 & 92,42 & 565 & 77 & 4,10 & & 223,34 & . & 35,10 & 21 \\
\hline Triturus pygmaeus & 29SPC68 & 101,00 & 165,88 & 113,77 & 39,39 & 5827,84 & 333,01 & 48,04 & 284,97 & 102,98 & 241,62 & 243,26 & 94,4 & 550,29 & 75,81 & 4,00 & 53,27 & $\begin{array}{l}216,66 \\
\end{array}$ & 33,90 & 34,73 & 207,97 \\
\hline Triturus pygmaeus & 29SPC69 & 100,00 & 168,82 & 114,62 & 39,47 & 5851,69 & 336,48 & 49,70 & 286,78 & 105,11 & 244,84 & 246,10 & 96,77 & 535,56 & 74,10 & 4,00 & 52,84 & 210,37 & 33,94 & 34,49 & 201,39 \\
\hline
\end{tabular}




\begin{tabular}{|c|c|c|c|c|c|c|c|c|c|c|c|c|c|c|c|c|c|c|c|c|c|}
\hline TAXON & UTM & $\mathrm{km} 2$ & BIO1 & B1O2 & $\mathrm{BIO3}$ & B104 & B105 & B106 & B107 & B108 & 8109 & BIO10 & B1011 & B1012 & B1013 & B1014 & BIO15 & B1016 & B1017 & 81018 & 81019 \\
\hline Triturus pygmaeus & 29SPC70 & 100,00 & 161,09 & 106,73 & 38,95 & 5675,07 & 318,19 & 46,80 & 271,38 & 100,66 & 233,89 & 236,54 & 91,70 & 571,07 & 80,41 & 3,15 & 57,24 & 232,70 & 26,59 & 31,03 & 220,35 \\
\hline Triturus pygmaeus & $29 S P C 71$ & 101,00 & 158,40 & 108,44 & 38,92 & 5732,58 & 318,87 & 43,40 & 275,47 & 97,48 & 232,29 & 234,86 & 88,52 & 587,30 & 81,78 & 3,33 & 56,56 & 237,71 & 28,70 & 32,39 & 226,39 \\
\hline Triturus pygmaeus & 29SPC72 & 100,00 & 165,22 & 109,58 & 39,03 & 5735,12 & 326,20 & 49,42 & $\begin{array}{l}276,78 \\
276,7\end{array}$ & $\begin{array}{l}103,68 \\
103\end{array}$ & 239,04 & 241,32 & $\begin{array}{l}95,01 \\
95,01\end{array}$ & 543,63 & $\begin{array}{l}76,32 \\
76\end{array}$ & 3 & 56,35 & 219,52 & 26,65 & 30,28 & 208,00 \\
\hline Triturus pygmaeus & 29SPC74 & 100,00 & 162,33 & 111,87 & 39,01 & 5819,58 & 327,60 & 45,12 & 282,49 & 99,79 & 237,63 & 239,69 & 91,24 & 560,86 & 77,53 & 3,71 & 54,81 & 223,50 & 30,66 & 33,10 & 213,25 \\
\hline Triturus pygmaeus & 29SPC75 & 100,00 & 160,62 & 112,54 & 38,99 & 5859,96 & 327,79 & 43,08 & 284,70 & 97,82 & 236,75 & 238,66 & 89,31 & 570,99 & 78,47 & 4,01 & 54,31 & 226,36 & 32,31 & 34,26 & 216,50 \\
\hline Triturus pygmaeus & 29SPC77 & 99,00 & 161,64 & 113,86 & 39,01 & 5906,86 & 330,81 & 43,08 & 287,73 & 97,98 & 238,62 & 240,14 & 89,56 & 564,18 & 77,44 & 4,05 & 53,31 & 221,79 & 34,09 & 35,34 & 212,05 \\
\hline Triturus pygmaeus & 29SPC78 & 101,00 & 164,72 & 114,89 & 39,01 & 5922,38 & 334,61 & 44,63 & 289,98 & 100,47 & 241,89 & 243,01 & 92,16 & 543,85 & 75,06 & 4,00 & 52,70 & 213,05 & 33,86 & 34,86 & 202,97 \\
\hline Triturus pygmaeus & $29 S P C 80$ & 101,00 & 154,66 & 107,93 & 38,41 & 5795,37 & 315,84 & 39,03 & 276,81 & 93,23 & 229,63 & 232,06 & 84,21 & 614,21 & 85,61 & 3,64 & 56,86 & 248,62 & 29,24 & 33,59 & 236,45 \\
\hline Triturus pygmaeus & 29SPC81 & 99,00 & 159,18 & 109,25 & 38,81 & 5818,30 & 321,64 & 42,67 & 278,97 & 97,08 & 234,43 & 236,60 & 88,26 & 583,86 & 81,56 & 3,29 & 56,41 & 235,44 & 28,32 & 32,34 & 223,32 \\
\hline |Triturus pygmaeus & $29 S P C 82$ & 101,00 & 160,19 & 110,52 & 38,84 & 5854,69 & 324,58 & 42,86 & 281,71 & 97,50 & 235.97 & 238,01 & 88,63 & 575,40 & 80,09 & 3,43 & 55,90 & 230,86 & 28,88 & 32.50 & 219,15 \\
\hline Triturus pygmaeus & \begin{tabular}{|l|}
$29 S P C 85$ \\
\end{tabular} & 100,00 & 154,08 & 112,77 & 38,61 & 5968,82 & 324,12 & 35,77 & 288,36 & 90,35 & 231,94 & 233,88 & 81,75 & 611,60 & 83,11 & 4,36 & 53,93 & 241,21 & 34,97 & 36,92 & 231,16 \\
\hline Triturus pygmaeus & $295 P C 86$ & 100,00 & 156,27 & 113,57 & 38,80 & 5976,05 & 326,95 & 37,27 & 289,67 & 92,08 & 234,28 & 235,96 & 83,77 & 595,57 & 81,03 & 4,27 & 53,38 & 233,99 & 35,05 & 36,73 & 223,79 \\
\hline Triturus pygmaeus & 29SPC87 & 101,00 & 159,43 & 114,49 & 38,96 & 6000,35 & 331,08 & 39,33 & 291,75 & 94,80 & 237,95 & 239,14 & 86,38 & 570,55 & 78,01 & 4,14 & 52,95 & 223,31 & 34,51 & 36,02 & 212,68 \\
\hline Triturus pygmaeus & 29SPC88 & 100,00 & 163,88 & 115,66 & 39,00 & 5993,57 & 335,55 & 42,50 & 293,05 & 98,77 & 242,25 & 243,16 & 90,53 & 537,45 & 74,13 & 4,00 & 52,71 & 209,84 & 33,10 & 34,49 & 198,71 \\
\hline Triturus pygmaeus & 29SPC90 & 100,00 & 155,39 & 109,04 & 38,17 & 5882,69 & 318,88 & 38,08 & 280,80 & 92,63 & 231,65 & 233,82 & 83,79 & 613,37 & 85,57 & 3,45 & 56,86 & 247,51 & 28,96 & 33,52 & 234,93 \\
\hline Triturus pygmaeus & 29SPC91 & 101,00 & 158,57 & 110,27 & 38,30 & 5915,33 & 323,67 & 40,32 & 283,35 & 95,27 & 235,23 & 237,27 & 86,32 & 589,82 & 82,32 & 3,35 & 56,42 & 237,01 & 28,48 & 32,65 & 224,46 \\
\hline Triturus pygmaeus & 29SPC95 & 101,00 & 153,03 & 113,44 & 38,21 & 6051,86 & 325,26 & 33,25 & 292,01 & 88,29 & 232,23 & 233,77 & 79,68 & 615,80 & 83,41 & 4,51 & 53,75 & 241,99 & 35,09 & 37,22 & 231,30 \\
\hline Triturus pygmaeus & 29SPC99 & 100,00 & 165,35 & 116,18 & 38,94 & 6062,52 & 338,82 & 42,56 & 296,26 & 99,26 & 244,25 & 245,25 & 90,75 & 516,90 & 71,06 & 4,00 & 51,87 & 200,16 & 32,14 & 34,00 & 187,97 \\
\hline Triturus pygmaeus & 29SPD28 & 101,00 & 163,53 & 98,34 & 37,12 & 5619,06 & 318,43 & 57,26 & 261,16 & 101,12 & 236,92 & 238,95 & 95,64 & 774,94 & 110,22 & 5,99 & 54,79 & 312,52 & 47,14 & 48,58 & 312,37 \\
\hline Triturus pygmaeus & 29SPD29 & 101,00 & 165,74 & 99,41 & 37,31 & 5638,23 & 320,90 & 57,92 & 262,98 & 103,96 & 239,38 & 240,89 & 97,06 & 762,84 & 108,38 & 5,99 & 54,66 & 306,90 & 46,46 & 48,16 & 306,55 \\
\hline Triturus pygmaeus & $29 S P D 38$ & 101,00 & 162,82 & 98,87 & 36,98 & 5732,46 & 319,80 & 55,39 & 264,41 & 101,39 & 237,89 & 239,77 & 93,75 & 761,73 & 107,66 & 5,93 & 54,35 & 305,98 & 46,83 & 48,18 & 305,15 \\
\hline Triturus pygmaeus & 29SPD39 & 101,00 & 163,06 & 99,01 & 36,69 & 5777,13 & 320,64 & 54,43 & 266,21 & 100,55 & 238,81 & 240,35 & \begin{tabular}{ll|}
3,17 \\
93,17
\end{tabular} & 767,51 & 108,81 & 5,99 & 54,15 & 307,94 & $\begin{array}{l}4,38 \\
47,38 \\
\end{array}$ & $\begin{array}{l}40,106 \\
48,78 \\
\end{array}$ & 307,06 \\
\hline Triturus pygmaeus & 29SPD46 & 100,00 & 156,64 & 97,92 & 36,98 & 5715,55 & 313,60 & 51,85 & 261,75 & 96,79 & 231,46 & 234,36 & 88,84 & 779,71 & 109,38 & 6,38 & 54,05 & 313,09 & 48,41 & 49,55 & 311,72 \\
\hline Triturus pygmaeus & 29SPD47 & 100,00 & 161,78 & 99,90 & 37,00 & 5777,09 & 320,23 & 53,95 & 266,28 & 100,13 & 237,49 & 239,55 & 92,44 & 738,82 & 103,05 & 5,96 & 53,79 & 295,82 & 45,84 & 47,24 & 293,69 \\
\hline Triturus pygmaeus & 29SPD48 & 100,00 & 163,51 & 100,30 & 37,01 & 5812,85 & 322,29 & 54,38 & 267,91 & 100,95 & 239,86 & 241,48 & 93,31 & 729,76 & 101,92 & 5,83 & 53,78 & 291,85 & 45,22 & 46,76 & 289,49 \\
\hline Triturus pygmaeus & 29SPD54 & 100,00 & 159,58 & 104,37 & 37,96 & 5772,25 & 321,21 & 50,21 & 271,00 & 98,48 & 235,00 & 237,44 & 90,46 & 698,68 & $\begin{array}{l}94,38 \\
\end{array}$ & 5,69 & 53,15 & 277,95 & 44,20 & 45,22 & 273,87 \\
\hline Triturus pygmaeus & $\begin{array}{l}295 \mathrm{PSD} 56 \\
29 \mathrm{~s}\end{array}$ & 101,00 & $\begin{array}{l}157,50 \\
157,86\end{array}$ & 100,85 & 37,00 & 5829,21 & 317,95 & \begin{tabular}{|l|l|}
49,67 \\
492
\end{tabular} & 268,29 & $\begin{array}{l}0,40 \\
96,27 \\
\end{array}$ & 234,37 & \begin{tabular}{|l|}
236,51 \\
\end{tabular} & 80,25 & | & \begin{tabular}{|l|} 
\\
101,26 \\
\end{tabular} & $\begin{array}{l}3,00 \\
6,06\end{array}$ & 53,23 & 293,24 & $\begin{array}{l}44,20 \\
46,52\end{array}$ & $\begin{array}{l}43,242 \\
47,58\end{array}$ & 289,84 \\
\hline Triturus pygmaeus & 29SPD65 & 99,00 & 159,07 & 105,07 & 37,66 & 5905,09 & 322,77 & 47,30 & 275,47 & 96,15 & 236,66 & 238,35 & 88,16 & 682,61 & 91,35 & 5,51 & 52,42 & 269,79 & 43,77 & 44,68 & 264,17 \\
\hline Triturus pygmaeus & 29SPD66 & 100,00 & 155,77 & 102,29 & 36,99 & 5927,89 & 318,27 & 45,51 & 272,75 & 92,83 & 233,73 & 235,56 & 84,82 & 719,31 & 97,68 & 5,96 & 52,67 & 284,73 & 46,32 & 47,04 & 279,75 \\
\hline Triturus pygmaeus & 29SPD67 & 100,00 & 160,17 & 102,90 & 37,00 & 5953,39 & 322,70 & 48,59 & 274,10 & 96,39 & 238,64 & 239,99 & 88,50 & 689,63 & 93,57 & 5,52 & 52,62 & 272,83 & 43,92 & 45,00 & 267,58 \\
\hline Triturus pygmaeus & 29SPD68 & 100,00 & 162,31 & 102,78 & 37,01 & 5974,32 & 324,56 & 49,86 & 274,70 & 97,69 & 240,99 & 242,01 & 89,96 & \begin{tabular}{|l|l|}
677,68 \\
\end{tabular} & 92,17 & 5,34 & 52,48 & 267,94 & 43,03 & 44,25 & 262,65 \\
\hline Triturus pygmaeus & $\begin{array}{l}\text { 25SPDD70 } \\
295 P D\end{array}$ & 101,00 & $\begin{array}{ll}16,58,47 \\
168\end{array}$ & $\begin{array}{l}10,10 \\
116,41\end{array}$ & 39,00 & 5985,76 & $33,59,92$ & $\begin{array}{l}4,00 \\
46,32 \\
\end{array}$ & 293,60 & \begin{tabular}{|r|}
102,76 \\
\end{tabular} & 244,53 & \begin{tabular}{|l|}
247,24 \\
247
\end{tabular} & $\begin{array}{l}93,58 \\
94,5 \\
\end{array}$ & $\begin{array}{l}1,00 \\
521,55\end{array}$ & $\begin{array}{l}32,11 \\
72,42\end{array}$ & $\begin{array}{l}3,434 \\
4,00\end{array}$ & $\begin{array}{l}2,40 \\
51,71\end{array}$ & \begin{tabular}{|l|}
202,79 \\
204
\end{tabular} & $\begin{array}{l}3,304 \\
34,94 \\
\end{array}$ & $\begin{array}{l}44,25 \\
35,31 \\
\end{array}$ & $\begin{array}{l}202,03 \\
192,28\end{array}$ \\
\hline Triturus pygmaeus & 29SPD71 & 100,00 & 168,40 & 116,38 & 39,05 & 5976,06 & 339,55 & 46,77 & 292,79 & 102,82 & 246,31 & 247,10 & 94,75 & 533,62 & 73,51 & 4,00 & 51,58 & 207,55 & 35,67 & 36,27 & 197,40 \\
\hline Triturus pygmaeus & 29SPD73 & 100,00 & 164,64 & 112,88 & 38,83 & 5980,29 & 333,86 & 46,27 & 287,60 & 99,49 & 242,99 & 243,82 & 91,55 & 586,46 & 78,71 & 4,75 & 51,56 & 228,94 & 38,45 & 39,36 & 220,19 \\
\hline Triturus pygmaeus & $29 S P D 74$ & 101,00 & 160,95 & 109,50 & 38,06 & 5989,27 & 328,78 & 45,17 & 283,62 & 96,34 & 239,74 & 240,83 & 88,44 & 626,49 & 83,05 & 5,03 & 51,66 & 245,22 & 40,97 & 41,77 & 237,36 \\
\hline Triturus pygmaeus & $29 S P D 75$ & 100,00 & 160,41 & 107,47 & 37,79 & 6004,66 & 327,26 & 45,64 & 281,61 & 95,76 & 239,45 & 240,56 & 87,78 & 640,06 & 84,48 & 5,02 & 51,79 & 250,86 & 41,51 & 42,46 & 243,36 \\
\hline Triturus pygmaeus & 29SPD77 & 100,00 & 163,55 & 105,60 & 37,01 & 6029,43 & 328,94 & 49,05 & 279,88 & 98,36 & 243,08 & 243,80 & 90,37 & 630,06 & 83,43 & 4,99 & 51,70 & 246,92 & 40,79 & 42,02 & 239,72 \\
\hline Triturus pygmaeus & 29SPD78 & 101,00 & 163,18 & 104,46 & 36,98 & 6042,43 & 327,73 & 48,82 & 278,91 & 97,58 & 242,86 & 243,48 & 89,67 & 638,86 & 85,31 & 4,99 & 51,72 & 250,58 & 41,22 & 42,48 & 243,70 \\
\hline Triturus pygmaeus & 29SPD79 & 100,00 & 164,08 & 103,93 & 36,99 & 6046,74 & 328,12 & 49,56 & 278,56 & 98,21 & 243,88 & 244,25 & 90,47 & 634,59 & 85,11 & 4,96 & 51,67 & 248,84 & 40,90 & 42,10 & 242,06 \\
\hline Triturus pygmaeus & 29SPD80 & 100,00 & 166,48 & 116,63 & 39,00 & 6016,54 & 338,82 & 43,80 & 295,03 & 101,63 & 244,73 & 245,60 & 92,25 & 515,78 & 71,39 & 4,00 & 51,66 & 200,01 & 33,50 & 34,65 & 188,28 \\
\hline Triturus pygmaeus & 29SPD81 & 100,00 & 167,66 & 116,18 & 39,00 & 6007,36 & 339,61 & 45,34 & 294,27 & 101,59 & 245,93 & 246,56 & 93,46 & 517,34 & $\begin{array}{l}1,1,18 \\
718\end{array}$ & 4,00 & 51,31 & 200,32 & 33,97 & 35,08 & 188,84 \\
\hline Triturus pygmaeus & 29SPD83 & 100,00 & 164,86 & 113,41 & 38,41 & 6057,41 & 336,19 & 44,88 & 291,31 & 98,84 & 244,34 & 244,99 & 90,78 & 559,73 & 75,01 & 4,28 & 51,20 & 216,95 & 36,56 & 37,66 & 206,87 \\
\hline Triturus pygmaeus & 29SPD84 & 100,00 & 164,51 & 111,56 & 38,02 & 6072,79 & 334,88 & 45,70 & 289,18 & 98,41 & 244,35 & 244,90 & 90,37 & 571,99 & 76,07 & 4,41 & 51,20 & 222,03 & 37,21 & 38,09 & 212,37 \\
\hline Triturus pygmaeus & $29 S P D 86$ & 100,00 & 160,82 & 107,20 & 37,01 & 6100,64 & 329,33 & 44,68 & 284,66 & 94,91 & 241,38 & 242,02 & 86,92 & 614,69 & 80,48 & 4,97 & 51,01 & 238,84 & 40,42 & 41,25 & 230,18 \\
\hline Triturus pygmaeus & 29SPD87 & 100,00 & 162,66 & 106,46 & 37,01 & 6105,22 & 330,23 & 46,67 & 283,56 & $\begin{array}{l}96,46 \\
96,1\end{array}$ & 243,22 & $\begin{array}{l}243,79 \\
243\end{array}$ & 88,46 & 606,97 & 79,40 & 4,95 & 50,99 & 235,81 & 40,01 & 41,02 & 227,34 \\
\hline Triturus pygmaeus & $\begin{array}{l}\text { 25PSPD89 } \\
\text { 29SPD }\end{array}$ & 100,00 & $\begin{array}{l}10,00,42 \\
160,4\end{array}$ & $\begin{array}{l}104,40 \\
104,07\end{array}$ & 30,01 & $\begin{array}{ll}6124,24 \\
6124,59\end{array}$ & 326,65 & $\begin{array}{l}40,32 \\
45,32 \\
\end{array}$ & \begin{tabular}{|l|}
281,34 \\
28
\end{tabular} & $\begin{array}{l}0,40 \\
93,82 \\
\end{array}$ & $\begin{array}{l}243,42 \\
241,47 \\
\end{array}$ & 241,73 & $\begin{array}{l}80,404 \\
86,14 \\
\end{array}$ & |627,26 & 83,17 & $\begin{array}{ll}4,350 \\
5,00\end{array}$ & 51,11 & \begin{tabular}{|l|}
244,16 \\
\end{tabular} & \begin{tabular}{|l|}
41,07 \\
41,0
\end{tabular} & $\begin{array}{l}41,74 \\
41,74\end{array}$ & 236,20 \\
\hline Triturus pygmaeus & 29SPD90 & 100,00 & 167,01 & 116,32 & 38,96 & 6058,01 & 340,22 & 44,05 & 296,17 & 103,28 & 245,93 & 246,77 & 92,34 & 505,06 & 69,48 & 4,00 & 51,58 & 195,03 & 31,97 & 33,93 & 182,48 \\
\hline Triturus pygmaeus & 29SPD93 & 100,00 & 163,21 & 113,01 & 37,98 & 6135,61 & 336,21 & 42,49 & 293,72 & 96,36 & 243,83 & 244,27 & 88,26 & 551,54 & 73,30 & 4,07 & 51,00 & 212,45 & 35,73 & 36,68 & 201,47 \\
\hline Triturus pygmaeus & 29SPD95 & 100,00 & 161,11 & 109,48 & 37,20 & 6168,92 & 332,58 & 42,74 & 289,84 & 94,19 & 242,64 & 242,97 & 86,19 & 580,94 & 75,82 & 4,72 & 50,47 & 223,68 & 38,61 & 39,40 & 213,55 \\
\hline Triturus pygmaeus & 29SPD96 & 101,00 & 160,82 & 107,91 & 36,97 & 6178,85 & 331,39 & 43,34 & 288,05 & 93,88 & 242,63 & 242,93 & 85,88 & 586,53 & 76, & 4,6 & 50,48 & 226,01 & 38,76 & 39,28 & 216,13 \\
\hline Triturus pygmaeus & 29SPE70 & 101,00 & 160,68 & 102,50 & 36,39 & 6061,68 & 323,93 & 46,84 & 277,09 & $\begin{array}{l}0,70 \\
94,72 \\
\end{array}$ & 240,89 & 241,08 & 86,94 & 661,91 & 89,78 & $\begin{array}{ll}5,25 \\
5,4\end{array}$ & 51,91 & 259,85 & 42,67 & 4 & 253,48 \\
\hline Triturus pygmaeus & 29SPE71 & 100,00 & 159,82 & 101,92 & 36,35 & 6065,58 & 322,31 & 45,97 & 276,34 & 93,66 & 240,05 & 240,17 & 85,82 & 670,65 & 91,49 & 5,45 & 51,84 & 263,29 & 43,56 & 44,06 & 257,20 \\
\hline Triturus pygmaeus & 29SPE81 & 100,00 & 160,04 & 103,15 & 36,37 & 6120,16 & 324,52 & 44,95 & 279,57 & 93,18 & 240,99 & 241,01 & 85,30 & 632,97 & 84,87 & 5,11 & 51,11 & 246,61 & 41,57 & 41,67 & 239,18 \\
\hline Triturus pygmaeus & 29SPE92 & 101,00 & 158,55 & 103,70 & 36,20 & 6167,91 & 324,27 & 42,50 & 281,77 & 90,89 & 240,40 & 240,40 & 83,11 & 606,08 & 80,10 & 5,12 & 50,16 & 234,10 & 40,88 & 40,88 & 225,58 \\
\hline Triturus pygmaeus & 29SQA29 & 85,00 & 178,83 & 87,79 & 37,13 & 5027,68 & 304,23 & 72,22 & 232,02 & \begin{tabular}{r|r|}
143,22 \\
140
\end{tabular} & 241,99 & 245,02 & $\begin{array}{l}11,111 \\
116,11\end{array}$ & 528,25 & 81,26 & $\begin{array}{l}3,1,00 \\
1,4\end{array}$ & 64,74 & 230,03 & $\begin{array}{l}\mid 4,15 \\
14,15 \\
\end{array}$ & $\begin{array}{l}2,00 \\
22,00\end{array}$ & 210,30 \\
\hline Triturus pygmaeus & 29SQA36 & 95,00 & 177,07 & 84,66 & 38,31 & 4649,30 & 293,27 & 75,19 & 218,08 & 153,02 & 235,24 & 238,90 & 119,87 & 554,28 & 90,71 & 0,00 & 66,75 & 246,68 & 13,00 & 20,40 & 228,02 \\
\hline Triturus pygmaeus & 29SQA37 & 70,00 & 177,22 & 84,36 & 37,45 & 4807,11 & 296,27 & 74,12 & 222,15 & 152,46 & 237,56 & 241,03 & 117,86 & 551,16 & 87,79 & 0,53 & 65,83 & 242,48 & 13,59 & 21,43 & 223,57 \\
\hline Triturus pygmaeus & 29SQA44 & 26,00 & 179,26 & 71,10 & 35,90 & 4487,74 & 281,03 & 85,62 & 195,41 & 157,85 & 234,28 & 238,97 & 123,28 & 601,95 & 100,23 & 0,38 & 68,10 & 258,90 & 11,90 & 21,03 & 243,23 \\
\hline Triturus pygmaeus & 29SQA45 & 69,00 & 176,93 & 76,35 & 36,36 & 4649,63 & 286,27 & 79,15 & 207,12 & 153,94 & 234,81 & 238,93 & 119,44 & 587,01 & 95,92 & 0,38 & 66,81 & 255,15 & 13,02 & 21,31 & 237,94 \\
\hline Triturus pygmaeus & 29SQA52 & & & & & & & & & & & & & & & & & & & & \\
\hline
\end{tabular}




\begin{tabular}{|c|c|c|c|c|c|c|c|c|c|c|c|c|c|c|c|c|c|c|c|c|c|}
\hline TAXON & UTM & $\mathrm{km} 2$ & B101 & B102 & $\mathrm{BIO3}$ & BIO4 & B105 & B106 & B107 & B108 & B109 & B1010 & BIO11 & BIO12 & 81013 & BIO14 & BIO15 & B1016 & B1017 & BIO18 & B1019 \\
\hline Triturus pygmaeus & 29SQA53 & 100,00 & 177,64 & 70,43 & 35,65 & 4493,07 & 279,11 & 84,29 & 194,82 & 143,26 & 232,93 & 237,52 & 121,50 & 635,77 & 110,43 & 1,00 & 69,06 & 277,45 & 13,16 & 23,23 & 262,34 \\
\hline Triturus pygmaeus & 29SQA54 & 93,00 & 177,06 & 70,42 & 34,92 & 4627,92 & 281,23 & 82,24 & 198,99 & 149,73 & 234,27 & 238,95 & 119,38 & 623,61 & 105,06 & 1,00 & 68,15 & 269,05 & 13,48 & 23,19 & 253,37 \\
\hline Triturus pygmaeus & 29SQA56 & 100,00 & 173,87 & 72,93 & 33,94 & 4924,18 & 286,72 & 74,69 & 212,03 & 144,30 & 235,60 & 239,56 & 112,85 & 606,72 & 95,02 & 1,00 & 65,93 & 257,52 & 15,55 & 23,43 & 241,52 \\
\hline Triturus pygmaeus & 29SQA61 & 69,00 & 173,72 & 74,04 & 37,77 & 4251,75 & 275,40 & 81,89 & 193,51 & 129,78 & 226,25 & 230,55 & 120,81 & $\begin{array}{l}723,45 \\
\end{array}$ & \begin{tabular}{ll|}
126,98 \\
\end{tabular} & 0,92 & 71,45 & 326,94 & 14,62 & 23,06 & 313,23 \\
\hline Triturus pygmaeus & 29SQA62 & 96,00 & 173,91 & 72,69 & 36,69 & 4381,85 & 276,29 & \begin{tabular}{ll|}
80,88 \\
\end{tabular} & 195,42 & 128,33 & 228,08 & 232,35 & 119,18 & 703,15 & 122,12 & 1,00 & 70,45 & 313,64 & 14,39 & 23,54 & 299,47 \\
\hline Triturus pygmaeus & 29SQA63 & 91,00 & 174,26 & 71,55 & 35,73 & 4530,08 & 278,14 & 80,13 & 198,02 & 127,05 & 230,42 & 234,79 & 117,85 & 680,79 & 116,33 & 1,00 & 69,49 & 299,66 & 14,39 & 23,80 & 284,77 \\
\hline Triturus pygmaeus & 29SQA64 & 82,00 & 173,11 & 71,60 & 34,77 & 4697,90 & 280,25 & 77,27 & 202,98 & 123,76 & 231,64 & 235,93 & 114,68 & 667,31 & \begin{tabular}{|l|l|}
111,07 \\
\end{tabular} & 1,00 & 68,47 & 289,70 & 14,79 & 24,00 & 274,71 \\
\hline Triturus pygmaeus & 29SQBOA & 46,00 & 176,74 & 85,34 & 37,00 & 5008,82 & 299,92 & 71,94 & 227,98 & 123,20 & 239,08 & 242,08 & 114,04 & 511,26 & 79,38 & 1,00 & 64,36 & 221,58 & 14,00 & 23,00 & 200,42 \\
\hline Triturus pygmaeus & 29SQB01 & 100,00 & 177,03 & 85,80 & 36,91 & 5086,65 & 301,93 & 71,36 & 230,57 & 128,89 & 240,26 & 243,19 & 113,39 & 505,93 & 78,73 & 1,00 & 63,83 & 218,10 & 14,01 & 23,13 & 196,75 \\
\hline Triturus pygmaeus & 29SQB02 & 100,00 & 175,71 & 87,83 & 36,78 & 5211,77 & 304,69 & 68,22 & 236,47 & 121,68 & 240,67 & 243,42 & 110,32 & 511,72 & 79,20 & 1,00 & 63,09 & 218,53 & 14,72 & 23,99 & 197,38 \\
\hline Triturus pygmaeus & 29SQB03 & 100,00 & 176,62 & 90,04 & 36,92 & 5313,06 & 309,19 & 67,62 & 241,57 & 130,20 & 243,06 & 245,67 & 110,08 & 505,56 & 78,12 & 1,00 & 62,66 & 214,59 & 15,01 & 23,97 & 193,80 \\
\hline Triturus pygmaeus & 29SQB04 & 100,00 & 175,53 & 93,32 & 37,02 & 5425,44 & 312,93 & 64,53 & 248,41 & 120,14 & 243,71 & 246,19 & 107,63 & 511,63 & 78,33 & 1,29 & 61,96 & 215,68 & 16,04 & 24,62 & 195,76 \\
\hline Triturus pygmaeus & 29SQB06 & 101,00 & 165,53 & 101,65 & 37,97 & 5683,37 & 315,98 & 50,49 & 265,49 & 104,53 & 238,24 & 240,44 & 95,45 & 566,49 & 83,17 & 2,01 & 59,96 & 234,53 & 21,17 & 28,32 & 217,67 \\
\hline Triturus pygmaeus & 29SQB07 & 100,00 & 164,82 & 104,21 & 38,00 & 5762,46 & 319,25 & 48,34 & 270,91 & 102,79 & 238,75 & 240,87 & 93,82 & 569,38 & 82,77 & 2,29 & 59,36 & 234,26 & 22,28 & 28,82 & 218,29 \\
\hline Triturus pygmaeus & 29SQB08 & 100,00 & 163,17 & 106,56 & 38,00 & 5835,67 & 321,68 & 45,53 & 276,15 & 100,43 & 238,34 & 240,40 & 91,52 & 576,80 & 82,82 & 2,68 & 58,52 & 235,69 & 23,96 & 29,93 & 220,70 \\
\hline Triturus pygmaeus & 29SQB09 & 101,00 & 149,98 & 109,34 & 38,00 & 5955,40 & 315,23 & 31,79 & 283,43 & 86,71 & 227,37 & 229,53 & 77,75 & 655,52 & 90,98 & 3,83 & 57,21 & 264,65 & 30,41 & 35,23 & 252,11 \\
\hline Triturus pygmaeus & 29SQB10 & 96,00 & 177,80 & 87,58 & 37,01 & 5066,93 & 303,78 & 71,44 & 232,34 & 130,63 & 241,16 & 244,08 & 114,66 & 518,74 & 80,20 & 1,00 & 64,27 & 224,79 & 14,00 & 22,93 & 204,25 \\
\hline Triturus pygmaeus & 29SQB11 & 100,00 & 178,60 & 89,13 & 37,01 & 5175,99 & 307,72 & 70,57 & 237,15 & 130,95 & 243,40 & 246,23 & 113,90 & 513,12 & 79,52 & 1,00 & 63,83 & 220,93 & 14,38 & 23,00 & 200,28 \\
\hline Triturus pygmaeus & 29SQB12 & 99,00 & 177,09 & 91,82 & 37,01 & 5318,58 & 311,16 & 67,03 & 244,13 & 119,89 & 244,00 & 246,56 & 110,55 & 519,52 & 80,10 & 1,00 & 63,16 & 221,75 & 15,04 & 23,39 & 201,42 \\
\hline Triturus pygmaeus & 29SQB14 & 100,00 & 177,04 & 97,18 & 37,40 & 5528,40 & 319,21 & 63,27 & 255,94 & 117,12 & 247,02 & 249,25 & 108,02 & 518,64 & 79,16 & 1,11 & 62,08 & 218,60 & 16,14 & 24,15 & 199,43 \\
\hline Triturus pygmaeus & 29SQB15 & 100,00 & 171,39 & 101,11 & 37,85 & 5671,57 & 320,33 & 55,58 & 264,75 & 110,05 & 243,75 & 245,90 & 101,01 & 548,55 & 81,87 & 1,99 & 60,71 & 228,67 & 19,41 & 26,72 & 210,85 \\
\hline Triturus pygmaeus & 29SQB16 & 99,00 & 168,83 & 104,02 & 38,00 & 5771,93 & 322,70 & 51,44 & 271,26 & 106,39 & 242,73 & 244,82 & 97,38 & 560,74 & 82,61 & 2,01 & 60,17 & 232,12 & 20,69 & 27,51 & 215,31 \\
\hline Triturus pygmaeus & 29SQB17 & 101,00 & 163,36 & 107,06 & 38,00 & 5877,79 & 322,84 & 44,57 & 278,27 & 99,97 & 239,10 & 241,08 & 90,98 & 589,06 & 85,03 & 2,50 & 59,22 & 241,64 & 23,35 & 29,53 & 226,20 \\
\hline Triturus pygmaeus & 29SQB18 & 100,00 & 159,01 & 109,34 & 38,00 & 5957,20 & 322,97 & 39,38 & 283,59 & 95,16 & 236,25 & 238,07 & 86,15 & 610,38 & 86,62 & 2,97 & 58,25 & 248,23 & 25,93 & 31,53 & 233,97 \\
\hline Triturus pygmaeus & 29SQB19 & 99,00 & 151,81 & 111,03 & 38,00 & 6028,69 & 319,92 & 31,80 & 288,13 & 87,58 & 230,39 & 232,23 & 78,65 & 649,94 & 90,32 & 3,61 & 57,35 & 262,00 & 29,59 & 34,50 & 249,20 \\
\hline Triturus pygmaeus & 29SQB20 & 100,00 & 179,04 & 89,73 & 37,08 & 5151,40 & 308,35 & 70,87 & 237,48 & \begin{tabular}{r|r|}
134,68 \\
\end{tabular} & 243,99 & 246,81 & 114,96 & 524,89 & 80,86 & 1,00 & 64,52 & 227,17 & 14,90 & 22,01 & 207,32 \\
\hline Triturus pygmaeus & $29 \mathrm{SQBZ21}$ & 101,00 & 179,80 & $\begin{array}{l}92,42 \\
92\end{array}$ & 37,20 & 5285,69 & 313,51 & 69,27 & 244,24 & \begin{tabular}{|l|}
131,97 \\
\end{tabular} & $\begin{array}{l}246,44 \\
240\end{array}$ & \begin{tabular}{|l|}
249,12 \\
\end{tabular} & 113,76 & 522,48 & 80,46 & $\begin{array}{l}1,00 \\
1,00\end{array}$ & 63,68 & 224,48 & 15,00 & 22,31 & 204,82 \\
\hline Triturus pygmaeus & 29SQB22 & 100,00 & 178,30 & 95,58 & 37,40 & 5428,78 & 317,33 & 65,47 & 251,87 & 119,33 & 247,04 & 249,51 & 110,55 & 529,87 & 81,28 & 1,00 & 63,28 & 226,09 & 15,47 & 22,99 & 206,78 \\
\hline Triturus pygmaeus & 29SQB24 & 100,00 & 175,60 & 101,94 & 37,95 & 5673,27 & 325,06 & 58,67 & 266,40 & 114,06 & 248,11 & 250,25 & 104,99 & 543,60 & 81,97 & 1,36 & 61,76 & 228,44 & 18,02 & 24,99 & 210,41 \\
\hline Triturus pygmaeus & 29SQB31 & 100,00 & 180,39 & 95,44 & 37,43 & 5399,35 & 319,24 & 67,63 & 251,61 & 121,85 & 248,92 & 251,55 & 113,18 & 535,35 & 82,11 & 1,00 & 63,83 & 229,68 & 15,20 & 22,00 & 210,79 \\
\hline Triturus pygmaeus & 29SQB35 & 101,00 & 175,74 & 109,07 & 38,05 & 5890,17 & 336,24 & 54,13 & 282,11 & 111,61 & 251,58 & 253,33 & 102,63 & 558,45 & 83,11 & 1,74 & 61,18 & 233,21 & 19,53 & 25,44 & 216,83 \\
\hline Triturus pygmaeus & 29SQB45 & 99,00 & 179,99 & $\begin{array}{ll}113,45 \\
\end{array}$ & 38,61 & 5980,75 & 346,22 & 55,51 & \begin{tabular}{|l|}
290,71 \\
\end{tabular} & $\begin{array}{l}11,01 \\
114,92\end{array}$ & \begin{tabular}{|l|}
257,41 \\
\end{tabular} & \begin{tabular}{|l|}
259,01 \\
\end{tabular} & $\begin{array}{l}105,74 \\
105\end{array}$ & $\begin{array}{l}550,452 \\
555,42\end{array}$ & $\begin{array}{l}80,11 \\
82,92\end{array}$ & $\begin{array}{l}1,1 / 41 \\
1,41\end{array}$ & $\begin{array}{l}1,11,79 \\
61,7\end{array}$ & \begin{tabular}{|l|}
232,99 \\
232
\end{tabular} & $\begin{array}{ll}18,81 \\
18,\end{array}$ & 24,00 & 217,38 \\
\hline Triturus pygmaeus & 29SQB54 & 100,00 & 179,52 & 116,15 & 38,86 & 6034,62 & 349,50 & 53,49 & 296,01 & 113,93 & 257,94 & 259,54 & 104,97 & 580,19 & 86,72 & 1,33 & 62,52 & 245,06 & 19,19 & 23,63 & 230,07 \\
\hline Triturus pygmaeus & 29 QB 55 & 100,00 & 182,80 & 117,92 & 38,98 & 6077,18 & 354,84 & 55,47 & 299,36 & 116,50 & 261,79 & 263,16 & 107,47 & 559,71 & 83,53 & 1,13 & 62,24 & 235,80 & 18,43 & 23,01 & 221,17 \\
\hline Triturus pygmaeus & 29SQB56 & 100,00 & 176,11 & 118,63 & 38,93 & 6163,05 & 350,68 & 48,61 & 302,07 & 109,00 & 256,31 & 257,66 & 100,02 & 582,65 & 85,06 & 1,97 & 61,03 & 242,14 & 20,77 & 25,32 & 228,14 \\
\hline Triturus pygmaeus & 29SQB58 & 100,00 & 164,45 & 119,16 & 38,45 & 6288,16 & 342,96 & 37,21 & 305,74 & 96,54 & 246,97 & 248,00 & 87,55 & 621,15 & 87,10 & 2,57 & 59,09 & 252,23 & 24,62 & 29,52 & 239,62 \\
\hline Triturus pygmaeus & 29SQB630 & 57,00 & $\begin{array}{l}104,45 \\
184,32\end{array}$ & $\begin{array}{l}116,90 \\
110\end{array}$ & $\frac{0,45}{39,00}$ & 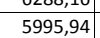 & 353,94 & $\begin{array}{ll}1,21,03 \\
88,\end{array}$ & $\mid 295,91$ & $\mid$\begin{tabular}{|l|}
119,06 \\
19,06
\end{tabular} & \begin{tabular}{|l|}
240,14 \\
262,14
\end{tabular} & $\begin{array}{l}240,000 \\
263,82\end{array}$ & \begin{tabular}{|l|}
110,10 \\
110
\end{tabular} & $\mid \begin{array}{l}\mid 2,1,13 \\
574,31\end{array}$ & $\begin{array}{l}80,10 \\
86,98\end{array}$ & $\frac{2,00}{1,00}$ & $\begin{array}{l}03,84 \\
63,84\end{array}$ & \begin{tabular}{|l|}
245,33 \\
\end{tabular} & $\begin{array}{l}4,005 \\
18,05 \\
\end{array}$ & 22,11 & 230,18 \\
\hline Triturus pygmaeus & $29 S Q C 00$ & 100,00 & 152,57 & 110,61 & 38,01 & 5987,54 & 319,70 & 33,50 & 286,20 & 88,75 & 230,46 & 232,42 & 79,85 & 634,96 & 88,02 & 3,70 & 56,71 & 255,20 & 30,10 & 34,59 & 242,76 \\
\hline Triturus pygmaeus & $29 S Q C 01$ & 100,00 & 150,73 & 111,68 & 38,02 & 6030,24 & 320,13 & 31,31 & 288,82 & 86,57 & 229,46 & 231,34 & 77,71 & $|643,26|$ & 88,33 & 4,06 & 56,03 & 256,93 & 31,92 & 35,85 & 245,11 \\
\hline Triturus pygmaeus & $295 Q C 02$ & 101,00 & 150,90 & 112,55 & 38,00 & 6064,71 & 322,05 & 30,95 & 291,10 & 86,38 & 230,08 & 231,97 & 77,51 & 638,97 & 87,25 & 4,11 & 55,41 & 253,83 & 32,80 & 36,32 & 242,32 \\
\hline Triturus pygmaeus & $295 Q C 06$ & 100,00 & 151,43 & 114,50 & 38,00 & 6152,60 & 326,90 & 30,33 & 296,57 & 85,56 & 232,32 & 233,59 & 77,10 & 619,90 & 83,06 & 4,68 & 53,24 & 241,60 & 36,05 & 38,10 & 230,70 \\
\hline Triturus pygmaeus & $29 S Q C 07$ & 101,00 & 159,48 & 115,70 & 38, & 6144,17 & 334,83 & 36,68 & 298,15 & 92,88 & 239,97 & 240,98 & 84,56 & 561,93 & 76,14 & 4,06 & 52,88 & 218,36 & 32,93 & 35,15 & 206,60 \\
\hline Triturus pygmaeus & $29 \mathrm{SQC10}$ & 101,00 & 157,87 & 112,11 & 38,00 & 6052,92 & 326,94 & 36,77 & 290,16 & 92,90 & 236,66 & 238,34 & 84,15 & 608,89 & 85,03 & 3,21 & 57,12 & 244,71 & 27,85 & 32,59 & 231,55 \\
\hline Triturus pygmaeus & $29 \mathrm{SQC11}$ & 100,00 & 148,36 & 113,07 & 38,00 & 6121,03 & 320,93 & 27,46 & 293,47 & 83,27 & 228,53 & 230,22 & 74,29 & 662,73 & 90,34 & 4,26 & 56,03 & 263,69 & 32,92 & 36,88 & 252,11 \\
\hline Triturus pygmaeus & 29SQC12 & 100,00 & 150,30 & 113,83 & 38,00 & 6146,70 & 324,17 & 28,77 & 295,39 & 84,84 & 230,91 & 232,48 & 75,97 & 644,97 & 87,74 & 4,05 & 55,47 & 255,49 & 32,72 & 36,30 & 243,86 \\
\hline Triturus pygmaeus & 29SQC14 & 101,00 & 159,23 & $\begin{array}{l}115,59 \\
115\end{array}$ & 38,01 & 6171,35 & 334,37 & 35,95 & 298,41 & $\begin{array}{l}4,, 44 \\
92,41 \\
\end{array}$ & 239,95 & 241,13 & 83,86 & 579,12 & 79,00 & 3,69 & 54,64 & 227,61 & 30,38 & 33,67 & $\begin{array}{l}24,00 \\
215,52 \\
\end{array}$ \\
\hline Triturus pygmaeus & $29 \mathrm{SQC15}$ & 100,00 & 153,88 & 115,50 & 38,00 & 6216,08 & 330,77 & 31,06 & 299,71 & 87,03 & 235,64 & 236,60 & 78,50 & 607,10 & 81,63 & 4,19 & 53,79 & 236,94 & 33,57 & 36,28 & 225,45 \\
\hline Triturus pygmaeus & $29 S a C 16$ & 100,00 & 158,39 & 116,15 & 38,01 & 6218,94 & 335,43 & 34,82 & 300,61 & 91,30 & 240,07 & 241,02 & 82,66 & 573,53 & 77,26 & 4,05 & 53,32 & 222,97 & 32,25 & 34,93 & 211,15 \\
\hline Triturus pygmaeus & $295 Q C 24$ & 99,00 & 155,97 & 116,59 & 38,00 & 6269,81 & 334,19 & 31,82 & 302,37 & 88,53 & 238,37 & 239,35 & 79,85 & 601,12 & 80,98 & 3,94 & 54,55 & 235,10 & 31,61 & 34,93 & 223,33 \\
\hline Triturus pygmaeus & $295 Q C 25$ & 100,00 & 154,87 & 116,72 & 38,00 & 6296,31 & 333,94 & 30,57 & 303,37 & 86,94 & 237,62 & 238,51 & 78,50 & \begin{tabular}{|c|}
601,18 \\
\end{tabular} & 80,36 & 4,00 & 53,84 & 233,81 & 32,68 & 35,64 & 222,19 \\
\hline Triturus pygmaeus & $295 \mathrm{SQC28}$ & $\begin{array}{l}101,00 \\
100\end{array}$ & $\begin{array}{l}134,07 \\
162,42\end{array}$ & $\begin{array}{l}110,1 / 2 \\
117,04\end{array}$ & $\begin{array}{l}30, \\
38,\end{array}$ & | & 341 & $\begin{array}{l}30,13 \\
37,15 \\
\end{array}$ & \begin{tabular}{|l|}
304,44 \\
30,4
\end{tabular} & \begin{tabular}{|l|l|}
93,96 \\
93
\end{tabular} & \begin{tabular}{|l|}
$245,39<$ \\
245
\end{tabular} & \begin{tabular}{|l|}
$245,72,7$ \\
245
\end{tabular} & 85,55 & S37,24 & $\begin{array}{l}\mid c 0,1,0 \\
71,40\end{array}$ & $\begin{array}{l}4,407 \\
3,97\end{array}$ & $\begin{array}{l}52,04 \\
52,31\end{array}$ & \begin{tabular}{|l|}
206,15 \\
20,1
\end{tabular} & $\begin{array}{l}32,00 \\
31,56\end{array}$ & $\begin{array}{l}33,04 \\
33,13\end{array}$ & $\begin{array}{l}2,2,19 \\
193,92\end{array}$ \\
\hline Triturus pygmaeus & $295 \mathrm{SQC29}$ & 99,00 & 163,70 & 116,98 & 37,99 & 6310,48 & 342,96 & 38,34 & 304,62 & 94,99 & 247,14 & 247,18 & 86,50 & 523,24 & 69,29 & 3,71 & 51,97 & 200,01 & 30,94 & 31,56 & 187,75 \\
\hline Triturus pygmaeus & 29SQC31 & 101,00 & 143,35 & 115,71 & 37,99 & 6285,63 & 321,80 & 20,01 & 301,79 & 76,51 & 226,30 & 227,65 & 67,74 & 700,80 & 93,93 & 4,65 & 55,87 & 276,69 & 34,98 & 38,88 & 265,89 \\
\hline Triturus pygmaeus & $295 Q C 32$ & 100,00 & 150,07 & 116,82 & 38,00 & 6311,19 & 329,47 & 25,56 & 303,92 & 82,63 & 233,28 & 234,30 & 73,90 & 652,92 & 87,76 & 4,06 & 55,58 & 257,04 & 32,41 & 36,21 & 245,72 \\
\hline Triturus pygmaeus & $295 Q C 33$ & 100,00 & 153,02 & 117,28 & 38,00 & 6330,62 & 333,25 & 27,94 & 305,31 & 85,31 & 236,62 & 237,48 & 76,49 & 627 & 84,15 & 4,00 & 55,13 & 245,93 & 31,71 & 35,48 & 234 \\
\hline Triturus pygmaeus & 2950 (2955 & $\begin{array}{l}100,00 \\
100\end{array}$ & 153,02 & $\begin{array}{l}117,59 \\
117\end{array}$ & 38,00 & $\begin{array}{l}0530,024 \\
6363,24\end{array}$ & 335,03 & $\begin{array}{ll}28,24 \\
28,\end{array}$ & \begin{tabular}{|c|}
305,31 \\
306,79 \\
\end{tabular} & 85,10 & 237,65 & 238,31 & 76,50 & 609,65 & 80,58 & 4,00 & 54,00 & 236,09 & 32,50 & 35,71 & 224,86 \\
\hline Triturus pygmaeus & 2950 C37 & 100,00 & 160,43 & 117,97 & 38,00 & 6361,74 & 341,86 & 34,42 & 307,44 & 91,44 & 244,49 & 244,74 & 82,93 & 555,56 & 73,23 & 3,90 & 52,90 & 213,13 & 31,30 & 33,37 & 201,28 \\
\hline Triturus pygmaeus & $29 S Q C 46$ & 100,00 & 159,70 & 119,06 & 37,99 & 6443,91 & 343,06 & 32,26 & 310,81 & 89,84 & 244,80 & 244,96 & 81,12 & 569,21 & 75,04 & 3,69 & 53,64 & 218,71 & 30,47 & 32,42 & 207,26 \\
\hline Triturus pygmaeus & 29SQC49 & 99,00 & 163,25 & 117,95 & 37,60 & 6448,65 & 346,10 & 36,12 & 309,98 & 92,98 & 248,56 & 248,66 & 84 & 523,97 & 68,46 & 3,31 & 52,23 & 198,42 & 29,73 & 30,41 & 186,63 \\
\hline Triturus pygmaeus & $29 \mathrm{SQC5}$ & 100,00 & 158,74 & 120,32 & 38,00 & 6435,63 & 342,47 & 30,48 & 311,99 & 89,27 & 243,72 & 244,24 & 80,33 & 613,54 & 82,38 & 3,19 & 56,22 & 241,10 & 28,37 & 32,57 & 229,94 \\
\hline
\end{tabular}




\begin{tabular}{|c|c|c|c|c|c|c|c|c|c|c|c|c|c|c|c|c|c|c|c|c|c|}
\hline TAXON & UTM & $\mathrm{km} 2$ & BIO1 & B102 & $B 103$ & BIO4 & B105 & B106 & B107 & B108 & B109 & B1010 & BIO11 & B1012 & BIO13 & B1014 & BIO15 & B1016 & B1017 & B1018 & B1019 \\
\hline Triturus pygmaeus & 29SQC53 & 100,00 & 152,34 & 119,87 & 38,00 & 6469,16 & 337,34 & 24,95 & 312,39 & 82,86 & 237,97 & 238,62 & 74,10 & 638,24 & 84,75 & 3,94 & 55,30 & 248,30 & 31,58 & 35,35 & 237,69 \\
\hline Triturus pygmaeus & 29SQC55 & 100,00 & 158,21 & 120,08 & 38,00 & 6492,21 & 343,57 & 29,89 & 313,68 & 87,86 & 244,27 & 244,42 & 79,23 & 588,23 & 77,81 & 3,70 & 54,34 & 226,40 & 30,18 & 32,39 & 215,47 \\
\hline Triturus pygmaeus & $29 S Q C 56$ & 99,00 & 160,23 & 120,02 & 37,93 & 6499,58 & $\begin{array}{ll}345,58 \\
\end{array}$ & 31,79 & 313,79 & 89,49 & 246,42 & 246,50 & 81,13 & 566,80 & 74,75 & 3,33 & 53,84 & 216,93 & 29,53 & 31,24 & 205,91 \\
\hline Triturus pygmaeus & 29SQC57 & 101,00 & 157,18 & 119,37 & 37,73 & $\begin{array}{l}6509,74 \\
\end{array}$ & 342,79 & 29,19 & 313,61 & 86,55 & 243,60 & 243,67 & 77,96 & 573,23 & 74,97 & 3,87 & 53,01 & 217,74 & 31,36 & 32,25 & 206,81 \\
\hline Triturus pygmaeus & 29SQC58 & 100,00 & 160,35 & 119,09 & $\begin{array}{l}37,65 \\
\end{array}$ & \begin{tabular}{|l|l|}
6510,78 \\
\end{tabular} & 345,55 & 32,21 & 313,33 & 89,57 & 246,70 & 246,74 & 81,06 & 547,69 & 71,51 & 3,60 & 52,61 & 207,06 & 30,33 & 30,64 & 195,84 \\
\hline Triturus pygmaeus & 29SQC59 & 100,00 & 160,74 & 118,62 & 37,32 & 6523,95 & 345,77 & 32,92 & 312,85 & 90,06 & 247,48 & 247,51 & 81,41 & 535,84 & 69,69 & 3,57 & 52,03 & 201,52 & 30,46 & 30,61 & 190,22 \\
\hline Triturus pygmaeus & 29SQD03 & 99,00 & 162,05 & 112,89 & 37,65 & 6217,30 & 336,97 & 40,74 & 296,23 & 94,54 & 244,16 & 244,37 & 86,30 & 543,79 & 71,43 & 4,07 & 50,64 & 207,91 & 35,20 & 35,89 & 196,42 \\
\hline Triturus pygmaeus & 29SQD05 & 99,00 & 159,20 & 109,38 & 36,93 & 6248,82 & 332,70 & 40,15 & 292,56 & 91,71 & 242,11 & 242,33 & 83,56 & \begin{tabular}{|l|l}
570,26 \\
\end{tabular} & 73,62 & 4,45 & 50,23 & 217,73 & 37,80 & 38,31 & 206,77 \\
\hline Triturus pygmaeus & 29SQD06 & 100,00 & 162,13 & 108,65 & 36,89 & $\begin{array}{l}6249,81 \\
\end{array}$ & 334,75 & 43,05 & 291,70 & 94,37 & 244,94 & 245,01 & 86,27 & \begin{tabular}{ll|}
553,42 \\
\end{tabular} & 71,32 & 4,17 & 50,11 & 211,10 & 36,57 & 36,87 & 200,20 \\
\hline Triturus pygmaeus & 29SQD09 & 99,00 & 158,24 & 105,39 & 36,01 & \begin{tabular}{ll|}
6260,37 \\
\end{tabular} & $\begin{array}{l}328,33 \\
\end{array}$ & 40,89 & 287,44 & 90,36 & 241,45 & 241,47 & 82,33 & 580,27 & 74,52 & 4,97 & 49,78 & 221,52 & 39,41 & 39,46 & 211,38 \\
\hline Triturus pygmaeus & 29SQD15 & 100,00 & 160,22 & 109,91 & 36,91 & 6318,99 & 335,55 & 39,81 & 295,74 & 91,89 & 244,16 & 244,19 & 83,61 & 543,83 & 69,39 & 4,14 & 49,90 & 205,40 & 36,18 & 36,36 & 193,78 \\
\hline Triturus pygmaeus & 29SQD17 & 100,00 & 159,88 & 107,54 & 36,00 & 6335,02 & 333,55 & $\begin{array}{ll}40,64 \\
\end{array}$ & 292,92 & 91,31 & 244,13 & 244,13 & 83,15 & 544,58 & 68,94 & 4,05 & 49,74 & 205,57 & 36,49 & 36,51 & 194,10 \\
\hline Triturus pygmaeus & 29SQD19 & 101,00 & 162,86 & 107,15 & 36,24 & 6303,35 & 334,62 & 43,71 & 290,90 & 94,08 & 246,61 & 246,61 & 86,02 & 526,36 & 66,90 & 4,10 & 49,34 & 198,82 & 35,70 & 35,70 & 187,74 \\
\hline Triturus pygmaeus & 29SQD20 & 99,00 & 165,92 & 116,54 & \begin{tabular}{l|l|}
37,99 \\
\end{tabular} & 6306,84 & 344,73 & 40,70 & 304,03 & 97,01 & 249,04 & 249,12 & 88,66 & 506,59 & 66,95 & 3,20 & 51,86 & $\begin{array}{l}193,22 \\
\end{array}$ & 29,84 & 30,62 & 180,89 \\
\hline Triturus pygmaeus & 29SQD21 & 101,00 & 167,54 & $\begin{array}{ll}115,88 \\
\end{array}$ & 37,93 & \begin{tabular}{ll|l|}
6306,67 \\
\end{tabular} & 345,66 & 42,66 & 302,99 & 98,62 & 250,56 & 250,69 & 90,15 & $\begin{array}{l}493,85 \\
\end{array}$ & 65,03 & 3,03 & 51,52 & 187,80 & 29,46 & 30,62 & 175,35 \\
\hline Triturus pygmaeus & 29SQD22 & 99,00 & 166,10 & 114,86 & $\begin{array}{l}37,35 \\
\end{array}$ & \begin{tabular}{|l|}
6329,11 \\
\end{tabular} & 344,38 & 41,63 & 302,75 & 96,99 & 249,73 & 249,83 & 88,67 & 500,07 & 65,06 & 3,38 & 50,77 & \begin{tabular}{|l|l|}
189,08 \\
\end{tabular} & 31,18 & 31,49 & 176,83 \\
\hline Triturus pygmaeus & 29SQD23 & 100,00 & 162,78 & $\begin{array}{l}113,37 \\
\end{array}$ & 37,00 & 6357,80 & 341,02 & 39,52 & 301,50 & 93,64 & 247,12 & 247,14 & 85,36 & 515,75 & 66,36 & 4,00 & 50,40 & 194,20 & 32,93 & 33,12 & 182,06 \\
\hline Triturus pygmaeus & 29SQD27 & 100,00 & 160,06 & 107,97 & 36,00 & 6397,26 & 335,49 & 39,85 & 295,64 & 90,75 & 245,32 & 245,32 & 82,60 & 521,58 & 66,06 & 4,07 & 49,38 & $\begin{array}{l}194,52 \\
\end{array}$ & 35,48 & 35,48 & 182,45 \\
\hline Triturus pygmaeus & 29SQD28 & 101,00 & 162,73 & 108,12 & 36,03 & 6376,15 & 337,02 & 42,26 & 294,77 & 93,22 & 247,57 & 247,57 & 85,14 & 506,04 & 63,53 & 4,00 & 48,92 & \begin{tabular}{|l|l|}
188,88 \\
\end{tabular} & 34,67 & 34,67 & 177,03 \\
\hline Triturus pygmaeus & 29SQD29 & 99,00 & 160,44 & 107,57 & 36,00 & \begin{tabular}{|l|l|}
6372,07 \\
\end{tabular} & 334,12 & 40,52 & 293,60 & 91,04 & 245,34 & 245,34 & 82,97 & \begin{tabular}{|l|l|}
514,47 \\
\end{tabular} & 64,45 & 4,02 & 48,64 & $\begin{array}{l}191,95 \\
\end{array}$ & 35,61 & 35,61 & 180,30 \\
\hline Triturus pygmaeus & 29SQD31 & 100,00 & 165,92 & 116,10 & $\begin{array}{ll}37,53 \\
\end{array}$ & 6383,78 & 346,06 & 40,36 & 305,70 & 96,25 & 250,19 & 250,23 & 87,68 & 499,24 & 64,97 & 3,08 & 51,30 & 188,50 & 29,97 & 30,39 & 176,32 \\
\hline Triturus pygmaeus & 29SQD32 & 99,00 & 163,79 & 115,06 & \begin{tabular}{l|l|}
37,05 \\
\end{tabular} & 6406,58 & \begin{tabular}{|l|l|}
344,01 \\
\end{tabular} & 38,80 & 305,22 & 94,02 & 248,83 & 248,84 & 85,67 & 506,41 & 65,30 & 3,67 & 50,66 & $\begin{array}{l}190,02 \\
\end{array}$ & 31,50 & 31,52 & 177,81 \\
\hline Triturus pygmaeus & 29SQD33 & 100,00 & 159,75 & 113,57 & 36,93 & 6431,24 & 339,81 & 35,92 & 303,89 & 90,02 & 245,19 & 245,19 & 81,60 & 523,70 & 66,91 & 4,03 & 50,19 & 195,72 & 33,60 & 33,66 & 183,56 \\
\hline Triturus pygmaeus & 29SQD35 & 99,00 & 158,47 & 110,82 & 36,14 & 6450,33 & 337,36 & 36,26 & 301,10 & 88,72 & 244,43 & 244,43 & 80,42 & 519,96 & 66,67 & 4,00 & 49,57 & 192,81 & 34,79 & 34,79 & 180,51 \\
\hline Triturus pygmaeus & 29SQD41 & 100,00 & 167,40 & 116,77 & 37,13 & 6444,88 & 349,11 & 40,70 & 308,41 & 96,92 & 252,81 & 252,81 & 88,49 & 488,53 & 63,47 & 3,01 & 51,48 & $\begin{array}{l}183,45 \\
\end{array}$ & 28,49 & 28,51 & 171,45 \\
\hline Triturus pygmaeus & 29SQD43 & 101,00 & 161,52 & 114,56 & 37,00 & 6485,11 & 343,00 & 36,40 & 306,60 & 90,96 & 247,73 & 247,73 & 82,47 & 504,86 & 64,52 & 3,99 & 50,27 & 187,34 & 32,06 & 32,06 & 175,22 \\
\hline Triturus pygmaeus & 29SQD45 & 101,00 & 156,92 & 111,98 & 36,18 & 6502,96 & 337,50 & 33,38 & 304,12 & 86,42 & 243,73 & 243,73 & 78,09 & \begin{tabular}{l|l|}
515,62 \\
\end{tabular} & 66,49 & 4,00 & 49,19 & 189,75 & 34,48 & $\begin{array}{ll}34,48 \\
\end{array}$ & 177,47 \\
\hline Triturus pygmaeus & 29SQD54 & 90,00 & 156,13 & 113,97 & 36,59 & \begin{tabular}{ll|}
6540,17 \\
\end{tabular} & 338,76 & 31,17 & 307,59 & 85,11 & 243,50 & 243,50 & 76,94 & \begin{tabular}{|l|l|}
517,89 \\
\end{tabular} & 66,59 & 4,21 & 49,36 & 189,84 & 34,20 & 34,20 & 177,86 \\
\hline Triturus pygmaeus & 29SQD55 & 82,00 & 156,69 & 113,12 & 36,23 & 6542,17 & 338,71 & 32,22 & 306,49 & 85,59 & 244,25 & 244,25 & 77,52 & 505,80 & 65,25 & 4,08 & 48,90 & 184,66 & 34,11 & 34,11 & 172,52 \\
\hline Triturus pygmaeus & 29SQD56 & 87,00 & 157,94 & 112,30 & 36,01 & 6536,19 & 338,98 & 33,71 & 305,27 & 86,92 & 245,25 & 245,25 & 78,64 & 492,20 & 63,35 & 4,02 & 48,53 & 179,17 & 33,79 & 33,79 & 166,85 \\
\hline Triturus pygmaeus & 29SQD58 & 72,00 & 159,68 & 111,35 & \begin{tabular}{l|l|l|}
36,05 \\
\end{tabular} & \begin{tabular}{ll|}
6490,86 \\
\end{tabular} & 338,59 & 36,23 & 302,36 & 89,04 & 246,51 & 246,51 & 80,72 & $\begin{array}{l}470,35 \\
\end{array}$ & 59,39 & 4,00 & 47,57 & 170,54 & 33,51 & 33,51 & 158,14 \\
\hline Triturus pygmaeus & 29SQE11 & 101,00 & 157,74 & 105,92 & 36,02 & \begin{tabular}{|l|l|}
6286,97 \\
\end{tabular} & 328,03 & 39,43 & 288,61 & 89,15 & 241,37 & 241,37 & 81,21 & 550,67 & 70,10 & 5,05 & 48,66 & 208,12 & 38,66 & 38,66 & 197,41 \\
\hline Triturus pygmaeus & 29SQE12 & 101,00 & 159,51 & 106,20 & 36,38 & 6265,51 & 328,80 & 40,89 & 287,91 & 90,55 & 242,56 & 242,56 & 82,76 & 537,63 & 68,69 & 4,94 & 48,43 & 203,31 & 37,95 & 37,95 & 192,75 \\
\hline Triturus pygmaeus & 29SQE42 & 100,00 & 153,12 & 109,16 & 36,26 & 6395,85 & 327,66 & 32,03 & 295,63 & 82,96 & 238,64 & 238,64 & 75,36 & 489,82 & 60,62 & 5,12 & 46,01 & \begin{tabular}{|l|l|}
178,57 \\
\end{tabular} & 37,77 & 37,77 & 166,24 \\
\hline Triturus pygmaeus & 29SQE50 & 70,00 & 159,94 & 110,91 & 36,59 & 6450,74 & 336,84 & 36,84 & 300,00 & 89,39 & 246,15 & 246,15 & 81,11 & 456,27 & 56,13 & 4,02 & 46,66 & 165,05 & 33,50 & 33,50 & 152,85 \\
\hline Triturus pygmaeus & 29SQE51 & 63,00 & 158,98 & 110,69 & $\begin{array}{l}36,68 \\
\end{array}$ & \begin{tabular}{|l|l|}
6427,51 \\
\end{tabular} & 334,89 & 36,06 & 298,83 & 88,21 & 244,68 & 244,68 & 80,34 & 454,36 & 55,83 & 4,50 & 46,13 & 164,21 & 34,23 & 34,23 & 151,88 \\
\hline Triturus pygmaeus & 29SQE52 & 66,00 & 155,05 & 110,34 & \begin{tabular}{l|l|}
36,55 \\
\end{tabular} & 6425,27 & 330,51 & 32,56 & 297,95 & 84,20 & 240,69 & 240,69 & 76,57 & 463,73 & 57,01 & 5,01 & 45,64 & 167,40 & 36,06 & 36,06 & 154,87 \\
\hline Triturus pygmaeus & $\begin{array}{l}\text { 29TPE74 } \\
\end{array}$ & 100,00 & 151,09 & 99,45 & 35,99 & 6044,12 & 311,10 & 38,55 & 272,55 & 85,01 & 231,27 & 231,27 & 77,25 & 730,10 & 101,60 & 6,54 & 51,86 & 286,93 & \begin{tabular}{ll|}
48,63 \\
\end{tabular} & 48,65 & 281,99 \\
\hline Triturus pygmaeus & $\begin{array}{l}\text { 29TPE84 } \\
\end{array}$ & 101,00 & 146,87 & 99,36 & 35,82 & 6104,88 & 308,40 & 33,98 & 274,42 & 80,31 & 227,97 & 228,03 & 72,56 & \begin{tabular}{|l|l|}
717,78 \\
\end{tabular} & $\begin{array}{l}98,46 \\
\end{array}$ & 6,86 & 51,03 & 280,18 & 49,20 & 9,35 & 273,80 \\
\hline Triturus pygmaeus & \begin{tabular}{|l|} 
29TPE93 \\
\end{tabular} & 100,00 & 159,60 & 104,03 & \begin{tabular}{l|l}
36,55 \\
\end{tabular} & 6147,39 & 324,55 & 43,22 & 281,32 & 91,70 & 240,92 & 240,92 & 84,00 & 597,31 & 79,00 & 5,03 & 50,11 & 230,72 & 40,36 & 40,36 & 222,36 \\
\hline Triturus pygmaeus & $\begin{array}{l}\text { 29TPE94 } \\
\end{array}$ & 99,00 & 150,74 & 101,88 & \begin{tabular}{l|l|l}
36,05 \\
\end{tabular} & 6149,45 & $\begin{array}{ll}314,58 \\
\end{array}$ & 35,85 & 278,73 & 83,35 & 232,37 & 232,43 & 75,59 & \begin{tabular}{ll|}
651,22 \\
\end{tabular} & 87,12 & 6,18 & 50,01 & 251,82 & 45,26 & 45,42 & 243,87 \\
\hline Triturus pygmaeus & 29TQE03 & 101,00 & \begin{tabular}{ll|}
157,84 \\
\end{tabular} & 104,90 & 36,25 & \begin{tabular}{|l|l|}
6197,98 \\
\end{tabular} & 324,68 & 40,68 & 284,00 & 89,63 & 240,05 & 240,05 & 81,88 & 573,08 & 74,32 & 5,06 & 49,47 & 219,34 & 39,70 & 39,70 & 209,86 \\
\hline Triturus pygmaeus & 29TQE04 & 100,00 & 154,81 & 104,37 & 36,24 & 6192,69 & 321,03 & 38,01 & 283,02 & 86,55 & 237,01 & 237,01 & 78,85 & 586,07 & 76,24 & 5,54 & 48,99 & 224,24 & 41,44 & 41,44 & 214,93 \\
\hline Triturus pygmaeus & 29TQE15 & 100,00 & 146,55 & 104,35 & 36,06 & 6231,45 & 313,85 & 29,86 & 283,99 & 78,17 & 229,47 & 229,52 & 70,50 & 592,07 & 76,03 & 6,48 & 47,61 & 224,16 & 44,50 & 44,61 & 213,74 \\
\hline Triturus pygmaeus & 29TQE25 & 100,00 & 144,28 & 105,56 & 36,2 & 6274,53 & 313,42 & 26,70 & 286,71 & 75,50 & 227,90 & 227,97 & 67,85 & 568,92 & 72,27 & 6,7 & 46,51 & 212,81 & 44,44 & 44,51 & 201,38 \\
\hline Triturus pygmaeus & 29TQE26 & 101,00 & 136,78 & 104,80 & \begin{tabular}{|c|}
36,17 \\
\end{tabular} & \begin{tabular}{ll|}
6252,37 \\
\end{tabular} & 305,10 & 20,15 & 284,95 & $\begin{array}{l}68,32 \\
\end{array}$ & 220,21 & 220,43 & \begin{tabular}{ll|l}
60,87 \\
\end{tabular} & 600,82 & 76,44 & 7,80 & 46,06 & 224,75 & 48,41 & 48,75 & 212,96 \\
\hline Triturus pygmaeus & 29TQE35 & 99,00 & $\begin{array}{l}149,72 \\
\end{array}$ & 108,06 & 36,90 & \begin{tabular}{|l|}
6304,32 \\
\end{tabular} & 320,61 & 30,16 & 290,45 & 80,12 & 233,76 & 233,76 & 72,64 & $\begin{array}{l}508,86 \\
\end{array}$ & 64,10 & 6,03 & 45,44 & $\begin{array}{l}187,75 \\
\end{array}$ & 40,64 & $\begin{array}{ll}40,64 \\
\end{array}$ & 175,75 \\
\hline Triturus pygmaeus & 29TQE38 & 100,00 & 110,46 & 103,62 & 36,32 & \begin{tabular}{ll|l|}
6198,67 \\
\end{tabular} & 278,44 & $-3,04$ & 281,49 & 43,78 & 193,30 & 194,22 & 36,73 & 697,16 & 88,05 & 11,78 & 43,03 & 256,34 & 63,16 & 65,78 & 241,57 \\
\hline Triturus pygmaeus & 29TQE43 & 100,00 & 153,78 & 109,25 & 36,69 & \begin{tabular}{|l|l|}
6364,03 \\
\end{tabular} & 327,23 & 32,72 & 294,51 & 83,69 & 238,77 & 238,77 & 76,06 & 479,93 & 59,67 & 5,32 & 45,56 & 174,91 & 37,56 & 37,56 & 162,53 \\
\hline Triturus pygmaeus & 29TQE44 & 100,00 & 152,58 & 109,43 & 36,98 & 6344,64 & 325,43 & 31,54 & 293,89 & 82,55 & 237,27 & 237,27 & 74,89 & 477,37 & \begin{tabular}{r|r}
59,45 \\
\end{tabular} & 5,67 & 45,00 & 173,76 & 38,39 & 38,39 & 161,35 \\
\hline Triturus pygmaeus & 29TQE45 & 100,00 & 151,61 & 109,59 & 37,00 & \begin{tabular}{|l|l|}
6324,97 \\
\end{tabular} & 323,68 & 30,62 & 293,06 & 81,56 & 235,82 & 235,82 & 74,03 & 473,99 & 59,14 & 5,99 & 44,33 & 172,29 & 39,09 & 39,09 & 159,80 \\
\hline Triturus pygmaeus & 29TQE53 & 60,00 & 149,80 & 109,92 & 36,70 & 6408,64 & 324,57 & 27,94 & 296,63 & 79,16 & 235,42 & 235,42 & 71,58 & 480,32 & 59,08 & 5,85 & 44,56 & 173,02 & 39,20 & 39,20 & 160,24 \\
\hline Triturus pygmaeus & 30STE69 & 90,00 & 166,92 & 83,47 & \begin{tabular}{|c|}
39,98 \\
\end{tabular} & \begin{tabular}{|l|l|}
4208,93 \\
\end{tabular} & 277,68 & 71,14 & 206,55 & 123,23 & 220,05 & 223,59 & 115,12 & 848,89 & 146,18 & 0, & 76,41 & $\begin{array}{l}404,67 \\
\end{array}$ & 13,56 & 22,34 & 401,74 \\
\hline Triturus pygmaeus & 305 & 80,6 & 165, & 86 & 40, & 4236 & 280,03 & 69,61 & 210,41 & 121,75 & 219 & 223 & 114 & 815,53 & 141 & 0,9 & 76,60 & 396 & 13,03 & 22,71 & 390,32 \\
\hline Triturus pygmaeus & 30STF33 & 90,00 & 171,30 & 73,63 & 35,99 & 4544,89 & 278,05 & 76,28 & 201,77 & 123,77 & 228,06 & 232,17 & 114,86 & 724,33 & 122,30 & 1,00 & 70,20 & 322,57 & 15,14 & 23,99 & 307,85 \\
\hline Triturus pygmaeus & 30STF35 & 81,00 & $\begin{array}{ll}172,92 \\
\end{array}$ & 73,12 & 34,53 & 4830,34 & 284,27 & 75,48 & 208,79 & 121,93 & 233,49 & 237,52 & $\begin{array}{l}113,13 \\
\end{array}$ & \begin{tabular}{ll|l}
668,82 \\
\end{tabular} & $\begin{array}{l}108,03 \\
\end{array}$ & 1,00 & 68,07 & 290,48 & 15,98 & 23,88 & 274,22 \\
\hline Triturus pygmaeus & 30STF40 & 79,00 & 170,05 & 77,24 & 38,86 & \begin{tabular}{|l|l|}
4149,76 \\
\end{tabular} & 273,55 & 77,47 & 196,08 & 127,19 & 221,86 & 225,45 & 118,45 & 822,55 & 142,23 & 0,24 & 73,99 & 380,45 & 15,04 & 22,30 & 370,92 \\
\hline Triturus & 30STF42 & 100,00 & 172,28 & 74,59 & 37,45 & 11 & 275,88 & 79,09 & 96,79 & 127,13 & 226 & 229 & & 768,15 & 131,0 & 0,67 & 71,80 & 349 & $\mid$\begin{tabular}{|c|}
15,67 \\
\end{tabular} & 22,89 & $33 !$ \\
\hline Triturus pygmaeus & 30STF43 & 100,00 & 171,37 & 75,07 & 36,61 & \begin{tabular}{ll|}
4494,42 \\
\end{tabular} & 278,71 & 76,42 & 202,28 & 124,26 & 227,63 & 231,5 & 115,7 & 748,11 & 125,94 & 1,00 & 70,66 & 337,59 & $\begin{array}{l}15,96 \\
\end{array}$ & 23,63 & 322,29 \\
\hline Triturus pygmaeus & 30STF45 & 100,00 & 169,68 & 78,14 & 35,66 & 4861,25 & 286,50 & 70,68 & 215,82 & 118,62 & 231,10 & 234,95 & 109,92 & $\begin{array}{l}708,52 \\
\end{array}$ & $\begin{array}{l}114,95 \\
\end{array}$ & 1,00 & 68,80 & 313,47 & 16,20 & 24,13 & 296,85 \\
\hline
\end{tabular}




\begin{tabular}{|c|c|c|c|c|c|c|c|c|c|c|c|c|c|c|c|c|c|c|c|c|c|}
\hline TAXON & UTM & $\mathrm{km} 2$ & B101 & B102 & $\mathrm{BIO3}$ & BIO4 & B105 & B106 & B107 & B108 & B109 & B1010 & BIO11 & BIO12 & 81013 & BIO14 & BIO15 & B1016 & B1017 & B1018 & B1019 \\
\hline Triturus pygmaeus & 30STF46 & 100,00 & 172,40 & 79,32 & 35,49 & 4987,73 & 292,23 & 71,79 & 220,45 & 119,53 & 235,35 & 239,11 & 110,95 & 673,38 & 107,45 & 1,00 & 67,82 & 295,25 & 16,53 & 23,51 & 277,60 \\
\hline Triturus pygmaeus & 30STF52 & 100,00 & 169,60 & 77,73 & 38,01 & 4336,43 & 276,87 & 74,98 & 201,89 & 124,45 & 224,16 & 227,73 & 116,00 & 802,55 & 136,23 & 0,89 & 72,62 & 371,01 & 15,89 & 23,25 & 357,32 \\
\hline Triturus pygmaeus & 30STF53 & 100,00 & 171,09 & 77,64 & 37,41 & 4455,91 & 280,34 & 75,76 & 204,58 & 124,36 & 227,16 & 230,82 & 116,13 & 768,19 & 129,70 & 1,00 & 71,54 & 353,12 & 16,00 & 23,21 & 336,74 \\
\hline Triturus pygmaeus & 30STF55 & 100,00 & 165,22 & 84,72 & 37,05 & 4918,91 & 289,35 & 63,82 & 225,53 & 113,95 & 227,76 & 231,43 & 105,18 & 749,39 & 121,80 & 1,00 & 69,44 & 337,26 & 17,08 & 24,59 & 320,86 \\
\hline Triturus pygmaeus & 30STF60 & 100,00 & 163,12 & 85,08 & 39,39 & \begin{tabular}{|l|l|}
4376,18 \\
\end{tabular} & 278,43 & 65,18 & 213,25 & 118,40 & 218,60 & 222,23 & 109,53 & 853,79 & 144,88 & 0,93 & 75,37 & 403,55 & 14,45 & 23,76 & 398,62 \\
\hline Triturus pygmaeus & 30STF61 & 100,00 & 164,61 & 83,27 & 39,14 & 4365,90 & 278,12 & 67,86 & 210,26 & $\begin{array}{ll}120,64 \\
\end{array}$ & 219,93 & 223,56 & 111,16 & 840,99 & 143,07 & 1,00 & 74,27 & 396,99 & 15,20 & 23,82 & 386,95 \\
\hline Triturus pygmaeus & 30STF62 & 100,00 & 165,14 & 82,93 & 38,78 & 4449,51 & 279,79 & 68,02 & 211,77 & \begin{tabular}{|l|l|}
119,86 \\
\end{tabular} & \begin{tabular}{|l|l|}
221,57 \\
\end{tabular} & 225,24 & 110,77 & 820,39 & 138,76 & 1,00 & 73,24 & 384,86 & 15,59 & 23,91 & 371,59 \\
\hline Triturus pygmaeus & \begin{tabular}{|l|} 
30STF63 \\
\end{tabular} & 100,00 & 164,08 & 84,68 & 38,34 & 4621,54 & 283,21 & 65,09 & 218,12 & 116,82 & 222,88 & 226,50 & 107,74 & 800,63 & 133,64 & 1,01 & 71,88 & 371,84 & 16,41 & 24,50 & 356,97 \\
\hline Triturus pygmaeus & 30STF64 & 100,00 & 153,75 & 92,74 & 38,40 & 5017,22 & 287,09 & 48,51 & 238,58 & 102,94 & 218,40 & 221,77 & 93,13 & 819,93 & \begin{tabular}{|l|l|}
131,07 \\
\end{tabular} & 1,40 & 70,22 & 371,48 & 18,62 & 27,59 & 360,28 \\
\hline Triturus pygmaeus & 30STF65 & 100,00 & 165,30 & 87,84 & 37,91 & 4897,96 & 291,96 & 63,35 & 228,62 & 114,42 & 227,81 & 231,30 & 105,79 & 754,59 & 123,63 & 1,03 & 69,99 & 344,99 & 16,89 & 24,36 & 327,48 \\
\hline Triturus pygmaeus & 30STF66 & 100,00 & 165,34 & 90,67 & 37,88 & 5056,80 & 297,25 & 61,18 & 236,06 & 112,45 & 230,04 & 233,33 & 103,99 & 737,02 & 119,37 & 1,00 & 69,04 & 333,87 & 17,22 & 24,32 & 315,92 \\
\hline Triturus pygmaeus & 30STF70 & 100,00 & 170,76 & 82,27 & 40,56 & 4070,03 & 278,45 & 77,89 & 200,57 & $\begin{array}{lll}129,87 \\
\end{array}$ & 222,10 & 225,97 & 121,34 & 806,82 & 143,07 & 1,00 & 76,03 & 396,34 & 13,86 & 22,01 & 381,87 \\
\hline Triturus pygmaeus & 30STF71 & 100,00 & 168,40 & 83,23 & 40,00 & 4224,27 & 279,62 & 73,68 & 205,94 & 126,16 & 221,77 & 225,72 & 117,17 & 808,52 & 141,14 & 1,00 & 75,01 & 393,01 & 14,41 & 22,69 & 376,83 \\
\hline Triturus pygmaeus & 30STF72 & 100,00 & 166,30 & 84,93 & 39,37 & 4410,77 & 282,35 & 69,29 & 213,06 & 121,98 & 222,38 & 226,13 & 112,89 & 800,83 & 137,35 & 1,00 & 73,74 & 383,87 & 15,21 & 23,45 & 367,23 \\
\hline Triturus pygmaeus & 30STF73 & 100,00 & 163,52 & 87,45 & 39,04 & 4622,44 & 285,46 & 63,84 & 221,63 & 116,84 & 222,47 & 226,19 & 107,54 & 793,29 & 133,20 & 1,00 & 72,50 & 374,14 & 15,97 & 24,37 & 357,96 \\
\hline Triturus pygmaeus & 30STF74 & 100,00 & 158,09 & 92,03 & 38,87 & 4898,94 & 288,79 & 54,41 & 234,38 & 108,48 & 221,05 & 224,46 & 98,97 & 797,05 & 129,72 & 1,23 & 70,83 & 367,79 & 17,65 & 26,06 & 353,45 \\
\hline Triturus pygmaeus & 30STF75 & 100,00 & 157,73 & 94,24 & 38,77 & 5045,92 & 292,93 & 52,28 & 240,65 & 106,20 & 222,78 & 226,04 & 96,92 & 784,05 & 126,18 & 1,29 & 69,82 & 358,35 & 18,22 & 26,35 & 343,30 \\
\hline Triturus pygmaeus & 30STF76 & 100,00 & 162,57 & 94,47 & 38,71 & 5093,79 & 298,56 & 57,03 & 241,52 & \begin{tabular}{l|}
109,78 \\
\end{tabular} & 228,15 & 231,24 & 101,07 & 750,01 & 121,26 & 1,13 & 69,25 & 342,29 & 17,83 & 25,01 & 324,72 \\
\hline Triturus pygmaeus & 30STF77 & 100,00 & 158,26 & 99,27 & 38,87 & 5321,01 & 302,43 & 49,17 & 253,27 & 103,04 & 227,22 & 230,04 & 94,22 & 756,27 & 119,35 & 1,35 & 67,90 & 339,33 & 19,30 & 26,55 & 323,32 \\
\hline Triturus pygmaeus & 30STF80 & 43,00 & 175,91 & 82,28 & 41,56 & 3927,69 & 281,94 & 86,09 & \begin{tabular}{|l|l|}
195,84 \\
\end{tabular} & 137,66 & 225,39 & 229,80 & 129,36 & 749,14 & 138,61 & 1,00 & 76,92 & 382,69 & 13,02 & 20,77 & 358,81 \\
\hline Triturus pygmaeus & 30STF83 & 100,00 & 173,10 & 84,66 & 39,84 & 4358,86 & 287,95 & 77,71 & 210,25 & 129,07 & 228,36 & 232,25 & 120,63 & 739,53 & 129,64 & 1,00 & 73,58 & 361,28 & 14,88 & 21,88 & 337,73 \\
\hline Triturus pygmaeus & 30STF85 & 100,00 & 147,33 & 100,24 & 39,00 & 5242,53 & 291,33 & 37,85 & 253,47 & 94,49 & 215,79 & 218,57 & 84,58 & 816,53 & 126,63 & 2,14 & 68,67 & 367,17 & 21,33 & 30,02 & 356,10 \\
\hline Triturus pygmaeus & 30STF86 & 100,00 & 139,97 & 104,57 & 39,00 & 5481,88 & 291,96 & 26,83 & 265,13 & 84,45 & 212,01 & 214,44 & 74,54 & 840,73 & 126,14 & 2,85 & 66,86 & 369,18 & 24,63 & 33,24 & 359,97 \\
\hline Triturus pygmaeus & \begin{tabular}{|l|} 
30STF87 \\
\end{tabular} & 100,00 & 144,08 & 105,08 & 39,00 & 5527,88 & 297,17 & 30,56 & 266,61 & 87,53 & 216,61 & 219,03 & 77,99 & 815,38 & 123,04 & 2,60 & 66,53 & 358,10 & 23,87 & 31,97 & 346,90 \\
\hline Triturus pygmaeus & 30STF9O & & & & & & & & & & & & & & & & & & & & \\
\hline Triturus pygmaeus & 30STF96 & 100,00 & 140,76 & 105,24 & 39,02 & 772,22 & 292,95 & 27,36 & 265,59 & 85,59 & 212,85 & 215,11 & 75,54 & 823,41 & 123,36 & 2,90 & 66,79 & 362,83 & 24,15 & 32,79 & 353,24 \\
\hline Triturus pygmaeus & 30STF97 & 100,00 & 150,34 & 103,86 & 39,00 & 5436,48 & 300,43 & 38,15 & 262,28 & \begin{tabular}{l|l|}
94,78 \\
\end{tabular} & 221,63 & $\begin{array}{l}223,92 \\
22,1\end{array}$ & 85,39 & $\mid 776,73$ & 119,36 & 2,20 & 67,05 & $\begin{array}{l}346,44 \\
3\end{array}$ & 21,62 & 29,46 & 332,90 \\
\hline Triturus pygmaeus & 30STF99 & 100,00 & 162,62 & 106,09 & 39,23 & 5534,61 & 315,61 & 49,36 & 266,25 & 104,63 & 234,77 & 236,86 & 96,04 & 712,37 & 111,81 & 1,42 & 66,75 & 318,54 & 19,35 & 25,61 & 301,63 \\
\hline Triturus pygmaeus & 30STG34 & 56,00 & 185,45 & 121,81 & 39,35 & 6122,18 & 361,35 & 56,06 & 305,29 & 118,62 & 264,96 & 266,55 & 109,75 & 574,53 & 86,42 & 1,00 & 63,36 & 244,78 & 18,00 & 22,00 & 230,79 \\
\hline Triturus pygmaeus & 30STG49 & 100,00 & 165,69 & 122,71 & 38,70 & 6434,94 & 349,90 & 35,92 & 313,99 & 95,88 & 250,41 & 251,07 & 87,03 & 620,24 & 85,77 & 2,65 & 58,86 & 249,59 & 24,31 & 29,03 & 238,44 \\
\hline Triturus pygmaeus & 30STG59 & 100,00 & 162,75 & 123,58 & 38,49 & 6489,78 & 349,12 & 32,60 & 316,52 & 92,60 & 248,53 & 249,06 & 83,68 & 639,22 & 88,46 & 2,57 & 58,97 & 255,99 & 24,94 & 29,09 & 245,75 \\
\hline Triturus pygmaeus & \begin{tabular}{|l|l|}
30 STG69 \\
\end{tabular} & 100,00 & 158,30 & 123,72 & 38,13 & | 6543,04 & 346,16 & $\begin{array}{ll}27,98 \\
27\end{array}$ & $\begin{array}{ll}318,18 \\
\end{array}$ & 87,73 & 245,06 & \begin{tabular}{|l|}
245,34 \\
\end{tabular} & $\begin{array}{l}30,009 \\
78,92\end{array}$ & |664,30 & $\begin{array}{l}90,1,73 \\
11\end{array}$ & 2,86 & 58,72 & 264,30 & 26,15 & 28,46 & 255,15 \\
\hline Triturus pygmaeus & 30STG79 & 100,00 & 158,45 & 124,13 & 38,25 & 6569,95 & 347,11 & 27,77 & 319,34 & 87,62 & 245,74 & 245,83 & 78,66 & 668,05 & 92,56 & 2,95 & 58,80 & 264,92 & 25,84 & 27,06 & 256,60 \\
\hline Triturus pygmaeus & 30STH43 & 100,00 & 152,44 & 121,60 & 38,00 & 6564,90 & 340,64 & 23,11 & 317,53 & 81,97 & 239,73 & 240,03 & 72,92 & 641,43 & 85,26 & 4,01 & 55,44 & 247,99 & 30,97 & 34,01 & 238,21 \\
\hline Triturus pygmaeus & 30STH45 & 100,00 & 156,29 & 121,34 & 37,90 & 6582,55 & 344,70 & 26,89 & 317,80 & 85,22 & 243,84 & 243,96 & 76,47 & 599,57 & 79,15 & 3,77 & 54,35 & 229,14 & 30,18 & 31,53 & 219,06 \\
\hline Triturus pygmaeus & 30STH46 & 100,00 & 155,29 & 120,92 & 37,69 & 6598,03 & 343,72 & 26,13 & 317,59 & 83,97 & 243,16 & 243,18 & 75,32 & 593,16 & 77,76 & 3,99 & 53,64 & 225,08 & 30,95 & 31,10 & 214,95 \\
\hline Triturus pygmaeus & 30STH50 & 100,00 & 154,55 & 122,76 & 38,00 & 6541,03 & 342,21 & 24,70 & 317,51 & 84,12 & 241,26 & 241,71 & 75,17 & 667,25 & 90,76 & 3,32 & 57,67 & 263,34 & 28,34 & 32,51 & 253,95 \\
\hline Triturus pygmaeus & 30STH57 & 100,00 & 158,29 & 121,34 & 37,48 & 6635,21 & 347,64 & 28,06 & 319,58 & 86,25 & 246,79 & 246,79 & 77,69 & 566,59 & 74,11 & 3,67 & 53,32 & 212,71 & 29,75 & 29,75 & 202,91 \\
\hline Triturus pygmaeus & 30STH59 & 100,00 & 158,08 & 120,01 & 37,01 & 6644,11 & 346,61 & 28,50 & 318,10 & 85,85 & 246,69 & 246,69 & 77,37 & 543,94 & 70,90 & 3,76 & 51,89 & 201,49 & 30,76 & 30,76 & 191,24 \\
\hline Triturus pygmaeus & 30STH60 & 100,00 & 154,76 & 123,63 & 38,00 & 6584,50 & 343,96 & 24,34 & 319,62 & 83,79 & 242,28 & 242,47 & 74,96 & 669,32 & 91,24 & 3,44 & 57,66 & 263,09 & 28,16 & 29,76 & 254,51 \\
\hline Triturus pygmaeus & 30STH63 & 100,00 & 157,68 & 123,72 & 38,00 & 6652,56 & 348,56 & 26,31 & 322,26 & 85,60 & 246,30 & 246,33 & 76,89 & 621,23 & 83,23 & 3,3 & 56,03 & 238,75 & 28,07 & 28,60 & 230,16 \\
\hline Triturus pygmaeus & 30STH66 & 100,00 & 152,23 & 122,15 & 37,22 & 6697,95 & 343,97 & 21,39 & 322,58 & 79,81 & 241,83 & 241,83 & 71,41 & 607,75 & 80,32 & 4,09 & 53,43 & 227,41 & 31,95 & 31,95 & 218,64 \\
\hline Triturus pygmaeus & 30STH68 & 100,00 & 158,55 & 121,57 & 37,19 & 6686,85 & 349,00 & 27,63 & 321,37 & 85,77 & 247,87 & 247,87 & 77,34 & 551,79 & 72,81 & 3,78 & 52,64 & 204,48 & 29,63 & 29,63 & 195,11 \\
\hline Triturus pygmaeus & 30STH69 & 100,00 & 160,45 & 120,86 & 37,00 & 6684,73 & 350,04 & 29,56 & 320,48 & 87,46 & 249,60 & 249,60 & 79,00 & 529,86 & 69,74 & 3,37 & 52,25 & 195,47 & 28,90 & 28,90 & 185,73 \\
\hline Triturus pygmaeus & 30STH70 & 100,00 & 151,81 & 123,86 & 38,00 & 6621,13 & 342,2 & 21,17 & 321,08 & 80,58 & 240,03 & 240,17 & 71,88 & \begin{tabular}{|c|c|}
685,67 \\
\end{tabular} & 93,23 & 3,7 & 57,39 & 67,92 & 29,08 & 30,53 & 260,25 \\
\hline Triturus pygmaeus & 30STH73 & 100,00 & 157,96 & 124,19 & 38,00 & 6695,41 & $\begin{array}{l}350, \\
350,\end{array}$ & 25,70 & 324,46 & $\begin{array}{l}0,30 \\
85,29 \\
\end{array}$ & $\begin{array}{l}247,26 \\
\end{array}$ & 247,26 & 76,62 & |621,96 & 83,71 & 3, & 55,96 & 237,66 & 27,83 & 27,83 & 229,96 \\
\hline Triturus pygmaeus & 30STH76 & 100,00 & 152,99 & 122,95 & 37,08 & 6744,62 & 346 & 21,23 & 324,86 & 80,04 & 243,23 & 243,23 & 71,27 & 602,77 & 80,62 & 4,09 & 53,45 & 224,19 & 31,37 & 31,37 & 216,19 \\
\hline Triturus pygmaeus & \begin{tabular}{|l|}
30 STH77 \\
\end{tabular} & 100,00 & 153,77 & 122,52 & 37,05 & 6741,82 & 346,30 & 22,12 & 324,18 & 80,67 & 243,93 & 243,93 & 72,03 & 585,37 & 78,13 & 4,07 & 52,76 & 216,22 & 31,41 & 31,41 & 207,88 \\
\hline Triturus pygmaeus & 30STH79 & 100,00 & 161,64 & 121,60 & 37,05 & 6709,72 & 352,14 & 29,99 & 322,15 & 88,46 & 251,24 & 251,24 & 79,87 & 522,23 & 69,38 & 3,30 & 52,32 & 191,36 & 28,09 & 28,09 & 182,27 \\
\hline Triturus pygmaeus & 30STH86 & 100,00 & 156,58 & 123,79 & 37,37 & 6782,16 & 350,26 & 23,82 & 326,44 & 82,86 & 247,33 & 247,33 & 74,38 & 585,63 & 79,31 & 3,89 & 53,74 & 216,73 & 29,32 & 29,32 & 209,48 \\
\hline Triturus pygmaeus & \begin{tabular}{|l|}
30 STH 89 \\
\end{tabular} & 100,00 & $\begin{array}{l}150,50 \\
160,79\end{array}$ & \begin{tabular}{|l|}
122,07 \\
12,0
\end{tabular} & 37, & $\mid 6751,70$ & 352,34 & 28,51 & \begin{tabular}{|l|l|}
323,83 \\
\end{tabular} & $\begin{array}{l}8,00 \\
87,16 \\
\end{array}$ & $\begin{array}{l}251,17 \\
251 \\
\end{array}$ & \begin{tabular}{|l|}
251,17 \\
253
\end{tabular} & 78,56 & $\begin{array}{l}503,03 \\
523,03\end{array}$ & $\begin{array}{l}\mid r, 5,94 \\
69,9\end{array}$ & $\frac{3,0}{3,4}$ & 52,02 & \begin{tabular}{|l|}
$189,93,13$ \\
\end{tabular} & 28,30 & $\frac{25,32}{28,30}$ & $\begin{array}{l}20,40 \\
181,55\end{array}$ \\
\hline Triturus pygmaeus & 30STH94 & 100,00 & 155,75 & 124,84 & 37,59 & 6791,60 & 350,71 & 22,55 & 328,16 & 82,34 & 246,94 & 246,94 & 73,25 & 617,97 & 85,14 & 3,79 & 55,09 & 230,59 & 28,66 & 28,66 & 224,83 \\
\hline Triturus pygmaeus & 30STJ47 & 80,00 & 158,34 & 112,88 & 36,33 & 6544,45 & 339,35 & 33,48 & 305,87 & 86,83 & 245,83 & 245,83 & 78,67 & 472,85 & 60,15 & 4,06 & 47,72 & 170,54 & 33,28 & 33,28 & 158,29 \\
\hline Triturus pygmaeus & 30STJ51 & 100,00 & 166,13 & 118,88 & 37,00 & 6600,50 & 352,20 & 36,54 & 315,66 & 93,81 & 254,05 & 254,05 & 85,33 & 485,22 & 62,98 & 3,01 & 51,23 & 178,56 & 28,03 & 28,03 & 167,7 \\
\hline Triturus pygmaeus & 30STJS5 & 100,00 & 158,09 & 115,29 & 36,66 & 6600,31 & 342,14 & 31,33 & 310,82 & 86,12 & 246,40 & 246 & 77,93 & 481,99 & 61,95 & 4,14 & 48,14 & 173,26 & 32,86 & 32,86 & 16 \\
\hline Triturus pygmaeus & 30STJ57 & 100,00 & 153,24 & 113,56 & 36,34 & 6576,88 & 335,72 & 27,88 & $\begin{array}{l}307,84 \\
\end{array}$ & $\begin{array}{l}, 1256 \\
81,56\end{array}$ & 241,36 & 241,36 & 73,40 & 485,68 & 61,27 & 4,99 & 46,87 & 173,18 & 35,75 & 35,75 & 160,91 \\
\hline Triturus pygmaeus & 30STIS9 & 100,00 & 153,68 & 112,63 & 36,43 & 6536,26 & 333,96 & 28,91 & 305,05 & 82,08 & 241,23 & 241,23 & 74,07 & 466,74 & 57,20 & 4,98 & 45,69 & 165,74 & 35,83 & 35,83 & 153,15 \\
\hline Triturus pygmaeus & 30STJ60 & 100,00 & 162,60 & 120,19 & 37,01 & 6670,16 & 351,09 & 32,07 & 319,02 & 89,56 & 251,53 & 251,53 & 81,13 & 507,73 & 66,73 & 3,06 & 51,73 & 186,28 & 28,21 & 28,21 & 176,27 \\
\hline Triturus pygmaeus & 30STJ61 & 100,00 & 165,51 & 119,52 & 37,00 & 6647,77 & 352,82 & 35,38 & 317,43 & 92,67 & 254,06 & 254 & 84 & 483,15 & 63,18 & 3,00 & 51,24 & \begin{tabular}{ll|}
176,44 \\
\end{tabular} & 27,62 & 27,62 & 166,13 \\
\hline Triturus pygmaeus & 30STJ64 & 100,00 & 162,51 & 117,17 & 37,00 & 6632,60 & 347,78 & 33,68 & 314,10 & 89,64 & 251,03 & 251,03 & 81,49 & 464,40 & 59,96 & 3,73 & 48,80 & 166,62 & 29,91 & 29,91 & 155,51 \\
\hline
\end{tabular}




\begin{tabular}{|c|c|c|c|c|c|c|c|c|c|c|c|c|c|c|c|c|c|c|c|c|c|}
\hline TAXON & UTM & $\mathrm{km} 2$ & B101 & B102 & $\mathrm{BIO3}$ & BIO4 & B105 & B106 & B107 & B108 & B109 & B1010 & BIO11 & BIO12 & B1013 & BIO14 & BIO15 & B1016 & B1017 & BIO18 & B1019 \\
\hline Triturus pygmaeus & 30STJ67| & 100,00 & 146,09 & 114,28 & 36,10 & 6615,83 & 330,29 & 20,18 & 310,11 & 74,11 & 235,11 & 235,11 & 66,36 & 505,77 & 62,89 & 5,54 & 45,92 & 178,34 & 38,77 & 38,77 & 165,94 \\
\hline Triturus pygmaeus & 30STJ68 & 100,00 & 152,12 & 114,12 & 36,43 & 6587,83 & 334,79 & 26,04 & 308,75 & 80,00 & 240,53 & 240,53 & 72,31 & 468,32 & 57,84 & 4,97 & 45,61 & 164,79 & 35,90 & 35,90 & 152,42 \\
\hline Triturus pygmaeus & 30STI70 & 100,00 & 162,94 & 120,93 & 37,00 & 6711,61 & 352,53 & 31,34 & 321,19 & 89,45 & 252,49 & 252,49 & 80,99 & 503,63 & 66,61 & 3,16 & 51,62 & 183,48 & 27,84 & 27,84 & 174,04 \\
\hline Triturus pygmaeus & 30STJ75 & 100,00 & 156,64 & 117,10 & 36,93 & 6659,80 & 342,72 & 27,78 & 314,95 & 83,69 & 245,82 & 245,82 & 75,59 & 470,78 & 60,01 & 4,24 & 47,59 & 166,20 & 32,63 & 32,63 & 154,99 \\
\hline Triturus pygmaeus & 30STJ76 & 100,00 & 140,27 & 115,77 & 36,36 & 6661,01 & 326,81 & 13,58 & 313,23 & 68,12 & 230,10 & 230,10 & 60,34 & 531,60 & 65,98 & 6,25 & 45,55 & 185,83 & 41,36 & 41,36 & 173,77 \\
\hline Triturus pygmaeus & 30STJ77 & 100,00 & 147,64 & 115,50 & 36,43 & 6635,54 & 332,56 & 20,52 & 312,04 & 75,32 & 236,87 & 236,87 & 67,48 & 485,83 & 60,11 & 5,42 & 45,44 & 169,46 & 37,52 & 37,52 & 157,28 \\
\hline Triturus pygmaeus & 30STI82 & 100,00 & 159,71 & 120,06 & 37,00 & 6722,78 & 349,14 & 28,61 & 320,54 & 86,01 & 249,70 & 249,70 & 77,87 & 486,66 & 63,75 & 3,78 & 49,62 & 173,27 & 29,86 & 29,86 & 163,70 \\
\hline Triturus pygmaeus & 30STJ83 & 100,00 & 164,26 & 119,30 & 37,00 & 6693,97 & 351,82 & 33,32 & 318,50 & 91,13 & 253,90 & 253,90 & 82,54 & 454,95 & 59,16 & 3,09 & 49,66 & 161,80 & 27,59 & 27,59 & 151,82 \\
\hline Triturus pygmaeus & 30STJ85 & 100,00 & 156,96 & 117,95 & \begin{tabular}{|l|l|}
36,97 \\
\end{tabular} & 6694,57 & 344,17 & 27,14 & 317,03 & 83,64 & 246,83 & 246,83 & 75,42 & 460,36 & 58,52 & 4,14 & 47,29 & 161,05 & 31,85 & 31,85 & 150,23 \\
\hline Triturus pygmaeus & 30STJ87 & 100,00 & 139,50 & 116,00 & 36,29 & 6660,10 & 326,07 & 12,18 & 313,89 & 67,07 & 229,44 & 229,44 & 59,43 & 510,14 & 62,04 & 6,55 & 44,22 & 175,34 & 41,84 & 41,84 & 162,97 \\
\hline Triturus pygmaeus & 30STI88 & 100,00 & 139,32 & 115,41 & 36,44 & 6633,73 & 324,53 & 12,55 & 311,98 & 67,20 & 228,75 & 228,76 & 59,59 & 498,80 & 59,71 & 6,71 & 43,49 & 170,82 & 42,19 & 42,20 & 158,02 \\
\hline Triturus pygmaeus & 30STJ92 & 100,00 & 162,71 & 120,71 & 37,00 & 6751,35 & 352,47 & 30,39 & 322,09 & 91,52 & 253,05 & 253,05 & 80,01 & 468,96 & 61,53 & 3,40 & 49,86 & 165,95 & 28,06 & 28,06 & 156,97 \\
\hline Triturus pygmaeus & 30STJ93 & 100,00 & 161,94 & 119,95 & 37,00 & 6733,40 & 350,90 & 30,21 & 320,68 & 92,86 & 252,06 & 252,06 & 79,61 & 459,79 & 59,58 & 3,71 & 48,80 & 161,48 & 29,06 & 29,06 & 152,00 \\
\hline Triturus pygmaeus & 30STK40 & 70,00 & 157,68 & 111,55 & 36,40 & 6477,31 & 335,56 & 33,93 & 301,63 & 86,53 & 244,31 & 244,31 & 78,84 & 455,27 & 55,76 & 4,71 & 46,00 & 163,25 & 34,57 & 34,57 & 150,81 \\
\hline Triturus pygmaeus & 30STK41 & 70,00 & 160,83 & 111,62 & 36,88 & 6438,31 & 337,22 & 37,00 & 300,22 & 89,67 & 246,68 & 246,68 & 81,92 & 435,49 & 53,34 & 4,25 & 45,75 & 156,26 & 32,98 & 32,98 & $\begin{array}{l}143,93 \\
\end{array}$ \\
\hline Triturus pygmaeus & 30STK42 & 61,00 & 159,72 & 111,47 & 37,00 & 6405,93 & 335,10 & 36,22 & 298,88 & 88,79 & 244,95 & 244,95 & 80,91 & 433,38 & 53,14 & 4,72 & 45,05 & 155,24 & 33,98 & 33,98 & 142,80 \\
\hline Triturus pygmaeus & 30STK51 & 100,00 & 161,28 & 112,52 & 36,93 & 6469,97 & 338,53 & 36,40 & 302,13 & 89,56 & 247,40 & 247,40 & 81,93 & 420,85 & 51,29 & 4,13 & 45,34 & 149,64 & 32,44 & 32,44 & 137,23 \\
\hline Triturus pygmaeus & 30STK61 & 100,00 & 161,41 & 113,45 & 37,00 & 6464,10 & 339,30 & 35,73 & $\begin{array}{l}03,57 \\
\end{array}$ & 89,90 & 247,71 & 247,71 & 82,00 & 405,86 & 49,08 & 4,07 & 44,62 & 142,62 & 31,97 & 31,97 & 130,32 \\
\hline Triturus pygmaeus & 30STK81 & 100,00 & 157,36 & 114,90 & 37,00 & 6538,47 & 337,27 & 30,14 & 307,14 & 109,29 & 244,77 & 244,77 & 77,19 & 397,06 & 46,97 & 5,00 & 43,09 & 135,98 & 33,42 & 33,42 & 123,21 \\
\hline Triturus pygmaeus & 30STK82 & 100,00 & 159,99 & 114,49 & 37,00 & 6497,45 & 338,29 & 33,01 & 305,28 & 118,40 & 246,75 & 246,75 & 80,04 & 379,04 & 44,91 & 5,00 & 42,66 & 130,14 & 32,23 & 32,23 & 117,00 \\
\hline Triturus pygmaeus & 30SUF29 & 100,00 & 159,16 & 105,45 & 39,00 & 5574,05 & 311,62 & 44,54 & 267,08 & 101,34 & 232,83 & 234,14 & 92,55 & 696,91 & 106,71 & 2,18 & 65,71 & 309,96 & 20,84 & 27,23 & 294,31 \\
\hline Triturus pygmaeus & 30SUF39 & 100,00 & 163,16 & 103,55 & 38,99 & 5526,19 & 312,55 & 49,03 & 263,52 & 105,89 & 236,23 & 237,36 & 97,02 & 666,41 & 102,47 & 2,11 & 65,86 & 298,11 & 20,08 & 26,09 & 281,61 \\
\hline Triturus pygmaeus & 30SUF69 & 100,00 & 148,18 & 108,52 & 38,10 & 5824,46 & 308,79 & 29,03 & 279,76 & 87,60 & 226,42 & 226,51 & 78,91 & 649,50 & 94,31 & 4,30 & 61,40 & 276,40 & 25,32 & 26,83 & 264,26 \\
\hline Triturus pygmaeus & 30SUF77 & 100,00 & 159,55 & 100,20 & 38,38 & 5393,29 & 303,62 & 46,13 & 257,50 & 104,07 & 231,38 & 231,93 & 95,20 & 575,35 & 88,88 & 3,26 & 63,66 & 255,70 & 21,20 & 24,50 & 240,32 \\
\hline Triturus pygmaeus & 30SUF79 & 100,00 & 146,45 & 109,68 & 38,06 & 5890,52 & 309,60 & 26,14 & 283,45 & 84,89 & 225,82 & 225,82 & 76,33 & 629,21 & 90,48 & 4,67 & 60,19 & 264,72 & 26,09 & 26,35 & 253,12 \\
\hline Triturus pygmaeus & 30SUF89 & 100,00 & 138,18 & 113,21 & 38,01 & 6037,40 & 308,46 & 15,46 & 293,00 & 75,24 & 219,99 & 219,99 & 66,65 & 639,85 & 88,60 & 5,89 & 57,88 & 261,41 & 29,57 & 29,63 & 252,07 \\
\hline Triturus pygmaeus & \begin{tabular}{|l|l|}
30 SUF98 \\
\end{tabular} & 100,00 & 164,71 & 100,24 & 38,00 & 5490,06 & 309,73 & 49,53 & 260,20 & \begin{tabular}{|c|}
107,06 \\
\end{tabular} & 238,20 & 238,29 & 98,92 & \begin{tabular}{|l|l|}
499,38 \\
\end{tabular} & 77,35 & 3,34 & 61,90 & 218,94 & 19,81 & 20,69 & 203,59 \\
\hline Triturus pygmaeus & 30SUF99 & 100,00 & 131,28 & 115,92 & 38,00 & 6159,14 & 307,14 & 6,72 & 300,42 & 67,43 & 214,93 & 214,93 & 58,55 & 651,95 & 87,41 & 7,08 & 55,91 & 259,09 & 33,13 & 33,13 & 251,82 \\
\hline Triturus pygmaeus & 30SUG09 & 100,00 & 171,41 & 123,90 & 38,02 & 6601,14 & 359,11 & 39,39 & 319,72 & 99,62 & 259,17 & 259,17 & 90,60 & 629,89 & 89,50 & 2,11 & 60,41 & 248,30 & 20,38 & 20,38 & 242,66 \\
\hline Triturus pygmaeus & 30SUG17 & 100,00 & 176,59 & 120,83 & 38,41 & 6426,45 & 357,16 & 46,85 & 310,31 & 106,78 & 261,70 & 261,72 & 97,71 & 630,39 & 92,22 & 2,00 & 62,09 & 254,40 & 18,00 & 18,23 & 248,02 \\
\hline Triturus pygmaeus & 30SUG19 & 100,00 & 170,83 & 123,41 & 38,00 & 6637,60 & 358,88 & 38,45 & 320,44 & 98,80 & 259,16 & 259,16 & 89,47 & 637,10 & 91,01 & 2,26 & 60,45 & 249,29 & 20,32 & 20,32 & 245,07 \\
\hline Triturus pygmaeus & 30SUG39 & 100,00 & 172,72 & 121,66 & 37,46 & 6673,92 & 360,28 & $\begin{array}{l}0,49,74 \\
39,\end{array}$ & 320,55 & \begin{tabular}{|r|}
103,10 \\
\end{tabular} & \begin{tabular}{|l|}
261,75 \\
\end{tabular} & 261,75 & $\begin{array}{l}50,77 \\
90,7\end{array}$ & \begin{tabular}{|l|l|}
634,97 \\
\end{tabular} & $\begin{array}{l}1,11 \\
94,36 \\
\end{array}$ & 2,40 & $\begin{array}{ll}60,84 \\
60\end{array}$ & 247,91 & \begin{tabular}{|l|l|}
19,40 \\
\end{tabular} & 19,40 & 242,96 \\
\hline Triturus pygmaeus & 30SUG41 & 100,00 & 163,92 & 107,10 & \begin{tabular}{|l|}
38,08 \\
\end{tabular} & 5819,24 & 321,13 & 45,30 & 275,83 & 102,48 & 241,36 & 241,74 & 94,05 & 648,59 & 96,53 & 2,91 & 63,63 & 280,68 & 21,20 & 25,07 & 267,16 \\
\hline Triturus pygmaeus & 30SUG49 & 100,00 & 177,84 & 119,92 & $\begin{array}{l}37,05 \\
\end{array}$ & 6641,07 & 362,81 & 45,38 & 317,43 & 108,48 & 266,49 & 266,49 & 96,15 & 608,36 & 91,39 & 2,03 & 61,38 & 238,32 & 17,34 & 17,34 & 233,03 \\
\hline Triturus pygmaeus & 30SUG51 & 100,00 & 162,12 & 107,03 & 38,00 & 5867,14 & 320,73 & 42,83 & 277,90 & 100,31 & 240,56 & 240,65 & 91,79 & 632,73 & 92,63 & 3,03 & 62,66 & 271,50 & 21,88 & 24,04 & 258,61 \\
\hline Triturus pygmaeus & 30SUG54 & 100,00 & 169,43 & 111,11 & 37,68 & 6182,19 & 337,53 & 45,85 & 291,68 & 103,08 & 251,95 & 251,95 & 94,54 & 619,52 & 89,40 & 2,85 & 61,66 & 255,64 & 20,03 & 20,03 & 247,58 \\
\hline Triturus pygmaeus & 30SUG55 & 100,00 & 170,56 & 112,87 & 37,33 & 6300,87 & 342,64 & 45,02 & 297,62 & 102,83 & 254,71 & 254,71 & 94,03 & 619,35 & 88,62 & 2,86 & 61,12 & 251,06 & 20,03 & 20,03 & 245,03 \\
\hline Triturus pygmaeus & 30SUG59 & 100,00 & 177,31 & 118,25 & 37,00 & 6620,24 & 360,45 & 45,90 & 314,55 & 108,36 & 265,77 & 265,77 & 96,05 & 591,19 & 87,92 & 2,13 & 60,54 & 230,87 & 17,76 & 17,76 & 225,69 \\
\hline Triturus pygmaeus & 30SUG75 & 100,00 & 155,82 & 114,23 & 37,00 & 6483,09 & 334,95 & 29,28 & 305,67 & 86,84 & 243,34 & 243,34 & 78,06 & 628,75 & 85,66 & 4,59 & 57,93 & 245,89 & 25,79 & 25,79 & 242,22 \\
\hline Triturus pygmaeus & 30SUG80 & 100,00 & 145,86 & 111,84 & 38,00 & 6057,58 & 314,52 & 23,17 & 291,35 & 81,99 & 227,83 & 227,83 & 73,82 & 607,50 & 85,53 & 5,29 & 58,42 & 250,28 & 26,89 & 26,89 & 239,62 \\
\hline Triturus pygmaeus & 30SUG81 & 100,00 & 153,52 & 110,27 & 37,74 & 6081,48 & 320,52 & 31,07 & 289,45 & 88,59 & 235,66 & 235,66 & 80,89 & 579,69 & 82,66 & 4,74 & 58,76 & 239,96 & 24,57 & 24,57 & 228,61 \\
\hline Triturus pygmaeus & 30 SUG 82 & 100,00 & 160,03 & 108,95 & 37,09 & 6113,47 & 325,95 & 37,62 & 288,34 & 94,39 & 242,38 & 242,38 & 86,69 & 565,50 & 80,03 & 4,0 & 59,18 & 233,26 & 22,71 & 22,71 & 222,88 \\
\hline Triturus pygmaeus & 30SUG84 & 100,00 & 153,59 & 113,48 & 36,98 & 6436,52 & 331,44 & 27,62 & 303,83 & 84,82 & 240,74 & 240,74 & 76,60 & 607,21 & 80,98 & 4,97 & 57,11 & 237,89 & 26,17 & 26,17 & 233,38 \\
\hline Triturus pygmaeus & 30SUG85 & 100,00 & 148,31 & 115,62 & 36,83 & 6568,63 & 331,42 & 20,96 & 310,46 & 80,28 & 237,43 & 237,43 & 69,99 & 636,94 & 86,21 & 5,68 & 56,18 & 244,56 & 29,24 & 29,24 & 241,33 \\
\hline Triturus pygmaeus & 30SUG91 & 100,00 & 154,26 & 110,16 & 37,5 & 6085,34 & 321,2 & 31,49 & 289,75 & 89,03 & 236,53 & 236,53 & 81,49 & 549,58 & 78,5 & 4,79 & 58,01 & 226,02 & 24,42 & 24,42 & 214,44 \\
\hline Triturus pygmaeus & 30SUG97 & 100,00 & 170,74 & 111,06 & 36,0 & 6573,88 & 348, & $\begin{array}{ll}4,16 \\
4\end{array}$ & 304,05 & \begin{tabular}{|l|}
103,03 \\
\end{tabular} & 259,23 & 259,23 & $\begin{array}{l}1,4,30 \\
91,3\end{array}$ & 551,62 & $\begin{array}{l}78,58 \\
78,5\end{array}$ & 3,5 & 57,69 & \begin{tabular}{|l|}
214,80 \\
\end{tabular} & 21,00 & 21,00 & 209,27 \\
\hline Triturus pygmaeus & $30 \mathrm{SUH}$ & 100,00 & 156,72 & 124,97 & 37,22 & 6812,88 & 351 & 22,94 & 328,90 & 84,97 & 248,16 & 248,16 & 73,96 & 629,18 & 88,10 & 3,4 & 56,14 & 235,71 & 27,18 & 27,18 & 231,01 \\
\hline Triturus pygmaeus & \begin{tabular}{|l|l|}
30 SUHOG \\
\end{tabular} & 100,00 & 156,69 & 124,19 & 37,01 & 6840,76 & 351,82 & 22,84 & 328,98 & 84,58 & 248,40 & 248,40 & 73,47 & 581,11 & 80,24 & 3,99 & 53,46 & 211,54 & 29,10 & 29,10 & 206,06 \\
\hline Triturus pygmaeus & 30SUH18 & 100,00 & 160,50 & 123,94 & 37,00 & 6853,55 & 354,88 & 26,04 & 328,84 & 87,45 & 252,51 & 252,51 & 76,96 & 528,38 & 72,45 & 3,32 & 52,48 & 188,55 & 27,29 & 27,29 & 183,01 \\
\hline Triturus pygmaeus & 30SUH31 & 100,00 & 159,11 & 123,50 & $\begin{array}{l}37,05 \\
\end{array}$ & 6820,64 & 352,68 & 25,53 & 327,15 & 88,65 & 250,72 & 250,72 & 76,22 & 643,77 & 93,65 & 3,54 & 57,47 & 45 & 25,46 & 25,46 & 239,30 \\
\hline Triturus pygmaeus & $30 \mathrm{SUH}$ & 100,00 & $\begin{array}{l}13,11 \\
156,88\end{array}$ & 123,97 & 37,00 & $\begin{array}{l}6020,045 \\
6859,15\end{array}$ & 351 & \begin{tabular}{|l|l|}
22,99 \\
22,
\end{tabular} & \begin{tabular}{|l|l|}
328,88 \\
\end{tabular} & \begin{tabular}{|l|l|}
86,10 \\
86,10
\end{tabular} & $\begin{array}{l}249,13 \\
249\end{array}$ & $\begin{array}{l}249,13 \\
249\end{array}$ & 73,61 & \begin{tabular}{|l|l|}
635,38 \\
\end{tabular} & \begin{tabular}{|l|}
32,001 \\
92,01
\end{tabular} & $\begin{array}{l}3,44 \\
3,77\end{array}$ & 56,51 & \begin{tabular}{|l|}
240,96 \\
240,
\end{tabular} & 26,70 & 26,70 & 233,23 \\
\hline Triturus pygmaeus & 30SUH37 & 100,00 & 158,19 & 124,25 & 37,00 & 6893,18 & 353,98 & 23,16 & 330,82 & 87,52 & 250,85 & 250,85 & 74,40 & 543,75 & 75,72 & 3,51 & 52,56 & 194,90 & 27,77 & 27,77 & 188,42 \\
\hline Triturus pygmaeus & 30SUH38 & 100,00 & 160,64 & 124,02 & 37,00 & 6885,64 & 355,60 & 25,47 & 330,13 & 89,97 & 253,13 & 253,13 & 76,72 & 517,02 & 71,21 & 3,28 & 52,03 & 182,91 & 26,94 & 26,94 & 177,24 \\
\hline Triturus pygmaeus & $30 \mathrm{SUH} 40$ & 100,00 & 166,59 & 121,69 & 37,01 & 6766,19 & 356,73 & 33,38 & 323,35 & 96,41 & 257,32 & 257,32 & 83,97 & 627,45 & 92,90 & 3,00 & 58,99 & 243,12 & 22,05 & 22,05 & 235,93 \\
\hline Triturus pygmaeus & $30 \mathrm{SUH} 46$ & 100,00 & 157,91 & 124,35 & 37,00 & 6911,92 & 354,04 & 22,60 & 331,45 & 87,01 & 250,81 & 250 & 73,84 & 555,28 & 78,31 & 3,76 & 52,91 & 201,13 & 27,90 & 27,90 & 193 \\
\hline Triturus pygmaeus & |30SUH47 & $\begin{array}{l}100,00 \\
100\end{array}$ & 156,62 & $\begin{array}{l}124,53 \\
124,50\end{array}$ & 37,00 & $\begin{array}{ll}651,12,72 \\
6912,72\end{array}$ & $35,4,94$ & $\begin{array}{l}22,40 \\
21,42\end{array}$ & $\begin{array}{l}51,45 \\
331,48\end{array}$ & 85,87 & 249,65 & 249,65 & 72,71 & 541,91 & 75,45 & 3,73 & 52,08 & 193,57 & 28,44 & 28,44 & 186,43 \\
\hline Triturus pygmaeus & 30SUH49 & 100,00 & 156,20 & 124,03 & 37,00 & 6904,72 & 351,85 & 21,02 & 330,83 & 85,84 & 249,25 & 249,25 & 72,32 & 508,38 & 68,64 & 3,86 & 50,16 & 176,05 & 29,40 & 29,40 & 170,30 \\
\hline Triturus pygmaeus & 30SUH50 & 100,00 & 175,19 & 119,49 & 37,00 & 6695,72 & 361,25 & 42,80 & 318,44 & 105,48 & 264,70 & 264,70 & 93,00 & 587,42 & 87,73 & 2,28 & 59,74 & 228,21 & 18,78 & 18,78 & 221,46 \\
\hline Triturus pygmaeus & 30SUH57 & 100,00 & 151,04 & 124,89 & 37,00 & 6933,85 & 348,32 & 15,91 & 332,42 & 80,23 & 244,52 & 244 & 67,21 & 552,66 & 76,26 & 4,34 & 50,95 & 195,91 & 31,15 & 31,15 & 188,14 \\
\hline Triturus pygmaeus & 30SUH61 & 100,00 & 168,19 & 119,91 & 36,98 & 6799,46 & 357,62 & 35,53 & 322,10 & 98,02 & 259,55 & 259,55 & 85,31 & 583,79 & 86,68 & 3,14 & 57,68 & 224,48 & 22,09 & 22,09 & 215,60 \\
\hline
\end{tabular}




\begin{tabular}{|c|c|c|c|c|c|c|c|c|c|c|c|c|c|c|c|c|c|c|c|c|c|}
\hline TAXON & UTM & $\mathrm{km} 2$ & BIO1 & B102 & $B 103$ & BIO4 & B105 & B106 & 8107 & B108 & B109 & B1010 & BIO11 & B1012 & BIO13 & B1014 & BIO15 & B1016 & B1017 & B1018 & B1019 \\
\hline Triturus pygmaeus & 30SUH62 & 100,00 & 159,36 & 121,62 & 36,99 & 6883,64 & 352,88 & 26,08 & 326,81 & 88,66 & 252,18 & 252,18 & 76,03 & 598,82 & 88,01 & 3,83 & 55,69 & 227,40 & 26,00 & 26,00 & 217,16 \\
\hline Triturus pygmaeus & 30SUH66 & 100,00 & 147,75 & 124,62 & 37,00 & 6951,08 & 345,61 & 13,05 & 332,56 & 78,56 & 241,74 & 241,74 & 64,00 & 573,10 & 79,68 & 4,80 & 50,88 & 204,96 & 32,71 & 32,71 & 195,86 \\
\hline Triturus pygmaeus & 30SUH70 & 100,00 & 177,69 & 116,12 & 36,80 & 6647,14 & 359,74 & 47,10 & 312,63 & 108,78 & 266,65 & 266,65 & 96,31 & 544,59 & 80,35 & 2,31 & 58,69 & 210,57 & 18,35 & 18,35 & 204,07 \\
\hline Triturus pygmaeus & 30SUH71 & 100,00 & 173,71 & 117,85 & 36,75 & 6743,01 & 359,66 & 42,01 & 317,65 & $\begin{array}{l}103,97 \\
\end{array}$ & 264,08 & 264,08 & 91,19 & 550,19 & 81,64 & 2,86 & 57,58 & 211,40 & 20,33 & 20,33 & 203,06 \\
\hline Triturus pygmaeus & 30SUH74 & 100,00 & 151,78 & 123,02 & $37,00 \mid$ & 6941,81 . & 348,19 & 17,94 & 330,25 & 80,72 & 245,66 & 245,66 & 68,25 & 582,21 & 83,49 & 4,44 & 52,59 & 214,36 & 30,20 & 30,20 & 203,55 \\
\hline Triturus pygmaeus & 30SUH76 & 100,00 & 141,94 & 124,88 & 37,00 & 6962,21 & 340,69 & 7,44 & 333,25 & 90,01 & 236,19 & 236,19 & 58,53 & 583,66 & 80,33 & 5,47 & 49,59 & 208,01 & 35,86 & 35,86 & 197,16 \\
\hline Triturus pygmaeus & 30SUH83 & 100,00 & 150,42 & 121,94 & 36,52 & 6952,54 & 346,31 & 17,11 & 329,19 & 79,19 & 244,50 & 244,50 & 66,77 & 593,26 & 85,86 & 4,98 & 52,75 & 220,49 & 31,11 & 31,11 & 208,25 \\
\hline Triturus pygmaeus & 30SUH84 & 100,00 & 154,04 & 122,48 & 36,91 & 6943,70 & 349,56 & 20,06 & 329,49 & 83,92 & 247,77 & 247,77 & 70,27 & 563,59 & 80,97 & 4,26 & 52,42 & 207,25 & 29,19 & 29,19 & 196,12 \\
\hline Triturus pygmaeus & 30SUH85 & 100,00 & 141,49 & $\begin{array}{ll}124,08 \\
\end{array}$ & 37,00 & 6965,81 & 339,93 & 7,69 & 332,24 & 91,04 & 235,90 & 235,90 & 58,33 & 591,33 & 82,19 & 5,76 & 49,85 & 213,17 & 36,21 & 36,21 & 200,69 \\
\hline Triturus pygmaeus & 30SUH86 & 100,00 & 145,59 & \begin{tabular}{ll|}
124,74 \\
\end{tabular} & 37,00 & 6964,43 & 343,72 & $\begin{array}{ll}10,73 \\
\end{array}$ & 332,99 & 98,61 & 239,85 & 239,85 & 61,92 & 559,53 & 77,06 & 5,04 & 49,66 & 200,49 & 33,95 & 33,95 & 188,22 \\
\hline Triturus pygmaeus & 30SUH92 & 100,00 & 163,76 & 118,20 & \begin{tabular}{l|l|l}
36,05 \\
\end{tabular} & 6865,54 & 353,73 & 32,17 & 321,56 & 93,18 & 256,31 & 256,31 & 80,76 & 550,32 & 81,49 & 3,78 & 54,71 & 208,74 & 24,99 & 24,99 & 196,92 \\
\hline Triturus pygmaeus & 30SUH94 & 100,00 & 155,04 & 121,73 & 36,89 & 6927,27 & 349,65 & 21,51 & 328,14 & 100,29 & 248,67 & \begin{tabular}{|l|l|}
248,67 \\
\end{tabular} & 71,53 & $\begin{array}{l}549,85 \\
\end{array}$ & 78,94 & 4,31 & 52,02 & 202,57 & 29,14 & 29,14 & 190,15 \\
\hline Triturus pygmaeus & 30SUH97 & 100,00 & 146,86 & 125,39 & 37,00 & 6938,87 & 344,56 & 11,62 & 332,94 & 100,52 & 240,75 & 240,75 & 63,27 & 525,40 & 70,56 & 4,64 & 48,40 & $\mid 186,60$ & 33,58 & 33,58 & 173,00 \\
\hline Triturus pygmaeus & 30SUH98 & 100,00 & 147,00 & 125,99 & 37,00 & \begin{tabular}{ll|l}
6930,67 \\
\end{tabular} & 344,96 & \begin{tabular}{|l|l}
11,24 \\
\end{tabular} & 333,72 & 118,62 & 240,77 & 240,77 & 63,63 & $\begin{array}{l}505,15 \\
\end{array}$ & 66,19 & 4,32 & 47,51 & 177,79 & 33,52 & 33,52 & 163,80 \\
\hline Triturus pygmaeus & 30SUH99 & 100,00 & 146,58 & 126,61 & 37,44 & \begin{tabular}{ll|l|}
6909,73 \\
\end{tabular} & 344,29 & 10,52 & 333,77 & 129,35 & 239,97 & 239,97 & 63,37 & $\begin{array}{ll}489,23 \\
\end{array}$ & 62,42 & 4,24 & 46,61 & \begin{tabular}{ll|}
171,92 \\
\end{tabular} & 33,88 & 33,88 & 156,11 \\
\hline Triturus pygmaeus & 30SUJ02 & 100,00 & 159,36 & 121,10 & 37,00 & \begin{tabular}{|l|l|}
6790,35 \\
\end{tabular} & 350,59 & 26,64 & 323,95 & 89,07 & 250,54 & 250,54 & 76,72 & \begin{tabular}{|l|l|}
476,07 \\
\end{tabular} & 62,28 & 3,92 & 49,00 & \begin{tabular}{|l|l|}
166,33 \\
\end{tabular} & 29,72 & 29,72 & 157,84 \\
\hline Triturus pygmaeus & 30SUJ13 & 100,00 & 156,64 & 121,00 & 37,00 & 6801,50 & 347,80 & 23,78 & 324,02 & $\begin{array}{l}105,67 \\
\end{array}$ & 248,01 & 248,01 & 73,92 & 465,89 & 59,87 & 4,12 & 47,67 & 160,01 & 31,00 & 31,00 & 151,35 \\
\hline Triturus pygmaeus & 30SUJ14 & 100,00 & 158,51 & 120,24 & 37,00 & 6776,48 & 348,22 & 25,77 & 322,45 & \begin{tabular}{|l|l|}
113,71 \\
\end{tabular} & 249,50 & 249,50 & 75,81 & \begin{tabular}{|l|l|}
446,28 \\
\end{tabular} & 56,61 & \begin{tabular}{|l|l|l|}
4,03 \\
\end{tabular} & 47,15 & $\mid 153,15$ & 30,48 & 30,48 & 143,51 \\
\hline Triturus pygmaeus & 30SUJ15 & 100,00 & 156,77 & 119,64 & 36,98 & 6758,22 & 345,78 & 24,61 & 321,17 & 114,42 & 247,55 & 247,55 & 74,36 & $\begin{array}{l}439,26 \\
\end{array}$ & 54,84 & 4,23 & 46,27 & $\begin{array}{l}149,96 \\
\end{array}$ & 31,43 & 31,43 & 139,35 \\
\hline Triturus pygmaeus & 30SUJ19 & 100,00 & 148,04 & 116,97 & \begin{tabular}{|l|l|}
36,97 \\
\end{tabular} & 6669,21 & 333,37 & 18,23 & 315,14 & 109,39 & 237,87 & 237,87 & 67,00 & \begin{tabular}{|l|l|}
421,03 \\
\end{tabular} & 48,6 & 5,94 & 41,92 & 140,41 & 37,41 & 37,41 & 126,60 \\
\hline Triturus pygmaeus & 30SUJ20 & 100,00 & 156,96 & 123,03 & 37,00 & 6860,53 & 351,14 & 22,51 & 328,63 & 86,62 & 249,08 & 249,08 & 73,57 & 503,85 & 67,41 & 3,88 & 50,11 & 174,82 & 29,59 & 29,59 & 168,86 \\
\hline Triturus pygmaeus & 30SUJ21 & 100,00 & 150,90 & 122,81 & 37,00 & 6860,03 & 345,34 & 17,14 & 328,20 & 83,00 & 243,38 & 243,38 & 67,96 & \begin{tabular}{ll|}
511,42 \\
\end{tabular} & 67,13 & 4,54 & 48,50 & $\begin{array}{l}175,59 \\
\end{array}$ & 32,87 & 32,87 & 168,88 \\
\hline Triturus pygmaeus & 30 SUJ22 & 100,00 & 154,62 & 122,09 & 37,00 & 6835,34 & 347,53 & 20,91 & 326,62 & 106,33 & 246,51 & 246,51 & 71,58 & $\mid$\begin{tabular}{|l|l|}
481,43 \\
\end{tabular} & 62,50 & 4,12 & 48,03 & $\mid$ & 31,29 & 31,29 & 157,19 \\
\hline Triturus pygmaeus & 30SUJ23 & 100,00 & 154,21 & 121,51 & 37,00 _ & 6828,54 & 346,38 & 21,01 & 325,37 & 117,96 & 246,11 & 246,11 & 71,29 & 468,02 & 59,81 & 4,23 & 47,12 & 159,10 & 31,90 & 31,90 & 150,66 \\
\hline Triturus pygmaeus & 30SUJ24 & 100,00 & 155,18 & 120,80 & 37,00 & 6806,05 & 346,03 & 22,25 & 323,78 & 119,90 & 246,76 & 246,76 & 72,42 & 450,64 & 56,65 & 4,29 & 46,35 & 153,20 & 31,85 & 31,85 & 143,24 \\
\hline Triturus pygmaeus & 30SUJ30 & 100,00 & 155,59 & 123,52 & 37,00 & 6887,42 & 350,41 & 20,78 & 329,63 & 88,74 & 248,21 & 248,21 & 71,77 & 501,47 & 66,86 & 4,02 & 49,37 & 172,05 & 30,23 & 30,23 & 166,73 \\
\hline Triturus pygmaeus & 30SUJ31 & 100,00 & 150,96 & 123,14 & 37,00 & 6882,02 & 345,94 & 16,56 & 329,38 & 115,15 & 243,83 & 243,83 & 67,74 & $\begin{array}{l}502,99 \\
\end{array}$ & 65,85 & 4,31 & 48,20 & \begin{tabular}{ll|l}
171,38 \\
\end{tabular} & 32,64 & 32,64 & 164,81 \\
\hline 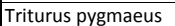 & 30 SUJ32 & 100,00 & 151,82 & $\mid 122,74$ & 37,00 & 6864,87 & $\mid 345,74$ & 17,56 & 328,18 & 132,25 & 244,36 & 244,36 & 68,72 & \begin{tabular}{|l|l|}
484,56 \\
\end{tabular} & 62,45 & 4,38 & 47,40 & \begin{tabular}{|c|c|}
164,73 \\
\end{tabular} & \begin{tabular}{|l|l|l|}
32,69 \\
\end{tabular} & $|32,69|$ & $\begin{array}{ll}156,66 \\
\end{array}$ \\
\hline Triturus pygmaeus & 30SUJ33 & 100,00 & 149,19 & 122,03 & 37,00 & 6854,45 & 342,55 & 15,48 & 327,07 & 131,88 & 241,58 & 241,58 & 66,27 & 479,43 & 60,62 & 4,86 & 46,07 & 162,71 & 34,47 & 34,47 & 152,56 \\
\hline Triturus pygmaeus & 30SUJ35 & 100,00 & 152,93 & 120,36 & 37,00 & 6810,05 & 343,39 & 19,86 & 323,53 & 133,26 & 244,65 & 244,65 & 70,08 & 439,24 & 53,72 & 4,65 & 44,76 & 148,41 & 33,46 & 33,46 & 136,42 \\
\hline Triturus pygmaeus & 30SUJ41 & 100,00 & 150,18 & 123,80 & 37,00 & 6888,35 & 345,62 & 15,44 & 330,18 & 133,39 & 243,10 & 243,10 & 66,82 & \begin{tabular}{|l|l|}
497,24 \\
\end{tabular} & 64,62 & 4,46 & 47,59 & \begin{tabular}{|l|l|}
170,07 \\
\end{tabular} & 32,98 & 32,98 & 161,42 \\
\hline Triturus pygmaeus & 30SUJ43 & 100,00 & 145,44 & 122,64 & 37,00 & \begin{tabular}{ll|l|}
6874,67 \\
\end{tabular} & 339,72 & 11,30 & 328,42 & 128,48 & 238,21 & 238,21 & 62,43 & 485,61 & 60,68 & 5,23 & 45,29 & \begin{tabular}{ll|}
165,68 \\
\end{tabular} & 36,31 & 36,31 & 152,99 \\
\hline Triturus pygmaeus & 30SUJ45 & 100,00 & 150,62 & 120,88 & 36,99 & 6831,53 & 341,75 & 17,01 & 324,75 & 134,62 & 242,70 & 242,70 & 67,85 & \begin{tabular}{|l|l|}
440,17 \\
\end{tabular} & 53,18 & 4,99 & 44,07 & 149,37 & 34,59 & 34,59 & 135,15 \\
\hline Triturus pygmaeus & 30SUJ47 & 100,00 & 139,20 & 1119,04 & 36,58 & 6777,43 & 328,92 & 7,78 & 321,14 & 122,71 & 231,06 & 231,06 & 57,63 & 456,81 & 52,81 & 6,85 & 41,34 & $\begin{array}{l}153,92 \\
\end{array}$ & 41,97 & \begin{tabular}{ll|}
41,97 \\
\end{tabular} & 135,41 \\
\hline Triturus pygmaeus & 30SUJ50 & 100,00 & 148,90 & 124,47 & 37,00 & 6917,34 & 345,44 & 13,79 & 331,64 & 128,63 & 242,25 & 242,25 & 65,34 & 509,58 & 66,83 & 4,47 & 47,94 & 175,40 & 33,10 & 33,10 & 166,39 \\
\hline Triturus pygmaeus & 30SUJ53 & 100,00 & 149,64 & 122,92 & 37,00 & \begin{tabular}{ll|l}
6866,68 \\
\end{tabular} & 343,38 & 14,90 & 328,48 & 133,16 & 242,41 & 242,41 & 66,54 & $\begin{array}{l}462,56 \\
4\end{array}$ & 57,40 & 4,74 & 45,35 & $\begin{array}{l}158,46 \\
\end{array}$ & 34,27 & 34,27 & 144,74 \\
\hline Triturus pygmaeus & 30SUJ55 & 100,00 & 146,73 & 121,31 & 37,00 & 6863,51 & 338,99 & 12,70 & 326,29 & 130,64 & 239,38 & 239,38 & 63,78 & 446,39 & 53,20 & 5,31 & 43,38 & $\begin{array}{l}152,17 \\
\end{array}$ & 36,42 & 36,42 & 135,53 \\
\hline Triturus pygmaeus & 30SUJ56 & 100,00 & 144,03 & 120,42 & 36,71 & 6835,28 & 335,41 & 10,61 & 324,80 & 127,69 & 236,51 & 236,51 & 61,60 & $\begin{array}{l}443,45 \\
\end{array}$ & 51,75 & 5,95 & 42,22 & 150,82 & 38,71 & 38,71 & 132,20 \\
\hline Triturus pygmaeus & 30SUJ61 & 100,00 & 147,49 & 124,72 & 37,00 & 6918,40 & 343,85 & 11,91 & 331,94 & 130,79 & 240,96 & 240,96 & 63,70 & 489,01 & 62,27 & 4,62 & 46,51 & 169,13 & 34,19 & 34,19 & 155,95 \\
\hline Triturus pygmaeus & 30SUJ63 & 100,00 & 145,25 & 123,52 & 37,00 & 6890,92 & 340,28 & 10,49 & 329,79 & 128,27 & 238,45 & 238,45 & 62,09 & 469,25 & 57,34 & 5,25 & 44,38 & 161,49 & 36,57 & 36,57 & 145,12 \\
\hline Triturus pygmaeus & 30SUJ64 & 100,00 & 145,08 & \begin{tabular}{ll|}
122,74 \\
\end{tabular} & 37,00 & 6870,34 & 338,94 & 10,49 & 328,45 & $\begin{array}{l}128,49 \\
\end{array}$ & 238,01 & 238,01 & 62,12 & 457,61 & 54,77 & 5,32 & 43,57 & $\begin{array}{l}157,08 \\
\end{array}$ & 37,04 & 37,04 & 139,56 \\
\hline Triturus pygmaeus & 30SUJ66 & 100,00 & \begin{tabular}{ll|}
138,87 \\
\end{tabular} & $\begin{array}{ll}120,82 \\
\end{array}$ & 36,84 & 6853,41 & 330,98 & 5,46 & 325,52 & $\begin{array}{l}122,02 \\
\end{array}$ & 231,64 & 231,64 & 56,39 & $\begin{array}{l}456,53 \\
\end{array}$ & 52,59 & 6,61 & 41,24 & 155,54 & 41,78 & 41,78 & 134,68 \\
\hline Triturus pygmaeus & 30SUJ67 & 100,00 & 133,27 & 119,57 & $\begin{array}{l}36,55 \\
\end{array}$ & \begin{tabular}{ll|l|}
6810,94 \\
\end{tabular} & 324,28 & 1,23 & 323,05 & 116,30 & 225,70 & 225,72 & 51,75 & \begin{tabular}{|l|l|}
467,28 \\
\end{tabular} & 54,22 & 7,76 & 39,82 & \begin{tabular}{|l|l|}
158,18 \\
\end{tabular} & 45,99 & 46,01 & 135,44 \\
\hline Triturus pygmaeus & 30SUJ70 & 100,00 & 149,86 & 125,35 & 37,00 & 6926,91 & 346,50 & 13,57 & 332,92 & 133,03 & 243,32 & 243,32 & 66,07 & 485,27 & 62,41 & 4,04 & 47,35 & 168,93 & 32,20 & 32,20 & 156,07 \\
\hline Triturus pygmaeus & 30suJ75 & 100,00 & 140,25 & 122,33 & 37,00 & 6876,04 & 333,81 & 5,96 & 327,85 & $\begin{array}{l}123,67 \\
\end{array}$ & 233,36 & 233,36 & 57,40 & 456,66 & 52,75 & 6,19 & 41,78 & 156,56 & 40,66 & 40,66 & 135,52 \\
\hline Triturus pygmaeus & 30SUJ76 & 100,00 & 131,62 & 121,11 & 36,99 & $\begin{array}{l}6845,36 \\
\end{array}$ & 324,71 & $\begin{array}{ll}-0,64 \\
\end{array}$ & 325,36 & 114,22 & 224,64 & 224,64 & 49,95 & \begin{tabular}{ll|}
478,72 \\
\end{tabular} & 55,45 & 7,72 & 40,05 & \begin{tabular}{|l|l|}
163,20 \\
\end{tabular} & 46,50 & 46,50 & 139,57 \\
\hline Triturus pygmaeus & 30SUJ84 & 100,00 & 147,10 & 123,58 & 37,00 & \begin{tabular}{|l|l|}
6891,58 \\
\end{tabular} & 341,06 & 11,29 & 329,77 & 130,97 & 240,20 & 240,20 & $\begin{array}{ll}63,63 \\
\end{array}$ & $\begin{array}{l}435,05 \\
\end{array}$ & 50,60 & 5,04 & 43,12 & $\begin{array}{l}150,06 \\
\end{array}$ & 36,03 & 36,03 & 130,50 \\
\hline Triturus pygmaeus & 30SUJ85 & 100,00 & 139,86 & 122,68 & 37,00 & 6883,90 & 333,48 & 5,15 & 328,33 & 123,22 & 233,10 & 233,10 & 57,01 & 452,03 & 52,22 & 6,18 & 41,36 & 154,99 & 41,14 & 41,14 & 133,15 \\
\hline Triturus pygmaeus & 30SUJ86 & 100,00 & 139,18 & 121,51 & 37,00 & 6872,99 & 331,72 & 5,03 & 326,69 & 122,69 & 232,32 & 232,32 & 56,42 & 445,18 & 51,66 & 6,55 & 40,38 & 151,85 & 42,23 & 42,23 & 129,33 \\
\hline Triturus pygmaeus & $30 \mathrm{SUJ \varepsilon}$ & 100,00 & 128,53 & 120,22 & 36,90 & 6825,34 & 320,44 & $-3,11$ & 323,55 & 111,06 & 221,42 & 221,42 & 47,25 & 476,9 & 56,08 & 8,54 & 38,63 & 161,68 & 49,58 & 49,58 & 136,07 \\
\hline Triturus pygmaeus & 30SUJ88 & 100,00 & 137,01 & 118,73 & 36,06 & 6843,51 & 326,82 & 3,88 & 322,94 & 120,65 & 229,86 & 229,86 & 54,64 & \begin{tabular}{|l|l|}
436,48 \\
\end{tabular} & 51,38 & 7,67 & 38,58 & 147,06 & 45,13 & 45,13 & 123,42 \\
\hline Triturus pygmaeus & 30SUJ90 & 100,00 & 147,43 & 126,93 & 37,81 & $\begin{array}{l}6900,37 \\
\end{array}$ & 344,48 & 11,01 & 333,48 & 130,56 & 240,56 & 240,56 & 64,01 & 470,35 & 58,48 & 4,19 & 45,79 & 164,89 & 33,69 & 33,69 & 147,89 \\
\hline Triturus pygmaeus & 30SUJ91 & 100,00 & 147,66 & 126,60 & 37,5 & \begin{tabular}{|l|l|}
6892,61 \\
\end{tabular} & 344,21 & 11,08 & 333,13 & 131,09 & 240,71 & 240,71 & 64, & 455, & 55,28 & 4,29 & 45,06 & 159,29 & \begin{tabular}{|l|l|}
33,96 \\
\end{tabular} & $\begin{array}{l}33,96 \\
\end{array}$ & 141,21 \\
\hline Triturus pygmaeus & 30 SUJ & 100 & 146 & 126,23 & 37, & 6888 & 342 & 10,26 & 332,64 & 130,50 & 239,83 & 235 & 63,38 & 447 & 53,12 & $4,3,3,-3$ & 44,15 & 155,79 & 34,83 & 34,83 & 136,70 \\
\hline Triturus pygmaeus & 30SUJ96 & 100,00 & 140,58 & 121,71 & 36,98 & 6881,84 & 332,97 & 5,60 & 327,37 & 124,21 & 233,66 & 233,66 & 57,52 & 435,73 & 50,77 & 6,36 & 40,32 & 148,64 & 41,68 & 41,68 & 125,90 \\
\hline Triturus pygmaeus & 30SUK01 & 100,00 & $\begin{array}{l}154,70 \\
\end{array}$ & 115,56 & 37,00 & 6570,73 & 335,95 & 26,02 & 309,94 & 112,48 & 242,89 & 242,89 & 74,18 & $\begin{array}{l}386,27 \\
\end{array}$ & 44,60 & 5,27 & 41,76 & 130,38 & 34,47 & 34,47 & $\begin{array}{ll}115,88 \\
\end{array}$ \\
\hline Triturus pygmaeus & 30SUK10 & 100,00 & 155,03 & 116,19 & \begin{tabular}{|l|l}
36,88 \\
\end{tabular} & 6631,04 & 337,90 & 25,12 & 312,77 & 112,80 & 243,99 & 243,99 & 73,90 & 387,96 & 44,67 & 5,10 & 41,97 & 130,74 & 33,97 & 33,97 & 116,10 \\
\hline Triturus & 30SUK12 & 100,00 & 155,81 & 115,07 & 37,00 & 556,55 & 335,75 & 26,94 & 89 & 113,23 & 243 & 243 & 75 & 366,27 & \begin{tabular}{|l|l|}
42,02 \\
\end{tabular} & 5,35 & $\sqrt{16}$ & 123,19 & \begin{tabular}{|c|c|}
34,38 \\
\end{tabular} & \begin{tabular}{|l|l|l|}
34,38 &
\end{tabular} & 107 \\
\hline Triturus pygmaeus & 30SUK32 & 100,00 & 151,96 & 115,00 & 36,26 & 6621,24 & 332,95 & 22,09 & 310,85 & 111,36 & 240,81 & 240,81 & 70,9 & 366,31 & 42,20 & 6,19 & 39,38 & \begin{tabular}{|l|l|}
121,68 \\
\end{tabular} & 36,48 & 36,48 & 104,07 \\
\hline Triturus pygmaeus & 30SUK42 & 100,00 & 153,17 & 114,75 & 36,09 & 6644,08 & 333,95 & 22,73 & 311,21 & 112,53 & 242,41 & 242,41 & 71,86 & 359,77 & 41,62 & 6,11 & 39,30 & 1119,29 & 36,19 & 36,19 & 101,33 \\
\hline
\end{tabular}




\begin{tabular}{|c|c|c|c|c|c|c|c|c|c|c|c|c|c|c|c|c|c|c|c|c|c|}
\hline TAXON & UTM & $\mathrm{km} 2$ & B101 & B102 & $\mathrm{BIO3}$ & B104 & B105 & B106 & B107 & B108 & B109 & BIO10 & BIO11 & BIO12 & B1013 & BIO14 & BIO15 & B1016 & B1017 & BIO18 & B1019 \\
\hline Triturus pygmaeus & 30SVF09 & 100,00 & 136,99 & 115,65 & 38,00 & 6143,62 & 311,83 & 11,90 & 299,92 & 72,73 & 220,46 & 220,46 & 64,20 & 596,54 & 80,01 & 6,42 & 55,62 & 238,08 & 29,95 & 29,95 & 229,69 \\
\hline Triturus pygmaeus & 30SVG01 & 100,00 & 158,93 & 109,21 & 37,43 & 6048,53 & 323,79 & 36,26 & 287,53 & 93,18 & 240,85 & 240,85 & 86,47 & 493,41 & 72,84 & 4,53 & 57,51 & 204,53 & 22,43 & 22,43 & 190,89 \\
\hline Triturus pygmaeus & 30SVG02 & 100,00 & 150,38 & 113,64 & 37,05 & 6307,82 & 325,61 & 24,74 & 300,86 & 82,49 & 236,10 & 236,10 & 75,05 & 546,70 & 74,73 & 5,65 & 55,64 & 217,00 & 26,42 & 26,42 & 207,91 \\
\hline Triturus pygmaeus & 30SVG03 & 100,00 & 144,25 & 116,31 & 37,00 & 6493,53 & 326,55 & 16,71 & 309,84 & 75,08 & 232,55 & 232,55 & 66,95 & 591,22 & 77,10 & 6,41 & 54,50 & 226,69 & 29,73 & 29,73 & 221,93 \\
\hline Triturus pygmaeus & 30SVG04 & 100,00 & 153,14 & 113,90 & 36,66 & \begin{tabular}{ll|}
6516,42 \\
\end{tabular} & 333,25 & 26,35 & 306,90 & 83,34 & 241,63 & 241,63 & 75,37 & 567,18 & 73,69 & 5,63 & 55,34 & 216,96 & 26,66 & 26,66 & 213,60 \\
\hline Triturus pygmaeus & 30SVG05 & 100,00 & 160,37 & 111,84 & 36,06 & 6553,34 & 339,08 & 34,10 & 304,97 & 92,30 & 249,14 & 249,14 & 81,81 & 554,87 & 74,29 & 4,92 & 55,97 & 212,51 & 24,45 & 24,45 & 209,51 \\
\hline Triturus pygmaeus & 30SVG06 & 100,00 & 159,20 & 112,65 & 36,05 & 6647,09 & 340,97 & 32,25 & 308,72 & 91,17 & 249,27 & 249,27 & 79,61 & 574,35 & 80,27 & 5,09 & 55,89 & 221,47 & 25,64 & 25,64 & 215,16 \\
\hline Triturus pygmaeus & $\begin{array}{l}30 \text { SVG07 } \\
\end{array}$ & 100,00 & 168,36 & 110,49 & 35,88 & 6646,22 & 347,64 & 41,99 & 305,65 & 100,01 & 258,01 & 258,01 & 88,29 & 551,40 & 79,78 & 4,04 & 57,01 & 215,75 & 22,23 & 22,23 & 207,42 \\
\hline Triturus pygmaeus & 30SVG08 & 100,00 & 171,91 & 110,63 & 35,73 & 6666,36 & 351,30 & 45,10 & 306,20 & 103,21 & 261,64 & 261,64 & 91,40 & 539,60 & 79,57 & 3,61 & 57,24 & 211,39 & 21,10 & 21,10 & 201,90 \\
\hline Triturus pygmaeus & 30SVG09 & 100,00 & 173,32 & 111,54 & 35,91 & 6694,79 & 353,79 & \begin{tabular}{|l|l|}
45,67 \\
\end{tabular} & 308,12 & 104,30 & 263,36 & 263,36 & 92,20 & 530,16 & 78,97 & 3,19 & 56,99 & 206,95 & 20,62 & 20,62 & 196,72 \\
\hline Triturus pygmaeus & 30SVG13 & 100,00 & 138,03 & 118,49 & 37,01 & 6573,18 & 324,53 & 9,28 & 315,26 & 68,87 & 227,57 & 227,57 & 60,05 & 604,05 & 78,08 & 7,40 & 53,03 & 225,93 & 32,95 & 32,95 & 222,81 \\
\hline Triturus pygmaeus & 30SVG14 & 100,00 & 143,62 & 117,40 & 36,89 & 6630,32 & 330,15 & 14,90 & 315,25 & 75,28 & 233,90 & 233,90 & 64,83 & 589,65 & 77,39 & 6,85 & 53,37 & 220,12 & 31,00 & 31,00 & 217,41 \\
\hline Triturus pygmaeus & 30SVG15 & 100,00 & 153,21 & 114,31 & 36,15 & 6658,71 & 337,18 & 25,51 & 311,67 & 85,32 & 243,65 & 243,65 & 73,77 & 567,08 & 76,80 & 5,90 & 54,41 & 214,94 & 27,50 & 27,50 & 210,31 \\
\hline Triturus pygmaeus & 30SVG18 & 100,00 & 169,51 & 109,81 & 35,04 & 6741,25 & 350,59 & 43,18 & 307,41 & 100,09 & 260,53 & 260,53 & 88,44 & 545,42 & 82,57 & 4,19 & 56,62 & 215,55 & 22,63 & 22,63 & 202,51 \\
\hline Triturus pygmaeus & 30SVG22 & 100,00 & 153,52 & 114,99 & 37,21 & 6338,62 & 330,23 & 26,31 & 303,92 & 84,42 & 239,78 & 239,78 & 77,80 & 473,18 & 65,41 & 5,45 & 54,03 & 185,84 & 24,53 & 24,53 & $\begin{array}{l}175,09 \\
\end{array}$ \\
\hline Triturus pygmaeus & 30 SVG23 & 100,00 & 143,48 & 118,29 & 37,00 & 6569,32 & 329,22 & 14,20 & 315,02 & 73,80 & 232,93 & 232,93 & 65,32 & 558,01 & 71,92 & 6,87 & 52,63 & 208,01 & 30,10 & 30,10 & 204,63 \\
\hline Triturus pygmaeus & 30 SVG24 & 100,00 & 144,54 & 117,80 & 36,96 & 6647,62 & 331,67 & 15,37 & 316,30 & 75,56 & 235,03 & 235,03 & 65,56 & 568,15 & 74,36 & 6,89 & 52,60 & 210,27 & 30,69 & 30,69 & 207,29 \\
\hline Triturus pygmaeus & 30SVG28 & 100,00 & 167,47 & 109,58 & 35,04 & 6784,30 & 349,56 & 41,31 & 308,25 & 97,45 & 259,05 & 259,05 & 86,04 & 545,37 & 83,71 & 4,61 & 56,18 & 215,71 & 23,85 & 23,85 & 200,56 \\
\hline Triturus pygmaeus & 30SVG33 & 100,00 & 145,52 & 118,63 & 37,00 & 6567,88 & 331,36 & 15,78 & 315,57 & 76,20 & 235,00 & 235,00 & 67,37 & 530,49 & 68,97 & 6,75 & 52,08 & 196,18 & 29,18 & 29,18 & $\begin{array}{ll}192,47 \\
\end{array}$ \\
\hline Triturus pygmaeus & 30 SVG36 & 100,00 & 132,62 & 119,55 & 36,53 & 6795,28 & 325,48 & 2,86 & 322,62 & 75,23 & 225,41 & 225,41 & 52,59 & 626,85 & 85,85 & 9,01 & 50,08 & 230,35 & 40,13 & 40,13 & 219,61 \\
\hline Triturus pygmaeus & 30SVG43 & 100,00 & 147,47 & 119,11 & 37,00 & 6579,18 & 333,78 & 17,30 & 316,48 & 78,58 & 237,05 & 237,05 & 69,25 & 511,75 & 66,96 & 6,32 & 51,82 & 186,44 & 27,85 & 27,85 & 184,32 \\
\hline Triturus pygmaeus & 30SVG59 & 100,00 & 171,17 & 110,18 & 35,92 & 6609,16 & 348,34 & 44,54 & 303,81 & \begin{tabular}{|l|}
124,97 \\
\end{tabular} & 259,99 & 259,99 & 91,48 & 451,57 & 64,77 & 3,78 & 52,74 & $\begin{array}{l}169,93 \\
\end{array}$ & 22,11 & 22,11 & 158,86 \\
\hline Triturus pygmaeus & 30SVH01 & 100,00 & 173,25 & 114,34 & 36,00 & $\begin{array}{lll}6739,98 \\
\end{array}$ & 356,56 & 43,78 & 312,78 & 103,74 & 263,86 & 263,86 & 91,44 & 511,77 & 75,83 & 3,23 & 55,60 & 195,58 & 21,62 & 21,62 & 185,27 \\
\hline Triturus pygmaeus & 30SVHO3 & 100,00 & 155,87 & 119,93 & 36,17 & 6936,06 & 349,27 & 23,47 & 325,80 & 103,94 & 249,62 & 249,62 & 72,41 & 553,67 & 80,94 & 4,54 & 52,48 & 207,08 & 29,00 & 29,00 & 192,78 \\
\hline Triturus pygmaeus & 30SVHO4 & 100,00 & 152,67 & 121,54 & 36,70 & 6943,12 & 347,59 & 19,47 & 328,12 & 105,63 & 246,53 & 246,53 & 69,13 & 547,43 & 78,34 & 4,60 & 51,14 & 202,35 & 30,55 & 30,55 & 187,44 \\
\hline Triturus pygmaeus & 30SVH05 & 100,00 & 144,87 & 123,50 & 37,00 & 6956,21 & 342,06 & 11,07 & 330,99 & 97,66 & 239,15 & 239,15 & 61,62 & 557,74 & 77,2 & 5,44 & 49,29 & 202,56 & 34,99 & 34,99 & 186,84 \\
\hline Triturus pygmaeus & 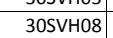 & 100,00 & 146,68 & 126,35 & 37,34 & 6917,47 & 344,27 & 10,82 & 333,44 & 123,90 & $\begin{array}{l}240,12 \\
240\end{array}$ & 240,12 & $\begin{array}{ll}63,49 \\
\end{array}$ & $\mid 495,58$ & 64,12 & $\frac{3,44}{4,31}$ & $\begin{array}{ll}4,2,88 \\
4,\end{array}$ & 175,07 & 33,86 & 33,86 & 159,05 \\
\hline Triturus pygmaeus & 30SVHO9 & 100,00 & 146,35 & 127,13 & \begin{tabular}{|l|l|}
37,87 \\
\end{tabular} & 6903,11 & 343,78 & 9,97 & 333,81 & 129,14 & 239,60 & 239,60 & 63,14 & 478,40 & 60,09 & 4,12 & 46,07 & 168,82 & 33,85 & 33,85 & 151,16 \\
\hline Triturus pygmaeus & 30SVH11 & 100,00 & 173,27 & 113,34 & 36,00 & 6740,93 & 355,86 & 44,18 & \begin{tabular}{|l|}
311,68 \\
\end{tabular} & 103,58 & 263,83 & 263,83 & 91,41 & 500,60 & 74,46 & 3,27 & 55,22 & 191,21 & 21,66 & 21,66 & 180,09 \\
\hline Triturus pygmaeus & 30SVH12 & 100,00 & 165,95 & 116,11 & 36,00 & 6846,00 & 353,68 & 35,44 & 318,24 & 105,58 & 258,18 & 258,18 & 83,22 & 519,72 & 77,25 & 3,74 & 53,92 & 197,10 & 24,62 & 24,62 & 183,63 \\
\hline Triturus pygmaeus & 30SVH13 & 100,00 & 163,29 & 117,95 & 36,05 & 6870,86 & 352,93 & 31,71 & 321,22 & 115,03 & 255,89 & 255,89 & 80,25 & 515,05 & 75,36 & 3,79 & 52,75 & 193,19 & 25,86 & 25,86 & 179,25 \\
\hline Triturus pygmaeus & 30SVH17 & 100,00 & 147,46 & 125,23 & 37,01 & 6913,02 & 344,08 & $\begin{array}{ll}1,32,32 \\
\end{array}$ & \begin{tabular}{|l|l|l|l|l|}
331,76 \\
\end{tabular} & \begin{tabular}{|l|l|l}
104,38 \\
\end{tabular} & \begin{tabular}{|l|}
240,95 \\
240
\end{tabular} & \begin{tabular}{|l|}
240,95 \\
240
\end{tabular} & $\begin{array}{ll}64,36 \\
64,\end{array}$ & \begin{tabular}{|l|l|}
499,75 \\
\end{tabular} & $\begin{array}{l}, 3,80 \\
65,82\end{array}$ & 4,52 & 47,34 & \begin{tabular}{|l|l|}
177,79 \\
\end{tabular} & 33,55 & 33,55 & 161,52 \\
\hline Triturus pygmaeus & 30SVH18 & 100,00 & 141,26 & 126,56 & \begin{tabular}{|l|l|l|l}
37,49 \\
\end{tabular} & 6920,60 & 339,46 & 5,81 & 333,64 & 122,40 & 234,95 & 234,95 & 58,32 & 507,36 & 64,76 & 5,18 & 45,75 & 179,45 & 37,25 & 37,25 & 160,72 \\
\hline Triturus pygmaeus & $30 \mathrm{SVH} 22$ & 100,00 & 167,66 & 115,08 & 36,00 & 6811,41 & 353,58 & 37,68 & 315,90 & 117,58 & 259,44 & 259,44 & 85,38 & 498,74 & 73,72 & 3,62 & 53,34 & 188,84 & 24,08 & 24,08 & 174,98 \\
\hline Triturus pygmaeus & $30 \mathrm{SVH} 23$ & 100,00 & 159,30 & 118,18 & 36,02 & 6893,52 & 349,99 & 27,74 & 322,25 & 112,12 & 252,44 & 252,44 & 76,32 & 517,86 & 75,42 & 4,36 & 51,70 & 194,73 & 28,09 & 28,09 & 177,84 \\
\hline Triturus pygmaeus & $30 \mathrm{SVH} 25$ & 100,00 & 145,86 & 122,79 & 36,97 & 6929,03 & 341,56 & 12,40 & 329,17 & 98,79 & 239,69 & 239,69 & 62,92 & 532,36 & 72,99 & 5,53 & 48,12 & 193,73 & 35,29 & 35,29 & 175,10 \\
\hline Triturus pygmaeus & $30 \mathrm{SVH} 28$ & 100,00 & 144,50 & 126,24 & 37,59 & 6887,54 & 341,26 & 9,10 & 332,16 & 126,84 & 237,76 & 237,76 & 61,79 & 484,93 & 61,33 & 4,74 & 45,53 & 171,86 & 35,68 & 35,68 & 152,64 \\
\hline Triturus pygmaeus & $30 \mathrm{SVH} 42$ & 100,00 & 168,91 & 114,17 & 36,00 & 6738,83 & 351,87 & 39,52 & 312,34 & 122,59 & 259,43 & 259,43 & 87,43 & 461,65 & 66,40 & 3,64 & 51,84 & 173,28 & 24,00 & 24,00 & 158,57 \\
\hline Triturus pygmaeus & $30 \mathrm{SVH} 43$ & 100,00 & 163,33 & 116,73 & $\begin{array}{l}36,05 \\
\end{array}$ & \begin{tabular}{|l|l|l|}
6798,84 \\
\end{tabular} & 349,91 & 32,62 & 317,29 & 116,79 & 254,96 & 254,96 & 81,34 & 471,24 & 66,79 & 4,03 & 50,53 & 175,58 & 26,70 & 26,70 & 158,96 \\
\hline Triturus pygmaeus & $30 \mathrm{SVH} 44$ & 100,00 & 148,33 & 120,66 & 36,76 & 6890,83 & 341,28 & 15,92 & 325,37 & 100,84 & 241,58 & 241,58 & 65,94 & 515,72 & 70,99 & 5,67 & 47,88 & 189,17 & 34,67 & 34,67 & 168,88 \\
\hline Triturus pygmaeus & $30 \mathrm{SVH} 46$ & 100,00 & 146,07 & 123,18 & 37,00 & 6878,33 & 340,31 & 12,33 & 327,98 & 99,86 & 239,18 & 239,18 & 63,76 & 494,85 & 65,02 & 5,43 & 45,99 & 177,10 & 36,01 & 36,01 & 157,28 \\
\hline Triturus pygmaeus & 30SVH53 & 100,00 & 163,20 & 116,49 & 36,24 & 6752,17 & 348,31 & 32,62 & 315,69 & 116,77 & 254,13 & 254,13 & 81,79 & 455,50 & 63,27 & 4,0 & 49,48 & 168,26 & 26,90 & 26,90 & 151,61 \\
\hline Triturus pygmaeus & $30 \mathrm{SVH} 54$ & 100,00 & 152,54 & 119,68 & 36,80 & 6830,84 & 342,73 & 20,42 & 322,31 & 105,50 & 244,79 & 244,79 & 70,64 & 485,61 & 65,96 & 5,25 & 47,56 & 177,26 & 32,77 & 32,77 & 157,69 \\
\hline Triturus pygmaeus & 30SVH55 & 100,00 & 144,77 & 121,94 & 37,00 & 6869,73 & 338,06 & 11,91 & 326,15 & 97,47 & 237,79 & 237,79 & 62,63 & 502,61 & 66,60 & 6,10 & 45,87 & 180,92 & 37,33 & 37,33 & 159,71 \\
\hline Triturus pygmaeus & 30 SVH56 & 100,00 & 144,76 & 122,97 & 37,00 & 6864,75 & 338,35 & 11,25 & 327,10 & 104,27 & 237,83 & 237,83 & 62,92 & 490,56 & 63,53 & 5,96 & 45,01 & 174,62 & 37,62 & 37,62 & 153,92 \\
\hline Triturus pygmaeus & $\begin{array}{l}30 \text { SVH57 } \\
\end{array}$ & 100,00 & 146,16 & 123,48 & 37,01 & 6850,53 & 339,36 & $\frac{11,25}{11,95}$ & 327,41 & 127,02 & 238,77 & $\begin{array}{l}238,77 \\
\end{array}$ & $\begin{array}{l}63,90 \\
63,\end{array}$ & 471,66 & \begin{tabular}{|l|l|}
59,66 \\
\end{tabular} & 5,38 & 44,42 & 167,22 & $\begin{array}{ll}1,062 \\
6,88\end{array}$ & 36,88 & 146,25 \\
\hline Triturus pygmaeus & 30 SVH64 & 100,00 & 154,19 & 119,16 & 36,95 & 6780,69 & 342,24 & 22,47 & 319,76 & 107,34 & 245,70 & 245,70 & 72,69 & 464,67 & 61,84 & $5, \mathrm{C}$ & 46,69 & 168,01 & 32,31 & 32,31 & 148,91 \\
\hline Triturus pygmaeus & 30 SVH 65 & 100,00 & 145,01 & 121,56 & 37,00 & 6830,51 & 336,83 & 12,36 & 324,47 & 98,63 & 237,55 & 237,55 & 63,40 & 490,13 & 63,78 & 6,22 & 44,91 & \begin{tabular}{|l|}
175,06 \\
\end{tabular} & 37,89 & 37,89 & 153,67 \\
\hline Triturus pygmaeus & 30SVH67 & 100,00 & 145,63 & 123,05 & 37,01 & 6821,12 & 337,65 & 11,86 & 325,78 & 127,34 & 237,73 & 237,73 & 63,69 & 465,95 & 58,14 & 5,86 & 43,54 & 164,86 & 38,03 & 38,03 & 142,61 \\
\hline Triturus pygmaeus & 30SVH74 & 100,00 & 156,35 & 118,46 & 37,00 & 6713,76 & 341,89 & 24,83 & 317,06 & 109,79 & 246,80 & 246,80 & 75,59 & 442,10 & 57,42 & 4,87 & 45,98 & 158,07 & 31,52 & 31,52 & 139,85 \\
\hline Triturus pygmaeus & 30SVH75 & 100,00 & $\begin{array}{l}130,50,09 \\
148,\end{array}$ & $\begin{array}{l}110,40 \\
120,87\end{array}$ & 37,00 & 6772,70 & $\begin{array}{l}34,05 \\
337,37\end{array}$ & $\begin{array}{l}4,03 \\
15,63 \\
\end{array}$ & \begin{tabular}{|l|}
321,74 \\
\end{tabular} & \begin{tabular}{|l|}
110,62 \\
10,5
\end{tabular} & \begin{tabular}{|l|}
239,640 \\
230
\end{tabular} & \begin{tabular}{|l|}
239,64 \\
230
\end{tabular} & $\begin{array}{l}\mid 5,35 \\
66,96\end{array}$ & \begin{tabular}{|l|l|}
$446,38,38$ \\
4
\end{tabular} & $\begin{array}{l}30,446 \\
59,56\end{array}$ & $\begin{array}{ll}4,019 \\
5,92\end{array}$ & $\begin{array}{l}44,40 \\
44,41\end{array}$ & \begin{tabular}{|l|}
165,41 \\
16,1
\end{tabular} & $\begin{array}{l}\mid l, 1,2 \\
36,67\end{array}$ & $\begin{array}{l}1,24 \\
36,67\end{array}$ & $\begin{array}{l}13,05 \\
144,59\end{array}$ \\
\hline Triturus pygmaeus & 30SVH76 & 100,00 & 142,16 & 122,42 & 37,00 & 6812,50 & 333,83 & 9,07 & 324,76 & 123,00 & 234,41 & 234,41 & 60,91 & 480,67 & 60,20 & 6,83 & 42,80 & 170,17 & 40,83 & 40,83 & 146,37 \\
\hline Triturus pygmaeus & 30 SVH81 & 100,00 & 159,91 & 114,97 & 36,91 & 6589,05 & 339,97 & 30,88 & 309,10 & 113,51 & 24,51 & 248,56 & 80,65 & 429,66 & 56,23 & 4,73 & 47,06 & 154,55 & 28.56 & 29,46 & 139,10 \\
\hline Triturus pygmaeus & 30SVH83 & 100,00 & 152,89 & 118,31 & 37,00 & 6684,40 & 337,84 & 21,87 & 315,97 & 105,94 & 242,93 & 242,93 & 72,76 & 448,93 & 57,69 & 5,49 & 45,15 & 159,88 & 33,55 & 33,55 & 140,90 \\
\hline Triturus pygmaeus & 30SVH85 & 100,00 & 146,29 & 120,92 & 37,01 & 6742,36 & 334,64 & 13,91 & 320,72 & 123,55 & 237,31 & 237 & 65,56 & 461,99 & 57,69 & 6,39 & 43,18 & 163,03 & 38,59 & 38,59 & $14 C$ \\
\hline Triturus pygmaeus & 30SVH95 & 100,00 & 143,64 & 121,02 & 37,12 & 6708,19 & 331,32 & 11,41 & 319,91 & 124,45 & 234,24 & 234,24 & 63,41 & 460,92 & 57,49 & 6,88 & 41,94 & 162,34 & 40,95 & 40,95 & 137,51 \\
\hline Triturus pygmaeus & 30SVJO0 & 100,00 & 148,87 & 127,44 & 38,00 & 6881,30 & 345,65 & 11,99 & 333,65 & 132,29 & 241,78 & 241,78 & 65,87 & 452,13 & 55,12 & 4,00 & 45,43 & 158,93 & 32,90 & 32,90 & 140,79 \\
\hline Triturus pygmaeus & 30SVJ03 & 100,00 & 142,10 & 126,30 & 37,46 & 6881,69 & 338,09 & 5,64 & 332,45 & 125,62 & 235,12 & 235,12 & 59,01 & 445,49 & 52,57 & 5,19 & 42,22 & 154,66 & 38,37 & 38,37 & 132,61 \\
\hline Triturus pygmaeus & 30SVJ05 & 100,00 & 130,97 & 123,47 & 37,00 & 6870,26 & 325,77 & $-2,56$ & 328,3 & 113,5 & 224 & 224 & 48 & 475,61 & 55,56 & 7,50 & 39,55 & 162,95 & 47,10 & 47,10 & 137, \\
\hline Triturus pygmaeus & 30 SVJ06 & 100,00 & 129,19 & 121,97 & 37,00 & 6851,31 & 322,54 & $-3,91$ & 326,45 & 111,79 & 222,27 & 222,27 & 47,47 & 477,10 & 55,90 & 8,28 & 38,71 & 162,20 & 49,38 & 49,38 & 136,5 \\
\hline
\end{tabular}




\begin{tabular}{|c|c|c|c|c|c|c|c|c|c|c|c|c|c|c|c|c|c|c|c|c|c|}
\hline TAXON & UTM & $\mathrm{km} 2$ & B101 & B102 & $\mathrm{BIO3}$ & BIO4 & B105 & B106 & B107 & B108 & B109 & BIO10 & BIO11 & BIO12 & B1013 & BIO14 & BIO15 & B1016 & B1017 & BIO18 & B1019 \\
\hline Triturus pygmaeus & 305VJ23 & 100,00 & 145,52 & 126,56 & 37,99 & 6840,83 & 340,04 & 8,74 & 331,30 & 129,61 & 237,74 & 237,74 & 62,74 & 420,08 & 50,24 & 4,60 & 42,20 & 145,53 & 36,85 & 36,85 & 123,39 \\
\hline Triturus pygmaeus & 30SVJ32 & 100,00 & 147,26 & 126,73 & 38,00 & 6819,47 & 341,26 & 10,77 & 330,49 & 131,51 & 239,21 & 239,21 & 64,75 & 418,02 & 50,40 & 4,12 & 42,60 & 145,18 & 35,91 & 35,91 & 123,62 \\
\hline Triturus pygmaeus & 30 SVJ 42 & 100,00 & 147,07 & 125,73 & 37,80 & 6824,05 & 340,22 & 11,03 & 329,18 & 130,93 & 239,08 & 239,08 & 64,71 & 419,65 & 50,44 & 4,93 & 41,76 & 145,29 & 36,93 & 36,93 & 123,44 \\
\hline Triturus pygmaeus & $305 \mathrm{~V} J 45$ & 100,00 & 128,65 & 123,56 & 37,03 & \begin{tabular}{ll|l|}
6835,67 \\
\end{tabular} & 322,47 & $-4,44$ & 326,91 & 111,14 & 221,50 & 221,50 & 47,35 & 478,31 & 55,59 & 8,50 & 37,84 & 162,32 & 50,98 & 50,98 & 136,15 \\
\hline Triturus pygmaeus & 30SWHOO & 100,00 & 135,70 & 118,81 & \begin{tabular}{|l|l|}
37,07 \\
\end{tabular} & 6620,45 & 321,12 & 5,99 & 315,12 & 97,55 & 225,36 & 225,55 & 57,45 & 503,33 & 63,04 & 9,04 & 42,12 & 176,09 & 44,77 & 46,68 & 153,98 \\
\hline Triturus pygmaeus & 30SWHO4 & 100,00 & 153,38 & 118,44 & 37,31 & 6570,38 & 334,75 & 22,41 & 312,34 & 134,77 & 241,78 & 241,81 & 74,35 & 415,06 & 52,06 & 5,56 & 42,79 & 144,82 & 34,95 & 35,32 & 123,95 \\
\hline Triturus pygmaeus & 30SWH23 & 100,00 & 135,81 & 119,95 & \begin{tabular}{|l|l|}
37,88 \\
\end{tabular} & 6573,86 & 319,58 & 5,31 & 314,27 & \begin{tabular}{|l|l|}
115,67 \\
\end{tabular} & 224,68 & 224,79 & 57,81 & 473,78 & 60,36 & 9,25 & 39,12 & 164,77 & 48,83 & 49,47 & 135,25 \\
\hline Triturus pygmaeus & 30SWH27 & 100,00 & 136,53 & 122,09 & 38,00 & 6621,28 & 322,34 & 4,31 & 318,03 & 117,43 & 226,03 & 226,05 & 57,70 & 455,02 & 57,62 & 8,86 & 37,61 & 158,18 & 50,57 & 50,66 & 124,84 \\
\hline Triturus pygmaeus & 30SWH33 & 100,00 & 115,28 & 121,64 & 37,99 & 6624,59 & 303,36 & $-14,60$ & 317,95 & 93,55 & 205,45 & 205,58 & 37,90 & 563,74 & 71,58 & 14,55 & 35,49 & 195,09 & 67,78 & 68,03 & 155,56 \\
\hline Triturus pygmaeus & 30SWH44 & 100,00 & 120,14 & 121,30 & 38,00 & 6578,54 & 305,68 & $-10,05$ & 315,73 & 98,81 & 209,57 & 209,66 & 42,99 & 529,28 & 67,71 & 13,53 & 35,21 & 182,61 & 64,91 & 65,25 & 142,30 \\
\hline Triturus pygmaeus & 30SWH45 & 100,00 & 122,26 & 121,51 & 38,00 & 6578,14 & 307,64 & $-8,31$ & 315,95 & 101,38 & 211,55 & 211,58 & 44,91 & 515,95 & 65,98 & 13,00 & 35,23 & 178,04 & 63,34 & 64,24 & 137,55 \\
\hline Triturus pygmaeus & 30SWH59 & 100,00 & 129,59 & 122,39 & 38,30 & 6539,40 & 312,89 & $-1,79$ & 314,68 & 110,51 & 217,68 & 218,04 & 51,72 & 460,34 & 58,64 & 11,23 & 34,25 & 157,76 & 58,58 & 62,27 & 115,81 \\
\hline Triturus pygmaeus & 30SWJ10 & 100,00 & 133,74 & 123,38 & 38,00 & 6685,27 & 322,20 & 0,64 & 321,56 & $\begin{array}{ll}115,28 \\
\end{array}$ & 223,74 & 224,19 & 53,98 & 461,31 & 56,75 & 9,04 & 36,79 & 159,66 & 52,44 & 53,18 & 125,69 \\
\hline Triturus pygmaeus & 30SWJ11 & 100,00 & 132,95 & 123,77 & 38,00 & 6688,70 & 321,48 & $-0,02$ & 321,50 & 114,59 & 222,89 & 223,38 & 53,13 & 461,69 & 56,23 & 9,45 & 36,06 & 159,09 & 53,73 & 54,64 & 124,72 \\
\hline Triturus pygmaeus & 30SWJ30 & 100,00 & 128,96 & 123,06 & 38,00 & 6630,43 & 315,81 & $-3,09$ & 318,89 & 110,17 & 218,38 & 218,71 & 49,96 & 471,51 & 58,39 & 10,96 & 34,82 & 162,29 & 57,77 & 60,31 & 123,33 \\
\hline Triturus pygmaeus & 30TTK43 & 60,00 & 149,16 & 110,74 & 36,88 & 6409,49 & 324,89 & 26,98 & 297,91 & 78,57 & 234,93 & 234,93 & 71,07 & 468,07 & 57,26 & 5,87 & 44,11 & 167,16 & 38,90 & 38,90 & 154,18 \\
\hline Triturus pygmaeus & 30TTK44 & 60,00 & 132,45 & 109,16 & 36,60 & 6377,70 & 307,43 & 12,65 & 294,78 & 62,97 & 217,85 & 218,38 & 55,81 & 543,52 & 66,52 & 8,45 & 42,58 & 193,49 & 48,58 & 49,33 & 179,36 \\
\hline Triturus pygmaeus & 30TTK54 & 100,00 & 126,02 & 109,80 & 36,64 & 6379,98 & 302,00 & 6,26 & 295,74 & 56,83 & 211,49 & 212,14 & 49,72 & 553,85 & 67,17 & 9,55 & 41,46 & 194,51 & 51,85 & 52,86 & 179,58 \\
\hline Triturus pygmaeus & 30TTK56 & 100,00 & 125,09 & 110,34 & 36,99 & 6336,47 & 299,69 & 5,54 & 294,16 & 55,85 & 209,65 & 210,40 & 48,89 & 532,56 & 65,03 & 9,79 & 40,50 & 186,53 & 52,18 & 52,97 & 171,06 \\
\hline Triturus pygmaeus & 30TTK64 & 100,00 & 125,55 & 110,94 & 36,79 & 6392,01 & 302,50 & 4,83 & 297,67 & 56,05 & 211,25 & 211,87 & 49,11 & 535,59 & 64,29 & 9,79 & 40,50 & 185,12 & 51,99 & 53,12 & 169,90 \\
\hline Triturus pygmaeus & 30TTK74 & 100,00 & 134,76 & 112,76 & 36,99 & 6418,78 & 312,39 & 11,83 & 300,57 & 68,51 & 220,79 & 221,21 & 57,26 & 470,09 & 55,91 & 8,4 & 40,06 & 159,85 & 46,18 & 46,69 & 145,14 \\
\hline Triturus pygmaeus & 30TTK84 & 100,00 & 134,41 & 113,27 & 37,00 & 6425,82 & 312,65 & 10,59 & 302,07 & 81,47 & 220,52 & 220,95 & 56,82 & 456,62 & 53,71 & 8,67 & 39,33 & 153,00 & 46,50 & 47,06 & 137,83 \\
\hline Triturus pygmaeus & 30TTK85 & 100,00 & 78,37 & 108,42 & 36,60 & 6264,29 & 255,69 & $-36,63$ & 292,32 & 13,03 & 163,74 & 164,41 & 6,90 & 760,19 & 88,73 & 20,16 & 35,67 & 253,42 & 86,09 & 91,79 & 233,99 \\
\hline Triturus pygmaeus & 30TTK93 & 100,00 & 158,23 & 114,87 & 37,00 & 6478,21 & 336,17 & 31,10 & 305,07 & 116,45 & 244,77 & 244,77 & 78,48 & 365,64 & 43,12 & 5,03 & 41,74 & 124,73 & 32,99 & 32,99 & 110,07 \\
\hline Triturus pygmaeus & 30TTK94 & 100,00 & 150,38 & 114,48 & 37,00 & 6451,97 & 328,03 & 24,12 & 303,91 & 108,28 & 236,77 & 236,78 & 71,27 & 381,23 & 44,71 & 6,37 & 39,86 & 128,30 & 37,38 & 37,38 & 113,13 \\
\hline Triturus pygmaeus & 30TTK95 & 100,00 & 94,42 & 110,80 & 36,89 & 6314,75 & 272,60 & $-23,77$ & 296,37 & 36,90 & 179,93 & 180,69 & 21,05 & 643,16 & 74,43 & 17,05 & 35,56 & 210,75 & 74,63 & 78,42 & 191,89 \\
\hline Triturus pygmaeus & 30TTM98 & 100,00 & 115,31 & 115,94 & 39,65 & 5873,47 & 283,65 & $-6,28$ & 289,93 & 80,58 & \begin{tabular}{|l|l}
192,79 \\
\end{tabular} & \begin{tabular}{|l|}
192,79 \\
\end{tabular} & 41,40 & 486,16 & $\begin{array}{l}4,435 \\
61,73\end{array}$ & 21,00 & 31,12 & 173,32 & 82,64 & 82,64 & 131,60 \\
\hline Triturus pygmaeus & 30TUK03 & 100,00 & 156,90 & 114,99 & 37,00 & 6503,86 & 335,39 & 28,88 & 306,51 & 114,68 & 243,94 & 243,94 & 76,89 & 361,34 & 42,13 & 5,25 & 40,71 & 122,40 & 33,81 & 33,81 & 106,76 \\
\hline Triturus pygmaeus & 30TUK04 & 100,00 & 152,48 & 114,92 & 37,00 & 6473,37 & 330,21 & 25,06 & 305,15 & 110,58 & 239,14 & 239,14 & 72,90 & 365,59 & 42,55 & 6,31 & 39,21 & 122,56 & 36,52 & 36,52 & 106,51 \\
\hline Triturus pygmaeus & 30TUK13 & 100,00 & 153,80 & 115,00 & 37,00 & 6529,68 & 332,82 & 25,31 & 307,51 & 111,49 & 241,18 & 241,18 & 73,63 & 362,19 & 41,65 & 5,97 & 39,65 & 121,37 & 35,44 & 35,44 & 104,84 \\
\hline Triturus pygmaeus & 30TUK14 & 100,00 & 151,35 & 114,68 & 37,00 & 6499,67 & 329,40 & 23,35 & 306,06 & 109,40 & 238,49 & 238,49 & 71,49 & 361,03 & 41,78 & 6,41 & 38,95 & 120,26 & 36,98 & 36,98 & 103,24 \\
\hline Triturus pygmaeus & 30TUK23 & 100,00 & 151,83 & 114,05 & 37,00 & 6558,41 & 331,25 & 23,05 & 308,19 & $\begin{array}{l}109,52 \\
\end{array}$ & \begin{tabular}{|l|}
239,88 \\
23,45
\end{tabular} & \begin{tabular}{|l|}
239,88 \\
\end{tabular} & 71,45 & \begin{tabular}{|l|}
361,57 \\
\end{tabular} & $\begin{array}{l}41,168 \\
41,58\end{array}$ & $\begin{array}{l}0,4+19 \\
6,19\end{array}$ & 39,18 & $\begin{array}{l}120,32 \\
\end{array}$ & $\begin{array}{l}36,54 \\
36,\end{array}$ & $\begin{array}{l}36,54 \\
36,5\end{array}$ & 102,94 \\
\hline Triturus pygmaeus & 30TUK24 & 100,00 & 148,45 & 114,23 & 37,00 & 6501,82 & 326,70 & 20,22 & 306,48 & 106,40 & 235,77 & 235,77 & 68,69 & 362,49 & 42,40 & 6,90 & 38,08 & 119,71 & 38,77 & 38,77 & 101,54 \\
\hline Triturus pygmaeus & 30TUK25 & 100,00 & 135,47 & 113,90 & 37,00 & 6441,15 & 313,42 & 9,08 & 304,35 & 104,99 & 222,13 & 222,33 & 57,18 & 389,31 & 47,34 & 8,90 & 36,26 & 126,13 & 46,22 & 46,31 & 105,63 \\
\hline Triturus pygmaeus & 30 TUK26 & 100,00 & 94,91 & 111,68 & 37,00 & 6277,75 & 272,94 & $-24,75$ & 297,69 & 72,72 & 179,80 & 180,69 & 21,95 & 555,93 & 68,55 & 16,80 & 33,22 & 175,91 & 73,17 & 76,48 & 149,86 \\
\hline Triturus pygmaeus & $\begin{array}{l} \\
30 T U K 34 \\
\end{array}$ & 100,00 & 146,30 & 113,97 & 36,92 & 6520,96 & 324,74 & 17,80 & 306,94 & 108,63 & 233,89 & 233,89 & 66,48 & 363,94 & 43,27 & 7,34 & 37,36 & 119,40 & 40,36 & 40,36 & 99,86 \\
\hline Triturus pygmaeus & 30TUK43 & 100,00 & 145,94 & 114,02 & 36,11 & 6601,61 & 326,07 & 16,37 & 309,70 & $\begin{array}{l}117,03 \\
\end{array}$ & 234,62 & 234,62 & 65,32 & 370,04 & 44,08 & 7,20 & 37,97 & 121,24 & 40,37 & 40,37 & 101,62 \\
\hline Triturus pygmaeus & 30TUK45 & 100,00 & 146,31 & 112,88 & 36,51 & 6512,57 & 323,18 & $\begin{array}{ll}17,87 \\
\end{array}$ & 305,31 & 107,34 & 233,69 & 233,69 & 66,26 & 353,29 & 42, & 7,55 & 37,12 & 115,64 & 40,71 & 40,71 & 94,95 \\
\hline Triturus pygmaeus & 30TUK46 & 100,00 & 100,93 & 111,37 & 36,83 & 6305,77 & 278,33 & $-20,28$ & 298,61 & 82,70 & 186,21 & 186,97 & 27,26 & 508,86 & 65,08 & 15,92 & 33,13 & $\mid 163,43$ & 70,14 & 72,82 & 130,45 \\
\hline Triturus pygmaeus & 30TUK54 & 100,00 & 131,14 & 112,60 & 36,09 & 6545,57 & 310,48 & 3,62 & 306,87 & 113,72 & 219,40 & 219,58 & 52,15 & 401,54 & 50,23 & 9,73 & 35,69 & 130,93 & 49,81 & 49,99 & 104,96 \\
\hline Triturus pygmaeus & 30TUK55 & 100,00 & 140,85 & 112,00 & 36,01 & 6541,56 & 318,01 & 12,68 & 305,33 & 110,79 & 228,88 & 228,88 & 60,92 & 365,31 & 44,80 & 8,45 & 35,97 & 118,38 & 44,29 & 44,29 & 96,25 \\
\hline Triturus pygmaeus & 30TUK56 & 100,00 & 118,29 & 111,17 & 36,41 & 6398,64 & 294,72 & $-5,92$ & 300,64 & 92,11 & 204,53 & 204,95 & 41,94 & 438,19 & 55,93 & 12,85 & 34,18 & 141,45 & 59,34 & 60,68 & 111,31 \\
\hline Triturus pygmaeus & $\begin{array}{l}\text { 30TUK57 } \\
\end{array}$ & 100,00 & 117,59 & 110,53 & 36,51 & 6344,52 & 292,32 & $-6,49$ & 298,81 & \begin{tabular}{|l|l|l|}
102,44 \\
\end{tabular} & 202,68 & 203,47 & 41,46 & 410,25 & 54,77 & 12,60 & 34,25 & 132,62 & 58,94 & 59,81 & 98,93 \\
\hline Triturus pygmaeus & 30TUK64 & 100,00 & 143,47 & 111,86 & 36,00 & 6613,83 & 321,64 & 14,24 & 307,40 & 113,18 & 232,51 & 232,51 & 62,66 & 368,43 & 44,41 & 8,08 & 36,43 & 120,08 & 43,36 & 43,36 & 98,32 \\
\hline Triturus pygmaeus & 30TUK65 & 100,00 & 132,66 & 111,17 & 36,00 & 6534,47 & 309,78 & 5,08 & 304,70 & 113,12 & 220,75 & 220,75 & 53,25 & 387,33 & 48,71 & 9,88 & 35,14 & 25,27 & 49,91 & 49,91 & 99,34 \\
\hline Triturus pygmaeus & $\begin{array}{l}\text { 30TUK66 } \\
\end{array}$ & 100,00 & 113,97 & 110,31 & 36,34 & 6387,97 & 290, & $\begin{array}{l}-9,62 \\
-9,62\end{array}$ & 299,73 & \begin{tabular}{|c|c|}
93,62 \\
\end{tabular} & 200,12 & 200,66 & 38,09 & |443,80 & $\begin{array}{l}40,11 \\
57,94 \\
\end{array}$ & \begin{tabular}{|l|l|}
13,48 \\
13
\end{tabular} & 33,95 & 143,79 & \begin{tabular}{|c|c|}
62,19 \\
\end{tabular} & 63,67 & 109,62 \\
\hline Triturus pygmaeus & 30TUK73 & 100,00 & 149 & 11 & 35,82 & 6700,78 & 329,16 & 19,16 & 310,00 & 106,77 & 239,81 & 239,81 & 67,62 & 362,88 & 42,42 & 7,16 & 37,32 & 119,15 & 40,05 & 40,05 & 99,37 \\
\hline Triturus pygmaeus & 30TUK74 & 100,00 & 148,29 & 111,08 & 35,77 & 6661,16 & 326,08 & 18,42 & 307,66 & 106,53 & $\begin{array}{l}237,77 \\
\end{array}$ & 237,77 & 66,49 & 360,88 & 42,33 & 7,73 & 36,76 & 118,60 & 41,34 & 41,34 & 97,94 \\
\hline Triturus pygmaeus & 30TUK75 & 100,00 & 136,04 & 110,17 & 35,75 & 6585,37 & 312,70 & 8,06 & 304,64 & 107,44 & 224,68 & 224,68 & 55,91 & 383,44 & 47,17 & 9,64 & 35,07 & 123,98 & 48,72 & 48,72 & 99,62 \\
\hline Triturus pygmaeus & 30TUK76 & 100,00 & 126,44 & 109,29 & 35,91 & 6486,12 & 301,51 & 0,41 & 301,10 & 104,01 & 213,75 & 214,03 & 48,02 & 399,10 & 51,13 & 11,25 & 34,41 & 128,63 & 54,68 & 54,91 & 99,41 \\
\hline Triturus pygmaeus & $\begin{array}{l}\text { 30TUK77 } \\
\end{array}$ & 100,00 & $\begin{array}{l}128,44 \\
128,57\end{array}$ & 108,45 & 35 & $\begin{array}{ll}040,0,114 \\
6458,48\end{array}$ & 301 & $\begin{array}{l}0,41 \\
2,79 \\
\end{array}$ & $\mid \begin{array}{l}\mid 01,10 \\
299,00\end{array}$ & $\begin{array}{r}08,01 \\
98,53 \\
\end{array}$ & \begin{tabular}{|l|}
215,16 \\
215
\end{tabular} & $\frac{14}{215}$ & $\begin{array}{ll}40,0,04 \\
50,03\end{array}$ & $\mid \begin{array}{l}\mid 387,77 \\
387\end{array}$ & \begin{tabular}{l|}
1,13 \\
49,53
\end{tabular} & $\begin{array}{l}1,23 \\
11,21\end{array}$ & 34,19 & $\begin{array}{l}124,903 \\
124\end{array}$ & $\begin{array}{l}43,00 \\
53,75\end{array}$ & 54,05 & $\begin{array}{l}99,41 \\
96,10\end{array}$ \\
\hline Triturus pygmaeus & 30TUK86 & 100,00 & 133,66 & 108,22 & 35,36 & 6561,83 & 308,14 & 6,79 & 301,35 & 98,74 & 221,89 & 222,00 & 53,67 & 390,65 & 47,58 & 10,50 & 34,35 & 125,95 & 51,28 & 51,34 & 101,24 \\
\hline Triturus pygmaeus & 30TUK87 & 100,00 & 133,51 & 107,34 & 35,38 & 6530,87 & 306,06 & 7,06 & 299,00 & 93,52 & 220,89 & 221,09 & 53,58 & 385,86 & 47,13 & 10,80 & 34,08 & 124,41 & 51,68 & 51.78 & 99,15 \\
\hline Triturus pygmaeus & 30TUK88 & 100,00 & 120,92 & 106,42 & 35,70 & 6408,92 & 291,84 & $-2,97$ & 294,81 & 109,49 & 205,88 & 207,34 & 43,50 & 407,06 & 52,75 & 12,92 & 33,55 & 130,32 & 59,09 & 60,40 & 98,12 \\
\hline Triturus pygmaeus & 30TUK89 & 100,00 & 98,05 & 106,76 & 36,38 & 6211,20 & 268,70 & $-21,19$ & 289,90 & 113,77 & 181,84 & 182,58 & 25,62 & 478,86 & 64,70 & 17,80 & 32,27 & 155,90 & 74,58 & 78,62 & 110,54 \\
\hline Triturus pygmaeus & 30TUK97 & 100,00 & 130,01 & 106,23 & 35,08 & 6535,23 & 302,11 & 4,72 & 297,39 & 91,01 & 217,24 & 217,90 & 50,46 & 406,46 & 48,70 & 11,65 & 33,54 & 131,35 & 54,53 & 54,97 & 105,93 \\
\hline Triturus pygmaeus & 30TUK98 & 100,00 & 117,08 & 105,55 & 35,46 & 6424,03 & 287,68 & $-5,43$ & 293,11 & 92,36 & 202,24 & 203,76 & 39,80 & 433,53 & 54,70 & 14,08 & 32,57 & 137,60 & 62,24 & 64,39 & 106,93 \\
\hline Triturus op & 30TUK99 & 100,00 & 96.32 & 106,41 & $\begin{array}{l}36,45 \\
\end{array}$ & 6227,65 & 266.97 & $\mid-2179$ & 288.76 & 105.56 & $|180,69|$ & 181.32 & 24,05 & 503,34 & 65,66 & 18,77 & 31.15 & 161.06 & 76,80 & 81.29 & 120,12 \\
\hline Triturus : & 30TVK07 & 100,00 & 138,22 & 105,19 & 35,00 & 6599,22 & 309,76 & 12,52 & 297,24 & 95,99 & 226,1 & 226 & 57, & 400,96 & 47,07 & 10,68 & 34,48 & 133,24 & 50,14 & 50,30 & 110,73 \\
\hline Triturus pygmaeus & 30TVK08 & 100,00 & 124,39 & 104,41 & 35,06 & 6501,56 & 294,21 & 1,24 & 292,97 & 83,41 & 209,89 & 211,86 & 45,44 & 432,64 & 51,12 & 13,14 & 32,69 & 139,51 & 58,66 & 60,32 & 113,69 \\
\hline
\end{tabular}




\begin{tabular}{|c|c|c|c|c|c|c|c|c|c|c|c|c|c|c|c|c|c|c|c|c|c|}
\hline TAXON & UTM & $\mathrm{km} 2$ & BIO1 & B102 & $\mathrm{BIO3}$ & B104 & B105 & B106 & 8107 & B108 & 8109 & B1010 & B1011 & B1O12 & B1013 & B1014 & B1015 & B1016 & B1017 & B1018 & B1019 \\
\hline Triturus pygmaeus & 30TVK09 & 100,00 & 113,60 & 104,19 & 35,39 & 6407,64 & 282,44 & $-7,01$ & 289,45 & 85,27 & 198,75 & 200,05 & 36,88 & 464,05 & 56,18 & 15,15 & 31,66 & 147,87 & 65,86 & 69,08 & 118,12 \\
\hline Triturus pygmaeus & 30TVK18 & 100,00 & 131,85 & 103,41 & 34,97 & 6562,13 & 301,39 & 8,21 & 293,18 & $\begin{array}{ll}90,01 \\
\end{array}$ & 218,54 & 219,79 & 51,45 & $\begin{array}{l}430,06 \\
\end{array}$ & 51,12 & 11,99 & 33,87 & 143,24 & 54,72 & 55,46 & 120,27 \\
\hline Triturus pygmaeus & 30TVK19 & 100,00 & 122,10 & 103,03 & 35,01 & 6504,33 & 290,27 & 0,24 & 290,03 & 80,60 & 207,63 & 209,40 & 43,13 & 452,22 & 52,58 & 13,31 & 32,24 & 146,66 & \begin{tabular}{ll|}
60,58 \\
\end{tabular} & 63,19 & 121,45 \\
\hline Triturus pygmaeus & 30TVK29 & 100,00 & 123,83 & 102,72 & 35,00 & 6522,81 & 292,25 & 2,43 & 289,82 & 82,35 & 209,81 & 211,40 & 44,65 & 461,17 & 55,11 & 13,13 & 33,00 & 152,18 & 60,21 & 62,15 & 128,16 \\
\hline Triturus pygmaeus & 30TVK39 & 100,00 & 132,33 & 102,09 & 34,58 & 6564,50 & 301,02 & 9,65 & 291,37 & 90,28 & 219,68 & 220,00 & 51,72 & 447,13 & 56,23 & 11,54 & 35,06 & 153,56 & 55,03 & 55,22 & 130,17 \\
\hline Triturus pygmaeus & 30TVK49 & 100,00 & 134,81 & 102,96 & 34,73 & 6603,20 & 305,15 & 11,37 & 293,78 & 92,12 & 222,82 & 222,82 & 53,66 & 442,82 & 58,10 & 10,74 & 36,60 & 155,84 & 52,14 & 52,14 & 130,55 \\
\hline Triturus pygmaeus & 30TVL10 & 100,00 & 112,46 & 102,96 & 35,38 & \begin{tabular}{ll|l}
6427,44 \\
\end{tabular} & 279,75 & $-7,11$ & 286,86 & 80,22 & 197,93 & 199,25 & 35,60 & 478,21 & 56,21 & 15,01 & 30,94 & 150,99 & 67,21 & 71,88 & 123,97 \\
\hline Triturus pygmaeus & 30TVL11 & 100,00 & 77,29 & 106,95 & 37,36 & 6068,16 & 247,71 & $-34,23$ & 281,95 & 70,78 & 161,14 & 161,28 & 9,66 & 626,03 & 76,40 & 24,97 & 27,68 & 194,81 & 96,49 & 99,25 & $\begin{array}{ll}157,99 \\
\end{array}$ \\
\hline Triturus pygmaeus & 30TVL20 & 100,00 & 116,65 & 102,55 & 35,13 & \begin{tabular}{ll|}
6465,02 \\
\end{tabular} & 284,01 & $-3,38$ & 287,39 & 75,82 & 202,20 & 203,73 & 38,82 & 477,18 & 55,71 & 14,20 & 31,40 & 153,59 & 64,93 & 68,63 & 128,32 \\
\hline Triturus pygmaeus & 30TVL21 & 100,00 & 84,19 & 106,10 & 36,89 & 6169,99 & 254,29 & $-29,16$ & 283,45 & 61,23 & 168,71 & 169,10 & 14,22 & 607,58 & 72,58 & 23,35 & 27,95 & 188,62 & 92,03 & 95,29 & 156,05 \\
\hline Triturus pygmaeus & 30TVL22 & 100,00 & 89,15 & 105,22 & 36,69 & 6195,81 & 257,50 & $-25,31$ & 282,81 & 82,82 & 173,58 & 173,95 & 18,03 & 575,22 & 68,69 & 21,29 & 27,97 & 177,58 & 86,99 & 92,20 & \begin{tabular}{ll|}
146,47 \\
\end{tabular} \\
\hline Triturus pygmaeus & 30TVL30 & 100,00 & 119,57 & 102,73 & 35,07 & 6498,95 & 287,51 & $-0,85$ & 288,36 & 77,69 & 205,32 & 206,90 & 41,19 & $\begin{array}{l}476,05 \\
\end{array}$ & 56,83 & 13,65 & 32,14 & 156,14 & 63,41 & 66,05 & 131,37 \\
\hline Triturus pygmae & 30TVL31 & 100,00 & 112,12 & 103,04 & 35,52 & 6428,78 & 279,39 & $-6,72$ & 286,11 & 73,78 & 197,50 & 198,75 & 35,20 & 496,87 & 58,38 & 15,25 & 30,58 & 158,92 & \begin{tabular}{ll|}
69,08 \\
\end{tabular} & 73,27 & 133,32 \\
\hline Triturus pygmaeus & 30TVL42 & 100,00 & 106,04 & 103,99 & 36,08 & $\begin{array}{ll}6376,62 \\
\end{array}$ & 273,74 & $\mid-11,87$ & 285,61 & 69,50 & 191,23 & 192,10 & 30,35 & 516,25 & 60,00 & 16,95 & 29,25 & 161,85 & 74,57 & 79,67 & 136,35 \\
\hline Triturus pygmaeus & 30TVL51 & 100,00 & 128,43 & 102,74 & 35,00 & 6538.75 & 296,04 & 670 & 289,35 & 86,38 & 215,28 & 215.54 & 48,77 & 440,69 & 55.86 & 11,65 & 33,64 & 149,99 & 57,75 & 58.04 & 122.79 \\
\hline
\end{tabular}


SUPPLEMENTARY MATERIAL ESM 2

\section{FOSSIL SITES. REFERENCES AND HISTORICAL FAUNISTIC LISTS}

Internet web resources, such as Böhme; Ilg (2003) or Martin; Sanchiz (2015), are only included if no other published reference exists.

Abric Romaní (Barcelona). Upper Pleistocene.

Blain et al. 2008c ---> Rana temporaria.

Burjachs et al. 2012 ---> Bufo bufo; Bufo calamita; Rana temporaria.

Abrigo del Monte (Madrid). Upper Pleistocene.

López-García et al. 2011a ---> (Blain, unpublished): Rana iberica.

Aitzbitarte 4 (Guipúzcoa). Upper Pleistocene.

Sanchiz 1977a ---> Bufo bufo; Rana temporaria; Rana sp.

Sanchiz 1984 ---> Rana cf. dalmatina.

Holman 1998 ---> Bufo bufo; Rana temporaria; Rana sp.

Sanchiz 1998 ---> Bufo bufo; Rana temporaria; Rana sp.

Blain et al. 2008c ---> Rana temporaria.

Aizkoltxo (Guipúzcoa). Holocene.

Murelaga et al. 2008 ---> Bufo calamita.

Almenara-Casablanca 1 (Castellón). Lower Pleistocene.

Blain 2005 ---> Bufo bufo; cf. Discoglossus sp.; Pelodytes cf. punctatus; Rana sp.

Furió et al. 2005 ---> Anura indet.; Bufo sp.; Pelodytes punctatus; Rana cf. perezi.

Blain; Bailon 2006 ---> Bufo sp.; cf. Rana.

Agustí et al. 2009 ---> Bufo bufo; cf. Discoglossus sp; Pelodytes sp.; Pelophylax sp.

Blain 2009 ---> Bufo bufo; cf. Discoglossus; Pelodytes cf. punctatus; Pelophylax sp.

Agustí et al. 2011 ---> Bufo bufo; cf. Discoglossus sp.; Pelodytes cf. punctatus; Pelophylax sp.

López-García et al. 2011a ---> Discoglossus.

Almenara-Casablanca 3 (Castellón). Lower Pleistocene.

Blain 2005 ---> Bufo bufo; cf. Discoglossus sp.; Pelobates cultripes; Pelodytes cf. punctatus; Rana cf. perezi.

Furió et al. 2005 ---> Anura indet.; Bufo bufo; cf. Discoglossus sp.; Pelobates cultripes; Pelodytes punctatus; Rana cf. perezi.

Blain; Bailon 2006 ---> Bufo bufo.

Blain et al. 2007 ---> Bufo bufo; Bufo sp.; cf. Discoglossus; Pelobates cultripes; Pelodytes cf. punctatus; Pelophylax cf. perezi.

Agustí et al. 2009 ---> Bufo bufo; Bufo sp.; Discoglossus sp.; Pelobates cultripes; Pelodytes cf. punctatus; Pelophylax cf. perezi.

Blain 2009 ---> Bufo bufo; cf. Discoglossus; Pelobates cultripes; Pelodytes cf. punctatus; Pelophylax cf. perezi.

Blain et al. 2010b ---> Bufo viridis group.

Agustí et al. 2011 ---> Bufo sp.; Bufo bufo; cf. Discoglossus sp.; Pelobates cultripes; Pelodytes cf. punctatus; Pelophylax cf. perezi.

Blain et al. 2011b ---> Bufo sp. [Bufo viridis group].

López-García et al. 2011a ---> Discoglossus.

Almenara-Casablanca 4 (Castellón). Lower Pleistocene. 
Blain 2005 ---> Bufo bufo; Pelodytes sp.; Rana sp. ('verte').

Agustí et al. 2009 ---> Bufo bufo; Pelodytes sp.; Pelophylax sp.

Blain 2009 ---> Bufo bufo; Pelodytes sp.; Pelophylax sp.

Agustí et al. 2011 ---> Bufo bufo; cf. Discoglossus sp.; cf. Pelobates; Pelodytes sp.; Pelophylax sp.

Alquería (Granada). Lower Pleistocene.

Blain 2005 ---> Bufo sp.

Blain 2009 ---> Bufo sp.

Amarejo (Albacete). Holocene.

Morales; Moreno 1989 ---> Bufo calamita.

Ambrona (Soria). Middle Pleistocene.

Aguirre; Fuentes 1969 ---> Pelobatidae indet.

Sanchiz 1977b ---> Bufo cf. bufo; Rana sp.

Sanchiz 1977a ---> Bufo cf. bufo; Rana sp.

Sanchiz 1990 ---> Bufo bufo; Bufo calamita; Discoglossus galganoi; Hyla sp.; Pelobates cultripes; Pelodytes punctatus; Rana perezi.

Howell et al. 1995 ---> Bufo bufo; Bufo calamita; cf. Discoglossus pictus; Hyla arborea vs Hyla meridionalis; Pelobates cultripes; Pelodytes punctatus; Rana perezi.

Pérez-González et al. 1997 ---> Bufo bufo; Bufo calamita; Discoglossus galganoi; Hyla sp.; Pelobates cultripes; Pelodytes punctatus; Rana perezi.

Holman 1998 ---> Bufo bufo; Bufo calamita; Discoglossus galganoi; Hyla sp.; Pelobates cultripes; Pelodytes punctatus; Rana perezi.

Sanchiz 1998 ---> Bufo bufo; Bufo calamita; Discoglossus galganoi; Hyla sp.; Pelobates cultripes; Pelodytes punctatus; Rana perezi;

Blain 2005 ---> Pelobates cultripes;

Martínez-Solano; Sanchiz 2005 ---> Bufo bufo; Bufo calamita; Discoglossus cf. jeanneae; Pelobates cultripes; Pelodytes punctatus; Rana perezi.

Blain et al. 2007 ---> Pelobates cultripes.

Blain 2009 ---> Hyla arborea; Pelobates cultripes.

López-García et al. 2011a ---> Discoglossus jeanneae.

Amutxate (Navarra). Upper Pleistocene.

Martín; Sanchiz 2014 ---> Rana (temporaria) sp.; Salamandra salamandra.

Angel (Córdoba). Middle Pleistocene.

Barroso et al. 2011 ---> Alytidae indet.; Bufo bufo; Bufo calamita; Discoglossus sp.;

Antoliñaco Koba (Vizcaya). Upper Pleistocene.

Zubeldia et al. 2003 ---> Bufo sp.; Rana temporaria-iberica [sic!]; Salamandridae indet.

Blain et al. 2008c ---> Rana temporaria.

Arbreda (Girona). Holocene.

Fèlix 1985 ---> Bufo bufo; Bufo (calamita) sp.; cf. Hyla sp.; Pelodytes punctatus.

Fèlix 2002 ---> Alytes obstetricans; Bufo sp.; Pelobates cultripes; Pelodytes punctatus; Rana perezi.

Arbreda (Girona). Upper Pleistocene.

Fèlix 1985 ---> (Postsolutrean level): Bufo calamita; cf. Bufo sp.; Pelobates cultripes; Pelodytes punctatus; (Upper Solutrean): Rana sp.; (Lower Solutrean): Bufo cf. calamita; cf. Bufo sp.; (Upper Gravetian): Bufo cf. calamita; (Lower Gravetian): cf. Alytes sp.; Bufo bufo; Bufo (calamita) sp.; (Musterian): Bufo cf. bufo; Bufo cf. calamita; Pelobatidae indet; Rana sp.

Holman 1998 ---> cf. Alytes; Bufo bufo; Bufo calamita; cf. Hyla; Pelobates cultripes; Pelodytes punctatus; Rana sp. 
Sanchiz 1998 ---> cf. Alytes; Bufo bufo; Bufo calamita; cf. Hyla; Pelobates cultripes; Pelodytes punctatus; Rana sp.

Fèlix 2002 ---> (Level I): Bufo bufo; Bufo calamita; Pelodytes punctatus; Rana temporaria; (Level H): Bufo bufo; Bufo calamita?; Pelodytes punctatus; (Level G): Bufo bufo; Bufo calamita; Pelodytes punctatus; Rana perezi; (Level F): Bufo sp.; Pelodytes punctatus; (Level E): Bufo calamita; (Levels B, C, D): Bufo calamita; Rana sp.

\section{Arcaraz (Madrid). Middle Pleistocene.}

Gamazo 1982 ---> Pelobates cultripes; Rana perezi.

Sesé; Soto 2002a ---> Pelobates cultripes; Rana perezi.

Sesé; Soto 2002b ---> Pelobates cultripes; Rana perezi.

\section{Aridos 1 (Madrid). Middle Pleistocene.}

Sanchiz 1977a ---> Alytes sp.; Bufo bufo; Discoglossus pictus; Hyla (arborea) sp.; Pelobates cultripes; Rana ridibunda.

Santonja et al. 1978 ---> Alytes sp.; Bufo bufo; Discoglossus pictus; Hyla sp.; Pelobates cultripes; Rana ridibunda.

Santonja et al. 1979 ---> Alytes sp.; Bufo bufo; Discoglossus pictus; Hyla sp.; Pelobates cultripes; Rana ridibunda;

Sanchiz; Sanz 1980 ---> aff. Alytes; Bufo bufo; Discoglossus pictus; Hyla arborea vs Hyla meridionalis; Pelobates cultripes; Rana ridibunda.

Kotsakis 1981 ---> Discoglossus pictus; Rana ridibunda.

Busack 1986 ---> Discoglossus pictus (Discoglossus galganoi ?).

Lanza et al. 1986 ---> Discoglossus.

Aguirre1989 ---> aff. Alytes; Bufo bufo; Discoglossus pictus; Hyla arborea / meridionalis; Pelobates cultripes; Rana ridibunda.

Sanchiz 1990 ---> Bufo bufo; Pelobates cultripes; Rana perezi.

Holman 1998 ---> cf. Alytes; Bufo bufo; Discoglossus galganoi; Hyla sp.; Pelobates cultripes; Rana perezi;

Sanchiz 1998 ---> cf. Alytes; Bufo bufo; Discoglossus galganoi; Hyla sp.; Pelobates cultripes; Rana perezi;

Sesé; Soto 2002a ---> aff. Alytes; Bufo bufo; Discoglossus galganoi; Hyla sp.; Pelobates cultripes; Rana perezi;

Sesé; Soto 2002b ---> aff. Alytes; Bufo bufo; Discoglossus galganoi; Hyla sp.; Pelobates cultripes; Rana perezi;

Blain 2005 ---> Pelobates cultripes;

Martínez-Solano; Sanchiz 2005 ---> Hyla sp.

Blain et al. 2007 ---> Pelobates cultripes.

Blain 2009 ---> Pelobates cultripes.

López-García et al. 2011a ---> Discoglossus.

Arriaga 1 (Madrid). Middle Pleistocene.

Gamazo 1982 ---> Bufo bufo; Pelobates sp.

Sanchiz 1990 ---> Bufo bufo; Pelobates cultripes; Rana perezi;

Holman 1998 ---> Bufo bufo; Pelobates cultripes; Rana perezi.

Sanchiz 1998 ---> Bufo bufo; Pelobates cultripes; Rana perezi;

Sesé; Soto 2002a ---> Bufo bufo; Pelobates cultripes; Rana perezi;

Sesé; Soto 2002b ---> Bufo bufo; Pelobates cultripes; Rana perezi;

Blain 2005 ---> Pelobates cultripes.

Blain et al. 2007 ---> Pelobates cultripes.

Blain 2009 ---> Pelobates cultripes.

Sesé; López-Martínez 2013 ---> Bufo bufo; Pelobates cultripes; Rana perezi.

\section{Atapuerca (SH) (Burgos). Middle Pleistocene.}

Sanchiz 1998 ---> Alytes obstetricans; Bufo bufo; Bufo calamita; Pelobates sp.; Pelodytes punctatus; Rana temporaria; Rana sp. 
Atapuerca (Tres Simas) (Burgos). Middle Pleistocene.

Sanchiz 1987 ---> Alytes obstetricans; Bufo calamita; Rana sp.; (as TS-4): Alytes obstetricans; Bufo calamita; Rana sp.;

Bagur 1 (Girona). Middle Pleistocene.

Blain 2005 ---> cf. Bufo sp.; Pelobates cf. cultripes.

Blain; Bailon 2006 ---> Bufo cf. bufo; Pelobates cf. cultripes.

Blain 2009 ---> cf. Bufo; Pelobates cf. cultripes.

Bagur 2 (GIrona). Lower Pleistocene.

Sanchiz 1977a ---> Bufo bufo; Pelobates cf. cultripes.

Holman 1998 ---> Bufo bufo; Pelobates cf. cultripes.

Sanchiz 1998 ---> Bufo bufo; Pelobates cf. cultripes.

Blain 2005 ---> Bufo bufo; Bufo calamita; Pelobates cf. cultripes; Pelodytes cf. punctatus.

Blain; Bailon 2006 ---> Bufo bufo; Bufo calamita; Pelobates cf. cultripes; Pelodytes cf. punctatus.

Agustí et al. 2009 ---> Bufo bufo; Bufo calamita; Pelobates cf. cultripes; Pelodytes cf. punctatus.

Blain 2009 ---> Bufo bufo; Bufo calamita; Pelobates cf. cultripes; Pelodytes cf. punctatus.

Barranco Conejos (Granada). Lower Pleistocene.

Blain 2005 ---> Rana cf. perezi.

Agustí et al. 2009 ---> Discoglossus sp.; Pelophylax sp.

Blain 2009 ---> Pelophylax cf. perezi.

Agustí et al. 2010 ---> cf. Discoglossus sp.; Pelophylax cf. perezi;

Barranco León D (Granada). Lower Pleistocene.

Blain 2003 ---> Bufo bufo; Bufo calamita; Discoglossus galganoi vs Discoglossus jeanneae; Pelobates cultripes; Pelodytes punctatus; Rana cf. perezi.

Blain 2005 ---> Bufo bufo; Bufo calamita; Discoglossus cf. jeanneae; Hyla meridionalis; Pelobates cultripes; Rana cf. perezi.

Blain et al. 2007 ---> Pelobates cultripes.

Agustí et al. 2009 ---> Bufo bufo; Bufo calamita; Discoglossus cf. jeanneae; Hyla meridionalis; Pelobates cultripes; Pelophylax cf. perezi.

Blain 2009 ---> Bufo bufo; Bufo calamita; Discoglossus cf. jeanneae; Hyla meridionalis; Pelobates cultripes; Pelophylax cf. perezi.

Agustí et al. 2010 ---> Bufo bufo; Bufo calamita; Bufo sp.; Discoglossus cf. jeanneae; Hyla meridionalis; Pelobates cultripes; Pelophylax cf. perezi.

Blain; Bailon 2010 ---> Bufo bufo; Bufo calamita; Bufo sp.; Discoglossus cf. jeanneae; Hyla meridionalis; Pelobates cultripes; Rana cf. perezi.

Blain et al. 2010a ---> Pelobates cultripes.

Blain et al. 2010b ---> Bufo (viridis) [Bufo viridis group].

Blain et al. 2011b ---> Anura indet.; Bufo (viridis) sp. [Bufo sp. (viridis group)]; Bufo bufo; Bufo calamita; Discoglossus cf. jeanneae; Hyla sp. [Hyla meridionalis ?]; Pelobates cultripes; Pelophylax cf. perezi.

Buena Pinta (Madrid). Upper Pleistocene.

López-García et al. 2011a ---> (Blain, unpublished): Rana iberica.

Cabeza de la Fuente (Cuenca). Holocene.

López Martínez; Sanchiz 1985 ---> Bufo bufo; Pelodytes punctatus.

Sanchiz 1998 ---> Bufo bufo; Pelodytes punctatus.

Crespo 2001 ---> Bufo bufo; Pelodytes punctatus;

Cal Guardiola (Barcelona). Lower Pleistocene.

Blain 2005 ---> Bufo bufo; Bufo calamita; Rana cf. temporaria.

Blain et al. 2008c ---> Rana temporaria. 
Agustí et al. 2009 ---> Bufo bufo; Bufo calamita; Rana cf. temporaria.

Blain 2009 ---> Bufo bufo; Bufo calamita; Rana cf. temporaria.

Caldas (Asturias). Upper Pleistocene.

Blain et al. 2008c ---> Rana temporaria.

Calor (Murcia). Holocene.

Morales et al. 1991 ---> Bufo bufo; Rana perezi.

Sanchiz 1998 ---> Bufo bufo; Rana perezi.

Camino (Madrid). Upper Pleistocene.

López-García et al. 2011a ---> (Blain, unpublished): Rana iberica.

Laplana et al. 2013 ---> Alytes cf. obstetricans; Bufo bufo; Bufo calamita; Hyla sp.; Pelobates cultripes;

Pelophylax perezi; Rana iberica.

Can Altisench (Barcelona). Lower Pleistocene.

Blain 2005 ---> Bufo bufo; Pelobates cf. cultripes; Pelodytes cf. punctatus; Rana sp. ('groupe des grenouilles rousses').

Blain 2009 ---> Bufo bufo; Pelobates cf. cultripes; Pelodytes cf. punctatus; Rana sp..

Cañada de Murcia 1 (Granada). Lower Pleistocene.

Blain 2005 ---> Rana cf. perezi.

Blain 2009 ---> Pelophylax cf. perezi.

Canyars (Barcelona). Upper Pleistocene.

López-García et al. 2013 ---> Bufo cf. bufo; Bufo calamita; Pelodytes punctatus.

Castelldefels (Barcelona). Lower Pleistocene.

Sanchiz 1977a ---> Bufo bufo.

Holman 1998 ---> Bufo bufo.

Sanchiz 1998 ---> Bufo bufo.

Castillo (Cantabria). Upper Pleistocene.

Sanchiz; Lobo 2006 ---> Bufo bufo; Rana temporaria

Chaparral (Cádiz). Lower Pleistocene.

Giles et al. 2011 ---> Bufo bufo; Bufo calamita; Discoglossus sp.; Pelodytes sp.; Salamandra salamandra.

López-García et al. 2012a ---> Bufo bufo; Bufo calamita; Discoglossus sp.; Pelodytes sp.; Salamandra salamandra.

Chufín (Cantabria). Upper Pleistocene.

Sanchiz 1977a ---> Bufo bufo; Rana sp.

Holman 1998 ---> Bufo bufo; Rana sp.

Sanchiz 1998 ---> Bufo bufo; Rana sp.

Cobrante (Cantabria). Upper Pleistocene.

Martín et al. 2009 ---> Alytes obstetricans; Bufo bufo; Bufo calamita ?; Rana temporaria.

Colomera $(\mathrm{H})$ (Lleida). Holocene.

López-García et al. 2010a ---> Alytes obstetricans; Calotriton asper; Rana temporaria.

Colomera (P) (Lleida). Upper Pleistocene.

López García et al. 2010 ---> Alytes obstetricans; Rana temporaria. 
Conde (Asturias). Upper Pleistocene.

López-García et al. 2011b ---> Alytes cf. obstetricans; Bufo bufo; Rana temporaria; Salamandra salamandra.

Cortes de Baza (Granada). Lower Pleistocene.

Blain 2005 ---> cf. Discoglossus; Rana cf. perezi.

Blain 2009 ---> cf. Discoglossus; Pelophylax cf. perezi.

Cova Rosa (Asturias). Upper Pleistocene.

Sanchiz 1977a ---> Alytes obstetricans; Bufo bufo; Bufo calamita; Rana iberica; Rana temporaria; Salamandra salamandra; Triturus marmoratus.

Sanchiz 1982 ---> Alytes obstetricans; Bufo bufo; Bufo calamita; Rana iberica; Rana temporaria; Salamandra salamandra; Triturus marmoratus.

Esteban; Sanchiz 1990 ---> Rana iberica.

Holman 1998 ---> Alytes obstetricans; Bufo bufo; Bufo calamita; Rana iberica; Rana temporaria; Salamandra salamandra; Triturus marmoratus.

Sanchiz 1998 ---> Alytes obstetricans; Bufo bufo; Bufo calamita; Rana temporaria; Rana iberica;

Blain 2005 ---> Rana iberica.

Blain et al. 2008c ---> Rana iberica; Rana temporaria.

Blain 2009 ---> Rana iberica.

López-García et al. 2011a ---> Rana iberica.

Cova-120 (Girona). Holocene.

Fèlix 1985 ---> (Neolithic level): Alytes obstetricans; (Calcolithic level): Alytes obstetricans; (Bronze Age level): Pelobates cultripes.

Sanchiz 1998 ---> Alytes obstetricans; Pelobates cultripes;

Crespo 2001 ---> Alytes obstetricans; Pelobates cultripes.

Fèlix 2002 ---> (Level 1): Pelobates cultripes; (Level 2): Alytes obstetricans.

Cueto de la Mina (Asturias). Upper Pleistocene.

Sanchiz 1977a ---> Bufo bufo; Rana temporaria.

Sanchiz 1982 ---> Bufo bufo; Bufo calamita.

Holman 1998 ---> Bufo bufo; Rana temporaria.

Sanchiz 1998 ---> Rana temporaria.

Blain et al. 2008c ---> Rana temporaria.

Cueva Victoria (Murcia). Lower Pleistocene.

Sanchiz 1977a ---> (Unión 1): Bufo sp.; Rana cf. ridibunda; (Unión 2): Bufo bufo; (Unión 3): Bufo cf. bufo;

Holman 1998 ---> Bufo bufo; Rana cf. perezi;

Sanchiz 1998 ---> Bufo bufo; Rana cf. perezi;

Crespo 2001 ---> Bufo bufo; Rana cf. perezi; Rana sp.;

Blain 2005 ---> Bufo bufo; cf. Pelodytes sp.

Blain; Bailon 2006 ---> Bufo bufo; cf. Pelodytes.

Blain et al. 2008b ---> Bufo cf. bufo; cf. Pelodytes sp.

Agustí et al. 2009 ---> Bufo bufo; cf. Pelodytes sp.

Blain 2009 ---> Bufo bufo; cf. Pelodytes.

Blain et al. 2010b ---> Bufo viridis sensu lato.

Blain et al. 2011b ---> Bufo sp. viridis group.

Ekain (Guipúzcoa). Upper Pleistocene.

Sanchiz 1977a ---> Bufo bufo; Rana temporaria.

Sanchiz 1984 ---> Bufo bufo; Rana cf. dalmatina; Rana cf. temporaria.

Holman 1998 ---> Bufo bufo; Rana temporaria; Rana sp. 
Sanchiz 1998 ---> Bufo bufo; Rana temporaria; Rana sp.

Blain et al. 2008c ---> Rana temporaria.

Errekatxuetako Atxa (Vizcaya). Holocene.

Murelaga et al. 2007 ---> Alytes obstetricans; Bufo bufo; Rana temporaria; Salamandra salamandra.

Blain et al. 2008c ---> Rana temporaria;

Escala (Girona). Upper Pleistocene.

Blain 2005 ---> Bufo cf. bufo; Pelodytes cf. punctatus.

Blain; Bailon 2006 ---> Bufo cf. bufo; Pelodytes cf. punctatus.

Blain 2009 ---> Bufo cf. bufo; Pelodytes cf. punctatus.

Figueira Brava (Setúbal). Upper Pleistocene.

Antunes 1991 ---> Pelobates cultripes.

Jiménez et al. 1998 ---> Pelobates cultripes; Salamandra salamandra.

Antunes 2000 ---> Anura indet; Pelobates cultripes; Salamandra salamandra.

Crespo et al. 2000 ---> Anura indet; Pelobates cultripes; Salamandra salamandra.

Crespo 2001 ---> Bufo sp.; Pelobates cultripes; Salamandra salamandra;

Crespo 2002 ---> Bufo sp.; Pelobates cultripes; Salamandra salamandra.

Fuente Nueva 2 (Granada). Lower Pleistocene.

Blain 2005 ---> Rana cf. perezi.

Blain 2009 ---> Pelophylax cf. perezi.

Fuente Nueva 3 (Granada). Lower Pleistocene.

Blain 2003 ---> Bufo bufo; Pelodytes punctatus; Rana cf. perezi.

Blain 2005 ---> Discoglossus cf. jeanneae.

Blain et al. 2007 ---> Pelobates cultripes.

Agustí et al. 2009 ---> Bufo sp.; Discoglossus cf. jeanneae; Pelophylax perezi.

Blain 2009 ---> Bufo sp.; Discoglossus cf. jeanneae; Pelophylax cf. perezi.

Blain; Bailon 2010 ---> Bufo sp.; Discoglossus cf. jeanneae; Rana cf. perezi.

Blain et al. 2011b ---> Anura indet.; Bufo bufo; Discoglossus cf. jeanneae; Pelobates cultripes; Pelophylax cf. perezi.

Galera 1H (Granada). Lower Pleistocene.

Blain 2005 ---> Rana cf. perezi.

Blain 2009 ---> Pelophylax cf. perezi.

Galera 2 (Granada). Lower Pleistocene.

Sanchiz 1998 ---> Discoglossus sp.;

Rage; Rocek 2003 ---> Discoglossus sp.;

Blain 2005 ---> cf. Discoglossus.

Blain 2009 ---> cf. Discoglossus.

Agustí et al. 2010 ---> Bufo sp.; Discoglossus sp.; Pelophylax cf. perezi.

Galería (TN 4-6) (Burgos). Middle Pleistocene.

Aguirre 1989 ---> Alytes obstetricans; Bufo calamita; Rana sp.

Galls Carboners (Tarragona). Upper Pleistocene.

Böhme; llg 2003 (2014) ---> Alytes obstetricans; Bufo calamita; Rana cf. temporaria;

Gegant (Barcelona). Upper Pleistocene.

Blain; Bailon 2006 ---> Bufo bufo; Bufo calamita; Pelobates cultripes; Rana sp.

López-García et al. 2008a ---> Bufo bufo; Bufo calamita; Pelobates cultripes; Ranidae indet. 
López-García et al. 2012a ---> Anura indet.; Bufo cf. bufo; Bufo calamita; Pelobates cf. cultripes; Pelodytes sp.

Gorham (Gibraltar). Upper Pleistocene.

Gleed-Owen 2001 ---> Bufo bufo spinosus; Bufo calamita; Discoglossus sp.; Hyla meridionalis; Pelobates cultripes; Pleurodeles waltl; Rana sp.; Triturus marmoratus pygmaeus; Triturus sp.

Blain et al. 2013c ---> Alytes sp. (level 3b); Bufo spinosus (levels 3a, 3b, 4); Epidalea calamita (levels 3a, 3b, 4); Discoglossus sp. (level 3b); Hyla sp. (level 4); Lissotriton sp. (levels 3a, 3b, 4); Pelobates cultripes (levels 3a, 3b, 4); Pleurodeles waltl (levels 3a, 3b); Triturus cf. pygmaeus (levels 3a, 3b, 4).

Grajas (Málaga). Middle Pleistocene.

Sevilla 1988 ---> (Sanchiz, unpublished): Bufo cf. bufo; Bufo calamita; Discoglossus pictus; Rana ridibunda.

Sanchiz 1990 ---> Bufo bufo; Bufo calamita; Discoglossus galganoi sensu lato (including Discoglossus jeanneae); Rana perezi.

Holman 1998 ---> Bufo bufo; Bufo calamita; Discoglossus cf. jeanneae; Rana perezi.

Sanchiz 1998 ---> Bufo bufo; Bufo calamita; Discoglossus cf. jeanneae; Rana perezi.

Blain 2005 ---> Discoglossus cf. jeanneae.

López-García et al. 2011a ---> Discoglossus.

Gran Dolina TD-03 (Burgos). Lower Pleistocene.

Sanchiz 1987 ---> Bufo calamita.

Aguirre 1989 ---> Alytes obstetricans; Bufo calamita; Pelodytes punctatus.

Blain 2009 ---> Alytes obstetricans; Bufo bufo; Bufo calamita; Pelobates sp.; Pelodytes punctatus; Rana temporaria; Rana sp.; Triturus sp.

Gran Dolina TD-04 (Est) (Burgos). Lower Pleistocene.

Sanchiz 1987 ---> (as TD-4 undifferentiated): Alytes obstetricans; Bufo calamita; Pelodytes punctatus.

Aguirre1989 ---> (as TD-4): Alytes obstetricans; Bufo calamita; Pelodytes punctatus.

Pinto-Llona \& Andrews 1999 ---> Alytes obstetricans; Bufo calamita; Pelodytes punctatus.

Van der Made et al. 2003 ---> (as TD4): Alytes obstetricans.

Blain 2005 ---> (as TD4): Alytes obstetricans; Bufo calamita; Rana 'groupe des grenouilles rousses'.

Agustí et al. 2009 ---> (as TD4): Alytes obstetricans; Pelodytes punctatus; Bufo calamita; Rana sp.

Blain 2009 ---> Alytes obstetricans; Bufo calamita; Rana (temporaria) sp.

Gran Dolina TD-04 (West) (Burgos). Lower Pleistocene.

Sanchiz 1987 ---> (as TD-4 undifferentiated): Alytes obstetricans; Bufo calamita; Pelodytes punctatus.

Aguirre1989 ---> (as TD-4): Alytes obstetricans; Bufo calamita; Pelodytes punctatus.

Pinto; Andrews 1999 ---> Bufo calamita; Pelobates sp.; Pelodytes punctatus.

Van der Made et al. 2003 ---> (as TD4): Alytes obstetricans.

Blain 2005 ---> (as TD4): Alytes obstetricans; Bufo calamita; Rana 'groupe des grenouilles rousses'.

Agustí et al. 2009 ---> (as TD4): Alytes obstetricans; Pelodytes punctatus; Bufo calamita; Rana sp.

Blain 2009 ---> Alytes obstetricans; Bufo calamita; Rana (temporaria) sp.

\section{Gran Dolina TD-04+05 (Burgos). Lower Pleistocene.}

Sanchiz 1987 ---> Alytes obstetricans; Bufo bufo; Bufo calamita; Pelobates sp.; Pelodytes punctatus; Rana $\mathrm{sp}$.

Blain 2005 ---> (as TD4 and/or TD5): Alytes obstetricans; Bufo bufo; Bufo calamita; Pelodytes punctatus; Rana dalmatina; Rana temporaria; Rana 'groupe des grenouilles rousses'; Rana (ridibunda) sp.

Gran Dolina TD-05 (Burgos). Lower Pleistocene.

Sanchiz 1987 ---> Alytes obstetricans; Bufo bufo; Bufo calamita; Pelodytes punctatus; Rana sp.; Triturus sp. Aguirre1989 ---> Alytes obstetricans; Bufo calamita; Pelodytes punctatus; Triturus sp.

Pinto; Andrews 1999 ---> (level 5A): Bufo calamita; (level 5B): Bufo calamita; (level 5C): Alytes obstetricans; Pelodytes punctatus; (level 5D): Alytes obstetricans; Bufo calamita; Pelodytes punctatus; (level 5E): 
Alytes obstetricans; Bufo bufo; Bufo calamita; Pelobates sp.; Pelodytes punctatus; Rana sp.; (level 5F): Alytes obstetricans; Bufo calamita; Pelodytes punctatus; Rana sp.; (level 5G): Alytes obstetricans; Rana sp.

Blain 2005 ---> Alytes obstetricans; Bufo bufo; Bufo calamita; Pelodytes punctatus; Rana dalmatina; Rana temporaria; Rana ('groupe des grenouilles rousses'); Rana (ridibunda) sp.

Blain; Bailon 2006 ---> Rana temporaria.

Blain et al. 2008a ---> Alytes obstetricans; Bufo bufo; Bufo calamita; Pelodytes punctatus; Rana sp. ('brown frogs group'); Rana (ridibunda) sp.; Rana cf. dalmatina; Rana temporaria.

Blain et al. 2008c ---> Alytes obstetricans; Bufo calamita; Pelodytes punctatus; Pelophylax (ridibunda) sp. ['green frogs']; Rana sp. ['brown frogs']; Rana cf. dalmatina; Rana temporaria.

Agustí et al. 2009 ---> (Trinchera Dolina TD5low): Alytes obstetricans; Bufo calamita; Rana sp.; (Trinchera Dolina TD5up): Alytes obstetricans; Bufo bufo; Bufo calamita; Pelodytes punctatus; Rana sp.

Blain 2009 ---> Alytes obstetricans; Bufo bufo; Bufo calamita; Pelodytes punctatus; Pelophylax sp.; Rana cf. dalmatina; Rana temporaria.

Blain et al. 2009a ---> Alytes obstetricans; Bufo bufo; Bufo calamita; Pelodytes punctatus; Pelophylax (ridibunda) sp.; Rana sp.

Cuenca-Bescós et al. 2010 ---> Alytes obstetricans; Bufo bufo; Bufo calamita; Pelodytes punctatus; Pelophylax (ridibunda) sp.; Rana (temporaria) sp.; Rana cf. dalmatina; Rana temporaria.

Rodríguez et al. 2011 ---> Alytes obstetricans; Bufo bufo; Bufo calamita; Pelodytes punctatus; Pelophylax (ridibunda) sp.; Rana (temporaria) sp.; Rana cf. dalmatina; Rana temporaria.

Martín; Sanchiz 2015 ---> (pers. obs. BS): Triturus cf. helveticus.

Gran Dolina TD-06 (sensu lato) (Burgos). Lower Pleistocene.

Sanchiz 1987 ---> (as upper TD-6): Alytes obstetricans; Bufo calamita; Pelodytes punctatus; Pelobates; (as middle TD-6): Alytes obstetricans; Bufo calamita; Pelodytes punctatus; Rana sp.; (as lower TD-6): Alytes obstetricans; Bufo bufo; Bufo calamita; Pelodytes punctatus; Rana.

Aguirre1989 ---> Alytes obstetricans; Bufo calamita; Pelodytes punctatus; Triturus sp.;

Blain 2005 ---> Alytes obstetricans; Bufo bufo; Bufo calamita; Pelobates cultripes; Pelodytes punctatus; Rana 'groupe des grenouilles rousses'; Rana (ridibunda) sp.; Triturus (sensu stricto) sp.

Blain et al. 2008a ---> Alytes obstetricans; Bufo bufo; Bufo calamita; Pelobates cultripes; Pelodytes punctatus; Rana sp. ('brown frogs group'); Rana (ridibunda) sp.; Triturus sp.

Blain et al. 2008c ---> Alytes obstetricans; Bufo bufo; Bufo calamita; Pelodytes punctatus; Pelophylax (ridibunda) sp. ['ranas verdes']; Rana sp. ['ranas pardas']; Triturus sp.

Blain 2009 ---> Alytes obstetricans; Bufo bufo; Bufo calamita; Pelobates cultripes; Pelodytes punctatus; Pelophylax sp.; Rana (temporaria) sp.

Blain et al. 2009a ---> Alytes obstetricans; Bufo bufo; Bufo calamita; Pelobates cultripes; Pelodytes punctatus; Pelophylax (ridibunda); Rana sp.; Triturus sp.

Gran Dolina TD-06a (Burgos). Lower Pleistocene.

Sanchiz 1987 ---> (as lower TD-6): Alytes obstetricans; Bufo bufo; Bufo calamita; Pelodytes punctatus; Rana sp.

Cuenca-Bescós et al. 2010 ---> Alytes obstetricans; Bufo bufo; Bufo calamita; Pelobates cultripes; Pelodytes punctatus; Pelophylax (ridibunda) sp.; Rana (temporaria) sp.; Triturus sp.

Rodríguez et al. 2011 ---> (as TD 6-3): Alytes obstetricans; Bufo bufo; Bufo calamita; Pelobates cultripes; Pelodytes punctatus; Pelophylax (ridibunda) sp.; Rana (temporaria) sp.; Triturus sp.

Gran Dolina TD-06b (Burgos). Lower Pleistocene.

Sanchiz 1987 ---> (as upper TD-6): Alytes obstetricans; Bufo calamita; Pelodytes punctatus; Pelobates; (as middle TD-6): Alytes obstetricans; Bufo calamita; Pelodytes punctatus; Rana sp.

Agustí et al. 2009 ---> (as TD6up): Alytes obstetricans; Bufo bufo; Bufo calamita; Pelobates cultripes; Pelodytes punctatus; Rana sp.; Triturus sp.

Blain et al. 2010a --> (as TD6 Aurora Stratum): Alytes obstetricans; Hyla arborea; Rana sp.

Cuenca-Bescós et al. 2010 ---> (as TD 6b): Alytes obstetricans; Bufo bufo; Bufo calamita; Pelobates cultripes; Pelodytes punctatus; Pelophylax (ridibunda) sp.; Rana (temporaria) sp. 
Rodríguez et al. 2011 ---> (TD 6-1; TD 6-2): Alytes obstetricans; Bufo bufo; Bufo calamita; Pelobates cultripes; Pelodytes punctatus; Pelophylax (ridibunda) sp.; Rana (temporaria) sp.

Blain et al. 2013a ---> (TD6-2): Alytes obstetricans; Bufo bufo; Bufo calamita; Pelobates cultripes; Pelodytes punctatus; Rana sp.

Gran Dolina TD-07 (Burgos). Middle Pleistocene.

Sanchiz 1987 ---> Alytes obstetricans; Bufo calamita; Pelodytes punctatus.

Aguirre1989 ---> Alytes obstetricans; Bufo calamita; Pelodytes punctatus.

Blain 2005 ---> Alytes obstetricans; Bufo bufo; Bufo calamita; Pelodytes punctatus; Rana 'groupe des grenouilles rousses'.

Blain et al. 2008a ---> Alytes obstetricans; Bufo bufo; Bufo calamita; Pelodytes punctatus; Rana sp. ('brown frogs group').

Agustí et al. 2009 ---> Alytes obstetricans; Bufo bufo; Bufo calamita; Pelodytes punctatus; Rana sp.

Blain 2009 ---> Alytes obstetricans; Bufo bufo; Bufo calamita; Pelodytes punctatus; Rana (temporaria).

Blain et al. 2009a ---> Alytes obstetricans; Bufo bufo; Bufo calamita; Pelodytes punctatus; Rana sp.;

Cuenca-Bescós et al. 2010 ---> Alytes obstetricans; Bufo bufo; Bufo calamita; Pelodytes punctatus; Rana (temporaria) sp.

López-García et al. 2011a ---> Rana iberica.

Rodríguez et al. 2011 ---> Alytes obstetricans; Bufo bufo; Bufo calamita; Pelodytes punctatus; Rana (temporaria) sp.

Gran Dolina TD-08 (Burgos). Middle Pleistocene.

Sanchiz 1987 ---> Bufo calamita.

Aguirre1989 ---> Bufo calamita.

Blain 2005 ---> Alytes obstetricans; Bufo bufo; Bufo calamita; Hyla arborea; Pelobates cultripes; Pelodytes punctatus; Rana 'groupe des grenouilles rousses'; Rana (ridibunda) sp.

Blain et al. 2008a ---> (as TD8a): Alytes obstetricans; Bufo bufo; Bufo calamita; Hyla arborea; Pelobates cultripes; Pelodytes punctatus; Rana sp. ('brown frogs group'); Rana (ridibunda) sp.; (as TD8b): Bufo calamita.

Blain et al. 2008c ---> Alytes obstetricans; Bufo bufo; Bufo calamita; Hyla arborea; Pelobates cultripes; Pelodytes punctatus; Pelophylax (ridibunda) sp. ['green frogs']; Rana sp. ['brown frogs'].

Blain 2009 ---> (TD8a): Alytes obstetricans; Bufo bufo; Bufo calamita; Hyla arborea; Pelobates cultripes; Pelodytes punctatus; Pelophylax sp.; Rana (temporaria) sp.; (TD8b): Alytes obstetricans; Bufo bufo; Bufo calamita; Hyla arborea; Pelobates cultripes; Pelodytes punctatus; Rana (temporaria) sp.

Blain et al. 2009a ---> (TD8a): Alytes obstetricans; Bufo bufo; Bufo calamita; Hyla arborea; Pelobates cultripes; Pelodytes punctatus; Pelophylax (ridibunda) sp.; Rana sp.; (TD8b): Bufo calamita.

Cuenca-Bescós et al. 2010 ---> (TD 8a): Alytes obstetricans; Bufo bufo; Bufo calamita; Hyla arborea; Pelobates cultripes; Pelodytes punctatus; Pelophylax (ridibunda) sp.; Rana (temporaria) sp.

López-García et al. 2011b ---> Rana iberica.

Rodríguez et al. 2011 ---> Alytes obstetricans; Bufo bufo; Bufo calamita; Hyla arborea; Pelobates cultripes; Pelodytes punctatus; Pelophylax (ridibunda) sp.; Rana (temporaria) sp.

Gran Dolina TD-10/TD-11 (Burgos). Middle Pleistocene.

Aguirre1989 ---> (as TD 10-11): Rana sp.;

Blain 2005 ---> Alytes obstetricans; Bufo bufo; Bufo calamita; Hyla arborea; Pelobates cultripes; Pelodytes punctatus; Rana dalmatina; Rana cf. iberica; Rana (ridibunda) sp.; Rana temporaria.

Blain 2009 ---> Alytes obstetricans; Bufo bufo; Bufo calamita; Hyla arborea; Pelobates cultripes; Pelodytes punctatus; Pelophylax sp.; Rana (temporaria) sp.;Rana cf iberica.

Blain et al. 2008a ---> Alytes obstetricans; Bufo bufo; Bufo calamita; Hyla arborea; Pelobates cultripes; Pelodytes punctatus; Rana sp. ('brown frogs group'); Rana (ridibunda) sp.; Rana cf. dalmatina; Rana cf. iberica; Rana temporaria.

Blain et al. 2008c ---> Alytes obstetricans; Bufo bufo; Bufo calamita; Hyla arborea; Pelobates cultripes; Pelodytes punctatus; Pelophylax (ridibunda) sp. ['green frogs']; Rana sp. ['brown frogs']; Rana cf. dalmatina; Rana cf. iberica; Rana temporaria. 
Blain et al. 2009a ---> (TD10 by sublevels): Alytes obstetricans; Bufo bufo; Bufo calamita; Hyla arborea; Pelobates cultripes; Pelodytes punctatus; Pelophylax (ridibunda) sp.; Rana sp.

Cuenca-Bescós et al. 2010 ---> Alytes obstetricans; Bufo bufo; Bufo calamita; Hyla arborea; Pelobates cultripes; Pelodytes punctatus; Pelophylax (ridibunda) sp.; Rana (temporaria) sp.; Rana cf. dalmatina; Rana temporaria.

López-García et al. 2011a ---> Rana iberica.

Rodríguez et al. 2011 ---> Alytes obstetricans; Bufo bufo; Bufo calamita; Hyla arborea; Pelobates cultripes; Pelodytes punctatus; Pelophylax (ridibunda) sp.; Rana (temporaria) sp.; Rana cf. dalmatina; Rana temporaria.

\section{Gran Dolina TD-11 (Burgos). Middle Pleistocene.}

Sanchiz 1987 ---> Rana sp.

Aguirre1989 ---> (as TD 10-11) Rana sp.

Blain 2009 ---> Alytes obstetricans; Bufo bufo; Bufo calamita; Pelobates sp.; Pelodytes punctatus; Rana temporaria; Rana sp.; Triturus sp.

Cuenca-Bescós et al. 2010 ---> Alytes obstetricans; Bufo bufo; Bufo calamita; Hyla arborea; Pelobates cultripes; Pelodytes punctatus; Pelophylax (ridibunda) sp.; Rana (temporaria) sp.; Rana cf. dalmatina; Rana temporaria.

López-García et al. 2011 ---> Rana iberica;

Guia (Algarve). Upper Pleistocene.

Antunes et al. 1989 ---> Bufo bufo; Bufo calamita; Bufo sp.; Pelobates cultripes; Pleurodeles waltl; Rana perezi.

Sanchiz 1998 ---> Bufo bufo; Bufo calamita; Pelobates cultripes; Rana perezi.

Crespo 2001 ---> Bufo bufo; Bufo calamita; Pelobates cultripes; Pleurodeles waltl; Rana perezi;

Crespo 2002 ---> Bufo bufo; Bufo calamita; Pelobates cultripes; Pleurodeles waltl; Rana perezi.

HAT (Madrid). Upper Pleistocene.

Blain et al. 2013b ---> Bufo bufo; Pelobates cultripes; Pelodytes sp.; Pelophylax perezi;

Hienas (Asturias). Upper Pleistocene.

Sanchiz 1977a ---> Alytes obstetricans; Bufo bufo; Bufo calamita; cf. Euproctus sp.; Rana temporaria; Salamandra salamandra; Triturus marmoratus; Triturus sp.;

Sanchiz; Adrover 1977 ---> Ranidae;

Hoyos 1979 ---> Alytes obstetricans; Bufo bufo; Bufo calamita; Rana temporaria; Salamandra salamandra; Triturus marmoratus;

Martín; Sanchiz 1990 ---> Alytes obstetricans; Bufo bufo; Bufo calamita; Euproctus sp.; Rana temporaria; Salamandra salamandra; Triturus alpestris;

Holman 1998 ---> Alytes obstetricans; Bufo bufo; Bufo calamita; Euproctus sp.; Rana temporaria; Salamandra salamandra; Triturus alpestris; Triturus marmoratus; Triturus sp.

Sanchiz 1998 ---> Alytes obstetricans; Bufo bufo; Bufo calamita; Rana temporaria.

Sanchiz; Martin 2004 ---> Euproctus cf. asper nov. subsp.; Salamandra salamandra; Triturus alpestris; Triturus helveticus.

Carranza; Amat 2005 ---> Euproctus sp.

Blain et al. 2008c ---> Rana temporaria.

Higueral de Valleja Cádiz. Upper Pleistocene.

Böhme; Ilg 2003 (2014) ---> Bufo sp.; Bufo calamita; Discoglossus sp.; Discoglossus galganoi; Hyla sp.; Pelobates sp.; Pleurodeles waltl; Rana sp.;

Horá (Granada). Upper Pleistocene.

Fuentes; Meijide 1975 ---> (level 1); Bufo bufo; Bufo sp.; (level 4): Bufo bufo;

Bailon 1986 ---> cf. Alytes; Bufo bufo; Bufo calamita; Bufo aff. viridis; Discoglossus galganoi vs Discoglossus pictus; Rana aff. temporaria; Rana sp. 'complejo rana verde'. 
Sanchiz 1990 ---> Bufo bufo; Bufo calamita; Bufo viridis?; Discoglossus sp.; Rana perezi; Rana temporaria?.

Holman 1998 ---> cf. Alytes; Bufo bufo; Bufo calamita; Discoglossus cf. jeanneae; Rana cf. perezi;

Sanchiz 1998 ---> cf. Alytes; Bufo bufo; Bufo calamita; Discoglossus cf. jeanneae; Rana cf. perezi;

Blain 2005 ---> Discoglossus cf. jeanneae.

Blain 2009 ---> Discoglossus.

Blain et al. 2010b ---> Bufo calamita.

López-García et al. 2011a ---> Discoglossus.

Huesos (Asturias). Upper Pleistocene.

Sanchiz 1977a ---> Bufo bufo; Salamandra salamandra.

Holman 1998 ---> Bufo bufo; Salamandra salamandra.

Sanchiz 1998 ---> Bufo bufo.

Incarcal (Girona). Lower Pleistocene.

Felix 2003 ---> Bufo bufo; Triturus vulgaris;

Jarama 2 (Guadalajara). Upper Pleistocene.

Adán et al. 1995 ---> Bufo bufo.

Holman 1998 ---> Bufo bufo.

Sanchiz 1998 ---> Bufo bufo.

Jarama 6 (Guadalajara). Upper Pleistocene.

Adán et al. 1995 ---> Bufo bufo; Pelobates cultripes [intrusive?].

Holman 1998 ---> Bufo bufo; Pelobates cultripes.

Sanchiz 1998 ---> Bufo bufo; Pelobates cultripes.

Lorenzo et al. 2012 ---> Pelobates cultripes.

Kobeaga 2 (Vizcaya). Holocene.

Murelaga et al. 2007 ---> Alytes sp.

Laminak (Vizcaya). Upper Pleistocene.

Sanchiz; Esteban 1994 ---> Alytes obstetricans; Bufo bufo; Rana temporaria; Salamandra salamandra;

Salamandridae indet; Triturus helveticus.

Holman 1998 ---> Anura indet; Alytes obstetricans; Bufo bufo; Rana temporaria; Salamandra salamandra;

Salamandridae indet. Triturus helveticus.

Sanchiz 1998 ---> Alytes obstetricans; Bufo bufo; Rana temporaria.

Blain et al. 2008c ---> Rana temporaria.

Blain et al. 2011a ---> Lissotriton helveticus.

Lezika (Vizcaya). Upper Pleistocene.

Castaños et al. 2009 ---> Bufo calamita; Rana sp.;

Loma Quemada (Burgos). Lower Pleistocene.

Holman 1998 ---> Discoglossus sp.

Sanchiz 1998 ---> Discoglossus sp.

Blain 2005 ---> Discoglossus sp.

Millán (Burgos). Upper Pleistocene.

Esteban; Sanchiz 1990 ---> Rana iberica.

Holman 1998 ---> Rana iberica.

Sanchiz 1998 ---> Rana iberica.

Blain 2005 ---> Rana iberica.

Blain et al. 2008c ---> Rana iberica. 
Blain 2009 ---> Rana iberica.

López-García et al. 2011 ---> Rana iberica.

Mirador $(\mathrm{H})$ (Burgos). Holocene.

Blain et al. 2011b ---> Hyla arborea.

Mirador (P) (Burgos). Upper Pleistocene.

Cuenca-Bescós et al. 2010 ---> Alytes obstetricans; Bufo bufo; Bufo calamita; Hyla arborea; Rana (temporaria) sp.

Mirón (Cantabria). Holocene.

Altuna et al. 2004 ---> Alytes obstetricans; Bufo bufo; non Discoglossus galganoi; Rana temporaria; Salamandra salamandra.

Blain et al. 2008c ---> Rana temporaria.

Sanchiz et al. 2012 ---> Alytes obstetricans; Bufo bufo; Rana temporaria; Salamandra salamandra.

Mortero (Cantabria). Upper Pleistocene.

Chaline 1961 ---> Rana sp.

Chaline 1965 ---> Rana sp.

Vergnaud-Grazzini 1970 ---> Rana.

Sanchiz 1977a ---> Rana sp.

Holman 1998 ---> Rana temporaria.

Sanchiz 1998 ---> Rana temporaria.

Blain et al. 2008c ---> Rana temporaria.

Musclos (Barcelona). Upper Pleistocene.

Blain; Bailon 2006 ---> Pelobates cultripes; cf. Pelodytes sp; cf. Rana sp.

Olopte B (Girona). Middle Pleistocene.

Blain; Bailon 2006 ---> Bufo sp.; Bufo cf. calamita; Pelodytes cf. punctatus; Rana temporaria.; Rana sp.

Blain et al. 2008c ---> Rana temporaria.

Orce (Guardia Civil) (Granada). Lower Pleistocene.

Blain 2005 ---> Rana cf. perezi.

Blain 2009 ---> Pelophylax cf. perezi;

Orce 1 (Granada). Lower Pleistocene.

Holman 1998 ---> Rana cf. perezi.

Sanchiz 1998 ---> Rana cf. perezi.

Orce 4 (Granada). Lower Pleistocene.

Fèlix; Montori 1987 ---> Rana cf. perezi.

Sanchiz 1998 ---> Rana cf. perezi.

Blain 2005 ---> Discoglossus sp.

Blain 2009 ---> Discoglossus sp.

Orce D (Granada). Lower Pleistocene.

Blain 2005 ---> Rana sp. ('verte').

Blain 2009 ---> Pelophylax sp.

Oscura (Asturias). Upper Pleistocene.

Sanchiz 1977a ---> Salamandra salamandra.

Holman 1998 ---> Rana (ridibunda) sp.; Salamandra salamandra. 
Paloma (Asturias). Upper Pleistocene.

Sanchiz; Pérez 1974 ---> Bufo bufo.

Sanchiz 1977a ---> Bufo bufo; Bufo calamita; Rana temporaria.

Sanchiz 1980 ---> Bufo bufo; Bufo calamita; Discoglossus pictus (recent); Rana temporaria.

Sanchiz 1982 ---> Bufo bufo; Bufo calamita.

Esteban 1990 ---> Rana temporaria.

Holman 1998 ---> Bufo bufo; Bufo calamita; Rana temporaria.

Sanchiz 1998 ---> Bufo bufo; Bufo calamita; Rana temporaria.

Blain et al. 2008c ---> Rana temporaria.

Sanchiz et al. 2012 ---> Non Discoglossus galganoi.

Peña de Estebanvela (Segovia). Upper Pleistocene.

Sanchiz; Barbadillo 2007 ---> Bufo calamita.

Sanchiz; Bailon 2013 ---> Alytes sp.; Epidalea calamita.

Peña Larga (Álava). Holocene.

Murelaga et al. 2009 ---> Rana cf. temporaria.

Pinilla del Valle (Madrid). Middle Pleistocene.

Sesé; Soto 2000 ---> Bufo bufo; Bufo calamita.

Pontones (Jaén). Holocene.

López Martínez; Sanchiz 1981 ---> Bufo bufo; Salamandra salamandra.

Crespo 2001 ---> Salamandra salamandra.

Portalón (Burgos). Upper Pleistocene.

López-García et al. 2010b ---> (sublevel P1): Alytes obstetricans; Bufo calamita; Rana temporaria; (sublevel P2, P3P4,): Alytes obstetricans; Bufo bufo; Bufo calamita; Rana temporaria; (sublevel P5): Alytes obstetricans; Bufo calamita; Rana temporaria; (sublevel P6, P7, P8): Alytes obstetricans; Bufo bufo; Bufo calamita; Rana temporaria; (sublevel P9): Alytes obstetricans; Bufo calamita; Rana temporaria; (sublevel P10, P11): Alytes obstetricans; Bufo bufo; Bufo calamita; Rana temporaria; (sublevel P12, P13, P14, P15, P16): Alytes obstetricans; Bufo calamita; Rana temporaria.

Blain et al. 2011a ---> Rana.

Preresa (Madrid). Upper Pleistocene.

Blain et al. 2013b ---> Bufo bufo; Bufo calamita; Hyla sp.; Pelobates cultripes; Pelodytes sp.; Pelophylax perezi.

Quibas (Murcia). Lower Pleistocene.

Montoya et al. 1999 ---> Bufo bufo.

Montoya et al. 2001 ---> Bufo bufo.

Blain et al. 2008b ---> Bufo bufo.

Agustí et al. 2009 -.-> Bufo bufo.

Reixac (Girona). Holocene.

Fèlix 2002 ---> Bufo sp.; Pelobates cultripes.

Rincón de la Victoria (Málaga). Upper Pleistocene.

Sanchiz 1977a ---> Rana ridibunda.

Holman 1998 ---> Rana perezi.

Sanchiz 1998 ---> Rana perezi.

Rinoceront (Barcelona). Middle or Upper Pleistocene.

Blain 2005 ---> Bufo bufo. 
Blain 2009 ---> Bufo bufo;

Roa F (Zújar) (Granada). Lower Pleistocene.

Blain 2005 ---> cf. Rana.

Blain 2009 ---> cf. Pelophylax.

Sidrón (Asturias). Upper Pleistocene.

Sanchiz; Martín 2011 ---> Bufo bufo; Rana cf. temporaria; Salamandra salamandra.

Sima Elefante (TE-LRU) (Burgos). Lower Pleistocene.

Rosas et al. 2006 ---> (TE12): Bufo calamita; (TE10): Bufo bufo.

Agustí et al. 2009 ---> (TE9c): Alytes cf. obstetricans; Bufo bufo; Bufo calamita; Pelobates cultripes; Pelodytes cf. punctatus; Rana sp.; Triturus sp.

Cuenca-Bescós et al. 2010 ---> (TE-LRU): Alytes cf. obstetricans; Bufo bufo; Bufo calamita; Hyla arborea; Pelobates cultripes; Pelodytes punctatus; Pelophylax (ridibunda) sp.; Rana (temporaria) sp.; Triturus sp.

Blain et al. 2010a ---> Alytes obstetricans (TE9a, TE9b, TE9c, TE9a+, TE10, TE13, TE14); Bufo bufo (TE9a, TE9b, TE9c, TE10, TE11, TE14); Bufo calamita (TE9a, TE9b, TE9c, TEa+, TE10, TE11, TE12, TE13, TE14); Hyla arborea (TE-14); Pelobates cultripes (TE9a, TE9b, TE9c, TE10, TE11, TE12,); Pelodytes punctatus (TE9a, TE9b, TE9c, TE9a+, TE10, TE11, TE13, TE14); Pelophylax sp. (TE14); Rana sp. (TEa, TEb, TEc, TEa+, TE10, TE13, TE14; Salamandra salamandra (TE9b); Triturus marmoratus (TE9b, TE9c, TE14).

Blain et al. 2010b ---> Bufo bufo; Bufo calamita.

Blasco et al. 2011 ---> (TE-LRU): Bufo calamita; Pelobates cultripes.

Blain et al. 2011a ---> (TE8-TTE14): Alytes sp.; Bufo bufo; Bufo calamita; Hyla arborea; Pelobates cultripes; Pelodytes punctatus; Pelophylax perezi; cf. Rana sp.; Salamandra salamandra; Triturus marmoratus.

Blain et al. $2011 \mathrm{~b}--->$ Pelobates cultripes.

Rodríguez et al. 2011 ---> (TE 8-14): Alytes cf. obstetricans; Bufo bufo; Bufo calamita; Hyla arborea; Pelobates cultripes; Pelodytes punctatus; Pelophylax (ridibunda) sp.; Rana (temporaria) sp.; Salamandra salamandra.

Sima Elefante (TE-URU) (Burgos). Middle Pleistocene.

Rosas et al. 2006 ---> (TE19): Rana sp.

Blain et al. 2010b ---> Bufo bufo; Bufo calamita.

Cuenca-Bescós et al. 2010 ---> Bufo bufo; Bufo calamita; Hyla arborea; Triturus sp.

Blain et al. 2011a ---> (TE-URU, TE19; TE19): Alytes sp.; Bufo bufo; Bufo calamita; Discoglossus sp.; Hyla arborea; Lissotriton helveticus; Pelobates cultripes; Pelodytes punctatus; cf. Rana sp.; Salamandra salamandra.

Rodríguez et al. 2011 ---> (TE 19): Alytes cf. obstetricans; Bufo bufo; Bufo calamita; Hyla arborea; Salamandra salamandra.

Solana del Zamborino (Granada). Middle Pleistocene.

Bailon 1991 ---> Discoglossus sp.;

Holman 1998 ---> Discoglossus sp.

Sanchiz 1998 ---> Discoglossus sp.

Tafesa (Madrid). Middle Pleistocene.

Baena et al. 2010 ---> Pelobates cultripes.

Tamariz (Zaragoza). Holocene.

Laplana; Cuenca-Bescós 1995 ---> (pit 1): Bufo calamita; (pit 2): Pelobates cultripes; (pit 3): Bufo calamita; Pelobates cultripes.

Sanchiz 1998 ---> Bufo calamita; Pelobates cultripes.

Crespo 2001 ---> Bufo calamita; Pelobates cultripes. 
Teixoneres (Barcelona). Upper Pleistocene.

López-García et al. 2012c ---> Alytes obstetricans; Bufo bufo; Bufo calamita; Pelodytes punctatus; Rana temporaria; Salamandra salamandra;

Tomba (Girona). Holocene.

Fèlix 1985 ---> Bufo calamita; Bufo sp.; Pelobates cultripes.

Sanchiz 1998 ---> Bufo calamita; Bufo sp.; Pelobates cultripes.

Crespo 2001 ---> Bufo bufo; Bufo calamita; Pelobates cultripes.

Valdavara $1(\mathrm{H})$ (Lugo). Holocene.

Blain et al. 2009b ---> Chioglossa lusitanica.

Blain et al. 2009c ---> Chioglossa lusitanica.

López-García et al. 2011 ---> (Upper Unit): Bufo bufo; Chioglosa lusitanica; Discoglossus cf. galganoi; Rana iberica.

Valdavara 1 (P) (Lugo). Upper Pleistocene.

López-García et al. 2011a ---> (Lower Unit): Bufo bufo; Rana cf. temporaria; Salamandra salamandra.

Valdeganga 7 (Albacete). Lower Pleistocene.

Böhme; llg 2003 (2009) ---> Discoglossus sp.

Valdocarros 2 (Madrid). Middle Pleistocene.

Blain et al. 2012a ---> Anura indet.; Alytes sp.; Bufo bufo; Bufo calamita; Hyla arborea; Pelobates cultripes; Pelodytes sp.; Pelophylax perezi.

Vallparadis (Barcelona). Lower Pleistocene.

Martínez et al. 2010 ---> Anura indet.; Pelobates cf. cultripes.

Vanguard (Gibraltar). Upper Pleistocene.

Gleed-Owen 2001 ---> Bufo bufo spinosus; Bufo calamita; Hyla meridionalis; Pelobates cultripes;

Pleurodeles waltl; Rana sp.; Triturus marmoratus pygmaeus;

Martínez-Solano; Sanchiz 2005 ---> Hyla meridionalis.

Venta Micena 1 (Granada). Lower Pleistocene.

Fèlix; Montori 1987 ---> Discoglossidae indet; Rana perezi.

Bailon 1991 ---> Rana perezi.

Holman 1998 ---> Discoglossus sp.; Rana perezi; Rana sp.

Sanchiz 1998 ---> Discoglossus sp.; Rana perezi; Rana sp.

Agustí et al. 2010 ---> Discoglossus sp.

Ventana $(\mathrm{H})$ (Madrid). Holocene.

Sánchez et al. 2005 ---> Alytes cisternasii; Bufo calamita; Discoglossus jeanneae; Pelobates cultripes; Rana perezi.

Ventana (P) (Madrid). Upper Pleistocene.

Sánchez et al.2005 ---> Bufo calamita; Pelobates cultripes; Pleurodeles waltl; Rana perezi.

Villacastín (Segovia). Middle Pleistocene.

Arribas 1995 ---> Bufo calamita; Bufo sp.; Rana sp.

Holman 1998 ---> Bufo calamita; Bufo sp.; Rana sp.

Sanchiz 1998 ---> Bufo calamita; Bufo sp.; Rana sp. 
Xaragalls (Tarragona). Upper Pleistocene.

López-García et al. 2012b ---> Alytes obstetricans; Bufo calamita; Pelodytes cf. punctatus.

Yedras (Granada). Middle Pleistocene.

Sanchiz 1977a ---> Bufo bufo; Bufo cf. regularis.

López Martínez; Ruiz Bustos 1977 ---> Bufo bufo; Bufo aff. regularis.

Ruiz Bustos 1978 ---> Bufo bufo.

Sanchiz; Sanz 1980 ---> Bufo sp.

Sevilla 1988 ---> Bufo aff. regularis; Bufo bufo.

Holman 1998 ---> Bufo bufo; Bufo sp.

Sanchiz 1998 ---> Bufo bufo; Bufo sp.

Zafarraya (Málaga). Upper Pleistocene.

Barroso; Bailon 2003 ---> Bufo bufo; Bufo calamita; Hyla sp.; Pelobates cultripes; Pelodytes sp. (probable Pelodytes ibericus); Pleurodeles waltl; Rana cf. perezi.

Barroso; Bailon 2006 ---> (Boquete de Zafarraya): Bufo bufo cf. spinosus; Bufo calamita; Hyla sp.; Pelobates cultripes; Pelodytes punctatus; Pleurodeles waltl; Rana cf. perezi.

\section{REFERENCES}

Adán, G.; Arribas, A.; Barbadillo, L.J.; Cervera, J.; Estrada, R.; García, M.A.; Jordá, J.; Pastor, J.; Sánchez, B.; Sánchez, A.; Sanchiz, B.; Sesé, C. 1995. Prospecciones y excavaciones arqueológicas en el alto Valle del Jarama (Valdesotos, Guadalajara, Castilla-La Mancha). In: R. Balbín, J. Valiente; M.T. Musat (eds.), Arqueología en Guadalajara. Patrimonio Histórico Arqueología, volume 12. Junta de Castilla-La Mancha. Spain. 223 pp. :111-124.

Aguirre, E. 1989. Vertebrados del Pleistoceno continental. In: Mapa del Cuaternario de España. Escala 1:1000000. Instituto Tecnológico Geominero España, Madrid, Spain. :47-69.

Aguirre, E.; Fuentes, C. 1969. Los Vertebrados fósiles de Torralba y Ambrona. In: M. Ters (ed.), Études sur le Quaternaire dans le Monde. 8 Congrès Union Internationale pour I'Étude du Quaternaire and Centre National de la Recherche Scientifique, Paris, France. :433-437 (published 1971).

Agustí, J.; Blain, H.A.; Cuenca-Bescós, G.; Bailon, S.. 2009. Climate forcing of first hominid dispersal in western Europe. Journal of Human Evolution. 57: 815-821.

Agustí, J.; Blain, H.A.; Furió, M.; Marfá, R. de; Santos-Cubedo, A. 2010. The early Pleistocene small vertebrate succession from the Orce region (Guadix-Baza basin, SE Spain) and its bearing on the first human occupation of Europe. Quaternary International. 223-224: 162-169.

Agustí, J.; Santos-Cubedo, A.; Furió, M.; Marfá, R. de; Blain, H.A.; Oms, O.; Sevilla, P. 2011. The late Neogene - early Quaternary small vertebrate succession from the Almenara-Casablanca karst complex (Castellón, eastern Spain): Chronologic and paleoclimatic context. Quaternary International. 243: 183-191.

Altuna, J.; Cuenca-Bescós, G.; Elorza, M.; García Pimienta, J.C.; Lobo, J.M.; Mariezkurrena, K.; Pérez Ripoll, M.; Sanchiz, B.; González Morales, M.; Straus, L.G. 2004. Post-Pleistocene faunas from the archeological site of El Miron cave (Ramales de la Victoria, Cantabria, Spain): A preliminary summary. Zona Arqueológica. 4 (2): 40-49.

Antunes, M.T. 1991. O Homen da gruta da Figueira Brava (ca. 30000 BP). Contexto ecológico, alimentaçâo, canibalismo. Memórias da Academia de Ciências de Lisboa. Clase de Ciências. 31: 487-536 (1990-1991). 
Antunes, M.T. 2000. The Pleistocene fauna from Gruta da Figuerira Brava: a synthesis. In: M. Telles Antunes (ed.), Últimos neandertais em Portugal. Evidência, odontológica e outra. Last neanderthals in Portugal. Odontologic and other evidence. 415 pp. Memórias da Academia das Ciências de Lisboa. Classe de Ciências. 38: 259-282.

Antunes, M.T.; Crespo, E.G.; Mein, P.; Pais, J.; Teixeira, J.P. 1989. Guia (Algarve), gisement de vertébrés à caractère saisonnier. Ciências da Terra. 10: 97-106.

Arribas, A. 1995. Consideraciones cronológicas, tafonómicas y paleoecológicas del yacimiento cuaternario de Villacastín (Segovia, España). Boletín Geológico y Minero. 106 (1): 3-22.

Baena, J.; Baquedano, I.; Beneítez, P.; Cañaveras, J.C.; Carrión, E.; Lario, J.; Martín-Escorza, C.; Mazo, A.V.; Millán, A.; Sánchez del Moral, S.; Sanz, E.; Sesé, C.; Silva, P.G.; Yravedra, J. 2010. Síntesis: Interpretación general del yacimiento de TAFESA (Madrid). In: J. Baena Preysler; I. Baquedano Beltrán (eds.), Las huellas de nuestro pasado. Estudio del yacimiento del Pleistoceno madrileño de TAFESA (antigua TRANSFESA). Zona Arqueológica 14. Alcalá de Henares, Madrid, Spain. 14: 193-204

Bailon, S. 1986. Los anfibios y los reptiles del yacimiento de Cueva Horá (Darro, Granada). Antropología y Paleoecología Humana. 4: 131-155.

Bailon, S. 1991. Amphibiens et reptiles du Pliocène et du Quaternaire de France et d'Espagne: Mise en place et evolution des faunes. Ph.D. Thesis, Univ. Paris VII, Biologie et Sciences de la Nature, France. 499 pp., 89 plates.

Barroso, C.; Bailon, S. 2006. Les amphibiens et les reptiles du Pléistocène supérieur de la grotte du Boquete de Zafarraya. In: C. Barroso-Ruiz; H. de Lumley (eds.), La grotte du Boquete de Zafarraya (Málaga, Andalousie) II. Conserjería de Cultura, Junta de Andalucía, Sevilla, Spain. 2: 1053-1085.

Barroso, C.; Bailon, S. 2003. Los anfibios y los reptiles del Pleistoceno superior de la Cueva del Boquete de Zafarraya (Málaga, España). In: C. Barroso Ruiz (ed.), El Pleistoceno superior de la Cueva del Boquete de Zafarraya. Consejería de Cultura, Junta de Andalucía, Sevilla, Spain. Arqueología Monografías 15. 520 pp. :267-278, (+ erratum).

Barroso, C.; Botella, D.; Caparrós, M.; Moigne, A.M.; Celiberti, V.; Testu, A.; Barsky, D.; Notter, O.; Riquelme, J.A.; Poso, M.; Carretero, M.I.; Monge, G.; Khatib, S.; Saos, T.; Gregoire, S.; Bailon, S.; Garcís, J.A.; Cabral, A.L.; Djerrab, A.; Hedley, I.G.; Abdessadok, S.; Batalla, G.; Astier, N.; Bertin, L.; Boulbes, N.; Cauche, D.; Filoux, A.; Hanquet, C.; Milizia, C.; Moutoussamy, J.; Rossoni, E.; Verdú, L.; Lumley, H. de. 2011. The Cueva del Angel (Lucena, Spain): An Acheulean hunters habitat in the south of the Iberian Peninsula. Quaternary International. 243: 105-126.

Blain, H.A. 2003. Los anfibios y reptiles de los yacimientos del Pleistoceno inferior de Barranco León y Fuente Nueva-3 (Orce, Granada, España). In: I. Toro Moyano, J. Agustí; B. Martínez-Navarro (eds.), El Pleistoceno inferior de Barranco León y de Fuente Nueva 3, Orce (Granada): Memoria científica campañas 1999-2002. Junta de Andalucía, Sevilla. Arqueología. Monografías 17. 206 pp. :159-172.

Blain, H.A. 2005. Contribution de la paléoherpétofaune (Amphibia; Squamata) à la connaissance de l'évolution du climat et du paysage du Pliocène supérieur au Pléistocène moyen d'Espagne. Thèse du Museum National d'Histoire Naturelle de Paris, Institut de Paléontologie Humaine, France. 402 pp., 67 plates

Blain, H.A. 2009. Contribution de la paléoherpétofaune (Amphibia; Squamata) à la connaissance de l'évolution du climat et du paysage du Pliocène supérieur au Pléistocène moyen d'Espagne. Treballs del Museu de Geologia de Barcelona. 16: 39-170 
Blain, H.A. 2015. Anfibios y escamosos de Cueva Victoria. Mastia. 11-12-13: 175-197.

Blain, H.A.; Bailon, S. 2006. Catalogue of Spanish Plio-Pleistocene amphibians and squamate reptiles from the Museu de Geologia de Barcelona. Treballs del Museu de Geologia de Barcelona. 14: 61-80.

Blain, H.A.; Bailon, S. 2010. Anfibios y escamosos del Pleistoceno Inferior de Barranco León y de Fuente Nueva 3 (Orce, Andalucía, España). In: I. Toro, B. Martínez-Navarro; J. Agustí (eds.), Ocupaciones humanas en el Pleistoceno inferior y medio de la cuenca de Guadix-Baza. Arqueología Monografías. Junta de Andalucía, Sevilla, Spain. :165-183 (published 2011).

Blain, H.A.; Bailon, S.; Agustí, J. 2007. Anurans and squamate reptiles from the latest early Pleistocene of Almenara-Casablanca-3 (Castellón, East of Spain). Systematic, climatic and environmental considerations. Geodiversitas. 29 (2): 5-31.

Blain, H.A.; Bailon, S.; Agustí, J. 2008b. Amphibians and squamate reptiles from the latest early Pleistocene of Cueva Victoria (Murcia, southeastern Spain, SW Mediterranean): Paleobiogeographic and paleoclimatic implications. Geologica Acta. 6 (4): 345-361.

Blain, H.A.; Bailon, S.; Agustí, J..; Martínez-Navarro, B.; Toro, I. 2011b. Paleoenvironmental and paleoclimatic proxies to the early Pleistocene hominids of Barranco León D and Fuente Nueva 3 (Granada, Spain) by means of their amphibian and reptile assemblages. Quaternary International. 243: 44-53.

Blain, H.A.; Bailon, S.; Cuenca-Bescós, G. 2008a. The Early-Middle Pleistocene palaeoenvironmental change based on the squamate reptile and amphibian proxies at the Gran Dolina site, Atapuerca, Spain. Palaeogeography, Palaeoclimatology, Palaeoecology. 261: 177192.

Blain, H.A.; Bailon, S.; Cuenca-Bescós, G. 2008c. Los anfibios y escamosos del Pleistoceno Inferiormedio de Gran Dolina (Atapuerca, Burgos, España): Una perspectiva paleobiogeográfica. Studia Geologica Salmaticensia. (volumen especial) 8: 71-84.

Blain, H.A.; Bailon, S.; Cuenca-Bescós, G.; Arsuaga, J.L.; Bermúdez de Castro, J.M.; Carbonell, E.. 2009a. Long-term climate record inferred from early-Middle Pleistocene amphibian and squamate reptile assemblages at the Gran Dolina cave, Atapuerca, Spain. Journal Human Evolution. 56: 55-65.

Blain, H.A.; Bailon, S.; Cuenca-Bescós, G.; Bennàsar, M.; Rofes, J.; López-García, J.M.; Huguet, R.; Arsuaga, J.L.; Bermúdez de Castro, J.M.; Carbonell, E. 2010a. Climate and environment of the earliest West European hominids inferred from amphibian and squamate reptile assemblages: Sima del Elefante Lower Red Unit, Atapuerca, Spain. Quarternary Science Reviews. 29: 30343044.

Blain, H.A.; Cuenca-Bescós, G.; Burjachs, F.; López-García, J.M.; Lozano-Fernández, I.; Rosell, J. 2013a. Early Pleistocene palaeoenvironments at the time of the Homo antecessor settlement in the Gran Dolina cave (Atapuerca, Spain). Journal of Quaternary Science. 28 (3): 311-319.

Blain, H.A.; Gibert, L.; Ferràndez-Cañadell, C. 2010b. First report of a green toad (Bufo viridis sensu lato) in the early Pleistocene of Spain: Palaeobiogeographical and palaeoecological implications. Comptes Rendus Palevol. 9: 487-497.

Blain, H.A.; Gleed-Owen, C.P.; López-García, J.M.; Sebastián Carrión, J.; Jennings, R.; Finlayson, G.; Finlayson, C.; Giles, F. 2013c. Climatic conditions for the last neanderthals: Herpetofaunal record of Gorham's Cave, Gibraltar. Journal of Human Evolution. 64: 289-299. 
Blain, H.A.; López-García, J.M.; Cuenca-Bescós, G. 2011a. A very diverse amphibian and reptile assemblage from the late Middle Pleistocene of the Sierra de Atapuerca (Sima del Elefante, Burgos, northwestern Spain). Geobios. 44: 157-172.

Blain, H.A.; López-García, J.M.; Cuenca-Bescós, G.; Alonso, C.; Vaquero, M.; Alonso, S. 2009b. Première mise en évidence fossile du chioglosse portugais Chioglossa lusitanica (Amphibia, Caudata) et son implication pour l'histoire biogéographique de l'espèce. Comptes Rendus Palevol. 8: 693-703.

Blain, H.A.; López-García, J.M.; Cuenca-Bescós, G.; Vaquero, M.; Alonso, S. 2009c. First fossil evidence for Chioglossa lusitanica (Amphibia, Caudata) in the Holocene of Western Europe. Journal of Vertebrate Paleontology. 29 (3, Abstracts supplement): 65A.

Blain, H.A.; Panera, J.; Uribelarrea, D.; Rubio-Jara, S.; Pérez-González, A. 2012a. Characterization of a rapid climate shift at the MIS 8/7 transition in central Spain (Valdocarros II, Autonomous Region of Madrid) by means of the herpetological assemblages. Quaternary Science Reviews. 47: 73-81.

Blain, H.A.; Sesé, C.; Rubio-Jara, S.; Panera, J.; Uribelarrea, D.; Pérez-González, A. 2013b. Reconstitution paléoenvironnementale et paléoclimatique du Pleistocène Supérieur ancien (MIS 5A) dans le centre de l'Espagne: Les petits vertébrés (Amphibia, Reptilia; Mammalia) des gisements de HAT et Presesa (sud-est de Madrid). Quaternaire. 24 (2): 191-205.

Blasco, R.; Blain, H.A.; Rosell, J.; Díez, J.C.; Huguet, R.; Rodríguez, J.; Arsuaga, J.L.; Bermúdez de Castro, J.M.; Carbonell, E. 2011. Earliest evidence for human consumption of tortoises in the European Early Pleistocene from Sima del Elefante, Sierra de Atapuerca, Spain. Journal of Human Evolution. 61: 503-509.

Böhme, M.; llg, A. 2003 (year access). fosFARbase. www.wahre-staerke.com.

Burjachs, F.; López-García, J.M.; Allué, E.; Blain, H.A.; Rivals, F.; Bennàsar, M.; Expósito, I. 2012. Palaeoecology of neanderthals during Dansgaard-Oeschger cycles in northeastern Iberia (Abric Romaní): From regional to global scale. Quaternary International. 247: 26-37.

Busack, S.D. 1986. Biochemical and morphological differentiation in Spanish and Maroccan populations of Discoglossus and the description of a new species from southern Spain (Amphibia, Anura, Discoglossidae). Annals of the Carnegie Museum. 55 (3): 41-61.

Carranza, S.; Amat, F. 2005. Taxonomy, biogeography and evolution of Euproctus (Amphibia: Salamandridae), with the resurrection of the genus Calotriton and the description of a new endemic species from the Iberian Peninsula. Zoological Journal of the Linnean Society. 145: 555-582.

Castaños, P.; Murelaga, X.; Bailon, S.; Castaños, J.; Saez de Lafuente, X.; Suarez, O. 2009. Estudio de los vertebrados del yacimiento de Lezikako Koba (Kortezubi, Bizkaia). Kobie. Serie Paleoantropología. 28: 25-50.

Chaline, J. 1965. Observaciones preliminares sobre los terrenos cuaternarios en los alrededores de Arredondo (provincia de Santander). Cuadernos de Espeleología. 1: 21-26.

Chaline, J.. 1961. Observations preliminaires sur les terrains quaternaires des environs d'Arredondo (province de Santander). Sous le Plancher. Spéléo-Club de Dijon. (4-5): 50-57.

Crespo, E.G. 2001. Paleo-herpetofauna de Portugal. Publicações avulsas do Museu Bocage. 7: 1186.

Crespo, E.G. 2002. Paleoherpetofauna portuguesa. Revista Española de Herpetologia. (volumen especial): 17-35. 
Crespo, E.G.; Patrício, G.A.; Antunes, M.T. 2000. Pleistocene Reptilia and Amphibia from Gruta da Figueira Brava (Arrábida, Portugal). In: M. Telles Antunes (ed.), Últimos neandertais em Portugal. Evidência, odontológica e outra. Last neanderthals in Portugal. Odontologic and other evidence. 415 pp. Memórias da Academia das Ciências de Lisboa. Classe de Ciências. 38: 117-127.

Cuenca-Bescós, G.; Rofes, J.; López-García, J.M.; Blain, H.A.; Marfá, R. de.; Galindo-Pellicena, M.A.; Bennásar, M.L.; Melero-Rubio, M.; Arsuaga, J.L.; Bermúdez de Castro, J.M.; Carbonell, E. 2010. Biochronology of Spanish Quaternary small vertebrate faunas. Quaternary International. 212: 109-119.

Esteban, M.L. 1990. Environmental influences on the skeletochronological record among Recent and fossil frogs. Annales des Sciences Naturelles. Zoologie et Biologie Animale. 11: 201-204.

Esteban, M.L.; Sanchiz, B. 1990. Sobre la presencia de Rana iberica en el Pleistoceno burgalés. Revista Española de Herpetologia. 5: 93-99 (published 1991).

Fèlix, J. 1985. Contribució al coneixement dels amfibis anurs del quaternary del nord-est de Catalunya. Paleontologia i Evolució. 19: 163-165.

Fèlix, J. 2002. Els amfibis i els rèptils del Quaternari. In: J. Maroto, S. Ramió; A. Galobart (eds.), Els vertebrats fòssils del Pla de l'Estany. Quaderns C.E.C.B., Banyoles, Spain. 23: 71-86.

Fèlix, J. 2003. Los anfibios y reptiles de los yacimientos del Pleistoceno inferior de Incarcal (Girona, NE de la Península Ibérica). Paleontologia i Evolució. 34: 57-59.

Fèlix, J.; Montori, A. 1987. Los anfibios y los reptiles del Plio-Pleistoceno de la depresión de GuadixBaza (Granada). Paleontologia i Evolució (Memoria especial). 1: 283-286.

Fuentes, C.; Meijide, M. 1975. Fauna fósil de la Cueva Horá (Granada). Estudios Geológicos. 31 (56): 777-784.

Furió, M.; Santos-Cubedo, A.; Blain, H.A.; Blaya, E.; Casanovas-Villar, D.; Madurell, J.; MartínezAlba, D. 2005. Síntesis sobre las faunas fósiles del complejo cárstico de Almanara-Casablanca (Castellón). In: G. Meléndez, C. Martínez-Pérez, S. Ros, H. Botella; P. Plasencia (eds.), Miscelánea Paleontológica. Publicaciones del Seminario de Paleontología de Zaragoza. 6: 273-386

Gamazo, M. 1982. Prospecciones en las terrazas de la margen derecha del rio Manzanares (Getafe y Rivas-Vaciamadrid). Noticiario Arqueológico Hispánico. 14: 9-148.

Giles, F.; Santiago, A.; Gutiérrez, J.M.; López-García, J.M.; Blain, H.A.; Cuenca-Bescós, G.; Van der Made, J.; Cáceres, I.; García, N. 2011. The early Pleistocene paleontological site in the Sierra del Chaparral (Villaluenga del Rosario, Cádiz, southwestern Spain). Quaternary International. 243: 92-104.

Gleed-Owen, C.P. 2001. A preliminary report on the late Pleistocene amphibians and reptiles from Gorham's Cave and Vanguard Cave, Gibraltar. Herpetological Journal. 11 (4): 167-170.

Holman, J.A. 1998. Pleistocene amphibians and reptiles in Britain and Europe. Oxford Univ. Press, Oxford; Nueva York. 254 pp.

Howell, F.C.; Butzer, K.W.; Freeman, L.G.; Klein, R.G. 1995. Observations on the Acheulean occupation site of Ambrona (Soria province, Spain) with particular reference to recent investigations (1980-1983) and the lower occupation. Jahrbuch des Römisch-Germanischen Zentralmuseums Mainz. 38: 33-82.

Hoyos, M. 1979. El karst de Asturias en el Pleistoceno superior y Holoceno. Ph.D. Thesis. Facultad Ciencias Geológicas, Universidad Complutense. Madrid, Spain. 
Jiménez, E.; Cardoso, J.L.; Crespo, E.G. 1998. Presencia de Agrionemys (= Testudo) hermanni (Gmelin, 1789) en el Paleolítico medio de la Gruta Nova da Columbeira (Bombarral, provincia de Estremadura, Portugal). Studia Geologica Salmanticensia. 34: 123-139.

Kotsakis, T. 1981. Gli anfibi e I rettili del Pleistocene del Lazio (Italia centrale). Geologica Romana. 20: 57-67 (1982).

Lanza, B.; Nascetti, G.; Capula, M.; Bullini, L. 1986. Les discoglosses de la région méditerranéenne occidentale (Amphibia; Anura; Discoglossidae). Bulletin de la Société Herpétologique de France. 40: 16-27 (published 1987).

Laplana, C.; Blain, H.A.; Sevilla, P.; Arsuaga, J.L.; Baquedano, E.; Pérez-González, A. 2013. Un assemblage de petits vertébrés hautement diversifié de la fin du MIS 5 dans un environnement montagnard au centre de l'Espagne (Cueva del Camino, Pinilla del Valle, Communauté Autonome de Madrid). Quaternaire. 24 (2): 207-216.

Laplana, C.; Cuenca-Bescós, G. 1995. Los microvertebrados (anfibios, reptiles y mamíferos) asociados al yacimiento de la edad del Bronce de La Balsa la Tamariz (Tauste, Zaragoza). COL-PA. Coloquios de Paleontología. Publicaciones del Departamento de Paleontología, Universidad Complutense. 47: 55-69.

López-García, J.M.; Blain, H.A.; Allué, E.; Bañuls, S.; Bargalló, A.; Martín, P.; Morales, J.I.; Pedro, M.; Rodríguez, A.; Solé, A.; Oms, F.X. 2010a. First fossil evidence of an 'interglacial refugium' in the Pyrenean region. Naturwissenschaften. 97: 753-761.

López-García, J.M.; Blain, H.A.; Bennàsar, M.L.; Euba, I.; Bañuls, S.; Bischoff, J.; López-Ortega, E.; Saladié, P.; Uzquiano, P.; Vallverdú, J. 2012b. A multiproxy reconstruction of the palaeoenvironment and palaeoclimate of the late Pleistocene in northeastern Iberia: Cova dels Xaragalls, Vimbodí-Poblet, Paratge Natural de Poblet, Catalonia. Boreas. 41: 235-249.

López-García, J.M.; Blain, H.A.; Bennàsar, M.L.; Sanz, M.; Daura, J. 2013. Heinrich event 4 characterized by terrestrial proxies in southwestern Europe. Climate of the Past. 9: 1053-1064.

López-García, J.M.; Blain, H.A.; Burjachs, F.; Ballesteros, A.; Allué, E.; Cuevas-Ruiz, G.E.; Rivals, F.; Blasco, R.; Morales, J.I.; Rodríguez Hidalgo A.; Carbonell, E.; Serrat, D.; Rosell, J. 2012c. A multidisciplinary approach to reconstructing the chronology and environment of southwestern European neanderthals: The contribution of Teixoneres cave (Moià, Barcelona, Spain). Quaternary Science Reviews. 43: 33-44.

López-García, J.M.; Blain, H.A.; Cuenca-Bescós, G.; Alonso, C.; Alonso, S.; Vaquero, M. $2011 a$. Small vertebrates (Amphibia, Squamata, Mammalia) from the late Pleistocene-Holocene of Valdavara-1 cave (Galicia, northwestern Spain). Geobios. 44: 253-269.

López-García, J.M.; Blain, H.A.; Cuenca-Bescós, G.; Arsuaga, J.L. 2008a. Chronological, environmental, and climatic precisions on the Neanderthal site of the Cova del Gegant (Sitges, Barcelona, Spain). Journal of Human Evolution. 55: 1151-1155.

López-García, J.M.; Blain, H.A.; Cuenca-Bescós, G.; Ruiz-Zapata, M.B.; Dorado-Valiño, M.; GilGarcía, M.J.; Valdeolmillos, A.; Ortega, A.I.; Carretero, J.M.; Arsuaga, J.L.; Bermúdez de Castro, J.M.; Carbonell, E. 2010b. Palaeoenvironmental and palaeoclimatic reconstruction of the latest Pleistocene of El Portalón site, Sierra de Atapuerca, northwestern Spain. Palaeogeography Palaeoclimatology Palaeoecology. 292: 453-464.

López-García, J.M.; Blain, H.A.; Sanz, M.; Daura, J. 2012a. A coastal reservoir of terrestrial resources for Neanderthal populations in north-eastern Iberia: palaeoenvironmental data inferred from the small-vertebrate assemblage of Cova del Gegant, Sitges, Barcelona. Journal of Quaternary Science. 27 (1): 105-113. 
López-García, J.M.; Cuenca-Bescós, G.; Blain, H.A.; Álvarez-Lao, D.; Uzquiano, P.; Adán, G.; Arbizu, M.; Arsuaga, J.L. 2011b. Palaeoenvironment and palaeoclimate of the MousterianAurignacian transition in northern Iberia: The small-vertebrate assemblage from Cueva del Conde (Santo Adriano, Asturias). Journal of Human Evolution. 61: 108-116.

López-Martínez, N.; Ruiz Bustos, A. 1977. Descubrimiento de dos yacimientos del Pleistoceno medio en el karst de la Sierra de Alfaguara (Granada). Síntesis estratigráfica de este período en la región Bética. Estudios Geológicos. 33: 255-265.

López-Martínez, N.; Sanchiz, B. 1981. Notas sobre los microvertebrados del yacimiento arqueológico de Pontones (Jaén). In: M.D. Asquerino; P. López, La Cueva del Nacimiento (Pontones): Un yacimiento neolítico en la Sierra del Segura. Trabajos de Prehistoria. 38: 134-138.

López-Martínez, N.; Sanchiz, B. 1985. Microvertebrados del yacimiento arqueológico sima 'Cabeza de la Fuente' (Boniches, Cuenca). In: M.I. Martínez Navarrete; J.V. Pérez de la Sierra (eds.), La sima del Cerro Cabeza de la Fuente, Boniches (Cuenca). Serie Arqueología Conquense 6, Publicaciones Diputación Provincial de Cuenca, Cuenca.189 pp. :175-182.

Lorenzo, C.; Navazo, M.; Díez, J.C.; Sesé, C.; Arceredillo, D.; Jordá, J. 2012. New human fossil to the last neanderthals in central Spain (Jarama VI, Valdesotos, Guadalajara, Spain). Journal of Human Evolution. 62: 720-725.

Martín, C.; Sanchiz, B. 1990. Anuros pleistocénicos de la Cueva de las Hienas (Las Caldas, Asturias). Munibe. Ciencias Naturales. 41: 75-77.

Martín, C.; Sanchiz, B. 2014. Reptiles y anfibios de Amutxate. In: T. Torres (ed.), La historia del Oso de las Cavernas: Vida y muerte de un animal desaparecido. Escuela Técnica Superior de Ingenieros de Minas y Energía. Universidad Politécnica de Madrid. 235 pp. :202-206, 213-220, 231

Martín, C.; Sanchiz, B. 2015. Lisanfos KMS. Version 1.2. Online reference accessible at http://www.lisanfos.mncn.csic.es/. Museo Nacional de Ciencias Naturales, MNCN-CSIC. Madrid, Spain.

Martín, C.; Szyndlar, Z.; Sanchiz, B. 2009. Herpetofauna del Pleistoceno Superior de la cueva de Cobrante. Sautuola. 15: 107-114 (published 2010)

Martínez, K.; García, J.; Carbonell, E.; Agustí, J.; Bahain, J.J.; Blain, H.A.; Burjachs, F.; Cáceres, I.; Duval, M-; Falguères, C.; Garces, M.; Gómez, M.; Huguet, R. 2010. A new Lower Pleistocene archeological site in Europe: Vallparadís (Barcelona, Spain). Proceedings of the National Academy of Science USA. 107: 5762-5767.

Martínez-Solano, I.; Sanchiz, B. 2005. Anfibios y reptiles del Pleistoceno medio de Ambrona. In: M. Santonja; A. Pérez González (eds.), Los yacimientos paleolíticos de Ambrona y Torralba (Soria): Un siglo de investigaciones arqueológicas. Zona Arqueológica 5. :231-239.

Montoya, P.; Alberdi, M.T.; Barbadillo, L.J.; Van der Made, J.; Morales, J.; Murelaga, X.; Peñalver, E.; Robles, F.; Ruiz Bustos, A.; Sánchez, A.; Sanchiz, B.; Soria, D.; Szyndlar, Z. 2001. Une faune très diversifiée du pléistocène inférieur de la Sierra de Quibas (province de Murcia, Espagne). Comptes Rendus de l'Académie des Sciences. Série 2. Sciences de la Terre et des Planètes. 332: 387-393.

Montoya, P.; Alberdi, M.T.; Blázquez, A.M.; Barbadillo, L.J.; Fumanal, M.P.; Van der Made, J.; Marín, J.M.; Molina, A.; Morales, J.; Murelaga, X.; Peñalver, E.; Robles, F.; Ruiz Bustos, A.; Sánchez, A.; Sanchiz, B.; Soria, D.; Szyndlar, Z. 1999. La fauna del Pleistoceno inferior de la Sierra de Quibas (Abanilla, Murcia). Estudios Geológicos. 55 (3-4): 127-161. 
Morales, A.; Cereijo, M.A.; Moreno, R. 1991. Una secuencia faunística de la comarca noroeste: La Cueva del Calor. In: P. López (ed.), El cambio cultural del IV al II milenios a.C. en la comarca noroeste de Murcia. Ed. Consejo Superior de Investigaciones Científicas. Madrid, Spain. :247272.

Morales, A.; Moreno, R. 1989. Informe faunístico del depósito votivo de El Amarejo. In: S. Broncano (ed.), El depósito votivo de El Amarejo (Bonete, Albacete). Excavaciones Arqueológicas en España 156, Ministerio de Cultura, Madrid, Spain. 241 pp. :64-77.

Murelaga, X.; Bailon, S.; Castaños, P.; López Quintana, J.C.; Guenaga Lizasu, A.; Saez de Lafuente, X.; Zubeidia, H. 2007. La fauna de vertebrados del Dolmen de Errekatxuetako Atxa (Holoceno) (Zeanuri, Bizkaia). Geogaceta. 43: 123-126.

Murelaga, X.; Fernández Eraso, J.; Bailon, S.; Saez de Lafuente, X. 2009. La fauna de microvertebrados del yacimiento holoceno de Peña Larga (Cripán, Álava). Revista de la Sociedad Geológica de España. 22 (3-4): 155-162.

Murelaga, X.; López Quintana, J.C.; Castaños, P.; Guenaga Lizasu, A.; Bailon, S.; Zubeldia, H. 2007a. Vertebrados del yacimiento Holoceno de Kobeaga II (Ispaster, Bizkaia). Geogaceta. 41: 147-150.

Murelaga, X.; Mujica, J.A.; Bailon, S.; Castaños, P. 2008. La fauna de vertebrados del yacimiento Holoceno (Aziliense) de Aizkoltxo (Mendaro, Gipuzkoa). Geogaceta. 45: 71-74.

Pérez-González, A.; Santonja, M.; Mora, R.; Sesé, C.; Soto, E.; Aleixandre, T.; Villa, P.; Gallardo, J. 1997. Ambrona y Torralba. Actividad humana y procesos naturales. In: J. Rodríguez Vidal (ed.), Cuaternario Ibérico. Asociación Española para el Estudio del Cuaternario (AEQUA). Huelva. i-xi, 393 pp. :235-247.

Pinto-Llona, A.C.; Andrews, P.J. 1999. Amphibian taphonomy and its application to the fossil record of Dolina (Middle Pleistocene, Atapuerca, Spain). Palaeogeography, Palaeoclimatology, Palaeoecology. 149: 411-429.

Rage, J.C.; Roček, Z. 2003. Evolution of anuran assemblages in the Tertiary and Quaternary of Europe, in the context of palaeoclimate and palaeogeography. Amphibia-Reptilia. 24: 133-167.

Rodríguez, J.; Burjachs, F.; Cuenca-Bescós, G.; García, N.; Van der Made, J.; Pérez González, A.; Blain, H.A.; Expósito, I.; López-García, J.M.; García Antón, M.; Allué, E.; Cáceres, I.; Huguet, R.; Mosquera, M.; Ollé, A.; Rosell, J.; Parés, J.M.; Rodríguez, X.P.; Díez, C.; Rofes, J.; Sala, R.; Saladié, P.; Vallverdú, J.; Bennàsar, M.L.; Blasco, R.; Bermúdez de Castro, J.M.; Carbonell, E. 2011. One million years of cultural evolution in a stable environment at Atapuerca (Burgos, Spain). Quaternary Science Reviews. 30: 1396-1412.

Rosas, A.; Huguet, R.; Pérez-González, A.; Carbonell, E.; Bermúdez de Castro, J.M.; Vallverdú, J.; Van der Made, J.; Allué, E.; García, N.; Martínez-Pérez, R.; Rodríguez, J.; Sala, R.; Saladie, P.; Benito, A.; Martínez-Maza, C.; Bastir, M.; Sánchez, A.; Parés, J.M. 2006. The 'Sima del Elefante' cave site at Atapuerca (Spain). Estudios Geológicos. 62 (1): 327-348 (published 2007).

Ruiz Bustos, A. 1978. Edad y estudio faunístico del yacimiento kárstico de Las Yedras (sierra de la Alfaguara, Granada). Estudios Geológicos. 34 (3-6): 323-330.

Sánchez, A.; Fraile, S.; Van der Made, J.; Morales, J.; Quiralte, V.; Salesa, M.J.; Sánchez, I.M.; Sanchiz, B.; Soria, D.; Jiménez, J.; Barbadillo, L.J.; Laplana, C.; Szyndlar, Z. 2005. Primeros datos faunísticos del Neolítico madrileño: la cueva de La Ventana (Torrelaguna, Madrid). In: P. Arias; R. Ontañón; C. García-Moncó (eds.), Actas del III Congreso del Neolítico en la 
Península Ibérica. Monografías del Instituto Internacional de Investigaciones Prehistóricas de Cantabria. volume 1: 1076 pp. :155-165.

Sanchiz, B. 1977a. Catálogo de los anfibios fosiles de España (Noviembre de 1977). Acta Geologica Hispanica. 12 (4-6): 103-107.

Sanchiz, B. 1977b. Nuevos anfibios del Neógeno y Cuaternario de Europa. Origen, desarrollo y relaciones de la batracofauna española. Ph.D. Thesis, Universidad Complutense de Madrid. 863 pp. Available at http://digital.csic.es/handle/10261/109567.

Sanchiz, B. 1980. Anfibios fósiles de la Cueva de la Paloma (Pleistoceno terminal, Asturias). In: M. Hoyos Gómez; M.I. Martínez Navarrete; T. Chapa Brunet; P. Castaños; F.B. Sanchiz (eds.), La cueva de la Paloma, Soto de las Regueras (Asturias). Excavaciones Arqueológicas en España 116, Ministerio de Cultura, Madrid, Spain. 227 pp. :101-108.

Sanchiz, B. 1982. Herpetologia de Cova Rosa. In: F. Jordá, M. Hoyos Gómez; al. (eds.), Cova RosaA. Publicaciones Departamento de Prehistoria y Arqueología, Univ. Salamanca, Spain. 107 pp. :83-89.

Sanchiz, B. 1984. Herpetofauna de Ekain. In: J. Altuna; J. M. Merino (eds.), El yacimiento Prehistórico de la cueva de Ekain (Deba, Guipúzcoa). Eusko Ikaskuntza, San Sebastián, Spain. 351pp. :345-351.

Sanchiz, B. 1987. Nota preliminar sobre ictiofauna y herpetofauna del Pleistoceno de Atapuerca (Burgos). In: E. Aguirre, E. Carbonell; J.M. Bermúdez de Castro (eds.), El hombre fósil de Ibeas y el Pleistoceno de la Sierra de Atapuerca. Investigaciones arqueológicas en Castilla y León. Monografías, Consejería de Cultura, Castilla-León, Spain. 439 pp. :61-65.

Sanchiz, B. 1990. Algunas herpetofaunas de yacimientos del Pleistoceno medio ibérico. Revista Española de Herpetologia. 5: 9-13 (published 1991).

Sanchiz, B. 1998. Salientia. Handbuch der Paläoherpetologie. Pars 4. Dr. Friedrich Pfeil, Munich, Gerrmany. 275 pp.

Sanchiz, B.; Adrover, R. 1977. Anfibios del Pleistoceno de Mallorca. Doñana. Acta Vertebrata. 4: 525.

Sanchiz, B.; Bailon, S. 2013. Nuevos datos sobre la herpetofauna tardiglaciar de La Peña de Estebanvela (Segovia). In: C. Cacho (ed.), Ocupaciones magdalenienses en el interior de la Península Ibérica. La Peña de Estebanvela (Ayllón, Segovia). :141-148.

Sanchiz, B.; Barbadillo, L.J. 2007. Herpetofauna tardiglaciar de la Peña de Estebanvela (Segovia). In: C. Cacho, S. Ripoll; F. Muñoz (eds.), La Peña de Estebanvela (Estebanvela-Ayllón, Segovia): Grupos magdalenienses en el Sur del Duero. Memorias Arqueología en Castilla y León, 17. 444 pp. :133-140.

Sanchiz, B.; Esteban, M.L. 1994. Herpetofauna del Pleistoceno terminal de Laminak II. Kobie. Serie Paleoantropología. 21: 235-242.

Sanchiz, B.; Lobo, J.M. 2006. Restos herpetológicos de niveles auriñacienses de la cueva de El Castillo (Puente Viesgo, Cantabria). In: V. Cabrera, F. Bernaldo de Quirós; J.M. Maíllo (eds.), En el centenario de la Cueva de El Castillo: El ocaso de los neandertales. Centro Asociado a la Universidad Nacional de Educación a Distancia en Cantabria, Santander. 537 pp. :403-416.

Sanchiz, B.; Lobo, J.M.; Bailon, S. 2012. The Holocene herpetofauna of El Mirón Cave. In: L.G. Straus; M.R. González Morales (eds.), El Mirón Cave, Cantabrian Spain. University of New Mexico Press, Alburquerque, NM, U.S.A. 444 pp. :250-261. 
Sanchiz, B.; Martín, C. 2004. Salamándridos pleistocenos de la Cueva de las Hienas (Asturias). In: Libro de Resúmenes. $8^{\circ}$ Congreso Luso-Español y $12^{\circ}$ Congreso Español de Herpetología. Asociación Herpetológica Española, Málaga, Spain. 134 pp.

Sanchiz, B.; Martín, C. 2011. La herpetofauna del yacimiento de El Sidrón. In: M. de la Rasilla, A. Rosas, J.C. Cañaveras; C. Lalueza-Fox (eds.), La Cueva de El Sidrón (Borines, Piloña, Asturias). Investigación interdisciplinar de un grupo neandertal. Conserjería de Cultura, Principado de Asturias, Oviedo, Spain. 211 pp. :155-157.

Sanchiz, B.; Pérez, P.J. 1974. Frecuencia de anomalías óseas en la población de Discoglossus pictus (Anura, Discoglossidae) de Campos (Asturias). Boletín de la Estación Central de Ecología. 3 (6): 69-77.

Sanchiz, B.; Sanz, J.L. 1980. Los anfibios del Pleistoceno medio de Aridos-1 (Arganda, Madrid). In: M. Santonja, N. López Martínez; A. Pérez Gonzálezi (eds.), Ocupaciones achelenses en el valle del Jarama (Arganda, Madrid). Arqueología y paleoecología 1. Publ. Diputación de Madrid, Madrid, Spain. 352 pp. :105-126.

Santonja, M.; López-Martínez, N.; Pérez-González, A. 1978. Acheulean occupation sites in the Jarama Valley (Madrid, Spain). Current Anthropology. 19 (2): 394-395.

Santonja, M.; López-Martínez, N.; Sanchiz, B.; Pérez-González, A. 1979. Sitios de ocupación achelense en el valle del Jarama (Arganda, Madrid). Campaña de 1976. Resultados preliminares. Noticiario Arqueológico Hispánico. 6: 9-17.

Sesé, C.; López-Martínez, N. 2013. Nuevos datos paleontológicos del Pleistoceno en el Valle del Manzanares (Madrid, España): Los micromamíferos del yacimiento del Arenero de Arriaga. Estudios Geológicos. 69 (2): 271-282.

Sesé, C.; Soto, E. 2000. Vertebrados del Pleistoceno de Madrid. In: J. Morales et alii (eds.), Patrimonio paleontológico de la Comunidad de Madrid. Arqueología Paleontología y Etnografía, Monográfico 6. Comunidad de Madrid, Madrid, Spain. 371 pp. :216-243.

Sesé, C.; Soto, E. 2002a. Vertebrados del Pleistoceno del Jarama y Manzanares. Zona Arqueológica. 1: 319-337.

Sesé, C.; Soto, E. 2002b. Catálogo de los yacimientos de vertebrados del Pleistoceno en las terrazas de los ríos Jarama y Manzanares. Zona Arqueológica. 1: 431-457, 493-510.

Sevilla, P. 1988. Estudio paleontológico de los quirópteros del Cuaternario español. Paleontologia $i$ Evolució. 22: 113-233.

Van der Made, J.; Aguirre, E.; Bastir, M.; Fernández-Jalvo, Y.; Huguet, R.; Laplana, C.; Márquez, B.; Martínez, C.; Martinón, M.; Rosas, A.; Rodríguez, J.; Sánchez, A.; Sarmiento, S.; Bermúdez de Castro, J.M. 2003. El registro paleontológico y arqueológico de los yacimientos de la Trinchera del Ferrocarril en la Sierra de Atapuerca. COL-PA. Coloquios de Paleontología. Publicaciones del Departamento de Paleontología, Universidad Complutense. (vol. extraordinario) 1: 345372.

Vergnaud-Grazzini, C. 1970. Les amphibiens fossiles du gisement d'Arondelli. Palaeontographia Italica. 66 (N.S. 36): 47-65.

Zubeldia, H.; Murelaga, X.; Bailon, S.; Aguirre, M.; Sáez de Lafuente, X. 2003. Microvertebrados del Pleistoceno superior del yacimiento de Antoliñako Koba (Gauteguiz-Arteaga, Bizcaia). In: J. Lario; P.G. Silva (eds.), Contribuciones al estudio del Periodo Cuaternario. AEQUA, Ávila. :63-64. 
